UNITED STATES

DEPARTMENT OF THE INTERIOR

GEOLOGICAL SURVEY

STREAMFLON CHARACTERISTICS OF THE

COLORADO RIVER BASIN IN UTAH

THROUGH SEPTEMBER 1981

By R. C. Christensen, E. B. Johnson, and G. G. Plantz

UTAH HYDROLOGIC-DATA REPORT NO. 42

U.S. GEOLOGICAL SURVEY

Open-File Report $85-421$

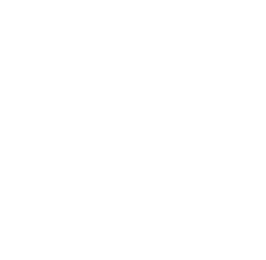

Prepared in cooperation with the

U.S. BUREAU OF LAND MANAGEMENT

Salt Lake City, Utah 


\author{
DEPARTMENT OF THE INTERIOR \\ DONALD PAUL HODEL, Secretary \\ U.S. GEOLOGICAL SURVEY \\ Dallas L. Peck, Director
}

For additional information write to:

District Chief

U.S. Geological Survey Water Resources Division

1016 Administration Building

1745 West 1700 South

Salt Lake City, Utah 84104 be purchased from:

U.S. Geological Survey Books and Open-File Reports Federal Center, Bldg. 41 Box 25425 Denver, Colorado 80225 [Telephone: (303) 236-7476] 


\section{CONIENTS}

Page

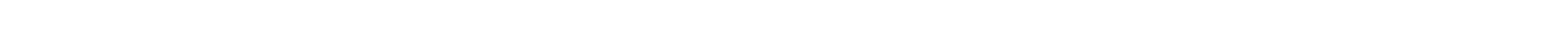

Purpose and scope ..................................... I

Previously published streamflow characteristics $\ldots \ldots \ldots \ldots \ldots \ldots \ldots . \ldots 3$

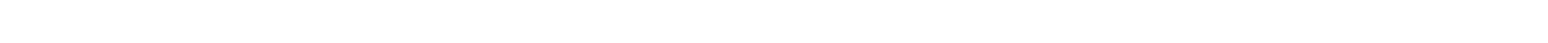

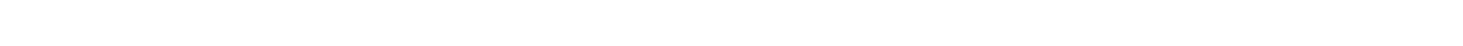

Lowest mean discharge and ranking for the indicated number of consecutive days for each climatic year ................. 7

Highest mean discharge and ranking for the indicated number of

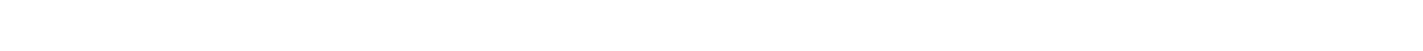

Duration of discharge for each water year $\ldots \ldots \ldots \ldots \ldots \ldots \ldots \ldots \ldots . . .6$

Duration table of discharge $\ldots \ldots \ldots \ldots \ldots \ldots \ldots \ldots \ldots \ldots \ldots \ldots \ldots \ldots$

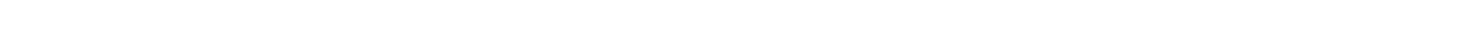

Annual peak discharge and corresponding gage height for each water year .............................................. 8

Magnitude and probability of annual lowest mean discharge based on

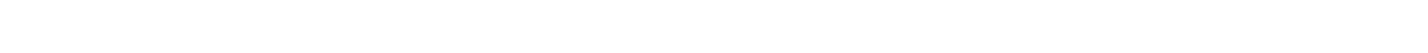

Magnitude and probability of annual highest mean discharge based on

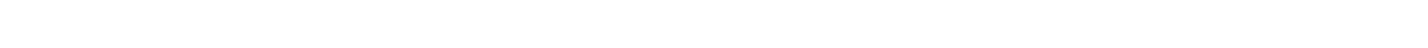

Effects of regulation by reservoirs or diversions on natural streamflow 10

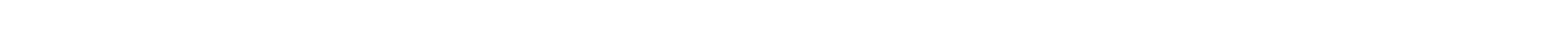

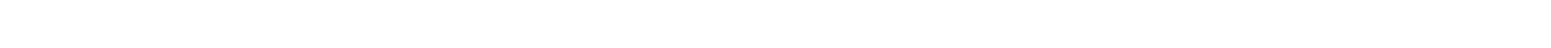

\section{ILLUSTRATIONS}

Page

Figure 1. Map showing study area with index of areas

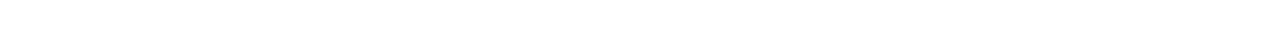

2-4. Maps showing locations of gaging stations in the Colorado River Basin in Utah and proximity:

2. Northern area ............................. 4

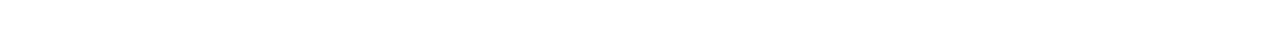

4. Southwestern area $\ldots \ldots \ldots \ldots \ldots \ldots \ldots \ldots \ldots \ldots \ldots \ldots \ldots$

TABLES

Table 1.--Gaging stations in downstream order with period of

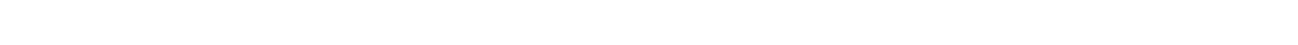

2.--Gaging-station descriptions and statistical sumaries ....... 20 
For readers who prefer to use metric units, factors for converting the inch-pound units used in this report are listed below:

Multiply inch-pound units

acre-foot (acre-ft)

1,233

cubic foot $\left[\left(\mathrm{ft}^{3} / \mathrm{s}\right) \mathrm{day}\right] \quad 2,447$ per second-day

cubic foot $\left(\mathrm{ft}^{3} / \mathrm{s}\right)$ per second

foot

(ft)

(mi)

mile

square mile $\left(\mathrm{mi}^{2}\right)$
0.001233

By

0.002447

0.02832

0.3048

1.609

2.590
To obtain metric units

cubic meter $\left(\mathrm{m}^{3}\right)$ cubic hectometer $\left(\mathrm{mm}^{3}\right)$ cubic meter $\left(\mathrm{m}^{3}\right)$ cubic hectometer $\left(\mathrm{hm}^{3}\right)$ cubic meter per $\left(\mathrm{m}^{3} / \mathrm{s}\right)$ second

meter

kilometer

(km) 


\title{
STREAMFLOW CHARACTERISTICS OF THE
}

\author{
COLORADO RIVER BASIN IN UTAH
}

THROUGH SEPTEMBER 1981

By R. C. Christensen, E. B. Johnson, and G. G. Plantz

\section{INIRODUCTION}

\section{Purpose and Scope}

This report summarizes discharge data and other streamflow characteristics developed from gaging-station records collected through September 1981 at 337 stations in the Colorado River Basin in Utah. Data also are included for 14 stations in adjacent areas of the bordering states of Arizona, Colorado, and Wyoming (fig. 1). The study leading to this report was done in cooperation with the U.S. Bureau of Land Management, which needs the streamflow data in order to evaluate impacts of mining on the hydrologic system. The report also will be beneficial to other Federal, State, and county agencies and to individuals concerned with water supply and water problems in the colorado River Basin.

The streamflow characteristics in the report could be useful in many water-related studies that involve the following:

Definition of baseline-hydrologic conditions; studies of the effects of man's activities on streamflow; frequency analyses of low and high flows; regional analyses of streamflow characteristics; design of water-supply systems; water-power studies; forecasting of stream discharge; time-series analyses of streamflow; design of flood-control structures; stream-pollution studies; and water-chemistry transport studies.

The basic data used to develop the summaries in this report are records of daily and peak discharge collected by the U.S. Geological Survey and other Federal agencies. Much of the work of the Geological Survey was done in cooperation with Federal, State, and county agencies. Discharge records included in the report generally were for stations with at least 1 complete water year of record and nearby stations that were on the same stream and had different streamflow characteristics. A water year is a 12-month period ending September 30, and it is designated by the calendar year in which it ends. For streams that have had significant changes in regulation by reservoirs or diversions, the records before and after those changes were used separately to provide streamflow characteristics for each period of homogeneous streamflow and to show the change in the characteristics. Summaries for annual peak discharge are included only for stations with 5 or more years of data. The summaries of annual lowest and highest mean-discharge frequency are reported for stations with 10 or more years of daily-discharge record and for which computer-generated frequency curves provided a reasonable fit of the plotted data. 


\section{EXPLANATION}

$\square \triangle$ STUDY AREA-Colorado River Basin in Utah

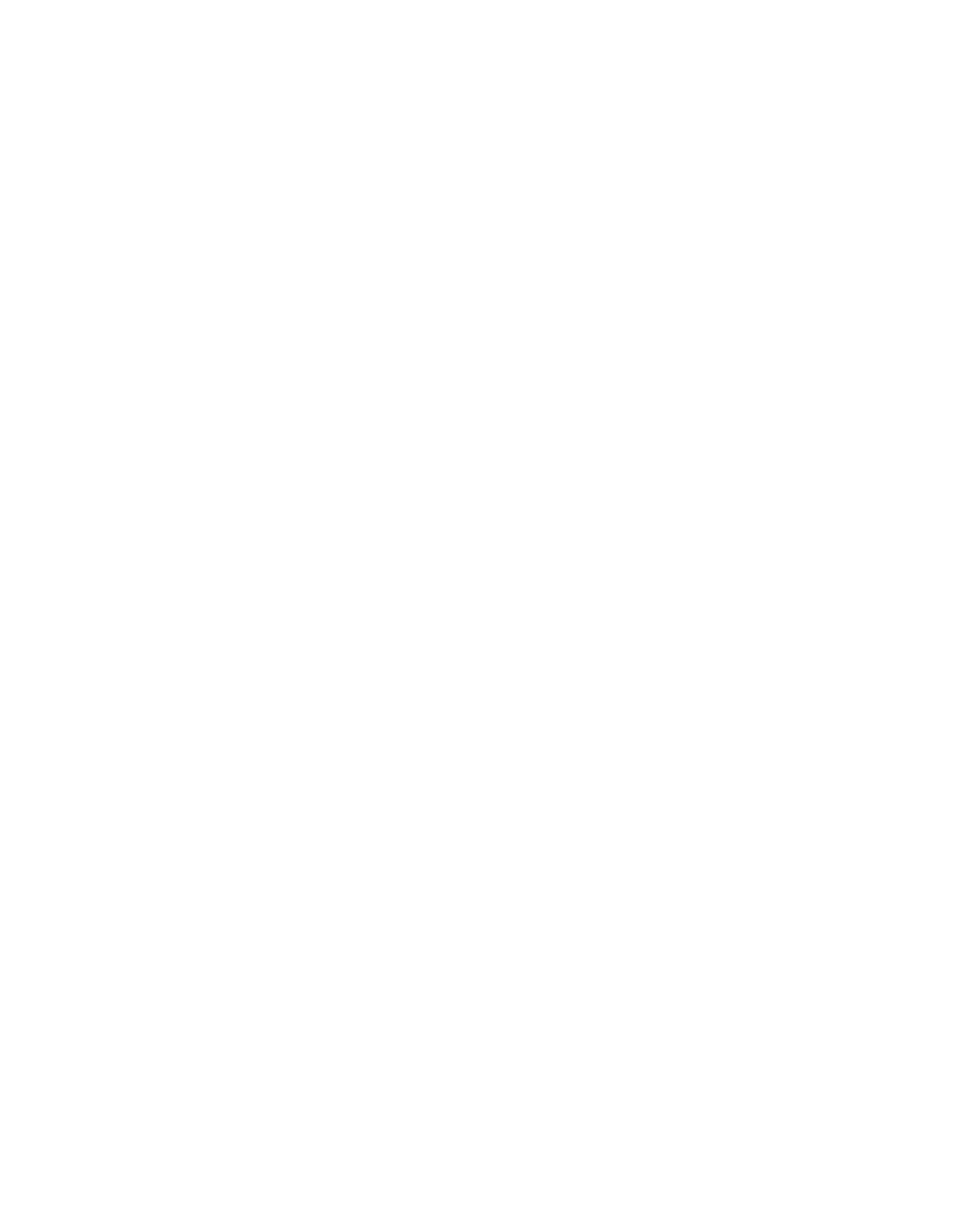

Figure 1.-Study area with index ot areas covered by figures 2-4. 


\section{Previously Published Streamflow Characteristics}

Jeppson and others (1968) presented the following information for 48 gaging stations in the Colorado River Basin: average discharge, duration of daily discharge, magnitude and frequency of low- and high-mean discharge, and annual peak discharge. Whitaker (1971) evaluated the accuracy of mean annual streamflow (average discharge) and 7-day high streamflow at recurrence intervals of 2,10 , and 50 years by regionalization of the streamflow data available through the 1970 water year. Fields (1975) reported summaries of discharge records collected through september 1971 at 74 gaging stations. The summaries included annual lowest- and highest-mean discharge and duration of daily discharge and monthly mean discharge compared through correlation with discharge of 1,2 , and 12 months in the future.

PRESENTATION OF DATA

Station descriptions and streamflow summaries are presented in this report for 351 gaging stations, of which 337 are in Utah, 4 in Arizona, 4 in Colorado, and 6 in wyoming. The gaging stations are of two types: dailydischarge stations, where continuous records of discharge are obtained, and peak-discharge stations, where noncontinuous records of discharge are collected systematically to determine annual peak discharges and times of occurrence. Station locations and types are shown in figures 2-4. Station names are listed in table 1 in downstream order by the standard station numbers of the U.S. Geological Survey. Table 1 also includes the period of record used in the streamflow summaries in table 2 and the page on which the station summaries begin.

The detailed information in table 2 is described in the following sections of this report. The lowest- and highest-mean discharges, duration and summary of daily discharges, and frequency analys is of the lowest- and highest-mean discharges were compiled with a method outlined by Meeks (1977, revised by Dempster, 1983, p. G7-G24). Monthly mean discharges were computed by a method described by Price and Meeks (1977, p. F5-F18).

\section{Station Description}

The description of each gaging station provides the following information when known and applicable:

LOCATION.--A description of the location of the principal gage with respect to the cultural and physical features in the vicinity and with respect to the reference place mentioned in the station name.

DRAINAGE AREA.-The drainage area is given for the most recent location. If only part of the drainage area is considered to be contributing to direct surface runoff, an estimate of the nonoontributing area is included.

MEAN BASIN ELEVATION.--The average height, in feet, of the basin as related to the National Geodetic Vertical Datum of 1929, (NGVD of 1929) formerly called "mean sea level". It is measured from topographic maps by transparent grid-sampling method, averaging 20 to 80 equally spaced points across the basin. 


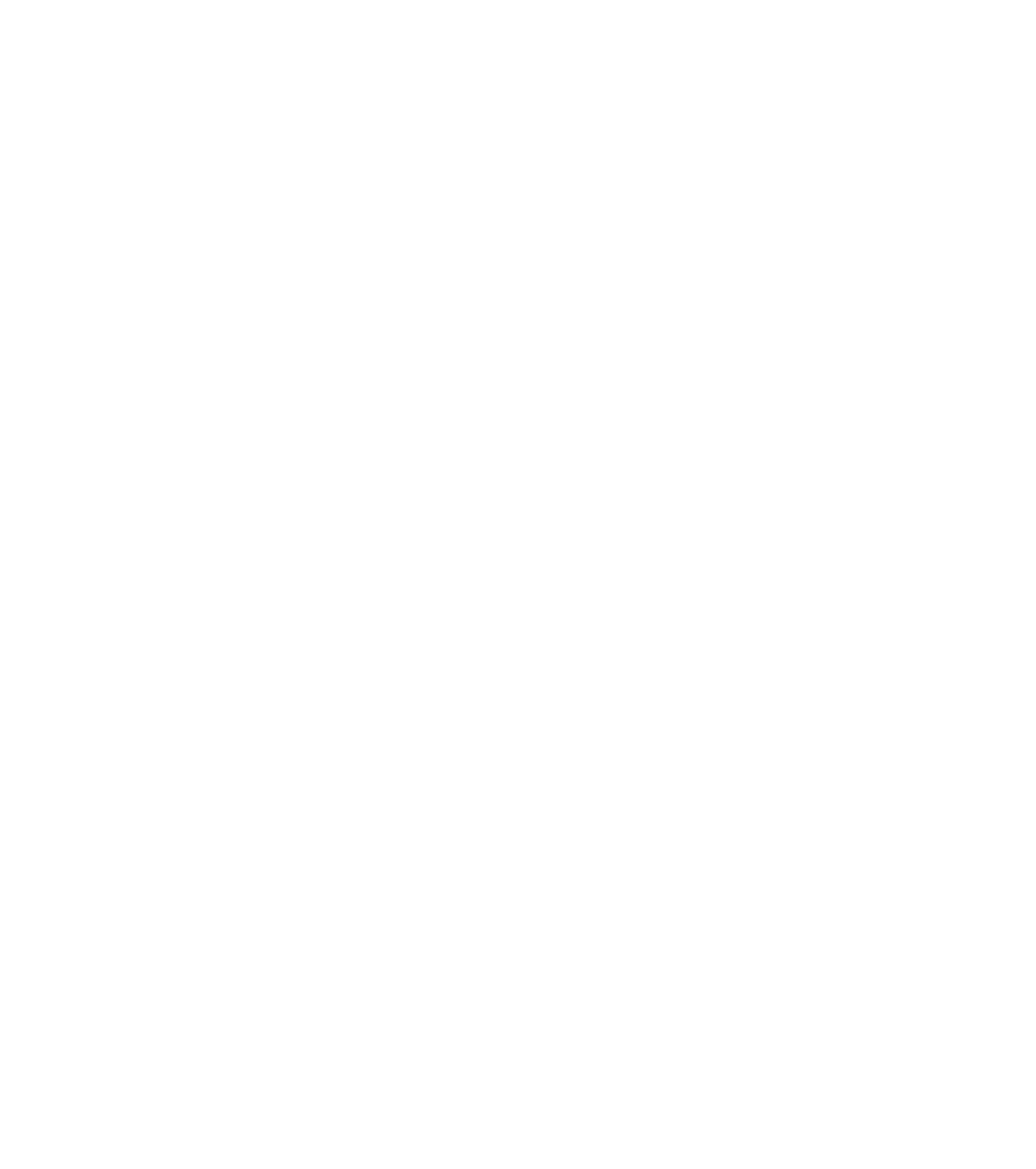

Figure 2.-Location of gaging stations in the northern area of the Colorado River Basin in Utah and proximity. 


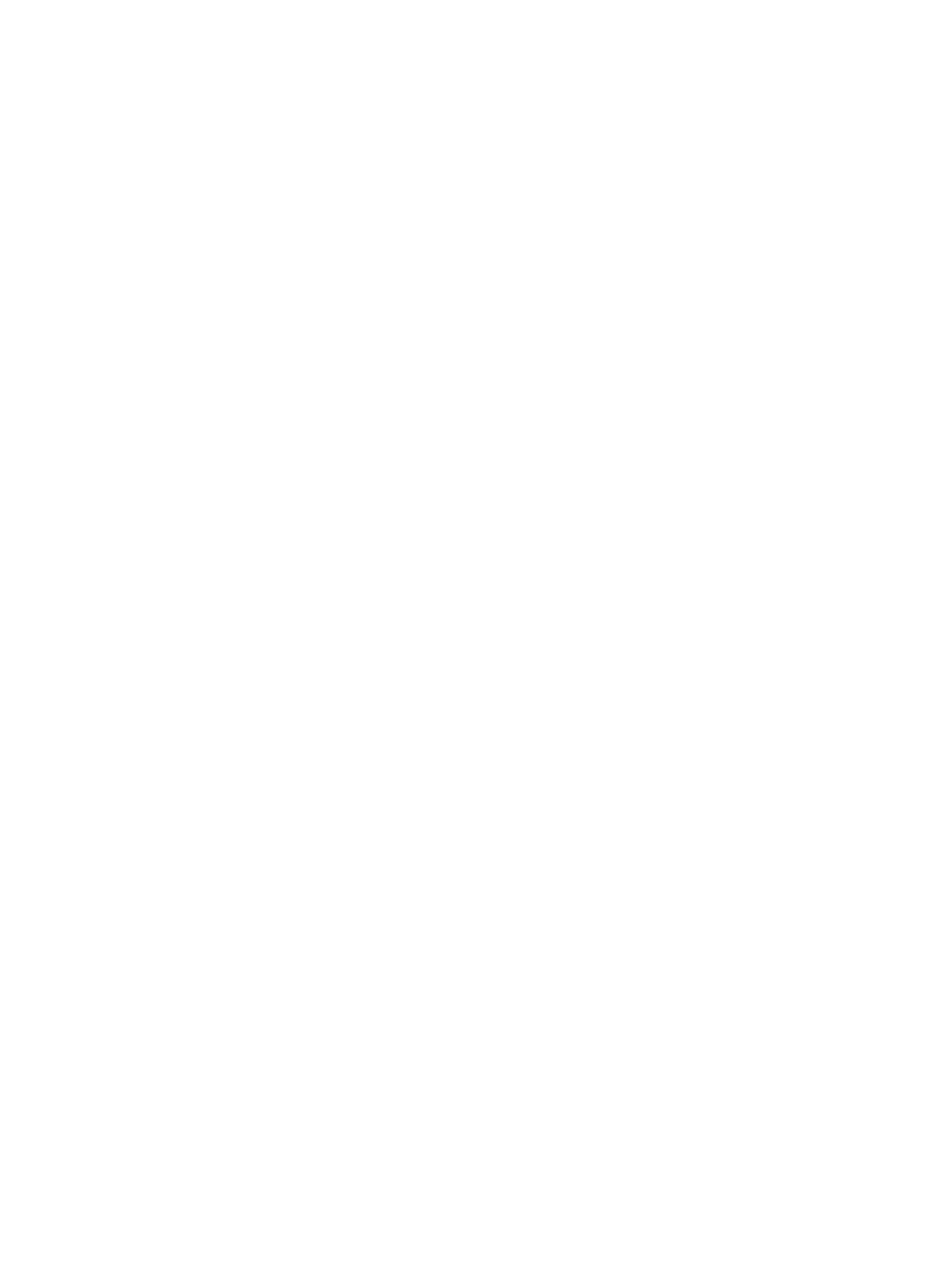

Figure 3.-Location of gaging stations in the southeastern area of the Colorado River Basin in Utah and proximity. 


\section{EXPLANATION}

$3240 \triangle$ DAILY-DISCHARGE STATION $3286 \triangle$ PEAK-DISCHARGE STATION

Station numbers have been abbreviated by omitting the first two digits, 09, and the last one or two digits if they are zero

- BOUNDARY OF DRAINAGE BASIN
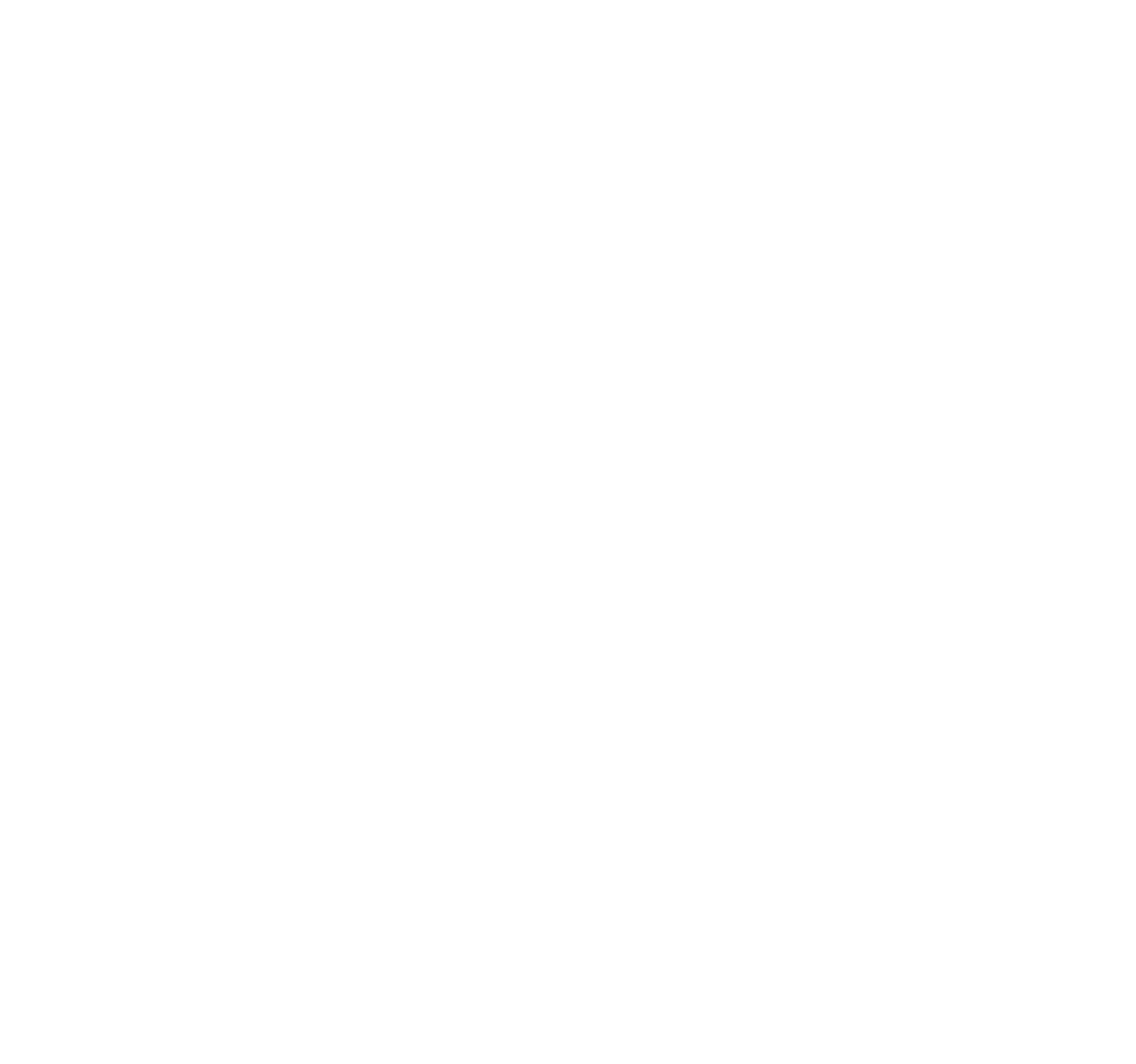

Figure 4.-Location of gaging stations in the southwestern area of the Colorado River Basin in Utah and proximity. 
PERIOD OF RECORD AVAILABLE.-The period through September 1981 for which record has been collected for the station or for a combination of the station and other stations for which records are considered equivalent. The record is in published reports or in the files of the agency that collected the record.

REVISED RECORDS.--Lists name of report in which revisions have been published, the type of data revised, and the water year for the revision. Revisions include daily, monthly, or annual discharge unless the year is followed by: "(M)", which means that only the annual peak discharge was revised; "(m)", which means that only the minimum discharge was revised; or "(P)", which means that some peak discharges above a base discharge were revised. If the drainage area has been revised, the report is noted in which the revised figure was first published. "WDR" is used as an abbreviation to refer to the Utah annual basic-data report, published by the U.S. Geological Survey for the year indicated. "WSP" is used as an abbreviation for reports in the Water-Supply Paper series of the Geological Survey.

GAGE.--Identifys the gage as recording or nonrecording; describes any artificial-control structure that is used to stabilize the stage-discharge relation; gives the altitude of the gage as referred to sea level (National Geodetic Vertical Datum of 1929); and gives a condensed history of the types, locations, and datums of previous gages used during the period of record.

REMARKS.--Includes information on conditions that affect the natural streamflow. If the "REMARKS" paragraph is not included, the record is considered to be of natural streamflow.

COOPERATION.--Acknowledges a cooperating party that furnished all or part of the daily-discharge reoord.

AVERAGE DISCHARGE.--The average discharge is given for the water years indicated. It is not given unless 5 complete water years of record are available.

EXIREMES FOR PERIOD OF RECORD.-The momentary or daily maximum and minimum discharges and gage heights for the period of record.

EXIREMES OUTSIDE PERIOD OF RECORD.-Includes reliable reports of maximum and minimum discharge and gage height outside the period of record, results of discharge measurements or reports of no flow that are less than the minimum during the period of record, and reliable information concerning major floods that occurred outside the period of record.

Lowest Mean Discharge and Ranking for the Indicated Number of Consecutive Days for Each Climatic Year

This summary in table 2 shows the lowest mean discharge for periods of 1 , $3,7,14,30,60,90,120,183$ consecutive days, and all year for each climatic year. In the last two columns, the mean discharges for the climatic years are ranked according to ascending magnitude. 
Highest Mean Discharge and Ranking for the Indicated Number of Consecutive Days for Each Water Year

This summary shows the highest mean discharge for periods of $1,3,7,15$, $30,60,90,120,183$ consecutive days, and all year for each water year. In the last two columns, the mean discharges for the water years are ranked according to descending magnitude.

\section{Duration of Discharge for Each Water Year}

This summary shows the number of days that discharges were in each of a maximum of 35 class intervals according to magnitude and the sum of the daily discharges for each water year.

\section{Duration Table of Discharge}

This summary shows the duration of discharge for the 35 class intervals and period of record listed in the previous summary. It includes the lowest discharge in each class, the number of days within each class, the cumulative number of days in all classes beginning with the highest interval, and the percentage of days during the period of record that the lowest discharge in each class was either equaled or exceeded.

A discharge-duration curve may be prepared directly from the summary by plotting on graph paper the discharge for each class, as the ordinate, against the corresponding percentage of days that the lowest discharge was equaled or exceeded, as the abscissa. Logarithmic probability paper is recommended for plotting discharge-duration curves because that type of paper tends to straighten out the curve, and it also provides an expanded discharge scale for the lower discharges. Discharge-duration curves show the percntage of time within the period of record that a specified discharge was equaled or exceeded. If a shorter period of record is chosen for comparison with another station, a new summary should be prepared for that period from the water-year distribution of daily discharges by class listed in the summary, "Duration of Discharge for Each Water Year".

\section{Monthly Mean Discharges for Each Water Year}

This summary shows the monthly mean discharges for each water year for which a complete year of monthly discharges are available. The monthly discharges are based on an annual complete daily-discharge record or estimated on the basis of an annual incomplete daily-discharge record and records for stations on nearby streams.

Annual Peak Discharge and Corresponding Gage Height for Each water Year

This summary shows the peak discharge for each water year for each gaging station for which there is 5 or more years of data. Also shown are the date and gage height corresponding to the peak discharge. Methods for estimating peak discharge and areas inundated by selected recurrence-interval floods are described by Thomas and Lindskov (1983). 
Magnitude and Probability of Annual Lowest Mean Discharge Based on Climatic Years of Record

This summary shows values for frequency distributions fit to the lowest mean-discharge data, which are listed for each climatic year for the indicated number of consecutive days. A low-flow frequency curve defines the relationship between recurrence interval or nonexceedance probability of annual lowest mean discharge and the magnitude of discharge. The recurrence interval is the average interval of time, in years, within which the lowest mean discharge of a given magnitude will be equaled or not exceeded once. The reciprocal of the recurrence interval multiplied by 100 is the nonexceedance probability of the given magnitude recurring in any year. Low-flow frequency curves are more fully described by Riggs (1968 and 1972).

The tabulation shows the annual lowest mean discharge for periods of 1 , $7,14,30,60$, and 90 consecutive days for recurrence intervals of $2,5,10$, 20,50 , and 100 years. The associated nonexceedance probabilities are 50, $20,10,5,2$, and 1 percent. Low-flow frequency information is given for recurrence intervals of as much as twice the period of record for stations with 10 to 40 years of record, and they include the 100-year (1-percent) interval for stations with more than 40 years. No frequency information is shown for a consecutive-day period when less than 10 years of discharge data were available for analysis or when the log Pearson III frequency curve failed to show a reasonable fit with the plotted data. A graphical plot of the log Pearson III frequency curve and the data for a gaging station can be prepared by the U.S. Geological Survey in Salt Lake City, Utah.

\section{Magnitude and Probability of Annual Highest Mean Discharge Based on Water Years of Record}

This summary shows the values for frequency distributions fit to the highest mean-discharge data, which are listed for each water year for the indicated number of consecutive days. A high-flow frequency curve defines the relationship between recurrence interval or exceedance probability of annual highest mean discharge and the magnitude of discharge. The recurrence interval is the average interval of time, in years, within which the highest mean discharge of a given magnitude will be equaled or exceeded once. The reciprocal of the recurrence interval multiplied by 100 is the exceedance probability of the given magnitude recurring in any year.

The tabulation shows the annual highest mean discharge for periods of 1 , 3,7 , and 15 consecutive days for recurrence intervals of $2,5,10,25,50$, and 100 years. The associated exceedance probabilities are 50, 20, 10, 4, 2, and 1 percent. The criteria for reporting and extending high-flow frequency information based on length of record, for omitted information, and. for obtaining graphical plots of frequency curves and associated data are the same as described in the preceding section. 


\section{EFFECTS OF REGULATION BY RESERVOIRS OR DIVERSIONS ON NATURAL STREAMFLOW}

Many streams in the Colorado River Basin in Utah are regulated by reservoirs or diversions for irrigation, municipal, or industrial use. Thus, the data in this report for many stations reflect the pattern of operation of reservoirs and diversions. Regulation by reservoirs and diversions is noted under "Remarks" in the station description in table 2. Periods of streamflow prior to regulation were segregated in tables 1 and 2 from periods of streamflow affected by reservoirs or diversions for stations 09218500, 09232000, 09234500, 09261000, 09274000, 09277500, 09285000, 09285700, 09287500, 09288180, 09307000, 09313500,09315000,09324500,09379500, and 09380000. Similar information for other stations is available from the U.S. Geological Survey in Salt Lake City.

\section{REFERENCES CITED}

Fields, F. K., 1975, Streamflow characteristics in northeastern Utah and adjacent areas: U.S. Geological Survey Open-File Report, duplicated as Utah Basic-Data Release No. 25, 190 p.

Jeppson, R. W., Ashcroft, G. L., Huber, A. L., Skogerboe, G. V., and Bagley, J. M., 1968, Hydrologic atlas of Utah: Utah Water Research Laboratory, Utah State University, 306 p.

Meeks, W. C., 1977, revised by Dempster, G. R., Jr., 1983, Daily values statistics (Programs A969 and Al93), v. 1, Chapter IV, Section G, of WATSTORE User's Guide: U.S. Geological Survey Open-File Report 75-426, p. G-1 to $G-39$.

Price, W. E., Jr., and Meeks, W. C., 1977, Daily values monthly and annual statistics (Program W4422), v. 1, Chapter IV, Section F, of WATSTORE User's Guide: U.S. Geological Survey Open-File Report 75-426, p. F-1 to $\mathrm{F}-46$.

Riggs, H. C., 1968, Frequency curves: U.S. Geological Survey Techniques of Water Resources Investigations, Book 4, Chapter A2, 15 p.

1972, Low-flow investigations: U.S. Geological Survey Techniques of Water Resources Investigations, Book 4, Chapter Bl, 18 p.

Thomas, B. E., and Lindskov, K. L., 1983, Methods for estimating peak discharge and flood boundaries of streams in Utah: U.S. Geological Survey Water-Resources Investigations Report 83-4129, 77 p.

Whitaker, G. L., 1971, A proposed streamflow data program for Utah: U.S. Geological Survey Open-File Report, 46 p. 
Period of record: Complete record of daily discharge, discharge,

Page: Page number on which station summary begins in table 2 .

\begin{tabular}{l|}
\hline Station \\
\hline Number
\end{tabular}

COLORADO RIVER BASIN

09163500 Colorado River near Colorado-Utah State line TRIBUTARTES BETWEEN COLORADO-UTAH STATE LINE AND DOLORES RIVER Westwater Wash:

09163550 09163700

09169000 09170500

09177500

09178000

09178500

09179000

09180000

09180500

09180920

09180970

09181000

09181500

09182000

09182500

09182600

09182900

09183000

09183500

09184000

09184500

09185000

09185200

09185500

09186000

09186500

09187000

09187500

09217500

09217900

09218500

09220000

09220500

09226000

09226500

09227000

09227500

09228500

09229450

09229500

09232000
Harley Dome Wash near Harley Dome

Cisco Wash near Cisco

DOLORES RIVER BASIN

Dolores River:

La Sal Creek:

Twomile Creek near La Sal

West Paradox Creek near Paradox, $C O$ Roc Creek:

Taylor Creek near Gateway, $\infty O$

Deep Creek near Paradox, $\mathrm{CO}$

Geyser Creek near Paradox, $\subset$

Roc Creek near Uranium, $\infty O$

Dolores River near Cisco

Colorado River near Cisco ${ }^{1}$

TRIBUTARIES BETWEEN DOLORES RIVER AND GREEN RIVER

Onion Creek above onion Creek bridge, near Moab

onion Creek below onion Creek bridge, near Moab

onion Creek near Moab

Professor Creek near Moab

Castle Creek above diversions, near Moab

Castle Creek near Moab

Salt Wash near Thompson

Courthouse wash at Arches Highway Crossing, near Moab -Courthouse Wash near Moab

Mill Creek at Sheley Tunnel, near Moab

Mill Creek near Moab

Pack Creek at M4 Ranch, near Moab

pack Creek near Moab

Kane Springs Canyon near Moab

Hatch Wash near La Sal -

Indian Creek near Monticello

Indian Creek above Cottonwood Creek, near Monticello --...

Cottonwood Creek near Monticello

Indian Creek above Harts Draw, near Monticello GREEN RIVER BASIN

Green River:

Blacks Fork above Blacks Fork Ranger Station

Blacks Fork near Robertson, wY

Blacks Fork near Millburne, WY

Period prior to regulation by Meeks

Cabin Reservoir -

Period after completion of Meeks Cabin Reservoir - Smiths Fork:

East Fork of Smiths Fork near Robertson, WY West Fork of Smiths Fork near Robertson, WY Henrys Fork near Lonetree, WY

$$
\text { Beaver Creek: }
$$

Middle Fork Beaver Creek near Lonetree, East Fork Beaver Creek near Lonetree, WY West Fork Beaver Creek near Lonetree, WY Burnt Fork near Burntfork, wY

Henrys Fork tributary near Manila

Henrys Fork near Manila

sheep Creek near Manila

Period prior to diversions through

Sheep Creek Canals -

period after diversions through

Sheep Creek Canals -
Period of record (Water years)

Page

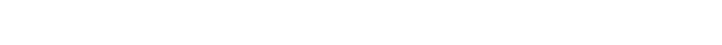

\section{(1)}

23

23

24

25

27

30

31

32

44

46

50

51

51

53

61

62

64 


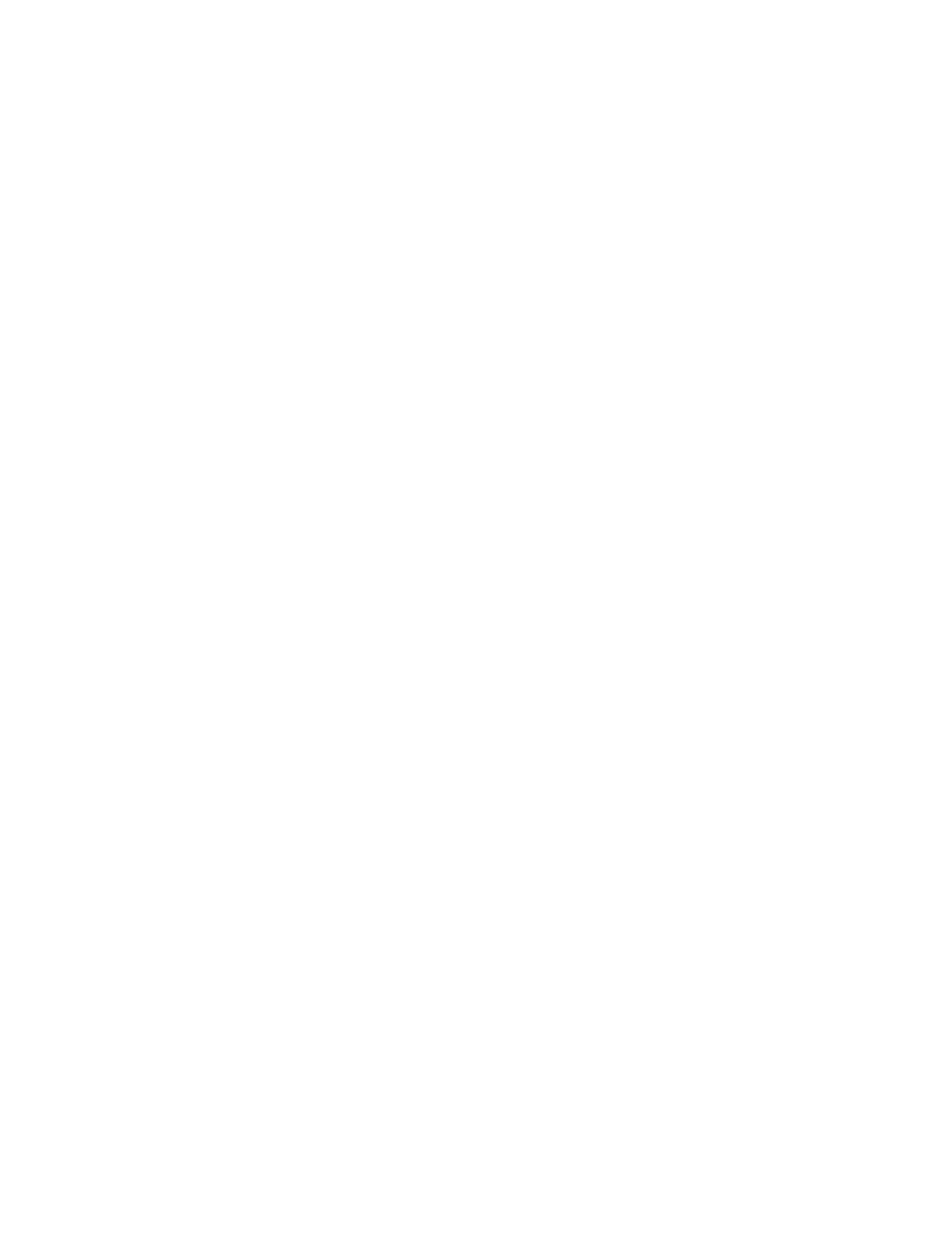




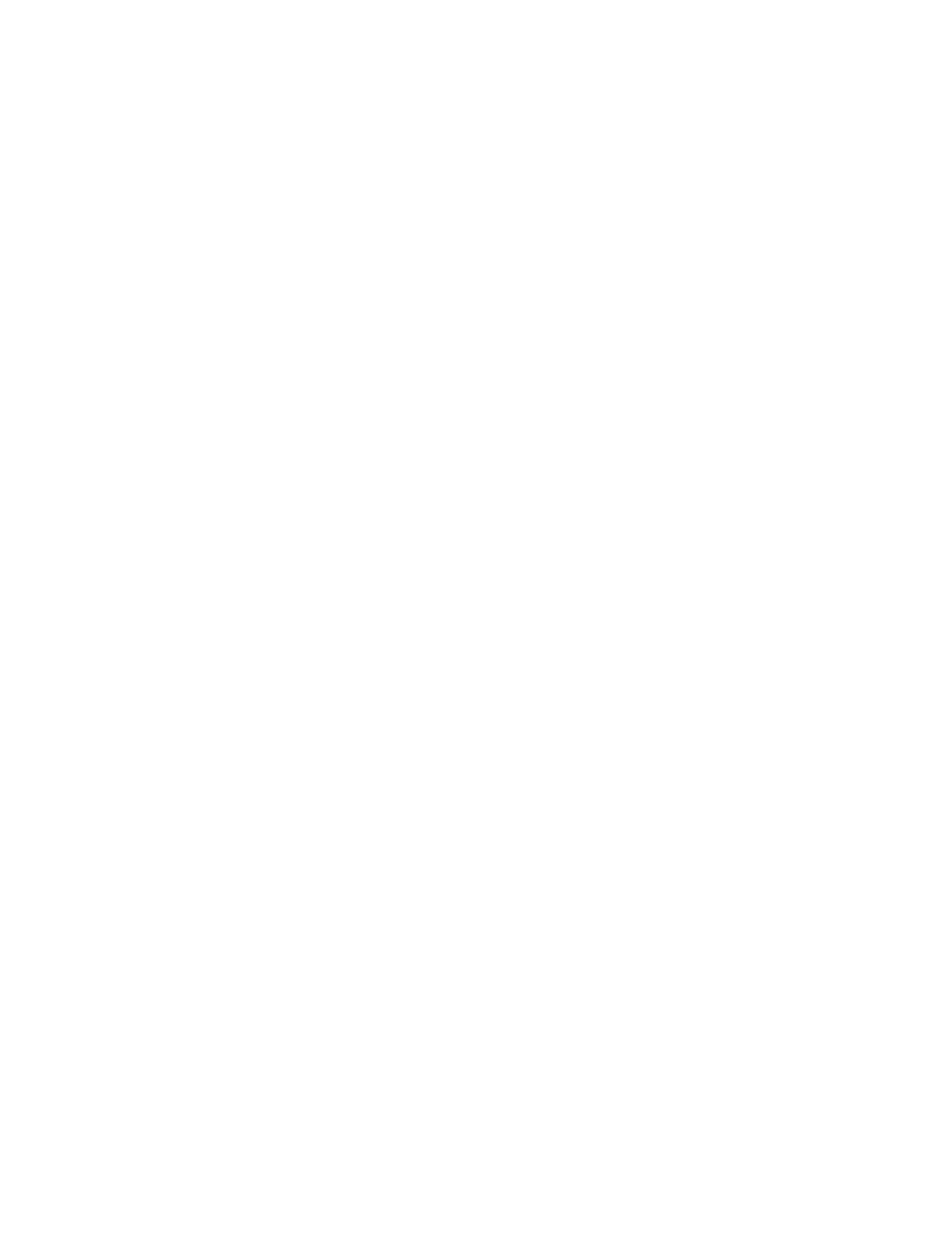




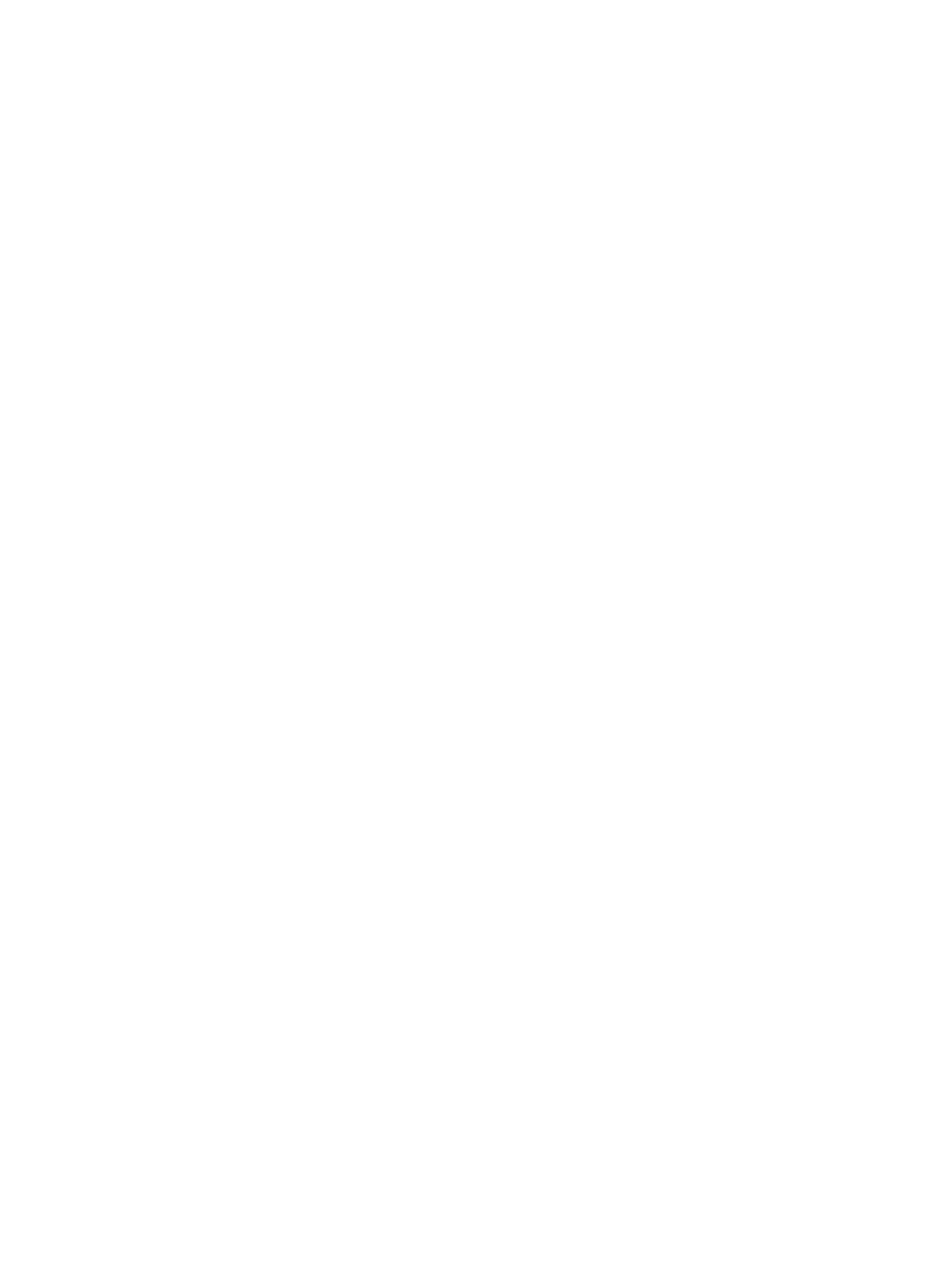




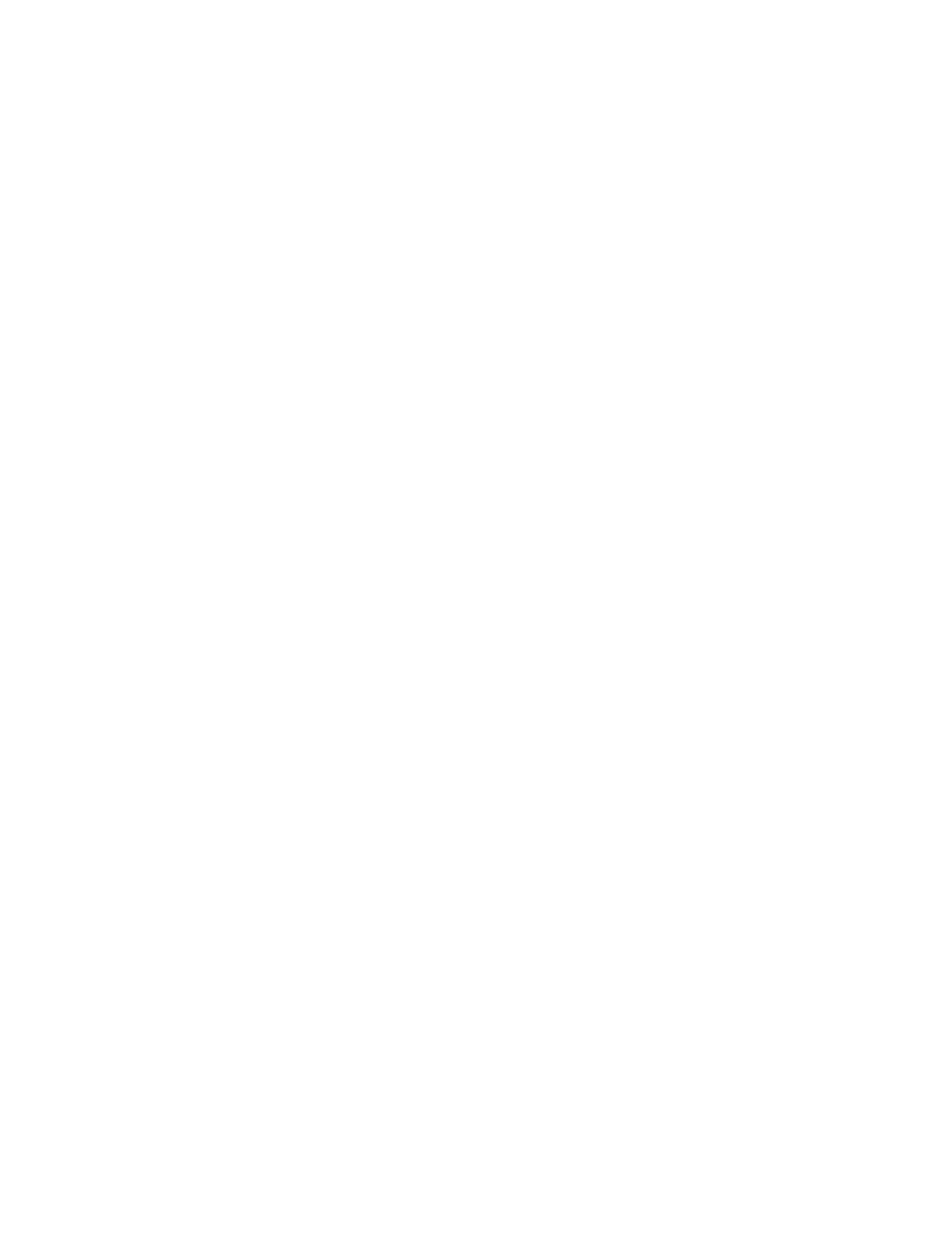




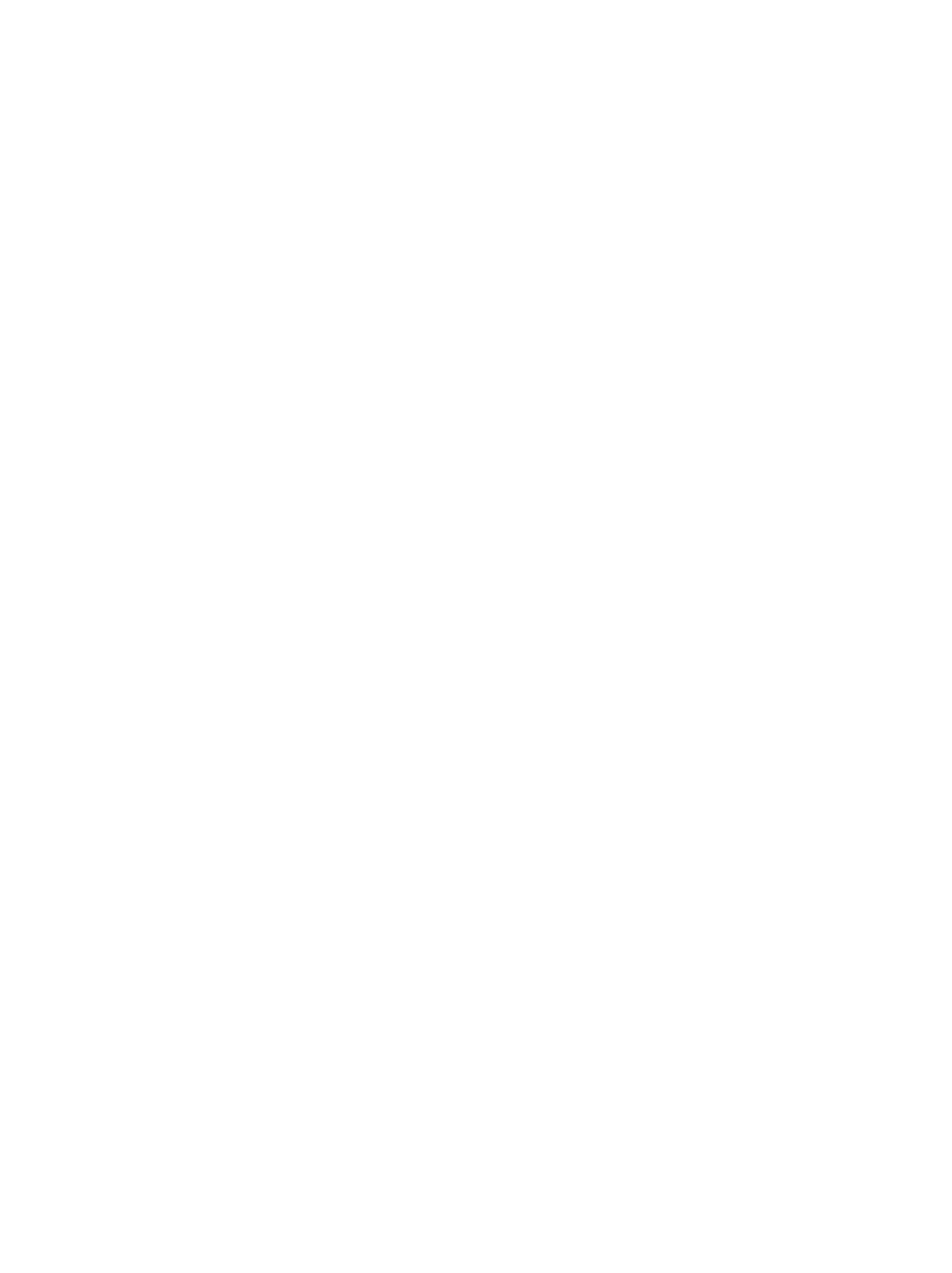




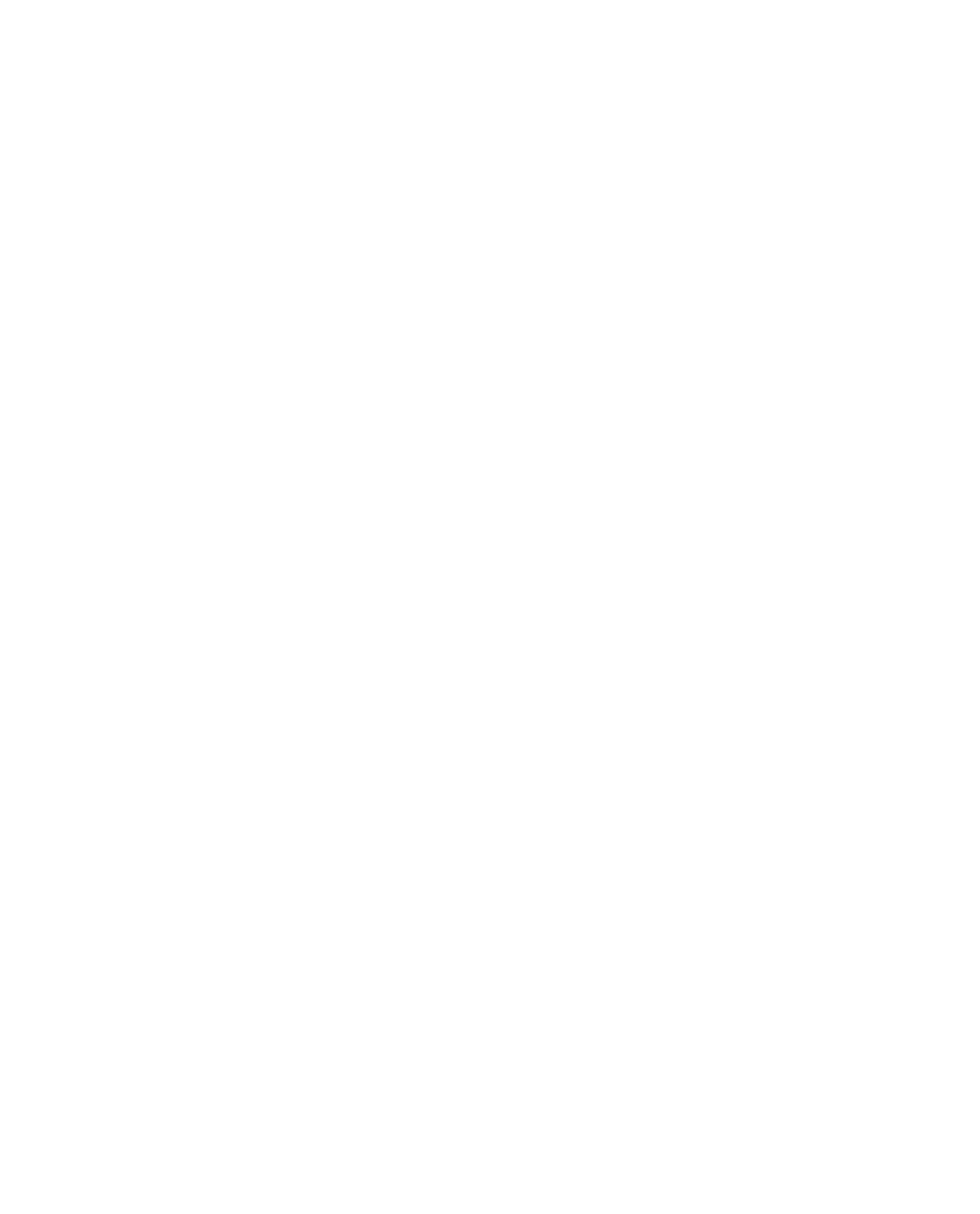




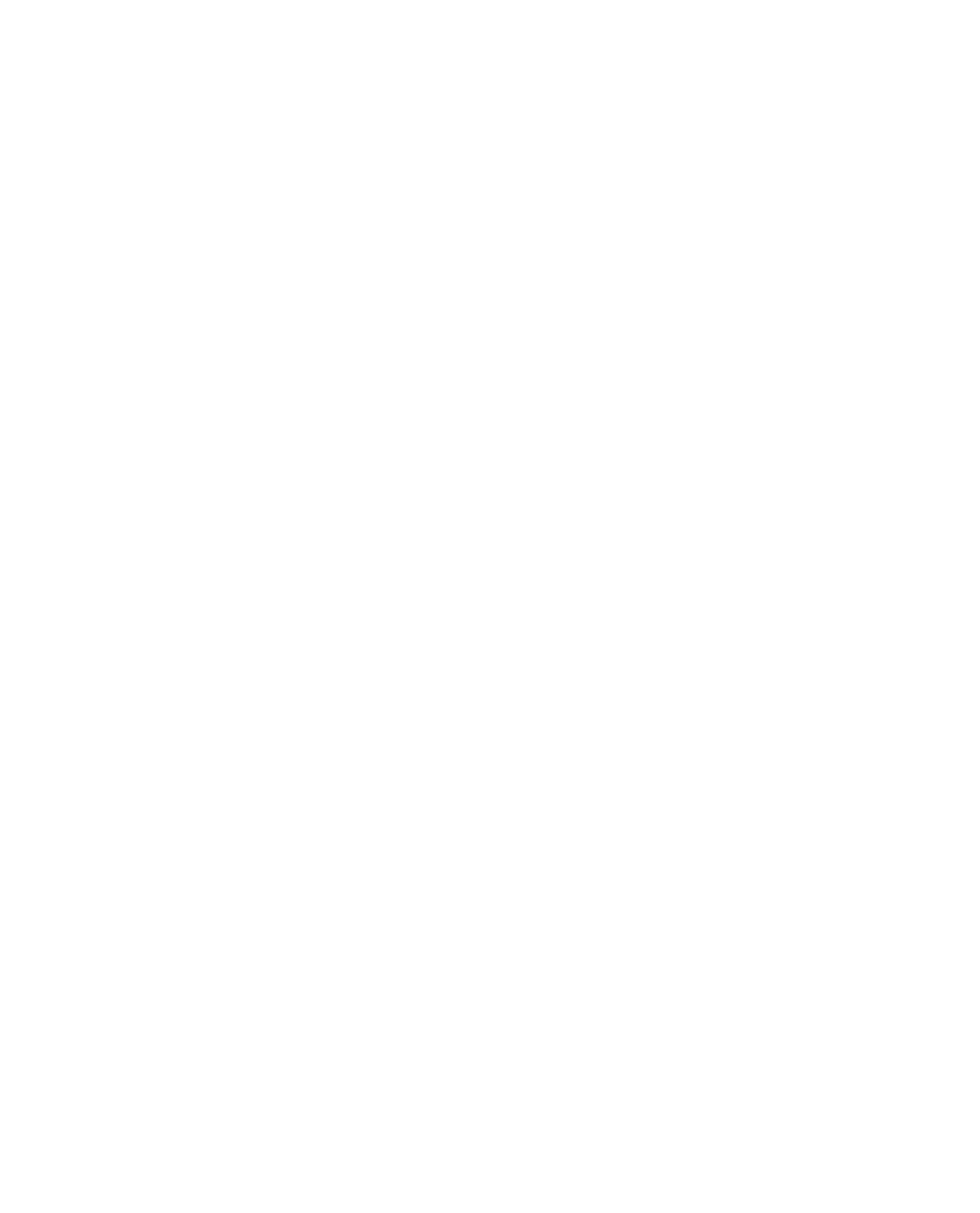


TABLE 1.--GAGING STATIONS IN DOWNSTREAM ORDER WITH PERICD OF RECORD--Continued

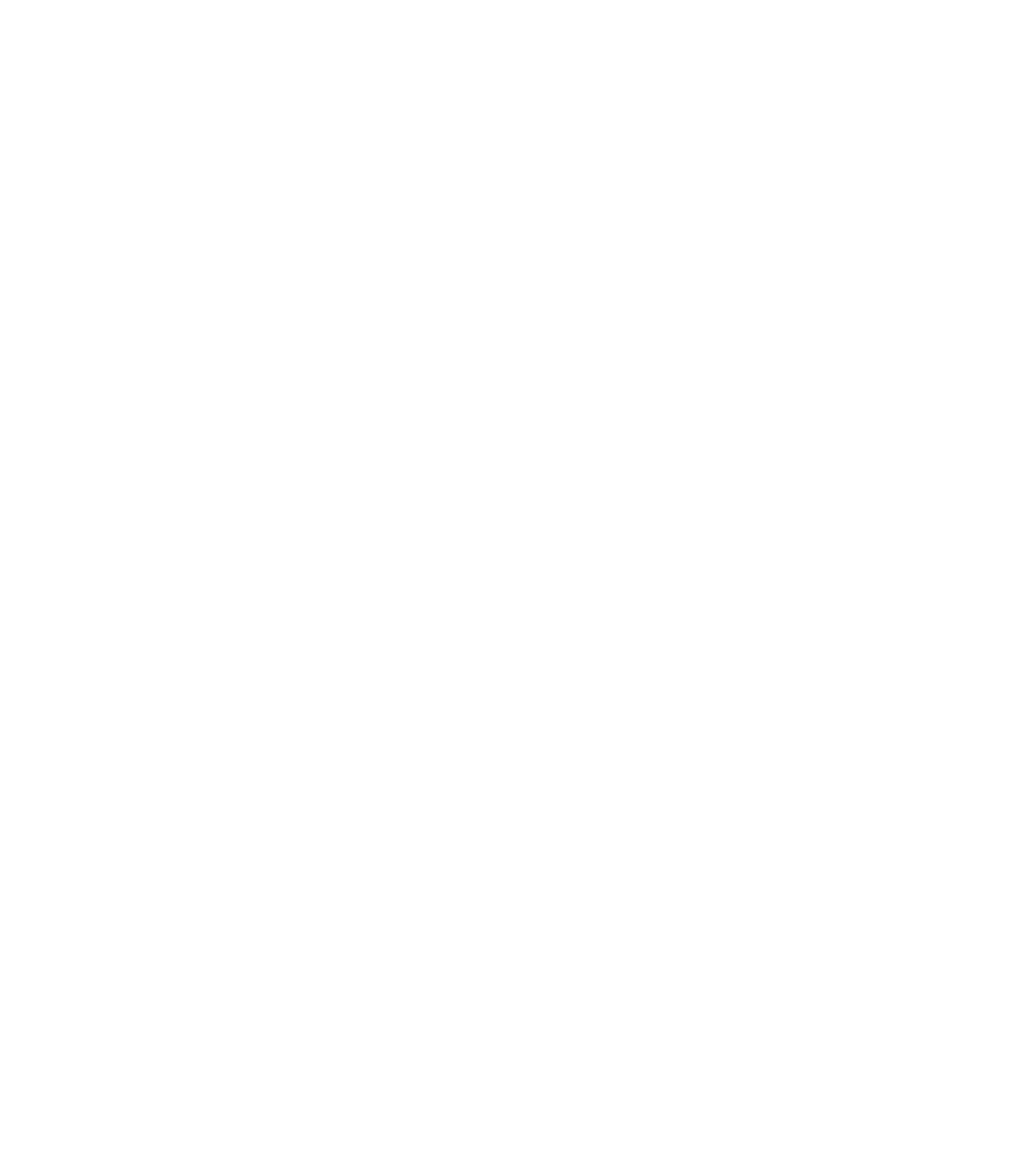

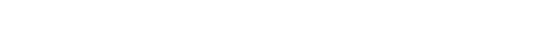

${ }^{2}$ Station number is not in downstream order. 
Table 2.--GAGING-STATION DESCRIPTIONS AND STATISTICAL SUMMARIES

COLORADO RIVER MAIN STEM

09163500 COLORADO RIVER NEAR COLORADO-UTAH STATE LINE

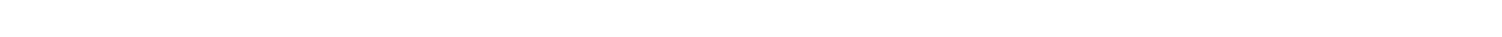
$0.7 \mathrm{mi}$ downstream from McDonald Creek, $12 \mathrm{mi}$ southwest of Mack, Colorado, and $1.5 \mathrm{mi}$ upstream fram Colorado-Utah State 1 ine.

DRAINAGE AREA. $--17,843 \mathrm{mi}^{2}$.

PERIOD OF RECORD AVAILABLE.--May 1951 to September 1981.

REVISED RECORDS.--WDR COLO-74-1: Drainage area.

GAGE.-Water-stage recorder. Altitude of gage is 4,325 ft tran topographic map. May 1951 to October 1980 , water-stage recorder at sites $5.7 \mathrm{mi}$ upstream at different datum.

REMARKS.--Natural tlow of strean affected by transmountain diversions, storage reservoirs, power development, and diversions for irrigation. (Records include all return flow tran irrigated areas.)

AVERAGE DISCHARGE. - -30 years, $5,719 \mathrm{ft}^{3} / \mathrm{s}, 4,143,000$ acre-ft/yr.

EXTREMES FOR PERICD OF RECORD.--Maximum discharge, 56,800 $\mathrm{ft}^{3} / \mathrm{s}$ June 9, 1957, gage height, $16.40 \mathrm{ft}$, site and datum then in use, minimum daily, $960 \mathrm{ft}^{3} / \mathrm{s}$ Sept. $7,1956$.

LONEST MEAN DISCHARGE, IN CUBIC FEET PER SECOND, AND RANKING FOR THE INDICATED NUMBER OF CONSECUTIVE DAYS FOR EACH CLIMATIC YEAR, APRII 1-MARCH 31

YEAR

CONSECUTIVE DAYS

\begin{tabular}{|c|c|c|c|c|c|c|c|c|c|c|c|c|c|c|c|c|c|c|c|c|}
\hline & 1 & & 3 & & 7 & & 14 & & 30 & & 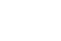 & & 90 & & 120 & & 183 & & ALL & \\
\hline $\begin{array}{l}1953 \\
1954 \\
1955\end{array}$ & $\begin{array}{l}2050 \\
1800 \\
1000\end{array}$ & $\begin{array}{r}20 \\
14 \\
2\end{array}$ & $\begin{array}{l}2160 \\
1890 \\
1030\end{array}$ & $\begin{array}{r}20 \\
16 \\
2\end{array}$ & $\begin{array}{l}2320 \\
1900 \\
1110\end{array}$ & $\begin{array}{r}21 \\
14 \\
1\end{array}$ & $\begin{array}{l}2450 \\
1930 \\
1300\end{array}$ & $\begin{array}{r}22 \\
13 \\
4\end{array}$ & $\begin{array}{l}2510 \\
1950 \\
1500\end{array}$ & $\begin{array}{r}20 \\
11 \\
4\end{array}$ & $\begin{array}{l}2600 \\
2180 \\
1820\end{array}$ & $\begin{array}{r}16 \\
10 \\
4\end{array}$ & $\begin{array}{l}2650 \\
2390 \\
2090\end{array}$ & $\begin{array}{r}13 \\
10 \\
6\end{array}$ & $\begin{array}{l}2730 \\
2430 \\
2250\end{array}$ & $\begin{array}{r}12 \\
9 \\
6\end{array}$ & $\begin{array}{l}2790 \\
2510 \\
2360\end{array}$ & $\begin{array}{r}12 \\
9 \\
6\end{array}$ & $\begin{array}{l}9460 \\
5100 \\
2860\end{array}$ & $\begin{array}{r}28 \\
14 \\
2\end{array}$ \\
\hline $\begin{array}{l}1956 \\
1957 \\
1958 \\
1959 \\
1960\end{array}$ & $\begin{array}{r}1400 \\
960 \\
2320 \\
1200 \\
1310\end{array}$ & $\begin{array}{r}9 \\
1 \\
23 \\
6 \\
7\end{array}$ & $\begin{array}{l}1430 \\
1000 \\
2390 \\
1210 \\
1320\end{array}$ & $\begin{array}{r}8 \\
1 \\
23 \\
5 \\
7\end{array}$ & $\begin{array}{l}1470 \\
1110 \\
2410 \\
1280 \\
1350\end{array}$ & $\begin{array}{r}8 \\
2 \\
23 \\
6 \\
7\end{array}$ & $\begin{array}{l}1520 \\
1200 \\
2500 \\
1430 \\
1470\end{array}$ & $\begin{array}{r}8 \\
1 \\
23 \\
6 \\
7\end{array}$ & $\begin{array}{l}1810 \\
1310 \\
2860 \\
1680 \\
1800\end{array}$ & $\begin{array}{r}9 \\
1 \\
23 \\
6 \\
8\end{array}$ & $\begin{array}{l}1870 \\
1460 \\
3060 \\
1900 \\
2010\end{array}$ & $\begin{array}{r}6 \\
1 \\
23 \\
7 \\
9\end{array}$ & $\begin{array}{l}2040 \\
1590 \\
3250 \\
2130 \\
2370\end{array}$ & $\begin{array}{r}5 \\
2 \\
22 \\
7 \\
9\end{array}$ & $\begin{array}{l}2220 \\
1760 \\
3350 \\
2280 \\
2530\end{array}$ & $\begin{array}{r}5 \\
2 \\
20 \\
7 \\
10\end{array}$ & $\begin{array}{l}2280 \\
1920 \\
3620 \\
2440 \\
2680\end{array}$ & $\begin{array}{r}4 \\
1 \\
20 \\
7 \\
11\end{array}$ & $\begin{array}{r}3970 \\
4540 \\
11100 \\
6950 \\
4330\end{array}$ & $\begin{array}{r}5 \\
11 \\
29 \\
21 \\
7\end{array}$ \\
\hline $\begin{array}{l}1961 \\
1962 \\
1963 \\
1964 \\
1965\end{array}$ & $\begin{array}{l}1190 \\
1340 \\
1800 \\
1020 \\
1870\end{array}$ & $\begin{array}{r}5 \\
8 \\
15 \\
3 \\
18\end{array}$ & $\begin{array}{l}1220 \\
1450 \\
1800 \\
1060 \\
1920\end{array}$ & $\begin{array}{r}6 \\
9 \\
14 \\
3 \\
17\end{array}$ & $\begin{array}{l}1230 \\
1500 \\
2060 \\
1200 \\
2060\end{array}$ & $\begin{array}{r}5 \\
9 \\
16 \\
4 \\
17\end{array}$ & $\begin{array}{l}1280 \\
1590 \\
2290 \\
1380 \\
2160\end{array}$ & $\begin{array}{r}3 \\
9 \\
19 \\
5 \\
16\end{array}$ & $\begin{array}{l}1400 \\
1770 \\
2410 \\
1650 \\
2260\end{array}$ & $\begin{array}{r}3 \\
7 \\
18 \\
5 \\
16\end{array}$ & $\begin{array}{l}1690 \\
1910 \\
2730 \\
1840 \\
2350\end{array}$ & $\begin{array}{r}3 \\
8 \\
20 \\
5 \\
12\end{array}$ & $\begin{array}{l}1900 \\
2630 \\
2700 \\
1880 \\
2450\end{array}$ & $\begin{array}{r}4 \\
12 \\
14 \\
3 \\
11\end{array}$ & $\begin{array}{l}2150 \\
3370 \\
2830 \\
1920 \\
2530\end{array}$ & $\begin{array}{r}4 \\
21 \\
13 \\
3 \\
11\end{array}$ & $\begin{array}{l}2280 \\
3460 \\
3270 \\
2130 \\
2570\end{array}$ & $\begin{array}{r}5 \\
18 \\
15 \\
3 \\
10\end{array}$ & $\begin{array}{l}4910 \\
4450 \\
8310 \\
2990 \\
4510\end{array}$ & $\begin{array}{r}13 \\
9 \\
26 \\
3 \\
10\end{array}$ \\
\hline $\begin{array}{l}1966 \\
1967 \\
1968 \\
1969 \\
1970\end{array}$ & $\begin{array}{l}2000 \\
1620 \\
1570 \\
2200 \\
2510\end{array}$ & $\begin{array}{l}19 \\
11 \\
10 \\
21 \\
25\end{array}$ & $\begin{array}{l}2030 \\
1700 \\
1600 \\
2350 \\
2600\end{array}$ & $\begin{array}{l}19 \\
12 \\
10 \\
22 \\
25\end{array}$ & $\begin{array}{l}2170 \\
1770 \\
1640 \\
2390 \\
2760\end{array}$ & $\begin{array}{l}19 \\
12 \\
10 \\
22 \\
25\end{array}$ & $\begin{array}{l}2270 \\
1790 \\
1800 \\
2440 \\
2910\end{array}$ & $\begin{array}{l}18 \\
10 \\
11 \\
21 \\
25\end{array}$ & $\begin{array}{l}2500 \\
1920 \\
2210 \\
2550 \\
3120\end{array}$ & $\begin{array}{l}19 \\
10 \\
15 \\
21 \\
25\end{array}$ & $\begin{array}{l}2720 \\
2190 \\
2610 \\
3000 \\
3560\end{array}$ & $\begin{array}{l}19 \\
11 \\
17 \\
22 \\
25\end{array}$ & $\begin{array}{l}2960 \\
2290 \\
2760 \\
3320 \\
3980\end{array}$ & $\begin{array}{r}20 \\
8 \\
16 \\
23 \\
27\end{array}$ & $\begin{array}{l}3150 \\
2430 \\
2950 \\
3580 \\
4100\end{array}$ & $\begin{array}{r}17 \\
8 \\
15 \\
23 \\
28\end{array}$ & $\begin{array}{l}3610 \\
2440 \\
3240 \\
3710 \\
4240\end{array}$ & $\begin{array}{r}19 \\
8 \\
14 \\
21 \\
27\end{array}$ & $\begin{array}{l}8410 \\
3580 \\
4340 \\
5440 \\
6210\end{array}$ & $\begin{array}{r}27 \\
4 \\
8 \\
15 \\
17\end{array}$ \\
\hline $\begin{array}{l}1976 \\
1977 \\
1978 \\
1979 \\
1980\end{array}$ & $\begin{array}{l}2440 \\
1650 \\
1050 \\
1860 \\
3060\end{array}$ & $\begin{array}{r}24 \\
12 \\
4 \\
17 \\
28\end{array}$ & $\begin{array}{l}2460 \\
1660 \\
1140 \\
1970 \\
3100\end{array}$ & $\begin{array}{r}24 \\
11 \\
4 \\
18 \\
28\end{array}$ & $\begin{array}{l}2510 \\
1720 \\
1160 \\
2130 \\
3280\end{array}$ & $\begin{array}{r}24 \\
11 \\
3 \\
18 \\
28\end{array}$ & $\begin{array}{l}2610 \\
1810 \\
1220 \\
2230 \\
3410\end{array}$ & $\begin{array}{r}24 \\
12 \\
2 \\
17 \\
28\end{array}$ & $\begin{array}{l}3000 \\
2020 \\
1320 \\
2320 \\
3590\end{array}$ & $\begin{array}{r}24 \\
12 \\
2 \\
17 \\
27\end{array}$ & $\begin{array}{l}3260 \\
2370 \\
1480 \\
2710 \\
3600\end{array}$ & $\begin{array}{r}24 \\
14 \\
2 \\
18 \\
26\end{array}$ & $\begin{array}{l}3590 \\
2710 \\
1580 \\
2820 \\
3640\end{array}$ & $\begin{array}{r}24 \\
15 \\
1 \\
18 \\
25\end{array}$ & $\begin{array}{l}3890 \\
2940 \\
1740 \\
3150 \\
3740\end{array}$ & $\begin{array}{r}25 \\
14 \\
1 \\
16 \\
24\end{array}$ & $\begin{array}{l}4020 \\
3170 \\
1920 \\
3380 \\
3850\end{array}$ & $\begin{array}{r}25 \\
13 \\
2 \\
17 \\
24\end{array}$ & $\begin{array}{l}6710 \\
4110 \\
2160 \\
6220 \\
7710\end{array}$ & $\begin{array}{r}19 \\
6 \\
1 \\
18 \\
23\end{array}$ \\
\hline 981 & 2220 & 22 & 2240 & 21 & 2310 & 20 & 2370 & 20 & 2660 & 22 & 2900 & 21 & 3220 & 21 & 3490 & 22 & 3780 & 22 & 6980 & 22 \\
\hline
\end{tabular}


COLORADO RIVER MAIN STEM

09163500 COLORADO RIVER NEAR COLORADO-UTAH STATE LINE--Continued

HIGHEST MEAN DISCHARGE, IN COBIC FEET PER SECOND, AND RANKING FOR THE INDICATED NUMBER OF CONSECUTIVE DAYS FOR EACH WATER YEAR, OCTOBER 1-SEPTEMBER 30

YEAR

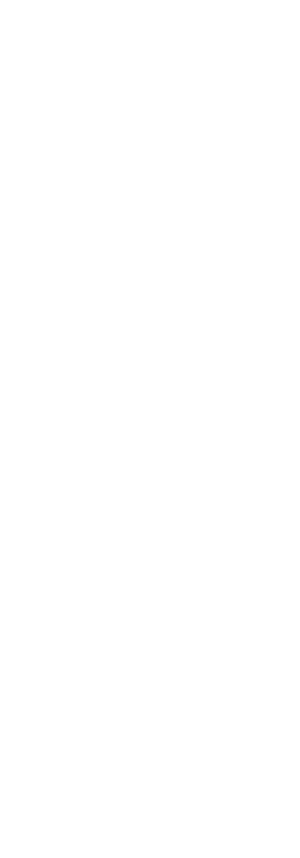

CONSEOUTIVE DAYS
30

15

$\begin{array}{rr}2 & 49500 \\ 7 & 30600 \\ 29 & 9630\end{array}$

2414700

1125800

$\begin{array}{ll}1 & 53200 \\ 3 & 42700\end{array}$

$\begin{array}{rr}3 & 42700 \\ 18 & 20400\end{array}$

1621900

2017800

435900

2810100

13
54600

2512500

2315800

$21 \quad 15500$

930000

1920800

2216500

830100

1423000

$26 \quad 12500$

$30 \quad 4370$

$12 \quad 25400$

631800

1027700

2710500

$\begin{array}{rr}2 & 45400 \\ 7 & 26000 \\ 29 & 8360 \\ 24 & 12800\end{array}$

2412800

$\begin{array}{rr}11 & 24400 \\ 1 & 47800\end{array}$

$\begin{array}{ll}1 & 47800 \\ 3 & 40600\end{array}$

1818700

1619500

2015600

$\begin{array}{rr}4 & 29700 \\ 28 & 9430\end{array}$

1221700

2510100

$\begin{array}{ll}22 & 14100\end{array}$

$\begin{array}{ll}15 & 19100 \\ 23 & 15000\end{array}$

928000

1719800

$21 \quad 15700$

$\begin{array}{rr}824900 \\ 19 & 17600\end{array}$

1421600

2611600

$\begin{array}{ll}30 & 3940\end{array}$

1322600

628100
$10 \quad 25600$

$27 \quad 9750$
237000
824300

$29 \quad 6680$

1120800

$\begin{array}{rr}11 & 45900 \\ 3 & 36100\end{array}$

$\begin{array}{rr}3 & 36100 \\ 18 & 15500\end{array}$

$\begin{array}{ll}18 & 15500 \\ 16 & 17600\end{array}$

$$
\begin{array}{ll}
233800 \\
9 & 16200
\end{array}
$$

$29 \quad 4970$

2510500

2113600

$\begin{array}{rr}5 & 27100 \\ 28 & 8550\end{array}$

$\begin{array}{lr}28 & 8550 \\ 13 & 18100\end{array}$

426800

$\begin{array}{rr}11 & 15400 \\ 1 & 37200\end{array}$

$\begin{array}{ll}1 & 37200 \\ 3 & 26700\end{array}$

$\begin{array}{rr}326700 \\ 19 & 12000\end{array}$

1614200

$26 \quad 9460$

$\begin{array}{ll}23 & 12700\end{array}$

$\begin{array}{ll}17 & 17300 \\ 22 & 13800\end{array}$

$\begin{array}{rl}22 & 13800 \\ 7 & 25000\end{array}$

$21 \quad 9840$

$\begin{array}{rr}4 & 23700 \\ 27 & 6510\end{array}$

$\begin{array}{rr}27 & 6510 \\ 14 & 13300\end{array}$

523000

1518100

2013300

1023600

1915800

$26 \quad 7730$

2310000

$\begin{array}{ll}17 & 13100 \\ 20 & 12600\end{array}$

$\begin{array}{rr}20 & 12600 \\ 7 & 21300\end{array}$

2511200

$\begin{array}{rr}15 & 15300 \\ 22 & 9990\end{array}$

$\begin{array}{rr}22 & 9990 \\ 10 & 20800\end{array}$

$\begin{array}{ll}18 & 13800 \\ 13 & 17800\end{array}$

$30 \quad 3750$

$\begin{array}{ll}32 & 39700\end{array}$

$\begin{array}{rr}12 & 19700 \\ 6 & 26600\end{array}$

$24 \quad 8950$

$30 \quad 3710$

1216500

$\begin{array}{ll}6 & 22000 \\ 8 & 21400\end{array}$

$27 \quad 7080$

$28 \quad 5630$
183

AL.
222300

1310300

$\begin{array}{ll}29 & 3840 \\ 21 & 7200\end{array}$

$\begin{array}{ll}29 & 4300 \\ 21 & 8650\end{array}$

1311800

131200

320500

$\begin{array}{rr}20 & 9130 \\ 15 & 12400\end{array}$

$16 \quad 9680$

$\begin{array}{ll}1 & 25600 \\ 4 & 16300\end{array}$

$\begin{array}{rr}4 & 16300 \\ 20 & 7440\end{array}$

$\begin{array}{rr}20 & 7440 \\ 14 & 10500\end{array}$

$24 \quad 7450$

$\begin{array}{rr}4 & 22500 \\ 27 & 5530\end{array}$

$\begin{array}{rr}27 & 5530 \\ 17 & 10000\end{array}$

$24 \quad 6220$

$\begin{array}{rr}3 & 18600 \\ 27 & 4820\end{array}$

$\begin{array}{rr}27 & 4820 \\ 19 & 8390 \\ 5 & 17400\end{array}$

520200

$26 \quad 6090$

$\begin{array}{ll}22 & 6670\end{array}$

$18 \quad 8950$

1510300
913800

10200

1911800

1911800

$\begin{array}{lr}14 & 13400 \\ 23 & 7840\end{array}$

$9 \begin{array}{rr}9 & 17100\end{array}$

$\begin{array}{ll}16 & 11200 \\ 10 & 14800\end{array}$

$\begin{array}{rr}11 & 11900 \\ 23 & 6860\end{array}$

$\begin{array}{rr}23 & 6860 \\ 8 & 14200\end{array}$

$\begin{array}{rr}8 & 14200 \\ 17 & 9760\end{array}$

1012400

$25 \quad 7320$

$\begin{array}{lr}30 & 3620 \\ 11 & 13300\end{array}$

$\begin{array}{ll}25 & 6390 \\ 30 & 3570\end{array}$

$618200 \quad 615400$

714300

$28 \quad 4840$

$28 \quad 4220$

$\begin{array}{rrrr}2 & 16100 & 2 & 9430\end{array}$

$\begin{array}{llll}29 & 3350 & 29 & 5210 \\ & 2880\end{array}$

215670

$17 \quad 7150$

118400

511800

$\begin{array}{ll}20 & 5750 \\ 13 & 7760\end{array}$

$22 \quad 4010$

$\begin{array}{rr}17 & 4610 \\ 1 & 10400\end{array}$

$\begin{array}{rr}1 & 10400 \\ 6 & 7490\end{array}$

$\begin{array}{rr}6 & 7490 \\ 21 & 4110\end{array}$

$\begin{array}{ll}21 & 4110 \\ 15 & 5160\end{array}$

$25 \quad 5100$

$\begin{array}{rr}3 & 13600 \\ 27 & 4140\end{array}$

$\begin{array}{llll}19 & 6440 & 27 & 3570 \\ 4 & 19 & 4290\end{array}$

$\begin{array}{rrr}413200 & 4 & 7890\end{array}$

$\begin{array}{llll}26 & 4940 & 26 & 4090\end{array}$

$23 \quad 5340$

$\begin{array}{ll}23 & 5340 \\ 18 & 6950\end{array}$

$\begin{array}{llll}14 & 8030 & 14 & 5980\end{array}$

119870

225860

810600

$16 \quad 8240$

109470

245490

$30 \quad 3160$

128290

611800

710800

107420

$\begin{array}{rr}10 & 4760 \\ 9 & 7450\end{array}$

$\begin{array}{rrr}9 & 7450 & 8\end{array}$

$\begin{array}{lll}13 & 6000 & 12 \\ 11 & 6550 & 11\end{array}$

DURATION OF DISCHARGE FOR EACH WATER YEAR

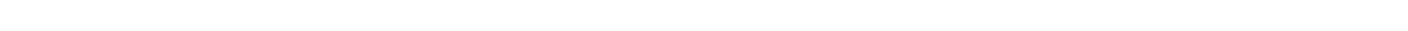

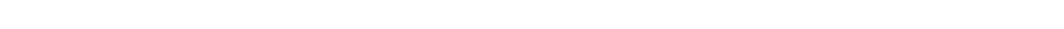

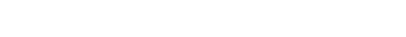

1952
1953
1954
1955
1956
1957
1958
1959
1960
1961
1962
1963
1964
1965
1966
1967
1968
1969
1970
1971
1972
1973
1974
1975
1976
1977
1978
1979
1980

$$
\begin{array}{rrrrrrrrrrrrrrrrrrrrrrrr}
3 & 4 & 10 & 5 & 8 & 22 & 71 & 66 & 49 & 57 & 30 & 11 & 5 & 3 & 2 & 6 & 4 & 4 & 2 & 2 & 1 & 2 & 2 & 4 \\
& & 12 & 4 & 38 & 71 & 47 & 44 & 31 & 15 & 15 & 11 & 7 & 5 & 7 & 7 & 9 & 11 & 7 & 13 & 3 & 7 & 1
\end{array}
$$

3451790.0

1902030.0

1051690.0

$\begin{array}{lllllllllllllllllllllllllllll}5 & 5 & 23 & 15 & 11 & 36 & 40 & 72 & 38 & 15 & 13 & 12 & 8 & 8 & 4 & 4 & 5 & 6 & 3 & 2 & 8 & 1 & 4 & 7 & 5 & 7 & 7 & 2\end{array}$

686220.0

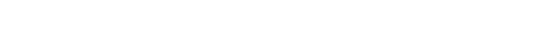

$\begin{array}{lllllllllllllllll}8 & 5 & 8 & 15 & 16 & 27 & 25 & 40 & 53 & 37 & 29 & 16 & 5 & 4 & 1 & 4 & 7\end{array}$

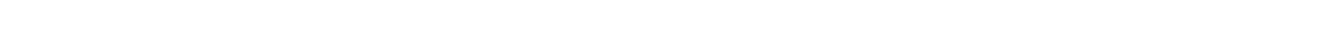

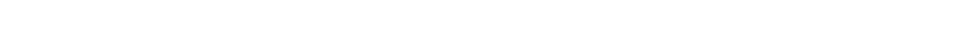

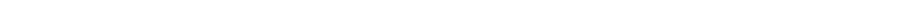

$\begin{array}{llllllllllllllllllllllllllllll}2 & 6 & 2 & 1 & 11 & 19 & 26 & 33 & 59 & 38 & 24 & 23 & 9 & 19 & 5 & 2 & 2 & 2 & 3 & 2 & 5 & 11 & 17 & 18 & 18 & 8 & 3 & 4 & 1\end{array}$

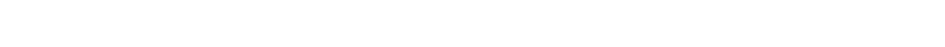

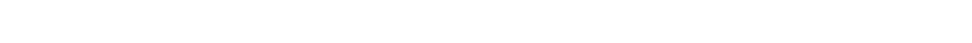

$\begin{array}{llllllllllllllllll}11 & 11 & 27 & 42 & 42 & 21 & 50 & 34 & 33 & 27 & 21 & 13 & 7 & 8 & 5 & 7 & 3 & 3\end{array}$

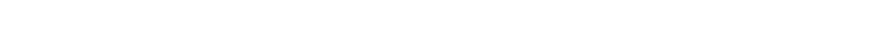

$\begin{array}{rlllllllllllllllllll}34 & 60 & 62 & 58 & 38 & 12 & 18 & 9 & 14 & 13 & 8 & 2 & 4 & 6 & 2 & 6 & 11 & 3 & 4 & 2\end{array}$

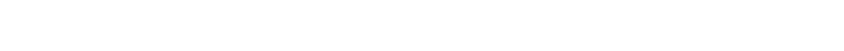

$\begin{array}{llllllllllllllll}8 & 15 & 26 & 82 & 87 & 32 & 11 & 14 & 14 & 13 & 17 & 3 & 10 & 14 & 13 & 1\end{array}$

$\begin{array}{llllllllllllllllllll}3 & 6 & 25 & 14 & 15 & 15 & 39 & 87 & 81 & 26 & 12 & 2 & 2 & 1 & 11 & 7 & 4 & 2 & 9 & 5\end{array}$

$\begin{array}{lllllllllllll}7 & 2 & 5 & 5 & 13 & 1 & 5 & 12 & 16 & 10 & 3 & 7\end{array}$

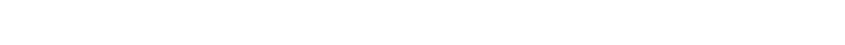

$\begin{array}{lllllllllllllllll}1 & 21 & 7 & 18 & 47 & 55 & 57 & 61 & 37 & 11 & 10 & 6 & 7 & 5 & 5 & 14 & 4\end{array}$

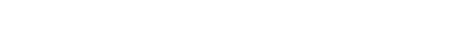

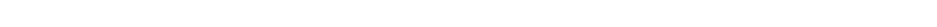

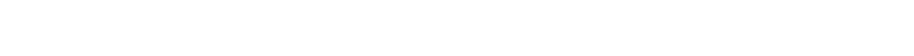

1500180.0

1391420.0

3123750.0

1303550.0

1568940.0

2880780.0

1491610.0

1442570.0

2181900.0

2766860.0

2709630.0

1742070.0

2719510.0

2191440.0

2391070.0

681300.0

933860.0
1948630.0

2853250.0

2640310.0

1981

$\begin{array}{llllllllllllllllll}1 & 7 & 9 & 16 & 30 & 18 & 92 & 43 & 51 & 66 & 9 & 3 & 2 & 1 & 4 & 7 & 3 & 3\end{array}$

1358890.0 
DURATION TABLE OF DISCHARGE FOR WATER YEARS 1952-81

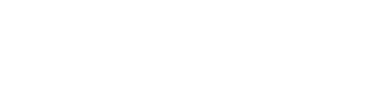

$\begin{array}{lrrrr}0 & 0.00 & 0 & 10958 & 100.00\end{array}$

$\begin{array}{lrrrr}1 & 960.00 & 11 & 10958 & 100.0\end{array}$

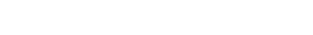

$\begin{array}{lllll}3 & 1200.00 & 97 & 10918 & 99.6\end{array}$

$\begin{array}{lllll}4 & 1400.00 & 111 & 10821 & 98.7\end{array}$

$\begin{array}{lllll}5 & 1600.00 & 190 & 10710 & 97.7\end{array}$

$61800.0038910520 \quad 96.0$

$2000.00817 \quad 10131 \quad 92.5$

$82300.00 \quad 1132 \quad 9314 \quad 85.0$
CUBIC $\mathrm{ACOU}-\mathrm{O}$ $\begin{array}{lclcrl}\text { FEET } & \text { MU- } & \text { PER- } & \text { FEIC } & \text { ACOU- } \\ \text { PER TOTAL LATED } & \text { CENT } & \text { FEET } & \text { MU- } & \text { PER- } \\ & & \text { PER TOTAL LATED } & \text { CENT }\end{array}$ CLASS SEDOND DAYS DAYS DAYS CLASS SECOND DAYS DAYS DAYS

$\begin{array}{rrrrr}9 & 2600.00 & 915 & 8182 & 74.7 \\ 10 & 2900.00 & 996 & 7267 & 66.3 \\ 11 & 3300.00 & 1023 & 6271 & 57.2 \\ 12 & 3700.00 & 1136 & 5248 & 47.9 \\ 13 & 4200.00 & 893 & 4112 & 37.5 \\ 14 & 4800.00 & 589 & 3219 & 29.4 \\ 15 & 5400.00 & 409 & 2630 & 24.0 \\ 16 & 6100.00 & 264 & 2221 & 20.3 \\ 17 & 6900.00 & 164 & 1957 & 17.9\end{array}$

CUBIC $3 \mathrm{COU}-$ $\begin{array}{ll}\text { FEET TOR TOTAL LATED } & \text { PER- } \\ \text { PENI }\end{array}$ CLASS SECOND DAYS DAYS DAYS

$\begin{array}{rrrrr}27 & 24000.0 & 109 & 310 & 2.8 \\ 28 & 27000.0 & 62 & 201 & 1.8 \\ 29 & 30000.0 & 42 & 139 & 1.3 \\ 30 & 34000.0 & 36 & 97 & 0.9 \\ 31 & 39000.0 & 31 & 61 & 0.6 \\ 32 & 44000.0 & 16 & 30 & 0.3 \\ 33 & 49000.0 & 13 & 14 & 0.1 \\ 34 & 56000.0 & 1 & 1 & 0.0\end{array}$

MONIHLY MEAN DISCHARGES, IN CUBIC FEET PER SECOND, FOR EACH WATER YEAR

\begin{tabular}{|c|c|c|c|c|c|c|c|c|c|c|c|c|}
\hline YEAR & $\propto C T$ & NOV & DEC & JAN & FEBB & MAR & APR & MAY & JUNE & JULY & AUG & SEP \\
\hline $\begin{array}{l}1952 \\
1953 \\
1954 \\
1955\end{array}$ & $\begin{array}{l}2726 \\
2683 \\
2548 \\
3213\end{array}$ & $\begin{array}{l}2967 \\
2999 \\
3179 \\
2685\end{array}$ & $\begin{array}{l}2832 \\
2910 \\
2452 \\
2214\end{array}$ & $\begin{array}{l}2830 \\
2799 \\
2477 \\
2057\end{array}$ & $\begin{array}{l}2431 \\
2514 \\
2321 \\
2060\end{array}$ & $\begin{array}{l}2810 \\
2802 \\
2464 \\
2907\end{array}$ & $\begin{array}{r}11290 \\
3557 \\
3013 \\
4265\end{array}$ & $\begin{array}{r}30500 \\
8905 \\
6256 \\
10130\end{array}$ & $\begin{array}{r}36080 \\
22050 \\
3481 \\
10760\end{array}$ & $\begin{array}{l}9887 \\
5341 \\
2341 \\
3233\end{array}$ & $\begin{array}{l}5451 \\
3888 \\
1514 \\
2703\end{array}$ & $\begin{array}{l}3427 \\
2142 \\
2496 \\
1814\end{array}$ \\
\hline $\begin{array}{l}1956 \\
1957 \\
1958 \\
1959 \\
1960\end{array}$ & $\begin{array}{l}1932 \\
1916 \\
4206 \\
2404 \\
3951\end{array}$ & $\begin{array}{l}2726 \\
2549 \\
4411 \\
3074 \\
3129\end{array}$ & $\begin{array}{l}2650 \\
2071 \\
3543 \\
2715 \\
2430\end{array}$ & $\begin{array}{l}2353 \\
2248 \\
2881 \\
2544 \\
2490\end{array}$ & $\begin{array}{l}2293 \\
2587 \\
3486 \\
2616 \\
2358\end{array}$ & $\begin{array}{l}2792 \\
2494 \\
3625 \\
2312 \\
3898\end{array}$ & $\begin{array}{l}5056 \\
4878 \\
7379 \\
2425 \\
8628\end{array}$ & $\begin{array}{r}15640 \\
18710 \\
28820 \\
8337 \\
11170\end{array}$ & $\begin{array}{l}14270 \\
43830 \\
23960 \\
15300 \\
16790\end{array}$ & $\begin{array}{r}2553 \\
29590 \\
3349 \\
3219 \\
3745\end{array}$ & $\begin{array}{l}1672 \\
9183 \\
1692 \\
2364 \\
1635\end{array}$ & $\begin{array}{l}1361 \\
4379 \\
2437 \\
2078 \\
1877\end{array}$ \\
\hline $\begin{array}{l}1961 \\
1962 \\
1963 \\
1964 \\
1965\end{array}$ & $\begin{array}{l}2480 \\
5116 \\
4185 \\
2186 \\
2418\end{array}$ & $\begin{array}{l}2866 \\
3978 \\
3953 \\
2924 \\
2888\end{array}$ & $\begin{array}{l}2559 \\
3109 \\
2886 \\
2048 \\
2749\end{array}$ & $\begin{array}{l}2328 \\
2825 \\
2639 \\
1871 \\
2581\end{array}$ & $\begin{array}{l}2383 \\
4140 \\
3151 \\
1815 \\
2377\end{array}$ & $\begin{array}{l}2506 \\
3649 \\
3012 \\
1984 \\
2406\end{array}$ & $\begin{array}{r}2559 \\
15010 \\
3259 \\
2981 \\
6677\end{array}$ & $\begin{array}{r}9300 \\
23650 \\
7579 \\
12520 \\
16890\end{array}$ & $\begin{array}{r}10160 \\
22990 \\
5226 \\
12600 \\
26140\end{array}$ & $\begin{array}{r}1962 \\
12000 \\
1731 \\
4353 \\
17090\end{array}$ & $\begin{array}{l}1968 \\
3278 \\
2453 \\
3575 \\
6627\end{array}$ & $\begin{array}{l}4694 \\
2867 \\
2773 \\
2556 \\
5652\end{array}$ \\
\hline $\begin{array}{l}1966 \\
1967 \\
1968 \\
1969 \\
1970\end{array}$ & $\begin{array}{l}5014 \\
2845 \\
2840 \\
3532 \\
5454\end{array}$ & $\begin{array}{l}3786 \\
2568 \\
3662 \\
4373 \\
4832\end{array}$ & $\begin{array}{l}3567 \\
2629 \\
4174 \\
4188 \\
4189\end{array}$ & $\begin{array}{l}2770 \\
2254 \\
3314 \\
4369 \\
3820\end{array}$ & $\begin{array}{l}2763 \\
2368 \\
3442 \\
3326 \\
3940\end{array}$ & $\begin{array}{l}3624 \\
2815 \\
2835 \\
4087 \\
4462\end{array}$ & $\begin{array}{l}4982 \\
3146 \\
3258 \\
8796 \\
4804\end{array}$ & $\begin{array}{r}8995 \\
6899 \\
8895 \\
13490 \\
19720\end{array}$ & $\begin{array}{r}6215 \\
11460 \\
16730 \\
11440 \\
21430\end{array}$ & $\begin{array}{l}2828 \\
4941 \\
4572 \\
6860 \\
8399\end{array}$ & $\begin{array}{l}1929 \\
2560 \\
5248 \\
3167 \\
3887\end{array}$ & $\begin{array}{l}2475 \\
2925 \\
2643 \\
4007 \\
5889\end{array}$ \\
\hline $\begin{array}{l}1971 \\
1972 \\
1973 \\
1974 \\
1975\end{array}$ & $\begin{array}{l}5602 \\
4354 \\
4624 \\
3987 \\
3320\end{array}$ & $\begin{array}{l}5446 \\
4620 \\
4872 \\
4090 \\
4209\end{array}$ & $\begin{array}{l}5002 \\
4343 \\
4629 \\
4784 \\
3656\end{array}$ & $\begin{array}{l}5271 \\
3884 \\
4496 \\
5073 \\
3849\end{array}$ & $\begin{array}{l}5773 \\
3904 \\
3593 \\
5333 \\
3823\end{array}$ & $\begin{array}{l}6465 \\
4209 \\
3603 \\
5920 \\
3909\end{array}$ & $\begin{array}{l}9013 \\
3325 \\
3731 \\
5452 \\
5155\end{array}$ & $\begin{array}{r}11570 \\
7386 \\
17710 \\
15230 \\
13150\end{array}$ & $\begin{array}{l}18010 \\
12310 \\
21540 \\
12120 \\
18710\end{array}$ & $\begin{array}{r}8456 \\
3135 \\
11570 \\
4781 \\
11750\end{array}$ & $\begin{array}{l}3879 \\
2132 \\
5183 \\
2544 \\
3713\end{array}$ & $\begin{array}{l}4681 \\
3618 \\
3614 \\
2683 \\
3269\end{array}$ \\
\hline $\begin{array}{l}1976 \\
1977 \\
1978 \\
1979 \\
1980\end{array}$ & $\begin{array}{l}3945 \\
3562 \\
2198 \\
3209 \\
3615\end{array}$ & $\begin{array}{l}4814 \\
3678 \\
2363 \\
3975 \\
3724\end{array}$ & $\begin{array}{l}4620 \\
3619 \\
2178 \\
3833 \\
4072\end{array}$ & $\begin{array}{l}4000 \\
3375 \\
2275 \\
3829 \\
3996\end{array}$ & $\begin{array}{l}3768 \\
2730 \\
2383 \\
4529 \\
4139\end{array}$ & $\begin{array}{l}3658 \\
2023 \\
2831 \\
5529 \\
4169\end{array}$ & $\begin{array}{l}3555 \\
1631 \\
5260 \\
7914 \\
6551\end{array}$ & $\begin{array}{r}8843 \\
2283 \\
11540 \\
18650 \\
20300\end{array}$ & $\begin{array}{r}8881 \\
2688 \\
19690 \\
22760 \\
22290\end{array}$ & $\begin{array}{r}3583 \\
1662 \\
7878 \\
11580 \\
7143\end{array}$ & $\begin{array}{l}2491 \\
1350 \\
2458 \\
4308 \\
3073\end{array}$ & $\begin{array}{l}2973 \\
2114 \\
3009 \\
3594 \\
3535\end{array}$ \\
\hline 1981 & 3775 & 4572 & 4297 & 3894 & 3123 & 2681 & 2727 & 4600 & 6516 & 2954 & 2278 & 3322 \\
\hline
\end{tabular}

ANNUAL PEAK DISCHARGE, IN OBBIC FEET PER SECOND, AND CORRESPONDING GAGE HEIGHT, IN FEET, FOR EACH WATER YEAR

\begin{tabular}{|c|c|c|c|c|c|c|c|c|c|c|c|}
\hline $\begin{array}{l}\text { WATER } \\
\text { YEAR }\end{array}$ & DAYE & $\begin{array}{c}\text { GAGE } \\
\text { HEIGHT }\end{array}$ & $\begin{array}{c}\text { PEAK } \\
\text { DISCHARGE }\end{array}$ & $\begin{array}{l}\text { WATER } \\
\text { YEAR }\end{array}$ & DATE & $\begin{array}{c}\text { GAGE } \\
\text { HEIGHT }\end{array}$ & $\begin{array}{c}\text { PEAK } \\
\text { DISCHARGE }\end{array}$ & $\begin{array}{l}\text { WATERR } \\
\text { YEAR }\end{array}$ & DATE & $\begin{array}{c}\text { GAGE } \\
\text { HEIGETT }\end{array}$ & $\begin{array}{c}\text { PEAK } \\
\text { DISCHARGE }\end{array}$ \\
\hline $\begin{array}{l}1951 \\
1952 \\
1953 \\
1954 \\
1955 \\
1956 \\
1957 \\
1958 \\
1959 \\
1960 \\
1961\end{array}$ & $\begin{array}{ll}\text { JUNE } 23, & 1951 \\
\text { JUNE } 09, & 1952 \\
\text { JUNE } 15, & 1953 \\
\text { MAY } 23, & 1954 \\
\text { JUNE } 10, & 1955 \\
\text { JUNE } 04, & 1956 \\
\text { JUNE } 09, & 1957 \\
\text { MAY } 31, & 1958 \\
\text { JUNE } 11, & 1959 \\
\text { JUNE } 05,1960 \\
\text { MAY } 31,1961\end{array}$ & $\begin{array}{r}11.24 \\
15.25 \\
12.86 \\
7.27 \\
8.52 \\
11.13 \\
16.40 \\
14.18 \\
9.88 \\
10.28 \\
9.18\end{array}$ & $\begin{array}{l}30200 \\
52000 \\
37300 \\
11600 \\
17100 \\
28900 \\
56800 \\
45000 \\
23200 \\
24700 \\
19300\end{array}$ & $\begin{array}{l}1962 \\
1963 \\
1964 \\
1965 \\
1966 \\
1967 \\
1968 \\
1969 \\
1970 \\
1971\end{array}$ & $\begin{array}{lll}\text { MAY } & 14,1962 \\
\text { MAY } & 20,1963 \\
\text { MAY } & 27,1964 \\
\text { JUNE } & 20,1965 \\
\text { MAY } & 11,1966 \\
\text { MAY } & 27,1967 \\
\text { JUNE } & 07,1968 \\
\text { JUNE } 26,1969 \\
\text { MAY } & 24,1970 \\
\text { JUNE } & 19,1971\end{array}$ & $\begin{array}{r}13.51 \\
7.11 \\
10.80 \\
12.61 \\
8.01 \\
9.22 \\
10.78 \\
9.40 \\
12.03 \\
9.79\end{array}$ & $\begin{array}{l}40500 \\
11300 \\
27300 \\
36400 \\
14400 \\
19400 \\
26600 \\
20400 \\
33000 \\
22200\end{array}$ & $\begin{array}{l}1972 \\
1973 \\
1974 \\
1975 \\
1976 \\
1977 \\
1978 \\
1979 \\
1980 \\
1981\end{array}$ & $\begin{array}{lll}\text { JUNE } 09, & 1972 \\
\text { JUNE } 16,1973 \\
\text { MAY } 11,1974 \\
\text { JUNE } 09,1975 \\
\text { JUNE } 07,1976 \\
\text { JUNE } 10,1977 \\
\text { JUNE } 17,1978 \\
\text { MAY } 30,1979 \\
\text { MAY } 24,1980 \\
\text { JUNE } 09,1981\end{array}$ & $\begin{array}{r}8.96 \\
12.50 \\
10.11 \\
10.60 \\
8.18 \\
5.15 \\
11.07 \\
12.55 \\
10.82 \\
5.84\end{array}$ & $\begin{array}{r}18400 \\
35000 \\
22800 \\
26300 \\
14400 \\
5080 \\
27800 \\
36000 \\
32100 \\
12100\end{array}$ \\
\hline
\end{tabular}


COLORADO RIVER MAIN STEM

09163500 COLORADO RIVER NEAR COLORADO-UTAH STATE LINE--Continued

\begin{tabular}{|c|c|c|c|c|c|c|}
\hline \multicolumn{7}{|c|}{$\begin{array}{l}\text { MAGNITUDE AND PRCBABILITY OF ANNUAL LOWEST MEAN DISCHARGE } \\
\text { BASED ON CLIMATIC YEARS 1953-81 }\end{array}$} \\
\hline \multirow{2}{*}{$\begin{array}{l}\text { PERIOD } \\
\text { (CON- } \\
\text { SECU- } \\
\text { TIVE } \\
\text { DAYS) }\end{array}$} & \multicolumn{6}{|c|}{$\begin{array}{l}\text { DISCHARGE, IN OUBIC FEET PER SECOND, FOR } \\
\text { INDICATED RECURRENCE INTERVAL, IN YEARS, AND } \\
\text { ANNUAL NONEXCEEDANCE PRCBABILITY, IN PERCENT }\end{array}$} \\
\hline & $\begin{array}{c}2 \\
508\end{array}$ & $\begin{array}{c}5 \\
208\end{array}$ & $\begin{array}{l}10 \\
108\end{array}$ & $\begin{array}{l}20 \\
58\end{array}$ & $\begin{array}{l}50 \\
28\end{array}$ & $\begin{array}{r}100 \\
18\end{array}$ \\
\hline $\begin{array}{r}1 \\
7 \\
14 \\
30 \\
60 \\
90\end{array}$ & $\begin{array}{l}1760 \\
1900 \\
2010 \\
2210 \\
2470 \\
2700\end{array}$ & $\begin{array}{l}1310 \\
1430 \\
1530 \\
1710 \\
1930 \\
2140\end{array}$ & $\begin{array}{l}1120 \\
1230 \\
1330 \\
1500 \\
1710 \\
1890\end{array}$ & $\begin{array}{r}982 \\
1080 \\
1190 \\
1350 \\
1540 \\
1710\end{array}$ & $\begin{array}{r}844 \\
942 \\
1050 \\
1200 \\
1380 \\
1520\end{array}$ & $\begin{array}{l}-- \\
-- \\
-- \\
--\end{array}$ \\
\hline
\end{tabular}

\begin{tabular}{|c|c|c|c|c|c|c|}
\hline \multirow{2}{*}{$\begin{array}{l}\text { PERIOD } \\
\text { (CON- } \\
\text { SECU- } \\
\text { TIVE } \\
\text { SAYS) }\end{array}$} & \multicolumn{6}{|c|}{$\begin{array}{l}\text { DISCHARGE, IN CUBIC FEET PER SECOND, FOR } \\
\text { INDICATED RECURRENCE INIERVAL, IN YEARS, AND } \\
\text { ANNUAL EXCEETANCE PRCBABILITY, IN PERCENT }\end{array}$} \\
\hline & $\begin{array}{c}2 \\
508\end{array}$ & $\begin{array}{c}5 \\
208\end{array}$ & $\begin{array}{l}10 \\
108\end{array}$ & $\begin{array}{l}25 \\
48\end{array}$ & $\begin{array}{l}50 \\
28\end{array}$ & $\begin{array}{r}100 \\
18\end{array}$ \\
\hline $\begin{array}{r}1 \\
3 \\
7 \\
15\end{array}$ & $\begin{array}{l}24400 \\
23600 \\
22300 \\
20000\end{array}$ & $\begin{array}{l}35800 \\
34900 \\
33200 \\
29800\end{array}$ & $\begin{array}{l}42200 \\
41400 \\
39500 \\
35600\end{array}$ & $\begin{array}{l}49100 \\
48600 \\
46600 \\
42000\end{array}$ & $\begin{array}{l}53400 \\
53100 \\
51100 \\
46200\end{array}$ & - \\
\hline
\end{tabular}

TRIBUTARIES BETWEEN COLORADO-UTAH STATE LINE AND DOLORES RIVER

09163550 HARLEY DOME WASH NEAR HARLEY DOME, UT

LOCATION.--Lat $39^{\circ} 09^{\prime} 25^{\prime \prime}$, long $109^{\circ} 08^{\prime} 40^{\prime \prime}$, in NE's sec.16, T.19 S., R.25 E., Grand County, Hydrologic Unit $14030001,1.3$ mi southwest of Harley Dome and $17 \mathrm{mi}$ northeast of Cisco.

DRAINAGE ARFA. $--3.1 \mathrm{mi}^{2}$.

PERIOD OF RECORD AVAILABLE.--Water years 1959-68, annual peak discharge only.

GAGE.--Crest-stage gage. Altitude of gage is 4,700 ft from topographic map.

ANNUAL PEAK DISCHARGE, IN CUBIC FEET PER SECOND, AND CORRFSPONDING GAGE HEIGHT, IN FEET, FOR EACH WATER YEAR

\begin{tabular}{|c|c|c|c|c|c|c|c|c|c|c|c|c|}
\hline $\begin{array}{l}\text { WATER } \\
\text { YEAR }\end{array}$ & DATE & $\begin{array}{l}\text { GAGE } \\
\text { HEIGHT }\end{array}$ & $\begin{array}{c}\text { PEAK } \\
\text { DISCHARGE }\end{array}$ & $\begin{array}{l}\text { WATER } \\
\text { YEAR }\end{array}$ & DATE & $\begin{array}{c}\text { GAGE } \\
\text { HEIGHT }\end{array}$ & $\begin{array}{c}\text { PEAR } \\
\text { DISCHARGE }\end{array}$ & $\begin{array}{l}\text { WATER } \\
\text { YEAR }\end{array}$ & & DATE & $\begin{array}{c}\text { GAGE } \\
\text { HEIGHT }\end{array}$ & $\begin{array}{c}\text { PEAK } \\
\text { DISCHARGE }\end{array}$ \\
\hline 1959 & AUG. 19,1959 & 14.02 & 634 & 1962 & ○CT. 08,1961 & 10.55 & 14 & 1965 & JULY & 31,1965 & 10.58 & 14 \\
\hline $\begin{array}{l}1960 \\
1961\end{array}$ & $\begin{array}{lll}\text { OCT. } & 28,1959 \\
\text { AUG. } & 31,1961\end{array}$ & $\begin{array}{l}10.80 \\
11.35\end{array}$ & $\begin{array}{r}6 \\
59\end{array}$ & $\begin{array}{l}1963 \\
1964\end{array}$ & $\begin{array}{l}\text { AUG. } 31,1963 \\
\text { JULY } 31,1964\end{array}$ & $\begin{array}{l}11.60 \\
10.35\end{array}$ & $\begin{array}{l}50 \\
14\end{array}$ & $\begin{array}{l}1966 \\
1967 \\
1968\end{array}$ & $\overline{\mathrm{DEC}}$ & $\overline{06}, \overline{1966}$ & $10 \overline{60}$ & $\begin{array}{r}1 \\
25 \\
\\
\quad 0\end{array}$ \\
\hline
\end{tabular}

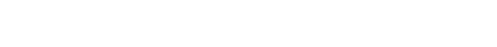

09163700 CISCO WASH NEAR CISCO, UT

LOCATION.--Lat $38^{\circ} 57^{\prime} 50^{\prime \prime}$, long $109^{\circ} 20^{\prime} 10^{\prime \prime}$, in SE⿺ sec.23, T.21 S., R. 23 E., Grand County, Hydrologic Unit 14030001,1 mi west of Cisco and $7.5 \mathrm{mi}$ above mouth.

DRAINAGE AREA. $-29 \mathrm{mi}^{2}$.

PERIOD OF RECORD AVAILABLE.--Water years 1959-73, annual peak discharge only.

GAGE.--Crest-stage gage. Altitude of gage is 4,350 ft from topographic map.

ANNUAL PEAK DISCHARGE, IN OABIC FEET PER SECOND, AND CORRESPONDING GAGE HEIGHT, IN FEET, FOR EACH WATER YEAR

\begin{tabular}{|c|c|c|c|c|c|c|c|c|c|c|c|}
\hline $\begin{array}{l}\text { WATER } \\
\text { YEAR }\end{array}$ & DATE & $\begin{array}{c}\text { GAGE } \\
\text { HEIGHT }\end{array}$ & $\begin{array}{c}\text { PEAK } \\
\text { DISCHARGE }\end{array}$ & $\begin{array}{l}\text { WATER } \\
\text { YEAR }\end{array}$ & DATE & $\begin{array}{c}\text { GAGE } \\
\text { HEIGHT }\end{array}$ & $\begin{array}{c}\text { PEAK } \\
\text { DISCHARGE }\end{array}$ & $\begin{array}{l}\text { WATEER } \\
\text { YEAR }\end{array}$ & DATE & $\begin{array}{c}\text { GAGE } \\
\text { HEIGHT }\end{array}$ & $\begin{array}{c}\text { FEAK } \\
\text { DISCHARGE }\end{array}$ \\
\hline $\begin{array}{l}1959 \\
1960 \\
1961 \\
1962 \\
1963\end{array}$ & $\begin{array}{l}\text { SEPT.17, } 1959 \\
\text { OCT. 28, } 1959 \\
\text { SEPT. 09, } 1961 \\
\text { SEPT. 21, } 1962 \\
\text { AUG. 03, } 1963\end{array}$ & $\begin{array}{l}13.72 \\
12.60 \\
16.90 \\
15.83 \\
17.80\end{array}$ & $\begin{array}{r}1470 \\
900 \\
3220 \\
2700 \\
3650\end{array}$ & $\begin{array}{l}1964 \\
1965 \\
1966 \\
1967 \\
1968\end{array}$ & $\begin{array}{l}\text { JULY } 31,1964 \\
\text { JULY } 22,1965 \\
\text { AUG. } 31,1966 \\
\text { AUG. } 10,1967 \\
\text { AUG. } 02,1968\end{array}$ & $\begin{array}{l}14.78 \\
17.75 \\
11.55 \\
15.95 \\
14.45\end{array}$ & $\begin{array}{r}2300 \\
3600 \\
700 \\
3100 \\
2400\end{array}$ & $\begin{array}{l}1969 \\
1970 \\
1971 \\
1972 \\
1973\end{array}$ & $\begin{array}{l}\text { AUG. } 29,1969 \\
\text { SEPT. 06, } 1970 \\
\text { AUG. } 25,1971 \\
\text { JULY 19, } 1972 \\
\text { OCT. } 06,1972\end{array}$ & $\begin{array}{l}9.91 \\
12.97 \\
12.30 \\
10.20 \\
15.05\end{array}$ & $\begin{array}{r}310 \\
1650 \\
1600 \\
380 \\
2730\end{array}$ \\
\hline
\end{tabular}


LOCATION.-Lat $38^{\circ} 21^{\prime}$, long $109^{\circ} 07$ ', in sec. 24, T.28 S., R. 25 E., San Juan County, Hydrologic Unit 14030004, on left bank just downstream from pole Springs Canyon, 2 mi upstream fram mouth, and 8.5 mi northeast of La Sal.

DRATNAGE AREA. $-13.9 \mathrm{mi}^{2}$.

MEAN BASIN ELEVATION. $-8,340 \mathrm{ft}$.

PERIOD OF RECORD AVAIIABLE.--August 1944 to September 1951.

GAGE.-Water-stage recorder. Altitude of gage is 7,840 ft by barameter.

REMARKS. - Two diversions for irrigation of hay meadows above station. one diversion above station exports water to West Paradox Creek basin.

AVERAGE DISCHARGE. -7 years, $2.22 \mathrm{ft}^{3} / \mathrm{s}, 1,610$ acre- $\mathrm{ft} / \mathrm{yr}$.

EXIREMES FOR PERIOD OF RECORD.- Maximum discharge, $96 \mathrm{ft}^{3} / \mathrm{s}$ May 1, 1945, gage height, $3.07 \mathrm{ft}$, from rating curve extended above 57 $\mathrm{ft}^{3} / \mathrm{s} ;$ minimum daily, $0.1 \mathrm{ft}^{3} / \mathrm{s}$ July $1-8$, July 10 to September $17,1946$.

LOWEST MEAN DISCHARGE, IN CUBIC FEET PER SECOND, AND RANKING FOR THE INDICATED NUMBER OF CONSECITIVE DAYS FOR EACH OLIMATIC YEAR, APRIL 1-MARCH 31

YEAR

$\begin{array}{ccccccc} & 1 & & 3 & & 7 & \\ 1946 & 0.20 & 5 & 0.27 & 5 & 0.29 & 5 \\ 1947 & 0.10 & 1 & 0.10 & 1 & 0.10 & 1 \\ 1948 & 0.30 & 6 & 0.30 & 6 & 0.30 & 6 \\ 1949 & 0.20 & 2 & 0.20 & 2 & 0.24 & 3 \\ 1950 & 0.20 & 3 & 0.20 & 3 & 0.20 & 2 \\ 1951 & 0.20 & 4 & 0.23 & 4 & 0.29 & 4\end{array}$

$14 \quad 30$ CONSECITTVE DAYS
0.294

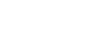

$\begin{array}{ll}0.30 & 5 \\ 0.26 & 3\end{array}$

$\begin{array}{ll}0.26 & 3 \\ 0.24 & 2\end{array}$

$0.30 \quad 3$

0.101

0.304

$\begin{array}{ll}0.33 & 5 \\ 0.27 & 2\end{array}$

0.316

0.356

$0.34 \quad 4$

$\begin{array}{ll}0.10 & 1 \\ 0.33 & 2\end{array}$

$\begin{array}{ll}0.33 & 2 \\ 0.36 & 5\end{array}$

$\begin{array}{ll}0.36 & 5 \\ 0.33 & 3\end{array}$

90

120

183

ALL

0.376

$\begin{array}{ll}0.11 & 1 \\ 0.34 & 2\end{array}$

0.373

$\begin{array}{ll}0.37 & 3 \\ 0.37 & 4\end{array}$

0.415

0.171

0.362

$\begin{array}{ll}0.40 & 4 \\ 0.44 & 6\end{array}$

0.425

$\begin{array}{llll}0.27 & 1 & 0.76 & 1\end{array}$

$0.393 \quad 1.40 \quad 2$

$\begin{array}{llll}0.39 & 3 & 2.70 & 4 \\ 0.48 & 6 & 4.50 & 6\end{array}$

$\begin{array}{llll}0.36 & 6 & 0.37 & 5\end{array}$

0.383

0.414

1.703

HIGHEST MEAN DISCHARGE, IN OBIC FEET PER SECOND, AND RANKING FOR THE INDICATED NUMBER OF OONSECUTIVE DAYS FOR EACH WATER YEAR, OCTCBER 1-SEPTEMBER 30

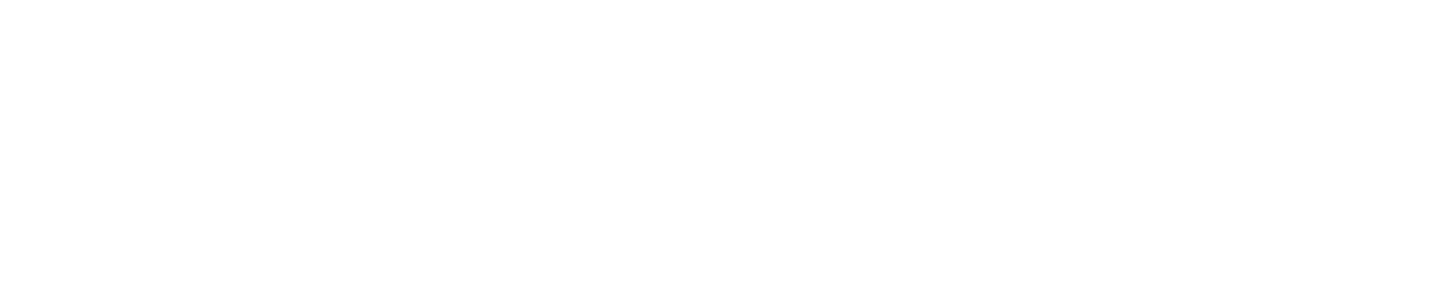

DURATION OF DISCHARGE FOR EACH WATER YEAR

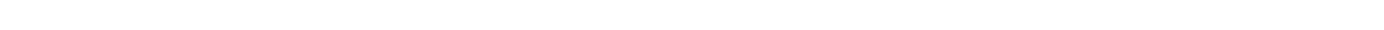
YEAR NUMBER OF DAYS IN CLASS CUBIC FEET -DAYS

\begin{tabular}{|c|c|c|c|c|c|c|c|c|c|c|c|c|c|c|c|c|c|c|c|c|c|c|c|c|c|c|c|c|}
\hline 1945 & & 4 & 7 & 1336537 & 3 & 34 & 5 & 1 & 2 & 4 & 6 & 3 & 5 & 9 & 3 & 2 & 1 & 1 & 7 & 4 & 1 & 6 & 6 & 9 & . & 7 & 2 & 1438.0 \\
\hline $\begin{array}{l}1946 \\
1947 \\
1948 \\
1949 \\
1950\end{array}$ & 78 & $\begin{array}{r}13 \\
2\end{array}$ & $\begin{array}{l}51 \\
48 \\
47 \\
50 \\
27\end{array}$ & $\begin{array}{rrr}52 & 86 & 15 \\
94 & 18 & 92 \\
162 & 18 & 34 \\
122 & 51 & 25 \\
92 & 86 & 56\end{array}$ & $\begin{array}{r}5 \\
36 \\
10 \\
8 \\
14\end{array}$ & $\begin{array}{r}5 \\
3 \\
12 \\
4 \\
5\end{array}$ & $\begin{array}{r}3 \\
1 \\
1 \\
4 \\
13\end{array}$ & $\begin{array}{r}8 \\
9 \\
7 \\
7 \\
11\end{array}$ & $\begin{array}{l}6 \\
6 \\
8 \\
4 \\
6\end{array}$ & $\begin{array}{r}18 \\
14 \\
7 \\
3 \\
6\end{array}$ & $\begin{array}{l}4 \\
4 \\
5 \\
3 \\
8\end{array}$ & $\begin{array}{r}12 \\
6 \\
9 \\
2 \\
4\end{array}$ & $\begin{array}{l}7 \\
7 \\
1 \\
1 \\
4\end{array}$ & $\begin{array}{l}3 \\
4 \\
4\end{array}$ & $\begin{array}{l}2 \\
2\end{array}$ & $\begin{array}{l}5 \\
2 \\
4 \\
2\end{array}$ & $\begin{array}{l}9 \\
3 \\
9 \\
3\end{array}$ & $\begin{array}{l}1 \\
1 \\
2 \\
4\end{array}$ & $\begin{array}{l}2 \\
4 \\
2 \\
8\end{array}$ & $\begin{array}{r}3 \\
10 \\
8 \\
7\end{array}$ & $\begin{array}{l}3 \\
2 \\
4 \\
2\end{array}$ & $\begin{array}{r}7 \\
12 \\
3\end{array}$ & $\begin{array}{r}6 \\
11 \\
2\end{array}$ & $\begin{array}{l}2 \\
6\end{array}$ & $\begin{array}{l}2 \\
5\end{array}$ & 3 & & $\begin{array}{r}254.8 \\
522.7 \\
982.5 \\
1615.1 \\
671.8\end{array}$ \\
\hline 951 & & & 19 & 1439754 & 12 & 11 & 6 & 17 & 5 & 1 & & & & & & & & & & & & & & & & & & \\
\hline
\end{tabular}
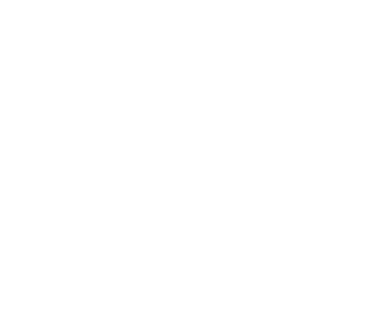

DURATION TABLE OF DISCHARGE FOR WATER YEARS 1945-51

\begin{tabular}{rrrrr}
\multicolumn{4}{c}{ CUBIC } & \multicolumn{3}{c}{ ACCU- } \\
FEET & MU- & PER- \\
PER & TOTAL LATED & CENNT \\
CLASS SECOND & DAYS & DAYS & DAYS \\
9 & & & & \\
10 & 0.48 & 421 & 1400 & 54.8 \\
11 & 0.59 & 313 & 979 & 38.3 \\
11 & 0.72 & 88 & 666 & 26.1 \\
12 & 0.87 & 74 & 578 & 22.6 \\
13 & 1.10 & 33 & 504 & 19.7 \\
14 & 1.30 & 60 & 471 & 18.4 \\
15 & 1.60 & 37 & 411 & 16.1 \\
16 & 1.90 & 53 & 374 & 14.6 \\
17 & 2.30 & 30 & 321 & 12.6
\end{tabular}

CIAS

बBIC ACOUFEET MU- PERCASS SECOND DAYS DAYS DAYS

$\begin{array}{rrrrr}18 & 2.8 & 36 & 291 & 11.4 \\ 19 & 3.5 & 25 & 255 & 10.0 \\ 20 & 4.2 & 20 & 230 & 9.0 \\ 21 & 5.1 & 7 & 210 & 8.2 \\ 22 & 6.2 & 15 & 203 & 7.9 \\ 23 & 7.6 & 25 & 188 & 7.4 \\ 24 & 9.2 & 9 & 163 & 6.4 \\ 25 & 11.0 & 23 & 154 & 6.0 \\ 26 & 14.0 & 32 & 131 & 5.1\end{array}$

PER TOTAL LATED CENI
CLASS SECOND DAYS DAYS DAYS

$\begin{array}{rrrrr}27 & 17.0 & 12 & 99 & 3.9 \\ 28 & 20.0 & 28 & 87 & 3.4 \\ 29 & 25.0 & 25 & 59 & 2.3 \\ 30 & 30.0 & 17 & 34 & 1.3 \\ 31 & 37.0 & 9 & 17 & 0.7 \\ 32 & 45.0 & 6 & 8 & 0.3 \\ 33 & 54.0 & 0 & 2 & 0.1 \\ 34 & 66.0 & 2 & 2 & 0.1\end{array}$


DOLORES RIVER BASIN

09169000 TWOMIIE CREEK NEAR LA SAL, UTAH--Continued

MONIHLY MEAN DISCHARGES, IN OBBIC FEET PER SECOND, FOR EAOH WATER YEAR

$\begin{array}{lllllllllllll}\text { YEAR } & \text { NCT } & \text { NOV } & \text { DEC } & \text { JAN } & \text { FEB } & \text { MAR } & \text { APR } & \text { MAY } & \text { JUNE } & \text { JULY } & \text { AUG } & \text { SEP } \\ 1945 & 0.40 & 0.41 & 0.36 & 0.47 & 0.52 & 0.90 & 14.8 & 2 . .6 & 2.09 & 0.59 & 0.52 & 0.40 \\ 1946 & 0.49 & 0.44 & 0.30 & 0.40 & 0.50 & 1.29 & 2.88 & 1.35 & 0.37 & 0.10 & 0.10 & 0.18 \\ 1947 & 0.42 & 0.43 & 0.73 & 0.69 & 0.73 & 1.17 & 3.56 & 7.58 & 0.74 & 0.37 & 0.37 & 0.30 \\ 1948 & 0.39 & 0.40 & 0.40 & 0.30 & 0.70 & 1.15 & 15.7 & 11.0 & 1.09 & 0.43 & 0.37 & 0.39 \\ 1949 & 0.41 & 0.47 & 0.40 & 0.37 & 0.35 & 0.89 & 21.5 & 22.6 & 4.70 & 0.60 & 0.28 & 0.40 \\ 1950 & 0.58 & 0.64 & 0.54 & 0.48 & 0.45 & 1.49 & 14.3 & 1.98 & 0.63 & 0.44 & 0.35 & 0.38 \\ 1951 & 0.40 & 0.42 & 0.51 & 0.55 & 0.50 & 0.70 & 0.78 & 1.19 & 0.50 & 0.39 & 0.42 & 0.40\end{array}$

ANNUAL PEAK DISCHARGE, IN OUBIC FEET PER SECOND, AND CORRESPONDING GAGE HEIGHT, IN FEET, FOR EAOH WATER YEAR

\begin{tabular}{|c|c|c|c|c|c|c|c|c|c|c|c|}
\hline $\begin{array}{l}\text { WATER } \\
\text { YEAR }\end{array}$ & DATE & $\begin{array}{c}\text { GAGE } \\
\text { HEIGHT }\end{array}$ & $\begin{array}{c}\text { PEAK } \\
\text { DISCHARGE }\end{array}$ & $\begin{array}{l}\text { WATER } \\
\text { YEAR }\end{array}$ & DATE & $\begin{array}{c}\text { GAGE } \\
\text { HEIGHT }\end{array}$ & $\begin{array}{c}\text { PEAK } \\
\text { DISCHARGE }\end{array}$ & $\begin{array}{l}\text { WATER } \\
\text { YEAR }\end{array}$ & DATE & $\begin{array}{c}\text { GAGE } \\
\text { HEIGHT }\end{array}$ & $\begin{array}{c}\text { PEAK } \\
\text { DISCHARGE }\end{array}$ \\
\hline $\begin{array}{l}1945 \\
1946 \\
1947\end{array}$ & $\begin{array}{lll}\text { MAY } & 01,1945 \\
\text { APR. } & 16,1946 \\
\text { MAY } & 03,1947\end{array}$ & $\begin{array}{l}3.07 \\
2.14 \\
2.39\end{array}$ & $\begin{array}{l}96 \\
7.0 \\
24\end{array}$ & $\begin{array}{l}1948 \\
1949\end{array}$ & $\begin{array}{l}\text { APR. } 18,1948 \\
\text { APR. } 24,1949\end{array}$ & $\begin{array}{l}2.75 \\
2.95\end{array}$ & $\begin{array}{l}61 \\
82\end{array}$ & $\begin{array}{l}1950 \\
1951\end{array}$ & $\begin{array}{lll}\text { APR. } & 07,1950 \\
\text { MAY } & 28,1951\end{array}$ & $\begin{array}{l}2.59 \\
1.99\end{array}$ & $\begin{array}{l}43 \\
3.0\end{array}$ \\
\hline
\end{tabular}

09170500 WEST PARADOX CREER NEAR PARADOX, $\infty$

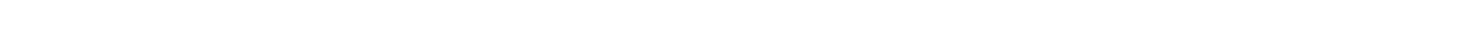
bank at La Sal National Forest boundary, 2 mi northwest of Paradox.

DRANAGE AREA. $-25 \mathrm{mi}^{2}$, approximately.

PERIOD OF RECORD AVAIIABLE.--August 1944 to September 1952.

GAGE. Water stage recorder. Altitude of gage is 5,590 ft fram topographic map.

REMARKS. -Water diverted from Geyser and Deep Creeks in Rock Creek basin is stored in Buckeye Reservoir (capacity 3,000 acre-ft) and released down West Paradox Creek for irrigation below station. one diversion above station for irrigation of about 50 acres below. One diversion imports water from Twamile creek to West Paradox Creek below Buckeye Reservoir.

AVERAGE DISQHARGE. -8 years, $8.61 \mathrm{ft}^{3} / \mathrm{s}, 6,340$ acre- $\mathrm{ft} / \mathrm{yr}$.

EXIREMES FOR PERIOD OF RECORD.--Maximum discharge, $678 \mathrm{ft}^{3} / \mathrm{s}$, sept. 27,1948 , gage height $5.96 \mathrm{ft}$, fram rating curve extended above 90 $\mathrm{ft}^{3} / \mathrm{s}$, minimum daily, $0.1 \mathrm{ft}^{3} / \mathrm{s}$ Mar 1-13, 1946, Jan. 28, 29, Dec.2-10, 1948 , Feb. 25, Mar. 18, $19,1951$.

LOWEST MEAN DISCHARGE, IN OBBIC FEET PER SECOND, AND RANKING FOR THE INDICATED NUMBER OF CONSEOTTIVE DAYS FOR EAQH OIIMATIC YEAR, APRIL 1-MAROH 31

\begin{tabular}{|c|c|c|c|c|c|c|c|c|c|c|c|c|c|c|c|c|c|c|c|}
\hline YEAR & 1 & & 3 & & 7 & & 14 & & $\begin{array}{l}\text { CONSE } \\
30\end{array}$ & arI & $\begin{array}{l}\text { DAYS } \\
60\end{array}$ & & 90 & & 120 & & 183 & & ALL \\
\hline $\begin{array}{l}1946 \\
1947 \\
1948 \\
1949 \\
1950\end{array}$ & $\begin{array}{l}0.10 \\
0.20 \\
0.10 \\
0.10 \\
0.20\end{array}$ & $\begin{array}{l}1 \\
6 \\
2 \\
3 \\
7\end{array}$ & $\begin{array}{l}0.10 \\
0.20 \\
0.13 \\
0.10 \\
0.20\end{array}$ & $\begin{array}{l}1 \\
7 \\
4 \\
2 \\
5\end{array}$ & $\begin{array}{l}0.10 \\
0.20 \\
0.21 \\
0.10 \\
0.23\end{array}$ & $\begin{array}{l}1 \\
5 \\
6 \\
2 \\
7\end{array}$ & $\begin{array}{l}0.11 \\
0.25 \\
0.24 \\
0.17 \\
0.24\end{array}$ & $\begin{array}{l}1 \\
7 \\
5 \\
2 \\
6\end{array}$ & $\begin{array}{l}0.29 \\
0.29 \\
0.26 \\
0.27 \\
0.29\end{array}$ & $\begin{array}{l}6 \\
7 \\
3 \\
4 \\
5\end{array}$ & $\begin{array}{l}0.49 \\
0.35 \\
0.27 \\
0.29 \\
0.36\end{array}$ & $\begin{array}{l}7 \\
5 \\
2 \\
3 \\
6\end{array}$ & $\begin{array}{l}0.57 \\
0.40 \\
0.31 \\
0.31 \\
0.39\end{array}$ & $\begin{array}{l}7 \\
5 \\
2 \\
3 \\
4\end{array}$ & $\begin{array}{l}0.57 \\
0.59 \\
0.33 \\
0.32 \\
0.49\end{array}$ & $\begin{array}{l}6 \\
7 \\
3 \\
2 \\
4\end{array}$ & $\begin{array}{l}1.00 \\
0.99 \\
0.96 \\
0.87 \\
1.10\end{array}$ & $\begin{array}{l}6 \\
5 \\
4 \\
1 \\
7\end{array}$ & $\begin{array}{r}8.70 \\
3.20 \\
6.80 \\
8.50 \\
15.0\end{array}$ \\
\hline $\begin{array}{l}1951 \\
952 .\end{array}$ & $\begin{array}{l}0.10 \\
0.20\end{array}$ & $\begin{array}{l}4 \\
5\end{array}$ & $\begin{array}{l}0.13 \\
0.20\end{array}$ & $\begin{array}{l}3 \\
6\end{array}$ & $\begin{array}{l}0.17 \\
0.20\end{array}$ & $\begin{array}{l}3 \\
4\end{array}$ & $\begin{array}{l}0.19 \\
0.22\end{array}$ & $\begin{array}{l}3 \\
4\end{array}$ & $\begin{array}{l}0.19 \\
0.25\end{array}$ & $\begin{array}{l}1 \\
2\end{array}$ & $\begin{array}{l}0.24 \\
0.34\end{array}$ & $\begin{array}{l}1 \\
4\end{array}$ & $\begin{array}{l}0.29 \\
0.50\end{array}$ & $\begin{array}{l}1 \\
6\end{array}$ & $\begin{array}{l}0.30 \\
0.53\end{array}$ & $\begin{array}{l}1 \\
5\end{array}$ & $\begin{array}{l}0.89 \\
0.89\end{array}$ & $\begin{array}{l}2 \\
3\end{array}$ & $\begin{array}{l}7.10 \\
3.30\end{array}$ \\
\hline
\end{tabular}

HIGHEST MEAN DISCHARGE, IN OUBIC FEET FER SECOND, AND RANKING FOR THE INDICATED NUMBER OF CONSECUTIVE DAYS FOR EAQH WATER YEAR, OCTOBER I-SEPTEMBER 30

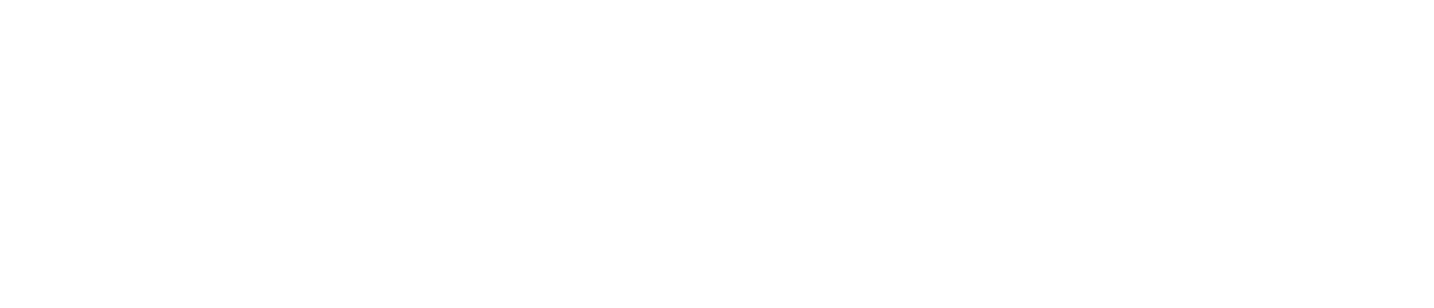


DOLORES RIVER BASIN

09170500 WEST PARADOX CREER NEAR PARADOX, CO-Continued

DURATION OF DISCHARGE FOR EACH WATER YEAR

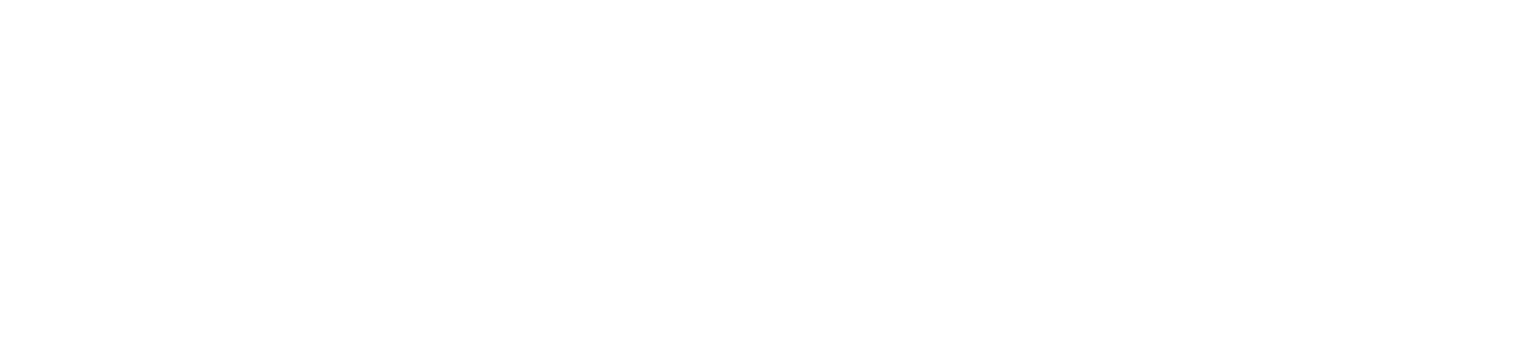

DURATION TABLE OF DISCHARGE FOR WATER YEARS 1945-52

\begin{tabular}{|c|c|c|c|c|c|c|c|c|c|c|c|c|c|c|c|c|c|c|c|}
\hline CL.ASS & $\begin{array}{c}\text { OUBIC } \\
\text { FEET } \\
\text { PER } \\
\text { SECOND }\end{array}$ & TOTAL & $\begin{array}{c}\text { ACOU- } \\
\text { MU- } \\
\text { LATED } \\
\text { DAYS }\end{array}$ & $\begin{array}{l}\text { PER- } \\
\text { CENT } \\
\text { DAYS }\end{array}$ & CLASS & $\begin{array}{c}\text { CUBIC } \\
\text { FEET } \\
\text { PER } \\
\text { SECOND }\end{array}$ & $\begin{array}{r}\text { TOTAL } \\
\text { DAYS }\end{array}$ & $\begin{array}{c}\text { ACOU- } \\
\text { MU- } \\
\text { IATED } \\
\text { DAYS }\end{array}$ & $\begin{array}{l}\text { PER- } \\
\text { CENT } \\
\text { DAYS }\end{array}$ & CLASS & $\begin{array}{c}\text { CUBIC } \\
\text { FEET } \\
\text { PER } \\
\text { SECOND }\end{array}$ & $\begin{array}{l}\text { TOTAL } \\
\text { DAYS }\end{array}$ & $\begin{array}{c}\text { ACOU- } \\
\text { MU- } \\
\text { LATED } \\
\text { DAYS }\end{array}$ & $\begin{array}{l}\text { PER- } \\
\text { CENT } \\
\text { DAYS }\end{array}$ & CLASS & $\begin{array}{c}\text { OUBIC } \\
\text { FEET } \\
\text { PER } \\
\text { SECOND }\end{array}$ & $\begin{array}{l}\text { TOTAL } \\
\text { DAYS }\end{array}$ & $\begin{array}{c}\text { ACOU- } \\
\text { MU- } \\
\text { LATED } \\
\text { DAYS }\end{array}$ & $\begin{array}{l}\text { PER- } \\
\text { CENI } \\
\text { DAYS }\end{array}$ \\
\hline $\begin{array}{l}0 \\
1 \\
2 \\
3 \\
4 \\
5 \\
6 \\
7 \\
8\end{array}$ & $\begin{array}{l}0.00 \\
0.10 \\
0.12 \\
0.15 \\
0.19 \\
0.23 \\
0.29 \\
0.35 \\
0.44\end{array}$ & $\begin{array}{r}0 \\
27 \\
0 \\
0 \\
136 \\
0 \\
240 \\
244 \\
211\end{array}$ & $\begin{array}{l}2922 \\
2922 \\
2895 \\
2895 \\
2895 \\
2759 \\
2759 \\
2519 \\
2275\end{array}$ & $\begin{array}{r}100.0 \\
100.0 \\
99.1 \\
99.1 \\
99.1 \\
94.4 \\
94.4 \\
86.2 \\
77.9\end{array}$ & $\begin{array}{r}9 \\
10 \\
11 \\
12 \\
13 \\
14 \\
15 \\
16 \\
17\end{array}$ & $\begin{array}{l}0.54 \\
0.66 \\
0.82 \\
1.00 \\
1.20 \\
1.50 \\
1.90 \\
2.30 \\
2.90\end{array}$ & $\begin{array}{r}105 \\
133 \\
27 \\
52 \\
68 \\
48 \\
50 \\
81 \\
91\end{array}$ & $\begin{array}{l}2064 \\
1959 \\
1826 \\
1799 \\
1747 \\
1679 \\
1631 \\
1581 \\
1500\end{array}$ & $\begin{array}{l}70.6 \\
67.0 \\
62.5 \\
61.6 \\
59.8 \\
57.5 \\
55.8 \\
54.1 \\
51.3\end{array}$ & $\begin{array}{l}18 \\
19 \\
20 \\
21 \\
22 \\
23 \\
24 \\
25 \\
26\end{array}$ & $\begin{array}{r}3.6 \\
4.4 \\
5.4 \\
6.7 \\
8.2 \\
10.0 \\
13.0 \\
15.0 \\
19.0\end{array}$ & $\begin{array}{r}118 \\
168 \\
102 \\
122 \\
161 \\
150 \\
92 \\
102 \\
84\end{array}$ & $\begin{array}{r}1409 \\
1291 \\
1123 \\
1021 \\
899 \\
738 \\
588 \\
496 \\
394\end{array}$ & $\begin{array}{l}48.2 \\
44.2 \\
38.4 \\
34.9 \\
30.8 \\
25.3 \\
20.1 \\
17.0\end{array}$ & $\begin{array}{l}27 \\
28 \\
29 \\
30 \\
31 \\
32 \\
33 \\
34\end{array}$ & $\begin{array}{r}23.0 \\
29.0 \\
36.0 \\
44.0 \\
54.0 \\
67.0 \\
83.0 \\
100.0\end{array}$ & $\begin{array}{r}61 \\
50 \\
69 \\
53 \\
60 \\
8 \\
6 \\
3\end{array}$ & $\begin{array}{r}310 \\
249 \\
199 \\
130 \\
77 \\
17 \\
9 \\
3\end{array}$ & $\begin{array}{r}10.6 \\
8.5 \\
6.8 \\
4.4 \\
2.6 \\
0.6 \\
0.3 \\
0.1\end{array}$ \\
\hline
\end{tabular}

MONLHLY MEAN DISCHARGES, IN OUBIC FEET PER SECOND, FOR EACH WATER YEAR

\begin{tabular}{|c|c|c|c|c|c|c|c|c|c|c|c|c|}
\hline YEAR & $\infty \mathrm{CT}$ & $\mathrm{NON}$ & DEC & JAN & FEB & MAR & APR & MAY & JUNE & JULY & AUG & SEP \\
\hline 1945 & 1.88 & 0.56 & 0.50 & 0.50 & 0.40 & 0.69 & 10.8 & 25.8 & 28.7 & 17.4 & 6.33 & 9.59 \\
\hline $\begin{array}{l}1946 \\
1947 \\
1948 \\
1949 \\
1950\end{array}$ & $\begin{array}{l}3.05 \\
1.87 \\
3.25 \\
1.96 \\
2.50\end{array}$ & $\begin{array}{l}0.53 \\
1.34 \\
0.38 \\
0.38 \\
0.93\end{array}$ & $\begin{array}{l}0.58 \\
0.95 \\
0.28 \\
0.33 \\
0.51\end{array}$ & $\begin{array}{l}0.77 \\
0.30 \\
0.27 \\
0.30 \\
0.41\end{array}$ & $\begin{array}{l}0.61 \\
0.42 \\
0.58 \\
0.29 \\
0.32\end{array}$ & $\begin{array}{l}0.41 \\
1.46 \\
0.98 \\
1.82 \\
1.47\end{array}$ & $\begin{array}{c}3.10 \\
7.26 \\
17.6 \\
38.6 \\
13.5\end{array}$ & $\begin{array}{c}8.86 \\
27.8 \\
33.2 \\
46.2 \\
18.9\end{array}$ & $\begin{array}{c}8.01 \\
15.2 \\
18.3 \\
50.2 \\
20.2\end{array}$ & $\begin{array}{l}4.49 \\
12.2 \\
11.3 \\
18.8 \\
12.5\end{array}$ & $\begin{array}{c}4.26 \\
8.71 \\
6.81 \\
11.5 \\
9.82\end{array}$ & $\begin{array}{l}2.56 \\
3.96 \\
8.76 \\
5.81 \\
4.95\end{array}$ \\
\hline $\begin{array}{l}1951 \\
1952\end{array}$ & $\begin{array}{l}3.34 \\
2.31\end{array}$ & $\begin{array}{l}0.59 \\
0.63\end{array}$ & $\begin{array}{l}0.33 \\
0.67\end{array}$ & $\begin{array}{l}0.39 \\
0.75\end{array}$ & $\begin{array}{l}0.29 \\
0.39\end{array}$ & $\begin{array}{l}0.19 \\
0.77\end{array}$ & $\begin{array}{c}2.89 \\
59.4\end{array}$ & $\begin{array}{c}7.86 \\
50.4\end{array}$ & $\begin{array}{l}7.43 \\
41.5\end{array}$ & $\begin{array}{c}8.04 \\
19.0\end{array}$ & $\begin{array}{c}3.77 \\
12.5\end{array}$ & $\begin{array}{c}3.96 \\
10.9\end{array}$ \\
\hline
\end{tabular}

ANNUAL PEAK DISCHARGE, IN CUBIC FEET PER SECOND, AND CORRESPONDING GAGE HEIGHT, IN FEET, FOR EACH WATER YEAR

\begin{tabular}{|c|c|c|c|c|c|c|c|c|c|c|c|}
\hline $\begin{array}{l}\text { WATER } \\
\text { YEAR }\end{array}$ & DATE & $\begin{array}{c}\text { GAGE } \\
\text { HEIGHT }\end{array}$ & $\begin{array}{c}\text { PEAK } \\
\text { DISCHARGE }\end{array}$ & $\begin{array}{l}\text { WATEER } \\
\text { YEAR }\end{array}$ & DATE & $\begin{array}{c}\text { GAGE } \\
\text { HETGHT }\end{array}$ & $\begin{array}{c}\text { PEAK } \\
\text { DISCHARGE }\end{array}$ & $\begin{array}{l}\text { WANERR } \\
\text { YEAR }\end{array}$ & DATE & $\begin{array}{c}\text { GAGE } \\
\text { HEIGHT }\end{array}$ & $\begin{array}{c}\text { PEAK } \\
\text { DISCHARGE }\end{array}$ \\
\hline $\begin{array}{l}1945 \\
1946 \\
1947\end{array}$ & $\begin{array}{lll}\text { MAY } 01, & 1945 \\
\text { SEPT. } 12, & 1946 \\
\text { MAY } 16, & 1947\end{array}$ & $\begin{array}{l}3.15 \\
3.21 \\
2.70\end{array}$ & $\begin{array}{r}102 \\
101 \\
60\end{array}$ & $\begin{array}{l}1948 \\
1949 \\
1950\end{array}$ & $\begin{array}{ll}\text { SEPT. } 27, & 1948 \\
\text { APR. 24, } & 1949 \\
\text { APR. } 07, & 1950\end{array}$ & $\begin{array}{l}5.96 \\
3.60 \\
2.58\end{array}$ & $\begin{array}{r}678 \\
182 \\
41\end{array}$ & $\begin{array}{l}1951 \\
1952\end{array}$ & $\begin{array}{lll}\text { MAY } & 15,1951 \\
\text { APR. } & 18,1952\end{array}$ & $\begin{array}{l}2.15 \\
4.15\end{array}$ & $\begin{array}{r}18 \\
273\end{array}$ \\
\hline
\end{tabular}


LOCATION. - Lat $38^{\circ} 31^{\prime} 10^{*}$, long $109^{\circ} 06^{\prime} 32^{*}$, in sec.24, T.26 S., R. 25 E., Grand County, UT, Hydrologic Unit 14030004, on 1eft bank at downstream side of bridge, $0.2 \mathrm{mi}$ downstream from South Taylor Creek, and $12 \mathrm{mi}$ southwest of Gateway.

DRAINAGE AREA. $-12 \mathrm{mi}^{2}$ approximately.

MEAN BASIN ELEVATION. $-9,000 \mathrm{ft}$.

PERIOD OF RECORD AVAIlLABLE.-October 1944 to September 1967.

REVISED RECORDS. -WDR CO-65-1: 1964.

GAGE. -Water-stage recorder and plank control since June 19, 1964. Altitude of gage is 8,120 ft by barometer. Prior to Aug. 31 , 1949 , at site $770 \mathrm{ft}$ dowstream at datum $6.00 \mathrm{ft} 10 \mathrm{wer}$

REMARKS. - Transbasin diversion above station by Hubbard ditch for irrigation in John Brown Creek basin began in spring of 1956. Since May 1962, water imported from Beaver Creek basin enters Taylor Creek above Hubbard ditch (quantities unknown prior to October 1965).

AVERAGE DISCHARGE, - 23 years, $3.17 \mathrm{ft}^{3} / 5,2,300$ acre- $\mathrm{ft} / \mathrm{yr}$, unadjusted.

EXIREMES FOR PERIOD OF RECORD. - Maximum discharge, $555 \mathrm{ft}^{3} / \mathrm{s} \mathrm{Apr.} \mathrm{18,} \mathrm{1948,} \mathrm{gage} \mathrm{height,} 3.40 \mathrm{ft}$, site and datum then in use, fram rating curve extended above $220 \mathrm{ft}^{3} / 5$; maximum gage height, $5.72 \mathrm{ft}$ Aug. 6,1945 , site and datum then in use; no flow at times June to August 1946, Sept. 29, 1949, May 17, 18, 1964.

IOWEST MEAN DISCHARGE, IN OBIC FEET PER SECOND, AND RANKING FOR THE INDICATED NUMBER OF OONSECUTIVE DAYS FOR EACH CLIMATIC YEAR, APRIL 1-MARCH 31

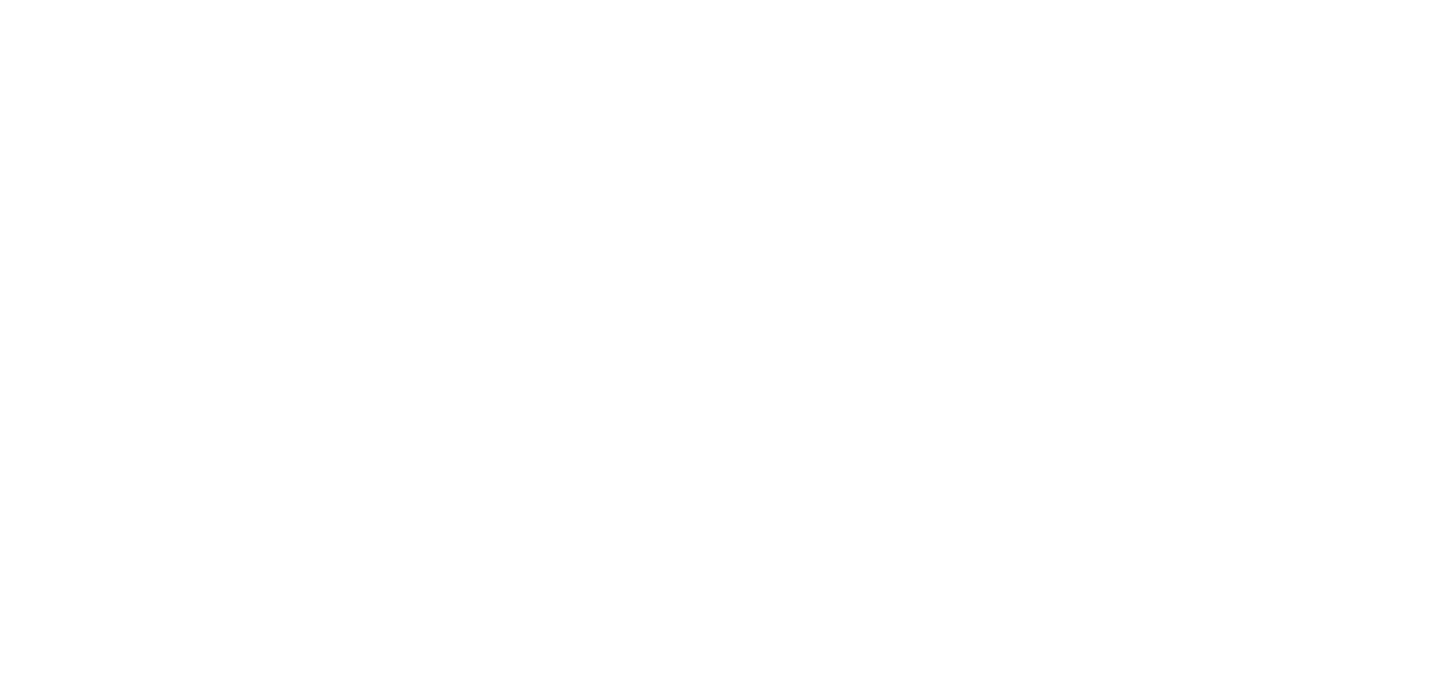

HIGHEST MEAN DISCHARGE, IN OBIC FEET PER SECOND, AND RANKING FOR THE INDICATED NUMBER OF CONSECUTIVE DAYS FOR EACH WATER YEAR, $O$ CTOBER 1-SEPIEMBER 30

YEAR

1945

1946

1947

1949

1950

1952

1953

1955

$\begin{array}{crcr}1 & & 3 & \\ 54.0 & 8 & 51.0 & 8 \\ 25.0 & 17 & 24.0 & 17 \\ 32.0 & 15 & 30.0 & 14 \\ 242 & 1 & 145 & 1 \\ 158 & 2 & 143 & 3 \\ 53.0 & 9 & 39.0 & 11 \\ & & & \\ 8.80 & 21 & 7.40 & 21 \\ 124 & 5 & 120 & 5 \\ 14.0 & 18 & 12.0 & 18 \\ 7.20 & 22 & 7.00 & 22 \\ 36.0 & 14 & 26.0 & 15\end{array}$

7

46.07

$23.0 \quad 14$

28.013 122

$30.0 \quad 11$

6.4021 108.4 $\begin{array}{cc}11.0 & 18 \\ 7.00 & 19\end{array}$ 20.016

$$
15
$$

39.06

$20.0 \quad 14$

23.010

$\begin{array}{ll}84.0 & 3 \\ 83.0 & 4\end{array}$

$\begin{array}{ll}83.0 & 4 \\ 27.0 & 9\end{array}$

5.6020

88.01

9.5018
7.0019

$15.0 \quad 15$
CONSECUTIVE DAYS

$30 \quad 60 \quad 90$

30.06

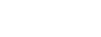

$\begin{array}{ll}22.0 & 8 \\ 56.0 & 4\end{array}$

$64.0 \quad 3$

24.07

4.4020

71.011

7.2018
6.2019

15.013
20.06

$11.0 \quad 11$

$\begin{array}{ll}16.0 & 9 \\ 35.0 & 4\end{array}$

45.01

17.07

3.5020
45.0

45.0
6.6016

4.9019

$11.0 \quad 12$ $\begin{array}{llll}16.0 & 6 & 12.0 & 6\end{array}$

$\begin{array}{rr}7.50 & 12 \\ 12.0 & 9\end{array}$

$\begin{array}{ll}24.0 & 4 \\ 34.0 & 1\end{array}$

13.07

5.9012

9.70

$\begin{array}{lll}19.0 & 4 & 6.60\end{array}$

$\begin{array}{llll}19.0 & 4 & 12.0 & 4 \\ 26.0 & 1 & 17.0 & 1\end{array}$

11.0

7.307

$\begin{array}{lll}2.6020 & 1.8020\end{array}$

$\begin{array}{lll}3.0 & 2 & 16.0\end{array}$

4.3016
3.0019

3.0019
6.2011
ALC.

4.506

2.2011

$\begin{array}{ll}3.50 & 8 \\ 6.30 & 4\end{array}$

8.701

4.007

$\begin{array}{ll}1.10 & 21 \\ 8.40 & 2\end{array}$

..70 15

1.7015
1.1919

2.2012 
DOLORES RIVER BASIN

09177500 TAYLOR CREEK NEAR GATEWAY, $\infty$-Continued

HIGHEST MEAN DISCHARGE, IN OBBIC FEET PER SECOND, AND RANKING FOR THE INDICATED NUMBER OF CONSECUTIVE DAYS

FOR EACH WATER YEAR, OCICBER 1-SEPTEMBER 30-Continued

\begin{tabular}{|c|c|c|c|c|c|c|c|c|c|c|c|c|c|c|c|c|c|}
\hline YEAR & 1 & & 3 & & 7 & & 15 & & $\begin{array}{l}\text { Cons } \\
30\end{array}$ & EOUTIV & $\begin{array}{l}\text { E DAYS } \\
60\end{array}$ & & 90 & & 120 & 183 & ALL \\
\hline $\begin{array}{l}1956 \\
1957 \\
1958 \\
1959 \\
1960\end{array}$ & $\begin{array}{c}7.00 \\
41.0 \\
154 \\
9.20 \\
49.0\end{array}$ & $\begin{array}{r}23 \\
13 \\
3 \\
20 \\
10\end{array}$ & $\begin{array}{c}5.70 \\
35.0 \\
144 \\
8.00 \\
43.0\end{array}$ & $\begin{array}{r}23 \\
12 \\
2 \\
20 \\
9\end{array}$ & $\begin{array}{c}4.40 \\
30.0 \\
124 \\
6.10 \\
35.0\end{array}$ & $\begin{array}{r}23 \\
12 \\
1 \\
22 \\
9\end{array}$ & $\begin{array}{c}3.20 \\
22.0 \\
84.0 \\
3.90 \\
22.0\end{array}$ & $\begin{array}{r}23 \\
11 \\
2 \\
22 \\
12\end{array}$ & $\begin{array}{c}2.50 \\
18.0 \\
64.0 \\
2.60 \\
13.0\end{array}$ & $\begin{array}{r}23 \\
11 \\
2 \\
22 \\
14\end{array}$ & $\begin{array}{c}1.60 \\
16.0 \\
38.0 \\
1.70 \\
8.20\end{array}$ & $\begin{array}{r}23 \\
8 \\
3 \\
22 \\
15\end{array}$ & $\begin{array}{c}1.30 \\
12.0 \\
26.0 \\
1.30 \\
6.10\end{array}$ & $\begin{array}{r}22 \\
8 \\
3 \\
23 \\
15\end{array}$ & $\begin{array}{rr}1.10 & 22 \\
9.40 & 9 \\
19.0 & 3 \\
1.10 & 23 \\
4.70 & 15\end{array}$ & $\begin{array}{rr}0.86 & 22 \\
6.40 & 9 \\
13.0 & 3 \\
0.84 & 23 \\
3.20 & 15\end{array}$ & $\begin{array}{rr}0.54 & 23 \\
3.40 & 9 \\
6.90 & 3 \\
0.56 & 22 \\
1.70 & 16\end{array}$ \\
\hline $\begin{array}{l}1961 \\
1962 \\
1963 \\
1964\end{array}$ & $\begin{array}{c}47.0 \\
134 \\
27.0 \\
60.0 \\
48.0\end{array}$ & $\begin{array}{r}12 \\
4 \\
16 \\
7 \\
11\end{array}$ & $\begin{array}{c}30.0 \\
124 \\
26.0 \\
58.0 \\
43.0\end{array}$ & $\begin{array}{r}13 \\
4 \\
16 \\
6 \\
10\end{array}$ & $\begin{array}{c}17.0 \\
113 \\
22.0 \\
47.0 \\
30.0\end{array}$ & $\begin{array}{r}17 \\
3 \\
15 \\
6 \\
10\end{array}$ & $\begin{array}{l}11.0 \\
78.0 \\
12.0 \\
33.0 \\
21.0\end{array}$ & $\begin{array}{r}17 \\
5 \\
16 \\
7 \\
13\end{array}$ & $\begin{array}{l}9.10 \\
51.0 \\
7.20 \\
20.0 \\
13.0\end{array}$ & $\begin{array}{r}16 \\
5 \\
17 \\
9 \\
15\end{array}$ & $\begin{array}{c}6.50 \\
28.0 \\
5.20 \\
11.0 \\
8.70\end{array}$ & $\begin{array}{r}17 \\
5 \\
18 \\
13 \\
14\end{array}$ & $\begin{array}{c}5.00 \\
20.0 \\
4.10 \\
7.30 \\
6.40\end{array}$ & $\begin{array}{r}17 \\
5 \\
18 \\
13 \\
14\end{array}$ & $\begin{array}{rr}3.80 & 17 \\
15.0 & 5 \\
3.30 & 18 \\
5.60 & 13 \\
5.00 & 14\end{array}$ & $\begin{array}{rr}2.60 & 17 \\
10.0 & 5 \\
2.40 & 18 \\
3.90 & 13 \\
3.50 & 14\end{array}$ & $\begin{array}{rrr}1.40 & 17 \\
5.40 & 5 \\
1.40 & 18 \\
2.00 & 13 \\
1.90 & 14\end{array}$ \\
\hline $\begin{array}{l}1966 \\
1967\end{array}$ & $\begin{array}{l}65.0 \\
14.0\end{array}$ & $\begin{array}{r}6 \\
19\end{array}$ & $\begin{array}{c}56.0 \\
9.50\end{array}$ & $\begin{array}{r}7 \\
19\end{array}$ & $\begin{array}{c}42.0 \\
6.90\end{array}$ & $\begin{array}{r}8 \\
20\end{array}$ & $\begin{array}{r}29.0 \\
5.20\end{array}$ & $\begin{array}{r}8 \\
21\end{array}$ & $\begin{array}{c}19.0 \\
3.60\end{array}$ & $\begin{array}{l}10 \\
21\end{array}$ & $\begin{array}{l}12.0 \\
2.30\end{array}$ & $\begin{array}{l}10 \\
21\end{array}$ & $\begin{array}{l}9.20 \\
2.60\end{array}$ & $\begin{array}{l}10 \\
21\end{array}$ & $\begin{array}{ll}7.20 & 10 \\
2.30 & 21\end{array}$ & $\begin{array}{ll}5.00 & 10 \\
1.70 & 21\end{array}$ & $\begin{array}{ll}2.80 & 10 \\
1.10 & 20\end{array}$ \\
\hline
\end{tabular}

DURATION OF DISCHARGE FOR EACH WATER YEAR

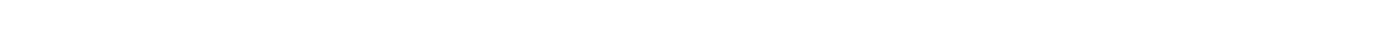

YEAR

NUMBER OF DAYS IN CLASS

OBIC FEET -DAYS

$\begin{array}{llllllllllllllllllllllllllllllllll}1945 & 50 & 37 & 57 & 25 & 49 & 9 & 8 & 5 & 7 & 2 & 8 & 6 & 3 & 2 & 13 & 4 & 9 & 35 & 7 & 2 & 4 & 4 & 7 & 6 & 4 & 2 & & & & & & 1637.5\end{array}$

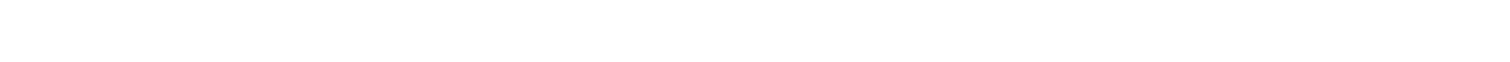

$\begin{array}{lllllllllllllllllllllllllllllllll}1948 & 110 & 88 & 9 & 5 & 31 & 1 & 4 & 37 & 2 & 4 & 2 & 2 & 3 & 4 & 8 & 7 & 11 & 2 & 4 & 9 & 2 & 7 & 4 & 3 & 1 & 3 & 1 & 1 & 1 & 2306 & 6\end{array}$

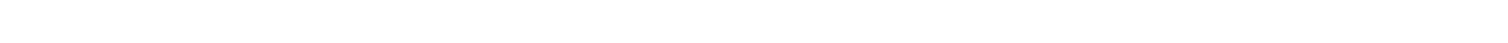

$\begin{array}{llllllllllllllllllllllllll}1950 & 22 & 15 & 35 & 10 & 20 & 15 & 38 & 91 & 10 & 10 & 5 & 13 & 6 & 4 & 3 & 13 & 10 & 11 & 9 & 7 & 8 & 6 & 3 & 1 & \end{array}$

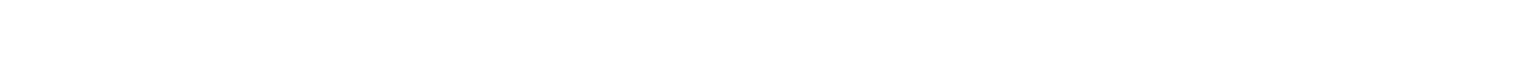

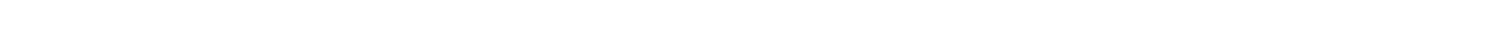

$\begin{array}{rrrrrrrrrrrrrrrrrrrrrrrrrrrrrrr}1954 & 44 & 45 & 10 & 68 & 64 & 34 & 12 & 4 & 1 & 5 & 22 & 3 & 10 & 12 & 8 & 2 & 21 & & & & & & & & & 447.9 \\ 1955 & 6 & 106 & 70 & 73 & 13 & 7 & 3 & 5 & 2 & 1 & 4 & 2 & 6 & 12 & 5 & 6 & 9 & 7 & 15 & 5 & 2 & 3 & 2 & 1 & & & & & & 812.7\end{array}$

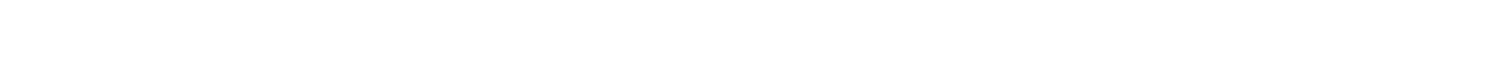

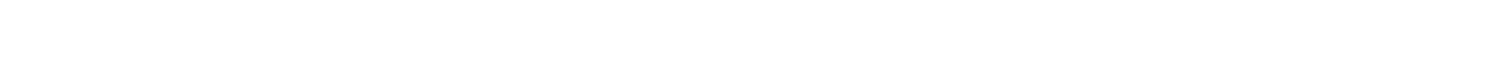

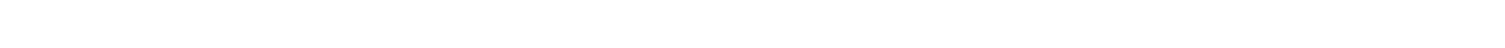

$\begin{array}{llllllllllllllllllll}1960 & 18 & 139 & 88 & 20 & 2 & 7 & 5 & 5 & 9 & 6 & 2 & 9 & 20 & 7 & 9 & 7 & 1 & 1 & 2\end{array}$

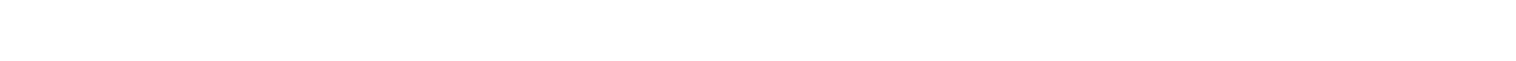

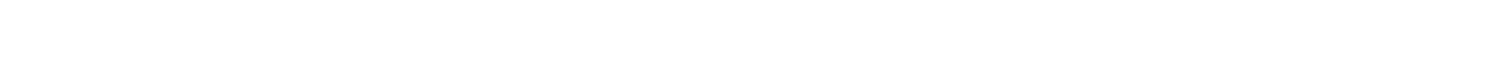

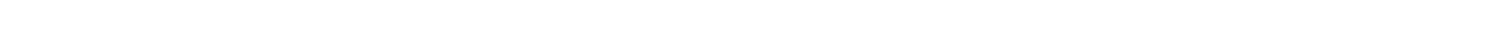

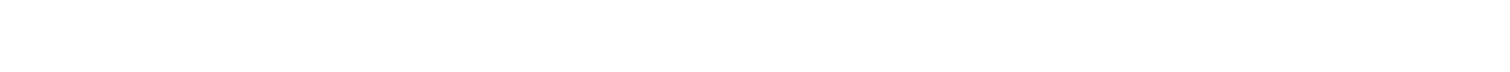

DURATION TABLE OF DISCBARGE FOR WATER YEARS I945-67

$\begin{array}{ccc}\text { OBBIC } & \text { ACOU- } \\ \text { FEET } & \text { MU- } & \text { PER- } \\ \text { PER } & \text { TOTAL LATED } & \text { CENT } \\ \text { CIASS SECOND DAYS } & \text { DAYS } & \text { DAYS }\end{array}$

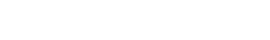

$\begin{array}{lrrr}0.10 & 550 & 8363 & 99.6\end{array}$

$\begin{array}{llll}0.13 & 29 & 7813 & 93.0\end{array}$

$\begin{array}{llll}0.16 & \text { II } & 7784 & 92.7\end{array}$

$\begin{array}{llll}0.20 & 1346 & 7773 & 92.5\end{array}$

$\begin{array}{llll}0.24 & 1209 & 6427 & 76.5\end{array}$

$\begin{array}{lrrr}0.31 & 33 & 5218 & 62.1\end{array}$

$\begin{array}{lrrr}0.31 & 33 & 5218 & 62.1 \\ 0.38 & 933 & 5185 & 61.7\end{array}$

$\begin{array}{llll}0.38 & 933 & 5185 & 61.7 \\ 0.48 & 742 & 4252 & 50.6\end{array}$

\begin{tabular}{|c|c|c|c|c|}
\hline & $\begin{array}{c}\text { CUBIC } \\
\text { FEET } \\
\text { PERR } \\
\text { SECOND }\end{array}$ & $\begin{array}{l}\text { TOTAL } \\
\text { DAYS }\end{array}$ & $\begin{array}{l}\text { ACOU- } \\
\text { MU- } \\
\text { LATED } \\
\text { DAYS }\end{array}$ & $\begin{array}{l}\text { PER- } \\
\text { CENI }\end{array}$ \\
\hline $\begin{array}{r}9 \\
10 \\
11 \\
12 \\
12\end{array}$ & $\begin{array}{l}0.60 \\
0.75 \\
0.93 \\
1.20 \\
1.50 \\
1.80 \\
2.30 \\
2.80\end{array}$ & $\begin{array}{l}702 \\
299 \\
225 \\
278 \\
203 \\
197 \\
188 \\
213\end{array}$ & $\begin{array}{l}3510 \\
2808 \\
2509 \\
2284 \\
2006 \\
1803 \\
1606 \\
1418\end{array}$ & \\
\hline
\end{tabular}

\begin{tabular}{|c|c|c|c|c|}
\hline LASS & $\begin{array}{c}\text { CUBIC } \\
\text { FEET } \\
\text { PER } \\
\text { SECOND }\end{array}$ & $\begin{array}{l}\text { TOTAL } \\
\text { DAYS }\end{array}$ & $\begin{array}{l}\text { ACOU- } \\
\text { MU- } \\
\text { LATED } \\
\text { DAYS }\end{array}$ & $\begin{array}{l}\text { PER- } \\
\text { CENT } \\
\text { DAYS }\end{array}$ \\
\hline $\begin{array}{l}18 \\
19 \\
20 \\
21 \\
22 \\
23 \\
24 \\
25\end{array}$ & $\begin{array}{r}4.4 \\
5.6 \\
7.0 \\
8.7 \\
11.0 \\
14.0 \\
17.0 \\
21.0\end{array}$ & $\begin{array}{r}151 \\
93 \\
124 \\
123 \\
112 \\
98 \\
69 \\
79\end{array}$ & $\begin{array}{r}1077 \\
926 \\
833 \\
709 \\
586 \\
474 \\
376 \\
307\end{array}$ & $\begin{array}{r}12.8 \\
11.0 \\
9.9 \\
8.4 \\
7.0 \\
5.6 \\
4.5\end{array}$ \\
\hline
\end{tabular}

\begin{tabular}{|c|c|c|c|c|}
\hline & $\begin{array}{c}\text { CBIIC } \\
\text { FEET } \\
\text { PER }\end{array}$ & TOTAL & $\begin{array}{l}\text { ACOJ- } \\
\text { MU- } \\
\text { LAIED }\end{array}$ & $\begin{array}{l}\text { PER- } \\
\text { CENT }\end{array}$ \\
\hline C_ASS & SECOND & DAYS & DAYS & DAYS \\
\hline $\begin{array}{l}27 \\
28 \\
29 \\
30 \\
31 \\
32 \\
33 \\
34\end{array}$ & $\begin{array}{r}33.0 \\
41.0 \\
52.0 \\
65.0 \\
81.0 \\
100.0 \\
130.0 \\
160.0\end{array}$ & $\begin{array}{r}57 \\
39 \\
28 \\
19 \\
12 \\
13 \\
8 \\
1\end{array}$ & $\begin{array}{r}177 \\
120 \\
81 \\
53 \\
34 \\
22 \\
9 \\
1\end{array}$ & $\begin{array}{l}2.1 \\
1.4 \\
1.0 \\
0.6 \\
0.4 \\
0.3 \\
0.1 \\
0.0\end{array}$ \\
\hline
\end{tabular}


DOLORES RIVER BASIN

09177500 TAYLOR CREEK NEAR GATEWAY, $\infty$-Continued

MONTHLY MEAN DISCHARGES, IN CUBIC FEET PER SECOND, FOR EAOH WATER YEAR

$\begin{array}{lllllllllllll}\text { YEAR } & \text { OCT } & \text { NOV } & \text { DEC } & \text { JAN } & \text { FEB } & \text { MAR } & \text { APR } & \text { MAY } & \text { JUNE } & \text { JUL } & \text { AUG } & \text { SEP } \\ 1945 & 0.24 & 0.31 & 0.15 & 0.10 & 0.30 & 0.50 & 10.0 & 29.1 & 7.09 & 1.63 & 3.58 & 0.44 \\ 1946 & 0.74 & 0.63 & 0.50 & 0.30 & 0.50 & 1.50 & 15.1 & 5.87 & 1.02 & 0.05 & 0.10 & 0.10 \\ 1947 & 0.61 & 0.72 & 0.65 & 0.60 & 0.60 & 2.50 & 18.5 & 13.8 & 3.57 & 0.41 & 0.26 & 0.22 \\ 1948 & 0.35 & 0.25 & 0.20 & 0.20 & 0.60 & 1.40 & 46.1 & 22.1 & 4.04 & 0.35 & 0.25 & 0.25 \\ 1949 & 0.31 & 0.37 & 0.32 & 0.30 & 0.30 & 0.35 & 38.4 & 43.3 & 16.8 & 2.94 & 0.51 & 0.19 \\ 1950 & 0.88 & 1.06 & 1.00 & 1.16 & 1.28 & 2.11 & 23.8 & 11.0 & 4.79 & 0.70 & 0.27 & 0.41 \\ 1951 & 0.36 & 0.34 & 0.39 & 0.41 & 0.55 & 1.61 & 2.60 & 4.22 & 1.57 & 0.24 & 0.45 & 0.21 \\ 1952 & 0.34 & 0.36 & 0.48 & 0.50 & 0.50 & 0.60 & 49.5 & 36.6 & 10.4 & 0.73 & 0.45 & 0.47 \\ 1953 & 0.47 & 0.43 & 0.46 & 0.49 & 0.41 & 1.32 & 6.55 & 6.13 & 2.79 & 0.46 & 0.53 & 0.30 \\ 1954 & 0.60 & 0.50 & 0.40 & 0.40 & 0.50 & 1.60 & 6.19 & 3.45 & 0.50 & 0.18 & 0.23 & 0.19 \\ 1955 & 0.20 & 0.29 & 0.35 & 0.35 & 0.38 & 0.50 & 10.9 & 10.5 & 2.61 & 0.23 & 0.25 & 0.22 \\ 1956 & 0.24 & 0.26 & 0.35 & 0.41 & 0.38 & 1.70 & 1.37 & 0.91 & 0.19 & 0.18 & 0.22 & 0.23 \\ 1957 & 0.28 & 0.20 & 0.20 & 0.33 & 0.43 & 0.78 & 5.77 & 17.4 & 12.4 & 1.32 & 0.84 & 0.28 \\ 1958 & 0.81 & 2.50 & 0.97 & 0.56 & 1.04 & 1.31 & 44.7 & 29.1 & 1.35 & 0.33 & 0.37 & 0.28 \\ 1959 & 0.29 & 0.41 & 0.38 & 0.37 & 0.50 & 0.80 & 2.53 & 0.48 & 0.20 & 0.23 & 0.30 & 0.27 \\ 1960 & 0.26 & 0.22 & 0.20 & 0.27 & 0.30 & 0.59 & 12.9 & 3.30 & 1.82 & 0.24 & 0.21 & 0.15 \\ 1961 & 0.19 & 0.20 & 0.25 & 0.20 & 0.27 & 1.15 & 9.01 & 3.94 & 0.95 & 0.41 & 0.26 & 0.40 \\ 1962 & 0.92 & 0.78 & 0.61 & 0.41 & 1.47 & 1.17 & 49.0 & 7.32 & 2.81 & 0.57 & 0.27 & 0.26 \\ 1963 & 0.26 & 0.23 & 0.24 & 0.25 & 1.22 & 6.05 & 2.07 & 3.56 & 0.83 & 0.18 & 1.62 & 0.19 \\ 1964 & 0.12 & 0.20 & 0.20 & 0.10 & 0.10 & 0.76 & 19.6 & 1.45 & 0.35 & 0.21 & 1.05 & 0.20 \\ 1965 & 0.13 & 0.25 & 0.48 & 0.33 & 0.47 & 0.47 & 9.89 & 6.42 & 2.11 & 1.43 & 0.59 & 0.71 \\ 1966 & 0.64 & 0.46 & 0.74 & 0.60 & 0.38 & \mathbf{6 . 1 6} & 15.5 & 4.37 & 2.03 & 1.49 & 0.54 & 0.29 \\ 1967 & 0.42 & 0.42 & 1.47 & 0.34 & 0.37 & 3.52 & 1.00 & 3.08 & 1.38 & 0.29 & 0.18 & 0.15\end{array}$

ANNUAL PEAK DISCHARGE, IN OUBIC FEET PER SECOND, AND CORRESPONDING GAGE HEIGHT, IN FEET, FOR EACH WAIER YEAR

\begin{tabular}{|c|c|c|c|c|c|c|c|c|c|c|c|}
\hline $\begin{array}{l}\text { WATER } \\
\text { YEAR }\end{array}$ & DATE & $\begin{array}{c}\text { GAGE } \\
\text { HEIGHT }\end{array}$ & $\begin{array}{c}\text { PEAK } \\
\text { DISCHARGE }\end{array}$ & $\begin{array}{l}\text { WAIER } \\
\text { YEAR }\end{array}$ & DATE & $\begin{array}{c}\text { GAGE } \\
\text { HEIGHT }\end{array}$ & $\begin{array}{c}\text { PEAK } \\
\text { DISCHARGE }\end{array}$ & $\begin{array}{l}\text { WATER } \\
\text { YEAR }\end{array}$ & DATE & $\begin{array}{c}\text { GAGE } \\
\text { HEIGHT }\end{array}$ & $\begin{array}{c}\text { PEAK } \\
\text { DISCHARGE }\end{array}$ \\
\hline $\begin{array}{l}1945 \\
1946 \\
1947 \\
1948 \\
1949 \\
1950 \\
1951 \\
1952\end{array}$ & $\begin{array}{l}\text { AUG. } 06,1945 \\
\text { APR. } 15,1946 \\
\text { APR. } 17,1947 \\
\text { APR. } 18,1948 \\
\text { APR. 25, } 1949 \\
\text { APR. } 07,1950 \\
\text { AUG. } 01,1951 \\
\text { APR. } 25,1952\end{array}$ & $\begin{array}{l}5.72 \\
1.25 \\
1.39 \\
3.40 \\
3.02 \\
3.53 \\
2.83 \\
4.25\end{array}$ & $\begin{array}{r}413 \\
40 \\
50 \\
555 \\
403 \\
83 \\
19 \\
212\end{array}$ & $\begin{array}{l}1953 \\
1954 \\
1955 \\
1956 \\
1957 \\
1958 \\
1959 \\
1960\end{array}$ & $\begin{array}{l}\text { APR. } 26,1953 \\
\text { APR. } \frac{19}{16} 1954 \\
\text { APR. } 16,1955 \\
\text { AUG. } 01,1956 \\
\text { JULY } 19,1957 \\
\text { APR. 18, } 1958 \\
\text { AUG. } 03,1959 \\
\text { APR. } 10,1960\end{array}$ & $\begin{array}{l}2.86 \\
3.27 \\
3.43 \\
2.67 \\
4.18 \\
4.40 \\
-\overline{3.66}\end{array}$ & $\begin{array}{r}21 \\
70 \\
67 \\
13 \\
201 \\
217 \\
48 \\
111\end{array}$ & $\begin{array}{l}1961 \\
1962 \\
1963 \\
1964 \\
1965 \\
1966 \\
1967\end{array}$ & $\begin{array}{l}\text { APR. } 04,1961 \\
\text { APR. } 15,1962 \\
\text { AUG. } 10,1963 \\
\text { APR. 16, } 1964 \\
\text { APR. 22, } 1965 \\
\text { JULY 21, } 1966 \\
\text { MAR. 16, } 1967\end{array}$ & $\begin{array}{l}3.65 \\
4.25 \\
4.83 \\
4.07 \\
3.66 \\
4.78 \\
2.97\end{array}$ & $\begin{array}{r}115 \\
218 \\
349 \\
160 \\
129 \\
343 \\
48\end{array}$ \\
\hline
\end{tabular}

1951 AUG. 01, $1951 \quad 2.83$

\begin{tabular}{|c|c|c|c|c|c|c|}
\hline \multirow{3}{*}{$\begin{array}{l}\text { PERIOD } \\
\text { (CON- } \\
\text { SECU- } \\
\text { TrVE } \\
\text { DAYS) }\end{array}$} & \multicolumn{6}{|c|}{$\begin{array}{l}\text { TTUDE AND PRCBABIIITYY OF ANNUAL LOWEST MEAN DISCHARGE } \\
\text { BASED ON CLIMATIC YEARS } 1946-67\end{array}$} \\
\hline & \multicolumn{6}{|c|}{$\begin{array}{l}\text { DISCHARGE, IN CUBIC FEET PER SECOND, FOR } \\
\text { INDICATED RECURRENCE INIERNAL, IN YFARS, AND } \\
\text { ANNUAL NONEXCEEDANCE PRCBABILITY, IN PERCENT }\end{array}$} \\
\hline & $\begin{array}{c}2 \\
508\end{array}$ & $\begin{array}{c}5 \\
208\end{array}$ & $\begin{array}{l}10 \\
108\end{array}$ & $\begin{array}{l}20 \\
58\end{array}$ & $\begin{array}{l}50 \\
28\end{array}$ & $\begin{array}{r}100 \\
18\end{array}$ \\
\hline $\begin{array}{l}30 \\
60 \\
90\end{array}$ & $\begin{array}{l}0.20 \\
0.25 \\
0.28\end{array}$ & $\begin{array}{l}0.12 \\
0.16 \\
0.18\end{array}$ & $\begin{array}{l}0.10 \\
0.12 \\
0.14\end{array}$ & $\begin{array}{l}0.09 \\
0.09 \\
0.11\end{array}$ & $\overline{-}$ & $\bar{z}$ \\
\hline
\end{tabular}


DOLORES RIVER BASIN

09178000 DEEP CREEK NEAR PARADOX, $\infty$

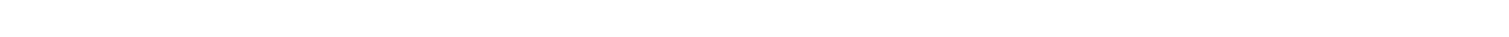
bank $0.2 \mathrm{mi}$ downstream fram diversion to Buckeye Reservoir and $13 \mathrm{mi}$ northwest of Paradox.

PERIOD OF REOORD AVAII.ABLE.-August 1944 to September 1953.

GAGE. -Water-stage recorder and $\log$ control. Datum of gage is $8,659.59 \mathrm{ft}$ NGVD of 1929, Bureau of Reclamation datum.

REMARKS.-Most of the flow diverted $0.2 \mathrm{mi}$ above station to Buckeye Reservoir in West Paradox Creek basin.

AVERAGE DISCHARGE. -9 years, $1.80 \mathrm{ft}^{3} / 5,1,300$ acre-ft/yr.

EXIREMES FOR PERIOD OF RECORD. - Maximum discharge, $29 \mathrm{ft}^{3} / \mathrm{s}$ June 18, 1949, from rating curve extended above $15 \mathrm{ft}^{3} / \mathrm{s} ; \mathrm{maximum}$ gage height, $1.67 \mathrm{ft}$ June 15, 1952; no flow Oct. 15-23, 27, Nov. 1, 4-6, 1948, Oct. 3-8, 1951, and probably at other times during the winter months.

LOWEST MEAN DISCHARGE, IN CUBIC FEET PER SECOND, AND RANKING FOR THE INDICATED NUMBER OF CONSECUTIVE DAYS FOR EACH CIIMATIC YEAR, APRIL 1-MARCH 31

\begin{tabular}{|c|c|c|c|c|c|c|c|c|c|c|c|c|c|c|c|c|c|c|c|}
\hline YEAR & 1 & & 3 & & 7 & & 14 & & $\begin{array}{l}\text { CONSE } \\
\mathbf{3 0}\end{array}$ & art & $\begin{array}{l}\text { DAYS } \\
60\end{array}$ & & 90 & & 120 & & 183 & & ALL \\
\hline $\begin{array}{l}1946 \\
1947 \\
1948 \\
1949 \\
1950\end{array}$ & $\begin{array}{l}0.20 \\
0.10 \\
0.10 \\
0.00 \\
0.20\end{array}$ & $\begin{array}{l}7 \\
4 \\
5 \\
1 \\
8\end{array}$ & $\begin{array}{l}0.23 \\
0.10 \\
0.10 \\
0.00 \\
0.20\end{array}$ & $\begin{array}{l}8 \\
4 \\
5 \\
1 \\
7\end{array}$ & $\begin{array}{l}0.27 \\
0.10 \\
0.10 \\
0.00 \\
0.20\end{array}$ & $\begin{array}{l}8 \\
4 \\
5 \\
1 \\
7\end{array}$ & $\begin{array}{l}0.29 \\
0.10 \\
0.10 \\
0.03 \\
0.20\end{array}$ & $\begin{array}{l}8 \\
4 \\
5 \\
1 \\
7\end{array}$ & $\begin{array}{l}0.30 \\
0.10 \\
0.10 \\
0.05 \\
0.21\end{array}$ & $\begin{array}{l}8 \\
3 \\
4 \\
1 \\
7\end{array}$ & $\begin{array}{l}0.31 \\
0.10 \\
0.10 \\
0.08 \\
0.23\end{array}$ & $\begin{array}{l}8 \\
3 \\
4 \\
1 \\
7\end{array}$ & $\begin{array}{l}0.49 \\
0.11 \\
0.10 \\
0.08 \\
0.48\end{array}$ & $\begin{array}{l}8 \\
4 \\
3 \\
1 \\
7\end{array}$ & $\begin{array}{l}0.60 \\
0.12 \\
0.11 \\
0.09 \\
1.19\end{array}$ & $\begin{array}{l}7 \\
4 \\
3 \\
1\end{array}$ & $\begin{array}{l}1.50 \\
0.21 \\
0.11 \\
0.10 \\
1.80\end{array}$ & $\begin{array}{l}7 \\
4 \\
2 \\
1 \\
8\end{array}$ & $\begin{array}{l}2.20 \\
0.57 \\
0.82 \\
2.00 \\
5.30\end{array}$ \\
\hline $\begin{array}{l}1951 \\
1952 \\
1953\end{array}$ & $\begin{array}{l}0.10 \\
0.00 \\
0.10\end{array}$ & $\begin{array}{l}6 \\
2 \\
3\end{array}$ & $\begin{array}{l}0.10 \\
0.00 \\
0.10\end{array}$ & $\begin{array}{l}6 \\
2 \\
3\end{array}$ & $\begin{array}{l}0.10 \\
0.01 \\
0.10\end{array}$ & $\begin{array}{l}6 \\
2 \\
3\end{array}$ & $\begin{array}{l}0.10 \\
0.06 \\
0.10\end{array}$ & $\begin{array}{l}6 \\
2 \\
3\end{array}$ & $\begin{array}{l}0.13 \\
0.08 \\
0.15\end{array}$ & $\begin{array}{l}5 \\
2 \\
6\end{array}$ & $\begin{array}{l}0.18 \\
0.09 \\
0.17\end{array}$ & $\begin{array}{l}6 \\
2 \\
5\end{array}$ & $\begin{array}{l}0.18 \\
0.10 \\
0.18\end{array}$ & $\begin{array}{l}5 \\
2 \\
6\end{array}$ & $\begin{array}{l}0.19 \\
0.11 \\
0.20\end{array}$ & $\begin{array}{l}2 \\
6\end{array}$ & $\begin{array}{l}0.21 \\
0.14 \\
0.79\end{array}$ & $\begin{array}{l}5 \\
3 \\
6\end{array}$ & $\begin{array}{l}0.90 \\
0.78 \\
3.10\end{array}$ \\
\hline
\end{tabular}

HIGHEST MEAN DISCHARGE, IN OUBIC FEET PER SECOND, AND RANKING FOR THE INDICATED NUMBER OF CONSECUTIVE DAYS FOR EACH WATER YEAR, OCTOBER 1-SEPTEMBER 30

\begin{tabular}{|c|c|c|c|c|c|c|c|c|c|c|c|c|c|c|c|c|c|c|}
\hline YEAR & & 3 & & 7 & & 15 & & $\begin{array}{l}\text { CONSE } \\
30\end{array}$ & arTIVE & $\begin{array}{l}\text { E DAYS } \\
60\end{array}$ & & 90 & & 120 & & 183 & & ALL \\
\hline 4.70 & 5 & 4.60 & 5 & 4.50 & 5 & 4.30 & 5 & 4.20 & 5 & 3.70 & 4 & 2.80 & 7 & 2.30 & 7 & 1.80 & 7 & 1.10 \\
\hline
\end{tabular}

DURATION OF DISCHARGE FOR EACH WATER YEAR

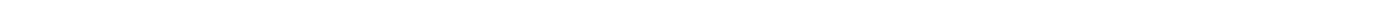

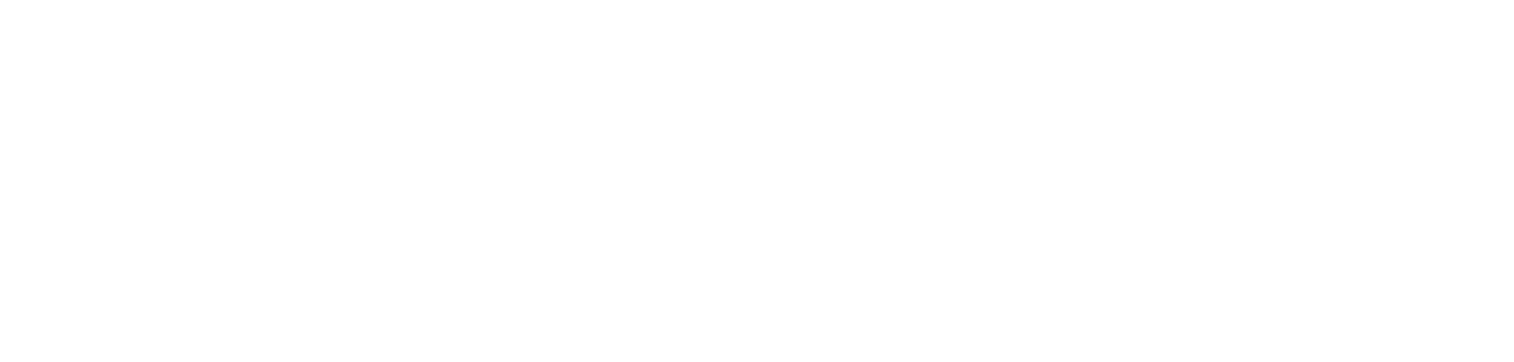

DURATION TABLE OF DISCHARGB FOR WATER YEARS 1945-53
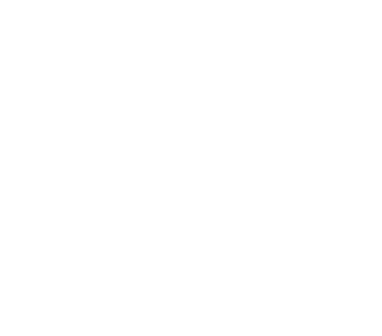

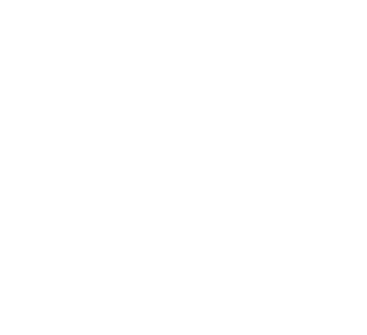

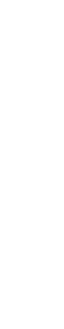

CUBIC $\mathrm{ACOU}$

FEET

CIASS SECOND DAYS DAYS DAYS

$\begin{array}{rrrrr}18 & 1.7 & 117 & 1056 & 32.1 \\ 19 & 2.0 & 100 & 939 & 28.6 \\ 20 & 2.4 & 221 & 839 & 25.5 \\ 21 & 2.8 & 209 & 618 & 18.8 \\ 22 & 3.3 & 69 & 409 & 12.4 \\ 23 & 3.9 & 50 & 340 & 10.3 \\ 24 & 4.6 & 7 & 290 & 8.8 \\ 25 & 5.4 & 63 & 283 & 8.6 \\ 26 & 6.4 & 16 & 320 & 6.7\end{array}$

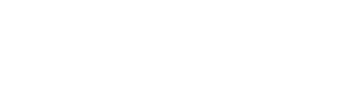

$\begin{array}{rrrrr}27 & 7.5 & 17 & 204 & 6.2 \\ 28 & 8.9 & 55 & 187 & 5.7 \\ 29 & 10.0 & 15 & 132 & 4.0 \\ 30 & 12.0 & 82 & 117 & 3.6 \\ 31 & 15.0 & 12 & 35 & 1.1 \\ 32 & 17.0 & 7 & 23 & 0.7 \\ 33 & 20.0 & 13 & 16 & 0.5 \\ 34 & 24.0 & 3 & 3 & 0.1\end{array}$


DOLORES RIVER BASIN

09178000 DEEP CREEK NEAR PARADOX, $\infty$-Continued

MONIHLY MEAN DISCHARGES, IN OUBIC FEET PER SECOND, FOR EACH WATER YEAR

$\begin{array}{lllllllllllll}\text { YEAR } & \text { OCT } & \text { NOV } & \text { DEC } & \text { JAN } & \text { FEB } & \text { MAR } & \text { APR } & \text { MAY } & \text { JUNE } & \text { JULY } & \text { AUG } & \text { SEP } \\ 1945 & 0.50 & 0.18 & 0.10 & 0.10 & 0.20 & 1.00 & 4.00 & 3.25 & 0.71 & 0.53 & 0.30 & 1.80 \\ 1946 & 3.29 & 3.15 & 2.70 & 2.50 & 2.20 & 2.50 & 2.78 & 0.47 & 0.11 & 0.10 & 0.14 & 0.25 \\ 1947 & 0.37 & 0.53 & 0.43 & 0.47 & 0.40 & 0.80 & 1.39 & 0.55 & 4.06 & 1.99 & 0.11 & 0.16 \\ 1948 & 0.12 & 0.10 & 0.10 & 0.10 & 0.20 & 1.00 & 9.00 & 8.76 & 4.49 & 0.20 & 0.16 & 0.10 \\ 1949 & 0.07 & 0.09 & 0.10 & 0.10 & 0.20 & 0.30 & 6.00 & 12.4 & 18.3 & 11.1 & 1.43 & 0.25 \\ 1950 & 0.54 & 3.19 & 3.20 & 2.80 & 2.40 & 2.20 & 2.01 & 0.32 & 0.24 & 0.20 & 0.20 & 0.22 \\ 1951 & 0.14 & 0.98 & 1.50 & 1.60 & 1.70 & 1.80 & 1.15 & 0.26 & 0.20 & 0.12 & 0.13 & 0.10 \\ 1952 & 0.08 & 1.29 & 1.40 & 1.50 & 1.50 & 1.70 & 3.12 & 11.4 & 10.1 & 0.30 & 0.21 & 0.15 \\ 1953 & 0.21 & 1.60 & 3.00 & 2.50 & 2.50 & 2.50 & 2.66 & 0.28 & 0.32 & 0.17 & 0.16 & 0.12\end{array}$

ANNUAL PEAK DISCHARGE, IN OBBIC FEET PER SECOND, AND CORRESPONDING GAGE HEIGHT, IN FEET, FOR EACH WATER YEAR

\begin{tabular}{|c|c|c|c|c|c|c|c|c|c|c|c|}
\hline $\begin{array}{l}\text { WATER } \\
\text { YEAR }\end{array}$ & DATE & $\begin{array}{c}\text { GAGE } \\
\text { HEIGHT }\end{array}$ & $\begin{array}{c}\text { PEAK } \\
\text { DISQHARGE }\end{array}$ & $\begin{array}{l}\text { WATER } \\
\text { YEAR }\end{array}$ & DATE & $\begin{array}{c}\text { GAGE } \\
\text { HEIGHT }\end{array}$ & $\begin{array}{c}\text { PEAK } \\
\text { DISCHARGE }\end{array}$ & $\begin{array}{l}\text { WATER } \\
\text { YEAR }\end{array}$ & DATE & $\begin{array}{c}\text { GAGE } \\
\text { HEIGHT }\end{array}$ & $\begin{array}{c}\text { PEAK } \\
\text { DISQHARGE }\end{array}$ \\
\hline $\begin{array}{l}1945 \\
1946 \\
1947\end{array}$ & $\begin{array}{l}\text { MAY } 03,1945 \\
\text { MAY } 04,1946 \\
\text { JUNE } 11,1947\end{array}$ & $\begin{array}{l}1.26 \\
1.18 \\
1.18\end{array}$ & $\begin{array}{l}5.0 \\
5.0 \\
9.0\end{array}$ & $\begin{array}{l}1948 \\
1949 \\
1950\end{array}$ & $\begin{array}{l}\text { MAY } 19,1948 \\
\text { JUNE } 18,1949 \\
\text { DEC. } 09,1949\end{array}$ & $\begin{array}{l}1.39 \\
1.52 \\
-\end{array}$ & $\begin{array}{l}22 \\
29 \\
4.0\end{array}$ & $\begin{array}{l}1951 \\
1952 \\
1953\end{array}$ & $\begin{array}{l}\text { NOV. } 19,1950 \\
\text { JUNE } 15,1952 \\
\text { APR. 24, } 1953\end{array}$ & $\begin{array}{l}1.28 \\
1.67 \\
1.37\end{array}$ & $\begin{array}{c}2.0 \\
19 \\
7.0\end{array}$ \\
\hline
\end{tabular}

09178500 GEYSER CREEK NEAR PARADOX, $\infty$

LOCATION.-Lat $38^{\circ} 28^{\prime}$, long $109^{\circ} 09^{\prime}$, in $\mathrm{NE}_{\frac{1}{4}}^{\frac{1}{4}}$ sec. 15, T.27 S., R.25 E., San Juan County, UT, Hydrologic Unit 14030004, at spillway of Geyser Creek Reservoir, $11 \mathrm{mi}$ northwest of Paradox.

PERIOD OF RECORD AVAII.ABLE.--August 1944 to september 1951.

GAGE.-Water-stage recorder. Sharp-crested weir since Sept. 1, 1949. Datum of gage is 8,628.00 ft NGVD of 1929 , Bureau of Reclamation datum.

REMARKS. -No flow since June 1949. Flow diverted just above station to Buckeye Reservoir in West Paradox Creek basin.

AVERAGE DISCHARGE. -7 years, $0.28 \mathrm{ft}^{3} / \mathrm{s}, 203$ acre- $\mathrm{ft} / \mathrm{yr}$.

EXIREMES FOR PERIOD OF RECORD.--Maximum discharge, $134 \mathrm{ft}^{3} / \mathrm{s}$ June 18, 1949, gage height, $2.88 \mathrm{ft}$, by computation of flow over broadcrested weir; no flow for most of each year.

LOWEST MEAN DISCHARGE, IN OUBIC FEET PER SECOND, AND RANKING FOR THE INDICATED NUMBER OF CONSEQUTIVE DAYS FOR EAOH CLIMATIC YEAR, APRIL 1-MARCH 31

YEAR

$\begin{array}{cccccccc}1 & & 3 & & 7 & & 14 & \\ 0.00 & 1 & 0.00 & 1 & 0.00 & 1 & 0.00 & 1 \\ 0.00 & 2 & 0.00 & 2 & 0.00 & 2 & 0.00 & 2 \\ 0.00 & 3 & 0.00 & 3 & 0.00 & 3 & 0.00 & 3 \\ 0.00 & 4 & 0.00 & 4 & 0.00 & 4 & 0.00 & 4 \\ 0.00 & 5 & 0.00 & 5 & 0.00 & 5 & 0.00 & 5\end{array}$

$\begin{array}{llllllllll}0.00 & 6 & 0.00 & 6 & 0.00 & 6 & 0.00 & 6\end{array}$

CONSEOTTIVE DAYS

0.001

0.003

$\begin{array}{llll}0.00 & 4 & 0.00 & 4 \\ 0.00 & 5 & 0.00 & 5\end{array}$

$\begin{array}{llll}0.00 & 6 & 0.00 & 6\end{array}$

0.001

120

$0.00 \quad 1$

183

0.001

$\begin{array}{llllllll}0.00 & 4 & 0.00 & 4 & 0.00 & 4 & 0.09 & 5 \\ 0.00 & 5 & 0.00 & 5 & 0.00 & 5 & 1.90 & 6\end{array}$

HIGHEST MEAN DISQHARGE, IN GBIC FEET PER SECOND, AND RANKING FOR THE INDICATED NUMBER OF CONSEGTIVE DAYS FOR EAOH WATER YEAR, OCTCBER 1-SEPTEMBER 30

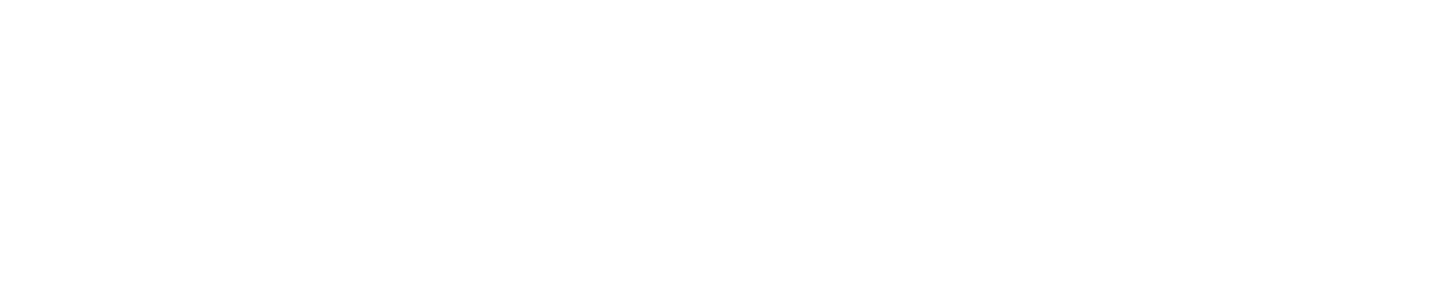


DOLORES RIVER BASIN

09178500 GEYSER CREEK NEAR PARADOX, co-continued

DURATION OF DISCHARGE FOR EACH WATER YEAR

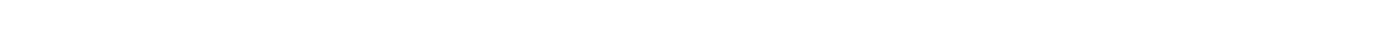
YEAR NUMBER OF DAYS IN CLASS

OBBIC FEET PER SECOND

1945365

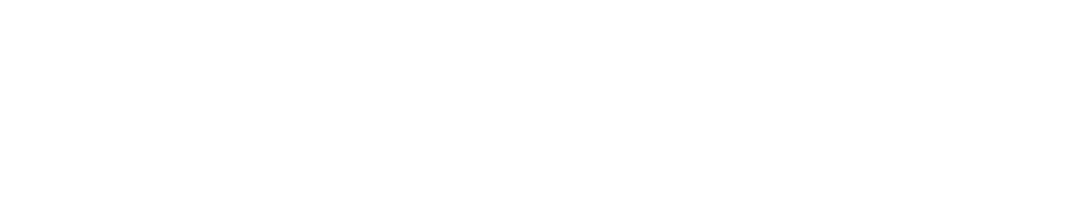

DURATION TABLE OF DISCHARGE FOR WATER YEARS 1945-51

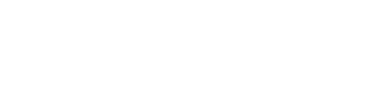

\begin{tabular}{|c|c|c|c|c|}
\hline & $\begin{array}{r}\text { OBBIC } \\
\text { FEET }\end{array}$ & & $\begin{array}{c}\mathrm{ACOU}- \\
\mathrm{MU}-\end{array}$ & PERR- \\
\hline CIASS & $\begin{array}{c}\text { PER } \\
\text { SECOND }\end{array}$ & $\begin{array}{l}\text { TOTAL } \\
\text { DAYS }\end{array}$ & $\begin{array}{l}\text { LATEDD } \\
\text { DAYS }\end{array}$ & $\begin{array}{l}\text { CBNT } \\
\text { DAYS }\end{array}$ \\
\hline $\begin{array}{r}9 \\
10 \\
11 \\
12 \\
13 \\
14 \\
15 \\
16 \\
17\end{array}$ & $\begin{array}{l}0.52 \\
0.64 \\
0.78 \\
0.96 \\
1.20 \\
1.50 \\
1.80 \\
2.20 \\
2.70\end{array}$ & $\begin{array}{l}0 \\
0 \\
3 \\
3 \\
1 \\
0 \\
0 \\
1 \\
0\end{array}$ & $\begin{array}{l}39 \\
39 \\
39 \\
36 \\
33 \\
32 \\
32 \\
32 \\
31\end{array}$ & $\begin{array}{l}1.5 \\
1.5 \\
1.5 \\
1.4 \\
1.3 \\
1.3 \\
1.3 \\
1.3 \\
1.2\end{array}$ \\
\hline
\end{tabular}

$\begin{array}{ccc}\text { OUBIC } & \text { ACOJ- } \\ \text { FEET } & \text { MU- } & \text { PER- } \\ \text { PER } & \text { TOTAL LATED } & \text { CENT } \\ \text { CIASS SECOND } & \text { DAYS DAYS } & \text { DAYS }\end{array}$

$\begin{array}{rrrrr}18 & 3.3 & 0 & 31 & 1.2 \\ 19 & 4.1 & 2 & 31 & 1.2 \\ 20 & 5.0 & 2 & 29 & 1.1 \\ 21 & 6.1 & 3 & 27 & 1.1 \\ 22 & 7.5 & 1 & 24 & 0.9 \\ 23 & 9.3 & 0 & 23 & 0.9 \\ 24 & 11.0 & 1 & 23 & 0.9 \\ 25 & 14.0 & 8 & 22 & 0.9 \\ 26 & 17.0 & 2 & 14 & 0.5\end{array}$

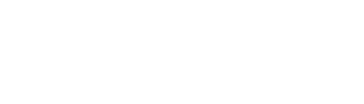

$\begin{array}{rrrrr}27 & 21.0 & 1 & 12 & 0.5 \\ 28 & 26.0 & 4 & 11 & 0.4 \\ 29 & 32.0 & 3 & 7 & 0.3 \\ 30 & 39.0 & 1 & 4 & 0.2 \\ 31 & 48.0 & 1 & 3 & 0.1 \\ 32 & 59.0 & 0 & 2 & 0.1 \\ 33 & 72.0 & 0 & 2 & 0.1 \\ 34 & 89.0 & 2 & 2 & 0.1\end{array}$

MONIHLY MEAN DISCHARGES, IN CUBIC FEET PER SECOND, FOR EACH WATER YEAR

$\begin{array}{lllllllllllll}\text { YEAR } & \text { OCT } & \text { NOV } & \text { DEC } & \text { JAN } & \text { FEB } & \text { MAR } & \text { APR } & \text { MAY } & \text { JUNE } & \text { JULY } & \text { AUG } & \text { SEP } \\ 1945 & 0.00 & 0.00 & 0.00 & 0.00 & 0.00 & 0.00 & 0.00 & 0.00 & 0.00 & 0.00 & 0.00 & 0.00 \\ 1946 & 0.00 & 0.00 & 0.00 & 0.00 & 0.00 & 0.00 & 0.00 & 0.00 & 0.00 & 0.00 & 0.00 & 0.00 \\ 1947 & 0.00 & 0.00 & 0.00 & 0.00 & 0.00 & 0.00 & 0.00 & 0.00 & 0.00 & 0.00 & 0.00 & 0.00 \\ 1948 & 0.00 & 0.00 & 0.00 & 0.00 & 0.00 & 0.00 & 0.00 & 1.05 & 0.00 & 0.00 & 0.00 & 0.00 \\ 1949 & 0.00 & 0.00 & 0.00 & 0.00 & 0.00 & 0.00 & 2.21 & 6.85 & 13.9 & 0.00 & 0.00 & 0.00 \\ 1950 & 0.00 & 0.00 & 0.00 & 0.00 & 0.00 & 0.00 & 0.00 & 0.00 & 0.00 & 0.00 & 0.00 & 0.00 \\ 1951 & 0.00 & 0.00 & 0.00 & 0.00 & 0.00 & 0.00 & 0.00 & 0.00 & 0.00 & 0.00 & 0.00 & 0.00\end{array}$

09179000 ROC CREEK NEAR URANIUM, $\infty$

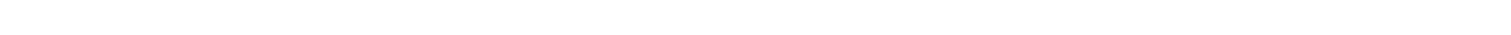
bank at La Sal National Forest boundary, $1.2 \mathrm{mi}$ west of Uranium.

DRAINAGE AREA. $-69.5 \mathrm{mi}^{2}$.

PERIOD OF RECORD AVALIABLE.--August 1944 to September 1952.

GAGE.--Water-stage recorder. Altitude of gage is 5,200 ft from topographic map. Prior to July 26, 1946, at site 0.2 mi downstream at different datum.

REMARKS.-Most of flow of Geyser and Deep Creeks in Roc Creek basin is diverted to Buckeye Reservoir in West Paradox Creek basin; release through Buckeye Reservoir outlet shows approximately the diversion from Roc Creek basin. Between the present gage and the site $0.2 \mathrm{mi}$ downstream used prior to July 26, 1946, there is one small diversion for irrigation of a few acres below station.

AVERAGE DISCHARGE. -8 years, $10.5 \mathrm{ft}^{3} / \mathrm{s}, 7,600$ acre- $\mathrm{ft} / \mathrm{yr}$.

EXTREMES FOR PERIOD OF RECORD.--Maximum discharge, $885 \mathrm{ft}^{3} / \mathrm{s}$ July 10, 1952, gage height, $5.55 \mathrm{ft}$, on basis of slope-area measurement of peak flow; no flow July 7, 1946, Dec, 3-7, 13-22, 1948. 
DOLORES RIVER BASIN

09179000 ROC CREEK NEAR URANIUM, CO--Continued

LONEST MEAN DISCHARGE, IN OUBIC FEET PER SECOND, AND RANRING FOR THE INDICATED NUMBER OF CONSECUTIVE DAYS FOR EACH CLIMATIC YEAR, APRIL I-MARCH 31

\begin{tabular}{|c|c|c|c|c|c|c|c|c|c|c|c|c|c|c|c|c|c|c|c|}
\hline YEAR & 1 & & 3 & & 7 & & 14 & & $\begin{array}{l}\text { CONSE } \\
30\end{array}$ & QTTIVE & $\begin{array}{l}\text { DAYS } \\
60\end{array}$ & & 90 & & 120 & & 183 & & ALL \\
\hline $\begin{array}{l}1946 \\
1947 \\
1948 \\
1949 \\
1950\end{array}$ & $\begin{array}{l}1.19 \\
0.00 \\
0.60 \\
0.00 \\
1.19\end{array}$ & $\begin{array}{l}7 \\
1 \\
5 \\
2 \\
6\end{array}$ & $\begin{array}{l}1.30 \\
0.23 \\
0.60 \\
0.00 \\
1.30\end{array}$ & $\begin{array}{l}7 \\
3 \\
5 \\
1 \\
6\end{array}$ & $\begin{array}{l}1.60 \\
0.31 \\
0.66 \\
0.00 \\
1.40\end{array}$ & $\begin{array}{l}7 \\
4 \\
5 \\
1 \\
6\end{array}$ & $\begin{array}{l}1.90 \\
0.36 \\
0.68 \\
0.04 \\
1.50\end{array}$ & $\begin{array}{l}7 \\
2 \\
5 \\
1 \\
6\end{array}$ & $\begin{array}{l}2.00 \\
0.42 \\
0.71 \\
0.08 \\
1.60\end{array}$ & $\begin{array}{l}7 \\
2 \\
5 \\
1 \\
6\end{array}$ & $\begin{array}{l}3.20 \\
0.72 \\
0.76 \\
0.35 \\
1.70\end{array}$ & $\begin{array}{l}7 \\
3 \\
5 \\
1 \\
6\end{array}$ & $\begin{array}{l}3.90 \\
0.95 \\
0.96 \\
0.59 \\
2.40\end{array}$ & $\begin{array}{l}7 \\
3 \\
4 \\
1 \\
6\end{array}$ & $\begin{array}{l}4.50 \\
0.96 \\
1.19 \\
0.71 \\
3.10\end{array}$ & $\begin{array}{l}7 \\
2 \\
5 \\
1 \\
6\end{array}$ & $\begin{array}{l}4.80 \\
1.19 \\
1.40 \\
0.87 \\
4.10\end{array}$ & $\begin{array}{l}7 \\
2 \\
3 \\
1 \\
6\end{array}$ & $\begin{array}{c}11.0 \\
3.30 \\
5.70 \\
11.0 \\
21.0\end{array}$ \\
\hline $\begin{array}{l}951 \\
952\end{array}$ & $\begin{array}{l}0.10 \\
0.30\end{array}$ & $\begin{array}{l}3 \\
4\end{array}$ & $\begin{array}{l}0.17 \\
0.30\end{array}$ & $\begin{array}{l}2 \\
4\end{array}$ & $\begin{array}{l}0.23 \\
0.31\end{array}$ & $\begin{array}{l}2 \\
3\end{array}$ & $\begin{array}{l}0.44 \\
0.39\end{array}$ & $\begin{array}{l}4 \\
3\end{array}$ & $\begin{array}{l}0.47 \\
0.51\end{array}$ & $\begin{array}{l}3 \\
4\end{array}$ & $\begin{array}{l}0.63 \\
0.73\end{array}$ & $\begin{array}{l}2 \\
4\end{array}$ & $\begin{array}{l}0.97 \\
0.86\end{array}$ & $\begin{array}{l}5 \\
2\end{array}$ & $\begin{array}{l}0.99 \\
1.10\end{array}$ & $\begin{array}{l}3 \\
4\end{array}$ & $\begin{array}{l}1.50 \\
1.60\end{array}$ & $\begin{array}{l}4 \\
5\end{array}$ & $\begin{array}{l}7.30 \\
3.40\end{array}$ \\
\hline
\end{tabular}

HIGHEST MEAN DISCHARGE, IN OBBIC FEET PER SECOND, AND RANKING FOR THE INDICATED MUMBER OF CONSECUTIVE DAYS FOR EACH WATER YEAR, OCTOBER 1-SEPTEMBER 30

\begin{tabular}{|c|c|c|c|c|c|c|c|c|c|c|c|c|c|c|c|c|c|c|c|}
\hline YEAR & 1 & & 3 & & 7 & & 15 & & $\begin{array}{l}\text { CONSE } \\
30\end{array}$ & II & $\begin{array}{l}\text { VE DAYS } \\
60\end{array}$ & & 90 & & 120 & & 183 & & ALL \\
\hline 1945 & 84.0 & 4 & 80.0 & 4 & 72.0 & 4 & 60.0 & 4 & 48.0 & 4 & 32.0 & 4 & 25.0 & 4 & 21.0 & 4 & 16.0 & 4 & 9.60 \\
\hline
\end{tabular}

\section{DURATION OF DISCHARGE FOR EACH WATER YEAR}

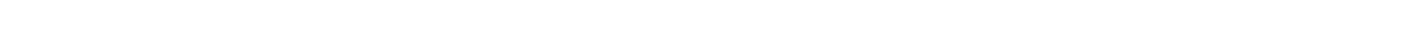
YEAR NUMBR OF DAYS IN CTASS
-DAYS

$\begin{array}{lllllllllllllllllllllllllllll}1945 & 1 & 9 & 20 & 25 & 20 & 94 & 55 & 11 & 14 & 39 & 5 & 32 & 7 & 6 & 4 & 6 & 8 & 5 & 4 & & & & & 3507.7\end{array}$

$\begin{array}{lllllllllllllllllllllll}1946 & 1 & 7 & 16 & 37 & 17 & 8 & 10 & 11 & 8 & 5 & 10 & 10 & 67 & 38 & 49 & 35 & 11 & 9 & 16 & & & \end{array}$

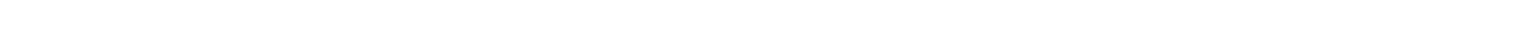

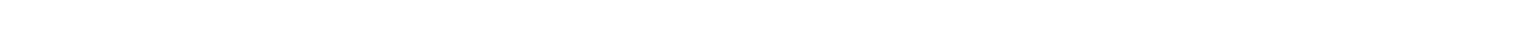

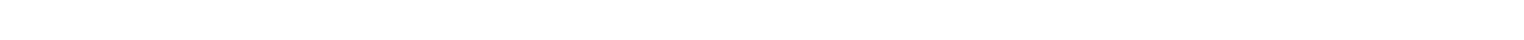

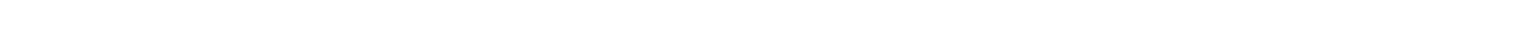

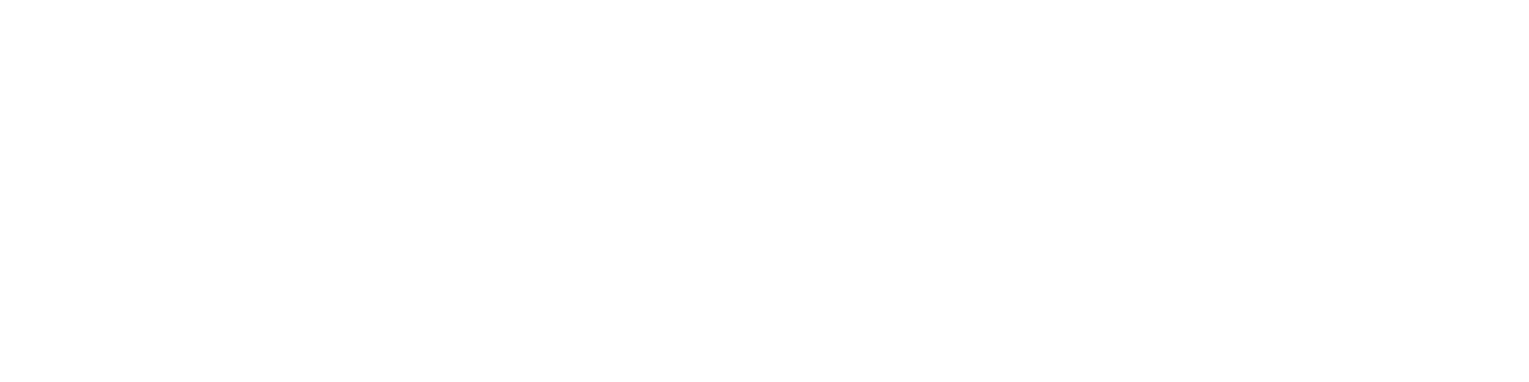

MONIHLY MEAN DISCHARGES, IN CUBIC FEET PER SECOND, FOR EACH WATER YEAR

$\begin{array}{lllllllllllll}\text { YEAR } & \text { OCT } & \text { NOV } & \text { DEC } & \text { JAN } & \text { FEB } & \text { MAR } & \text { APR } & \text { MAY } & \text { JUNE } & \text { JULY } & \text { AUG } & \text { SEP } \\ 1945 & 2.79 & 4.58 & 4.00 & 4.00 & 5.00 & 9.00 & 20.3 & 43.1 & 10.3 & 3.37 & 5.50 & 2.88 \\ 1946 & 6.45 & 5.78 & 5.37 & 6.64 & 5.00 & 11.8 & 14.5 & 5.79 & 1.09 & 1.39 & 0.95 & 0.49 \\ 1947 & 1.65 & 1.87 & 1.97 & 2.61 & 2.46 & 4.36 & 19.6 & 18.8 & 10.4 & 3.33 & 2.02 & 1.42 \\ 1948 & 1.88 & 1.40 & 0.74 & 0.80 & 3.20 & 4.90 & 59.1 & 35.7 & 12.0 & 0.99 & 1.42 & 1.06 \\ 1949 & 1.06 & 0.65 & 0.08 & 3.00 & 5.00 & 6.67 & 74.7 & 78.6 & 47.5 & 13.6 & 3.52 & 1.63 \\ 1950 & 2.73 & 5.53 & 5.30 & 5.83 & 8.14 & 9.38 & 44.9 & 16.6 & 5.60 & 1.70 & 0.53 & 1.12 \\ 1951 & 1.32 & 1.98 & 2.41 & 3.03 & 3.84 & 4.79 & 5.74 & 5.73 & 2.41 & 0.52 & 1.09 & 1.02 \\ 1952 & 1.95 & 2.64 & 3.77 & 4.60 & 5.30 & 5.55 & 83.6 & 97.4 & 41.9 & 3.14 & 1.84 & 1.38\end{array}$


DOLORES RIVER BASIN

09179000 ROC CREEK NEAR URANIUM, CO--Continued

ANNUAL PEAK DISCHARGE, IN CUBIC FEET PER SECOND, AND CORRESPONDING GAGE HEIGHT, IN FEET, FOR EACH WATER YEAR

\begin{tabular}{|c|c|c|c|c|c|c|c|c|c|c|c|}
\hline $\begin{array}{l}\text { WATERR } \\
\text { YEAR }\end{array}$ & DATE & $\begin{array}{c}\text { GAGE } \\
\text { HEIGHT }\end{array}$ & $\begin{array}{c}\text { PEAK } \\
\text { DISCHARGE }\end{array}$ & $\begin{array}{l}\text { WATER } \\
\text { YEAR }\end{array}$ & DATE & $\begin{array}{l}\text { GAGE } \\
\text { HEIGHT }\end{array}$ & $\begin{array}{c}\text { PEAK } \\
\text { DISCHARGE }\end{array}$ & $\begin{array}{l}\text { WATER } \\
\text { YEAR }\end{array}$ & DATE & $\begin{array}{l}\text { GAGE } \\
\text { HEIGHT }\end{array}$ & $\begin{array}{c}\text { PEAK } \\
\text { DISCHARGE }\end{array}$ \\
\hline $\begin{array}{l}1945 \\
1946 \\
1947\end{array}$ & $\begin{array}{l}\text { AUG. } 06,1945 \\
\text { MAY } 10,1946 \\
\text { AUG. } 22,1947\end{array}$ & $\begin{array}{l}4.69 \\
4.24 \\
2.27\end{array}$ & $\begin{array}{l}146 \\
102 \\
145\end{array}$ & $\begin{array}{l}1948 \\
1949 \\
1950\end{array}$ & $\begin{array}{l}\text { APR. } 18,1948 \\
\text { APR. } 24,1949 \\
\text { APR. } 06,1950\end{array}$ & $\begin{array}{l}3.93 \\
3.85 \\
2.48\end{array}$ & $\begin{array}{l}508 \\
488 \\
164\end{array}$ & $\begin{array}{l}1951 \\
1952\end{array}$ & $\begin{array}{l}\text { AUG. } 20,1951 \\
\text { JULY } 10,1952\end{array}$ & $\begin{array}{l}1.21 \\
5.55\end{array}$ & $\begin{array}{r}18 \\
885\end{array}$ \\
\hline
\end{tabular}

09180000 DOLORES RTVER NEAR CISCO, UT

LOCATION.--Lat $38^{\circ} 47^{\prime} 50$, long $109^{\circ} 11^{\prime} 40^{\prime \prime}$, in SW $^{1} \mathrm{SE}^{\prime} / \mathrm{sec} .18$, T.23 S., R. 25 E., Grand County, Hydrologic Unit 14030004, on left bank $0.2 \mathrm{mi}$ downstream from Line Canyon, $9.1 \mathrm{mi}$ upstream from mouth, $13.5 \mathrm{mi}$ downstream from Colorado-Utah State 1 ine, and $13.9 \mathrm{mi}$ southeast of Cisco.

DRAINAGE AREA. $--4,580 \mathrm{mi}^{2}$, approximately.

PERIOD OF RECORD AVAILABLE. --October 1950 to September 1981.

REVISED RECORDS. --WDR UT-75: 1974.

GAGE.-Water-stage recorder. Altitude of gage is 4,165 ft from river-profile map. Dec. 6, 1950 to Apr. 18, 1956 , at site 200 ft downstream at different datum; Apr.19, 1965 to Sept, 3, 1975, at site $10 \mathrm{ft}$ downstream at different datum.

RFMARKS.--Many diversions for irrigation above station.

AVERAGE DISCHARGE. --31 years, $739 \mathrm{ft}^{3} / \mathrm{s}, 535,400 \mathrm{acre}-\mathrm{ft} / \mathrm{yr}$.

EXTREMES FOR PERIOD OF RECORD.-Maximum discharge, 17,400 ft ${ }^{3} / \mathrm{s} \mathrm{Apr.} \mathrm{21,} \mathrm{1958,} \mathrm{gage} \mathrm{height,} 9.84$ ft, at different datum; minimum, $3.4 \mathrm{ft}^{3} / \mathrm{s}$ Sept. 23,1956 .

LOWEST MEAN DISCHARGE, IN CUBIC FEET PER SECOND, AND RANKING FOR THE INDICATED NUMBER OF CONSECUTIVE DAYS FOR EACH CLIMATIC YEAR, APRIL 1-MARCH 31

YEAR

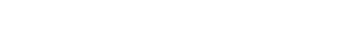

\begin{tabular}{|c|c|c|c|c|c|c|c|c|c|c|c|c|c|c|c|c|c|c|c|c|}
\hline Lis & 1 & & 3 & & 7 & & 14 & & 30 & 0 & 60 & & 90 & & 120 & & 183 & & ALLL & \\
\hline $\begin{array}{l}1956 \\
1957 \\
1958 \\
1959 \\
1960\end{array}$ & $\begin{array}{c}36.0 \\
4.20 \\
139 \\
64.0 \\
30.0\end{array}$ & $\begin{array}{r}12 \\
1 \\
29 \\
23 \\
9\end{array}$ & $\begin{array}{c}37.0 \\
5.50 \\
143 \\
67.0 \\
31.0\end{array}$ & $\begin{array}{r}12 \\
1 \\
29 \\
23 \\
9\end{array}$ & $\begin{array}{c}37.0 \\
9.20 \\
150 \\
70.0 \\
33.0\end{array}$ & $\begin{array}{r}11 \\
1 \\
28 \\
21 \\
7\end{array}$ & $\begin{array}{r}39.0 \\
12.0 \\
169 \\
80.0 \\
42.0\end{array}$ & $\begin{array}{r}8 \\
1 \\
28 \\
21 \\
10\end{array}$ & $\begin{array}{l}42.0 \\
14.0 \\
207 \\
121 \\
56.0\end{array}$ & $\begin{array}{r}6 \\
1 \\
28 \\
24 \\
11\end{array}$ & $\begin{array}{c}55.0 \\
18.0 \\
257 \\
131 \\
97.0\end{array}$ & $\begin{array}{r}5 \\
1 \\
29 \\
24 \\
16\end{array}$ & $\begin{array}{l}71.0 \\
43.0 \\
284 \\
135 \\
121\end{array}$ & $\begin{array}{r}5 \\
1 \\
29 \\
22 \\
17\end{array}$ & $\begin{array}{l}89.0 \\
55.0 \\
338 \\
141 \\
121\end{array}$ & $\begin{array}{r}7 \\
1 \\
30 \\
21 \\
15\end{array}$ & $\begin{array}{l}106 \\
70.0 \\
395 \\
146 \\
129\end{array}$ & $\begin{array}{r}7 \\
1 \\
30 \\
18 \\
12\end{array}$ & $\begin{array}{r}456 \\
364 \\
1660 \\
1330 \\
276\end{array}$ & $\begin{array}{r}12 \\
7 \\
29 \\
25 \\
4\end{array}$ \\
\hline $\begin{array}{l}1961 \\
1962 \\
1963 \\
1964 \\
1965\end{array}$ & $\begin{array}{l}28.0 \\
59.0 \\
45.0 \\
35.0 \\
53.0\end{array}$ & $\begin{array}{r}7 \\
20 \\
17 \\
11 \\
19\end{array}$ & $\begin{array}{l}29.0 \\
60.0 \\
47.0 \\
35.0 \\
54.0\end{array}$ & $\begin{array}{r}7 \\
20 \\
17 \\
11 \\
19\end{array}$ & $\begin{array}{l}34.0 \\
71.0 \\
48.0 \\
41.0 \\
59.0\end{array}$ & $\begin{array}{l}10 \\
22 \\
15 \\
13 \\
19\end{array}$ & $\begin{array}{l}44.0 \\
80.0 \\
50.0 \\
50.0 \\
64.0\end{array}$ & $\begin{array}{l}12 \\
22 \\
15 \\
16 \\
19\end{array}$ & $\begin{array}{c}48.0 \\
131 \\
63.0 \\
66.0 \\
96.0\end{array}$ & $\begin{array}{r}9 \\
26 \\
13 \\
15 \\
19\end{array}$ & $\begin{array}{c}55.0 \\
139 \\
112 \\
81.0 \\
109\end{array}$ & $\begin{array}{r}6 \\
25 \\
19 \\
12 \\
18\end{array}$ & $\begin{array}{c}68.0 \\
157 \\
123 \\
89.0 \\
117\end{array}$ & $\begin{array}{r}4 \\
25 \\
18 \\
11 \\
16\end{array}$ & $\begin{array}{c}81.0 \\
178 \\
140 \\
94.0 \\
124\end{array}$ & $\begin{array}{r}4 \\
25 \\
20 \\
9 \\
16\end{array}$ & $\begin{array}{c}89.0 \\
214 \\
133 \\
97.0 \\
140\end{array}$ & $\begin{array}{r}2 \\
25 \\
15 \\
5 \\
17\end{array}$ & $\begin{array}{l}614 \\
540 \\
745 \\
268 \\
431\end{array}$ & $\begin{array}{r}17 \\
14 \\
19 \\
3 \\
10\end{array}$ \\
\hline $\begin{array}{l}1966 \\
1967 \\
1968 \\
1969 \\
1970\end{array}$ & $\begin{array}{c}151 \\
11.0 \\
60.0 \\
38.0 \\
102\end{array}$ & $\begin{array}{r}30 \\
2 \\
21 \\
13 \\
27\end{array}$ & $\begin{array}{c}166 \\
13.0 \\
61.0 \\
41.0 \\
104\end{array}$ & $\begin{array}{r}30 \\
2 \\
21 \\
14 \\
27\end{array}$ & $\begin{array}{c}186 \\
16.0 \\
70.0 \\
44.0 \\
128\end{array}$ & $\begin{array}{r}30 \\
2 \\
20 \\
14 \\
27\end{array}$ & $\begin{array}{r}201 \\
20.0 \\
80.0 \\
49.0 \\
144\end{array}$ & $\begin{array}{r}30 \\
2 \\
20 \\
13 \\
27\end{array}$ & $\begin{array}{c}227 \\
47.0 \\
90.0 \\
67.0 \\
180\end{array}$ & $\begin{array}{r}30 \\
8 \\
18 \\
16 \\
27\end{array}$ & $\begin{array}{r}284 \\
56.0 \\
97.0 \\
90.0 \\
190\end{array}$ & $\begin{array}{r}30 \\
7 \\
17 \\
13 \\
26\end{array}$ & $\begin{array}{l}315 \\
75.0 \\
101 \\
102 \\
197\end{array}$ & $\begin{array}{r}30 \\
7 \\
13 \\
14 \\
27\end{array}$ & $\begin{array}{c}322 \\
85.0 \\
103 \\
102 \\
204\end{array}$ & $\begin{array}{r}29 \\
5 \\
12 \\
11 \\
27\end{array}$ & $\begin{array}{l}373 \\
128 \\
122 \\
130 \\
215\end{array}$ & $\begin{array}{l}29 \\
11 \\
10 \\
13 \\
26\end{array}$ & $\begin{array}{r}1270 \\
550 \\
302 \\
700 \\
829\end{array}$ & $\begin{array}{r}24 \\
15 \\
5 \\
18 \\
21\end{array}$ \\
\hline $\begin{array}{l}1971 \\
1972 \\
1973 \\
1974 \\
1975\end{array}$ & $\begin{array}{r}130 \\
43.0 \\
14.0 \\
61.0 \\
16.0\end{array}$ & $\begin{array}{r}28 \\
16 \\
4 \\
22 \\
5\end{array}$ & $\begin{array}{r}134 \\
45.0 \\
16.0 \\
67.0 \\
16.0\end{array}$ & $\begin{array}{r}28 \\
16 \\
3 \\
22 \\
4\end{array}$ & $\begin{array}{r}158 \\
49.0 \\
21.0 \\
79.0 \\
17.0\end{array}$ & $\begin{array}{r}29 \\
16 \\
5 \\
23 \\
3\end{array}$ & $\begin{array}{c}200 \\
60.0 \\
27.0 \\
100 \\
22.0\end{array}$ & $\begin{array}{r}29 \\
18 \\
5 \\
24 \\
3\end{array}$ & $\begin{array}{c}214 \\
107 \\
30.0 \\
107 \\
28.0\end{array}$ & $\begin{array}{r}29 \\
21 \\
4 \\
22 \\
2\end{array}$ & $\begin{array}{c}240 \\
191 \\
52.0 \\
126 \\
39.0\end{array}$ & $\begin{array}{r}28 \\
27 \\
4 \\
22 \\
3\end{array}$ & $\begin{array}{c}250 \\
185 \\
75.0 \\
129 \\
59.0\end{array}$ & $\begin{array}{r}28 \\
26 \\
8 \\
21 \\
3\end{array}$ & $\begin{array}{c}252 \\
195 \\
131 \\
148 \\
78.0\end{array}$ & $\begin{array}{r}28 \\
26 \\
18 \\
23 \\
2\end{array}$ & $\begin{array}{c}258 \\
202 \\
264 \\
158 \\
92.0\end{array}$ & $\begin{array}{r}27 \\
24 \\
28 \\
21 \\
3\end{array}$ & $\begin{array}{r}827 \\
609 \\
385 \\
1750 \\
435\end{array}$ & $\begin{array}{r}20 \\
16 \\
8 \\
30 \\
11\end{array}$ \\
\hline $\begin{array}{l}1976 \\
1977 \\
1978 \\
1979 \\
1980\end{array}$ & $\begin{array}{l}83.0 \\
30.0 \\
13.0 \\
21.0 \\
49\end{array}$ & $\begin{array}{r}25 \\
8 \\
3 \\
6 \\
18\end{array}$ & $\begin{array}{l}85.0 \\
31.0 \\
16.0 \\
22.0 \\
49.0\end{array}$ & $\begin{array}{r}25 \\
8 \\
5 \\
6 \\
18\end{array}$ & $\begin{array}{l}90.0 \\
33.0 \\
18.0 \\
24.0 \\
49.0\end{array}$ & $\begin{array}{r}25 \\
8 \\
4 \\
6 \\
17\end{array}$ & $\begin{array}{r}103 \\
42.0 \\
40.0 \\
25.0 \\
50.0\end{array}$ & $\begin{array}{r}25 \\
11 \\
9 \\
4 \\
14\end{array}$ & $\begin{array}{r}121 \\
63.0 \\
59.0 \\
29.0 \\
54.0\end{array}$ & $\begin{array}{r}25 \\
14 \\
12 \\
3 \\
10\end{array}$ & $\begin{array}{r}127 \\
74.0 \\
93.0 \\
35.0 \\
72.0\end{array}$ & $\begin{array}{r}23 \\
10 \\
15 \\
2 \\
9\end{array}$ & $\begin{array}{r}128 \\
83.0 \\
99.0 \\
56.0 \\
89.0\end{array}$ & $\begin{array}{r}20 \\
9 \\
12 \\
2 \\
10\end{array}$ & $\begin{array}{r}134 \\
93.0 \\
109 \\
86.0 \\
98.0\end{array}$ & $\begin{array}{r}19 \\
8 \\
13 \\
6 \\
10\end{array}$ & $\begin{array}{c}153 \\
100 \\
121 \\
96.0 \\
135\end{array}$ & $\begin{array}{r}19 \\
6 \\
9 \\
4 \\
16\end{array}$ & $\begin{array}{r}1240 \\
492 \\
162 \\
1040 \\
1490\end{array}$ & $\begin{array}{r}23 \\
13 \\
1 \\
22 \\
27\end{array}$ \\
\hline 1981 & 79.0 & 24 & 80.0 & 24 & 81.0 & 24 & 86.0 & 23 & 99.0 & 20 & 123 & 20 & 125 & 19 & 129 & 17 & 132 & 14 & 1410 & 26 \\
\hline
\end{tabular}


DOLORES RIVER BASIN

09180000 DOLORES RIVER NEAR CISCO, UT--Continued

HIGHEST MEAN DISCHARGE, IN CABIC FEET PER SECOND, AND RANKING FOR THE INDICATED NUMBER OF CONSECTTIVE DAYS FOR EACH WATER YEAR, OCTOBER I-SEPTEMBER 30

YEAR

\begin{tabular}{|c|c|c|c|c|c|c|c|c|c|c|c|c|c|c|c|c|c|c|c|c|}
\hline & 1 & & 3 & & . & & 15 & & 30 & & 60 & & $x$ & & 120 & & 183 & & ALI & \\
\hline $\begin{array}{l}1952 \\
1953 \\
1954 \\
1955\end{array}$ & $\begin{array}{r}10400 \\
2850 \\
2010 \\
3350\end{array}$ & $\begin{array}{r}5 \\
21 \\
26 \\
18\end{array}$ & $\begin{array}{r}10300 \\
2640 \\
1270 \\
3090\end{array}$ & $\begin{array}{r}4 \\
22 \\
30 \\
18\end{array}$ & $\begin{array}{l}9230 \\
2250 \\
1110 \\
2650\end{array}$ & $\begin{array}{r}4 \\
22 \\
28 \\
18\end{array}$ & $\begin{array}{l}8690 \\
1990 \\
1080 \\
2310\end{array}$ & $\begin{array}{r}4 \\
22 \\
28 \\
20\end{array}$ & $\begin{array}{r}8250 \\
1840 \\
880 \\
2100\end{array}$ & $\begin{array}{r}2 \\
22 \\
27 \\
20\end{array}$ & $\begin{array}{r}6400 \\
1390 \\
820 \\
1760\end{array}$ & $\begin{array}{r}5 \\
23 \\
26 \\
20\end{array}$ & $\begin{array}{r}5230 \\
1070 \\
640 \\
1380\end{array}$ & $\begin{array}{r}3 \\
23 \\
27 \\
20\end{array}$ & $\begin{array}{r}4190 \\
902 \\
524 \\
1160\end{array}$ & $\begin{array}{r}3 \\
23 \\
28 \\
18\end{array}$ & $\begin{array}{r}2850 \\
663 \\
399 \\
849\end{array}$ & $\begin{array}{r}4 \\
22 \\
28 \\
18\end{array}$ & $\begin{array}{r}1500 \\
402 \\
288 \\
497\end{array}$ & $\begin{array}{r}3 \\
22 \\
27 \\
18\end{array}$ \\
\hline $\begin{array}{l}1956 \\
1957 \\
1958 \\
1959 \\
1960\end{array}$ & $\begin{array}{r}2250 \\
8780 \\
16100 \\
1460 \\
5180\end{array}$ & $\begin{array}{r}25 \\
8 \\
1 \\
30 \\
13\end{array}$ & $\begin{array}{r}2220 \\
8530 \\
15600 \\
1360 \\
4970\end{array}$ & $\begin{array}{r}24 \\
8 \\
1 \\
29 \\
13\end{array}$ & $\begin{array}{r}2130 \\
8000 \\
13900 \\
1090 \\
4470\end{array}$ & $\begin{array}{r}24 \\
8 \\
1 \\
29 \\
13\end{array}$ & $\begin{array}{r}1950 \\
6760 \\
10100 \\
711 \\
3520\end{array}$ & $\begin{array}{r}23 \\
7 \\
2 \\
29 \\
14\end{array}$ & $\begin{array}{r}1630 \\
5920 \\
8220 \\
642 \\
2660\end{array}$ & $\begin{array}{r}23 \\
6 \\
3 \\
29 \\
14\end{array}$ & $\begin{array}{r}1400 \\
5400 \\
6620 \\
542 \\
2260\end{array}$ & $\begin{array}{r}22 \\
6 \\
4 \\
29 \\
15\end{array}$ & $\begin{array}{r}1160 \\
4640 \\
4880 \\
500 \\
2100\end{array}$ & $\begin{array}{r}22 \\
6 \\
5 \\
29 \\
14\end{array}$ & $\begin{array}{r}926 \\
3970 \\
3820 \\
424 \\
1760\end{array}$ & $\begin{array}{r}22 \\
5 \\
6 \\
29 \\
12\end{array}$ & $\begin{array}{r}656 \\
2870 \\
2650 \\
336 \\
1230\end{array}$ & $\begin{array}{r}23 \\
3 \\
6 \\
29 \\
14\end{array}$ & $\begin{array}{r}371 \\
1500 \\
1470 \\
235 \\
672\end{array}$ & $\begin{array}{r}23 \\
4 \\
5 \\
29 \\
15\end{array}$ \\
\hline $\begin{array}{l}1961 \\
1962 \\
1963 \\
1964 \\
1965\end{array}$ & $\begin{array}{r}2910 \\
5840 \\
2600 \\
3530 \\
10300\end{array}$ & $\begin{array}{r}20 \\
11 \\
23 \\
16 \\
6\end{array}$ & $\begin{array}{l}2880 \\
5630 \\
2480 \\
3330 \\
9880\end{array}$ & $\begin{array}{r}20 \\
11 \\
23 \\
17 \\
5\end{array}$ & $\begin{array}{l}2610 \\
5160 \\
2190 \\
3230 \\
8680\end{array}$ & $\begin{array}{r}20 \\
11 \\
23 \\
16 \\
6\end{array}$ & $\begin{array}{l}2330 \\
4620 \\
1550 \\
2950 \\
7120\end{array}$ & $\begin{array}{r}18 \\
11 \\
24 \\
15 \\
6\end{array}$ & $\begin{array}{l}2120 \\
3950 \\
1210 \\
2130 \\
5270\end{array}$ & $\begin{array}{r}19 \\
11 \\
25 \\
18 \\
8\end{array}$ & $\begin{array}{l}1890 \\
2730 \\
1020 \\
1540 \\
4180\end{array}$ & $\begin{array}{r}17 \\
12 \\
24 \\
21 \\
8\end{array}$ & $\begin{array}{r}1450 \\
2280 \\
840 \\
1180 \\
3540\end{array}$ & $\begin{array}{r}18 \\
11 \\
24 \\
21 \\
9\end{array}$ & $\begin{array}{r}1160 \\
1850 \\
676 \\
990 \\
2930\end{array}$ & $\begin{array}{r}19 \\
11 \\
24 \\
21 \\
8\end{array}$ & $\begin{array}{r}832 \\
1320 \\
519 \\
717 \\
2060\end{array}$ & $\begin{array}{r}19 \\
12 \\
24 \\
21 \\
8\end{array}$ & $\begin{array}{r}478 \\
747 \\
340 \\
409 \\
1100\end{array}$ & $\begin{array}{r}19 \\
12 \\
24 \\
21 \\
8\end{array}$ \\
\hline $\begin{array}{l}1966 \\
1967 \\
1968 \\
1969 \\
1970\end{array}$ & $\begin{array}{l}3890 \\
2270 \\
4450 \\
6020 \\
5600\end{array}$ & $\begin{array}{l}15 \\
24 \\
14 \\
10 \\
12\end{array}$ & $\begin{array}{l}3700 \\
2070 \\
4410 \\
5930 \\
5350\end{array}$ & $\begin{array}{l}15 \\
25 \\
14 \\
10 \\
12\end{array}$ & $\begin{array}{l}3370 \\
1880 \\
4290 \\
5310 \\
4630\end{array}$ & $\begin{array}{l}15 \\
25 \\
14 \\
10 \\
12\end{array}$ & $\begin{array}{l}2760 \\
1540 \\
3930 \\
4920 \\
4560\end{array}$ & $\begin{array}{l}17 \\
25 \\
13 \\
10 \\
12\end{array}$ & $\begin{array}{l}2340 \\
1280 \\
3350 \\
4030 \\
3840\end{array}$ & $\begin{array}{l}16 \\
24 \\
13 \\
10 \\
12\end{array}$ & $\begin{array}{r}2270 \\
864 \\
2730 \\
3250 \\
2750\end{array}$ & $\begin{array}{l}14 \\
25 \\
13 \\
10 \\
11\end{array}$ & $\begin{array}{r}1930 \\
685 \\
2140 \\
2550 \\
2100\end{array}$ & $\begin{array}{l}15 \\
25 \\
12 \\
10 \\
13\end{array}$ & $\begin{array}{r}1580 \\
613 \\
1750 \\
2070 \\
1670\end{array}$ & $\begin{array}{l}15 \\
26 \\
13 \\
10 \\
14\end{array}$ & $\begin{array}{r}1140 \\
503 \\
1260 \\
1440 \\
1320\end{array}$ & $\begin{array}{l}15 \\
25 \\
13 \\
10 \\
11\end{array}$ & $\begin{array}{l}699 \\
330 \\
688 \\
796 \\
769\end{array}$ & $\begin{array}{l}13 \\
25 \\
14 \\
10 \\
11\end{array}$ \\
\hline $\begin{array}{l}1971 \\
1972 \\
1973 \\
1974 \\
1975\end{array}$ & $\begin{array}{r}3240 \\
1720 \\
13000 \\
3500 \\
9920\end{array}$ & $\begin{array}{r}19 \\
28 \\
2 \\
17 \\
7\end{array}$ & $\begin{array}{r}3010 \\
1440 \\
12600 \\
3330 \\
8890\end{array}$ & $\begin{array}{r}19 \\
28 \\
2 \\
16 \\
7\end{array}$ & $\begin{array}{r}2450 \\
1340 \\
11300 \\
2890 \\
8320\end{array}$ & $\begin{array}{r}21 \\
27 \\
2 \\
17 \\
7\end{array}$ & $\begin{array}{r}2140 \\
1190 \\
10700 \\
2780 \\
6690\end{array}$ & $\begin{array}{r}21 \\
26 \\
1 \\
16 \\
8\end{array}$ & $\begin{array}{r}1870 \\
940 \\
9540 \\
2490 \\
5680\end{array}$ & $\begin{array}{r}21 \\
26 \\
1 \\
15 \\
7\end{array}$ & $\begin{array}{r}1770 \\
759 \\
7640 \\
1770 \\
4870\end{array}$ & $\begin{array}{r}18 \\
27 \\
1 \\
19 \\
7\end{array}$ & $\begin{array}{r}1690 \\
646 \\
6190 \\
1380 \\
4200\end{array}$ & $\begin{array}{r}16 \\
26 \\
1 \\
19 \\
7\end{array}$ & $\begin{array}{r}1450 \\
614 \\
4920 \\
1120 \\
3410\end{array}$ & $\begin{array}{r}16 \\
25 \\
1 \\
20 \\
7\end{array}$ & $\begin{array}{r}1040 \\
477 \\
3370 \\
809 \\
2320\end{array}$ & $\begin{array}{r}16 \\
26 \\
1 \\
20 \\
7\end{array}$ & $\begin{array}{r}641 \\
313 \\
1850 \\
467 \\
1230\end{array}$ & $\begin{array}{r}16 \\
26 \\
1 \\
20 \\
7\end{array}$ \\
\hline $\begin{array}{l}1976 \\
1977 \\
1978 \\
1979 \\
1980\end{array}$ & $\begin{array}{r}2800 \\
1930 \\
7820 \\
12200 \\
10400\end{array}$ & $\begin{array}{r}22 \\
27 \\
9 \\
3 \\
4\end{array}$ & $\begin{array}{r}2750 \\
1560 \\
7290 \\
11700 \\
9830\end{array}$ & $\begin{array}{r}21 \\
26 \\
9 \\
3 \\
6\end{array}$ & $\begin{array}{r}2620 \\
1050 \\
5860 \\
11200 \\
8820\end{array}$ & $\begin{array}{r}19 \\
30 \\
9 \\
3 \\
5\end{array}$ & $\begin{array}{r}2320 \\
603 \\
4950 \\
9370 \\
8140\end{array}$ & $\begin{array}{r}19 \\
30 \\
9 \\
3 \\
5\end{array}$ & $\begin{array}{r}2170 \\
449 \\
4290 \\
7220 \\
7310\end{array}$ & $\begin{array}{r}17 \\
30 \\
9 \\
5 \\
4\end{array}$ & $\begin{array}{r}1930 \\
301 \\
4070 \\
6780 \\
6650\end{array}$ & $\begin{array}{r}16 \\
30 \\
9 \\
2 \\
3\end{array}$ & $\begin{array}{r}1620 \\
243 \\
3580 \\
5390 \\
5200\end{array}$ & $\begin{array}{r}17 \\
30 \\
8 \\
2 \\
4\end{array}$ & $\begin{array}{r}1280 \\
205 \\
2860 \\
4210 \\
4000\end{array}$ & $\begin{array}{r}17 \\
30 \\
9 \\
2 \\
4\end{array}$ & $\begin{array}{r}914 \\
177 \\
1930 \\
2890 \\
2710\end{array}$ & $\begin{array}{r}17 \\
30 \\
9 \\
2 \\
5\end{array}$ & $\begin{array}{r}522 \\
138 \\
1020 \\
1510 \\
1420\end{array}$ & $\begin{array}{r}17 \\
30 \\
9 \\
2 \\
6\end{array}$ \\
\hline 981 & 1630 & 29 & 1530 & 27 & 1360 & 26 & 1150 & 27 & 812 & 28 & 735 & 28 & 637 & 28 & 573 & 27 & 436 & 27 & 285 & 28 \\
\hline
\end{tabular}

DURATION OF DISCHARGE FOR EACH WATER YEAR

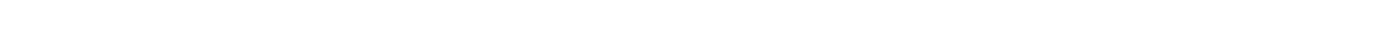

NUMBER OF DAYS IN CIASS

CUBIC FEET

PER SECOND

547511.0

146613.0

105138.0

181489.0

$\begin{array}{lllllllllllllllllll}3 & 7 & 7 & 6 & 12 & 63 & 65 & 81 & 16 & 20 & 13 & 8 & 15 & 8 & 8 & 15 & 9 & 7 & 2\end{array}$

$\begin{array}{lllllllllllllllll}6 & 11 & 11 & 13 & 23 & 31 & 99 & 55 & 29 & 15 & 10 & 7 & 16 & 24 & 13 & 1 & 1\end{array}$

$\begin{array}{lrrrrrrrrrrrrrrrrr}3 & 15 & 4 & 10 & 53 & 47 & 42 & 31 & 30 & 19 & 15 & 9 & 8 & 16 & 14 & 18 & 13 & 15\end{array}$

135947.

547513.0

538193.0

85704.0
245873.0

$\begin{array}{rrrrrrrrrrrrrrrrr}1 & 10 & 8 & 15 & 11 & 24 & 19 & 27 & 32 & 34 & 51 & 34 & 18 & 21 & 16 & 9 & 11\end{array}$

1960

$\begin{array}{llllllllllllllllll}2 & 11 & 16 & 67 & 81 & 21 & 27 & 18 & 26 & 13 & 13 & 5 & 6 & 6 & 20 & 10 & 19 & 4\end{array}$

$\begin{array}{llllllllllllllllllllll}11 & 4 & 14 & 33 & 43 & 66 & 32 & 21 & 10 & 10 & 12 & 18 & 21 & 15 & 8 & 8 & 8 & 13 & 6 & 2\end{array}$

$\begin{array}{lllllllllllllllll}1 & 11 & 20 & 37 & 39 & 76 & 40 & 23 & 30 & 23 & 13 & 8 & 17 & 15 & 6 & 1 & 5\end{array}$

$\begin{array}{lllllllllllllllllll}3 & 17 & 19 & 31 & 55 & 67 & 31 & 20 & 21 & 11 & 10 & 13 & 9 & 10 & 22 & 11 & 2 & 2 & 11\end{array}$

$\begin{array}{rrrrrrrrrrrrrrrrrrrrr}r 1 & 55 & 67 & 31 & 20 & 21 & 11 & 10 & 13 & 9 & 10 & 22 & 11 & 2 & 2 & 11 & 1 & & & \\ 2 & 39 & 46 & 69 & 28 & 18 & 14 & 15 & 11 & 6 & 5 & 14 & 12 & 17 & 17 & 23 & 11 & 7 & 4 & 3 & 4\end{array}$

174458.0

272673.0

124111.0

149530.0

402895.0

$\begin{array}{llllllllllllllllllllllll}3 & 2 & 4 & 5 & 8 & 3 & 7 & 13 & 7 & 8 & 11 & 22 & 46 & 61 & 43 & 15 & 18 & 5 & 7 & 24 & 24 & 12 & 15 & 2\end{array}$

$\begin{array}{lllllllllllllllll}1 & 2 & 11 & 43 & 67 & 33 & 52 & 35 & 35 & 25 & 14 & 10 & 12 & 8 & 11 & 5 & 1\end{array}$

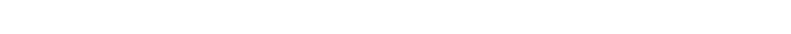

$\begin{array}{rrrrrrrrrrrrrrrrrrrrrrr}1 & -2 & 1 & 4 & 45 & 63 & 44 & 37 & 28 & 17 & 13 & 4 & 6 & 19 & 10 & 11 & 3 & 21 & 19 & 6 & 8 & 3\end{array}$

$\begin{array}{rrrrrrrrrrrrrrrrr}5 & 29 & 106 & 80 & 18 & 13 & 14 & 16 & 8 & 12 & 18 & 8 & 6 & 10 & 13 & 9\end{array}$

1970

$\begin{array}{llllllllllllllllll}5 & 5 & 9 & 15 & 4 & 15 & 36 & 111 & 42 & 11 & 6 & 3 & 1 & 25 & 38 & 22 & 13 & 4\end{array}$

$\begin{array}{lllllllllllllllllllll}1 & 2 & 4 & 8 & 16 & 5 & 5 & 12 & 20 & 18 & 45 & 67 & 46 & 21 & 25 & 20 & 17 & 19 & 9 & 5 & 1\end{array}$

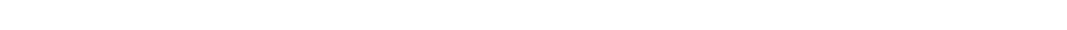

$\begin{array}{llllllllllllllllllllll}6 & 2 & 16 & 17 & 3 & 2 & 12 & 18 & 35 & 70 & 43 & 26 & 9 & 20 & 16 & 15 & 7 & 9 & 6 & 10 & 11 & 11\end{array}$

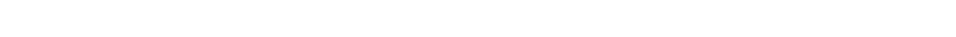

$\begin{array}{llllllllllllllllllll}1 & 5 & 6 & 12 & 8 & 8 & 75 & 90 & 29 & 19 & 15 & 8 & 10 & 3 & 8 & 5 & 15 & 26 & 21 & 2\end{array}$

$\begin{array}{lllllllllllllllllllll}1 & 9 & 2 & 5 & 9 & 12 & 25 & 75 & 81 & 55 & 44 & 15 & 14 & 5 & 4 & & 1 & 2 & 2 & 1 & 3\end{array}$

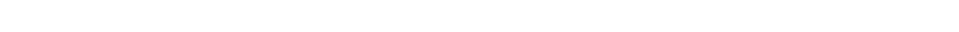

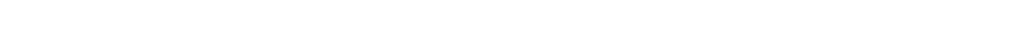

255138.0

120515.0

251954.0

290438.0

233815.0

233815.0

114670.0

676061.0

170319.0
447441.0

191038.0

50515.0

371484.0

550713.0

521507.0

1981

104151.0 
DOLORES RIVER BASIN

09180000 DOLORES RTVER NEAR CISCO, UT-Continued

DURATION TABLE OF DISOHARGE FOR WATER YEARS 1952-81

$\begin{array}{ccc}\text { OUBIC } & \text { ACOU- } \\ \text { FEET } & \text { MU- } & \text { PER- } \\ \text { PER TOTAL LATED } & \text { CENT } \\ \text { OLASS SECOOND DAYS DAYS } & \text { DAYS }\end{array}$

$\begin{array}{rrrrr}0 & 0.00 & 0 & 10958 & 100.0 \\ & 4.20 & 2 & 10958 & 100.0 \\ 2 & 5.40 & 0 & 10956 & 100.0 \\ & 6.90 & 1 & 10956 & 100.0 \\ 4 & 8.90 & 1 & 10955 & 100.0 \\ 5 & 11.00 & 22 & 10954 & 100.0 \\ 6 & 15.00 & 33 & 10932 & 99.8 \\ & 19.00 & 31 & 10899 & 99.5 \\ 8 & 24.00 & 68 & 10868 & 99.2\end{array}$

$\begin{array}{lcl}\text { OUBIC } & \text { ACOJ- } \\ \text { FEET } & \text { MU- } & \\ \text { PER TER- } & \end{array}$

PER TOTAL LATED CENT
CLASS SECOND DAYS DAYS DAYS

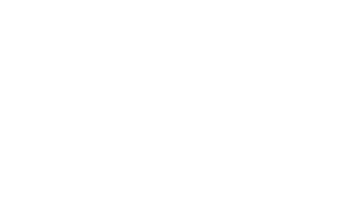

FEET ACOJPER TOTAL LATED CENI
CLASS SECOND DAYS DAYS DAYS

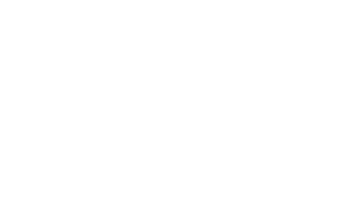

$\begin{array}{lll}\text { CUBIC } & \text { ACOJ- } \\ \text { FEET } & \text { MU- } & \text { PER- } \\ \text { PER TOTAL LATED } & \text { CENI }\end{array}$ C.ASS SEOOND DAYS DAYS DAYS

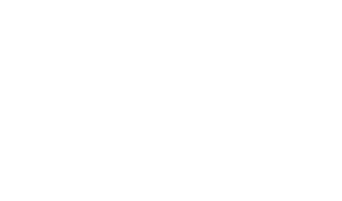

MONIHLY MEAN DISCHARGES, IN OUBIC FEET PER SECOND, FOR EACH WATER YEAR

\begin{tabular}{|c|c|c|c|c|c|c|c|c|c|c|c|c|}
\hline YEAR & OCT & NOV & DEC & JAN & FEB & MAR & APR & MAY & JUNE & JULY & AUG & SEP \\
\hline $\begin{array}{l}1951 \\
1952 \\
1953 \\
1954 \\
1955\end{array}$ & $\begin{array}{l}80.0 \\
67.0 \\
136 \\
265 \\
327\end{array}$ & $\begin{array}{l}90.0 \\
95.2 \\
122 \\
189 \\
150\end{array}$ & $\begin{array}{l}122 \\
108 \\
162 \\
133 \\
109\end{array}$ & $\begin{array}{c}148 \\
234 \\
184 \\
143 \\
92.1\end{array}$ & $\begin{array}{l}160 \\
164 \\
166 \\
170 \\
129\end{array}$ & $\begin{array}{l}127 \\
251 \\
196 \\
165 \\
515\end{array}$ & $\begin{array}{r}123 \\
5450 \\
660 \\
724 \\
1094\end{array}$ & $\begin{array}{r}620 \\
5930 \\
1035 \\
866 \\
1884\end{array}$ & $\begin{array}{r}806 \\
4076 \\
1481 \\
309 \\
1108\end{array}$ & $\begin{array}{r}192 \\
1093 \\
297 \\
158 \\
205\end{array}$ & $\begin{array}{l}186 \\
343 \\
315 \\
107 \\
276\end{array}$ & $\begin{array}{c}64.3 \\
176 \\
66.4 \\
226 \\
57.5\end{array}$ \\
\hline $\begin{array}{l}1956 \\
1957 \\
1958 \\
1959 \\
1960\end{array}$ & $\begin{array}{l}58.0 \\
30.0 \\
511 \\
126 \\
171\end{array}$ & $\begin{array}{l}101 \\
106 \\
451 \\
157 \\
150\end{array}$ & $\begin{array}{l}143 \\
87.3 \\
320 \\
157 \\
107\end{array}$ & $\begin{array}{l}128 \\
95.0 \\
208 \\
159 \\
138\end{array}$ & $\begin{array}{l}150 \\
230 \\
578 \\
176 \\
160\end{array}$ & $\begin{array}{l}265 \\
207 \\
573 \\
175 \\
712\end{array}$ & $\begin{array}{r}946 \\
1912 \\
5726 \\
420 \\
2631\end{array}$ & $\begin{array}{r}1372 \\
4818 \\
5981 \\
536 \\
1808\end{array}$ & $\begin{array}{r}1052 \\
5916 \\
2757 \\
534 \\
1743\end{array}$ & $\begin{array}{r}131 \\
2562 \\
322 \\
113 \\
330\end{array}$ & $\begin{array}{c}105 \\
1280 \\
136 \\
210 \\
79.7\end{array}$ & $\begin{array}{l}13.8 \\
720 \\
146 \\
55.8 \\
60.6\end{array}$ \\
\hline $\begin{array}{l}1961 \\
1962 \\
1963 \\
1964 \\
1965\end{array}$ & $\begin{array}{l}81.4 \\
292 \\
191 \\
80.8 \\
111\end{array}$ & $\begin{array}{l}117 \\
200 \\
144 \\
136 \\
108\end{array}$ & $\begin{array}{l}111 \\
154 \\
132 \\
93.9 \\
154\end{array}$ & $\begin{array}{l}97.2 \\
131 \\
102 \\
72.9 \\
179\end{array}$ & $\begin{array}{l}126 \\
449 \\
311 \\
103 \\
158\end{array}$ & $\begin{array}{l}199 \\
273 \\
581 \\
114 \\
149\end{array}$ & $\begin{array}{r}967 \\
3195 \\
858 \\
625 \\
2926\end{array}$ & $\begin{array}{r}2134 \\
2186 \\
917 \\
1905 \\
3959\end{array}$ & $\begin{array}{r}1180 \\
1351 \\
309 \\
940 \\
2776\end{array}$ & $\begin{array}{r}180 \\
533 \\
136 \\
228 \\
1564\end{array}$ & $\begin{array}{l}221 \\
126 \\
237 \\
455 \\
679\end{array}$ & $\begin{array}{l}310 \\
107 \\
163 \\
135 \\
450\end{array}$ \\
\hline $\begin{array}{l}1966 \\
1967 \\
1968 \\
1969 \\
1970\end{array}$ & $\begin{array}{c}492 \\
103 \\
101 \\
99.9 \\
240\end{array}$ & $\begin{array}{l}346 \\
115 \\
101 \\
130 \\
242\end{array}$ & $\begin{array}{l}351 \\
272 \\
109 \\
99.7 \\
229\end{array}$ & $\begin{array}{l}366 \\
138 \\
123 \\
282 \\
205\end{array}$ & $\begin{array}{l}244 \\
174 \\
191 \\
189 \\
201\end{array}$ & $\begin{array}{r}1089 \\
317 \\
165 \\
211 \\
187\end{array}$ & $\begin{array}{r}2185 \\
313 \\
904 \\
3584 \\
859\end{array}$ & $\begin{array}{r}2165 \\
943 \\
2736 \\
2735 \\
3723\end{array}$ & $\begin{array}{r}744 \\
761 \\
2660 \\
1254 \\
1488\end{array}$ & $\begin{array}{l}223 \\
274 \\
433 \\
626 \\
464\end{array}$ & $\begin{array}{l}85.2 \\
381 \\
655 \\
204 \\
291\end{array}$ & $\begin{array}{c}72.2 \\
158 \\
82.2 \\
239 \\
1069\end{array}$ \\
\hline $\begin{array}{l}1971 \\
1972 \\
1973 \\
1974 \\
1975\end{array}$ & $\begin{array}{c}267 \\
263 \\
645 \\
136 \\
79.8\end{array}$ & $\begin{array}{l}247 \\
165 \\
386 \\
131 \\
137\end{array}$ & $\begin{array}{l}245 \\
220 \\
300 \\
206 \\
117\end{array}$ & $\begin{array}{l}266 \\
219 \\
300 \\
166 \\
120\end{array}$ & $\begin{array}{l}273 \\
208 \\
315 \\
184 \\
164\end{array}$ & $\begin{array}{l}687 \\
547 \\
539 \\
388 \\
223\end{array}$ & $\begin{array}{r}1363 \\
464 \\
3265 \\
1294 \\
2528\end{array}$ & $\begin{array}{r}1769 \\
631 \\
8877 \\
2112 \\
5121\end{array}$ & $\begin{array}{r}1739 \\
790 \\
5393 \\
622 \\
3660\end{array}$ & $\begin{array}{r}405 \\
122 \\
1771 \\
243 \\
2107\end{array}$ & $\begin{array}{l}281 \\
33.8 \\
213 \\
70.6 \\
256\end{array}$ & $\begin{array}{c}139 \\
98.8 \\
130 \\
28.3 \\
145\end{array}$ \\
\hline $\begin{array}{l}1976 \\
1977 \\
1978 \\
1979 \\
1980\end{array}$ & $\begin{array}{l}131 \\
137 \\
168 \\
63.5 \\
82.2\end{array}$ & $\begin{array}{c}128 \\
99.1 \\
95.7 \\
174 \\
120\end{array}$ & $\begin{array}{c}135 \\
69.1 \\
97.6 \\
103 \\
129\end{array}$ & $\begin{array}{l}160 \\
85.5 \\
139 \\
126 \\
206\end{array}$ & $\begin{array}{l}232 \\
136 \\
143 \\
220 \\
287\end{array}$ & $\begin{array}{c}205 \\
99.5 \\
258 \\
502 \\
222\end{array}$ & $\begin{array}{r}1352 \\
137 \\
3960 \\
4699 \\
3642\end{array}$ & $\begin{array}{c}2150 \\
93.6 \\
4016 \\
6323 \\
6621\end{array}$ & $\begin{array}{r}1281 \\
164 \\
2688 \\
4400 \\
4577\end{array}$ & $\begin{array}{r}240 \\
311 \\
537 \\
1169 \\
924\end{array}$ & $\begin{array}{c}130 \\
239 \\
84.1 \\
242 \\
177\end{array}$ & $\begin{array}{c}125 \\
89.0 \\
29.0 \\
64.9 \\
128\end{array}$ \\
\hline 1981 & 124 & 133 & 145 & 138 & 133 & 132 & 492 & 506 & 767 & 496 & 135 & 223 \\
\hline
\end{tabular}

ANNUAL FEAK DISCHARGE, IN GBIC FEET PER SECOND, AND CORRESPONDING GAGE HEIGHT, IN FEET, FOR EACH WATER YEAR

\begin{tabular}{|c|c|c|c|c|c|c|c|c|c|c|c|}
\hline $\begin{array}{l}\text { WATERR } \\
\text { YEAR }\end{array}$ & DATE & $\begin{array}{c}\text { GAGE } \\
\text { HEIGHT }\end{array}$ & $\begin{array}{c}\text { PEAK } \\
\text { DISQHARGE }\end{array}$ & $\begin{array}{l}\text { WATER } \\
\text { YEAR }\end{array}$ & DATE & $\begin{array}{c}\text { GAGE } \\
\text { HEIGHT }\end{array}$ & $\begin{array}{c}\text { PEAK } \\
\text { DISCHARGE }\end{array}$ & $\begin{array}{l}\text { WATER } \\
\text { YEAR }\end{array}$ & DATE & $\begin{array}{c}\text { GAGE } \\
\text { HEIGHT }\end{array}$ & $\begin{array}{c}\text { PEAK } \\
\text { DISCHARGE }\end{array}$ \\
\hline $\begin{array}{l}1951 \\
1952 \\
1953 \\
1954 \\
1955 \\
1956 \\
1957 \\
1958 \\
1959 \\
1960 \\
1961\end{array}$ & $\begin{array}{lll}\text { MAY } & 28,1951 \\
\text { MAY } & 06,1952 \\
\text { JUNE } & 14,1953 \\
\text { OCr. } 23,1953 \\
\text { MAY } & 10,1955 \\
\text { JUNE } 02,1956 \\
\text { JUNE } 07,1957 \\
\text { APR. } 21,1958 \\
\text { AUG. } 05,1959 \\
\text { APR. } 11,1960 \\
\text { MAY } & 03,1961\end{array}$ & $\begin{array}{l}3.70 \\
7.67 \\
4.33 \\
4.45 \\
4.49 \\
3.77 \\
6.99 \\
9.84 \\
4.38 \\
5.90 \\
4.76\end{array}$ & $\begin{array}{r}2140 \\
11100 \\
3060 \\
3220 \\
3690 \\
2470 \\
9500 \\
17400 \\
3300 \\
6160 \\
3510\end{array}$ & $\begin{array}{l}1962 \\
1963 \\
1964 \\
1965 \\
1966 \\
1967 \\
1968 \\
1969 \\
1970 \\
1971\end{array}$ & $\begin{array}{l}\text { APR. } 21,1962 \\
\text { MAR. } 31,1963 \\
\text { AUG. } 13,1964 \\
\text { APR. } 24,1965 \\
\text { APR. } 03,1966 \\
\text { MAY } 27,1967 \\
\text { MAY } 30,1968 \\
\text { APR. } 23,1969 \\
\text { MAY } 07,1970 \\
\text { MAR. } 28,1971\end{array}$ & $\begin{array}{l}6.10 \\
4.49 \\
5.50 \\
7.70 \\
4.88 \\
4.03 \\
5.22 \\
6.00 \\
6.09 \\
4.69\end{array}$ & $\begin{array}{r}6760 \\
3080 \\
5310 \\
11000 \\
4040 \\
2650 \\
4870 \\
6480 \\
7000 \\
4140\end{array}$ & $\begin{array}{l}1972 \\
1973 \\
1974 \\
1975 \\
1976 \\
1977 \\
1978 \\
1979 \\
1980 \\
1981\end{array}$ & $\begin{array}{l}\text { OCT. } 18,1971 \\
\text { APR. } 30,1973 \\
\text { APR. } 26,1974 \\
\text { APR. } 27,1975 \\
\text { MAY } 19,1976 \\
\text { JULY } 24,1977 \\
\text { MAY } 17,1978 \\
\text { APR. } 24,1979 \\
\text { APR. } 23,1980 \\
\text { JULY } 18,1981\end{array}$ & $\begin{array}{r}3.88 \\
9.10 \\
5.35 \\
7.03 \\
9.68 \\
12.53 \\
11.64 \\
14.00 \\
13.56 \\
8.93\end{array}$ & $\begin{array}{r}2410 \\
14600 \\
4500 \\
11900 \\
3030 \\
12000 \\
8740 \\
13600 \\
12200 \\
2110\end{array}$ \\
\hline
\end{tabular}




\begin{tabular}{|c|c|c|c|c|c|c|}
\hline \multirow{3}{*}{$\begin{array}{l}\text { PERIOD } \\
\text { (CON- } \\
\text { SECU- } \\
\text { TIVE } \\
\text { DAYS) }\end{array}$} & IUD & \multicolumn{5}{|c|}{$\begin{array}{l}\text { AND PRCBABILITY OF ANRUAL LOWEST MEAN DISCHARGE } \\
\text { BASED ON CLIMATIC YEARS 1952-81 }\end{array}$} \\
\hline & & \multicolumn{5}{|c|}{$\begin{array}{l}\text { DISCHARGE, IN OUBIC FEET PER SECOND, FOR } \\
\text { INDICATED RECURRENCE INTERNAL, IN YEARS, AND } \\
\text { ANNUAL NONEXCEEDANCE PRCBABILITY, IN PERCENT }\end{array}$} \\
\hline & $\begin{array}{c}2 \\
508\end{array}$ & $\begin{array}{c}5 \\
208\end{array}$ & $\begin{array}{l}10 \\
108\end{array}$ & $\begin{array}{l}20 \\
58\end{array}$ & $\begin{array}{l}50 \\
28\end{array}$ & $\begin{array}{r}100 \\
18\end{array}$ \\
\hline $\begin{array}{r}1 \\
7 \\
14 \\
30 \\
60 \\
90\end{array}$ & $\begin{array}{r}45 \\
49 \\
57 \\
75 \\
97 \\
108\end{array}$ & $\begin{array}{l}22 \\
26 \\
32 \\
42 \\
57 \\
74\end{array}$ & $\begin{array}{l}14 \\
19 \\
24 \\
31 \\
42 \\
62\end{array}$ & $\begin{array}{l}9.4 \\
14 \\
18 \\
23 \\
32 \\
54\end{array}$ & $\begin{array}{c}5 . \\
10 \\
14 \\
17 \\
23 \\
46\end{array}$ & $\bar{z}$ \\
\hline
\end{tabular}

MAGNITUDE AND PRCBABILITY OF ANMUAL MIGHEST MEAN DISCHARGE BASED ON WATER YEARS 1952-81

\begin{tabular}{lcccccc}
\hline & \multicolumn{5}{c}{$\begin{array}{c}\text { DISCHARGE, IN OBBIC FEET PER SECOND, FOR } \\
\text { PERIOD } \\
\text { (CON- }\end{array}$} & $\begin{array}{c}\text { INDICATED RECURRENCE INTERNAL, IN YEARS, AND } \\
\text { ANNUAL EXCEFDANCE PRCBABILITY, }\end{array}$ \\
$\begin{array}{l}\text { SECU- } \\
\text { TIVE }\end{array}$ & 2 & 5 & 10 & 25 & 50 & 100 \\
DAYS) & 508 & 208 & 108 & 48 & 28 & 18 \\
\hline & & & & & & \\
\hline 1 & 4300 & 7890 & 11000 & 15900 & 20200 & - \\
3 & 4060 & 7620 & 10700 & 15400 & 19500 & - \\
7 & 3640 & 6920 & 9710 & 14000 & 17700 & - \\
15 & 3200 & 6130 & 8470 & 11800 & 14600 & -
\end{tabular}

COLORADO RIVER MAIN STEM

09180500 COLORADO RIVER NEAR CISCO, UT

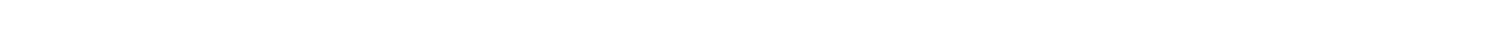
$1 \mathrm{mi}$ downstream from Dolores River, il mi south of Cisco, $36 \mathrm{mi}$ downstream from Colorado-Utah State line, $97 \mathrm{mi}$ upstream from Green River, and $235 \mathrm{mi}$ upstream fram San Juan River, at mile $1,022.3$.

DRAINAGE AREA. - 24,100 $\mathrm{mi}^{2}$, approximately.

PERIOD OF RBCORD AVAILABLE. -January 1895 to September 1981 (1895 to 1910, calender-year estimates only). Monthly mean discharge only for some periods prior to October 1922. published in WSP 1313. Published as "Grand River near Moab" October 1913 to Novenber 1914, and as "Grand River near Cisco", November 1914 to September 1917.

REVISED RECOROS.-WSP 918: 1913, 1937. WSP 1313: 1918-22.

GAGE.- Water-stage recorder. Altitude of gage is 4,090 ft from river-profile map. Prior to Nov. 10, 1914, several staff and chain gages at bridge near Moab, 31 mi downstream at datum, 3,937.73 ft, NGVD of 1929.

REMARKS.-Diversions above station for irrigation and power, including several transmountain diversions. (Flow regulated by Blue Mesa Reservoir since Nov. 27, 1965.)

AVERAGE DISCHARGE. --70 years (water years 1912-81), 7,500 $\mathrm{ft}^{3} / \mathrm{s}, 5,434,000 \mathrm{acre}-\mathrm{ft} / \mathrm{yr}$.

EXIREMPS FOR PERIOD OF REOORD.-Maximum discharge, 76,800 ft ${ }^{3} / \mathrm{s}$ June 19, 1917, gage height, $19.7 \mathrm{ft}$; minimum recorded, $558 \mathrm{ft} 3 / \mathrm{s}$ July 2, 1934, gage height, $0.44 \mathrm{ft}$.

EXTREMES OUTSIDE PERIOD OF RBCORD.-Maximum discharge known, about $125,000 \mathrm{ft}^{3} / \mathrm{s}$ July 4, 1884 , from flocd record at Fruita, co.

LOWEST MEAN DISCHARGE, IN OUBIC FEET PER SEOOND, AND RANKING FOR THE INDICATED NUMBER OF CONSECUTIVE DAYS FOR EACH CLIMATIC YEAR, APRIL 1-MARCH 31

YEAR

$\begin{array}{rrrrrr}1916 & 1520 & 25 & 1580 & 25 & 1640 \\ 1917 & 2000 & 44 & 2000 & 43 & 2000 \\ 1924 & 2200 & 49 & 2200 & 48 & 2200 \\ 1925 & 866 & 3 & 908 & 3 & 925 \\ & & & & & \\ 1926 & 2100 & 46 & 2100 & 44 & 2130 \\ 1927 & 1460 & 20 & 1470 & 18 & 1520 \\ 1928 & 3080 & 58 & 3140 & 58 & 3170 \\ 1929 & 1700 & 34 & 1700 & 33 & 1760 \\ 1930 & 1500 & 24 & 1500 & 21 & 1790 \\ 1931 & 1640 & 31 & 1730 & 34 & 1860 \\ 1932 & 885 & 4 & 911 & 4 & 930 \\ 1933 & 1740 & 37 & 1750 & 36 & 1800 \\ 1934 & 1190 & 12 & 1250 & 12 & 1330 \\ 1935 & 640 & 1 & 664 & 1 & 736 \\ 1936 & 1720 & 36 & 1740 & 35 & 1860 \\ 1937 & 1700 & 35 & 1780 & 37 & 1900 \\ 1938 & 1170 & 10 & 1190 & 10 & 1400 \\ 1939 & 1840 & 41 & 1860 & 41 & 1940 \\ 1940 & 904 & 5 & 941 & 5 & 976\end{array}$

CONSEOUTIVE DAYS
30

$\begin{array}{rr}22 & 1680 \\ 42 & 2000 \\ 48 & 2310 \\ 3 & 968 \\ & \\ 44 & 2190 \\ 17 & 1620 \\ 57 & 3190 \\ 30 & 1970 \\ 31 & 1980 \\ & \\ 35 & 1930 \\ 4 & 968 \\ 32 & 1800 \\ 12 & 1420 \\ 1 & 844 \\ & \\ 36 & 2030 \\ 39 & 1900 \\ 15 & 1510 \\ 40 & 2340 \\ 5 & 1100\end{array}$

$\begin{array}{ll}20 & 1770 \\ 38 & 2000 \\ 47 & 2430\end{array}$

$42 \quad 2300$

$18 \quad 1690$

$56 \quad 3320$

$\begin{array}{ll}36 & 2090 \\ 37 & 2350\end{array}$

$32 \quad 2060$

32
4
2010

251840

$10 \quad 1650$

2914

$39 \quad 2190$

$30 \quad 1900$

$15 \quad 2050$

$48 \quad 2460$

51640

$\begin{array}{ll}15 & 2390 \\ 25 & 2240 \\ 42 & 2610\end{array}$

$42 \quad 2610$

51900

$\begin{array}{ll}38 & 2440 \\ 13 & 2350 \\ 56 & 3360\end{array}$

$\begin{array}{ll}56 & 3360 \\ 32 & 2210\end{array}$

$\begin{array}{ll}32 & 2210 \\ 39 & 2720\end{array}$

$30 \quad 2250$

$2 \quad 1370$

$\begin{array}{ll}18 & 2070 \\ 11 & 2230\end{array}$

$\begin{array}{rr}11 & 2230 \\ 1 & 961\end{array}$

$\begin{array}{ll}34 & 2300 \\ 19 & 2140\end{array}$

$\begin{array}{ll}19 & 2140 \\ 29 & 2230\end{array}$

$\begin{array}{ll}29 & 2230 \\ 46 & 2530\end{array}$

$\begin{array}{ll}46 & 2530 \\ 10 & 2010\end{array}$

$\begin{array}{rr} & 90 \\ 32 & 2480 \\ 25 & 2400 \\ 40 & 2820 \\ 8 & 2320 \\ 34 & 2520 \\ 30 & 2580 \\ 54 & 3440 \\ 22 & 2310 \\ 43 & 2990 \\ & \\ 26 & 2360 \\ 2 & 2140 \\ 14 & 2190 \\ 23 & 2250 \\ 1 & 1030 \\ & \\ 28 & 2420 \\ 17 & 2230 \\ 24 & 2500 \\ 37 & 2600 \\ 13 & 2150\end{array}$

90

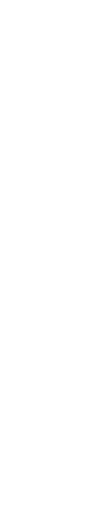

ALL

$\begin{array}{rrrrr}20 & 2660 & 20 & 7510 & 33 \\ 19 & 3460 & 43 & 10300 & 54 \\ 36 & 3410 & 42 & 10300 & 55 \\ 21 & 2480 & 13 & 7920 & 37 \\ 29 & 3360 & 40 & 7190 & 31 \\ 31 & 2690 & 22 & 8960 & 46 \\ 52 & 4260 & 56 & 11000 & 58 \\ 23 & 2950 & 33 & 9810 & 52 \\ 42 & 4000 & 51 & 12100 & 59 \\ & & & & \\ 15 & 2740 & 24 & 7800 & 35 \\ 10 & 2320 & 6 & 3960 & 5 \\ 12 & 2450 & 11 & 9130 & 48 \\ 9 & 2400 & 9 & 6330 & 24 \\ 1 & 1370 & 1 & 2810 & 2 \\ 18 & 2680 & 21 & 6850 & 27 \\ 13 & 2470 & 12 & 7890 & 36 \\ 24 & 2610 & 19 & 6660 & 25 \\ 33 & 3050 & 34 & 10400 & 56 \\ 7 & 2310 & 5 & 5430 & 17\end{array}$


LOWEST MEAN DISCHARGE, IN CUBIC FEET PER SECOND, AND RANKING FOR THE INDICATED NUMBER OF CONSEOUTIVE DAYS FOR EACH CLIMATIC YEAR, APFIL 1-MARCH 31--Continued

YEAR

\begin{tabular}{|c|c|c|c|c|c|c|c|c|c|}
\hline $\begin{array}{l}1941 \\
1942 \\
1943 \\
1944 \\
1945\end{array}$ & $\begin{array}{r}704 \\
1200 \\
1640 \\
1600 \\
1480\end{array}$ & $\begin{array}{r}2 \\
13 \\
32 \\
29 \\
22\end{array}$ & $\begin{array}{r}715 \\
1480 \\
1650 \\
1670 \\
1530\end{array}$ & $\begin{array}{r}2 \\
19 \\
28 \\
31 \\
22\end{array}$ & $\begin{array}{r}742 \\
1800 \\
1740 \\
1760 \\
1580\end{array}$ & $\begin{array}{r}2 \\
33 \\
26 \\
27 \\
19\end{array}$ & $\begin{array}{r}842 \\
1940 \\
1870 \\
1930 \\
1600\end{array}$ & $\begin{array}{r}1 \\
34 \\
28 \\
33 \\
17\end{array}$ & \\
\hline $\begin{array}{l}1946 \\
1947 \\
1948 \\
1949 \\
1950\end{array}$ & $\begin{array}{l}2060 \\
1650 \\
2400 \\
1500 \\
1920\end{array}$ & $\begin{array}{l}45 \\
33 \\
53 \\
23 \\
42\end{array}$ & $\begin{array}{l}2110 \\
1680 \\
2530 \\
1550 \\
1950\end{array}$ & $\begin{array}{l}45 \\
32 \\
53 \\
23 \\
42\end{array}$ & $\begin{array}{l}2160 \\
1760 \\
2670 \\
1630 \\
2000\end{array}$ & $\begin{array}{l}45 \\
28 \\
54 \\
21 \\
43\end{array}$ & $\begin{array}{l}2230 \\
1920 \\
2810 \\
1720 \\
2140\end{array}$ & $\begin{array}{l}43 \\
31 \\
54 \\
21 \\
41\end{array}$ & \\
\hline $\begin{array}{l}1951 \\
1952 \\
1953 \\
1954 \\
1955\end{array}$ & $\begin{array}{l}1190 \\
1560 \\
2120 \\
1820 \\
1060\end{array}$ & $\begin{array}{r}11 \\
26 \\
47 \\
40 \\
7\end{array}$ & $\begin{array}{l}1250 \\
1590 \\
2230 \\
1840 \\
1100\end{array}$ & $\begin{array}{r}13 \\
26 \\
49 \\
39 \\
8\end{array}$ & $\begin{array}{l}1380 \\
1670 \\
2330 \\
1860 \\
1180\end{array}$ & $\begin{array}{r}14 \\
23 \\
50 \\
37 \\
7\end{array}$ & $\begin{array}{l}1510 \\
1800 \\
2460 \\
1900 \\
1360\end{array}$ & $\begin{array}{r}16 \\
26 \\
50 \\
29 \\
8\end{array}$ & \\
\hline $\begin{array}{l}1956 \\
1957 \\
1958 \\
1959 \\
1960\end{array}$ & $\begin{array}{l}1370 \\
1000 \\
2610 \\
1200 \\
1240\end{array}$ & $\begin{array}{r}18 \\
6 \\
56 \\
14 \\
16\end{array}$ & $\begin{array}{l}1380 \\
1040 \\
2630 \\
1280 \\
1270\end{array}$ & $\begin{array}{r}16 \\
6 \\
54 \\
15 \\
14\end{array}$ & $\begin{array}{l}1420 \\
1120 \\
2650 \\
1350 \\
1300\end{array}$ & $\begin{array}{r}16 \\
6 \\
53 \\
13 \\
11\end{array}$ & $\begin{array}{l}1470 \\
1210 \\
2780 \\
1510 \\
1450\end{array}$ & $\begin{array}{r}13 \\
6 \\
53 \\
14 \\
11\end{array}$ & \\
\hline $\begin{array}{l}1961 \\
1962 \\
1963 \\
1964 \\
1965\end{array}$ & $\begin{array}{l}1220 \\
1470 \\
1250 \\
1070 \\
1800\end{array}$ & $\begin{array}{r}15 \\
21 \\
17 \\
8 \\
38\end{array}$ & $\begin{array}{l}1230 \\
1550 \\
1430 \\
1090 \\
1840\end{array}$ & $\begin{array}{r}11 \\
24 \\
17 \\
7 \\
40\end{array}$ & $\begin{array}{l}1250 \\
1590 \\
1840 \\
1270 \\
1950\end{array}$ & $\begin{array}{r}8 \\
20 \\
34 \\
10 \\
41\end{array}$ & $\begin{array}{l}1310 \\
1650 \\
2280 \\
1460 \\
2050\end{array}$ & $\begin{array}{r}7 \\
19 \\
44 \\
12 \\
40\end{array}$ & \\
\hline $\begin{array}{l}1966 \\
1967 \\
1968 \\
1969 \\
1970\end{array}$ & $\begin{array}{l}2300 \\
1600 \\
1440 \\
2290 \\
2550\end{array}$ & $\begin{array}{l}52 \\
27 \\
19 \\
51 \\
55\end{array}$ & $\begin{array}{l}2400 \\
1650 \\
1490 \\
2380 \\
2640\end{array}$ & $\begin{array}{l}52 \\
29 \\
20 \\
51 \\
55\end{array}$ & $\begin{array}{l}2510 \\
1730 \\
1530 \\
2410 \\
2690\end{array}$ & $\begin{array}{l}52 \\
25 \\
18 \\
51 \\
55\end{array}$ & $\begin{array}{l}2670 \\
1740 \\
1750 \\
2470 \\
2920\end{array}$ & $\begin{array}{l}52 \\
22 \\
23 \\
51 \\
55\end{array}$ & \\
\hline $\begin{array}{l}1971 \\
1972 \\
1973 \\
1974 \\
1975\end{array}$ & $\begin{array}{l}3160 \\
2540 \\
1600 \\
3120 \\
1800\end{array}$ & $\begin{array}{l}60 \\
54 \\
28 \\
59 \\
39\end{array}$ & $\begin{array}{l}3240 \\
2720 \\
1630 \\
3200 \\
1830\end{array}$ & $\begin{array}{l}60 \\
56 \\
27 \\
59 \\
38\end{array}$ & $\begin{array}{l}3360 \\
3120 \\
1690 \\
3290 \\
1880\end{array}$ & $\begin{array}{l}60 \\
56 \\
24 \\
58 \\
38\end{array}$ & $\begin{array}{l}3770 \\
3390 \\
1800 \\
3470 \\
1950\end{array}$ & $\begin{array}{l}60 \\
57 \\
24 \\
58 \\
35\end{array}$ & \\
\hline $\begin{array}{l}1976 \\
1977 \\
1978 \\
1979 \\
1980\end{array}$ & $\begin{array}{l}2210 \\
1640 \\
1100 \\
1980 \\
3080\end{array}$ & $\begin{array}{r}50 \\
30 \\
9 \\
43 \\
57\end{array}$ & $\begin{array}{l}2240 \\
1660 \\
1160 \\
2110 \\
3140\end{array}$ & $\begin{array}{r}50 \\
30 \\
9 \\
46 \\
57\end{array}$ & $\begin{array}{l}2290 \\
1760 \\
1260 \\
2190 \\
3350\end{array}$ & $\begin{array}{r}49 \\
29 \\
9 \\
46 \\
59\end{array}$ & $\begin{array}{l}2400 \\
1820 \\
1400 \\
2280 \\
3480\end{array}$ & $\begin{array}{r}49 \\
27 \\
9 \\
45 \\
59\end{array}$ & \\
\hline & & & & & & & & & \\
\hline
\end{tabular}

CONSEOTTIVE DAYS
30

$\begin{array}{rrrr}3 & 1650 & 4 & 2260 \\ 50 & 2950 & 49 & 3120 \\ 33 & 2290 & 27 & 2540 \\ 36 & 2440 & 35 & 2540 \\ 12 & 1910 & 9 & 2170 \\ & & & \\ 44 & 2790 & 47 & 2860 \\ 37 & 2530 & 38 & 2620 \\ 52 & 3130 & 53 & 3360 \\ 27 & 2390 & 31 & 2670 \\ 45 & 2790 & 48 & 3140 \\ & & & \\ 8 & 1980 & 11 & 2040 \\ 28 & 2420 & 33 & 2610 \\ 48 & 2740 & 44 & 2810 \\ 22 & 2200 & 21 & 2670 \\ 9 & 1910 & 10 & 2210 \\ 17 & 1870 & 7 & 2100 \\ 4 & 1540 & 3 & 1710 \\ 55 & 3430 & 55 & 3620 \\ 14 & 2010 & 12 & 2250 \\ 20 & 2140 & 18 & 2500 \\ & & & \\ 6 & 1760 & 5 & 1990 \\ 21 & 2120 & 16 & 2970 \\ 43 & 2770 & 45 & 2850 \\ 16 & 2090 & 15 & 2110 \\ 41 & 2470 & 36 & 2550 \\ 53 & 3040 & 51 & 3290 \\ 23 & 2170 & 19 & 2290 \\ 35 & 2650 & 41 & 2800 \\ 49 & 3030 & 50 & 3320 \\ 54 & 3610 & 56 & 3960 \\ & & & \\ 60 & 5190 & 60 & 5400 \\ 59 & 4150 & 59 & 4280 \\ 24 & 2200 & 20 & 2670 \\ 57 & 3830 & 58 & 3940 \\ 31 & 2590 & 39 & 2850 \\ & & & \\ 51 & 3120 & 52 & 3460 \\ 26 & 2320 & 29 & 2670 \\ 7 & 1790 & 6 & 1890 \\ 40 & 2790 & 46 & 2910 \\ 58 & 3660 & 57 & 3690 \\ & & & \\ 47 & 2720 & 42 & 3060\end{array}$

90 120

$16 \quad 2580$ $\begin{array}{ll}48 & 3340\end{array}$ $\begin{array}{ll}27 & 2630 \\ 28 & 2670\end{array}$ $28 \quad 2670$ 102460

$\begin{array}{ll}43 & 2920 \\ 33 & 2840\end{array}$ $\begin{array}{ll}33 & 2840 \\ 52 & 3530\end{array}$ $34 \quad 2790$ 493150 $\begin{array}{rr}5 & 2160\end{array}$ $\begin{array}{ll}32 & 2640 \\ 39 & 2890\end{array}$ $\begin{array}{ll}35 & 2710\end{array}$ $12 \quad 2350$ 62300 $\begin{array}{ll}6 & 2300 \\ 2 & 1880\end{array}$ $55 \quad 3760$ $\begin{array}{ll}14 & 2410 \\ 25 & 2730\end{array}$ $4 \quad 2230$ $\begin{array}{rr}45 & 2230 \\ 4640\end{array}$ $41 \quad 2960$ 79
29650 $50 \quad 3490$ $\begin{array}{ll}50 & 3490 \\ 17 & 2430\end{array}$ $38 \quad 2990$ $\begin{array}{ll}51 & 3550 \\ 58 & 4090\end{array}$

\section{$\begin{array}{ll}60 & 5480\end{array}$}

$\begin{array}{ll}59 & 4330\end{array}$ $\begin{array}{ll}36 & 3290 \\ 57 & 4110\end{array}$ $\begin{array}{ll}57 & 4110 \\ 42 & 3220\end{array}$

$\begin{array}{ll}54 & 3750 \\ 37 & 2890\end{array}$ $\begin{array}{rr}37 & 2890 \\ 3 & 2000 \\ 44 & 3260\end{array}$ $\begin{array}{ll}44 & 3260 \\ 56 & 3820\end{array}$ $47 \quad 3330$
183

ALL $\begin{array}{llll}22 & 2790 & 27 & 5150 \\ 48 & 4700 & 59 & 9870\end{array}$ $\begin{array}{llll}25 & 2590 & 18 & 9660\end{array}$ $\begin{array}{ll}28 & 2870 \\ 17 & 2500\end{array}$ $5660 \quad 51$ $\begin{array}{lll}29 & 7160 & 29 \\ 15 & 8090 & 39\end{array}$

$\begin{array}{lllll}39 & 3060 & 35 & 7660 & 34\end{array}$ $\begin{array}{lllll}35 & 2920 & 32 & 5560 & 20 \\ 50 & 4000 & 52 & 8840 & 44\end{array}$ $\begin{array}{llll}34 & 2880 & 30 & 8650 \\ 43 & 3200 & 38 & 8740\end{array}$

$5 \quad 2330$

$7 \quad 5430$ $26 \quad 2740$ $37 \quad 2890$ $30 \quad 2780$ $11 \quad 2530$ $\begin{array}{lll}25 & 5590 & 218\end{array}$ $\begin{array}{lrr}31 & 10600 & 57\end{array}$ $\begin{array}{llr}16 & 3130 & 3\end{array}$

82400 $\begin{array}{rr}2 & 2100 \\ 55 & 4090\end{array}$ $\begin{array}{ll}55 & 4090 \\ 14 & 2570\end{array}$ $10 \quad 4430$ $3 \quad 4950$ $5312500 \quad 60$ $\begin{array}{lllll}32 & 2860 & 28 & 4580 & 10\end{array}$

$6 \quad 2380$ $\begin{array}{lll}8 & 5360 & 16\end{array}$ $\begin{array}{lllll}53 & 3800 & 48 & 5010 & 14 \\ 40 & 3350 & 39 & 8930 & 45\end{array}$

$\begin{array}{rrrrr}4 & 2290 & 4 & 3290 & 4\end{array}$ 272720

$\begin{array}{llll}49 & 4140 & 54 & 9550\end{array}$ $\begin{array}{llll}16 & 2490 & 14 & 4120\end{array}$ $\begin{array}{llll}41 & 3190 & 37 & 4470\end{array}$ $\begin{array}{llll}51 & 3660 & 46 & 5960 \\ 57 & 4220 & 55 & 6820\end{array}$ $\begin{array}{llll}60 & 5470 \quad 60 & 8730\end{array}$ $59 \quad 4420$ $46 \quad 3710$ $\begin{array}{ll}44 & 3400\end{array}$ $\begin{array}{ll}48 & 4850 \\ 5130\end{array}$ $\begin{array}{ll}58 & 9130 \\ 41 & 5710\end{array}$

543810 $\begin{array}{rrrr}38 & 3150 & 36 & 4420 \\ 3 & 2090 & 2 & 2280\end{array}$

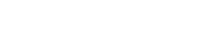
$\begin{array}{llll}45 & 3490 & 44 & 7190 \\ 56 & 3990 & 50 & 9000\end{array}$ $47 \quad 3560$

458290

HIGHEST MEAN DISCHARGE, IN CUBIC FEET PER SECOND, AND RANKING FOR THE INDICATED NUMBER OF CONSECUTIVE DAYS FOR EACH WATER YEAR, OCTOBER 1-SEPTEMBER 30

YEAR

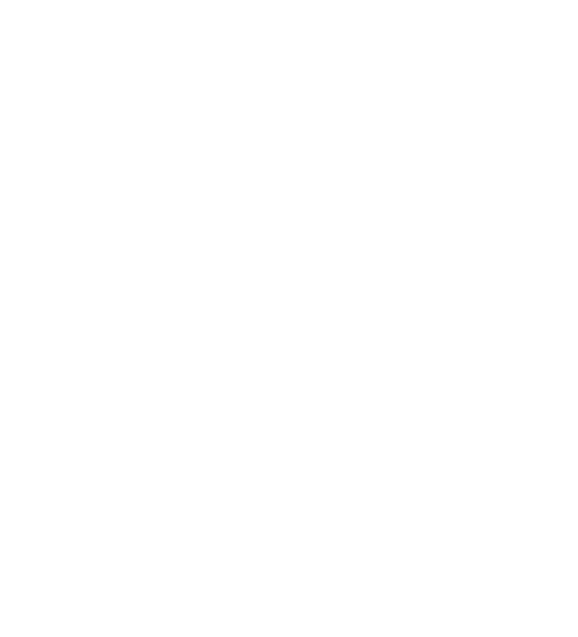

CONSEOUTIVE DAYS
120

251600

2134000

159200

1439100

1932400
4019800

1338200

1834800

541600

645600
2928700

5413000

1035300

1635800

5611400

$23 \quad 32100$

2727400

$\begin{array}{rr}27 & 27400 \\ 7 & 42100\end{array}$

$\begin{array}{rr}44 & 20400 \\ 47 & 19200\end{array}$
242400

1830800

145600

$\begin{array}{rr}9 & 33700 \\ 22 & 28200\end{array}$

$\begin{array}{ll}22 & 28200 \\ 41 & 18300\end{array}$

1230400

1732800

634800

438300
$27 \quad 22100$

5410400

1631500

1524900

$\begin{array}{ll}58 & 8560 \\ 19 & 24200\end{array}$

$23 \quad 27700$

3021100

534300

$\begin{array}{rr}5 & 34300 \\ 40 & 17800\end{array}$

$\begin{array}{ll}40 & 17800 \\ 45 & 15500\end{array}$
233500

$\begin{array}{rl}15 & 26400 \\ 1 & 35400\end{array}$ 827800
1823000 3616000

1626100

927600

628400

$31 \quad 19800$

$54 \quad 8540$

$\begin{array}{ll}12 & 26400 \\ 27 & 18100\end{array}$

$58 \quad 6500$

2818600

1922600

3217800

730100

$\begin{array}{ll}37 & 14500 \\ 44 & 12100\end{array}$

$\begin{array}{rr}3 & 27900 \\ 12 & 22800 \\ 1 & 29100 \\ 9 & 23100 \\ 20 & 18700 \\ 36 & 13800 \\ & \\ 13 & 21300 \\ 10 & 22900 \\ 8 & 23100 \\ 5 & 26200 \\ 27 & 16700 \\ & \\ 54 & 7010 \\ 11 & 22000 \\ 31 & 14300 \\ 58 & 5450 \\ 29 & 15200\end{array}$

$\begin{array}{ll}22 & 18400 \\ 32 & 14500\end{array}$

3214500

$\begin{array}{rr}6 & 24300 \\ 37 & 12200\end{array}$

$\begin{array}{rr}37 & 12200 \\ 46 & 9930\end{array}$
183
320300

$11 \quad 17600$

120700

2213300

3611000

1315200

$\begin{array}{rr}10 & 17800 \\ 9 & 16700\end{array}$

$\begin{array}{rr}9 & 16700 \\ 4 & 20300\end{array}$

2812900

$\begin{array}{lr}57 & 5450 \\ 12 & 15800\end{array}$

$\begin{array}{ll}12 & 15800 \\ 34 & 10400\end{array}$

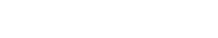

11000

2313200

3310500

$\begin{array}{rr}6 & 17500 \\ 38 & 8890\end{array}$

$\begin{array}{ll}38 & 8890 \\ 48 & 7330\end{array}$
ALL

$411800 \quad 3$

$\begin{array}{rrr}7 & 10300 & 10 \\ 2 & 12100 & 1\end{array}$

$910000 \quad 11$

$\begin{array}{lll}25 & 8170 & 25 \\ 31 & 6940 & 33\end{array}$

$13 \quad 9120 \quad 14$

$6 \quad 10400$
1110300

$\begin{array}{rr}11 & 10300 \\ 3 & 11800\end{array}$

$27 \quad 8420 \quad 23$

$57 \quad 3960 \quad 57$

$32 \quad 6470 \quad 35$

$\begin{array}{lll}26 & 7940 \quad 28\end{array}$

$\begin{array}{lll}34 & 6440 & 36\end{array}$

$\begin{array}{rrr}8 & 10300 & 9\end{array}$

$\begin{array}{lll}48 & 4770 & 51\end{array}$ 
HIGHEST MEAN DISCHARGE, IN OUIC FEET PER SECOND, AND RANKING FOR THE INDICATED NUMBER OF CONSECUTIVE DAYS FOR EAOH WATER YEAR, OCTCBER 1-SEPT'EMBER 30--Continued

YEAR

\begin{tabular}{|c|c|c|c|}
\hline $\begin{array}{l}1941 \\
1942 \\
1943 \\
1944 \\
1945\end{array}$ & $\begin{array}{l}63400 \\
50000 \\
32700 \\
51900 \\
32400\end{array}$ & $\begin{array}{rr}3 & 60200 \\
13 & 47800 \\
33 & 30200 \\
11 & 50500 \\
34 & 32000\end{array}$ & $\begin{array}{rr}5 & 53500 \\
14 & 44800 \\
35 & 27100 \\
11 & 43300 \\
33 & 30800\end{array}$ \\
\hline $\begin{array}{l}1946 \\
1947 \\
1948 \\
1949 \\
1950\end{array}$ & $\begin{array}{l}26600 \\
38100 \\
50800 \\
53200 \\
23300\end{array}$ & $\begin{array}{rr}42 & 25600 \\
29 & 36300 \\
12 & 49700 \\
9 & 51300 \\
47 & 22500\end{array}$ & $\begin{array}{ll}42 & 24900 \\
31 & 32900 \\
12 & 46500 \\
10 & 45500 \\
48 & 22200\end{array}$ \\
\hline $\begin{array}{l}1951 \\
1952 \\
1953 \\
1954 \\
1955\end{array}$ & $\begin{array}{l}29100 \\
56300 \\
38000 \\
12200 \\
17200\end{array}$ & $\begin{array}{rr}39 & 28300 \\
7 & 55700 \\
30 & 36700 \\
59 & 11800 \\
55 & 16400\end{array}$ & $\begin{array}{rr}39 & 26200 \\
6 & 54200 \\
30 & 32600 \\
60 & 10700 \\
57 & 15700\end{array}$ \\
\hline $\begin{array}{l}1956 \\
1957 \\
1958 \\
1959 \\
1960\end{array}$ & $\begin{array}{l}30000 \\
63400 \\
48800 \\
21200 \\
25200\end{array}$ & $\begin{array}{rr}3728900 \\
463000 \\
1748600 \\
5021000 \\
43 \quad 24900\end{array}$ & $\begin{array}{rr}37 & 27700 \\
3 & 60000 \\
13 & 47300 \\
50 & 20100 \\
43 & 23500\end{array}$ \\
\hline $\begin{array}{l}1961 \\
1962 \\
1963 \\
1964 \\
1965\end{array}$ & $\begin{array}{l}20500 \\
43800 \\
12100 \\
28600 \\
37700\end{array}$ & $\begin{array}{ll}51 & 20300 \\
23 & 42600 \\
60 & 12000 \\
40 & 27800 \\
31 & 37400\end{array}$ & $\begin{array}{ll}51 & 19800 \\
23 & 40200 \\
59 & 11200 \\
40 & 27500 \\
28 & 36700\end{array}$ \\
\hline $\begin{array}{l}1966 \\
1967 \\
1968 \\
1969 \\
1970\end{array}$ & $\begin{array}{l}17200 \\
20500 \\
30600 \\
22200 \\
35000\end{array}$ & $\begin{array}{ll}56 & 17000 \\
52 & 19500 \\
36 & 29100 \\
49 & 21500 \\
32 & 34300\end{array}$ & $\begin{array}{ll}54 & 15800 \\
52 & 17600 \\
36 & 27900 \\
49 & 18900 \\
32 & 33100\end{array}$ \\
\hline $\begin{array}{l}1971 \\
1972 \\
1973 \\
1974 \\
1975\end{array}$ & $\begin{array}{l}22800 \\
19000 \\
41600 \\
24700 \\
29200\end{array}$ & $\begin{array}{ll}48 & 22700 \\
53 & 18600 \\
24 & 39400 \\
46 & 24300 \\
38 & 28700\end{array}$ & $\begin{array}{ll}47 & 22300 \\
53 & 17600 \\
24 & 37800 \\
44 & 22300 \\
38 & 26800\end{array}$ \\
\hline $\begin{array}{l}1976 \\
1977 \\
1978 \\
1979 \\
1980\end{array}$ & $\begin{array}{r}15600 \\
4970 \\
30800 \\
44600 \\
38400\end{array}$ & $\begin{array}{rr}58 & 14700 \\
62 & 4740 \\
35 & 30200 \\
22 & 43900 \\
27 & 36700\end{array}$ & $\begin{array}{rr}58 & 14100 \\
62 & 4520 \\
34 & 29100 \\
22 & 40300 \\
29 & 33600\end{array}$ \\
\hline 1981 & 11800 & 6111700 & 6111100 \\
\hline
\end{tabular}

\section{CONSECUTIVE DAYS
30}

646200

839100

$\begin{array}{ll}12 & 38600 \\ 36 & 23100\end{array}$

3824700

1838600

3327900

$32 \begin{array}{ll}25100 \\ 32\end{array}$

$\begin{array}{ll}10 & 32800 \\ 11 & 31700 \\ 34 & 19500 \\ 14 & 31400 \\ 33 & 23400\end{array}$

4123600

3130000

1240400

3917300

3128200

$\begin{array}{ll}31 & 28200 \\ 15 & 37200\end{array}$

1340000
4821300

1732400

4715000

2925900

1330300

4215600

4022500

3817200

3227600

439800

$\begin{array}{rr}738000 \\ 3217200 \\ 60 & 5690\end{array}$

617430

5613500

5512400

$56 \quad 12000$

90
1025700

$\begin{array}{ll}11 & 28800 \\ 35 & 17700\end{array}$

1324100

2919500

4712900

2522300

1724500

$\begin{array}{ll}20 & 23900 \\ 42 & 13800\end{array}$

3813700

531600

3913300

$\begin{array}{rr}61 & 4870 \\ 51 & 10100\end{array}$

3625600

3421900

3716500

4012800

352900

350400

340300

4012800

$\begin{array}{rrrr}1044600 & 939700 & 831400\end{array}$

334500
1424500

4918700

$\begin{array}{ll}49 & 15600 \\ 46 & 18800\end{array}$

$\begin{array}{ll}50 & 12300 \\ 46 & 15300\end{array}$

$\begin{array}{rr}50 & 9430 \\ 45 & 13700\end{array}$

5017500

2333200

5910600

$\begin{array}{llll}50 & 15100 & 51 & 11200\end{array}$

2630900

$\begin{array}{llll}59 & 9450 & 59 & 7120\end{array}$

$52 \quad 8680$

2324300

$59 \quad 6330$

4910800

$2428500 \quad 2825100$

2622600

34000

5711600

$57 \quad 9740$

$57 \quad 8800$

5315500

5313700

5210700

$3523300 \quad 4120500 \quad 3915500$

$\begin{array}{llllll}51 & 17100 & 51 & 16200 & 49 & 15000 \\ 30 & 30400 & 30 & 26800 & 31 & 23100\end{array}$

$53 \quad 8500$
$43 \quad 12000$

4312000

4613900

3018400

4621100

5216400

4519200

4416400

4114300

$2513700 \quad 5310200$

$2529500 \quad 2626400$

$\begin{array}{llll}4719400 & 4817200 & \mathbf{4 8} 14700\end{array}$

$55 \quad 8030$

2222000

4811900

3620400

5813100

3722400

5510200

$56 \quad 8510$
62

$\begin{array}{lllrll}62 & 3970 & 62 & 3790 & 62 & 3690\end{array}$

$3425600 \quad 3522900 \quad 3519700$

2235900
2930700

2232400

$\begin{array}{ll}21 & 25900 \\ 25 & 27000\end{array}$

623610

3416100

2422700

2122500

6010200

607370

616000

$60 \quad 5120$

120

183

ALL

$\begin{array}{llll}14 & 20800 \quad 1415000 \quad 14 \quad 9080\end{array}$

$723800 \quad 716800 \quad 1010600$

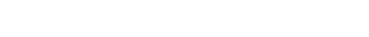

$\begin{array}{lllll}2816900 & 2712200 & 28 & 7470\end{array}$

$\begin{array}{llllll}44 \quad 10800 & 44 & 8170 & 45 & 5610\end{array}$

$\begin{array}{lllll}2518300 & 2413600 & 22 & 8360\end{array}$

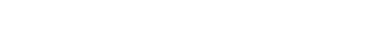

$1919800 \quad 1814400 \quad 18 \quad 8690$

$\begin{array}{rrrr}18 & 14400 & 18 & 8690 \\ 41 & 8830 & 40 & 5850\end{array}$

$40 \quad 5850 \quad 41$

$\begin{array}{llllll}41 & 11400 & 42 & 8360 & 44 & 5420\end{array}$

425500

4311200

$\begin{array}{ll}61 & 4310 \\ 50 & 8300\end{array}$

518300

438390

$\begin{array}{llll}50 & 6490 & 51 & 3220 \\ & & & 4480\end{array}$

4510500

228700

1619500

517750

$45 \quad 7750$

220800

1914100

526000

$\begin{array}{ll}52 & 6000 \\ 40 & 8640\end{array}$

$47 \quad 4970$

111700

$20 \quad 8780$

$54 \quad 4300$

$\begin{array}{ll}54 & 4300 \\ 41 & 5690\end{array}$

$53 \quad 7190$

1720200

$54 \quad 5870$

1514800

$\begin{array}{ll}56 & 4260 \\ 16 & 9250\end{array}$

$\begin{array}{llll}49 & 6960 & 49 & 4620\end{array}$

$16 \quad 14900 \quad 15 \quad 8850$

$51 \quad 6160$

$55 \quad 5710$

$46 \quad 8030$

$\begin{array}{ll}46 & 9030 \\ 39 & 9280\end{array}$

$\begin{array}{rr}31 & 9280 \\ 31 & 11700\end{array}$

$51 \quad 4840$

$\begin{array}{ll}56 & 4170\end{array}$

$46 \quad 5640$

$38 \quad 6570$

298060

$\begin{array}{lll}37 & 10400 \quad 35 \quad 7780\end{array}$

$56 \quad 6070$

2513400

337210

$53 \quad 6050$

$53 \quad 4810$

$\begin{array}{llll}62 & 3130 & 62 & 2630\end{array}$

$\begin{array}{lll}35 & 10100 \quad 37 \quad 6260\end{array}$

2114300

$\begin{array}{ll}37 & 6260 \\ 19 & 9100\end{array}$

$\begin{array}{ll}19 & 9100 \\ & 8570\end{array}$

$60 \quad 4030$

$60 \quad 3690$

DURATION OF DISCHARGE FOR EACH WATER YEAR

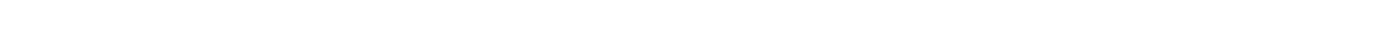
YEAR

NUMBER OF DAYS IN CLASS

OBIC FEET PER SECOND

-DAYS

1914

1916

1917

1923
1924

1925

1926

1927

1928

1929
1930

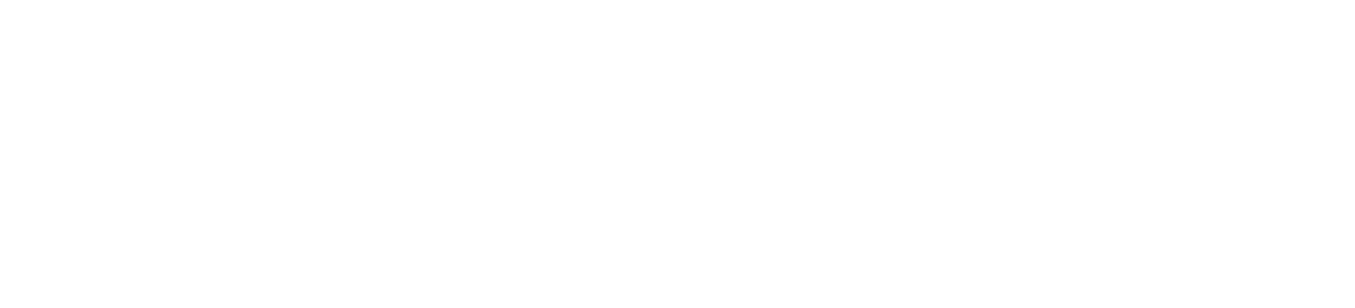


COLORADO RIVER MAIN STEM

09180500 COLORADO RIVER NEAR CISCO, UT--Continued

DURATION OF DISCHARGE FOR EACH WATER YEAR-Continued

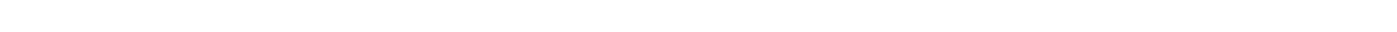

YEAR

NUMBER OF DAYS IN CLASS

ABBIC FEET

PER SECOND

1931

1932

$\begin{array}{llllllllllllllllllllll}8 & 21 & 10 & 5 & 8 & 12 & 35 & 85 & 52 & 18 & 21 & 13 & 8 & 6 & 12 & 14 & 4 & 4 & 13 & 7 & 7 & 2\end{array}$ $\begin{array}{rrrrrrrrrrrrrrrrrrrrrrrrrrrr}2 & 8 & 33 & 33 & 35 & 56 & 34 & 22 & 8 & 6 & 8 & 4 & 8 & 7 & 4 & 8 & 13 & 5 & 11 & 6 & 12 & 16 & 13 & 2 & 7 & 5\end{array}$

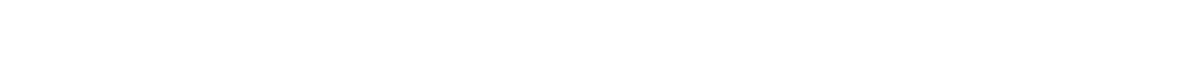

1934
1935

$\begin{array}{lrrrrrrrrrrrrrrrrrrrrrrrrrrrrrrrrr}11 & 23 & 20 & 53 & 68 & 25 & 15 & 18 & 16 & 9 & 13 & 14 & 3 & 6 & 6 & 4 & 15 & 4 & 4 & 6 & 5 & 7 & 2 & 7 & 3 & 3 & 5\end{array}$

1936

1937

$\begin{array}{llllllllllllllllllllll}13 & 24 & 84 & 72 & 28 & 15 & 9 & 9 & 13 & 8 & 7 & 4 & 2 & 4 & 4 & 6 & 8 & 11 & 14 & 9 & 9 & 13\end{array}$

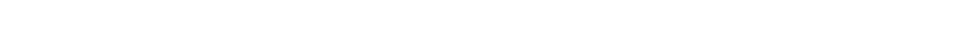

$\begin{array}{rrrrrrrrrrrrrrrrrrrrrrrrrr}10 & 27 & 54 & 45 & 41 & 25 & 23 & 13 & 7 & 12 & 3 & 7 & 12 & 7 & 2 & 5 & 4 & 4 & 6 & 8 & 19 & 13 & 8 & 10\end{array}$

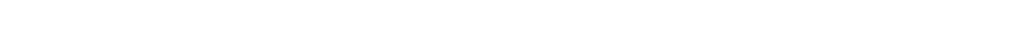

$\begin{array}{rrrrrrrrrrrrrrrrrrrrrrrrrrrrr} & 3 & 11 & 30 & 55 & 50 & 32 & 14 & 17 & 16 & 25 & 14 & 11 & 5 & 6 & 7 & 3 & 3 & 5 & 8 & 3 & 14 & 15 & 6 & 5 & 4 & 2 & 1\end{array}$

$\begin{array}{rrrrrrrrrrrrrrrrrrrrr}2 & 21 & 88 & 60 & 31 & 8 & 12 & 11 & 15 & 9 & 14 & 13 & 5 & 10 & 8 & 5 & 17 & 15 & 15 & 4 & 2\end{array}$

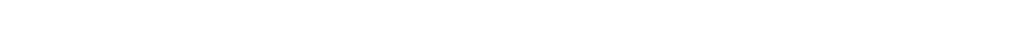

$\begin{array}{lllllllllllllllllllll}2 & 11 & 6 & 53 & 68 & 62 & 39 & 12 & 13 & 13 & 13 & 7 & 8 & 12 & 5 & 15 & 8 & 5 & 3 & 8 & 2\end{array}$

$\begin{array}{lllllllllllllllllllll}11 & 51 & 30 & 80 & 28 & 9 & 26 & 22 & 10 & 8 & 7 & 4 & 2 & 5 & 3 & 9 & 17 & 14 & 15 & 11 & 3\end{array}$

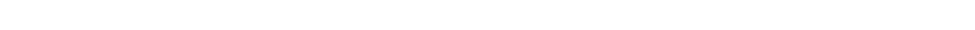

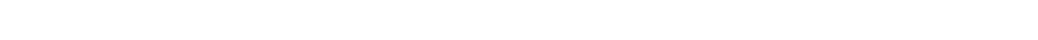

$\begin{array}{lllllllllll}5 & 8 & 13 & 12 & 8 & 11 & 9 & 10 & 11 & 13 & 2\end{array}$

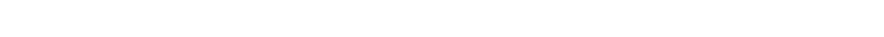

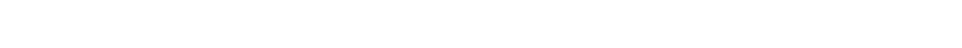

1952

1953

1954
1955

1956

1957

1958

1959

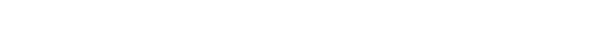

$\begin{array}{llllllllllllllllll}1 & 10 & 7 & 5 & 23 & 29 & 80 & 62 & 68 & 30 & 19 & 9 & 1 & 3 & 6 & 7 & 2 & 3\end{array}$

$\begin{array}{rllllllllllllllllll}10 & 4 & 27 & 66 & 60 & 49 & 28 & 17 & 12 & 11 & 6 & 7 & 9 & 14 & 11 & 11 & 13 & 9 & 1\end{array}$

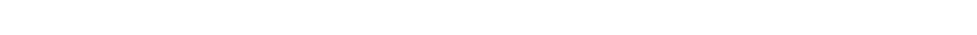

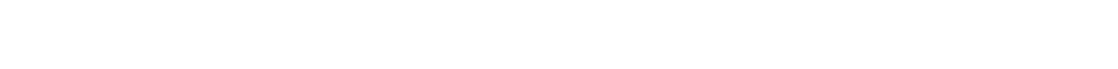

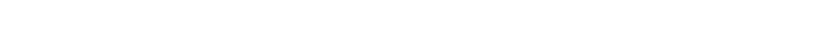

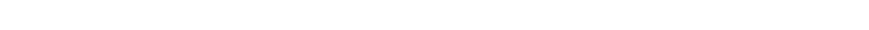

1961

962

1963

1965

1966

1967

1968

1970

1971

1972

1973
1974

1975

1976

1977

1978

1980

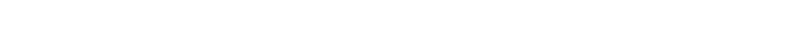

$\begin{array}{rrrrrrrrrrrrrrrrrrrrrrrrr}1 & 15 & 21 & 31 & 84 & 92 & 22 & 11 & 9 & 9 & 11 & 9 & 8 & 6 & 7 & 10 & 4 & 7 & 4 & 4 & & & \\ & & 3 & 12 & 24 & 29 & 35 & 63 & 27 & 24 & 19 & 15 & 13 & 7 & 2 & 4 & 2 & 9 & 14 & 13 & 20 & 14 & 9 & 3 & 4\end{array}$

$\begin{array}{rrrrrrrrrrrrrrrrrrr}2 & 3 & 7 & 7 & 18 & 17 & 66 & 41 & 48 & 42 & 36 & 22 & 15 & 8 & 13 & 5 & 9 & 6\end{array}$

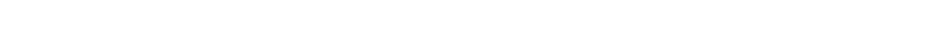

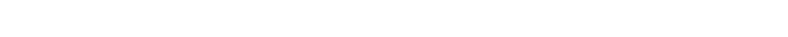

$\begin{array}{rrrrrrrrrrrrrrrrrrrr}6 & 13 & 41101 & 53 & 40 & 23 & 15 & 9 & 12 & 3 & 9 & 7 & 2 & 14 & 6 & 5 & 4 & 3 & & \end{array}$

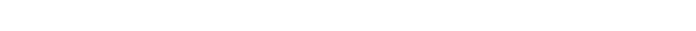

$\begin{array}{rrrrrrrrrrrrrrrrrrrr}27 & 32 & 77 & 84 & 16 & 11 & 7 & 7 & 7 & 14 & 20 & 15 & 19 & 14 & 4 & & & \\ 3 & 26 & 41 & 109 & 59 & 30 & 6 & 10 & 2 & 10 & 7 & 6 & 3 & 8 & 16 & 14 & 7 & 7 & 1\end{array}$

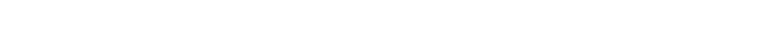

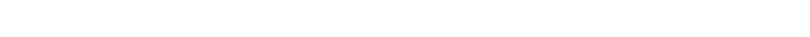

$\begin{array}{llrrrrrrrrrrrrrrrr}17 & 5 & 11 & 37 & 26 & 54 & 71 & 54 & 11 & 2 & 5 & 7 & 18 & 16 & 6 & 11 & 1 & 4\end{array}$

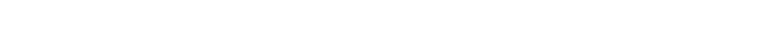

$\begin{array}{llllllllllllllll}14 & 9 & 13 & 30 & 73 & 55 & 63 & 40 & 11 & 9 & 8 & 11 & 4 & 11 & 14 & 1\end{array}$

$\begin{array}{llllllllllll}17 & 22 & 24 & 55 & 46 & 30 & 34 & 73 & 53 & 10 & 1\end{array}$

$\begin{array}{llllllllllllllllllllll}3 & 15 & 61 & 98 & 29 & 23 & 15 & 4 & 2 & 2 & 8 & 21 & 21 & 10 & 1 & 3 & 2 & 12 & 22 & 6 & 5 & 2\end{array}$

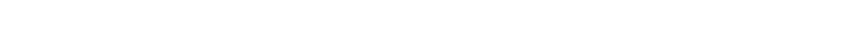

1981

$\begin{array}{llllllllllllllll}5 & 3 & 17 & 20 & 36 & 76 & 44 & 65 & 61 & 12 & 5 & 2 & 3 & 5 & 7 & 4\end{array}$

1444695.0

3371350.0

2334660.0

1119254.0

2360070.0

2906690.0

2351400.0

3741890.0

2143634.0

1746223.0

3315860.0

3885140.0

2589460.0

2976310.0

2726010.0

2046960.0

3050550.0

3304330.0

3170100.0

2135430.0

1977050.0

3885890.0

2034910.0

1174090.0

1633730.0

1817250.0

4278270.0

3203640.0

32040

2083380.0

1554790.0

3375720.0

1421540.0

1692610.0

3228510.0

1767870.0

1523840.0

2063490.0

(3)

2399500.0

2839780.0

1783650.0

3244720.0

2275770.0

2631530.0

1762270.0

960280.0
2285240.0

3322980.0

3135380.0

1345970.0 
09180500 COLORADO RIVER NEAR CISCO, UT-Continued

DURATION TABLE OF DISCHARGE FOR WATER YEARS 1914, 1916-17, 1923-81

\begin{tabular}{|c|c|c|c|c|c|c|c|c|c|c|c|c|c|}
\hline ASS & $\begin{array}{c}\text { CUBIC } \\
\text { FEET } \\
\text { PER } \\
\text { SECOND }\end{array}$ & $\begin{array}{r}\text { TOTAL } \\
\text { DAYS }\end{array}$ & $\begin{array}{c}\text { ACOJ- } \\
\text { MU- } \\
\text { LATED } \\
\text { DAYS }\end{array}$ & $\begin{array}{l}\text { PER- } \\
\text { CENT } \\
\text { DAYS }\end{array}$ & $\begin{array}{r}\text { QUBIC } \\
\text { FEET } \\
\text { PER } \\
\text { CLASS SECOND }\end{array}$ & $\begin{array}{r}\text { TOTAL } \\
\text { DAYS }\end{array}$ & $\begin{array}{l}\text { ACOJ- } \\
\text { MU- } \\
\text { LATED } \\
\text { DAYS }\end{array}$ & $\begin{array}{l}\text { PER- } \\
\text { CENT } \\
\text { DAYS }\end{array}$ & CLASS & $\begin{array}{l}\text { OUBIC } \\
\text { FEET } \\
\text { PER } \\
\text { SECOND }\end{array}$ & $\begin{array}{r}\text { TOTAL } \\
\text { DAYS }\end{array}$ & $\begin{array}{l}\text { ACOJ- } \\
\text { MU- } \\
\text { LATED } \\
\text { DAYS }\end{array}$ & 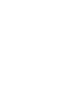 \\
\hline 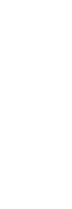 & $\begin{array}{r}0.00 \\
640.00 \\
740.00 \\
850.00 \\
980.00 \\
1100.00 \\
1300.00 \\
1500.00 \\
1700.00\end{array}$ & $\begin{array}{r}0 \\
10 \\
15 \\
46 \\
62 \\
116 \\
175 \\
296 \\
837\end{array}$ & $\begin{array}{l}22646 \\
22646 \\
22636 \\
22621 \\
22575 \\
22513 \\
22397 \\
22222 \\
21926\end{array}$ & $\begin{array}{r}100.0 \\
100.0 \\
100.0 \\
99.9 \\
99.7 \\
99.4 \\
98.9 \\
98.1 \\
96.8\end{array}$ & $\begin{array}{rr}9 & 2000.00 \\
10 & 2300.00 \\
11 & 2700.00 \\
12 & 3100.00 \\
13 & 3600.00 \\
14 & 4100.00 \\
15 & 4700.00 \\
16 & 5400.00 \\
17 & 6300.00\end{array}$ & $\begin{array}{r}1412 \\
3061 \\
2636 \\
2590 \\
1895 \\
1491 \\
1114 \\
876 \\
535\end{array}$ & $\begin{array}{r}21089 \\
19677 \\
16616 \\
13980 \\
11390 \\
9495 \\
8004 \\
6890 \\
6014\end{array}$ & $\begin{array}{l}93.1 \\
86.9 \\
73.4 \\
61.7 \\
50.3 \\
41.9 \\
35.3 \\
30.4 \\
26.6\end{array}$ & $\begin{array}{l}18 \\
19 \\
20 \\
21 \\
22 \\
23 \\
24 \\
25 \\
26\end{array}$ & $\begin{array}{r}7200.0 \\
8400.0 \\
9600.0 \\
11000.0 \\
13000.0 \\
15000.0 \\
17000.0 \\
20000.0 \\
23000.0\end{array}$ & $\begin{array}{l}562 \\
468 \\
446 \\
552 \\
426 \\
396 \\
513 \\
492 \\
357\end{array}$ & $\begin{array}{l}5479 \\
4917 \\
4449 \\
4003 \\
3451 \\
3025 \\
2629 \\
2116 \\
1624\end{array}$ & \\
\hline
\end{tabular}

MONTHLY MEAN DISCHARGES, IN CUBIC FEET PER SECOND, FOR EACH WATER YEAR

\begin{tabular}{|c|c|c|c|c|c|c|c|c|c|c|c|c|}
\hline YEAR & $\infty T$ & NOV & DEC & JAN & FEB & MAR & APR & MAY & JUNE & JULY & AUG & SEF \\
\hline $\begin{array}{l}1912 \\
1913 \\
1914 \\
1915\end{array}$ & $\begin{array}{l}7630 \\
4550 \\
4055 \\
6076\end{array}$ & $\begin{array}{l}3700 \\
3850 \\
3610 \\
3525\end{array}$ & $\begin{array}{l}2980 \\
2780 \\
2306 \\
2350\end{array}$ & $\begin{array}{l}2800 \\
2910 \\
2931 \\
2120\end{array}$ & $\begin{array}{l}2710 \\
2790 \\
2727 \\
2535\end{array}$ & $\begin{array}{l}3660 \\
3380 \\
3645 \\
2872\end{array}$ & $\begin{array}{r}6500 \\
11600 \\
9815 \\
9711\end{array}$ & $\begin{array}{l}32500 \\
21300 \\
33820 \\
18170\end{array}$ & $\begin{array}{l}45500 \\
19800 \\
47190 \\
26020\end{array}$ & $\begin{array}{r}22800 \\
7730 \\
18360 \\
10010\end{array}$ & $\begin{array}{l}7920 \\
2930 \\
8115 \\
2995\end{array}$ & $\begin{array}{l}4220 \\
4120 \\
4459 \\
2172\end{array}$ \\
\hline $\begin{array}{l}1916 \\
1917 \\
1918 \\
1919 \\
1920\end{array}$ & $\begin{array}{l}2790 \\
6889 \\
3038 \\
3718 \\
2561\end{array}$ & $\begin{array}{l}2770 \\
3460 \\
3106 \\
3711 \\
3111\end{array}$ & $\begin{array}{l}2527 \\
2706 \\
2778 \\
3321 \\
2809\end{array}$ & $\begin{array}{l}2953 \\
2000 \\
2527 \\
2466 \\
2895\end{array}$ & $\begin{array}{l}3237 \\
2500 \\
2868 \\
2449 \\
3312\end{array}$ & $\begin{array}{l}6872 \\
3145 \\
4285 \\
4050 \\
3285\end{array}$ & $\begin{array}{r}12680 \\
8909 \\
6773 \\
9739 \\
4682\end{array}$ & $\begin{array}{l}27300 \\
24660 \\
23000 \\
23420 \\
46270\end{array}$ & $\begin{array}{l}33810 \\
55530 \\
39530 \\
15620 \\
51930\end{array}$ & $\begin{array}{r}13890 \\
24610 \\
10850 \\
6057 \\
16520\end{array}$ & $\begin{array}{r}10350 \\
6869 \\
3298 \\
3464 \\
6165\end{array}$ & $\begin{array}{l}4807 \\
3887 \\
3976 \\
2514 \\
3455\end{array}$ \\
\hline $\begin{array}{l}1921 \\
1922 \\
1923 \\
1924 \\
1925\end{array}$ & $\begin{array}{l}3993 \\
3446 \\
2253 \\
4875 \\
3199\end{array}$ & $\begin{array}{l}4052 \\
3850 \\
3163 \\
4086 \\
3192\end{array}$ & $\begin{array}{l}3038 \\
3703 \\
3067 \\
2988 \\
2430\end{array}$ & $\begin{array}{l}3067 \\
2910 \\
2988 \\
2445 \\
2200\end{array}$ & $\begin{array}{l}3140 \\
2701 \\
2776 \\
3284 \\
2600\end{array}$ & $\begin{array}{l}4515 \\
4196 \\
2791 \\
2766 \\
3563\end{array}$ & $\begin{array}{r}5516 \\
7388 \\
7253 \\
10440 \\
9485\end{array}$ & $\begin{array}{l}31090 \\
36120 \\
28460 \\
25540 \\
17800\end{array}$ & $\begin{array}{l}58630 \\
34480 \\
37070 \\
30240 \\
18500\end{array}$ & $\begin{array}{r}16330 \\
7888 \\
16900 \\
7647 \\
8925\end{array}$ & $\begin{array}{l}8537 \\
4219 \\
8524 \\
1827 \\
5002\end{array}$ & $\begin{array}{l}5442 \\
2822 \\
5003 \\
2079 \\
6293\end{array}$ \\
\hline $\begin{array}{l}1926 \\
1927 \\
1928 \\
1929 \\
1930\end{array}$ & $\begin{array}{l}5172 \\
3433 \\
5828 \\
4101 \\
6558\end{array}$ & $\begin{array}{l}3756 \\
3125 \\
4623 \\
3784 \\
4607\end{array}$ & $\begin{array}{l}2795 \\
2705 \\
3765 \\
2361 \\
3324\end{array}$ & $\begin{array}{l}2313 \\
2657 \\
3400 \\
2281 \\
2360\end{array}$ & $\begin{array}{l}2587 \\
2887 \\
3331 \\
2314 \\
3719\end{array}$ & $\begin{array}{l}3452 \\
3395 \\
4581 \\
4348 \\
3292\end{array}$ & $\begin{array}{r}12870 \\
10450 \\
8736 \\
11370 \\
15450\end{array}$ & $\begin{array}{l}27400 \\
33680 \\
37770 \\
34320 \\
16780\end{array}$ & $\begin{array}{l}31780 \\
31570 \\
31380 \\
40120 \\
26030\end{array}$ & $\begin{array}{r}11980 \\
14270 \\
13150 \\
14350 \\
7075\end{array}$ & $\begin{array}{r}3423 \\
7712 \\
4151 \\
10120 \\
8534\end{array}$ & $\begin{array}{r}1693 \\
8887 \\
2866 \\
11330 \\
3383\end{array}$ \\
\hline $\begin{array}{l}1931 \\
1932 \\
1933 \\
1934 \\
1935\end{array}$ & $\begin{array}{l}3796 \\
3393 \\
2719 \\
2610 \\
1353\end{array}$ & $\begin{array}{l}2902 \\
2802 \\
3012 \\
2554 \\
1730\end{array}$ & $\begin{array}{l}2325 \\
2118 \\
2158 \\
2500 \\
2073\end{array}$ & $\begin{array}{l}2203 \\
1903 \\
2150 \\
2279 \\
2059\end{array}$ & $\begin{array}{l}2749 \\
3083 \\
2274 \\
2258 \\
2015\end{array}$ & $\begin{array}{l}2393 \\
3159 \\
2872 \\
2215 \\
2095\end{array}$ & $\begin{array}{r}3547 \\
12280 \\
3023 \\
3815 \\
4461\end{array}$ & $\begin{array}{r}8907 \\
33530 \\
13170 \\
10930 \\
11950\end{array}$ & $\begin{array}{r}11540 \\
28350 \\
33670 \\
4390 \\
33060\end{array}$ & $\begin{array}{r}3266 \\
12490 \\
6830 \\
1057 \\
10450\end{array}$ & $\begin{array}{l}1500 \\
4766 \\
2398 \\
1017 \\
3508\end{array}$ & $\begin{array}{l}2400 \\
2563 \\
2616 \\
1078 \\
2938\end{array}$ \\
\hline $\begin{array}{l}1936 \\
1937 \\
1938 \\
1939 \\
1940\end{array}$ & $\begin{array}{l}3055 \\
2547 \\
2994 \\
3573 \\
2407\end{array}$ & $\begin{array}{l}3060 \\
2900 \\
3039 \\
3301 \\
2532\end{array}$ & $\begin{array}{l}2326 \\
2416 \\
2754 \\
2875 \\
2044\end{array}$ & $\begin{array}{l}2314 \\
1900 \\
2430 \\
2608 \\
2131\end{array}$ & $\begin{array}{l}2673 \\
2400 \\
2526 \\
2498 \\
2389\end{array}$ & $\begin{array}{l}2710 \\
3193 \\
4149 \\
4536 \\
2769\end{array}$ & $\begin{array}{r}13180 \\
9738 \\
15430 \\
8651 \\
6314\end{array}$ & $\begin{array}{l}30560 \\
25970 \\
28120 \\
19640 \\
17050\end{array}$ & $\begin{array}{l}21120 \\
14680 \\
40400 \\
14570 \\
12420\end{array}$ & $\begin{array}{r}6557 \\
6726 \\
11960 \\
3050 \\
2916\end{array}$ & $\begin{array}{l}4867 \\
21.85 \\
3293 \\
1786 \\
1406\end{array}$ & $\begin{array}{l}2818 \\
2390 \\
5953 \\
3262 \\
2888\end{array}$ \\
\hline $\begin{array}{l}1941 \\
1942 \\
1943 \\
1944 \\
1945\end{array}$ & $\begin{array}{l}4795 \\
9416 \\
2629 \\
3000 \\
2588\end{array}$ & $\begin{array}{l}3017 \\
5232 \\
3125 \\
3619 \\
3289\end{array}$ & $\begin{array}{l}2514 \\
3730 \\
2670 \\
3082 \\
2782\end{array}$ & $\begin{array}{l}2265 \\
2939 \\
2490 \\
2275 \\
2423\end{array}$ & $\begin{array}{l}2754 \\
2983 \\
2632 \\
2644 \\
2709\end{array}$ & $\begin{array}{l}3358 \\
3718 \\
2834 \\
2708 \\
2892\end{array}$ & $\begin{array}{r}7478 \\
22590 \\
11910 \\
5102 \\
5521\end{array}$ & $\begin{array}{l}38310 \\
29420 \\
16190 \\
29020 \\
24320\end{array}$ & $\begin{array}{l}26590 \\
32950 \\
22930 \\
30970 \\
22040\end{array}$ & $\begin{array}{r}9422 \\
9411 \\
8166 \\
11010 \\
11000\end{array}$ & $\begin{array}{l}4076 \\
3002 \\
5980 \\
2419 \\
7260\end{array}$ & $\begin{array}{l}3975 \\
2256 \\
3565 \\
1664 \\
2454\end{array}$ \\
\hline $\begin{array}{l}1946 \\
1947 \\
1948 \\
1949 \\
1950\end{array}$ & $\begin{array}{l}3528 \\
3355 \\
5340 \\
2842 \\
3669\end{array}$ & $\begin{array}{l}3767 \\
3467 \\
4648 \\
3436 \\
3529\end{array}$ & $\begin{array}{l}2973 \\
3386 \\
3623 \\
3018 \\
2932\end{array}$ & $\begin{array}{l}2834 \\
2361 \\
3101 \\
3052 \\
3232\end{array}$ & $\begin{array}{l}2789 \\
2708 \\
3658 \\
3368 \\
3616\end{array}$ & $\begin{array}{l}3101 \\
3075 \\
3977 \\
3951 \\
3399\end{array}$ & $\begin{array}{r}8816 \\
5301 \\
13950 \\
10340 \\
9091\end{array}$ & $\begin{array}{l}11800 \\
23150 \\
31870 \\
20970 \\
12420\end{array}$ & $\begin{array}{l}17270 \\
26780 \\
25190 \\
32100 \\
18700\end{array}$ & $\begin{array}{r}5034 \\
16010 \\
7254 \\
14760 \\
5637\end{array}$ & $\begin{array}{l}3182 \\
6005 \\
3658 \\
3645 \\
1780\end{array}$ & $\begin{array}{l}2276 \\
4353 \\
2040 \\
2664 \\
2314\end{array}$ \\
\hline
\end{tabular}


COLORADO RIVER MAIN STEM

09180500 COLORADO RIVER NEAR CISCO, UT-Continued

MONTHLY MEAN DISCHARGES, IN CUBIC FEET PER SECOND, FOR EACH WATER YEAR.-Continued

\begin{tabular}{|c|c|c|c|c|c|c|c|c|c|c|c|c|}
\hline YEAR & OCT & NOV & DEC & JAN & FEB & MAR & APR & MAY & JUNE & JUY & AUG & SEP \\
\hline $\begin{array}{l}1951 \\
1952 \\
1953 \\
1954 \\
1955\end{array}$ & $\begin{array}{l}2037 \\
2749 \\
2696 \\
2886 \\
3502\end{array}$ & $\begin{array}{l}2712 \\
2995 \\
2971 \\
3475 \\
2760\end{array}$ & $\begin{array}{l}2723 \\
2797 \\
3051 \\
2782 \\
2275\end{array}$ & $\begin{array}{l}2484 \\
3103 \\
3015 \\
2870 \\
2171\end{array}$ & $\begin{array}{l}2721 \\
2706 \\
2563 \\
2574 \\
2185\end{array}$ & $\begin{array}{l}2625 \\
3150 \\
3036 \\
2612 \\
3219\end{array}$ & $\begin{array}{r}2904 \\
16290 \\
4200 \\
3714 \\
5384\end{array}$ & $\begin{array}{r}12330 \\
35000 \\
9857 \\
7089 \\
12230\end{array}$ & $\begin{array}{r}19720 \\
38890 \\
23510 \\
3644 \\
11580\end{array}$ & $\begin{array}{r}8610 \\
10430 \\
5741 \\
2439 \\
3486\end{array}$ & $\begin{array}{l}3875 \\
5817 \\
4161 \\
1602 \\
3008\end{array}$ & $\begin{array}{l}2193 \\
3585 \\
2148 \\
2879 \\
1811\end{array}$ \\
\hline $\begin{array}{l}1956 \\
1957 \\
1958 \\
1959 \\
1960\end{array}$ & $\begin{array}{l}1941 \\
1964 \\
4750 \\
2522 \\
4075\end{array}$ & $\begin{array}{l}2833 \\
2782 \\
5034 \\
3188 \\
3533\end{array}$ & $\begin{array}{l}2862 \\
2305 \\
3882 \\
2860 \\
2652\end{array}$ & $\begin{array}{l}2521 \\
2671 \\
3255 \\
2725 \\
2666\end{array}$ & $\begin{array}{l}2458 \\
3018 \\
4053 \\
2752 \\
2490\end{array}$ & $\begin{array}{l}3043 \\
2724 \\
4134 \\
2432 \\
4442\end{array}$ & $\begin{array}{r}5976 \\
6685 \\
12700 \\
2735 \\
10580\end{array}$ & $\begin{array}{r}16350 \\
22360 \\
33050 \\
8710 \\
12330\end{array}$ & $\begin{array}{l}15520 \\
48040 \\
26220 \\
15520 \\
17950\end{array}$ & $\begin{array}{r}2800 \\
31750 \\
3805 \\
3482 \\
4075\end{array}$ & $\begin{array}{r}1931 \\
10750 \\
1779 \\
2595 \\
1716\end{array}$ & $\begin{array}{l}1369 \\
5273 \\
2573 \\
2087 \\
1959\end{array}$ \\
\hline $\begin{array}{l}1961 \\
1962 \\
1963 \\
1964 \\
1965\end{array}$ & $\begin{array}{l}2485 \\
5805 \\
4268 \\
2183 \\
2659\end{array}$ & $\begin{array}{l}2972 \\
4232 \\
4082 \\
3004 \\
3057\end{array}$ & $\begin{array}{l}2677 \\
3203 \\
2930 \\
2250 \\
2948\end{array}$ & $\begin{array}{l}2545 \\
2964 \\
2658 \\
2146 \\
2631\end{array}$ & $\begin{array}{l}2514 \\
4705 \\
3480 \\
2102 \\
2531\end{array}$ & $\begin{array}{l}2634 \\
4002 \\
3568 \\
2090 \\
2509\end{array}$ & $\begin{array}{r}3469 \\
17710 \\
4110 \\
3603 \\
9450\end{array}$ & $\begin{array}{r}11010 \\
26070 \\
8402 \\
14000 \\
20680\end{array}$ & $\begin{array}{r}11170 \\
23520 \\
5578 \\
13110 \\
27800\end{array}$ & $\begin{array}{r}2122 \\
12440 \\
1863 \\
4489 \\
18160\end{array}$ & $\begin{array}{l}2241 \\
3351 \\
2727 \\
3919 \\
7264\end{array}$ & $\begin{array}{l}5305 \\
2908 \\
3069 \\
2564 \\
6203\end{array}$ \\
\hline $\begin{array}{l}1966 \\
1967 \\
1968 \\
1969 \\
1970\end{array}$ & $\begin{array}{l}5854 \\
2834 \\
2838 \\
3470 \\
5272\end{array}$ & $\begin{array}{l}4190 \\
2577 \\
3543 \\
4309 \\
4855\end{array}$ & $\begin{array}{l}3849 \\
2842 \\
3919 \\
4039 \\
4100\end{array}$ & $\begin{array}{l}3246 \\
2376 \\
3339 \\
4219 \\
3834\end{array}$ & $\begin{array}{l}3040 \\
2443 \\
3357 \\
3396 \\
3957\end{array}$ & $\begin{array}{l}4524 \\
3017 \\
2782 \\
4063 \\
4499\end{array}$ & $\begin{array}{r}7368 \\
3333 \\
3869 \\
12000 \\
5501\end{array}$ & $\begin{array}{r}11330 \\
7506 \\
10850 \\
16060 \\
22520\end{array}$ & $\begin{array}{r}7207 \\
11990 \\
19670 \\
12290 \\
22520\end{array}$ & $\begin{array}{l}3014 \\
5319 \\
4969 \\
7673 \\
8745\end{array}$ & $\begin{array}{l}1949 \\
2844 \\
5935 \\
3236 \\
3985\end{array}$ & $\begin{array}{l}2432 \\
2984 \\
2667 \\
4032 \\
6836\end{array}$ \\
\hline $\begin{array}{l}1971 \\
1972 \\
1973 \\
1974 \\
1975\end{array}$ & $\begin{array}{l}5852 \\
4548 \\
4916 \\
4080 \\
3348\end{array}$ & $\begin{array}{l}5685 \\
4640 \\
4727 \\
4159 \\
4351\end{array}$ & $\begin{array}{l}5155 \\
4621 \\
4345 \\
4717 \\
3674\end{array}$ & $\begin{array}{l}5399 \\
4346 \\
4595 \\
5067 \\
3835\end{array}$ & $\begin{array}{l}5773 \\
3941 \\
3793 \\
5295 \\
3731\end{array}$ & $\begin{array}{l}6712 \\
4537 \\
3908 \\
5909 \\
3910\end{array}$ & $\begin{array}{l}9738 \\
3389 \\
6520 \\
6072 \\
6337\end{array}$ & $\begin{array}{r}12490 \\
7366 \\
25320 \\
16530 \\
16380\end{array}$ & $\begin{array}{l}19180 \\
12750 \\
26170 \\
12550 \\
20890\end{array}$ & $\begin{array}{r}8708 \\
3115 \\
12990 \\
5097 \\
13120\end{array}$ & $\begin{array}{l}4000 \\
1943 \\
5377 \\
2614 \\
3682\end{array}$ & $\begin{array}{l}4746 \\
3373 \\
3705 \\
2653 \\
3112\end{array}$ \\
\hline $\begin{array}{l}1976 \\
1977 \\
1978 \\
1979 \\
1980\end{array}$ & $\begin{array}{l}3790 \\
3559 \\
2296 \\
3256 \\
3660\end{array}$ & $\begin{array}{l}4682 \\
3691 \\
2392 \\
4189 \\
3795\end{array}$ & $\begin{array}{l}4266 \\
3567 \\
2109 \\
3969 \\
4197\end{array}$ & $\begin{array}{l}3733 \\
3359 \\
2221 \\
3884 \\
4259\end{array}$ & $\begin{array}{l}3584 \\
2631 \\
2493 \\
4521 \\
4475\end{array}$ & $\begin{array}{l}3581 \\
2009 \\
3113 \\
6041 \\
4437\end{array}$ & $\begin{array}{r}4649 \\
1638 \\
8010 \\
12030 \\
9507\end{array}$ & $\begin{array}{r}10400 \\
2322 \\
15560 \\
24610 \\
26920\end{array}$ & $\begin{array}{r}9946 \\
2820 \\
22570 \\
26140 \\
26520\end{array}$ & $\begin{array}{r}3760 \\
2064 \\
8707 \\
12280 \\
8283\end{array}$ & $\begin{array}{l}2446 \\
1767 \\
2593 \\
4526 \\
3303\end{array}$ & $\begin{array}{l}2963 \\
2135 \\
3053 \\
3664 \\
3469\end{array}$ \\
\hline 1981 & 3582 & 4437 & 4148 & 3721 & 2921 & 2525 & 2942 & 4821 & 6836 & 3184 & 2066 & 3076 \\
\hline
\end{tabular}

ANNUAL PEAK DISCHARGE, IN CUBIC FEET PER SECOND, AND CORRESPONDING GAGE HEIGHT, IN FEET, FOR EACH WATER YEAR

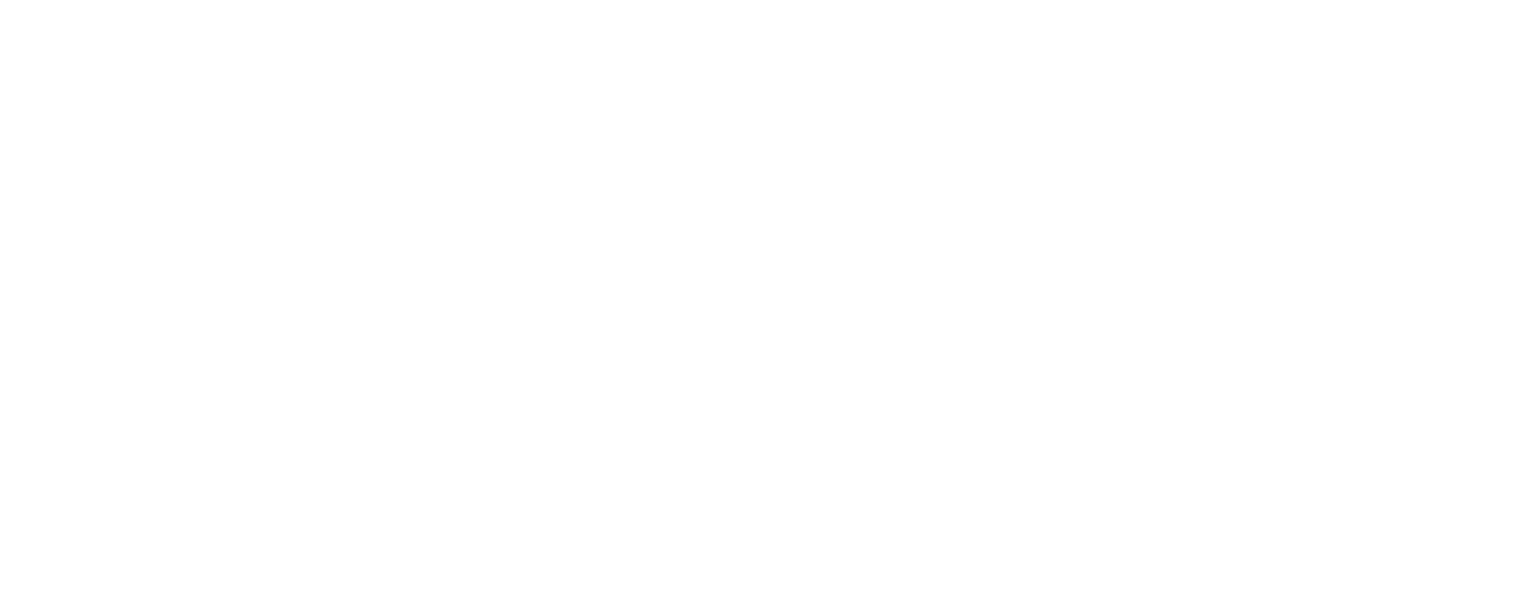




\begin{tabular}{|c|c|c|c|c|c|c|}
\hline \multirow{2}{*}{$\begin{array}{l}\text { PERIOD } \\
\text { (CON- } \\
\text { SECU- } \\
\text { TIVE } \\
\text { DAYS) }\end{array}$} & \multicolumn{6}{|c|}{$\begin{array}{l}\text { DISCHARGE, IN CUBIC FEET PER SECOND, FOR } \\
\text { INDICATED RECURRENCE INTERNAL, IN YEARS, AND } \\
\text { ANNUAL NONEXCEEDANCE PRCBABILITY, IN PERCENT }\end{array}$} \\
\hline & $\begin{array}{c}2 \\
508\end{array}$ & $\begin{array}{c}5 \\
208\end{array}$ & $\begin{array}{l}10 \\
108\end{array}$ & $\begin{array}{l}20 \\
58\end{array}$ & $\begin{array}{l}50 \\
28\end{array}$ & $\begin{array}{r}100 \\
18\end{array}$ \\
\hline $\begin{array}{r}1 \\
7 \\
14 \\
30 \\
60 \\
90\end{array}$ & $\begin{array}{l}1630 \\
1780 \\
1900 \\
2130 \\
2420 \\
2660\end{array}$ & $\begin{array}{l}1200 \\
1320 \\
1420 \\
1630 \\
1920 \\
2150\end{array}$ & $\begin{array}{l}1010 \\
1120 \\
1220 \\
1410 \\
1690 \\
1910\end{array}$ & $\begin{array}{r}870 \\
967 \\
1060 \\
1250 \\
1520 \\
1720\end{array}$ & $\begin{array}{r}733 \\
816 \\
909 \\
1080 \\
1350 \\
1520\end{array}$ & $\begin{array}{r}653 \\
727 \\
817 \\
980 \\
1240 \\
1400\end{array}$ \\
\hline
\end{tabular}

\begin{tabular}{|c|c|c|c|c|c|c|}
\hline \multirow{2}{*}{$\begin{array}{l}\text { PERIOD } \\
\text { CON- } \\
\text { SECU- } \\
\text { TIVE } \\
\text { DAYS) }\end{array}$} & \multicolumn{6}{|c|}{$\begin{array}{l}\text { DISCHARGE, IN CUBIC FEET PER SEOOND, FOR } \\
\text { INDICATED RECURRENCE INTERNAL, IN YEARS, AND } \\
\text { ANNUAL EXCEEDANCE PRCBABILITY, IN PERCENT }\end{array}$} \\
\hline & $\begin{array}{c}2 \\
508\end{array}$ & $\begin{array}{c}5 \\
208\end{array}$ & $\begin{array}{l}10 \\
108\end{array}$ & $\begin{array}{l}25 \\
48\end{array}$ & $\begin{array}{l}50 \\
28\end{array}$ & $\begin{array}{r}100 \\
18\end{array}$ \\
\hline $\begin{array}{r}1 \\
3 \\
7 \\
15\end{array}$ & $\begin{array}{l}35100 \\
34100 \\
32100 \\
28900\end{array}$ & $\begin{array}{l}50400 \\
49000 \\
46000 \\
41600\end{array}$ & $\begin{array}{l}58300 \\
56600 \\
53300 \\
48300\end{array}$ & $\begin{array}{l}66300 \\
64300 \\
60500 \\
54900\end{array}$ & $\begin{array}{l}70900 \\
68800 \\
64700 \\
58900\end{array}$ & $\begin{array}{l}74700 \\
72500 \\
68200 \\
62100\end{array}$ \\
\hline
\end{tabular}

TRIBUTARIES BETWEEN DOLORES RIVER AND GREEN RIVER

09180920 ONION CREEK ABOVE ONION CREEK BRIDGE, NEAR MOAB, UT

LOCATION. - Lat $38^{\circ} 41^{\prime} 49^{\prime \prime}$, long $109^{\circ} 15^{\prime} 16^{\prime \prime}$, in SE $\frac{1}{4} \mathrm{SW}^{\frac{1}{4}}$ sec. 22, T.24 S., R.24 E., Grand County, Hydrologic unit 14030005 , on right bank $7.3 \mathrm{mi}$ unstream from Highway $128,18.0 \mathrm{mi}$ northeast of Moab.

DRAINAGE AREA. $-2.9 \mathrm{mi}^{2}$

PERIOD OF RECORD AVAIIABLE.-August 1979 to September 1981.

GAGE.-Water-stage recorder. Altitude of gage is 5,120 ft from topographic map.

EXTREMES FOR PERIOD OF RECORD.-Maximum discharge, $180 \mathrm{ft}^{3} / \mathrm{s}$ Sept. 6, 1981, gage height, $4.32 \mathrm{ft}$ fram floodmarks; minimum, 0.49 $\mathrm{ft}^{3} / \mathrm{s}$ June 29,1980 .

LOWEST MEAN DISCHARGE, IN CUBIC FEET PER SECOND, AND RANKING FOR THE INDICATED NLMBER OF CONSECUTIVE DAYS FOR EACH CLIMATIC YEAR, APRIL 1-MARCH 31

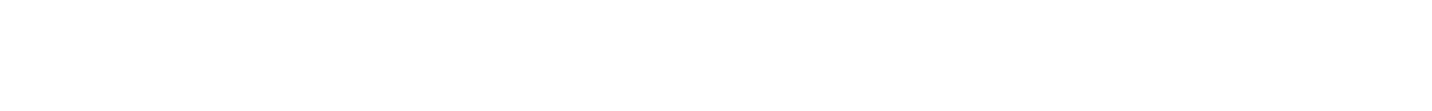

HIGHEST MEAN DISCHARGE, IN CUBIC FEET PER SECOND, AND RANKING FOR THE INDICATED NUMBER OF CONSEOUTIVE DAYS FOR EACH WATER YEAR, OCTOBER I-SEPTEMBER 30

\begin{tabular}{|c|c|c|c|c|c|c|c|c|c|c|c|c|c|c|c|c|c|c|c|}
\hline YEAR & 1 & & 3 & & 7 & & 15 & & $\begin{array}{l}\text { CONSE } \\
30\end{array}$ & QrT & $\begin{array}{l}\text { DAYS } \\
60\end{array}$ & & 90 & & 120 & & 183 & & ALL \\
\hline 1980 & 1.80 & 2 & 1.60 & 2 & 1.60 & 2 & 1.50 & 2 & 1.50 & 2 & 1.40 & 2 & 1.40 & 2 & 1.30 & 2 & 1.30 & 2 & 1.20 \\
\hline
\end{tabular}

DURATION OF DISCHARGE FOR EACH WATER YEAR

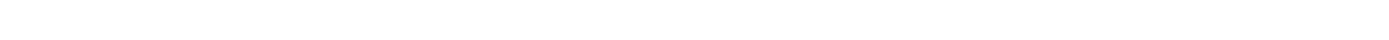
YEAR NUMBER OF DAYS IN CLASS OUBIC FEET PER SBCOND
-DAYS

$\begin{array}{lllllllllllllllllllllllll}1980 & 5 & 1 & 2 & 23 & 13 & 24 & 10 & 56 & 33 & 56 & 38 & 54 & 37 & 13 & 1 & & & & & & & & & \end{array}$

$\begin{array}{lllllllllllllllllllllllllll}1981 & 2 & 11 & 1 & 4 & 25 & 20 & 18 & 11 & 20 & 18 & 38 & 48 & 70 & 21 & 37 & 4 & 1 & 2 & 8 & 3 & & 1 & 2 & 528.3\end{array}$

$\begin{array}{crc}\text { OUBIC } & \text { ACOU- } \\ \text { FEET } & \text { MU- } & \text { PER- } \\ \text { PER } & \text { TOTAL IATED } & \text { CENT } \\ \text { CLASS SECOND DAYS DAYS } & \text { DAYS }\end{array}$

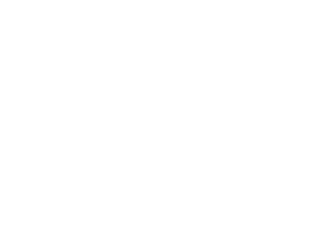

DURATION TABLE OF DISCHARGE FOR WATER YEARS 1980-81

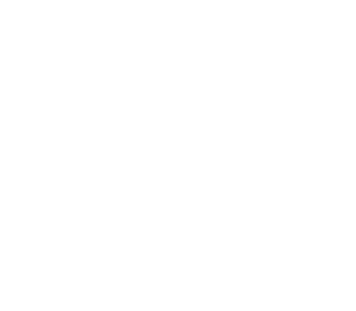

OUBIC ACOU-

FEET TOTAL LATED CENT

CLASS SECOND DAYS DAYS DAYS

$\begin{array}{rrrrr}18 & 1.7 & 21 & 80 & 10.9 \\ 19 & 1.8 & 38 & 59 & 8.1 \\ 20 & 2.0 & 4 & 21 & 2.9 \\ 21 & 2.1 & 1 & 17 & 2.3 \\ 22 & 2.2 & 2 & 16 & 2.2 \\ 23 & 2.4 & 8 & 14 & 1.9 \\ 24 & 2.6 & 0 & 6 & 0.8 \\ 25 & 2.7 & 3 & 6 & 0.8 \\ 26 & 2.9 & 0 & 3 & 0.4\end{array}$

$\begin{array}{lll}\text { QUBIC } & \text { ACOU- } \\ \text { FEET } & \text { MU- } & \text { PER- } \\ \text { PER TOTAL LATED } & \text { CENT }\end{array}$ CLASS SECOND DAYS DAYS DAYS

$\begin{array}{lllll}27 & 3.1 & 0 & 3 & 0.4 \\ 28 & 3.4 & 0 & 3 & 0.4 \\ 29 & 3.6 & 0 & 3 & 0.4 \\ 30 & 3.8 & 1 & 3 & 0.4 \\ 31 & 4.1 & 0 & 2 & 0.3 \\ 32 & 4.4 & 0 & 2 & 0.3 \\ 33 & 4.7 & 2 & 2 & 0.3 \\ 34 & & & & \end{array}$


TRIBUTARIES BETWEEN DOLORES RIVER AND GREEN RIVER

09180920 ONION CREEK ABONE ONION CREEK BRIDGE, NEAR MOAB, UT.--Continued

MOMILLY MEAN DISCHARGES, IN OUBIC FEET PER SECOND, FOR EACH WATER YEAR

$\begin{array}{llllllllllrrr}\text { YEAR } & \text { OCT } & \text { NOV } & \text { DEC } & \text { JAN } & \text { FEB } & \text { MAR } & \text { APR } & \text { MAY } & \text { JUNE } & \text { JULY } & \text { AUG } & \text { SEP } \\ 1980 & 1.04 & 1.33 & 1.25 & 1.39 & 1.35 & 1.09 & 1.27 & 1.43 & 1.17 & 0.89 & 0.83 & 1.01 \\ 1981 & 1.42 & 1.47 & 1.56 & 1.67 & 1.74 & 1.75 & 1.39 & 1.46 & 1.16 & 1.15 & 1.76 & 0.83\end{array}$

09180970 ONION CREEK BELOW ONION CREER BRIDGE, NEAR MOAB, UT

LOCATION. $-38^{\circ} 42^{\prime} 23^{\prime \prime}$, long $109^{\circ} 18^{\prime} 52^{\prime \prime}$, in $\mathrm{NE}^{\frac{1}{4}} \mathrm{NE}^{\frac{1}{4}}$, sec.24, T.24 S., R.24 E., Grand County, Hydrologic Unit 14030005, on right

bank $2.8 \mathrm{mi}$ upstream from Highway $128,15.5 \mathrm{mi}$ northeast of Moab.

DRAINAGE AREA. $-16.8 \mathrm{mi}^{2}$.

PERIOD OF RECORD AVALABLE.--August 1979 to September 1981.

REVISED RECORDS. -WDR UT-80-1: 1979 (M).

GAGE.--Water-stage recorder. Altitude of gage is 4,480 ft from topographic map.

EXTREMES FOR PERIOD OF RECORD. --Maximum discharge, $480 \mathrm{ft}^{3} / \mathrm{s}$ Sept. 5, 1981, gage height, $4.05 \mathrm{ft}$; no flow for part of several days during 1980.

LOWEST MEAN DISCHARGE, IN CUBIC FEET PER SECOND, AND RANKING FOR THE INDICATED NUMBER OF CONSECUTIVE DAYS FOR EACH CLIMATIC YEAR, APRIL 1-MARCH 31

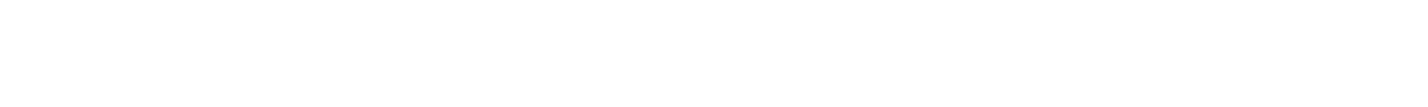

HIGHEST MEAN DISCHARGE, IN OUBIC FEET PER SECOND, AND RANKING FOR THE INDICATED NUMBER OF CONSECUTIVE DAYS FOR EACH WATER YEAR, OCTOBER 1-SEPTEMBER 30

\begin{tabular}{|c|c|c|c|c|c|c|c|c|c|c|c|c|c|c|c|c|c|c|c|}
\hline YEAR & 1 & & 3 & & 7 & & 15 & & $\begin{array}{l}\text { CONSE } \\
30\end{array}$ & OTIVE & $\begin{array}{l}\text { DAYS } \\
60\end{array}$ & & 90 & & 120 & & 183 & & ALL \\
\hline
\end{tabular}

DURATION OF DISCHARGE FOR EACH WATER YEAR

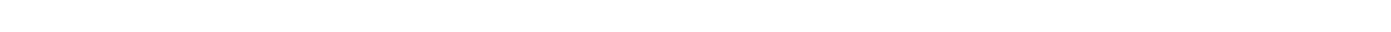
CUBIC FEET
YEAR

DURATION TABLE OF DISCHARGE FOR WATER YEARS 1980-81

\begin{tabular}{|c|c|c|c|c|c|c|c|c|c|c|c|c|c|c|c|c|c|c|}
\hline $\begin{array}{l}\text { DUBIC } \\
\text { FEET } \\
\text { PER } \\
\text { DCOND }\end{array}$ & $\begin{array}{l}\text { TOTAL } \\
\text { DAYS }\end{array}$ & $\begin{array}{l}\text { ACOU- } \\
\text { MU- } \\
\text { LATED } \\
\text { DAYS }\end{array}$ & $\begin{array}{l}\text { PER- } \\
\text { CENT } \\
\text { DAYS }\end{array}$ & & $\begin{array}{c}\text { CUBIC } \\
\text { FEET } \\
\text { PER } \\
\text { SECOND }\end{array}$ & $\begin{array}{l}\text { TOTAL } \\
\text { DAYS }\end{array}$ & $\begin{array}{l}\text { ACOU- } \\
\text { MU- } \\
\text { LATED } \\
\text { DAYS }\end{array}$ & $\begin{array}{l}\text { PER- } \\
\text { CENT } \\
\text { DAYS }\end{array}$ & & $\begin{array}{c}\text { OUBIC } \\
\text { FEET } \\
\text { PER } \\
\text { SECOND }\end{array}$ & $\begin{array}{l}\text { TOTAL } \\
\text { DAYS }\end{array}$ & $\begin{array}{l}\text { ACOJ- } \\
\text { MU- } \\
\text { LATED } \\
\text { DAYS }\end{array}$ & $\begin{array}{l}\text { PER- } \\
\text { CENT } \\
\text { DAYS }\end{array}$ & & $\begin{array}{c}\text { CUBIC } \\
\text { FEET } \\
\text { PER } \\
\text { SECOND }\end{array}$ & $\begin{array}{l}\text { TOTAL } \\
\text { DAYS }\end{array}$ & $\begin{array}{l}\text { ACOU- } \\
\text { MU- } \\
\text { LATED } \\
\text { DAYS }\end{array}$ & $\begin{array}{l}\text { PER- } \\
\text { CENT } \\
\text { DAYS }\end{array}$ \\
\hline
\end{tabular}

MONTHLY MEAN DISCHARGES, IN CUBIC FEET PER SECOND, FOR EACH WATER YEAR

\begin{tabular}{|c|c|c|c|c|c|c|c|c|c|c|c|c|}
\hline YEAR & $\infty T$ & NOV & DEC & JAN & FEB & MAR & APR & MAY & JUNE & JULY & AUG & SEP \\
\hline 1980 & 0.81 & 1.03 & 1.00 & 1.27 & 3.35 & 10.8 & 3.05 & 2.10 & 1.30 & 0.64 & 0.50 & 0.87 \\
\hline 1981 & 1.07 & 1.34 & 1.31 & 1.43 & 1.56 & 1.44 & 1.50 & 1.30 & 0.98 & 1.08 & 1.96 & 0.82 \\
\hline
\end{tabular}


LOCATION.--Lat $38^{\circ} 43^{\prime} 30^{\prime \prime}$, long $109^{\circ} 20^{\prime} 40^{\prime \prime}$, in SW sec.11, T.24 S., R. 23 E., Grand County, Hydrologic Unit 14030005, on right bank $1.2 \mathrm{mi}$ upstream from mouth and $15 \mathrm{mi}$ northeast of Moab.

DRAINAGE AREA. $--18.8 \mathrm{mi}^{2}$.

MEAN BASIN ELEVATION. $--5,700 \mathrm{ft}$.

PERIOD OF RECORD AVAILABLE.--July 1950 to September 1955, and annual peak discharge only, water years $1961-68$.

GAGE.-Water-stage recorder and concrete control. Altitude of gage is 4,160 ft from topographic map.

REMARKS.--Diversions above station for irrigation.

AVERAGE DISCHARGE.--5 vears (water years 1951-55), $1.13 \mathrm{ft}^{3} / \mathrm{s}, 8.18 \mathrm{acre}-\mathrm{ft} / \mathrm{yr}$.

EXIREMES FOR PERIOD OF RECORD. --Maximum discharge, 2,100 ft ${ }^{3} / \mathrm{s}$ Aug. 29, 1951, gage height, $5.10 \mathrm{ft}$, from slope-area measurenent of peak flow; no flow Aug. 17, oct. 24, 1950, and parts of several days in 1953-54.

LOWEST MEAN DISCHARGE, IN CUBIC FEET PER SECOND, AND RANKING FOR THE INDICATED NUMBER OF CONSECUTIVE DAYS FOR EACH CLIMATIC YEAR, APRIL 1-MARCH 31

\begin{tabular}{|c|c|c|c|c|c|c|c|c|c|c|c|c|c|c|c|c|c|c|c|}
\hline YEAR & & & & & & & & & CONSEX & CUTIVE & DAYS & & & & & & & & \\
\hline & 1 & & 3 & & 7 & & 14 & & 30 & & 60 & & 90 & & 120 & & 183 & & ALL \\
\hline 1952 & 0.10 & 1 & 0.10 & 1 & 0.10 & 1 & 0.12 & 2 & 0.15 & 1 & 0.26 & 1 & 0.34 & 1 & 0.48 & 2 & 0.96 & 4 & 1.40 \\
\hline 1953 & 0.20 & 4 & 0.20 & 4 & 0.20 & 4 & 0.20 & 3 & 0.25 & 2 & 0.33 & 2 & 0.36 & 2 & 0.39 & 1 & 0.52 & 1 & 0.76 \\
\hline
\end{tabular}

HIGHEST MEAN DISCHARGE, IN CUBIC FEET PER SECOND, AND RANKING FOR THE INDICATED NUMBER OF CONSBOUTIVE DAYS FOR EACH WATER YEAR, OTTCBER 1-SEPTEMBER 30

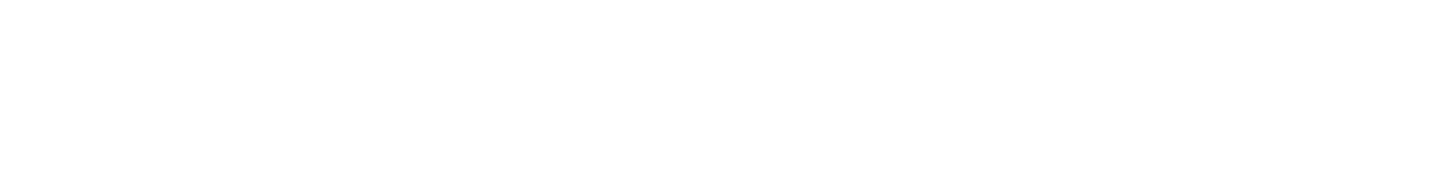

DURATION OF DISCHARGE FOR EACH WATER YEAR

$\begin{array}{llllllllllllllllllllllllllllllllllll}\text { CLASS } & 0 & 1 & 2 & 3 & 4 & 5 & 6 & 7 & 8 & 9 & 10 & 11 & 12 & 13 & 14 & 15 & 16 & 17 & 18 & 19 & 20 & 21 & 22 & 23 & 24 & 25 & 26 & 27 & 28 & 29 & 30 & 31 & 32 & 33 & 34\end{array}$ YEAR

NUMBER OF DAYS IN CLASS

CUBIC FEET PER SECOND -DAYS

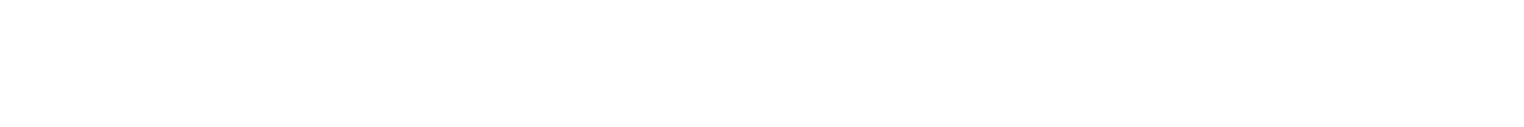

DURATION TABLE OF DISCHARGE FOR WATER YEARS 1951-55

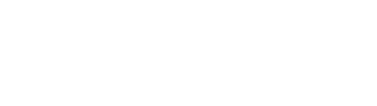

$\begin{array}{lllll}0 & 0.00 \quad 1 & 1826 & 100.0\end{array}$
CUBIC ACCU- CUBIC ACCU$\begin{array}{lclccc}\text { FEET } & \text { ACCU- } & & \text { CUBIC } & \text { ACCU- } \\ \text { PER TOTAL LATED } & \text { PER- } & \text { FEET } & \text { MEN- } & \text { PER- } \\ & \text { PER TOTAL LATFE } & \text { CFNT }\end{array}$ CLASS SECOND DAYS DAYS DAYS

$\begin{array}{rrrrr}9 & 0.44 & 161 & 1357 & 74.3 \\ 10 & 0.52 & 118 & 1196 & 65.5 \\ 11 & 0.63 & 299 & 1078 & 59.0 \\ 12 & 0.76 & 315 & 779 & 42.7 \\ 13 & 0.91 & 185 & 464 & 25.4 \\ 14 & 1.10 & 87 & 279 & 15.3 \\ 15 & 1.30 & 70 & 192 & 10.5 \\ 16 & 1.60 & 32 & 122 & 6.7 \\ 17 & 1.90 & 25 & 90 & 4.9\end{array}$

CLASS SECOND DAYS DAYS DAYS

$\begin{array}{rrrrr}18 & 2.3 & 15 & 65 & 3.6 \\ 19 & 2.7 & 5 & 50 & 2.7 \\ 20 & 3.3 & 2 & 45 & 2.5 \\ 21 & 4.0 & 4 & 43 & 2.4 \\ 22 & 4.7 & 4 & 39 & 2.1 \\ 23 & 5.7 & 0 & 35 & 1.9 \\ 24 & 6.9 & 3 & 35 & 1.9 \\ 25 & 8.2 & 2 & 32 & 1.8 \\ 26 & 9.9 & 7 & 30 & 1.6\end{array}$

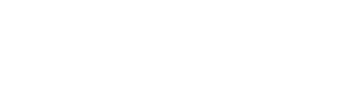

$\begin{array}{rrrrr}27 & 12.0 & 2 & 23 & 1.3 \\ 28 & 14.0 & 7 & 21 & 1.2 \\ 29 & 17.0 & 7 & 14 & 0.8 \\ 30 & 21.0 & 1 & 7 & 0.4 \\ 31 & 25.0 & 4 & 6 & 0.3 \\ 32 & 30.0 & 0 & 2 & 0.1 \\ 33 & 36.0 & 0 & 2 & 0.1 \\ 34 & 43.0 & 2 & 2 & 0.1\end{array}$

MONTHLY MEAN DISCHARGES, IN CUBIC FEET PER SECOND, FOR EACH WATER YEAR

\begin{tabular}{|c|c|c|c|c|c|c|c|c|c|c|c|c|}
\hline YEAR & $\infty \mathrm{CT}$ & NOV & DEC & JAN & FEBB & MAR & APR & MAY & JUNE & JULY & AUG & SEP \\
\hline $\begin{array}{l}1951 \\
1952 \\
1953 \\
1954 \\
1955\end{array}$ & $\begin{array}{l}0.52 \\
0.60 \\
0.81 \\
1.07 \\
0.61\end{array}$ & $\begin{array}{l}0.65 \\
0.76 \\
0.97 \\
1.00 \\
1.96\end{array}$ & $\begin{array}{l}0.57 \\
1.34 \\
0.80 \\
0.72 \\
1.59\end{array}$ & $\begin{array}{l}0.65 \\
1.31 \\
0.92 \\
0.84 \\
0.80\end{array}$ & $\begin{array}{l}0.57 \\
1.52 \\
1.08 \\
0.87 \\
1.86\end{array}$ & $\begin{array}{l}0.68 \\
1.59 \\
1.02 \\
1.50 \\
9.36\end{array}$ & $\begin{array}{l}0.88 \\
1.12 \\
1.04 \\
0.82 \\
1.20\end{array}$ & $\begin{array}{l}0.57 \\
0.70 \\
0.91 \\
0.81 \\
1.87\end{array}$ & $\begin{array}{l}0.40 \\
0.47 \\
0.54 \\
0.46 \\
0.70\end{array}$ & $\begin{array}{l}0.16 \\
0.35 \\
1.02 \\
0.76 \\
0.40\end{array}$ & $\begin{array}{l}7.28 \\
0.41 \\
1.25 \\
1.18 \\
1.25\end{array}$ & $\begin{array}{l}0.33 \\
0.47 \\
0.57 \\
1.53 \\
0.31\end{array}$ \\
\hline
\end{tabular}


TRIBUTARIES BEIWEEN DOLORES RIVER AND GREEN RIVER

09181000 ONION CREEK NEAR MOAB, UT--Continued

ANNUAL PEAK DISCHARGE, IN OIBIC FEET ZER SECOND, AND CORRESFONDING GAGE HEIGHT, IN FEET, FOR EAGH WATER YEAR

\begin{tabular}{|c|c|c|c|c|c|c|c|c|c|c|c|}
\hline $\begin{array}{l}\text { WATERR } \\
\text { YEAR }\end{array}$ & DATE & $\begin{array}{c}\text { GAGE } \\
\text { HEIGHT }\end{array}$ & $\begin{array}{l}\text { PEAK } \\
\text { DISCHARGE }\end{array}$ & $\begin{array}{l}\text { WATER } \\
\text { YEAR }\end{array}$ & DATE & $\begin{array}{c}\text { GAGE } \\
\text { HEIGHT }\end{array}$ & $\begin{array}{c}\text { PEAK } \\
\text { DISOHARGE }\end{array}$ & $\begin{array}{l}\text { WATER } \\
\text { YEAR }\end{array}$ & DATE & $\begin{array}{c}\text { GAGE } \\
\text { HEIGHT }\end{array}$ & $\begin{array}{c}\text { PEAK } \\
\text { DISCHARGE }\end{array}$ \\
\hline $\begin{array}{l}1951 \\
1952 \\
1953 \\
1954 \\
1955\end{array}$ & $\begin{array}{l}\text { AUG. } 29,1951 \\
\text { JUNE } 02,1952 \\
\text { AUG. } 01,1953 \\
\text { AUG. } 13,1954 \\
\text { MAY } 22,1955\end{array}$ & $\begin{array}{l}5.10 \\
2.12 \\
3.20 \\
3.63 \\
3.60\end{array}$ & $\begin{array}{r}2100 \\
167 \\
902 \\
1270 \\
1020\end{array}$ & $\begin{array}{l}1961 \\
1962 \\
1963 \\
1964\end{array}$ & $\begin{array}{l}\text { AUG. } 29,1961 \\
\text { JUNE } 30,1962 \\
\text { AUG. } 31,1963 \\
\text { AUG. } 12,1964\end{array}$ & $\begin{array}{l}3.75 \\
3.16 \\
2.70 \\
3.48\end{array}$ & $\begin{array}{r}1300 \\
510 \\
175 \\
900\end{array}$ & $\begin{array}{l}1965 \\
1966 \\
1967 \\
1968\end{array}$ & $\begin{array}{l}\text { SEPT. } 06,1965 \\
\text { MAR. } 28,1966 \\
\text { AUG. } 07,1967 \\
\text { JULY } 30,1968\end{array}$ & $\begin{array}{l}3.52 \\
2.40 \\
3.50 \\
3.00\end{array}$ & $\begin{array}{r}1130 \\
280 \\
1100 \\
750\end{array}$ \\
\hline
\end{tabular}

09181500 PROFESSOR CREEK NEAR MOAB, UT

LOCATION.--Lat $38^{\circ} 43^{\prime} 15^{\prime \prime}$, long $109^{\circ} 22^{\prime} 30$ ", in $\mathrm{NE}_{\frac{1}{4}}^{\frac{3}{4}}$ sec.16, T.24 S., R.23 E., Grand County, Hydrologic Unit 14030005 , on left bank 0.2 mi upstream from mouth and $14 \mathrm{mi}$ northeast of Moab.

DRAINAGE AREA. $--336 \mathrm{mi}^{2}$.

PERIOD OF RECORD AVALLABLE.--JUly 1950 to September 1953.

GAGE.-Water-stage recorder. Altitude of gage is 4,070 ft, by barcmeter.

REMARKS.--Diversions above station for irrigation.

EXIREMES FOR PERIOD OF RECORD.--Maximum discharge, 3,330 ft ${ }^{3} / \mathrm{s}$ Aug. 29, 1951, gage height, $8.26 \mathrm{ft}$, fram rating curve extended above $6 \mathrm{ft}^{3} / \mathrm{s}$ on basis of slope-area measurements at gage heights 3.53 and $8.26 \mathrm{ft}$; no flow sept. 6-15, Oct. 7, 1951.

LOWEST MEAN DISCHARGE, IN CUBIC FEET PER SECOND, AND RANKING FOR THE INDICATED NUMBER OF CONSEOUTIVE DAYS FOR EACH OLIMATIC YEAR, APRIL 1-MAROH 31

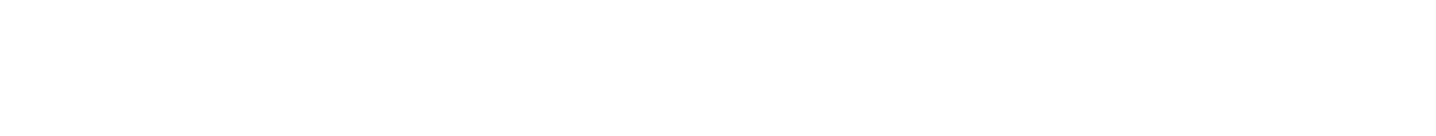

HIGHEST NEAN DISCHARGE, IN OBIC FEET PER SECOND, AND RANKING FOR THE INDICATED NUMBER OF CONSEOUTIVE DAYS FOR EACH WATER YEAR, OCTOBER 1-SEPTEMBER 30

\begin{tabular}{|c|c|c|c|c|c|c|c|c|c|c|c|c|c|c|c|c|c|c|c|}
\hline YEAR & & & & & & & & & CONSE & QT & DAYS & & & & & & & & \\
\hline $\begin{array}{l}1951 \\
1952 \\
1953\end{array}$ & $\begin{array}{r}182 \\
23.0 \\
5.50\end{array}$ & $\begin{array}{l}1 \\
2 \\
3\end{array}$ & $\begin{array}{r}61.0 \\
14.0 \\
5.40\end{array}$ & $\begin{array}{l}1 \\
2 \\
3\end{array}$ & $\begin{array}{c}26.0 \\
12.0 \\
5.40\end{array}$ & $\begin{array}{l}1 \\
2 \\
3\end{array}$ & $\begin{array}{r}13.0 \\
8.90 \\
5.20\end{array}$ & $\begin{array}{l}1 \\
2 \\
3\end{array}$ & $\begin{array}{l}6.60 \\
7.50 \\
5.00\end{array}$ & $\begin{array}{l}2 \\
1 \\
3\end{array}$ & $\begin{array}{l}3.60 \\
5.60 \\
4.30\end{array}$ & $\begin{array}{l}3 \\
1 \\
2\end{array}$ & $\begin{array}{l}3.00 \\
4.80 \\
3.90\end{array}$ & $\begin{array}{l}3 \\
1 \\
2\end{array}$ & $\begin{array}{l}2.80 \\
4.60 \\
4.00\end{array}$ & $\begin{array}{l}3 \\
1 \\
2\end{array}$ & $\begin{array}{l}2.80 \\
4.00 \\
3.40\end{array}$ & $\begin{array}{l}3 \\
1 \\
2\end{array}$ & $\begin{array}{l}2.10 \\
2.30 \\
2.00\end{array}$ \\
\hline
\end{tabular}

DURATION OF DISCHARGE FOR EACH WATER YEAR

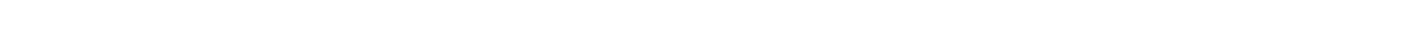
YEAR NUMBER OF DAYS IN CLASS

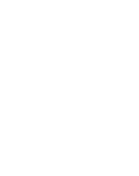

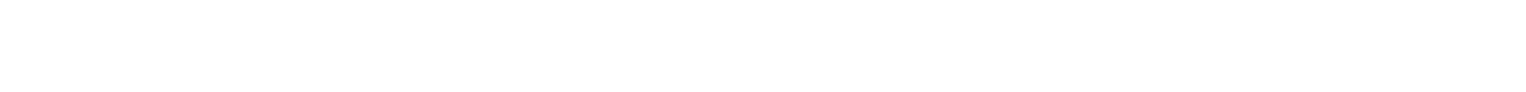
DURATION TABLE OF DISCHARGE FOR WATER YEARS $1951-53$
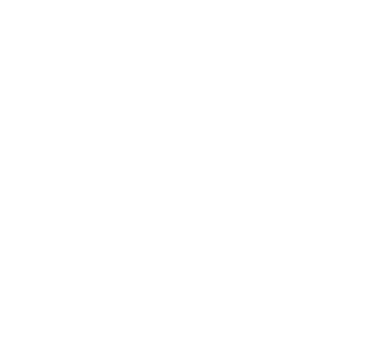

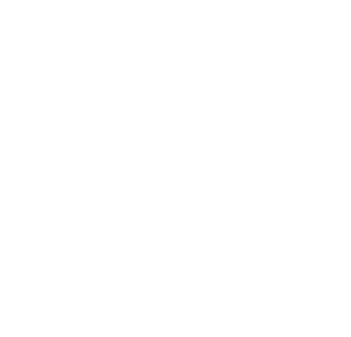

OLA

$\begin{array}{rrrr}\begin{array}{c}\text { OBIC } \\ \text { FEET }\end{array} & \begin{array}{c}\text { ACOU- } \\ \text { MU- }\end{array} & \text { PER } \\ \text { PER } & \text { TOTAL } & \text { LATED } & \text { CENI } \\ \text { SECOND } & \text { DAYS } & \text { DAYS } & \text { DAYS } \\ & & & \\ 3.5 & 109 & 241 & 22.0 \\ 4.3 & 77 & 132 & 12.0 \\ 5.3 & 25 & 55 & 5.0 \\ 6.5 & 18 & 30 & 2.7 \\ 8.0 & 4 & 12 & 1.1 \\ 9.9 & 3 & 8 & 0.7 \\ 12.0 & 2 & 5 & 0.5 \\ 15.0 & 0 & 3 & 0.3 \\ 18.0 & 1 & 3 & 0.3\end{array}$

$\begin{array}{lll}\text { ORIC } & \text { ACQU- } \\ \text { FEET } & \text { MU- } & \text { PER- } \\ \text { PER TOTAL LATED } & \text { CENT }\end{array}$ OLASS SECOND DAYS DAYS DAYS

$\begin{array}{lllll}27 & 23.0 & 1 & 2 & 0.2 \\ 28 & 28.0 & 0 & 1 & 0.1 \\ 29 & 35.0 & 0 & 1 & 0.1 \\ 30 & 43.0 & 0 & 1 & 0.1 \\ 31 & 52.0 & 0 & 1 & 0.1 \\ 32 & 65.0 & 0 & 1 & 0.1 \\ 33 & 80.0 & 0 & 1 & 0.1 \\ 34 & 98.0 & 1 & 1 & 0.1\end{array}$


TRIBUTARIES BEIWEEN DOLORES RTVER AND GREEN RIVER

09181500 PROFESSOR CREEK NEAR MOAB, UT--Continued

MONHLY MEAN DISCHARGES, IN UBIC FEET PER SECOND, FOR EAOH WATER YEAR

\begin{tabular}{|c|c|c|c|c|c|c|c|c|c|c|c|c|}
\hline YEAR & OCT & NON & DEC & JAN & FEB & MAR & APR & MAY & JUNE & JULY & AUG & SEP \\
\hline $\begin{array}{l}1951 \\
1952 \\
1953\end{array}$ & $\begin{array}{l}3.72 \\
1.25 \\
2.48\end{array}$ & $\begin{array}{l}2.62 \\
3.51 \\
4.96\end{array}$ & $\begin{array}{l}2.14 \\
2.79 \\
3.07\end{array}$ & $\begin{array}{l}2.80 \\
3.40 \\
3.60\end{array}$ & $\begin{array}{l}3.46 \\
3.33 \\
4.54\end{array}$ & $\begin{array}{l}2.28 \\
4.08 \\
1.29\end{array}$ & $\begin{array}{l}0.26 \\
6.14 \\
1.77\end{array}$ & $\begin{array}{l}0.26 \\
0.17 \\
0.20\end{array}$ & $\begin{array}{l}0.20 \\
0.38 \\
0.20\end{array}$ & $\begin{array}{l}0.20 \\
0.23 \\
0.48\end{array}$ & $\begin{array}{l}6.43 \\
1.34 \\
1.30\end{array}$ & $\begin{array}{l}0.59 \\
0.22 \\
0.47\end{array}$ \\
\hline
\end{tabular}

09182000 CASTLE CREEK ABOVE DIVERSIONS, NEAR MOAB, UT

LOCATION.-Lat $38^{\circ} 35^{\prime} 34^{\prime \prime}$, long $109^{\circ} 15^{\prime} 54^{\prime \prime}$, in NE $\mathrm{NEE}_{4}^{\frac{1}{4}}$ sec.33, T.25 S., R.24 E., Grand County, Hydrologic Unit 14030005, on left bank

$1 \mathrm{mi}$ east of LaSal National Forest boundary and $15 \mathrm{mi}$ east of Moab.

DRATNAGE AREA. $-7.58 \mathrm{mi}^{2}$.

MEAN BASIN ELEVATION. $-9,480 \mathrm{ft}$.

PERIOD OF RECORD AVAL_ABLE.--July 1950 to September 1955, April 1957 to September 1975.

REVISED RECORDS.-WSP 1563: Drainage area. WSP 1633: 1952, 1953 (M), 1955, 1957.

GAGE.-Water-stage recorder and concrete control. Altitude of gage is 7,070 ft by barameter.

AVERAGE DISCHARGE. -23 years $(1951-55,1958-75), 1.16 \mathrm{ft}^{3} / \mathrm{s}, 840$ acre-ft/yr.

EXIREMES FOR PERدUD OF RECORD.-Maximum discharge, $27 \mathrm{ft}^{3} / \mathrm{s}$ Aug. 11, 1967, gage height, $1.71 \mathrm{ft}$; no flow for many days in $1959-61$, $1963-64$.

LONEST MEAN DISCHARGE, IN CUBIC FEET PER SECOND, AND RANKING FOR THE INDICATED NUMBER OF CONSEOUTIVE DAYS FOR EACH CLIMATIC YEAR, APRIL 1-MARQH 31

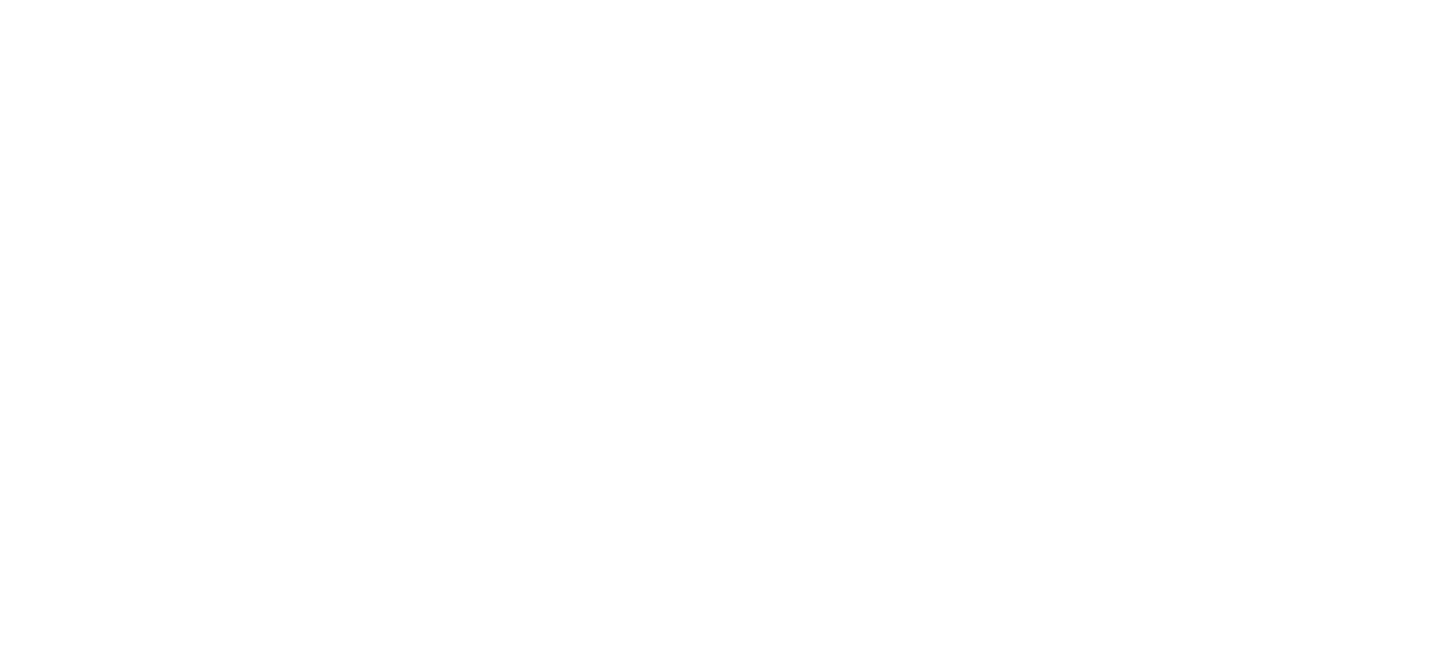


HIGHEST MEAN DISGAARG, IN GBIC FEET PER SECOND, AND RANKING FOR THE INDICATED NUMBER OF CONSEUTTIV DAYS FOR EAGH WATER YEAR, OCTOBER I-SEPTEMBER 30

\begin{tabular}{|c|c|c|c|c|c|c|c|c|c|c|c|c|c|}
\hline \multirow[t]{2}{*}{ YEAR } & \multicolumn{13}{|c|}{ CONSEQUTIVE DAYS } \\
\hline & 1 & 3 & 7 & 15 & 30 & & 60 & & 90 & 120 & 183 & & ALL \\
\hline $\begin{array}{l}1951 \\
1952 \\
1953 \\
1954 \\
1955\end{array}$ & $\begin{array}{rr}0.80 & 21 \\
21.0 & 1 \\
6.00 & 12 \\
1.60 & 20 \\
8.60 & 7\end{array}$ & $\begin{array}{rr}0.67 & 21 \\
20.0 & 1 \\
6.00 & 12 \\
1.60 & 20 \\
8.30 & 7\end{array}$ & $\begin{array}{rr}0.60 & 21 \\
18.0 & 1 \\
5.70 & 13 \\
1.50 & 20 \\
7.00 & 10\end{array}$ & $\begin{array}{cc}0.57 & 21 \\
16.0 & 1 \\
5.10 & 12 \\
1.50 & 20 \\
5.20 & 11\end{array}$ & $\begin{array}{c}0.55 \\
14.0 \\
4.40 \\
1.30 \\
3.70\end{array}$ & $\begin{array}{l}21 \\
1 \\
11 \\
20 \\
14\end{array}$ & $\begin{array}{c}0.54 \\
13.0 \\
3.10 \\
1.10 \\
3.00\end{array}$ & $\begin{array}{r}21 \\
1 \\
13 \\
20 \\
14\end{array}$ & $\begin{array}{rr}0.49 & 21 \\
11.0 & 1 \\
2.50 & 12 \\
0.92 & 19 \\
2.30 & 14\end{array}$ & $\begin{array}{rr}0.47 & 21 \\
8.40 & 1 \\
2.10 & 12 \\
0.79 & 19 \\
1.80 & 16\end{array}$ & $\begin{array}{l}0.41 \\
5.80 \\
1.60 \\
0.63 \\
1.40\end{array}$ & $\begin{array}{r}21 \\
1 \\
12 \\
19 \\
13\end{array}$ & $\begin{array}{rr}0.33 & 20 \\
3.10 & 1 \\
1.00 & 12 \\
0.47 & 19 \\
0.85 & 15\end{array}$ \\
\hline $\begin{array}{l}958 \\
959 \\
960\end{array}$ & $\begin{array}{cc}16.0 & 2 \\
0.60 & 22 \\
2.00 & 19\end{array}$ & $\begin{array}{cc}15.0 & 2 \\
0.47 & 23 \\
2.00 & 19\end{array}$ & $\begin{array}{cc}13.0 & 3 \\
0.40 & 23 \\
1.90 & 19\end{array}$ & $\begin{array}{rr}12.0 & 3 \\
0.35 & 23 \\
1.60 & 19\end{array}$ & $\begin{array}{c}11.0 \\
0.33 \\
1.50\end{array}$ & & $\begin{array}{l}8.30 \\
0.25 \\
1.19\end{array}$ & $\begin{array}{r}3 \\
23 \\
19\end{array}$ & $\begin{array}{lr}6.40 & 3 \\
0.20 & 23 \\
0.86 & 20\end{array}$ & $\begin{array}{lr}5.00 & 3 \\
0.18 & 23 \\
0.65 & 20\end{array}$ & $\begin{array}{l}3.50 \\
0.14 \\
0.42\end{array}$ & $\begin{array}{r}3 \\
23 \\
20\end{array}$ & $\begin{array}{rr}1.90 & 3 \\
0.13 & 23 \\
0.21 & 21\end{array}$ \\
\hline $\begin{array}{l}1961 \\
1962 \\
1963 \\
1964 \\
1965\end{array}$ & $\begin{array}{rrr}4.00 & 15 \\
7.90 & 10 \\
0.50 & 23 \\
6.40 & 11 \\
9.90 & 4\end{array}$ & $\begin{array}{rr}3.90 & 15 \\
7.70 & 10 \\
0.50 & 22 \\
6.20 & 11 \\
9.90 & 4\end{array}$ & $\begin{array}{rrr}3.60 & 15 \\
7.30 & 7 \\
0.50 & 22 \\
5.90 & 11 \\
9.00 & 4\end{array}$ & $\begin{array}{rr}3.30 & 15 \\
6.70 & 7 \\
0.45 & 22 \\
5.30 & 10 \\
8.60 & 4\end{array}$ & $\begin{array}{l}3.00 \\
5.70 \\
0.41 \\
4.40 \\
7.30\end{array}$ & $\begin{array}{r}15 \\
8 \\
22 \\
12 \\
4\end{array}$ & $\begin{array}{l}2.20 \\
4.80 \\
0.36 \\
3.20 \\
5.90\end{array}$ & $\begin{array}{r}17 \\
8 \\
22 \\
12 \\
4\end{array}$ & $\begin{array}{rr}1.80 & 17 \\
4.10 & 8 \\
0.31 & 22 \\
2.50 & 13 \\
4.90 & 4\end{array}$ & $\begin{array}{rr}1.60 & 17 \\
3.50 & 7 \\
0.26 & 22 \\
2.10 & 13 \\
4.20 & 4\end{array}$ & $\begin{array}{l}1.10 \\
2.50 \\
0.22 \\
1.40 \\
3.10\end{array}$ & $\begin{array}{r}17 \\
7 \\
22 \\
14 \\
4\end{array}$ & $\begin{array}{rr}0.55 & 18 \\
1.50 & 7 \\
0.20 & 22 \\
0.71 & 17 \\
1.70 & 5\end{array}$ \\
\hline $\begin{array}{l}1966 \\
1967 \\
1968 \\
1969 \\
1970\end{array}$ & $\begin{array}{rr}8.40 & 8 \\
3.30 & 17 \\
7.90 & 9 \\
5.90 & 13 \\
9.10 & 5\end{array}$ & $\begin{array}{rr}8.20 & 8 \\
3.20 & 17 \\
7.70 & 9 \\
5.90 & 13 \\
8.70 & 5\end{array}$ & $\begin{array}{rr}7.20 & 8 \\
3.10 & 17 \\
7.00 & 9 \\
5.70 & 12 \\
8.40 & 5\end{array}$ & $\begin{array}{rr}6.50 & 8 \\
3.00 & 17 \\
5.90 & 9 \\
5.00 & 13 \\
8.30 & 5\end{array}$ & $\begin{array}{l}6.30 \\
2.70 \\
5.00 \\
4.40 \\
7.10\end{array}$ & & $\begin{array}{l}5.20 \\
2.40 \\
3.70 \\
3.80 \\
5.90\end{array}$ & $\begin{array}{r}6 \\
15 \\
10 \\
9 \\
5\end{array}$ & $\begin{array}{rr}4.20 & 7 \\
2.10 & 15 \\
3.10 & 10 \\
3.40 & 9 \\
4.70 & 5\end{array}$ & $\begin{array}{rr}3.50 & 8 \\
1.80 & 14 \\
2.70 & 10 \\
3.00 & 9 \\
3.70 & 5\end{array}$ & $\begin{array}{l}2.70 \\
1.401 \\
1.90 \\
2.30 \\
2.70\end{array}$ & $\begin{array}{r}5 \\
15 \\
10 \\
9 \\
6\end{array}$ & $\begin{array}{rr}1.80 & 4 \\
0.99 & 14 \\
1.19 & 10 \\
1.40 & 8 \\
1.60 & 6\end{array}$ \\
\hline $\begin{array}{l}1971 \\
1972 \\
1973 \\
1974 \\
1975\end{array}$ & $\begin{array}{rr}3.5016 \\
2.0018 \\
15.0 \quad 3 \\
4.6014 \\
8.60 \quad 6\end{array}$ & $\begin{array}{rr}3.5016 \\
2.0018 \\
14.0 \quad 3 \\
4.5014 \\
8.306\end{array}$ & $\begin{array}{rr}3.50 & 16 \\
2.00 & 18 \\
14.0 & 2 \\
4.40 & 14 \\
7.70 & 6\end{array}$ & $\begin{array}{rr}3.3016 \\
2.0018 \\
13.0 \quad 2 \\
4.0014 \\
7.306\end{array}$ & $\begin{array}{r}2.90 \\
1.80 \\
11.0 \\
3.70 \\
6.10\end{array}$ & $\begin{array}{r}16 \\
18 \\
3 \\
13 \\
7\end{array}$ & $\begin{array}{c}2.30 \\
1.50 \\
10.0 \\
3.20 \\
5.10\end{array}$ & $\begin{array}{r}16 \\
18 \\
2 \\
11 \\
7\end{array}$ & $\begin{array}{lr}2.00 & 16 \\
1.19 & 18 \\
8.40 & 2 \\
2.70 & 11 \\
4.20 & 6\end{array}$ & $\begin{array}{rr}1.80 & 15 \\
1.10 & 18 \\
6.70 & 2 \\
2.30 & 11 \\
3.50 & 6\end{array}$ & $\begin{array}{l}1.40 \\
0.91 \\
4.60 \\
1.70 \\
2.40\end{array}$ & $\begin{array}{r}16 \\
18 \\
2 \\
11 \\
8\end{array}$ & $\begin{array}{rr}1.00 & 13 \\
0.73 & 16 \\
2.70 & 2 \\
1.10 & 11 \\
1.40 & 9\end{array}$ \\
\hline
\end{tabular}

DURATION OF DISCHARGE FOR EAOH WATER YEAR

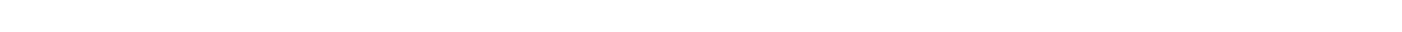
YEAR NUMBER OF DAYS IN CLASS वUBIC FEE -DAYS

\begin{tabular}{|c|c|c|c|c|c|c|c|c|c|c|c|c|c|c|c|c|c|c|c|c|c|c|c|c|c|c|c|}
\hline $\begin{array}{l}1951 \\
1952 \\
1953 \\
1954 \\
1955\end{array}$ & $\begin{array}{l}7 \\
1\end{array}$ & $\begin{array}{r}38 \\
135\end{array}$ & $\begin{array}{r}136 \\
88 \\
14 \\
171 \\
37\end{array}$ & $\begin{array}{l}26 \\
86 \\
40 \\
29 \\
60\end{array}$ & $\begin{array}{r}68 \\
15 \\
106 \\
50 \\
14\end{array}$ & $\begin{array}{r}24 \\
1 \\
57 \\
12 \\
6\end{array}$ & $\begin{array}{r}1 \\
9 \\
34 \\
5 \\
24\end{array}$ & $\begin{array}{r}1 \\
18 \\
6 \\
5\end{array}$ & $\begin{array}{r}4 \\
5 \\
13 \\
15\end{array}$ & $\begin{array}{r}16 \\
16 \\
12 \\
5\end{array}$ & $\begin{array}{r}21 \\
20 \\
17 \\
3\end{array}$ & $\begin{array}{l}4 \\
5 \\
5 \\
4\end{array}$ & $\begin{array}{l}8 \\
8\end{array}$ & $\begin{array}{l}3 \\
6\end{array}$ & $\begin{array}{l}9 \\
5\end{array}$ & $\begin{array}{l}8 \\
8\end{array}$ & $\begin{array}{l}1 \\
4\end{array}$ & $\begin{array}{l}3 \\
8\end{array}$ & 2 & $\begin{array}{l}4 \\
5\end{array}$ & 3 & 6181 & 1713 & 6 & 7 & 3 & $\begin{array}{r}120.7 \\
1127.1 \\
382.4 \\
170.2 \\
309.8\end{array}$ \\
\hline $\begin{array}{l}1958 \\
1959 \\
1960\end{array}$ & $\begin{array}{r}29 \\
42212 \\
275 \quad 14\end{array}$ & $\begin{array}{r}9 \\
83 \\
4\end{array}$ & $\begin{array}{r}53 \\
19 \\
5\end{array}$ & $\begin{array}{r}45 \\
5 \\
9\end{array}$ & $\begin{array}{r}29 \\
2 \\
5\end{array}$ & $\begin{array}{r}44 \\
2 \\
2\end{array}$ & 44 & 4 & 7 & 14 & 15 & 3 & $\begin{array}{l}7 \\
7\end{array}$ & 6 & 4 & 10 & 4 & 7 & 9 & 3 & 6 & 18 & 95 & 1 & & & $\begin{array}{r}711.7 \\
47.7 \\
77.7\end{array}$ \\
\hline $\begin{array}{l}1961 \\
1962 \\
1963 \\
1964 \\
1965\end{array}$ & $\begin{array}{r}223 \quad 7 \\
52 \\
30134 \\
210 \quad 10 \\
1\end{array}$ & $\begin{array}{r}2 \\
10 \\
68 \\
7 \\
56\end{array}$ & $\begin{array}{r}52 \\
73 \\
2 \\
89\end{array}$ & $\begin{array}{r}4 \\
22 \\
51 \\
1 \\
44\end{array}$ & $\begin{array}{r}2 \\
20 \\
9 \\
4 \\
9\end{array}$ & $\begin{array}{r}2 \\
14 \\
19 \\
12\end{array}$ & $\begin{array}{r}7 \\
22 \\
21 \\
4\end{array}$ & $\begin{array}{r}32 \\
13 \\
\\
5 \\
1\end{array}$ & $\begin{array}{r}22 \\
4\end{array}$ & $\begin{array}{c}14 \\
20 \\
19 \\
1\end{array}$ & $\begin{array}{l}10 \\
19 \\
4\end{array}$ & $\begin{array}{r}3 \\
17 \\
8 \\
28\end{array}$ & $\begin{array}{r}3 \\
7 \\
10 \\
18\end{array}$ & $\begin{array}{r}4 \\
10 \\
8 \\
8 \\
14\end{array}$ & $\begin{array}{l}9 \\
6 \\
\\
5 \\
8\end{array}$ & $\begin{array}{c}16 \\
241 \\
\\
8 \\
181\end{array}$ & $\begin{array}{r}4 \\
11\end{array}$ & $\begin{array}{l}7 \\
71\end{array}$ & $\begin{array}{c}6 \\
6 \\
6 \\
151\end{array}$ & 11 & 4 & 75 & & & & & $\begin{array}{r}202.4 \\
550.8 \\
73.8 \\
261.2 \\
618.6\end{array}$ \\
\hline $\begin{array}{l}1966 \\
1967 \\
1968 \\
1969 \\
1970\end{array}$ & & 4 & 19 & 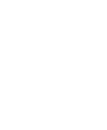 & $\begin{array}{l}21 \\
44 \\
22 \\
54 \\
63\end{array}$ & $\begin{array}{l}23 \\
26 \\
31 \\
33 \\
29\end{array}$ & $\begin{array}{r}31 \\
89 \\
22 \\
2 \\
25\end{array}$ & $\begin{array}{r}20 \\
23 \\
8 \\
5 \\
52\end{array}$ & $\begin{array}{r}42 \\
13 \\
6 \\
5 \\
22\end{array}$ & $\begin{array}{r}60 \\
6 \\
10 \\
36 \\
9\end{array}$ & $\begin{array}{r}11 \\
10 \\
12 \\
13 \\
4\end{array}$ & $\begin{array}{r}21 \\
12 \\
17 \\
13 \\
4\end{array}$ & $\begin{array}{r}17 \\
17 \\
15 \\
6 \\
5\end{array}$ & $\begin{array}{c}17 \\
20 \\
18 \\
16 \\
4\end{array}$ & $\begin{array}{r}6 \\
18 \\
7 \\
15 \\
6\end{array}$ & $\begin{array}{c}10 \\
8 \\
5 \\
28 \\
3\end{array}$ & $\begin{array}{r}11 \\
21 \\
6\end{array}$ & $\begin{array}{r}11 \\
5 \\
92\end{array}$ & $\begin{array}{r}4 \\
4 \\
22\end{array}$ & $\begin{array}{l}2 \\
5 \\
6\end{array}$ & $\begin{array}{lr}5 & 5 \\
3 & 2 \\
6 & 12\end{array}$ & $\begin{array}{l}5 \\
2 \\
2 \\
2\end{array}$ & & & & & $\begin{array}{l}643.7 \\
359.9 \\
447.7 \\
508.9 \\
598.0\end{array}$ \\
\hline $\begin{array}{l}1971 \\
1972 \\
1973 \\
1974 \\
1975\end{array}$ & & & $\begin{array}{l}1 \\
26 \\
69\end{array}$ & $\begin{array}{rrr} & & 50 \\
4 & 17 & 77 \\
& & 34 \\
30 & 39 & 13 \\
45 & 14 & 31\end{array}$ & $\begin{array}{l}91 \\
36 \\
59 \\
46 \\
50\end{array}$ & $\begin{array}{r}34 \\
93 \\
47 \\
22 \\
6\end{array}$ & $\begin{array}{r}28 \\
57 \\
21 \\
49 \\
5\end{array}$ & $\begin{array}{l}24 \\
20 \\
18 \\
29 \\
11\end{array}$ & $\begin{array}{r}20 \\
17 \\
25 \\
6 \\
9\end{array}$ & $\begin{array}{r}34 \\
8 \\
31 \\
9 \\
7\end{array}$ & $\begin{array}{r}10 \\
8 \\
26 \\
4 \\
9\end{array}$ & $\begin{array}{r}30 \\
8 \\
8 \\
19 \\
8\end{array}$ & $\begin{array}{r}11 \\
20 \\
4 \\
13 \\
4\end{array}$ & $\begin{array}{l}4 \\
9 \\
5\end{array}$ & $\begin{array}{l}3 \\
7 \\
6\end{array}$ & $\begin{array}{r}2 \\
191 \\
9\end{array}$ & $\begin{array}{r}5 \\
12 \\
9\end{array}$ & $\begin{array}{c}3 \\
13 \\
23\end{array}$ & 11 & 6 & 712 & 2251 & 1011 & 1 & & & $\begin{array}{l}366.6 \\
268.8 \\
980.2 \\
406.9 \\
515.4\end{array}$ \\
\hline
\end{tabular}

DURATION TABLE OF DISCAARGE FOR WATER YEARS 1951-55, 1958-75

\begin{tabular}{crrrr}
\multicolumn{4}{c}{ CUBIC } & \multicolumn{3}{c}{ ACO- } \\
FEET & M- & PER- \\
PER & TOTAL & LATED & CENT \\
CLASS SECOND & DAYS & DAYS & DAYS \\
& & & & \\
0 & 0.00 & 781 & 8400 & 100.0 \\
1 & 0.10 & 483 & 7619 & 90.7 \\
2 & 0.12 & 0 & 7136 & 85.0 \\
3 & 0.14 & 0 & 7136 & 85.0 \\
4 & 0.16 & 0 & 7136 & 85.0 \\
5 & 0.19 & 520 & 7136 & 85.0 \\
6 & 0.22 & 17 & 6616 & 78.8 \\
7 & 0.26 & 854 & 6599 & 78.6 \\
8 & 0.31 & 79 & 5745 & 68.4
\end{tabular}

\begin{tabular}{|c|c|c|c|c|}
\hline & $\begin{array}{c}\text { OBIC } \\
\text { FEET } \\
\text { PER }\end{array}$ & TOTAL & $\begin{array}{c}\text { ACOH- } \\
\text { MU- } \\
\text { LATED }\end{array}$ & $\begin{array}{l}\text { PER- } \\
\text { CENT }\end{array}$ \\
\hline ILASS & SECOND & DAYS & DAYS & DAYS \\
\hline $\begin{array}{r}9 \\
10 \\
11 \\
12 \\
13 \\
14 \\
15 \\
16\end{array}$ & $\begin{array}{l}0.36 \\
0.42 \\
0.50 \\
0.59 \\
0.69 \\
0.81 \\
0.95 \\
1.10\end{array}$ & $\begin{array}{l}681 \\
445 \\
819 \\
539 \\
502 \\
298 \\
246 \\
332\end{array}$ & $\begin{array}{l}5666 \\
4985 \\
4540 \\
3721 \\
3182 \\
2680 \\
2382 \\
2136\end{array}$ & $\begin{array}{l}67.5 \\
59.3 \\
54.0 \\
44.3 \\
37.9 \\
31.9 \\
28.4 \\
25.4\end{array}$ \\
\hline
\end{tabular}

\begin{tabular}{|c|c|c|c|c|}
\hline CIASS & $\begin{array}{c}\text { QUBIC } \\
\text { FEET } \\
\text { PER } \\
\text { SECOND }\end{array}$ & $\begin{array}{l}\text { TOTAL } \\
\text { DAYS }\end{array}$ & $\begin{array}{l}\text { ACOU- } \\
\text { MU- } \\
\text { LATED } \\
\text { DAYS }\end{array}$ & $\begin{array}{l}\text { PER- } \\
\text { CENT } \\
\text { DAYS }\end{array}$ \\
\hline $\begin{array}{l}18 \\
19 \\
20 \\
21 \\
22 \\
23 \\
24 \\
25\end{array}$ & $\begin{array}{l}1.5 \\
1.8 \\
2.1 \\
2.5 \\
2.9 \\
3.4 \\
4.0 \\
4.7\end{array}$ & $\begin{array}{l}221 \\
189 \\
160 \\
130 \\
205 \\
120 \\
132 \\
104\end{array}$ & $\begin{array}{r}1584 \\
1363 \\
1174 \\
1014 \\
884 \\
679 \\
559 \\
427\end{array}$ & $\begin{array}{r}18.9 \\
16.2 \\
14.0 \\
12.1 \\
10.5 \\
8.1 \\
6.7 \\
5.1\end{array}$ \\
\hline
\end{tabular}

$\begin{array}{lll}\text { OBIC } & \text { ACOU- } \\ \text { FEET } & \text { MU- } & \text { PER- } \\ \text { DER TOTAL LATED } & \text { CENT }\end{array}$ PER TOTAL LATED CENT
CLASS SECOND DAYS DAYS DAYS

$\begin{array}{rrrrr}27 & 6.5 & 46 & 253 & 3.0 \\ 28 & 7.6 & 56 & 207 & 2.5 \\ 29 & 9.0 & 68 & 151 & 1.8 \\ 30 & 11.0 & 36 & 83 & 1.0 \\ 31 & 12.0 & 29 & 47 & 0.6 \\ 32 & 15.0 & 8 & 18 & 0.2 \\ 33 & 17.0 & 7 & 10 & 0.1 \\ 34 & 20.0 & 3 & 3 & 0.0\end{array}$


TRIBUTARIES BETWEEN DOLORES RIVER AND GREEN RIVER

09182000 CASTHE CREEK ABOVE DIVERSION, NEAR MOAB, UT-Continued

MONIHLY MEAN DISGHARGES, IN UBIC FEET PER SECOND, FOR EAG WATER YEAR

$\begin{array}{lllllllllllll}\text { IEAR } & \text { OCT } & \text { NOV } & \text { DEC } & \text { JAN } & \text { FEB } & \text { MAR } & \text { ARR } & \text { MAY } & \text { JUNE } & \text { JULY } & \text { AUG } & \text { SEP } \\ 1951 & 0.20 & 0.27 & 0.30 & 0.30 & 0.20 & 0.25 & 0.23 & 0.35 & 0.54 & 0.49 & 0.43 & 0.40 \\ 1952 & 0.42 & 0.29 & 0.30 & 0.30 & 0.35 & 0.40 & 3.61 & 11.5 & 12.8 & 4.36 & 1.61 & 1.05 \\ 1953 & 0.76 & 0.58 & 0.50 & 0.57 & 0.42 & 0.39 & 0.51 & 1.37 & 4.28 & 1.56 & 1.11 & 0.52 \\ 1954 & 0.32 & 0.31 & 0.30 & 0.30 & 0.34 & 0.36 & 0.22 & 0.97 & 1.12 & 0.65 & 0.37 & 0.33 \\ 1955 & 0.35 & 0.37 & 0.23 & 0.20 & 0.20 & 0.97 & 0.26 & 2.15 & 3.61 & 1.01 & 0.49 & 0.33 \\ 1958 & 0.73 & 0.58 & 0.16 & 0.25 & 0.37 & 0.48 & 1.13 & 8.79 & 7.61 & 2.07 & 0.68 & 0.45 \\ 1959 & 0.32 & 0.17 & 0.11 & 0.10 & 0.09 & 0.07 & 0.12 & 0.20 & 0.10 & 0.14 & 0.11 & 0.03 \\ 1960 & 0.00 & 0.00 & 0.00 & 0.00 & 0.00 & 0.01 & 0.00 & 0.53 & 1.45 & 0.53 & 0.03 & 0.00 \\ & & & & & & & & & & & & \\ 1961 & 0.00 & 0.00 & 0.00 & 0.00 & 0.00 & 0.00 & 0.00 & 0.38 & 3.01 & 1.24 & 0.92 & 1.11 \\ 1962 & 1.32 & 0.85 & 0.22 & 0.10 & 0.38 & 0.41 & 1.69 & 5.58 & 3.77 & 2.38 & 1.04 & 0.28 \\ 1963 & 0.21 & 0.34 & 0.35 & 0.14 & 0.16 & 0.10 & 0.10 & 0.26 & 0.40 & 0.25 & 0.13 & 0.00 \\ 1964 & 0.00 & 0.00 & 0.02 & 0.00 & 0.00 & 0.00 & 0.00 & 1.70 & 3.72 & 1.56 & 0.91 & 0.66 \\ 1965 & 0.47 & 0.32 & 0.25 & 0.28 & 0.27 & 0.25 & 0.41 & 2.22 & 6.50 & 5.13 & 2.54 & 1.64 \\ 1966 & 1.20 & 1.22 & 1.13 & 0.68 & 0.43 & 0.50 & 1.40 & 5.45 & 4.66 & 2.24 & 1.39 & 0.76 \\ 1967 & 0.71 & 0.75 & 0.74 & 0.54 & 0.40 & 0.41 & 0.46 & 0.98 & 2.67 & 1.98 & 1.32 & 0.84 \\ 1968 & 0.67 & 0.54 & 0.44 & 0.42 & 0.48 & 0.44 & 0.42 & 1.35 & 4.97 & 2.33 & 1.71 & 0.94 \\ 1969 & 0.56 & 0.45 & 0.56 & 0.46 & 0.40 & 0.50 & 1.25 & 3.70 & 3.82 & 2.45 & 1.38 & 1.14 \\ 1970 & 0.89 & 0.64 & 0.58 & 0.49 & 0.41 & 0.47 & 0.49 & 5.63 & 5.32 & 2.79 & 0.98 & 0.87 \\ 1971 & 0.70 & 0.65 & 0.52 & 0.54 & 0.53 & 0.46 & 0.68 & 1.31 & 2.58 & 2.07 & 1.13 & 0.86 \\ 1972 & 0.61 & 0.65 & 0.71 & 0.54 & 0.46 & 0.40 & 0.45 & 0.80 & 1.73 & 1.14 & 0.71 & 0.60 \\ 1973 & 0.89 & 1.13 & 0.72 & 0.58 & 0.52 & 0.48 & 0.53 & 7.50 & 10.8 & 6.19 & 1.73 & 1.01 \\ 1974 & 0.80 & 0.69 & 0.53 & 0.45 & 0.37 & 0.29 & 0.36 & 2.97 & 3.34 & 1.78 & 1.09 & 0.66 \\ 1975 & 0.53 & 0.47 & 0.30 & 0.33 & 0.33 & 0.30 & 0.34 & 1.97 & 6.01 & 3.97 & 1.54 & 0.82\end{array}$

ANNUAL PEAK DISCHARGE, IN CUBIC FEET PER SECOND, AND CORRESPONDING GAGE HEIGHT, IN FEET, FOR EAOH WATER YEAR

\begin{tabular}{|c|c|c|c|c|c|c|c|c|c|c|c|}
\hline $\begin{array}{l}\text { WATER } \\
\text { YEAR }\end{array}$ & DATE & $\begin{array}{c}\text { GAGE } \\
\text { HEIGHT }\end{array}$ & $\begin{array}{c}\text { PEAK } \\
\text { DISQHARGE }\end{array}$ & $\begin{array}{l}\text { WATER } \\
\text { YEAR }\end{array}$ & DATE & $\begin{array}{c}\text { GAGE } \\
\text { HEIGHT }\end{array}$ & $\begin{array}{c}\text { PEAK } \\
\text { DISCHARGE }\end{array}$ & $\begin{array}{l}\text { WATER } \\
\text { YEAR }\end{array}$ & DATE & $\begin{array}{c}\text { GAGE } \\
\text { HEIGHT }\end{array}$ & $\begin{array}{c}\text { FEAK } \\
\text { DISOHARGE }\end{array}$ \\
\hline $\begin{array}{l}1951 \\
1952 \\
1953 \\
1954 \\
1955 \\
1957 \\
1958 \\
1959\end{array}$ & $\begin{array}{l}\text { ARR. } 10,1951 \\
\text { JUNE 07, } 1952 \\
\text { AUG. 01, } 1953 \\
\text { AFR. } 20,1954 \\
\text { JUNE } 12,1955 \\
\text { JUNE 06, } 1957 \\
\text { MAY } 30,1958 \\
\text { SEPT. } 15,1959\end{array}$ & $\begin{array}{l}0.89 \\
1.20 \\
1.15 \\
1.17 \\
1.16 \\
1.72 \\
1.47 \\
1.23\end{array}$ & $\begin{array}{l}3.0 \\
23 \\
20 \\
5.0 \\
10 \\
19 \\
18 \\
1.0\end{array}$ & $\begin{array}{l}1960 \\
1961 \\
1962 \\
1963 \\
1964 \\
1965 \\
1966 \\
1967\end{array}$ & $\begin{array}{l}\text { JUNE } 10,1960 \\
\text { JUNE } 03,1961 \\
\text { MAY } 14,1962 \\
\text { AUG. } 06,1963 \\
\text { AUG. } 12,1964 \\
\text { JULY } 18,1965 \\
\text { MAY } 31,1966 \\
\text { AUG. } 11,1967\end{array}$ & $\begin{array}{l}1.32 \\
1.36 \\
1.44 \\
1.30 \\
1.60 \\
1.68 \\
1.46 \\
1.71\end{array}$ & $\begin{array}{c}3.0 \\
4.0 \\
8.0 \\
3.0 \\
17 \\
26 \\
9.0 \\
27\end{array}$ & $\begin{array}{l}1968 \\
1969 \\
1970 \\
1971 \\
1972 \\
1973 \\
1974 \\
1975\end{array}$ & $\begin{array}{l}\text { JULY } 27,1968 \\
\text { JULY } 24,1969 \\
\text { MAY } 20,1970 \\
\text { JUNE } 21,1971 \\
\text { SEPT. 19, } 1972 \\
\text { JUNE } 15,1973 \\
\text { JUNE 01, } 1974 \\
\text { JUNE } 18,1975\end{array}$ & $\begin{array}{l}1.64 \\
1.43 \\
1.59 \\
1.36 \\
1.46 \\
1.78 \\
1.39 \\
1.78\end{array}$ & $\begin{array}{l}24 \\
7.0 \\
11 \\
4.0 \\
6.9 \\
19 \\
4.7 \\
20\end{array}$ \\
\hline
\end{tabular}

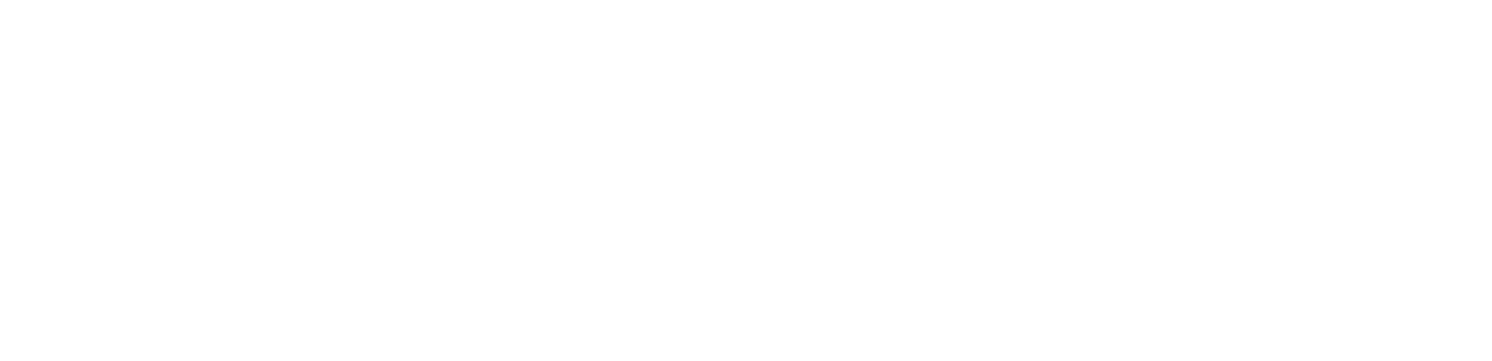


LOCATION.--Lat $38^{\circ} 40^{\prime} 45^{\prime \prime}$, long $109^{\circ} 26^{\prime} 55^{\prime \prime}$, in NW/ sec.35, T.24 S., R.22 E., Grand County, Hydrologic Unit 1 an30005, on right bank at downstream side of highway bridge, $0.5 \mathrm{mi}$ upstream from mouth, and $8.8 \mathrm{mi}$ northeast of Moab.

DRAINAGE AREA. $-53.1 \mathrm{mi}^{2}$.

MEAN BASIN ELLVVATION. $-6,380 \mathrm{ft}$.

EERIOD OF RECORD AVAILABLE.--July 1950 to September 1955, May 1957 to September 1958.

GAGE.--Water-stage recorder. Altitude of gage is 4,060 ft from river-profile map.

REMARKS. --Small diversions above station for irrigation.

AVERAGE DISCHARGE. -6 years $(1950-55,1957-58), 5.25 \mathrm{ft}^{3} / \mathrm{s}, 3,800$ acre-ft/yr.

EXTREMES FOR PERIOD OF RECORD.-Maximum discharge, $11,000 \mathrm{ft}^{3} / \mathrm{s}$ Aug. 13, 1954, gage height, $16.9 \mathrm{ft}$ from floodmark, from ratina curve extended above $15 \mathrm{ft}^{3} / \mathrm{s}$ on basis of slope-area measurements at gage heights $4.45,10.35$, and $16.9 \mathrm{ft}$; no flow for several days in most years.

LOWEST MEAN DISGHARGE, IN CUBIC FEET PER SECOND, AND RANKING FOR THE INDICATED NUMBER OF CONSEOUTIVE DAYS FOR EAOH CLIMATIC YEAR, AFRIL 1-MAROH 31

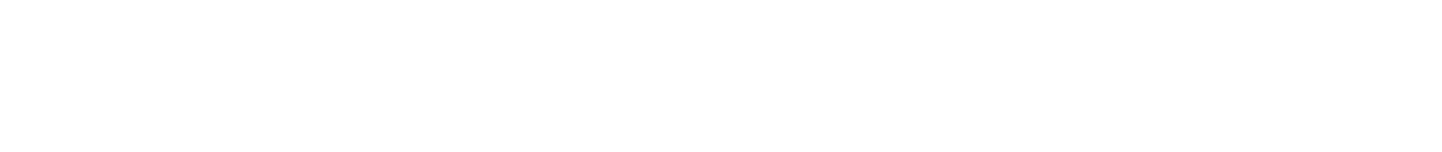

HIGHEST MEAN DISCHARGE, IN GUIC FEET FER SECOND, AND RANKING FOR THE INDICATED NUMBER OF CONSEOUTTVE DAYS FOR EACH WATER YEAR, OCTOBER I-SEPTEMBER 30

\begin{tabular}{|c|c|c|c|c|c|c|c|c|c|c|c|c|c|c|c|c|c|c|c|}
\hline YEAR & & & & & & & & & CONSE & QUTT & E DAYS & & & & & & & & \\
\hline $\begin{array}{l}1951 \\
1952 \\
1953 \\
1955 \\
1958\end{array}$ & $\begin{array}{r}116 \\
22.0 \\
12.0 \\
80.0 \\
19.0\end{array}$ & $\begin{array}{l}1 \\
3 \\
5 \\
2 \\
4\end{array}$ & $\begin{array}{c}43.0 \\
15.0 \\
9.20 \\
40.0 \\
18.0\end{array}$ & $\begin{array}{l}1 \\
4 \\
5 \\
2 \\
3\end{array}$ & $\begin{array}{c}21.0 \\
12.0 \\
8.60 \\
31.0 \\
15.0\end{array}$ & $\begin{array}{l}2 \\
4 \\
5 \\
1 \\
3\end{array}$ & $\begin{array}{c}12.0 \\
10.0 \\
8.60 \\
24.0 \\
13.0\end{array}$ & $\begin{array}{l}3 \\
4 \\
5 \\
1 \\
2\end{array}$ & $\begin{array}{c}8.10 \\
8.90 \\
8.50 \\
18.0 \\
12.0\end{array}$ & $\begin{array}{l}5 \\
3 \\
4 \\
1 \\
2\end{array}$ & $\begin{array}{c}7.70 \\
7.90 \\
8.10 \\
13.0 \\
11.0\end{array}$ & $\begin{array}{l}5 \\
4 \\
3 \\
1 \\
2\end{array}$ & $\begin{array}{c}7.30 \\
7.90 \\
7.80 \\
12.0 \\
9.90\end{array}$ & $\begin{array}{l}5 \\
3 \\
4 \\
1 \\
2\end{array}$ & $\begin{array}{r}7.20 \\
7.80 \\
7.50 \\
11.0 \\
9.60\end{array}$ & $\begin{array}{l}5 \\
3 \\
4 \\
1 \\
2\end{array}$ & $\begin{array}{l}6.40 \\
7.50 \\
6.70 \\
9.80 \\
9.20\end{array}$ & $\begin{array}{l}5 \\
3 \\
4 \\
1 \\
2\end{array}$ & $\begin{array}{l}4.40 \\
4.80 \\
4.00 \\
6.00 \\
6.40\end{array}$ \\
\hline
\end{tabular}

DURATION OF DISCHARGE FOR EACH WATER YEAR

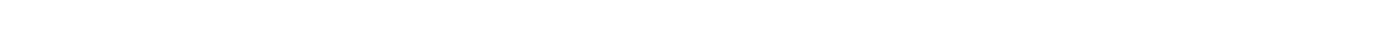
YEAR

NUMBER OF DAYS IN OLASS

OUBIC FEET FER SECOND

\begin{tabular}{|c|c|c|c|c|c|c|c|c|c|c|c|c|c|c|c|c|c|c|c|c|c|}
\hline 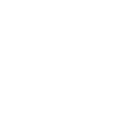 & $\begin{array}{r}14 \\
1 \\
37\end{array}$ & $\begin{array}{r}5 \\
1 \\
14\end{array}$ & $\begin{array}{lr}10 & 2 \\
18 & \\
16 & 11 \\
& 1 \\
3 & 1\end{array}$ & $\begin{array}{r}4 \\
3 \\
23 \\
5 \\
4\end{array}$ & $\begin{array}{ll}2 & 5 \\
8 & 4 \\
2 & 7 \\
5 & 10 \\
1 & 1\end{array}$ & $\begin{array}{r}12 \\
8 \\
9 \\
27 \\
3\end{array}$ & $\begin{array}{l}8 \\
9 \\
9 \\
6 \\
6\end{array}$ & $\begin{array}{r}25 \\
36 \\
3 \\
11 \\
5\end{array}$ & $\begin{array}{l}7 \\
6 \\
8 \\
5 \\
5\end{array}$ & $\begin{array}{r}23 \\
12 \\
6 \\
5 \\
7\end{array}$ & $\begin{array}{l}38 \\
35 \\
53 \\
33 \\
12\end{array}$ & $\begin{array}{l}39 \\
30 \\
15 \\
25 \\
43\end{array}$ & $\begin{array}{r}103 \\
86 \\
97 \\
60 \\
49\end{array}$ & $\begin{array}{r}17 \\
52 \\
36 \\
78 \\
126\end{array}$ & $\begin{array}{r}1 \\
9 \\
2 \\
20 \\
20\end{array}$ & $\begin{array}{r}5 \\
14\end{array}$ & $\begin{array}{l}7 \\
4\end{array}$ & 1 & 2 & 1 & $\begin{array}{l}1602.5 \\
1757.4 \\
1455.5 \\
2199.1 \\
2339.3\end{array}$ \\
\hline
\end{tabular}

DURATTON TABLE OF DISCHARGE FOR WATER YEARS 1951-53, 1955, 1958

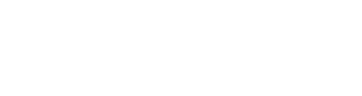

CLASS SECOND DAYS DAYS DAYS

$\begin{array}{rrrrr}0 & 0.00 & 104 & 1826 & 100.0 \\ 1 & 0.10 & 84 & 1722 & 94.3\end{array}$

$\begin{array}{rrrrr}2 & 0.13 & 84 & 1722 & 94.3 \\ 3 & 0.16 & 0 & 1638 & 89.7\end{array}$

$\begin{array}{rrrrr}3 & 0.16 & 87 & 1638 & 89.7 \\ 4 & 0.21 & 0 & 1551 & 84.9\end{array}$

$\begin{array}{lllll}5 & 0.21 & 0 & 1551 & 84.9 \\ 6 & 0.27 & 24 & 1551 & 84.9\end{array}$

$\begin{array}{lllll}6 & 0.34 & 47 & 1527 & 83.6\end{array}$

$\begin{array}{lllll}7 & 0.43 & 15 & 1480 & 81.1 \\ 8 & 0.55 & 39 & 1465 & 80.2\end{array}$
CUBIC ACOU-

PER TOTAL LATED

CLASS SECOND DAYS DAYS DAYS

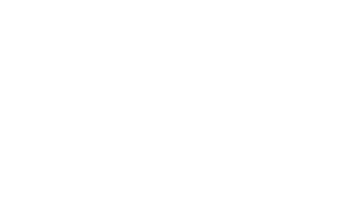

\begin{tabular}{|c|c|c|c|}
\hline & $\begin{array}{c}\text { CUBIC } \\
\text { FEET } \\
\text { PER } \\
\text { SECOND }\end{array}$ & $\begin{array}{l}\text { TOTAL } \\
\text { DAYS }\end{array}$ & $\begin{array}{l}\text { ACQU- } \\
\text { MU- } \\
\text { LATED } \\
\text { DAYS }\end{array}$ \\
\hline $\begin{array}{l}18 \\
19 \\
20 \\
21 \\
22 \\
23 \\
24 \\
25 \\
26\end{array}$ & $\begin{array}{r}6.4 \\
8.2 \\
10.0 \\
13.0 \\
17.0 \\
22.0 \\
28.0 \\
35.0 \\
45.0\end{array}$ & $\begin{array}{r}395 \\
309 \\
52 \\
21 \\
12 \\
4 \\
2 \\
0 \\
0\end{array}$ & $\begin{array}{r}797 \\
402 \\
93 \\
41 \\
20 \\
8 \\
4 \\
2 \\
2\end{array}$ \\
\hline
\end{tabular}

CUBIC ACUI-

FEET MU- FERCIASS SECOND DAYS DAYS

$\begin{array}{rrrrr}27 & 58.0 & 0 & 2 & 0.1 \\ 28 & 74.0 & 1 & 2 & 0.1 \\ 29 & 94.0 & 1 & 1 & 0.1 \\ 30 & 120.0 & 0 & 0 & 0.0 \\ 31 & 150.0 & 0 & 0 & 0.0 \\ 32 & 200.0 & 0 & 0 & 0.0 \\ 33 & 250.0 & 0 & 0 & 0.0 \\ 34 & 320.0 & 0 & 0 & 0.0\end{array}$


TRIBUTARIES BETWEEN DOLORES RIVER AND GREEN RIVER

09182500 CASTLE CREEK NEAR MOAB, UT-Continued

MONTHLY MEAN DISCHARGES, IN OBIC FEET PER SECOND, FOR EACH WATER YEAR

$\begin{array}{llccccccccrrr}\text { YEAR } & \text { OCT } & \text { NOV } & \text { DEC } & \text { JAN } & \text { FEB } & \text { MAR } & \text { AFR } & \text { MAY } & \text { JUNE } & \text { JULY } & \text { AUG } & \text { SEP } \\ 1951 & 4.63 & 6.41 & 6.69 & 6.78 & 8.07 & 6.45 & 0.66 & 3.13 & 0.94 & 0.15 & 6.65 & 2.24 \\ 1952 & 2.99 & 8.42 & 5.71 & 8.29 & 7.07 & 7.73 & 7.72 & 3.45 & 2.99 & 0.15 & 0.88 & 2.44 \\ 1953 & 3.07 & 4.32 & 7.31 & 8.03 & 8.10 & 6.55 & 5.05 & 0.10 & 0.08 & 1.07 & 3.67 & 0.72 \\ 1954 & 3.18 & 7.77 & 7.95 & 7.21 & 7.39 & 5.95 & 2.89 & 0.17 & 0.23 & 0.85 & 20.5 & 6.33 \\ 1955 & 5.33 & 8.09 & 9.26 & 8.78 & 10.7 & 14.9 & 7.33 & 2.69 & 0.03 & 0.48 & 3.49 & 1.34 \\ 1958 & 7.98 & 11.8 & 8.30 & 8.32 & 8.91 & 8.13 & 9.01 & 4.92 & 3.00 & 0.17 & 2.09 & 4.64\end{array}$

ANNUAL FEAK DISCHARGE, IN OBBIC FEET PER SECOND, AND CORRESPONDING GAGE HEIGHT, IN FEET, FOR EACH WATER YEAR

\begin{tabular}{|c|c|c|c|c|c|c|c|c|c|c|c|}
\hline $\begin{array}{l}\text { WATER } \\
\text { YEAR }\end{array}$ & DATE & $\begin{array}{c}\text { GAGE } \\
\text { HEIGHT }\end{array}$ & $\begin{array}{c}\text { FEAK } \\
\text { DISCHARGE }\end{array}$ & $\begin{array}{l}\text { WATER } \\
\text { YEAR }\end{array}$ & DATE & $\begin{array}{c}\text { GAGE } \\
\text { HEIGHT }\end{array}$ & $\begin{array}{c}\text { FEAK } \\
\text { DISCHARGE }\end{array}$ & $\begin{array}{l}\text { WATER } \\
\text { YEAR }\end{array}$ & DATE & $\begin{array}{c}\text { GAGE } \\
\text { HEIGHT }\end{array}$ & $\begin{array}{c}\text { PEAK } \\
\text { DISCHARGE }\end{array}$ \\
\hline $\begin{array}{l}1950 \\
1951 \\
1952\end{array}$ & $\begin{array}{l}\text { SEPT. 19, } 1950 \\
\text { AUG. 29, } 1951 \\
\text { AUG. } 21,1952\end{array}$ & $\begin{array}{r}5.08 \\
10.35 \\
3.25\end{array}$ & $\begin{array}{r}539 \\
4360 \\
174\end{array}$ & $\begin{array}{l}1953 \\
1954 \\
1955\end{array}$ & $\begin{array}{l}\text { JULY } 30,1953 \\
\text { AUG. } 13,1954 \\
\text { AUG. } 25,1955\end{array}$ & $\begin{array}{r}3.75 \\
16.90 \\
5.26\end{array}$ & $\begin{array}{r}230 \\
11000 \\
552\end{array}$ & $\begin{array}{l}1957 \\
1958\end{array}$ & $\begin{array}{l}\text { AUG. 05, } 1957 \\
\text { NOV. 04, } 1957\end{array}$ & $\begin{array}{r}11.60 \\
7.23\end{array}$ & $\begin{array}{r}5000 \\
187\end{array}$ \\
\hline
\end{tabular}

O91 82600 SALT WASH NEAR THOMESON, UT

LOCATION.--Lat $38^{\circ} 57^{\prime} 10^{\prime \prime}$, long $109^{\circ} 39^{\prime} 30^{\prime \prime}$, in SE $\frac{1}{4} W^{\frac{1}{4}}$ sec. 25, T.21 S., R.20 E., Grand County, Hydrologic Unit 14030005 , 3 mi east of Thampson.

DRAINAGE AREA. $-3.9 \mathrm{mi}^{2}$.

MEAN BASIN ELEVATION, $--5,510 \mathrm{ft}$.

PERIOD OF RECORD AVAILABLE.--Water years 1959-71, 1973-74, annual peak discharge only.

GAGE.--Crest-stage gage. Altitude of gage is 4,950 ft from topographic map.

ANNUAL FEAK DISCHARGE, IN OUBIC FEET FER SECOND, AND CORRESPONDING GAGE HEIGHT, IN FEET, FOR EACH WATER YEAR

\begin{tabular}{|c|c|c|c|c|c|c|c|c|c|c|c|}
\hline $\begin{array}{l}\text { WATER } \\
\text { YEAR }\end{array}$ & DATE & $\begin{array}{c}\text { GAGE } \\
\text { HEIGTT }\end{array}$ & $\begin{array}{c}\text { PEAK } \\
\text { DISCHARGE }\end{array}$ & $\begin{array}{l}\text { WATER } \\
\text { YEAR }\end{array}$ & DATE & $\begin{array}{c}\text { GAGE } \\
\text { HEIGHT }\end{array}$ & $\begin{array}{c}\text { PEAK } \\
\text { DISCHARGE }\end{array}$ & $\begin{array}{l}\text { WATER } \\
\text { YEAR }\end{array}$ & DATE & $\begin{array}{c}\text { GAGE } \\
\text { HEIGHT }\end{array}$ & $\begin{array}{c}\text { PEAK } \\
\text { DISCHARGE }\end{array}$ \\
\hline $\begin{array}{l}1959 \\
1960 \\
1961 \\
1962 \\
1963\end{array}$ & $\begin{array}{l}\text { AUG. } 19,1959 \\
\text { OCT. } 28,1959 \\
\text { AUG. } 03,1961 \\
\text { JUNE. } 30,1962 \\
\text { AUG. } 31,1963\end{array}$ & $\begin{array}{ll}9 & 17.52 \\
9 & 10.88 \\
1 & 15.60 \\
2 & 12.41 \\
3 & 15.78\end{array}$ & $\begin{array}{r}1380 \\
41 \\
1110 \\
251 \\
930\end{array}$ & $\begin{array}{l}1964 \\
1965 \\
1966 \\
1967 \\
1968\end{array}$ & $\begin{array}{l}\text { JULY } 31,1964 \\
\text { AUG. } 29,1965 \\
\text { SEPT.15, } 1966 \\
\text { JULY } 17,1967 \\
\text { AUG. } 02,1968\end{array}$ & $\begin{array}{ll}4 & 11.46 \\
5 & 13.63 \\
6 & 11.48 \\
7 & 15.88 \\
8 & 14.48\end{array}$ & $\begin{array}{l}110 \\
480 \\
111 \\
950 \\
650\end{array}$ & $\begin{array}{l}1969 \\
1970 \\
1971 \\
1973 \\
1974\end{array}$ & $\begin{array}{l}\text { SEPT.10, } 1969 \\
\text { SEPT.06, } 1970 \\
\text { MAY } 19,1971 \\
\text { MAY } 05,1973\end{array}$ & $\begin{array}{l}12.79 \\
12.61 \\
10.90 \\
11.88 \\
11.20\end{array}$ & $\begin{array}{r}317 \\
287 \\
44 \\
170 \\
79\end{array}$ \\
\hline
\end{tabular}

09182900 COURTHOUSE WASH AT ARGHES HIGHWAY CROSSING, NEAR MOAB, UT

LOCATION.--Lat $38^{\mathrm{O}_{3}} 38^{\prime} 55^{\prime \prime}$, long $109^{\circ} 35^{\prime} 55^{\prime \prime}$, in NE' $\mathrm{NE}^{\frac{1}{4}}$ sec.9, T.25 S., R.21 E., Grand County, Hydrologic Unit 14030005 , on left bank under bridge on access road into Arches National Monument, $5.5 \mathrm{mi}$ upstream from mouth, and 5.8 mi nor thwest of Moab.

DRAINAGE AREA. $-143 \mathrm{mi}^{2}$.

PERIOD OF RECORD AVAILABLE.--October 1958 to July 1966.

REVISED RECORDS.--WSP 1733: Drainage area.

GAGE.-Water-stage recorder. Altitude of gage is 4,100 ft, fron topographic map.

AVERAGE DISCHARGE. --7 years, $1.47 \mathrm{ft}^{3} / \mathrm{s}, 1,060$ acre- $\mathrm{ft} / \mathrm{yr}$.

EXIREMES FOR IERIOD OF RECORD.--Maximum discharge, 4,530 ft ${ }^{3} / \mathrm{s}$ Sept. 9, 1961, gage height, $6.26 \mathrm{ft}$, from rating curve extended above $2,000 \mathrm{ft}^{3} / \mathrm{s}$ by logarithmic plotting; no flow for many days in each year. 
LONEST MEAN DISCHARGE, IN OUBIC FEET FER SECOND, AND RANRING FOR THE INDICATED NUMBER OF OONSEQUTIVE DAYS FOR EAOH OIMATIC YEAR, APRII I-MAROH 31

\begin{tabular}{|c|c|c|c|c|c|c|c|c|c|c|c|c|c|c|c|c|c|c|c|}
\hline YEAR & 1 & & 3 & & 7 & & 14 & & $\begin{array}{l}\text { CNSE } \\
30\end{array}$ & OUTIVE & $\begin{array}{l}\text { DAYS } \\
60\end{array}$ & & 90 & & 120 & & 183 & & ALL \\
\hline 1960 & 0.00 & 1 & 0.00 & 1 & 0.00 & 1 & 0.00 & 1 & 0.00 & 1 & 0.00 & 1 & 0.00 & 1 & 0.00 & 1 & 0.37 & 3 & 0.50 \\
\hline
\end{tabular}

HIGHEST MEAN DISCHARGE, IN OBBIC FEET FER SECOND, AND RANKING FOR THE INDICATED NUMBER OF CONSECUTIVE DAYS FOR EACH WATER YEAR, OCTOBER I-SEPTEMBER 30.

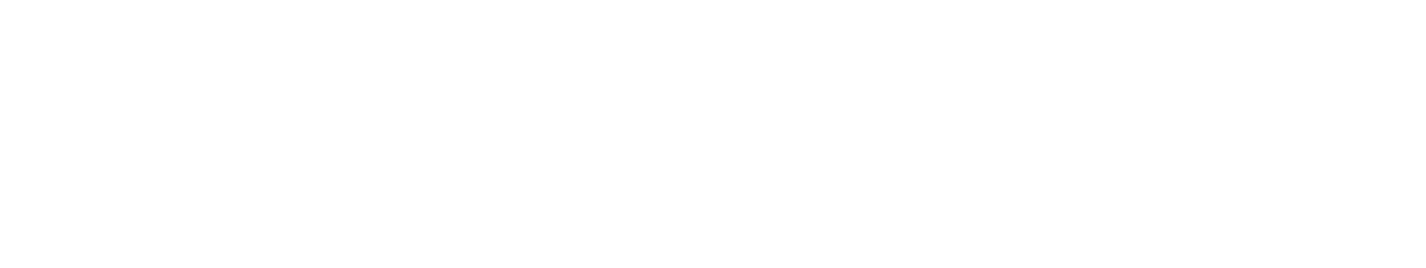

DURATION OF DISOHARGE FOR EACH WATER YEAR

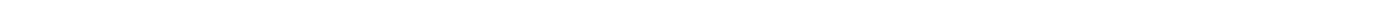
YEAR

ABIC FEET PER SECOND

124.0 112.4

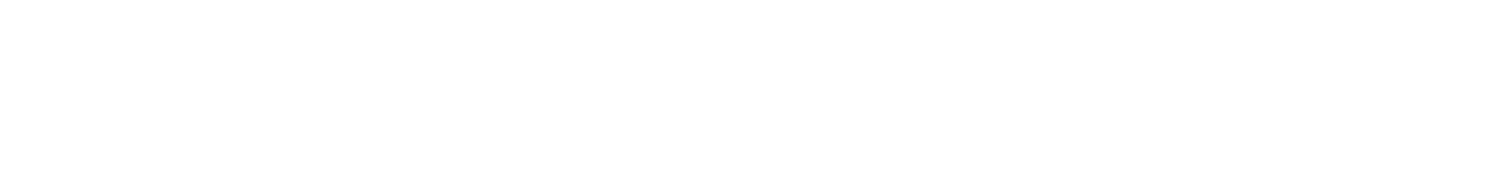

DURATION TABLE OF DISCHARGE FOR WATER YEARS $1959-65$

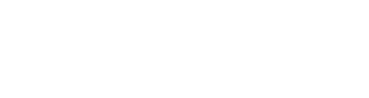

\begin{tabular}{|c|c|c|c|c|}
\hline & $\begin{array}{c}\text { CUBIC } \\
\text { FEET } \\
\text { FER }\end{array}$ & TOTAL & $\begin{array}{l}\text { ACOU- } \\
\text { MU- } \\
\text { LATED }\end{array}$ & $\begin{array}{l}\text { PER- } \\
\text { CENT }\end{array}$ \\
\hline CLASS & SECOND & DAYS & DAYS & DAYS \\
\hline $\begin{array}{r}9 \\
10 \\
11 \\
12 \\
13 \\
14 \\
15 \\
16 \\
17\end{array}$ & $\begin{array}{l}0.79 \\
1.00 \\
1.30 \\
1.70 \\
2.20 \\
2.80 \\
3.70 \\
4.80 \\
6.20\end{array}$ & $\begin{array}{r}20 \\
51 \\
14 \\
6 \\
1 \\
2 \\
0 \\
13 \\
4\end{array}$ & $\begin{array}{r}152 \\
132 \\
81 \\
67 \\
61 \\
60 \\
58 \\
58 \\
45\end{array}$ & $\begin{array}{l}5.9 \\
5.2 \\
3.2 \\
2.6 \\
2.4 \\
2.3 \\
2.3 \\
2.3 \\
1.8\end{array}$ \\
\hline
\end{tabular}

$\begin{array}{lll}\text { GUIC } & \text { ACQU- } \\ \text { FEET } & \text { MU- } & \text { PER- } \\ \text { FER TOTAL LATED } & \text { CENT }\end{array}$ PER TOTAL LATED CENT
GLASS SECOND DAYS DAYS DAYS

$\begin{array}{lr}18 & 8.0 \\ 19 & 10.0 \\ 20 & 13.0 \\ 21 & 17.0 \\ 22 & 22.0 \\ 23 & 29.0 \\ 24 & 37.0 \\ 25 & 48.0 \\ 26 & 62.0\end{array}$

वBBIC ACOUFEET MU- PERCLASS SECOND TOTAL LATED CEN

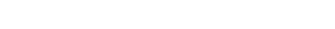
$\begin{array}{llll}0.10 & 303 & 852 & 33.3\end{array}$ $\begin{array}{llll}0.13 \quad 0 & 549 & 21.5\end{array}$ $\begin{array}{llll}0.17 & 234 & 549 & 21.5\end{array}$

$\begin{array}{llll}0.22 & 0 & 315 & 12.3\end{array}$

$\begin{array}{llll}0.28 & 72 & 315 & 12.3\end{array}$

$\begin{array}{llll}0.36 & 31 & 243 & 9.5 \\ 0.47 & 52 & 212 & 8.3\end{array}$

$\begin{array}{rrrr}0.47 & 52 & 212 & 8.3 \\ 0.61 & 8 & 160 & 6.3\end{array}$

MONIHLY MEAN DISCHARGES, IN OBIC FEET FER SECOND, FOR EACH WATER YEAR

$\begin{array}{lllllllllllrr}\text { YEAR } & \text { OCT } & \text { NOV } & \text { DEC } & \text { JAN } & \text { FEB } & \text { MAR } & \text { AFR } & \text { MAY } & \text { JUNE } & \text { JULY } & \text { AUG } & \text { SEP } \\ 1959 & 0.00 & 0.00 & 0.06 & 0.00 & 0.12 & 0.18 & 0.03 & 0.00 & 0.00 & 0.00 & 2.70 & 0.95 \\ 1960 & 0.39 & 0.00 & 0.30 & 0.52 & 0.84 & 0.26 & 0.06 & 0.18 & 0.00 & 0.00 & 0.26 & 0.90 \\ & & & & & & & & & & & & \\ 1961 & 0.02 & 0.02 & 0.00 & 0.00 & 0.00 & 0.07 & 0.40 & 0.00 & 0.00 & 0.00 & 2.85 & 21.5 \\ 1962 & 1.76 & 0.20 & 0.06 & 0.00 & 0.77 & 0.20 & 0.10 & 0.00 & 0.24 & 0.02 & 0.00 & 5.54 \\ 1963 & 0.00 & 0.00 & 0.10 & 8.03 & 8.62 & 0.25 & 0.02 & 0.00 & 0.00 & 1.34 & 8.96 & 8.93 \\ 1964 & 2.19 & 0.07 & 0.10 & 0.13 & 0.37 & 0.76 & 4.04 & 0.52 & 0.20 & 0.45 & 0.00 & 0.50 \\ 1965 & 0.00 & 0.00 & 0.04 & 0.40 & 0.17 & 0.42 & 0.31 & 1.03 & 0.17 & 24.3 & 12.3 & 0.00\end{array}$


TRIBUTARIES BETWEEN DOLORES RIVER AND GREEN RIVER

09182900 COURTHUISE WASH AT ARCHES HIGHAY CROSSING, NEAR MDAB, UT-Continued

ANNUAL PEAK DISGHARGE, IN GBIC FEET PER SECOND, AND CORRESFONDING GAGE HEIGHT, IN FEET, FOR EACH WATER YEAR

$\begin{array}{lcccccccccc}\begin{array}{l}\text { WATER } \\ \text { YEAR }\end{array} & \text { DATE } & \begin{array}{c}\text { GAGE } \\ \text { HEIGHT }\end{array} & \begin{array}{c}\text { PEAK } \\ \text { DISGHARGE }\end{array} & \begin{array}{l}\text { WATER } \\ \text { YEAR }\end{array} & \text { DATE } & \begin{array}{c}\text { GAGE } \\ \text { HEIGHT }\end{array} & \begin{array}{c}\text { PEAK } \\ \text { DISCHARGE }\end{array} & \begin{array}{l}\text { WATER } \\ \text { YEAR }\end{array} & \begin{array}{c}\text { GAGE } \\ \text { DATE }\end{array} & \begin{array}{c}\text { PEAK } \\ \text { HEIGHT }\end{array} \\ \text { DISCHARGE }\end{array}$

09183000 COURIHQUSE WASH NEAR MOAB, UT

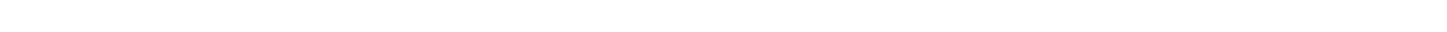
bank 0.6 mi upstream from bridge on U.S. Highway $160,0.8 \mathrm{mi}$ upstream from mouth, and 3.0 mi nor thwest of Moab.

DRAINAGE AREA. $-162 \mathrm{mi}^{2}$.

MEAN BASIN ELEVATION. $-4,810 \mathrm{ft}$.

PERIOD OF RECORD AVAILABLE.--October 1949 to September 1955, April to September 1957 , July 1966 to September 1981 . Records for

station at site $5 \mathrm{mi}$ upstream published as "at Arches Highway Crossing near Moab" September 1958 to July 1966 , not equivalent at all times due to possibility that some sumer storm runoff would be from intermediate area.

GAGE. -Water-stage recorder. Altitude of gage is 3,980 ft from river-prof ile map.

AVERAGE DISGHARGE. --2l years $(1949-55,1966-81), 1.81 \mathrm{ft}^{3} / \mathrm{s}, 1,310$ acre-ft/yr.

EXIREMES FOR FERIOD OF RECORD.--Maximum discharge, 12,300 ft $3 / \mathrm{s}$ Aug. 5, 1957, gage height, $9.38 \mathrm{ft}$, from rating curve extended above $500 \mathrm{ft}^{3} / \mathrm{s}$ on basis of slope-area measurement of peak flow; no flow at times.

LOWEST MEAN DISGHARGE, IN OUBIC FEET FER SECOND, AND RANKING FOR THE INDICATED NUMBER OF OONSEOUTIVE DAYS FOR EACH CLIMATIC YEAR, APRII 1-MARGH 31

YE

\section{1}

0.0010 .001

$\begin{array}{llll}0.00 & 1 & 0.00 & 1 \\ 0.00 & 2 & 0.00 & 2\end{array}$

$\begin{array}{llll}0.00 & 2 & 0.00 & 2 \\ 0.00 & 3 & 0.00 & 3\end{array}$

$\begin{array}{llll}0.00 & 3 & 0.00 & 3 \\ 0.00 & 4 & 0.00 & 4 \\ 0.00 & 5 & 0.00 & 5\end{array}$

$\begin{array}{llll}0.00 & 6 & 0.00 \quad 6\end{array}$

$\begin{array}{lll}0.007 & 0.007\end{array}$

$\begin{array}{llll}0.00 & 8 & 0.00 & 8\end{array}$

$\begin{array}{rrrr}0.00 \quad 9 & 0.00 & 9 \\ 0.0010 & 0.00 & 10\end{array}$

$\begin{array}{ll}0.0010 & 0.0010 \\ 0.0011 & 0.0011\end{array}$

$0.0215 \quad 0.0317$

$\begin{array}{ll}0.0215 & 0.0317\end{array}$

0.0519

$0.0418 \quad 0.0418$

$\begin{array}{ll}0.0012 & 0.0012 \\ 0.0113 & 0.0214\end{array}$

$0.0216 \quad 0.0315$

$\begin{array}{lll}0.0317 & 0.0316\end{array}$

0.0114

0.0113

$\begin{array}{lr}7 & \\ 0.00 & 1 \\ 0.00 & 2 \\ 0.00 & 3 \\ 0.00 & 4 \\ 0.00 & 5 \\ 0.00 & 6 \\ 0.00 & 7 \\ 0.02 & 11 \\ 0.00 & 8 \\ 0.03 & 16 \\ 0.00 & 9 \\ 0.03 & 17 \\ 0.06 & 19 \\ & \\ 0.05 & 18 \\ 0.02 & 12 \\ 0.02 & 13 \\ 0.03 & 14 \\ 0.03 & 15 \\ & \\ 0.01 & 10\end{array}$

14

0.001

0.0518

$0.00^{2}$

0.003

0.005

$\begin{array}{ll}0.00 & 5 \\ 0.01 & 7\end{array}$

0.0415

0.0310

0.0310
0.0416

0.0416
$0.00 \quad 6$

0.006
0.0311

0.0311
0.0619

0.0517

0.0312

0.028

0.0413

0.0414

0.029

CONSEOUTIVE DAYS

$30 \quad 60$

0.001

$\begin{array}{rrr}0.10 & 17 \\ 0.04 & 8\end{array}$

$\begin{array}{ll}0.04 & 8 \\ 0.03 & 2\end{array}$

$\begin{array}{lll}0.06 & 13\end{array}$

0.0811

0.1216

$\begin{array}{ll}0.05 & 5 \\ 0.07 & 8\end{array}$

0.0912

$0.0614 \quad 0.1217$

$0.0715 \quad 0.1115$

$0.1218 \quad 0.4419$

0.049

0.0510

0.033

0.0511

0.0716

0.089

$\begin{array}{ll}0.08 & 9 \\ 0.05 & 6\end{array}$

0.041

0.067

0.0913

$\begin{array}{rr}0.06 & 12 \\ 0.04 & 4\end{array}$

0.1219

$\begin{array}{ll}0.04 & 5 \\ 0.04 & 6\end{array}$

0.0810

0.042

0.1618

0.043

0.054

0.047

0.1114

90

0.2016

0.1613

0.074
0.2918

0.2918
0.1311

0.1312

0.1915

0.5319

0.107

0.118

$\begin{array}{ll}0.05 & 2 \\ 0.07 & 3\end{array}$

$\begin{array}{ll}0.07 & 3 \\ 0.12 & 10\end{array}$

0.085

$0.10 \quad 6$

0.1814

0.041

0.2117

120

0.2412

0.4517

0.124

0.3215
0.6519

0.136

0.2210

0.5718

0.219

$\begin{array}{ll}0.21 & 9 \\ 0.14 & 7\end{array}$

0.072

0.158

0.2714

0.3516

0.125

$\begin{array}{lll}0.23 & 11 \\ 0.04 & 1\end{array}$

$\begin{array}{ll}0.04 & 1 \\ 0.11 & 3\end{array}$

0.2513
183

$\begin{array}{llll}0.34 & 8 & 1.60 & 8\end{array}$

$1.1917 \quad 2.4015$

$\begin{array}{llll}0.31 & 7 & 0.431\end{array}$

$\begin{array}{ll}1.9019 & 3.0017\end{array}$

$\begin{array}{ll}1.5018 & 2.0014\end{array}$

$\begin{array}{lll}0.20 \quad 4 \quad 4.3019 & 9\end{array}$

$0.4011 \quad 1.8012$

$0.6414 \quad 4.0018$

$\begin{array}{llll}0.27 & 6 & 0.57 & 2\end{array}$

$\begin{array}{lll}0.359 & 1.7010\end{array}$

$\begin{array}{lll}0.163 & 3.6016\end{array}$

$\begin{array}{lrlr}0.83 & 15 & 1.80 & 11 \\ 0.25 & 5 & 1.19 & 5\end{array}$

$0.3910 \quad 1.00 \quad 3$

$0.4312 \quad 1.609$

$0.6313 \quad 1.9013$

0.162

$0.8416 \quad 1.00 \quad 4$ 
HIGHEST MEAN DISCHARGE, IN OUBIC FEET PER SECOND, AND RANKING FOR THE INDICATED NUMBER OF CONSEOUTIVE DAYS FOR EACH WATER YEAR, OCIOBER 1-SEPIEMBER 30.

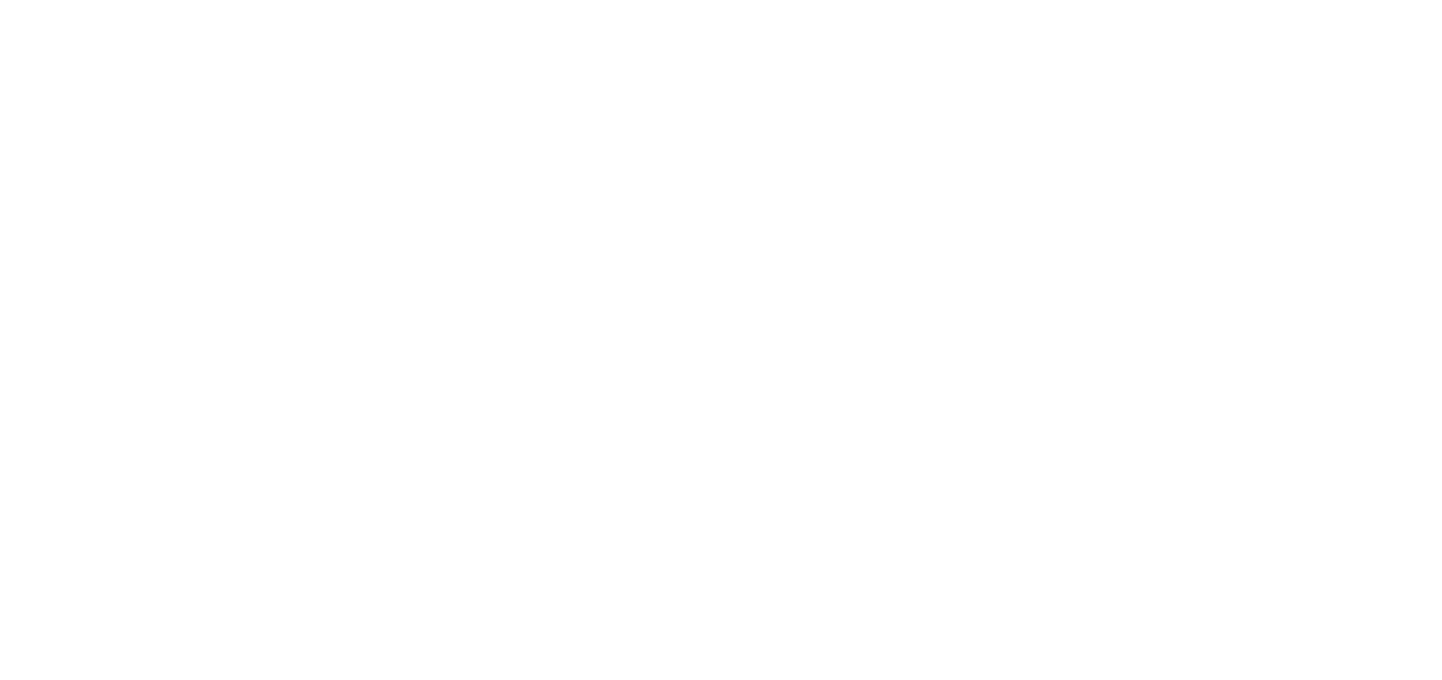

DURATION OF DISCHARGE FOR EACH WATER YEAR

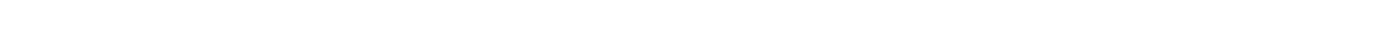
YEAR

NUMBER OF DAYS IN CLASS

CUBIC FEET PER SECON

$\begin{array}{llllllllllllllllllllllll}1950 & 52 & 81 & 40 & 99 & 14 & 29 & 4 & 7 & 20 & 8 & 1 & 3 & 1 & & 1 & 1 & 1 & 1 & 1 & 1 & & 851.4\end{array}$

19517

195239

195366

195436

81
135
123
112
104

$\begin{array}{rrrrrrr}99 & 14 & 29 & 4 & 7 & 20 & \\ 68 & 6 & 12 & 14 & 3 & 2 & \\ 35 & 19 & 28 & 14 & 13 & 11 & \\ 37 & 18 & 14 & 3 & 3 & 1 & \\ 53 & 8 & 44 & 8 & 8 & 6 & \\ 51 & 12 & 5 & 6 & 2 & 4 & 10\end{array}$

$\begin{array}{lrllllrllllllllllll}1967 & 1 & 1 & & & & 3 & 85 & 62 & 96 & 30 & 26 & 16 & 9 & 6 & 4 & 3 & 6 \\ 1968 & 20 & 5 & 5 & 15 & 2 & 40 & 27 & 49 & 87 & 17 & 16 & 24 & 17 & 16 & 5 & 8 & 3\end{array}$

$\begin{array}{lllllllllll}1 & 1 & 1 & 1 & 1 & 1 & 1 & 2 & 4 & 1 \\ & & 1 & & 1\end{array}$

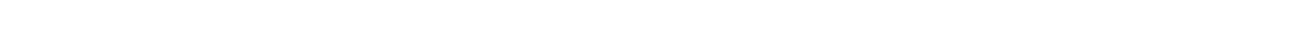

$\begin{array}{llllllllllllllllllllllll}1971 & 1 & 1 & 15 & 126 & 56 & 26 & 34 & 17 & 19 & 32 & 24 & 5 & 2 & 1 & 2 & 1 & 1 & 1 & 1 & 131.1\end{array}$

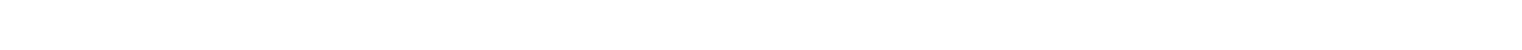

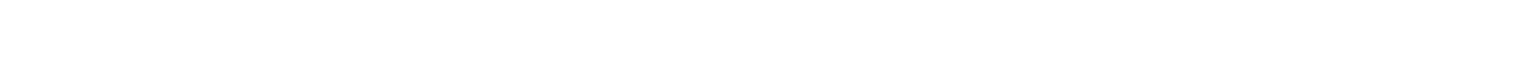

$\begin{array}{llllllllllllllllllllllllllllllll}1976 & 2 & 14 & 1 & 35 & 29 & 40 & 71 & 32 & 21 & 9 & 22 & 24 & 15 & 17 & 6 & 8 & 4 & 1 & 1 & 1 & 1 & 4 & 4 & 1 & 4 & & & & & & 665.0\end{array}$

$\begin{array}{lllllllllllllllllllllllllllllllllll}1977 & 1 & 15 & 13 & 1 & 36101 & 88 & 15 & 7 & 25 & 43 & 3 & & 3 & 3 & 2 & & & & & 1 & 1 & 1 & 1 & 1 & 2 & 1 & 1 & & & & & & & 637.6\end{array}$

$\begin{array}{llllllllllllllllllllllll}1978 & 2 & 23 & 54 & 42 & 18 & 41 & 42 & 22 & 19 & 34 & 17 & 13 & 14 & 11 & 6 & 2 & 1 & & 2 & 1 & 1 & 1 & 1 \\ 1979 & & 5 & 22 & 52105 & 68 & 13 & 6 & 10 & 21 & 16 & 13 & 10 & 4 & 3 & 5 & 2 & 2 & 1 & 3 & 1 & 3 & \end{array}$

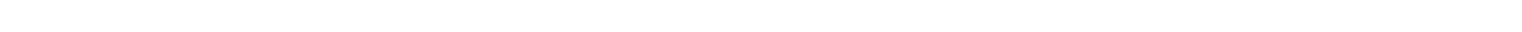

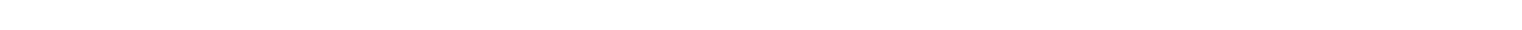

DURATION TABIE OF DISCHARGE FOR WATER YEARS 1950-55, 1967-81

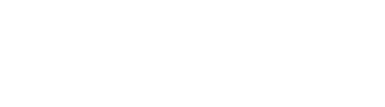

\begin{tabular}{|c|c|c|c|c|c|c|c|c|c|c|c|c|c|c|}
\hline ILASS & $\begin{array}{c}\text { OUBIC } \\
\text { FEET } \\
\text { PER } \\
\text { SECOND }\end{array}$ & $\begin{array}{l}\text { TOTAL } \\
\text { DAYS }\end{array}$ & $\begin{array}{l}\text { ACOU- } \\
\text { MU- } \\
\text { LATED } \\
\text { DAYS }\end{array}$ & $\begin{array}{l}\text { PER } \\
\text { CENT } \\
\text { DAYS }\end{array}$ & & $\begin{array}{c}\text { CUBIC } \\
\text { FEET } \\
\text { PER } \\
\text { SECOND }\end{array}$ & $\begin{array}{l}\text { TOTAL } \\
\text { DAYS }\end{array}$ & $\begin{array}{c}\text { ACO- } \\
\text { MU- } \\
\text { LATED } \\
\text { DAYS }\end{array}$ & $\begin{array}{l}\text { PER- } \\
\text { CENT } \\
\text { DAYS }\end{array}$ & CLASS & $\begin{array}{c}\text { OUBIC } \\
\text { FEET } \\
\text { PER } \\
\text { SECOND }\end{array}$ & $\begin{array}{r}\text { TOTAL } \\
\text { DAYS }\end{array}$ & $\begin{array}{c}\text { ACOH- } \\
\text { MU- } \\
\text { LATED } \\
\text { DAYS }\end{array}$ & $\begin{array}{l}\text { PER- } \\
\text { CENT } \\
\text { DAYS }\end{array}$ \\
\hline $\begin{array}{r}9 \\
10 \\
11 \\
12 \\
13 \\
14 \\
15 \\
16 \\
17\end{array}$ & $\begin{array}{l}0.21 \\
0.29 \\
0.41 \\
0.58 \\
0.81 \\
1.10 \\
1.60 \\
2.20 \\
3.10\end{array}$ & $\begin{array}{r}266 \\
775 \\
486 \\
451 \\
206 \\
153 \\
114 \\
81 \\
38\end{array}$ & $\begin{array}{r}2841 \\
2575 \\
1800 \\
1314 \\
863 \\
657 \\
504 \\
390 \\
309\end{array}$ & $\begin{array}{r}37.0 \\
33.6 \\
23.5 \\
17.1 \\
11.3 \\
8.6 \\
6.6 \\
5.1 \\
4.0\end{array}$ & $\begin{array}{l}18 \\
19 \\
20 \\
21 \\
22 \\
23 \\
24 \\
25 \\
26\end{array}$ & $\begin{array}{r}4.4 \\
6.2 \\
8.6 \\
12.0 \\
17.0 \\
24.0 \\
33.0 \\
47.0 \\
66.0\end{array}$ & $\begin{array}{l}42 \\
34 \\
32 \\
33 \\
25 \\
19 \\
21 \\
22 \\
13\end{array}$ & $\begin{array}{r}271 \\
229 \\
195 \\
163 \\
130 \\
105 \\
86 \\
65 \\
43\end{array}$ & $\begin{array}{l}3.5 \\
3.0 \\
2.5 \\
2.1 \\
1.7 \\
1.4 \\
1.1 \\
0.8 \\
0.6\end{array}$ & $\begin{array}{l}27 \\
28 \\
29 \\
30 \\
31 \\
32 \\
33 \\
34\end{array}$ & $\begin{array}{r}92.0 \\
130.0 \\
180.0 \\
250.0 \\
360.0 \\
500.0 \\
700.0\end{array}$ & $\begin{array}{r}12 \\
5 \\
7 \\
2 \\
3 \\
0 \\
1\end{array}$ & $\begin{array}{r}30 \\
18 \\
13 \\
6 \\
4 \\
1 \\
1\end{array}$ & $\begin{array}{l}0.4 \\
0.2 \\
0.2 \\
0.1 \\
0.1 \\
0.0 \\
0.0\end{array}$ \\
\hline
\end{tabular}


TRIBUTARIES BETWEEN DOLORES RIVER AND GREEN RIVER

09183000 COURTHOUSE WASH NEAR MOAB, UT-Continued

MONTHLY MEAN DISCHARGES, IN CUBIC FEET PER SECOND, FOR EACH WATER YEAR

$\begin{array}{lcccccccccccc}\text { YEAR } & \text { OCT } & \text { NOV } & \text { DEC } & \text { JAN } & \text { FEB } & \text { MAR } & \text { APR } & \text { MAY } & \text { JUNE } & \text { JULY } & \text { AUG } & \text { SEP } \\ 1950 & 7.16 & 0.43 & 0.84 & 0.40 & 1.69 & 0.55 & 0.15 & 1.99 & 0.10 & 3.98 & 0.09 & 10.6 \\ & & & & & & & & & & & & \\ 1951 & 0.16 & 0.20 & 0.28 & 0.40 & 0.71 & 0.38 & 1.36 & 0.28 & 0.11 & 0.13 & 6.05 & 0.11 \\ 1952 & 0.33 & 0.77 & 7.84 & 10.2 & 0.80 & 1.02 & 0.43 & 0.13 & 0.07 & 0.06 & 2.11 & 0.30 \\ 1953 & 0.13 & 0.20 & 0.23 & 0.61 & 0.50 & 0.40 & 0.39 & 0.72 & 0.04 & 4.23 & 16.7 & 0.08 \\ 1954 & 6.49 & 2.44 & 0.47 & 1.14 & 0.66 & 2.04 & 1.01 & 1.40 & 0.08 & 0.11 & 3.12 & 3.18 \\ 1955 & 3.57 & 8.25 & 0.35 & 0.24 & 0.87 & 1.47 & 0.27 & 0.95 & 0.10 & 0.23 & 2.47 & 0.13 \\ 1967 & 0.15 & 0.13 & 0.47 & 0.10 & 0.20 & 0.27 & 0.18 & 3.42 & 33.2 & 4.65 & 7.96 & 0.44 \\ 1968 & 0.13 & 0.14 & 0.18 & 0.06 & 0.88 & 0.54 & 4.69 & 0.28 & 0.12 & 8.23 & 4.34 & 0.08 \\ 1969 & 0.37 & 0.16 & 0.41 & 1.09 & 0.60 & 0.62 & 0.40 & 1.10 & 18.7 & 1.27 & 15.7 & 6.58 \\ 1970 & 0.16 & 1.23 & 0.58 & 0.54 & 0.65 & 0.82 & 0.70 & 0.12 & 1.88 & 0.06 & 1.86 & 0.05 \\ 1971 & 0.13 & 0.53 & 0.23 & 0.48 & 0.57 & 0.30 & 0.54 & 0.07 & 0.06 & 0.21 & 1.13 & 0.08 \\ 1972 & 15.1 & 0.36 & 0.47 & 0.45 & 0.79 & 0.34 & 0.39 & 0.11 & 0.07 & 0.05 & 0.10 & 0.25 \\ 1973 & 21.6 & 2.35 & 0.75 & 0.30 & 0.72 & 4.67 & 3.03 & 8.15 & 1.88 & 0.10 & 0.07 & 0.27 \\ 1974 & 3.51 & 0.76 & 0.61 & 0.20 & 0.34 & 2.16 & 4.80 & 0.13 & 0.09 & 1.01 & 0.11 & 0.12 \\ 1975 & 0.27 & 0.61 & 0.22 & 0.54 & 0.73 & 5.87 & 3.93 & 1.42 & 0.19 & 2.22 & 0.06 & 0.10 \\ 1976 & 1.09 & 0.82 & 0.18 & 0.09 & 1.39 & 1.15 & 0.53 & 4.04 & 0.04 & 3.45 & 5.42 & 3.51 \\ 1977 & 1.33 & 0.10 & 0.12 & 0.15 & 0.52 & 0.40 & 0.24 & 0.83 & 1.80 & 11.0 & 0.66 & 3.70 \\ 1978 & 0.21 & 0.20 & 0.26 & 1.37 & 0.88 & 1.25 & 8.86 & 0.35 & 0.06 & 0.04 & 0.04 & 0.04 \\ 1979 & 0.10 & 1.74 & 1.61 & 0.11 & 0.14 & 1.52 & 0.77 & 2.61 & 0.10 & 0.05 & 1.80 & 0.09 \\ 1980 & 0.11 & 0.15 & 0.10 & 0.17 & 1.68 & 6.69 & 0.96 & 0.29 & 0.06 & 0.50 & 0.26 & 4.91 \\ 1981 & 1.98 & 0.37 & 0.13 & 0.83 & 0.46 & 1.80 & 3.80 & 0.16 & 0.14 & 0.08 & 0.58 & 10.7\end{array}$

ANNUAL PEAK DISCHARGE, IN CUBIC FEET PER SECOND, AND OORRESPONDING GAGE HEIGHT, IN FEET, FOR EACH WATER YEAR

\begin{tabular}{|c|c|c|c|c|c|c|c|c|c|c|c|}
\hline $\begin{array}{l}\text { WATER } \\
\text { YEAR }\end{array}$ & DATE & $\begin{array}{c}\text { GAGE } \\
\text { HEIGHT }\end{array}$ & $\begin{array}{c}\text { PEAK } \\
\text { DISCHARGE }\end{array}$ & $\begin{array}{l}\text { WATERR } \\
\text { YEAR }\end{array}$ & DATE & $\begin{array}{c}\text { GAGE } \\
\text { HEIGHT }\end{array}$ & $\begin{array}{c}\text { PEAK } \\
\text { DISCHARGE }\end{array}$ & $\begin{array}{l}\text { WATER } \\
\text { YEAR }\end{array}$ & DATE & $\begin{array}{c}\text { GAGE } \\
\text { HEIGHT }\end{array}$ & $\begin{array}{c}\text { PEAK } \\
\text { DISCHARGE }\end{array}$ \\
\hline $\begin{array}{l}1950 \\
1951 \\
1952 \\
1953 \\
1954 \\
1955 \\
1957 \\
1966\end{array}$ & $\begin{array}{l}\text { SEPT. } 19,1950 \\
\text { AUG. } 29,1951 \\
\text { JAN. } 18,1952 \\
\text { AUG. 27, } 1953 \\
\text { AUG. 13, } 1954 \\
\text { NOV. 13, } 1954 \\
\text { AUG. 05, } 1957 \\
\text { JULY } 17,1966\end{array}$ & $\begin{array}{l}3.50 \\
2.60 \\
2.25 \\
4.53 \\
4.00 \\
3.40 \\
9.38 \\
4.79\end{array}$ & $\begin{array}{r}1810 \\
902 \\
630 \\
3140 \\
2420 \\
1700 \\
12300 \\
2740\end{array}$ & $\begin{array}{l}1967 \\
1968 \\
1969 \\
1970 \\
1971 \\
1972 \\
1973 \\
1974\end{array}$ & $\begin{array}{lll}\text { JUNE } 20, & 1967 \\
\text { JULY } & 30, & 1968 \\
\text { AUG. } 29, & 1969 \\
\text { AUG. } 05, & 1970 \\
\text { AUG. } 20, & 1971 \\
\text { OCT. } 29, & 1971 \\
\text { OCT. } 15, & 1972 \\
\text { JULY } 22, & 1974\end{array}$ & $\begin{array}{l}7.00 \\
4.95 \\
4.40 \\
2.90 \\
2.27 \\
2.45 \\
3.77 \\
2.78\end{array}$ & $\begin{array}{r}7430 \\
3720 \\
2650 \\
1100 \\
643 \\
782 \\
2130 \\
1040\end{array}$ & $\begin{array}{l}1975 \\
1976 \\
1977 \\
1978 \\
1979 \\
1980 \\
1981\end{array}$ & $\begin{array}{l}\text { JULY } 16,1975 \\
\text { AUG. 01, } 1976 \\
\text { JULY } 27,1977 \\
\text { APR. 10, } 1978 \\
\text { MAY 10, } 1979 \\
\text { SEPT. 07, } 1980 \\
\text { SEPT.06, } 1981\end{array}$ & $\begin{array}{l}3.24 \\
3.75 \\
3.80 \\
3.80 \\
2.45 \\
7.00 \\
8.04\end{array}$ & $\begin{array}{l}1510 \\
2100 \\
2160 \\
2170 \\
782 \\
7430 \\
9500\end{array}$ \\
\hline
\end{tabular}

MAGNITUDE AND PROBABILITY OF ANNUAL LONEST MEAN DISCHARGE BASED ON CLIMATIC YEARS 1951-55, AND 1968-81

\begin{tabular}{|c|c|c|c|c|c|c|}
\hline \multirow{2}{*}{$\begin{array}{l}\text { PERIOD } \\
\text { (CON- } \\
\text { SECU- } \\
\text { TIVE } \\
\text { DAYS) }\end{array}$} & \multicolumn{6}{|c|}{$\begin{array}{l}\text { DISCHARGE, IN CUBIC FEET PER SECOND, FOR } \\
\text { INDICATED RECURREANE INTERNAL, IN YEARS, AND } \\
\text { ANNUAL NONEXCEEMANCE PROBABILITY, IN PERCENT }\end{array}$} \\
\hline & $\begin{array}{c}2 \\
508\end{array}$ & $\begin{array}{c}5 \\
208\end{array}$ & $\begin{array}{l}10 \\
108\end{array}$ & $\begin{array}{l}20 \\
58\end{array}$ & $\begin{array}{l}50 \\
28\end{array}$ & $\begin{array}{r}100 \\
18\end{array}$ \\
\hline $\begin{array}{r}1 \\
7 \\
14 \\
30 \\
60 \\
90\end{array}$ & $\begin{array}{l}0.00 \\
0.01 \\
0.03 \\
0.05 \\
0.07 \\
0.12\end{array}$ & $\begin{array}{l}0.00 \\
0.00 \\
0.00 \\
0.03 \\
0.05 \\
0.07\end{array}$ & $\begin{array}{l}0.00 \\
0.00 \\
0.00 \\
0.03 \\
0.04 \\
0.06\end{array}$ & $\begin{array}{l}0.00 \\
0.00 \\
0.00 \\
0.03 \\
0.04 \\
0.05\end{array}$ & $\begin{array}{l}- \\
- \\
- \\
\overline{-}\end{array}$ & $\begin{array}{l}- \\
- \\
- \\
-\end{array}$ \\
\hline
\end{tabular}

MAGNITUDE AND PROBABILITY OF ANNLAL HIGHEST MEAN DISCHARGE BASED ON WATER YEARS 1950-55, AND 1967-81

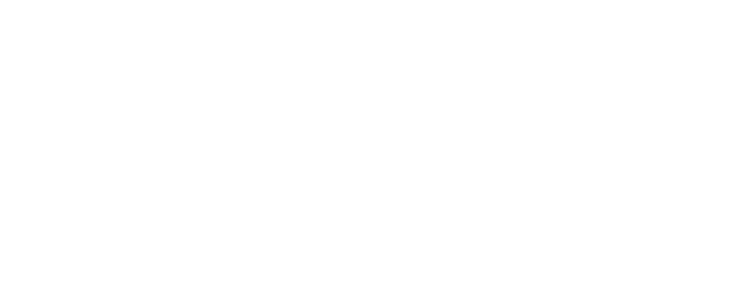




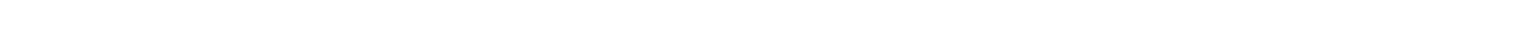
$\mathrm{mi}$ southeast of Moab.

DRAINAGE AREA. $--27.4 \mathrm{mi}^{2}$.

MEAN BASIN ELEVATION. $-8,700 \mathrm{ft}$.

PERIOD OF RECORD AVAILABLE. - October 1954 to September 1959.

GAGE. - Water-stage recorder. Altitude of gage is 5,400 ft from topographic map.

RFMARKS.--Small diversion for irrigation above station.

AVERAGE DISQHARGE. -5 years, $11.4 \mathrm{ft}^{3} / \mathrm{s}, 8,250$ acre-ft/yr.

EXIREMES FOR FERIOD OF RECORD.-Maximum discharge, $204 \mathrm{ft}^{3} / \mathrm{s}$ Aug. 30, 1957, gage height, $3.97 \mathrm{ft}$, from rating curve extended above $96 \mathrm{ft}^{3} / \mathrm{s}$ on basis of logarithmic plotting; minimum recorded, $2.1 \mathrm{ft} / \mathrm{s} \mathrm{Apr} .5,1955$.

LONEST MEAN DISCHARGE, IN GBIC FEET PER SECOND, AND RANKING FOR THE INDICATED NUMBER OF CONSEQUTIVE DAYS FOR EACH CIMATIC YEAR, AFRII I-MARQH 31

\begin{tabular}{|c|c|c|c|c|c|c|c|c|c|c|c|c|c|c|c|c|c|c|c|c|}
\hline YEAR & 1 & & 3 & & 7 & & 14 & & $\begin{array}{l}\text { CONSE } \\
30\end{array}$ & WTIV & $\begin{array}{l}\text { DAYS } \\
60\end{array}$ & & 90 & & 120 & & 183 & & ALL & \\
\hline $\begin{array}{l}1956 \\
1957 \\
1958 \\
1959\end{array}$ & $\begin{array}{l}3.30 \\
2.80 \\
5.10 \\
5.20\end{array}$ & $\begin{array}{l}2 \\
1 \\
3 \\
4\end{array}$ & $\begin{array}{l}3.80 \\
3.00 \\
5.50 \\
5.30\end{array}$ & $\begin{array}{l}2 \\
1 \\
4 \\
3\end{array}$ & $\begin{array}{l}4.10 \\
3.20 \\
5.70 \\
5.60\end{array}$ & $\begin{array}{l}2 \\
1 \\
4 \\
3\end{array}$ & $\begin{array}{l}4.40 \\
3.50 \\
5.90 \\
5.60\end{array}$ & $\begin{array}{l}2 \\
1 \\
4 \\
3\end{array}$ & $\begin{array}{l}4.40 \\
3.70 \\
6.70 \\
5.80\end{array}$ & $\begin{array}{l}2 \\
1 \\
4 \\
3\end{array}$ & $\begin{array}{l}4.60 \\
4.10 \\
7.10 \\
5.90\end{array}$ & $\begin{array}{l}2 \\
1 \\
4 \\
3\end{array}$ & $\begin{array}{l}4.70 \\
4.40 \\
7.50 \\
6.00\end{array}$ & $\begin{array}{l}2 \\
1 \\
4 \\
3\end{array}$ & $\begin{array}{l}4.70 \\
4.50 \\
7.80 \\
6.20\end{array}$ & $\begin{array}{l}2 \\
1 \\
4 \\
3\end{array}$ & $\begin{array}{l}4.80 \\
4.70 \\
8.80 \\
6.80\end{array}$ & $\begin{array}{l}2 \\
1 \\
4 \\
3\end{array}$ & $\begin{array}{c}8.40 \\
6.40 \\
18.0 \\
19.0\end{array}$ & 2 \\
\hline
\end{tabular}

HIGHEST MEAN DISCHARGE, IN OUBIC FEET PER SECOND, AND RANKING FOR THE INDICATFD NUMBER OF CONSEOUTIVE DAYS FOR EACH WATER YEAR, OCTOBER 1-SEPTEMBER 30

\begin{tabular}{|c|c|c|c|c|c|c|c|c|c|c|c|c|c|c|c|c|c|c|c|}
\hline YEAR & 1 & & 3 & & 7 & & 15 & & $\begin{array}{l}\text { CON } \\
30\end{array}$ & at & $\begin{array}{c}\text { E DAYS } \\
60\end{array}$ & & 90 & & 120 & & 183 & & $A L L$ \\
\hline
\end{tabular}

DURATION OF DISQHARGE FOR EACH WATER YEAR

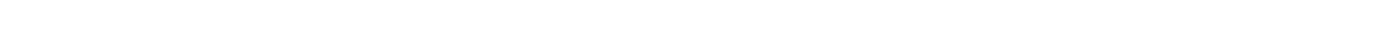
YEAR -DAYS

$\begin{array}{lllllllllllllllllllllllllll}1955 & 1 & 12 & 23 & 46 & 76 & 13 & 26 & 32 & 6 & 13 & 23 & 8 & 9 & 18 & 7 & 14 & 8 & 6 & 14 & 4 & 2 & 3 & 1 & & & \end{array}$

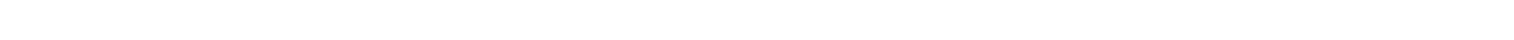

$\begin{array}{lllllllllllllllllllllllllllllllllllllll}1957 & 5 & 3 & 16 & 19 & 41 & 68 & 21 & 17 & 9 & 4 & 4 & 5 & 3 & 17 & 7 & 9 & 20 & 13 & 7 & 4 & 11 & 4 & 8 & 6 & 3 & 3 & 3 & 5 & 5 & 12 & 5 & 2 & 5 & 1 & 5761.8\end{array}$

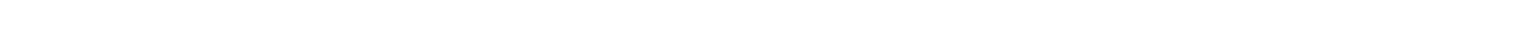

\begin{tabular}{|c|c|c|c|c|c|c|c|c|c|c|c|c|c|c|c|c|c|c|c|}
\hline \multicolumn{20}{|c|}{ DURATION TABLE OF DISQHARGE FOR WATER YEARS 1955-59 } \\
\hline CLASS & $\begin{array}{c}\text { CUBIC } \\
\text { FEET } \\
\text { PER } \\
\text { SECOND }\end{array}$ & TOTAL & $\begin{array}{c}\text { ACOU- } \\
\text { MU- } \\
\text { LATED } \\
\text { DAYS }\end{array}$ & $\begin{array}{l}\text { PER- } \\
\text { CENT } \\
\text { DAYS }\end{array}$ & CLASS & $\begin{array}{c}\text { CBIC } \\
\text { FEET } \\
\text { PER } \\
\text { SECOND }\end{array}$ & $\begin{array}{l}\text { TOTAL } \\
\text { DAYS }\end{array}$ & $\begin{array}{l}\text { ACO- } \\
\text { MU- } \\
\text { LATED } \\
\text { DAYS }\end{array}$ & $\begin{array}{l}\text { PER- } \\
\text { CENT } \\
\text { DAYS }\end{array}$ & CLASS & $\begin{array}{c}\text { WBIC } \\
\text { FEET } \\
\text { PER } \\
\text { SECOND }\end{array}$ & $\begin{array}{l}\text { TOTAL } \\
\text { DAYS }\end{array}$ & $\begin{array}{l}\text { ACOJ- } \\
\text { MU- } \\
\text { LATED } \\
\text { DAYS }\end{array}$ & $\begin{array}{l}\text { PER- } \\
\text { CENT } \\
\text { DAYS }\end{array}$ & GASS & $\begin{array}{c}\text { OBIC } \\
\text { FEET } \\
\text { PER } \\
\text { SECOND }\end{array}$ & $\begin{array}{l}\text { TOTAL } \\
\text { DAYS }\end{array}$ & $\begin{array}{l}\text { ACOU- } \\
\text { MU- } \\
\text { LATED } \\
\text { DAYS }\end{array}$ & $\begin{array}{l}\text { PER- } \\
\text { CENT } \\
\text { DAYS }\end{array}$ \\
\hline $\begin{array}{l}0 \\
1 \\
2 \\
3 \\
4 \\
5 \\
6 \\
7 \\
8\end{array}$ & $\begin{array}{l}0.00 \\
2.80 \\
3.10 \\
3.50 \\
3.90 \\
4.30 \\
4.80 \\
5.30 \\
5.90\end{array}$ & $\begin{array}{r}0 \\
5 \\
5 \\
40 \\
60 \\
152 \\
300 \\
134 \\
162\end{array}$ & $\begin{array}{l}1826 \\
1826 \\
1821 \\
1816 \\
1776 \\
1716 \\
1564 \\
1264 \\
1130\end{array}$ & $\begin{array}{r}100.0 \\
100.0 \\
99.7 \\
99.5 \\
97.3 \\
94.0 \\
85.7 \\
69.2 \\
61.9\end{array}$ & $\begin{array}{r}9 \\
10 \\
11 \\
12 \\
13 \\
14 \\
15 \\
16 \\
17\end{array}$ & $\begin{array}{r}6.50 \\
7.30 \\
8.10 \\
9.00 \\
10.00 \\
11.00 \\
12.00 \\
14.00 \\
15.00\end{array}$ & $\begin{array}{r}142 \\
123 \\
109 \\
83 \\
41 \\
51 \\
87 \\
40 \\
67\end{array}$ & $\begin{array}{l}968 \\
826 \\
703 \\
594 \\
511 \\
470 \\
419 \\
332 \\
292\end{array}$ & $\begin{array}{l}53.0 \\
45.2 \\
38.5 \\
32.5 \\
28.0 \\
25.7 \\
22.9 \\
18.2 \\
16.0\end{array}$ & $\begin{array}{l}18 \\
19 \\
20 \\
21 \\
22 \\
23 \\
24 \\
25 \\
26\end{array}$ & $\begin{array}{l}17.0 \\
19.0 \\
21.0 \\
23.0 \\
26.0 \\
29.0 \\
32.0 \\
36.0 \\
39.0\end{array}$ & $\begin{array}{l}27 \\
17 \\
21 \\
19 \\
11 \\
16 \\
13 \\
10 \\
9\end{array}$ & $\begin{array}{r}225 \\
198 \\
181 \\
160 \\
141 \\
130 \\
114 \\
101 \\
91\end{array}$ & $\begin{array}{r}12.3 \\
10.8 \\
9.9 \\
8.8 \\
7.7 \\
7.1 \\
6.2 \\
5.5 \\
5.0\end{array}$ & $\begin{array}{l}27 \\
28 \\
29 \\
30 \\
31 \\
32 \\
33 \\
34\end{array}$ & $\begin{array}{l}44.0 \\
49.0 \\
54.0 \\
60.0 \\
67.0 \\
74.0 \\
83.0 \\
92.0\end{array}$ & $\begin{array}{r}6 \\
7 \\
10 \\
15 \\
16 \\
13 \\
13 \\
2\end{array}$ & $\begin{array}{r}82 \\
76 \\
69 \\
59 \\
44 \\
28 \\
15 \\
2\end{array}$ & $\begin{array}{l}4.5 \\
4.2 \\
3.8 \\
3.2 \\
2.4 \\
1.5 \\
0.8 \\
0.1\end{array}$ \\
\hline
\end{tabular}

MONTHLY MEAN DISCHARGES, IN GBIC FEET FER SECOND, FOR EAGH WATER YEAR

$\begin{array}{lcccccccccccc}\text { YEAR } & \text { OCT } & \text { NOV } & \text { DEC } & \text { JAN } & \text { FEB } & \text { MAR } & \text { AFR } & \text { MAY } & \text { JUNE } & \text { JULY } & \text { AUG } & \text { SEP } \\ 1955 & 7.41 & 4.44 & 4.30 & 4.88 & 4.61 & 5.07 & 7.59 & 21.6 & 15.9 & 10.0 & 9.37 & 6.60 \\ 1956 & 5.15 & 4.58 & 4.79 & 4.96 & 4.48 & 5.02 & 6.71 & 11.9 & 10.9 & 7.46 & 5.72 & 5.40 \\ 1957 & 4.84 & 3.89 & 5.01 & 4.60 & 4.89 & 4.88 & 7.44 & 23.1 & 67.9 & 33.7 & 16.3 & 12.7 \\ 1958 & 12.1 & 9.49 & 8.79 & 8.06 & 7.41 & 6.87 & 22.2 & 70.5 & 49.0 & 15.6 & 12.9 & 11.6 \\ 1959 & 8.28 & 6.94 & 6.97 & 6.16 & 5.83 & 6.17 & 8.24 & 10.3 & 7.08 & 5.32 & 5.77 & 5.00\end{array}$


TRIBUTARIES BETWEEN DOLORES RIVER AND GREEN RIVER

09183500 MILL CREEK AT SHELEY TUNNEL, NEAR MOAB, UT--Continued

ANNUAL PEAK DISCHARGE, IN CUBIC FEET PER SECOND, AND CORRESPONDING GAGE HEIGHT, IN FEET, FOR EACH WATER YEAR

\begin{tabular}{|c|c|c|c|c|c|c|c|c|c|c|c|}
\hline $\begin{array}{l}\text { WATER } \\
\text { YEAR }\end{array}$ & DATE & $\begin{array}{l}\text { GAGE } \\
\text { HEIGHT }\end{array}$ & $\begin{array}{c}\text { PEAK } \\
\text { DISCHARGE }\end{array}$ & $\begin{array}{l}\text { WATER } \\
\text { YEAR }\end{array}$ & DATE & $\begin{array}{c}\text { GAGE } \\
\text { HEIGHT }\end{array}$ & $\begin{array}{c}\text { PEAK } \\
\text { DISCHARGE }\end{array}$ & $\begin{array}{l}\text { WATER } \\
\text { YEAR }\end{array}$ & DATE & $\begin{array}{l}\text { GAGE } \\
\text { HEIGHT }\end{array}$ & $\begin{array}{c}\text { PEAK } \\
\text { DISCHARGE }\end{array}$ \\
\hline $\begin{array}{l}1955 \\
1956\end{array}$ & $\begin{array}{l}\text { ○T. } 07,1954 \\
\text { JULY } 31,1956\end{array}$ & $\begin{array}{l}2.83 \\
2.86\end{array}$ & $\begin{array}{l}112 \\
118\end{array}$ & $\begin{array}{l}1957 \\
1958\end{array}$ & $\begin{array}{l}\text { AUG. } 30,1957 \\
\text { SEPT. } 12,1958\end{array}$ & $\begin{array}{l}3.97 \\
2.83\end{array}$ & $\begin{array}{l}204 \\
116\end{array}$ & 1959 & AUG. 19,1959 & 3.52 & 171 \\
\hline
\end{tabular}

09184000 MILL CREFK NEAR MOAB, UT

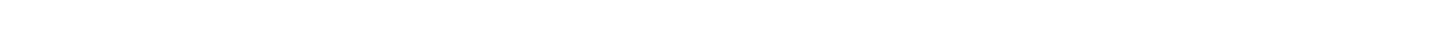
bank $0.5 \mathrm{mi}$ downstream from North Fork, $1.5 \mathrm{mi}$ Southeast of Moab, and $3.5 \mathrm{mi}$ upstream from mouth.

DRAINAGE AREA. $-74.9 \mathrm{mi}^{2}$.

MEAN BASIN ELEVATION. $-7,170 \mathrm{tt}$.

PERIOD OF RECORD AVAILABLE.--October to November 1914, February to November 1915, February 1916 to June 1917 , April to July 1918 , April to July 1919, July 1949 to September 1971, October 1972 to September 1981. Monthly mean discharge for some periods prior to October 1949, publ ished in WSP 1313.

GAGE.-Water-stage recorder and sharp-crested weir. Altitude of gage is 4,240 ft from topographic map. Prior to Apr. 28, 1918 , nonrecording gage, and Apr. 28, 1918 to Aug. 2. 1919, July 1949 to Mar. 15, 1962, water-stage recorder, 0.4 mi upstream at various datums.

REMARKS.--Diversion into Sheley Tunnel, for storage in R. E. McDougald Reservoir began in March, 1981. Diversion approximately $6.0 \mathrm{mi}$ above station. Records do not include approximately 2,410 acre-ft diverted during the 1981 water year.

AVERAGE DISCHARGE.--30 years (water years 1950-71, 1973-80), $14.3 \mathrm{ft}^{3} / \mathrm{s}, 10,360 \mathrm{acre-ft} / \mathrm{yr}$, prior to diversion to Sheley $\mathrm{Tunnel}$.

EXIREMES FOR PERIOD OF RECORD.-Maximum recorded discharge, about 5,110 ft $3 / \mathrm{s}$ Aug. 21, 1953, gage height, $10.74 \mathrm{ft} \mathrm{fram}$ floodmark, site and datum then in use from rating curve extended above $700 \mathrm{ft}^{3} / \mathrm{s}$ on basis of slope-area measurements at gage heights 8.24 $\mathrm{ft}, 8.62 \mathrm{ft}, 9.81 \mathrm{ft}$, and $11.1 \mathrm{ft}$; maximum gage height, $11.6 \mathrm{ft}$ Aug. 26, 1961, site and datum then in use; minimum recorded, $0.2 \mathrm{ft}^{3} / \mathrm{s}$ Feb. 15, 1964 .

LOWEST MEAN DISCHARGE, IN CUBIC FEET PER SECOND, AND RANKING FOR THE INDICATED NUMBER OF CONSECUTIVE DAYS FOR EACH CLIMATIC YEAR, APRIL 1-MAPCH 31

YEAR

137

CONSEOUTTVE DAYS

$\begin{array}{llll}5.70 & 21 & 5.90 & 18\end{array}$

6.2014

14

30

90

120

183

ALL

\begin{tabular}{|c|c|}
\hline $\begin{array}{l}1952 \\
1953 \\
1954 \\
1955\end{array}$ & $\begin{array}{ll}5.60 & 16 \\
7.30 & 26 \\
7.10 & 25 \\
5.70 & 20\end{array}$ \\
\hline $\begin{array}{l}1956 \\
1957 \\
1958 \\
1959 \\
1960\end{array}$ & $\begin{array}{l}5.2016 \\
4.8010 \\
8.4029 \\
7.8028 \\
4.70\end{array}$ \\
\hline
\end{tabular}

8.6026

6.7012

7.3013

7.6012

$7.50 \quad 9$

7.6015

7.1014

9.0025

8.5024

8.8024

9.3024

8.9021

7.6013

7.6013
9.4023

8.9021

8.2020

8.3018

8.1014

.5022

7.607

8.4014

9.7021

9.8022

$\begin{array}{ll}9.80 & 22 \\ 9.20 & 19\end{array}$

6.6018

6.5015

6.7013

7.0012

6.3016
5.7012

9.9029

8.9028

\begin{tabular}{rr}
6.50 & 15 \\
\hline
\end{tabular}

6.208

$\begin{array}{llll}10.0 & 29 & 10.0 \quad 29\end{array}$

$\begin{array}{rrrr}9.20 & 28 & 9.40 & 26 \\ 5.30 & 5 & 6.10 & 7\end{array}$

$6.607 \quad 6.806$

$\begin{array}{llll}11.0 & 29 & 11.0 & 29\end{array}$

9.7026

$11.0 \quad 29$

6.608

9.90
$6.70 \quad 5$

7.5010

$\begin{array}{llll}12.0 & 28 & 14.0 & 29\end{array}$

$\begin{array}{ll}14.0 & 29 \\ 11.0 & 26\end{array}$

$6.80 \quad 4$

$7.00 \quad 2$

$13.0 \quad 13$

14.014

10.05

11.06

$9.20 \quad 3$

$23.0 \quad 27$

21.026 
09184000 MILL, CREEK NEAR MOAB, UT--Continued

LOWEST MEAN DISCHARGE, IN CUBIC FEET PER SECOND, AND RANKING FOR THE INDICATED NUMBER OF CONSECUTIVE DAYS FOR EACH CLIMATIC YEAR, APRIL 1-MARCH 31 -Continued

YEAR

\begin{tabular}{rrrrrr} 
& \multicolumn{1}{c}{1} & \multicolumn{3}{c}{3} \\
1961 & 5.10 & 13 & 5.30 & 11 \\
1962 & 5.30 & 17 & 5.90 & 17 \\
1963 & 4.90 & 11 & 5.10 & 7 \\
1964 & 4.80 & 9 & 5.20 & 8 \\
1965 & 3.80 & 2 & 3.90 & 2 \\
& & & & & \\
1966 & 6.00 & 22 & 6.30 & 20 \\
1967 & 5.20 & 14 & 5.70 & 15 \\
1968 & 4.50 & 5 & 4.50 & 4 \\
1969 & 4.30 & 4 & 7.00 & 23 \\
1970 & 6.40 & 2.3 & 6.80 & 22 \\
& & & & \\
1971 & 7.50 & 27 & 7.90 & 27 \\
1974 & 7.00 & 24 & 7.80 & 26 \\
1975 & 5.50 & 18 & 6.00 & 19 \\
& & & & \\
1976 & 5.10 & 12 & 5.20 & 9 \\
1977 & 4.60 & 6 & 4.70 & 5 \\
1978 & 3.00 & 1 & 3.00 & 1 \\
1979 & 5.20 & 15 & 5.40 & 12 \\
1980 & 4.70 & 7 & 5.40 & 13 \\
& & & &
\end{tabular}

$\begin{array}{lrllr}7 & & & \\ & & & \\ 5.60 & 10 & & 5.90 & 9 \\ 7.00 & 21 & & 7.70 & 21 \\ 5.70 & 11 & & 6.20 & 12 \\ 5.40 & 8 & & 5.90 & 10 \\ 4.30 & 3 & & 5.50 & 6 \\ 7.40 & 22 & & 8.50 & 25 \\ 6.00 & 13 & & 6.50 & 16 \\ 4.50 & 4 & & 4.50 & 3 \\ 7.60 & 23 & & 7.80 & 22 \\ 6.90 & 19 & & 7.00 & 18 \\ 8.00 & 25 & & 8.00 & 23 \\ 8.10 & 26 & & 9.00 & 27 \\ 6.90 & 20 & & 7.00 & 19 \\ & & & & \\ 5.30 & 7 & & 5.90 & 7 \\ 4.80 & 5 & & 4.90 & 4 \\ 3.20 & 1 & & 3.60 & 1 \\ 5.50 & 9 & & 6.00 & 11 \\ 6.30 & 17 & & 7.00 & 20\end{array}$

$\begin{array}{llll}4.20 & 2 & 4.50 & 2\end{array}$ $\begin{array}{ll}\text { CONSECUTTVE DAYS } \\ 30 & 60\end{array}$

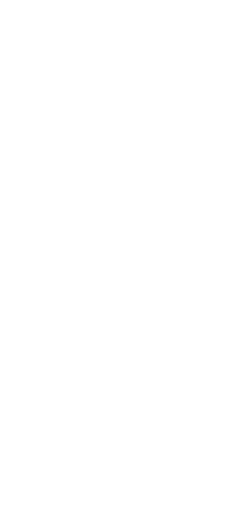

$$
90
$$

6.907 9.5024 8.3019 $\begin{array}{rr}8.30 & 19 \\ 7.20 & 8\end{array}$ $\begin{array}{ll}7.20 & 8 \\ 6.50 & 4\end{array}$

$11.0 \quad 27$

$\begin{array}{cc}11.0 & 27 \\ 8.00 & 16\end{array}$ 8.0016
6.40 $6.40 \quad 3$
8.3020 8.3020
9.5025

\subsection{2} $11.0 \quad 28$ 8.1017

7.4011

7.40
6.30

$\begin{array}{ll}6.30 & 2 \\ 4.80 & 1\end{array}$ $\begin{array}{ll}4.80 & 1 \\ 7.20 & 9\end{array}$ $\begin{array}{rr}7.20 & 9 \\ 7.70 & 14\end{array}$
7.20

$10.0 \quad 26$ 8.6020 7.30
6.90 $\begin{array}{ll}7.30 & 8 \\ 6.90 & 5\end{array}$

$12.0 \quad 29$

8.4016

6.603

$\begin{array}{ll}8.40 & 17 \\ 9.80 & 24\end{array}$

9.6023

9.60
$11.0 \quad 27$

8.4018

$\begin{array}{lr}7.70 & 11 \\ 6.50 & 2\end{array}$

$\begin{array}{ll}6.50 & 2 \\ 4.80 & 1\end{array}$

$\begin{array}{lll}4.80 & 1 \\ 7.80 & 13\end{array}$

7.7012

8.6019
183

$7.40 \quad 5$

11.0
9.4020

7.708

$\begin{array}{ll}7.70 & 8 \\ 7.40 & 6\end{array}$

$13.0 \quad 28$

8.7015

7.104

8.9017

$10.0 \quad 23$

$11.0 \quad 24$

11.025

8.8016

8.1012
7.00

$\begin{array}{ll}7.00 & 3 \\ 5.30 & 1\end{array}$

$\begin{array}{ll}5.30 & 1 \\ 7.80 & 9\end{array}$

8.1013

9.2018
ALL

11.07 17.023 16.021 $\begin{array}{cc}9.60 & 4 \\ 11.0 & 8\end{array}$

$18.0 \quad 24$ $14.0 \quad 15$ 11.09 $\begin{array}{ll}14.0 & 16 \\ 14.0 & 17\end{array}$

$17.0 \quad 22$ $24.0 \quad 28$ $14.0 \quad 18$

$13.0 \quad 12$ 11.010 6.401 $\begin{array}{ll}14.0 & 19 \\ 16.0 & 20\end{array}$ $21.0 \quad 25$

HIGHEST MEAN DISCHARGE, IN OUBIC FEET PER SECOND, AND RANKING FOR THE TNDICATED NUMBER OF CONSECUTIVE DAYS FOR EACH WATER YEAR, OCTOBER I-SEPTEMBER 30

\begin{tabular}{|c|c|c|c|c|c|c|c|c|c|c|c|c|c|c|c|c|c|c|c|c|}
\hline $\begin{array}{l}\text { YEAR } \\
1950\end{array}$ & \multicolumn{20}{|c|}{ OONSECUTTVE DAYS } \\
\hline $\begin{array}{l}1961 \\
1962 \\
1963 \\
1964 \\
1965\end{array}$ & $\begin{array}{c}489 \\
176 \\
128 \\
47.0 \\
114\end{array}$ & $\begin{array}{r}1 \\
6 \\
10 \\
26 \\
13\end{array}$ & $\begin{array}{c}219 \\
79.0 \\
84.0 \\
46.0 \\
70.0\end{array}$ & $\begin{array}{l}1 \\
12 \\
10 \\
24 \\
15\end{array}$ & $\begin{array}{r}104 \\
64.0 \\
48.0 \\
45.0 \\
46.0\end{array}$ & $\begin{array}{r}1 \\
11 \\
16 \\
19 \\
17\end{array}$ & $\begin{array}{l}73.0 \\
54.0 \\
31.0 \\
41.0 \\
35.0\end{array}$ & $\begin{array}{r}5 \\
9 \\
21 \\
15 \\
19\end{array}$ & $\begin{array}{l}65.0 \\
51.0 \\
21.0 \\
31.0 \\
32.0\end{array}$ & $\begin{array}{r}6 \\
9 \\
25 \\
17 \\
16\end{array}$ & $\begin{array}{l}39.0 \\
37.0 \\
15.0 \\
22.0 \\
32.0\end{array}$ & $\begin{array}{r}8 \\
10 \\
26 \\
20 \\
12\end{array}$ & $\begin{array}{l}29.0 \\
33.0 \\
14.0 \\
19.0 \\
28.0\end{array}$ & $\begin{array}{r}10 \\
8 \\
26 \\
20 \\
12\end{array}$ & $\begin{array}{l}26.0 \\
27.0 \\
13.0 \\
17.0 \\
26.0\end{array}$ & $\begin{array}{r}11 \\
8 \\
26 \\
21 \\
9\end{array}$ & $\begin{array}{l}22.0 \\
22.0 \\
12.0 \\
14.0 \\
21.0\end{array}$ & $\begin{array}{r}8 \\
9 \\
26 \\
24 \\
10\end{array}$ & $\begin{array}{l}15.0 \\
16.0 \\
10.0 \\
11.0 \\
14.0\end{array}$ & $\begin{array}{l}12 \\
10 \\
27 \\
24 \\
13\end{array}$ \\
\hline $\begin{array}{l}1971 \\
1973 \\
1974 \\
1975\end{array}$ & $\begin{array}{l}34.0 \\
140 \\
460 \\
60.0\end{array}$ & $\begin{array}{r}30 \\
8 \\
2 \\
24\end{array}$ & $\begin{array}{l}27.0 \\
108 \\
183 \\
58.0\end{array}$ & $\begin{array}{r}29 \\
5 \\
2 \\
18\end{array}$ & $\begin{array}{c}25.0 \\
101 \\
86.0 \\
53.0\end{array}$ & $\begin{array}{r}27 \\
2 \\
5 \\
13\end{array}$ & $\begin{array}{l}23.0 \\
99.0 \\
46.0 \\
47.0\end{array}$ & $\begin{array}{r}26 \\
1 \\
12 \\
11\end{array}$ & $\begin{array}{l}20.0 \\
86.0 \\
35.0 \\
40.0\end{array}$ & $\begin{array}{r}26 \\
1 \\
14 \\
12\end{array}$ & $\begin{array}{l}19.0 \\
78.0 \\
29.0 \\
33.0\end{array}$ & $\begin{array}{r}23 \\
1 \\
15 \\
11\end{array}$ & $\begin{array}{l}17.0 \\
62.0 \\
29.0 \\
27.0\end{array}$ & $\begin{array}{r}24 \\
1 \\
11 \\
14\end{array}$ & $\begin{array}{l}15.0 \\
50.0 \\
25.0 \\
23.0\end{array}$ & $\begin{array}{r}24 \\
2 \\
12 \\
15\end{array}$ & $\begin{array}{l}14.0 \\
37.0 \\
21.0 \\
19.0\end{array}$ & $\begin{array}{r}21 \\
2 \\
11 \\
15\end{array}$ & $\begin{array}{l}12.0 \\
24.0 \\
16.0 \\
14.0\end{array}$ & $\begin{array}{r}19 \\
2 \\
8 \\
15\end{array}$ \\
\hline
\end{tabular}


TRIBUTARIES BETWEEN DOLORES RIVER AND GREEN RIVER

09184000 MILL CREER NEAR MOAB, UT--Continued

HIGHEST MEAN DISCHARGE, IN CUBIC FEET PER SECOND, AND RANKING FOR THE INDICATED NUMBER OF CONSECUTIVE DAYS FOR EACH WATER YEAR, OCTOBER 1-SEPTEMBER 30--Continued

\begin{tabular}{|c|c|c|c|c|c|c|c|c|c|c|c|c|c|c|c|c|c|c|c|c|}
\hline YEAR & 1 & & 3 & & 7 & & 15 & & $\begin{array}{l}\text { CONSS } \\
30\end{array}$ & ECUT & $\begin{array}{l}\text { E DAYS } \\
60\end{array}$ & & 90 & & 120 & & 183 & & ALL & \\
\hline $\begin{array}{l}1976 \\
1977 \\
1978 \\
1979 \\
1980\end{array}$ & $\begin{array}{c}356 \\
42.0 \\
123 \\
77.0 \\
107\end{array}$ & $\begin{array}{r}4 \\
28 \\
11 \\
22 \\
17\end{array}$ & $\begin{array}{c}130 \\
20.0 \\
54.0 \\
74.0 \\
90.0\end{array}$ & $\begin{array}{r}4 \\
30 \\
19 \\
14 \\
8\end{array}$ & $\begin{array}{l}65.0 \\
12.0 \\
52.0 \\
72.0 \\
82.0\end{array}$ & $\begin{array}{r}10 \\
31 \\
14 \\
9 \\
6\end{array}$ & $\begin{array}{c}37.0 \\
8.10 \\
48.0 \\
64.0 \\
69.0\end{array}$ & $\begin{array}{r}16 \\
31 \\
10 \\
7 \\
6\end{array}$ & $\begin{array}{c}23.0 \\
7.50 \\
44.0 \\
54.0 \\
66.0\end{array}$ & $\begin{array}{r}24 \\
31 \\
10 \\
7 \\
5\end{array}$ & $\begin{array}{c}18.0 \\
7.40 \\
38.0 \\
45.0 \\
63.0\end{array}$ & $\begin{array}{r}24 \\
31 \\
9 \\
7 \\
4\end{array}$ & $\begin{array}{c}18.0 \\
7.30 \\
31.0 \\
38.0 \\
54.0\end{array}$ & $\begin{array}{r}22 \\
31 \\
9 \\
6 \\
3\end{array}$ & $\begin{array}{c}16.0 \\
7.30 \\
26.0 \\
32.0 \\
44.0\end{array}$ & $\begin{array}{r}22 \\
31 \\
10 \\
6 \\
3\end{array}$ & $\begin{array}{c}14.0 \\
7.10 \\
20.0 \\
25.0 \\
33.0\end{array}$ & $\begin{array}{r}22 \\
31 \\
12 \\
6 \\
3\end{array}$ & $\begin{array}{c}11.0 \\
6.20 \\
14.0 \\
16.0 \\
20.0\end{array}$ & $\begin{array}{r}22 \\
31 \\
16 \\
9 \\
4\end{array}$ \\
\hline 1981 & 60.0 & 23 & 35.0 & 27 & 25.0 & 28 & 17.0 & 29 & 14.0 & 28 & 12.0 & 30 & 11.0 & 30 & 11.0 & 30 & 9.40 & 30 & 9.30 & 29 \\
\hline
\end{tabular}

DURATION OF DISCHARGE FOR EACH WATER YEAR

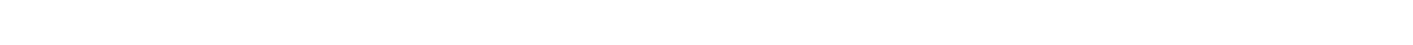

YEAR

NUMBER OF DAYS IN CLASS

1950

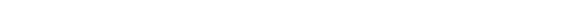

1 PER SECOND

1950

$\begin{array}{llllllll}93132 & 43 & 33 & 26 & 9 & 7 & 3 & 1\end{array}$

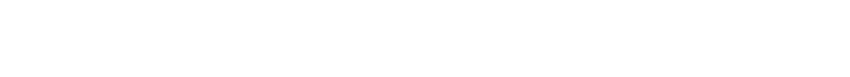

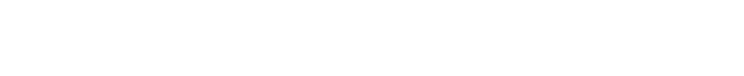

1954

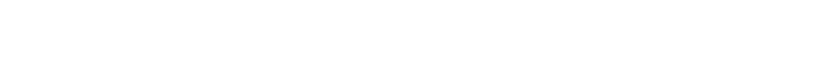

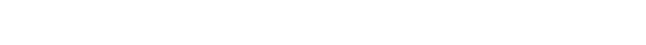

$\begin{array}{rrrrrrrrrrrrrrrrrrrrr}2 & 39 & 67 & 73 & 63 & 17 & 33 & 17 & 15 & 17 & 7 & 3 & 2 & 2 & 1 & & 1 & 1 & & 1 & 1 \\ 3 & 3 & 12 & 12 & 81 & 96 & 47 & 11 & 25 & 17 & 16 & 3 & 7 & 2 & 7 & 8 & 8 & 5 & & & 1\end{array}$

$\begin{array}{lllllllrrrrrrrrr}6 & 14 & 43104 & 87 & 53 & 22 & 14 & 9 & 5 & & 2 & & 1 & 1 & 2 & 1\end{array}$

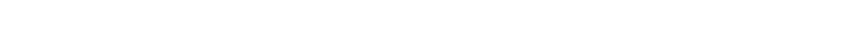

$\begin{array}{lllllllllllllll}2 & 4 & 10 & 23 & 70 & 63 & 69 & 35 & 16 & 19 & 12 & 20 & 14 & 7\end{array}$

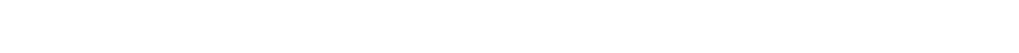

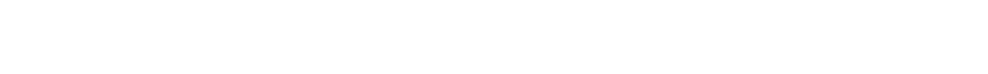

$\begin{array}{rrrrrrrrrrrrrrrrrrrrrr} & 1 & 2 & 44 & 73 & 81 & 72 & 28 & 30 & 21 & 6 & 6 & & 1 & & & & & & & \\ 1 & 3 & 18 & 32 & 96 & 41 & 38 & 19 & 13 & 11 & 4 & 6 & 6 & 8 & 6 & 7 & 13 & 14 & 8 & 11 & 9 & 1\end{array}$

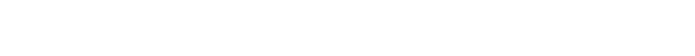

$\begin{array}{lllllllllll}15 & 14 & 59106 & 73 & 46 & 11 & 7 & 15 & 10 & 2 & 2\end{array}$

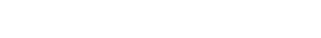

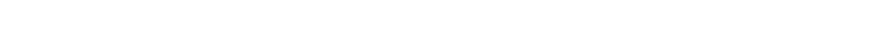

$\begin{array}{rrrrrrrrrrrrrrrrrrrrr}4 & 42 & 41 & 57 & 49 & 41 & 19 & 12 & 8 & 7 & 9 & 13 & 10 & 19 & 11 & 9 & 4 & 7 & 3 & & \\ 2 & 3 & 58 & 76 & 68 & 29 & 18 & 8 & 7 & 5 & 3 & 4 & 2 & 10 & 11 & 20 & 18 & 13 & 6 & 3 & 2\end{array}$

1981

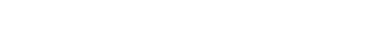

$\begin{array}{llll}1 & 1 & 1 & 1\end{array}$

$1 \quad 1 \quad 1 \quad 5345.0$

6022.4

3817.8

3929.7
5230.8

6071.0

4292.7

4840.5

4977.6

4458.6

8707.3

8707.3

5024.0

4041.1

2258.1

5073.9

5984.2

7482.4

3397.7

DURATION TABLE OF DISCHARGE FOR WATER YEARS 1950-71, 1973-81
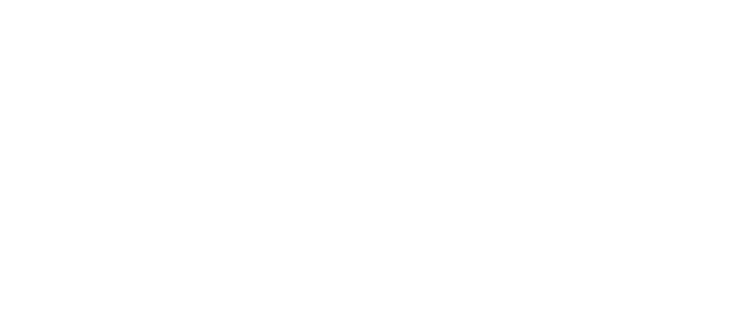

\begin{tabular}{|c|c|c|c|c|}
\hline ILASS & $\begin{array}{c}\text { OUBIC } \\
\text { FEET } \\
\text { PER } \\
\text { SECOND }\end{array}$ & $\begin{array}{l}\text { TOIAL } \\
\text { DAYS }\end{array}$ & $\begin{array}{l}\text { ACOU- } \\
\text { MU- } \\
\text { LATED } \\
\text { DAYS }\end{array}$ & $\begin{array}{l}\text { PER- } \\
\text { CENT } \\
\text { DAYS }\end{array}$ \\
\hline $\begin{array}{l}18 \\
19 \\
20 \\
21 \\
22 \\
23 \\
24 \\
25 \\
26\end{array}$ & $\begin{array}{r}40.0 \\
47.0 \\
54.0 \\
63.0 \\
74.0 \\
86.0 \\
100.0 \\
120.0 \\
140.0\end{array}$ & $\begin{array}{r}148 \\
112 \\
92 \\
99 \\
54 \\
41 \\
20 \\
6 \\
2\end{array}$ & $\begin{array}{r}583 \\
435 \\
323 \\
231 \\
132 \\
78 \\
37 \\
17 \\
11\end{array}$ & $\begin{array}{l}5.1 \\
3.8 \\
2.9 \\
2.0 \\
1.2 \\
0.7 \\
0.3 \\
0.2 \\
0.1\end{array}$ \\
\hline
\end{tabular}

\begin{tabular}{|c|c|c|c|c|}
\hline & $\begin{array}{c}\text { CUBIC } \\
\text { FEET } \\
\text { PER }\end{array}$ & TOTAL & $\begin{array}{c}\text { ACOU- } \\
\text { MU- } \\
\text { LATED }\end{array}$ & $\begin{array}{l}\text { PER- } \\
\text { CENI }\end{array}$ \\
\hline CLASS & SECOND & DAYS & DAYS & DAYS \\
\hline 27 & 160.0 & 2 & 9 & 0.1 \\
\hline 28 & 180.0 & 0 & 7 & 0.1 \\
\hline 29 & 210.0 & 1 & 7 & 0.1 \\
\hline 30 & 250.0 & 0 & 6 & 0.1 \\
\hline 31 & 290.0 & 0 & 6 & 0.1 \\
\hline 32 & 340.0 & 2 & 6 & 0.1 \\
\hline 33 & 390.0 & 2 & 4 & 0.0 \\
\hline & 460.0 & 2 & 2 & \\
\hline
\end{tabular}


IRIBUTARIES BETWEEN DOLORES RIVER AND GREEN RIVER

09184000 MILL CREEK NEAR MOAB, UT-Continued

MONIHLY MEAN DISCHARGES, IN OBBIC FEET PER SECOND, FOR EACH WATER YEAR

\begin{tabular}{|c|c|c|c|c|c|c|c|c|c|c|c|c|}
\hline YEAR & $\infty C I$ & NOV & $\mathrm{DEC}$ & JAN & FEB & MAR & APR & MAY & JUNE & JULY & ALG & SEP \\
\hline 1950 & 16.8 & 13.3 & 11.6 & 8.71 & 11.7 & 11.0 & 22.8 & 28.6 & 24.6 & 13.3 & 9.68 & 10.0 \\
\hline $\begin{array}{l}1951 \\
1952 \\
1953 \\
1954 \\
1955\end{array}$ & $\begin{array}{c}7.43 \\
8.10 \\
10.1 \\
13.3 \\
10.7\end{array}$ & $\begin{array}{l}8.17 \\
7.51 \\
9.47 \\
9.77 \\
8.29\end{array}$ & $\begin{array}{c}7.24 \\
10.1 \\
9.90 \\
8.99 \\
8.51\end{array}$ & $\begin{array}{l}8.07 \\
9.43 \\
9.58 \\
8.92 \\
8.50\end{array}$ & $\begin{array}{l}7.85 \\
8.05 \\
9.04 \\
8.83 \\
9.26\end{array}$ & $\begin{array}{c}6.77 \\
9.39 \\
10.0 \\
9.10 \\
9.67\end{array}$ & $\begin{array}{l}8.68 \\
41.9 \\
13.0 \\
11.3 \\
11.7\end{array}$ & $\begin{array}{l}12.7 \\
76.3 \\
22.7 \\
14.2 \\
25.9\end{array}$ & $\begin{array}{l}11.6 \\
58.4 \\
27.2 \\
10.5 \\
20.6\end{array}$ & $\begin{array}{c}8.09 \\
20.8 \\
16.5 \\
8.63 \\
11.1\end{array}$ & $\begin{array}{l}25.3 \\
18.4 \\
19.5 \\
10.1 \\
10.4\end{array}$ & $\begin{array}{c}7.90 \\
14.3 \\
9.74 \\
12.2 \\
7.68\end{array}$ \\
\hline $\begin{array}{l}1956 \\
1957 \\
1958 \\
1959 \\
1960\end{array}$ & $\begin{array}{c}7.02 \\
6.92 \\
19.9 \\
11.4 \\
7.08\end{array}$ & $\begin{array}{c}7.15 \\
7.56 \\
13.7 \\
12.6 \\
7.04\end{array}$ & $\begin{array}{c}8.15 \\
8.70 \\
11.8 \\
10.6 \\
8.58\end{array}$ & $\begin{array}{c}8.96 \\
9.05 \\
10.6 \\
10.5 \\
7.46\end{array}$ & $\begin{array}{c}8.83 \\
9.06 \\
14.8 \\
9.97 \\
9.99\end{array}$ & $\begin{array}{c}8.39 \\
8.47 \\
12.4 \\
9.48 \\
8.80\end{array}$ & $\begin{array}{l}9.76 \\
12.8 \\
32.0 \\
10.9 \\
13.0\end{array}$ & $\begin{array}{l}14.3 \\
32.1 \\
68.2 \\
12.8 \\
19.9\end{array}$ & $\begin{array}{c}11.5 \\
72.2 \\
44.0 \\
8.35 \\
20.4\end{array}$ & $\begin{array}{c}8.46 \\
36.0 \\
15.4 \\
6.20 \\
9.92\end{array}$ & $\begin{array}{c}9.89 \\
22.6 \\
14.2 \\
7.62 \\
11.8\end{array}$ & $\begin{array}{c}6.41 \\
13.5 \\
16.3 \\
6.35 \\
7.08\end{array}$ \\
\hline $\begin{array}{l}1961 \\
1962 \\
1963 \\
1964 \\
1965\end{array}$ & $\begin{array}{c}7.94 \\
16.9 \\
12.0 \\
8.51 \\
6.31\end{array}$ & $\begin{array}{c}8.44 \\
10.5 \\
9.90 \\
7.67 \\
6.85\end{array}$ & $\begin{array}{l}7.91 \\
9.45 \\
8.86 \\
6.72 \\
6.85\end{array}$ & $\begin{array}{l}6.23 \\
8.66 \\
7.50 \\
7.62 \\
8.31\end{array}$ & $\begin{array}{c}7.06 \\
12.4 \\
8.97 \\
7.70 \\
8.56\end{array}$ & $\begin{array}{c}7.72 \\
10.4 \\
9.24 \\
8.37 \\
8.44\end{array}$ & $\begin{array}{c}9.74 \\
34.2 \\
7.59 \\
12.5 \\
12.5\end{array}$ & $\begin{array}{l}17.5 \\
36.3 \\
13.4 \\
27.9 \\
23.7\end{array}$ & $\begin{array}{c}17.2 \\
25.5 \\
8.29 \\
14.3 \\
31.6\end{array}$ & $\begin{array}{l}9.28 \\
10.5 \\
10.8 \\
10.0 \\
29.0\end{array}$ & $\begin{array}{c}32.7 \\
10.5 \\
18.7 \\
8.95 \\
17.1\end{array}$ & $\begin{array}{c}44.0 \\
12.9 \\
10.0 \\
8.36 \\
12.3\end{array}$ \\
\hline $\begin{array}{l}1966 \\
1967 \\
1968 \\
1969 \\
1970\end{array}$ & $\begin{array}{c}17.7 \\
9.23 \\
7.09 \\
9.74 \\
11.7\end{array}$ & $\begin{array}{c}16.2 \\
9.18 \\
7.52 \\
10.1 \\
11.3\end{array}$ & $\begin{array}{c}13.5 \\
9.31 \\
5.87 \\
8.55 \\
10.3\end{array}$ & $\begin{array}{c}10.9 \\
7.79 \\
6.02 \\
8.50 \\
9.26\end{array}$ & $\begin{array}{l}9.94 \\
8.12 \\
8.36 \\
8.38 \\
9.78\end{array}$ & $\begin{array}{c}15.4 \\
8.55 \\
8.41 \\
8.15 \\
9.81\end{array}$ & $\begin{array}{c}21.8 \\
8.80 \\
10.4 \\
18.7 \\
11.3\end{array}$ & $\begin{array}{l}34.5 \\
16.8 \\
25.4 \\
26.9 \\
48.0\end{array}$ & $\begin{array}{l}23.1 \\
18.2 \\
38.3 \\
20.8 \\
43.2\end{array}$ & $\begin{array}{l}12.9 \\
14.5 \\
16.1 \\
14.2 \\
17.4\end{array}$ & $\begin{array}{l}12.7 \\
18.6 \\
15.5 \\
17.8 \\
11.5\end{array}$ & $\begin{array}{c}10.6 \\
11.6 \\
9.85 \\
11.5 \\
14.3\end{array}$ \\
\hline $\begin{array}{l}1971 \\
1973 \\
1974 \\
1975\end{array}$ & $\begin{array}{c}13.3 \\
19.6 \\
11.5 \\
8.24\end{array}$ & $\begin{array}{c}12.4 \\
11.5 \\
11.8 \\
8.15\end{array}$ & $\begin{array}{c}9.95 \\
9.16 \\
10.0 \\
8.81\end{array}$ & $\begin{array}{c}9.02 \\
9.00 \\
10.7 \\
10.3\end{array}$ & $\begin{array}{c}9.56 \\
8.64 \\
12.3 \\
8.78\end{array}$ & $\begin{array}{c}9.77 \\
8.45 \\
11.8 \\
8.75\end{array}$ & $\begin{array}{r}11.9 \\
13.7 \\
16.0 \\
9.81\end{array}$ & $\begin{array}{l}17.8 \\
73.0 \\
35.0 \\
24.9\end{array}$ & $\begin{array}{l}20.1 \\
76.1 \\
19.9 \\
38.8\end{array}$ & $\begin{array}{l}11.6 \\
32.3 \\
28.1 \\
17.1\end{array}$ & $\begin{array}{l}12.1 \\
13.5 \\
10.1 \\
11.0\end{array}$ & $\begin{array}{c}9.24 \\
10.5 \\
8.90 \\
10.4\end{array}$ \\
\hline $\begin{array}{l}1976 \\
1977 \\
1978 \\
1975 \\
1980\end{array}$ & $\begin{array}{c}7.22 \\
6.62 \\
10.2 \\
6.73 \\
8.36\end{array}$ & $\begin{array}{l}7.00 \\
6.22 \\
6.56 \\
8.81 \\
7.38\end{array}$ & $\begin{array}{l}8.37 \\
7.25 \\
6.64 \\
8.96 \\
7.72\end{array}$ & $\begin{array}{l}8.36 \\
7.32 \\
7.16 \\
7.08 \\
7.93\end{array}$ & $\begin{array}{l}8.57 \\
7.31 \\
6.65 \\
7.71 \\
9.19\end{array}$ & $\begin{array}{c}8.94 \\
7.15 \\
7.51 \\
10.4 \\
9.87\end{array}$ & $\begin{array}{c}10.7 \\
7.05 \\
17.5 \\
18.4 \\
22.4\end{array}$ & $\begin{array}{c}18.4 \\
6.29 \\
32.1 \\
47.5 \\
61.9\end{array}$ & $\begin{array}{c}12.6 \\
4.36 \\
41.9 \\
41.9 \\
61.4\end{array}$ & $\begin{array}{c}22.3 \\
5.15 \\
13.4 \\
18.7 \\
26.7\end{array}$ & $\begin{array}{c}7.97 \\
4.86 \\
9.47 \\
10.6 \\
9.97\end{array}$ & $\begin{array}{c}11.8 \\
4.68 \\
7.59 \\
9.51 \\
12.5\end{array}$ \\
\hline 1981 & 10.2 & 10.9 & 11.2 & 10.2 & 7.97 & 4.89 & 7.34 & 8.05 & 9.34 & 9.12 & 11.1 & 11.3 \\
\hline
\end{tabular}

AINUAL PEAK IISCHARGE, IN OUBIC FEET PER SECOND, AND CORRESPONDING GAGE HEIGHT, IN FEET, FOR EACH WATER YEAR

\begin{tabular}{|c|c|c|c|c|c|c|c|c|c|c|c|}
\hline $\begin{array}{l}\text { WATER } \\
\text { YE:AR }\end{array}$ & DATE & $\begin{array}{c}\text { GAGE: } \\
\text { HEIGHT }\end{array}$ & $\begin{array}{c}\text { PEAK } \\
\text { DISCHARGE }\end{array}$ & $\begin{array}{l}\text { WATER } \\
\text { YEAR }\end{array}$ & DATE & $\begin{array}{l}\text { GAGE } \\
\text { HEIGHT }\end{array}$ & $\begin{array}{c}\text { PEAK } \\
\text { DISCHARGE }\end{array}$ & $\begin{array}{l}\text { WATER } \\
\text { YEAR }\end{array}$ & DATE & $\begin{array}{l}\text { GAGE } \\
\text { HEIGHT }\end{array}$ & $\begin{array}{c}\text { PEAK } \\
\text { DISCHARGE }\end{array}$ \\
\hline $\begin{array}{l}1915 \\
1916 \\
1917 \\
1949 \\
1950 \\
1951 \\
1952 \\
1953 \\
1954 \\
1955 \\
1556\end{array}$ & $\begin{array}{l}\text { AFR. } 29,1915 \\
\text { AUG. } 12,1916 \\
\text { OCT. } 07,1916 \\
\text { JULY } 09,1949 \\
\text { CCT. } 19,1949 \\
\text { AUG. } 29,1951 \\
\text { JUIY } 29,1952 \\
\text { AUG. 21, } 1953 \\
\text { AUG. } 13,1954 \\
\text { NON. 12, } 1954 \\
\text { AUG. 15, } 1956\end{array}$ & $\begin{array}{r}2.20 \\
2.30 \\
3.50 \\
3.44 \\
4.07 \\
8.24 \\
3.80 \\
10.74 \\
6.62 \\
3.78 \\
4.38\end{array}$ & $\begin{array}{r}220 \\
235 \\
450 \\
163 \\
255 \\
2940 \\
202 \\
5110 \\
2080 \\
163 \\
257\end{array}$ & $\begin{array}{l}1958 \\
1959 \\
1960 \\
1961 \\
1962 \\
1963 \\
1964 \\
1965 \\
1966 \\
1967 \\
1968\end{array}$ & $\begin{array}{l}\text { SEPT. 12, } 1958 \\
\text { AUG. 19, } 1959 \\
\text { JULY 31, } 1960 \\
\text { AUG. 26, } 1961 \\
\text { JUNE } 30,1962 \\
\text { AUG. 02, } 1963 \\
\text { SEPT. 15, } 1964 \\
\text { AUG. 18, } 1965 \\
\text { OCT. 16, } 1965 \\
\text { AUG. 07, } 1967 \\
\text { AUG. 02, } 1968\end{array}$ & $\begin{array}{r}6.81 \\
4.84 \\
4.40 \\
11.60 \\
6.01 \\
8.50 \\
4.20 \\
5.55 \\
4.78 \\
6.70 \\
4.26\end{array}$ & $\begin{array}{r}1060 \\
228 \\
212 \\
5100 \\
3010 \\
3160 \\
895 \\
1690 \\
1230 \\
2290 \\
917\end{array}$ & $\begin{array}{l}1970 \\
1971 \\
1973 \\
1974 \\
1975 \\
1976 \\
1977 \\
1978 \\
1979 \\
1980 \\
1981\end{array}$ & $\begin{array}{l}\text { JUNE } 11,1970 \\
\text { AUG. } 30,1971 \\
\text { JUNE } 02,1973 \\
\text { JULY } 19,1974 \\
\text { MAY } 14,1975 \\
\text { JULY 31, } 1976 \\
\text { JULY 24, } 1977 \\
\text { OCT. 06, } 1977 \\
\text { MAY 27, } 1979 \\
\text { SEPT. 06, } 1980 \\
\text { SEPT.06, } 1981\end{array}$ & $\begin{array}{l}2.90 \\
3.17 \\
4.05 \\
8.95 \\
2.52 \\
8.50 \\
3.28 \\
6.28 \\
3.65 \\
3.97 \\
3.80\end{array}$ & $\begin{array}{r}194 \\
322 \\
790 \\
3450 \\
106 \\
3160 \\
375 \\
2080 \\
600 \\
768 \\
685\end{array}$ \\
\hline
\end{tabular}

1957 AUG, 05, I957 $11.10 \quad 4450 \quad 1969$ AUG, 29, 1969

MAGNITUDE AND PPORAEILITY OF ANNUAL LONEST MEAN DISCHARGE

\begin{tabular}{|c|c|c|c|c|c|}
\hline $\begin{array}{l}\text { PERIOL } \\
\text { (CON)- }\end{array}$ & & $\begin{array}{l}\text { DISCHPRGE, IN CUEI } \\
\text { INDICATED RECURRENCE } \\
\text { ANNUAL NONEXCEEDANCE }\end{array}$ & $\begin{array}{l}\text { C FEET FER SEC } \\
\text { INTERNAL, IN } \\
\text { FROBAEILITY, }\end{array}$ & $\begin{array}{l}\text { OND, FOR } \\
\text { YEARS, AND } \\
\text { IN PERCENT }\end{array}$ & \\
\hline $\begin{array}{l}\text { SEU- } \\
\text { TIVE: }\end{array}$ & 2 & 10 & 20 & 50 & 100 \\
\hline DAYS) & $50 \%$ & $10 \%$ & 58 & $2 \%$ & 18 \\
\hline
\end{tabular}

MAGNITUDE AND PROBABILITY OF ANNUAL HIGHEST MEAN DISCHARGE BASED ON WATER YEARS 1950-71 AND 1973-81

\begin{tabular}{|c|c|c|c|c|c|c|}
\hline \multirow{2}{*}{$\begin{array}{l}\text { PERIOD } \\
\text { (CON- } \\
\text { SECU- } \\
\text { TIVE } \\
\text { DAYS) }\end{array}$} & \multicolumn{6}{|c|}{$\begin{array}{l}\text { DISCHARGE, IN OUBIC FEET PER SECOND, FOR } \\
\text { INDICATED RECURRENCE INTERNAL, IN YEARS, AND } \\
\text { ANNUAL EXCEEDANCE PROBABILITY, IN PERCENT }\end{array}$} \\
\hline & $\begin{array}{c}2 \\
50 \%\end{array}$ & $\begin{array}{c}5 \\
208\end{array}$ & $\begin{array}{l}10 \\
10 \%\end{array}$ & $\begin{array}{l}25 \\
48\end{array}$ & $\begin{array}{l}50 \\
28\end{array}$ & $\begin{array}{r}100 \\
18\end{array}$ \\
\hline 1 & 99 & 192 & 279 & 425 & 565 & - \\
\hline 3 & 64 & 106 & 136 & 178 & 211 & - \\
\hline 7 & 50 & 76 & 91 & 110 & 122 & - \\
\hline 15 & 39 & 62 & 76 & 93 & 105 & - \\
\hline
\end{tabular}


LOCATION.--Lat $38^{\circ} 26^{\prime} 19^{\prime \prime}$, long $109^{\circ} 21$ ' $15^{\prime \prime}$, in SE s. $_{4}$ sec. 23, T.27 S., R 23 E., Grand County, Hydrologic Unit 14030005 , on left bank 0.5 mi upstream fram $\mathrm{M} 4$ Ranch and $14 \mathrm{mi}$ southeast of Moab.

DRAINAGE AREA. $-15.8 \mathrm{mi}^{2}$.

MEAN BASIN ELEVATION. $--9,200 \mathrm{ft}$.

FERIOD OF RECORD AVAIIABLE.--October 1954 to September 1959.

GAGE.-Water-stage recorder and concrete control. Altitude of gage is 6,140 ft from topographic map.

REMARKS.--Small diversion for irrigation above station.

AVERAGE DISOHARGE. --5 years, $2.54 \mathrm{ft}^{3} / \mathrm{s}, 1,840$ acre- $\mathrm{ft} / \mathrm{yr}$.

EXIREMES FOR PERIOD OF RECORD.--Maximum discharge, 1,200 ft $3 / \mathrm{s}$ July 26,1955 , gage height, $9.02 \mathrm{ft}$, fram rating curve extended above $80 \mathrm{ft}^{3} / \mathrm{s}$ on basis of slope-area measurement of peak flow; minimum daily, $0.3 \mathrm{ft}^{3} / \mathrm{s} \mathrm{Sept.} \mathrm{2,} \mathrm{4,} 1956$.

LOWEST MEAN DISOHARGE, IN OBIC FEET PER SECOND, AND RANKING FOR THE INDICATED NUMBER OF CONSEOUTIVE DAYS FOR EAOH C.IMATIC YEAR, APRIL I-MAROH 31

\begin{tabular}{|c|c|c|c|c|c|c|c|c|c|c|c|c|c|c|c|c|c|c|c|}
\hline \multirow[t]{2}{*}{ YEAR } & \multirow[b]{2}{*}{1} & & \multirow{2}{*}{\multicolumn{2}{|c|}{3}} & \multirow{2}{*}{\multicolumn{2}{|c|}{7}} & \multirow{2}{*}{\multicolumn{2}{|c|}{14}} & \multicolumn{4}{|c|}{ CONSEOUTIVE DAYS } & \multirow[b]{2}{*}{90} & \multirow{2}{*}{\multicolumn{2}{|c|}{120}} & \multirow{2}{*}{\multicolumn{2}{|c|}{183}} & \multirow{2}{*}{\multicolumn{2}{|c|}{ ALL }} \\
\hline & & & & & & & & & 30 & & 60 & & & & & & & & \\
\hline $\begin{array}{l}1956 \\
1957 \\
958 \\
959\end{array}$ & $\begin{array}{l}0.50 \\
0.30 \\
0.50 \\
0.60\end{array}$ & $\begin{array}{l}3 \\
1 \\
2 \\
4\end{array}$ & $\begin{array}{l}0.57 \\
0.33 \\
0.57 \\
0.60\end{array}$ & $\begin{array}{l}3 \\
1 \\
2 \\
4\end{array}$ & $\begin{array}{l}0.61 \\
0.37 \\
0.59 \\
0.63\end{array}$ & $\begin{array}{l}3 \\
1 \\
2 \\
4\end{array}$ & $\begin{array}{l}0.66 \\
0.39 \\
0.64 \\
0.71\end{array}$ & $\begin{array}{l}3 \\
1 \\
2 \\
4\end{array}$ & $\begin{array}{l}0.68 \\
0.39 \\
0.66 \\
0.86\end{array}$ & $\begin{array}{l}3 \\
1 \\
2 \\
4\end{array}$ & $\begin{array}{l}0.68 \\
0.43 \\
0.87 \\
0.91\end{array}$ & $\begin{array}{l}2 \\
1 \\
3 \\
4\end{array}$ & $\begin{array}{l}0.69 \\
0.45 \\
0.90 \\
0.93\end{array}$ & $\begin{array}{l}2 \\
1 \\
3 \\
4\end{array}$ & $\begin{array}{l}0.70 \\
0.46 \\
0.95 \\
0.95\end{array}$ & $\begin{array}{l}2 \\
1 \\
3 \\
4\end{array}$ & $\begin{array}{l}0.72 \\
0.47 \\
1.10 \\
0.96\end{array}$ & $\begin{array}{l}2 \\
1 \\
4 \\
3\end{array}$ & $\begin{array}{l}1.50 \\
0.56 \\
4.80 \\
5.00\end{array}$ \\
\hline
\end{tabular}

HIGHEST MEAN DISCHARGE, IN OUBIC FEET PER SECOND, AND RANKING FOR THE INDICATED NUMBER OF CONSECUTTVE DAYS FOR EAG WATER YEAR, OCTOBER I-SEPTEMBER 30

\begin{tabular}{|c|c|c|c|c|c|c|c|c|c|c|c|c|c|c|c|c|c|c|}
\hline YE.AR & & & & & & & & CONSE & WTI & DAYS & & & & & & & & \\
\hline 46.0 & 2 & 17.0 & 3 & 8.10 & 3 & 5.00 & 3 & 4.30 & 3 & 3.70 & 3 & 3.50 & 3 & 3.00 & 3 & 2.30 & 3 & 1.60 \\
\hline
\end{tabular}

DURATION OF DISCHARGE FOR EAOH WATER YEAR

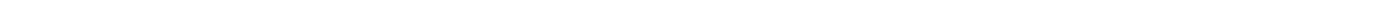
YEAR NUMBER OF DAYS IN OLASS

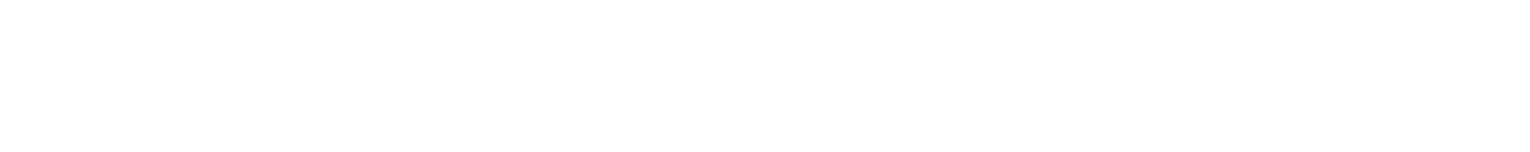

DURATION TABLE OF DISOHARGE FOR WATER YEARS 1955-59

\begin{tabular}{|c|c|c|c|c|c|c|c|c|c|c|c|c|c|c|c|c|c|c|}
\hline $\begin{array}{c}\text { OBIC } \\
\text { FEET } \\
\text { EER } \\
\text { SEOOND }\end{array}$ & $\begin{array}{l}\text { TOTAL } \\
\text { DALS }\end{array}$ & $\begin{array}{l}\text { ACQJ- } \\
\text { MU- } \\
\text { LATED } \\
\text { DAYS }\end{array}$ & $\begin{array}{l}\text { PER- } \\
\text { CENT } \\
\text { DAYS }\end{array}$ & G.ASS & $\begin{array}{c}\text { OUBIC } \\
\text { FEET } \\
\text { PER } \\
\text { SECOND }\end{array}$ & $\begin{array}{r}\text { TOTAL } \\
\text { DAYS }\end{array}$ & $\begin{array}{l}\text { ACQU- } \\
\text { MU- } \\
\text { LATED } \\
\text { DAYS }\end{array}$ & $\begin{array}{l}\text { PER- } \\
\text { CENT } \\
\text { DAYS }\end{array}$ & CLASS & $\begin{array}{c}\text { OBIC } \\
\text { FEET } \\
\text { PER } \\
\text { SECOND }\end{array}$ & $\begin{array}{r}\text { TOTAL } \\
\text { DAYS }\end{array}$ & $\begin{array}{c}\text { ACQU- } \\
\text { MU- } \\
\text { LATED } \\
\text { DAYS }\end{array}$ & $\begin{array}{l}\text { QER- } \\
\text { CENT } \\
\text { DAYS }\end{array}$ & CLASS & $\begin{array}{c}\text { OBIC } \\
\text { EEET } \\
\text { PER } \\
\text { SEOOND }\end{array}$ & $\begin{array}{l}\text { TOTAL } \\
\text { DAYS }\end{array}$ & $\begin{array}{c}\text { ACOU- } \\
\text { MU- } \\
\text { LATED } \\
\text { DAYS }\end{array}$ & $\begin{array}{l}\text { PER- } \\
\text { CENT } \\
\text { DAYS }\end{array}$ \\
\hline
\end{tabular}


TRIBUTARIES BETWEEN DOLORES RIVER AND GREEN RIVER

09184500 PACX CREEK AT M4 RANCH, NEAR MOAB, UT-Continued

MONIHLY MEAN DISCHARGES, IN GBIC FEET FER SECOND, FOR EAQH WATER YEAR

$\begin{array}{lcccccccccccc}\text { YEAR } & \text { OCT } & \text { NOV } & \text { DEC } & \text { JAN } & \text { FEB } & \text { MAR } & \text { APR } & \text { MAY } & \text { JUNE } & \text { JULY } & \text { AUG } & \text { SEP } \\ 1955 & 0.97 & 0.79 & 0.70 & 0.67 & 0.79 & 0.98 & 1.08 & 4.19 & 3.07 & 3.07 & 1.56 & 0.79 \\ & & & & & & & & & & & \\ 1956 & 0.74 & 0.80 & 0.73 & 0.72 & 0.68 & 0.68 & 0.62 & 0.77 & 0.62 & 0.51 & 0.50 & 0.40 \\ 1957 & 0.49 & 0.51 & 0.47 & 0.50 & 0.61 & 0.70 & 0.69 & 1.96 & 37.5 & 8.05 & 2.29 & 1.54 \\ 1958 & 1.39 & 1.13 & 0.97 & 0.79 & 1.06 & 1.07 & 3.53 & 30.9 & 13.8 & 2.91 & 1.45 & 1.14 \\ 1959 & 0.90 & 1.08 & 0.98 & 0.88 & 0.96 & 1.00 & 1.00 & 0.92 & 0.89 & 0.68 & 0.60 & 0.63\end{array}$

ANNUAL PEAK DISCHARGE, IN OUBIC FEET FER SECOND, AND CORRESPONDING GAGE HEIGHT, IN FEET, FOR EAOH WATER YEAR

\begin{tabular}{|c|c|c|c|c|c|c|c|c|c|c|c|}
\hline $\begin{array}{l}\text { WATER } \\
\text { YEAR }\end{array}$ & DATE & $\begin{array}{c}\text { GAGE } \\
\text { HEIGHT }\end{array}$ & $\begin{array}{c}\text { PEAK } \\
\text { DISQHARGE }\end{array}$ & $\begin{array}{l}\text { WAIER } \\
\text { YEAR }\end{array}$ & DATE & $\begin{array}{l}\text { GAGE } \\
\text { HEIGHT }\end{array}$ & $\begin{array}{c}\text { PEAK } \\
\text { DISQHARGE }\end{array}$ & $\begin{array}{l}\text { WATER } \\
\text { YEAR }\end{array}$ & DATE & $\begin{array}{l}\text { GAGE } \\
\text { HEIGHT }\end{array}$ & $\begin{array}{c}\text { PEAK } \\
\text { DISCHARGE }\end{array}$ \\
\hline $\begin{array}{l}1955 \\
1956\end{array}$ & $\begin{array}{lll}\text { JULY } 26,1955 \\
\text { JULY } 31,1956\end{array}$ & $\begin{array}{l}9.02 \\
1.52\end{array}$ & $\begin{array}{r}1200 \\
10\end{array}$ & $\begin{array}{l}1957 \\
1958\end{array}$ & $\begin{array}{l}\text { JUNE } 10,1957 \\
\text { MAY } 24,1958\end{array}$ & $\begin{array}{l}3.05 \\
2.36\end{array}$ & $\begin{array}{r}118 \\
47\end{array}$ & 1959 & SEPT.16, 1959 & 1.28 & 4.8 \\
\hline
\end{tabular}

09185000 PACK CREEK NEAR MOAB, UT

LOCATION.--Lat $38^{\circ} 32^{\prime} 25^{\prime \prime}$, long $109^{\circ} 30^{\prime} 00$ ", in SW'sec.16, T.26 S., R.22 E., Grand County, Hydrologic Unit 14030005 , on left bank 3.5 $\mathrm{mi}$ southeast of Moab.

DRAINAGE AREA. $--57.4 \mathrm{mi}^{2}$.

MEAN BASIN ELEVATION. $-6,340 \mathrm{ft}$.

PERIOD OF RECORD AVAIIABLE.-OCtober 1954 to September 1959.

GAGE.-Water-stage recorder and concrete control.

REMARRS.--Several diversions for irrigation above station.

AVERAGE DISCHARGE. -5 years, $4.02 \mathrm{ft}^{3} / \mathrm{s}, 2,910$ acre- $\mathrm{ft} / \mathrm{yr}$.

EXTREMES FOR FERIOD OF RECORD.--Maximum discharge, $510 \mathrm{ft}^{3} / \mathrm{s}$ oct. 8, 1954, gage height, 4.05 ft, fran rating curve extended above 60 $\mathrm{ft}^{3} / \mathrm{s}$ on basis of slope-area measurement of peak flow; minimum, $0.7 \mathrm{ft}^{3} / \mathrm{s}$ Aug. 27,1956 .

LOWEST MEAN DISQHARGE, IN OUBIC FEET TER SECOND, AND RANKING FOR THE INDICATED NUMBER OF CONSEOTIVE DAYS FOR EACH CLIMATIC YEAR, ARIL 1-MARG 31

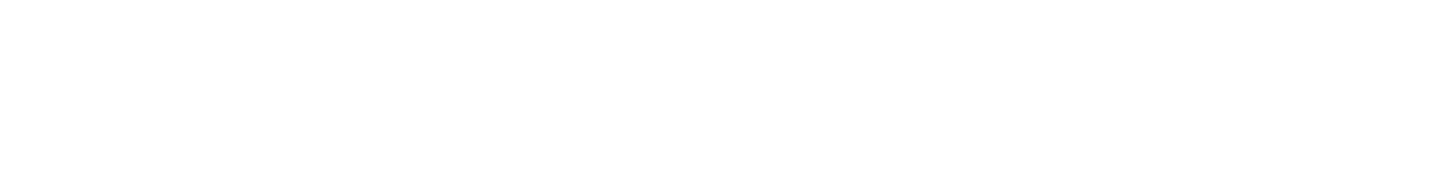

HIGHEST MEAN DISCHARGE, IN OUBIC FEET PER SECOND, AND RANKING FOR THE INDICATED NUMBER OF CONSECUTIVE DAYS FOR EACH WATER YEAR, OCTOBER 1-SEPTEMBER 30

\begin{tabular}{|c|c|c|c|c|c|c|c|c|c|c|c|c|c|c|c|c|c|c|c|}
\hline YEAR & 1 & & 3 & & 7 & & 15 & & $\begin{array}{l}\text { CONSE } \\
30\end{array}$ & WTIV & $\begin{array}{c}\text { E DAYS } \\
60\end{array}$ & & 90 & & 120 & & 183 & & ALL \\
\hline 1955 & 30.0 & 3 & 17.0 & 3 & 12.0 & 3 & 9.40 & 3 & 7.10 & 3 & 5.70 & 3 & 5.20 & 3 & 5.00 & 3 & 4.70 & 3 & 3.60 \\
\hline
\end{tabular}

DURATION OF DISCHARGE FOR EAOH WATER YEAR

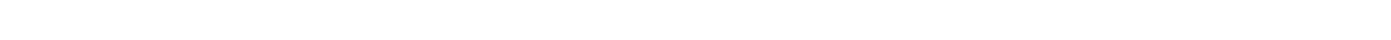
YEAR NUMBER OF DAYS IN OLASS 
TRIBUTARIES BETWEEN DOLORES RIVER AND GREFN RIVER

09185000 PACK CRERK NEAR MOAB, UT--Continued

DURATION TABLE OF DISCHARGE FOR WATER YEARS 1955-59

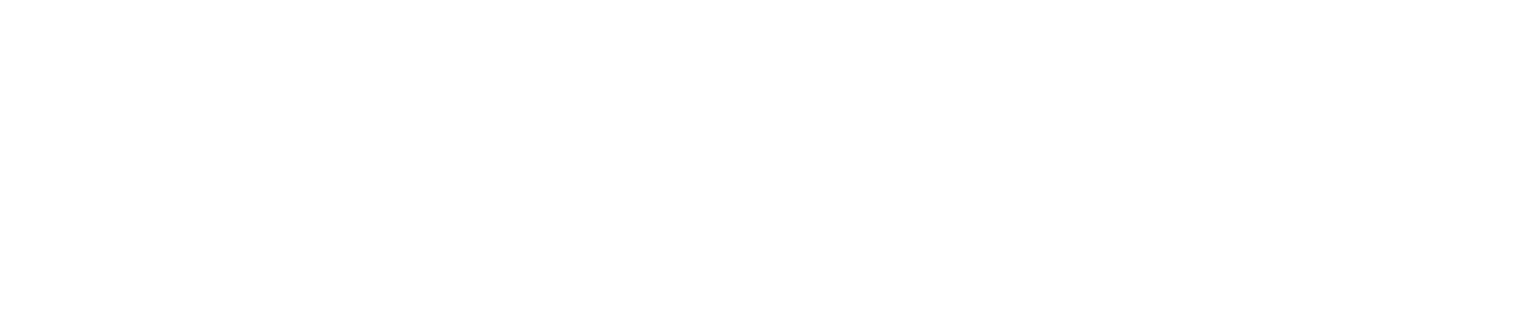

MONTHLY MEAN DISCHARGES, IN CIBIC FEET PER SECOND, FOR EACA WATER YEAR

$\begin{array}{llcccccccccrr}\text { YEAR } & \text { OCT } & \text { NOV } & \text { DEC } & \text { JAN } & \text { FEB } & \text { MAR } & \text { APR } & \text { MAY } & \text { JUNE } & \text { JULY } & \text { AUG } & \text { SEP } \\ 1955 & 4.34 & 3.93 & 4.34 & 4.19 & 5.61 & 5.76 & 3.86 & 3.09 & 2.47 & 1.88 & 2.17 & 1.81 \\ & & & & & & & & & & & \\ 1956 & 2.41 & 3.49 & 3.93 & 4.31 & 4.45 & 3.79 & 3.09 & 2.93 & 2.42 & 1.70 & 2.08 & 1.55 \\ 1957 & 2.25 & 3.11 & 3.10 & 3.15 & 3.32 & 3.34 & 3.13 & 3.38 & 24.3 & 3.89 & 2.96 & 2.63 \\ 1958 & 4.86 & 3.68 & 3.73 & 3.90 & 4.05 & 3.91 & 4.77 & 22.3 & 12.0 & 1.51 & 1.46 & 1.88 \\ 1959 & 2.48 & 3.08 & 3.67 & 3.95 & 4.42 & 4.16 & 3.94 & 2.98 & 1.86 & 1.48 & 1.56 & 1.69\end{array}$

ANNUAL PEAK DISCHARGE, IN CUBIC FEET PER SECOND, AND CORRESPONDING GAGE HEIGHT, IN FEET, FOR EACH WATER YEAR

\begin{tabular}{|c|c|c|c|c|c|c|c|c|c|c|c|}
\hline $\begin{array}{l}\text { WATERR } \\
\text { YEAR }\end{array}$ & DATE & $\begin{array}{c}\text { GAGE } \\
\text { HEIGHT }\end{array}$ & $\begin{array}{c}\text { PEAK } \\
\text { DISCHARGE }\end{array}$ & $\begin{array}{l}\text { WATER } \\
\text { YEAR }\end{array}$ & DATE & $\begin{array}{c}\text { GAGE } \\
\text { HEIGHT }\end{array}$ & $\begin{array}{c}\text { PEAK } \\
\text { DISCHARGE }\end{array}$ & $\begin{array}{l}\text { WATER } \\
\text { YEAR }\end{array}$ & DATE & $\begin{array}{c}\text { GAGE } \\
\text { HEIGHT }\end{array}$ & $\begin{array}{l}\text { PEAK } \\
\text { DISCHARGE }\end{array}$ \\
\hline $\begin{array}{l}1955 \\
1956\end{array}$ & $\begin{array}{l}\text { @T. } 08,1954 \\
\text { AUG. } 15,1956\end{array}$ & $\begin{array}{l}4.05 \\
2.28\end{array}$ & $\begin{array}{l}510 \\
177\end{array}$ & $\begin{array}{l}1957 \\
1958\end{array}$ & $\begin{array}{l}\text { AUG. } 30,1957 \\
\text { ФT. } 21,1957\end{array}$ & $\begin{array}{l}3.62 \\
2.67\end{array}$ & $\begin{array}{l}390 \\
151\end{array}$ & 1959 & FEB. 12,1959 & 1.58 & 6.2 \\
\hline
\end{tabular}

09185200 KANE SPRINGS CANYON NEAR MOAB, UT

LOCATION.--Lat $38^{\circ} 23^{\prime} 45^{\prime \prime}$, long $109^{\circ} 27^{\prime} 00^{\prime \prime}$, in center of sec. 1, T.28 S., R.22 E., San Juan County, Hydrologic Unit 14030005,

$7 \mathrm{mi}$ northwest of La Sal Junction and $15 \mathrm{mi}$ south of Moab.

DRAINAGE AREA. $--17.8 \mathrm{mi}^{2}$.

MEAN BASIN ELEVATION. $-6,620 \mathrm{tt}$.

PERIOD OF RECORD AVAILABLE.--Water years 1959, 1961-74, annual peak discharge only.

GAGE.--Crest-stage gage. Altitude of gage is $5,120 \mathrm{ft}$ from topographic map.

ANNUAL PEAK DISCHARGE, IN CUBIC FEET PER SECOND, AND CORRESPONDING GAGE HEIGHT, IN FEET, FOR EACH WATER YEAR

\begin{tabular}{|c|c|c|c|c|c|c|c|c|c|c|c|}
\hline $\begin{array}{l}\text { WATTER } \\
\text { YEAR }\end{array}$ & DATE & $\begin{array}{c}\text { GAGE } \\
\text { HEIGHT }\end{array}$ & $\begin{array}{c}\text { PEAK } \\
\text { DISCHARGE }\end{array}$ & $\begin{array}{l}\text { WATER } \\
\text { YEAR }\end{array}$ & DATE & $\begin{array}{c}\text { GAGE } \\
\text { HEIGHT }\end{array}$ & $\begin{array}{c}\text { PEAK } \\
\text { DISCHARGE }\end{array}$ & $\begin{array}{l}\text { WATER } \\
\text { YEAR }\end{array}$ & DATE & $\begin{array}{c}\text { GAGE } \\
\text { HEIGHT }\end{array}$ & $\begin{array}{c}\text { PEAK } \\
\text { DISCHARG }\end{array}$ \\
\hline $\begin{array}{l}1959 \\
1961 \\
1962 \\
1963 \\
1964\end{array}$ & $\begin{array}{l}\text { SEPT. 15, } 1959 \\
\text { AUG. } 18,1961 \\
\text { SEPT. 28, } 1962 \\
\text { AUG. } 03,1963 \\
\text { OCT. 20, } 1963\end{array}$ & $\begin{array}{l}10.72 \\
11.60 \\
11.10 \\
11.84 \\
12.93\end{array}$ & $\begin{array}{l}168 \\
435 \\
270 \\
480 \\
850\end{array}$ & $\begin{array}{l}1965 \\
1966 \\
1967 \\
1968 \\
1969\end{array}$ & $\begin{array}{l}\text { JULY } 18,1965 \\
\text { AUG. } 31,1966 \\
\text { AUG. } 10,1967 \\
\text { JULY } 27,1968 \\
\text { AUG. } 29,1969\end{array}$ & $\begin{array}{l}11.59 \\
12.08 \\
13.50 \\
12.00 \\
12.38\end{array}$ & $\begin{array}{r}405 \\
544 \\
1080 \\
530 \\
650\end{array}$ & $\begin{array}{l}1970 \\
1971 \\
1972 \\
1973 \\
1974\end{array}$ & $\begin{array}{lr}\text { SEPPT. 06, } 1970 \\
\text { AUG. } 02,1971 \\
\text { AUG. } 29,1972 \\
\text { JULY } 20, & 1973 \\
-\quad-- & -\end{array}$ & $\begin{array}{l}14.05 \\
11.42 \\
12.56 \\
11.31 \\
13.35\end{array}$ & $\begin{array}{r}1290 \\
320 \\
720 \\
335 \\
960\end{array}$ \\
\hline
\end{tabular}


LOCATION.--Lat $38^{\circ} 14^{\prime} 36^{\prime \prime}$, long $109^{\circ} 26^{\prime} 22^{\prime \prime}$, in SW SWW $^{\frac{1}{4}}$ sec.30, T.29 S., R.23 E., San Juan County, Hydrologic Unit 14030005, on right bank $10 \mathrm{mi}$ southwest of La Sal.

DRAINAGE AREA. $--378 \mathrm{mi}^{2}$.

MEAN BASIN ELEVATION. $-6,550 \mathrm{ft}$.

FERIOD OF RECORD AVAILABLE.--July 1950 to september 1971.

REVISED RECORDS.-WSP 1713: Drainage area.

GACE.-Water-stage recorder and concrete control. Prior to Apr. 28, 1967, at site 60 ft upstream at higher datum. Altitude of gage is $5,500 \mathrm{ft}$ from topographic map.

AVERAGE DISCHPRGE. - -21 years, $1.60 \mathrm{ft}^{3} / \mathrm{s}, 1,160$ acre- $\mathrm{ft} / \mathrm{yr}$.

EXTREMES FOR PERIOD OF RECORD.--Maximum discharge, 4,650 ft ${ }^{3} / \mathrm{s}$ Aug. 20, 1970, gage height, 5.96 ft fran high-water mark, fran rating curve extended above $160 \mathrm{ft}^{3} / \mathrm{s}$ on basis of slope-area measurement of peak flow; no flow for many days in most years.

LOWEST MEAN DISGHARGE, IN OBIIC FEET PER SECOND, AND RANKING FOR THE INDICATED NUMBER OF CONSEOUTIVE DAYS FOR EACH OLIMATIC YEAR, APRIL 1-MARQH 31

YE

1

1952

1953

1954
1955

1956

1957

1958

1959
1960

196

1962
1963

1564

1565

1566

1567

1568
1969

1970

1971

0.001

0.002

0.003

0.004

0.005

0.006

0.00

$\begin{array}{ll}0.00 & 8 \\ 0.00 & 9\end{array}$

0.0010

0.0011

0.0012

0.0013

0.0014

0.0015

0.0016

0.011

0.0118

0.0120

\subsection{1}

0.002

0.003

$0.00 \quad 5$

0.006

0.007

$\begin{array}{ll}0.00 & 8 \\ 0.00 & 9\end{array}$

0.0010

0.0011

0.0012

0.0013

0.0015

0.0016

0.0117

0.0118

0.0120

$\begin{array}{ll}7 & \\ 0.00 & 1 \\ 0.00 & 2 \\ 0.00 & 3 \\ 0.00 & 4 \\ 0.00 & 5 \\ 0.00 & 6 \\ 0.00 & 7 \\ 0.00 & 8 \\ 0.00 & 9 \\ 0.00 & 10 \\ 0.00 & 11 \\ 0.00 & 12 \\ 0.00 & 13 \\ 0.00 & 14 \\ 0.00 & 15 \\ 0.00 & 16 \\ 0.01 & 17 \\ 0.01 & 18 \\ 0.01 & 19\end{array}$

14
0.00
0.00
0.00
0.00
0.00
0.00
0.00
0.00
0.00
0.001
0.0011
0.0011
0.0013
0.001
0.0015
0.0016
0.0219
0.011
0.011

CONSECUTIVE DAYS

0.001

0.002

0.003

$0.00 \quad 4$

$0.00 \quad 5$

$\begin{array}{ll}0.00 & 6 \\ 0.00 & 7\end{array}$

$\begin{array}{ll}0.00 & 8 \\ 0.00 & 9\end{array}$

0.0010

0.0010

0.0012

0.0013

0.0013
0.0014

0.0015

0.0015
0.0016

0.0219

0.0117

0.0218

0.0220

0.0320

0.0420
9

\begin{tabular}{lr}
\multicolumn{1}{l}{$\begin{array}{l}\text { 0.01 } \\
0.03\end{array}$} & 9 \\
0.03 & 15 \\
0.03 & 16 \\
0.02 & 12 \\
0.01 & 10 \\
0.02 & 11 \\
0.13 & 20 \\
0.00 & 1 \\
0.00 & 2 \\
0.00 & 3 \\
0.00 & 4 \\
0.00 & 5 \\
0.00 & 6 \\
0.00 & 7 \\
0.03 & 13 \\
0.00 & 8 \\
0.04 & 17 \\
0.03 & 14 \\
0.04 & 18 \\
0.05 & 19
\end{tabular}

120

$\begin{array}{lll}0.02 \quad 3 & 0.1814\end{array}$

$0.1813-2.3015$

$\begin{array}{lllll}0.0618 & 0.1212 & 0.21 & 4\end{array}$

$\begin{array}{lll}0.0414 & 0.3516 & 1.1013\end{array}$

$\begin{array}{lllll}0.0310 & 0.05 .6 & 0.11 & 2\end{array}$

$\begin{array}{lllll}0.0411 & 0.0710 & 0.56 & 8\end{array}$

$\begin{array}{lllll}0.3720 & 2.9020 & 3.7018\end{array}$

$\begin{array}{llllll}0.02 & 4 & 0.11 & 11 & 0.14 & 3 \\ 0.0412 & 0.19 & 15 & 6.60 & 20\end{array}$

$\begin{array}{llll}0.00 & 1 & 0.00 & 1\end{array}$

$\begin{array}{lll}0.02 & 5 & 0.3717\end{array}$

$\begin{array}{llll}0.02 & 6 & 0.03 \quad 2\end{array}$

$\begin{array}{llll}0.02 & 7 & 0.03 & 2\end{array}$

$\begin{array}{lll}0.02 & 8 & 0.4719\end{array}$

$0.2119 \quad 0.3918$

$\begin{array}{llll}0.01 & 2 & 0.03 & 3\end{array}$

0.0413

0.039

0.0515

0.068

$\begin{array}{ll}0.04 & 4 \\ 0.05 & 5\end{array}$

0.0616

0.069

0.426

0.447

$\begin{array}{ll}0.04 & 1 \\ 0.59 & 9\end{array}$

$\begin{array}{ll}0.59 & 9 \\ 2.30 & 14\end{array}$

4.5019

0.265

0.7110

3.4017
0.8812

0.8511

HIGHEST MEAN DISCHARGE, IN OUBIC FEET PER SECOND, AND RANKING FOR THE INDICATED NUMBER OF CONSECITIVE DAYS FOR EACH WATER YEAR, OCTOBER 1-SEPTEMBER 30

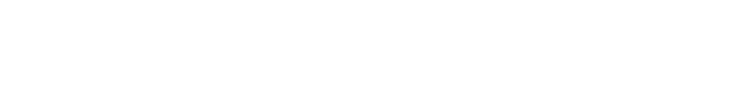

$\begin{array}{lcccccc}1951 & 218 & 9 & 86.0 & 10 & 37.0 & 10 \\ 1952 & 304 & 3 & 278 & 3 & 204 & 1 \\ 1953 & 22.0 & 19 & 7.70 & 20 & 3.40 & 20 \\ 1954 & 20.0 & 20 & 15.0 & 19 & 6.60 & 19 \\ 1955 & 71.0 & 16 & 43.0 & 14 & 20.0 & 14\end{array}$

26.08

13.08

$\begin{array}{cccc}1.60 & 20 & 48.0 & 1 \\ 3.40 & 20\end{array}$

$3.1019 \quad 1.8019$

5.6016

$\begin{array}{ll}6.70 & 9 \\ 24.0 & 1\end{array}$

$\begin{array}{rr}24.0 & 1 \\ 0.7420\end{array}$

0.9718

90

$11.0 \quad 15$

1.1021

$\begin{array}{cccccc}19.0 & 21 & 6.70 & 21 & 2.90 & 21 \\ 226 & 8 & 90.0 & 8 & 39.0 & 9\end{array}$

1.3021

1957
1958
1959

$\begin{array}{lll}139 & 12 & 10\end{array}$

1600340

$\begin{array}{cc}39.0 & 9 \\ 46.0 & 7 \\ 146 & 4\end{array}$

$\begin{array}{ll}31.0 & 6 \\ 22.0 & 9 \\ 68.0 & 4 \\ 73.0 & 3\end{array}$

20.06

$\begin{array}{ll}12.0 & 9 \\ 34.0 & 4\end{array}$

$\begin{array}{cr}0.5421 \\ 13.0 & 6 \\ 5.90 & 10\end{array}$

45.03

$\begin{array}{rr}5.90 & 10 \\ 17.0 & 4\end{array}$

$\begin{array}{ll}17.0 & 4 \\ 23.0 & 3\end{array}$

4.6017

9.1016

$\begin{array}{cc}19.0 & 15 \\ 7.50 & 18\end{array}$

7.5018
29.0
40.0

3.5018

1.8018

2.3017
0.9019
3.4014

9.407

$\begin{array}{rrrrrr}40.0 & 8 & 19.0 & 10 & 12.0 & 10 \\ 14.0 & 17 & 11.0 & 14 & 7.00 & 13\end{array}$

$12.0 \quad 10$

3.5013

4.40

$$
120
$$

183

ALL

$$
\begin{array}{lllllll}
1966 & 292 & 4 & 258 & 4 & 192 & 2
\end{array}
$$

$94.0 \quad 2$

$47.0 \quad 2$

24.02

$8.5017 \quad 5.6015$

17.011

$\begin{array}{rr}5.60 & 15 \\ 11.0 & 11\end{array}$

$\begin{array}{rr}11.0 & 11 \\ 32.0 & 5\end{array}$

$\begin{array}{rr}3.30 & 15 \\ 5.60 & 11 \\ 16.0 & 5\end{array}$

$\begin{array}{rrrr}95.0 & 5 & 65.0 & 5 \\ 35.0 & 12 & 16.0 & 12\end{array}$

9.6012

$\begin{array}{rr}16.0 & 5 \\ 4.90 & 12\end{array}$

16.0

$\begin{array}{lll}0.6718 & 0.3820\end{array}$

$2.0016 \quad 1.5016$

$\begin{array}{rr}2.20 & 10 \\ 8.30 & 2\end{array}$

8.3022

0.3519

0.4321

1.5016

1.8012

1.1910

4.302

0.2418

0.9612

8.706

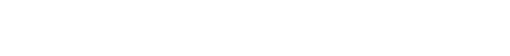

$\begin{array}{rr}0.32 & 21 \\ 6.60 \quad 6\end{array}$

0.2421

0.1421

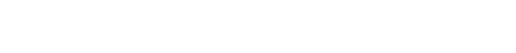

1.6017

0.6119

2.2015

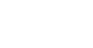

1.1917

$0.4619 \quad 1.1016$

$\begin{array}{lll}0.4619 & 0.4618 \\ 1.7015 & 1.1017\end{array}$

$\begin{array}{lll}5.30 & 7 & 3.50\end{array}$

$\begin{array}{lll}1.8014 & 1.4014\end{array}$

0.5816

0.2419

0.5817

$\begin{array}{ll}1.80 & 7 \\ 0.77 & 14\end{array}$

$\begin{array}{llll}16.0 & 2 & 12.0 & 2\end{array}$

$8.70 \quad 1$

$\begin{array}{rrrrr}16.4013 & 2.0013 & 1.3015\end{array}$

$\begin{array}{llll}2.80 & 11 & 1.90 & 11 \\ 8.60 & 5 & 6.60 & 4\end{array}$

11.05

8.605

$\begin{array}{ll}6.60 & 4 \\ 1.6013\end{array}$

$4.60 \quad 1$

$\begin{array}{llll}28.0 & 7 & 14.0 \quad 7\end{array}$

$7.10 \quad 8$

4.808

3.608

2.409

0.6915

0.9911

$\begin{array}{lll}3.30 & 4\end{array}$

1.199 
TRIBUTARIES BETWEEN DOLORES RIVER AND GREEN RTVER

09185500 HATCH WASH NEAR LA SAL, UT-Continued

DURATION OF DISCHARGE FOR EACH WATER YEAR

CLASS $0 \begin{array}{llllllllllllllllllllllllllllllllllll}1 & 1 & 3 & 4 & 5 & 6 & 7 & 8 & 9 & 10 & 11 & 12 & 13 & 14 & 15 & 16 & 17 & 18 & 19 & 20 & 21 & 22 & 23 & 24 & 25 & 26 & 27 & 28 & 29 & 30 & 31 & 32 & 33 & 34\end{array}$

YEAR

NUMBER OF DAYS IN CLASS

CUBIC FEET PER SEOOND

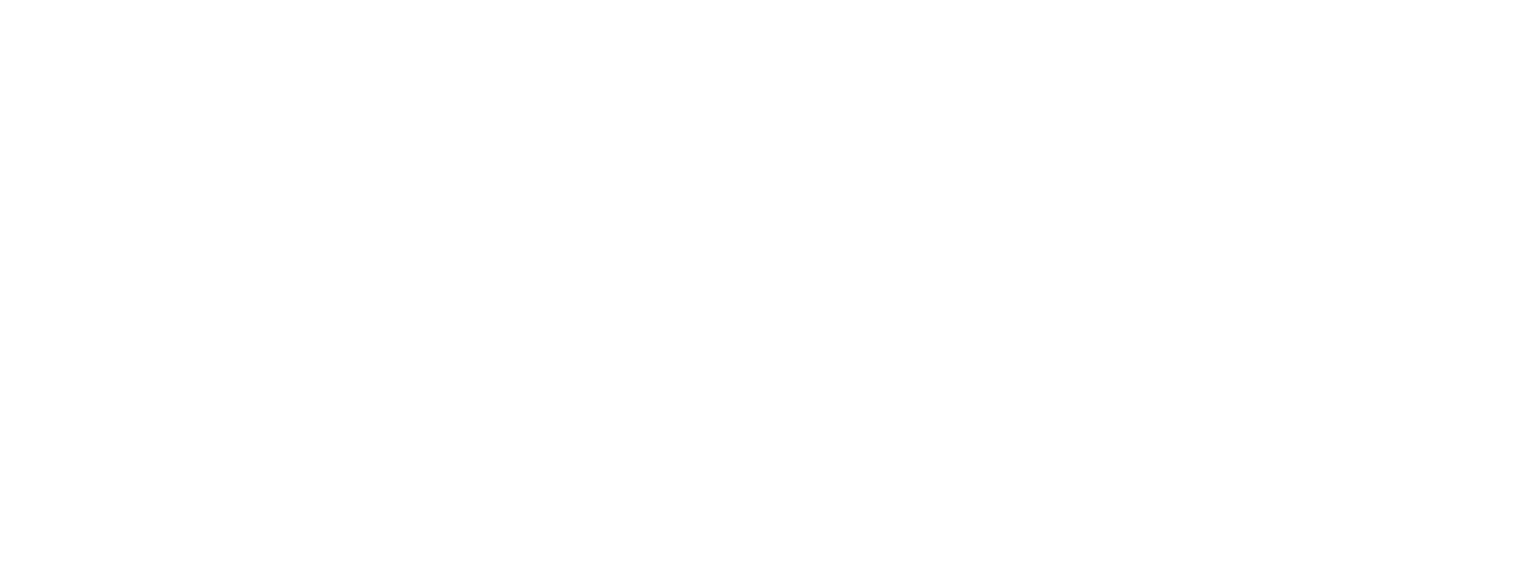

DURATION TABIE OF DISCHARGE FOR WATER YEARS 1951-71

\begin{tabular}{|c|c|c|c|c|c|c|c|c|c|c|c|c|c|c|c|c|c|c|c|}
\hline CLASS & $\begin{array}{c}\text { CUBIC } \\
\text { FEET } \\
\text { PER } \\
\text { SECOND }\end{array}$ & TOTAL & $\begin{array}{l}\text { ACOU- } \\
\text { MU- } \\
\text { LATED } \\
\text { DAYS }\end{array}$ & $\begin{array}{l}\text { PER- } \\
\text { CENT } \\
\text { DAYS }\end{array}$ & & $\begin{array}{c}\text { CUBIC } \\
\text { FEET } \\
\text { PER } \\
\text { SECOND }\end{array}$ & $\begin{array}{l}\text { TOTAL } \\
\text { DAYS }\end{array}$ & $\begin{array}{l}\text { ACOH- } \\
\text { ML- } \\
\text { LATED } \\
\text { DAYS }\end{array}$ & $\begin{array}{l}\text { PER- } \\
\text { CENT } \\
\text { DAYS }\end{array}$ & & $\begin{array}{c}\text { वUIC } \\
\text { FEET } \\
\text { PER } \\
\text { SECOND }\end{array}$ & $\begin{array}{l}\text { TOTAL } \\
\text { DAYS }\end{array}$ & $\begin{array}{l}\text { ACOU- } \\
\text { MU- } \\
\text { LATED } \\
\text { DAYS }\end{array}$ & $\begin{array}{l}\text { PER- } \\
\text { CENT } \\
\text { DAYS }\end{array}$ & CLASS & $\begin{array}{c}\text { CUBIC } \\
\text { FEET } \\
\text { PER } \\
\text { SECOND }\end{array}$ & $\begin{array}{r}\text { TONAL } \\
\text { DAYS }\end{array}$ & $\begin{array}{c}\text { ACOU- } \\
\text { MU- } \\
\text { LATED } \\
\text { DAYS }\end{array}$ & $\begin{array}{l}\text { PER- } \\
\text { CENT } \\
\text { DAYS }\end{array}$ \\
\hline $\begin{array}{l}0 \\
1 \\
2 \\
3 \\
4 \\
5 \\
6 \\
7 \\
8\end{array}$ & $\begin{array}{l}0.00 \\
0.01 \\
0.02 \\
0.03 \\
0.04 \\
0.05 \\
0.07 \\
0.09 \\
0.13\end{array}$ & $\begin{array}{r}3255 \\
233 \\
93 \\
456 \\
59 \\
450 \\
210 \\
1804 \\
79\end{array}$ & $\begin{array}{l}7670 \\
4415 \\
4182 \\
4089 \\
3633 \\
3574 \\
3124 \\
2914 \\
1110\end{array}$ & $\begin{array}{r}100.0 \\
57.6 \\
54.5 \\
53.3 \\
47.4 \\
46.6 \\
40.7 \\
38.0 \\
14.5\end{array}$ & $\begin{array}{r}9 \\
10 \\
11 \\
12 \\
13 \\
14 \\
15 \\
16 \\
17\end{array}$ & $\begin{array}{l}0.18 \\
0.24 \\
0.33 \\
0.46 \\
0.63 \\
0.87 \\
1.20 \\
1.60 \\
2.30\end{array}$ & $\begin{array}{r}331 \\
129 \\
132 \\
72 \\
37 \\
31 \\
24 \\
30 \\
22\end{array}$ & $\begin{array}{r}1031 \\
700 \\
571 \\
439 \\
367 \\
330 \\
299 \\
275 \\
245\end{array}$ & $\begin{array}{r}13.4 \\
9.1 \\
7.4 \\
5.7 \\
4.8 \\
4.3 \\
3.9 \\
3.6 \\
3.2\end{array}$ & $\begin{array}{l}18 \\
19 \\
20 \\
21 \\
22 \\
23 \\
24 \\
25 \\
26\end{array}$ & $\begin{array}{r}3.1 \\
4.3 \\
5.9 \\
8.1 \\
11.0 \\
15.0 \\
21.0 \\
29.0 \\
40.0\end{array}$ & $\begin{array}{r}17 \\
20 \\
22 \\
23 \\
17 \\
30 \\
19 \\
8 \\
13\end{array}$ & $\begin{array}{r}223 \\
206 \\
186 \\
164 \\
141 \\
124 \\
94 \\
75 \\
67\end{array}$ & $\begin{array}{l}2.9 \\
2.7 \\
2.4 \\
2.1 \\
1.8 \\
1.6 \\
1.2 \\
1.0 \\
0.9\end{array}$ & $\begin{array}{l}27 \\
28 \\
29 \\
30 \\
31 \\
32 \\
33 \\
34\end{array}$ & $\begin{array}{r}55.0 \\
75.0 \\
100.0 \\
140.0 \\
200.0 \\
270.0 \\
370.0\end{array}$ & $\begin{array}{r}10 \\
6 \\
12 \\
9 \\
10 \\
5 \\
2\end{array}$ & $\begin{array}{r}54 \\
44 \\
38 \\
26 \\
17 \\
7 \\
2\end{array}$ & $\begin{array}{l}0.7 \\
0.6 \\
0.5 \\
0.3 \\
0.2 \\
0.1 \\
0.0\end{array}$ \\
\hline
\end{tabular}

MONTHLY MEAN DISCHARGES, IN CUBIC FEET PER SECOND, FOR EACH WATER YEAR

$\begin{array}{lllllllllllll}\text { YEAR } & \text { OCT } & \text { NOV } & \text { DEC } & \text { JAN } & \text { FEB } & \text { MAR } & \text { APR } & \text { MAY } & \text { JUNE } & \text { JULY } & \text { AUG } & \text { SEP } \\ 1951 & 0.03 & 0.07 & 0.06 & 0.10 & 0.45 & 0.25 & 0.04 & 0.02 & 0.01 & 0.01 & 12.8 & 0.04 \\ 1952 & 0.03 & 0.03 & 0.13 & 0.42 & 0.44 & 22.5 & 25.2 & 0.04 & 0.02 & 0.12 & 2.11 & 0.05 \\ 1953 & 0.06 & 0.10 & 0.09 & 0.21 & 0.31 & 0.12 & 0.13 & 0.09 & 0.00 & 0.32 & 1.08 & 0.04 \\ 1954 & 0.17 & 0.14 & 0.06 & 0.14 & 0.19 & 0.11 & 0.07 & 0.03 & 0.00 & 0.07 & 0.18 & 1.75 \\ 1955 & 4.26 & 0.22 & 0.11 & 0.10 & 0.22 & 5.45 & 0.20 & 0.06 & 0.04 & 0.02 & 0.61 & 0.00 \\ 1956 & 0.00 & 0.04 & 0.07 & 0.10 & 0.08 & 0.09 & 0.03 & 0.20 & 0.00 & 0.63 & 0.41 & 0.00 \\ 1957 & 0.02 & 0.07 & 0.10 & 0.10 & 5.48 & 0.11 & 0.18 & 0.37 & 0.05 & 10.4 & 14.6 & 0.09 \\ 1958 & 10.6 & 0.76 & 0.17 & 0.06 & 6.17 & 0.46 & 0.29 & 0.14 & 0.02 & 0.00 & 0.00 & 0.59 \\ 1959 & 0.26 & 0.06 & 0.04 & 0.12 & 0.10 & 0.10 & 0.12 & 0.03 & 0.00 & 0.00 & 32.9 & 0.83 \\ 1960 & 0.03 & 0.00 & 0.09 & 0.12 & 0.14 & 44.0 & 0.12 & 0.07 & 0.10 & 0.00 & 0.21 & 0.00 \\ 1961 & 0.00 & 0.00 & 0.00 & 0.00 & 0.00 & 4.40 & 0.05 & 0.13 & 0.00 & 0.00 & 0.16 & 2.18 \\ 1962 & 1.71 & 0.02 & 0.04 & 0.00 & 0.24 & 0.72 & 0.00 & 0.00 & 0.08 & 0.00 & 0.00 & 0.07 \\ 1963 & 0.00 & 0.04 & 0.05 & 0.00 & 0.12 & 0.08 & 0.09 & 0.00 & 0.00 & 0.03 & 6.47 & 0.01 \\ 1964 & 0.05 & 0.04 & 0.09 & 0.10 & 0.00 & 0.10 & 0.06 & 0.00 & 0.00 & 4.78 & 6.72 & 9.40 \\ 1965 & 0.00 & 0.07 & 0.02 & 0.00 & 0.00 & 6.73 & 0.05 & 0.05 & 0.01 & 1.25 & 0.32 & 0.64 \\ 1966 & 4.30 & 0.32 & 0.82 & 0.04 & 0.08 & 45.5 & 0.08 & 0.03 & 0.00 & 0.00 & 1.26 & 1.56 \\ 1967 & 0.03 & 0.02 & 0.04 & 0.03 & 0.03 & 0.05 & 0.02 & 0.81 & 0.60 & 0.31 & 4.15 & 2.08 \\ 1968 & 0.03 & 0.05 & 0.05 & 0.07 & 0.11 & 0.15 & 0.15 & 0.13 & 0.03 & 2.31 & 8.55 & 0.02 \\ 1969 & 0.04 & 0.04 & 0.03 & 0.05 & 0.08 & 28.9 & 2.47 & 0.44 & 0.06 & 4.79 & 1.24 & 1.17 \\ 1970 & 0.07 & 0.07 & 0.04 & 0.03 & 0.06 & 0.06 & 0.08 & 0.05 & 0.12 & 0.05 & 7.95 & 1.50 \\ 1971 & 0.05 & 0.06 & 0.07 & 0.05 & 0.06 & 0.07 & 0.05 & 0.04 & 0.04 & 0.02 & 13.7 & 0.05\end{array}$


TRIBUTARIES BETWEEN DOLORES RIVER AND GREEN RIVER

09185500 HATCH WASH NEAR LA SAL, UT-Continued

ANNUAL PEAK DISCHARGE, IN OBBIC FEET PER SECOND, AND CORRESPONDING GAGE HEIGHT, IN FEET, FOR EACH WATER YEAR

\begin{tabular}{|c|c|c|c|c|c|c|c|c|c|c|c|}
\hline $\begin{array}{l}\text { WATER } \\
\text { YEAR }\end{array}$ & DATE & $\begin{array}{c}\text { GAGE } \\
\text { HEIGHT }\end{array}$ & $\begin{array}{c}\text { PEAK } \\
\text { DISCHARGE }\end{array}$ & $\begin{array}{l}\text { WATER } \\
\text { YEAR }\end{array}$ & DATE & $\begin{array}{c}\text { GAGE } \\
\text { HEIGHT }\end{array}$ & $\begin{array}{c}\text { PEAK } \\
\text { DISCHARGE }\end{array}$ & $\begin{array}{l}\text { WATER } \\
\text { YEAR }\end{array}$ & DATE & $\begin{array}{c}\text { GAGE } \\
\text { HEIGHT }\end{array}$ & $\begin{array}{c}\text { PEAK } \\
\text { DISCHARGE }\end{array}$ \\
\hline $\begin{array}{l}1950 \\
1951 \\
1952 \\
1953 \\
1954 \\
1955 \\
1956 \\
1957\end{array}$ & $\begin{array}{l}\text { SEPT. 20, } 1950 \\
\text { AUG. 30, } 1951 \\
\text { MAR. 30, } 1952 \\
\text { JULY 31, } 1953 \\
\text { SEPT. 08, } 1954 \\
\text { MAR. --, } 1955 \\
\text { JULY 31, } 1956 \\
\text { JULY } 18,1957\end{array}$ & $\begin{array}{l}3.25 \\
3.00 \\
3.78 \\
2.08 \\
1.68 \\
3.00 \\
2.44 \\
3.11\end{array}$ & $\begin{array}{r}728 \\
574 \\
1100 \\
157 \\
61 \\
574 \\
253 \\
640\end{array}$ & $\begin{array}{l}1958 \\
1959 \\
1960 \\
1961 \\
1962 \\
1963 \\
1964\end{array}$ & $\begin{array}{l}\text { NOV. } 03,1957 \\
\text { AUG. } 04,1959 \\
\text { MAR. } 22,1960 \\
\text { MAR. } 15,1961 \\
\text { OCT. 09, } 1961 \\
\text { AUG. 21, } 1963 \\
\text { SEPT. 14, } 1964\end{array}$ & $\begin{array}{l}2.82 \\
6.43 \\
2.95 \\
2.28 \\
2.40 \\
3.61 \\
4.37\end{array}$ & $\begin{array}{r}497 \\
3210 \\
462 \\
139 \\
215 \\
961 \\
1160\end{array}$ & $\begin{array}{l}1965 \\
1966 \\
1967 \\
1968 \\
1969 \\
1970 \\
1971\end{array}$ & $\begin{array}{l}\text { JULY } 12,1965 \\
\text { MAR. } 10,1966 \\
\text { SEPT. 06, } 1967 \\
\text { AUG. 01, } 1968 \\
\text { JULY 20, } 1969 \\
\text { AUG. 20, } 1970 \\
\text { AUG. } 25,1971\end{array}$ & $\begin{array}{l}3.03 \\
3.47 \\
2.41 \\
1.52 \\
1.78 \\
5.96 \\
3.60\end{array}$ & $\begin{array}{r}160 \\
424 \\
760 \\
196 \\
337 \\
4650 \\
1850\end{array}$ \\
\hline
\end{tabular}

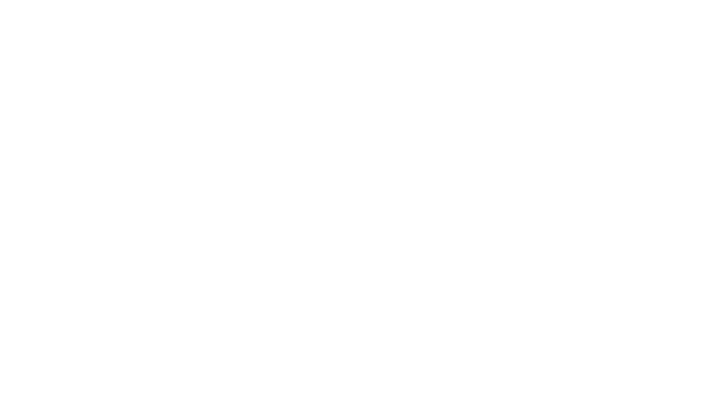

\begin{tabular}{ccccccc}
\multicolumn{2}{c}{ MAGNITUDE AND PROBABIIITY OF ANNUAL HIGHEST MEAN DISCHARGE } \\
BASED ON WATER YEARS $1951-71$
\end{tabular}

09186000 INDIAN CREEK NEAR MONTICELLO, UT

LOCATION. -Lat $37^{\circ} 50^{\prime} 40^{\prime \prime}$, long 109 $31^{\prime} 05^{\prime \prime}$, in SW' sec.4, T.34 S., R. 22 E., (unsurveyed), San Juan County, Hydrologic Unit 14030005, on left bank $1 \mathrm{mi}$ northwest of Indian Creek guard station and $10 \mathrm{mi}$ west of Monticello.

DRAINAGE AREA. $-4.70 \mathrm{mi}^{2}$.

MEAN BASIN ELEVATION. $-9,620 \mathrm{ft}$.

PERIOD OF RECORD AVAIIABLE. --October 1949 to September 1957.

GAGE.-Water-stage recorder. Altitude of gage is $8,700 \mathrm{ft}$ from topographic map.

REMARKS. - A tunnel diverts water about $1 \mathrm{mi}$ above station (diversion began June 1952) to San Juan River basin for domestic use and irrigation in the vicinity of Blanding.

AVERAGE DISCHARGE. --8 years, $2.88 \mathrm{ft}^{3} / \mathrm{s}, 2,090 \mathrm{acre}-\mathrm{ft} / \mathrm{yr}$.

EXIREMES FOR PERIOD OF RECORD.-Maximum discharge, $122 \mathrm{ft} 3 / \mathrm{s}$ Aug. 6, 1955, gage height, $2.74 \mathrm{ft}$, from rating curve extended above 50 $\mathrm{ft}^{3} / \mathrm{s}$ on basis of logarithmic plotting; no flow for several days in September, October, and November 1956.

LOWEST MEAN DISCHARGE, IN CUBIC FEET PER SECOND, AND RANKING FOR THE INDICATED NUMBER OF OONSECUTTVE DAYS FOR EACH CLIMATIC YEAR, APRIL 1-MARCH 31

YEAR

13

0.20

3

7

14

30

60

0.205

$\begin{array}{llll}0.20 & 5 & 0.20 & 5 \\ 0.30 & 7 & 0.307\end{array}$

$\begin{array}{llll}0.30 & 7 & 0.30 & 7 \\ 0.20 & 6 & 0.20 & 6\end{array}$

$0.2060 .20 \quad 6$

$\begin{array}{ll}0.20 & 6 \\ 0.10 & 2\end{array}$

0.226

0.307

0.205

$\begin{array}{ll}0.10 & 2 \\ 0.10 & 3\end{array}$

0.256

0.307

0.205

$\begin{array}{ll}0.10 & 2 \\ 0.10 & 3\end{array}$

0.306

0.307
0.20

$\begin{array}{ll}0.20 & 4 \\ 0.10 & 2\end{array}$

$0.103 \quad 0.10 \quad 3$

0.20

0.204

0.103

90

120

183

ALL

$\begin{array}{lllllll}1956 & 0.20 & 4 & 0.20 & 4 & 0.20 & 4 \\ 1957 & 0.00 & 1 & 0.00 & 1 & 0.00 & 1\end{array}$

$\begin{array}{llllll}0.00 & 1 & 0.05 & 1 & 0.23 & 5 \\ & & 0.06 & 1\end{array}$

0.316

0.337

0.204

$\begin{array}{ll}0.10 & 2 \\ 0.13 & 3\end{array}$

0.316

0.36

0.2044

0.376

0.487

0.223

0.14

2.806

7.107

$\begin{array}{llll}0.23 & 5 & 0.27 \quad 5\end{array}$

0.295

0.295

1.19
1.60

0.27
0.07

0.081

0.091

$\begin{array}{ll}2.80 & 5 \\ 0.72 & 1\end{array}$ 
09186000 INDIAN CREEK NEAR MONTTCELLO, UT--Continued

HIGHEST MEAN DISGHARGE, IN GBIC FEET PER SECOND, AND RANKING FOR THE INDICATED NUMBER OF CONSEOUTIVE DAYS FOR EAOH WATER YEAR, OCTCBER 1-SEPTEMBER 30

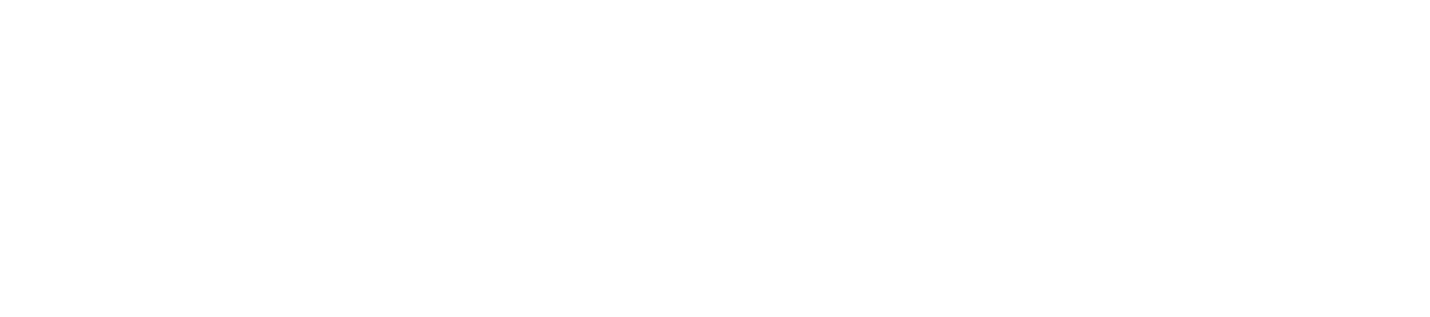

DURATION OF DISOHARGE FOR EACH WATER YEAR

\begin{tabular}{|c|c|c|c|c|c|c|c|c|c|c|c|c|c|c|c|c|c|c|c|c|c|c|c|c|c|c|c|}
\hline CLASS & 0 & 4 & 6 & 91 & 01 & & 12 & 13 & 14 & 15 & DAY & S I I & $\alpha$ & 19 & 20 & 21 & 22 & 232 & 2425 & 2526 & & & & 29 & 303132 & & $\begin{array}{l}\text { OUIC FEET } \\
\text { PER SECOND } \\
\text {-DAYS }\end{array}$ \\
\hline 1950 & & & & 8 & 6 & 25 & 59 & 7 & 62 & 86 & 7 & 9 & 7 & 7 & 11 & 7 & 14 & 72 & 251 & & & & & & & & 1231.2 \\
\hline $\begin{array}{l}1951 \\
1952 \\
1953 \\
1954 \\
1955\end{array}$ & $\begin{array}{r}119 \\
59\end{array}$ & $\begin{array}{r}15 \\
7 \\
177 \\
95 \\
83\end{array}$ & $\begin{array}{ll}97 & 45 \\
72 & 51 \\
27 & 26 \\
23 & 20 \\
32 & 28\end{array}$ & $\begin{array}{l}54 \\
451 \\
17 \\
11 \\
14\end{array}$ & $\begin{array}{l}5 \\
8 \\
9 \\
3 \\
7\end{array}$ & $\begin{array}{r}21 \\
28 \\
13 \\
6 \\
5\end{array}$ & $\begin{array}{r}18 \\
6 \\
2 \\
2 \\
8\end{array}$ & $\begin{array}{r}19 \\
5 \\
17 \\
2 \\
8\end{array}$ & $\begin{array}{r}17 \\
14 \\
5 \\
10 \\
12\end{array}$ & $\begin{array}{r}13 \\
11 \\
7 \\
9 \\
7\end{array}$ & $\begin{array}{l}3 \\
4 \\
7 \\
8 \\
2\end{array}$ & $\begin{array}{r}7 \\
6 \\
5 \\
5 \\
11\end{array}$ & $\begin{array}{l}6 \\
3 \\
7 \\
6 \\
6\end{array}$ & $\begin{array}{r}10 \\
11 \\
15 \\
4 \\
8\end{array}$ & $\begin{array}{r}19 \\
7 \\
6 \\
8 \\
12\end{array}$ & $\begin{array}{r}7 \\
10 \\
8 \\
9 \\
10\end{array}$ & $\begin{array}{r}8 \\
3 \\
10 \\
6 \\
8\end{array}$ & $\begin{array}{r}1 \\
7 \\
2 \\
1 \\
11\end{array}$ & $\begin{array}{l}5 \\
5 \\
310 \\
8\end{array}$ & $\begin{array}{l}4 \\
0 \\
512\end{array}$ & $\begin{array}{l}4 \\
5 \\
2\end{array}$ & 4 & 2 & 3 & 81412 & 2 & $\begin{array}{r}488.1 \\
2633.0 \\
472.2 \\
571.3 \\
1029.9\end{array}$ \\
\hline $\begin{array}{l}1956 \\
1957\end{array}$ & $\begin{array}{r}543 \\
22158\end{array}$ & $\begin{array}{r}90 \\
2\end{array}$ & $\begin{array}{rr}73 & 50 \\
5 & 25\end{array}$ & $\begin{array}{r}11 \\
8\end{array}$ & $\begin{array}{l}2 \\
2\end{array}$ & $\begin{array}{r}15 \\
7\end{array}$ & $\begin{array}{l}2 \\
9\end{array}$ & $\begin{array}{l}4 \\
8\end{array}$ & $\begin{array}{r}13 \\
4\end{array}$ & $\begin{array}{l}2 \\
9\end{array}$ & $\begin{array}{l}6 \\
9\end{array}$ & $\begin{array}{l}23 \\
12\end{array}$ & $\begin{array}{l}9 \\
7\end{array}$ & $\begin{array}{r}11 \\
7\end{array}$ & $\begin{array}{l}6 \\
5\end{array}$ & $\begin{array}{l}1 \\
2\end{array}$ & & 101 & 10 & 4 & 2 & 6 & 3 & 9 & 2 & & $\begin{array}{r}299.9 \\
1703.8\end{array}$ \\
\hline
\end{tabular}

DURATION TABLE OF DISCHARGE FOR WATER YEARS 1950-57
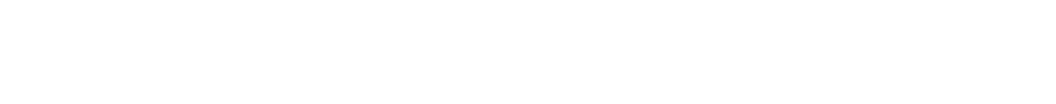

FEET $M$ MU- PER- $\quad$ FEET $M$ MU- PER-

CLASS SECOND DAYS DAYS DAYS

CLASS SECOND DAYS DAYS DAYS

CLASS SECOND DAYS DAYS DAYS

$\begin{array}{ccc}\text { OUBIC } & \text { ACOU- } \\ \text { FEET } & \text { MU- } & \text { PER- } \\ \text { PER TOTAL LATED } & \text { CENT } \\ \text { CLASS SECOND } & \text { DAYS DAYS } & \text { DAYS }\end{array}$

$\begin{array}{lllll}0 & 0.00 & 27 & 2922 & 100.0\end{array}$

$\begin{array}{llll}0.10 & 379 & 2895 & 99.1\end{array}$

$\begin{array}{llll}0.12 & 0 & 2516 & 86.1\end{array}$

$\begin{array}{llll}0.15 & 0 & 2516 & 86.1\end{array}$

$\begin{array}{llll}0.18 & 469 & 2516 & 86.1\end{array}$

$\begin{array}{llll}0.22 & 0 & 2047 & 70\end{array}$

$\begin{array}{llll}0.27 & 329 & 2047 & 70.1\end{array}$

$\begin{array}{rrrrr}9 & 0.50 & 168 & 1473 & 50.4 \\ 10 & 0.62 & 52 & 1305 & 44.7 \\ 11 & 0.75 & 120 & 1253 & 42.9 \\ 12 & 0.92 & 106 & 1133 & 38.8 \\ 13 & 1.10 & 70 & 1027 & 35.1 \\ 14 & 1.40 & 137 & 957 & 32.8 \\ 15 & 1.70 & 144 & 820 & 28.1 \\ 16 & 2.10 & 46 & 676 & 23.1 \\ 17 & 2.50 & 78 & 630 & 21.6\end{array}$

$\begin{array}{rrrrr}18 & 3.1 & 51 & 552 & 18.9 \\ 19 & 3.8 & 73 & 501 & 17.1 \\ 20 & 4.6 & 74 & 428 & 14.6 \\ 21 & 5.7 & 54 & 354 & 12.1 \\ 22 & 6.9 & 56 & 300 & 10.3 \\ 23 & 8.5 & 39 & 244 & 8.4 \\ 24 & 10.0 & 56 & 205 & 7.0 \\ 25 & 13.0 & 41 & 149 & 5.1 \\ 26 & 16.0 & 23 & 108 & 3.7\end{array}$

$\begin{array}{rrrrr}27 & 19.0 & 19 & 85 & 2.9 \\ 28 & 23.0 & 5 & 66 & 2.3 \\ 29 & 28.0 & 12 & 61 & 2.1 \\ 30 & 35.0 & 10 & 49 & 1.7 \\ 31 & 43.0 & 20 & 39 & 1.3 \\ 32 & 52.0 & 17 & 19 & 0.7 \\ 33 & 64.0 & 0 & 2 & 0.1 \\ 34 & 78.0 & 2 & 2 & 0.1\end{array}$

MONTHLY MEAN DISCHARGES, IN OUBIC FEET PER SECOND, FOR EACH WATER YEAR

$\begin{array}{lllllllllllll}\text { YEAR } & \text { OCT } & \text { NOV } & \text { DEC } & \text { JAN } & \text { FEB } & \text { MAR } & \text { APR } & \text { MAY } & \text { JUNE } & \text { JULY } & \text { AUG } & \text { SEP } \\ 1950 & 2.00 & 1.75 & 1.16 & 1.00 & 1.50 & 2.00 & 6.89 & 10.4 & 9.36 & 2.57 & 1.08 & 0.78 \\ 1951 & 0.55 & 0.33 & 0.35 & 0.30 & 0.30 & 0.35 & 0.97 & 4.78 & 4.68 & 1.30 & 0.91 & 1.19 \\ 1952 & 0.82 & 0.57 & 0.40 & 0.30 & 0.30 & 0.50 & 5.95 & 45.1 & 26.5 & 3.95 & 1.21 & 0.42 \\ 1953 & 0.31 & 0.20 & 0.20 & 0.20 & 0.20 & 0.28 & 2.24 & 5.34 & 5.00 & 0.83 & 0.47 & 0.23 \\ 1954 & 0.20 & 0.14 & 0.10 & 0.10 & 0.10 & 0.20 & 3.93 & 10.8 & 1.97 & 0.47 & 0.20 & 0.44 \\ 1955 & 0.77 & 0.23 & 0.22 & 0.10 & 0.10 & 0.20 & 5.99 & 15.6 & 6.38 & 1.15 & 2.54 & 0.40 \\ 1956 & 0.24 & 0.35 & 0.35 & 0.35 & 0.20 & 0.29 & 1.53 & 3.45 & 2.25 & 0.43 & 0.31 & 0.08 \\ 1957 & 0.05 & 0.08 & 0.10 & 0.10 & 0.10 & 0.10 & 1.24 & 10.8 & 36.7 & 4.64 & 1.83 & 0.49\end{array}$

ANNUAL PEAK DISCHARGE, IN OBIC FEET PER SECOND, AND CORRESPONDING GAGE HEIGHT, IN FEET, FOR EACH WATER YEAR

\begin{tabular}{|c|c|c|c|c|c|c|c|c|c|c|c|}
\hline $\begin{array}{l}\text { WATER } \\
\text { YEAR }\end{array}$ & DATE & $\begin{array}{c}\text { GAGE } \\
\text { HEIGHT }\end{array}$ & $\begin{array}{c}\text { PEAK } \\
\text { DISCHARGE }\end{array}$ & $\begin{array}{l}\text { WATER } \\
\text { YEAR }\end{array}$ & DATE & $\begin{array}{c}\text { GAGE } \\
\text { HEIGHT }\end{array}$ & $\begin{array}{c}\text { PEAK } \\
\text { DISAHARGE }\end{array}$ & $\begin{array}{l}\text { WATER } \\
\text { YEAR }\end{array}$ & DATE & $\begin{array}{c}\text { GAGE } \\
\text { HEIGHT }\end{array}$ & $\begin{array}{c}\text { PEAK } \\
\text { DISQHARGE }\end{array}$ \\
\hline $\begin{array}{l}1950 \\
1951 \\
1952\end{array}$ & $\begin{array}{l}\text { JUNE 01, } 1950 \\
\text { AUG. 29, } 1951 \\
\text { JUNE 03, } 1952\end{array}$ & $\begin{array}{l}\overline{1.74} \\
2.57\end{array}$ & $\begin{array}{c}14 \\
20 \\
108\end{array}$ & $\begin{array}{l}1953 \\
1954 \\
1955\end{array}$ & $\begin{array}{lll}\text { MAY } & 24,1953 \\
\text { MAY } & 22,1954 \\
\text { AUG. } & 06,1955\end{array}$ & $\begin{array}{l}1.40 \\
1.58 \\
2.74\end{array}$ & $\begin{array}{r}12 \\
19 \\
122\end{array}$ & $\begin{array}{l}1956 \\
1957\end{array}$ & $\begin{array}{l}\text { AUG. } 15,1956 \\
\text { JUNE } 11,1957\end{array}$ & 1.67 & $\begin{array}{l}17 \\
62\end{array}$ \\
\hline
\end{tabular}




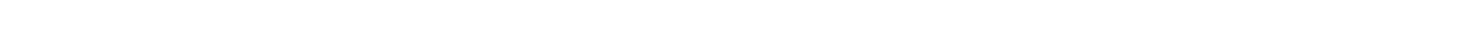
right bank $0.8 \mathrm{mi}$ upstream from right bank tributary, $8 \mathrm{mi}$ upstream from Cottonwood Creek, and 12 mi northwest of Monticello. DRAINAGE AREA. $--31.2 \mathrm{mi}^{2}$.

MEAN BASIN ELEVATION. $-8,590 \mathrm{ft}$.

PERIOD OF RECORD AVAIIABLE. -October 1949 to September 1971.

REVISED RECORD.-WSP 1213: 1950(M). WSP 1633: Drainage area.

GAGE.-Water-stage recorder. Altitude of gage is $6,290 \mathrm{ft}$ by barcmeter.

REMARKS.--Indian Creek tunnel diverts water above station to San Juan River basin for irrigation and municipal supply.

AVERAGE DISCHARGE. --22 years, $4.40 \mathrm{ft}^{3} / \mathrm{s}, 3,190$ acre- $\mathrm{ft} / \mathrm{yr}$.

EXIREMES FOR FERIOD OF RECORD.--Maximum đischarge, 2,330 ft ${ }^{3} / \mathrm{s}$ Aug. 28,1971 , gage height, $12.45 \mathrm{ft}$; no flow all or part of many days in some years.

LONEST MEAN DISQHARGE, IN OBBIC FEET RER SECOND, AND RANKING FOR THE INDICATED NUMBER OF OONSECUTIVE DAYS FOR EACH OLIMATIC YEAR, APRII 1-MAROH 31

YEAR

1

0.4016

$\begin{array}{lr}0.10 & 5 \\ 0.30 & 13\end{array}$

0.2010

0.001

0.2011

0.106

0.4017

0.4017
0.2012

0.002

0.107

0.108

0.109

0.003

0.6021

0.4018

0.4519

0.3914

0.3915

0.5020 $\begin{array}{ll}3 & \\ 0.40 & 14 \\ 0.13 & 9 \\ 0.50 & 20 \\ 0.20 & 10 \\ 0.00 & 1\end{array}$

0.00

0.105

0.4316

0.2712

0.002

0.106

0.107

$\begin{array}{ll}0.10 & 8 \\ 0.00 & \end{array}$

0.104

0.6721

0.4717

0.4718

0.4015
0.3913

0.5019
7

0.4114

0.4115

0.6020

0.209

0.2410

0.104

0.4916

0.3311

$\begin{array}{lll}0.33 & 11 \\ 0.00 & 1\end{array}$

0.105

$\begin{array}{ll}0.10 & 6 \\ 0.10 & 7\end{array}$

$\begin{array}{ll}0.00 & 2 \\ 0.13 & 8\end{array}$

0.7121

0.4917

0.5018

0.4013

0.4013
0.3912

0.5019

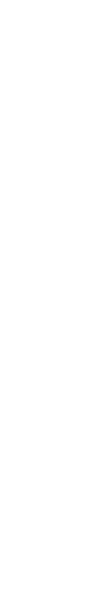

0.7020
CONSECUTIVE DAYS

0.7718

$\begin{array}{ll}0.75 & 17 \\ 1.00 & 21\end{array}$

$\begin{array}{ll}0.28 & 5 \\ 0.35 & 7\end{array}$

$0.38 \quad 8$

0.113

0.8219

0.4310

0.071

0.4311

0.7116

0.124

$\begin{array}{ll}0.10 & 2 \\ 0.29 & 6\end{array}$

0.9820

0.5312

0.5413

0.429

$\begin{array}{ll}0.42 & 9 \\ 0.54 & 14\end{array}$

0.7015
90

0.8717

0.8514

1.1019

$\begin{array}{ll}0.48 & 5 \\ 0.85 & 15\end{array}$

0.599

0.313

0.31
1.0018

$\begin{array}{rr}1.00 & 18 \\ 0.56 & 7\end{array}$

$\begin{array}{ll}0.56 & 7 \\ 0.12 & 1\end{array}$

0.578

0.528

0.8418

0.334

$\begin{array}{ll}0.28 & 3 \\ 0.35 & 5\end{array}$

0.579
0.6611

$\begin{array}{ll}0.29 & 2 \\ 0.47 & 4\end{array}$

1.6021

0.7614

0.5712

0.539

0.6413

2.2021

0.8516

0.6010

$\begin{array}{rr}0.60 & 10 \\ 0.51 & 6\end{array}$

$\begin{array}{lll}0.51 & 6 \\ 0.6812\end{array}$

$0.8015 \quad 0.8313$
0.9415

0.8813

1.1018

0.638

0.616

0.333

$\begin{array}{lll}0.33 & 3 \\ 1.10 & 17\end{array}$

0.639

$\begin{array}{ll}0.63 & 9 \\ 0.151\end{array}$

0.7711

0.1919
0.8814

$\begin{array}{ll}0.33 & 2 \\ 0.55 & 4\end{array}$

$2.30 \quad 21$

1.1920

0.617

$\begin{array}{ll}0.61 & 7 \\ 0.56 & 5\end{array}$

0.7610

0.8712
183

1.1014

0.9411

1.1918

$\begin{array}{lll}0.69 & 7 \\ 1.10 & 15\end{array}$

0.636

$0.37 \quad 2$

1.8020

$\begin{array}{ll}1.80 & 20 \\ 0.89 & 9\end{array}$

$\begin{array}{ll}0.89 & 9 \\ 0.21 & 1\end{array}$

1.1016

1.7019

0.9110

$\begin{array}{ll}0.62 & 4 \\ 0.57 & 3\end{array}$

2.5021

1.1917

0.635

$\begin{array}{ll}0.76 & 8 \\ 0.99 & 12\end{array}$

1.0013
ALL

4.8013

2.004

$12.0 \quad 21$

$\begin{array}{ll}2.20 & 7 \\ 3.00 & 8\end{array}$

4.5012

1.302

8.4019

8.9020

0.721

3.709

3.8010

5.9017

2.105

6.5018

5.7016

$2.10 \quad 6$

5.0014

5.5015

3.8011

HIGHEST MEAN DISQHARGE, IN OUBIC FEET FER SECOND, AND RANKING FOR THE INDICATED NUMBER OF CONSEOUTIVE DAYS FOR EAGH WATER YEAR, OCTCBER 1-SEPTEMBER 30

YEAR

1950

1951

1952

1953

1955

1956

1957

1959
1960

1961

1962

1963
1964

1965

1966

1967

1969
1970

1971 $\begin{array}{lllll}1 & & & & \text { ONSECUTIVE DAYS } \\ 60 & 3 & 15 & 30 & 60\end{array}$

$\begin{array}{llllll}26.0 & 13 & 26.0 & 12 & 25.0 & 11\end{array}$

$\begin{array}{llllll}14.0 & 20 & 14.0 & 20 & 13.0 & 20\end{array}$

$94.0 \quad 4 \quad 88.0 \quad 3$

$\begin{array}{llll}16.0 & 19 & 15.0 & 18\end{array}$

$\begin{array}{llllll}33.0 & 11 & 32.0 & 14 & 20.0 & 14 \\ & & & \end{array}$

$\begin{array}{llll}9.30 & 21 & 8.10 & 21\end{array}$

99.03

$6.2022 \quad 4.4022$
$26.0 \quad 14$

$26.0 \quad 14$

$19.0 \quad 17$

$\begin{array}{rr}57.0 & 7 \\ 22.0 & 16\end{array}$

$\begin{array}{rrrr}36.0 & 9 & 33.0 & 10\end{array}$

$\begin{array}{llll}34.0 & 10 & 34.0\end{array}$

$\begin{array}{llll}28.0 & 12 & 15.0 & 17\end{array}$

87.05

$\begin{array}{lll}43.0 & 8 & 39.0 \\ 81.0 & 6 & 60.0\end{array}$

152
23.010

$11.0 \quad 19$

$\begin{array}{rr}74.0 & 2 \\ 13.0 & 16\end{array}$

13.016

$\begin{array}{rr}19.0 & 13 \\ 27.0 & 9\end{array}$

7.7021

$\begin{array}{lr}7.70 & 21 \\ 83.0 & 2\end{array}$

92.01

$\begin{array}{rr}3.30 & 22 \\ 24.0 \quad 12\end{array}$

6.8021

$\begin{array}{ll}6.80 & 21 \\ 73.0 & 3\end{array}$

81.01

$\begin{array}{cc}3.10 & 22 \\ 21.0 & 11\end{array}$

$19.0 \quad 15$

42.05

37.0

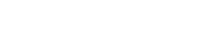

$\begin{array}{rrrr}16.0 & 16 & 14.0 & 15 \\ 32.0 & 9 & 31.0 & 7\end{array}$

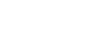

$\begin{array}{rrrr}33.0 & 8 & 30.0 & 8 \\ 13.0 & 19 & 11.0 & 20\end{array}$

$\begin{array}{rrrr}13.0 & 19 & 11.0 & 20 \\ 43.0 & 4 & 34.0 & 6\end{array}$

$\begin{array}{llll}38.0 & 6 & 35.0 & 5\end{array}$

$20.0 \quad 12$

$12.0 \quad 28$

$24.0 \quad 13$

53.0
$21.0 \quad 10$

8.6019

$68.0 \quad 1$

$11.0 \quad 16$

$\begin{array}{rr}16.0 & 13 \\ 24.0 & 9\end{array}$

6.5020

56.03

66.02

2.9022

19.011 
TRIBUTARIES BETWEEN DOLORES RIVER AND GREEN RTVER

09186500 INDIAN CREEK ABOVE COTTONWOOD CREEK, NEAR MONIICELLO, UT-Continued

DURATION OF DISCHARGE FOR EACH WATER YEAR

$\begin{array}{lllllllllllllllllllllllllllllllllllllllll}\text { CLASS } & 0 & 1 & 2 & 3 & 4 & 5 & 6 & 7 & 8 & 9 & 10 & 11 & 12 & 13 & 14 & 15 & 16 & 17 & 18 & 19 & 20 & 21 & 22 & 23 & 24 & 25 & 26 & 27 & 28 & 29 & 30 & 31 & 32 & 33 & 34\end{array}$

YEAR

NUMBER OF DAYS IN CLASS

OUBIC FEET

-DAYS

$\begin{array}{llllllllllllllllllllll}1950 & 6 & 2 & 8 & 9 & 6 & 17 & 29 & 46 & 45 & 53 & 43 & 8 & 7 & 6 & 10 & 16 & 14 & 22 & 18 & 18 & \end{array}$

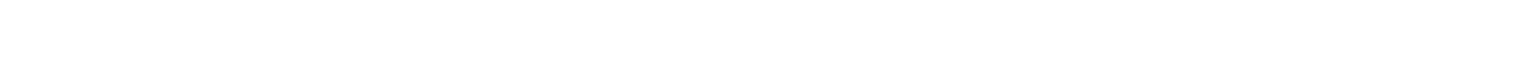

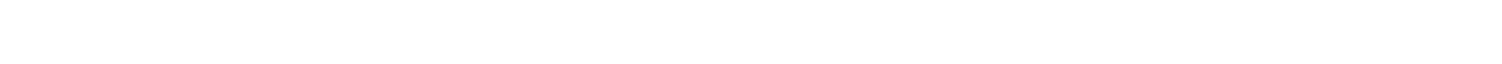

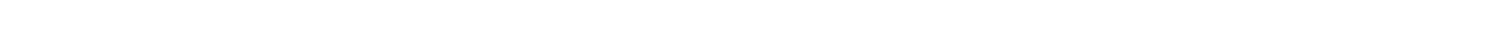

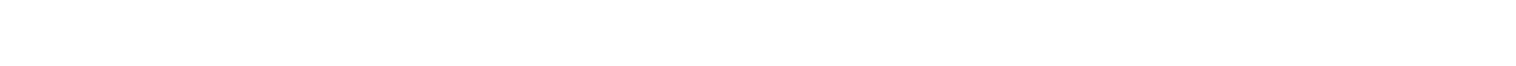

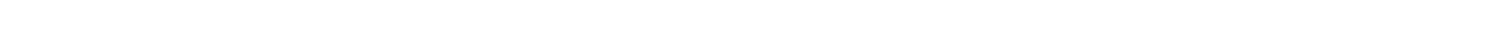

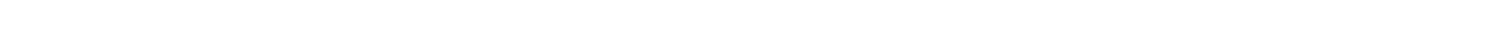

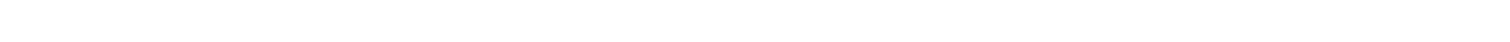

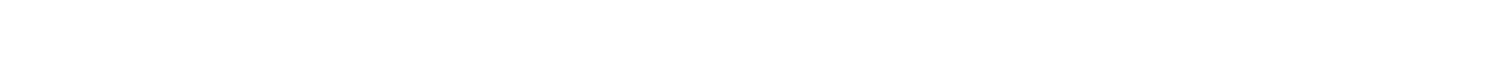

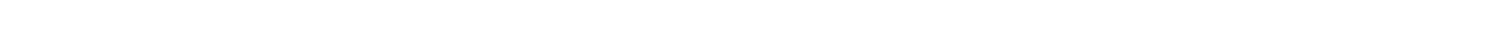

$\begin{array}{lllllllllllllllllllllllll}1966 & 5 & 36 & 24 & 22 & 22 & 38 & 31 & 69 & 14 & 8 & 9 & 4 & 8 & 10 & 17 & 15 & 8 & 19 & 6 & & & & \end{array}$

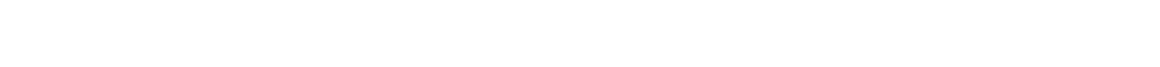

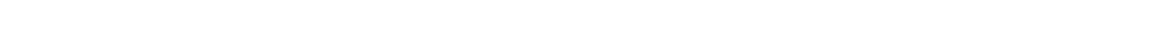

$\begin{array}{lllllllllllllllllllllll}10 & 9 & 1 & 59 & 48 & 25 & 53 & 44 & 22 & 10 & 14 & 6 & 5 & 6 & 7 & 10 & 7 & 6 & 13 & 6 & 2 & 1 & 1\end{array}$

$\begin{array}{llllllllllllllllllllllllllll}1971 & 5 & 9 & 23 & 3 & 4 & 5 & 4 & 12 & 5 & 37 & 25 & 68 & 31 & 26 & 13 & 26 & 14 & 29 & 22 & 3 & & 758.3\end{array}$

DURATION TABLE OF DISCHARGE FOR WATER YEARS 1950-71

\begin{tabular}{|c|c|c|c|c|c|c|c|c|c|c|c|c|c|c|c|c|c|c|c|}
\hline & $\begin{array}{c}\text { QUBIC } \\
\text { FEET } \\
\text { PER } \\
\text { SECOND }\end{array}$ & $\begin{array}{r}\text { TOTAL } \\
\text { DAYS }\end{array}$ & $\begin{array}{c}\text { ACCU- } \\
\text { MU- } \\
\text { LATED } \\
\text { DAYS }\end{array}$ & $\begin{array}{l}\text { PER- } \\
\text { CENT } \\
\text { DAYS }\end{array}$ & CLASS & $\begin{array}{c}\text { OBBIC } \\
\text { FEET } \\
\text { PER } \\
\text { SECOND }\end{array}$ & $\begin{array}{r}\text { TOTAL } \\
\text { DAYS }\end{array}$ & $\begin{array}{c}\text { ACOU- } \\
\text { MU- } \\
\text { LATED } \\
\text { DAYS }\end{array}$ & $\begin{array}{l}\text { PER- } \\
\text { CENT } \\
\text { DAYS }\end{array}$ & CLASS & $\begin{array}{c}\text { CUBIC } \\
\text { FEET } \\
\text { PER } \\
\text { SECOND }\end{array}$ & $\begin{array}{r}\text { TOTAL } \\
\text { DAYS }\end{array}$ & $\begin{array}{c}\text { ACOU- } \\
\text { MU- } \\
\text { LATED } \\
\text { DAYS }\end{array}$ & $\begin{array}{l}\text { PER- } \\
\text { CENT } \\
\text { DAYS }\end{array}$ & CLASS & $\begin{array}{c}\text { CJBIC } \\
\text { FEET } \\
\text { PER } \\
\text { SECOND }\end{array}$ & $\begin{array}{r}\text { TOTAL } \\
\text { DAYS }\end{array}$ & $\begin{array}{l}\text { ACOU- } \\
\text { MU- } \\
\text { LATED } \\
\text { DAYS }\end{array}$ & $\begin{array}{l}\text { PER- } \\
\text { CENT } \\
\text { DAYS }\end{array}$ \\
\hline $\begin{array}{l}0 \\
1 \\
2 \\
3 \\
4 \\
5 \\
6 \\
7 \\
8\end{array}$ & $\begin{array}{l}0.00 \\
0.07 \\
0.09 \\
0.11 \\
0.14 \\
0.17 \\
0.21 \\
0.26 \\
0.33\end{array}$ & $\begin{array}{r}27 \\
5 \\
210 \\
0 \\
23 \\
250 \\
4 \\
256 \\
297\end{array}$ & $\begin{array}{l}8035 \\
8008 \\
8003 \\
7793 \\
7793 \\
7770 \\
7520 \\
7516 \\
7260\end{array}$ & $\begin{array}{r}100.0 \\
99.7 \\
99.6 \\
97.0 \\
97.0 \\
96.7 \\
93.6 \\
93.5 \\
90.4\end{array}$ & $\begin{array}{r}9 \\
10 \\
11 \\
12 \\
13 \\
14 \\
15 \\
16 \\
17\end{array}$ & $\begin{array}{l}0.41 \\
0.51 \\
0.63 \\
0.79 \\
0.98 \\
1.20 \\
1.50 \\
1.90 \\
2.40\end{array}$ & $\begin{array}{l}316 \\
466 \\
509 \\
823 \\
634 \\
778 \\
515 \\
410 \\
360\end{array}$ & $\begin{array}{l}6963 \\
6647 \\
6181 \\
5672 \\
4849 \\
4215 \\
3437 \\
2922 \\
2512\end{array}$ & $\begin{array}{l}86.7 \\
82.7 \\
76.9 \\
70.6 \\
60.3 \\
52.5 \\
42.8 \\
36.4 \\
31.3\end{array}$ & $\begin{array}{l}18 \\
19 \\
20 \\
21 \\
22 \\
23 \\
24 \\
25 \\
26\end{array}$ & $\begin{array}{r}3.0 \\
3.7 \\
4.6 \\
5.7 \\
7.1 \\
8.9 \\
11.0 \\
14.0 \\
17.0\end{array}$ & $\begin{array}{l}307 \\
255 \\
206 \\
178 \\
170 \\
154 \\
174 \\
147 \\
170\end{array}$ & $\begin{array}{r}2152 \\
1845 \\
1590 \\
1384 \\
1206 \\
1036 \\
882 \\
708 \\
561\end{array}$ & $\begin{array}{r}26.8 \\
23.0 \\
19.8 \\
17.2 \\
15.0 \\
12.9 \\
11.0 \\
8.8 \\
7.0\end{array}$ & $\begin{array}{l}27 \\
28 \\
29 \\
30 \\
31 \\
32 \\
33 \\
34\end{array}$ & $\begin{array}{r}21.0 \\
27.0 \\
33.0 \\
41.0 \\
52.0 \\
64.0 \\
80.0 \\
100.0\end{array}$ & $\begin{array}{r}148 \\
71 \\
62 \\
33 \\
23 \\
32 \\
20 \\
2\end{array}$ & $\begin{array}{r}391 \\
243 \\
172 \\
110 \\
77 \\
54 \\
22 \\
2\end{array}$ & $\begin{array}{l}4.9 \\
3.0 \\
2.1 \\
1.4 \\
1.0 \\
0.7 \\
0.3 \\
0.0\end{array}$ \\
\hline
\end{tabular}

MONTHLY MEAN DISCHARGES, IN OUBIC FEET PER SECOND, FOR EACH WATER YEAR

$\begin{array}{lllllllllllll}\text { YEAR } & \text { OCT } & \text { NOV } & \text { DEC } & \text { JAN } & \text { FEB } & \text { MAR } & \text { APR } & \text { MAY } & \text { JUNE } & \text { JULY } & \text { AUG } & \text { SEP } \\ 1950 & 4.33 & 3.52 & 2.26 & 1.80 & 2.42 & 3.28 & 11.4 & 17.5 & 15.8 & 4.03 & 1.19 & 1.52 \\ 1951 & 1.34 & 1.35 & 1.16 & 0.92 & 0.80 & 0.89 & 1.77 & 6.88 & 5.87 & 1.15 & 1.53 & 1.46 \\ 1952 & 1.20 & 0.93 & 0.76 & 0.89 & 0.97 & 1.16 & 18.6 & 64.5 & 39.5 & 7.19 & 3.06 & 1.15 \\ 1953 & 1.29 & 1.39 & 1.03 & 1.08 & 1.19 & 1.08 & 3.59 & 7.73 & 7.79 & 1.14 & 1.20 & 0.47 \\ 1954 & 0.87 & 1.09 & 0.98 & 0.45 & 0.36 & 0.72 & 5.52 & 15.8 & 4.38 & 0.97 & 0.45 & 1.78 \\ 1955 & 1.41 & 1.13 & 1.02 & 0.90 & 0.90 & 1.77 & 6.72 & 24.0 & 12.9 & 2.44 & 3.39 & 0.62 \\ 1956 & 0.69 & 0.72 & 0.59 & 0.51 & 0.73 & 0.72 & 2.25 & 6.33 & 3.00 & 0.50 & 0.39 & 0.12 \\ 1957 & 0.44 & 0.51 & 0.41 & 0.41 & 0.48 & 0.22 & 3.42 & 20.1 & 55.0 & 7.64 & 3.10 & 1.03 \\ 1958 & 2.75 & 3.83 & 1.00 & 1.22 & 0.98 & 1.52 & 12.5 & 60.7 & 22.9 & 2.37 & 1.05 & 1.40 \\ 1959 & 1.18 & 1.61 & 0.74 & 0.62 & 0.51 & 0.66 & 2.07 & 2.77 & 0.92 & 0.11 & 0.19 & 0.08 \\ 1960 & 0.29 & 0.29 & 0.32 & 0.35 & 0.29 & 0.95 & 8.03 & 15.7 & 11.2 & 0.85 & 1.17 & 0.86 \\ 1961 & 2.07 & 1.29 & 1.24 & 0.64 & 0.45 & 0.99 & 5.80 & 15.5 & 7.91 & 0.99 & 1.67 & 2.39 \\ 1962 & 2.98 & 2.07 & 1.22 & 0.73 & 1.66 & 2.03 & 24.4 & 24.2 & 11.4 & 2.31 & 0.26 & 0.65 \\ 1963 & 1.41 & 1.49 & 0.96 & 1.09 & 0.95 & 2.02 & 4.05 & 9.96 & 2.13 & 0.10 & 1.78 & 3.22 \\ 1964 & 1.12 & 1.21 & 0.46 & 0.30 & 0.31 & 0.33 & 3.21 & 9.89 & 4.25 & 0.93 & 1.01 & 0.35 \\ 1965 & 0.55 & 0.76 & 0.67 & 0.62 & 0.65 & 0.71 & 3.32 & 15.5 & 25.8 & 8.26 & 3.57 & 5.08 \\ 1966 & 2.92 & 2.18 & 3.34 & 2.66 & 0.96 & 4.15 & 16.0 & 28.9 & 11.1 & 2.71 & 1.59 & 1.13 \\ 1967 & 1.19 & 1.25 & 2.09 & 0.91 & 0.64 & 1.10 & 2.37 & 8.08 & 5.99 & 2.21 & 2.51 & 0.56 \\ 1968 & 0.60 & 0.68 & 0.60 & 0.70 & 0.65 & 0.68 & 2.57 & 16.5 & 22.9 & 6.30 & 5.53 & 1.12 \\ 1969 & 1.25 & 1.05 & 0.64 & 0.49 & 0.58 & 0.62 & 12.4 & 29.1 & 12.9 & 2.58 & 1.46 & 1.35 \\ 1970 & 1.49 & 1.39 & 0.99 & 0.57 & 0.77 & 0.71 & 2.62 & 16.0 & 7.16 & 1.80 & 8.71 & 2.73 \\ 1971 & 1.42 & 1.10 & 0.71 & 0.92 & 0.87 & 1.38 & 2.80 & 4.53 & 4.09 & 1.03 & 5.67 & 0.29\end{array}$


TRIBUTARIES BETWEFN DOLORES RIVER AND GREDN RIVER

09186500 INDIAN CREEK ABOVE COTTOWWOD CREEK, NEAR MONTICELLO, UT--Continued

ANNUAL PEAK DISCHARGE, IN CUBIC FEET PER SECOND, AND CORRESPONDING GAGE HEIGHT, IN FEET, FOR EACH WATER YFAR

\begin{tabular}{|c|c|c|c|c|c|c|c|c|c|c|c|}
\hline $\begin{array}{l}\text { WATER } \\
\text { YEAR }\end{array}$ & DATE & $\begin{array}{c}\text { GAGE } \\
\text { HEIGHT }\end{array}$ & $\begin{array}{c}\text { PEAK } \\
\text { DISCHARGE }\end{array}$ & $\begin{array}{l}\text { WATER } \\
\text { YEAR }\end{array}$ & DATE & $\begin{array}{c}\text { GAGE } \\
\text { HEIGHT }\end{array}$ & $\begin{array}{c}\text { PEAK } \\
\text { DISCHARGE }\end{array}$ & $\begin{array}{l}\text { WATER } \\
\text { YEAR }\end{array}$ & DATE & $\begin{array}{c}\text { GAGE } \\
\text { HEIGHT }\end{array}$ & $\begin{array}{c}\text { PEAK } \\
\text { DISCHARGE }\end{array}$ \\
\hline $\begin{array}{l}1950 \\
1951 \\
1952 \\
1953 \\
1954 \\
1955 \\
1956 \\
1957\end{array}$ & $\begin{array}{ll}\text { SEPT. 19, } 1950 \\
\text { JULY } 27,1951 \\
\text { JULY } 10,1952 \\
\text { JULY } 30,1953 \\
\text { SEPT. 25, } 1954 \\
\text { JULY } 20,1955 \\
\text { JULY } 28,1956 \\
\text { JUNE } 10,1957\end{array}$ & $\begin{array}{l}5.58 \\
6.31 \\
7.15 \\
5.37 \\
5.22 \\
8.15 \\
5.70 \\
6.07\end{array}$ & $\begin{array}{r}90 \\
179 \\
293 \\
63 \\
53 \\
582 \\
107 \\
138\end{array}$ & $\begin{array}{l}1958 \\
1959 \\
1960 \\
1961 \\
1962 \\
1963 \\
1964\end{array}$ & $\begin{array}{l}\text { MAY } 23,1958 \\
\text { NOV. } 12,1958 \\
\text { AUG. } 23,1960 \\
\text { JULY } 29,1961 \\
\text { SEPT. 24, } 1962 \\
\text { SEPT. 20, } 1963 \\
\text { JULY } 30,1964\end{array}$ & $\begin{array}{l}5.89 \\
5.09 \\
5.71 \\
5.58 \\
5.90 \\
6.80 \\
5.44\end{array}$ & $\begin{array}{r}108 \\
18 \\
62 \\
55 \\
86 \\
240 \\
31\end{array}$ & $\begin{array}{l}1965 \\
1966 \\
1967 \\
1968 \\
1969 \\
1970 \\
1971\end{array}$ & $\begin{array}{l}\text { AUG. } 16,1965 \\
\text { JULY } 17,1966 \\
\text { AUG. } 08,1967 \\
\text { AUG. } 13,1968 \\
\text { AUG. } 16,1969 \\
\text { SEPT. 12, } 1970 \\
\text { AUG. 28, } 1971\end{array}$ & $\begin{array}{r}5.95 \\
5.68 \\
8.70 \\
8.70 \\
5.85 \\
8.40 \\
12.45\end{array}$ & $\begin{array}{r}86 \\
53 \\
709 \\
709 \\
134 \\
652 \\
2330\end{array}$ \\
\hline
\end{tabular}

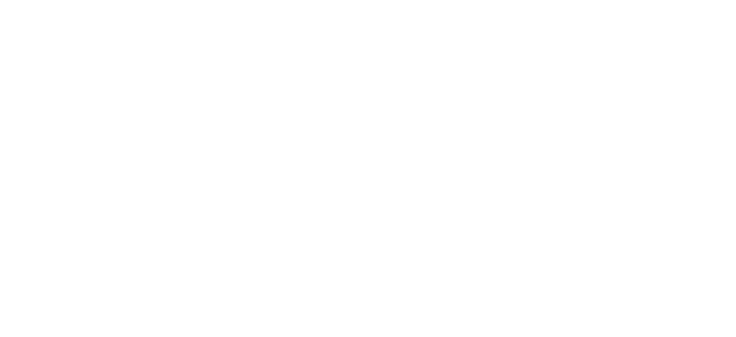

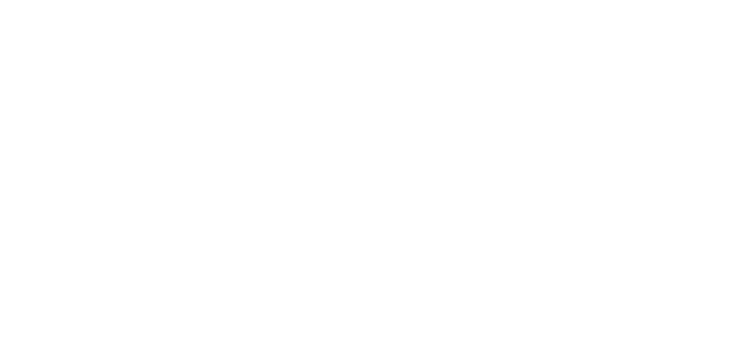

09187000 COTTONWOCO CREEK NEAR MONTICELLO, UT

LOCATION.--Lat $38^{\circ} 03^{\prime} 45^{\prime \prime}$, long $109^{\circ} 34^{\prime} 25^{\prime \prime}$, in SE't sec.23, T.31 S., R.21 E., San Juan County, Hydrologic unit 14030005, on left bank

$1 \mathrm{mi}$ upstream from mouth and $10 \mathrm{mi}$ northwest of Monticello.

DRAINAGE AREA.-- $115 \mathrm{mi}^{2}$.

MEAN BASIN ELEVATION. - -7,210 ft.

PERIOD OF RECORD AVAILABLE.--October 1949 to september 1957, and annual peak discharge only, water years $1960-68$.

GAGE.--Water-stage recorder and control of bedrock capped with concrete. Altitude of gage is 5,340 ft from topographic map.

AVERAGE DISCHARGE. --8 years, $3.10 \mathrm{ft}^{3} / \mathrm{s}, 2,240 \mathrm{acre}-\mathrm{ft} / \mathrm{yr}$.

EXTREMES FOR PERIOD OF RECORD.-Maximum discharge, 2,200 $\mathrm{ft}^{3} / \mathrm{s}$ Aug, 18, 1963, gage height, $6.82 \mathrm{ft}$; no flow for some days in most years.

LOWEST MEAN DISCHARGE, IN CUBIC FEET PER SECOND, AND RANKING FOR THE INDICATED NUMBER OF CONSECUTIVE DAYS FOR EACH CLIMATIC YEAR, APRIL 1-MARCH 31

YEAR

1951

1951
1952

1953

1954
1955

1956

1957

$\begin{array}{cccccc}1 & & 3 & & 7 & \\ 0.30 & 6 & 0.37 & 6 & 0.41 & 6 \\ 0.00 & 1 & 0.00 & 1 & 0.00 & 1 \\ 0.60 & 7 & 0.70 & 7 & 0.81 & 7 \\ 0.10 & 5 & 0.10 & 5 & 0.10 & 4 \\ 0.00 & 2 & 0.00 & 2 & 0.07 & 3 \\ 0.00 & 3 & 0.00 & 3 & 0.11 & 5 \\ 0.00 & 4 & 0.00 & 4 & 0.00 & 2\end{array}$

14

0.526

$\begin{array}{ll}0.52 & 6 \\ 0.00 & 1\end{array}$

0.897

0.305

0.123

$\begin{array}{ll}0.21 & 4\end{array}$
CONSEDUTIVE DAYS

$\begin{array}{ll}0.65 & 6 \\ 0.03 & 2\end{array}$

$\begin{array}{ll}0.03 & 2 \\ 1.40 & 7\end{array}$

0.565

0.293

60

90

$0.77 \quad 4$

0.402

$\begin{array}{llll}1.60 & 6 & 0.71 & 2 \\ 1.90 & 6\end{array}$

$\begin{array}{lll}1.607 & 1.907\end{array}$

$\begin{array}{lll}0.82 & 5 & 1.00 \quad 5\end{array}$

$0.34 \quad 4$

0.513

$\begin{array}{ll}0.51 & 3 \\ 0.07 & 1\end{array}$

0.833
120

1.103

$\begin{array}{llllll}2.10 & 6 & 2.20 & 6 & 2.40 & 4 \\ 1.10 & 4 & 1.40 & 3 & 2.40 & 5\end{array}$

$\begin{array}{llllll}1.00 & 2 & 1.40 & 4 & 2.60 & 6\end{array}$

$0.571 \quad 1.0011 \quad 1.50$ 
HIGHEST MEAN DISOHARGE, IN ABIC FEET PER SECOND, AND RANKING FOR THE INDICATED NUMBER OF CONSEOUTIVE DAYS FOR EAOH WATER YEAR, OCTOBER 1-SEPTEMBER 30

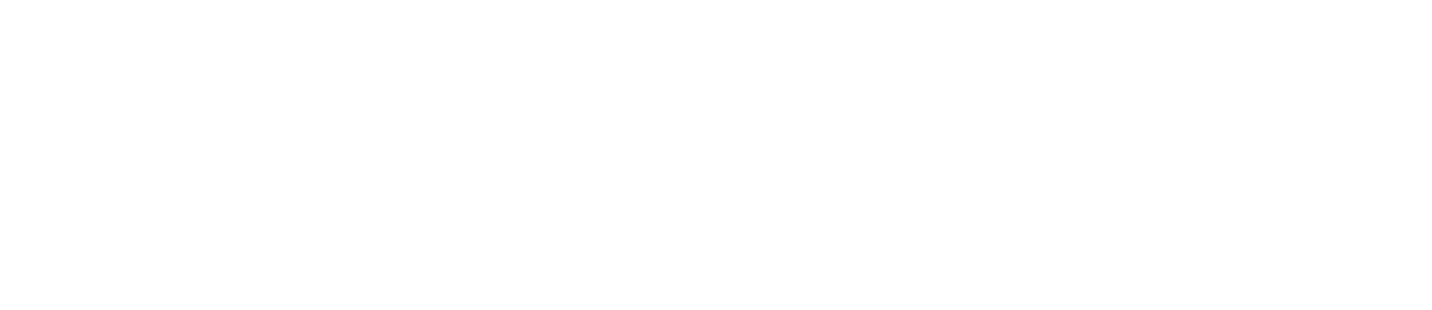

DUKATION OF DISOHARGE FOR EACH WATER YEAR

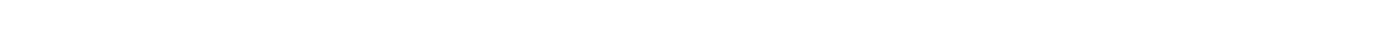

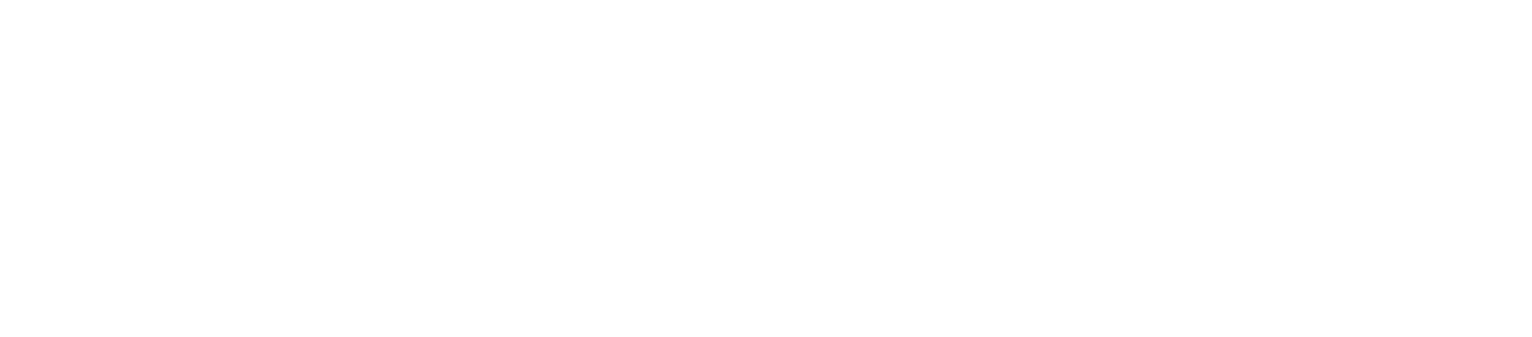

DURATION TABLE OF DISCHARGE FOR WATER YEARS 1950-57

\begin{tabular}{|c|c|c|c|c|c|c|c|c|c|c|c|c|c|c|c|c|c|c|c|}
\hline ZASS & $\begin{array}{c}\text { UBIC } \\
\text { FEET } \\
\text { FER } \\
\text { SECOND }\end{array}$ & $\begin{array}{r}\text { TOTAL } \\
\text { DAYS }\end{array}$ & $\begin{array}{l}\text { ACQU- } \\
\text { NU- } \\
\text { LATED } \\
\text { DAYS }\end{array}$ & $\begin{array}{l}\text { PER- } \\
\text { CENT } \\
\text { DAYS }\end{array}$ & C.ASS & $\begin{array}{c}\text { OBBIC } \\
\text { FEET } \\
\text { PER } \\
\text { SECOND }\end{array}$ & $\begin{array}{l}\text { TOTAL } \\
\text { DAYS }\end{array}$ & $\begin{array}{c}\text { ACOJ- } \\
\text { MU- } \\
\text { LATED } \\
\text { DAYS }\end{array}$ & $\begin{array}{l}\text { PER- } \\
\text { CENT } \\
\text { DAYS }\end{array}$ & CLASS & $\begin{array}{c}\text { OBBIC } \\
\text { FEET } \\
\text { FER } \\
\text { SECOND }\end{array}$ & $\begin{array}{l}\text { TOTAL } \\
\text { DAYS }\end{array}$ & $\begin{array}{c}\text { ACOJ- } \\
\text { MU- } \\
\text { LATED } \\
\text { DAYS }\end{array}$ & $\begin{array}{l}\text { PER- } \\
\text { CENI } \\
\text { DAYS }\end{array}$ & & $\begin{array}{c}\text { OUBIC } \\
\text { FEET } \\
\text { PER } \\
\text { SECOND }\end{array}$ & $\begin{array}{r}\text { TOTAL } \\
\text { DAYS }\end{array}$ & $\begin{array}{c}\text { ACOU- } \\
\text { MU- } \\
\text { LATED } \\
\text { DAYS }\end{array}$ & $\begin{array}{l}\text { PER- } \\
\text { CENT } \\
\text { DAYS }\end{array}$ \\
\hline $\begin{array}{l}0 \\
1 \\
2 \\
3 \\
4 \\
5 \\
6 \\
7 \\
8\end{array}$ & $\begin{array}{l}0.00 \\
0.10 \\
0.12 \\
0.15 \\
0.18 \\
0.21 \\
0.26 \\
0.31 \\
0.38\end{array}$ & $\begin{array}{r}115 \\
50 \\
0 \\
0 \\
45 \\
0 \\
38 \\
0 \\
60\end{array}$ & $\begin{array}{l}2922 \\
2807 \\
2757 \\
2757 \\
2757 \\
2712 \\
2712 \\
2674 \\
2674\end{array}$ & $\begin{array}{r}100.0 \\
96.1 \\
94.4 \\
94.4 \\
94.4 \\
92.8 \\
92.8 \\
91.5 \\
91.5\end{array}$ & $\begin{array}{r}9 \\
10 \\
11 \\
12 \\
13 \\
14 \\
15 \\
16 \\
17\end{array}$ & $\begin{array}{l}0.45 \\
0.55 \\
0.66 \\
0.80 \\
0.97 \\
1.20 \\
1.40 \\
1.70 \\
2.10\end{array}$ & $\begin{array}{r}60 \\
59 \\
44 \\
131 \\
182 \\
140 \\
208 \\
325 \\
257\end{array}$ & $\begin{array}{l}2614 \\
2554 \\
2495 \\
2451 \\
2320 \\
2138 \\
1998 \\
1790 \\
1465\end{array}$ & $\begin{array}{l}89.5 \\
87.4 \\
85.4 \\
83.9 \\
79.4 \\
73.2 \\
68.4 \\
61.3 \\
50.1\end{array}$ & $\begin{array}{l}18 \\
19 \\
20 \\
21 \\
22 \\
23 \\
24 \\
25 \\
26\end{array}$ & $\begin{array}{r}2.5 \\
3.0 \\
3.6 \\
4.4 \\
5.3 \\
6.4 \\
7.7 \\
9.3 \\
11.0\end{array}$ & $\begin{array}{r}349 \\
282 \\
196 \\
104 \\
52 \\
49 \\
26 \\
12 \\
30\end{array}$ & $\begin{array}{r}1208 \\
859 \\
577 \\
381 \\
277 \\
225 \\
176 \\
150 \\
138\end{array}$ & $\begin{array}{r}41.3 \\
29.4 \\
19.7 \\
13.0 \\
9.5 \\
7.7 \\
6.0 \\
5.1 \\
4.7\end{array}$ & $\begin{array}{l}27 \\
28 \\
29 \\
30 \\
31 \\
32 \\
33 \\
34\end{array}$ & $\begin{array}{l}14.0 \\
16.0 \\
20.0 \\
24.0 \\
29.0 \\
35.0 \\
42.0 \\
51.0\end{array}$ & $\begin{array}{r}23 \\
26 \\
20 \\
12 \\
15 \\
9 \\
1 \\
2\end{array}$ & $\begin{array}{r}108 \\
85 \\
59 \\
39 \\
27 \\
12 \\
3 \\
2\end{array}$ & $\begin{array}{l}3.7 \\
2.9 \\
2.0 \\
1.3 \\
0.9 \\
0.4 \\
0.1 \\
0.1\end{array}$ \\
\hline
\end{tabular}

MONIHLY MEAN DISGARGES, IN OUBIC FEET PER SECOND, FOR EACH WATER YEAR

$\begin{array}{lllllllllllll}\text { YEAR } & \text { OCT } & \text { NOV } & \text { DEC } & \text { JAN } & \text { FEB } & \text { MAR } & \text { ALR } & \text { MAY } & \text { JUNE } & \text { JULY } & \text { AUG } & \text { SEP } \\ 1950 & 3.32 & 2.25 & 2.33 & 2.50 & 3.12 & 2.76 & 2.98 & 2.79 & 3.00 & 1.44 & 0.65 & 1.03 \\ 1951 & 1.21 & 1.96 & 1.15 & 2.95 & 5.16 & 2.79 & 2.55 & 2.56 & 0.54 & 0.57 & 4.67 & 0.25 \\ 1952 & 1.19 & 2.06 & 1.44 & 3.15 & 3.50 & 3.69 & 26.2 & 17.2 & 13.6 & 4.16 & 3.42 & 1.44 \\ 1953 & 1.83 & 2.42 & 3.07 & 3.64 & 2.88 & 3.24 & 2.78 & 2.23 & 1.90 & 4.00 & 3.23 & 0.67 \\ 1954 & 2.55 & 2.75 & 2.51 & 2.28 & 2.24 & 1.87 & 3.51 & 4.92 & 1.62 & 0.91 & 0.99 & 1.76 \\ 1955 & 1.65 & 1.90 & 2.61 & 2.58 & 2.43 & 4.44 & 3.98 & 4.29 & 4.95 & 0.95 & 5.47 & 0.34 \\ 1956 & 0.85 & 1.77 & 1.62 & 2.35 & 2.38 & 2.04 & 1.69 & 1.96 & 0.16 & 0.73 & 3.92 & 0.07 \\ 1957 & 0.42 & 1.20 & 1.23 & 1.69 & 2.83 & 2.37 & 4.33 & 7.96 & 11.3 & 5.70 & 7.21 & 1.05\end{array}$

ANNUAL PEAK DISCHARGE, IN OUBIC FEET PER SECOND, AND CORRESPONDING GAGE HEIGHT, IN FEET, FOR EACH WATER YEAR

\begin{tabular}{|c|c|c|c|c|c|c|c|c|c|c|c|}
\hline $\begin{array}{l}\text { WATER } \\
\text { YEAR }\end{array}$ & DATE & $\begin{array}{c}\text { GAGE } \\
\text { HEIGHT }\end{array}$ & $\begin{array}{c}\text { PEAK } \\
\text { DISOHARGE }\end{array}$ & $\begin{array}{l}\text { WATER } \\
\text { YEAR }\end{array}$ & DATE & $\begin{array}{c}\text { GAGE } \\
\text { HEIGHT }\end{array}$ & $\begin{array}{c}\text { PEAK } \\
\text { DISCHARGE }\end{array}$ & $\begin{array}{l}\text { WATER } \\
\text { YEAR }\end{array}$ & DATE & $\begin{array}{c}\text { GAGE } \\
\text { HEIGHT }\end{array}$ & $\begin{array}{c}\text { PEAR } \\
\text { DISCHARGE }\end{array}$ \\
\hline $\begin{array}{l}1950 \\
1951 \\
1952 \\
1953\end{array}$ & $\begin{array}{l}\text { OCT. } 19,1949 \\
\text { AUG. } 29,1951 \\
\text { JAN. } 18,1952 \\
\text { JULY } 10,1953\end{array}$ & $\begin{array}{l}-\overline{4.80} \\
1.35 \\
5.00\end{array}$ & $\begin{array}{r}30 \\
1520 \\
112 \\
2140\end{array}$ & $\begin{array}{l}1956 \\
1957 \\
1960 \\
1961\end{array}$ & $\begin{array}{lll}\text { MAY } & 22,1956 \\
\text { JULY } 17,1957 \\
\text { ARR. } 10,1960 \\
\text { JULY } 31,1961\end{array}$ & $\begin{array}{l}1.88 \\
3.18 \\
1.37 \\
5.81\end{array}$ & $\begin{array}{r}236 \\
766 \\
67 \\
1680\end{array}$ & $\begin{array}{l}1964 \\
1965 \\
1966 \\
1967\end{array}$ & $\begin{array}{l}\text { AUG. } 02,1964 \\
\text { SEPP. 08, } 1965 \\
\text { JULY 17, } 1966 \\
\text { JULY 15, } 1967\end{array}$ & $\begin{array}{l}6.34 \\
1.48 \\
2.25 \\
2.86\end{array}$ & $\begin{array}{r}1950 \\
100 \\
275 \\
450\end{array}$ \\
\hline $\begin{array}{l}1954 \\
1955\end{array}$ & $\begin{array}{l}\text { SEPT.12, } 1954 \\
\text { AUG. } 16,1955\end{array}$ & $\begin{array}{l}1.13 \\
1.83\end{array}$ & $\begin{array}{r}78 \\
167\end{array}$ & $\begin{array}{l}1962 \\
1963\end{array}$ & $\begin{array}{l}\text { SEPT. 20, } 1962 \\
\text { AUG. } 18,1963\end{array}$ & $\begin{array}{l}2.02 \\
6.82\end{array}$ & $\begin{array}{r}290 \\
2200\end{array}$ & 1968 & & 6.10 & 1830 \\
\hline
\end{tabular}

${ }^{1}$ Peak discharge occurred between June 5 and Aug. 16. 


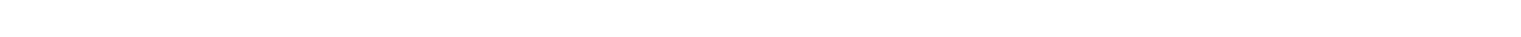
fram Harts Draw and $24 \mathrm{mi}$ northwest of Monticello.

DRAINAGE AREA. $-258 \mathrm{mi}^{2}$.

MEAN BASIN ELEVATION. $-6,580 \mathrm{ft}$.

PERIOD OF RECORD AVAIIABLE.--October 1949 to September 1957.

GAGE.-Water-stage recorder. Altitude of gage is 4,920 ft by barometer.

REMARKS.--Diversions for irrigation of 600 acres above station.

AVERAGE DISCHARGE.--8 years, $5.99 \mathrm{ft}^{3} / \mathrm{s}, 4,340$ acre- $\mathrm{ft} / \mathrm{yr}$.

EXTREMES FOR PERIOD OF RECORD.--Maximum discharge, 3,120 $\mathrm{ft}^{3} / \mathrm{s}$ Aug. 30, 1957, gage height, $9.2 \mathrm{ft}$ fran floodmark; no flow for many days in most years.

LONEST MEAN DISCHARGE, IN OBIC FEET FER SECOND, AND RANKING FOR THE INDICATED NUMBER OF CONSECUTIVE DAYS FOR EACH CIMATIC YEAR, AFRIL 1-MARQH 31

\begin{tabular}{|c|c|c|c|c|c|c|c|c|c|c|c|c|c|c|c|c|c|c|c|}
\hline YEAR & 1 & & 3 & & 7 & & 14 & & $\begin{array}{l}\text { CNSE } \\
30\end{array}$ & OTIVE & $\begin{array}{l}\text { DAYS } \\
60\end{array}$ & & 90 & & 120 & & 183 & & ALL \\
\hline $\begin{array}{l}1951 \\
1952 \\
1953 \\
1954 \\
1955\end{array}$ & $\begin{array}{l}0.20 \\
0.00 \\
0.50 \\
0.00 \\
0.00\end{array}$ & $\begin{array}{l}6 \\
1 \\
7 \\
2 \\
3\end{array}$ & $\begin{array}{l}0.20 \\
0.00 \\
0.50 \\
0.00 \\
0.00\end{array}$ & $\begin{array}{l}6 \\
1 \\
7 \\
2 \\
3\end{array}$ & $\begin{array}{l}0.21 \\
0.00 \\
0.50 \\
0.00 \\
0.00\end{array}$ & $\begin{array}{l}6 \\
1 \\
7 \\
2 \\
3\end{array}$ & $\begin{array}{l}0.30 \\
0.00 \\
0.50 \\
0.00 \\
0.00\end{array}$ & $\begin{array}{l}6 \\
1 \\
7 \\
2 \\
3\end{array}$ & $\begin{array}{l}0.33 \\
0.02 \\
0.93 \\
0.14 \\
0.00\end{array}$ & $\begin{array}{l}6 \\
4 \\
7 \\
5 \\
1\end{array}$ & $\begin{array}{l}0.61 \\
0.13 \\
1.19 \\
0.29 \\
1.10\end{array}$ & $\begin{array}{l}5 \\
3 \\
7 \\
4 \\
6\end{array}$ & $\begin{array}{l}0.77 \\
0.37 \\
1.19 \\
0.42 \\
1.00\end{array}$ & $\begin{array}{l}5 \\
3 \\
7 \\
4 \\
6\end{array}$ & $\begin{array}{l}0.76 \\
0.54 \\
1.80 \\
2.10 \\
1.40\end{array}$ & $\begin{array}{l}3 \\
2 \\
6 \\
7 \\
5\end{array}$ & $\begin{array}{l}1.10 \\
1.50 \\
2.60 \\
3.00 \\
2.80\end{array}$ & $\begin{array}{l}1 \\
3 \\
5 \\
7 \\
6\end{array}$ & $\begin{array}{c}2.10 \\
2.10 \\
17.0 \\
3.80 \\
3.40\end{array}$ \\
\hline $\begin{array}{l}1956 \\
1957\end{array}$ & $\begin{array}{l}0.00 \\
0.00\end{array}$ & $\begin{array}{l}4 \\
5\end{array}$ & $\begin{array}{l}0.00 \\
0.00\end{array}$ & $\begin{array}{l}4 \\
5\end{array}$ & $\begin{array}{l}0.00 \\
0.00\end{array}$ & $\begin{array}{l}4 \\
5\end{array}$ & $\begin{array}{l}0.00 \\
0.00\end{array}$ & $\begin{array}{l}4 \\
5\end{array}$ & $\begin{array}{l}0.00 \\
0.00\end{array}$ & $\begin{array}{l}2 \\
3\end{array}$ & $\begin{array}{l}0.00 \\
0.04\end{array}$ & $\frac{1}{2}$ & $\begin{array}{l}0.31 \\
0.20\end{array}$ & $\begin{array}{l}2 \\
1\end{array}$ & $\begin{array}{l}1.00 \\
0.22\end{array}$ & $\begin{array}{l}4 \\
1\end{array}$ & $\begin{array}{l}1.70 \\
1.10\end{array}$ & $\begin{array}{l}4 \\
2\end{array}$ & $\begin{array}{l}3.70 \\
1.70\end{array}$ \\
\hline
\end{tabular}

HIGHEST MEAN DISOHARGE, IN CUBIC FEET PER SECOND, AND RANKING FOR THE INDICATED NUMBER OF CONSEQUTIVE DAYS FOR EAOH WATER YEAR, OCTOBER 1 -SEPTEMBER 30

\begin{tabular}{|c|c|c|c|c|c|c|c|c|c|c|c|c|c|c|c|c|c|c|c|}
\hline YEAR & 1 & & 3 & & 7 & & 15 & & $\begin{array}{l}\text { CONSE } \\
30\end{array}$ & & $\begin{array}{l}\text { E DAYS } \\
60\end{array}$ & & 90 & & 120 & & 183 & & ALL \\
\hline 1950 & 255 & 1 & 94.0 & 3 & 43.0 & 3 & 22.0 & 4 & 12.0 & 5 & 7.60 & 5 & 6.40 & 5 & 7.00 & 4 & 5.40 & 4 & 3.80 \\
\hline
\end{tabular}

DURATION OF DISCHARGE FOR EACH WATER YEAR

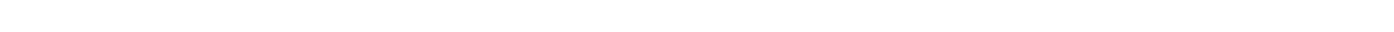
YEAR NUMBER OF DAYS IN OLASS

OBBIC FEET PER SECOND -DAYS

1950

19512953

$1952 \quad 5$

$\begin{array}{lll}1953 & 20 & 34\end{array}$

19548610

$\begin{array}{rrr}1954 & 86 & 10 \\ 1955 & 47 & 1\end{array}$

$1956126 \quad 8$

$\begin{array}{lr}1956126 & 8 \\ 19573022\end{array}$ $\begin{array}{llllllllllllllllllllll}13 & 12 & 29 & 26 & 33 & 10 & 32 & 15 & 17 & 18 & 20 & 68 & 17 & 13 & 15 & 9 & 8 & 3 & 3 & 1 & 1 & 1\end{array}$

$1 \quad 1383.8$

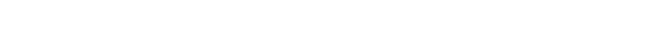

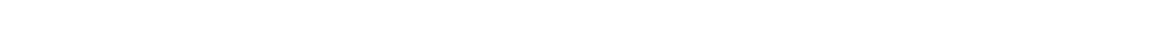

$\begin{array}{lllllllllllllll}4 & 7 & 13 & 5 & 12 & & 32 & 22 & 13 & 79 & 30 & 22 & 5 & 4 & 4\end{array}$

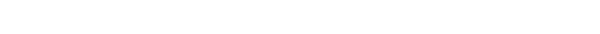

$618 \quad 30 \quad 510$ $\begin{array}{rr}5 & 5 \\ 2 & 1 \\ 4 & 1 \\ 14 & 7\end{array}$

$\begin{array}{cccccccccccc}2 & 3 & 3 & 5 & 1 & 2 & 15 & 18 & 14 & 3 & & 1 \\ 1 & & 1 & 1 & & 2 & 1 & & 2 & 1 & \end{array}$

$\begin{array}{lllllllllll}14 & 7 & 6 & 1 & 1 & 2 & 3 & 2 & 1 & 1 & 1\end{array}$

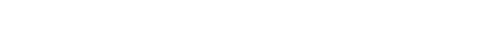

1113.6

687.8 
DURATION TABLE OF DISCHARGE FOR WATER YEARS 1950-57

$\begin{array}{ccc}\text { OBIC } & \text { ACQU- } \\ \text { FEET } & \text { MN- } & \text { PER- } \\ \text { PER TOTAL LATPED } & \text { OENT } \\ \text { G.ASS SECOND DAYS DAYS } & \text { DAYS }\end{array}$

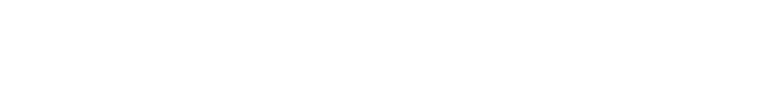

$\begin{array}{crc}\text { OUBIC } & \text { ACOU } \\ \text { FEET } & \text { MU- } & \text { PER- } \\ \text { PER TOTAL LATED } & \text { CENT } \\ \text { G.ASS SECOND DAYS } & \text { DAYS } & \text { DAYS }\end{array}$

$\begin{array}{rrrrr}0 & 0.00 & 338 & 2922 & 100.0 \\ 1 & 0.10 & 133 & 2584 & 88.4 \\ 2 & 0.13 & 0 & 2451 & 83.9 \\ 3 & 0.16 & 0 & 2451 & 83.9 \\ 4 & 0.20 & 80 & 2451 & 83.9 \\ 5 & 0.25 & 114 & 2371 & 81.1 \\ 6 & 0.32 & 0 & 2257 & 77.2 \\ 7 & 0.40 & 170 & 2257 & 77.2 \\ 8 & 0.51 & 103 & 2087 & 71.4\end{array}$

$\begin{array}{rrrrr}9 & 0.64 & 149 & 1984 & 67.9 \\ 10 & 0.81 & 27 & 1835 & 62.8 \\ 11 & 1.00 & 229 & 1808 & 61.9 \\ 12 & 1.30 & 118 & 1579 & 54.0 \\ 13 & 1.60 & 92 & 1461 & 50.0 \\ 14 & 2.00 & 373 & 1369 & 46.9 \\ 15 & 2.60 & 228 & 996 & 34.1 \\ 16 & 3.20 & 224 & 768 & 26.3 \\ 17 & 4.10 & 140 & 544 & 18.6\end{array}$

$\begin{array}{rrrrr}18 & 5.2 & 50 & 404 & 13.8 \\ 19 & 6.5 & 53 & 354 & 12.1 \\ 20 & 8.2 & 23 & 301 & 10.3 \\ 21 & 10.0 & 54 & 278 & 9.5 \\ 22 & 13.0 & 30 & 224 & 7.7 \\ 23 & 16.0 & 23 & 194 & 6.6 \\ 24 & 21.0 & 13 & 171 & 5.9 \\ 25 & 26.0 & 12 & 158 & 5.4 \\ 26 & 33.0 & 20 & 146 & 5.0\end{array}$

$\begin{array}{rrrrr}27 & 41.0 & 32 & 126 & 4.3 \\ 28 & 52.0 & 26 & 94 & 3.2 \\ 29 & 66.0 & 23 & 68 & 2.3 \\ 30 & 83.0 & 20 & 45 & 1.5 \\ 31 & 100.0 & 15 & 25 & 0.9 \\ 32 & 130.0 & 4 & 10 & 0.3 \\ 33 & 170.0 & 4 & 6 & 0.2 \\ 34 & 210.0 & 2 & 2 & 0.1\end{array}$

NONIHLY MEAN DISCHARGES, IN OBIC FEET PER SECOND, FOR EACH WATER YEAR

$\begin{array}{lllllllllllrr}\text { YEAR } & \text { OCT } & \text { NOV } & \text { DEC } & \text { JAN } & \text { FEB } & \text { MAR } & \text { AFR } & \text { MAY } & \text { JUNE } & \text { JULY } & \text { AUG } & \text { SEP } \\ 1950 & 10.8 & 2.57 & 3.72 & 4.00 & 10.2 & 1.47 & 1.00 & 4.09 & 5.02 & 1.29 & 0.35 & 1.45 \\ 1951 & 0.56 & 1.29 & 2.69 & 2.93 & 3.70 & 1.41 & 1.06 & 0.84 & 0.19 & 0.13 & 10.7 & 0.10 \\ 1952 & 0.45 & 0.95 & 1.15 & 3.94 & 2.50 & 2.95 & 53.0 & 65.6 & 51.7 & 4.69 & 4.05 & 1.05 \\ 1953 & 1.26 & 1.40 & 3.54 & 4.75 & 4.60 & 3.29 & 0.82 & 0.54 & 0.23 & 16.2 & 7.23 & 0.37 \\ 1954 & 8.69 & 2.41 & 1.91 & 2.00 & 2.94 & 1.59 & 1.14 & 4.00 & 0.35 & 2.18 & 0.55 & 8.85 \\ 1955 & 7.66 & 1.76 & 3.12 & 3.08 & 2.93 & 5.35 & 1.20 & 10.1 & 4.07 & 1.30 & 16.0 & 0.01 \\ 1956 & 0.00 & 1.41 & 2.99 & 2.94 & 3.09 & 0.75 & 0.30 & 1.25 & 0.00 & 1.75 & 7.95 & 0.03 \\ 1957 & 0.36 & 0.27 & 0.80 & 2.35 & 4.10 & 0.82 & 4.07 & 18.3 & 71.9 & 23.7 & 24.1 & 1.06\end{array}$

ANNUAL PEAK DISCHARGE, IN OUBIC FEET PER SECOND, AND CORRESPONDING GAGE HEIGHT, IN FEET, FOR EACH WATER YEAR

$\begin{array}{lcccccccccc}\begin{array}{l}\text { WATER } \\ \text { YEAR }\end{array} & \text { DATE } & \begin{array}{c}\text { GAGE } \\ \text { HEIGHT }\end{array} & \begin{array}{c}\text { PEAK } \\ \text { DISGHARGE }\end{array} & \begin{array}{c}\text { WATER } \\ \text { YEAR }\end{array} & \text { DATE } & \begin{array}{c}\text { GAGE } \\ \text { HEIGHT }\end{array} & \begin{array}{c}\text { PEAK } \\ \text { DISCHARGE }\end{array} & \begin{array}{c}\text { WATER } \\ \text { YEAR }\end{array} & \begin{array}{c}\text { GAGE } \\ \text { DATE }\end{array} & \begin{array}{c}\text { PEAK } \\ \text { HEIGHT }\end{array} \\ \text { DISCHARGE }\end{array}$

GREEN RIVER BASIN

09217500 BLACKS FORK ABOVE BL.ACKS FORK RANGER STATION, UT

LOCATION. -Lat $40^{\circ} 56^{\prime} 00^{\prime \prime}$, long $110^{\circ} 36^{\prime} 10^{\prime \prime}$, in sec.5, T.2 N., R.12 E., Sumnit County, Hydrologic Unit 14040107, 1 mi upstream fram Middle Fork, $3 \mathrm{mi}$ upstream fram Blacks Fork ranger station, and $29 \mathrm{mi}$ southwest of Fort Bridger, WY.

DRAINAGE AREA. $-48.8 \mathrm{mi}^{2}$.

FERIOD OF RECORD AVAII.ABLE.--October 1937 to December 1938.

GAGE.-Water-stage recorder. Altitude of gage is 9,050 ft from topographic map.

EXIREMES FOR PERIOD OF RECORD.-Maximum discharge, $643 \mathrm{ft}^{3} / \mathrm{s}$ June 6,1938 , gage height, $3.92 \mathrm{ft}$; minimum not determined, occurred during period of no gage-height record.

HIGHEST MEAN DISCHARGE, IN GUBIC FEET PER SECOND, AND RANKING FOR THE INDICATED NUMBER OF CONSEQITIVE DAYS FOR EAOH WATER YEAR, OCTOBER 1-SEPTEMBER 30

\begin{tabular}{|c|c|c|c|c|c|c|c|c|c|c|c|c|c|c|c|c|c|c|c|}
\hline YEAR & & & & & & & & & & WT & VE $D$ & & & & & & & & \\
\hline & 1 & & 3 & & 7 & & 15 & & 30 & & 60 & & 9 & & 120 & & 183 & & ALL \\
\hline 193 & 524 & 1 & 517 & 1 & 488 & 1 & 454 & 1 & 357 & 1 & 256 & 1 & 201 & 1 & 162 & 1 & 115 & 1 & 68.0 \\
\hline
\end{tabular}

DURATION OF DISCHARGE FOR EACH WATER YEAR

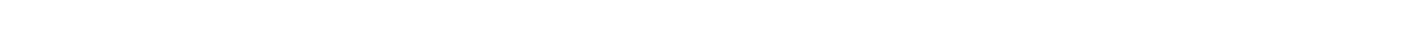
YEAR

NUMBER OF DAYS IN CLASS OUBIC FEET
PER SECOND -DAYS

$\begin{array}{llllllllllllllllllllllllllllllllllllllll}1938 & 1 & 9 & 5 & 21 & 20 & 39 & 31 & 42 & 63 & 14 & 8 & 5 & 3 & 8 & 1 & 4 & 4 & 16 & 3 & 8 & 4 & 7 & 7 & 2 & 6 & 6 & 6 & 4 & 3 & 5 & 2 & 6 & 2 & 24835.0\end{array}$ 
GREEN RIVER BASIN

09217500 BLACKS FORK ABOVE BLACRS FORK RANGER STATION, UT--Continued

DURATION TABIE OF DISCHARGE FOR WATER YEAR 1938
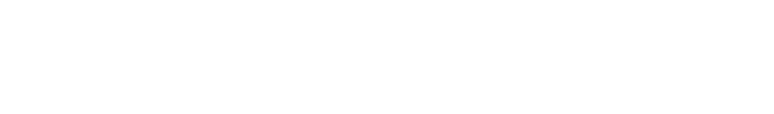

$\begin{array}{ccc}\text { CUBIC } & \text { ACO- } \\ \text { FEET } & \text { MU- } & \text { PER- } \\ \text { PER TOTAL LATED } & \text { CENT } \\ \text { CIJASS SECOND DAYS DAYS } & \text { DAYS }\end{array}$

$\begin{array}{crc}\text { CUBIC } & \text { ACOU- } \\ \text { FEET } & \text { MU- } & \text { PER- } \\ \text { PER TOTAL LATED } & \text { CENT } \\ \text { CLASS SECOND DAYS DAYS DAYS }\end{array}$

$\begin{array}{rrrrr}0 & 0.00 & 0 & 365 & 100.0 \\ 1 & 10.00 & 1 & 365 & 100.0 \\ 2 & 11.00 & 9 & 364 & 99.7 \\ 3 & 13.00 & 5 & 355 & 97.3 \\ 4 & 14.00 & 21 & 350 & 95.9 \\ 5 & 16.00 & 20 & 329 & 90.1 \\ 6 & 18.00 & 39 & 309 & 84.7 \\ 7 & 21.00 & 31 & 270 & 74.0 \\ 8 & 23.00 & 42 & 239 & 65.5\end{array}$

$\begin{array}{rrrrr}9 & 26.00 & 63 & 197 & 54.0 \\ 10 & 29.00 & 14 & 134 & 36.7 \\ 11 & 33.00 & 8 & 120 & 32.9 \\ 12 & 37.00 & 5 & 112 & 30.7 \\ 13 & 42.00 & 3 & 107 & 29.3 \\ 14 & 47.00 & 8 & 104 & 28.5 \\ 15 & 54.00 & 1 & 96 & 26.3 \\ 16 & 60.00 & 4 & 95 & 26.0 \\ 17 & 68.00 & 4 & 91 & 24.9\end{array}$

$\begin{array}{rrr}18 & 77.0 & 16 \\ 19 & 86.0 & 3 \\ 20 & 97.0 & 8 \\ 21 & 110.0 & 4 \\ 22 & 120.0 & 7 \\ 23 & 140.0 & 7 \\ 24 & 160.0 & 2 \\ 25 & 180.0 & 6 \\ 26 & 200.0 & 6\end{array}$
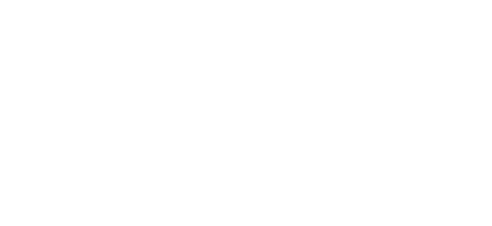

$\begin{array}{rrrrr}27 & 230.0 & 6 & 28 & 7.7 \\ 28 & 250.0 & 4 & 22 & 6.0 \\ 29 & 290.0 & 0 & 18 & 4.9 \\ 30 & 320.0 & 3 & 18 & 4.9 \\ 31 & 360.0 & 5 & 15 & 4.1 \\ 32 & 410.0 & 2 & 10 & 2.7 \\ 33 & 460.0 & 6 & 8 & 2.2 \\ 34 & 520.0 & 2 & 2 & 0.5\end{array}$

MONTHLY MEAN DISCHARGES, IN CUBIC FEET PER SECOND, FOR EACH WATER YEAR

\begin{tabular}{|c|c|c|c|c|c|c|c|c|c|c|c|c|}
\hline YEAR & $\infty \mathrm{CT}$ & $\mathrm{NOV}$ & $\mathrm{DEC}$ & JAN & FEB & MAR & APR & MAY & JUNE & JULY & AUG & SEP \\
\hline 1938 & 27.0 & 18.8 & 14.1 & 23.3 & 19.2 & 23.9 & 49.9 & 203 & 306 & 76.7 & 28.0 & \\
\hline
\end{tabular}

09217900 BLACKS FORK NEAR RCBERTSON, WY

LOCATION.--Lat $40^{\circ} 57^{\prime} 53^{\prime \prime}$, long $110^{\circ} 34^{\prime} 38^{\prime \prime}$, in NW'35W/4 sec. 27, T. 3 N., R. 12 E., Summit County, UT, Hydrologic Unit 14140107 , on left bank $1 \mathrm{mi}$ downstream from East Fork, $2.5 \mathrm{mi}$ south of Utah-Wyoming State i ine, and $17 \mathrm{mi}$ south of Robertson.

DRAINAGE AREA. $-130 \mathrm{mi}^{2}$, approximately.

MEAN BASIN ELEVATION.- $-10,640 \mathrm{ft}$.

PERIOD OF RECORD AVAILABLE.--October 1937 to July 1939 (published as "at Blacks Fork Ranger Station"), July 1966 to September 1981.

GAGE.-Water-stage recorder. Datum of gage is $8,804.8 \mathrm{ft}$, NGVD of 1929, levels by Bureau of Reclamation. Datums published from October 1968 to September 1978 are incorrect. October 1937 to July 1939, water-stage recorder at site $85 \mathrm{ft}$ upstream at different datum.

AVERAGE DISCHARGE.--16 years (water years 1938, 1967-81), $155 \mathrm{ft}^{3} / \mathrm{s}, 112,300$ acre-ft/yr.

EXTREMES FOR PERIOD OF RECORD.-Maximum discharge, 2,420 $\mathrm{ft}^{3} / \mathrm{s}$ June 9, 1981; maximum gage height, $4.91 \mathrm{ft}$ June 6, 1968 ; minimum daily discharge, $5.5 \mathrm{ft}^{3} / \mathrm{s} \mathrm{Jan} .7,1977$.

LOWEST MEAN DISCHARGE, IN CUBIC FEET PER SECOND, AND RANKING FOR THE INDICATED NUMBER OF CONSECUTIVE DAYS FOR EACH CLIMATIC YEAR, APRIL 1-MARCH 31

\begin{tabular}{|c|c|c|c|c|c|c|c|c|c|c|c|c|c|c|c|c|c|c|c|c|}
\hline YEAR & 1 & & 3 & & 7 & & 14 & & $\begin{array}{l}\text { CONS } \\
30\end{array}$ & ECUT & $\begin{array}{l}\text { E DAYS } \\
60\end{array}$ & & 90 & & 120 & & 183 & & ALCL & \\
\hline $\begin{array}{l}1968 \\
1969 \\
1970\end{array}$ & $\begin{array}{l}18.0 \\
25.0 \\
23.0\end{array}$ & $\begin{array}{r}8 \\
12 \\
9\end{array}$ & $\begin{array}{l}18.0 \\
25.0 \\
25.0\end{array}$ & $\begin{array}{r}8 \\
11 \\
12\end{array}$ & $\begin{array}{l}18.0 \\
26.0 \\
26.0\end{array}$ & $\begin{array}{r}8 \\
11 \\
12\end{array}$ & $\begin{array}{l}19.0 \\
29.0 \\
26.0\end{array}$ & $\begin{array}{r}8 \\
14 \\
11\end{array}$ & $\begin{array}{l}19.0 \\
30.0 \\
26.0\end{array}$ & $\begin{array}{r}7 \\
14 \\
10\end{array}$ & $\begin{array}{l}21.0 \\
35.0 \\
26.0\end{array}$ & $\begin{array}{r}8 \\
14 \\
9\end{array}$ & $\begin{array}{l}22.0 \\
36.0 \\
27.0\end{array}$ & $\begin{array}{r}7 \\
14 \\
9\end{array}$ & $\begin{array}{l}25.0 \\
36.0 \\
29.0\end{array}$ & $\begin{array}{r}8 \\
13 \\
9\end{array}$ & $\begin{array}{l}34.0 \\
40.0 \\
37.0\end{array}$ & $\begin{array}{r}8 \\
12 \\
9\end{array}$ & $\begin{array}{l}180 \\
184 \\
142\end{array}$ & $\begin{array}{r}11 \\
12 \\
4\end{array}$ \\
\hline $\begin{array}{l}1971 \\
1972 \\
1973 \\
1974 \\
1975\end{array}$ & $\begin{array}{l}24.0 \\
23.0 \\
27.0 \\
26.0 \\
15.0\end{array}$ & $\begin{array}{r}11 \\
10 \\
14 \\
13 \\
7\end{array}$ & $\begin{array}{l}24.0 \\
24.0 \\
27.0 \\
27.0 \\
15.0\end{array}$ & $\begin{array}{r}9 \\
10 \\
13 \\
14 \\
7\end{array}$ & $\begin{array}{l}24.0 \\
24.0 \\
28.0 \\
28.0 \\
16.0\end{array}$ & $\begin{array}{r}9 \\
10 \\
13 \\
14 \\
6\end{array}$ & $\begin{array}{l}25.0 \\
24.0 \\
28.0 \\
28.0 \\
16.0\end{array}$ & $\begin{array}{r}10 \\
9 \\
12 \\
13 \\
4\end{array}$ & $\begin{array}{l}26.0 \\
25.0 \\
29.0 \\
29.0 \\
17.0\end{array}$ & $\begin{array}{r}11 \\
9 \\
12 \\
13 \\
4\end{array}$ & $\begin{array}{l}31.0 \\
26.0 \\
31.0 \\
33.0 \\
17.0\end{array}$ & $\begin{array}{r}12 \\
10 \\
11 \\
13 \\
3\end{array}$ & $\begin{array}{l}32.0 \\
28.0 \\
32.0 \\
36.0 \\
19.0\end{array}$ & $\begin{array}{r}12 \\
10 \\
11 \\
13 \\
3\end{array}$ & $\begin{array}{l}35.0 \\
31.0 \\
34.0 \\
39.0 \\
22.0\end{array}$ & $\begin{array}{r}12 \\
10 \\
11 \\
14 \\
4\end{array}$ & $\begin{array}{l}41.0 \\
39.0 \\
39.0 \\
49.0 \\
26.0\end{array}$ & $\begin{array}{r}13 \\
10 \\
11 \\
14 \\
5\end{array}$ & $\begin{array}{l}156 \\
200 \\
171 \\
180 \\
151\end{array}$ & $\begin{array}{r}7 \\
13 \\
9 \\
10 \\
5\end{array}$ \\
\hline $\begin{array}{l}1976 \\
1977 \\
1978 \\
1979 \\
1980\end{array}$ & $\begin{array}{c}14.0 \\
5.50 \\
10.0 \\
13.0 \\
15.0\end{array}$ & $\begin{array}{l}5 \\
1 \\
2 \\
4 \\
6\end{array}$ & $\begin{array}{c}14.0 \\
5.60 \\
11.0 \\
14.0 \\
15.0\end{array}$ & $\begin{array}{l}4 \\
1 \\
2 \\
5 \\
6\end{array}$ & $\begin{array}{c}15.0 \\
5.80 \\
13.0 \\
14.0 \\
18.0\end{array}$ & $\begin{array}{l}5 \\
1 \\
2 \\
3 \\
7\end{array}$ & $\begin{array}{c}17.0 \\
6.00 \\
16.0 \\
15.0 \\
18.0\end{array}$ & $\begin{array}{l}6 \\
1 \\
5 \\
2 \\
7\end{array}$ & $\begin{array}{c}19.0 \\
6.70 \\
17.0 \\
15.0 \\
19.0\end{array}$ & $\begin{array}{l}8 \\
1 \\
5 \\
2 \\
6\end{array}$ & $\begin{array}{c}20.0 \\
7.50 \\
20.0 \\
16.0 \\
20.0\end{array}$ & $\begin{array}{l}5 \\
1 \\
6 \\
2 \\
7\end{array}$ & $\begin{array}{c}22.0 \\
8.50 \\
21.0 \\
17.0 \\
20.0\end{array}$ & $\begin{array}{l}8 \\
1 \\
6 \\
2 \\
4\end{array}$ & $\begin{array}{c}24.0 \\
9.30 \\
22.0 \\
19.0 \\
20.0\end{array}$ & $\begin{array}{l}7 \\
1 \\
5 \\
2 \\
3\end{array}$ & $\begin{array}{l}31.0 \\
17.0 \\
24.0 \\
23.0 \\
25.0\end{array}$ & $\begin{array}{l}7 \\
1 \\
3 \\
2 \\
4\end{array}$ & $\begin{array}{c}207 \\
95.0 \\
83.0 \\
159 \\
103\end{array}$ & $\begin{array}{r}14 \\
2 \\
1 \\
8 \\
3\end{array}$ \\
\hline 1981 & 12.0 & 3 & 13.0 & 3 & 14.0 & 4 & 15.0 & 3 & 17.0 & 3 & 19.0 & 4 & 20.0 & 5 & 23.0 & 6 & 28.0 & 6 & 152 & 6 \\
\hline
\end{tabular}


GREEN RIVER BASIN

09217900 BLACKS FORK NEAR ROBERTSON, WY-Continued

HIGHEST MEAN DISCHARGE, IN OBIC FEET PER SECOND, AND RANKING FOR THE INDICATED NUMBER OF CONSECUTIVE DAYS FOR EACH WATER YEAR, $O$ CTOBER 1-SEPTEMBER 30

$1967 \quad 1370$

$\begin{array}{rr}1968 & 1810 \\ 1969 & 936\end{array}$

$\begin{array}{rr}1969 & 936 \\ 1970 & 1100\end{array}$

$1971 \quad 1760$

$1972 \quad 1690$

19731490

19751560

$\begin{array}{llll}1976 & 697 & 16 & 689 \\ 1977 & 800 & 15 & 793\end{array}$

$\begin{array}{rr}1977 & 800 \\ 1978 & 1620\end{array}$

19791370

19801210

19811840

$\begin{array}{ll}6 & 1550 \\ 9 & 1140\end{array}$

$\begin{array}{rr}9 & 1140 \\ 11 & 1160\end{array}$
CONSEOUTIVE DAYS

15

30

$\begin{array}{rr}10 & 1040 \\ 9 & 1100 \\ 4 & 1290 \\ 14 & 795 \\ 12 & 941\end{array}$

$\begin{array}{rrrr}8 & 814 & 11 & 594 \\ 7 & 907 & 7 & 790 \\ 4 & 1170 & 1 & 789\end{array}$

$\begin{array}{rrrr}7 & 907 & 7 & 790 \\ 4 & 1170 & 1 & 789 \\ 13 & 690 & 13 & 528 \\ 11 & 790 & 12 & 645\end{array}$

60

-12
9
9

90
466
605
589
423
481

$\begin{array}{rrrrrr} & 120 & & 183 & & \text { ALL } \\ 12 & 380 & 12 & 273 & 10 & 157 \\ 3 & 476 & 3 & 327 & 3 & 185 \\ 4 & 473 & 4 & 327 & 4 & 181 \\ 13 & 343 & 13 & 247 & 13 & 143 \\ 11 & 381 & 11 & 269 & 11 & 153\end{array}$

$31710 \quad 11670$

$\begin{array}{llllll}1 & 1480 & 1 & 1120 & 4 & 812 \\ 3 & 1410 & 2 & 1130 & 3 & 766\end{array}$

$\begin{array}{rrrrrr}3 & 1410 & 2 & 1130 & 3 & 766 \\ 8 & 914 & 12 & 837 & 10 & 653\end{array}$

$\begin{array}{ll}7 & 1030 \\ 5 & 1390\end{array}$

$\begin{array}{rr}9 & 874 \\ 3 & 1170\end{array}$

$\begin{array}{ll}4 & 1310 \\ 7 & 1470\end{array}$

51390

2961

$16 \quad 664$

$5 \quad 1440$

$\begin{array}{rr}12 & 869 \\ 11 & 1030\end{array}$

$\begin{array}{rrrrrr}16 & 608 & 15 & 542 & 15 & 398 \\ 15 & 603 & 16 & 415 & 16 & 28 \\ 6 & 1270 & 5 & 1020 & 5 & 724\end{array}$

$\begin{array}{rrrrrr}6 & 1270 & 5 & 1020 & 5 & 724 \\ 13 & 689 & 14 & 592 & 14 & 417\end{array}$

$11 \quad 974$

$10 \quad 846$

9640

21540

$6 \quad 927$

$6 \quad 623$

$\begin{array}{ll}2 & 635 \\ 5 & 562 \\ 8 & 530 \\ 7 & 508\end{array}$

2511

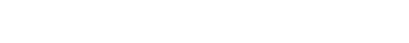

DURATION OF DISCHARGE FOR EACH WATER YEAR

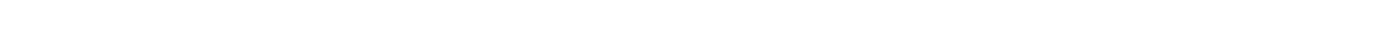
YEAR

NUMBER OF DAYS IN CLASS CUBIC FEET
PER SECOND
-DAYS

1938
1967
1968
1969

$\begin{array}{llllllllllllllllllllllll}3 & 7 & 13 & 73 & 54 & 22 & 37 & 14 & 13 & 17 & 10 & 6 & 13 & 13 & 12 & 8 & 7 & 4 & 10 & 8 & 4 & 4 & 7 & 6\end{array}$

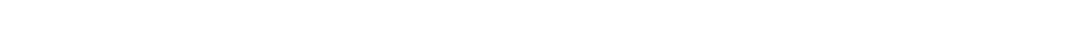

$\begin{array}{llllllllllllllllllllllll}45 & 32 & 23 & 26 & 28 & 13 & 28 & 10 & 9 & 10 & 8 & 17 & 9 & 7 & 6 & 4 & 6 & 6 & 4 & 4 & 3 & 8 & 6\end{array}$

$\begin{array}{rrrrrrrrrrrrrrrrrrrrrrrrrrrr}41 & 59 & 46 & 17 & 35 & 32 & 17 & 11 & 13 & 11 & 6 & 7 & 8 & 5 & 1 & 6 & 8 & 5 & 7 & 6 & 15 & 8 & 1\end{array}$

1970

$\begin{array}{lllllllllllllllllllllllll}11 & 34 & 32 & 36 & 63 & 26 & 17 & 15 & 11 & 8 & 6 & 11 & 14 & 7 & 5 & 9 & 9 & 10 & 7 & 9 & 7 & 5 & 1 & 3 & 9\end{array}$

$\begin{array}{llllllllllllllllllllllllll}38 & 46 & 17 & 45 & 65 & 38 & 20 & 4 & 8 & 4 & 4 & 10 & 8 & 7 & 2 & 3 & 6 & 3 & 6 & 6 & 6 & 4 & 5 & 6 & 5\end{array}$

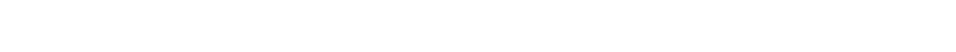

1973

1974
1975

$\begin{array}{llll}1 & 31 & 38 & 75 \\ 25 & 46 & 37 & 13\end{array}$

$\begin{array}{rrrrrrrrrrrrrrrrrrrrrrrrrrrrr}2 & 64 & 36 & 25 & 46 & 37 & 13 & 9 & 7 & 7 & 12 & 6 & 3 & 6 & 3 & 12 & 9 & 3 & 4 & 3 & 5 & 9 & 5 & 8 & 8 & 8 & 10 & 5\end{array}$

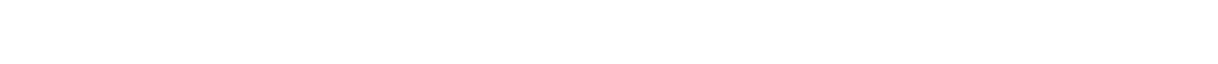

1980

$\begin{array}{lllllllllllllllllllllllllll}717 & 17 & 97 & 20 & 22 & 17 & 30 & 14 & 22 & 10 & 8 & 4 & 6 & 3 & 5 & 6 & 6 & 5 & 5 & 7 & 9 & 5 & 6 & 3 & 8 & 4 & 2\end{array}$

$\begin{array}{lllllllllllllllllllllllllll}37 & 23 & 37 & 33 & 42 & 36 & 22 & 6 & 11 & 22 & 12 & 9 & 9 & 7 & 7 & 2 & 5 & 11 & 4 & 7 & 7 & 6 & 7 & 1 & 1 & 1\end{array}$

$\begin{array}{llllllllllllllllllllllllll}1 & 29 & 89 & 22 & 13 & 27 & 27 & 21 & 9 & 14 & 7 & 7 & 7 & 4 & 10 & 9 & 6 & 5 & 7 & 8 & 10 & 3 & 10 & 10 & 9 & 2\end{array}$

1981

$\begin{array}{llllllllllll}1 & 8 & 19 & 30 & 40 & 30 & 35 & 27 & 32 & 21 & 15 & 10\end{array}$

$\begin{array}{lllllllllllllllll}1 & 5 & 2 & 12 & 12 & 12 & 5 & 3 & 6 & 11 & 3 & 3 & 5 & 1 & 3 & 3 & 1\end{array}$

DURATION TABIE OF DISCHARGE FOR WATER YEARS 1938, 1967-81

$\begin{array}{ccc}\text { CUBIC } & \text { ACCU- } \\ \text { FEET } & \text { MU- } & \text { PER- } \\ \text { PER TOTAL LATEED } & \text { CENT } \\ \text { CIASS SECOND DAYS DAYS } & \text { DAYS }\end{array}$

$\begin{array}{rrrrr}0 & 0.00 & 0 & 5844 & 100.0 \\ 1 & 5.50 & 13 & 5844 & 100.0 \\ 2 & 6.60 & 23 & 5831 & 99.8 \\ 3 & 7.80 & 19 & 5808 & 99.4 \\ 4 & 9.30 & 36 & 5789 & 99.1 \\ 5 & 11.00 & 23 & 5753 & 98.4 \\ 6 & 13.00 & 73 & 5730 & 98.0 \\ 7 & 16.00 & 167 & 5657 & 96.8 \\ 8 & 19.00 & 292 & 5490 & 93.9\end{array}$

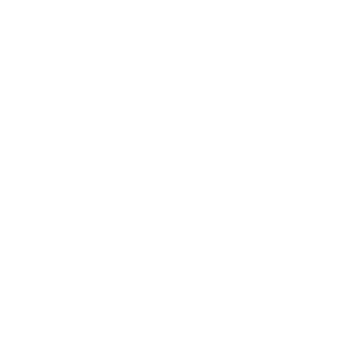

$\begin{array}{lll}\text { CUBIC } & \text { ACOU- } \\ \text { FEET TOTAL MU- } & \text { PER- } \\ \text { PER TOTED } & \text { CENT }\end{array}$ CLASS SECOND DAYS DAYS DAYS

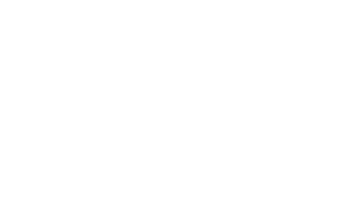

$\begin{array}{ccc}\text { CUBIC } & \text { ACOU- } \\ \text { FEET } & \text { MU- } & \text { PER- } \\ \text { PER TOTAL LATED } & \text { CENT }\end{array}$ CLASS SECOND DAYS DAYS DAYS

$\begin{array}{rrrrr}27 & 530.0 & 116 & 529 & 9.1 \\ 28 & 630.0 & 106 & 413 & 7.1 \\ 29 & 750.0 & 102 & 307 & 5.3 \\ 30 & 900.0 & 86 & 205 & 3.5 \\ 31 & 1100.0 & 48 & 119 & 2.0 \\ 32 & 1300.0 & 40 & 71 & 1.2 \\ 33 & 1500.0 & 29 & 31 & 0.5 \\ 34 & 1800.0 & 2 & 2 & 0.0\end{array}$


GREEN RIVER BASIN

09217900 BLACKS FORK NEAR ROBERTSON, WY--Continued

MONHLY MEAN DISGHARGES, IN UBIC FEET PER SECOND, FOR EACH WATER YEAR

\begin{tabular}{|c|c|c|c|c|c|c|c|c|c|c|c|c|}
\hline YEAR & OCT & $\mathrm{NON}$ & $\mathrm{DEC}$ & JAN & FEB & MAR & AFR & MAY & JUNE & JULY & AUG & SEP \\
\hline $\begin{array}{l}1938 \\
1967 \\
1968 \\
1969 \\
1970\end{array}$ & $\begin{array}{l}58.9 \\
66.9 \\
56.5 \\
51.5 \\
53.3\end{array}$ & $\begin{array}{l}43.7 \\
47.6 \\
43.9 \\
39.5 \\
50.4\end{array}$ & $\begin{array}{l}33.3 \\
41.5 \\
34.6 \\
37.2 \\
34.9\end{array}$ & $\begin{array}{l}39.1 \\
34.3 \\
23.3 \\
37.1 \\
26.7\end{array}$ & $\begin{array}{l}31.2 \\
29.6 \\
19.8 \\
34.6 \\
26.3\end{array}$ & $\begin{array}{l}36.3 \\
26.9 \\
23.4 \\
38.6 \\
27.2\end{array}$ & $\begin{array}{l}94.9 \\
29.0 \\
30.4 \\
77.7 \\
32.6\end{array}$ & $\begin{array}{l}455 \\
337 \\
210 \\
616 \\
414\end{array}$ & $\begin{array}{r}711 \\
855 \\
1162 \\
421 \\
744\end{array}$ & $\begin{array}{l}211 \\
536 \\
350 \\
214 \\
257\end{array}$ & $\begin{array}{c}80.6 \\
138 \\
150 \\
90.9 \\
84.9\end{array}$ & $\begin{array}{l}85.2 \\
66.1 \\
71.8 \\
53.3 \\
85.6\end{array}$ \\
\hline $\begin{array}{l}1971 \\
1972 \\
1973 \\
1974 \\
1975\end{array}$ & $\begin{array}{l}55.7 \\
56.3 \\
53.0 \\
72.5 \\
35.9\end{array}$ & $\begin{array}{l}48.8 \\
51.2 \\
43.7 \\
62.0 \\
30.7\end{array}$ & $\begin{array}{l}44.5 \\
41.9 \\
38.2 \\
50.0 \\
31.1\end{array}$ & $\begin{array}{l}35.2 \\
30.7 \\
35.0 \\
41.4 \\
22.2\end{array}$ & $\begin{array}{l}33.4 \\
24.5 \\
33.0 \\
36.9 \\
16.5\end{array}$ & $\begin{array}{l}27.6 \\
28.2 \\
29.0 \\
29.2 \\
18.1\end{array}$ & $\begin{array}{l}90.7 \\
41.3 \\
41.1 \\
48.1 \\
19.4\end{array}$ & $\begin{array}{l}386 \\
506 \\
453 \\
628 \\
134\end{array}$ & $\begin{array}{r}1074 \\
969 \\
727 \\
690 \\
897\end{array}$ & $\begin{array}{r}426 \\
193 \\
352 \\
185 \\
1003\end{array}$ & $\begin{array}{c}131 \\
65.5 \\
165 \\
63.5 \\
179\end{array}$ & $\begin{array}{r}68.5 \\
50.4 \\
125 \\
38.5 \\
67.1\end{array}$ \\
\hline $\begin{array}{l}1976 \\
1977 \\
1978 \\
1979 \\
1980\end{array}$ & $\begin{array}{l}47.2 \\
37.2 \\
29.6 \\
31.3 \\
35.1\end{array}$ & $\begin{array}{l}39.6 \\
26.4 \\
24.2 \\
30.0 \\
36.8\end{array}$ & $\begin{array}{l}31.1 \\
11.1 \\
24.1 \\
24.4 \\
20.8\end{array}$ & $\begin{array}{c}23.0 \\
6.73 \\
23.1 \\
18.9 \\
19.5\end{array}$ & $\begin{array}{c}20.0 \\
9.32 \\
18.9 \\
15.4 \\
20.7\end{array}$ & $\begin{array}{l}23.6 \\
10.2 \\
26.4 \\
16.4 \\
19.0\end{array}$ & $\begin{array}{l}35.1 \\
54.9 \\
57.4 \\
41.2 \\
46.7\end{array}$ & $\begin{array}{l}345 \\
155 \\
264 \\
363 \\
325\end{array}$ & $\begin{array}{r}406 \\
413 \\
1018 \\
421 \\
824\end{array}$ & $\begin{array}{l}158 \\
115 \\
306 \\
147 \\
327\end{array}$ & $\begin{array}{l}57.4 \\
71.5 \\
79.8 \\
70.2 \\
77.7\end{array}$ & $\begin{array}{l}37.3 \\
43.4 \\
46.9 \\
38.8 \\
50.9\end{array}$ \\
\hline 1981 & 39.6 & 35.7 & 31.1 & 19.1 & 18.4 & 23.3 & 97.0 & 374 & 869 & 159 & 59.7 & 51.8 \\
\hline
\end{tabular}

ANNUAL FEAK DISGHARGE, IN OUBIC FEET FER SECOND, AND CORRESPONDING GAGE HEIGHT, IN FEET, FOR EAOH WATER YEAR

\begin{tabular}{|c|c|c|c|c|c|c|c|c|c|c|c|}
\hline $\begin{array}{l}\text { WATER } \\
\text { YEAR }\end{array}$ & DATE & $\begin{array}{c}\text { GAGE } \\
\text { HEIGHT }\end{array}$ & $\begin{array}{c}\text { FEAK } \\
\text { DISCHARGE }\end{array}$ & $\begin{array}{l}\text { WATERR } \\
\text { YEAR }\end{array}$ & DATE & $\begin{array}{c}\text { GAGE } \\
\text { HEIGHT }\end{array}$ & $\begin{array}{c}\text { PEAK } \\
\text { DISQHARGE }\end{array}$ & $\begin{array}{l}\text { WATER } \\
\text { YEAR }\end{array}$ & DATE & $\begin{array}{c}\text { GAGE } \\
\text { HEIGHT }\end{array}$ & $\begin{array}{c}\text { PEAK } \\
\text { DISCHARGE }\end{array}$ \\
\hline $\begin{array}{l}1938 \\
1939 \\
1967 \\
1968 \\
1969\end{array}$ & $\begin{array}{l}\text { JUNE 05, } 1938 \\
\text { MAY } 04,1939 \\
\text { JUNE } 23,1967 \\
\text { JUNE } 06,1968 \\
\text { MAY } 26,1969\end{array}$ & $\begin{array}{l}4.90 \\
4.83 \\
4.29 \\
4.91 \\
3.70 \\
3.77\end{array}$ & $\begin{array}{l}1400 \\
1020 \\
1540 \\
2160 \\
1100\end{array}$ & $\begin{array}{l}1971 \\
1972 \\
1973 \\
1974 \\
1975 \\
1976\end{array}$ & $\begin{array}{l}\text { JUNE } 18,1971 \\
\text { JUNE } 04,1972 \\
\text { JUNE } 10,1973 \\
\text { MAY 29, } 1974 \\
\text { JULY 11, } 1975\end{array}$ & $\begin{array}{l}4.36 \\
4.25 \\
3.77 \\
3.94 \\
3.92\end{array}$ & $\begin{array}{l}2080 \\
2070 \\
1720 \\
1980 \\
2160\end{array}$ & $\begin{array}{l}1977 \\
1978 \\
1979 \\
1980 \\
1981\end{array}$ & $\begin{array}{l}\text { JUNE } 04,1977 \\
\text { JUNE } 15,1978 \\
\text { MAY } 28,1979 \\
\text { JUNE } 12,1980 \\
\text { JUNE } 09,1981\end{array}$ & $\begin{array}{l}2.55 \\
3.57 \\
3.44 \\
3.24 \\
3.87\end{array}$ & $\begin{array}{r}866 \\
1890 \\
1700 \\
1440 \\
2420\end{array}$ \\
\hline
\end{tabular}

MAGNTUUDE AND PROBABIITTY OF ANNUAL IONEST MEAN DISCHARGE BASED ON CIIMATIC YEARS $1968-8$

MAGNITUDE AND PROBABILITY OF ANNUAL HIGHEST MEAN DISGHARGE BASED ON WATER YEARS 1938 AND 1967-81

\begin{tabular}{|c|c|c|c|c|c|c|}
\hline \multirow{2}{*}{$\begin{array}{l}\text { PERIOD } \\
\text { (CON- } \\
\text { SEOU- } \\
\text { TIVE } \\
\text { DAYS) }\end{array}$} & \multicolumn{6}{|c|}{$\begin{array}{l}\text { DISCHARGE, IN OUBIC FEET PER SECOND, FOR } \\
\text { INDICATED REQURRENCE INTERVAL, IN YEARS, AND } \\
\text { ANNUAL NONEXCEEDANCE FRCBABILITY, IN EERCENT }\end{array}$} \\
\hline & $\begin{array}{c}2 \\
50 \%\end{array}$ & $\begin{array}{c}5 \\
208\end{array}$ & $\begin{array}{l}10 \\
108\end{array}$ & $\begin{array}{l}20 \\
58\end{array}$ & $\begin{array}{l}50 \\
28\end{array}$ & $\begin{array}{r}100 \\
18\end{array}$ \\
\hline
\end{tabular}

\begin{tabular}{|c|c|c|c|c|c|c|}
\hline \multirow{2}{*}{$\begin{array}{l}\text { PERIOD } \\
\text { (CON- } \\
\text { SECU- } \\
\text { TIVE } \\
\text { DAYS) }\end{array}$} & \multicolumn{6}{|c|}{$\begin{array}{l}\text { DISCHARGE, IN OUBIC FEET FER SECOND, FOR } \\
\text { INDICATED RECURRENCE INTEERNAL, IN YEARS, AND } \\
\text { ANNUAL EXCEEDANCE PROBABILITY, IN PERCENT }\end{array}$} \\
\hline & $\begin{array}{c}2 \\
50 \%\end{array}$ & $\begin{array}{c}5 \\
20 \%\end{array}$ & $\begin{array}{l}10 \\
108\end{array}$ & $\begin{array}{l}25 \\
48\end{array}$ & $\begin{array}{l}50 \\
28\end{array}$ & $\begin{array}{r}100 \\
18\end{array}$ \\
\hline $\begin{array}{r}1 \\
3 \\
7 \\
15\end{array}$ & $\begin{array}{l}1400 \\
1310 \\
1180 \\
1040\end{array}$ & $\begin{array}{l}1710 \\
1590 \\
1460 \\
1300\end{array}$ & $\begin{array}{l}1860 \\
1730 \\
1620 \\
1430\end{array}$ & $\begin{array}{l}2000 \\
1860 \\
1780 \\
1580\end{array}$ & $=$ & $\bar{z}$ \\
\hline
\end{tabular}


LOCATION.--Lat $41^{\circ} 01^{\prime} 54^{\prime \prime}$, long $110^{\circ} 34^{\prime} 43^{\prime \prime}$, in $\mathrm{NW}^{\frac{1}{4}} \mathrm{NE}^{\frac{1}{4}} \mathrm{SW}^{\frac{1}{4}} \mathrm{sec} .11, \mathrm{~T} .12 \mathrm{~N} .$, R.117 W. , Uinta County, Hydrologic Unit 14040107, on left bank $0.4 \mathrm{mi}$ downstream from Meeks Cabin Dam, $2.7 \mathrm{mi}$ north of Utah-Wyaming State 1 ine, and $17 \mathrm{mi}$ southwest of Miliburne.

DRAINAGE AREA. $-152 \mathrm{mi}^{2}$.

MEAN BASIN ELEVATION. $--10,270 \mathrm{ft}$.

PERIOD OF RECORD AVAIIABLE.--July 1939 to September 1981.

REVISED RECORDS.--WSP 929: 1940.

GAGE.--Water-stage recorder. Datum of gage is $8,512.27 \mathrm{ft}$ NGVD of 1929, Bureau of Reclamation datum. Prior to Oct. 1, 1971, at several sites about $2.0 \mathrm{mi}$ downstream at various datums.

REMARKS.--Flow completely regulated by Meeks Cabin Reservoir, capacity, 32,470 acre-ft since June 1971 . No diversion above station. AVERAGE DISCHARGE. --42 years, $158 \mathrm{ft}^{3} / \mathrm{s}, 114,500$ acre $-\mathrm{ft} / \mathrm{yr}$, unadjusted.

EXIREYES FOR PERIOD OF RECORD.--Maximum discharge, 2,530 ft $3 / \mathrm{s}$ June 7,1957 , from rating curve extended above $1,500 \mathrm{ft}{ }^{3} / \mathrm{s}$; maximum gage height, $6.46 \mathrm{ft}$ in gage well, $6.76 \mathrm{ft}$ fram floodmarks, June 12, 1965, site and datum then in use; minimum daily discharge, $3.7 \mathrm{ft}^{3} / \mathrm{s}$ Nov.12, 1970, due to regulation by Meeks Cabin Dam.

DATA BELOW BASED ON PERIOD OF RECORD PRIOR TO RFGULATION BY MEEKS CABIN RESERVOIR LOWEST MEAN DISCHARGE, IN COBIC FEET PER SECOND, AND RANKING FOR THE INDICATED NUMBER OF' CONSECUTIVE DAYS FOR EACH CLIMATIC YEAR, APRIL I-MARCH 31

YEAR

\begin{tabular}{|c|c|c|c|c|c|c|c|c|c|c|c|c|c|c|c|c|c|c|c|}
\hline YEAR & 1 & & 3 & & 7 & & 14 & & 30 & 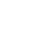 & $\begin{array}{l}\text { DAYS } \\
60\end{array}$ & & 90 & & 120 & & 183 & & ALL \\
\hline $\begin{array}{l}1941 \\
1942 \\
1943 \\
1944 \\
1945\end{array}$ & $\begin{array}{l}22.0 \\
30.0 \\
30.0 \\
23.0 \\
20.0\end{array}$ & $\begin{array}{l}16 \\
26 \\
27 \\
19 \\
12\end{array}$ & $\begin{array}{l}22.0 \\
30.0 \\
30.0 \\
23.0 \\
20.0\end{array}$ & $\begin{array}{r}14 \\
26 \\
27 \\
18 \\
9\end{array}$ & $\begin{array}{l}22.0 \\
30.0 \\
30.0 \\
23.0 \\
20.0\end{array}$ & $\begin{array}{r}11 \\
26 \\
27 \\
12 \\
7\end{array}$ & $\begin{array}{l}22.0 \\
30.0 \\
30.0 \\
23.0 \\
20.0\end{array}$ & $\begin{array}{r}9 \\
26 \\
27 \\
10 \\
7\end{array}$ & $\begin{array}{l}22.0 \\
30.0 \\
30.0 \\
23.0 \\
20.0\end{array}$ & $\begin{array}{r}8 \\
23 \\
24 \\
9 \\
7\end{array}$ & $\begin{array}{l}25.0 \\
33.0 \\
30.0 \\
26.0 \\
20.0\end{array}$ & $\begin{array}{r}9 \\
27 \\
20 \\
12 \\
7\end{array}$ & $\begin{array}{l}27.0 \\
33.0 \\
32.0 \\
28.0 \\
22.0\end{array}$ & $\begin{array}{r}10 \\
24 \\
22 \\
11 \\
7\end{array}$ & $\begin{array}{l}29.0 \\
36.0 \\
33.0 \\
29.0 \\
23.0\end{array}$ & $\begin{array}{r}12 \\
28 \\
21 \\
13 \\
7\end{array}$ & $\begin{array}{l}41.0 \\
44.0 \\
36.0 \\
33.0 \\
29.0\end{array}$ & $\begin{array}{r}26 \\
28 \\
19 \\
15 \\
8\end{array}$ & $\begin{array}{l}115 \\
189 \\
156 \\
158 \\
164\end{array}$ \\
\hline $\begin{array}{l}1946 \\
1947 \\
1948 \\
1949 \\
1950\end{array}$ & $\begin{array}{l}30.0 \\
14.0 \\
30.0 \\
16.0 \\
18.0\end{array}$ & $\begin{array}{r}28 \\
3 \\
29 \\
5 \\
6\end{array}$ & $\begin{array}{l}30.0 \\
14.0 \\
30.0 \\
16.0 \\
18.0\end{array}$ & $\begin{array}{r}28 \\
3 \\
29 \\
5 \\
6\end{array}$ & $\begin{array}{l}30.0 \\
14.0 \\
30.0 \\
16.0 \\
18.0\end{array}$ & $\begin{array}{r}28 \\
1 \\
29 \\
4 \\
5\end{array}$ & $\begin{array}{l}30.0 \\
14.0 \\
30.0 \\
16.0 \\
18.0\end{array}$ & $\begin{array}{r}28 \\
1 \\
29 \\
4 \\
5\end{array}$ & $\begin{array}{l}30.0 \\
14.0 \\
30.0 \\
16.0 \\
18.0\end{array}$ & $\begin{array}{r}25 \\
1 \\
26 \\
3 \\
5\end{array}$ & $\begin{array}{l}32.0 \\
16.0 \\
31.0 \\
17.0 \\
19.0\end{array}$ & $\begin{array}{r}25 \\
1 \\
22 \\
3 \\
6\end{array}$ & $\begin{array}{l}33.0 \\
21.0 \\
32.0 \\
17.0 \\
20.0\end{array}$ & $\begin{array}{r}25 \\
6 \\
23 \\
1 \\
5\end{array}$ & $\begin{array}{l}35.0 \\
22.0 \\
33.0 \\
18.0 \\
22.0\end{array}$ & $\begin{array}{r}25 \\
4 \\
22 \\
1 \\
5\end{array}$ & $\begin{array}{l}39.0 \\
26.0 \\
43.0 \\
23.0 \\
29.0\end{array}$ & $\begin{array}{r}22 \\
2 \\
27 \\
1 \\
9\end{array}$ & $\begin{array}{l}164 \\
136 \\
189 \\
134 \\
148\end{array}$ \\
\hline $\begin{array}{l}1951 \\
1952 \\
1953 \\
1954 \\
1955\end{array}$ & $\begin{array}{l}18.0 \\
27.0 \\
27.0 \\
22.0 \\
20.0\end{array}$ & $\begin{array}{r}7 \\
24 \\
25 \\
17 \\
8\end{array}$ & $\begin{array}{l}18.0 \\
28.0 \\
27.0 \\
22.0 \\
21.0\end{array}$ & $\begin{array}{r}7 \\
25 \\
23 \\
15 \\
10\end{array}$ & $\begin{array}{l}18.0 \\
28.0 \\
27.0 \\
24.0 \\
24.0\end{array}$ & $\begin{array}{r}6 \\
25 \\
22 \\
16 \\
17\end{array}$ & $\begin{array}{l}18.0 \\
28.0 \\
27.0 \\
26.0 \\
24.0\end{array}$ & $\begin{array}{r}6 \\
22 \\
21 \\
19 \\
13\end{array}$ & $\begin{array}{l}18.0 \\
28.0 \\
27.0 \\
28.0 \\
25.0\end{array}$ & $\begin{array}{r}6 \\
21 \\
17 \\
18 \\
14\end{array}$ & $\begin{array}{l}18.0 \\
29.0 \\
29.0 \\
29.0 \\
27.0\end{array}$ & $\begin{array}{r}5 \\
16 \\
17 \\
18 \\
13\end{array}$ & $\begin{array}{l}19.0 \\
29.0 \\
29.0 \\
29.0 \\
28.0\end{array}$ & $\begin{array}{r}3 \\
16 \\
17 \\
18 \\
12\end{array}$ & $\begin{array}{l}20.0 \\
30.0 \\
30.0 \\
29.0 \\
29.0\end{array}$ & $\begin{array}{r}2 \\
17 \\
18 \\
14 \\
15\end{array}$ & $\begin{array}{l}28.0 \\
40.0 \\
35.0 \\
31.0 \\
31.0\end{array}$ & $\begin{array}{r}6 \\
23 \\
17 \\
10 \\
11\end{array}$ & $\begin{array}{c}161 \\
160 \\
179 \\
157 \\
99.0\end{array}$ \\
\hline $\begin{array}{l}1956 \\
1957 \\
1958 \\
1959 \\
1960\end{array}$ & $\begin{array}{l}25.0 \\
24.0 \\
35.0 \\
20.0 \\
20.0\end{array}$ & $\begin{array}{r}23 \\
20 \\
30 \\
9 \\
10\end{array}$ & $\begin{array}{l}27.0 \\
25.0 \\
35.0 \\
20.0 \\
22.0\end{array}$ & $\begin{array}{r}24 \\
21 \\
30 \\
8 \\
8 \\
16\end{array}$ & $\begin{array}{l}28.0 \\
25.0 \\
35.0 \\
21.0 \\
23.0\end{array}$ & $\begin{array}{r}23 \\
18 \\
30 \\
8 \\
13\end{array}$ & $\begin{array}{l}29.0 \\
25.0 \\
35.0 \\
23.0 \\
25.0\end{array}$ & $\begin{array}{l}23 \\
16 \\
30 \\
11 \\
17\end{array}$ & $\begin{array}{l}30.0 \\
25.0 \\
35.0 \\
24.0 \\
27.0\end{array}$ & $\begin{array}{l}22 \\
15 \\
29 \\
10 \\
16\end{array}$ & $\begin{array}{l}31.0 \\
25.0 \\
35.0 \\
24.0 \\
27.0\end{array}$ & $\begin{array}{r}23 \\
10 \\
29 \\
8 \\
14\end{array}$ & $\begin{array}{l}32.0 \\
25.0 \\
35.0 \\
25.0 \\
28.0\end{array}$ & $\begin{array}{r}19 \\
8 \\
27 \\
9 \\
13\end{array}$ & $\begin{array}{l}32.0 \\
26.0 \\
36.0 \\
26.0 \\
30.0\end{array}$ & $\begin{array}{r}19 \\
8 \\
26 \\
9 \\
16\end{array}$ & $\begin{array}{l}34.0 \\
29.0 \\
38.0 \\
27.0 \\
40.0\end{array}$ & $\begin{array}{r}16 \\
7 \\
20 \\
3 \\
24\end{array}$ & $\begin{array}{l}121 \\
169 \\
211 \\
157 \\
165\end{array}$ \\
\hline $\begin{array}{l}1961 \\
1962 \\
1963 \\
1964 \\
1965\end{array}$ & $\begin{array}{l}21.0 \\
24.0 \\
14.0 \\
12.0 \\
20.0\end{array}$ & $\begin{array}{r}13 \\
21 \\
4 \\
2 \\
11\end{array}$ & $\begin{array}{l}22.0 \\
24.0 \\
14.0 \\
13.0 \\
21.0\end{array}$ & $\begin{array}{r}17 \\
19 \\
4 \\
2 \\
11\end{array}$ & $\begin{array}{l}23.0 \\
26.0 \\
14.0 \\
14.0 \\
21.0\end{array}$ & $\begin{array}{r}14 \\
21 \\
2 \\
3 \\
9\end{array}$ & $\begin{array}{l}24.0 \\
29.0 \\
14.0 \\
15.0 \\
22.0\end{array}$ & $\begin{array}{r}14 \\
24 \\
2 \\
3 \\
8\end{array}$ & $\begin{array}{l}24.0 \\
37.0 \\
17.0 \\
15.0 \\
24.0\end{array}$ & $\begin{array}{r}11 \\
30 \\
4 \\
2 \\
12\end{array}$ & $\begin{array}{l}26.0 \\
39.0 \\
17.0 \\
16.0 \\
30.0\end{array}$ & $\begin{array}{r}11 \\
30 \\
4 \\
2 \\
21\end{array}$ & $\begin{array}{l}28.0 \\
42.0 \\
19.0 \\
18.0 \\
32.0\end{array}$ & $\begin{array}{r}14 \\
30 \\
4 \\
2 \\
20\end{array}$ & $\begin{array}{l}28.0 \\
43.0 \\
23.0 \\
20.0 \\
33.0\end{array}$ & $\begin{array}{r}10 \\
30 \\
6 \\
3 \\
20\end{array}$ & $\begin{array}{l}31.0 \\
55.0 \\
27.0 \\
28.0 \\
32.0\end{array}$ & $\begin{array}{r}12 \\
29 \\
4 \\
5 \\
14\end{array}$ & $\begin{array}{l}134 \\
112 \\
185 \\
116 \\
152\end{array}$ \\
\hline $\begin{array}{l}1966 \\
1967 \\
1968 \\
1969 \\
1970\end{array}$ & $\begin{array}{c}22.0 \\
21.0 \\
21.0 \\
24.0 \\
5.10\end{array}$ & $\begin{array}{r}18 \\
14 \\
15 \\
22 \\
1\end{array}$ & $\begin{array}{c}24.0 \\
22.0 \\
22.0 \\
26.0 \\
7.10\end{array}$ & $\begin{array}{r}20 \\
12 \\
13 \\
22 \\
1\end{array}$ & $\begin{array}{l}25.0 \\
24.0 \\
25.0 \\
28.0 \\
21.0\end{array}$ & $\begin{array}{l}19 \\
15 \\
20 \\
24 \\
10\end{array}$ & $\begin{array}{l}25.0 \\
27.0 \\
26.0 \\
30.0 \\
23.0\end{array}$ & $\begin{array}{l}15 \\
20 \\
18 \\
25 \\
12\end{array}$ & $\begin{array}{l}32.0 \\
28.0 \\
28.0 \\
32.0 \\
25.0\end{array}$ & $\begin{array}{l}27 \\
19 \\
20 \\
28 \\
13\end{array}$ & $\begin{array}{l}34.0 \\
32.0 \\
29.0 \\
33.0 \\
27.0\end{array}$ & $\begin{array}{l}28 \\
24 \\
19 \\
26 \\
15\end{array}$ & $\begin{array}{l}39.0 \\
35.0 \\
32.0 \\
34.0 \\
28.0\end{array}$ & $\begin{array}{l}29 \\
28 \\
21 \\
26 \\
15\end{array}$ & $\begin{array}{l}41.0 \\
36.0 \\
34.0 \\
34.0 \\
28.0\end{array}$ & $\begin{array}{l}29 \\
27 \\
23 \\
24 \\
11\end{array}$ & $\begin{array}{l}56.0 \\
41.0 \\
38.0 \\
36.0 \\
31.0\end{array}$ & $\begin{array}{l}30 \\
25 \\
21 \\
18 \\
13\end{array}$ & $\begin{array}{l}237 \\
125 \\
167 \\
194 \\
150\end{array}$ \\
\hline
\end{tabular}


HIGIIEST MEAN DISCHARGE, IN CUBIC FEET PER SECOND, ANN KANKING FOR THE INDICATED NUMBER OF CONSECUTIVE DAYS FOR EACH WATER YEAR, OCTOBER 1-SEPTEMBER 30

\begin{tabular}{|c|c|c|c|c|c|c|c|c|c|c|c|c|c|c|c|c|c|c|c|c|}
\hline YEAR & 1 & & 3 & & 7 & & 15 & & 30 & & E D & & 90 & & 120 & & 183 & & ALL & \\
\hline 1940 & 1000 & 24 & 955 & 24 & 921 & 24 & 798 & 23 & 665 & 24 & 456 & 27 & 338 & 29 & 264 & 29 & 190 & 29 & 109 & 29 \\
\hline $\begin{array}{l}1951 \\
1952 \\
1953 \\
1954 \\
1955\end{array}$ & $\begin{array}{r}1410 \\
1380 \\
2110 \\
810 \\
974\end{array}$ & $\begin{array}{r}9 \\
11 \\
2 \\
29 \\
25\end{array}$ & $\begin{array}{r}1290 \\
1320 \\
2020 \\
754 \\
915\end{array}$ & $\begin{array}{r}10 \\
8 \\
2 \\
29 \\
25\end{array}$ & $\begin{array}{r}1110 \\
1180 \\
1730 \\
664 \\
818\end{array}$ & $\begin{array}{r}12 \\
10 \\
2 \\
29 \\
26\end{array}$ & $\begin{array}{r}840 \\
1010 \\
1420 \\
593 \\
647\end{array}$ & $\begin{array}{r}19 \\
11 \\
1 \\
28 \\
26\end{array}$ & $\begin{array}{r}737 \\
828 \\
1030 \\
449 \\
562\end{array}$ & $\begin{array}{r}19 \\
14 \\
5 \\
31 \\
26\end{array}$ & $\begin{array}{l}616 \\
677 \\
690 \\
341 \\
466\end{array}$ & $\begin{array}{l}18 \\
14 \\
11 \\
31 \\
26\end{array}$ & $\begin{array}{l}486 \\
550 \\
510 \\
280 \\
356\end{array}$ & $\begin{array}{r}18 \\
8 \\
15 \\
30 \\
26\end{array}$ & $\begin{array}{l}395 \\
455 \\
407 \\
230 \\
289\end{array}$ & $\begin{array}{r}17 \\
8 \\
15 \\
30 \\
26\end{array}$ & $\begin{array}{l}280 \\
324 \\
282 \\
166 \\
207\end{array}$ & $\begin{array}{r}18 \\
8 \\
17 \\
31 \\
27\end{array}$ & $\begin{array}{c}154 \\
182 \\
159 \\
99.0 \\
119\end{array}$ & $\begin{array}{r}19 \\
6 \\
16 \\
31 \\
27\end{array}$ \\
\hline $\begin{array}{l}1961 \\
1962 \\
1963 \\
1964 \\
1965\end{array}$ & $\begin{array}{r}776 \\
1180 \\
786 \\
1160 \\
1680\end{array}$ & $\begin{array}{r}31 \\
16 \\
30 \\
18 \\
5\end{array}$ & $\begin{array}{r}741 \\
1170 \\
673 \\
1100 \\
1650\end{array}$ & $\begin{array}{r}30 \\
13 \\
31 \\
18 \\
5\end{array}$ & $\begin{array}{r}648 \\
1100 \\
644 \\
1060 \\
1440\end{array}$ & $\begin{array}{r}30 \\
13 \\
31 \\
15 \\
5\end{array}$ & $\begin{array}{r}551 \\
987 \\
570 \\
826 \\
1140\end{array}$ & $\begin{array}{r}31 \\
12 \\
29 \\
20 \\
9\end{array}$ & $\begin{array}{r}473 \\
865 \\
523 \\
773 \\
1010\end{array}$ & $\begin{array}{r}30 \\
12 \\
29 \\
17 \\
6\end{array}$ & $\begin{array}{l}350 \\
718 \\
451 \\
655 \\
847\end{array}$ & $\begin{array}{r}30 \\
8 \\
28 \\
17 \\
2\end{array}$ & $\begin{array}{l}262 \\
603 \\
351 \\
498 \\
692\end{array}$ & $\begin{array}{r}31 \\
4 \\
27 \\
17 \\
1\end{array}$ & $\begin{array}{l}212 \\
491 \\
282 \\
393 \\
583\end{array}$ & $\begin{array}{r}31 \\
4 \\
28 \\
18 \\
1\end{array}$ & $\begin{array}{l}168 \\
342 \\
204 \\
271 \\
419\end{array}$ & $\begin{array}{r}30 \\
4 \\
28 \\
20 \\
1\end{array}$ & $\begin{array}{l}100 \\
199 \\
116 \\
149 \\
226\end{array}$ & $\begin{array}{r}30 \\
3\end{array}$ \\
\hline $\begin{array}{l}1966 \\
1967 \\
1968 \\
1969 \\
1970\end{array}$ & $\begin{array}{r}845 \\
1090 \\
1810 \\
1110 \\
1300\end{array}$ & $\begin{array}{r}28 \\
22 \\
4 \\
21 \\
13\end{array}$ & $\begin{array}{r}822 \\
1060 \\
1740 \\
1090 \\
1280\end{array}$ & $\begin{array}{r}28 \\
21 \\
4 \\
19 \\
11\end{array}$ & $\begin{array}{r}696 \\
950 \\
1520 \\
1020 \\
1220\end{array}$ & $\begin{array}{r}28 \\
22 \\
4 \\
16 \\
9\end{array}$ & $\begin{array}{r}553 \\
893 \\
1320 \\
971 \\
1190\end{array}$ & $\begin{array}{r}30 \\
17 \\
4 \\
13 \\
7\end{array}$ & $\begin{array}{r}539 \\
759 \\
1250 \\
831 \\
1010\end{array}$ & $\begin{array}{r}28 \\
18 \\
2 \\
13 \\
7\end{array}$ & $\begin{array}{l}424 \\
683 \\
847 \\
607 \\
810\end{array}$ & $\begin{array}{r}29 \\
13 \\
3 \\
20 \\
4\end{array}$ & $\begin{array}{l}340 \\
537 \\
629 \\
471 \\
597\end{array}$ & $\begin{array}{r}28 \\
11 \\
3 \\
21 \\
5\end{array}$ & $\begin{array}{l}284 \\
426 \\
507 \\
378 \\
469\end{array}$ & $\begin{array}{r}27 \\
11 \\
3 \\
22 \\
7\end{array}$ & $\begin{array}{l}209 \\
297 \\
352 \\
269 \\
330\end{array}$ & $\begin{array}{r}26 \\
11 \\
3 \\
21 \\
7\end{array}$ & $\begin{array}{l}132 \\
169 \\
195 \\
153 \\
181\end{array}$ & 20 \\
\hline
\end{tabular}

DURATION OF DISCHARGE FOR EACH WATER YEAR

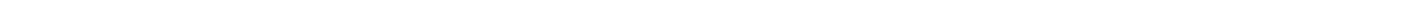

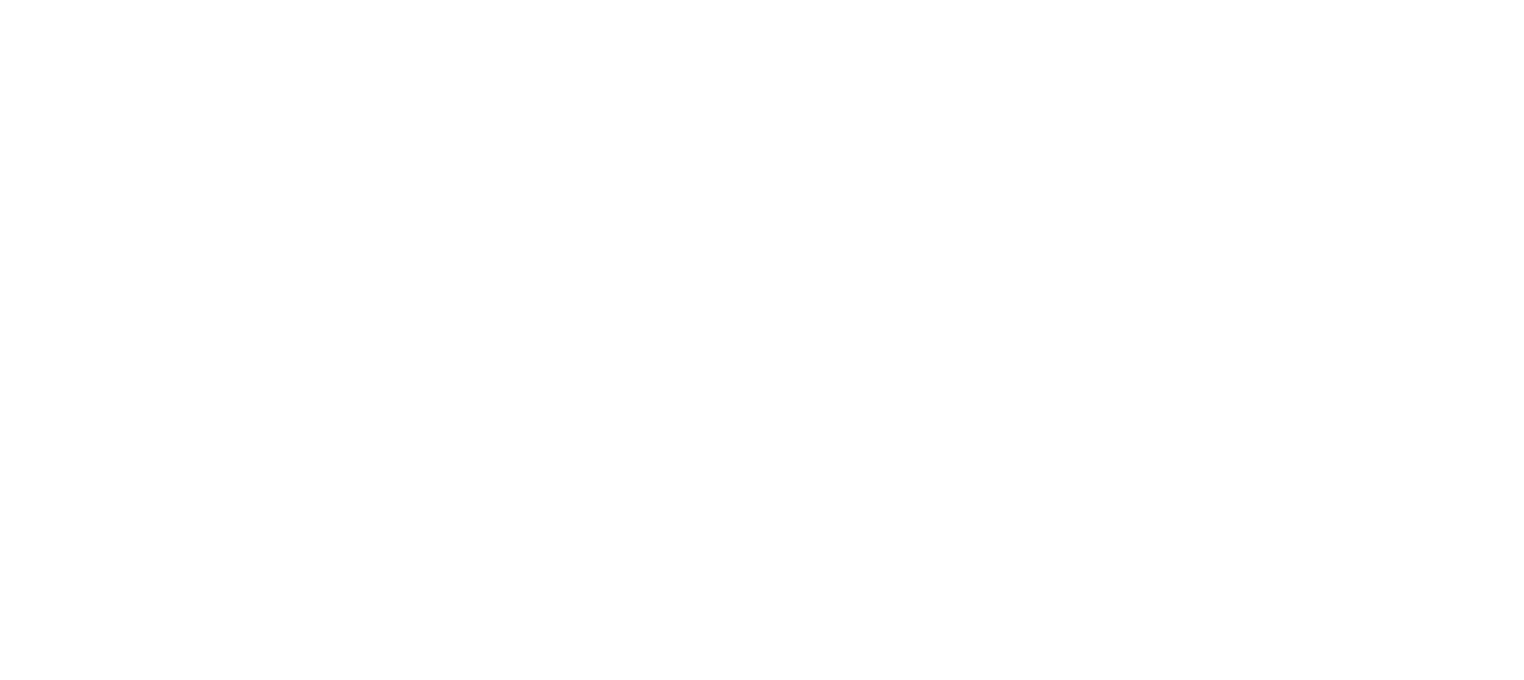


GREEN RTVER BASIN

09218500 BLACKS FORK NEAR MHIJUBURNE, WY-Continued

DURATION OF DISCHARGE FOR EACH WATER YEAR-Continued

$\begin{array}{llllllllllllllllllllllllllllllllllll}\text { CLASS } & 0 & 1 & 2 & 3 & 4 & 5 & 6 & 7 & 8 & 9 & 10 & 11 & 12 & 13 & 14 & 15 & 16 & 17 & 18 & 19 & 20 & 21 & 22 & 23 & 24 & 25 & 26 & 27 & 28 & 29 & 30 & 31 & 32 & 33 & 34\end{array}$

YEAR

NUMBER OF DAYS IN CLASS

CUBIC FEET PER SECOND

1961
1962
1963
1964
1965
1966
1967
1968
1969
1970

$\begin{array}{lllllllllllllllllllll}1 & 46 & 59 & 65 & 28 & 26 & 19 & 12 & 14 & 8 & 13 & 10 & 15 & 8 & 6 & 5 & 10 & 9 & 6 & 3 & 2\end{array}$

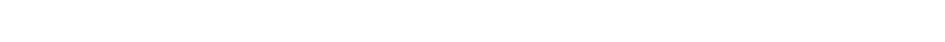

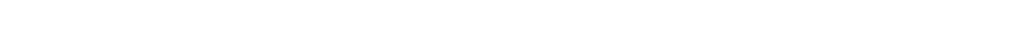

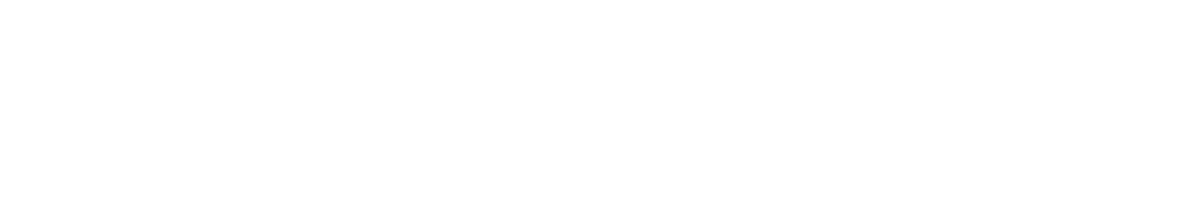

DURATION TABLE OF DISCHARGE FOR WATER YEARS 1940-70

\begin{tabular}{|c|c|c|c|c|c|c|c|c|c|c|c|c|c|c|c|c|c|c|c|}
\hline CI.ASS & $\begin{array}{c}\text { OUBIC } \\
\text { FEET } \\
\text { PER } \\
\text { SECOND }\end{array}$ & $\begin{array}{l}\text { TOTAL } \\
\text { DAYS }\end{array}$ & $\begin{array}{c}\text { ACOU- } \\
\text { MU- } \\
\text { LATED } \\
\text { DAYS }\end{array}$ & $\begin{array}{l}\text { PER- } \\
\text { CENT } \\
\text { DAYS }\end{array}$ & CLASS & $\begin{array}{c}\text { CUBIC } \\
\text { FEET } \\
\text { PER } \\
\text { SECOND }\end{array}$ & $\begin{array}{r}\text { TOTAL } \\
\text { DAYS }\end{array}$ & $\begin{array}{c}\text { ACOU- } \\
\text { MU- } \\
\text { LATED } \\
\text { DAYS }\end{array}$ & $\begin{array}{l}\text { PER- } \\
\text { CENT } \\
\text { DAYS }\end{array}$ & & $\begin{array}{c}\text { QUBIC } \\
\text { EEET } \\
\text { PER } \\
\text { SECOND }\end{array}$ & $\begin{array}{r}\text { TOTAL } \\
\text { DAYS }\end{array}$ & $\begin{array}{c}\text { ACOU- } \\
\text { MU- } \\
\text { LATED } \\
\text { DAYS }\end{array}$ & $\begin{array}{l}\text { PER- } \\
\text { CENT } \\
\text { DAYS }\end{array}$ & CLASS & $\begin{array}{c}\text { CABIC } \\
\text { FEET } \\
\text { PER } \\
\text { SECOND }\end{array}$ & $\begin{array}{r}\text { TOTAL } \\
\text { DAYS }\end{array}$ & $\begin{array}{c}\text { ACOJ- } \\
\text { MU- } \\
\text { LATED } \\
\text { DAYS }\end{array}$ & $\begin{array}{l}\text { PER- } \\
\text { CENT } \\
\text { DAYS }\end{array}$ \\
\hline $\begin{array}{l}0 \\
1 \\
2 \\
3 \\
4 \\
5 \\
6 \\
7 \\
8\end{array}$ & $\begin{array}{r}0.00 \\
5.10 \\
6.10 \\
7.40 \\
8.80 \\
11.00 \\
13.00 \\
15.00 \\
18.00\end{array}$ & $\begin{array}{r}0 \\
2 \\
0 \\
0 \\
0 \\
3 \\
52 \\
95 \\
465\end{array}$ & $\begin{array}{l}11323 \\
11323 \\
11321 \\
11321 \\
11321 \\
11321 \\
11318 \\
11266 \\
11171\end{array}$ & $\begin{array}{r}100.0 \\
100.0 \\
100.0 \\
100.0 \\
100.0 \\
100.0 \\
100.0 \\
99.5 \\
98.7\end{array}$ & $\begin{array}{r}9 \\
10 \\
11 \\
12 \\
13 \\
14 \\
15 \\
16 \\
17\end{array}$ & $\begin{array}{l}22.00 \\
26.00 \\
32.00 \\
38.00 \\
46.00 \\
55.00 \\
66.00 \\
79.00 \\
95.00\end{array}$ & $\begin{array}{r}677 \\
1490 \\
1692 \\
1161 \\
770 \\
678 \\
449 \\
318 \\
256\end{array}$ & $\begin{array}{r}10706 \\
10029 \\
8539 \\
6847 \\
5686 \\
4916 \\
4238 \\
3789 \\
3471\end{array}$ & $\begin{array}{l}94.6 \\
88.6 \\
75.4 \\
60.5 \\
50.2 \\
43.4 \\
37.4 \\
33.5 \\
30.7\end{array}$ & $\begin{array}{l}18 \\
19 \\
20 \\
21 \\
22 \\
23 \\
24 \\
25 \\
26\end{array}$ & $\begin{array}{l}110.0 \\
140.0 \\
160.0 \\
200.0 \\
240.0 \\
280.0 \\
340.0 \\
410.0 \\
490.0\end{array}$ & $\begin{array}{l}381 \\
186 \\
321 \\
249 \\
196 \\
219 \\
272 \\
226 \\
293\end{array}$ & $\begin{array}{l}3215 \\
2834 \\
2648 \\
2327 \\
2078 \\
1882 \\
1663 \\
1391 \\
1165\end{array}$ & $\begin{array}{l}28.4 \\
25.0 \\
23.4 \\
20.6 \\
18.4 \\
16.6 \\
14.7 \\
12.3 \\
10.3\end{array}$ & $\begin{array}{l}27 \\
28 \\
29 \\
30 \\
31 \\
32 \\
33 \\
34\end{array}$ & $\begin{array}{r}590.0 \\
710.0 \\
850.0 \\
1000.0 \\
1200.0 \\
1500.0 \\
1800.0 \\
2100.0\end{array}$ & $\begin{array}{r}256 \\
213 \\
156 \\
143 \\
72 \\
22 \\
7 \\
3\end{array}$ & $\begin{array}{r}872 \\
616 \\
403 \\
247 \\
104 \\
32 \\
10 \\
3\end{array}$ & $\begin{array}{l}7.7 \\
5.4 \\
3.6 \\
2.2 \\
0.9 \\
0.3 \\
0.1 \\
0.0\end{array}$ \\
\hline
\end{tabular}

MONIHLY MEAN DISCHARGES, IN CUBIC FEET PER SECOND, FOR EACH WATER YEAR

\begin{tabular}{|c|c|c|c|c|c|c|c|c|c|c|c|c|}
\hline YEAR & OCI & $\mathrm{NOV}$ & DEC & JAN & FEB & MAR & APR & MAY & JUNE & JULY & AUG & SEP \\
\hline 1940 & 45.8 & 27.9 & 21.0 & 20.0 & 22.0 & 28.1 & 74.0 & 620 & 272 & 65.9 & 34.1 & 67.3 \\
\hline $\begin{array}{l}1941 \\
1942 \\
1943 \\
1944 \\
1945\end{array}$ & $\begin{array}{l}84.3 \\
63.7 \\
38.2 \\
39.9 \\
47.2\end{array}$ & $\begin{array}{l}40.8 \\
51.0 \\
35.6 \\
34.3 \\
30.4\end{array}$ & $\begin{array}{l}34.0 \\
45.0 \\
35.0 \\
30.0 \\
20.0\end{array}$ & $\begin{array}{l}30.0 \\
35.0 \\
30.0 \\
23.0 \\
20.0\end{array}$ & $\begin{array}{l}22.0 \\
30.0 \\
30.0 \\
30.0 \\
25.0\end{array}$ & $\begin{array}{l}28.5 \\
35.0 \\
50.0 \\
40.0 \\
30.0\end{array}$ & $\begin{array}{r}55.0 \\
50.0 \\
255 \\
60.0 \\
40.0\end{array}$ & $\begin{array}{l}655 \\
457 \\
497 \\
492 \\
370\end{array}$ & $\begin{array}{l}781 \\
769 \\
545 \\
763 \\
635\end{array}$ & $\begin{array}{l}316 \\
261 \\
257 \\
350 \\
433\end{array}$ & $\begin{array}{c}129 \\
65.4 \\
100 \\
79.5 \\
189\end{array}$ & $\begin{array}{l}68.5 \\
44.7 \\
43.0 \\
39.4 \\
72.3\end{array}$ \\
\hline $\begin{array}{l}1946 \\
1947 \\
1948 \\
1949 \\
1950\end{array}$ & $\begin{array}{l}47.2 \\
34.8 \\
71.6 \\
38.2 \\
48.3\end{array}$ & $\begin{array}{l}44.0 \\
31.1 \\
51.5 \\
24.1 \\
34.5\end{array}$ & $\begin{array}{l}37.0 \\
29.3 \\
38.0 \\
20.0 \\
18.0\end{array}$ & $\begin{array}{l}33.0 \\
14.0 \\
34.0 \\
18.0 \\
20.0\end{array}$ & $\begin{array}{l}30.0 \\
19.0 \\
30.0 \\
16.0 \\
22.0\end{array}$ & $\begin{array}{l}40.0 \\
30.0 \\
32.0 \\
18.0 \\
28.6\end{array}$ & $\begin{array}{r}297 \\
50.5 \\
70.9 \\
83.0 \\
64.7\end{array}$ & $\begin{array}{l}442 \\
692 \\
711 \\
430 \\
370\end{array}$ & $\begin{array}{l}488 \\
669 \\
488 \\
674 \\
840\end{array}$ & $\begin{array}{c}150 \\
378 \\
94.7 \\
274 \\
333\end{array}$ & $\begin{array}{c}60.8 \\
133 \\
58.8 \\
91.5 \\
97.5\end{array}$ & $\begin{array}{l}31.5 \\
77.6 \\
38.8 \\
46.8 \\
63.1\end{array}$ \\
\hline $\begin{array}{l}1951 \\
1952 \\
1953 \\
1954 \\
1955\end{array}$ & $\begin{array}{l}45.2 \\
77.7 \\
50.0 \\
33.9 \\
33.2\end{array}$ & $\begin{array}{l}39.9 \\
40.0 \\
35.5 \\
29.4 \\
29.9\end{array}$ & $\begin{array}{l}23.0 \\
32.0 \\
33.0 \\
30.0 \\
25.5\end{array}$ & $\begin{array}{l}18.0 \\
30.0 \\
30.0 \\
28.0 \\
30.3\end{array}$ & $\begin{array}{l}18.0 \\
28.0 \\
27.0 \\
30.0 \\
33.5\end{array}$ & $\begin{array}{l}22.0 \\
30.0 \\
31.0 \\
35.0 \\
35.1\end{array}$ & $\begin{array}{l}52.3 \\
92.8 \\
50.7 \\
86.5 \\
53.4\end{array}$ & $\begin{array}{l}476 \\
544 \\
199 \\
429 \\
42.6\end{array}$ & $\begin{array}{r}617 \\
805 \\
1029 \\
237 \\
488\end{array}$ & $\begin{array}{l}333 \\
274 \\
273 \\
140 \\
142\end{array}$ & $\begin{array}{r}129 \\
150 \\
106 \\
54.8 \\
83.8\end{array}$ & $\begin{array}{l}68.2 \\
75.7 \\
41.9 \\
45.0 \\
45.8\end{array}$ \\
\hline $\begin{array}{l}1956 \\
1957 \\
1958 \\
1959 \\
1960\end{array}$ & $\begin{array}{l}35.6 \\
29.5 \\
44.3 \\
29.6 \\
62.3\end{array}$ & $\begin{array}{l}32.2 \\
25.0 \\
35.0 \\
25.5 \\
48.8\end{array}$ & $\begin{array}{l}34.2 \\
25.0 \\
35.0 \\
28.2 \\
33.1\end{array}$ & $\begin{array}{l}31.0 \\
25.0 \\
35.0 \\
24.2 \\
26.9\end{array}$ & $\begin{array}{l}31.7 \\
35.0 \\
40.0 \\
26.4 \\
26.9\end{array}$ & $\begin{array}{l}46.0 \\
70.0 \\
40.0 \\
31.8 \\
71.7\end{array}$ & $\begin{array}{l}110 \\
110 \\
47.5 \\
63.3 \\
176\end{array}$ & $\begin{array}{l}693 \\
246 \\
713 \\
365 \\
403\end{array}$ & $\begin{array}{r}739 \\
1251 \\
706 \\
909 \\
616\end{array}$ & $\begin{array}{l}175 \\
516 \\
142 \\
245 \\
147\end{array}$ & $\begin{array}{c}58.6 \\
127 \\
57.1 \\
78.6 \\
47.6\end{array}$ & $\begin{array}{l}31.8 \\
56.7 \\
41.4 \\
50.3 \\
38.6\end{array}$ \\
\hline $\begin{array}{l}1961 \\
1962 \\
1963 \\
1964 \\
1965\end{array}$ & $\begin{array}{l}40.0 \\
94.7 \\
39.8 \\
51.6 \\
31.2\end{array}$ & $\begin{array}{l}32.9 \\
60.7 \\
32.0 \\
35.7 \\
30.5\end{array}$ & $\begin{array}{l}29.5 \\
44.8 \\
33.7 \\
24.2 \\
37.3\end{array}$ & $\begin{array}{l}30.3 \\
47.8 \\
18.9 \\
20.1 \\
35.4\end{array}$ & $\begin{array}{l}24.6 \\
40.4 \\
17.6 \\
16.7 \\
36.1\end{array}$ & $\begin{array}{l}29.2 \\
38.5 \\
20.5 \\
18.2 \\
24.6\end{array}$ & $\begin{array}{c}44.0 \\
182 \\
41.4 \\
37.8 \\
42.7\end{array}$ & $\begin{array}{l}363 \\
529 \\
361 \\
418 \\
291\end{array}$ & $\begin{array}{l}330 \\
844 \\
479 \\
667 \\
971\end{array}$ & $\begin{array}{l}78.2 \\
368 \\
197 \\
348 \\
706\end{array}$ & $\begin{array}{c}63.0 \\
86.2 \\
75.9 \\
108 \\
315\end{array}$ & $\begin{array}{r}133 \\
42.2 \\
67.4 \\
45.2 \\
186\end{array}$ \\
\hline $\begin{array}{l}1966 \\
1967 \\
1968 \\
1969 \\
1970\end{array}$ & $\begin{array}{c}108 \\
64.4 \\
51.2 \\
45.9 \\
40.4\end{array}$ & $\begin{array}{l}53.4 \\
37.5 \\
40.0 \\
31.9 \\
33.2\end{array}$ & $\begin{array}{l}49.7 \\
38.1 \\
38.8 \\
34.8 \\
27.1\end{array}$ & $\begin{array}{l}46.9 \\
40.9 \\
37.5 \\
34.6 \\
27.0\end{array}$ & $\begin{array}{l}35.4 \\
35.6 \\
30.0 \\
32.7 \\
29.6\end{array}$ & $\begin{array}{l}34.8 \\
28.2 \\
28.8 \\
36.7 \\
28.2\end{array}$ & $\begin{array}{r}116 \\
40.1 \\
32.6 \\
71.1 \\
44.9\end{array}$ & $\begin{array}{l}519 \\
315 \\
279 \\
743 \\
542\end{array}$ & $\begin{array}{r}316 \\
719 \\
1241 \\
448 \\
949\end{array}$ & $\begin{array}{l}158 \\
499 \\
348 \\
199 \\
278\end{array}$ & $\begin{array}{l}72.1 \\
140 \\
144 \\
89.5 \\
83.1\end{array}$ & $\begin{array}{l}67.8 \\
66.5 \\
74.6 \\
52.8 \\
87.5\end{array}$ \\
\hline
\end{tabular}


GREEN RIVER BASIN

09218500 BLACKS FORK NEAR MILLBURNE, WY--Continued

ANNUAL PEAK DISCHARGE, IN CUBIC FEET PER SECOND, AND CORRESPONDING GAGE HEIGHT, IN FEET, FOR EACH WATER YEAR

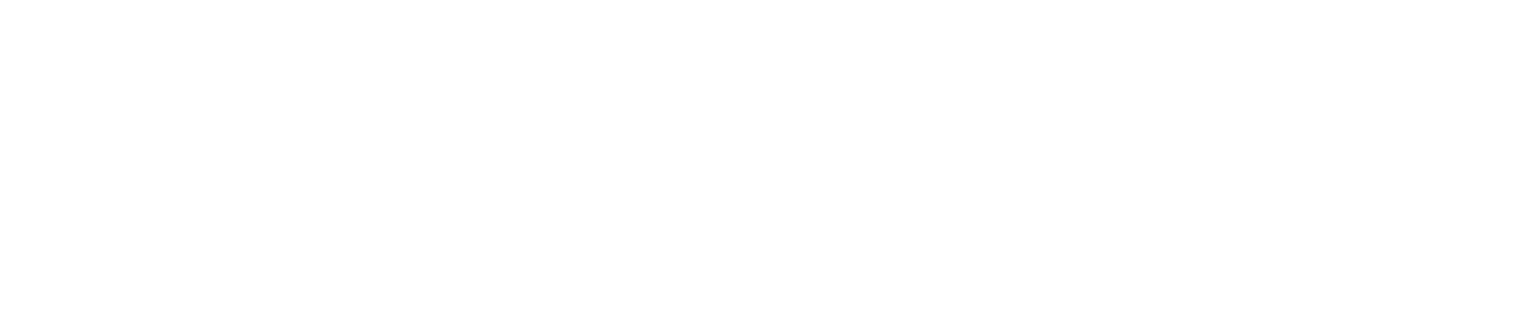

MAGNITUDE AND PROBABILITY OF ANNUAL LONEST MEAN DISCHARGE BASED ON OLIMATIC YEARS 1941-70

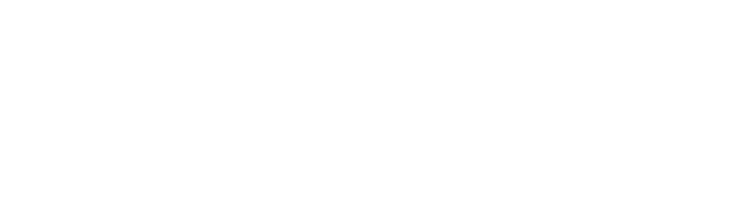

$\begin{array}{llllll}23 & 17 & 13 & 9.9 & 7.1 & - \\ 24 & 19 & 17 & 15 & 13 & = \\ 24 & 20 & 17 & 15 & 13 & - \\ 25 & 20 & 18 & 15 & 13 & = \\ 27 & 21 & 19 & 16 & 14 & = \\ 28 & 23 & 20 & 18 & 16 & -\end{array}$

DATA BELOW BASED ON PERIOD OF RECORD AFTER COMPLETION OF MEEKS CABIN RESERVOIR

LONEST MEAN DISCHARGE, IN OUBIC FEET PER SECOND, AND RANKING FOR THE INDICATED NUMBER OF CONSECUTIVE DAYS FOR EACH CLIMATIC YEAR, APRIL I-MARCH 31

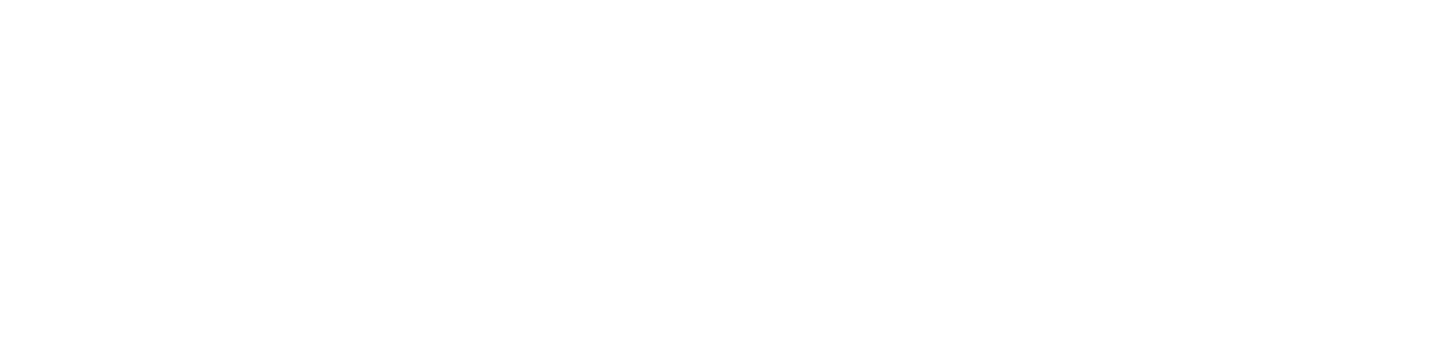

HIGHEST MEAN DISCHARGE, IN CUBIC FEET PER SECOND, AND RANKING FOR THE INDICATED NUMBER OF CONSECUTIVE DAYS FOR EACH WATER YEAR, OCTOBER I-SEPTEMBER 30

\begin{tabular}{|c|c|c|c|c|c|c|c|c|c|c|c|c|c|c|c|c|c|c|c|c|}
\hline YEAR & 1 & \multicolumn{19}{|c|}{ CONSEOUTIVE DAYS } \\
\hline $\begin{array}{l}1972 \\
1973 \\
1974 \\
1975\end{array}$ & $\begin{array}{r}1270 \\
750 \\
1430 \\
1760\end{array}$ & $\begin{array}{r}4 \\
10 \\
3 \\
1\end{array}$ & $\begin{array}{r}1260 \\
750 \\
1370 \\
1690\end{array}$ & $\begin{array}{r}4 \\
10 \\
3 \\
1\end{array}$ & $\begin{array}{r}1210 \\
744 \\
1260 \\
1620\end{array}$ & $\begin{array}{r}4 \\
10 \\
3 \\
1\end{array}$ & $\begin{array}{r}1080 \\
688 \\
1090 \\
1470\end{array}$ & $\begin{array}{l}4 \\
9 \\
3 \\
1\end{array}$ & $\begin{array}{r}897 \\
624 \\
918 \\
1230\end{array}$ & $\begin{array}{l}4 \\
7 \\
2 \\
1\end{array}$ & $\begin{array}{l}653 \\
560 \\
718 \\
950\end{array}$ & $\begin{array}{l}5 \\
7 \\
2 \\
1\end{array}$ & $\begin{array}{l}527 \\
471 \\
561 \\
718\end{array}$ & $\begin{array}{l}4 \\
7 \\
3 \\
1\end{array}$ & $\begin{array}{l}437 \\
385 \\
461 \\
577\end{array}$ & $\begin{array}{l}4 \\
7 \\
3 \\
1\end{array}$ & $\begin{array}{l}304 \\
271 \\
321 \\
398\end{array}$ & $\begin{array}{l}4 \\
7 \\
3 \\
1\end{array}$ & $\begin{array}{l}175 \\
164 \\
189 \\
216\end{array}$ & $\begin{array}{l}3 \\
5 \\
2 \\
1\end{array}$ \\
\hline $\begin{array}{l}1976 \\
1977 \\
1978 \\
1979 \\
1980\end{array}$ & $\begin{array}{r}777 \\
900 \\
1250 \\
860 \\
920\end{array}$ & $\begin{array}{l}9 \\
7 \\
5 \\
8 \\
6\end{array}$ & $\begin{array}{r}777 \\
897 \\
1190 \\
857 \\
869\end{array}$ & $\begin{array}{l}9 \\
6 \\
5 \\
8 \\
7\end{array}$ & $\begin{array}{r}777 \\
824 \\
1060 \\
849 \\
857\end{array}$ & $\begin{array}{l}9 \\
8 \\
5 \\
7 \\
6\end{array}$ & $\begin{array}{l}726 \\
663 \\
976 \\
773 \\
815\end{array}$ & $\begin{array}{r}8 \\
10 \\
5 \\
7 \\
6\end{array}$ & $\begin{array}{l}607 \\
464 \\
858 \\
614 \\
786\end{array}$ & $\begin{array}{r}9 \\
10 \\
5 \\
8 \\
6\end{array}$ & $\begin{array}{l}498 \\
316 \\
681 \\
508 \\
645\end{array}$ & $\begin{array}{r}9 \\
10 \\
3 \\
8 \\
6\end{array}$ & $\begin{array}{l}401 \\
247 \\
566 \\
400 \\
522\end{array}$ & $\begin{array}{r}8 \\
10 \\
2 \\
9 \\
5\end{array}$ & $\begin{array}{l}323 \\
210 \\
473 \\
320 \\
423\end{array}$ & $\begin{array}{r}8 \\
10 \\
2 \\
9 \\
5\end{array}$ & $\begin{array}{l}227 \\
149 \\
323 \\
220 \\
286\end{array}$ & $\begin{array}{r}8 \\
10 \\
2 \\
9 \\
5\end{array}$ & $\begin{array}{c}146 \\
83.0 \\
168 \\
120 \\
151\end{array}$ & $\begin{array}{r}8 \\
10\end{array}$ \\
\hline 1981 & 1670 & 2 & 1550 & 2 & 1400 & 2 & 1110 & 2 & 897 & 3 & 659 & 4 & 500 & 6 & 403 & 6 & 276 & 6 & 146 & 7 \\
\hline
\end{tabular}


GREEN RIVER BASIN

09218500 BLACRS FORK NEAR MULLBURNE WY--Continued

DURATION OF DISCHARGE FOR EACH WATER YEAR

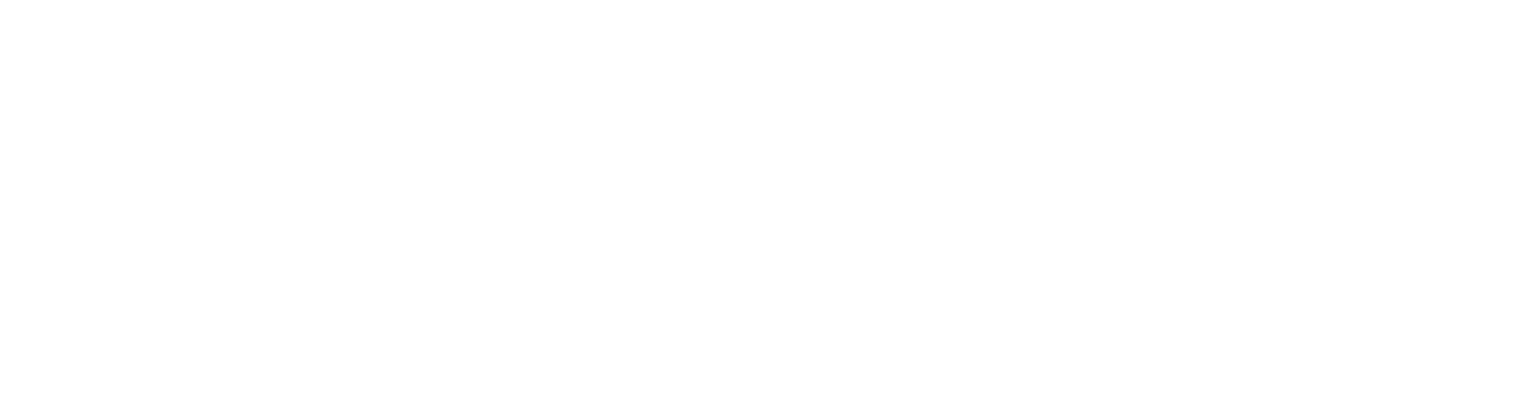

DURATION TABLE OF DISCHARGE FOR WATER YEARS 1972-81

\begin{tabular}{|c|c|c|c|c|c|c|c|c|c|c|c|c|c|c|c|c|c|c|c|}
\hline IASS & $\begin{array}{c}\text { CUBIC } \\
\text { FEET } \\
\text { PER } \\
\text { SECOND }\end{array}$ & $\begin{array}{r}\text { TOIAL } \\
\text { DAYS }\end{array}$ & $\begin{array}{l}\text { ACOU- } \\
\text { MU-- } \\
\text { LATED } \\
\text { DAYS }\end{array}$ & $\begin{array}{l}\text { PER- } \\
\text { CENT } \\
\text { DAYS }\end{array}$ & CIASS & $\begin{array}{c}\text { CUBIC } \\
\text { FEET } \\
\text { PER } \\
\text { SECOND }\end{array}$ & $\begin{array}{r}\text { TOTAL } \\
\text { DAYS }\end{array}$ & $\begin{array}{c}\text { ACOU- } \\
\text { MU- } \\
\text { LATED } \\
\text { DAYS }\end{array}$ & $\begin{array}{l}\text { PER- } \\
\text { CENT } \\
\text { DAYS }\end{array}$ & CLASS & $\begin{array}{c}\text { OJBIC } \\
\text { FEET } \\
\text { PER } \\
\text { SECOND }\end{array}$ & $\begin{array}{l}\text { TOTAL } \\
\text { DAYS }\end{array}$ & $\begin{array}{c}\text { ACQU- } \\
\text { MU- } \\
\text { LATED } \\
\text { DAYS }\end{array}$ & $\begin{array}{l}\text { PER- } \\
\text { CENT } \\
\text { DAYS }\end{array}$ & CAASS & $\begin{array}{c}\text { CUBIC } \\
\text { FEET } \\
\text { PER } \\
\text { SECOND }\end{array}$ & $\begin{array}{r}\text { TOTAL } \\
\text { DAYS }\end{array}$ & $\begin{array}{l}\text { ACOU- } \\
\text { MU- } \\
\text { LATED } \\
\text { DAYS }\end{array}$ & $\begin{array}{l}\text { PER- } \\
\text { CENI } \\
\text { DAYS }\end{array}$ \\
\hline $\begin{array}{l}0 \\
1 \\
2 \\
3 \\
4 \\
5 \\
6 \\
7 \\
8\end{array}$ & $\begin{array}{r}0.00 \\
6.10 \\
7.20 \\
8.60 \\
10.00 \\
12.00 \\
14.00 \\
17.00 \\
20.00\end{array}$ & $\begin{array}{r}0 \\
95 \\
158 \\
167 \\
132 \\
271 \\
53 \\
50 \\
46\end{array}$ & $\begin{array}{l}3653 \\
3653 \\
3558 \\
3400 \\
3233 \\
3101 \\
2830 \\
2777 \\
2727\end{array}$ & $\begin{array}{r}100.0 \\
100.0 \\
97.4 \\
93.1 \\
88.5 \\
84.9 \\
77.5 \\
76.0 \\
74.7\end{array}$ & $\begin{array}{r}9 \\
10 \\
11 \\
12 \\
13 \\
14 \\
15 \\
16 \\
17\end{array}$ & $\begin{array}{l}24.00 \\
29.00 \\
34.00 \\
40.00 \\
48.00 \\
57.00 \\
67.00 \\
80.00 \\
95.00\end{array}$ & $\begin{array}{r}277 \\
284 \\
337 \\
149 \\
90 \\
59 \\
72 \\
154 \\
87\end{array}$ & $\begin{array}{l}2681 \\
2404 \\
2120 \\
1783 \\
1634 \\
1544 \\
1485 \\
1413 \\
1259\end{array}$ & $\begin{array}{l}73.4 \\
65.8 \\
58.0 \\
48.8 \\
44.7 \\
42.3 \\
40.7 \\
38.7 \\
34.5\end{array}$ & $\begin{array}{l}18 \\
19 \\
20 \\
21 \\
22 \\
23 \\
24 \\
25 \\
26\end{array}$ & $\begin{array}{l}110.0 \\
130.0 \\
160.0 \\
190.0 \\
220.0 \\
260.0 \\
310.0 \\
370.0 \\
440.0\end{array}$ & $\begin{array}{r}79 \\
126 \\
131 \\
107 \\
62 \\
98 \\
65 \\
73 \\
94\end{array}$ & $\begin{array}{r}1172 \\
1093 \\
967 \\
836 \\
729 \\
667 \\
569 \\
504 \\
431\end{array}$ & $\begin{array}{l}32.1 \\
29.9 \\
26.5 \\
22.9 \\
20.0 \\
18.3 \\
15.6 \\
13.8 \\
11.8\end{array}$ & $\begin{array}{l}27 \\
28 \\
29 \\
30 \\
31 \\
32 \\
33 \\
34\end{array}$ & $\begin{array}{r}520.0 \\
620.0 \\
740.0 \\
880.0 \\
1000.0 \\
1200.0 \\
1500.0 \\
1700.0\end{array}$ & $\begin{array}{r}62 \\
81 \\
112 \\
28 \\
21 \\
22 \\
9 \\
2\end{array}$ & $\begin{array}{r}337 \\
275 \\
194 \\
82 \\
54 \\
33 \\
11 \\
2\end{array}$ & $\begin{array}{l}9.2 \\
7.5 \\
5.3 \\
2.2 \\
1.5 \\
0.9 \\
0.3 \\
0.1\end{array}$ \\
\hline
\end{tabular}

MONTHLY MEAN DISCHARGES, IN ABIC FEET PER SECOND, FOR EACH WATER YEAR

$\begin{array}{lcccccccccccc}\text { YEAR } & \text { OCT } & \text { NOV } & \text { DEC } & \text { JAN } & \text { FEB } & \text { MAR } & \text { APR } & \text { MAY } & \text { JUNE } & \text { JULY } & \text { AUG } & \text { SEP } \\ 1972 & 101 & 36.2 & 34.2 & 34.9 & 33.9 & 33.5 & 33.7 & 348 & 819 & 307 & 210 & 108 \\ 1973 & 104 & 121 & 30.8 & 30.5 & 29.1 & 28.0 & 28.3 & 291 & 622 & 419 & 139 & 126 \\ 1974 & 109 & 59.1 & 52.3 & 42.5 & 36.4 & 33.1 & 32.5 & 477 & 792 & 330 & 162 & 131 \\ 1975 & 45.7 & 38.8 & 33.2 & 26.1 & 25.9 & 26.5 & 25.7 & 117 & 769 & 1081 & 252 & 136 \\ 1976 & 160 & 65.3 & 46.5 & 45.1 & 38.1 & 32.7 & 32.4 & 265 & 495 & 381 & 114 & 69.9 \\ 1977 & 36.6 & 23.6 & 15.7 & 8.21 & 6.10 & 6.54 & 7.37 & 91.6 & 464 & 162 & 85.4 & 89.1 \\ 1978 & 28.9 & 16.2 & 9.14 & 7.92 & 7.32 & 8.03 & 8.75 & 280 & 845 & 446 & 214 & 145 \\ 1979 & 34.9 & 26.0 & 13.9 & 13.0 & 13.0 & 13.0 & 13.0 & 320 & 509 & 306 & 95.5 & 74.9 \\ 1980 & 34.2 & 12.8 & 10.7 & 10.8 & 11.0 & 11.6 & 12.0 & 203 & 776 & 432 & 199 & 96.3 \\ 1981 & 46.5 & 12.9 & 9.71 & 7.92 & 9.01 & 9.54 & 9.00 & 208 & 847 & 380 & 127 & 86.9\end{array}$

ANNUAL PEAK DISCHARGE, IN OUBIC FEET PER SECOND, AND CORRESPONDING GAGE HEIGHT, IN FEET, FOR EACH WATER YEAR

\begin{tabular}{|c|c|c|c|c|c|c|c|c|c|c|c|}
\hline $\begin{array}{l}\text { WATER } \\
\text { YEAR }\end{array}$ & DATE & $\begin{array}{c}\text { GAGE } \\
\text { HEIGHT }\end{array}$ & $\begin{array}{c}\text { PEAK } \\
\text { DISCHARGE }\end{array}$ & $\begin{array}{l}\text { WATERR } \\
\text { YEAR }\end{array}$ & DATE & $\begin{array}{c}\text { GAGE } \\
\text { HEIGHI }\end{array}$ & $\begin{array}{c}\text { PEAK } \\
\text { DISCHARGE }\end{array}$ & $\begin{array}{l}\text { WATER } \\
\text { YEAR }\end{array}$ & DATE & $\begin{array}{l}\text { GAGE } \\
\text { HEIGHT }\end{array}$ & $\begin{array}{c}\text { PEAK } \\
\text { DISCHARGE }\end{array}$ \\
\hline $\begin{array}{l}1971 \\
1972 \\
1973 \\
1974\end{array}$ & $\begin{array}{l}\text { APR. } 19,1971 \\
\text { JUNE 07, } 1972 \\
\text { JUNE 16, } 1973 \\
\text { MAY } 29,1974\end{array}$ & $\begin{array}{l}5.49 \\
4.49 \\
3.96 \\
4.70\end{array}$ & $\begin{array}{r}1_{1400} \\
1370 \\
759 \\
1600\end{array}$ & $\begin{array}{l}1975 \\
1976 \\
1977 \\
1978\end{array}$ & $\begin{array}{l}\text { JULY 05, } 1975 \\
\text { JUNE 03, } 1976 \\
\text { JUNE 04, } 1977 \\
\text { JUNE 25, } 1978\end{array}$ & $\begin{array}{l}4.79 \\
4.15 \\
4.18 \\
4.42\end{array}$ & $\begin{array}{r}1960 \\
795 \\
930 \\
1330\end{array}$ & $\begin{array}{l}1979 \\
1980 \\
1981\end{array}$ & $\begin{array}{lll}\text { MAY } & 30,1979 \\
\text { MAY } & 24,1980 \\
\text { JUNE } & 09,1981\end{array}$ & $\begin{array}{l}4.15 \\
4.32 \\
4.88\end{array}$ & $\begin{array}{r}870 \\
941 \\
1850\end{array}$ \\
\hline
\end{tabular}

MAGNITUDE AND PRCBABILITY OF ANNUAL HIGHEST MEAN DISCHARGE
BASED ON WATER YEARS

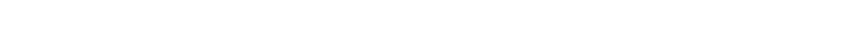




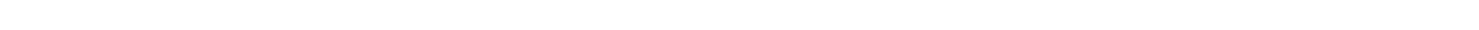
National Forest, on left bank $60 \mathrm{ft}$ downstream from bridge, $1.0 \mathrm{mi}$ upstream from Gilbert Creek, 6.1 mi downstream fram State ine Reservoir, and $9.0 \mathrm{mi}$ south of Robertson.

DRAINAGE AREA. $--53.0 \mathrm{mi}^{2}$.

MEAN BASIN ELEVATION. $--10,250 \mathrm{ft}$.

PERIOD OF RECORD AVAILABLE.--JulY 1939 to September 1981 (no winter records since 1971). Prior to Oct. 1, 1978, published as "East Fork of Smith Fork near Robertson".

REVISED RECORDS.--WSP 979: Drainage area.

GAGE. -Water-stage recorder. Altitude of gage is $8,470 \mathrm{ft}$ from topographic map. Prior to July 12, 1957, at datum $3.96 \mathrm{ft}$ higher.

REMARKS.--Flow completely regulated by State Line Reservoir, $6.1 \mathrm{mi}$ upstream, total capacity, 14,000 acre-ft, dead storage is about 2,000 acre-ft, since May 1979.

COOPERATION.--Records collected and computed by office of the Wyoning State Engineer and reviewed by the Geological Survey.

AVERAGE DISCHARGE. -32 years, (water years $1940-71$ ), $47.1 \mathrm{ft}^{3} / \mathrm{s}, 34,120 \mathrm{acre}-\mathrm{ft} / \mathrm{yr}$.

EXIRPMES FOR PERIOD OF RECORD. - Maximum discharge, 1,450 $\mathrm{ft}^{3} / \mathrm{s}$ June 10, 1965, gage height, $6.75 \mathrm{ft}$; no flow part of each day Apr. 17-22, 24, 25, 1950; minimum gage height, $3.26 \mathrm{ft}$, present datum, Apr. 22, 1950.

LOWEST MEAN DISCHARGE, IN CUBIC FEET PER SBCOND, AND RANKING FOR THE INDICATED NUMBER OF CONSECUTTVE DAYS FOR EACH CLIMATIC YEAR, APRIL I-MARCH 31

\section{1}

13

4.6012

5.2017

7.6028
6.0021

$6.0022 \quad 6.0021$

6.0022

7

14

4.9011

5.4015

8.4029

6.0021

5.3011

5.6014

9.0029

6.0018

6.0019

CONSECUTIVE DAYS
30

6.0020

5.8014

9.0028

6.0015

6.0013

5.9011
9.0027

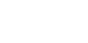

6.0012

90

120

6.4013

6.6014

9.3026

7.0019
6.3011

$\begin{array}{ll}7.2015 \\ 8.00 & 20\end{array}$

8.0020
9.8027

$\begin{array}{ll}9.80 & 27 \\ 7.60 & 19\end{array}$

7.0013

11.024

13.028

$11.0 \quad 25$

8.9012

$\begin{array}{llll}9.90 & 30 & 10.0 \quad 30\end{array}$

$10.0 \quad 30$

$10.0 \quad 30$

$10.0 \quad 29$

$10.0 \quad 28$

$\begin{array}{llll}6.5022 & 7.0023\end{array}$

$\begin{array}{lll}7.0024 & 7.0024\end{array}$

$7.0026 \quad 7.0024$

$5.6019 \quad 5.7019$

$\begin{array}{ll}4.2011 & 4.2010\end{array}$

5.9019

7.0024
6.0020

$\begin{array}{rr}10.0 & 29 \\ 7.5024\end{array}$

$\begin{array}{ll}7.50 & 24 \\ 7.0022\end{array}$

$\begin{array}{ll}7.00 & 22 \\ 6.00 & 17\end{array}$

$\begin{array}{rr}10.0 & 28 \\ 8.0022\end{array}$

8.0022
7.20

$10.0 \quad 28$

$11.0 \quad 29$

12.027

$\begin{array}{ll}8.70 & 23 \\ 7.30 & 20\end{array}$

$\begin{array}{ll}7.30 & 20 \\ 6.30 & 12\end{array}$

$\begin{array}{lr}6.30 & 14 \\ 4.70 & 5\end{array}$

5.006

9.0024

7.4017

6.5010

$\begin{array}{rr}12.0 & 27 \\ 9.5018\end{array}$

9.5018

$6.90 \quad 4$

$\begin{array}{ll}6.90 & 4\end{array}$

6.0018

$\begin{array}{llll}5.7018 & 6.0021\end{array}$

$\begin{array}{rr}4.8013 & 5.0013 \\ 10.0 \quad 31 & 10.0 \quad 31\end{array}$

$\begin{array}{cccc}10.0 & 31 & 10.0 & 31 \\ 6.90 & 24 & 7.50 & 26\end{array}$

$5.6020 \quad 5.6018$

$10.0 \quad 31$

$\begin{array}{cc}6.00 & 21 \\ 10.0 \quad 31\end{array}$

8.0027

8.0017
5.6017

8.0027
5.60
15

10.030

6.4015

6.8016

$\begin{array}{ccc}10.0 \quad 29 & 11.0 \quad 30\end{array}$

8.4010

$\begin{array}{rr}7.30 & 16 \\ 12.0 \quad 30\end{array}$

8.4010

8.3022

8.0025

8.3023

6.2010

8.5022

6.5011

7.10

7.708

$\begin{array}{llll}5.0014 & 5.0014\end{array}$

$\begin{array}{rrrr}4.008 & 8 & 4.00 & 7\end{array}$

$\begin{array}{llll}4.00 & 8 & 4.00 & 7 \\ 4.00 & 9 & 4.00 & 8\end{array}$

5.3014

5.3012

5.4010

6.5016

6.7015

6.7012

6.0019

$\begin{array}{llll}4.006 & 4.00 \quad 5\end{array}$

4.107

4.207

4.003

$\begin{array}{rr}6.50 & 16 \\ 4.20 & 3\end{array}$

6.70
4.30

$10.0 \quad 30$

$\begin{array}{cr}4.30 & 3 \\ 10.0 & 29\end{array}$

4.503

$10.0 \quad 28$

7.406

.40
4.80

$11.0 \quad 26$

4.905

$5.30 \quad 5$

$\begin{array}{cc}11.0 & 26 \\ 6.20 & 3\end{array}$

$\begin{array}{llll}4.80 & 8 & 4.90 & 6 \\ 3.00 & 2 & 3.20 & 2\end{array}$

3.502

4.202

8.7011

7.3025

7.4025

$7.50 \quad 23$

7.7021

7.9021

8.4021

9.3015

9.7026

1.301

9.3027

1.801

$16.0 \quad 30$

4.001

8.40

6.109

9.5025

9.7020

$\begin{array}{llll}5.10 & 13 & 5.50 & 13\end{array}$

$\begin{array}{rr}4.60 & 7 \\ 5.70 & 13\end{array}$

8.7026

$15.0 \quad 31$

$13.0 \quad 31$

$14.0 \quad 31$

$\begin{array}{rr}9.00 & 28 \\ 4.00 \quad 6\end{array}$

$3.80 \quad 4$

$\begin{array}{rrrr}7.50 & 27 & 7.70 & 27 \\ 3.50 & 4 & 3.70 & 4\end{array}$

$\begin{array}{rrrr}3.50 & 4 & 3.70 & 4 \\ 5.30 & 18 & 5.80 & 20\end{array}$

5.2016
3.505

6.5023

6.9022

$4.30 \quad 4$

$\begin{array}{rr}4.30 & 4 \\ 8.20 & 27\end{array}$

$\begin{array}{cc}14.0 & 31 \\ 5.20 & 7\end{array}$

$15.0 \quad 31$

5.507

8.9024

$\begin{array}{cc}15.0 & 31 \\ 5.40 & 6\end{array}$

$18.0 \quad 31$

9.8021

8.7023

7.1014

$10.0 \quad 22$

$\begin{array}{lll}6.20 & 21 & 6.8018\end{array}$

7.0017

4.804

9.3016

7.607

7.0018

7.5018

$10.0 \quad 23$

ALC.

29.03

$\begin{array}{ll}57.0 & 26 \\ 45.0 & 17\end{array}$

$43.0 \quad 14$

$\begin{array}{ll}43.0 & 14 \\ 55.0 & 25\end{array}$

$52.0 \quad 22$

$40.0 \quad 10$

$50.0 \quad 20$

$\begin{array}{rr}36.0 & 6 \\ 55.0 & 23\end{array}$

$43.0 \quad 15$

$47.0 \quad 18$

67.030

$\begin{array}{rr}40.0 & 11 \\ 26.0 & 1\end{array}$

$29.0 \quad 2$

$40.0 \quad 12$

$58.0 \quad 27$

$41.0 \quad 13$

44.016

$35.0 \quad 5$

33.04

$47.0 \quad 19$

$\begin{array}{ll}37.0 & 7 \\ 55.0 & 24\end{array}$

$93.0 \quad 31$

$39.0 \quad 9$

$58.0 \quad 28$

$61.0 \quad 29$

4.8010

$5.00 \quad 9 \quad 7.1019$

7.0018

$51.0 \quad 21$ 
GREEN RIVER BASIN

09220000 EAST FORK OF SMITHS FORK NEAR ROBERTSON, WY--Continued

HIGHEST MEAN DISCHARGE, IN CUBIC FEET PER SECOND, AND RANKING FOR THE INDICATED NUMBER OF CONSECUTIVE DAYS FOR EACH WATER YEAR, OCIOBER 1-SEPTEMBER 30

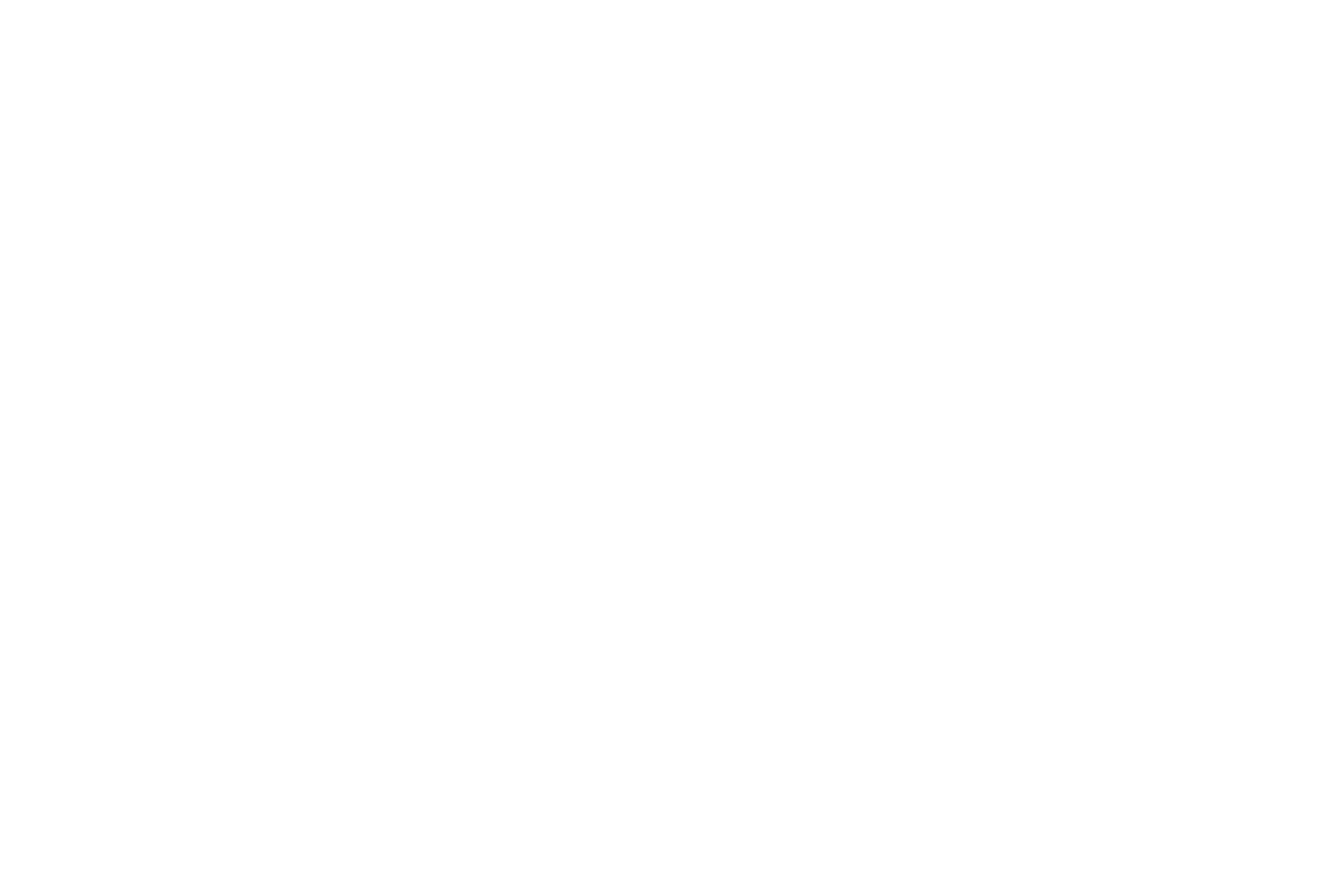

DURATION OF DISCHARGE FOR EACH WATER YEAR

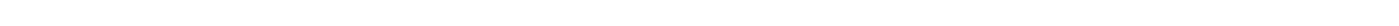
YEAR

NUMBER OF DAYS IN CLASS

CUBIC FEET
PER SECOND -DAYS

1940
1941
1942
1943
1944
1945

1946
1947
1948
1949
1950

1951
1952
1953
1954
1955
1956
1957
1958
1959
1960

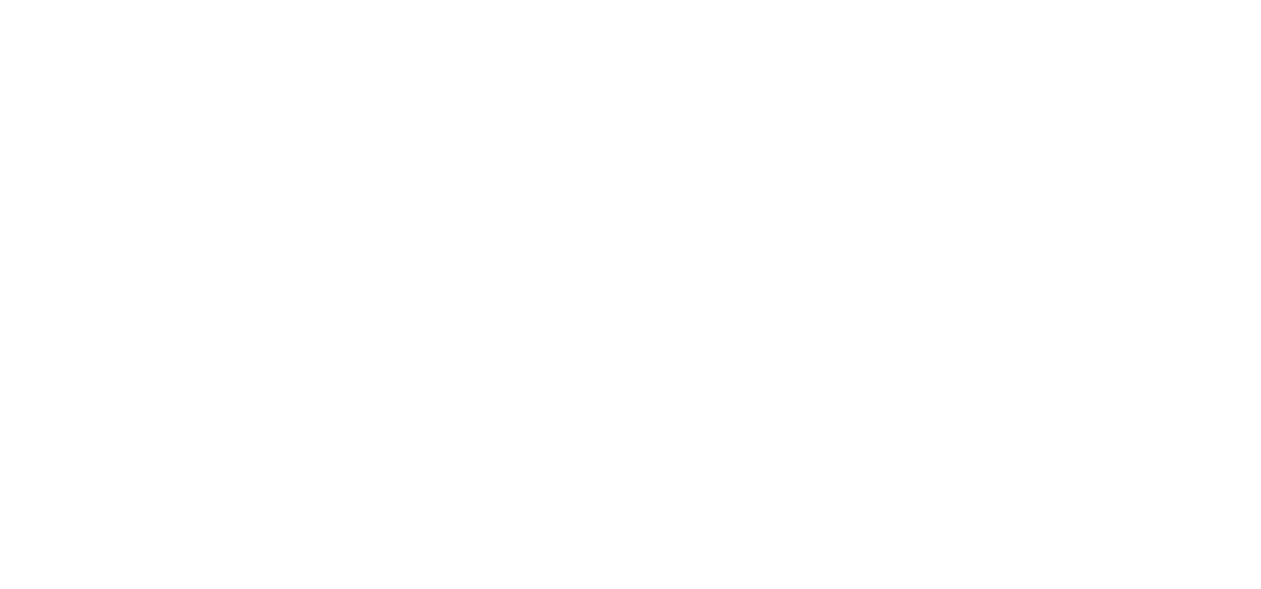


GREEN RIVER BASIN

09220000 EAST FORK OF SMITHS FORK NEAR ROBERTSON, WY-Continued

DURATION OF DISCHARGE FOR EACH WATER YEAR-Continued

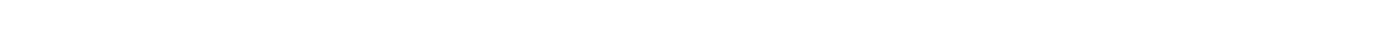

YEAR

NUMBER OF DAYS IN CJASS

CUBIC FEET

-DAYS

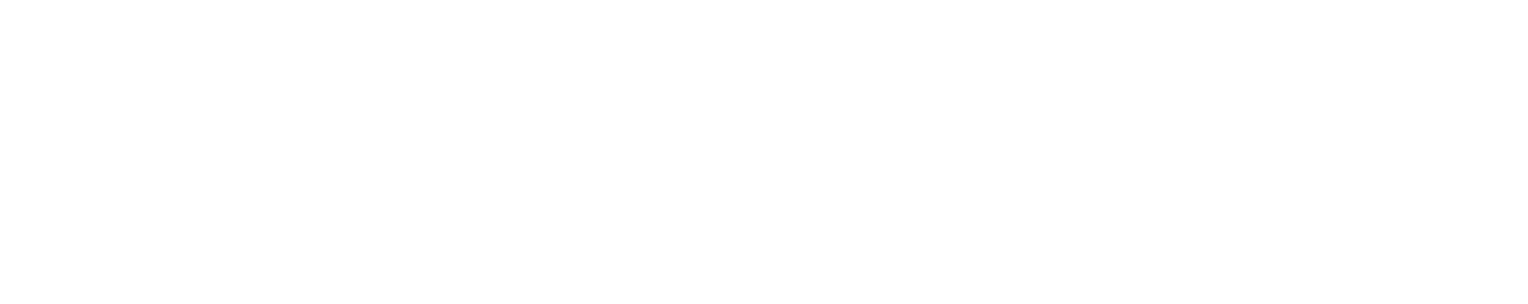

DURATION TABLE OF DISCHARGE FOR WATER YEARS 1940-71

\begin{tabular}{|c|c|c|c|c|c|c|c|c|c|c|c|c|c|c|c|c|c|c|c|}
\hline CLASS & $\begin{array}{c}\text { OABIC } \\
\text { FEET } \\
\text { PER } \\
\text { SECOND }\end{array}$ & $\begin{array}{r}\text { TOTAL } \\
\text { DAYS }\end{array}$ & $\begin{array}{c}\text { ACOU- } \\
\text { MU- } \\
\text { LATED } \\
\text { DAYS }\end{array}$ & $\begin{array}{l}\text { PER- } \\
\text { CENT } \\
\text { DAYS }\end{array}$ & CJASS & $\begin{array}{c}\text { CUBIC } \\
\text { FEET } \\
\text { PER } \\
\text { SECOND }\end{array}$ & TOTAL & $\begin{array}{c}\text { ACCU- } \\
\text { MU- } \\
\text { LATED } \\
\text { DAYS }\end{array}$ & $\begin{array}{l}\text { PER } \\
\text { CENT } \\
\text { DAYS }\end{array}$ & & $\begin{array}{c}\text { CUBIC } \\
\text { FEET } \\
\text { PER } \\
\text { SECOND }\end{array}$ & $\begin{array}{r}\text { TOMAL } \\
\text { DAYS }\end{array}$ & $\begin{array}{c}\text { ACOU- } \\
\mathbf{M -} \\
\text { LATED } \\
\text { DAYS }\end{array}$ & $\begin{array}{l}\text { PER- } \\
\text { CENT } \\
\text { DAYS }\end{array}$ & & $\begin{array}{c}\text { CUBIC } \\
\text { FEET } \\
\text { PER } \\
\text { SECOND }\end{array}$ & $\begin{array}{l}\text { TOIAL } \\
\text { DAYS }\end{array}$ & $\begin{array}{l}\text { ACOU- } \\
\text { MU- } \\
\text { LATED } \\
\text { DAYS }\end{array}$ & $\begin{array}{l}\text { PER- } \\
\text { CENT } \\
\text { DAYS }\end{array}$ \\
\hline $\begin{array}{l}0 \\
1 \\
2 \\
3 \\
4 \\
5 \\
6 \\
7 \\
8\end{array}$ & $\begin{array}{l}0.00 \\
1.00 \\
1.20 \\
1.50 \\
1.90 \\
2.30 \\
2.80 \\
3.50 \\
4.30\end{array}$ & $\begin{array}{r}0 \\
16 \\
32 \\
39 \\
12 \\
9 \\
54 \\
263 \\
513\end{array}$ & $\begin{array}{l}11688 \\
11688 \\
11672 \\
11640 \\
11601 \\
11589 \\
11580 \\
11526 \\
11263\end{array}$ & $\begin{array}{r}100.0 \\
100.0 \\
99.9 \\
99.6 \\
99.3 \\
99.2 \\
99.1 \\
98.6 \\
96.4\end{array}$ & $\begin{array}{r}9 \\
10 \\
11 \\
12 \\
13 \\
14 \\
15 \\
16 \\
17\end{array}$ & $\begin{array}{r}5.30 \\
6.50 \\
7.90 \\
9.80 \\
12.00 \\
15.00 \\
18.00 \\
22.00 \\
28.00\end{array}$ & $\begin{array}{r}845 \\
1095 \\
1259 \\
1017 \\
1034 \\
683 \\
573 \\
508 \\
352\end{array}$ & $\begin{array}{r}10750 \\
9905 \\
8810 \\
7551 \\
6534 \\
5500 \\
4817 \\
4244 \\
3736\end{array}$ & $\begin{array}{l}92.0 \\
84.7 \\
75.4 \\
64.6 \\
55.9 \\
47.1 \\
41.2 \\
36.3 \\
32.0\end{array}$ & $\begin{array}{l}18 \\
19 \\
20 \\
21 \\
22 \\
23 \\
24 \\
25 \\
26\end{array}$ & $\begin{array}{r}34.0 \\
42.0 \\
51.0 \\
63.0 \\
78.0 \\
95.0 \\
120.0 \\
140.0 \\
180.0\end{array}$ & $\begin{array}{l}372 \\
312 \\
339 \\
314 \\
293 \\
350 \\
209 \\
367 \\
266\end{array}$ & $\begin{array}{r}3384 \\
3012 \\
2700 \\
2361 \\
2047 \\
1754 \\
1404 \\
1195 \\
828\end{array}$ & $\begin{array}{r}29.0 \\
25.8 \\
23.1 \\
20.2 \\
17.5 \\
15.0 \\
12.0 \\
10.2 \\
7.1\end{array}$ & $\begin{array}{l}27 \\
28 \\
29 \\
30 \\
31 \\
32 \\
33 \\
34\end{array}$ & $\begin{array}{l}220.0 \\
270.0 \\
330.0 \\
410.0 \\
500.0 \\
620.0 \\
760.0 \\
930.0\end{array}$ & $\begin{array}{r}208 \\
150 \\
119 \\
41 \\
21 \\
13 \\
8 \\
2\end{array}$ & $\begin{array}{r}562 \\
354 \\
204 \\
85 \\
44 \\
23 \\
10 \\
2\end{array}$ & $\begin{array}{l}4.8 \\
3.0 \\
1.7 \\
0.7 \\
0.4 \\
0.2 \\
0.1 \\
0.0\end{array}$ \\
\hline
\end{tabular}

MONIHLY MEAN DISCHARGES, IN CUBIC FEET PER SECOND, FOR EACH WATER YEAR

\begin{tabular}{|c|c|c|c|c|c|c|c|c|c|c|c|c|}
\hline YEAR & $\propto C 1$ & NOV & $\mathrm{DEC}$ & JAN & FEB & MAR & APR & MAY & JUNE & JLY & ALUG & SEP \\
\hline 1940 & 15.8 & 6.16 & 4.00 & 3.70 & 4.50 & 5.40 & 19.7 & 164 & 59.6 & 15.9 & 6.64 & 17.3 \\
\hline $\begin{array}{l}1941 \\
1942 \\
1943 \\
1944 \\
1945\end{array}$ & $\begin{array}{l}24.1 \\
28.3 \\
11.3 \\
12.3 \\
14.9\end{array}$ & $\begin{array}{c}14.5 \\
16.3 \\
11.0 \\
9.92 \\
10.5\end{array}$ & $\begin{array}{c}9.50 \\
12.0 \\
10.0 \\
7.16 \\
6.00\end{array}$ & $\begin{array}{l}6.00 \\
8.00 \\
9.00 \\
6.00 \\
6.00\end{array}$ & $\begin{array}{l}6.00 \\
6.00 \\
9.00 \\
8.00 \\
7.00\end{array}$ & $\begin{array}{c}7.20 \\
5.83 \\
15.0 \\
10.0 \\
9.00\end{array}$ & $\begin{array}{l}12.0 \\
12.0 \\
75.2 \\
18.0 \\
12.0\end{array}$ & $\begin{array}{l}197 \\
118 \\
126 \\
142 \\
121\end{array}$ & $\begin{array}{l}243 \\
228 \\
144 \\
262 \\
197\end{array}$ & $\begin{array}{l}85.7 \\
80.5 \\
66.4 \\
143 \\
144\end{array}$ & $\begin{array}{l}43.3 \\
26.2 \\
36.9 \\
32.4 \\
61.0\end{array}$ & $\begin{array}{l}25.5 \\
13.5 \\
13.5 \\
12.2 \\
19.1\end{array}$ \\
\hline $\begin{array}{l}1946 \\
1947 \\
1948 \\
1949 \\
1950\end{array}$ & $\begin{array}{c}15.9 \\
11.3 \\
15.3 \\
7.35 \\
18.8\end{array}$ & $\begin{array}{c}11.9 \\
12.1 \\
10.2 \\
7.84 \\
14.0\end{array}$ & $\begin{array}{c}11.0 \\
10.0 \\
8.00 \\
7.00 \\
8.00\end{array}$ & $\begin{array}{c}10.0 \\
7.50 \\
7.50 \\
6.50 \\
5.50\end{array}$ & $\begin{array}{c}10.0 \\
8.50 \\
7.00 \\
6.00 \\
5.00\end{array}$ & $\begin{array}{c}13.0 \\
10.0 \\
7.30 \\
6.50 \\
4.46\end{array}$ & $\begin{array}{l}90.0 \\
15.0 \\
13.8 \\
17.9 \\
12.8\end{array}$ & $\begin{array}{c}122 \\
159 \\
163 \\
142 \\
94.4\end{array}$ & $\begin{array}{l}127 \\
190 \\
147 \\
276 \\
234\end{array}$ & $\begin{array}{c}55.2 \\
114 \\
38.1 \\
115 \\
83.4\end{array}$ & $\begin{array}{l}16.6 \\
41.9 \\
18.5 \\
35.9 \\
25.5\end{array}$ & $\begin{array}{c}7.80 \\
20.2 \\
7.69 \\
11.7 \\
13.8\end{array}$ \\
\hline $\begin{array}{l}1951 \\
1952 \\
1953 \\
1954 \\
1955\end{array}$ & $\begin{array}{c}11.2 \\
24.5 \\
14.5 \\
8.19 \\
12.8\end{array}$ & $\begin{array}{c}10.00 \\
19.0 \\
9.27 \\
8.63 \\
9.45\end{array}$ & $\begin{array}{c}7.58 \\
16.0 \\
9.00 \\
7.40 \\
5.52\end{array}$ & $\begin{array}{c}6.00 \\
23.0 \\
8.50 \\
5.60 \\
5.81\end{array}$ & $\begin{array}{c}7.00 \\
11.0 \\
8.00 \\
6.00 \\
6.04\end{array}$ & $\begin{array}{c}8.50 \\
10.0 \\
8.50 \\
7.00 \\
6.25\end{array}$ & $\begin{array}{l}14.3 \\
27.2 \\
14.9 \\
24.3 \\
10.0\end{array}$ & $\begin{array}{l}120 \\
201 \\
31.6 \\
97.8 \\
95.4\end{array}$ & $\begin{array}{c}177 \\
323 \\
270 \\
59.3 \\
122\end{array}$ & $\begin{array}{c}92.5 \\
124 \\
82.2 \\
45.0 \\
41.8\end{array}$ & $\begin{array}{l}43.2 \\
47.8 \\
35.3 \\
17.6 \\
25.3\end{array}$ & $\begin{array}{l}20.6 \\
25.9 \\
10.0 \\
15.8 \\
12.3\end{array}$ \\
\hline $\begin{array}{l}1956 \\
1957 \\
1958 \\
1959 \\
1960\end{array}$ & $\begin{array}{c}9.68 \\
5.21 \\
13.2 \\
8.53 \\
21.7\end{array}$ & $\begin{array}{c}6.60 \\
5.50 \\
10.6 \\
7.05 \\
11.0\end{array}$ & $\begin{array}{c}7.08 \\
5.00 \\
10.0 \\
6.41 \\
3.50\end{array}$ & $\begin{array}{c}7.04 \\
4.00 \\
10.0 \\
4.84 \\
3.00\end{array}$ & $\begin{array}{c}6.34 \\
4.50 \\
11.5 \\
5.00 \\
4.00\end{array}$ & $\begin{array}{c}7.59 \\
4.35 \\
13.1 \\
5.00 \\
8.92\end{array}$ & $\begin{array}{c}18.8 \\
5.65 \\
20.0 \\
8.17 \\
26.0\end{array}$ & $\begin{array}{c}164 \\
56.5 \\
164 \\
97.7 \\
107\end{array}$ & $\begin{array}{l}190 \\
349 \\
182 \\
254 \\
162\end{array}$ & $\begin{array}{c}52.8 \\
161 \\
49.8 \\
67.4 \\
41.4\end{array}$ & $\begin{array}{l}17.4 \\
39.6 \\
22.0 \\
29.4 \\
12.0\end{array}$ & $\begin{array}{c}6.68 \\
15.8 \\
17.7 \\
19.5 \\
11.6\end{array}$ \\
\hline $\begin{array}{l}1961 \\
1962 \\
1963 \\
1964 \\
1965\end{array}$ & $\begin{array}{l}11.6 \\
34.8 \\
10.5 \\
15.7 \\
10.2\end{array}$ & $\begin{array}{c}9.95 \\
18.1 \\
6.05 \\
9.30 \\
9.72\end{array}$ & $\begin{array}{r}8.27 \\
9.58 \\
2.11 \\
7.00 \\
10.7\end{array}$ & $\begin{array}{l}7.50 \\
8.00 \\
1.34 \\
7.89 \\
9.84\end{array}$ & $\begin{array}{c}8.00 \\
11.4 \\
1.55 \\
5.81 \\
9.87\end{array}$ & $\begin{array}{c}12.2 \\
10.3 \\
2.14 \\
4.75 \\
7.69\end{array}$ & $\begin{array}{c}17.2 \\
47.5 \\
5.88 \\
5.72 \\
16.1\end{array}$ & $\begin{array}{l}101 \\
116 \\
95.0 \\
167 \\
112\end{array}$ & $\begin{array}{l}103 \\
225 \\
153 \\
257 \\
430\end{array}$ & $\begin{array}{c}25.1 \\
115 \\
77.0 \\
120 \\
269\end{array}$ & $\begin{array}{r}18.2 \\
29.8 \\
29.0 \\
35.7 \\
120\end{array}$ & $\begin{array}{l}44.6 \\
11.2 \\
29.7 \\
13.9 \\
59.8\end{array}$ \\
\hline $\begin{array}{l}1966 \\
1967 \\
1968 \\
1969 \\
1970\end{array}$ & $\begin{array}{l}30.5 \\
25.4 \\
16.1 \\
16.3 \\
15.6\end{array}$ & $\begin{array}{c}18.0 \\
10.7 \\
10.5 \\
9.83 \\
10.7\end{array}$ & $\begin{array}{c}16.9 \\
4.58 \\
8.52 \\
6.64 \\
5.88\end{array}$ & $\begin{array}{c}16.4 \\
6.05 \\
9.86 \\
6.99 \\
4.53\end{array}$ & $\begin{array}{c}13.4 \\
6.26 \\
8.29 \\
7.42 \\
4.42\end{array}$ & $\begin{array}{c}13.7 \\
4.92 \\
8.74 \\
7.58 \\
4.32\end{array}$ & $\begin{array}{c}24.0 \\
8.16 \\
9.78 \\
22.8 \\
5.01\end{array}$ & $\begin{array}{l}151 \\
120 \\
68.7 \\
173 \\
151\end{array}$ & $\begin{array}{l}115 \\
270 \\
426 \\
103 \\
247\end{array}$ & $\begin{array}{l}65.1 \\
161 \\
101 \\
59.4 \\
86.2\end{array}$ & $\begin{array}{l}31.0 \\
46.2 \\
52.8 \\
30.1 \\
22.9\end{array}$ & $\begin{array}{l}27.2 \\
23.1 \\
26.9 \\
16.0 \\
34.0\end{array}$ \\
\hline 1971 & 16.6 & 14.6 & 9.00 & 6.93 & 7.35 & 6.79 & 25.2 & 109 & 391 & 119 & 48.9 & 22.2 \\
\hline
\end{tabular}


GREEN RIVER BASIN

09220000 EAST FORK OF SMITHS FORK NEAR RCBERTSON, WY--Continued

ANNUAL PEAK DISCHARGE, IN CUBIC FEET PER SECOND, AND CORRESPONDING GAGE HEIGHT, IN FEET, FOR EACH WATER YEAR

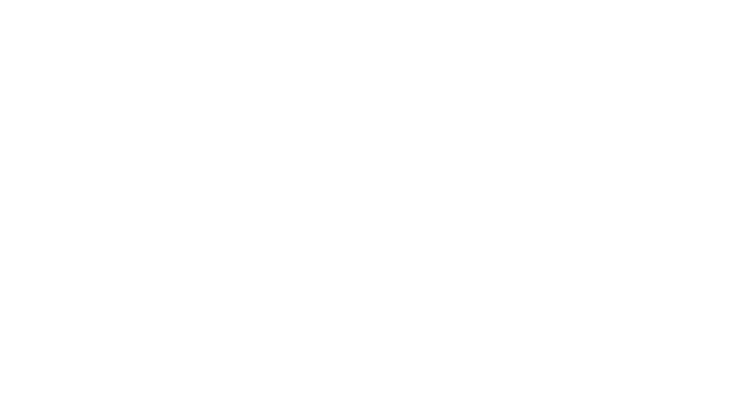

MAGNITUDE AND PROBABILITY OF ANNUAL LONEST MEAN DISCHARGE RASED ON CIMATIC YEARS 1941-71

\begin{tabular}{|c|c|c|c|c|c|c|}
\hline \multirow{2}{*}{$\begin{array}{l}\text { PERIOD } \\
\text { (CON- } \\
\text { SECU- } \\
\text { TIVE } \\
\text { DAYS) }\end{array}$} & \multicolumn{6}{|c|}{$\begin{array}{l}\text { DISCHARGE, IN CNBIC FEET PER SECOND, FOR } \\
\text { INDICATED REGURRENCE INTERNAL, IN YEARS, AND } \\
\text { ANNUAL NONEXCEEDANCE PRCBABIIITY, IN PERCENT }\end{array}$} \\
\hline & $\begin{array}{c}2 \\
508\end{array}$ & $\begin{array}{c}5 \\
208\end{array}$ & $\begin{array}{l}10 \\
108\end{array}$ & $\begin{array}{l}20 \\
58\end{array}$ & $\begin{array}{l}50 \\
28\end{array}$ & $\begin{array}{r}100 \\
18\end{array}$ \\
\hline
\end{tabular}

$\begin{array}{rrrrrrr}1 & 5.5 & 3.7 & 2.8 & 2.1 & 1.5 & = \\ 7 & 5.9 & 3.9 & 2.9 & 2.2 & 1.5 & = \\ 14 & 6.2 & 4.1 & 3.0 & 2.3 & 1.5 & = \\ 30 & 6.5 & 4.4 & 3.3 & 2.5 & 1.7 & = \\ 60 & 7.1 & 4.8 & 3.6 & 2.8 & 1.9 & = \\ 90 & 7.4 & 5.0 & 3.8 & 2.9 & 2.1 & -\end{array}$

$\begin{array}{cr}\text { GAGE } & \text { PEAK } \\ \text { HEIGHT } & \text { DISCH } \\ - & 263 \\ - & 377 \\ - & 494 \\ - & 734 \\ \mathbf{6 . 1 8} & 540 \\ \mathbf{6 . 0 1} & 476 \\ 5.95 & 364 \\ 5.59 & 313 \\ \mathbf{6 . 0 8} & 401 \\ 5.82 & 325 \\ \mathbf{6 . 4 7} & 6554 \\ \mathbf{6 . 7 5} & 1450 \\ 5.21 & 315 \\ \mathbf{5 . 6 3} & 460\end{array}$

YEAR DATE

PEAK

1968 JUNE 06, $1968 \quad 6.63 \quad 1280$

1969 MAY 20, $1969 \quad 5.44 \quad 365$

1970 MAY 28, 1970

1971 JUNE 17, 1971

1972 JUNE 01, 1972

1973 JUNE 10, 1973

1974 MAY 29, 1974

1975 JUNE 16, 1975

1976 MAY 20, 1976

1977 JUNE 05, 1977

1978 JUNE 14, 1978

1979 JULY 06, 1979

1979 JULY 06, 1979

1980 JUNE 11, 1980
1981 JUNE 09, 1981

5.70

6.38

654

$6.21 \quad 879$

$6.08 \quad 774$

$5.18 \quad 273$

$5.67-273$

$5.67 \quad 430$

$6.33 \quad 987$

$5.48 \quad 400$

$6.12 \quad 806$

MAGNITUDE AND PRCBABILITY OF ANNUAL HIGHEST MEAN DISCHARGE BASED ON WATER YEARS 1940-71

\begin{tabular}{|c|c|c|c|c|c|c|}
\hline \multirow{2}{*}{$\begin{array}{l}\text { PERIOD } \\
\text { (CON- } \\
\text { SECU- } \\
\text { PIVE } \\
\text { DAYS) }\end{array}$} & \multicolumn{6}{|c|}{$\begin{array}{l}\text { DISCHARGE, IN CUBIC FEET PER SECOND, FOR } \\
\text { INDICATED RECURRENCE INTERNAL, IN YEARS, AND } \\
\text { ANNUAL EXCEEDANCE PRCBABILITY, IN PERCENT }\end{array}$} \\
\hline & $\begin{array}{c}2 \\
508\end{array}$ & $\begin{array}{c}5 \\
208\end{array}$ & $\begin{array}{l}10 \\
108\end{array}$ & $\begin{array}{l}25 \\
48\end{array}$ & $\begin{array}{l}50 \\
28\end{array}$ & $\begin{array}{r}100 \\
18\end{array}$ \\
\hline $\begin{array}{r}1 \\
3 \\
7 \\
15\end{array}$ & $\begin{array}{l}390 \\
363 \\
325 \\
279\end{array}$ & $\begin{array}{l}567 \\
522 \\
465 \\
385\end{array}$ & $\begin{array}{l}707 \\
640 \\
566 \\
455\end{array}$ & $\begin{array}{l}911 \\
807 \\
705 \\
544\end{array}$ & $\begin{array}{r}1090 \\
943 \\
816 \\
610\end{array}$ & $\overline{-}$ \\
\hline
\end{tabular}




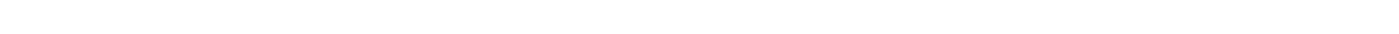
Wasatch National Forest, on left bank $0.8 \mathrm{mi}$ downstream from Archie Creek and $11.6 \mathrm{mi}$ southwest of Robertson.

DRAINAGE AREA. $-37.2 \mathrm{mi}^{2}$.

MEAN BASIN ETLEVATION.--9,790 ft.

PERIOD O RECORD AVAILABLE.--July 1939 to September 1981 (no winter records since 1971). Prior to Oct. 1, 1978, published as "West Fork of Stith Fork near Robertson".

REVISED RECORDS.--WSP 929: 1940. WSP 1343, 1733: 1943.

GAGE.-Water-stage recorder. Datum of gage is $8,615.0 \mathrm{ft}$, NGVD of 1929 . July 13, 1939, to Aug. 16, 1949, at site $75 \mathrm{ft}$ upstream at datum $2.00 \mathrm{ft}$ higher, Aug. 17, 1949, to June 13, 1965, at present site at datum $2.00 \mathrm{ft}$ higher.

COOPERATION.--Records collected and computed by office of the Wyoning State Engineer and reviewed by Geological Survey.

AVERAGE DISCHARGE.--32 years (water years 1940-71), $21.5 \mathrm{ft}^{3} / \mathrm{s}, 15,580 \mathrm{acre}-\mathrm{ft} / \mathrm{yr}$.

EXIREMES FOR PERIOD OF REOORD.--Maximum discharge, 2,100 ft 3 s, June 10, 1965, gage height, $5.20 \mathrm{ft}$, in gage well, $5.60 \mathrm{ft}$, from floodmarks, present datum; minimum observed, $0.2 \mathrm{ft} 3 / \mathrm{s}$ Aug. 13, 1940, Feb. 25, 1942 (discharge measurement).

LOWEST MEAN DISCHARGE, IN OUBIC FEET PER SEOOND, AND RANKING FOR THE INDICATED NUMBER OF CONSECUTIVE DAYS FOR EACH CLIMATIC YEAR, APRIL I-MARCH 31

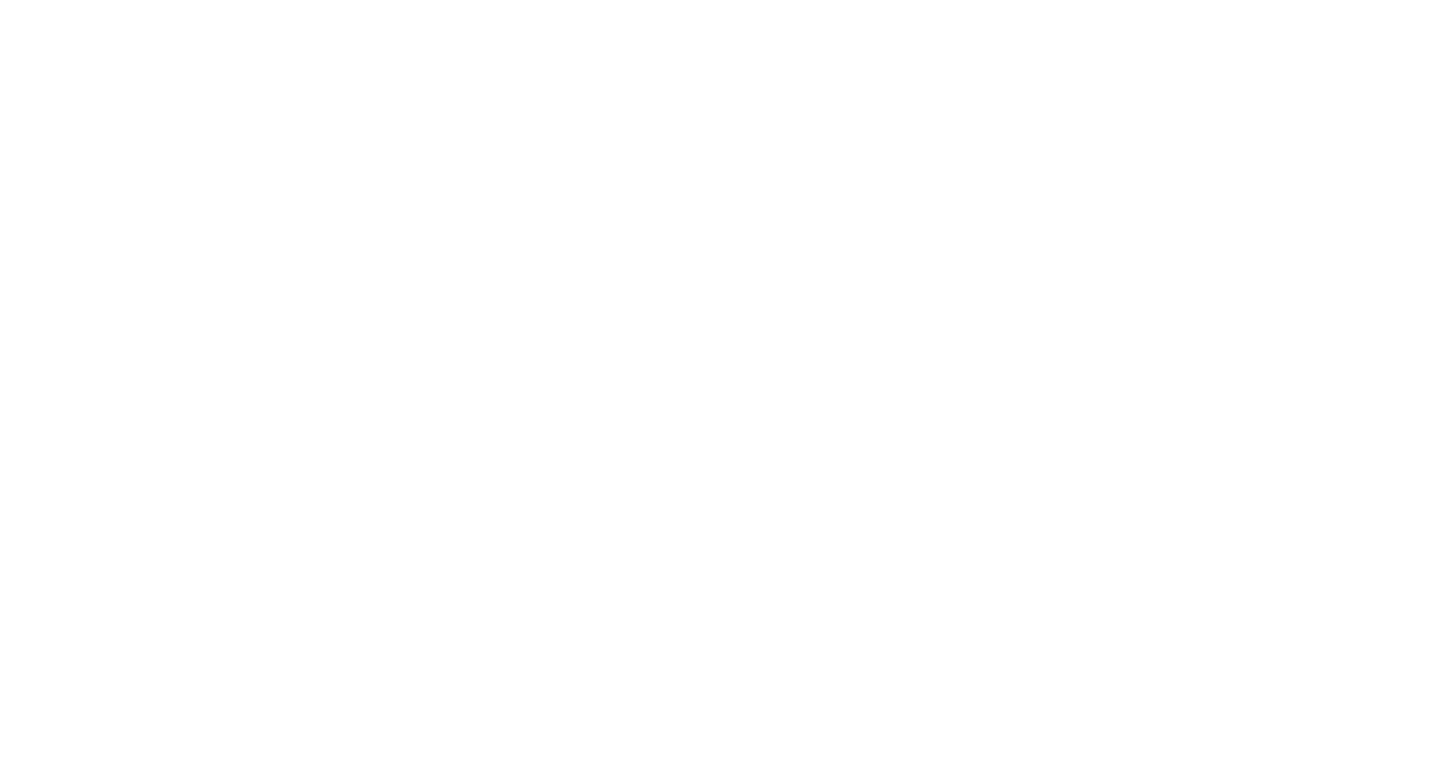


GREEN RIVER BASIN

09220500 WEST FORK QF SMITHS FORK NEAR ROBERTSON, WY--Continued

LOWEST MEAN DISCHARGE, IN OBBIC FEET PER SECOND, AND RANKING FOR THE INDICATED NUNBER OF CONSECUTIVE DAYS FOR EACH CLIMATIC YEAR, APRIL 1-MARCH 31-Continued

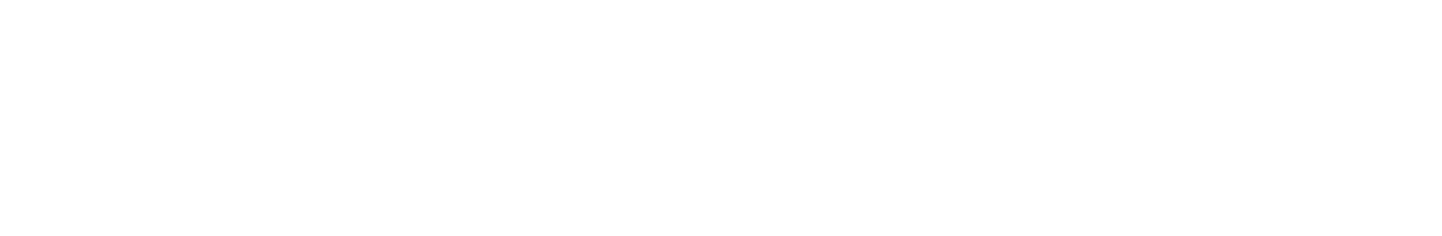

HIGHEST MEAN DISCHARGE, IN CUBIC FEET PER SECOND, AND RANKING FOR THE INDICATED NUMBER OF CONSECUTIVE DAYS FOR EACH WATER YEAR, OCTOBER 1-SEPTEMBER 30

\begin{tabular}{|c|c|c|c|c|c|c|c|c|c|c|c|c|c|c|c|c|c|c|c|c|}
\hline YEAR & 1 & & 3 & & 7 & & 15 & & $\begin{array}{l}\mathrm{CON} \\
30\end{array}$ & & $\begin{array}{l}\text { DAYS } \\
60\end{array}$ & & 90 & & 120 & & 183 & & ALL & \\
\hline 1940 & 246 & 21 & 242 & 20 & 222 & 19 & 162 & 22 & 108 & 25 & 66.0 & 29 & 45.0 & 29 & 35.0 & 29 & 23.0 & 30 & 12.0 & 31 \\
\hline $\begin{array}{l}1951 \\
1952 \\
1953 \\
1954 \\
1955\end{array}$ & $\begin{array}{l}363 \\
234 \\
309 \\
116 \\
147\end{array}$ & $\begin{array}{r}9 \\
23 \\
15 \\
31 \\
29\end{array}$ & $\begin{array}{l}340 \\
220 \\
294 \\
106 \\
138\end{array}$ & $\begin{array}{r}8 \\
23 \\
15 \\
31 \\
30\end{array}$ & $\begin{array}{c}285 \\
196 \\
268 \\
95.0 \\
116\end{array}$ & $\begin{array}{r}99 \\
23 \\
12 \\
32 \\
30\end{array}$ & $\begin{array}{l}207 \\
184 \\
226 \\
69.0 \\
94.0\end{array}$ & $\begin{array}{l}13 \\
17 \\
10 \\
32 \\
30\end{array}$ & $\begin{array}{c}143 \\
165 \\
176 \\
51.0 \\
84.0\end{array}$ & $\begin{array}{r}16 \\
11 \\
9 \\
32 \\
30\end{array}$ & $\begin{array}{l}102 \\
122 \\
101 \\
35.0 \\
61.0\end{array}$ & $\begin{array}{r}16 \\
9 \\
17 \\
32 \\
30\end{array}$ & & $\begin{array}{r}18 \\
7 \\
19 \\
32 \\
30\end{array}$ & & $\begin{array}{r}15 \\
7 \\
19 \\
32 \\
30\end{array}$ & & $\begin{array}{r}15 \\
8 \\
19 \\
32 \\
29\end{array}$ & $\begin{array}{c}23.0 \\
26.0 \\
20.0 \\
8.80 \\
13.0\end{array}$ & $\begin{array}{r}15 \\
6 \\
19 \\
32 \\
29\end{array}$ \\
\hline $\begin{array}{l}1961 \\
1962 \\
1963 \\
1964 \\
1965\end{array}$ & $\begin{array}{r}109 \\
321 \\
146 \\
384 \\
1640\end{array}$ & $\begin{array}{r}32 \\
12 \\
30 \\
7 \\
1\end{array}$ & $\begin{array}{r}101 \\
303 \\
143 \\
379 \\
1150\end{array}$ & $\begin{array}{r}32 \\
12 \\
29 \\
6 \\
1\end{array}$ & $\begin{array}{l}97.0 \\
265 \\
135 \\
362 \\
812\end{array}$ & $\begin{array}{r}31 \\
13 \\
29 \\
3 \\
1\end{array}$ & $\begin{array}{l}83.0 \\
178 \\
110 \\
276 \\
613\end{array}$ & $\begin{array}{r}31 \\
19 \\
29 \\
4 \\
1\end{array}$ & $\begin{array}{c}67.0 \\
129 \\
89.0 \\
189 \\
423\end{array}$ & $\begin{array}{r}31 \\
21 \\
29 \\
8 \\
1\end{array}$ & $\begin{array}{c}49.0 \\
103 \\
69.0 \\
123 \\
276\end{array}$ & $\begin{array}{r}31 \\
15 \\
28 \\
8 \\
1\end{array}$ & $\begin{array}{r}38.0 \\
83.0 \\
51.0 \\
86.0 \\
198\end{array}$ & $\begin{array}{r}31 \\
12 \\
28 \\
9 \\
1\end{array}$ & $\begin{array}{c}30.0 \\
66.0 \\
40.0 \\
66.0 \\
155\end{array}$ & $\begin{array}{r}31 \\
10 \\
28 \\
11 \\
1\end{array}$ & $\begin{array}{r}21.0 \\
45.0 \\
27.0 \\
45.0 \\
106\end{array}$ & $\begin{array}{r}31 \\
10 \\
28 \\
11 \\
1\end{array}$ & & $\begin{array}{r}30 \\
10 \\
28 \\
11 \\
1\end{array}$ \\
\hline $\begin{array}{l}1966 \\
1967 \\
1968 \\
1969 \\
1970\end{array}$ & $\begin{array}{l}310 \\
423 \\
744 \\
176 \\
314\end{array}$ & $\begin{array}{r}14 \\
5 \\
2 \\
27 \\
13\end{array}$ & $\begin{array}{l}299 \\
385 \\
537 \\
163 \\
297\end{array}$ & $\begin{array}{r}13 \\
5 \\
2 \\
27 \\
14\end{array}$ & $\begin{array}{l}253 \\
331 \\
413 \\
159 \\
276\end{array}$ & $\begin{array}{r}14 \\
5 \\
2 \\
26 \\
11\end{array}$ & $\begin{array}{l}164 \\
271 \\
303 \\
143 \\
246\end{array}$ & $\begin{array}{r}21 \\
5 \\
2 \\
25 \\
7\end{array}$ & $\begin{array}{l}116 \\
201 \\
215 \\
107 \\
194\end{array}$ & $\begin{array}{r}23 \\
4 \\
2 \\
26 \\
7\end{array}$ & $\begin{array}{l}75.0 \\
141 \\
129 \\
70.0 \\
121\end{array}$ & $\begin{array}{r}25 \\
3 \\
5 \\
27 \\
10\end{array}$ & $\begin{array}{c}55.0 \\
100 \\
91.0 \\
53.0 \\
85.0\end{array}$ & $\begin{array}{r}25 \\
3 \\
6 \\
27 \\
10\end{array}$ & $\begin{array}{l}43.0 \\
77.0 \\
70.0 \\
42.0 \\
65.0\end{array}$ & $\begin{array}{r}25 \\
3 \\
6 \\
26 \\
12\end{array}$ & $\begin{array}{l}30.0 \\
52.0 \\
48.0 \\
29.0 \\
44.0\end{array}$ & $\begin{array}{r}24 \\
3 \\
5 \\
26 \\
12\end{array}$ & $\begin{array}{l}18.0 \\
28.0 \\
25.0 \\
17.0 \\
24.0\end{array}$ & $\begin{array}{r}22 \\
3 \\
8 \\
23 \\
12\end{array}$ \\
\hline
\end{tabular}

DURATION OF DISCHARGE FOR EACH WATER YEAR

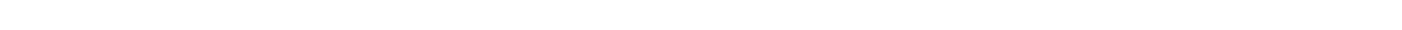

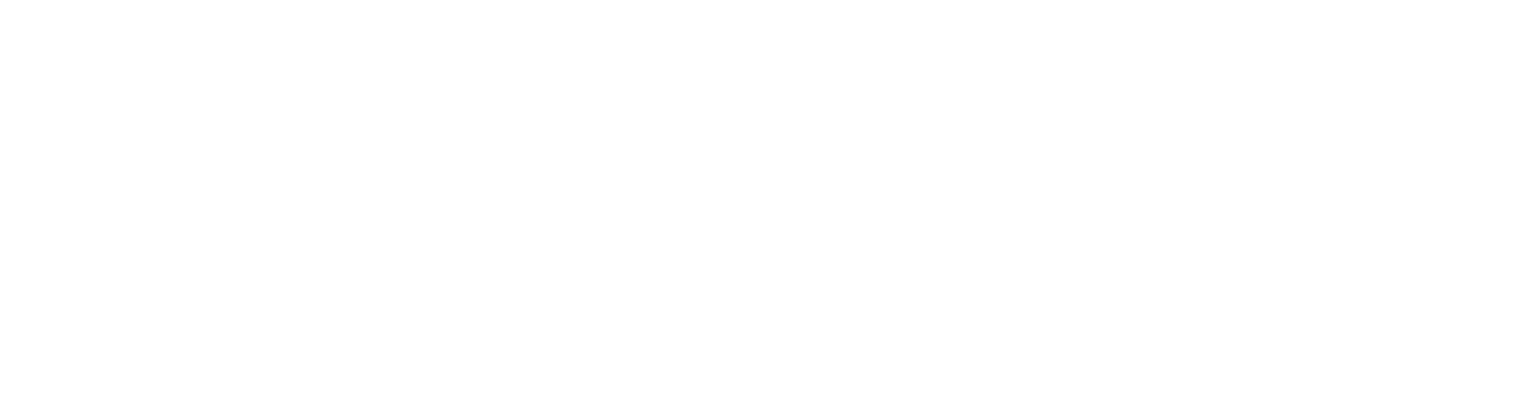


GREEN RIVER BASIN

09220500 WEST FORK OF SMITHS FORK NEAR RCBERTSav, WY--Continued

DURATION OF DISCHARGE FOR EACH WATER YEAR-Continued

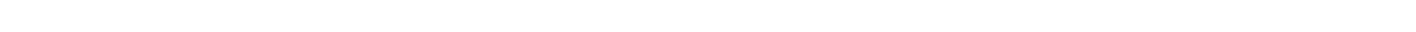
YEAR

NUMBER OF DAYS IN OLASS

OBBIC FEET

1951
1952
1953
1954
1955
1956
1957
1958
1959
1960
1961
1962
1963
1964
1965
1966
1967
1968
1969
1970 ER SECOND

$\begin{array}{lllllllllllllllllllll}1 & 1 & 107 & 91 & 17 & 10 & 9 & 12 & 16 & 20 & 15 & 10 & 5 & 9 & 19 & 8 & 4 & 3 & 2 & 3 & 3\end{array}$

8371.3

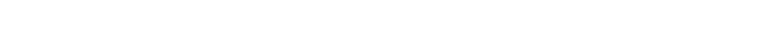
$\begin{array}{rrrrrrrrrrrrrrrrrrrrrrr}2 & 1 & 5 & 2 & 7 & 13 & 19 & 44 & 56 & 105 & 21 & 9 & 16 & 9 & 10 & 10 & 10 & 7 & 8 & 3 & 2 & 5 & 1 \\ 3 & 4 & 11 & 5 & 13 & 23 & 47 & 68 & 57 & 17 & 17 & 14 & 11 & 8 & 9 & 5 & 8 & 1 & 9 & 10 & 7 & 13 & 4\end{array}$

7157.7

3208.7

4689.4

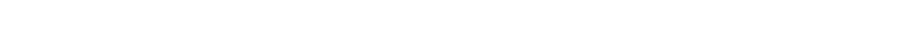

$\begin{array}{lllllllllllllllllllllll}14 & 52 & 142 & 12 & 13 & 15 & 9 & 10 & 20 & 8 & 11 & 10 & 7 & 6 & 4 & 8 & 4 & 7 & 3 & 4 & 4 & 2\end{array}$

7681.7

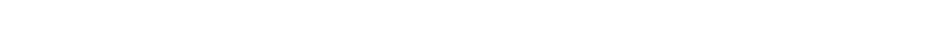

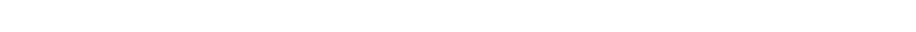

9038.8

6115.2

5422.6

$\begin{array}{lllllllllllllllllll}3 & 6 & 42 & 85 & 41 & 34 & 32 & 15 & 15 & 9 & 5 & 5 & 4 & 22 & 9 & 15 & 8 & 5 & 10\end{array}$

$\begin{array}{rlllrllllllllllllllrrrrrrrrrr}10 & 17 & 24 & 18 & 5 & 25 & 10 & 48 & 30 & 35 & 64 & 49 & 41 & 12 & 9 & 12 & 6 & 6 & 4 & 9 & 9 & 33 & 18 & 1 & & 3 & 3 & 2 \\ & 12 & 20 & 16 & 11 & 8 & 11 & 6 & 7 & 9 & 6 & 17 & 9 & 6 & 7 & 3 & & & \end{array}$

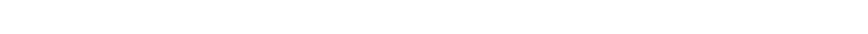

$\begin{array}{lllllllllllllllllll}5 & 46 & 57 & 92 & 27 & 15 & 28 & 17 & 13 & 16 & 6 & 10 & 11 & 9 & 4 & 1 & 2 & 1 & 4\end{array}$

$\begin{array}{lllllllllllllllllllllll}22 & 102 & 88 & 29 & 17 & 18 & 8 & 7 & 6 & 10 & 4 & 5 & 5 & 2 & 9 & 11 & 2 & 8 & 8 & 2 & 2\end{array}$

$\begin{array}{lllllllllllllllllllllll}2 & 65 & 101 & 50 & 22 & 17 & 19 & 10 & 8 & 6 & 14 & 10 & 4 & 5 & 3 & 4 & 6 & 7 & 3 & 5 & 2 & 2\end{array}$

$\begin{array}{lllllllllllllllll}6 & 64 & 132 & 28 & 24 & 13 & 16 & 8 & 3 & 13 & 18 & 9 & 4 & 9 & 5 & 3 & 10\end{array}$

4226.6

8928.3

8728.0

$\begin{array}{lllllllllllllllllllll}1 & 9 & 110 & 76 & 25 & 18 & 10 & 5 & 13 & 11 & 10 & 7 & 11 & 8 & 6 & 5 & 6 & 9 & 15 & 8 & 2\end{array}$

6586.5

10135.7

9271.6

8657.5

1971

DURATION TABLE OF DISCHARGE FOR WATER YEARS 1940-71

\begin{tabular}{|c|c|c|c|c|c|c|c|c|c|c|c|c|c|c|c|c|c|c|c|}
\hline C.ASS & $\begin{array}{c}\text { CABIC } \\
\text { FEET } \\
\text { PER } \\
\text { SECOND }\end{array}$ & $\begin{array}{l}\text { TOTAL } \\
\text { DAYS }\end{array}$ & $\begin{array}{l}\text { ACOU- } \\
\text { MU- } \\
\text { LATED } \\
\text { DAYS }\end{array}$ & $\begin{array}{l}\text { PER- } \\
\text { CENT } \\
\text { DAYS }\end{array}$ & & $\begin{array}{c}\text { CUBIC } \\
\text { FEET } \\
\text { PER } \\
\text { SECOND }\end{array}$ & $\begin{array}{r}\text { TOTAL, } \\
\text { DAYS }\end{array}$ & $\begin{array}{c}\text { ACOU- } \\
\text { MU- } \\
\text { LATED } \\
\text { DAYS }\end{array}$ & $\begin{array}{l}\text { PER- } \\
\text { CENT } \\
\text { DAYS }\end{array}$ & & $\begin{array}{c}\text { CUBIC } \\
\text { FEET } \\
\text { PER } \\
\text { SECOND }\end{array}$ & $\begin{array}{l}\text { TOTIAL } \\
\text { DAYS }\end{array}$ & $\begin{array}{c}\text { ACOU- } \\
\text { MU- } \\
\text { LATED } \\
\text { DAYS }\end{array}$ & $\begin{array}{l}\text { PER- } \\
\text { CENT } \\
\text { DAYS }\end{array}$ & & $\begin{array}{c}\text { CRBIC } \\
\text { FEET } \\
\text { PER } \\
\text { SECOND }\end{array}$ & $\begin{array}{r}\text { TOTAL } \\
\text { DAYS }\end{array}$ & $\begin{array}{l}\text { ACOU- } \\
\text { MU- } \\
\text { LATED } \\
\text { DAYS }\end{array}$ & $\begin{array}{l}\text { PER- } \\
\text { CENT } \\
\text { DAYS }\end{array}$ \\
\hline $\begin{array}{l}0 \\
1 \\
2 \\
3 \\
4 \\
5 \\
6 \\
7\end{array}$ & $\begin{array}{l}0.00 \\
0.20 \\
0.26 \\
0.34 \\
0.44 \\
0.57 \\
0.74 \\
0.96\end{array}$ & $\begin{array}{r}0 \\
1 \\
18 \\
45 \\
40 \\
147 \\
72 \\
254 \\
599\end{array}$ & $\begin{array}{l}11688 \\
11688 \\
11687 \\
11669 \\
11624 \\
11584 \\
11437 \\
11365\end{array}$ & $\begin{array}{r}100.0 \\
100.0 \\
100.0 \\
99.8 \\
99.5 \\
99.1 \\
97.9 \\
97.2\end{array}$ & $\begin{array}{r}9 \\
10 \\
11 \\
12 \\
13 \\
14 \\
15 \\
16 \\
17\end{array}$ & $\begin{array}{r}1.60 \\
2.10 \\
2.70 \\
3.60 \\
4.60 \\
6.00 \\
7.80 \\
10.00 \\
13.00\end{array}$ & $\begin{array}{r}1227 \\
1229 \\
1886 \\
1274 \\
880 \\
543 \\
344 \\
331 \\
344\end{array}$ & $\begin{array}{r}10512 \\
9285 \\
8056 \\
6170 \\
4896 \\
4016 \\
3473 \\
3129 \\
2798\end{array}$ & $\begin{array}{l}89.9 \\
79.4 \\
68.9 \\
52.8 \\
41.9 \\
34.4 \\
29.7 \\
26.8 \\
23.9\end{array}$ & $\begin{array}{l}18 \\
19 \\
20 \\
21 \\
22 \\
23 \\
24 \\
25 \\
26\end{array}$ & $\begin{array}{r}17.0 \\
22.0 \\
29.0 \\
37.0 \\
49.0 \\
63.0 \\
82.0 \\
110.0\end{array}$ & $\begin{array}{l}291 \\
302 \\
211 \\
255 \\
238 \\
253 \\
267 \\
193 \\
150\end{array}$ & $\begin{array}{r}2454 \\
2163 \\
1861 \\
1650 \\
1395 \\
1157 \\
904 \\
637\end{array}$ & $\begin{array}{r}21.0 \\
18.5 \\
15.9 \\
14.1 \\
.11 .9 \\
9.9 \\
7.7 \\
5.5\end{array}$ & $\begin{array}{l}27 \\
28 \\
29 \\
30 \\
31 \\
32 \\
33 \\
34\end{array}$ & $\begin{array}{r}180.0 \\
230.0 \\
300.0 \\
390.0 \\
510.0 \\
660.0 \\
860.0 \\
1100.0\end{array}$ & $\begin{array}{r}128 \\
101 \\
43 \\
13 \\
5 \\
2 \\
0 \\
2\end{array}$ & $\begin{array}{r}294 \\
166 \\
65 \\
22 \\
9 \\
4 \\
2 \\
2\end{array}$ & $\begin{array}{l}2.5 \\
1.4 \\
0.6 \\
0.2 \\
0.1 \\
0.0 \\
0.0 \\
0.0\end{array}$ \\
\hline
\end{tabular}

MONIHLY MEAN DISCHARGES, IN OBBIC FEET PER SECOND, FOR EACH WATER YEAR

\begin{tabular}{|c|c|c|c|c|c|c|c|c|c|c|c|c|}
\hline YEAR & $\infty T$ & NOW & DEC & JAN & FEBB & MAR & APR & MAY & JUNE & JULY & AJG & SEP \\
\hline 1940 & 2.00 & 1.39 & 1.50 & 1.40 & 1.00 & 2.00 & 13.9 & 106 & 13.0 & 1.94 & 0.61 & 1.60 \\
\hline $\begin{array}{l}1941 \\
1942 \\
1943 \\
1944 \\
1945\end{array}$ & $\begin{array}{l}3.11 \\
5.78 \\
2.07 \\
3.17 \\
2.92\end{array}$ & $\begin{array}{l}2.89 \\
2.47 \\
2.51 \\
3.17 \\
3.22\end{array}$ & $\begin{array}{l}2.80 \\
1.60 \\
2.00 \\
2.00 \\
3.00\end{array}$ & $\begin{array}{l}2.00 \\
1.50 \\
1.80 \\
1.60 \\
1.60\end{array}$ & $\begin{array}{l}0.70 \\
1.80 \\
2.00 \\
1.80 \\
1.80\end{array}$ & $\begin{array}{l}1.20 \\
2.00 \\
3.00 \\
2.00 \\
3.00\end{array}$ & $\begin{array}{c}4.20 \\
10.0 \\
58.9 \\
20.0 \\
15.0\end{array}$ & $\begin{array}{l}152 \\
121 \\
117 \\
110 \\
138\end{array}$ & $\begin{array}{c}105 \\
71.1 \\
66.6 \\
88.5 \\
107\end{array}$ & $\begin{array}{c}13.0 \\
8.57 \\
11.4 \\
15.3 \\
29.3\end{array}$ & $\begin{array}{r}6.66 \\
2.78 \\
4.74 \\
2.01 \\
14.2\end{array}$ & $\begin{array}{l}3.30 \\
1.62 \\
1.85 \\
1.38 \\
4.48\end{array}$ \\
\hline $\begin{array}{l}1946 \\
1947 \\
1948 \\
1949 \\
1950\end{array}$ & $\begin{array}{l}4.84 \\
5.46 \\
7.19 \\
1.36 \\
6.00\end{array}$ & $\begin{array}{l}5.80 \\
5.03 \\
5.08 \\
1.99 \\
2.56\end{array}$ & $\begin{array}{l}5.25 \\
4.40 \\
4.00 \\
1.70 \\
1.50\end{array}$ & $\begin{array}{l}5.00 \\
2.70 \\
3.50 \\
1.50 \\
1.60\end{array}$ & $\begin{array}{l}5.00 \\
4.00 \\
3.00 \\
1.40 \\
1.80\end{array}$ & $\begin{array}{l}6.60 \\
7.80 \\
3.50 \\
2.18 \\
2.00\end{array}$ & $\begin{array}{c}75.0 \\
19.0 \\
8.13 \\
18.9 \\
13.0\end{array}$ & $\begin{array}{l}86.3 \\
147 \\
123 \\
122 \\
111\end{array}$ & $\begin{array}{r}28.0 \\
74.5 \\
34.5 \\
78.1 \\
118\end{array}$ & $\begin{array}{c}5.40 \\
21.4 \\
5.68 \\
10.4 \\
14.5\end{array}$ & $\begin{array}{l}1.85 \\
9.15 \\
1.89 \\
2.86 \\
2.50\end{array}$ & $\begin{array}{l}1.27 \\
3.89 \\
0.62 \\
1.90 \\
3.27\end{array}$ \\
\hline $\begin{array}{l}1951 \\
1952 \\
1953 \\
1954 \\
1955\end{array}$ & $\begin{array}{l}3.63 \\
9.54 \\
3.09 \\
2.65 \\
2.35\end{array}$ & $\begin{array}{l}4.13 \\
5.83 \\
2.52 \\
3.46 \\
2.45\end{array}$ & $\begin{array}{l}4.08 \\
5.20 \\
2.67 \\
3.58 \\
1.32\end{array}$ & $\begin{array}{l}3.00 \\
5.00 \\
2.50 \\
3.65 \\
1.91\end{array}$ & $\begin{array}{l}3.50 \\
4.70 \\
2.35 \\
3.66 \\
2.13\end{array}$ & $\begin{array}{l}4.50 \\
4.50 \\
1.51 \\
2.77 \\
2.96\end{array}$ & $\begin{array}{c}16.4 \\
13.2 \\
7.00 \\
17.1 \\
9.84\end{array}$ & $\begin{array}{c}130 \\
138 \\
54.5 \\
47.0 \\
77.9\end{array}$ & $\begin{array}{l}70.0 \\
102 \\
146 \\
11.9 \\
41.7\end{array}$ & $\begin{array}{c}18.9 \\
16.0 \\
9.85 \\
5.28 \\
6.12\end{array}$ & $\begin{array}{c}11.4 \\
8.56 \\
3.18 \\
1.75 \\
3.33\end{array}$ & $\begin{array}{l}3.73 \\
3.73 \\
1.44 \\
2.13 \\
1.27\end{array}$ \\
\hline $\begin{array}{l}1956 \\
1957 \\
1958 \\
1959 \\
1960\end{array}$ & $\begin{array}{l}1.64 \\
2.42 \\
2.95 \\
1.75 \\
4.34\end{array}$ & $\begin{array}{l}2.08 \\
2.84 \\
2.51 \\
2.00 \\
3.04\end{array}$ & $\begin{array}{l}2.98 \\
3.17 \\
2.62 \\
1.74 \\
0.60\end{array}$ & $\begin{array}{l}2.36 \\
2.60 \\
2.30 \\
1.50 \\
0.60\end{array}$ & $\begin{array}{l}2.37 \\
2.90 \\
2.50 \\
1.50 \\
1.60\end{array}$ & $\begin{array}{l}4.62 \\
2.80 \\
2.50 \\
1.68 \\
6.04\end{array}$ & $\begin{array}{c}17.4 \\
11.3 \\
7.00 \\
3.17 \\
26.4\end{array}$ & $\begin{array}{c}153 \\
47.6 \\
128 \\
66.6 \\
92.8\end{array}$ & $\begin{array}{c}52.6 \\
190 \\
40.9 \\
78.8 \\
47.2\end{array}$ & $\begin{array}{c}7.08 \\
24.5 \\
4.06 \\
14.1 \\
6.03\end{array}$ & $\begin{array}{l}2.73 \\
6.05 \\
2.11 \\
2.89 \\
1.14\end{array}$ & $\begin{array}{l}1.60 \\
2.57 \\
1.77 \\
2.15 \\
1.45\end{array}$ \\
\hline $\begin{array}{l}1961 \\
1962 \\
1963 \\
1964 \\
1965\end{array}$ & $\begin{array}{l}2.01 \\
5.88 \\
2.12 \\
2.64 \\
2.75\end{array}$ & $\begin{array}{l}2.58 \\
4.15 \\
1.80 \\
3.74 \\
3.44\end{array}$ & $\begin{array}{l}2.00 \\
4.08 \\
0.99 \\
2.68 \\
3.02\end{array}$ & $\begin{array}{l}1.50 \\
3.69 \\
0.40 \\
2.32 \\
3.57\end{array}$ & $\begin{array}{l}1.60 \\
5.55 \\
0.52 \\
2.74 \\
2.62\end{array}$ & $\begin{array}{l}3.81 \\
7.40 \\
1.71 \\
4.39 \\
3.21\end{array}$ & $\begin{array}{c}25.5 \\
46.9 \\
12.7 \\
6.17 \\
8.11\end{array}$ & $\begin{array}{c}64.5 \\
125 \\
85.1 \\
151 \\
111\end{array}$ & $\begin{array}{r}23.4 \\
71.8 \\
48.5 \\
85.2 \\
407\end{array}$ & $\begin{array}{c}2.84 \\
13.3 \\
9.77 \\
16.7 \\
71.9\end{array}$ & $\begin{array}{c}3.05 \\
3.31 \\
4.96 \\
4.66 \\
22.5\end{array}$ & $\begin{array}{r}5.56 \\
1.62 \\
2.83 \\
2.80 \\
16.3\end{array}$ \\
\hline
\end{tabular}


GREEN RIVER BASIN

09220500 WEST FORK OF SMITHS FORK NEAR RCBERISON, WY--Continued

MONIHLY MEAN DISCHARGES, IN CUBIC FEET PER SECOND, FOR EACH WATER YEAR--Continued

\begin{tabular}{|c|c|c|c|c|c|c|c|c|c|c|c|c|}
\hline YEAR & $\infty T$ & NOV & $\mathrm{DEC}$ & JAN & FEB & MAR & APR & MAY & JUNE & JULY & AUG & SEP \\
\hline $\begin{array}{l}1966 \\
1967 \\
1968 \\
1969 \\
1970\end{array}$ & $\begin{array}{c}12.4 \\
4.77 \\
3.06 \\
5.01 \\
5.26\end{array}$ & $\begin{array}{l}6.33 \\
2.66 \\
3.03 \\
3.64 \\
4.07\end{array}$ & $\begin{array}{l}5.42 \\
3.14 \\
2.50 \\
3.37 \\
2.52\end{array}$ & $\begin{array}{l}4.95 \\
4.12 \\
2.58 \\
3.49 \\
2.51\end{array}$ & $\begin{array}{l}3.58 \\
3.91 \\
2.62 \\
3.78 \\
2.70\end{array}$ & $\begin{array}{l}3.48 \\
3.21 \\
3.34 \\
4.46 \\
2.65\end{array}$ & $\begin{array}{c}22.9 \\
6.12 \\
4.86 \\
17.8 \\
4.11\end{array}$ & $\begin{array}{l}114 \\
122 \\
69.0 \\
105 \\
134\end{array}$ & $\begin{array}{c}25.3 \\
147 \\
186 \\
31.9 \\
101\end{array}$ & $\begin{array}{c}7.31 \\
26.4 \\
15.0 \\
11.0 \\
16.0\end{array}$ & $\begin{array}{l}4.79 \\
6.56 \\
8.38 \\
5.26 \\
3.68\end{array}$ & $\begin{array}{l}4.68 \\
3.05 \\
4.90 \\
3.23 \\
4.23\end{array}$ \\
\hline 1971 & 3.79 & 3.60 & 3.36 & 3.62 & 3.21 & 3.56 & 24.1 & 132 & 170 & 20.2 & 7.54 & 4.07 \\
\hline
\end{tabular}

ANNUAL PEAK DISCHARGE, IN CUBIC FEET PER SECOND, AND CORRESPONDING GAGE HEIGHT, IN FEET, FOR EACH WATER YEAR

\begin{tabular}{|c|c|c|c|c|c|c|c|c|c|c|c|c|c|c|}
\hline $\begin{array}{l}\text { WATERR } \\
\text { YEAR }\end{array}$ & & DATE & $\begin{array}{c}\text { GAGE } \\
\text { HEIGHT }\end{array}$ & $\begin{array}{c}\text { PEAK } \\
\text { DISCHARGE }\end{array}$ & $\begin{array}{l}\text { WATER } \\
\text { YEAR }\end{array}$ & & DATE & $\begin{array}{c}\text { GAGE } \\
\text { HEIGHT }\end{array}$ & $\begin{array}{c}\text { PEAR } \\
\text { DISCHARGE }\end{array}$ & $\begin{array}{l}\text { WATER } \\
\text { YEAR }\end{array}$ & & DATE & $\begin{array}{c}\text { GAGE } \\
\text { HEIGHT }\end{array}$ & $\begin{array}{c}\text { PEAK } \\
\text { DISCHARGE }\end{array}$ \\
\hline $\begin{array}{l}1940 \\
1941 \\
1942 \\
1943 \\
1944 \\
1945 \\
1946 \\
1947 \\
1948 \\
1949 \\
1950 \\
1951 \\
1952 \\
1953\end{array}$ & $\begin{array}{l}\text { MAY } \\
\text { MAY } \\
\text { MAY } \\
\text { MAY } \\
\text { MAY } \\
\text { MAY } \\
\text { MAY } \\
\text { MAY } \\
\text { MAY } \\
\text { MAY } \\
\text { MAY } \\
\text { MAY } \\
\text { MAY } \\
\text { JUNE }\end{array}$ & $\begin{array}{ll}11, & 1940 \\
13, & 1941 \\
25, & 1942 \\
02, & 1943 \\
22, & 1944 \\
12, & 1945 \\
04, & 1946 \\
16, & 1947 \\
19, & 1948 \\
25, & 1949 \\
30, & 1950 \\
27, & 1951 \\
13, & 1952 \\
10, & 1953\end{array}$ & $\begin{array}{l}2.37 \\
2.60 \\
2.76 \\
2.39 \\
2.40 \\
2.24 \\
2.19 \\
2.28 \\
2.99 \\
2.11 \\
3.08 \\
3.00 \\
2.31 \\
2.66\end{array}$ & $\begin{array}{l}363 \\
465 \\
540 \\
380 \\
340 \\
278 \\
256 \\
296 \\
812 \\
244 \\
920 \\
840 \\
336 \\
552\end{array}$ & $\begin{array}{l}1954 \\
1955 \\
1956 \\
1957 \\
1958 \\
1959 \\
1960 \\
1961 \\
1962 \\
1963 \\
1964 \\
1965 \\
1966 \\
1967\end{array}$ & $\begin{array}{l}\text { MAY } \\
\text { MAY } \\
\text { MAY } \\
\text { JUNE } \\
\text { MAY } \\
\text { JUNE } \\
\text { MAY } \\
\text { MAY } \\
\text { MAY } \\
\text { JUNE } \\
\text { MAY } \\
\text { JUNE } \\
\text { MAY } \\
\text { MAY }\end{array}$ & $\begin{array}{ll}09, & 1954 \\
13, & 1955 \\
22, & 1956 \\
06, & 1957 \\
25, & 1958 \\
06, & 1959 \\
12, & 1960 \\
11, & 1961 \\
06,1962 \\
18, & 1963 \\
24, & 1964 \\
10, & 1965 \\
06, & 1966 \\
24, & 1967\end{array}$ & $\begin{array}{l}1.92 \\
2.08 \\
2.40 \\
3.00 \\
2.44 \\
1.91 \\
2.34 \\
1.56 \\
2.32 \\
1.86 \\
-- \\
-- \\
--\end{array}$ & $\begin{array}{r}190 \\
244 \\
410 \\
850 \\
455 \\
234 \\
365 \\
155 \\
508 \\
274 \\
610 \\
2100 \\
528 \\
738\end{array}$ & $\begin{array}{l}1968 \\
1969 \\
1970 \\
1971 \\
1972 \\
1973 \\
1974 \\
1975 \\
1976 \\
1977 \\
1978 \\
1979 \\
1980 \\
1981\end{array}$ & $\begin{array}{l}\text { JUNE } \\
\text { MAY } \\
\text { MAY } \\
\text { MAY } \\
\text { JUNE } \\
\text { JUNE } \\
\text { MAY } \\
\text { JUNE } \\
\text { MAY } \\
\text { APR. } \\
\text { JUNE } \\
\text { MAY } \\
\text { MAY } \\
\text { MAY }\end{array}$ & $\begin{array}{l}05,1968 \\
14,1969 \\
27,1970 \\
27,1971 \\
05,1972 \\
01,1973 \\
28,1974 \\
14,1975 \\
17,1976 \\
29,1977 \\
09,1978 \\
24,1979 \\
22,1980 \\
31,1981\end{array}$ & $\begin{array}{l}4.15 \\
2.89 \\
3.22 \\
3.34 \\
3.57 \\
2.81 \\
3.62 \\
3.50 \\
2.82 \\
2.26 \\
3.43 \\
2.91 \\
3.68 \\
3.11\end{array}$ & $\begin{array}{r}1060 \\
306 \\
444 \\
520 \\
618 \\
289 \\
838 \\
762 \\
399 \\
165 \\
720 \\
358 \\
679 \\
480\end{array}$ \\
\hline
\end{tabular}

\begin{tabular}{|c|c|c|c|c|c|c|}
\hline MAG & [TUDE & $\begin{array}{l}\text { AND PROB } \\
\text { BASED }\end{array}$ & $\begin{array}{l}Y \text { OF } \\
\text { MATI }\end{array}$ & $\begin{array}{l}\text { LO } \\
19\end{array}$ & GAN & RGE \\
\hline \multirow{2}{*}{$\begin{array}{l}\text { PERIOD } \\
\text { (CON- } \\
\text { SECU- } \\
\text { TIVE } \\
\text { DAYS) }\end{array}$} & \multicolumn{6}{|c|}{$\begin{array}{l}\text { DISCHARGE, IN OUBIC FEET PER SECOND, FOR } \\
\text { INDICATED RECURRENCE INTERVAL, IN YEARS, AND } \\
\text { ANNUAL NONEXCEEDANCE PRCBABILITY, IN PERCENT }\end{array}$} \\
\hline & $\begin{array}{c}2 \\
50 \%\end{array}$ & $\begin{array}{c}5 \\
208\end{array}$ & $\begin{array}{l}10 \\
10 \%\end{array}$ & $\begin{array}{l}20 \\
58\end{array}$ & $\begin{array}{l}50 \\
28\end{array}$ & $\begin{array}{r}100 \\
18\end{array}$ \\
\hline 90 & 2.3 & 1.5 & 1.2 & 0.5 & 0.7 & - \\
\hline
\end{tabular}

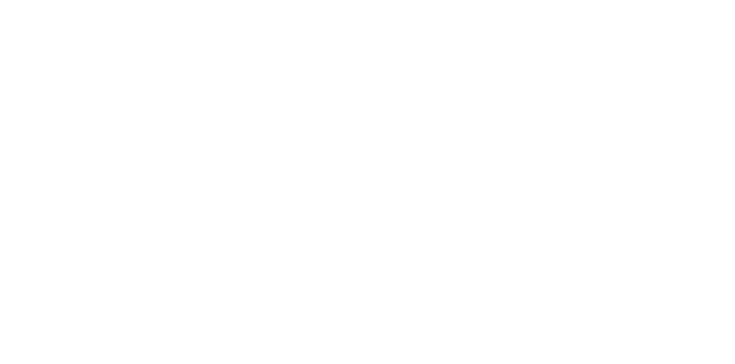

09226000 HENRYS FORK NEAR LONETREE, WY

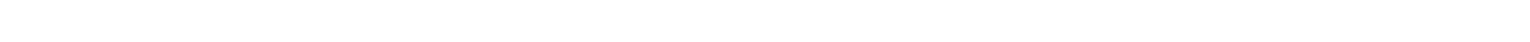
bank $0.6 \mathrm{mi}$ downstream from Wasatch National Forest boundry, $1 \mathrm{mi}$ downstream from West Fork, $1.5 \mathrm{mi}$ downstream from Utah-Wyaming State line, and $7 \mathrm{mi}$ southwest of Lonetree.

DRAINAGE AREA. $-56 \mathrm{mi}^{2}$, approximately.

MEAN BASIN ELEVATION. - 10,270 ft.

PERIOD OF RECORD AVAIIABLE.--October 1942 to October 1971, May to september 1972.

GAGE.--Water-stage recorder. Altitude of gage is 8,350 ft fran topographic map. Prior to Aug. 12, 1953, at site 0.5 mi upstream at different datum.

REMARKS.--one diversion in Utah above station for irrigation of land below station.

AVERAGE DISCHARGE.--29 years (water years 1943-71), $40.8 \mathrm{ft}^{3} / \mathrm{s}, 29,560$ acre- $\mathrm{ft} / \mathrm{yr}$.

EXTREMES FOR PERIOD OF RECORD.--Maximum discharge, 2,010 ft $3 / \mathrm{s}$ June 10, 1965, gage height, $5.70 \mathrm{ft}$ in gage well, $6.30 \mathrm{ft} \mathrm{fram}$

floodmarks, on basis of slope-area measurement of peak flow; minimum daily, $1.8 \mathrm{ft}^{3} / \mathrm{s}$ Jan. $12,19,26,27,1963$, but may have been less on individual days during periods of ice ef fect or no gage-height record. 
09226000 HENRYS FORK NEAR LONETREE, WY--Continued

LONEST MEAN DISCHARGE, IN OUBIC FEET PER SECOND, AND RANKING FOR THE INDICATED MUMBER OF CONSEQUTIVE DAYS FOR EACH CLIMATIC YEAR, APRIL I-MARCH 31

YEAR

$\begin{array}{llr} & 1 & \\ 1947 & 5.60 & 22 \\ 1948 & 7.50 & 24 \\ 1949 & 4.00 & 9 \\ 1950 & 3.70 & 8 \\ 1951 & 5.40 & 20 \\ 1952 & 5.60 & 21 \\ 1953 & 3.20 & 5 \\ 1954 & 5.00 & 15 \\ 1955 & 4.50 & 12 \\ & & \\ 1956 & 3.50 & 6 \\ 1957 & 3.00 & 4 \\ 1958 & 4.50 & 13 \\ 1959 & 5.00 & 16 \\ 1960 & 5.00 & 17 \\ & & \\ 1961 & 5.10 & 18 \\ 1962 & 2.00 & 2 \\ 1963 & 1.80 & 1 \\ 1964 & 2.20 & 3 \\ 1965 & 4.60 & 14 \\ 1966 & 8.20 & 25 \\ 1967 & 5.20 & 19 \\ 1968 & 3.60 & 7 \\ 1969 & 5.80 & 23 \\ 1970 & 4.20 & 10 \\ 1971 & 4.20 & 11 \\ & & \end{array}$

37

5.9023 7.5024

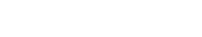
$\begin{array}{lll}3.80 & 8 & 4.8011\end{array}$

5.4020

5.7021

3.205

.1017

4.5012

3.706

$\begin{array}{lll}3.00 & 4\end{array}$

$\begin{array}{ll}4.80 & 13 \\ 5.00 & 14\end{array}$

5.0014
5.0015

5.3018

2.002

1.901

2.303

$5.00 \quad 16$

8.3025

5.4019

3.707

5.9022
4.3011

4.2010

\subsection{8}

\subsection{2}

$3.20 \quad 5$

$\begin{array}{ll}5.10 & 15 \\ 4.6010\end{array}$

$3.80 \quad 6$

$\begin{array}{ll}3.00 & 4 \\ 5.40 & 16\end{array}$

5.4016
5.0012

5.0013

5.5019

$\begin{array}{rl}2.00 & 1 \\ 2.00 & 2\end{array}$

$2.40 \quad 3$

$\begin{array}{ll}2.40 & 3 \\ 5.10 & 14\end{array}$

8.6025

5.6020
3.907

$\begin{array}{ll}3.90 & 7 \\ 6.30 & 21\end{array}$

$\begin{array}{rr}6.30 & 21 \\ 4.30 & 9\end{array}$

5.4017

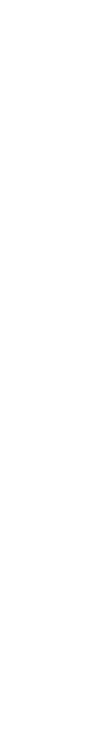

$\begin{array}{ll}\text { CONSEOUTIVE DAYS } \\ 30 & 60\end{array}$

8.5024

7.5022
4.00

$4.00 \quad 6$
6.0016
5.4013

8.0023

$\begin{array}{lr}8.00 & 5 \\ 6.00 \quad 17\end{array}$

6.0017
4.7010

$4.10 \quad 7$

$\begin{array}{ll}4.10 & 7 \\ 3.00 & 4\end{array}$

6.0018
5.3012

5.3012
5.0011

5.5014

2.402

2.201

$\begin{array}{rr}2.70 & 3 \\ 5.80 & 15\end{array}$

5.8015

9.1025

6.1019
4.10

$\begin{array}{lr}4.10 & 8 \\ 7.20 & 21 \\ 4.50 & 9\end{array}$

6.5020
60
8.8023

$\begin{array}{ll}8.8023 \\ 7.5020 \\ 4.00 & 6\end{array}$

$4.00 \quad 6$
6.3016

5.5012

8.3022

$\begin{array}{rr}3.60 & 5 \\ 6.20 & 15\end{array}$

6.2015
4.8010

4.207

$\begin{array}{rr}3.30 & 4 \\ 10.0 \quad 25\end{array}$

10.025

5.6013

5.7014

3.203

2.50

$\begin{array}{lr}3.10 & 2 \\ 6.60 & 17\end{array}$

$9.50 \quad 24$

6.6018
4.20

$4.20 \quad 8$
7.3019

7.3019
$4.50 \quad 9$

8.2021
90120

9.0023
7.7020

7.70
4.20

$\begin{array}{rr}4.20 & 6 \\ 6.30 & 15\end{array}$

5.6011

8.5021

$\begin{array}{ll}4.00 \quad 4 \\ 6.40 & 16\end{array}$

6.4016

$4.20 \quad 7$

$\begin{array}{ll}4.20 & 7 \\ 3.50 & 3\end{array}$

$\begin{array}{cc}11.0 & 25 \\ 6.10 & 14\end{array}$

$\begin{array}{ll}6.10 & 14 \\ 5.80 & 12\end{array}$

6.0013

4.105

2.801

$\begin{array}{rr}3.40 & 2 \\ 7.20 & 18\end{array}$

$10.0 \quad 24$

7.1017

4.508

$\begin{array}{rr}7.40 & 19 \\ 4.70 \quad 9\end{array}$

8.9022
$120 \quad 183$

9.3023

7.9019

4.406

6.8016

5.8011

8.7021

4.204

6.6015

$5.10 \quad 8$

$\begin{array}{ll}4.30 & 5 \\ 3.80 & 2\end{array}$

$\begin{array}{rr}3.80 & 2 \\ 11.0 & 24\end{array}$

6.3012
6.3013

6.3014

5.409

3.101

4.103

$\begin{array}{ll}4.10 & 3 \\ 7.20 & 17\end{array}$

$11.0 \quad 25$

7.9020

4.807

7.7018

5.5010

9.1022

ALL

$\begin{array}{cc}10.0 & 21 \\ 9.70 & 16\end{array}$

9.7016

5.203
$11.0 \quad 22$

$6.50 \quad 8$

$10.0 \quad 17$

6.005

7.1011

$5.40-4$

$\begin{array}{rr}5.40 & 4 \\ 4.30 & 2\end{array}$

12.023

6.8010
9.2015

7.7014

$12.0 \quad 24$

4.201
6.60

$\begin{array}{ll}6.60 & 9 \\ 7.50 & 12\end{array}$

$16.0 \quad 25$

$10.0 \quad 18$

6.307
$10.0 \quad 19$

$\begin{array}{cc}10.0 & 19 \\ 7.60 & 13\end{array}$

$10.0 \quad 20$

$\begin{array}{rr}30.0 & 6 \\ 47.0 & 22\end{array}$

32.07

46.020

$39.0 \quad 14$

41.016

57.024

$\begin{array}{rr}40.0 & 15 \\ 20.0 & 1\end{array}$

26.02

29.04

$47.0 \quad 21$

$\begin{array}{ll}36.0 & 13 \\ 34.0 & 12\end{array}$

$32.0 \quad 8$

$29.0 \quad 5$

$\begin{array}{rr}45.0 & 18 \\ 28.0 & 3\end{array}$

$\begin{array}{ll}28.0 & 3 \\ 49.0 & 23\end{array}$

$97.0 \quad 25$

33.09

$44.0 \quad 17$

$\begin{array}{ll}46.0 & 19 \\ 33.0 & 10\end{array}$

$34.0 \quad 11$

HIGHEST MEAN DISCHARGE, IN OUBIC FEET PER SECOND, AND RANRING FOR THE INDICATED NUMBER OF CONSECUTIVE DAYS FOR EACH WATER YEAR, OCTOBER I-SEPTEMBER 30

\begin{tabular}{|c|c|c|c|c|c|c|c|c|c|c|c|c|c|c|c|c|}
\hline YEAR & 1 & & 3 & & 7 & & 15 & & $\begin{array}{l}\infty \\
30\end{array}$ & EOUT & $\begin{array}{l}\text { VE DAYS } \\
60\end{array}$ & & 90 & & 120 & \\
\hline $\begin{array}{l}1946 \\
1947 \\
1948 \\
1949 \\
1950\end{array}$ & $\begin{array}{l}207 \\
362 \\
493 \\
611 \\
410\end{array}$ & $\begin{array}{r}25 \\
17 \\
9 \\
4 \\
15\end{array}$ & $\begin{array}{l}192 \\
321 \\
380 \\
497 \\
349\end{array}$ & $\begin{array}{r}25 \\
18 \\
13 \\
7 \\
15\end{array}$ & $\begin{array}{l}159 \\
233 \\
361 \\
403 \\
271\end{array}$ & $\begin{array}{r}25 \\
19 \\
10 \\
9 \\
17\end{array}$ & $\begin{array}{l}125 \\
200 \\
300 \\
326 \\
243\end{array}$ & $\begin{array}{r}25 \\
20 \\
10 \\
7 \\
15\end{array}$ & $\begin{array}{l}101 \\
186 \\
229 \\
251 \\
233\end{array}$ & $\begin{array}{r}25 \\
20 \\
11 \\
8 \\
10\end{array}$ & $\begin{array}{l}96.0 \\
174 \\
146 \\
192 \\
177\end{array}$ & $\begin{array}{r}24 \\
11 \\
15 \\
6 \\
10\end{array}$ & $\begin{array}{l}82.0 \\
146 \\
108 \\
149 \\
130\end{array}$ & $\begin{array}{r}23 \\
9 \\
15 \\
5 \\
12\end{array}$ & $\begin{array}{c}68.0 \\
119 \\
85.0 \\
118 \\
102\end{array}$ & $\begin{array}{r}23 \\
6 \\
15 \\
8 \\
13\end{array}$ \\
\hline
\end{tabular}

$\begin{array}{lllllllll}1951 & 436 & 12 & 418 & 10 & 339 & 12 & 240\end{array}$

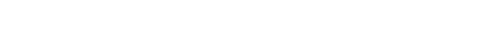

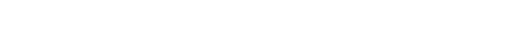

$\begin{array}{llll}1956 & 263 & 21 & 247\end{array}$

$\begin{array}{rrrr}1956 & 263 & 21 & 247 \\ 1958 & 452 & 7 & 528 \\ 1959 & 341 & 10 & 443 \\ 18 & 322\end{array}$

$\begin{array}{rrrr}21 & 226 & 20 & 219 \\ 6 & 451 & 5 & 332\end{array}$

$\begin{array}{rr}9 & 422 \\ 17 & 286 \\ 14 & 310\end{array}$

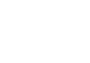

$\begin{array}{llll}1960 & 372 & 16 & 361\end{array}$

14310

13241

$\begin{array}{rr}17 & 216 \\ 2 & 307 \\ 3 & 284\end{array}$

$13 \quad 162$

$\begin{array}{rrrrrrrr}26 & 284 & 6 & 180 & 2 & 185 & 2 \\ 26.0 & 26 & 68.0 & 26 & 55 & 11\end{array}$

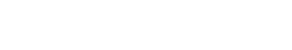

$\begin{array}{ll}55.0 & 26 \\ 81.0 & 24\end{array}$

$\begin{array}{rrrr}152 & 2 & 108 & 2 \\ 105 & 11 & 72.0 & 11\end{array}$

$\begin{array}{llll}46.0 & 26 & 34.0 & 26\end{array}$

47.024

$53.0 \quad 21$

82.09

$\begin{array}{ll}65.0 & 14 \\ 58.0 & 17\end{array}$

57.019

$47.0 \quad 25$

85.00

$\begin{array}{rr}50.0 & 22 \\ 90.0 & 4\end{array}$

$\begin{array}{cc}90.0 & 4 \\ 178 & 1\end{array}$

$\begin{array}{lr}1965 & 1500\end{array}$

$\begin{array}{rr}23 & 237 \\ 13 & 382 \\ 22 & 200 \\ 8 & 473 \\ 1 & 1350\end{array}$

$\begin{array}{rr}22 & 199 \\ 12 & 340 \\ 24 & 174 \\ 8 & 404 \\ 1 & 979\end{array}$

$\begin{array}{rr}22 & 163 \\ 11 & 283 \\ 24 & 146 \\ 8 & 305 \\ 1 & 678\end{array}$

$\begin{array}{rr}22 & 136 \\ 11 & 226 \\ 23 & 127 \\ 9 & 277 \\ 1 & 537\end{array}$

$\begin{array}{rr}22 & \\ 12 & 171 \\ 24 & 112 \\ 7 & 227 \\ 1 & 407\end{array}$

312

$\begin{array}{rrrrrrrr}1966 & 245 & 24 & 235 & 23 & 182 & 23 & 139 \\ 1967 & 441 & 11 & 383 & 11 & 278 & 16 & 227\end{array}$

$\begin{array}{llllllllll}1969 & 298 & 20 & 285 & 19 & 215 & 7 & 334 & 5 & 304 \\ & 19 & 18 & 257 & 13 & 200\end{array}$

$\begin{array}{llllllll}1970 & 413 & 14 & 343 & 16 & 286 & 14 & 259\end{array}$

$13 \quad 200$

1971580

$6 \quad 548$

515

414

4302

$\begin{array}{rr}19 & 181 \\ 3 & 191 \\ 14 & 132 \\ 15 & 135\end{array}$

$\begin{array}{rcr}22 & 90.0 & 21 \\ 8 & 147 & 8 \\ 7 & 143 & 10 \\ 19 & 101 & 19\end{array}$

$\begin{array}{rlr}21 & 75.0 & 21 \\ 8 & 117 & 9 \\ 10 & 117 & 10 \\ 19 & 83.0 & 16 \\ 6 & 83.0 & 17\end{array}$

$\begin{array}{rrrr}56.0 & 20 & 36.0 & 15 \\ 81.0 & 10 & 46.0 & 7\end{array}$

$\begin{array}{llll}83.0 & 7 & 45.0 & 8\end{array}$

$\begin{array}{llll}59.0 & 15 & 34.0 & 16 \\ 58.0 & 18 & 33.0 & 19\end{array}$

$4 \quad 213$

164

$4 \quad 131$

92.03

51.03 
GREEN RIVER BASIN

09226000 HENRYS FORK NEAR LONEIREE, WY--Continued

\section{DURATION OF DISCHARGE FOR EACH WATER YEAR}

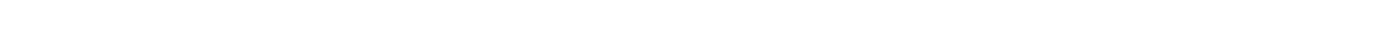

YEAR

1946
1947
1948
1949
1950
1951
1952
1953
1954
1955
1956
1957
1958
1959
1960
1961
1962
1963
1964
1965
1966
1967
1968
1969
1970

1971
NUMBER OF DAYS IN CLASS

CUBIC FEET

PER SBCON

10167.4

17278.0

12592 .

15995.1

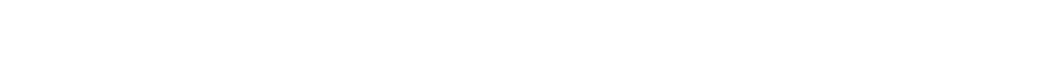

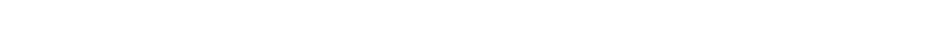

14230.3

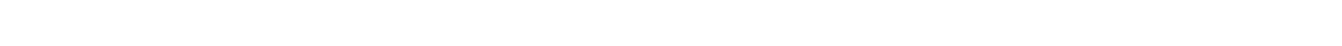

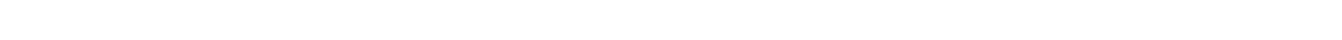

7492.7

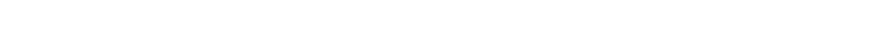

$\begin{array}{llllllllllllllllllllll}5105 & 22 & 53 & 27 & 17 & 20 & 12 & 3 & 16 & 9 & 4 & 8 & 9 & 4 & 15 & 7 & 1 & 2 & 7 & 8 & 9 & 3\end{array}$

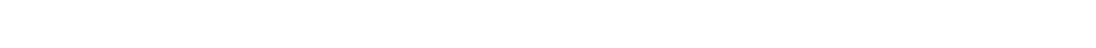
$\begin{array}{rrrrrrrrrrrrrrrrrrr}60103 & 56 & 21 & 25 & 22 & 4 & 17 & 5 & 5 & 5 & 4 & 8 & 7 & 2 & 5 & 5 & 2 & 3 & 6\end{array}$

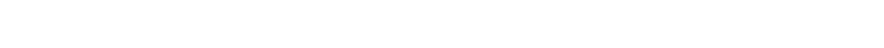

$\begin{array}{llllllllllllllllllll}31 & 99 & 9 & 31 & 27 & 30 & 18 & 10 & 10 & 17 & 21 & 10 & 13 & 5 & 9 & 3 & 11 & 6 & 2 & 3\end{array}$

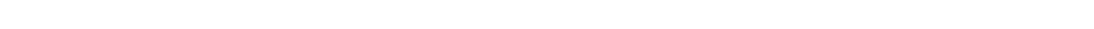

$\begin{array}{lllllllllllllllllllllllllll}12 & 27 & 32 & 30 & 24 & 29 & 23 & 21 & 7 & 3 & 14 & 26 & 28 & 7 & 8 & 5 & 6 & 7 & 12 & 8 & 8 & 11 & 13 & 3 & 1\end{array}$

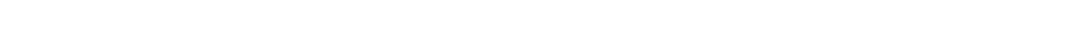

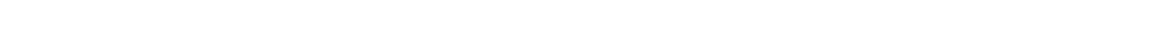

$\begin{array}{lllllllllllllllllll}6 & 58 & 33 & 57 & 22 & 37 & 19 & 25 & 19 & 7 & 20 & 9 & 16 & 11 & 18 & 4 & 1 & 3\end{array}$

$\begin{array}{rrrrrrrrrrrrrrrrrrrrrrrrrrrr}14 & & 16 & 29 & 40 & 43 & 48 & 38 & 9 & 25 & 14 & 9 & 10 & & 2 & 5 & 8 & 6 & 24 & 10 & 10 & 13 & 4 & & 2 & & & \\ 148 & 30 & 32 & 18 & 7 & 9 & 4 & 3 & 18 & 19 & 28 & 13 & 15 & 14 & 10 & & 2 & 2 & 8 & 4 & 4 & 7 & 2 & & 1 & 1 & 1\end{array}$

$\begin{array}{rrrrrrrrrrrrrrrrrrrrrrrr}65 & 25 & 88 & 24 & 39 & 45 & 11 & 13 & 14 & 22 & 20 & 10 & 8 & 8 & 8 & 2 & 7 & 2 & 4 & 4 & 11 & & \\ 65 & 15 & 25 & 22 & 39 & 29 & 20 & 13 & 10 & 9 & 10 & 15 & 8 & 5 & 8 & 5 & 9 & 5 & 2 & 6 & 6 & 1 & 1\end{array}$

$\begin{array}{lllllllllllllllllllllllll}1 & 17 & 21 & 77 & 55 & 33 & 15 & 22 & 9 & 11 & 11 & 13 & 6 & 6 & 16 & 4 & 12 & 9 & 5 & 4 & 5 & 4 & 2 & 6 & 1\end{array}$

10747.5

15706.0

14210.0

11821.5

953.0

17660.7

176917.8

17678.10

33850.7

13114.5

16740.9

16323.3

12563.6
12083.2

18708.5

DURATION TABLE OF DISCHARGE FOR WATER YEARS 1946-71

$\begin{array}{ccc}\text { CUBIC } & \text { AOCU- } \\ \text { FEET } & \text { MU- } & \text { PER- } \\ \text { PER } & \text { TOTAL LATFD } & \text { CENI' } \\ \text { ILASS SECOND DAYS } & \text { DAYS } & \text { DAYS }\end{array}$

$0.00 \quad 0 \quad 9496 \quad 100.0$

$\begin{array}{llll}1.80 & 23 & 9496 & 100.0\end{array}$

$\begin{array}{rrrr}2.20 & 57 & 9473 & 99.8\end{array}$

$\begin{array}{llll}2.70 & 119 & 9416 & 99.2\end{array}$

$\begin{array}{llll}3.30 & 130 & 9297 & 97.9\end{array}$

$\begin{array}{llll}4.00 & 569 & 9167 & 96.5\end{array}$

$\begin{array}{llll}4.80 & 749 & 8598 & 90.5 \\ 5.90 & 959 & 7849 & 82.7\end{array}$

$\begin{array}{llll}5.90 & 959 & 7849 & 82.7 \\ 7.20 & 882 & 6890 & 72.6\end{array}$ $\begin{array}{lcc}\text { CUBIC } & \text { ACOU- } \\ \text { FEET } & \text { MU- } & \text { PER- } \\ \text { PER } & \text { TOTAL LATED } & \text { CENT }\end{array}$ CLASS SECOND DAYS DAYS DAYS

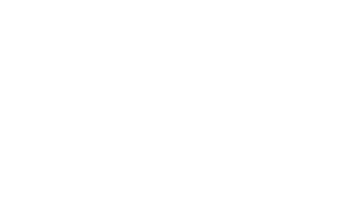

$\begin{array}{ccc}\text { CUBIC } & \text { AOCI- } \\ \text { FEET } & \text { MU- } & \text { PER- } \\ \text { PER TOTAL LATED } & \text { CENT }\end{array}$ CLASS SFCOND DAYS DAYS DAYS

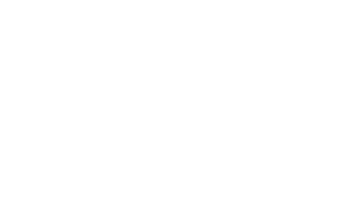

CUBIC ACCU-

$\begin{array}{lll}\text { FEET } & \text { MU- } & \text { PER- } \\ \text { PER TOTAL IATED } & \text { CENT }\end{array}$ CLASS SEDOND DAYS DAYS DAYS

$\begin{array}{rrrrr}27 & 310.0 & 61 & 150 & 1.6 \\ 28 & 380.0 & 43 & 89 & 0.9 \\ 29 & 460.0 & 25 & 46 & 0.5 \\ 30 & 560.0 & 12 & 21 & 0.2 \\ 31 & 680.0 & 3 & 9 & 0.1 \\ 32 & 830.0 & 2 & 6 & 0.1 \\ 33 & 1000.0 & 1 & 4 & 0.0 \\ 34 & 1200.0 & 3 & 3 & 0.0\end{array}$

MONTHLY MEAN DISCHARGES, IN CUBIC FEET PER SECOND, FOR EACH WATER YEAR

\begin{tabular}{|c|c|c|c|c|c|c|c|c|c|c|c|c|}
\hline YEAR & $\propto T^{\prime}$ & NOW & DEC & JAN & FFB & MAR & $\mathrm{APR}$ & MAY & JUNE & JULY & AUG & SEP \\
\hline $\begin{array}{l}1943 \\
1944 \\
1945\end{array}$ & $\begin{array}{l}10 \\
11.6 \\
13.7\end{array}$ & $\begin{array}{l}10 \\
11.2 \\
8.54\end{array}$ & $\begin{array}{l}8 \\
7 \\
6\end{array}$ & $\begin{array}{l}7 \\
6 \\
5\end{array}$ & $\begin{array}{l}7 \\
8 \\
6\end{array}$ & $\begin{array}{r}8 \\
10 \\
8\end{array}$ & $\begin{array}{l}27.9 \\
20 \\
15\end{array}$ & $\begin{array}{l}111 \\
169 \\
131\end{array}$ & $\begin{array}{l}111 \\
281 \\
185\end{array}$ & $\begin{array}{l}50.0 \\
141 \\
125\end{array}$ & $\begin{array}{l}24.5 \\
28.0 \\
54.9\end{array}$ & $\begin{array}{l}11.5 \\
11.0 \\
18.4\end{array}$ \\
\hline $\begin{array}{l}1946 \\
1947 \\
1948 \\
1949 \\
1950\end{array}$ & $\begin{array}{c}11.5 \\
13.1 \\
15.9 \\
6.62 \\
22.5\end{array}$ & $\begin{array}{c}7.34 \\
10.0 \\
10.4 \\
7.20 \\
13.6\end{array}$ & $\begin{array}{l}5.40 \\
9.50 \\
8.50 \\
5.00 \\
8.00\end{array}$ & $\begin{array}{l}4.50 \\
8.50 \\
8.00 \\
4.50 \\
6.50\end{array}$ & $\begin{array}{l}4.00 \\
9.00 \\
7.50 \\
4.00 \\
6.00\end{array}$ & $\begin{array}{c}5.00 \\
10.0 \\
7.50 \\
4.00 \\
6.50\end{array}$ & $\begin{array}{l}40.8 \\
20.0 \\
14.8 \\
16.1 \\
13.6\end{array}$ & $\begin{array}{l}84.6 \\
174 \\
166 \\
120 \\
86.7\end{array}$ & $\begin{array}{l}97.5 \\
162 \\
118 \\
240 \\
219\end{array}$ & $\begin{array}{l}41.1 \\
95.8 \\
30.3 \\
81.7 \\
77.0\end{array}$ & $\begin{array}{l}19.4 \\
35.2 \\
15.4 \\
22.6 \\
18.9\end{array}$ & $\begin{array}{c}12.3 \\
18.5 \\
8.57 \\
14.1 \\
11.0\end{array}$ \\
\hline $\begin{array}{l}1951 \\
1952 \\
1953 \\
1954 \\
1955\end{array}$ & $\begin{array}{c}8.38 \\
16.8 \\
12.6 \\
7.36 \\
9.02\end{array}$ & $\begin{array}{c}7.33 \\
11.1 \\
5.53 \\
9.00 \\
8.16\end{array}$ & $\begin{array}{l}6.40 \\
9.00 \\
3.20 \\
7.00 \\
5.27\end{array}$ & $\begin{array}{l}5.80 \\
8.60 \\
4.00 \\
6.00 \\
4.84\end{array}$ & $\begin{array}{l}5.60 \\
8.00 \\
4.80 \\
6.40 \\
4.76\end{array}$ & $\begin{array}{l}5.40 \\
9.00 \\
5.20 \\
6.80 \\
5.49\end{array}$ & $\begin{array}{c}9.60 \\
23.5 \\
10.8 \\
14.7 \\
9.58\end{array}$ & $\begin{array}{l}105 \\
169 \\
41.1 \\
81.0 \\
80.9\end{array}$ & $\begin{array}{c}176 \\
284 \\
283 \\
48.9 \\
125\end{array}$ & $\begin{array}{l}81.2 \\
96.8 \\
64.9 \\
33.0 \\
33.3\end{array}$ & $\begin{array}{l}41.5 \\
48.9 \\
27.2 \\
13.4 \\
22.1\end{array}$ & $\begin{array}{c}13.9 \\
24.5 \\
9.83 \\
11.4 \\
12.5\end{array}$ \\
\hline $\begin{array}{l}1956 \\
1957 \\
1958 \\
1959 \\
1960\end{array}$ & $\begin{array}{c}8.90 \\
5.27 \\
15.8 \\
8.09 \\
16.6\end{array}$ & $\begin{array}{c}5.05 \\
5.28 \\
15.0 \\
6.60 \\
11.3\end{array}$ & $\begin{array}{c}4.32 \\
4.75 \\
12.0 \\
7.65 \\
7.00\end{array}$ & $\begin{array}{c}4.24 \\
3.00 \\
10.0 \\
5.65 \\
6.00\end{array}$ & $\begin{array}{c}4.19 \\
3.50 \\
10.0 \\
5.46 \\
5.00\end{array}$ & $\begin{array}{c}5.83 \\
4.00 \\
12.0 \\
7.00 \\
8.90\end{array}$ & $\begin{array}{c}13.2 \\
5.97 \\
18.5 \\
11.3 \\
21.6\end{array}$ & $\begin{array}{c}121 \\
36.5 \\
169 \\
65.5 \\
103\end{array}$ & $\begin{array}{l}131 \\
280 \\
141 \\
192 \\
163\end{array}$ & $\begin{array}{c}36.2 \\
123 \\
32.0 \\
44.3 \\
31.6\end{array}$ & $\begin{array}{c}12.1 \\
30.1 \\
16.3 \\
22.3 \\
9.86\end{array}$ & $\begin{array}{c}6.37 \\
15.5 \\
14.1 \\
13.7 \\
9.50\end{array}$ \\
\hline $\begin{array}{l}1961 \\
1962 \\
1963 \\
1964 \\
1965\end{array}$ & $\begin{array}{c}10.6 \\
31.6 \\
7.08 \\
12.4 \\
7.16\end{array}$ & $\begin{array}{c}10.3 \\
17.2 \\
5.42 \\
10.5 \\
8.65\end{array}$ & $\begin{array}{l}7.23 \\
9.13 \\
3.66 \\
6.23 \\
7.28\end{array}$ & $\begin{array}{l}5.50 \\
3.87 \\
2.39 \\
2.69 \\
8.47\end{array}$ & $\begin{array}{l}6.00 \\
3.21 \\
2.75 \\
3.59 \\
6.02\end{array}$ & $\begin{array}{l}6.52 \\
5.23 \\
3.57 \\
4.05 \\
7.36\end{array}$ & $\begin{array}{c}11.7 \\
61.9 \\
8.95 \\
7.05 \\
16.7\end{array}$ & $\begin{array}{c}88.8 \\
114 \\
86.3 \\
142 \\
82.8\end{array}$ & $\begin{array}{l}95.0 \\
221 \\
118 \\
244 \\
484\end{array}$ & $\begin{array}{r}23.2 \\
82.6 \\
51.0 \\
106 \\
318\end{array}$ & $\begin{array}{r}18.2 \\
23.7 \\
18.9 \\
28.9 \\
113\end{array}$ & $\begin{array}{c}44.0 \\
7.20 \\
16.9 \\
11.6 \\
51.1\end{array}$ \\
\hline
\end{tabular}


09226000 HENRYS FORK NEAR LONETREE, WY--Continued

MONHLY MEAN DISGHARGES, IN OBIC FEET PER SECOND, FOR EACH WATER YEAR

\begin{tabular}{|c|c|c|c|c|c|c|c|c|c|c|c|c|}
\hline YEAR & OCT & NOV & $\mathrm{DEC}$ & JAN & FEB & MAR & APR & MAY & JUNE & JULY & AUG & SEP \\
\hline $\begin{array}{l}1966 \\
1967 \\
1968 \\
1969 \\
1970\end{array}$ & $\begin{array}{l}33.4 \\
19.3 \\
11.8 \\
17.3 \\
12.3\end{array}$ & $\begin{array}{c}17.0 \\
10.9 \\
6.60 \\
11.1 \\
10.9\end{array}$ & $\begin{array}{c}14.9 \\
9.29 \\
4.84 \\
8.43 \\
8.20\end{array}$ & $\begin{array}{c}12.2 \\
7.87 \\
4.07 \\
7.75 \\
5.00\end{array}$ & $\begin{array}{l}9.56 \\
6.02 \\
4.62 \\
7.26 \\
4.59\end{array}$ & $\begin{array}{l}9.30 \\
8.38 \\
5.94 \\
7.23 \\
4.46\end{array}$ & $\begin{array}{c}15.4 \\
11.5 \\
8.20 \\
18.1 \\
6.48\end{array}$ & $\begin{array}{c}124 \\
104 \\
55.9 \\
180 \\
114\end{array}$ & $\begin{array}{l}85.1 \\
172 \\
301 \\
78.6 \\
143\end{array}$ & $\begin{array}{c}57.1 \\
137 \\
66.2 \\
38.5 \\
49.9\end{array}$ & $\begin{array}{l}27.5 \\
44.2 \\
40.7 \\
22.4 \\
20.4\end{array}$ & $\begin{array}{l}22.6 \\
16.9 \\
27.8 \\
12.8 \\
17.7\end{array}$ \\
\hline 1971 & 12.2 & 11.6 & 8.21 & 8.42 & 10.4 & 9.75 & 21.8 & 93.5 & 299 & 94.5 & 30.9 & 15.5 \\
\hline
\end{tabular}

ANNUAL PEAK DISCHARGE, IN GBIC FEET PER SECOND, AND CORRESPONDING GAGE HEIGHT, IN FEET, FOR EACH WATER YEAR

\begin{tabular}{|c|c|c|c|c|c|c|c|c|c|c|c|}
\hline $\begin{array}{l}\text { WATER } \\
\text { YEAR }\end{array}$ & DATE & $\begin{array}{c}\text { GAGE } \\
\text { HEIGHT }\end{array}$ & $\begin{array}{c}\text { DEAK } \\
\text { DISCHARGE }\end{array}$ & $\begin{array}{l}\text { WATER } \\
\text { YEAR }\end{array}$ & DATE & $\begin{array}{c}\text { GAGE } \\
\text { HEIGHT }\end{array}$ & $\begin{array}{c}\text { PEAR } \\
\text { DISCHARGE }\end{array}$ & $\begin{array}{l}\text { WATER } \\
\text { YEAR }\end{array}$ & DATE & $\begin{array}{c}\text { GAGE } \\
\text { HEIGHT }\end{array}$ & $\begin{array}{c}\text { PEAK } \\
\text { DISCHARGE }\end{array}$ \\
\hline $\begin{array}{l}1943 \\
1944 \\
1945 \\
1946 \\
1947 \\
1948 \\
1949 \\
1950 \\
1951 \\
1952\end{array}$ & $\begin{array}{lll}\text { MAY } & 03,1943 \\
\text { JUNE } & 26,1944 \\
\text { JUNE } & 24,1945 \\
\text { JUNE } & 05,1946 \\
\text { MAY } & 08,1947 \\
\text { MAY } & 19,1948 \\
\text { JUNE } 19,1949 \\
\text { MAY } 30,1950 \\
\text { MAY } & 27,1951 \\
\text { JUNE } & 06,1952\end{array}$ & $\begin{array}{l}= \\
= \\
= \\
= \\
= \\
=\end{array}$ & $\begin{array}{l}343 \\
822 \\
434 \\
294 \\
562 \\
625 \\
710 \\
665 \\
629 \\
719\end{array}$ & $\begin{array}{l}1953 \\
1954 \\
1955 \\
1956 \\
1957 \\
1958 \\
1959 \\
1960 \\
1961 \\
1962\end{array}$ & $\begin{array}{lll}\text { JUNE } 13, & 1953 \\
\text { MAY } 22, & 1954 \\
\text { JUNE } 09,1955 \\
\text { JUNE } 02,1956 \\
\text { JUNE } 08,1957 \\
\text { MAY } 25,1958 \\
\text { JUNE } 07,1959 \\
\text { JUNE } 03,1960 \\
\text { NAY } 27,1961 \\
\text { JUNE } 21,1962\end{array}$ & $\begin{array}{l}-- \\
4.09 \\
4.61 \\
4.36 \\
5.28 \\
4.74 \\
4.66 \\
4.65 \\
4.37 \\
4.84\end{array}$ & $\begin{array}{r}1860 \\
252 \\
496 \\
370 \\
828 \\
592 \\
416 \\
530 \\
337 \\
534\end{array}$ & $\begin{array}{l}1963 \\
1964 \\
1965 \\
1966 \\
1967 \\
1968 \\
1969 \\
1970 \\
1971 \\
1972\end{array}$ & $\begin{array}{lll}\text { JUNE } 18,1963 \\
\text { MAY } & 25,1964 \\
\text { JUNE } & 10,1965 \\
\text { MAY } & 07,1966 \\
\text { MAY } & 24,1967 \\
\text { JUNE } & 06,1968 \\
\text { MAY } & 20,1969 \\
\text { MAY } & 28,1970 \\
\text { JUNE } & 22,1971 \\
\text { MAY } & 31, & 1972\end{array}$ & $\begin{array}{l}4.40 \\
5.16 \\
5.70 \\
3.80 \\
3.57 \\
5.24 \\
4.62 \\
4.93 \\
5.40 \\
5.01\end{array}$ & $\begin{array}{r}375 \\
815 \\
2010 \\
400 \\
672 \\
1490 \\
416 \\
611 \\
980 \\
695\end{array}$ \\
\hline
\end{tabular}

NAGNITUDE AND PROBABILITY OF ANNUAL LOWEST MEAN DISCHABGE BASED ON CLIMATIC YEARS 1947-71

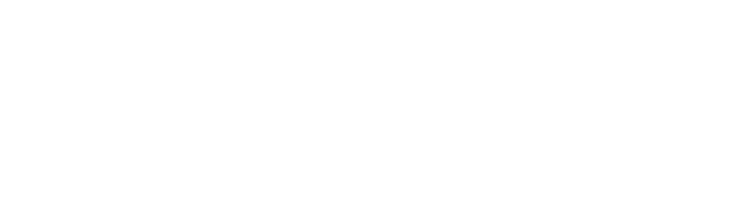

MAGNITUDE AND RRCBABILITY OF ANNUAL HIGHEST MEAN DISCHARGE BASED ON WATER YEARS 1946-71

\begin{tabular}{|c|c|c|c|c|c|c|}
\hline \multirow{2}{*}{$\begin{array}{l}\text { PERIOD } \\
\text { (OON- } \\
\text { SEOU- } \\
\text { TIVE } \\
\text { DAYS) }\end{array}$} & \multicolumn{6}{|c|}{$\begin{array}{l}\text { DISCHARGE, IN GIBIC FEET PER SECOND, FOR } \\
\text { INDICATED RECURRENCE INTERNAL, IN YEARS, AND } \\
\text { ANNUAL EXCEEDANCE PROBABILITY, IN PERCENT }\end{array}$} \\
\hline & $\begin{array}{c}2 \\
50 \%\end{array}$ & $\begin{array}{c}5 \\
208\end{array}$ & $\begin{array}{l}10 \\
10 \%\end{array}$ & $\begin{array}{l}25 \\
48\end{array}$ & $\begin{array}{l}50 \\
28\end{array}$ & $\begin{array}{r}100 \\
18\end{array}$ \\
\hline $\begin{array}{r}1 \\
3 \\
7 \\
15\end{array}$ & $\begin{array}{l}399 \\
358 \\
304 \\
252\end{array}$ & $\begin{array}{l}630 \\
550 \\
453 \\
360\end{array}$ & $\begin{array}{l}831 \\
706 \\
566 \\
434\end{array}$ & $\begin{array}{r}1150 \\
943 \\
726 \\
532\end{array}$ & $\begin{array}{r}1440 \\
1150 \\
858 \\
607\end{array}$ & $\begin{array}{l}-- \\
-- \\
-\end{array}$ \\
\hline
\end{tabular}


LOCATION, --Lat $40^{\circ} 56^{\prime} 40^{\prime \prime}$, long $110^{\circ} 10^{\prime} 43^{\prime \prime}$, in SW $\frac{1}{4} \mathrm{SW}_{\frac{1}{4}}^{2}$ sec.31, T.3 N., R.16 E., Summit County, UT, Hydrologic Unit 14040106, on left bank $500 \mathrm{ft}$ north of Wasatch National Forest boundary, 1 mi southwest of Hole-in-the-Rock ranger station, $3.5 \mathrm{mi}$ south of UtahWyoming State line, and $7.5 \mathrm{mi}$ south of Lonetree.

DRAINAGE AREA. $--28 \mathrm{mi}^{2}$.

MEAN BASIN ELEVATION. $--10,480 \mathrm{ft}$.

PERIOD OF RECORD AVAILABLE.--October 1948 to September 1970.

GAGE.--Water-stage recorder. Altitude of gage is 8,450 ft from topographic map.

AVERAGE DISCHARGE. --22 years, $23.0 \mathrm{ft}^{3} / \mathrm{s}, 16,660$ acre-ft/yr.

EXTREMES FOR PERIOD OF RECORD.--Maximum discharge, $775 \mathrm{ft}^{3} / \mathrm{s}$ June 11,1965 , gage height, $4.36 \mathrm{ft}$; minimum recorded, $2.1 \mathrm{ft}{ }^{3} / \mathrm{s}$ Nov. 13,1958 , result of freezeup.

LOWEST MEAN DISCHARGE, IN CUBIC FEET PER SEOOND, AND RANKING FOR THE INDICATED NUMBER OF CONSECUTIVE DAYS FOR EACH CLIMATIC YEAR, APRIL I-MARCH 31

YEAR

1950

1951
1952

1954
1955

1956

1957

1958

1959

1961

1963

1964

1965

1966

1967

1970

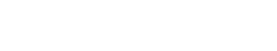

\begin{tabular}{|c|c|c|}
\hline 1 & 3 & 7 \\
\hline 4.0019 & 4.0019 & 4.0018 \\
\hline $\begin{array}{rr}3.50 & 9 \\
4.00 & 20 \\
3.50 & 10 \\
4.00 & 21 \\
3.50 & 11\end{array}$ & $\begin{array}{rr}3.50 & 9 \\
4.00 & 20 \\
3.50 & 10 \\
4.00 & 21 \\
3.50 & 11\end{array}$ & $\begin{array}{rr}3.50 & 8 \\
4.00 & 19 \\
3.50 & 9 \\
4.00 & 20 \\
3.50 & 10\end{array}$ \\
\hline $\begin{array}{rr}3.70 & 17 \\
3.00 & 3 \\
3.50 & 12 \\
3.00 & 4 \\
3.50 & 13\end{array}$ & $\begin{array}{rr}3.70 & 17 \\
3.00 & 2 \\
3.50 & 12 \\
3.00 & 3 \\
3.50 & 13\end{array}$ & $\begin{array}{rr}3.80 & 16 \\
3.00 & 2 \\
3.50 & 11 \\
3.00 & 3 \\
3.50 & 12\end{array}$ \\
\hline $\begin{array}{rr}3.00 & 5 \\
3.50 & 14 \\
3.00 & 6 \\
3.00 & 7 \\
4.00 & 18\end{array}$ & $\begin{array}{rr}3.00 & 4 \\
3.50 & 14 \\
3.00 & 5 \\
3.00 & 6 \\
4.00 & 18\end{array}$ & $\begin{array}{rr}3.00 & 4 \\
3.50 & 13 \\
3.00 & 5 \\
3.00 & 6 \\
4.00 & 21\end{array}$ \\
\hline $\begin{array}{rr}3.50 & 15 \\
3.40 & 8 \\
3.60 & 16 \\
2.80 & 1 \\
3.00 & 2\end{array}$ & $\begin{array}{rr}3.50 & 15 \\
3.40 & 8 \\
3.70 & 16 \\
2.80 & 1 \\
3.10 & 7\end{array}$ & $\begin{array}{rr}3.50 & 14 \\
3.50 & 15 \\
3.90 & 17 \\
2.90 & 1 \\
3.10 & 7\end{array}$ \\
\hline
\end{tabular}

CONSECUTIVE DAYS

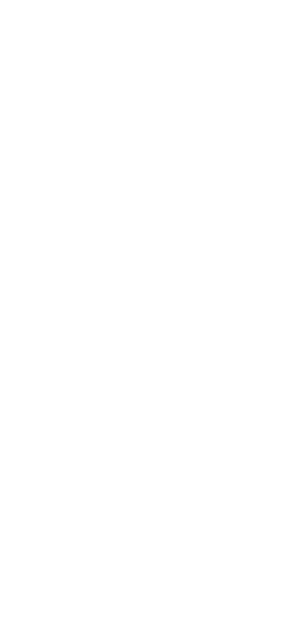

\begin{tabular}{|c|c|c|c|c|}
\hline & 90 & 120 & 183 & ALL \\
\hline 2016 & 4.4016 & $5.10 \quad 20$ & 7.2019 & 27.0 \\
\hline $\begin{array}{rr}60 & 9 \\
20 & 17 \\
80 & 12 \\
30 & 18 \\
50 & 7\end{array}$ & $\begin{array}{rr}3.80 & 7 \\
4.40 & 17 \\
4.00 & 11 \\
4.50 & 18 \\
3.50 & 5\end{array}$ & $\begin{array}{rr}3.90 & 6 \\
4.70 & 16 \\
4.10 & 7 \\
4.80 & 17 \\
3.70 & 5\end{array}$ & $\begin{array}{rr}4.60 & 3 \\
5.80 & 13 \\
5.00 & 6 \\
5.60 & 10 \\
4.70 & 4\end{array}$ & $\begin{array}{l}19.0 \\
18.0 \\
33.0 \\
20.0 \\
11.0\end{array}$ \\
\hline $\begin{array}{rr}10 & 15 \\
00 & 1 \\
50 & 20 \\
00 & 2 \\
70 & 10\end{array}$ & $\begin{array}{rr}4.10 & 14 \\
3.20 & 1 \\
4.70 & 19 \\
3.20 & 2 \\
3.90 & 8\end{array}$ & $\begin{array}{rr}4.30 & 12 \\
3.30 & 1 \\
4.90 & 18 \\
3.50 & 2 \\
4.40 & 14\end{array}$ & $\begin{array}{rr}5.20 & 8 \\
3.60 & 1 \\
5.90 & 14 \\
4.50 & 2 \\
6.50 & 18\end{array}$ & $\begin{array}{l}16.0 \\
14.0 \\
32.0 \\
20.0 \\
19.0\end{array}$ \\
\hline $\begin{array}{rr}30 & 5 \\
70 & 21 \\
10 & 3 \\
20 & 4 \\
30 & 19\end{array}$ & $\begin{array}{rr}3.90 & 9 \\
5.10 & 21 \\
3.30 & 3 \\
3.30 & 4 \\
4.70 & 20\end{array}$ & $\begin{array}{rr}4.30 & 13 \\
5.70 & 21 \\
3.50 & 3 \\
3.60 & 4 \\
5.10 & 19\end{array}$ & $\begin{array}{rr}5.20 & 9 \\
10.0 & 21 \\
4.90 & 5 \\
5.10 & 7 \\
5.80 & 11\end{array}$ & $\begin{array}{l}18.0 \\
19.0 \\
28.0 \\
14.0 \\
30.0\end{array}$ \\
\hline $\begin{array}{rr}0 & 11 \\
0 & 13 \\
0 & 14 \\
0 & 8 \\
0 & 6\end{array}$ & $\begin{array}{rr}4.00 & 12 \\
4.20 & 15 \\
4.10 & 13 \\
3.80 & 6 \\
3.90 & 10\end{array}$ & $\begin{array}{rr}4.20 & 10 \\
4.60 & 15 \\
4.30 & 11 \\
4.10 & 8 \\
4.20 & 9\end{array}$ & $\begin{array}{ll}7.60 & 20 \\
6.30 & 17 \\
6.00 & 15 \\
6.00 & 16 \\
5.80 & 12\end{array}$ & $\begin{array}{l}50.0 \\
17.0 \\
28.0 \\
29.0 \\
20.0\end{array}$ \\
\hline
\end{tabular}

HIGHEST MEAN DISCHARGE, IN CUBIC FEET PER SECOND, AND RANKING FOR THE INDICATED NUMBER OF CONSECITIVE DAYS FOR EACH WATER YEAR, OCTCBER 1-SEPTEMBER 30

\begin{tabular}{|c|c|c|c|c|c|c|c|c|c|c|c|c|c|c|c|c|c|c|c|c|}
\hline YEAR & 1 & & 3 & & 7 & & 15 & & $\begin{array}{l}\text { ONs } \\
30\end{array}$ & & $\begin{array}{l}\text { VE DAYS } \\
60\end{array}$ & & 90 & & 120 & & 183 & & ALL & \\
\hline $\begin{array}{l}1949 \\
1950\end{array}$ & $\begin{array}{l}308 \\
189\end{array}$ & $\begin{array}{r}6 \\
15\end{array}$ & $\begin{array}{l}277 \\
174\end{array}$ & $\begin{array}{r}7 \\
15\end{array}$ & $\begin{array}{l}231 \\
137\end{array}$ & $\begin{array}{r}7 \\
16\end{array}$ & $\begin{array}{l}196 \\
124\end{array}$ & $\begin{array}{r}5 \\
14\end{array}$ & $\begin{array}{l}145 \\
107\end{array}$ & $\begin{array}{r}6 \\
12\end{array}$ & $\begin{array}{l}108 \\
77.0\end{array}$ & $\begin{array}{r}8 \\
12\end{array}$ & $\begin{array}{l}83.0 \\
58.0\end{array}$ & $\begin{array}{r}8 \\
12\end{array}$ & $\begin{array}{l}67.0 \\
47.0\end{array}$ & $\begin{array}{r}8 \\
13\end{array}$ & $\begin{array}{l}47.0 \\
34.0\end{array}$ & $\begin{array}{r}8 \\
12\end{array}$ & $\begin{array}{l}0 \\
0\end{array}$ & $\begin{array}{r}8 \\
10\end{array}$ \\
\hline $\begin{array}{l}1951 \\
1952 \\
1953 \\
1954 \\
1955\end{array}$ & $\begin{array}{c}216 \\
415 \\
397 \\
84.0 \\
178\end{array}$ & $\begin{array}{r}10 \\
3 \\
4 \\
22 \\
16\end{array}$ & $\begin{array}{c}196 \\
374 \\
357 \\
67.0 \\
153\end{array}$ & $\begin{array}{r}12 \\
3 \\
5 \\
22 \\
17\end{array}$ & $\begin{array}{c}156 \\
324 \\
272 \\
55.0 \\
125\end{array}$ & $\begin{array}{r}14 \\
3 \\
5 \\
22 \\
18\end{array}$ & $\begin{array}{c}106 \\
245 \\
191 \\
52.0 \\
94.0\end{array}$ & $\begin{array}{r}17 \\
2 \\
6 \\
22 \\
19\end{array}$ & $\begin{array}{c}93.0 \\
172 \\
134 \\
40.0 \\
74.0\end{array}$ & $\begin{array}{r}16 \\
4 \\
9 \\
22 \\
19\end{array}$ & $\begin{array}{c}65.0 \\
129 \\
81.0 \\
31.0 \\
55.0\end{array}$ & $\begin{array}{r}16 \\
4 \\
11 \\
22 \\
18\end{array}$ & $\begin{array}{c}51.0 \\
103 \\
60.0 \\
27.0 \\
42.0\end{array}$ & $\begin{array}{r}16 \\
2 \\
11 \\
22 \\
19\end{array}$ & $\begin{array}{l}43.0 \\
85.0 \\
48.0 \\
23.0 \\
35.0\end{array}$ & $\begin{array}{r}15 \\
2 \\
11 \\
22 \\
18\end{array}$ & $\begin{array}{l}30.0 \\
60.0 \\
34.0 \\
18.0 \\
26.0\end{array}$ & $\begin{array}{r}16 \\
2 \\
13 \\
22 \\
19\end{array}$ & $\begin{array}{l}18.0 \\
33.0 \\
20.0 \\
12.0 \\
15.0\end{array}$ & $\begin{array}{r}16 \\
2 \\
13 \\
22 \\
19\end{array}$ \\
\hline $\begin{array}{l}1956 \\
1957 \\
1958 \\
1959 \\
1960\end{array}$ & $\begin{array}{l}167 \\
377 \\
256 \\
215 \\
196\end{array}$ & $\begin{array}{r}17 \\
5 \\
8 \\
11 \\
13\end{array}$ & $\begin{array}{l}160 \\
361 \\
250 \\
201 \\
184\end{array}$ & $\begin{array}{r}16 \\
4 \\
8 \\
11 \\
13\end{array}$ & $\begin{array}{l}141 \\
326 \\
227 \\
170 \\
158\end{array}$ & $\begin{array}{r}15 \\
2 \\
8 \\
11 \\
12\end{array}$ & $\begin{array}{l}123 \\
245 \\
180 \\
143 \\
127\end{array}$ & $\begin{array}{r}15 \\
3 \\
7 \\
11 \\
13\end{array}$ & $\begin{array}{l}95.0 \\
218 \\
133 \\
104 \\
101\end{array}$ & $\begin{array}{r}15 \\
2 \\
10 \\
13 \\
14\end{array}$ & $\begin{array}{c}60.0 \\
141 \\
84.0 \\
71.0 \\
72.0\end{array}$ & $\begin{array}{r}17 \\
2 \\
10 \\
15 \\
13\end{array}$ & $\begin{array}{c}44.0 \\
103 \\
61.0 \\
54.0 \\
53.0\end{array}$ & $\begin{array}{r}17 \\
3 \\
10 \\
14 \\
15\end{array}$ & & $\begin{array}{r}19 \\
3 \\
10 \\
14 \\
16\end{array}$ & & $\begin{array}{r}20 \\
3 \\
10 \\
14 \\
15\end{array}$ & $\begin{array}{l}15.0 \\
31.0 \\
21.0 \\
18.0 \\
19.0\end{array}$ & $\begin{array}{r}20 \\
3 \\
11 \\
17 \\
14\end{array}$ \\
\hline $\begin{array}{l}1961 \\
1962 \\
1963 \\
1964 \\
1965\end{array}$ & $\begin{array}{c}167 \\
215 \\
99.0 \\
307 \\
599\end{array}$ & $\begin{array}{r}18 \\
12 \\
21 \\
7 \\
1\end{array}$ & $\begin{array}{c}152 \\
203 \\
97.0 \\
277 \\
533\end{array}$ & $\begin{array}{r}18 \\
10 \\
21 \\
6 \\
1\end{array}$ & $\begin{array}{c}127 \\
181 \\
93.0 \\
243 \\
459\end{array}$ & $\begin{array}{r}17 \\
10 \\
20 \\
6 \\
1\end{array}$ & $\begin{array}{c}101 \\
160 \\
79.0 \\
176 \\
342\end{array}$ & $\begin{array}{r}18 \\
10 \\
20 \\
8 \\
1\end{array}$ & $\begin{array}{c}79.0 \\
135 \\
59.0 \\
172 \\
281\end{array}$ & $\begin{array}{r}18 \\
8 \\
21 \\
5 \\
1\end{array}$ & $\begin{array}{c}51.0 \\
109 \\
48.0 \\
132 \\
209\end{array}$ & $\begin{array}{r}20 \\
7 \\
21 \\
3 \\
1\end{array}$ & $\begin{array}{r}39.0 \\
88.0 \\
39.0 \\
98.0 \\
163\end{array}$ & $\begin{array}{r}20 \\
7 \\
21 \\
4 \\
1\end{array}$ & $\begin{array}{r}34.0 \\
72.0 \\
32.0 \\
77.0 \\
132\end{array}$ & $\begin{array}{r}20 \\
6 \\
21 \\
4 \\
1\end{array}$ & & $\begin{array}{r}18 \\
6 \\
21 \\
4 \\
1\end{array}$ & $\begin{array}{l}16.0 \\
31.0 \\
14.0 \\
29.0 \\
49.0\end{array}$ & $\begin{array}{l}8 \\
4 \\
1\end{array}$ \\
\hline
\end{tabular}


GREEN RIVER BASIN

09226500 MIDDLE FORK BEAVER CREEK NEAR LONETREE, WY-Continued

DURATION OF DISCHARGE FOR EACH WATER YEAR

\begin{tabular}{|c|c|c|c|c|c|c|c|c|c|c|c|c|c|c|c|c|c|c|c|c|c|c|c|c|c|c|c|c|c|c|c|c|c|c|c|c|c|}
\hline $\begin{array}{l}\text { CLASS } \\
\text { YEAR }\end{array}$ & 1 & 2 & & & & & & & & & & & & & 3 & JUMBE & & & AYS & $\mathrm{IN}$ & $C C_{A}$ & & 20 & & & & & & & & 202 & & & & & & $\begin{array}{l}\text { CUBIC FEET } \\
\text { PER SECOND } \\
\text {-DAYS }\end{array}$ \\
\hline $\begin{array}{l}1949 \\
1950\end{array}$ & & 28 & $\begin{array}{l}79 \\
43\end{array}$ & & & & & & & & & & $\begin{array}{r}5 \\
24\end{array}$ & $\begin{array}{r}6 \\
22\end{array}$ & $\begin{array}{r}13 \\
6\end{array}$ & $\begin{array}{r}10 \\
5\end{array}$ & $\begin{array}{r}9 \\
11\end{array}$ & & $\begin{array}{l}6 \\
3\end{array}$ & & $\begin{array}{l}4 \\
8\end{array}$ & $\begin{array}{l}4 \\
7\end{array}$ & $\frac{11}{1}$ & $\begin{array}{r}13 \\
7\end{array}$ & $\begin{array}{l}4 \\
7\end{array}$ & $\begin{array}{l}6 \\
4\end{array}$ & $\begin{array}{l}7 \\
7\end{array}$ & $\begin{array}{l}4 \\
3\end{array}$ & $\begin{array}{l}3 \\
4\end{array}$ & $\begin{array}{l}2 \\
2\end{array}$ & 3 & 2 & 2 & & & & $\begin{array}{l}9479.3 \\
7571.8\end{array}$ \\
\hline $\begin{array}{l}1951 \\
1952 \\
1953 \\
1954 \\
1955\end{array}$ & & $\begin{array}{l}44 \\
28 \\
95\end{array}$ & $\begin{array}{l}58 \\
35 \\
31 \\
28 \\
35\end{array}$ & $\begin{array}{l}59 \\
72 \\
72 \\
19\end{array}$ & $\begin{array}{l}33 \\
226 \\
248 \\
23\end{array}$ & 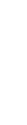 & 4 & $\begin{array}{l}19 \\
19 \\
32\end{array}$ & 1 & $\begin{array}{l}11 \\
15 \\
22\end{array}$ & $\begin{array}{ll}1 & 5 \\
212 & 15\end{array}$ & & $\begin{array}{r}9 \\
8 \\
14 \\
17 \\
25\end{array}$ & $\begin{array}{r}11 \\
7 \\
17 \\
18 \\
12\end{array}$ & $\begin{array}{r}17 \\
9 \\
5 \\
15 \\
16\end{array}$ & $\begin{array}{r}13 \\
7 \\
10 \\
13 \\
9\end{array}$ & $\begin{array}{r}8 \\
12 \\
11 \\
8 \\
2\end{array}$ & 10 & $\begin{array}{ll}4 & \\
0 & 1 \\
4 & \\
6 & \\
5 & \end{array}$ & $\begin{array}{r}5 \\
14 \\
2 \\
5\end{array}$ & $\begin{array}{l}5 \\
8 \\
4 \\
7 \\
8\end{array}$ & $\begin{array}{l}3 \\
2 \\
1 \\
9\end{array}$ & $\begin{array}{l}5 \\
6 \\
2 \\
6 \\
6\end{array}$ & $\begin{array}{r}4 \\
12 \\
3 \\
5\end{array}$ & $\begin{array}{r}3 \\
19 \\
7 \\
1 \\
2\end{array}$ & $\begin{array}{l}3 \\
4 \\
4 \\
2\end{array}$ & $\begin{array}{l}2 \\
6 \\
2 \\
3\end{array}$ & $\begin{array}{l}3 \\
7 \\
2 \\
1\end{array}$ & $\begin{array}{l}3 \\
5 \\
2 \\
1\end{array}$ & $\begin{array}{l}3 \\
2 \\
1\end{array}$ & $\begin{array}{l}2 \\
1\end{array}$ & $\begin{array}{l}2 \\
1\end{array}$ & & $\begin{array}{l}2 \\
1\end{array}$ & $\begin{array}{l}2 \\
1\end{array}$ & & $\begin{array}{r}6400.9 \\
12039.8 \\
7170.3 \\
4339.5 \\
5601.5\end{array}$ \\
\hline $\begin{array}{l}1956 \\
1957 \\
1958 \\
1959 \\
1960\end{array}$ & $\begin{array}{l}59 \\
59\end{array}$ & $\begin{array}{l}87 \\
37 \\
34\end{array}$ & $\begin{array}{r}95 \\
23 \\
14\end{array}$ & $\begin{array}{r}54 \\
38 \\
102 \\
63 \\
23\end{array}$ & $\begin{array}{r}47 \\
4 \\
65 \\
65 \\
17 \\
27\end{array}$ & $\begin{array}{l}3 \\
1 \\
1 \\
2\end{array}$ & $\begin{array}{l}0 \\
1 \\
8 \\
9\end{array}$ & $\begin{array}{r}28 \\
2 \\
7\end{array}$ & $\begin{array}{l}1 \\
1\end{array}$ & 19 & $\begin{array}{r}7 \\
8 \\
25 \\
18 \\
28\end{array}$ & & $\begin{array}{r}9 \\
9 \\
18 \\
16 \\
18\end{array}$ & $\begin{array}{r}7 \\
8 \\
19 \\
16 \\
7\end{array}$ & $\begin{array}{r}5 \\
14 \\
16 \\
12 \\
6\end{array}$ & $\begin{array}{r}11 \\
25 \\
6 \\
9 \\
11\end{array}$ & $\begin{array}{r}6 \\
12 \\
3 \\
8 \\
2\end{array}$ & & & 6 & $\begin{array}{l}3 \\
5 \\
9 \\
6 \\
2\end{array}$ & $\begin{array}{l}2 \\
3 \\
6 \\
4 \\
2\end{array}$ & $\begin{array}{l}5 \\
7 \\
2 \\
6 \\
4\end{array}$ & $\begin{array}{l}1 \\
4 \\
1 \\
6 \\
7\end{array}$ & $\begin{array}{l}1 \\
4 \\
3 \\
4 \\
7\end{array}$ & $\begin{array}{l}4 \\
1 \\
1 \\
3\end{array}$ & $\begin{array}{l}7 \\
2 \\
2 \\
1 \\
7\end{array}$ & $\begin{array}{l}3 \\
6 \\
6 \\
7 \\
2\end{array}$ & $\begin{array}{l}4 \\
5 \\
3 \\
3 \\
3\end{array}$ & $\begin{array}{l}5 \\
3 \\
2 \\
3\end{array}$ & $\begin{array}{l}3 \\
3 \\
1\end{array}$ & $\begin{array}{l}6 \\
3\end{array}$ & 1 & 4 & 1 & & \\
\hline $\begin{array}{l}1961 \\
1962 \\
1963 \\
1964 \\
1965\end{array}$ & $\begin{array}{l}44 \\
49 \\
31\end{array}$ & $\begin{array}{l}15 \\
49 \\
60\end{array}$ & $\begin{array}{l}20 \\
25 \\
43 \\
50 \\
31\end{array}$ & $\begin{array}{r}31 \\
29 \\
11 \\
4 \\
43\end{array}$ & $\begin{array}{r}50 \\
41 \\
7 \\
7 \\
8 \\
36\end{array}$ & $\begin{array}{l}2 \\
1 \\
2\end{array}$ & $\begin{array}{l}3 \\
6 \\
7\end{array}$ & 21 & $\begin{array}{l}18 \\
17 \\
31\end{array}$ & $\begin{array}{r}8 \\
21 \\
26\end{array}$ & $\begin{array}{l}321 \\
15 \\
25 \\
9\end{array}$ & & $\begin{array}{r}22 \\
16 \\
15 \\
7 \\
2\end{array}$ & $\begin{array}{r}22 \\
15 \\
11 \\
3 \\
3\end{array}$ & $\begin{array}{r}19 \\
29 \\
12 \\
7 \\
5\end{array}$ & $\begin{array}{r}12 \\
18 \\
8 \\
4 \\
8\end{array}$ & $\begin{array}{r}11 \\
19 \\
15 \\
14 \\
9\end{array}$ & 10 & $\begin{array}{ll}6 & \\
0 & \\
2 & \\
3 & \\
7 & 1\end{array}$ & $\begin{array}{l}5 \\
5 \\
4 \\
5\end{array}$ & $\begin{array}{l}5 \\
5 \\
4 \\
4 \\
7\end{array}$ & $\begin{array}{l}4 \\
7 \\
6 \\
2 \\
3\end{array}$ & $\begin{array}{r}3 \\
8 \\
9 \\
5 \\
13\end{array}$ & $\begin{array}{l}6 \\
9 \\
6 \\
6 \\
9\end{array}$ & $\begin{array}{l}8 \\
7 \\
2 \\
2 \\
5\end{array}$ & $\begin{array}{l}1 \\
7 \\
6 \\
8 \\
6\end{array}$ & $\begin{array}{l}2 \\
7 \\
8 \\
8\end{array}$ & $\begin{array}{r}2 \\
8 \\
6 \\
10\end{array}$ & $\begin{array}{r}2 \\
9 \\
10 \\
8\end{array}$ & $\begin{array}{l}4 \\
3 \\
9\end{array}$ & $\begin{array}{l}3 \\
3 \\
4\end{array}$ & $\begin{array}{l}4 \\
6\end{array}$ & $\begin{array}{l}3 \\
3\end{array}$ & 4 & & 3 & $\begin{array}{r}5947.3 \\
11202.3 \\
5247.1 \\
10649.9 \\
17784.7\end{array}$ \\
\hline $\begin{array}{l}1966 \\
1967 \\
1968 \\
1969 \\
1970\end{array}$ & $\begin{array}{l}11 \\
18\end{array}$ & $\begin{array}{r}34 \\
23 \\
2 \\
20 \\
27\end{array}$ & $\begin{array}{l}26 \\
48 \\
81 \\
68 \\
31\end{array}$ & $\begin{array}{l}55 \\
36 \\
38 \\
13\end{array}$ & $\begin{array}{r}10 \\
29 \\
17 \\
8 \\
27\end{array}$ & 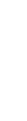 & & $\begin{array}{l}15 \\
16\end{array}$ & & $\begin{array}{l}17 \\
26\end{array}$ & 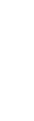 & & $\begin{array}{l}31 \\
10 \\
15 \\
20\end{array}$ & $\begin{array}{l}30 \\
14 \\
17 \\
17 \\
27\end{array}$ & $\begin{array}{r}20 \\
6 \\
9 \\
9 \\
15\end{array}$ & $\begin{array}{r}10 \\
11 \\
5 \\
11 \\
7\end{array}$ & $\begin{array}{r}18 \\
4 \\
11 \\
19 \\
9\end{array}$ & $\begin{array}{l}10 \\
11 \\
13 \\
10\end{array}$ & $\begin{array}{l}1 \\
1\end{array}$ & $\begin{array}{r}11 \\
5 \\
14\end{array}$ & $\begin{array}{r}10 \\
6 \\
9 \\
3 \\
8\end{array}$ & $\begin{array}{r}15 \\
8 \\
11 \\
7 \\
6\end{array}$ & $\begin{array}{r}5 \\
5 \\
1 \\
10 \\
4\end{array}$ & $\begin{array}{r}5 \\
2 \\
2 \\
12 \\
2\end{array}$ & $\begin{array}{l}2 \\
3 \\
1 \\
3\end{array}$ & $\begin{array}{r}1 \\
6 \\
7 \\
6 \\
10\end{array}$ & $\begin{array}{r}3 \\
12 \\
2 \\
2 \\
17\end{array}$ & $\begin{array}{r}10 \\
1 \\
8 \\
4\end{array}$ & $\begin{array}{l}7 \\
3 \\
5\end{array}$ & $\begin{array}{l}5 \\
5 \\
2\end{array}$ & $\begin{array}{l}4 \\
6\end{array}$ & 2 & 2 & 1 & 1 & 1 & $\begin{array}{r}6550.6 \\
10376.0 \\
10689.6 \\
7421.8 \\
8818.2\end{array}$ \\
\hline
\end{tabular}

DURATION TABLE OF DISCHARGE FOR WATER YEARS 1949-70

\begin{tabular}{|c|c|c|c|c|c|c|c|c|c|c|c|c|c|c|c|c|c|c|c|}
\hline CLASS & $\begin{array}{c}\text { CUBIC } \\
\text { FEET } \\
\text { PER } \\
\text { SECOND }\end{array}$ & $\begin{array}{l}\text { TOTAL } \\
\text { DAYS }\end{array}$ & $\begin{array}{c}\text { ACOU- } \\
\text { MU- } \\
\text { LATED } \\
\text { DAYS }\end{array}$ & $\begin{array}{l}\text { PER- } \\
\text { CENT } \\
\text { DAYS }\end{array}$ & CLASS & $\begin{array}{c}\text { OUBIC } \\
\text { FEET } \\
\text { PER } \\
\text { SECOND }\end{array}$ & $\begin{array}{l}\text { TOTAL, } \\
\text { DAYS }\end{array}$ & $\begin{array}{c}\text { ACOU- } \\
\text { MU- } \\
\text { LATED } \\
\text { DAYS }\end{array}$ & $\begin{array}{l}\text { PER- } \\
\text { CENT } \\
\text { DAYS }\end{array}$ & & $\begin{array}{c}\text { CUBIC } \\
\text { FEET } \\
\text { PER } \\
\text { SECOND }\end{array}$ & $\begin{array}{l}\text { TOTAL } \\
\text { DAYS }\end{array}$ & $\begin{array}{c}\text { ACCU- } \\
\text { MU- } \\
\text { LATEDD } \\
\text { DAYS }\end{array}$ & $\begin{array}{l}\text { PER- } \\
\text { CENT } \\
\text { DAYS }\end{array}$ & CLASS & $\begin{array}{c}\text { CUBIC } \\
\text { FEET } \\
\text { PER } \\
\text { SECOND }\end{array}$ & $\begin{array}{l}\text { TOTAL } \\
\text { DAYS }\end{array}$ & $\begin{array}{l}\text { ACOU- } \\
\text { MU- } \\
\text { LATED } \\
\text { DAYS }\end{array}$ & $\begin{array}{l}\text { PER- } \\
\text { CENT } \\
\text { DAYS }\end{array}$ \\
\hline $\begin{array}{l}0 \\
1 \\
2 \\
3 \\
4 \\
5 \\
6 \\
7 \\
8\end{array}$ & $\begin{array}{l}0.00 \\
2.80 \\
3.30 \\
3.80 \\
4.50 \\
5.30 \\
6.20 \\
7.20 \\
8.40\end{array}$ & $\begin{array}{r}0 \\
271 \\
583 \\
894 \\
949 \\
585 \\
485 \\
388 \\
413\end{array}$ & $\begin{array}{l}8035 \\
8035 \\
7764 \\
7181 \\
6287 \\
5338 \\
4753 \\
4268 \\
3880\end{array}$ & $\begin{array}{r}100.0 \\
100.0 \\
96.6 \\
89.4 \\
78.2 \\
66.4 \\
59.2 \\
53.1 \\
48.3\end{array}$ & $\begin{array}{r}9 \\
10 \\
11 \\
12 \\
13 \\
14 \\
15 \\
16 \\
17\end{array}$ & $\begin{array}{r}9.90 \\
12.00 \\
14.00 \\
16.00 \\
19.00 \\
22.00 \\
25.00 \\
30.00 \\
35.00\end{array}$ & $\begin{array}{l}365 \\
376 \\
323 \\
309 \\
265 \\
223 \\
221 \\
141 \\
129\end{array}$ & $\begin{array}{l}3467 \\
3102 \\
2726 \\
2403 \\
2094 \\
1829 \\
1606 \\
1385 \\
1244\end{array}$ & $\begin{array}{l}43.1 \\
38.6 \\
33.9 \\
29.9 \\
26.1 \\
22.8 \\
20.0 \\
17.2 \\
15.5\end{array}$ & $\begin{array}{l}18 \\
19 \\
20 \\
21 \\
22 \\
23 \\
24 \\
25 \\
26\end{array}$ & $\begin{array}{r}41.0 \\
48.0 \\
56.0 \\
65.0 \\
76.0 \\
89.0 \\
100.0 \\
120.0 \\
140.0\end{array}$ & $\begin{array}{r}130 \\
126 \\
124 \\
122 \\
95 \\
90 \\
107 \\
93 \\
80\end{array}$ & $\begin{array}{r}1115 \\
985 \\
859 \\
735 \\
613 \\
518 \\
428 \\
321 \\
228\end{array}$ & $\begin{array}{r}13.9 \\
12.3 \\
10.7 \\
9.1 \\
7.6 \\
6.4 \\
5.3 \\
4.0 \\
2.8\end{array}$ & $\begin{array}{l}27 \\
28 \\
29 \\
30 \\
31 \\
32 \\
33 \\
34\end{array}$ & $\begin{array}{l}170.0 \\
200.0 \\
230.0 \\
270.0 \\
310.0 \\
370.0 \\
430.0 \\
500.0\end{array}$ & $\begin{array}{r}51 \\
33 \\
26 \\
14 \\
12 \\
6 \\
4 \\
2\end{array}$ & $\begin{array}{r}148 \\
97 \\
64 \\
38 \\
24 \\
12 \\
6\end{array}$ & $\begin{array}{l}1.8 \\
1.2 \\
0.8 \\
0.5 \\
0.3 \\
0.1 \\
0.1 \\
0.0\end{array}$ \\
\hline
\end{tabular}

MONIHLY MEAN DISCHARGES, IN CUBIC FEET PER SECOND, FOR EACH WATER YEAR

$\begin{array}{lcccccccccccc}\text { YEAR } & \text { OCT } & \text { NOV } & \text { DEC } & \text { JAN } & \text { FEB } & \text { MAR } & \text { APR } & \text { MAY } & \text { JUNE } & \text { JULY } & \text { AUG } & \text { SEP } \\ 1949 & 7.61 & 5.88 & 4.32 & 3.80 & 3.50 & 4.00 & 10.4 & 68.0 & 136 & 42.2 & 16.9 & 9.06 \\ 1950 & 12.7 & 9.58 & 7.10 & 5.00 & 4.00 & 4.26 & 9.95 & 48.3 & 90.7 & 32.7 & 13.9 & 10.3 \\ & & & & & & & & & & & & \\ 1951 & 6.65 & 5.09 & 4.31 & 3.74 & 3.50 & 4.00 & 5.50 & 49.5 & 69.5 & 26.5 & 20.9 & 10.6 \\ 1952 & 9.77 & 6.38 & 4.97 & 4.40 & 4.00 & 5.32 & 12.3 & 92.4 & 164 & 50.5 & 27.4 & 13.4 \\ 1953 & 7.22 & 6.04 & 4.50 & 4.00 & 3.50 & 4.50 & 8.21 & 19.2 & 131 & 24.7 & 16.2 & 7.54 \\ 1954 & 7.24 & 7.06 & 5.50 & 5.00 & 4.00 & 4.50 & 8.49 & 36.6 & 23.2 & 19.6 & 11.5 & 9.21 \\ 1955 & 7.75 & 5.64 & 4.13 & 3.50 & 3.50 & 3.64 & 4.95 & 41.4 & 65.9 & 15.8 & 16.9 & 10.7 \\ 1956 & 8.21 & 5.91 & 4.65 & 4.20 & 4.00 & 4.21 & 5.68 & 66.2 & 49.7 & 14.2 & 7.57 & 5.43 \\ 1957 & 4.82 & 3.90 & 3.50 & 3.50 & 3.00 & 3.00 & 4.50 & 22.2 & 214 & 66.5 & 24.9 & 14.4 \\ 1958 & 9.61 & 6.09 & 5.50 & 5.00 & 4.50 & 4.50 & 5.73 & 91.6 & 70.8 & 18.3 & 14.6 & 11.6 \\ 1959 & 7.13 & 5.35 & 4.50 & 3.24 & 3.00 & 3.26 & 5.50 & 32.5 & 103 & 22.9 & 16.8 & 10.8 \\ 1960 & 12.8 & 8.34 & 5.48 & 4.00 & 3.50 & 4.50 & 9.39 & 57.6 & 81.7 & 17.4 & 9.15 & 8.27 \\ 1961 & 7.67 & 6.32 & 5.57 & 5.00 & 3.54 & 3.00 & 5.32 & 46.8 & 52.8 & 14.9 & 17.5 & 26.7 \\ 1962 & 22.9 & 15.2 & 7.65 & 6.00 & 5.18 & 4.19 & 16.8 & 76.4 & 132 & 51.6 & 18.9 & 10.6 \\ 1963 & 9.08 & 6.54 & 4.05 & 3.50 & 3.27 & 3.00 & 4.10 & 51.5 & 42.0 & 20.5 & 12.7 & 11.5 \\ 1964 & 8.75 & 7.06 & 4.69 & 3.50 & 3.50 & 3.00 & 4.07 & 83.3 & 145 & 55.9 & 20.6 & 10.1 \\ 1965 & 7.41 & 6.94 & 6.47 & 5.50 & 4.50 & 4.00 & 7.10 & 30.3 & 256 & 160 & 66.8 & 29.7 \\ & & & & & & & & & & & & \\ 1966 & 17.1 & 10.1 & 4.66 & 4.24 & 3.50 & 5.01 & 10.8 & 61.4 & 37.7 & 28.6 & 16.3 & 14.5 \\ 1967 & 12.1 & 7.27 & 5.70 & 4.70 & 3.85 & 3.95 & 6.25 & 54.2 & 139 & 62.5 & 26.4 & 14.2 \\ 1968 & 10.2 & 8.49 & 5.06 & 4.24 & 4.01 & 4.17 & 5.84 & 26.9 & 195 & 40.5 & 32.2 & 15.9 \\ 1969 & 11.1 & 8.30 & 4.96 & 4.12 & 3.84 & 3.45 & 12.6 & 80.5 & 57.3 & 27.7 & 17.5 & 11.2 \\ 1970 & 9.61 & 7.81 & 5.36 & 4.49 & 3.72 & 3.32 & 4.63 & 66.5 & 105 & 38.3 & 18.8 & 22.1\end{array}$


GREEN RIVER BASIN

09226500 MIDLLE FORK BEAVER CREEK NEAR LONEIREE, WY-Continued.

ANNUAL PEAK DISCHARGE, IN GBIC FEET PER SECOND, AND CORRESPONDING GAGE HEIGHT, IN FEET, FOR EACH WATER YEAR

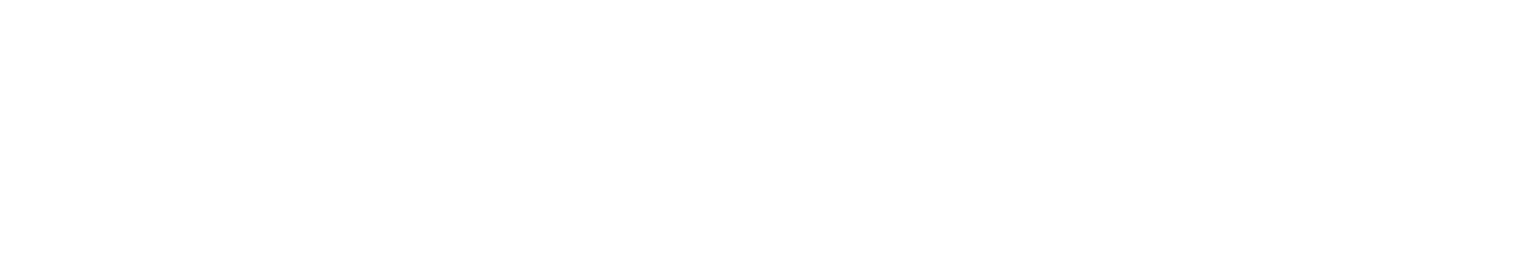

MAGNITUDE AND PRCBABILITY OF ANNUAL LONEST MEAN DISCHARGE BASED ON CLIMATIC YEARS $1950-70$

MAGNITUDE AND PRCBABILITY OF ANNUAL HIGHEST MEAN DISCHARGE BASED ON WATER YEARS 1949-70

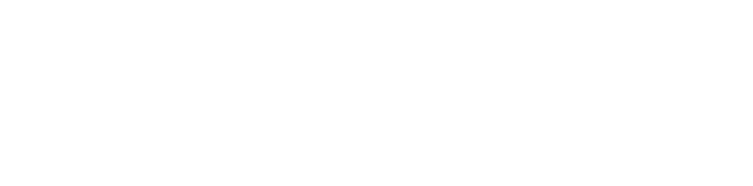

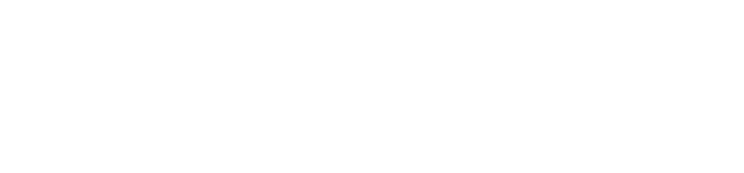

$\begin{array}{rrrrrrr}1 & 3.4 & 3.1 & 2.9 & 2.8 & - & - \\ 7 & 3.4 & 3.1 & 3.0 & 2.9 & - & - \\ 14 & 3.5 & 3.2 & 3.0 & 2.9 & - & - \\ 30 & 3.6 & 3.2 & 3.0 & 2.9 & - & - \\ 60 & 3.8 & 3.3 & 3.1 & 3.0 & - & - \\ 90 & 4.0 & 3.6 & 3.3 & 3.2 & - & -\end{array}$


GREEN RIVER BASIN

09227000 EAST FORK BEAVER CREER NEAR LONETREE, WY

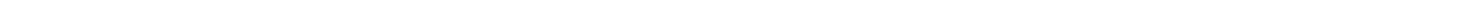

14040106, on right bank at forest boundary, $1 \mathrm{mi}$ south of Hole-in-the-Rock ranger station, $3.5 \mathrm{mi}$ south of Utah-Wyoming State line, and $7.5 \mathrm{mi}$ south of Lonetree.

DRAINAGE AREA. $--8.2 \mathrm{mi}^{2}$.

MEAN BASIN EI.EVATION. $-10,680 \mathrm{ft}$.

PERIOD OF RECORD AVAIIABLE.--October 1948 to Septenber 1962.

GAGE.--Water-stage recorder. Concrete control since August 1954. Altitude of gage is 8,600 ft from topographic map. Prior to Oct. 11, 1950, at site $50 \mathrm{ft}$ upstream at different datum.

REMARKS.--Same regulation by Hoop Lake, capacity, 3,920 acre-ft, which receives water from Thompson Creek, a tributary to Burnt Fork.

AVERAGE DISCHARGE. --14 years, $7.19 \mathrm{ft}^{3} / \mathrm{s}, 5,210$ acre- $\mathrm{ft} / \mathrm{yr}$.

EXTREMES FOR PERTOD OF RECORD.-Maximum daily discharge, $74 \mathrm{ft}^{3} / \mathrm{s}$ May 31, June 1, 1952; minimum daily, $2.4 \mathrm{ft}{ }^{3} / \mathrm{s}$ Mar. $30,1950$.

LOWEST MEAN DISCHARGE, IN OBIC FEET PER SECOND, AND RANKING FOR THE TNDICATED NUMBER OF CONSECUTIVE DAYS FOR EACH CLIMATIC YEAR, APRIL 1-MARCH 31

\begin{tabular}{|c|c|c|c|c|c|c|c|c|c|c|c|c|c|c|c|c|c|c|c|}
\hline YEAR & 1 & & 3 & & 7 & & 14 & & $\begin{array}{l}\text { CONSEX } \\
30\end{array}$ & CATIVE & $\begin{array}{l}\text { DAYS } \\
60\end{array}$ & & 90 & & 120 & & 183 & & ALL \\
\hline 1950 & 2.40 & 1 & 2.50 & 1 & 2.70 & 2 & 2.80 & 2 & 3.10 & 6 & 3.20 & 6 & 3.30 & 6 & 3.40 & 6 & 3.70 & 7 & 8.10 \\
\hline $\begin{array}{l}1961 \\
1962\end{array}$ & $\begin{array}{l}2.90 \\
2.50\end{array}$ & $\begin{array}{l}5 \\
2\end{array}$ & $\begin{array}{l}2.90 \\
2.50\end{array}$ & $\begin{array}{l}5 \\
2\end{array}$ & $\begin{array}{l}2.90 \\
2.50\end{array}$ & $\begin{array}{l}5 \\
1\end{array}$ & $\begin{array}{l}2.90 \\
2.50\end{array}$ & $\begin{array}{l}3 \\
1\end{array}$ & $\begin{array}{l}3.00 \\
2.50\end{array}$ & $\begin{array}{l}5 \\
1\end{array}$ & $\begin{array}{l}3.10 \\
2.60\end{array}$ & $\begin{array}{l}5 \\
1\end{array}$ & $\begin{array}{l}3.30 \\
2.60\end{array}$ & $\begin{array}{l}5 \\
1\end{array}$ & $\begin{array}{l}3.40 \\
2.60\end{array}$ & $\begin{array}{l}5 \\
1\end{array}$ & $\begin{array}{l}3.40 \\
3.20\end{array}$ & $\begin{array}{l}2 \\
1\end{array}$ & $\begin{array}{l}7.40 \\
5.70\end{array}$ \\
\hline
\end{tabular}

HIGHEST MEAN DISCHARGE, IN OUBIC FEET PER SECOND, AND RANKING FOR THE INDICATED NUMBER OF CONSECUTIVE DAYS FOR EACH WATER YEAR, OCTOBER 1-SEPTEMBER 30

\begin{tabular}{|c|c|c|c|c|c|c|c|c|c|c|c|c|c|c|c|c|c|c|}
\hline \multicolumn{19}{|c|}{ CONSECUTIVE DAYS } \\
\hline 1 & 3 & & 7 & & 15 & & 30 & & 60 & & 90 & & 120 & & 183 & & ALL & \\
\hline $\begin{array}{l}6 \\
4\end{array}$ & $\begin{array}{l}33.0 \\
47.0\end{array}$ & $\begin{array}{l}6 \\
4\end{array}$ & $\begin{array}{l}30.0 \\
46.0\end{array}$ & $\begin{array}{r}10 \\
4\end{array}$ & $\begin{array}{l}28.0 \\
46.0\end{array}$ & $\begin{array}{l}8 \\
2\end{array}$ & $\begin{array}{l}23.0 \\
44.0\end{array}$ & $\begin{array}{l}7 \\
1\end{array}$ & $\begin{array}{l}18.0 \\
29.0\end{array}$ & $\begin{array}{l}7 \\
1\end{array}$ & $\begin{array}{l}16.0 \\
23.0\end{array}$ & $\begin{array}{l}6 \\
1\end{array}$ & $\begin{array}{l}16.0 \\
19.0\end{array}$ & $\begin{array}{l}3 \\
2\end{array}$ & $\begin{array}{l}13.0 \\
14.0\end{array}$ & $\begin{array}{l}3 \\
2\end{array}$ & $\begin{array}{l}8.00 \\
8.70\end{array}$ & $\begin{array}{l}4 \\
2\end{array}$ \\
\hline $\begin{array}{r}3 \\
1 \\
2 \\
7 \\
11\end{array}$ & $\begin{array}{l}56.0 \\
65.0 \\
62.0 \\
33.0 \\
31.0\end{array}$ & $\begin{array}{r}3 \\
1 \\
2 \\
7 \\
10\end{array}$ & $\begin{array}{l}51.0 \\
47.0 \\
58.0 \\
31.0 \\
30.0\end{array}$ & $\begin{array}{l}2 \\
3 \\
1 \\
7 \\
8\end{array}$ & $\begin{array}{l}36.0 \\
34.0 \\
50.0 \\
28.0 \\
27.0\end{array}$ & $\begin{array}{r}3 \\
5 \\
1 \\
9 \\
10\end{array}$ & $\begin{array}{l}23.0 \\
31.0 \\
36.0 \\
21.0 \\
17.0\end{array}$ & $\begin{array}{r}8 \\
3 \\
2 \\
11 \\
13\end{array}$ & $\begin{array}{l}17.0 \\
23.0 \\
26.0 \\
14.0 \\
12.0\end{array}$ & $\begin{array}{r}8 \\
3 \\
2 \\
12 \\
13\end{array}$ & $\begin{array}{l}14.0 \\
18.0 \\
21.0 \\
11.0 \\
12.0\end{array}$ & $\begin{array}{r}8 \\
4 \\
2 \\
14 \\
12\end{array}$ & $\begin{array}{c}12.0 \\
15.0 \\
20.0 \\
9.60 \\
10.0\end{array}$ & $\begin{array}{r}9 \\
4 \\
1 \\
14 \\
13\end{array}$ & $\begin{array}{c}9.00 \\
12.0 \\
15.0 \\
7.60 \\
8.20\end{array}$ & $\begin{array}{r}9 \\
4 \\
1 \\
14 \\
13\end{array}$ & $\begin{array}{l}6.30 \\
8.00 \\
9.20 \\
5.80 \\
6.10\end{array}$ & $\begin{array}{r}11 \\
3 \\
1 \\
14 \\
12\end{array}$ \\
\hline $\begin{array}{r}5 \\
8 \\
9 \\
14 \\
10\end{array}$ & $\begin{array}{l}39.0 \\
31.0 \\
32.0 \\
24.0 \\
32.0\end{array}$ & $\begin{array}{r}5 \\
11 \\
8 \\
14 \\
9\end{array}$ & $\begin{array}{l}38.0 \\
28.0 \\
31.0 \\
23.0 \\
30.0\end{array}$ & $\begin{array}{r}5 \\
11 \\
6 \\
14 \\
9\end{array}$ & $\begin{array}{l}35.0 \\
23.0 \\
30.0 \\
23.0 \\
29.0\end{array}$ & $\begin{array}{r}4 \\
12 \\
6 \\
13 \\
7\end{array}$ & $\begin{array}{l}24.0 \\
20.0 \\
29.0 \\
22.0 \\
27.0\end{array}$ & $\begin{array}{r}6 \\
12 \\
4 \\
9 \\
5\end{array}$ & $\begin{array}{l}16.0 \\
16.0 \\
20.0 \\
20.0 \\
21.0\end{array}$ & $\begin{array}{r}9 \\
10 \\
5 \\
6 \\
4\end{array}$ & $\begin{array}{l}14.0 \\
13.0 \\
18.0 \\
16.0 \\
17.0\end{array}$ & $\begin{array}{r}9 \\
10 \\
3 \\
7 \\
5\end{array}$ & $\begin{array}{l}11.0 \\
11.0 \\
15.0 \\
15.0 \\
15.0\end{array}$ & $\begin{array}{r}10 \\
11 \\
5 \\
6 \\
7\end{array}$ & $\begin{array}{r}9.00 \\
8.90 \\
11.0 \\
12.0 \\
11.0\end{array}$ & $\begin{array}{r}10 \\
11 \\
8 \\
5 \\
6\end{array}$ & $\begin{array}{l}6.40 \\
6.50 \\
7.80 \\
7.70 \\
7.60\end{array}$ & $\begin{array}{r}10 \\
9 \\
5 \\
6 \\
7\end{array}$ \\
\hline $\begin{array}{l}13 \\
12\end{array}$ & $\begin{array}{l}26.0 \\
29.0\end{array}$ & $\begin{array}{l}13 \\
12\end{array}$ & $\begin{array}{l}25.0 \\
27.0\end{array}$ & $\begin{array}{l}13 \\
12\end{array}$ & $\begin{array}{l}21.0 \\
24.0\end{array}$ & $\begin{array}{l}14 \\
11\end{array}$ & $\begin{array}{l}14.0 \\
21.0\end{array}$ & $\begin{array}{l}14 \\
10\end{array}$ & $\begin{array}{l}11.0 \\
16.0\end{array}$ & $\begin{array}{l}14 \\
11\end{array}$ & $\begin{array}{l}11.0 \\
13.0\end{array}$ & $\begin{array}{l}13 \\
11\end{array}$ & $\begin{array}{l}10.0 \\
13.0\end{array}$ & $\begin{array}{r}12 \\
8\end{array}$ & $\begin{array}{r}8.20 \\
11.0\end{array}$ & $\begin{array}{r}12 \\
7\end{array}$ & $\begin{array}{l}5.80 \\
6.91\end{array}$ & $\begin{array}{r}13 \\
8\end{array}$ \\
\hline
\end{tabular}


GREEN RIVER BASIN

09227000 EAST FORK BEAVER CREEK NEAR LONEIREE, WY-Continued

DURATION OF DISCHARGE FOR EACH WATER YEAR

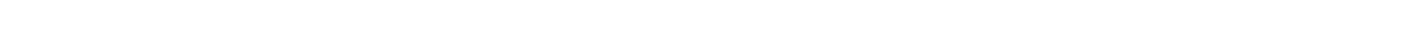

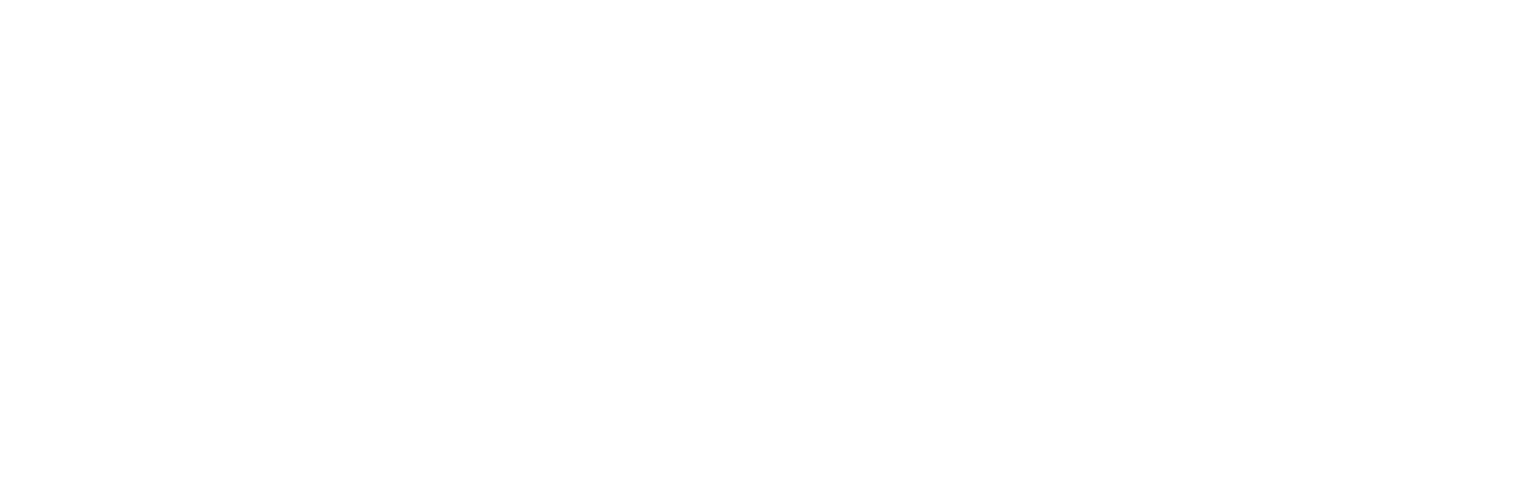

DURATION TABLE OF DISCHARGE FOR WATER YEARS 1949-62

\begin{tabular}{|c|c|c|c|c|c|c|c|c|c|c|c|c|c|c|c|c|c|c|c|}
\hline CLASS & $\begin{array}{c}\text { OUBIC } \\
\text { FEET } \\
\text { PER } \\
\text { SECOND }\end{array}$ & $\begin{array}{r}\text { TOTAL } \\
\text { DAYS }\end{array}$ & $\begin{array}{l}\text { ACO- } \\
\text { MU- } \\
\text { LATED } \\
\text { DAYS }\end{array}$ & $\begin{array}{l}\text { PER- } \\
\text { CENT } \\
\text { DAYS }\end{array}$ & & $\begin{array}{c}\text { OJBIC } \\
\text { FEET } \\
\text { PER } \\
\text { SECOND }\end{array}$ & $\begin{array}{l}\text { TOTAL } \\
\text { DAYS }\end{array}$ & $\begin{array}{c}\text { ACOU- } \\
\text { MU- } \\
\text { LATED } \\
\text { DAYS }\end{array}$ & $\begin{array}{l}\text { PER- } \\
\text { CENT } \\
\text { DAYS }\end{array}$ & & $\begin{array}{c}\text { OBIC } \\
\text { FEET } \\
\text { PER } \\
\text { SECOND }\end{array}$ & $\begin{array}{r}\text { TOTAL } \\
\text { DAYS }\end{array}$ & $\begin{array}{c}\text { ACOU- } \\
\text { MU- } \\
\text { LATED } \\
\text { DAYS }\end{array}$ & $\begin{array}{l}\text { PER- } \\
\text { CENT } \\
\text { DAYS }\end{array}$ & CLASS & $\begin{array}{c}\text { CIBIC } \\
\text { FEET } \\
\text { PER } \\
\text { SECOND }\end{array}$ & $\begin{array}{r}\text { TOTAL } \\
\text { DAYS }\end{array}$ & $\begin{array}{c}\text { ACCU- } \\
\text { MU- } \\
\text { LATED } \\
\text { DAYS }\end{array}$ & $\begin{array}{l}\text { PER- } \\
\text { CENT } \\
\text { DAYS }\end{array}$ \\
\hline $\begin{array}{l}0 \\
1 \\
2 \\
3 \\
4 \\
5 \\
6 \\
7 \\
8\end{array}$ & $\begin{array}{l}0.00 \\
2.40 \\
2.70 \\
3.00 \\
3.30 \\
3.60 \\
4.00 \\
4.40 \\
4.90\end{array}$ & $\begin{array}{r}0 \\
83 \\
80 \\
334 \\
377 \\
1078 \\
737 \\
529 \\
297\end{array}$ & $\begin{array}{l}5113 \\
5113 \\
5030 \\
4950 \\
4616 \\
4239 \\
3161 \\
2424 \\
1895\end{array}$ & $\begin{array}{r}100.0 \\
100.0 \\
98.4 \\
96.8 \\
90.3 \\
82.9 \\
61.8 \\
47.4 \\
37.1\end{array}$ & $\begin{array}{r}9 \\
10 \\
11 \\
12 \\
13 \\
14 \\
15 \\
16 \\
17\end{array}$ & $\begin{array}{r}5.50 \\
6.10 \\
6.70 \\
7.40 \\
8.20 \\
9.10 \\
10.00 \\
11.00 \\
12.00\end{array}$ & $\begin{array}{r}183 \\
109 \\
97 \\
144 \\
86 \\
75 \\
84 \\
96 \\
125\end{array}$ & $\begin{array}{r}1598 \\
1415 \\
1306 \\
1209 \\
1065 \\
979 \\
904 \\
820 \\
724\end{array}$ & $\begin{array}{l}31.3 \\
27.7 \\
25.5 \\
23.6 \\
20.8 \\
19.1 \\
17.7 \\
16.0 \\
14.2\end{array}$ & $\begin{array}{l}18 \\
19 \\
20 \\
21 \\
22 \\
23 \\
24 \\
25 \\
26\end{array}$ & $\begin{array}{l}14.0 \\
15.0 \\
17.0 \\
19.0 \\
21.0 \\
23.0 \\
25.0 \\
28.0 \\
31.0\end{array}$ & $\begin{array}{l}47 \\
77 \\
49 \\
71 \\
80 \\
42 \\
67 \\
63 \\
34\end{array}$ & $\begin{array}{l}599 \\
552 \\
475 \\
426 \\
355 \\
275 \\
233 \\
166 \\
103\end{array}$ & $\begin{array}{r}11.7 \\
10.8 \\
9.3 \\
8.3 \\
6.9 \\
5.4 \\
4.6 \\
3.2 \\
2.0\end{array}$ & $\begin{array}{l}27 \\
28 \\
29 \\
30 \\
31 \\
32 \\
33 \\
34\end{array}$ & $\begin{array}{l}35.0 \\
38.0 \\
43.0 \\
47.0 \\
52.0 \\
58.0 \\
64.0 \\
71.0\end{array}$ & $\begin{array}{r}11 \\
18 \\
16 \\
9 \\
10 \\
2 \\
0 \\
3\end{array}$ & $\begin{array}{r}69 \\
58 \\
40 \\
24 \\
15 \\
5 \\
3 \\
3\end{array}$ & $\begin{array}{l}1.3 \\
1.1 \\
0.8 \\
0.5 \\
0.3 \\
0.1 \\
0.1 \\
0.1\end{array}$ \\
\hline
\end{tabular}

MONTHLY MEAN DISCHARGES, IN OUBIC FEET PER SECOND, FOR EACH WATER YEAR

\begin{tabular}{|c|c|c|c|c|c|c|c|c|c|c|c|c|}
\hline YEAR & $\propto T$ & $\mathrm{NOV}$ & $\mathrm{DEC}$ & JAN & FEB & MAR & APT. & MAY & JUNE & JULY & AUG & SEP \\
\hline $\begin{array}{l}1949 \\
1950\end{array}$ & $\begin{array}{l}3.69 \\
4.12\end{array}$ & $\begin{array}{l}3.63 \\
4.59\end{array}$ & $\begin{array}{l}3.45 \\
3.65\end{array}$ & $\begin{array}{l}3.23 \\
3.27\end{array}$ & $\begin{array}{l}3.19 \\
3.24\end{array}$ & $\begin{array}{l}3.63 \\
3.45\end{array}$ & $\begin{array}{l}5.53 \\
4.83\end{array}$ & $\begin{array}{c}15.5 \\
9.16\end{array}$ & $\begin{array}{r}13.0 \\
8.40\end{array}$ & $\begin{array}{l}14.9 \\
40.7\end{array}$ & $\begin{array}{l}19.5 \\
14.1\end{array}$ & $\begin{array}{l}6.11 \\
4.22\end{array}$ \\
\hline $\begin{array}{l}1951 \\
1952 \\
1953 \\
1954 \\
1955\end{array}$ & $\begin{array}{l}3.17 \\
3.98 \\
3.70 \\
4.19 \\
4.20\end{array}$ & $\begin{array}{l}3.13 \\
3.62 \\
3.64 \\
4.01 \\
4.20\end{array}$ & $\begin{array}{l}3.38 \\
3.28 \\
3.67 \\
3.99 \\
3.94\end{array}$ & $\begin{array}{l}3.60 \\
3.33 \\
3.68 \\
3.73 \\
3.70\end{array}$ & $\begin{array}{l}3.87 \\
3.80 \\
4.15 \\
4.01 \\
4.03\end{array}$ & $\begin{array}{l}3.70 \\
4.00 \\
4.18 \\
4.02 \\
4.10\end{array}$ & $\begin{array}{l}4.71 \\
7.03 \\
4.47 \\
5.55 \\
5.45\end{array}$ & $\begin{array}{c}10.2 \\
27.6 \\
9.97 \\
6.95 \\
11.1\end{array}$ & $\begin{array}{c}8.76 \\
17.1 \\
12.2 \\
16.6 \\
7.54\end{array}$ & $\begin{array}{c}21.8 \\
6.35 \\
35.2 \\
8.50 \\
16.2\end{array}$ & $\begin{array}{c}4.40 \\
5.39 \\
14.6 \\
3.81 \\
4.16\end{array}$ & $\begin{array}{c}3.89 \\
10.3 \\
10.4 \\
4.39 \\
4.25\end{array}$ \\
\hline $\begin{array}{l}1956 \\
1957 \\
1958 \\
1959 \\
1960\end{array}$ & $\begin{array}{l}4.10 \\
4.10 \\
4.91 \\
3.61 \\
4.56\end{array}$ & $\begin{array}{l}4.02 \\
4.04 \\
5.08 \\
3.65 \\
3.96\end{array}$ & $\begin{array}{l}3.92 \\
4.20 \\
4.08 \\
3.52 \\
3.67\end{array}$ & $\begin{array}{l}3.39 \\
4.26 \\
3.83 \\
3.16 \\
3.35\end{array}$ & $\begin{array}{l}3.46 \\
4.29 \\
4.06 \\
3.12 \\
3.01\end{array}$ & $\begin{array}{l}3.57 \\
3.90 \\
4.13 \\
3.67 \\
4.26\end{array}$ & $\begin{array}{l}5.15 \\
4.62 \\
4.99 \\
5.03 \\
6.40\end{array}$ & $\begin{array}{l}9.87 \\
15.3 \\
12.4 \\
11.8 \\
10.8\end{array}$ & $\begin{array}{c}6.20 \\
17.2 \\
8.10 \\
8.78 \\
7.73\end{array}$ & $\begin{array}{c}23.7 \\
6.91 \\
28.6 \\
15.6 \\
23.7\end{array}$ & $\begin{array}{r}4.40 \\
4.72 \\
8.63 \\
21.8 \\
15.1\end{array}$ & $\begin{array}{l}4.22 \\
4.94 \\
4.07 \\
7.47 \\
3.90\end{array}$ \\
\hline $\begin{array}{l}1961 \\
1962\end{array}$ & $\begin{array}{l}3.58 \\
5.22\end{array}$ & $\begin{array}{l}3.55 \\
3.38\end{array}$ & $\begin{array}{l}3.70 \\
2.72\end{array}$ & $\begin{array}{l}3.27 \\
2.60\end{array}$ & $\begin{array}{l}3.00 \\
2.59\end{array}$ & $\begin{array}{l}3.45 \\
2.60\end{array}$ & $\begin{array}{c}5.14 \\
12.0\end{array}$ & $\begin{array}{l}12.1 \\
16.9\end{array}$ & $\begin{array}{l}8.24 \\
8.24\end{array}$ & $\begin{array}{l}13.4 \\
11.1\end{array}$ & $\begin{array}{l}5.09 \\
8.74\end{array}$ & $\begin{array}{l}4.86 \\
5.97\end{array}$ \\
\hline
\end{tabular}

\begin{tabular}{|c|c|c|c|c|c|c|}
\hline \multirow{2}{*}{$\begin{array}{l}\text { PERIOD } \\
\text { (CON- } \\
\text { SECU- } \\
\text { IIVE } \\
\text { DAYS) }\end{array}$} & \multicolumn{6}{|c|}{$\begin{array}{l}\text { DISCHARGE, IN OUBIC FEET PER SECOND, FOR } \\
\text { INDICATED RECURRENCE INTERNAL, IN YEARS, AND } \\
\text { ANNUAL NONEXCEEDANCE PROBABILITY, IN PERCENT }\end{array}$} \\
\hline & $\begin{array}{c}2 \\
50 \%\end{array}$ & $\begin{array}{c}5 \\
20 \%\end{array}$ & $\begin{array}{l}10 \\
108\end{array}$ & $\begin{array}{l}20 \\
58\end{array}$ & $\begin{array}{l}50 \\
28\end{array}$ & $\begin{array}{r}100 \\
18\end{array}$ \\
\hline $\begin{array}{r}1 \\
7 \\
14 \\
30 \\
60 \\
90\end{array}$ & $\begin{array}{l}3.1 \\
3.1 \\
3.2 \\
3.3 \\
3.4 \\
3.5\end{array}$ & $\begin{array}{l}2.7 \\
2.8 \\
2.9 \\
2.9 \\
3.0 \\
3.1\end{array}$ & $\begin{array}{l}2.6 \\
2.7 \\
2.7 \\
2.8 \\
2.9 \\
2.9\end{array}$ & $\begin{array}{l}2.4 \\
2.5 \\
2.6 \\
2.6 \\
2.7 \\
2.8\end{array}$ & $\begin{array}{l}- \\
- \\
-- \\
-\end{array}$ & $\begin{array}{l}- \\
\overline{-} \\
-\end{array}$ \\
\hline
\end{tabular}

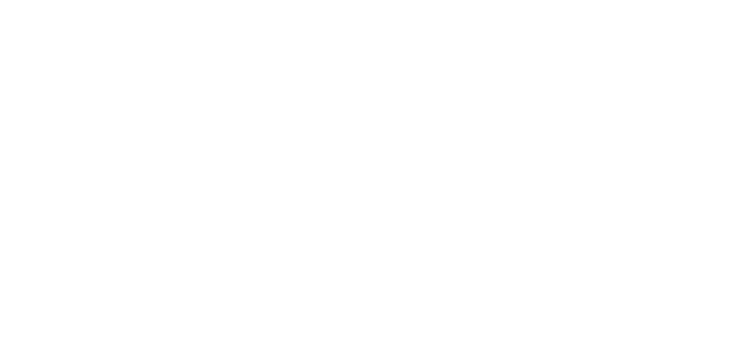


LOCATION. --Lat $40^{\circ} 56^{\prime} 50^{\prime \prime}$, long $110^{\circ} 13^{\prime} 00^{\prime \prime}$, in SW' sec.35, T. 3 N., R.15 E., Salt Lake Meridian, Summit County, UT, Hydrologic Unit 14040106, an right bank at forest boundary, $0.1 \mathrm{mi}$ upstream from Fellow Creek, $3.5 \mathrm{mi}$ south of Utah-Wyoming State 1 ine, and 7.5 mi southwest of Lonetree.

DRAINAGE AREA. $-23 \mathrm{mi}^{2}$.

MEAN BASIN ELEVATION. $-10,490 \mathrm{ft}$.

PERTOD OF RECORD AVAILABLE. - -October 1948 to September 1962.

GAGE.-Water-stage recorder. Altitude of gage is $8,700 \mathrm{ft}$ from topographic map.

AVERAGE DISCHARGE. -14 years, $16.2 \mathrm{ft}^{3} / \mathrm{s}, 11,730$ acre-ft/yr.

EXIREMES FOR PERIOD OF RECORD. --Maximum discharge, $417 \mathrm{ft}^{3} / \mathrm{s}$ June 13, 1953, from rating curve extended above $250 \mathrm{ft}^{3} / \mathrm{s}$ on basis of logarithmic plotting, maximum gage height, $3.25 \mathrm{ft}$ June 7, 1957; minimum discharge observed, $2.0 \mathrm{ft}^{3} / \mathrm{s} \mathrm{Mar.} 1$ 1954, discharge measurement.

LOWEST MEAN DISCHARGE, IN OBIC FEET PER SECOND, AND RANKING FOR THE INDICATED NUMBER OF OONSEOUTIVE DAYS FOR EACH CLIMATIC YEAR, APRIL 1-MARCH 31

\begin{tabular}{|c|c|c|c|c|c|c|c|c|c|c|c|c|c|c|c|c|c|c|c|c|}
\hline \multirow[t]{2}{*}{ YEAR } & \multicolumn{20}{|c|}{ CONSECUTIVE DAYS } \\
\hline & 1 & & 3 & & 7 & & 14 & & 30 & & 60 & & 90 & & 120 & & 183 & & ALL & \\
\hline $\begin{array}{l}1961 \\
1962\end{array}$ & $\begin{array}{l}3.00 \\
3.50\end{array}$ & $\begin{array}{l}11 \\
13\end{array}$ & $\begin{array}{l}3.00 \\
3.50\end{array}$ & $\begin{array}{l}11 \\
13\end{array}$ & $\begin{array}{l}3.00 \\
3.50\end{array}$ & $\begin{array}{l}11 \\
13\end{array}$ & $\begin{array}{l}3.00 \\
3.50\end{array}$ & $\begin{array}{l}10 \\
13\end{array}$ & $\begin{array}{l}3.00 \\
3.60\end{array}$ & $\begin{array}{l}10 \\
13\end{array}$ & $\begin{array}{l}3.00 \\
3.90\end{array}$ & $\begin{array}{r}7 \\
13\end{array}$ & $\begin{array}{l}3.20 \\
4.30\end{array}$ & $\begin{array}{r}7 \\
13\end{array}$ & $\begin{array}{l}3.40 \\
4.80\end{array}$ & $\begin{array}{r}7 \\
13\end{array}$ & $\begin{array}{l}4.30 \\
8.50\end{array}$ & $\begin{array}{r}9 \\
13\end{array}$ & $\begin{array}{l}15.0 \\
17.0\end{array}$ & 8 \\
\hline
\end{tabular}

HIGHEST MEAN DISCHARGE, IN OUBIC FEET PER SECOND, AND RANKING FOR THE INDICATED NUMBER OF CONSECUTIVE DAYS FOR EACH WATER YEAR, OCTCBER 1-SEPTEMBER 30

\begin{tabular}{|c|c|c|c|c|c|c|c|c|c|c|c|c|c|c|c|c|c|c|c|c|}
\hline YEAR & 1 & & 3 & & 7 & & 15 & & $\begin{array}{l}\text { CONs } \\
30\end{array}$ & ECUT & $\begin{array}{l}\text { VE DAY } \\
60\end{array}$ & & 90 & & 120 & & 183 & & ALL & \\
\hline $\begin{array}{l}1949 \\
1950\end{array}$ & $\begin{array}{l}188 \\
90.0\end{array}$ & $\begin{array}{r}4 \\
12\end{array}$ & $\begin{array}{r}162 \\
87.0\end{array}$ & $\begin{array}{r}4 \\
12\end{array}$ & $\begin{array}{r}133 \\
73.0\end{array}$ & $\begin{array}{r}5 \\
12\end{array}$ & $\begin{array}{l}116 \\
69.0\end{array}$ & $\begin{array}{r}4 \\
10\end{array}$ & $\begin{array}{l}90.0 \\
63.0\end{array}$ & $\begin{array}{l}5 \\
9\end{array}$ & $\begin{array}{l}68.0 \\
51.0\end{array}$ & $\begin{array}{r}5 \\
10\end{array}$ & $\begin{array}{l}55.0 \\
41.0\end{array}$ & $\begin{array}{r}4 \\
10\end{array}$ & $\begin{array}{l}45.0 \\
34.0\end{array}$ & $\begin{array}{r}4 \\
10\end{array}$ & $\begin{array}{l}32.0 \\
25.0\end{array}$ & $\begin{array}{r}4 \\
11\end{array}$ & $\begin{array}{l}18.0 \\
15.0\end{array}$ & $\begin{array}{r}4 \\
10\end{array}$ \\
\hline $\begin{array}{l}1951 \\
1952 \\
1953 \\
1954 \\
1955\end{array}$ & $\begin{array}{c}116 \\
216 \\
310 \\
68.0 \\
118\end{array}$ & $\begin{array}{r}9 \\
3 \\
1 \\
14 \\
8\end{array}$ & $\begin{array}{c}106 \\
198 \\
273 \\
53.0 \\
102\end{array}$ & $\begin{array}{r}9 \\
3 \\
1 \\
14 \\
10\end{array}$ & $\begin{array}{c}93.0 \\
174 \\
212 \\
42.0 \\
82.0\end{array}$ & $\begin{array}{r}9 \\
3 \\
1 \\
14 \\
10\end{array}$ & $\begin{array}{l}77.0 \\
140 \\
158 \\
37.0 \\
62.0\end{array}$ & $\begin{array}{r}9 \\
3 \\
1 \\
14 \\
11\end{array}$ & $\begin{array}{l}62.0 \\
108 \\
105 \\
29.0 \\
48.0\end{array}$ & $\begin{array}{r}10 \\
2 \\
3 \\
14 \\
13\end{array}$ & $\begin{array}{l}54.0 \\
83.0 \\
69.0 \\
25.0 \\
38.0\end{array}$ & $\begin{array}{r}8 \\
2 \\
4 \\
14 \\
13\end{array}$ & $\begin{array}{l}45.0 \\
72.0 \\
52.0 \\
23.0 \\
30.0\end{array}$ & $\begin{array}{r}8 \\
2 \\
5 \\
14 \\
13\end{array}$ & $\begin{array}{l}37.0 \\
60.0 \\
42.0 \\
20.0 \\
26.0\end{array}$ & $\begin{array}{r}7 \\
2 \\
5 \\
14 \\
12\end{array}$ & $\begin{array}{l}26.0 \\
43.0 \\
30.0 \\
15.0 \\
19.0\end{array}$ & $\begin{array}{r}9 \\
2 \\
5 \\
14 \\
12\end{array}$ & $\begin{array}{c}15.0 \\
24.0 \\
17.0 \\
9.40 \\
11.0\end{array}$ & $\begin{array}{r}11 \\
1 \\
5 \\
14 \\
12\end{array}$ \\
\hline $\begin{array}{l}1961 \\
1962\end{array}$ & $\begin{array}{l}95.0 \\
133\end{array}$ & $\begin{array}{r}11 \\
6\end{array}$ & $\begin{array}{l}87.0 \\
130\end{array}$ & $\begin{array}{r}11 \\
6\end{array}$ & $\begin{array}{l}73.0 \\
120\end{array}$ & $\begin{array}{r}11 \\
6\end{array}$ & $\begin{array}{l}62.0 \\
104\end{array}$ & $\begin{array}{r}13 \\
6\end{array}$ & $\begin{array}{l}56.0 \\
91.0\end{array}$ & $\begin{array}{r}11 \\
4\end{array}$ & $\begin{array}{l}42.0 \\
71.0\end{array}$ & $\begin{array}{r}11 \\
3\end{array}$ & $\begin{array}{l}34.0 \\
61.0\end{array}$ & $\begin{array}{r}11 \\
3\end{array}$ & $\begin{array}{l}32.0 \\
51.0\end{array}$ & $\begin{array}{r}11 \\
3\end{array}$ & $\begin{array}{l}26.0 \\
37.0\end{array}$ & $\begin{array}{l}8 \\
3\end{array}$ & $\begin{array}{l}15.0 \\
23.0\end{array}$ & $\begin{array}{l}9 \\
3\end{array}$ \\
\hline
\end{tabular}


GREEN RIVER BASIN

09227500 WEST FORK BEAVER CREER NEAR LONETREE, WY--Continued

DURATION OF DISCHARGE FOR EACH WATER YEAR

\begin{tabular}{|c|c|c|c|c|c|c|c|c|c|c|c|c|c|c|c|c|c|c|c|c|c|c|c|c|c|c|c|c|c|c|c|c|c|c|}
\hline $\begin{array}{l}\text { CLASS } 0 \\
\text { YEAR }\end{array}$ & 1 & 2 & 3 & 4 & 5 & 6 & 7 & & & 910 & 11 & 12 & 13 & & & & & & & & 20 & 21 & 22 & & & & & $27 \quad 28$ & 2829 & 2930 & 31 & 323 & 33 & $\begin{array}{l}\text { CUBIC FEET } \\
\text { PER SECOND } \\
\text {-DAYS }\end{array}$ \\
\hline $\begin{array}{l}1949 \\
1950\end{array}$ & & 64 & $\begin{array}{l}42 \\
43\end{array}$ & $\begin{array}{r}9 \\
47\end{array}$ & & $\begin{array}{r}10 \\
7\end{array}$ & $\begin{array}{l}24 \\
15\end{array}$ & $\begin{array}{l}42 \\
18\end{array}$ & $\begin{array}{l}19 \\
25\end{array}$ & $\begin{array}{ll}9 & 15 \\
5 & 31\end{array}$ & $\begin{array}{r}7 \\
29\end{array}$ & $\begin{array}{r}7 \\
25\end{array}$ & $\begin{array}{r}7 \\
14\end{array}$ & 9 & & $\begin{array}{l}4 \\
3\end{array}$ & $\begin{array}{r}10 \\
8\end{array}$ & $\begin{array}{l}5 \\
6\end{array}$ & $\begin{array}{l}6 \\
9\end{array}$ & $\begin{array}{r}12 \\
8\end{array}$ & $\begin{array}{r}11 \\
6\end{array}$ & $\begin{array}{l}7 \\
8\end{array}$ & $\begin{array}{r}5 \\
11\end{array}$ & $\begin{array}{l}11 \\
13\end{array}$ & $\begin{array}{l}9 \\
5\end{array}$ & $\begin{array}{l}6 \\
5\end{array}$ & $\begin{array}{l}3 \\
5\end{array}$ & 5 & 2 & 2 & 2 & & & $\begin{array}{l}6481.2 \\
5494.3\end{array}$ \\
\hline $\begin{array}{l}1951 \\
1952 \\
1953 \\
1954 \\
1955\end{array}$ & 35 & $\begin{array}{l}86 \\
\\
63 \\
69\end{array}$ & $\begin{array}{r}29 \\
33 \\
28 \\
4 \\
60\end{array}$ & $\begin{array}{r}55 \\
34 \\
31 \\
30 \\
8\end{array}$ & $\begin{array}{l}12 \\
27 \\
69 \\
10 \\
31\end{array}$ & $\begin{array}{r}12 \\
31 \\
12 \\
9 \\
21\end{array}$ & $\begin{array}{l}11 \\
21 \\
19 \\
33 \\
17\end{array}$ & $\begin{array}{l}10 \\
29 \\
13 \\
18\end{array}$ & $\begin{array}{r}9 \\
14 \\
18 \\
14\end{array}$ & $\begin{array}{ll}1 & 11 \\
9 & 12 \\
4 & 49 \\
8 & 22 \\
4 & 7\end{array}$ & $\begin{array}{r}9 \\
15 \\
11 \\
13 \\
6\end{array}$ & $\begin{array}{r}5 \\
10 \\
12 \\
11 \\
15\end{array}$ & $\begin{array}{l}13 \\
10 \\
11 \\
15 \\
12\end{array}$ & $\begin{array}{r}9 \\
4 \\
10 \\
14 \\
14\end{array}$ & 1 & $\begin{array}{l}3 \\
4 \\
8 \\
6 \\
3\end{array}$ & $\begin{array}{r}3 \\
6 \\
7 \\
10 \\
11\end{array}$ & $\begin{array}{r}4 \\
12 \\
9 \\
18 \\
5\end{array}$ & $\begin{array}{r}7 \\
9 \\
6 \\
16 \\
9\end{array}$ & $\begin{array}{r}17 \\
5 \\
12 \\
9 \\
8\end{array}$ & $\begin{array}{r}17 \\
10 \\
6 \\
7 \\
7\end{array}$ & $\begin{array}{r}7 \\
14 \\
10 \\
2 \\
9\end{array}$ & $\begin{array}{r}5 \\
11 \\
6 \\
1 \\
3\end{array}$ & $\begin{array}{r}8 \\
11 \\
3 \\
3\end{array}$ & $\begin{array}{r}6 \\
101 \\
2 \\
4\end{array}$ & $\begin{array}{r}5 \\
16 \\
2 \\
1 \\
2\end{array}$ & $\begin{array}{l}4 \\
7 \\
3\end{array}$ & $\begin{array}{l}5 \\
5 \\
2\end{array}$ & $\begin{array}{l}1 \\
3\end{array}$ & $\begin{array}{l}2 \\
2\end{array}$ & $\begin{array}{l}2 \\
2\end{array}$ & 2 & 2 & $\begin{array}{l}5381.2 \\
8769.1 \\
6359.0 \\
3436.4 \\
4046.2\end{array}$ \\
\hline $\begin{array}{l}1956 \\
1957 \\
1958 \\
1959 \\
1960\end{array}$ & & $\begin{array}{r}121 \\
43 \\
46\end{array}$ & $\begin{array}{l}1 \\
27 \\
71 \\
55 \\
48\end{array}$ & $\begin{array}{r}111 \\
30 \\
31 \\
21 \\
14\end{array}$ & $\begin{array}{l}52 \\
20 \\
31 \\
38 \\
21\end{array}$ & $\begin{array}{r}19 \\
7 \\
18 \\
6 \\
10\end{array}$ & $\begin{array}{r}20 \\
4 \\
22 \\
20 \\
9\end{array}$ & $\begin{array}{r}36 \\
8 \\
23 \\
18 \\
37\end{array}$ & & $\begin{array}{rr}0 & 6 \\
6 & 5 \\
9 & 18 \\
1 & 7 \\
4 & 24\end{array}$ & $\begin{array}{r}5 \\
1 \\
10 \\
5 \\
17\end{array}$ & $\begin{array}{r}8 \\
12 \\
14 \\
14 \\
15\end{array}$ & $\begin{array}{r}8 \\
6 \\
22 \\
13 \\
14\end{array}$ & $\begin{array}{r}11 \\
7 \\
11 \\
9 \\
6\end{array}$ & 8 & $\begin{array}{ll}7 & 1 \\
7 & \\
9 & 1 \\
8 & 1 \\
4 & \end{array}$ & $\begin{array}{r}13 \\
7 \\
17 \\
13 \\
3\end{array}$ & $\begin{array}{r}3 \\
11 \\
7 \\
10 \\
2\end{array}$ & $\begin{array}{r}10 \\
9 \\
7 \\
14 \\
1\end{array}$ & $\begin{array}{r}8 \\
5 \\
2 \\
5 \\
12\end{array}$ & 6 & $\begin{array}{l}2 \\
9 \\
7 \\
7 \\
3\end{array}$ & $\begin{array}{l}8 \\
4 \\
8 \\
1 \\
7\end{array}$ & $\begin{array}{l}8 \\
4 \\
2 \\
5 \\
2\end{array}$ & $\begin{array}{l}5 \\
5 \\
3 \\
7 \\
7\end{array}$ & $\begin{array}{lr}4 & 1 \\
5 & 11 \\
3 & 5 \\
2 & 7 \\
7 & 7\end{array}$ & $\begin{array}{cc}1 & \\
11 & 6 \\
5 & 1 \\
7 & 5 \\
7 & 5\end{array}$ & $\begin{array}{l}6 \\
1 \\
5 \\
5\end{array}$ & $\begin{array}{l}5 \\
3 \\
2\end{array}$ & $\begin{array}{l}5 \\
2\end{array}$ & $\begin{array}{l}5 \\
1\end{array}$ & 2 & 2 & $\begin{array}{l}4059.1 \\
8561.6 \\
5698.5 \\
5300.0 \\
5515.7\end{array}$ \\
\hline$\left[\begin{array}{l}961 \\
962\end{array}\right.$ & & & 59 & $\begin{array}{l}46 \\
25\end{array}$ & $\begin{array}{l}40 \\
29\end{array}$ & & $\begin{array}{l}27 \\
51\end{array}$ & & $\begin{array}{r}6 \\
13\end{array}$ & $\begin{array}{rr}6 & 4 \\
3 & 16\end{array}$ & $\begin{array}{r}2 \\
12\end{array}$ & $\begin{array}{r}3 \\
15\end{array}$ & $\begin{array}{r}9 \\
19\end{array}$ & $\begin{array}{l}10 \\
16\end{array}$ & s & 9 & $\begin{array}{l}21 \\
22\end{array}$ & $\begin{array}{l}24 \\
13\end{array}$ & & $\begin{array}{l}12 \\
15\end{array}$ & $\begin{array}{r}12 \\
9\end{array}$ & $\begin{array}{l}9 \\
8\end{array}$ & $\begin{array}{r}10 \\
4\end{array}$ & $\begin{array}{l}8 \\
71\end{array}$ & $\begin{array}{r}7 \\
12\end{array}$ & $\begin{array}{l}1 \\
8\end{array}$ & $\begin{array}{l}2 \\
9\end{array}$ & $\begin{array}{l}1 \\
9\end{array}$ & 4 & 3 & & & & $\begin{array}{l}5516.8 \\
8268.9\end{array}$ \\
\hline
\end{tabular}

DURATION TABLE OF DISCHARGE FOR WATER YEARS 1949-62

\begin{tabular}{|c|c|c|c|c|c|c|c|c|c|c|c|c|c|c|c|c|c|c|c|}
\hline CLASS & $\begin{array}{c}\text { CUBIC } \\
\text { FEET } \\
\text { PER } \\
\text { SECOND }\end{array}$ & TOMAL & $\begin{array}{l}\text { ACCU- } \\
\text { NU- } \\
\text { LATED } \\
\text { DAYS }\end{array}$ & $\begin{array}{l}\text { PER- } \\
\text { CENT } \\
\text { DAYS }\end{array}$ & CLASS & $\begin{array}{c}\text { CBBIC } \\
\text { FEET } \\
\text { PER } \\
\text { SECOND }\end{array}$ & $\begin{array}{c}\text { TOTAL } \\
\text { DAYS }\end{array}$ & $\begin{array}{c}\text { ACCU- } \\
\text { MU- } \\
\text { IATED } \\
\text { DAYS }\end{array}$ & $\begin{array}{l}\text { PER- } \\
\text { CENT } \\
\text { DAYS }\end{array}$ & & $\begin{array}{c}\text { CUBIC } \\
\text { FEET } \\
\text { PER } \\
\text { SECOND }\end{array}$ & $\begin{array}{l}\text { TOTAL } \\
\text { DAYS }\end{array}$ & $\begin{array}{c}\text { ACOU- } \\
\text { MU- } \\
\text { LATED } \\
\text { DAYS }\end{array}$ & $\begin{array}{l}\text { PER- } \\
\text { CBNT } \\
\text { DAYS }\end{array}$ & & $\begin{array}{c}\text { CUBIC } \\
\text { FEET } \\
\text { PER } \\
\text { SECOND }\end{array}$ & $\begin{array}{r}\text { TOTAL } \\
\text { DAYS }\end{array}$ & $\begin{array}{l}\text { ACOU- } \\
\text { MU- } \\
\text { LATED } \\
\text { DAYS }\end{array}$ & $\begin{array}{l}\text { PER- } \\
\text { CENT } \\
\text { DAYS }\end{array}$ \\
\hline $\begin{array}{l}0 \\
1 \\
2 \\
3 \\
4 \\
5 \\
6 \\
7 \\
8\end{array}$ & $\begin{array}{l}0.00 \\
2.00 \\
2.30 \\
2.70 \\
3.10 \\
3.60 \\
4.20 \\
4.80 \\
5.60\end{array}$ & $\begin{array}{r}0 \\
35 \\
492 \\
499 \\
492 \\
406 \\
170 \\
293 \\
297\end{array}$ & $\begin{array}{l}5113 \\
5113 \\
5078 \\
4586 \\
4087 \\
3595 \\
3189 \\
3019 \\
2726\end{array}$ & $\begin{array}{r}100.0 \\
100.0 \\
99.3 \\
89.7 \\
79.9 \\
70.3 \\
62.4 \\
59.0 \\
53.3\end{array}$ & $\begin{array}{r}9 \\
10 \\
11 \\
12 \\
13 \\
14 \\
15 \\
16 \\
17\end{array}$ & $\begin{array}{r}6.50 \\
7.50 \\
8.70 \\
10.00 \\
12.00 \\
14.00 \\
16.00 \\
18.00 \\
21.00\end{array}$ & $\begin{array}{l}219 \\
227 \\
142 \\
166 \\
173 \\
137 \\
104 \\
151 \\
129\end{array}$ & $\begin{array}{l}2429 \\
2210 \\
1983 \\
1841 \\
1675 \\
1502 \\
1365 \\
1261 \\
1110\end{array}$ & $\begin{array}{l}47.5 \\
43.2 \\
38.8 \\
36.0 \\
32.8 \\
29.4 \\
26.7 \\
24.7 \\
21.7\end{array}$ & $\begin{array}{l}18 \\
19 \\
20 \\
21 \\
22 \\
23 \\
24 \\
25 \\
26\end{array}$ & $\begin{array}{l}24.0 \\
28.0 \\
33.0 \\
38.0 \\
44.0 \\
51.0 \\
59.0 \\
68.0 \\
79.0\end{array}$ & $\begin{array}{r}135 \\
130 \\
113 \\
102 \\
84 \\
85 \\
82 \\
67 \\
64\end{array}$ & $\begin{array}{l}981 \\
846 \\
716 \\
603 \\
501 \\
417 \\
332 \\
250 \\
183\end{array}$ & $\begin{array}{r}19.2 \\
16.5 \\
14.0 \\
11.8 \\
9.8 \\
8.2 \\
6.5 \\
4.9 \\
3.6\end{array}$ & $\begin{array}{l}27 \\
28 \\
29 \\
30 \\
31 \\
32 \\
33 \\
34\end{array}$ & $\begin{array}{r}91.0 \\
110.0 \\
120.0 \\
140.0 \\
160.0 \\
190.0 \\
220.0 \\
260.0\end{array}$ & $\begin{array}{r}44 \\
22 \\
19 \\
13 \\
12 \\
4 \\
4 \\
1\end{array}$ & $\begin{array}{r}119 \\
75 \\
53 \\
34 \\
21 \\
9 \\
5 \\
1\end{array}$ & $\begin{array}{l}2.3 \\
1.5 \\
1.0 \\
0.7 \\
0.4 \\
0.2 \\
0.1 \\
0.0\end{array}$ \\
\hline
\end{tabular}

MONTHLY MEAN DISCHAPGES, IN OBIC FEET FER SECOND, FOR EACH WATER YEAR

\begin{tabular}{|c|c|c|c|c|c|c|c|c|c|c|c|c|}
\hline YEAR & $\propto C T$ & NOV & DEC & JAN & FEB & MAR & APR & MAY & JUNE & JULY & AUG & SEP \\
\hline $\begin{array}{l}1949 \\
1950\end{array}$ & $\begin{array}{l}6.07 \\
9.09\end{array}$ & $\begin{array}{l}5.42 \\
7.38\end{array}$ & $\begin{array}{l}3.49 \\
4.97\end{array}$ & $\begin{array}{l}2.60 \\
3.50\end{array}$ & $\begin{array}{l}2.50 \\
3.00\end{array}$ & $\begin{array}{l}2.60 \\
3.26\end{array}$ & $\begin{array}{l}7.04 \\
7.67\end{array}$ & $\begin{array}{l}34.0 \\
30.9\end{array}$ & $\begin{array}{l}87.2 \\
58.1\end{array}$ & $\begin{array}{l}40.5 \\
30.9\end{array}$ & $\begin{array}{l}14.5 \\
12.7\end{array}$ & $\begin{array}{l}6.71 \\
8.58\end{array}$ \\
\hline $\begin{array}{l}1951 \\
1952 \\
1953 \\
1954 \\
1955\end{array}$ & $\begin{array}{l}4.02 \\
8.11 \\
8.28 \\
4.51 \\
4.84\end{array}$ & $\begin{array}{l}3.47 \\
5.44 \\
6.72 \\
5.31 \\
3.93\end{array}$ & $\begin{array}{l}3.27 \\
4.01 \\
4.00 \\
3.91 \\
3.12\end{array}$ & $\begin{array}{l}2.74 \\
3.05 \\
3.50 \\
2.50 \\
2.50\end{array}$ & $\begin{array}{l}2.50 \\
2.90 \\
3.00 \\
2.00 \\
2.50\end{array}$ & $\begin{array}{l}2.50 \\
4.27 \\
4.00 \\
2.42 \\
2.70\end{array}$ & $\begin{array}{c}4.05 \\
10.3 \\
7.51 \\
7.11 \\
3.88\end{array}$ & $\begin{array}{l}27.1 \\
59.9 \\
18.0 \\
27.4 \\
27.5\end{array}$ & $\begin{array}{c}58.6 \\
104 \\
105 \\
20.4 \\
46.1\end{array}$ & $\begin{array}{l}37.8 \\
48.9 \\
28.8 \\
19.7 \\
16.1\end{array}$ & $\begin{array}{c}21.6 \\
25.2 \\
15.0 \\
8.60 \\
12.0\end{array}$ & $\begin{array}{c}8.51 \\
11.0 \\
5.67 \\
8.52 \\
7.58\end{array}$ \\
\hline $\begin{array}{l}1956 \\
1957 \\
1958 \\
1959 \\
1960\end{array}$ & $\begin{array}{l}6.09 \\
4.31 \\
6.98 \\
6.49 \\
8.68\end{array}$ & $\begin{array}{l}4.91 \\
3.09 \\
4.78 \\
4.52 \\
5.37\end{array}$ & $\begin{array}{l}3.69 \\
2.50 \\
4.00 \\
3.56 \\
3.15\end{array}$ & $\begin{array}{l}3.50 \\
2.50 \\
3.50 \\
2.85 \\
2.82\end{array}$ & $\begin{array}{l}3.20 \\
2.30 \\
3.00 \\
2.50 \\
2.50\end{array}$ & $\begin{array}{l}3.35 \\
2.34 \\
3.00 \\
2.76 \\
3.34\end{array}$ & $\begin{array}{l}6.28 \\
3.33 \\
4.53 \\
4.72 \\
6.33\end{array}$ & $\begin{array}{l}33.4 \\
17.9 \\
61.5 \\
22.7 \\
39.5\end{array}$ & $\begin{array}{r}40.3 \\
135 \\
55.0 \\
74.6 \\
72.3\end{array}$ & $\begin{array}{l}17.3 \\
70.8 \\
167 \\
25.6 \\
20.9\end{array}$ & $\begin{array}{c}6.84 \\
27.5 \\
12.3 \\
14.8 \\
7.93\end{array}$ & $\begin{array}{r}3.97 \\
9.81 \\
11.2 \\
9.18 \\
8.14\end{array}$ \\
\hline $\begin{array}{l}1961 \\
1962\end{array}$ & $\begin{array}{c}7.47 \\
18.6\end{array}$ & $\begin{array}{c}4.71 \\
12.8\end{array}$ & $\begin{array}{l}4.00 \\
6.32\end{array}$ & $\begin{array}{l}3.50 \\
5.00\end{array}$ & $\begin{array}{l}3.00 \\
4.18\end{array}$ & $\begin{array}{l}3.00 \\
3.60\end{array}$ & $\begin{array}{l}5.02 \\
14.8\end{array}$ & $\begin{array}{l}34.3 \\
50.1\end{array}$ & $\begin{array}{l}46.3 \\
85.9\end{array}$ & $\begin{array}{l}18.8 \\
45.4\end{array}$ & $\begin{array}{l}23.5 \\
15.7\end{array}$ & $\begin{array}{r}27.4 \\
8.81\end{array}$ \\
\hline
\end{tabular}

ANNUAL PEAK DISCHARgE, IN CUBIC FEET PER SECOND, AND CORRESPONDING GAGE HEIGHT, IN FEET, FOR EACH WATER YEAR

\begin{tabular}{|c|c|c|c|c|c|c|c|c|c|c|c|c|}
\hline $\begin{array}{l}\text { WATER } \\
\text { YEAR }\end{array}$ & DATE & $\begin{array}{c}\text { GAGE } \\
\text { HEIGHT }\end{array}$ & $\begin{array}{c}\text { PEAK } \\
\text { DISCHARGE }\end{array}$ & $\begin{array}{l}\text { WATER } \\
\text { YEAR }\end{array}$ & DAT & & $\begin{array}{c}\text { GAGE } \\
\text { HEIGHT }\end{array}$ & $\begin{array}{c}\text { PEAK } \\
\text { DISCHARGE }\end{array}$ & $\begin{array}{l}\text { WATER } \\
\text { YEAR }\end{array}$ & DATE & $\begin{array}{c}\text { GAGE } \\
\text { HEIGHT }\end{array}$ & $\begin{array}{c}\text { PEAK } \\
\text { DISCHARGE }\end{array}$ \\
\hline $\begin{array}{l}1949 \\
1950 \\
1951 \\
1952 \\
1953\end{array}$ & $\begin{array}{l}\text { JUNE 18, } 1949 \\
\text { MAY } 30,1950 \\
\text { JUNE 17, } 1951 \\
\text { JUNE 07, } 1952 \\
\text { JUNE 13, } 1953\end{array}$ & $\begin{array}{l}3.13 \\
2.28 \\
2.43 \\
2.91 \\
3.17\end{array}$ & $\begin{array}{l}289 \\
110 \\
145 \\
255 \\
417\end{array}$ & $\begin{array}{l}1954 \\
1955 \\
1956 \\
1957 \\
1958\end{array}$ & $\begin{array}{ll}\text { MAY } 22 \\
\text { JUNE } 09 \\
\text { MAY } 25 \\
\text { JUNE } 07 \\
\text { MAY } 26\end{array}$ & $\begin{array}{l}1954 \\
1955 \\
1956 \\
1957 \\
1958\end{array}$ & $\begin{array}{l}2.03 \\
2.44 \\
2.28 \\
3.25 \\
2.92\end{array}$ & $\begin{array}{r}74 \\
168 \\
100 \\
330 \\
200\end{array}$ & $\begin{array}{l}1959 \\
1960 \\
1961 \\
1962\end{array}$ & $\begin{array}{lll}\text { JUNE } 06, & 1959 \\
\text { JUNE } 02, & 1960 \\
\text { MAY } 28, & 1961 \\
\text { JUNE } 21, & 1962\end{array}$ & $\begin{array}{l}2.61 \\
2.65 \\
2.58 \\
2.67\end{array}$ & $\begin{array}{l}135 \\
151 \\
114 \\
154\end{array}$ \\
\hline
\end{tabular}


GREEN RTVER BASIN

09227500 WEST FORK BEAVER CREEX NEAR LONETREE, WY--Continued

\begin{tabular}{|c|c|c|c|c|c|c|}
\hline \multirow{3}{*}{$\begin{array}{l}\text { PERIOD } \\
\text { (CON- } \\
\text { SEOU- } \\
\text { TIVE } \\
\text { DAYS) }\end{array}$} & \multicolumn{6}{|c|}{$\begin{array}{l}\text { E AND PROBABILITY OF ANNUAL LOWEST MEAN DISCHARGE } \\
\text { BASED ON CLIMATIC YEARS } 1950-62\end{array}$} \\
\hline & \multicolumn{6}{|c|}{$\begin{array}{l}\text { DISCHARGE, IN CUBIC FEET PER SECOND, FOR } \\
\text { INDICATED RECURRENCE INTERNAL, IN YEARS, AND } \\
\text { ANNUAL NONEXCEEDANCE PROBABILITY, IN PERCENI }\end{array}$} \\
\hline & $\begin{array}{c}2 \\
508\end{array}$ & $\begin{array}{c}5 \\
208\end{array}$ & $\begin{array}{l}10 \\
108\end{array}$ & $\begin{array}{l}20 \\
58\end{array}$ & $\begin{array}{l}50 \\
28\end{array}$ & $\begin{array}{r}100 \\
18\end{array}$ \\
\hline $\begin{array}{r}1 \\
7 \\
14 \\
30 \\
60 \\
90\end{array}$ & $\begin{array}{l}2.6 \\
2.7 \\
2.7 \\
2.8 \\
2.8 \\
3.0\end{array}$ & $\begin{array}{l}2.3 \\
2.4 \\
2.4 \\
2.4 \\
2.5 \\
2.6\end{array}$ & $\begin{array}{l}2.2 \\
2.2 \\
2.2 \\
2.2 \\
2.3 \\
2.4\end{array}$ & $\begin{array}{l}2.1 \\
2.1 \\
2.1 \\
2.1 \\
2.2 \\
2.3\end{array}$ & $\begin{array}{l}- \\
\overline{-} \\
\overline{-} \\
-\end{array}$ & $\begin{array}{l}-- \\
- \\
- \\
-\end{array}$ \\
\hline
\end{tabular}

MAGNITUDE AND PRCBABILITY OF ANNUAL HIGHEST MEAN DISCHARGE BASED ON WATER YEARS 1949-62

\begin{tabular}{|c|c|c|c|c|c|c|}
\hline \multirow{2}{*}{$\begin{array}{l}\text { PERIOD } \\
\text { (CON- } \\
\text { SECU- } \\
\text { TIVE } \\
\text { DAYS) }\end{array}$} & \multicolumn{6}{|c|}{$\begin{array}{l}\text { DISCHARGE, IN CUBIC FEET PER SECOND, FOR } \\
\text { INDICATED RECURRENCE INTERNAL, IN YEARS, AND } \\
\text { ANNUAL EXCEEDANCE PRCBABILITY, IN PERCENT }\end{array}$} \\
\hline & $\begin{array}{c}2 \\
508\end{array}$ & $\begin{array}{c}5 \\
208\end{array}$ & $\begin{array}{l}10 \\
108\end{array}$ & $\begin{array}{l}25 \\
48\end{array}$ & $\begin{array}{l}50 \\
28\end{array}$ & $\begin{array}{r}100 \\
18\end{array}$ \\
\hline
\end{tabular}

$\begin{array}{rrrrrrr}1 & 131 & 193 & 242 & 311 & - & - \\ 3 & 122 & 179 & 220 & 273 & -- & - \\ 7 & 107 & 156 & 188 & 228 & -- & - \\ 15 & 92 & 127 & 148 & 172 & --\end{array}$

09228500 BURNT FORK NEAR BURNIFORK, WY

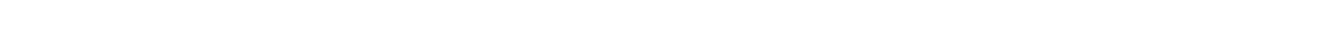

14040106 , Wasatch National Forest, on left bank $0.6 \mathrm{mi}$ upstream from forest boundary and $6.5 \mathrm{mi}$ southwest of Burntfork.

DRAINAGE ARFA. $--52.8 \mathrm{mi}^{2}$.

MEAN BASIN ELEVATION. $--10,300 \mathrm{ft}$.

PERIOD OF RECORD AVAILABLE.--April 1943 to September 1981 (no winter records since 1971). Monthly mean discharge prior to October 1943, published in WSP 1313 .

REVISED RECORDS.--WSP 1243: 1944.

CAGE.--Water-stage recorder. Altitude of gage is $8,430 \mathrm{ft}$, from topographic map. Prior to June 10, 1965, water-stage recorder at site $0.5 \mathrm{mi}$ downstream at different datum. June 10 to Oct. 5,1965 , water-stage recorder at site $400 \mathrm{ft}$ downstream at different datum.

REMARKS.--Flow is partially regulated by Island Lake, capacity, 797 acre-ft, and Beaver Meadows Reservoir, capacity, 1,722 acre-ft. Diversion out of basin above station into Hoop Lake, capacity, 3,920 acre-ft.

COOPERATION.--Records collected and computed by office of the Wyoming State Engineer and reviewed by Geological survey.

AVERAGE DISCHARGE.--28 years (water years 1944-71), $31.1 \mathrm{ft}^{3} / \mathrm{s}, 22,530 \mathrm{acre}-\mathrm{ft} / \mathrm{yr}$.

EXIRPMES FOR PERIOD OF RECORD.-Maximum discharge, 3,200 $\mathrm{ft}^{3} / \mathrm{s}$ June 10, 1965 (gage height, not determined), from slope-area measurement of peak flow; minimum daily, $0.65 \mathrm{ft}^{3} / \mathrm{s} \mathrm{Mar.} \mathrm{31,} 1967$.

LOWEST MEAN DISCHARGE, IN OUBIC FEET PER SECOND, AND RANKING FOR THE INDICATED NUMBER OF CONSBCUTIVE DAYS FOR FACH CLIMATIC YEAR, APRIL 1-MARCH 31

YEAR

1

7.0024

7.0025

3.409

3.208

3.6011

4.8019

5.8023

1.804

3.5010

4.0012

4.0013

4.0013
4.2017

4.0014

4.0015

4.5018

4.2016

3.006

5.0021

$\begin{array}{lr}5.50 & 22 \\ 0.65 & 1\end{array}$

$\begin{array}{ll}0.65 & 1 \\ 0.80 & 2\end{array}$

$\begin{array}{ll}0.80 & 2 \\ 2.50 & 5\end{array}$

1.193

3.107

\begin{abstract}
3
\end{abstract}
7.0024

7.0025

.5010

3.308

4.1013

5.9023

1.804

3.509

4.4016

4.0011

4.4017
4.3014

4.3014
4.0012

4.5018

4.4015

$\begin{array}{ll}3.10 & 6\end{array}$

$\begin{array}{ll}5.50 & 21 \\ 5.2019\end{array}$

5.8022

0.681

0.842

$\begin{array}{ll}3.00 & 5 \\ 1.19 & 3\end{array}$

3.207
14

$7.00 \quad 24$

7.0025

3.508

3.8010

4.5016

6.1022

6.1023

1.904

$3.50 \quad 9$

4.70 18

4.0011
4.5017

$\begin{array}{lll}4.50 & 17 \\ 4.40 & 13\end{array}$

$\begin{array}{ll}4.40 & 13 \\ 4.00 & 12\end{array}$

4. 5014

4. 5015

3.305

5.6019
5.6020

6.0021

$\begin{array}{ll}6.00 & 21 \\ 0.78 & 1\end{array}$

0.932

$\begin{array}{ll}3.30 & 6 \\ 1.19 & 3\end{array}$

3.307
CONSEOUTTVE DAYS

$30 \quad 60$

7.0024

3.507

4.0010

7.0024

$\begin{array}{rr}3.50 & 4 \\ 4.00 & 8\end{array}$

$\begin{array}{ll}4.70 & 15 \\ .3022\end{array}$

6.7023

$\begin{array}{ll}2.70 & 4 \\ 3.60 & 8\end{array}$

$\begin{array}{ll}6.40 & 21 \\ 6.80 & 22\end{array}$

$\begin{array}{ll}6.80 & 22 \\ 4.10 & 10\end{array}$

3.605

4.7016

4.0011

4.8017

4.5014
4.0012

4.9014

4.009

5.3017

$\begin{array}{ll}5.00 & 15 \\ 4.40 & 12\end{array}$

4.5013

4.9018

$\begin{array}{ll}3.90 & 9\end{array}$

$4.80 \quad 13$

6.2018

$4.301]$

6.2019
6.3020

5.7019

6.3021

0.921

0.992

$\begin{array}{ll}3.40 & 5 \\ 1.40 & 3\end{array}$

$\begin{array}{rr}7.20 & 25 \\ 1.19 & 2\end{array}$

$\begin{array}{ll}1.19 & 2 \\ 1.10 & 1\end{array}$

$\begin{array}{ll}3.80 & 7 \\ 1.70 & 3\end{array}$

3.406

3.706
7.3023

7.0021

$\begin{array}{ll}3.50 & 4 \\ 4.00 & 6\end{array}$

5.0014

6.7019

6.9020

4.6010
$3.70 \quad 5$

5.1016

$\begin{array}{rr}4.10 & 16\end{array}$

$\begin{array}{rr}4.20 & 8 \\ 6.00 \quad 17\end{array}$

$\begin{array}{rr}5.00 & 15 \\ 4.40 & 9\end{array}$

$4.90 \quad 12$

$10.0 \quad 25$

4.7011

6.3018

7.3022

7.5024

1.601

2.703

4.10
2.20

5.0013
90

7.5023

7.3020

$\begin{array}{ll}3.70 & 4 \\ 4.20 & 7\end{array}$

5.2012

6.9019

7.4021

4.609
$3.90 \quad 5$

5.4015

$\begin{array}{rr}5.40 & 15 \\ 4.30 & 8\end{array}$

$\begin{array}{lll}6.30 & 8\end{array}$

5.3013

4.9010

$\begin{array}{rr}4.90 & 11 \\ 11.0 & 25\end{array}$

5.8016

6.5018

7.5022

8.1024

2.101

$\begin{array}{ll}2.70 & 2 \\ 4.20 & 6\end{array}$

$\begin{array}{ll}4.20 & 6 \\ 2.70 & 3\end{array}$

5.4014
$7.80 \quad 22$

7.7021

3.803

4.507

\section{$8.40 \quad 21$}

183

9.7023

4.301

6.2013

5.3011
7.2019

8.0023

$4.70 \quad 9$

5.9010

8.3020

4.903

$\begin{array}{ll}4.90 & 3 \\ 5.40 & 6\end{array}$

5.4012

$\begin{array}{rr}5.40 & 12 \\ 4.50 & 8\end{array}$

$\begin{array}{rrr}4.50 & 8 \\ 6.80 & 18\end{array}$

6.8018
5.5013

$\begin{array}{rrr}5.90 & 11 \\ 4.90 & 4\end{array}$

$\begin{array}{rr}4.90 & 4 \\ 8.30 \quad 18\end{array}$

$\begin{array}{lr}8.30 & 18 \\ 5.70 & 7\end{array}$

$\begin{array}{ll}5.40 & 15\end{array}$

5.0010

$11.0 \quad 25$

6.4016

6.8017

$5.70 \quad 8$
15.0

$\begin{array}{ll}15.0 & 25 \\ 8.30 & 19\end{array}$

7.8016

8.5022

8.5024

$\begin{array}{rr}8.50 & 24 \\ 2.40 & 1\end{array}$

$\begin{array}{ll}2.40 & 1 \\ 3.10 & 2\end{array}$

$\begin{array}{cr}14.0 & 24 \\ 4.40 & 2\end{array}$

$\begin{array}{rr}4.40 & 2 \\ 6.10 \quad 12\end{array}$

$\begin{array}{lr}6.10 & 12 \\ 5.40 & 5\end{array}$

5.40
$5.70 \quad 9$

5.7015

7.2014
ALL

$21.0 \quad 4$

39.021

$27.0 \quad 12$

$29.0 \quad 15$

$27.0 \quad 13$

$41.0 \quad 24$

17.01

$21.0 \quad 2$

$21.0 \quad 3$

$37.0 \quad 19$

$\begin{array}{rr}26.0 & 11 \\ 24.0 & 8\end{array}$

$24.0 \quad 9$

$28.0 \quad 14$

39.020

23

$62.0 \quad 25$

$22.0 \quad 6$

32.016

24.07

$32.0 \quad 17$ 
GREEN RIVER BASIN

09228500 BURNT FORK NEAR BURNIFORK, WY--Continued

HIGHEST MEAN DISCHARGE, IN CUBIC FEET PER SECOND, AND RANKING FOR THE INDICATED NUMBER OF CONSECUTIVE DAYS FOR EACH WATEER YEAR, OCTOBER 1-SEPTEMBER 30

\begin{tabular}{|c|c|c|c|c|c|c|c|c|c|c|c|c|c|c|c|c|c|c|c|c|}
\hline YEAR & 1 & & 3 & & 7 & & 15 & & $\begin{array}{l}C O N \\
30\end{array}$ & & $\begin{array}{l}\text { DAY } \\
60\end{array}$ & & 90 & & 120 & & 183 & & ALL & \\
\hline $\begin{array}{l}1946 \\
1947 \\
1948 \\
1949 \\
1950\end{array}$ & $\begin{array}{l}88.0 \\
229 \\
344 \\
362 \\
205\end{array}$ & $\begin{array}{r}26 \\
10 \\
8 \\
5 \\
13\end{array}$ & $\begin{array}{l}80.0 \\
198 \\
269 \\
323 \\
183\end{array}$ & $\begin{array}{r}26 \\
11 \\
8 \\
5 \\
13\end{array}$ & $\begin{array}{c}76.0 \\
150 \\
231 \\
268 \\
159\end{array}$ & $\begin{array}{r}26 \\
15 \\
8 \\
6 \\
13\end{array}$ & $\begin{array}{l}73.0 \\
128 \\
197 \\
233 \\
156\end{array}$ & $\begin{array}{r}25 \\
17 \\
8 \\
5 \\
11\end{array}$ & $\begin{array}{l}60.0 \\
124 \\
165 \\
185 \\
138\end{array}$ & $\begin{array}{r}25 \\
14 \\
9 \\
6 \\
11\end{array}$ & $\begin{array}{l}54.0 \\
120 \\
111 \\
146 \\
109\end{array}$ & $\begin{array}{r}25 \\
10 \\
12 \\
5 \\
13\end{array}$ & $\begin{array}{c}51.0 \\
107 \\
87.0 \\
120 \\
87.0\end{array}$ & $\begin{array}{r}25 \\
9 \\
12 \\
3 \\
13\end{array}$ & $\begin{array}{c}44.0 \\
93.0 \\
71.0 \\
104 \\
71.0\end{array}$ & $\begin{array}{r}25 \\
7 \\
12 \\
2 \\
13\end{array}$ & $\begin{array}{l}34.0 \\
68.0 \\
50.0 \\
73.0 \\
51.0\end{array}$ & $\begin{array}{r}25 \\
6 \\
13 \\
3 \\
12\end{array}$ & $\begin{array}{l}20.0 \\
38.0 \\
30.0 \\
39.0 \\
29.0\end{array}$ & $\begin{array}{r}25 \\
6 \\
12 \\
5 \\
13\end{array}$ \\
\hline $\begin{array}{l}1951 \\
1952 \\
1953 \\
1954 \\
1955\end{array}$ & $\begin{array}{l}158 \\
520 \\
388 \\
117 \\
162\end{array}$ & $\begin{array}{r}18 \\
3 \\
4 \\
25 \\
17\end{array}$ & $\begin{array}{c}148 \\
420 \\
320 \\
95.0 \\
145\end{array}$ & $\begin{array}{r}18 \\
2 \\
6 \\
25 \\
20\end{array}$ & $\begin{array}{c}131 \\
333 \\
256 \\
79.0 \\
129\end{array}$ & $\begin{array}{r}19 \\
2 \\
7 \\
25 \\
20\end{array}$ & $\begin{array}{c}118 \\
245 \\
209 \\
64.0 \\
114\end{array}$ & $\begin{array}{r}20 \\
4 \\
7 \\
26 \\
21\end{array}$ & $\begin{array}{l}100 \\
175 \\
156 \\
54.0 \\
92.0\end{array}$ & $\begin{array}{r}21 \\
7 \\
10 \\
26 \\
22\end{array}$ & $\begin{array}{c}86.0 \\
135 \\
106 \\
52.0 \\
69.0\end{array}$ & $\begin{array}{r}18 \\
7 \\
14 \\
26 \\
23\end{array}$ & $\begin{array}{r}76.0 \\
118 \\
82.0 \\
44.0 \\
57.0\end{array}$ & $\begin{array}{r}16 \\
4 \\
14 \\
26 \\
23\end{array}$ & $\begin{array}{c}64.0 \\
104 \\
66.0 \\
38.0 \\
50.0\end{array}$ & $\begin{array}{r}15 \\
3 \\
14 \\
26 \\
23\end{array}$ & & $\begin{array}{r}14 \\
2 \\
15 \\
26 \\
22\end{array}$ & & $\begin{array}{r}17 \\
3 \\
14 \\
26 \\
23\end{array}$ \\
\hline $\begin{array}{l}1956 \\
1957 \\
1958 \\
1959 \\
1960\end{array}$ & $\begin{array}{l}153 \\
358 \\
208 \\
174 \\
179\end{array}$ & $\begin{array}{r}19 \\
6 \\
12 \\
16 \\
15\end{array}$ & $\begin{array}{l}147 \\
342 \\
197 \\
155 \\
176\end{array}$ & $\begin{array}{r}19 \\
4 \\
12 \\
16 \\
14\end{array}$ & $\begin{array}{l}135 \\
293 \\
168 \\
142 \\
158\end{array}$ & $\begin{array}{r}18 \\
3 \\
11 \\
17 \\
14\end{array}$ & $\begin{array}{l}122 \\
216 \\
146 \\
136 \\
134\end{array}$ & $\begin{array}{r}18 \\
6 \\
13 \\
14 \\
15\end{array}$ & $\begin{array}{l}108 \\
196 \\
123 \\
113 \\
114\end{array}$ & $\begin{array}{r}18 \\
4 \\
15 \\
17 \\
16\end{array}$ & $\begin{array}{c}79.0 \\
144 \\
96.0 \\
85.0 \\
90.0\end{array}$ & $\begin{array}{r}21 \\
6 \\
15 \\
19 \\
16\end{array}$ & $\begin{array}{c}61.0 \\
116 \\
78.0 \\
70.0 \\
73.0\end{array}$ & $\begin{array}{r}21 \\
6 \\
15 \\
19 \\
18\end{array}$ & $\begin{array}{l}51.0 \\
94.0 \\
63.0 \\
58.0 \\
58.0\end{array}$ & $\begin{array}{r}22 \\
5 \\
16 \\
18 \\
19\end{array}$ & $\begin{array}{l}36.0 \\
65.0 \\
46.0 \\
42.0 \\
42.0\end{array}$ & $\begin{array}{r}24 \\
7 \\
16 \\
17 \\
18\end{array}$ & & $\begin{array}{r}24 \\
7 \\
15 \\
20 \\
18\end{array}$ \\
\hline $\begin{array}{l}1966 \\
1967 \\
1968 \\
1969 \\
1970\end{array}$ & $\begin{array}{l}150 \\
180 \\
580 \\
152 \\
153\end{array}$ & $\begin{array}{r}23 \\
14 \\
2 \\
21 \\
20\end{array}$ & $\begin{array}{l}140 \\
173 \\
391 \\
142 \\
148\end{array}$ & $\begin{array}{r}23 \\
15 \\
3 \\
22 \\
17\end{array}$ & $\begin{array}{l}106 \\
164 \\
286 \\
129 \\
145\end{array}$ & $\begin{array}{r}24 \\
12 \\
4 \\
21 \\
16\end{array}$ & $\begin{array}{l}86.0 \\
153 \\
251 \\
114 \\
131\end{array}$ & $\begin{array}{r}23 \\
12 \\
3 \\
22 \\
16\end{array}$ & $\begin{array}{l}82.0 \\
137 \\
217 \\
106 \\
126\end{array}$ & $\begin{array}{r}23 \\
12 \\
2 \\
20 \\
13\end{array}$ & $\begin{array}{l}71.0 \\
123 \\
150 \\
88.0 \\
115\end{array}$ & $\begin{array}{r}22 \\
9 \\
3 \\
17 \\
11\end{array}$ & $\begin{array}{l}60.0 \\
101 \\
117 \\
74.0 \\
95.0\end{array}$ & $\begin{array}{r}22 \\
10 \\
5 \\
17 \\
11\end{array}$ & $\begin{array}{l}51.0 \\
83.0 \\
93.0 \\
60.0 \\
80.0\end{array}$ & $\begin{array}{r}21 \\
10 \\
6 \\
17 \\
11\end{array}$ & $\begin{array}{l}39.0 \\
57.0 \\
64.0 \\
42.0 \\
57.0\end{array}$ & $\begin{array}{r}21 \\
10 \\
8 \\
19 \\
11\end{array}$ & $\begin{array}{l}26.0 \\
31.0 \\
35.0 \\
24.0 \\
31.0\end{array}$ & $\begin{array}{r}16 \\
10 \\
8 \\
19 \\
11\end{array}$ \\
\hline 97 & 307 & 9 & 306 & 7 & 280 & 5 & 257 & 2 & 206 & 3 & 148 & 4 & 111 & 8 & 89.0 & 9 & 62.0 & 9 & 35.0 & \\
\hline
\end{tabular}

DURATION OF DISCHARGE FOR EACH WATER YEAR

$\begin{array}{llllllllllllllllllllllllllllllllllll}\text { CLASS } & 0 & 1 & 2 & 3 & 4 & 5 & 6 & 7 & 8 & 9 & 10 & 11 & 12 & 13 & 14 & 15 & 16 & 17 & 18 & 19 & 20 & 21 & 22 & 23 & 24 & 25 & 26 & 27 & 28 & 29 & 30 & 31 & 32 & 33 & 34\end{array}$ YEAR

NUMBER OF DAYS IN CLASS

OUIC FEET

-DAYS

1946

1947

1948

1950

1951

1952

1953

1955

1956

1957

1959

1960

1961

1962

1963

1965

1966

1967

1968

1970

$\begin{array}{lllllllllllllll}90 & 31 & 23 & 12 & 27 & 15 & 18 & 44 & 10 & 7 & 16 & 48 & 9 & 14 & 1\end{array}$

$\begin{array}{llllllllllllllll}91 & 71 & 18 & 34 & 9 & 16 & 1 & 8 & 21 & 20 & 11 & 20 & 36 & 5 & 3 & 1\end{array}$

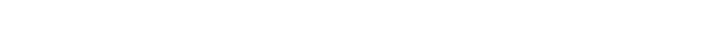

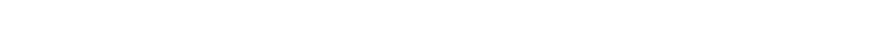

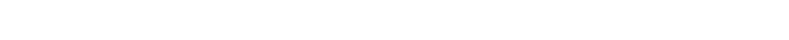

$\begin{array}{rrrrrrrrrrrrrrrr}2 & 83107 & 9 & 8 & 12 & 21 & 9 & 7 & 9 & 5 & 30 & 22 & 12 & 16 & 8 & 5\end{array}$ $\begin{array}{rrrrrrrrrrrrrrrrrrrr}37 & 110 & 44 & 11 & 11 & 6 & 7 & 14 & 4 & 4 & 25 & 34 & 31 & 15 & 1 & 6 & 1 & 3 & 1 & 1\end{array}$

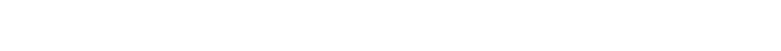

$\begin{array}{lllllllllllllllll}68 & 54 & 24 & 40 & 25 & 11 & 15 & 11 & 16 & 26 & 18 & 20 & 13 & 7 & 8 & 7 & 2\end{array}$

$\begin{array}{lllllllllllllllll}1 & 78 & 81 & 49 & 20 & 11 & 14 & 21 & 16 & 11 & 16 & 4 & 12 & 6 & 16 & 6 & 4\end{array}$

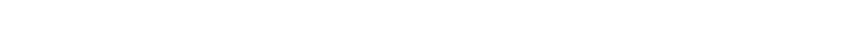

$\begin{array}{rrrrrrrrrrrrrrrr}64 & 67 & 47 & 18 & 33 & 38 & 9 & 5 & 6 & 27 & 10 & 11 & 10 & 11 & 3 & 6\end{array}$

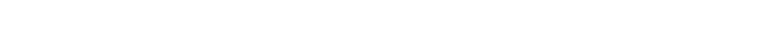

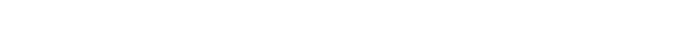

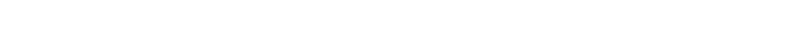

$\begin{array}{rrrrrrrrrrrrrrrrrrr}1100 & 59 & 29 & 26 & 17 & 22 & 10 & 3 & 3 & 9 & 18 & 10 & 16 & 10 & 11 & 10 & 10 & 2\end{array}$

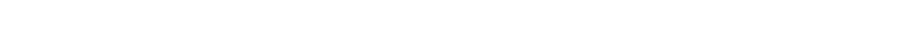

13921.9

11004.3

10493.9

$\begin{array}{lllllllllllllll}1 & 76 & 74 & 5 & 27 & 31 & 27 & 23 & 33 & 11 & 30 & 16 & 8 & 1 & 2\end{array}$

$\begin{array}{llllllllllrrrrrrrrrrrrrrr}7 & 12 & 25 & 15 & 14 & 22 & 38 & 18 & 21 & 28 & 4 & 7 & 8 & 4 & 9 & 18 & 17 & 13 & 11 & 8 & 4 & 23 & 22 & 14 & 3\end{array}$

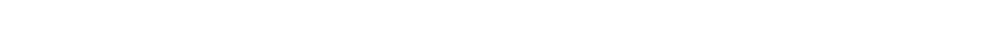
$\begin{array}{rrrrrrrrrrrrrrrrrrrrrr}5 & 1 & & 4 & 10 & 41 & 90 & 25 & 15 & 23 & 22 & 24 & 13 & 8 & 5 & 6 & 17 & 17 & 15 & 16 & 10 & 3 \\ & 7 & 16 & 29 & 37 & 23 & 12 & 24 & 23 & 24 & 8 & 8 & 17 & 14 & 11 & 11 & 16 & 10 & 15 & 34 & 6\end{array}$

9399.9

15147.3

9961.2

6235.7
7663.7

7721.3

12840.0

9908.9

8621.8

9001.8

8327.2

15613.0

8195.8

14415.3
21868.7

1971

$\begin{array}{llllllllllllllllllll}9 & 45 & 73 & 59 & 10 & 2 & 28 & 26 & 20 & 16 & 11 & 4 & 8 & 10 & 6 & 14 & 3 & 6 & 10 & 5\end{array}$

9542.5

11288.5

12786.6

8715.7

11386.6

12671.9 
GRERN RIVER BASIN

09228500 BURAN FORK NEAR BURNIFORK, WY--Continued

DURATION TABLE OF DISCHARGE FOR WATER YEARS 1946-71
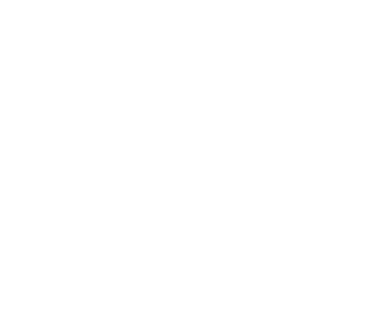

9496100.0

9436100.0

$9489 \quad 99.9$

947799.8

944799.5

$\begin{array}{ll}9424 & 99.2 \\ 9387 & 98.9\end{array}$

930998.0

CUBIC ACCU-

PER TOTAL LATED CENT

CIASS SECOND DAYS DAYS DAYS

$\begin{array}{lll}\text { CUBIC } & \text { ACCU- } \\ \text { FEET } & \text { MU- } & \text { PER- } \\ \text { PER TOTAL IATED } & \text { CENT }\end{array}$ CLASS SECOND DAYS DAYS DAYS

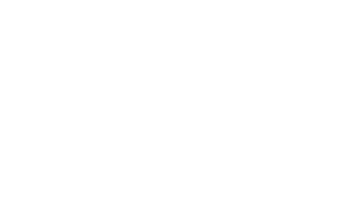

$\begin{array}{rrr}18 & 34.0 & 321 \\ 19 & 43.0 & 401 \\ 20 & 54.0 & 421 \\ 21 & 68.0 & 334 \\ 22 & 86.0 & 324 \\ 23 & 110.0 & 276 \\ 24 & 140.0 & 145 \\ 25 & 170.0 & 100\end{array}$

$\begin{array}{rr}2414 & 25.4 \\ 2093 & 22.0 \\ 1692 & 17.8 \\ 1271 & 13.4 \\ 937 & 9.9 \\ 613 & 6.5 \\ 337 & 3.5 \\ 192 & 2.0 \\ 92 & 1.0\end{array}$

MONIHLY MEAN DISCHARGES, IN OBBIC FEET RER SECOND, FOR EACH WATER YEAR

\begin{tabular}{|c|c|c|c|c|c|c|c|c|c|c|c|c|}
\hline YEAR & $\propto T$ & NOV & $\mathrm{DEC}$ & JAN & FEB & MAR & APR & MAY & JUNE & JULY & AUG & SEP \\
\hline $\begin{array}{l}1944 \\
1945\end{array}$ & $\begin{array}{l}12.7 \\
15.2\end{array}$ & $\begin{array}{l}7.5 \\
8.54\end{array}$ & $\begin{array}{l}7 \\
6\end{array}$ & $\begin{array}{l}6 \\
5\end{array}$ & $\begin{array}{l}8 \\
6\end{array}$ & $\begin{array}{r}10 \\
8\end{array}$ & $\begin{array}{l}17 \\
12\end{array}$ & $\begin{array}{c}115 \\
59.1\end{array}$ & $\begin{array}{l}215 \\
98.6\end{array}$ & $\begin{array}{l}103 \\
76.2\end{array}$ & $\begin{array}{l}47.0 \\
47.0\end{array}$ & $\begin{array}{l}25.4 \\
18.9\end{array}$ \\
\hline $\begin{array}{l}1946 \\
1947 \\
1948 \\
1949 \\
1950\end{array}$ & $\begin{array}{c}10.3 \\
10.9 \\
15.6 \\
5.93 \\
11.9\end{array}$ & $\begin{array}{c}6.51 \\
8.50 \\
11.6 \\
4.97 \\
7.04\end{array}$ & $\begin{array}{l}4.50 \\
8.00 \\
9.00 \\
4.00 \\
4.50\end{array}$ & $\begin{array}{l}3.50 \\
7.00 \\
8.00 \\
4.00 \\
4.00\end{array}$ & $\begin{array}{l}3.30 \\
7.50 \\
7.00 \\
3.50 \\
4.00\end{array}$ & $\begin{array}{l}3.50 \\
8.50 \\
7.00 \\
3.50 \\
5.40\end{array}$ & $\begin{array}{c}22.0 \\
16.0 \\
11.0 \\
11.3 \\
8.92\end{array}$ & $\begin{array}{l}43.3 \\
110 \\
104 \\
75.9 \\
54.0\end{array}$ & $\begin{array}{l}60.1 \\
122 \\
102 \\
180 \\
125\end{array}$ & $\begin{array}{l}46.7 \\
84.5 \\
41.5 \\
90.5 \\
68.8\end{array}$ & $\begin{array}{l}19.6 \\
49.7 \\
31.7 \\
61.6 \\
29.9\end{array}$ & $\begin{array}{l}12.0 \\
23.1 \\
11.7 \\
18.3 \\
21.0\end{array}$ \\
\hline $\begin{array}{l}1951 \\
1952 \\
1953 \\
1954 \\
1955\end{array}$ & $\begin{array}{c}8.14 \\
12.6 \\
8.38 \\
5.08 \\
8.14\end{array}$ & $\begin{array}{l}5.71 \\
8.40 \\
8.37 \\
4.28 \\
7.36\end{array}$ & $\begin{array}{l}5.50 \\
8.00 \\
9.50 \\
5.40 \\
4.84\end{array}$ & $\begin{array}{l}5.00 \\
7.40 \\
8.50 \\
4.60 \\
3.85\end{array}$ & $\begin{array}{l}5.00 \\
7.00 \\
7.00 \\
5.00 \\
3.63\end{array}$ & $\begin{array}{l}5.50 \\
6.40 \\
6.79 \\
5.23 \\
4.28\end{array}$ & $\begin{array}{c}6.50 \\
11.2 \\
8.14 \\
9.33 \\
7.21\end{array}$ & $\begin{array}{l}45.4 \\
91.3 \\
28.5 \\
45.1 \\
37.4\end{array}$ & $\begin{array}{c}95.0 \\
170 \\
156 \\
51.0 \\
91.3\end{array}$ & $\begin{array}{l}58.3 \\
88.0 \\
49.8 \\
33.0 \\
39.2\end{array}$ & $\begin{array}{l}50.6 \\
62.5 \\
27.1 \\
19.5 \\
28.5\end{array}$ & $\begin{array}{c}17.1 \\
23.5 \\
9.98 \\
16.8 \\
15.7\end{array}$ \\
\hline $\begin{array}{l}1956 \\
1957 \\
1958 \\
1959 \\
1960\end{array}$ & $\begin{array}{c}7.61 \\
6.19 \\
13.3 \\
5.90 \\
12.5\end{array}$ & $\begin{array}{l}5.28 \\
5.00 \\
9.00 \\
5.89 \\
9.73\end{array}$ & $\begin{array}{l}5.67 \\
4.50 \\
8.00 \\
6.00 \\
7.61\end{array}$ & $\begin{array}{l}5.99 \\
4.00 \\
7.00 \\
5.00 \\
5.29\end{array}$ & $\begin{array}{l}4.91 \\
4.50 \\
6.00 \\
5.00 \\
4.52\end{array}$ & $\begin{array}{l}5.74 \\
4.96 \\
6.00 \\
6.00 \\
4.84\end{array}$ & $\begin{array}{c}10.1 \\
5.25 \\
10.0 \\
6.50 \\
9.69\end{array}$ & $\begin{array}{l}57.5 \\
16.5 \\
81.7 \\
26.4 \\
57.5\end{array}$ & $\begin{array}{c}90.2 \\
188 \\
99.1 \\
112 \\
105\end{array}$ & $\begin{array}{l}32.3 \\
98.8 \\
49.3 \\
57.9 \\
50.5\end{array}$ & $\begin{array}{l}20.2 \\
60.9 \\
20.3 \\
30.5 \\
15.4\end{array}$ & $\begin{array}{c}7.73 \\
23.5 \\
14.8 \\
15.8 \\
12.4\end{array}$ \\
\hline $\begin{array}{l}1961 \\
1962 \\
1963 \\
1964 \\
1965\end{array}$ & $\begin{array}{c}8.33 \\
25.7 \\
14.5 \\
12.4 \\
12.4\end{array}$ & $\begin{array}{c}5.47 \\
19.3 \\
7.55 \\
7.21 \\
7.84\end{array}$ & $\begin{array}{c}5.00 \\
10.0 \\
4.56 \\
7.71 \\
7.63\end{array}$ & $\begin{array}{c}5.00 \\
10.0 \\
5.53 \\
6.71 \\
7.95\end{array}$ & $\begin{array}{c}4.73 \\
12.9 \\
8.91 \\
6.38 \\
8.39\end{array}$ & $\begin{array}{c}5.26 \\
13.0 \\
7.73 \\
6.40 \\
6.29\end{array}$ & $\begin{array}{c}6.24 \\
28.0 \\
8.02 \\
7.34 \\
9.90\end{array}$ & $\begin{array}{l}49.8 \\
69.6 \\
45.9 \\
79.5 \\
41.7\end{array}$ & $\begin{array}{c}92.7 \\
169 \\
74.6 \\
178 \\
330\end{array}$ & $\begin{array}{r}39.4 \\
89.6 \\
42.0 \\
96.3 \\
168\end{array}$ & $\begin{array}{l}20.8 \\
34.5 \\
28.0 \\
46.2 \\
71.3\end{array}$ & $\begin{array}{l}30.7 \\
31.0 \\
21.5 \\
18.1 \\
47.7\end{array}$ \\
\hline $\begin{array}{l}1966 \\
1967 \\
1968 \\
1969 \\
1970\end{array}$ & $\begin{array}{c}31.7 \\
10.7 \\
17.3 \\
9.71 \\
10.4\end{array}$ & $\begin{array}{c}14.4 \\
5.48 \\
6.61 \\
4.93 \\
6.16\end{array}$ & $\begin{array}{l}9.70 \\
3.52 \\
3.93 \\
4.81 \\
9.14\end{array}$ & $\begin{array}{l}9.40 \\
2.96 \\
2.75 \\
3.88 \\
2.91\end{array}$ & $\begin{array}{l}7.40 \\
2.11 \\
2.96 \\
4.50 \\
2.11\end{array}$ & $\begin{array}{l}7.51 \\
1.20 \\
2.68 \\
4.45 \\
3.10\end{array}$ & $\begin{array}{l}9.10 \\
1.07 \\
4.35 \\
5.80 \\
3.74\end{array}$ & $\begin{array}{l}78.8 \\
41.6 \\
22.3 \\
72.8 \\
61.5\end{array}$ & $\begin{array}{c}60.1 \\
128 \\
217 \\
87.9 \\
125\end{array}$ & $\begin{array}{c}38.0 \\
105 \\
79.4 \\
56.2 \\
79.0\end{array}$ & $\begin{array}{l}24.3 \\
41.3 \\
44.9 \\
18.9 \\
36.4\end{array}$ & $\begin{array}{l}21.5 \\
26.8 \\
16.1 \\
11.2 \\
33.1\end{array}$ \\
\hline 1971 & 13.0 & 6.75 & 6.89 & 6.07 & 5.21 & 4.78 & 6.14 & 46.9 & 206 & 71.5 & 27.1 & 16.8 \\
\hline
\end{tabular}

ANNUAL PEAK DISCHARGE, IN GBIC FEET PER SECOND, AND CORRESPONDING GAGE HEIGHT, IN FEET, FOR EACH WATER YEAR

\begin{tabular}{|c|c|c|c|c|c|c|c|c|c|c|c|}
\hline $\begin{array}{l}\text { WATER } \\
\text { YEAR }\end{array}$ & DATE & $\begin{array}{l}\text { GAGE } \\
\text { HEIGHT }\end{array}$ & $\begin{array}{c}\text { PEAK } \\
\text { DISCHARGE }\end{array}$ & $\begin{array}{l}\text { WATER } \\
\text { YEAR }\end{array}$ & DATE & $\begin{array}{c}\text { GAGE } \\
\text { HEIGHT }\end{array}$ & $\begin{array}{c}\text { PEAK } \\
\text { DISCHARGE }\end{array}$ & $\begin{array}{l}\text { WATER } \\
\text { YEAR }\end{array}$ & DATE & $\begin{array}{l}\text { GAGE } \\
\text { HEIGHT }\end{array}$ & $\begin{array}{c}\text { PEAR } \\
\text { DISCHARGE }\end{array}$ \\
\hline $\begin{array}{l}1944 \\
1945 \\
1946 \\
1947 \\
1948 \\
1949 \\
1950 \\
1951 \\
1952 \\
1953 \\
1954 \\
1955 \\
1956\end{array}$ & 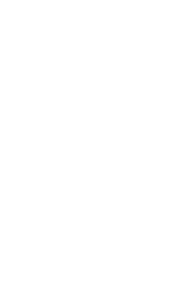 & $\begin{array}{l}7.28 \\
6.09 \\
5.54 \\
6.43 \\
7.56 \\
8.07 \\
6.41 \\
6.39 \\
8.13 \\
7.55 \\
6.81 \\
6.51 \\
6.51\end{array}$ & $\begin{array}{l}540 \\
239 \\
104 \\
241 \\
452 \\
561 \\
221 \\
201 \\
599 \\
442 \\
174 \\
198 \\
198\end{array}$ & $\begin{array}{l}1957 \\
1958 \\
1959 \\
1960 \\
1961 \\
1962 \\
1963 \\
1964 \\
1965 \\
1966 \\
1967 \\
1968 \\
1969\end{array}$ & $\begin{array}{l}\text { JUNE } 07,1957 \\
\text { JUNE } 07,1958 \\
\text { JUNE } 16,1959 \\
\text { JUNE } 04,1960 \\
\text { MAY } 29,1961 \\
\text { JUNE } 24,1962 \\
\text { JUNE } 18,1963 \\
\text { JUNE } 07,1964 \\
\text { JUNE } 10,1965 \\
\text { MAY } 05,1966 \\
\text { JUNE } 05,1967 \\
\text { JUNE } 05,1968 \\
\text { JUNE } 20,1969\end{array}$ & $\begin{array}{l}7.94 \\
7.15 \\
6.97 \\
6.96 \\
6.78 \\
7.22 \\
6.81 \\
7.49 \\
-- \\
-- \\
4.35 \\
2.73\end{array}$ & $\begin{array}{r}482 \\
250 \\
201 \\
206 \\
166 \\
247 \\
174 \\
439 \\
3200 \\
150 \\
203 \\
782 \\
205\end{array}$ & $\begin{array}{l}1970 \\
1971 \\
1972 \\
1973 \\
1974 \\
1975 \\
1976 \\
1977 \\
1978 \\
1979 \\
1980 \\
1981\end{array}$ & $\begin{array}{l}\text { JUNE } 23,1970 \\
\text { JUNE } 17,1971 \\
\text { JUNE } 03,1972 \\
\text { JUNE } 08,1973 \\
\text { MAY 29, } 1974 \\
\text { JULY } 04,1975 \\
\text { JUNE } 03,1976 \\
\text { JUNE } 07,1977 \\
\text { JUNE } 10,1978 \\
\text { MAY 20, } 1979 \\
\text { JUNE } 10,1980 \\
\text { JUNE } 09,1981\end{array}$ & $\begin{array}{l}2.69 \\
3.49 \\
3.02 \\
3.77 \\
2.90 \\
3.53 \\
2.87 \\
2.53 \\
3.32 \\
2.90 \\
3.41 \\
2.83\end{array}$ & $\begin{array}{l}183 \\
422 \\
274 \\
528 \\
222 \\
436 \\
167 \\
123 \\
362 \\
222 \\
394 \\
209\end{array}$ \\
\hline
\end{tabular}




\begin{tabular}{|c|c|c|c|c|c|c|}
\hline \multirow{2}{*}{$\begin{array}{l}\text { ERIOD } \\
\text { CON- } \\
\text { EOU- } \\
\text { TIVE } \\
\text { AYYS) }\end{array}$} & \multicolumn{6}{|c|}{$\begin{array}{l}\text { DISCHARGE, IN OUBIC FEET PER SECOND, FOR } \\
\text { INDICATED RECURRENCE INIERNAL, IN YEARS, AND } \\
\text { ANNUAL NONEXCEEDANCE PRCBABILITY, IN PERCENT }\end{array}$} \\
\hline & $\begin{array}{c}2 \\
50 \%\end{array}$ & $\begin{array}{c}5 \\
208\end{array}$ & $\begin{array}{l}10 \\
108\end{array}$ & $\begin{array}{l}20 \\
58\end{array}$ & $\begin{array}{l}50 \\
28\end{array}$ & $\begin{array}{r}100 \\
18\end{array}$ \\
\hline $\begin{array}{l}60 \\
90\end{array}$ & $\begin{array}{l}5.1 \\
5.3\end{array}$ & $\begin{array}{l}3.5 \\
3.8\end{array}$ & $\begin{array}{l}2.8 \\
3.1\end{array}$ & $\begin{array}{l}2.3 \\
2.6\end{array}$ & $\begin{array}{l}1.8 \\
2.1\end{array}$ & - \\
\hline
\end{tabular}

\begin{tabular}{|c|c|c|c|c|c|c|}
\hline MAGI & NITUDE & $\begin{array}{l}\text { D PRCBAF } \\
\text { BASEI }\end{array}$ & $\begin{array}{l}\text { TY OF } \\
\text { WATER }\end{array}$ & $\begin{array}{l}\text { IAL HIGH } \\
\text { RS } 1946 \text { - }\end{array}$ & $\begin{array}{l}\text { ST MEAN } \\
11\end{array}$ & \\
\hline \multirow{2}{*}{$\begin{array}{l}\text { PERIOD } \\
\text { CON- } \\
\text { SECU- } \\
\text { TIVE } \\
\text { DAYS) }\end{array}$} & \multicolumn{6}{|c|}{$\begin{array}{l}\text { DISCHARGE, IN OUBIC FEET PER SECOND, FOR } \\
\text { INDICATED RECORRENCE INTERVAL, IN YEARS, AND } \\
\text { ANNUAL EXCEEDANCE PRCBABIIITY, IN PERCENT }\end{array}$} \\
\hline & $\begin{array}{c}2 \\
508\end{array}$ & $\begin{array}{c}5 \\
208\end{array}$ & $\begin{array}{l}10 \\
108\end{array}$ & $\begin{array}{l}25 \\
48\end{array}$ & $\begin{array}{l}50 \\
28\end{array}$ & $\begin{array}{r}100 \\
18\end{array}$ \\
\hline $\begin{array}{r}1 \\
3 \\
7 \\
15\end{array}$ & $\begin{array}{l}205 \\
184 \\
163 \\
147\end{array}$ & $\begin{array}{l}358 \\
309 \\
259 \\
219\end{array}$ & $\begin{array}{l}519 \\
435 \\
346 \\
273\end{array}$ & $\begin{array}{l}822 \\
664 \\
490 \\
350\end{array}$ & $\begin{array}{r}1150 \\
900 \\
627 \\
415\end{array}$ & $\overline{-}$ \\
\hline
\end{tabular}

09229450 HENRYS FORK TRIBUTARY NEAR MANILA, UT

LOCATION.--Lat $41^{\circ} 01^{\prime}$ 14", long $109^{\circ} 40^{\prime}$ 46", in $\mathrm{NW}^{\frac{1}{4}} \mathrm{SE}_{\frac{1}{4}}^{\frac{1}{4}}$ sec.15, T.12 N., R.109 W., Sweetwater County, WY, Hydrologic Unit 14040106 , $500 \mathrm{ft}$ upstream from mouth, $1.4 \mathrm{mi}$ north of Wyaning-Utah State line, and $4.5 \mathrm{mi}$ northeast of Manila.

DRAINAGE AREA. $-3.15 \mathrm{mi}^{2}$.

MEAN BASIN ELEVATION. $-6,600 \mathrm{ft}$.

PERIOD OF RECORD AVAIIABLE.-Water years 1965-74, annual peak discharge only.

GAGE.--Crest-stage gage. Altitude of gage is $6,100 \mathrm{ft}$ from topographic map.

ANNUAL PEAK DISCHARGE, IN OUBIC FEET PER SECOND, AND CORRESPONDING GAGE HEIGHT, IN FEET, FOR EACH WATER YEAR

$\begin{array}{llcccccccccc}\begin{array}{l}\text { WATER } \\ \text { YEAR }\end{array} & \text { DATE } & \begin{array}{c}\text { GAGE } \\ \text { HEIGHT }\end{array} & \begin{array}{c}\text { PEAK } \\ \text { DISCHARGE }\end{array} & \begin{array}{l}\text { WATER } \\ \text { YEAR }\end{array} & \text { DATE } & \begin{array}{c}\text { GAGE } \\ \text { HEIGHT }\end{array} & \begin{array}{c}\text { PEAK } \\ \text { DISCHARGE }\end{array} & \begin{array}{l}\text { WATER } \\ \text { YEAR }\end{array} & \text { DATE } & \text { GAGE } & \begin{array}{c}\text { PEAK } \\ \text { HEIGHT }\end{array} \\ \text { DISCHARGE }\end{array}$

09229500 HENRYS FORK NEAR MANILA, UT

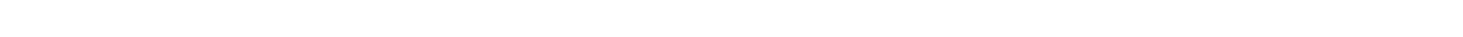
right bank $0.8 \mathrm{mi}$ north of Wyoming-Utah State line, $1.3 \mathrm{mi}$ upstream from normal high-water line of Flaming Gorge Reservoir at elevation $6,045 \mathrm{ft}$, and $3.0 \mathrm{mi}$ northeast of Manila.

DRAINAGE AREA. $-520 \mathrm{mi}^{2}$, approximately.

PERIOD OF RECORD AVAILABLE.--October 1928 to September 1981. Prior to October 1971, published as "at Linwood, UT."

REVISED RECORDS.-WSP 1443: 1955. WDR WY-76-2: 1970.

GAGE. - Water-stage recorder. Altitude of gage is 6,060 ft from topographic map. Prior to Oct. 1, 1957, nonrecording gages or water-stage recorder at several sites about $2.0 \mathrm{mi}$ downstream at various datums. Oct. 1, 1957, to Dec. 2, 1965, water-stage recorders at sites about $1.0 \mathrm{mi}$ upstream at different datums.

REMARKS.--Peoples Irrigation Canal diverts $5.9 \mathrm{mi}$ upstream. Natural flow of stream affected by transbasin diversions, small storage reservoirs, diversions for irrigation, and return flow from irrigated areas.

AVERAGE DISOHARGE. --53 years, $80.4 \mathrm{ft}^{3} / \mathrm{s}, 58,250$ acre- $\mathrm{ft} / \mathrm{yr}$.

EXTREMES FOR PERIOD OF RECORD.-Maximum discharge determined, 6,750 $\mathrm{ft}^{3} / \mathrm{s}$ Aug. 3, 1936, gage height, $7.19 \mathrm{ft}$, site and datum then in use, from floodmarks, from rating curve extended above $570 \mathrm{ft} 3 / \mathrm{s}$ on basis of slope-area measurement of peak flow; higher discharge occurred July 15, 1959, gage height, $9.42 \mathrm{ft}$, site and datum then in use, discharge not determined; no flow for several days in 1933-35, 1939-40.

LOWEST MEAN DISCHARGE, IN OBBIC FEET PER SECOND, AND RANKING FOR THE INDICATED NUMBER OF CONSECUTIVE DAYS FOR EACH CIIMATIC YEAR, APRII 1-MARCH 31

YEAR

CONSEOUTIVE DAYS

\begin{tabular}{|c|c|c|c|c|c|c|c|c|c|c|c|c|c|c|c|c|c|c|c|}
\hline . & 1 & & 3 & & 7 & & 14 & & 30 & ז & 60 & & 90 & & 120 & & 183 & & ALL \\
\hline
\end{tabular}


LOWEST MEAN DISCHARGE, IN CUBIC FEET PER SECOND, AND RANKING FOR THE INDICATED NUMBER OF CONSECUTIVE DAYS FOR FACH CLIMATIC YFAR, APRIL 1-MARCH 31--Cont inued

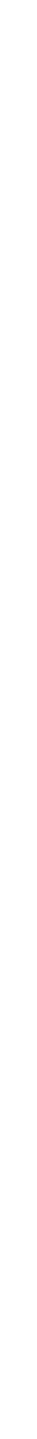

1

$\begin{array}{cc}10.0 & 40 \\ 0.10 & 8 \\ 9.00 & 38 \\ 0.00 & \end{array}$

0.002

$0.20 \quad 9$

2.6024

5.8033

6.5035
0.003

0.004

$12.0 \quad 43$

$\begin{array}{cc}11.0 & 41 \\ 8.70 & 37\end{array}$

3.7026

$27.0 \quad 46$

$4.80 \quad 30$

$\begin{array}{cc}36.0 & 49 \\ 0.80 & 15\end{array}$

$10.0 \quad 39$

$\begin{array}{cc}11.0 & 42 \\ 4.40 & 28\end{array}$

29.047

3.8012
0.3012

0.8016

0.2010

$\begin{array}{cc}18.0 & 45 \\ 0.30 & 11\end{array}$

0.4013

0.105

0.106

$\begin{array}{rr}1.40 & 19 \\ 0.10 & 7\end{array}$

0.8017

$48.0 \quad 52$

$\begin{array}{cc}48.0 & 52 \\ 4.80 & 29\end{array}$

5.8034

$\begin{array}{cc}38.0 & 50 \\ 2.80 & 25\end{array}$

$17.0 \quad 44$

$\begin{array}{r}5.7032 \\ \hline\end{array}$

2.3023

$\begin{array}{cc}41.0 & 51 \\ 1.80 & 21\end{array}$

8.5036

1.9022

0.9218
1.5020

0.4514

5.1031

\begin{tabular}{|c|c|c|}
\hline 3 & & 7 \\
\hline & 41 & 12.0 \\
\hline & 8 & 0.16 \\
\hline .00 & & $\begin{array}{l}0.03 \\
0.00\end{array}$ \\
\hline
\end{tabular}

0.2710

3.4025

6.2033

6.8035
0.00

0.3311

4.2026

7.1033

8.7035
$0.00 \quad 2$

0.004

$14.0 \quad 43$

9.4037

0.003

$\begin{array}{ll}17.0 & 43 \\ 12.0 & 39\end{array}$

9.8037

4.7027

$\begin{array}{cc}35.0 & 48 \\ 4.80 & 28\end{array}$

$\begin{array}{cc}4.80 & 28 \\ 37.0 \quad 49\end{array}$

1.0018

$10.0 \quad 39$

$37.0 \quad 48$

37.048
$5.30 \quad 27$

$37.0 \quad 49$

$1.10 \quad 18$
$12.0 \quad 40$

$11.0 \quad 40$

4.8029
$31.0 \quad 47$

3.9026

$12.0 \quad 41$
5.70

$\begin{array}{cc}5.70 & 29 \\ 34.0 \quad 47\end{array}$

3.9024
$0.36 \quad 12$

0.8315

0.209

$\begin{array}{rr}0.20 & 9 \\ 19.0 \quad 45\end{array}$

$\begin{array}{cc}19.0 & 45 \\ 0.30 & 11\end{array}$

$\begin{array}{lll}0.30 & 11 \\ 0.4013\end{array}$

0.8715

$\begin{array}{rr}0.87 & 9 \\ 22.0 \quad 45\end{array}$

$\begin{array}{cc}22.0 & 45 \\ 0.30 & 10\end{array}$

0.4013

$\begin{array}{ll}0.10 & 5 \\ 0.13 & 6\end{array}$

$0.13 \quad 6$
$1.40 \quad 19$

0.137

$\begin{array}{ll}0.10 & 5 \\ 0.17 & 7\end{array}$

1.6019

0.178

0.8316

0.8916

$49.0 \quad 52$

4.9030

6.2034
$41.0 \quad 50$

$53.0 \quad 52$

5.3028

7.0032
$42.0 \quad 50$

3.9025

$\begin{array}{cc}18.0 & 44 \\ 5.80 & 32\end{array}$

$\begin{array}{ll}5.80 & 32 \\ 2.50 & 23\end{array}$

$20.0 \quad 44$

6.0031

2.9023
$44.0 \quad 5$

$\begin{array}{ccc}42.0 & 51 \\ 1.90 & 21\end{array}$

$\begin{array}{cc}44.0 & 51 \\ 2.10 & 21\end{array}$

$\begin{array}{ll}8.80 & 36 \\ 1.90 & 22\end{array}$

$\begin{array}{ll}0.9217 \\ 1.60 & 20\end{array}$

9.5036

2.1022

0.9717

$\begin{array}{ll}1.70 & 20 \\ 0.77 & 14\end{array}$

5.2031

5.8030

CONSBCUTIVE DAYS

\begin{tabular}{crcc} 
& \multicolumn{4}{c}{ CONSECUTIVE } \\
14 & \multicolumn{3}{c}{30} \\
& & \\
20.0 & 42 & 30.0 & 44 \\
0.17 & 6 & 0.35 & 7 \\
12.0 & 34 & 14.0 & 33 \\
0.05 & 4 & 0.08 & 3 \\
0.00 & 1 & 0.00 & 1
\end{tabular}

$\begin{array}{cccc}60 & & 90 & \\ & & & \\ 30.0 & 37 & 32.0 & 37 \\ 2.10 & 10 & 4.70 & 13 \\ 14.0 & 27 & 17.0 & 25 \\ 0.18 & 3 & 0.63 & 5 \\ 0.00 & 1 & 0.02 & 1 \\ & & & \\ 1.10 & 8 & 1.00 & 7 \\ 34.0 & 39 & 39.0 & 38 \\ 41.0 & 44 & 49.0 & 47 \\ 40.0 & 42 & 44.0 & 43 \\ 5.40 & 20 & 6.30 & 26\end{array}$

120

$\begin{array}{cc}35.0 & 35 \\ 4.90 & 11 \\ 27.0 & 27 \\ 2.20 & 6 \\ 0.52 & 1 \\ & \\ 2.20 & 7 \\ 47.0 & 41 \\ 52.0 & 48 \\ 50.0 & 45 \\ 13.0 & 18\end{array}$

183

$47.0 \quad 38$

$\begin{array}{rr}11.0 & 9 \\ 28.0 & 21\end{array}$

10.06

$12.0 \quad 10$

$\begin{array}{llll}12.0 & 10 & 42.0 & 11 \\ 55.0 & 46 & 80.0 & 29\end{array}$

$0.3911 \quad 0.6610$

7.7030

$\begin{array}{lll}7.70 & 20.0 & 39\end{array}$

$\begin{array}{cc}15.0 & 37 \\ 0.79 & 11\end{array}$

5.4020

6.3026

1.80

0.002

$0.00 \quad 2$

$0.05 \quad 2$
46.0

$\begin{array}{lrrr}46.0 & 49 & 0.07 & 2\end{array}$

$\begin{array}{llll}18.0 & 30 & 24.0 & 30\end{array}$

$\begin{array}{llll}20.0 & 33 & 25.0 & 31\end{array}$

$\begin{array}{llll}13.0 & 38 & 15.0 & 35\end{array}$

8.4032

$\begin{array}{rr}15.0 & 35 \\ 8.80 & 27\end{array}$

$\begin{array}{llll}37.0 & 48 & 38.0 & 46\end{array}$

$\begin{array}{lr}8.0031 & 9.2030\end{array}$

$\begin{array}{llll}8.0 & 49 & 39.0 & 47\end{array}$

$\begin{array}{lll}1.4017 & 1.8014\end{array}$

$13.0 \quad 39$

$\begin{array}{cc}1.80 & 14 \\ 18.0 \quad 38\end{array}$

$41.0 \quad 45$

$21.0 \quad 34$

$42.0 \quad 46$
2.10

$\begin{array}{cc}2.10 & 11 \\ 23.0 & 35\end{array}$

$\begin{array}{rr}28.0 & 33 \\ 44.0 & 44\end{array}$

$\begin{array}{ll}44.0 & 44 \\ 22.0 & 29\end{array}$

$\begin{array}{lll}46.0 & 45\end{array}$

$\begin{array}{rr}2.50 & 9 \\ 30.0 & 36\end{array}$

$\begin{array}{cc}55.0 & 49 \\ 32.0 & 31\end{array}$

$26.0 \quad 25$

$32.0 \quad 32$

$47.0 \quad 42$

$32.0 \quad 33$

50.0
$4.40 \quad 10$

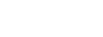

$\begin{array}{ll}13.0 & 40 \\ 12.0 & 36\end{array}$

$35.0 \quad 47$

4.0024
0.4612

$15.0 \quad 36$

$\begin{array}{ll}24.0 & 36 \\ 35.0 & 40\end{array}$

$\begin{array}{ll}28.0 & 34 \\ 41.0 & 40\end{array}$

$31.0 \quad 30$

$\begin{array}{ll}44.0 & 39 \\ 48.0 & 43\end{array}$

$\begin{array}{ll}46.0 & 20 \\ 5.80 & 10\end{array}$

$\begin{array}{rr}4.20 & 22 \\ 0.61 & 9\end{array}$

4.9019

4.8014

$0.9014 \quad 1.6013$

0.248

$\begin{array}{rrr}0.3310 & 0.428\end{array}$

4.3018

4.3018
$0.42 \quad 5$

$\begin{array}{cc}0.42 & 5 \\ 40.0 \quad 43\end{array}$

3.9011

$\begin{array}{rr}3.90 & 11 \\ 0.62 \quad 4\end{array}$

5.801

8.0015

$\begin{array}{rr}1.40 & 4 \\ 49.0 \quad 44\end{array}$

$\begin{array}{cr}49.0 & 44 \\ 0.91 \quad 3\end{array}$

$\begin{array}{cr}0.91 & 3 \\ 18.0 \quad 21\end{array}$

3.4014

$\begin{array}{rr}0.66 & 6 \\ 6.70 & 17\end{array}$

0.105

0.134

0.194

0.413

$0.82 \quad 2$

$\begin{array}{lll}0.19 & 7 & 0.22 \\ 1.90 & 19 & 2.10\end{array}$

$0.269 \quad 5.1024$

$\begin{array}{lll}0.80 & 7 \\ 6.60 & 23\end{array}$

9.0024

$11.0 \quad 23$

$\begin{array}{cc}19.0 & 26 \\ 8.50 & 19\end{array}$

9.1020

$\begin{array}{ll}27.0 & 28\end{array}$

$\begin{array}{ll}26.0 & 26 \\ 12.0 & 17\end{array}$

15.019

$\begin{array}{cccc}54.0 & 52 & 57.0 & 52 \\ 7.30 & 29 & 8.80 & 28\end{array}$

$58.0 \quad 52$

$\begin{array}{ll}58.0 & 52 \\ 18.0 & 31\end{array}$

$\begin{array}{ll}61.0 & 52 \\ 21.0 & 28\end{array}$

$67.0 \quad 52$

$\begin{array}{ll}25.0 & 24 \\ 34.0 & 34\end{array}$

$\begin{array}{llll}9.80 & 33 & 13.0 & 32 \\ 46.0 & 50 & 47.0 & 50\end{array}$

$\begin{array}{cccc}5.50 & 25 & 47.0 & 50 \\ & 7.00 & 25\end{array}$

$52.0 \quad 50$

$30.0 \quad 35$

$\begin{array}{ll}51.0 & 49 \\ 20.0 & 27\end{array}$

$\begin{array}{ll}34.0 & 34 \\ 52.0 & 47\end{array}$

$\begin{array}{ll}52.0 & 47 \\ 29.0 & 29\end{array}$

$53.0 \quad 50$

$60.0 \quad 50$

$\begin{array}{llll}21.0 & 43 & 29.0 & 42 \\ 6.90 & 28 & 10.0 & 31\end{array}$

$44.0 \quad 47$

3.6023

$\begin{array}{cc}17.0 & 29 \\ 5.80 & 21\end{array}$

53.051

$\begin{array}{ll}27.0 & 32 \\ 10.0 & 21\end{array}$ 53.051

5.1015

$\begin{array}{ll}37.0 & 36 \\ 18.0 & 22\end{array}$

60.051

$\begin{array}{lllll}17.0 & 41 \quad 21.0 & 40\end{array}$

$\begin{array}{cc}32.0 & 38 \\ 3.70 & 17\end{array}$

1.1016

$\begin{array}{ll}1.90 & 20 \\ 1.50 & 18\end{array}$

2.9020

1.3012

$42.0 \quad 42$

47.0

$\begin{array}{rr}8.30 & 16\end{array}$

$2.80 \quad 8$

$\begin{array}{rr}7.00 & 13 \\ 4.30 & 9\end{array}$

$\begin{array}{ll}2.40 & 12 \\ 2.50 & 13\end{array}$

3.1010

4.3012

6.8027

8.9029

$14.0 \quad 26$

$13.0 \quad 24$

$23.0 \quad 23$

$\begin{array}{rrrr}53.0 & 43 & 95.0 & 36\end{array}$

$\begin{array}{rrrr}69.0 & 49 & 117 . & 43 \\ 23.0 & 18 & 51.0 & 14\end{array}$

$\begin{array}{llll}11.0 & 7 & 33.0 & 6\end{array}$

80.0 51 124.046

$\begin{array}{llll}42.0 & 34 & 106 & 39\end{array}$

$\begin{array}{cccc}36.0 & 25 & 51.0 & 15 \\ 36 & 123 & 45\end{array}$

$\begin{array}{llll}49.0 & 40 \quad 90.0 & 33\end{array}$

$\begin{array}{llll}42.0 & 35 & 63.0 & 22\end{array}$

$\begin{array}{llll}53.0 & 44 & 119 & 44\end{array}$

$\begin{array}{rrrr}15.0 & 13 & 62.0 & 21\end{array}$

$\begin{array}{lllll}36.0 & 28 & 74.0 & 27\end{array}$

$\begin{array}{llll}44.0 & 36 & 66.0 & 25\end{array}$

$52.0 \quad 41 \quad 153.49$

$\begin{array}{lrrr}23.0 & 19 & 67.0 & 26\end{array}$

$\begin{array}{llll}15.0 & 14 & 37.0 & 10\end{array}$

$\begin{array}{rrrr}11.0 & 8 & 36.0 & 8\end{array}$

$55.0 \quad 45 \quad 107.41$

$\begin{array}{llll}9.20 & 5 & 46.0 & 13\end{array}$

$\begin{array}{llll}8.90 & 4 & 45.0^{\circ} & 12\end{array}$

$\begin{array}{llll}39.0 & 31 & 61.0 & 19\end{array}$

$\begin{array}{rrrr}27.0 & 20 & 89.0 & 32\end{array}$

$\begin{array}{llll}30.0 & 23 & 106 & 40\end{array}$

$84.0 \quad 52 \quad 259.52$

$\begin{array}{rrrr}36.0 & 29 & 56.0 & 16\end{array}$

$\begin{array}{llll}39.0 & 32 & 94.0 & 35\end{array}$

$\begin{array}{cccc}52.0 & 42 & 113 & 42 \\ 37.0 & 30 & 62.0 & 20\end{array}$

$\begin{array}{llll}62.0 & 47 & 102 & 38\end{array}$

$\begin{array}{cccc}41.0 & 33 & 127 & 47 \\ 31.0 & 24 & 85.0 & 31\end{array}$ 
GREEN RIVER BASIN

09229500 HENRYS FORK NEAR MANILA, UT-Continued

HIGHEST MEAN DISCHARGE, IN CUBIC FEET PER SECOND, AND RANKING FOR THE INDICATED NUMBER OF CONSECUTIVE DAYS FOR EACH WATER YEAR, OCTCBER 1-SEPTEMBER 30--Continued

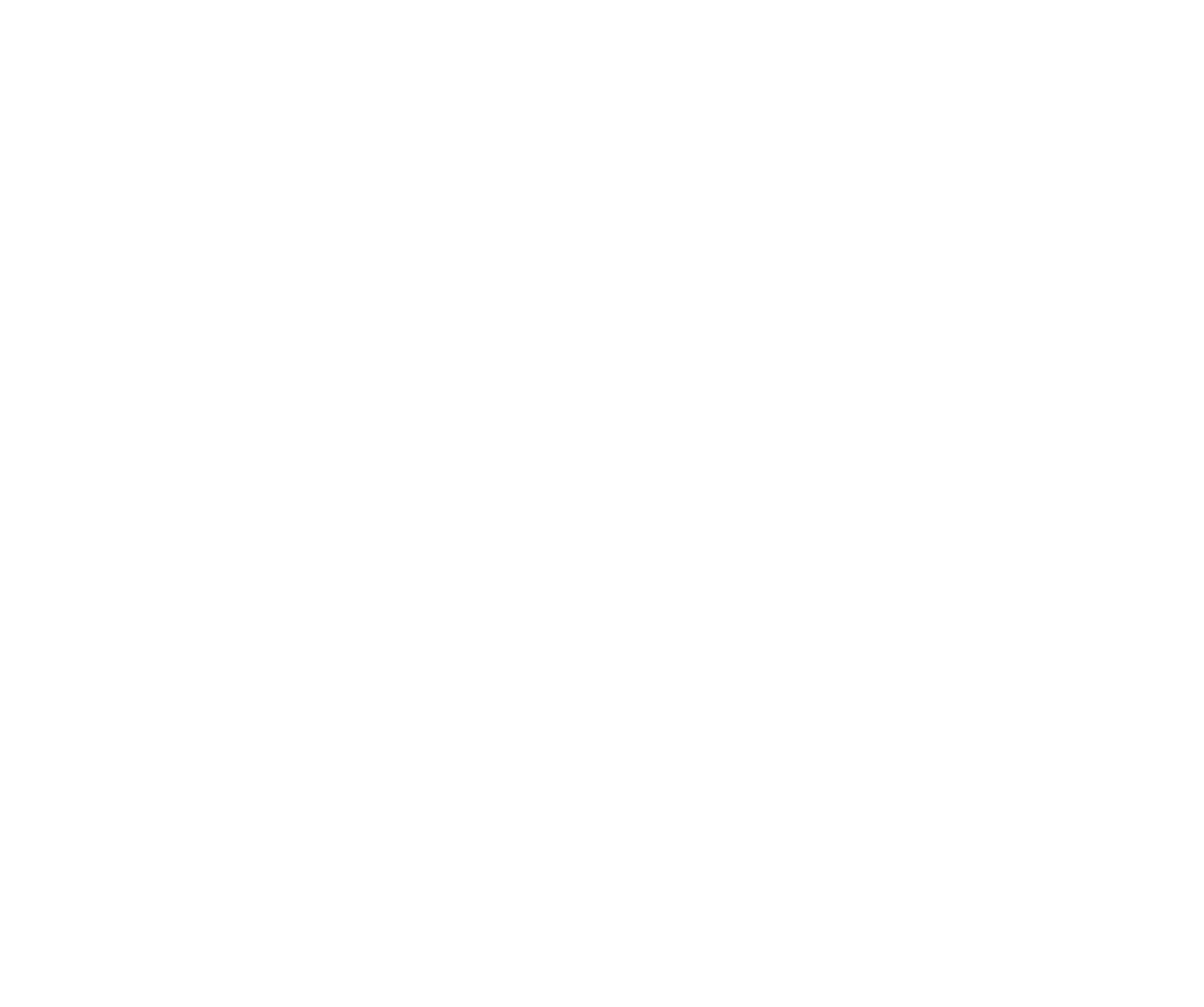

DURATION OF DISCHARGE FOR EACH WATER YEAR

$\begin{array}{lllllllllllllllllllllllllllllllllllllllll}\text { CIASS } & 0 & 1 & 2 & 3 & 4 & 5 & 6 & 7 & 8 & 9 & 10 & 11 & 12 & 13 & 14 & 15 & 16 & 17 & 18 & 19 & 20 & 21 & 22 & 23 & 24 & 25 & 26 & 27 & 28 & 29 & 30 & 31 & 32 & 33 & 34\end{array}$ YEAR

1929

$$
\begin{array}{rrrrrrrrrrrrrrrr} 
& & 11 & 1 & 40 & 91 & 32 & 43 & 45 & 24 & 26 & 21 & 15 & 10 & 6 & \\
2 & 6 & 2 & 4 & 79 & .47 & 42 & 70 & 72 & 18 & 7 & 8 & 5 & & 2 & 1
\end{array}
$$

1930

$$
\begin{array}{rrrrrrrrrrr}
4 & 7 & 8 & 11 & 116 & 36 & 37 & 47 & 3 & 2 & 1
\end{array}
$$

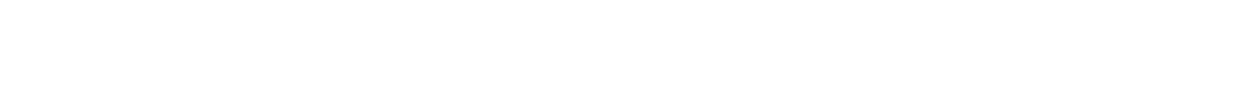

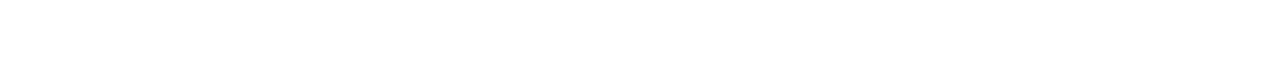

52909.0

36742.0

$$
\begin{aligned}
& \begin{array}{llllllllllllllllllllll}
6 & 7 & 2 & 2 & 4 & 3 & 24 & 10 & 10 & 5 & 41 & 57 & 52 & 37 & 42 & 36 & 11 & 6 & 1 & 2 & 4 & 2
\end{array} \\
& \begin{array}{rrrrrrrrrrrrrrrrr}
2 & 11 & 2 & & 3 & 36 & 35 & 33 & 119 & 39 & 18 & 25 & 26 & 11 & 5 & \\
& 3 & 8 & 7 & 7 & 6 & 8 & 113 & 84 & 38 & 27 & 25 & 12 & 4 & 12 & 7
\end{array} \\
& \begin{array}{rrrrrrrrrrrrrrrrrrrrrrrrrrrrrr}
19338 & 8 & 7 & & 1 & 7 & 15 & 4 & 1 & 7 & 4 & 1 & 2 & 3 & 3 & 10 & 8 & 7 & 12 & 1 & 43 & 58 & 43 & 58 & 25 & 10 & 23 & 4 \\
1940 & 73 & 3 & & 4 & 10 & 9 & 1 & 1 & 1 & & 2 & 1 & 1 & 1 & & 1 & 4 & 9 & 24 & 97 & 74 & 29 & 7 & 5 & 2 & 6 & 1
\end{array} \\
& \begin{array}{rrrrrrrrrrrrrrrrr}
4 & 3 & 7 & 5 & 10 & 42 & 87 & 55 & 29 & 37 & 21 & 10 & 12 & 19 & 21 & 3 \\
& 2 & 27 & 10 & 16 & 23 & 76 & 52 & 41 & 46 & 34 & 12 & 4 & 3 & 12 & 7
\end{array} \\
& \begin{array}{rrrrrrrrrrrrr}
2 & 27 & 10 & 16 & 23 & 76 & 52 & 41 & 46 & 34 & 12 & 4 \\
10 & 20 & 15 & 31 & 22 & 108 & 92 & 43 & 10 & 10 & 3 & 1
\end{array} \\
& \begin{array}{lllrrrrrrrrrrrrrrr}
2 & 1 & 10 & 18 & 8 & 15 & 27 & 64 & 83 & 15 & 28 & 18 & 14 & 5 & 12 & 34 & 10 & 2
\end{array} \\
& \begin{array}{lllllllll}
29 & 149 & 65 & 38 & 34 & 20 & \text { I8 } & \text { II } & \text { I }
\end{array} \\
& \begin{array}{lllllllllllllll}
8 & 25 & 20 & 5 & 7 & 15 & 48 & 108 & 38 & 42 & 9 & 37 & 1 & 1 & 1
\end{array}
\end{aligned}
$$

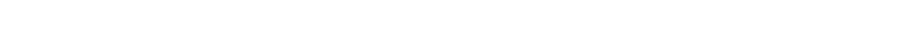

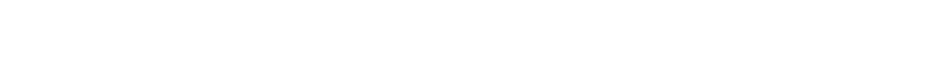$$
1941
$$$$
1942
$$$$
1943
$$$$
\begin{aligned}
& 1944 \\
& 1945
\end{aligned}
$$

$13890 . y$
27734.7

23073.8

6032.1

14977.2

1946

1947
1948

1949

23654.9

34385.3

39733.9

24888.9

12955.1

37058.1

42768.0

21485.5
43674.7

32072.0

22069.8

44096.0

26206.0

32495.1 
GREEN RIVER BASIN

09229500 HENRYS FORK NEAR MANILA, UT--Continued

DURATION OF DISCHARGE FOR EAG WATER YEAR--Continued

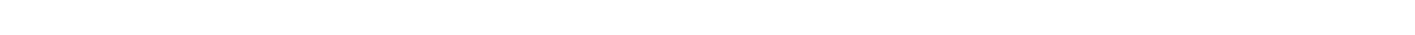

YEAR

NUMBER OF DAYS IN CI.ASS

CUBIC FEET

PER SECOND

-DAYS

1951

1952
1953
1954

$\begin{array}{lllllllllllllllll}1 & 3 & 7 & 6 & 8 & 21 & 23 & 98 & 86 & 38 & 27 & 20 & 10 & 11 & 2 & 4\end{array}$

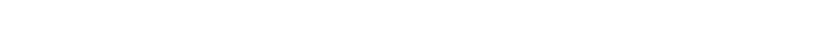

23134.6

55065.0

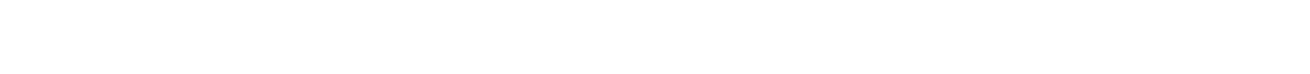

1955

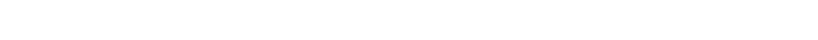

15560.0

$\begin{array}{lllllllllllllllllllllllll}17 & 9 & 6 & 18 & 11 & 4 & 7 & 7 & 8 & 1 & 5 & 6 & 2 & 4 & 42 & 39 & 56 & 28 & 51 & 19 & 10 & 4 & 7 & 5\end{array}$

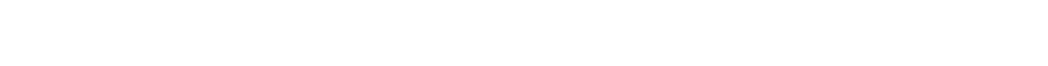

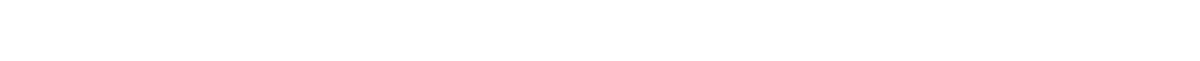

$\begin{array}{lllllllllllllllllllllllllllll}1960 & 33 & 12 & 9 & 7 & 8 & 7 & 1 & 1 & 3 & 10 & 1 & 3 & 3 & 3 & 3 & 8 & 18 & 74 & 72 & 26 & 15 & 17 & 5 & 10 & 11 & 6\end{array}$

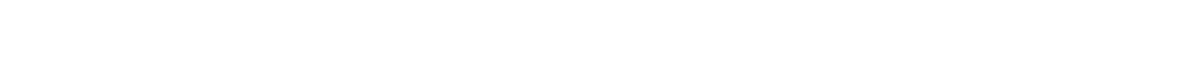

1963

1964

$\begin{array}{llllllllllllllllllllllll}2 & 7 & 1 & 2 & 2 & 4 & 4 & 4 & 10 & 7 & 4 & 6 & 11 & 11 & 15 & 22 & 74 & 46 & 93 & 21 & 10 & 5 & 2 & 2\end{array}$

$\begin{array}{rrrrrrrrrrrrrrrrrrrrrrr}11 & 2 & 1 & 5 & 5 & 13 & 13 & 13 & 6 & 4 & 13 & 82 & 67 & 33 & 14 & 18 & 8 & 6 & 13 & 17 & 10 & 3\end{array}$

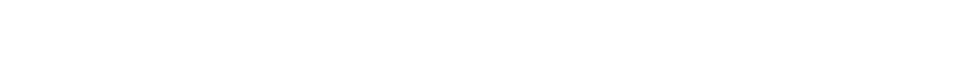

1966

$\begin{array}{llllllllllllll}8 & 11 & 23 & 22 & 12 & 11 & 13 & 40 & 100 & 74 & 36 & 7 & 6 & 2\end{array}$

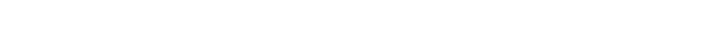

1968

1969 $\begin{array}{llllllllllllllllll}7 & 7 & 3 & 7 & 5 & 37 & 100 & 101 & 49 & 22 & 5 & 6 & 1 & 3 & 15 & 2 & 2 & 1\end{array}$

$\begin{array}{rrrrrrrrrrrrrrrrrrr}2 & 5 & 2 & 22 & 13 & 9 & 6 & 11 & 14 & 132 & 69 & 31 & 18 & 15 & 15 & 1 & & & \\ & & & 1 & 2 & & 11 & 14 & 63 & 119 & 48 & 42 & 17 & 9 & 24 & 10 & 3 & 1 & 1\end{array}$

$\begin{array}{llllllllllllllllll}9 & 8 & 2 & 5 & 19 & 7 & 32 & 42 & 71 & 57 & 32 & 27 & 17 & 11 & 7 & 8 & 3 & 8\end{array}$

$\begin{array}{rrrrrrrrrrrrrrrrrrrrrrr}1 & 9 & 18 & 7 & 17 & 12 & 4 & 7 & 10 & 40 & 77 & 62 & 29 & 31 & 13 & 7 & 7 & 5 & 3 & 7 & \end{array}$

$\begin{array}{rrrrrrrrrrrrrrrrrrr}7 & 29 & 25 & 9 & 6 & 2 & 3 & 1 & 3 & 22 & 89 & 47 & 40 & 35 & 36 & 37 & 21 & 10 & 10 \\ 1 & 7 & 3 & 7 & 8 & 4 & 3 & 5 & 4 & 72 & 55 & 86 & 24 & 10 & 11 & 6 & 1 & 3\end{array}$

33874.7

19594.2

21440.9

13408.2

40030.7

1971

1973
1974

1975

$\begin{array}{llllllllllllllll}9 & 26 & 12 & 14 & 14 & 7 & 7 & 3 & 11 & 32 & 131 & 58 & 27 & 8 & 5 & 2\end{array}$

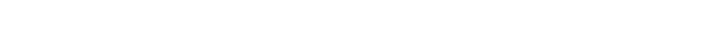

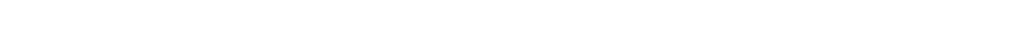

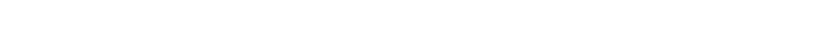

24919.5

36372.1

39866.0

23758.3

31209.0

49389.7

32629.1

57944.9

27628.5
57524.7

1977

1978

1980

$\begin{array}{lllllllllllllllllll}11 & 18 & 11 & 7 & 12 & 21 & 21 & 14 & 7 & 8 & 35 & 113 & 62 & 6 & 2 & 2 & 8 & 4 & 3\end{array}$

16880.7

7112.7

23957.9

9623.4
27828.6

1981

17837.2

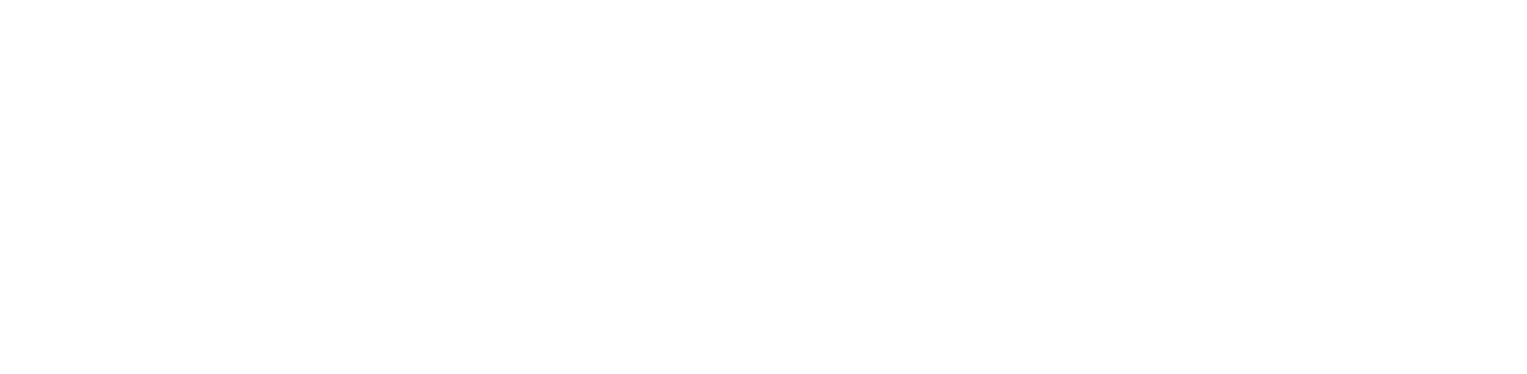

MONIHLY MEAN DISCHARGES, IN OABIC FEET PER SEOOND, FOR EACH WATER YEAR

$\begin{array}{lcccccccccccc}\text { YEAR } & \text { OCT } & \text { NOV } & \text { DEC } & \text { JAN } & \text { FEB } & \text { MAR } & \text { APR } & \text { MAY } & \text { JUNE } & \text { JULY } & \text { AUG } & \text { SEP } \\ 1929 & 36.8 & 50.4 & 42.0 & 35.0 & 50.0 & 165 & 115 & 227 & 511 & 169 & 147 & 191 \\ 1930 & 117 & 96.3 & 50.0 & 30.0 & 40.0 & 52.9 & 125 & 154 & 171 & 39.9 & 248 & 80.7 \\ 1931 & 83.6 & 51.4 & 30.0 & 30.0 & 40.0 & 44.5 & 55.3 & 60.6 & 44.8 & 6.26 & 9.83 & 0.48 \\ 1932 & 3.89 & 27.1 & 22.0 & 20.0 & 30.0 & 87.4 & 85.7 & 249 & 272 & 63.9 & 24.6 & 23.4 \\ 1933 & 34.1 & 59.3 & 20.5 & 15.2 & 15.0 & 71.0 & 77.2 & 88.1 & 352 & 27.3 & 1.90 & 0.12 \\ 1934 & 0.86 & 17.7 & 25.0 & 30.0 & 40.0 & 45.0 & 34.1 & 5.38 & 0.10 & 0.00 & 2.01 & 0.00 \\ 1935 & 0.00 & 12.8 & 34.1 & 24.0 & 32.0 & 34.0 & 3.94 & 18.2 & 328 & 8.08 & 1.46 & 0.86 \\ & & & & & & & & & & & & \\ 1936 & 3.40 & 28.8 & 30.5 & 20.0 & 28.0 & 41.9 & 51.4 & 58.6 & 30.5 & 105 & 298 & 74.6 \\ 1937 & 68.8 & 65.5 & 55.8 & 27.0 & 41.0 & 72.0 & 108 & 252 & 204 & 149 & 22.5 & 61.6 \\ 1938 & 64.3 & 62.0 & 58.8 & 48.0 & 45.0 & 63.1 & 109 & 247 & 371 & 89.4 & 16.8 & 134 \\ 1939 & 116 & 77.6 & 57.7 & 42.0 & 38.6 & 103 & 98.5 & 209 & 50.6 & 9.83 & 3.12 & 8.20 \\ 1940 & 37.8 & 40.0 & 42.6 & 32.5 & 34.3 & 50.1 & 52.2 & 121 & 9.05 & 0.09 & 0.09 & 3.73 \\ & & & & & & & & & & & & \\ 1941 & 16.4 & 36.9 & 30.3 & 30.4 & 39.5 & 60.0 & 45.2 & 250 & 377 & 147 & 101 & 84.4 \\ 1942 & 159 & 97.6 & 70.5 & 46.6 & 44.6 & 57.7 & 121 & 282 & 388 & 98.0 & 20.1 & 18.0 \\ 1943 & 34.4 & 73.9 & 59.1 & 46.4 & 56.5 & 74.6 & 80.2 & 119 & 81.9 & 22.7 & 42.3 & 16.2 \\ 1944 & 26.0 & 58.4 & 40.2 & 39.5 & 39.0 & 53.2 & 196 & 295 & 469 & 186 & 21.2 & 11.9 \\ 1945 & 51.8 & 44.9 & 42.0 & 44.0 & 45.0 & 75.0 & 102 & 175 & 184 & 150 & 92.6 & 45.4\end{array}$


GREEN RIVER BASIN

09229500 HENRYS FORK NEAR MANILA, UT--Continued

MONIHLY MEAN DISCHARGES, IN CUBIC FEET PER SECOND, FOR EACH WATER YEAR--Continued

\begin{tabular}{|c|c|c|c|c|c|c|c|c|c|c|c|c|}
\hline YEAR & $\propto T$ & NOV & $\mathrm{DEC}$ & JAN & FEB & MAR & APR & MAY & JUNE & JULY & AUG & SEP \\
\hline $\begin{array}{l}1946 \\
1947 \\
1948 \\
1949 \\
1950\end{array}$ & $\begin{array}{l}60.8 \\
60.7 \\
58.0 \\
11.2 \\
75.6\end{array}$ & $\begin{array}{l}53.5 \\
57.2 \\
68.6 \\
38.0 \\
63.8\end{array}$ & $\begin{array}{l}50.0 \\
52.0 \\
59.0 \\
37.8 \\
41.6\end{array}$ & $\begin{array}{l}45.0 \\
30.5 \\
46.0 \\
34.8 \\
50.3\end{array}$ & $\begin{array}{l}37.0 \\
47.9 \\
40.1 \\
33.0 \\
47.8\end{array}$ & $\begin{array}{c}80.0 \\
109 \\
63.0 \\
65.6 \\
48.8\end{array}$ & $\begin{array}{c}160 \\
83.5 \\
144 \\
81.6 \\
74.8\end{array}$ & $\begin{array}{l}98.3 \\
300 \\
251 \\
156 \\
129\end{array}$ & $\begin{array}{l}47.7 \\
375 \\
120 \\
444 \\
283\end{array}$ & $\begin{array}{c}29.3 \\
175 \\
3.48 \\
121 \\
73.0\end{array}$ & $\begin{array}{c}16.2 \\
108 \\
2.34 \\
28.3 \\
26.4\end{array}$ & $\begin{array}{c}47.6 \\
46.5 \\
2.89 \\
18.6 \\
24.2\end{array}$ \\
\hline $\begin{array}{l}1951 \\
1952 \\
1953 \\
1954 \\
1955\end{array}$ & $\begin{array}{c}37.3 \\
54.1 \\
45.0 \\
8.30 \\
8.29\end{array}$ & $\begin{array}{l}45.0 \\
49.0 \\
47.6 \\
34.5 \\
16.7\end{array}$ & $\begin{array}{l}47.2 \\
50.8 \\
46.4 \\
38.6 \\
25.0\end{array}$ & $\begin{array}{l}34.9 \\
37.3 \\
54.9 \\
37.6 \\
25.0\end{array}$ & $\begin{array}{l}54.0 \\
49.9 \\
62.9 \\
32.0 \\
30.0\end{array}$ & $\begin{array}{l}57.0 \\
69.1 \\
77.0 \\
27.3 \\
45.0\end{array}$ & $\begin{array}{c}51.0 \\
184 \\
76.9 \\
43.8 \\
63.6\end{array}$ & $\begin{array}{c}91.8 \\
371 \\
62.4 \\
13.9 \\
35.0\end{array}$ & $\begin{array}{c}197 \\
571 \\
439 \\
3.91 \\
86.5\end{array}$ & $\begin{array}{c}48.7 \\
170 \\
22.7 \\
11.8 \\
1.69\end{array}$ & $\begin{array}{c}68.3 \\
140 \\
29.6 \\
0.66 \\
6.75\end{array}$ & $\begin{array}{r}30.1 \\
60.8 \\
4.45 \\
7.38 \\
5.18\end{array}$ \\
\hline $\begin{array}{l}1956 \\
1957 \\
1958 \\
1959 \\
1960\end{array}$ & $\begin{array}{c}20.0 \\
7.57 \\
57.8 \\
1.59 \\
33.3\end{array}$ & $\begin{array}{l}31.3 \\
31.7 \\
82.7 \\
20.5 \\
52.6\end{array}$ & $\begin{array}{l}33.9 \\
33.1 \\
70.0 \\
49.3 \\
46.7\end{array}$ & $\begin{array}{l}37.7 \\
27.5 \\
40.0 \\
35.0 \\
38.8\end{array}$ & $\begin{array}{l}42.7 \\
41.9 \\
40.0 \\
31.4 \\
35.6\end{array}$ & $\begin{array}{l}76.8 \\
24.9 \\
45.6 \\
58.5 \\
119\end{array}$ & $\begin{array}{l}71.4 \\
66.9 \\
71.6 \\
92.5 \\
57.1\end{array}$ & $\begin{array}{c}94.0 \\
49.4 \\
184 \\
67.0 \\
145\end{array}$ & $\begin{array}{l}100 \\
47.4 \\
93.0 \\
218 \\
172\end{array}$ & $\begin{array}{c}2.62 \\
207 \\
1.09 \\
66.6 \\
1.40\end{array}$ & $\begin{array}{c}0.64 \\
100.0 \\
0.44 \\
6.37 \\
0.14\end{array}$ & $\begin{array}{c}0.28 \\
53.1 \\
0.66 \\
2.44 \\
0.46\end{array}$ \\
\hline $\begin{array}{l}1961 \\
1962 \\
1963 \\
1964 \\
1965\end{array}$ & $\begin{array}{l}1.60 \\
98.8 \\
30.9 \\
13.0 \\
16.3\end{array}$ & $\begin{array}{l}22.1 \\
79.0 \\
46.7 \\
43.1 \\
33.3\end{array}$ & $\begin{array}{l}31.0 \\
49.9 \\
33.9 \\
34.4 \\
61.2\end{array}$ & $\begin{array}{l}25.5 \\
59.7 \\
25.2 \\
33.9 \\
63.5\end{array}$ & $\begin{array}{l}30.6 \\
71.1 \\
25.5 \\
45.2 \\
59.4\end{array}$ & $\begin{array}{l}58.7 \\
97.5 \\
47.3 \\
52.1 \\
79.0\end{array}$ & $\begin{array}{c}84.8 \\
170 \\
54.9 \\
104 \\
98.0\end{array}$ & $\begin{array}{l}47.5 \\
192 \\
39.2 \\
260 \\
163\end{array}$ & $\begin{array}{c}51.1 \\
344 \\
75.8 \\
444 \\
1259\end{array}$ & $\begin{array}{c}0.23 \\
125 \\
13.9 \\
137 \\
592\end{array}$ & $\begin{array}{l}14.3 \\
28.6 \\
10.5 \\
10.6 \\
323\end{array}$ & $\begin{array}{c}75.5 \\
2.44 \\
12.4 \\
2.00 \\
170\end{array}$ \\
\hline $\begin{array}{l}1966 \\
1967 \\
1968 \\
1969 \\
1970\end{array}$ & $\begin{array}{r}134 \\
52.9 \\
21.2 \\
50.0 \\
58.2\end{array}$ & $\begin{array}{l}97.1 \\
64.3 \\
53.1 \\
55.8 \\
60.8\end{array}$ & $\begin{array}{l}79.5 \\
59.0 \\
44.8 \\
47.6 \\
41.3\end{array}$ & $\begin{array}{l}59.7 \\
60.7 \\
49.9 \\
59.7 \\
40.4\end{array}$ & $\begin{array}{l}57.9 \\
48.5 \\
51.6 \\
49.1 \\
49.5\end{array}$ & $\begin{array}{l}74.6 \\
68.1 \\
68.2 \\
72.2 \\
47.9\end{array}$ & $\begin{array}{l}76.8 \\
46.5 \\
80.4 \\
95.7 \\
69.1\end{array}$ & $\begin{array}{l}135 \\
114 \\
80.6 \\
156 \\
156\end{array}$ & $\begin{array}{l}34.5 \\
404 \\
598 \\
130 \\
293\end{array}$ & $\begin{array}{c}20.6 \\
197 \\
96.5 \\
31.3 \\
120\end{array}$ & $\begin{array}{c}29.1 \\
57.0 \\
113 \\
25.3 \\
33.2\end{array}$ & $\begin{array}{c}18.0 \\
24.0 \\
57.1 \\
7.03 \\
58.5\end{array}$ \\
\hline $\begin{array}{l}1971 \\
1972 \\
1973 \\
1974 \\
1975\end{array}$ & $\begin{array}{c}69.0 \\
46.3 \\
39.8 \\
101 \\
13.8\end{array}$ & $\begin{array}{l}79.6 \\
72.0 \\
61.8 \\
87.1 \\
36.7\end{array}$ & $\begin{array}{l}63.2 \\
50.4 \\
52.3 \\
53.4 \\
46.7\end{array}$ & $\begin{array}{l}95.3 \\
42.6 \\
44.5 \\
54.8 \\
31.6\end{array}$ & $\begin{array}{l}62.9 \\
65.5 \\
47.8 \\
51.5 \\
34.4\end{array}$ & $\begin{array}{l}130 \\
133 \\
109 \\
87.1 \\
57.1\end{array}$ & $\begin{array}{c}111 \\
89.0 \\
171 \\
92.0 \\
54.9\end{array}$ & $\begin{array}{l}198 \\
140 \\
325 \\
251 \\
156\end{array}$ & $\begin{array}{l}644 \\
401 \\
486 \\
105 \\
644\end{array}$ & $\begin{array}{c}137 \\
15.6 \\
302 \\
15.4 \\
703\end{array}$ & $\begin{array}{c}20.1 \\
4.80 \\
136 \\
3.20 \\
83.3\end{array}$ & $\begin{array}{c}16.4 \\
15.4 \\
127 \\
4.41 \\
21.3\end{array}$ \\
\hline $\begin{array}{l}1976 \\
1977 \\
1978 \\
1979 \\
1980\end{array}$ & $\begin{array}{c}45.6 \\
16.3 \\
4.66 \\
10.6 \\
6.58\end{array}$ & $\begin{array}{l}61.0 \\
42.8 \\
31.6 \\
29.6 \\
37.3\end{array}$ & $\begin{array}{l}61.0 \\
32.7 \\
31.0 \\
25.2 \\
38.4\end{array}$ & $\begin{array}{l}52.3 \\
21.4 \\
33.7 \\
22.9 \\
44.9\end{array}$ & $\begin{array}{l}45.6 \\
29.6 \\
45.7 \\
37.6 \\
58.1\end{array}$ & $\begin{array}{l}47.6 \\
33.0 \\
62.5 \\
73.8 \\
58.6\end{array}$ & $\begin{array}{l}58.1 \\
17.8 \\
34.0 \\
46.9 \\
88.0\end{array}$ & $\begin{array}{c}97.8 \\
3.79 \\
56.5 \\
34.7 \\
158\end{array}$ & $\begin{array}{c}62.6 \\
29.2 \\
466 \\
22.3 \\
307\end{array}$ & $\begin{array}{c}8.09 \\
4.86 \\
22.6 \\
2.96 \\
91.2\end{array}$ & $\begin{array}{c}10.4 \\
2.42 \\
3.85 \\
8.31 \\
12.3\end{array}$ & $\begin{array}{c}3.20 \\
1.28 \\
2.31 \\
2.48 \\
15.6\end{array}$ \\
\hline 1981 & 31.9 & 55.8 & 60.7 & 48.5 & 51.4 & 43.2 & 51.5 & 42.3 & 184 & 10.6 & 3.70 & 5.89 \\
\hline
\end{tabular}

ANNUAL PEAK DISCHARGE, IN CUBIC FEET PER SECOND, AND CORRESPONDING GAGE HEIGHT, IN FEET, FOR EACH WATER YEAR

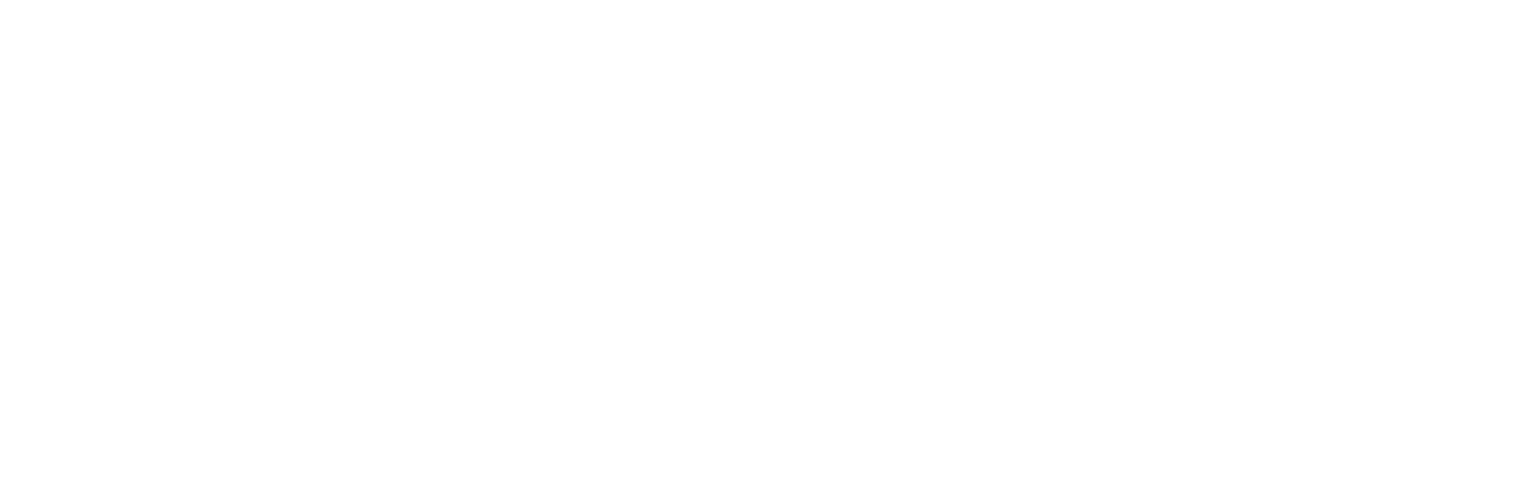

MAGNITUDE AND PRCBABILITY OF ANNUAL HIGHEST MEAN DISCHARGE BASED ON WATER YEARS $1929-81$

\begin{tabular}{|c|c|c|c|c|c|c|}
\hline \multirow{2}{*}{$\begin{array}{l}\text { PERIOD } \\
\text { (CON- } \\
\text { SEOU- } \\
\text { TIVE } \\
\text { DAYS) }\end{array}$} & \multicolumn{6}{|c|}{$\begin{array}{l}\text { DISCHARGE, IN CUBIC FEET PER SECOND, FOR } \\
\text { INDICATED REOURRENCE INTERNAL, IN YEARS, AND } \\
\text { ANNUAL EXCEEDANCE PRCBABILITY, IN PERCENT }\end{array}$} \\
\hline & $\begin{array}{c}2 \\
508\end{array}$ & $\begin{array}{c}5 \\
208\end{array}$ & $\begin{array}{l}10 \\
108\end{array}$ & $\begin{array}{l}25 \\
48\end{array}$ & $\begin{array}{l}50 \\
28\end{array}$ & $\begin{array}{r}100 \\
18\end{array}$ \\
\hline $\begin{array}{r}1 \\
3 \\
7 \\
15\end{array}$ & $\begin{array}{l}640 \\
558 \\
460 \\
364\end{array}$ & $\begin{array}{r}1180 \\
1020 \\
848 \\
662\end{array}$ & $\begin{array}{r}1630 \\
1380 \\
1140 \\
869\end{array}$ & $\begin{array}{l}2290 \\
1870 \\
1520 \\
1130\end{array}$ & $\begin{array}{l}2860 \\
2260 \\
1810 \\
1320\end{array}$ & $\begin{array}{l}3490 \\
2670 \\
2100 \\
1500\end{array}$ \\
\hline
\end{tabular}


GREEN RIVER BASIN

09232000 SHEEP CREEK NEAR MANILA, UT

LOCATION.--Lat $40^{\circ} 53^{\prime} 10^{\prime \prime}$, long $109^{\circ} 54^{\prime} 10^{\prime \prime}$, in NE立 sec.28, T.2 N., R.18 E., Daggett County, Hydrologic Unit 14040106, on left bank $350 \mathrm{ft}$ downstream from confluence of North and South Forks and $12 \mathrm{mi}$ southwest of Manila.

DRAINAGE AREA. $--42 \mathrm{mi}^{2}$.

PERIOD OF RECORD AVAILABLE.--OCtober 1942 and April 1943 to September 1961 (monthly mean discharge for some periods, published in WSP 1313).

REVISED RBCORDS.--WSP 1733: Drainage area.

GAGE.--Water-stage recorder. Altitude of gage is $8,680 \mathrm{ft}$ from topographic map.

REMARKS.--Transbasin diversions by Sheep Creek canals above station. Since June 1954, water has been diverted from Carter Creek drainage to Sheep Creek above Sheep Creek lower canal to increase irrigation supply in that canal, flow at this station could be affected. Some storage in several small mountain lakes.

AVERAGE DISCHARGE. -18 years, $12.0 \mathrm{ft}^{3} / \mathrm{s}, 8,690 \mathrm{acre}-\mathrm{ft} / \mathrm{Yr}$.

EXTREMES FOR PERIOD OF RBCORD.--Maximum discharge, $1,020 \mathrm{ft}^{3} / \mathrm{s}$ May 19, 1948, gage height, $6.05 \mathrm{ft}$, from rating curve extended above $250 \mathrm{ft}^{3} / \mathrm{s} ;$ no flow Nov. $5-7,9,10,1956$.

EXTREMES OUTSIDE OF PERIOD OF RECORD.-Maximum discharge known, 2,320 $\mathrm{ft}^{3} / \mathrm{s}$ June 10 or 11, 1965, gage height, $9.36 \mathrm{ft}$ from floodmarks, frorn an estimate based on a field survey.

DATA BELOW BASED ON PERIOD OF RECORD PRIOR TO DIVERSIONS THROUGH SHEEP CREEK CANALS

LOWEST MEAN DISCHARGE, IN CUBIC FEET PER SECOND, AND RANKING FOR THE INDICATED NUMBER OF CONSECUTIVE DAYS FOR EACH CLIMATIC YEAR, APRIL I-MARCH 31

YEA

$\begin{array}{rcrrrrrrr} & 1 & & 3 & & 7 & & 14 & \\ 1945 & 0.30 & 6 & 0.30 & 6 & 0.31 & 5 & 0.36 & 5 \\ 1946 & 0.20 & 3 & 0.23 & 3 & 0.31 & 6 & 0.36 & 6 \\ 1947 & 0.10 & 1 & 0.10 & 1 & 0.10 & 1 & 0.10 & 1 \\ 1948 & 0.40 & 7 & 0.40 & 7 & 0.40 & 7 & 0.41 & 7 \\ 1949 & 0.70 & 10 & 0.70 & 10 & 0.70 & 10 & 0.71 & 10 \\ 1950 & 0.40 & 8 & 0.40 & 8 & 0.46 & 8 & 0.49 & 8 \\ 1951 & 0.20 & 2 & 0.20 & 2 & 0.20 & 2 & 0.20 & 2 \\ 1952 & 0.50 & 9 & 0.50 & 9 & 0.57 & 9 & 0.63 & 9 \\ 1953 & 0.30 & 4 & 0.30 & 4 & 0.30 & 3 & 0.30 & 3 \\ 1954 & 0.30 & 5 & 0.30 & 5 & 0.30 & 4 & 0.36 & 4\end{array}$

$\begin{array}{ll}\text { CONSECUTIVE DAYS } \\ 30 & 60\end{array}$

$$
30
$$$$
0.445
$$$$
0.797
$$

0.578

0.111

$\begin{array}{ll}0.11 & 1 \\ 0.52 & 6\end{array}$

$0.76 \quad 10$

0.547

0.242

0.689

0.353

0.404

2.8010

0.161

1.909

0.848

0.615

0.292

0.776

0.373

0.484

$\begin{array}{lr}90 & \\ 1.10 & 8 \\ 4.00 & 9 \\ 0.40 & 2 \\ 6.10 & 10 \\ 0.88 & 7 \\ 0.65 & 5 \\ 0.35 & 1 \\ 0.85 & 6 \\ 0.45 & 3 \\ 0.52 & 4\end{array}$

120

183

ALL
$1.50 \quad 5$

4.309

0.694

$6.90 \quad 10$

6.9010

$\begin{array}{ll}2.50 & 7 \\ 2.80 & 8\end{array}$

0.431

2.106

0.673

0.602 $\begin{array}{llll}3.10 & 5 & 32.0 & 10\end{array}$

$\begin{array}{llll}5.30 & 9 & 8.70 & 5\end{array}$

$\begin{array}{llll}1.10 & 2 & 6.30 & 2\end{array}$

$7.6010 \quad 28.0 \quad 9$

$\begin{array}{llll}3.90 & 7 & 22.0 & 7\end{array}$

$\begin{array}{llll}3.60 & 6 & 21.0 & 6\end{array}$

$\begin{array}{llll}1.30 & 3 & 8.20 & 4\end{array}$

$\begin{array}{llll}4.00 & 8 & 6.10 & 1\end{array}$

$2.30 \quad 4 \quad 27.0 \quad 8$

$\begin{array}{rrrr}0.99 & 1 & 8.10 & 3\end{array}$

HIGHEST MEAN DISCHARGE, IN CUBIC FEET PER SECOND, AND RANKING FOR THE INDICATED NMMBER OF CONSECUTIVE DAYS FOR EACH WATER YEAR, OCTOBER 1-SEPTFMBER 30

YEAR

\begin{tabular}{|c|c|c|c|c|c|c|c|c|c|c|c|c|c|c|c|c|c|c|c|}
\hline 1 & & 3 & & 7 & & 15 & & $\begin{array}{l}\text { CON } \\
30\end{array}$ & & $\begin{array}{c}E \text { DAYS } \\
60\end{array}$ & & 90 & & 120 & & 183 & & ALL & \\
\hline $\begin{array}{l}460 \\
50.0\end{array}$ & $\begin{array}{r}3 \\
10\end{array}$ & $\begin{array}{l}433 \\
40.0\end{array}$ & $\begin{array}{r}2 \\
10\end{array}$ & $\begin{array}{l}320 \\
37.0\end{array}$ & $\begin{array}{r}2 \\
10\end{array}$ & $\begin{array}{l}271 \\
36.0\end{array}$ & $\begin{array}{l}2 \\
9\end{array}$ & $\begin{array}{l}234 \\
26.0\end{array}$ & $\begin{array}{l}1 \\
9\end{array}$ & $\begin{array}{l}165 \\
21.0\end{array}$ & $\begin{array}{l}1 \\
8\end{array}$ & $\begin{array}{l}116 \\
17.0\end{array}$ & $\begin{array}{l}1 \\
8\end{array}$ & $\begin{array}{l}90.0 \\
15.0\end{array}$ & $\begin{array}{l}1 \\
8\end{array}$ & $\begin{array}{l}62.0 \\
12.0\end{array}$ & $\begin{array}{l}1 \\
8\end{array}$ & $\begin{array}{c}33.0 \\
8.70\end{array}$ & $\begin{array}{l}1 \\
8\end{array}$ \\
\hline $\begin{array}{l}60.0 \\
466 \\
748 \\
340 \\
140\end{array}$ & $\begin{array}{l}9 \\
2 \\
1 \\
4 \\
7\end{array}$ & $\begin{array}{l}57.0 \\
400 \\
538 \\
256 \\
131\end{array}$ & $\begin{array}{l}9 \\
3 \\
1 \\
5\end{array}$ & $\begin{array}{l}52.0 \\
313 \\
404 \\
231 \\
95.0\end{array}$ & $\begin{array}{l}8 \\
3 \\
1 \\
5 \\
7\end{array}$ & $\begin{array}{l}42.0 \\
219 \\
308 \\
180 \\
77.0\end{array}$ & $\begin{array}{l}8 \\
3 \\
1 \\
5 \\
7\end{array}$ & $\begin{array}{l}28.0 \\
153 \\
198 \\
124 \\
59.0\end{array}$ & $\begin{array}{l}8 \\
4 \\
2 \\
5 \\
7\end{array}$ & $\begin{array}{c}19.0 \\
114 \\
111 \\
91.0 \\
37.0\end{array}$ & $\begin{array}{l}9 \\
3 \\
4 \\
5 \\
7\end{array}$ & $\begin{array}{l}15.0 \\
88.0 \\
77.0 \\
72.0 \\
27.0\end{array}$ & $\begin{array}{l}9 \\
3 \\
4 \\
5 \\
7\end{array}$ & & $\begin{array}{l}9 \\
3 \\
4 \\
5 \\
7\end{array}$ & & $\begin{array}{l}9 \\
3 \\
4 \\
5 \\
7\end{array}$ & $\begin{array}{c}5.70 \\
27.0 \\
23.0 \\
22.0 \\
9.40\end{array}$ & $\begin{array}{l}9 \\
3\end{array}$ \\
\hline $\begin{array}{l}68.0 \\
312 \\
151 \\
28.0\end{array}$ & $\begin{array}{r}8 \\
5 \\
6 \\
11\end{array}$ & $\begin{array}{c}61.0 \\
279 \\
122 \\
25.0\end{array}$ & $\begin{array}{r}8 \\
4 \\
7 \\
11\end{array}$ & $\begin{array}{c}46.0 \\
247 \\
115 \\
23.0\end{array}$ & $\begin{array}{r}9 \\
4 \\
6 \\
11\end{array}$ & $\begin{array}{c}25.0 \\
202 \\
94.0 \\
18.0\end{array}$ & $\begin{array}{r}10 \\
4 \\
6 \\
11\end{array}$ & $\begin{array}{c}17.0 \\
173 \\
66.0 \\
11.0\end{array}$ & $\begin{array}{r}10 \\
3 \\
6 \\
11\end{array}$ & $\begin{array}{c}12.0 \\
136 \\
42.0 \\
6.40\end{array}$ & $\begin{array}{r}10 \\
2 \\
6 \\
11\end{array}$ & $\begin{array}{c}10.0 \\
99.0 \\
30.0 \\
4.60\end{array}$ & $\begin{array}{r}10 \\
2 \\
6 \\
11\end{array}$ & $\begin{array}{c}8.70 \\
76.0 \\
24.0 \\
3.90\end{array}$ & $\begin{array}{r}10 \\
2 \\
6 \\
11\end{array}$ & $\begin{array}{c}6.90 \\
52.0 \\
18.0 \\
3.20\end{array}$ & $\begin{array}{r}10 \\
2 \\
6 \\
11\end{array}$ & $\begin{array}{c}4.10 \\
28.0 \\
9.60 \\
2.10\end{array}$ & $\begin{array}{r}10 \\
2 \\
6 \\
11\end{array}$ \\
\hline
\end{tabular}


GREEN RIVER BASIN

09232000 SHEEP CREEK NEAR MANILA, UT-Continued

DURATION OF DISCHARGE FOR EAOH WATER YEAR

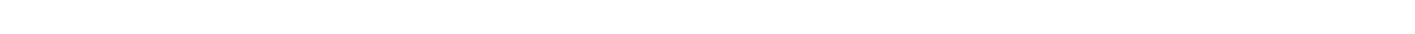

\begin{tabular}{|c|c|c|c|c|c|c|c|c|c|c|c|c|c|c|c|c|c|c|c|c|c|c|c|c|c|c|c|c|c|c|}
\hline EAR & & & & & & & & & MBER & OF & DAYS & $5 \mathrm{IN}$ & CLAS & & & & & & & & & & & & & & & & & $\begin{array}{l}\text { OUBIC FEET } \\
\text { PER SECOND } \\
\text {-DAYS }\end{array}$ \\
\hline & & $\begin{array}{rrr}4 & 25 & 44 \\
6 & 8 & 1\end{array}$ & & & $\begin{array}{l}5 \\
2\end{array}$ & $\begin{array}{r}2 \\
11\end{array}$ & $\begin{array}{r}1 \\
33\end{array}$ & $\begin{array}{r}2 \\
22\end{array}$ & $\begin{array}{l}4 \\
3\end{array}$ & $\begin{array}{l}5 \\
4\end{array}$ & $\begin{array}{r}5 \\
64\end{array}$ & $\begin{array}{l}24 \\
97\end{array}$ & $\begin{array}{l}71 \\
35\end{array}$ & $\begin{array}{l}70 \\
17\end{array}$ & $\begin{array}{r}8 \\
26\end{array}$ & $\begin{array}{l}4 \\
3\end{array}$ & $\begin{array}{r}2 \\
15\end{array}$ & $\begin{array}{r}3 \\
17\end{array}$ & 2 & $\begin{array}{l}4 \\
1\end{array}$ & 8 & 9 & 7 & & 813 & & & & 3 & $\begin{array}{r}12074.8 \\
3157.4\end{array}$ \\
\hline $\begin{array}{l}12 \\
22\end{array}$ & $\begin{array}{r}17 \\
7\end{array}$ & $\begin{array}{rrr}3 & 19 & 16 \\
13 & 15 \\
& & \\
& 3 & 41 \\
1 & 20 & 46\end{array}$ & $\begin{array}{r}2 \\
5 \\
28 \\
13 \\
14\end{array}$ & $\begin{array}{r}4 \\
8 \\
37 \\
12 \\
15\end{array}$ & $\begin{array}{r}31 \\
5 \\
15 \\
5\end{array}$ & $\begin{array}{r}42 \\
6 \\
14\end{array}$ & $\begin{array}{r}24 \\
1 \\
1 \\
15\end{array}$ & $\begin{array}{r}15 \\
1 \\
1 \\
1\end{array}$ & $\begin{array}{l}2 \\
1 \\
1 \\
1 \\
2\end{array}$ & $\begin{array}{r}3 \\
2 \\
1 \\
88\end{array}$ & $\begin{array}{r}64 \\
2 \\
40 \\
46\end{array}$ & $\begin{array}{r}48 \\
35 \\
122 \\
137 \\
18\end{array}$ & $\begin{array}{l}34 \\
96 \\
48 \\
10 \\
15\end{array}$ & $\begin{array}{r}5 \\
25 \\
21 \\
8 \\
15\end{array}$ & $\begin{array}{r}6 \\
12 \\
23 \\
6 \\
15\end{array}$ & $\begin{array}{r}4 \\
31 \\
11 \\
8 \\
7\end{array}$ & $\begin{array}{r}2 \\
6 \\
3 \\
14 \\
9\end{array}$ & $\begin{array}{l}1 \\
3 \\
9 \\
6 \\
6\end{array}$ & $\begin{array}{r}4 \\
10 \\
4 \\
12 \\
6\end{array}$ & $\begin{array}{r}7 \\
18 \\
3 \\
15 \\
3\end{array}$ & $\begin{array}{r}9 \\
16 \\
6\end{array}$ & $\begin{array}{r}10 \\
2 \\
5 \\
2\end{array}$ & $\begin{array}{l}9 \\
3 \\
6 \\
2\end{array}$ & $\frac{9}{3}$ & $\begin{array}{l}6 \\
2 \\
3 \\
2\end{array}$ & & & & $\begin{array}{l}2 \\
1\end{array}$ & $\begin{array}{l}2075.5 \\
9841.3 \\
8525.3 \\
8106.5 \\
3430.4\end{array}$ \\
\hline & 19 & $\begin{array}{rrr}30 & 1 & 12 \\
11 & 6 & 25 \\
27 & 29 & 87 \\
11 & 4 & 48\end{array}$ & $\begin{array}{r}11 \\
3 \\
7 \\
20\end{array}$ & $\begin{array}{r}35 \\
8 \\
1 \\
68\end{array}$ & $\begin{array}{r}34 \\
8 \\
1 \\
25\end{array}$ & $\begin{array}{r}7 \\
24 \\
1 \\
74\end{array}$ & $\begin{array}{r}12 \\
4 \\
1 \\
54\end{array}$ & $\begin{array}{r}6 \\
27\end{array}$ & $\begin{array}{r}128 \\
1 \\
1 \\
5\end{array}$ & $\begin{array}{r}10 \\
8 \\
5\end{array}$ & $\begin{array}{r}18 \\
96 \\
97 \\
5\end{array}$ & $\begin{array}{r}3 \\
50 \\
49 \\
4\end{array}$ & $\begin{array}{r}7 \\
31 \\
10 \\
2\end{array}$ & $\begin{array}{r}7 \\
13 \\
2\end{array}$ & $\begin{array}{r}10 \\
7 \\
5 \\
4\end{array}$ & $\begin{array}{l}6 \\
9 \\
5 \\
1\end{array}$ & $\begin{array}{l}3 \\
4 \\
7 \\
8\end{array}$ & $\begin{array}{l}1 \\
4 \\
6\end{array}$ & $\begin{array}{l}1 \\
6 \\
4\end{array}$ & $\begin{array}{l}2 \\
4 \\
1\end{array}$ & $\begin{array}{l}2 \\
5 \\
1\end{array}$ & $\begin{array}{l}6 \\
7\end{array}$ & 11 & & $\begin{array}{ll}\frac{1}{2} & 11\end{array}$ & 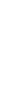 & & & & $\begin{array}{r}1482.4 \\
10296.9 \\
3517.7 \\
781.6\end{array}$ \\
\hline
\end{tabular}

DURATION TABLE OF DISCHARGE FOR WATER YEARS 1944-54

\begin{tabular}{|c|c|c|c|c|c|c|c|c|c|c|c|c|c|c|c|c|c|c|c|}
\hline CLASS & $\begin{array}{c}\text { OBBIC } \\
\text { FEET } \\
\text { PER } \\
\text { SECOND }\end{array}$ & $\begin{array}{r}\text { TOTAL } \\
\text { DAYS }\end{array}$ & $\begin{array}{c}\text { ACOU- } \\
\text { WU- } \\
\text { LATEDD } \\
\text { DAYS }\end{array}$ & $\begin{array}{l}\text { PER- } \\
\text { CENT } \\
\text { DAYS }\end{array}$ & CLASS & $\begin{array}{l}\text { OBBIC } \\
\text { FEET } \\
\text { PER } \\
\text { SECOND }\end{array}$ & $\begin{array}{l}\text { TOTAL } \\
\text { DAYS }\end{array}$ & $\begin{array}{c}\text { ACOU- } \\
\text { WU- } \\
\text { LATED } \\
\text { DAYS }\end{array}$ & $\begin{array}{l}\text { PER- } \\
\text { CENT } \\
\text { DAYS }\end{array}$ & & $\begin{array}{c}\text { OUBIC } \\
\text { FEET } \\
\text { PER } \\
\text { SECOND }\end{array}$ & $\begin{array}{r}\text { TOTAL } \\
\text { DAYS }\end{array}$ & $\begin{array}{c}\text { ACOU- } \\
\text { MU- } \\
\text { LATED } \\
\text { DAYS }\end{array}$ & $\begin{array}{l}\text { PER- } \\
\text { CENT } \\
\text { DAYS }\end{array}$ & & $\begin{array}{c}\text { OBBIC } \\
\text { FEET } \\
\text { PER } \\
\text { SECOND }\end{array}$ & TOTAL & $\begin{array}{c}\text { ACOU- } \\
\text { MU- } \\
\text { LATED } \\
\text { DAYS }\end{array}$ & $\begin{array}{l}\text { PER- } \\
\text { CENT } \\
\text { DAYS }\end{array}$ \\
\hline $\begin{array}{l}0 \\
1 \\
2 \\
3 \\
4 \\
5 \\
6 \\
7 \\
8\end{array}$ & $\begin{array}{l}0.00 \\
0.10 \\
0.13 \\
0.17 \\
0.22 \\
0.28 \\
0.36 \\
0.47\end{array}$ & $\begin{array}{r}0 \\
34 \\
0 \\
43 \\
0 \\
93 \\
128 \\
335\end{array}$ & $\begin{array}{l}4018 \\
4018 \\
3984 \\
3984 \\
3941 \\
3941 \\
3848 \\
3720 \\
3395\end{array}$ & $\begin{array}{r}100.0 \\
100.0 \\
99.2 \\
99.1 \\
98.1 \\
98.1 \\
95.7 \\
92.6\end{array}$ & $\begin{array}{r}9 \\
10 \\
11 \\
12 \\
13 \\
14 \\
15 \\
16\end{array}$ & $\begin{array}{l}0.78 \\
1.00 \\
1.30 \\
1.70 \\
2.20 \\
2.80 \\
3.70 \\
4.70\end{array}$ & $\begin{array}{r}198 \\
131 \\
187 \\
146 \\
75 \\
149 \\
126 \\
437\end{array}$ & $\begin{array}{l}3269 \\
3071 \\
2940 \\
2753 \\
2607 \\
2532 \\
2383 \\
2257\end{array}$ & $\begin{array}{l}81.3 \\
76.4 \\
73.1 \\
68.5 \\
64.9 \\
63.0 \\
59.3 \\
56.2\end{array}$ & $\begin{array}{l}18 \\
19 \\
20 \\
21 \\
22 \\
23 \\
24 \\
25\end{array}$ & $\begin{array}{r}7.9 \\
10.0 \\
13.0 \\
17.0 \\
22.0 \\
29.0 \\
37.0 \\
48.0\end{array}$ & $\begin{array}{r}359 \\
183 \\
122 \\
89 \\
73 \\
56 \\
49 \\
58\end{array}$ & $\begin{array}{r}1233 \\
874 \\
691 \\
569 \\
480 \\
407 \\
351 \\
302\end{array}$ & $\begin{array}{r}30.7 \\
21.8 \\
17.2 \\
14.2 \\
11.9 \\
10.1 \\
8.7 \\
7.5\end{array}$ & $\begin{array}{l}27 \\
28 \\
29 \\
30 \\
31 \\
32 \\
33 \\
34\end{array}$ & $\begin{array}{r}80.0 \\
100.0 \\
130.0 \\
170.0 \\
220.0 \\
290.0 \\
370.0 \\
480.0\end{array}$ & $\begin{array}{r}41 \\
44 \\
34 \\
35 \\
27 \\
8 \\
6 \\
2\end{array}$ & $\begin{array}{r}197 \\
156 \\
112 \\
78 \\
43 \\
16 \\
8 \\
2\end{array}$ & $\begin{array}{l}4.9 \\
3.9 \\
2.8 \\
1.9 \\
1.1 \\
0.4 \\
0.2 \\
0.0\end{array}$ \\
\hline
\end{tabular}

MONIHLY MEAN DISCHARGES, IN OBIC FEET PER SBCOND, FOR EACH WATER YEAR

$\begin{array}{lcccccccccccc}\text { YEAR } & \text { OCT } & \text { NOV } & \text { DEC } & \text { JAN } & \text { FEB } & \text { MAR } & \text { APR } & \text { MAY } & \text { JUNE } & \text { JULY } & \text { AUG } & \text { SEP } \\ 1944 & 0.61 & 5.10 & 9.00 & 8.00 & 10.0 & 12.0 & 10.6 & 164 & 154 & 21.3 & 0.66 & 1.15 \\ 1945 & 1.78 & 4.30 & 6.00 & 6.50 & 7.20 & 7.50 & 8.50 & 25.0 & 17.6 & 3.86 & 2.00 & 13.7 \\ & & & & & & & & & & & & \\ 1946 & 1.17 & 5.11 & 6.00 & 5.40 & 7.00 & 9.50 & 27.8 & 1.65 & 2.46 & 1.60 & 0.95 & 0.18 \\ 1947 & 0.15 & 9.93 & 8.00 & 7.50 & 8.00 & 8.50 & 18.0 & 150 & 73.9 & 27.8 & 0.78 & 9.28 \\ 1948 & 13.3 & 9.13 & 7.50 & 7.00 & 6.50 & 6.80 & 13.0 & 176 & 32.3 & 0.78 & 0.90 & 4.08 \\ 1949 & 7.55 & 6.34 & 6.50 & 7.00 & 6.50 & 6.00 & 20.9 & 66.4 & 112 & 26.0 & 0.56 & 0.71 \\ 1950 & 3.02 & 9.13 & 4.30 & 5.00 & 4.00 & 4.47 & 14.7 & 43.1 & 22.5 & 1.28 & 0.58 & 0.45 \\ & & & & & & & & & & & & \\ 1951 & 0.30 & 1.80 & 3.50 & 3.00 & 3.50 & 3.50 & 9.03 & 15.2 & 6.31 & 0.94 & 0.74 & 0.89 \\ 1952 & 9.26 & 7.96 & 5.60 & 5.40 & 5.20 & 6.40 & 25.8 & 153 & 110 & 7.35 & 0.92 & 0.41 \\ 1953 & 0.35 & 3.98 & 5.96 & 5.66 & 5.59 & 5.98 & 13.1 & 24.1 & 49.9 & 0.58 & 0.55 & 0.42 \\ 1954 & 1.38 & 1.60 & 1.86 & 2.04 & 1.54 & 1.07 & 10.8 & 1.75 & 0.78 & 0.83 & 0.57 & 1.61\end{array}$

ANNUAL, PEAK DISCHARGE, IN OBBIC FEET PER SECOND, AND CORRESPONDING GAGE HEIGHT, IN FEET, FOR EACH WATER YEAR

\begin{tabular}{|c|c|c|c|c|c|c|c|c|c|c|c|c|c|}
\hline $\begin{array}{l}\text { WATER } \\
\text { YEAR }\end{array}$ & & ATE & $\begin{array}{c}\text { GAGE } \\
\text { HEIGHT }\end{array}$ & $\begin{array}{c}\text { PEAK } \\
\text { DISCHARGE }\end{array}$ & $\begin{array}{l}\text { WAT'ER } \\
\text { YEAR }\end{array}$ & & DATE & $\begin{array}{c}\text { GAGE } \\
\text { HEIGHT }\end{array}$ & $\begin{array}{c}\text { PEAK } \\
\text { DISCHARGE }\end{array}$ & $\begin{array}{l}\text { WATERR } \\
\text { YEAR }\end{array}$ & DATE & $\begin{array}{l}\text { GAGE } \\
\text { HEIGHT }\end{array}$ & $\begin{array}{c}\text { PEAK } \\
\text { DISCHARGE }\end{array}$ \\
\hline $\begin{array}{l}1943 \\
1944 \\
1945 \\
1946\end{array}$ & $\begin{array}{ll}\text { MAY } & 0 \\
\text { MAY } & 1 \\
\text { JUNE } & 2 \\
\text { APR. } & 2\end{array}$ & $\begin{array}{ll}02, & 1943 \\
16, & 1944 \\
22, & 1945 \\
27, & 1946\end{array}$ & $\begin{array}{l}3.87 \\
5.05 \\
4.01 \\
3.78\end{array}$ & $\begin{array}{r}73 \\
472 \\
100 \\
58\end{array}$ & $\begin{array}{l}1947 \\
1948 \\
1949 \\
1950\end{array}$ & $\begin{array}{l}\text { MAY } \\
\text { MAY } \\
\text { JUNE } \\
\text { MAY }\end{array}$ & $\begin{array}{ll}08, & 1947 \\
19, & 1948 \\
19, & 1949 \\
22, & 1950\end{array}$ & $\begin{array}{l}5.60 \\
6.05 \\
5.48 \\
4.91\end{array}$ & $\begin{array}{r}694 \\
1020 \\
499 \\
259\end{array}$ & $\begin{array}{l}1951 \\
1952 \\
1953 \\
1954\end{array}$ & $\begin{array}{lll}\text { MAY } & 27,1951 \\
\text { JUNE } 07,1952 \\
\text { JUNE } 13,1953 \\
\text { MAY } 22,1954\end{array}$ & $\begin{array}{l}4.29 \\
5.39 \\
5.02 \\
3.80\end{array}$ & $\begin{array}{r}87 \\
438 \\
208 \\
45\end{array}$ \\
\hline
\end{tabular}

MAGNITUDE AND PRCBABILITY OF ANNUAL LOWEST MEAN DISCHARGE BASED ON CLIMATIC YEARS 1945-54

\begin{tabular}{|c|c|c|c|c|c|c|}
\hline \multirow{2}{*}{$\begin{array}{l}\text { PERIOD } \\
\text { (CON- } \\
\text { SECU- } \\
\text { TIVE } \\
\text { DAYS) }\end{array}$} & \multicolumn{6}{|c|}{$\begin{array}{l}\text { DISCHARGE, IN OBBIC FEET PER SECOND, FOR } \\
\text { INDICATED RECURRENCE INTERNAL, IN YEARS, AND } \\
\text { ANNUAL NONEXCEEDANCE PRCBABILITY, IN PERCENT }\end{array}$} \\
\hline & $\begin{array}{c}2 \\
508\end{array}$ & $\begin{array}{c}5 \\
208\end{array}$ & $\begin{array}{l}10 \\
108\end{array}$ & $\begin{array}{l}20 \\
58\end{array}$ & $\begin{array}{l}50 \\
28\end{array}$ & $\begin{array}{r}100 \\
18\end{array}$ \\
\hline $\begin{array}{r}1 \\
7 \\
14 \\
30 \\
60 \\
90\end{array}$ & $\begin{array}{l}0.32 \\
0.35 \\
0.39 \\
0.47 \\
0.63 \\
0.76\end{array}$ & $\begin{array}{l}0.19 \\
0.21 \\
0.23 \\
0.28 \\
0.32 \\
0.41\end{array}$ & $\begin{array}{l}0.15 \\
0.16 \\
0.16 \\
0.19 \\
0.22 \\
0.32\end{array}$ & $\begin{array}{l}0.11 \\
0.12 \\
0.12 \\
0.14 \\
0.17 \\
0.28\end{array}$ & $\begin{array}{l}\overline{-} \\
\bar{z} \\
\overline{-}\end{array}$ & $\begin{array}{l}= \\
-- \\
= \\
=\end{array}$ \\
\hline
\end{tabular}

MAGNITUDE AND PRCBABILITY OF ANNUAL HIGHEST MEAN DISCHARGE BASED ON WATER YEARS 1944-54

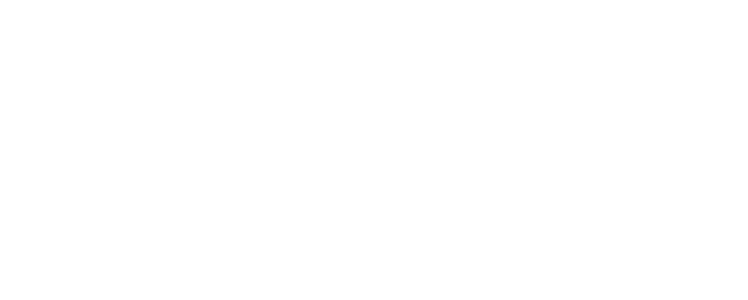


LOWEST MEAN DISOHARGE, IN OUBIC FEET PER SECOND, AND RANKING FOR THE INDICATED NUMBER OF CONSEQUTIVE DAYS FOR EAOH OIIMATIC YEAR, AFRIL 1-MAROH 31

\begin{tabular}{|c|c|c|c|c|c|c|c|c|c|c|c|c|c|c|c|c|c|c|c|}
\hline YEAR & 1 & & 3 & & 7 & & 14 & & $\begin{array}{l}\text { CONSE } \\
30\end{array}$ & DTIV & $\begin{array}{l}\text { DAYS } \\
60\end{array}$ & & 90 & & 120 & & 183 & & ALL \\
\hline $\begin{array}{l}1956 \\
1957 \\
1958 \\
1959 \\
1960\end{array}$ & $\begin{array}{l}0.00 \\
0.20 \\
0.20 \\
0.10 \\
0.30\end{array}$ & $\begin{array}{l}1 \\
4 \\
5 \\
2 \\
6\end{array}$ & $\begin{array}{l}0.00 \\
0.20 \\
0.27 \\
0.10 \\
0.30\end{array}$ & $\begin{array}{l}1 \\
4 \\
5 \\
2 \\
6\end{array}$ & $\begin{array}{l}0.03 \\
0.20 \\
0.29 \\
0.10 \\
0.30\end{array}$ & $\begin{array}{l}1 \\
4 \\
5 \\
2 \\
6\end{array}$ & $\begin{array}{l}0.08 \\
0.20 \\
0.36 \\
0.10 \\
0.30\end{array}$ & $\begin{array}{l}1 \\
4 \\
6 \\
2 \\
5\end{array}$ & $\begin{array}{l}0.23 \\
0.21 \\
0.40 \\
0.10 \\
0.30\end{array}$ & $\begin{array}{l}4 \\
3 \\
6 \\
1 \\
5\end{array}$ & $\begin{array}{l}0.33 \\
0.23 \\
1.10 \\
0.10 \\
0.37\end{array}$ & $\begin{array}{l}4 \\
3 \\
6 \\
1 \\
5\end{array}$ & $\begin{array}{l}0.37 \\
0.30 \\
1.19 \\
0.12 \\
0.47\end{array}$ & $\begin{array}{l}4 \\
3 \\
6 \\
1 \\
5\end{array}$ & $\begin{array}{l}0.40 \\
0.36 \\
1.40 \\
0.15 \\
0.56\end{array}$ & $\begin{array}{l}4 \\
3 \\
6 \\
1 \\
5\end{array}$ & $\begin{array}{l}1.10 \\
1.00 \\
3.60 \\
0.19 \\
1.40\end{array}$ & $\begin{array}{l}4 \\
3 \\
6 \\
1 \\
5\end{array}$ & $\begin{array}{c}3.00 \\
3.00 \\
17.0 \\
5.30 \\
4.80\end{array}$ \\
\hline 1961 & 0.10 & 3 & 0.10 & 3 & 0.10 & 3 & 0.10 & 3 & 0.10 & 2 & 0.10 & 2 & 0.22 & 2 & 0.22 & 2 & 0.64 & 2 & 5.20 \\
\hline
\end{tabular}

HIGHEST MEAN DISGHARGE, IN OUBIC FEET FER SECOND, AND RANKING FOR THE INDICATED NUMBER OF CONSEQUTIVE DAYS FOR EACH WATER YEAR, OCTOBER 1-SEPTEMBER 30

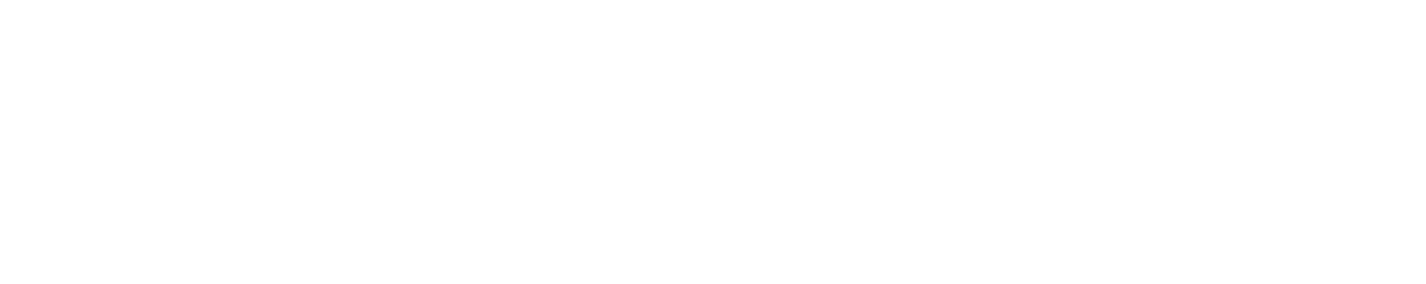

DURATION OF DISCHARGE FOR EACH WATER YEAR

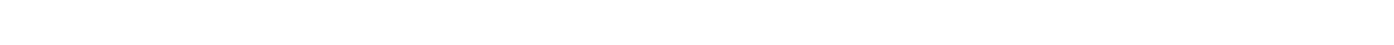

YEAR

NUMBER OF DAYS IN CLASS

OUBIC FEET PER SECOND

986.2

\begin{tabular}{|c|c|c|c|c|c|c|c|c|c|c|c|c|c|c|c|c|c|c|c|c|c|c|c|c|c|c|c|c|c|c|}
\hline 1955 & 3 & 493 & 45 & 51 & 01 & 619 & 8 & 3 & 7 & 1 & 1 & 10 & 73 & 50 & 6 & 5 & 2 & 2 & 5 & 2 & 3 & 1 & & & & & & & & 986.2 \\
\hline $\begin{array}{l}1956 \\
1957 \\
1958 \\
1959 \\
1960\end{array}$ & $\begin{array}{r}2 \\
69 \\
18\end{array}$ & $\begin{array}{ll}62 & \\
21 & 1 \\
78 & 2 \\
& 5 \\
38 & 2\end{array}$ & $\begin{array}{ll}9 & \\
3 & 2 \\
26 & 1 \\
54 & \\
4 & 1\end{array}$ & $\begin{array}{l}9 \\
4 \\
5 \\
9 \\
6\end{array}$ & $\begin{array}{ll}6 & 3 \\
1 \\
3 \\
6 \\
9\end{array}$ & $\begin{array}{cc}0 & 12 \\
1 & 1 \\
7 & 17 \\
2 & 30\end{array}$ & $\begin{array}{r}12 \\
6 \\
22 \\
4 \\
32\end{array}$ & $\begin{array}{l}5 \\
6 \\
3 \\
1 \\
7\end{array}$ & $\begin{array}{l}7 \\
6 \\
1 \\
3 \\
3\end{array}$ & $\begin{array}{r}3 \\
22 \\
1\end{array}$ & $\begin{array}{r}4 \\
16 \\
1 \\
3 \\
4\end{array}$ & $\begin{array}{l}9 \\
4 \\
1 \\
6 \\
2\end{array}$ & $\begin{array}{r}79 \\
100 \\
2 \\
96 \\
70\end{array}$ & $\begin{array}{l}67 \\
57 \\
15 \\
21 \\
66\end{array}$ & $\begin{array}{r}8 \\
10 \\
78 \\
10 \\
2\end{array}$ & $\begin{array}{r}6 \\
9 \\
40 \\
14 \\
3\end{array}$ & $\begin{array}{r}7 \\
1 \\
48 \\
4 \\
3\end{array}$ & $\begin{array}{l}2 \\
1 \\
5 \\
3 \\
3\end{array}$ & $\begin{array}{l}1 \\
1 \\
4 \\
4\end{array}$ & $\begin{array}{l}3 \\
2 \\
1 \\
5 \\
4\end{array}$ & $\begin{array}{l}3 \\
1 \\
3 \\
8 \\
9\end{array}$ & $\begin{array}{l}2 \\
2 \\
4 \\
5\end{array}$ & $\begin{array}{rr}1 & \\
5 & 17 \\
7 & 4 \\
3 & 3 \\
5 & 2\end{array}$ & $\begin{array}{l}6 \\
1 \\
\end{array}$ & $\begin{array}{l}4 \\
4\end{array}$ & $\begin{array}{l}6 \\
1\end{array}$ & 2 & 4 & & $\begin{array}{l}1088.2 \\
5665.1 \\
2558.0 \\
1638.7 \\
1994.5\end{array}$ \\
\hline 1961 & 65 & 218 & 35 & 1 & 2 & 1 & & & 2 & 4 & 3 & 2 & 74 & 61 & 11 & 2 & 5 & 1 & 5 & 1 & 1 & 3 & 5 & 1 & 2 & 1 & 2 & & & 1984.2 \\
\hline
\end{tabular}

DURATION TABLE OF DISGHARGE FOR WATER YEARS 1955-61

\begin{tabular}{|c|c|c|c|c|c|c|c|c|c|c|c|c|c|c|c|c|c|c|c|}
\hline C_ASS & $\begin{array}{c}\text { OJBIC } \\
\text { FEET } \\
\text { PER } \\
\text { SECOND }\end{array}$ & $\begin{array}{l}\text { TOTAL } \\
\text { DAYS }\end{array}$ & $\begin{array}{l}\text { ACO- } \\
\text { MU- } \\
\text { LATED } \\
\text { DAYS }\end{array}$ & $\begin{array}{l}\text { PER- } \\
\text { CENT } \\
\text { DAYS }\end{array}$ & & $\begin{array}{c}\text { OBIC } \\
\text { FEET } \\
\text { PER } \\
\text { SECOND }\end{array}$ & $\begin{array}{l}\text { TOTAL } \\
\text { DAYS }\end{array}$ & $\begin{array}{l}\text { ACU- } \\
\text { MU- } \\
\text { LATED } \\
\text { DAYS }\end{array}$ & $\begin{array}{l}\text { PER- } \\
\text { CENT } \\
\text { DAYS }\end{array}$ & C.ASS & $\begin{array}{c}\text { OBIC } \\
\text { FEET } \\
\text { FER } \\
\text { SECOND }\end{array}$ & $\begin{array}{l}\text { TOTAL } \\
\text { DAYS }\end{array}$ & $\begin{array}{l}\text { ACQ- } \\
\text { MU- } \\
\text { LATED } \\
\text { DAYS }\end{array}$ & $\begin{array}{l}\text { PER- } \\
\text { CENT } \\
\text { DAYS }\end{array}$ & CLASS & $\begin{array}{c}\text { OUBIC } \\
\text { FEET } \\
\text { PER } \\
\text { SECOND }\end{array}$ & $\begin{array}{l}\text { TOTAL } \\
\text { DAYS }\end{array}$ & $\begin{array}{c}\text { ACQU- } \\
\text { MU- } \\
\text { LATED } \\
\text { DAYS }\end{array}$ & $\begin{array}{l}\text { PER- } \\
\text { CENT } \\
\text { DAYS }\end{array}$ \\
\hline $\begin{array}{l}0 \\
1 \\
2 \\
3 \\
4 \\
5 \\
6 \\
7 \\
8\end{array}$ & $\begin{array}{l}0.00 \\
0.10 \\
0.13 \\
0.16 \\
0.20 \\
0.26 \\
0.32 \\
0.41 \\
0.52\end{array}$ & $\begin{array}{r}5 \\
174 \\
0 \\
0 \\
269 \\
245 \\
129 \\
47 \\
67\end{array}$ & $\begin{array}{l}2557 \\
2552 \\
2378 \\
2378 \\
2378 \\
2109 \\
1864 \\
1735 \\
1688\end{array}$ & $\begin{array}{r}100.0 \\
99.8 \\
93.0 \\
93.0 \\
93.0 \\
82.5 \\
72.9 \\
67.9 \\
66.0\end{array}$ & $\begin{array}{r}9 \\
10 \\
11 \\
12 \\
13 \\
14 \\
15 \\
16 \\
17\end{array}$ & $\begin{array}{l}0.66 \\
0.83 \\
1.10 \\
1.30 \\
1.70 \\
2.10 \\
2.70 \\
3.40 \\
4.30\end{array}$ & $\begin{array}{r}79 \\
84 \\
25 \\
29 \\
31 \\
32 \\
34 \\
494 \\
337\end{array}$ & $\begin{array}{r}1621 \\
1542 \\
1458 \\
1433 \\
1404 \\
1373 \\
1341 \\
1307 \\
813\end{array}$ & $\begin{array}{l}63.4 \\
60.3 \\
57.0 \\
56.0 \\
54.9 \\
53.7 \\
52.4 \\
51.1 \\
31.8\end{array}$ & $\begin{array}{l}18 \\
19 \\
20 \\
21 \\
22 \\
23 \\
24 \\
25 \\
26\end{array}$ & $\begin{array}{r}5.5 \\
6.9 \\
8.7 \\
11.0 \\
14.0 \\
18.0 \\
22.0 \\
28.0 \\
36.0\end{array}$ & $\begin{array}{r}125 \\
79 \\
70 \\
17 \\
20 \\
18 \\
28 \\
17 \\
26\end{array}$ & $\begin{array}{l}476 \\
351 \\
272 \\
202 \\
185 \\
165 \\
147 \\
119 \\
102\end{array}$ & $\begin{array}{r}18.6 \\
13.7 \\
10.6 \\
7.9 \\
7.2 \\
6.5 \\
5.7 \\
4.7 \\
4.0\end{array}$ & $\begin{array}{l}27 \\
28 \\
29 \\
30 \\
31 \\
32 \\
33 \\
34\end{array}$ & $\begin{array}{r}45.0 \\
57.0 \\
72.0 \\
92.0 \\
120.0 \\
150.0 \\
19 C .0 \\
24 C .0\end{array}$ & $\begin{array}{r}30 \\
12 \\
10 \\
10 \\
4 \\
4 \\
5\end{array}$ & $\begin{array}{r}76 \\
46 \\
34 \\
24 \\
14 \\
10 \\
6 \\
1\end{array}$ & $\begin{array}{l}3.0 \\
1.8 \\
1.3 \\
0.9 \\
0.5 \\
0.4 \\
0.2 \\
0.0\end{array}$ \\
\hline
\end{tabular}

MONIHLY MEAN DISCHARGES, IN OBIC FEET PER SECOND, FOR EACH WATER YEAR

$\begin{array}{lllllllllllll}\text { YEAR } & \text { OCT } & \text { NOV } & \text { DEC } & \text { JAN } & \text { FEB } & \text { MAR } & \text { APR } & \text { MAY } & \text { JUNE } & \text { JULY } & \text { AUG } & \text { SEP } \\ 1955 & 1.08 & 0.24 & 2.71 & 3.50 & 3.55 & 4.91 & 9.03 & 2.91 & 3.32 & 0.49 & 0.51 & 0.3 \\ 1956 & 1.59 & 1.95 & 4.35 & 4.27 & 3.41 & 3.98 & 5.83 & 7.85 & 1.34 & 0.60 & 0.24 & 0.2 \\ 1957 & 0.44 & 3.44 & 4.08 & 3.93 & 4.16 & 4.08 & 5.71 & 33.9 & 120 & 4.42 & 1.54 & 1.5 \\ 1958 & 2.15 & 5.99 & 8.93 & 7.01 & 5.81 & 5.65 & 7.39 & 36.3 & 3.73 & 0.22 & 0.22 & 0.1 \\ 1959 & 0.10 & 0.10 & 3.15 & 3.97 & 4.00 & 4.00 & 9.77 & 16.0 & 11.4 & 0.30 & 0.45 & 0.6 \\ 1960 & 0.85 & 1.37 & 4.55 & 4.14 & 4.20 & 4.46 & 22.3 & 15.9 & 4.41 & 2.64 & 0.23 & 0.4 \\ 1961 & 0.11 & 0.10 & 4.04 & 4.06 & 3.50 & 4.25 & 9.36 & 32.4 & 5.83 & 0.29 & 0.28 & 0.6\end{array}$


GREEN RIVER BASIN

09232000 SHEEP CREEX NEAR MANIIA, UT--Continued

ANNUAL PEAK DISCHARGE, IN CUBIC FEET PER SECOND, AND CORRESPONDING GAGE HEIGHT, IN FEET, FOR EACH WATER YEAR

\begin{tabular}{|c|c|c|c|c|c|c|c|c|c|c|c|c|c|}
\hline $\begin{array}{l}\text { WATER } \\
\text { YEAR }\end{array}$ & DATE & $\begin{array}{c}\text { GAGE } \\
\text { HEIGHT }\end{array}$ & $\begin{array}{c}\text { PEAK } \\
\text { DISCHARGE }\end{array}$ & $\begin{array}{l}\text { WATER } \\
\text { YEAR }\end{array}$ & & DATE & $\begin{array}{l}\text { GAGE } \\
\text { HEIGHT }\end{array}$ & $\begin{array}{c}\text { PEAK } \\
\text { DISCHARGE }\end{array}$ & $\begin{array}{l}\text { WATER } \\
\text { YEAR }\end{array}$ & & DATE & $\begin{array}{l}\text { GAGE } \\
\text { HEIGHT }\end{array}$ & $\begin{array}{c}\text { PEAK } \\
\text { DISCHARGE }\end{array}$ \\
\hline $\begin{array}{l}1955 \\
1956\end{array}$ & $\begin{array}{lll}\text { APR. } & 25,1955 \\
\text { MAY } & 29,1956\end{array}$ & $\begin{array}{l}3.86 \\
3.87\end{array}$ & $\begin{array}{l}50 \\
46\end{array}$ & $\begin{array}{l}1958 \\
1959\end{array}$ & $\begin{array}{l}\text { MAY } \\
\text { MAY }\end{array}$ & $\begin{array}{l}26,1958 \\
02,1959\end{array}$ & $\begin{array}{l}4.67 \\
4.28\end{array}$ & $\begin{array}{r}138 \\
86\end{array}$ & $\begin{array}{l}1960 \\
1961\end{array}$ & $\begin{array}{l}\text { MAY } \\
\text { MAY }\end{array}$ & $\begin{array}{l}12,1960 \\
28,1961\end{array}$ & $\begin{array}{l}4.79 \\
4.83\end{array}$ & $\begin{array}{l}182 \\
178\end{array}$ \\
\hline 1957 & JUNE 08,1957 & 5.54 & 359 & & & & & & 1965 & JUNE & 11965 & 9.36 & 2320 \\
\hline
\end{tabular}

$1_{\text {JUNE } 10 \text { OR } 11 .}$

09232500 SHEEP CREEK AT MOUTH, NEAR MANILA, UT

LOCATION.--Lat $40^{\circ} 56^{\prime} 00^{\prime \prime}$, long $109^{\circ} 39^{\prime} 20^{\prime \prime}$, in NE $\frac{1}{4}$ sec.10 (unsurveyed), T.2 N., R.20 E., Daggett County, Hydrologic Unit 14040106, on right bank $1 \mathrm{mi}$ upstream from mouth and $6 \mathrm{mi}$ southeast of Manila.

DRATNAGE AREA.--111 $\mathrm{mi}^{2}$.

PERIOD OF RECORD AVAIIABLE.--October 1946 to September 1961.

GAGE.--Water-stage recorder. Datum of gage is 5,870.87 ft NGVD of 1929 (levels by Bureau of Reclamation).

REMARKS.--Diversions above station for irrigation, including transbasin diversions for irrigation in vicinity of Manila, via Sheep Creek canals. Some storage in several small mountain lakes.

AVERAGE DISCHARGE. -15 years, $22.5 \mathrm{ft}^{3} / \mathrm{s}, 16,290$ acre- $\mathrm{ft} / \mathrm{yr}$.

EXIREMES FOR PERIOD OF RECORD.--Maximum discharge, $450 \mathrm{ft}^{3} / \mathrm{s}$ May 20,1948 , gage height, $3.49 \mathrm{ft}$, fran rating curve extended above $230 \mathrm{ft}^{3} / \mathrm{s}$; minimum recorded, $2.1 \mathrm{ft}^{3} / \mathrm{s} \mathrm{Dec.} 27,1959$, result of freezeup.

EXTREMES OUTSIDE PERIOD OF RECORD.--June 11, 1965, peak flow at the Gap, about $4 \mathrm{mi}$ upstream fran gaging station, was $2,620 \mathrm{ft}{ }^{3} / \mathrm{s}$.

LOWEST MEAN DISCHARGE, IN CUBIC FEET PER SECOND, AND RANKING FOR THE INDICATED NUMBER OF CONSECUTIVE DAYS FOR EACH CLIMATIC YEAR, APRIL 1-MARCH 31

\begin{tabular}{|c|c|c|c|c|c|c|c|c|c|c|c|c|c|c|c|c|c|c|}
\hline YEAR & & & & & & & & CONSEOU' & E DAYS & & & & & & & & & \\
\hline $\begin{array}{l}1948 \\
1949 \\
1950\end{array}$ & $\begin{array}{rr}8.10 & 13 \\
6.80 & 9 \\
8.90 & 14\end{array}$ & $\begin{array}{l}8.201 \\
6.90 \\
9.003\end{array}$ & $\begin{array}{r}11 \\
5 \\
13\end{array}$ & $\begin{array}{l}8.20 \\
7.00 \\
9.10\end{array}$ & $\begin{array}{r}10 \\
4 \\
13\end{array}$ & $\begin{array}{l}8.70 \\
7.10 \\
9.30\end{array}$ & $\begin{array}{r}11 \\
4 \\
13\end{array}$ & $\begin{array}{rr}9.30 & 11 \\
7.10 & 3 \\
9.80 & 12\end{array}$ & $\begin{array}{c}12.0 \\
7.40 \\
11.0\end{array}$ & $\begin{array}{r}14 \\
3 \\
11\end{array}$ & $\begin{array}{c}14.0 \\
8.10 \\
11.0\end{array}$ & $\begin{array}{r}14 \\
3 \\
10\end{array}$ & $\begin{array}{c}15.0 \\
9.50 \\
12.0\end{array}$ & $\begin{array}{r}14 \\
7 \\
11\end{array}$ & $\begin{array}{l}16.0 \\
11.0 \\
13.0\end{array}$ & $\begin{array}{r}14 \\
8 \\
12\end{array}$ & $\begin{array}{l}40.0 \\
27.0 \\
35.0\end{array}$ & $\begin{array}{l}13 \\
10 \\
12\end{array}$ \\
\hline $\begin{array}{l}1951 \\
1952 \\
1953 \\
1954 \\
1955\end{array}$ & $\begin{array}{rr}8.00 & 12 \\
5.00 & 1 \\
6.90 & 10 \\
6.10 & 4 \\
5.60 & 2\end{array}$ & $\begin{array}{l}9.001 \\
5.00 \\
7.701 \\
6.50 \\
5.70\end{array}$ & $\begin{array}{r}14 \\
1 \\
10 \\
4 \\
2\end{array}$ & $\begin{array}{l}9.10 \\
5.00 \\
7.80 \\
7.10 \\
6.00\end{array}$ & $\begin{array}{r}14 \\
1 \\
9 \\
6 \\
2\end{array}$ & $\begin{array}{l}9.30 \\
5.00 \\
7.90 \\
7.20 \\
6.50\end{array}$ & $\begin{array}{r}14 \\
1 \\
8 \\
5 \\
2\end{array}$ & $\begin{array}{cc}10.0 & 13 \\
5.00 & 1 \\
8.50 & 8 \\
7.60 & 4 \\
6.70 & 2\end{array}$ & $\begin{array}{r}11.0 \\
5.30 \\
8.80 \\
8.30 \\
7.10\end{array}$ & $\begin{array}{r}12 \\
1 \\
8 \\
6 \\
2\end{array}$ & $\begin{array}{c}11.0 \\
6.80 \\
9.60 \\
8.50 \\
7.50\end{array}$ & $\begin{array}{r}11 \\
1 \\
8 \\
4 \\
2\end{array}$ & $\begin{array}{c}12.0 \\
8.10 \\
11.0 \\
9.20 \\
8.10\end{array}$ & $\begin{array}{r}12 \\
1 \\
10 \\
5 \\
2\end{array}$ & $\begin{array}{c}12.0 \\
10.0 \\
12.0 \\
10.0 \\
8.70\end{array}$ & $\begin{array}{r}9 \\
5 \\
10 \\
6 \\
1\end{array}$ & $\begin{array}{l}22.0 \\
15.0 \\
43.0 \\
20.0 \\
11.0\end{array}$ & $\begin{array}{r}9 \\
5 \\
14 \\
8 \\
1\end{array}$ \\
\hline $\begin{array}{l}1956 \\
1957 \\
1958 \\
1959 \\
1960\end{array}$ & $\begin{array}{ll}6.60 & 6 \\
6.60 & 7 \\
6.60 & 8 \\
6.00 & 3 \\
6.30 & 5\end{array}$ & $\begin{array}{l}7.00 \\
7.10 \\
7.40 \\
6.20 \\
7.00\end{array}$ & $\begin{array}{l}6 \\
8 \\
9 \\
3 \\
7\end{array}$ & $\begin{array}{l}7.00 \\
7.50 \\
8.50 \\
6.30 \\
7.60\end{array}$ & $\begin{array}{r}5 \\
7 \\
11 \\
3 \\
8\end{array}$ & $\begin{array}{l}7.30 \\
7.90 \\
8.90 \\
7.10 \\
8.00\end{array}$ & $\begin{array}{r}6 \\
7 \\
12 \\
3 \\
9\end{array}$ & $\begin{array}{rr}8.40 & 7 \\
8.10 & 6 \\
11.0 & 14 \\
7.90 & 5 \\
8.80 & 9\end{array}$ & $\begin{array}{c}8.80 \\
8.20 \\
11.0 \\
8.20 \\
9.00\end{array}$ & $\begin{array}{r}7 \\
4 \\
13 \\
5 \\
9\end{array}$ & $\begin{array}{c}9.00 \\
8.50 \\
12.0 \\
8.60 \\
11.0\end{array}$ & $\begin{array}{r}7 \\
5 \\
13 \\
6 \\
12\end{array}$ & $\begin{array}{c}9.30 \\
8.60 \\
13.0 \\
8.90 \\
10.0\end{array}$ & $\begin{array}{r}6 \\
3 \\
13 \\
4 \\
8\end{array}$ & $\begin{array}{c}9.50 \\
10.0 \\
15.0 \\
9.00 \\
11.0\end{array}$ & $\begin{array}{r}3 \\
4 \\
13 \\
2 \\
7\end{array}$ & $\begin{array}{l}11.0 \\
12.0 \\
34.0 \\
15.0 \\
16.0\end{array}$ & $\begin{array}{r}2 \\
3 \\
11 \\
4 \\
6\end{array}$ \\
\hline 961 & 8.0011 & 8.401 & 12 & 8.50 & 12 & 8.50 & 10 & $8.90 \quad 10$ & 9.60 & 10 & 10.0 & 9 & 11.0 & 9 & 12.0 & 11 & 17.0 & 7 \\
\hline
\end{tabular}

HIGHEST MEAN DISCHARGE, IN CUBIC FEET PER SECOND, AND RANKING FOR THE INDICATED NUMBER OF CONSECUTIVE DAYS FOR EACH WATER YEAR, OCTOBER 1-SEPTEMBER 30

\begin{tabular}{|c|c|c|c|c|c|c|c|c|c|c|c|c|c|c|c|c|c|c|c|}
\hline YEAR & 1 & & 3 & & 7 & & 15 & & $\begin{array}{l}\text { CN } \\
30\end{array}$ & & $\begin{array}{c}\text { E DAY } \\
60\end{array}$ & & 90 & & 120 & & 183 & & ALL \\
\hline $\begin{array}{l}1947 \\
1948 \\
1949 \\
1950\end{array}$ & $\begin{array}{l}330 \\
364 \\
294 \\
182\end{array}$ & $\begin{array}{l}2 \\
1 \\
5 \\
7\end{array}$ & $\begin{array}{l}313 \\
309 \\
257 \\
160\end{array}$ & $\begin{array}{l}2 \\
4 \\
5 \\
7\end{array}$ & $\begin{array}{l}287 \\
266 \\
243 \\
126\end{array}$ & $\begin{array}{l}1 \\
4 \\
5 \\
7\end{array}$ & $\begin{array}{l}237 \\
234 \\
206 \\
115\end{array}$ & $\begin{array}{l}2 \\
3 \\
5 \\
7\end{array}$ & $\begin{array}{c}175 \\
168 \\
158 \\
98.0\end{array}$ & $\begin{array}{l}2 \\
4 \\
5 \\
6\end{array}$ & $\begin{array}{r}138 \\
105 \\
125 \\
66.0\end{array}$ & $\begin{array}{l}2 \\
5 \\
3 \\
7\end{array}$ & $\begin{array}{r}111 \\
76.0 \\
99.0 \\
51.0\end{array}$ & $\begin{array}{l}2 \\
5 \\
3 \\
6\end{array}$ & $\begin{array}{l}88.0 \\
61.0 \\
79.0 \\
42.0\end{array}$ & $\begin{array}{l}2 \\
5 \\
3 \\
6\end{array}$ & & $\begin{array}{l}2 \\
5 \\
3 \\
6\end{array}$ & $\begin{array}{l}39.0 \\
29.0 \\
34.0 \\
23.0\end{array}$ \\
\hline $\begin{array}{l}1951 \\
1952 \\
1953 \\
1954 \\
1955\end{array}$ & $\begin{array}{c}72.0 \\
324 \\
227 \\
39.0 \\
47.0\end{array}$ & $\begin{array}{r}11 \\
3 \\
6 \\
15 \\
13\end{array}$ & $\begin{array}{l}65.0 \\
312 \\
194 \\
35.0 \\
39.0\end{array}$ & $\begin{array}{r}11 \\
3 \\
6 \\
15 \\
13\end{array}$ & $\begin{array}{c}54.0 \\
286 \\
168 \\
32.0 \\
34.0\end{array}$ & $\begin{array}{r}12 \\
2 \\
6 \\
14 \\
13\end{array}$ & $\begin{array}{c}44.0 \\
254 \\
132 \\
30.0 \\
28.0\end{array}$ & $\begin{array}{r}12 \\
1 \\
6 \\
13 \\
14\end{array}$ & $\begin{array}{c}39.0 \\
232 \\
97.0 \\
23.0 \\
22.0\end{array}$ & $\begin{array}{r}12 \\
1 \\
7 \\
13 \\
14\end{array}$ & $\begin{array}{c}29.0 \\
179 \\
67.0 \\
18.0 \\
19.0\end{array}$ & $\begin{array}{r}12 \\
1 \\
6 \\
14 \\
13\end{array}$ & $\begin{array}{c}25.0 \\
134 \\
50.0 \\
16.0 \\
17.0\end{array}$ & $\begin{array}{r}12 \\
1 \\
7 \\
15 \\
13\end{array}$ & $\begin{array}{c}22.0 \\
105 \\
41.0 \\
15.0 \\
15.0\end{array}$ & $\begin{array}{r}12 \\
1 \\
7 \\
13 \\
14\end{array}$ & $\begin{array}{l}19.0 \\
74.0 \\
31.0 \\
14.0 \\
14.0\end{array}$ & $\begin{array}{r}12 \\
1 \\
7 \\
13 \\
14\end{array}$ & $\begin{array}{l}15.0 \\
42.0 \\
21.0 \\
12.0 \\
12.0\end{array}$ \\
\hline $\begin{array}{l}1956 \\
1957 \\
1958 \\
1959\end{array}$ & $\begin{array}{c}42.0 \\
324 \\
120 \\
71.0 \\
119 \\
165\end{array}$ & $\begin{array}{r}14 \\
4 \\
9 \\
12 \\
10 \\
8\end{array}$ & $\begin{array}{l}36.0 \\
316 \\
114 \\
65.0 \\
100 \\
157\end{array}$ & $\begin{array}{r}14 \\
1 \\
9 \\
12 \\
10 \\
8\end{array}$ & $\begin{array}{c}26.0 \\
282 \\
104 \\
58.0 \\
74.0 \\
119\end{array}$ & $\begin{array}{r}15 \\
3 \\
9 \\
11 \\
10 \\
8\end{array}$ & $\begin{array}{c}21.0 \\
232 \\
78.0 \\
51.0 \\
49.0 \\
97.0\end{array}$ & $\begin{array}{r}15 \\
4 \\
9 \\
10 \\
11 \\
8\end{array}$ & $\begin{array}{r}18.0 \\
174 \\
56.0 \\
40.0 \\
43.0 \\
68.0\end{array}$ & $\begin{array}{r}15 \\
3 \\
9 \\
11 \\
10 \\
8\end{array}$ & $\begin{array}{r}17.0 \\
125 \\
39.0 \\
35.0 \\
40.0 \\
49.0\end{array}$ & $\begin{array}{r}15 \\
4 \\
10 \\
11 \\
9 \\
8\end{array}$ & $\begin{array}{l}16.0 \\
91.0 \\
31.0 \\
30.0 \\
33.0 \\
38.0\end{array}$ & $\begin{array}{r}14 \\
4 \\
10 \\
11 \\
9 \\
8\end{array}$ & $\begin{array}{l}14.0 \\
73.0 \\
26.0 \\
26.0 \\
28.0 \\
32.0\end{array}$ & $\begin{array}{r}15 \\
4 \\
10 \\
11 \\
9 \\
8\end{array}$ & $\begin{array}{l}12.0 \\
52.0 \\
23.0 \\
21.0 \\
23.0 \\
26.0\end{array}$ & $\begin{array}{r}15 \\
4 \\
9 \\
11 \\
10 \\
8\end{array}$ & $\begin{array}{l}11.0 \\
32.0 \\
18.0 \\
15.0 \\
17.0 \\
18.0\end{array}$ \\
\hline
\end{tabular}


GREEN RIVER BASIN

09232500 SHEEP CREEX AT MOUTH, NEAR MANILA, UT-Continued

DURATION OF DISCHARGE FOR EACH WATER YEAR

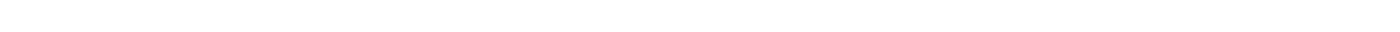

YEAR

MUMBER OF DAYS IN CLASS

OBIC FEET

PER SECON

-DAYS

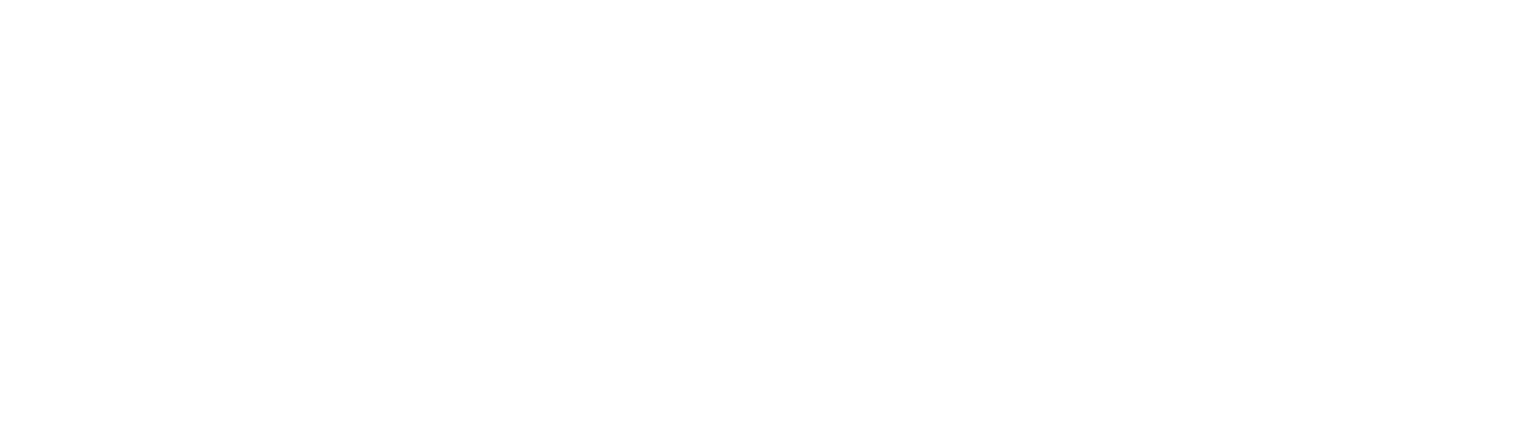

DURATION TABLE OF DISCHARGE FOR WATER YEARS 1947-61

\begin{tabular}{|c|c|c|c|c|c|c|c|c|c|}
\hline & $\begin{array}{c}\text { CUBIC } \\
\text { FEET } \\
\text { PER }\end{array}$ & TOTAL & $\begin{array}{c}\text { ACOI- } \\
\text { NU- } \\
\text { LATED }\end{array}$ & $\begin{array}{l}\text { PER } \\
\text { CENT }\end{array}$ & & $\begin{array}{c}\text { CUBIC } \\
\text { FEET } \\
\text { PER } \\
\text { SECOND }\end{array}$ & $\begin{array}{l}\text { TOTAL } \\
\text { DAYS }\end{array}$ & $\begin{array}{l}\text { ACOU- } \\
\text { NU- } \\
\text { LATED } \\
\text { DAYS }\end{array}$ & $\begin{array}{l}P E \\
C E\end{array}$ \\
\hline CLASS & SECOND & DAYS & DAYS & DAYS & CJASS & SECOND & DAYS & DAYS & \\
\hline $\begin{array}{l}0 \\
1 \\
2 \\
3 \\
4 \\
5 \\
6 \\
7 \\
8\end{array}$ & $\begin{array}{r}0.00 \\
5.00 \\
5.70 \\
6.50 \\
7.30 \\
8.30 \\
9.40 \\
11.00 \\
12.00\end{array}$ & $\begin{array}{r}0 \\
52 \\
40 \\
98 \\
250 \\
516 \\
584 \\
628 \\
938\end{array}$ & $\begin{array}{l}5479 \\
5479 \\
5427 \\
5387 \\
5289 \\
5039 \\
4523 \\
3939 \\
3311\end{array}$ & $\begin{array}{r}100.0 \\
100.0 \\
99.1 \\
98.3 \\
96.5 \\
92.0 \\
82.6 \\
71.9 \\
60.4\end{array}$ & $\begin{array}{l}9 \\
10 \\
11 \\
12 \\
13 \\
14 \\
15 \\
16 \\
17\end{array}$ & $\begin{array}{l}14.00 \\
16.00 \\
18.00 \\
20.00 \\
23.00 \\
26.00 \\
30.00 \\
34.00 \\
38.00\end{array}$ & $\begin{array}{r}705 \\
391 \\
178 \\
209 \\
120 \\
115 \\
61 \\
54 \\
51\end{array}$ & $\begin{array}{r}2373 \\
1668 \\
1277 \\
1099 \\
890 \\
770 \\
655 \\
594 \\
540\end{array}$ & \\
\hline
\end{tabular}

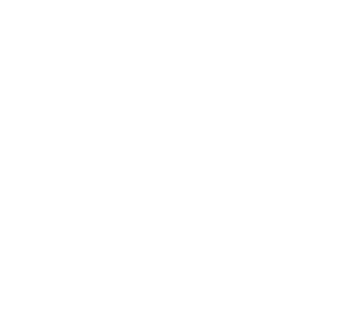

\begin{tabular}{|c|c|c|c|c|}
\hline LASS & $\begin{array}{c}\text { OUBIC } \\
\text { FEET } \\
\text { PER } \\
\text { SECOND }\end{array}$ & $\begin{array}{c}\text { TOTAL } \\
\text { DAYS }\end{array}$ & $\begin{array}{l}\text { ACO- } \\
\text { MU- } \\
\text { LAIED } \\
\text { DAYS }\end{array}$ & $\begin{array}{l}\text { PER- } \\
\text { CENT } \\
\text { DAYS }\end{array}$ \\
\hline $\begin{array}{l}27 \\
28 \\
29 \\
30 \\
31 \\
32 \\
33 \\
34\end{array}$ & $\begin{array}{l}140.0 \\
150.0 \\
170.0 \\
200.0 \\
230.0 \\
260.0 \\
290.0 \\
330.0\end{array}$ & $\begin{array}{r}11 \\
23 \\
22 \\
29 \\
23 \\
12 \\
10 \\
2\end{array}$ & $\begin{array}{r}132 \\
121 \\
98 \\
76 \\
47 \\
24 \\
12 \\
2\end{array}$ & $\begin{array}{l}2.4 \\
2.2 \\
1.8 \\
1.4 \\
0.9 \\
0.4 \\
0.2 \\
0.0\end{array}$ \\
\hline
\end{tabular}

MONIHLY MEAN DISCHAFGES, IN OUBIC FEET PER SECOND, FOR EACH WATER YEAR

\begin{tabular}{|c|c|c|c|c|c|c|c|c|c|c|c|c|}
\hline YEAR & $\infty \mathrm{CT}$ & $\mathrm{NOV}$ & DEC & JAN & FEB & MAR & APR & MAY & JUNE & JULY & AUG & SEP \\
\hline $\begin{array}{l}1947 \\
1948 \\
1949 \\
1950\end{array}$ & $\begin{array}{l}10.5 \\
21.9 \\
15.2 \\
13.3\end{array}$ & $\begin{array}{l}23.0 \\
18.8 \\
14.7 \\
16.1\end{array}$ & $\begin{array}{l}16.5 \\
17.4 \\
12.8 \\
14.2\end{array}$ & $\begin{array}{l}14.0 \\
14.0 \\
11.0 \\
12.0\end{array}$ & $\begin{array}{l}14.3 \\
13.6 \\
11.0 \\
13.8\end{array}$ & $\begin{array}{l}16.0 \\
17.6 \\
14.0 \\
16.5\end{array}$ & $\begin{array}{l}25.9 \\
26.6 \\
29.0 \\
27.6\end{array}$ & $\begin{array}{l}171 \\
151 \\
107 \\
70.4\end{array}$ & $\begin{array}{c}100 \\
41.7 \\
139 \\
53.1\end{array}$ & $\begin{array}{c}48.5 \\
8.64 \\
38.2 \\
16.0\end{array}$ & $\begin{array}{l}10.3 \\
7.34 \\
11.9 \\
10.6\end{array}$ & $\begin{array}{c}15.8 \\
9.11 \\
9.88 \\
11.5\end{array}$ \\
\hline $\begin{array}{l}1951 \\
1952 \\
1953 \\
1954 \\
1955\end{array}$ & $\begin{array}{l}12.6 \\
18.3 \\
8.48 \\
11.2 \\
10.5\end{array}$ & $\begin{array}{c}11.7 \\
14.0 \\
9.61 \\
12.6 \\
9.17\end{array}$ & $\begin{array}{c}13.3 \\
11.0 \\
13.6 \\
12.2 \\
9.94\end{array}$ & $\begin{array}{l}11.0 \\
5.59 \\
13.7 \\
11.0 \\
10.0\end{array}$ & $\begin{array}{l}11.5 \\
5.00 \\
12.7 \\
11.2 \\
10.0\end{array}$ & $\begin{array}{l}10.9 \\
12.9 \\
13.9 \\
12.3 \\
12.0\end{array}$ & $\begin{array}{l}17.4 \\
50.2 \\
24.2 \\
22.5 \\
17.7\end{array}$ & $\begin{array}{c}27.7 \\
206 \\
44.5 \\
12.4 \\
16.5\end{array}$ & $\begin{array}{c}29.4 \\
133 \\
79.8 \\
8.94 \\
15.2\end{array}$ & $\begin{array}{c}11.9 \\
23.8 \\
9.03 \\
7.22 \\
8.63\end{array}$ & $\begin{array}{c}13.5 \\
15.5 \\
7.92 \\
7.02 \\
9.77\end{array}$ & $\begin{array}{c}8.40 \\
10.9 \\
8.94 \\
10.1 \\
8.68\end{array}$ \\
\hline $\begin{array}{l}1956 \\
1957 \\
1958 \\
1959 \\
1960\end{array}$ & $\begin{array}{c}10.5 \\
11.5 \\
14.0 \\
8.47 \\
11.6\end{array}$ & $\begin{array}{c}10.3 \\
15.6 \\
18.6 \\
9.41 \\
11.0\end{array}$ & $\begin{array}{l}9.63 \\
11.8 \\
20.0 \\
10.1 \\
13.0\end{array}$ & $\begin{array}{c}8.87 \\
10.5 \\
16.3 \\
9.10 \\
11.0\end{array}$ & $\begin{array}{c}9.55 \\
13.0 \\
13.8 \\
8.99 \\
10.0\end{array}$ & $\begin{array}{l}12.4 \\
14.6 \\
13.4 \\
12.0 \\
15.1\end{array}$ & $\begin{array}{l}16.7 \\
16.3 \\
18.9 \\
22.1 \\
36.7\end{array}$ & $\begin{array}{l}17.2 \\
70.2 \\
54.5 \\
37.3 \\
37.5\end{array}$ & $\begin{array}{c}9.29 \\
174 \\
15.3 \\
29.4 \\
21.0\end{array}$ & $\begin{array}{c}9.46 \\
27.5 \\
9.59 \\
13.6 \\
13.2\end{array}$ & $\begin{array}{c}8.32 \\
10.7 \\
10.3 \\
9.07 \\
12.8\end{array}$ & $\begin{array}{l}8.25 \\
11.0 \\
7.94 \\
11.5 \\
16.2\end{array}$ \\
\hline 1961 & 12.7 & 8.91 & 11.9 & 11.0 & 11.6 & 13.0 & 21.3 & 64.3 & 26.5 & 13.5 & 14.4 & 11.9 \\
\hline
\end{tabular}

ANNUAL PEAK DISCHAFGE, IN CUBIC FEET PER SECOND, AND CORRESPONDING GAGE HEIGHT, IN FEET, FOR EACH WATER YEAR

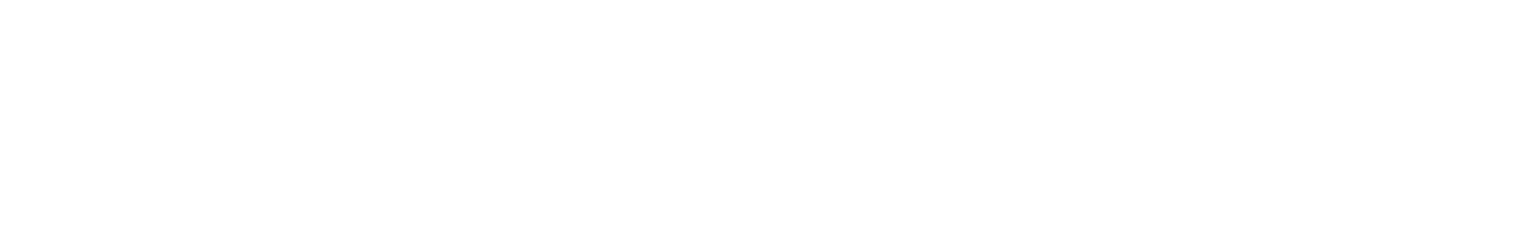

${ }^{1}$ Peak discharge was determined $4 \mathrm{mi}$ upstream from gaging station. 


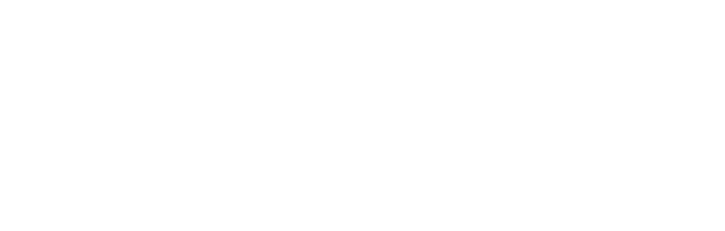

$\begin{array}{rrrrrrr}1 & 6.7 & 5.9 & 5.5 & 5.2 & - & - \\ 7 & 7.6 & 6.5 & 5.9 & 5.4 & - & - \\ 14 & 7.9 & 6.8 & 6.1 & 5.6 & - & - \\ 30 & 8.5 & 7.1 & 6.3 & 5.7 & - & - \\ 60 & 9.0 & 7.4 & 6.6 & 5.9 & - & - \\ 90 & 9.4 & 8.0 & 7.4 & 7.0 & - & -\end{array}$

MAGNITUDE AND PRCBABIIITY OF ANNUAL, HIGHEST MEAN DISGHARGE BASED ON WATER YEARS $1947-61$

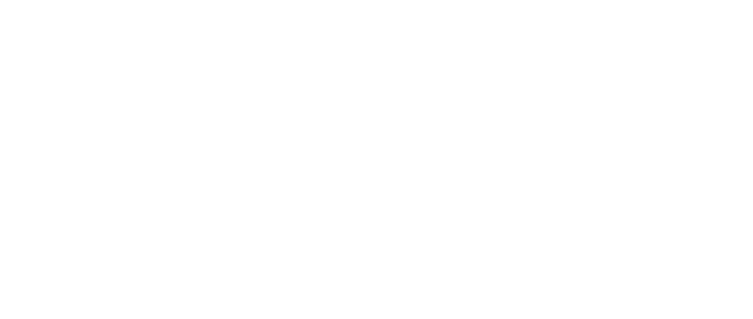

09233000 CARTER CREEK NEAR MANILA, UT

LOCATION,-Lat $40^{\circ} 50^{\prime} 20^{\prime \prime}$, long $109^{\circ} 49^{\prime} 50^{\prime \prime}$, in $\mathrm{N}^{\frac{1}{4}}$ sec.7, T.1 N., R.19 E. (unsurveyed), Daggett County, Hydrologic Unit 14040106, on right bank $2 \mathrm{mi}$ upstream from Beaver Creek, $3 \mathrm{mi}$ southwest of Ute Mountain Lookout Tower, and $12 \mathrm{mi}$ southwest of Manila.

DRAINAGE AREA. $--11.3 \mathrm{mi}^{2}$ (revised).

MEAN BASIN ELEVATION. $-10,280 \mathrm{ft}$.

PERIOD OF RECORD AVALLABLE,--October 1948 to September 1954.

GAGE.--Water-stage recorder. Altitude of gage is $8,600 \mathrm{ft}$ from topographic map.

REMARKS.--Transbasin diversion above station to Sheep Creek began in June 1954.

AVERAGE DISOHARGE. -6 years, $9.32 \mathrm{ft}^{3} / \mathrm{s}, 6,750$ acre-ft/yr.

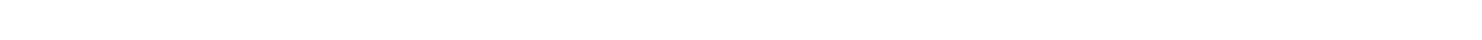
16,1954 .

LOWEST MEAN DISGHARGE, IN OUBIC FEET PER SECOND, AND RANKING FOR THE INDICATED NUMBER OF CONSEQUTTVE DAVS FOR EACH CLIMATTC YEAR, APRII 1-MARCH 31

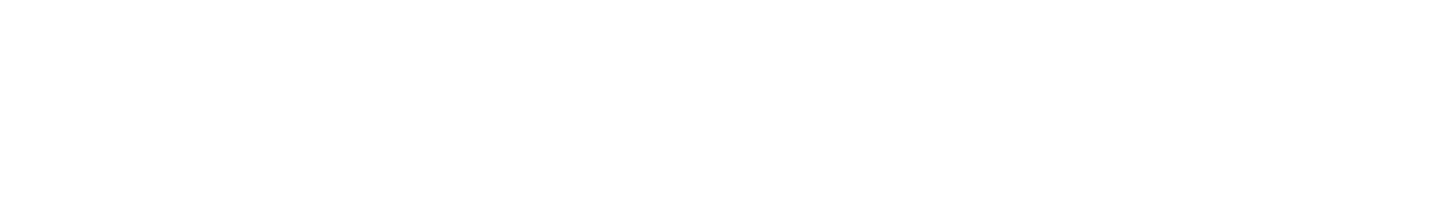

HIGHEST MEAN DISCHARGE, IN OUIC FEET PER SECOND, AND RANKING FOR THE INDICATED NUMBER OF CONSEQUTIVE DAYS FOR EACH WATER YEAR, OCTCBER 1-SEPTEMBER 30

\begin{tabular}{|c|c|c|c|c|c|c|c|c|c|c|c|c|c|c|c|c|c|c|c|}
\hline YEAR & 1 & & 3 & & 7 & & 15 & & $\begin{array}{l}\text { CONS } \\
30\end{array}$ & & $\begin{array}{c}\text { E DAYS } \\
60\end{array}$ & & 90 & & 120 & & 183 & & ALL \\
\hline $\begin{array}{l}1949 \\
1950\end{array}$ & $\begin{array}{l}130 \\
74.0\end{array}$ & $\begin{array}{l}1 \\
4\end{array}$ & $\begin{array}{l}114 \\
70.0\end{array}$ & $\begin{array}{l}2 \\
4\end{array}$ & $\begin{array}{l}98.0 \\
56.0\end{array}$ & $\begin{array}{l}2 \\
4\end{array}$ & $\begin{array}{l}88.0 \\
50.0\end{array}$ & $\begin{array}{l}2 \\
4\end{array}$ & $\begin{array}{l}70.0 \\
44.0\end{array}$ & $\begin{array}{l}2 \\
3\end{array}$ & $\begin{array}{l}54.0 \\
33.0\end{array}$ & $\begin{array}{l}2 \\
3\end{array}$ & $\begin{array}{l}41.0 \\
26.0\end{array}$ & $\begin{array}{l}2 \\
3\end{array}$ & & $\begin{array}{l}2 \\
3\end{array}$ & $\begin{array}{l}23.0 \\
15.0\end{array}$ & $\begin{array}{l}2 \\
3\end{array}$ & $\begin{array}{c}13.0 \\
9.10\end{array}$ \\
\hline
\end{tabular}


GREEN RIVER BASIN

09233000 CARTER CREEK NEAR MANILA, UT-Continued

DURATION OF DISCHARGE FOR EACH WATER YEAR

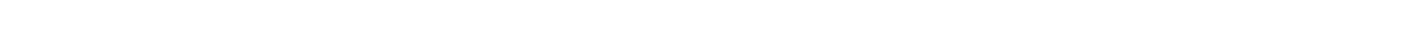
YEAR

NUMBER OF DAYS IN CLASS

GBIC FEET PER SECOND -DAYS

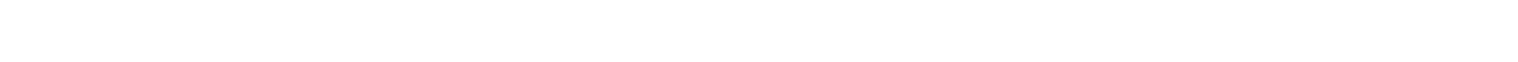

1951

1953

$\begin{array}{lllllllllllllllllllllllllll}59 & 36 & 26 & 51 & 16 & 19 & 17 & 16 & 8 & 10 & 10 & 25 & 8 & 20 & 12 & 12 & 4 & 5 & 4 & 2 & 3 & & 2 & & 2750.2\end{array}$

$\begin{array}{llllllllllllllllllllllllllll}6 & 60 & 32 & 4 & 4 & 36 & 15 & 14 & 28 & 17 & 7 & 12 & 4 & 13 & 9 & 10 & 16 & 11 & 12 & 17 & 14 & 7 & 3 & 6 & 3 & 6 & & 5597.3\end{array}$

$\begin{array}{rrrrrrrrrrrrrrrrrrrrrrrrrrrrrrrr}1953 & 38 & 41 & 20 & 25 & 18 & 18 & 21 & 33 & 43 & 13 & 14 & 13 & 10 & 8 & 5 & 4 & 6 & 4 & 5 & 9 & 3 & 5 & 4 & 2 & 3 & & & 2642.1 \\ 1954 & 2 & 10 & 14 & 5 & 7 & 2 & 38 & 7102 & 5 & 18 & 20 & 34 & 6 & 12 & 13 & 7 & 11 & 4 & 12 & 8 & 5 & 8 & 9 & 3 & 1 & 1 & 1 & & & & \\ \end{array}$

DURATION TABLE OF DISCHARGE FOR WATER YEARS 1949-54

\begin{tabular}{|c|c|c|c|c|c|c|c|c|c|c|c|c|c|c|c|c|c|c|c|}
\hline CLASS & $\begin{array}{c}\text { OUBIC } \\
\text { FEET } \\
\text { PER } \\
\text { SECOND }\end{array}$ & $\begin{array}{l}\text { TOTAL } \\
\text { DAYS }\end{array}$ & $\begin{array}{l}\text { ACCU- } \\
\text { MU- } \\
\text { LATED } \\
\text { DAYS }\end{array}$ & $\begin{array}{l}\text { PER- } \\
\text { CENT } \\
\text { DAYS }\end{array}$ & CLASS & $\begin{array}{c}\text { COBIC } \\
\text { FEET } \\
\text { PER } \\
\text { SECOND }\end{array}$ & $\begin{array}{r}\text { TOTAL } \\
\text { DAYS }\end{array}$ & $\begin{array}{c}\text { ACOI- } \\
\text { MU- } \\
\text { LATED } \\
\text { DAYS }\end{array}$ & $\begin{array}{l}\text { PER- } \\
\text { CENT } \\
\text { DAYS }\end{array}$ & CJASS & $\begin{array}{c}\text { QBIC } \\
\text { FEET } \\
\text { PER } \\
\text { SEOOND }\end{array}$ & $\begin{array}{r}\text { TOTAL } \\
\text { DAYS }\end{array}$ & $\begin{array}{c}\text { ACOU- } \\
\text { MU- } \\
\text { LATED } \\
\text { DAYS }\end{array}$ & $\begin{array}{l}\text { PER } \\
\text { CENT } \\
\text { DAYS }\end{array}$ & CJASS & $\begin{array}{c}\text { CABIC } \\
\text { FEET } \\
\text { PER } \\
\text { SECOND }\end{array}$ & $\begin{array}{r}\text { TOTAL } \\
\text { DAYS }\end{array}$ & $\begin{array}{l}\text { ACOU- } \\
\text { MU- } \\
\text { LATED } \\
\text { DAYS }\end{array}$ & $\begin{array}{l}\text { PER- } \\
\text { CENT } \\
\text { DAYS }\end{array}$ \\
\hline $\begin{array}{l}0 \\
1 \\
2 \\
3 \\
4 \\
5 \\
6 \\
7 \\
8\end{array}$ & $\begin{array}{l}0.00 \\
0.30 \\
0.36 \\
0.43 \\
0.52 \\
0.62 \\
0.75 \\
0.90 \\
1.10\end{array}$ & $\begin{array}{r}0 \\
2 \\
10 \\
14 \\
5 \\
7 \\
2 \\
76 \\
113\end{array}$ & $\begin{array}{l}2191 \\
2191 \\
2189 \\
2179 \\
2165 \\
2160 \\
2153 \\
2151 \\
2075\end{array}$ & $\begin{array}{r}100.0 \\
100.0 \\
99.9 \\
99.5 \\
98.8 \\
98.6 \\
98.3 \\
98.2 \\
94.7\end{array}$ & $\begin{array}{r}9 \\
10 \\
11 \\
12 \\
13 \\
14 \\
15 \\
16 \\
17\end{array}$ & $\begin{array}{l}1.30 \\
1.60 \\
1.90 \\
2.20 \\
2.70 \\
3.20 \\
3.90 \\
4.70 \\
5.60\end{array}$ & $\begin{array}{r}289 \\
117 \\
122 \\
173 \\
149 \\
122 \\
159 \\
117 \\
82\end{array}$ & $\begin{array}{r}1962 \\
1673 \\
1556 \\
1434 \\
1261 \\
1112 \\
990 \\
831 \\
714\end{array}$ & $\begin{array}{l}89.5 \\
76.4 \\
71.0 \\
65.4 \\
57.6 \\
50.8 \\
45.2 \\
37.9 \\
32.6\end{array}$ & $\begin{array}{l}18 \\
19 \\
20 \\
21 \\
22 \\
23 \\
24 \\
25 \\
26\end{array}$ & $\begin{array}{r}6.7 \\
8.1 \\
9.7 \\
12.0 \\
14.0 \\
17.0 \\
20.0 \\
24.0 \\
29.0\end{array}$ & $\begin{array}{l}75 \\
50 \\
64 \\
47 \\
54 \\
45 \\
56 \\
36 \\
48\end{array}$ & $\begin{array}{l}632 \\
557 \\
507 \\
443 \\
396 \\
342 \\
297 \\
241 \\
205\end{array}$ & $\begin{array}{r}28.8 \\
25.4 \\
23.1 \\
20.2 \\
18.1 \\
15.6 \\
13.6 \\
11.0 \\
9.4\end{array}$ & $\begin{array}{l}27 \\
28 \\
29 \\
30 \\
31 \\
32 \\
33 \\
34\end{array}$ & $\begin{array}{r}35.0 \\
42.0 \\
50.0 \\
60.0 \\
72.0 \\
87.0 \\
100.0 \\
130.0\end{array}$ & $\begin{array}{r}48 \\
38 \\
20 \\
15 \\
20 \\
7 \\
8 \\
1\end{array}$ & $\begin{array}{r}157 \\
109 \\
71 \\
51 \\
36 \\
16 \\
9 \\
1\end{array}$ & $\begin{array}{l}7.2 \\
5.0 \\
3.2 \\
2.3 \\
1.6 \\
0.7 \\
0.4 \\
0.0\end{array}$ \\
\hline
\end{tabular}

MONTHLY MEAN DISCHARGES, IN CUBIC FEET PER SECOND, FOR EACH WATER YEAR

\begin{tabular}{|c|c|c|c|c|c|c|c|c|c|c|c|c|}
\hline YEAR & $\infty C T$ & NOV & $\mathrm{DEC}$ & JAN & FEB & MAR & APR & MAY & JUNE & JULY & AUUG & SEP \\
\hline $\begin{array}{l}1949 \\
1950\end{array}$ & $\begin{array}{l}3.39 \\
4.37\end{array}$ & $\begin{array}{l}2.48 \\
3.54\end{array}$ & $\begin{array}{l}1.60 \\
2.74\end{array}$ & $\begin{array}{l}1.20 \\
2.08\end{array}$ & $\begin{array}{l}1.10 \\
2.00\end{array}$ & $\begin{array}{l}1.44 \\
2.50\end{array}$ & $\begin{array}{l}4.21 \\
4.15\end{array}$ & $\begin{array}{l}31.2 \\
19.9\end{array}$ & $\begin{array}{l}66.7 \\
38.8\end{array}$ & $\begin{array}{l}23.9 \\
16.6\end{array}$ & $\begin{array}{l}8.85 \\
7.08\end{array}$ & $\begin{array}{l}4.86 \\
5.36\end{array}$ \\
\hline $\begin{array}{l}1951 \\
1952 \\
1953 \\
1954\end{array}$ & $\begin{array}{l}3.65 \\
5.42 \\
4.13 \\
2.87\end{array}$ & $\begin{array}{l}2.54 \\
3.58 \\
3.15 \\
2.34\end{array}$ & $\begin{array}{l}1.98 \\
3.00 \\
1.96 \\
1.50\end{array}$ & $\begin{array}{l}1.70 \\
1.60 \\
1.10 \\
1.30\end{array}$ & $\begin{array}{l}1.50 \\
1.50 \\
1.04 \\
1.00\end{array}$ & $\begin{array}{l}1.50 \\
1.50 \\
1.20 \\
1.50\end{array}$ & $\begin{array}{l}2.50 \\
5.85 \\
1.74 \\
5.00\end{array}$ & $\begin{array}{c}17.5 \\
33.0 \\
7.25 \\
18.4\end{array}$ & $\begin{array}{l}24.9 \\
69.3 \\
42.9 \\
11.1\end{array}$ & $\begin{array}{c}11.9 \\
35.7 \\
12.1 \\
1.74\end{array}$ & $\begin{array}{c}13.5 \\
15.4 \\
6.42 \\
0.64\end{array}$ & $\begin{array}{l}6.84 \\
7.53 \\
4.01 \\
2.35\end{array}$ \\
\hline
\end{tabular}

ANNUAL PEAK DISCHARGE, IN OBIC FEET PER SECOND, AND CORRESPONDING GAGE HEIGHT, IN FEET, FOR EACH WATER YEAR

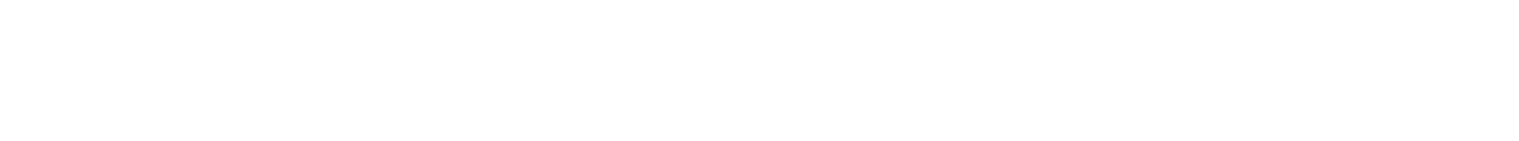


GREEN RIVER BASIN

09233500 RED LAKE OUILET NEAR MANLA, UT

LOCATION.--Lat $40^{\circ} 50^{\prime} 45^{\prime \prime}$, long $109^{\circ} 48^{\prime} 07^{\prime \prime}$, in sec.5,T.1 N., R.18 E. (unsurveyed), Daggett County, Hydrologic Unit 14040106, 0.4 mi upstream from mouth and $11 \mathrm{mi}$ southwest of Manila

DRATNAGE AREA. $-8.5 \mathrm{mi}^{2}$ (revised).

PERIOD OF RECORD AVAILABLE.-October 1945 to September 1949.

GAGE.-Water-stage recorder. Altitude of gage is $8,250 \mathrm{ft}$ fram topographic map.

EXTREMES FOR PERIOD OF RECORD.--Maximum discharge, $175 \mathrm{ft}^{3} / \mathrm{s}$ June 19, 1949, gage height, $2.64 \mathrm{ft}$, fran rating curve extended above $§ \mathrm{ft}^{3} / \mathrm{s}$; minimum not determined.

LOWEST MEAN DISCHARGE, IN OUBIC FEET PER SECOND, AND RANKING FOR THE INDICATED NUMBER OF CONSEOUTIVE DAYS FOR EAOH OLIMATIC YEAR, APRIL 1-MARCH 31

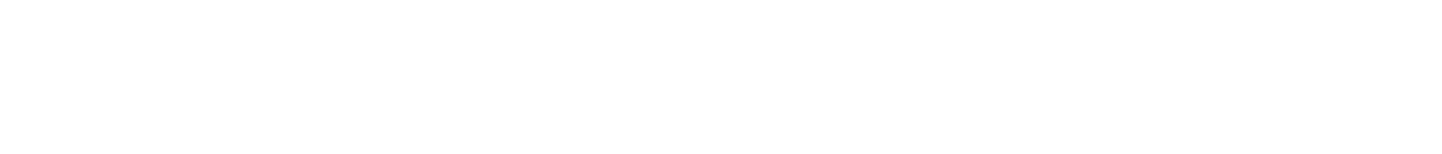

HIGHEST MEAN DISCHARGE, IN OBIC FEET PER SECOND, AND RANKING FOR THE INDICATED NUMBER OF CONSECUTIVE DAYS FOR EACH WATER YEAR, OCTCBER 1-SEPTEMBER 30

\begin{tabular}{|c|c|c|c|c|c|c|c|c|c|c|c|c|c|c|c|c|c|c|c|}
\hline YEAR & & & & & & & & & $\infty \mathrm{N}$ & DT & IE DAYS & & & & & & & & \\
\hline $\begin{array}{l}1946 \\
1947 \\
1948 \\
1949\end{array}$ & $\begin{array}{r}28.0 \\
85.0 \\
80.0 \\
160\end{array}$ & $\begin{array}{l}4 \\
2 \\
3 \\
1\end{array}$ & $\begin{array}{r}26.0 \\
79.0 \\
66.0 \\
139\end{array}$ & $\begin{array}{l}4 \\
2 \\
3 \\
1\end{array}$ & $\begin{array}{r}24.0 \\
76.0 \\
59.0 \\
117\end{array}$ & $\begin{array}{l}4 \\
2 \\
3 \\
1\end{array}$ & $\begin{array}{l}21.0 \\
69.0 \\
55.0 \\
96.0\end{array}$ & $\begin{array}{l}4 \\
2 \\
3 \\
1\end{array}$ & $\begin{array}{l}18.0 \\
59.0 \\
48.0 \\
75.0\end{array}$ & $\begin{array}{l}4 \\
2 \\
3 \\
1\end{array}$ & $\begin{array}{l}17.0 \\
49.0 \\
33.0 \\
55.0\end{array}$ & $\begin{array}{l}4 \\
2 \\
3 \\
1\end{array}$ & $\begin{array}{l}15.0 \\
42.0 \\
25.0 \\
43.0\end{array}$ & $\begin{array}{l}4 \\
2 \\
3 \\
1\end{array}$ & $\begin{array}{l}12.0 \\
35.0 \\
20.0 \\
35.0\end{array}$ & $\begin{array}{l}4 \\
1 \\
3 \\
2\end{array}$ & $\begin{array}{l}9.70 \\
25.0 \\
14.0 \\
24.0\end{array}$ & $\begin{array}{l}4 \\
1 \\
3 \\
2\end{array}$ & $\begin{array}{c}6.60 \\
14.0 \\
9.50 \\
13.0\end{array}$ \\
\hline
\end{tabular}

DURATTON OF DISCHARGE FOR EACH WATER YEAR

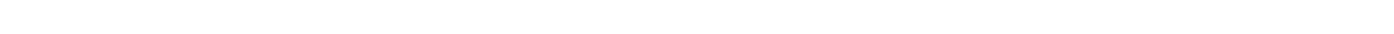
YEAR

NUMBER OF DAYS IN CLASS OBIC FEET PER SEOOND

$\begin{array}{lrrrrrrrrrrrrrrrrrrrrrrrrrrrrrrrrrrr}1946 & 80 & 31 & 31 & 13 & 3 & 20 & 51 & 39 & 7 & 10 & 5 & 1 & 21 & 13 & 14 & 13 & 3 & 8 & 2 & & & & 2398.2 \\ 1947 & & 90 & 54 & 13 & 12 & 23 & 9 & 16 & 5 & 21 & 6 & 11 & 10 & 4 & 7 & 2 & 4 & 7 & 11 & 19 & 7 & 10 & 6 & 11 & 4 & 3 & & & 5282.8 \\ 1948 & & & & 98 & 58 & 55 & 24 & 31 & 25 & 4 & 8 & 4 & 10 & 5 & 1 & 4 & 1 & 3 & 2 & 3 & 3 & 6 & 11 & 6 & 3 & & 1 & & & & 3476.5\end{array}$

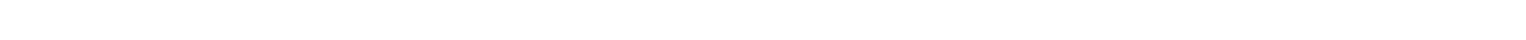

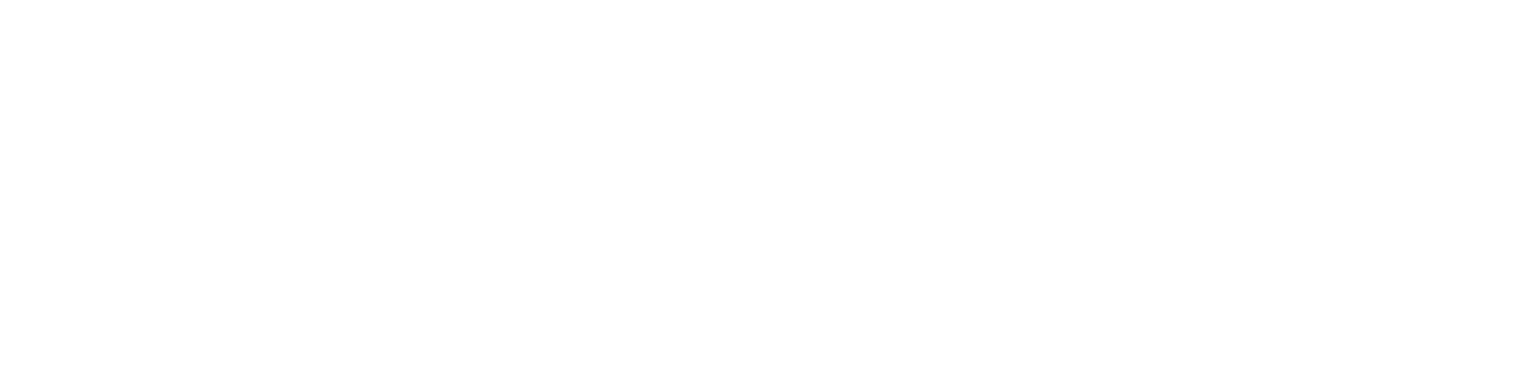

MONTHLY MEAN DISCHARGES, IN OBIC FEET PER SECOND, FOR EACH WATER YEAR

\begin{tabular}{|c|c|c|c|c|c|c|c|c|c|c|c|c|}
\hline YEAR & OCT & $\mathrm{NOV}$ & DEC & JAN & FEB & MAR & APR & MAY & JUNE & JULY & AUG & SEP \\
\hline $\begin{array}{l}1946 \\
1947 \\
1948 \\
1949\end{array}$ & $\begin{array}{l}5.85 \\
5.63 \\
6.78 \\
3.42\end{array}$ & $\begin{array}{l}4.32 \\
4.27 \\
5.25 \\
2.42\end{array}$ & $\begin{array}{l}3.00 \\
3.60 \\
4.50 \\
2.00\end{array}$ & $\begin{array}{l}2.60 \\
3.20 \\
4.00 \\
1.60\end{array}$ & $\begin{array}{l}2.50 \\
3.00 \\
3.80 \\
1.50\end{array}$ & $\begin{array}{l}2.30 \\
3.00 \\
3.60 \\
1.84\end{array}$ & $\begin{array}{l}5.58 \\
5.48 \\
3.70 \\
6.31\end{array}$ & $\begin{array}{l}15.2 \\
33.3 \\
27.2 \\
26.9\end{array}$ & $\begin{array}{l}17.6 \\
53.7 \\
34.7 \\
71.8\end{array}$ & $\begin{array}{c}8.72 \\
37.4 \\
9.99 \\
27.9\end{array}$ & $\begin{array}{c}5.72 \\
12.2 \\
6.24 \\
8.82\end{array}$ & $\begin{array}{l}5.31 \\
8.25 \\
4.13 \\
5.30\end{array}$ \\
\hline
\end{tabular}




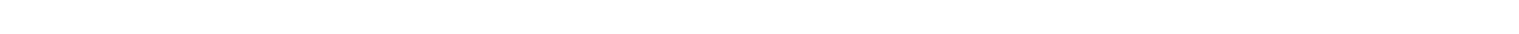
left bank $600 \mathrm{ft}$ upstream from mouth and $10 \mathrm{mi}$ southeast of Manila.

DRAINAGE AREA. $-110 \mathrm{mi}^{2}$.

MEAN BASIN ELEVATTON. $-9,010 \mathrm{ft}$.

PERIOD OF RECORD AVAII.ABLE. -OCtcoser 1946 to September 1955.

GAGE.-Water-stage recorder. Altitude of gage is 5,880 ft from river-prof ile map.

REMARRS.--Transbasin diversion above station to Sheep Creek began in June 1954.

AVERAGE DISCHARGE. --9 years, $60.0 \mathrm{ft}^{3} / \mathrm{s}, 43,440$ acre-ft/yr.

EXTREMES FOR PERIOD OF RECORD.--Maximum discharge, $928 \mathrm{ft}^{3} / \mathrm{s}$ June 4, 1952, gage height, $3.74 \mathrm{ft}$; minimum not determined.

LOWEST MEAN DISCHARGE, IN OUBIC FEET PER SECOND, AND RANKING FOR THE INDICATED NUMBER OF CONSEOUTTVE DAYS FOR EAOH CIIMATIC YEAR, ARRII 1-MARCH 31

YEAR

\begin{tabular}{|c|c|c|c|c|c|c|c|c|c|c|c|c|c|c|c|c|c|c|}
\hline 1 & & 3 & & 7 & & 14 & & $\begin{array}{l}\text { CONSE } \\
30\end{array}$ & GUT & $\begin{array}{c}\text { E DAYS } \\
60\end{array}$ & & 90 & & 120 & & 183 & & ALL \\
\hline $\begin{array}{c}16.0 \\
9.50 \\
12.0\end{array}$ & $\begin{array}{l}8 \\
1 \\
3\end{array}$ & $\begin{array}{c}17.0 \\
9.50 \\
12.0\end{array}$ & $\begin{array}{l}8 \\
1 \\
3\end{array}$ & $\begin{array}{c}17.0 \\
9.50 \\
12.0\end{array}$ & $\begin{array}{l}8 \\
1 \\
3\end{array}$ & $\begin{array}{c}17.0 \\
9.50 \\
12.0\end{array}$ & $\begin{array}{l}8 \\
1 \\
3\end{array}$ & $\begin{array}{c}18.0 \\
9.50 \\
12.0\end{array}$ & $\begin{array}{l}8 \\
1 \\
3\end{array}$ & $\begin{array}{c}18.0 \\
9.90 \\
12.0\end{array}$ & $\begin{array}{l}8 \\
1 \\
3\end{array}$ & $\begin{array}{l}18.0 \\
10.0 \\
13.0\end{array}$ & $\begin{array}{l}8 \\
1 \\
5\end{array}$ & $\begin{array}{l}18.0 \\
11.0 \\
13.0\end{array}$ & $\begin{array}{l}8 \\
1 \\
4\end{array}$ & $\begin{array}{l}21.0 \\
13.0 \\
17.0\end{array}$ & $\begin{array}{l}8 \\
2 \\
6\end{array}$ & $\begin{array}{l}87.0 \\
60.0 \\
82.0\end{array}$ \\
\hline $\begin{array}{l}12.0 \\
13.0 \\
13.0 \\
12.0 \\
10.0\end{array}$ & $\begin{array}{l}4 \\
6 \\
7 \\
5 \\
2\end{array}$ & $\begin{array}{l}12.0 \\
13.0 \\
13.0 \\
12.0 \\
10.0\end{array}$ & $\begin{array}{l}4 \\
6 \\
7 \\
5 \\
2\end{array}$ & $\begin{array}{l}12.0 \\
13.0 \\
14.0 \\
12.0 \\
10.0\end{array}$ & $\begin{array}{l}4 \\
6 \\
7 \\
5 \\
2\end{array}$ & $\begin{array}{l}12.0 \\
13.0 \\
14.0 \\
12.0 \\
10.0\end{array}$ & $\begin{array}{l}4 \\
6 \\
7 \\
5 \\
2\end{array}$ & $\begin{array}{l}12.0 \\
13.0 \\
14.0 \\
12.0 \\
10.0\end{array}$ & $\begin{array}{l}4 \\
6 \\
7 \\
5 \\
2\end{array}$ & $\begin{array}{l}12.0 \\
14.0 \\
15.0 \\
13.0 \\
10.0\end{array}$ & $\begin{array}{l}4 \\
6 \\
7 \\
5 \\
2\end{array}$ & $\begin{array}{l}12.0 \\
15.0 \\
15.0 \\
13.0 \\
10.0\end{array}$ & $\begin{array}{l}3 \\
6 \\
7 \\
4 \\
2\end{array}$ & $\begin{array}{l}12.0 \\
16.0 \\
15.0 \\
14.0 \\
11.0\end{array}$ & $\begin{array}{l}3 \\
7 \\
6 \\
5 \\
2\end{array}$ & $\begin{array}{l}15.0 \\
19.0 \\
17.0 \\
14.0 \\
12.0\end{array}$ & $\begin{array}{l}4 \\
7 \\
5 \\
3 \\
1\end{array}$ & $\begin{array}{l}65.0 \\
46.0 \\
94.0 \\
45.0 \\
30.0\end{array}$ \\
\hline
\end{tabular}

HIGHEST MEAN DISCHARGE, IN GUIC FEET PER SECOND, AND RANKTNG FOR THE INDICATED NUMBER OF CONSECUTTVE DAYS FOR EAOH WATER YEAR, OCTCBER 1-SEPTEMBER 30

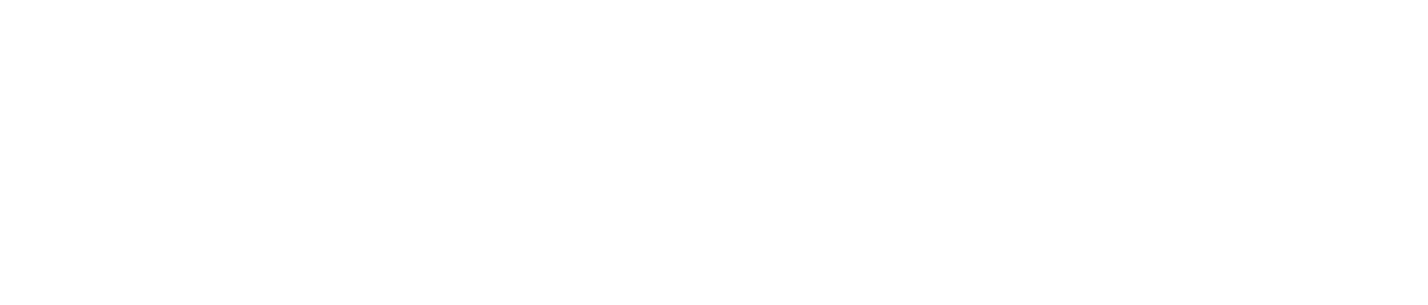

DURATTON OF DISCHARGE FOR EACH WATER YEAR

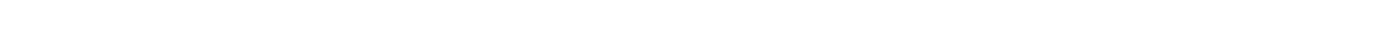
YEAR

NUMBER OF DAYS IN CLASS

OUBIC. FEET PER SECOND -DAYS

\begin{tabular}{|c|c|c|c|c|c|c|c|c|c|c|c|c|c|c|c|c|c|c|c|c|c|c|c|c|c|c|c|c|c|c|}
\hline $\begin{array}{l}947 \\
948 \\
949\end{array}$ & 5421 & $\begin{array}{l}1262 \\
754\end{array}$ & $\begin{array}{ll} & 17 \\
23 & 41 \\
40 & 10\end{array}$ & $\begin{array}{r}9850 \\
2215 \\
16\end{array}$ & $\begin{array}{rr}110 \\
0 & 34 \\
5 & 7 \\
6 & 18\end{array}$ & $\begin{array}{ll}44 & 2 \\
40 & 1 \\
11 & 1 \\
37 & 1\end{array}$ & & $\begin{array}{r}25 \\
6 \\
8 \\
13\end{array}$ & $\begin{array}{r}23 \\
7 \\
6 \\
8\end{array}$ & $\begin{array}{r}10 \\
7 \\
7 \\
12\end{array}$ & $\begin{array}{l}5 \\
6 \\
7 \\
6\end{array}$ & $\begin{array}{r}18 \\
4 \\
4 \\
5\end{array}$ & $\begin{array}{l}2 \\
3 \\
5 \\
8\end{array}$ & $\begin{array}{r}5 \\
4 \\
3 \\
16\end{array}$ & $\begin{array}{r}4 \\
1 \\
4 \\
14\end{array}$ & $\begin{array}{l}8 \\
4 \\
1 \\
3\end{array}$ & $\begin{array}{r}11 \\
14 \\
7 \\
8\end{array}$ & $\begin{array}{l}1 \\
6 \\
7 \\
5\end{array}$ & $\begin{array}{r}4 \\
13 \\
13 \\
4\end{array}$ & $\begin{array}{l}4 \\
6 \\
1 \\
7\end{array}$ & $\begin{array}{l}2 \\
3 \\
8 \\
8\end{array}$ & $\begin{array}{rr}5 & 12 \\
2 & 3 \\
3 & 3 \\
4 & 3\end{array}$ & $\begin{array}{rrr}2 & 22 & 13 \\
3 & 4 & 2 \\
3 & 9 & 7 \\
3 & 7 & 10\end{array}$ & $\begin{array}{l}3 \\
1 \\
81 \\
5\end{array}$ & $\begin{array}{r}5 \\
7 \\
10 \\
2\end{array}$ & $\begin{array}{l}8 \\
9 \\
2 \\
3\end{array}$ & 8 & 1 & & $\begin{array}{l}32787.0 \\
23233.0 \\
29326.0 \\
24146.0\end{array}$ \\
\hline $\begin{array}{l}95 \\
95 \\
95\end{array}$ & 6188 & $\begin{array}{r}1252 \\
373 \\
26 \\
7212 \\
8404\end{array}$ & $\begin{array}{ll}38 & 28 \\
62 & 87 \\
21 & 37 \\
46 & 23\end{array}$ & $\begin{array}{ll}9 & 17 \\
25 & 19 \\
14 & 38 \\
10 & 13 \\
14 & 7\end{array}$ & $\begin{array}{rr}7 & 25 \\
9 & 17 \\
8 & 26 \\
3 & 6 \\
7 & 6\end{array}$ & $\begin{array}{rl}29 & 1 \\
27 & 1 \\
16 \\
9 \\
4\end{array}$ & 7 & $\begin{array}{r}5 \\
11 \\
5 \\
4 \\
4\end{array}$ & $\begin{array}{l}7 \\
5 \\
7 \\
7 \\
5\end{array}$ & $\begin{array}{r}20 \\
4 \\
9 \\
12 \\
4\end{array}$ & $\begin{array}{r}12 \\
4 \\
9 \\
15 \\
6\end{array}$ & $\begin{array}{r}8 \\
15 \\
16 \\
6 \\
5\end{array}$ & $\begin{array}{r}11 \\
2 \\
9 \\
10 \\
9\end{array}$ & $\begin{array}{r}6 \\
11 \\
7 \\
8 \\
6\end{array}$ & $\begin{array}{r}4 \\
10 \\
6 \\
3 \\
11\end{array}$ & $\begin{array}{l}1 \\
1 \\
6 \\
5 \\
7\end{array}$ & $\begin{array}{r}3 \\
8 \\
4 \\
6 \\
10\end{array}$ & $\begin{array}{l}4 \\
7 \\
2\end{array}$ & $\begin{array}{l}3 \\
7 \\
5 \\
5 \\
2\end{array}$ & $\begin{array}{l}51 \\
8 \\
2 \\
2\end{array}$ & $\begin{array}{r}14 \\
4 \\
7 \\
1\end{array}$ & $\begin{array}{l}6 \\
5 \\
6\end{array}$ & $\begin{array}{lr}2 & 3 \\
9 & 16 \\
4 & 3\end{array}$ & $\begin{array}{r}10 \\
2\end{array}$ & $\begin{array}{l}6 \\
1\end{array}$ & 3 & 2 & & 3 & $\begin{array}{r}16185.0 \\
34371.0 \\
16953.0 \\
11242.0 \\
9176.0\end{array}$ \\
\hline
\end{tabular}


DURATION TABLE OF DISCHARGE FOR WATER YEARS 1947-55
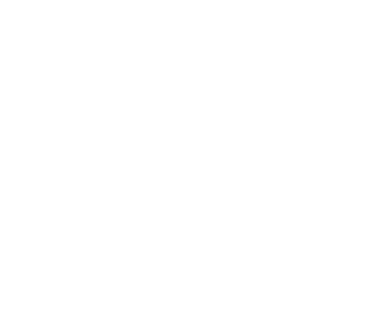

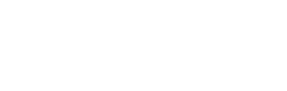

CLASS SECOND DAYS DAYS DAYS

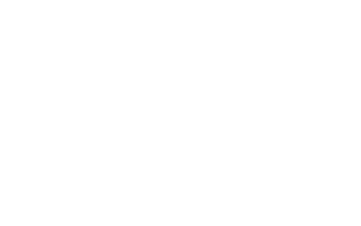

$\begin{array}{ccc}\text { GBIC } & \text { ACUU- } \\ \text { FEET } & \text { MU- } & \text { PER- } \\ \text { PER TOTAL LATED } & \text { CENT } \\ \text { CLASS SECOND DAYS } & \text { DAYS } & \text { DAYS }\end{array}$

$\begin{array}{rrr}18 & 81.0 & 57 \\ 19 & 92.0 & 36 \\ 20 & 100.0 & 71 \\ 21 & 120.0 & 38 \\ 22 & 130.0 & 56 \\ 23 & 150.0 & 35 \\ 24 & 170.0 & 47 \\ 25 & 200.0 & 31 \\ 26 & 220.0 & 31\end{array}$

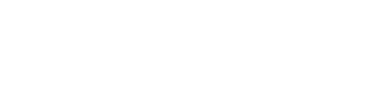

MONTHLY MEAN DISCHARGES, IN OBIC FEET PER SECOND, FOR EACH WATER YEAR

\begin{tabular}{|c|c|c|c|c|c|c|c|c|c|c|c|c|}
\hline YEAR & $\infty C T$ & NOV & DEC & JAN & FEB & MAR & APR & MAY & JUNE & JULY & AUG & SEP \\
\hline $\begin{array}{l}1947 \\
1948 \\
1949 \\
1950\end{array}$ & $\begin{array}{l}29.3 \\
27.6 \\
17.7 \\
26.7\end{array}$ & $\begin{array}{l}36.9 \\
24.3 \\
16.2 \\
22.5\end{array}$ & $\begin{array}{l}27.4 \\
20.4 \\
12.8 \\
14.0\end{array}$ & $\begin{array}{l}23.0 \\
18.0 \\
10.5 \\
12.2\end{array}$ & $\begin{array}{c}23.0 \\
17.5 \\
9.50 \\
12.3\end{array}$ & $\begin{array}{l}24.0 \\
18.2 \\
11.9 \\
14.0\end{array}$ & $\begin{array}{l}63.8 \\
72.1 \\
64.4 \\
64.0\end{array}$ & $\begin{array}{l}290 \\
254 \\
284 \\
178\end{array}$ & $\begin{array}{l}304 \\
209 \\
362 \\
277\end{array}$ & $\begin{array}{c}164 \\
51.4 \\
108 \\
98.4\end{array}$ & $\begin{array}{l}53.4 \\
28.8 \\
40.2 \\
41.9\end{array}$ & $\begin{array}{l}34.4 \\
19.4 \\
24.8 \\
30.9\end{array}$ \\
\hline $\begin{array}{l}1951 \\
1952 \\
1953 \\
1954 \\
1955\end{array}$ & $\begin{array}{l}24.8 \\
28.2 \\
23.8 \\
14.8 \\
14.2\end{array}$ & $\begin{array}{l}15.4 \\
20.8 \\
18.4 \\
15.6 \\
13.4\end{array}$ & $\begin{array}{l}13.0 \\
18.8 \\
16.5 \\
15.2 \\
11.0\end{array}$ & $\begin{array}{l}12.0 \\
15.9 \\
16.0 \\
13.0 \\
10.0\end{array}$ & $\begin{array}{l}12.0 \\
15.0 \\
14.7 \\
12.0 \\
10.0\end{array}$ & $\begin{array}{l}12.6 \\
13.0 \\
14.9 \\
14.0 \\
11.0\end{array}$ & $\begin{array}{l}19.9 \\
96.0 \\
38.3 \\
41.8 \\
23.0\end{array}$ & $\begin{array}{c}85.4 \\
324 \\
88.8 \\
103 \\
70.9\end{array}$ & $\begin{array}{l}181 \\
375 \\
215 \\
77.7 \\
87.4\end{array}$ & $\begin{array}{c}72.6 \\
112 \\
57.9 \\
30.0 \\
22.7\end{array}$ & $\begin{array}{l}51.6 \\
73.9 \\
32.5 \\
15.0 \\
15.5\end{array}$ & $\begin{array}{l}30.9 \\
34.8 \\
20.4 \\
16.9 \\
12.2\end{array}$ \\
\hline
\end{tabular}

ANNUAL PEAK DISqHARGE, IN CUBIC FEET PER SECOND, AND CORRESPONDING GAGE HEIGHT, IN FEET, FOR EAOH WATER YEAR

\begin{tabular}{|c|c|c|c|c|c|c|c|c|c|c|c|}
\hline $\begin{array}{l}\text { WATEER } \\
\text { YEAR }\end{array}$ & DATE & $\begin{array}{c}\text { GAGE } \\
\text { HEIGHT }\end{array}$ & $\begin{array}{c}\text { PEAK } \\
\text { DISCHARGE }\end{array}$ & $\begin{array}{l}\text { WATER } \\
\text { YEAR }\end{array}$ & DATE & $\begin{array}{c}\text { GAGE } \\
\text { HEIGHT }\end{array}$ & $\begin{array}{c}\text { PEAK } \\
\text { DISCHARGE }\end{array}$ & $\begin{array}{l}\text { WATEER } \\
\text { YEAR }\end{array}$ & DATE & $\begin{array}{c}\text { GAGE } \\
\text { HEIGHT }\end{array}$ & $\begin{array}{c}\text { PEAK } \\
\text { DISCHARGE }\end{array}$ \\
\hline $\begin{array}{l}1947 \\
1948 \\
1949\end{array}$ & $\begin{array}{lll}\text { MAY } & 09,1947 \\
\text { MAY } & 20,1948 \\
\text { JUNE } & 12,1949\end{array}$ & $\begin{array}{l}3.62 \\
3.67 \\
3.71\end{array}$ & $\begin{array}{l}495 \\
560 \\
646\end{array}$ & $\begin{array}{l}1950 \\
1951 \\
1952\end{array}$ & $\begin{array}{lll}\text { JUNE } & 02, & 1950 \\
\text { MAY } & 28, & 1951 \\
\text { JUNE } & 04, & 1952\end{array}$ & $\begin{array}{l}3.24 \\
2.71 \\
3.74\end{array}$ & $\begin{array}{l}498 \\
342 \\
928\end{array}$ & $\begin{array}{l}1953 \\
1954 \\
1955\end{array}$ & $\begin{array}{l}\text { JUNE } 13,1953 \\
\text { MAY 22, } 1954 \\
\text { JUNE } 10,1955\end{array}$ & $\begin{array}{l}2.39 \\
1.85 \\
1.40\end{array}$ & $\begin{array}{l}422 \\
234 \\
141\end{array}$ \\
\hline
\end{tabular}

09234500 GREEN RIVER NEAR GREENDALE, UT

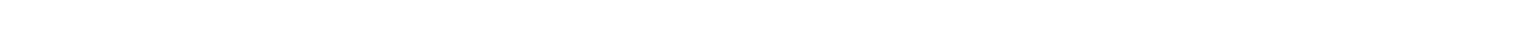
Forest, on right bank $0.5 \mathrm{mi}$ downstream fram Flaming Gorge Dam, $2 \mathrm{mi}$ south of Dutch Jchn, $4 \mathrm{mi}$ northeast of Greendale, and 407.0 mi fram mouth.

DRAINAGE AREA.--19,350 $\mathrm{mi}^{2}$, approximately, of which about 4,260 $\mathrm{mi}^{2}$ is probably noncontributing. This noncontributing area includes $3,959 \mathrm{mi}^{2}$ in Great Divide basin in southern Wyaming.

PERIOD OF RECORD AVAII.ABLE.-Octcber 1950 to September 1989.

REVISED RECORDS.-WDR UT-76-1: Drainage area.

GAGE. - Water-stage recorder. Datum of gage is 5,594.48 ft, NGVD of 1929. Prior to Sept. 2, 1959, water-stage recorder at site 2.2 mi upstream at different datum.

REMARKS.-Flow completely regulated by Flaming Gorge Reservoir 0.5 mi upstream, beginning Nov. $1,1962$.

AVERAGE DISCHARGE. -31 years, $2,029 \mathrm{ft}^{3} / \mathrm{s}, 1,470,000$ acre-ft/yr, unadjusted.

EXIREMES FOR PERIOD OF RECORD.--Maximum discharge, 19,600 ft ${ }^{3} / \mathrm{s}$ June 12, 1957, gage height, $10.60 \mathrm{ft}$, site and datum then in use; minimum, $2.3 \mathrm{ft}^{3} / \mathrm{s}$ Mar. 20, 22, 27, 28, 1963.

DATA BELCW BASED ON PERIOD OF RECORD PRIOR TO REGULATION BY FLAMING GORGE RESERNOIR

LOWEST MEAN DISCHARGE, IN CUBIC FEET PER SECOND, AND RANKING FOR THE INDICATED NUMBER OF CONSEQUTIVE DAYS FOR EAOH OLIMATIC YEAR, APRIL 1-MARCH 31

YEAR CONSECUTIVE DAVS

\begin{tabular}{|c|c|c|c|c|c|c|c|c|c|c|c|c|c|c|c|c|c|c|c|c|}
\hline & 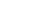 & & & & & & 1 & & 30 & & 6 & & 90 & & 12 & & 183 & & ALL & \\
\hline $\begin{array}{l}1952 \\
1953 \\
1954 \\
1955\end{array}$ & $\begin{array}{l}450 \\
365 \\
330 \\
230\end{array}$ & $\begin{array}{r}11 \\
9 \\
5 \\
1\end{array}$ & $\begin{array}{l}497 \\
367 \\
363 \\
255\end{array}$ & $\begin{array}{r}11 \\
9 \\
8 \\
1\end{array}$ & $\begin{array}{l}580 \\
376 \\
389 \\
292\end{array}$ & $\begin{array}{r}11 \\
5 \\
7 \\
1\end{array}$ & $\begin{array}{l}719 \\
404 \\
412 \\
308\end{array}$ & $\begin{array}{r}11 \\
6 \\
7 \\
1\end{array}$ & $\begin{array}{l}788 \\
486 \\
435 \\
322\end{array}$ & $\begin{array}{r}11 \\
7 \\
5 \\
1\end{array}$ & $\begin{array}{l}812 \\
578 \\
468 \\
355\end{array}$ & $\begin{array}{r}11 \\
7 \\
5 \\
1\end{array}$ & $\begin{array}{l}830 \\
642 \\
523 \\
383\end{array}$ & $\begin{array}{r}11 \\
8 \\
5 \\
1\end{array}$ & $\begin{array}{l}854 \\
684 \\
560 \\
442\end{array}$ & $\begin{array}{r}11 \\
8 \\
5 \\
1\end{array}$ & $\begin{array}{r}1030 \\
771 \\
607 \\
528\end{array}$ & $\begin{array}{r}11 \\
8 \\
4 \\
1\end{array}$ & $\begin{array}{l}3160 \\
2960 \\
1710 \\
1670\end{array}$ & $\begin{array}{r}11 \\
10 \\
5 \\
4\end{array}$ \\
\hline
\end{tabular}


GREEN RIVER BASIN

09234500 GREEN RIVER NEAR GREENDALE, UT-Continued

LOWEST MEAN DISCHARGE, IN OBBIC FEET PER SECOND, AND RANKING FOR THE INDICATED NUMBER OF CONSEOUTIVE DAYS FOR EACH CLIMATIC YEAR, APRIL 1-MARCH 31-Continued

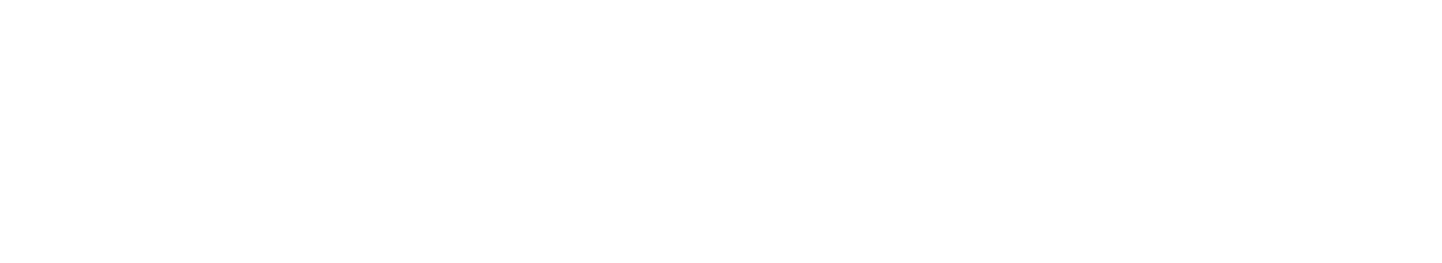

HIGHFST MEAN DISCHARGE, IN OUBIC FEET PER SECOND, AND RANKING FOR THE INDICATFD NUMBER OF CONSEOUTIVE DAYS FOR EACH WATER YEAR, OCTCBER 1-SEPTEMBER 30

YEAR

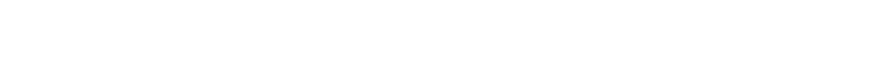

\begin{tabular}{|c|c|c|c|c|c|c|c|c|c|c|c|c|c|c|c|c|c|c|c|}
\hline $\begin{array}{l}1951 \\
1952 \\
1953 \\
1954 \\
1955\end{array}$ & $\begin{array}{r}16900 \\
14700 \\
13400 \\
10800 \\
7000\end{array}$ & $\begin{array}{r}2 \\
4 \\
5 \\
9 \\
10\end{array}$ & $\begin{array}{r}16800 \\
14500 \\
13300 \\
10300 \\
6900\end{array}$ & $\begin{array}{r}2 \\
4 \\
5 \\
9 \\
10\end{array}$ & $\begin{array}{r}15700 \\
13500 \\
12900 \\
9280 \\
6620\end{array}$ & $\begin{array}{r}2 \\
4 \\
5 \\
9 \\
10\end{array}$ & $\begin{array}{r}12900 \\
11800 \\
10900 \\
7580 \\
5880\end{array}$ & $\begin{array}{r}3 \\
4 \\
5 \\
9 \\
10\end{array}$ & $\begin{array}{r}11100 \\
10000 \\
7880 \\
5480 \\
4920\end{array}$ & $\begin{array}{r}3 \\
4 \\
7 \\
9 \\
10\end{array}$ & $\begin{array}{l}9070 \\
9650 \\
5420 \\
5130 \\
3970\end{array}$ & $\begin{array}{r}3 \\
1 \\
7 \\
8 \\
10\end{array}$ & $\begin{array}{l}7830 \\
8300 \\
4250 \\
4360 \\
3290\end{array}$ & $\begin{array}{r}2 \\
1 \\
8 \\
7 \\
10\end{array}$ & $\begin{array}{l}6880 \\
6960 \\
3650 \\
3740 \\
2900\end{array}$ & $\begin{array}{r}2 \\
1 \\
8 \\
7 \\
10\end{array}$ & $\begin{array}{l}5360 \\
5120 \\
2830 \\
2840 \\
2250\end{array}$ & $\begin{array}{r}2 \\
8 \\
10\end{array}$ & $\begin{array}{l}3230 \\
3070 \\
1780 \\
1730 \\
1380\end{array}$ \\
\hline $\begin{array}{l}1956 \\
1957 \\
1958 \\
1959 \\
1960\end{array}$ & $\begin{array}{r}16400 \\
19200 \\
12600 \\
10800 \\
6010\end{array}$ & $\begin{array}{r}3 \\
1 \\
7 \\
8 \\
11\end{array}$ & $\begin{array}{r}15500 \\
18600 \\
12500 \\
10500 \\
5690\end{array}$ & $\begin{array}{r}3 \\
1 \\
6 \\
8 \\
11\end{array}$ & $\begin{array}{r}14200 \\
17900 \\
12100 \\
9840 \\
5280\end{array}$ & $\begin{array}{r}3 \\
1 \\
6 \\
8 \\
11\end{array}$ & $\begin{array}{r}14000 \\
15400 \\
10500 \\
8840 \\
4580\end{array}$ & $\begin{array}{r}2 \\
1 \\
6 \\
8 \\
11\end{array}$ & $\begin{array}{r}12100 \\
12000 \\
8520 \\
7000 \\
3640\end{array}$ & $\begin{array}{r}1 \\
2 \\
5 \\
8 \\
11\end{array}$ & $\begin{array}{l}8280 \\
9270 \\
6050 \\
4550 \\
2860\end{array}$ & $\begin{array}{r}4 \\
2 \\
6 \\
9 \\
11\end{array}$ & $\begin{array}{l}6840 \\
7780 \\
4820 \\
3640 \\
2880\end{array}$ & $\begin{array}{r}5 \\
3 \\
6 \\
9 \\
11\end{array}$ & $\begin{array}{l}5960 \\
6360 \\
3960 \\
3160 \\
2720\end{array}$ & $\begin{array}{r}5 \\
4 \\
6 \\
9 \\
11\end{array}$ & $\begin{array}{l}4520 \\
4660 \\
2960 \\
2510 \\
2070\end{array}$ & 5 & $\begin{array}{l}2610 \\
2680 \\
1910 \\
1570 \\
1370\end{array}$ \\
\hline
\end{tabular}

DURATION OF DISCHARGE FOR EACH WATER YEAR

$\begin{array}{llllllllllllllllllllllllllllllllllll}\text { CJASS } & 0 & 1 & 2 & 3 & 4 & 5 & 6 & 7 & 8 & 9 & 10 & 11 & 12 & 13 & 14 & 15 & 16 & 17 & 18 & 19 & 20 & 21 & 22 & 23 & 24 & 25 & 26 & 27 & 28 & 29 & 30 & 31 & 32 & 33 & 34\end{array}$ YEAR NUMBER OF DAYS IN CLASS

CRBIC FEET
PER SECOND PER SECOND

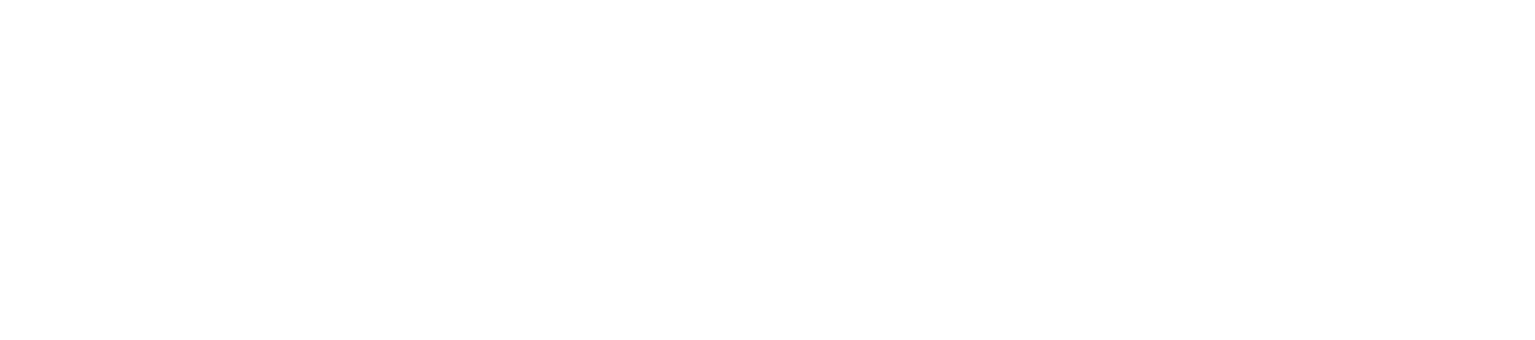

DURATION TABLE OF DISCHARGE FOR WATER YEARS 1951-62

\begin{tabular}{|c|c|c|c|c|}
\hline CLASS & $\begin{array}{c}\text { CUBIC } \\
\text { FEET } \\
\text { PER } \\
\text { SECOND }\end{array}$ & $\begin{array}{r}\text { TOTAL } \\
\text { DAYS }\end{array}$ & $\begin{array}{c}\mathrm{ACOU}- \\
\mathrm{MU}- \\
\mathrm{LATED} \\
\mathrm{DAYS}\end{array}$ & $\begin{array}{l}\text { PER- } \\
\text { CENT } \\
\text { DAYS }\end{array}$ \\
\hline $\begin{array}{l}0 \\
1 \\
2 \\
3 \\
4 \\
5 \\
6 \\
7 \\
8\end{array}$ & $\begin{array}{r}0.00 \\
230.00 \\
260.00 \\
300.00 \\
340.00 \\
390.00 \\
450.00 \\
510.00 \\
580.00\end{array}$ & $\begin{array}{r}0 \\
3 \\
4 \\
25 \\
59 \\
162 \\
224 \\
204 \\
342\end{array}$ & $\begin{array}{l}4383 \\
4383 \\
4380 \\
4376 \\
4351 \\
4292 \\
4130 \\
3906 \\
3702\end{array}$ & $\begin{array}{r}100.0 \\
100.0 \\
99.9 \\
99.8 \\
99.2 \\
97.9 \\
94.2 \\
89.1 \\
84.4\end{array}$ \\
\hline
\end{tabular}

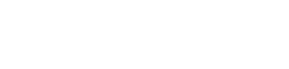
PER TOTAL LATED
CENT
CLASS SECOND DAYS DAYS DAYS

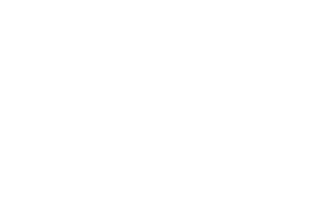

\section{OBBIC}

FEET MU- PERPER TOTAL LATED CENT
CLASS SECOND DAYS DAYS DAYS

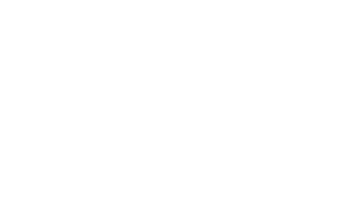

\begin{tabular}{|c|c|c|c|c|}
\hline & $\begin{array}{c}\text { arBIC } \\
\text { FEET }\end{array}$ & & $\begin{array}{c}\mathrm{ACOU}- \\
\mathbf{M U}-\end{array}$ & PER- \\
\hline & PER & TOTAL & LATED & CENT \\
\hline IASSS & SECOND & DAYS & DAYS & DAYS \\
\hline 27 & 7300.0 & 69 & 253 & 5. \\
\hline 28 & 8300.0 & 46 & 184 & \\
\hline 29 & 9500.0 & 53 & 138 & 3.1 \\
\hline 30 & 11000.0 & 21 & 85 & 1. \\
\hline 31 & 12000.0 & 37 & 64 & \\
\hline 32 & & 13 & 27 & \\
\hline 33 & & 13 & 14 & \\
\hline & & 1 & & \\
\hline
\end{tabular}


GREEN RIVER BASIN

09234500 GREEN RIVER NEAR GREENDALE, UT--Continued

MONIHLY MEAN DISCHARGES, IN COBIC FEET PER SECOND, FOR EACH WATER YEAR

\begin{tabular}{|c|c|c|c|c|c|c|c|c|c|c|c|c|}
\hline YEAR & OCT & NON & DEC & JAN & FEB & MAR & APR & MAY & JUNE & JULY & AUG & SEP \\
\hline $\begin{array}{l}1951 \\
1952 \\
1953 \\
1954 \\
1955\end{array}$ & $\begin{array}{r}1232 \\
1608 \\
805 \\
573 \\
693\end{array}$ & $\begin{array}{r}1338 \\
954 \\
621 \\
702 \\
686\end{array}$ & $\begin{array}{l}988 \\
877 \\
553 \\
513 \\
323\end{array}$ & $\begin{array}{l}726 \\
804 \\
775 \\
454 \\
391\end{array}$ & $\begin{array}{r}1102 \\
908 \\
868 \\
703 \\
443\end{array}$ & $\begin{array}{r}1510 \\
1032 \\
1184 \\
1002 \\
709\end{array}$ & $\begin{array}{l}3560 \\
5320 \\
1612 \\
1695 \\
1785\end{array}$ & $\begin{array}{l}6378 \\
9610 \\
1745 \\
4869 \\
2695\end{array}$ & $\begin{array}{r}10510 \\
9285 \\
7577 \\
3735 \\
4823\end{array}$ & $\begin{array}{l}5943 \\
3311 \\
3207 \\
4311 \\
2111\end{array}$ & $\begin{array}{l}3711 \\
1961 \\
1707 \\
1314 \\
1297\end{array}$ & $\begin{array}{r}1640 \\
1121 \\
720 \\
762 \\
643\end{array}$ \\
\hline $\begin{array}{l}1956 \\
1957 \\
1958 \\
1959 \\
1960\end{array}$ & $\begin{array}{r}615 \\
746 \\
1252 \\
586 \\
1101\end{array}$ & $\begin{array}{l}608 \\
649 \\
958 \\
576 \\
851\end{array}$ & $\begin{array}{l}739 \\
416 \\
743 \\
618 \\
607\end{array}$ & $\begin{array}{l}814 \\
453 \\
706 \\
476 \\
426\end{array}$ & $\begin{array}{l}652 \\
774 \\
992 \\
571 \\
500\end{array}$ & $\begin{array}{l}2434 \\
1069 \\
1072 \\
1058 \\
2419\end{array}$ & $\begin{array}{l}3408 \\
1446 \\
2256 \\
1655 \\
2356\end{array}$ & $\begin{array}{l}5946 \\
4421 \\
6280 \\
1845 \\
2058\end{array}$ & $\begin{array}{r}10290 \\
11420 \\
5628 \\
6158 \\
3637\end{array}$ & $\begin{array}{l}3340 \\
6995 \\
1408 \\
2870 \\
1262\end{array}$ & $\begin{array}{r}1696 \\
2306 \\
934 \\
1513 \\
700\end{array}$ & $\begin{array}{r}806 \\
1380 \\
659 \\
982 \\
586\end{array}$ \\
\hline $\begin{array}{l}1961 \\
1962\end{array}$ & $\begin{array}{r}795 \\
1039\end{array}$ & $\begin{array}{l}908 \\
907\end{array}$ & $\begin{array}{l}435 \\
720\end{array}$ & $\begin{array}{l}440 \\
697\end{array}$ & $\begin{array}{r}489 \\
1503\end{array}$ & $\begin{array}{l}1035 \\
2432\end{array}$ & $\begin{array}{l}1274 \\
6288\end{array}$ & $\begin{array}{l}1278 \\
6416\end{array}$ & $\begin{array}{l}3227 \\
7661\end{array}$ & $\begin{array}{r}909 \\
4836\end{array}$ & $\begin{array}{r}698 \\
1777\end{array}$ & $\begin{array}{l}918 \\
739\end{array}$ \\
\hline
\end{tabular}

ANNUAL PEAK DISCHARGE, IN CUBIC FEET PER SECOND, AND CORRESPONDING GAGE HEIGHT, IN FEET, FOR EACH WATER YEAR

\begin{tabular}{|c|c|c|c|c|c|c|c|c|c|c|c|}
\hline $\begin{array}{l}\text { WAITER } \\
\text { YEAR }\end{array}$ & DATE & $\begin{array}{c}\text { GAGE } \\
\text { HEIGHT }\end{array}$ & $\begin{array}{c}\text { PEAK } \\
\text { DISCHARGE }\end{array}$ & $\begin{array}{l}\text { WATERR } \\
\text { YEAR }\end{array}$ & DATE & $\begin{array}{l}\text { GAGE } \\
\text { HEIGHT }\end{array}$ & $\begin{array}{c}\text { PEAK } \\
\text { DISCHARGE }\end{array}$ & $\begin{array}{l}\text { WATER } \\
\text { YEAR }\end{array}$ & DATE & $\begin{array}{c}\text { GAGE } \\
\text { HEIGHT }\end{array}$ & $\begin{array}{c}\text { PEAR } \\
\text { DISCHARGE }\end{array}$ \\
\hline $\begin{array}{l}1951 \\
1952 \\
1953 \\
1954\end{array}$ & $\begin{array}{l}\text { JUNE 03, } 1951 \\
\text { JUNE 11, } 1952 \\
\text { JUNE 19, } 1953 \\
\text { MAY } 26,1954\end{array}$ & $\begin{array}{r}10.04 \\
9.03 \\
8.57 \\
7.38\end{array}$ & $\begin{array}{l}17200 \\
14800 \\
13600 \\
10900\end{array}$ & $\begin{array}{l}1955 \\
1956 \\
1957 \\
1958\end{array}$ & $\begin{array}{lll}\text { JUNE } & 18, & 1955 \\
\text { MAY } & 30, & 1956 \\
\text { JUNE } & 12, & 1957 \\
\text { MAY } & 29, & 1958\end{array}$ & $\begin{array}{r}9 . \overline{9} \\
10.60 \\
8.17\end{array}$ & $\begin{array}{r}7000 \\
16800 \\
19600 \\
12800\end{array}$ & $\begin{array}{l}1959 \\
1960 \\
1961 \\
1962\end{array}$ & $\begin{array}{ll}\text { JUNE } 21, & 1959 \\
\text { MAR. } 22, & 1960 \\
\text { JUNE } 02, & 1961 \\
\text { MAR. } 29, & 1962\end{array}$ & $\begin{array}{r}7.31 \\
10.07 \\
6.38 \\
12.75\end{array}$ & $\begin{array}{r}11000 \\
9100 \\
4660 \\
15100\end{array}$ \\
\hline
\end{tabular}

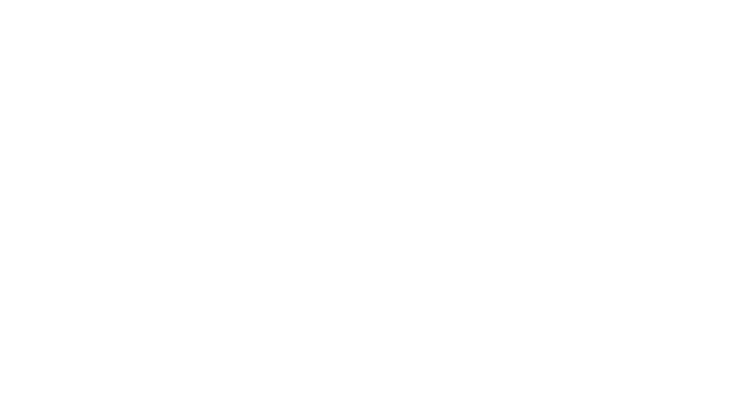

MAGNITUDE AND PROBABILITY OF ANNUAL HIGHEST MEAN DISCHARGE BASED ON WATER YEARS 1951-62

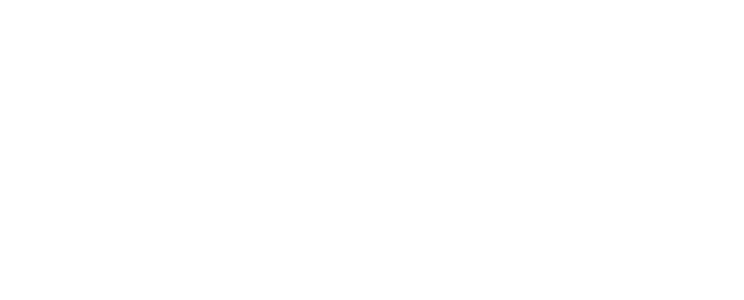

DATA BELCW BASED ON PERTOD OF RECORD AFTER COMPLETION OF FLAMING GORGE RESERNOIR

LOWEST MEAN DISCHARGE, IN CUBIC FEET PER SECY, ID, AND RANKING FOR THE INDICATED NUMBER OF CONSECUTTVE DAYS FOR EACH CIIMATIC YEAR, APRIL I-MARCH 31

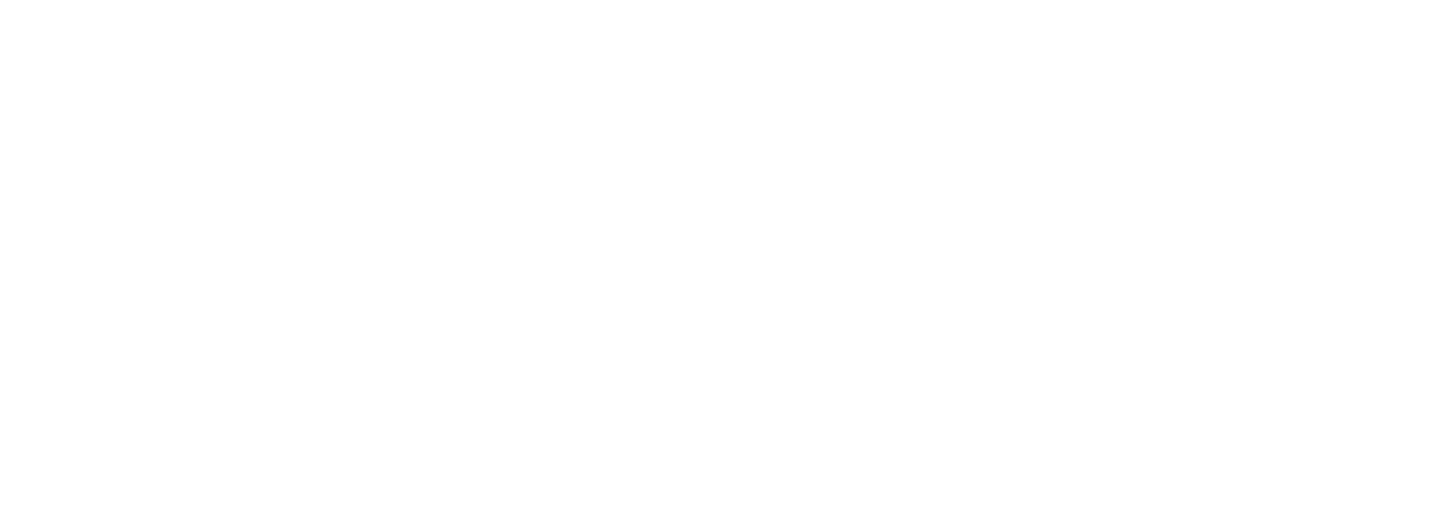


HIGHEST MEAN DISCHARGE, IN CUBIC FEET PER SECOND, AND RANKING FOR THE INDICATED NUMBER OF CONSECUTIVE DAYS FOR EACH WATER YEAR, OCTOBER I-SEPTEMBER 30

YEAR

$\begin{array}{rrrr}1965 & 4260 & 8 & 4140 \\ 1966 & 2930 & 16 & 2750 \\ 1967 & 3780 & 12 & 3740 \\ 1968 & 3940 & 11 & 3920 \\ 1969 & 4480 & 4 & 4480 \\ 1970 & 3650 & 13 & 3590\end{array}$

$\begin{array}{llll}1971 & 2770 \quad 17 \quad 2680\end{array}$

$\begin{array}{llll}1972 & 4590 & 3 & 4420 \\ 1973 & 4360 & 7 & 4260\end{array}$

$\begin{array}{llll}1974 & 4360 & 7 & 4260 \\ 1974 & 5010 & 5 & 4420\end{array}$

$1975 \quad 5010$

$1976 \quad 4430$

$\begin{array}{ll}1977 & 4640 \\ 1978 & 3140\end{array}$

19793960

19803980

19813550

15010

$\begin{array}{ll}2 & 4370\end{array}$

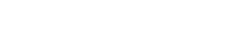

15

CONSBOUTTVE DAYS

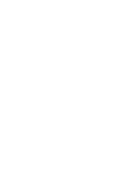

$7 \quad 4040$

$6 \quad 4000$

53800

90
43800

90

120

183

ALI

$\begin{array}{ll}15 & 2640 \\ 11 & 3570\end{array}$

$\begin{array}{llll}15 & 2490 & 15 & 2000\end{array}$

$\begin{array}{cc}15 & 1900 \\ 9 & 3070\end{array}$

13680

13340

12230

93770

$\begin{array}{rr}2 & 4250 \\ 12 & 3420\end{array}$

$8 \begin{array}{r}3650 \\ 8\end{array}$

44080

$\begin{array}{ll}9 & 3150 \\ 8 & 3260\end{array}$

$\begin{array}{ll}8 & 3260 \\ 4 & 3810\end{array}$

$\begin{array}{rr}4 & 3810 \\ 11 & 2740\end{array}$

\begin{tabular}{ll}
9 & 3070 \\
\hline & 3200
\end{tabular}

$\begin{array}{rr}3 & 3400 \\ 11 & 2530\end{array}$

$\begin{array}{rr}15 & 1830 \\ 9 & 3050\end{array}$

$\begin{array}{ll}9 & 3050 \\ 8 & 3070\end{array}$

$\begin{array}{rr}5 & 3160 \\ 12 & 2300\end{array}$

$\begin{array}{rrrrr}15 & 1800 & 15 & 1630 & 14\end{array}$

$17 \quad 2620 \quad 16 \quad 2540$

$16 \quad 2520$

$13 \quad 2380$

$13 \quad 2220$

$14 \quad 2090$

82600

$\begin{array}{rrrrr}6 & 2900 & 5 & 2690 & 3 \\ 12 & 1980 & 12 & 1850 & 12\end{array}$

$\begin{array}{llll}3 & 4330 & 5 & 4290 \\ 7 & 4040 & 8 & 3950\end{array}$

$\begin{array}{llll}4 & 4390 & 4 & 3730\end{array}$

$\begin{array}{ll}3 & 4110 \\ 7 & 3770\end{array}$

$\begin{array}{ll}3 & 3610 \\ 7 & 3690\end{array}$

$\begin{array}{ll}6 & 3390 \\ 5 & 3670\end{array}$

63230

$14 \quad 1850$

$\begin{array}{rr}14 & 1420 \\ 6 & 2670\end{array}$

$\begin{array}{rrrr}9 & 3240 & 10 & 2820\end{array}$

$10 \quad 2710$

$\begin{array}{rr}3 & 3640 \\ 10 & 2440\end{array}$

$\begin{array}{rr}10 & 2440 \\ 2 & 3240\end{array}$

$\begin{array}{ll}5 & 2860 \\ 2 & 3220\end{array}$

\begin{tabular}{rr}
20 & 3220 \\
\hline & 250
\end{tabular}

\begin{tabular}{ll}
6 & 2670 \\
2 & 2910 \\
\hline 1 & 1960
\end{tabular}

$11 \quad 1960$

$\begin{array}{lll}4340 \quad 2 & 4120\end{array}$

3580

$\begin{array}{rr}4 & 3370 \\ 7 & 3150 \\ 16 & 1740\end{array}$

$\begin{array}{llll}5 & 4410 & 3 & 4400 \\ 6 & 4160 & 6 & 4100\end{array}$

$\begin{array}{ll}2 & 4380 \\ 5 & 3930\end{array}$

$\begin{array}{ll}1 & 4010 \\ 6 & 3410\end{array}$

$\begin{array}{rrrr}17 & 2160 & 17 & 1930 \\ 11 & 3000 & 12 & 2670\end{array}$

73280

$4 \quad 2570$

92490

$3 \begin{array}{llll}3 & 3040 & 4 & 2650\end{array}$

$103860 \quad 10 \quad 3440$

i1 3000

$\begin{array}{ll}12 & 2670 \\ 14 & 2330\end{array}$

$12 \quad 2580$

$\begin{array}{ll}16 & 1740 \\ 11 & 2440\end{array}$

$\begin{array}{ll}11 & 2440 \\ 13 & 2210\end{array}$

$16 \quad 1570$

$\begin{array}{ll}11 & 2180 \\ 13 & 1970\end{array}$

$\begin{array}{ll}16 & 1390 \\ 10 & 1850\end{array}$

$\begin{array}{ll}10 & 1850 \\ 13 & 1660\end{array}$

$13 \quad 2790$

$14 \quad 2320$

$16 \quad 1940$

$16 \quad 1840$

171660

$\begin{array}{lllll}17 & 1490 & 17 & 1440 \quad 15\end{array}$

DURATION OF DISCHARGE FOR EACH WATER YEAR

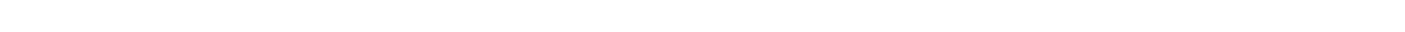
YEAR

OUBIC FEET -DAYS

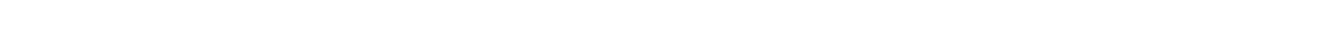
812772.0

1966

$\begin{array}{llll}2 & 2 & 4 & 4\end{array}$

$6 \begin{array}{lllll}6 & 4 & 10 & 11\end{array}$

$\begin{array}{rrr}5 & 12 & 13 \\ 3 & 8 & 13\end{array}$

32
11

$\begin{array}{rrrrrrrrrrrrrrrrrrrrr}3 & 9 & 3 & 3 & 8 & 13 & 11 & 8 & 11 & 33 & 18 & 28 & 9 & 33 & 16 & 23 & 28 & 23 & 37 & 25 & 5 \\ 9 & 16 & 10 & 2 & 7 & 5 & 2 & 5 & 2 & 8 & 2 & 15 & 10 & 18 & 59 & 18 & 33 & 33 & 41 & 31 & 36\end{array}$

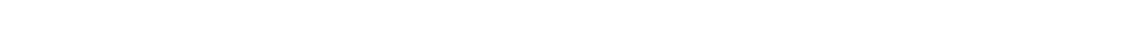

$\begin{array}{lllllllllllllllllllllllll}4 & 1 & 1 & 1 & 3 & 4 & 21 & 31 & 27 & 17 & 7 & 8 & 34 & 13 & 11 & 10 & 8 & 46 & 18 & 24 & 12 & 11 & 27 & 23 & 3\end{array}$

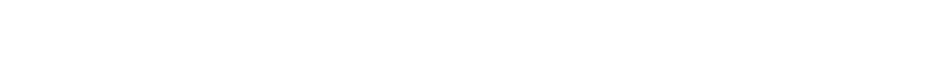
$\begin{array}{rrrrrrrrrrrrrrrrrrrrrrrrrrr}6 & 20 & 4 & & 4 & 5 & 11 & 3 & 3 & 11 & & 11 & 7 & 6 & 14 & 8 & 19 & 33 & 48 & 61 & 57 & 33 & 1\end{array}$

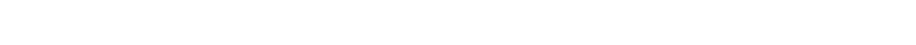

596282.0 789311.0 924813.0 982864.0

674128.0

1971

1973
1974

2

$\begin{array}{rrrrrrrrrrrrrrrrrrrr}5 & 10 & 8 & 6 & 2 & 23 & 10 & 21 & 6 & 20 & 17 & 36 & 52 & 31 & 32 & 14 & 9 & 9 & 40 & \\ 1 & 3 & 3 & 14 & 10 & 15 & 8 & 14 & 13 & 35 & 19 & 28 & 39 & 49 & 58 & 23 & 15 & 11 & 6 & 1\end{array}$

$\begin{array}{lllllllllllllllll}4 & 90 & 22 & 20 & 45 & 44 & 14 & 15 & 27 & 13 & 11 & 12 & 13 & 16 & 13 & 4 & 1\end{array}$

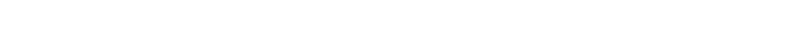

$\begin{array}{lllllllllllllllllll}51 & 41 & 14 & 35 & 26 & 19 & 11 & 32 & 26 & 23 & 31 & 17 & 10 & 9 & 7 & 4 & 1 & 4 & 4\end{array}$

516764.0

977230.0

715678.0

3910351.0

970607.0

988520.0

505984.0

675383.0

609203.0

1981

525276.0

DURATION TABLE OF DISCHARGE FOR WATER YEARS 1965-81

$\begin{array}{ccc}\text { CUBIC } & \text { ACOJ- } \\ \text { FEET } & \text { MU- } & \text { PER- } \\ \text { PER TOTIAL LATED } & \text { CENT } \\ \text { CIASS SECOND IAYS LAYYS } & \text { DAYS }\end{array}$

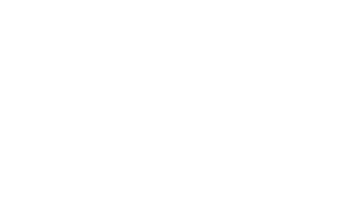

$\begin{array}{lll}\text { OUBIC } & \text { ACOU- } \\ \text { FEET } & \text { MU- } & \text { PER- } \\ \text { PER TOTAL LATED } & \text { CENT }\end{array}$ CIASS SECOND DAYS DAYS DAYS

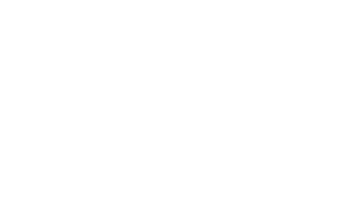

CUBIC ACOUFEET TOTAL LATED CLASS SECOND DAYS DAYS DAYS

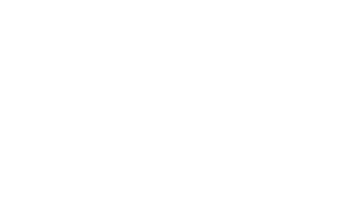

$\begin{array}{ccc}\text { CUBIC } & \text { ACCU- } \\ \text { FEET } & \text { MU- } & \text { PER- } \\ \text { PER } & \text { TOTAL IATED } & \text { CENT } \\ \text { CIAASS SECOND DAYS DAYS } & \text { DAYS }\end{array}$

$\begin{array}{lllll}27 & 2900.0 & 299 & 1484 & 23.9\end{array}$ $\begin{array}{lllll}28 & 3100.0 & 396 & 1185 & 19.1\end{array}$ $\begin{array}{rrrrr}29 & 3400.0 & 286 & 789 & 12.7\end{array}$ $\begin{array}{llllr}29 & 3700.0 & 225 & 503 & 8.1\end{array}$ $\begin{array}{lllll}30 & 3700.0 & 225 & 503 & 8.1\end{array}$ $\begin{array}{rrrrr}32 & 4300.0 & 98 & 102 & 1.6\end{array}$ $\begin{array}{rrrrr}32 & 4300.0 & 98 & 102 & 1.6 \\ 33 & 4600.0 & 1 & 4 & 0.1\end{array}$ $\begin{array}{lllll}34 & 5000.0 & 3 & 4 & 0.1 \\ & & 3 & 0.0\end{array}$

MONTHLY MEAN DISCHARGES, IN OUBIC FEET PER SECOND, FOR EACH WATER YEAR

\begin{tabular}{|c|c|c|c|c|c|c|c|c|c|c|c|c|}
\hline YEAR & $\infty C T$ & NOV & DEC & JAN & FEBB & MAR & APR & MAY & JUNE & JULY & AUG & SEP \\
\hline 1965 & 2583 & 2343 & 3151 & 3506 & 3838 & 3782 & 3420 & 1078 & 1439 & 474 & 497 & 734 \\
\hline $\begin{array}{l}1966 \\
1967 \\
1968 \\
1969 \\
1970\end{array}$ & $\begin{array}{l}1278 \\
2015 \\
3063 \\
2283 \\
2098\end{array}$ & $\begin{array}{l}2024 \\
1430 \\
2911 \\
2308 \\
2173\end{array}$ & $\begin{array}{l}1881 \\
1810 \\
3203 \\
2234 \\
3183\end{array}$ & $\begin{array}{l}1164 \\
2311 \\
3038 \\
2972 \\
1639\end{array}$ & $\begin{array}{l}1293 \\
1734 \\
2141 \\
3954 \\
1397\end{array}$ & $\begin{array}{l}1152 \\
1080 \\
1230 \\
2702 \\
1324\end{array}$ & $\begin{array}{l}2184 \\
1433 \\
1609 \\
2522 \\
1826\end{array}$ & $\begin{array}{l}1352 \\
1982 \\
1932 \\
3103 \\
1045\end{array}$ & $\begin{array}{l}1590 \\
3272 \\
1632 \\
1823 \\
1465\end{array}$ & $\begin{array}{l}1697 \\
2776 \\
3225 \\
2571 \\
1937\end{array}$ & $\begin{array}{l}1921 \\
3058 \\
3249 \\
3151 \\
2070\end{array}$ & $\begin{array}{l}2078 \\
3025 \\
3035 \\
2768 \\
1965\end{array}$ \\
\hline
\end{tabular}


GREFN RIVER BASIN

09234500 GREEN RIVER NEAR GREENDALE, UT--Continued

MONIHLY MEAN DISCHARGES, IN CUBIC FEET PER SECOND, FOR EACH WATER YEAR--Continued

\begin{tabular}{|c|c|c|c|c|c|c|c|c|c|c|c|c|}
\hline YEAR & $\propto C T$ & NOV & DEC & JAN & FEB & MAR & APR & MAY & JUNE & JULY & AUG & SEP \\
\hline $\begin{array}{l}1971 \\
1972 \\
1973 \\
1974 \\
1975\end{array}$ & $\begin{array}{r}960 \\
1911 \\
3168 \\
2402 \\
2928\end{array}$ & $\begin{array}{l}1111 \\
2878 \\
3621 \\
2593 \\
2476\end{array}$ & $\begin{array}{l}1304 \\
3257 \\
3626 \\
2533 \\
2412\end{array}$ & $\begin{array}{r}903 \\
2762 \\
3578 \\
2068 \\
2509\end{array}$ & $\begin{array}{r}773 \\
2925 \\
3651 \\
808 \\
2941\end{array}$ & $\begin{array}{r}781 \\
1662 \\
1834 \\
826 \\
1598\end{array}$ & $\begin{array}{l}1355 \\
2348 \\
1038 \\
1010 \\
1046\end{array}$ & $\begin{array}{l}1457 \\
3973 \\
2612 \\
2966 \\
1440\end{array}$ & $\begin{array}{l}1673 \\
3188 \\
3170 \\
2215 \\
3454\end{array}$ & $\begin{array}{l}1899 \\
2944 \\
2710 \\
1415 \\
4324\end{array}$ & $\begin{array}{l}2453 \\
2620 \\
3426 \\
2225 \\
3218\end{array}$ & $\begin{array}{l}2283 \\
1566 \\
2517 \\
2369 \\
1581\end{array}$ \\
\hline $\begin{array}{l}1976 \\
1977 \\
1978 \\
1979 \\
1980\end{array}$ & $\begin{array}{l}1403 \\
2721 \\
1149 \\
1274 \\
1487\end{array}$ & $\begin{array}{l}2115 \\
2820 \\
1075 \\
1630 \\
1913\end{array}$ & $\begin{array}{l}3449 \\
3114 \\
1038 \\
1951 \\
2064\end{array}$ & $\begin{array}{l}2906 \\
2894 \\
1229 \\
2248 \\
2292\end{array}$ & $\begin{array}{l}1930 \\
2658 \\
1266 \\
2836 \\
2286\end{array}$ & $\begin{array}{l}1760 \\
3818 \\
1613 \\
2350 \\
1687\end{array}$ & $\begin{array}{l}2321 \\
2909 \\
1243 \\
2083 \\
1371\end{array}$ & $\begin{array}{l}4212 \\
2907 \\
1075 \\
1464 \\
1047\end{array}$ & $\begin{array}{l}3568 \\
2429 \\
1649 \\
1468 \\
1216\end{array}$ & $\begin{array}{l}2793 \\
2276 \\
2030 \\
2022 \\
1360\end{array}$ & $\begin{array}{l}2627 \\
2128 \\
1713 \\
1539 \\
1618\end{array}$ & $\begin{array}{l}2695 \\
1791 \\
1542 \\
1410 \\
1657\end{array}$ \\
\hline 1981 & 1723 & 1448 & 1144 & 1128 & 1496 & 1397 & 1261 & 1077 & 1105 & 1612 & 1606 & 2288 \\
\hline
\end{tabular}

ANNUAL PEAK DISCHARGE, IN CUBIC FEET PER SECOND, AND CORRESPONDING GAGE HEIGHT, IN FEET, FOR EACH WATER YEAR

\begin{tabular}{|c|c|c|c|c|c|c|c|c|c|c|c|}
\hline $\begin{array}{l}\text { WATER } \\
\text { YEAR }\end{array}$ & DATE & $\begin{array}{c}\text { GAGE } \\
\text { HEIGHT }\end{array}$ & $\begin{array}{c}\text { PEAK } \\
\text { DISCHARGE }\end{array}$ & $\begin{array}{l}\text { WATER } \\
\text { YEAR }\end{array}$ & DATE & $\begin{array}{c}\text { GAGE } \\
\text { HEIGHT }\end{array}$ & $\begin{array}{c}\text { PEAK } \\
\text { DISCHARGE }\end{array}$ & $\begin{array}{l}\text { WATLER } \\
\text { YEAR }\end{array}$ & DATE & $\begin{array}{c}\text { GAGE } \\
\text { HEIGHT }\end{array}$ & $\begin{array}{c}\text { PEAK } \\
\text { DISCHARGE }\end{array}$ \\
\hline 1963 & ОС. 24, 1962 & 2.27 & $1_{833}$ & 1970 & JULY 29,1970 & 6.67 & 4780 & 1976 & JUNE 09, 1976 & 6.47 & 4650 \\
\hline $\begin{array}{l}1964 \\
1965 \\
1966 \\
1967 \\
1968 \\
1969\end{array}$ & $\begin{array}{l}\text { SEPT. } 28,1964 \\
\text { JAN. } 15,1965 \\
\text { APR. } 04,1966 \\
\text { JAN. } 03,1967 \\
\text { JULY 20, } 1968 \\
\text { APR. 03, } 1969\end{array}$ & $\begin{array}{l}6.58 \\
6.37 \\
5.94 \\
6.02 \\
6.05 \\
6.40\end{array}$ & $\begin{array}{r}1_{4400} \\
4560 \\
3910 \\
4120 \\
4090 \\
4600\end{array}$ & $\begin{array}{l}1971 \\
1972 \\
1973 \\
1974 \\
1975\end{array}$ & $\begin{array}{l}\text { SEPT. 07, } 1971 \\
\text { NOV. 22, } 1971 \\
\text { JAN. 11, } 1973 \\
\text { JAN. 09, } 1974 \\
\text { JULY 07, } 1975\end{array}$ & $\begin{array}{l}6.54 \\
6.65 \\
6.43 \\
6.43 \\
6.80\end{array}$ & $\begin{array}{l}4690 \\
4940 \\
4690 \\
4600 \\
5170\end{array}$ & $\begin{array}{l}1977 \\
1978 \\
1979 \\
1980 \\
1981\end{array}$ & $\begin{array}{l}\text { APR. } 28,1977 \\
\text { JUNE } 05,1978 \\
\text { MAR. 27, } 1979 \\
\text { NOV. 06, } 1979 \\
\text { APR. 06, } 1981\end{array}$ & $\begin{array}{l}6.55 \\
6.47 \\
6.37 \\
6.41 \\
6.05\end{array}$ & $\begin{array}{l}4800 \\
4680 \\
4530 \\
4720 \\
4260\end{array}$ \\
\hline
\end{tabular}

\begin{tabular}{|c|c|c|c|c|c|c|c|c|c|c|c|c|c|}
\hline \multicolumn{2}{|c|}{ MAGNITUDE } & \multicolumn{5}{|c|}{$\begin{array}{l}\text { AND PROBABILITY OF ANNUAL LOWEST MEAN DISCHARGE } \\
\text { BASED ON OLIMATIC YEARS 1966-81 }\end{array}$} & \multicolumn{7}{|c|}{$\begin{array}{l}\text { MAGNITUDE AND PRCBABILITY OF ANNUAL HIGHEST MEAN DISCHARGE } \\
\text { BASED ON WATER YEARS 1965-81 }\end{array}$} \\
\hline \multirow{2}{*}{$\begin{array}{l}\text { PERIOD } \\
\text { (CON- } \\
\text { SEOU- } \\
\text { TIVE } \\
\text { DAYS) }\end{array}$} & \multicolumn{6}{|c|}{$\begin{array}{l}\text { DISCHARGE, IN OUBIC FEET PER SECOND, FOR } \\
\text { INDICATED REOURRENCE INTERRVL, IN YEARS, AND } \\
\text { ANNUAL NONEXCEEDANCE PRCBABILITY, IN PERCENT }\end{array}$} & \multirow{2}{*}{$\begin{array}{l}\text { PERIOD } \\
\text { (CON- } \\
\text { SECU- } \\
\text { TIVE } \\
\text { DAYS) }\end{array}$} & \multicolumn{6}{|c|}{$\begin{array}{l}\text { DISCHARGE, IN CUBIC FEET PER SECOND, FOR } \\
\text { INDICATED RECURRENCE INTERRNAL, IN YEARS, AND } \\
\text { ANNUAL EXCEEDANCE PROBABILITY, IN PERCENT }\end{array}$} \\
\hline & $\begin{array}{c}2 \\
508\end{array}$ & $\begin{array}{c}5 \\
208\end{array}$ & $\begin{array}{l}10 \\
108\end{array}$ & $\begin{array}{l}20 \\
5 \%\end{array}$ & $\begin{array}{l}50 \\
28\end{array}$ & $\begin{array}{r}100 \\
18\end{array}$ & & $\begin{array}{c}2 \\
508\end{array}$ & $\begin{array}{c}5 \\
208\end{array}$ & $\begin{array}{l}10 \\
108\end{array}$ & $\begin{array}{l}25 \\
48\end{array}$ & $\begin{array}{l}50 \\
28\end{array}$ & $\begin{array}{r}100 \\
18\end{array}$ \\
\hline $\begin{array}{r}1 \\
7 \\
14 \\
30 \\
90\end{array}$ & $\begin{array}{r}688 \\
822 \\
919 \\
1060 \\
1510\end{array}$ & $\begin{array}{r}516 \\
637 \\
708 \\
788 \\
1050\end{array}$ & $\begin{array}{l}433 \\
551 \\
604 \\
671 \\
845\end{array}$ & $\begin{array}{l}370 \\
485 \\
523 \\
586 \\
691\end{array}$ & $\bar{z}$ & $\begin{array}{l}\overline{-} \\
\overline{-} \\
\overline{-}\end{array}$ & $\begin{array}{r}1 \\
3 \\
7 \\
15\end{array}$ & $\begin{array}{l}4040 \\
3920 \\
3800 \\
3570\end{array}$ & $\begin{array}{l}4550 \\
4480 \\
4360 \\
4190\end{array}$ & $\begin{array}{l}4790 \\
4740 \\
4610 \\
4490\end{array}$ & $\begin{array}{l}5020 \\
4980 \\
4860 \\
4790\end{array}$ & $\bar{z}$ & $\overline{-}$ \\
\hline
\end{tabular}

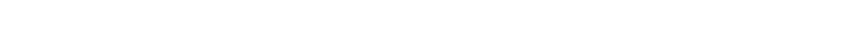

09234700 RED CREEK NEAR DUTCH JOHN, UT

LOCATION.-Lat $40^{\circ} 58^{\prime} 11^{\prime \prime}$, long $109^{\circ} 14^{\prime} 12 "$, in SE $\frac{1}{4} W^{\frac{1}{4}}$ sec. 29, T.3 N., R.24 E., Daggett County, Hydrologic Unit 14040106, on right bank $0.5 \mathrm{mi}$ downstream fram Clay Basin Creek, $7.4 \mathrm{mi}$ upstream from mouth, and $9.0 \mathrm{mi}$ east of Dutch John.

DRAINAGE AREA. $-140 \mathrm{mi}^{2}$.

MEAN BASIN ELLVATION. $-7,420 \mathrm{ft}$.

PERIOD OF RECORD AVAIIABLE.--February 1971 to September 1976.

GAGE.--Water-stage recorder. Altitude of gage is 6,180 ft from topographic map.

AVERAGE DISCHARGE. -5 years, $7.76 \mathrm{ft}^{3} / \mathrm{s}, 5,620$ acre- $\mathrm{ft} / \mathrm{yr}$.

EXIREMES FOR PERIOD OF RECORD.--Maximum discharge, 1,440 $\mathrm{ft}^{3} / \mathrm{s}$ Aug. 4, 1976, gage height unknown, from slope area measurement of the peak flow; no flow for several days during August and september 1971. 
GREEN RIVER BASIN

09234700 RED CREEK NEAR DUTCH JOHN, UT-Continued

LOWEST MEAN DISCHARGE, IN QUBIC FEET PER SECOND, AND RANKING FOR THE INDICATED NUMBER OF CONSECUTTVE DAYS FOR EACH CLIMATIC YEAR, APRII I-MARCH 31

\begin{tabular}{|c|c|c|c|c|c|c|c|c|c|c|c|c|c|c|c|c|c|c|c|}
\hline YEAR & 1 & & 3 & & 7 & & 14 & & $\begin{array}{l}\text { CONSE } \\
30\end{array}$ & OTTVE & $\begin{array}{l}\text { DAYS } \\
60\end{array}$ & & 90 & & 120 & & 183 & & ALL \\
\hline $\begin{array}{l}1972 \\
1973 \\
1974 \\
1975\end{array}$ & $\begin{array}{l}0.00 \\
0.19 \\
0.55 \\
0.12\end{array}$ & $\begin{array}{l}1 \\
3 \\
5 \\
2\end{array}$ & $\begin{array}{l}0.00 \\
0.21 \\
0.63 \\
0.13\end{array}$ & $\begin{array}{l}1 \\
3 \\
5 \\
2\end{array}$ & $\begin{array}{l}0.00 \\
0.33 \\
0.72 \\
0.13\end{array}$ & $\begin{array}{l}1 \\
3 \\
5 \\
2\end{array}$ & $\begin{array}{l}0.00 \\
0.50 \\
1.00 \\
0.17\end{array}$ & $\begin{array}{l}1 \\
3 \\
5 \\
2\end{array}$ & $\begin{array}{l}0.51 \\
0.55 \\
2.00 \\
0.29\end{array}$ & $\begin{array}{l}2 \\
3 \\
5 \\
1\end{array}$ & $\begin{array}{l}1.50 \\
0.61 \\
2.20 \\
0.80\end{array}$ & $\begin{array}{l}3 \\
1 \\
4 \\
2\end{array}$ & $\begin{array}{l}2.00 \\
0.87 \\
2.30 \\
1.50\end{array}$ & $\begin{array}{l}3 \\
1 \\
4 \\
2\end{array}$ & $\begin{array}{l}2.90 \\
1.10 \\
2.50 \\
2.10\end{array}$ & $\begin{array}{l}4 \\
1 \\
3 \\
2\end{array}$ & $\begin{array}{l}3.40 \\
1.80 \\
2.90 \\
2.10\end{array}$ & $\begin{array}{l}5 \\
1 \\
3 \\
2\end{array}$ & $\begin{array}{l}9.60 \\
6.10 \\
8.80 \\
6.50\end{array}$ \\
\hline 1976 & 0.47 & 4 & 0.52 & 4 & 0.65 & 4 & 0.76 & 4 & 1.80 & 4 & 2.90 & 5 & 3.20 & 5 & 3.30 & 5 & 3.40 & 4 & 9.80 \\
\hline
\end{tabular}

HIGHEST MEAN DISCHARGE, IN OUBIC FEET PER SECOND, AND RANKING FOR THE INDICATED NUMBER OF CONSEOTTIVE DAYS FOR EACH WATER YEAR, OCTCBER I-SEPTEMBER 30

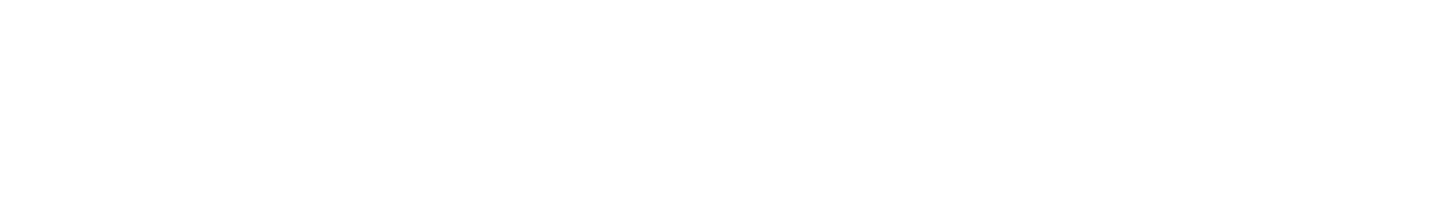

DURATION OF DISCHARGE FOR EACH WATER YEAR

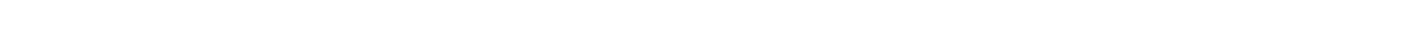
YEAR NUMBR OF DAYS IN CLASS
PER SECOND
-DAYS

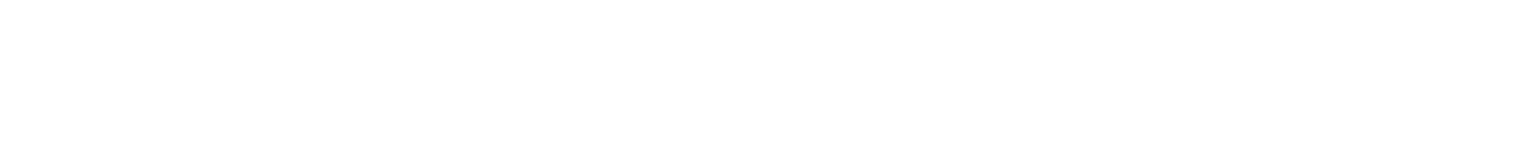

\begin{tabular}{|c|c|c|c|c|c|c|c|c|c|c|c|c|c|c|c|c|c|c|c|}
\hline CLASS & $\begin{array}{c}\text { CUBIC } \\
\text { FEET } \\
\text { PER } \\
\text { SECOND }\end{array}$ & $\begin{array}{c}\text { TOTAL } \\
\text { DAYS }\end{array}$ & $\begin{array}{c}\text { ACOD- } \\
\text { MU- } \\
\text { LATED } \\
\text { DAYS }\end{array}$ & $\begin{array}{l}\text { PER- } \\
\text { CENT } \\
\text { DAYS }\end{array}$ & CLASS & $\begin{array}{c}\text { OBIC } \\
\text { FEET } \\
\text { PER } \\
\text { SECOND }\end{array}$ & $\begin{array}{l}\text { TOTAL } \\
\text { DAYS }\end{array}$ & $\begin{array}{c}\text { ACCU- } \\
\text { MU- } \\
\text { LATED } \\
\text { DAYS }\end{array}$ & $\begin{array}{l}\text { PER- } \\
\text { CENT } \\
\text { DAYS }\end{array}$ & CLASS & $\begin{array}{c}\text { OBIC } \\
\text { FEET } \\
\text { PER } \\
\text { SECOND }\end{array}$ & $\begin{array}{l}\text { TOTAL } \\
\text { DAYS }\end{array}$ & $\begin{array}{c}\text { ACOU- } \\
\text { MN- } \\
\text { LATED } \\
\text { DAYS }\end{array}$ & $\begin{array}{l}\text { PER- } \\
\text { CENT } \\
\text { DAYS }\end{array}$ & CIASS & $\begin{array}{c}\text { OUBIC } \\
\text { FEET } \\
\text { PER } \\
\text { SECOND }\end{array}$ & $\begin{array}{c}\text { TOTAL } \\
\text { DAYS }\end{array}$ & $\begin{array}{c}\text { ACCU- } \\
\text { MU- } \\
\text { LATED } \\
\text { DAYS }\end{array}$ & $\begin{array}{l}\text { PER- } \\
\text { CENT } \\
\text { DAYS }\end{array}$ \\
\hline $\begin{array}{l}0 \\
1 \\
2 \\
3 \\
4 \\
5 \\
6 \\
7 \\
8\end{array}$ & $\begin{array}{l}0.00 \\
0.09 \\
0.11 \\
0.14 \\
0.18 \\
0.22 \\
0.28 \\
0.35 \\
0.43\end{array}$ & $\begin{array}{r}0 \\
5 \\
6 \\
12 \\
16 \\
24 \\
11 \\
26 \\
39\end{array}$ & $\begin{array}{l}1827 \\
1827 \\
1822 \\
1816 \\
1804 \\
1788 \\
1764 \\
1753 \\
1727\end{array}$ & $\begin{array}{r}100.0 \\
100.0 \\
99.7 \\
99.4 \\
98.7 \\
97.9 \\
96.6 \\
95.9 \\
94.5\end{array}$ & $\begin{array}{r}9 \\
10 \\
11 \\
12 \\
13 \\
14 \\
15 \\
16 \\
17\end{array}$ & $\begin{array}{l}0.54 \\
0.68 \\
0.85 \\
1.10 \\
1.30 \\
1.70 \\
2.10 \\
2.60 \\
3.30\end{array}$ & $\begin{array}{r}68 \\
39 \\
68 \\
55 \\
125 \\
114 \\
116 \\
171 \\
137\end{array}$ & $\begin{array}{r}1688 \\
1620 \\
1581 \\
1513 \\
1458 \\
1333 \\
1219 \\
1103 \\
932\end{array}$ & $\begin{array}{l}92.4 \\
88.7 \\
86.5 \\
82.8 \\
79.8 \\
73.0 \\
66.7 \\
60.4 \\
51.0\end{array}$ & $\begin{array}{l}18 \\
19 \\
20 \\
21 \\
22 \\
23 \\
24 \\
25 \\
26\end{array}$ & $\begin{array}{r}4.1 \\
5.2 \\
6.5 \\
8.1 \\
10.0 \\
13.0 \\
16.0 \\
20.0 \\
25.0\end{array}$ & $\begin{array}{r}101 \\
73 \\
72 \\
88 \\
113 \\
99 \\
66 \\
60 \\
46\end{array}$ & $\begin{array}{l}795 \\
694 \\
621 \\
549 \\
461 \\
348 \\
249 \\
183 \\
123\end{array}$ & $\begin{array}{r}43.5 \\
38.0 \\
34.0 \\
30.0 \\
25.2 \\
19.0 \\
13.6 \\
10.0 \\
6.7\end{array}$ & $\begin{array}{l}27 \\
28 \\
29 \\
30 \\
31 \\
32 \\
33 \\
34\end{array}$ & $\begin{array}{r}31.0 \\
39.0 \\
49.0 \\
61.0 \\
76.0 \\
96.0 \\
120.0 \\
150.0\end{array}$ & $\begin{array}{r}40 \\
9 \\
8 \\
6 \\
4 \\
4 \\
4 \\
2\end{array}$ & $\begin{array}{r}77 \\
37 \\
28 \\
20 \\
14 \\
10 \\
6 \\
2\end{array}$ & $\begin{array}{l}4.2 \\
2.0 \\
1.5 \\
1.1 \\
0.8 \\
0.5 \\
0.3 \\
0.1\end{array}$ \\
\hline
\end{tabular}

MONTHLY MEAN DISCHARGES, IN OUBIC FEET PER SEOOND, FOR EACH WATER YEAR

$\begin{array}{llccccccccccc}\text { YEAR } & \text { OCT } & \text { NOV } & \text { DEC } & \text { JAN } & \text { FEB } & \text { MAR } & \text { APR } & \text { MAY } & \text { JUNE } & \text { JULY } & \text { AUG } & \text { SEP } \\ 1972 & 4.92 & 8.81 & 2.12 & 1.10 & 34.5 & 20.9 & 11.5 & 22.3 & 10.7 & 1.02 & 1.12 & 2.62 \\ 1973 & 3.94 & 1.70 & 1.31 & 0.56 & 0.86 & 15.5 & 19.3 & 28.2 & 11.0 & 6.94 & 2.27 & 5.86 \\ 1974 & 2.60 & 2.86 & 2.42 & 2.00 & 3.29 & 18.4 & 19.8 & 23.5 & 8.37 & 3.71 & 1.87 & 1.04 \\ 1975 & 4.08 & 4.29 & 1.77 & 0.29 & 2.74 & 6.84 & 9.16 & 38.5 & 21.3 & 8.62 & 2.24 & 4.43 \\ 1976 & 3.29 & 3.65 & 3.89 & 3.11 & 5.54 & 13.5 & 12.0 & 11.9 & 2.83 & 1.07 & 8.17 & 0.45\end{array}$

ANNUAL PEAK DISCHARGE, IN OUBIC FEET PER SECOND, AND CORRESPONDING GAGE HEIGHT, IN FEET, FOR EACH WATEER YEAR

\begin{tabular}{|c|c|c|c|c|c|c|c|c|c|c|c|}
\hline $\begin{array}{l}\text { WATER } \\
\text { YEAR }\end{array}$ & DATE & $\begin{array}{c}\text { GAGE } \\
\text { HEIGHT }\end{array}$ & $\begin{array}{c}\text { PEAK } \\
\text { DISCHARGE }\end{array}$ & $\begin{array}{l}\text { WATER } \\
\text { YEAR }\end{array}$ & DAIE & $\begin{array}{c}\text { GAGE } \\
\text { HEIGHT }\end{array}$ & $\begin{array}{c}\text { PEAR } \\
\text { DISCHARGE }\end{array}$ & $\begin{array}{l}\text { WATER } \\
\text { YEAR }\end{array}$ & DAIE & $\begin{array}{c}\text { GAGE } \\
\text { HEIGHT }\end{array}$ & $\begin{array}{c}\text { PEAK } \\
\text { DISCHARGE }\end{array}$ \\
\hline $\begin{array}{l}1971 \\
1972\end{array}$ & $\begin{array}{l}\text { AUG. } 30,1971 \\
\text { MAR. } 06,1972\end{array}$ & $\begin{array}{l}3.40 \\
3.32\end{array}$ & $\begin{array}{l}149 \\
273\end{array}$ & $\begin{array}{l}1973 \\
1974\end{array}$ & $\begin{array}{l}\text { JULY } 13,1973 \\
\text { JULY } 17,1974\end{array}$ & $\begin{array}{l}3.25 \\
2.50\end{array}$ & $\begin{array}{l}656 \\
283\end{array}$ & $\begin{array}{l}1975 \\
1976\end{array}$ & $\begin{array}{l}\text { JULY 16, } 1975 \\
\text { AUG. 04, } 1976\end{array}$ & 2.87 & $\begin{array}{r}793 \\
1440\end{array}$ \\
\hline
\end{tabular}


GREEN RIVER BASIN

09235000 GREFN RIVER AT BRIDGEPORT, UT

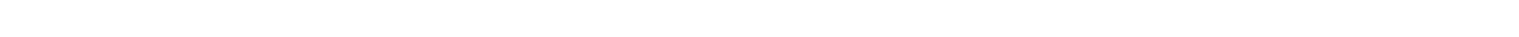
downstream from Sears Creek, $0.5 \mathrm{mi}$ east of Brigeport, $6.5 \mathrm{mi}$ upstream from Utah-Colorado State line, 28 mi southeast of Linwood, UT, and at mile 267.8 on river-profile map by Geological Survey.

DRAINAGE AREA. $--15,700 \mathrm{mi}^{2}$.

PERIOD OF RBCORD AVAIIABLE.-OCtober 1911 to September 1915 (fragmentary).

GAGE.--Water-stage recorder after Sept. 29, 1914. Altitude of gage is 5,390 ft from river-profile map. Prior to Sept. 29, 1914, staff gage $4.5 \mathrm{mi}$ downstream at different datum.

REMARKS.--Diversions for irrigation of about 225,000 acres above station.

EXIREMES FOR PERIOD OF RBOORD. - Maximum discharge observed, 16,900 $\mathrm{ft}^{3} / \mathrm{s} \mathrm{June} 13,14,1912$, gage height, $13.4 \mathrm{ft}$, site and datum then in use; minimum not determined.

LONEST MEAN DISCHARGE, IN CUBIC FEET PER SECOND, AND RANKING FOR THE INDICATED NUMBER OF CONSEOUTIVE DAYS FOR EACH CLIMATIC YEAR, APRIL I-MARCH 31

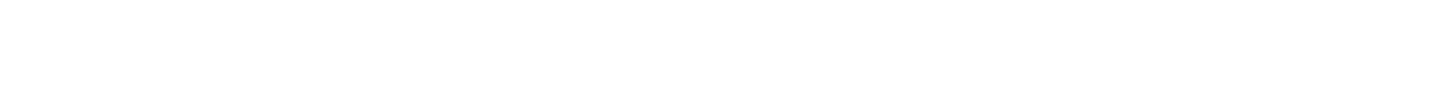

HIGHEST MEAN DISCHARGE, IN CUBIC FEET PER SECOND, AND RANKING FOR THE INDICATED NUMBER OF CONSECUTIVE DAYS FOR EACH WATER YEAR, OCTOBER I-SEPIEMBER 30

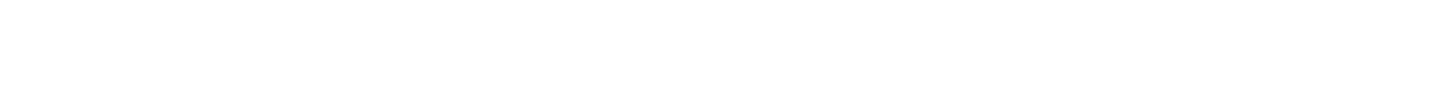

DURATION OF DISCHARGE FOR EACH WATER YEAR

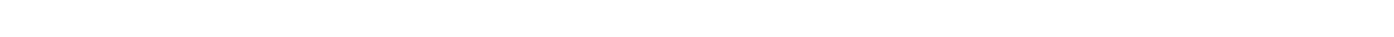
YEAR

NUMBER OF DAYS IN CLASS CUBIC FEET PER SECON

$\begin{array}{llllllllllllllllllllllllll}1915 & 87 & 10 & 13 & 6 & 9 & 3 & 18 & 8 & 14 & 24 & 21 & 16 & 10 & 10 & 17 & 9 & 15 & 18 & 14 & 10 & 14 & 13 & 3 & 2 & 1\end{array}$

634570.0

DURATION TABLE OF DISCHARGE FOR WATER YEAR 1915

\begin{tabular}{|c|c|c|c|c|c|c|c|c|c|c|c|c|c|c|}
\hline LASS & $\begin{array}{c}\text { CUBIC } \\
\text { FEET } \\
\text { PER } \\
\text { SECOND }\end{array}$ & $\begin{array}{r}\text { TOTAL } \\
\text { DAYS }\end{array}$ & $\begin{array}{l}\text { ACOU- } \\
\text { MU- } \\
\text { LATED } \\
\text { DAYS }\end{array}$ & $\begin{array}{l}\text { PER- } \\
\text { CENT } \\
\text { DAYS }\end{array}$ & $\begin{array}{r}\text { COBIC } \\
\text { FEET } \\
\text { PER } \\
\text { CIASS SECOND }\end{array}$ & $\begin{array}{r}\text { TOTAL } \\
\text { DAYS }\end{array}$ & $\begin{array}{l}\text { ACOU- } \\
\text { MU- } \\
\text { LATED } \\
\text { DAYS }\end{array}$ & $\begin{array}{l}\text { PER- } \\
\text { CENT } \\
\text { DAYS }\end{array}$ & CIASS & $\begin{array}{c}\text { CUBIC } \\
\text { FEET } \\
\text { PER } \\
\text { SECOND }\end{array}$ & $\begin{array}{r}\text { TOTAL } \\
\text { DAYS }\end{array}$ & $\begin{array}{c}\text { ACOU- } \\
\text { MU- } \\
\text { LATED } \\
\text { DAYS }\end{array}$ & $\begin{array}{l}\text { PER- } \\
\text { CENT } \\
\text { DAYS }\end{array}$ & CTAS: \\
\hline $\begin{array}{l}0 \\
1 \\
2 \\
3 \\
4 \\
5 \\
6 \\
7 \\
8\end{array}$ & $\begin{array}{r}0.00 \\
465.00 \\
520.00 \\
580.00 \\
640.00 \\
720.00 \\
800.00 \\
890.00 \\
990.00\end{array}$ & $\begin{array}{r}0 \\
87 \\
10 \\
13 \\
6 \\
9 \\
3 \\
3 \\
18 \\
8\end{array}$ & $\begin{array}{l}365 \\
365 \\
278 \\
268 \\
255 \\
249 \\
240 \\
237 \\
219\end{array}$ & $\begin{array}{r}100.0 \\
100.0 \\
76.2 \\
73.4 \\
69.9 \\
68.2 \\
65.8 \\
64.9 \\
60.0\end{array}$ & $\begin{array}{rl}9 & 1100.00 \\
10 & 1200.00 \\
11 & 1400.00 \\
12 & 1500.00 \\
13 & 1700.00 \\
14 & 1900.00 \\
15 & 2100.00 \\
16 & 2400.00 \\
17 & 2600.00\end{array}$ & $\begin{array}{r}14 \\
24 \\
21 \\
16 \\
10 \\
10 \\
17 \\
9 \\
15\end{array}$ & $\begin{array}{r}211 \\
197 \\
173 \\
152 \\
136 \\
126 \\
116 \\
99 \\
90\end{array}$ & $\begin{array}{l}57.8 \\
54.0 \\
47.4 \\
41.6 \\
37.3 \\
34.5 \\
31.8 \\
27.1 \\
24.7\end{array}$ & $\begin{array}{l}18 \\
19 \\
20 \\
21 \\
22 \\
23 \\
24 \\
25 \\
26\end{array}$ & $\begin{array}{l}2900.0 \\
3300.0 \\
3700.0 \\
4100.0 \\
4500.0 \\
5100.0 \\
5600.0 \\
6300.0 \\
7000.0\end{array}$ & $\begin{array}{r}18 \\
14 \\
10 \\
14 \\
13 \\
3 \\
2 \\
1 \\
0\end{array}$ & $\begin{array}{r}75 \\
57 \\
43 \\
33 \\
19 \\
6 \\
3 \\
1 \\
0\end{array}$ & $\begin{array}{r}20.5 \\
15.6 \\
11.8 \\
9.0 \\
5.2 \\
1.6 \\
0.8 \\
0.3 \\
0.0\end{array}$ & $\begin{array}{l}27 \\
28 \\
29 \\
30 \\
31 \\
32 \\
33 \\
34\end{array}$ \\
\hline
\end{tabular}

MONTHLY MEAN DISCHARGES, IN CUBIC FEET PER SBCOND, FOR EACH WATER YEAR

\begin{tabular}{|c|c|c|c|c|c|c|c|c|c|c|c|c|}
\hline YEAR & $\propto C I$ & NOV & $D E C$ & JAN & FEB & MAR & APR & MAY & JUNE & JULY & AUG & SEP \\
\hline $\begin{array}{l}1912 \\
1913 \\
1914\end{array}$ & $\begin{array}{r}980 \\
1331 \\
1856\end{array}$ & $\begin{array}{r}822 \\
1100 \\
1154\end{array}$ & $\begin{array}{l}580 \\
700 \\
750\end{array}$ & $\begin{array}{l}550 \\
850 \\
780\end{array}$ & $\begin{array}{r}590 \\
800 \\
1020\end{array}$ & $\begin{array}{r}774 \\
1800 \\
1972\end{array}$ & $\begin{array}{l}1628 \\
5068 \\
5128\end{array}$ & $\begin{array}{l}4025 \\
6328 \\
8873\end{array}$ & $\begin{array}{l}11850 \\
10950 \\
11780\end{array}$ & $\begin{array}{l}7695 \\
6723 \\
5981\end{array}$ & $\begin{array}{l}3392 \\
2717 \\
2480\end{array}$ & $\begin{array}{r}1543 \\
1850 \\
903\end{array}$ \\
\hline 1915 & 1260 & 841 & 479 & 480 & 494 & 950 & 2235 & 2995 & 4746 & 3208 & 1349 & 1790 \\
\hline
\end{tabular}




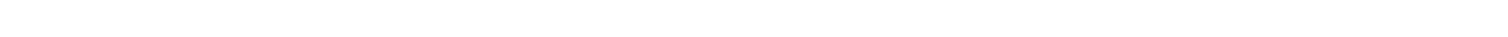
mi upstream fram Matt Warner Reservoir and 27 mi northeast of Vernal.

DRAINAGE AREA. $--24.6 \mathrm{mi}^{2}$.

MEAN BASIN ELEVATION. $-8,170 \mathrm{ft}$.

PERIOD OF RECORD AVAIIABLE.--September 1957 to September 1981.

REVISED RECORDS.-WDR UT-78- • Drainage area.

GAGE. -Water-stage recorder. Altitude of gage is $7,550 \mathrm{ft}$ from topographic map. Prior to Aug. 26, 1965 , at site 0.2 mi downstream at different datum. Prior to July 28, 1978 , datum of gage $1.20 \mathrm{ft}$ higher at same site.

AVERAGE DISCHARGE. --24 years, $3.46 \mathrm{ft}^{3} / \mathrm{s}, 2,510$ acre-ft/yr.

EXTREMES FOR PERIOD OE RECORD.--Maximum discharge recorded, $28 \mathrm{ft}^{3} / \mathrm{s}$ May 10, 1973 , gage height, $3.55 \mathrm{ft}$; maximum Gage height recorded, $4.57 \mathrm{ft}$ Apr. 11, 1969 (backwater from ice); no flow for part of each year.

LOWEST MEAN DISCHARGE, IN OUBIC FEET PER SECOND, AND RANKING FOR THE INDICATEE nOMBEF $\%$ CONSEOUTIVE DAYS FOR EACH CIIMATIC YEAR, APRIL I-MAROH 31

YEAR

13

1959

1960

1961

1962

1963

1965

1966

1967

1968

1969

1970

1971

1972

1974

1975

1976

1977
1978

1978
1979

1980

1981 $\begin{array}{llll}0.00 & 1 & 0.00 & 1\end{array}$

$\begin{array}{llll}0.00 & 2 & 0.00 & 2\end{array}$

$\begin{array}{llll}0.00 & 3 & 0.00 & 3\end{array}$

$\begin{array}{llll}0.00 & 4 & 0.00 & 4\end{array}$

$\begin{array}{llll}0.00 & 5 & 0.00 & 5 \\ 0.00 & 6 & 0.00 & 6\end{array}$

$\begin{array}{llll}0.00 & 7 & 0.00 & 7\end{array}$

$\begin{array}{llll}0.00 & 8 & 0.00 & 8\end{array}$

$\begin{array}{llll}0.00 & 9 & 0.00 & 9\end{array}$

0.0010

0.0011

0.0012

0.0013

0.0014
0.0015

0.0016

0.0016
0.0017

0.0018

0.0019

0.0020

0.0021
0.0022

0.0023

0.0010

0.0012

0.0013

0.0014

0.0015

0.0016

0.0018

0.0018
0.0019

0.0019

0.0020
0.0021

0.0021
0.0022

0.0023

0.001

0.002

0.003

0.004

0.005

0.007

0.008

0.009

0.0010

0.0011
0.0012

0.0013

0.0014

0.0015

0.0016

0.0017

0.0018

0.0019

0.0020

0.0021
0.0022

0.0023

$\begin{array}{ll}14 & \\ 0.00 & 1 \\ 0.00 & 2 \\ 0.00 & 3 \\ 0.00 & 4 \\ 0.00 & 5 \\ 0.00 & 6 \\ 0.00 & 7 \\ 0.00 & 8 \\ 0.00 & 9 \\ 0.00 & 10 \\ 0.00 & 11 \\ 0.00 & 12 \\ 0.00 & 13 \\ 0.00 & 14 \\ 0.00 & 15 \\ 0.00 & 16 \\ 0.00 & 17 \\ 0.00 & 18 \\ 0.00 & 19 \\ 0.00 & 20 \\ 0.00 & 21 \\ 0.00 & 22 \\ 0.00 & 23\end{array}$

CONSECUTTVE DAYS

30

$\begin{array}{ll}0.00 & 1 \\ 0.00 & 2\end{array}$

60
0.00

90

$\begin{array}{llll}0.00 & 3 & 0.00 & 3\end{array}$

0.004

$\begin{array}{ll}0.00 & 5 \\ 0.00 & 6\end{array}$

0.006
0.007

0.005

0.006

0.007

0.008

0.009

0.0010

0.0011

$\begin{array}{ll}0.00 & 8 \\ 0.00 & 9\end{array}$

0.0010

0.0011
0.0012

0.001

0.0013

0.0013

0.0014

0.0016

0.0014

0.0015

0.0016
0.0017

0.0018

0.0018

0.0019

0.0020

0.0021

0.0018
0.0019

0.0020

0.0021

0.0022

0.0023

0.0023

HIGHEST MEAN DISCHARGE, IN OUBIC FEET PER SECOND, AND RANKING FOR THE INDICATED NUMBER OF CONSEOUTIVE DAYS

FOR EACH WATER YEAR, OCTCBER 1-SEPTEMBER 30

YEAR

1958

1959
1960

$\begin{array}{llll}39.0 & 15 & 31.0 & 16\end{array}$

$\begin{array}{ll}1961 \\ 1962 & 190 \\ 1963 & 106\end{array}$

1964

1955

1966

$26.0 \quad 19 \quad 24.0$

$\begin{array}{lllll}1967 & 27.0 & 17 & 25.0 & 17\end{array}$

$\begin{array}{lllll}1968 & 62.0 & 9 & 59.0 & 9 \\ 1969 & 68.0 & 8 & 65.0 & 7\end{array}$

1970

$\begin{array}{lllllll}1970 & 41.0 & 14 & 39.0 & 14 & 34.0 & 13 \\ 1971 & 50.0 & 12 & 43.0 & 12 & 37.0 & 10\end{array}$

$\begin{array}{lllllll}1972 & 22.0 & 21 & 43.0 & 12 & 37.0 & 10\end{array}$

1973

1975

\begin{tabular}{|c|c|c|c|c|c|c|}
\hline $\begin{array}{l}0.00 \\
0.00\end{array}$ & $\begin{array}{l}1 \\
2\end{array}$ & $\begin{array}{l}0.00 \\
0.00\end{array}$ & $\begin{array}{l}1 \\
2\end{array}$ & $\begin{array}{l}0.00 \\
0.00\end{array}$ & $\begin{array}{l}1 \\
2\end{array}$ & $\begin{array}{l}2.3010 \\
1.80\end{array}$ \\
\hline $\begin{array}{l}0.00 \\
0.00 \\
0.00 \\
0.00 \\
0.00\end{array}$ & $\begin{array}{l}3 \\
4 \\
5 \\
6 \\
7\end{array}$ & $\begin{array}{l}0.00 \\
0.00 \\
0.00 \\
0.00 \\
0.00\end{array}$ & $\begin{array}{l}3 \\
4 \\
5 \\
6 \\
7\end{array}$ & $\begin{array}{l}0.00 \\
0.05 \\
0.00 \\
0.00 \\
0.00\end{array}$ & $\begin{array}{r}3 \\
11 \\
4 \\
5 \\
6\end{array}$ & $\begin{array}{l}1.50 \\
1.90 \\
7.70 \\
0.40 \\
1.50\end{array}$ \\
\hline $\begin{array}{l}0.00 \\
0.00 \\
0.00 \\
0.00 \\
0.02\end{array}$ & $\begin{array}{r}8 \\
9 \\
10 \\
11 \\
22\end{array}$ & $\begin{array}{l}0.21 \\
0.02 \\
0.00 \\
0.01 \\
0.09\end{array}$ & $\begin{array}{r}23 \\
14 \\
8 \\
12 \\
18\end{array}$ & $\begin{array}{l}0.32 \\
0.09 \\
0.01 \\
0.10 \\
0.30\end{array}$ & $\begin{array}{r}23 \\
13 \\
8 \\
15 \\
22\end{array}$ & $\begin{array}{l}5.601 \\
1.90 \\
2.301 \\
5.101 \\
3.901\end{array}$ \\
\hline $\begin{array}{l}0.00 \\
0.05 \\
0.00 \\
0.00 \\
0.00\end{array}$ & $\begin{array}{l}12 \\
23 \\
13 \\
14 \\
15\end{array}$ & $\begin{array}{l}0.091 \\
0.18 \\
0.04 \\
0.13 \\
0.02\end{array}$ & $\begin{array}{l}19 \\
22 \\
15 \\
21 \\
13\end{array}$ & $\begin{array}{l}0.16 \\
0.20 \\
0.18 \\
0.25 \\
0.09\end{array}$ & $\begin{array}{l}18 \\
20 \\
19 \\
21 \\
14\end{array}$ & $\begin{array}{l}4.0010 \\
5.401 \\
2.00 \\
9.102 \\
3.601\end{array}$ \\
\hline $\begin{array}{l}0.00 \\
0.00 \\
0.00 \\
0.00 \\
0.00\end{array}$ & $\begin{array}{l}16 \\
17 \\
18 \\
19 \\
20\end{array}$ & $\begin{array}{l}0.041 \\
0.04 \\
0.00 \\
0.00 \\
0.00\end{array}$ & $\begin{array}{r}16 \\
17 \\
9 \\
10 \\
11\end{array}$ & $\begin{array}{l}0.13 \\
0.05 \\
0.03 \\
0.00 \\
0.02\end{array}$ & $\begin{array}{r}16 \\
12 \\
10 \\
7 \\
9\end{array}$ & $\begin{array}{ll}7.30 & 21 \\
3.20 & 13 \\
0.26 & 1 \\
1.40 & 3 \\
2.90 & 12\end{array}$ \\
\hline 0.02 & 21 & 0.112 & 20 & 0.16 & 17 & 6.202 \\
\hline
\end{tabular}

CONSECUTTVE DAVS

$$
30 \quad 60
$$

90

120

183

ALL

$\begin{array}{llll}40.0 & 9 & 24.0 & 12\end{array}$

$\begin{array}{llll}21.0 & 12 & 14.0 & 13\end{array}$

$\begin{array}{lll}12.0 & 20 & 9.4018 \\ 10.0 & 21 & 8.4021\end{array}$

9.4014

6.6019

7.0015
5.1019

4.6015

$\begin{array}{lll}4.6015 & 2.3015 \\ 3.4019 & 1.7019 \\ 3.00 & 21 & 1.5020\end{array}$

$\begin{array}{llll}25.0 & 17 & 17.0 & 17\end{array}$

$\begin{array}{lll}13.0 & 17\end{array}$

$10.0 \quad 17$

7.8017

5.9017

3.9017

1.5020

$\begin{array}{cccc}73.0 & 2 & 45.0 & 2\end{array}$

3.4023

2.8023

$31.0 \quad 2$

$\begin{array}{rr}5.90 & 17 \\ 23.0 & 2\end{array}$

3.9017
15.0

1.9017

$2.00 \quad 23$

6.2020

1.6023

$\begin{array}{cr}15.0 & 3 \\ 1.00 & 23\end{array}$

4.7020
$16.0 \quad 5$

3.1020

$\begin{array}{rr}7.70 & 2 \\ 0.52 & 23\end{array}$

0.5223

$30.0 \quad 5$

21.0

6.1016

4.0016

5.305

$15.0 \quad 14$

$\begin{array}{rr}14.0 & 15 \\ 42.0 & 5\end{array}$

$\begin{array}{ll}12.0 & 14 \\ 11.0 & 15\end{array}$

8.1016
9.3015

20.06

$\begin{array}{ll}15.0 & 6\end{array}$

4.7014

2.2016

$\begin{array}{lllll}15.0 & 6 & 10.0 & 6 & 5.00 \quad 6\end{array}$

$20.0 \quad 13 \quad 18.0 \quad 11$

5.0 9

12.0

$\begin{array}{rr}7.30 & 10 \\ 7.70 & 8\end{array}$

$\begin{array}{rr}3.70 & 10 \\ 4.00 \quad 8\end{array}$

$\begin{array}{llllllll}183 & 1 & 158 & 1 & 153.0 & 20 & 12.0 & 19\end{array}$

$\begin{array}{rrrr}22.0 & 7 & 18.0 & 7\end{array}$

14.07

8.907

$\begin{array}{ll}4.60 & 7\end{array}$

$\begin{array}{rrrrrrrrrrrrrr}188 & 1 & 183 & 1 & 158 & 1 & 123 & 1 & 92.0 & 1 & 53.0 & 1 & 35.0 & 1\end{array}$

$\begin{array}{llllll}8.70 & 13 & 5.70 & 13 & 3.00 & 12 \\ 27.0 & 1 & 18.0 & 1 & 8.90 & 1\end{array}$

5.7013

3.0012

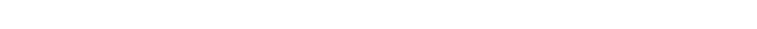

29.03

22.0

$\begin{array}{llll}7.40 & 9 & 3.80 & 9\end{array}$ 
GREEN RIVER BASIN

09235600 POT CREEK ABOVE DIVERSIONS, NEAR VERNAL, UT-Continued

HIGHEST MEAN DISCHARGE, IN CUBIC FEET PER SECOND, AND RANKING FOR THE INDICATED NUMBER OF CONSEOUTIVE DAYS FOR EACH WATER YEAR, OCTOBER 1-SEPTEMBER 30-Continued

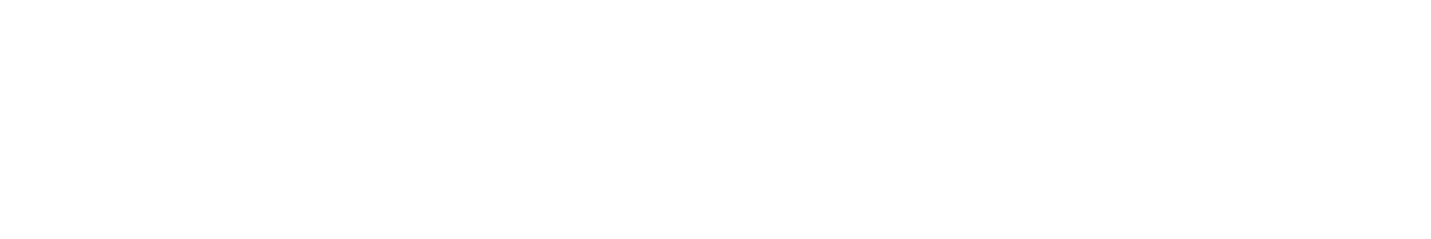

DURATION OF DISCHARGE FOR EACH WATER YEAR

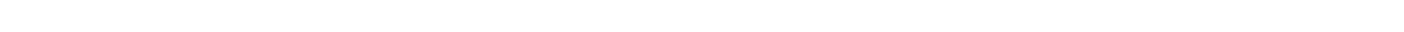
YEAR NUMBER OF DAYS IN CLASS OUBIC FEET

1958287

1959278
1960280

$\begin{array}{lllllllllllllll}2 & 1 & 3 & 2 & 3 & 3 & 4 & 5 & 5 & 14 & 6 & 4 & 3 & 2 & 1\end{array}$ -DAYS

1961269

1962237

1963235

1964289

1965228

1966182

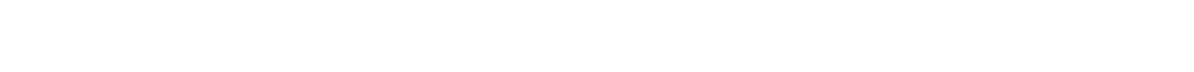

$\begin{array}{rrrrrrrrrrrrrrrrrrrrrrrrrrrrrr}1969 & 131 & 2 & 2 & 2 & 5 & 2 & 15 & 7 & 21 & 30 & 19 & 20 & 12 & 6 & 4 & 5 & 7 & 10 & 7 & 5 & 6 & 4 & 5 & 3 & 6 & 21 & 3 & 2 & 3 \\ 1970 & 101 & 8 & 9 & 10 & 23 & 1 & 12 & 5 & 8 & 8 & 8 & 9 & 19 & 10 & 28 & 11 & 8 & 6 & 5 & 4 & 7 & 9 & 9 & 8 & 17 & 14 & 8 & & \end{array}$

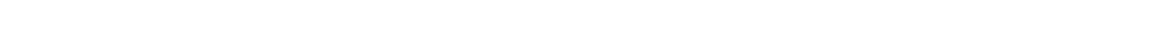

$\begin{array}{llllllllllllllllllllllllll}1972 & 123 & 2 & 5 & 1 & 4 & 5 & 11 & 12 & 2 & 17 & 15 & 14 & 25 & 8 & 7 & 4 & 6 & 3 & 7 & 8 & 7 & 27 & 31 & 15 & 7\end{array}$

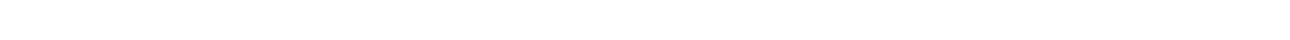

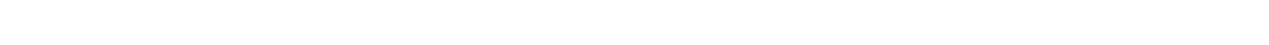

$\begin{array}{rrrrrrrrrrrrrrrrrrrrrrrrrrrr}1976 & 154 & 2 & 4 & 1 & 3 & 2 & 12 & 14 & 16 & 18 & 20 & 23 & 17 & 5 & 2 & 2 & 9 & 3 & 2 & 2 & 3 & 2 & 5 & 5 & 21 & 15 & 4 \\ 1977 & 115 & & 45 & 11 & 21 & 43 & 7 & 18 & 26 & 4 & 2 & 2 & 10 & 12 & 17 & 12 & 11 & 7 & 2 & & & & & & & & \end{array}$

$\begin{array}{rrrrrrrrrrrrrrrrrrrrrrrrrrrrr}1978 & 113 & 3 & 3 & 99 & 2 & 14 & 46 & 2 & 3 & 1 & 2 & 2 & 2 & 2 & 3 & 3 & 9 & 7 & 3 & 12 & 20 & 14 & 3\end{array}$

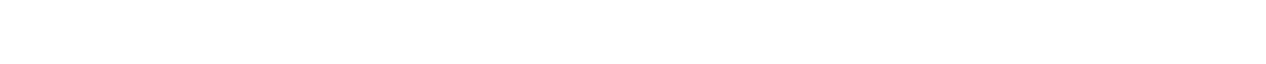

845.2
616.0

616.0
540.1

$1981 \quad 85$

$\begin{array}{lllllllll}7 & 5 & 1 & 1 & 4 & 48 & 83 & 16 & 15\end{array}$

DURATION TABLE OF DISCHARGE FOR WATER YEARS 1958-81

$\begin{array}{ccc}\text { CUBIC } & \text { ACQU- } \\ \text { FEET } & \text { MU- } & \text { PER- } \\ \text { PER TOTAL LATED } & \text { CENT } \\ \text { CLASS SECOND DAYS DAYS } & \text { DAYS }\end{array}$

$\begin{array}{lll}\text { CUBIC } & \text { ACCU- } \\ \text { FEET } & \text { MU- } & \text { PER- } \\ \text { PER TOTAL L LATED } & \text { CENT }\end{array}$ CLASS SECOND DAYS DAYS DAYS

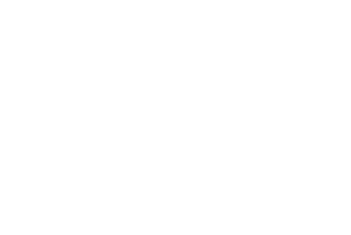

$\begin{array}{lll}\text { OUBIC } & \text { ACOU- } \\ \text { FEET } & \text { MU- } & \text { PER- } \\ \text { PER TOTAL LATED } & \text { CENT }\end{array}$ CLASS SECOND DAYS DAYS DAYS

$\begin{array}{rrrrr}18 & 2.9 & 135 & 1528 & 17.4 \\ 19 & 3.9 & 139 & 1393 & 15.9 \\ 20 & 5.2 & 135 & 1254 & 14.3 \\ 21 & 7.0 & 243 & 1119 & 12.8 \\ 22 & 9.5 & 177 & 876 & 10.0 \\ 23 & 13.0 & 134 & 699 & 8.0 \\ 24 & 17.0 & 155 & 565 & 6.4 \\ 25 & 23.0 & 165 & 410 & 4.7 \\ 26 & 31.0 & 110 & 245 & 2.8\end{array}$

706.8

2823.8

191.2

562.1
1946.4

786.5

878.4

1828.4

1353.5

1451.5

1663.3

1082.0

3253.0

1391.4
2675.9

1178.9

104.4

512.2

1059.5

2184.8

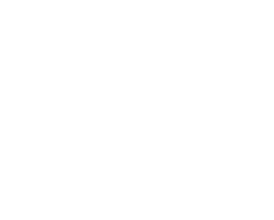

MONTHLY MEAN DISCHARGES, IN OBIC FEET PER SECOND, FOR EACH WATER YEAR

\begin{tabular}{|c|c|c|c|c|c|c|c|c|c|c|c|c|}
\hline YEAR & $\infty \mathrm{OT}$ & $\mathrm{NOV}$ & DEC & JAN & FEBB & MAR & APR & MAY & JUNE & JULY & AUG & SEP \\
\hline $\begin{array}{l}1958 \\
1959 \\
1960\end{array}$ & $\begin{array}{l}0.00 \\
0.00 \\
0.00\end{array}$ & $\begin{array}{l}0.09 \\
0.00 \\
0.00\end{array}$ & $\begin{array}{l}0.00 \\
0.00 \\
0.00\end{array}$ & $\begin{array}{l}0.00 \\
0.00 \\
0.00\end{array}$ & $\begin{array}{l}0.00 \\
0.00 \\
0.00\end{array}$ & $\begin{array}{l}0.00 \\
0.19 \\
1.13\end{array}$ & $\begin{array}{c}12.3 \\
12.5 \\
9.60\end{array}$ & $\begin{array}{r}14.5 \\
6.32 \\
6.40\end{array}$ & $\begin{array}{l}0.76 \\
1.08 \\
0.62\end{array}$ & $\begin{array}{l}0.00 \\
0.25 \\
0.00\end{array}$ & $\begin{array}{l}0.00 \\
0.00 \\
0.00\end{array}$ & $\begin{array}{l}0.00 \\
0.00 \\
0.00\end{array}$ \\
\hline $\begin{array}{l}1961 \\
1962 \\
1963 \\
1964 \\
1965\end{array}$ & $\begin{array}{l}0.00 \\
0.29 \\
0.00 \\
0.00 \\
0.00\end{array}$ & $\begin{array}{l}0.00 \\
0.02 \\
0.00 \\
0.00 \\
0.00\end{array}$ & $\begin{array}{l}0.00 \\
0.00 \\
0.00 \\
0.00 \\
0.00\end{array}$ & $\begin{array}{l}0.00 \\
0.00 \\
0.00 \\
0.00 \\
0.00\end{array}$ & $\begin{array}{l}0.00 \\
0.18 \\
0.12 \\
0.00 \\
0.00\end{array}$ & $\begin{array}{l}1.67 \\
0.97 \\
1.37 \\
0.00 \\
0.00\end{array}$ & $\begin{array}{c}12.5 \\
69.5 \\
2.02 \\
1.91 \\
5.42\end{array}$ & $\begin{array}{c}8.15 \\
19.9 \\
2.56 \\
13.2 \\
31.3\end{array}$ & $\begin{array}{r}0.95 \\
2.62 \\
0.18 \\
3.21 \\
24.7\end{array}$ & $\begin{array}{l}0.00 \\
0.00 \\
0.00 \\
0.00 \\
1.69\end{array}$ & $\begin{array}{l}0.00 \\
0.00 \\
0.00 \\
0.00 \\
0.50\end{array}$ & $\begin{array}{l}0.00 \\
0.00 \\
0.00 \\
0.00 \\
0.17\end{array}$ \\
\hline
\end{tabular}


GREEN RIVER BASIN

09235600 POT CREEK ABOVE DIVERSIONS, NEAR VERNAL, UT-Continued

MONIHLY MEAN DISCHARGES, IN OBIC FEET PER SECOND, FOR EACH WATER YEAR--continued

\begin{tabular}{|c|c|c|c|c|c|c|c|c|c|c|c|c|}
\hline YEAR & $O C T$ & NON & $D E C$ & JAN & FEB & MAR & AFR & MAY & JUNE & JULY & AUG & SEP \\
\hline $\begin{array}{l}1966 \\
1967 \\
1968 \\
1969 \\
1970\end{array}$ & $\begin{array}{l}0.32 \\
0.13 \\
0.01 \\
0.21 \\
0.90\end{array}$ & $\begin{array}{l}0.97 \\
0.24 \\
0.05 \\
0.34 \\
0.49\end{array}$ & $\begin{array}{l}0.58 \\
0.18 \\
0.00 \\
0.06 \\
0.02\end{array}$ & $\begin{array}{l}0.00 \\
0.00 \\
0.00 \\
0.00 \\
0.00\end{array}$ & $\begin{array}{l}0.00 \\
0.00 \\
0.00 \\
0.00 \\
0.05\end{array}$ & $\begin{array}{l}1.55 \\
0.12 \\
0.00 \\
0.00 \\
0.91\end{array}$ & $\begin{array}{c}14.9 \\
7.44 \\
0.10 \\
17.9 \\
10.6\end{array}$ & $\begin{array}{l}6.85 \\
12.1 \\
39.3 \\
19.2 \\
18.0\end{array}$ & $\begin{array}{c}0.71 \\
8.12 \\
19.3 \\
4.99 \\
16.3\end{array}$ & $\begin{array}{l}0.00 \\
0.55 \\
0.30 \\
0.65 \\
0.53\end{array}$ & $\begin{array}{l}0.00 \\
0.01 \\
0.47 \\
0.71 \\
0.01\end{array}$ & $\begin{array}{l}0.00 \\
0.00 \\
0.08 \\
0.33 \\
0.02\end{array}$ \\
\hline $\begin{array}{l}1971 \\
1972 \\
1973 \\
1974 \\
1975\end{array}$ & $\begin{array}{l}0.17 \\
0.55 \\
0.34 \\
0.50 \\
0.21\end{array}$ & $\begin{array}{l}0.45 \\
0.50 \\
0.58 \\
0.68 \\
0.32\end{array}$ & $\begin{array}{l}0.32 \\
0.07 \\
0.18 \\
0.20 \\
0.00\end{array}$ & $\begin{array}{l}0.00 \\
0.00 \\
0.00 \\
0.00 \\
0.00\end{array}$ & $\begin{array}{l}0.00 \\
0.50 \\
0.00 \\
0.00 \\
0.00\end{array}$ & $\begin{array}{c}1.42 \\
11.4 \\
0.00 \\
1.87 \\
0.07\end{array}$ & $\begin{array}{c}11.9 \\
10.3 \\
0.49 \\
21.0 \\
19.1\end{array}$ & $\begin{array}{l}24.9 \\
10.00 \\
88.9 \\
18.6 \\
34.2\end{array}$ & $\begin{array}{c}14.8 \\
1.86 \\
13.3 \\
2.63 \\
32.1\end{array}$ & $\begin{array}{l}0.47 \\
0.06 \\
1.00 \\
0.10 \\
1.86\end{array}$ & $\begin{array}{l}0.00 \\
0.00 \\
0.29 \\
0.01 \\
0.08\end{array}$ & $\begin{array}{l}0.05 \\
0.06 \\
0.33 \\
0.00 \\
0.05\end{array}$ \\
\hline $\begin{array}{l}1976 \\
1977 \\
1978 \\
1979 \\
1980\end{array}$ & $\begin{array}{l}0.32 \\
0.09 \\
0.02 \\
0.00 \\
0.04\end{array}$ & $\begin{array}{l}0.35 \\
0.11 \\
0.11 \\
0.00 \\
0.08\end{array}$ & $\begin{array}{l}0.07 \\
0.07 \\
0.09 \\
0.00 \\
0.00\end{array}$ & $\begin{array}{l}0.00 \\
0.03 \\
0.05 \\
0.00 \\
0.00\end{array}$ & $\begin{array}{l}0.00 \\
0.02 \\
0.05 \\
0.00 \\
0.00\end{array}$ & $\begin{array}{l}0.11 \\
0.33 \\
0.06 \\
0.00 \\
0.00\end{array}$ & $\begin{array}{c}14.5 \\
1.76 \\
4.29 \\
7.27 \\
19.9\end{array}$ & $\begin{array}{c}21.0 \\
0.92 \\
9.70 \\
23.7 \\
46.4\end{array}$ & $\begin{array}{l}2.16 \\
0.09 \\
2.38 \\
3.44 \\
4.48\end{array}$ & $\begin{array}{l}0.08 \\
0.01 \\
0.00 \\
0.07 \\
0.37\end{array}$ & $\begin{array}{l}0.01 \\
0.00 \\
0.00 \\
0.00 \\
0.00\end{array}$ & $\begin{array}{l}0.00 \\
0.00 \\
0.00 \\
0.00 \\
0.02\end{array}$ \\
\hline 1981 & 0.27 & 0.26 & 0.27 & 0.26 & 0.32 & 0.79 & 12.2 & 5.51 & 1.80 & 0.08 & 0.00 & 0.00 \\
\hline
\end{tabular}

ANNUAL PEAK DISCHARGE, IN OBIC FEET PER SECOND, AND CORRESPONDING GAGE HEIGHT, IN FEET, FOR EACH WATER YEAR

\begin{tabular}{|c|c|c|c|c|c|c|c|c|c|c|c|c|}
\hline $\begin{array}{l}\text { WATERR } \\
\text { YEAR }\end{array}$ & DATE & $\begin{array}{c}\text { GAGE } \\
\text { HEIGHT }\end{array}$ & $\begin{array}{c}\text { PEAR } \\
\text { DISCHARGE }\end{array}$ & $\begin{array}{l}\text { WATER } \\
\text { YEAR }\end{array}$ & & DATE & $\begin{array}{c}\text { GAGE } \\
\text { HEIGHT }\end{array}$ & $\begin{array}{c}\text { PEAK } \\
\text { DISCHARGE }\end{array}$ & $\begin{array}{l}\text { WATER } \\
\text { YEAR }\end{array}$ & DATE & $\begin{array}{c}\text { GAGE } \\
\text { HEIGHT }\end{array}$ & $\begin{array}{c}\text { PEAK } \\
\text { DISCHARGE }\end{array}$ \\
\hline $\begin{array}{l}1958 \\
1959 \\
1960 \\
1961 \\
1963 \\
1964 \\
1965 \\
1966\end{array}$ & $\begin{array}{l}\text { APR. } 20,1958 \\
\text { APR. } 15,1959 \\
\text { APR. 05, } 1960 \\
\text { APR. } 02,1961 \\
\text { MAR. } 28,1963 \\
\text { MAY 01, } 1964 \\
\text { JUNE 11, } 1965 \\
\text { APR. } 18,1966\end{array}$ & $\begin{array}{l}2.64 \\
1.78 \\
2.37 \\
3.82 \\
1.56 \\
1.87 \\
3.70 \\
1.96\end{array}$ & $\begin{array}{r}78 \\
37 \\
63 \\
235 \\
26 \\
39 \\
151 \\
41\end{array}$ & $\begin{array}{l}1967 \\
1968 \\
1969 \\
1970 \\
1971 \\
1972 \\
1973 \\
1974\end{array}$ & $\begin{array}{l}\text { MAY } \\
\text { MAY } \\
\text { APR. } \\
\text { APR. } \\
\text { MAY } \\
\text { MAR. } \\
\text { MAY } \\
\text { APR. }\end{array}$ & $\begin{array}{ll}25, & 1967 \\
05, & 1968 \\
22, & 1969 \\
26, & 1970 \\
30, & 1971 \\
26, & 1972 \\
10, & 1973 \\
25, & 1974\end{array}$ & $\begin{array}{l}2.01 \\
2.92 \\
3.09 \\
2.61 \\
2.70 \\
1.96 \\
3.55 \\
3.01\end{array}$ & $\begin{array}{r}41 \\
74 \\
84 \\
58 \\
57 \\
32 \\
286 \\
161\end{array}$ & $\begin{array}{l}1975 \\
1976 \\
1977 \\
1978 \\
1979 \\
1980 \\
1981\end{array}$ & $\begin{array}{l}\text { APR. 21, } 1975 \\
\text { APR. } 24,1976 \\
\text { APR. } 14,1977 \\
\text { MAY } 26,1978 \\
\text { MAY } 01,1979 \\
\text { APR. 28, } 1980 \\
\text { APR. 11, } 1981\end{array}$ & $\begin{array}{l}3.11 \\
2.35 \\
0.76 \\
1.48 \\
3.67 \\
4.49 \\
3.96\end{array}$ & $\begin{array}{c}164 \\
47 \\
5.6 \\
17 \\
66 \\
183 \\
111\end{array}$ \\
\hline
\end{tabular}

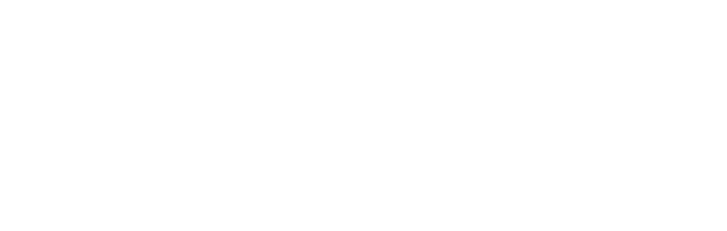

MAGNITUDE AND PRCBABILITY OF ANNUAL HIGHEST MEAN DISCHARGE BASED ON WATER YEARS 1958-81

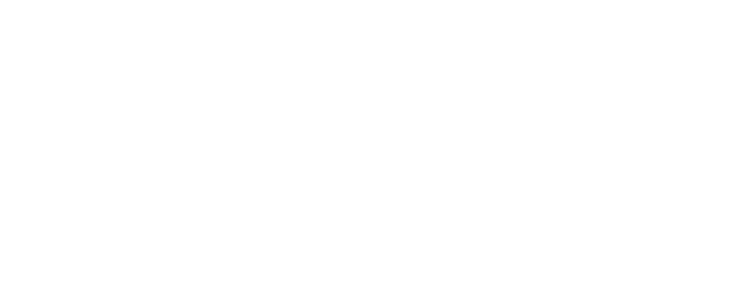




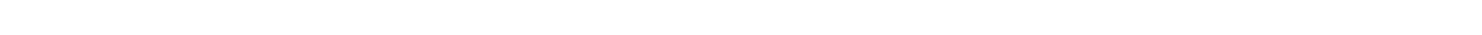
bank 0.2 mi upstream from Utah-Colorado State 1 ine, $7 \mathrm{mi}$ upstream from mouth, and 29 mi northeast of vernal

DRAINAGE AREA. $-107 \mathrm{mi}^{2}$.

PERIOD OF RECORD AVAIIABLE, --August 1957 to September 1981 .

REVISED RECORDS.-WDR UT-77-1: Drainage area.

GAGE.-Water-stage recorder and concrete control. Altitude of gage is 6,900 ft from topographic map.

REMARKS.--FIow regulated by Matt Warner and Crouse Reservoirs, $14 \mathrm{mi}$ and $7 \mathrm{mi}$ upstream, respectively, combined capacity, about 4,000 acre-ft. Several diversions for irrigation above station, including one to Crouse Creek basin for irrigation of about 100 acres in Browns Park.

AVERAGE DISCHARGE.--24 years, $1.84 \mathrm{ft}^{3} / \mathrm{s}, 1,330$ acre-ft/yr.

EXTREMES FOR PERIOD OF RECORD.--Maximum discharge, $286 \mathrm{ft}^{3} / \mathrm{s} \mathrm{Apr} .7,1962$, gage height, $3.85 \mathrm{ft}$, from rating curve extended above $170 \mathrm{ft}^{3} / \mathrm{s}$; maximum gage height, $3.99 \mathrm{ft} \mathrm{Mar.} \mathrm{15,} 1966$ (backwater frcm ice); no flow for part of each year.

LONEST MEAN DISCHARGE, IN OUBIC FEET PER SECOND, AND RANKING FOR THE INDICATED NUMBER OF CONSECUTIVE DAYS FOR EACH CLIMATIC YEAR, APRIL 1-MARCH 31

YEAR

195

1960

196

196

1963

1965

1966

1966
1967
1958

1968

1969
1970

197

1972
1973
1974

1974
1975

1976

1977

1978

1980

1981

HIGHEST MEAN DISCHARGE, IN OBIIC FEET PER SECOND, AND RANKING FOR THE INDICATED NUMBER OF CONSECUTIVE DAYS FOR EACH WATER YEAR, OCTOBER 1-SEPTEMBER 30

YE

\begin{tabular}{|c|c|c|c|c|}
\hline & 1 & & 3 & \\
\hline $\begin{array}{l}958 \\
959\end{array}$ & $\begin{array}{c}23.0 \\
1.00 \\
5.30\end{array}$ & $\begin{array}{l}12 \\
23 \\
21\end{array}$ & $\begin{array}{r}15.0 \\
0.53 \\
3.30\end{array}$ & $\begin{array}{l}11 \\
24 \\
21\end{array}$ \\
\hline $\begin{array}{l}61 \\
61 \\
62 \\
63 \\
64\end{array}$ & $\begin{array}{c}12.0 \\
198 \\
1.00 \\
11.0 \\
19.0\end{array}$ & $\begin{array}{r}16 \\
1 \\
24 \\
17 \\
13\end{array}$ & $\begin{array}{c}9.80 \\
181 . \\
0.83 \\
11.0 \\
9.50\end{array}$ & $\begin{array}{r}16 \\
1 \\
23 \\
15 \\
17\end{array}$ \\
\hline 969 & $\begin{array}{r}65.0 \\
13.0 \\
45.0 \\
110 \\
43.0\end{array}$ & $\begin{array}{r}5 \\
14 \\
8 \\
4 \\
9\end{array}$ & $\begin{array}{l}58.0 \\
13.0 \\
42.0 \\
84.0 \\
23.0\end{array}$ & $\begin{array}{r}5 \\
13 \\
6 \\
4 \\
9\end{array}$ \\
\hline 971 & $\begin{array}{r}31.0 \\
50.0 \\
113 \\
24.0 \\
52.0\end{array}$ & $\begin{array}{r}10 \\
7 \\
3 \\
11 \\
6\end{array}$ & $\begin{array}{c}15.0 \\
42.0 \\
104 \\
22.0 \\
39.0\end{array}$ & $\begin{array}{r}12 \\
7 \\
3 \\
10 \\
8\end{array}$ \\
\hline
\end{tabular}

$\begin{array}{crccc}7 & & 15 & \\ 8.20 & 15 & 4.10 & 17 \\ 0.36 & 24 & & 0.26 & 24 \\ 1.40 & 21 & & 1.10 & 21 \\ & & & & \\ 5.30 & 19 & 2.50 & 19 \\ 157 & 1 & 133 & 1 \\ 0.46 & 23 & 0.27 & 23 \\ 7.50 & 16 & 3.50 & 18 \\ 8.60 & 14 & 7.00 & 14 \\ 42.0 & 5 & 35.0 & 5 \\ 13.0 & 10 & 8.50 & 12 \\ 35.0 & 6 & 33.0 & 6 \\ 68.0 & 4 & 43.0 & 4 \\ 13.0 & 11 & 9.30 & 11 \\ & & & & \\ 10.0 & 13 & 8.30 & 13 \\ 27.0 & 8 & 18.0 & 8 \\ 94.0 & 2 & 86.0 & 2 \\ 17.0 & 9 & 9.80 & 9 \\ 33.0 & 7 & 21.0 & 7\end{array}$

\section{CONSECUTIVE DAYS}

0.001

$0.00 \quad 2$

0.003

$\begin{array}{ll}0.00 & 4 \\ 0.00 & 5\end{array}$

$\begin{array}{ll}0.00 & 5 \\ 0.00 & 6\end{array}$

$\begin{array}{ll}0.00 & 6 \\ 0.007\end{array}$

0.008

$0.00 \quad 9$

0.0010

0.0011

0.0013

0.0014

0.0015

0.0016

0.0017

0.0018

0.0019

0.0020

0.0021

0.0022

0.0023
0.001

0.002

0.003

$\begin{array}{ll}0.00 & 4 \\ 0.00 & 5\end{array}$

0.006

0.007

0.008

$\begin{array}{ll}0.00 \quad 9 \\ 0.00 & 0\end{array}$

0.0010

0.0011

0.0013

0.0223

0.0014

0.0015

0.0016

0.0017

0.0018

0.0019

0.0020

0.0021

0.0022
CONSECUTTVE DAYS

$30 \quad 60$

$\begin{array}{lll}2.1017 & 1.3016\end{array}$

$0.1324 \quad 0.0724$

$\begin{array}{llll}0.13 & 24 & 0.07 & 24 \\ 0.60 & 21 & 0.31 & 21\end{array}$

$\begin{array}{ll}1.3019 & 0.6419\end{array}$

9.01

0.1623

$\begin{array}{ll}1.8018 & 1.0018\end{array}$

26.06

4.3014

$\begin{array}{ll}29.0 & 4 \\ 28.0 & 5\end{array}$

$\begin{array}{cc}28.0 & 5 \\ 7.10 & 9\end{array}$

6.2010

$\begin{array}{rr}6.20 & 10 \\ 9.80 & 8 \\ 72.0 & 2\end{array}$

5.3012
16.07
15.06

2.2014

$\begin{array}{lr}2.20 & 14 \\ 18.0 \quad 4\end{array}$

$\begin{array}{cc}15.0 & 5 \\ 3.70 & 9\end{array}$

3.3010

$\begin{array}{rr}3.30 & 10 \\ 5.10 \quad 8\end{array}$

43.02

2.7012
$12.0 \quad 7$

\section{0}

0.9716

0.0424

0.2021

0.4319

$41.0 \quad 1$

0.0723

2.7011

10.07

1.5014

$\begin{array}{ll}12.0 & 4 \\ 11.0 & 5\end{array}$

3.309

2.9010

$\begin{array}{cr}4.30 & 8 \\ 30.0 & 2\end{array}$

$\begin{array}{rr}30.0 & 2 \\ 1.80 & 12\end{array}$

1.8012
0.8316

0.0324

0.1521

0.3319

$\begin{array}{cc}31.0 & 1 \\ 0.05 & 23\end{array}$

0.5318

8.306

$8.30 \quad 6$
1.1915

1.19
9.904

7.907

3.308

2.7010

3.30
23.0

$\begin{array}{cr}23.0 & 2 \\ 1.40 & 12\end{array}$

1.4012
9.50

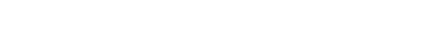

$\begin{array}{lllllllll}0.00 & 1 & 0.00 & 1 & 0.00 & 1 & 0.08 & 4\end{array}$

$\begin{array}{llllll}0.00 \quad 2 \quad 0.00 \quad 2 & 0.00 \quad 2 & 0.06 & 2\end{array}$

$\begin{array}{llllllll}0.00 & 3 & 0.00 & 3 & 0.00 & 3 & 0.07 & 3\end{array}$

$\begin{array}{llllll}0.00 & 4 & 0.0217 & 0.0314 & 0.0712\end{array}$

$\begin{array}{llllllll}0.00 & 5 & 0.00 & 4 & 0.00 & 4 & 9.5023\end{array}$

$\begin{array}{llllllll}0.00 & 6 & 0.00 & 5 & 0.00 & 5 & 0.02 & 1 \\ 0.00 & 7 & 0.00 & 6 & 0.00 & 6 & 0.20 & 7\end{array}$

$\begin{array}{lllllll}0.00 & 8 & 0.0320 & 0.0718 & 2.4016\end{array}$

$\begin{array}{llllll}0.0422 & 0.0622 & 0.2420 & 1.5015\end{array}$

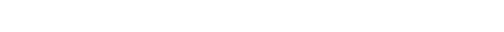

$\begin{array}{llllll}0.0010 & 0.00 & 8 & 0.0516 & 3.9020\end{array}$

$\begin{array}{lllllll}0.0011 & 0.00 & 9 & 0.00 & 8 & 2.60 & 18\end{array}$

$\begin{array}{lllll}0.0012 & 0.0115 & 0.0719 & 1.4014\end{array}$

$\begin{array}{lllll}0.9923 & 1.6023 & 1.6023 & 2.5017\end{array}$

$\begin{array}{llllll}0.0013 & 0.0010 & 0.0112 & 0.186\end{array}$

$\begin{array}{llllll}0.0014 & 0.0321 & 0.9222 & 7.9022\end{array}$

$\begin{array}{llllll}0.0015 & 0.0218 & 0.0315 & 0.9913\end{array}$

$\begin{array}{llllll}0.0016 & 0.0011 & 0.8521 & 3.3019\end{array}$

$\begin{array}{lllll}0.0017 & 0.0116 & 0.0213 & 0.5411\end{array}$

$\begin{array}{llllll}0.0018 & 0.0012 & 0.009 & 0.30 & 5\end{array}$

$0.0019 \quad 0.0013-0.0010 \quad 0.105$

$\begin{array}{lllll}0.0020 & 0.0014 & 0.0011 & 0.4810\end{array}$

$\begin{array}{llllll}0.0321 & 0.0319 & 0.0617 & 4.7021\end{array}$
183 ALI

$\begin{array}{lll}0.5516 & 0.2816\end{array}$

$0.0224 \quad 0.0124$

$\begin{array}{lll}0.1521 & 0.0721\end{array}$

$0.2919 \quad 0.1519$

$20.011 \quad 10.01$

$0.0323 \quad 0.0223$

$0.3418 \quad 0.1718$

$\begin{array}{llll}5.70 & 6 & 3.00 & 6\end{array}$

$1.1013 \quad 0.6414$

$\begin{array}{llll}7.60 & 4 & 3.80 & 4\end{array}$

$\begin{array}{llll}5.207 & 7.607\end{array}$

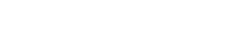

$\begin{array}{rrrr}3.20 & 8 & 1.10 & 10 \\ 15.0 & 2 & 7.50 & 8\end{array}$

$\begin{array}{cccc}3.20 & 8 & 1.80 & 8 \\ 15.0 & 2 & 7.50 & 2\end{array}$

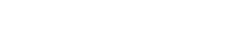


HIGHEST MEAN DISCHARGE, IN CUBIC FEET PER SECOND, AND RANKING FOR THE INDICATED NUMBER OF ONSECUTIVE DAYS FOR EACH WATER YEAR, $\bigcirc$ CTOBER 1-SEPTEMBER 30--Continued

\begin{tabular}{|c|c|c|c|c|c|c|c|c|c|c|c|c|}
\hline YEAR & \multicolumn{12}{|c|}{ CONSECUTIVE DAYS } \\
\hline $\begin{array}{l}1976 \\
1977 \\
1978 \\
1979 \\
1980\end{array}$ & $\begin{array}{r}13.0 \\
6.60 \\
6.90 \\
7.60 \\
121\end{array}$ & $\begin{array}{r}15 \\
20 \\
19 \\
18 \\
2\end{array}$ & $\begin{array}{c}12.0 \\
6.40 \\
6.70 \\
7.50 \\
116\end{array}$ & $\begin{array}{r}14 \\
20 \\
19 \\
18 \\
2\end{array}$ & $\begin{array}{cc}12.0 & 12 \\
4.00 & 20 \\
6.60 & 18 \\
7.50 & 17 \\
88.0 & 3\end{array}$ & $\begin{array}{rr}9.50 & 10 \\
1.90 & 20 \\
5.20 & 16 \\
6.50 & 15 \\
69.0 & 3\end{array}$ & $\begin{array}{rr}4.90 & 13 \\
0.99 & 20 \\
2.60 & 16 \\
3.30 & 15 \\
47.0 & 3\end{array}$ & $\begin{array}{rr}2.50 & 13 \\
0.55 & 20 \\
1.30 & 17 \\
1.60 & 15 \\
27.0 & 3\end{array}$ & $\begin{array}{cc}1.70 & 13 \\
0.38 & 20 \\
0.91 & 17 \\
1.30 & 15 \\
18.0 & 3\end{array}$ & $\begin{array}{rr}1.30 & 14 \\
0.29 & 20 \\
0.72 & 17 \\
1.40 & 13 \\
14.0 & 3\end{array}$ & $\begin{array}{lr}1.40 & 12 \\
0.19 & 20 \\
0.47 & 17 \\
0.94 & 15 \\
9.20 & 3\end{array}$ & $\begin{array}{rr}1.10 & 11 \\
0.10 & 20 \\
0.24 & 17 \\
0.47 & 15 \\
4.60 & 3\end{array}$ \\
\hline 1981 & 5.10 & 22 & 2.50 & 22 & $1.10 \quad 22$ & 0.4922 & $0.25 \quad 22$ & 0.1422 & 0.1122 & 0.1122 & 0.0822 & 0.0622 \\
\hline
\end{tabular}

DURATION OF DISCHARGE FOR EACH WATER YEAR

CLASS $\begin{array}{llllllllllllllllllllllllllllllllllllllll} & 0 & 2 & 3 & 4 & 5 & 6 & 7 & 8 & 9 & 10 & 11 & 12 & 13 & 14 & 15 & 16 & 17 & 18 & 19 & 20 & 21 & 22 & 23 & 24 & 25 & 26 & 27 & 28 & 29 & 30 & 31 & 32 & 33 & 34\end{array}$ YEAR

NUMBER OF DAYS IN CLASS

OUBIC FEET PER SECOID

\begin{tabular}{|c|c|c|c|c|c|c|c|c|c|c|c|c|c|c|c|c|c|c|c|c|c|c|c|c|c|c|c|c|c|c|c|c|c|}
\hline 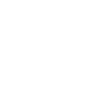 & & & & & 13 & 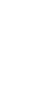 & & & & $\begin{array}{l}7 \\
2 \\
1\end{array}$ & $\begin{array}{l}4 \\
1 \\
1\end{array}$ & $\begin{array}{l}3 \\
2\end{array}$ & $\begin{array}{l}5 \\
1\end{array}$ & $\begin{array}{l}1 \\
1 \\
1\end{array}$ & 5 & & 1 & 5 & 1 & 3 & 1 & 1 & & 1 & & 1 & & & & & & & \\
\hline $\begin{array}{ll}1961 & 325 \\
1962 & 248 \\
1963 & 347 \\
1964 & 334 \\
1965 & 250\end{array}$ & & & & & 16 & 5 & & & $\begin{array}{l}9 \\
2 \\
4 \\
2 \\
5 \\
\end{array}$ & $\begin{array}{l}4 \\
3 \\
1 \\
2\end{array}$ & $\begin{array}{l}1 \\
2\end{array}$ & $\begin{array}{r}1 \\
5 \\
3 \\
1 \\
12\end{array}$ & $\begin{array}{l}1 \\
2 \\
3 \\
8\end{array}$ & $\begin{array}{r}1 \\
3 \\
2 \\
14\end{array}$ & 1 & & 7 & $\begin{array}{l}1 \\
7\end{array}$ & 5 & $\begin{array}{l}2 \\
8 \\
2 \\
2 \\
5\end{array}$ & $\begin{array}{r}2 \\
2 \\
1 \\
10\end{array}$ & 4 & $\begin{array}{l}2 \\
3 \\
4 \\
4\end{array}$ & 4 & 1 & 12 & 9 & 3 & 3 & 3 & 4 & 6 & 7 \\
\hline $\begin{array}{ll}1966 & 178 \\
1967 & 231 \\
1968 & 193 \\
1969 & 240 \\
1970 & 215\end{array}$ & $\begin{array}{l}2 \\
6 \\
5\end{array}$ & $\begin{array}{l}3 \\
8 \\
7\end{array}$ & 1 & $\begin{array}{l}1 \\
1 \\
5\end{array}$ & 72 & 7 & $\frac{5}{5}$ & $\begin{array}{l}5 \\
2 \\
91\end{array}$ & $\begin{array}{l}1 \\
7 \\
7 \\
3 \\
2 \\
3 \\
3\end{array}$ & $\begin{array}{l}5 \\
2 \\
7 \\
3 \\
0\end{array}$ & $\begin{array}{r}9 \\
21 \\
1 \\
17 \\
7\end{array}$ & $\begin{array}{r}15 \\
8 \\
8 \\
11 \\
6\end{array}$ & $\begin{array}{r}11 \\
11 \\
12 \\
6 \\
3\end{array}$ & $\begin{array}{r}16 \\
4 \\
5 \\
1 \\
3\end{array}$ & $\begin{array}{r}15 \\
3 \\
5 \\
11 \\
1\end{array}$ & & $\begin{array}{l}9 \\
4 \\
9 \\
4 \\
1\end{array}$ & $\begin{array}{r}11 \\
4 \\
3 \\
7 \\
1\end{array}$ & $\begin{array}{r}16 \\
5 \\
1 \\
3 \\
15\end{array}$ & $\begin{array}{r}10 \\
3 \\
5 \\
4 \\
23\end{array}$ & $\begin{array}{r}9 \\
2 \\
6 \\
2 \\
11\end{array}$ & $\begin{array}{r}5 \\
1 \\
16 \\
2 \\
5\end{array}$ & $\begin{array}{r}2 \\
3 \\
18 \\
7 \\
6\end{array}$ & $\begin{array}{l}3 \\
3 \\
6 \\
5 \\
7 \\
7 \\
2\end{array}$ & $\begin{array}{l}4 \\
7 \\
5 \\
1\end{array}$ & $\begin{array}{r}12 \\
5 \\
1\end{array}$ & $\begin{array}{r}2 \\
15 \\
2\end{array}$ & $\begin{array}{l}2 \\
2 \\
2 \\
1\end{array}$ & 列 & 2 & 1 & 1 & \\
\hline $\begin{array}{ll}1971 & 171 \\
1972 & 134 \\
1973 & 120 \\
1974 & 156 \\
1975 & 158\end{array}$ & $\begin{array}{rr}6 & 1 \\
21 & 1 \\
43 & 2 \\
43 & 1 \\
22 & 1\end{array}$ & & $\begin{array}{ll}3 & \\
4 & 1 \\
7 & 1 \\
8 & 1 \\
3 & \end{array}$ & $\begin{array}{l}9 \\
101 \\
14 \\
12 \\
5\end{array}$ & $\begin{array}{l}818 \\
11 \\
7 \\
6 \\
2\end{array}$ & $\begin{array}{rr}3 & 6 \\
3 & 9 \\
8 & 3 \\
16 \\
5 & 4\end{array}$ & $\begin{array}{ll}5 & 1 \\
9 & 1 \\
3 & \\
6 & 1 \\
4 & 1\end{array}$ & $\begin{array}{ll}9 & \\
9 & 1 \\
7 & \\
3 & 1 \\
3 & 1\end{array}$ & $\begin{array}{l}91 \\
41 \\
5 \\
51\end{array}$ & $\begin{array}{l}9 \\
0 \\
4 \\
0 \\
0\end{array}$ & $\begin{array}{r}6 \\
12 \\
4 \\
11 \\
6\end{array}$ & $\begin{array}{r}3 \\
12 \\
9 \\
6 \\
9\end{array}$ & $\begin{array}{l}6 \\
4 \\
6 \\
5 \\
7\end{array}$ & $\begin{array}{l}9 \\
8 \\
6 \\
7 \\
7\end{array}$ & 6 & & $\begin{array}{l}4 \\
2 \\
4 \\
4 \\
2\end{array}$ & $\begin{array}{r}3 \\
12 \\
12 \\
3 \\
6\end{array}$ & $\begin{array}{l}10 \\
10 \\
19 \\
\\
8\end{array}$ & $\begin{array}{l}7 \\
5 \\
8 \\
2 \\
8\end{array}$ & $\begin{array}{r}16 \\
2 \\
7 \\
1 \\
8\end{array}$ & $\begin{array}{r}10 \\
1 \\
2 \\
4 \\
13\end{array}$ & $\begin{array}{r}4 \\
4 \\
4 \\
2 \\
11\end{array}$ & $\begin{array}{r}3 \\
12 \\
1 \\
5 \\
5 \\
11\end{array}$ & $\begin{array}{l}5 \\
1 \\
3 \\
2\end{array}$ & $\begin{array}{r}1 \\
1 \\
1 \\
12\end{array}$ & $\begin{array}{l}1 \\
3 \\
7 \\
4\end{array}$ & $\begin{array}{l}1 \\
6 \\
4\end{array}$ & & 813 & & 2 & \\
\hline $\begin{array}{ll}1976 & 160 \\
1977 & 234 \\
1978 & 279 \\
1979 & 268 \\
1980 & 192\end{array}$ & $\begin{array}{l}3 \\
3 \\
41 \\
8 \\
8\end{array}$ & $\begin{array}{r}4 \\
4 \\
10 \\
6 \\
6\end{array}$ & $\begin{array}{rr}4 & 1 \\
19 & 4 \\
4 \\
4 \\
6 & 1\end{array}$ & $\begin{array}{r}171 \\
471 \\
9 \\
6 \\
12\end{array}$ & $\begin{array}{l}19 \\
1419 \\
410 \\
4 \\
8\end{array}$ & $\begin{array}{rr}9 & 9 \\
9 & 10 \\
& 5 \\
2 & 1 \\
3 & 19\end{array}$ & $\begin{array}{l}9 \\
0 \\
5 \\
1 \\
9\end{array}$ & $\begin{array}{ll}1 & 1 \\
6 \\
9 \\
1 \\
1 \\
8\end{array}$ & $\begin{array}{l}41 \\
2 \\
0 \\
3 \\
7\end{array}$ & $\begin{array}{l}2 \\
2 \\
6 \\
2 \\
5\end{array}$ & $\begin{array}{l}6 \\
2\end{array}$ & $\begin{array}{l}9 \\
4\end{array}$ & $\begin{array}{l}1 \\
4 \\
2\end{array}$ & $\begin{array}{l}1 \\
4 \\
3\end{array}$ & 6 & & $\begin{array}{l}\frac{1}{5} \\
9\end{array}$ & $\begin{array}{r}5 \\
11\end{array}$ & $\begin{array}{l}6 \\
1\end{array}$ & $\begin{array}{r}16 \\
1 \\
4 \\
1\end{array}$ & $\begin{array}{r}6 \\
4 \\
11 \\
2 \\
3\end{array}$ & $\begin{array}{r}11 \\
4\end{array}$ & 10 & 510 & 6 & 5 & 3 & 4 & 1 & 1 & 3 & 4 & \\
\hline $1981 \quad 138$ & 371 & 16 & 1410 & & 1118 & & & & 4 & 1 & & & & & & & & 1 & 1 & & & & & & & & & & & & & & \\
\hline
\end{tabular}

DURATION TABLE OF DISCHARGE FOR WATER YEARS 1958-81

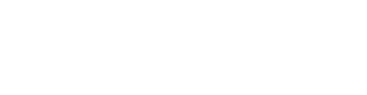
CLASS SECOND DAYS DAYS DAYS

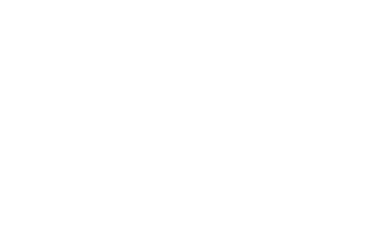

\begin{tabular}{|c|c|c|c|c|}
\hline & $\begin{array}{c}\text { CUBIC } \\
\text { FEET } \\
\text { PER }\end{array}$ & TOTAL & $\begin{array}{c}\text { ACOU- } \\
\text { MU- } \\
\text { LATED }\end{array}$ & $\begin{array}{l}\text { PER- } \\
\text { CENT }\end{array}$ \\
\hline LASS & SECOND & DAYS & DAYS & \\
\hline 9 & 0.20 & 185 & 1949 & 22.2 \\
\hline 10 & 0.26 & 148 & 1764 & 20.1 \\
\hline 11 & 0.36 & 119 & 1616 & 18.4 \\
\hline 12 & 0.48 & 135 & 1497 & 17.1 \\
\hline 13 & 0.65 & 107 & 1362 & 15.5 \\
\hline 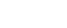 & 0.87 & 106 & 1255 & 14.3 \\
\hline 15 & 1.20 & 94 & 1149 & 13.1 \\
\hline 16 & 1.60 & 128 & 1055 & 12.0 \\
\hline 17 & 2.10 & 108 & 927 & 10.6 \\
\hline
\end{tabular}

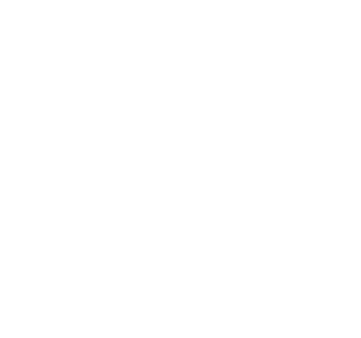

$\begin{array}{lllll}26 & 31.0 & 51 & 181 & 2.1\end{array}$
100.5

3.9
27.1

54.2

3738.0

5.9

271.4

1079.2

234.3

1398.6

958.8
441.1

411.1

640.5

2738.4

1245.0

401.4

36.1

86.2

172.8

1695.7

23.4

MONIHLY MEAN DISCHARGES, IN CUBIC FEET PER SECOND, FOR EACH WATER YEAR

\begin{tabular}{|c|c|c|c|c|c|c|c|c|c|c|c|c|}
\hline YEAR & $\propto C T$ & $\mathrm{NOV}$ & DEC & JAN & FEB & MAR & APR & MAY & JUNE & JULY & AUG & SEP \\
\hline $\begin{array}{l}1958 \\
1959 \\
1960\end{array}$ & $\begin{array}{l}0.00 \\
0.00 \\
0.00\end{array}$ & $\begin{array}{l}0.02 \\
0.00 \\
0.00\end{array}$ & $\begin{array}{l}0.00 \\
0.00 \\
0.00\end{array}$ & $\begin{array}{l}0.00 \\
0.00 \\
0.00\end{array}$ & $\begin{array}{l}0.45 \\
0.00 \\
0.00\end{array}$ & $\begin{array}{l}1.89 \\
0.05 \\
0.58\end{array}$ & $\begin{array}{l}0.20 \\
0.08 \\
0.00\end{array}$ & $\begin{array}{l}0.12 \\
0.00 \\
0.01\end{array}$ & $\begin{array}{l}0.64 \\
0.00 \\
0.00\end{array}$ & $\begin{array}{l}0.00 \\
0.00 \\
0.00\end{array}$ & $\begin{array}{l}0.00 \\
0.00 \\
0.28\end{array}$ & $\begin{array}{l}0.00 \\
0.00 \\
0.00\end{array}$ \\
\hline $\begin{array}{l}1961 \\
1962 \\
1963 \\
1964 \\
1965\end{array}$ & $\begin{array}{l}0.01 \\
0.07 \\
0.00 \\
0.00 \\
0.00\end{array}$ & $\begin{array}{l}0.00 \\
0.00 \\
0.00 \\
0.00 \\
0.00\end{array}$ & $\begin{array}{l}0.01 \\
0.00 \\
0.00 \\
0.00 \\
0.00\end{array}$ & $\begin{array}{l}0.00 \\
0.10 \\
0.00 \\
0.00 \\
0.00\end{array}$ & $\begin{array}{l}0.02 \\
1.36 \\
0.01 \\
0.00 \\
0.00\end{array}$ & $\begin{array}{l}0.44 \\
7.26 \\
0.02 \\
0.03 \\
0.35\end{array}$ & $\begin{array}{c}0.01 \\
96.0 \\
0.16 \\
0.30 \\
1.98\end{array}$ & $\begin{array}{c}0.00 \\
18.0 \\
0.00 \\
1.71 \\
1.00\end{array}$ & $\begin{array}{l}0.00 \\
0.99 \\
0.00 \\
0.01 \\
4.62\end{array}$ & $\begin{array}{l}1.19 \\
0.00 \\
0.00 \\
0.00 \\
0.96\end{array}$ & $\begin{array}{l}0.04 \\
0.00 \\
0.00 \\
0.00 \\
0.00\end{array}$ & $\begin{array}{l}0.02 \\
0.00 \\
0.00 \\
0.00 \\
0.05\end{array}$ \\
\hline
\end{tabular}


GREEN RIVER BASIN

09235800 POT CREFR NEAR VERNAL, UT-Continued

MONITLY MEAN DISCHARGES, IN CUBIC FEET PER SECOND, FOR EACH WATER YEAR--Continued

\begin{tabular}{|c|c|c|c|c|c|c|c|c|c|c|c|c|}
\hline YEAR & $\infty T$ & NON & DEC & JAN & FEB & MAR & APR & MAY & JUNE & JULY & AUG & SEP \\
\hline $\begin{array}{l}1966 \\
1967 \\
1968 \\
1969 \\
1970\end{array}$ & $\begin{array}{l}0.08 \\
0.60 \\
0.00 \\
0.27 \\
0.01\end{array}$ & $\begin{array}{l}0.27 \\
0.06 \\
0.00 \\
0.01 \\
0.00\end{array}$ & $\begin{array}{l}0.00 \\
0.16 \\
0.00 \\
0.00 \\
0.00\end{array}$ & $\begin{array}{l}0.00 \\
0.00 \\
0.00 \\
0.00 \\
0.00\end{array}$ & $\begin{array}{l}0.00 \\
0.00 \\
0.05 \\
0.00 \\
0.00\end{array}$ & $\begin{array}{c}19.5 \\
1.78 \\
0.16 \\
0.25 \\
0.67\end{array}$ & $\begin{array}{c}7.55 \\
0.73 \\
2.32 \\
28.3 \\
0.62\end{array}$ & $\begin{array}{c}3.62 \\
0.05 \\
19.5 \\
2.20 \\
3.01\end{array}$ & $\begin{array}{c}1.24 \\
0.05 \\
14.9 \\
0.76 \\
4.20\end{array}$ & $\begin{array}{l}0.97 \\
0.95 \\
0.00 \\
0.04 \\
0.00\end{array}$ & $\begin{array}{l}1.30 \\
3.20 \\
4.03 \\
0.00 \\
4.13\end{array}$ & $\begin{array}{l}0.61 \\
0.00 \\
4.89 \\
0.00 \\
1.80\end{array}$ \\
\hline $\begin{array}{l}1971 \\
1972 \\
1973 \\
1974 \\
1975\end{array}$ & $\begin{array}{l}0.10 \\
6.20 \\
0.03 \\
5.06 \\
0.03\end{array}$ & $\begin{array}{l}0.06 \\
0.25 \\
0.03 \\
0.19 \\
0.04\end{array}$ & $\begin{array}{l}0.01 \\
2.69 \\
0.01 \\
0.04 \\
0.00\end{array}$ & $\begin{array}{l}0.00 \\
0.10 \\
0.00 \\
0.01 \\
0.00\end{array}$ & $\begin{array}{l}0.00 \\
8.89 \\
0.00 \\
0.00 \\
0.19\end{array}$ & $\begin{array}{l}2.47 \\
1.46 \\
0.40 \\
0.22 \\
7.99\end{array}$ & $\begin{array}{l}1.98 \\
0.24 \\
3.32 \\
0.44 \\
9.80\end{array}$ & $\begin{array}{c}2.61 \\
0.09 \\
70.0 \\
0.05 \\
6.80\end{array}$ & $\begin{array}{c}0.13 \\
0.27 \\
12.8 \\
0.00 \\
14.0\end{array}$ & $\begin{array}{l}5.41 \\
1.08 \\
1.63 \\
1.90 \\
1.83\end{array}$ & $\begin{array}{l}0.55 \\
0.00 \\
0.49 \\
0.91 \\
0.00\end{array}$ & $\begin{array}{l}0.01 \\
0.00 \\
0.13 \\
0.08 \\
0.26\end{array}$ \\
\hline $\begin{array}{l}1976 \\
1977 \\
1978 \\
1979 \\
1980\end{array}$ & $\begin{array}{l}4.72 \\
0.01 \\
0.00 \\
0.00 \\
0.01\end{array}$ & $\begin{array}{l}0.06 \\
0.03 \\
0.00 \\
0.00 \\
0.00\end{array}$ & $\begin{array}{l}0.00 \\
0.00 \\
0.00 \\
0.00 \\
0.00\end{array}$ & $\begin{array}{l}0.00 \\
0.00 \\
0.00 \\
0.00 \\
0.04\end{array}$ & $\begin{array}{l}0.00 \\
0.02 \\
0.00 \\
0.00 \\
0.05\end{array}$ & $\begin{array}{l}1.97 \\
0.06 \\
0.10 \\
0.18 \\
0.13\end{array}$ & $\begin{array}{l}2.64 \\
0.10 \\
0.13 \\
2.06 \\
6.97\end{array}$ & $\begin{array}{c}0.46 \\
0.94 \\
0.05 \\
0.26 \\
45.5\end{array}$ & $\begin{array}{l}0.08 \\
0.00 \\
2.20 \\
0.00 \\
1.24\end{array}$ & $\begin{array}{l}1.70 \\
0.00 \\
0.37 \\
3.15 \\
0.00\end{array}$ & $\begin{array}{l}1.27 \\
0.00 \\
0.00 \\
0.00 \\
0.29\end{array}$ & $\begin{array}{l}0.15 \\
0.00 \\
0.00 \\
0.00 \\
0.74\end{array}$ \\
\hline 1981 & 0.21 & 0.02 & 0.02 & 0.04 & 0.04 & 0.07 & 0.06 & 0.05 & 0.00 & 0.24 & 0.00 & 0.00 \\
\hline
\end{tabular}

ANNUAL PEAK DISCHARGE, IN CUBIC FEET PER SECOND, AND CORRESPONDING GAGE HEIGHT, IN FEET, FOR EACH WATER YEAR

\begin{tabular}{|c|c|c|c|c|c|c|c|c|c|c|c|}
\hline $\begin{array}{l}\text { WATEER } \\
\text { YEAR }\end{array}$ & DATE & $\begin{array}{c}\text { GAGE } \\
\text { HEIGHT }\end{array}$ & $\begin{array}{c}\text { PEAK } \\
\text { DISCHARGE }\end{array}$ & $\begin{array}{l}\text { WATER } \\
\text { YEAR }\end{array}$ & DATE & $\begin{array}{c}\text { GAGE } \\
\text { HEIGHT }\end{array}$ & $\begin{array}{c}\text { PEAK } \\
\text { DISCHARGE }\end{array}$ & $\begin{array}{l}\text { WATER } \\
\text { YEAR }\end{array}$ & DATE & $\begin{array}{c}\text { GAGE } \\
\text { HEIGHT }\end{array}$ & $\begin{array}{c}\text { PEAK } \\
\text { DISCHARGE }\end{array}$ \\
\hline $\begin{array}{l}1958 \\
1959 \\
1960 \\
1961 \\
1962 \\
1963 \\
1964 \\
1965\end{array}$ & $\begin{array}{l}\text { MAR. 22, } 1958 \\
\text { MAR. } 24,1959 \\
\text { AUG. } 22,1960 \\
\text { MAR. } 14,1961 \\
\text { APR. } 07,1962 \\
\text { APR. 26, } 1963 \\
\text { APR. } 01,1964 \\
\text { JUNE } 10,1965\end{array}$ & $\begin{array}{l}2.25 \\
1.21 \\
2.01 \\
1.62 \\
3.85 \\
1.08 \\
1.25 \\
2.27\end{array}$ & $\begin{array}{c}80 \\
11 \\
60 \\
32 \\
286 \\
7.1 \\
13 \\
82\end{array}$ & $\begin{array}{l}1966 \\
1967 \\
1968 \\
1969 \\
1970 \\
1971 \\
1972 \\
1973\end{array}$ & $\begin{array}{l}\text { MAR. } 25,1966 \\
\text { AUG. } 07,1967 \\
\text { JUNE } 11,1968 \\
\text { APR. } 23,1969 \\
\text { JUNE } 11,1970 \\
\text { MAY } 09,1971 \\
\text { FEB. } 28,1972 \\
\text { MAY } 27,1973\end{array}$ & $\begin{array}{l}3.21 \\
1.27 \\
1.84 \\
2.90 \\
2.18 \\
1.87 \\
2.67 \\
2.77\end{array}$ & $\begin{array}{r}197 \\
14 \\
47 \\
148 \\
73 \\
50 \\
120 \\
118\end{array}$ & $\begin{array}{l}1974 \\
1975 \\
1976 \\
1977 \\
1978 \\
1979 \\
1980 \\
1981\end{array}$ & $\begin{array}{lll}\text { OCT. } 10, & 1973 \\
\text { APR. } 15,1975 \\
\text { MAR. } 24,1976 \\
\text { MAY } 08,1977 \\
\text { JUNE } 27,1978 \\
\text { APR. } 17,1979 \\
\text { MAY } 12,1980 \\
\text { JULY } 05,1981\end{array}$ & $\begin{array}{l}1.53 \\
2.52 \\
1.67 \\
1.20 \\
1.18 \\
1.36 \\
2.65 \\
1.10\end{array}$ & $\begin{array}{c}26 \\
92 \\
25 \\
7.0 \\
7.3 \\
11 \\
133 \\
5.5\end{array}$ \\
\hline
\end{tabular}

MAGNITUDE AND PRCBABILITY OF ANNUAL LONEST MEAN DISCHARGE BASED ON CLIMATIC XEARS 1959-81

\begin{tabular}{|c|c|c|c|c|c|c|}
\hline \multirow{2}{*}{$\begin{array}{l}\text { PERIOD } \\
\text { (CON- } \\
\text { SECU- } \\
\text { TIVE } \\
\text { DAYS) }\end{array}$} & \multicolumn{6}{|c|}{$\begin{array}{l}\text { DISCHARGE, IN CUBIC FEET PER SECOND, FOR } \\
\text { INDICATED RECURRENCE INIERVAL, IN YEARS, AND } \\
\text { ANNUAL NONEXCEEDANCE PRCBABILITY, IN PERCENT }\end{array}$} \\
\hline & $\begin{array}{c}2 \\
508\end{array}$ & $\begin{array}{c}5 \\
208\end{array}$ & $\begin{array}{l}10 \\
108\end{array}$ & $\begin{array}{l}20 \\
58\end{array}$ & $\begin{array}{l}50 \\
28\end{array}$ & $\begin{array}{r}100 \\
18\end{array}$ \\
\hline
\end{tabular}

$\begin{array}{lllllll}1 & 0.00 & - & - & - & - & - \\ 7 & 0.00 & - & - & - & - & - \\ 14 & 0.00 & - & - & - & - & - \\ 30 & 0.00 & - & - & - & - & - \\ 60 & 0.00 & - & - & - & - & -\end{array} 9$

MAGNITUDE AND PRCBABILITY OF ANNUAL HIGHEST MEAN DISCHARGE BASED ON WATER YEARS 1958-81

\begin{tabular}{|c|c|c|c|c|c|c|}
\hline \multirow{2}{*}{$\begin{array}{l}\text { PERIOD } \\
\text { (OON- } \\
\text { SECU- } \\
\text { TIVE } \\
\text { DAYS) }\end{array}$} & \multicolumn{6}{|c|}{$\begin{array}{l}\text { DISCHARGE, IN CUBIC FEET PER SECOND, FOR } \\
\text { INDICATED RECURRENCE INTERNAL, IN YEARS, AND } \\
\text { ANNUAL EXCEEDANCE PRCBABILITY, IN PERCENT }\end{array}$} \\
\hline & $\begin{array}{c}2 \\
508\end{array}$ & $\begin{array}{c}5 \\
208\end{array}$ & $\begin{array}{l}10 \\
108\end{array}$ & $\begin{array}{l}25 \\
48\end{array}$ & $\begin{array}{l}50 \\
28\end{array}$ & $\begin{array}{r}100 \\
18\end{array}$ \\
\hline
\end{tabular}

$\begin{array}{rrrrrrr}1 & 21 & 64 & 107 & 178 & - & - \\ 3 & 17 & 53 & 90 & 155 & - & - \\ 7 & 12 & 42 & 75 & 132 & - & - \\ 15 & 8.1 & 31 & 60 & 114 & - & -\end{array}$




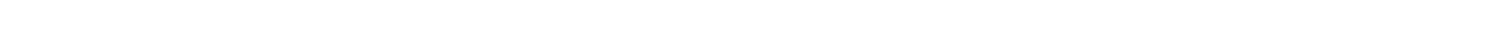
$\mathrm{mi}$ south of Dinosaur National Monument boundary line, $5 \mathrm{mi}$ northeast of Ruple Ranch (Island Park Ranch), and $20 \mathrm{mi}$ northeast of Jensen.

DRAINAGE AREA. $--120 \mathrm{mi}^{2}$.

PERIOD OF RECORD AVAIIABLE.--October 1950 to September 1956, October 1960 to September 1961.

GAGE.--Water-stage recorder. Altitude of gage is 5,200 ft from topograph ic map.

AVERAGE DISCHARGE. -7 years, $36.3 \mathrm{ft}^{3} / \mathrm{s}, 26,280$ acre- $\mathrm{ft} / \mathrm{yr}$.

EXIREMES FOR PERIOD OF RECORD. -Maximum discharge, $968 \mathrm{ft}^{3} / \mathrm{s} \mathrm{Apr.} \mathrm{26,} \mathrm{1952,} \mathrm{gage} \mathrm{height,} 5.40 \mathrm{ft}$, from rating curve extended above $320 \mathrm{ft}^{3} / \mathrm{s}$ on basis of slope-area measurement of peak flow; minimum daily recorded, $31 \mathrm{ft}^{3} / \mathrm{s}$ for many days in $1960-61$.

LONEST MEAN DISCHARGE, IN GUIC FEET PER SECOND, AND RANKING FOR THE INDICATED NUNBER OF CONSEOUTTVE DAYS FOR EAOH CLIMATIC YEAR, APRIL I-MARCH 31

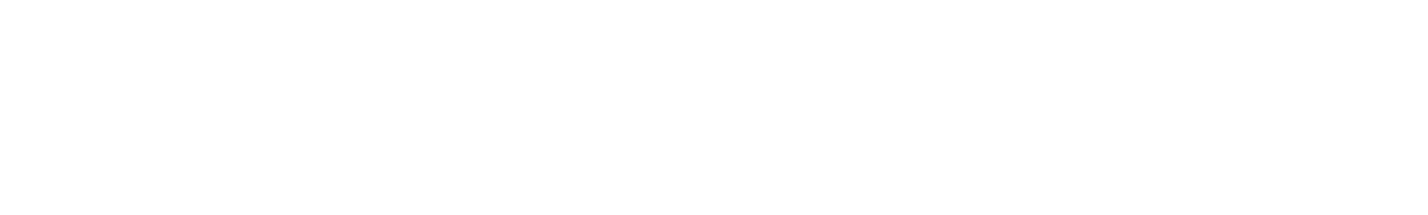

HIGHEST MEAN DISQHARGE, IN OUBIC FEET PER SECOND, AND RANKING FOR THE INDICATED NUMBER OF CONSEOITIVE DAYS FOR EAOH WATER YEAR, OCTCBER 1-SEPTEMBER 30

\begin{tabular}{|c|c|c|c|c|c|c|c|c|c|c|c|c|c|c|c|c|c|c|}
\hline YEAR & & 3 & & 7 & & 15 & & $\begin{array}{l}\text { CONS } \\
30\end{array}$ & $y 0 \mathrm{r}$ & $\begin{array}{l}\text { E DAYS } \\
60\end{array}$ & & 90 & & 120 & & 183 & & ALL \\
\hline $\begin{array}{c}64.0 \\
430 \\
37.0 \\
269 \\
63.0\end{array}$ & $\begin{array}{l}4 \\
1 \\
7 \\
2 \\
5\end{array}$ & $\begin{array}{c}50.0 \\
374 \\
36.0 \\
153 \\
53.0\end{array}$ & $\begin{array}{l}5 \\
1 \\
6 \\
2 \\
4\end{array}$ & $\begin{array}{c}44.0 \\
274 \\
36.0 \\
113 \\
45.0\end{array}$ & $\begin{array}{l}5 \\
1 \\
6 \\
2 \\
4\end{array}$ & $\begin{array}{c}41.0 \\
192 \\
36.0 \\
89.0 \\
39.0\end{array}$ & $\begin{array}{l}4 \\
1 \\
6 \\
2 \\
5\end{array}$ & $\begin{array}{c}39.0 \\
128 \\
36.0 \\
63.0 \\
37.0\end{array}$ & $\begin{array}{l}4 \\
1 \\
6 \\
2 \\
5\end{array}$ & $\begin{array}{l}39.0 \\
87.0 \\
35.0 \\
51.0 \\
36.0\end{array}$ & $\begin{array}{l}3 \\
1 \\
7 \\
2 \\
5\end{array}$ & $\begin{array}{l}39.0 \\
72.0 \\
35.0 \\
46.0 \\
35.0\end{array}$ & $\begin{array}{l}3 \\
1 \\
5 \\
2 \\
6\end{array}$ & $\begin{array}{l}38.0 \\
64.0 \\
35.0 \\
43.0 \\
35.0\end{array}$ & $\begin{array}{l}3 \\
1 \\
4 \\
2 \\
5\end{array}$ & $\begin{array}{l}37.0 \\
56.0 \\
35.0 \\
40.0 \\
35.0\end{array}$ & $\begin{array}{l}3 \\
1 \\
4 \\
2 \\
5\end{array}$ & $\begin{array}{l}36.0 \\
45.0 \\
34.0 \\
37.0 \\
35.0\end{array}$ \\
\hline
\end{tabular}

DURATION OF DISGHARGE FOR EAOH WATER YEAR

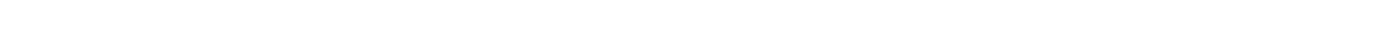
YEAR

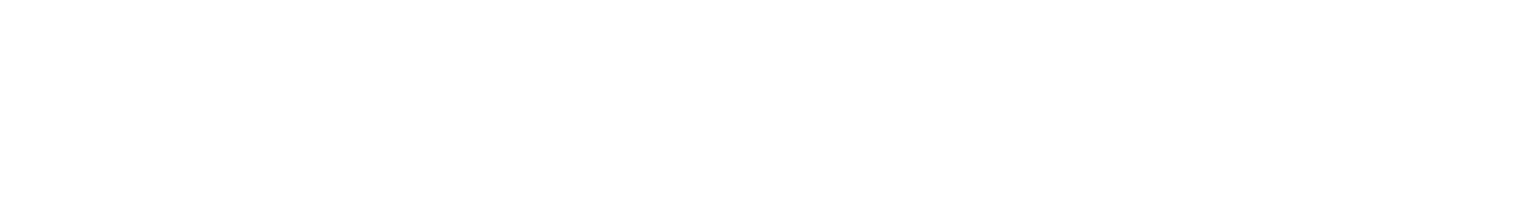

DURATION TABLE OF DISCHARGE FOR WATER YEARS $1951-56,1961$

$\begin{array}{lll}\text { OJBIC } & \text { ACOU- } \\ \text { FEET } & \text { MU- } & \text { PER- } \\ \text { PER TOTAL LATED } & \text { CENT }\end{array}$ SECOND DAYS DAYS DAYS

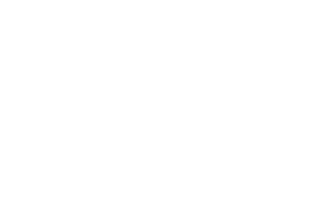

FEET MU- PERPER TOTAL LATED CENT
CLASS SECOND DAYS DAYS DAYS

$$
\begin{array}{rr}
9 & 57.00 \\
10 & 61.00 \\
11 & 66.00 \\
12 & 72.00 \\
13 & 77.00 \\
14 & 83.00 \\
15 & 90.00 \\
16 & 97.00 \\
17 & 100.00
\end{array}
$$

OBIC

FEET MU- PERPER TOTAL LATED CENT

$\begin{array}{lll}18 & 110.0 & 1 \\ 19 & 120.0 & 3 \\ 20 & 130.0 & 0 \\ 21 & 140.0 & 1 \\ 22 & 150.0 & 1 \\ 23 & 170.0 & 1 \\ 24 & 180.0 & 190 \\ 25 & 190.0 & 1 \\ 26 & 210.0 & \end{array}$
$\begin{array}{lcl}\text { OBIC } & \text { ACOJ- } \\ \text { FEET } & \text { MU- } & \text { PER- } \\ \text { PER TOTAL } & \text { LATED } & \text { CENT }\end{array}$ CIASS SECOND DAYS DAYS DAYS

$\begin{array}{lllll}27 & 220.0 & 0 & 5 & 0.2 \\ 28 & 240.0 & 1 & 5 & 0.2 \\ 29 & 260.0 & 1 & 4 & 0.2 \\ 30 & 280.0 & 0 & 3 & 0.1 \\ 31 & 300.0 & 1 & 3 & 0.1 \\ 32 & 330.0 & 0 & 2 & 0.1 \\ 33 & 350.0 & 0 & 2 & 0.1 \\ 34 & 380.0 & 2 & 2 & 0.1\end{array}$


GRETWN RIVER BASIN

09260500 JONES HOAE CREEK NEAR JENSEN, UT-Continued

MONIHLY MEAN DISCHARGES, IN CUBIC FEET PER SEOOND, FOR EACH WATER YEAR

\begin{tabular}{|c|c|c|c|c|c|c|c|c|c|c|c|c|}
\hline YEAR & $\propto T$ & NOV & $\mathrm{DEC}$ & JAN & FEBB & MAR & APR & MAY & JUNE & JULY & AUG & SEP \\
\hline $\begin{array}{l}1951 \\
1952 \\
1953 \\
1954 \\
1955\end{array}$ & $\begin{array}{l}36.0 \\
33.6 \\
35.9 \\
33.4 \\
35.6\end{array}$ & $\begin{array}{l}37.3 \\
34.7 \\
35.0 \\
34.4 \\
35.0\end{array}$ & $\begin{array}{l}38.0 \\
34.3 \\
34.4 \\
34.8 \\
35.0\end{array}$ & $\begin{array}{l}35.6 \\
32.7 \\
33.6 \\
35.6 \\
34.2\end{array}$ & $\begin{array}{l}34.0 \\
33.0 \\
33.9 \\
34.4 \\
34.0\end{array}$ & $\begin{array}{l}37.5 \\
34.5 \\
34.6 \\
38.3 \\
34.0\end{array}$ & $\begin{array}{c}39.4 \\
103 \\
34.3 \\
63.1 \\
36.6\end{array}$ & $\begin{array}{l}38.1 \\
67.1 \\
34.5 \\
35.2 \\
34.5\end{array}$ & $\begin{array}{l}35.8 \\
44.3 \\
34.0 \\
34.3 \\
34.8\end{array}$ & $\begin{array}{l}34.5 \\
41.3 \\
33.2 \\
34.9 \\
34.0\end{array}$ & $\begin{array}{l}34.0 \\
40.0 \\
34.1 \\
35.1 \\
35.0\end{array}$ & $\begin{array}{l}33.7 \\
38.0 \\
33.6 \\
35.6 \\
34.1\end{array}$ \\
\hline 1956 & 34.5 & 34.8 & 33.6 & 33.0 & 32.9 & 33.5 & 33.6 & 34.0 & 33.2 & 33.9 & 33.5 & 32.3 \\
\hline 1961 & 33.0 & 32.8 & 31.4 & 31.2 & 31.0 & 38.8 & 34.3 & 33.0 & 33.6 & 33.2 & 33.0 & 34.5 \\
\hline
\end{tabular}

ANNUAL PEAK DISCHARGE, IN CUBIC FEET PER SBCOND, AND CORRESPONDING GAGE HEIGHT, IN FEET, FOR EACH WATER YEAR

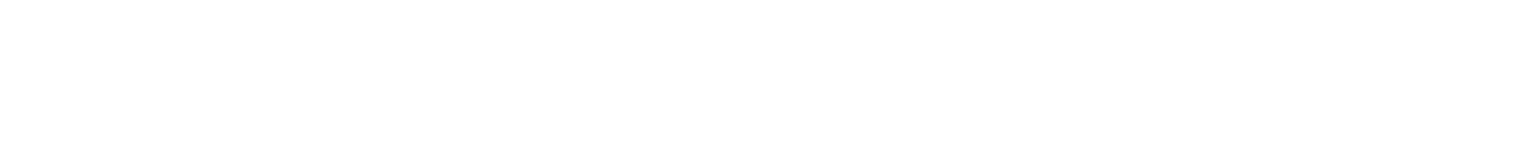

09261000 GREEN RIVER NEAR JENSEN, UT

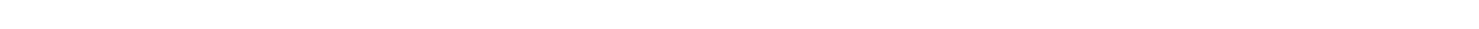
National Monument, on right bank $300 \mathrm{ft}$ upstream from highway bridge, 1 mi downstream from Cub Creek and Chew Ranch, $4 \mathrm{mi}$ southeast of Dinosaur National Monument headquarters, $6.5 \mathrm{mi}$ northeast of Jensen, $12 \mathrm{mi}$ ustream from Brush Creek, and $313.9 \mathrm{mi}$ southeast of

DRAINAGE AREA.--29,660 $\mathrm{mi}^{2}$, approximately, of which about 4,260 $\mathrm{mi}^{2}$ is probably noncontributing. This noncontributing area includes $3,959 \mathrm{mi}^{2}$ in Great Divide basin in southern Wyoming.

PERIOD OF RECORD AVAILABLE.--October 1903 to December 1904, June to August 1905 (gage heights only), March to September 1906, July to October 1914, August to December 1915, october 1946 to September 1981. Monthly mean discharge for some periods prior to December 1915, published in WSP 1313. Prior to October 1946, published as "at Jensen", except October to December 1903, which was published as "near Vernal".

REVISED RECORDS.--WSP 1243: 1904(M). WOR UT-73: 1972. WDR UT-76-1. Drainage area.

GAGE.-Water-stage recorder. Altitude of gage is 4,758 ft from river-profile map. Prior to oct. 1, 1946, nonrecording gages at site $15 \mathrm{mi}$ downstream at different datums. Dec. 13, 1946 to Sept. 30, 1948, water-stage recorder at present site at datum 1.50 ft higher.

REMARKS.--Transbasin diversions and diversions for irrigation above station. Flow regulated by Flaming Gorge Reservoir 93.1 mi upstream beginning Nov. 1, 1962 .

AVERAGE DISCHARGE.--36 years (water years 1904, 1947-81), 4,307 ft $3 / \mathrm{s}, 3,120,000$ acre-ft/yr, unadjusted.

EXTREMES FOR PERIOD OF RECORD.--Maximum discharge, 36,500 ft $\mathrm{ft}^{3} / \mathrm{s}$ June 16, 1957, gage height, $13.22 \mathrm{ft} ; \mathrm{minimum}$ observed, $102 \mathrm{ft} / \mathrm{s}$ Dec. 6, 1904.

DATA BELOW BASED ON PERIOD OF RECORD PRIOR TO REGUIATION BY FLAMING GORGE RESERVOIR

LOWEST MEAN DISCHARGE, IN OUBIC FEET PER SECOND, AND RANKING FOR THE INDICATED NUMBER OF CONSECUTTVE DAYS FOR EACH CLIMATIC YEAR, APRIL 1-MARCH 31

\begin{tabular}{|c|c|c|c|c|c|c|c|c|c|c|c|c|c|c|c|c|c|c|c|c|}
\hline \multirow[t]{2}{*}{ YEAR } & \multicolumn{20}{|c|}{ CONSECUTIVE DAYS } \\
\hline & & & the & & 7 & & 14 & & 3 & & 6 & & 90 & & 120 & & 183 & & ALL & \\
\hline $\begin{array}{l}1948 \\
1949 \\
1950\end{array}$ & $\begin{array}{l}950 \\
570 \\
476\end{array}$ & $\begin{array}{r}15 \\
9 \\
6\end{array}$ & $\begin{array}{l}973 \\
587 \\
500\end{array}$ & $\begin{array}{r}15 \\
9 \\
6\end{array}$ & $\begin{array}{r}1010 \\
627 \\
582\end{array}$ & $\begin{array}{r}15 \\
9 \\
5\end{array}$ & $\begin{array}{r}1040 \\
654 \\
746\end{array}$ & $\begin{array}{r}15 \\
5 \\
10\end{array}$ & $\begin{array}{r}1120 \\
699 \\
905\end{array}$ & $\begin{array}{r}15 \\
4 \\
10\end{array}$ & $\begin{array}{r}1290 \\
836 \\
1120\end{array}$ & $\begin{array}{r}15 \\
6 \\
11\end{array}$ & $\begin{array}{r}1340 \\
875 \\
1190\end{array}$ & $\begin{array}{r}14 \\
6 \\
12\end{array}$ & $\begin{array}{r}1470 \\
875 \\
1340\end{array}$ & $\begin{array}{r}14 \\
2 \\
11\end{array}$ & $\begin{array}{r}1610 \\
894 \\
1390\end{array}$ & $\begin{array}{r}14 \\
2 \\
10\end{array}$ & $\begin{array}{l}5550 \\
3900 \\
5000\end{array}$ & $\begin{array}{r}12 \\
7 \\
11\end{array}$ \\
\hline $\begin{array}{l}1951 \\
1952 \\
1953 \\
1954 \\
1955\end{array}$ & $\begin{array}{l}760 \\
702 \\
480 \\
620 \\
330\end{array}$ & $\begin{array}{r}14 \\
13 \\
7 \\
11 \\
1\end{array}$ & $\begin{array}{l}760 \\
749 \\
487 \\
640 \\
383\end{array}$ & $\begin{array}{r}13 \\
12 \\
4 \\
11 \\
1\end{array}$ & $\begin{array}{l}773 \\
864 \\
515 \\
680 \\
466\end{array}$ & $\begin{array}{r}12 \\
13 \\
4 \\
11 \\
1\end{array}$ & $\begin{array}{l}839 \\
981 \\
600 \\
718 \\
491\end{array}$ & $\begin{array}{r}12 \\
14 \\
4 \\
9 \\
1\end{array}$ & $\begin{array}{r}1040 \\
1090 \\
803 \\
790 \\
530\end{array}$ & $\begin{array}{r}12 \\
13 \\
9 \\
8 \\
1\end{array}$ & $\begin{array}{r}1250 \\
1120 \\
925 \\
855 \\
564\end{array}$ & $\begin{array}{r}14 \\
12 \\
9 \\
8 \\
1\end{array}$ & $\begin{array}{r}1420 \\
1180 \\
992 \\
952 \\
614\end{array}$ & $\begin{array}{r}15 \\
11 \\
9 \\
8 \\
1\end{array}$ & $\begin{array}{r}1480 \\
1210 \\
1040 \\
931 \\
735\end{array}$ & $\begin{array}{r}15 \\
10 \\
9 \\
7 \\
1\end{array}$ & $\begin{array}{r}1590 \\
1450 \\
1160 \\
1010 \\
905\end{array}$ & $\begin{array}{r}13 \\
11 \\
8 \\
6 \\
3\end{array}$ & $\begin{array}{l}5610 \\
4950 \\
6140 \\
3390 \\
2760\end{array}$ & $\begin{array}{r}13 \\
10 \\
14 \\
6 \\
1\end{array}$ \\
\hline $\begin{array}{l}1956 \\
1957 \\
1958 \\
1959 \\
1960\end{array}$ & $\begin{array}{l}456 \\
433 \\
700 \\
420 \\
600\end{array}$ & $\begin{array}{r}5 \\
4 \\
12 \\
3 \\
10\end{array}$ & $\begin{array}{l}489 \\
534 \\
767 \\
443 \\
600\end{array}$ & $\begin{array}{r}5 \\
8 \\
14 \\
3 \\
10\end{array}$ & $\begin{array}{l}603 \\
653 \\
919 \\
484 \\
600\end{array}$ & $\begin{array}{r}7 \\
10 \\
14 \\
2 \\
6\end{array}$ & $\begin{array}{l}706 \\
693 \\
944 \\
574 \\
678\end{array}$ & $\begin{array}{r}8 \\
7 \\
13 \\
2 \\
6\end{array}$ & $\begin{array}{r}784 \\
697 \\
1100 \\
721 \\
785\end{array}$ & $\begin{array}{r}6 \\
3 \\
14 \\
5 \\
7\end{array}$ & $\begin{array}{r}819 \\
737 \\
1140 \\
814 \\
842\end{array}$ & $\begin{array}{r}5 \\
3 \\
13 \\
4 \\
7\end{array}$ & $\begin{array}{r}866 \\
792 \\
1180 \\
889 \\
869\end{array}$ & $\begin{array}{r}4 \\
3 \\
10 \\
7 \\
5\end{array}$ & $\begin{array}{r}925 \\
883 \\
1410 \\
923 \\
995\end{array}$ & $\begin{array}{r}6 \\
3 \\
12 \\
5 \\
8\end{array}$ & $\begin{array}{r}1010 \\
948 \\
1630 \\
932 \\
1290\end{array}$ & $\begin{array}{r}7 \\
5 \\
15 \\
4 \\
9\end{array}$ & $\begin{array}{l}3170 \\
4470 \\
6320 \\
4040 \\
3390\end{array}$ & $\begin{array}{r}4 \\
9 \\
15 \\
8\end{array}$ \\
\hline $\begin{array}{l}1961 \\
1962\end{array}$ & $\begin{array}{l}380 \\
490\end{array}$ & $\begin{array}{l}2 \\
8\end{array}$ & $\begin{array}{l}398 \\
517\end{array}$ & $\begin{array}{l}2 \\
7\end{array}$ & $\begin{array}{l}512 \\
612\end{array}$ & $\begin{array}{l}3 \\
8\end{array}$ & $\begin{array}{l}587 \\
825\end{array}$ & $\begin{array}{r}3 \\
11\end{array}$ & $\begin{array}{l}631 \\
960\end{array}$ & ${ }_{11}^{2}$ & $\begin{array}{r}718 \\
1010\end{array}$ & $\begin{array}{r}2 \\
10\end{array}$ & $\begin{array}{r}780 \\
1220\end{array}$ & $\begin{array}{r}2 \\
13\end{array}$ & $\begin{array}{r}894 \\
1470\end{array}$ & $\begin{array}{r}4 \\
13\end{array}$ & $\begin{array}{r}875 \\
1480\end{array}$ & $\begin{array}{r}1 \\
12\end{array}$ & $\begin{array}{l}2950 \\
2980\end{array}$ & \\
\hline
\end{tabular}


HIGHEST MEAN DISCHARGE, IN OUBIC FEET PER SECOND, AND RANKING FOR THE INDICATED NUMBER OF CONSECUTIVE DAYS FOR FACH WATER YEAR, $\propto$ CTCBER 1-SEPTTEMER 30

YEAR

$\begin{array}{rrrrrr}1947 & 27800 & 4 & 27100 & 4 & 25400 \\ 1948 & 22100 & 10 & 21900 & 10 & 20900 \\ 1949 & 22800 & 9 & 22300 & 9 & 21400 \\ 1950 & 23800 & 8 & 23000 & 8 & 22100 \\ & & & & & \\ 1951 & 26600 & 5 & 26000 & 5 & 24500 \\ 1952 & 32800 & 2 & 32200 & 2 & 30500 \\ 1953 & 22000 & 11 & 21700 & 11 & 21400 \\ 1954 & 15800 & 12 & 15400 & 13 & 14400 \\ 1955 & 11700 & 16 & 11600 & 16 & 11200 \\ 1956 & 26000 & 6 & 25500 & 6 & 24800 \\ 1957 & 36200 & 1 & 35900 & 1 & 35400 \\ 1958 & 28800 & 3 & 28600 & 3 & 27800 \\ 1959 & 15700 & 13 & 15600 & 12 & 14900 \\ 1960 & 13300 & 14 & 12900 & 14 & 12300 \\ & & & & & \\ 1961 & 12000 & 15 & 11800 & 15 & 11300 \\ 1962 & 25200 & 7 & 25000 & 7 & 24200\end{array}$

$\begin{array}{ll}\text { CONSEDUTTVE DAYS } \\ 30 & 60\end{array}$

15

519200 1017800

918700

$\begin{array}{rr}7 & 17900 \\ 10 & 14100\end{array}$

816800

518100

618200

621200

$\begin{array}{ll}6 & 21200 \\ 2 & 27300\end{array}$

$\begin{array}{ll}2 & 27300 \\ 9 & 19000\end{array}$

$\begin{array}{rr}9 & 19000 \\ 13 & 12400\end{array}$

1610200

224100

$\begin{array}{rr}2 & 24100 \\ 11 & 15900\end{array}$

$\begin{array}{rr}11 & 15900 \\ 13 & 9830\end{array}$

915600

$\begin{array}{ll}9 & 15600 \\ 2 & 23100\end{array}$

223100
1111500

$\begin{array}{rr}11 & 11500 \\ 14 & 7860 \\ 15 & 9190\end{array}$

169690

$\begin{array}{rr}5 & 24300 \\ 1 & 32500 \\ 3 & 25400 \\ 12 & 14000\end{array}$

420800

$\begin{array}{ll}1 & 27100 \\ 3 & 21900\end{array}$

$\begin{array}{ll}4 & 16400 \\ 1 & 21900\end{array}$

\begin{tabular}{rr}
1 & 21900 \\
3 & 16300 \\
\hline & 9740
\end{tabular}

1212100

$\begin{array}{ll}12 & 9740 \\ 13 & 8850\end{array}$

1411300

1510500

159250

$\begin{array}{rr}15 & 9250 \\ 8 & 20400\end{array}$
90

120

183

ALL

DURATION OF DISCHARGE FOR EACH WATER YEAR

CIASS $\begin{array}{llllllllllllllllllllllllllllllllllll} & 0 & 1 & 2 & 3 & 4 & 5 & 6 & 7 & 8 & 9 & 10 & 11 & 12 & 13 & 14 & 15 & 16 & 17 & 18 & 19 & 20 & 21 & 22 & 23 & 24 & 25 & 26 & 27 & 28 & 29 & 30 & 31 & 32 & 33 & 34\end{array}$

YEAR

NUMBR OF DAYS IN CLASS

CUBIC FHET

DAYS

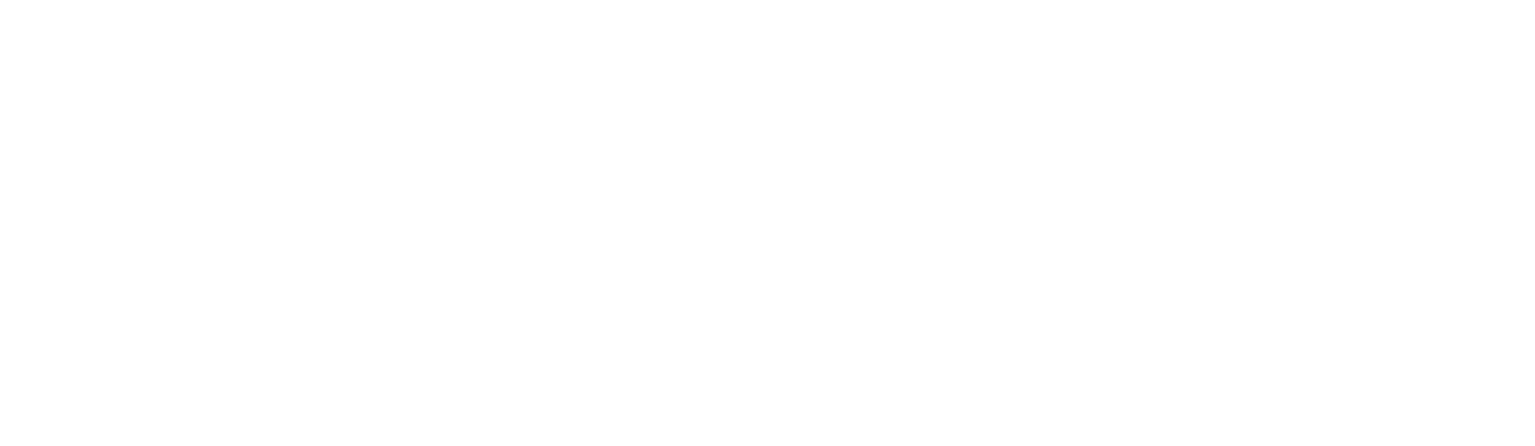

DURATION TABLE OF DISCHARGE FOR WATER YEARS 1947-62

\begin{tabular}{|c|c|c|c|c|}
\hline CLASS & $\begin{array}{c}\text { CUBIC } \\
\text { FEET } \\
\text { PER } \\
\text { SECOND }\end{array}$ & TOTAL & $\begin{array}{l}\text { AOCU- } \\
\text { MU- } \\
\text { LATED } \\
\text { DAYS }\end{array}$ & $\begin{array}{l}\text { PER- } \\
\text { CENT } \\
\text { DAYS }\end{array}$ \\
\hline $\begin{array}{l}0 \\
1 \\
2 \\
3 \\
4 \\
5 \\
6 \\
7 \\
8\end{array}$ & $\begin{array}{r}0.00 \\
330.00 \\
380.00 \\
440.00 \\
510.00 \\
580.00 \\
670.00 \\
770.00 \\
890.00\end{array}$ & $\begin{array}{r}0 \\
2 \\
5 \\
25 \\
51 \\
92 \\
231 \\
349 \\
383\end{array}$ & $\begin{array}{l}5844 \\
5844 \\
5842 \\
5837 \\
5812 \\
5761 \\
5669 \\
5438 \\
5089\end{array}$ & $\begin{array}{r}100.0 \\
100.0 \\
100.0 \\
99.9 \\
99.5 \\
98.6 \\
97.0 \\
93.1 \\
87.1\end{array}$ \\
\hline
\end{tabular}

$\begin{array}{lll}\text { CUBIC } & \text { AOCU- } \\ \text { FEET } & \text { ME- } & \\ \text { PER- } & & \end{array}$ CTASS SECOND DAYS DAYS DAYS

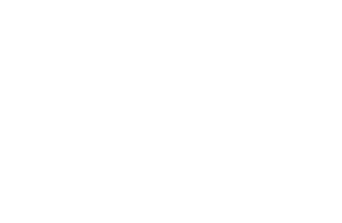

OUBIC ACCUFEET TOTAL LATED PERCIASS SECOND DAYS DAYS DAYS

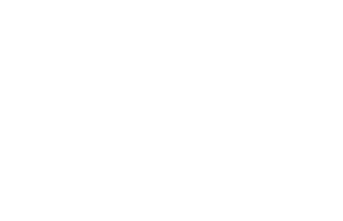

\begin{tabular}{|c|c|c|c|}
\hline $\begin{array}{l}\text { GBBIC } \\
\text { FEET } \\
\text { PER }\end{array}$ & TOTAL & $\begin{array}{l}\text { AOCU- } \\
\text { MU- } \\
\text { LATED }\end{array}$ & $\begin{array}{l}\text { PER- } \\
\text { CENT }\end{array}$ \\
\hline CLASS SECOND & DAYS & DAYS & DAYS \\
\hline $\begin{array}{ll}27 & 13000.0 \\
28 & 15000.0 \\
29 & 18000.0 \\
30 & 20000.0 \\
31 & 24000.0 \\
32 & 27000.0 \\
33 & 31000.0 \\
34 & 36000.0\end{array}$ & $\begin{array}{r}130 \\
131 \\
95 \\
125 \\
40 \\
21 \\
13 \\
2\end{array}$ & $\begin{array}{r}557 \\
427 \\
296 \\
201 \\
76 \\
36 \\
15 \\
2\end{array}$ & $\begin{array}{l}9.5 \\
7.3 \\
5.1 \\
3.4 \\
1.3 \\
0.6 \\
0.3 \\
0.0\end{array}$ \\
\hline
\end{tabular}

MONTELY MEAN DISCHARGES, IN CUBIC FEET PER SBCOND, FOR EACH WATER YEAR

\begin{tabular}{|c|c|c|c|c|c|c|c|c|c|c|c|c|}
\hline YEAR & $\propto T$ & $\mathrm{NOV}$ & $D E C$ & JAN & FEB & MAR & APR & MAY & JUNE & JULY & $A C G$ & SEPP \\
\hline 1904 & 1600 & 1333 & 1726 & 1800 & 2000 & 3547 & 7583 & 20400 & 23000 & 9485 & 3103 & 1214 \\
\hline $\begin{array}{l}1947 \\
1948 \\
1949 \\
1950\end{array}$ & $\begin{array}{r}1600 \\
1900 \\
964 \\
1929\end{array}$ & $\begin{array}{r}1500 \\
1685 \\
949 \\
1788\end{array}$ & $\begin{array}{r}1378 \\
1494 \\
871 \\
1041\end{array}$ & $\begin{array}{r}822 \\
1372 \\
855 \\
1255\end{array}$ & $\begin{array}{l}1223 \\
1440 \\
1005 \\
1293\end{array}$ & $\begin{array}{l}4969 \\
3165 \\
2582 \\
3386\end{array}$ & $\begin{array}{l}6021 \\
7187 \\
6817 \\
8917\end{array}$ & $\begin{array}{l}18320 \\
14460 \\
15290 \\
13710\end{array}$ & $\begin{array}{l}16990 \\
12760 \\
18140 \\
20200\end{array}$ & $\begin{array}{l}8284 \\
2982 \\
6047 \\
9378\end{array}$ & $\begin{array}{l}4002 \\
1399 \\
1798 \\
3132\end{array}$ & $\begin{array}{r}1840 \\
726 \\
1081 \\
1774\end{array}$ \\
\hline $\begin{array}{l}1951 \\
1952 \\
1953 \\
1954 \\
1955\end{array}$ & $\begin{array}{r}1648 \\
2250 \\
1128 \\
864 \\
1259\end{array}$ & $\begin{array}{r}1805 \\
1387 \\
976 \\
1132 \\
1217\end{array}$ & $\begin{array}{r}1471 \\
1204 \\
894 \\
917 \\
533\end{array}$ & $\begin{array}{r}1130 \\
1161 \\
1195 \\
852 \\
598\end{array}$ & $\begin{array}{r}1715 \\
1288 \\
1307 \\
1318 \\
721\end{array}$ & $\begin{array}{l}2389 \\
1477 \\
2049 \\
1872 \\
1658\end{array}$ & $\begin{array}{r}5782 \\
13000 \\
3320 \\
4280 \\
4554\end{array}$ & $\begin{array}{r}12810 \\
23110 \\
6849 \\
9301 \\
9132\end{array}$ & $\begin{array}{r}17360 \\
20150 \\
15740 \\
5575 \\
9082\end{array}$ & $\begin{array}{l}8160 \\
5311 \\
4566 \\
4997 \\
2889\end{array}$ & $\begin{array}{l}4479 \\
2893 \\
2319 \\
1644 \\
1817\end{array}$ & $\begin{array}{r}2024 \\
1570 \\
990 \\
1208 \\
846\end{array}$ \\
\hline
\end{tabular}


GREEN RIVER BASIN

09261000 GREEN RIVER NEAR JENSEN, UT-Continued

MONIHLY MEAN DISCHARGES, IN OUBIC FEET PER SECOND, FOR EACH WATER YEAR--Continued

\begin{tabular}{|c|c|c|c|c|c|c|c|c|c|c|c|c|}
\hline YEAR & OCT & $\mathrm{NOV}$ & DEC & JAN & FEB & MAR & APR & MAY & JUNE & JULY & AUG & SEP \\
\hline $\begin{array}{l}1956 \\
1957 \\
1958 \\
1959 \\
1960\end{array}$ & $\begin{array}{r}833 \\
969 \\
1988 \\
949 \\
1995\end{array}$ & $\begin{array}{r}932 \\
1047 \\
1714 \\
1015 \\
1722\end{array}$ & $\begin{array}{r}1244 \\
770 \\
1225 \\
1000 \\
906\end{array}$ & $\begin{array}{r}1304 \\
755 \\
1101 \\
768 \\
818\end{array}$ & $\begin{array}{r}877 \\
1163 \\
1834 \\
993 \\
900\end{array}$ & $\begin{array}{l}4422 \\
2296 \\
2484 \\
1711 \\
4416\end{array}$ & $\begin{array}{l}7632 \\
4437 \\
5980 \\
3340 \\
7856\end{array}$ & $\begin{array}{r}14920 \\
13890 \\
17940 \\
7127 \\
7995\end{array}$ & $\begin{array}{r}16670 \\
26440 \\
13530 \\
11700 \\
9315\end{array}$ & $\begin{array}{r}4105 \\
14740 \\
2302 \\
4222 \\
2105\end{array}$ & $\begin{array}{r}2308 \\
3835 \\
1222 \\
2064 \\
924\end{array}$ & $\begin{array}{r}1022 \\
2051 \\
901 \\
1463 \\
645\end{array}$ \\
\hline $\begin{array}{l}1961 \\
1962\end{array}$ & $\begin{array}{l}1036 \\
2402\end{array}$ & $\begin{array}{l}1302 \\
1733\end{array}$ & $\begin{array}{r}741 \\
1149\end{array}$ & $\begin{array}{r}744 \\
1023\end{array}$ & $\begin{array}{r}861 \\
4676\end{array}$ & $\begin{array}{l}1866 \\
4435\end{array}$ & $\begin{array}{r}2710 \\
15360\end{array}$ & $\begin{array}{r}5758 \\
17080\end{array}$ & $\begin{array}{r}7932 \\
13780\end{array}$ & $\begin{array}{l}1531 \\
7339\end{array}$ & $\begin{array}{l}1002 \\
2346\end{array}$ & $\begin{array}{r}1584 \\
981\end{array}$ \\
\hline
\end{tabular}

ANNUAL PEAK DISQHARGE, IN OUIC FEET PER SECOND, AND CORRESPONDING GAGE HEIGHT, IN FEET, FOR EACH WATER YEAR

\begin{tabular}{|c|c|c|c|c|c|c|c|c|c|c|c|}
\hline $\begin{array}{l}\text { WATER } \\
\text { YEAR }\end{array}$ & DATE & $\begin{array}{c}\text { GAGE } \\
\text { HEIGHT }\end{array}$ & $\begin{array}{c}\text { PEAK } \\
\text { DISCHARGE }\end{array}$ & $\begin{array}{l}\text { WATER } \\
\text { YEAR }\end{array}$ & DATE & $\begin{array}{c}\text { GAGE } \\
\text { HEIGHT }\end{array}$ & $\begin{array}{c}\text { PEAK } \\
\text { DISQHARGE }\end{array}$ & $\begin{array}{l}\text { WATER } \\
\text { YEAR }\end{array}$ & DATE & $\begin{array}{c}\text { GAGE } \\
\text { HEIGHT }\end{array}$ & $\begin{array}{c}\text { PEAK } \\
\text { DISCHARGE }\end{array}$ \\
\hline $\begin{array}{l}1904 \\
1906 \\
1947 \\
1948 \\
1949 \\
1950\end{array}$ & $\begin{array}{lll}\text { MAY } & 29,1904 \\
\text { JUNE } & 17,1906 \\
\text { MAY } & 13,1947 \\
\text { MAY } & 24,1948 \\
\text { JUNE } & 15,1949 \\
\text { JUNE } & 04,1950\end{array}$ & $\begin{array}{r}11.80 \\
12.05 \\
10.25 \\
8.85 \\
10.51 \\
10.92\end{array}$ & $\begin{array}{l}32100 \\
30500 \\
28800 \\
22400 \\
23200 \\
24200\end{array}$ & $\begin{array}{l}1951 \\
1952 \\
1953 \\
1954 \\
1955 \\
1956\end{array}$ & $\begin{array}{l}\text { JUNE } 03,1951 \\
\text { MAY 08, } 1952 \\
\text { JUNE 17, } 1953 \\
\text { MAY 25, } 1954 \\
\text { JUNE 19, } 1955 \\
\text { JUNE 01, } 1956\end{array}$ & $\begin{array}{r}11.40 \\
12.86 \\
10.34 \\
8.60 \\
7.54 \\
11.34\end{array}$ & $\begin{array}{l}26900 \\
33400 \\
22300 \\
15900 \\
11900 \\
26500\end{array}$ & $\begin{array}{l}1957 \\
1958 \\
1959 \\
1960 \\
1961 \\
1962\end{array}$ & $\begin{array}{l}\text { JUNE } 16,1957 \\
\text { MAY 29, } 1958 \\
\text { JUNE 22, } 1959 \\
\text { APR. 13, } 1960 \\
\text { JUNE 01, } 1961 \\
\text { MAY 14, } 1962\end{array}$ & $\begin{array}{r}13.22 \\
11.81 \\
8.68 \\
8.21 \\
7.37 \\
10.92\end{array}$ & $\begin{array}{l}36500 \\
29050 \\
16000 \\
14400 \\
12100 \\
25400\end{array}$ \\
\hline
\end{tabular}

\begin{tabular}{|c|c|c|c|c|c|c|}
\hline \multirow{2}{*}{$\begin{array}{l}\text { PERIOL } \\
\text { (OON- } \\
\text { SECU- } \\
\text { ITVE } \\
\text { DAYSS) }\end{array}$} & \multicolumn{6}{|c|}{$\begin{array}{l}\text { DISCHARGE, IN ONBIC FEET PER SECOND, FOR } \\
\text { INDICATED RECURRENCE INTERNAL, IN YEARS, AND } \\
\text { ANNUAL NONEXCEEDANCE PRCBABIIITY, IN PERCENT }\end{array}$} \\
\hline & $\begin{array}{c}2 \\
508\end{array}$ & $\begin{array}{c}5 \\
208\end{array}$ & $\begin{array}{l}10 \\
108\end{array}$ & $\begin{array}{l}20 \\
58\end{array}$ & $\begin{array}{l}50 \\
28\end{array}$ & $\begin{array}{r}100 \\
18\end{array}$ \\
\hline $\begin{array}{r}1 \\
7 \\
14 \\
30 \\
60 \\
90\end{array}$ & $\begin{array}{l}529 \\
629 \\
720 \\
831 \\
923 \\
993\end{array}$ & $\begin{array}{l}420 \\
526 \\
604 \\
686 \\
756 \\
812\end{array}$ & $\begin{array}{l}375 \\
485 \\
552 \\
618 \\
676 \\
728\end{array}$ & $\begin{array}{l}343 \\
457 \\
513 \\
566 \\
615 \\
664\end{array}$ & $\begin{array}{l}- \\
- \\
- \\
- \\
-\end{array}$ & $\begin{array}{l}- \\
\overline{-} \\
\overline{-}\end{array}$ \\
\hline
\end{tabular}

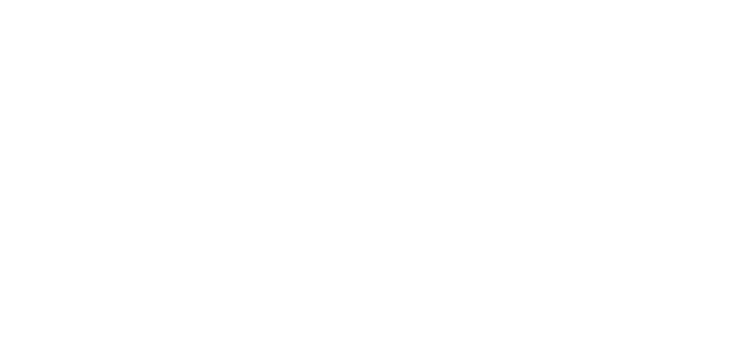

DATA BELOW BASED ON PERIOD OF RECORD AFTER COMPLETION OF FLAMING GORGE RESERNOIR

LOWEST MEAN DISCHARGE, IN OBIC FEET PER SECOND, AND RANKING FOR THE INDICATED NUMBER OF CONSEQUTIVE DAYS FOR EACH CLIMATIC YEAR, APRII 1-MAROH 31

\begin{tabular}{|c|c|c|c|c|c|c|c|c|c|c|c|c|c|c|c|c|c|c|c|c|}
\hline YEAR & 1 & & 3 & & 7 & & 14 & & $\begin{array}{l}\infty \\
30\end{array}$ & EQU' & TVE & & 90 & & 120 & & 183 & & ALL & \\
\hline $\begin{array}{l}1966 \\
1967 \\
1968 \\
1969 \\
1970\end{array}$ & $\begin{array}{r}808 \\
942 \\
1440 \\
1570 \\
1470\end{array}$ & $\begin{array}{r}2 \\
3 \\
12 \\
14 \\
13\end{array}$ & $\begin{array}{r}836 \\
1210 \\
1620 \\
1750 \\
1510\end{array}$ & $\begin{array}{r}2 \\
6 \\
13 \\
14 \\
12\end{array}$ & $\begin{array}{r}952 \\
1550 \\
1680 \\
2020 \\
1570\end{array}$ & $\begin{array}{r}2 \\
11 \\
13 \\
15 \\
12\end{array}$ & $\begin{array}{l}1060 \\
1700 \\
1930 \\
2530 \\
1720\end{array}$ & $\begin{array}{r}1 \\
10 \\
13 \\
15 \\
11\end{array}$ & $\begin{array}{l}1310 \\
1870 \\
2160 \\
2780 \\
1840\end{array}$ & $\begin{array}{l}1 \\
11 \\
12 \\
16 \\
10\end{array}$ & $\begin{array}{l}1720 \\
2040 \\
2420 \\
2960 \\
2140\end{array}$ & $\begin{array}{r}6 \\
10 \\
13 \\
16 \\
11\end{array}$ & $\begin{array}{l}1940 \\
2150 \\
2780 \\
2990 \\
2300\end{array}$ & $\begin{array}{r}6 \\
8 \\
14 \\
16 \\
10\end{array}$ & $\begin{array}{l}2110 \\
2210 \\
3000 \\
3000 \\
2660\end{array}$ & $\begin{array}{r}6 \\
7 \\
15 \\
16 \\
11\end{array}$ & $\begin{array}{l}2160 \\
2190 \\
3180 \\
3330 \\
2750\end{array}$ & $\begin{array}{r}4 \\
6 \\
14 \\
16 \\
9\end{array}$ & $\begin{array}{l}4260 \\
3080 \\
4480 \\
5110 \\
4600\end{array}$ & $\begin{array}{r}4 \\
2 \\
7 \\
16 \\
9\end{array}$ \\
\hline $\begin{array}{l}1976 \\
1977 \\
1978 \\
1979 \\
1980\end{array}$ & $\begin{array}{l}1140 \\
1810 \\
1130 \\
1180 \\
1070\end{array}$ & $\begin{array}{r}6 \\
16 \\
5 \\
8 \\
4\end{array}$ & $\begin{array}{l}1240 \\
2390 \\
1160 \\
1200 \\
1100\end{array}$ & $\begin{array}{r}7 \\
16 \\
4 \\
5 \\
3\end{array}$ & $\begin{array}{l}1440 \\
2510 \\
1290 \\
1260 \\
1280\end{array}$ & $\begin{array}{r}8 \\
16 \\
6 \\
4 \\
5\end{array}$ & $\begin{array}{l}1640 \\
2650 \\
1350 \\
1350 \\
1440\end{array}$ & $\begin{array}{r}9 \\
16 \\
4 \\
5 \\
7\end{array}$ & $\begin{array}{l}1700 \\
2750 \\
1400 \\
1590 \\
1500\end{array}$ & $\begin{array}{r}9 \\
15 \\
5 \\
7 \\
6\end{array}$ & $\begin{array}{l}1850 \\
2830 \\
1420 \\
1680 \\
1620\end{array}$ & $\begin{array}{r}8 \\
15 \\
1 \\
5 \\
3\end{array}$ & $\begin{array}{l}2100 \\
2940 \\
1420 \\
1880 \\
1820\end{array}$ & $\begin{array}{r}7 \\
15 \\
1 \\
4 \\
3\end{array}$ & $\begin{array}{l}2490 \\
3000 \\
1470 \\
2030 \\
1940\end{array}$ & $\begin{array}{r}9 \\
14 \\
1 \\
5 \\
3\end{array}$ & $\begin{array}{l}2800 \\
3080 \\
1590 \\
2210 \\
2170\end{array}$ & $\begin{array}{r}10 \\
13 \\
1 \\
7 \\
5\end{array}$ & $\begin{array}{l}4940 \\
4660 \\
2590 \\
4530 \\
4310\end{array}$ & $\begin{array}{r}13 \\
11 \\
1 \\
8\end{array}$ \\
\hline
\end{tabular}


GREEN RIVER BASIN

09261000 GREEN RIVER NEAR JENSEN, UT-Continued

HIGHEST MEAN DISCHARGE, IN OUBIC FEET PER SECOND, AND RANKING FOR THE INDICATED NUMBER OF CONSECUTIVE DAYS

FOR EACH WATER YEAR, OCTOBER 1-SEPIEMBER 30

\begin{tabular}{|c|c|c|c|c|c|c|c|c|c|c|c|c|c|c|}
\hline YEAR & 3 & 7 & 15 & $\begin{array}{l}\infty O \\
30\end{array}$ & OUTIVE DA & & 90 & & 120 & & 183 & & ALL & \\
\hline 196516800 & 1016400 & 1016200 & 814400 & 812400 & 1110800 & 10 & 9480 & 9 & 8330 & 8 & 6930 & 4 & 4800 & 6 \\
\hline $\begin{array}{rr}1976 & 15900 \\
1977 & 7360 \\
1978 & 17600 \\
1979 & 19100 \\
1980 & 18000\end{array}$ & $\begin{array}{rr}13 & 15100 \\
17 & 7120 \\
9 & 16800 \\
6 & 18400 \\
8 & 17200\end{array}$ & $\begin{array}{rr}13 & 14000 \\
17 & 6550 \\
9 & 16300 \\
5 & 18100 \\
8 & 15700\end{array}$ & $\begin{array}{rr}13 & 13000 \\
17 & 5700 \\
7 & 14700 \\
5 & 16100 \\
9 & 14200\end{array}$ & $\begin{array}{rr}13 & 12300 \\
17 & 5490 \\
7 & 13800 \\
5 & 13900 \\
9 & 13500\end{array}$ & $\begin{array}{rr}13 & 10500 \\
17 & 5260 \\
6 & 11900 \\
5 & 11000 \\
8 & 12200\end{array}$ & $\begin{array}{r}11 \\
17 \\
7 \\
9 \\
5\end{array}$ & $\begin{array}{l}8800 \\
4890 \\
9960 \\
9400 \\
9900\end{array}$ & $\begin{array}{r}12 \\
16 \\
6 \\
10 \\
7\end{array}$ & $\begin{array}{l}7530 \\
4610 \\
8680 \\
8100 \\
8130\end{array}$ & $\begin{array}{r}12 \\
16 \\
5 \\
10 \\
9\end{array}$ & $\begin{array}{l}5980 \\
4120 \\
6590 \\
6420 \\
6510\end{array}$ & $\begin{array}{r}12 \\
16 \\
9 \\
11 \\
10\end{array}$ & $\begin{array}{l}4460 \\
3420 \\
4100 \\
4270 \\
4310\end{array}$ & $\begin{array}{r}9 \\
15 \\
13 \\
12 \\
11\end{array}$ \\
\hline
\end{tabular}

DURATION OF DISCHARGE FOR EACH WATER YEAR

$\begin{array}{llllllllllllllllllllllllllllllllllll}\text { CLASS } 0 & 1 & 2 & 3 & 4 & 5 & 6 & 7 & 8 & 9 & 10 & 11 & 12 & 13 & 14 & 15 & 16 & 17 & 18 & 19 & 20 & 21 & 22 & 23 & 24 & 25 & 26 & 27 & 28 & 29 & 30 & 31 & 32 & 33 & 34\end{array}$

NUMBER OF DAYS IN CLASS

OBBIC FEET -DAYS

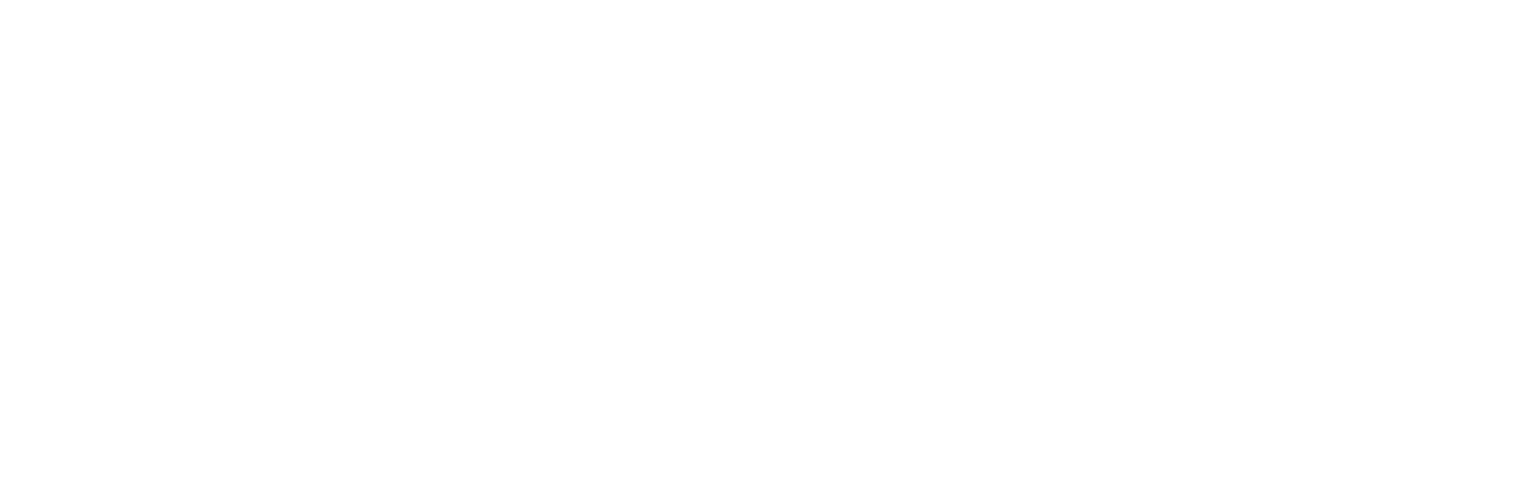

DURATION TABLE OF DISCHARGE FOR WATER YEARS 1965-81

\begin{tabular}{|c|c|c|c|c|c|c|c|c|c|c|c|c|c|c|c|c|c|c|}
\hline CLASS & $\begin{array}{l}\text { CUBIC } \\
\text { FEET } \\
\text { PER } \\
\text { SECOND }\end{array}$ & $\begin{array}{l}\text { TOTAL } \\
\text { DAYS }\end{array}$ & $\begin{array}{l}\text { ACOU- } \\
\text { MU- } \\
\text { LATED } \\
\text { DAYS }\end{array}$ & $\begin{array}{l}\text { PER- } \\
\text { CENT } \\
\text { DAYS }\end{array}$ & $\begin{array}{r}\text { CUBIC } \\
\text { FEET } \\
\text { PER } \\
\text { CIASS SECOND }\end{array}$ & $\begin{array}{l}\text { TOTAL } \\
\text { DAYS }\end{array}$ & $\begin{array}{l}\text { ACOU- } \\
\text { MU- } \\
\text { LATED } \\
\text { DAYS }\end{array}$ & $\begin{array}{l}\text { PER- } \\
\text { CENNT } \\
\text { DAYS }\end{array}$ & CLASS & $\begin{array}{c}\text { OUBIC } \\
\text { FEET } \\
\text { PER } \\
\text { SECOND }\end{array}$ & $\begin{array}{l}\text { TOTAL } \\
\text { DAYS }\end{array}$ & $\begin{array}{l}\text { ACOU- } \\
\text { MU- } \\
\text { LATED } \\
\text { DAYS }\end{array}$ & $\begin{array}{l}\text { PER- } \\
\text { CENT } \\
\text { DAYS }\end{array}$ & CLASS & $\begin{array}{c}\text { QUBIC } \\
\text { FEET } \\
\text { PER } \\
\text { SECOND }\end{array}$ & $\begin{array}{l}\text { TOTAL } \\
\text { DAYS }\end{array}$ & $\begin{array}{l}\text { ACOU- } \\
\text { MU- } \\
\text { LAIED } \\
\text { DAYS }\end{array}$ & $\begin{array}{l}\text { PER- } \\
\text { CENT } \\
\text { DAYS }\end{array}$ \\
\hline $\begin{array}{l}0 \\
1 \\
2 \\
3 \\
4 \\
5 \\
6 \\
6 \\
7 \\
8 \\
8 \\
1\end{array}$ & $\begin{array}{r}0.00 \\
683.00 \\
760.00 \\
850.00 \\
950.00 \\
1100.00 \\
1200.00 \\
1300.00 \\
1500.00\end{array}$ & $\begin{array}{r}0 \\
4 \\
3 \\
5 \\
10 \\
24 \\
53 \\
257 \\
102\end{array}$ & $\begin{array}{l}6209 \\
6209 \\
6205 \\
6202 \\
6197 \\
6187 \\
6163 \\
6110 \\
5853\end{array}$ & $\begin{array}{r}100.0 \\
100.0 \\
99.9 \\
99.9 \\
99.8 \\
99.6 \\
99.3 \\
98.4 \\
94.3\end{array}$ & $\begin{array}{rr}9 & 1600.00 \\
10 & 1800.00 \\
11 & 2000.00 \\
12 & 2300.00 \\
13 & 2500.00 \\
14 & 2800.00 \\
15 & 3200.00 \\
16 & 3500.00 \\
17 & 3900.00\end{array}$ & $\begin{array}{l}269 \\
320 \\
482 \\
334 \\
549 \\
717 \\
463 \\
487 \\
392\end{array}$ & $\begin{array}{l}5751 \\
5482 \\
5162 \\
4680 \\
4346 \\
3797 \\
3080 \\
2617 \\
2130\end{array}$ & $\begin{array}{l}92.6 \\
88.3 \\
83.1 \\
75.4 \\
70.0 \\
61.2 \\
49.6 \\
42.1 \\
34.3\end{array}$ & $\begin{array}{l}18 \\
19 \\
20 \\
21 \\
22 \\
23 \\
24 \\
25 \\
26\end{array}$ & $\begin{array}{r}4400.0 \\
4900.0 \\
5500.0 \\
6100.0 \\
6800.0 \\
7600.0 \\
8500.0 \\
9500.0 \\
11000.0\end{array}$ & $\begin{array}{r}343 \\
185 \\
135 \\
140 \\
94 \\
95 \\
94 \\
142 \\
149\end{array}$ & $\begin{array}{r}1738 \\
1395 \\
1210 \\
1075 \\
935 \\
841 \\
746 \\
652 \\
510\end{array}$ & $\begin{array}{r}28.0 \\
22.5 \\
19.5 \\
17.3 \\
15.1 \\
13.5 \\
12.0 \\
10.5 \\
8.2\end{array}$ & $\begin{array}{l}27 \\
28 \\
29 \\
30 \\
31 \\
32 \\
33 \\
34\end{array}$ & $\begin{array}{l}12000.0 \\
13000.0 \\
15000.0 \\
16000.0 \\
18000.0 \\
20000.0 \\
23000.0 \\
25000.0\end{array}$ & $\begin{array}{r}116 \\
112 \\
39 \\
60 \\
24 \\
6 \\
1 \\
3\end{array}$ & $\begin{array}{r}361 \\
245 \\
133 \\
94 \\
34 \\
10 \\
4 \\
3\end{array}$ & $\begin{array}{l}5.8 \\
3.9 \\
2.1 \\
1.5 \\
0.5 \\
0.2 \\
0.1 \\
0.0\end{array}$ \\
\hline
\end{tabular}


GREFN RIVER BASIN

09261000 GREEN RIVER NEAR JENSEN, UT-Continued

\begin{tabular}{|c|c|c|c|c|c|c|c|c|c|c|c|c|}
\hline YEAR & $\propto T$ & NOV & $\mathrm{DEC}$ & JAN & FEB & MAR & APR & MAY & JUNE & JULY & AUG & SEP \\
\hline 1965 & 2737 & 2657 & 3484 & 4206 & 4448 & 4421 & 6936 & 9718 & 11680 & 3860 & 1686 & 1829 \\
\hline $\begin{array}{l}1966 \\
1967 \\
1968 \\
1969 \\
1970\end{array}$ & $\begin{array}{l}2444 \\
2520 \\
3609 \\
2919 \\
2950\end{array}$ & $\begin{array}{l}2699 \\
1918 \\
3438 \\
3059 \\
2881\end{array}$ & $\begin{array}{l}2584 \\
2203 \\
3587 \\
2971 \\
3731\end{array}$ & $\begin{array}{l}1816 \\
2656 \\
3542 \\
3619 \\
2437\end{array}$ & $\begin{array}{l}1879 \\
2189 \\
2660 \\
4745 \\
2147\end{array}$ & $\begin{array}{l}3992 \\
2334 \\
2190 \\
3872 \\
2292\end{array}$ & $\begin{array}{l}5415 \\
3677 \\
3821 \\
8199 \\
3931\end{array}$ & $\begin{array}{r}6799 \\
7535 \\
10040 \\
11700 \\
12930\end{array}$ & $\begin{array}{r}4312 \\
11370 \\
13150 \\
7168 \\
12480\end{array}$ & $\begin{array}{l}2137 \\
5182 \\
5597 \\
4397 \\
4930\end{array}$ & $\begin{array}{l}2185 \\
3566 \\
4172 \\
3779 \\
2840\end{array}$ & $\begin{array}{l}2238 \\
3420 \\
3401 \\
3407 \\
2448\end{array}$ \\
\hline $\begin{array}{l}1971 \\
1972 \\
1973 \\
1974 \\
1975\end{array}$ & $\begin{array}{l}1939 \\
2289 \\
3655 \\
2814 \\
3422\end{array}$ & $\begin{array}{l}1878 \\
3275 \\
4233 \\
3216 \\
3154\end{array}$ & $\begin{array}{l}1953 \\
3603 \\
4071 \\
3027 \\
2842\end{array}$ & $\begin{array}{l}2489 \\
3122 \\
3927 \\
2707 \\
2941\end{array}$ & $\begin{array}{l}1790 \\
3703 \\
4287 \\
1401 \\
3437\end{array}$ & $\begin{array}{l}2595 \\
3600 \\
3022 \\
2622 \\
2632\end{array}$ & $\begin{array}{l}7128 \\
4920 \\
3694 \\
5806 \\
3193\end{array}$ & $\begin{array}{r}10570 \\
9685 \\
14000 \\
16870 \\
9141\end{array}$ & $\begin{array}{r}13160 \\
9977 \\
12020 \\
11770 \\
14160\end{array}$ & $\begin{array}{l}4629 \\
3554 \\
5660 \\
3146 \\
8835\end{array}$ & $\begin{array}{l}2762 \\
2913 \\
4016 \\
2738 \\
4002\end{array}$ & $\begin{array}{l}2550 \\
1318 \\
2949 \\
2537 \\
1979\end{array}$ \\
\hline $\begin{array}{l}1976 \\
1977 \\
1978 \\
1979 \\
1980\end{array}$ & $\begin{array}{l}1872 \\
3065 \\
1441 \\
1619 \\
1779\end{array}$ & $\begin{array}{l}2643 \\
3153 \\
1432 \\
2114 \\
2223\end{array}$ & $\begin{array}{l}3999 \\
3440 \\
1426 \\
2449 \\
2497\end{array}$ & $\begin{array}{l}3462 \\
3266 \\
1628 \\
2714 \\
2721\end{array}$ & $\begin{array}{l}2824 \\
3044 \\
1679 \\
3394 \\
3680\end{array}$ & $\begin{array}{l}3115 \\
4299 \\
2715 \\
3356 \\
3174\end{array}$ & $\begin{array}{l}4675 \\
4271 \\
5274 \\
5570 \\
5441\end{array}$ & $\begin{array}{r}11400 \\
5287 \\
9538 \\
11200 \\
13390\end{array}$ & $\begin{array}{r}9441 \\
4273 \\
13540 \\
10550 \\
9772\end{array}$ & $\begin{array}{l}4181 \\
2572 \\
6003 \\
4456 \\
3225\end{array}$ & $\begin{array}{l}3032 \\
2297 \\
2459 \\
2238 \\
1942\end{array}$ & $\begin{array}{l}2812 \\
2000 \\
1990 \\
1633 \\
1931\end{array}$ \\
\hline 981 & 2115 & 2018 & 1619 & 1450 & 1961 & 2069 & 2949 & 5445 & 5308 & 2337 & 1823 & 2465 \\
\hline
\end{tabular}

ANNUAL PEAK DISCHARGE, IN GUBIC FEET PER SECOND, AND CORRESPONDING GAGE HEIGHT, IN FEET, FOR FACH WATER YEAR

\begin{tabular}{|c|c|c|c|c|c|c|c|c|c|c|c|c|c|}
\hline $\begin{array}{l}\text { WATER } \\
\text { YEAR }\end{array}$ & & DATE & $\begin{array}{l}\text { GAGE } \\
\text { HEIGHT }\end{array}$ & $\begin{array}{c}\text { PEAK } \\
\text { DISCHARGE }\end{array}$ & $\begin{array}{l}\text { WATFER } \\
\text { YEAR }\end{array}$ & & DATE & $\begin{array}{c}\text { GAGE } \\
\text { HEIGHT }\end{array}$ & $\begin{array}{c}\text { PEAR } \\
\text { DISCHARGE }\end{array}$ & $\begin{array}{l}\text { WATER } \\
\text { YEAR }\end{array}$ & DATE & $\begin{array}{c}\text { GAGE } \\
\text { HEIGHT }\end{array}$ & $\begin{array}{c}\text { PEAR } \\
\text { DISCHARGE }\end{array}$ \\
\hline 1963 & MAY & 03,1963 & 6.21 & ${ }^{1} 8620$ & 1970 & MAY & 23,1970 & 9.87 & 20600 & 1977 & JUNE 07, 1977 & 6.10 & 7880 \\
\hline $\begin{array}{l}1964 \\
1965 \\
1967 \\
1968 \\
1969\end{array}$ & $\begin{array}{l}\text { MAY } \\
\text { JUNE } \\
\text { MAY } \\
\text { JUNE } \\
\text { MAY }\end{array}$ & $\begin{array}{l}24,1964 \\
11,1965 \\
28,1967 \\
08,1968 \\
09,1969\end{array}$ & $\begin{array}{l}8.68 \\
9.50 \\
8.80 \\
9.51 \\
8.49\end{array}$ & $\begin{array}{r}{ }_{1} 16300 \\
18400 \\
16700 \\
18800 \\
15000\end{array}$ & $\begin{array}{l}1971 \\
1973 \\
1974 \\
1975 \\
1976\end{array}$ & $\begin{array}{l}\text { JUNE } \\
\text { MAY } \\
\text { MAY } \\
\text { JUNE } \\
\text { MAY }\end{array}$ & $\begin{array}{ll}01, & 1971 \\
23, & 1973 \\
12, & 1974 \\
10, & 1975 \\
25, & 1976\end{array}$ & $\begin{array}{r}9.89 \\
10.41 \\
11.11 \\
9.90 \\
8.73\end{array}$ & $\begin{array}{l}20800 \\
23400 \\
27000 \\
20900 \\
16600\end{array}$ & $\begin{array}{l}1978 \\
1979 \\
1980 \\
1981\end{array}$ & $\begin{array}{l}\text { JUNE } 14,1978 \\
\text { MAY } 31,1979 \\
\text { MAY } 14,1980 \\
\text { JUNE } 10,1981\end{array}$ & $\begin{array}{l}9.58 \\
9.71 \\
9.32 \\
6.73\end{array}$ & $\begin{array}{r}18800 \\
19300 \\
18700 \\
9610\end{array}$ \\
\hline
\end{tabular}

MAGNITUDE AND PRCBABILITYY OF ANNUAL LONEST MEAN DISCHARGE BASED ON OIMATIC YEARS 1966-81

\begin{tabular}{lcccccc}
\hline & \multicolumn{5}{c}{$\begin{array}{c}\text { DISCHARGE, IN CUBIC FEET PER SECOND, FOR } \\
\text { PERIOD } \\
\text { (CON- }\end{array}$} & $\begin{array}{c}\text { INDICATED RECURRENCE INTERVAL, IN YEARS, AND } \\
\text { ANNUAL NONEXCEEDANCE PRCBABILITY, IN PEERENT }\end{array}$ \\
$\begin{array}{l}\text { SEOU- } \\
\text { TIVE }\end{array}$ & 2 & 5 & 10 & 20 & 50 & 100 \\
DAYS) & 508 & 208 & 108 & 58 & 28 & 18 \\
\hline
\end{tabular}

$\begin{array}{rrrrrrr}1 & 1220 & 973 & 853 & 760 & - & - \\ 7 & 1450 & 1140 & 1010 & 905 & - & = \\ 14 & 1590 & 1290 & 1170 & 1080 & - & - \\ 30 & 1730 & 1420 & 1290 & 1210 & - & - \\ 60 & 1970 & 1640 & 1500 & 1400 & - & - \\ 90 & 2210 & 1840 & 1660 & 1520 & - & -\end{array}$

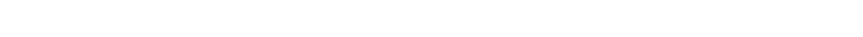

MAGNTTUDE AND PRCBABIL ITY OF ANNUAL HTGHEST MEAN DISCHARGE BASED ON WATER YEARS 1965-81

\begin{tabular}{lcccccc}
\hline \multicolumn{7}{c}{ DISCHARGE, IN OUBIC FEET PER SECOND, FOR } \\
$\begin{array}{c}\text { PERIOD } \\
\text { (CON- }\end{array}$ & $\begin{array}{c}\text { INDICATED RDCURRENCE INIEENAL, IN YEARS, AND } \\
\text { ANNUAL EXCEEDANCE PRCBABILITY, IN PERCENT }\end{array}$ \\
$\begin{array}{l}\text { SECU- } \\
\text { TIVE }\end{array}$ & 2 & 5 & 10 & 25 & 50 & 100 \\
DAYS) & 508 & 208 & 108 & 48 & 28 & 18 \\
\hline & & & & & - & - \\
1 & 17200 & 21300 & 23100 & 24600 & - & - \\
3 & 16500 & 20400 & 22200 & 23800 & - & - \\
7 & 15500 & 19100 & 20700 & 22000 & - & - \\
15 & 14300 & 17300 & 18400 & 19300 & - &
\end{tabular}


LOCATION.--Lat $40^{\circ} 42^{\prime} 15^{\prime \prime}$, Long $109^{\circ} 35^{\prime} 45^{\prime \prime}$, in SE $\frac{1}{4}$ sec.30, T.1 S., R.21 E., Uintah County, Hydrologic Unit 14060002, on right bank at road bridge $0.2 \mathrm{mi}$ downstream from Government Creek, $1 \mathrm{mi}$ upstream from cave, and $17.5 \mathrm{mi}$ northwest of Vernal.

DRAINAGE AREA. $-23 \mathrm{mi}^{2}$.

PERIOD OF RECORD AVAILABLE.--April 1946 to June 1955 (published as "Brush Creek above cave, near Vernal").

GAGE.--Water-stage recorder. Altitude of gage is $8,360 \mathrm{ft}$ by baraneter.

REMARKS.--Oaks Park Canal diverts above station from Big Brush Creek to Ashley Creek basin. Flow regulated by Caks Park Reservoir, capacity, 6,250 acre-ft.

AVERAGE DISCHARGE.--8 years, $9.90 \mathrm{ft}^{3} / \mathrm{s}, 7,170$ acre- $\mathrm{ft} / \mathrm{yr}$.

EXTREMES FOR PERIOD OF RECOFD. -Maximum discharge, $261 \mathrm{ft}^{3} / \mathrm{s}$ June 3, 1952; maximum gage height, $4.22 \mathrm{ft}$ May 8 , 1947 ; no $\mathrm{flow}$ for part of each day Nov. 8,9, 1954 .

LONEST MEAN DISCHARGE, IN CUBIC FEET PER SECOND, AND RANKING FOR THE INDICATED NUMBER OF CONSECUTIVE DAYS FOR EACH CLIMATIC YEAR, APRIL I-MARCH 31

\begin{tabular}{|c|c|c|c|c|c|c|c|c|c|c|c|c|c|c|c|c|c|c|c|c|}
\hline YEAR & \multicolumn{20}{|c|}{ CONSEOUTTVE DAYS } \\
\hline $\begin{array}{l}1948 \\
1949 \\
1950\end{array}$ & $\begin{array}{l}0.10 \\
0.30 \\
0.50\end{array}$ & $\begin{array}{l}1 \\
3 \\
6\end{array}$ & $\begin{array}{l}0.13 \\
0.30 \\
0.50\end{array}$ & $\begin{array}{l}1 \\
3 \\
6\end{array}$ & $\begin{array}{l}0.20 \\
0.30 \\
0.50\end{array}$ & $\begin{array}{l}1 \\
3 \\
6\end{array}$ & $\begin{array}{l}0.20 \\
0.30 \\
0.51\end{array}$ & $\begin{array}{l}1 \\
3 \\
6\end{array}$ & $\begin{array}{l}0.20 \\
0.30 \\
1.19\end{array}$ & $\begin{array}{l}1 \\
3 \\
8\end{array}$ & $\begin{array}{l}0.20 \\
0.33 \\
1.19\end{array}$ & $\begin{array}{l}1 \\
3 \\
8\end{array}$ & $\begin{array}{l}0.21 \\
0.35 \\
1.30\end{array}$ & $\begin{array}{l}2 \\
3 \\
8\end{array}$ & $\begin{array}{l}0.24 \\
0.39 \\
1.50\end{array}$ & $\begin{array}{l}2 \\
3 \\
8\end{array}$ & $\begin{array}{l}1.00 \\
0.66 \\
1.80\end{array}$ & $\begin{array}{l}5 \\
3 \\
8\end{array}$ & $\begin{array}{c}16.0 \\
8.10 \\
13.0\end{array}$ & \\
\hline $\begin{array}{l}1951 \\
1952 \\
1953 \\
1954 \\
1955\end{array}$ & $\begin{array}{l}0.70 \\
0.40 \\
0.60 \\
0.30 \\
0.20\end{array}$ & $\begin{array}{l}8 \\
5 \\
7 \\
4 \\
2\end{array}$ & $\begin{array}{l}0.70 \\
0.40 \\
0.60 \\
0.30 \\
0.20\end{array}$ & $\begin{array}{l}8 \\
5 \\
7 \\
4 \\
2\end{array}$ & $\begin{array}{l}0.70 \\
0.40 \\
0.60 \\
0.30 \\
0.20\end{array}$ & $\begin{array}{l}8 \\
5 \\
7 \\
4 \\
2\end{array}$ & $\begin{array}{l}0.70 \\
0.40 \\
0.60 \\
0.36 \\
0.20\end{array}$ & $\begin{array}{l}8 \\
5 \\
7 \\
4 \\
2\end{array}$ & $\begin{array}{l}0.70 \\
0.40 \\
0.60 \\
0.39 \\
0.20\end{array}$ & $\begin{array}{l}7 \\
5 \\
6 \\
4 \\
2\end{array}$ & $\begin{array}{l}0.75 \\
0.40 \\
0.60 \\
0.40 \\
0.20\end{array}$ & $\begin{array}{l}7 \\
4 \\
6 \\
5 \\
2\end{array}$ & $\begin{array}{l}0.77 \\
0.43 \\
0.63 \\
0.40 \\
0.20\end{array}$ & $\begin{array}{l}7 \\
5 \\
6 \\
4 \\
1\end{array}$ & $\begin{array}{l}0.80 \\
0.49 \\
0.68 \\
0.40 \\
0.20\end{array}$ & $\begin{array}{l}7 \\
5 \\
6 \\
4 \\
1\end{array}$ & $\begin{array}{l}1.19 \\
0.87 \\
1.19 \\
0.44 \\
0.30\end{array}$ & $\begin{array}{l}6 \\
4 \\
7 \\
2 \\
1\end{array}$ & $\begin{array}{c}13.0 \\
5.20 \\
16.0 \\
4.30 \\
3.40\end{array}$ & \\
\hline
\end{tabular}

HIGHEST MEAN DISCHARGE, IN CUBIC FEET PER SECOND, AND RANKING FOR THE INDICATED NUMBER OF CONSBCUTTVE DAYS FOR EACH WATER YEAR, OCTCBER I-SEPTEMBER 30

\begin{tabular}{|c|c|c|c|c|c|c|c|c|c|c|c|c|c|c|c|c|c|c|}
\hline YEAR & & 3 & & 7 & & 15 & & $\begin{array}{l}\text { CONs } \\
30\end{array}$ & CUT & $\begin{array}{l}\text { E DAYS } \\
60\end{array}$ & & 90 & & 120 & & 183 & & ALL \\
\hline $\begin{array}{l}160 \\
117 \\
136 \\
127\end{array}$ & $\begin{array}{l}2 \\
5 \\
3 \\
4\end{array}$ & $\begin{array}{l}152 \\
107 \\
130 \\
117\end{array}$ & $\begin{array}{l}2 \\
5 \\
3 \\
4\end{array}$ & $\begin{array}{c}134 \\
88.0 \\
124 \\
104\end{array}$ & $\begin{array}{l}2 \\
5 \\
3 \\
4\end{array}$ & $\begin{array}{c}116 \\
66.0 \\
106 \\
94.0\end{array}$ & $\begin{array}{l}2 \\
5 \\
3 \\
4\end{array}$ & $\begin{array}{l}96.0 \\
63.0 \\
80.0 \\
87.0\end{array}$ & $\begin{array}{l}2 \\
5 \\
4 \\
3\end{array}$ & $\begin{array}{l}86.0 \\
38.0 \\
64.0 \\
59.0\end{array}$ & $\begin{array}{l}1 \\
5 \\
3 \\
4\end{array}$ & $\begin{array}{l}62.0 \\
28.0 \\
46.0 \\
44.0\end{array}$ & $\begin{array}{l}1 \\
5 \\
3 \\
4\end{array}$ & $\begin{array}{l}48.0 \\
23.0 \\
36.0 \\
35.0\end{array}$ & $\begin{array}{l}1 \\
5 \\
3 \\
4\end{array}$ & $\begin{array}{l}32.0 \\
15.0 \\
24.0 \\
24.0\end{array}$ & $\begin{array}{l}1 \\
5 \\
3 \\
4\end{array}$ & $\begin{array}{c}16.0 \\
8.20 \\
12.0 \\
13.0\end{array}$ \\
\hline $\begin{array}{r}75.0 \\
199 \\
53.0 \\
48.0\end{array}$ & $\begin{array}{l}6 \\
1 \\
7 \\
8\end{array}$ & $\begin{array}{c}69.0 \\
187 \\
43.0 \\
43.0\end{array}$ & $\begin{array}{l}6 \\
1 \\
7 \\
8\end{array}$ & $\begin{array}{c}66.0 \\
168 \\
39.0 \\
37.0\end{array}$ & $\begin{array}{l}6 \\
1 \\
7 \\
8\end{array}$ & $\begin{array}{c}55.0 \\
145 \\
34.0 \\
28.0\end{array}$ & $\begin{array}{l}6 \\
1 \\
7 \\
8\end{array}$ & $\begin{array}{c}39.0 \\
102 \\
25.0 \\
23.0\end{array}$ & $\begin{array}{l}6 \\
1 \\
7 \\
8\end{array}$ & $\begin{array}{l}23.0 \\
78.0 \\
17.0 \\
15.0\end{array}$ & $\begin{array}{l}6 \\
2 \\
7 \\
8\end{array}$ & $\begin{array}{l}17.0 \\
57.0 \\
14.0 \\
11.0\end{array}$ & $\begin{array}{l}6 \\
2 \\
7 \\
8\end{array}$ & $\begin{array}{c}14.0 \\
45.0 \\
12.0 \\
9.10\end{array}$ & $\begin{array}{l}6 \\
2 \\
7 \\
8\end{array}$ & $\begin{array}{c}9.60 \\
31.0 \\
8.10 \\
6.50\end{array}$ & $\begin{array}{l}6 \\
2 \\
7 \\
8\end{array}$ & $\begin{array}{c}5.40 \\
16.0 \\
4.60 \\
3.50\end{array}$ \\
\hline
\end{tabular}

DURATION OF DISCHARGE FOR EACH WATER YEAR

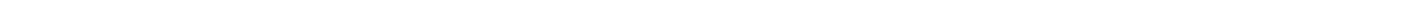
YEAR

NUMBER OF DAYS IN CIASS OBBIC FEET

$$
\begin{aligned}
& 1947 \\
& 1948 \\
& 1949 \\
& 1950 \\
& 1951 \\
& 1952 \\
& 1953 \\
& 1954
\end{aligned}
$$$$
2
$$$$
812
$$
-DAYS

\begin{tabular}{|c|c|c|c|c|c|c|c|c|c|c|c|c|c|c|c|c|c|c|c|c|c|c|c|c|c|c|c|c|}
\hline $\begin{array}{l}1947 \\
1948 \\
1949\end{array}$ & $\begin{array}{rr}1 & \\
81.29 \\
46\end{array}$ & $\begin{array}{r}121 \\
3917 \\
4850\end{array}$ & $\begin{array}{rr}25 & 25 \\
1 & 3 \\
10 & 25\end{array}$ & $\begin{array}{r}37 \\
3 \\
10 \\
43\end{array}$ & $\begin{array}{r}2 \\
2 \\
2 \\
50\end{array}$ & $\begin{array}{r}2 \\
10 \\
25 \\
33\end{array}$ & $\begin{array}{l}14 \\
16 \\
21 \\
47\end{array}$ & $\begin{array}{r}9 \\
12 \\
9 \\
19\end{array}$ & $\begin{array}{r}19 \\
1 \\
7 \\
23\end{array}$ & $\begin{array}{r}14 \\
16 \\
4 \\
21\end{array}$ & $\begin{array}{r}10 \\
30 \\
3 \\
21\end{array}$ & $\begin{array}{r}6 \\
26 \\
16 \\
7\end{array}$ & $\begin{array}{r}6 \\
23 \\
13 \\
18\end{array}$ & $\begin{array}{r}12 \\
7 \\
5\end{array}$ & $\begin{array}{r}1 \\
9 \\
10 \\
12\end{array}$ & $\begin{array}{r}2 \\
3 \\
2 \\
13\end{array}$ & $\begin{array}{l}1 \\
3 \\
5 \\
5\end{array}$ & $\begin{array}{l}2 \\
4 \\
5 \\
7\end{array}$ & $\begin{array}{l}4 \\
3 \\
4 \\
2\end{array}$ & $\begin{array}{l}2 \\
4 \\
8 \\
3\end{array}$ & $\begin{array}{r}7 \\
4 \\
11 \\
5\end{array}$ & $\begin{array}{r}19 \\
5 \\
4 \\
9\end{array}$ & $\begin{array}{r}18 \\
6 \\
5 \\
11\end{array}$ & $\begin{array}{r}4 \\
9 \\
10\end{array}$ & 5 & 1 & & $\begin{array}{l}5959.0 \\
3007.9 \\
4512.4 \\
4760.8\end{array}$ \\
\hline 195 & 11 & $\begin{array}{r}6046 \\
59 \\
145 \quad 17\end{array}$ & $\begin{array}{rr}31118 \\
15 \\
31 & 41 \\
1 & 1\end{array}$ & $\begin{array}{l}30 \\
31 \\
40 \\
27\end{array}$ & $\begin{array}{r}11 \\
9\end{array}$ & $\begin{array}{r}3 \\
7 \\
2 \\
13\end{array}$ & $\begin{array}{l}20 \\
26 \\
11 \\
31\end{array}$ & $\begin{array}{l}48 \\
13 \\
42 \\
10\end{array}$ & $\begin{array}{l}23 \\
16 \\
16 \\
22\end{array}$ & $\begin{array}{l}12 \\
27 \\
12 \\
24\end{array}$ & $\begin{array}{r}30 \\
11 \\
25 \\
8\end{array}$ & $\begin{array}{r}10 \\
16 \\
17 \\
4\end{array}$ & $\begin{array}{r}4 \\
10 \\
15 \\
10\end{array}$ & $\begin{array}{l}1 \\
2 \\
5 \\
4\end{array}$ & $\begin{array}{r}8 \\
2 \\
16 \\
6\end{array}$ & $\begin{array}{r}1 \\
16 \\
2 \\
7\end{array}$ & $\begin{array}{l}6 \\
7 \\
5 \\
4\end{array}$ & $\begin{array}{r}3 \\
12 \\
5 \\
6\end{array}$ & $\begin{array}{l}5 \\
6 \\
8 \\
3\end{array}$ & $\begin{array}{l}2 \\
6 \\
1 \\
2\end{array}$ & $\begin{array}{l}2 \\
5 \\
1\end{array}$ & $\begin{array}{l}8 \\
7\end{array}$ & 6 & 6 & 7 & 4 & 2 & $\begin{array}{l}1691 . \\
1268 .\end{array}$ \\
\hline
\end{tabular}

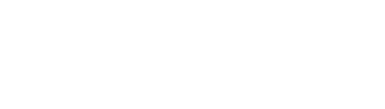

$\begin{array}{rrrrr}0 & 0.00 & 0 & 2922 & 100.0 \\ 1 & 0.10 & 2 & 2922 & 100.0 \\ 2 & 0.13 & 0 & 2920 & 99.9 \\ 3 & 0.16 & 0 & 2920 & 99.9 \\ 4 & 0.20 & 82 & 2920 & 99.9 \\ 5 & 0.25 & 86 & 2838 & 97.1 \\ 6 & 0.32 & 0 & 2752 & 94.2 \\ 7 & 0.40 & 292 & 2752 & 94.2 \\ 8 & 0.50 & 310 & 2460 & 84.2\end{array}$

DURATION TABLE OF DISCHARGE FOR WATER YEARS 1947-54

\begin{tabular}{|c|c|c|c|c|}
\hline & $\begin{array}{l}\text { CUBIC } \\
\text { FEET } \\
\text { PER }\end{array}$ & TOTAL & $\begin{array}{c}\text { ACCU- } \\
\text { MU- } \\
\text { LATED }\end{array}$ & $\begin{array}{l}\text { PER- } \\
\text { CENTT }\end{array}$ \\
\hline IASS & SECOND & DAYS & DAYS & DAYS \\
\hline 9 & 0.63 & 99 & 2150 & 73.6 \\
\hline 10 & 0.79 & 228 & 2051 & 70 \\
\hline 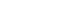 & 0.99 & 221 & 1823 & \\
\hline 12 & 1.30 & 76 & 1602 & 54.8 \\
\hline & 1.6 & 95 & 1526 & 52.2 \\
\hline 14 & 2.00 & 186 & 1431 & 49.0 \\
\hline 15 & 2.5 & 162 & 1245 & 42.6 \\
\hline & & 12 & 108 & \\
\hline 1 & & 30 & 956 & 32.7 \\
\hline
\end{tabular}

CLAS
18
19
20
21
22
23
24
25
26

CUBIC AOCUFEET AOCUCLASS SECOND DAYS DAYS DAYS

$\begin{array}{rrrrr}18 & 4.9 & 138 & 826 & 28.3 \\ 19 & 6.2 & 102 & 688 & 23.5 \\ 20 & 7.8 & 99 & 586 & 20.1 \\ 21 & 9.8 & 36 & 487 & 16.7 \\ 22 & 12.0 & 64 & 451 & 15.4 \\ 23 & 16.0 & 46 & 387 & 13.2 \\ 24 & 20.0 & 36 & 341 & 11.7 \\ 25 & 25.0 & 44 & 305 & 10.4 \\ 26 & 31.0 & 35 & 261 & 8.9\end{array}$

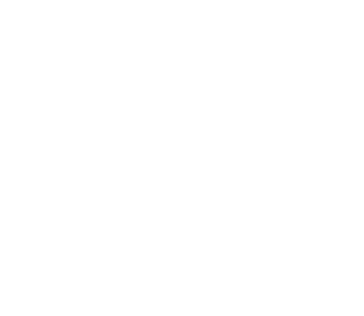


GREEN RIVER BASIN

09261500 BIG BRUSH CREEK (BRUSH CREEK) ABOVE CAVE, NEAR VERNAL, UT-Continued

MONTHLY MEAN DISCHARGES, IN OBIC FEET PER SECOND, FOR EACH WATER YEAR

$\begin{array}{llccccccccrrr}\text { YEAR } & \text { OCT } & \text { NOV } & \text { DEC } & \text { JAN } & \text { FEB } & \text { MAR } & \text { APR } & \text { MAY } & \text { JUNE } & \text { JULY } & \text { AUG } & \text { SEP } \\ 1947 & 1.13 & 0.80 & 0.65 & 0.50 & 0.50 & 0.50 & 0.77 & 83.6 & 83.4 & 16.9 & 3.53 & 2.78 \\ 1948 & 4.54 & 0.41 & 0.23 & 0.20 & 0.20 & 0.40 & 2.62 & 41.3 & 33.0 & 8.18 & 5.11 & 2.04 \\ 1949 & 1.42 & 0.87 & 0.51 & 0.40 & 0.30 & 0.35 & 2.25 & 58.6 & 67.0 & 9.77 & 4.48 & 1.91 \\ 1950 & 2.58 & 2.32 & 1.85 & 1.50 & 1.20 & 1.25 & 8.81 & 52.7 & 62.9 & 11.8 & 5.28 & 4.01 \\ & & & & & & & & & & & & \\ 1951 & 2.91 & 0.95 & 0.80 & 0.70 & 0.80 & 0.90 & 1.00 & 33.8 & 11.0 & 4.94 & 3.62 & 2.68 \\ 1952 & 2.23 & 0.65 & 0.50 & 0.40 & 0.40 & 1.00 & 17.5 & 79.7 & 71.8 & 7.43 & 4.24 & 3.66 \\ 1953 & 2.74 & 1.54 & 0.80 & 0.60 & 0.60 & 0.70 & 0.93 & 20.3 & 13.7 & 6.87 & 4.42 & 1.98 \\ 1954 & 0.60 & 0.43 & 0.40 & 0.40 & 0.40 & 0.40 & \mathbf{6 . 2 0} & 20.5 & 4.84 & 3.57 & 2.12 & 1.49\end{array}$

ANNUAL PEAK DISCHARGE, IN OUBIC FEET PER SECOND, AND CORRESPONDING GAGE HEIGHT, IN FEET, FOR EAOA WATER YEAR

\begin{tabular}{|c|c|c|c|c|c|c|c|c|c|c|c|c|c|c|}
\hline $\begin{array}{l}\text { WATER } \\
\text { YEAR }\end{array}$ & & DATE & $\begin{array}{c}\text { GAGE } \\
\text { HEIGHT }\end{array}$ & $\begin{array}{c}\text { PEAK } \\
\text { DISCHARGE }\end{array}$ & $\begin{array}{l}\text { WATER } \\
\text { YEAR }\end{array}$ & & DATE & $\begin{array}{c}\text { GAGE } \\
\text { HEIGHT }\end{array}$ & $\begin{array}{c}\text { PEAK } \\
\text { DISCHARGE }\end{array}$ & $\begin{array}{l}\text { WATER } \\
\text { YEAR }\end{array}$ & & DATE & $\begin{array}{c}\text { GAGE } \\
\text { HEIGHT }\end{array}$ & $\begin{array}{l}\text { PEAK } \\
\text { DISCHARGE }\end{array}$ \\
\hline $\begin{array}{l}1946 \\
1947\end{array}$ & $\begin{array}{l}\text { APR. } \\
\text { MAY }\end{array}$ & $\begin{array}{l}25,1946 \\
08,1947\end{array}$ & $\overline{4.22}$ & $\begin{array}{l}1_{52} \\
234\end{array}$ & $\begin{array}{l}1950 \\
1951\end{array}$ & $\begin{array}{l}\text { MAY } \\
\text { MAY }\end{array}$ & $\begin{array}{ll}24, & 1950 \\
25, & 1951\end{array}$ & $\begin{array}{l}3.92 \\
3.59\end{array}$ & $\begin{array}{l}199 \\
124\end{array}$ & $\begin{array}{l}1953 \\
1954\end{array}$ & $\begin{array}{l}\text { MAY } \\
\text { MAY }\end{array}$ & $\begin{array}{l}23,1953 \\
09,1954\end{array}$ & $\begin{array}{l}3.29 \\
3.12\end{array}$ & $\begin{array}{l}86 \\
72\end{array}$ \\
\hline $\begin{array}{l}1948 \\
1949\end{array}$ & MAY & $\begin{array}{ll}19, & 1948 \\
15, & 1949\end{array}$ & $\begin{array}{l}3.86 \\
3.93\end{array}$ & $\begin{array}{l}165 \\
186\end{array}$ & 1952 & JUNE & E 03,1952 & 4.09 & 261 & 1955 & MAY & 12,1955 & 2.75 & \\
\hline
\end{tabular}

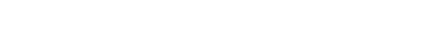

${ }^{2}$ Peak for period Oct. 1 to June 30 .

09261700 BIG BRUSH CREEK (BRUSH CREEK) ABOVE RED FLEET RESERVOIR, NEAR VERNAL, UT

LOCATION.--Lat $40^{\circ} 35^{\prime} 20^{\prime \prime}$, long $109^{\circ} 27^{\prime} 53^{\prime \prime}$, in $\mathrm{NW}_{4} \mathrm{SE}_{4}^{\prime} \mathrm{NE}_{4}^{l}$ sec.5, T.3 S., R.22 E., Uintah County, Hydrologic Unit 14060002, on right bank $950 \mathrm{ft}$ below State Highway 44, $5.5 \mathrm{mi}$ upstream from Little Brush Creek, and $10.5 \mathrm{mi}$ northeast of Vernal.

DRAINAGE AREA. $--77.2 \mathrm{mi}^{2}$.

PERIOD OF RECORD AVAIIABLE.--October 1979 to September 1981.

GAGE. -Water-stage recorder. Altitude of gage is 5,625 ft from topographic map. Prior to Sept. 1980, water-stage recorder at site $250 \mathrm{ft}$ upstream at different datum.

REMARKS.-Water from Daks Park Reservoir on headwaters, capacity, 6,250 acre-ft, diverted through Caks Park Canal to Ashley Creek basin.

EXIREMES FOR PERIOD OF RECORD.--Maximum discharge, $314 \mathrm{ft}^{3} / \mathrm{s}$ May 23,1980 , gage height, $3.06 \mathrm{ft}$ at different datum; minimum daily, $11.0 \mathrm{ft}^{3} / \mathrm{s}$, several days $1979-81$.

LONEST MEAN DISCHARGE, IN OUBIC FEET PER SECOND, AND RANKING FOR THE INDICATED NUMBER OF OONSECUTIVE DAYS FOR EACH OLIMATIC YEAR, APRIL 1-MARCH 31

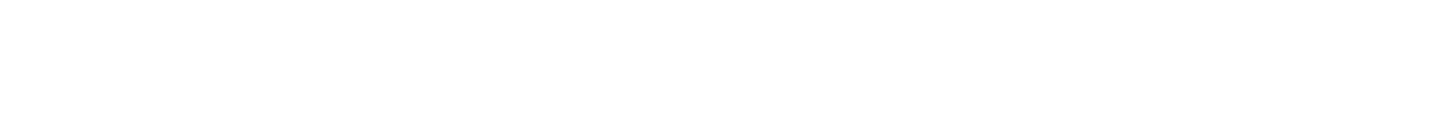

HIGHEST MEAN DISCHARGE, IN OBBIC FEET PER SECOND, AND RANKING FOR THE INDICATED NUMBER OF DONSEOUTIVE DAYS FOR EACH WATER YEAR, OCTOBER 1-SEPTEMBER 30

\begin{tabular}{|c|c|c|c|c|c|c|c|c|c|c|c|c|c|c|c|c|c|c|c|}
\hline YEAR & \multicolumn{19}{|c|}{ CONSECTTIVE DAYS } \\
\hline 1980 & 295 & I & 288 & 1 & 276 & 1 & 252 & 1 & 236 & 1 & 176 & 1 & 133 & 1 & 108 & 1 & 78.0 & 1 & 45.0 \\
\hline
\end{tabular}

DURATION OF DISCHARGE FOR EACH WATER YEAR

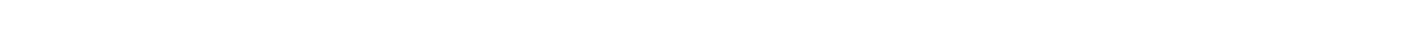
YEAR

NUMBER OF DAYS IN CLASS CUBIC FEET PER SECOND

$\begin{array}{llllllllllllllllllllllllllllllllllllllllll}1980 & 12 & 66106 & 11 & 14 & 11 & 2 & 8 & 4 & 6 & 14 & 12 & 14 & 9 & 7 & 5 & 4 & 2 & 1 & 3 & 1 & 5 & 5 & 2 & 4 & 2 & 1 & 2 & 5 & 9 & 9 & 2 & 6 & 2 & 16573.0\end{array}$

$\begin{array}{lllllllllllllllllllllllllllll}1981 & 44 & 50 & 32 & 28 & 39 & 13 & 17 & 11 & 11 & 8 & 1 & 11 & 27 & 5 & 10 & 10 & 7 & 15 & 4 & 4 & 11 & 2 & 3 & 1 & 1 & & & \end{array}$ 
GREEN RIVER BASIN

09261700 BIG BRDSH CREFK (BRUSH CREFK) ABOVE RED FLEET RESERVOIR, NEAR VERNAL, UT--Continued

DURATION TABLE OF DISCHARGE FOR WATER YEARS 1980-81

\begin{tabular}{|c|c|c|c|c|c|c|c|c|c|c|c|c|c|c|c|c|c|c|c|}
\hline CLASS & $\begin{array}{c}\text { CUBIC } \\
\text { FEET } \\
\text { PER } \\
\text { SEDOND }\end{array}$ & TOTAL & $\begin{array}{l}\text { AOCU- } \\
\text { MU- } \\
\text { LATED } \\
\text { DAYS }\end{array}$ & $\begin{array}{l}\text { PER- } \\
\text { CENT } \\
\text { DAYS }\end{array}$ & CLASS & $\begin{array}{c}\text { CUBIC } \\
\text { FEET } \\
\text { PER } \\
\text { SECOND }\end{array}$ & $\begin{array}{r}\text { TOTAL } \\
\text { DAYS }\end{array}$ & $\begin{array}{l}\text { AOCU- } \\
\text { MU- } \\
\text { LATED } \\
\text { DAYS }\end{array}$ & $\begin{array}{l}\text { PER- } \\
\text { CENT } \\
\text { DAYS }\end{array}$ & CLASS & $\begin{array}{c}\text { CUBIC } \\
\text { FEET } \\
\text { PER } \\
\text { SECOND }\end{array}$ & $\begin{array}{l}\text { TOTAL } \\
\text { DAYS }\end{array}$ & $\begin{array}{l}\text { ACOU- } \\
\text { MU- } \\
\text { LATBD } \\
\text { DAYS }\end{array}$ & $\begin{array}{l}\text { PER- } \\
\text { CENT } \\
\text { DAYS }\end{array}$ & CLASS & $\begin{array}{c}\text { CUBIC } \\
\text { FEET } \\
\text { PER } \\
\text { SECOND }\end{array}$ & $\begin{array}{r}\text { TOTAL } \\
\text { DAYS }\end{array}$ & $\begin{array}{l}\text { ACOJ- } \\
\text { MU- } \\
\text { LATED } \\
\text { DAYS }\end{array}$ & $\begin{array}{l}\text { PER- } \\
\text { CENT } \\
\text { DAYS }\end{array}$ \\
\hline $\begin{array}{l}0 \\
1 \\
2 \\
3 \\
4 \\
5 \\
6 \\
7 \\
8\end{array}$ & $\begin{array}{r}0.00 \\
11.00 \\
12.00 \\
13.00 \\
15.00 \\
16.00 \\
18.00 \\
20.00 \\
22.00\end{array}$ & $\begin{array}{r}0 \\
56 \\
116 \\
138 \\
39 \\
53 \\
24 \\
19 \\
19\end{array}$ & $\begin{array}{l}731 \\
731 \\
675 \\
559 \\
421 \\
382 \\
329 \\
305 \\
286\end{array}$ & $\begin{array}{r}100.0 \\
100.0 \\
92.3 \\
76.5 \\
57.6 \\
52.3 \\
45.0 \\
41.7 \\
39.1\end{array}$ & $\begin{array}{r}9 \\
10 \\
11 \\
12 \\
13 \\
14 \\
15 \\
16 \\
17\end{array}$ & $\begin{array}{l}24.00 \\
27.00 \\
30.00 \\
33.00 \\
36.00 \\
40.00 \\
44.00 \\
49.00 \\
54.00\end{array}$ & $\begin{array}{l}15 \\
14 \\
15 \\
23 \\
41 \\
14 \\
17 \\
15 \\
11\end{array}$ & $\begin{array}{l}267 \\
252 \\
238 \\
223 \\
200 \\
159 \\
145 \\
128 \\
113\end{array}$ & $\begin{array}{l}36.5 \\
34.5 \\
32.6 \\
30.5 \\
27.4 \\
21.8 \\
19.8 \\
17.5\end{array}$ & $\begin{array}{l}18 \\
19 \\
20 \\
21 \\
22 \\
23 \\
24 \\
25 \\
26\end{array}$ & $\begin{array}{r}59.0 \\
66.0 \\
73.0 \\
80.0 \\
88.0 \\
98.0 \\
110.0 \\
120.0\end{array}$ & $\begin{array}{r}17 \\
5 \\
7 \\
12 \\
7 \\
8 \\
3 \\
4 \\
3\end{array}$ & $\begin{array}{r}102 \\
85 \\
80 \\
73 \\
61 \\
54 \\
46 \\
43 \\
39\end{array}$ & $\begin{array}{r}14.0 \\
11.6 \\
10.9 \\
10.0 \\
8.3 \\
7.4 \\
6.3 \\
5.9 \\
5.3\end{array}$ & $\begin{array}{l}27 \\
28 \\
29 \\
30 \\
31 \\
32 \\
33 \\
34\end{array}$ & $\begin{array}{l}150.0 \\
160.0 \\
180.0 \\
200.0 \\
220.0 \\
240.0 \\
260.0 \\
290.0\end{array}$ & $\begin{array}{l}1 \\
2 \\
5 \\
9 \\
9 \\
2 \\
6 \\
2\end{array}$ & $\begin{array}{r}36 \\
35 \\
33 \\
28 \\
19 \\
10 \\
8 \\
2\end{array}$ & $\begin{array}{l}4.9 \\
4.8 \\
4.5 \\
3.8 \\
2.6 \\
1.4 \\
1.1 \\
0.3\end{array}$ \\
\hline
\end{tabular}

MONTHLY MEAN DISCHARGES, IN CUBIC FEET PER SECOND, FOR EACH WATER YEAR

\begin{tabular}{|c|c|c|c|c|c|c|c|c|c|c|c|c|}
\hline YEAR & $\propto C T$ & $\mathrm{NOV}$ & DEC & JAN & FEB & MAR & APR & MAY & JUNE & JULY & AUG & SEP \\
\hline 1980 & 14.8 & 13.0 & 12.0 & 12.4 & 13.0 & 13.0 & 21.5 & 160 & 186 & 43.7 & 32.8 & 20.9 \\
\hline 1981 & 17.7 & 15.4 & 14.0 & 11.5 & 11.5 & 11.7 & 38.9 & 71.2 & 56.6 & 38.3 & 25.3 & 17.9 \\
\hline
\end{tabular}

LOCATION.--Lat $40^{\circ} 34^{\prime} 54^{\prime \prime}$, long $109^{\circ} 26^{\prime} 03^{\prime \prime}$, in SElaSE $\}_{4}^{\prime}$ sec.3, T.3 S., R.22 E., Uintah County, Hydrologic Unit 14060002, on left bank 3 mi upstream from Little Brush Creek and $10 \mathrm{mi}$ northeast of Vernal.

DRAINAGE AREA. $--79.6 \mathrm{mi}^{2}$.

PERIOD OF RECORD AVAILABLE.--March 1939 to September 1979. Prior to October 1964, published as "Brush Creek near Vernal".

REVISED RECORDS.--KDR UT-77-1: Drainage area.

GAGE. -Water-stage recorder and concrete control. Altitude of gage is 5,530 ft from topographic map. Prior to Apr. 25, 1959, water-stage recorder at site $0.4 \mathrm{mi}$ downstream at different datum. Apr. 25, 1959 to Mar. 5, 1968, water-stage recorder at present site at datum $1.00 \mathrm{ft}$ higher.

REYARKS.--Two small diversions above station for irrigation of about 80 acres above and below station. Since July 1940 , water from Caks Park Reservoir on headwaters, capacity, 6,250 acre-ft, has been diverted through Oaks Park Canal to Ashley Creek basin.

AVERAGE DISCHARGE. -40 years, $35.1 \mathrm{ft}^{3} / \mathrm{s}, 25,430$ acre- $\mathrm{ft} / \mathrm{yr}$.

EXIREAES FOR PERIOD OF RECORD.--Maximum discharge, $543 \mathrm{ft}^{3} / \mathrm{s}$ July 12,1962 , gage height, $4.73 \mathrm{ft}$ present datum, from rating curve extended above $370 \mathrm{ft}^{3} / \mathrm{s}$; minimum recorded, $1.6 \mathrm{ft}^{3} / \mathrm{s} \mathrm{Mar.} 12,1951$.

LOWEST MEAN DISCHARGE, IN CUBIC FEET PER SECOND, AND RANKING FOR THE INDICATED NUMBER OF CONSBCUTTVE DAYS FOR EACH CLIMATIC YEAR, APRIL I-HARCH 31

\begin{tabular}{|c|c|c|c|c|c|c|c|c|}
\hline YEAR & 1 & & 3 & & 7 & & 14 & \\
\hline $\begin{array}{l}1941 \\
1942 \\
1943 \\
1944 \\
1945\end{array}$ & $\begin{array}{l}10.0 \\
12.0 \\
10.0 \\
12.0 \\
14.0\end{array}$ & $\begin{array}{l}15 \\
28 \\
16 \\
29 \\
38\end{array}$ & $\begin{array}{l}10.0 \\
12.0 \\
11.0 \\
12.0 \\
14.0\end{array}$ & $\begin{array}{l}15 \\
27 \\
21 \\
28 \\
38\end{array}$ & $\begin{array}{l}10.0 \\
12.0 \\
12.0 \\
12.0 \\
14.0\end{array}$ & $\begin{array}{l}13 \\
21 \\
22 \\
23 \\
35\end{array}$ & $\begin{array}{l}10.0 \\
12.0 \\
12.0 \\
12.0 \\
14.0\end{array}$ & $\begin{array}{l}14 \\
21 \\
22 \\
23 \\
36\end{array}$ \\
\hline $\begin{array}{l}1946 \\
1947 \\
1948 \\
1949 \\
1950\end{array}$ & $\begin{array}{l}11.0 \\
14.0 \\
12.0 \\
12.0 \\
13.0\end{array}$ & $\begin{array}{l}22 \\
39 \\
30 \\
31 \\
37\end{array}$ & $\begin{array}{l}12.0 \\
14.0 \\
12.0 \\
12.0 \\
13.0\end{array}$ & $\begin{array}{l}29 \\
39 \\
30 \\
31 \\
35\end{array}$ & $\begin{array}{l}12.0 \\
14.0 \\
12.0 \\
12.0 \\
14.0\end{array}$ & $\begin{array}{l}24 \\
36 \\
25 \\
26 \\
37\end{array}$ & $\begin{array}{l}12.0 \\
14.0 \\
12.0 \\
12.0 \\
14.0\end{array}$ & $\begin{array}{l}24 \\
37 \\
25 \\
26 \\
38\end{array}$ \\
\hline $\begin{array}{l}1951 \\
1952 \\
1953 \\
1954 \\
1955\end{array}$ & $\begin{array}{c}12.0 \\
9.00 \\
13.0 \\
11.0 \\
7.60\end{array}$ & $\begin{array}{r}32 \\
9 \\
33 \\
23 \\
2\end{array}$ & $\begin{array}{c}12.0 \\
9.00 \\
14.0 \\
11.0 \\
7.90\end{array}$ & $\begin{array}{r}32 \\
9 \\
36 \\
22 \\
3\end{array}$ & $\begin{array}{c}12.0 \\
9.00 \\
14.0 \\
12.0 \\
8.40\end{array}$ & $\begin{array}{r}27 \\
9 \\
38 \\
28 \\
5\end{array}$ & $\begin{array}{c}12.0 \\
9.30 \\
14.0 \\
12.0 \\
8.70\end{array}$ & $\begin{array}{r}27 \\
10 \\
39 \\
28 \\
5\end{array}$ \\
\hline $\begin{array}{l}1956 \\
1957 \\
1958 \\
1959 \\
1960\end{array}$ & $\begin{array}{c}10.0 \\
10.0 \\
10.0 \\
9.00 \\
8.30\end{array}$ & $\begin{array}{r}17 \\
18 \\
19 \\
10 \\
8\end{array}$ & $\begin{array}{c}10.0 \\
10.0 \\
10.0 \\
9.10 \\
8.40\end{array}$ & $\begin{array}{r}16 \\
17 \\
18 \\
10 \\
7\end{array}$ & $\begin{array}{c}10.0 \\
10.0 \\
10.0 \\
9.10 \\
8.70\end{array}$ & $\begin{array}{r}14 \\
15 \\
16 \\
10 \\
7\end{array}$ & $\begin{array}{c}10.0 \\
11.0 \\
10.0 \\
9.20 \\
8.70\end{array}$ & $\begin{array}{r}11 \\
15 \\
12 \\
9 \\
6\end{array}$ \\
\hline
\end{tabular}

\begin{tabular}{|c|c|c|c|}
\hline $\begin{array}{l}\text { CONSE } \\
30\end{array}$ & & $\begin{array}{l}\text { E DAYS } \\
60\end{array}$ & \\
\hline $\begin{array}{l}10.0 \\
13.0 \\
12.0 \\
12.0 \\
14.0\end{array}$ & $\begin{array}{l}12 \\
28 \\
20 \\
21 \\
35\end{array}$ & $\begin{array}{l}11.0 \\
17.0 \\
13.0 \\
12.0 \\
15.0\end{array}$ & $\begin{array}{l}15 \\
39 \\
29 \\
22 \\
36\end{array}$ \\
\hline $\begin{array}{l}12.0 \\
14.0 \\
13.0 \\
12.0 \\
14.0\end{array}$ & $\begin{array}{l}22 \\
36 \\
29 \\
23 \\
37\end{array}$ & $\begin{array}{l}12.0 \\
15.0 \\
13.0 \\
13.0 \\
15.0\end{array}$ & $\begin{array}{l}23 \\
37 \\
30 \\
31 \\
38\end{array}$ \\
\hline $\begin{array}{c}13.0 \\
9.70 \\
14.0 \\
12.0 \\
9.80\end{array}$ & $\begin{array}{r}30 \\
9 \\
38 \\
24 \\
10\end{array}$ & $\begin{array}{c}13.0 \\
9.80 \\
14.0 \\
12.0 \\
10.0\end{array}$ & $\begin{array}{r}32 \\
7 \\
33 \\
24 \\
8\end{array}$ \\
\hline $\begin{array}{l}11.0 \\
11.0 \\
10.0 \\
9.50 \\
8.90\end{array}$ & $\begin{array}{r}13 \\
14 \\
11 \\
8 \\
5\end{array}$ & $\begin{array}{c}11.0 \\
11.0 \\
11.0 \\
10.0 \\
9.10\end{array}$ & $\begin{array}{r}16 \\
17 \\
18 \\
9 \\
4\end{array}$ \\
\hline
\end{tabular}

$\begin{array}{cc}90 & \\ 11.0 & 13 \\ 17.0 & 39 \\ 13.0 & 26 \\ 12.0 & 21 \\ 15.0 & 35 \\ & \\ 13.0 & 27 \\ 15.0 & 36 \\ 13.0 & 28 \\ 13.0 & 29 \\ 15.0 & 37 \\ & \\ 13.0 & 30 \\ 10.0 & 7 \\ 14.0 & 31 \\ 12.0 & 22 \\ 11.0 & 14 \\ 11.0 & 15 \\ 11.0 & 16 \\ 12.0 & 17 \\ 10.0 & 8 \\ 9.30 & 3\end{array}$

$\begin{array}{lr}120 & \\ 11.0 & 9 \\ 19.0 & 39 \\ 14.0 & 32 \\ 13.0 & 24 \\ 15.0 & 36 \\ 13.0 & 25 \\ 15.0 & 37 \\ 13.0 & 26 \\ 13.0 & 27 \\ 16.0 & 38 \\ 14.0 & 33 \\ 11.0 & 10 \\ 14.0 & 34 \\ 13.0 & 28 \\ 11.0 & 11 \\ 11.0 & 12 \\ 11.0 & 13 \\ 12.0 & 19 \\ 11.0 & 14 \\ 9.30 & 1\end{array}$

ALL,

$\begin{array}{llll}12.0 & 14 & 24.0 & 10\end{array}$

$29.0 \quad 39 \quad 53.0 \quad 36$

$\begin{array}{llll}15.0 & 28 & 49.0 & 31\end{array}$

$\begin{array}{llll}13.0 & 20 & 27.0 & 14\end{array}$

$17.0 \quad 37$

53.037

$\begin{array}{llll}15.0 & 29 & 30.0 & 17\end{array}$

$\begin{array}{llll}15.0 & 30 & 21.0 & 7\end{array}$

$\begin{array}{llll}15.0 & 31 & 57.0 & 39\end{array}$

$\begin{array}{llll}14.0 & 26 & 34.0 & 22 \\ 19.0 & 38 & 50.0 & 32\end{array}$

$\begin{array}{lllll}16.0 & 32 & 48.0 & 30\end{array}$

$\begin{array}{llll}12.0 & 15 & 25.0 & 11\end{array}$

$\begin{array}{llll}15.0 & 27 & 50.0 & 33\end{array}$

$\begin{array}{llll}13.0 & 21 & 26.0 & 12\end{array}$

$\begin{array}{lllr}12.0 & 16 & 22.0 & 8\end{array}$

$\begin{array}{llll}12.0 & 17 & 20.0 & 5\end{array}$

$\begin{array}{lrrr}11.0 & 8 & 22.0 & 9\end{array}$

$\begin{array}{llll}13.0 & 18 & 39.0 & 24\end{array}$

$\begin{array}{rrrr}11.0 & 9 & 32.0 & 20 \\ 10.0 & 3 & 21.0 & 6\end{array}$ 
GREEN RIVER BASIN

09262000 BIG BRUSH CREEK (BRUSH CREEK) NEAR VERNAL, UT-Continued

LONEST MEAN DISCHARGE, IN CUBIC FEET PER SECOND, AND RANRING FOR THE INDICATED NUMBER OF CONSECUTIVE DAYS FOR EACH CLIMATIC YEAR, APRIL 1-MARCH 31 -Continued

\begin{tabular}{|c|c|c|c|c|c|c|c|c|c|c|c|c|c|c|c|c|c|c|c|c|}
\hline YEAR & 1 & & 3 & & 7 & & 14 & & $\begin{array}{l}\text { CONS } \\
30\end{array}$ & $P \cap$ & $\begin{array}{l}\text { DAYS } \\
60\end{array}$ & & 90 & & 120 & & 183 & & ALL & \\
\hline $\begin{array}{l}1961 \\
1962 \\
1963 \\
1964 \\
1965\end{array}$ & $\begin{array}{l}8.20 \\
8.00 \\
7.60 \\
8.30 \\
7.50\end{array}$ & $\begin{array}{l}6 \\
5 \\
3 \\
7 \\
1\end{array}$ & $\begin{array}{l}8.20 \\
8.00 \\
7.80 \\
8.60 \\
7.60\end{array}$ & $\begin{array}{l}6 \\
4 \\
2 \\
8 \\
1\end{array}$ & $\begin{array}{l}8.60 \\
8.00 \\
7.90 \\
8.80 \\
7.80\end{array}$ & $\begin{array}{l}6 \\
4 \\
2 \\
8 \\
1\end{array}$ & $\begin{array}{l}8.90 \\
8.10 \\
8.10 \\
9.00 \\
7.90\end{array}$ & $\begin{array}{l}7 \\
3 \\
4 \\
8 \\
1\end{array}$ & $\begin{array}{l}9.00 \\
8.40 \\
8.60 \\
9.10 \\
8.00\end{array}$ & $\begin{array}{l}6 \\
3 \\
4 \\
7 \\
1\end{array}$ & $\begin{array}{c}9.20 \\
8.70 \\
10.0 \\
9.30 \\
8.30\end{array}$ & $\begin{array}{r}5 \\
2 \\
10 \\
6 \\
1\end{array}$ & $\begin{array}{c}9.40 \\
9.40 \\
10.0 \\
9.40 \\
8.80\end{array}$ & $\begin{array}{l}4 \\
5 \\
9 \\
6 \\
1\end{array}$ & $\begin{array}{c}10.0 \\
9.90 \\
10.0 \\
9.50 \\
9.70\end{array}$ & $\begin{array}{l}7 \\
5 \\
6 \\
2 \\
3\end{array}$ & $\begin{array}{c}11.0 \\
11.0 \\
12.0 \\
9.90 \\
10.0\end{array}$ & $\begin{array}{r}4 \\
5 \\
10 \\
1 \\
2\end{array}$ & $\begin{array}{l}18.0 \\
19.0 \\
50.0 \\
16.0 \\
27.0\end{array}$ & $\begin{array}{r}2 \\
3 \\
34 \\
1 \\
13\end{array}$ \\
\hline $\begin{array}{l}1966 \\
1967 \\
1968 \\
1969 \\
1970\end{array}$ & $\begin{array}{c}10.0 \\
9.70 \\
12.0 \\
13.0 \\
12.0\end{array}$ & $\begin{array}{l}20 \\
11 \\
24 \\
34 \\
25\end{array}$ & $\begin{array}{c}10.0 \\
9.80 \\
12.0 \\
13.0 \\
12.0\end{array}$ & $\begin{array}{l}19 \\
11 \\
23 \\
33 \\
24\end{array}$ & $\begin{array}{l}11.0 \\
10.0 \\
12.0 \\
13.0 \\
12.0\end{array}$ & $\begin{array}{l}17 \\
11 \\
29 \\
33 \\
30\end{array}$ & $\begin{array}{l}11.0 \\
11.0 \\
12.0 \\
13.0 \\
12.0\end{array}$ & $\begin{array}{l}16 \\
17 \\
29 \\
33 \\
30\end{array}$ & $\begin{array}{l}13.0 \\
11.0 \\
12.0 \\
13.0 \\
12.0\end{array}$ & $\begin{array}{l}31 \\
15 \\
25 \\
32 \\
26\end{array}$ & $\begin{array}{l}13.0 \\
11.0 \\
13.0 \\
13.0 \\
12.0\end{array}$ & $\begin{array}{l}25 \\
11 \\
26 \\
27 \\
19\end{array}$ & $\begin{array}{l}14.0 \\
11.0 \\
13.0 \\
14.0 \\
13.0\end{array}$ & $\begin{array}{l}32 \\
10 \\
23 \\
33 \\
24\end{array}$ & $\begin{array}{l}14.0 \\
12.0 \\
13.0 \\
13.0 \\
13.0\end{array}$ & $\begin{array}{l}29 \\
15 \\
20 \\
21 \\
22\end{array}$ & $\begin{array}{l}16.0 \\
12.0 \\
14.0 \\
16.0 \\
14.0\end{array}$ & $\begin{array}{l}33 \\
11 \\
22 \\
34 \\
23\end{array}$ & $\begin{array}{l}47.0 \\
31.0 \\
44.0 \\
46.0 \\
37.0\end{array}$ & $\begin{array}{l}29 \\
18 \\
26 \\
28 \\
23\end{array}$ \\
\hline $\begin{array}{l}1971 \\
1972 \\
1973 \\
1974 \\
1975\end{array}$ & $\begin{array}{l}11.0 \\
13.0 \\
12.0 \\
13.0 \\
10.0\end{array}$ & $\begin{array}{l}21 \\
35 \\
26 \\
36 \\
12\end{array}$ & $\begin{array}{l}11.0 \\
14.0 \\
12.0 \\
13.0 \\
10.0\end{array}$ & $\begin{array}{l}20 \\
37 \\
25 \\
34 \\
12\end{array}$ & $\begin{array}{l}11.0 \\
14.0 \\
12.0 \\
13.0 \\
10.0\end{array}$ & $\begin{array}{l}18 \\
39 \\
31 \\
34 \\
12\end{array}$ & $\begin{array}{l}11.0 \\
14.0 \\
12.0 \\
14.0 \\
10.0\end{array}$ & $\begin{array}{l}18 \\
34 \\
31 \\
35 \\
13\end{array}$ & $\begin{array}{l}11.0 \\
14.0 \\
13.0 \\
14.0 \\
11.0\end{array}$ & $\begin{array}{l}16 \\
39 \\
33 \\
34 \\
17\end{array}$ & $\begin{array}{l}12.0 \\
14.0 \\
13.0 \\
14.0 \\
11.0\end{array}$ & $\begin{array}{l}20 \\
34 \\
28 \\
35 \\
12\end{array}$ & $\begin{array}{l}12.0 \\
15.0 \\
13.0 \\
14.0 \\
11.0\end{array}$ & $\begin{array}{l}18 \\
38 \\
25 \\
34 \\
11\end{array}$ & $\begin{array}{l}12.0 \\
15.0 \\
14.0 \\
14.0 \\
11.0\end{array}$ & $\begin{array}{r}16 \\
35 \\
30 \\
31 \\
8\end{array}$ & $\begin{array}{l}13.0 \\
16.0 \\
14.0 \\
16.0 \\
11.0\end{array}$ & $\begin{array}{r}19 \\
35 \\
24 \\
36 \\
6\end{array}$ & $\begin{array}{l}44.0 \\
42.0 \\
29.0 \\
55.0 \\
30.0\end{array}$ & $\begin{array}{l}27 \\
25 \\
15 \\
38 \\
16\end{array}$ \\
\hline
\end{tabular}

HIGHEST MEAN DISCHARGE, IN OUBIC FEET PER SECOND, AND RANKING FOR THE INDICATED NUMBER OF CONSECUTIVE DAYS FOR EACH WATER YEAR, OCTCBER 1-SEPTEMBER 30

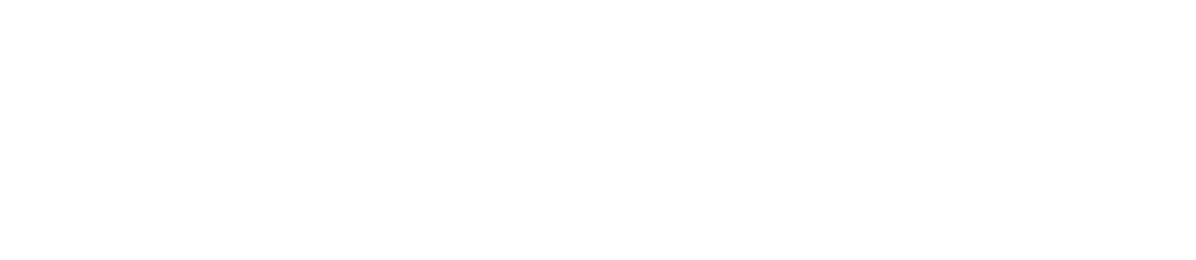

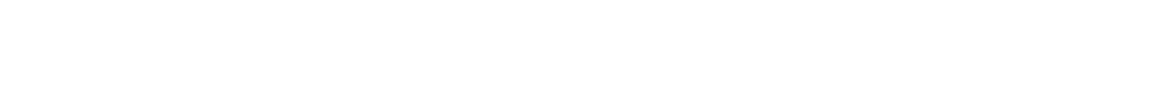

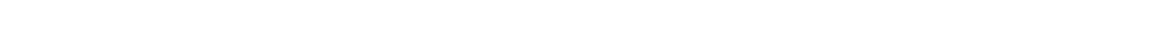

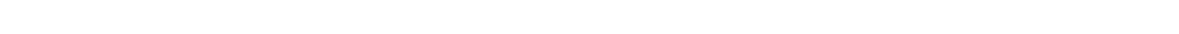

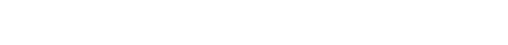

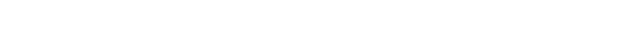

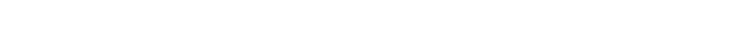

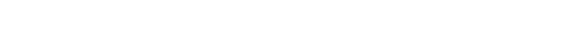

$\begin{array}{llllllll}1956 & 159 & 30 & 153 & 30 & 135 & 31 & 1 \\ 1957 & 243 & 17 & 240 & 17 & 236 & 17 & 231 \\ 1958 & 241 & 18 & 240 & 18 & 232 & 18 & 226\end{array}$

$\begin{array}{llllll}1958 & 241 & 18 & 240 & 18 & 232\end{array}$

$1959 \quad 133$

$1961 \quad 107$

1962

1964
1965

1965320

$\begin{array}{rrrrrrrrrrrrrrrrr}1966 & 268 & 10 & 268 & 10 & 256 & 11 & 217 & 19 & 169 & 21 & 113 & 21 & 85.0 & 22 & 68.0 & 22 \\ 1967 & 252 & 15 & 249 & 15 & 243 & 16 & 238 & 12 & 227 & 13 & 171 & 14 & 125 & 14 & 100 & 14 \\ 1968 & 435 & 1 & 420 & 1 & 377 & 1 & 327 & 1 & 270 & 2 & 177 & 13 & 131 & 13 & 105 & 12 \\ 1969 & 233 & 19 & 230 & 19 & 223 & 19 & 222 & 18 & 190 & 18 & 129 & 17 & 102 & 17 & 83.0 & 17\end{array}$

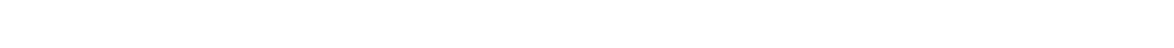

$\begin{array}{rrrr}1971 & 260 & 11 & 259 \\ 1972 & 176 & 27 & 174 \\ 1973 & 324 & 2 & 319 \\ 1974 & 217 & 22 & 214\end{array}$

$\begin{array}{rrrr}1974 & 217 & 22 & 214 \\ 1975 & 276 & 8 & 271\end{array}$

$\begin{array}{llllllllllll}1976 & 211 & 24 & 204 & 24 & 197 & 24 & 187 & 24 & 158 & 22 & 107 \\ 1977 & 43.0 & 40 & 43.0 & 40 & 41.0 & 40 & 38.0 & 40 & 35.0 & 40 & 33.0\end{array}$

$\begin{array}{llllllllllll}1978 & 162 & 29 & 153 & 31 & 145 & 30 & 138 & 30 & 134 & 25 & 100 \\ 1979 & 216 & 23 & 213 & 23 & 208 & 22 & 191 & 21 & 143 & 24 & 97.0\end{array}$ $\begin{array}{rrrr}62.0 & 30 & 52.0 & 29\end{array}$

$\begin{array}{llll}49.0 & 34 & 42.0 & 34 \\ 42.0 & 35 & 36.0 & 35\end{array}$

$\begin{array}{llll}53.0 & 32 & 44.0 & 32\end{array}$

$113 \quad 15$

91.018

$\begin{array}{ll}52.0 & 33 \\ 36.0 & 38\end{array}$

92.015

43.033

$\begin{array}{ll}43.0 & 33 \\ 31.0 & 38\end{array}$

$\begin{array}{llll}40.0 & 36 & 33.0 & 36\end{array}$

$\begin{array}{rrrr}159 & 4 & 126 & 4 \\ 35.0 & 39 & 29.0 & 40\end{array}$

$\begin{array}{llll}74.0 & 26 & 59.0 & 26\end{array}$

$\begin{array}{rr}59.0 & 26 \\ 112 & 9\end{array}$

183 ALU

$\begin{array}{llll}36.0 & 31 & 24.0 & 31\end{array}$

$\begin{array}{llll}76.0 & 12 & 44.0 & 13\end{array}$

$\begin{array}{llll}84.0 & 7 & 56.0 & 2\end{array}$

$\begin{array}{llll}40.0 & 28 & 28.0 & 27\end{array}$

$\begin{array}{lrrr}89.0 & 3 & 51.0 & 4 \\ 45.0 & 25 & 31.0 & 25\end{array}$

$\begin{array}{llll}26.0 & 37 & 20.0 & 35\end{array}$

$\begin{array}{llll}98.0 & 1 & 57.0 & 1\end{array}$

$\begin{array}{rrrr}80.0 & 9 & 35.0 & 18\end{array}$

$81.0 \quad 850.0$

$\begin{array}{llll}39.0 & 30 & 27.0 & 28\end{array}$

$85.0 \quad 6 \quad 49.0 \quad 8$

$\begin{array}{llll}40.0 & 29 & 27.0 & 29\end{array}$

$\begin{array}{llll}32.0 & 34 & 23.0 & 32 \\ 28.0 & 35 & 20.0 & 36\end{array}$

$\begin{array}{llll}34.0 & 32 & 23.0 & 33\end{array}$

$\begin{array}{llll}66.0 & 16 & 39.0 & 16\end{array}$

$\begin{array}{llll}53.0 & 19 & 33.0 & 19\end{array}$

$\begin{array}{llll}33.0 & 33 & 22.0 & 34\end{array}$

$\begin{array}{llll}26.0 & 36 & 18.0 & 37\end{array}$

$\begin{array}{rrrr}89.0 & 4 & 50.0 & 6\end{array}$

$\begin{array}{llll}23.0 & 40 & 17.0 & 40\end{array}$

$\begin{array}{llll}43.0 & 26 & 27.0 & 30 \\ 79.0 & 10 & 45.0 & 10\end{array}$

$\begin{array}{llll}50.0 & 23 & 33.0 & 20\end{array}$

$\begin{array}{llll}73.0 & 14 & 43.0 & 14\end{array}$

$\begin{array}{llll}76.0 & 11 & 45.0 & 11\end{array}$

$\begin{array}{llll}61.0 & 17 & 38.0 & 17 \\ 75.0 & 13 & 44.0 & 12\end{array}$

$\begin{array}{llll}67.0 & 15 & 40.0 \quad 15\end{array}$

$\begin{array}{llll}43.0 & 27 & 30.0 & 26\end{array}$

$95.0255 .0 \quad 3$

$\begin{array}{rrrr}50.0 & 24 & 32.0 & 23 \\ 87.0 & 5 & 49.0 & 7\end{array}$

$\begin{array}{cccc}86.0 & 20 & 68.0 & 23 \\ 152 & 5 & 123 & 5\end{array}$

$\begin{array}{llllllll}86.0 & 21 & 71.0 & 20 & 52.0 & 20 & 33.0 & 21 \\ 30.0 & 40 & 30.0 & 39 & 25.0 & 39 & 18.0 & 38\end{array}$

$\begin{array}{llllllll}81.0 & 23 & 69.0 & 21 & 51.0 & 21 & 32.0 & 22 \\ 77.0 & 24 & 67.0 & 24 & 51.0 & 22 & 31.0 & 24\end{array}$ 
09262000 BIG BRUSH CREFK (BRUSH CREEK) NEAR VERNAL, UT-Continued

DURATION OF DISCHARGE FOR EACH WATER YEAR

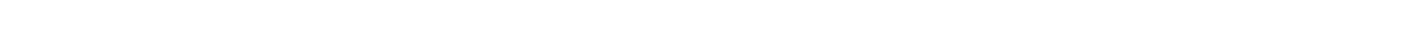

YEAR

NUMBER OF DAYS IN CLASS

OUIC FEET

-DAYS

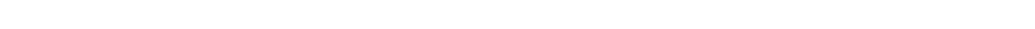

8843.0

1940
1941
1942
1943
194
1945
1946
1947
1948
1949

$\begin{array}{lllllllllllllllllllllllll}43 & 56 & 92 & 16 & 5 & 9 & 18 & 28 & 8 & 10 & 8 & 2 & 11 & 2 & 3 & 2 & 1 & 2 & 2 & 2 & 2 & 2 & 1 & 16 & 24\end{array}$

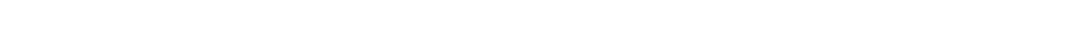

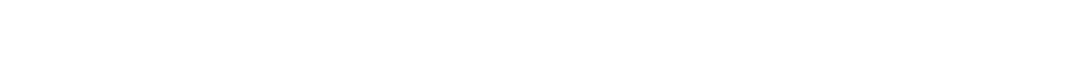

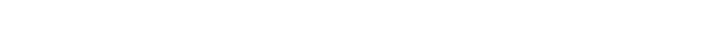

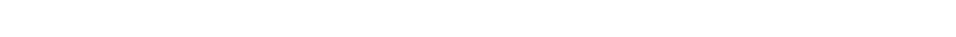

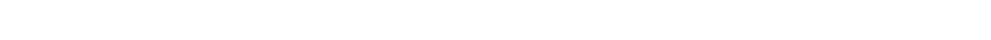

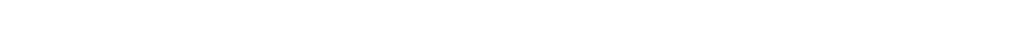

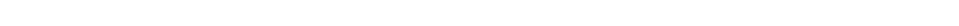

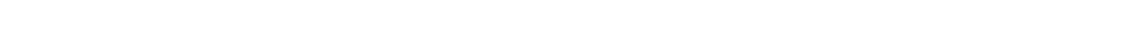

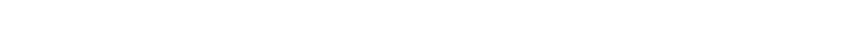

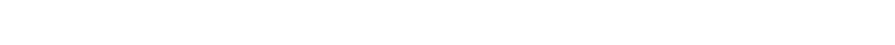

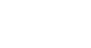

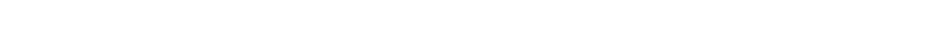

$\begin{array}{lrrrrrrrrrrrrrrrrrrrrrrrrrrrrr}19100 & 93 & 3 & 9 & 8 & 7 & 5 & 18 & 26 & 4 & 2 & 6 & 3 & 5 & 3 & 5 & 8 & 4 & 3 & 3 & 1 & 3 & 4 & 13 & 10\end{array}$

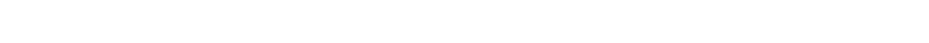

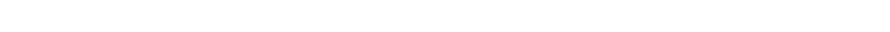

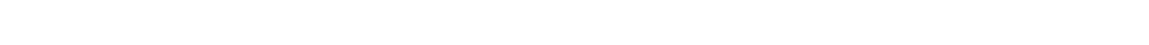

$\begin{array}{lllllllllllllllllllll}13 & 43 & 58 & 75 & 66 & 11 & 23 & 12 & 5 & 5 & 6 & 4 & 4 & 5 & 9 & 5 & 7 & 8 & 3 & 1 & 2\end{array}$

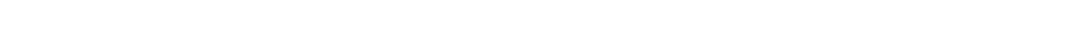

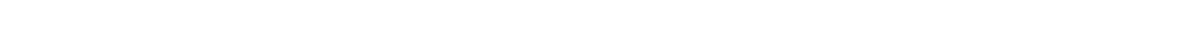

16071.0

20621.0

10067.0

18746.0

1339.0

7402.0

20781.0

12653.0

18287.0

9918.0

17856.0

9918.0

8291.0

7264.3

8256.0

14056.0

12023.0

6364.3

$\begin{array}{lllllllllllllllllllllllll}42 & 75 & 89 & 36 & 29 & 13 & 6 & 7 & 5 & 7 & 7 & 2 & 4 & 4 & 5 & 3 & 5 & 4 & 2 & 3 & 6 & 2 & 3 & 2 & 4\end{array}$

$\begin{array}{llllllllllllllllllllllllllllllllll}4 & 60103 & 22 & 5 & 8 & 14 & 22 & 44 & 4 & 8 & 5 & 7 & 4 & 3 & 1 & 4 & & 1 & 2 & 1 & 1 & 3 & 5 & 5 & 9 & 20 & 15567.4\end{array}$

$\begin{array}{llllllllllllllllllllllllllllllll}100 & 51 & 21 & 41 & 29 & 15 & 6 & 12 & 13 & 4 & 10 & 9 & & 4 & 6 & 5 & 2 & 3 & 2 & 2 & 2 & 2 & 3 & 2 & 4 & 8 & 4 & 3 & 2 & 1 & 16423.0\end{array}$

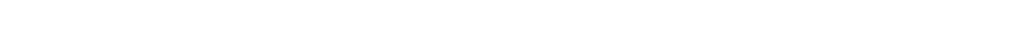

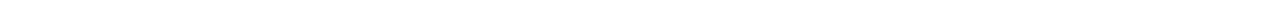

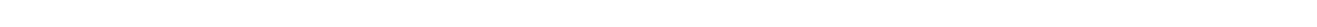

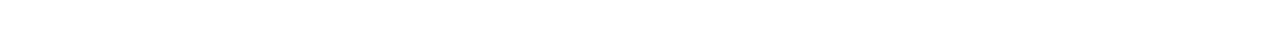

$\begin{array}{llllllllllllllllllllllllllll}44119 & 9 & 28 & 6 & 17 & 11 & 16 & 18 & 7 & 15 & 3 & 5 & 4 & 5 & 4 & 4 & 2 & 2 & 1 & 2 & 1 & 1 & 3 & 9 & 15 & 14 & & 19915.0\end{array}$

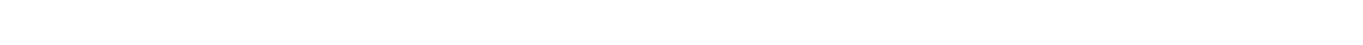

$\begin{array}{lllllllllllllllllllllllllllll}104 & 73 & 35 & 20 & 5 & 23 & 10 & 5 & 5 & 3 & 13 & 15 & 18 & 3 & 3 & 2 & 2 & 2 & 1 & 3 & 2 & 8 & 8 & 3 & & & 12139.0\end{array}$

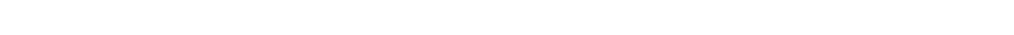

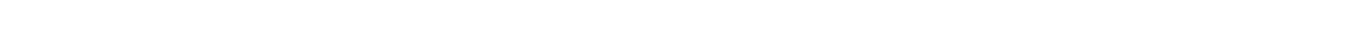

$\begin{array}{llllllllllllllllllllllllllllll}20 & 29 & 34 & 32 & 78 & 4 & 6 & 6 & 10 & 10 & 9 & 14 & 27 & 23 & 14 & 9 & 5 & 4 & 4 & 4 & 1 & 2 & 2 & 2 & 2 & 3 & 5 & 6 & & \end{array}$

DURATION TABLE OF DISCHARGE FOR WATER YEARS 1940-79

$\begin{array}{ccc}\text { CUBIC } & \text { ACOU- } & \\ \text { FEET } & \text { MU- } & \text { PER- } \\ \text { PER } & \text { TOTAL LATED } & \text { CEENT } \\ \text { CIASS SECOND DAYS } & \text { DAYS } & \text { DAYS }\end{array}$

$0.00 \quad 0 \quad 14610 \quad 100.0$

$\begin{array}{llll}7.50 & 88 & 14610 & 100.0\end{array}$

$8.50 \quad 485 \quad 14522 \quad 99.4$

$9.60 \quad 583 \quad 14037 \quad 96.1$

$11.001060 \quad 13454 \quad 92.1$

$12.002870 \quad 1239484.8$

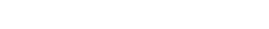

$14.002283 \quad 952465.2$

$\begin{array}{rrrr}16.00 & 1170 & 7241 & 49.6 \\ 18.00 & 861 & 6071 & 41.6\end{array}$ $\begin{array}{lll}\text { ABIIC } & \text { ACOU- } \\ \text { FEET } & \text { MU- } & \text { PER- } \\ \text { PER TOTAL } & \text { LATED } & \text { CENT }\end{array}$ CLASS SECOND DAYS DAYS DAYS

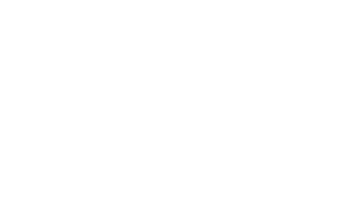

$\begin{array}{lll}\text { OUBIC } & \text { ACOU- } \\ \text { FEET TOT- } & \\ \text { PER TOTAL LATED } & \text { OENT }\end{array}$

CLASS SECOND DAYS DAYS DAYS

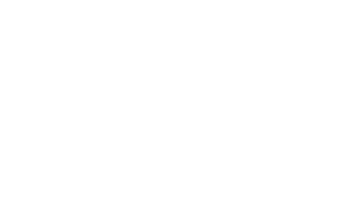

$\begin{array}{lll}\text { OBIC } & \text { ACOU- } \\ \text { FEET } & \text { MU- } & \text { PER- } \\ \text { PER TOTAL ILATED } & \text { CENT }\end{array}$ CLASS SECOND DAYS DAYS DAYS

$\begin{array}{rrrrr}27 & 180.0 & 122 & 733 & 5.0 \\ 28 & 200.0 & 242 & 611 & 4.2 \\ 29 & 230.0 & 233 & 369 & 2.5 \\ 30 & 260.0 & 105 & 136 & 0.9 \\ 31 & 290.0 & 25 & 31 & 0.2 \\ 32 & 330.0 & 3 & 6 & 0.0 \\ 33 & 370.0 & 2 & 3 & 0.0 \\ 34 & 420.0 & 1 & 1 & 0.0\end{array}$


GREEN RIVER BASIN

09262000 BIG BRDSH CREEK (BRUSH CREEK) NEAR VERNAL, UT-Continued

MONIHLY MEAN DISCHARGES, IN CUBIC FEET PER SECOND, FOR EACH WATER YEAR

\begin{tabular}{|c|c|c|c|c|c|c|c|c|c|c|c|c|}
\hline YEAR & $\propto C T$ & NOV & DEC & JAN & FEB & MAR & APR & MAY & JUNE & JULY & AUG & SEP \\
\hline 1940 & 16.7 & 12.7 & 11.4 & 11.4 & 11.3 & 11.8 & 37.6 & 116 & 20.4 & 14.8 & 12.1 & 12.8 \\
\hline $\begin{array}{l}1941 \\
1942 \\
1943 \\
1944 \\
1945\end{array}$ & $\begin{array}{l}13.1 \\
55.4 \\
17.8 \\
14.6 \\
20.1\end{array}$ & $\begin{array}{l}12.5 \\
40.8 \\
16.4 \\
13.5 \\
18.4\end{array}$ & $\begin{array}{l}10.1 \\
24.0 \\
13.5 \\
13.0 \\
16.6\end{array}$ & $\begin{array}{l}11.0 \\
18.0 \\
12.6 \\
12.0 \\
14.9\end{array}$ & $\begin{array}{l}11.3 \\
16.7 \\
13.6 \\
12.0 \\
14.3\end{array}$ & $\begin{array}{l}11.2 \\
17.4 \\
14.5 \\
13.3 \\
14.8\end{array}$ & $\begin{array}{l}13.1 \\
61.2 \\
58.4 \\
15.6 \\
16.1\end{array}$ & $\begin{array}{c}183 \\
159 \\
84.4 \\
170 \\
98.6\end{array}$ & $\begin{array}{c}181 \\
192 \\
45.8 \\
242 \\
94.6\end{array}$ & $\begin{array}{l}34.1 \\
44.3 \\
20.6 \\
57.2 \\
25.8\end{array}$ & $\begin{array}{l}22.1 \\
27.1 \\
17.2 \\
28.6 \\
18.9\end{array}$ & $\begin{array}{l}24.7 \\
20.5 \\
15.6 \\
23.1 \\
18.7\end{array}$ \\
\hline $\begin{array}{l}1946 \\
1947 \\
1948 \\
1949 \\
1950\end{array}$ & $\begin{array}{l}18.3 \\
15.2 \\
20.2 \\
16.9 \\
30.3\end{array}$ & $\begin{array}{l}16.5 \\
15.9 \\
15.8 \\
13.8 \\
19.4\end{array}$ & $\begin{array}{l}14.4 \\
16.3 \\
14.0 \\
13.0 \\
17.6\end{array}$ & $\begin{array}{l}13.0 \\
15.0 \\
14.0 \\
13.0 \\
16.3\end{array}$ & $\begin{array}{l}12.3 \\
14.5 \\
12.9 \\
12.7 \\
15.0\end{array}$ & $\begin{array}{l}12.8 \\
15.2 \\
13.1 \\
13.0 \\
14.4\end{array}$ & $\begin{array}{l}40.2 \\
35.0 \\
19.3 \\
34.0 \\
52.5\end{array}$ & $\begin{array}{l}40.4 \\
221 \\
136 \\
198 \\
164\end{array}$ & $\begin{array}{c}27.1 \\
200 \\
89.6 \\
158 \\
186\end{array}$ & $\begin{array}{l}17.7 \\
72.6 \\
31.7 \\
38.0 \\
38.5\end{array}$ & $\begin{array}{l}16.3 \\
34.5 \\
26.2 \\
31.9 \\
25.4\end{array}$ & $\begin{array}{l}14.1 \\
26.0 \\
21.5 \\
19.7 \\
20.2\end{array}$ \\
\hline $\begin{array}{l}1951 \\
1952 \\
1953 \\
1954 \\
1955\end{array}$ & $\begin{array}{l}19.2 \\
15.2 \\
16.6 \\
14.0 \\
13.7\end{array}$ & $\begin{array}{l}16.9 \\
13.3 \\
14.8 \\
14.0 \\
12.9\end{array}$ & $\begin{array}{c}16.3 \\
11.2 \\
14.5 \\
12.5 \\
9.82\end{array}$ & $\begin{array}{c}13.4 \\
9.68 \\
14.3 \\
12.3 \\
11.0\end{array}$ & $\begin{array}{l}13.5 \\
10.0 \\
14.0 \\
12.1 \\
11.0\end{array}$ & $\begin{array}{l}13.5 \\
13.2 \\
14.4 \\
13.6 \\
12.5\end{array}$ & $\begin{array}{l}16.8 \\
47.3 \\
19.6 \\
35.8 \\
16.9\end{array}$ & $\begin{array}{c}98.7 \\
230 \\
62.8 \\
82.3 \\
58.8\end{array}$ & $\begin{array}{c}59.4 \\
158 \\
93.5 \\
25.6 \\
41.4\end{array}$ & $\begin{array}{l}25.2 \\
32.4 \\
26.9 \\
19.9 \\
21.5\end{array}$ & $\begin{array}{l}17.9 \\
26.8 \\
20.5 \\
14.5 \\
15.9\end{array}$ & $\begin{array}{l}13.9 \\
17.6 \\
13.9 \\
14.8 \\
12.5\end{array}$ \\
\hline $\begin{array}{l}1956 \\
1957 \\
1958 \\
1959 \\
1960\end{array}$ & $\begin{array}{l}12.0 \\
11.8 \\
16.7 \\
11.2 \\
12.8\end{array}$ & $\begin{array}{c}11.0 \\
11.6 \\
13.7 \\
10.9 \\
9.97\end{array}$ & $\begin{array}{c}11.0 \\
11.3 \\
11.9 \\
12.1 \\
9.61\end{array}$ & $\begin{array}{c}11.0 \\
11.0 \\
10.8 \\
11.0 \\
9.46\end{array}$ & $\begin{array}{c}12.0 \\
11.0 \\
12.4 \\
10.4 \\
9.08\end{array}$ & $\begin{array}{c}13.7 \\
11.1 \\
13.2 \\
9.93 \\
10.0\end{array}$ & $\begin{array}{l}21.7 \\
12.4 \\
17.8 \\
15.7 \\
21.5\end{array}$ & $\begin{array}{c}97.7 \\
73.6 \\
161 \\
76.4 \\
43.5\end{array}$ & $\begin{array}{c}35.2 \\
213 \\
83.7 \\
56.4 \\
40.5\end{array}$ & $\begin{array}{l}17.6 \\
47.4 \\
23.2 \\
18.7 \\
15.7\end{array}$ & $\begin{array}{l}14.8 \\
28.7 \\
16.3 \\
15.7 \\
15.6\end{array}$ & $\begin{array}{l}11.9 \\
19.5 \\
12.6 \\
13.5 \\
10.8\end{array}$ \\
\hline $\begin{array}{l}1961 \\
1962 \\
1963 \\
1964 \\
1965\end{array}$ & $\begin{array}{l}12.1 \\
11.4 \\
15.8 \\
11.3 \\
12.4\end{array}$ & $\begin{array}{c}11.4 \\
10.9 \\
11.4 \\
9.75 \\
9.72\end{array}$ & $\begin{array}{c}12.3 \\
9.55 \\
10.6 \\
9.28 \\
8.46\end{array}$ & $\begin{array}{c}9.55 \\
8.40 \\
10.6 \\
9.26 \\
9.03\end{array}$ & $\begin{array}{l}9.13 \\
13.1 \\
11.2 \\
10.3 \\
12.5\end{array}$ & $\begin{array}{c}9.60 \\
16.9 \\
11.7 \\
9.69 \\
9.82\end{array}$ & $\begin{array}{l}12.0 \\
89.2 \\
15.2 \\
12.3 \\
13.6\end{array}$ & $\begin{array}{c}63.7 \\
230 \\
53.4 \\
105 \\
108\end{array}$ & $\begin{array}{c}39.3 \\
145 \\
33.5 \\
89.1 \\
243\end{array}$ & $\begin{array}{l}14.0 \\
28.1 \\
10.9 \\
23.6 \\
58.8\end{array}$ & $\begin{array}{c}12.4 \\
18.6 \\
9.92 \\
16.3 \\
31.8\end{array}$ & $\begin{array}{l}13.5 \\
18.7 \\
12.9 \\
12.9 \\
17.3\end{array}$ \\
\hline $\begin{array}{l}1966 \\
1967 \\
1968 \\
1969 \\
1970\end{array}$ & $\begin{array}{l}18.0 \\
14.1 \\
19.3 \\
23.8 \\
13.9\end{array}$ & $\begin{array}{l}20.5 \\
12.1 \\
14.5 \\
15.2 \\
13.7\end{array}$ & $\begin{array}{l}15.2 \\
12.0 \\
12.9 \\
13.0 \\
13.3\end{array}$ & $\begin{array}{l}13.6 \\
11.5 \\
13.0 \\
14.0 \\
12.0\end{array}$ & $\begin{array}{l}13.3 \\
11.6 \\
12.1 \\
13.8 \\
13.3\end{array}$ & $\begin{array}{l}14.7 \\
11.6 \\
13.3 \\
13.3 \\
15.0\end{array}$ & $\begin{array}{l}51.3 \\
18.6 \\
18.6 \\
33.5 \\
15.9\end{array}$ & $\begin{array}{c}165 \\
117 \\
91.2 \\
187 \\
130\end{array}$ & $\begin{array}{l}32.8 \\
211 \\
255 \\
66.8 \\
223\end{array}$ & $\begin{array}{l}17.3 \\
44.7 \\
42.2 \\
34.2 \\
39.9\end{array}$ & $\begin{array}{l}17.4 \\
24.3 \\
29.5 \\
22.5 \\
22.4\end{array}$ & $\begin{array}{l}15.3 \\
23.8 \\
19.0 \\
17.5 \\
18.4\end{array}$ \\
\hline $\begin{array}{l}1971 \\
1972 \\
1973 \\
1974 \\
1975\end{array}$ & $\begin{array}{l}17.4 \\
20.1 \\
14.5 \\
21.3 \\
11.2\end{array}$ & $\begin{array}{l}12.5 \\
15.1 \\
14.0 \\
16.2 \\
12.0\end{array}$ & $\begin{array}{l}12.0 \\
14.8 \\
14.4 \\
15.1 \\
11.8\end{array}$ & $\begin{array}{l}11.4 \\
14.3 \\
13.5 \\
14.6 \\
10.6\end{array}$ & $\begin{array}{l}13.7 \\
14.9 \\
12.7 \\
14.0 \\
10.7\end{array}$ & $\begin{array}{l}13.6 \\
18.2 \\
15.4 \\
14.4 \\
11.6\end{array}$ & $\begin{array}{l}17.5 \\
25.6 \\
20.1 \\
20.1 \\
14.1\end{array}$ & $\begin{array}{l}95.4 \\
110 \\
195 \\
161 \\
65.7\end{array}$ & $\begin{array}{c}204 \\
63.5 \\
233 \\
67.6 \\
236\end{array}$ & $\begin{array}{l}34.4 \\
20.7 \\
56.8 \\
18.3 \\
139\end{array}$ & $\begin{array}{l}25.9 \\
20.8 \\
37.7 \\
13.1 \\
40.8\end{array}$ & $\begin{array}{l}25.1 \\
17.3 \\
26.1 \\
11.1 \\
29.6\end{array}$ \\
\hline $\begin{array}{l}1976 \\
1977 \\
1978 \\
1979\end{array}$ & $\begin{array}{l}18.7 \\
12.1 \\
12.7 \\
12.5\end{array}$ & $\begin{array}{l}15.0 \\
12.3 \\
12.7 \\
11.9\end{array}$ & $\begin{array}{c}12.6 \\
12.5 \\
12.0 \\
9.90\end{array}$ & $\begin{array}{l}12.0 \\
11.1 \\
12.0 \\
8.45\end{array}$ & $\begin{array}{c}12.8 \\
11.0 \\
11.7 \\
9.61\end{array}$ & $\begin{array}{l}13.7 \\
11.5 \\
11.1 \\
11.6\end{array}$ & $\begin{array}{l}15.6 \\
16.9 \\
20.9 \\
19.4\end{array}$ & $\begin{array}{c}131 \\
32.1 \\
95.6 \\
123\end{array}$ & $\begin{array}{c}76.1 \\
31.9 \\
101 \\
68.2\end{array}$ & $\begin{array}{l}45.8 \\
24.9 \\
43.0 \\
35.7\end{array}$ & $\begin{array}{l}26.5 \\
29.0 \\
30.1 \\
35.0\end{array}$ & $\begin{array}{l}16.2 \\
14.5 \\
17.1 \\
21.8\end{array}$ \\
\hline
\end{tabular}

ANNUAL PEAK DISCHARGE, IN CUBIC FEET PER SECOND, AND CORRESPONDING GAGE HEIGHT, IN FEET, FOR EACH WATER YEAR

\begin{tabular}{|c|c|c|c|c|c|c|c|c|c|c|c|c|c|}
\hline $\begin{array}{l}\text { WATERR } \\
\text { YEAR }\end{array}$ & & DATE & $\begin{array}{c}\text { GAGE } \\
\text { HEIGHT }\end{array}$ & $\begin{array}{c}\text { PEAR } \\
\text { DISCHARGE }\end{array}$ & $\begin{array}{l}\text { WATER } \\
\text { YEAR }\end{array}$ & & DATE & $\begin{array}{c}\text { GAGE } \\
\text { HEIGHT }\end{array}$ & $\begin{array}{c}\text { PEAK } \\
\text { DISCHARGE }\end{array}$ & $\begin{array}{l}\text { WATERR } \\
\text { YEAR }\end{array}$ & DATE & $\begin{array}{c}\text { GAGE } \\
\text { HEIGHT }\end{array}$ & $\begin{array}{l}\text { PEAK } \\
\text { DISCHARGE }\end{array}$ \\
\hline $\begin{array}{l}1939 \\
1940 \\
1941 \\
1942 \\
1943 \\
1944 \\
1945 \\
1946 \\
1947 \\
1948 \\
1949 \\
1950 \\
1951 \\
1952\end{array}$ & $\begin{array}{l}\text { MAY } \\
\text { MAY } \\
\text { AUG. } \\
\text { MAY } \\
\text { MAY } \\
\text { MAY } \\
\text { JULY } \\
\text { AUG. } \\
\text { JUNE } \\
\text { MAY } \\
\text { JUNE } \\
\text { APR. } \\
\text { JULY } \\
\text { JUNE }\end{array}$ & $\begin{array}{ll}06, & 1939 \\
16, & 1940 \\
17, & 1941 \\
30, & 1942 \\
02, & 1943 \\
14, & 1944 \\
21, & 1945 \\
27, & 1946 \\
23,1947 \\
20,1948 \\
08,1949 \\
23,1950 \\
28,1951 \\
03,1952\end{array}$ & $\begin{array}{l}3.55 \\
3.10 \\
4.50 \\
3.89 \\
2.39 \\
4.65 \\
3.60 \\
2.24 \\
5.08 \\
3.28 \\
4.32 \\
3.40 \\
4.19 \\
5.34\end{array}$ & $\begin{array}{l}257 \\
202 \\
360 \\
293 \\
137 \\
380 \\
275 \\
116 \\
433 \\
227 \\
377 \\
264 \\
330 \\
442\end{array}$ & $\begin{array}{l}1953 \\
1954 \\
1955 \\
1956 \\
1957 \\
1958 \\
1959 \\
1960 \\
1961 \\
1962 \\
1963 \\
1964 \\
1965 \\
1966\end{array}$ & $\begin{array}{l}\text { MAY } \\
\text { MAY } \\
\text { OCT. } \\
\text { MAY } \\
\text { JUNE } \\
\text { MAY } \\
\text { AUG. } \\
\text { AUG. } \\
\text { AUG. } \\
\text { JULY } \\
\text { JUNE } \\
\text { MAY } \\
\text { JULY } \\
\text { MAY }\end{array}$ & $\begin{array}{l}30,1953 \\
10,1954 \\
08,1954 \\
23,1956 \\
16,1957 \\
31,1958 \\
19,1959 \\
26,1960 \\
17,1961 \\
12,1962 \\
02,1963 \\
22,1964 \\
19,1965 \\
10,1966\end{array}$ & $\begin{array}{l}3.07 \\
2.78 \\
2.73 \\
2.84 \\
4.05 \\
3.78 \\
1.73 \\
2.87 \\
2.63 \\
3.73 \\
2.00 \\
2.23 \\
3.00 \\
1.99\end{array}$ & $\begin{array}{l}176 \\
155 \\
145 \\
167 \\
261 \\
242 \\
160 \\
370 \\
308 \\
543 \\
280 \\
229 \\
438 \\
279\end{array}$ & $\begin{array}{l}1967 \\
1968 \\
1969 \\
1970 \\
1971 \\
1972 \\
1973 \\
1974 \\
1975 \\
1976 \\
1977 \\
1978 \\
1979\end{array}$ & $\begin{array}{lll}\text { JUNEE } & 10, & 1967 \\
\text { JUNE } & 08,1968 \\
\text { JULY } 19,1969 \\
\text { JUNE } 17,1970 \\
\text { JUNE } 18,1971 \\
\text { MAY } & 20, & 1972 \\
\text { MAY } & 25, & 1973 \\
\text { MAY } & 11, & 1974 \\
\text { JUNE } & 28, & 1975 \\
\text { MAY } & 20, & 1976 \\
\text { JULY } 24, & 1977 \\
\text { MAY } & 16, & 1978 \\
\text { MAY } & 23, & 1979\end{array}$ & $\begin{array}{l}2.22 \\
3.60 \\
3.66 \\
2.79 \\
2.85 \\
2.28 \\
3.08 \\
2.29 \\
2.68 \\
2.29 \\
1.95 \\
2.39 \\
2.47\end{array}$ & $\begin{array}{l}317 \\
445 \\
538 \\
277 \\
266 \\
180 \\
336 \\
219 \\
285 \\
221 \\
156 \\
171 \\
225\end{array}$ \\
\hline
\end{tabular}


GREEN RIVER BASIN

09262000 BIG BRUSH CREEK (BRUSH CREEK) NEAR VERNAL, UT-Continued

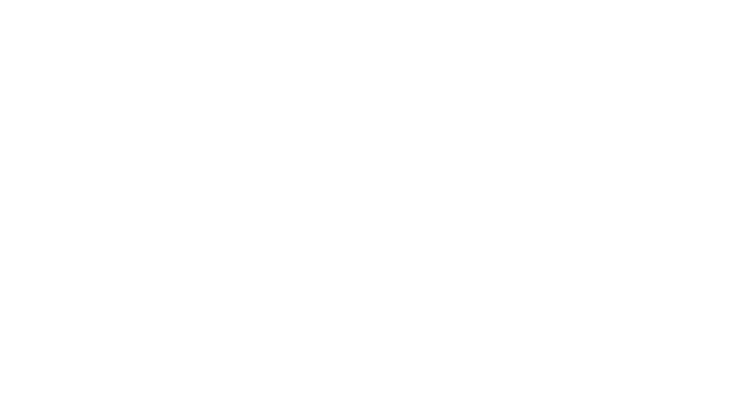

\begin{tabular}{|c|c|c|c|c|c|c|}
\hline \multirow{2}{*}{$\begin{array}{l}\text { ERIO } \\
\text { ONA- } \\
\text { EAU- } \\
\text { TIVE } \\
\text { AUS') }\end{array}$} & \multicolumn{6}{|c|}{$\begin{array}{l}\text { DISGHARGE, IN OBBIC FEET PER SECOND, FOR } \\
\text { INDICATED REOURRENCE INTERNAL, IN YEARS, AND } \\
\text { ANNUAL EXCEEDANCE PRCBABLITY, IN PERCENT }\end{array}$} \\
\hline & $\begin{array}{c}2 \\
508\end{array}$ & $\begin{array}{c}5 \\
208\end{array}$ & $\begin{array}{l}10 \\
10 \%\end{array}$ & $\begin{array}{l}25 \\
48\end{array}$ & $\begin{array}{l}50 \\
28\end{array}$ & $\begin{array}{r}100 \\
18\end{array}$ \\
\hline $\begin{array}{r}1 \\
3 \\
7 \\
15\end{array}$ & $\begin{array}{l}216 \\
211 \\
200 \\
184\end{array}$ & $\begin{array}{l}287 \\
283 \\
275 \\
260\end{array}$ & $\begin{array}{l}319 \\
316 \\
310\end{array}$ & $\begin{array}{l}346 \\
346 \\
342 \\
333\end{array}$ & $\begin{array}{l}362 \\
362 \\
359 \\
353\end{array}$ & $\bar{z}$ \\
\hline
\end{tabular}

09262500 LIT'LE BRUSH CREEK BELW EAST PARK RESERNOIR, NEAR VERNAL, UT

LOCATION.--Lat $40^{\circ} 45^{\prime} 30^{\prime \prime}$, long $109^{\circ} 32^{\prime} 00^{\prime \prime}$, in SW/ sec.2, T.2 S., R.21 E., Uintah County, Hydrologic Unit 14060002, on right bank 2 $\mathrm{mi}$ downstream fram East Park Reservoir and $20 \mathrm{mi}$ north of Vernal.

DRAINAGE AREA. $--20 \mathrm{mi}^{2}$, approximately.

PERIOD OF RECORD AVAIIABLE.--JUly 1949 to September 1955.

GAGE.-Water-stage recorder. Altitude of gage is $8,650 \mathrm{ft}$ from topographic map.

REMARKS.-Flow regulated by East Park Reservoir. No diversions above station.

AVERAGE DISCAARGE. -6 years, $13.3 \mathrm{ft}^{3} / \mathrm{s}, 9,630$ acre- $\mathrm{ft} / \mathrm{yr}$.

EXIREMES FOR PERIOD OF RECORD.--Maximum discharge, $409 \mathrm{ft}^{3} / \mathrm{s}$ May 30, 1950 , gage height, $4.43 \mathrm{ft} ;$ minimum recorded, $0.1 \mathrm{ft} / \mathrm{st}^{3} \mathrm{NOv} .4$,

5, 1954, but may have been less during periods of ice effect or no gage-height record.

LONEST MEAN DISOHARGE, IN OBBIC FEET PER SECOND, AND RANKING FOR THE INDICATED NUMBER OF CONSEOUTTVE DAYS FOR EAOH CIMATIC YEAR, APRII I-MARCH 31

\begin{tabular}{|c|c|c|c|c|c|c|c|c|c|c|c|c|c|c|c|c|c|c|c|}
\hline YEAR & 1 & & 3 & & 7 & & 14 & & $\begin{array}{l}\text { CONSE } \\
30\end{array}$ & OTTVE & $\begin{array}{l}\text { DAYS } \\
60\end{array}$ & & 90 & & 120 & & 183 & & ALL \\
\hline $\begin{array}{l}1951 \\
1952 \\
1953 \\
1954 \\
1955\end{array}$ & $\begin{array}{l}0.80 \\
0.50 \\
0.50 \\
0.80 \\
0.20\end{array}$ & $\begin{array}{l}5 \\
2 \\
3 \\
4 \\
1\end{array}$ & $\begin{array}{l}0.80 \\
0.50 \\
0.50 \\
0.80 \\
0.20\end{array}$ & $\begin{array}{l}5 \\
2 \\
3 \\
4 \\
1\end{array}$ & $\begin{array}{l}0.80 \\
0.50 \\
0.50 \\
0.80 \\
0.20\end{array}$ & $\begin{array}{l}5 \\
2 \\
3 \\
4 \\
1\end{array}$ & $\begin{array}{l}0.80 \\
0.50 \\
0.50 \\
0.80 \\
0.20\end{array}$ & $\begin{array}{l}5 \\
2 \\
3 \\
4 \\
1\end{array}$ & $\begin{array}{l}0.80 \\
0.50 \\
0.50 \\
0.80 \\
0.20\end{array}$ & $\begin{array}{l}5 \\
2 \\
3 \\
4 \\
1\end{array}$ & $\begin{array}{l}0.85 \\
0.50 \\
0.50 \\
0.80 \\
0.20\end{array}$ & $\begin{array}{l}5 \\
2 \\
3 \\
4 \\
1\end{array}$ & $\begin{array}{l}0.87 \\
0.53 \\
0.53 \\
0.80 \\
0.20\end{array}$ & $\begin{array}{l}5 \\
2 \\
3 \\
4 \\
1\end{array}$ & $\begin{array}{l}0.90 \\
0.59 \\
0.55 \\
0.85 \\
0.20\end{array}$ & $\begin{array}{l}5 \\
3 \\
2 \\
4 \\
1\end{array}$ & $\begin{array}{l}0.99 \\
0.74 \\
0.64 \\
0.96 \\
0.30\end{array}$ & $\begin{array}{l}5 \\
3 \\
2 \\
4 \\
1\end{array}$ & $\begin{array}{c}20.0 \\
11.0 \\
21.0 \\
11.0 \\
7.90\end{array}$ \\
\hline
\end{tabular}

HIGHEST MEAN DISCHARGE, IN OBBIC FEET PER SEOOND, AND RANKING FOR THE INDICATED NURBER OF CONSEOUTIVE DAYS FOR EAOH WATER YEAR, OCTCBER 1-SEPTEMBER 30

\begin{tabular}{|c|c|c|c|c|c|c|c|c|c|c|c|c|c|c|c|c|c|c|c|}
\hline YEAR & & & & & & & & & CONS & QUT & VE DAYS & & & & & & & & \\
\hline 1950 & 314 & 1 & 297 & 1 & 236 & 1 & 190 & 1 & 150 & 1 & 94.0 & 2 & 70.0 & 2 & 57.0 & 2 & 38.0 & 2 & 20.0 \\
\hline
\end{tabular}

DURATION OF DISOHARGE FOR EAOH WATER YEAR

\begin{tabular}{|c|c|c|c|c|c|c|c|c|c|c|c|c|c|c|c|c|c|c|c|c|c|c|c|c|c|c|c|c|c|c|}
\hline $\begin{array}{l}\text { CLASS } \\
\text { YEAR }\end{array}$ & 0 & 2 & 3 & 4 & 6 & 7 & 8 & 910 & 11 & 12 & & MBER & OF & 16 & IN & CLAS & 19 & 20 & 21 & 222 & 232 & 425 & 262 & 272 & 2829 & 3031 & 3132 & 33 & & $\begin{array}{l}\text { BIC FEET } \\
\text { R SECOND } \\
\text {-DAYS }\end{array}$ \\
\hline 1950 & & & & & & 1 & 3 & 105 & 36 & 34 & 15 & 24 & 12 & 5 & 2 & 7 & 14 & 9 & 14 & 27 & 7 & 2 & 4 & 5 & 4 & 75 & 5 & 3 & & 7446.4 \\
\hline $\begin{array}{l}1951 \\
1952 \\
1953 \\
1954 \\
1955\end{array}$ & & & & $\begin{array}{r}106 \\
121 \\
14 \\
1449\end{array}$ & {$\left[\begin{array}{c}21 \\
28 \\
31 \\
6\end{array}\right.$} & $\begin{array}{l}248 \\
281 \\
342 \\
21 \\
124\end{array}$ & $\begin{array}{ll}80 & 1 \\
11 & 2 \\
28 & 1 \\
40 & 4 \\
7\end{array}$ & $\begin{array}{rr}17 & 19 \\
21 & 38 \\
10 & 25 \\
44 & 17 \\
4 & 7\end{array}$ & $\begin{array}{r}9 \\
8 \\
7 \\
13 \\
8\end{array}$ & $\begin{array}{r}5 \\
1 \\
11 \\
7\end{array}$ & $\begin{array}{l}5 \\
1 \\
2 \\
5 \\
3\end{array}$ & $\begin{array}{l}5 \\
1 \\
2 \\
1 \\
3\end{array}$ & $\begin{array}{l}5 \\
4\end{array}$ & $\begin{array}{l}3 \\
8\end{array}$ & $\begin{array}{l}1 \\
1 \\
1 \\
1\end{array}$ & $\begin{array}{r}2 \\
2 \\
8 \\
13 \\
2\end{array}$ & $\begin{array}{r}5 \\
14 \\
13 \\
8 \\
4\end{array}$ & $\begin{array}{l}19 \\
15 \\
14 \\
25 \\
10\end{array}$ & $\begin{array}{l}7 \\
39 \\
14 \\
19 \\
21\end{array}$ & $\begin{array}{r}8 \\
11 \\
10 \\
6 \\
18\end{array}$ & $\begin{array}{l}7 \\
8 \\
3 \\
8 \\
4 \\
1\end{array}$ & $\begin{array}{rr}9 & 11 \\
6 & 3 \\
3 & 2 \\
3 & 2 \\
8 & 10\end{array}$ & $\begin{array}{l}4 \\
2 \\
4 \\
5 \\
2\end{array}$ & $\begin{array}{r}4 \\
3 \\
8 \\
12\end{array}$ & $\begin{array}{rr}6 & 2 \\
7 & 12 \\
4 & 12\end{array}$ & $\begin{array}{lr}3 & 2 \\
9 & 10 \\
1 & \end{array}$ & $\begin{array}{ll}2 & \\
10 & 1\end{array}$ & & & $\begin{array}{l}7849 \\
4090 \\
3005 \\
2579\end{array}$ \\
\hline
\end{tabular}


GREEN RIVER BASIN

09262500 LITILE BRUSH CREEK BELCW EAST PARK RESERVOIR, NEAR VERNAL, OT-Continued

DURATTON TABLE OF DISCHARGE FOR WATER YEARS 1950-55

\begin{tabular}{|c|c|c|c|c|c|c|c|c|c|c|c|c|c|c|c|c|c|c|c|}
\hline C.ASS & $\begin{array}{c}\text { QUBIC } \\
\text { FEET } \\
\text { PER } \\
\text { SECOND }\end{array}$ & $\begin{array}{l}\text { TOTAL } \\
\text { DAYS }\end{array}$ & $\begin{array}{l}\text { ACO- } \\
\text { MU- } \\
\text { LATED } \\
\text { DAYS }\end{array}$ & $\begin{array}{l}\text { PER- } \\
\text { CENT } \\
\text { DAYS }\end{array}$ & CLASS & $\begin{array}{c}\text { OUBIC } \\
\text { FEET } \\
\text { PER } \\
\text { SECOND }\end{array}$ & $\begin{array}{l}\text { TOTAL } \\
\text { DAYS }\end{array}$ & $\begin{array}{c}\text { ACOU- } \\
\text { MU- } \\
\text { LATED } \\
\text { DAYS }\end{array}$ & $\begin{array}{l}\text { PER- } \\
\text { CENT } \\
\text { DAYS }\end{array}$ & CIASS & $\begin{array}{c}\text { वBBIC } \\
\text { FEET } \\
\text { PER } \\
\text { SECOND }\end{array}$ & $\begin{array}{l}\text { TOTAL } \\
\text { DAYS }\end{array}$ & $\begin{array}{l}\text { ACO- } \\
\text { MU- } \\
\text { LATED } \\
\text { DAYS }\end{array}$ & $\begin{array}{l}\text { PER- } \\
\text { CENT } \\
\text { DAYS }\end{array}$ & CASS & $\begin{array}{c}\text { OBIC } \\
\text { FEET } \\
\text { PER } \\
\text { SEOOND }\end{array}$ & $\begin{array}{l}\text { TOTAL } \\
\text { DAYS }\end{array}$ & $\begin{array}{c}\text { ACQU- } \\
\text { MU- } \\
\text { LATED } \\
\text { DAYS }\end{array}$ & $\begin{array}{l}\text { PER- } \\
\text { CENT } \\
\text { DAYS }\end{array}$ \\
\hline $\begin{array}{l}0 \\
1 \\
2 \\
3 \\
4 \\
5 \\
6 \\
7 \\
8\end{array}$ & $\begin{array}{l}0.00 \\
0.20 \\
0.25 \\
0.31 \\
0.39 \\
0.49 \\
0.61 \\
0.76 \\
0.95\end{array}$ & $\begin{array}{r}0 \\
141 \\
5 \\
0 \\
14 \\
290 \\
39 \\
320 \\
169\end{array}$ & $\begin{array}{l}2191 \\
2191 \\
2050 \\
2045 \\
2045 \\
2031 \\
1741 \\
1702 \\
1382\end{array}$ & $\begin{array}{r}100.0 \\
100.0 \\
93.6 \\
93.3 \\
93.3 \\
92.7 \\
79.5 \\
77.7 \\
63.1\end{array}$ & $\begin{array}{l}9 \\
10 \\
11 \\
12 \\
13 \\
14 \\
15 \\
16 \\
17\end{array}$ & $\begin{array}{l}1.20 \\
1.50 \\
1.90 \\
2.30 \\
2.90 \\
3.60 \\
4.50 \\
5.60 \\
7.00\end{array}$ & $\begin{array}{r}98 \\
211 \\
81 \\
58 \\
31 \\
36 \\
27 \\
22 \\
6\end{array}$ & $\begin{array}{r}1213 \\
1115 \\
904 \\
823 \\
765 \\
734 \\
698 \\
671 \\
649\end{array}$ & $\begin{array}{l}55.4 \\
50.9 \\
41.3 \\
37.6 \\
34.9 \\
33.5 \\
31.9 \\
30.6 \\
29.6\end{array}$ & $\begin{array}{l}18 \\
19 \\
20 \\
21 \\
22 \\
23 \\
24 \\
25 \\
26\end{array}$ & $\begin{array}{r}8.8 \\
11.0 \\
14.0 \\
17.0 \\
21.0 \\
27.0 \\
33.0 \\
42.0 \\
52.0\end{array}$ & $\begin{array}{r}34 \\
58 \\
92 \\
114 \\
80 \\
37 \\
47 \\
30 \\
21\end{array}$ & $\begin{array}{l}643 \\
609 \\
551 \\
459 \\
345 \\
265 \\
228 \\
181 \\
151\end{array}$ & $\begin{array}{r}29.3 \\
27.8 \\
25.1 \\
20.9 \\
15.7 \\
12.1 \\
10.4 \\
8.3 \\
6.9\end{array}$ & $\begin{array}{l}27 \\
28 \\
29 \\
30 \\
31 \\
32 \\
33 \\
34\end{array}$ & $\begin{array}{r}65.0 \\
81.0 \\
100.0 \\
130.0 \\
160.0 \\
200.0 \\
250.0 \\
310.0\end{array}$ & $\begin{array}{r}32 \\
21 \\
35 \\
20 \\
17 \\
1 \\
3 \\
1\end{array}$ & $\begin{array}{r}130 \\
98 \\
77 \\
42 \\
22 \\
5 \\
4 \\
1\end{array}$ & $\begin{array}{l}5.9 \\
4.5 \\
3.5 \\
1.9 \\
1.0 \\
0.2 \\
0.2 \\
0.0\end{array}$ \\
\hline
\end{tabular}

MONUHLY MEAN DISCHARGES, IN OUBIC FEET PER SECOND, FOR EACH WATER YEAR

\begin{tabular}{|c|c|c|c|c|c|c|c|c|c|c|c|c|}
\hline YEAR & $\infty T$ & $\mathrm{NOV}$ & DEC & JAN & FEBB & MAR & APR & MAY & JUNE & JULY & AUG & SEP \\
\hline 1950 & 3.28 & 3.41 & 2.16 & 1.80 & 1.50 & 1.60 & 13.2 & 83.0 & 102 & 14.1 & 15.3 & 2.55 \\
\hline $\begin{array}{l}1951 \\
1952 \\
1953 \\
1954 \\
1955\end{array}$ & $\begin{array}{l}1.21 \\
1.09 \\
0.88 \\
1.10 \\
0.54\end{array}$ & $\begin{array}{l}1.08 \\
0.75 \\
0.72 \\
1.23 \\
0.45\end{array}$ & $\begin{array}{l}0.90 \\
0.60 \\
0.60 \\
1.00 \\
0.20\end{array}$ & $\begin{array}{l}0.80 \\
0.50 \\
0.50 \\
0.80 \\
0.20\end{array}$ & $\begin{array}{l}0.90 \\
0.50 \\
0.50 \\
0.80 \\
0.20\end{array}$ & $\begin{array}{l}1.00 \\
1.50 \\
0.60 \\
0.80 \\
0.20\end{array}$ & $\begin{array}{c}1.17 \\
20.0 \\
1.10 \\
7.87 \\
0.63\end{array}$ & $\begin{array}{c}60.9 \\
123 \\
35.2 \\
51.6 \\
33.4\end{array}$ & $\begin{array}{l}39.7 \\
76.4 \\
72.6 \\
14.8 \\
24.5\end{array}$ & $\begin{array}{l}22.4 \\
16.9 \\
16.8 \\
15.6 \\
19.5\end{array}$ & $\begin{array}{c}3.61 \\
13.2 \\
3.67 \\
1.39 \\
3.54\end{array}$ & $\begin{array}{l}1.00 \\
1.56 \\
1.32 \\
0.81 \\
0.81\end{array}$ \\
\hline
\end{tabular}

ANNUAL PEAK DISCHARGE, IN OJBIC FEET PER SECOND, AND CORRESPONDING GAGE HEIGHT, IN FEET, FOR EACH WATER YEAR

\begin{tabular}{|c|c|c|c|c|c|c|c|c|c|c|c|c|c|}
\hline $\begin{array}{l}\text { WATER } \\
\text { YEAR }\end{array}$ & & DATE & $\begin{array}{c}\text { GAGE } \\
\text { HEIGHT }\end{array}$ & $\begin{array}{c}\text { PEAK } \\
\text { DISCHARGE }\end{array}$ & $\begin{array}{l}\text { WATERR } \\
\text { YEAR }\end{array}$ & DATE & $\begin{array}{c}\text { GAGE } \\
\text { HEIGHT }\end{array}$ & $\begin{array}{c}\text { PEAK } \\
\text { DISCHARGE }\end{array}$ & $\begin{array}{l}\text { WATER } \\
\text { YEAR }\end{array}$ & & ATE & $\begin{array}{c}\text { GAGE } \\
\text { HEIGHT }\end{array}$ & $\begin{array}{c}\text { PEAR } \\
\text { DISAHARGE }\end{array}$ \\
\hline $\begin{array}{l}1950 \\
1951\end{array}$ & $\begin{array}{l}\text { MAY } \\
\text { MAY }\end{array}$ & $\begin{array}{ll}30, & 1950 \\
27, & 1951\end{array}$ & $\begin{array}{l}4.43 \\
3.58\end{array}$ & $\begin{array}{l}409 \\
213\end{array}$ & $\begin{array}{l}1952 \\
1953\end{array}$ & $\begin{array}{l}\text { JUNE 03， } 1952 \\
\text { JUNE 02， } 1953\end{array}$ & $\begin{array}{l}3.93 \\
3.26\end{array}$ & $\begin{array}{l}273 \\
152\end{array}$ & $\begin{array}{l}1954 \\
1955\end{array}$ & $\begin{array}{l}\text { MAY } \\
\text { MAY }\end{array}$ & $\begin{array}{l}09,1954 \\
20,1955\end{array}$ & $\begin{array}{l}2.85 \\
3.07\end{array}$ & $\begin{array}{l}108 \\
207\end{array}$ \\
\hline
\end{tabular}

09263000 LITTLE BRUSH CREEX NEAR VERNAL, UT

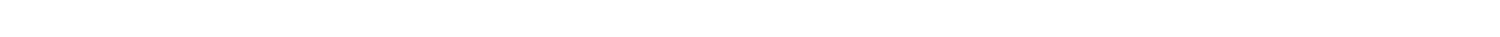
$0.5 \mathrm{mi}$ upstream fram cave, $0.75 \mathrm{mi}$ upstream fram Kane Hollow, and $17.5 \mathrm{mi}$ north of Vernal.

DRAINAGE AREA. $-\mathbf{- 2 8} \mathrm{mi}^{2}$, approximately.

PERIOD OF RECORD AVAIIABLE.--October 1945 to September 1952.

GAGE.-Water-stage recorder. Altitude of gage is 8,000 ft from topographic map.

RFMARKS.-Flow regulated by East Park Reservoir. No diversion above station.

AVERAGE DISCHARGE.--7 years, $19.9 \mathrm{ft}^{3} / \mathrm{s}, 14,410$ acre-ft/yr.

EXTREMES FOR PERIOD OF RECORD.--Maximum discharge, $608 \mathrm{ft}^{3} / \mathrm{s}$ May 30, 1950, gage height, $3.71 \mathrm{ft}$; minimum recorded, $0.1 \mathrm{ft}{ }^{3} / \mathrm{s} \mathrm{Sept.}$

18,1951 .

LOWEST MEAN DISCHARGE, IN OBBIC FEET PER SECOND, AND RANKING FOR THE INDICATED NUMBER OF CONSECUTIVE DAYS FOR EACH OLIMATIC YEAR, APRIL I-MAROH 31

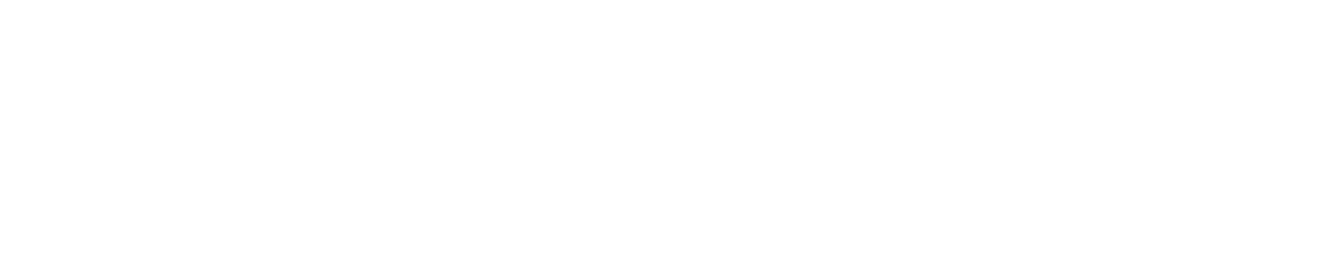


GREEN RIVER BASIN

09263000 LITTLE BRUSH CREEK NEAR VERNAL, UT--Continued

HIGHEST MEAN DISCHARGE, IN OUBIC FEET PER SECOND, AND RANKING FOR THE INDICATED NUMBER OF CONSEQUTIVE DAYS FOR EACH WATER YEAR, OCTOBER 1-SEPTEMBER 30

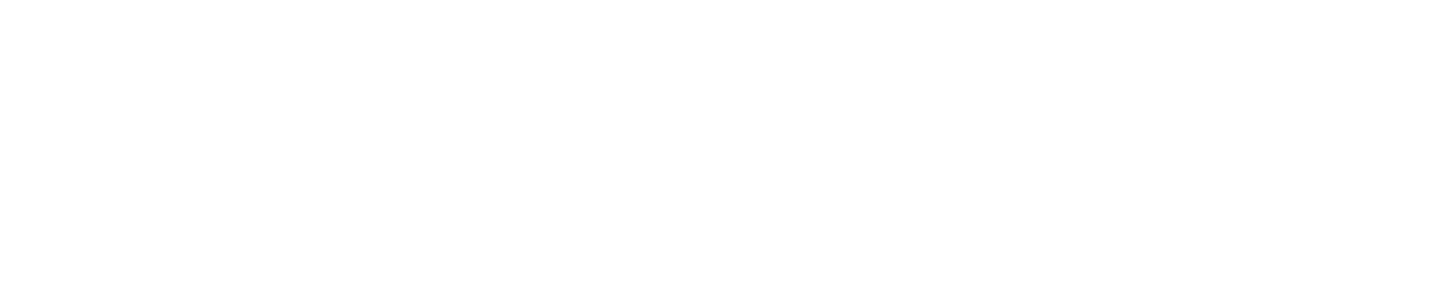

DURATION OF DISCHARGE FOR EACH WATER YEAR

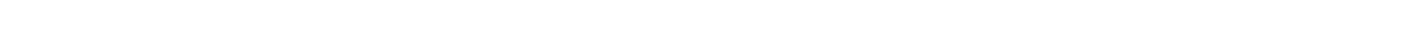
YEAR

NUMBER OF DAYS IN CLASS OUBIC FEET PER SECOND

1946

1947

1948

1949
1950 -DAYS

1951

1952

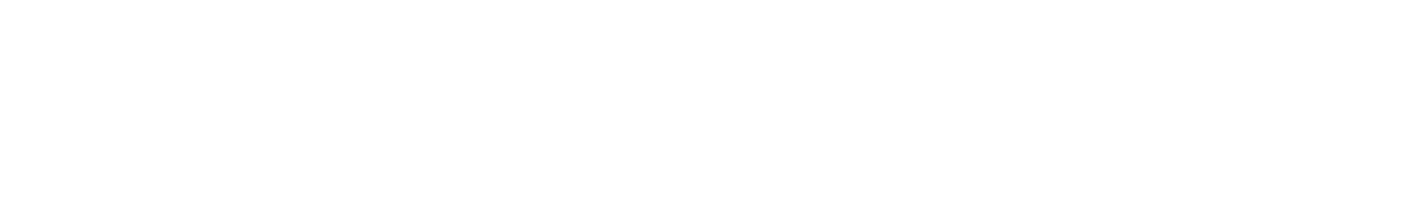

DURATION TABLE OF DISCHARGE FOR WATER YEARS 1946-52

\begin{tabular}{|c|c|c|c|c|c|c|c|c|c|c|c|c|c|c|c|c|c|c|c|}
\hline ASS & $\begin{array}{c}\text { QUBIC } \\
\text { FEET } \\
\text { PER } \\
\text { SECOND }\end{array}$ & $\begin{array}{l}\text { TOTAL } \\
\text { DAYS }\end{array}$ & $\begin{array}{l}\text { ACOU- } \\
\text { MU- } \\
\text { LATED } \\
\text { DAYS }\end{array}$ & $\begin{array}{l}\text { PER- } \\
\text { CEN } \\
\text { DAYS }\end{array}$ & CLASS & $\begin{array}{r}\text { OUBIC } \\
\text { FEET } \\
\text { PER } \\
\text { SECOND }\end{array}$ & $\begin{array}{c}\text { TOTAL } \\
\text { DAYS }\end{array}$ & $\begin{array}{c}\text { ACCU- } \\
\text { MU- } \\
\text { LATED } \\
\text { DAYS }\end{array}$ & $\begin{array}{l}\text { PER- } \\
\text { CENT } \\
\text { DAYS }\end{array}$ & & $\begin{array}{c}\text { OUBIC } \\
\text { FEET } \\
\text { PER } \\
\text { SECOND }\end{array}$ & $\begin{array}{c}\text { TOTAL } \\
\text { DAYS }\end{array}$ & $\begin{array}{c}\text { ACOU- } \\
\text { MU- } \\
\text { LATED } \\
\text { DAYS }\end{array}$ & $\begin{array}{l}\text { PER } \\
\text { CENT } \\
\text { DAYS }\end{array}$ & GLASS & $\begin{array}{c}\text { CUBIC } \\
\text { FEET } \\
\text { PER } \\
\text { SECOND }\end{array}$ & $\begin{array}{c}\text { TOTAL } \\
\text { DAYS }\end{array}$ & $\begin{array}{c}\text { ACOU- } \\
\text { MU- } \\
\text { LATHED } \\
\text { DAYS }\end{array}$ & $\begin{array}{l}\text { PER- } \\
\text { CENT } \\
\text { DAYS }\end{array}$ \\
\hline $\begin{array}{l}0 \\
1 \\
2 \\
3 \\
4 \\
5 \\
6 \\
7 \\
8\end{array}$ & $\begin{array}{l}0.00 \\
0.20 \\
0.25 \\
0.32 \\
0.40 \\
0.51 \\
0.64 \\
0.81 \\
1.00\end{array}$ & $\begin{array}{r}0 \\
4 \\
1 \\
0 \\
186 \\
186 \\
186 \\
51 \\
338\end{array}$ & $\begin{array}{l}2557 \\
2557 \\
2553 \\
2552 \\
2552 \\
2366 \\
2180 \\
1994 \\
1943\end{array}$ & $\begin{array}{r}100.0 \\
100.0 \\
99.8 \\
99.8 \\
99.8 \\
92.5 \\
85.3 \\
78.0 \\
76.0\end{array}$ & $\begin{array}{r}9 \\
10 \\
11 \\
12 \\
13 \\
14 \\
15 \\
16 \\
17\end{array}$ & $\begin{array}{l}1.30 \\
1.60 \\
2.10 \\
2.60 \\
3.30 \\
4.10 \\
5.20 \\
6.60 \\
8.30\end{array}$ & $\begin{array}{r}219 \\
264 \\
71 \\
36 \\
41 \\
46 \\
38 \\
98 \\
39\end{array}$ & $\begin{array}{r}1605 \\
1386 \\
1122 \\
1051 \\
1015 \\
974 \\
928 \\
890 \\
792\end{array}$ & $\begin{array}{l}62.8 \\
54.2 \\
43.9 \\
41.1 \\
39.7 \\
38.1 \\
36.3 \\
34.8 \\
31.0\end{array}$ & $\begin{array}{l}18 \\
19 \\
20 \\
21 \\
22 \\
23 \\
24 \\
25 \\
26\end{array}$ & $\begin{array}{l}10.0 \\
13.0 \\
17.0 \\
21.0 \\
26.0 \\
33.0 \\
42.0 \\
53.0 \\
67.0\end{array}$ & $\begin{array}{l}89 \\
98 \\
81 \\
76 \\
67 \\
58 \\
41 \\
27 \\
22\end{array}$ & $\begin{array}{l}753 \\
664 \\
566 \\
485 \\
409 \\
342 \\
284 \\
243 \\
216\end{array}$ & $\begin{array}{r}29.4 \\
26.0 \\
22.1 \\
19.0 \\
16.0 \\
13.4 \\
11.1 \\
9.5 \\
8.4\end{array}$ & $\begin{array}{l}27 \\
28 \\
29 \\
30 \\
31 \\
32 \\
33 \\
34\end{array}$ & $\begin{array}{r}85.0 \\
110.0 \\
130.0 \\
170.0 \\
210.0 \\
270.0 \\
340.0 \\
430.0\end{array}$ & $\begin{array}{r}42 \\
26 \\
45 \\
40 \\
30 \\
8 \\
1 \\
2\end{array}$ & $\begin{array}{r}194 \\
152 \\
126 \\
81 \\
41 \\
11 \\
3 \\
2\end{array}$ & $\begin{array}{l}7.6 \\
5.9 \\
4.9 \\
3.2 \\
1.6 \\
0.4 \\
0.1 \\
0.1\end{array}$ \\
\hline
\end{tabular}

MONTHLY MEAN DISCHARGES, IN OUBIC FEET PER SECOND, FOR EACH WATER YEAR

\begin{tabular}{|c|c|c|c|c|c|c|c|c|c|c|c|c|}
\hline YEAR & $\infty \mathrm{CT}$ & NOV & DEC & JAN & FEB & MAR & APR & MAY & JUNE & JULY & AUG & SEP \\
\hline $\begin{array}{l}1946 \\
1947 \\
1948 \\
1949 \\
1950\end{array}$ & $\begin{array}{l}4.25 \\
1.58 \\
1.48 \\
1.83 \\
3.84\end{array}$ & $\begin{array}{l}2.21 \\
0.93 \\
1.39 \\
0.62 \\
3.78\end{array}$ & $\begin{array}{l}1.50 \\
0.75 \\
0.76 \\
0.50 \\
1.12\end{array}$ & $\begin{array}{l}1.20 \\
0.60 \\
0.60 \\
0.50 \\
1.90\end{array}$ & $\begin{array}{l}1.00 \\
0.50 \\
0.60 \\
0.47 \\
1.80\end{array}$ & $\begin{array}{l}1.00 \\
0.50 \\
0.80 \\
0.45 \\
1.85\end{array}$ & $\begin{array}{c}10.2 \\
3.17 \\
4.67 \\
9.24 \\
17.3\end{array}$ & $\begin{array}{l}32.2 \\
182 \\
115 \\
141 \\
132\end{array}$ & $\begin{array}{c}16.7 \\
103 \\
32.8 \\
66.6 \\
128\end{array}$ & $\begin{array}{c}12.9 \\
26.1 \\
8.49 \\
11.0 \\
17.3\end{array}$ & $\begin{array}{c}6.72 \\
9.85 \\
6.95 \\
13.6 \\
15.4\end{array}$ & $\begin{array}{l}1.14 \\
8.67 \\
3.88 \\
1.19 \\
2.75\end{array}$ \\
\hline $\begin{array}{l}1951 \\
1952\end{array}$ & $\begin{array}{l}1.25 \\
1.18\end{array}$ & $\begin{array}{l}1.45 \\
0.85\end{array}$ & $\begin{array}{l}1.40 \\
0.70\end{array}$ & $\begin{array}{l}1.00 \\
0.60\end{array}$ & $\begin{array}{l}1.20 \\
0.60\end{array}$ & $\begin{array}{l}1.40 \\
2.00\end{array}$ & $\begin{array}{c}1.60 \\
24.4\end{array}$ & $\begin{array}{ll}71.1 \\
161\end{array}$ & $\begin{array}{l}42.5 \\
88.7\end{array}$ & $\begin{array}{l}25.6 \\
17.5\end{array}$ & $\begin{array}{c}3.58 \\
12.6\end{array}$ & $\begin{array}{l}0.84 \\
1.09\end{array}$ \\
\hline
\end{tabular}

ANNUAL PEAK DISCHARGE, IN OUBIC FEET PER SECOND, AND CORRESPONDING GAGE HEIGHT, IN FEET, FOR EACH WATER YEAR

\begin{tabular}{|c|c|c|c|c|c|c|c|c|c|c|c|c|c|}
\hline $\begin{array}{l}\text { WATEER } \\
\text { YEAR }\end{array}$ & DATE & $\begin{array}{c}\text { GAGE } \\
\text { HEIGHT }\end{array}$ & $\begin{array}{c}\text { PEAK } \\
\text { DISCHARGE }\end{array}$ & $\begin{array}{l}\text { WATER } \\
\text { YEAR }\end{array}$ & & DATE & $\begin{array}{c}\text { GAGE } \\
\text { HEIGHT }\end{array}$ & $\begin{array}{c}\text { PEAR } \\
\text { DISCHARGE }\end{array}$ & $\begin{array}{l}\text { WATER } \\
\text { YEAR }\end{array}$ & & DATE & $\begin{array}{c}\text { GAGE } \\
\text { HEIGHT }\end{array}$ & $\begin{array}{c}\text { PEAK } \\
\text { DISCHARGE }\end{array}$ \\
\hline $\begin{array}{l}1946 \\
1947 \\
1948\end{array}$ & $\begin{array}{lll}\text { APR. } & 25,1946 \\
\text { MAY } & 08,1947 \\
\text { MAY } & 21,1948\end{array}$ & $\begin{array}{l}-\overline{2} \\
2.98 \\
2.98\end{array}$ & $\begin{array}{r}60 \\
384 \\
388\end{array}$ & $\begin{array}{l}1949 \\
1950\end{array}$ & $\begin{array}{l}\text { MAY } \\
\text { MAY }\end{array}$ & $\begin{array}{ll}15, & 1949 \\
30, & 1950\end{array}$ & $\begin{array}{l}3.08 \\
3.71\end{array}$ & $\begin{array}{l}365 \\
608\end{array}$ & $\begin{array}{l}1951 \\
1952\end{array}$ & $\begin{array}{l}\text { MAY } \\
\text { MAY }\end{array}$ & $\begin{array}{l}27,1951 \\
08,1952\end{array}$ & $\begin{array}{l}2.93 \\
3.37\end{array}$ & $\begin{array}{l}221 \\
358\end{array}$ \\
\hline
\end{tabular}


GREEN RIVER BASIN

09263500 BRUSH CREEK NEAR JENSEN, UT

LOCATION. --Lat $40^{\circ} 24^{\prime} 31^{\prime \prime}$, long $109^{\circ} 20^{\prime} 25^{\prime \prime}$, in SW $\frac{1}{4}$ sec. 4 , T. 5 S., R. 23 E., Uintah County, Hydrologic Unit 14060002 , on right bank 280 $\mathrm{ft}$ upstream fram bridge on State highway $149,2,000 \mathrm{ft}$ upstream fram mouth, and $2.75 \mathrm{mi}$ north of Jensen.

DRAINAGE AREA. $--255 \mathrm{mi}^{2}$.

PERIOD OF RECORD AVAIIABLE.--April 1939 to September 1965.

REVISED RECORDS. -WSP 1513: 1946 .

GAGE.--Digital water-stage recorder. Altitude of gage is 4,730 ft from river-profile map. Prior to Nov. 24, 1947, staff gages at three sites within $80 \mathrm{ft}$ upstream at different datums. Nov. 24, 1947, to Oct. 20, 1954, graphic water-stage recorder at site $15 \mathrm{ft}$ upstream at different datum. Oct. 2l, 1954, to Dec. 2, 1964, graphic water-stage recorder at present site and datum.

REMARKS.--Many diversions above station for irrigation.

AVERAGE DISCHARGE. --26 years, $18.5 \mathrm{ft}^{3} / \mathrm{s}, 13,390$ acre-ft/yr.

EXTREMES FOR PERIOD OF RECORD. -Maximum discharge observed, $900 \mathrm{ft}^{3} / \mathrm{s} \mathrm{Aug.} \mathrm{17,} \mathrm{1941,} \mathrm{gage} \mathrm{height,} 5.50 \mathrm{ft}$, datum then in use, fram rating curve extended above $150 \mathrm{ft}^{3} / \mathrm{s}$; no flow for many days in scme years.

LOWEST MEAN DISOHARGE, IN OUBIC FEET PER SECOND, AND RANKING FOR THE INDICATED NUMBER OF CONSECUTIVE DAYS FOR EAOH OLIMATIC YEAR, APRIL 1-MARCH 31

194

1943

1944
1945

1946

1947

1948

1949
1950

1951

1952

1953

1954
1955

1956

1957

958

1959

1961

1962

1963

1964

$\begin{array}{lr}3 & \\ & \\ 0.00 & 1 \\ 0.00 & 2 \\ 0.00 & 3 \\ 0.00 & 4 \\ 0.20 & 23 \\ 0.10 & 17 \\ 0.00 & 5 \\ 0.20 & 24 \\ 0.10 & 18 \\ 0.10 & 19 \\ 0.47 & 25 \\ 0.07 & 9 \\ 0.20 & 20 \\ 0.20 & 21 \\ 0.10 & 10 \\ 0.00 & 6 \\ 0.00 & 7 \\ 0.20 & 22 \\ 0.10 & 11 \\ 0.10 & 12 \\ 0.00 & 8 \\ 0.10 & 13 \\ 0.10 & 14 \\ 0.10 & 15 \\ 0.10 & 16\end{array}$

$\begin{array}{lr}7 & \\ & \\ 0.00 & 1 \\ 0.00 & 2 \\ 0.00 & 3 \\ 0.00 & 4 \\ 0.21 & 21 \\ 0.10 & 13 \\ 0.00 & 5 \\ 0.24 & 22 \\ 0.10 & 14 \\ 0.10 & 15 \\ 0.50 & 25 \\ 0.10 & 16 \\ 0.31 & 24 \\ 0.24 & 23 \\ 0.10 & 17 \\ 0.00 & 6 \\ 0.00 & 7 \\ 0.20 & 20 \\ 0.10 & 18 \\ 0.10 & 19 \\ 0.00 & 8 \\ 0.10 & 9 \\ 0.10 & 10 \\ 0.10 & 11 \\ 0.10 & 12\end{array}$

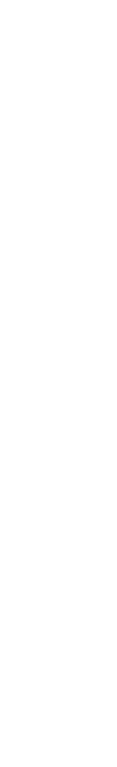

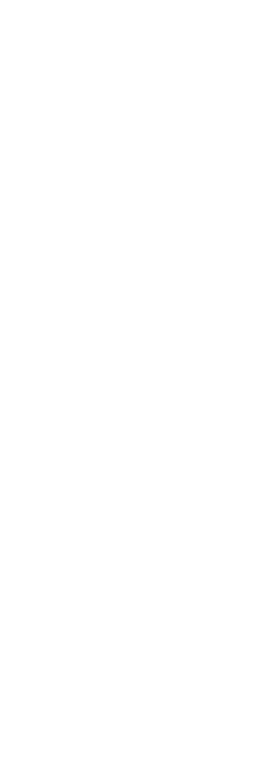

90

0.031

$\begin{array}{cc}0.03 & 1 \\ 10.0 & 25\end{array}$

0.266

0.9820

0.5314

0.7818

0.3611

4.6024

1.3022

0.6516

1.3023

0.6817

0.5815

0.4913

0.235

0.329

$\begin{array}{ll}0.09 & 2 \\ 1.19 & 21\end{array}$

$0.20 \quad 4$
0.3712

0.3210

0.297

0.7919

0.183
120

\begin{tabular}{|c|c|}
\hline \multicolumn{2}{|l|}{20} \\
\hline $\begin{array}{l}1.80 \\
0.54 \\
7.20 \\
1.80 \\
3.60\end{array}$ & $\begin{array}{l}801 \\
54 \\
202 \\
802 \\
60\end{array}$ \\
\hline $\begin{array}{l}1.40 \\
0.83 \\
0.81 \\
0.48 \\
0.58\end{array}$ & $\begin{array}{l}40 \\
83 \\
81 \\
48 \\
58\end{array}$ \\
\hline $\begin{array}{l}0.36 \\
0.12 \\
2.00 \\
0.30 \\
0.42\end{array}$ & $\begin{array}{l}36 \\
12 \\
50 \\
30 \\
42\end{array}$ \\
\hline $\begin{array}{l}0.95 \\
2.20 \\
1.00 \\
0.22 \\
0.35\end{array}$ & $\begin{array}{l}95 \\
20 \\
00 \\
22\end{array}$ \\
\hline
\end{tabular}

183

$0.75 \quad 4$ $\begin{array}{ll}27.0 & 25\end{array}$

7.1023

2.8011

5.0018

5.0019

1.195

9.7024

3.4014
6.7022

.7022

5.1020

3.2013

3.5015

$0.4025 .00 \quad 4$

$0.72 \quad 3$

5.6021

$\begin{array}{rrrr}1.60 & 7 & 11.0 & 11 \\ 1.40 & 6 & 5.20 & 2\end{array}$

$\begin{array}{llll}2.00 & 9 & 5.20 \quad 3\end{array}$

$3.5016 \quad 15.0 \quad 14$

$2.3010 \quad 33.020$

0.31120

$\begin{array}{llll}0.31 & 1 & 3.90 \quad 1\end{array}$

HIGHEST MEAN DISCHARGE, IN OUBIC FEET PER SECOND, AND RANKING FOR THE INDICATED NUMBER OF CONSECUTIVE DAYS FOR EAOH WATER YEAR, OCTOBER 1-SEPTEMBER 30

YEAR

1940
1941
1942
1943
1944
1945
1946
1947
1948
1949
1950
1951
1952
1953
1954
1955

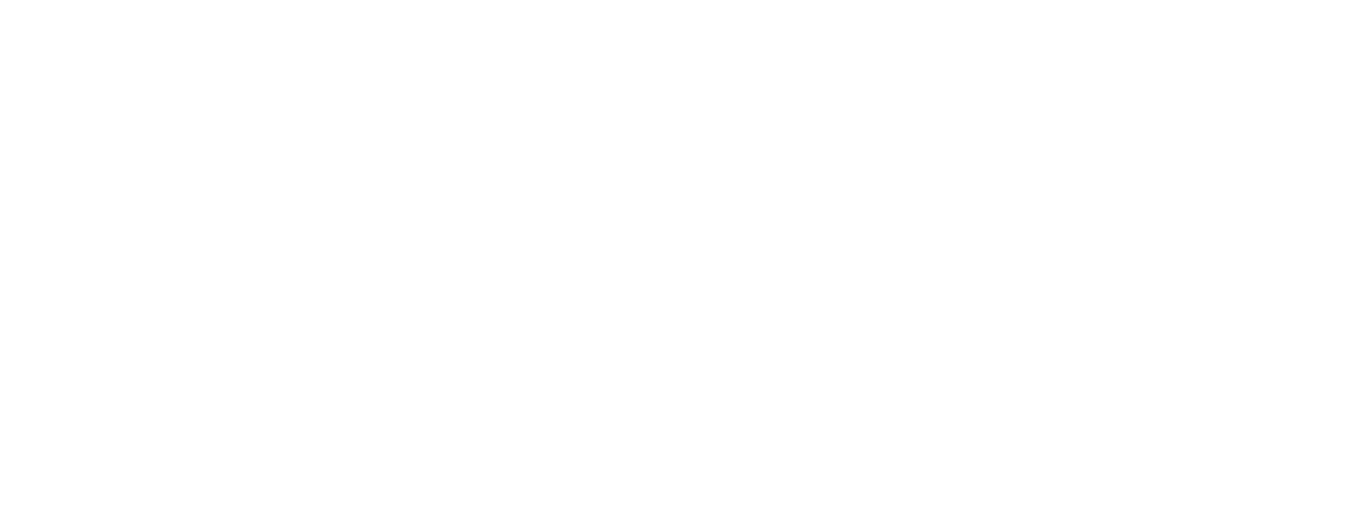


09263500 BRUSH CREEK NEAR JENSEN, UT-Continued

HIGHEST MEAN DISCHARGE, IN CUBIC FEET PER SECOND, AND RANKING FOR THE INDICATED NUMBER OF CONSECUTIVE DAYS FOR EACH WATER YEAR, OCTCBER 1-SEPTEMBER 30-continued

\begin{tabular}{|c|c|c|c|c|c|c|c|c|c|c|c|c|c|c|c|c|c|c|c|}
\hline YEAR & 1 & & 3 & & 7 & & 15 & & $\begin{array}{l}\text { CONS } \\
30\end{array}$ & EOTT & $\begin{array}{c}\text { E DAYS } \\
60\end{array}$ & & 90 & & 120 & & 183 & & ALL \\
\hline $\begin{array}{l}1956 \\
1957 \\
1958 \\
1959 \\
1960\end{array}$ & $\begin{array}{l}79.0 \\
192 \\
127 \\
34.0 \\
177\end{array}$ & $\begin{array}{l}22 \\
10 \\
17 \\
26 \\
11\end{array}$ & $\begin{array}{l}78.0 \\
184 \\
126 \\
18.0 \\
60.0\end{array}$ & $\begin{array}{r}20 \\
9 \\
14 \\
26 \\
23\end{array}$ & $\begin{array}{l}60.0 \\
173 \\
122 \\
17.0 \\
26.0\end{array}$ & $\begin{array}{r}19 \\
9 \\
13 \\
26 \\
24\end{array}$ & $\begin{array}{c}34.0 \\
158 \\
113 \\
16.0 \\
19.0\end{array}$ & $\begin{array}{r}21 \\
9 \\
11 \\
26 \\
25\end{array}$ & $\begin{array}{c}21.0 \\
137 \\
85.0 \\
14.0 \\
16.0\end{array}$ & $\begin{array}{l}21 \\
10 \\
11 \\
26 \\
24\end{array}$ & $\begin{array}{l}16.0 \\
73.0 \\
46.0 \\
12.0 \\
13.0\end{array}$ & $\begin{array}{l}21 \\
10 \\
13 \\
26 \\
25\end{array}$ & $\begin{array}{l}15.0 \\
50.0 \\
33.0 \\
11.0 \\
12.0\end{array}$ & $\begin{array}{l}21 \\
10 \\
13 \\
26 \\
25\end{array}$ & $\begin{array}{c}14.0 \\
40.0 \\
29.0 \\
9.30 \\
11.0\end{array}$ & $\begin{array}{l}21 \\
10 \\
13 \\
26 \\
23\end{array}$ & $\begin{array}{r}12.0 \\
31.0 \\
24.0 \\
6.40 \\
9.30\end{array}$ & $\begin{array}{l}21 \\
10 \\
13 \\
26 \\
23\end{array}$ & $\begin{array}{c}6.70 \\
17.0 \\
14.0 \\
3.90 \\
5.60\end{array}$ \\
\hline $\begin{array}{l}1961 \\
1962 \\
1963 \\
1964\end{array}$ & $\begin{array}{c}219 \\
306 \\
60.0 \\
128 \\
380\end{array}$ & $\begin{array}{r}6 \\
4 \\
25 \\
16 \\
2\end{array}$ & $\begin{array}{c}88.0 \\
243 \\
47.0 \\
123 \\
285\end{array}$ & $\begin{array}{r}18 \\
4 \\
24 \\
15 \\
3\end{array}$ & $\begin{array}{c}39.0 \\
224 \\
30.0 \\
119 \\
257\end{array}$ & $\begin{array}{r}22 \\
4 \\
23 \\
14 \\
3\end{array}$ & $\begin{array}{c}21.0 \\
196 \\
23.0 \\
102 \\
235\end{array}$ & $\begin{array}{r}23 \\
4 \\
22 \\
15 \\
3\end{array}$ & $\begin{array}{c}15.0 \\
191 \\
17.0 \\
67.0 \\
179\end{array}$ & $\begin{array}{r}25 \\
3 \\
23 \\
14 \\
4\end{array}$ & $\begin{array}{c}15.0 \\
162 \\
14.0 \\
40.0 \\
118\end{array}$ & $\begin{array}{r}22 \\
4 \\
24 \\
14 \\
8\end{array}$ & $\begin{array}{r}13.0 \\
137 \\
12.0 \\
27.0 \\
82.0\end{array}$ & $\begin{array}{r}23 \\
2 \\
24 \\
14 \\
14 \\
8\end{array}$ & $\begin{array}{c}11.0 \\
111 \\
9.70 \\
23.0 \\
66.0\end{array}$ & $\begin{array}{r}24 \\
2 \\
25 \\
15 \\
9\end{array}$ & $\begin{array}{c}8.40 \\
78.0 \\
7.30 \\
19.0 \\
48.0\end{array}$ & $\begin{array}{r}24 \\
2 \\
25 \\
15 \\
7\end{array}$ & $\begin{array}{c}5.90 \\
43.0 \\
4.00 \\
10.0 \\
27.0\end{array}$ \\
\hline
\end{tabular}

DURATION OF DISCHARGE FOR EACH WATER YEAR

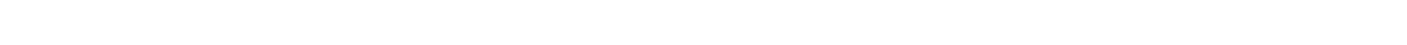
YEAR NUMBER OF DAYS IN CLASS CUBIC FEET PER SECOND
-DAYS

\begin{tabular}{|c|c|c|c|c|c|c|c|c|c|c|c|c|c|c|c|c|c|c|c|c|c|c|c|c|c|c|c|c|c|c|}
\hline 940 & 130 & & & & & 142 & & & 52 & & 7 & 4 & 2 & & 2 & 1 & 2 & 2 & 1 & 2 & 2 & 6 & 5 & 1 & & & & & & 1870.0 \\
\hline $\begin{array}{l}941 \\
.942 \\
.943 \\
944 \\
945\end{array}$ & $\begin{array}{l}51 \\
70 \\
92\end{array}$ & $\begin{array}{r}6 \\
19\end{array}$ & $\begin{array}{ll}6 & 18 \\
8 & 15\end{array}$ & $\begin{array}{r}35 \\
8\end{array}$ & $\left.\begin{array}{l}9 \\
9\end{array}\right]$ & $\begin{array}{r}3 \\
18\end{array}$ & & $\begin{array}{l}21 \\
29\end{array}$ & $\begin{array}{r}2 \\
2 \\
32 \\
21 \\
11\end{array}$ & $\begin{array}{l}11 \\
10\end{array}$ & $\begin{array}{r}10 \\
2 \\
1 \\
5 \\
4\end{array}$ & $\begin{array}{l}4 \\
3 \\
6 \\
3 \\
3\end{array}$ & $\begin{array}{r}13 \\
1 \\
8 \\
4\end{array}$ & $\begin{array}{r}15 \\
1 \\
3 \\
6 \\
8\end{array}$ & $\begin{array}{r}22 \\
6 \\
4 \\
20\end{array}$ & $\begin{array}{r}18 \\
6 \\
8 \\
5 \\
14\end{array}$ & $\begin{array}{r}72 \\
1 \\
6 \\
70 \\
14\end{array}$ & $\begin{array}{r}37 \\
4 \\
38 \\
45 \\
94\end{array}$ & $\begin{array}{r}12 \\
87 \\
86 \\
19 \\
3\end{array}$ & $\begin{array}{r}5 \\
43 \\
27 \\
8 \\
8\end{array}$ & $\begin{array}{r}3 \\
31 \\
17 \\
4 \\
6 \\
6\end{array}$ & $\begin{array}{c}1 \\
19 \\
3 \\
3 \\
5\end{array}$ & $\begin{array}{cc}2 \\
33 & 1 \\
2 \\
2 \\
6 & 1\end{array}$ & $\begin{array}{c}1 \\
16 \\
1\end{array}$ & 3 & $\begin{array}{rr}26 & 19 \\
13 & 15 \\
1 & 1 \\
7 & 16 \\
5 & 1\end{array}$ & $\begin{array}{ll}9 & \\
5 & \\
1 \\
6 & \\
1 & 16\end{array}$ & 6 & 2 & $\begin{array}{r}10597.0 \\
15414.0 \\
5173.0 \\
15299.8 \\
5701.2\end{array}$ \\
\hline $\begin{array}{l}1946 \\
1947 \\
1948 \\
1949 \\
1950\end{array}$ & $\begin{array}{r}1722 \\
\\
38 \\
130\end{array}$ & $\begin{array}{r}22 \\
20 \\
15 \\
33 \\
6\end{array}$ & $\begin{array}{rr}12 & 35 \\
18 & 1 \\
8 & 1 \\
6 & 5\end{array}$ & $\begin{array}{r}35 \\
1 \\
3 \\
3 \\
26\end{array}$ & $\begin{array}{r}3 \\
8 \\
8 \\
7 \\
15\end{array}$ & $\begin{array}{ll}3 & \\
7 & 1 \\
7 & 8 \\
3 & 28\end{array}$ & & $\begin{array}{l}6 \\
3 \\
6 \\
6 \\
8\end{array}$ & $\begin{array}{r}5 \\
17 \\
8 \\
4 \\
1\end{array}$ & $\begin{array}{r}11 \\
6 \\
3 \\
6 \\
10\end{array}$ & $\begin{array}{l}4 \\
7 \\
4 \\
6 \\
7\end{array}$ & $\begin{array}{l}3 \\
5 \\
4 \\
3 \\
3\end{array}$ & $\begin{array}{r}20 \\
8 \\
19 \\
7 \\
1\end{array}$ & $\begin{array}{r}11 \\
2 \\
8 \\
9 \\
16\end{array}$ & $\begin{array}{r}11 \\
3 \\
16 \\
7 \\
6\end{array}$ & $\begin{array}{l}31 \\
15 \\
13 \\
48 \\
48\end{array}$ & $\begin{array}{l}75 \\
16 \\
55 \\
49 \\
68\end{array}$ & $\begin{array}{r}21 \\
117 \\
59 \\
42 \\
18\end{array}$ & $\begin{array}{r}1 \\
22 \\
42 \\
13 \\
12\end{array}$ & $\begin{array}{r}4 \\
10 \\
7 \\
6 \\
7\end{array}$ & $\begin{array}{r}3 \\
9 \\
7 \\
1 \\
13 \\
13\end{array}$ & $\begin{array}{r}5 \\
6 \\
2 \\
2 \\
11\end{array}$ & $\begin{array}{l}4 \\
3 \\
2 \\
7 \\
7\end{array}$ & & $\begin{array}{l}12 \\
12 \\
21\end{array}$ & $\begin{array}{rr}7 & 4 \\
6 & 18\end{array}$ & $\begin{array}{l}4 \\
8\end{array}$ & & & $\begin{array}{r}2929.9 \\
15160.5 \\
6064.2 \\
9512.4 \\
11474.3\end{array}$ \\
\hline $\begin{array}{l}1951 \\
1952 \\
1953 \\
1954 \\
1955\end{array}$ & $\begin{array}{r}132 \\
2 \\
\\
7 \quad 26 \\
739\end{array}$ & $\begin{array}{r}35 \\
3 \\
4 \\
53 \\
44\end{array}$ & $\begin{array}{ll}18 & 24 \\
12 & 21 \\
15 & 57 \\
11 & 29 \\
29 & 12\end{array}$ & $\begin{array}{r}8 \\
31 \\
2 \\
16 \\
5\end{array}$ & $\begin{array}{r}17 \\
9 \\
46 \\
11 \\
7\end{array}$ & $\begin{array}{rl}8 & 1 \\
12 & \\
13 & 3 \\
7 & \\
5 & \end{array}$ & 1 & $\begin{array}{r}16 \\
2 \\
3 \\
5 \\
6\end{array}$ & $\begin{array}{r}20 \\
3 \\
2 \\
4 \\
5\end{array}$ & $\begin{array}{r}3 \\
18 \\
15 \\
6 \\
31\end{array}$ & $\begin{array}{r}17 \\
11 \\
4 \\
4 \\
11\end{array}$ & $\begin{array}{r}1 \\
12 \\
3 \\
10 \\
9\end{array}$ & $\begin{array}{l}4 \\
3 \\
7 \\
9 \\
3\end{array}$ & $\begin{array}{r}2 \\
4 \\
33 \\
4\end{array}$ & $\begin{array}{r}2 \\
4 \\
1 \\
14 \\
2\end{array}$ & $\begin{array}{r}11 \\
13 \\
2 \\
7 \\
43\end{array}$ & $\begin{array}{r}83 \\
80 \\
5 \\
96 \\
64\end{array}$ & $\begin{array}{r}36 \\
26 \\
128 \\
4 \\
30\end{array}$ & $\begin{array}{l}11 \\
1 \\
2\end{array}$ & $\begin{array}{l}1 \\
8 \\
2 \\
3\end{array}$ & $\begin{array}{l}2 \\
5 \\
4\end{array}$ & $\begin{array}{l}1 \\
6 \\
71 \\
2\end{array}$ & $\begin{array}{r}2 \\
9 \\
10 \\
2 \\
1\end{array}$ & $\begin{array}{l}1 \\
7 \\
3 \\
1\end{array}$ & & $\begin{array}{ll}4 & \\
6 & 17\end{array}$ & 8 & 5 & & $\begin{array}{r}3842.8 \\
13985.3 \\
3846.1 \\
2570.8 \\
2398.3\end{array}$ \\
\hline $\begin{array}{l}1956 \\
1957 \\
1958 \\
1959 \\
1960\end{array}$ & $\begin{array}{rr}2066 \\
& 24 \\
& 48 \\
& 51 \\
23 & 36\end{array}$ & $\begin{array}{l}48 \\
22 \\
31 \\
48 \\
43\end{array}$ & $\begin{array}{rr}26 & 7 \\
12 & 15 \\
7 & 3 \\
19 & 29 \\
16 & 17\end{array}$ & $\begin{array}{r}20 \\
15 \\
5 \\
20 \\
6\end{array}$ & $\begin{array}{l}12 \\
41 \\
13 \\
30 \\
11\end{array}$ & $\begin{array}{r}5 \\
10 \\
3 \\
8 \\
7\end{array}$ & 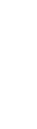 & $\begin{array}{l}4 \\
5 \\
2 \\
3 \\
5\end{array}$ & $\begin{array}{l}3 \\
5 \\
4 \\
9 \\
7\end{array}$ & $\begin{array}{r}1 \\
10 \\
5 \\
25\end{array}$ & $\begin{array}{l}1 \\
6 \\
3 \\
2 \\
9\end{array}$ & $\begin{array}{r}1 \\
10 \\
11 \\
11 \\
9\end{array}$ & $\begin{array}{r}4 \\
15 \\
30 \\
10 \\
8\end{array}$ & $\begin{array}{r}5 \\
8 \\
27 \\
15 \\
6\end{array}$ & $\begin{array}{r}5 \\
10 \\
14 \\
54 \\
28\end{array}$ & $\begin{array}{l}68 \\
64 \\
33 \\
16 \\
78\end{array}$ & $\begin{array}{r}32 \\
29 \\
50 \\
21 \\
3\end{array}$ & $\begin{array}{r}16 \\
22 \\
40 \\
9 \\
18\end{array}$ & $\begin{array}{l}4 \\
1 \\
1 \\
1 \\
4\end{array}$ & $\begin{array}{l}5 \\
3 \\
1\end{array}$ & $\begin{array}{l}1 \\
1 \\
1\end{array}$ & $\begin{array}{l}1 \\
5\end{array}$ & $\begin{array}{l}3 \\
2 \\
6\end{array}$ & $\begin{array}{l}3 \\
4 \\
41\end{array}$ & 6 & 13 & 1 & & & $\begin{array}{l}2456.0 \\
6239.5 \\
5041.1 \\
1430.3 \\
2037.3\end{array}$ \\
\hline $\begin{array}{l}1961 \\
1962 \\
1963 \\
1964\end{array}$ & $\begin{array}{r}51 \\
25 \\
52 \\
30 \\
4\end{array}$ & $\begin{array}{l}46 \\
25 \\
27 \\
27 \\
42\end{array}$ & $\begin{array}{rr}22 & 36 \\
8 & 7 \\
19 & 25 \\
34 & 39 \\
14 & 9\end{array}$ & $\begin{array}{r}9 \\
4 \\
16 \\
11 \\
5\end{array}$ & $\begin{array}{l}10 \\
11 \\
31 \\
29 \\
11\end{array}$ & $\begin{array}{ll}8 & 12 \\
3 & \\
9 & 1 \\
9 \\
4\end{array}$ & & $\begin{array}{l}4 \\
4 \\
8 \\
7\end{array}$ & $\begin{array}{r}6 \\
4 \\
12 \\
2 \\
2\end{array}$ & $\begin{array}{r}3 \\
1 \\
19 \\
7 \\
3\end{array}$ & $\begin{array}{r}5 \\
1 \\
13 \\
2 \\
6\end{array}$ & $\begin{array}{r}15 \\
1 \\
25 \\
7 \\
2\end{array}$ & $\begin{array}{r}14 \\
15 \\
6 \\
5\end{array}$ & $\begin{array}{r}17 \\
8 \\
5 \\
4 \\
9\end{array}$ & $\begin{array}{r}6 \\
20 \\
6 \\
6 \\
14\end{array}$ & $\begin{array}{l}25 \\
77 \\
51 \\
94 \\
47\end{array}$ & $\begin{array}{r}64 \\
22 \\
7 \\
15 \\
76\end{array}$ & $\begin{array}{r}1 \\
25 \\
8 \\
2 \\
32\end{array}$ & $\begin{array}{r}5 \\
8 \\
3 \\
14\end{array}$ & $\begin{array}{l}3 \\
8 \\
1 \\
9 \\
4\end{array}$ & $\begin{array}{l}1 \\
5 \\
1 \\
4 \\
3\end{array}$ & $\begin{array}{l}7 \\
1 \\
4 \\
5\end{array}$ & $\begin{array}{l}5 \\
1 \\
3 \\
6\end{array}$ & $\begin{array}{l}1 \\
81\end{array}$ & 8 & 2023 & $\begin{array}{l}1 \\
9\end{array}$ & 1 & 1 & $\begin{array}{r}2154.8 \\
15586.2 \\
1451.9 \\
3811.0 \\
9881.2\end{array}$ \\
\hline
\end{tabular}

DURATION TABLE OF DISCHARGE FOR WATER YEARS 1940-65

\begin{tabular}{|c|c|c|c|c|c|c|c|c|c|c|c|c|c|c|c|c|c|c|c|}
\hline CJASS & $\begin{array}{c}\text { CUBIC } \\
\text { FEET } \\
\text { PER } \\
\text { SECOND }\end{array}$ & $\begin{array}{r}\text { TOTAL } \\
\text { DAYS }\end{array}$ & $\begin{array}{l}\text { ACCU- } \\
\text { MU- } \\
\text { LATED } \\
\text { DAYS }\end{array}$ & $\begin{array}{l}\text { PER- } \\
\text { CENT } \\
\text { DAYS }\end{array}$ & CLASS & $\begin{array}{c}\text { CBBIC } \\
\text { FEET } \\
\text { PER } \\
\text { SECOND }\end{array}$ & $\begin{array}{r}\text { TOTAL } \\
\text { DAYS }\end{array}$ & $\begin{array}{l}\text { ACOU- } \\
\text { MU- } \\
\text { LATED } \\
\text { DAYS }\end{array}$ & $\begin{array}{l}\text { PER- } \\
\text { CENT } \\
\text { DAYS }\end{array}$ & CIASS & $\begin{array}{c}\text { OUBIC } \\
\text { FEET } \\
\text { PER } \\
\text { SEOOND }\end{array}$ & TOTAL & $\begin{array}{c}\text { ACOJ- } \\
\text { MU- } \\
\text { LATED } \\
\text { DAYS }\end{array}$ & $\begin{array}{l}\text { PER- } \\
\text { CENI } \\
\text { DAYS }\end{array}$ & CLASS & $\begin{array}{c}\text { OUBIC } \\
\text { FEET } \\
\text { PER } \\
\text { SECOND }\end{array}$ & $\begin{array}{l}\text { TOTAL } \\
\text { DAYS }\end{array}$ & $\begin{array}{l}\text { ACCU- } \\
\text { MU- } \\
\text { LATED } \\
\text { DAYS }\end{array}$ & $\begin{array}{l}\text { PER- } \\
\text { CENT } \\
\text { DAYS }\end{array}$ \\
\hline $\begin{array}{l}0 \\
1 \\
2 \\
3 \\
4 \\
5 \\
6 \\
7 \\
8\end{array}$ & $\begin{array}{l}0.00 \\
0.10 \\
0.13 \\
0.17 \\
0.22 \\
0.28 \\
0.36 \\
0.46 \\
0.60\end{array}$ & $\begin{array}{r}412 \\
585 \\
0 \\
619 \\
0 \\
320 \\
405 \\
314 \\
348\end{array}$ & $\begin{array}{l}9497 \\
9085 \\
8500 \\
8500 \\
7881 \\
7881 \\
7561 \\
7156 \\
6842\end{array}$ & $\begin{array}{r}100.0 \\
95.7 \\
89.5 \\
89.5 \\
83.0 \\
83.0 \\
79.6 \\
75.4 \\
72.0\end{array}$ & $\begin{array}{r}9 \\
10 \\
11 \\
12 \\
13 \\
14 \\
15 \\
16 \\
17\end{array}$ & $\begin{array}{l}0.77 \\
0.99 \\
1.30 \\
1.70 \\
2.10 \\
2.80 \\
3.60 \\
4.60 \\
5.90\end{array}$ & $\begin{array}{l}152 \\
401 \\
153 \\
243 \\
204 \\
152 \\
168 \\
216 \\
226\end{array}$ & $\begin{array}{l}6494 \\
6342 \\
5941 \\
5788 \\
5545 \\
5341 \\
5189 \\
5021 \\
4805\end{array}$ & $\begin{array}{l}68.4 \\
66.8 \\
62.6 \\
60.9 \\
58.4 \\
56.2 \\
54.6 \\
52.9 \\
50.6\end{array}$ & $\begin{array}{l}18 \\
19 \\
20 \\
21 \\
22 \\
23 \\
24 \\
25 \\
26\end{array}$ & $\begin{array}{r}7.6 \\
9.8 \\
13.0 \\
16.0 \\
21.0 \\
27.0 \\
35.0 \\
45.0 \\
59.0\end{array}$ & $\begin{array}{r}283 \\
836 \\
1075 \\
874 \\
353 \\
175 \\
124 \\
102 \\
123\end{array}$ & $\begin{array}{r}4579 \\
4296 \\
3460 \\
2385 \\
1511 \\
1158 \\
983 \\
859 \\
757\end{array}$ & $\begin{array}{r}48.2 \\
45.2 \\
36.4 \\
25.1 \\
15.9 \\
12.2 \\
10.4 \\
9.0 \\
8.0\end{array}$ & $\begin{array}{l}27 \\
28 \\
29 \\
30 \\
31 \\
32 \\
33 \\
34\end{array}$ & $\begin{array}{r}76.0 \\
98.0 \\
130.0 \\
160.0 \\
210.0 \\
270.0 \\
350.0 \\
450.0\end{array}$ & $\begin{array}{r}96 \\
150 \\
153 \\
169 \\
48 \\
12 \\
3 \\
3 .\end{array}$ & $\begin{array}{r}634 \\
538 \\
388 \\
235 \\
66 \\
18 \\
6 \\
3\end{array}$ & $\begin{array}{l}6.7 \\
5.7 \\
4.1 \\
2.5 \\
0.7 \\
0.2 \\
0.1 \\
0.0\end{array}$ \\
\hline
\end{tabular}


GREEN RTVER BASIN

09263500 BRUSH CREEK NEAR JENSEN, UT--Continued

MONIHLY MEAN DISCHARGES, IN OUBIC FEET PER SECOND, FOR EACH WATER YEAR

\begin{tabular}{|c|c|c|c|c|c|c|c|c|c|c|c|c|}
\hline YEAR & OCT & $\mathrm{NON}$ & $\mathrm{DEC}$ & JAN & FEB & MAR & $\mathrm{AFR}$ & MAY & JUNE & JULY & AUG & SEP \\
\hline 1940 & 0.61 & 1.00 & 1.00 & 1.00 & 2.00 & 1.81 & 5.30 & 47.4 & 0.43 & 0.00 & 0.10 & 0.00 \\
\hline $\begin{array}{l}1941 \\
1942 \\
1943 \\
1944 \\
1945\end{array}$ & $\begin{array}{c}0.00 \\
56.4 \\
0.23 \\
3.70 \\
1.09\end{array}$ & $\begin{array}{c}6.40 \\
41.0 \\
12.8 \\
1.99 \\
7.08\end{array}$ & $\begin{array}{l}13.0 \\
30.0 \\
25.7 \\
14.7 \\
16.0\end{array}$ & $\begin{array}{l}14.0 \\
25.0 \\
22.0 \\
15.0 \\
16.0\end{array}$ & $\begin{array}{l}18.0 \\
23.7 \\
23.9 \\
14.0 \\
16.5\end{array}$ & $\begin{array}{l}7.94 \\
26.1 \\
18.3 \\
20.3 \\
11.4\end{array}$ & $\begin{array}{c}4.40 \\
85.4 \\
25.8 \\
18.2 \\
4.92\end{array}$ & $\begin{array}{c}123 \\
104 \\
11.0 \\
201 \\
51.9\end{array}$ & $\begin{array}{l}118 \\
111 \\
27.7 \\
200 \\
60.7\end{array}$ & $\begin{array}{c}0.52 \\
4.00 \\
0.00 \\
12.0 \\
0.36\end{array}$ & $\begin{array}{l}21.0 \\
0.42 \\
2.03 \\
0.53 \\
1.03\end{array}$ & $\begin{array}{c}21.9 \\
0.23 \\
1.87 \\
0.44 \\
1.00\end{array}$ \\
\hline $\begin{array}{l}1946 \\
1947 \\
1948 \\
1949 \\
1950\end{array}$ & $\begin{array}{r}5.29 \\
9.26 \\
2.95 \\
3.68 \\
12.8\end{array}$ & $\begin{array}{c}11.4 \\
13.7 \\
9.45 \\
5.03 \\
11.3\end{array}$ & $\begin{array}{l}14.4 \\
19.5 \\
15.8 \\
11.0 \\
14.6\end{array}$ & $\begin{array}{l}13.0 \\
20.0 \\
15.4 \\
14.0 \\
13.0\end{array}$ & $\begin{array}{l}12.3 \\
20.0 \\
18.2 \\
16.4 \\
11.0\end{array}$ & $\begin{array}{l}13.2 \\
20.7 \\
22.0 \\
22.5 \\
18.0\end{array}$ & $\begin{array}{l}24.1 \\
17.8 \\
20.0 \\
21.9 \\
62.9\end{array}$ & $\begin{array}{c}1.15 \\
154 \\
61.2 \\
118 \\
117\end{array}$ & $\begin{array}{c}0.44 \\
174 \\
28.8 \\
97.6 \\
113\end{array}$ & $\begin{array}{c}0.33 \\
26.7 \\
2.44 \\
0.93 \\
0.92\end{array}$ & $\begin{array}{c}1.28 \\
18.8 \\
2.29 \\
0.30 \\
0.58\end{array}$ & $\begin{array}{l}0.12 \\
3.58 \\
0.16 \\
1.48 \\
2.50\end{array}$ \\
\hline $\begin{array}{l}1951 \\
1952 \\
1953 \\
1954 \\
1955\end{array}$ & $\begin{array}{l}2.02 \\
3.73 \\
1.65 \\
0.89 \\
5.61\end{array}$ & $\begin{array}{c}9.00 \\
9.29 \\
7.62 \\
10.8 \\
2.82\end{array}$ & $\begin{array}{l}16.1 \\
15.4 \\
16.5 \\
14.5 \\
11.7\end{array}$ & $\begin{array}{l}14.0 \\
13.4 \\
16.7 \\
14.3 \\
13.0\end{array}$ & $\begin{array}{l}15.0 \\
14.0 \\
16.6 \\
10.3 \\
14.0\end{array}$ & $\begin{array}{c}10.4 \\
22.4 \\
20.0 \\
6.40 \\
18.8\end{array}$ & $\begin{array}{c}0.51 \\
98.9 \\
1.15 \\
3.19 \\
5.98\end{array}$ & $\begin{array}{c}43.9 \\
188 \\
16.4 \\
21.1 \\
5.52\end{array}$ & $\begin{array}{c}12.7 \\
92.1 \\
28.7 \\
1.03 \\
0.46\end{array}$ & $\begin{array}{l}0.26 \\
0.67 \\
0.40 \\
0.16 \\
0.30\end{array}$ & $\begin{array}{l}1.15 \\
0.56 \\
0.48 \\
0.19 \\
0.61\end{array}$ & $\begin{array}{l}1.05 \\
0.57 \\
0.61 \\
1.55 \\
0.27\end{array}$ \\
\hline $\begin{array}{l}1956 \\
1957 \\
1958 \\
1959 \\
1960\end{array}$ & $\begin{array}{l}0.34 \\
0.20 \\
4.05 \\
1.40 \\
4.79\end{array}$ & $\begin{array}{c}5.21 \\
3.81 \\
12.6 \\
2.39 \\
3.88\end{array}$ & $\begin{array}{c}11.6 \\
12.0 \\
12.5 \\
7.89 \\
9.35\end{array}$ & $\begin{array}{c}12.8 \\
12.0 \\
14.5 \\
9.40 \\
10.3\end{array}$ & $\begin{array}{c}12.6 \\
14.7 \\
17.3 \\
14.1 \\
9.76\end{array}$ & $\begin{array}{c}16.0 \\
12.1 \\
9.31 \\
3.95 \\
15.7\end{array}$ & $\begin{array}{l}0.50 \\
2.51 \\
7.04 \\
0.38 \\
3.12\end{array}$ & $\begin{array}{c}20.5 \\
8.08 \\
65.2 \\
0.67 \\
2.80\end{array}$ & $\begin{array}{c}0.27 \\
136 \\
22.5 \\
0.62 \\
0.72\end{array}$ & $\begin{array}{l}0.18 \\
4.21 \\
0.24 \\
0.16 \\
0.09\end{array}$ & $\begin{array}{l}0.09 \\
1.47 \\
0.15 \\
1.92 \\
5.84\end{array}$ & $\begin{array}{l}0.08 \\
0.38 \\
0.30 \\
4.85 \\
0.24\end{array}$ \\
\hline $\begin{array}{l}1961 \\
1962 \\
1963 \\
1964 \\
1965\end{array}$ & $\begin{array}{c}3.29 \\
18.7 \\
2.41 \\
0.37 \\
0.20\end{array}$ & $\begin{array}{c}4.21 \\
10.3 \\
3.23 \\
0.60 \\
4.81\end{array}$ & $\begin{array}{c}10.1 \\
11.7 \\
7.71 \\
10.0 \\
12.8\end{array}$ & $\begin{array}{l}15.0 \\
9.76 \\
12.4 \\
11.2 \\
13.4\end{array}$ & $\begin{array}{l}13.4 \\
38.2 \\
15.0 \\
12.0 \\
13.2\end{array}$ & $\begin{array}{c}4.14 \\
70.4 \\
4.03 \\
9.29 \\
14.2\end{array}$ & $\begin{array}{c}0.64 \\
113 \\
0.60 \\
1.46 \\
13.2\end{array}$ & $\begin{array}{c}6.51 \\
169 \\
1.93 \\
46.4 \\
48.0\end{array}$ & $\begin{array}{c}1.82 \\
69.6 \\
0.51 \\
32.1 \\
178\end{array}$ & $\begin{array}{c}0.19 \\
0.50 \\
0.28 \\
0.39 \\
15.0\end{array}$ & $\begin{array}{l}0.24 \\
0.21 \\
0.11 \\
0.58 \\
3.31\end{array}$ & $\begin{array}{c}11.8 \\
1.78 \\
0.22 \\
0.31 \\
10.5\end{array}$ \\
\hline
\end{tabular}

ANNUAL PEAK DISCHARGE, IN OUBIC FEET PER SECOND, AND CORRESPONDING GAGE HEIGHT, IN FEET, FOR EACH WATER YEAR

\begin{tabular}{|c|c|c|c|c|c|c|c|c|c|c|c|}
\hline $\begin{array}{l}\text { WATER } \\
\text { YEAR }\end{array}$ & DATE & $\begin{array}{c}\text { GAGE } \\
\text { HEIGHT }\end{array}$ & $\begin{array}{c}\text { PEAK } \\
\text { DISOHARGE }\end{array}$ & $\begin{array}{l}\text { WATER } \\
\text { YEAR }\end{array}$ & DATE & $\begin{array}{c}\text { GAGE } \\
\text { HEIGHT }\end{array}$ & $\begin{array}{c}\text { PEAK } \\
\text { DISCHARGE }\end{array}$ & $\begin{array}{l}\text { WATER } \\
\text { YEAR }\end{array}$ & DATE & $\begin{array}{c}\text { GAGE } \\
\text { HEIGHT }\end{array}$ & $\begin{array}{c}\text { PEAK } \\
\text { DISQHARGE }\end{array}$ \\
\hline $\begin{array}{l}1940 \\
1941 \\
1942 \\
1943 \\
1944 \\
1945 \\
1946 \\
1947 \\
1948\end{array}$ & $\begin{array}{lll}\text { MAY } & 25,1940 \\
\text { AUG. } 17,1941 \\
\text { JUNE } 01,1942 \\
\text { JUNE } 02,1943 \\
\text { MAY } 16,1944 \\
\text { MAY } & 06,1945 \\
\text { APR. } 27,1946 \\
\text { JUNE } 17,1947 \\
\text { JULY } 20,1948\end{array}$ & $\begin{array}{l}2.76 \\
5.50 \\
3.34 \\
3.30 \\
4.30 \\
2.40 \\
1.48 \\
2.60 \\
3.14\end{array}$ & $\begin{array}{r}125 \\
900 \\
212 \\
256 \\
680 \\
214 \\
75 \\
232 \\
194\end{array}$ & $\begin{array}{l}1949 \\
1950 \\
1951 \\
1952 \\
1953 \\
1954 \\
1955 \\
1956 \\
1957\end{array}$ & $\begin{array}{lll}\text { MAY } & 18,1949 \\
\text { OCT. } 19,1949 \\
\text { MAY } & 31,1951 \\
\text { MAY } & 03,1952 \\
\text { MAY } & 30,1953 \\
\text { SEPT. } 26,1954 \\
\text { OCT. } 08,1954 \\
\text { MAY } & 20,1956 \\
\text { JUNE } & 15,1957\end{array}$ & $\begin{array}{l}2.96 \\
3.89 \\
2.87 \\
3.71 \\
2.29 \\
2.32 \\
4.05 \\
2.61 \\
2.96\end{array}$ & $\begin{array}{r}212 \\
521 \\
156 \\
383 \\
96 \\
104 \\
762 \\
140 \\
240\end{array}$ & $\begin{array}{l}1958 \\
1959 \\
1960 \\
1961 \\
1962 \\
1963 \\
1964 \\
1965\end{array}$ & $\begin{array}{l}\text { MAY } 13,1958 \\
\text { SEPT. 16, } 1959 \\
\text { AJG. } 23,1960 \\
\text { SEPT.18, } 1961 \\
\text { MAR. 28, } 1962 \\
\text { MAR. 29, } 1963 \\
\text { MAY 26, } 1964 \\
\text { JUNE 11, } 1965\end{array}$ & $\begin{array}{l}2.57 \\
2.81 \\
4.88 \\
4.38 \\
4.25 \\
2.75 \\
2.37 \\
5.03\end{array}$ & $\begin{array}{l}158 \\
190 \\
603 \\
486 \\
478 \\
166 \\
132 \\
628\end{array}$ \\
\hline
\end{tabular}

\begin{tabular}{|c|c|c|c|c|c|c|}
\hline \multirow{3}{*}{$\begin{array}{l}\text { PERIOD } \\
\text { (CON- } \\
\text { SECU- } \\
\text { TIVE } \\
\text { DAYS) }\end{array}$} & \multicolumn{6}{|c|}{$\begin{array}{l}\text { E AND PROBABILITY OF ANNUAL LOWEST MEAN DISOHARGE } \\
\text { BASED ON CLIMATIC YEARS } 1941-65\end{array}$} \\
\hline & \multicolumn{6}{|c|}{$\begin{array}{l}\text { DISOHARGE, IN GUBIC FEET PER SECOND, FOR } \\
\text { INDICATED RECURRENCE INTERNAL, IN YEARS, AND } \\
\text { ANNUAL NONEXCEEDANCE PROBABILITY, IN PERCENT }\end{array}$} \\
\hline & $\begin{array}{c}2 \\
50 \%\end{array}$ & $\begin{array}{c}5 \\
208\end{array}$ & $\begin{array}{l}10 \\
108\end{array}$ & $\begin{array}{l}20 \\
58\end{array}$ & $\begin{array}{l}50 \\
28\end{array}$ & $\begin{array}{r}100 \\
18\end{array}$ \\
\hline $\begin{array}{r}1 \\
7 \\
14 \\
30 \\
60 \\
90\end{array}$ & $\begin{array}{l}0.09 \\
0.10 \\
0.12 \\
0.17 \\
0.27 \\
0.47\end{array}$ & $\begin{array}{l}0.00 \\
0.00 \\
0.02 \\
0.07 \\
0.13 \\
0.19\end{array}$ & $\begin{array}{l}0.00 \\
0.00 \\
0.00 \\
0.03 \\
0.10 \\
0.12\end{array}$ & $\begin{array}{l}0.00 \\
0.00 \\
0.00 \\
0.01 \\
0.08 \\
0.08\end{array}$ & $\begin{array}{l}0.0 \\
0.0 \\
0.0 \\
0.0 \\
0.0 \\
0.0\end{array}$ & $\begin{array}{l}-- \\
-- \\
-- \\
-- \\
--\end{array}$ \\
\hline
\end{tabular}

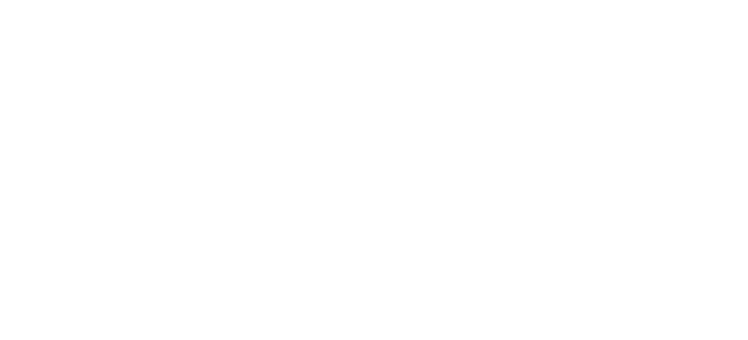


LOCATION.--Lat $40^{\circ} 18^{\prime} 00^{\prime \prime}$, Iong $109^{\circ} 08^{\prime} 00^{\prime \prime}$, in $\mathrm{NW}^{\frac{1}{4}} \mathrm{sec} .20$, T.6 S., R.25 E., Uintah County, Hydrologic Unit 14060001 , about 0.7 mi. north on Harper road and $13 \mathrm{mi}$ east from Jensen bridge.

DRAINAGE AREA. $-64 \mathrm{mi}^{2}$.

MEAN BASIN ELEVATION. $-6,570 \mathrm{ft}$.

PERIOD OF RECORD AVAILABLE. - Water years 1960-1974, annual peak discharge only.

GAGE.--Crest-stage gage. Altitude of gage is 5,270 ft from topographic map.

REMARRS.-Several small storage reservoirs above station. Diversions for irrigation above station.

ANNUAL PEAK DISCHARGE, IN OUBIC FEET PER SECOND, AND CORRESPONDING GAGE HEIGHT, IN FEET, FOR EACH WATER YEAR

\begin{tabular}{|c|c|c|c|c|c|c|c|c|c|c|c|}
\hline $\begin{array}{l}\text { WATERR } \\
\text { YEAR }\end{array}$ & DATE & $\begin{array}{l}\text { GAGE } \\
\text { HEIGHT }\end{array}$ & $\begin{array}{c}\text { PEAK } \\
\text { DISCHARGE }\end{array}$ & $\begin{array}{l}\text { WATERR } \\
\text { YEAR }\end{array}$ & DATE & $\begin{array}{l}\text { GAGE } \\
\text { HEIGHT }\end{array}$ & $\begin{array}{c}\text { PEAK } \\
\text { DISCHARGE }\end{array}$ & $\begin{array}{l}\text { WATER } \\
\text { YEAR }\end{array}$ & DATE & $\begin{array}{l}\text { GAGE } \\
\text { HEIGHT }\end{array}$ & $\begin{array}{c}\text { PEAK } \\
\text { DISCHARGE }\end{array}$ \\
\hline $\begin{array}{l}1960 \\
1961 \\
1962 \\
1963 \\
1964\end{array}$ & $\begin{array}{l}\text { AUG. 23, } 1960 \\
\text { SEPT.23, } 1961 \\
\text { OCT. 08, } 1961 \\
\text { AUG. 24, } 1963 \\
\text { SEPT.05, } 1964\end{array}$ & $\begin{array}{l}10.92 \\
14.12 \\
12.52 \\
14.88 \\
14.28\end{array}$ & $\begin{array}{r}30 \\
737 \\
550 \\
1360 \\
1150\end{array}$ & $\begin{array}{l}1965 \\
1966 \\
1967 \\
1968 \\
1969\end{array}$ & 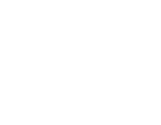 & $\begin{array}{c}11.11 \\
11.45 \\
9.30 \\
- \\
10.26\end{array}$ & $\begin{array}{l}350 \\
410 \\
5.5 \\
0 \\
59\end{array}$ & $\begin{array}{l}1970 \\
1971 \\
1972 \\
1973 \\
1974\end{array}$ & $\begin{array}{l}\text { OCT. } 18,1969 \\
\text { MAR. 26, } 1971 \\
\text { JUNE 05, } 1972 \\
\text { JULY 20, } 1973 \\
\end{array}$ & $\begin{array}{r}10.10 \\
10.60 \\
14.45 \\
9.47 \\
12.10\end{array}$ & $\begin{array}{r}46 \\
90 \\
1330 \\
13 \\
360\end{array}$ \\
\hline
\end{tabular}

09263800 COW WASH NEAR JENSEN, UT

LOCATION.-Lat $40^{\circ} 18^{\prime} 30^{\prime \prime}$, long $109^{\circ} 13^{\prime} 00^{\prime \prime}$, in NE $\frac{1}{4}$ sec.16, T.6 S., R.24 E., Uintah County, Hydrologic Unit 14060001, on U.S.

Highway $40,7.8 \mathrm{mi}$ east of Jensen bridge.

DRAINAGE AREA. $-3.9 \mathrm{mi}^{2}$.

MEAN BASIN ELEVATION. $-5,360 \mathrm{ft}$.

PERIOD OF RECORD AVAIIABLE.-Water years 1960-1971, 1973-74, annual peak discharge only.

GAGE.--Crest-stage gage. Altitude of gage is 5,110 ft fram topographic map.

REMARKS.-One small tributary storage reservoir above station.

ANNUAL PEAK DISCHARGE, IN CUBIC FEET PER SECOND, AND CORRESPONDING GAGE HEIGHT, IN FEET, FOR EACH WATER YEAR

\begin{tabular}{|c|c|c|c|c|c|c|c|c|c|c|c|}
\hline $\begin{array}{l}\text { WATERR } \\
\text { YEAR }\end{array}$ & DATE & $\begin{array}{c}\text { GAGE } \\
\text { HEIGHT }\end{array}$ & $\begin{array}{c}\text { PEAR } \\
\text { DISCHARGE }\end{array}$ & $\begin{array}{l}\text { WATER } \\
\text { YEAR }\end{array}$ & DATE & $\begin{array}{c}\text { GAGE } \\
\text { HEIGHT }\end{array}$ & $\begin{array}{c}\text { PEAK } \\
\text { DISCHARGE }\end{array}$ & $\begin{array}{l}\text { WATER } \\
\text { YEAR }\end{array}$ & DATE & $\begin{array}{c}\text { GAGE } \\
\text { HEIGHT }\end{array}$ & $\begin{array}{c}\text { PEAK } \\
\text { DISCHARGE }\end{array}$ \\
\hline $\begin{array}{l}1960 \\
1961 \\
1962 \\
1963 \\
1964\end{array}$ & $\begin{array}{l}\text { SEPT.16, } 1960 \\
\text { SEPT.09, } 1961 \\
\text { OCT. 08, } 1961 \\
\text { SEPT.20, } 1963 \\
\text { JUL 14, } 1964\end{array}$ & $\begin{array}{l}11.80 \\
13.83 \\
12.15 \\
14.25 \\
13.95\end{array}$ & $\begin{array}{r}200 \\
830 \\
250 \\
1060 \\
900\end{array}$ & $\begin{array}{l}1965 \\
1966 \\
1967 \\
1968 \\
1969\end{array}$ & $\begin{array}{l}\text { JULY } 18,1965 \\
\text { JULY } 18,1966 \\
\text { JULY } 16,1967 \\
\text { SEPT.15， } 1968 \\
\text { JUNE } 17,1969\end{array}$ & $\begin{array}{l}10.54 \\
18.85 \\
12.33 \\
11.80 \\
11.10\end{array}$ & $\begin{array}{r}38 \\
2950 \\
340 \\
230 \\
108\end{array}$ & $\begin{array}{l}1970 \\
1971 \\
1973 \\
1974\end{array}$ & $\begin{array}{l}\text { OCT. } 18,1969 \\
\text { JUNE 11, } 1971 \\
\text { AUG. } 21,1973 \\
-\quad-\end{array}$ & $\begin{array}{l}12.75 \\
11.69 \\
10.39 \\
11.87\end{array}$ & $\begin{array}{r}425 \\
188 \\
46 \\
220\end{array}$ \\
\hline
\end{tabular}

09264000 ASHLEY CREEK BELON TROUT CREEK, NEAR VERNAL, UT

LOCATION.--Lat $40^{\circ} 44^{\prime} 00^{\prime \prime}$, Iong $109^{\circ} 40^{\prime} 40^{\prime \prime}$, in NE' sec.16, T.I S., R.20 E., Uintah County, Hydrologic Unit 14060002 , on right bank

$1,000 \mathrm{ft}$ downstream from Trout Creek, $3 \mathrm{mi}$ upstream from South Fork, and $21 \mathrm{mi}$ northwest of Vernal.

DRAINAGE AREA. $--27 \mathrm{mi}^{2}$, approximately.

MEAN BASIN ELEVATION. $--9,930 \mathrm{ft}$.

PERIOD OF RECORD AVAIIABLE.--October 1943 to September 1954.

GAGE.-Water-stage recorder. Altitude of gage is 9,200 ft from topographic map.

AVERAGE DISCHARGE.--II years, $24.1 \mathrm{ft}^{3} / \mathrm{s}, 17,450 \mathrm{acre}-\mathrm{ft} / \mathrm{yr}$.

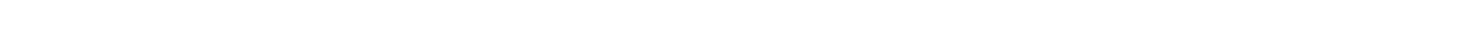

24, 1950 (discharge measurement), but may have been less during periods of ice effect or no gage-height record. 
LOWEST MEAN DISCHARGE, IN CUBIC FEET PER SECOND, AND RANKING FOR THE INDICATED NUMBER OF CONSECUTTVE DAYS FOR EAOH CLIMATIC YEAR, APRII 1-MARCH 31

\begin{tabular}{|c|c|c|c|c|c|c|c|c|c|c|c|c|c|c|c|c|c|c|c|c|}
\hline YEAR & & & & & & & & & CONSE & QuTt & DAYS & & & & & & & & & \\
\hline & 1 & & 3 & & 7 & & 14 & & 30 & & 60 & & 90 & & 120 & & 183 & & ALL & \\
\hline 1945 & 1.00 & 1 & 1.00 & 1 & 1.00 & 1 & 1.00 & 1 & 1.00 & 1 & 1.00 & 1 & 1.00 & 1 & 1.10 & 1 & 1.40 & 1 & 36.0 & 9 \\
\hline
\end{tabular}

HIGHEST MEAN DISCHARGE, IN OBIC FEET PER SECOND, AND RANKING FOR THE INDICATED NUMBER OF CONSEOUTIVE DAYS FOR EACH WATER YEAR, OCTCBER 1-SEPTENBER 30

\begin{tabular}{|c|c|c|c|c|c|c|c|c|c|c|c|c|c|c|c|c|c|c|c|}
\hline YEAR & 1 & & 3 & & 7 & & 15 & & $\begin{array}{l}\text { CONS } \\
30\end{array}$ & EOT' & $\begin{array}{c}\text { VE DAYS } \\
60\end{array}$ & & 90 & & 120 & & 183 & & ALL \\
\hline $\begin{array}{l}1944 \\
1945\end{array}$ & $\begin{array}{l}412 \\
198\end{array}$ & $\begin{array}{l}1 \\
9\end{array}$ & $\begin{array}{l}396 \\
181\end{array}$ & $\begin{array}{l}1 \\
9\end{array}$ & $\begin{array}{l}338 \\
147\end{array}$ & $\begin{array}{r}1 \\
10\end{array}$ & $\begin{array}{l}311 \\
135\end{array}$ & $\begin{array}{r}1 \\
10\end{array}$ & $\begin{array}{l}281 \\
121\end{array}$ & $\begin{array}{l}1 \\
8\end{array}$ & $\begin{array}{r}197 \\
90.0\end{array}$ & $\begin{array}{l}1 \\
7\end{array}$ & $\begin{array}{l}140 \\
65.0\end{array}$ & $\begin{array}{l}1 \\
7\end{array}$ & $\begin{array}{l}107 \\
51.0\end{array}$ & $\begin{array}{l}1 \\
7\end{array}$ & $\begin{array}{l}71.0 \\
35.0\end{array}$ & $\begin{array}{l}1 \\
7\end{array}$ & $\begin{array}{l}36.0 \\
18.0\end{array}$ \\
\hline $\begin{array}{l}946 \\
947 \\
948 \\
949 \\
950\end{array}$ & $\begin{array}{l}110 \\
405 \\
393 \\
317 \\
358\end{array}$ & $\begin{array}{r}11 \\
2 \\
3 \\
6 \\
4\end{array}$ & $\begin{array}{l}110 \\
360 \\
360 \\
294 \\
342\end{array}$ & $\begin{array}{r}11 \\
2 \\
3 \\
6 \\
4\end{array}$ & $\begin{array}{l}97.0 \\
293 \\
329 \\
270 \\
275\end{array}$ & $\begin{array}{r}11 \\
4 \\
2 \\
6 \\
5\end{array}$ & $\begin{array}{l}79.0 \\
238 \\
288 \\
221 \\
240\end{array}$ & $\begin{array}{r}11 \\
5 \\
2 \\
6 \\
4\end{array}$ & $\begin{array}{l}61.0 \\
216 \\
200 \\
209 \\
197\end{array}$ & $\begin{array}{r}11 \\
2 \\
5 \\
3 \\
6\end{array}$ & $\begin{array}{l}45.0 \\
165 \\
113 \\
150 \\
124\end{array}$ & $\begin{array}{r}11 \\
3 \\
6 \\
4 \\
5\end{array}$ & $\begin{array}{c}34.0 \\
122 \\
79.0 \\
111 \\
91.0\end{array}$ & $\begin{array}{r}11 \\
3 \\
6 \\
4 \\
5\end{array}$ & $\begin{array}{l}28.0 \\
96.0 \\
61.0 \\
88.0 \\
70.0\end{array}$ & $\begin{array}{r}11 \\
3 \\
6 \\
4 \\
5\end{array}$ & $\begin{array}{l}20.0 \\
65.0 \\
41.0 \\
59.0 \\
48.0\end{array}$ & $\begin{array}{r}11 \\
3 \\
6 \\
4 \\
5\end{array}$ & $\begin{array}{l}11.0 \\
34.0 \\
22.0 \\
31.0 \\
25.0\end{array}$ \\
\hline $\begin{array}{l}1951 \\
1952 \\
1953 \\
1954\end{array}$ & $\begin{array}{l}222 \\
354 \\
226 \\
196\end{array}$ & $\begin{array}{r}8 \\
5 \\
7 \\
10\end{array}$ & $\begin{array}{l}201 \\
338 \\
220 \\
175\end{array}$ & $\begin{array}{r}8 \\
5 \\
7 \\
10\end{array}$ & $\begin{array}{l}195 \\
309 \\
195 \\
163\end{array}$ & $\begin{array}{l}7 \\
3 \\
8 \\
9\end{array}$ & $\begin{array}{l}168 \\
267 \\
170 \\
147\end{array}$ & $\begin{array}{l}8 \\
3 \\
7 \\
9\end{array}$ & $\begin{array}{l}121 \\
209 \\
128 \\
108\end{array}$ & $\begin{array}{r}9 \\
4 \\
7 \\
10\end{array}$ & $\begin{array}{r}75.0 \\
166 \\
76.0 \\
71.0\end{array}$ & $\begin{array}{r}9 \\
2 \\
8 \\
10\end{array}$ & $\begin{array}{r}57.0 \\
123 \\
57.0 \\
51.0\end{array}$ & $\begin{array}{r}8 \\
2 \\
9 \\
10\end{array}$ & $\begin{array}{r}46.0 \\
102 \\
44.0 \\
41.0\end{array}$ & $\begin{array}{r}8 \\
2 \\
9 \\
10\end{array}$ & $\begin{array}{l}32.0 \\
71.0 \\
30.0 \\
28.0\end{array}$ & $\begin{array}{r}8 \\
2 \\
9 \\
10\end{array}$ & $\begin{array}{l}17.0 \\
38.0 \\
17.0 \\
15.0\end{array}$ \\
\hline
\end{tabular}

DURATION OF DISCHARGE FOR EACH WATER YEAR

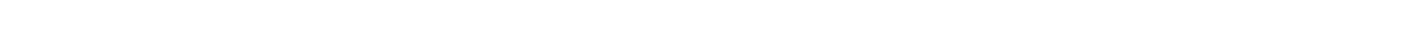
YEAR NUMBER OF DAYS IN CLASS

ABIC FEET PER SECOND -DAYS

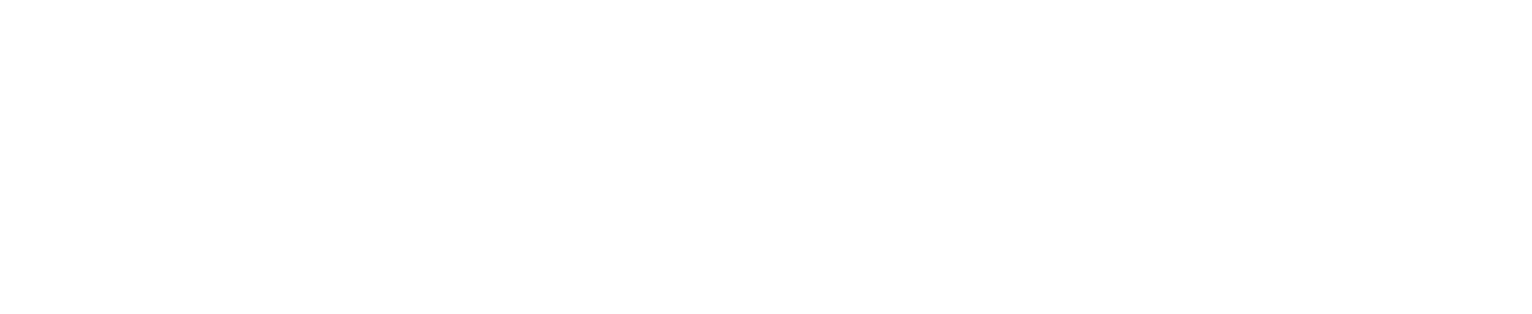

DURATION TABLE OF DISGHARGE FOR WATER YEARS 1944-54

\begin{tabular}{|c|c|c|c|c|c|c|c|c|c|c|c|c|c|c|c|c|c|c|c|}
\hline CLASS & $\begin{array}{c}\text { CBIC } \\
\text { FEET } \\
\text { PER } \\
\text { SEOOND }\end{array}$ & $\begin{array}{l}\text { TOTAE } \\
\text { DAYS }\end{array}$ & $\begin{array}{c}\text { ACQU- } \\
\text { MU- } \\
\text { LATED } \\
\text { DAYS }\end{array}$ & $\begin{array}{l}\text { PER- } \\
\text { CENT } \\
\text { DAYS }\end{array}$ & CLASS & $\begin{array}{c}\text { CBIIC } \\
\text { FEET } \\
\text { PER } \\
\text { SECOND }\end{array}$ & $\begin{array}{l}\text { TOTAL } \\
\text { DAYS }\end{array}$ & $\begin{array}{c}\text { ACOU- } \\
\text { MU- } \\
\text { LATED } \\
\text { DAYS }\end{array}$ & $\begin{array}{l}\text { PER- } \\
\text { CENT } \\
\text { DAYS }\end{array}$ & & $\begin{array}{c}\text { QUBIC } \\
\text { FEET } \\
\text { PER } \\
\text { SECOND }\end{array}$ & $\begin{array}{l}\text { TOTAL } \\
\text { DAYS }\end{array}$ & $\begin{array}{l}\text { ACOU- } \\
\text { MU- } \\
\text { LATED } \\
\text { DAYS }\end{array}$ & $\begin{array}{l}\text { PER- } \\
\text { CENT } \\
\text { DAYS }\end{array}$ & CLASS & $\begin{array}{c}\text { CUBIC } \\
\text { FEET } \\
\text { PER } \\
\text { SECOND }\end{array}$ & $\begin{array}{l}\text { TOTAL } \\
\text { DAYS }\end{array}$ & $\begin{array}{c}\text { ACOU- } \\
\text { MU- } \\
\text { LATED } \\
\text { DAYS }\end{array}$ & $\begin{array}{l}\text { PER- } \\
\text { CENT } \\
\text { DAYS }\end{array}$ \\
\hline $\begin{array}{l}0 \\
1 \\
2 \\
3 \\
4 \\
5 \\
6 \\
7 \\
8\end{array}$ & $\begin{array}{l}0.00 \\
1.00 \\
1.20 \\
1.40 \\
1.70 \\
2.10 \\
2.50 \\
3.00 \\
3.60\end{array}$ & $\begin{array}{r}0 \\
175 \\
62 \\
285 \\
314 \\
304 \\
473 \\
375 \\
230\end{array}$ & $\begin{array}{l}4018 \\
4018 \\
3843 \\
3781 \\
3496 \\
3182 \\
2878 \\
2405 \\
2030\end{array}$ & $\begin{array}{r}100.0 \\
100.0 \\
95.6 \\
94.1 \\
87.0 \\
79.2 \\
71.6 \\
59.9 \\
50.5\end{array}$ & $\begin{array}{r}9 \\
10 \\
11 \\
12 \\
13 \\
14 \\
15 \\
16 \\
17\end{array}$ & $\begin{array}{r}4.30 \\
5.10 \\
6.20 \\
7.40 \\
8.90 \\
11.00 \\
13.00 \\
15.00 \\
18.00\end{array}$ & $\begin{array}{r}179 \\
185 \\
126 \\
83 \\
113 \\
57 \\
68 \\
68 \\
101\end{array}$ & $\begin{array}{c}1800 \\
1621 \\
1436 \\
1310 \\
1227 \\
1114 \\
1057 \\
989 \\
921\end{array}$ & $\begin{array}{l}44.8 \\
40.3 \\
35.7 \\
32.6 \\
30.5 \\
27.7 \\
26.3 \\
24.6 \\
22.9\end{array}$ & $\begin{array}{l}18 \\
19 \\
20 \\
21 \\
22 \\
23 \\
24 \\
25 \\
26\end{array}$ & $\begin{array}{l}22.0 \\
26.0 \\
32.0 \\
38.0 \\
46.0 \\
55.0 \\
66.0 \\
79.0 \\
94.0\end{array}$ & $\begin{array}{l}85 \\
81 \\
82 \\
80 \\
41 \\
47 \\
41 \\
40 \\
31\end{array}$ & $\begin{array}{l}820 \\
735 \\
654 \\
572 \\
492 \\
451 \\
404 \\
363 \\
323\end{array}$ & $\begin{array}{r}20.4 \\
18.3 \\
16.3 \\
14.2 \\
12.2 \\
11.2 \\
10.1 \\
9.0 \\
8.0\end{array}$ & $\begin{array}{l}27 \\
28 \\
29 \\
30 \\
31 \\
32 \\
33 \\
34\end{array}$ & $\begin{array}{l}110.0 \\
140.0 \\
160.0 \\
200.0 \\
230.0 \\
280.0 \\
340.0 \\
410.0\end{array}$ & $\begin{array}{r}62 \\
43 \\
66 \\
37 \\
47 \\
28 \\
8 \\
1\end{array}$ & $\begin{array}{r}292 \\
230 \\
187 \\
-121 \\
84 \\
37 \\
9 \\
1\end{array}$ & $\begin{array}{l}7.3 \\
5.7 \\
4.7 \\
3.0 \\
2.1 \\
0.9 \\
0.2 \\
0.0\end{array}$ \\
\hline
\end{tabular}


MONTHLY MEAN DISCHARGES, IN OUBIC FEET PER SECOND, FOR EACH WATER YEAR

\begin{tabular}{|c|c|c|c|c|c|c|c|c|c|c|c|c|}
\hline YEAR & $\infty \mathrm{OT}$ & NOW & DEC & JAN & FEB & MAR & APR & MAY & JUNE & JULY & AUG & SEP \\
\hline $\begin{array}{l}1944 \\
1945\end{array}$ & $\begin{array}{l}3.03 \\
2.61\end{array}$ & $\begin{array}{l}2.00 \\
1.40\end{array}$ & $\begin{array}{l}2.00 \\
1.20\end{array}$ & $\begin{array}{l}1.50 \\
1.10\end{array}$ & $\begin{array}{l}1.50 \\
1.00\end{array}$ & $\begin{array}{l}1.00 \\
1.00\end{array}$ & $\begin{array}{l}2.00 \\
1.50\end{array}$ & $\begin{array}{c}129 \\
88.8\end{array}$ & $\begin{array}{l}243 \\
84.6\end{array}$ & $\begin{array}{l}38.4 \\
18.6\end{array}$ & $\begin{array}{c}11.7 \\
8.84\end{array}$ & $\begin{array}{l}3.42 \\
7.54\end{array}$ \\
\hline $\begin{array}{l}1946 \\
1947 \\
1948 \\
1949 \\
1950\end{array}$ & $\begin{array}{l}7.16 \\
4.68 \\
4.74 \\
2.48 \\
5.20\end{array}$ & $\begin{array}{l}2.60 \\
3.70 \\
4.17 \\
2.20 \\
4.40\end{array}$ & $\begin{array}{l}1.70 \\
3.19 \\
3.59 \\
1.90 \\
2.74\end{array}$ & $\begin{array}{l}1.50 \\
2.50 \\
3.00 \\
1.24 \\
2.00\end{array}$ & $\begin{array}{l}1.40 \\
2.00 \\
2.50 \\
1.00 \\
1.50\end{array}$ & $\begin{array}{l}1.30 \\
2.00 \\
2.50 \\
1.34 \\
2.00\end{array}$ & $\begin{array}{c}27.5 \\
5.83 \\
3.18 \\
18.8 \\
3.46\end{array}$ & $\begin{array}{c}45.3 \\
206 \\
153 \\
141 \\
97.3\end{array}$ & $\begin{array}{c}21.6 \\
118 \\
64.2 \\
156 \\
136\end{array}$ & $\begin{array}{l}13.5 \\
35.9 \\
15.0 \\
26.0 \\
34.1\end{array}$ & $\begin{array}{c}6.67 \\
14.7 \\
5.44 \\
9.97 \\
9.71\end{array}$ & $\begin{array}{l}3.83 \\
6.34 \\
2.62 \\
4.09 \\
6.11\end{array}$ \\
\hline $\begin{array}{l}1951 \\
1952 \\
1953 \\
1954\end{array}$ & $\begin{array}{l}4.09 \\
5.57 \\
5.48 \\
2.45\end{array}$ & $\begin{array}{l}3.13 \\
4.68 \\
2.93 \\
2.60\end{array}$ & $\begin{array}{l}2.80 \\
4.00 \\
2.60 \\
2.60\end{array}$ & $\begin{array}{l}2.50 \\
3.35 \\
2.50 \\
2.50\end{array}$ & $\begin{array}{l}2.30 \\
3.20 \\
2.40 \\
2.40\end{array}$ & $\begin{array}{l}2.10 \\
3.00 \\
2.30 \\
2.30\end{array}$ & $\begin{array}{c}2.40 \\
35.5 \\
2.75 \\
12.0\end{array}$ & $\begin{array}{c}77.4 \\
179 \\
44.8 \\
106\end{array}$ & $\begin{array}{c}66.0 \\
139 \\
105 \\
29.3\end{array}$ & $\begin{array}{c}20.5 \\
29.3 \\
18.9 \\
9.85\end{array}$ & $\begin{array}{c}15.4 \\
32.4 \\
6.94 \\
4.94\end{array}$ & $\begin{array}{c}8.48 \\
11.4 \\
3.38 \\
3.72\end{array}$ \\
\hline
\end{tabular}

ANNUAL PEAK DISCHARGE, IN CUBIC FEET PER SECOND, AND CORRESPONDING GAGE HEIGHT, IN FEET, FOR EACH WATER YEAR

\begin{tabular}{|c|c|c|c|c|c|c|c|c|c|c|c|}
\hline $\begin{array}{l}\text { WATER } \\
\text { YEAR }\end{array}$ & DATE & $\begin{array}{c}\text { GAGE } \\
\text { HEIGHT }\end{array}$ & $\begin{array}{c}\text { PEAK } \\
\text { DISCHARGE }\end{array}$ & $\begin{array}{l}\text { WATER } \\
\text { YEAR }\end{array}$ & DATE & $\begin{array}{c}\text { GAGE } \\
\text { HEIGHT }\end{array}$ & $\begin{array}{c}\text { PEAK } \\
\text { DISCHARGE }\end{array}$ & $\begin{array}{l}\text { WATER } \\
\text { YEAR }\end{array}$ & DATE & $\begin{array}{c}\text { GAGE } \\
\text { HEIGHT }\end{array}$ & $\begin{array}{c}\text { PEAK } \\
\text { DISAHARGE }\end{array}$ \\
\hline $\begin{array}{l}1944 \\
1945 \\
1946 \\
1947\end{array}$ & $\begin{array}{lll}\text { MAY } & 30,1944 \\
\text { JUNE } & 04,1945 \\
\text { APR. } & 24,1946 \\
\text { MAY } & 08,1947\end{array}$ & $\begin{array}{c}3.68 \\
3.34 \\
- \\
3.64\end{array}$ & $\begin{array}{l}432 \\
279 \\
112 \\
601\end{array}$ & $\begin{array}{l}1948 \\
1949 \\
1950 \\
1951\end{array}$ & $\begin{array}{lll}\text { MAY } & 19,1948 \\
\text { JUNE } & 08,1949 \\
\text { MAY } & 30,1950 \\
\text { MAY } & 27,1951\end{array}$ & $\begin{array}{l}3.67 \\
3.48 \\
3.58 \\
-\end{array}$ & $\begin{array}{l}630 \\
478 \\
558 \\
500\end{array}$ & $\begin{array}{l}1952 \\
1953 \\
1954\end{array}$ & 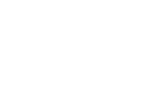 & $\begin{array}{l}3.52 \\
3.12 \\
3.14\end{array}$ & $\begin{array}{l}518 \\
308 \\
315\end{array}$ \\
\hline
\end{tabular}

MAGNITUDE AND PROBABILITY OF ANNUAL HIGHEST MEAN DISGHARGE BASED ON WATER YEARS $1944-54$

\begin{tabular}{|c|c|c|c|c|c|c|}
\hline \multirow{2}{*}{$\begin{array}{l}\text { PERIOD } \\
\text { (CON- } \\
\text { SEQU- } \\
\text { TIVE } \\
\text { DAYS) }\end{array}$} & \multicolumn{6}{|c|}{$\begin{array}{l}\text { DISGAARE, IN OUIC FEET PER SECOND, FOR } \\
\text { INDICATED REOURRENCE INTERNAL, IN YEARS, AND } \\
\text { ANNUAL EXCEEDANCE PRCBABILITY, IN PERCENT }\end{array}$} \\
\hline & $\begin{array}{c}2 \\
508\end{array}$ & $\begin{array}{c}5 \\
208\end{array}$ & $\begin{array}{l}10 \\
108\end{array}$ & $\begin{array}{l}25 \\
48\end{array}$ & $\begin{array}{l}50 \\
28\end{array}$ & $\begin{array}{r}100 \\
18\end{array}$ \\
\hline $\begin{array}{r}1 \\
3 \\
7 \\
15\end{array}$ & $\begin{array}{l}289 \\
267 \\
236 \\
206\end{array}$ & $\begin{array}{l}386 \\
358 \\
313 \\
272\end{array}$ & $\begin{array}{l}434 \\
406 \\
351 \\
304\end{array}$ & $\overline{-}$ & $\begin{array}{l}\overline{-} \\
\overline{-}\end{array}$ & $\begin{array}{l}-- \\
-- \\
--\end{array}$ \\
\hline
\end{tabular}

09264500 SOUTH FORK ASHLEY CREEK NEAR VERNAL, UT

LOCATION.-Lat $40^{\circ} 44^{\prime} 00^{\prime \prime}$, long $109^{\circ} 42^{\prime} 10^{\prime \prime}$, in NE $\mathrm{N}^{\frac{1}{4}}$ sec.17, T.1 S., R.20 E., Uintah County, Hydrologic Unit 14060002 , on right bank at lower end of Hicks Park, $3.25 \mathrm{mi}$ upstream from mouth, and $21 \mathrm{mi}$ southwest of Vernal.

DRAINAGE AREA. $-20 \mathrm{mi}^{2}$, approximately.

MEAN BASTN ELEVATION. $--10,480 \mathrm{ft}$.

PERIOD OF RECORD AVAILABLE.--October 1943 to September 1955.

GAGE.--Water-stage recorder. Altitude of gage is $9,360 \mathrm{ft}$ by barcmeter.

AVERAGE DISOHARGE.--12 years, $19.9 \mathrm{ft}^{3} / \mathrm{s}, 14,410$ acre-ft/yr.

EXTREMES FOR PERIOD OF RECORD.--Maximum discharge, $460 \mathrm{ft}^{3} / \mathrm{s}$ June 18,1949 , gage height, $3.84 \mathrm{ft}$ minimum observed, $0.8 \mathrm{ft}^{3} / \mathrm{s}$ Feb.

23, 1950 (discharge measurement), but may have been less during periods of ice effect or no gage-height record.

LOWEST MEAN DISGHARGE, IN OUBIC FEET PER SECOND, AND RANKING FOR THE INDICATED NUMBER OF CONSEOUTIVE DAYS FOR EACH OLIMATIC YEAR, APRIL 1-MARQ 31

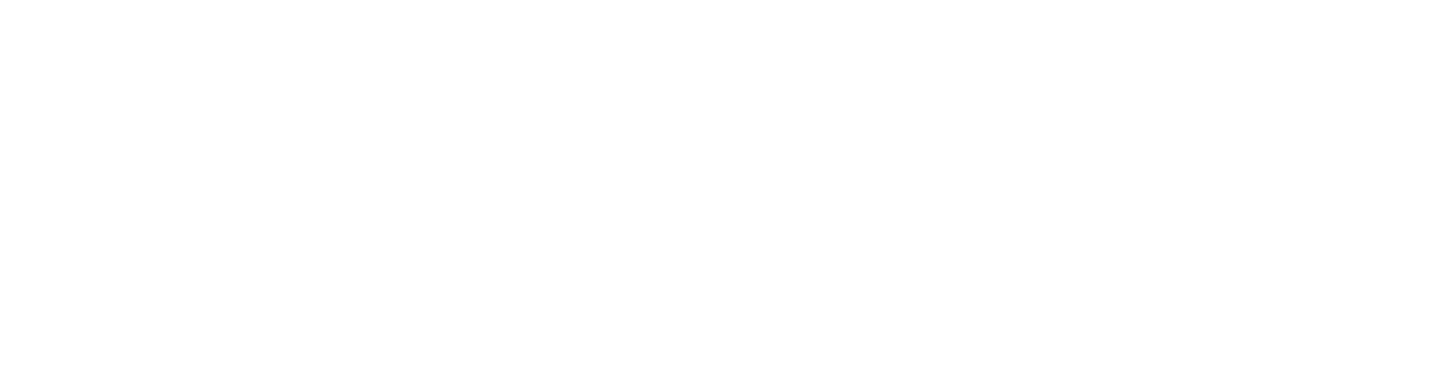


GREEN RIVER BASIN

09264500 SOUTH FORR ASHLEY CREEK NEAR VERNAL, UI--Continued

HIGHEST MEAN DISCHARGE, IN CUBIC FEET PER SECOND, AND RANKING FOR THE INDICATED NUMBER OF CONSECUTIVE DAYS FOR EAG WATER YEAR, OCTCBER I-SEPTEMBER 30

\begin{tabular}{|c|c|c|c|c|c|c|c|c|c|c|c|c|c|c|c|c|c|c|c|c|}
\hline YEAR & 1 & & 3 & & 7 & & 15 & & $\begin{array}{l}\text { CON } \\
30\end{array}$ & & $\begin{array}{c}\text { JE DAY } \\
60\end{array}$ & & 90 & & 120 & & 183 & & ALL & \\
\hline $\begin{array}{l}1944 \\
1945\end{array}$ & $\begin{array}{l}245 \\
124\end{array}$ & $\begin{array}{r}7 \\
10\end{array}$ & $\begin{array}{l}228 \\
112\end{array}$ & $\begin{array}{r}7 \\
10\end{array}$ & $\begin{array}{l}207 \\
92.0\end{array}$ & $\begin{array}{r}5 \\
11\end{array}$ & $\begin{array}{l}191 \\
83.0\end{array}$ & $\begin{array}{r}3 \\
11\end{array}$ & $\begin{array}{l}182 \\
79.0\end{array}$ & $\begin{array}{r}1 \\
10\end{array}$ & $\begin{array}{l}141 \\
70.0\end{array}$ & $\begin{array}{l}1 \\
9\end{array}$ & $\begin{array}{l}103 \\
57.0\end{array}$ & $\begin{array}{l}1 \\
7\end{array}$ & $\begin{array}{l}80.0 \\
46.0\end{array}$ & $\begin{array}{l}1 \\
7\end{array}$ & $\begin{array}{l}54.0 \\
32.0\end{array}$ & $\begin{array}{l}2 \\
7\end{array}$ & $\begin{array}{l}28.0 \\
17.0\end{array}$ & $\begin{array}{l}3 \\
7\end{array}$ \\
\hline $\begin{array}{l}1946 \\
1947 \\
1948 \\
1949 \\
1950\end{array}$ & $\begin{array}{l}80.0 \\
240 \\
248 \\
274 \\
264\end{array}$ & $\begin{array}{r}12 \\
8 \\
6 \\
3 \\
4\end{array}$ & $\begin{array}{l}65.0 \\
213 \\
233 \\
246 \\
253\end{array}$ & $\begin{array}{r}12 \\
8 \\
5 \\
4 \\
3\end{array}$ & $\begin{array}{l}56.0 \\
181 \\
208 \\
219 \\
206\end{array}$ & $\begin{array}{r}12 \\
8 \\
4 \\
3 \\
6\end{array}$ & $\begin{array}{l}44.0 \\
147 \\
181 \\
197 \\
184\end{array}$ & $\begin{array}{r}12 \\
8 \\
5 \\
2 \\
4\end{array}$ & $\begin{array}{l}37.0 \\
141 \\
138 \\
159 \\
160\end{array}$ & $\begin{array}{r}12 \\
5 \\
6 \\
3 \\
2\end{array}$ & $\begin{array}{l}33.0 \\
122 \\
80.0 \\
112 \\
115\end{array}$ & $\begin{array}{r}12 \\
2 \\
7 \\
5 \\
4\end{array}$ & & $\begin{array}{r}12 \\
2 \\
8 \\
4 \\
5\end{array}$ & $\begin{array}{l}20.0 \\
76.0 \\
44.0 \\
67.0\end{array}$ & $\begin{array}{r}12 \\
3 \\
8 \\
4 \\
5\end{array}$ & $\begin{array}{l}15.0 \\
53.0 \\
30.0 \\
46.0 \\
45.0\end{array}$ & $\begin{array}{r}12 \\
3 \\
8 \\
4 \\
5\end{array}$ & $\begin{array}{c}9.10 \\
29.0 \\
17.0 \\
24.0 \\
24.0\end{array}$ & $\begin{array}{r}12 \\
2 \\
8 \\
4\end{array}$ \\
\hline
\end{tabular}

DURATION OF DISCHARGE FOR EACH WATER YEAR

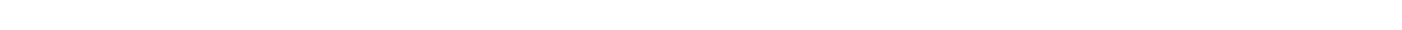
YEAR NUMBER OF DAYS IN CEASS

CUBIC FEET PER SECOND

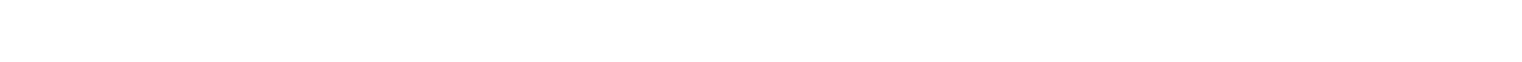

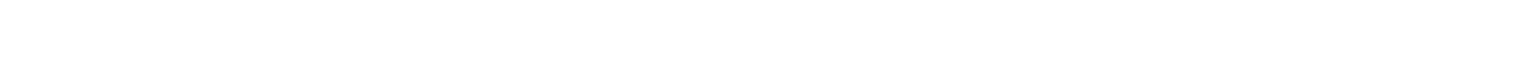

1946

1947

1948

1950

1951

1952

1953
1954

1955

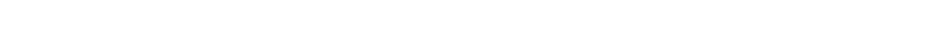

$\begin{array}{rrrrrrrrrrrrrrrrrrrrrrrr}3318.9 & \\ 90 & 66 & 7 & 18 & 26 & 9 & 20 & 5 & 8 & 3 & 8 & 7 & 14 & 12 & 4 & 6 & 7 & 1 & 1 & & \end{array}$

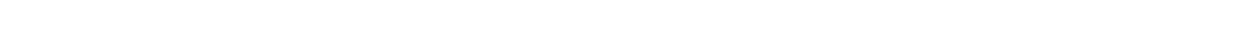

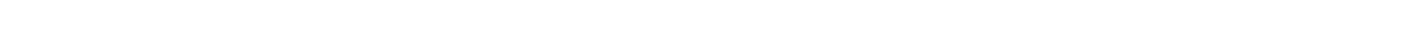

$\begin{array}{llllllllllllllllllllllllllllll}31 & 90 & 38 & 28 & 24 & 7 & 4 & 6 & 5 & 5 & 6 & 12 & 17 & 10 & 22 & 6 & 8 & 2 & 7 & 5 & 11 & 7 & 3 & 4 & 2 & 4 & 1 & 6848.7\end{array}$ $\begin{array}{lllllllllllllllllllllllllllllllll}6 & 61 & 29 & 36 & 21 & 11 & 12 & 15 & 12 & 6 & 4 & 3 & 6 & 12 & 14 & 11 & 24 & 8 & 7 & 8 & 11 & 8 & 12 & 5 & 5 & 5 & 3 & 6 & 5 & & 11185.3\end{array}$

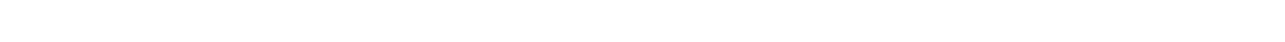

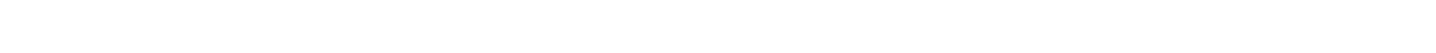

DURATION TABLE OF DISCHARGE FOR WATER YEARS 1944-55

\begin{tabular}{|c|c|c|c|c|c|c|c|c|c|c|c|c|c|c|c|c|c|c|c|}
\hline CIASS & $\begin{array}{c}\text { CUBIC } \\
\text { FEET } \\
\text { PER } \\
\text { SECOND }\end{array}$ & $\begin{array}{r}\text { TOTAL } \\
\text { DAYS }\end{array}$ & $\begin{array}{l}\text { ACO- } \\
\text { MU- } \\
\text { LATED } \\
\text { DAYS }\end{array}$ & $\begin{array}{l}\text { PER- } \\
\text { CENT } \\
\text { DAYS }\end{array}$ & CIASS & $\begin{array}{c}\text { OBIC } \\
\text { FEET } \\
\text { PER } \\
\text { SEOOND }\end{array}$ & $\begin{array}{l}\text { TOIAL } \\
\text { DAYS }\end{array}$ & $\begin{array}{l}\text { ACOU- } \\
\text { MU- } \\
\text { LATED } \\
\text { DAYS }\end{array}$ & $\begin{array}{l}\text { PER- } \\
\text { CENT } \\
\text { DAYS }\end{array}$ & & $\begin{array}{c}\text { CUBIC } \\
\text { FEET } \\
\text { PER } \\
\text { SECOND }\end{array}$ & $\begin{array}{l}\text { TOIAL } \\
\text { DAYS }\end{array}$ & $\begin{array}{l}\text { ACO- } \\
\text { MU- } \\
\text { LATED } \\
\text { DAYS }\end{array}$ & $\begin{array}{l}\text { PER- } \\
\text { CENI } \\
\text { DAYS }\end{array}$ & & $\begin{array}{c}\text { CUBIC } \\
\text { FEET } \\
\text { PER } \\
\text { SECOND }\end{array}$ & $\begin{array}{r}\text { TOTAL } \\
\text { DAYS }\end{array}$ & $\begin{array}{c}\text { ACOU- } \\
\text { MU- } \\
\text { LATED } \\
\text { DAYS }\end{array}$ & $\begin{array}{l}\text { PER- } \\
\text { CENT } \\
\text { DAYS }\end{array}$ \\
\hline $\begin{array}{l}0 \\
1 \\
2 \\
3 \\
4 \\
5 \\
6 \\
7 \\
8\end{array}$ & $\begin{array}{l}0.00 \\
1.00 \\
1.20 \\
1.40 \\
1.70 \\
2.00 \\
2.40 \\
2.80 \\
3.30\end{array}$ & $\begin{array}{r}0 \\
174 \\
109 \\
257 \\
116 \\
508 \\
516 \\
238 \\
296\end{array}$ & $\begin{array}{l}4383 \\
4383 \\
4209 \\
4100 \\
3843 \\
3727 \\
3219 \\
2703 \\
2465\end{array}$ & $\begin{array}{r}100.0 \\
100.0 \\
96.0 \\
93.5 \\
87.7 \\
85.0 \\
73.4 \\
61.7 \\
56.2\end{array}$ & $\begin{array}{r}9 \\
10 \\
11 \\
12 \\
13 \\
14 \\
15 \\
16 \\
17\end{array}$ & $\begin{array}{r}3.90 \\
4.60 \\
5.50 \\
6.50 \\
7.70 \\
9.20 \\
11.00 \\
13.00 \\
15.00\end{array}$ & $\begin{array}{r}212 \\
177 \\
135 \\
148 \\
90 \\
101 \\
92 \\
79 \\
98\end{array}$ & $\begin{array}{l}2169 \\
1957 \\
1780 \\
1645 \\
1497 \\
1407 \\
1306 \\
1214 \\
1135\end{array}$ & $\begin{array}{l}49.5 \\
44.6 \\
40.6 \\
37.5 \\
34.2 \\
32.1 \\
29.8 \\
27.7 \\
25.9\end{array}$ & $\begin{array}{l}18 \\
19 \\
20 \\
21 \\
22 \\
23 \\
24 \\
25 \\
26\end{array}$ & $\begin{array}{l}18.0 \\
21.0 \\
25.0 \\
30.0 \\
36.0 \\
42.0 \\
50.0 \\
60.0 \\
71.0\end{array}$ & $\begin{array}{r}117 \\
108 \\
89 \\
93 \\
52 \\
58 \\
68 \\
83 \\
47\end{array}$ & $\begin{array}{r}1037 \\
920 \\
812 \\
723 \\
630 \\
578 \\
520 \\
452 \\
369\end{array}$ & $\begin{array}{r}23.7 \\
21.0 \\
18.5 \\
16.5 \\
14.4 \\
13.2 \\
11.9 \\
10.3 \\
8.4\end{array}$ & $\begin{array}{l}27 \\
28 \\
29 \\
30 \\
31 \\
32 \\
33 \\
34\end{array}$ & $\begin{array}{r}84.0 \\
100.0 \\
120.0 \\
140.0 \\
170.0 \\
200.0 \\
230.0 \\
280.0\end{array}$ & $\begin{array}{l}67 \\
71 \\
49 \\
50 \\
39 \\
21 \\
24 \\
1\end{array}$ & $\begin{array}{r}322 \\
255 \\
184 \\
135 \\
85 \\
46 \\
25 \\
1\end{array}$ & $\begin{array}{l}7.3 \\
5.8 \\
4.2 \\
3.1 \\
1.9 \\
1.0 \\
0.6 \\
0.0\end{array}$ \\
\hline
\end{tabular}


GREEN RIVER BASIN

09264500 SOU'H FORK ASHLEY CREEK NEAR VERNAL, UT-Continued

MONTHLY MEAN DISCHARGES, IN OBIC FEET PER SECOND, FOR EACH WATER YEAR

\begin{tabular}{|c|c|c|c|c|c|c|c|c|c|c|c|c|}
\hline YEAR & $\propto T$ & NOV & $D E C$ & JAN & FEB & MAR & APR & MAY & JUNE & JULY & AUG & SEP \\
\hline $\begin{array}{l}1944 \\
1945\end{array}$ & $\begin{array}{l}2.72 \\
2.98\end{array}$ & $\begin{array}{l}2.00 \\
1.50\end{array}$ & $\begin{array}{l}2.00 \\
1.40\end{array}$ & $\begin{array}{l}1.50 \\
1.30\end{array}$ & $\begin{array}{l}1.50 \\
1.20\end{array}$ & $\begin{array}{l}1.00 \\
1.20\end{array}$ & $\begin{array}{l}2.00 \\
1.70\end{array}$ & $\begin{array}{l}75.5 \\
61.4\end{array}$ & $\begin{array}{c}175 \\
72.6\end{array}$ & $\begin{array}{l}51.5 \\
31.8\end{array}$ & $\begin{array}{l}13.5 \\
15.8\end{array}$ & $\begin{array}{l}4.30 \\
7.26\end{array}$ \\
\hline $\begin{array}{l}1946 \\
1947 \\
1948 \\
1949 \\
1950\end{array}$ & $\begin{array}{l}5.72 \\
6.85 \\
5.24 \\
3.18 \\
5.12\end{array}$ & $\begin{array}{l}3.63 \\
4.83 \\
3.80 \\
2.55 \\
4.08\end{array}$ & $\begin{array}{l}2.50 \\
4.15 \\
3.23 \\
2.04 \\
2.24\end{array}$ & $\begin{array}{l}2.20 \\
3.70 \\
2.80 \\
1.70 \\
1.50\end{array}$ & $\begin{array}{l}2.10 \\
3.50 \\
2.50 \\
1.60 \\
1.00\end{array}$ & $\begin{array}{l}1.90 \\
3.50 \\
2.50 \\
1.87 \\
1.50\end{array}$ & $\begin{array}{c}5.50 \\
6.37 \\
2.89 \\
10.7 \\
3.62\end{array}$ & $\begin{array}{c}37.3 \\
129 \\
97.3 \\
77.4 \\
76.0\end{array}$ & $\begin{array}{c}27.3 \\
109 \\
56.7 \\
138 \\
128\end{array}$ & $\begin{array}{c}6.81 \\
45.1 \\
12.5 \\
29.8 \\
41.8\end{array}$ & $\begin{array}{c}7.72 \\
17.5 \\
6.48 \\
13.5 \\
11.0\end{array}$ & $\begin{array}{l}5.96 \\
9.20 \\
3.28 \\
4.59 \\
7.68\end{array}$ \\
\hline $\begin{array}{l}1951 \\
1952 \\
1953 \\
1954 \\
1955\end{array}$ & $\begin{array}{l}3.79 \\
7.24 \\
4.28 \\
2.72 \\
3.78\end{array}$ & $\begin{array}{l}2.81 \\
4.20 \\
2.69 \\
2.50 \\
2.09\end{array}$ & $\begin{array}{l}2.50 \\
3.50 \\
2.50 \\
2.50 \\
1.38\end{array}$ & $\begin{array}{l}2.20 \\
2.65 \\
2.40 \\
2.40 \\
1.10\end{array}$ & $\begin{array}{l}2.00 \\
2.60 \\
2.30 \\
2.30 \\
1.00\end{array}$ & $\begin{array}{l}1.80 \\
2.40 \\
2.20 \\
2.20 \\
1.00\end{array}$ & $\begin{array}{c}2.00 \\
21.2 \\
2.65 \\
8.65 \\
1.33\end{array}$ & $\begin{array}{c}74.6 \\
112 \\
38.5 \\
80.9 \\
65.0\end{array}$ & $\begin{array}{c}75.9 \\
129 \\
104 \\
24.7 \\
44.8\end{array}$ & $\begin{array}{l}19.1 \\
27.4 \\
15.6 \\
15.5 \\
10.1\end{array}$ & $\begin{array}{c}25.5 \\
41.1 \\
7.37 \\
14.5 \\
17.8\end{array}$ & $\begin{array}{c}11.8 \\
13.0 \\
3.57 \\
5.56 \\
7.32\end{array}$ \\
\hline
\end{tabular}

ANNUAL PEAK DISCHARGE, IN CUBIC FEET PER SECOND, AND CORRESPONDING GAGE HEIGHT, IN FEET, FOR EACH WATER YEAR

\begin{tabular}{|c|c|c|c|c|c|c|c|c|c|c|c|}
\hline $\begin{array}{l}\text { WATER } \\
\text { YEAR }\end{array}$ & DATE & $\begin{array}{c}\text { GAGE } \\
\text { HEIGHT }\end{array}$ & $\begin{array}{c}\text { PEAK } \\
\text { DISCHARGE }\end{array}$ & $\begin{array}{l}\text { WATER } \\
\text { YEAR }\end{array}$ & DATE & $\begin{array}{c}\text { GAGE } \\
\text { HEIGHT }\end{array}$ & $\begin{array}{c}\text { PEAK } \\
\text { DISCHARGE }\end{array}$ & $\begin{array}{l}\text { WATER } \\
\text { YEAR }\end{array}$ & DATE & $\begin{array}{c}\text { GAGE } \\
\text { HEIGHT }\end{array}$ & $\begin{array}{c}\text { PEAK } \\
\text { DISCHARGE }\end{array}$ \\
\hline $\begin{array}{l}1944 \\
1945 \\
1946 \\
1947\end{array}$ & $\begin{array}{l}\text { JUNE } 26,1944 \\
\text { JUNE 04, } 1945 \\
\text { MAY 06, } 1946 \\
\text { JUNE 20, } 1947\end{array}$ & $\begin{array}{l}3.72 \\
3.00 \\
2.47 \\
3.21\end{array}$ & $\begin{array}{r}391 \\
198 \\
93 \\
248\end{array}$ & $\begin{array}{l}1948 \\
1949 \\
1950 \\
1951\end{array}$ & $\begin{array}{l}\text { MAY } 19,1948 \\
\text { JUNE } 18,1949 \\
\text { JUNE 01, } 1950 \\
\text { MAY } 27,1951\end{array}$ & $\begin{array}{l}3.53 \\
3.84 \\
3.46 \\
3.54\end{array}$ & $\begin{array}{l}343 \\
460 \\
359 \\
404\end{array}$ & $\begin{array}{l}1952 \\
1953 \\
1954 \\
1955\end{array}$ & 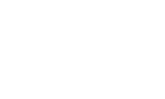 & $\begin{array}{l}3.73 \\
3.54 \\
3.15 \\
3.07\end{array}$ & $\begin{array}{l}452 \\
402 \\
229 \\
207\end{array}$ \\
\hline
\end{tabular}

MAGNITUDE AND PROBABILITY OF ANNUAL LOWEST MEAN DISCHARGE BASED ON CLIMATIC YEARS 1945-55

\begin{tabular}{|c|c|c|c|c|c|c|}
\hline \multirow{2}{*}{$\begin{array}{l}\text { PERIOD } \\
\text { (CON- } \\
\text { SEO- } \\
\text { TIVE } \\
\text { DAYS) }\end{array}$} & \multicolumn{6}{|c|}{$\begin{array}{l}\text { DISCHARGE, IN OUBIC FEET PER SECOND, FOR } \\
\text { MNDICATED REQURRENCE INTERVAL, IN YEARS, AND } \\
\text { ANNUAL NONEXCEEDANCE PROBABILITY, IN PERCENT }\end{array}$} \\
\hline & $\begin{array}{c}2 \\
508\end{array}$ & $\begin{array}{c}5 \\
20 \%\end{array}$ & $\begin{array}{l}10 \\
108\end{array}$ & $\begin{array}{l}20 \\
58\end{array}$ & $\begin{array}{l}50 \\
28\end{array}$ & $\begin{array}{r}100 \\
18\end{array}$ \\
\hline
\end{tabular}

$\begin{array}{llllll}1.7 & 1.3 & 1.1 & 0.93 & - & - \\ 1.7 & 1.3 & 1.1 & 0.93 & - & = \\ 1.7 & 1.3 & 1.1 & 0.93 & = & = \\ 1.8 & 1.3 & 1.1 & 0.94 & - & - \\ 1.9 & 1.4 & 1.2 & 0.99 & - & = \\ 2.0 & 1.4 & 1.2 & 0.99 & - & -\end{array}$

MAGNITUDE AND PROBABIIITYY OF ANNUAL HIGHEST MEAN DISGHARGE BASED ON WATER YEARS 1944-55

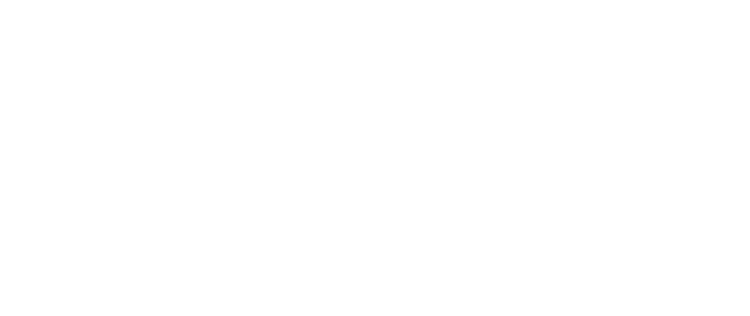

09265300 ASHLEY CREEK ABOVE RED PINE CREEK, NEAR VERNAL, UT

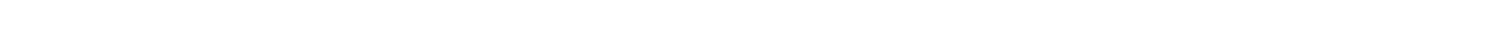

Forest, on right bank $0.2 \mathrm{mi}$ upstream from Cow Hollow and $17 \mathrm{mi}$ north-northwest of Vernal.

DRAINAGE AREA. $--55.8 \mathrm{mi}^{2}$.

MEAN BASIN ELEVATION. $-9,810 \mathrm{ft}$.

PERIOD OF RECORD AVAILABLE. - October 1964 to September 1975.

GAGE.--Water-stage recorder. Datum of gage is 7,870,03 ft NGVD of 1929 (levels by Bureau of Reclamation).

REMARKS.--Flow partly regulated by Long Park Reservoir, capacity, 520 acre-ft. No diversions above station.

AVERAGE DISCHARGE. --11 years, $67.1 \mathrm{ft}^{3} / \mathrm{s}, 48,610$ acre-ft/yr.

EXTREMES FOR PERIOD OF RECORD.--Maximum discharge, about 7,400 $\mathrm{ft}^{3} / \mathrm{s}$ June 10,1965 , gage height, $12.13 \mathrm{ft}$ fram floodmarks, fram rating curve extended above $420 \mathrm{ft}^{3} / \mathrm{s}$ on basis of an estimate at peak flow based on a field survey; minimum recorded, about 0.80 $\mathrm{ft}^{3} / \mathrm{s}$ Apr. 22, 1968 , result of freezeup. 
GREEN RIVER BASIN

09265300 ASHLEY CREER ABOVE RED PINE CREEK, NEAR VERNAL, UT--Continued

LOWEST MEAN DISCHARGE, IN CUBIC FEET PER SECOND, AND RANKING FOR THE INDICATED NUMBER OF CONSECUTIVE DAYS FOR EACH CLIMATIC YEAR, APRIL 1-MARCH 31

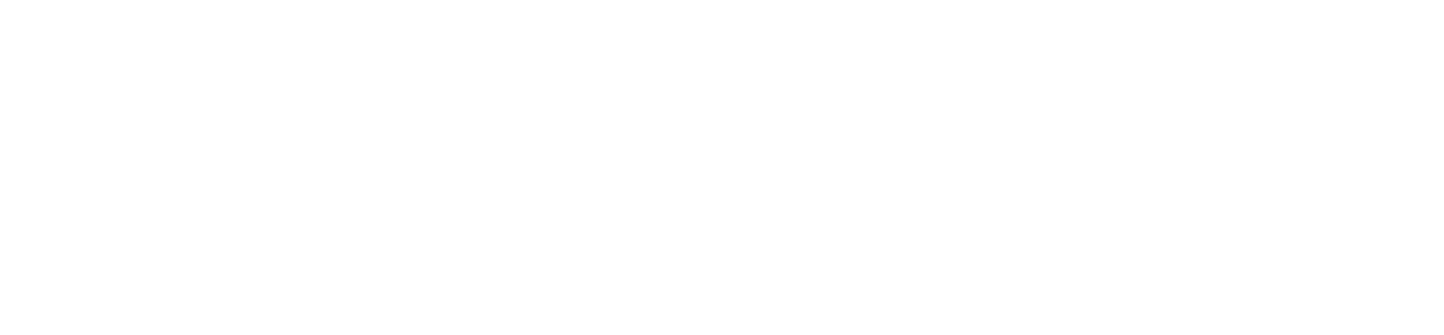

HIGHEST MEAN DISCHARGE, IN OBIC FEET PER SECOND, AND RANKING FOR THE INDICATED NUMBER OF CONSECUTIVE DAYS FOR EACH WATER YEAR, OCTCBER 1-SEPTEMBER 30

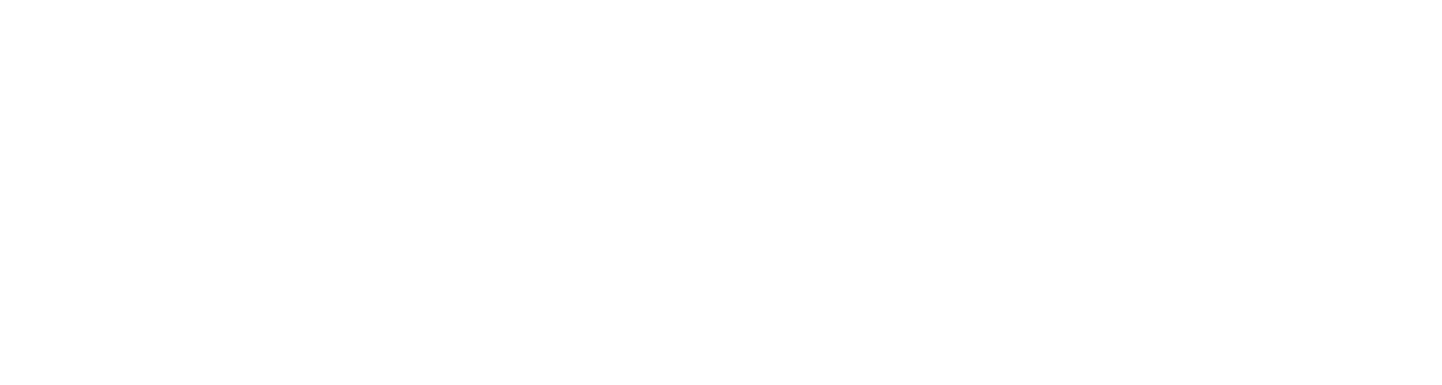

DURATION OF DISCHARGE FOR EACH WATER YEAR

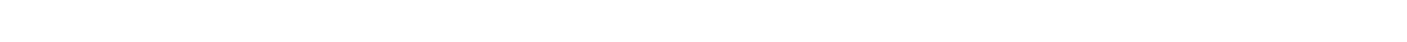

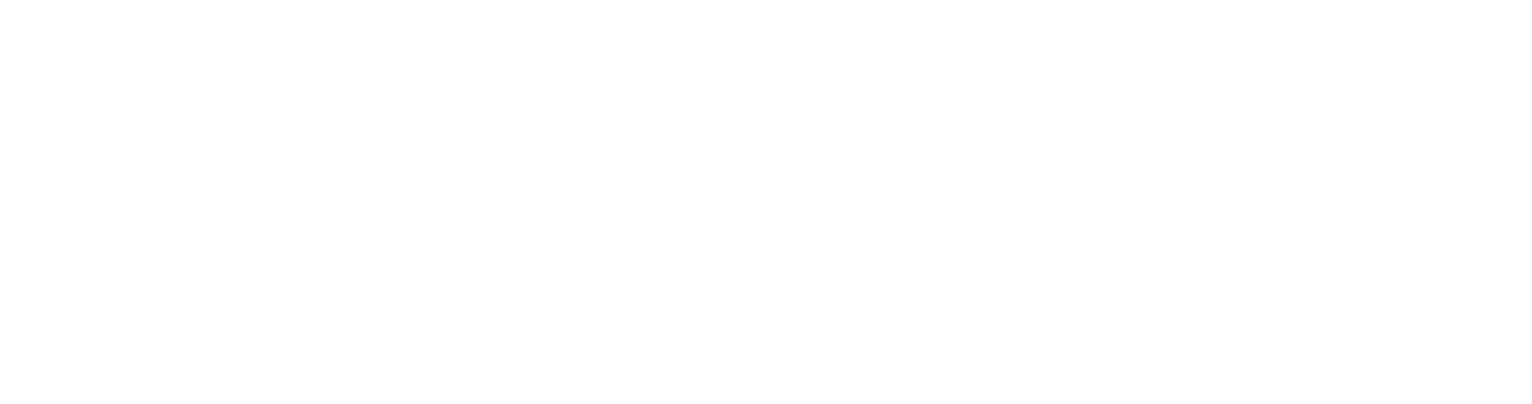

DURATION TABLE OF DISCHARGE FOR WATER YEARS 1965-75

\begin{tabular}{|c|c|c|c|c|c|c|c|c|c|c|c|c|c|c|c|c|c|c|c|}
\hline CLASS & $\begin{array}{c}\text { OBBIC } \\
\text { FEET } \\
\text { PER } \\
\text { SECOND }\end{array}$ & $\begin{array}{r}\text { TOTAL } \\
\text { DAYS }\end{array}$ & $\begin{array}{c}\text { ACOU- } \\
\text { MU- } \\
\text { LATED } \\
\text { DAYS }\end{array}$ & $\begin{array}{l}\text { PER- } \\
\text { CENT } \\
\text { DAYS }\end{array}$ & CLASS & $\begin{array}{c}\text { OUBIC } \\
\text { FEET } \\
\text { PER } \\
\text { SECOND }\end{array}$ & $\begin{array}{l}\text { TOTAL } \\
\text { DAYS }\end{array}$ & $\begin{array}{c}\text { ACOU- } \\
\text { MU- } \\
\text { LATED } \\
\text { DAYS }\end{array}$ & $\begin{array}{l}\text { PER- } \\
\text { CENT } \\
\text { DAYS }\end{array}$ & CLASS & $\begin{array}{c}\text { OUBIC } \\
\text { FEET } \\
\text { PER } \\
\text { SECOND }\end{array}$ & $\begin{array}{r}\text { TOTAL } \\
\text { DAYS }\end{array}$ & $\begin{array}{c}\text { ACOU- } \\
\text { MU- } \\
\text { LATED } \\
\text { DAYS }\end{array}$ & $\begin{array}{l}\text { PER- } \\
\text { CENT } \\
\text { DAYS }\end{array}$ & CLASS & $\begin{array}{c}\text { CUBIC } \\
\text { FEET } \\
\text { PER } \\
\text { SECOND }\end{array}$ & $\begin{array}{r}\text { TOTAL } \\
\text { DAYS }\end{array}$ & $\begin{array}{c}\text { ACOU- } \\
\text { MU- } \\
\text { LATED } \\
\text { DAYS }\end{array}$ & $\begin{array}{l}\text { PER- } \\
\text { CENT } \\
\text { DAYS }\end{array}$ \\
\hline $\begin{array}{l}0 \\
1 \\
2 \\
3 \\
4 \\
5 \\
6 \\
7 \\
8\end{array}$ & $\begin{array}{l}0.00 \\
1.30 \\
1.60 \\
2.00 \\
2.50 \\
3.10 \\
3.80 \\
4.70 \\
5.90\end{array}$ & $\begin{array}{r}0 \\
22 \\
1 \\
51 \\
61 \\
78 \\
292 \\
497 \\
514\end{array}$ & $\begin{array}{l}4017 \\
4017 \\
3995 \\
3994 \\
3943 \\
3882 \\
3804 \\
3512 \\
3015\end{array}$ & $\begin{array}{r}100.0 \\
100.0 \\
99.5 \\
99.4 \\
98.2 \\
96.6 \\
94.7 \\
87.4 \\
75.1\end{array}$ & $\begin{array}{r}9 \\
10 \\
11 \\
12 \\
13 \\
14 \\
15 \\
16 \\
17\end{array}$ & $\begin{array}{r}7.30 \\
9.10 \\
11.00 \\
14.00 \\
17.00 \\
21.00 \\
27.00 \\
33.00 \\
41.00\end{array}$ & $\begin{array}{l}324 \\
137 \\
307 \\
140 \\
156 \\
139 \\
124 \\
120 \\
139\end{array}$ & $\begin{array}{l}2501 \\
2177 \\
2040 \\
1733 \\
1593 \\
1437 \\
1298 \\
1174 \\
1054\end{array}$ & $\begin{array}{l}62.3 \\
54.2 \\
50.8 \\
43.1 \\
39.7 \\
35.8 \\
32.3 \\
29.2 \\
26.2\end{array}$ & $\begin{array}{l}18 \\
19 \\
20 \\
21 \\
22 \\
23 \\
24 \\
25 \\
26\end{array}$ & $\begin{array}{r}51.0 \\
63.0 \\
78.0 \\
97.0 \\
120.0 \\
150.0 \\
190.0 \\
230.0 \\
290.0\end{array}$ & $\begin{array}{r}101 \\
78 \\
93 \\
85 \\
73 \\
56 \\
48 \\
64 \\
49\end{array}$ & $\begin{array}{l}915 \\
814 \\
736 \\
643 \\
558 \\
485 \\
429 \\
381 \\
317\end{array}$ & $\begin{array}{r}22.8 \\
20.3 \\
18.3 \\
16.0 \\
13.9 \\
12.1 \\
10.7 \\
9.5 \\
7.9\end{array}$ & $\begin{array}{l}27 \\
28 \\
29 \\
30 \\
31 \\
32 \\
33 \\
34\end{array}$ & $\begin{array}{r}350.0 \\
440.0 \\
540.0 \\
680.0 \\
840.0 \\
1000.0 \\
1300.0 \\
1600.0\end{array}$ & $\begin{array}{r}101 \\
73 \\
58 \\
20 \\
7 \\
6 \\
1 \\
2\end{array}$ & $\begin{array}{r}268 \\
167 \\
94 \\
36 \\
16 \\
9 \\
3 \\
2\end{array}$ & $\begin{array}{l}6.7 \\
4.2 \\
2.3 \\
0.9 \\
0.4 \\
0.2 \\
0.1 \\
0.0\end{array}$ \\
\hline
\end{tabular}


GRBEN RIVER BASIN

09265300 ASHLEY CREER ABOVE RED PINE CREER, NEAR VERNAL, UT-Continued

MONTHLY MEAN DISQHARGES, IN OBIC FEET PER SECOND, FOR EAOH WATER YEAR

\begin{tabular}{|c|c|c|c|c|c|c|c|c|c|c|c|c|}
\hline YEAR & $\infty T$ & NOV & DEC & JAN & $\mathrm{FBB}$ & MAR & APR & MAY & JUNE & JULY & AUG & SEP \\
\hline 1965 & 8.37 & 7.33 & 6.00 & 5.00 & 4.00 & 3.00 & 3.33 & 180 & 603 & 171 & 118 & 60.1 \\
\hline $\begin{array}{l}1966 \\
1967 \\
1968 \\
1969 \\
1970\end{array}$ & $\begin{array}{l}34.7 \\
11.7 \\
12.6 \\
12.8 \\
11.8\end{array}$ & $\begin{array}{c}14.4 \\
7.23 \\
6.47 \\
8.49 \\
8.62\end{array}$ & $\begin{array}{l}9.85 \\
6.84 \\
4.53 \\
6.63 \\
6.35\end{array}$ & $\begin{array}{l}7.32 \\
5.73 \\
4.16 \\
6.16 \\
5.83\end{array}$ & $\begin{array}{l}5.96 \\
5.07 \\
4.79 \\
5.59 \\
4.95\end{array}$ & $\begin{array}{l}4.75 \\
4.64 \\
5.04 \\
4.51 \\
4.37\end{array}$ & $\begin{array}{c}18.2 \\
6.21 \\
4.88 \\
15.4 \\
6.80\end{array}$ & $\begin{array}{l}281 \\
253 \\
80.9 \\
368 \\
276\end{array}$ & $\begin{array}{l}90.5 \\
461 \\
574 \\
160 \\
357\end{array}$ & $\begin{array}{c}38.6 \\
155 \\
87.8 \\
63.6 \\
89.1\end{array}$ & $\begin{array}{l}23.7 \\
37.0 \\
71.1 \\
23.4 \\
31.4\end{array}$ & $\begin{array}{l}12.9 \\
30.3 \\
33.4 \\
17.8 \\
25.2\end{array}$ \\
\hline $\begin{array}{l}1971 \\
1972 \\
1973 \\
1974 \\
1975\end{array}$ & $\begin{array}{c}11.6 \\
12.5 \\
24.9 \\
13.9 \\
6.93\end{array}$ & $\begin{array}{c}7.78 \\
11.0 \\
18.7 \\
6.29 \\
6.34\end{array}$ & $\begin{array}{c}6.84 \\
7.67 \\
11.3 \\
4.00 \\
5.50\end{array}$ & $\begin{array}{l}5.37 \\
6.49 \\
8.88 \\
3.50 \\
5.06\end{array}$ & $\begin{array}{l}4.75 \\
4.76 \\
7.65 \\
3.00 \\
4.59\end{array}$ & $\begin{array}{l}4.62 \\
9.49 \\
7.03 \\
2.00 \\
3.26\end{array}$ & $\begin{array}{c}9.86 \\
19.2 \\
8.31 \\
2.94 \\
3.86\end{array}$ & $\begin{array}{c}176 \\
270 \\
346 \\
233 \\
82.2\end{array}$ & $\begin{array}{c}328 \\
212 \\
429 \\
64.2 \\
534\end{array}$ & $\begin{array}{r}76.4 \\
51.4 \\
95.3 \\
36.3 \\
279\end{array}$ & $\begin{array}{l}20.8 \\
16.0 \\
50.7 \\
13.3 \\
42.6\end{array}$ & $\begin{array}{c}13.2 \\
15.0 \\
37.9 \\
7.44 \\
23.3\end{array}$ \\
\hline
\end{tabular}

ANNUAL PEAR DISGHARGE, IN OUBIC FEET PER SECOND, AND CORRESPONDING GAGE HEIGHT, IN FEET, FOR EACH WATER YEAR

\begin{tabular}{|c|c|c|c|c|c|c|c|c|c|c|c|c|}
\hline $\begin{array}{l}\text { WATER } \\
\text { YEAR }\end{array}$ & DATE & $\begin{array}{c}\text { GAGE } \\
\text { HEIGHT }\end{array}$ & $\begin{array}{c}\text { PEAK } \\
\text { DISCHARGE }\end{array}$ & $\begin{array}{l}\text { WATER } \\
\text { YEAR }\end{array}$ & & DATE & $\begin{array}{c}\text { GAGE } \\
\text { HEIGHT }\end{array}$ & $\begin{array}{c}\text { PEAK } \\
\text { DISOHARGE }\end{array}$ & $\begin{array}{l}\text { WATER } \\
\text { YEAR }\end{array}$ & DATE & $\begin{array}{c}\text { GAGE } \\
\text { HEIGHT }\end{array}$ & $\begin{array}{c}\text { PEAK } \\
\text { DISQHARGE }\end{array}$ \\
\hline $\begin{array}{l}1965 \\
1966 \\
1968 \\
1969\end{array}$ & $\begin{array}{l}\text { JUNE } 10,1965 \\
\text { MAY } 06,1966 \\
\text { JUNE 05, } 1968 \\
\text { MAY } 14,1969\end{array}$ & $\begin{array}{r}12.13 \\
5.88 \\
7.43 \\
5.72\end{array}$ & $\begin{array}{r}7400 \\
979 \\
1730 \\
729\end{array}$ & $\begin{array}{l}1970 \\
1971 \\
1972\end{array}$ & $\begin{array}{l}\text { MAY } \\
\text { MAY } \\
\text { MAY }\end{array}$ & $\begin{array}{ll}26, & 1970 \\
27, & 1971 \\
28, & 1972\end{array}$ & $\begin{array}{l}6.38 \\
5.97 \\
5.80\end{array}$ & $\begin{array}{l}980 \\
\text { g16 } \\
708\end{array}$ & $\begin{array}{l}1973 \\
1974 \\
1975\end{array}$ & $\begin{array}{l}\text { JUNE } 08,1973 \\
\text { MAY } 09,1974 \\
\text { JUNE } 15,1975\end{array}$ & $\begin{array}{l}6.80 \\
6.55 \\
7.45\end{array}$ & $\begin{array}{l}1280 \\
1050 \\
1600\end{array}$ \\
\hline
\end{tabular}

\begin{tabular}{|c|c|c|c|c|c|c|}
\hline MAG & ITUDE & $\begin{array}{l}\text { PRCBA } \\
\text { SED }\end{array}$ & $\begin{array}{l}\text { Y OF } \\
\text { WATC }\end{array}$ & $\begin{array}{l}\text { LOW } \\
196\end{array}$ & & \\
\hline \multirow{2}{*}{$\begin{array}{l}\text { PERIOD } \\
\text { (CON- } \\
\text { SEOJ- } \\
\text { TIVE } \\
\text { DAYS) }\end{array}$} & \multicolumn{6}{|c|}{$\begin{array}{l}\text { DISCHARGE, IN OUBIC FEET PER SECOND, FOR } \\
\text { INDICATED REOURRENCE INIERNAL, IN YEARS, AND } \\
\text { ANNUAL NONEXCEEDANCE PRCBABILITY, IN PERCENT }\end{array}$} \\
\hline & $\begin{array}{c}2 \\
508\end{array}$ & $\begin{array}{c}5 \\
208\end{array}$ & $\begin{array}{l}10 \\
108\end{array}$ & $\begin{array}{l}20 \\
58\end{array}$ & $\begin{array}{l}50 \\
28\end{array}$ & $\begin{array}{r}100 \\
18\end{array}$ \\
\hline $\begin{array}{l}60 \\
90\end{array}$ & $\begin{array}{l}4.9 \\
5.2\end{array}$ & $\begin{array}{l}3.8 \\
4.1\end{array}$ & $\begin{array}{l}3.2 \\
3.5\end{array}$ & $\begin{array}{l}2.8 \\
3.1\end{array}$ & $\overline{-}$ & -- \\
\hline
\end{tabular}

09265500 ASHLEY CREER ABOVE SPRINGS, NEAR VERNAL, UT

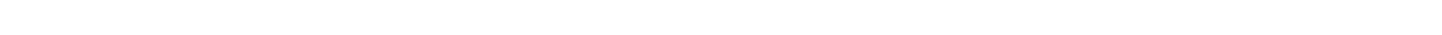
upstream from Ashley Creek Springs, $5 \mathrm{mi}$ upstream from Dry Fork, and $10.5 \mathrm{mi}$ northwest of Vernal.

DRAINAGE AREA. $--100 \mathrm{mi}^{2}$, approximately.

PERIOD OF RECORD AVAII.ABLE.--June 1941 to September 1945.

GAGE.-Water-stage recorder. Altitude of gage is $6,300 \mathrm{ft}$ from river-profile map.

REMARKS.-Flow is increased by water released from Oaks Park Reservoir, capacity, 6,250 acre-ft, on Brush Creek and diverted to Ashley Creek basin for irrigation. No diversion above station.

EXTREMES FOR PERIOD OF RECORD.--Maximum discharge, 1,400 ft $3 / \mathrm{s}$ May 13, 1941 , gage height, $4.50 \mathrm{ft}$, from rating curve extended above $860 \mathrm{ft}^{3} / \mathrm{s}$; maximum stage, $4.52 \mathrm{ft}$ May 30,1944 ; minimum discharge recorded, $1.0 \mathrm{ft}{ }^{3} / \mathrm{s}$ several times during March 1945 , but may have been less during period of ice effect.

LCWEST MEAN DISCHARGE, IN OUBIC FEET PER SECOND, AND RANKING FOR THE INDICATED NUNBER OF CONSEOJTIVE DAYS FOR EAOH CLIMATIC YEAR, APRIL 1-MAROH 31

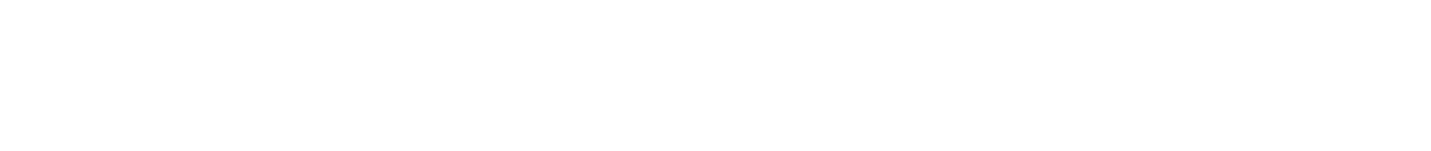


GREEN RIVER BASIN

09265500 ASHLEY CREEK ABOVE SPRINGS, NEAR VERNAL, UT--Continued

HIGHEST MEAN DISCHARGE, IN OUBIC FEET PER SEOOND, AND RANKING FOR THE INDICATED NUMBER OF CONSECOTIVE DAYS FOR EACH WATER YEAR, OCTOBER 1-SEPTEMBER 30

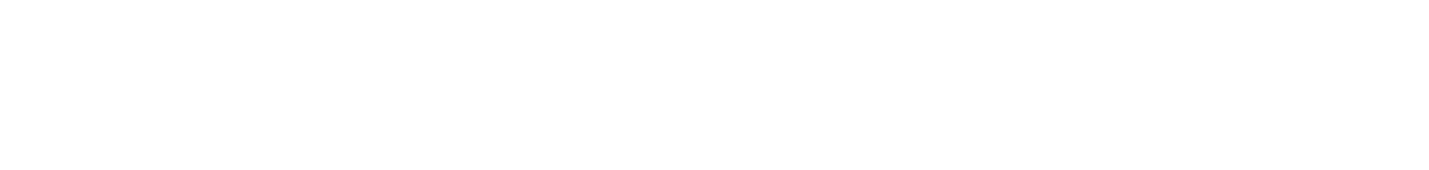

DURATION OF DISCHARGE FOR EACH WATER YEAR

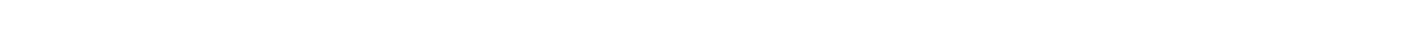
YEAR NUMBER OF DAYS IN CLASS

CUBIC FEET PER SECON
-DAYS

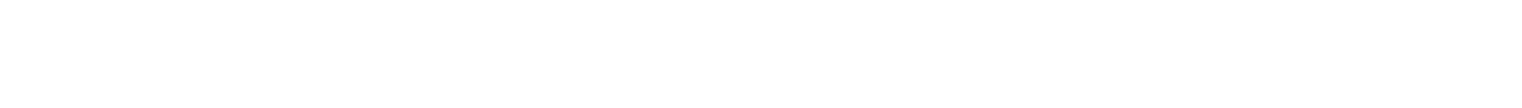

DURATION TABLE OF DISCHARGE FOR WATER YEARS 1942-45

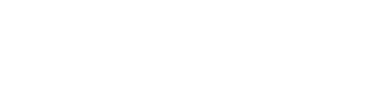

$\begin{array}{lcc}\text { OBBIC } & \text { ACOU- } \\ \text { FEET } & \text { MU- } & \text { PER- } \\ \text { PER TOTAL LATED } & \text { CENT }\end{array}$

CLASS SECOND DAYS DAYS DAYS

$\begin{array}{lll}\text { CABIC } & \text { ACCU- } \\ \text { EEET } & \text { MU- } & \text { PER- } \\ \text { PER TOTAL LATED } & \text { CENT }\end{array}$ CLASS SECOND DAYS DAYS DAYS

$\begin{array}{ccc}\text { CUBIC } & \text { ACOU- } \\ \text { FEET } & \text { MU- } & \text { PER- } \\ \text { PER } & \text { TOTAL LATED } & \text { CENT } \\ \text { CLASS SECOND } & \text { DAYS DAYS } & \text { DAYS }\end{array}$

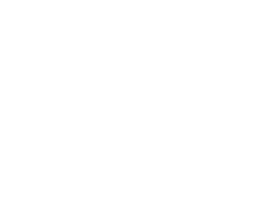

$\begin{array}{rrrrr}9 & 6.10 & 41 & 905 & 61.9 \\ 10 & 7.40 & 47 & 864 & 59.1 \\ 11 & 9.10 & 32 & 817 & 55.9 \\ 12 & 11.00 & 19 & 785 & 53.7 \\ 13 & 14.00 & 37 & 766 & 52.4 \\ 14 & 17.00 & 12 & 729 & 49.9 \\ 15 & 20.00 & 31 & 717 & 49.1 \\ 16 & 25.00 & 75 & 686 & 47.0 \\ 17 & 31.00 & 41 & 611 & 41.8\end{array}$

$\begin{array}{rrr}18 & 38.0 & 23 \\ 19 & 46.0 & 66 \\ 20 & 56.0 & 80 \\ 21 & 69.0 & 81 \\ 22 & 84.0 & 66 \\ 23 & 100.0 & 76 \\ 24 & 130.0 & 22 \\ 25 & 160.0 & 23 \\ 26 & 190.0 & 28\end{array}$

$\begin{array}{rr}570 & 39.0 \\ 547 & 37.4 \\ 481 & 32.9 \\ 401 & 27.4 \\ 320 & 21.9 \\ 254 & 17.4 \\ 178 & 12.2 \\ 156 & 10.7 \\ 133 & 9.1\end{array}$

$\begin{array}{rrrrr}27 & 230.0 & 20 & 105 & 7.2 \\ 28 & 280.0 & 18 & 85 & 5.8 \\ 29 & 350.0 & 13 & 67 & 4.6 \\ 30 & 430.0 & 12 & 54 & 3.7 \\ 31 & 520.0 & 26 & 42 & 2.9 \\ 32 & 640.0 & 11 & 16 & 1.1 \\ 33 & 780.0 & 4 & 5 & 0.3 \\ 34 & 960.0 & 1 & 1 & 0.1\end{array}$

MONTHLY MEAN DISCHARGES, IN OBIC FEET PER SECOND, FOR EACH WATER YEAR

\begin{tabular}{|c|c|c|c|c|c|c|c|c|c|c|c|c|}
\hline YEAR & $\infty \mathrm{CT}$ & NOV & $\mathrm{DEC}$ & JAN & FEB & MAR & APR & MAY & JUNE & JULY & AJUG & SEP \\
\hline $\begin{array}{l}1942 \\
1943 \\
1944 \\
1945\end{array}$ & $\begin{array}{c}98.1 \\
19.7 \\
8.04 \\
10.2\end{array}$ & $\begin{array}{r}45.1 \\
6.33 \\
5.15 \\
3.68\end{array}$ & $\begin{array}{r}18.2 \\
3.97 \\
3.85 \\
2.66\end{array}$ & $\begin{array}{l}8.97 \\
3.00 \\
3.00 \\
2.00\end{array}$ & $\begin{array}{l}6.54 \\
2.00 \\
2.00 \\
1.50\end{array}$ & $\begin{array}{l}6.35 \\
2.68 \\
1.85 \\
1.29\end{array}$ & $\begin{array}{l}57.3 \\
99.0 \\
3.58 \\
1.54\end{array}$ & $\begin{array}{l}270 \\
183 \\
327 \\
177\end{array}$ & $\begin{array}{l}343 \\
102 \\
542 \\
187\end{array}$ & $\begin{array}{r}76.5 \\
80.2 \\
118 \\
78.6\end{array}$ & $\begin{array}{l}51.4 \\
42.4 \\
71.6 \\
51.9\end{array}$ & $\begin{array}{l}42.7 \\
25.1 \\
33.0 \\
43.4\end{array}$ \\
\hline
\end{tabular}

09266000 ASHLEY CREEK SPRING NEAR VERNAL, UT

LOCATION,--Lat $40^{\circ} 35^{\prime} 10^{\prime \prime}$, long $109^{\circ} 37^{\prime} 20^{\prime \prime}$, in $\mathrm{NW}^{\frac{1}{2}} \mathrm{SE}_{\frac{1}{4}}^{\mathrm{l}}$ sec.1, T.3 S., R. 20 E., Uintah County, Hydrologic Unit 14060002 , 350 ft upstream from Ashley Creek and $10.25 \mathrm{mi}$ northwest of Vernal.

PERIOD OF RECORD AVAILABLE.--October 1943 to September 1945, July 1954 to September 1955.

GAGE.--Water-stage recorder. Altitude of gage is 6,300 ft from topographic map.

REMARKS. - This spring is the largest spring in the Ashley Creek Spring area. Total flow of spring in this area may be obtained by subtracting the flow for Ashley Creek above Springs, near Vernal, from the flow for Ashley Creek near Vernal. Pipeline for city of Vernal (capacity, approximately $5 \mathrm{ft}^{3} / \mathrm{s}$ ) diverted fram spring imnediately upstream fran gage.

EXTREMES FOR PERIOD OF RECORD.--Maximum discharge, $49 \mathrm{ft}^{3} / \mathrm{s}$ June 1-7, 1944, gage height, $0.98 \mathrm{ft}$; minimum $15 \mathrm{ft} / \mathrm{s}$ on many days January to April 1944.

LOWEST MEAN DISCHARGE, IN CUBIC FEET PER SECOND, AND RANKING FOR THE INDICATED NUMBER OF CONSECOTIVE DAYS FOR EACH CLIMATIC YEAR, APRIL 1-MARCH 31

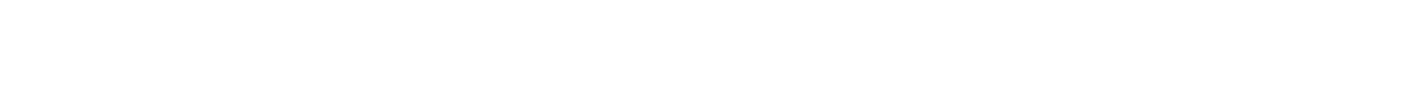


GREFN RIVER BASIN

09266000 ASHLEY CREEK SPRING NEAR VERNAL, UT--Continued

HIGHEST MEAN DISCHARGE, IN CUBIC FEET PER SECOND, AND RANKING FOR THE INDICATED NUMBER OF CONSECUTTVE DAYS FOR EACH WATER YEAR, OCTCBER 1-SEPTEMBER 30

\begin{tabular}{|c|c|c|c|c|c|c|c|c|c|c|c|c|c|c|c|c|c|c|c|c|}
\hline YEAR & 1 & & 3 & & 7 & & 15 & & $\begin{array}{l}\text { CONS } \\
30\end{array}$ & Cart & $\begin{array}{l}\text { E DAYS } \\
60\end{array}$ & & 90 & & 120 & & 183 & & ALL & \\
\hline $\begin{array}{l}1944 \\
1945\end{array}$ & $\begin{array}{l}49.0 \\
46.0\end{array}$ & $\begin{array}{l}1 \\
2\end{array}$ & $\begin{array}{l}49.0 \\
45.0\end{array}$ & $\begin{array}{l}1 \\
2\end{array}$ & $\begin{array}{l}49.0 \\
45.0\end{array}$ & $\begin{array}{l}1 \\
2\end{array}$ & $\begin{array}{l}48.0 \\
44.0\end{array}$ & $\begin{array}{l}1 \\
2\end{array}$ & $\begin{array}{l}47.0 \\
44.0\end{array}$ & $\begin{array}{l}1 \\
2\end{array}$ & $\begin{array}{l}47.0 \\
43.0\end{array}$ & $\begin{array}{l}1 \\
2\end{array}$ & $\begin{array}{l}46.0 \\
43.0\end{array}$ & $\begin{array}{l}1 \\
2\end{array}$ & $\begin{array}{l}44.0 \\
42.0\end{array}$ & $\begin{array}{l}1 \\
2\end{array}$ & $\begin{array}{l}37.0 \\
37.0\end{array}$ & $\begin{array}{l}1 \\
2\end{array}$ & $\begin{array}{l}28.0 \\
29.0\end{array}$ & $\begin{array}{l}2 \\
1\end{array}$ \\
\hline 55 & 45.0 & 3 & 45.0 & 3 & 45.0 & 3 & 44.0 & 3 & 42.0 & 3 & 42.0 & 3 & 39.0 & 3 & 38.0 & 3 & 33.0 & 3 & 27.0 & \\
\hline
\end{tabular}

DURATION OF DISCHARGE FOR EACH WATER YEAR

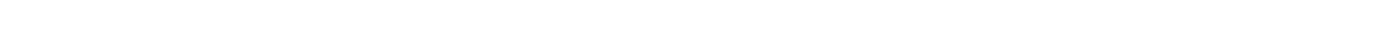
YEAR NUMBER OF DAYS IN OLASS

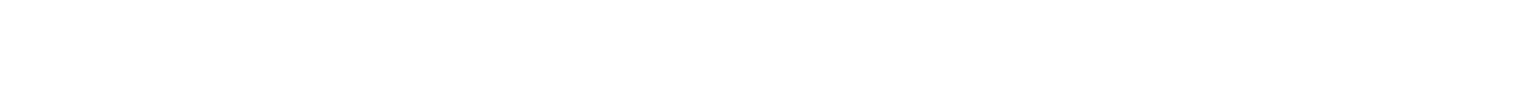

DURATION TABLE OF DISCHARGE FOR WATER YEARS 1944-45, 1955

$\begin{array}{ccc}\text { CUBIC } & \text { ACCU- } \\ \text { FEET } & \text { MU- } & \text { PER- } \\ \text { PER TOTAL LATED } & \text { CENT } \\ \text { CLASS SECOND DAYS DAYS } & \text { DAYS }\end{array}$

$\begin{array}{lll}\text { CUBIC } & \text { ACON- } \\ \text { FEET } & \text { MU- } & \text { PER- } \\ \text { PER TOTAL LATED } & \text { CENT }\end{array}$

$\begin{array}{ccc}\text { OBBIC } & \text { ACOU- } \\ \text { FEET } & \text { MU- } & \text { PER- } \\ \text { PER TOTAL LATED } & \text { CENT }\end{array}$

GLASS SECOND DAYS DAYS DAYS

$\begin{array}{ccc}\text { CUBIC } & \text { ACOU- } \\ \text { FEET } & \text { MJ- } & \text { PER- } \\ \text { PER } & \text { TOTAL LATED } & \text { CENT } \\ \text { CLASS SECOND DAYS DAYS } & \text { DAYS }\end{array}$

$\begin{array}{rrrrr}0 & 0.00 & 0 & 1096 & 100.0 \\ 1 & 15.00 & 53 & 1096 & 100.0 \\ 2 & 16.00 & 63 & 1043 & 95.2 \\ 3 & 17.00 & 56 & 980 & 89.4 \\ 4 & 18.00 & 130 & 924 & 84.3 \\ 5 & 19.00 & 49 & 794 & 72.4 \\ 6 & 20.00 & 55 & 745 & 68.0 \\ 7 & 21.00 & 36 & 690 & 63.0 \\ 8 & 22.00 & 24 & 654 & 59.7\end{array}$

$\begin{array}{rrr}9 & 23.00 & 29 \\ 10 & 24.00 & 48 \\ 11 & 25.00 & 36 \\ 12 & 26.00 & 36 \\ 13 & 27.00 & 19 \\ 14 & 28.00 & 35 \\ 15 & 29.00 & 10 \\ 16 & 30.00 & 14 \\ 17 & 31.00 & 22\end{array}$

$\begin{array}{ll}630 & 57.5 \\ 601 & 54.8 \\ 553 & 50.5 \\ 517 & 47.2 \\ 481 & 43.9 \\ 462 & 42.2 \\ 427 & 39.0 \\ 417 & 38.0 \\ 403 & 36.8\end{array}$

$\begin{array}{lllll}18 & 33.0 & 11 & 381 & 34.8 \\ 19 & 34.0 & 12 & 370 & 33.8 \\ 20 & 35.0 & 16 & 358 & 32.7 \\ 21 & 36.0 & 37 & 342 & 31.2 \\ 22 & 38.0 & 31 & 305 & 27.8 \\ 23 & 39.0 & 10 & 274 & 25.0 \\ 24 & 40.0 & 69 & 264 & 24.1 \\ 25 & 42.0 & 33 & 195 & 17.8 \\ 26 & 43.0 & 86 & 162 & 14.8\end{array}$

$\begin{array}{rrrrr}27 & 45.0 & 18 & 76 & 6.9 \\ 28 & 46.0 & 49 & 58 & 5.3 \\ 29 & 48.0 & 9 & 9 & 0.8\end{array}$

MONIHLY MEAN DISCHARGES, IN CUBIC FEET PER SECOND, FOR EACH WATER YEAR

\begin{tabular}{|c|c|c|c|c|c|c|c|c|c|c|c|c|}
\hline YEAR & $\propto \Gamma$ & $\mathrm{NOV}$ & DEC & JAN & FEB & MAR & APR & MAY & JUNE & JULY & AUG & SEP \\
\hline $\begin{array}{l}1944 \\
1945\end{array}$ & $\begin{array}{l}24.3 \\
27.4\end{array}$ & $\begin{array}{l}21.9 \\
25.1\end{array}$ & $\begin{array}{l}19.3 \\
20.8\end{array}$ & $\begin{array}{l}16.5 \\
19.2\end{array}$ & $\begin{array}{l}15.3 \\
18.0\end{array}$ & $\begin{array}{l}15.1 \\
18.0\end{array}$ & $\begin{array}{l}16.7 \\
19.2\end{array}$ & $\begin{array}{l}37.9 \\
40.5\end{array}$ & $\begin{array}{l}47.3 \\
42.9\end{array}$ & $\begin{array}{l}45.0 \\
41.9\end{array}$ & $\begin{array}{l}42.1 \\
38.9\end{array}$ & $\begin{array}{l}32.4 \\
36.7\end{array}$ \\
\hline 1955 & 26.0 & 24.2 & 21.7 & 18.9 & 17.4 & 16.5 & 19.2 & 40.3 & 41.2 & 36.4 & 32.0 & 28.1 \\
\hline
\end{tabular}

09266500 ASHLEY CREEK NEAR VERNAL, UT

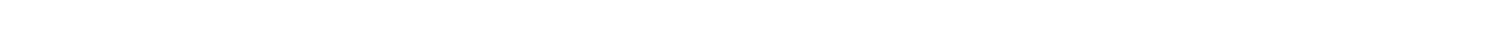
bank $0.8 \mathrm{mi}$ upstream fram head of Utah Power \& Light Co.'s canal, $4.5 \mathrm{mi}$ upstream fram Dry Fork, and $10 \mathrm{mi}$ northwest of Vernal.

DRATNAGE AREA.--101 $\mathrm{mi}^{2}$.

MEAN BASIN ELEVATION.--9,440 ft.

PERIOD OF RECORD AVAIIABLE.--October 1911 to April 1912 and August to December 1912 (monthly mean discharge only, published in wSP 1313). October 1913 to September 1981 (October 1913 to September 1914, October 1917 to September 1918, monthly mean discharge only).

GAGE,--Water-stage recorder. Datum of gage is $6,230 \mathrm{ft}$ NGVD of 1929 . Prior to Nov. 13, 1917, nonrecording and water-stage recorder at several sites within $1.5 \mathrm{mi}$ of present site at various datums. Nov. 14, 1917 to July 15, 1965, water-stage recorder at site $75 \mathrm{ft}$ downstream at various datums. July 15, 1965 to July 30, 1968, water-stage recorder at site $75 \mathrm{ft}$ downstream at daturn $0.09 \mathrm{ft}$ higher.

REMARKS.--Flow increased since July 1940 by water released from Oaks Park Reservoir, capacity, 6,250 acre-ft, on Big Brush Creek and diverted to Ashley Creek basin for irrigation. City of Vernal pipeline, capacity, approximately $11 \mathrm{ft}^{3} / \mathrm{s}$, diverts water from tributary spring about 1,000 ft above station (diversion began Aug. 1, 1941); at times, part of this flow is returned to Ashley Creek $2.5 \mathrm{mi}$ below station. Prior to September 191, pipeline capacity was approximately $5 \mathrm{ft}^{3} / \mathrm{s}$ and the return flow entered Ashley Creek $0.5 \mathrm{mi}$ below station.

AVERAGE DISCHARGE. -68 years (water years 1914-81), $98.5 \mathrm{ft}^{3} / \mathrm{s}, 71,360 \mathrm{acre}-\mathrm{ft} / \mathrm{yr}$.

EXIREMES FOR PERIOD OF RECORD.--Maximum discharge, about 3,500 ft $3 / \mathrm{s}$ June 11, 1965, from rating table extended above 1,060 $\mathrm{ft}^{3} / \mathrm{s}$; maximum gage height, $6.09 \mathrm{ft}$ June 16,1929 , present datum; minimum discharge, $3.2 \mathrm{ft}^{3} / \mathrm{s} \mathrm{Mar} .16,1978$. 
GREEN RIVER BASIN

09266500 ASHLEY CREEK NEAR VERNAL, UT--Continued

LOWEST MEAN DISCHARGE, IN CUBIC FEET PER SECOND, AND RANKING FOR THE INDICATED NUMBER OF CONSECUTIVE DAYS FOR EACH CLIMATIC YEAR, APRIL 1-MARCH 31

\begin{tabular}{|c|c|c|c|c|c|c|c|c|c|c|c|c|c|c|c|c|c|c|c|c|}
\hline 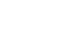 & 1 & & 3 & & 7 & & 14 & & 30 & 政 & 60 & & 90 & & 120 & & 183 & & ALL & \\
\hline $\begin{array}{l}1916 \\
1917 \\
1920\end{array}$ & $\begin{array}{l}33.0 \\
30.0 \\
26.0\end{array}$ & $\begin{array}{l}62 \\
58 \\
52\end{array}$ & $\begin{array}{l}33.0 \\
30.0 \\
26.0\end{array}$ & $\begin{array}{l}62 \\
58 \\
52\end{array}$ & $\begin{array}{l}33.0 \\
30.0 \\
27.0\end{array}$ & $\begin{array}{l}60 \\
57 \\
52\end{array}$ & $\begin{array}{l}33.0 \\
30.0 \\
28.0\end{array}$ & $\begin{array}{l}60 \\
56 \\
51\end{array}$ & $\begin{array}{l}33.0 \\
30.0 \\
28.0\end{array}$ & $\begin{array}{l}58 \\
53 \\
49\end{array}$ & $\begin{array}{l}35.0 \\
30.0 \\
29.0\end{array}$ & $\begin{array}{l}59 \\
52 \\
50\end{array}$ & $\begin{array}{l}37.0 \\
32.0 \\
30.0\end{array}$ & $\begin{array}{l}60 \\
52 \\
49\end{array}$ & $\begin{array}{l}40.0 \\
35.0 \\
30.0\end{array}$ & $\begin{array}{l}58 \\
52 \\
47\end{array}$ & $\begin{array}{l}50.0 \\
48.0 \\
38.0\end{array}$ & $\begin{array}{l}56 \\
54 \\
47\end{array}$ & $\begin{array}{c}127 \\
110 \\
67.0\end{array}$ & $\begin{array}{l}52 \\
42 \\
11\end{array}$ \\
\hline $\begin{array}{l}1921 \\
1922 \\
1923 \\
1924 \\
1925\end{array}$ & $\begin{array}{l}28.0 \\
35.0 \\
33.0 \\
33.0 \\
29.0\end{array}$ & $\begin{array}{l}53 \\
63 \\
59 \\
60 \\
56\end{array}$ & $\begin{array}{l}28.0 \\
35.0 \\
33.0 \\
33.0 \\
29.0\end{array}$ & $\begin{array}{l}53 \\
63 \\
59 \\
60 \\
55\end{array}$ & $\begin{array}{l}29.0 \\
35.0 \\
34.0 \\
34.0 \\
29.0\end{array}$ & $\begin{array}{l}54 \\
64 \\
61 \\
62 \\
55\end{array}$ & $\begin{array}{l}29.0 \\
35.0 \\
35.0 \\
34.0 \\
30.0\end{array}$ & $\begin{array}{l}54 \\
63 \\
64 \\
61 \\
57\end{array}$ & $\begin{array}{l}30.0 \\
36.0 \\
35.0 \\
34.0 \\
30.0\end{array}$ & $\begin{array}{l}54 \\
64 \\
63 \\
60 \\
55\end{array}$ & $\begin{array}{l}34.0 \\
37.0 \\
37.0 \\
35.0 \\
30.0\end{array}$ & $\begin{array}{l}56 \\
62 \\
63 \\
60 \\
51\end{array}$ & $\begin{array}{l}35.0 \\
39.0 \\
40.0 \\
36.0 \\
30.0\end{array}$ & $\begin{array}{l}56 \\
61 \\
63 \\
57 \\
50\end{array}$ & $\begin{array}{l}38.0 \\
41.0 \\
43.0 \\
37.0 \\
31.0\end{array}$ & $\begin{array}{l}57 \\
59 \\
63 \\
54 \\
48\end{array}$ & $\begin{array}{l}44.0 \\
51.0 \\
52.0 \\
43.0 \\
33.0\end{array}$ & $\begin{array}{l}53 \\
57 \\
58 \\
50 \\
43\end{array}$ & $\begin{array}{c}129 \\
181 \\
176 \\
135 \\
73.0\end{array}$ & $\begin{array}{l}55 \\
64 \\
63 \\
57 \\
15\end{array}$ \\
\hline $\begin{array}{l}1926 \\
1927 \\
1928 \\
1929 \\
1930\end{array}$ & $\begin{array}{l}28.0 \\
25.0 \\
26.0 \\
29.0 \\
35.0\end{array}$ & $\begin{array}{l}54 \\
50 \\
51 \\
57 \\
64\end{array}$ & $\begin{array}{l}29.0 \\
25.0 \\
26.0 \\
29.0 \\
35.0\end{array}$ & $\begin{array}{l}56 \\
50 \\
51 \\
57 \\
64\end{array}$ & $\begin{array}{l}30.0 \\
25.0 \\
27.0 \\
29.0 \\
35.0\end{array}$ & $\begin{array}{l}58 \\
50 \\
51 \\
56 \\
63\end{array}$ & $\begin{array}{l}30.0 \\
25.0 \\
28.0 \\
29.0 \\
35.0\end{array}$ & $\begin{array}{l}58 \\
49 \\
52 \\
55 \\
62\end{array}$ & $\begin{array}{l}30.0 \\
26.0 \\
35.0 \\
29.0 \\
35.0\end{array}$ & $\begin{array}{l}56 \\
46 \\
61 \\
52 \\
62\end{array}$ & $\begin{array}{l}31.0 \\
26.0 \\
37.0 \\
31.0 \\
36.0\end{array}$ & $\begin{array}{l}53 \\
44 \\
64 \\
54 \\
61\end{array}$ & $\begin{array}{l}34.0 \\
27.0 \\
40.0 \\
33.0 \\
39.0\end{array}$ & $\begin{array}{l}54 \\
45 \\
64 \\
53 \\
62\end{array}$ & $\begin{array}{l}38.0 \\
28.0 \\
44.0 \\
33.0 \\
42.0\end{array}$ & $\begin{array}{l}55 \\
45 \\
64 \\
51 \\
62\end{array}$ & $\begin{array}{l}57.0 \\
32.0 \\
64.0 \\
38.0 \\
55.0\end{array}$ & $\begin{array}{l}61 \\
39 \\
63 \\
48 \\
60\end{array}$ & $\begin{array}{l}93.0 \\
88.0 \\
135 \\
108 \\
142\end{array}$ & $\begin{array}{l}33 \\
29 \\
58 \\
40 \\
60\end{array}$ \\
\hline $\begin{array}{l}1931 \\
1932 \\
1933 \\
1934 \\
1935\end{array}$ & $\begin{array}{l}33.0 \\
28.0 \\
20.0 \\
20.0 \\
21.0\end{array}$ & $\begin{array}{l}61 \\
55 \\
42 \\
43 \\
45\end{array}$ & $\begin{array}{l}33.0 \\
28.0 \\
21.0 \\
20.0 \\
21.0\end{array}$ & $\begin{array}{l}61 \\
54 \\
44 \\
42 \\
45\end{array}$ & $\begin{array}{l}33.0 \\
28.0 \\
21.0 \\
20.0 \\
21.0\end{array}$ & $\begin{array}{l}59 \\
53 \\
45 \\
42 \\
43\end{array}$ & $\begin{array}{l}33.0 \\
28.0 \\
21.0 \\
20.0 \\
25.0\end{array}$ & $\begin{array}{l}59 \\
53 \\
44 \\
41 \\
50\end{array}$ & $\begin{array}{l}33.0 \\
28.0 \\
22.0 \\
20.0 \\
26.0\end{array}$ & $\begin{array}{l}59 \\
50 \\
42 \\
37 \\
47\end{array}$ & $\begin{array}{l}34.0 \\
28.0 \\
23.0 \\
20.0 \\
26.0\end{array}$ & $\begin{array}{l}57 \\
48 \\
38 \\
31 \\
45\end{array}$ & $\begin{array}{l}36.0 \\
29.0 \\
24.0 \\
20.0 \\
26.0\end{array}$ & $\begin{array}{l}58 \\
47 \\
37 \\
28 \\
42\end{array}$ & $\begin{array}{l}38.0 \\
29.0 \\
25.0 \\
21.0 \\
27.0\end{array}$ & $\begin{array}{l}56 \\
46 \\
37 \\
26 \\
42\end{array}$ & $\begin{array}{l}50.0 \\
30.0 \\
33.0 \\
23.0 \\
29.0\end{array}$ & $\begin{array}{l}55 \\
35 \\
40 \\
21 \\
31\end{array}$ & $\begin{array}{c}114 \\
49.0 \\
104 \\
62.0 \\
46.0\end{array}$ & $\begin{array}{r}43 \\
3 \\
36 \\
9 \\
2\end{array}$ \\
\hline $\begin{array}{l}1941 \\
1942 \\
1943 \\
1944 \\
1945\end{array}$ & $\begin{array}{l}24.0 \\
25.0 \\
17.0 \\
17.0 \\
18.0\end{array}$ & $\begin{array}{l}48 \\
49 \\
32 \\
33 \\
38\end{array}$ & $\begin{array}{l}24.0 \\
25.0 \\
17.0 \\
17.0 \\
18.0\end{array}$ & $\begin{array}{l}48 \\
49 \\
32 \\
33 \\
38\end{array}$ & $\begin{array}{l}24.0 \\
25.0 \\
17.0 \\
17.0 \\
19.0\end{array}$ & $\begin{array}{l}48 \\
49 \\
29 \\
30 \\
39\end{array}$ & $\begin{array}{l}25.0 \\
25.0 \\
17.0 \\
18.0 \\
20.0\end{array}$ & $\begin{array}{l}47 \\
48 \\
28 \\
33 \\
39\end{array}$ & $\begin{array}{l}28.0 \\
27.0 \\
17.0 \\
18.0 \\
20.0\end{array}$ & $\begin{array}{l}51 \\
48 \\
27 \\
31 \\
38\end{array}$ & $\begin{array}{l}28.0 \\
31.0 \\
18.0 \\
18.0 \\
20.0\end{array}$ & $\begin{array}{l}49 \\
55 \\
26 \\
27 \\
32\end{array}$ & $\begin{array}{l}29.0 \\
35.0 \\
19.0 \\
19.0 \\
21.0\end{array}$ & $\begin{array}{l}48 \\
55 \\
24 \\
25 \\
33\end{array}$ & $\begin{array}{l}31.0 \\
42.0 \\
21.0 \\
21.0 \\
22.0\end{array}$ & $\begin{array}{l}49 \\
61 \\
28 \\
29 \\
30\end{array}$ & $\begin{array}{l}44.0 \\
72.0 \\
28.0 \\
25.0 \\
27.0\end{array}$ & $\begin{array}{l}52 \\
64 \\
30 \\
23 \\
27\end{array}$ & $\begin{array}{c}74.0 \\
142 \\
118 \\
86.0 \\
131\end{array}$ & $\begin{array}{l}16 \\
61 \\
47 \\
27 \\
56\end{array}$ \\
\hline $\begin{array}{l}1946 \\
1947 \\
1948 \\
1949 \\
1950\end{array}$ & $\begin{array}{l}18.0 \\
19.0 \\
20.0 \\
15.0 \\
15.0\end{array}$ & $\begin{array}{l}39 \\
40 \\
41 \\
22 \\
23\end{array}$ & $\begin{array}{l}18.0 \\
19.0 \\
20.0 \\
15.0 \\
15.0\end{array}$ & $\begin{array}{l}39 \\
40 \\
41 \\
23 \\
24\end{array}$ & $\begin{array}{l}18.0 \\
20.0 \\
20.0 \\
15.0 \\
16.0\end{array}$ & $\begin{array}{l}37 \\
40 \\
41 \\
23 \\
24\end{array}$ & $\begin{array}{l}18.0 \\
20.0 \\
21.0 \\
16.0 \\
18.0\end{array}$ & $\begin{array}{l}34 \\
40 \\
43 \\
24 \\
35\end{array}$ & $\begin{array}{l}19.0 \\
25.0 \\
21.0 \\
16.0 \\
22.0\end{array}$ & $\begin{array}{l}34 \\
45 \\
39 \\
21 \\
41\end{array}$ & $\begin{array}{l}20.0 \\
26.0 \\
22.0 \\
16.0 \\
23.0\end{array}$ & $\begin{array}{l}33 \\
46 \\
36 \\
19 \\
40\end{array}$ & $\begin{array}{l}20.0 \\
28.0 \\
24.0 \\
16.0 \\
24.0\end{array}$ & $\begin{array}{l}30 \\
46 \\
39 \\
19 \\
40\end{array}$ & $\begin{array}{l}22.0 \\
31.0 \\
26.0 \\
17.0 \\
25.0\end{array}$ & $\begin{array}{l}31 \\
50 \\
40 \\
18 \\
38\end{array}$ & $\begin{array}{l}31.0 \\
38.0 \\
37.0 \\
20.0 \\
33.0\end{array}$ & $\begin{array}{l}36 \\
49 \\
45 \\
13 \\
41\end{array}$ & $\begin{array}{r}88.0 \\
69.0 \\
127 \\
85.0 \\
117\end{array}$ & $\begin{array}{l}30 \\
14 \\
53 \\
24 \\
45\end{array}$ \\
\hline $\begin{array}{l}1961 \\
1962 \\
1963 \\
1964 \\
1965\end{array}$ & $\begin{array}{c}11.0 \\
12.0 \\
9.60 \\
11.0 \\
10.0\end{array}$ & $\begin{array}{r}16 \\
19 \\
9 \\
17 \\
12\end{array}$ & $\begin{array}{c}11.0 \\
13.0 \\
9.60 \\
11.0 \\
10.0\end{array}$ & $\begin{array}{r}16 \\
20 \\
8 \\
17 \\
12\end{array}$ & $\begin{array}{c}11.0 \\
13.0 \\
9.70 \\
11.0 \\
10.0\end{array}$ & $\begin{array}{r}12 \\
20 \\
8 \\
13 \\
9\end{array}$ & $\begin{array}{c}11.0 \\
14.0 \\
9.80 \\
11.0 \\
10.0\end{array}$ & $\begin{array}{r}13 \\
20 \\
7 \\
14 \\
10\end{array}$ & $\begin{array}{c}11.0 \\
15.0 \\
9.90 \\
12.0 \\
11.0\end{array}$ & $\begin{array}{r}9 \\
19 \\
6 \\
13 \\
10\end{array}$ & $\begin{array}{l}12.0 \\
28.0 \\
10.0 \\
12.0 \\
11.0\end{array}$ & $\begin{array}{r}10 \\
47 \\
6 \\
11 \\
7\end{array}$ & $\begin{array}{l}13.0 \\
31.0 \\
11.0 \\
12.0 \\
12.0\end{array}$ & $\begin{array}{r}11 \\
51 \\
6 \\
7 \\
8\end{array}$ & $\begin{array}{l}15.0 \\
36.0 \\
13.0 \\
13.0 \\
13.0\end{array}$ & $\begin{array}{r}15 \\
53 \\
7 \\
8 \\
9\end{array}$ & $\begin{array}{l}18.0 \\
53.0 \\
20.0 \\
18.0 \\
19.0\end{array}$ & $\begin{array}{r}8 \\
59 \\
16 \\
9 \\
11\end{array}$ & $\begin{array}{c}58.0 \\
91.0 \\
124 \\
56.0 \\
84.0\end{array}$ & $\begin{array}{r}7 \\
31 \\
50 \\
5 \\
22\end{array}$ \\
\hline $\begin{array}{l}1966 \\
1967 \\
1968 \\
1969 \\
1970\end{array}$ & $\begin{array}{c}9.70 \\
10.0 \\
11.0 \\
11.0 \\
-12.0\end{array}$ & $\begin{array}{l}10 \\
13 \\
14 \\
15 \\
18\end{array}$ & $\begin{array}{r}9.90 \\
11.0 \\
11.0 \\
11.0 \\
12.0\end{array}$ & $\begin{array}{r}9 \\
13 \\
14 \\
15 \\
18\end{array}$ & $\begin{array}{l}10.0 \\
12.0 \\
12.0 \\
11.0 \\
13.0\end{array}$ & $\begin{array}{l}10 \\
16 \\
17 \\
14 \\
18\end{array}$ & $\begin{array}{l}10.0 \\
12.0 \\
12.0 \\
11.0 \\
13.0\end{array}$ & $\begin{array}{l}11 \\
15 \\
16 \\
12 \\
17\end{array}$ & $\begin{array}{l}12.0 \\
12.0 \\
12.0 \\
11.0 \\
13.0\end{array}$ & $\begin{array}{l}14 \\
15 \\
16 \\
11 \\
17\end{array}$ & $\begin{array}{l}13.0 \\
12.0 \\
13.0 \\
12.0 \\
14.0\end{array}$ & $\begin{array}{l}15 \\
12 \\
16 \\
13 \\
17\end{array}$ & $\begin{array}{l}14.0 \\
13.0 \\
13.0 \\
13.0 \\
15.0\end{array}$ & $\begin{array}{l}17 \\
12 \\
13 \\
14 \\
18\end{array}$ & & $\begin{array}{l}19 \\
16 \\
13 \\
10 \\
17\end{array}$ & $\begin{array}{l}32.0 \\
18.0 \\
22.0 \\
23.0 \\
21.0\end{array}$ & $\begin{array}{l}38 \\
10 \\
19 \\
20 \\
17\end{array}$ & $\begin{array}{l}127 \\
75.0 \\
116 \\
115 \\
104\end{array}$ & $\begin{array}{l}51 \\
20 \\
45 \\
44 \\
37\end{array}$ \\
\hline $\begin{array}{l}1971 \\
1972 \\
1973 \\
1974 \\
1975\end{array}$ & $\begin{array}{c}9.50 \\
9.20 \\
16.0 \\
16.0 \\
5.50\end{array}$ & $\begin{array}{r}8 \\
7 \\
25 \\
26 \\
4\end{array}$ & $\begin{array}{c}9.50 \\
9.90 \\
16.0 \\
16.0 \\
5.60\end{array}$ & $\begin{array}{r}7 \\
10 \\
27 \\
28 \\
4\end{array}$ & $\begin{array}{c}9.60 \\
11.0 \\
16.0 \\
16.0 \\
5.60\end{array}$ & $\begin{array}{r}7 \\
15 \\
26 \\
27 \\
3\end{array}$ & $\begin{array}{c}9.80 \\
13.0 \\
16.0 \\
17.0 \\
5.60\end{array}$ & $\begin{array}{r}8 \\
18 \\
23 \\
26 \\
3\end{array}$ & $\begin{array}{c}10.0 \\
17.0 \\
16.0 \\
17.0 \\
5.80\end{array}$ & $\begin{array}{r}7 \\
25 \\
20 \\
26 \\
3\end{array}$ & $\begin{array}{c}11.0 \\
22.0 \\
17.0 \\
17.0 \\
6.90\end{array}$ & $\begin{array}{r}8 \\
37 \\
22 \\
23 \\
3\end{array}$ & $\begin{array}{c}12.0 \\
23.0 \\
19.0 \\
18.0 \\
7.70\end{array}$ & $\begin{array}{r}9 \\
36 \\
27 \\
22 \\
3\end{array}$ & $\begin{array}{c}13.0 \\
24.0 \\
21.0 \\
19.0 \\
8.30\end{array}$ & $\begin{array}{r}11 \\
36 \\
25 \\
22 \\
3\end{array}$ & $\begin{array}{l}20.0 \\
28.0 \\
30.0 \\
28.0 \\
10.0\end{array}$ & $\begin{array}{r}12 \\
28 \\
34 \\
29 \\
3\end{array}$ & $\begin{array}{c}104 \\
95.0 \\
92.0 \\
138 \\
54.0\end{array}$ & $\begin{array}{r}38 \\
34 \\
32 \\
59 \\
4\end{array}$ \\
\hline $\begin{array}{l}1976 \\
1977 \\
1978 \\
1979 \\
1980\end{array}$ & $\begin{array}{l}5.20 \\
3.50 \\
3.70 \\
7.00 \\
7.40\end{array}$ & $\begin{array}{l}3 \\
1 \\
2 \\
5 \\
6\end{array}$ & $\begin{array}{l}5.50 \\
3.60 \\
3.80 \\
7.00 \\
7.60\end{array}$ & $\begin{array}{l}3 \\
1 \\
2 \\
5 \\
6\end{array}$ & $\begin{array}{l}5.60 \\
3.80 \\
3.90 \\
7.20 \\
7.90\end{array}$ & $\begin{array}{l}4 \\
1 \\
2 \\
5 \\
6\end{array}$ & $\begin{array}{l}5.70 \\
4.60 \\
4.10 \\
7.60 \\
8.30\end{array}$ & $\begin{array}{l}4 \\
2 \\
1 \\
5 \\
6\end{array}$ & $\begin{array}{c}6.20 \\
5.00 \\
4.10 \\
7.80 \\
12.0\end{array}$ & $\begin{array}{r}4 \\
2 \\
1 \\
5 \\
12\end{array}$ & $\begin{array}{r}8.30 \\
5.00 \\
4.50 \\
7.90 \\
12.0\end{array}$ & $\begin{array}{r}5 \\
2 \\
1 \\
4 \\
14\end{array}$ & $\begin{array}{r}9.50 \\
5.10 \\
5.00 \\
8.20 \\
13.0\end{array}$ & $\begin{array}{r}5 \\
2 \\
1 \\
4 \\
15\end{array}$ & $\begin{array}{c}11.0 \\
6.10 \\
5.80 \\
8.80 \\
14.0\end{array}$ & $\begin{array}{r}5 \\
2 \\
1 \\
4 \\
12\end{array}$ & $\begin{array}{c}17.0 \\
9.60 \\
10.0 \\
11.0 \\
15.0\end{array}$ & $\begin{array}{l}7 \\
1 \\
2 \\
4 \\
5\end{array}$ & $\begin{array}{l}128 \\
74.0 \\
32.0 \\
68.0 \\
66.0\end{array}$ & $\begin{array}{r}54 \\
19 \\
1 \\
13 \\
10\end{array}$ \\
\hline 1981 & 9.80 & 11 & 10.0 & 11 & 10.0 & 11 & 10.0 & 9 & 11.0 & 8 & 11.0 & 9 & 12.0 & 10 & 12.0 & 6 & 17.0 & 6 & 104 & \\
\hline
\end{tabular}


GREEN RIVER BASIN

09266500 ASHLEY CREEK NEAR VERNAL, UT-Continued

HIGHEST MEAN DISCHARGE, IN CUBIC FEET PER SECOND, AND RANKING FOR THE INDICATED NUMBER OF CONSECUTIVE DAYS FOR EACH WATER YEAR, OCIOBER 1-SEPTEMBER 30

\begin{tabular}{|c|c|c|c|c|c|c|c|c|c|c|c|c|c|c|c|c|c|c|c|c|}
\hline YEAR & 1 & & 3 & & 7 & & 15 & & $\alpha$ & & $\begin{array}{c}\text { VE DAYS } \\
60\end{array}$ & & 90 & & 120 & & 183 & & ALL & \\
\hline 1915 & 855 & 30 & 818 & 28 & 681 & 32 & 526 & 36 & 518 & 25 & 410 & 20 & 318 & 22 & 265 & 22 & 203 & 20 & 126 & \\
\hline $\begin{array}{l}1916 \\
1917 \\
1919 \\
1920\end{array}$ & $\begin{array}{r}585 \\
798 \\
225 \\
1140\end{array}$ & $\begin{array}{r}45 \\
34 \\
65 \\
7\end{array}$ & $\begin{array}{r}570 \\
798 \\
225 \\
1090\end{array}$ & $\begin{array}{c}44 \\
31 \\
64 \\
7\end{array}$ & $\begin{array}{r}536 \\
798 \\
225 \\
1080\end{array}$ & $\begin{array}{r}44 \\
21 \\
64 \\
7\end{array}$ & $\begin{array}{l}417 \\
798 \\
225 \\
943\end{array}$ & $\begin{array}{r}47 \\
8 \\
63 \\
4\end{array}$ & $\begin{array}{l}392 \\
798 \\
225 \\
797\end{array}$ & $\begin{array}{r}41 \\
5 \\
61 \\
6\end{array}$ & $\begin{array}{l}345 \\
603 \\
172 \\
516\end{array}$ & $\begin{array}{r}32 \\
3 \\
61 \\
7\end{array}$ & $\begin{array}{l}274 \\
482 \\
140 \\
377\end{array}$ & $\begin{array}{r}31 \\
3 \\
62 \\
11\end{array}$ & $\begin{array}{l}230 \\
394 \\
121 \\
301\end{array}$ & $\begin{array}{r}30 \\
3 \\
62 \\
13\end{array}$ & $\begin{array}{c}172 \\
282 \\
96.0 \\
213\end{array}$ & $\begin{array}{r}31 \\
3 \\
60 \\
13\end{array}$ & $\begin{array}{c}111 \\
165 \\
70.0 \\
126\end{array}$ & 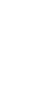 \\
\hline $\begin{array}{l}1921 \\
1922 \\
1923 \\
1924 \\
1925\end{array}$ & $\begin{array}{r}1750 \\
1480 \\
1010 \\
538 \\
354\end{array}$ & $\begin{array}{r}4 \\
5 \\
12 \\
48 \\
62\end{array}$ & $\begin{array}{r}1670 \\
1390 \\
972 \\
527 \\
325\end{array}$ & $\begin{array}{r}1 \\
5 \\
11 \\
48 \\
61\end{array}$ & $\begin{array}{r}1640 \\
1260 \\
879 \\
501 \\
258\end{array}$ & $\begin{array}{r}1 \\
3 \\
12 \\
47 \\
62\end{array}$ & $\begin{array}{r}1510 \\
1160 \\
750 \\
444 \\
250\end{array}$ & $\begin{array}{r}1 \\
2 \\
11 \\
44 \\
60\end{array}$ & $\begin{array}{r}1120 \\
1000 \\
699 \\
349 \\
233\end{array}$ & $\begin{array}{r}1 \\
2 \\
9 \\
46 \\
59\end{array}$ & $\begin{array}{l}732 \\
711 \\
509 \\
239 \\
216\end{array}$ & $\begin{array}{r}1 \\
2 \\
8 \\
49 \\
54\end{array}$ & $\begin{array}{l}544 \\
522 \\
396 \\
184 \\
181\end{array}$ & $\begin{array}{r}1 \\
2 \\
7 \\
51 \\
53\end{array}$ & $\begin{array}{l}435 \\
420 \\
319 \\
152 \\
158\end{array}$ & $\begin{array}{r}1 \\
2 \\
8 \\
53 \\
50\end{array}$ & $\begin{array}{l}312 \\
299 \\
227 \\
114 \\
128\end{array}$ & $\begin{array}{r}1 \\
2 \\
10 \\
52 \\
46\end{array}$ & $\begin{array}{r}178 \\
175 \\
140 \\
79.0 \\
81.0\end{array}$ & \\
\hline $\begin{array}{l}1926 \\
1927 \\
1928 \\
1929 \\
1930\end{array}$ & $\begin{array}{l}564 \\
954 \\
550 \\
852 \\
744\end{array}$ & $\begin{array}{l}46 \\
19 \\
47 \\
31 \\
37\end{array}$ & $\begin{array}{l}552 \\
894 \\
550 \\
817 \\
728\end{array}$ & $\begin{array}{l}45 \\
16 \\
46 \\
29 \\
36\end{array}$ & $\begin{array}{l}480 \\
735 \\
550 \\
661 \\
619\end{array}$ & $\begin{array}{l}49 \\
28 \\
43 \\
33 \\
37\end{array}$ & $\begin{array}{l}385 \\
565 \\
550 \\
623 \\
524\end{array}$ & $\begin{array}{l}51 \\
31 \\
33 \\
28 \\
37\end{array}$ & $\begin{array}{l}351 \\
443 \\
550 \\
549 \\
443\end{array}$ & $\begin{array}{l}45 \\
36 \\
21 \\
22 \\
37\end{array}$ & $\begin{array}{l}285 \\
356 \\
389 \\
488 \\
339\end{array}$ & $\begin{array}{l}41 \\
29 \\
25 \\
12 \\
33\end{array}$ & $\begin{array}{l}226 \\
289 \\
295 \\
378 \\
266\end{array}$ & $\begin{array}{l}41 \\
27 \\
26 \\
10 \\
32\end{array}$ & $\begin{array}{l}192 \\
245 \\
241 \\
310 \\
226\end{array}$ & $\begin{array}{l}41 \\
26 \\
28 \\
11 \\
31\end{array}$ & $\begin{array}{l}144 \\
206 \\
178 \\
230 \\
178\end{array}$ & $\begin{array}{r}40 \\
19 \\
27 \\
8 \\
28\end{array}$ & $\begin{array}{l}100 \\
119 \\
121 \\
134 \\
116\end{array}$ & \\
\hline $\begin{array}{l}1931 \\
1932 \\
1933 \\
1934 \\
1935\end{array}$ & $\begin{array}{l}359 \\
990 \\
913 \\
201 \\
900\end{array}$ & $\begin{array}{l}60 \\
16 \\
23 \\
66 \\
25\end{array}$ & $\begin{array}{l}321 \\
920 \\
838 \\
167 \\
867\end{array}$ & $\begin{array}{l}62 \\
15 \\
27 \\
66 \\
23\end{array}$ & $\begin{array}{l}250 \\
804 \\
725 \\
157 \\
821\end{array}$ & $\begin{array}{l}63 \\
20 \\
30 \\
66 \\
17\end{array}$ & $\begin{array}{l}210 \\
625 \\
535 \\
151 \\
665\end{array}$ & $\begin{array}{l}64 \\
27 \\
35 \\
65 \\
24\end{array}$ & $\begin{array}{l}169 \\
488 \\
360 \\
136 \\
508\end{array}$ & $\begin{array}{l}64 \\
34 \\
43 \\
65 \\
27\end{array}$ & $\begin{array}{l}124 \\
369 \\
222 \\
106 \\
338\end{array}$ & $\begin{array}{l}64 \\
27 \\
53 \\
65 \\
34\end{array}$ & $\begin{array}{c}99.0 \\
287 \\
171 \\
87.0 \\
256\end{array}$ & $\begin{array}{l}64 \\
29 \\
56 \\
65 \\
35\end{array}$ & $\begin{array}{c}85.0 \\
237 \\
139 \\
75.0 \\
207\end{array}$ & $\begin{array}{l}64 \\
29 \\
55 \\
65 \\
37\end{array}$ & $\begin{array}{c}68.0 \\
174 \\
100 \\
64.0 \\
147\end{array}$ & $\begin{array}{l}64 \\
30 \\
56 \\
65 \\
37\end{array}$ & $\begin{array}{c}59.0 \\
102 \\
67.0 \\
43.0 \\
88.0\end{array}$ & \\
\hline $\begin{array}{l}1936 \\
1937 \\
1938 \\
1939 \\
1940\end{array}$ & $\begin{array}{l}334 \\
920 \\
900 \\
531 \\
495\end{array}$ & $\begin{array}{l}63 \\
22 \\
26 \\
49 \\
55\end{array}$ & $\begin{array}{l}319 \\
878 \\
860 \\
499 \\
462\end{array}$ & $\begin{array}{l}63 \\
22 \\
25 \\
49 \\
55\end{array}$ & $\begin{array}{l}296 \\
830 \\
806 \\
490 \\
417\end{array}$ & $\begin{array}{l}60 \\
16 \\
19 \\
48 \\
53\end{array}$ & $\begin{array}{l}246 \\
722 \\
690 \\
413 \\
381\end{array}$ & $\begin{array}{l}61 \\
15 \\
20 \\
48 \\
52\end{array}$ & $\begin{array}{l}198 \\
555 \\
544 \\
325 \\
289\end{array}$ & $\begin{array}{l}63 \\
19 \\
23 \\
49 \\
54\end{array}$ & $\begin{array}{l}152 \\
396 \\
382 \\
237 \\
215\end{array}$ & $\begin{array}{l}63 \\
23 \\
26 \\
50 \\
55\end{array}$ & $\begin{array}{l}124 \\
311 \\
298 \\
186 \\
173\end{array}$ & $\begin{array}{l}63 \\
23 \\
25 \\
50 \\
55\end{array}$ & $\begin{array}{l}113 \\
257 \\
248 \\
155 \\
139\end{array}$ & $\begin{array}{l}63 \\
23 \\
25 \\
51 \\
56\end{array}$ & $\begin{array}{l}92.0 \\
186 \\
183 \\
124 \\
105\end{array}$ & $\begin{array}{l}63 \\
25 \\
26 \\
48 \\
55\end{array}$ & $\begin{array}{c}57.0 \\
109 \\
106 \\
92.0 \\
74.0\end{array}$ & \\
\hline $\begin{array}{l}1941 \\
1942 \\
1943 \\
1944 \\
1945\end{array}$ & $\begin{array}{r}1000 \\
1050 \\
507 \\
1020 \\
490\end{array}$ & $\begin{array}{r}13 \\
9 \\
52 \\
11 \\
56\end{array}$ & $\begin{array}{r}885 \\
941 \\
479 \\
1000 \\
446\end{array}$ & $\begin{array}{r}17 \\
13 \\
52 \\
9 \\
56\end{array}$ & $\begin{array}{l}749 \\
808 \\
452 \\
901 \\
364\end{array}$ & $\begin{array}{l}26 \\
18 \\
50 \\
10 \\
58\end{array}$ & $\begin{array}{l}675 \\
729 \\
380 \\
790 \\
340\end{array}$ & $\begin{array}{r}22 \\
12 \\
53 \\
9 \\
55\end{array}$ & $\begin{array}{l}602 \\
598 \\
299 \\
711 \\
322\end{array}$ & $\begin{array}{r}13 \\
16 \\
53 \\
8 \\
51\end{array}$ & $\begin{array}{l}447 \\
404 \\
259 \\
531 \\
265\end{array}$ & $\begin{array}{r}14 \\
22 \\
45 \\
6 \\
43\end{array}$ & $\begin{array}{l}346 \\
322 \\
219 \\
409 \\
223\end{array}$ & $\begin{array}{r}15 \\
21 \\
43 \\
6 \\
42\end{array}$ & $\begin{array}{l}286 \\
274 \\
193 \\
337 \\
193\end{array}$ & $\begin{array}{r}16 \\
19 \\
39 \\
6 \\
40\end{array}$ & $\begin{array}{l}211 \\
207 \\
147 \\
234 \\
145\end{array}$ & $\begin{array}{r}14 \\
18 \\
38 \\
7 \\
39\end{array}$ & $\begin{array}{c}127 \\
139 \\
87.0 \\
129 \\
86.0\end{array}$ & \\
\hline $\begin{array}{l}1946 \\
1947 \\
1948 \\
1949 \\
1950\end{array}$ & $\begin{array}{l}359 \\
894 \\
970 \\
720 \\
876\end{array}$ & $\begin{array}{l}61 \\
27 \\
17 \\
39 \\
28\end{array}$ & $\begin{array}{l}340 \\
885 \\
864 \\
658 \\
842\end{array}$ & $\begin{array}{l}60 \\
18 \\
24 \\
39 \\
26\end{array}$ & $\begin{array}{l}292 \\
771 \\
779 \\
615 \\
738\end{array}$ & $\begin{array}{l}61 \\
23 \\
22 \\
38 \\
27\end{array}$ & $\begin{array}{l}242 \\
580 \\
668 \\
516 \\
707\end{array}$ & $\begin{array}{l}62 \\
30 \\
23 \\
38 \\
18\end{array}$ & $\begin{array}{l}199 \\
527 \\
504 \\
503 \\
583\end{array}$ & $\begin{array}{l}62 \\
24 \\
28 \\
29 \\
17\end{array}$ & $\begin{array}{l}170 \\
431 \\
318 \\
425 \\
405\end{array}$ & $\begin{array}{l}62 \\
17 \\
37 \\
19 \\
21\end{array}$ & $\begin{array}{l}147 \\
346 \\
251 \\
333 \\
325\end{array}$ & $\begin{array}{l}61 \\
16 \\
37 \\
17 \\
20\end{array}$ & $\begin{array}{l}124 \\
290 \\
210 \\
281 \\
280\end{array}$ & $\begin{array}{l}61 \\
15 \\
34 \\
17 \\
18\end{array}$ & $\begin{array}{l}99.0 \\
216 \\
150 \\
202 \\
208\end{array}$ & $\begin{array}{l}57 \\
12 \\
36 \\
21 \\
16\end{array}$ & $\begin{array}{c}65.0 \\
127 \\
93.0 \\
111 \\
121\end{array}$ & \\
\hline $\begin{array}{l}1951 \\
1952 \\
1953 \\
1954 \\
1955\end{array}$ & $\begin{array}{r}745 \\
1040 \\
513 \\
496 \\
460\end{array}$ & $\begin{array}{l}36 \\
10 \\
51 \\
54 \\
57\end{array}$ & $\begin{array}{l}705 \\
998 \\
486 \\
466 \\
437\end{array}$ & $\begin{array}{l}37 \\
10 \\
50 \\
53 \\
57\end{array}$ & $\begin{array}{l}645 \\
885 \\
437 \\
446 \\
379\end{array}$ & $\begin{array}{l}35 \\
11 \\
52 \\
51 \\
56\end{array}$ & $\begin{array}{l}490 \\
723 \\
397 \\
410 \\
340\end{array}$ & $\begin{array}{l}41 \\
14 \\
50 \\
49 \\
56\end{array}$ & $\begin{array}{l}352 \\
599 \\
345 \\
314 \\
287\end{array}$ & $\begin{array}{l}44 \\
14 \\
48 \\
52 \\
55\end{array}$ & $\begin{array}{l}251 \\
501 \\
241 \\
226 \\
224\end{array}$ & $\begin{array}{r}46 \\
9 \\
48 \\
51 \\
52\end{array}$ & $\begin{array}{l}210 \\
392 \\
201 \\
193 \\
182\end{array}$ & $\begin{array}{r}45 \\
8 \\
47 \\
49 \\
52\end{array}$ & $\begin{array}{l}182 \\
337 \\
168 \\
166 \\
152\end{array}$ & $\begin{array}{r}44 \\
7 \\
46 \\
49 \\
52\end{array}$ & $\begin{array}{l}134 \\
247 \\
122 \\
122 \\
111\end{array}$ & $\begin{array}{r}43 \\
5 \\
49 \\
50 \\
53\end{array}$ & $\begin{array}{c}82.0 \\
141 \\
80.0 \\
74.0 \\
68.0\end{array}$ & \\
\hline $\begin{array}{l}1956 \\
1957 \\
1958 \\
1959 \\
1960\end{array}$ & $\begin{array}{l}634 \\
936 \\
754 \\
389 \\
527\end{array}$ & $\begin{array}{l}42 \\
21 \\
35 \\
59 \\
50\end{array}$ & $\begin{array}{l}577 \\
883 \\
740 \\
384 \\
486\end{array}$ & $\begin{array}{l}42 \\
19 \\
34 \\
59 \\
51\end{array}$ & $\begin{array}{l}564 \\
840 \\
699 \\
333 \\
384\end{array}$ & $\begin{array}{l}41 \\
14 \\
31 \\
59 \\
54\end{array}$ & $\begin{array}{l}498 \\
702 \\
633 \\
254 \\
307\end{array}$ & $\begin{array}{l}40 \\
19 \\
26 \\
59 \\
57\end{array}$ & $\begin{array}{l}418 \\
550 \\
495 \\
230 \\
282\end{array}$ & $\begin{array}{l}39 \\
20 \\
31 \\
60 \\
57\end{array}$ & $\begin{array}{l}286 \\
366 \\
323 \\
184 \\
203\end{array}$ & $\begin{array}{l}40 \\
28 \\
36 \\
60 \\
58\end{array}$ & $\begin{array}{l}230 \\
288 \\
256 \\
151 \\
163\end{array}$ & $\begin{array}{l}39 \\
28 \\
36 \\
60 \\
58\end{array}$ & $\begin{array}{l}190 \\
243 \\
210 \\
128 \\
138\end{array}$ & $\begin{array}{l}42 \\
27 \\
35 \\
60 \\
58\end{array}$ & $\begin{array}{c}136 \\
176 \\
151 \\
94.0 \\
99.0\end{array}$ & $\begin{array}{l}42 \\
29 \\
34 \\
61 \\
58\end{array}$ & $\begin{array}{l}80.0 \\
98.0 \\
92.0 \\
57.0 \\
59.0\end{array}$ & \\
\hline $\begin{array}{l}1961 \\
1962 \\
1963 \\
1964 \\
1965\end{array}$ & $\begin{array}{r}588 \\
996 \\
448 \\
1000 \\
1790\end{array}$ & $\begin{array}{r}44 \\
15 \\
58 \\
14 \\
2\end{array}$ & $\begin{array}{r}571 \\
954 \\
390 \\
934 \\
1550\end{array}$ & $\begin{array}{r}43 \\
12 \\
58 \\
14 \\
4\end{array}$ & $\begin{array}{r}502 \\
862 \\
369 \\
909 \\
1150\end{array}$ & $\begin{array}{r}45 \\
13 \\
57 \\
9 \\
5\end{array}$ & $\begin{array}{l}427 \\
621 \\
346 \\
678 \\
885\end{array}$ & $\begin{array}{r}46 \\
29 \\
54 \\
21 \\
7\end{array}$ & $\begin{array}{l}348 \\
497 \\
283 \\
509 \\
682\end{array}$ & $\begin{array}{l}47 \\
30 \\
56 \\
26 \\
10\end{array}$ & $\begin{array}{l}246 \\
444 \\
194 \\
346 \\
493\end{array}$ & $\begin{array}{l}47 \\
15 \\
59 \\
31 \\
11\end{array}$ & $\begin{array}{l}201 \\
372 \\
157 \\
265 \\
378\end{array}$ & $\begin{array}{r}48 \\
13 \\
59 \\
33 \\
9\end{array}$ & $\begin{array}{l}168 \\
311 \\
128 \\
215 \\
312\end{array}$ & $\begin{array}{r}47 \\
10 \\
59 \\
33 \\
9\end{array}$ & $\begin{array}{c}130 \\
227 \\
94.0 \\
150 \\
222\end{array}$ & $\begin{array}{r}45 \\
9 \\
62 \\
35 \\
11\end{array}$ & $\begin{array}{c}74.0 \\
140 \\
57.0 \\
84.0 \\
121\end{array}$ & \\
\hline $\begin{array}{l}1966 \\
1967 \\
1968 \\
1969 \\
1970\end{array}$ & $\begin{array}{r}664 \\
1140 \\
1970 \\
910 \\
940\end{array}$ & $\begin{array}{r}40 \\
8 \\
1 \\
24 \\
20\end{array}$ & $\begin{array}{r}628 \\
1080 \\
1630 \\
798 \\
880\end{array}$ & $\begin{array}{r}40 \\
8 \\
2 \\
30 \\
21\end{array}$ & $\begin{array}{r}551 \\
965 \\
1300 \\
763 \\
758\end{array}$ & $\begin{array}{r}42 \\
8 \\
2 \\
24 \\
25\end{array}$ & $\begin{array}{r}440 \\
762 \\
1030 \\
713 \\
724\end{array}$ & $\begin{array}{r}45 \\
10 \\
3 \\
17 \\
13\end{array}$ & $\begin{array}{l}387 \\
647 \\
794 \\
558 \\
608\end{array}$ & $\begin{array}{r}42 \\
11 \\
7 \\
18 \\
12\end{array}$ & $\begin{array}{l}268 \\
498 \\
485 \\
394 \\
431\end{array}$ & $\begin{array}{l}42 \\
10 \\
13 \\
24 \\
18\end{array}$ & $\begin{array}{l}213 \\
373 \\
366 \\
309 \\
331\end{array}$ & $\begin{array}{l}44 \\
12 \\
14 \\
24 \\
18\end{array}$ & $\begin{array}{l}179 \\
303 \\
295 \\
257 \\
271\end{array}$ & $\begin{array}{l}45 \\
12 \\
14 \\
24 \\
21\end{array}$ & $\begin{array}{l}132 \\
210 \\
207 \\
187 \\
189\end{array}$ & $\begin{array}{l}44 \\
15 \\
17 \\
24 \\
23\end{array}$ & $\begin{array}{l}82.0 \\
114 \\
115 \\
105 \\
105\end{array}$ & \\
\hline $\begin{array}{l}1971 \\
1972 \\
1973 \\
1974 \\
1975\end{array}$ & $\begin{array}{r}829 \\
644 \\
1400 \\
859 \\
1780\end{array}$ & $\begin{array}{r}33 \\
41 \\
6 \\
29 \\
3\end{array}$ & $\begin{array}{r}738 \\
628 \\
1300 \\
777 \\
1550\end{array}$ & $\begin{array}{r}35 \\
41 \\
6 \\
33 \\
3\end{array}$ & $\begin{array}{r}594 \\
567 \\
1120 \\
620 \\
1230\end{array}$ & $\begin{array}{r}39 \\
40 \\
6 \\
36 \\
4\end{array}$ & $\begin{array}{l}515 \\
537 \\
897 \\
468 \\
928\end{array}$ & $\begin{array}{r}39 \\
34 \\
6 \\
42 \\
5\end{array}$ & $\begin{array}{l}493 \\
468 \\
864 \\
324 \\
800\end{array}$ & $\begin{array}{r}32 \\
35 \\
3 \\
50 \\
4\end{array}$ & $\begin{array}{l}353 \\
326 \\
568 \\
209 \\
564\end{array}$ & $\begin{array}{r}30 \\
35 \\
4 \\
57 \\
5\end{array}$ & $\begin{array}{l}276 \\
258 \\
430 \\
167 \\
425\end{array}$ & $\begin{array}{r}30 \\
34 \\
4 \\
57 \\
5\end{array}$ & $\begin{array}{l}226 \\
209 \\
352 \\
139 \\
349\end{array}$ & $\begin{array}{r}32 \\
36 \\
4 \\
57 \\
5\end{array}$ & $\begin{array}{c}162 \\
154 \\
248 \\
97.0 \\
239\end{array}$ & $\begin{array}{r}32 \\
33 \\
4 \\
59 \\
6\end{array}$ & $\begin{array}{c}91.0 \\
91.0 \\
139 \\
63.0 \\
125\end{array}$ & \\
\hline $\begin{array}{l}1976 \\
1977 \\
1978 \\
1979 \\
1980\end{array}$ & $\begin{array}{l}844 \\
238 \\
596 \\
724 \\
961\end{array}$ & $\begin{array}{l}32 \\
64 \\
43 \\
38 \\
18\end{array}$ & $\begin{array}{l}794 \\
217 \\
548 \\
692 \\
882\end{array}$ & $\begin{array}{l}32 \\
65 \\
47 \\
38 \\
20\end{array}$ & $\begin{array}{l}730 \\
190 \\
501 \\
651 \\
839\end{array}$ & $\begin{array}{l}29 \\
65 \\
46 \\
34 \\
15\end{array}$ & $\begin{array}{l}644 \\
150 \\
468 \\
563 \\
714\end{array}$ & $\begin{array}{l}25 \\
66 \\
43 \\
32 \\
16\end{array}$ & $\begin{array}{l}492 \\
116 \\
421 \\
401 \\
599\end{array}$ & $\begin{array}{l}33 \\
66 \\
38 \\
40 \\
15\end{array}$ & $\begin{array}{l}317 \\
90.0 \\
286 \\
262 \\
432\end{array}$ & $\begin{array}{l}38 \\
66 \\
39 \\
44 \\
16\end{array}$ & $\begin{array}{c}249 \\
73.0 \\
226 \\
207 \\
328\end{array}$ & $\begin{array}{l}38 \\
66 \\
40 \\
46 \\
19\end{array}$ & $\begin{array}{l}199 \\
63.0 \\
184 \\
167 \\
272\end{array}$ & $\begin{array}{l}38 \\
66 \\
43 \\
48 \\
20\end{array}$ & $\begin{array}{c}137 \\
53.0 \\
126 \\
118 \\
191\end{array}$ & $\begin{array}{l}41 \\
66 \\
47 \\
51 \\
22\end{array}$ & $\begin{array}{c}77.0 \\
31.0 \\
68.0 \\
64.0 \\
103\end{array}$ & \\
\hline
\end{tabular}


09266500 ASHLEY CREEK NEAR VERNAL, UT-Continued

DURATION OF DISCHARGE FOR EACH WATER YEAR

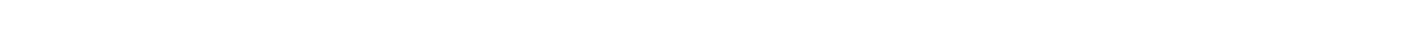
YEAR

1915

1916

1917
1919

1920

1921
1922

1923

1925

1926

1927
1928

1929
1930

1931

1932

1933
1934
1935

1935

1936

1937
1938
1939

1940

1941
1942

1943

1945

1946

1947
1948
1949

1950

1951

1952

1954

1956

1957

1959

1960

1961

1963

1964

1966

1967
1968

1969

1970

1971

1972

1974

1975

1976

1977

1978
1979

1980

1981 $\begin{array}{lllllllllllllllllll}59 & 31 & 31 & 33 & 69 & 61 & 5 & 9 & 7 & 8 & 8 & 7 & 11 & 8 & 5 & 7 & 4 & 2 & 46002.0\end{array}$

$\begin{array}{llllllllllllllllll}30 & 45 & 43 & 52 & 35 & 35 & 38 & 13 & 8 & 7 & 4 & 11 & 15 & 14 & 9 & 6 & 1 & 40700.0\end{array}$

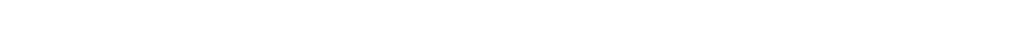
$\begin{array}{llllllllllllll}59 & 70 & 22 & 70 & 17 & 66 & & 30 & & & 31 & & & \end{array}$

$\begin{array}{lllllllllllllllllllll}145 & 1 & 29 & 15 & 65 & 14 & 24 & 5 & 4 & 5 & 7 & 8 & 4 & 2 & 2 & 4 & 5 & 8 & 5 & 7 & \end{array}$

$\begin{array}{llllllllllllllllllllllll}28 & 68 & 52 & 52 & 13 & 3 & 38 & 18 & 4 & 27 & 3 & 7 & 8 & 5 & 8 & 5 & 4 & 2 & 2 & 2 & 8 & 8 & 64991.0\end{array}$ $\begin{array}{llllllllllllllllllllll}87 & 44 & 38 & 21 & 19 & 49 & 29 & 8 & 6 & 6 & 7 & 4 & 4 & 5 & 1 & 2 & 11 & 9 & 11 & 4 & & 63902.0\end{array}$

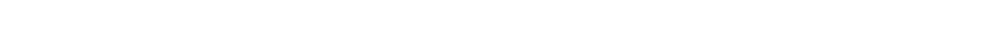
$\begin{array}{llllllllllllllllll}3 & 123 & 72 & 53 & 36 & 16 & 17 & 4 & 2 & 7 & 1 & 13 & 3 & 5 & 6 & 5 & \end{array}$ $\begin{array}{llllllllllllll}114 & 81 & 1 & 13 & 42 & 34 & 14 & 2 & 27 & 12 & 19 & 5 & 1\end{array}$

$\begin{array}{llllllllllllllll}62 & 33 & 36 & 31 & 21 & 36 & 62 & 20 & 5 & 9 & 9 & 12 & 11 & 10 & 2 & 6\end{array}$

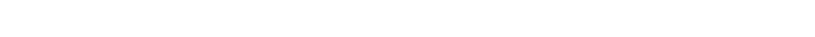

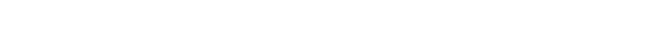

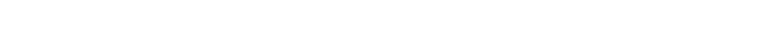

$\begin{array}{lllllllllllllllll}59 & 31 & 48 & 21 & 19 & 99 & 14 & 6 & 15 & 9 & 11 & 3 & 2 & 23 & & 3 & 2\end{array}$

$\begin{array}{llllllllllllll}57 & 96 & 91 & 18 & 28 & 17 & 28 & 10 & 7 & 4 & 2 & 3 & 3 & 1\end{array}$

$\begin{array}{lllllllllllllllllll}193 & 21 & 1 & 1 & 16 & 27 & 24 & 16 & 6 & 10 & 2 & 5 & 17 & 7 & 8 & 4 & 3 & 1 & 4\end{array}$

$\begin{array}{lllllllllllllllllllll}55 & 90 & 32 & 39 & 25 & 33 & 17 & 28 & 14 & 5 & 4 & 1 & 2 & 3 & 5 & 3 & 1 & 2 & 2 & 3 & 1\end{array}$

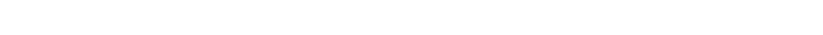

$\begin{array}{lllllllllllllllll}41 & 72 & 41 & 46 & 3 & 1 & 14 & 49 & 36 & 24 & 6 & 8 & 12 & 3 & 4 & 5 & 1\end{array}$

$\begin{array}{lllllllllllll}60 & 24 & 34 & 20 & 14 & 24 & 38 & 16 & 26 & 13 & 14 & 17 & 8\end{array}$

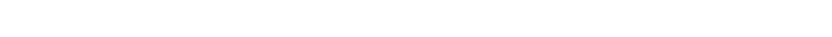

$\begin{array}{rlrrrrrrrrrrrrrrrr}3 & 91 & 16 & 67 & 45 & 38 & 44 & 29 & 54 & 16 & 8 & 13 & 8 & 8 & 7 & 4 & 3 & 5 \\ & 41 & 40 & 25 & 26 & 13 & 28 & 43 & 8 & 6 & 14 & 7 & 6 & 3 & 5 & 6 & 1\end{array}$

$\begin{array}{llllllllllllllllllll}36 & 80 & 29 & 11 & 18 & 10 & 32 & 30 & 34 & 8 & 23 & 5 & 2 & 5 & 7 & 9 & 13 & 7 & 4 & 1\end{array}$

$\begin{array}{llllllllllllllllllll}59 & 25 & 16 & 18 & 20 & 18 & 42 & 50 & 18 & 42 & 15 & 8 & 5 & 5 & 3 & 1 & 13 & 5 & 1 & 1\end{array}$

$\begin{array}{lllllllllllllllllll}44 & 46 & 32 & 24 & 24 & 7 & 41 & 13 & 15 & 5 & 26 & 16 & 27 & 12 & 13 & 10 & 3 & 5 & 2\end{array}$

$\begin{array}{rrrrrrrrrrrrrrrrrrrrrr}54 & 54 & 28 & 27 & 4 & 5 & 18 & 2 & 9 & 10 & 17 & 22 & 6 & 3 & 5 & 5 & 9 & 7 & 14 & 8 & 2 & 2\end{array}$

$\begin{array}{lllllllllllllllll}14 & 81 & 34 & 18 & 24 & 24 & 21 & 29 & 29 & 23 & 10 & 30 & 14 & 5 & 5 & 2 & 2\end{array}$

$\begin{array}{lllllllllllllllllllll}46 & 54 & 24 & 34 & 38 & 9 & 6 & 37 & 18 & 12 & 17 & 9 & 4 & 13 & 15 & 13 & 9 & 2 & 1 & 4\end{array}$

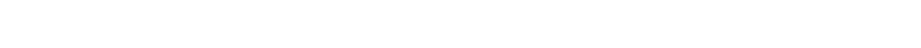

$\begin{array}{rrrrrrrrrrrrrrrrrrrrr}22 & 56 & 51 & 15 & 28 & 27 & 6 & 13 & 24 & 14 & 24 & 27 & 12 & 8 & 7 & 5 & 7 & 4 & 7 & 6 & 2\end{array}$

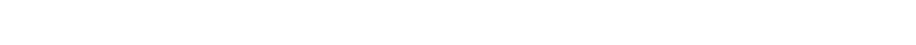

$\begin{array}{llllllllllllllllll}26 & 57 & 55 & 45 & 13 & 21 & 30 & 29 & 13 & 14 & 20 & 11 & 2 & 5 & 4 & 12 & 6 & 2\end{array}$

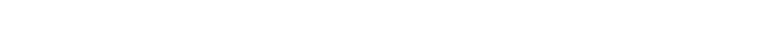

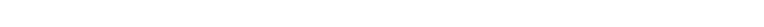

$\begin{array}{llllllllllllllllllll}11 & 79 & 65 & 52 & 18 & 11 & 17 & 12 & 8 & 18 & 20 & 12 & 6 & 4 & 4 & 7 & 6 & 6 & 8 & 2\end{array}$

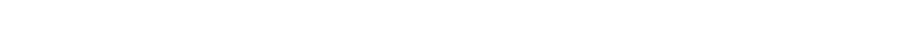

$\begin{array}{llllllllllllllllllll}37 & 37 & 80 & 27 & 25 & 32 & 15 & 21 & 12 & 19 & 19 & 4 & 2 & 6 & 5 & 4 & 6 & 2 & 8 & 4\end{array}$

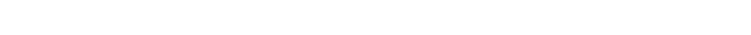

$\begin{array}{llllllllllllllllllll}86 & 43 & 48 & 13 & 27 & 30 & 12 & 11 & 12 & 13 & 16 & 14 & 4 & 5 & 8 & 10 & 9 & 1 & 2 & 2\end{array}$

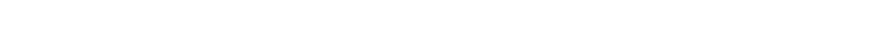
$\begin{array}{llllllllllllllllllllllll}36 & 36 & 50 & & 7 & 77 & 14 & 12 & 24 & 33 & 42 & 29 & 24 & 14 & 12 & 2 & 7 & 20 & 17 & 16 & 6 & 1 & 3 & 5\end{array}$

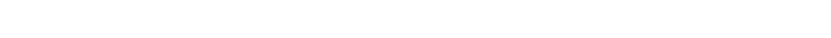

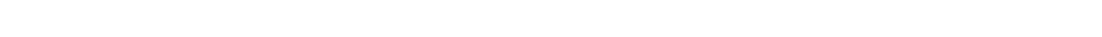

36645.0

43462.0

44186.0

48186.0

42445.0

21472.0

37287.0
24375.0

24375.0
15763.0

32252.0

21022.0

39631.0

38848.0

33489.0

27182.0

46535.0
50898.0

31892.0

47293.0

31528.0

23850.0

46474.0

34198.0

40546.0

44058.0

30035.0

51673.0

29288.0

26916.0

29415.0

35895.0

33624.0

20978.0

21686.0

26961.0

51206.0

20781.5

30697.0

44086.7

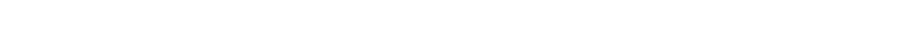

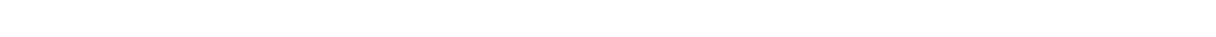

$\begin{array}{lrrrrrrrrrrrrrrrrrrrrrrrrrrr}16131 & 4 & 26 & 4 & 3 & 2 & 23 & 12 & 12 & 28 & 18 & 20 & 10 & 16 & 7 & 3 & 3 & 1 & 2 & 2 & 6 & 9 & 3 & 2 & 1 & 1 & 1 & 41964.0\end{array}$

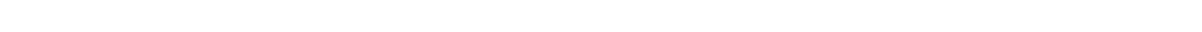

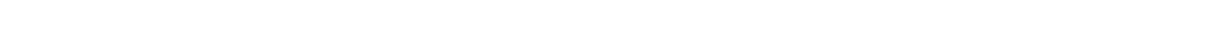

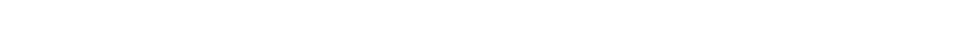

$\begin{array}{llllllllllllllllllll}42 & 76 & 43 & 40 & 19 & 22 & 27 & 4 & 13 & 14 & 12 & 10 & 7 & 8 & 3 & 3 & 7 & 13 & 3\end{array}$

$\begin{array}{lllllllllllllllllllllll}6 & 28 & 26 & 13 & 12 & 18 & 16 & 11 & 15 & 17 & 29 & 13 & 6 & 10 & 5 & 1 & 6 & 2 & 5 & 5 & 8 & 6 & 3\end{array}$

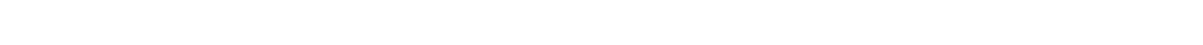

33106.7

33141.0

50906.0

22818.0

45617.0

$\begin{array}{llllllllllllllllllllllllllll}1 & 21 & 32 & 21 & 31 & 38 & 30 & 15 & 27 & 17 & 8 & 9 & 15 & 14 & 1 & 11 & 17 & 18 & 7 & 3 & 4 & 4 & 2 & 4 & 5 & 7 & 3 & 1\end{array}$

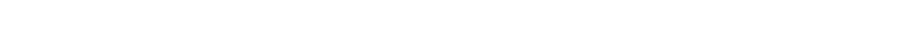

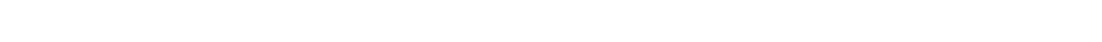

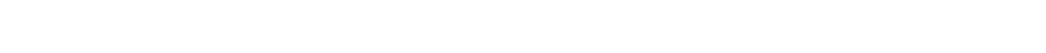

$\begin{array}{llllllllllllllllllllll}2 & 15 & 66 & 46 & 19 & 26 & 32 & 11 & 8 & 16 & 21 & 4 & 10 & 15 & 17 & 7 & 16 & 15 & 11 & 4 & 3 & 1\end{array}$

28165.8

11485.4

24815.8

23454.4

37598.2

22812.5 
DURATION TABLE OF DISCHARGE FOR WATER YEARS 1915-17, 1919-81

\begin{tabular}{|c|c|c|c|c|c|c|c|c|c|c|c|c|c|c|c|c|c|c|c|}
\hline CIASS & $\begin{array}{c}\text { OUBIC } \\
\text { FEET } \\
\text { PER } \\
\text { SECOND }\end{array}$ & $\begin{array}{r}\text { TOTAL } \\
\text { DAYS }\end{array}$ & $\begin{array}{c}\text { ACOU- } \\
\text { MU- } \\
\text { LATED } \\
\text { DAYS }\end{array}$ & $\begin{array}{l}\text { PER- } \\
\text { CENI } \\
\text { DAYS }\end{array}$ & CIASS & $\begin{array}{c}\text { CBIIC } \\
\text { FEET } \\
\text { PER } \\
\text { SECOND }\end{array}$ & $\begin{array}{r}\text { TOTAL } \\
\text { DAYS }\end{array}$ & $\begin{array}{c}\text { ACOU- } \\
\text { MU- } \\
\text { LATED } \\
\text { DAYS }\end{array}$ & $\begin{array}{l}\text { PER- } \\
\text { CENT } \\
\text { DAYS }\end{array}$ & CIASS & $\begin{array}{c}\text { OBBIC } \\
\text { FEET } \\
\text { PER } \\
\text { SEOOND }\end{array}$ & $\begin{array}{r}\text { TOTAL } \\
\text { DAYS }\end{array}$ & $\begin{array}{c}\text { ACOU- } \\
\text { MU- } \\
\text { LATED } \\
\text { DAYS }\end{array}$ & $\begin{array}{l}\text { PER- } \\
\text { CENT } \\
\text { DAYS }\end{array}$ & CLASS & $\begin{array}{c}\text { CUBIC } \\
\text { FEET } \\
\text { PER } \\
\text { SECOND }\end{array}$ & $\begin{array}{l}\text { TOIAL } \\
\text { DAYS }\end{array}$ & $\begin{array}{l}\text { ACOU- } \\
\text { MU- } \\
\text { LAIED } \\
\text { DAYS }\end{array}$ & $\begin{array}{l}\text { PER- } \\
\text { CENT } \\
\text { DAYS }\end{array}$ \\
\hline $\begin{array}{l}0 \\
1 \\
2 \\
3 \\
4 \\
5 \\
6 \\
7 \\
8\end{array}$ & $\begin{array}{r}0.00 \\
3.50 \\
4.20 \\
5.10 \\
6.20 \\
7.50 \\
9.00 \\
11.00 \\
13.00\end{array}$ & $\begin{array}{r}0 \\
24 \\
73 \\
139 \\
70 \\
187 \\
253 \\
652 \\
1000\end{array}$ & $\begin{array}{l}24107 \\
24107 \\
24083 \\
24010 \\
23871 \\
23801 \\
23614 \\
23361 \\
22709\end{array}$ & $\begin{array}{r}100.0 \\
100.0 \\
99.9 \\
99.6 \\
99.0 \\
98.7 \\
98.0 \\
96.9 \\
94.2\end{array}$ & $\begin{array}{l}9 \\
10 \\
11 \\
12 \\
13 \\
14 \\
15 \\
16 \\
17\end{array}$ & $\begin{array}{l}16.00 \\
19.00 \\
23.00 \\
28.00 \\
34.00 \\
41.00 \\
49.00 \\
60.00 \\
72.00\end{array}$ & $\begin{array}{l}1203 \\
1794 \\
1797 \\
2396 \\
1964 \\
1425 \\
1445 \\
1189 \\
1282\end{array}$ & $\begin{array}{r}21709 \\
20506 \\
18712 \\
16915 \\
14519 \\
12555 \\
11130 \\
9685 \\
8496\end{array}$ & $\begin{array}{l}90.1 \\
85.1 \\
77.6 \\
70.2 \\
60.2 \\
52.1 \\
46.2 \\
40.2 \\
35.2\end{array}$ & $\begin{array}{l}18 \\
19 \\
20 \\
21 \\
22 \\
23 \\
24 \\
25 \\
26\end{array}$ & $\begin{array}{r}87.0 \\
110.0 \\
130.0 \\
150.0 \\
190.0 \\
220.0 \\
270.0 \\
330.0 \\
390.0\end{array}$ & $\begin{array}{r}1711 \\
1078 \\
714 \\
796 \\
392 \\
477 \\
404 \\
324 \\
453\end{array}$ & $\begin{array}{l}7214 \\
5503 \\
4425 \\
3711 \\
2915 \\
2523 \\
2046 \\
1642 \\
1318\end{array}$ & $\begin{array}{r}29.9 \\
22.8 \\
18.4 \\
15.4 \\
12.1 \\
10.5 \\
8.5 \\
6.8 \\
5.5\end{array}$ & $\begin{array}{l}27 \\
28 \\
29 \\
30 \\
31 \\
32 \\
33 \\
34\end{array}$ & $\begin{array}{r}480.0 \\
580.0 \\
700.0 \\
840.0 \\
1000.0 \\
1200.0 \\
1500.0 \\
1800.0\end{array}$ & $\begin{array}{r}285 \\
204 \\
208 \\
95 \\
41 \\
17 \\
14 \\
1\end{array}$ & $\begin{array}{r}865 \\
580 \\
376 \\
168 \\
73 \\
32 \\
15 \\
1\end{array}$ & $\begin{array}{l}3.6 \\
2.4 \\
1.6 \\
0.7 \\
0.3 \\
0.1 \\
0.1 \\
0.0\end{array}$ \\
\hline
\end{tabular}

MONTHLY MEAN DISCHARGES, IN OBBIC FEET PER SECOND, FOR EACH WATER YEAR

\begin{tabular}{|c|c|c|c|c|c|c|c|c|c|c|c|c|}
\hline YEAR & OCT & $\mathrm{NON}$ & DEC & JAN & FEB & MAR & APR & MAY & JUNE & JULY & AUG & SEP \\
\hline $\begin{array}{l}1914 \\
1915\end{array}$ & $\begin{array}{l}68.3 \\
79.0\end{array}$ & $\begin{array}{l}53.8 \\
65.0\end{array}$ & $\begin{array}{l}39.0 \\
44.0\end{array}$ & $\begin{array}{l}30.9 \\
37.0\end{array}$ & $\begin{array}{l}34.2 \\
33.0\end{array}$ & $\begin{array}{l}37.4 \\
30.0\end{array}$ & $\begin{array}{l}55.5 \\
109\end{array}$ & $\begin{array}{l}639 \\
401\end{array}$ & $\begin{array}{l}395 \\
403\end{array}$ & $\begin{array}{l}137 \\
137\end{array}$ & $\begin{array}{l}159 \\
83.5\end{array}$ & $\begin{array}{l}80.7 \\
88.0\end{array}$ \\
\hline $\begin{array}{l}1916 \\
1917 \\
1918 \\
1919 \\
1920\end{array}$ & $\begin{array}{l}82.3 \\
85.8 \\
86.2 \\
75.0 \\
63.2\end{array}$ & $\begin{array}{l}57.8 \\
61.0 \\
75.6 \\
55.0 \\
42.9\end{array}$ & $\begin{array}{l}44.7 \\
43.4 \\
55.3 \\
40.0 \\
31.1\end{array}$ & $\begin{array}{l}38.5 \\
35.6 \\
43.9 \\
35.0 \\
32.7\end{array}$ & $\begin{array}{l}34.0 \\
30.0 \\
39.6 \\
30.0 \\
29.2\end{array}$ & $\begin{array}{l}43.3 \\
30.0 \\
37.4 \\
30.0 \\
28.2\end{array}$ & $\begin{array}{r}114 \\
36.9 \\
47.1 \\
75.0 \\
29.7\end{array}$ & $\begin{array}{l}376 \\
407 \\
246 \\
225 \\
493\end{array}$ & $\begin{array}{l}281 \\
798 \\
192 \\
115 \\
503\end{array}$ & $\begin{array}{c}113 \\
236 \\
87.8 \\
63.2 \\
112\end{array}$ & $\begin{array}{c}85.8 \\
120 \\
81.3 \\
49.3 \\
76.2\end{array}$ & $\begin{array}{l}60.3 \\
95.3 \\
62.2 \\
49.4 \\
65.2\end{array}$ \\
\hline $\begin{array}{l}1921 \\
1922 \\
1923 \\
1924 \\
1925\end{array}$ & $\begin{array}{l}56.4 \\
79.4 \\
75.4 \\
61.4 \\
38.7\end{array}$ & $\begin{array}{l}55.8 \\
59.5 \\
62.9 \\
49.0 \\
35.5\end{array}$ & $\begin{array}{l}45.0 \\
47.4 \\
52.1 \\
41.9 \\
32.7\end{array}$ & $\begin{array}{l}38.0 \\
41.9 \\
44.3 \\
36.8 \\
30.2\end{array}$ & $\begin{array}{l}33.0 \\
37.8 \\
39.3 \\
35.7 \\
30.4\end{array}$ & $\begin{array}{l}34.0 \\
36.2 \\
35.5 \\
34.5 \\
29.9\end{array}$ & $\begin{array}{l}45.3 \\
43.5 \\
47.0 \\
48.8 \\
57.0\end{array}$ & $\begin{array}{l}534 \\
541 \\
496 \\
308 \\
231\end{array}$ & $\begin{array}{l}907 \\
846 \\
490 \\
159 \\
198\end{array}$ & $\begin{array}{l}172 \\
159 \\
182 \\
76.7 \\
110\end{array}$ & $\begin{array}{c}108 \\
113 \\
88.5 \\
46.8 \\
82.2\end{array}$ & $\begin{array}{r}107 \\
93.9 \\
54.6 \\
40.7 \\
90.4\end{array}$ \\
\hline $\begin{array}{l}1926 \\
1927 \\
1928 \\
1929 \\
1930\end{array}$ & $\begin{array}{c}109 \\
44.3 \\
114 \\
50.0 \\
91.4\end{array}$ & $\begin{array}{l}78.5 \\
35.7 \\
91.8 \\
47.0 \\
68.4\end{array}$ & $\begin{array}{l}52.1 \\
31.8 \\
55.0 \\
34.0 \\
50.0\end{array}$ & $\begin{array}{l}38.5 \\
27.4 \\
45.0 \\
37.0 \\
45.0\end{array}$ & $\begin{array}{l}31.8 \\
26.8 \\
40.0 \\
32.0 \\
37.0\end{array}$ & $\begin{array}{l}30.3 \\
25.7 \\
35.0 \\
29.0 \\
35.0\end{array}$ & $\begin{array}{r}142 \\
42.3 \\
70.0 \\
42.0 \\
109\end{array}$ & $\begin{array}{l}340 \\
424 \\
550 \\
444 \\
388\end{array}$ & $\begin{array}{l}152 \\
284 \\
215 \\
528 \\
256\end{array}$ & $\begin{array}{l}97.1 \\
148 \\
104 \\
151 \\
103\end{array}$ & $\begin{array}{c}78.2 \\
104 \\
74.7 \\
106 \\
113\end{array}$ & $\begin{array}{c}50.5 \\
230 \\
47.4 \\
106 \\
94.2\end{array}$ \\
\hline $\begin{array}{l}1931 \\
1932 \\
1933 \\
1934 \\
1935\end{array}$ & $\begin{array}{l}88.5 \\
32.3 \\
59.8 \\
28.9 \\
34.4\end{array}$ & $\begin{array}{l}57.3 \\
31.9 \\
40.0 \\
24.7 \\
32.8\end{array}$ & $\begin{array}{l}46.0 \\
30.0 \\
27.9 \\
21.0 \\
28.6\end{array}$ & $\begin{array}{l}40.0 \\
29.0 \\
25.0 \\
21.0 \\
26.3\end{array}$ & $\begin{array}{l}34.0 \\
29.0 \\
23.9 \\
20.0 \\
25.8\end{array}$ & $\begin{array}{l}33.0 \\
28.0 \\
21.7 \\
20.0 \\
25.6\end{array}$ & $\begin{array}{l}45.0 \\
33.9 \\
23.1 \\
63.8 \\
29.3\end{array}$ & $\begin{array}{l}151 \\
398 \\
152 \\
127 \\
191\end{array}$ & $\begin{array}{c}92.3 \\
307 \\
259 \\
59.1 \\
456\end{array}$ & $\begin{array}{c}46.1 \\
136 \\
75.4 \\
39.6 \\
107\end{array}$ & $\begin{array}{l}38.1 \\
90.7 \\
55.4 \\
49.4 \\
65.0\end{array}$ & $\begin{array}{l}32.1 \\
73.5 \\
36.8 \\
41.8 \\
39.3\end{array}$ \\
\hline $\begin{array}{l}1936 \\
1937 \\
1938 \\
1939 \\
1940\end{array}$ & $\begin{array}{c}31.3 \\
54.2 \\
49.1 \\
108 \\
91.2\end{array}$ & $\begin{array}{l}27.7 \\
41.3 \\
34.9 \\
81.2 \\
58.3\end{array}$ & $\begin{array}{l}23.2 \\
26.9 \\
26.3 \\
53.9 \\
35.1\end{array}$ & $\begin{array}{l}19.4 \\
22.6 \\
23.2 \\
40.2 \\
26.4\end{array}$ & $\begin{array}{l}18.6 \\
18.1 \\
21.2 \\
34.8 \\
23.4\end{array}$ & $\begin{array}{l}17.8 \\
18.1 \\
21.0 \\
33.9 \\
23.6\end{array}$ & $\begin{array}{c}36.1 \\
37.7 \\
40.3 \\
128 \\
77.9\end{array}$ & $\begin{array}{l}186 \\
512 \\
331 \\
288 \\
284\end{array}$ & $\begin{array}{l}113 \\
262 \\
411 \\
122 \\
116\end{array}$ & $\begin{array}{c}69.7 \\
142 \\
145 \\
70.0 \\
66.6\end{array}$ & $\begin{array}{l}77.4 \\
92.7 \\
90.1 \\
47.0 \\
35.4\end{array}$ & $\begin{array}{l}67.5 \\
65.1 \\
80.5 \\
89.7 \\
50.1\end{array}$ \\
\hline $\begin{array}{l}1941 \\
1942 \\
1943 \\
1944 \\
1945\end{array}$ & $\begin{array}{c}78.0 \\
154 \\
51.2 \\
35.9 \\
41.5\end{array}$ & $\begin{array}{c}56.1 \\
104 \\
32.1 \\
29.3 \\
33.2\end{array}$ & $\begin{array}{l}37.1 \\
64.2 \\
25.8 \\
24.6 \\
26.3\end{array}$ & $\begin{array}{l}30.8 \\
41.8 \\
21.3 \\
21.6 \\
22.8\end{array}$ & $\begin{array}{l}28.8 \\
32.6 \\
18.4 \\
18.5 \\
20.2\end{array}$ & $\begin{array}{l}27.5 \\
29.3 \\
17.7 \\
17.7 \\
19.7\end{array}$ & $\begin{array}{l}27.4 \\
101 \\
147 \\
20.5 \\
21.6\end{array}$ & $\begin{array}{l}491 \\
365 \\
270 \\
375 \\
250\end{array}$ & $\begin{array}{l}374 \\
425 \\
177 \\
606 \\
260\end{array}$ & $\begin{array}{l}151 \\
155 \\
136 \\
197 \\
138\end{array}$ & $\begin{array}{c}106 \\
113 \\
93.6 \\
134 \\
109\end{array}$ & $\begin{array}{r}114 \\
83.3 \\
54.6 \\
69.7 \\
88.9\end{array}$ \\
\hline $\begin{array}{l}1946 \\
1947 \\
1948 \\
1949 \\
1950\end{array}$ & $\begin{array}{l}61.1 \\
55.5 \\
71.3 \\
29.7 \\
51.9\end{array}$ & $\begin{array}{l}36.4 \\
48.7 \\
43.5 \\
23.0 \\
41.1\end{array}$ & $\begin{array}{l}26.4 \\
39.0 \\
34.5 \\
18.9 \\
28.9\end{array}$ & $\begin{array}{l}22.0 \\
31.4 \\
27.9 \\
16.6 \\
26.9\end{array}$ & $\begin{array}{l}20.7 \\
26.3 \\
23.0 \\
16.0 \\
22.7\end{array}$ & $\begin{array}{l}18.7 \\
26.3 \\
20.7 \\
15.6 \\
22.6\end{array}$ & $\begin{array}{c}108 \\
63.0 \\
32.0 \\
41.9 \\
94.8\end{array}$ & $\begin{array}{l}156 \\
514 \\
407 \\
442 \\
409\end{array}$ & $\begin{array}{l}134 \\
337 \\
215 \\
399 \\
378\end{array}$ & $\begin{array}{l}81.4 \\
173 \\
116 \\
144 \\
166\end{array}$ & $\begin{array}{c}53.7 \\
114 \\
84.9 \\
117 \\
120\end{array}$ & $\begin{array}{l}63.8 \\
90.2 \\
39.9 \\
62.0 \\
82.0\end{array}$ \\
\hline $\begin{array}{l}1951 \\
1952 \\
1953 \\
1954 \\
1955\end{array}$ & $\begin{array}{l}53.5 \\
63.2 \\
70.5 \\
30.2 \\
39.1\end{array}$ & $\begin{array}{l}34.0 \\
38.2 \\
45.0 \\
28.8 \\
30.3\end{array}$ & $\begin{array}{l}28.8 \\
30.8 \\
34.4 \\
28.0 \\
24.5\end{array}$ & $\begin{array}{l}25.6 \\
28.9 \\
28.7 \\
25.5 \\
20.9\end{array}$ & $\begin{array}{l}20.7 \\
25.6 \\
25.0 \\
20.5 \\
18.6\end{array}$ & $\begin{array}{l}18.7 \\
23.3 \\
22.8 \\
18.3 \\
17.3\end{array}$ & $\begin{array}{l}19.7 \\
70.0 \\
30.7 \\
64.9 \\
21.1\end{array}$ & $\begin{array}{l}259 \\
590 \\
155 \\
305 \\
259\end{array}$ & $\begin{array}{l}203 \\
390 \\
290 \\
137 \\
176\end{array}$ & $\begin{array}{l}133 \\
169 \\
133 \\
113 \\
101\end{array}$ & $\begin{array}{c}105 \\
161 \\
87.7 \\
63.6 \\
64.0\end{array}$ & $\begin{array}{l}79.5 \\
97.8 \\
38.1 \\
44.0 \\
44.7\end{array}$ \\
\hline $\begin{array}{l}1956 \\
1957 \\
1958 \\
1959 \\
1960\end{array}$ & $\begin{array}{l}34.4 \\
22.7 \\
55.7 \\
25.9 \\
34.2\end{array}$ & $\begin{array}{l}28.6 \\
25.0 \\
38.2 \\
24.5 \\
25.2\end{array}$ & $\begin{array}{l}25.1 \\
20.4 \\
30.1 \\
23.1 \\
17.5\end{array}$ & $\begin{array}{l}22.0 \\
17.9 \\
28.0 \\
16.6 \\
14.9\end{array}$ & $\begin{array}{l}20.2 \\
16.9 \\
25.1 \\
16.1 \\
13.3\end{array}$ & $\begin{array}{l}19.5 \\
16.0 \\
22.2 \\
16.9 \\
13.8\end{array}$ & $\begin{array}{l}35.1 \\
15.7 \\
34.7 \\
17.8 \\
59.4\end{array}$ & $\begin{array}{l}383 \\
111 \\
430 \\
179 \\
219\end{array}$ & $\begin{array}{l}177 \\
548 \\
199 \\
177 \\
163\end{array}$ & $\begin{array}{c}119 \\
165 \\
122 \\
90.8 \\
92.4\end{array}$ & $\begin{array}{c}61.1 \\
127 \\
72.7 \\
57.4 \\
36.1\end{array}$ & $\begin{array}{l}34.4 \\
96.6 \\
40.1 \\
41.2 \\
20.6\end{array}$ \\
\hline $\begin{array}{l}1961 \\
1962 \\
1963 \\
1964 \\
1965\end{array}$ & $\begin{array}{l}24.8 \\
99.5 \\
43.1 \\
35.4 \\
39.8\end{array}$ & $\begin{array}{l}22.3 \\
72.1 \\
23.2 \\
20.7 \\
20.9\end{array}$ & $\begin{array}{l}20.1 \\
52.1 \\
18.2 \\
16.2 \\
14.8\end{array}$ & $\begin{array}{l}15.2 \\
35.0 \\
12.6 \\
13.3 \\
13.4\end{array}$ & $\begin{array}{l}12.7 \\
28.3 \\
10.3 \\
11.9 \\
11.2\end{array}$ & $\begin{array}{l}11.6 \\
28.6 \\
11.2 \\
11.5 \\
11.0\end{array}$ & $\begin{array}{c}14.9 \\
162 \\
14.1 \\
11.4 \\
13.5\end{array}$ & $\begin{array}{l}252 \\
469 \\
251 \\
339 \\
234\end{array}$ & $\begin{array}{l}226 \\
394 \\
124 \\
292 \\
658\end{array}$ & $\begin{array}{l}112 \\
155 \\
82.6 \\
123 \\
190\end{array}$ & $\begin{array}{c}74.0 \\
110 \\
43.5 \\
73.3 \\
138\end{array}$ & $\begin{array}{r}96.7 \\
72.3 \\
44.6 \\
55.7 \\
105\end{array}$ \\
\hline
\end{tabular}


MONTHLY MEAN DISCHARGES, IN CUBIC FEET PER SECOND, FOR EACH WATER YEAR--Continued

\begin{tabular}{|c|c|c|c|c|c|c|c|c|c|c|c|c|}
\hline YEAR & $\propto T$ & NOV & DEC & JAN & FEB & MAR & APR & MAY & JUNE & JULY & AUG & SEP \\
\hline $\begin{array}{l}1966 \\
1967 \\
1968 \\
1969 \\
1970\end{array}$ & $\begin{array}{l}77.0 \\
27.6 \\
53.8 \\
55.0 \\
35.8\end{array}$ & $\begin{array}{l}41.6 \\
20.5 \\
23.4 \\
25.3 \\
25.8\end{array}$ & $\begin{array}{l}24.8 \\
18.9 \\
14.7 \\
15.5 \\
21.4\end{array}$ & $\begin{array}{l}17.5 \\
15.2 \\
12.8 \\
13.8 \\
17.2\end{array}$ & $\begin{array}{l}13.3 \\
12.0 \\
13.8 \\
12.9 \\
14.4\end{array}$ & $\begin{array}{l}12.2 \\
12.0 \\
13.8 \\
11.4 \\
12.8\end{array}$ & $\begin{array}{l}61.5 \\
18.4 \\
14.0 \\
32.2 \\
14.8\end{array}$ & $\begin{array}{l}383 \\
363 \\
146 \\
543 \\
361\end{array}$ & $\begin{array}{l}135 \\
523 \\
754 \\
231 \\
430\end{array}$ & $\begin{array}{l}101 \\
186 \\
141 \\
138 \\
159\end{array}$ & $\begin{array}{l}62.8 \\
110 \\
115 \\
100 \\
94.7\end{array}$ & $\begin{array}{l}42.4 \\
61.8 \\
80.1 \\
67.7 \\
72.6\end{array}$ \\
\hline $\begin{array}{l}1971 \\
1972 \\
1973 \\
1974 \\
1975\end{array}$ & $\begin{array}{l}43.7 \\
34.8 \\
51.9 \\
58.4 \\
15.5\end{array}$ & $\begin{array}{l}19.8 \\
33.6 \\
45.7 \\
29.2 \\
11.7\end{array}$ & $\begin{array}{l}16.7 \\
27.9 \\
28.3 \\
22.6 \\
10.1\end{array}$ & $\begin{array}{c}13.2 \\
24.4 \\
21.3 \\
20.4 \\
9.34\end{array}$ & $\begin{array}{c}11.5 \\
21.6 \\
18.3 \\
18.0 \\
8.04\end{array}$ & $\begin{array}{c}10.3 \\
22.8 \\
16.5 \\
16.8 \\
5.84\end{array}$ & $\begin{array}{c}16.8 \\
37.5 \\
19.3 \\
20.6 \\
6.22\end{array}$ & $\begin{array}{l}262 \\
368 \\
537 \\
310 \\
113\end{array}$ & $\begin{array}{c}411 \\
272 \\
551 \\
99.3 \\
750\end{array}$ & $\begin{array}{c}141 \\
122 \\
164 \\
82.9 \\
360\end{array}$ & $\begin{array}{c}77.7 \\
62.3 \\
117 \\
49.4 \\
117\end{array}$ & $\begin{array}{l}60.9 \\
56.4 \\
96.3 \\
15.8 \\
93.5\end{array}$ \\
\hline $\begin{array}{l}1976 \\
1977 \\
1978 \\
1979 \\
1980\end{array}$ & $\begin{array}{l}36.6 \\
17.8 \\
23.3 \\
14.9 \\
20.1\end{array}$ & $\begin{array}{l}19.9 \\
14.8 \\
13.6 \\
12.8 \\
12.6\end{array}$ & $\begin{array}{c}14.9 \\
9.40 \\
8.10 \\
10.6 \\
15.6\end{array}$ & $\begin{array}{c}12.0 \\
5.12 \\
5.82 \\
8.65 \\
13.9\end{array}$ & $\begin{array}{c}9.21 \\
5.14 \\
4.60 \\
8.12 \\
13.0\end{array}$ & $\begin{array}{r}7.42 \\
4.96 \\
4.54 \\
7.78 \\
11.8\end{array}$ & $\begin{array}{c}10.4 \\
22.2 \\
9.59 \\
12.5 \\
21.0\end{array}$ & $\begin{array}{c}367 \\
71.7 \\
246 \\
308 \\
319\end{array}$ & $\begin{array}{l}225 \\
101 \\
284 \\
182 \\
523\end{array}$ & $\begin{array}{l}126 \\
39.2 \\
116 \\
114 \\
132\end{array}$ & $\begin{array}{r}61.6 \\
39.0 \\
70.5 \\
48.3 \\
104\end{array}$ & $\begin{array}{l}27.8 \\
47.0 \\
26.6 \\
37.4 \\
46.6\end{array}$ \\
\hline 1981 & 35.9 & 19.2 & 14.0 & 12.4 & 12.0 & 10.8 & 75.5 & 235 & 146 & 114 & 46.2 & 24.5 \\
\hline
\end{tabular}

ANNUAL PEAK DISCHARGE, IN OUBIC FEET PER SECOND, AND CORRESPONDING GAGE HEIGHT, IN FEET, FOR EACH WATER YEAR

\begin{tabular}{|c|c|c|c|c|c|c|c|c|c|c|c|c|c|c|}
\hline $\begin{array}{l}\text { WATER } \\
\text { YEAR }\end{array}$ & & DATE & $\begin{array}{c}\text { GAGE } \\
\text { HEIGHT }\end{array}$ & $\begin{array}{c}\text { PEAK } \\
\text { DISCHARGE }\end{array}$ & $\begin{array}{l}\text { WATER } \\
\text { YEAR }\end{array}$ & & DATE & $\begin{array}{c}\text { GAGE } \\
\text { HEIGHT }\end{array}$ & $\begin{array}{c}\text { PEAR } \\
\text { DISCHARGE }\end{array}$ & $\begin{array}{l}\text { WATER } \\
\text { YEAR }\end{array}$ & & DATE & $\begin{array}{c}\text { GAGE } \\
\text { HEIGHT }\end{array}$ & $\begin{array}{l}\text { PEAK } \\
\text { DISCHARG }\end{array}$ \\
\hline $\begin{array}{l}1912 \\
1914 \\
1915 \\
1916 \\
1917 \\
1918 \\
1919 \\
1920 \\
1921 \\
1922 \\
1923 \\
1924 \\
1925 \\
1926 \\
1927 \\
1928 \\
1929 \\
1930 \\
1931 \\
1932 \\
1933 \\
1934 \\
1935\end{array}$ & $\begin{array}{l}\text { MAY } \\
\text { MAY } \\
\text { MAY } \\
\text { MAY } \\
\text { JUNE } \\
\text { MAY } \\
\text { MAY } \\
\text { MAY } \\
\text { MAY } \\
\text { JUNE } \\
\text { MAY } \\
\text { MAY } \\
\text { JUNE } \\
\text { MAY } \\
\text { SEPT } \\
\text { MAY } \\
\text { JUNE } \\
\text { MAY } \\
\text { MAY } \\
\text { MAI } \\
\text { JUNE } \\
\text { MAY } \\
\text { JUNE }\end{array}$ & $\begin{array}{l}27,1912 \\
23,1914 \\
14,1915 \\
08,1916 \\
24,1917 \\
25,1918 \\
10,1919 \\
28,1920 \\
29,1921 \\
08,1922 \\
25,1923 \\
17,1924 \\
09,1925 \\
20,1926 \\
10,1927 \\
01,1928 \\
16,1929 \\
28,1930 \\
15,11931 \\
21,1932 \\
01,11933 \\
10,11934 \\
09,1935\end{array}$ & $\begin{array}{l}3.90 \\
4.50 \\
4.15 \\
4.44 \\
4.50 \\
4.20 \\
7.05 \\
8.35 \\
8.67 \\
8.47 \\
7.91 \\
7.42 \\
7.90 \\
8.70 \\
8.50 \\
9.05 \\
8.20 \\
7.56 \\
8.55 \\
8.45 \\
6.60 \\
8.30\end{array}$ & $\begin{array}{r}880 \\
1350 \\
1260 \\
820 \\
1350 \\
324 \\
278 \\
1360 \\
2050 \\
1700 \\
1250 \\
736 \\
507 \\
729 \\
1250 \\
1110 \\
1560 \\
1040 \\
560 \\
1340 \\
1260 \\
201 \\
1140\end{array}$ & $\begin{array}{l}1936 \\
1937 \\
1938 \\
1939 \\
1940 \\
1941 \\
1942 \\
1943 \\
1944 \\
1945 \\
1946 \\
1947 \\
1948 \\
1949 \\
1950 \\
1951 \\
1952 \\
1953 \\
1954 \\
1955 \\
1956 \\
1957 \\
1958\end{array}$ & $\begin{array}{l}\text { MAY } \\
\text { MAY } \\
\text { MAY } \\
\text { APR. } \\
\text { MAY } \\
\text { MAY } \\
\text { MAY } \\
\text { APR. } \\
\text { JUNE } \\
\text { JUNE } \\
\text { APR. } \\
\text { MAY } \\
\text { MAY } \\
\text { MAY } \\
\text { MAY } \\
\text { MAY } \\
\text { MAY } \\
\text { JUNE } \\
\text { MAY } \\
\text { MAY } \\
\text { MAY } \\
\text { JUNE } \\
\text { MAY }\end{array}$ & $\begin{array}{r}15,1936 \\
14,1937 \\
06,1938 \\
29,1939 \\
09,1940 \\
13,1941 \\
25,1942 \\
30,1943 \\
E 2,1944 \\
E 04,1945 \\
25,1946 \\
08,1947 \\
19,1948 \\
29,1949 \\
30,1950 \\
25,1951 \\
04,1952 \\
12,1953 \\
09,1954 \\
12,1955 \\
23,1956 \\
07,1957 \\
24,1958\end{array}$ & $\begin{array}{l}7.39 \\
8.39 \\
8.55 \\
7.62 \\
7.78 \\
8.55 \\
8.52 \\
2.97 \\
3.86 \\
3.11 \\
2.95 \\
3.94 \\
3.70 \\
3.14 \\
3.36 \\
3.14 \\
3.24 \\
2.22 \\
2.37 \\
2.12 \\
2.68 \\
2.92 \\
2.30\end{array}$ & $\begin{array}{r}524 \\
1210 \\
1340 \\
649 \\
703 \\
1340 \\
1270 \\
702 \\
1200 \\
616 \\
521 \\
1190 \\
1370 \\
945 \\
1250 \\
1070 \\
1330 \\
658 \\
720 \\
628 \\
792 \\
1260 \\
980\end{array}$ & $\begin{array}{l}1959 \\
1960 \\
1961 \\
1962 \\
1963 \\
1964 \\
1965 \\
1966 \\
1967 \\
1968 \\
1969 \\
1970 \\
1971 \\
1972 \\
1973 \\
1974 \\
1975 \\
1976 \\
1977 \\
1978 \\
1979 \\
1980 \\
1981\end{array}$ & $\begin{array}{l}\text { MAY } \\
\text { MAY } \\
\text { MAY } \\
\text { MAY } \\
\text { MAY } \\
\text { MAY } \\
\text { JUNE } \\
\text { MAY } \\
\text { MAY } \\
\text { JUNE } \\
\text { MAY } \\
\text { MAY } \\
\text { MAY } \\
\text { MAY } \\
\text { MAY } \\
\text { MAY } \\
\text { JUNE } \\
\text { MAY } \\
\text { JUNE } \\
\text { MAY } \\
\text { MAY } \\
\text { JUNE } \\
\text { MAY }\end{array}$ & $\begin{array}{l}15,1959 \\
12,1960 \\
27,1961 \\
10,1962 \\
10,1963 \\
21,1964 \\
11,1965 \\
06,1966 \\
24,1967 \\
05,1968 \\
14,1969 \\
20,1970 \\
27,1971 \\
16,1972 \\
18,1973 \\
09,1974 \\
15,1995 \\
19,1976 \\
02,1977 \\
29,1978 \\
28,1979 \\
04,1980 \\
01,1981\end{array}$ & $\begin{array}{l}1.81 \\
2.13 \\
2.94 \\
3.70 \\
2.80 \\
3.48 \\
4.42 \\
2.45 \\
3.14 \\
3.94 \\
3.69 \\
3.67 \\
3.70 \\
3.30 \\
4.17 \\
3.62 \\
4.30 \\
3.27 \\
1.99 \\
2.88 \\
3.20 \\
3.94 \\
2.68\end{array}$ & $\begin{array}{r}581 \\
796 \\
758 \\
1280 \\
730 \\
1720 \\
3500 \\
900 \\
1640 \\
2540 \\
1540 \\
1460 \\
1330 \\
913 \\
1870 \\
1440 \\
2590 \\
1150 \\
322 \\
831 \\
1010 \\
1430 \\
706\end{array}$ \\
\hline
\end{tabular}

MAGNITUDE AND PRCBABII.ITY OF ANNUAL HIGHEST MEAN DISGHARGE BASED ON WATER YEARS 191 5-17 AND 191 9-81

\begin{tabular}{|c|c|c|c|c|c|c|}
\hline \multirow{2}{*}{$\begin{array}{l}\text { PERIOD } \\
\text { (CON- } \\
\text { SEOU- } \\
\text { TTVE } \\
\text { DAYS) }\end{array}$} & \multicolumn{6}{|c|}{$\begin{array}{l}\text { DISGAARGE, IN OUBIC FEET PER SECOND, FOR } \\
\text { INDICATED REOURRENCE INTERNAL, IN YEARS, AND } \\
\text { ANNUAL EXCEEDANCE PRCBABILITY, IN PERCENT }\end{array}$} \\
\hline & $\begin{array}{c}2 \\
50 \%\end{array}$ & $\begin{array}{c}5 \\
208\end{array}$ & $\begin{array}{l}10 \\
108\end{array}$ & $\begin{array}{l}25 \\
48\end{array}$ & $\begin{array}{l}50 \\
28\end{array}$ & $\begin{array}{r}100 \\
18\end{array}$ \\
\hline $\begin{array}{r}1 \\
3 \\
7 \\
15\end{array}$ & $\begin{array}{l}747 \\
709 \\
635 \\
538\end{array}$ & $\begin{array}{r}1090 \\
1020 \\
909 \\
767\end{array}$ & $\begin{array}{r}1310 \\
1200 \\
1070 \\
902\end{array}$ & $\begin{array}{l}1560 \\
1410 \\
1240 \\
1050\end{array}$ & $\begin{array}{l}1740 \\
1550 \\
1360 \\
1150\end{array}$ & $\begin{array}{l}1910 \\
1680 \\
1460 \\
1250\end{array}$ \\
\hline
\end{tabular}




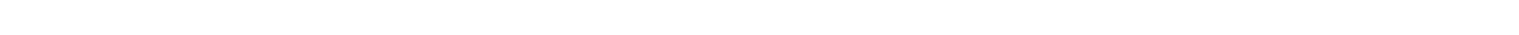
$0.9 \mathrm{mi}$ upstream from Dry Fork and $4 \mathrm{mi}$ southwest of town of Dry Fork.

DRAINAGE AREA. $-110 \mathrm{mi}^{2}$.

PERIOD OF RECORD AVAIIABLE.--June 1969 to September 1972.

GAGE.-Water-stage recorder. Al titude of gage is 5,910 ft from topographic map.

REMARKS.-Flow slightly regulated by small reservoirs upstream. Flow increased by water released from Oaks Park Reservoir (capacity, 6,250 acre-ft/yr) on Big Brush Creek and diverted to Ashley Creek basin for irrigation. City of Vernal pipeline (capacity, approximately $11 \mathrm{ft}^{3} / \mathrm{s}$ ) diverts water from tributary spring about $6 \mathrm{mi}$ upstream. Small diversions for irrigation of about 200 acres lying mostly above station.

EXTREMES FOR PERIOD OF REOORD.--Maximum discharge, $920 \mathrm{ft}^{3} / \mathrm{s}$ May 20, 1970, gage height, $4.15 \mathrm{ft}$; maximum gage height, $4.38 \mathrm{ft}$ May 19, 1970 ; minimum discharge, $11 \mathrm{ft}^{3} / \mathrm{s} \mathrm{Apr.} \mathrm{1,} \mathrm{1970,} \mathrm{Mar.} \mathrm{19,} 1971$.

LOWEST MEAN DISCHARGE, IN CIBIC FEET PER SECOND, AND RANKING FOR THE INDICATED NUMBER OF CONSEOUTIVE DAYS FOR EACH OLIMATIC YEAR, APRIL I-MAROA 31

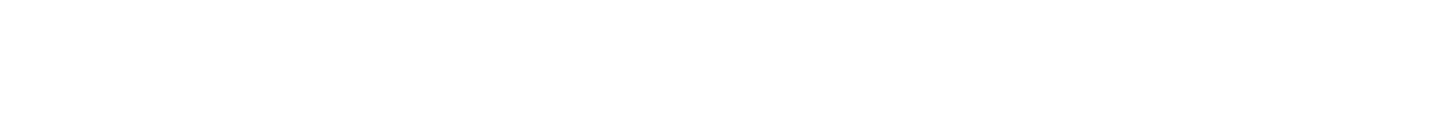

HIGHEST MEAN DISCHARGE, IN OUBIC FEET PER SECOND, AND RANKING FOR THE INDICATED NUMBER OF CONSEOUTTVE DAYS FOR EACH WATER YEAR, OCTCBER 1-SEPIEMBER 30

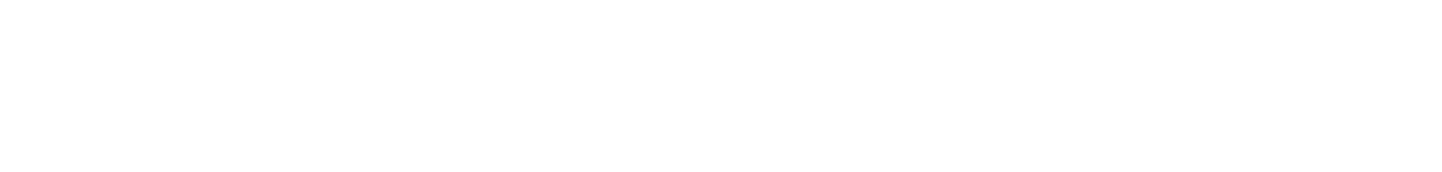

DURATION OF DISGHARGE FOR EACH WATER YEAR

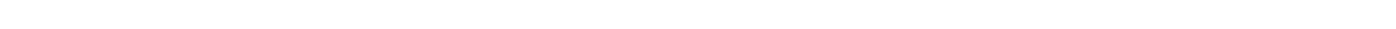
$\begin{array}{lll}\text { YEAR NUMBER OF DAYS IN OLASS } & \text { OUBIC FEET } \\ \text {-DAYS }\end{array}$

$\begin{array}{lllllllllllllllllllllllllllllllllllllllll}1970 & 30 & 28 & 24 & 65 & 16 & 6 & 13 & 12 & 29 & 1 & 7 & 4 & 3 & 7 & 12 & 12 & 9 & 4 & 10 & 6 & 9 & 5 & 4 & 5 & 2 & 2 & 3 & 9 & 6 & 4 & 6 & 4 & 7 & 1 & 34842.0\end{array}$

$\begin{array}{lllllllllllllllllllllllllllllllllllllllll}1971 & 36 & 46 & 30 & 38 & 22 & 9 & 9 & 2 & 9 & 7 & 4 & 23 & 6 & 18 & 17 & 12 & 4 & 2 & 9 & 9 & 2 & 4 & 5 & 1 & 4 & 2 & 7 & 3 & 7 & 14 & 2 & 1 & 1 & 33282.0\end{array}$

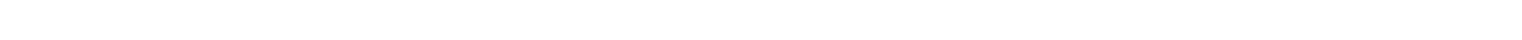

DURATION TABLE OF DISCHARGE FOR WATER YEARS 1970-72

\begin{tabular}{|c|c|c|c|c|c|c|c|c|c|c|c|c|c|c|c|c|c|c|c|}
\hline CLASS & $\begin{array}{c}\text { OBBIC } \\
\text { FEET } \\
\text { PER } \\
\text { SECOND }\end{array}$ & $\begin{array}{l}\text { TOTAL } \\
\text { DAYS }\end{array}$ & $\begin{array}{l}\text { ACOJ- } \\
\text { MU- } \\
\text { LATED } \\
\text { DAYS }\end{array}$ & $\begin{array}{l}\text { PER- } \\
\text { CENT } \\
\text { DAYS }\end{array}$ & & $\begin{array}{c}\text { dBIC } \\
\text { FEET } \\
\text { PERR } \\
\text { SECOND }\end{array}$ & $\begin{array}{l}\text { TOTAL } \\
\text { DAYSS }\end{array}$ & $\begin{array}{l}\text { ACOJ- } \\
\text { MU- } \\
\text { LATWED } \\
\text { DAYS }\end{array}$ & $\begin{array}{l}\text { PER- } \\
\text { CENT } \\
\text { DAYS }\end{array}$ & & $\begin{array}{c}\text { OJBIC } \\
\text { FEET } \\
\text { PER } \\
\text { SEOOND }\end{array}$ & $\begin{array}{l}\text { TOTAL } \\
\text { DALS }\end{array}$ & $\begin{array}{c}\text { ACOJ- } \\
\text { MU- } \\
\text { LATED } \\
\text { DAYS }\end{array}$ & $\begin{array}{l}\text { PER- } \\
\text { CENT } \\
\text { DAYS }\end{array}$ & CLASS & $\begin{array}{c}\text { ONBIC } \\
\text { FEET } \\
\text { PER } \\
\text { SECOND }\end{array}$ & $\begin{array}{c}\text { TOTAL } \\
\text { DAYS }\end{array}$ & $\begin{array}{l}\text { ACOD- } \\
\text { MN- } \\
\text { LATED } \\
\text { DAYS }\end{array}$ & $\begin{array}{l}\text { PER- } \\
\text { CENT } \\
\text { DAYS }\end{array}$ \\
\hline $\begin{array}{l}0 \\
1 \\
2 \\
3 \\
4 \\
5 \\
6 \\
7 \\
8\end{array}$ & $\begin{array}{r}0.00 \\
12.00 \\
14.00 \\
15.00 \\
17.00 \\
20.00 \\
22.00 \\
25.00 \\
28.00\end{array}$ & $\begin{array}{r}0 \\
66 \\
74 \\
54 \\
103 \\
38 \\
23 \\
117 \\
53\end{array}$ & $\begin{array}{r}1096 \\
1096 \\
1030 \\
956 \\
902 \\
799 \\
761 \\
738 \\
621\end{array}$ & $\begin{array}{r}100.0 \\
100.0 \\
94.0 \\
87.2 \\
82.3 \\
72.9 \\
69.4 \\
67.3 \\
56.7\end{array}$ & $\begin{array}{r}9 \\
10 \\
11 \\
12 \\
13 \\
14 \\
15 \\
16 \\
17\end{array}$ & $\begin{array}{l}32.00 \\
36.00 \\
41.00 \\
47.00 \\
53.00 \\
60.00 \\
67.00 \\
76.00 \\
86.00\end{array}$ & $\begin{array}{l}72 \\
30 \\
28 \\
21 \\
54 \\
20 \\
35 \\
30 \\
30\end{array}$ & $\begin{array}{l}568 \\
496 \\
466 \\
438 \\
417 \\
363 \\
343 \\
308 \\
278\end{array}$ & $\begin{array}{l}51.8 \\
45.3 \\
42.5 \\
40.0 \\
38.0 \\
33.1 \\
31.3 \\
28.1 \\
25.4\end{array}$ & $\begin{array}{l}18 \\
19 \\
20 \\
21 \\
22 \\
23 \\
24 \\
25 \\
26\end{array}$ & $\begin{array}{r}98.0 \\
110.0 \\
120.0 \\
140.0 \\
160.0 \\
180.0 \\
200.0 \\
230.0 \\
260.0\end{array}$ & $\begin{array}{r}17 \\
22 \\
27 \\
21 \\
10 \\
14 \\
14 \\
8 \\
10\end{array}$ & $\begin{array}{l}248 \\
231 \\
209 \\
182 \\
161 \\
151 \\
137 \\
123 \\
115\end{array}$ & $\begin{array}{l}22.6 \\
21.1 \\
19.1 \\
16.6 \\
14.7 \\
13.8 \\
12.5 \\
11.2 \\
10.5\end{array}$ & $\begin{array}{l}27 \\
28 \\
29 \\
30 \\
31 \\
32 \\
33 \\
34\end{array}$ & $\begin{array}{l}300.0 \\
330.0 \\
380.0 \\
430.0 \\
480.0 \\
550.0 \\
620.0 \\
700.0\end{array}$ & $\begin{array}{r}7 \\
17 \\
15 \\
18 \\
30 \\
8 \\
8 \\
2\end{array}$ & $\begin{array}{r}105 \\
98 \\
81 \\
66 \\
48 \\
18 \\
10 \\
2\end{array}$ & $\begin{array}{l}9.6 \\
8.9 \\
7.4 \\
6.0 \\
4.4 \\
1.6 \\
0.9 \\
0.2\end{array}$ \\
\hline
\end{tabular}

MONTHLY MEAN DISGHARGES, IN OBBIC FEET PER SECOND, FOR EAOH WATER YEAR

\begin{tabular}{|c|c|c|c|c|c|c|c|c|c|c|c|c|}
\hline YEAR & $\propto T$ & $\mathrm{NON}$ & DEC & JAN & FEB & MAR & APR & MAY & JUNE & JULY & AUG & SEP \\
\hline 1970 & 32.6 & 24.5 & 18.5 & 17.6 & 15.8 & 13.6 & 14.1 & 305 & 388 & 155 & 85.9 & 70.6 \\
\hline $\begin{array}{l}1971 \\
1972\end{array}$ & $\begin{array}{r}41.5 \\
34.9\end{array}$ & $\begin{array}{l}21.4 \\
34.3\end{array}$ & $\begin{array}{l}17.6 \\
28.5\end{array}$ & $\begin{array}{l}14.4 \\
26.4\end{array}$ & $\begin{array}{l}14.0 \\
24.9\end{array}$ & $\begin{array}{l}13.0 \\
25.2\end{array}$ & $\begin{array}{l}16.6 \\
35.8\end{array}$ & $\begin{array}{l}266 \\
348\end{array}$ & $\begin{array}{l}411 \\
271\end{array}$ & $\begin{array}{l}136 \\
114\end{array}$ & $\begin{array}{l}78.5 \\
59.2\end{array}$ & $\begin{array}{l}60.7 \\
54.9\end{array}$ \\
\hline
\end{tabular}


GREEN RIVER BASIN

09268000 DRY FORK ABOVE SINKS, NEAR DRY FORK, UT

LOCATION.-Lat $40^{\circ} 37^{\prime} 35^{\prime \prime}$, long $109^{\circ} 49^{\prime} 10^{\prime \prime}$, in sec.20, T.2 S., R.19 E., (unsurveyed), Uintah County, Hydrologic Unit 14060002, Ashley National Forest, on left bank 9 mi northwest of town of Dry Fork.

DRAINAGE AREA. $-44.4 \mathrm{mi}^{2}$

MEAN BASIN ELEVATION. $-10,240 \mathrm{ft}$.

PERIOD OF RECORD AVAIIABLE. - March 1939 to September 1975.

GAGE. -Water-stage recorder. Datum of gage is 8,108.51 ft NGVD of 1929 (levels by utah State Water and Power Board).

REMARKS. -Mosby Canal has diverted water above station for irrigation in Deep Creek basin since 1942 or 1943.

AVERAGE DISCHARGE. -36 years, $36.0 \mathrm{ft}^{3} / \mathrm{s}, 26,080$ acre- $\mathrm{ft} / \mathrm{yr}$.

EXTREMES FOR PERIOD OF RECORD. --Maximum discharge,1,010 $\mathrm{ft}^{3} / \mathrm{s}$ June 10, 1965, gage height, $4.78 \mathrm{ft}$, from rating curve extended above $490 \mathrm{ft}^{3} / \mathrm{s}$; no flow for part of each day Apr. 22, May 1-3, 1951.

LOWEST MEAN DISCHARGE, IN OUBIC FEET PER SECOND, AND RANKING FOR THE INDICATED NUMBER OF CONSECUTIVE DAYS FOR EACH CLIMATIC YEAR, APRIL I-MARCH 31

\begin{tabular}{|c|c|c|c|c|c|c|c|c|c|c|c|c|c|c|c|c|c|}
\hline YEAR & 1 & 3 & 7 & & 14 & & $\begin{array}{l}\text { CONSEOUTIV } \\
30\end{array}$ & $\begin{array}{l}\text { E DAYS } \\
60\end{array}$ & & 90 & & 120 & & 183 & & ALL & \\
\hline $\begin{array}{l}1941 \\
1942 \\
1943 \\
1944 \\
1945\end{array}$ & $\begin{array}{rr}6.00 & 34 \\
5.00 & 27 \\
2.00 & 8 \\
5.00 & 28 \\
4.50 & 24\end{array}$ & $\begin{array}{rr}6.00 & 33 \\
5.00 & 27 \\
2.00 & 8 \\
6.00 & 34 \\
4.50 & 24\end{array}$ & $\begin{array}{ll}6.00 & 3 \\
5.00 & 2 \\
2.00 & \\
7.00 & 3 \\
4.50 & 2\end{array}$ & $\begin{array}{r}33 \\
27 \\
7 \\
34 \\
24\end{array}$ & $\begin{array}{l}6.20 \\
5.00 \\
2.00 \\
7.00 \\
4.50\end{array}$ & $\begin{array}{r}33 \\
27 \\
7 \\
34 \\
21\end{array}$ & $\begin{array}{rr}7.00 & 32 \\
5.00 & 23 \\
2.00 & 6 \\
7.00 & 33 \\
4.50 & 18\end{array}$ & $\begin{array}{l}7.10 \\
5.00 \\
2.50 \\
7.00 \\
4.50\end{array}$ & $\begin{array}{r}32 \\
19 \\
4 \\
31 \\
13\end{array}$ & $\begin{array}{l}8.00 \\
5.70 \\
2.70 \\
7.00 \\
4.70\end{array}$ & $\begin{array}{r}32 \\
21 \\
4 \\
30 \\
13\end{array}$ & $\begin{array}{l}8.50 \\
7.30 \\
3.00 \\
7.20 \\
4.90\end{array}$ & $\begin{array}{r}32 \\
29 \\
4 \\
28 \\
11\end{array}$ & $\begin{array}{c}21.0 \\
19.0 \\
5.20 \\
8.50 \\
6.20\end{array}$ & $\begin{array}{r}35 \\
34 \\
9 \\
24 \\
13\end{array}$ & $\begin{array}{l}28.0 \\
61.0 \\
42.0 \\
32.0 \\
57.0\end{array}$ & $\begin{array}{l}12 \\
35 \\
22 \\
17 \\
33\end{array}$ \\
\hline $\begin{array}{l}1946 \\
1947 \\
1948 \\
1949 \\
1950\end{array}$ & $\begin{array}{rr}5.00 & 29 \\
5.50 & 33 \\
11.0 & 35 \\
3.50 & 17 \\
4.00 & 20\end{array}$ & $\begin{array}{rr}5.00 & 28 \\
5.50 & 32 \\
11.0 & 35 \\
3.50 & 17 \\
4.00 & 18\end{array}$ & $\begin{array}{rl}5.00 & 2 \\
5.50 & 3 \\
11.0 & 3 \\
3.50 & 1 \\
4.00 & 1\end{array}$ & $\begin{array}{l}28 \\
31 \\
35 \\
16 \\
18\end{array}$ & $\begin{array}{c}5.00 \\
5.90 \\
11.0 \\
3.50 \\
4.00\end{array}$ & $\begin{array}{l}28 \\
32 \\
35 \\
16 \\
17\end{array}$ & $\begin{array}{cc}5.00 & 24 \\
12.0 & 35 \\
11.0 & 34 \\
3.50 & 13 \\
4.00 & 15\end{array}$ & $\begin{array}{c}5.40 \\
12.0 \\
11.0 \\
3.60 \\
4.00\end{array}$ & $\begin{array}{r}22 \\
35 \\
34 \\
9 \\
11\end{array}$ & $\begin{array}{c}5.90 \\
12.0 \\
11.0 \\
3.90 \\
4.30\end{array}$ & $\begin{array}{r}22 \\
35 \\
34 \\
8 \\
11\end{array}$ & $\begin{array}{c}6.60 \\
12.0 \\
12.0 \\
4.00 \\
5.20\end{array}$ & $\begin{array}{r}22 \\
34 \\
35 \\
8 \\
14\end{array}$ & $\begin{array}{c}8.10 \\
15.0 \\
13.0 \\
5.20 \\
9.20\end{array}$ & $\begin{array}{l}23 \\
32 \\
31 \\
10 \\
26\end{array}$ & $\begin{array}{l}33.0 \\
26.0 \\
55.0 \\
27.0 \\
42.0\end{array}$ & $\begin{array}{l}20 \\
10 \\
31 \\
11 \\
23\end{array}$ \\
\hline $\begin{array}{l}1951 \\
1952 \\
1953 \\
1954 \\
1955\end{array}$ & $\begin{array}{rr}4.00 & 21 \\
2.00 & 9 \\
5.00 & 30 \\
2.70 & 14 \\
3.20 & 15\end{array}$ & $\begin{array}{rr}4.00 & 19 \\
2.20 & 9 \\
5.00 & 29 \\
3.00 & 14 \\
3.30 & 15\end{array}$ & $\begin{array}{ll}4.00 & 1 \\
2.70 & 1 \\
5.00 & 2 \\
3.10 & 1 \\
3.50 & 1\end{array}$ & $\begin{array}{l}19 \\
12 \\
29 \\
13 \\
17\end{array}$ & $\begin{array}{l}4.00 \\
3.00 \\
5.50 \\
3.30 \\
4.40\end{array}$ & $\begin{array}{l}18 \\
11 \\
30 \\
14 \\
19\end{array}$ & $\begin{array}{rr}4.00 & 16 \\
3.30 & 9 \\
5.50 & 28 \\
3.40 & 11 \\
5.00 & 25\end{array}$ & $\begin{array}{l}4.50 \\
3.80 \\
5.80 \\
3.40 \\
5.00\end{array}$ & $\begin{array}{r}14 \\
10 \\
24 \\
7 \\
20\end{array}$ & $\begin{array}{l}5.00 \\
3.90 \\
6.20 \\
3.40 \\
5.30\end{array}$ & $\begin{array}{r}15 \\
9 \\
25 \\
6 \\
18\end{array}$ & $\begin{array}{l}5.40 \\
4.20 \\
6.60 \\
3.50 \\
5.80\end{array}$ & $\begin{array}{r}15 \\
9 \\
23 \\
6 \\
17\end{array}$ & $\begin{array}{l}6.90 \\
7.30 \\
9.00 \\
3.60 \\
7.40\end{array}$ & $\begin{array}{r}16 \\
17 \\
25 \\
5 \\
18\end{array}$ & $\begin{array}{l}45.0 \\
36.0 \\
57.0 \\
21.0 \\
25.0\end{array}$ & $\begin{array}{r}27 \\
21 \\
34 \\
5 \\
9\end{array}$ \\
\hline $\begin{array}{l}1961 \\
1962 \\
1963 \\
1964 \\
1965\end{array}$ & $\begin{array}{rr}1.10 & 2 \\
1.30 & 4 \\
2.30 & 12 \\
2.20 & 11 \\
1.10 & 3\end{array}$ & $\begin{array}{rr}1.19 & 2 \\
1.40 & 4 \\
2.40 & 12 \\
2.20 & 10 \\
1.19 & 3\end{array}$ & $\begin{array}{l}1.19 \\
1.70 \\
2.50 \\
2.40 \\
1.30\end{array}$ & $\begin{array}{r}2 \\
6 \\
11 \\
9 \\
3\end{array}$ & $\begin{array}{l}1.50 \\
1.90 \\
2.60 \\
3.30 \\
1.40\end{array}$ & $\begin{array}{r}4 \\
6 \\
9 \\
13 \\
2\end{array}$ & $\begin{array}{rr}1.80 & 3 \\
2.10 & 7 \\
3.00 & 8 \\
4.60 & 19 \\
1.90 & 4\end{array}$ & $\begin{array}{l}1.90 \\
9.30 \\
4.20 \\
5.00 \\
3.20\end{array}$ & $\begin{array}{r}2 \\
33 \\
12 \\
21 \\
6\end{array}$ & $\begin{array}{l}2.30 \\
9.30 \\
4.40 \\
5.30 \\
4.30\end{array}$ & $\begin{array}{l}3 \\
33 \\
12 \\
19 \\
10\end{array}$ & $\begin{array}{l}2.70 \\
9.70 \\
4.90 \\
5.90 \\
4.50\end{array}$ & $\begin{array}{l}3 \\
33 \\
13 \\
18 \\
10\end{array}$ & $\begin{array}{c}3.20 \\
18.0 \\
4.80 \\
6.20 \\
4.60\end{array}$ & $\begin{array}{r}3 \\
33 \\
8 \\
12 \\
6\end{array}$ & $\begin{array}{l}18.0 \\
30.0 \\
45.0 \\
21.0 \\
30.0\end{array}$ & $\begin{array}{r}2 \\
13 \\
26 \\
4 \\
14\end{array}$ \\
\hline $\begin{array}{l}1966 \\
1967 \\
1968 \\
1969 \\
1970\end{array}$ & $\begin{array}{rr}4.00 & 22 \\
1.80 & 7 \\
5.20 & 32 \\
4.60 & 25 \\
5.00 & 31\end{array}$ & $\begin{array}{rr}4.00 & 21 \\
2.00 & 7 \\
5.30 & 31 \\
4.70 & 25 \\
5.00 & 30\end{array}$ & $\begin{array}{ll}4.20 & 2] \\
2.20 & \\
5.50 & 32 \\
4.80 & 25 \\
5.10 & 30\end{array}$ & $\begin{array}{r}21 \\
8 \\
32 \\
25 \\
30\end{array}$ & $\begin{array}{l}4.50 \\
3.00 \\
5.60 \\
4.80 \\
5.20\end{array}$ & $\begin{array}{l}20 \\
10 \\
31 \\
24 \\
29\end{array}$ & $\begin{array}{ll}4.60 & 20 \\
3.90 & 14 \\
5.90 & 30 \\
4.90 & 21 \\
6.10 & 31\end{array}$ & $\begin{array}{l}4.90 \\
6.50 \\
6.10 \\
5.00 \\
6.60\end{array}$ & $\begin{array}{l}16 \\
29 \\
27 \\
17 \\
30\end{array}$ & $\begin{array}{l}5.30 \\
7.30 \\
6.20 \\
5.20 \\
6.90\end{array}$ & $\begin{array}{l}20 \\
31 \\
24 \\
16 \\
28\end{array}$ & $\begin{array}{l}6.10 \\
8.00 \\
6.40 \\
5.40 \\
7.20\end{array}$ & $\begin{array}{l}20 \\
31 \\
21 \\
16 \\
26\end{array}$ & $\begin{array}{c}9.90 \\
10.0 \\
7.90 \\
6.50 \\
9.90\end{array}$ & $\begin{array}{l}27 \\
29 \\
22 \\
14 \\
28\end{array}$ & $\begin{array}{l}56.0 \\
24.0 \\
50.0 \\
47.0 \\
43.0\end{array}$ & $\begin{array}{r}32 \\
8 \\
30 \\
28 \\
24\end{array}$ \\
\hline
\end{tabular}


09268000 DRY FORK ABOVE SINKS, NEAR DRY FORK, UT-Continued

HIGHEST MEAN DISCHARGE, IN CUBIC FEET PER SECOND, AND RANKING FOR THE INDICATED NUMBER OF CONSECUTIVE DAYS FOR EACH WATER YEAR, OCTCBER I-SEPTEMBER 30

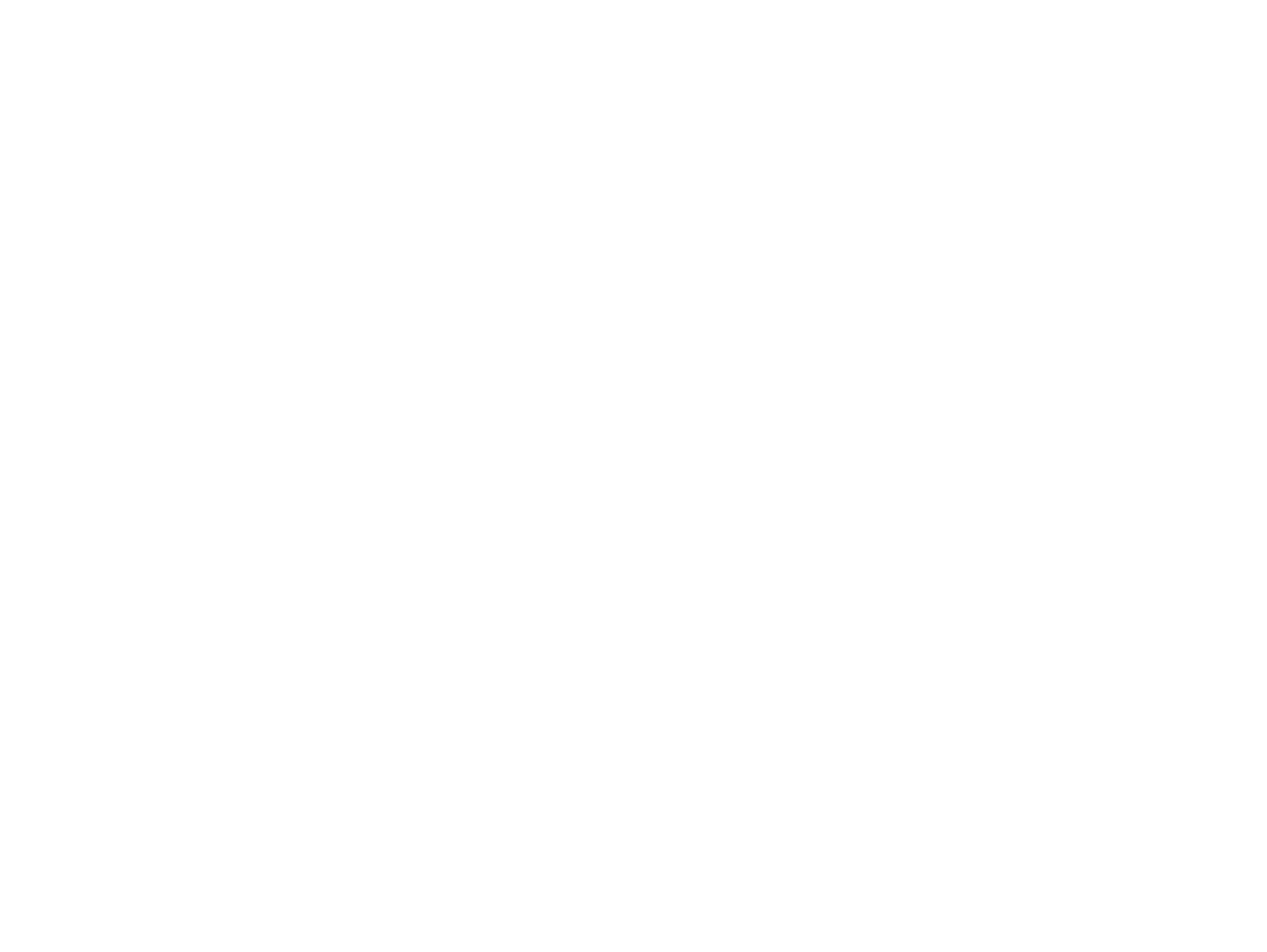


GREEN RIVER BASIN

09268000 DRY FORK ABOVE SINKS, NEAR DRY FORK, UT-Continued

DURATION OF DISCHARGE FOR EACH WATER YEAR

\begin{tabular}{|c|c|c|c|c|c|c|c|c|c|c|c|c|c|c|c|c|c|c|c|c|c|c|c|c|c|c|c|c|c|c|c|c|c|c|}
\hline $\begin{array}{l}\text { CLASS } 0 \\
\text { YEAR }\end{array}$ & & & & & & & . & 0 & & & $\perp$ & 2 & & 14 & 10 & 6 & & $C L A$ & & & & 2 & & & & & & & & & & & & $\begin{array}{l}\text { CUBIC FEET } \\
\text { PER SEDOND } \\
\text {-DAYS }\end{array}$ \\
\hline 940 & & & & & & & & & & & & 154 & 9 & 14 & 23 & 20 & 43 & 17 & 19 & 20 & 10 & 11 & 5 & 3 & 3 & 3 & 9 & 3 & & & & & & 8963.0 \\
\hline $\begin{array}{l}1941 \\
1942 \\
1943 \\
1944 \\
1945\end{array}$ & & & & & & & 31 & & & $\begin{array}{l}32 \\
59\end{array}$ & $\begin{array}{r}1 \\
59 \\
7 \\
62\end{array}$ & $\begin{array}{l}73 \\
23 \\
18 \\
91 \\
47\end{array}$ & $\begin{array}{r}4 \\
18 \\
6 \\
62 \\
15\end{array}$ & $\begin{array}{l}72 \\
18 \\
10 \\
48 \\
23\end{array}$ & $\begin{array}{r}2 \\
11 \\
36 \\
34 \\
4\end{array}$ & $\begin{array}{l}1 \\
34 \\
25 \\
18 \\
16\end{array}$ & $\begin{array}{r}1 \\
29 \\
15 \\
9 \\
15\end{array}$ & $\begin{array}{l}12 \\
26 \\
31 \\
11 \\
10\end{array}$ & $\begin{array}{r}65 \\
32 \\
14 \\
9 \\
12\end{array}$ & $\begin{array}{r}26 \\
24 \\
9 \\
6 \\
19\end{array}$ & $\begin{array}{r}15 \\
17 \\
4 \\
4 \\
10\end{array}$ & $\begin{array}{r}181 \\
221 \\
11 \\
7 \\
14\end{array}$ & $\begin{array}{r}12 \\
12 \\
9 \\
6 \\
8\end{array}$ & $\begin{array}{r}8 \\
4 \\
20 \\
4 \\
61\end{array}$ & $\begin{array}{l}7 \\
4 \\
9 \\
5 \\
16 \quad 1\end{array}$ & $\begin{array}{l}1 \\
3 \\
5 \\
5 \\
161\end{array}$ & $\begin{array}{r}41 \\
4 \\
7 \\
4 \\
13\end{array}$ & $\begin{array}{rl}14 & 1 \\
5 & \\
4 \\
8 & 1\end{array}$ & $\begin{array}{rr}12 & 1 \\
4 \\
3 \\
11 & 1\end{array}$ & $\begin{array}{r}12 \\
7 \\
13\end{array}$ & $\begin{array}{l}5 \\
7 \\
7\end{array}$ & 3 & 1 & $\begin{array}{l}22473.0 \\
17900.0 \\
11027.0 \\
21257.0 \\
11883.1\end{array}$ \\
\hline $\begin{array}{l}946 \\
947 \\
948 \\
.949 \\
.950\end{array}$ & & & & & & & & & & $\begin{array}{l}78 \\
59\end{array}$ & $\begin{array}{l}15 \\
34\end{array}$ & $\begin{array}{l}23 \\
25\end{array}$ & $\begin{array}{r}17 \\
1\end{array}$ & $\begin{array}{l}33 \\
25 \\
35 \\
14\end{array}$ & $\begin{array}{r}41 \\
134 \\
154 \\
20 \\
11\end{array}$ & $\begin{array}{r}36 \\
9 \\
60 \\
21 \\
28\end{array}$ & $\begin{array}{l}26 \\
57 \\
44 \\
17 \\
67\end{array}$ & $\begin{array}{r}14 \\
28 \\
21 \\
9 \\
17\end{array}$ & $\begin{array}{r}10 \\
14 \\
11 \\
9 \\
15\end{array}$ & $\begin{array}{r}14 \\
19 \\
7 \\
6 \\
15\end{array}$ & $\begin{array}{r}13 \\
15 \\
6 \\
4 \\
11\end{array}$ & $\begin{array}{r}14 \\
7 \\
6 \\
9 \\
6\end{array}$ & $\begin{array}{rr}8 & \\
11 & \\
2 & \\
7 & \\
8 & 1\end{array}$ & $\begin{array}{ll}6 \\
3 & 1 \\
3 \\
81 \\
11\end{array}$ & $\begin{array}{l}5 \\
10 \\
6 \\
1 \\
5\end{array}$ & $\begin{array}{c}6 \\
13 \\
2 \\
2 \\
6 \\
7\end{array}$ & $\begin{array}{cc}2 & \\
14 & 1 \\
6 & \\
7 \\
5\end{array}$ & $\begin{array}{rl}1 & \\
15 & 1 \\
5 \\
3 \\
8\end{array}$ & $\begin{array}{r}13 \\
5 \\
8 \\
9\end{array}$ & $\begin{array}{l}2 \\
3 \\
4 \\
5\end{array}$ & $\begin{array}{l}1 \\
4 \\
2\end{array}$ & $\begin{array}{l}1 \\
2\end{array}$ & & $\begin{array}{r}8295.9 \\
20328.0 \\
11427.3 \\
14492.8 \\
16777.0\end{array}$ \\
\hline $\begin{array}{l}1951 \\
1952 \\
1953 \\
1954\end{array}$ & & & & & & & 2 & & $\begin{array}{r}193 \\
6 \\
160\end{array}$ & $\begin{array}{r}37 \\
85 \\
35 \\
4\end{array}$ & $\begin{array}{l}31 \\
37 \\
60 \\
15 \\
66\end{array}$ & $\begin{array}{l}76 \\
31 \\
71 \\
17 \\
99\end{array}$ & $\begin{array}{r}14 \\
13 \\
41 \\
9 \\
36\end{array}$ & $\begin{array}{r}19 \\
17 \\
6 \\
16\end{array}$ & $\begin{array}{r}15 \\
3 \\
28 \\
9 \\
39\end{array}$ & $\begin{array}{r}10 \\
5 \\
38 \\
8 \\
19\end{array}$ & $\begin{array}{l}11 \\
25 \\
43 \\
12 \\
21\end{array}$ & $\begin{array}{r}23 \\
15 \\
14 \\
5 \\
6\end{array}$ & $\begin{array}{r}22 \\
10 \\
13 \\
35 \\
5\end{array}$ & $\begin{array}{r}13 \\
11 \\
7 \\
15 \\
3\end{array}$ & $\begin{array}{r}9 \\
22 \\
5 \\
4 \\
7\end{array}$ & $\begin{array}{r}91 \\
171 \\
2 \\
6 \\
9\end{array}$ & $\begin{array}{cc}10 & 1 \\
14 & 1 \\
1 & \\
2 & \\
9 & \end{array}$ & $\begin{array}{cl}11 & 1 \\
17 & 1 \\
3 \\
5 \\
7\end{array}$ & $\begin{array}{l}11 \\
12 \\
5 \\
2 \\
7\end{array}$ & $\begin{array}{l}3 \\
7 \\
7 \\
3 \\
3 \\
5\end{array}$ & $\begin{array}{r}5 \\
10 \\
4 \\
4 \\
5\end{array}$ & $\begin{array}{r}3 \\
4 \\
1 \\
10 \\
2\end{array}$ & $\begin{array}{l}4 \\
8 \\
3 \\
1\end{array}$ & $\begin{array}{l}4 \\
1\end{array}$ & $\begin{array}{l}2 \\
6 \\
2\end{array}$ & $\begin{array}{ll}2 & 1 \\
2 & 2\end{array}$ & $\begin{array}{l}1 \\
2\end{array}$ & $\begin{array}{r}12936.1 \\
20685.3 \\
8690.7 \\
8598.5 \\
7917.9\end{array}$ \\
\hline $\begin{array}{l}1956 \\
1957 \\
1958 \\
1959 \\
1960\end{array}$ & 11 & 2 & 2 & 1 & 8 & $\begin{array}{l}10 \\
23\end{array}$ & $\begin{array}{r}9 \\
4 \\
24 \\
23\end{array}$ & $\begin{array}{l}24 \\
46 \\
15 \\
221 \\
11\end{array}$ & $\begin{array}{c}24 \\
131 \\
24 \\
116 \\
5\end{array}$ & $\begin{array}{r}74 \\
127 \\
10 \\
51 \\
6\end{array}$ & $\begin{array}{l}84 \\
23 \\
59 \\
26 \\
18\end{array}$ & $\begin{array}{r}31 \\
4 \\
66 \\
8 \\
111\end{array}$ & $\begin{array}{r}12 \\
1 \\
26 \\
8 \\
39\end{array}$ & $\begin{array}{r}4 \\
2 \\
46 \\
9 \\
10\end{array}$ & $\begin{array}{r}7 \\
6 \\
12 \\
12 \\
25\end{array}$ & $\begin{array}{r}5 \\
12 \\
17 \\
10 \\
11\end{array}$ & $\begin{array}{r}10 \\
11 \\
4 \\
7 \\
13\end{array}$ & $\begin{array}{r}8 \\
3 \\
12 \\
4 \\
3\end{array}$ & $\begin{array}{r}6 \\
20 \\
5 \\
3 \\
7\end{array}$ & $\begin{array}{r}5 \\
22 \\
8 \\
4 \\
4\end{array}$ & $\begin{array}{r}5 \\
14 \\
5 \\
11 \\
4\end{array}$ & $\begin{array}{r}2 \\
10 \\
18 \\
13 \\
10\end{array}$ & $\begin{array}{l}6 \\
5 \\
6 \\
9 \\
5\end{array}$ & $\begin{array}{l}6 \\
9 \\
2 \\
4 \\
6 \\
6\end{array}$ & $\begin{array}{l}4 \\
4 \\
3 \\
6 \\
12\end{array}$ & $\begin{array}{l}1 \\
4 \\
1 \\
5 \\
4\end{array}$ & $\begin{array}{l}6 \\
7 \\
2 \\
2 \\
2 \\
5\end{array}$ & $\begin{array}{r}5 \\
10 \\
3 \\
1 \\
1\end{array}$ & $\begin{array}{l}1 \\
2 \\
6 \\
1\end{array}$ & $\begin{array}{l}7 \\
3 \\
4\end{array}$ & $\begin{array}{l}2 \\
3\end{array}$ & $\begin{array}{l}2 \\
4\end{array}$ & 3 & $\begin{array}{r}8908.0 \\
15226.5 \\
12507.9 \\
5996.0 \\
7524.3\end{array}$ \\
\hline $\begin{array}{l}1961 \\
1962 \\
1963 \\
1964 \\
1965\end{array}$ & & & & 1 & $\begin{array}{r}4 \\
10\end{array}$ & 11 & $\begin{array}{r}59 \\
1 \\
5 \\
4\end{array}$ & $\begin{array}{r}26 \\
3 \\
22 \\
6\end{array}$ & $\begin{array}{r}56 \\
25 \\
16 \\
4 \\
1\end{array}$ & $\begin{array}{r}43 \\
5 \\
84 \\
12 \\
79\end{array}$ & $\begin{array}{r}33 \\
3 \\
47 \\
99 \\
81\end{array}$ & $\begin{array}{r}6 \\
3 \\
81 \\
85 \\
12\end{array}$ & $\begin{array}{r}4 \\
21 \\
25 \\
19 \\
29\end{array}$ & $\begin{array}{r}8 \\
112 \\
5 \\
34 \\
4\end{array}$ & $\begin{array}{r}7 \\
11 \\
5 \\
5 \\
5\end{array}$ & $\begin{array}{r}7 \\
18 \\
3 \\
3 \\
5\end{array}$ & $\begin{array}{r}11 \\
13 \\
7 \\
2 \\
2\end{array}$ & $\begin{array}{r}8 \\
16 \\
8 \\
4\end{array}$ & $\begin{array}{r}17 \\
14 \\
4 \\
6 \\
2\end{array}$ & $\begin{array}{r}11 \\
20 \\
5 \\
5 \\
15\end{array}$ & $\begin{array}{r}10 \\
28 \\
3 \\
8 \\
22\end{array}$ & $\begin{array}{r}14 \\
17 \\
14 \\
6 \\
14\end{array}$ & $\begin{array}{rr}5 \\
7 \\
5 \\
1 \\
13 \\
13\end{array}$ & $\begin{array}{ll}5 \\
9 & 1 \\
3 \\
11 & 1 \\
17 & \end{array}$ & $\begin{array}{r}5 \\
17 \\
6 \\
14 \\
8\end{array}$ & $\begin{array}{l}9 \\
6 \\
6 \\
6 \\
2 \\
1\end{array}$ & $\begin{array}{rl}3 \\
6 & 1 \\
5 \\
5 \\
18\end{array}$ & $\begin{array}{rl}3 \\
13 & 1 \\
4 \\
1 \\
6\end{array}$ & $\begin{array}{r}3 \\
10 \\
2 \\
2 \\
7\end{array}$ & $\begin{array}{l}3 \\
2\end{array}$ & $\begin{array}{l}5 \\
6\end{array}$ & 2 & 1 & $\begin{array}{r}8400.1 \\
18587.0 \\
7663.9 \\
11287.7 \\
19654.2\end{array}$ \\
\hline $\begin{array}{l}1966 \\
1967 \\
1968 \\
1969\end{array}$ & & & & & & 1 & 4 & 3 & 15 & 21 & $\begin{array}{r}63 \\
18 \\
104 \\
7\end{array}$ & $\begin{array}{r}44 \\
55 \\
119 \\
52 \\
71\end{array}$ & $\begin{array}{l}40 \\
56 \\
57 \\
27 \\
76\end{array}$ & $\begin{array}{l}26 \\
44 \\
11 \\
25 \\
17\end{array}$ & $\begin{array}{l}17 \\
35 \\
37 \\
33 \\
25\end{array}$ & $\begin{array}{r}8 \\
22 \\
23 \\
15 \\
31\end{array}$ & $\begin{array}{l}20 \\
32 \\
17 \\
20 \\
45\end{array}$ & $\begin{array}{r}28 \\
15 \\
6 \\
16 \\
6\end{array}$ & $\begin{array}{r}20 \\
10 \\
16 \\
5 \\
16\end{array}$ & $\begin{array}{r}15 \\
5 \\
11 \\
4 \\
8\end{array}$ & $\begin{array}{r}7 \\
8 \\
11 \\
5 \\
10\end{array}$ & $\begin{array}{r}1 \\
4 \\
11 \\
6 \\
7\end{array}$ & $\begin{array}{l}3 \\
4 \\
8 \\
5 \\
2\end{array}$ & $\begin{array}{l}51 \\
5 \\
5 \\
3 \\
2\end{array}$ & $\begin{array}{r}11 \\
2 \\
3 \\
3 \\
3 \\
8\end{array}$ & $\begin{array}{ll}4 & \\
4 & 1 \\
1 \\
2 \\
7 & 1\end{array}$ & $\begin{array}{r}3 \\
15 \\
6 \\
4 \\
13 \\
13\end{array}$ & $\begin{array}{r}6 \\
8 \\
3 \\
6 \\
10\end{array}$ & $\begin{array}{l}8 \\
5 \\
4 \\
4\end{array}$ & $\begin{array}{l}5 \\
2 \\
7\end{array}$ & $\begin{array}{l}8 \\
5 \\
9\end{array}$ & $\frac{1}{7}$ & $\begin{array}{l}1 \\
2\end{array}$ & $\begin{array}{r}8567.5 \\
19604.6 \\
17414.1 \\
15208.6 \\
12335.6\end{array}$ \\
\hline $\begin{array}{l}1971 \\
1972 \\
1973 \\
1974 \\
1975\end{array}$ & & & & & & & $\begin{array}{l}19 \\
12\end{array}$ & $\begin{array}{l}111 \\
15\end{array}$ & $\begin{array}{c}111 \\
21\end{array}$ & $\begin{array}{r}6 \\
12\end{array}$ & $\begin{array}{l}83 \\
24 \\
26 \\
21 \\
14\end{array}$ & $\begin{array}{r}73 \\
85 \\
57 \\
38 \\
8\end{array}$ & $\begin{array}{l}67 \\
80 \\
38 \\
33 \\
11\end{array}$ & $\begin{array}{r}22 \\
53 \\
46 \\
13 \\
9\end{array}$ & $\begin{array}{r}22 \\
28 \\
31 \\
12 \\
5\end{array}$ & $\begin{array}{r}8 \\
16 \\
14 \\
9 \\
10\end{array}$ & $\begin{array}{r}6 \\
7 \\
28 \\
11 \\
7\end{array}$ & $\begin{array}{r}11 \\
6 \\
20 \\
6 \\
2\end{array}$ & $\begin{array}{r}11 \\
4 \\
13 \\
4 \\
3\end{array}$ & $\begin{array}{l}6 \\
3 \\
8 \\
3 \\
4\end{array}$ & $\begin{array}{r}3 \\
1 \\
9 \\
1 \\
11\end{array}$ & $\begin{array}{l}5 \\
3 \\
7 \\
2 \\
8\end{array}$ & $\begin{array}{l}3 \\
5 \\
9 \\
1 \\
2\end{array}$ & $\begin{array}{l}4 \\
6 \\
5 \\
2 \\
4\end{array}$ & $\begin{array}{l}4 \\
6 \\
7 \\
3 \\
3\end{array}$ & $\begin{array}{r}7 \\
3 \\
11 \\
4 \\
6\end{array}$ & $\begin{array}{l}6 \\
8 \\
5 \\
1 \\
8\end{array}$ & $\begin{array}{l}5 \\
6 \\
9 \\
1 \\
1 \\
8\end{array}$ & $\begin{array}{r}7 \\
6 \\
12 \\
8\end{array}$ & $\begin{array}{l}3 \\
4 \\
5\end{array}$ & 3 & 2 & & $\begin{array}{r}11696.8 \\
11008.3 \\
18152.5 \\
4024.2 \\
16660.0\end{array}$ \\
\hline
\end{tabular}

DURATION TABLE OF DISCHARGE FOR WATER YEARS 1940-75

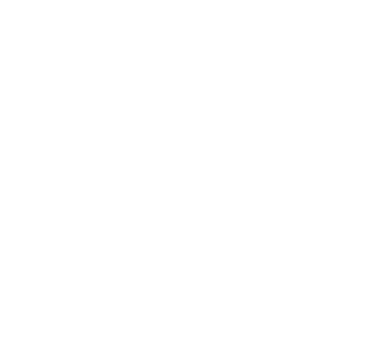

\begin{tabular}{rrrrr}
\multicolumn{4}{c}{ OBIC } & \multicolumn{2}{c}{$\begin{array}{c}\text { ACOU- } \\
\text { FEET } \\
\text { PER }\end{array}$} & $\begin{array}{c}\text { MU- } \\
\text { TOTAL }\end{array}$ LATED & PER- \\
CENT \\
CLASS SECOND & DAYS & DAYS & DAYS \\
& & & & \\
9 & 2.90 & 718 & 12484 & 94.9 \\
10 & 3.70 & 991 & 11766 & 89.5 \\
11 & 4.60 & 1262 & 10775 & 81.9 \\
12 & 5.70 & 1818 & 9513 & 72.3 \\
13 & 7.10 & 928 & 7695 & 58.5 \\
14 & 8.90 & 850 & 6767 & 51.5 \\
15 & 11.00 & 904 & 5917 & 45.0 \\
16 & 14.00 & 595 & 5013 & 38.1 \\
17 & 17.00 & 708 & 4418 & 33.6
\end{tabular}

\begin{tabular}{|c|c|c|c|c|}
\hline CIASS & $\begin{array}{c}\text { OUBIC } \\
\text { FEET } \\
\text { PER } \\
\text { SEOOND }\end{array}$ & $\begin{array}{l}\text { TOTAL } \\
\text { DAYS }\end{array}$ & $\begin{array}{c}\text { ACOU- } \\
\text { MU- } \\
\text { LATED } \\
\text { DAYS }\end{array}$ & $\begin{array}{l}\text { PER- } \\
\text { CENT } \\
\text { DAYS }\end{array}$ \\
\hline $\begin{array}{l}18 \\
19 \\
20 \\
21 \\
22 \\
23 \\
24 \\
25 \\
26\end{array}$ & $\begin{array}{r}22.0 \\
27.0 \\
34.0 \\
42.0 \\
52.0 \\
65.0 \\
81.0 \\
100.0 \\
130.0\end{array}$ & $\begin{array}{l}441 \\
481 \\
380 \\
332 \\
340 \\
228 \\
232 \\
257 \\
185\end{array}$ & $\begin{array}{l}3710 \\
3269 \\
2788 \\
2408 \\
2076 \\
1736 \\
1508 \\
1276 \\
1019\end{array}$ & $\begin{array}{r}28.2 \\
24.9 \\
21.2 \\
18.3 \\
15.8 \\
13.2 \\
11.5 \\
9.7 \\
7.7\end{array}$ \\
\hline
\end{tabular}

\begin{tabular}{rrrrr}
\multicolumn{4}{c}{$\begin{array}{c}\text { CUBIC } \\
\text { FEET }\end{array}$} & \multicolumn{2}{c}{$\begin{array}{c}\text { ACCU- } \\
\text { PU- }\end{array}$} & PER- \\
PER & TOTAL & LATED & CENT \\
CIASS SECOND & DAYS & DAYS & DAYS \\
& & & & \\
27 & 160.0 & 231 & 834 & 6.3 \\
28 & 200.0 & 195 & 603 & 4.6 \\
29 & 250.0 & 169 & 408 & 3.1 \\
30 & 310.0 & 103 & 239 & 1.8 \\
31 & 380.0 & 88 & 136 & 1.0 \\
32 & 480.0 & 36 & 48 & 0.4 \\
33 & 600.0 & 11 & 12 & 0.1 \\
34 & 750.0 & 1 & 1 & 0.0
\end{tabular}


GREEN RTVER BASIN

09268000 DRY FORK ABOVE SINKS, NEAR DRY FORK, UT-Continued

MONIHLY MEAN DISCHARGES, IN CUBIC FEET PER SECOND, FOR EACH WATER YEAR

\begin{tabular}{|c|c|c|c|c|c|c|c|c|c|c|c|c|}
\hline YEAR & $\infty r$ & $\mathrm{NON}$ & $D E C$ & JAN & FEB & MAR & AFR & MAY & JUNE & JULY & $A U G$ & SEP \\
\hline 1940 & 35.5 & 17.0 & 7.00 & 6.00 & 6.00 & 6.00 & 21.2 & 115 & 25.2 & 12.1 & 9.55 & 31.6 \\
\hline $\begin{array}{l}1941 \\
1942 \\
1943 \\
1944 \\
1945\end{array}$ & $\begin{array}{l}54.8 \\
51.9 \\
12.3 \\
12.4 \\
10.2\end{array}$ & $\begin{array}{c}30.0 \\
28.5 \\
6.67 \\
9.43 \\
7.36\end{array}$ & $\begin{array}{c}10.0 \\
12.4 \\
4.00 \\
8.00 \\
5.50\end{array}$ & $\begin{array}{c}10.0 \\
6.97 \\
2.00 \\
7.00 \\
5.00\end{array}$ & $\begin{array}{l}7.00 \\
5.00 \\
3.00 \\
7.00 \\
4.50\end{array}$ & $\begin{array}{l}7.03 \\
5.00 \\
3.00 \\
7.00 \\
4.50\end{array}$ & $\begin{array}{c}7.83 \\
17.3 \\
43.0 \\
8.00 \\
6.00\end{array}$ & $\begin{array}{l}229 \\
121 \\
125 \\
133 \\
105\end{array}$ & $\begin{array}{c}249 \\
247 \\
94.3 \\
361 \\
136\end{array}$ & $\begin{array}{c}60.8 \\
55.4 \\
30.4 \\
111 \\
54.4\end{array}$ & $\begin{array}{l}37.2 \\
23.0 \\
23.6 \\
23.4 \\
31.7\end{array}$ & $\begin{array}{l}33.8 \\
15.2 \\
13.4 \\
11.8 \\
18.6\end{array}$ \\
\hline $\begin{array}{l}1946 \\
1947 \\
1948 \\
1949 \\
1950\end{array}$ & $\begin{array}{c}12.6 \\
20.8 \\
17.9 \\
9.07 \\
16.9\end{array}$ & $\begin{array}{c}9.59 \\
17.6 \\
14.8 \\
5.87 \\
16.9\end{array}$ & $\begin{array}{c}8.40 \\
12.9 \\
13.0 \\
4.50 \\
7.81\end{array}$ & $\begin{array}{c}7.00 \\
12.0 \\
11.0 \\
4.00 \\
5.00\end{array}$ & $\begin{array}{c}5.80 \\
12.0 \\
11.0 \\
3.50 \\
4.00\end{array}$ & $\begin{array}{c}5.00 \\
12.4 \\
11.5 \\
4.02 \\
4.00\end{array}$ & $\begin{array}{l}45.3 \\
17.2 \\
13.3 \\
11.5 \\
21.0\end{array}$ & $\begin{array}{l}72.2 \\
227 \\
138 \\
124 \\
150\end{array}$ & $\begin{array}{c}37.9 \\
184 \\
90.7 \\
234 \\
215\end{array}$ & $\begin{array}{l}14.6 \\
80.0 \\
25.8 \\
46.8 \\
68.6\end{array}$ & $\begin{array}{l}29.8 \\
43.0 \\
15.9 \\
18.0 \\
24.6\end{array}$ & $\begin{array}{l}23.7 \\
26.0 \\
10.4 \\
11.3 \\
17.0\end{array}$ \\
\hline $\begin{array}{l}1951 \\
1952 \\
1953 \\
1954 \\
1955\end{array}$ & $\begin{array}{c}11.3 \\
19.8 \\
15.3 \\
4.04 \\
11.1\end{array}$ & $\begin{array}{c}7.96 \\
6.83 \\
11.5 \\
3.48 \\
9.94\end{array}$ & $\begin{array}{l}6.50 \\
5.16 \\
8.00 \\
3.66 \\
7.00\end{array}$ & $\begin{array}{l}6.00 \\
3.90 \\
7.00 \\
3.50 \\
6.00\end{array}$ & $\begin{array}{l}5.00 \\
3.70 \\
6.00 \\
3.40 \\
5.00\end{array}$ & $\begin{array}{l}4.00 \\
4.00 \\
5.50 \\
3.40 \\
5.00\end{array}$ & $\begin{array}{c}3.30 \\
12.6 \\
8.57 \\
11.9 \\
6.50\end{array}$ & $\begin{array}{c}116 \\
199 \\
34.9 \\
153 \\
107\end{array}$ & $\begin{array}{l}142 \\
265 \\
144 \\
45.3 \\
63.2\end{array}$ & $\begin{array}{l}32.1 \\
60.2 \\
24.0 \\
30.2 \\
17.8\end{array}$ & $\begin{array}{c}60.9 \\
65.0 \\
15.0 \\
7.42 \\
11.1\end{array}$ & $\begin{array}{c}28.5 \\
32.7 \\
6.74 \\
10.4 \\
9.55\end{array}$ \\
\hline $\begin{array}{l}1956 \\
1957 \\
1958 \\
1959 \\
1960\end{array}$ & $\begin{array}{l}6.13 \\
2.81 \\
9.70 \\
1.95 \\
6.82\end{array}$ & $\begin{array}{c}5.81 \\
3.24 \\
9.38 \\
4.41 \\
13.1\end{array}$ & $\begin{array}{l}5.68 \\
4.21 \\
8.48 \\
4.04 \\
8.00\end{array}$ & $\begin{array}{l}4.77 \\
4.50 \\
7.00 \\
3.50 \\
7.00\end{array}$ & $\begin{array}{l}4.50 \\
4.00 \\
6.00 \\
3.50 \\
6.00\end{array}$ & $\begin{array}{l}4.77 \\
4.10 \\
5.00 \\
3.00 \\
6.52\end{array}$ & $\begin{array}{c}7.83 \\
4.96 \\
8.67 \\
3.25 \\
17.9\end{array}$ & $\begin{array}{l}155 \\
20.4 \\
191 \\
54.7 \\
86.8\end{array}$ & $\begin{array}{l}80.4 \\
301 \\
128 \\
87.4 \\
84.8\end{array}$ & $\begin{array}{c}11.5 \\
78.2 \\
27.5 \\
15.6 \\
5.66\end{array}$ & $\begin{array}{c}1.89 \\
42.7 \\
3.62 \\
8.51 \\
2.15\end{array}$ & $\begin{array}{c}2.44 \\
32.3 \\
3.98 \\
7.13 \\
2.15\end{array}$ \\
\hline $\begin{array}{l}1961 \\
1962 \\
1963 \\
1964 \\
1965\end{array}$ & $\begin{array}{c}3.98 \\
44.8 \\
4.98 \\
6.76 \\
5.35\end{array}$ & $\begin{array}{c}2.76 \\
20.6 \\
5.52 \\
6.77 \\
5.80\end{array}$ & $\begin{array}{c}4.77 \\
11.1 \\
5.90 \\
7.65 \\
5.00\end{array}$ & $\begin{array}{l}4.00 \\
9.00 \\
4.66 \\
6.00 \\
5.00\end{array}$ & $\begin{array}{l}3.00 \\
9.64 \\
4.18 \\
5.00 \\
4.50\end{array}$ & $\begin{array}{l}2.00 \\
9.35 \\
5.55 \\
5.00 \\
4.18\end{array}$ & $\begin{array}{c}2.12 \\
39.9 \\
7.00 \\
5.50 \\
5.43\end{array}$ & $\begin{array}{l}87.7 \\
141 \\
122 \\
140 \\
53.6\end{array}$ & $\begin{array}{c}94.7 \\
242 \\
63.7 \\
129 \\
328\end{array}$ & $\begin{array}{c}13.2 \\
61.3 \\
7.54 \\
45.9 \\
124\end{array}$ & $\begin{array}{c}15.2 \\
18.1 \\
5.70 \\
9.05 \\
58.4\end{array}$ & $\begin{array}{c}42.5 \\
3.79 \\
14.3 \\
2.14 \\
48.0\end{array}$ \\
\hline $\begin{array}{l}1966 \\
1967 \\
1968 \\
1969 \\
1970\end{array}$ & $\begin{array}{c}24.9 \\
15.2 \\
11.3 \\
9.16 \\
17.5\end{array}$ & $\begin{array}{c}8.76 \\
13.7 \\
10.3 \\
7.99 \\
12.1\end{array}$ & $\begin{array}{l}8.48 \\
9.90 \\
6.99 \\
5.92 \\
8.18\end{array}$ & $\begin{array}{l}6.02 \\
8.55 \\
6.15 \\
5.58 \\
7.71\end{array}$ & $\begin{array}{l}5.21 \\
7.44 \\
6.03 \\
5.14 \\
7.03\end{array}$ & $\begin{array}{l}4.64 \\
5.95 \\
6.43 \\
4.86 \\
6.09\end{array}$ & $\begin{array}{c}13.1 \\
5.85 \\
7.80 \\
9.45 \\
6.08\end{array}$ & $\begin{array}{c}135 \\
148 \\
31.7 \\
276 \\
96.1\end{array}$ & $\begin{array}{l}40.8 \\
264 \\
378 \\
117 \\
162\end{array}$ & $\begin{array}{l}16.5 \\
93.2 \\
58.0 \\
23.7 \\
44.6\end{array}$ & $\begin{array}{l}6.68 \\
25.7 \\
39.9 \\
12.7 \\
20.0\end{array}$ & $\begin{array}{l}9.13 \\
12.7 \\
13.0 \\
18.5 \\
17.7\end{array}$ \\
\hline $\begin{array}{l}1971 \\
1972 \\
1973 \\
1974 \\
1975\end{array}$ & $\begin{array}{c}9.71 \\
7.23 \\
20.4 \\
8.18 \\
3.39\end{array}$ & $\begin{array}{c}7.54 \\
10.6 \\
16.0 \\
4.90 \\
4.59\end{array}$ & $\begin{array}{l}7.80 \\
8.85 \\
9.00 \\
4.00 \\
1.80\end{array}$ & $\begin{array}{l}5.79 \\
7.72 \\
7.81 \\
3.50 \\
1.70\end{array}$ & $\begin{array}{l}5.05 \\
6.42 \\
6.59 \\
3.50 \\
1.60\end{array}$ & $\begin{array}{l}5.00 \\
6.62 \\
5.48 \\
3.50 \\
1.50\end{array}$ & $\begin{array}{c}7.53 \\
12.1 \\
7.00 \\
4.35 \\
1.40\end{array}$ & $\begin{array}{l}68.5 \\
141 \\
154 \\
69.1 \\
30.3\end{array}$ & $\begin{array}{l}226 \\
134 \\
254 \\
15.2 \\
272\end{array}$ & $\begin{array}{c}28.1 \\
11.8 \\
73.1 \\
6.90 \\
208\end{array}$ & $\begin{array}{c}8.70 \\
5.41 \\
27.5 \\
5.58 \\
15.8\end{array}$ & $\begin{array}{c}6.08 \\
8.22 \\
14.6 \\
2.27 \\
4.83\end{array}$ \\
\hline
\end{tabular}

ANNUAL PEAK DISCHARGE, IN OUBIC FEET PER SECOND, AND CORRESPONDING GAGE HEIGHT, IN FEET, FOR EACH WATER YEAR

\begin{tabular}{|c|c|c|c|c|c|c|c|c|c|c|c|c|}
\hline $\begin{array}{l}\text { WATER } \\
\text { YEAR }\end{array}$ & DATE & $\begin{array}{c}\text { GAGE } \\
\text { HEIGHT }\end{array}$ & $\begin{array}{c}\text { PEAK } \\
\text { DISCHARGE }\end{array}$ & $\begin{array}{l}\text { WATER } \\
\text { YEAR }\end{array}$ & DATE & & $\begin{array}{c}\text { GAGE } \\
\text { HEIGHT }\end{array}$ & $\begin{array}{c}\text { PEAK } \\
\text { DISCHARGE }\end{array}$ & $\begin{array}{l}\text { WATER } \\
\text { YEAR }\end{array}$ & DATE & $\begin{array}{c}\text { GAGE } \\
\text { HEIGHT }\end{array}$ & $\begin{array}{c}\text { PEAK } \\
\text { DISCHARGE }\end{array}$ \\
\hline $\begin{array}{l}1939 \\
1940 \\
1941 \\
1942 \\
1943 \\
1944 \\
1945 \\
1946 \\
1947 \\
1948 \\
1949 \\
1950 \\
1951\end{array}$ & $\begin{array}{l}\text { SEPT. } 13,1939 \\
\text { MAY } 09,1940 \\
\text { MAY } 23,1941 \\
\text { JUNE } 07,1942 \\
\text { MAY } 02,1943 \\
\text { JUNE } 26,1944 \\
\text { JUNE } 22,1945 \\
\text { APR. } 25,1946 \\
\text { MAY } 08,1947 \\
\text { MAY } 19,1948 \\
\text { JUNE } 18,1949 \\
\text { JUNE } 01,1950 \\
\text { MAY } 27,1951\end{array}$ & $\begin{array}{l}-\overline{7} \\
3.75 \\
4.37 \\
4.35 \\
3.91 \\
4.54 \\
3.56 \\
3.66 \\
4.45 \\
4.38 \\
4.85 \\
4.67 \\
4.65\end{array}$ & $\begin{array}{l}370 \\
334 \\
575 \\
610 \\
392 \\
784 \\
240 \\
280 \\
569 \\
547 \\
880 \\
753 \\
817\end{array}$ & $\begin{array}{l}1952 \\
1953 \\
1954 \\
1955 \\
1956 \\
1957 \\
1958 \\
1959 \\
1960 \\
1961 \\
1962 \\
1963\end{array}$ & $\begin{array}{l}\text { JUNE } 06, \\
\text { JUNE } 12, \\
\text { MAY 22, } \\
\text { MAY 11, } \\
\text { MAY 25, } \\
\text { JUNE 08, } \\
\text { MAY 27, } \\
\text { JUNE 06, } \\
\text { MAY 13, } \\
\text { MAY 27, } \\
\text { JUNE 13, } \\
\text { MAY 18, }\end{array}$ & $\begin{array}{l}1952 \\
1953 \\
1954 \\
1955 \\
1956 \\
1957 \\
1958 \\
1959 \\
1960 \\
1961 \\
1962 \\
1963\end{array}$ & $\begin{array}{l}4.49 \\
4.37 \\
3.67 \\
3.46 \\
3.80 \\
4.59 \\
4.38 \\
3.36 \\
3.66 \\
3.84 \\
4.04 \\
3.88\end{array}$ & $\begin{array}{l}866 \\
652 \\
385 \\
276 \\
415 \\
926 \\
780 \\
262 \\
356 \\
380 \\
515 \\
458\end{array}$ & $\begin{array}{l}1964 \\
1965 \\
1966 \\
1967 \\
1968 \\
1969 \\
1970 \\
1971 \\
1972 \\
1973 \\
1974 \\
1975\end{array}$ & $\begin{array}{lll}\text { MAY } & 21,1964 \\
\text { JUNE } & 10,1965 \\
\text { MAY } & 07,1966 \\
\text { MAY } & 24,1967 \\
\text { JUNE } & 17,1968 \\
\text { MAY } & 18,1969 \\
\text { MAY } & 26,1970 \\
\text { JUNE } & 17,1971 \\
\text { MAY } & 28,1972 \\
\text { JUNE } & 14,1973 \\
\text { MAY } & 10,1974 \\
\text { JUNE } & 15,1975\end{array}$ & $\begin{array}{l}4.38 \\
4.78 \\
3.63 \\
4.33 \\
4.48 \\
3.79 \\
3.57 \\
4.19 \\
3.73 \\
4.55 \\
3.56 \\
4.59\end{array}$ & $\begin{array}{r}762 \\
1010 \\
325 \\
720 \\
858 \\
510 \\
329 \\
607 \\
381 \\
871 \\
295 \\
792\end{array}$ \\
\hline
\end{tabular}

MAGNITUDE AND PRCBABILITY OF ANNUAL LOWEST MEAN DISCHARGE BASED ON CLIMATIC YEARS $1941-75$

\begin{tabular}{|c|c|c|c|c|c|c|}
\hline \multirow{2}{*}{$\begin{array}{l}\text { PERIOD } \\
\text { (COAN- } \\
\text { SECU- } \\
\text { TTVE } \\
\text { DAYS) }\end{array}$} & \multicolumn{6}{|c|}{$\begin{array}{l}\text { DISCHARGE, IN OUBIC FEET PER SECOND, FOR } \\
\text { INDICATED RECURRENCE INIERNAL, IN YEARS, AND } \\
\text { ANNUAL NONEXCEEDANCE PRCBABILITY, IN PERCENT }\end{array}$} \\
\hline & $\begin{array}{c}2 \\
50 \%\end{array}$ & $\begin{array}{c}5 \\
208\end{array}$ & $\begin{array}{l}10 \\
108\end{array}$ & $\begin{array}{l}20 \\
58\end{array}$ & $\begin{array}{l}50 \\
28\end{array}$ & $\begin{array}{r}100 \\
18\end{array}$ \\
\hline $\begin{array}{r}1 \\
7 \\
14 \\
30 \\
60 \\
90\end{array}$ & $\begin{array}{l}3.3 \\
3.6 \\
3.9 \\
4.1 \\
4.8 \\
5.2\end{array}$ & $\begin{array}{l}1.9 \\
2.1 \\
2.3 \\
2.6 \\
3.3 \\
3.6\end{array}$ & $\begin{array}{l}1.3 \\
1.5 \\
1.6 \\
2.0 \\
2.6 \\
2.8\end{array}$ & $\begin{array}{l}0.98 \\
1.1 \\
1.2 \\
1.7 \\
2.2 \\
2.3\end{array}$ & $\begin{array}{l}0.67 \\
0.73 \\
0.82 \\
1.3 \\
1.7 \\
1.9\end{array}$ & 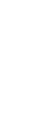 \\
\hline
\end{tabular}

MAGNITUDE AND PROBABILITY OF ANNUAL HIGHEST MEAN DISCHARGE BASED ON WATER YEARS 1940-75

\begin{tabular}{|c|c|c|c|c|c|c|}
\hline \multirow{2}{*}{$\begin{array}{l}\text { PERIOD } \\
\text { (CON- } \\
\text { SEOU- } \\
\text { TIVE } \\
\text { DAYS) }\end{array}$} & \multicolumn{6}{|c|}{$\begin{array}{l}\text { DISCHARGE, IN CUBIC FEET PER SECOND, FOR } \\
\text { INDICATYD RECURRENCE INIERVAL, IN YEARS, AND } \\
\text { ANNUAL EXCEEDANCE PROBABIIITY, IN PERCENI }\end{array}$} \\
\hline & $\begin{array}{c}2 \\
508\end{array}$ & $\begin{array}{c}5 \\
208\end{array}$ & $\begin{array}{l}10 \\
108\end{array}$ & $\begin{array}{l}25 \\
48\end{array}$ & $\begin{array}{l}50 \\
28\end{array}$ & $\begin{array}{r}100 \\
18\end{array}$ \\
\hline $\begin{array}{r}1 \\
3 \\
7 \\
15\end{array}$ & $\begin{array}{l}396 \\
366 \\
318 \\
263\end{array}$ & $\begin{array}{l}562 \\
511 \\
442 \\
364\end{array}$ & $\begin{array}{l}672 \\
604 \\
517 \\
425\end{array}$ & $\begin{array}{l}808 \\
717 \\
607 \\
495\end{array}$ & $\begin{array}{l}909 \\
798 \\
669 \\
544\end{array}$ & $\begin{array}{l}\overline{-} \\
\overline{-}\end{array}$ \\
\hline
\end{tabular}




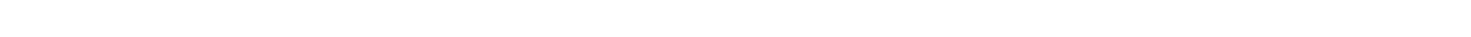
National Forest, on left bank $2 \mathrm{mi}$ upstream fram mouth and $9.5 \mathrm{mi}$ northwest of town of Dry Fork.

DRATNAGE AREA. $-8.62 \mathrm{mi}^{2}$.

MEAN BASIN ELEVATION. $-10,120 \mathrm{ft}$.

PERICD OF RECORD AVAII.ABLE.-April 1946 to September 1981.

REVISED RECORDS. -WSP 2125: Drainage area, WDR UT-77-1: 1976.

GAGE.-Water-stage recorder. Datum of gage is 8,284.28 ft NGVD of 1929 (levels by Utah Water and Power Board).

REVARS. - Irrigation diversions above station.

AVERAGE DISOHARGE. -35 years, $6.57 \mathrm{ft}^{3} / 5,4,760$ acre- $\mathrm{ft} / \mathrm{yr}$.

EXIRENES FOR PERICD OF RECORD. - Maximum discharge, $169 \mathrm{ft}^{3} / \mathrm{s}$ June 5,1968 , gage height, $3.34 \mathrm{ft}$; maximum gage height, $3.60 \mathrm{ft}$ May 7 , 1947; no flow for part of Apr. 21, 1961 , May $1,1963$.

LOWEST MEAN DISGHARGE, IN OUIC FEET PER SECOND, AND RANKING FOR THE INDICATED NUMBER OF CONSEQUTTVE DAVS FOR EAOH OLIMATIC YEAR, APRII 1-MARCA 31

\begin{tabular}{|c|c|c|c|}
\hline . & 1 & 3 & 7 \\
\hline $\begin{array}{l}1948 \\
1949 \\
1950\end{array}$ & $\begin{array}{ll}0.60 & 27 \\
0.40 & 18 \\
0.90 & 34\end{array}$ & $\begin{array}{ll}0.60 & 27 \\
0.40 & 19 \\
0.90 & 34\end{array}$ & $\begin{array}{l}0.601 \\
0.401 \\
0.903\end{array}$ \\
\hline $\begin{array}{l}1951 \\
1952 \\
1953 \\
1954 \\
1955\end{array}$ & $\begin{array}{rr}0.30 & 13 \\
0.20 & 7 \\
0.20 & 8 \\
0.20 & 9 \\
0.10 & 1\end{array}$ & $\begin{array}{rr}0.33 & 15 \\
0.20 & 7 \\
0.20 & 8 \\
0.20 & 9 \\
0.10 & 1\end{array}$ & $\begin{array}{l}0.36 \\
0.20 \\
0.20 \\
0.20 \\
0.10\end{array}$ \\
\hline $\begin{array}{l}1956 \\
1957 \\
1958 \\
1959 \\
1960\end{array}$ & $\begin{array}{ll}0.20 & 10 \\
0.30 & 14 \\
0.30 & 15 \\
0.40 & 19 \\
0.40 & 20\end{array}$ & $\begin{array}{ll}0.20 & 10 \\
0.30 & 11 \\
0.30 & 12 \\
0.40 & 20 \\
0.40 & 21\end{array}$ & $\begin{array}{l}0.201 \\
0.301 \\
0.301 \\
0.401 \\
0.40\end{array}$ \\
\hline $\begin{array}{l}1961 \\
1962 \\
1963 \\
1964 \\
1965\end{array}$ & $\begin{array}{rr}0.40 & 21 \\
0.10 & 2 \\
0.10 & 3 \\
0.10 & 4 \\
0.30 & 16\end{array}$ & $\begin{array}{rr}0.40 & 22 \\
0.13 & 4 \\
0.10 & 2 \\
0.10 & 3 \\
0.37 & 17\end{array}$ & $\begin{array}{l}0.402 \\
0.16 \\
0.10 \\
0.10 \\
0.391\end{array}$ \\
\hline $\begin{array}{l}1966 \\
1967 \\
1968 \\
1969 \\
1970\end{array}$ & $\begin{array}{ll}0.60 & 28 \\
0.50 & 24 \\
0.55 & 25 \\
0.70 & 32 \\
0.60 & 29\end{array}$ & $\begin{array}{ll}0.6028 \\
0.53 & 24 \\
0.58 & 25 \\
0.70 & 32 \\
0.60 & 29\end{array}$ & $\begin{array}{l}0.602 \\
0.542 \\
0.622 \\
0.703 \\
0.60\end{array}$ \\
\hline $\begin{array}{l}1971 \\
1972 \\
1973 \\
1974 \\
1975\end{array}$ & $\begin{array}{ll}0.65 & 31 \\
0.60 & 30 \\
0.75 & 33 \\
0.59 & 26 \\
0.40 & 22\end{array}$ & $\begin{array}{ll}0.65 & 30 \\
0.67 & 31 \\
0.78 & 33 \\
0.59 & 26 \\
0.40 & 18\end{array}$ & $\begin{array}{l}0.66 \\
0.76 \\
0.79 \\
0.59 \\
0.40\end{array}$ \\
\hline $\begin{array}{l}1976 \\
1977 \\
1978 \\
1979 \\
1980\end{array}$ & $\begin{array}{rr}0.29 & 11 \\
0.15 & 5 \\
0.15 & 6 \\
0.32 & 17 \\
0.30 & 12\end{array}$ & $\begin{array}{rr}0.31 & 14 \\
0.15 & 5 \\
0.15 & 6 \\
0.34 & 16 \\
0.30 & 13\end{array}$ & $\begin{array}{l}0.33 \\
0.15 \\
0.15 \\
0.35 \\
0.30\end{array}$ \\
\hline 98 & 0.4723 & 0.4823 & 0.8 \\
\hline
\end{tabular}

\section{CONSECUTIVE DAYS}

0.6026

0.4019

0.9033

0.3816

0.2410

0.207

0.208

$\begin{array}{ll}0.20 & 8 \\ 0.10 & 1\end{array}$

0.209

0.3011

0.3012

0.4020

0.4322

0.4021

0.186

0.102

0.103

$\begin{array}{ll}0.10 & 3 \\ 0.3917\end{array}$

0.6929

0.5524

0.6930

0.7031

0.6027

0.6828

1.0034

0.8032

0.5925

0.5925
0.4018

0.3414

0.154

0.165

0.3515

0.5023

0.4019

0.4019
0.9133

0.3010

0.227

$0.30 \quad 8$
0.3311

0.5022

0.4017

0.206

0.102

0.4018

0.7831

0.5623
0.7730

0.7730
0.7128

0.6026

1.6034

0.8432

0.4520

0.3814

0.174

$0.30 \quad 9$
0.3513

0.3312

0.7429 $\begin{array}{lll}0.6025 & 0.6023\end{array}$

0.4312
0.9830

0.256

0.306

0.101

0.265

0.358

1.1031
0.4514

$\begin{array}{ll}0.45 & 14 \\ 0.53 & 17\end{array}$

0.4515

1.1032

0.142

$\begin{array}{ll}0.35 & 9 \\ 0.58 & 20\end{array}$

0.8027

0.5921
1.3033

$\begin{array}{ll}1.3033 \\ 0.72 & 25\end{array}$

0.6424

0.7526

1.8034
0.9229

0.6022

0.6022
0.5318

0.5519

$\begin{array}{ll}0.55 & 19 \\ 0.18 & 3\end{array}$

0.317

$0.391]$

0.3610
90

0.6321

0.4712
1.1029

120

0.6619

0.5011

1.3029

0.6016

$\begin{array}{lll}0.55 & 14\end{array}$

0.416

0.342

0.5316

0.304

0.10

0.316

0.409

1.3033

0.5014
0.5717

0.385

0.458

1.4030

0.5715

0.6217

0.4713

1.1931

0.4310

0.4810

1.4031

$0.45,9$

0.5413
0.6620

0.6620

0.9027

0.6523

1.3032

1.1928

1.8323
1.4032

0.9025

0.7825

0.8126

1.9034
1.1030

0.6422

0.6422
0.5818

0.8924

1.9034

1.4033

0.7021

0.6418

0.6320

0.263

0.337

$\begin{array}{rr}0.44 & 11 \\ 0.40 \quad 8\end{array}$

0.7222

0.353

0.384

$\begin{array}{ll}0.51 & 12 \\ 0.44 & 7\end{array}$

1.1027

1.0020

0.7411

1.6027

0.8816

0.69

.502

0.50

0.604

0.583

1.9029
0.7813

0.7813
1.0017

0.646

2.7034

1.0018

1.0019

0.8214

2.1031

1.4023

2.0030

1.4024
1.5025

$1.50 \quad 26$

2.2032

2.2033

1.3022

0.8615

1.1021

0.677

0.615

$\begin{array}{lr}0.77 & 12 \\ 0.68 & 8\end{array}$

1.7028

ALL

$11.0 \quad 32$

4.4010
7.1020

8.2023

4.9012

7.9021

4.108

4.109

3.104

5.7016

8.2024

8.3025

2.702

3.105

4.007

3.506

$\begin{array}{lll}3.50 & 6\end{array}$

$11.0 \quad 33$

5.8017

$11.0 \quad 34$

9.6026

10.030

6.8018

8.0022

7.1019

11.031

9.8027

5.4015

$1.40 \quad 1$

4.5011
5.2014

$10.0 \quad 28$

HIGHEST MEAN DISOHARGE, IN CUBIC FEET PER SECOND, AND RANKING FOR THE INDICATED NUMBER OF CONSEOUTTVE DAYS FOR EAQH WATER YEAR, OCTCBER 1-SEPTEMBER 30

YEAR

$\begin{array}{ccccccc} & 1 & & 3 & & 7 & \\ 1947 & 103 & 4 & 94.0 & 4 & 82.0 & \\ 1948 & 56.0 & 20 & 53.0 & 20 & 48.0 & 20 \\ 1949 & 43.0 & 25 & 41.0 & 25 & 38.0 & 2 \\ 1950 & 76.0 & 11 & 75.0 & 11 & 68.0 & 11 \\ & & & & & & \\ 1951 & 69.0 & 14 & 67.0 & 13 & 56.0 & 13 \\ 1952 & 64.0 & 15 & 60.0 & 15 & 53.0 & 17 \\ 1953 & 32.0 & 30 & 31.0 & 29 & 28.0 & 2 \\ 1954 & 42.0 & 26 & 39.0 & 26 & 36.0 & 25 \\ 1955 & 29.0 & 31 & 28.0 & 31 & 24.0 & 31\end{array}$

15

$67.0 \quad 8$

40.021

$\begin{array}{ll}34.0 & 24 \\ 62.0 & 10\end{array}$

41.020

48.014

26.028

$33.0 \quad 25$

\section{CONSECUTIVE DAYS
30}

58.07

$29.0 \quad 24$

$33.0 \quad 19$

$29.0 \quad 25$

$43.0 \quad 13$

$24.0 \quad 27$

26.026

$16.0 \quad 32$

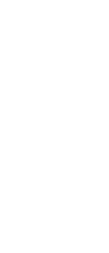

90

$35.0 \quad 5$

$\begin{array}{ll}14.0 & 27 \\ 22.0 & 15\end{array}$

27.011

$15.0 \quad 25$

$26.0 \quad 12$

$13.0 \quad 28$

14.0
8.6032
120

28.05

$11.0 \quad 26$

18.015

22.011

$22.0 \quad 12$

$\begin{array}{ll}22.0 & 12 \\ 11.0 & 27\end{array}$

$\begin{array}{ll}11.0 & 27 \\ 11.0 & 28\end{array}$

7.5032
20.0

8.0026

$13.0 \quad 15$

15.011

9.1024

$15.0 \quad 12$
7.70

7.7028

7.8027
5.6030 
GREEN RIVER BASIN

09268500 NORIH FORK OF DRY FORK NEAR DRY FORK, UT-Continued

HIGAEST MEAN DISCHARGE, IN GBIC FEET PER SECOND, AND RANKING FOR THE INDICATED NUMBER OF CONSEOUTIVE DAYS FOR EACH WATER YEAR, OCTCBER 1-SEPTEMBER 30--Continued

$\begin{array}{rrrrrrrrr}\text { YEAR } & & & & & & & & \\ & 1 & & 3 & & 7 & & 15 & \\ 1956 & 59.0 & 16 & 58.0 & 16 & 55.0 & 15 & 48.0 & 15 \\ 1957 & 80.0 & 9 & 79.0 & 9 & 77.0 & 7 & 65.0 & 9 \\ 1958 & 105 & 3 & 101 & 3 & 95.0 & 2 & 80.0 & 2 \\ 1959 & 19.0 & 34 & 17.0 & 34 & 14.0 & 34 & 11.0 & 34 \\ 1960 & 39.0 & 27 & 36.0 & 28 & 28.0 & 29 & 21.0 & 30 \\ 1961 & 25.0 & 33 & 23.0 & 33 & 22.0 & 33 & 20.0 & 31 \\ 1962 & 85.0 & 8 & 81.0 & 8 & 74.0 & 9 & 56.0 & 12 \\ 1963 & 35.0 & 29 & 30.0 & 30 & 26.0 & 30 & 24.0 & 29 \\ 1964 & 75.0 & 12 & 66.0 & 14 & 56.0 & 14 & 44.0 & 18 \\ 1965 & 100 & 5 & 89.0 & 5 & 80.0 & 5 & 69.0 & 5 \\ 1966 & 44.0 & 22 & 42.0 & 22 & 39.0 & 23 & 35.0 & 23 \\ 1967 & 72.0 & 13 & 69.0 & 12 & 65.0 & 12 & 60.0 & 11 \\ 1968 & 135 & 1 & 115 & 1 & 91.0 & 3 & 76.0 & 3 \\ 1969 & 76.0 & 10 & 75.0 & 10 & 71.0 & 10 & 68.0 & 6 \\ 1970 & 44.0 & 23 & 42.0 & 23 & 40.0 & 22 & 37.0 & 22 \\ 1971 & 57.0 & 19 & 55.0 & 18 & 50.0 & 19 & 45.0 & 17 \\ 1972 & 45.0 & 21 & 44.0 & 21 & 44.0 & 21 & 41.0 & 19 \\ 1973 & 91.0 & 7 & 85.0 & 7 & 75.0 & 8 & 67.0 & 7 \\ 1974 & 29.0 & 32 & 27.0 & 32 & 23.0 & 32 & 19.0 & 33 \\ 1975 & 94.0 & 6 & 87.0 & 6 & 78.0 & 6 & 70.0 & 4 \\ 1976 & 59.0 & 17 & 54.0 & 19 & 51.0 & 18 & 49.0 & 13 \\ 1977 & 15.0 & 35 & 15.0 & 35 & 11.0 & 35 & 7.70 & 35 \\ 1978 & 39.0 & 28 & 38.0 & 27 & 35.0 & 26 & 33.0 & 26 \\ 1979 & 59.0 & 18 & 57.0 & 17 & 53.0 & 16 & 46.0 & 16 \\ 1980 & 125 & 2 & 110 & 2 & 98.0 & 1 & 82.0 & 1\end{array}$

\begin{tabular}{|c|c|c|c|c|c|c|c|c|c|c|c|}
\hline $\begin{array}{l}\text { CONS } \\
30\end{array}$ & & $\begin{array}{l}\text { DAYS } \\
60\end{array}$ & & 90 & & 120 & & 183 & & ALL & \\
\hline $\begin{array}{c}38.0 \\
49.0 \\
61.0 \\
9.60 \\
17.0\end{array}$ & $\begin{array}{r}16 \\
11 \\
5 \\
34 \\
30\end{array}$ & $\begin{array}{c}27.0 \\
35.0 \\
40.0 \\
8.50 \\
13.0\end{array}$ & $\begin{array}{l}16 \\
11 \\
10 \\
34 \\
30\end{array}$ & $\begin{array}{c}20.0 \\
26.0 \\
29.0 \\
6.90 \\
9.80\end{array}$ & $\begin{array}{l}18 \\
13 \\
10 \\
34 \\
30\end{array}$ & $\begin{array}{r}16.0 \\
21.0 \\
23.0 \\
6.00 \\
8.00\end{array}$ & $\begin{array}{l}18 \\
13 \\
10 \\
34 \\
30\end{array}$ & $\begin{array}{c}11.0 \\
15.0 \\
16.0 \\
4.40 \\
5.60\end{array}$ & $\begin{array}{l}18 \\
13 \\
10 \\
34 \\
31\end{array}$ & $\begin{array}{l}5.70 \\
7.60 \\
8.80 \\
2.60 \\
3.30\end{array}$ & $\begin{array}{l}20 \\
13 \\
10 \\
34 \\
30\end{array}$ \\
\hline $\begin{array}{l}17.0 \\
44.0 \\
20.0 \\
33.0 \\
60.0\end{array}$ & $\begin{array}{r}31 \\
12 \\
29 \\
20 \\
6\end{array}$ & $\begin{array}{l}13.0 \\
41.0 \\
14.0 \\
24.0 \\
46.0\end{array}$ & $\begin{array}{r}31 \\
9 \\
29 \\
21 \\
1\end{array}$ & $\begin{array}{c}9.50 \\
34.0 \\
10.0 \\
18.0 \\
36.0\end{array}$ & $\begin{array}{r}31 \\
6 \\
29 \\
22 \\
2\end{array}$ & $\begin{array}{c}7.50 \\
27.0 \\
8.40 \\
14.0 \\
29.0\end{array}$ & $\begin{array}{r}31 \\
6 \\
29 \\
22 \\
2\end{array}$ & $\begin{array}{c}5.40 \\
19.0 \\
6.00 \\
9.60 \\
20.0\end{array}$ & $\begin{array}{r}32 \\
5 \\
29 \\
23 \\
2\end{array}$ & $\begin{array}{r}3.00 \\
11.0 \\
3.50 \\
5.30 \\
11.0\end{array}$ & $\begin{array}{r}32 \\
2 \\
29 \\
23 \\
3\end{array}$ \\
\hline $\begin{array}{l}31.0 \\
54.0 \\
63.0 \\
57.0 \\
32.0\end{array}$ & $\begin{array}{r}22 \\
9 \\
2 \\
8 \\
21\end{array}$ & $\begin{array}{l}22.0 \\
46.0 \\
42.0 \\
44.0 \\
26.0\end{array}$ & $\begin{array}{r}22 \\
2 \\
8 \\
7 \\
19\end{array}$ & $\begin{array}{l}17.0 \\
36.0 \\
32.0 \\
34.0 \\
21.0\end{array}$ & $\begin{array}{r}23 \\
3 \\
9 \\
7 \\
16\end{array}$ & $\begin{array}{l}14.0 \\
28.0 \\
26.0 \\
27.0 \\
17.0\end{array}$ & $\begin{array}{r}23 \\
3 \\
9 \\
7 \\
16\end{array}$ & $\begin{array}{l}10.0 \\
19.0 \\
18.0 \\
19.0 \\
12.0\end{array}$ & $\begin{array}{r}19 \\
6 \\
9 \\
7 \\
16\end{array}$ & $\begin{array}{c}6.10 \\
10.0 \\
9.80 \\
10.0 \\
6.80\end{array}$ & $\begin{array}{r}18 \\
5 \\
7 \\
6 \\
16\end{array}$ \\
\hline $\begin{array}{l}41.0 \\
38.0 \\
62.0 \\
14.0 \\
63.0\end{array}$ & $\begin{array}{r}14 \\
17 \\
4 \\
33 \\
3\end{array}$ & $\begin{array}{l}31.0 \\
27.0 \\
46.0 \\
10.0 \\
46.0\end{array}$ & $\begin{array}{r}14 \\
17 \\
3 \\
33 \\
4\end{array}$ & $\begin{array}{c}24.0 \\
21.0 \\
37.0 \\
8.00 \\
35.0\end{array}$ & $\begin{array}{r}14 \\
17 \\
1 \\
33 \\
4\end{array}$ & $\begin{array}{c}19.0 \\
17.0 \\
30.0 \\
6.70 \\
28.0\end{array}$ & $\begin{array}{r}14 \\
17 \\
1 \\
33 \\
4\end{array}$ & $\begin{array}{c}14.0 \\
12.0 \\
20.0 \\
4.90 \\
19.0\end{array}$ & $\begin{array}{r}14 \\
17 \\
3 \\
33 \\
4\end{array}$ & $\begin{array}{r}7.60 \\
7.00 \\
11.0 \\
3.10 \\
9.70\end{array}$ & $\begin{array}{r}14 \\
15 \\
4 \\
31 \\
8\end{array}$ \\
\hline $\begin{array}{c}40.0 \\
5.30 \\
29.0 \\
35.0 \\
64.0\end{array}$ & $\begin{array}{c}15 \\
35 \\
23 \\
18 \\
1\end{array}$ & $\begin{array}{c}26.0 \\
3.60 \\
20.0 \\
24.0 \\
45.0\end{array}$ & $\begin{array}{r}18 \\
35 \\
24 \\
20 \\
5\end{array}$ & $\begin{array}{c}19.0 \\
2.90 \\
15.0 \\
18.0 \\
34.0\end{array}$ & $\begin{array}{r}19 \\
35 \\
24 \\
20 \\
8\end{array}$ & $\begin{array}{c}15.0 \\
2.80 \\
12.0 \\
14.0 \\
27.0\end{array}$ & $\begin{array}{r}19 \\
35 \\
25 \\
20 \\
8\end{array}$ & $\begin{array}{c}10.0 \\
2.20 \\
8.30 \\
9.70 \\
18.0\end{array}$ & $\begin{array}{r}20 \\
35 \\
25 \\
22 \\
8\end{array}$ & $\begin{array}{l}5.60 \\
1.40 \\
4.50 \\
5.30 \\
9.50\end{array}$ & $\begin{array}{r}21 \\
35 \\
25 \\
22 \\
9\end{array}$ \\
\hline 3.0 & 28 & 22.0 & 23 & 18.0 & 21 & 14.0 & 21 & 10.0 & 21 & 5.90 & 19 \\
\hline
\end{tabular}

DURATION OF DISCHARGE FOR EACH WATER YEAR

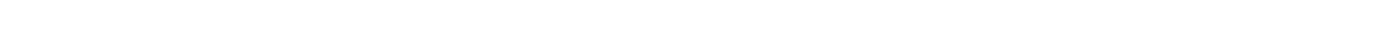

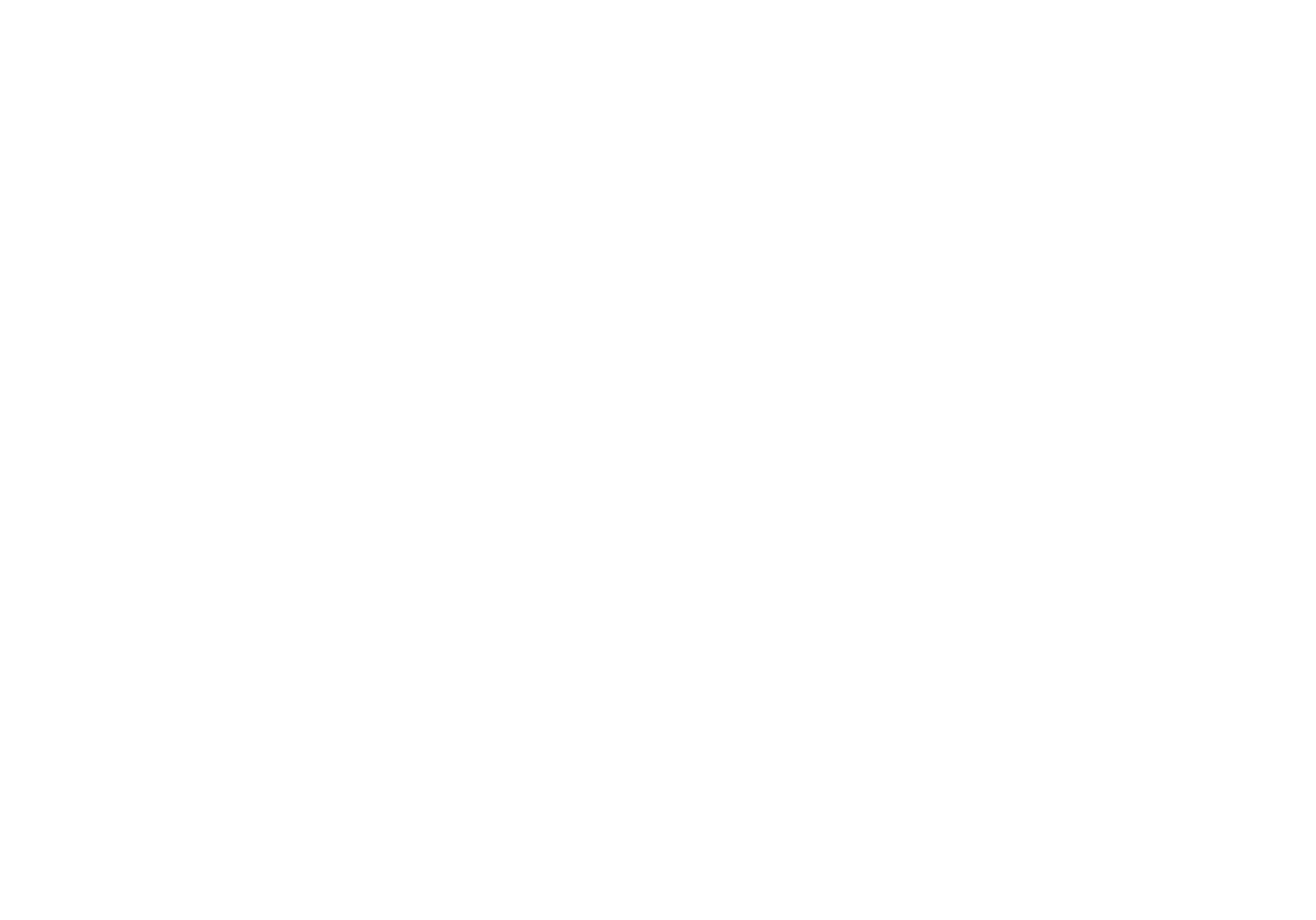


GREEN RIVER BASIN

09268500 NORIH FORK OF DRY FORK NEAR DRY FORK, UT-Continued

DURATION TABLE OF DISCHARGE FOR WATER YEARS 1947-81

$\begin{array}{ccc}\text { CUBIC } & \text { ACQU- } \\ \text { FEET } & \text { MD- } & \text { PER- } \\ \text { PER TOTAL LATED } & \text { CENT } \\ \text { CLASS SECOND DAYS DAYS } & \text { DAYS }\end{array}$

$\begin{array}{ll}\text { COBIC } & \text { ACOU- } \\ \text { FEET } & \text { MU- } \\ \text { PER TOR- } & \end{array}$

$\begin{array}{lll}\text { CUBIC } & \text { ACOU- } \\ \text { FEET } & \text { MU- } & \\ \text { PER- } & \end{array}$

CIASS SECOND DAYS DAYS DAYS

CJASS SECOND DAYS DAYS DAYS
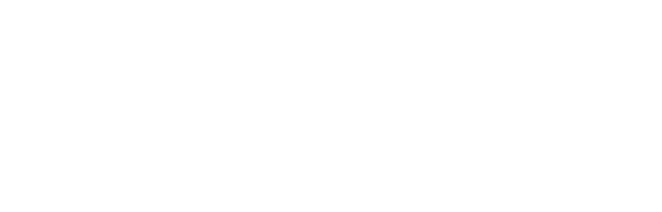

$\begin{array}{rrrrr}18 & 3.9 & 573 & 4002 & 31.3 \\ 19 & 4.9 & 431 & 3429 & 26.8 \\ 20 & 6.1 & 382 & 2998 & 23.5 \\ 21 & 7.5 & 431 & 2616 & 20.5 \\ 22 & 9.4 & 298 & 2185 & 17.1 \\ 23 & 12.0 & 192 & 1887 & 14.8 \\ 24 & 14.0 & 298 & 1695 & 13.3 \\ 25 & 18.0 & 246 & 1397 & 10.9 \\ 26 & 22.0 & 283 & 1151 & 9.0\end{array}$

MONTHLY MEAN DISCHARGES, IN OUBIC FEET PER SEOOND, FOR EACH WATER YEAR

\begin{tabular}{|c|c|c|c|c|c|c|c|c|c|c|c|c|}
\hline YEAR & $\infty T$ & NOV & DEC & JAN & FEB & MAR & APR & MAY & JUNE & JULY & AUG & SEP \\
\hline $\begin{array}{l}1947 \\
1948 \\
1949 \\
1950\end{array}$ & $\begin{array}{l}1.63 \\
2.27 \\
1.55 \\
2.26\end{array}$ & $\begin{array}{l}0.95 \\
1.20 \\
0.81 \\
2.23\end{array}$ & $\begin{array}{l}0.96 \\
0.74 \\
0.60 \\
1.76\end{array}$ & $\begin{array}{l}0.90 \\
0.70 \\
0.50 \\
1.44\end{array}$ & $\begin{array}{l}0.90 \\
0.60 \\
0.40 \\
1.00\end{array}$ & $\begin{array}{l}0.95 \\
0.60 \\
0.50 \\
0.96\end{array}$ & $\begin{array}{l}4.51 \\
1.26 \\
2.82 \\
7.35\end{array}$ & $\begin{array}{l}56.2 \\
24.5 \\
26.6 \\
32.4\end{array}$ & $\begin{array}{l}31.1 \\
13.0 \\
29.1 \\
34.0\end{array}$ & $\begin{array}{c}16.6 \\
4.31 \\
10.5 \\
11.3\end{array}$ & $\begin{array}{l}7.15 \\
2.47 \\
4.15 \\
5.05\end{array}$ & $\begin{array}{l}4.31 \\
2.22 \\
2.55 \\
2.71\end{array}$ \\
\hline $\begin{array}{l}1951 \\
1952 \\
1953 \\
1954 \\
1955\end{array}$ & $\begin{array}{l}1.69 \\
1.19 \\
1.54 \\
1.02 \\
0.81\end{array}$ & $\begin{array}{l}1.10 \\
0.73 \\
1.08 \\
0.59 \\
0.48\end{array}$ & $\begin{array}{l}0.82 \\
0.62 \\
0.73 \\
0.45 \\
0.22\end{array}$ & $\begin{array}{l}0.70 \\
0.48 \\
0.40 \\
0.30 \\
0.10\end{array}$ & $\begin{array}{l}0.50 \\
0.50 \\
0.30 \\
0.30 \\
0.10\end{array}$ & $\begin{array}{l}0.39 \\
0.60 \\
0.20 \\
0.30 \\
0.10\end{array}$ & $\begin{array}{l}0.50 \\
1.45 \\
1.27 \\
1.39 \\
0.23\end{array}$ & $\begin{array}{c}20.1 \\
39.7 \\
9.50 \\
23.8 \\
14.8\end{array}$ & $\begin{array}{c}16.4 \\
27.1 \\
22.1 \\
9.64 \\
6.91\end{array}$ & $\begin{array}{l}7.31 \\
9.28 \\
7.92 \\
6.55 \\
3.36\end{array}$ & $\begin{array}{l}7.24 \\
8.88 \\
3.75 \\
3.88 \\
4.38\end{array}$ & $\begin{array}{l}2.89 \\
3.03 \\
1.97 \\
1.05 \\
3.50\end{array}$ \\
\hline $\begin{array}{l}1956 \\
1957 \\
1958 \\
1959 \\
1960\end{array}$ & $\begin{array}{l}1.41 \\
0.96 \\
3.14 \\
1.41 \\
2.12\end{array}$ & $\begin{array}{l}0.67 \\
0.70 \\
2.27 \\
0.91 \\
1.55\end{array}$ & $\begin{array}{l}0.59 \\
0.60 \\
1.91 \\
0.79 \\
0.78\end{array}$ & $\begin{array}{l}0.36 \\
0.50 \\
1.60 \\
0.60 \\
0.60\end{array}$ & $\begin{array}{l}0.30 \\
0.40 \\
1.20 \\
0.50 \\
0.50\end{array}$ & $\begin{array}{l}0.26 \\
0.30 \\
1.00 \\
0.40 \\
0.60\end{array}$ & $\begin{array}{l}1.77 \\
0.33 \\
1.50 \\
0.54 \\
2.93\end{array}$ & $\begin{array}{c}33.1 \\
5.53 \\
45.7 \\
7.45 \\
14.0\end{array}$ & $\begin{array}{c}20.2 \\
49.0 \\
32.1 \\
8.31 \\
10.7\end{array}$ & $\begin{array}{c}5.43 \\
19.6 \\
8.50 \\
4.35 \\
3.75\end{array}$ & $\begin{array}{l}2.45 \\
7.23 \\
3.56 \\
3.30 \\
1.40\end{array}$ & $\begin{array}{l}1.41 \\
5.87 \\
2.40 \\
2.47 \\
0.60\end{array}$ \\
\hline $\begin{array}{l}1961 \\
1962 \\
1963 \\
1964 \\
1965\end{array}$ & $\begin{array}{l}1.11 \\
6.57 \\
2.62 \\
2.45 \\
1.27\end{array}$ & $\begin{array}{l}0.78 \\
3.80 \\
1.59 \\
1.60 \\
0.98\end{array}$ & $\begin{array}{l}0.54 \\
1.90 \\
1.23 \\
0.89 \\
0.80\end{array}$ & $\begin{array}{l}0.50 \\
1.08 \\
0.28 \\
0.60 \\
0.70\end{array}$ & $\begin{array}{l}0.50 \\
1.27 \\
0.19 \\
0.40 \\
0.60\end{array}$ & $\begin{array}{l}0.40 \\
1.35 \\
0.10 \\
0.30 \\
0.55\end{array}$ & $\begin{array}{c}0.20 \\
10.6 \\
0.10 \\
0.40 \\
0.84\end{array}$ & $\begin{array}{l}10.4 \\
41.0 \\
16.0 \\
21.4 \\
17.7\end{array}$ & $\begin{array}{l}12.7 \\
38.9 \\
10.1 \\
20.0 \\
58.1\end{array}$ & $\begin{array}{c}4.58 \\
15.8 \\
3.90 \\
9.50 \\
26.1\end{array}$ & $\begin{array}{c}1.64 \\
4.85 \\
2.82 \\
3.84 \\
10.2\end{array}$ & $\begin{array}{l}2.84 \\
3.01 \\
2.83 \\
2.10 \\
8.54\end{array}$ \\
\hline $\begin{array}{l}1966 \\
1967 \\
1968 \\
1969 \\
1970\end{array}$ & $\begin{array}{l}4.43 \\
3.06 \\
4.11 \\
2.80 \\
3.10\end{array}$ & $\begin{array}{l}2.85 \\
2.17 \\
2.10 \\
1.84 \\
1.98\end{array}$ & $\begin{array}{l}2.12 \\
1.37 \\
1.51 \\
1.27 \\
1.34\end{array}$ & $\begin{array}{l}0.99 \\
0.76 \\
1.37 \\
0.91 \\
1.05\end{array}$ & $\begin{array}{l}0.83 \\
0.61 \\
1.30 \\
0.70 \\
0.65\end{array}$ & $\begin{array}{l}0.87 \\
0.56 \\
1.30 \\
0.73 \\
0.63\end{array}$ & $\begin{array}{l}5.03 \\
0.77 \\
1.20 \\
2.56 \\
0.71\end{array}$ & $\begin{array}{l}30.5 \\
25.2 \\
10.5 \\
52.5 \\
18.2\end{array}$ & $\begin{array}{l}13.2 \\
49.2 \\
62.2 \\
33.2 \\
24.9\end{array}$ & $\begin{array}{c}5.03 \\
26.9 \\
18.7 \\
13.4 \\
14.6\end{array}$ & $\begin{array}{l}3.89 \\
9.39 \\
9.02 \\
6.40 \\
7.98\end{array}$ & $\begin{array}{l}3.26 \\
5.13 \\
5.08 \\
3.98 \\
6.04\end{array}$ \\
\hline $\begin{array}{l}1971 \\
1972 \\
1973 \\
1974 \\
1975\end{array}$ & $\begin{array}{l}3.58 \\
3.28 \\
3.93 \\
3.19 \\
1.35\end{array}$ & $\begin{array}{l}1.83 \\
2.39 \\
3.89 \\
1.51 \\
1.18\end{array}$ & $\begin{array}{l}1.16 \\
1.92 \\
2.24 \\
0.90 \\
0.83\end{array}$ & $\begin{array}{l}0.92 \\
1.89 \\
1.50 \\
0.71 \\
0.68\end{array}$ & $\begin{array}{l}0.80 \\
1.80 \\
0.97 \\
0.62 \\
0.60\end{array}$ & $\begin{array}{l}0.70 \\
1.94 \\
0.85 \\
0.59 \\
0.46\end{array}$ & $\begin{array}{l}1.60 \\
3.62 \\
0.96 \\
1.01 \\
0.38\end{array}$ & $\begin{array}{c}17.8 \\
28.0 \\
40.3 \\
13.8 \\
7.48\end{array}$ & $\begin{array}{c}38.6 \\
25.7 \\
44.9 \\
6.09 \\
58.7\end{array}$ & $\begin{array}{c}14.2 \\
7.41 \\
20.5 \\
3.74 \\
33.4\end{array}$ & $\begin{array}{r}6.18 \\
3.42 \\
10.00 \\
2.82 \\
7.95\end{array}$ & $\begin{array}{l}4.18 \\
2.73 \\
5.11 \\
1.76 \\
3.56\end{array}$ \\
\hline $\begin{array}{l}1976 \\
1977 \\
1978 \\
1979 \\
1980\end{array}$ & $\begin{array}{l}2.32 \\
1.53 \\
1.27 \\
1.53 \\
1.49\end{array}$ & $\begin{array}{l}1.47 \\
1.02 \\
0.80 \\
1.03 \\
0.79\end{array}$ & $\begin{array}{l}1.00 \\
0.63 \\
0.54 \\
0.72 \\
0.55\end{array}$ & $\begin{array}{l}0.80 \\
0.40 \\
0.37 \\
0.53 \\
0.35\end{array}$ & $\begin{array}{l}0.60 \\
0.20 \\
0.33 \\
0.43 \\
0.37\end{array}$ & $\begin{array}{l}0.50 \\
0.17 \\
0.30 \\
0.35 \\
0.48\end{array}$ & $\begin{array}{l}0.51 \\
0.60 \\
0.69 \\
0.64 \\
1.30\end{array}$ & $\begin{array}{c}25.8 \\
2.15 \\
14.6 \\
23.1 \\
17.7\end{array}$ & $\begin{array}{c}23.2 \\
4.96 \\
23.0 \\
21.2 \\
63.6\end{array}$ & $\begin{array}{c}5.80 \\
1.61 \\
6.14 \\
7.86 \\
18.8\end{array}$ & $\begin{array}{l}3.01 \\
1.80 \\
3.44 \\
3.37 \\
5.63\end{array}$ & $\begin{array}{l}1.98 \\
2.30 \\
2.10 \\
1.98 \\
3.84\end{array}$ \\
\hline 1981 & 3.28 & 2.34 & 1.56 & 1.20 & 0.92 & 0.74 & 5.25 & 22.6 & 20.0 & 6.59 & 3.53 & 3.08 \\
\hline
\end{tabular}

ANNUAL PEAK DISCHARGE, IN CUBIC FEET PER SECOND, AND CORRESPONDING GAGE HEIGHT, IN FEET, FOR EACH WATER YEAR

\begin{tabular}{|c|c|c|c|c|c|c|c|c|c|c|c|c|c|}
\hline $\begin{array}{l}\text { WATER } \\
\text { YEAR }\end{array}$ & DATE & $\begin{array}{c}\text { GAGE } \\
\text { HEIGHT }\end{array}$ & $\begin{array}{c}\text { PEAK } \\
\text { DISCHARGE }\end{array}$ & $\begin{array}{l}\text { WATER } \\
\text { YEAR }\end{array}$ & & DATE & $\begin{array}{c}\text { GAGE } \\
\text { HEIGHT }\end{array}$ & $\begin{array}{c}\text { PEAK } \\
\text { DISCHARGE }\end{array}$ & $\begin{array}{l}\text { WATER } \\
\text { YEAR }\end{array}$ & & DATE & $\begin{array}{c}\text { GAGE } \\
\text { HEIGHT }\end{array}$ & $\begin{array}{c}\text { PEAK } \\
\text { DISCHARGE }\end{array}$ \\
\hline $\begin{array}{l}1946 \\
1947 \\
1948 \\
1949 \\
1950 \\
1951 \\
1952 \\
1953 \\
1954 \\
1955 \\
1956 \\
1957\end{array}$ & $\begin{array}{lll}\text { AIR } & 25, & 1946 \\
\text { MAY } & 07, & 1947 \\
\text { MAY } & 17, & 1948 \\
\text { JUNE } 11, & 1949 \\
\text { MAY } & 30, & 1950 \\
\text { MAY } & 27, & 1951 \\
\text { JUNE } 03, & 1952 \\
\text { JUNE } 12, & 1953 \\
\text { MAY } 22, & 1954 \\
\text { MAY } & 11, & 1955 \\
\text { MAY } & 21, & 1956 \\
\text { JUNE } 04, & 1957\end{array}$ & $\begin{array}{l}2.85 \\
3.60 \\
3.18 \\
2.94 \\
3.34 \\
3.26 \\
3.03 \\
2.72 \\
2.76 \\
2.64 \\
3.06 \\
3.16\end{array}$ & $\begin{array}{r}58 \\
136 \\
86 \\
60 \\
101 \\
101 \\
73 \\
47 \\
48 \\
38 \\
81 \\
111\end{array}$ & $\begin{array}{l}1958 \\
1959 \\
1960 \\
1961 \\
1962 \\
1963 \\
1964 \\
1965 \\
1966 \\
1967 \\
1968 \\
1969\end{array}$ & $\begin{array}{l}\text { MAY } \\
\text { MAY } \\
\text { MAY } \\
\text { MAY } \\
\text { MAY } \\
\text { MAY } \\
\text { MAY } \\
\text { JUNE } \\
\text { MAY } \\
\text { MAY } \\
\text { JUNE } \\
\text { MAY }\end{array}$ & $\begin{array}{l}26,1958 \\
15,1959 \\
12,1960 \\
23,1961 \\
09,1962 \\
18,1963 \\
21,1964 \\
11,1965 \\
06,1966 \\
24,1967 \\
05,1968 \\
17,1969\end{array}$ & $\begin{array}{l}3.38 \\
2.45 \\
3.08 \\
2.66 \\
3.08 \\
2.79 \\
3.34 \\
3.29 \\
2.88 \\
3.17 \\
3.34 \\
2.98\end{array}$ & $\begin{array}{r}139 \\
28 \\
84 \\
42 \\
98 \\
58 \\
141 \\
133 \\
65 \\
123 \\
169 \\
92\end{array}$ & $\begin{array}{l}1970 \\
1971 \\
1972 \\
1973 \\
1974 \\
1975 \\
1976 \\
1977 \\
1978 \\
1979 \\
1980 \\
1981\end{array}$ & $\begin{array}{l}\text { MAY } \\
\text { JUNE } \\
\text { MAY } \\
\text { MAY } \\
\text { MAY } \\
\text { JUNE } \\
\text { MAY } \\
\text { JUNE } \\
\text { JUNE } \\
\text { MAY } \\
\text { JUNE } \\
\text { MAY }\end{array}$ & $\begin{array}{l}20,1970 \\
17,1971 \\
28,1972 \\
18,1973 \\
09,1974 \\
14,1975 \\
28,1976 \\
01,1977 \\
07,1978 \\
28,1979 \\
11,1980 \\
02,1981\end{array}$ & $\begin{array}{l}2.84 \\
2.86 \\
2.78 \\
3.12 \\
2.71 \\
3.24 \\
2.94 \\
2.48 \\
2.76 \\
2.95 \\
3.23 \\
2.81\end{array}$ & $\begin{array}{r}63 \\
69 \\
57 \\
114 \\
46 \\
127 \\
72 \\
25 \\
45 \\
77 \\
132 \\
54\end{array}$ \\
\hline
\end{tabular}


GREEN RIVER BASIN

09268500 NORTH FORK OF DRY FORK NEAR DRY FORK, UT--Continued

\begin{tabular}{|c|c|c|c|c|c|c|}
\hline \multirow{2}{*}{$\begin{array}{l}\text { PERIOD } \\
\text { (CON- } \\
\text { SEQU- } \\
\text { TIVE } \\
\text { DAYS) }\end{array}$} & \multicolumn{6}{|c|}{$\begin{array}{l}\text { DISCHARGE, IN CABIC FEET PER SECOND, FOR } \\
\text { INDICATED RECURRENCE INIERNAL, IN YEARS, AND } \\
\text { ANNUAL NONEXCEEDANCE PRCBABILITY, IN PERCENT }\end{array}$} \\
\hline & $\begin{array}{c}2 \\
508\end{array}$ & $\begin{array}{c}5 \\
208\end{array}$ & $\begin{array}{l}10 \\
108\end{array}$ & $\begin{array}{l}20 \\
58\end{array}$ & $\begin{array}{l}50 \\
28\end{array}$ & $\begin{array}{r}100 \\
18\end{array}$ \\
\hline $\begin{array}{r}1 \\
7 \\
14 \\
30 \\
60 \\
90\end{array}$ & $\begin{array}{l}0.34 \\
0.36 \\
0.37 \\
0.42 \\
0.52 \\
0.59\end{array}$ & $\begin{array}{l}0.20 \\
0.21 \\
0.21 \\
0.23 \\
0.30 \\
0.35\end{array}$ & $\begin{array}{l}0.14 \\
0.15 \\
0.15 \\
0.17 \\
0.22 \\
0.25\end{array}$ & $\begin{array}{l}0.11 \\
0.11 \\
0.11 \\
0.13 \\
0.17 \\
0.19\end{array}$ & $\begin{array}{l}0.0 \\
0.0 \\
0.0 \\
0.0 \\
0.1 \\
0.1\end{array}$ & $\begin{array}{l}-- \\
-- \\
-- \\
-- \\
-\end{array}$ \\
\hline
\end{tabular}

MAGNITUDE AND PRCBABILITY OF ANNUAL HIGHEST MEAN DISCHARGE BASED ON WATER YEARS 1947-81

\begin{tabular}{|c|c|c|c|c|c|c|}
\hline \multirow{2}{*}{$\begin{array}{l}\text { PERIOD } \\
\text { (CON- } \\
\text { SECU- } \\
\text { TIVE } \\
\text { DAYS) }\end{array}$} & \multicolumn{6}{|c|}{$\begin{array}{l}\text { DISCHARGE, IN CUBIC FEET PER SECOND, FOR } \\
\text { INDICAIED RECURRENCE INTERVAL, IN YEARS, AND } \\
\text { ANNUAL EXCEEDANCE PRCBABILITY, IN PERCENT }\end{array}$} \\
\hline & $\begin{array}{c}2 \\
508\end{array}$ & $\begin{array}{c}5 \\
208\end{array}$ & $\begin{array}{l}10 \\
108\end{array}$ & $\begin{array}{l}25 \\
48\end{array}$ & $\begin{array}{l}50 \\
28\end{array}$ & $\begin{array}{r}100 \\
18\end{array}$ \\
\hline
\end{tabular}

$\begin{array}{rrrrrrr}1 & 57 & 86 & 104 & 125 & 140 & \\ 3 & 54 & 80 & 96 & 114 & 127 & - \\ 7 & 49 & 73 & 86 & 101 & 110 & - \\ 15 & 43 & 64 & 74 & 84 & 90 & -\end{array}$

09268900 BROWNIE CANYON ABOVE SINKS, NEAR DRY FORK, UT

LOCATION.--Lat $40^{\circ} 39^{\prime} 34^{\prime \prime}$, long $109^{\circ} 45^{\prime} 01^{\prime \prime}$, in SW ${ }^{\frac{3}{4} \mathrm{NE}^{\frac{1}{4}}} \mathrm{sec} .11, \mathrm{~T} .2$ S., R.19 E. (unsurveyed), Uintah County, Hydrologic Unit 14060002, Ashley National Forest, on right bank $4.5 \mathrm{mi}$ upstream from mouth and $8.5 \mathrm{mi}$ northwest of town of Dry Fork.

DRAINAGE AREA. $--8.24 \mathrm{mi}^{2}$

MEAN BASIN ELEVATION. $-10,110 \mathrm{ft}$.

PERIOD OF RECORD AVAILABLE.-October 1960 to September 1981. Published as "East Fork of Dry Fork above sinks, near Dry Fork" prior to October 1967.

GAGE. -Water-stage recorder. Altitude of gage is $8,300 \mathrm{ft}$ from topographic map. Prior to July 28,1978 , at $0.53 \mathrm{ft}$ higher datum. AVERAGE DISCHARGE. -21 years, $12.7 \mathrm{ft}^{3} / \mathrm{s}, 9,200$ acre- $\mathrm{ft} / \mathrm{yr}$.

EXIREMES FOR PERIOD OF RECORD.--Maximum discharge, $395 \mathrm{ft}^{3} / \mathrm{s}$ June 10, 1965, gage height, $2.12 \mathrm{ft}$, from rating curve extended abnve $160 \mathrm{ft}^{3} / \mathrm{s}$; no flow for part of Apr. 23, 1961.

LONEST MEAN DISCHARGE, IN CUBIC FEET PER SECOND, AND RANKING FOR THE INDICATED NUMBER OF CONSBCUTIVE DAYS FOR FACH CLIMATIC YEAR, APRIL I-MARCH 31

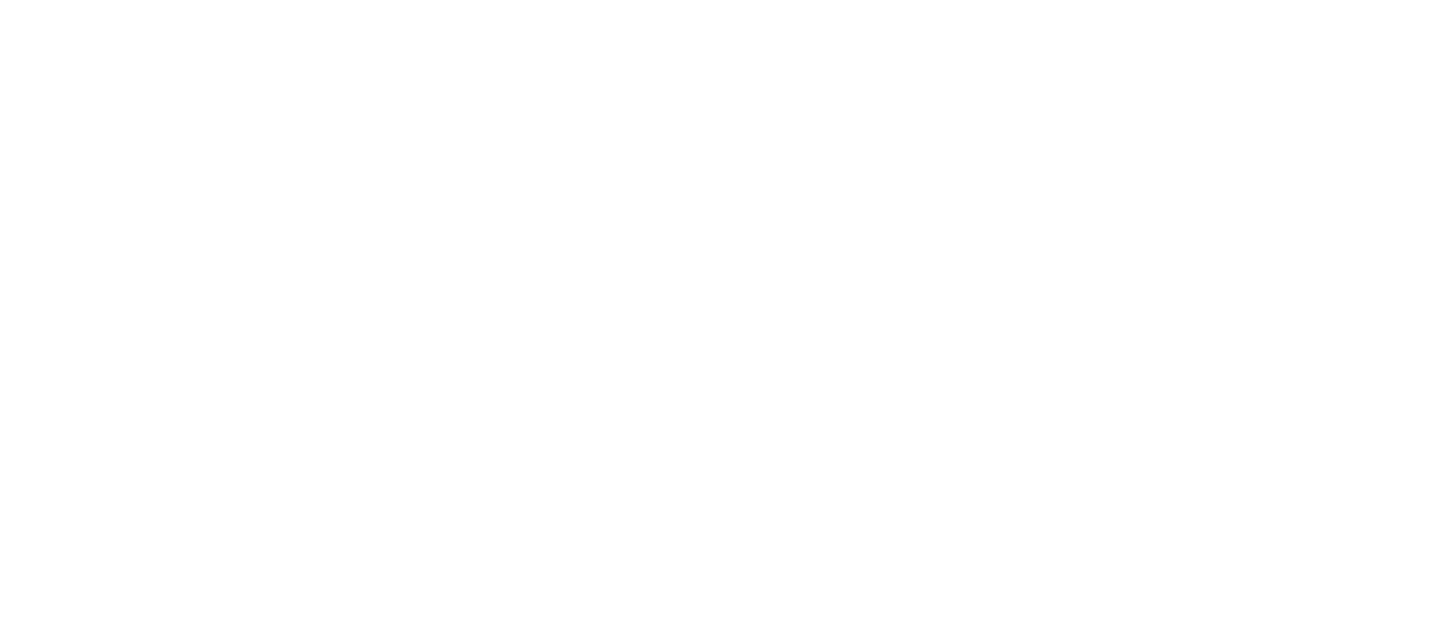


GREEN RIVER BASIN

09268900 BRONNIE CANYON ABOVE SINRS, NEAR DRY FORK, UT-Continued

HIGHEST MEAN DISCHARGE, IN CUBIC FEET PER SECOND, AND RANKING FOR THE INDICATED NUMBER OF CONSECUTIVE DAYS FOR EACH WATER YEAR, OCTCBER 1-SEPTETBER 30

\begin{tabular}{|c|c|c|c|c|c|c|c|c|c|c|c|c|c|c|c|c|c|c|c|c|}
\hline YEAR & 1 & & 3 & & 7 & & 15 & & $\begin{array}{l}\text { CONS } \\
30\end{array}$ & & $\begin{array}{l}\text { DAYS } \\
60\end{array}$ & & 90 & & 120 & & 183 & & ALL & \\
\hline $\begin{array}{l}1961 \\
1962 \\
1963 \\
1964 \\
1965\end{array}$ & $\begin{array}{c}82.0 \\
120 \\
83.0 \\
162 \\
168\end{array}$ & $\begin{array}{r}18 \\
11 \\
17 \\
6 \\
4\end{array}$ & $\begin{array}{c}77.0 \\
109 \\
75.0 \\
145 \\
145\end{array}$ & $\begin{array}{r}17 \\
11 \\
18 \\
6 \\
7\end{array}$ & $\begin{array}{l}69.0 \\
91.0 \\
63.0 \\
129 \\
116\end{array}$ & $\begin{array}{r}17 \\
12 \\
18 \\
6 \\
8\end{array}$ & $\begin{array}{r}60.0 \\
74.0 \\
53.0 \\
98.0 \\
101\end{array}$ & $\begin{array}{r}17 \\
15 \\
18 \\
7 \\
6\end{array}$ & $\begin{array}{l}48.0 \\
70.0 \\
44.0 \\
72.0 \\
87.0\end{array}$ & $\begin{array}{r}17 \\
13 \\
18 \\
11 \\
7\end{array}$ & $\begin{array}{l}31.0 \\
63.0 \\
29.0 \\
47.0 \\
66.0\end{array}$ & $\begin{array}{r}18 \\
8 \\
19 \\
12 \\
7\end{array}$ & $\begin{array}{l}22.0 \\
50.0 \\
22.0 \\
34.0 \\
52.0\end{array}$ & $\begin{array}{r}18 \\
8 \\
19 \\
12 \\
6\end{array}$ & & $\begin{array}{r}18 \\
8 \\
19 \\
13 \\
6\end{array}$ & $\begin{array}{l}13.0 \\
29.0 \\
12.0 \\
19.0 \\
30.0\end{array}$ & $\begin{array}{r}18 \\
7 \\
19 \\
13 \\
6\end{array}$ & $\begin{array}{c}7.20 \\
17.0 \\
7.10 \\
10.0 \\
16.0\end{array}$ & $\begin{array}{r}18 \\
5 \\
19 \\
13 \\
6\end{array}$ \\
\hline $\begin{array}{l}966 \\
967 \\
968 \\
969 \\
970\end{array}$ & $\begin{array}{l}101 \\
165 \\
240 \\
150 \\
126\end{array}$ & $\begin{array}{r}14 \\
5 \\
1 \\
8 \\
10\end{array}$ & $\begin{array}{l}94.0 \\
163 \\
215 \\
146 \\
120\end{array}$ & $\begin{array}{r}15 \\
4 \\
1 \\
5 \\
10\end{array}$ & $\begin{array}{l}84.0 \\
151 \\
168 \\
135 \\
111\end{array}$ & $\begin{array}{r}15 \\
3 \\
1 \\
5 \\
9\end{array}$ & $\begin{array}{l}66.0 \\
120 \\
146 \\
124 \\
96.0\end{array}$ & $\begin{array}{r}16 \\
5 \\
1 \\
3 \\
8\end{array}$ & $\begin{array}{l}60.0 \\
103 \\
122 \\
101 \\
84.0\end{array}$ & $\begin{array}{r}16 \\
3 \\
2 \\
4 \\
8\end{array}$ & $\begin{array}{l}45.0 \\
93.0 \\
78.0 \\
77.0 \\
59.0\end{array}$ & $\begin{array}{r}13 \\
2 \\
3 \\
4 \\
9\end{array}$ & & $\begin{array}{r}13 \\
2 \\
3 \\
4 \\
9\end{array}$ & & $\begin{array}{r}12 \\
2 \\
3 \\
4 \\
9\end{array}$ & & $\begin{array}{r}12 \\
2 \\
3 \\
4 \\
9\end{array}$ & $\begin{array}{l}12.0 \\
21.0 \\
18.0 \\
17.0 \\
14.0\end{array}$ & $\begin{array}{r}12 \\
2\end{array}$ \\
\hline $\begin{array}{l}1972 \\
1973 \\
1974 \\
1975\end{array}$ & $\begin{array}{c}113 \\
106 \\
210 \\
81.0 \\
158\end{array}$ & $\begin{array}{r}12 \\
13 \\
2 \\
19 \\
7\end{array}$ & $\begin{array}{c}101 \\
104 \\
187 \\
75.0 \\
142\end{array}$ & $\begin{array}{r}13 \\
12 \\
2 \\
19 \\
8\end{array}$ & $\begin{array}{l}89.0 \\
101 \\
157 \\
63.0 \\
117\end{array}$ & $\begin{array}{r}13 \\
11 \\
2 \\
19 \\
7\end{array}$ & $\begin{array}{c}87.0 \\
94.0 \\
145 \\
48.0 \\
96.0\end{array}$ & $\begin{array}{r}12 \\
10 \\
2 \\
20 \\
9\end{array}$ & $\begin{array}{c}78.0 \\
84.0 \\
137 \\
35.0 \\
89.0\end{array}$ & $\begin{array}{r}10 \\
9 \\
1 \\
20 \\
6\end{array}$ & $\begin{array}{l}54.0 \\
56.0 \\
98.0 \\
24.0 \\
72.0\end{array}$ & $\begin{array}{r}11 \\
10 \\
1 \\
20 \\
5\end{array}$ & & $\begin{array}{r}10 \\
11 \\
1 \\
20 \\
5\end{array}$ & & $\begin{array}{r}10 \\
11 \\
1 \\
20 \\
5\end{array}$ & & $\begin{array}{r}10 \\
11 \\
1 \\
20 \\
5\end{array}$ & $\begin{array}{c}13.0 \\
13.0 \\
23.0 \\
6.90 \\
16.0\end{array}$ & $\begin{array}{r}10 \\
11 \\
1 \\
20 \\
7\end{array}$ \\
\hline 98 & 76.0 & 20 & 70.0 & 20 & 56.0 & 20 & 51.0 & 19 & 43.0 & 19 & 37.0 & 17 & 28.0 & 17 & 23.0 & 17 & 16.0 & 17 & 9.00 & \\
\hline
\end{tabular}

DURATION OF DISCHARGE FOR EACH WATER YEAR

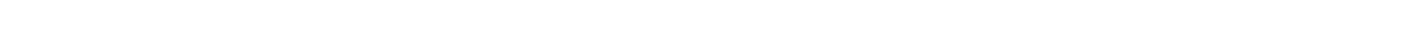

YEAR

NUMBER OF DAYS IN CLASS

CUBIC FEET

PER SECOND

$\begin{array}{llllllllllllllllllllllllll}1 & 17 & 84 & 17 & 7 & 8 & 48 & 9 & 20 & 8 & 24 & 16 & 14 & 13 & 15 & 13 & 7 & 6 & 4 & 3 & 4 & 6 & 9 & 6 & 5 & 1\end{array}$

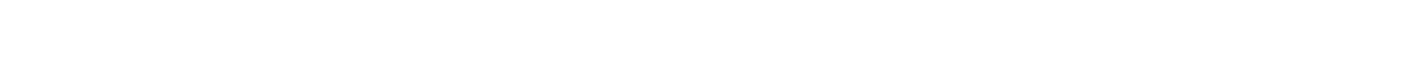

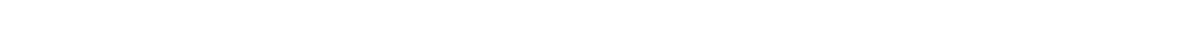

1964

1965

$\begin{array}{lllllllllllllllllllll}47 & 15 & 35 & 24 & 40 & 24 & 21 & 25 & 18 & 20 & 24 & 6 & 8 & 11 & 7 & 6 & 10 & 14 & 5 & 4 & 1\end{array}$

$\begin{array}{lllllllllllllllllllllllll}58 & 17 & 18 & 23 & 24 & 17 & 21 & 10 & 7 & 4 & 11 & 16 & 8 & 9 & 4 & 6 & 3 & 9 & 11 & 13 & 18 & 5 & 5 & & 7545.8\end{array}$

$\begin{array}{lllllllllllllllllllllllllll}57 & 73 & 39 & 8 & 12 & 14 & 16 & 4 & 14 & 15 & 13 & 14 & 17 & 18 & 8 & 5 & 4 & 4 & 1 & 7 & 8 & 9 & 3 & 1 & 2 & 6431.9\end{array}$

$\begin{array}{rrrrrrrrrrrrrrrrrrrrrrrrrr}47 & 46 & 24 & 42 & 15 & 8 & 7 & 32 & 22 & 8 & 14 & 9 & 13 & 11 & 6 & 4 & 4 & 9 & 11 & 6 & 5 & 15 & 3 & 4 & & 6146.2 \\ 48 & 69 & 44 & 9 & 14 & 31 & 12 & 13 & 25 & 9 & 16 & 7 & 11 & 6 & 5 & 2 & 13 & 3 & 10 & 11 & 5 & 2 & & & 4941.8\end{array}$

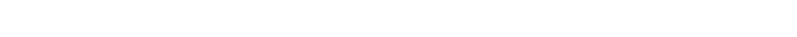

1972

1973

$\begin{array}{lllllllllllllllllllll}44 & 81 & 13 & 26 & 23 & 46 & 23 & 25 & 26 & 6 & 9 & 4 & 15 & 7 & 4 & 5 & 2 & 2 & 2 & 2\end{array}$

1975

$\begin{array}{llllllllllllllllllllllll}63 & 29 & 32 & 31 & 26 & 13 & 17 & 25 & 26 & 16 & 5 & 10 & 4 & 9 & 9 & 8 & 7 & 5 & 3 & 4 & 5 & 7 & 11 & 1\end{array}$

$\begin{array}{lllllllllllllllllllllllll}1976 & 39 & 28 & 11 & 17 & 23 & 3 & 42 & 6 & 6 & 14 & 18 & 12 & 24 & 25 & 23 & 19 & 11 & 26 & 9 & 3 & 2 & 3 & 1\end{array}$

1978

1979

1981

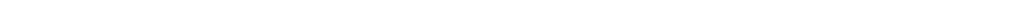

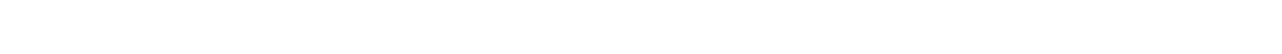

$\begin{array}{lllllllllllllllllllllll}11 & 60 & 9 & 43 & 13 & 19 & 5 & 20 & 45 & 38 & 10 & 11 & 9 & 7 & 6 & 10 & 8 & 10 & 5 & 10 & 14 & 1 & 1\end{array}$

3301.3

DURATION TABLE OF DISCHARGE FOR WATER YEARS 1961-81

$\begin{array}{rrr}\text { OUBIC } & \text { ACOU- } \\ \text { FEET } & \text { MU- } & \text { PER- } \\ \text { PER } & \text { TOTAL LAIED } & \text { CENT } \\ \text { CLASS SEOOND DAYS DAYS } & \text { DAYS }\end{array}$

$\begin{array}{lllll}0 & 0.00 & 0 & 7670 & 100.0\end{array}$

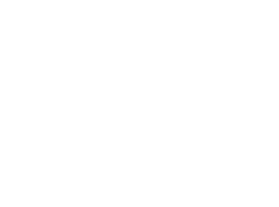

OUBIC ACQUCIASS SECOND DAYS DAYS DAYS

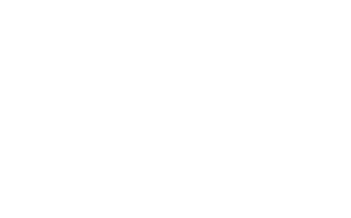

COBIC
FEET

PER TOTAL LATED CENT

18
19
20
21
22
23
24
25
26

$\begin{array}{llll}7.4 & 302 & 2316 & 30.2\end{array}$

$9.1211 \quad 2014 \quad 26.3$

$\begin{array}{llll}11.0 & 246 & 1803 & 23.5\end{array}$

$\begin{array}{llll}14.0 & 209 & 1557 & 20.3\end{array}$

$\begin{array}{llll}17.0 & 188 & 1348 & 17.6\end{array}$

$21.0 \quad 152 \quad 1160 \quad 15.1$

$26.0 \quad 145 \quad 1008 \quad 13.1$

$\begin{array}{rrrr}33.0 & 106 & 863 & 11.3\end{array}$ $\begin{array}{cc}\text { OBIC } & \text { ACOU- } \\ \text { FEET } & \text { MU- } \\ \text { PER- } & \text { PER }\end{array}$

CIASS SECOND DAYS DAYS DAYS

$\begin{array}{rrrrr}27 & 50.0 & 167 & 620 & 8.1 \\ 28 & 62.0 & 128 & 453 & 5.9 \\ 29 & 76.0 & 151 & 325 & 4.2 \\ 30 & 94.0 & 102 & 174 & 2.3 \\ 31 & 120.0 & 36 & 72 & 0.9 \\ 32 & 140.0 & 28 & 36 & 0.5 \\ 33 & 180.0 & 6 & 8 & 0.1 \\ 34 & 220.0 & 2 & 2 & 0.0\end{array}$


GREEN RIVER BASIN

09268900 BRCWNIE CANYON ABOVE SINKS, NEAR DRY FORK, UT-Continued

MONTHLY MEAN DISOGARGES, IN OUBIC FEET PER SECOND, FOR EACH WATER YEAR

$\begin{array}{lllllllllllrr}\text { YEAR } & \text { OCT } & \text { NOV } & \text { DEC } & \text { JAN } & \text { FEB } & \text { MAR } & \text { APR } & \text { MAY } & \text { JUNE } & \text { JULY } & \text { AUG } & \text { SEP } \\ 1961 & 2.24 & 1.49 & 1.29 & 0.60 & 0.70 & 0.75 & 0.52 & 29.6 & 30.1 & 5.88 & 4.04 & 8.48 \\ 1962 & 9.99 & 6.38 & 3.48 & 2.16 & 2.27 & 2.35 & 13.9 & 50.0 & 69.6 & 25.4 & 7.93 & 4.94 \\ 1963 & 4.67 & 3.48 & 2.15 & 0.69 & 0.31 & 0.20 & 0.20 & 37.0 & 19.4 & 7.81 & 4.31 & 4.79 \\ 1964 & 5.21 & 3.69 & 2.82 & 0.63 & 0.30 & 0.40 & 0.96 & 48.4 & 39.0 & 12.0 & 6.99 & 4.49 \\ 1965 & 3.11 & 2.58 & 2.00 & 1.50 & 1.00 & 1.18 & 2.14 & 25.4 & 83.6 & 37.8 & 17.7 & 15.3 \\ 1966 & 8.44 & 3.61 & 2.91 & 1.73 & 1.66 & 2.08 & 8.02 & 58.6 & 28.9 & 10.7 & 7.40 & 4.68 \\ 1967 & 4.78 & 3.34 & 2.35 & 1.50 & 1.35 & 1.28 & 1.63 & 58.7 & 92.6 & 53.5 & 17.8 & 8.09 \\ 1968 & 4.66 & 2.54 & 1.94 & 1.73 & 1.60 & 1.58 & 2.08 & 20.1 & 120 & 28.2 & 18.5 & 9.02 \\ 1969 & 4.58 & 2.48 & 2.12 & 1.57 & 1.30 & 1.34 & 3.67 & 94.6 & 55.6 & 17.7 & 9.73 & 5.78 \\ 1970 & 4.64 & 3.11 & 2.16 & 1.97 & 1.65 & 1.64 & 1.68 & 46.0 & 61.3 & 20.3 & 9.64 & 7.91 \\ & & & & & & & & & & & & \\ 1971 & 4.85 & 2.75 & 2.08 & 1.42 & 1.31 & 1.20 & 2.37 & 28.1 & 71.9 & 20.0 & 10.1 & 5.72 \\ 1972 & 4.05 & 3.15 & 2.38 & 2.31 & 2.19 & 2.69 & 3.96 & 59.4 & 49.5 & 11.8 & 5.85 & 4.92 \\ 1973 & 9.73 & 5.89 & 3.79 & 2.88 & 2.60 & 2.36 & 2.79 & 77.0 & 106 & 36.5 & 18.8 & 10.4 \\ 1974 & 6.75 & 3.92 & 2.28 & 1.87 & 1.70 & 1.53 & 1.89 & 33.7 & 13.5 & 7.18 & 4.62 & 3.31 \\ 1975 & 2.34 & 1.96 & 1.80 & 1.60 & 1.60 & 1.45 & 1.32 & 16.2 & 83.5 & 59.8 & 15.4 & 6.02 \\ 1976 & 3.30 & 1.90 & 1.50 & 1.20 & 0.80 & 0.60 & 0.60 & 42.5 & 39.6 & 12.4 & 5.31 & 3.70 \\ 1977 & 2.67 & 1.44 & 0.98 & 0.60 & 0.40 & 0.30 & 3.21 & 5.93 & 12.0 & 5.29 & 9.18 & 9.49 \\ 1978 & 4.36 & 2.49 & 1.53 & 0.84 & 0.59 & 0.55 & 1.05 & 29.2 & 53.7 & 11.2 & 5.38 & 3.33 \\ 1979 & 2.51 & 1.88 & 1.57 & 1.29 & 0.94 & 0.53 & 0.95 & 43.7 & 40.5 & 10.5 & 5.76 & 3.27 \\ 1980 & 2.53 & 2.13 & 1.42 & 0.55 & 0.59 & 0.71 & 1.93 & 28.1 & 95.6 & 28.5 & 9.09 & 5.91 \\ 1981 & 4.64 & 2.90 & 1.61 & 1.35 & 0.98 & 0.93 & 7.65 & 34.2 & 35.6 & 9.05 & 5.02 & 4.28\end{array}$

ANNUAL PEAK DISCAARGE, IN OUBIC FEET PER SECOND, AND CORRESPONDING GAGE HEIGHT, IN FEET, FOR EACA WATER YEAR

\begin{tabular}{|c|c|c|c|c|c|c|c|c|c|c|c|c|}
\hline $\begin{array}{l}\text { WATER } \\
\text { YEAR }\end{array}$ & & DAIE & $\begin{array}{c}\text { GAGE } \\
\text { HEIGHT }\end{array}$ & $\begin{array}{c}\text { PEAK } \\
\text { DISCHARGE }\end{array}$ & $\begin{array}{l}\text { WATER } \\
\text { YEAR }\end{array}$ & DAIE & $\begin{array}{c}\text { GAGE } \\
\text { HEIGHT }\end{array}$ & $\begin{array}{c}\text { PEAR } \\
\text { DISCHARGE }\end{array}$ & $\begin{array}{l}\text { WATER } \\
\text { YEAR }\end{array}$ & DAIE & $\begin{array}{c}\text { GAGE } \\
\text { HEIGHT }\end{array}$ & $\begin{array}{c}\text { PEAK } \\
\text { DISCHARGE }\end{array}$ \\
\hline $\begin{array}{l}1961 \\
1962 \\
1963 \\
1964 \\
1965 \\
1966 \\
1967\end{array}$ & $\begin{array}{l}\text { MAY } \\
\text { MAY } \\
\text { MAY } \\
\text { MAY } \\
\text { JUNE } \\
\text { MAY } \\
\text { MAY }\end{array}$ & $\begin{array}{l}29,1961 \\
10,1962 \\
18,1963 \\
21,1964 \\
10,1965 \\
05,1966 \\
24,1967\end{array}$ & $\begin{array}{l}1.42 \\
1.62 \\
1.63 \\
1.94 \\
2.12 \\
1.19 \\
1.52\end{array}$ & $\begin{array}{l}102 \\
144 \\
159 \\
322 \\
395 \\
120 \\
224\end{array}$ & $\begin{array}{l}1968 \\
1969 \\
1970 \\
1971 \\
1972 \\
1973 \\
1974\end{array}$ & $\begin{array}{l}\text { JUNE } 05,1968 \\
\text { JUNE } 16,1969 \\
\text { MAY } 26,1970 \\
\text { JUNE } 07,1971 \\
\text { MAY } 27,1972 \\
\text { MAY } 31,1973 \\
\text { MAY } 09,1974\end{array}$ & $\begin{array}{l}-- \\
1.85 \\
1.87 \\
1.72 \\
1.69 \\
2.14 \\
1.46\end{array}$ & $\begin{array}{l}240 \\
223 \\
217 \\
156 \\
151 \\
308 \\
121\end{array}$ & $\begin{array}{l}1975 \\
1976 \\
1977 \\
1978 \\
1979 \\
1980 \\
1981\end{array}$ & 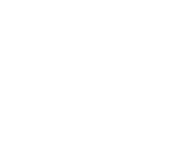 & $\begin{array}{l}2.02 \\
1.56 \\
1.18 \\
1.47 \\
2.44 \\
3.25 \\
2.35\end{array}$ & $\begin{array}{r}265 \\
128 \\
64 \\
114 \\
233 \\
310 \\
97\end{array}$ \\
\hline
\end{tabular}

09269000 EAST FORK OF DRY FORR NEAR DRY FORR, UT

LOCATION.--Lat $40^{\circ} 39^{\prime} 00^{\prime \prime}$, long $109^{\circ} 45^{\prime} 40^{n}$, in sec.14,T.2 S., R.19 E. (unsurveyed), Uintah County, Hydrologic Unit 14060002 , on right bank $3.5 \mathrm{mi}$ upstream fram mouth and $8 \mathrm{mi}$ northwest of town of Dry Fork.

DRAINAGE AREA. $-12 \mathrm{mi}^{2}$, approximately.

MEAN BASIN EJEVATION. $-9,360 \mathrm{ft}$.

PERIOD OF RECORD AVAIIABLE. - April 1946 to September 1963.

GAGE.-Water-stage recorder. Altitude of gage is $8,150 \mathrm{ft}$ by barameter.

AVERAGE DISGAARGE. --17 years, $7.97 \mathrm{ft}^{3} / \mathrm{s}, 5,770$ acre- $\mathrm{ft} / \mathrm{yr}$.

EXIREMES FOR PERIOD OF RECORD.-Maximum discharge, $240 \mathrm{ft}^{3} / \mathrm{s}$ June 18,1949 , gage height, $4.27 \mathrm{ft}$, fram rating curve extended above $100 \mathrm{ft}^{3} / \mathrm{s}$ on basis of slope-area measurement of peak flow; no flow at times.

LOWEST MEAN DISCHARGE, IN OUBIC FEET PER SECOND, AND RANKING FOR THE INDICATED NUMBER OF CONSEOUTIVE DAYS FOR EACH CIIMATIC YEAR, APRIL 1-MARCH 31

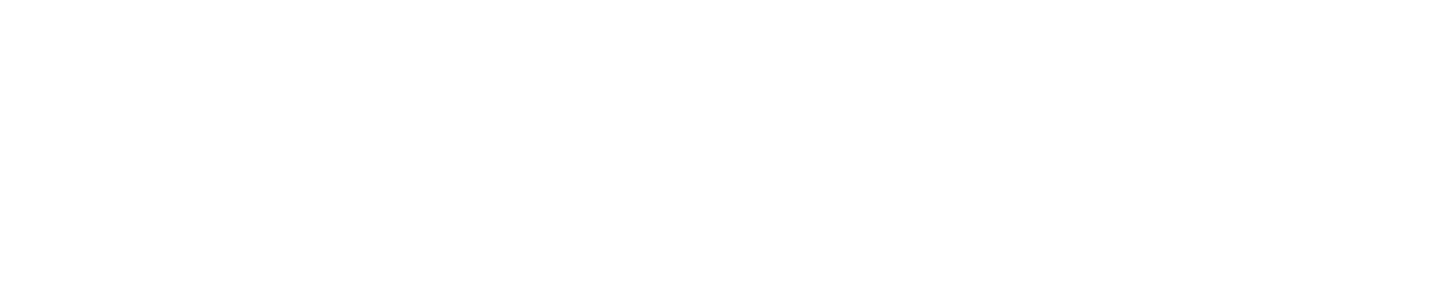


LOWEST MEAN DISGHARGE, IN OUBIC FEET PER SECOND, AND RANKING FOR THE INDICATED NUMBER OF CONSEOUTIVE DAYS FOR EACH CLIMATIC YEAR, APRII 1-MARCH 31-Continued

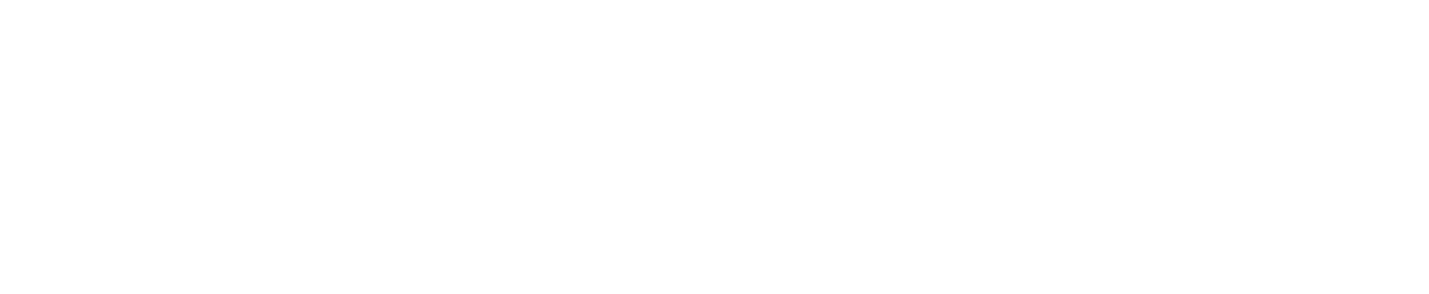

HIGHEST MEAN DISGARGE, IN OBBIC FEET PER SECOND, AND RANKING FOR THE INDICATED NUMBER OF CONSECUTIVE DAYS FOR EACH WATER YEAR, OCTCBER 1-SEPTEMBER 30

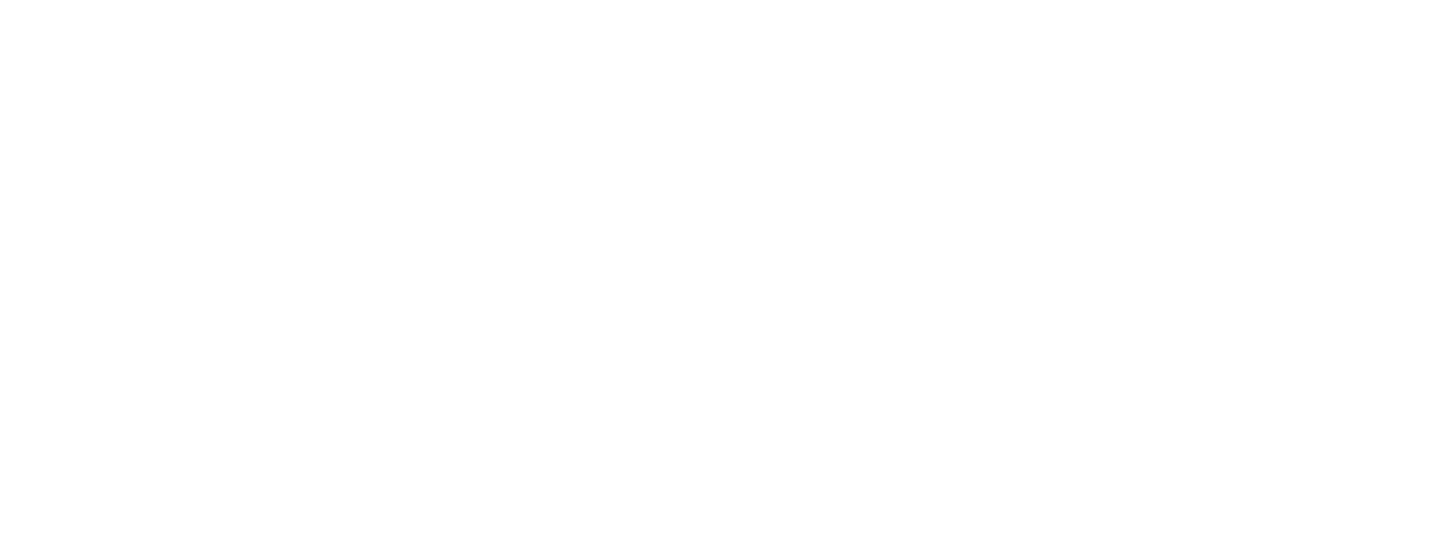

DURATION OF DISQHARGE FOR EAOH WATER YEAR

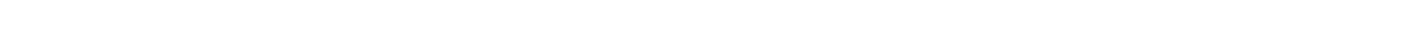
YEAR

NUMBER OF DAYS IN CLASS OABIC FEET -DAYS

$\begin{array}{lllllllllllllllllllllllllllllllllll}1951 & 189 & & & 9 & & 8 & 23 & 1 & & & 1 & 1 & 7 & 10 & 29 & 17 & 10 & 7 & 3 & 4 & 4 & 4 & 5 & 12 & 4 & 10 & 1 & 1 & 3 & 2 & & 2326.4 \\ 1952 & 13712 & 11 & 6 & 7 & 5 & 4 & & & 5 & 11 & 10 & 12 & 11 & 4 & 8 & 11 & 12 & 9 & 12 & 6 & 7 & 9 & 12 & 13 & 8 & 6 & 5 & 3 & 9 & 1 & & 4309.5\end{array}$

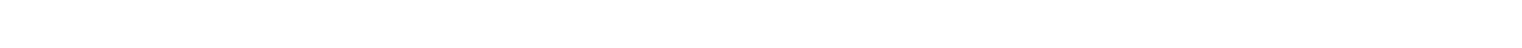
$\begin{array}{lllllllllllllllllllllllllll}8 & 8 & 4 & 8 & 14 & 38 & 17 & 9 & 7 & 8 & 5 & 18 & 16 & 13 & 5 & 6 & 5 & 6 & 5 & 5 & 2 & 3 & 1 & & & 2078.1\end{array}$

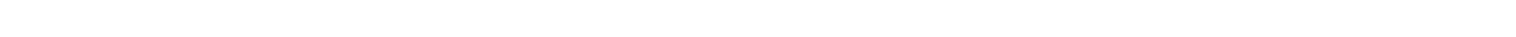

$\begin{array}{lllllllllllllllllllllllllllllllllllllll}1956 & 114 & 2 & 18 & 12 & 1 & 18 & 8 & 10 & 30 & 13 & 17 & 25 & 7 & 11 & 6 & 9 & 5 & 5 & 5 & 8 & 3 & 8 & 5 & 3 & 4 & 3 & 7 & 8 & 1 & & & 2850.6\end{array}$

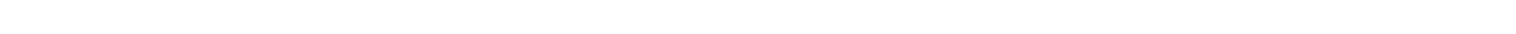
$\begin{array}{llllllllllllllllllllllllllllllllll}1958 & 79 & 10 & 14 & 20 & 12 & 36 & 50 & 21 & 20 & 19 & 6 & 7 & 7 & 6 & 8 & 8 & 4 & 7 & 2 & 3 & 3 & 3 & 6 & 7 & 6 & 1 & 3406.0 & \end{array}$ $\begin{array}{llllllllllllllllll}6 & 14 & 40 & 7 & 9 & 5 & 8 & 4 & 7 & 19 & 20 & 19 & 10 & 12 & 17 & 15 & 9 & 9\end{array}$

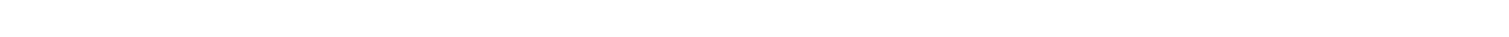

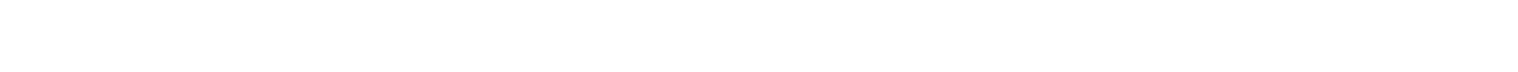

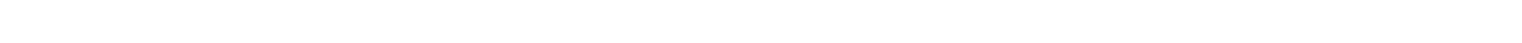

DURATION TABLE OF DISGHARGE FOR WATER YEARS 1947-63

\begin{tabular}{|c|c|c|c|c|c|c|c|c|c|c|c|c|c|c|c|c|c|c|c|}
\hline ASS & $\begin{array}{r}\text { OUBIC } \\
\text { FEET } \\
\text { PER } \\
\text { SECOND }\end{array}$ & $\begin{array}{l}\text { TOTAL } \\
\text { DAYS }\end{array}$ & $\begin{array}{c}\text { ACOJ- } \\
\text { MU- } \\
\text { LATED } \\
\text { DAYS }\end{array}$ & $\begin{array}{l}\text { PER- } \\
\text { CENT } \\
\text { DAYS }\end{array}$ & OLASS & $\begin{array}{c}\text { COBIC } \\
\text { FEET } \\
\text { PER } \\
\text { SECOND }\end{array}$ & $\begin{array}{r}\text { TOTAL } \\
\text { DAYS }\end{array}$ & $\begin{array}{c}\text { ACOU- } \\
\text { MU- } \\
\text { LATED } \\
\text { DAYS }\end{array}$ & $\begin{array}{l}\text { PER- } \\
\text { CENT } \\
\text { DAYS }\end{array}$ & & $\begin{array}{c}\text { QBIC } \\
\text { FEET } \\
\text { PER } \\
\text { SECOND }\end{array}$ & $\begin{array}{r}\text { TOTAL, } \\
\text { DAYS }\end{array}$ & $\begin{array}{c}\text { ACOJ- } \\
\text { MU- } \\
\text { LATED } \\
\text { DAYS }\end{array}$ & $\begin{array}{l}\text { PER- } \\
\text { CENT } \\
\text { DAYS }\end{array}$ & CLASS & $\begin{array}{c}\text { OUBIC } \\
\text { FEET } \\
\text { PER } \\
\text { SECOND }\end{array}$ & $\begin{array}{r}\text { TOTAL. } \\
\text { DAYS }\end{array}$ & $\begin{array}{c}\text { ACOU- } \\
\text { MU- } \\
\text { LATED } \\
\text { DAYS }\end{array}$ & $\begin{array}{l}\text { PER- } \\
\text { CENT } \\
\text { DAYS }\end{array}$ \\
\hline $\begin{array}{l}0 \\
1 \\
2 \\
3 \\
4 \\
5 \\
6 \\
7 \\
8\end{array}$ & $\begin{array}{l}0.00 \\
0.10 \\
0.13 \\
0.16 \\
0.20 \\
0.25 \\
0.31 \\
0.38 \\
0.48\end{array}$ & $\begin{array}{r}1598 \\
84 \\
0 \\
0 \\
163 \\
135 \\
0 \\
64 \\
278\end{array}$ & $\begin{array}{l}6209 \\
4611 \\
4527 \\
4527 \\
4527 \\
4364 \\
4229 \\
4229 \\
4165\end{array}$ & $\begin{array}{r}100.0 \\
74.3 \\
72.9 \\
72.9 \\
72.9 \\
70.3 \\
68.1 \\
68.1 \\
67.1\end{array}$ & $\begin{array}{l}9 \\
10 \\
11 \\
12 \\
13 \\
14 \\
15 \\
16 \\
17\end{array}$ & $\begin{array}{l}0.60 \\
0.75 \\
0.94 \\
1.20 \\
1.50 \\
1.80 \\
2.30 \\
2.90 \\
3.60\end{array}$ & $\begin{array}{r}280 \\
85 \\
192 \\
183 \\
233 \\
441 \\
339 \\
269 \\
243\end{array}$ & $\begin{array}{l}3887 \\
3607 \\
3522 \\
3330 \\
3147 \\
2914 \\
2473 \\
2134 \\
1865\end{array}$ & $\begin{array}{l}62.6 \\
58.1 \\
56.7 \\
53.6 \\
50.7 \\
46.9 \\
39.8 \\
34.4 \\
30.0\end{array}$ & $\begin{array}{l}18 \\
19 \\
20 \\
21 \\
22 \\
23 \\
24 \\
25 \\
26\end{array}$ & $\begin{array}{r}4.5 \\
5.6 \\
7.0 \\
8.8 \\
11.0 \\
14.0 \\
17.0 \\
21.0 \\
27.0\end{array}$ & $\begin{array}{r}190 \\
195 \\
148 \\
116 \\
110 \\
88 \\
93 \\
105 \\
111\end{array}$ & $\begin{array}{r}1622 \\
1432 \\
1237 \\
1089 \\
973 \\
863 \\
775 \\
682 \\
577\end{array}$ & $\begin{array}{r}26.1 \\
23.1 \\
19.9 \\
17.5 \\
15.7 \\
13.9 \\
12.5 \\
11.0 \\
9.3\end{array}$ & $\begin{array}{l}27 \\
28 \\
29 \\
30 \\
31 \\
32 \\
33 \\
34\end{array}$ & $\begin{array}{r}34.0 \\
42.0 \\
53.0 \\
66.0 \\
82.0 \\
100.0 \\
130.0 \\
160.0\end{array}$ & $\begin{array}{r}102 \\
97 \\
72 \\
82 \\
67 \\
36 \\
8 \\
2\end{array}$ & $\begin{array}{r}466 \\
364 \\
267 \\
195 \\
113 \\
46 \\
10 \\
2\end{array}$ & $\begin{array}{l}7.5 \\
5.9 \\
4.3 \\
3.1 \\
1.8 \\
0.7 \\
0.2 \\
0.0\end{array}$ \\
\hline
\end{tabular}


GREEN RIVER BASIN

09269000 EAST FORK OF DRY FORK NEAR DRY FORK, UT—Continued

MONTHLY MEAN DLSCHARGES, IN OUBIC FEET PER SECOND, FOR EAOH WATER YEAR

\begin{tabular}{|c|c|c|c|c|c|c|c|c|c|c|c|c|}
\hline YEAR & $\infty T$ & NOV & $\mathrm{DEC}$ & JAN & FEB & MAR & APR & MAY & JUNE & JULY & AUG & SEP \\
\hline $\begin{array}{l}1947 \\
1948 \\
1949 \\
1950\end{array}$ & $\begin{array}{l}3.75 \\
1.67 \\
1.45 \\
2.29\end{array}$ & $\begin{array}{l}2.96 \\
0.87 \\
0.74 \\
2.17\end{array}$ & $\begin{array}{l}2.44 \\
0.64 \\
0.40 \\
0.76\end{array}$ & $\begin{array}{l}2.00 \\
0.60 \\
0.30 \\
0.60\end{array}$ & $\begin{array}{l}2.00 \\
0.50 \\
0.20 \\
0.50\end{array}$ & $\begin{array}{l}2.27 \\
0.50 \\
0.25 \\
0.50\end{array}$ & $\begin{array}{l}4.73 \\
0.59 \\
1.16 \\
3.12\end{array}$ & $\begin{array}{l}83.6 \\
37.5 \\
29.2 \\
38.0\end{array}$ & $\begin{array}{l}60.0 \\
26.4 \\
60.9 \\
72.7\end{array}$ & $\begin{array}{c}20.3 \\
4.25 \\
13.6 \\
19.0\end{array}$ & $\begin{array}{l}6.71 \\
1.36 \\
3.29 \\
3.01\end{array}$ & $\begin{array}{l}4.38 \\
1.53 \\
2.19 \\
1.18\end{array}$ \\
\hline $\begin{array}{l}1951 \\
1952 \\
1953 \\
1954 \\
1955\end{array}$ & $\begin{array}{l}0.62 \\
2.22 \\
0.50 \\
1.80 \\
2.71\end{array}$ & $\begin{array}{l}0.09 \\
0.20 \\
0.17 \\
0.87 \\
1.83\end{array}$ & $\begin{array}{l}0.00 \\
0.00 \\
0.00 \\
0.00 \\
0.15\end{array}$ & $\begin{array}{l}0.00 \\
0.00 \\
0.00 \\
0.00 \\
0.00\end{array}$ & $\begin{array}{l}0.00 \\
0.00 \\
0.00 \\
0.00 \\
0.00\end{array}$ & $\begin{array}{l}0.00 \\
0.00 \\
0.00 \\
0.00 \\
0.00\end{array}$ & $\begin{array}{l}0.00 \\
0.23 \\
0.00 \\
0.05 \\
0.02\end{array}$ & $\begin{array}{c}20.9 \\
46.3 \\
2.63 \\
34.4 \\
22.6\end{array}$ & $\begin{array}{l}36.8 \\
64.0 \\
38.0 \\
13.6 \\
18.0\end{array}$ & $\begin{array}{c}9.91 \\
15.9 \\
6.08 \\
10.1 \\
4.63\end{array}$ & $\begin{array}{l}4.61 \\
9.02 \\
3.34 \\
4.05 \\
5.05\end{array}$ & $\begin{array}{l}3.41 \\
3.31 \\
1.95 \\
2.63 \\
3.96\end{array}$ \\
\hline $\begin{array}{l}1956 \\
1957 \\
1958 \\
1959 \\
1960\end{array}$ & $\begin{array}{l}1.98 \\
1.04 \\
3.28 \\
1.14 \\
2.25\end{array}$ & $\begin{array}{l}0.64 \\
0.59 \\
2.04 \\
0.49 \\
1.92\end{array}$ & $\begin{array}{l}0.33 \\
0.02 \\
1.32 \\
0.52 \\
0.20\end{array}$ & $\begin{array}{l}0.00 \\
0.00 \\
0.39 \\
0.00 \\
0.00\end{array}$ & $\begin{array}{l}0.00 \\
0.00 \\
0.00 \\
0.00 \\
0.00\end{array}$ & $\begin{array}{l}0.00 \\
0.00 \\
0.00 \\
0.00 \\
0.00\end{array}$ & $\begin{array}{l}0.39 \\
0.00 \\
0.03 \\
0.00 \\
1.63\end{array}$ & $\begin{array}{c}48.7 \\
1.81 \\
48.5 \\
7.28 \\
23.0\end{array}$ & $\begin{array}{l}31.0 \\
68.7 \\
43.3 \\
13.4 \\
20.3\end{array}$ & $\begin{array}{c}6.16 \\
22.0 \\
8.02 \\
7.01 \\
4.41\end{array}$ & $\begin{array}{l}2.54 \\
6.62 \\
2.52 \\
4.53 \\
1.07\end{array}$ & $\begin{array}{l}1.25 \\
5.38 \\
1.93 \\
2.90 \\
1.12\end{array}$ \\
\hline $\begin{array}{l}1961 \\
1962 \\
1963\end{array}$ & $\begin{array}{l}1.31 \\
5.84 \\
2.77\end{array}$ & $\begin{array}{l}0.53 \\
2.84 \\
1.30\end{array}$ & $\begin{array}{l}0.23 \\
1.50 \\
0.90\end{array}$ & $\begin{array}{l}0.03 \\
0.66 \\
0.12\end{array}$ & $\begin{array}{l}0.00 \\
0.50 \\
0.00\end{array}$ & $\begin{array}{l}0.00 \\
0.48 \\
0.00\end{array}$ & $\begin{array}{l}0.00 \\
9.77 \\
0.00\end{array}$ & $\begin{array}{l}18.9 \\
49.5 \\
29.4\end{array}$ & $\begin{array}{l}24.9 \\
68.2 \\
16.5\end{array}$ & $\begin{array}{c}3.62 \\
24.0 \\
4.76\end{array}$ & $\begin{array}{l}1.85 \\
6.59 \\
2.61\end{array}$ & $\begin{array}{l}4.62 \\
3.28 \\
3.33\end{array}$ \\
\hline
\end{tabular}

ANNUAL PEAK DISQHARGE, IN OBIC FEET PER SECOND, AND CORRESPONDING GAGE HEIGHT, IN FEET, FOR EAOH WAIER YEAR

\begin{tabular}{|c|c|c|c|c|c|c|c|c|c|c|c|c|}
\hline $\begin{array}{l}\text { WAIER } \\
\text { YEAR }\end{array}$ & DATE & $\begin{array}{c}\text { GAGE } \\
\text { HEIGHT }\end{array}$ & $\begin{array}{c}\text { PEAK } \\
\text { DISOHARGE }\end{array}$ & $\begin{array}{l}\text { WATER } \\
\text { YEAR }\end{array}$ & DATE & $\begin{array}{c}\text { GAGE } \\
\text { HEIGHT }\end{array}$ & $\begin{array}{c}\text { PEAR } \\
\text { DISCHARGE }\end{array}$ & $\begin{array}{l}\text { WATER } \\
\text { YEAR }\end{array}$ & & DATE & $\begin{array}{c}\text { GAGE } \\
\text { HEIGHT }\end{array}$ & $\begin{array}{c}\text { PEAR } \\
\text { DISCHARGE }\end{array}$ \\
\hline $\begin{array}{l}1946 \\
1947 \\
1948 \\
1949 \\
1950 \\
1951\end{array}$ & $\begin{array}{lll}\text { MAY } & 05,1946 \\
\text { MAY } & 08,1947 \\
\text { MAY } & 19,1948 \\
\text { JUNE } & 18,1949 \\
\text { JUNE } & 01,1950 \\
\text { MAY } & 28,1951\end{array}$ & $\begin{array}{l}2.63 \\
3.54 \\
3.62 \\
4.27 \\
3.86 \\
3.65\end{array}$ & $\begin{array}{r}29 \\
234 \\
134 \\
240 \\
185 \\
139\end{array}$ & $\begin{array}{l}1952 \\
1953 \\
1954 \\
1955 \\
1956 \\
1957\end{array}$ & $\begin{array}{lll}\text { JUNE } & 03, & 1952 \\
\text { JUNE } 12, & 1953 \\
\text { MAY } & 22, & 1954 \\
\text { MAY } & 20, & 1955 \\
\text { MAY } & 22,1956 \\
\text { JUNE } & 10,1957\end{array}$ & $\begin{array}{l}3.66 \\
3.18 \\
3.22 \\
2.87 \\
3.29 \\
3.66\end{array}$ & $\begin{array}{r}152 \\
126 \\
109 \\
66 \\
147 \\
202\end{array}$ & $\begin{array}{l}1958 \\
1959 \\
1960 \\
1961 \\
1962 \\
1963\end{array}$ & $\begin{array}{l}\text { MAY } \\
\text { MAY } \\
\text { MAY } \\
\text { MAY } \\
\text { MAY } \\
\text { MAY }\end{array}$ & $\begin{array}{l}29,1958 \\
15,1959 \\
13,1960 \\
29,1961 \\
10,1962 \\
17,1963\end{array}$ & $\begin{array}{l}3.50 \\
2.63 \\
3.20 \\
2.98 \\
3.35 \\
3.06\end{array}$ & $\begin{array}{r}167 \\
36 \\
102 \\
97 \\
149 \\
110\end{array}$ \\
\hline
\end{tabular}

MAGNITUDE AND PRCBABILITY OF ANNUAL LONEST MEAN DISCHARGE BASED ON CLIMATIC YEARS $1948-63$

\begin{tabular}{|c|c|c|c|c|c|c|}
\hline \multirow{2}{*}{$\begin{array}{l}\text { PERIOD } \\
\text { (CON- } \\
\text { SEOU- } \\
\text { TTVE } \\
\text { DAYS) }\end{array}$} & \multicolumn{6}{|c|}{$\begin{array}{l}\text { DISCHARGE, IN CUBIC FEET PER SECOND, FOR } \\
\text { INDICATED RECURRENCE INIERVAL, IN YEARS, AND } \\
\text { ANNUAL NONEXCEEDANCE PRCBABILITY, IN PERCENT }\end{array}$} \\
\hline & $\begin{array}{c}2 \\
508\end{array}$ & $\begin{array}{c}5 \\
208\end{array}$ & $\begin{array}{l}10 \\
108\end{array}$ & $\begin{array}{l}20 \\
58\end{array}$ & $\begin{array}{l}50 \\
28\end{array}$ & $\begin{array}{r}200 \\
18\end{array}$ \\
\hline 1 & 0.00 & - & - & - & - & - \\
\hline 7 & 0.00 & - & - & - & - & - \\
\hline 14 & 0.00 & - & - & - & - & - \\
\hline 30 & 0.00 & - & - & - & - & - \\
\hline 60 & 0.00 & - & - & - & - & - \\
\hline 90 & 0.00 & - & - & - & - & - \\
\hline
\end{tabular}

09269500 EAST FORK OF DRY FORR AT MOUTH, NEAR DRY FORK, UT

LOCATION. - Lat $40^{\circ} 38^{\prime} 00^{\prime \prime}$, long $109^{\circ} 46^{\prime} 00^{\prime \prime}$, in $W^{\frac{1}{4}}$ sec.23, T.2 S., R.19 E., Uintah County, Hydrologic Unit 14060002 , on right bank

$1.8 \mathrm{mi}$ upstream from mouth and $8.5 \mathrm{mi}$ northwest of town of Dry Fork.

DRAINATE AREA. $-18 \mathrm{mi}^{2}$.

PERIOD OF RECORD AVAILABLE.--JUIY 1949 to September 1952.

GAGE.--Water-stage recorder. Altitude of gage is 7,700 ft from topographic map.

EXIREMES FOR PERIOD OF RECORD.-Maximum discharge, $162 \mathrm{ft}^{3} / \mathrm{s}$ June 1,1950 , gage height, 3.31 ft, from rating curve extended above 80 $\mathrm{ft}^{3} / \mathrm{s}$ by logarithmic plotting; no flow at times in each year.

LOWEST MEAN DISCHARGE, IN OUBIC FEET PER SECOND, AND RANKING FOR THE INDICATED NUMBER OF CONSECJTIVE DAYS FOR EAOH CLIMATIC YEAR, APRIL I-MAROH 31

YEAR

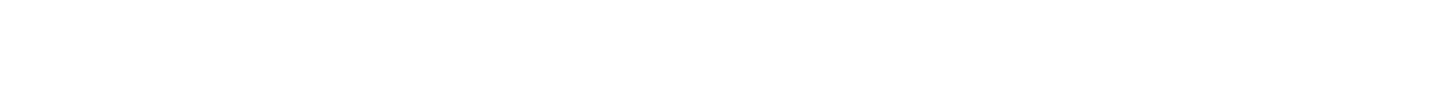


GREEN RIVER BASIN

09269500 EAST FORK OF DRY FORK AT MOUTH, NEAR DRY FORK, UT-Continued

HIGHEST MEAN DISCHARGE, IN CUBIC FEET PER SECOND, AND RANKING FOR THE INDICATED NUMBER OF CONSECUTIVE DAYS FOR EACH WATER YEAR, OCTOBER I-SEPTEMBER 30

\begin{tabular}{|c|c|c|c|c|c|c|c|c|c|c|c|c|c|c|c|c|c|c|c|c|}
\hline YEAR & \multicolumn{20}{|c|}{ CONSECUTIVE DAYS } \\
\hline 950 & 119 & 2 & 113 & 3 & 95.0 & 2 & 86.0 & 2 & 78.0 & 2 & 55.0 & 2 & 39.0 & 2 & 30.0 & 2 & 20.0 & 2 & 10.0 & 2 \\
\hline
\end{tabular}

\section{DURATION OF DISCHARGE FOR EACH WATER YEAR}

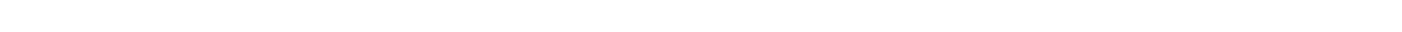
YEAR NUMBER OF DAYS IN CLASS CUBIC FEET
PER SECOND $\begin{array}{lllllllllllllllllllllllllllllllllllllllll}1950 & 6 & 8 & 127 & 17 & 38 & 3 & 6 & 23 & 12 & 7 & 19 & 10 & 4 & 3 & 3 & 3 & 1 & 1 & 2 & 3 & 4 & 5 & 6 & 3 & 10 & 4 & 5 & 9 & 9 & 9 & 5 & & 3642.2\end{array}$

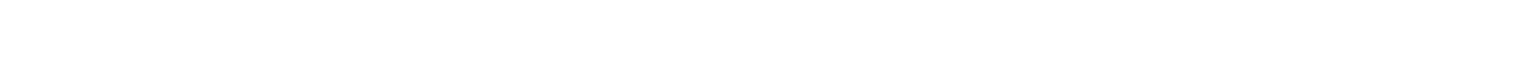

DURATION TABLE OF DISCHARGE FOR WATER YEARS 1950-52

\begin{tabular}{|c|c|c|c|c|c|c|c|c|c|c|c|c|c|c|c|c|c|c|c|}
\hline CLASS & $\begin{array}{c}\text { CUBIC } \\
\text { FEET } \\
\text { PER } \\
\text { SECOND }\end{array}$ & $\begin{array}{c}\text { TOTAL } \\
\text { DAYS }\end{array}$ & $\begin{array}{l}\text { ACCU- } \\
\text { MU- } \\
\text { LATED } \\
\text { DAYS }\end{array}$ & $\begin{array}{l}\text { PER- } \\
\text { CENT } \\
\text { DAYS }\end{array}$ & & $\begin{array}{c}\text { CUBIC } \\
\text { FEET } \\
\text { PER } \\
\text { SECOND }\end{array}$ & $\begin{array}{r}\text { TOTAL } \\
\text { DAYS }\end{array}$ & $\begin{array}{l}\text { ACCU- } \\
\text { MU- } \\
\text { LATED } \\
\text { DAYS }\end{array}$ & $\begin{array}{l}\text { PER- } \\
\text { CENT } \\
\text { DAYS }\end{array}$ & CLASS & $\begin{array}{c}\text { CUBIC } \\
\text { FEET } \\
\text { PER } \\
\text { SECOND }\end{array}$ & $\begin{array}{r}\text { TOTAL } \\
\text { DAYS }\end{array}$ & $\begin{array}{l}\text { ACCU- } \\
\text { MU- } \\
\text { LATES } \\
\text { DAYS }\end{array}$ & $\begin{array}{l}\text { PER- } \\
\text { CENT } \\
\text { DAYS }\end{array}$ & CLASS & $\begin{array}{c}\text { CUBIC } \\
\text { FEET } \\
\text { PER } \\
\text { SECOND }\end{array}$ & $\begin{array}{r}\text { TOTAL } \\
\text { DAYS }\end{array}$ & $\begin{array}{c}\text { ACCU-- } \\
\mathbf{M U -} \\
\text { LATED } \\
\text { DAYS }\end{array}$ & $\begin{array}{l}\text { PER- } \\
\text { CENT } \\
\text { DAYS }\end{array}$ \\
\hline $\begin{array}{l}0 \\
1 \\
2 \\
3 \\
4 \\
5 \\
6 \\
7 \\
8\end{array}$ & $\begin{array}{l}0.00 \\
0.10 \\
0.12 \\
0.15 \\
0.19 \\
0.24 \\
0.29 \\
0.36 \\
0.45\end{array}$ & $\begin{array}{r}365 \\
30 \\
0 \\
0 \\
150 \\
0 \\
26 \\
45 \\
6\end{array}$ & $\begin{array}{r}1096 \\
731 \\
701 \\
701 \\
701 \\
551 \\
551 \\
525 \\
480\end{array}$ & $\begin{array}{r}100.0 \\
66.7 \\
64.0 \\
64.0 \\
64.0 \\
50.3 \\
50.3 \\
47.9 \\
43.8\end{array}$ & $\begin{array}{r}9 \\
10 \\
11 \\
12 \\
13 \\
14 \\
15 \\
16 \\
17\end{array}$ & $\begin{array}{l}0.56 \\
0.69 \\
0.86 \\
1.10 \\
1.30 \\
1.60 \\
2.00 \\
2.50 \\
3.10\end{array}$ & $\begin{array}{r}8 \\
25 \\
27 \\
13 \\
32 \\
25 \\
28 \\
17 \\
26\end{array}$ & $\begin{array}{l}474 \\
466 \\
441 \\
414 \\
401 \\
369 \\
344 \\
316 \\
299\end{array}$ & $\begin{array}{l}43.2 \\
42.5 \\
40.2 \\
37.8 \\
36.6 \\
33.7 \\
31.4 \\
28.8 \\
27.3\end{array}$ & $\begin{array}{l}18 \\
19 \\
20 \\
21 \\
22 \\
23 \\
24 \\
25 \\
26\end{array}$ & $\begin{array}{r}3.9 \\
4.8 \\
5.9 \\
7.4 \\
9.1 \\
11.0 \\
14.0 \\
17.0 \\
22.0\end{array}$ & $\begin{array}{l}13 \\
11 \\
20 \\
14 \\
16 \\
19 \\
14 \\
11 \\
15\end{array}$ & $\begin{array}{l}273 \\
260 \\
249 \\
229 \\
215 \\
199 \\
180 \\
166 \\
155\end{array}$ & $\begin{array}{l}24.9 \\
23.7 \\
22.7 \\
20.9 \\
19.6 \\
18.2 \\
16.4 \\
15.1 \\
14.1\end{array}$ & $\begin{array}{l}27 \\
28 \\
29 \\
30 \\
31 \\
32 \\
33 \\
34\end{array}$ & $\begin{array}{r}27.0 \\
33.0 \\
41.0 \\
51.0 \\
63.0 \\
78.0 \\
97.0 \\
120.0\end{array}$ & $\begin{array}{r}25 \\
23 \\
22 \\
19 \\
15 \\
15 \\
18 \\
3\end{array}$ & $\begin{array}{r}140 \\
115 \\
92 \\
70 \\
51 \\
36 \\
21 \\
3\end{array}$ & $\begin{array}{r}12.8 \\
10.5 \\
8.4 \\
6.4 \\
4.7 \\
3.3 \\
1.9 \\
0.3\end{array}$ \\
\hline
\end{tabular}

MONTHLY MEAN DISCHARGES, IN CUBIC FEET PER SECOND, FOR EACH WATER YEAR

\begin{tabular}{|c|c|c|c|c|c|c|c|c|c|c|c|c|}
\hline YEAR & $\infty \mathrm{Cr}$ & NOV & $\mathrm{DEC}$ & JAN & FEB & MAR & APR & MAY & JUNE & JULY & AUG & SEP \\
\hline 1950 & 0.94 & 0.36 & 0.20 & 0.20 & 0.20 & 0.20 & 0.39 & 30.6 & 65.9 & 18.0 & 1.99 & 0.72 \\
\hline $\begin{array}{l}1951 \\
1952\end{array}$ & $\begin{array}{l}0.16 \\
0.93\end{array}$ & $\begin{array}{l}0.03 \\
0.13\end{array}$ & $\begin{array}{l}0.00 \\
0.00\end{array}$ & $\begin{array}{l}0.00 \\
0.00\end{array}$ & $\begin{array}{l}0.00 \\
0.00\end{array}$ & $\begin{array}{l}0.00 \\
0.00\end{array}$ & $\begin{array}{l}0.00 \\
0.00\end{array}$ & $\begin{array}{l}20.4 \\
52.5\end{array}$ & $\begin{array}{l}37.5 \\
65.2\end{array}$ & $\begin{array}{l}8.16 \\
14.1\end{array}$ & $\begin{array}{l}3.04 \\
7.85\end{array}$ & $\begin{array}{l}1.73 \\
3.30\end{array}$ \\
\hline
\end{tabular}

09270000 DRY FORK BELOW SPRINGS, NEAR DRY FORK, UT

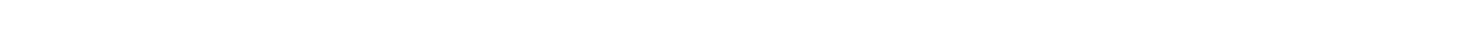
bank $1.5 \mathrm{mi}$ nor thwest of town of Dry Fork and $6 \mathrm{mi}$ ustream from mouth.

DRAINAGE AREA. $-97.4 \mathrm{mi}^{2}$.

MEAN BASIN ELEVATION.--9,360 ft.

PERIOD OF RECORD AVAILABLE.--January to December 1904 (monthly mean discharge only, published in wSP 1313), October 1940 to September 1945, October 1953 to September 1969.

GAGE.-Water-stage recorder since April 1941. Datum of gage is 6,706.95 ft NGVD of 1929 (levels by Utah Water and Power Board) May to July 1904 , nonrecording gage at different datum.

REMARKS.--Small diversions for irrigation above station. Mosby Canal has diverted water above station for irrigation in Deep Creek basin since 1942 or 1943

AVERAGE DISCHARGE.--20 years $(1941-45,1953-69), 31.8 \mathrm{ft}^{3} / \mathrm{s}, 23,040 \mathrm{acre}-\mathrm{ft} / \mathrm{Yr}$.

EXTREMES FOR PERIOD OF REOORD.--Maximum discharge, $974 \mathrm{ft}^{3} / \mathrm{s}$ June 11, 1965, from rating curve extended above $700 \mathrm{ft}{ }^{3} / \mathrm{s}$; maximum gage neight, 5.75 tt May 27, 1958; no flow for long periods in each year. 
LONEST MEAN DISOHARGE, IN CUIC FEET PER SECOND, AND RANKING FOR THE INDICATED NUMBER OF CONSEQUTIVE DAYS FOR EAOH OLIMATIC YEAR, APRIL I-MAROH 31

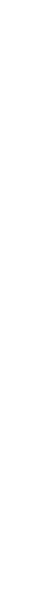

3

\begin{tabular}{|c|c|c|c|c|c|c|c|c|c|c|c|c|c|}
\hline 14 & & $\begin{array}{l}\text { CONSE } \\
30\end{array}$ & QUTTVE & $\begin{array}{l}\text { DAYS } \\
60\end{array}$ & & 90 & & 120 & & 183 & & ALL & \\
\hline $\begin{array}{l}0.00 \\
0.00 \\
0.00 \\
0.00\end{array}$ & $\begin{array}{l}1 \\
2 \\
3 \\
4\end{array}$ & $\begin{array}{l}0.00 \\
0.00 \\
0.00 \\
0.00\end{array}$ & $\begin{array}{l}1 \\
2 \\
3 \\
4\end{array}$ & $\begin{array}{l}0.00 \\
0.00 \\
0.00 \\
0.00\end{array}$ & $\begin{array}{l}1 \\
2 \\
3 \\
4\end{array}$ & $\begin{array}{l}0.00 \\
0.00 \\
0.00 \\
0.00\end{array}$ & $\begin{array}{l}1 \\
2 \\
3 \\
4\end{array}$ & $\begin{array}{l}0.00 \\
0.00 \\
0.00 \\
0.00\end{array}$ & $\begin{array}{l}1 \\
2 \\
3 \\
4\end{array}$ & $\begin{array}{l}5.20 \\
0.00 \\
0.00 \\
0.00\end{array}$ & $\left\{\begin{array}{l}19 \\
1 \\
2 \\
3\end{array}\right.$ & $\begin{array}{l}62.0 \\
43.0 \\
22.0 \\
67.0\end{array}$ & $\begin{array}{r}17 \\
13 \\
8 \\
19\end{array}$ \\
\hline 0.00 & 5 & 0.00 & 5 & 0.00 & 5 & 0.00 & 5 & 0.00 & 5 & 0.00 & 4 & 16.0 & 6 \\
\hline $\begin{array}{l}0.00 \\
0.00 \\
0.00 \\
0.00 \\
0.00\end{array}$ & $\begin{array}{r}6 \\
7 \\
8 \\
9 \\
10\end{array}$ & $\begin{array}{l}0.00 \\
0.00 \\
0.00 \\
0.00 \\
0.00\end{array}$ & $\begin{array}{r}6 \\
7 \\
8 \\
9 \\
10\end{array}$ & $\begin{array}{l}0.00 \\
0.00 \\
0.00 \\
0.00 \\
0.00\end{array}$ & $\begin{array}{r}6 \\
7 \\
8 \\
9 \\
10\end{array}$ & $\begin{array}{l}0.00 \\
0.00 \\
0.00 \\
0.00 \\
0.00\end{array}$ & $\begin{array}{r}6 \\
7 \\
8 \\
9 \\
10\end{array}$ & $\begin{array}{l}0.00 \\
0.00 \\
0.00 \\
0.00 \\
0.00\end{array}$ & $\begin{array}{r}6 \\
7 \\
8 \\
9 \\
10\end{array}$ & $\begin{array}{l}0.00 \\
0.00 \\
0.00 \\
0.00 \\
0.00\end{array}$ & $\begin{array}{l}5 \\
6 \\
7 \\
8 \\
9\end{array}$ & $\begin{array}{c}12.0 \\
23.0 \\
38.0 \\
36.0 \\
5.90\end{array}$ & $\begin{array}{r}3 \\
9 \\
12 \\
11 \\
1\end{array}$ \\
\hline $\begin{array}{l}0.00 \\
0.00 \\
0.00 \\
0.00 \\
0.00\end{array}$ & $\begin{array}{l}11 \\
12 \\
13 \\
14 \\
15\end{array}$ & $\begin{array}{l}0.00 \\
0.00 \\
0.00 \\
0.00 \\
0.00\end{array}$ & $\begin{array}{l}11 \\
12 \\
13 \\
14 \\
15\end{array}$ & $\begin{array}{l}0.00 \\
0.00 \\
0.00 \\
0.00 \\
0.00\end{array}$ & $\begin{array}{l}11 \\
12 \\
13 \\
14 \\
15\end{array}$ & $\begin{array}{l}0.00 \\
0.00 \\
0.00 \\
0.00 \\
0.00\end{array}$ & $\begin{array}{l}11 \\
12 \\
13 \\
14 \\
15\end{array}$ & $\begin{array}{l}0.00 \\
0.00 \\
0.00 \\
0.00 \\
0.00\end{array}$ & $\begin{array}{l}11 \\
12 \\
13 \\
14 \\
15\end{array}$ & $\begin{array}{l}0.00 \\
1.50 \\
0.00 \\
0.00 \\
0.00\end{array}$ & $\begin{array}{l}10 \\
18 \\
11 \\
12 \\
13\end{array}$ & $\begin{array}{l}11.0 \\
14.0 \\
47.0 \\
13.0 \\
26.0\end{array}$ & $\begin{array}{r}2 \\
5 \\
14 \\
4 \\
10\end{array}$ \\
\hline $\begin{array}{l}0.00 \\
0.00 \\
0.00 \\
0.00\end{array}$ & $\begin{array}{l}16 \\
17 \\
18 \\
19\end{array}$ & $\begin{array}{l}0.00 \\
0.00 \\
0.00 \\
0.00\end{array}$ & $\begin{array}{l}16 \\
17 \\
18 \\
19\end{array}$ & $\begin{array}{l}0.00 \\
0.00 \\
0.00 \\
0.00\end{array}$ & $\begin{array}{l}16 \\
17 \\
18 \\
19\end{array}$ & $\begin{array}{l}0.00 \\
0.00 \\
0.00 \\
0.00\end{array}$ & $\begin{array}{l}16 \\
17 \\
18 \\
19\end{array}$ & $\begin{array}{l}0.00 \\
0.00 \\
0.00 \\
0.00\end{array}$ & $\begin{array}{l}16 \\
17 \\
18 \\
19\end{array}$ & $\begin{array}{l}0.25 \\
0.00 \\
0.00 \\
0.00\end{array}$ & $\begin{array}{l}17 \\
14 \\
15 \\
16\end{array}$ & $\begin{array}{l}57.0 \\
18.0 \\
63.0 \\
52.0\end{array}$ & $\begin{array}{r}16 \\
7 \\
18\end{array}$ \\
\hline
\end{tabular}

HIGHEST MEAN DISOHARGE, IN CBIC FEET PER SECOND, AND RANKING FOR THE INDICATED NUMBER OF CONSEQUTIVE DAYS FOR EAOH WATER YEAR, OCICBER I-SEPTEMBER 30

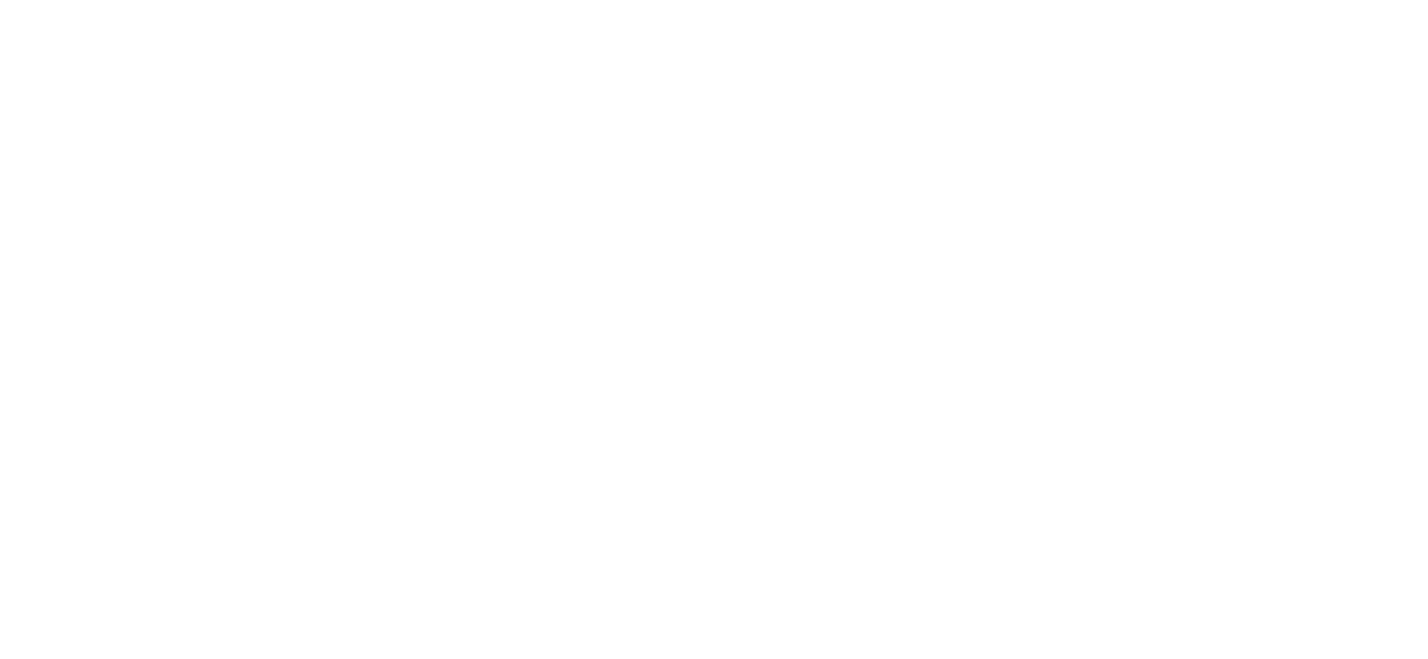

\section{DURATION OF DISCHARGE FOR EAQH WATER YEAR}

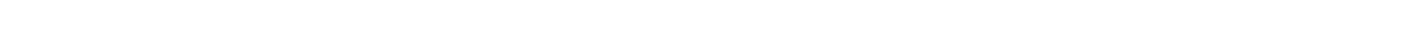
YEAR NUMBER OF DAYS IN CLASS

GBIC FEET -DAYS

$\begin{array}{ll}1941 & 239 \\ 1942 & 233 \\ 1943 & 273 \\ 1944 & 269 \\ 1945 & 251 \\ 1 & \\ 1954 & 291 \\ 1955 & 303 \\ 1956 & 304 \\ 1957 & 259 \\ 1958 & 290 \\ 1959 & 307 \\ 1960 & 316\end{array}$

\begin{tabular}{|c|c|c|c|c|c|c|c|c|c|c|c|c|c|c|c|c|c|c|c|c|c|c|}
\hline & & & & & BER & $O F$ & AYS & IN & LAS & & & & & & & & & & & & & $\begin{array}{l}\text { OBIC FEET } \\
\text { PER SECOND } \\
\text {-DAYS }\end{array}$ \\
\hline & 1 & & $\begin{array}{l}1 \\
1\end{array}$ & 2 & 1 & $\begin{array}{l}5 \\
2 \\
1\end{array}$ & 1 & $\begin{array}{l}3 \\
2 \\
1 \\
2\end{array}$ & $\begin{array}{l}7 \\
4 \\
1 \\
1 \\
3\end{array}$ & $\begin{array}{l}8 \\
7 \\
3 \\
1 \\
3\end{array}$ & $\begin{array}{r}11 \\
4 \\
3 \\
1 \\
1\end{array}$ & $\begin{array}{r}7 \\
10 \\
3 \\
3 \\
5\end{array}$ & $\begin{array}{rr}4 & 6 \\
15 & 23 \\
5 & 7 \\
2 & 5 \\
9 & 7\end{array}$ & $\begin{array}{rr}6 & 4 \\
23 & 9 \\
7 & 12 \\
5 & 6 \\
7 & 6\end{array}$ & $\begin{array}{r}4 \\
11 \\
12 \\
5 \\
15\end{array}$ & $\begin{array}{r}9 \\
6 \\
27 \\
9 \\
17\end{array}$ & $\begin{array}{r}5 \\
7 \\
5 \\
8 \\
13\end{array}$ & $\begin{array}{r}3 \\
3 \\
4 \\
8 \\
22\end{array}$ & $\begin{array}{rr}3 & 26 \\
7 & 3 \\
6 & 3 \\
5 & 11 \\
6 & \end{array}$ & $\begin{array}{l}18 \\
12 \\
23\end{array}$ & 5 & $\begin{array}{r}21826.0 \\
16537.0 \\
7968.0 \\
24383.5 \\
10253.6\end{array}$ \\
\hline & 1 & & $\begin{array}{l}1 \\
1\end{array}$ & 1 & 1 & 1 & 3 & $\begin{array}{l}1 \\
1\end{array}$ & $\begin{array}{l}1 \\
1\end{array}$ & $\begin{array}{l}2 \\
1\end{array}$ & $\begin{array}{l}2 \\
1\end{array}$ & $\begin{array}{l}8 \\
2\end{array}$ & $\begin{array}{ll}8 & 8 \\
2 & 7\end{array}$ & $\begin{array}{ll}8 & 8 \\
7 & 8\end{array}$ & $\begin{array}{r}6 \\
14\end{array}$ & $\begin{array}{r}6 \\
12\end{array}$ & $\begin{array}{l}2 \\
7\end{array}$ & $\begin{array}{l}5 \\
4\end{array}$ & 81 & 1 & & $\begin{array}{l}5867.8 \\
4212.5\end{array}$ \\
\hline & 1 & $\begin{array}{l}2 \\
1\end{array}$ & 1 & & & $\begin{array}{l}1 \\
3 \\
2 \\
1\end{array}$ & $\begin{array}{l}1 \\
1\end{array}$ & $\begin{array}{r}10 \\
1 \\
1\end{array}$ & $\begin{array}{l}1 \\
8 \\
1 \\
1\end{array}$ & $\begin{array}{l}2 \\
6 \\
2 \\
2 \\
1\end{array}$ & $\begin{array}{l}4 \\
5 \\
1 \\
1 \\
1\end{array}$ & $\begin{array}{l}2 \\
7 \\
3 \\
1 \\
1\end{array}$ & $\begin{array}{rr}2 & 5 \\
7 & 5 \\
2 & 8 \\
13 & 12 \\
2 & 4\end{array}$ & $\begin{array}{rr}5 & 12 \\
5 & 3 \\
8 & 11 \\
2 & 10 \\
4 & 8\end{array}$ & $\begin{array}{r}3 \\
6 \\
8 \\
11 \\
9\end{array}$ & $\begin{array}{r}7 \\
7 \\
5 \\
4 \\
11\end{array}$ & $\begin{array}{l}2 \\
3 \\
3\end{array}$ & $\begin{array}{l}2 \\
4 \\
3\end{array}$ & $\begin{array}{rr}7 & 8 \\
12 & 7 \\
4 & 10\end{array}$ & $\begin{array}{l}3 \\
5 \\
3\end{array}$ & $\begin{array}{l}4 \\
6\end{array}$ & $\begin{array}{r}8214.7 \\
13840.1 \\
13137.1 \\
2144.4 \\
3990.0\end{array}$ \\
\hline
\end{tabular}




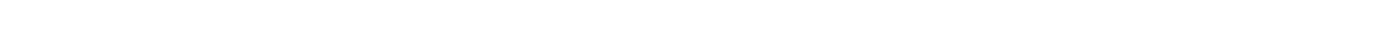
YEAR

OBIC FEET -DAYS

\section{4}

1962232

1963312

1964295
1965230

1966286

1967268

1968258

1969272

11

$\begin{array}{ll}1 & 1 \\ 2 & \end{array}$

$\begin{array}{lllll}1 & & 1 & 1 & 1 \\ & & 2 & 1 & 2 \\ & 1 & & & 1\end{array}$

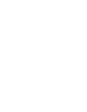

$\begin{array}{ll}1 & 2 \\ 6 & 4 \\ 1 & 1 \\ 2 & 1\end{array}$

$\begin{array}{lllllllll}8 & 3 & 5 & 7 & 4 & 5 & 4 & 10 & 5\end{array}$

$\begin{array}{rrrrrrrrrr}6 & 10 & 4 & 6 & 14 & 8 & 14 & 12 & 18 & 19 \\ 1 & 2 & 8 & 11 & 3 & 2 & 7 & 5 & 5 & 2\end{array}$

$\begin{array}{rrrrrrrrrrrrr}1 & 2 & 6 & 5 & 4 & 5 & 15 & 4 & 6 & 6 & 2 & 6 & 1 \\ 13 & 10 & 8 & 14 & 10 & 19 & 14 & 2 & 4 & 9 & 20 & 8 & 3\end{array}$

4889.7

17508.0

4937.8
9380.5

9380.5

20610.1

6695.6

23168.2

18891.9

15966.4

DURATION TABIE OF DISCHARGE FOR WATER YEARS 1941-45, 1954-69

$\begin{array}{rrr}\text { CUBIC } & \text { ACOU- } \\ \text { FEET } & \text { MU- } & \text { PER- } \\ \text { PER TOTAL LATED } & \text { CENT } \\ \text { CLASS SECOND DAYS DAYS } & \text { DAYS }\end{array}$

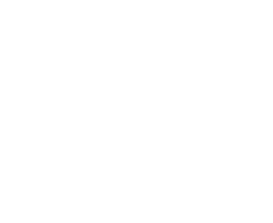

$\begin{array}{ccc}\text { CUBIC } & \text { ACCU- } \\ \text { FEET } & \text { MU- } & \text { PER- } \\ \text { PER TOTAL LATED } & \text { CFNT }\end{array}$ PER TOTAL LATED
CENT
CLASS SECOND DAYS DAYS DAYS

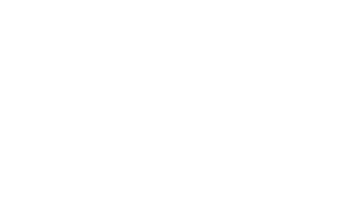

OBIC ACOUPER TOTAL LATED CENI CLASS SECOND DAYS DAYS DAYS $\begin{array}{lcl}\text { OBIC } & \text { ACOJ- } \\ \text { FEET } & \text { MU- } & \\ \text { PER- }\end{array}$ PER TOTAL LATED CENT
CLASS SECOND DAYS DAYS DAYS

$\begin{array}{rrrrr}27 & 110.0 & 117 & 678 & 8.8 \\ 28 & 150.0 & 129 & 561 & 7.3 \\ 29 & 210.0 & 139 & 432 & 5.6 \\ 30 & 300.0 & 136 & 293 & 3.8 \\ 31 & 430.0 & 113 & 157 & 2.0 \\ 32 & 600.0 & 43 & 44 & 0.6 \\ 33 & 850.0 & 1 & 1 & 0.0 \\ 34 & 0.0 & 0 & 0 & 0.0\end{array}$

MONTHLY MEAN DISCHARGES, IN OBBIC FEET PER SEOOND, FOR EACH WATER YEAR

\begin{tabular}{|c|c|c|c|c|c|c|c|c|c|c|c|c|}
\hline YEAR & $\infty C T$ & NOV & DEC & JAN & FEB & MAR & APR & MAY & JUNE & JULY & AUG & SEP \\
\hline $\begin{array}{l}1941 \\
1942 \\
1943 \\
1944 \\
1945\end{array}$ & $\begin{array}{c}0.00 \\
26.3 \\
0.00 \\
0.00 \\
0.00\end{array}$ & $\begin{array}{l}0.00 \\
4.17 \\
0.00 \\
0.00 \\
0.00\end{array}$ & $\begin{array}{l}0.00 \\
0.00 \\
0.00 \\
0.00 \\
0.00\end{array}$ & $\begin{array}{l}0.00 \\
0.00 \\
0.00 \\
0.00 \\
0.00\end{array}$ & $\begin{array}{l}0.00 \\
0.00 \\
0.00 \\
0.00 \\
0.00\end{array}$ & $\begin{array}{l}0.00 \\
0.00 \\
0.00 \\
0.00 \\
0.00\end{array}$ & $\begin{array}{l}0.00 \\
0.00 \\
8.97 \\
0.00 \\
0.00\end{array}$ & $\begin{array}{c}296 \\
139 \\
130 \\
147 \\
82.6\end{array}$ & $\begin{array}{l}348 \\
325 \\
101 \\
508 \\
173\end{array}$ & $\begin{array}{c}61.1 \\
48.2 \\
20.2 \\
137 \\
66.9\end{array}$ & $\begin{array}{c}8.29 \\
1.13 \\
0.00 \\
10.8 \\
13.4\end{array}$ & $\begin{array}{l}2.30 \\
0.00 \\
0.00 \\
0.00 \\
0.00\end{array}$ \\
\hline $\begin{array}{l}1954 \\
1955\end{array}$ & $\begin{array}{l}0.00 \\
0.00\end{array}$ & $\begin{array}{l}0.00 \\
0.00\end{array}$ & $\begin{array}{l}0.00 \\
0.00\end{array}$ & $\begin{array}{l}0.00 \\
0.00\end{array}$ & $\begin{array}{l}0.00 \\
0.00\end{array}$ & $\begin{array}{l}0.00 \\
0.00\end{array}$ & $\begin{array}{l}0.00 \\
0.00\end{array}$ & $\begin{array}{r}144 \\
84.4\end{array}$ & $\begin{array}{l}40.2 \\
51.0\end{array}$ & $\begin{array}{l}6.74 \\
2.18\end{array}$ & $\begin{array}{l}0.00 \\
0.00\end{array}$ & $\begin{array}{l}0.00 \\
0.00\end{array}$ \\
\hline $\begin{array}{l}1956 \\
1957 \\
1958 \\
1959 \\
1960\end{array}$ & $\begin{array}{l}0.00 \\
0.00 \\
0.00 \\
0.00 \\
0.00\end{array}$ & $\begin{array}{l}0.00 \\
0.00 \\
0.00 \\
0.00 \\
0.00\end{array}$ & $\begin{array}{l}0.00 \\
0.00 \\
0.00 \\
0.00 \\
0.00\end{array}$ & $\begin{array}{l}0.00 \\
0.00 \\
0.00 \\
0.00 \\
0.00\end{array}$ & $\begin{array}{l}0.00 \\
0.00 \\
0.00 \\
0.00 \\
0.00\end{array}$ & $\begin{array}{l}0.00 \\
0.00 \\
0.00 \\
0.00 \\
0.00\end{array}$ & $\begin{array}{l}0.00 \\
0.00 \\
0.00 \\
0.00 \\
0.00\end{array}$ & $\begin{array}{c}163 \\
0.00 \\
219 \\
16.9 \\
67.9\end{array}$ & $\begin{array}{l}103 \\
361 \\
196 \\
49.1 \\
62.8\end{array}$ & $\begin{array}{c}2.00 \\
84.6 \\
14.6 \\
4.77 \\
0.00\end{array}$ & $\begin{array}{l}0.00 \\
7.33 \\
0.00 \\
0.00 \\
0.00\end{array}$ & $\begin{array}{l}0.00 \\
5.59 \\
0.00 \\
0.00 \\
0.00\end{array}$ \\
\hline $\begin{array}{l}1961 \\
1962 \\
1963 \\
1964 \\
1965\end{array}$ & $\begin{array}{l}0.00 \\
8.59 \\
0.00 \\
0.00 \\
0.00\end{array}$ & $\begin{array}{l}0.00 \\
0.00 \\
0.00 \\
0.00 \\
0.00\end{array}$ & $\begin{array}{l}0.00 \\
0.00 \\
0.00 \\
0.00 \\
0.00\end{array}$ & $\begin{array}{l}0.00 \\
0.00 \\
0.00 \\
0.00 \\
0.00\end{array}$ & $\begin{array}{l}0.00 \\
0.00 \\
0.00 \\
0.00 \\
0.00\end{array}$ & $\begin{array}{l}0.00 \\
0.00 \\
0.00 \\
0.00 \\
0.00\end{array}$ & $\begin{array}{c}0.00 \\
12.7 \\
0.00 \\
0.00 \\
0.00\end{array}$ & $\begin{array}{l}54.7 \\
173 \\
110 \\
157 \\
37.2\end{array}$ & $\begin{array}{c}99.2 \\
295 \\
50.5 \\
128 \\
430\end{array}$ & $\begin{array}{c}2.59 \\
82.2 \\
0.04 \\
21.9 \\
151\end{array}$ & $\begin{array}{c}0.00 \\
3.02 \\
0.00 \\
0.00 \\
43.7\end{array}$ & $\begin{array}{r}4.63 \\
0.00 \\
0.00 \\
0.00 \\
16.7\end{array}$ \\
\hline $\begin{array}{l}1966 \\
1967 \\
1968 \\
1969\end{array}$ & $\begin{array}{l}1.14 \\
0.00 \\
0.00 \\
0.00\end{array}$ & $\begin{array}{l}0.00 \\
0.00 \\
0.00 \\
0.00\end{array}$ & $\begin{array}{l}0.00 \\
0.00 \\
0.00 \\
0.00\end{array}$ & $\begin{array}{l}0.00 \\
0.00 \\
0.00 \\
0.00\end{array}$ & $\begin{array}{l}0.00 \\
0.00 \\
0.00 \\
0.00\end{array}$ & $\begin{array}{l}0.00 \\
0.00 \\
0.00 \\
0.00\end{array}$ & $\begin{array}{l}0.00 \\
0.00 \\
0.00 \\
0.00\end{array}$ & $\begin{array}{l}160 \\
177 \\
12.6 \\
296\end{array}$ & $\begin{array}{l}52.5 \\
435 \\
508 \\
181\end{array}$ & $\begin{array}{c}3.62 \\
134 \\
80.8 \\
43.4\end{array}$ & $\begin{array}{c}0.00 \\
15.7 \\
24.0 \\
0.24\end{array}$ & $\begin{array}{l}0.00 \\
0.00 \\
0.02 \\
0.00\end{array}$ \\
\hline
\end{tabular}

ANNUAL PEAK DISCHARGE, IN OUBIC FEET PER SEOOND, AND CORRESPONDING GAGE HEIGHT, IN FEET, FOR EACH WATER YEAR

\begin{tabular}{|c|c|c|c|c|c|c|c|c|c|c|c|c|c|c|c|}
\hline $\begin{array}{l}\text { WATER } \\
\text { YEAR }\end{array}$ & & DATE & & $\begin{array}{c}\text { GAGE } \\
\text { HEIGHT }\end{array}$ & $\begin{array}{c}\text { PEAK } \\
\text { DISCHARGE }\end{array}$ & $\begin{array}{l}\text { WATER } \\
\text { YEAR }\end{array}$ & & DATE & $\begin{array}{c}\text { GAGE } \\
\text { HEIGHT }\end{array}$ & $\begin{array}{c}\text { PEAK } \\
\text { DISCHARGE }\end{array}$ & $\begin{array}{l}\text { WATER } \\
\text { YEAR }\end{array}$ & & DATE & $\begin{array}{c}\text { GAGE } \\
\text { HEIGHT }\end{array}$ & $\begin{array}{c}\text { PEAK } \\
\text { DISCHARGE }\end{array}$ \\
\hline $\begin{array}{l}1941 \\
1942 \\
1943 \\
1944 \\
1945 \\
1954 \\
1955\end{array}$ & $\begin{array}{l}\text { MAY } \\
\text { MAY } \\
\text { MAY } \\
\text { JUNE } \\
\text { JUNE } \\
\text { MAY } \\
\text { MAY }\end{array}$ & $\begin{array}{l}23, \\
28, \\
02, \\
26, \\
04, \\
22, \\
14,\end{array}$ & $\begin{array}{l}1941 \\
1942 \\
1943 \\
1944 \\
1945 \\
1954 \\
1955\end{array}$ & $\begin{array}{l}4.50 \\
4.72 \\
4.09 \\
4.82 \\
3.60 \\
4.27 \\
3.70\end{array}$ & $\begin{array}{l}611 \\
697 \\
409 \\
720 \\
267 \\
492 \\
228\end{array}$ & $\begin{array}{l}1956 \\
1957 \\
1958 \\
1959 \\
1960 \\
1961 \\
1962\end{array}$ & $\begin{array}{l}\text { MAY } \\
\text { JUNE } \\
\text { MAY } \\
\text { JUNE } \\
\text { MAY } \\
\text { MAY } \\
\text { JUNE }\end{array}$ & $\begin{array}{l}25,1956 \\
10,1957 \\
27,1958 \\
08,1959 \\
13,1960 \\
28,1961 \\
15,1962\end{array}$ & $\begin{array}{l}4.57 \\
5.26 \\
5.75 \\
3.50 \\
4.31 \\
4.32 \\
4.86\end{array}$ & $\begin{array}{l}573 \\
882 \\
972 \\
132 \\
345 \\
316 \\
455\end{array}$ & $\begin{array}{l}1963 \\
1964 \\
1965 \\
1966 \\
1967 \\
1968 \\
1969\end{array}$ & $\begin{array}{l}\text { MAY } \\
\text { MAY } \\
\text { JUNE } \\
\text { MAY } \\
\text { MAY } \\
\text { JUNE } \\
\text { MAY }\end{array}$ & $\begin{array}{r}18,1963 \\
22,1964 \\
11,1965 \\
08,1966 \\
25,1967 \\
05,1968 \\
21,1969\end{array}$ & $\begin{array}{l}4.64 \\
5.21 \\
5.53 \\
3.74 \\
5.22 \\
5.43 \\
4.24\end{array}$ & $\begin{array}{l}425 \\
725 \\
974 \\
364 \\
818 \\
938 \\
622\end{array}$ \\
\hline
\end{tabular}


GREEN RIVER BASIN

09270000 DRY FORK BELOW SPRINGS, NEAR DRY FORK, UT--Continued

\begin{tabular}{|c|c|c|c|c|c|c|}
\hline \multirow{2}{*}{$\begin{array}{l}\text { PERIOD } \\
\text { (CON- } \\
\text { SEU- } \\
\text { TIVE } \\
\text { DAYS) }\end{array}$} & \multicolumn{6}{|c|}{$\begin{array}{l}\text { DISCHARGE, IN OBBIC FEET PER SECOND, FOR } \\
\text { INDICATED RECIRRENCE INTERNAL, IN YEARS, AND } \\
\text { ANNUAL NONEXCEEDANCE PRCBABILITY, IN PERCENT }\end{array}$} \\
\hline & $\begin{array}{c}2 \\
50 \%\end{array}$ & $\begin{array}{c}5 \\
208\end{array}$ & $\begin{array}{l}10 \\
108\end{array}$ & $\begin{array}{l}20 \\
58\end{array}$ & $\begin{array}{l}50 \\
28\end{array}$ & $\begin{array}{r}100 \\
18\end{array}$ \\
\hline 1 & 0.00 & - & - & - & - & - \\
\hline 7 & 0.00 & - & - & - & - & - \\
\hline 14 & 0.00 & - & - & - & - & - \\
\hline 30 & 0.00 & - & - & - & - & - \\
\hline 60 & 0.00 & - & - & - & - & - \\
\hline 90 & 0.00 & - & - & - & - & - \\
\hline
\end{tabular}

MAGNITUDE AND PRCBABILITY OF ANNUAL HIGHEST MEAN DISQHARGE BASED ON WATER YEARS 1941-45 AND 1954-69

\begin{tabular}{|c|c|c|c|c|c|c|}
\hline \multirow{2}{*}{$\begin{array}{l}\text { PERIOD } \\
\text { CON- } \\
\text { SEO- } \\
\text { TIVE } \\
\text { DAYS) }\end{array}$} & \multicolumn{6}{|c|}{$\begin{array}{l}\text { DISOHARGE, IN OUBC FEET PER SECOND, FOR } \\
\text { INDICATED RECURRENCE INIERVAL, IN YEARS, AND } \\
\text { ANNUAL EXCEEDANCE PRCBABILITY, IN PERCENT }\end{array}$} \\
\hline & $\begin{array}{c}2 \\
508\end{array}$ & $\begin{array}{c}5 \\
208\end{array}$ & $\begin{array}{l}10 \\
108\end{array}$ & $\begin{array}{l}25 \\
48\end{array}$ & $\begin{array}{l}50 \\
28\end{array}$ & $\begin{array}{r}100 \\
18\end{array}$ \\
\hline
\end{tabular}

$\begin{array}{rrrrrrr}1 & 468 & 688 & 808 & 931 & - & - \\ 3 & 435 & 649 & 767 & 891 & - & - \\ 7 & 381 & 585 & 700 & 824 & - & - \\ 15 & 318 & 503 & 614 & 737 & - & -\end{array}$

09270500 DRY FORK AT MOUTH, NEAR DRY FORK, UT

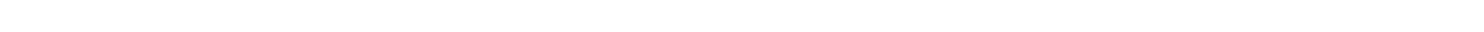
bank $900 \mathrm{ft}$ upstream from mouth and $4 \mathrm{mi}$ southeast of town of Dry Fork.

DRAINAGE AREA. $-115 \mathrm{mi}^{2}$.

MEAN BASIN ELEVATION. $-9,190 \mathrm{ft}$.

PERIOD OF RECORD. AVAILABLE--July 1954 to September 1981 .

REVISED RECORDS.-WDR UT-77-1: Drainage area.

GAGE.--Water-stage recorder. Datum of gage is 5,842.9 ft NGVD of 1929 .

REMARKS.--Several diversions above station for irrigation, including Mosby Canal which began diverting water for irrigation in Deep Creek basin during 1942 or 1943

AVERAGE DISQHARGE.--27 years, $25.1 \mathrm{ft}^{3} / \mathrm{s}, 18,180$ acre-ft/yr.

EXTREMES FOR PERIOD OF RECORD.-Maximum discharge, 1,210 ft $3 / \mathrm{s}$ Aug. 25, 1955, from rating curve extended above $450 \mathrm{ft} / \mathrm{s}$ on basis of comparison with Ashley Creek at Sign of the Maine; maximum gage height, $6.01 \mathrm{ft} J u n e 11$, 1980 ; no flow for several periods in $1956-61,1963,1966,1974$.

LOWEST MEAN DISQHARGE, IN GBIC FEET PER SECOND, AND RANKING FOR THE INDICATED NUMBER OF CONSEQUTIVE DAYS FOR EAG OLIMATIC YEAR, APRII 1-MARG 31

YEAR

13

$0.1010 \quad 0.2012$

0.00110 .001

$\begin{array}{lll}0.00 & 2 & 0.00\end{array}$

$\begin{array}{llll}0.00 & 3 & 0.00 & 3 \\ 0.00 & 4 & 0.00 & 4\end{array}$

$\begin{array}{llll}0.00 & 5 & 0.00 \quad 5\end{array}$

$\begin{array}{llll}0.00 & 6 & 0.00 & 6\end{array}$

$\begin{array}{llll}0.3015 & 0.3015\end{array}$

$\begin{array}{llll}0.30 & 15 & 0.30 & 15 \\ 0.00 & 7 & 0.00 & 7\end{array}$

$0.1011 \quad 0.1010$

1.4025

0.3016

0.2013

1.0024

1.4025

0.3816

1.1024

0.7121

0.1512

0.6721

0.5020

1.5026

0.1511

0.7322

0.5520

1.5026

$\begin{array}{rr}1.50 & 26 \\ 0.00 & 8\end{array}$

$\begin{array}{lll}0.3818 & 0.4317\end{array}$

0.4619

0.02

0.4317
0.5419

0.5419

$\begin{array}{ll}0.03 & 9 \\ 0.23 & 14\end{array}$

0.2314
0.5218

$1.0023 \quad 1.0023$
714

0.3715

0.016

0.03

0.001

0.00

0.004

$\begin{array}{lll}0.30 & 14\end{array}$

$\begin{array}{rr}0.01 & 7 \\ 0.10 & 10\end{array}$

$1.50 \quad 25$

0.4817

0.4817

1.1023

1.4024

0.1911

0.7921

0.5718

1.7026

$0.00 \quad 5$

0.4416

0.6820

0.049

0.2613

0.5919

1.0022
14

0.4916

0.067

0.056

0.128

$0.00 \quad 2$

0.003

0.3012

0.129

1.7025

0.5517

0.4314

$\begin{array}{ll}1.30 & 23 \\ 1.50 & 24\end{array}$

0.3613

0.8321

0.6518

2.3026

0.4915

0.7120

0.055

0.2711

0.6719

1.1922
CONSEOUTIVE DAYS

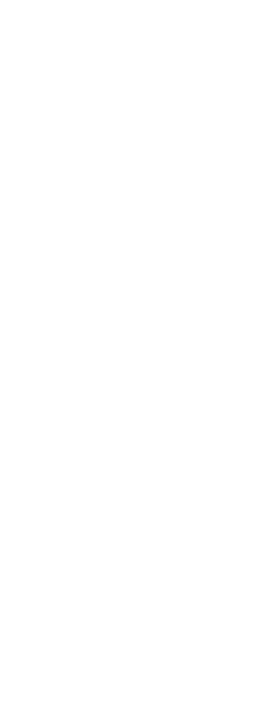

90

1.3015

0.356

2.7024

$\begin{array}{ll}0.71 & 7 \\ 0.75 & 8\end{array}$

0.031

0.194

0.889

$\begin{array}{ll}0.88 & 9 \\ 0.25 & 5\end{array}$

0.9412

2.3021

0.8910

2.2020

1.9018

2.2019

3.2025

2.6023

1.5016

3.6026

$\begin{array}{rr}3.60 & 26 \\ 0.07 & 2\end{array}$

$2.40 \quad 22$

1.1913

0.113

0.9011
1.1914

$\begin{array}{llll}1.8024 & 1.8019 & 1.9017\end{array}$

$\begin{array}{lr}120 & \\ 1.40 & 15 \\ 0.41 & 5 \\ 3.30 & 24 \\ 0.91 & 6 \\ 0.94 & 7 \\ & \\ 0.35 & 3 \\ 1.00 & 8 \\ 1.10 & 9 \\ 0.40 & 4 \\ 1.10 & 10 \\ 2.70 & 22 \\ 1.10 & 11 \\ 2.30 & 19 \\ 2.00 & 16 \\ 2.50 & 21 \\ & 21 \\ 3.30 & 25 \\ 3.00 & 23 \\ 2.00 & 17 \\ 3.60 & 26 \\ 0.10 & 1 \\ & \\ 2.40 & 20 \\ 1.30 & 14 \\ 0.14 & 2 \\ 1.10 & 12 \\ 1.30 & 13\end{array}$

183

1.5014

0.452

3.2022

$\begin{array}{cccr}1.30 & 8 & 32.0 & 17 \\ 1.30 & 9 & 2.30 & 2\end{array}$

$0.80 \quad 5$

1.8015

1.4010

$0.68 \quad 4$

1.4011

4.1026

1.306

2.5020

$\begin{array}{ll}2.30 & 17 \\ 2.70 & 21\end{array}$

3.5024

3.3023

2.4018

3.8025

$\begin{array}{lr}3.80 & 25 \\ 0.45 & 3\end{array}$

2.4019

1.307

0.331

1.4012
1.5013

2.1018

2.2016
ALI

$8.30 \quad 5$

$18.0 \quad 11$

$\begin{array}{ll}6.40 & 4 \\ 8.80 & 6\end{array}$

$42.0 \quad 21$

9.307

$21.0 \quad 14$

$53.0 \quad 24$

15.08

54.025

$\begin{array}{ll}48.0 & 22 \\ 41.0 & 19\end{array}$

$20.0 \quad 12$

$27.0 \quad 16$

$23.0 \quad 15$

$55.0 \quad 26$

$48.0 \quad 23$

$21.0 \quad 13$

0.801

$\begin{array}{rr}17.0 & 9 \\ 17.0 \quad 10\end{array}$

$41.0 \quad 20$ 
GREEN RIVER BASIN

09270500 DRY FORK AT MOUTY, NEAR DRY FORK, UT-Continued

HIGHEST MEAN DISCHARGE, IN CUBIC FEET PER SECOND, AND RANKING FOR THE INDICATED NUMBER OF CONSECOMIVE DAYS FOR EACH WATER YEAR, OCTCBER I-SEPTEMBER 30

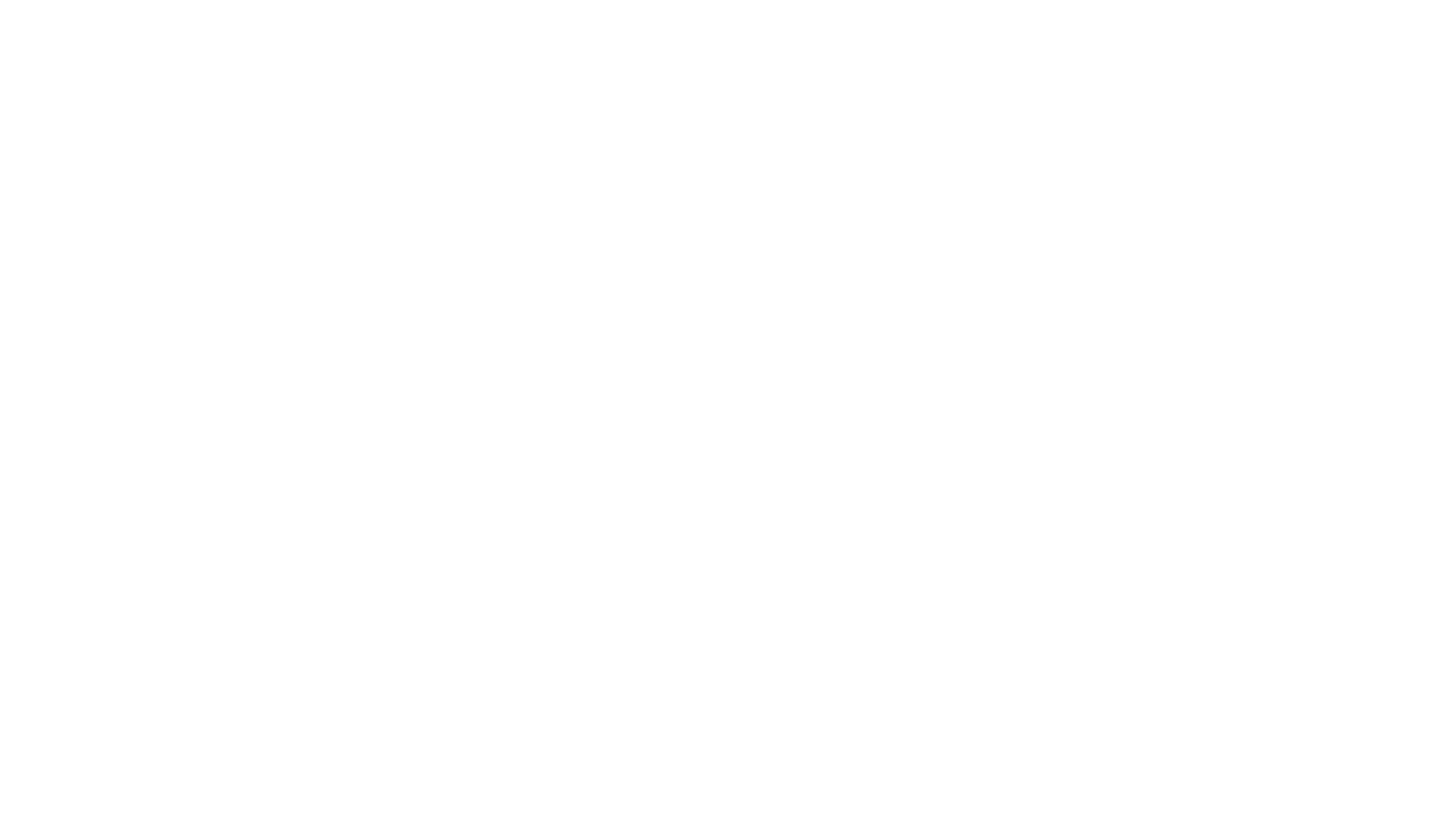

DURATION OF DISCHARGE FOR EACH WATER YEAR

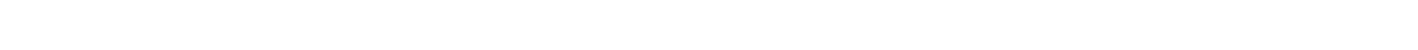
YEAR

NUMBER OF DAYS IN CLASS

CUBIC FEET -DAYS

\begin{tabular}{|c|c|c|c|c|c|c|c|c|c|c|c|c|c|c|c|c|c|c|c|c|c|c|c|c|c|c|c|c|c|c|c|c|}
\hline 1955 & & & & & & 2 & & & 3 & 11 & 34 & 179 & 68 & 9 & 1 & 4 & 1 & 1 & 1 & 3 & 8 & 81 & 101 & 12 & 5 & 5 & & & & & & 2942.6 \\
\hline $\begin{array}{l}1956 \\
1957 \\
1958 \\
1959 \\
1960\end{array}$ & $\begin{array}{r}6 \\
8 \\
7 \\
53 \\
80\end{array}$ & & & & & $\begin{array}{r}21 \\
18 \\
3 \\
20 \\
14\end{array}$ & $\begin{array}{r}16 \\
32 \\
5 \\
7 \\
5\end{array}$ & $\begin{array}{cc}23 & 2 \\
36 & 3 \\
10 & 3 \\
3 \\
7\end{array}$ & $\begin{array}{r}20 \\
38 \\
34 \\
9 \\
9\end{array}$ & $\begin{array}{r}11 \\
17 \\
19 \\
3 \\
7\end{array}$ & $\begin{array}{r}23 \\
57 \\
1 \\
6 \\
10\end{array}$ & $\begin{array}{l}51 \\
35 \\
12 \\
18 \\
12\end{array}$ & $\begin{array}{l}59 \\
16 \\
18 \\
68 \\
73\end{array}$ & $\begin{array}{r}51 \\
21 \\
32 \\
133 \\
67\end{array}$ & $\begin{array}{l}31 \\
12 \\
87 \\
11 \\
23\end{array}$ & $\begin{array}{r}9 \\
6 \\
32 \\
5 \\
9\end{array}$ & $\begin{array}{r}2 \\
5 \\
39 \\
7 \\
6\end{array}$ & $\begin{array}{l}2 \\
4 \\
8 \\
2 \\
4\end{array}$ & $\begin{array}{l}3 \\
6 \\
5 \\
4 \\
1\end{array}$ & $\begin{array}{l}1 \\
3 \\
9 \\
4\end{array}$ & $\begin{array}{l}4 \\
5 \\
6 \\
4 \\
9\end{array}$ & $\begin{array}{l}4 \\
4 \\
4 \\
2 \\
3\end{array}$ & $\begin{array}{l}6 \\
3 \\
6 \\
1 \\
8\end{array}$ & $\begin{array}{l}1 \\
4 \\
5\end{array}$ & $\begin{array}{l}2 \\
3 \\
2\end{array}$ & $\begin{array}{l}3 \\
3 \\
2 \\
5\end{array}$ & $\begin{array}{rr}3 & 4 \\
3 & 10 \\
4 & 2 \\
& \\
1 & \end{array}$ & $\begin{array}{rr}4 & 10 \\
0 & 9 \\
2 & 6\end{array}$ & $\begin{array}{l}1 \\
6 \\
7\end{array}$ & $\begin{array}{l}3 \\
6\end{array}$ & & $\begin{array}{r}6860.8 \\
12038.0 \\
12074.4 \\
869.3 \\
2450.5\end{array}$ \\
\hline $\begin{array}{l}1961 \\
1962 \\
1963 \\
1964 \\
1965\end{array}$ & 14 & & & & & $\begin{array}{l}18 \\
10\end{array}$ & $\begin{array}{l}29 \\
50\end{array}$ & $\begin{array}{r}39 \\
42\end{array}$ & $\begin{array}{r}7 \\
26\end{array}$ & $\begin{array}{l}22 \\
22\end{array}$ & $\begin{array}{r}44 \\
7 \\
33 \\
63 \\
38\end{array}$ & $\begin{array}{r}21 \\
7 \\
29 \\
68 \\
14\end{array}$ & $\begin{array}{l}12 \\
63 \\
34 \\
47 \\
60\end{array}$ & $\begin{array}{l}29 \\
52 \\
86 \\
15 \\
79\end{array}$ & $\begin{array}{r}21 \\
36 \\
6 \\
6 \\
26\end{array}$ & $\begin{array}{r}1 \\
57 \\
5 \\
2 \\
15\end{array}$ & $\begin{array}{r}2 \\
27 \\
2\end{array}$ & $\begin{array}{l}1 \\
8 \\
5 \\
3 \\
6\end{array}$ & $\begin{array}{r}1 \\
11 \\
2 \\
2 \\
9\end{array}$ & $\begin{array}{l}5 \\
3 \\
3 \\
8\end{array}$ & $\begin{array}{c}6 \\
6 \\
4 \\
21\end{array}$ & $\begin{array}{l}6 \\
41 \\
4 \\
3 \\
13\end{array}$ & $\begin{array}{r}4 \\
13 \\
3 \\
4 \\
91\end{array}$ & $\begin{array}{r}1 \\
6 \\
2 \\
9 \\
17\end{array}$ & $\begin{array}{l}6 \\
5 \\
3 \\
7 \\
7 \\
4\end{array}$ & $\begin{array}{r}5 \\
11 \\
7 \\
5 \\
3\end{array}$ & $\begin{array}{rr}2 & 3 \\
15 & 14 \\
6 & 2 \\
6 & 4 \\
2 & 18\end{array}$ & $\begin{array}{lr}3 & \\
4 & 17 \\
2 & \\
4 & 2 \\
8 & 10\end{array}$ & $\begin{array}{l}1 \\
5 \\
7\end{array}$ & 5 & 1 & $\begin{array}{r}2862.4 \\
15667.9 \\
3536.3 \\
7361.0 \\
18834.1\end{array}$ \\
\hline $\begin{array}{l}1966 \\
1967 \\
1968 \\
1969 \\
1970\end{array}$ & & & & & & & 4 & $\begin{array}{l}1 \\
2\end{array}$ & $\begin{array}{l}1 \\
5\end{array}$ & $\begin{array}{r}4 \\
13\end{array}$ & $\begin{array}{r}5 \\
47 \\
3 \\
3 \\
11\end{array}$ & $\begin{array}{r}3 \\
51 \\
3 \\
4 \\
17\end{array}$ & $\begin{array}{l}18 \\
39 \\
31 \\
48 \\
22\end{array}$ & $\begin{array}{r}114 \\
37 \\
95 \\
104 \\
30\end{array}$ & $\begin{array}{r}68 \\
25 \\
91 \\
76 \\
154\end{array}$ & $\begin{array}{l}32 \\
46 \\
22 \\
26 \\
46\end{array}$ & $\begin{array}{r}44 \\
7 \\
24 \\
10 \\
3\end{array}$ & $\begin{array}{r}16 \\
4 \\
5 \\
10 \\
5\end{array}$ & $\begin{array}{r}2 \\
4 \\
3 \\
12 \\
3\end{array}$ & $\begin{array}{l}5 \\
5 \\
2 \\
3 \\
4\end{array}$ & $\begin{array}{l}6 \\
41 \\
8 \\
3 \\
2\end{array}$ & $\begin{array}{r}8 \\
10 \\
26 \\
4 \\
\end{array}$ & $\begin{array}{r}6 \\
5 \\
13 \\
1 \\
101\end{array}$ & $\begin{array}{r}31 \\
5 \\
5 \\
4 \\
18\end{array}$ & $\begin{array}{c}11 \\
1 \\
3 \\
9 \\
8\end{array}$ & $\begin{array}{r}5 \\
2 \\
3 \\
12 \\
4\end{array}$ & $\begin{array}{rr}7 & 6 \\
5 & 15 \\
3 & 6 \\
7 & 7 \\
6 & 10\end{array}$ & $\begin{array}{rr}6 & \\
5 & 8 \\
6 & 4 \\
7 & 13 \\
0 & 1\end{array}$ & $\begin{array}{r}15 \\
8 \\
9\end{array}$ & $\begin{array}{r}5 \\
10\end{array}$ & $I$ & $\begin{array}{r}5882.5 \\
19546.5 \\
17536.1 \\
14781.8 \\
7258.7\end{array}$ \\
\hline $\begin{array}{l}1971 \\
1972 \\
1973 \\
1974 \\
1975\end{array}$ & 12 & 719 & 5 & $\begin{array}{l}4 \\
3\end{array}$ & 3 & $\begin{array}{rr}620 \\
1\end{array}$ & $\begin{array}{r}26 \\
2\end{array}$ & $\begin{array}{l}7 \\
2\end{array}$ & $\begin{array}{l}1 \\
3\end{array}$ & $\begin{array}{r}1 \\
27\end{array}$ & $\begin{array}{r}8 \\
33 \\
\\
5 \\
18\end{array}$ & $\begin{array}{r}14 \\
39 \\
2 \\
13 \\
25\end{array}$ & $\begin{array}{r}35 \\
26 \\
29 \\
13 \\
106\end{array}$ & $\begin{array}{l}29 \\
39 \\
75 \\
27 \\
46\end{array}$ & $\begin{array}{l}78 \\
54 \\
59 \\
13 \\
27\end{array}$ & $\begin{array}{r}106 \\
99 \\
54 \\
158 \\
11\end{array}$ & $\begin{array}{r}20 \\
20 \\
33 \\
8 \\
2\end{array}$ & $\begin{array}{l}3 \\
1 \\
3 \\
3 \\
2\end{array}$ & $\begin{array}{l}1 \\
1 \\
7\end{array}$ & $\begin{array}{r}2 \\
1 \\
10 \\
8\end{array}$ & $\begin{array}{r}11 \\
2 \\
6 \\
2 \\
9\end{array}$ & $\begin{array}{l}9 \\
4 \\
1 \\
2 \\
5\end{array}$ & $\begin{array}{l}6 \\
5 \\
6 \\
2 \\
4\end{array}$ & $\begin{array}{rl}2 & 1 \\
2 & \\
15 & 1 \\
2 \\
5\end{array}$ & $\begin{array}{rl}10 & 1 \\
7 & 1 \\
11 & \\
1 \\
5\end{array}$ & $\begin{array}{r}11 \\
11 \\
9 \\
1 \\
4\end{array}$ & $\begin{array}{rr}4 & 7 \\
4 & 6 \\
11 & 9 \\
3 & 1 \\
3 & 13\end{array}$ & $\begin{array}{rr}7 & 5 \\
5 & 9 \\
9 & 6 \\
1 & \\
3 & 19\end{array}$ & $\begin{array}{r}4 \\
13 \\
8\end{array}$ & 6 & & $\begin{array}{r}9762.6 \\
8346.9 \\
19944.6 \\
2046.4 \\
17415.4\end{array}$ \\
\hline $\begin{array}{l}1976 \\
1977 \\
1978 \\
1979 \\
1980\end{array}$ & & 2 & 32 & 20 & 141 & 1630 & 58 & $\begin{array}{l}19 \\
201\end{array}$ & $\begin{array}{r}4 \\
13\end{array}$ & $\begin{array}{r}5 \\
6 \\
13 \\
5 \\
5\end{array}$ & $\begin{array}{r}19 \\
4 \\
37 \\
13 \\
12\end{array}$ & $\begin{array}{l}21 \\
49 \\
82 \\
42 \\
15\end{array}$ & $\begin{array}{l}38 \\
62 \\
98 \\
52 \\
71\end{array}$ & $\begin{array}{r}101 \\
73 \\
20 \\
160 \\
95\end{array}$ & $\begin{array}{r}117 \\
2 \\
16 \\
18 \\
65\end{array}$ & $\begin{array}{l}14 \\
10 \\
17 \\
11\end{array}$ & $\begin{array}{l}1 \\
5 \\
4 \\
4\end{array}$ & $\begin{array}{l}1 \\
1 \\
1 \\
5 \\
1\end{array}$ & $\begin{array}{l}2 \\
3 \\
1\end{array}$ & $\begin{array}{l}3 \\
1 \\
3\end{array}$ & $\begin{array}{r}5 \\
7 \\
12\end{array}$ & $\begin{array}{l}4 \\
5 \\
7\end{array}$ & $\begin{array}{l}4 \\
2 \\
5\end{array}$ & $\begin{array}{l}6 \\
4 \\
7\end{array}$ & $\begin{array}{l}4 \\
4 \\
6 \\
7\end{array}$ & $\begin{array}{l}31 \\
6 \\
5 \\
9\end{array}$ & $\begin{array}{rr}11 & 6 \\
7 & 3 \\
9 & 4 \\
3 & 10\end{array}$ & $\begin{array}{ll}3 & 6 \\
4 & 3 \\
0 & 9\end{array}$ & $\begin{array}{l}1 \\
7\end{array}$ & 4 & & $\begin{array}{r}7777.7 \\
333.6 \\
6058.9 \\
6286.4 \\
14889.9\end{array}$ \\
\hline 198 & & & & & & & & & & 4 & 18 & 42 & 45 & 121 & 64 & 4 & 1 & 6 & 3 & 1 & 5 & 19 & 5 & 5 & & 12 & 1 & & & & & 4461.1 \\
\hline
\end{tabular}


GREEN RIVER BASIN

09270500 DRY FORK AT MOUTH, NEAR DRY FORK, UT-Continued

DURATION TABLE OF DISGHARGE FOR WATER YEARS 1955-81

\begin{tabular}{|c|c|c|c|c|c|c|c|c|c|c|c|c|c|c|c|c|c|c|c|}
\hline C.ASS & $\begin{array}{c}\text { वBIC } \\
\text { FEET } \\
\text { PER } \\
\text { SECOND }\end{array}$ & TOTAL & $\begin{array}{l}\text { ACOS- } \\
\text { MU- } \\
\text { LATED } \\
\text { DAYS }\end{array}$ & $\begin{array}{l}\text { PER- } \\
\text { CENT } \\
\text { DAVS }\end{array}$ & CLASS & $\begin{array}{c}\text { QUBIC } \\
\text { FEET } \\
\text { PER } \\
\text { SECOND }\end{array}$ & TOTAL & $\begin{array}{c}\text { ACON- } \\
\text { NU- } \\
\text { LATED } \\
\text { DAYS }\end{array}$ & $\begin{array}{l}\text { PER- } \\
\text { CENT } \\
\text { DAYS }\end{array}$ & CASS & $\begin{array}{c}\text { वBBIC } \\
\text { FEET } \\
\text { PER } \\
\text { SECOND }\end{array}$ & TOTAL & $\begin{array}{l}\text { ACOU- } \\
\text { MU- } \\
\text { LATED } \\
\text { DAYS }\end{array}$ & $\begin{array}{l}\text { PER- } \\
\text { CENT } \\
\text { DAYS }\end{array}$ & OLASS & $\begin{array}{c}\text { OUBIC } \\
\text { FEET } \\
\text { PER } \\
\text { SECOND }\end{array}$ & TOTAL & $\begin{array}{l}\text { ACOJ- } \\
\text { MN- } \\
\text { LAIED } \\
\text { DAYS }\end{array}$ & $\begin{array}{l}\text { PER- } \\
\text { CENT } \\
\text { DAYS }\end{array}$ \\
\hline $\begin{array}{l}0 \\
1 \\
2 \\
3 \\
4 \\
5 \\
6 \\
7 \\
8\end{array}$ & $\begin{array}{l}0.00 \\
0.01 \\
0.02 \\
0.03 \\
0.04 \\
0.06 \\
0.08 \\
0.11 \\
0.15\end{array}$ & $\begin{array}{r}235 \\
7 \\
21 \\
8 \\
27 \\
17 \\
177 \\
51 \\
260\end{array}$ & $\begin{array}{l}9822 \\
9627 \\
9620 \\
9599 \\
9591 \\
9564 \\
9547 \\
9370 \\
9319\end{array}$ & $\begin{array}{r}100.0 \\
97.6 \\
97.5 \\
97.3 \\
97.3 \\
97.0 \\
96.8 \\
95.0 \\
94.5\end{array}$ & $\begin{array}{l}9 \\
10 \\
11 \\
12 \\
13 \\
14 \\
15 \\
16 \\
17\end{array}$ & $\begin{array}{l}0.22 \\
0.31 \\
0.43 \\
0.60 \\
0.85 \\
1.20 \\
1.70 \\
2.40 \\
3.30\end{array}$ & $\begin{array}{r}209 \\
194 \\
224 \\
549 \\
868 \\
1251 \\
1740 \\
1187 \\
801\end{array}$ & $\begin{array}{l}9059 \\
8850 \\
8656 \\
8432 \\
7883 \\
7015 \\
5764 \\
4024 \\
2837\end{array}$ & $\begin{array}{l}91.9 \\
89.7 \\
87.8 \\
85.5 \\
79.9 \\
71.1 \\
58.4 \\
40.8 \\
28.8\end{array}$ & $\begin{array}{l}18 \\
19 \\
20 \\
21 \\
22 \\
23 \\
24 \\
25 \\
26\end{array}$ & $\begin{array}{r}4.7 \\
6.6 \\
9.3 \\
13.0 \\
18.0 \\
26.0 \\
37.0 \\
51.0 \\
72.0\end{array}$ & $\begin{array}{r}277 \\
111 \\
95 \\
92 \\
159 \\
161 \\
143 \\
150 \\
134\end{array}$ & $\begin{array}{r}2036 \\
1759 \\
1648 \\
1553 \\
1461 \\
1302 \\
1141 \\
998 \\
848\end{array}$ & $\begin{array}{r}20.6 \\
17.8 \\
16.7 \\
15.7 \\
14.8 \\
13.2 \\
11.6 \\
10.1 \\
8.6\end{array}$ & $\begin{array}{l}27 \\
28 \\
29 \\
30 \\
31 \\
32 \\
33 \\
34\end{array}$ & $\begin{array}{l}100.0 \\
140.0 \\
200.0 \\
280.0 \\
400.0 \\
560.0 \\
790.0\end{array}$ & $\begin{array}{r}146 \\
127 \\
161 \\
145 \\
92 \\
41 \\
2\end{array}$ & $\begin{array}{r}714 \\
568 \\
441 \\
280 \\
135 \\
43 \\
2\end{array}$ & $\begin{array}{l}7.2 \\
5.8 \\
4.5 \\
2.8 \\
1.4 \\
0.4 \\
0.0\end{array}$ \\
\hline
\end{tabular}

MONTHLY MEAN DISCHARGES, IN OBBIC FEET PER SECOND, FOR EACH WATER YEAR

\begin{tabular}{|c|c|c|c|c|c|c|c|c|c|c|c|c|}
\hline YEAR & $\infty \mathrm{CT}$ & NOV & $\mathrm{DEC}$ & JAN & FEB & MAR & APR & MAY & JUNE & JULY & AUG & SEP \\
\hline 1955 & 1.21 & 1.00 & 1.08 & 1.05 & 1.00 & 1.30 & 1.12 & 50.6 & 32.8 & 1.76 & 2.31 & 0.90 \\
\hline $\begin{array}{l}1956 \\
1957 \\
1958 \\
1959 \\
1960\end{array}$ & $\begin{array}{l}1.10 \\
0.30 \\
1.77 \\
1.43 \\
0.95\end{array}$ & $\begin{array}{l}2.09 \\
0.72 \\
5.60 \\
1.84 \\
1.98\end{array}$ & $\begin{array}{l}2.19 \\
0.76 \\
3.90 \\
2.09 \\
2.07\end{array}$ & $\begin{array}{l}1.49 \\
0.32 \\
2.50 \\
1.79 \\
1.42\end{array}$ & $\begin{array}{l}1.30 \\
0.46 \\
3.38 \\
1.80 \\
1.29\end{array}$ & $\begin{array}{l}2.03 \\
0.83 \\
3.41 \\
2.20 \\
2.79\end{array}$ & $\begin{array}{l}0.44 \\
0.47 \\
2.03 \\
0.64 \\
0.86\end{array}$ & $\begin{array}{c}137 \\
0.18 \\
191 \\
0.02 \\
30.5\end{array}$ & $\begin{array}{l}74.8 \\
327 \\
177 \\
11.2 \\
38.0\end{array}$ & $\begin{array}{c}0.59 \\
61.7 \\
4.05 \\
3.75 \\
0.50\end{array}$ & $\begin{array}{l}0.70 \\
3.01 \\
0.34 \\
1.17 \\
0.03\end{array}$ & $\begin{array}{l}0.26 \\
3.45 \\
0.99 \\
0.80 \\
0.00\end{array}$ \\
\hline $\begin{array}{l}1961 \\
1962 \\
1963 \\
1964 \\
1965\end{array}$ & $\begin{array}{l}1.06 \\
3.29 \\
2.06 \\
0.79 \\
1.29\end{array}$ & $\begin{array}{l}2.48 \\
3.82 \\
2.09 \\
1.57 \\
1.91\end{array}$ & $\begin{array}{l}1.15 \\
2.76 \\
1.41 \\
0.95 \\
2.24\end{array}$ & $\begin{array}{l}0.30 \\
1.72 \\
0.38 \\
0.40 \\
1.56\end{array}$ & $\begin{array}{l}0.62 \\
2.36 \\
1.06 \\
0.28 \\
0.91\end{array}$ & $\begin{array}{l}0.61 \\
3.52 \\
1.53 \\
0.42 \\
1.24\end{array}$ & $\begin{array}{c}0.21 \\
11.7 \\
1.02 \\
1.13 \\
3.00\end{array}$ & $\begin{array}{c}33.7 \\
159 \\
73.6 \\
130 \\
28.5\end{array}$ & $\begin{array}{c}53.0 \\
266 \\
31.1 \\
97.1 \\
409\end{array}$ & $\begin{array}{c}0.77 \\
54.6 \\
0.54 \\
6.80 \\
127\end{array}$ & $\begin{array}{l}0.09 \\
4.35 \\
0.15 \\
0.87 \\
29.3\end{array}$ & $\begin{array}{c}0.21 \\
1.53 \\
0.35 \\
0.85 \\
16.2\end{array}$ \\
\hline $\begin{array}{l}1966 \\
1967 \\
1968 \\
1969 \\
1970\end{array}$ & $\begin{array}{l}6.54 \\
1.80 \\
3.10 \\
2.76 \\
2.75\end{array}$ & $\begin{array}{l}6.25 \\
1.77 \\
2.48 \\
3.08 \\
3.36\end{array}$ & $\begin{array}{l}4.09 \\
1.15 \\
2.45 \\
2.12 \\
2.93\end{array}$ & $\begin{array}{l}2.28 \\
0.71 \\
2.41 \\
1.54 \\
3.15\end{array}$ & $\begin{array}{l}2.06 \\
0.81 \\
1.91 \\
2.10 \\
2.60\end{array}$ & $\begin{array}{l}2.55 \\
3.22 \\
2.41 \\
3.34 \\
2.22\end{array}$ & $\begin{array}{l}2.06 \\
0.98 \\
3.42 \\
4.34 \\
1.20\end{array}$ & $\begin{array}{c}124 \\
157 \\
7.34 \\
274 \\
61.6\end{array}$ & $\begin{array}{l}34.7 \\
370 \\
465 \\
157 \\
121\end{array}$ & $\begin{array}{l}3.15 \\
91.5 \\
54.8 \\
28.0 \\
32.4\end{array}$ & $\begin{array}{c}1.64 \\
9.95 \\
31.2 \\
2.06 \\
2.39\end{array}$ & $\begin{array}{l}1.63 \\
3.75 \\
5.10 \\
2.15 \\
3.00\end{array}$ \\
\hline $\begin{array}{l}1971 \\
1972 \\
1973 \\
1974 \\
1975\end{array}$ & $\begin{array}{l}4.43 \\
3.94 \\
2.29 \\
3.71 \\
0.77\end{array}$ & $\begin{array}{l}3.50 \\
4.26 \\
4.58 \\
4.45 \\
1.20\end{array}$ & $\begin{array}{l}4.05 \\
4.02 \\
2.89 \\
3.88 \\
1.35\end{array}$ & $\begin{array}{l}3.95 \\
3.08 \\
2.22 \\
3.90 \\
1.64\end{array}$ & $\begin{array}{l}3.12 \\
3.30 \\
1.82 \\
3.70 \\
1.45\end{array}$ & $\begin{array}{l}3.05 \\
1.64 \\
2.47 \\
3.11 \\
2.29\end{array}$ & $\begin{array}{l}1.49 \\
0.87 \\
2.85 \\
1.83 \\
0.84\end{array}$ & $\begin{array}{c}29.2 \\
93.0 \\
197 \\
41.3 \\
8.63\end{array}$ & $\begin{array}{c}227 \\
149 \\
322 \\
0.50 \\
317\end{array}$ & $\begin{array}{c}38.4 \\
7.87 \\
88.5 \\
0.12 \\
218\end{array}$ & $\begin{array}{c}2.50 \\
1.89 \\
22.9 \\
0.11 \\
17.2\end{array}$ & $\begin{array}{l}2.25 \\
1.42 \\
5.24 \\
0.01 \\
2.29\end{array}$ \\
\hline $\begin{array}{l}1976 \\
1977 \\
1978 \\
1979 \\
1980\end{array}$ & $\begin{array}{l}2.47 \\
1.82 \\
0.66 \\
1.56 \\
0.99\end{array}$ & $\begin{array}{l}2.85 \\
1.54 \\
1.18 \\
1.88 \\
2.00\end{array}$ & $\begin{array}{l}2.62 \\
1.27 \\
1.04 \\
1.91 \\
1.77\end{array}$ & $\begin{array}{l}1.90 \\
1.13 \\
1.16 \\
1.80 \\
1.50\end{array}$ & $\begin{array}{l}2.60 \\
1.56 \\
1.21 \\
1.75 \\
2.20\end{array}$ & $\begin{array}{l}2.70 \\
1.61 \\
2.27 \\
2.83 \\
2.83\end{array}$ & $\begin{array}{l}2.13 \\
0.33 \\
1.53 \\
2.29 \\
1.94\end{array}$ & $\begin{array}{c}90.6 \\
0.22 \\
14.9 \\
92.1 \\
32.1\end{array}$ & $\begin{array}{l}141 \\
1.16 \\
163 \\
91.4 \\
355\end{array}$ & $\begin{array}{c}4.56 \\
0.09 \\
12.8 \\
5.86 \\
85.8\end{array}$ & $\begin{array}{l}1.10 \\
0.14 \\
0.67 \\
1.74 \\
3.80\end{array}$ & $\begin{array}{l}1.01 \\
0.14 \\
0.62 \\
1.01 \\
2.17\end{array}$ \\
\hline 1981 & 2.32 & 2.49 & 2.46 & 2.10 & 1.88 & 1.84 & 1.43 & 62.1 & 65.0 & 2.71 & 0.84 & 1.15 \\
\hline
\end{tabular}

ANNUAL PEAK DISGHARGE, IN OBIC FEET PER SECOND, AND CORRESPONDING GAGE HEIGHT, IN FEET, FOR EACH WATER YEAR

\begin{tabular}{|c|c|c|c|c|c|c|c|c|c|c|c|}
\hline $\begin{array}{l}\text { WATER } \\
\text { YEAR }\end{array}$ & DATE & $\begin{array}{c}\text { GAGE } \\
\text { HEIGHT }\end{array}$ & $\begin{array}{c}\text { PEAR } \\
\text { DISCHARGE }\end{array}$ & $\begin{array}{l}\text { WATER } \\
\text { YEAR }\end{array}$ & DATE & $\begin{array}{c}\text { GAGE } \\
\text { HEIGHT }\end{array}$ & $\begin{array}{c}\text { PEAR } \\
\text { DISCHARGE }\end{array}$ & $\begin{array}{l}\text { WATER } \\
\text { YEAR }\end{array}$ & DATE & $\begin{array}{c}\text { GAGE } \\
\text { HEIGHT }\end{array}$ & $\begin{array}{c}\text { PEAR } \\
\text { DISOH ARGE }\end{array}$ \\
\hline $\begin{array}{l}1955 \\
1956 \\
1957 \\
1958 \\
1959 \\
1960 \\
1961 \\
1962 \\
1963\end{array}$ & $\begin{array}{lll}\text { AUG. } & 25, & 1955 \\
\text { MAY } & 26, & 1956 \\
\text { JUNE } & 09, & 1957 \\
\text { MAY } & 28, & 1958 \\
\text { JUNE } & 08, & 1959 \\
\text { MAY } & 13, & 1960 \\
\text { MAY } & 30, & 1961 \\
\text { MAY } & 10, & 1962 \\
\text { MAY } & 19, & 1963\end{array}$ & $\begin{array}{l}5.18 \\
3.67 \\
4.34 \\
4.52 \\
2.17 \\
3.41 \\
3.62 \\
4.50 \\
4.02\end{array}$ & $\begin{array}{r}1210 \\
485 \\
823 \\
812 \\
62 \\
245 \\
290 \\
527 \\
340\end{array}$ & $\begin{array}{l}1964 \\
1965 \\
1966 \\
1967 \\
1968 \\
1969 \\
1970 \\
1971 \\
1972\end{array}$ & $\begin{array}{lll}\text { MAY } & 23, & 1964 \\
\text { JUNE } & 11, & 1965 \\
\text { MAY } & 08,1966 \\
\text { MAY } & 26,1967 \\
\text { JUNE } & 05,1968 \\
\text { JUNE } & 17,1969 \\
\text { MAY } & 27,1970 \\
\text { JUNE } & 18,1971 \\
\text { JUNE } & 01, & 1972\end{array}$ & $\begin{array}{l}4.94 \\
- \\
3.81 \\
5.22 \\
5.63 \\
3.72 \\
3.05 \\
3.67 \\
3.34\end{array}$ & $\begin{array}{l}660 \\
985 \\
341 \\
944 \\
900 \\
817 \\
334 \\
545 \\
417\end{array}$ & $\begin{array}{l}1973 \\
1974 \\
1975 \\
1976 \\
1977 \\
1978 \\
1979 \\
1980 \\
1981\end{array}$ & $\begin{array}{l}\text { JUNE } 15,1973 \\
\text { MAY } 10,1974 \\
\text { JUNE } 16,1975 \\
\text { JUNE } 04,1976 \\
\text { JUNE } 04,1977 \\
\text { JUNE } 11,1978 \\
\text { MAY } 29,1979 \\
\text { JUNE } 11,1980 \\
\text { MAY } 03,1981\end{array}$ & $\begin{array}{l}4.56 \\
3.55 \\
4.77 \\
4.41 \\
3.21 \\
4.52 \\
4.63 \\
6.01 \\
4.34\end{array}$ & $\begin{array}{r}774 \\
246 \\
902 \\
382 \\
37 \\
418 \\
472 \\
1070 \\
333\end{array}$ \\
\hline
\end{tabular}


09270500 DRY FORK AT MOUTH, NEAR DRY FORK, UT--Continued

MAGNITUDE AND PRCBABILITY OF ANNUAL LOWEST MEAN DISCHARGE BASED ON CLIMATIC YEARS 1956-81

\begin{tabular}{|c|c|c|c|c|c|c|}
\hline \multirow{2}{*}{$\begin{array}{l}\text { PERIOD } \\
\text { (CON- } \\
\text { SEOU- } \\
\text { TIVE } \\
\text { DAYS) }\end{array}$} & \multicolumn{6}{|c|}{$\begin{array}{l}\text { DISCHARGE, IN CUBIC FEET PER SECOND, FOR } \\
\text { INDICATED RECURRENCE INTERVAL, IN YEARS, AND } \\
\text { ANNUAL NONEXCEEDANCE PRCBABILITY, IN PERCENT }\end{array}$} \\
\hline & $\begin{array}{c}2 \\
508\end{array}$ & $\begin{array}{c}5 \\
208\end{array}$ & $\begin{array}{l}10 \\
108\end{array}$ & $\begin{array}{l}20 \\
58\end{array}$ & $\begin{array}{l}50 \\
28\end{array}$ & $\begin{array}{r}100 \\
18\end{array}$ \\
\hline $\begin{array}{l}14 \\
30\end{array}$ & $\begin{array}{l}0.33 \\
0.50\end{array}$ & $\begin{array}{l}0.03 \\
0.05\end{array}$ & $\begin{array}{l}0.00 \\
0.00\end{array}$ & $=$ & $\overline{-}$ & $\overline{-}$ \\
\hline
\end{tabular}

09271000 ASHLEY CREER AT SIGN OF THE MAINE, NEAR VERNAL, UT

LOCATION.--Lat $40^{\circ} 31^{\prime} 00^{\prime \prime}$, long $109^{\circ} 35^{\prime} 40^{\prime \prime}$, in $\mathrm{NE}_{4}^{3}$ sec.31, T.3 S., R.21 E., Uintah County, Hydrologic Unit 14060002, on left bank

$0.75 \mathrm{mi}$ downstream from Dry Fork and $4.75 \mathrm{mi}$ northwest of Vernal.

DRAINAGE AREA. $--241 \mathrm{mi}^{2}$.

MEAN BASIN ELEVATION. $-9,100 \mathrm{ft}$.

PERIOD OF RECORD AVAIlABLE.--March 1900 to December 1904 (published as "near Vernal"), June 1939 to September 1965. Monthly mean discharge only for some periods, those for parts of water years 1900, 1905, and 1939 are published in WSP 1313.

GAGE.--Water-stage recorder. Altitude of gage is 5,750 ft from topographic map. Prior to Dec. 31, 1904, staff gages at sites about $0.25 \mathrm{mi}$ upstream at different datums. June 23,1939 , to Sept. 25, 1956, water-stage recorder at site $100 \mathrm{ft}$ upstream at datum $0.68 \mathrm{ft}$ higher.

REMARKS.--Flow increased since July 1940 by water released from Oaks Park Reservoir, capacity, 6,250 acre-ft, on Big Brush Creek and diverted to Ashley Creek basin for irrigation. Diversions above station for irrigation and municipal supply.

AVERAGE DISCHARGE. -30 years, $124 \mathrm{ft}^{3} / \mathrm{s}, 89,770$ acre- $\mathrm{ft} / \mathrm{yr}$.

EXTREMES FOR PERIOD OF RECORD.--Maximum discharge, 4,110 ft $3 / \mathrm{s}$ June 11, 1965, gage height, $5.34 \mathrm{ft}$, from rating curve extended above 3,100 $\mathrm{ft}^{3} / \mathrm{s}$; maximum gage height, $5.40 \mathrm{ft}$ July 21, 1945; minimum discharge recorded, $10 \mathrm{ft} / \mathrm{s}$ Feb. 24, 1961, Jan. 19, Mar. 5, 1963.

LOWEST MEAN DISCHARGE, IN CUBIC FEET PER SECOND, AND RANKING FOR THE INDICATED NUMBER OF CONSECUTIVE DAYS FOR EACH CIMATIC YEAR, APRIL 1-MARCH 31

YEAR
1941
1942
1943
1944
1945
1946
1947
1948
1949
1950
1951
1952
1953
1954
1955

$\begin{array}{cccccc}1 & & 3 & & 7 & \\ 22.0 & 18 & 22.0 & 18 & 22.0 & 15 \\ 24.0 & 22 & 24.0 & 21 & 25.0 & 22 \\ 24.0 & 23 & 24.0 & 22 & 25.0 & 23 \\ 20.0 & 12 & 20.0 & 10 & 20.0 & 10 \\ 24.0 & 24 & 25.0 & 24 & 25.0 & 24 \\ 22.0 & 19 & 22.0 & 19 & 22.0 & 16 \\ 21.0 & 15 & 21.0 & 14 & 22.0 & 17 \\ 23.0 & 21 & 24.0 & 23 & 24.0 & 21 \\ 19.0 & 10 & 20.0 & 11 & 20.0 & 11 \\ 20.0 & 13 & 20.0 & 12 & 21.0 & 13 \\ 22.0 & 20 & 22.0 & 20 & 23.0 & 20 \\ 21.0 & 16 & 21.0 & 15 & 22.0 & 18 \\ 30.0 & 25 & 30.0 & 25 & 30.0 & 25 \\ 21.0 & 17 & 21.0 & 16 & 22.0 & 19 \\ 20.0 & 14 & 21.0 & 17 & 21.0 & 14\end{array}$

$\begin{array}{cc}14 & \\ 23.0 & 17 \\ 26.0 & 22 \\ 26.0 & 23 \\ 20.0 & 10 \\ 26.0 & 24 \\ 23.0 & 18 \\ 23.0 & 19 \\ 24.0 & 20 \\ 20.0 & 11 \\ 22.0 & 13 \\ 24.0 & 21 \\ 22.0 & 14 \\ 31.0 & 25 \\ 22.0 & 15 \\ 22.0 & 16\end{array}$

$\begin{array}{ll}\text { CONSEOTT } \\ 30 \\ 27.0 & 21 \\ 28.0 & 22 \\ 26.0 & 19 \\ 21.0 & 11 \\ 26.0 & 20 \\ 23.0 & 16 \\ 31.0 & 23 \\ 25.0 & 17 \\ 20.0 & 9 \\ 31.0 & 24 \\ 25.0 & 18 \\ 22.0 & 12 \\ 31.0 & 25 \\ 22.0 & 13 \\ 22.0 & 14\end{array}$

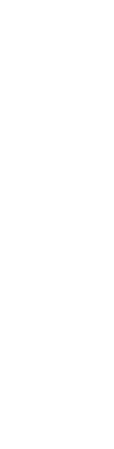
90

120
32.0

\begin{tabular}{rrrr}
183 & & \multicolumn{1}{c}{ ALL } \\
43.0 & 22 & 76.0 & 6 \\
83.0 & 25 & 197 & 24 \\
35.0 & 16 & 153 & 19 \\
28.0 & 10 & 108 & 13 \\
32.0 & 13 & 198 & 25 \\
36.0 & 17 & 112 & 15 \\
43.0 & 23 & 71.0 & 4 \\
39.0 & 19 & 183 & 22 \\
26.0 & 8 & 105 & 11 \\
40.0 & 20 & 151 & 18 \\
& & & \\
34.0 & 14 & 161 & 20 \\
35.0 & 15 & 105 & 12 \\
43.0 & 21 & 187 & 23 \\
29.0 & 11 & 83.0 & 8 \\
30.0 & 12 & 81.0 & 7
\end{tabular}


LOWEST MEAN DISOHARGE, IN OUBIC FEET PER SECOND, AND RANKING FOR THE INDICATED NUMBER OF CONSEOUTTVE DAYS FOR EACH CIMATIC YEAR, APRII 1-MARCH 31--Continued

\begin{tabular}{|c|c|c|c|c|c|c|c|c|c|c|c|c|c|c|c|c|c|c|c|}
\hline YEAR & & & & & & & & cans & EOU'T & E DAY & & & & & & & & & \\
\hline $\begin{array}{l}19.0 \\
18.0 \\
16.0 \\
17.0 \\
14.0\end{array}$ & $\begin{array}{r}11 \\
9 \\
7 \\
8 \\
4\end{array}$ & $\begin{array}{l}20.0 \\
18.0 \\
17.0 \\
17.0 \\
14.0\end{array}$ & $\begin{array}{r}13 \\
9 \\
7 \\
8 \\
4\end{array}$ & $\begin{array}{l}20.0 \\
18.0 \\
17.0 \\
18.0 \\
15.0\end{array}$ & $\begin{array}{r}12 \\
9 \\
7 \\
8 \\
4\end{array}$ & $\begin{array}{l}20.0 \\
18.0 \\
17.0 \\
18.0 \\
15.0\end{array}$ & $\begin{array}{r}12 \\
9 \\
7 \\
8 \\
4\end{array}$ & $\begin{array}{l}22.0 \\
20.0 \\
18.0 \\
19.0 \\
16.0\end{array}$ & $\begin{array}{r}15 \\
10 \\
7 \\
8 \\
4\end{array}$ & $\begin{array}{l}23.0 \\
22.0 \\
27.0 \\
20.0 \\
16.0\end{array}$ & $\begin{array}{r}12 \\
9 \\
18 \\
6 \\
3\end{array}$ & $\begin{array}{l}24.0 \\
22.0 \\
29.0 \\
20.0 \\
17.0\end{array}$ & $\begin{array}{r}11 \\
8 \\
19 \\
6 \\
3\end{array}$ & $\begin{array}{l}25.0 \\
22.0 \\
31.0 \\
22.0 \\
18.0\end{array}$ & $\begin{array}{r}10 \\
6 \\
19 \\
7 \\
3\end{array}$ & $\begin{array}{l}28.0 \\
23.0 \\
38.0 \\
25.0 \\
23.0\end{array}$ & $\begin{array}{r}9 \\
3 \\
18 \\
5 \\
4\end{array}$ & $\begin{array}{r}72.0 \\
93.0 \\
136 \\
121 \\
58.0\end{array}$ & $\begin{array}{r}5 \\
9 \\
17 \\
16 \\
1\end{array}$ \\
\hline $\begin{array}{l}13.0 \\
14.0 \\
13.0 \\
11.0 \\
15.0\end{array}$ & $\begin{array}{l}2 \\
5 \\
3 \\
1 \\
6\end{array}$ & $\begin{array}{l}13.0 \\
15.0 \\
13.0 \\
11.0 \\
15.0\end{array}$ & $\begin{array}{l}2 \\
5 \\
3 \\
1 \\
6\end{array}$ & $\begin{array}{l}13.0 \\
15.0 \\
13.0 \\
12.0 \\
16.0\end{array}$ & $\begin{array}{l}2 \\
5 \\
3 \\
1 \\
6\end{array}$ & $\begin{array}{l}13.0 \\
16.0 \\
13.0 \\
12.0 \\
17.0\end{array}$ & $\begin{array}{l}2 \\
5 \\
3 \\
1 \\
6\end{array}$ & $\begin{array}{l}13.0 \\
16.0 \\
13.0 \\
13.0 \\
17.0\end{array}$ & $\begin{array}{l}1 \\
5 \\
2 \\
3 \\
6\end{array}$ & $\begin{array}{l}14.0 \\
28.0 \\
14.0 \\
20.0 \\
20.0\end{array}$ & $\begin{array}{r}1 \\
20 \\
2 \\
4 \\
5\end{array}$ & $\begin{array}{l}15.0 \\
30.0 \\
15.0 \\
20.0 \\
20.0\end{array}$ & $\begin{array}{r}1 \\
21 \\
2 \\
4 \\
5\end{array}$ & $\begin{array}{l}16.0 \\
35.0 \\
16.0 \\
21.0 \\
22.0\end{array}$ & $\begin{array}{r}1 \\
23 \\
2 \\
4 \\
5\end{array}$ & $\begin{array}{l}18.0 \\
54.0 \\
23.0 \\
26.0 \\
26.0\end{array}$ & $\begin{array}{r}1 \\
24 \\
2 \\
6 \\
7\end{array}$ & $\begin{array}{c}62.0 \\
98.0 \\
167 \\
68.0 \\
110\end{array}$ & $\begin{array}{r}2 \\
10 \\
21 \\
3 \\
14\end{array}$ \\
\hline
\end{tabular}

HIGHEST MEAN DISGHARGE, IN OUBIC FEET PER SECOND, AND RANKING FOR THE INDICATED NUMBER OF CONSEOUTIVE DAYS FOR EAOH WATER YEAR, $O$ CTOBER 1-SEPTLMBER 30

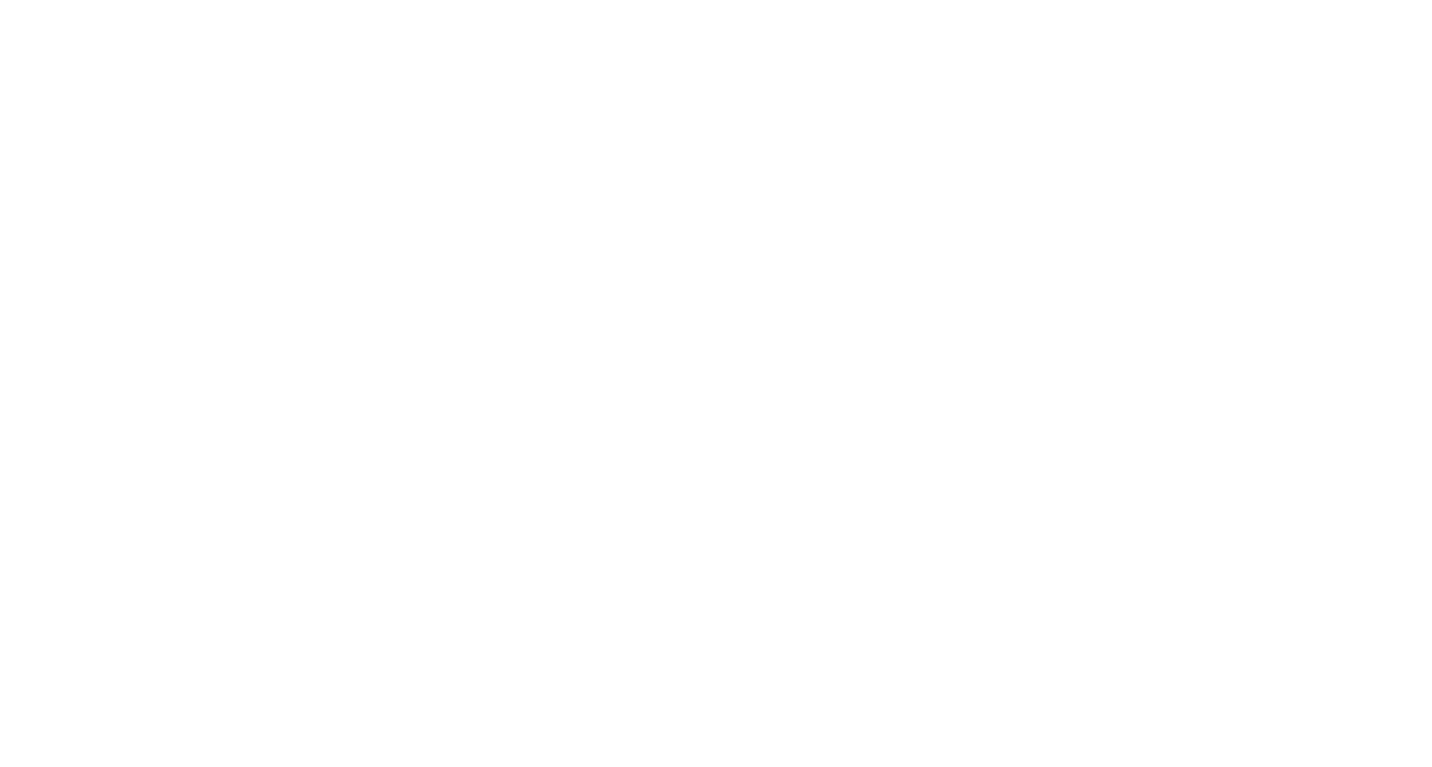

DURATION OF DISQHARGE FOR EAOH WATER YEAR

$\begin{array}{llllllllllllllllllllllllllllllllllll}\text { CLASS } 0 & 1 & 2 & 3 & 4 & 5 & 6 & 7 & 8 & 9 & 10 & 11 & 12 & 13 & 14 & 15 & 16 & 17 & 18 & 19 & 20 & 21 & 22 & 23 & 24 & 25 & 26 & 27 & 28 & 29 & 30 & 31 & 32 & 33 & 34\end{array}$ YEAR

NUMBER OF DAYS IN CLASS

OUBIC FEET PER SECOND

27857.0

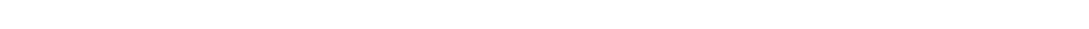

64668.0 64409.0 40778.0 71748.0 40237.0

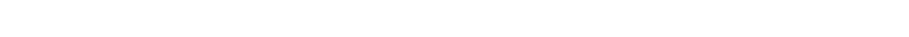

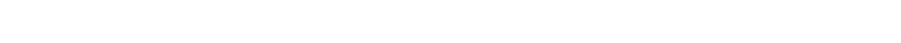

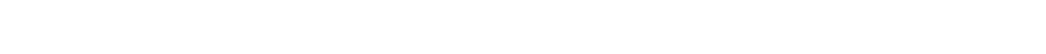

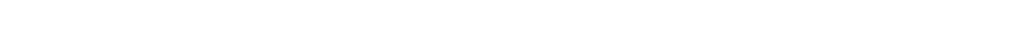

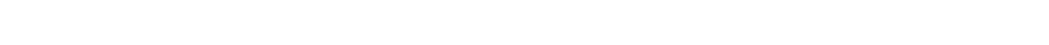

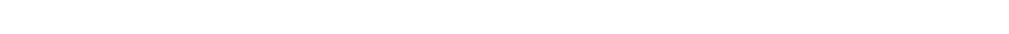

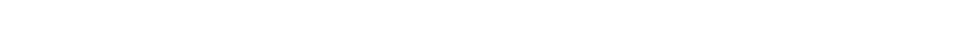

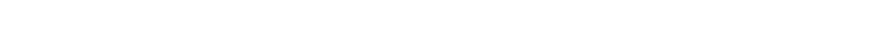

$\begin{array}{rrrrrrrrrrrrrrrrrrrr}7 & 61 & 39 & 99 & 14 & 17 & 11 & 9 & 8 & 9 & 23 & 24 & 5 & 10 & 3 & 4 & 3 & 2 & 6 & 6 \\ 8 & 82 & 45 & 31 & 47 & 29 & 18 & 12 & 21 & 14 & 4 & 5 & 3 & 4 & 13 & 11 & 5 & 6 & 4 & 3\end{array}$
24702.0 67576.0 40882.0 52705.0

5927.0

38230.0 66638.0 32835.0 29550.0 26429.0 
GREEN RIVER BASIN

09271000 ASHLEY CREEX AT SIGN OF THE MAINE, NEAR VERNAL, OT-Continued

DURATION OF DISCHARGE FOR EAOH WAIER YEAR-Continued

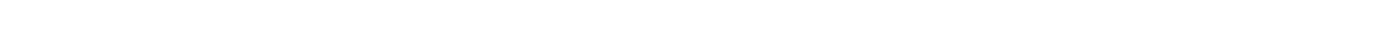
YEAR NUABER OF DAYS IN CLASS

ABIC FEET -DAYS

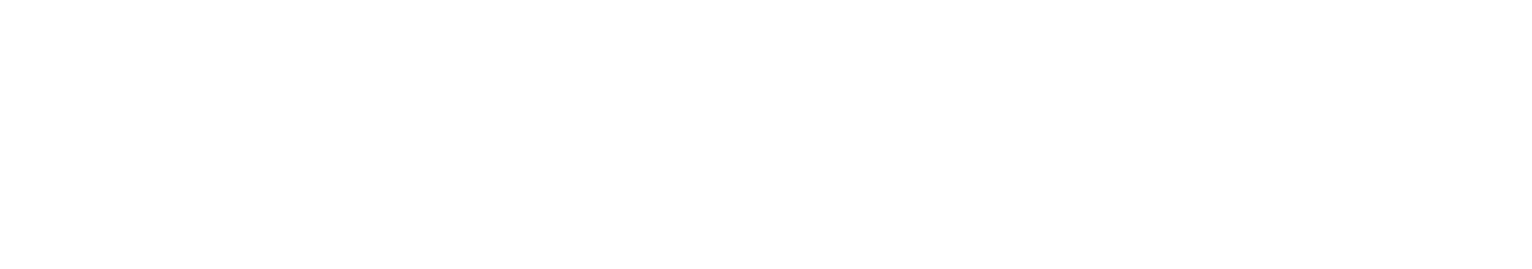

DURATION TABLE OF DISOHARGE FOR WATEK YEARS 1940-65

\begin{tabular}{|c|c|c|c|c|c|c|c|c|c|c|c|c|c|c|c|c|c|c|c|}
\hline ASS & $\begin{array}{c}\text { OBIC } \\
\text { FEET } \\
\text { PER } \\
\text { SECOND }\end{array}$ & $\begin{array}{l}\text { TOTAL } \\
\text { DAYS }\end{array}$ & $\begin{array}{c}\text { ACOJ- } \\
\text { MU- } \\
\text { LATED } \\
\text { DAYS }\end{array}$ & $\begin{array}{l}\text { PER- } \\
\text { CENT } \\
\text { DALS }\end{array}$ & C.ASS & $\begin{array}{c}\text { CBIC } \\
\text { FEET } \\
\text { PER } \\
\text { SECOND }\end{array}$ & $\begin{array}{l}\text { TOTAL } \\
\text { DAYS }\end{array}$ & $\begin{array}{c}\text { ACOU- } \\
\text { NU- } \\
\text { LAIED } \\
\text { DALS }\end{array}$ & $\begin{array}{l}\text { PER- } \\
\text { CENT } \\
\text { DAYS }\end{array}$ & C.ASS & $\begin{array}{c}\text { CBIC } \\
\text { FEET } \\
\text { PER } \\
\text { SECOND }\end{array}$ & $\begin{array}{l}\text { TOTAL } \\
\text { DAVS }\end{array}$ & $\begin{array}{l}\text { ACOJ- } \\
\text { MU- } \\
\text { LATED } \\
\text { DAYS }\end{array}$ & $\begin{array}{l}\text { PER- } \\
\text { CENT } \\
\text { DAYS }\end{array}$ & a.ASS & $\begin{array}{c}\text { CBBIC } \\
\text { FEET } \\
\text { PER } \\
\text { SECOND }\end{array}$ & $\begin{array}{r}\text { TOTAL } \\
\text { DAYS }\end{array}$ & $\begin{array}{c}\text { ACOU- } \\
\text { MU- } \\
\text { LAIED } \\
\text { DAYS }\end{array}$ & $\begin{array}{l}\text { PER- } \\
\text { CENT } \\
\text { DAYS }\end{array}$ \\
\hline $\begin{array}{l}0 \\
1 \\
2 \\
3 \\
4 \\
5 \\
6 \\
7 \\
8\end{array}$ & $\begin{array}{r}0.00 \\
11.00 \\
13.00 \\
15.00 \\
18.00 \\
22.00 \\
26.00 \\
30.00 \\
36.00\end{array}$ & $\begin{array}{r}0 \\
14 \\
120 \\
247 \\
542 \\
1060 \\
925 \\
1135 \\
655\end{array}$ & $\begin{array}{l}9497 \\
9497 \\
9483 \\
9363 \\
9116 \\
8574 \\
7514 \\
6589 \\
5454\end{array}$ & $\begin{array}{r}100.0 \\
100.0 \\
99.9 \\
98.6 \\
96.0 \\
90.3 \\
79.1 \\
69.4 \\
57.4\end{array}$ & $\begin{array}{l}9 \\
10 \\
11 \\
12 \\
13 \\
14 \\
15 \\
16 \\
17\end{array}$ & $\begin{array}{r}42.00 \\
50.00 \\
59.00 \\
70.00 \\
83.00 \\
98.00 \\
120.00 \\
140.00 \\
160.00\end{array}$ & $\begin{array}{l}551 \\
433 \\
409 \\
388 \\
341 \\
487 \\
379 \\
238 \\
219\end{array}$ & $\begin{array}{l}4799 \\
4248 \\
381.5 \\
3406 \\
3018 \\
2677 \\
2190 \\
1811 \\
1573\end{array}$ & $\begin{array}{l}50.5 \\
44.7 \\
40.2 \\
35.9 \\
31.8 \\
28.2 \\
23.1 \\
19.1 \\
16.6\end{array}$ & $\begin{array}{l}18 \\
19 \\
20 \\
21 \\
22 \\
23 \\
24 \\
25 \\
26\end{array}$ & $\begin{array}{l}190.0 \\
230.0 \\
270.0 \\
320.0 \\
380.0 \\
450.0 \\
530.0 \\
630.0 \\
740.0\end{array}$ & $\begin{array}{r}207 \\
144 \\
131 \\
124 \\
127 \\
115 \\
118 \\
84 \\
93\end{array}$ & $\begin{array}{r}1354 \\
1147 \\
1003 \\
872 \\
748 \\
621 \\
506 \\
388 \\
304\end{array}$ & $\begin{array}{r}14.3 \\
12.1 \\
10.6 \\
9.2 \\
7.9 \\
6.5 \\
5.3 \\
4.1 \\
3.2\end{array}$ & $\begin{array}{l}27 \\
28 \\
29 \\
30 \\
31 \\
32 \\
33 \\
34\end{array}$ & $\begin{array}{r}880.0 \\
1000.0 \\
1200.0 \\
1500.0 \\
1700.0 \\
2000.0 \\
2400.0 \\
2900.0\end{array}$ & $\begin{array}{r}56 \\
73 \\
60 \\
17 \\
2 \\
1 \\
1 \\
1\end{array}$ & $\begin{array}{r}211 \\
155 \\
82 \\
22 \\
5 \\
3 \\
2 \\
1\end{array}$ & $\begin{array}{l}2.2 \\
1.6 \\
0.9 \\
0.2 \\
0.1 \\
0.0 \\
0.0 \\
0.0\end{array}$ \\
\hline
\end{tabular}

MONTHLY MEAN DISCHARGES, IN OBIC FEET PER SECOND, FOR EACH WATER YEAR

\begin{tabular}{|c|c|c|c|c|c|c|c|c|c|c|c|c|}
\hline YEAR & $\infty \mathrm{CT}$ & NOV & DEC & JAN & FEBB & MAR & APR & MAY & JUNE & JULY & AUG & SEP \\
\hline $\begin{array}{l}1901 \\
1902 \\
1903 \\
1904\end{array}$ & $\begin{array}{l}44 \\
62 \\
52 \\
63.2\end{array}$ & $\begin{array}{l}42 \\
58 \\
46 \\
45.3\end{array}$ & $\begin{array}{l}38 \\
52 \\
45 \\
31\end{array}$ & $\begin{array}{l}36 \\
45 \\
45 \\
31\end{array}$ & $\begin{array}{l}36 \\
45 \\
45 \\
30.9\end{array}$ & $\begin{array}{l}37 \\
42 \\
42 \\
26.3\end{array}$ & $\begin{array}{r}122 \\
78 \\
94 \\
182\end{array}$ & $\begin{array}{l}683 \\
533 \\
602 \\
511\end{array}$ & $\begin{array}{l}232 \\
306 \\
893 \\
309\end{array}$ & $\begin{array}{l}100 \\
108 \\
172 \\
107\end{array}$ & $\begin{array}{c}149 \\
56 \\
76.4 \\
86.2\end{array}$ & $\begin{array}{l}96 \\
52 \\
60.2 \\
78.8\end{array}$ \\
\hline 1940 & 88.2 & 57.9 & 38.5 & 29.4 & 24.4 & 23.8 & 71.9 & 344 & 103 & 60.4 & 27.8 & 39.7 \\
\hline $\begin{array}{l}1941 \\
1942 \\
1943 \\
1944 \\
1945\end{array}$ & $\begin{array}{c}72.7 \\
184 \\
52.8 \\
38.3 \\
46.1\end{array}$ & $\begin{array}{c}55.4 \\
116 \\
39.8 \\
34.0 \\
36.3\end{array}$ & $\begin{array}{l}39.4 \\
71.0 \\
34.6 \\
28.9 \\
29.9\end{array}$ & $\begin{array}{l}32.9 \\
47.3 \\
29.4 \\
24.7 \\
27.5\end{array}$ & $\begin{array}{l}28.7 \\
37.6 \\
26.4 \\
21.7 \\
26.6\end{array}$ & $\begin{array}{l}26.6 \\
35.5 \\
26.6 \\
22.9 \\
25.7\end{array}$ & $\begin{array}{c}27.7 \\
102 \\
156 \\
30.1 \\
26.1\end{array}$ & $\begin{array}{l}735 \\
486 \\
402 \\
548 \\
312\end{array}$ & $\begin{array}{r}678 \\
690 \\
281 \\
1099 \\
405\end{array}$ & $\begin{array}{l}194 \\
171 \\
141 \\
303 \\
177\end{array}$ & $\begin{array}{c}109 \\
95.7 \\
91.2 \\
134 \\
118\end{array}$ & $\begin{array}{c}118 \\
77.5 \\
54.1 \\
70.8 \\
88.2\end{array}$ \\
\hline $\begin{array}{l}1946 \\
1947 \\
1948 \\
1949 \\
1950\end{array}$ & $\begin{array}{l}61.3 \\
52.2 \\
70.4 \\
32.8 \\
58.4\end{array}$ & $\begin{array}{l}41.7 \\
54.5 \\
43.8 \\
28.5 \\
46.8\end{array}$ & $\begin{array}{l}32.1 \\
46.4 \\
36.7 \\
25.2 \\
35.8\end{array}$ & $\begin{array}{l}27.3 \\
38.4 \\
30.4 \\
23.0 \\
32.2\end{array}$ & $\begin{array}{l}25.6 \\
31.3 \\
26.9 \\
21.2 \\
31.1\end{array}$ & $\begin{array}{l}23.2 \\
34.0 \\
25.6 \\
21.6 \\
31.8\end{array}$ & $\begin{array}{r}115 \\
57.7 \\
33.5 \\
41.9 \\
75.3\end{array}$ & $\begin{array}{l}173 \\
848 \\
529 \\
496 \\
586\end{array}$ & $\begin{array}{l}133 \\
587 \\
300 \\
690 \\
634\end{array}$ & $\begin{array}{l}72.2 \\
241 \\
113 \\
176 \\
223\end{array}$ & $\begin{array}{c}52.4 \\
126 \\
85.7 \\
113 \\
127\end{array}$ & $\begin{array}{l}54.4 \\
92.5 \\
39.2 \\
58.4 \\
72.8\end{array}$ \\
\hline $\begin{array}{l}1951 \\
1952 \\
1953 \\
1954 \\
1955\end{array}$ & $\begin{array}{l}52.5 \\
59.0 \\
71.9 \\
29.6 \\
41.7\end{array}$ & $\begin{array}{l}37.4 \\
37.7 \\
49.1 \\
33.6 \\
35.6\end{array}$ & $\begin{array}{l}33.0 \\
30.9 \\
37.4 \\
32.9 \\
28.8\end{array}$ & $\begin{array}{l}29.1 \\
29.2 \\
35.6 \\
29.8 \\
26.0\end{array}$ & $\begin{array}{l}24.9 \\
26.6 \\
32.0 \\
24.3 \\
22.7\end{array}$ & $\begin{array}{l}24.6 \\
25.2 \\
31.7 \\
22.2 \\
22.2\end{array}$ & $\begin{array}{l}22.5 \\
68.9 \\
36.0 \\
54.3 \\
26.0\end{array}$ & $\begin{array}{l}353 \\
757 \\
143 \\
378 \\
284\end{array}$ & $\begin{array}{l}376 \\
643 \\
380 \\
147 \\
187\end{array}$ & $\begin{array}{c}121 \\
186 \\
136 \\
111 \\
82.2\end{array}$ & $\begin{array}{l}105 \\
212 \\
86.2 \\
60.7 \\
64.7\end{array}$ & $\begin{array}{c}73.0 \\
103 \\
39.2 \\
41.7 \\
41.5\end{array}$ \\
\hline $\begin{array}{l}1956 \\
1957 \\
1958 \\
1959 \\
1960\end{array}$ & $\begin{array}{l}39.0 \\
23.9 \\
54.4 \\
33.7 \\
36.3\end{array}$ & $\begin{array}{l}29.3 \\
24.5 \\
48.0 \\
29.1 \\
30.3\end{array}$ & $\begin{array}{l}29.0 \\
22.4 \\
38.6 \\
26.6 \\
20.7\end{array}$ & $\begin{array}{l}26.3 \\
22.6 \\
31.8 \\
20.6 \\
17.2\end{array}$ & $\begin{array}{l}23.6 \\
23.5 \\
28.8 \\
21.6 \\
16.1\end{array}$ & $\begin{array}{l}22.3 \\
19.7 \\
25.8 \\
19.0 \\
17.5\end{array}$ & $\begin{array}{l}36.5 \\
17.7 \\
35.4 \\
18.2 \\
60.5\end{array}$ & $\begin{array}{l}514 \\
105 \\
617 \\
165 \\
241\end{array}$ & $\begin{array}{l}242 \\
857 \\
386 \\
179 \\
195\end{array}$ & $\begin{array}{c}102 \\
215 \\
134 \\
93.7 \\
\mathbf{8 . 4}\end{array}$ & $\begin{array}{c}53.1 \\
123 \\
73.7 \\
59.7 \\
31.1\end{array}$ & $\begin{array}{l}28.9 \\
91.0 \\
45.5 \\
40.4 \\
17.7\end{array}$ \\
\hline $\begin{array}{l}1961 \\
1962 \\
1963 \\
1964 \\
1965\end{array}$ & $\begin{array}{c}24.3 \\
106 \\
47.1 \\
45.5 \\
39.6\end{array}$ & $\begin{array}{l}22.5 \\
75.0 \\
23.7 \\
28.3 \\
28.6\end{array}$ & $\begin{array}{l}18.3 \\
45.2 \\
18.7 \\
23.2 \\
24.6\end{array}$ & $\begin{array}{l}16.1 \\
31.7 \\
15.7 \\
21.9 \\
22.0\end{array}$ & $\begin{array}{l}15.4 \\
29.8 \\
14.3 \\
20.7 \\
19.7\end{array}$ & $\begin{array}{l}13.5 \\
31.8 \\
14.2 \\
18.6 \\
19.7\end{array}$ & $\begin{array}{c}15.9 \\
174 \\
13.0 \\
16.9 \\
23.9\end{array}$ & $\begin{array}{l}265 \\
633 \\
323 \\
462 \\
299\end{array}$ & $\begin{array}{r}297 \\
674 \\
146 \\
396 \\
1235\end{array}$ & $\begin{array}{c}107 \\
208 \\
83.9 \\
144 \\
318\end{array}$ & $\begin{array}{c}74.0 \\
111 \\
41.8 \\
79.9 \\
171\end{array}$ & $\begin{array}{r}94.6 \\
70.1 \\
48.9 \\
55.3 \\
122\end{array}$ \\
\hline
\end{tabular}


GREEN RIVER BASIN

09271000 ASHLEY CREER AT SIGN OF THE MATNE, NEAR VERNAL, UT-Continued

ANNUAL PEAR DISCHARGE, IN CIBIC FEET PER SECOND, AND CORRESPONDING GAGE HEIGHT, IN FEET, FOR EACH WATER YEAR

\begin{tabular}{|c|c|c|c|c|c|c|c|c|c|c|c|c|c|}
\hline $\begin{array}{l}\text { WATERR } \\
\text { YEAR }\end{array}$ & & DATE & $\begin{array}{c}\text { GAGE } \\
\text { HEIGHT }\end{array}$ & $\begin{array}{c}\text { PEAR } \\
\text { DISCHARGE }\end{array}$ & $\begin{array}{l}\text { WATER } \\
\text { YEAR }\end{array}$ & DATE & $\begin{array}{c}\text { GAGE } \\
\text { HEIGHI }\end{array}$ & $\begin{array}{c}\text { PEAR } \\
\text { DISCHARGE }\end{array}$ & $\begin{array}{l}\text { WATER } \\
\text { YEAR }\end{array}$ & & DATE & $\begin{array}{c}\text { GAGE } \\
\text { HEIGHT }\end{array}$ & $\begin{array}{c}\text { PEAR } \\
\text { DISCHARGE }\end{array}$ \\
\hline $\begin{array}{l}1900 \\
1901 \\
1902 \\
1903 \\
1904 \\
1940 \\
1941 \\
1942 \\
1943 \\
1944 \\
1945\end{array}$ & $\begin{array}{l}\text { MAY } \\
\text { MAY } \\
\text { MAY } \\
\text { JUNE } \\
\text { MAY } \\
\text { MAY } \\
\text { MAY } \\
\text { MAY } \\
\text { MAY } \\
\text { MAY } \\
\text { JULY }\end{array}$ & $\begin{array}{ll}27, & 1900 \\
18, & 1901 \\
28, & 1902 \\
08, & 1903 \\
23, & 1904 \\
09, & 1940 \\
13, & 1941 \\
26, & 1942 \\
03, & 1943 \\
30, & 1944 \\
21, & 1945\end{array}$ & $\begin{array}{l}3.70 \\
4.30 \\
3.80 \\
4.70 \\
4.30 \\
3.52 \\
4.60 \\
4.72 \\
-. \\
4.68 \\
5.40\end{array}$ & $\begin{array}{r}960 \\
1140 \\
990 \\
2110 \\
1380 \\
844 \\
1650 \\
2000 \\
790 \\
1880 \\
2650\end{array}$ & $\begin{array}{l}1946 \\
1947 \\
1948 \\
1949 \\
1950 \\
1951 \\
1952 \\
1953 \\
1954 \\
1955\end{array}$ & $\begin{array}{lll}\text { APR. } & 26,1946 \\
\text { MAY } & 08,1947 \\
\text { MAY } 19,1948 \\
\text { JUNE } 18,1949 \\
\text { MAY } 30,1950 \\
\text { MAY } 28,1951 \\
\text { JUNE } 03,1952 \\
\text { JUNE } 13,1953 \\
\text { MAY 22, } 1954 \\
\text { AUG. } 25,1955\end{array}$ & $\begin{array}{l}3.42 \\
5.33 \\
4.76 \\
5.26 \\
5.40 \\
4.90 \\
4.98 \\
4.46 \\
4.02 \\
4.61\end{array}$ & $\begin{array}{r}519 \\
2090 \\
1700 \\
1610 \\
2220 \\
1710 \\
1520 \\
1160 \\
920 \\
1230\end{array}$ & $\begin{array}{l}1956 \\
1957 \\
1958 \\
1959 \\
1960 \\
1961 \\
1962 \\
1963 \\
1964 \\
1965\end{array}$ & $\begin{array}{l}\text { MAY } \\
\text { JUNE } \\
\text { MAY } \\
\text { MAY } \\
\text { MAY } \\
\text { MAY } \\
\text { MAY } \\
\text { MAY } \\
\text { MAY } \\
\text { JUNE }\end{array}$ & $\begin{array}{l}23,1956 \\
07,1957 \\
27,1958 \\
16,1959 \\
13,1960 \\
29,1961 \\
10,1962 \\
18,1963 \\
21,1964 \\
11,1965\end{array}$ & $\begin{array}{l}4.42 \\
4.85 \\
4.83 \\
3.42 \\
4.13 \\
4.02 \\
4.82 \\
3.91 \\
5.12 \\
5.34\end{array}$ & $\begin{array}{r}1230 \\
1950 \\
1690 \\
540 \\
954 \\
899 \\
1650 \\
915 \\
2130 \\
4110\end{array}$ \\
\hline
\end{tabular}

MAGNITUDE AND PRCBABILITY OF ANNUAL LONEST MEAN DISCHARGE BASED ON CLIMATIC YEARS 1941-65

\begin{tabular}{|c|c|c|c|c|c|c|}
\hline \multirow{2}{*}{$\begin{array}{l}\text { PERICD } \\
\text { (CON- } \\
\text { SEOJ- } \\
\text { TIVE } \\
\text { DAYS) }\end{array}$} & \multicolumn{6}{|c|}{$\begin{array}{l}\text { DISCHARGE, IN CUBIC FEET PER SECOED, FOR } \\
\text { INDICATED RECURRERNCE INTERNAL, IN YEARS, AND } \\
\text { ANNUAL NONEXCEEDANCE PROBABII.ITY, IN PERCENT }\end{array}$} \\
\hline & $\begin{array}{c}2 \\
50 \%\end{array}$ & $\begin{array}{c}5 \\
208\end{array}$ & $\begin{array}{l}10 \\
108\end{array}$ & $\begin{array}{l}20 \\
58\end{array}$ & $\begin{array}{l}50 \\
28\end{array}$ & $\begin{array}{r}100 \\
18\end{array}$ \\
\hline
\end{tabular}

$\begin{array}{rrrrrrr}1 & 19 & 15 & 14 & 12 & 11 & - \\ 7 & 20 & 16 & 14 & 13 & 11 & - \\ 14 & 20 & 16 & 15 & 13 & 11 & - \\ 30 & 22 & 17 & 15 & 13 & 12 & - \\ 60 & 24 & 19 & 17 & 15 & 13 & - \\ 90 & 25 & 20 & 18 & 16 & 14 & -\end{array}$

MAGNITUDE AND PRCBABILITY O ANNUAL HIGHEST MEAN DISCHARGE BASED UN WATER YEARS 1940-65

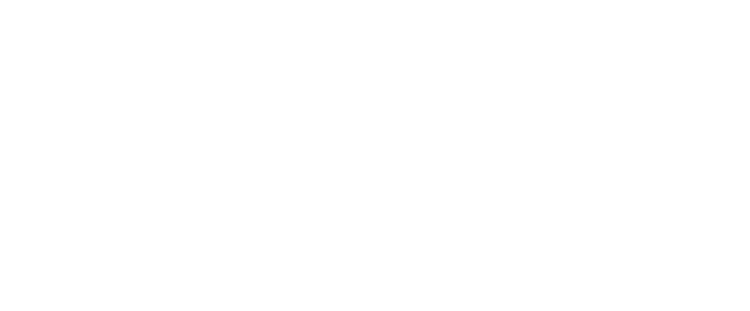

09271500 ASHLEY CREEX NEAR JENSEN, UI

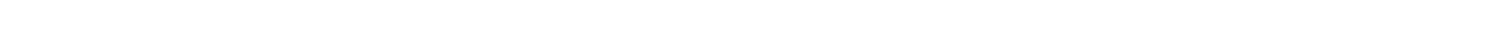
bank just downstream fram bridge on U.S. Highway 40, $3 \mathrm{mi}$ upstream from mouth, and $3 \mathrm{mi}$ west of Jensen.

DRAINAGE AREA. $-383 \mathrm{mi}^{2}$.

PERIOD OF RECORD AVAILABLE. - October 1946 to September 1981.

GAGE.-Water-stage recorder. Datum of gage is $4,795.36 \mathrm{ft}$ NGVD of 1929 .

REMARKS.--Flow increased since July 1940 by water released from Oaks Park Reservoir, capacity, 6,250 acre-ft, on Big Brush Creek and diverted to Ashley Creek basin for irrigation. Large diversion above station for irrigation and municipal water supply mostly
above station, including diversion to Steinaker Reservoir, constructed by the Bureau of Reclamation in 1961 , capacity, 38,090 acre-ft. Records of Steinaker Reservoir diversion are in the Bureau of Reclamation office at Provo, Utah.

AVERAGE DISCHARGE. -35 years, $52.0 \mathrm{ft}^{3} / \mathrm{s}, 37,670 \mathrm{acre}-\mathrm{ft} / \mathrm{yr}$.

EXIREMES FOR PERIOD OF RECORD.-Maximum discharge, 2,790 ft $3 / \mathrm{s}$ June 6,1968 , gage height, $7.04 \mathrm{ft}$; maximum gage height, $7.16 \mathrm{ft}$ June 11, 1965; no flow part of Aug. 9, 1956, and several days in August and September 1960.

LOWEST MEAN DISCHARGE, IN OUBIC FEET PER SEOOND, AND RANRING FOR THE INDICATED NUMBER OF CONSEOUTIVE DAYS FOR EACH CLIMATIC YEAR, APRII 1-MARCH 31

\begin{tabular}{|c|c|c|c|c|c|c|c|c|c|c|c|c|c|c|c|c|c|}
\hline YEAR & 1 & 3 & 7 & 14 & & $\begin{array}{l}\text { CONSEX } \\
30\end{array}$ & SOTI & $\begin{array}{l}\text { E DAYS } \\
60\end{array}$ & & 90 & & 120 & & 183 & & ALLL & \\
\hline $\begin{array}{l}1948 \\
1949 \\
1950\end{array}$ & $\begin{array}{ll}8.00 & 28 \\
1.60 & 18 \\
4.20 & 23\end{array}$ & $\begin{array}{ll}8.40 & 28 \\
1.70 & 18 \\
4.80 & 22\end{array}$ & $\begin{array}{ll}9.70 & 29 \\
1.70 & 15 \\
5.80 & 23\end{array}$ & $\begin{array}{c}12.0 \\
1.80 \\
6.30\end{array}$ & $\begin{array}{l}29 \\
13 \\
22\end{array}$ & $\begin{array}{r}15.0 \\
2.40 \\
6.90\end{array}$ & $\begin{array}{l}28 \\
14 \\
21\end{array}$ & $\begin{array}{r}21.0 \\
3.50 \\
8.40\end{array}$ & $\begin{array}{l}29 \\
13 \\
18\end{array}$ & $\begin{array}{c}21.0 \\
4.10 \\
13.0\end{array}$ & $\begin{array}{l}24 \\
13 \\
20\end{array}$ & $\begin{array}{c}25.0 \\
5.40 \\
27.0\end{array}$ & $\begin{array}{l}23 \\
13 \\
26\end{array}$ & $\begin{array}{l}34.0 \\
11.0 \\
38.0\end{array}$ & $\begin{array}{l}24 \\
13 \\
30\end{array}$ & $\begin{array}{l}117 \\
44.0 \\
96.0\end{array}$ & $\begin{array}{l}32 \\
19 \\
28\end{array}$ \\
\hline $\begin{array}{l}1951 \\
1952 \\
1953 \\
1954 \\
1955\end{array}$ & $\begin{array}{rr}4.00 & 22 \\
2.80 & 20 \\
8.00 & 29 \\
0.90 & 13 \\
0.50 & 9\end{array}$ & $\begin{array}{rr}4.90 & 24 \\
3.30 & 20 \\
8.40 & 29 \\
1.40 & 13 \\
0.57 & 9\end{array}$ & $\begin{array}{rr}5.80 & 24 \\
3.70 & 20 \\
9.60 & 28 \\
1.50 & 13 \\
0.66 & 9\end{array}$ & $\begin{array}{c}7.10 \\
4.20 \\
11.0 \\
1.80 \\
0.73\end{array}$ & $\begin{array}{r}23 \\
20 \\
28 \\
14 \\
7\end{array}$ & $\begin{array}{c}10.0 \\
4.80 \\
21.0 \\
2.20 \\
1.19\end{array}$ & $\begin{array}{r}24 \\
19 \\
32 \\
13 \\
8\end{array}$ & $\begin{array}{c}17.0 \\
9.40 \\
37.0 \\
2.40 \\
1.50\end{array}$ & $\begin{array}{r}25 \\
21 \\
33 \\
11 \\
8\end{array}$ & $\begin{array}{c}23.0 \\
13.0 \\
37.0 \\
2.50 \\
2.40\end{array}$ & $\begin{array}{r}25 \\
21 \\
32 \\
8 \\
7\end{array}$ & $\begin{array}{c}28.0 \\
21.0 \\
37.0 \\
3.80 \\
4.70\end{array}$ & $\begin{array}{r}27 \\
21 \\
32 \\
9 \\
10\end{array}$ & $\begin{array}{l}35.0 \\
34.0 \\
45.0 \\
12.0 \\
10.0\end{array}$ & $\begin{array}{l}28 \\
25 \\
32 \\
14 \\
12\end{array}$ & $\begin{array}{c}98.0 \\
50.0 \\
129 \\
26.0 \\
23.0\end{array}$ & $\begin{array}{r}29 \\
20 \\
33 \\
13 \\
9\end{array}$ \\
\hline $\begin{array}{l}1956 \\
1957 \\
1958 \\
1959 \\
1960\end{array}$ & $\begin{array}{rr}0.20 & 5 \\
0.10 & 3 \\
2.30 & 19 \\
0.60 & 10 \\
0.20 & 6\end{array}$ & $\begin{array}{rr}0.20 & 5 \\
0.13 & 3 \\
2.60 & 19 \\
0.60 & 10 \\
0.27 & 6\end{array}$ & $\begin{array}{rr}0.20 & 4 \\
0.14 & 3 \\
2.60 & 19 \\
0.67 & 10 \\
0.41 & 7\end{array}$ & $\begin{array}{l}0.48 \\
0.31 \\
3.80 \\
0.77 \\
0.94\end{array}$ & $\begin{array}{r}5 \\
3 \\
19 \\
9 \\
10\end{array}$ & $\begin{array}{l}0.70 \\
0.43 \\
5.60 \\
0.99 \\
1.19\end{array}$ & $\begin{array}{r}5 \\
3 \\
20 \\
6 \\
9\end{array}$ & $\begin{array}{l}1.40 \\
0.81 \\
8.50 \\
1.40 \\
1.50\end{array}$ & $\begin{array}{r}5 \\
2 \\
19 \\
6 \\
7\end{array}$ & $\begin{array}{c}1.30 \\
1.10 \\
14.0 \\
2.00 \\
2.80\end{array}$ & $\begin{array}{r}4 \\
3 \\
22 \\
5 \\
9\end{array}$ & $\begin{array}{c}1.80 \\
1.50 \\
18.0 \\
2.60 \\
2.90\end{array}$ & $\begin{array}{r}4 \\
3 \\
20 \\
5 \\
6\end{array}$ & $\begin{array}{c}6.90 \\
5.10 \\
34.0 \\
7.20 \\
4.30\end{array}$ & $\begin{array}{r}7 \\
4 \\
26 \\
8 \\
2\end{array}$ & $\begin{array}{l}17.0 \\
23.0 \\
60.0 \\
42.0 \\
15.0\end{array}$ & $\begin{array}{r}6 \\
10 \\
23 \\
17 \\
5\end{array}$ \\
\hline
\end{tabular}

\begin{tabular}{|c|c|c|c|c|c|c|c|c|c|c|c|c|c|c|c|c|c|}
\hline YEAR & 1 & 3 & 7 & 14 & & $\begin{array}{l}\text { CONSEX } \\
30\end{array}$ & SOTI & $\begin{array}{l}\text { E DAYS } \\
60\end{array}$ & & 90 & & 120 & & 183 & & ALLL & \\
\hline $\begin{array}{l}1948 \\
1949 \\
1950\end{array}$ & $\begin{array}{ll}8.00 & 28 \\
1.60 & 18 \\
4.20 & 23\end{array}$ & $\begin{array}{ll}8.40 & 28 \\
1.70 & 18 \\
4.80 & 22\end{array}$ & $\begin{array}{ll}9.70 & 29 \\
1.70 & 15 \\
5.80 & 23\end{array}$ & $\begin{array}{c}12.0 \\
1.80 \\
6.30\end{array}$ & $\begin{array}{l}29 \\
13 \\
22\end{array}$ & $\begin{array}{r}15.0 \\
2.40 \\
6.90\end{array}$ & $\begin{array}{l}28 \\
14 \\
21\end{array}$ & $\begin{array}{r}21.0 \\
3.50 \\
8.40\end{array}$ & $\begin{array}{l}29 \\
13 \\
18\end{array}$ & $\begin{array}{c}21.0 \\
4.10 \\
13.0\end{array}$ & $\begin{array}{l}24 \\
13 \\
20\end{array}$ & $\begin{array}{c}25.0 \\
5.40 \\
27.0\end{array}$ & $\begin{array}{l}23 \\
13 \\
26\end{array}$ & $\begin{array}{l}34.0 \\
11.0 \\
38.0\end{array}$ & $\begin{array}{l}24 \\
13 \\
30\end{array}$ & $\begin{array}{l}117 \\
44.0 \\
96.0\end{array}$ & $\begin{array}{l}32 \\
19 \\
28\end{array}$ \\
\hline $\begin{array}{l}1951 \\
1952 \\
1953 \\
1954 \\
1955\end{array}$ & $\begin{array}{rr}4.00 & 22 \\
2.80 & 20 \\
8.00 & 29 \\
0.90 & 13 \\
0.50 & 9\end{array}$ & $\begin{array}{rr}4.90 & 24 \\
3.30 & 20 \\
8.40 & 29 \\
1.40 & 13 \\
0.57 & 9\end{array}$ & $\begin{array}{rr}5.80 & 24 \\
3.70 & 20 \\
9.60 & 28 \\
1.50 & 13 \\
0.66 & 9\end{array}$ & $\begin{array}{c}7.10 \\
4.20 \\
11.0 \\
1.80 \\
0.73\end{array}$ & $\begin{array}{r}23 \\
20 \\
28 \\
14 \\
7\end{array}$ & $\begin{array}{c}10.0 \\
4.80 \\
21.0 \\
2.20 \\
1.19\end{array}$ & $\begin{array}{r}24 \\
19 \\
32 \\
13 \\
8\end{array}$ & $\begin{array}{c}17.0 \\
9.40 \\
37.0 \\
2.40 \\
1.50\end{array}$ & $\begin{array}{r}25 \\
21 \\
33 \\
11 \\
8\end{array}$ & $\begin{array}{c}23.0 \\
13.0 \\
37.0 \\
2.50 \\
2.40\end{array}$ & $\begin{array}{r}25 \\
21 \\
32 \\
8 \\
7\end{array}$ & $\begin{array}{c}28.0 \\
21.0 \\
37.0 \\
3.80 \\
4.70\end{array}$ & $\begin{array}{r}27 \\
21 \\
32 \\
9 \\
10\end{array}$ & $\begin{array}{l}35.0 \\
34.0 \\
45.0 \\
12.0 \\
10.0\end{array}$ & $\begin{array}{l}28 \\
25 \\
32 \\
14 \\
12\end{array}$ & $\begin{array}{c}98.0 \\
50.0 \\
129 \\
26.0 \\
23.0\end{array}$ & $\begin{array}{r}29 \\
20 \\
33 \\
13 \\
9\end{array}$ \\
\hline $\begin{array}{l}1956 \\
1957 \\
1958 \\
1959 \\
1960\end{array}$ & $\begin{array}{rr}0.20 & 5 \\
0.10 & 3 \\
2.30 & 19 \\
0.60 & 10 \\
0.20 & 6\end{array}$ & $\begin{array}{rr}0.20 & 5 \\
0.13 & 3 \\
2.60 & 19 \\
0.60 & 10 \\
0.27 & 6\end{array}$ & $\begin{array}{rr}0.20 & 4 \\
0.14 & 3 \\
2.60 & 19 \\
0.67 & 10 \\
0.41 & 7\end{array}$ & $\begin{array}{l}0.48 \\
0.31 \\
3.80 \\
0.77 \\
0.94\end{array}$ & $\begin{array}{r}5 \\
3 \\
19 \\
9 \\
10\end{array}$ & $\begin{array}{l}0.70 \\
0.43 \\
5.60 \\
0.99 \\
1.19\end{array}$ & $\begin{array}{r}5 \\
3 \\
20 \\
6 \\
9\end{array}$ & $\begin{array}{l}1.40 \\
0.81 \\
8.50 \\
1.40 \\
1.50\end{array}$ & $\begin{array}{r}5 \\
2 \\
19 \\
6 \\
7\end{array}$ & $\begin{array}{c}1.30 \\
1.10 \\
14.0 \\
2.00 \\
2.80\end{array}$ & $\begin{array}{r}4 \\
3 \\
22 \\
5 \\
9\end{array}$ & $\begin{array}{c}1.80 \\
1.50 \\
18.0 \\
2.60 \\
2.90\end{array}$ & $\begin{array}{r}4 \\
3 \\
20 \\
5 \\
6\end{array}$ & $\begin{array}{c}6.90 \\
5.10 \\
34.0 \\
7.20 \\
4.30\end{array}$ & $\begin{array}{r}7 \\
4 \\
26 \\
8 \\
2\end{array}$ & $\begin{array}{l}17.0 \\
23.0 \\
60.0 \\
42.0 \\
15.0\end{array}$ & $\begin{array}{r}6 \\
10 \\
23 \\
17 \\
5\end{array}$ \\
\hline
\end{tabular}


GREEN RTVER BASIN

09271500 ASHLEY CREEK NEAR JENSEN, UT-Continued

LONEST MEAN DISCHARGE, IN OBBIC FEET PER SECOND, AND RANKING FOR THE INDICATED NUMBER OF CONSECUTTVE DAYS FOR EACH CLIMATIC YEAR, APRIL 1-MARCH 31--Continued

\begin{tabular}{|c|c|c|c|c|c|c|c|c|c|c|c|c|c|c|c|c|c|c|c|c|}
\hline YEAR & 1 & & 3 & & 7 & & 14 & & $\begin{array}{l}\text { CONSE } \\
30\end{array}$ & & $\begin{array}{l}\text { E DAYS } \\
60\end{array}$ & & 90 & & 120 & & 183 & & ALC & \\
\hline $\begin{array}{l}1966 \\
1967 \\
1968 \\
1969 \\
1970\end{array}$ & $\begin{array}{c}5.70 \\
1.50 \\
1.30 \\
16.0 \\
9.70\end{array}$ & $\begin{array}{l}25 \\
17 \\
15 \\
34 \\
30\end{array}$ & $\begin{array}{r}6.30 \\
1.60 \\
1.40 \\
18.0 \\
11.0\end{array}$ & $\begin{array}{l}25 \\
17 \\
15 \\
34 \\
30\end{array}$ & $\begin{array}{l}7.40 \\
1.80 \\
1.60 \\
20.0 \\
13.0\end{array}$ & $\begin{array}{l}26 \\
16 \\
14 \\
34 \\
32\end{array}$ & $\begin{array}{r}9.70 \\
3.10 \\
2.00 \\
21.0 \\
14.0\end{array}$ & $\begin{array}{l}26 \\
18 \\
15 \\
33 \\
32\end{array}$ & $\begin{array}{c}11.0 \\
4.30 \\
4.20 \\
28.0 \\
16.0\end{array}$ & $\begin{array}{l}25 \\
18 \\
17 \\
33 \\
31\end{array}$ & $\begin{array}{c}21.0 \\
5.20 \\
23.0 \\
33.0 \\
19.0\end{array}$ & $\begin{array}{l}30 \\
17 \\
31 \\
32 \\
26\end{array}$ & $\begin{array}{c}50.0 \\
6.00 \\
24.0 \\
34.0 \\
25.0\end{array}$ & $\begin{array}{l}34 \\
16 \\
26 \\
30 \\
28\end{array}$ & $\begin{array}{c}52.0 \\
8.80 \\
25.0 \\
35.0 \\
30.0\end{array}$ & $\begin{array}{l}34 \\
16 \\
24 \\
30 \\
28\end{array}$ & $\begin{array}{l}95.0 \\
14.0 \\
25.0 \\
38.0 \\
32.0\end{array}$ & $\begin{array}{l}34 \\
16 \\
20 \\
29 \\
22\end{array}$ & $\begin{array}{r}116 \\
23.0 \\
90.0 \\
94.0 \\
61.0\end{array}$ & $\begin{array}{l}31 \\
11 \\
26 \\
27 \\
24\end{array}$ \\
\hline $\begin{array}{l}1971 \\
1972 \\
1973 \\
1974 \\
1975\end{array}$ & $\begin{array}{c}11.0 \\
12.0 \\
6.00 \\
12.0 \\
0.74\end{array}$ & $\begin{array}{l}31 \\
32 \\
26 \\
33 \\
12\end{array}$ & $\begin{array}{c}12.0 \\
12.0 \\
6.60 \\
12.0 \\
0.80\end{array}$ & $\begin{array}{l}31 \\
32 \\
26 \\
33 \\
12\end{array}$ & $\begin{array}{c}12.0 \\
13.0 \\
7.00 \\
18.0 \\
0.92\end{array}$ & $\begin{array}{l}30 \\
31 \\
25 \\
33 \\
12\end{array}$ & $\begin{array}{c}13.0 \\
14.0 \\
7.60 \\
23.0 \\
1.10\end{array}$ & $\begin{array}{l}30 \\
31 \\
25 \\
34 \\
11\end{array}$ & $\begin{array}{c}15.0 \\
15.0 \\
8.00 \\
34.0 \\
1.50\end{array}$ & $\begin{array}{l}29 \\
30 \\
22 \\
34 \\
11\end{array}$ & $\begin{array}{c}21.0 \\
21.0 \\
9.20 \\
41.0 \\
2.00\end{array}$ & $\begin{array}{l}27 \\
28 \\
20 \\
34 \\
10\end{array}$ & $\begin{array}{c}27.0 \\
24.0 \\
12.0 \\
46.0 \\
2.40\end{array}$ & $\begin{array}{r}29 \\
27 \\
19 \\
33 \\
6\end{array}$ & $\begin{array}{c}32.0 \\
26.0 \\
16.0 \\
46.0 \\
2.90\end{array}$ & $\begin{array}{r}29 \\
25 \\
19 \\
33 \\
7\end{array}$ & $\begin{array}{c}35.0 \\
33.0 \\
24.0 \\
49.0 \\
6.90\end{array}$ & $\begin{array}{r}27 \\
23 \\
19 \\
33 \\
6\end{array}$ & $\begin{array}{c}50.0 \\
44.0 \\
32.0 \\
144 \\
15.0\end{array}$ & $\begin{array}{l}21 \\
18 \\
15 \\
34\end{array}$ \\
\hline 1981 & 3.60 & 21 & 4.30 & 21 & 5.30 & 22 & 7.10 & 24 & 11.0 & 27 & 16.0 & 24 & 20.0 & 23 & 23.0 & 22 & 27.0 & 21 & 66.0 & 25 \\
\hline
\end{tabular}

HIGHEST MEAN DISCHARGE, IN OUBIC FEET PER SECOND, AND RANKING FOR THE INDICATED NUMBER OF CONSECUTIVE DAYS FOR EACH WATER YEAR, OCTCBER 1-SEPTEMBER 30

\begin{tabular}{|c|c|c|c|c|c|c|c|c|c|c|c|c|c|c|c|c|c|c|c|c|}
\hline EAR & 1 & & 3 & & 7 & & 15 & & $\begin{array}{l}\text { CON } \\
30\end{array}$ & & $\begin{array}{l}\text { DAY } \\
60\end{array}$ & & 90 & & 120 & & 183 & & ALL & \\
\hline $\begin{array}{l}947 \\
948 \\
949 \\
950\end{array}$ & $\begin{array}{r}1190 \\
712 \\
1220 \\
1190\end{array}$ & $\begin{array}{r}8 \\
15 \\
6 \\
7\end{array}$ & $\begin{array}{r}980 \\
623 \\
1120 \\
1150\end{array}$ & $\begin{array}{r}10 \\
16 \\
7 \\
6\end{array}$ & $\begin{array}{l}818 \\
529 \\
950 \\
887\end{array}$ & $\begin{array}{r}16 \\
5 \\
9\end{array}$ & $\begin{array}{l}612 \\
401 \\
801 \\
795\end{array}$ & $\begin{array}{r}10 \\
14 \\
5 \\
7\end{array}$ & $\begin{array}{l}567 \\
269 \\
605 \\
603\end{array}$ & $\begin{array}{r}9 \\
15 \\
6 \\
7\end{array}$ & $\begin{array}{l}518 \\
150 \\
361 \\
376\end{array}$ & $\begin{array}{r}2 \\
16 \\
8 \\
6\end{array}$ & $\begin{array}{l}356 \\
116 \\
248 \\
281\end{array}$ & $\begin{array}{r}3 \\
16 \\
8 \\
6\end{array}$ & $\begin{array}{l}275 \\
102 \\
200 \\
230\end{array}$ & $\begin{array}{r}3 \\
15 \\
8 \\
4\end{array}$ & $\begin{array}{l}200 \\
83.0 \\
145 \\
173\end{array}$ & $\begin{array}{r}3 \\
15 \\
8 \\
4\end{array}$ & $\begin{array}{r}111 \\
53.0 \\
80.0 \\
109\end{array}$ & $\begin{array}{r}3 \\
15 \\
9\end{array}$ \\
\hline $\begin{array}{l}952 \\
953 \\
954\end{array}$ & $\begin{array}{c}801 \\
1160 \\
521 \\
146 \\
77.0\end{array}$ & $\begin{array}{r}14 \\
9 \\
20 \\
27 \\
32\end{array}$ & $\begin{array}{c}750 \\
1110 \\
338 \\
126 \\
63.0\end{array}$ & $\begin{array}{r}14 \\
8 \\
22 \\
26 \\
31\end{array}$ & $\begin{array}{l}578 \\
980 \\
209 \\
87.0 \\
61.0\end{array}$ & $\begin{array}{r}14 \\
4 \\
22\end{array}$ & $\begin{array}{c}317 \\
793 \\
124 \\
70.0 \\
57.0\end{array}$ & $\begin{array}{r}17 \\
8 \\
22 \\
26 \\
30\end{array}$ & $\begin{array}{l}199 \\
573 \\
81.0 \\
52.0 \\
52.0\end{array}$ & $\begin{array}{r}19 \\
8 \\
23 \\
27 \\
28\end{array}$ & $\begin{array}{r}112 \\
471 \\
64.0 \\
45.0 \\
44.0\end{array}$ & $\begin{array}{r}19 \\
3 \\
22 \\
27 \\
28\end{array}$ & $\begin{array}{c}78.0 \\
368 \\
63.0 \\
43.0 \\
41.0\end{array}$ & $\begin{array}{r}20 \\
2 \\
21 \\
26 \\
27\end{array}$ & $\begin{array}{r}66 \\
295 \\
62 \\
39 \\
40\end{array}$ & $\begin{array}{r}19 \\
2 \\
21 \\
27 \\
26\end{array}$ & $\begin{array}{c}59.0 \\
210 \\
55.0 \\
35.0 \\
34.0\end{array}$ & $\begin{array}{r}19 \\
2 \\
21\end{array}$ & $\begin{array}{c}43.0 \\
128 \\
38.0 \\
22.0 \\
22.0\end{array}$ & $\begin{array}{r}20 \\
2 \\
21 \\
26 \\
27\end{array}$ \\
\hline 957 & $\begin{array}{l}491 \\
857 \\
888 \\
42.0 \\
82.0\end{array}$ & $\begin{array}{l}21 \\
13 \\
12 \\
33 \\
30\end{array}$ & $\begin{array}{r}396 \\
788 \\
841 \\
41.0 \\
76.0\end{array}$ & $\begin{array}{l}20 \\
12 \\
11 \\
33 \\
29\end{array}$ & $\begin{array}{l}333 \\
662 \\
729 \\
39.0 \\
72.0\end{array}$ & & $\begin{array}{l}226 \\
483 \\
506 \\
36.0 \\
64.0\end{array}$ & $\begin{array}{l}21 \\
12 \\
11 \\
32 \\
28\end{array}$ & $\begin{array}{r}138 \\
354 \\
333 \\
32.0 \\
52.0\end{array}$ & $\begin{array}{l}21 \\
11 \\
12 \\
32 \\
29\end{array}$ & $\begin{array}{c}76.0 \\
187 \\
179 \\
30.0 \\
42.0\end{array}$ & $\begin{array}{l}21 \\
13 \\
14 \\
31 \\
29\end{array}$ & $\begin{array}{l}3.0 \\
8 \\
1 \\
8.0 \\
7.0\end{array}$ & $\begin{array}{l}22 \\
15 \\
14\end{array}$ & $\begin{array}{c}48.0 \\
100 \\
111 \\
26.0 \\
33.0\end{array}$ & & & 23 & & $\begin{array}{l}19 \\
13 \\
33 \\
29\end{array}$ \\
\hline $\begin{array}{l}967 \\
968 \\
969\end{array}$ & $\begin{array}{r}350 \\
1440 \\
2370 \\
527 \\
641\end{array}$ & $\begin{array}{r}23 \\
4 \\
1 \\
19 \\
17\end{array}$ & $\begin{array}{r}350 \\
1170 \\
1870 \\
465 \\
628\end{array}$ & $\begin{array}{r}21 \\
5 \\
1 \\
19 \\
15\end{array}$ & $\begin{array}{r}346 \\
946 \\
1270 \\
379 \\
568\end{array}$ & $\begin{array}{r}20 \\
6 \\
2 \\
19 \\
15\end{array}$ & $\begin{array}{r}340 \\
798 \\
1010 \\
301 \\
422\end{array}$ & $\begin{array}{r}16 \\
6 \\
2 \\
19 \\
13\end{array}$ & $\begin{array}{l}270 \\
646 \\
688 \\
203 \\
243\end{array}$ & $\begin{array}{r}14 \\
4 \\
3 \\
18 \\
16\end{array}$ & $\begin{array}{l}173 \\
418 \\
365 \\
196 \\
140\end{array}$ & $\begin{array}{r}15 \\
5 \\
7 \\
12 \\
17\end{array}$ & $\begin{array}{l}288 \\
262 \\
146 \\
103\end{array}$ & $\begin{array}{r}13 \\
5 \\
7 \\
12 \\
17\end{array}$ & $\begin{array}{c}116 \\
221 \\
204 \\
125 \\
83.0\end{array}$ & $\begin{array}{r}13 \\
6 \\
7 \\
12 \\
17\end{array}$ & $\begin{array}{c}94.0 \\
153 \\
148 \\
94.0 \\
63.0\end{array}$ & $\begin{array}{r}12 \\
6 \\
7 \\
13\end{array}$ & & $\begin{array}{r}14 \\
5 \\
6 \\
11 \\
16\end{array}$ \\
\hline $\begin{array}{l}1972 \\
1973 \\
1974\end{array}$ & $\begin{array}{r}628 \\
255 \\
1670 \\
176 \\
1300\end{array}$ & $\begin{array}{r}18 \\
25 \\
3 \\
26 \\
5\end{array}$ & $\begin{array}{r}563 \\
222 \\
1520 \\
101 \\
1170\end{array}$ & $\begin{array}{r}18 \\
24 \\
3 \\
27 \\
4\end{array}$ & $\begin{array}{c}488 \\
134 \\
1350 \\
73.0 \\
930\end{array}$ & $\begin{array}{r}17 \\
25 \\
1 \\
28 \\
7\end{array}$ & $\begin{array}{c}292 \\
95.0 \\
1260 \\
67.0 \\
839\end{array}$ & $\begin{array}{r}20 \\
25 \\
1 \\
27 \\
4\end{array}$ & $\begin{array}{c}177 \\
73.0 \\
1070 \\
61.0 \\
725\end{array}$ & $\begin{array}{r}20 \\
24 \\
1 \\
26 \\
2\end{array}$ & $\begin{array}{c}105 \\
52.0 \\
633 \\
56.0 \\
428\end{array}$ & $\begin{array}{r}20 \\
24 \\
1 \\
23 \\
4\end{array}$ & $\begin{array}{c}80.0 \\
49.0 \\
438 \\
53.0 \\
296\end{array}$ & $\begin{array}{r}19 \\
25 \\
1 \\
23 \\
4\end{array}$ & $\begin{array}{c}66.0 \\
44.0 \\
340 \\
51.0 \\
230\end{array}$ & $\begin{array}{r}20 \\
25 \\
1 \\
22 \\
5\end{array}$ & $\begin{array}{c}56.0 \\
37.0 \\
240 \\
49.0 \\
156\end{array}$ & $\begin{array}{r}20 \\
25 \\
1 \\
22 \\
5\end{array}$ & & $\begin{array}{r}18 \\
22 \\
1 \\
23\end{array}$ \\
\hline $\begin{array}{l}976 \\
.977 \\
978 \\
.979\end{array}$ & $\begin{array}{c}664 \\
27.0 \\
115 \\
375 \\
1140\end{array}$ & $\begin{array}{l}16 \\
35 \\
28 \\
22 \\
10\end{array}$ & $\begin{array}{c}601 \\
25.0 \\
70.0 \\
257 \\
1070\end{array}$ & $\begin{array}{r}17 \\
35 \\
30 \\
23 \\
9\end{array}$ & $\begin{array}{c}439 \\
25.0 \\
60.0 \\
166 \\
912\end{array}$ & $\begin{array}{r}18 \\
35 \\
31 \\
24 \\
8\end{array}$ & $\begin{array}{c}304 \\
25.0 \\
52.0 \\
105 \\
708\end{array}$ & $\begin{array}{r}18 \\
35 \\
31 \\
24 \\
9\end{array}$ & $\begin{array}{c}208 \\
25.0 \\
39.0 \\
73.0 \\
490\end{array}$ & $\begin{array}{l}17 \\
34 \\
31 \\
25 \\
10\end{array}$ & $\begin{array}{c}125 \\
24.0 \\
28.0 \\
51.0 \\
276\end{array}$ & $\begin{array}{l}18 \\
34 \\
32 \\
25 \\
10\end{array}$ & $\begin{array}{r}92.0 \\
23.0 \\
24.0 \\
52.0 \\
191\end{array}$ & $\begin{array}{l}33 \\
24 \\
10\end{array}$ & $\begin{array}{r}81.0 \\
22.0 \\
22.0 \\
46.0 \\
148\end{array}$ & $\begin{array}{l}18 \\
33 \\
34 \\
24 \\
10\end{array}$ & $\begin{array}{r}65.0 \\
21.0 \\
19.0 \\
38.0 \\
108\end{array}$ & 11 & & $\begin{array}{l}17 \\
34 \\
32 \\
24 \\
12\end{array}$ \\
\hline
\end{tabular}


GREEN RTVER BASTN

09271500 ASHLEY CREER NEAR JENSEN, UTm-Continued

DURATION OF DISCHARGE FOR EACH WATER YEAR

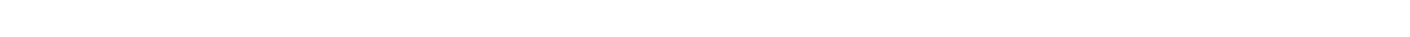
YEAR NUMBER OF DAYS IN CLASS

OBBIC FEET -DAYS

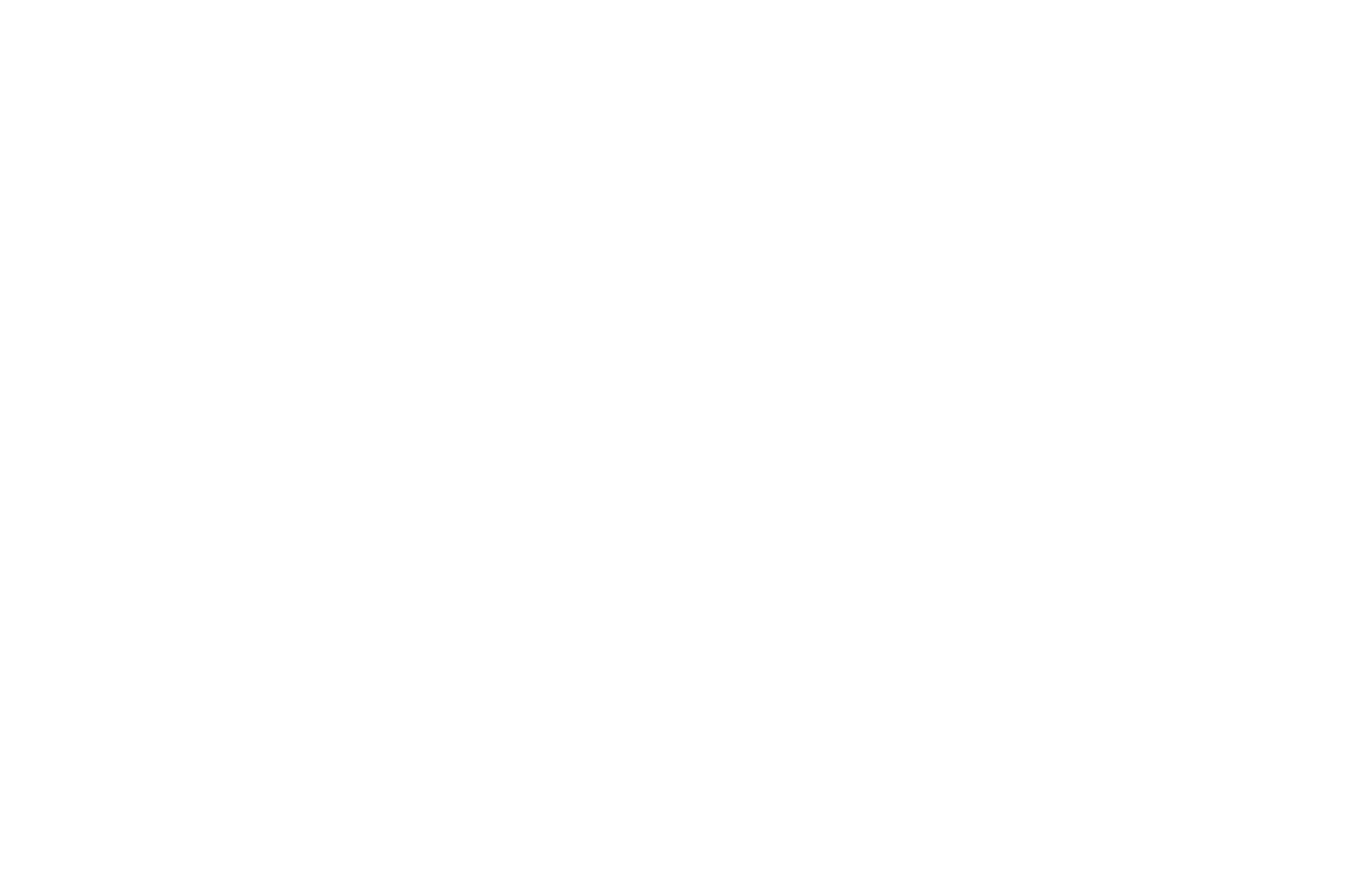

DURATION TABLE OF DISCHARGE FOR WATER YEARS 1947-81

$\begin{array}{ccc}\text { CUBIC } & \text { ACAT- } \\ \text { FEET } & \text { MU- } & \text { PER- } \\ \text { PER TOTAL LATED } & \text { CERT } \\ \text { CIASS SECOND } & \text { DAYS DAYS } & \text { DAYS }\end{array}$

$\begin{array}{llll}0.00 & 22 & 12784 & 100.0\end{array}$

$\begin{array}{llll}0.10 & 39 & 12762 & 99.8\end{array}$

$\begin{array}{lrll}0.14 & 0 & 12723 & 99.5\end{array}$

$\begin{array}{llll}0.18 & 37 & 12723 & 99.5\end{array}$

$\begin{array}{llll}0.25 & 29 & 12686 & 99.2\end{array}$

$0.33 \quad 48 \quad 12657 \quad 99.0$

$\begin{array}{llll}0.45 & 45 & 12609 & 98.6\end{array}$

$\begin{array}{rrrr}0.60 & 131 & 12564 & 98.3 \\ 0.81 & 80 & 12433 & 97.3\end{array}$
OBIC AOOU-
FEET METPER TOTAL LATED CENT

\section{CLASS SECOND DAYS DAYS DAYS}

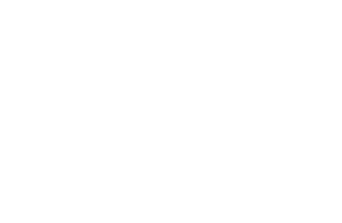

$\begin{array}{lll}\text { OBBIC } & \text { ACO- } \\ \text { FEET MU- } & \\ \text { PER TOTAL IATED } & \text { CENT }\end{array}$ PER TOTAL IATED CEN

$\begin{array}{rrrrrr}18 & 16.0 & 1425 & 8696 & 68.0 \\ 19 & 22.0 & 1800 & 7271 & 56.9 \\ 20 & 30.0 & 1768 & 5471 & 42.8 \\ 21 & 40.0 & 1604 & 3703 & 29.0 \\ 22 & 54.0 & 938 & 2099 & 16.4 \\ 23 & 72.0 & 273 & 1161 & 9.1 \\ 24 & 98.0 & 145 & 888 & 6.9 \\ 25 & 130.0 & 132 & 743 & 5.8 \\ 26 & 180.0 & 99 & 611 & 4.8\end{array}$

$\begin{array}{lll}\text { CUBIC } & \text { ACOT- } \\ \text { FEET } & \text { HU- } & \text { PER- } \\ \text { PER TOTAL LATED } & \text { CENT }\end{array}$ CIASS SBCOND DAYS DAYS DAYS

$\begin{array}{rrrrr}27 & 240.0 & 100 & 512 & 4.0 \\ 28 & 320.0 & 123 & 412 & 3.2 \\ 29 & 440.0 & 86 & 289 & 2.3 \\ 30 & 590.0 & 100 & 203 & 1.6 \\ 31 & 790.0 & 68 & 103 & 0.8 \\ 32 & 1100.0 & 22 & 35 & 0.3 \\ 33 & 1400.0 & 12 & 13 & 0.1 \\ 34 & 2000.0 & 1 & 1 & 0.0\end{array}$


GREEN RIVER BASIN

09271500 ASHLEY CREEK NEAR JENSEN, UT-Continued

MONTHLY MEAN DISCHARGES, IN CUBIC FEET PER SEOOND, FOR EACH WATER YEAR

\begin{tabular}{|c|c|c|c|c|c|c|c|c|c|c|c|c|}
\hline YEAR & OCT & $\mathrm{NOV}$ & $\mathrm{DEC}$ & JAN & FEB & MAR & APR & MAY & JUNE & JULY & AUG & SEP \\
\hline $\begin{array}{l}1947 \\
1948 \\
1949 \\
1950\end{array}$ & $\begin{array}{c}7.14 \\
29.8 \\
8.26 \\
61.6\end{array}$ & $\begin{array}{l}19.8 \\
47.7 \\
17.4 \\
63.5\end{array}$ & $\begin{array}{l}35.1 \\
53.8 \\
24.0 \\
56.2\end{array}$ & $\begin{array}{l}56.1 \\
46.6 \\
31.8 \\
55.0\end{array}$ & $\begin{array}{l}56.7 \\
53.9 \\
41.4 \\
51.4\end{array}$ & $\begin{array}{l}48.1 \\
64.8 \\
65.2 \\
89.7\end{array}$ & $\begin{array}{r}18.7 \\
35.3 \\
22.0 \\
104\end{array}$ & $\begin{array}{l}509 \\
202 \\
185 \\
383\end{array}$ & $\begin{array}{c}507 \\
91.3 \\
520 \\
333\end{array}$ & $\begin{array}{c}35.7 \\
8.65 \\
32.7 \\
69.4\end{array}$ & $\begin{array}{c}25.9 \\
4.27 \\
7.43 \\
14.9\end{array}$ & $\begin{array}{c}15.3 \\
2.79 \\
10.0 \\
21.2\end{array}$ \\
\hline $\begin{array}{l}1951 \\
1952 \\
1953 \\
1954 \\
1955\end{array}$ & $\begin{array}{c}35.1 \\
58.3 \\
36.8 \\
7.41 \\
15.5\end{array}$ & $\begin{array}{l}43.7 \\
55.8 \\
49.9 \\
23.4 \\
21.1\end{array}$ & $\begin{array}{l}51.5 \\
53.3 \\
65.0 \\
41.4 \\
34.8\end{array}$ & $\begin{array}{l}45.1 \\
48.9 \\
62.4 \\
45.0 \\
36.0\end{array}$ & $\begin{array}{l}45.8 \\
45.0 \\
56.4 \\
40.3 \\
35.0\end{array}$ & $\begin{array}{l}32.5 \\
67.1 \\
59.1 \\
25.5 \\
51.1\end{array}$ & $\begin{array}{c}11.8 \\
167 \\
25.8 \\
11.7 \\
21.1\end{array}$ & $\begin{array}{l}125 \\
515 \\
19.9 \\
42.3 \\
15.4\end{array}$ & $\begin{array}{c}91.6 \\
410 \\
76.5 \\
21.9 \\
25.7\end{array}$ & $\begin{array}{c}8.35 \\
30.4 \\
3.40 \\
2.82 \\
1.19\end{array}$ & $\begin{array}{c}11.9 \\
49.7 \\
2.57 \\
1.32 \\
2.00\end{array}$ & $\begin{array}{c}18.6 \\
39.1 \\
2.74 \\
3.46 \\
0.85\end{array}$ \\
\hline $\begin{array}{l}1956 \\
1957 \\
1958 \\
1959 \\
1960\end{array}$ & $\begin{array}{c}3.65 \\
2.42 \\
25.6 \\
3.09 \\
11.5\end{array}$ & $\begin{array}{l}12.7 \\
7.19 \\
66.0 \\
11.7 \\
13.4\end{array}$ & $\begin{array}{l}30.7 \\
17.4 \\
67.1 \\
20.6 \\
20.7\end{array}$ & $\begin{array}{l}35.8 \\
24.5 \\
49.5 \\
28.2 \\
26.7\end{array}$ & $\begin{array}{l}33.3 \\
36.6 \\
52.6 \\
30.0 \\
31.8\end{array}$ & $\begin{array}{l}27.6 \\
25.2 \\
50.6 \\
23.4 \\
50.5\end{array}$ & $\begin{array}{c}7.08 \\
11.1 \\
25.7 \\
8.86 \\
10.3\end{array}$ & $\begin{array}{c}105 \\
6.91 \\
222 \\
4.96 \\
12.5\end{array}$ & $\begin{array}{c}43.9 \\
348 \\
127 \\
3.54 \\
24.8\end{array}$ & $\begin{array}{c}3.03 \\
25.2 \\
5.81 \\
3.72 \\
1.52\end{array}$ & $\begin{array}{c}0.45 \\
10.0 \\
1.62 \\
1.69 \\
0.41\end{array}$ & $\begin{array}{c}1.38 \\
15.9 \\
1.37 \\
3.83 \\
0.11\end{array}$ \\
\hline $\begin{array}{l}1961 \\
1962 \\
1963 \\
1964 \\
1965\end{array}$ & $\begin{array}{c}3.81 \\
40.1 \\
21.8 \\
7.76 \\
10.2\end{array}$ & $\begin{array}{l}8.85 \\
43.8 \\
24.0 \\
13.8 \\
26.8\end{array}$ & $\begin{array}{l}13.0 \\
55.7 \\
26.2 \\
12.3 \\
27.8\end{array}$ & $\begin{array}{l}21.0 \\
34.5 \\
24.5 \\
12.3 \\
27.8\end{array}$ & $\begin{array}{l}20.4 \\
85.8 \\
29.6 \\
17.1 \\
35.8\end{array}$ & $\begin{array}{l}9.66 \\
86.8 \\
15.2 \\
21.7 \\
52.1\end{array}$ & $\begin{array}{l}5.90 \\
97.9 \\
10.0 \\
11.7 \\
30.5\end{array}$ & $\begin{array}{c}4.63 \\
243 \\
11.7 \\
51.4 \\
11.8\end{array}$ & $\begin{array}{c}22.4 \\
156 \\
14.9 \\
48.4 \\
584\end{array}$ & $\begin{array}{c}2.27 \\
39.5 \\
1.82 \\
4.46 \\
83.1\end{array}$ & $\begin{array}{c}0.21 \\
5.37 \\
1.68 \\
3.14 \\
43.6\end{array}$ & $\begin{array}{c}10.3 \\
4.75 \\
5.53 \\
3.44 \\
75.4\end{array}$ \\
\hline $\begin{array}{l}1966 \\
1967 \\
1968 \\
1969 \\
1970\end{array}$ & $\begin{array}{r}232 \\
21.4 \\
24.0 \\
48.8 \\
46.0\end{array}$ & $\begin{array}{l}108 \\
22.7 \\
30.2 \\
39.2 \\
38.3\end{array}$ & $\begin{array}{l}66.9 \\
26.8 \\
30.1 \\
38.4 \\
36.6\end{array}$ & $\begin{array}{l}50.0 \\
24.5 \\
18.9 \\
33.6 \\
35.1\end{array}$ & $\begin{array}{l}35.6 \\
29.6 \\
34.9 \\
32.7 \\
34.2\end{array}$ & $\begin{array}{l}69.8 \\
39.0 \\
46.8 \\
59.1 \\
27.1\end{array}$ & $\begin{array}{l}18.3 \\
14.9 \\
33.6 \\
46.7 \\
18.0\end{array}$ & $\begin{array}{c}56.0 \\
138 \\
38.4 \\
194 \\
24.2\end{array}$ & $\begin{array}{l}20.6 \\
627 \\
685 \\
190 \\
243\end{array}$ & $\begin{array}{l}5.47 \\
78.2 \\
32.0 \\
29.8 \\
33.7\end{array}$ & $\begin{array}{l}5.10 \\
21.2 \\
55.5 \\
16.9 \\
22.6\end{array}$ & $\begin{array}{l}7.87 \\
26.7 \\
35.2 \\
33.1 \\
26.6\end{array}$ \\
\hline $\begin{array}{l}1971 \\
1972 \\
1973 \\
1974 \\
1975\end{array}$ & $\begin{array}{c}48.0 \\
35.9 \\
33.9 \\
57.3 \\
5.70\end{array}$ & $\begin{array}{l}40.4 \\
50.2 \\
42.1 \\
52.2 \\
14.9\end{array}$ & $\begin{array}{l}40.5 \\
53.8 \\
32.1 \\
48.3 \\
15.7\end{array}$ & $\begin{array}{l}37.9 \\
33.5 \\
35.6 \\
42.2 \\
15.2\end{array}$ & $\begin{array}{l}39.4 \\
23.5 \\
36.5 \\
46.6 \\
20.4\end{array}$ & $\begin{array}{l}30.6 \\
24.9 \\
57.7 \\
48.6 \\
28.2\end{array}$ & $\begin{array}{l}22.6 \\
16.3 \\
34.3 \\
30.0 \\
15.9\end{array}$ & $\begin{array}{c}36.2 \\
30.4 \\
482 \\
28.4 \\
12.8\end{array}$ & $\begin{array}{c}173 \\
67.5 \\
770 \\
17.0 \\
481\end{array}$ & $\begin{array}{c}28.4 \\
12.0 \\
47.4 \\
3.15 \\
359\end{array}$ & $\begin{array}{c}15.6 \\
9.50 \\
34.8 \\
2.12 \\
32.4\end{array}$ & $\begin{array}{c}28.7 \\
13.9 \\
64.1 \\
1.98 \\
34.9\end{array}$ \\
\hline $\begin{array}{l}1976 \\
1977 \\
1978 \\
1979 \\
1980\end{array}$ & $\begin{array}{c}56.4 \\
20.2 \\
6.89 \\
9.29 \\
7.99\end{array}$ & $\begin{array}{l}43.0 \\
23.6 \\
13.9 \\
18.0 \\
16.0\end{array}$ & $\begin{array}{l}38.0 \\
24.3 \\
15.5 \\
24.9 \\
18.8\end{array}$ & $\begin{array}{l}30.0 \\
20.5 \\
13.0 \\
23.6 \\
20.0\end{array}$ & $\begin{array}{l}39.4 \\
18.3 \\
12.6 \\
24.1 \\
28.0\end{array}$ & $\begin{array}{l}44.7 \\
17.2 \\
38.0 \\
57.1 \\
38.6\end{array}$ & $\begin{array}{c}25.0 \\
5.65 \\
17.7 \\
41.9 \\
18.1\end{array}$ & $\begin{array}{c}140 \\
8.52 \\
10.6 \\
55.2 \\
36.9\end{array}$ & $\begin{array}{l}107 \\
2.00 \\
20.4 \\
25.6 \\
476\end{array}$ & $\begin{array}{c}12.2 \\
1.43 \\
1.76 \\
5.49 \\
55.2\end{array}$ & $\begin{array}{r}9.28 \\
0.65 \\
6.54 \\
4.31 \\
12.7\end{array}$ & $\begin{array}{c}13.1 \\
1.99 \\
5.01 \\
6.44 \\
26.2\end{array}$ \\
\hline 1981 & 44.4 & 32.6 & 26.2 & 23.3 & 21.1 & 21.5 & 14.6 & 25.5 & 12.1 & 9,44 & 5.63 & 7.27 \\
\hline
\end{tabular}

ANNUAL PEAK DISCHARGE, IN OUBIC FEET PER SECOND, AND CORRESPONDING GAGE HEIGHT, IN FEET, FOR EACH WATER YEAR

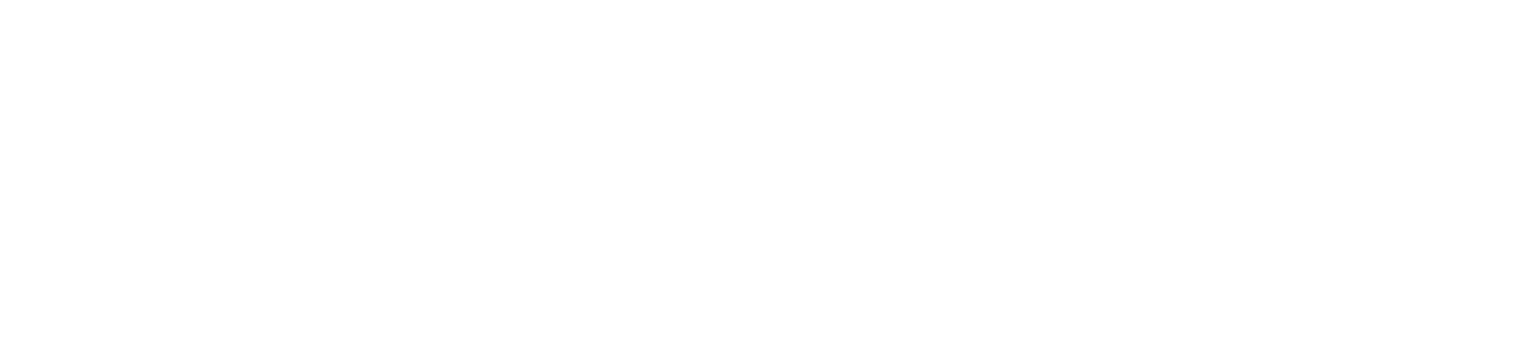

MAGNITUDE AND PRCBABILITY OF ANNUAL LONEST MEAN DISCHARGE BASED ON CLIMATIC YEARS 1948-81

\begin{tabular}{|c|c|c|c|c|c|c|}
\hline \multirow{2}{*}{$\begin{array}{l}\text { PERIOD } \\
\text { (CON- } \\
\text { SECU- } \\
\text { TIVE } \\
\text { DAYS) }\end{array}$} & \multicolumn{6}{|c|}{$\begin{array}{l}\text { DISCHARGE, IN OUBIC FEET PER SECOND, FOR } \\
\text { INDICATED RECIRRENCE INTERNAL, IN YEARS, AND } \\
\text { ANNUAL NONEXCEEDANCE PROBABILITY, IN PEERCENT }\end{array}$} \\
\hline & $\begin{array}{c}2 \\
508\end{array}$ & $\begin{array}{c}5 \\
20 \%\end{array}$ & $\begin{array}{l}10 \\
108\end{array}$ & $\begin{array}{l}20 \\
58\end{array}$ & $\begin{array}{l}50 \\
28\end{array}$ & $\begin{array}{r}100 \\
18\end{array}$ \\
\hline $\begin{array}{l}60 \\
90\end{array}$ & $\begin{array}{l}6.0 \\
8.1\end{array}$ & $\begin{array}{l}1.9 \\
2.7\end{array}$ & $\begin{array}{l}0 . \\
1 .\end{array}$ & $\begin{array}{l}0.5 \\
0.8\end{array}$ & $\begin{array}{l}0.2 \\
0.4\end{array}$ & $\overline{-}$ \\
\hline
\end{tabular}

MAGNITUDE AND I-ROBABILITY OF ANNUAL HIGHEST MEAN DISCHARGE BASED ON WATER YEARS 1947-81

\begin{tabular}{|c|c|c|c|c|c|c|}
\hline \multirow{2}{*}{$\begin{array}{l}\text { PERIOD } \\
\text { (CON- } \\
\text { SEOJ- } \\
\text { TIVE } \\
\text { DAYS) }\end{array}$} & \multicolumn{4}{|c|}{$\begin{array}{l}\text { DISCHARGE, IN OUBIC FEET PER } \\
\text { INDICATED RECURRENCE INTIERVAL, } \\
\text { ANNUAL EXCEEDANCE PRCBABILITY, }\end{array}$} & \multicolumn{2}{|c|}{$\begin{array}{l}\text { SECOND, FOR } \\
\text { IN YEARS, AND } \\
\text { IN PERCENT }\end{array}$} \\
\hline & $\begin{array}{c}2 \\
508\end{array}$ & $\begin{array}{c}5 \\
208\end{array}$ & $\begin{array}{l}10 \\
108\end{array}$ & $\begin{array}{l}25 \\
48\end{array}$ & $\begin{array}{l}50 \\
28\end{array}$ & $\begin{array}{r}100 \\
18\end{array}$ \\
\hline $\begin{array}{r}1 \\
3 \\
7 \\
15\end{array}$ & $\begin{array}{l}472 \\
395 \\
317 \\
237\end{array}$ & $\begin{array}{r}1180 \\
1020 \\
812 \\
611\end{array}$ & $\begin{array}{r}1760 \\
1560 \\
1250 \\
968\end{array}$ & $\begin{array}{l}2570 \\
2350 \\
1910 \\
1540\end{array}$ & $\begin{array}{l}3190 \\
2980 \\
2460 \\
2050\end{array}$ & $\overline{-}$ \\
\hline
\end{tabular}


LOCATION.--Lat $40^{\circ} 25^{\prime} 00^{\prime \prime}$, long $109^{\circ} 45^{\prime} 00^{\prime \prime}$, in NE⿺ sec.2, T.5 S., R.19 E., Uintah County, Hydrologic Unit 14060001, 3.0 mi east of Lapoint on State Highway 121 .

DRAINAGE AREA. $--5.6 \mathrm{mi}^{2}$.

MEAN BASIN ELEVATION. $-6,550 \mathrm{ft}$.

PERICD OF RECORD AVAILABLE.--Water years 1960-74, annual peak discharge only.

GAGE.--Crest-stage gage. Altitude of gage is 5,650 ft trom topographic map. ANNUAL PEAK DISCHARGE IN OBBIC FEET PER SECOND, AND CORRESPONDING GAGE HEIGHT, IN FEET, FOR EACH WATER YEAR

\begin{tabular}{|c|c|c|c|c|c|c|c|c|c|c|c|c|}
\hline $\begin{array}{l}\text { WATERR } \\
\text { YEAR }\end{array}$ & DATE & $\begin{array}{l}\text { GAGE } \\
\text { HEIGHT }\end{array}$ & $\begin{array}{c}\text { PEAR } \\
\text { DISCHARGE }\end{array}$ & $\begin{array}{l}\text { WATER } \\
\text { YEAR }\end{array}$ & DATE & $\begin{array}{l}\text { GAGE } \\
\text { HEIGHT }\end{array}$ & $\begin{array}{c}\text { PEAK } \\
\text { DISCHARGE }\end{array}$ & $\begin{array}{l}\text { WATER } \\
\text { YEAR }\end{array}$ & DATE & & $\begin{array}{c}\text { GAGE } \\
\text { HEIGHT }\end{array}$ & $\begin{array}{c}\text { PEAK } \\
\text { DISCHARGE }\end{array}$ \\
\hline $\begin{array}{l}1960 \\
1961 \\
1962 \\
1963 \\
1964\end{array}$ & $\begin{array}{l}\text { SEPT.06, } 1960 \\
\text { SEPT.09, } 1961 \\
\text { JULY 21, } 1962 \\
\text { AUG. 05, } 1963 \\
\text { JUNE 21, } 1964\end{array}$ & $\begin{array}{r}11.16 \\
10.01 \\
10.80 \\
13.30 \\
9.70\end{array}$ & $\begin{array}{r}120 \\
20 \\
91 \\
702 \\
16\end{array}$ & $\begin{array}{l}1965 \\
1966 \\
1967 \\
1968 \\
1969\end{array}$ & $\begin{array}{l}\text { JUNE } 25,1965 \\
\text { MAR. 22, } 1966 \\
\text { JUNE 05, } 1967 \\
\text { SEPT.15, } 1968 \\
\text { SEPT.16, } 1969\end{array}$ & $\begin{array}{r}11.10 \\
9.90 \\
10.62 \\
11.38 \\
12.35\end{array}$ & $\begin{array}{r}110 \\
15 \\
52 \\
240 \\
360\end{array}$ & $\begin{array}{l}1970 \\
1971 \\
1972 \\
1973 \\
1974\end{array}$ & $\begin{array}{l}\text { SEPT. 06, } \\
\text { AUG. 30, } \\
\text { JUNE 05, } \\
\text { JULY 13, } \\
-\quad-\end{array}$ & $\begin{array}{l}1970 \\
1971 \\
1972 \\
1973 \\
-\end{array}$ & $\begin{array}{r}9.99 \\
11.70 \\
10.23 \\
12.55 \\
12.23\end{array}$ & $\begin{array}{l}3.5 \\
191 \\
31 \\
420 \\
335\end{array}$ \\
\hline
\end{tabular}

09272000 TWELVEMILE WASH TRIBUTARY NEAR MAESER, ET

LOCATION.--Lat $40^{\circ} 27^{\prime} 00^{\prime \prime}$, long $109^{\circ} 38^{\prime} 00^{\prime \prime}$, in NE⿺辶 sec.26, T.4 S., R.20 E., Uintah County, Hydrologic Unit 14060001 , 3.8 mi west of Maeser on State Highway 245.

DRAINAGE AREA. $-0.12 \mathrm{mi}^{2}$.

PERICD OF RECORD AVAILABLE.--Water years 1960-68, annual peak discharge only.

GAGE.--Crest-stage gage. Altitude of gage is 5,880 ft fran topographic map.

ANNUAL, PEAK DISCHARGE, IN CUBIC FEET PER SECOND, AND CORRESPONDING GAGE HEIGHT, IN FEET, FOR EACH WATER YEAR

\begin{tabular}{|c|c|c|c|c|c|c|c|c|c|c|c|c|c|}
\hline $\begin{array}{l}\text { WATER } \\
\text { YEAR }\end{array}$ & DATE & $\begin{array}{l}\text { GAGE } \\
\text { HEIGHT }\end{array}$ & $\begin{array}{c}\text { PEAK } \\
\text { DISCHARGE }\end{array}$ & $\begin{array}{l}\text { WATER } \\
\text { YEAR }\end{array}$ & DATE & $\begin{array}{l}\text { GAGE } \\
\text { HEIGHT }\end{array}$ & $\begin{array}{c}\text { PEAK } \\
\text { DISCHARGE }\end{array}$ & $\begin{array}{l}\text { WATER } \\
\text { YEAR }\end{array}$ & & DATE & & $\begin{array}{l}\text { GAGE } \\
\text { HEIGHT }\end{array}$ & $\begin{array}{c}\text { PEAK } \\
\text { DISCHARGE }\end{array}$ \\
\hline $\begin{array}{l}1960 \\
1961 \\
1962\end{array}$ & $\begin{array}{ll}\text { AUG. } 22,1960 \\
\text { SEPT.18, } 1961 \\
\text { SEPT.21， } 1962\end{array}$ & $\begin{array}{l}11.70 \\
11.50 \\
11.87\end{array}$ & $\begin{array}{l}52 \\
41 \\
34\end{array}$ & $\begin{array}{l}1963 \\
1964 \\
1965\end{array}$ & $\begin{array}{r}\text { SEPT. 06, } 1963 \\
\overline{-}-\overline{-} \\
\text { AUG. } 18,1965\end{array}$ & $\begin{array}{l}11.70 \\
-- \\
11.85\end{array}$ & $\begin{array}{r}25 \\
0 \\
34\end{array}$ & $\begin{array}{l}1966 \\
1967 \\
1968\end{array}$ & $\begin{array}{l}\text { MAR. } \\
-- \\
-\end{array}$ & $\begin{array}{l}02, \\
-- \\
--\end{array}$ & $\begin{array}{c}1966 \\
-- \\
--\end{array}$ & $\begin{array}{c}10.96 \\
-- \\
--\end{array}$ & $\begin{array}{r}20 \\
0 \\
0\end{array}$ \\
\hline
\end{tabular}

09273000 DUCHESNE RIVER AT PROVO RIVER TRAIL, NEAR HANNA, UT

LOCATION.--Lat $40^{\circ} 37^{\prime} 30^{\prime \prime}$, long $110^{\circ} 53^{\prime} 20^{\prime \prime}$, in SE⿺ sec.27, T.3 N., R.9 W. , Uintah Meridian, Duchesne County, Hydrologic unit

14060003, on right bank $400 \mathrm{ft}$ downstream from Provo River Trail, 7 mi upstream from Hades Creek, and 12 mi northwest of Hanna.

DRAINAGE AREA.--39 $\mathrm{mi}^{2}$, approximately.

MEAN BASIN ELEVATION. $-9,730 \mathrm{ft}$.

PERIOD OF RECOPD AVAIIABLE.--July 1929 to September 1933 (published as North Fork Duchesne River), October 1933 to September 1943, October 1944 to September 1954. Monthly mean discharge only for some periods, those for part of 1929 water year are published in WSP 1313, and those for 1954 water year are published in WSP 1733.

GAGE. - Water-stage recorder. Datum of gage is $8,135.97 \mathrm{ft}$ NGVD of 1929 (levels by Bureau of Reclamation) .

REMARKS.--Since Oct. 20, 1953, practically all flow is diverted through Duchesne tunnel, a few hundred feet above station, for use in the Great Basin. Capacity of tunnel is about $600 \mathrm{ft}^{3} / \mathrm{s}$.

AVERAGE DISCHARGE.--21 years $(1929-33,1935-43,1944-53), 57.1 \mathrm{ft}^{3} / \mathrm{s}, 41,340 \mathrm{acre}-\mathrm{ft} / \mathrm{yr}$.

EXTREMES FOR PERIOD OF RECORD.--Maximum discharge, $1,180 \mathrm{ft}^{3} / \mathrm{s}$ June 13, 1953, gage height, $4.30 \mathrm{ft}$; no flow during part of 1954 . 
GREEN RIVER BASIN

09273000 DUCAESNE RIVER AT PROVO RIVER TRAIL, NEAR HANNA, UT-Continued

DATA BELOW BASED ON PERIOD OF RECORD PRIOR TO DIVERSION TO DUCHESNE TUNNEE

LOWEST MEAN DISCHARGE, IN OUBIC FEET PER SECOND, AND RANRING FOR THE INDICATED NUMBER OF CONSEOTTIVE DAYS FOR EAOH OIMATIC YEAR, APRIL 1-MARCH 31

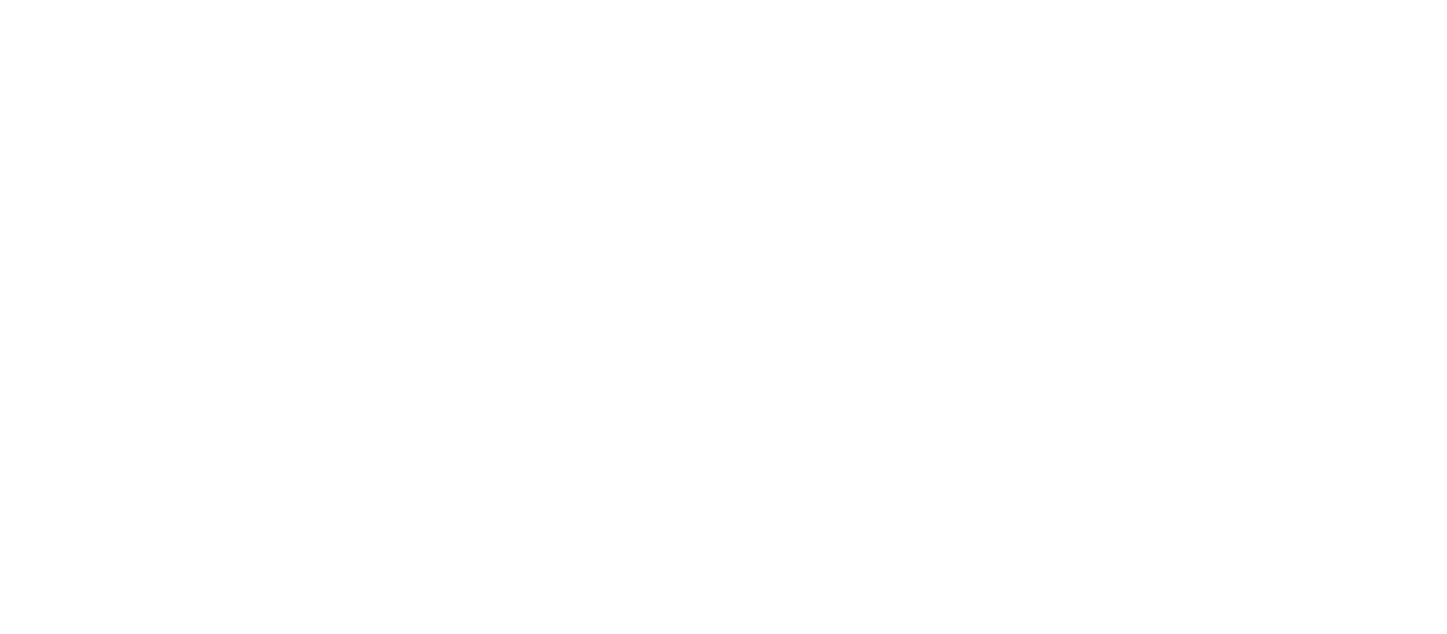

HIGHEST MEAN DISCHARGE, IN OUBIC FEET PER SECOND, AND RANRING FOR THE INDICATED NUMBER OF CONSECUTIVE DAYS FOR EACH WATER YEAR, OCTCBER 1-SEPTEMBER 30 CONSECUTIVE DAYS

$1 \quad 3 \quad 7$

15

30

60

90

120

183

ALL

$\begin{array}{rrrrrrrrrr}1931 & 356 & 19 & 317 & 21 & 236 & 21 & 203 & 21 & 182 \\ 1932 & 665 & 6 & 628 & 6 & 557 & 9 & 495 & 9 & 401 \\ 1933 & 626 & 8 & 604 & 8 & 577 & 8 & 522 & 8 & 379 \\ 1934 & 100 & 22 & 100 & 22 & 100 & 22 & 100 & 22 & 100 \\ 1935 & 350 & 20 & 350 & 19 & 350 & 19 & 350 & 18 & 350\end{array}$

$\begin{array}{rlr}21 & 114 & 21 \\ 7 & 318 & 7 \\ 12 & 218 & 16 \\ 22 & 71.0 & 22\end{array}$

$83.0 \quad 21$

$\begin{array}{llllllllll}71.0 & 16 & 151 & 17 & 116 & 17 & 78.0 & 17 & 41.0 & 18\end{array}$

$\begin{array}{llllll}1936 & 630 & 7 & 622 & 7 & 609\end{array}$

1937

1938

1940

$\begin{array}{rrrrr}600 & 9 & \mathbf{5 8 8} & 10 & \mathbf{5 4 7} \\ 600 & 10 & \mathbf{5 9 3} & 9 & \mathbf{5 7 7}\end{array}$

$\begin{array}{llll}6 & 554 & 5 & 461\end{array}$

$4321 \quad 5$ $\begin{array}{ccc}56.0 & 22 & 45.0 \\ 154 & 16 & 119\end{array}$

$\begin{array}{ll}2 & 32.0 \\ 6 & 81.0\end{array}$

$43.0 \quad 16$

1941
1942
1943

1945

1946
1947
1948
1949

$\begin{array}{llll}21 & 319 & 20 & 302 \\ 15 & 502 & 16 & 464\end{array}$

$\begin{array}{rrr}554 & 5 & 461 \\ 468 & 10 & 369 \\ 532 & 7 & 387 \\ 286 & 20 & 250\end{array}$

$\begin{array}{rr}4 & 321 \\ 13 & 256 \\ 9 & 248 \\ 20 & 176\end{array}$

$\begin{array}{rl}5 & 23 \\ 11 & 18 \\ 12 & 176 \\ 20 & 133\end{array}$

$\begin{array}{rr}6 & 190 \\ 11 & 142\end{array}$

$\begin{array}{rrr}4 & 131 & 4 \\ 13 & 97.0 & 12 \\ 15 & 94.0 & 14\end{array}$

$\begin{array}{rr}68.0 & 5 \\ 53.0 & 12\end{array}$

$\begin{array}{llll}20 & 286 & 20 & 250 \\ 17 & 407 & 14 & 312\end{array}$

$\begin{array}{ll}20 & 176 \\ 17 & 185\end{array}$

$\begin{array}{llll}19 & 132 & 19 & 106\end{array}$

$19 \quad 74.0 \quad 18$

$51.0 \quad 14$

$43.0 \quad 17$

$\begin{array}{lllll}540 & 14 & 507 & 15 & 474\end{array}$

14433

1239

$\begin{array}{rr}8 & 31 \\ 10 & 237\end{array}$

8229

$8 \quad 177$

$\begin{array}{rrr}9 & 121 & 9 \\ 14 & 94.0 & 15\end{array}$

38.020

$\begin{array}{llll}16 & 508 & 14 & 485\end{array}$

$16 \quad 343$

$15 \quad 291$

9229

$\begin{array}{rr}15 & 138 \\ 9 & 181\end{array}$

$\begin{array}{rr}14 & 124\end{array}$

$8 \quad 343$

$19 \quad 282$

$19 \quad 237$

$15 \quad 182$

$12 \quad 147$

$11 \quad 10$

$67.0 \quad 6$

$\begin{array}{llllll}580 & 12 & 547 & 11 & 479\end{array}$

\begin{tabular}{ll}
3 & 363 \\
6 & 390 \\
\hline & 499
\end{tabular}

$\begin{array}{ll}17 & 293 \\ 15 & 379 \\ 11 & 337\end{array}$

$\begin{array}{rrrr}18 & 257 & 10 & 193 \\ 11 & 322 & 4 & 24 \\ 16 & 198 & 18 & 140 \\ 5 & 319 & 6 & 240\end{array}$

$\begin{array}{rr}10 & 150 \\ 4 & 187 \\ 18 & 108\end{array}$

$\begin{array}{rr}10 & 102 \\ 18 & 128\end{array}$

$\begin{array}{ccc}5 & 128 & 5 \\ 8 & 74.0 & 19 \\ 6 & 126 & 6\end{array}$

65.09

$\begin{array}{lll}695 & 5 & 683\end{array}$

575

$\begin{array}{ll}2 & 440 \\ 4 & 527\end{array}$

519
$1 \quad 367$

$\begin{array}{ll}6 & 240 \\ 2 & 262\end{array}$

2204

2138

$\begin{array}{lllll}760 & 4 & 727 & 3 & 653\end{array}$

$\begin{array}{llll}4 & 547 & 6 & 465\end{array}$

$\begin{array}{llll}3 & 344 & 3 & 251 \\ 2 & 387 & 1 & 294\end{array}$

$3 \quad 197$

1953

2583

3403

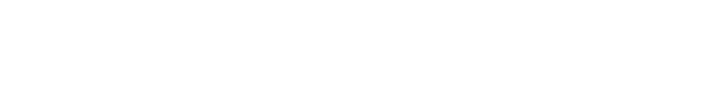


GREEN RIVER BASIN

09273000 DUCHESNE RIVER AT PROVO RIVER TRAII, NEAR HANNA, UT--Continued

DURATION OF DISCHARGE FOR EACH WATER YEAR

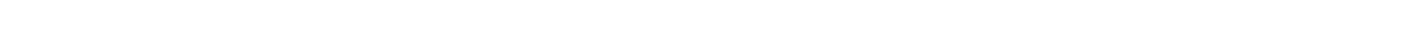

\begin{tabular}{|c|c|c|c|c|c|c|c|c|c|c|c|c|c|c|c|c|c|c|c|c|c|c|c|c|c|c|c|c|c|c|}
\hline YEAR & & & & & & & & & & MBER & $O F$ & DAYS & IN & QLASS & & & & & & & & & & & & & & & & $\begin{array}{l}\text { OBIC FEET } \\
\text { PER SECOND } \\
\text {-DAYS }\end{array}$ \\
\hline $\begin{array}{l}1931 \\
1932 \\
1933 \\
1934 \\
1935\end{array}$ & 2 & 9 & $\begin{array}{r}4 \\
90 \\
28\end{array}$ & $\begin{array}{rr}5 & 19 \\
& 21 \\
61 & \\
62 & 92 \\
90 & 61\end{array}$ & $\begin{array}{r}8 \\
10 \\
40 \\
30 \\
31\end{array}$ & $\begin{array}{l}8 \\
10 \\
30\end{array}$ & $\begin{array}{l}12 \\
61 \\
51 \\
31 \\
30\end{array}$ & $\begin{array}{r}7 \\
114 \\
25 \\
31\end{array}$ & $\begin{array}{r}4 \\
2 \\
5 \\
\\
31\end{array}$ & $\begin{array}{r}7 \\
17 \\
8\end{array}$ & $\begin{array}{r}176 \\
40 \\
4\end{array}$ & $\begin{array}{r}31 \\
6 \\
8 \\
30\end{array}$ & $\begin{array}{r}14 \\
3 \\
7\end{array}$ & $\begin{array}{r}10 \\
8 \\
31\end{array}$ & $\begin{array}{r}7 \\
9 \\
9 \\
30\end{array}$ & $\begin{array}{r}4 \\
2 \\
+6\end{array}$ & $\begin{array}{l}5 \\
8 \\
5\end{array}$ & $\begin{array}{r}3 \\
4 \\
3 \\
31\end{array}$ & $\begin{array}{r}5 \\
2 \\
31\end{array}$ & $\begin{array}{l}3 \\
8 \\
4\end{array}$ & $\begin{array}{l}7 \\
5 \\
3\end{array}$ & $\begin{array}{l}5 \\
4 \\
2\end{array}$ & $\begin{array}{l}5 \\
3 \\
2\end{array}$ & $\begin{array}{r}4 \\
12 \\
2\end{array}$ & $\begin{array}{r}1 \\
7 \\
30\end{array}$ & $\begin{array}{r}13 \\
6\end{array}$ & $\begin{array}{l}5 \\
8\end{array}$ & $\begin{array}{l}4 \\
4\end{array}$ & & $\begin{array}{r}11907.0 \\
23857.0 \\
15125.0 \\
6589.0 \\
15564.4\end{array}$ \\
\hline $\begin{array}{l}1936 \\
1937 \\
1938 \\
1939 \\
1940\end{array}$ & & & 86 & 744 & $\begin{array}{r}61 \\
593 \\
6 \\
38\end{array}$ & $\begin{array}{r}34 \\
61 \\
9 \\
4\end{array}$ & $\begin{array}{r}71 \\
107 \\
16 \\
36\end{array}$ & $\begin{array}{l}20 \\
46 \\
22 \\
46 \\
11\end{array}$ & $\begin{array}{r}2 \\
14 \\
12 \\
112 \\
19\end{array}$ & $\begin{array}{l}15 \\
41 \\
61 \\
61 \\
29\end{array}$ & $\begin{array}{r}12 \\
7 \\
11 \\
13 \\
7\end{array}$ & $\begin{array}{l}8 \\
6 \\
5 \\
8 \\
9\end{array}$ & $\begin{array}{r}17 \\
10 \\
16 \\
6 \\
5\end{array}$ & $\begin{array}{l}5 \\
3 \\
9 \\
5 \\
9\end{array}$ & $\begin{array}{r}9 \\
7 \\
5 \\
3 \\
11\end{array}$ & $\begin{array}{r}11 \\
8 \\
4 \\
35 \\
7\end{array}$ & $\begin{array}{l}9 \\
2 \\
3 \\
3 \\
8\end{array}$ & $\begin{array}{l}8 \\
3 \\
1 \\
3 \\
5\end{array}$ & $\begin{array}{r}11 \\
2 \\
6 \\
5 \\
2\end{array}$ & $\begin{array}{l}9 \\
6 \\
2 \\
3 \\
2\end{array}$ & $\begin{array}{l}4 \\
7 \\
7 \\
4 \\
2\end{array}$ & $\begin{array}{r}3 \\
10 \\
5 \\
8 \\
2\end{array}$ & $\begin{array}{l}6 \\
6 \\
5 \\
8 \\
3\end{array}$ & $\begin{array}{r}6 \\
3 \\
5 \\
14 \\
3\end{array}$ & $\begin{array}{l}7 \\
9 \\
4 \\
3 \\
9\end{array}$ & $\begin{array}{l}4 \\
2 \\
2\end{array}$ & $\begin{array}{l}9 \\
5 \\
7 \\
3\end{array}$ & $\begin{array}{l}8 \\
4 \\
5\end{array}$ & & $\begin{array}{l}24873.0 \\
19174.0 \\
18656.0 \\
15766.0 \\
13890.0\end{array}$ \\
\hline $\begin{array}{l}1941 \\
1942 \\
1943\end{array}$ & & 2 & 2 & $\begin{array}{r}2132 \\
3194\end{array}$ & $\begin{array}{r}6 \\
35\end{array}$ & $\begin{array}{l}4 \\
6\end{array}$ & $\begin{array}{l}61 \\
22 \\
15\end{array}$ & $\begin{array}{l}76 \\
24 \\
13\end{array}$ & $\begin{array}{l}34 \\
15 \\
14\end{array}$ & $\begin{array}{l}32 \\
25 \\
15\end{array}$ & $\begin{array}{l}30 \\
20 \\
12\end{array}$ & $\begin{array}{r}19 \\
11 \\
8\end{array}$ & $\begin{array}{r}16 \\
3 \\
11\end{array}$ & $\begin{array}{r}14 \\
2 \\
10\end{array}$ & $\begin{array}{l}6 \\
4 \\
8\end{array}$ & $\begin{array}{r}9 \\
26 \\
4\end{array}$ & $\begin{array}{r}6 \\
20 \\
8\end{array}$ & $\begin{array}{l}7 \\
5 \\
4\end{array}$ & $\begin{array}{l}1 \\
2 \\
6\end{array}$ & $\begin{array}{l}5 \\
3 \\
5\end{array}$ & $\begin{array}{l}1 \\
3 \\
8 \\
8\end{array}$ & $\begin{array}{r}2 \\
3 \\
17\end{array}$ & $\begin{array}{l}2 \\
1 \\
9\end{array}$ & $\begin{array}{l}5 \\
9 \\
9\end{array}$ & $\begin{array}{r}17 \\
4 \\
8\end{array}$ & $\begin{array}{r}17 \\
7 \\
8\end{array}$ & $\begin{array}{l}5 \\
8 \\
7\end{array}$ & & & $\begin{array}{l}24532.0 \\
18586.0 \\
23765.0\end{array}$ \\
\hline 1945 & & & & 138 & 202 & 25 & 14 & 6 & 6 & 17 & 7 & 10 & 7 & 6 & 20 & 11 & 6 & 4 & 4 & $6 I$ & 15 & 71 & 18 & 10 & 2 & 5 & 1 & & & 19625.4 \\
\hline $\begin{array}{l}1946 \\
1947 \\
1948 \\
1949 \\
1950\end{array}$ & & & & 110 & $\begin{array}{l}70 \\
908 \\
2810\end{array}$ & $\begin{array}{l}91 \\
88 \\
01\end{array}$ & $\begin{array}{l}72 \\
85 \\
37 \\
15 \\
24\end{array}$ & $\begin{array}{r}104 \\
89 \\
35 \\
22 \\
50\end{array}$ & $\begin{array}{r}50 \\
43 \\
9 \\
9 \\
24\end{array}$ & $\begin{array}{l}14 \\
16 \\
15 \\
11 \\
17\end{array}$ & $\begin{array}{r}6 \\
7 \\
10 \\
13 \\
8\end{array}$ & $\begin{array}{r}11 \\
14 \\
7 \\
5 \\
6\end{array}$ & $\begin{array}{r}5 \\
21 \\
12 \\
3 \\
11\end{array}$ & $\begin{array}{l}6 \\
6 \\
5 \\
8 \\
9\end{array}$ & $\begin{array}{r}6 \\
4 \\
10 \\
2 \\
9\end{array}$ & $\begin{array}{l}5 \\
4 \\
3 \\
6 \\
7\end{array}$ & $\begin{array}{l}4 \\
4 \\
4 \\
2 \\
6\end{array}$ & $\begin{array}{r}4 \\
2 \\
4 \\
10 \\
6\end{array}$ & $\begin{array}{l}3 \\
3 \\
3 \\
7 \\
3\end{array}$ & $\begin{array}{l}7 \\
3 \\
2 \\
8 \\
5\end{array}$ & $\begin{array}{ll}6 & 1 \\
6 \\
3 \\
8 \\
5\end{array}$ & $\begin{array}{r}13 \\
7 \\
3 \\
10 \\
3\end{array}$ & $\begin{array}{r}13 \\
12 \\
2 \\
9 \\
3\end{array}$ & $\begin{array}{r}11 \\
12 \\
5 \\
4 \\
5\end{array}$ & $\begin{array}{l}6 \\
8 \\
8 \\
8\end{array}$ & $\begin{array}{r}4 \\
10 \\
11 \\
4 \\
7\end{array}$ & $\begin{array}{lr}2 & 1 \\
8 & 1 \\
5 & \\
2 & 7 \\
5 & 15\end{array}$ & $\begin{array}{r}1 \\
1 \\
7 \\
7 \\
15\end{array}$ & 3 & $\begin{array}{l}20533.9 \\
25153.8 \\
14735.5 \\
24168.5 \\
26692.9\end{array}$ \\
\hline $\begin{array}{l}1951 \\
1952 \\
1953\end{array}$ & & & & 23 & $\begin{array}{c}1 \\
6910\end{array}$ & $\begin{array}{r}2 \\
06\end{array}$ & $\begin{array}{r}60 \\
131 \\
33\end{array}$ & $\begin{array}{r}124 \\
21 \\
12\end{array}$ & $\begin{array}{r}6 \\
12 \\
9\end{array}$ & $\begin{array}{l}23 \\
52 \\
10\end{array}$ & $\begin{array}{r}8 \\
10 \\
9\end{array}$ & $\begin{array}{r}12 \\
15 \\
1\end{array}$ & $\begin{array}{l}14 \\
13 \\
12\end{array}$ & $\begin{array}{l}18 \\
12 \\
15\end{array}$ & $\begin{array}{r}9 \\
6 \\
11\end{array}$ & $\begin{array}{r}5 \\
7 \\
22\end{array}$ & $\begin{array}{r}13 \\
4 \\
4\end{array}$ & $\begin{array}{l}7 \\
3 \\
7\end{array}$ & $\begin{array}{l}6 \\
2 \\
3\end{array}$ & $\begin{array}{l}4 \\
7 \\
3\end{array}$ & $\begin{array}{l}3 \\
5 \\
3\end{array}$ & $\begin{array}{l}4 \\
6 \\
6\end{array}$ & $\begin{array}{r}9 \\
17 \\
6\end{array}$ & $\begin{array}{r}7 \\
10 \\
5\end{array}$ & $\begin{array}{l}3 \\
6 \\
1\end{array}$ & $\begin{array}{r}10 \\
6 \\
3\end{array}$ & $\begin{array}{l}2 \\
5 \\
2\end{array}$ & $\begin{array}{l}8 \\
7 \\
4\end{array}$ & $\begin{array}{l}4 \\
6 \\
2\end{array}$ & $\begin{array}{l}26542.2 \\
30405.7 \\
18840.7\end{array}$ \\
\hline
\end{tabular}

DURATION TABLE OF DISCHARGE FOR WATER YEARS 1931-53

\begin{tabular}{|c|c|c|c|c|c|c|c|c|c|c|c|c|c|c|c|c|c|c|c|}
\hline CLASS & $\begin{array}{c}\text { GBIIC } \\
\text { FEET } \\
\text { PER } \\
\text { SECOND }\end{array}$ & TOTAL & $\begin{array}{l}\text { ACOU- } \\
\text { MU- } \\
\text { LATED } \\
\text { DAYS }\end{array}$ & $\begin{array}{l}\text { PER- } \\
\text { CENT } \\
\text { DAYS }\end{array}$ & CASS & $\begin{array}{c}\text { वBIC } \\
\text { FEET } \\
\text { PER } \\
\text { SEOOND }\end{array}$ & TOTAL & $\begin{array}{l}\text { ACOU- } \\
\text { MU- } \\
\text { LATED } \\
\text { DAYS }\end{array}$ & $\begin{array}{l}\text { PER- } \\
\text { CENT } \\
\text { DAYS }\end{array}$ & C.ASS & $\begin{array}{c}\text { OBIC } \\
\text { FEET } \\
\text { PER } \\
\text { SEOOND }\end{array}$ & TOTAL & $\begin{array}{c}\text { ACCU- } \\
\text { MU- } \\
\text { LATED } \\
\text { DAYS }\end{array}$ & $\begin{array}{l}\text { PER- } \\
\text { CENT } \\
\text { DAYS }\end{array}$ & & $\begin{array}{r}\text { CUBIC } \\
\text { FEET } \\
\text { PER } \\
\text { SEOOND }\end{array}$ & TOTAL & $\begin{array}{l}\text { ACOU- } \\
\text { MU- } \\
\text { LATED } \\
\text { DAYS }\end{array}$ & $\begin{array}{l}\text { PER- } \\
\text { CENT } \\
\text { DAYS }\end{array}$ \\
\hline $\begin{array}{l}0 \\
1 \\
2 \\
3 \\
4 \\
5 \\
6 \\
7 \\
8\end{array}$ & $\begin{array}{l}0.00 \\
1.00 \\
1.20 \\
1.50 \\
1.90 \\
2.30 \\
2.80 \\
3.40 \\
4.20\end{array}$ & $\begin{array}{r}0 \\
2 \\
0 \\
0 \\
11 \\
0 \\
210 \\
261 \\
756\end{array}$ & $\begin{array}{l}8035 \\
8035 \\
8033 \\
8033 \\
8033 \\
8022 \\
8022 \\
7812 \\
7551\end{array}$ & $\begin{array}{r}100.0 \\
100.0 \\
100.0 \\
100.0 \\
100.0 \\
99.8 \\
99.8 \\
97.2 \\
94.0\end{array}$ & $\begin{array}{r}9 \\
10 \\
11 \\
12 \\
13 \\
14 \\
15 \\
16 \\
17\end{array}$ & $\begin{array}{r}5.20 \\
6.30 \\
7.80 \\
9.50 \\
12.00 \\
14.00 \\
18.00 \\
22.00 \\
27.00\end{array}$ & $\begin{array}{l}597 \\
596 \\
984 \\
898 \\
432 \\
486 \\
410 \\
230 \\
206\end{array}$ & $\begin{array}{l}6795 \\
6198 \\
5602 \\
4618 \\
3720 \\
3288 \\
2802 \\
2392 \\
2162\end{array}$ & $\begin{array}{l}84.6 \\
77.1 \\
69.7 \\
57.5 \\
46.3 \\
40.9 \\
34.9 \\
29.8 \\
26.9\end{array}$ & $\begin{array}{l}18 \\
19 \\
20 \\
21 \\
22 \\
23 \\
24 \\
25 \\
26\end{array}$ & $\begin{array}{r}33.0 \\
40.0 \\
49.0 \\
60.0 \\
74.0 \\
91.0 \\
110.0 \\
140.0 \\
170.0\end{array}$ & $\begin{array}{r}191 \\
185 \\
186 \\
124 \\
124 \\
107 \\
95 \\
105 \\
120\end{array}$ & $\begin{array}{r}1956 \\
1765 \\
1580 \\
1394 \\
1270 \\
1146 \\
1039 \\
944 \\
839\end{array}$ & $\begin{array}{l}24.3 \\
22.0 \\
19.7 \\
17.3 \\
15.8 \\
14.3 \\
12.9 \\
11.7 \\
10.4\end{array}$ & $\begin{array}{l}27 \\
28 \\
29 \\
30 \\
31 \\
32 \\
33 \\
34\end{array}$ & $\begin{array}{l}210.0 \\
250.0 \\
310.0 \\
380.0 \\
470.0 \\
570.0 \\
700.0 \\
860.0\end{array}$ & $\begin{array}{r}139 \\
141 \\
141 \\
124 \\
89 \\
68 \\
15 \\
2\end{array}$ & $\begin{array}{r}719 \\
580 \\
439 \\
298 \\
174 \\
85 \\
17 \\
2\end{array}$ & $\begin{array}{l}8.9 \\
7.2 \\
5.5 \\
3.7 \\
2.2 \\
1.1 \\
0.2 \\
0.0\end{array}$ \\
\hline
\end{tabular}

MONTHLY MEAN DISCHARGES, IN CUBIC FEET PER SEOOND, FOR EACH WATER YEAR

$\begin{array}{ccccccccccccc}\text { YEAR } & \text { OCT } & \text { NOW } & \text { DEC } & \text { JAN } & \text { FEB } & \text { MAR } & \text { APR } & \text { MAY } & \text { JUNE } & \text { JULY } & \text { AUG } & \text { SEP } \\ 1930 & 15.7 & 15.0 & 12.0 & 12.0 & 12.0 & 15.0 & 39.9 & 152 & 309 & 37.7 & 48.8 & 27.0 \\ & & & & & & & & & & & & \\ 1931 & 29.4 & 20.7 & 19.0 & 18.0 & 18.0 & 18.0 & 18.4 & 136 & 88.1 & 14.2 & 5.87 & 4.00 \\ 1932 & 5.32 & 8.00 & 10.0 & 10.0 & 10.0 & 9.00 & 18.3 & 205 & 401 & 76.0 & 19.4 & 12.5 \\ 1933 & 8.48 & 6.00 & 4.00 & 3.00 & 3.00 & 3.00 & 4.00 & 42.9 & 364 & 40.8 & 12.9 & 8.03 \\ 1934 & 5.00 & 5.00 & 5.00 & 4.00 & 3.00 & 4.00 & 40.0 & 100 & 25.3 & 10.0 & 8.00 & 6.00 \\ 1935 & 5.40 & 5.00 & 4.00 & 4.00 & 4.00 & 5.00 & 8.00 & 75.0 & 350 & 35.0 & 12.0 & 7.00 \\ 1936 & 6.00 & 6.00 & 5.00 & 5.00 & 5.00 & 5.00 & 16.7 & 405 & 226 & 71.8 & 40.1 & 19.4 \\ 1937 & 10.6 & 9.53 & 8.00 & 7.00 & 6.00 & 6.00 & 15.0 & 337 & 164 & 38.9 & 14.0 & 9.67 \\ 1938 & 10.1 & 8.33 & 8.00 & 7.00 & 7.00 & 8.00 & 15.0 & 195 & 287 & 38.7 & 15.9 & 12.8 \\ 1939 & 16.1 & 15.0 & 13.0 & 12.0 & 10.0 & 13.0 & 50.0 & 247 & 96.0 & 21.7 & 9.94 & 11.1 \\ 1940 & 12.8 & 6.20 & 3.16 & 3.00 & 3.00 & 5.00 & 24.1 & 287 & 71.0 & 15.1 & 6.00 & 15.4 \\ 1941 & 28.0 & 16.2 & 10.0 & 8.00 & 8.00 & 10.0 & 13.9 & 306 & 316 & 53.3 & 22.7 & 11.4 \\ 1942 & 13.6 & 11.3 & 5.00 & 5.00 & 5.00 & 5.00 & 34.2 & 158 & 307 & 45.9 & 13.9 & 7.53 \\ 1943 & 6.71 & 6.07 & 5.00 & 4.00 & 5.00 & 6.42 & 50.6 & 274 & 306 & 76.9 & 27.5 & 11.1 \\ 1945 & 7.62 & 6.98 & 5.00 & 5.00 & 5.00 & 5.00 & 8.60 & 183 & 275 & 83.1 & 39.8 & 19.1 \\ 1946 & 11.5 & 12.0 & 10.0 & 9.32 & 9.00 & 10.1 & 87.6 & 238 & 234 & 31.9 & 13.1 & 8.24 \\ 1947 & 12.5 & 10.3 & 10.4 & 9.00 & 8.00 & 9.74 & 20.4 & 315 & 318 & 77.9 & 22.3 & 10.9 \\ 1948 & 8.56 & 8.75 & 6.93 & 6.00 & 6.00 & 6.50 & 13.6 & 228 & 159 & 22.5 & 10.8 & 5.05 \\ 1949 & 5.35 & 7.06 & 6.50 & 5.74 & 5.50 & 6.52 & 37.1 & 197 & 421 & 79.8 & 14.5 & 9.13 \\ 1950 & 11.7 & 10.2 & 7.14 & 6.50 & 6.00 & 7.00 & 30.4 & 170 & 503 & 99.5 & 16.6 & 10.6 \\ 1951 & 8.62 & 10.8 & 9.26 & 9.36 & 9.60 & 9.60 & 26.8 & 221 & 415 & 105 & 34.4 & 12.7 \\ 1952 & 14.4 & 9.59 & 9.00 & 8.00 & 8.00 & 8.00 & 36.1 & 298 & 469 & 89.8 & 30.4 & 17.9 \\ 1953 & 10.3 & 6.04 & 6.50 & 6.50 & 6.00 & 6.45 & 19.4 & 64.6 & 402 & 62.9 & 23.7 & 7.65\end{array}$


GREEN RIVER BASIN

09273000 DUGHESNE RIVER AT PROVO RIVER TRALl, NEAR HANNA, UT-Continued

ANNUAL PEAK DISOHARGE, IN OBBIC FEET PER SECOND, AND CORRESPONDING GAGE HEIGHT, IN FEET, FOR EAOH WATER YEAR

\begin{tabular}{|c|c|c|c|c|c|c|c|c|c|c|c|}
\hline $\begin{array}{l}\text { WATER } \\
\text { YEAR }\end{array}$ & DATE & $\begin{array}{c}\text { GAGE } \\
\text { HEIGHT }\end{array}$ & $\begin{array}{c}\text { PEAK } \\
\text { DISQHARGE }\end{array}$ & $\begin{array}{l}\text { WATER } \\
\text { YEAR }\end{array}$ & DATE & $\begin{array}{c}\text { GAGE } \\
\text { HEIGHT }\end{array}$ & $\begin{array}{c}\text { PEAK } \\
\text { DISOHARGE }\end{array}$ & $\begin{array}{l}\text { WATER } \\
\text { YEAR }\end{array}$ & DATE & $\begin{array}{c}\text { GAGE } \\
\text { HEIGHT }\end{array}$ & $\begin{array}{c}\text { PEAK } \\
\text { DISCHARGE }\end{array}$ \\
\hline $\begin{array}{l}1930 \\
1931 \\
1932 \\
1933 \\
1936 \\
1937 \\
1938\end{array}$ & $\begin{array}{lll}\text { JUNE } & 11, & 1930 \\
\text { MAY } & 16, & 1931 \\
\text { JUNE } & 24,1932 \\
\text { JUNE } & 10,1933 \\
\text { MAY } & 29,1936 \\
\text { MAY } & 17,1937 \\
\text { MAY } & 29,1938\end{array}$ & $\begin{array}{l}3.53 \\
2.90 \\
3.68 \\
3.40 \\
3.48 \\
3.38 \\
-\end{array}$ & $\begin{array}{l}851 \\
455 \\
888 \\
720 \\
768 \\
708 \\
600\end{array}$ & $\begin{array}{l}1939 \\
1940 \\
1941 \\
1942 \\
1943 \\
1945 \\
1946\end{array}$ & $\begin{array}{lll}\text { MAY } & 15,1939 \\
\text { MAY } & 15,1940 \\
\text { MAY } & 26,1941 \\
\text { JUNE } & 07,1942 \\
\text { MAY } & 27,1943 \\
\text { JUNE } & 22,1945 \\
\text { JUNE } & 05,1946\end{array}$ & $\begin{array}{l}2.65 \\
3.05 \\
3 . \overline{30} \\
3.14 \\
\overline{3.19}\end{array}$ & $\begin{array}{l}384 \\
566 \\
540 \\
670 \\
593 \\
480 \\
642\end{array}$ & $\begin{array}{l}1947 \\
1948 \\
1949 \\
1950 \\
1951 \\
1952 \\
1953\end{array}$ & $\begin{array}{l}\text { JUNE } 07,1947 \\
\text { MAY 21, } 1948 \\
\text { JUNE 12, } 1949 \\
\text { JUNE } 16,1950 \\
\text { JUNE 16, } 1951 \\
\text { JUNE 09, } 1952 \\
\text { JUNE } 13,1953\end{array}$ & $\begin{array}{l}3.32 \\
3.35 \\
3.80 \\
3.70 \\
3.98 \\
4.02 \\
4.30\end{array}$ & $\begin{array}{r}698 \\
598 \\
892 \\
880 \\
1020 \\
982 \\
1180\end{array}$ \\
\hline
\end{tabular}

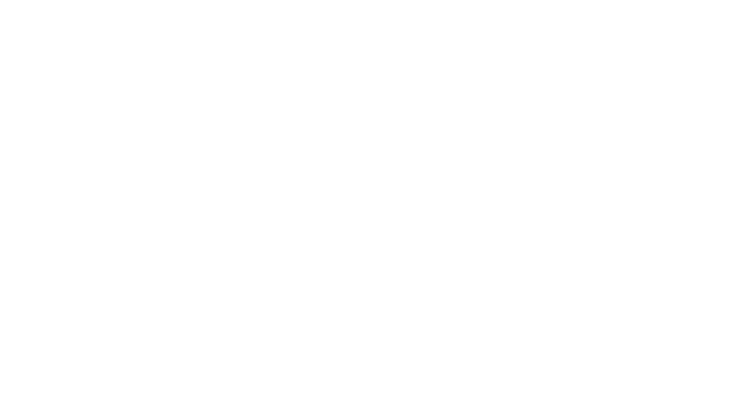

09273200 DUGESNE RIVER BELOW LITTLE DEER CREEK, NEAR HANNA, UT

LOCATION.--Lat $40^{\circ} 37^{\prime} 20^{\prime \prime}$, long $110^{\circ} 53^{\prime} 30^{\prime \prime}$, in $S_{\frac{1}{2}}^{\frac{1}{2}}$ sec. 27, T.3 N., R. 9 w., Uintah Meriđian, Duchesne County, Hydrologic unit 14060003 , on left bank $300 \mathrm{ft}$ downstream fram Little Deer Creek, $0.3 \mathrm{mi}$ downstream fram entranœ to Duchesne tunnel, and 13.5

mi northwest of Hanna.

DRAINAGE AREA. $--39 \mathrm{mi}^{2}$, approximately.

PERIOD OF RECORD AVAIIABLE.--Octaber 1964 to September 1968.

GAGE.--Water-stage recorder. Altitude of gage is $8,000 \mathrm{ft}$ fram topographic map. Prior to June 27,1966 , at site $250 \mathrm{ft}$ upstrean at aifferent datum.

REMARKS.--There is a transmountain diversion above station through Duchesne tunnel to the Great Basin.

EXIREMES FOR PERIOD OF RECORD.--Maximum discharge (not determined) occur red about June 13, 1965, stage unknown; minimum daily, 0.20

$\mathrm{ft}^{3} / \mathrm{s}$ for several days in most years.

EXIREMES OUISIDE PERIOD OF RECORD.--Maximum discharge,47,000 $\mathrm{ft}^{3} / \mathrm{s}$ (caused by failure of Little Deer Creek dam) June $16,1963$.

LOWEST MEAN DISOHARGE, IN OBBIC FEET PER SECOND, AND RANKING FOR THE INDICATED NUMBER OF CONSEOUTTVE DAYS

\begin{tabular}{|c|c|c|c|c|c|c|c|c|c|c|c|c|c|c|c|c|c|c|c|}
\hline YEAR & & & & & & & & & CONSE & UTT & DAYS & & & & & & & & \\
\hline $\begin{array}{l}1966 \\
1967 \\
1968\end{array}$ & $\begin{array}{l}0.20 \\
0.20 \\
0.20\end{array}$ & $\begin{array}{l}1 \\
2 \\
3\end{array}$ & $\begin{array}{l}0.20 \\
0.20 \\
0.20\end{array}$ & $\begin{array}{l}1 \\
2 \\
3\end{array}$ & $\begin{array}{l}0.20 \\
0.20 \\
0.20\end{array}$ & $\begin{array}{l}1 \\
2 \\
3\end{array}$ & $\begin{array}{l}0.21 \\
0.20 \\
0.20\end{array}$ & $\begin{array}{l}3 \\
1 \\
2\end{array}$ & $\begin{array}{l}0.26 \\
0.20 \\
0.20\end{array}$ & $\begin{array}{l}3 \\
1 \\
2\end{array}$ & $\begin{array}{l}3.00 \\
0.20 \\
0.23\end{array}$ & $\begin{array}{l}3 \\
1 \\
2\end{array}$ & $\begin{array}{l}5.80 \\
0.20 \\
0.24\end{array}$ & $\begin{array}{l}3 \\
1 \\
2\end{array}$ & $\begin{array}{l}7.20 \\
0.20 \\
0.25\end{array}$ & $\begin{array}{l}3 \\
1 \\
2\end{array}$ & $\begin{array}{c}11.0 \\
0.20 \\
0.26\end{array}$ & $\begin{array}{l}3 \\
1 \\
2\end{array}$ & $\begin{array}{c}45.0 \\
7.20 \\
35.0\end{array}$ \\
\hline
\end{tabular}

HIGHEST MEAN DISGHARGE, IN OUBIC FEET PER SECOND, AND RANKING FOR THE INDICATED NUMBER OF CONSECUTIVE DAYS FOR EACH WATER YEAR, OCTOBER 1-SEPTEMBER 30

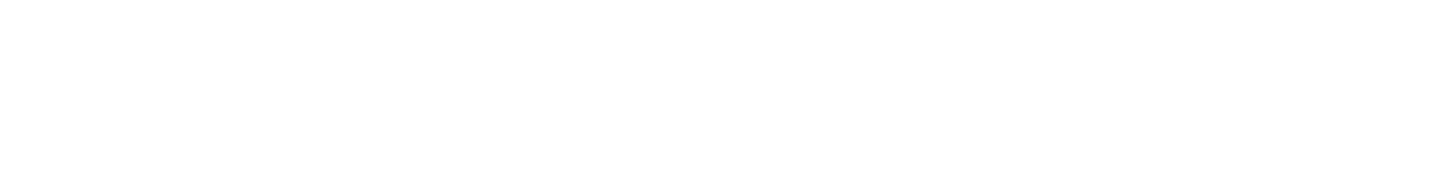


GREEN RIVER BASIN

09273200 DUOHESNE RIVER BELOW LITTHE DEER CREEK, NEAR HANNA, UT--Continued

DURATION OF DISCHARGE FOR EACH WATER YEAR

\begin{tabular}{|c|c|c|c|c|c|c|c|c|c|c|c|c|c|c|c|c|c|c|c|c|c|c|c|c|c|c|c|c|c|c|c|}
\hline $\begin{array}{l}\text { CLASS } \\
\text { YEAR }\end{array}$ & 0 & 2 & 3 & 4 & 5 & 6 & 8 & 3 & 10 & 1 & 2 & 13 & MBER & & 16 & & C.ASS & 9 & 0 & 1 & 22 & 232 & & 262 & 212 & & & & & & $\begin{array}{l}\text { OUIC FEET } \\
\text { PER SECOND } \\
\text {-DAVS }\end{array}$ \\
\hline 965 & 15 & 540 & 21 & 26 & & 678 & 6 & 21 & 8 & 2 & 3 & 4 & 3 & 3 & 3 & 7 & A & & 24 & 13 & 2 & & 1 & 2 & 1 & 3 & 9 & 2 & 3 & & \\
\hline $\begin{array}{l}960 \\
967\end{array}$ & $\begin{array}{r}14 \\
218 \\
148\end{array}$ & $\begin{array}{rr}4 & 8 \\
8 & 8 \\
8 & 62\end{array}$ & $\begin{array}{r}12 \\
1 \\
5\end{array}$ & $\begin{array}{l}5 \\
4\end{array}$ & $\begin{array}{l}3 \\
5 \\
1\end{array}$ & $\begin{array}{l}1 \\
7\end{array}$ & $\begin{array}{l}24 \\
10\end{array}$ & $\begin{array}{l}12 \\
21 \\
12\end{array}$ & $\begin{array}{r}1 \\
23 \\
20\end{array}$ & $\begin{array}{r}5 \\
11\end{array}$ & $\begin{array}{l}1 \\
1 \\
7\end{array}$ & & & & $\begin{array}{r}21 \\
1\end{array}$ & $\begin{array}{r}65 \\
1\end{array}$ & & $\begin{array}{r}40 \\
6 \\
27\end{array}$ & $\begin{array}{r}22 \\
2 \\
7\end{array}$ & $\begin{array}{r}13 \\
4\end{array}$ & $\begin{array}{r}13 \\
2\end{array}$ & $\begin{array}{ll}3 & \\
1 & 1 \\
1 & \end{array}$ & & & $\begin{array}{l}4 \\
1 \\
1\end{array}$ & $\begin{array}{r}4 \\
-\quad 4\end{array}$ & $\begin{array}{l}6 \\
4\end{array}$ & $\begin{array}{lr}5 & 9 \\
7 & 10\end{array}$ & $\begin{array}{ll}9 & 2 \\
0 & 6\end{array}$ & & \\
\hline
\end{tabular}

DURATION TABLE OF DISCHARGE FOR WATER YEARS 1965-68

\begin{tabular}{|c|c|c|c|c|c|c|c|c|c|c|c|c|c|c|c|c|c|c|c|}
\hline C.ASS & $\begin{array}{c}\text { OBIIC } \\
\text { FEET } \\
\text { PER } \\
\text { SECOND }\end{array}$ & $\begin{array}{l}\text { TOTAL } \\
\text { DAYS }\end{array}$ & $\begin{array}{l}\text { ACOU- } \\
\text { MU- } \\
\text { LATED } \\
\text { DAYS }\end{array}$ & $\begin{array}{l}\text { PER- } \\
\text { CENT } \\
\text { DALS }\end{array}$ & O.ASS & $\begin{array}{c}\text { OBBIC } \\
\text { FEET } \\
\text { PER } \\
\text { SECOND }\end{array}$ & $\begin{array}{l}\text { TOTAL } \\
\text { DAYS }\end{array}$ & $\begin{array}{c}\text { ACOJ- } \\
\text { MU- } \\
\text { LAIED } \\
\text { DAYS }\end{array}$ & $\begin{array}{l}\text { PER- } \\
\text { CENT } \\
\text { DAYS }\end{array}$ & G.ASS & $\begin{array}{c}\text { OBIC } \\
\text { FEET } \\
\text { PER } \\
\text { SECOND }\end{array}$ & $\begin{array}{l}\text { TOTAL } \\
\text { DAYS }\end{array}$ & $\begin{array}{c}\text { ACOJ- } \\
\text { MU- } \\
\text { LATED } \\
\text { DAYS }\end{array}$ & $\begin{array}{l}\text { PER- } \\
\text { CENT } \\
\text { DAYS }\end{array}$ & CJASS & $\begin{array}{c}\text { OBIC } \\
\text { FEET } \\
\text { PER } \\
\text { SEOOND }\end{array}$ & $\begin{array}{l}\text { TOTAL } \\
\text { DAYS }\end{array}$ & $\begin{array}{c}\text { ACOU- } \\
\text { MU- } \\
\text { LATED } \\
\text { DAYS }\end{array}$ & $\begin{array}{l}\text { PER- } \\
\text { CENT } \\
\text { DAYS }\end{array}$ \\
\hline $\begin{array}{l}0 \\
1 \\
2 \\
3 \\
4 \\
5 \\
6 \\
7 \\
8\end{array}$ & $\begin{array}{l}0.00 \\
0.20 \\
0.26 \\
0.33 \\
0.42 \\
0.54 \\
0.70 \\
0.90 \\
1.20\end{array}$ & $\begin{array}{r}0 \\
395 \\
118 \\
39 \\
11 \\
72 \\
14 \\
86 \\
40\end{array}$ & $\begin{array}{r}1461 \\
1461 \\
1066 \\
948 \\
909 \\
898 \\
826 \\
812 \\
726\end{array}$ & $\begin{array}{r}100.0 \\
100.0 \\
73.0 \\
64.9 \\
62.2 \\
61.5 \\
56.5 \\
55.6 \\
49.7\end{array}$ & $\begin{array}{r}9 \\
10 \\
11 \\
12 \\
13 \\
14 \\
15 \\
16 \\
17\end{array}$ & $\begin{array}{r}1.50 \\
1.90 \\
2.40 \\
3.10 \\
4.00 \\
5.20 \\
6.60 \\
8.50 \\
11.00\end{array}$ & $\begin{array}{r}66 \\
52 \\
18 \\
12 \\
8 \\
94 \\
21 \\
25 \\
73\end{array}$ & $\begin{array}{l}686 \\
620 \\
568 \\
550 \\
538 \\
530 \\
436 \\
415 \\
390\end{array}$ & $\begin{array}{l}47.0 \\
42.4 \\
38.9 \\
37.6 \\
36.8 \\
36.3 \\
29.8 \\
28.4 \\
26.7\end{array}$ & $\begin{array}{l}18 \\
19 \\
20 \\
21 \\
22 \\
23 \\
24 \\
25 \\
26\end{array}$ & $\begin{array}{r}14.0 \\
18.0 \\
23.0 \\
30.0 \\
38.0 \\
49.0 \\
63.0 \\
81.0 \\
100.0\end{array}$ & $\begin{array}{r}35 \\
78 \\
55 \\
30 \\
17 \\
5 \\
1 \\
1 \\
3\end{array}$ & $\begin{array}{r}317 \\
282 \\
204 \\
149 \\
119 \\
102 \\
97 \\
96 \\
95\end{array}$ & $\begin{array}{l}21.7 \\
19.3 \\
14.0 \\
10.2 \\
.8 .1 \\
7.0 \\
6.6 \\
6.6 \\
6.5\end{array}$ & $\begin{array}{l}27 \\
28 \\
29 \\
30 \\
31 \\
32 \\
33 \\
34\end{array}$ & $\begin{array}{l}130.0 \\
170.0 \\
220.0 \\
280.0 \\
360.0 \\
470.0 \\
600.0 \\
770.0\end{array}$ & $\begin{array}{r}2 \\
8 \\
11 \\
19 \\
14 \\
22 \\
14 \\
2\end{array}$ & $\begin{array}{r}92 \\
90 \\
82 \\
71 \\
52 \\
38 \\
16 \\
2\end{array}$ & $\begin{array}{l}6.3 \\
6.2 \\
5.6 \\
4.9 \\
3.6 \\
2.6 \\
1.1 \\
0.1\end{array}$ \\
\hline
\end{tabular}

MONTHLY MEAN DISCHARGES, IN OBBIC FEET PER SECOND, FOR EACH WATER YEAR

$\begin{array}{ccccccccccccc}\text { YEAR } & \text { OCT } & \text { NOV } & \text { DEC } & \text { JAN } & \text { FEB } & \text { MAR } & \text { APR } & \text { MAY } & \text { JUNE } & \text { JULY } & \text { AUG } & \text { SEP } \\ 1965 & 1.07 & 0.41 & 0.74 & 1.01 & 1.16 & 0.71 & 1.53 & 16.3 & 389 & 37.7 & 1.22 & 29.1 \\ 1966 & 20.5 & 13.3 & 7.98 & 5.60 & 5.60 & 11.8 & 36.0 & 9.83 & 0.65 & 16.5 & 16.3 & 5.16 \\ 1967 & 0.20 & 0.20 & 0.20 & 0.20 & 0.20 & 0.20 & 0.20 & 13.8 & 343 & 58.2 & 1.43 & 1.11 \\ 1968 & 0.25 & 0.28 & 0.28 & 0.25 & 0.25 & 0.22 & 0.26 & 37.0 & 455 & 9.52 & 5.11 & 20.7\end{array}$

09273500 HADES CREEK NEAR HANNA, UT

LOCATION. --Lat $40^{\circ} 32^{\prime} 10^{\prime \prime}$, long $110^{\circ} 52^{\prime} 00^{\prime \prime}$, in SE $\frac{1}{4}$ sec.26, T.2 N., R.9 W., Uintah Meridian, Duchesne County, Hydrologic Unit 14060003 , on right bank $0.25 \mathrm{mi}$ upstream from mouth and $11 \mathrm{mi}$ nor thwest of Hanna.

DRAINAGE AREA. $--7.5 \mathrm{mi}^{2}$.

MEAN BASIN ELEVATION. $--9,730 \mathrm{ft}$.

PERIOD OF RECORD AVAILABLE. - August 1949 to September 1968.

GAGE. -Water-stage recorder. Altitude of gage is 7,460 ft fron river-profile map.

REMARKS.-Two diversions $2,000 \mathrm{ft}$ above station to irrigate about 60 acres.

AVERAGE DISCHARGE. --19 years, $9.04 \mathrm{ft}^{3} / \mathrm{s}, 6,550$ acre-ft/yr.

EXTREMES FOR PERIOD OF RECORD.--Maximum discharge, $156 \mathrm{ft}^{3} / \mathrm{s}$ June 20,1968 , gage height, $2.67 \mathrm{ft}$, from rating curve extended above $100 \mathrm{ft}^{3} / \mathrm{s}$; maximum gage height recorded, $3.65 \mathrm{ft}$ Dec. 11,1961 (backwater from ice); no flow at times in $1956,1961$.

LONEST MEAN DISCHARGE, IN OBIC FEET PER SECOND, AND RANKING FOR THE INDICATED NUMBER OF CONSECUTIVE DAVS

YEAR

\begin{tabular}{llrlrlr} 
& 1 & \multicolumn{3}{c}{3} & 7 \\
1951 & 2.20 & 17 & 2.30 & 17 & 2.40 & 16 \\
1952 & 0.80 & 12 & 1.30 & 14 & 2.40 & 17 \\
1953 & 2.50 & 18 & 2.50 & 18 & 2.50 & 18 \\
1954 & 0.20 & 5 & 0.27 & 5 & 0.29 & 5 \\
1955 & 0.20 & 6 & 0.20 & 4 & 0.20 & 4 \\
1956 & 1.10 & 14 & 1.10 & 13 & 1.19 & 13 \\
1957 & 0.30 & 7 & 0.30 & 6 & 0.30 & 6 \\
1958 & 0.70 & 10 & 0.70 & 10 & 0.70 & 10 \\
1959 & 0.30 & 8 & 0.30 & 7 & 0.30 & 7 \\
1960 & 0.10 & 2 & 0.13 & 3 & 0.17 & 3
\end{tabular}

FOR EAOH OIMATIC YEAR, APRIL 1-MAROH 31

$\begin{array}{lr}14 & \\ 2.50 & 16 \\ 2.60 & 18 \\ 2.50 & 17 \\ 0.29 & 4 \\ 0.21 & 3 \\ 1.40 & 13 \\ 0.37 & 7 \\ 0.73 & 9 \\ 0.34 & 6 \\ 0.20 & 2\end{array}$

\begin{tabular}{|c|c|}
\hline $\begin{array}{l}\text { CONSECTTIVE } \\
30\end{array}$ & $\begin{array}{l}\text { DAYS } \\
60\end{array}$ \\
\hline $\begin{array}{rr}2.50 & 16 \\
3.00 & 18 \\
2.50 & 17 \\
0.42 & 5 \\
0.30 & 2\end{array}$ & $\begin{array}{rr}2.50 & 13 \\
3.30 & 18 \\
2.50 & 14 \\
0.91 & 6 \\
0.50 & 4\end{array}$ \\
\hline $\begin{array}{rr}1.80 & 13 \\
0.39 & 4 \\
1.00 & 9 \\
0.52 & 7 \\
0.48 & 6\end{array}$ & $\begin{array}{l}2.0011 \\
0.48 \\
1.60 \\
0.84 \\
1.00\end{array}$ \\
\hline
\end{tabular}

$\begin{array}{lr}90 \\ 2.70 & 14 \\ 3.40 & 17 \\ 2.70 & 15 \\ 1.50 & 6 \\ 0.94 & 4 \\ 2.00 & 10 \\ 0.49 & 2 \\ 1.60 & 7 \\ 1.10 & 5 \\ 1.70 & 8\end{array}$

$\begin{array}{lr}120 \\ 2.80 & 14 \\ 3.40 & 16 \\ 2.80 & 15 \\ 1.60 & 6 \\ 1.50 & 5 \\ & \\ 2.20 & 10 \\ 0.49 & 2 \\ 1.70 & 7 \\ 1.40 & 4 \\ 1.90 & 9\end{array}$

$\begin{array}{llll}3.20 & 13 & 12.0 & 14 \\ 3.50 & 14 & 12.0 & 15\end{array}$

$3.5015 \quad 15.0 \quad 17$

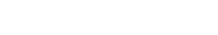

$\begin{array}{rrrr}2.40 & 10 & 6.50 & 6 \\ 0.51 & 1 & 8.10 & 9\end{array}$

$\begin{array}{rrrr}0.51 & 1 & 8.10 \quad 9\end{array}$

$\begin{array}{llll}2.00 & 8 & 10.0 & 12\end{array}$

$\begin{array}{llll}1.50 & 4 & 7.30 & 8 \\ 2.10 & 9 & 6.10 & 5\end{array}$ 
GREEN RIVER BASIN

09273500 HADES CREEK NEAR HANNA, UT--Continued

LOWEST MEAN DISCHARGE, IN OUBIC FEET PER SECOND, AND RANKING FOR THE INDICATED NUMBER OF CONSEQUTTVE DAYS FOR EACH CLIMATIC YEAR, APRII 1-MARQH 31--Continued

YEAR

137

0.103

0.001

0.8011

2.0016

0.204

0.509

0.8813

1.1915
0.102

0.001

0.8311

2.0016
$0.30 \quad 8$

0.579

0.9012

1.4015

7

0.102

$\begin{array}{ll}0.00 & 1 \\ 0.87 & 11\end{array}$

2.0015

0.308

0.599

0.9412

CONSEOUTIVE DAYS

$30 \quad 60$

\subsection{1}

60

90

$90 \quad 120$

120

183

ALL

$\begin{array}{llll}1.1912 & 1.5012 & 3.1016 \\ 0.8910 & 1.1010 & 1.7010\end{array}$

$2.0015 \quad 2.0014 \quad 2.1012$

$\begin{array}{llll}0.37 & 3 & 0.38 \quad 2\end{array}$

$\begin{array}{lr}0.61 & 3 \\ 3.30 & 16\end{array}$

$\begin{array}{ll}3.30 & 16 \\ 2.30 & 11\end{array}$

2.3012

0.391

$\begin{array}{rr}0.95 & 3 \\ 3.60 & 17\end{array}$

$\begin{array}{ll}3.6017 \\ 2.50 & 11\end{array}$

2.5012

0.421

1.303

$\begin{array}{ll}5.10 & 17 \\ 2.50 & 11\end{array}$

2.5011
3.5016

$\begin{array}{ll}3.50 & 16 \\ 0.54 & 2\end{array}$

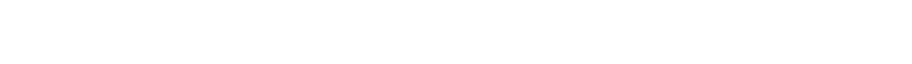

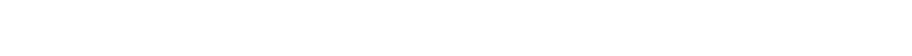

$\begin{array}{llllllllll}1.9014 & 2.3015 & 2.6015 & 2.7013 & 2.8013 & 2.90 & 12 & 11.0 & 13\end{array}$

HIGHEST MEAN DISOHARGE, IN GBIC FEET PER SECOND, AND RANKING FOR THE INDICATED NUMBER OF CONSEQUTIVE DAVS FOR EAOH WATER YEAR, OCTOBER 1-SEPTEMBER 30

YEAR

1950

1951

1952

1954

1955

1956

1957

1958
1959

1960

1961

1962

1964

1965

1966

1967
1968

HIGHBST MeAN DISQHARG, IN QUBIC

\begin{tabular}{|c|c|c|c|c|c|c|c|c|c|c|c|c|c|c|c|c|c|c|c|}
\hline 1 & & 3 & & 7 & & 15 & & $\begin{array}{l}C O N \\
30\end{array}$ & $\mathrm{BU}$ & $\begin{array}{l}\text { DAYS } \\
60\end{array}$ & & 90 & & 120 & & 183 & & ALL & \\
\hline 68.0 & 11 & 66.0 & 11 & 65.0 & 8 & 63.0 & 6 & 58.0 & 5 & 47.0 & 4 & 36.0 & 4 & 29.0 & 4 & 20.0 & 5 & 11.0 & 6 \\
\hline $\begin{array}{c}76.0 \\
101 \\
64.0 \\
29.0 \\
53.0\end{array}$ & $\begin{array}{r}8 \\
2 \\
12 \\
18 \\
13\end{array}$ & $\begin{array}{l}67.0 \\
96.0 \\
63.0 \\
28.0 \\
48.0\end{array}$ & $\begin{array}{r}10 \\
2 \\
12 \\
18 \\
13\end{array}$ & $\begin{array}{l}62.0 \\
94.0 \\
61.0 \\
26.0 \\
41.0\end{array}$ & $\begin{array}{r}11 \\
2 \\
12 \\
17 \\
14\end{array}$ & $\begin{array}{l}60.0 \\
87.0 \\
56.0 \\
25.0 \\
35.0\end{array}$ & $\begin{array}{r}9 \\
1 \\
12 \\
17 \\
14\end{array}$ & $\begin{array}{l}52.0 \\
72.0 \\
43.0 \\
21.0 \\
30.0\end{array}$ & $\begin{array}{r}9 \\
1 \\
12 \\
18 \\
14\end{array}$ & $\begin{array}{l}43.0 \\
53.0 \\
29.0 \\
14.0 \\
24.0\end{array}$ & $\begin{array}{r}7 \\
2 \\
13 \\
18 \\
14\end{array}$ & $\begin{array}{l}34.0 \\
44.0 \\
22.0 \\
11.0 \\
19.0\end{array}$ & $\begin{array}{r}7 \\
2 \\
12 \\
18 \\
14\end{array}$ & $\begin{array}{c}28.0 \\
37.0 \\
17.0 \\
8.70 \\
1.5 .0\end{array}$ & $\begin{array}{r}6 \\
2 \\
13 \\
18 \\
14\end{array}$ & $\begin{array}{c}20.0 \\
26.0 \\
12.0 \\
6.40 \\
11.0\end{array}$ & $\begin{array}{r}6 \\
2 \\
13 \\
18 \\
14\end{array}$ & $\begin{array}{r}12.0 \\
15.0 \\
7.90 \\
4.00 \\
6.40\end{array}$ & $\begin{array}{r}5 \\
1 \\
12 \\
18 \\
15\end{array}$ \\
\hline $\begin{array}{l}69.0 \\
85.0 \\
71.0 \\
40.0 \\
37.0\end{array}$ & $\begin{array}{r}10 \\
4 \\
9 \\
15 \\
16\end{array}$ & $\begin{array}{l}68.0 \\
80.0 \\
70.0 \\
39.0 \\
36.0\end{array}$ & $\begin{array}{r}9 \\
5 \\
8 \\
15 \\
16\end{array}$ & $\begin{array}{l}66.0 \\
78.0 \\
63.0 \\
37.0 \\
31.0\end{array}$ & $\begin{array}{r}7 \\
4 \\
10 \\
15 \\
16\end{array}$ & $\begin{array}{l}62.0 \\
68.0 \\
59.0 \\
34.0 \\
27.0\end{array}$ & $\begin{array}{r}8 \\
4 \\
10 \\
15 \\
16\end{array}$ & $\begin{array}{l}53.0 \\
60.0 \\
50.0 \\
29.0 \\
23.0\end{array}$ & $\begin{array}{r}8 \\
4 \\
10 \\
15 \\
16\end{array}$ & $\begin{array}{l}38.0 \\
44.0 \\
34.0 \\
22.0 \\
18.0\end{array}$ & $\begin{array}{r}10 \\
5 \\
11 \\
15 \\
16\end{array}$ & $\begin{array}{l}28.0 \\
32.0 \\
24.0 \\
17.0 \\
14.0\end{array}$ & $\begin{array}{r}10 \\
8 \\
11 \\
15 \\
17\end{array}$ & $\begin{array}{l}23.0 \\
26.0 \\
19.0 \\
14.0 \\
12.0\end{array}$ & $\begin{array}{r}10 \\
8 \\
11 \\
15 \\
17\end{array}$ & $\begin{array}{c}16.0 \\
18.0 \\
13.0 \\
9.90 \\
8.50\end{array}$ & $\begin{array}{r}10 \\
8 \\
11 \\
15 \\
17\end{array}$ & $\begin{array}{l}9.10 \\
9.30 \\
7.50 \\
5.70 \\
5.20\end{array}$ & $\begin{array}{r}10 \\
9 \\
14 \\
16 \\
17\end{array}$ \\
\hline $\begin{array}{l}17.0 \\
78.0 \\
51.0 \\
81.0 \\
90.0\end{array}$ & $\begin{array}{r}19 \\
7 \\
14 \\
6 \\
3\end{array}$ & $\begin{array}{l}14.0 \\
74.0 \\
48.0 \\
74.0 \\
85.0\end{array}$ & $\begin{array}{r}19 \\
6 \\
14 \\
7 \\
3\end{array}$ & $\begin{array}{l}13.0 \\
69.0 \\
45.0 \\
64.0 \\
79.0\end{array}$ & $\begin{array}{r}19 \\
6 \\
13 \\
9 \\
3\end{array}$ & $\begin{array}{l}12.0 \\
63.0 \\
39.0 \\
57.0 \\
74.0\end{array}$ & $\begin{array}{r}19 \\
7 \\
13 \\
11 \\
3\end{array}$ & $\begin{array}{l}11.0 \\
54.0 \\
37.0 \\
50.0 \\
68.0\end{array}$ & $\begin{array}{r}19 \\
7 \\
13 \\
11 \\
2\end{array}$ & $\begin{array}{l}9.60 \\
40.0 \\
29.0 \\
40.0 \\
59.0\end{array}$ & $\begin{array}{r}19 \\
8 \\
12 \\
9 \\
1\end{array}$ & $\begin{array}{l}7.30 \\
35.0 \\
21.0 \\
31.0 \\
47.0\end{array}$ & $\begin{array}{r}19 \\
5 \\
13 \\
9 \\
1\end{array}$ & $\begin{array}{l}6.50 \\
29.0 \\
18.0 \\
25.0 \\
38.0\end{array}$ & $\begin{array}{r}19 \\
5 \\
12 \\
9 \\
1\end{array}$ & $\begin{array}{l}5.50 \\
21.0 \\
13.0 \\
17.0 \\
27.0\end{array}$ & $\begin{array}{r}19 \\
4 \\
12 \\
9 \\
1\end{array}$ & $\begin{array}{c}3.50 \\
13.0 \\
7.90 \\
10.0 \\
14.0\end{array}$ & $\begin{array}{r}19 \\
3 \\
11 \\
7 \\
2\end{array}$ \\
\hline $\begin{array}{r}31.0 \\
84.0 \\
122\end{array}$ & $\begin{array}{r}17 \\
5 \\
1\end{array}$ & $\begin{array}{r}29.0 \\
80.0 \\
113\end{array}$ & $\begin{array}{r}17 \\
4 \\
1\end{array}$ & $\begin{array}{l}25.0 \\
74.0 \\
96.0\end{array}$ & $\begin{array}{r}18 \\
5 \\
1\end{array}$ & $\begin{array}{l}23.0 \\
67.0 \\
81.0\end{array}$ & $\begin{array}{r}18 \\
5 \\
2\end{array}$ & $\begin{array}{l}22.0 \\
55.0 \\
66.0\end{array}$ & $\begin{array}{r}17 \\
6 \\
3\end{array}$ & $\begin{array}{l}18.0 \\
44.0 \\
49.0\end{array}$ & $\begin{array}{r}17 \\
6 \\
3\end{array}$ & $\begin{array}{l}15.0 \\
34.0 \\
38.0\end{array}$ & $\begin{array}{r}16 \\
6 \\
3\end{array}$ & $\begin{array}{l}13.0 \\
27.0 \\
31.0\end{array}$ & $\begin{array}{r}16 \\
7 \\
3\end{array}$ & $\begin{array}{l}9.60 \\
19.0 \\
22.0\end{array}$ & $\begin{array}{r}16 \\
7 \\
3\end{array}$ & $\begin{array}{l}7.60 \\
10.0 \\
12.0\end{array}$ & $\begin{array}{r}13 \\
8 \\
4\end{array}$ \\
\hline
\end{tabular}

DURATION OF DISCHARGE FOR EAGH WATER YEAR

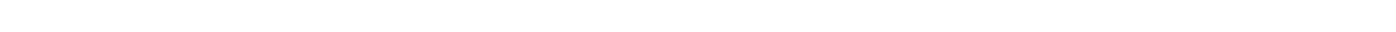

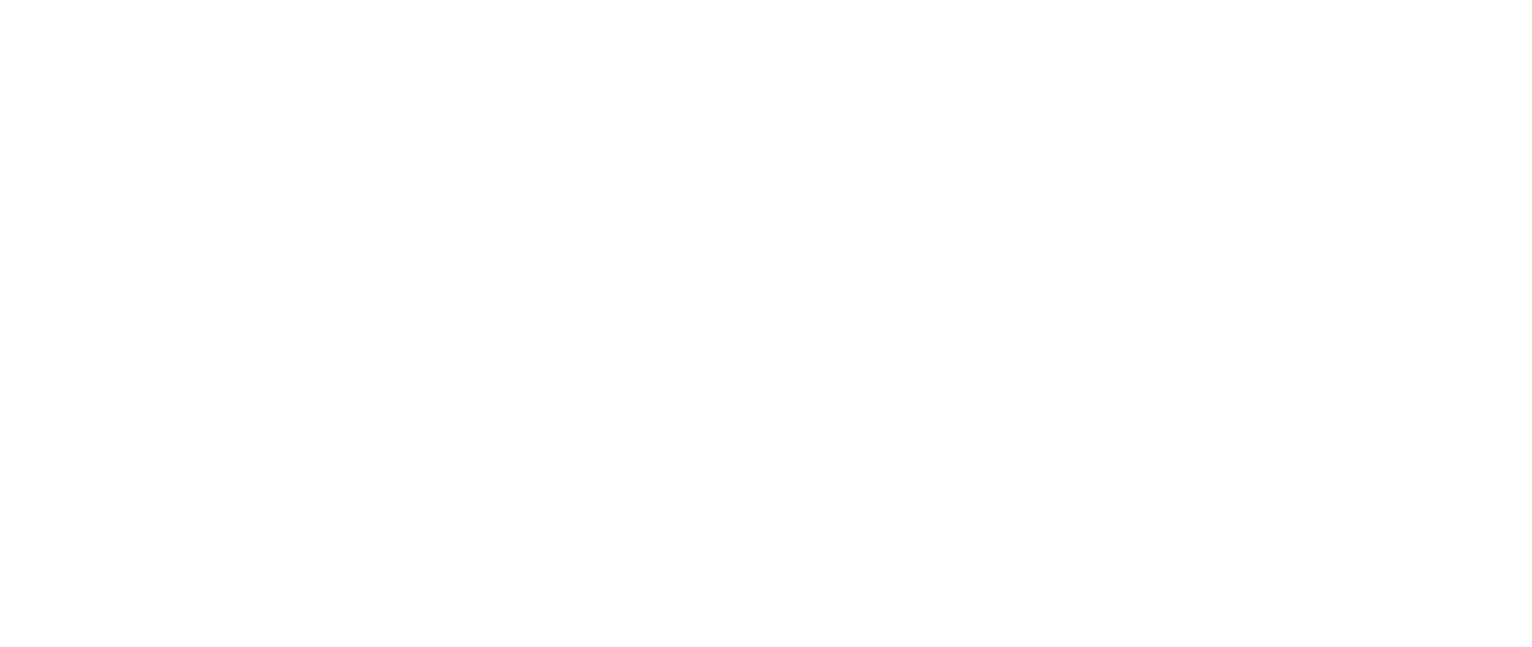


GREEN RIVER BASIN

09273500 HADES CREER NEAR HANNA, UT-COntinued

DURATION TABLE OF DISCHARGE FOR WATER YEARS 1950-68

\begin{tabular}{|c|c|c|c|c|c|c|c|c|c|c|c|c|c|c|c|c|c|c|c|}
\hline & $\begin{array}{c}\text { CUBIC } \\
\text { FEET } \\
\text { PER } \\
\text { SECOND }\end{array}$ & $\begin{array}{r}\text { TOTAL, } \\
\text { DAYS }\end{array}$ & $\begin{array}{c}\text { ACOU- } \\
\text { NO- } \\
\text { LATEDD } \\
\text { DAYS }\end{array}$ & $\begin{array}{l}\text { PER- } \\
\text { CENT } \\
\text { DAYS }\end{array}$ & & $\begin{array}{c}\text { OUBIC } \\
\text { FEET } \\
\text { PER } \\
\text { SECOND }\end{array}$ & $\begin{array}{r}\text { TOTAL } \\
\text { DAYS }\end{array}$ & $\begin{array}{c}\text { ACOU- } \\
\text { MU- } \\
\text { LATED } \\
\text { DAYS }\end{array}$ & $\begin{array}{l}\text { PER- } \\
\text { OENT } \\
\text { DAYS }\end{array}$ & CIASS & $\begin{array}{c}\text { CUBIC } \\
\text { FEET } \\
\text { PER } \\
\text { SECOND }\end{array}$ & $\begin{array}{l}\text { TOTAL } \\
\text { DAYS }\end{array}$ & $\begin{array}{c}\text { ACOU- } \\
\text { MU- } \\
\text { LAIEED } \\
\text { DAYS }\end{array}$ & $\begin{array}{l}\text { PER- } \\
\text { CENT } \\
\text { DAYS }\end{array}$ & & $\begin{array}{c}\text { OUBIC } \\
\text { FEET } \\
\text { PER } \\
\text { SECOND }\end{array}$ & $\begin{array}{l}\text { TOTAL } \\
\text { DAYS }\end{array}$ & $\begin{array}{l}\text { ACO- } \\
\text { MU- } \\
\text { LATED } \\
\text { DAYS }\end{array}$ & $\begin{array}{l}\text { QER- } \\
\text { CENI } \\
\text { DAYS }\end{array}$ \\
\hline $\begin{array}{l}0 \\
1 \\
2 \\
3 \\
4 \\
5 \\
6 \\
7 \\
8\end{array}$ & $\begin{array}{l}0.00 \\
0.10 \\
0.12 \\
0.15 \\
0.19 \\
0.24 \\
0.29 \\
0.36 \\
0.45\end{array}$ & $\begin{array}{r}7 \\
21 \\
0 \\
0 \\
59 \\
0 \\
65 \\
116 \\
166\end{array}$ & $\begin{array}{l}6940 \\
6933 \\
6912 \\
6912 \\
6912 \\
6853 \\
6853 \\
6788 \\
6672\end{array}$ & $\begin{array}{r}100.0 \\
99.9 \\
99.6 \\
99.6 \\
99.6 \\
98.7 \\
98.7 \\
97.8 \\
96.1\end{array}$ & $\begin{array}{r}9 \\
10 \\
11 \\
12 \\
13 \\
14 \\
15 \\
16 \\
17\end{array}$ & $\begin{array}{l}0.55 \\
0.68 \\
0.84 \\
1.10 \\
1.30 \\
1.60 \\
2.00 \\
2.50 \\
3.00\end{array}$ & $\begin{array}{r}139 \\
82 \\
76 \\
70 \\
284 \\
391 \\
739 \\
838 \\
924\end{array}$ & $\begin{array}{l}6506 \\
6367 \\
6285 \\
6209 \\
6139 \\
5855 \\
5464 \\
4725 \\
3887\end{array}$ & $\begin{array}{l}93.7 \\
91.7 \\
90.6 \\
89.5 \\
88.5 \\
84.4 \\
78.7 \\
68.1 \\
56.0\end{array}$ & $\begin{array}{l}18 \\
19 \\
20 \\
21 \\
22 \\
23 \\
24 \\
25 \\
26\end{array}$ & $\begin{array}{r}3.8 \\
4.7 \\
5.8 \\
7.1 \\
8.8 \\
11.0 \\
14.0 \\
17.0 \\
21.0\end{array}$ & $\begin{array}{l}416 \\
347 \\
268 \\
237 \\
243 \\
247 \\
178 \\
153 \\
175\end{array}$ & $\begin{array}{r}2963 \\
2547 \\
2200 \\
1932 \\
1695 \\
1452 \\
1205 \\
1027 \\
874\end{array}$ & $\begin{array}{l}42.7 \\
36.7 \\
31.7 \\
27.8 \\
24.4 \\
20.9 \\
17.4 \\
14.8 \\
12.6\end{array}$ & $\begin{array}{l}27 \\
28 \\
29 \\
30 \\
31 \\
32 \\
33 \\
34\end{array}$ & $\begin{array}{r}26.0 \\
32.0 \\
39.0 \\
49.0 \\
60.0 \\
74.0 \\
92.0 \\
110.0\end{array}$ & $\begin{array}{r}134 \\
147 \\
140 \\
119 \\
109 \\
40 \\
8 \\
2\end{array}$ & $\begin{array}{r}699 \\
565 \\
418 \\
278 \\
159 \\
50 \\
10 \\
2\end{array}$ & $\begin{array}{r}10.1 \\
8.1 \\
6.0 \\
4.0 \\
2.3 \\
0.7 \\
0.1 \\
0.0\end{array}$ \\
\hline
\end{tabular}

MONTHLY MEAN DISCHARGES, IN CUBIC FEET PER SECOND, FOR EACH WATER YEAR

$\begin{array}{lllllllllllrr}\text { YEAR } & \text { OCT } & \text { NOV } & \text { DEC } & \text { JAN } & \text { FEB } & \text { MAR } & \text { APR } & \text { MAY } & \text { JUNE } & \text { JULY } & \text { AUG } & \text { SEP } \\ 1950 & 1.05 & 3.44 & 3.00 & 2.50 & 2.09 & 2.00 & 6.14 & 19.7 & 58.2 & 28.2 & 6.84 & 3.98 \\ & & & & & & & & & & & \\ 1951 & 4.37 & 3.65 & 3.27 & 3.01 & 2.50 & 2.50 & 3.77 & 22.5 & 50.5 & 23.6 & 14.2 & 6.46 \\ 1952 & 3.29 & 3.50 & 3.59 & 3.50 & 3.50 & 3.50 & 9.50 & 32.0 & 70.4 & 28.2 & 12.7 & 5.66 \\ 1953 & 5.42 & 4.08 & 3.17 & 3.00 & 2.50 & 2.50 & 3.16 & 4.25 & 39.6 & 17.6 & 7.47 & 1.87 \\ 1954 & 0.45 & 2.40 & 2.22 & 2.00 & 1.90 & 1.90 & 2.47 & 18.5 & 8.29 & 4.69 & 2.34 & 0.53 \\ 1955 & 0.46 & 2.96 & 2.65 & 2.50 & 2.00 & 2.00 & 2.14 & 16.8 & 27.7 & 10.5 & 4.94 & 1.96 \\ 1956 & 2.96 & 2.69 & 2.82 & 2.00 & 2.00 & 2.10 & 3.92 & 26.2 & 46.1 & 12.2 & 4.96 & 1.10 \\ 1957 & 0.41 & 0.54 & 0.52 & 0.50 & 0.50 & 0.60 & 1.00 & 5.98 & 58.3 & 28.5 & 9.82 & 5.45 \\ 1958 & 2.80 & 2.37 & 2.15 & 1.70 & 1.60 & 1.54 & 2.75 & 24.7 & 38.8 & 8.74 & 1.81 & 0.99 \\ 1959 & 0.72 & 2.29 & 1.97 & 1.80 & 1.60 & 1.50 & 3.33 & 9.49 & 28.6 & 12.2 & 4.70 & 0.52 \\ 1960 & 1.92 & 4.17 & 2.61 & 1.74 & 1.50 & 2.00 & 4.93 & 10.6 & 23.1 & 7.84 & 2.18 & 0.19 \\ & & & & & & & & & & & & \\ 1961 & 0.28 & 1.90 & 1.86 & 2.00 & 1.50 & 1.68 & 1.51 & 5.16 & 10.5 & 5.70 & 2.75 & 7.29 \\ 1962 & 8.95 & 6.92 & 4.68 & 3.66 & 3.59 & 2.66 & 8.81 & 26.1 & 47.9 & 30.5 & 7.99 & 2.73 \\ 1963 & 1.38 & 2.91 & 3.18 & 2.86 & 2.77 & 2.68 & 2.75 & 14.6 & 36.0 & 12.8 & 5.59 & 7.47 \\ 1964 & 6.45 & 4.37 & 3.35 & 2.61 & 2.20 & 2.00 & 2.48 & 16.7 & 49.1 & 23.9 & 7.77 & 3.22 \\ 1965 & 0.91 & 0.52 & 0.37 & 0.40 & 0.40 & 0.55 & 0.97 & 13.2 & 61.5 & 54.4 & 18.9 & 12.1 \\ 1966 & 9.71 & 7.81 & 5.93 & 4.81 & 3.56 & 2.96 & 5.28 & 20.6 & 15.2 & 8.46 & 4.65 & 2.19 \\ 1967 & 1.15 & 3.12 & 1.85 & 1.61 & 1.52 & 2.16 & 2.78 & 12.7 & 50.3 & 32.1 & 9.45 & 4.50 \\ 1968 & 2.72 & 3.44 & 3.01 & 2.74 & 2.64 & 2.66 & 3.01 & 6.35 & 64.5 & 33.2 & 14.7 & 9.17\end{array}$

ANNUAL PEAK DISCHARGE, IN CUBIC FEET PER SECOND, AND CORRESPONDING GAGE HEIGHT, IN FEET, FOR EACH WATER YEAR

$\begin{array}{lccccccccrr}\begin{array}{l}\text { WATER } \\ \text { YEAR }\end{array} & \text { DATE } & \begin{array}{c}\text { GAGE } \\ \text { HEIGHT }\end{array} & \begin{array}{c}\text { PEAK } \\ \text { DISCHARGE }\end{array} & \begin{array}{l}\text { WATER } \\ \text { YEAR }\end{array} & \text { DATE } & \begin{array}{c}\text { GAGE } \\ \text { HEIGHT }\end{array} & \begin{array}{r}\text { PEAK } \\ \text { DISCHARGE }\end{array} & \begin{array}{l}\text { WATER } \\ \text { YEAR }\end{array} & \begin{array}{c}\text { GAGE } \\ \text { DATE }\end{array} & \begin{array}{c}\text { PEAK } \\ \text { HEIGHT }\end{array} \\ \text { DISCHARGE }\end{array}$

MAGNITUDE AND PROBABIUITY OF ANNUAC IONEST MEAN DISCHARGE BASED ON CLIMATIC YEARS 1951-68

\begin{tabular}{|c|c|c|c|c|c|c|}
\hline \multirow{2}{*}{$\begin{array}{l}\text { PERIOD } \\
\text { (CON- } \\
\text { SEQU- } \\
\text { TIVE } \\
\text { DAYS) }\end{array}$} & \multicolumn{6}{|c|}{$\begin{array}{l}\text { DISCHARGE, IN OUBIC FEET PER SECOND, FOR } \\
\text { INDICATED RECURRENCE INTERNAL, IN YEARS, AND } \\
\text { ANNUAL NONEXCEEDANCE PROBABILITY, IN PERCENT }\end{array}$} \\
\hline & $\begin{array}{c}2 \\
508\end{array}$ & $\begin{array}{c}5 \\
208\end{array}$ & $\begin{array}{l}10 \\
108\end{array}$ & $\begin{array}{l}20 \\
58\end{array}$ & $\begin{array}{l}50 \\
28\end{array}$ & $\begin{array}{r}100 \\
18\end{array}$ \\
\hline $\begin{array}{r}1 \\
7 \\
14 \\
30 \\
60 \\
90\end{array}$ & $\begin{array}{l}0.51 \\
0.61 \\
0.74 \\
0.97 \\
1.5 \\
1.8\end{array}$ & $\begin{array}{l}0.18 \\
0.22 \\
0.31 \\
0.44 \\
0.69 \\
0.98\end{array}$ & $\begin{array}{l}0.09 \\
0.11 \\
0.19 \\
0.28 \\
0.43 \\
0.67\end{array}$ & $\begin{array}{l}0.00 \\
0.00 \\
0.13 \\
0.19 \\
0.28 \\
0.47\end{array}$ & $\begin{array}{l}- \\
\overline{-} \\
z \\
-\end{array}$ & $\overline{-}$ \\
\hline
\end{tabular}

MAGNITUDE AND PROBABIIITY OF ANNUAL HTGHEST MEAN DISCAARGE BASED ON WATER YEARS 1950-68

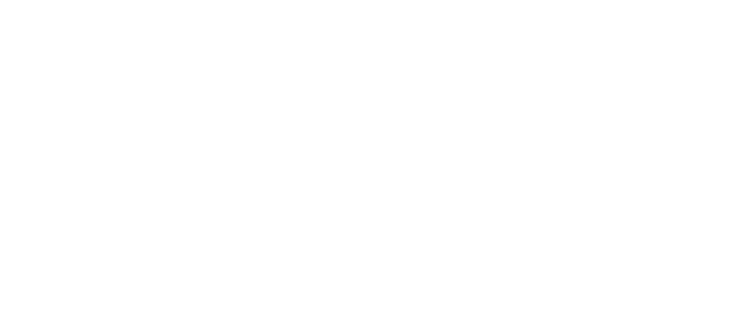


GREEN RIVER BASIN

09274000 DUCHESNE RIVER NEAR HANNA, UT

LOCATION.--Lat $40^{\circ} 32^{\prime} 00^{\prime \prime}$, long $110^{\circ} 52^{\prime} 00^{\prime \prime}$, in $\mathrm{NE}_{\frac{1}{4}}^{\frac{1}{4}} \mathrm{sec} .35$, T.2 N., R.9 W., Uintah Meridian, Duchesne County, Hydrologic Unit 14060003, on right bank $100 \mathrm{ft}$ downstream from Hades Creek and $11 \mathrm{mi}$ northwest of Hanna.

DRAINAGE AREA. $-78 \mathrm{mi}^{2}$, approximately.

MEAN BASIN ELEVATION. $-9,810 \mathrm{ft}$.

PERIOD OF RECORD AVAIIABLE.--August 1921 to September 1923, June 1929 to September 1930 (fragmentary), March 1946 to September 1963. Monthly mean discharge only for some periods, published in WSP 1313. Prior to 1946, published as "North Fork Duchesne River near Hanna".

GAGE.--Water-stage recorder. Altitude of gage is 7,380 ft from river-profile map. Prior to Mar. 28, 1946, staff gage at site 150 ft downstream at different datum. Mar. 28, 1946, to Sept. 9, 1953, water-stage recorder at site $150 \mathrm{ft}$ downstream at datum 0.42 ft lower.

REMARKS.--Diversions for irrigation of about 60 acres above station. Water is also diverted above station through Duchesne tunnel, capacity, about $600 \mathrm{ft}^{3} / \mathrm{s}$, to Provo River for use in the Great Basin; diversion began Oct. $20,1953$.

AVERAGE DISCHARGE. - -9 years (water years 1922-23, 1947-53), $122 \mathrm{ft}^{3} / \mathrm{s}, 88,390$ acre-ft/yr (prior to diversion through Duchesne tunnel).

EXTREMES'FOR PERIOD OF RECORD.--Maximum discharge, about $17,500 \mathrm{ft}^{3} / \mathrm{s}$ June 16,1963 , gage height, $12.38 \mathrm{ft}$ from $\mathrm{floodmarks,} \mathrm{result}$ of slope-area measurement of peak flow, caused by failure of Little Deer Creek Dam $8 \mathrm{mi}$ upstream; minimum recorded, $4.6 \mathrm{ft} 3 / \mathrm{s}$ Nov. 14, 1956, Mar. 1, 1961.

DATA BELOW BASED ON PERIOD OF RECORD PRIOR TO DIVERSION THROUGH DUCHESNE TUNNEL.

LOWEST MEAN DISCHARGE, IN CUBIC FEET PER SECOND, AND RANKING FOR THE INDICATED NUMBER OF CONSECUTIVE DAYS FOR EACH CLIMATIC YEAR, APRIL 1-MARCH 31

\begin{tabular}{|c|c|c|c|c|c|c|c|c|c|c|c|c|c|c|c|c|c|c|c|c|}
\hline YEAR & \multicolumn{20}{|c|}{ CONSECUTIVE DAYS } \\
\hline 23 & 21.0 & 8 & 21.0 & 8 & 21.0 & 8 & 21.0 & 8 & 21.0 & 8 & 21.0 & 8 & 22.0 & 8 & 22.0 & 8 & 24.0 & 8 & 161 & 8 \\
\hline
\end{tabular}

HIGHEST MEAN DISCHARGE, IN CUBIC FEET PER SEOOND, AND RANKING FOR THE INDICATED NUMBER OF CONSECUTIVE DAYS FOR EACH WATER YEAR, OCTCBER 1-SEPTPMBER 30

\begin{tabular}{|c|c|c|c|c|c|c|c|c|c|c|c|c|c|c|c|c|c|c|c|}
\hline YEAR & J & & 3 & & 7 & & 15 & & $a$ & & $\begin{array}{ll}\mathrm{VE} \\
6\end{array}$ & & 9 & & 120 & & 18 & & ALL \\
\hline $\begin{array}{l}1922 \\
1923\end{array}$ & $\begin{array}{l}1490 \\
1270\end{array}$ & $\begin{array}{l}1 \\
2\end{array}$ & $\begin{array}{l}1440 \\
1200\end{array}$ & $\begin{array}{l}1 \\
2\end{array}$ & $\begin{array}{l}1330 \\
1050\end{array}$ & $\begin{array}{l}1 \\
3\end{array}$ & $\begin{array}{r}1140 \\
799\end{array}$ & $\begin{array}{l}1 \\
6\end{array}$ & $\begin{array}{r}1020 \\
701\end{array}$ & $\begin{array}{l}1 \\
5\end{array}$ & $\begin{array}{l}701 \\
578\end{array}$ & & $\begin{array}{l}542 \\
451\end{array}$ & $\frac{1}{3}$ & $\begin{array}{l}434 \\
360\end{array}$ & $\begin{array}{l}1 \\
3\end{array}$ & $\begin{array}{l}298 \\
250\end{array}$ & $\begin{array}{l}1 \\
3\end{array}$ & $\begin{array}{l}161 \\
137\end{array}$ \\
\hline $\begin{array}{l}1947 \\
1948 \\
1949 \\
1950\end{array}$ & $\begin{array}{r}778 \\
856 \\
1050 \\
1060\end{array}$ & $\begin{array}{l}9 \\
8 \\
7 \\
6\end{array}$ & $\begin{array}{r}732 \\
841 \\
1010 \\
983\end{array}$ & $\begin{array}{l}9 \\
8 \\
6 \\
7\end{array}$ & $\begin{array}{l}694 \\
792 \\
981 \\
942\end{array}$ & $\begin{array}{l}9 \\
8 \\
6 \\
7\end{array}$ & $\begin{array}{l}615 \\
736 \\
869 \\
861\end{array}$ & $\begin{array}{l}9 \\
8 \\
3 \\
4\end{array}$ & $\begin{array}{l}572 \\
571 \\
668 \\
813\end{array}$ & $\begin{array}{l}8 \\
9 \\
6 \\
2\end{array}$ & $\begin{array}{l}510 \\
350 \\
515 \\
581\end{array}$ & $\begin{array}{l}9 \\
6\end{array}$ & $\begin{array}{l}391 \\
254 \\
404 \\
432\end{array}$ & $\begin{array}{l}7 \\
9 \\
5 \\
4\end{array}$ & $\begin{array}{l}311 \\
199 \\
321 \\
343\end{array}$ & $\begin{array}{l}7 \\
9 \\
6 \\
4\end{array}$ & $\begin{array}{l}217 \\
137 \\
221 \\
236\end{array}$ & $\begin{array}{l}7 \\
9 \\
6 \\
4\end{array}$ & $\begin{array}{l}119 \\
78.0 \\
118 \\
128\end{array}$ \\
\hline
\end{tabular}

DURATION OF DISCHARGE FOR EACH WATER YEAR

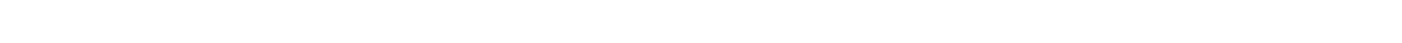
YEAR NUMBER OF DAYS IN CLASS

OUBIC FEET -DAYS

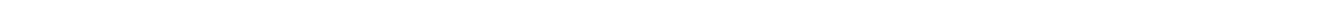

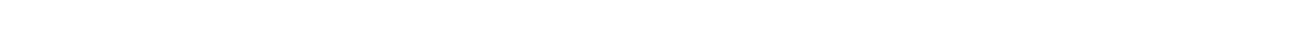
$\begin{array}{lllllllllllllllllllllllllllll}32 & 73 & 43 & 22 & 13 & 19 & 28 & 5 & 4 & 7 & 13 & 13 & 6 & 8 & 2 & 5 & 2 & 2 & 3 & 3 & 4 & 7 & 5 & 8 & 9 & 13 & 10 & 6\end{array}$

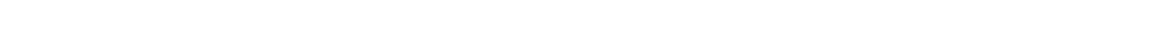

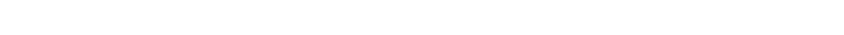

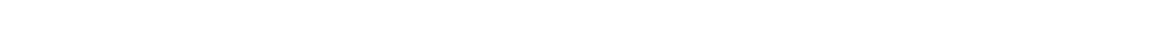

$\begin{array}{lllllllllllllllllllllllllllllll}1 & 11122 & 33 & 30 & 12 & 6 & 2 & 5 & 9 & 9 & 8 & 10 & 23 & 8 & 6 & 9 & 3 & 7 & 3 & 1 & 3 & 3 & 7 & 7 & 10 & 3 & 2 & 5 & 4 & 3\end{array}$

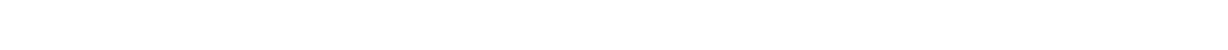

43339.0

28415.0 43206.0 46637.0

45733.0 54386.0 31190.0 
09274000 DUGHSNE RIVER NEAR HANNA, UT-Continued

DURATION TABLE OF DISCHARGE FOR WATER YEARS 1922-23, 1947-53
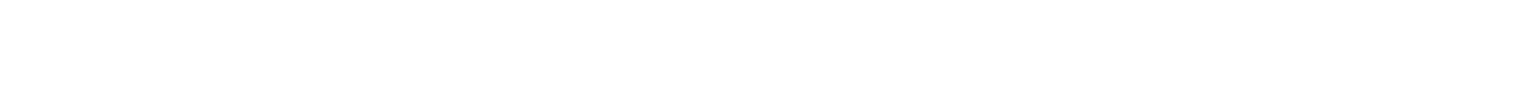

CLASS SECOND DAYS DAYS DAYS

$\begin{array}{lllll}18 & 150.0 & 36 & 628 & 19.1 \\ 19 & 170.0 & 25 & 592 & 18.0 \\ 20 & 190.0 & 38 & 567 & 17.2 \\ 21 & 220.0 & 46 & 529 & 16.1 \\ 22 & 260.0 & 55 & 483 & 14.7 \\ 23 & 300.0 & 47 & 428 & 13.0 \\ 24 & 340.0 & 33 & 381 & 11.6 \\ 25 & 390.0 & 64 & 348 & 10.6 \\ 26 & 460.0 & 43 & 284 & 8.6\end{array}$

$\begin{array}{rrrrr}27 & 520.0 & 57 & 241 & 7.3 \\ 28 & 600.0 & 47 & 184 & 5.6 \\ 29 & 700.0 & 36 & 137 & 4.2 \\ 30 & 800.0 & 40 & 101 & 3.1 \\ 31 & 930.0 & 36 & 61 & 1.9 \\ 32 & 1100.0 & 15 & 25 & 0.8 \\ 33 & 1200.0 & 7 & 10 & 0.3 \\ 34 & 1400.0 & 3 & 3 & 0.1\end{array}$

MONTHLY MEAN DISCHARGES, IN OBBIC FEET PER SECOND, FOR EAOH WATER YEAR

\begin{tabular}{|c|c|c|c|c|c|c|c|c|c|c|c|c|}
\hline YEAR & OCT & NOW & DEC & JAN & FEB & MAR & $\mathrm{APR}$ & MAY & JUNE & JULY & AUG & SEP \\
\hline $\begin{array}{l}1922 \\
1923\end{array}$ & $\begin{array}{l}29.7 \\
23.2\end{array}$ & $\begin{array}{l}23.5 \\
21.3\end{array}$ & $\begin{array}{l}22.1 \\
21.8\end{array}$ & $\begin{array}{l}20.0 \\
23.0\end{array}$ & $\begin{array}{l}20.0 \\
25.0\end{array}$ & $\begin{array}{l}22.0 \\
27.1\end{array}$ & $\begin{array}{l}40.1 \\
60.0\end{array}$ & $\begin{array}{l}382 \\
413\end{array}$ & $\begin{array}{l}941 \\
682\end{array}$ & $\begin{array}{l}270 \\
243\end{array}$ & ${ }_{66.6}^{121}$ & $\begin{array}{l}35.0 \\
34.2\end{array}$ \\
\hline $\begin{array}{l}1947 \\
1948 \\
1949 \\
1950\end{array}$ & $\begin{array}{l}23.7 \\
21.4 \\
15.2 \\
23.0\end{array}$ & $\begin{array}{l}20.8 \\
20.6 \\
16.5 \\
21.7\end{array}$ & $\begin{array}{l}18.1 \\
17.5 \\
15.0 \\
18.4\end{array}$ & $\begin{array}{l}16.0 \\
16.0 \\
13.5 \\
16.0\end{array}$ & $\begin{array}{l}17.0 \\
16.0 \\
13.9 \\
15.0\end{array}$ & $\begin{array}{l}26.9 \\
17.0 \\
21.1 \\
18.0\end{array}$ & $\begin{array}{l}61.8 \\
37.0 \\
97.9 \\
95.3\end{array}$ & $\begin{array}{l}528 \\
402 \\
367 \\
318\end{array}$ & $\begin{array}{l}478 \\
285 \\
639 \\
766\end{array}$ & $\begin{array}{c}145 \\
53.7 \\
160 \\
172\end{array}$ & $\begin{array}{l}54.6 \\
27.3 \\
39.5 \\
41.0\end{array}$ & $\begin{array}{l}28.0 \\
15.7 \\
21.0 \\
31.1\end{array}$ \\
\hline $\begin{array}{l}1951 \\
1952 \\
1953\end{array}$ & $\begin{array}{l}22.4 \\
30.2 \\
23.6\end{array}$ & $\begin{array}{l}24.6 \\
20.7 \\
18.0\end{array}$ & $\begin{array}{l}23.0 \\
18.0 \\
17.0\end{array}$ & $\begin{array}{l}20.4 \\
16.0 \\
16.0\end{array}$ & $\begin{array}{l}21.0 \\
15.0 \\
15.0\end{array}$ & $\begin{array}{l}21.0 \\
15.0 \\
16.2\end{array}$ & $\begin{array}{l}74.8 \\
95.0 \\
40.8\end{array}$ & $\begin{array}{l}393 \\
542 \\
115\end{array}$ & $\begin{array}{l}609 \\
742 \\
578\end{array}$ & $\begin{array}{l}181 \\
174 \\
114\end{array}$ & $\begin{array}{l}79.5 \\
75.6 \\
53.4\end{array}$ & $\begin{array}{l}32.2 \\
40.1 \\
21.4\end{array}$ \\
\hline
\end{tabular}

ANNUAL PEAK DISCHARGE, IN CUBIC FEET PER SECOND, AND CORRESPONDING GAGE HEIGHT, IN FEET, FOR EAOH WATER YEAR

\begin{tabular}{|c|c|c|c|c|c|c|c|c|c|c|c|}
\hline $\begin{array}{l}\text { WATER } \\
\text { YEAR }\end{array}$ & DATE & $\begin{array}{c}\text { GAGE } \\
\text { HEIGHTT }\end{array}$ & $\begin{array}{c}\text { PEAR } \\
\text { DISCHARGE }\end{array}$ & $\begin{array}{l}\text { WATERR } \\
\text { YEAR }\end{array}$ & DATE & $\begin{array}{c}\text { GAGE } \\
\text { HEIGHT }\end{array}$ & $\begin{array}{c}\text { PEAR } \\
\text { DISOHARGE }\end{array}$ & $\begin{array}{l}\text { WATER } \\
\text { YEAR }\end{array}$ & DATE & $\begin{array}{c}\text { GAGE } \\
\text { HEIGHT }\end{array}$ & $\begin{array}{c}\text { PEAR } \\
\text { DISOHARGE }\end{array}$ \\
\hline $\begin{array}{l}1922 \\
1923 \\
1946\end{array}$ & $\begin{array}{l}\text { JUNE } 08,1922 \\
\text { JUNE } 12,1923 \\
\text { JUNE } 05,1946\end{array}$ & $\begin{array}{l}4.65 \\
4.40 \\
4.60\end{array}$ & $\begin{array}{r}1490 \\
1350 \\
897\end{array}$ & $\begin{array}{l}1948 \\
1949 \\
1950\end{array}$ & $\begin{array}{ll}\text { MAY } & 21,1948 \\
\text { JUNE } & 12,1949 \\
\text { JUNE } & 06,1950\end{array}$ & $\begin{array}{l}4.72 \\
5.17 \\
5.08\end{array}$ & $\begin{array}{l}1000 \\
1240 \\
1190\end{array}$ & $\begin{array}{l}1951 \\
1952 \\
1953\end{array}$ & $\begin{array}{lll}\text { MAY } & 27,1951 \\
\text { JUNE } & 07,1952 \\
\text { JUNE } & 13,1953\end{array}$ & $\begin{array}{l}5.33 \\
5.45 \\
5.65\end{array}$ & $\begin{array}{l}1330 \\
1390 \\
1500\end{array}$ \\
\hline
\end{tabular}

DATA BELOW BASED ON PERTOD OF RECORD AFTER DIVERSION THROGGH DUOHESNE TUNNEE

LOWEST MEAN DISOHARGE, IN OJBIC FEET PER SECOND, AND RANKING FOR THE INDICATED NUMBER OF CONSEOJTTVE DAUS FOR EACH CLIMATIC YEAR, APRIL 1-MARGH 31

\begin{tabular}{|c|c|c|c|c|c|c|c|c|c|c|c|c|c|c|c|c|c|c|c|}
\hline YEAR & & & & & & & & & cons & UTTV & E DAYS & & & & & & & & \\
\hline 1955 & 5.50 & 3 & 5.50 & 3 & 5.50 & 3 & 5.50 & 3 & 5.50 & 3 & 5.50 & 3 & 5.70 & 2 & 6.00 & 2 & 6.70 & 1 & 21.0 \\
\hline
\end{tabular}

HIGHEST MEAN DISGGARGE, IN CUBIC FEET PER SECOND, AND RANKING FOR THE INDICATED NUMBER OF CONSEQJTTVE DAYS FOR EACH WATER YEAR, OCTOBER 1-SEPTEMBER 30

\begin{tabular}{|c|c|c|c|c|c|c|c|c|c|c|c|c|c|c|c|c|c|c|c|c|}
\hline YEAR & 1 & & 3 & & 7 & & 15 & & $\begin{array}{l}\text { cons } \\
30\end{array}$ & & $\begin{array}{c}\text { VE DAYS } \\
60\end{array}$ & & 90 & & 120 & & 183 & & ALL & \\
\hline $\begin{array}{l}1954 \\
1955\end{array}$ & $\begin{array}{l}201 \\
469\end{array}$ & $\begin{array}{l}7 \\
5\end{array}$ & $\begin{array}{l}173 \\
446\end{array}$ & $\begin{array}{l}8 \\
4\end{array}$ & $\begin{array}{l}152 \\
342\end{array}$ & $\begin{array}{l}8 \\
4\end{array}$ & $\begin{array}{l}145 \\
230\end{array}$ & $\begin{array}{l}8 \\
5\end{array}$ & $\begin{array}{l}111 \\
188\end{array}$ & $\begin{array}{l}9 \\
6\end{array}$ & $\begin{array}{l}77.0 \\
140\end{array}$ & $\begin{array}{l}9 \\
6\end{array}$ & $\begin{array}{l}60.0 \\
104\end{array}$ & $\begin{array}{l}9 \\
6\end{array}$ & $\begin{array}{l}49.0 \\
83.0\end{array}$ & $\begin{array}{r}10 \\
6\end{array}$ & $\begin{array}{l}36.0 \\
59.0\end{array}$ & $\begin{array}{r}10 \\
6\end{array}$ & $\begin{array}{l}22.0 \\
33.0\end{array}$ & $\begin{array}{r}10 \\
6\end{array}$ \\
\hline $\begin{array}{l}1956 \\
1957 \\
1958 \\
1959 \\
1960\end{array}$ & $\begin{array}{r}970 \\
1270 \\
1120 \\
184 \\
172\end{array}$ & $\begin{array}{l}3 \\
1 \\
2 \\
8 \\
9\end{array}$ & $\begin{array}{r}932 \\
1230 \\
1090 \\
178 \\
164\end{array}$ & $\begin{array}{l}3 \\
1 \\
2 \\
7 \\
9\end{array}$ & $\begin{array}{r}855 \\
1090 \\
1030 \\
169 \\
149\end{array}$ & $\begin{array}{l}3 \\
1 \\
2 \\
7 \\
9\end{array}$ & $\begin{array}{l}753 \\
863 \\
888 \\
154 \\
133\end{array}$ & $\begin{array}{l}3 \\
2 \\
1 \\
7 \\
9\end{array}$ & $\begin{array}{l}543 \\
652 \\
573 \\
127 \\
131\end{array}$ & $\begin{array}{l}3 \\
1 \\
2 \\
8 \\
7\end{array}$ & $\begin{array}{l}327 \\
377 \\
332 \\
104 \\
101\end{array}$ & $\begin{array}{l}3 \\
1 \\
2 \\
7 \\
8\end{array}$ & $\begin{array}{r}238 \\
273 \\
235 \\
82.0 \\
81.0\end{array}$ & $\begin{array}{l}2 \\
1 \\
3 \\
7 \\
8\end{array}$ & $\begin{array}{l}185 \\
213 \\
181 \\
68.0 \\
69.0\end{array}$ & $\begin{array}{l}2 \\
1 \\
3 \\
8 \\
7\end{array}$ & $\begin{array}{r}126 \\
145 \\
123 \\
51.0 \\
53.0\end{array}$ & $\begin{array}{l}2 \\
1 \\
3 \\
8 \\
7\end{array}$ & $\begin{array}{l}67.0 \\
76.0 \\
66.0 \\
29.0 \\
32.0\end{array}$ & $\begin{array}{l}2 \\
1 \\
3 \\
8 \\
7\end{array}$ \\
\hline $\begin{array}{l}1961 \\
1962 \\
1963\end{array}$ & $\begin{array}{l}163 \\
330 \\
630\end{array}$ & $\begin{array}{r}10 \\
6 \\
4\end{array}$ & $\begin{array}{l}147 \\
325 \\
382\end{array}$ & $\begin{array}{r}10 \\
6 \\
5\end{array}$ & $\begin{array}{l}123 \\
297 \\
254\end{array}$ & $\begin{array}{r}10 \\
5 \\
6\end{array}$ & $\begin{array}{l}109 \\
239 \\
219\end{array}$ & $\begin{array}{r}10 \\
4 \\
6\end{array}$ & $\begin{array}{l}86.0 \\
195 \\
213\end{array}$ & $\begin{array}{r}10 \\
5 \\
4\end{array}$ & $\begin{array}{l}71.0 \\
190 \\
150\end{array}$ & $\begin{array}{r}10 \\
4 \\
5\end{array}$ & $\begin{array}{l}58.0 \\
168 \\
114\end{array}$ & $\begin{array}{r}10 \\
4 \\
5\end{array}$ & $\begin{array}{c}50.0 \\
138 \\
95.0\end{array}$ & $\begin{array}{l}9 \\
4 \\
5\end{array}$ & $\begin{array}{l}40.0 \\
97.0 \\
72.0\end{array}$ & $\begin{array}{l}9 \\
4 \\
5\end{array}$ & $\begin{array}{l}24.0 \\
57.0 \\
40.0\end{array}$ & \\
\hline
\end{tabular}


GREEN RIVER BASIN

09274000 DUCHESNE RIVER NEAR HANNA, UT--Continued

DURATION OF DISCHARGE FOR EACH WATER YEAR

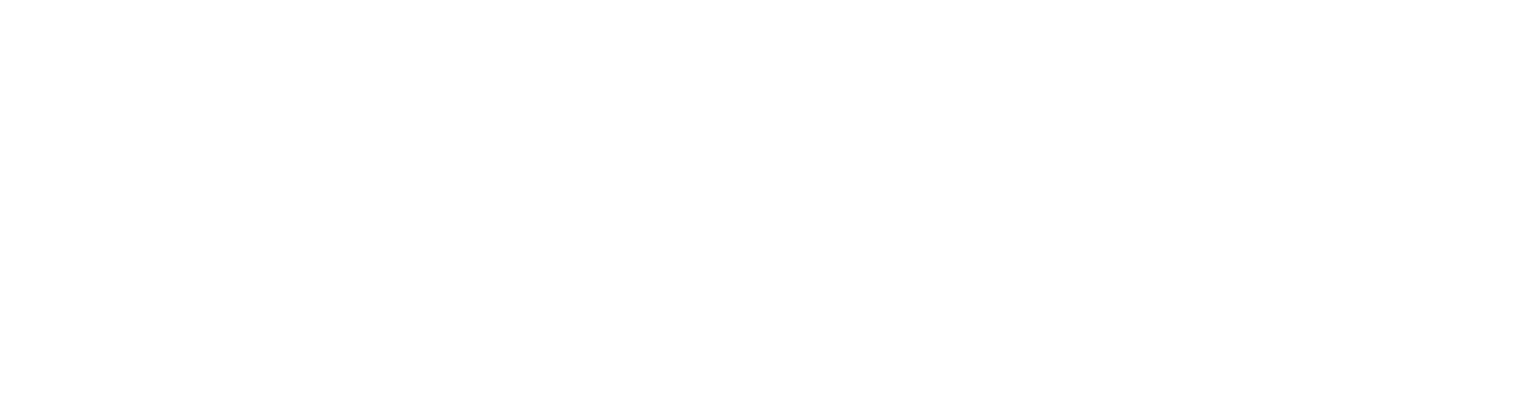

DURATION TABLE OF DISCHARGE FOR WATER YEARS 1954-63

\begin{tabular}{|c|c|c|c|c|c|c|c|c|c|c|c|c|c|c|c|c|c|c|c|}
\hline & $\begin{array}{c}\text { CUBIC } \\
\text { FEET } \\
\text { PER } \\
\text { SECOND }\end{array}$ & $\begin{array}{l}\text { TOTAL } \\
\text { DAYS }\end{array}$ & $\begin{array}{l}\text { ACOJ- } \\
\text { MU- } \\
\text { LATED } \\
\text { DAYS }\end{array}$ & $\begin{array}{l}\text { PER- } \\
\text { CENT } \\
\text { DAYS }\end{array}$ & & $\begin{array}{c}\text { CUBIC } \\
\text { FEET } \\
\text { PER } \\
\text { SECOND }\end{array}$ & $\begin{array}{l}\text { TOTAL } \\
\text { DAYS }\end{array}$ & $\begin{array}{l}\text { ACOU- } \\
\text { NU- } \\
\text { LATED } \\
\text { DAYS }\end{array}$ & $\begin{array}{l}\text { PER- } \\
\text { CENT } \\
\text { DAYS }\end{array}$ & & $\begin{array}{c}\text { CUBIC } \\
\text { FEET } \\
\text { PER } \\
\text { SECOND }\end{array}$ & TOTAL & $\begin{array}{c}\text { ACOU- } \\
\text { MU- } \\
\text { LATED } \\
\text { DAYS }\end{array}$ & $\begin{array}{l}\text { PER- } \\
\text { CENT }\end{array}$ & & $\begin{array}{c}\text { CUBIC } \\
\text { FEET } \\
\text { PER } \\
\text { SECOND }\end{array}$ & TOTAL & $\begin{array}{l}\text { ACOU- } \\
\text { MU- } \\
\text { LATED } \\
\text { DAYS }\end{array}$ & $\begin{array}{l}\text { PER- } \\
\text { CENT } \\
\text { DAYS }\end{array}$ \\
\hline & & DAYS & DAYS & DAYS & & SECOND & DAYS & DAYS & DAYS & CIASS & SECOND & DAYS & DAYS & DAYS & CIASS & SECOND & DAYS & DAYS & DAYS \\
\hline $\begin{array}{l}0 \\
1 \\
2 \\
3 \\
4 \\
5 \\
6 \\
7 \\
8\end{array}$ & $\begin{array}{r}0.00 \\
4.50 \\
5.30 \\
6.30 \\
7.50 \\
8.90 \\
11.00 \\
13.00 \\
15.00\end{array}$ & $\begin{array}{r}0 \\
72 \\
307 \\
407 \\
433 \\
329 \\
255 \\
157 \\
210\end{array}$ & $\begin{array}{l}3652 \\
3652 \\
3580 \\
3273 \\
2866 \\
2433 \\
2104 \\
1849 \\
1692\end{array}$ & $\begin{array}{r}100.0 \\
100.0 \\
98.0 \\
89.6 \\
78.5 \\
66.6 \\
57.6 \\
50.6 \\
46.3\end{array}$ & $\begin{array}{r}9 \\
10 \\
11 \\
12 \\
13 \\
14 \\
15 \\
16 \\
17\end{array}$ & $\begin{array}{l}18.00 \\
21.00 \\
25.00 \\
29.00 \\
35.00 \\
41.00 \\
49.00 \\
58.00 \\
69.00\end{array}$ & $\begin{array}{r}131 \\
145 \\
152 \\
139 \\
131 \\
106 \\
85 \\
70 \\
61\end{array}$ & $\begin{array}{r}1482 \\
1351 \\
1206 \\
1054 \\
915 \\
784 \\
678 \\
593 \\
523\end{array}$ & $\begin{array}{l}40.6 \\
37.0 \\
33.0 \\
28.9 \\
25.1 \\
21.5 \\
18.6 \\
16.2 \\
14.3\end{array}$ & $\begin{array}{l}18 \\
19 \\
20 \\
21 \\
22 \\
23 \\
24 \\
25 \\
26\end{array}$ & $\begin{array}{r}81.0 \\
96.0 \\
110.0 \\
140.0 \\
160.0 \\
190.0 \\
230.0 \\
270.0 \\
320.0\end{array}$ & $\begin{array}{r}57 \\
56 \\
115 \\
49 \\
48 \\
34 \\
14 \\
11 \\
10\end{array}$ & $\begin{array}{r}462 \\
405 \\
349 \\
234 \\
185 \\
137 \\
103 \\
89 \\
78\end{array}$ & $\begin{array}{r}12.7 \\
11.1 \\
9.6 \\
6.4 \\
5.1 \\
3.8 \\
2.8 \\
2.4 \\
2.1\end{array}$ & $\begin{array}{l}27 \\
28 \\
29 \\
30 \\
31 \\
32 \\
33 \\
34\end{array}$ & $\begin{array}{r}380.0 \\
450.0 \\
530.0 \\
630.0 \\
740.0 \\
880.0 \\
1000.0 \\
1200.0\end{array}$ & $\begin{array}{r}9 \\
12 \\
6 \\
13 \\
12 \\
7 \\
7 \\
2\end{array}$ & $\begin{array}{r}68 \\
59 \\
47 \\
41 \\
28 \\
16 \\
9 \\
2\end{array}$ & $\begin{array}{l}1.9 \\
1.6 \\
1.3 \\
1.1 \\
0.8 \\
0.4 \\
0.2 \\
0.1\end{array}$ \\
\hline
\end{tabular}

MONIHLY MEAN DISCHARGES, IN CUBIC FEET PER SECOND, FOR EACH WATER YEAR

$\begin{array}{lcccccccccccc}\text { YEAR } & \propto & \text { NOV } & \text { DEC } & \text { JAN } & \text { FEB } & \text { MAR } & \text { APR } & \text { MAY } & \text { JUNE } & \text { JULY } & \text { AUG } & \text { SEP } \\ 1954 & 13.9 & 9.58 & 8.37 & 7.37 & 7.18 & 7.33 & 27.8 & 107 & 38.4 & 19.9 & 11.2 & 8.58 \\ 1955 & 8.12 & 8.00 & 6.76 & 6.21 & 5.50 & 5.50 & 12.4 & 156 & 118 & 34.5 & 18.4 & 11.0 \\ & & & & & & & & & & & & \\ 1956 & 10.5 & 8.47 & 9.15 & 7.33 & 7.00 & 9.52 & 48.0 & 262 & 383 & 38.4 & 17.1 & 9.07 \\ 1957 & 8.81 & 7.21 & 6.65 & 6.06 & 6.00 & 7.90 & 17.1 & 76.0 & 643 & 95.9 & 30.9 & 17.6 \\ 1958 & 13.7 & 10.9 & 9.13 & 7.63 & 7.00 & 6.35 & 24.0 & 410 & 241 & 33.5 & 14.4 & 10.4 \\ 1959 & 9.17 & 9.83 & 7.71 & 6.01 & 5.27 & 6.23 & 23.6 & 78.9 & 124 & 38.6 & 25.7 & 14.5 \\ 1960 & 15.9 & 15.2 & 9.66 & 7.86 & 7.34 & 12.1 & 37.2 & 99.3 & 99.4 & 38.0 & 23.3 & 18.7 \\ 1961 & 13.2 & 9.44 & 7.16 & 6.00 & 5.00 & 5.48 & 12.1 & 54.0 & 84.6 & 35.4 & 27.2 & 27.5 \\ 1962 & 26.2 & 20.2 & 15.1 & 12.3 & 12.6 & 12.6 & 85.8 & 183 & 193 & 79.3 & 25.0 & 14.0 \\ 1963 & 11.3 & 9.61 & 7.79 & 6.40 & 6.24 & 8.03 & 16.3 & 125 & 170 & 41.3 & 38.4 & 40.0\end{array}$

ANNUAL PEAK DISCHARGE, IN OUBIC FEET PER SECOND, AND CORRESPONDING GAGE HEIGHT, IN FEET, FOR EACH WATER YEAR

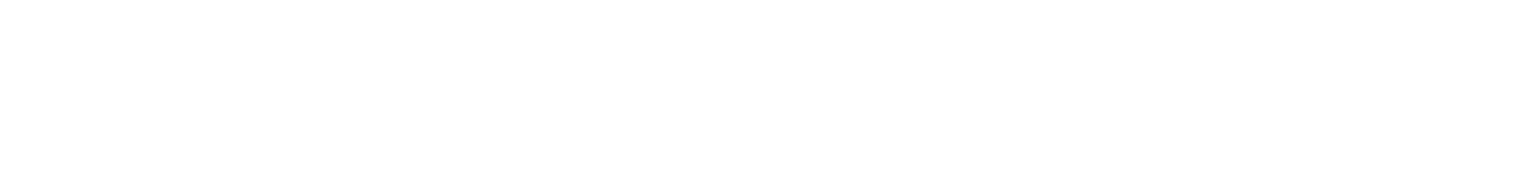

MAGNITUDE AND PROBABILITY OF ANNUAL HIGHEST MEAN DISCHARGE BASED ON WATER YEARS 1954-63

\begin{tabular}{rcccccc}
\hline & \multicolumn{2}{c}{$\begin{array}{c}\text { DISCHARGE, IN CUBIC FEET PER SECOND, FOR } \\
\text { PERIOD } \\
\text { (CON- }\end{array}$} & $\begin{array}{c}\text { INDICATED RECURRENCE INTERVAL, IN YEARS, AND } \\
\text { ANNUAL EXCEEDANCE PROBABIIITY, IN PERCENT }\end{array}$ \\
$\begin{array}{l}\text { SECU- } \\
\text { TIVE }\end{array}$ & 2 & 5 & 10 & 25 & 50 & 100 \\
DAYS) & 508 & 208 & 108 & 48 & 28 & 18 \\
\hline 1 & 401 & 812 & 1190 & - & - & - \\
\hline 3 & 354 & 732 & 1100 & - & - & - \\
7 & 298 & 632 & 978 & - & - & - \\
15 & 248 & 518 & 803 & - & - & -
\end{tabular}


GREEN RIVER BASIN

09275000 WEST FORK DUCHESNE RIVER BELCW DRY HOLOW, NEAR HANNA, UT

LOCATION.--Lat $40^{\circ} 26^{\prime} 55^{\prime \prime}$, long $110^{\circ} 58^{\prime} 30^{\prime \prime}$, in SW $3 W^{\frac{1}{4}}$ sec. 25, T.1 N., R.10 W., Uintah Meridian, wasatch County, Hydrologic Unit 14060003, on right bank $300 \mathrm{ft}$ downstream fram Dry Hollow, $5 \mathrm{mi}$ upstream fran Wolf Creek, and $12 \mathrm{mi}$ northwest of Hanna.

DRAINAGE AREA. $-43.8 \mathrm{mi}^{2}$.

MEAN BASIN ELEVATION. $-9,100 \mathrm{ft}$

PERICD OF RECORD AVAIIABLE.--August 1949 to September 1968 , August 1974 to September 1981.

REVISED RECORDS. -WDR UT-75-1: Drainage area.

GAGE.-Water-stage recorder. Altitude of gage is $7,656 \mathrm{ft}$ fram topographic map.

AVERAGE DISCHARGE.--26 years (water years 1950-68, 1975-81), $36.7 \mathrm{ft}^{3} / \mathrm{s}, 26,590$ acre-ft/yr.

EXTREMES FOR PERICO OF RECORD.--Maximum discharge, $740 \mathrm{ft}^{3} / \mathrm{s}$ June 14, 1975, gage height, $4.65 \mathrm{ft} ; \mathrm{minimum}, 2.6 \mathrm{ft} / \mathrm{s}$ sametime between Dec. 20, 1956 and Mar. 7. 1957, fram recorded range in stage, result of freezup.

LOWEST MEAN DISCHARGE, IN OBBIC FEET PER SECOND, AND RANKING FOR THE INDICATED NUMBER OF CONSEQUTIVE DAYS FOR EACH OLIMATIC YEAR, APRII 1-MARCH 31

YEAR

1951
1952
1953
1954
1955

$1956 \quad 6.10$

1957

1959

1959
1960

1961

1962

1963

1964

1966

1967

1968

1976

1977

1978
1979

1979
1980

1981
7.0014

8.0021

8.8023

6.108

$7.00 \quad 15$

6.509

6.00
$5.00 \quad 2$

5.203

5.204

7.0016

6.9010
7.0011

7.2018

8.0022

7.3019

7.4020

5.205

$\begin{array}{llr}4.00 & 1\end{array}$

$\begin{array}{ll}7.00 & 12 \\ 7.00 & 13\end{array}$

7.1017
$10.0 \quad 24$

8.3022

8.0020

9.0023

6.809

$\begin{array}{ll}6.10 & 7 \\ 7.00 & 10\end{array}$

7.0010

6.50

$\begin{array}{ll}6.00 & 6 \\ 5.00 \quad 2\end{array}$

5.304

5.203

7.001

7.0012

7.4017

8.1021

7.5018

8.0019

$\begin{array}{rr}8.00 & 19 \\ 4.60 & 5\end{array}$

4.601
7.0014

7.0015

7.4016

$\begin{array}{lrl}7 & \\ & & \\ 10.0 & 24 \\ 9.60 & 23 \\ 8.00 & 19 \\ 9.00 & 22 \\ 7.00 & 13 \\ & & \\ 6.10 & 6 \\ 7.00 & 14 \\ 6.50 & 8 \\ 6.00 & 5 \\ 5.00 & 2 \\ & & \\ 5.60 & 4 \\ 5.40 & 3 \\ 7.00 & 9 \\ 7.00 & 10 \\ 7.00 & 11 \\ 7.60 & 16 \\ 8.50 & 21 \\ 7.60 & 17 \\ 8.10 & 20 \\ 6.10 & 7 \\ 4.30 & 7 \\ 4.60 & 1 \\ 7.00 & 12 \\ 7.20 & 15 \\ 7.70 & 18\end{array}$

14

$10.0 \quad 24$

$\begin{array}{cc}10.0 & 24 \\ 9.90 & 23\end{array}$

8.0019

9.0022

7.0013

6.608

7.009

6.507

$\begin{array}{ll}6.10 & 5 \\ 5.00 & 2\end{array}$

5.703

5.904

7.5015

7.0010

7.8018

8.5021

7.7016

8.3020

8.3020
$6.40 \quad 6$

$6.40 \quad 6$
4.70

7.0012
7.2014 $\begin{array}{ll}\text { CONSEOUTIVE DAYS } & \\ 30 & 60\end{array}$

$10.0 \quad 23$

$10.0+24$

$8.0017 \quad 10.0 \quad 24$

7.0010

9.4022

$\begin{array}{lll}9.3011 & 7.40 & 8\end{array}$

7.0011

7.1012

6.707

$7.00 \quad 9$

7.3010

$\begin{array}{ll}6.90 & 7 \\ 6.40 & 5\end{array}$

$\begin{array}{ll}6.40 & 5 \\ 5.40 & 1\end{array}$

$7.40 \quad 9$

7.5011

7.4010

$\begin{array}{ll}6.50 & 4 \\ 5.50 & 1\end{array}$

5.202

6.103

5.903

6.204

8.1018

7.008

6.404

8.7018

7.008

6.303

6.605

8.7018

7.107

8.0012

8.3019

8.6020

8.8020

8.7019

9.4020

8.8019

8.0015

8.4016

9.0021

$\begin{array}{rr}9.00 & 21 \\ 6.606\end{array}$

9.4021

5.101

$7.00 \quad 9$
$7.70 \quad 15$

6.806

$5.50 \quad 2$

7.8013

$\begin{array}{rr}9.60 & 21 \\ 6.90 & 6\end{array}$

5.902

$\begin{array}{ll}8.10 & 13 \\ 8.20 & 14\end{array}$

8.3015

HIGHEST MEAN DISGHARGE, IN OBIC FEET PER SECOND, AND RANKING FOR THE INDICATED NUMBER OF CONSEQUTIVE DAYS FOR EACH WATER YEAR, OCTCBER 1-SEPTEHBER 30

YEAR

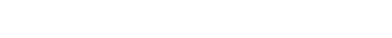

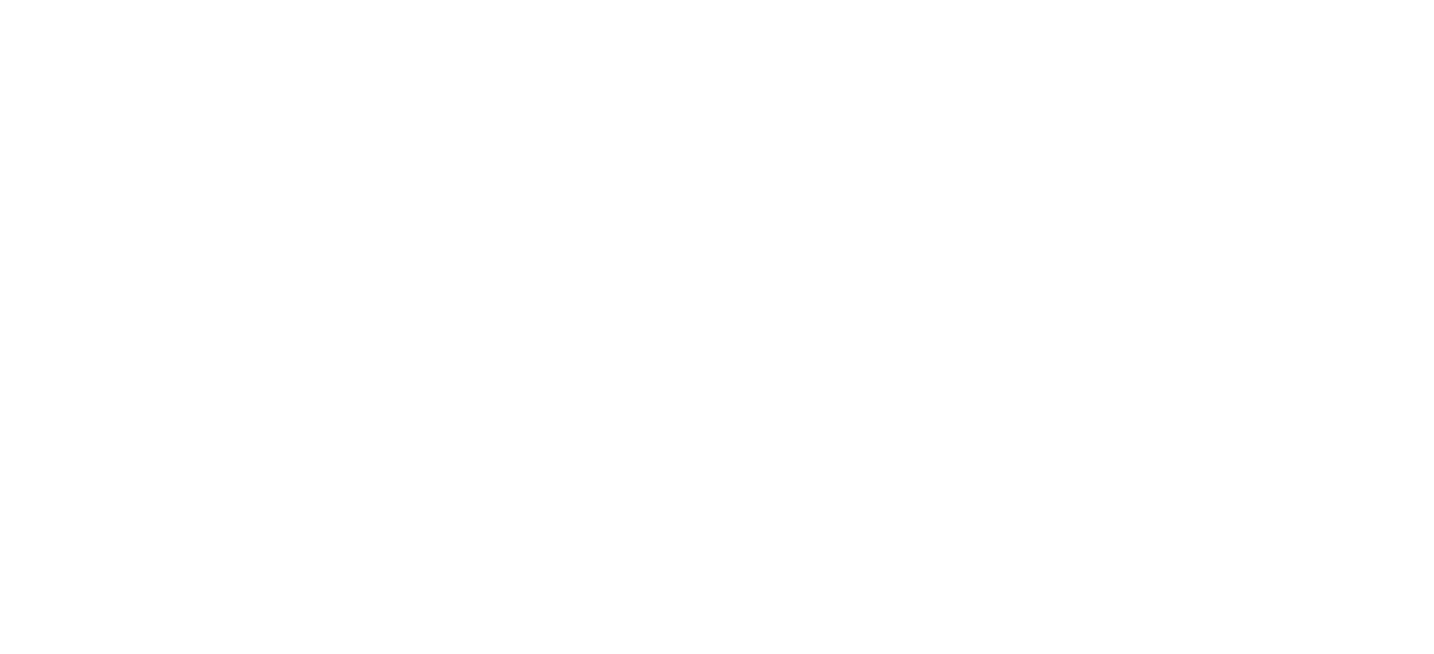


GREEN RIVER BASIN

09275000 WEST FORR DUCHESNE RIVER BEEOW DRY HOLLO, NEAR HANNA, UT-CONtinued

HIGHEST MEAN DISCHARGE, IN OBBIC FEET PER SECOND, AND RANRING FOR THE INDICATED NUMBER OF CONSECUTIVE DAYS FOR EAOH WATER YEAR, OCTCBER 1-SEPIEMBER 30-Continued

\begin{tabular}{|c|c|c|c|c|c|c|c|c|c|c|c|c|c|c|c|c|c|c|c|c|}
\hline YEAR & 1 & & 3 & & 7 & & 15 & & $\begin{array}{l}\text { cov } \\
30\end{array}$ & & $\begin{array}{l}\text { TE DAY } \\
60\end{array}$ & & 90 & & 120 & & 183 & & ALL & \\
\hline $\begin{array}{l}1976 \\
1977 \\
1978 \\
1979 \\
1980\end{array}$ & $\begin{array}{l}291 \\
45.0 \\
398 \\
490 \\
440\end{array}$ & $\begin{array}{r}17 \\
26 \\
12 \\
6 \\
9\end{array}$ & $\begin{array}{l}280 \\
42.0 \\
393 \\
392 \\
432\end{array}$ & $\begin{array}{r}17 \\
26 \\
10 \\
11 \\
7\end{array}$ & $\begin{array}{l}253 \\
38.0 \\
361 \\
315 \\
403\end{array}$ & $\begin{array}{r}17 \\
26 \\
9 \\
14 \\
5\end{array}$ & $\begin{array}{l}234 \\
34.0 \\
324 \\
266 \\
364\end{array}$ & $\begin{array}{r}17 \\
26 \\
8 \\
14 \\
6\end{array}$ & $\begin{array}{l}188 \\
28.0 \\
271 \\
206 \\
333\end{array}$ & $\begin{array}{r}17 \\
26 \\
8 \\
16 \\
2\end{array}$ & $\begin{array}{l}127 \\
27.0 \\
182 \\
126 \\
248\end{array}$ & $\begin{array}{r}17 \\
26 \\
9 \\
18 \\
2\end{array}$ & $\begin{array}{c}95.0 \\
23.0 \\
133 \\
91.0 \\
190\end{array}$ & $\begin{array}{r}17 \\
26 \\
9 \\
19 \\
2\end{array}$ & $\begin{array}{c}76.0 \\
19.0 \\
105 \\
72.0 \\
149\end{array}$ & $\begin{array}{r}17 \\
26 \\
9 \\
19 \\
2\end{array}$ & $\begin{array}{r}54.0 \\
15.0 \\
74.0 \\
51.0 \\
102\end{array}$ & $\begin{array}{r}18 \\
26 \\
9 \\
19 \\
2\end{array}$ & $\begin{array}{l}33.0 \\
11.0 \\
41.0 \\
30.0 \\
56.0\end{array}$ & $\begin{array}{r}17 \\
26 \\
9 \\
20 \\
2\end{array}$ \\
\hline 981 & 194 & 22 & 182 & 22 & 166 & 23 & 144 & 23 & 108 & 23 & 87.0 & 21 & 67.0 & 21 & 54.0 & 21 & 39.0 & 21 & 24.0 & \\
\hline
\end{tabular}

DURATION O DISCHARGE FOR EACH WATER YEAR

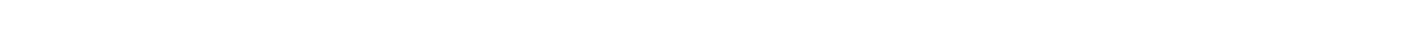

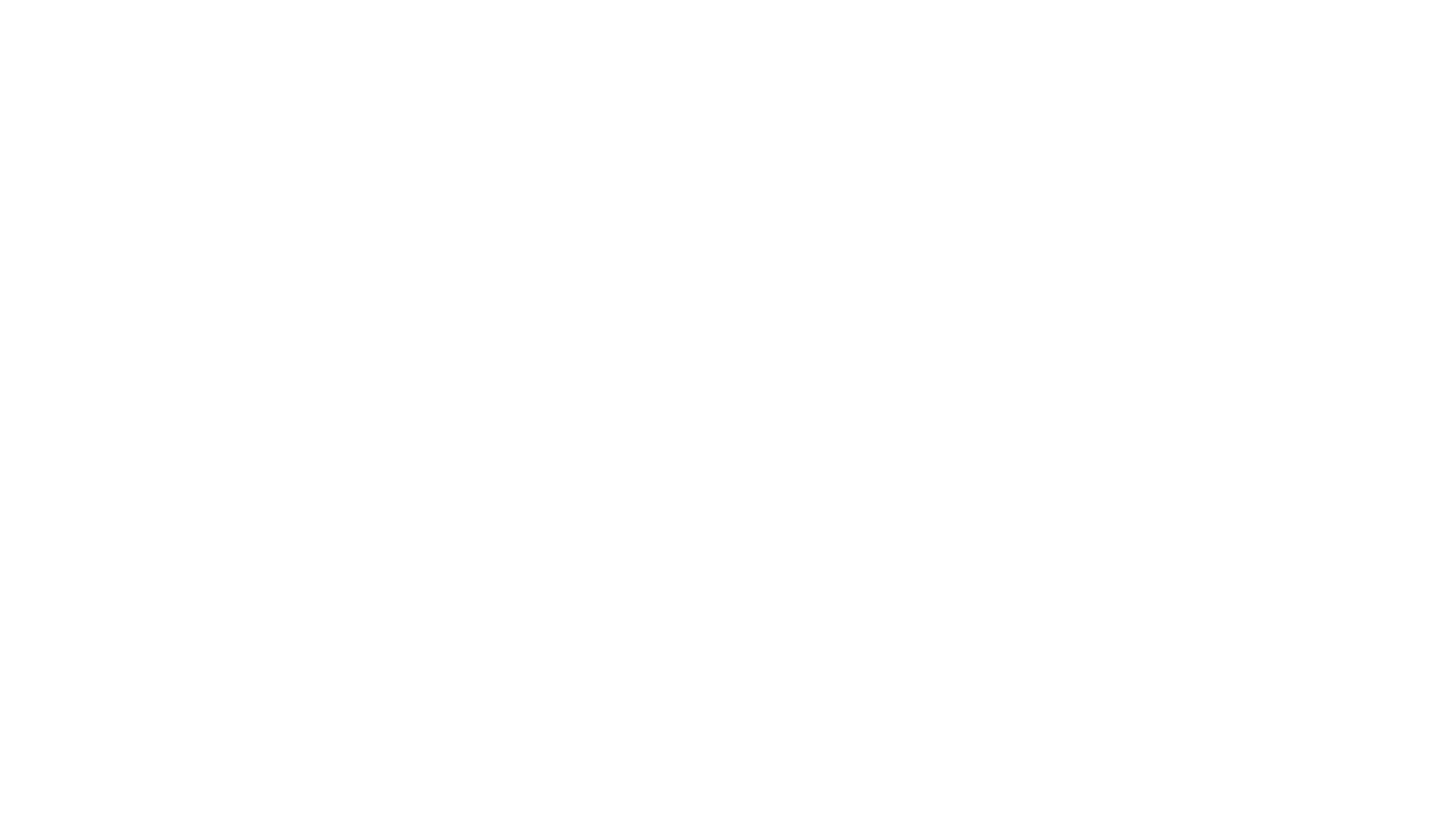

DURATION TABLE OF DISOAARGE FOR WATER YFARS 1950-68, 1975-81

\begin{tabular}{|c|c|c|c|c|}
\hline CLASS & $\begin{array}{c}\text { OBBIC } \\
\text { FEET } \\
\text { PER } \\
\text { SECOND }\end{array}$ & TOTAL & $\begin{array}{l}\text { ACOU- } \\
\text { MU- } \\
\text { LAIED } \\
\text { DALS }\end{array}$ & $\begin{array}{l}\text { PER- } \\
\text { CENT } \\
\text { DAYS }\end{array}$ \\
\hline $\begin{array}{l}0 \\
1 \\
2 \\
3 \\
4 \\
5 \\
6 \\
7 \\
8\end{array}$ & $\begin{array}{r}0.00 \\
4.00 \\
4.60 \\
5.40 \\
6.20 \\
7.20 \\
8.40 \\
9.70 \\
11.00\end{array}$ & $\begin{array}{r}0 \\
1 \\
62 \\
210 \\
811 \\
979 \\
1339 \\
873 \\
1057\end{array}$ & $\begin{array}{l}9497 \\
9497 \\
9496 \\
9434 \\
9224 \\
8413 \\
7434 \\
6095 \\
5222\end{array}$ & $\begin{array}{r}100.0 \\
100.0 \\
100.0 \\
99.3 \\
97.1 \\
88.6 \\
78.3 \\
64.2 \\
55.0\end{array}$ \\
\hline
\end{tabular}

$\begin{array}{ccc}\text { OBIC } & \text { ACOU- } & \\ \text { FEET } & \text { MU- } & \text { PER- } \\ \text { PER TOTAL LAIED } & \text { CENT }\end{array}$

CLASS SECOND DAYS DAYS DAYS

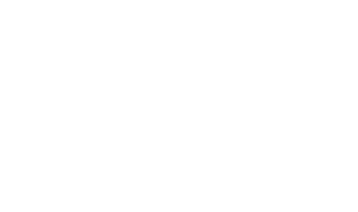

$\begin{array}{lll}\text { OBIC } & \text { ACOU- } \\ \text { FEET } & \text { MU- PER- }\end{array}$ PER TOTAL LATED
CLASS SECOND DAYS DAYS DAYS

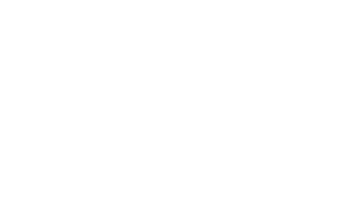

CUBIC ACOU-

FEET MU- PERPER TOTAL LATED CENT

$\begin{array}{rrrrr}27 & 180.0 & 109 & 508 & 5.3 \\ 28 & 210.0 & 109 & 399 & 4.2 \\ 29 & 250.0 & 102 & 290 & 3.1 \\ 30 & 290.0 & 73 & 188 & 2.0 \\ 31 & 330.0 & 62 & 115 & 1.2 \\ 32 & 390.0 & 29 & 53 & 0.6 \\ 33 & 450.0 & 23 & 24 & 0.3 \\ 34 & 520.0 & 1 & 1 & 0.0\end{array}$


GREFEN RIVER BASIN

09275000 WEST FORK DUCHESNE RIVER BELOW DRY HCLLON, NEAR HANNA, UT-Continued MONTHLY MEAN DISCHARGES, IN OBBIC FEET PER SECOND, FOR EAOH WATER YEAR

\begin{tabular}{|c|c|c|c|c|c|c|c|c|c|c|c|c|}
\hline YEAR & $\propto \mathbf{P r}$ & $\mathrm{NON}$ & DEC & JAN & FEB & MAR & APR & MAY & JUNE & JULY & AUG & SEP \\
\hline 1950 & 13.3 & 11.6 & 9.32 & 8.00 & 8.71 & 11.4 & 44.4 & 174 & 238 & 59.8 & 22.3 & 16.6 \\
\hline $\begin{array}{l}1951 \\
1952 \\
1953 \\
1954 \\
1955\end{array}$ & $\begin{array}{c}13.7 \\
13.0 \\
14.2 \\
12.2 \\
9.29\end{array}$ & $\begin{array}{c}13.9 \\
10.8 \\
10.8 \\
11.3 \\
8.19\end{array}$ & $\begin{array}{r}12.9 \\
10.5 \\
10.0 \\
9.66 \\
8.45\end{array}$ & $\begin{array}{c}11.6 \\
10.0 \\
9.00 \\
9.16 \\
7.63\end{array}$ & $\begin{array}{c}10.0 \\
11.0 \\
8.00 \\
10.0 \\
7.00\end{array}$ & $\begin{array}{c}10.0 \\
10.0 \\
8.74 \\
10.6 \\
7.50\end{array}$ & $\begin{array}{l}26.1 \\
42.5 \\
17.4 \\
32.8 \\
12.3\end{array}$ & $\begin{array}{l}151 \\
289 \\
62.1 \\
113 \\
160\end{array}$ & $\begin{array}{c}136 \\
296 \\
193 \\
35.6 \\
98.3\end{array}$ & $\begin{array}{l}36.0 \\
67.5 \\
38.2 \\
17.5 \\
28.1\end{array}$ & $\begin{array}{l}19.2 \\
31.5 \\
18.2 \\
11.3 \\
15.3\end{array}$ & $\begin{array}{c}12.7 \\
19.9 \\
13.5 \\
10.8 \\
9.05\end{array}$ \\
\hline $\begin{array}{l}1956 \\
1957 \\
1958 \\
1959 \\
1960\end{array}$ & $\begin{array}{c}7.62 \\
10.2 \\
12.0 \\
9.82 \\
10.3\end{array}$ & $\begin{array}{c}8.08 \\
9.38 \\
10.1 \\
9.19 \\
7.33\end{array}$ & $\begin{array}{l}8.28 \\
7.97 \\
9.03 \\
7.65 \\
5.60\end{array}$ & $\begin{array}{l}7.00 \\
7.24 \\
8.48 \\
6.40 \\
5.46\end{array}$ & $\begin{array}{l}7.00 \\
7.38 \\
7.00 \\
6.68 \\
5.86\end{array}$ & $\begin{array}{l}8.42 \\
8.25 \\
6.68 \\
7.20 \\
8.16\end{array}$ & $\begin{array}{l}30.4 \\
14.9 \\
21.2 \\
21.9 \\
26.1\end{array}$ & $\begin{array}{c}191 \\
95.3 \\
238 \\
80.8 \\
109\end{array}$ & $\begin{array}{r}111 \\
247 \\
143 \\
61.9 \\
54.4\end{array}$ & $\begin{array}{l}24.9 \\
54.2 \\
28.2 \\
13.2 \\
14.8\end{array}$ & $\begin{array}{c}14.5 \\
21.9 \\
15.8 \\
10.7 \\
8.23\end{array}$ & $\begin{array}{c}11.5 \\
14.1 \\
12.0 \\
10.1 \\
8.42\end{array}$ \\
\hline $\begin{array}{l}1961 \\
1962 \\
1963 \\
1964 \\
1965\end{array}$ & $\begin{array}{l}8.75 \\
9.56 \\
12.5 \\
11.7 \\
10.6\end{array}$ & $\begin{array}{c}7.18 \\
9.71 \\
10.8 \\
10.8 \\
10.1\end{array}$ & $\begin{array}{c}6.27 \\
8.27 \\
9.03 \\
7.88 \\
10.2\end{array}$ & $\begin{array}{l}6.07 \\
6.65 \\
8.35 \\
7.25 \\
8.78\end{array}$ & $\begin{array}{l}6.70 \\
6.82 \\
9.71 \\
7.00 \\
8.00\end{array}$ & $\begin{array}{l}8.39 \\
6.58 \\
8.85 \\
7.19 \\
7.29\end{array}$ & $\begin{array}{l}18.9 \\
67.2 \\
12.2 \\
12.2 \\
19.2\end{array}$ & $\begin{array}{l}61.6 \\
214 \\
123 \\
144 \\
138\end{array}$ & $\begin{array}{l}21.4 \\
226 \\
103 \\
144 \\
316\end{array}$ & $\begin{array}{l}7.67 \\
51.1 \\
24.4 \\
42.8 \\
76.0\end{array}$ & $\begin{array}{l}7.07 \\
18.4 \\
19.1 \\
18.9 \\
31.5\end{array}$ & $\begin{array}{l}9.73 \\
12.9 \\
14.6 \\
13.8 \\
20.8\end{array}$ \\
\hline $\begin{array}{l}1966 \\
1967 \\
1968\end{array}$ & $\begin{array}{l}15.7 \\
11.4 \\
12.8\end{array}$ & $\begin{array}{l}12.5 \\
10.7 \\
11.4\end{array}$ & $\begin{array}{r}11.4 \\
9.31 \\
9.63\end{array}$ & $\begin{array}{l}9.18 \\
8.79 \\
8.28\end{array}$ & $\begin{array}{l}8.34 \\
8.65 \\
7.89\end{array}$ & $\begin{array}{r}11.8 \\
9.73 \\
9.90\end{array}$ & $\begin{array}{l}54.5 \\
15.2 \\
17.8\end{array}$ & $\begin{array}{l}161 \\
122 \\
109\end{array}$ & $\begin{array}{l}56.6 \\
268 \\
201\end{array}$ & $\begin{array}{l}22.3 \\
73.0 \\
41.3\end{array}$ & $\begin{array}{l}14.1 \\
26.0 \\
24.2\end{array}$ & $\begin{array}{l}11.8 \\
16.8 \\
15.6\end{array}$ \\
\hline 1975 & 10.8 & 10.0 & 9.29 & 8.15 & 8.57 & 9.02 & 9.56 & 64.2 & 285 & 82.8 & 23.5 & 15.5 \\
\hline $\begin{array}{l}1976 \\
1977 \\
1978 \\
1979 \\
1980\end{array}$ & $\begin{array}{c}13.8 \\
8.64 \\
6.64 \\
10.0 \\
10.1\end{array}$ & $\begin{array}{c}10.9 \\
7.15 \\
7.24 \\
10.1 \\
9.62\end{array}$ & $\begin{array}{l}9.81 \\
7.06 \\
7.69 \\
9.53 \\
8.56\end{array}$ & $\begin{array}{l}8.99 \\
6.80 \\
6.75 \\
8.85 \\
7.98\end{array}$ & $\begin{array}{c}10.3 \\
6.97 \\
6.91 \\
8.54 \\
8.37\end{array}$ & $\begin{array}{c}11.7 \\
7.85 \\
9.46 \\
7.00 \\
9.22\end{array}$ & $\begin{array}{l}25.7 \\
20.8 \\
20.5 \\
10.5 \\
35.9\end{array}$ & $\begin{array}{l}164 \\
24.6 \\
122 \\
135 \\
208\end{array}$ & $\begin{array}{c}86.0 \\
21.7 \\
230 \\
109 \\
282\end{array}$ & $\begin{array}{c}24.9 \\
8.18 \\
42.8 \\
24.2 \\
55.0\end{array}$ & $\begin{array}{c}13.4 \\
5.76 \\
17.9 \\
13.5 \\
18.5\end{array}$ & $\begin{array}{c}10.4 \\
5.32 \\
11.5 \\
10.6 \\
14.3\end{array}$ \\
\hline 1981 & 12.0 & 10.2 & 9.27 & 8.34 & 7.93 & 8.65 & 29.2 & 92.5 & 72.7 & 18.1 & 9.63 & 9.59 \\
\hline
\end{tabular}

ANNUAL PEAK DISCHARGE, IN OUBIC FEET PER SECOND, AND CORRESPONDING GAGE HEIGHT, IN FEET, FOR EAOH WATER YEAR

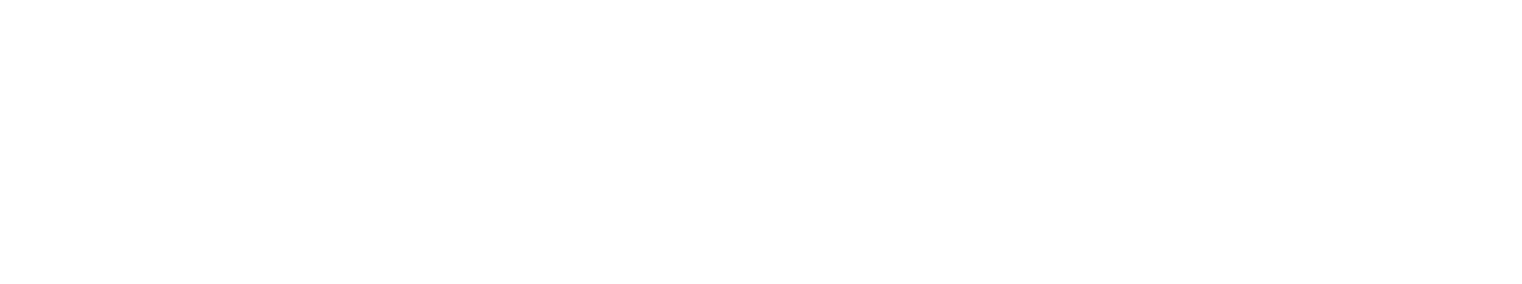

MAGNITUDE AND PROBABIITTY OF ANNUAL LONEST MEAN DISCHARGE BASED ON CLIMATIC YEARS $1951-68$ AND 1976-81

\begin{tabular}{|c|c|c|c|c|c|c|}
\hline \multirow{2}{*}{$\begin{array}{l}\text { PERIOD } \\
\text { (CON- } \\
\text { SEOU- } \\
\text { TIVE } \\
\text { DAYS) }\end{array}$} & \multicolumn{6}{|c|}{$\begin{array}{l}\text { DISCHARGE, IN GBIC FEET PER SECOND, FOR } \\
\text { INDICATED RECURRENCE INTERNAL, IN YEARS, AND } \\
\text { ANNUAL NONEXCEEDANCE PRCBABILITY, IN PERCENT }\end{array}$} \\
\hline & $\begin{array}{c}2 \\
508\end{array}$ & $\begin{array}{c}5 \\
208\end{array}$ & $\begin{array}{l}10 \\
108\end{array}$ & $\begin{array}{l}20 \\
58\end{array}$ & $\begin{array}{l}50 \\
28\end{array}$ & $\begin{array}{r}100 \\
18\end{array}$ \\
\hline $\begin{array}{r}1 \\
7 \\
14 \\
30 \\
60 \\
90\end{array}$ & $\begin{array}{l}6.7 \\
7.1 \\
7.2 \\
7.4 \\
7.6 \\
7.9\end{array}$ & $\begin{array}{l}5.6 \\
6.0 \\
6.1 \\
6.3 \\
6.6 \\
6.8\end{array}$ & $\begin{array}{l}5.1 \\
5.4 \\
5.6 \\
5.8 \\
6.1 \\
6.3\end{array}$ & $\begin{array}{l}4.7 \\
5.0 \\
5.2 \\
5.4 \\
5.7 \\
5.9\end{array}$ & $\begin{array}{l}\bar{z} \\
\bar{z} \\
\bar{z}\end{array}$ & $\begin{array}{l}\overline{-} \\
\overline{-} \\
\overline{-}\end{array}$ \\
\hline
\end{tabular}




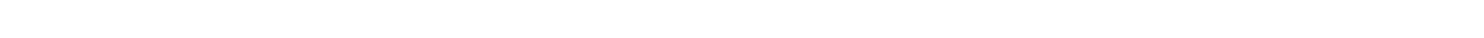
14060003 , on left bank 1,500 ft upstream from wolf Creek, and 7.1 mi northwest of Hanna.

DRAINAGE AREA. $-61.6 \mathrm{mi}^{2}$.

MEAN BASIN ELEVATION. $--8,840 \mathrm{ft}$.

PERIOD OF RECORD AVAIIABLE.-May to October 1904 (gage heights only, fragmentary), August 1921 to March 1922 , Octcber 1922 to September 1923, October 1945 to September 1981.

GAGE.--Water-stage recorder. Altitude of gage is 7,218 ft from topographic map. Prior to oct. 1. 1923, nonrecording gages at approximately same site at different datums.

REMARKS.--One small diversion for irrigation of about 100 acres above station.

AVERAGE DISCHARGE. -37 years (water years 1923, 1946-81), $47.7 \mathrm{ft}^{3} / \mathrm{s}, 34,560 \mathrm{acre}-\mathrm{ft} / \mathrm{yr}$.

EXIREMES FOR PERIOD OF RECORD. - Maximum discharge recorded, $758 \mathrm{ft}^{3} / \mathrm{s}$ June 5, 1967, maximum gage height $4.40 \mathrm{ft} \mathrm{June} 4$, 1952 ; minimum discharge recorded, $0.19 \mathrm{ft}^{3} / \mathrm{s}$ Mar. 29, 1975, result of freezeup.

LONEST MEAN DISCHARGE, IN OBIC FEET FER SECOND, AND RANKING FOR THE INDICATED NUMBER OF CONSECUTIVE DAYS FOR EACH CIMATIC YEAR, APRIL I-MARCH 31

YEA

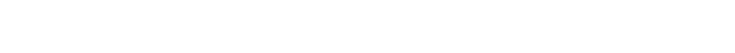

\section{$\begin{array}{llll}8.00 & 6 & 9.70 \quad 6\end{array}$}

7

$30 \quad 60$

$\begin{array}{rrrrrr}9.70 & 6 & 12.0 & 20 & 13.0 & 23\end{array}$

$\begin{array}{llllll}12.0 & 27 & 12.0 & 24 & 13.0 & 26\end{array}$

\section{$\begin{array}{llll}13.0 & 21 & 13.0 & 11\end{array}$}

$12.0 \quad 29 \quad 12.0 \quad 26$

$13.0 \quad 25$

$14.0 \quad 29$

$13.0 \quad 22$

14.020

14.021

90

120

183

ALI

$\begin{array}{llll}14.0 & 34 & 14.0 & 33 \\ 10.0 & 11 & 12.0 & 27\end{array}$

$\begin{array}{llllll}11.0 & 20 & 14.0 & 34 & 16.0 & 35\end{array}$

12.016

$12.0 \quad 13$

$\begin{array}{ll}14.0 & 22 \\ 14.0 & 23\end{array}$

$14.0 \quad 26$

$\begin{array}{cccc}7.30 & 3 & 8.80 & 4\end{array}$

$\begin{array}{rr}13.0 & 28 \\ 10.0 & 6\end{array}$

$14.0 \quad 23$

$14.0 \quad 22$

$13.0 \quad 15$

$14.0 \quad 15$

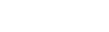

$\begin{array}{llll}15.0 & 22 & 15.0 & 11\end{array}$

$\begin{array}{llll}15.0 & 23 & 15.0 & 12\end{array}$

$42.0 \quad 13$ $34 \quad 17.034$ $\begin{array}{llll}13.0 & 17 & 13.0 & 14\end{array}$

14.023

14.024

14.016

$16.0 \quad 22$

50.021

$\begin{array}{llll}10.0 & 12 & 11.0 & 12\end{array}$

$12.0 \quad 22$

$14.0 \quad 28$

10.03

11.03

11.04

$\begin{array}{ll}16.0 & 29\end{array}$

$17.0 \quad 27$

$57.0 \quad 28$

$\begin{array}{llll}10.0 & 13 & 11.0 & 13\end{array}$

$\begin{array}{llll}13.0 & 31 & 13.0 & 29\end{array}$

$11.0 \quad 10$

$14.0 \quad 28$

13.023

$14.0 \quad 25$

$13.0 \quad 18$

$14.0 \quad 25$

$\begin{array}{llll}11.0 & 18 & 13.0 & 15\end{array}$

11.04

14.026

$14.0 \quad 17$

$\begin{array}{llll}17.0 & 30 & 19.0 \quad 32\end{array}$

$\begin{array}{llll}15.0 & 25 & 16.0 & 23\end{array}$

$65.0 \quad 30$

$45.0 \quad 16$

86.035

41.011

$10.0 \quad 14 \quad 10.07$

$\begin{array}{rr}11.0 & 11 \\ 10.0 & 7\end{array}$

10.05

12.0

$\begin{array}{rr}13.0 & 12 \\ 11.0 & 5\end{array}$

$\begin{array}{rr}12.0 & 8 \\ 15.0 & 26\end{array}$

15.026

$\begin{array}{ll}14.0 & 17\end{array}$

12.03

$10.0 \quad 15$

$10.0 \quad 8$

$10.0 \quad 8$

$\begin{array}{cc}10.0 & 6 \\ 8.60 & 2\end{array}$

$11.0 \quad 16$

$\begin{array}{rr}8.00 & 2 \\ 11.0 & 15\end{array}$

$\begin{array}{rr}10.0 & 8 \\ 8.30 & 2\end{array}$

10.0

$\begin{array}{cc}11.0 & 6 \\ 9.40 & 1\end{array}$

11.0

$\begin{array}{rrrr}12.0 & 6 & 13.0 & 6\end{array}$

$\begin{array}{llll}16.0 & 26 & 18.0 & 28\end{array}$

$\begin{array}{llll}14.0 & 18 & 15.0 & 15\end{array}$

10.0

$\begin{array}{rr}9.10 & 1 \\ 13.0 & 16\end{array}$

511.0

13.07

$\begin{array}{rr}39.0 & 9 \\ 44.0 & 14\end{array}$

$53.0 \quad 24$

$53.0 \quad 25$

$\begin{array}{llll}12.0 & 22 & 12.0 & 16 \\ 11.0 & 17 & 12.0 & 17\end{array}$

$\begin{array}{ll}12.0 & 12 \\ 13.0 & 24\end{array}$

$\begin{array}{ll}12.0 & 12 \\ 13.0 & 19\end{array}$

12.09

$13.0 \quad 13$

11.06

11.03

$\begin{array}{llll}12.0 & 4 & 28.0 & 5\end{array}$

$27.0 \quad 4$

$\begin{array}{llll}12.0 & 23 & 12.0 & 18\end{array}$

$12.0 \quad 13$

13.020

$13.0 \quad 17$

14.027

$\begin{array}{ll}14.0 & 18 \\ 13.0 & 10\end{array}$

11.04

$\begin{array}{llll}12.0 & 24 & 12.0 & 19\end{array}$

$\begin{array}{llll}9.50 & 9 & 12.0 & 20\end{array}$

$\begin{array}{llll}12.0 & 14 & 13.0 & 21\end{array}$

$14.0 \quad 26$

$14.0 \quad 28$

14.019

$24 \quad 65.031$

$\begin{array}{rrrrrr}13.0 & 9 & 14.0 & 8 & 36.0 & 6 \\ 14.0 & 10 & 15.0 & 16 & 46.0 & 17\end{array}$

$\begin{array}{llllll}13.0 & 18 & 13.0 & 15 & 13.0 & 11\end{array}$

$12.0 \quad 16 \quad 12.0 \quad 13 \quad 13.0$

13.016

$13.0 \quad 12$

$\begin{array}{llll}12.0 & 25 & 12.0 & 21 \\ 13.0 & 32 & 13.0 & 30\end{array}$

12.016

12.014

$12.0 \quad 10$

$\begin{array}{ll}13.0 & 17 \\ 15.0 & 29\end{array}$

$13.0 \quad 13$

$46.0 \quad 17$

$\begin{array}{llll}11.0 & 18 & 13.0 & 31\end{array}$

$\begin{array}{llll}14.0 & 30 & 14.0 & 30\end{array}$

$\begin{array}{rrr}9.20 & 8 & 10.0\end{array}$

$11.0 \quad 19$

$\begin{array}{llll}14.0 & 35 & 15.0 & 35\end{array}$

$\begin{array}{llll}12.0 & 17 & 14.0 & 31\end{array}$

12.018

$14.0 \quad 31$

$\begin{array}{ll}12.0 & 15 \\ 16.0 & 35\end{array}$

$15.0 \quad 30$

$\begin{array}{ll}15.0 & 30 \\ 15.0 & 31\end{array}$

13.020

$\begin{array}{llll}16.0 & 30 & 16.0 & 31\end{array}$

$\begin{array}{llll}16.0 & 31 & 16.0 & 32 \\ 13.0 & 18 & 13.0 & 14\end{array}$

$\begin{array}{llll}13.0 & 18 & 13.0 & 14 \\ 17.0 & 34 & 18.0 & 34\end{array}$

$\begin{array}{llllll}15.0 & 34 & 16.0 & 35 & 16.0 & 33 \\ 12.0 & 19 & 13.0 & 22 & 14.0 & 28\end{array}$

14.019

$\begin{array}{ll}18.0 & 34 \\ 15.0 & 27\end{array}$

17.031

$20.0 \quad 33$

$\begin{array}{llll}14.0 & 12 & 15.0 & 17\end{array}$

$14.0 \quad 13 \quad 16.019$

$16.0 \quad 27 \quad 18.0 \quad 29$

$71.0 \quad 33$

$8.00 \quad 5 \quad 8.00$

$\begin{array}{llll}9.60 & 3 & 10.0 & 7\end{array}$

$\begin{array}{rr}12.0 & 11 \\ 10.0 & 6\end{array}$

$\begin{array}{rr}12.0 & 10 \\ 11.0 & 7\end{array}$

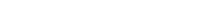

9.704

9.803

$14.0 \quad 20$

$\begin{array}{llll}17.0 & 32 & 17.0 & 25\end{array}$

$\begin{array}{llll}17.0 & 33 & 18.0 & 30\end{array}$

$\begin{array}{llll}14.0 & 14 & 16.0 & 20\end{array}$

$\begin{array}{llll}18.0 & 34 & 20.0 & 34 \\ 15.0 & 20 & 16.0 & 21\end{array}$

$\begin{array}{ll}42.0 & 12 \\ 58.0 & 29\end{array}$

50.022

$71.0 \quad 34$

$12.4026 \quad 7.60$

8.001

8.50
15.0

$9.30 \quad 2$

$\begin{array}{lll}11.0 & 2\end{array}$

$15.0 \quad 21$

$18.0 \quad 31$

$44.0 \quad 15$

$52.0 \quad 23$

47.018

55.026

48.020

$\begin{array}{lllll}1979 & 12.0 & 26 & 12.0 & 23 \\ 1980 & 10.0 & 10 & 10.0 & 11\end{array}$

$\begin{array}{rr}14.0 & 31 \\ 10.0 & 5\end{array}$

$\begin{array}{rr}15.0 & 32 \\ 11.0 & 8\end{array}$

$15.0 \quad 32$

$16.0 \quad 32$

11.0

12.07

13.05

$56.0 \quad 27$

$16.0 \quad 28 \quad 17.0 \quad 26 \quad 47.0 \quad 19$

1981

$\begin{array}{llll}13.0 & 33 & 13.0 & 32\end{array}$

$\begin{array}{llll}13.0 & 25 & 15.0 & 33\end{array}$

$18.0 \quad 35$

$19.0 \quad 35$

12.07

13.08

17.026

$\begin{array}{ll}47.0 & 19 \\ 40.0 & 10\end{array}$

$19.0 \quad 35$

$19.0 \quad 35$

$20.0 \quad 35$

$69.0 \quad 32$ 
GREEN RIVER BASIN

09275500 WEST FORR DUCHESNE RTVER NEAR HANNA, UT-Continued

HIGHEST MEAN DISCHARGE, IN CUBIC FEET PER SECOND, AND RANKING FOR THE INDICATED NMMER OF CONSECOTIVE DAYS FOR EACH WATER YEAR, OCIOBER 1-SEPTEMBER 30

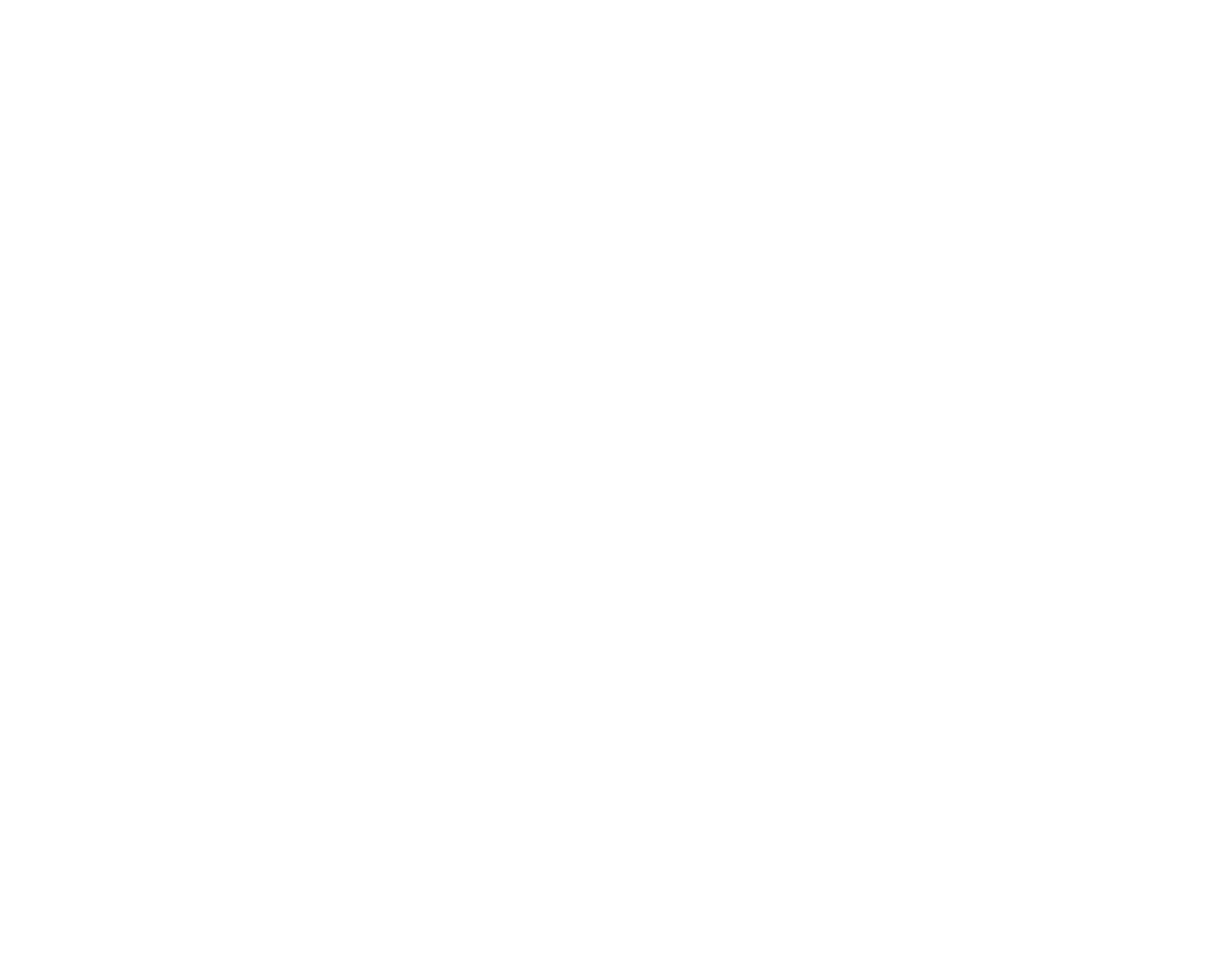

DURATION OF DISCHARGE FOR EACH WATER YEAR

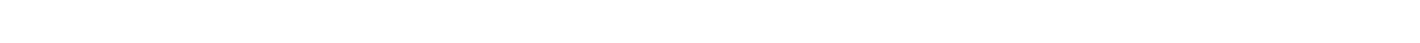
YEAR

NUMBER OF DAYS IN CIASS OBBIC FEET -DAYS

1923

361499

$\begin{array}{lllllllllllllll}6 & 8 & 3 & 7 & 7 & 12 & 1 & 3 & 4 & 10 & 8 & 4 & 2 & 1\end{array}$

24351.0

1946
1947

1948

1949

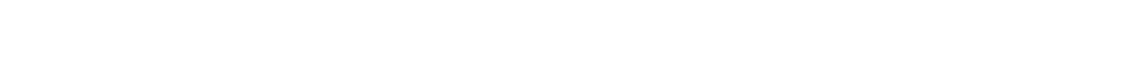

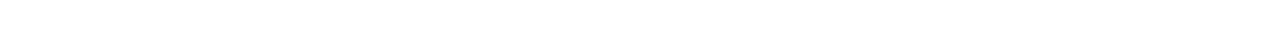

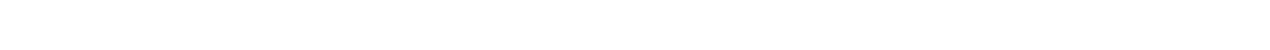

1951

1952

1953

$\begin{array}{lllllllllllllllllllllllllll}68 & 59 & 83 & 21 & 13 & 9 & 7 & 12 & 21 & 11 & 4 & 4 & 4 & 6 & 6 & 3 & 2 & 9 & 8 & 4 & 1 & 2 & 1 & 1 & 3 & 3\end{array}$

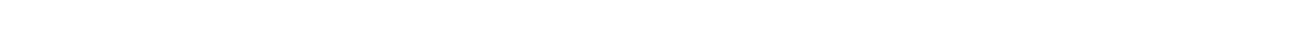

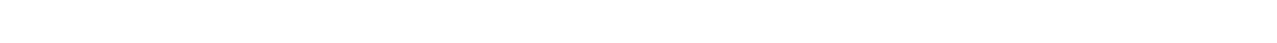

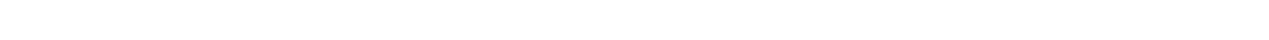
1955

1956

1957

195

1958
1960

1961

1961
1962
1963
1964

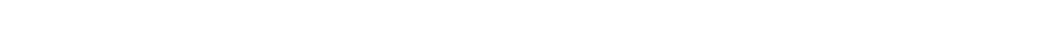

13688.5

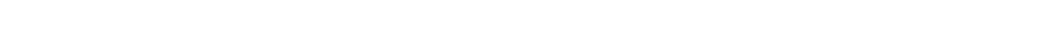

$\begin{array}{lllllllllllllllllllllllllllllll}1 & 84 & 51 & 39 & 16 & 17 & 24 & 5 & 22 & 9 & 8 & 8 & 5 & 5 & 6 & 7 & 9 & 6 & 2 & 5 & 5 & 6 & 5 & 6 & 1 & 1 & 4 & 4 & 2 & 2\end{array}$

$\begin{array}{rlllllllllllllllllll}23 & 40 & 46 & 87 & 47 & 10 & 11 & 8 & 12 & 7 & 4 & 6 & 8 & 2 & 5 & 2 & 4 & 4 & 3 & 8\end{array}$

$\begin{array}{rrrrrrrrrrrrrrrrrrrrrrr}32 & 51 & 74 & 63 & 46 & 14 & 5 & 7 & 10 & 8 & 9 & 3 & 4 & 7 & 3 & 4 & 8 & 7 & 8 & 2 & & & \\ 32119 & 20 & 43 & 33 & 14 & 10 & 10 & 6 & 17 & 12 & 8 & 3 & 4 & 3 & 1 & 4 & 3 & 3 & 10 & 3 & 5 & 1 & 2\end{array}$

16468.0

18254.0

19947.0

10120.0

$\begin{array}{llllllllllllllllllll}12 & 30 & 46 & 97 & 48 & 42 & 20 & 7 & 10 & 6 & 6 & 4 & 6 & 5 & 4 & 7 & 8 & 4 & 1 & 2\end{array}$

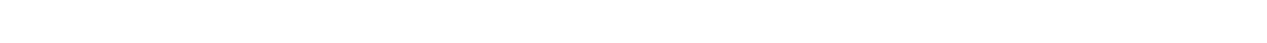

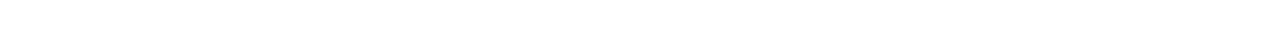

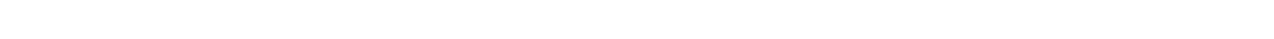


GREEN RIVER BASIN

09275500 WEST FORK DUCHESNE RIVER NEAR HANNA, UT--Continued

DURATION OF DISCHARGE FOR EACH WATER YEAR-Continued

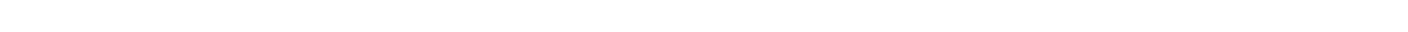

\begin{tabular}{|c|c|c|c|c|c|c|c|c|c|c|c|c|c|c|c|c|c|c|c|c|c|c|c|c|c|c|c|c|c|}
\hline YEAR & & & & & & & & & MBER & OF I & DAYS & IN & CJAS & & & & & & & & & & & & & & & & $\begin{array}{l}\text { PER SECOND } \\
\text {-DAYS }\end{array}$ \\
\hline $\begin{array}{l}1966 \\
1967 \\
1968 \\
1969 \\
1970\end{array}$ & & & 1 & $\begin{array}{r}7 \\
5 \\
21 \\
33\end{array}$ & $\begin{array}{rllll}6 & 35 & 45 & 61 & 38 \\
47 & 84 & 38 & 15 & 22 \\
42 & 28 & 36 & 40 & 30 \\
24 & 41 & 50 & 15 & 31 \\
2 & 38110 & 54 & 52\end{array}$ & $\begin{array}{l}34 \\
23 \\
39 \\
13 \\
14\end{array}$ & $\begin{array}{r}27 \\
28 \\
13 \\
19 \\
9\end{array}$ & $\begin{array}{r}13 \\
6 \\
17 \\
21 \\
13\end{array}$ & $\begin{array}{r}5 \\
5 \\
12 \\
8 \\
4\end{array}$ & $\begin{array}{r}6 \\
14 \\
10 \\
6 \\
4\end{array}$ & $\begin{array}{r}7 \\
5 \\
4 \\
11 \\
7\end{array}$ & $\begin{array}{r}10 \\
8 \\
5 \\
5 \\
8\end{array}$ & $\begin{array}{r}17 \\
3 \\
5 \\
8 \\
5\end{array}$ & $\begin{array}{r}6 \\
5 \\
10 \\
5 \\
2\end{array}$ & $\begin{array}{l}7 \\
3 \\
6 \\
5 \\
2\end{array}$ & $\begin{array}{l}7 \\
4 \\
9 \\
5 \\
3\end{array}$ & $\begin{array}{l}3 \\
2 \\
1 \\
3 \\
2\end{array}$ & $\begin{array}{l}5 \\
4 \\
7 \\
9 \\
6\end{array}$ & $\begin{array}{l}3 \\
2 \\
2 \\
8 \\
3\end{array}$ & $\begin{array}{l}8 \\
3 \\
4 \\
6 \\
3\end{array}$ & $\begin{array}{ll}8 & 2 \\
1 & 3 \\
2 & 4 \\
3 & 5 \\
6 & 5\end{array}$ & $\begin{array}{ll}2 & 4 \\
3 & 8 \\
4 & 5 \\
5 & 5 \\
5 & 7\end{array}$ & $\begin{array}{rr}4 & 1 \\
8 & 15 \\
5 & 4 \\
4 & 3 \\
7 & 2\end{array}$ & $\begin{array}{rr}1 & \\
5 & 10 \\
4 & 4 \\
3 & 5 \\
2 & 3\end{array}$ & $\begin{array}{l}0 \\
4 \\
5 \\
3\end{array}$ & $\begin{array}{lr}3 & 2 \\
5 & 1 \\
1 & 11\end{array}$ & $\begin{array}{l}2 \\
1 \\
1\end{array}$ & $\begin{array}{l}1 \\
3\end{array}$ & $\begin{array}{l}16204.0 \\
20973.0 \\
18451.5 \\
25461.0 \\
16036.0\end{array}$ \\
\hline $\begin{array}{l}1971 \\
1972 \\
1973 \\
1974 \\
1975\end{array}$ & 1 & 1 & 3 & $\begin{array}{rr}1 & 2 \\
1 \\
15\end{array}$ & $\begin{array}{rrrrr}7 & 36 & 77 & 66 & 26 \\
3 & 27 & 72 & 81 & 40 \\
46 & 56 & 38 & 27 & 12 \\
& 5 & 88100 & 55 \\
3 & 67 & 89 & 31 & 24\end{array}$ & $\begin{array}{l}18 \\
19 \\
31 \\
12 \\
16\end{array}$ & $\begin{array}{l}17 \\
10 \\
16 \\
10 \\
18\end{array}$ & $\begin{array}{r}8 \\
12 \\
11 \\
8 \\
9\end{array}$ & $\begin{array}{r}5 \\
10 \\
13 \\
8 \\
14\end{array}$ & $\begin{array}{r}12 \\
15 \\
7 \\
12 \\
5\end{array}$ & $\begin{array}{r}10 \\
4 \\
11 \\
6 \\
6\end{array}$ & $\begin{array}{r}8 \\
8 \\
17 \\
4 \\
6\end{array}$ & $\begin{array}{l}8 \\
4 \\
7 \\
4 \\
3\end{array}$ & $\begin{array}{l}5 \\
5 \\
3 \\
3 \\
3\end{array}$ & $\begin{array}{l}9 \\
5 \\
6 \\
3 \\
6\end{array}$ & $\begin{array}{l}3 \\
3 \\
4 \\
3 \\
6\end{array}$ & $\begin{array}{l}2 \\
4 \\
3 \\
1 \\
5\end{array}$ & $\begin{array}{l}4 \\
7 \\
3 \\
5 \\
7\end{array}$ & $\begin{array}{l}7 \\
4 \\
3 \\
5 \\
3\end{array}$ & $\begin{array}{l}6 \\
4 \\
3 \\
6 \\
5\end{array}$ & $\begin{array}{rr}1 & 13 \\
4 & 7 \\
7 & 9 \\
1 & 7 \\
7 & 8\end{array}$ & $\begin{array}{ll}3 & 9 \\
7 & 7 \\
9 & 6 \\
7 & 10 \\
8 & 2\end{array}$ & $\begin{array}{ll}9 & 4 \\
7 & 8 \\
6 & 3 \\
10 & 5 \\
2 & 6\end{array}$ & $\begin{array}{ll}4 & 2 \\
8 & \\
3 & 4 \\
5 & 1 \\
6 & 3\end{array}$ & $\begin{array}{l}4 \\
1 \\
3\end{array}$ & $\begin{array}{l}4 \\
2 \\
3\end{array}$ & $\begin{array}{l}1 \\
1\end{array}$ & 3 & $\begin{array}{l}19006.0 \\
17690.1 \\
19295.0 \\
18178.0 \\
20402.4\end{array}$ \\
\hline $\begin{array}{l}1976 \\
1977 \\
1978 \\
1979 \\
1980\end{array}$ & 1 & $\begin{array}{l}5 \\
5 \\
2\end{array}$ & $\begin{array}{r}5 \\
10 \\
8\end{array}$ & $\begin{array}{r}825 \\
5797 \\
14135 \\
2 \\
5 \quad 42\end{array}$ & $\begin{array}{rrrrr}7 & 22 & 77 & 25 & 65 \\
21 & 43 & 53 & 11 & 9 \\
10 & 7 & 14 & 32 & 22 \\
2 & 32174 & 33 & 14 \\
57 & 68 & 20 & 6 & 1\end{array}$ & $\begin{array}{r}25 \\
12 \\
8 \\
12 \\
11\end{array}$ & $\begin{array}{l}20 \\
15 \\
13 \\
11 \\
22\end{array}$ & $\begin{array}{l}16 \\
11 \\
11 \\
11 \\
22\end{array}$ & $\begin{array}{r}2 \\
12 \\
3 \\
7 \\
6\end{array}$ & $\begin{array}{l}8 \\
7 \\
8 \\
5 \\
7\end{array}$ & $\begin{array}{r}3 \\
2 \\
10 \\
12 \\
7\end{array}$ & $\begin{array}{r}1 \\
12 \\
5 \\
5\end{array}$ & $\begin{array}{l}4 \\
3 \\
3\end{array}$ & $\begin{array}{l}3 \\
5 \\
6\end{array}$ & $\begin{array}{l}3 \\
2 \\
2\end{array}$ & $\begin{array}{l}2 \\
2 \\
7\end{array}$ & 5 & $\begin{array}{l}4 \\
2 \\
4 \\
6\end{array}$ & $\begin{array}{r}4 \\
5 \\
7 \\
12\end{array}$ & $\begin{array}{l}5 \\
3 \\
7\end{array}$ & $\begin{array}{r}46 \\
15 \\
16\end{array}$ & $\begin{array}{ll}1 & 4 \\
6 & 6 \\
5 & 6 \\
6 & \end{array}$ & $\begin{array}{lr}6 & 6 \\
6 & 4 \\
9 & 11\end{array}$ & $\begin{array}{ll}6 & 4 \\
4 & 2 \\
1 & 7\end{array}$ & $\begin{array}{l}4 \\
2 \\
7\end{array}$ & $\begin{array}{l}1 \\
6\end{array}$ & $\begin{array}{l}1 \\
3\end{array}$ & & $\begin{array}{r}14250.5 \\
6032.6 \\
16242.9 \\
15123.0 \\
24194.0\end{array}$ \\
\hline 1981 & & & & & 18712624 & 22 & 18 & 12 & 9 & 4 & 5 & 3 & 9 & 15 & 7 & 6 & 1 & 5 & 4 & 7 & & & & & & & & & 12573.0 \\
\hline
\end{tabular}

DURATION TABLE OF DISCHARGE FOR WATER YEARS 1923, 1946-81

\begin{tabular}{|c|c|c|c|c|c|c|c|c|c|c|c|c|c|c|c|c|c|c|c|}
\hline LASS & $\begin{array}{c}\text { CUBIC } \\
\text { FEET } \\
\text { PER } \\
\text { SECOND }\end{array}$ & TOTAL & $\begin{array}{l}\text { ACOU- } \\
\text { MU- } \\
\text { LATED } \\
\text { DAYS }\end{array}$ & $\begin{array}{l}\text { PER- } \\
\text { CENT } \\
\text { DAYS }\end{array}$ & CLASS & $\begin{array}{c}\text { CUBIC } \\
\text { FEET } \\
\text { PER } \\
\text { SECOND }\end{array}$ & TOTAL & $\begin{array}{l}\text { ACOU- } \\
\text { MU- } \\
\text { LATED } \\
\text { DAYS }\end{array}$ & $\begin{array}{l}\text { PER- } \\
\text { CENT } \\
\text { DAYS }\end{array}$ & CLASS & $\begin{array}{c}\text { CUBIC } \\
\text { FEET } \\
\text { PER } \\
\text { SECOND }\end{array}$ & $\begin{array}{l}\text { TOTAL } \\
\text { DAYS }\end{array}$ & $\begin{array}{c}\text { ACOU- } \\
\text { MU- } \\
\text { LATED } \\
\text { DAYS }\end{array}$ & $\begin{array}{l}\text { PER- } \\
\text { CENT } \\
\text { DAYS }\end{array}$ & & $\begin{array}{l}\text { OUBIC } \\
\text { FEET } \\
\text { PER } \\
\text { SECOND }\end{array}$ & TOTAL & $\begin{array}{l}\text { ACCU- } \\
\text { MU- } \\
\text { LATED } \\
\text { DAYS }\end{array}$ & $\begin{array}{l}\text { PER- } \\
\text { CENT } \\
\text { DAYS }\end{array}$ \\
\hline $\begin{array}{l}0 \\
1 \\
2 \\
3 \\
4 \\
5 \\
6 \\
7 \\
8\end{array}$ & $\begin{array}{r}0.00 \\
6.40 \\
7.30 \\
8.40 \\
9.60 \\
11.00 \\
13.00 \\
14.00 \\
16.00\end{array}$ & $\begin{array}{r}0 \\
2 \\
27 \\
76 \\
249 \\
1038 \\
779 \\
1840 \\
2279\end{array}$ & $\begin{array}{r}13514 \\
13514 \\
13512 \\
13485 \\
13409 \\
13160 \\
12122 \\
11343 \\
9503\end{array}$ & $\begin{array}{r}100.0 \\
100.0 \\
100.0 \\
99.8 \\
99.2 \\
97.4 \\
89.7 \\
83.9 \\
70.3\end{array}$ & $\begin{array}{r}9 \\
10 \\
11 \\
12 \\
13 \\
14 \\
15 \\
16 \\
17\end{array}$ & $\begin{array}{l}19.00 \\
22.00 \\
25.00 \\
28.00 \\
32.00 \\
37.00 \\
42.00 \\
48.00 \\
55.00\end{array}$ & $\begin{array}{r}1571 \\
861 \\
522 \\
483 \\
439 \\
290 \\
317 \\
235 \\
245\end{array}$ & $\begin{array}{l}7224 \\
5653 \\
4792 \\
4270 \\
3787 \\
3348 \\
3058 \\
2741 \\
2506\end{array}$ & $\begin{array}{l}53.5 \\
41.8 \\
35.5 \\
31.6 \\
28.0 \\
24.8 \\
22.6 \\
20.3 \\
18.5\end{array}$ & $\begin{array}{l}18 \\
19 \\
20 \\
21 \\
22 \\
23 \\
24 \\
25 \\
26\end{array}$ & $\begin{array}{r}63.0 \\
73.0 \\
83.0 \\
95.0 \\
110.0 \\
120.0 \\
140.0 \\
160.0 \\
190.0\end{array}$ & $\begin{array}{l}225 \\
171 \\
168 \\
156 \\
101 \\
201 \\
173 \\
190 \\
117\end{array}$ & $\begin{array}{r}2261 \\
2036 \\
1865 \\
1697 \\
1541 \\
1440 \\
1239 \\
1066 \\
876\end{array}$ & $\begin{array}{r}16.7 \\
15.1 \\
13.8 \\
12.6 \\
11.4 \\
10.7 \\
9.2 \\
7.9 \\
6.5\end{array}$ & $\begin{array}{l}27 \\
28 \\
29 \\
30 \\
31 \\
32 \\
33 \\
34\end{array}$ & $\begin{array}{l}210.0 \\
240.0 \\
280.0 \\
320.0 \\
370.0 \\
420.0 \\
480.0 \\
550.0\end{array}$ & $\begin{array}{r}184 \\
181 \\
142 \\
112 \\
64 \\
47 \\
27 \\
2\end{array}$ & $\begin{array}{r}759 \\
575 \\
394 \\
252 \\
140 \\
76 \\
29 . \\
2\end{array}$ & $\begin{array}{l}5.6 \\
4.3 \\
2.9 \\
1.9 \\
1.0 \\
0.6 \\
0.2 \\
0.0\end{array}$ \\
\hline
\end{tabular}

MONTHLY MEAN DISCHARGES, IN OABIC FEET PER SECOND, FOR EACH WATER YEAR

\begin{tabular}{|c|c|c|c|c|c|c|c|c|c|c|c|c|}
\hline YEAR & OCT & $\mathrm{NON}$ & DEC & JAN & FEB & MAR & APR & MAY & JUNE & JULY & AUG & SEP \\
\hline 1923 & 18.6 & 17.4 & 20.0 & 20.0 & 20.0 & 20.0 & 34.5 & 223 & 260 & 89.2 & 40.2 & 36.2 \\
\hline $\begin{array}{l}1946 \\
1947 \\
1948 \\
1949 \\
1950\end{array}$ & $\begin{array}{l}18.7 \\
16.8 \\
17.0 \\
16.4 \\
20.1\end{array}$ & $\begin{array}{l}18.5 \\
15.8 \\
16.0 \\
16.7 \\
15.2\end{array}$ & $\begin{array}{l}15.7 \\
13.9 \\
15.6 \\
15.2 \\
13.7\end{array}$ & $\begin{array}{l}15.6 \\
13.0 \\
14.8 \\
15.0 \\
12.0\end{array}$ & $\begin{array}{l}15.0 \\
14.1 \\
14.1 \\
13.5 \\
14.3\end{array}$ & $\begin{array}{l}18.5 \\
17.7 \\
14.4 \\
14.3 \\
23.1\end{array}$ & $\begin{array}{l}86.4 \\
39.6 \\
27.4 \\
61.0 \\
65.8\end{array}$ & $\begin{array}{l}183 \\
250 \\
173 \\
221 \\
219\end{array}$ & $\begin{array}{c}84.3 \\
128 \\
90.5 \\
199 \\
271\end{array}$ & $\begin{array}{l}27.8 \\
47.9 \\
29.2 \\
56.4 \\
68.8\end{array}$ & $\begin{array}{l}19.4 \\
26.8 \\
17.8 \\
26.5 \\
31.5\end{array}$ & $\begin{array}{l}15.0 \\
18.1 \\
13.8 \\
19.5 \\
25.5\end{array}$ \\
\hline $\begin{array}{l}1951 \\
1952 \\
1953 \\
1954 \\
1955\end{array}$ & $\begin{array}{l}20.5 \\
17.4 \\
23.5 \\
19.0 \\
13.3\end{array}$ & $\begin{array}{l}20.0 \\
14.6 \\
19.1 \\
17.9 \\
12.0\end{array}$ & $\begin{array}{l}18.2 \\
15.6 \\
17.5 \\
15.1 \\
12.0\end{array}$ & $\begin{array}{l}16.4 \\
14.0 \\
17.2 \\
13.9 \\
11.0\end{array}$ & $\begin{array}{l}14.0 \\
15.0 \\
17.6 \\
15.0 \\
10.0\end{array}$ & $\begin{array}{l}14.3 \\
14.0 \\
18.3 \\
16.0 \\
11.0\end{array}$ & $\begin{array}{l}37.4 \\
59.1 \\
27.1 \\
40.2 \\
22.7\end{array}$ & $\begin{array}{l}174 \\
366 \\
75.2 \\
116 \\
174\end{array}$ & $\begin{array}{c}149 \\
335 \\
201 \\
44.8 \\
105\end{array}$ & $\begin{array}{l}46.0 \\
81.3 \\
50.4 \\
20.8 \\
35.2\end{array}$ & $\begin{array}{l}25.7 \\
41.3 \\
27.8 \\
14.7 \\
23.7\end{array}$ & $\begin{array}{l}18.3 \\
29.6 \\
19.1 \\
14.7 \\
17.0\end{array}$ \\
\hline $\begin{array}{l}1956 \\
1957 \\
1958 \\
1959 \\
1960\end{array}$ & $\begin{array}{l}16.2 \\
13.8 \\
23.1 \\
19.4 \\
15.3\end{array}$ & $\begin{array}{l}15.0 \\
13.3 \\
20.1 \\
16.8 \\
14.2\end{array}$ & $\begin{array}{l}15.3 \\
12.0 \\
18.8 \\
15.2 \\
10.8\end{array}$ & $\begin{array}{l}13.7 \\
11.2 \\
17.5 \\
13.5 \\
10.7\end{array}$ & $\begin{array}{l}14.0 \\
12.5 \\
14.5 \\
13.9 \\
11.7\end{array}$ & $\begin{array}{l}16.6 \\
13.5 \\
13.6 \\
12.2 \\
16.0\end{array}$ & $\begin{array}{l}42.5 \\
21.6 \\
34.4 \\
26.7 \\
37.1\end{array}$ & $\begin{array}{l}213 \\
108 \\
260 \\
91.5 \\
121\end{array}$ & $\begin{array}{r}117 \\
275 \\
167 \\
71.0 \\
60.0\end{array}$ & $\begin{array}{l}37.1 \\
65.6 \\
39.6 \\
22.8 \\
20.2\end{array}$ & $\begin{array}{l}23.0 \\
32.7 \\
23.2 \\
15.1 \\
12.0\end{array}$ & $\begin{array}{l}14.3 \\
21.9 \\
20.8 \\
13.9 \\
12.5\end{array}$ \\
\hline $\begin{array}{l}1961 \\
1962 \\
1963 \\
1964 \\
1965\end{array}$ & $\begin{array}{l}13.0 \\
13.2 \\
19.8 \\
16.5 \\
17.4\end{array}$ & $\begin{array}{l}13.5 \\
13.8 \\
16.5 \\
15.5 \\
16.5\end{array}$ & $\begin{array}{l}12.1 \\
11.5 \\
15.3 \\
13.8 \\
17.1\end{array}$ & $\begin{array}{c}10.7 \\
9.65 \\
12.5 \\
13.6 \\
13.9\end{array}$ & $\begin{array}{l}10.8 \\
10.8 \\
14.6 \\
13.2 \\
14.0\end{array}$ & $\begin{array}{l}12.6 \\
11.0 \\
16.3 \\
12.4 \\
13.0\end{array}$ & $\begin{array}{l}21.9 \\
82.4 \\
21.7 \\
21.7 \\
32.3\end{array}$ & $\begin{array}{l}63.6 \\
257 \\
137 \\
168 \\
178\end{array}$ & $\begin{array}{l}24.5 \\
235 \\
116 \\
169 \\
349\end{array}$ & $\begin{array}{l}10.5 \\
61.6 \\
32.5 \\
54.5 \\
91.8\end{array}$ & $\begin{array}{c}9.50 \\
28.8 \\
23.5 \\
26.7 \\
45.3\end{array}$ & $\begin{array}{l}11.8 \\
22.0 \\
20.2 \\
20.9 \\
30.5\end{array}$ \\
\hline $\begin{array}{l}1966 \\
1967 \\
1968 \\
1969 \\
1970\end{array}$ & $\begin{array}{l}27.8 \\
17.6 \\
22.5 \\
22.5 \\
22.9\end{array}$ & $\begin{array}{l}23.5 \\
15.1 \\
18.5 \\
16.6 \\
18.2\end{array}$ & $\begin{array}{l}20.0 \\
14.3 \\
16.5 \\
15.6 \\
15.0\end{array}$ & $\begin{array}{l}15.7 \\
13.3 \\
12.9 \\
14.6 \\
17.5\end{array}$ & $\begin{array}{l}13.5 \\
13.0 \\
12.8 \\
12.5 \\
16.5\end{array}$ & $\begin{array}{l}20.4 \\
15.5 \\
15.2 \\
13.6 \\
15.6\end{array}$ & $\begin{array}{l}71.6 \\
22.4 \\
25.3 \\
65.4 \\
21.0\end{array}$ & $\begin{array}{l}190 \\
143 \\
131 \\
373 \\
157\end{array}$ & $\begin{array}{l}73.0 \\
291 \\
239 \\
177 \\
158\end{array}$ & $\begin{array}{l}32.1 \\
81.9 \\
54.0 \\
62.8 \\
41.4\end{array}$ & $\begin{array}{l}21.9 \\
35.2 \\
33.7 \\
33.3 \\
23.1\end{array}$ & $\begin{array}{l}20.2 \\
27.2 \\
24.8 \\
24.6 \\
19.5\end{array}$ \\
\hline $\begin{array}{l}1971 \\
1972 \\
1973 \\
1974 \\
1975\end{array}$ & $\begin{array}{l}19.8 \\
21.9 \\
22.0 \\
23.2 \\
19.1\end{array}$ & $\begin{array}{l}17.6 \\
19.5 \\
16.5 \\
21.5 \\
17.9\end{array}$ & $\begin{array}{l}16.1 \\
16.4 \\
15.0 \\
19.6 \\
16.9\end{array}$ & $\begin{array}{l}17.3 \\
16.5 \\
12.9 \\
18.6 \\
15.0\end{array}$ & $\begin{array}{l}15.8 \\
15.5 \\
12.7 \\
16.2 \\
13.8\end{array}$ & $\begin{array}{l}18.7 \\
21.6 \\
15.3 \\
20.0 \\
15.8\end{array}$ & $\begin{array}{l}46.6 \\
43.6 \\
27.7 \\
26.3 \\
20.9\end{array}$ & $\begin{array}{r}164 \\
212 \\
209 \\
234 \\
85.8\end{array}$ & $\begin{array}{l}208 \\
131 \\
178 \\
136 \\
300\end{array}$ & $\begin{array}{c}52.8 \\
39.2 \\
60.0 \\
39.2 \\
103\end{array}$ & $\begin{array}{l}26.3 \\
22.5 \\
34.7 \\
22.2 \\
37.4\end{array}$ & $\begin{array}{l}21.6 \\
19.6 \\
27.5 \\
17.6 \\
25.7\end{array}$ \\
\hline
\end{tabular}


GREEN RIVER BASIN

09275500 WEST FORK DUCHESNE RIVER NEAR HANNA, UT--Continued

MONTHLY MEAN DISCHARGES, IN OBBIC FEET PER SECOND, FOR EACH WATER YEAR--Continued

\begin{tabular}{|c|c|c|c|c|c|c|c|c|c|c|c|c|}
\hline YEAR & $\infty \mathrm{OT}$ & NOV & DEC & JAN & FEB & MAR & APR & MAY & JUNE & JULY & AUG & SEP \\
\hline $\begin{array}{l}1976 \\
1977 \\
1978 \\
1979 \\
1980\end{array}$ & $\begin{array}{l}24.2 \\
17.5 \\
11.7 \\
17.3 \\
15.1\end{array}$ & $\begin{array}{l}18.6 \\
14.7 \\
10.8 \\
18.9 \\
15.4\end{array}$ & $\begin{array}{l}20.5 \\
12.1 \\
10.6 \\
16.0 \\
13.7\end{array}$ & $\begin{array}{l}15.5 \\
11.3 \\
10.9 \\
16.0 \\
11.7\end{array}$ & $\begin{array}{l}12.3 \\
11.2 \\
11.3 \\
16.0 \\
12.5\end{array}$ & $\begin{array}{l}13.9 \\
13.1 \\
13.6 \\
15.6 \\
13.0\end{array}$ & $\begin{array}{l}28.3 \\
28.0 \\
30.9 \\
26.3 \\
48.6\end{array}$ & $\begin{array}{l}170 \\
30.9 \\
128 \\
163 \\
225\end{array}$ & $\begin{array}{l}93.8 \\
26.0 \\
217 \\
139 \\
300\end{array}$ & $\begin{array}{l}30.6 \\
12.8 \\
48.6 \\
32.7 \\
76.4\end{array}$ & $\begin{array}{l}20.8 \\
11.3 \\
22.1 \\
20.2 \\
34.3\end{array}$ & $\begin{array}{c}17.2 \\
9.36 \\
19.1 \\
14.9 \\
28.6\end{array}$ \\
\hline 1981 & 24.1 & 19.8 & 18.6 & 18.8 & 18.5 & 19.1 & 41.2 & 103 & 83.6 & 27.4 & 18.0 & 21.0 \\
\hline
\end{tabular}

ANNUAL PEAK DISGHARGE, IN OBIC FEET PER SECOND, AND CORRESPONDING GAGE HEIGHT, IN FEET, FOR EAOH WATER YEAR

\begin{tabular}{|c|c|c|c|c|c|c|c|c|c|c|c|c|}
\hline $\begin{array}{l}\text { WATER } \\
\text { YEAR }\end{array}$ & DATE & $\begin{array}{c}\text { GAGE } \\
\text { HEIGT }\end{array}$ & $\begin{array}{c}\text { PEAK } \\
\text { DISAHARGE }\end{array}$ & $\begin{array}{l}\text { WATER } \\
\text { YEAR }\end{array}$ & & DATE & $\begin{array}{c}\text { GAGE } \\
\text { HEIGHT }\end{array}$ & $\begin{array}{c}\text { PEAK } \\
\text { DISCHARGE }\end{array}$ & $\begin{array}{l}\text { WATER } \\
\text { YEAR }\end{array}$ & DATE & $\begin{array}{c}\text { GAGE } \\
\text { HEIGHT }\end{array}$ & $\begin{array}{c}\text { PEAK } \\
\text { DISOHARG }\end{array}$ \\
\hline $\begin{array}{l}1923 \\
1946 \\
1947 \\
1948 \\
1949 \\
1950 \\
1951 \\
1952 \\
1953 \\
1954 \\
1955 \\
1956 \\
1957\end{array}$ & $\begin{array}{lll}\text { JUNE } & 12,1923 \\
\text { MAY } & 09,1946 \\
\text { MAY } & 08,1947 \\
\text { MAY } & 19,1948 \\
\text { MAY } & 28,1949 \\
\text { MAY } & 31,1950 \\
\text { MAY } & 27,1951 \\
\text { JUNE } & 04,1952 \\
\text { JUNE } & 10,1953 \\
\text { MAY } & 13,1954 \\
\text { MAY } & 21,1955 \\
\text { MAY } & 19,1956 \\
\text { JUNE } & 06,1957\end{array}$ & $\begin{array}{l}2.70 \\
2.95 \\
3.54 \\
3.85 \\
3.50 \\
- \\
4.33 \\
4.40 \\
3.95 \\
2.95 \\
3.45 \\
3.59 \\
4.22\end{array}$ & $\begin{array}{l}534 \\
293 \\
384 \\
438 \\
382 \\
550 \\
619 \\
652 \\
488 \\
235 \\
369 \\
446 \\
666\end{array}$ & $\begin{array}{l}1958 \\
1959 \\
1960 \\
1961 \\
1962 \\
1963 \\
1964 \\
1965 \\
1966 \\
1967 \\
1968 \\
1969\end{array}$ & $\begin{array}{l}\text { MAY } \\
\text { MAY } \\
\text { MAY } \\
\text { MAY } \\
\text { MAY } \\
\text { JUNE } \\
\text { MAY } \\
\text { JUNE } \\
\text { MAY } \\
\text { JUNE } \\
\text { JUNE } \\
\text { MAY }\end{array}$ & $\begin{array}{ll}29, & 1958 \\
15, & 1959 \\
12, & 1960 \\
11, & 1961 \\
09, & 1962 \\
04, & 1963 \\
23, & 1964 \\
08, & 1965 \\
09, & 1966 \\
05, & 1967 \\
05, & 1968 \\
25, & 1969\end{array}$ & $\begin{array}{l}3.97 \\
2.62 \\
3.08 \\
2.38 \\
3.43 \\
3.02 \\
3.48 \\
3.84 \\
3.09 \\
3.60 \\
3.59 \\
3.60\end{array}$ & $\begin{array}{l}551 \\
186 \\
304 \\
145 \\
461 \\
293 \\
470 \\
659 \\
410 \\
758 \\
680 \\
662\end{array}$ & $\begin{array}{l}1970 \\
1971 \\
1972 \\
1973 \\
1974 \\
1975 \\
1976 \\
1977 \\
1978 \\
1979 \\
1980 \\
1981\end{array}$ & $\begin{array}{lll}\text { MAY } & 26,1970 \\
\text { MAY } & 27,1971 \\
\text { MAY } & 27,1972 \\
\text { MAY } & 21,1973 \\
\text { MAY } & 28,1974 \\
\text { JUNE } & 14,1975 \\
\text { MAY } & 18,1976 \\
\text { JULY } 19,1977 \\
\text { JUNE } 10,1978 \\
\text { MAY } 28,1979 \\
\text { JUNE } 11,1980 \\
\text { MAY } & 31,1981\end{array}$ & $\begin{array}{l}3.25 \\
3.13 \\
2.89 \\
3.25 \\
3.35 \\
3.67 \\
2.87 \\
1.63 \\
3.17 \\
3.64 \\
3.50 \\
2.66\end{array}$ & $\begin{array}{r}487 \\
464 \\
390 \\
492 \\
572 \\
752 \\
338 \\
68 \\
438 \\
544 \\
530 \\
242\end{array}$ \\
\hline
\end{tabular}

\begin{tabular}{|c|c|c|c|c|c|c|}
\hline MAGN & NDDE & $\begin{array}{l}\text { AND PRCBAB] } \\
\text { BASED O }\end{array}$ & OF A & $\begin{array}{l}\text { LCW } \\
19\end{array}$ & AN D & \\
\hline \multirow{2}{*}{$\begin{array}{l}\text { PERIOD } \\
\text { (OON- } \\
\text { SEQU- } \\
\text { TTVE } \\
\text { DAYS) }\end{array}$} & \multicolumn{6}{|c|}{$\begin{array}{l}\text { DISCHARGE, IN OUBIC FEET PER SECOND, FOR } \\
\text { INDICATED RECIRRENCE INTERVAL, IN YEARS, AND } \\
\text { ANNUAL NONEXCEEDANCE PRCBABILITY, IN PERCENT }\end{array}$} \\
\hline & $\begin{array}{c}2 \\
508\end{array}$ & $\begin{array}{c}5 \\
208\end{array}$ & $\begin{array}{l}10 \\
108\end{array}$ & $\begin{array}{l}20 \\
58\end{array}$ & $\begin{array}{l}50 \\
28\end{array}$ & $\begin{array}{r}100 \\
18\end{array}$ \\
\hline $\begin{array}{r}1 \\
7 \\
14 \\
30 \\
60 \\
90\end{array}$ & $\begin{array}{l}11 \\
12 \\
12 \\
13 \\
13 \\
14\end{array}$ & $\begin{array}{l}9.0 \\
10 \\
11 \\
11 \\
12 \\
12\end{array}$ & $\begin{array}{c}8.1 \\
9.6 \\
9.9 \\
10 \\
11 \\
11\end{array}$ & $\begin{array}{l}7.3 \\
8.9 \\
9.2 \\
9.7 \\
10 \\
11\end{array}$ & $\begin{array}{r}6.5 \\
8.2 \\
8.4 \\
8.9 \\
9.7 \\
10\end{array}$ & $\overline{-}$ \\
\hline
\end{tabular}

09276000 WOLF CREEK ABOVE RHOADES CANYON, NEAR HANNA, UT

LOCATTON.--Lat $40^{\circ} 28^{\prime} 16^{\prime \prime}$, long $110^{\circ} 55^{\prime} 05^{\prime \prime}$, in NE'sW' 14060003, wasatch National Forest, on left bank $1.5 \mathrm{mi}$ upstream from Rhoades Canyon, $2.8 \mathrm{mi}$ upstream from mouth, and $9 \mathrm{mi}$ northwest of Hanna.

DRAINAGE AREA. $--10.6 \mathrm{mi}^{2}$.

MEAN BASIN ELEVATTON. - $9,040 \mathrm{ft}$.

PERIOD OF RECORD AVALLABLE. - - October 1945 to September 1981.

REVISED RECORDS.--WDR UT-77-1: Drainage area.

GAGE.-Water-stage recorder and masonary control, Altitude of gage is 7,740 ft from topographic map.

AVERAGE DISGHARGE. --36 years, $7.40 \mathrm{ft}^{3} / \mathrm{s}, 5,360$ acre-ft/yr.

EXTREMES FOR PERIOD OF RECORD.--Maximum discharge, $82 \mathrm{ft}^{3} / \mathrm{s}$ June 8,1952 , gage height, $2.64 \mathrm{ft}$; minimum, $0.2 \mathrm{ft} t^{3} / \mathrm{s}$ sanetime during Jan. 2-31, 1962 , probably result of temporary obstruction upstream. 
GREEN RIVER BASIN

09276000 WOLF CREEK ABOVE RHOADES CANYON, NEAR HANNA, UT--Continued

LOWEST MEAN DISCHARGE, IN OUBIC FEET PER SECOND, AND RANKING FOR THE INDICATED NUMBER OF CONSECUTIVE DAYS FOR EACH CLIMATIC YEAR, APRIL 1-MARCH 31

YEAR

1947

1948

1950

1951

195

1955

195

1957

1958
1959

1960

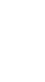

1962

1965

1966

1967

1968

1969
1970

1971

1972

1974
1975

1976

1977

1978

1980

1981
CONSECUTIVE DAYS

\begin{tabular}{|c|c|c|c|c|c|c|c|c|c|c|c|c|c|}
\hline 14 & & 30 & 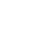 & 60 & & 90 & & 120 & & 183 & & ALL & \\
\hline $\begin{array}{l}2.90 \\
3.30 \\
2.80 \\
3.10\end{array}$ & & $\begin{array}{l}3.00 \\
3.50 \\
2.80 \\
3.60\end{array}$ & $\begin{array}{l}17 \\
25 \\
13 \\
30\end{array}$ & $\begin{array}{l}3.00 \\
4.00 \\
2.80 \\
3.80\end{array}$ & & $\begin{array}{l}3.00 \\
4.20 \\
2.90 \\
3.90\end{array}$ & $\begin{array}{r}11 \\
29 \\
9 \\
25\end{array}$ & $\begin{array}{l}3.10 \\
4.40 \\
3.00 \\
4.10\end{array}$ & & $\begin{array}{l}3.60 \\
4.80 \\
3.30 \\
4.70\end{array}$ & & $\begin{array}{l}6.50 \\
9.10 \\
5.70 \\
8.90\end{array}$ & $\begin{array}{r}11 \\
30 \\
9 \\
26\end{array}$ \\
\hline $\begin{array}{l}4.00 \\
3.40 \\
4.40 \\
3.80 \\
2.60\end{array}$ & $\begin{array}{r}34 \\
26 \\
35 \\
32 \\
7\end{array}$ & $\begin{array}{l}4.20 \\
3.40 \\
4.50 \\
3.80 \\
2.60\end{array}$ & $\begin{array}{r}34 \\
22 \\
35 \\
32 \\
6\end{array}$ & $\begin{array}{l}4.40 \\
3.50 \\
4.80 \\
3.90 \\
2.60\end{array}$ & $\begin{array}{r}32 \\
19 \\
35 \\
25 \\
5\end{array}$ & $\begin{array}{l}4.70 \\
3.50 \\
5.00 \\
4.00 \\
2.60\end{array}$ & $\begin{array}{r}32 \\
19 \\
34 \\
26 \\
4\end{array}$ & $\begin{array}{l}5.00 \\
3.60 \\
5.30 \\
4.10 \\
2.70\end{array}$ & $\begin{array}{r}32 \\
18 \\
35 \\
26 \\
4\end{array}$ & $\begin{array}{l}5.70 \\
4.20 \\
6.10 \\
4.40 \\
2.80\end{array}$ & $\begin{array}{r}32 \\
19 \\
34 \\
22 \\
3\end{array}$ & $\begin{array}{c}10.0 \\
8.30 \\
14.0 \\
7.20 \\
4.30\end{array}$ & $\begin{array}{r}32 \\
22 \\
35 \\
15 \\
3\end{array}$ \\
\hline $\begin{array}{l}2.60 \\
2.70 \\
3.10 \\
3.50 \\
2.80\end{array}$ & $\begin{array}{r}8 \\
10 \\
21 \\
29 \\
11\end{array}$ & $\begin{array}{l}2.70 \\
2.80 \\
3.10 \\
3.50 \\
2.80\end{array}$ & $\begin{array}{r}8 \\
9 \\
18 \\
26 \\
10\end{array}$ & $\begin{array}{l}2.70 \\
2.90 \\
3.90 \\
3.50 \\
2.90\end{array}$ & $\begin{array}{r}6 \\
9 \\
26 \\
20 \\
10\end{array}$ & $\begin{array}{l}2.70 \\
3.00 \\
4.00 \\
3.60 \\
2.90\end{array}$ & $\begin{array}{r}7 \\
10 \\
27 \\
20 \\
8\end{array}$ & $\begin{array}{l}2.80 \\
3.00 \\
4.10 \\
3.80 \\
3.00\end{array}$ & $\begin{array}{r}7 \\
8 \\
27 \\
20 \\
9\end{array}$ & $\begin{array}{l}3.10 \\
3.40 \\
4.70 \\
4.40 \\
3.30\end{array}$ & $\begin{array}{r}7 \\
10 \\
27 \\
23 \\
8\end{array}$ & $\begin{array}{l}5.10 \\
6.70 \\
8.40 \\
8.90 \\
5.10\end{array}$ & $\begin{array}{r}7 \\
13 \\
24 \\
25 \\
8\end{array}$ \\
\hline $\begin{array}{l}2.30 \\
1.80 \\
2.30 \\
2.60 \\
2.80\end{array}$ & $\begin{array}{r}3 \\
1 \\
4 \\
9 \\
12\end{array}$ & $\begin{array}{l}2.30 \\
1.80 \\
2.90 \\
2.60 \\
2.80\end{array}$ & $\begin{array}{r}3 \\
1 \\
14 \\
7 \\
11\end{array}$ & $\begin{array}{l}2.50 \\
1.90 \\
3.10 \\
2.70 \\
3.50\end{array}$ & $\begin{array}{r}4 \\
1 \\
16 \\
7 \\
21\end{array}$ & $\begin{array}{l}2.60 \\
1.90 \\
3.20 \\
2.70 \\
3.70\end{array}$ & $\begin{array}{r}5 \\
1 \\
16 \\
6 \\
23\end{array}$ & $\begin{array}{l}2.70 \\
2.00 \\
3.40 \\
2.80 \\
3.90\end{array}$ & $\begin{array}{r}5 \\
1 \\
16 \\
6 \\
23\end{array}$ & $\begin{array}{l}3.00 \\
2.00 \\
4.00 \\
3.00 \\
4.20\end{array}$ & $\begin{array}{r}5 \\
1 \\
16 \\
6 \\
20\end{array}$ & $\begin{array}{l}4.70 \\
2.40 \\
8.30 \\
4.90 \\
7.30\end{array}$ & $\begin{array}{r}4 \\
1 \\
23 \\
6 \\
16\end{array}$ \\
\hline $\begin{array}{l}3.10 \\
2.90 \\
3.10 \\
3.50 \\
3.80\end{array}$ & $\begin{array}{l}22 \\
16 \\
23 \\
30 \\
33\end{array}$ & $\begin{array}{l}3.40 \\
3.00 \\
3.20 \\
3.50 \\
3.90\end{array}$ & $\begin{array}{l}23 \\
15 \\
19 \\
27 \\
33\end{array}$ & $\begin{array}{l}4.60 \\
3.00 \\
4.00 \\
4.30 \\
4.10\end{array}$ & $\begin{array}{l}33 \\
13 \\
29 \\
31 \\
30\end{array}$ & $\begin{array}{l}4.80 \\
3.10 \\
4.20 \\
4.40 \\
4.40\end{array}$ & $\begin{array}{l}33 \\
12 \\
28 \\
30 \\
31\end{array}$ & $\begin{array}{l}5.20 \\
3.20 \\
4.30 \\
4.50 \\
4.50\end{array}$ & $\begin{array}{l}33 \\
12 \\
28 \\
30 \\
31\end{array}$ & $\begin{array}{l}6.10 \\
3.60 \\
4.90 \\
5.20 \\
5.10\end{array}$ & $\begin{array}{l}35 \\
11 \\
29 \\
31 \\
30\end{array}$ & $\begin{array}{c}11.0 \\
6.70 \\
9.00 \\
9.00 \\
9.80\end{array}$ & $\begin{array}{l}33 \\
14 \\
27 \\
28 \\
31\end{array}$ \\
\hline $\begin{array}{l}3.40 \\
3.50 \\
3.70 \\
2.80 \\
3.00\end{array}$ & $\begin{array}{l}27 \\
28 \\
31 \\
13 \\
18\end{array}$ & $\begin{array}{l}3.50 \\
3.50 \\
3.70 \\
2.80 \\
3.20\end{array}$ & $\begin{array}{l}28 \\
29 \\
31 \\
12 \\
20\end{array}$ & $\begin{array}{l}3.50 \\
3.50 \\
3.90 \\
2.90 \\
3.30\end{array}$ & $\begin{array}{l}22 \\
23 \\
27 \\
11 \\
17\end{array}$ & $\begin{array}{l}3.60 \\
3.60 \\
3.90 \\
3.10 \\
3.50\end{array}$ & $\begin{array}{l}21 \\
22 \\
24 \\
13 \\
17\end{array}$ & $\begin{array}{l}3.80 \\
3.80 \\
4.00 \\
3.20 \\
3.60\end{array}$ & $\begin{array}{l}21 \\
22 \\
24 \\
13 \\
17\end{array}$ & $\begin{array}{l}4.20 \\
4.50 \\
4.60 \\
3.80 \\
4.10\end{array}$ & $\begin{array}{l}21 \\
24 \\
25 \\
15 \\
17\end{array}$ & $\begin{array}{l}7.30 \\
9.10 \\
8.10 \\
7.60 \\
7.80\end{array}$ & $\begin{array}{l}17 \\
29 \\
21 \\
18 \\
19\end{array}$ \\
\hline $\begin{array}{l}3.30 \\
3.00 \\
2.20 \\
2.40 \\
2.40\end{array}$ & $\begin{array}{r}24 \\
19 \\
2 \\
5 \\
6\end{array}$ & $\begin{array}{l}3.40 \\
3.00 \\
2.30 \\
2.50 \\
2.40\end{array}$ & $\begin{array}{r}24 \\
16 \\
2 \\
5 \\
4\end{array}$ & $\begin{array}{l}4.60 \\
3.10 \\
2.30 \\
3.10 \\
2.50\end{array}$ & $\begin{array}{r}34 \\
14 \\
2 \\
15 \\
3\end{array}$ & $\begin{array}{l}5.10 \\
3.10 \\
2.30 \\
3.20 \\
2.60\end{array}$ & $\begin{array}{r}35 \\
14 \\
2 \\
15 \\
3\end{array}$ & $\begin{array}{l}5.30 \\
3.20 \\
2.30 \\
3.30 \\
2.70\end{array}$ & $\begin{array}{r}34 \\
14 \\
2 \\
15 \\
3\end{array}$ & $\begin{array}{l}5.80 \\
3.60 \\
2.40 \\
3.60 \\
2.90\end{array}$ & $\begin{array}{r}33 \\
12 \\
2 \\
13 \\
4\end{array}$ & $\begin{array}{c}11.0 \\
6.50 \\
2.70 \\
6.20 \\
4.80\end{array}$ & $\begin{array}{r}34 \\
12 \\
2 \\
10 \\
5\end{array}$ \\
\hline 2.80 & 14 & 3.202 & 21 & 3.50 & 18 & 3.50 & 18 & 3.70 & 19 & 4.20 & 18 & 7.90 & 20 \\
\hline
\end{tabular}

HIGHEST MEAN DISCHARGE, IN OUBIC FEET PER SECOND, AND RANKING FOR THE INDICATED NUMBER OF CONSECUTIVE DAYS FOR EACH WATER YEAR, OCTOBER 1-SEPTEMBER 30

YEAR

1946

1947

1949
1950

1951

1952

1953
1954

1955

1956

1957

1958

1960

1961

1962

1964

1965

1966

1967

1968

1970

$$
3
$$

1

2.9019

$\begin{array}{rr}3.20 & 25 \\ 2.70 & 14\end{array}$

2.7015

3.8034

$\begin{array}{ll}3.20 & 26 \\ 4.30 & 35\end{array}$

$4.50 \quad 32$
3.50

2.607

$2.60 \quad 8$

$\begin{array}{rr}2.60 & 9 \\ 3.10 & 23\end{array}$

$\begin{array}{ll}3.10 & 23 \\ 3.30 & 27\end{array}$

2.8016

$\begin{array}{ll}2.10 & 4 \\ 1.80 & 1\end{array}$

2.102

2.6011

3.0021

2.9020

$\begin{array}{ll}3.10 & 22 \\ 3.30 & 28\end{array}$

3.7033

3.3029

$\begin{array}{ll}3.30 & 30 \\ 3.30 & 31\end{array}$

2.7012

3.2024

2.9018

2.103

$\begin{array}{ll}2.30 & 5 \\ 2.40 & 6\end{array}$

3.2025

2.7014
2.7015

3.8034

3.2026
4.3035

3.5032
2.607

2.608

$\begin{array}{rr}2.60 & 9 \\ 3.10 & 21\end{array}$

3.4031

2.104

2.102

2.6011

3.1022

2.9017

3.3027

3.8033

3.3028

3.4029
3.4030

2.7012

3.2024

3.0020

$\begin{array}{ll}2.10 & 3 \\ 2.30 & 5\end{array}$
2.406

$\begin{array}{ll}3.20 & 24 \\ 3.00 & 20\end{array}$

2.203

$\begin{array}{ll}2.30 & 5 \\ 2.40 & 6\end{array}$

2.8016

2.608

3.1021

$\begin{array}{ll}3.40 & 27 \\ 2.80 & 15\end{array}$

$\begin{array}{ll}2.20 & 4 \\ 1.80 & 1\end{array}$

$\begin{array}{ll}2.20 & 2 \\ 2.6010\end{array}$

3.1022

$\begin{array}{ll}2.9018 \\ 3.10 & 23\end{array}$

$\begin{array}{ll}3.40 & 28 \\ 3.80 & 33\end{array}$

$\begin{array}{ll}3.40 & 29 \\ 3.50 & 30\end{array}$

3.5031

2.7012

IN OORIC

$\begin{array}{cc}1 & \\ 22.0 & 32 \\ 37.0 & 18 \\ 35.0 & 21 \\ 41.0 & 12\end{array}$

3

$\begin{array}{cc}7 \\ 20.0 \\ 36.0 & 32 \\ 32.0 & 20 \\ 36.0 & 13 \\ 40.0 & \end{array}$

$\begin{array}{ll}22.0 & 32 \\ 37.0 & 17\end{array}$

$37.0 \quad 17$

$34.0 \quad 21$

$\begin{array}{rr}38.0 & 14 \\ 44.0 & 8\end{array}$

49.07

$48.0 \quad 6$

61.01

$59.0 \quad 1$

$39.0 \quad 12$

$\begin{array}{llll}21.0 & 33 & 20.0 & 33 \\ 26.0 & 30 & 25.0 & 29\end{array}$

$32.0 \quad 24$

$32.0 \quad 22$

$\begin{array}{rr}49.0 & 4 \\ 52.0 & 2\end{array}$

$\begin{array}{rr}52.0 & 2 \\ 19.0 & 34\end{array}$

$\begin{array}{llll}20.0 & 34 & 19.0 & 34 \\ 28.0 & 28 & 25.0 & 30\end{array}$

7.6035

7.0035

$37.0 \quad 15$

23.031

$\begin{array}{rr}38.0 & 13 \\ 41.0 & 9\end{array}$

$29.0 \quad 27$

36.018

45.07

$\begin{array}{ll}41.0 & 10 \\ 31.0 & 24\end{array}$
43.06

$\begin{array}{rr}58.0 & 1 \\ 35.0 & 16\end{array}$

$\begin{array}{ll}20.0 & 33 \\ 22.0 & 30\end{array}$

$31.0 \quad 23$

48.02

$\begin{array}{lr}48.0 & 3 \\ 19.0 & 34\end{array}$

22.031

6.3035

$\begin{array}{llll}36.0 & 14 & 32.0 & 12 \\ 23.0 & 29 & 21.0 & 29\end{array}$

$\begin{array}{rr}32.0 & 21 \\ 40.0 & 7\end{array}$

$26.0 \quad 27$

$\begin{array}{rr}33.0 & 17 \\ 40.0 & 8\end{array}$

$\begin{array}{rrrr}39.0 & 10 & 36.0 & 8 \\ 29.0 & 24 & 26.0 & 25\end{array}$

$34.0 \quad 11$

29.020

$\begin{array}{ll}18.0 & 33 \\ 19.0 & 31\end{array}$

$29.0 \quad 21$

$\begin{array}{ll}16.0 & 34 \\ 19.0 & 32\end{array}$

5.7035

$\begin{array}{ll}32.0 & 12 \\ 21.0 & 29\end{array}$
15

\begin{abstract}
$\begin{array}{ll}\text { CONSECTTIVE DAYS } \\ 30 & 60\end{array}$
\end{abstract}
19.030

$31.0 \quad 15$

$\begin{array}{rr}32.0 & 14 \\ 38.0 & 5\end{array}$

$\begin{array}{ll}39.0 & 4 \\ 43.0 & 2\end{array}$

$\begin{array}{rrrr}21.0 & 29 & 17.0 & 30 \\ 30.0 & 16 & 25.0 & 19 \\ 37.0 & 6 & 34.0 & 5\end{array}$

$\begin{array}{ll}18.0 & 29 \\ 28.0 & 15 \\ 20.0 & 26\end{array}$

$\begin{array}{rr}29.0 & 12 \\ 35.0 & 4\end{array}$

$29.0 \quad 13$

$\begin{array}{rr}49.0 & 1 \\ 24.0 & 22\end{array}$

$\begin{array}{ll}14.0 & 34 \\ 16.0 & 31\end{array}$

$24.0 \quad 23$

$\begin{array}{rr}31.0 & 9 \\ 36.0 & 3\end{array}$

$\begin{array}{lr}36.0 & 3 \\ 15.0 & 33\end{array}$

$\begin{array}{ll}15.0 & 33 \\ 16.0 & 32\end{array}$

4.8035

$28.0 \quad 14$

$\begin{array}{rr}25.0 & 19 \\ 34.0 & 5\end{array}$

$\begin{array}{ll}19.0 & 27 \\ 30.0 & 10\end{array}$

$\begin{array}{rr}30.0 & 10 \\ 32.0 & 6\end{array}$

$\begin{array}{rr}32.0 & 7 \\ 23.0 & 24\end{array}$ $\begin{array}{rr}16.0 & 26 \\ 25.0 & 9 \\ 15.0 & 27 \\ 24.0 & 10 \\ 28.0 & 3\end{array}$

$\begin{array}{rr}25.0 & 7 \\ 24.0 & 12 \\ 26.0 & 5\end{array}$

$23.0 \quad 14$

$40.0 \quad 1$

$18.0 \quad 24$

$\begin{array}{ll}10.0 & 34 \\ 13.0 & 29\end{array}$

19.020

$24.0 \quad 11$

$\begin{array}{lr}26.0 & 6 \\ 12.0 & 30\end{array}$

12.031

3.9036

$23.0 \quad 15$

20.019

28.04

$\begin{array}{ll}16.0 & 25 \\ 25.0 & 7\end{array}$

$\begin{array}{ll}26.0 & 5\end{array}$

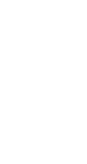

$23.0 \quad 3$

$19.0 \quad 12$

$\begin{array}{rr}34.0 & 1 \\ 15.0 & 21\end{array}$

$\begin{array}{rr}15.0 & 21 \\ 8.20 & 34\end{array}$

$11.0 \quad 29$

$\begin{array}{ll}15.0 & 22 \\ 19.0 & 13\end{array}$

$\begin{array}{rr}19.0 & 13 \\ 21.0 & 8\end{array}$

9.9032
9.2033

3.4036

$\begin{array}{cc}3.40 & 36 \\ 19.0 \quad 14\end{array}$

10.030

$\begin{array}{rr}16.0 & 19 \\ 23.0 & 4\end{array}$

$14.0 \quad 23$

$\begin{array}{rr}21.0 & 9 \\ 20.0 & 10\end{array}$

22.05

$\begin{array}{rr}22.0 & 5 \\ 15.0 & 20\end{array}$
120

$12.0 \quad 26$

18.07

10.028

$17.0 \quad 11$

$16.0 \quad 12$

$29.0 \quad 1$

29.0
13.0

$\begin{array}{cc}13.0 & 21 \\ 7.20 & 34\end{array}$

9.1029

$13.0 \quad 22$

16.013

18.0

8.6030
7.9033

3.2036

$16.0 \quad 14$

8.6031

$14.0 \quad 19$

20.04

$12.0 \quad 23$

18.09

19.0

13.020

183

$9.40 \quad 24$

$\begin{array}{rr}13.0 & 7 \\ 8.10 & 28\end{array}$

$\begin{array}{ll}13.0 & 8 \\ 15.0 & 3\end{array}$

$12.0 \quad 15$

23.01

$\begin{array}{rr}10.0 & 19 \\ 6.00 & 34\end{array}$

7.1029

9.9022

$12.0 \quad 16$

13.09

6.9030
6.3033

3.0036

13.010

6.8031

$\begin{array}{rr}10.0 & 20 \\ 15.0 & 4\end{array}$

9.7023

13.011 
GREEN RIVER BASIN

09276000 WOAF CREEK ABOVE RHQADES CANYON, NEAR HANNA, UT-Continued

HIGHEST MEAN DISQHARGE, IN OUBIC FEET PER SECOND, AND RANKING FOR THE INDICATED NUMBER OF CONSECJTIVE DAYS FOR EAOH WATER YEAR, OCTCBER 1-SEPTEMBER 30--Continued

\begin{tabular}{|c|c|c|c|c|c|c|c|c|c|c|c|c|c|c|c|c|c|c|c|c|}
\hline YEAR & & & & & & & & & cons & $E O I$ & E DAYS & & & & & & & & & \\
\hline $\begin{array}{l}1976 \\
1977 \\
1978 \\
1979 \\
1980\end{array}$ & $\begin{array}{c}30.0 \\
5.00 \\
36.0 \\
32.0 \\
52.0\end{array}$ & $\begin{array}{r}26 \\
36 \\
20 \\
23 \\
4\end{array}$ & $\begin{array}{c}29.0 \\
5.00 \\
34.0 \\
29.0 \\
48.0\end{array}$ & $\begin{array}{r}25 \\
36 \\
20 \\
26 \\
5\end{array}$ & $\begin{array}{c}28.0 \\
4.90 \\
32.0 \\
26.0 \\
43.0\end{array}$ & $\begin{array}{r}25 \\
36 \\
29 \\
26 \\
5\end{array}$ & $\begin{array}{c}27.0 \\
4.90 \\
29.0 \\
22.0 \\
37.0\end{array}$ & $\begin{array}{r}23 \\
36 \\
19 \\
28 \\
7\end{array}$ & $\begin{array}{c}24.0 \\
4.70 \\
24.0 \\
18.0 \\
30.0\end{array}$ & $\begin{array}{l}20 \\
36 \\
21 \\
28 \\
11\end{array}$ & $\begin{array}{c}18.0 \\
4.50 \\
18.0 \\
12.0 \\
23.0\end{array}$ & $\begin{array}{l}22 \\
35 \\
23 \\
33 \\
13\end{array}$ & $\begin{array}{c}14.0 \\
4.20 \\
14.0 \\
10.0 \\
18.0\end{array}$ & $\begin{array}{l}24 \\
35 \\
25 \\
31 \\
16\end{array}$ & $\begin{array}{c}12.0 \\
3.90 \\
12.0 \\
8.50 \\
15.0\end{array}$ & $\begin{array}{l}24 \\
35 \\
25 \\
32 \\
18\end{array}$ & $\begin{array}{r}9.30 \\
3.60 \\
8.80 \\
6.70 \\
12.0\end{array}$ & $\begin{array}{l}25 \\
35 \\
26 \\
32 \\
14\end{array}$ & $\begin{array}{l}7.60 \\
3.30 \\
5.70 \\
5.10 \\
7.20\end{array}$ & $\begin{array}{l}20 \\
35 \\
28 \\
31 \\
22\end{array}$ \\
\hline 1981 & 27.0 & 29 & 26.0 & 28 & 25.0 & 28 & 24.0 & 26 & 20.0 & 25 & 15.0 & 28 & 13.0 & 26 & 11.0 & 27 & 8.50 & 27 & 6.40 & 26 \\
\hline
\end{tabular}

DURATION $O$ F DISQHARGE FOR EAOH WATER YEAR

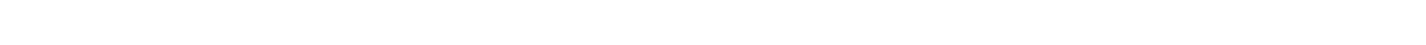

YEAR

NUMBER OF DAYS IN CLASS

OBIC FEET

1946

1947

1948

1950

1951
1952

1953

1954

1956

1957

1958
1959

1960

1961

1962

1963

1965

1966

1967
1968

1969

1970

1971

1972

1974

1975

1976

1977
1978

1979
1980

1981

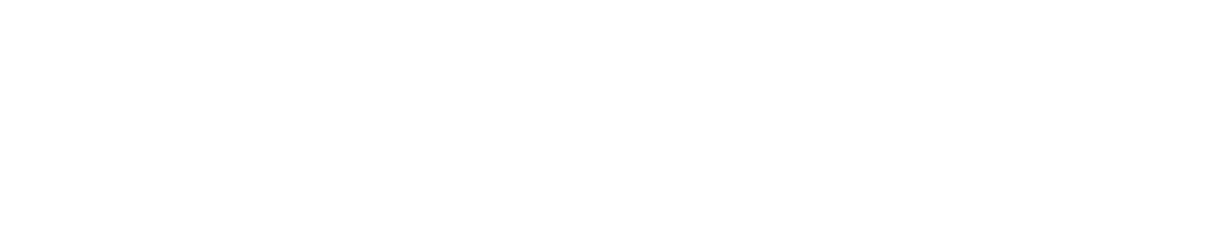

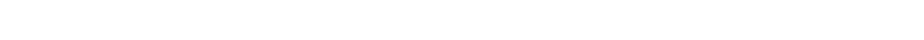

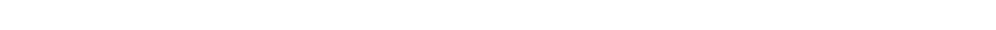

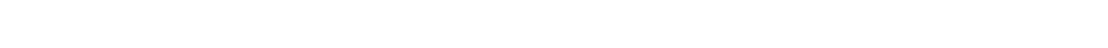
$\begin{array}{lllllllllllllllllllllllllll}114 & 33 & 33 & 4 & 24 & 22 & 27 & 17 & 8 & 9 & 9 & 7 & 9 & 5 & 1 & 4 & 6 & 6 & 4 & 3 & 5 & 3 & 6 & 2 & 2 & 2\end{array}$

$\begin{array}{rrrrrrrrrrrrrrrrrrrrrr}23 & 75 & 46 & 46 & 37 & 45 & 33 & 4 & 5 & 3 & 8 & 1 & 3 & 15 & 8 & 4 & 2 & 5 & 2 & & & \\ 48133 & 13 & 68 & 35 & 11 & 10 & 4 & 3 & 2 & 4 & 2 & 2 & 3 & 5 & 5 & 7 & 2 & 2 & 4 & 1 & 1 & 1\end{array}$

$\begin{array}{lllllllllllll}19 & 82 & 92 & 31 & 63 & 52 & 5 & 8 & 4 & 1 & 5 & 3\end{array}$

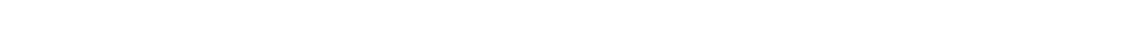

$\begin{array}{llllllllllllllllllllll}7 & 34 & 57 & 35 & 12 & 87 & 39 & 11 & 30 & 8 & 3 & 4 & 4 & 5 & 4 & 3 & 4 & 2 & 2 & 2 & 7 & 5\end{array}$

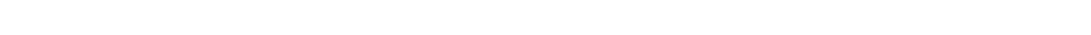

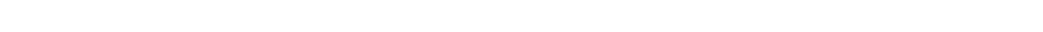

$\begin{array}{lllllllllllllllllll}41 & 50 & 41 & 44 & 31 & 37 & 27 & 32 & 5 & 8 & 6 & 5 & 18 & 3 & 6 & 5 & 1 & 2 & 3\end{array}$

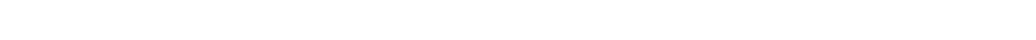

$\begin{array}{llllllllllllllllllllllllllll}432 & 34 & 70 & 30 & 19 & 19 & 17 & 25 & 17 & 6 & 10 & 15 & 5 & 12 & 5 & 3 & 6 & 7 & 3 & 6 & 4 & 7 & 6 & 2 & 1 & 1\end{array}$

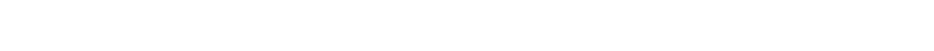

$\begin{array}{llllllllllllllllllllllll}5 & 65 & 55 & 39 & 37 & 10 & 6 & 11 & 19 & 8 & 12 & 8 & 13 & 6 & 8 & 10 & 2 & 710 & 7 & 4 & 7 & 8 & 4 & 4\end{array}$

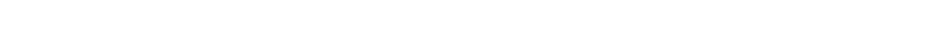

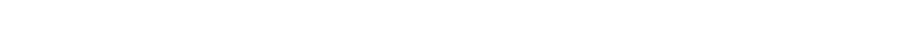

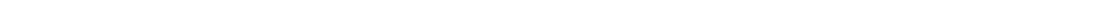

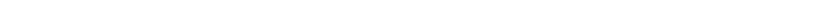

1158906459253523

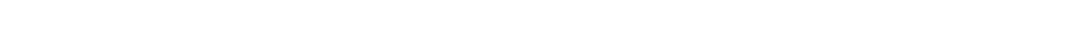

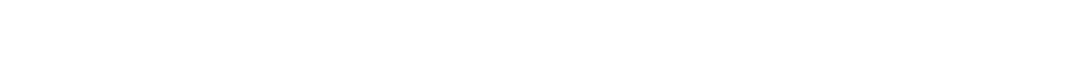

$\begin{array}{llllllllllllllllllllll}11 & 31 & 42 & 40 & 19 & 79 & 45 & 14 & 10 & 11 & 17 & 3 & 1 & 2 & 4 & 6 & 8 & 4 & 2 & 5 & 2 & 9\end{array}$
2370.6

3106.8

2355.0

2996.6
3603.9

3297.9

4926.3

896.0

1817.5

2381.1

2829.9

3307.1

2061.3

1064.8

2661.2

1969.6

3508.8

2887.2

3048.1

3254.1

3603.6

2839.3

3254.7

2942.6

2923.7

2778.7

2767.2

1214.6

2066.2

1874.1
2647.6

2322.2 
GREEN RIVER BASIN

09276000 WOF CREEK ABOVE RHOADES CANYON, NEAR HANNA, UT-Continued

DURATION TABLE OF DISCHARGE FOR WATER YEARS 1946-81

\begin{tabular}{|c|c|c|c|c|c|c|c|c|c|c|c|c|c|c|c|c|c|c|c|}
\hline CLASS & $\begin{array}{c}\text { OBIC } \\
\text { FEET } \\
\text { PER } \\
\text { SECOND }\end{array}$ & $\begin{array}{r}\text { TOTAL } \\
\text { DAYS }\end{array}$ & $\begin{array}{l}\text { ACOJ- } \\
\text { MU- } \\
\text { LATED } \\
\text { DAYS }\end{array}$ & $\begin{array}{l}\text { PER- } \\
\text { CENT } \\
\text { DAYS }\end{array}$ & & $\begin{array}{c}\text { OBIC } \\
\text { FEET } \\
\text { PER } \\
\text { SECOND }\end{array}$ & TOTAL & $\begin{array}{c}\text { ACOU- } \\
\text { HU- } \\
\text { LATED } \\
\text { DAYS }\end{array}$ & $\begin{array}{l}\text { PER } \\
\text { CENT } \\
\text { DAYS }\end{array}$ & & $\begin{array}{c}\text { OBIC } \\
\text { FEET } \\
\text { PER } \\
\text { SECOND }\end{array}$ & $\begin{array}{r}\text { TOTAL } \\
\text { DAYS }\end{array}$ & $\begin{array}{l}\text { ACOU- } \\
\text { MU- } \\
\text { LATED } \\
\text { DAYS }\end{array}$ & $\begin{array}{l}\text { PER } \\
\text { CENT } \\
\text { DAYS }\end{array}$ & CLASS & $\begin{array}{c}\text { OBIC } \\
\text { FEET } \\
\text { PER } \\
\text { SECOND }\end{array}$ & $\begin{array}{r}\text { TOTAL } \\
\text { DAYS }\end{array}$ & $\begin{array}{l}\text { ACOU- } \\
\text { MU- } \\
\text { LATED } \\
\text { DAYS }\end{array}$ & $\begin{array}{l}\text { PER } \\
\text { CENI } \\
\text { DAYS }\end{array}$ \\
\hline $\begin{array}{l}0 \\
1 \\
2 \\
3 \\
4 \\
5 \\
6 \\
7 \\
8\end{array}$ & $\begin{array}{l}0.00 \\
1.80 \\
2.00 \\
2.20 \\
2.50 \\
2.80 \\
3.10 \\
3.40 \\
3.80\end{array}$ & $\begin{array}{r}0 \\
33 \\
161 \\
290 \\
473 \\
951 \\
1057 \\
1045 \\
1269\end{array}$ & $\begin{array}{r}13149 \\
13149 \\
13116 \\
12955 \\
12665 \\
12192 \\
11241 \\
10184 \\
9139\end{array}$ & $\begin{array}{r}100.0 \\
100.0 \\
99.7 \\
98.5 \\
96.3 \\
92.7 \\
85.5 \\
77.5 \\
69.5\end{array}$ & $\begin{array}{l}9 \\
10 \\
11 \\
12 \\
13 \\
14 \\
15 \\
16 \\
17\end{array}$ & $\begin{array}{l}4.20 \\
4.70 \\
5.20 \\
5.80 \\
6.40 \\
7.10 \\
7.90 \\
8.80 \\
9.80\end{array}$ & $\begin{array}{r}1316 \\
1012 \\
695 \\
585 \\
536 \\
510 \\
411 \\
415 \\
185\end{array}$ & $\begin{array}{l}7870 \\
6554 \\
5542 \\
4847 \\
4262 \\
3726 \\
3216 \\
2805 \\
2390\end{array}$ & $\begin{array}{l}59.9 \\
49.8 \\
42.1 \\
36.9 \\
32.4 \\
28.3 \\
24.5 \\
21.3 \\
18.2\end{array}$ & $\begin{array}{l}18 \\
19 \\
20 \\
21 \\
22 \\
23 \\
24 \\
25 \\
26\end{array}$ & $\begin{array}{l}11.0 \\
12.0 \\
13.0 \\
15.0 \\
17.0 \\
18.0 \\
20.0 \\
23.0 \\
25.0\end{array}$ & $\begin{array}{r}201 \\
191 \\
247 \\
261 \\
92 \\
194 \\
258 \\
141 \\
184\end{array}$ & $\begin{array}{r}2205 \\
2004 \\
1813 \\
1566 \\
1305 \\
1213 \\
1019 \\
761 \\
620\end{array}$ & $\begin{array}{r}16.8 \\
15.2 \\
13.8 \\
11.9 \\
9.9 \\
9.2 \\
7.7 \\
5.8 \\
4.7\end{array}$ & $\begin{array}{l}27 \\
28 \\
29 \\
30 \\
31 \\
32 \\
33 \\
34\end{array}$ & $\begin{array}{l}28.0 \\
31.0 \\
35.0 \\
39.0 \\
43.0 \\
48.0 \\
53.0 \\
59.0\end{array}$ & $\begin{array}{r}115 \\
137 \\
81 \\
50 \\
20 \\
20 \\
10 \\
3\end{array}$ & $\begin{array}{r}436 \\
321 \\
184 \\
103 \\
53 \\
33 \\
13 \\
3\end{array}$ & 0 \\
\hline
\end{tabular}

MONTHLY MEAN DISCHARGES, IN OUBIC FEET PER SECOND, FOR EACH WATER YEAR

\begin{tabular}{|c|c|c|c|c|c|c|c|c|c|c|c|c|}
\hline YEAR & OCT & $\mathrm{NOV}$ & DEC & JAN & FEB & MAR & APR & MAY & JUNE & JULY & AUG & SEP \\
\hline $\begin{array}{l}1946 \\
1947 \\
1948 \\
1949 \\
1950\end{array}$ & $\begin{array}{l}4.46 \\
4.71 \\
5.67 \\
4.19 \\
6.50\end{array}$ & $\begin{array}{l}4.16 \\
4.17 \\
5.20 \\
3.75 \\
5.09\end{array}$ & $\begin{array}{l}3.67 \\
3.45 \\
5.14 \\
3.19 \\
4.68\end{array}$ & $\begin{array}{l}3.29 \\
3.02 \\
4.59 \\
3.00 \\
4.08\end{array}$ & $\begin{array}{l}3.00 \\
2.96 \\
4.12 \\
2.89 \\
3.92\end{array}$ & $\begin{array}{l}3.06 \\
3.10 \\
3.80 \\
2.78 \\
3.65\end{array}$ & $\begin{array}{l}7.31 \\
3.53 \\
3.49 \\
3.91 \\
4.92\end{array}$ & $\begin{array}{l}16.5 \\
26.0 \\
14.9 \\
18.0 \\
17.4\end{array}$ & $\begin{array}{l}13.4 \\
21.5 \\
12.7 \\
26.9 \\
31.5\end{array}$ & $\begin{array}{c}7.75 \\
13.1 \\
7.18 \\
13.3 \\
17.2\end{array}$ & $\begin{array}{r}5.96 \\
8.64 \\
5.77 \\
9.26 \\
10.7\end{array}$ & $\begin{array}{l}5.11 \\
7.52 \\
4.48 \\
7.11 \\
8.65\end{array}$ \\
\hline $\begin{array}{l}1951 \\
1952 \\
1953 \\
1954 \\
1955\end{array}$ & $\begin{array}{l}7.66 \\
5.74 \\
8.46 \\
5.23 \\
3.12\end{array}$ & $\begin{array}{l}6.45 \\
4.78 \\
6.77 \\
4.61 \\
2.98\end{array}$ & $\begin{array}{l}5.76 \\
3.96 \\
6.09 \\
4.38 \\
2.83\end{array}$ & $\begin{array}{l}5.16 \\
3.46 \\
5.58 \\
3.97 \\
2.68\end{array}$ & $\begin{array}{l}4.66 \\
3.47 \\
4.96 \\
4.06 \\
2.61\end{array}$ & $\begin{array}{l}4.22 \\
3.50 \\
4.55 \\
3.83 \\
2.60\end{array}$ & $\begin{array}{l}4.41 \\
8.50 \\
4.21 \\
3.61 \\
2.80\end{array}$ & $\begin{array}{c}17.1 \\
31.1 \\
6.43 \\
13.2 \\
12.7\end{array}$ & $\begin{array}{c}22.7 \\
47.2 \\
23.9 \\
6.38 \\
11.9\end{array}$ & $\begin{array}{r}13.5 \\
22.7 \\
11.3 \\
4.64 \\
6.09\end{array}$ & $\begin{array}{c}9.45 \\
15.1 \\
8.47 \\
3.75 \\
5.08\end{array}$ & $\begin{array}{c}7.13 \\
12.0 \\
6.08 \\
3.52 \\
4.16\end{array}$ \\
\hline $\begin{array}{l}1956 \\
1957 \\
1958 \\
1959 \\
1960\end{array}$ & $\begin{array}{l}3.93 \\
4.36 \\
6.24 \\
5.65 \\
3.99\end{array}$ & $\begin{array}{l}3.36 \\
3.75 \\
5.13 \\
5.24 \\
3.76\end{array}$ & $\begin{array}{l}2.85 \\
3.27 \\
4.57 \\
4.38 \\
3.15\end{array}$ & $\begin{array}{l}2.75 \\
3.07 \\
4.09 \\
3.84 \\
2.80\end{array}$ & $\begin{array}{l}2.80 \\
2.82 \\
4.00 \\
3.50 \\
3.09\end{array}$ & $\begin{array}{l}2.68 \\
2.96 \\
3.81 \\
3.49 \\
3.06\end{array}$ & $\begin{array}{l}3.30 \\
3.13 \\
3.80 \\
3.27 \\
3.38\end{array}$ & $\begin{array}{c}20.1 \\
6.28 \\
22.5 \\
9.99 \\
13.3\end{array}$ & $\begin{array}{c}16.1 \\
31.4 \\
27.3 \\
12.6 \\
9.01\end{array}$ & $\begin{array}{c}8.03 \\
15.6 \\
11.8 \\
6.11 \\
4.83\end{array}$ & $\begin{array}{l}6.59 \\
8.96 \\
8.28 \\
5.35 \\
4.10\end{array}$ & $\begin{array}{l}5.41 \\
7.41 \\
7.05 \\
4.24 \\
3.24\end{array}$ \\
\hline $\begin{array}{l}1961 \\
1962 \\
1963 \\
1964 \\
1965\end{array}$ & $\begin{array}{l}3.51 \\
2.09 \\
5.46 \\
3.79 \\
5.24\end{array}$ & $\begin{array}{l}3.34 \\
1.97 \\
4.56 \\
3.25 \\
4.61\end{array}$ & $\begin{array}{l}3.19 \\
1.81 \\
4.05 \\
3.00 \\
4.40\end{array}$ & $\begin{array}{l}2.86 \\
2.00 \\
3.44 \\
2.63 \\
4.01\end{array}$ & $\begin{array}{l}2.59 \\
2.07 \\
3.22 \\
2.67 \\
3.64\end{array}$ & $\begin{array}{l}2.33 \\
2.11 \\
2.94 \\
2.76 \\
3.44\end{array}$ & $\begin{array}{l}2.41 \\
4.01 \\
2.85 \\
2.81 \\
3.36\end{array}$ & $\begin{array}{l}4.42 \\
15.6 \\
11.9 \\
11.8 \\
10.1\end{array}$ & $\begin{array}{l}3.29 \\
27.8 \\
11.2 \\
22.6 \\
33.3\end{array}$ & $\begin{array}{c}2.33 \\
13.7 \\
5.89 \\
11.4 \\
21.5\end{array}$ & $\begin{array}{c}2.36 \\
8.16 \\
4.73 \\
7.54 \\
11.6\end{array}$ & $\begin{array}{l}2.35 \\
5.97 \\
4.32 \\
6.36 \\
9.99\end{array}$ \\
\hline $\begin{array}{l}1966 \\
1967 \\
1968 \\
1969 \\
1970\end{array}$ & $\begin{array}{l}8.48 \\
4.65 \\
6.84 \\
6.95 \\
6.99\end{array}$ & $\begin{array}{l}7.42 \\
4.05 \\
5.51 \\
5.83 \\
5.53\end{array}$ & $\begin{array}{l}6.25 \\
3.60 \\
4.70 \\
5.00 \\
5.01\end{array}$ & $\begin{array}{l}5.35 \\
3.26 \\
4.45 \\
4.69 \\
4.88\end{array}$ & $\begin{array}{l}4.67 \\
3.07 \\
4.23 \\
4.41 \\
4.33\end{array}$ & $\begin{array}{l}4.44 \\
3.01 \\
3.80 \\
4.10 \\
3.86\end{array}$ & $\begin{array}{l}6.35 \\
3.16 \\
3.52 \\
5.46 \\
3.93\end{array}$ & $\begin{array}{c}19.0 \\
10.6 \\
9.00 \\
27.9 \\
14.6\end{array}$ & $\begin{array}{l}12.4 \\
29.8 \\
31.2 \\
23.5 \\
18.7\end{array}$ & $\begin{array}{l}8.59 \\
16.8 \\
15.5 \\
12.3 \\
10.2\end{array}$ & $\begin{array}{c}6.28 \\
9.89 \\
10.2 \\
9.54 \\
7.94\end{array}$ & $\begin{array}{l}5.32 \\
8.18 \\
7.80 \\
8.37 \\
7.11\end{array}$ \\
\hline $\begin{array}{l}1971 \\
1972 \\
1973 \\
1974 \\
1975\end{array}$ & $\begin{array}{l}5.26 \\
6.39 \\
6.35 \\
5.35 \\
5.11\end{array}$ & $\begin{array}{l}4.66 \\
5.32 \\
4.71 \\
4.38 \\
4.57\end{array}$ & $\begin{array}{l}4.21 \\
4.55 \\
4.37 \\
3.65 \\
4.23\end{array}$ & $\begin{array}{l}3.83 \\
3.80 \\
4.05 \\
3.30 \\
3.69\end{array}$ & $\begin{array}{l}3.46 \\
3.50 \\
4.00 \\
3.01 \\
3.41\end{array}$ & $\begin{array}{l}3.54 \\
3.53 \\
3.75 \\
2.86 \\
3.26\end{array}$ & $\begin{array}{l}3.98 \\
3.75 \\
3.93 \\
3.16 \\
3.39\end{array}$ & $\begin{array}{c}15.4 \\
17.5 \\
19.1 \\
20.0 \\
6.23\end{array}$ & $\begin{array}{l}29.5 \\
21.9 \\
21.1 \\
20.8 \\
36.5\end{array}$ & $\begin{array}{l}15.6 \\
10.5 \\
10.2 \\
10.7 \\
26.2\end{array}$ & $\begin{array}{c}9.93 \\
8.51 \\
7.77 \\
7.68 \\
13.6\end{array}$ & $\begin{array}{l}7.39 \\
7.15 \\
6.62 \\
6.16 \\
9.70\end{array}$ \\
\hline $\begin{array}{l}1976 \\
1977 \\
1978 \\
1979 \\
1980\end{array}$ & $\begin{array}{l}7.67 \\
4.73 \\
2.43 \\
4.37 \\
3.50\end{array}$ & $\begin{array}{l}6.29 \\
4.20 \\
2.27 \\
3.83 \\
3.13\end{array}$ & $\begin{array}{l}5.70 \\
3.55 \\
2.31 \\
3.48 \\
2.82\end{array}$ & $\begin{array}{l}5.48 \\
3.24 \\
2.40 \\
3.42 \\
2.65\end{array}$ & $\begin{array}{l}5.24 \\
3.06 \\
2.40 \\
3.30 \\
2.50\end{array}$ & $\begin{array}{l}4.69 \\
3.04 \\
3.02 \\
2.90 \\
2.69\end{array}$ & $\begin{array}{l}4.15 \\
2.89 \\
2.54 \\
2.95 \\
3.47\end{array}$ & $\begin{array}{c}17.7 \\
3.46 \\
7.83 \\
11.4 \\
9.97\end{array}$ & $\begin{array}{c}15.5 \\
3.84 \\
23.1 \\
11.6 \\
29.7\end{array}$ & $\begin{array}{c}7.42 \\
2.85 \\
9.07 \\
5.64 \\
12.8\end{array}$ & $\begin{array}{l}5.67 \\
2.56 \\
5.88 \\
4.60 \\
7.73\end{array}$ & $\begin{array}{l}5.05 \\
2.50 \\
4.69 \\
4.03 \\
5.96\end{array}$ \\
\hline 1981 & 5.55 & 4.87 & 4.29 & 3.46 & 3.66 & 3.27 & 3.99 & 11.7 & 18.3 & 7.19 & 5.10 & 4.87 \\
\hline
\end{tabular}

ANNUAL PEAK DISQHARGE, IN OBIC FEET PER SECOND, AND CORRESPONDING GAGE HEIGHT, IN FEET, FOR EACH WATER YEAR

\begin{tabular}{|c|c|c|c|c|c|c|c|c|c|c|c|}
\hline $\begin{array}{l}\text { WATER } \\
\text { YEAR }\end{array}$ & DATE & $\begin{array}{c}\text { GAGE } \\
\text { HEIGHT }\end{array}$ & $\begin{array}{c}\text { PEAK } \\
\text { DISOAARGE }\end{array}$ & $\begin{array}{l}\text { WATER } \\
\text { YEAR }\end{array}$ & DATE & $\begin{array}{l}\text { GAGE } \\
\text { HEIGHT }\end{array}$ & $\begin{array}{c}\text { PEAR } \\
\text { DISOHARGE }\end{array}$ & $\begin{array}{l}\text { WATER } \\
\text { YEAR }\end{array}$ & DATE & $\begin{array}{c}\text { GAGE } \\
\text { HEIGHT }\end{array}$ & $\begin{array}{c}\text { PEAK } \\
\text { DISQHARGE }\end{array}$ \\
\hline $\begin{array}{l}1946 \\
1947 \\
1948 \\
1949 \\
1950 \\
1951 \\
1952 \\
1953 \\
1954 \\
1955 \\
1956 \\
1957\end{array}$ & $\begin{array}{lll}\text { APR. } & 26,1946 \\
\text { MAY } & 26,1947 \\
\text { MAY } & 21,1948 \\
\text { JUNE } 11,1949 \\
\text { JUNE } 05,1950 \\
\text { MAY } 29,1951 \\
\text { JUNE } 08,1952 \\
\text { JULY } 30,1953 \\
\text { MAY } 16,1954 \\
\text { MAY } & 21,1955 \\
\text { MAY } & 25,1956 \\
\text { JUNE } & 06, & 1957\end{array}$ & $\begin{array}{l}2.03 \\
2.28 \\
2.46 \\
2.60 \\
2.20 \\
2.30 \\
2.64 \\
2.44 \\
2.44 \\
2.32 \\
2.24 \\
2.44\end{array}$ & $\begin{array}{l}31 \\
48 \\
56 \\
72 \\
58 \\
61 \\
82 \\
60 \\
60 \\
44 \\
38 \\
60\end{array}$ & $\begin{array}{l}1958 \\
1959 \\
1960 \\
1961 \\
1962 \\
1963 \\
1964 \\
1965 \\
1966 \\
1967 \\
1968 \\
1969\end{array}$ & $\begin{array}{lll}\text { MAY } & 26,1958 \\
\text { JUNE } & 02,1959 \\
\text { MAY } & 12,1960 \\
\text { MAY } & 18,1961 \\
\text { JUNE } & 13,1962 \\
\text { MAY } & 26,1963 \\
\text { JUNE } & 06,1964 \\
\text { JUNE } & 13,1965 \\
\text { MAY } & 09,1966 \\
\text { JUNE } & 19,1967 \\
\text { JUNE } & 05,1968 \\
\text { MAY } & 25,1969\end{array}$ & $\begin{array}{l}2.48 \\
2.12 \\
2.21 \\
1.93 \\
2.38 \\
2.21 \\
2.42 \\
2.48 \\
2.26 \\
2.32 \\
2.48 \\
2.45\end{array}$ & $\begin{array}{l}67 \\
25 \\
35 \\
10 \\
49 \\
31 \\
54 \\
53 \\
38 \\
44 \\
63 \\
57\end{array}$ & $\begin{array}{l}1970 \\
1971 \\
1972 \\
1973 \\
1974 \\
1975 \\
1976 \\
1977 \\
1978 \\
1979 \\
1980 \\
1981\end{array}$ & $\begin{array}{ll}\text { MAY } & 28,1970 \\
\text { JUNE } 16,1971 \\
\text { MAY } 31,1972 \\
\text { MAY } 21,1973 \\
\text { MAY } 29,1974 \\
\text { JUNE } 15,1975 \\
\text { MAY } 27,1976 \\
\text { OCT. } 02,1976 \\
\text { JUNE } 10,1978 \\
\text { MAY 28, } 1979 \\
\text { JUNE 11, } 1980 \\
\text { JUNE } 05,1981\end{array}$ & $\begin{array}{l}2.28 \\
2.37 \\
2.33 \\
2.29 \\
2.31 \\
2.61 \\
2.26 \\
1.81 \\
2.38 \\
2.35 \\
2.51 \\
2.33\end{array}$ & $\begin{array}{l}37 \\
48 \\
46 \\
41 \\
41 \\
74 \\
34 \\
5.2 \\
43 \\
40 \\
68 \\
41\end{array}$ \\
\hline
\end{tabular}


GREEN RIVER BASIN

09276000 WOLF CREFR ABOVE RHOADES CANYON, NEAR HANNA, UT-Continued

\begin{tabular}{|c|c|c|c|c|c|c|}
\hline \multirow{2}{*}{$\begin{array}{l}\text { PERIOD } \\
\text { (OON- } \\
\text { SECU- } \\
\text { TIVE } \\
\text { DAYS) }\end{array}$} & \multicolumn{6}{|c|}{$\begin{array}{l}\text { DISCHARGE, IN OBBIC FEET PER SECOND, FOR } \\
\text { INDICATED RECURRENCE INTERNAL, IN YEARS, AND } \\
\text { ANNUAL NONEXCEEDANCE PRCBABILITY, IN PERCENT }\end{array}$} \\
\hline & $\begin{array}{c}2 \\
508\end{array}$ & $\begin{array}{c}5 \\
208\end{array}$ & $\begin{array}{l}10 \\
108\end{array}$ & $\begin{array}{l}20 \\
58\end{array}$ & $\begin{array}{l}50 \\
28\end{array}$ & $\begin{array}{r}100 \\
18\end{array}$ \\
\hline $\begin{array}{r}1 \\
7 \\
14 \\
30 \\
60 \\
90\end{array}$ & $\begin{array}{l}2.9 \\
2.9 \\
3.0 \\
3.1 \\
3.4 \\
3.4\end{array}$ & $\begin{array}{l}2.5 \\
2.5 \\
2.5 \\
2.6 \\
2.8 \\
2.8\end{array}$ & $\begin{array}{l}2.2 \\
2.3 \\
2.3 \\
2.4 \\
2.5 \\
2.5\end{array}$ & $\begin{array}{l}2.1 \\
2.1 \\
2.1 \\
2.2 \\
2.3 \\
2.3\end{array}$ & $\begin{array}{l}1.9 \\
1.9 \\
2.0 \\
2.0 \\
2.0 \\
2.1\end{array}$ & $\begin{array}{l}= \\
\bar{z} \\
\overline{-} \\
-\end{array}$ \\
\hline
\end{tabular}

09276500 WOLE CREER NEAR HANNA, UT

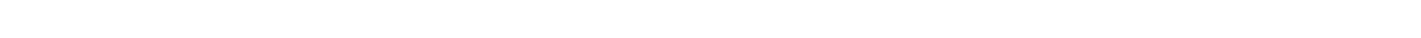
$14060003,600 \mathrm{ft}$ above mouth and $3.5 \mathrm{mi}$ west of Hanna.

DRATNAGE AREA. $--19 \mathrm{mi}^{2}$.

PERIOD OF RECORD AVAIIABLE.--August 1921 to September 1923. No daily discharge April to September 1922.

GAGE.--Staff gage. Altitude of gage is 7,210 ft from river-profile map.

REMARKS.--Small diversions above station for irrigation.

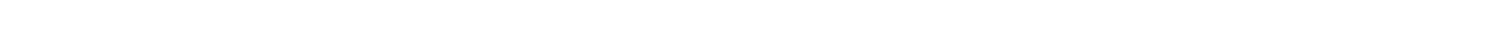
on many days during winter months of 1922 and 1923.

HIGHEST MEAN DISCHARGE, IN OUBIC FEET PER SECOND, AND RANKING FOR THE INDICATED NUMBER OF CONSECUTIVE DAYS FOR EACH WATER YEAR, OCTCBER 1-SEPTEMBER 30

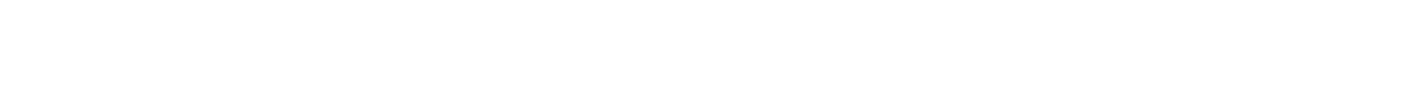

DURATION OF DISCHARGE FOR EACH WATER YEAR

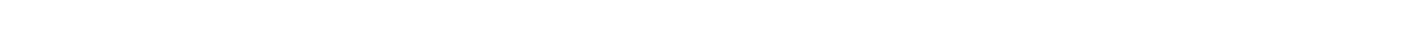
YEAR NUMBER OF DAYS IN CLASS OUBIC FEET -DAYS

1923

123

$\begin{array}{llllllll}8 & 9 & 12 & 6 & 3 & 2 & 9 & 6\end{array}$

$\begin{array}{llll}3 & 1 & 3 & 2\end{array}$

5272.0

DURATION TABLE OF DISCHARGE FOR WATER YEAR 1923

\begin{tabular}{|c|c|c|c|c|c|c|c|c|c|c|c|c|c|c|c|c|c|c|c|}
\hline C.ASS & $\begin{array}{c}\text { CUBIC } \\
\text { FEET } \\
\text { PER } \\
\text { SECOND }\end{array}$ & $\begin{array}{r}\text { TOTAL } \\
\text { DAYS }\end{array}$ & $\begin{array}{l}\text { ACOU- } \\
\text { MU- } \\
\text { LATED } \\
\text { DAYS }\end{array}$ & $\begin{array}{l}\text { PER- } \\
\text { CENT } \\
\text { DAYS }\end{array}$ & & $\begin{array}{c}\text { OUBIC } \\
\text { FEET } \\
\text { PER } \\
\text { SECOND }\end{array}$ & $\begin{array}{l}\text { TOTAL } \\
\text { DAYS }\end{array}$ & $\begin{array}{l}\text { ACOU- } \\
\text { MU- } \\
\text { LATED } \\
\text { DAYS }\end{array}$ & $\begin{array}{l}\text { PER- } \\
\text { CENT } \\
\text { DAYS }\end{array}$ & & $\begin{array}{c}\text { CUBIC } \\
\text { FEET } \\
\text { PER } \\
\text { SECOND }\end{array}$ & $\begin{array}{r}\text { TOTAL } \\
\text { DAYS }\end{array}$ & $\begin{array}{c}\text { ACOU- } \\
\text { MU- } \\
\text { LATED } \\
\text { DAYS }\end{array}$ & $\begin{array}{l}\text { PER- } \\
\text { CENT } \\
\text { DAYS }\end{array}$ & CLASS & $\begin{array}{c}\text { OUBIC } \\
\text { FEET } \\
\text { PER } \\
\text { SECOND }\end{array}$ & $\begin{array}{r}\text { TOTAL } \\
\text { DAYS }\end{array}$ & $\begin{array}{c}\text { ACOU- } \\
\text { MU- } \\
\text { LATED } \\
\text { DAYS }\end{array}$ & $\begin{array}{l}\text { PER- } \\
\text { CENT } \\
\text { DAYS }\end{array}$ \\
\hline $\begin{array}{l}0 \\
1 \\
2 \\
3 \\
4 \\
5 \\
6 \\
7 \\
8\end{array}$ & $\begin{array}{r}0.0 \\
8.0 \\
8.5 \\
8.9 \\
9.5 \\
10.0 \\
11.0 \\
12.0 \\
13.0\end{array}$ & $\begin{array}{r}0 \\
80 \\
0 \\
43 \\
0 \\
32 \\
38 \\
17 \\
62\end{array}$ & $\begin{array}{l}365 \\
365 \\
285 \\
285 \\
242 \\
242 \\
210 \\
172 \\
155\end{array}$ & $\begin{array}{r}100.0 \\
100.0 \\
78.1 \\
78.1 \\
66.3 \\
66.3 \\
57.5 \\
47.1 \\
42.5\end{array}$ & $\begin{array}{r}9 \\
10 \\
11 \\
12 \\
13 \\
14 \\
15 \\
16 \\
17\end{array}$ & $\begin{array}{l}14.0 \\
15.0 \\
16.0 \\
17.0 \\
18.0 \\
19.0 \\
21.0 \\
22.0 \\
23.0\end{array}$ & $\begin{array}{r}10 \\
4 \\
4 \\
0 \\
1 \\
2 \\
3 \\
0 \\
8\end{array}$ & $\begin{array}{l}93 \\
83 \\
79 \\
75 \\
75 \\
74 \\
72 \\
69 \\
69\end{array}$ & $\begin{array}{l}25.5 \\
22.7 \\
21.6 \\
20.6 \\
20.6 \\
20.3 \\
19.7 \\
19.0 \\
19.0\end{array}$ & $\begin{array}{l}18 \\
19 \\
20 \\
21 \\
22 \\
23 \\
24 \\
25 \\
26\end{array}$ & $\begin{array}{l}24.0 \\
26.0 \\
27.0 \\
29.0 \\
30.0 \\
32.0 \\
34.0 \\
36.0 \\
38.0\end{array}$ & $\begin{array}{r}9 \\
12 \\
6 \\
3 \\
2 \\
9 \\
6 \\
5 \\
0\end{array}$ & $\begin{array}{r}61 \\
52 \\
40 \\
34 \\
31 \\
29 \\
20 \\
14 \\
9\end{array}$ & $\begin{array}{r}16.7 \\
14.2 \\
11.0 \\
9.3 \\
8.5 \\
8.0 \\
5.5 \\
3.8 \\
2.5\end{array}$ & $\begin{array}{l}27 \\
28 \\
29 \\
30 \\
31 \\
32 \\
33 \\
34\end{array}$ & $\begin{array}{l}40.0 \\
42.0 \\
45.0 \\
47.0 \\
50.0\end{array}$ & $\begin{array}{l}3 \\
1 \\
0 \\
3 \\
2\end{array}$ & $\begin{array}{l}9 \\
6 \\
5 \\
5 \\
2\end{array}$ & $\begin{array}{l}2.5 \\
1.6 \\
1.4 \\
1.4 \\
0.6\end{array}$ \\
\hline
\end{tabular}

MONTHLY MEAN DISCHARGES, IN OUBIC FEET PER SECOND, FOR EACH WATER YEAR

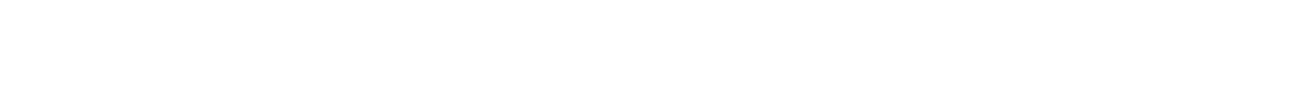




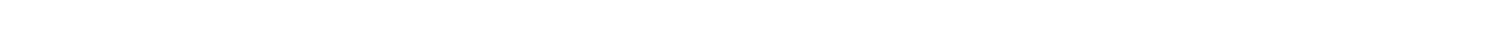
at downstream side of left abutment of road bridge, $1 \mathrm{mi}$ downstream from Sand Creek, and $1 \mathrm{mi}$ northwest of Hanna.

DRAINAGE AREA. $-230 \mathrm{mi}^{2}$, approximately.

PERIOD OF RECORD AVALLABLE.--August 1953 to September 1960.

GAGE.-Water-stage recorder.

REMARRS.--Several diversions above station for irrigation, including a transmountain diversion through Duchesne tunnel.

AVERAGE DISCHARGE. -7 years, $153 \mathrm{ft}^{3} / \mathrm{s}, 110,770$ acre- $\mathrm{ft} / \mathrm{yr}$.

EXTREMES FOR PERIOD OF RECORD.--Maximum discharge, 2,260 $\mathrm{ft}^{3} / \mathrm{s}$ June 7, 1957, gage height, $5.16 \mathrm{ft}$; minimum, $52 \mathrm{ft} t^{3} / \mathrm{s} \mathrm{Mar.} 12,15$, 1956.

LOWEST MEAN DISCHARGE, IN OUBIC FEET PER SECOND, AND RANKING FOR THE INDICATED NUMBER OF CONSEQITIVE DAYS FOR EACH OLIMATTC YEAR, APRII I-MAROH 31

\begin{tabular}{|c|c|c|c|c|c|c|c|c|c|c|c|c|c|c|c|c|c|c|c|}
\hline YEAR & & & & & & & & cons & QUT & E DAYS & & & & & & & & & \\
\hline 65.0 & 1 & 67.0 & 1 & 69.0 & 2 & 70.0 & 2 & 71.0 & 2 & 71.0 & 1 & 73.0 & 2 & 74.0 & 2 & 76.0 & 1 & 109 & 1 \\
\hline
\end{tabular}

HIGHEST MEAN DISCHARGE, IN OUBIC FEET PER SECOND, AND RANKING FOR THE INDICATED NUMBER OF CONSEQUTIVE DAYS FOR EACH WATER YEAR, OCTOBER I-SEPTEMBER 30

\begin{tabular}{|c|c|c|c|c|c|c|c|c|c|c|c|c|c|c|c|c|c|c|}
\hline YEAR & & 3 & & 7 & & 15 & & $\begin{array}{l}a \\
30\end{array}$ & & $\begin{array}{rl}\mathrm{VE} & \mathrm{D} \\
6\end{array}$ & & 90 & & 120 & & 183 & & ALL \\
\hline
\end{tabular}

DURATION OF DISGHARGE FOR EAGH WATER YEAR

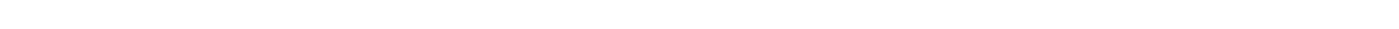

\begin{tabular}{|c|c|c|c|c|c|c|c|c|c|c|c|c|c|c|c|c|c|c|c|c|c|c|c|c|c|c|c|c|c|}
\hline YEAR & & & & & & & & MBE & DF & DAY & IN & $\alpha A$ & & & & & & & & & & & & & & & & & -DALS \\
\hline $\begin{array}{l}1954 \\
1955\end{array}$ & $\begin{array}{rrrrr}4 & 45132 & 63 & 34 & 12 \\
32130 & 70 & 16 & 23 & 6\end{array}$ & $\begin{array}{ll}8 & 22 \\
2 & 22 .\end{array}$ & $\begin{array}{l}4 \\
4\end{array}$ & $\begin{array}{l}7 \\
4\end{array}$ & $\begin{array}{l}7 \\
3\end{array}$ & $\begin{array}{l}4 \\
2\end{array}$ & $\begin{array}{l}2 \\
3\end{array}$ & $\begin{array}{l}1 \\
3\end{array}$ & $\begin{array}{l}3 \\
4\end{array}$ & $\begin{array}{l}1 \\
6\end{array}$ & $\begin{array}{l}2 \\
8\end{array}$ & $\begin{array}{l}3 \\
9\end{array}$ & $\begin{array}{l}9 \\
5\end{array}$ & $\begin{array}{l}1 \\
1\end{array}$ & $\begin{array}{l}1 \\
5\end{array}$ & 2 & 1 & 1 & 1 & 2 & & & & & & & & & $\begin{array}{l}41966.0 \\
48801.0\end{array}$ \\
\hline $\begin{array}{l}1956 \\
1957 \\
1958 \\
1959 \\
1960\end{array}$ & $\begin{array}{rrrrrrr}3 & 93 & 92 & 24 & 25 & 13 & 1 \\
2211 & 4 & 54 & 20 & 27 & 15 & 1 \\
21 & 73 & 79 & 81 & 5 \\
5 & 93 & 97 & 54 & 33 & 9 \\
51112 & 66 & 15 & 24 & 18 & 1\end{array}$ & $\begin{array}{rl}10 & 16 \\
14 & 11 \\
9 & 13 \\
6 & 11 \\
10 & 20\end{array}$ & $\begin{array}{l}6 \\
3 \\
21 \\
2 \\
3\end{array}$ & $\begin{array}{r}7 \\
4 \\
10 \\
3 \\
3\end{array}$ & $\begin{array}{l}8 \\
6 \\
3 \\
3 \\
3\end{array}$ & $\begin{array}{l}7 \\
9 \\
9 \\
7 \\
3\end{array}$ & $\begin{array}{l}5 \\
6 \\
2 \\
1 \\
3\end{array}$ & $\begin{array}{l}6 \\
3 \\
4 \\
8 \\
3\end{array}$ & $\begin{array}{l}5 \\
7 \\
3 \\
9 \\
3\end{array}$ & $\begin{array}{l}4 \\
5 \\
5 \\
5 \\
2\end{array}$ & $\begin{array}{l}4 \\
6 \\
5 \\
7 \\
5\end{array}$ & $\begin{array}{r}3 \\
3 \\
6 \\
5 \\
12\end{array}$ & $\begin{array}{l}2 \\
3 \\
7 \\
6 \\
6\end{array}$ & $\begin{array}{l}4 \\
2 \\
2 \\
1 \\
2\end{array}$ & $\begin{array}{l}1 \\
2\end{array}$ & $\begin{array}{l}1 \\
1\end{array}$ & 1 & $\begin{array}{l}1 \\
4 \\
2\end{array}$ & $\begin{array}{l}4 \\
3 \\
2\end{array}$ & $\begin{array}{l}8 \\
6 \\
2\end{array}$ & $\begin{array}{l}2 \\
6 \\
1\end{array}$ & $\begin{array}{l}5 \\
1 \\
1\end{array}$ & $\begin{array}{l}2 \\
1\end{array}$ & $\begin{array}{l}3 \\
1 \\
7\end{array}$ & $\begin{array}{l}2 \\
3 \\
2\end{array}$ & $\begin{array}{l}2 \\
3\end{array}$ & $\begin{array}{l}1 \\
1\end{array}$ & $\begin{array}{l}2 \\
2\end{array}$ & $\begin{array}{l}68479.0 \\
72311.0 \\
73119.0 \\
43580.0 \\
42977.0\end{array}$ \\
\hline
\end{tabular}

DURATION TABLE OF DISCHARGE FOR WATER YEARS 1954-60
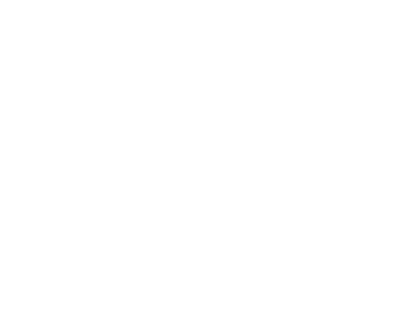

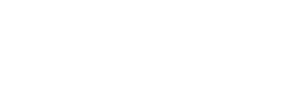

CLASS SECOND TOTAL LATED CENT

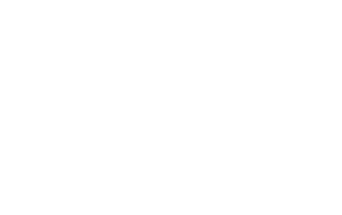

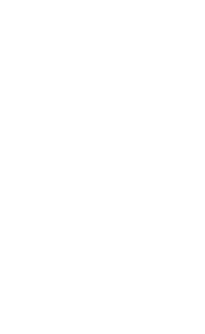

$\mathrm{ACOU}$ MU- PERDAS DAYS DAYS

$\begin{array}{rr}193 & 7.5 \\ 152 & 5.9 \\ 114 & 4.5 \\ 101 & 3.9 \\ 90 & 3.5 \\ 86 & 3.4 \\ 84 & 3.3 \\ 76 & 3.0 \\ 66 & 2.6\end{array}$

ABIC ACOUFEET MU- PERCLASS SECOND TOTAL LATED CEN

$\begin{array}{rrr}27 & 910.0 & 9 \\ 28 & 1000.0 & 7 \\ 29 & 1100.0 & 3 \\ 30 & 1200.0 & 11 \\ 31 & 1400.0 & 7 \\ 32 & 1500.0 & 5 \\ 33 & 1700.0 & 2 \\ 34 & 1800.0 & 4\end{array}$

$\begin{array}{ll}48 & 1.9\end{array}$ $\begin{array}{ll}39 & 1.5\end{array}$ 321.3 $\begin{array}{ll}29 & 1.1 \\ 18 & 0.7\end{array}$ 18 11 0.4 $\begin{array}{rr}11 & 0.4 \\ 6 & 0.2\end{array}$ 
GREEN RTVER BASIN

09277000 DUOHESNE RIVER AT HANNA, UT--Continued

MONIRLY MEAN DISCHARGES, IN OUIC FEET PER SECOND, FOR EAOH WATER YEAR

\begin{tabular}{|c|c|c|c|c|c|c|c|c|c|c|c|c|}
\hline YEAR & OCT & NON & DEC & JAN & FEB & MAR & APR & MAY & JUNE & JULY & AUG & SEP \\
\hline $\begin{array}{l}1954 \\
1955\end{array}$ & $\begin{array}{l}93.6 \\
79.0\end{array}$ & $\begin{array}{l}94.5 \\
78.3\end{array}$ & $\begin{array}{l}88.2 \\
78.5\end{array}$ & $\begin{array}{l}84.2 \\
76.7\end{array}$ & $\begin{array}{l}82.9 \\
71.8\end{array}$ & $\begin{array}{l}82.9 \\
70.6\end{array}$ & $\begin{array}{c}129 \\
90.0\end{array}$ & $\begin{array}{l}314 \\
419\end{array}$ & $\begin{array}{l}148 \\
319\end{array}$ & $\begin{array}{l}102 \\
139\end{array}$ & $\begin{array}{l}80.1 \\
96.5\end{array}$ & $\begin{array}{l}76.7 \\
81.1\end{array}$ \\
\hline $\begin{array}{l}1956 \\
1957 \\
1958 \\
1959 \\
1960\end{array}$ & $\begin{array}{l}83.6 \\
79.7 \\
96.8 \\
82.3 \\
82.8\end{array}$ & $\begin{array}{r}82.3 \\
84.5 \\
103 \\
87.6 \\
79.8\end{array}$ & $\begin{array}{l}85.9 \\
84.9 \\
96.2 \\
85.4 \\
71.8\end{array}$ & $\begin{array}{l}76.4 \\
74.4 \\
86.8 \\
76.9 \\
73.7\end{array}$ & $\begin{array}{l}76.4 \\
72.6 \\
83.6 \\
76.5 \\
71.0\end{array}$ & $\begin{array}{l}86.2 \\
72.7 \\
78.9 \\
76.0 \\
79.7\end{array}$ & $\begin{array}{c}153 \\
81.0 \\
122 \\
93.8 \\
117\end{array}$ & $\begin{array}{l}587 \\
244 \\
775 \\
234 \\
306\end{array}$ & $\begin{array}{r}670 \\
1071 \\
602 \\
316 \\
250\end{array}$ & $\begin{array}{l}157 \\
288 \\
163 \\
129 \\
117\end{array}$ & $\begin{array}{c}106 \\
126 \\
99.7 \\
94.6 \\
80.1\end{array}$ & $\begin{array}{c}81.6 \\
106 \\
89.9 \\
80.9 \\
79.1\end{array}$ \\
\hline
\end{tabular}

ANNAL PEAK DISCHARGE, IN UJBIC FEET PER SECOND, AND CORRESPONDING GAGE HEIGHT, IN FEET, FOR EAQH WATER YEAR

\begin{tabular}{|c|c|c|c|c|c|c|c|c|c|c|c|c|}
\hline $\begin{array}{l}\text { WATER } \\
\text { YEAR }\end{array}$ & & DATE & $\begin{array}{c}\text { GAGE } \\
\text { HEIGHT }\end{array}$ & $\begin{array}{c}\text { PEAK } \\
\text { DISCHARGE }\end{array}$ & $\begin{array}{l}\text { WATER } \\
\text { YEAR }\end{array}$ & DATE & $\begin{array}{c}\text { GAGE } \\
\text { HEIGHT }\end{array}$ & $\begin{array}{c}\text { PEAK } \\
\text { DISOHARGE }\end{array}$ & $\begin{array}{l}\text { WATER } \\
\text { YEAR }\end{array}$ & DATE & $\begin{array}{c}\text { GAGE } \\
\text { HEIGHT }\end{array}$ & $\begin{array}{c}\text { PEAK } \\
\text { DISCHARGE }\end{array}$ \\
\hline $\begin{array}{l}1954 \\
1955 \\
1956\end{array}$ & $\begin{array}{l}\text { MAY } \\
\text { MAY } \\
\text { JUNE }\end{array}$ & $\begin{array}{ll}12,1954 \\
22,1955 \\
02,1956\end{array}$ & $\begin{array}{l}3.66 \\
4.42 \\
4.98\end{array}$ & $\begin{array}{r}616 \\
1020 \\
1710\end{array}$ & $\begin{array}{l}1957 \\
1958\end{array}$ & $\begin{array}{lll}\text { JUNE } & 07, & 1957 \\
\text { MAY } & 28, & 1958\end{array}$ & $\begin{array}{l}5.16 \\
4.84\end{array}$ & $\begin{array}{l}2260 \\
2160\end{array}$ & $\begin{array}{l}1959 \\
1960\end{array}$ & $\begin{array}{l}\text { JUNE } 06,1959 \\
\text { MAY } 13,1960\end{array}$ & $\begin{array}{l}3.15 \\
3.34\end{array}$ & $\begin{array}{l}491 \\
580\end{array}$ \\
\hline
\end{tabular}

09277500 DUGESNE RTVER NEAR TABIONA, UT

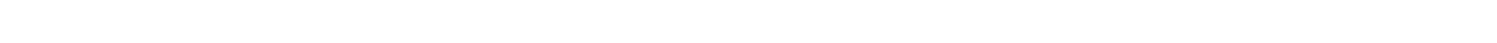
14060003, on left bank on upstream site of bridge on State Highway 35, $6 \mathrm{mi}$ upstream from Rock Creek, and $7 \mathrm{mi}$ southeast of Tabiona.

DRAINAGE AREA, $--356 \mathrm{mi}^{2}$.

MEAN BASIN ELEVATION. $-8,770 \mathrm{ft}$.

PERIOD OF RECORD AVLILABLE.--October 1918 to September 1981.

REVISED RECORDS.--WDR UT-77-1: Drainage area.

GAGE.-Water-stage recorder. Altitude of gage is $6,190 \mathrm{ft}$ from topographic map. Prior to oct. 15, 1934, nonrecording gage, and Oct. 16,1934 to Nov. 6, 1953, water-stage recorder at site $0.5 \mathrm{mi}$ upstream at various datuns. Nov. 7, 1953 to Nov. 7, 1972 , at site 1 mi upstream at different datum.

REMARKS.--Several diversions above station for irrigation, including a transmountain diversion through Duchesne tunnel 20 mi upstream.

AVERAGE DISGHARGE. -63 years, $197 \mathrm{ft}^{3} / \mathrm{s}, 142,700$ acre-ft/yr.

EXTREMES FOR PERIOD OF RECORD,--Maximum discharge, 5,260 ft ${ }^{3} / \mathrm{s}$ June 16, 1963, gage height, 7.97 ft, from floodnarks caused by failure of Little Deer Creek Dam $20 \mathrm{mi}$ upstream, from rating curve extended above $400 \mathrm{ft} / 3$ on basis of slope-area measurement and areavelocity study of peak flow; minimun recorded, $27 \mathrm{ft}^{3} / \mathrm{s}$ oct. $17,1934$.

DATA BELOW BASED ON PERIOD OF RECORD PRIOR TO DIVERSION THRCUG DUGESNE TUNAEL

LOWEST MEAN DISGHARGE, IN OBIC FEET PER SECOND, AND RANKING FOR THE INDICATED NUMBER OF CONSECUTIVE DAVS

\begin{tabular}{|c|c|c|c|c|c|c|c|c|c|c|c|c|c|c|c|c|c|c|c|c|}
\hline YEAR & 1 & & 3 & & 7 & & 14 & & $\begin{array}{l}\text { Con } \\
30\end{array}$ & & $\begin{array}{l}\text { E DAYS } \\
60\end{array}$ & & 90 & & 120 & & 183 & & A.LL & \\
\hline 920 & 49.0 & 6 & 54.0 & 8 & 60.0 & 10 & 63.0 & $10^{\circ}$ & 69.0 & 10 & 78.0 & 10 & 86.0 & 10 & 92.0 & 11 & 100 & 14 & 190 & 12 \\
\hline $\begin{array}{l}1931 \\
1932 \\
1933 \\
1934 \\
1935\end{array}$ & $\begin{array}{l}67.0 \\
37.0 \\
66.0 \\
42.0 \\
28.0\end{array}$ & $\begin{array}{r}16 \\
2 \\
15 \\
4\end{array}$ & $\begin{array}{l}76.0 \\
38.0 \\
67.0 \\
45.0 \\
28.0\end{array}$ & $\begin{array}{r}20 \\
2 \\
15 \\
5 \\
1\end{array}$ & $\begin{array}{l}79.0 \\
41.0 \\
74.0 \\
52.0 \\
30.0\end{array}$ & $\begin{array}{r}20 \\
3 \\
16 \\
6 \\
1\end{array}$ & $\begin{array}{l}82.0 \\
46.0 \\
80.0 \\
53.0 \\
32.0\end{array}$ & $\begin{array}{r}21 \\
3 \\
19 \\
6 \\
1\end{array}$ & $\begin{array}{l}84.0 \\
53.0 \\
81.0 \\
59.0 \\
37.0\end{array}$ & $\begin{array}{r}16 \\
2 \\
14 \\
5 \\
1\end{array}$ & $\begin{array}{l}87.0 \\
59.0 \\
88.0 \\
62.0 \\
43.0\end{array}$ & $\begin{array}{r}13 \\
2 \\
14 \\
3\end{array}$ & $\begin{array}{l}88.0 \\
62.0 \\
96.0 \\
66.0 \\
45.0\end{array}$ & $\begin{array}{r}12 \\
2 \\
18 \\
3 \\
1\end{array}$ & $\begin{array}{l}90.0 \\
65.0 \\
98.0 \\
70.0 \\
49.0\end{array}$ & $\begin{array}{r}10 \\
2 \\
17 \\
3 \\
1\end{array}$ & $\begin{array}{r}110 \\
75.0 \\
99.0 \\
75.0 \\
53.0\end{array}$ & $\begin{array}{r}19 \\
3 \\
12 \\
4 \\
1\end{array}$ & $\begin{array}{c}184 \\
102 \\
204 \\
139 \\
66.0\end{array}$ & $\begin{array}{r}11 \\
2 \\
15\end{array}$ \\
\hline
\end{tabular}


GREEN RIVER BASIN

09277500 DUCHESNE RIVER NEAR TABIONA, UT-Continued

LOWEST MEAN DISCHARGE, IN OBBIC FEET PER SECOND, AND RANKING FOR THE INDICATED NUMBER OF CONSECUTIVE DAYS FOR EACH CLIMATIC YEAR, APRIL 1-MARCH 31-Continued

\begin{tabular}{|c|c|c|c|c|c|c|c|c|c|c|c|c|c|c|c|c|c|c|c|c|}
\hline EAR & 1 & & 3 & & 7 & & 14 & & $\begin{array}{l}\infty \mathrm{N} \\
30\end{array}$ & & $\begin{array}{l}\text { DAYS } \\
60\end{array}$ & & 90 & & 120 & & 183 & & ALL & \\
\hline $\begin{array}{l}36 \\
37 \\
38 \\
39 \\
40\end{array}$ & $\begin{array}{l}43.0 \\
52.0 \\
51.0 \\
70.0 \\
55.0\end{array}$ & $\begin{array}{r}5 \\
10 \\
9 \\
17 \\
12\end{array}$ & $\begin{array}{l}44.0 \\
55.0 \\
54.0 \\
73.0 \\
56.0\end{array}$ & $\begin{array}{r}4 \\
10 \\
9 \\
17 \\
11\end{array}$ & $\begin{array}{l}47.0 \\
61.0 \\
58.0 \\
76.0 \\
59.0\end{array}$ & $\begin{array}{r}4 \\
11 \\
8 \\
18 \\
9\end{array}$ & & $\begin{array}{r}4 \\
12 \\
8 \\
25 \\
9\end{array}$ & $\begin{array}{l}63.0 \\
88.0 \\
74.0 \\
90.0 \\
64.0\end{array}$ & $\begin{array}{r}7 \\
21 \\
11 \\
22 \\
8\end{array}$ & $\begin{array}{l}68.0 \\
91.0 \\
88.0 \\
92.0 \\
74.0\end{array}$ & $\begin{array}{r}5 \\
18 \\
15 \\
19 \\
8\end{array}$ & $\begin{array}{l}69.0 \\
93.0 \\
95.0 \\
97.0 \\
81.0\end{array}$ & $\begin{array}{r}4 \\
15 \\
17 \\
19 \\
9\end{array}$ & $\begin{array}{r}72.0 \\
94.0 \\
97.0 \\
102 \\
85.0\end{array}$ & $\begin{array}{r}4 \\
13 \\
15 \\
20 \\
5\end{array}$ & $\begin{array}{r}74.0 \\
97.0 \\
99.0 \\
115 \\
88.0\end{array}$ & $\begin{array}{r}2 \\
9 \\
13 \\
26 \\
5\end{array}$ & $\begin{array}{l}139 \\
242 \\
220 \\
231 \\
149\end{array}$ & $\begin{array}{r}5 \\
23 \\
19 \\
22 \\
6\end{array}$ \\
\hline 42 & $\begin{array}{l}53.0 \\
75.0 \\
50.0 \\
80.0 \\
65.0\end{array}$ & $\begin{array}{r}11 \\
21 \\
8 \\
25 \\
14\end{array}$ & $\begin{array}{l}53.0 \\
77.0 \\
62.0 \\
81.0 \\
65.0\end{array}$ & $\begin{array}{r}7 \\
21 \\
12 \\
25 \\
13\end{array}$ & $\begin{array}{l}54.0 \\
79.0 \\
66.0 \\
83.0 \\
66.0\end{array}$ & $\begin{array}{r}7 \\
21 \\
12 \\
25 \\
13\end{array}$ & $\begin{array}{l}55.0 \\
81.0 \\
68.0 \\
83.0 \\
72.0\end{array}$ & $\begin{array}{r}7 \\
20 \\
11 \\
22 \\
13\end{array}$ & $\begin{array}{l}58.0 \\
85.0 \\
69.0 \\
86.0 \\
85.0\end{array}$ & $\begin{array}{r}4 \\
17 \\
+9 \\
19 \\
18\end{array}$ & $\begin{array}{c}64.0 \\
95.0 \\
84.0 \\
102 \\
88.0\end{array}$ & $\begin{array}{r}4 \\
20 \\
12 \\
28 \\
16\end{array}$ & $\begin{array}{c}71.0 \\
97.0 \\
92.0 \\
105 \\
94.0\end{array}$ & $\begin{array}{r}5 \\
20 \\
13 \\
29 \\
16\end{array}$ & $\begin{array}{c}88.0 \\
101 \\
97.0 \\
107 \\
96.0\end{array}$ & $\begin{array}{r}9 \\
18 \\
16 \\
24 \\
14\end{array}$ & $\begin{array}{c}97.0 \\
112 \\
97.0 \\
111 \\
102\end{array}$ & $\begin{array}{l}10 \\
22 \\
11 \\
20 \\
15\end{array}$ & $\begin{array}{l}137 \\
213 \\
195 \\
255 \\
220\end{array}$ & $\begin{array}{r}3 \\
17 \\
13 \\
26 \\
20\end{array}$ \\
\hline 14 & $\begin{array}{l}84.0 \\
64.0 \\
70.0 \\
71.0 \\
84.0\end{array}$ & $\begin{array}{l}28 \\
13 \\
18 \\
19 \\
29\end{array}$ & $\begin{array}{l}86.0 \\
65.0 \\
73.0 \\
72.0 \\
84.0\end{array}$ & $\begin{array}{l}28 \\
14 \\
18 \\
16 \\
26\end{array}$ & $\begin{array}{l}90.0 \\
68.0 \\
75.0 \\
72.0 \\
85.0\end{array}$ & $\begin{array}{l}30 \\
14 \\
17 \\
15 \\
26\end{array}$ & $\begin{array}{l}94.0 \\
76.0 \\
84.0 \\
74.0 \\
88.0\end{array}$ & $\begin{array}{l}31 \\
15 \\
23 \\
14 \\
26\end{array}$ & $\begin{array}{r}100 \\
81.0 \\
96.0 \\
75.0 \\
96.0\end{array}$ & $\begin{array}{l}32 \\
15 \\
28 \\
12 \\
29\end{array}$ & $\begin{array}{r}102 \\
88.0 \\
98.0 \\
76.0 \\
98.0\end{array}$ & $\begin{array}{r}29 \\
17 \\
26 \\
9 \\
27\end{array}$ & $\begin{array}{c}106 \\
92.0 \\
101 \\
80.0 \\
104\end{array}$ & $\begin{array}{r}30 \\
14 \\
23 \\
7 \\
26\end{array}$ & $\begin{array}{c}109 \\
103 \\
104 \\
86.0 \\
107\end{array}$ & $\begin{array}{r}29 \\
21 \\
22 \\
6 \\
25\end{array}$ & $\begin{array}{c}114 \\
108 \\
111 \\
93.0 \\
113\end{array}$ & $\begin{array}{r}25 \\
18 \\
21 \\
8 \\
23\end{array}$ & $\begin{array}{l}204 \\
199 \\
243 \\
167 \\
259\end{array}$ & $\begin{array}{r}16 \\
14 \\
24 \\
9 \\
27\end{array}$ \\
\hline
\end{tabular}

HIGHEST MEAN DISCHARGE, IN CUBIC FEET PER SECOND, AND RANKING FOR THE INDICATED NUMBER OF CONSECUTIVE DAYS FOR EACH WATER YEAR, OCTOBER 1-SEPTEMBER 30

YEAR

CONSECUTIVE DAYS

\begin{tabular}{|c|c|c|c|c|c|c|c|c|c|c|c|c|c|c|c|c|c|c|c|}
\hline $\begin{array}{l}1919 \\
1920\end{array}$ & $\begin{array}{l}1420 \\
1900\end{array}$ & $\begin{array}{r}16 \\
5\end{array}$ & $\begin{array}{l}1370 \\
1830\end{array}$ & $\begin{array}{r}15 \\
5\end{array}$ & $\begin{array}{l}1260 \\
1660\end{array}$ & $\begin{array}{r}15 \\
4\end{array}$ & $\begin{array}{l}1140 \\
1580\end{array}$ & $\begin{array}{r}14 \\
4\end{array}$ & $\begin{array}{r}874 \\
1400\end{array}$ & $\begin{array}{r}16 \\
4\end{array}$ & $\begin{array}{r}624 \\
1000\end{array}$ & $\begin{array}{r}20 \\
5\end{array}$ & $\begin{array}{l}468 \\
754\end{array}$ & $\begin{array}{r}22 \\
5\end{array}$ & $\begin{array}{l}382 \\
604\end{array}$ & $\begin{array}{r}23 \\
6\end{array}$ & $\begin{array}{l}281 \\
444\end{array}$ & $\begin{array}{r}23 \\
5\end{array}$ & $\begin{array}{l}199 \\
273\end{array}$ \\
\hline $\begin{array}{l}1921 \\
1922 \\
1923 \\
1924 \\
1925\end{array}$ & $\begin{array}{r}2490 \\
2300 \\
1920 \\
900 \\
930\end{array}$ & $\begin{array}{r}1 \\
2 \\
4 \\
30 \\
29\end{array}$ & $\begin{array}{r}2430 \\
2230 \\
1870 \\
880 \\
908\end{array}$ & $\begin{array}{r}1 \\
2 \\
4 \\
29 \\
28\end{array}$ & $\begin{array}{r}2290 \\
2210 \\
1650 \\
843 \\
689\end{array}$ & $\begin{array}{r}1 \\
2 \\
5 \\
28 \\
33\end{array}$ & $\begin{array}{r}2010 \\
2140 \\
1330 \\
768 \\
652\end{array}$ & $\begin{array}{r}2 \\
1 \\
6 \\
26 \\
33\end{array}$ & $\begin{array}{r}1670 \\
1830 \\
1320 \\
595 \\
555\end{array}$ & $\begin{array}{r}2 \\
1 \\
5 \\
30 \\
33\end{array}$ & $\begin{array}{r}1220 \\
1320 \\
1060 \\
410 \\
448\end{array}$ & $\begin{array}{r}3 \\
1 \\
4 \\
32 \\
29\end{array}$ & $\begin{array}{l}952 \\
998 \\
844 \\
320 \\
363\end{array}$ & $\begin{array}{r}3 \\
1 \\
4 \\
32 \\
28\end{array}$ & $\begin{array}{l}767 \\
801 \\
689 \\
267 \\
308\end{array}$ & $\begin{array}{r}3 \\
1 \\
4 \\
31 \\
27\end{array}$ & $\begin{array}{l}569 \\
581 \\
516 \\
212 \\
244\end{array}$ & $\begin{array}{r}3 \\
2 \\
4 \\
30 \\
26\end{array}$ & $\begin{array}{l}345 \\
354 \\
319 \\
163 \\
172\end{array}$ \\
\hline $\begin{array}{l}1926 \\
1927 \\
1928 \\
1929 \\
1930\end{array}$ & $\begin{array}{r}950 \\
1530 \\
1510 \\
1870 \\
1000\end{array}$ & $\begin{array}{r}28 \\
11 \\
12 \\
6 \\
25\end{array}$ & $\begin{array}{r}847 \\
1510 \\
1470 \\
1370 \\
912\end{array}$ & $\begin{array}{l}31 \\
10 \\
11 \\
16 \\
27\end{array}$ & $\begin{array}{r}788 \\
1410 \\
1390 \\
1100 \\
875\end{array}$ & $\begin{array}{l}29 \\
11 \\
12 \\
19 \\
26\end{array}$ & $\begin{array}{r}726 \\
1160 \\
1250 \\
857 \\
759\end{array}$ & $\begin{array}{l}29 \\
13 \\
10 \\
24 \\
27\end{array}$ & $\begin{array}{r}603 \\
963 \\
1010 \\
813 \\
656\end{array}$ & $\begin{array}{l}29 \\
13 \\
12 \\
21 \\
27\end{array}$ & $\begin{array}{l}482 \\
772 \\
737 \\
684 \\
481\end{array}$ & $\begin{array}{l}26 \\
11 \\
14 \\
18 \\
27\end{array}$ & $\begin{array}{l}368 \\
613 \\
551 \\
531 \\
388\end{array}$ & $\begin{array}{l}27 \\
12 \\
16 \\
17 \\
25\end{array}$ & $\begin{array}{l}303 \\
499 \\
448 \\
434 \\
321\end{array}$ & $\begin{array}{l}28 \\
12 \\
16 \\
17 \\
25\end{array}$ & $\begin{array}{l}231 \\
388 \\
333 \\
334 \\
258\end{array}$ & $\begin{array}{l}28 \\
10 \\
17 \\
16 \\
25\end{array}$ & $\begin{array}{l}164 \\
242 \\
238 \\
222 \\
190\end{array}$ \\
\hline $\begin{array}{l}1931 \\
1932 \\
1933 \\
1934 \\
1935\end{array}$ & $\begin{array}{r}521 \\
1100 \\
975 \\
209 \\
1130\end{array}$ & $\begin{array}{l}34 \\
24 \\
27 \\
35 \\
23\end{array}$ & $\begin{array}{r}469 \\
1050 \\
935 \\
204 \\
1130\end{array}$ & $\begin{array}{l}34 \\
24 \\
26 \\
35 \\
22\end{array}$ & $\begin{array}{r}395 \\
959 \\
872 \\
196 \\
1100\end{array}$ & $\begin{array}{l}34 \\
24 \\
27 \\
35 \\
20\end{array}$ & $\begin{array}{l}322 \\
876 \\
845 \\
169 \\
929\end{array}$ & $\begin{array}{l}34 \\
23 \\
25 \\
35 \\
21\end{array}$ & $\begin{array}{l}278 \\
768 \\
681 \\
157 \\
691\end{array}$ & $\begin{array}{l}34 \\
23 \\
25 \\
35 \\
24\end{array}$ & $\begin{array}{l}200 \\
645 \\
429 \\
122 \\
451\end{array}$ & $\begin{array}{l}34 \\
19 \\
30 \\
35 \\
28\end{array}$ & $\begin{array}{l}163 \\
504 \\
325 \\
108 \\
338\end{array}$ & $\begin{array}{l}34 \\
19 \\
31 \\
35 \\
29\end{array}$ & $\begin{array}{l}143 \\
416 \\
266 \\
101 \\
272\end{array}$ & $\begin{array}{l}34 \\
19 \\
32 \\
35 \\
30\end{array}$ & $\begin{array}{c}125 \\
309 \\
207 \\
96.0 \\
203\end{array}$ & $\begin{array}{l}34 \\
19 \\
31 \\
35 \\
32\end{array}$ & $\begin{array}{c}111 \\
200 \\
148 \\
79.0 \\
130\end{array}$ \\
\hline $\begin{array}{l}1941 \\
1942 \\
1943 \\
1944 \\
1945\end{array}$ & $\begin{array}{r}1220 \\
1250 \\
1200 \\
1180 \\
834\end{array}$ & $\begin{array}{l}20 \\
19 \\
21 \\
22 \\
32\end{array}$ & $\begin{array}{r}1160 \\
1160 \\
1130 \\
1150 \\
774\end{array}$ & $\begin{array}{l}19 \\
20 \\
23 \\
21 \\
32\end{array}$ & $\begin{array}{r}1070 \\
1030 \\
1120 \\
1060 \\
727\end{array}$ & $\begin{array}{l}21 \\
23 \\
17 \\
22 \\
31\end{array}$ & $\begin{array}{l}962 \\
987 \\
925 \\
934 \\
674\end{array}$ & $\begin{array}{l}18 \\
17 \\
22 \\
20 \\
32\end{array}$ & $\begin{array}{l}854 \\
858 \\
825 \\
889 \\
645\end{array}$ & $\begin{array}{l}18 \\
17 \\
20 \\
15 \\
28\end{array}$ & $\begin{array}{l}697 \\
579 \\
754 \\
759 \\
581\end{array}$ & $\begin{array}{l}17 \\
23 \\
13 \\
12 \\
22\end{array}$ & $\begin{array}{l}526 \\
472 \\
654 \\
572 \\
462\end{array}$ & $\begin{array}{r}18 \\
20 \\
8 \\
15 \\
23\end{array}$ & $\begin{array}{l}424 \\
391 \\
539 \\
466 \\
388\end{array}$ & $\begin{array}{r}18 \\
20 \\
8 \\
14 \\
21\end{array}$ & $\begin{array}{l}311 \\
290 \\
399 \\
342 \\
292\end{array}$ & $\begin{array}{r}18 \\
21 \\
8 \\
14 \\
20\end{array}$ & $\begin{array}{l}207 \\
200 \\
250 \\
226 \\
198\end{array}$ \\
\hline $\begin{array}{l}1946 \\
1947 \\
1948 \\
1949 \\
1950\end{array}$ & $\begin{array}{r}897 \\
1330 \\
1260 \\
1430 \\
1680\end{array}$ & $\begin{array}{r}31 \\
17 \\
18 \\
15 \\
8\end{array}$ & $\begin{array}{r}848 \\
1260 \\
1240 \\
1400 \\
1620\end{array}$ & $\begin{array}{r}30 \\
17 \\
18 \\
14 \\
7\end{array}$ & $\begin{array}{r}771 \\
1100 \\
1170 \\
1390 \\
1500\end{array}$ & $\begin{array}{r}30 \\
18 \\
16 \\
13 \\
7\end{array}$ & $\begin{array}{r}707 \\
956 \\
1030 \\
1240 \\
1350\end{array}$ & $\begin{array}{r}30 \\
19 \\
16 \\
11 \\
5\end{array}$ & $\begin{array}{r}664 \\
932 \\
800 \\
1050 \\
1280\end{array}$ & $\begin{array}{r}26 \\
14 \\
22 \\
9 \\
6\end{array}$ & $\begin{array}{l}601 \\
791 \\
510 \\
856 \\
958\end{array}$ & $\begin{array}{r}21 \\
10 \\
25 \\
7 \\
6\end{array}$ & $\begin{array}{l}472 \\
616 \\
385 \\
695 \\
747\end{array}$ & $\begin{array}{r}21 \\
11 \\
26 \\
7 \\
6\end{array}$ & $\begin{array}{l}384 \\
501 \\
316 \\
561 \\
610\end{array}$ & $\begin{array}{r}22 \\
11 \\
26 \\
7 \\
5\end{array}$ & $\begin{array}{l}287 \\
376 \\
241 \\
404 \\
440\end{array}$ & $\begin{array}{r}22 \\
12 \\
27 \\
7 \\
6\end{array}$ & $\begin{array}{l}198 \\
246 \\
172 \\
251 \\
278\end{array}$ \\
\hline $\begin{array}{l}1951 \\
1952 \\
1953\end{array}$ & $\begin{array}{l}1800 \\
1940 \\
1660\end{array}$ & $\begin{array}{l}7 \\
3 \\
9\end{array}$ & $\begin{array}{l}1770 \\
1910 \\
1570\end{array}$ & $\begin{array}{l}6 \\
3 \\
8\end{array}$ & $\begin{array}{l}1590 \\
1860 \\
1370\end{array}$ & $\begin{array}{r}6 \\
3 \\
14\end{array}$ & $\begin{array}{l}1200 \\
1740 \\
1110\end{array}$ & $\begin{array}{r}12 \\
3 \\
15\end{array}$ & $\begin{array}{r}1110 \\
1430 \\
834\end{array}$ & $\begin{array}{r}8 \\
3 \\
19\end{array}$ & $\begin{array}{r}827 \\
1230 \\
544\end{array}$ & $\begin{array}{r}8 \\
2 \\
24\end{array}$ & $\begin{array}{l}630 \\
986 \\
426\end{array}$ & $\begin{array}{r}9 \\
2 \\
24\end{array}$ & $\begin{array}{l}525 \\
798 \\
357\end{array}$ & $\begin{array}{r}10 \\
2 \\
24\end{array}$ & $\begin{array}{l}390 \\
582 \\
273\end{array}$ & $\begin{array}{r}9 \\
1 \\
24\end{array}$ & $\begin{array}{l}255 \\
348 \\
194\end{array}$ \\
\hline
\end{tabular}


GREEN RTVER BASIN

09277500 DUCHESNE RIVER NEAR TABIONA, UT--Continued

DURATION OF DISCHARGE FOR EACH WATER YEAR

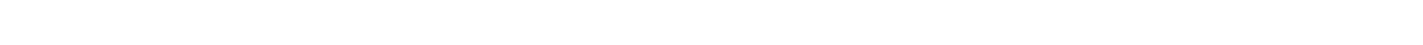

YEAR

NUMBER OF DAYS IN CIAASS

CUBIC FEET

R SECOND

1919
1920

1921

1922

1923
1924

1925

1926

1927

1928
1929

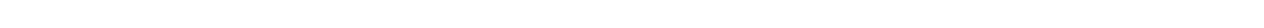
$\begin{array}{llllllllllllllllllllllllll}34 & 40 & 38 & 32 & 79 & 35 & 18 & 4 & 8 & 9 & 5 & 3 & 4 & 3 & 9 & 3 & 5 & 4 & 2 & 5 & 3 & 9 & 7 & 4 & 3 & 100020.0\end{array}$

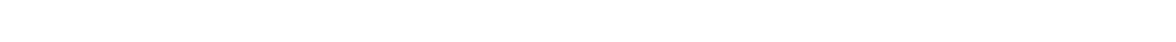

$\begin{array}{llllllllllllllllllllllllllllllll}16 & 5 & 22 & 48 & 43 & 71 & 29 & 16 & 18 & 13 & 11 & 2 & 4 & 8 & 4 & 2 & 3 & 4 & 6 & 5 & 7 & 6 & 1 & 11 & 10 & 129130.0\end{array}$

$\begin{array}{rrrrrrrrrrrrrrrrrrrrrrrrrrrrrr}9 & 18 & 49 & 10 & 43 & 52 & 53 & 18 & 13 & 10 & 9 & 4 & 2 & 5 & 5 & 6 & 6 & 9 & 10 & 14 & 3 & 5 & 4 & 2 & 5 & 116430.0\end{array}$

$\begin{array}{lllllllllllllllllll}7 & 49132 & 35 & 18 & 25 & 24 & 7 & 3 & 11 & 1 & 13 & 13 & 11 & 6 & 1 & 5 & 1 & 3\end{array}$

$\begin{array}{llllllllllllllllllllllll}6 & 4 & 3 & 3 & 8 & 65 & 49 & 70 & 34 & 27 & 22 & 10 & 4 & 1 & 8 & 5 & 6 & 4 & 10 & 5 & 6 & 7 & 7 & 1\end{array}$

$\begin{array}{llllllllllllllllllllllll}61 & 38 & 31 & 66 & 40 & 7 & 9 & 11 & 17 & 8 & 2 & 8 & 4 & 14 & 10 & 4 & 10 & 3 & 6 & 2 & 3 & 4 & 7\end{array}$

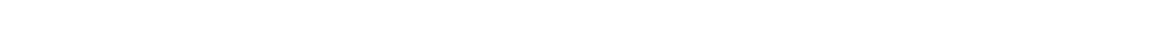

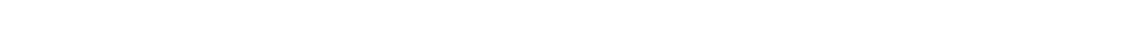

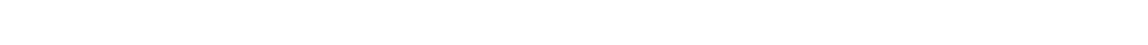

1931

1932

1933

1935

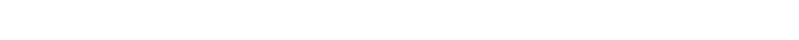

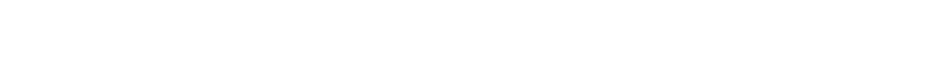

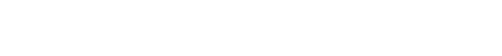

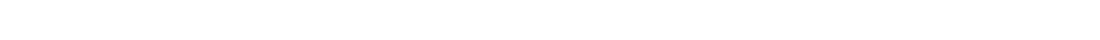

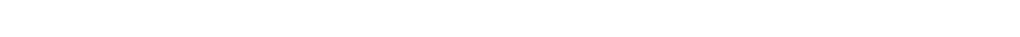

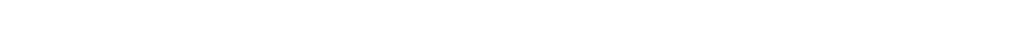

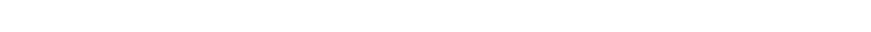

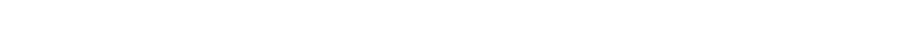

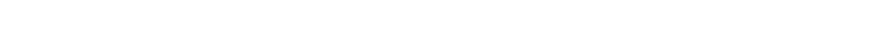

$\begin{array}{rrrrrrrrrrrrrrrrrrrrrrrrr}1 & 24 & 20 & 25 & 78 & 43 & 40 & 26 & 16 & 8 & 14 & 16 & 11 & 7 & 3 & 2 & 2 & 4 & 4 & 3 & 7 & 8 & 2 & 1 \\ 1 & 2 & 9 & 48 & 96 & 22 & 37 & 23 & 19 & 9 & 9 & 3 & 3 & 4 & 3 & 10 & 5 & 16 & 15 & 10 & 9 & 7 & 4 & 1\end{array}$

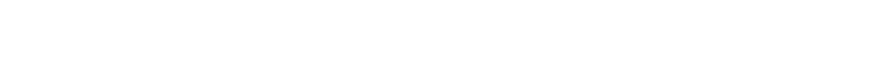

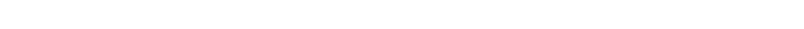

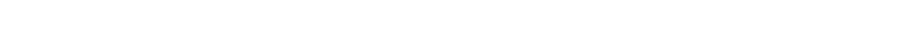

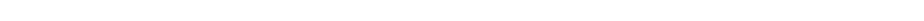

$\begin{array}{rrrrrrrrrrrrrrrrrrrrrrrr}1 & 16 & 61119 & 46 & 13 & 7 & 5 & 2 & 6 & 6 & 3 & 2 & 10 & 6 & 10 & 4 & 12 & 9 & 5 & 9 & 4 & 7 & 2 & \\ 12 & 11 & 99 & 33 & 48 & 42 & 14 & 3 & 5 & 18 & 7 & 6 & 6 & 5 & 8 & 6 & 4 & 3 & 3 & 7 & 5 & 13 & 4 & 3\end{array}$

40640.0

73299.0

53932.0

28738.0

47277.0

84338.0

79494.0

81551.0

59042.0

48188.0

$\begin{array}{rrrrrrrrrrrrrrrrrrrrrrrrrr}2 & 15 & 52 & 61 & 53 & 47 & 23 & 15 & 24 & 8 & 7 & 4 & 6 & 2 & 2 & 4 & 2 & 13 & 6 & 5 & 3 & 5 & 2 & 3 & 1 & 93037.0 \\ 3 & 10 & 67 & 31 & 78 & 12 & 32 & 14 & 18 & 11 & 4 & 5 & 4 & 3 & 3 & 4 & 3 & 10 & 8 & 12 & 6 & 7 & 8 & 6 & 7 & 127304.0\end{array}$

75596.0

72864.0

91245.0

82578.0
72420.0

1946
1947

1948
1949

1951

1952

1953

$\begin{array}{rrrrrrrrrrrrrrrrrrrrrrrrrr}10 & 12 & 6 & 49 & 82 & 86 & 39 & 15 & 7 & 7 & 8 & 3 & 5 & 5 & 4 & 4 & 4 & 5 & 2 & 2 & 3 & 1 & 3 & 2 & 1\end{array}$

72397.0

89826.0

63060.0

91764.0

101595.0

DURATION TABLE OF DISCHARGE FOR WATER YEARS 1919-53

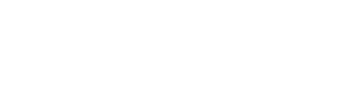

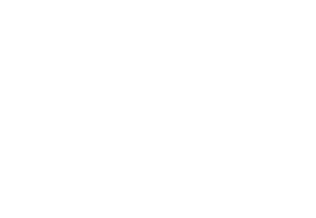

CUBIC ACCU- CUBIC ACCJ-

FEET $\quad$ MU- PERPER TOTAL LATED CENT
CLASS SECOND DAYS DAYS DAYS

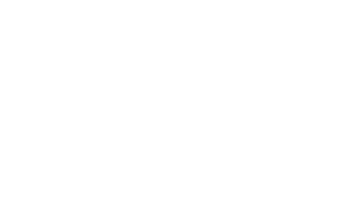

CUBIC ACCU-
FEET PER TOTAL LATED CENT
CLASS SECOND DAYS DAYS DAYS

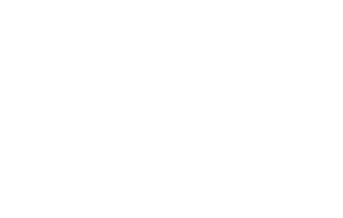

$\begin{array}{ccc}\text { CUBIC } & \text { ACOU- } \\ \text { FEET } & \text { ND- } & \text { PER- } \\ \text { PER TOTAL LATED } & \text { CENT }\end{array}$ CLASS SECOND DAYS DAYS DAYS

$\begin{array}{rrrrr}27 & 940.0 & 137 & 466 & 3.6 \\ 28 & 1100.0 & 78 & 329 & 2.6 \\ 29 & 1200.0 & 120 & 251 & 2.0 \\ 30 & 1400.0 & 57 & 131 & 1.0 \\ 31 & 1600.0 & 28 & 74 & 0.6 \\ 32 & 1800.0 & 30 & 46 & 0.4 \\ 33 & 2100.0 & 14 & 16 & 0.1 \\ 34 & 2400.0 & 2 & 2 & 0.0\end{array}$

MONIHLY MEAN DISCHARGES, IN CUBIC FEET PER SECOND, FOR EACH WATER YEAR

$\begin{array}{lcccccccccccc}\text { YEAR } & \text { OCT } & \text { NOW } & \text { DEC } & \text { JAN } & \text { FEB } & \text { MAR } & \text { APR } & \text { MAY } & \text { JUNE } & \text { JULY } & \text { AUG } & \text { SEP } \\ 1919 & 170 & 140 & 115 & 92.6 & 88.8 & 114 & 183 & 842 & 351 & 96.0 & 71.2 & 111 \\ 1920 & 131 & 117 & 91.4 & 80.0 & 91.1 & 106 & 130 & 811 & 1132 & 292 & 153 & 148 \\ & & & & & & & & & & & & \\ 1921 & 146 & 124 & 107 & 95.0 & 106 & 137 & 173 & 676 & 1657 & 498 & 212 & 207 \\ 1922 & 154 & 147 & 136 & 92.3 & 105 & 115 & 159 & 988 & 1580 & 388 & 207 & 170 \\ 1923 & 153 & 143 & 127 & 100 & 90.0 & 113 & 198 & 903 & 1132 & 469 & 195 & 197 \\ 1924 & 175 & 139 & 127 & 110 & 109 & 100 & 153 & 567 & 224 & 107 & 62.4 & 77.2 \\ 1925 & 102 & 108 & 101 & 91.7 & 94.3 & 97.1 & 144 & 514 & 367 & 190 & 107 & 143 \\ 1926 & 149 & 110 & 100 & 80.0 & 85.8 & 106 & 199 & 557 & 332 & 96.3 & 77.8 & 73.8 \\ 1927 & 100 & 114 & 92.7 & 80.0 & 86.8 & 100 & 170 & 675 & 862 & 258 & 133 & 233 \\ 1928 & 227 & 176 & 137 & 110 & 105 & 127 & 158 & 925 & 520 & 155 & 107 & 105 \\ 1929 & 119 & 124 & 112 & 90.0 & 100 & 108 & 114 & 476 & 767 & 307 & 160 & 180 \\ 1930 & 156 & 140 & 111 & 90.0 & 105 & 119 & 203 & 398 & 550 & 123 & 132 & 148\end{array}$


GREEN RIVER BASIN

09277500 DUCHESNE RIVER NEAR TABIONA, UT--Continued

MONIHLY MEAN DISCHARGES, IN OBBIC FEET PER SECOND, FOR EACH WATER YEAR---Continued

$\begin{array}{rcccccccccccc}\text { YEAR } & \text { OCT } & \text { NOV } & \text { DEC } & \text { JAN } & \text { FEB } & \text { MAR } & \text { APR } & \text { MAY } & \text { JUNE } & \text { JULY } & \text { AUG } & \text { SEP } \\ 1931 & 182 & 117 & 95.0 & 90.0 & 88.0 & 85.5 & 85.7 & 257 & 131 & 73.9 & 66.2 & 61.1 \\ 1932 & 60.0 & 97.4 & 104 & 100 & 101 & 90.9 & 147 & 480 & 761 & 258 & 101 & 107 \\ 1933 & 94.5 & 107 & 103 & 112 & 91.7 & 83.7 & 96.1 & 187 & 644 & 132 & 61.1 & 65.8 \\ 1934 & 71.8 & 82.5 & 86.6 & 82.6 & 77.4 & 81.1 & 114 & 122 & 59.3 & 59.6 & 58.7 & 48.7 \\ 1935 & 37.5 & 57.6 & 72.1 & 59.5 & 53.3 & 53.8 & 90.2 & 216 & 658 & 119 & 71.3 & 71.1 \\ & & & & & & & & & & & \\ 1936 & 66.2 & 85.6 & 75.8 & 75.9 & 74.4 & 74.0 & 189 & 1043 & 533 & 256 & 174 & 109 \\ 1937 & 97.4 & 106 & 101 & 95.0 & 90.0 & 93.0 & 155 & 956 & 475 & 255 & 76.7 & 101 \\ 1938 & 108 & 116 & 101 & 95.4 & 93.4 & 97.9 & 216 & 682 & 751 & 176 & 95.7 & 146 \\ 1939 & 139 & 132 & 115 & 95.0 & 90.0 & 132 & 215 & 556 & 214 & 95.6 & 71.9 & 79.2 \\ 1940 & 115 & 91.5 & 87.9 & 84.4 & 82.9 & 87.5 & 110 & 530 & 149 & 74.8 & 60.3 & 102 \\ & & & & & & & & & & & \\ 1941 & 146 & 111 & 91.7 & 85.0 & 84.1 & 93.7 & 118 & 715 & 656 & 185 & 93.6 & 99.7 \\ 1942 & 150 & 123 & 111 & 96.3 & 93.2 & 103 & 240 & 472 & 677 & 160 & 70.0 & 99.9 \\ 1943 & 111 & 110 & 99.1 & 92.6 & 100 & 115 & 348 & 751 & 756 & 278 & 147 \\ 1944 & 127 & 133 & 114 & 107 & 100 & 111 & 151 & 608 & 832 & 250 & 86.1 & 90.8 \\ 1945 & 120 & 119 & 103 & 95.4 & 91.5 & 95.0 & 113 & 513 & 629 & 230 & 160 & 107 \\ 1946 & 132 & 126 & 117 & 107 & 100 & 110 & 320 & 613 & 459 & 117 & 91.4 & 83.7 \\ 1947 & 126 & 134 & 116 & 100 & 106 & 119 & 163 & 888 & 671 & 242 & 153 & 126 \\ 1948 & 112 & 136 & 116 & 103 & 100 & 99.1 & 130 & 602 & 402 & 109 & 81.1 & 75.6 \\ 1949 & 86.2 & 115 & 108 & 93.5 & 89.7 & 102 & 236 & 726 & 972 & 285 & 103 & 98.3 \\ 1950 & 129 & 137 & 114 & 100 & 103 & 109 & 249 & 617 & 1186 & 361 & 106 & 130 \\ 1951 & 116 & 145 & 134 & 114 & 111 & 107 & 183 & 617 & 948 & 298 & 178 & 107 \\ 1952 & 126 & 128 & 118 & 104 & 106 & 102 & 301 & 1165 & 1286 & 364 & 209 & 166 \\ 1953 & 112 & 123 & 131 & 124 & 115 & 111 & 135 & 188 & 827 & 216 & 168 & 79.7\end{array}$

ANNUAL PEAK DISCHARGE, IN CUBIC FEET PER SECOND, AND CORRESPONDING GAGE HEIGHT, IN FEET, FOR EACH WATER YEAR

\begin{tabular}{|c|c|c|c|c|c|c|c|c|c|c|c|c|c|}
\hline $\begin{array}{l}\text { WATERR } \\
\text { YEAR }\end{array}$ & & DATE & $\begin{array}{c}\text { GAGE } \\
\text { HEIGHT }\end{array}$ & $\begin{array}{c}\text { PEAK } \\
\text { DISCHARGE }\end{array}$ & $\begin{array}{l}\text { WATER } \\
\text { YEAR }\end{array}$ & & DATE & $\begin{array}{l}\text { GAGE } \\
\text { HEIGHT }\end{array}$ & $\begin{array}{c}\text { PEAK } \\
\text { DISCHARGE }\end{array}$ & $\begin{array}{l}\text { WATER } \\
\text { YEAR }\end{array}$ & DATE & $\begin{array}{c}\text { GAGE } \\
\text { HEIGHT }\end{array}$ & $\begin{array}{c}\text { PEAK } \\
\text { DISCHARGE }\end{array}$ \\
\hline $\begin{array}{l}1919 \\
1920 \\
1921 \\
1922 \\
1923 \\
1924 \\
1925 \\
1926 \\
1927 \\
1928 \\
1929 \\
1930\end{array}$ & $\begin{array}{l}\text { MAY } \\
\text { JUNE } \\
\text { JUNE } \\
\text { JUNE } \\
\text { JUNE } \\
\text { MAY } \\
\text { MAY } \\
\text { MAY } \\
\text { JUNE } \\
\text { MAY } \\
\text { MAY } \\
\text { JUNE }\end{array}$ & $\begin{array}{ll}24, & 1919 \\
09, & 1920 \\
13, & 1921 \\
09, & 1922 \\
13, & 1923 \\
19, & 1924 \\
21, & 1925 \\
23, & 1926 \\
09, & 1927 \\
28, & 1928 \\
25, & 1929 \\
12, & 1930\end{array}$ & $\begin{array}{c}12.74 \\
13.53 \\
-. \\
14.40 \\
13.68 \\
12.08 \\
12.14 \\
12.22 \\
13.07 \\
13.34 \\
13.82 \\
12.27\end{array}$ & $\begin{array}{r}1420 \\
1900 \\
2500 \\
2350 \\
2010 \\
900 \\
930 \\
950 \\
1530 \\
1510 \\
1870 \\
1040\end{array}$ & $\begin{array}{l}1931 \\
1932 \\
1933 \\
1934 \\
1935 \\
1936 \\
1937 \\
1938 \\
1939 \\
1940 \\
1941 \\
1942\end{array}$ & $\begin{array}{l}\text { JULY } \\
\text { MAY } \\
\text { JUNE } \\
\text { MAY } \\
\text { JUNE } \\
\text { MAY } \\
\text { MAY } \\
\text { MAY } \\
\text { MAY } \\
\text { MAY } \\
\text { MAY } \\
\text { MAY }\end{array}$ & $\begin{array}{l}26,1931 \\
22,1932 \\
11,1933 \\
06,1934 \\
14,1935 \\
15,1936 \\
18,1937 \\
29,1938 \\
05,1939 \\
16,1940 \\
27,1941 \\
27,1942\end{array}$ & $\begin{array}{l}5.48 \\
6.62 \\
6.38 \\
4.52 \\
7.01 \\
6.89 \\
7.01 \\
7.08 \\
5.86 \\
6.25 \\
6.61 \\
6.68\end{array}$ & $\begin{array}{r}521 \\
1100 \\
975 \\
209 \\
1220 \\
1590 \\
1750 \\
1660 \\
811 \\
1060 \\
1330 \\
1370\end{array}$ & $\begin{array}{l}1943 \\
1944 \\
1945 \\
1946 \\
1947 \\
1948 \\
1949 \\
1950 \\
1951 \\
1952 \\
1953\end{array}$ & $\begin{array}{l}\text { JUNE } 01,1943 \\
\text { JUNE } 01,1944 \\
\text { JULY } 19,1945 \\
\text { JUNE } 06,1946 \\
\text { MAY } 09,1947 \\
\text { MAY } 22,1948 \\
\text { JUNE } 13,1949 \\
\text { JUNE } 02,1950 \\
\text { MAY } 29,1951 \\
\text { JUNE 06, } 1952 \\
\text { JUNE } 14,1953\end{array}$ & $\begin{array}{l}6.73 \\
6.74 \\
6.90 \\
6.19 \\
6.81 \\
6.79 \\
7.00 \\
7.49 \\
8.24 \\
6.63 \\
6.61\end{array}$ & $\begin{array}{l}1410 \\
1300 \\
1520 \\
1000 \\
1450 \\
1430 \\
1550 \\
1840 \\
1890 \\
2060 \\
1800\end{array}$ \\
\hline
\end{tabular}

\begin{tabular}{|c|c|c|c|c|c|c|}
\hline \multirow{2}{*}{$\begin{array}{l}\text { ERIOI } \\
\text { CON- } \\
\text { EOU- } \\
\text { TVE } \\
\text { AYS) }\end{array}$} & \multicolumn{6}{|c|}{$\begin{array}{l}\text { DISCHARGE, IN OUBIC FEET PER SECOND, FOR } \\
\text { INDICATED RECURRENCE INTERNAL, IN YEARS, AND } \\
\text { ANNUAL NONEXCEEDANCE PROBABILITY, IN PERCENT }\end{array}$} \\
\hline & $\begin{array}{c}2 \\
508\end{array}$ & $\begin{array}{c}5 \\
208\end{array}$ & $\begin{array}{l}10 \\
108\end{array}$ & $\begin{array}{l}20 \\
58\end{array}$ & $\begin{array}{l}50 \\
28\end{array}$ & $\begin{array}{r}100 \\
18\end{array}$ \\
\hline $\begin{array}{r}1 \\
7 \\
14 \\
30 \\
60 \\
90\end{array}$ & $\begin{array}{l}67 \\
73 \\
76 \\
83 \\
90 \\
95\end{array}$ & $\begin{array}{l}51 \\
56 \\
59 \\
66 \\
74 \\
79\end{array}$ & $\begin{array}{l}43 \\
47 \\
51 \\
57 \\
65 \\
70\end{array}$ & $\begin{array}{l}37 \\
40 \\
43 \\
50 \\
57 \\
61\end{array}$ & $\begin{array}{l}30 \\
33 \\
36 \\
42 \\
49 \\
52\end{array}$ & $\overline{-}$ \\
\hline
\end{tabular}

DATA BELOW BASED ON PERIOD OF RECORD AFTER DIVERSION THROUGH DUCHESNE TUNNEL

LOWEST MEAN DISCHARGE, IN CUBIC FEET PER SECOND, AND RANKING FOR THE INDICATED NUMBER OF OONSECUTIVE DAYS FOR EACH CLIMATIC YEAR, APRIL I-MARCH 31

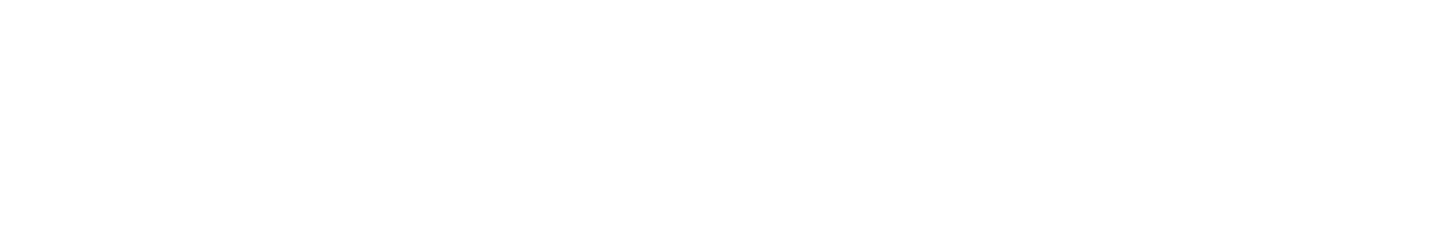


GREEN RIVER BASIN

09277500 DUCHESNE RIVER NEAR TABIONA, UT--Continued

LOWEST MEAN DISCHARGE, IN OBBIC FEET PER SECOND, AND RANKING FOR THE INDICATED NUMBER OF CONSECITIVE DAYS FOR EACH CLIMATIC YEAR, APRIL 1-MARCH 31-Continued

\begin{tabular}{|c|c|c|c|c|c|c|c|c|c|c|c|c|c|c|c|c|c|c|c|c|}
\hline YEAR & 1 & & 3 & & 7 & & 14 & & $\begin{array}{l}\text { cons } \\
30\end{array}$ & & $\begin{array}{l}\text { E DAYS } \\
60\end{array}$ & & 90 & & 120 & & 183 & & ALL & \\
\hline $\begin{array}{l}961 \\
962 \\
963 \\
964\end{array}$ & $\begin{array}{l}57.0 \\
32.0 \\
80.0 \\
77.0 \\
74.0\end{array}$ & $\begin{array}{r}6 \\
1 \\
21 \\
19 \\
16\end{array}$ & $\begin{array}{l}58.0 \\
34.0 \\
80.0 \\
79.0 \\
74.0\end{array}$ & $\begin{array}{r}6 \\
1 \\
21 \\
19 \\
16\end{array}$ & $\begin{array}{l}60.0 \\
37.0 \\
80.0 \\
81.0 \\
76.0\end{array}$ & $\begin{array}{r}6 \\
1 \\
18 \\
19 \\
16\end{array}$ & $\begin{array}{l}60.0 \\
43.0 \\
81.0 \\
83.0 \\
76.0\end{array}$ & $\begin{array}{r}6 \\
1 \\
16 \\
18 \\
14\end{array}$ & & $\begin{array}{r}6 \\
4 \\
20 \\
17 \\
14\end{array}$ & $\begin{array}{l}73.0 \\
74.0 \\
93.0 \\
90.0 \\
82.0\end{array}$ & $\begin{array}{r}5 \\
6 \\
19 \\
16 \\
13\end{array}$ & $\begin{array}{l}76.0 \\
83.0 \\
94.0 \\
92.0 \\
87.0\end{array}$ & $\begin{array}{r}4 \\
10 \\
19 \\
16\end{array}$ & & $\begin{array}{r}4 \\
8 \\
19 \\
15 \\
13\end{array}$ & $\begin{array}{c}83.0 \\
90.0 \\
102 \\
100 \\
95.0\end{array}$ & $\begin{array}{r}4 \\
8 \\
17 \\
16\end{array}$ & $\begin{array}{l}104 \\
94.0 \\
202 \\
138 \\
170\end{array}$ & $\begin{array}{r}4 \\
2 \\
18 \\
8 \\
12\end{array}$ \\
\hline $\begin{array}{l}1966 \\
1967 \\
1968 \\
1969 \\
1970\end{array}$ & $\begin{array}{l}99.0 \\
76.0 \\
80.0 \\
98.0 \\
84.0\end{array}$ & $\begin{array}{l}27 \\
18 \\
22 \\
26 \\
24\end{array}$ & $\begin{array}{c}102 \\
77.0 \\
82.0 \\
100 \\
87.0\end{array}$ & $\begin{array}{l}27 \\
18 \\
22 \\
26 \\
25\end{array}$ & $\begin{array}{c}106 \\
80.0 \\
83.0 \\
105 \\
93.0\end{array}$ & $\begin{array}{l}27 \\
17 \\
22 \\
26 \\
25\end{array}$ & $\begin{array}{c}110 \\
83.0 \\
89.0 \\
106 \\
95.0\end{array}$ & $\begin{array}{l}27 \\
19 \\
23 \\
26 \\
25\end{array}$ & $\begin{array}{c}118 \\
86.0 \\
99.0 \\
109 \\
97.0\end{array}$ & $\begin{array}{l}27 \\
18 \\
25 \\
26 \\
24\end{array}$ & $\begin{array}{c}128 \\
90.0 \\
101 \\
113 \\
104\end{array}$ & $\begin{array}{l}27 \\
17 \\
21 \\
26 \\
25\end{array}$ & $\begin{array}{c}136 \\
91.0 \\
107 \\
117 \\
104\end{array}$ & $\begin{array}{l}27 \\
15 \\
24 \\
26 \\
22\end{array}$ & $\begin{array}{l}140 \\
94.0 \\
111 \\
120 \\
108\end{array}$ & $\begin{array}{l}27 \\
14 \\
24 \\
26 \\
21\end{array}$ & $\begin{array}{c}144 \\
99.0 \\
114 \\
128 \\
120\end{array}$ & & $\begin{array}{l}275 \\
143 \\
227 \\
235 \\
259\end{array}$ & $\begin{array}{l}27 \\
10 \\
21 \\
23 \\
26\end{array}$ \\
\hline $\begin{array}{l}1971 \\
1972 \\
1973 \\
1974 \\
1975\end{array}$ & $\begin{array}{l}64.0 \\
83.0 \\
85.0 \\
74.0 \\
63.0\end{array}$ & $\begin{array}{l}11 \\
23 \\
25 \\
17 \\
10\end{array}$ & $\begin{array}{l}64.0 \\
85.0 \\
87.0 \\
76.0 \\
64.0\end{array}$ & $\begin{array}{r}9 \\
23 \\
24 \\
17 \\
10\end{array}$ & $\begin{array}{l}66.0 \\
87.0 \\
87.0 \\
82.0 \\
64.0\end{array}$ & $\begin{array}{r}10 \\
23 \\
24 \\
20 \\
8\end{array}$ & $\begin{array}{l}71.0 \\
90.0 \\
88.0 \\
87.0 \\
65.0\end{array}$ & $\begin{array}{r}12 \\
24 \\
22 \\
21 \\
7\end{array}$ & $\begin{array}{l}76.0 \\
94.0 \\
89.0 \\
95.0 \\
70.0\end{array}$ & $\begin{array}{r}12 \\
22 \\
19 \\
23 \\
7\end{array}$ & $\begin{array}{c}82.0 \\
102 \\
90.0 \\
101 \\
76.0\end{array}$ & $\begin{array}{r}14 \\
23 \\
15 \\
22 \\
9\end{array}$ & $\begin{array}{c}86.0 \\
110 \\
93.0 \\
101 \\
84.0\end{array}$ & $\begin{array}{l}13 \\
25 \\
17 \\
20 \\
11\end{array}$ & $\begin{array}{c}97.0 \\
115 \\
98.0 \\
108 \\
93.0\end{array}$ & $\begin{array}{l}16 \\
25 \\
17 \\
22 \\
12\end{array}$ & $\begin{array}{c}98.0 \\
114 \\
109 \\
112 \\
96.0\end{array}$ & & & $\begin{array}{l}11 \\
22 \\
16 \\
19 \\
17\end{array}$ \\
\hline 1981 & 62.0 & 9 & 64.0 & 11 & 69.0 & 13 & 78.0 & 15 & 85.0 & 16 & 92.0 & 18 & 94.0 & 18 & 98.0 & 18 & 104 & 18 & 244 & 24 \\
\hline
\end{tabular}

HIGHEST MEAN DISCHARGE, IN OBIC FEET PER SECOND, AND RANKING FOR THE INDICATED NUMBER OF CONSECUTIVE DAYS FOR EACH WATER YEAR, OCTOBER 1-SEPTEMBEER 30

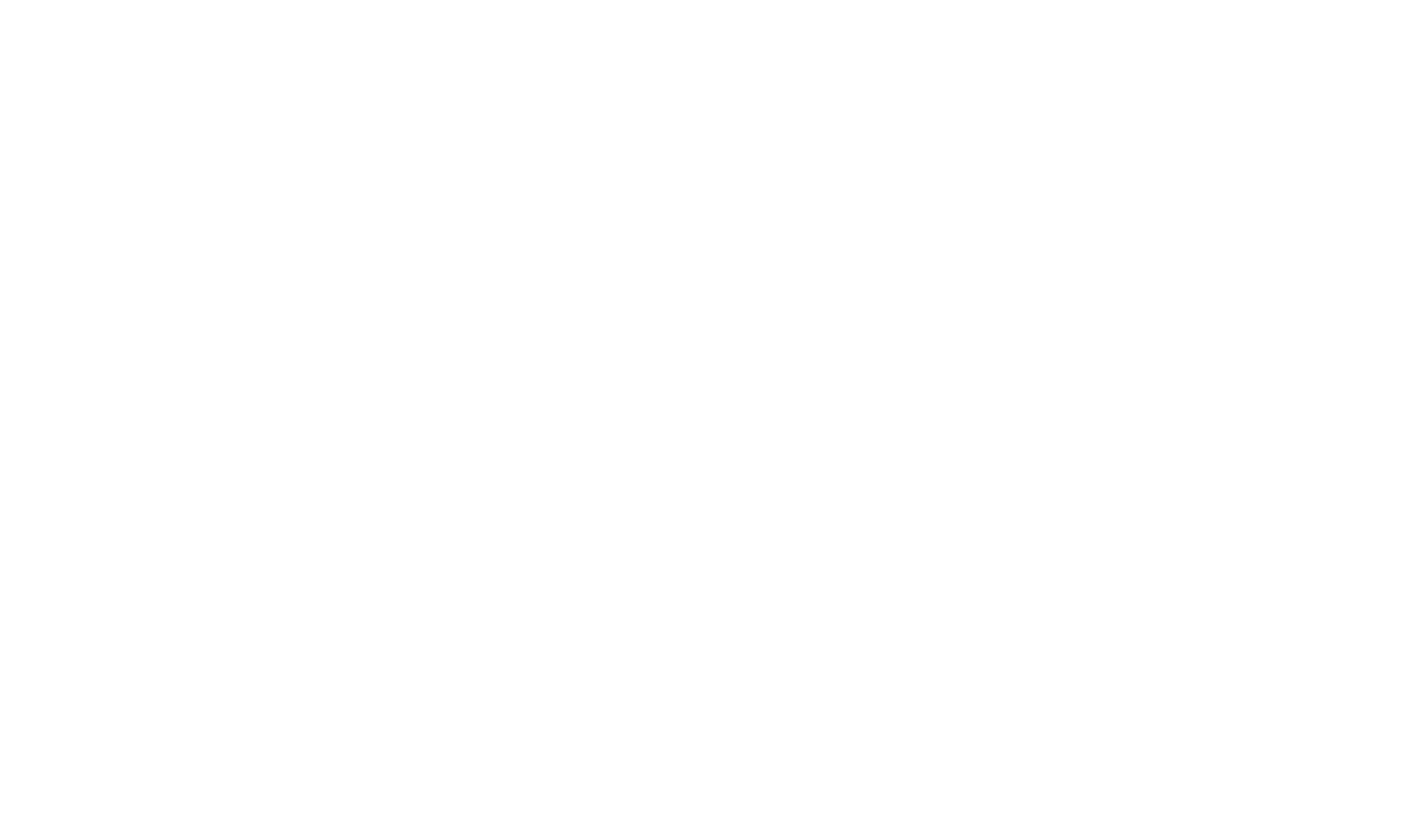


GREEN RIVER BASIN

09277500 DUCHESNE RIVER NEAR TABIONA, UT--Continued

DURATION OF DISCHARGE FOR EACH WATER YEAR

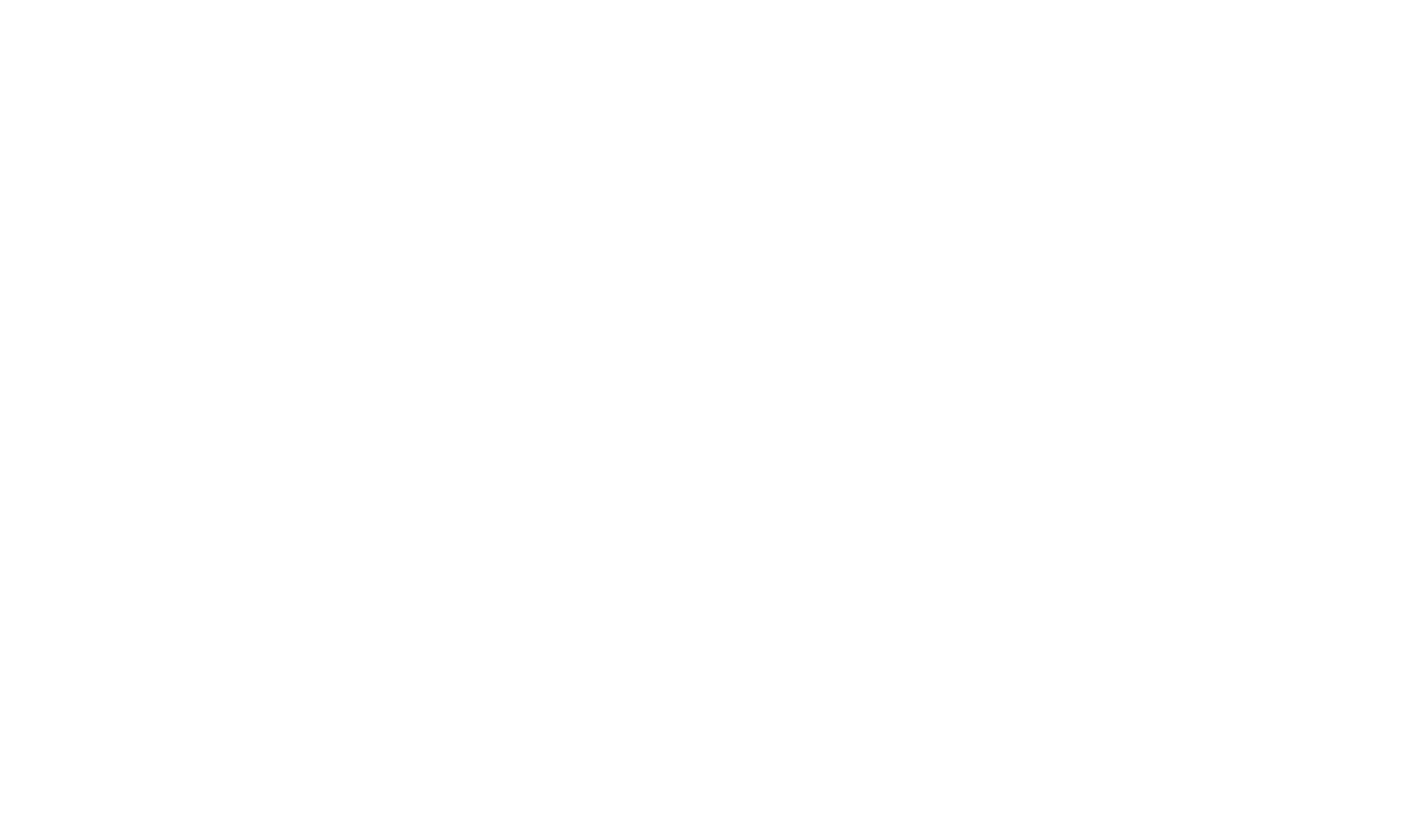

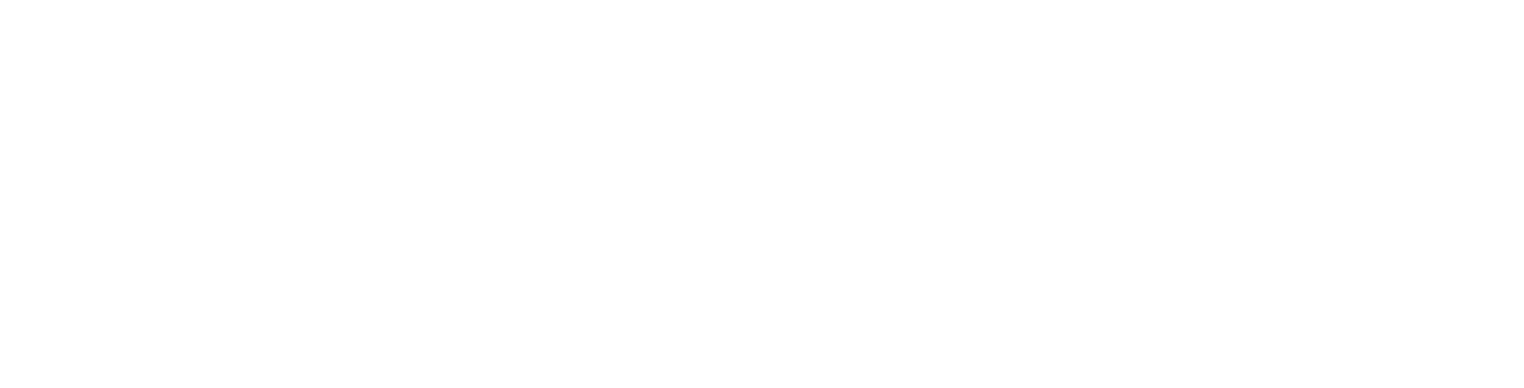

MONTHLY MEAN DISCHARGES, IN OBIC FEET PER SECOND, FOR EACH WATER YEAR

$\begin{array}{rcccccccccccc}\text { YEAR } & \text { OCT } & \text { NOV } & \text { DEC } & \text { JAN } & \text { FEB } & \text { MAR } & \text { APR } & \text { MAY } & \text { JUNE } & \text { JULY } & \text { AUG } & \text { SEP } \\ 1954 & 100 & 127 & 111 & 99.9 & 97.6 & 94.5 & 124 & 241 & 77.7 & 83.2 & 61.3 & 68.1 \\ 1955 & 95.7 & 100 & 95.4 & 91.4 & 84.5 & 88.8 & 104 & 353 & 243 & 111 & 88.2 & 71.1 \\ & & & & & & & & & & & & \\ 1956 & 75.9 & 113 & 115 & 99.7 & 94.0 & 104 & 159 & 518 & 576 & 124 & 90.3 & 71.3 \\ 1957 & 81.5 & 100 & 103 & 87.4 & 85.0 & 89.9 & 84.3 & 221 & 996 & 236 & 139 & 116 \\ 1958 & 113 & 138 & 120 & 113 & 109 & 100 & 132 & 676 & 502 & 136 & 88.8 & 82.8 \\ 1959 & 77.0 & 105 & 114 & 103 & 85.6 & 86.1 & 98.1 & 139 & 225 & 122 & 81.7 & 67.7 \\ 1960 & 107 & 111 & 95.7 & 83.0 & 80.4 & 96.4 & 109 & 208 & 163 & 104 & 77.3 & 78.1 \\ & & & & & & & & & & & & \\ 1961 & 75.8 & 92.6 & 99.5 & 84.7 & 77.8 & 78.6 & 62.1 & 102 & 102 & 88.3 & 68.2 & 121 \\ 1962 & 118 & 109 & 94.1 & 78.1 & 86.1 & 96.3 & 306 & 535 & 543 & 204 & 112 & 103 \\ 1963 & 117 & 105 & 109 & 90.3 & 98.7 & 96.0 & 106 & 270 & 332 & 104 & 113 & 127 \\ 1964 & 90.9 & 125 & 108 & 95.3 & 92.0 & 88.5 & 112 & 414 & 540 & 189 & 120 & 89.9 \\ 1965 & 78.5 & 103 & 114 & 103 & 92.2 & 86.1 & 149 & 372 & 1082 & 442 & 197 & 196 \\ & & & & & & & & & & & \\ 1966 & 147 & 147 & 145 & 147 & 121 & 151 & 234 & 370 & 163 & 138 & 93.0 & 95.7 \\ 1967 & 94.3 & 97.4 & 116 & 105 & 100 & 105 & 112 & 294 & 1019 & 389 & 115 & 110 \\ 1968 & 99.0 & 121 & 139 & 126 & 103 & 100 & 114 & 278 & 1170 & 211 & 154 & 130 \\ 1969 & 137 & 152 & 132 & 121 & 115 & 117 & 276 & 1113 & 560 & 183 & 122 & 120 \\ 1970 & 137 & 149 & 120 & 106 & 110 & 97.6 & 104 & 275 & 473 & 150 & 83.8 & 86.0\end{array}$


GREEN RIVER BASIN

09277500 DUCHESNE RIVER NEAR TABIONA, UT--Continued

NONIHLY MEAN DISCHARGES, IN OUBIC FEET PER SECOND, FOR EACH WATER YEAR--Continued

\begin{tabular}{|c|c|c|c|c|c|c|c|c|c|c|c|c|}
\hline YEAR & $\infty T$ & NOV & DEC & JAN & FEB & MAR & APR & MAY & JUNE & JULY & AUG & SEP \\
\hline $\begin{array}{l}1971 \\
1972 \\
1973 \\
1974 \\
1975\end{array}$ & $\begin{array}{l}94.6 \\
114 \\
132 \\
102 \\
103\end{array}$ & $\begin{array}{l}128 \\
140 \\
132 \\
134 \\
118\end{array}$ & $\begin{array}{l}98.4 \\
116 \\
113 \\
126 \\
101\end{array}$ & $\begin{array}{c}97.7 \\
106 \\
94.7 \\
112 \\
95.1\end{array}$ & $\begin{array}{r}106 \\
108 \\
88.9 \\
96.1 \\
93.5\end{array}$ & $\begin{array}{c}109 \\
133 \\
95.9 \\
110 \\
94.6\end{array}$ & $\begin{array}{c}180 \\
163 \\
130 \\
115 \\
92.3\end{array}$ & $\begin{array}{l}384 \\
461 \\
614 \\
763 \\
202\end{array}$ & $\begin{array}{r}1044 \\
725 \\
636 \\
614 \\
1103\end{array}$ & $\begin{array}{l}232 \\
166 \\
165 \\
116 \\
690\end{array}$ & $\begin{array}{c}134 \\
106 \\
94.9 \\
79.3 \\
129\end{array}$ & $\begin{array}{l}97.5 \\
101 \\
107 \\
77.8 \\
103\end{array}$ \\
\hline $\begin{array}{l}1976 \\
1977 \\
1978 \\
1979 \\
1980\end{array}$ & $\begin{array}{r}111 \\
91.8 \\
54.5 \\
78.9 \\
80.2\end{array}$ & $\begin{array}{c}133 \\
98.4 \\
78.9 \\
112 \\
103\end{array}$ & $\begin{array}{c}126 \\
97.6 \\
83.7 \\
97.6 \\
84.3\end{array}$ & $\begin{array}{r}105 \\
83.4 \\
76.5 \\
88.0 \\
81.8\end{array}$ & $\begin{array}{l}99.9 \\
80.9 \\
72.2 \\
85.3 \\
81.7\end{array}$ & $\begin{array}{l}99.9 \\
75.3 \\
80.4 \\
86.0 \\
82.1\end{array}$ & $\begin{array}{l}142 \\
53.9 \\
131 \\
121 \\
190\end{array}$ & $\begin{array}{c}488 \\
93.3 \\
289 \\
364 \\
686\end{array}$ & $\begin{array}{r}218 \\
104 \\
924 \\
281 \\
1030\end{array}$ & $\begin{array}{c}118 \\
66.2 \\
149 \\
90.6 \\
194\end{array}$ & $\begin{array}{l}91.5 \\
44.1 \\
88.0 \\
59.8 \\
86.0\end{array}$ & $\begin{array}{r}72.9 \\
55.6 \\
78.5 \\
56.0 \\
123\end{array}$ \\
\hline 1981 & 108 & 120 & 110 & 97.9 & 93.6 & 90.1 & 121 & 232 & 457 & 123 & 68.2 & 97.0 \\
\hline
\end{tabular}

ANNUAL PEAK DISCHARGE, IN CUBIC FEET PER SECOND, AND CORRESPONDING GAGE HEIGHT, IN FEET, FOR EACH WATER YEAR

\begin{tabular}{|c|c|c|c|c|c|c|c|c|c|c|c|c|c|}
\hline $\begin{array}{l}\text { WATER } \\
\text { YEAR }\end{array}$ & DATE & & $\begin{array}{c}\text { GAGE } \\
\text { HEIGHT }\end{array}$ & $\begin{array}{c}\text { PEAK } \\
\text { DISCHARGE }\end{array}$ & $\begin{array}{l}\text { WATER } \\
\text { YEAR }\end{array}$ & DATE & $\begin{array}{c}\text { GAGE } \\
\text { HEIGHT }\end{array}$ & $\begin{array}{c}\text { PEAK } \\
\text { DISCHARGE }\end{array}$ & $\begin{array}{l}\text { WATER } \\
\text { YEAR }\end{array}$ & & DATE & $\begin{array}{c}\text { GAGE } \\
\text { HEIGHT }\end{array}$ & $\begin{array}{c}\text { PEAK } \\
\text { DISCHARGE }\end{array}$ \\
\hline $\begin{array}{l}1954 \\
1955 \\
1956 \\
1957 \\
1958 \\
1959 \\
1960 \\
1961 \\
1962 \\
1963\end{array}$ & $\begin{array}{l}\text { MAY } 12, \\
\text { MAY } 23, \\
\text { JUNE } 02, \\
\text { JUNE } 07, \\
\text { MAY 28, } \\
\text { JUNE } 07, \\
\text { SEPT. } 02, \\
\text { AUG. 25, } \\
\text { MAY } 11, \\
\text { JUNE } 16,\end{array}$ & $\begin{array}{l}1954 \\
1955 \\
1956 \\
1957 \\
1958 \\
1959 \\
1960 \\
1961 \\
1962 \\
1963\end{array}$ & $\begin{array}{l}3.91 \\
4.59 \\
5.29 \\
5.93 \\
5.82 \\
3.51 \\
5.23 \\
4.50 \\
4.68 \\
7.97\end{array}$ & $\begin{array}{r}542 \\
961 \\
1450 \\
2080 \\
1830 \\
357 \\
1410 \\
849 \\
1000 \\
5260\end{array}$ & $\begin{array}{l}1964 \\
1965 \\
1966 \\
1967 \\
1968 \\
1969 \\
1970 \\
1971 \\
1972\end{array}$ & $\begin{array}{l}\text { JUNE } 07,1964 \\
\text { JUNE } 13,1965 \\
\text { MAY } 10,1966 \\
\text { JUNE } 21,1967 \\
\text { JUNE 05, } 1968 \\
\text { MAY } 27,1969 \\
\text { JUNE 10, } 1970 \\
\text { JUNE 18, } 1971 \\
\text { JUNE 04, } 1972\end{array}$ & $\begin{array}{l}4.97 \\
5.60 \\
3.77 \\
5.21 \\
5.44 \\
5.40 \\
4.45 \\
5.62 \\
6.15\end{array}$ & $\begin{array}{r}1400 \\
1850 \\
730 \\
1690 \\
1900 \\
1640 \\
972 \\
1800 \\
2630\end{array}$ & $\begin{array}{l}1973 \\
1974 \\
1975 \\
1976 \\
1977 \\
1978 \\
1979 \\
1980 \\
1981\end{array}$ & $\begin{array}{l}\text { MAY } \\
\text { MAY } \\
\text { JUNE } \\
\text { MAY } \\
\text { JUNE } \\
\text { JUNE } \\
\text { MAY } \\
\text { JUNE } \\
\text { JUNE }\end{array}$ & $\begin{array}{l}22,1973 \\
29,1974 \\
16,1975 \\
19,1976 \\
04 ; 1977 \\
10,1978 \\
29,1979 \\
11,1980 \\
07,1981\end{array}$ & $\begin{array}{l}3.70 \\
3.97 \\
5.92 \\
4.12 \\
2.54 \\
4.93 \\
4.17 \\
5.17 \\
--\end{array}$ & $\begin{array}{r}1480 \\
2120 \\
2200 \\
1060 \\
329 \\
1460 \\
1160 \\
1910 \\
980\end{array}$ \\
\hline
\end{tabular}

\begin{tabular}{lcccccc}
\multicolumn{3}{c}{ MAGNITUDE AND PROBABILITY OF ANNUAL LOWEST MEAN DISCHARGE } \\
BASED ON CLIMATIC YEARS $1955-81$
\end{tabular}

09277800 ROCK CREEK ABOVE SCUTH FORK, NEAR HANNA, UT

LOCATION,--Lat $40^{\circ} 33^{\prime} 27^{\prime \prime}$, Iong $110^{\circ} 41^{\prime} 50^{\prime \prime}$, in $\mathrm{NE}^{\frac{1}{4}}$ sec. 20, T.2 N., R.7 W., Uintah Meridian, Duchesne County, Hydrologic Unit

14060003, Ashley National Forest, on right bank 1,000 ft downstream fram Upper Stillwater campground horsetrail bridge, $0.9 \mathrm{mi}$ upstream from South Fork, and 11.2 mi north of Banna.

DRAINAGE AREA. $--98.9 \mathrm{mi}^{2}$.

MEAN BASIN ELEVATION. - $-10,360 \mathrm{ft}$.

PERIOD OF RECORD AVAIIABLE.--October 1965 to September 1981.

REVISED RECORDS. -WDR UT-77-1: Drainage area.

GAGE.--Water-stage recorder. Altitude of gage is 7,967.7 ft, levels by Bureau of Reclamation.

AVERAGE DISCHARGE. -16 years, $133 \mathrm{ft}^{3} / \mathrm{s}, 96,400$ acre-ft.

EXIREYIS FOR PERIOD OF RECORD.--Maximum discharge, 2,760 ft $3 / \mathrm{s}$ June 17, 1971, gage height, $4.95 \mathrm{ft}$; minimum measured, $6.9 \mathrm{ft} 3 / \mathrm{s}$ Dec. 23, 1976 . 
GREEN RIVER BASIN

09277800 ROCK CREEK ABOVE SOUTH FORK, NEAR HANNA, UT--Continued

LOWEST MEAN DISCHARGE, IN CUBIC FEET PER SECOND, AND RANKING FOR THE INDICATED NUMBER OF CONSECUTIVE DAYS FOR EACH CLIMATIC YEAR, APRIL 1-MARCH 31

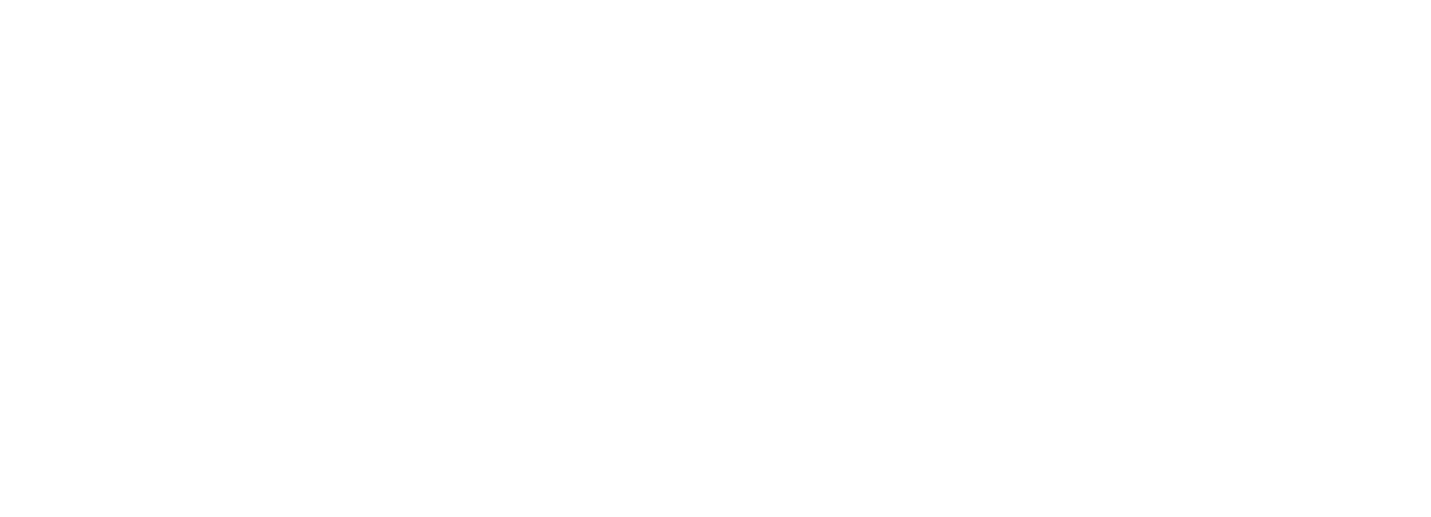

HIGHEST MEAN DISCHARGE, IN OUBIC FEET PER SECOND, AND RANKING FOR THE INDICAIED NUMBER OF CONSECUTIVE DAYS FOR EACH WATER YEAR, OCTOBER I-SEPTEMBER 30

\begin{tabular}{|c|c|c|c|c|c|c|c|c|c|c|c|c|c|c|c|c|c|c|c|c|}
\hline YEAR & 1 & & 3 & & 7 & & 15 & & $\begin{array}{l}\infty \\
30\end{array}$ & EOTT & $\begin{aligned} & D \\
60 & \end{aligned}$ & & 90 & & 120 & & 183 & & ALL & \\
\hline $\begin{array}{l}1966 \\
1967 \\
1968 \\
1969 \\
1970\end{array}$ & $\begin{array}{r}749 \\
1450 \\
1680 \\
1240 \\
1120\end{array}$ & $\begin{array}{r}16 \\
9 \\
3 \\
11 \\
13\end{array}$ & $\begin{array}{r}688 \\
1370 \\
1620 \\
1190 \\
1050\end{array}$ & $\begin{array}{r}16 \\
8 \\
3 \\
10 \\
13\end{array}$ & $\begin{array}{r}626 \\
1290 \\
1500 \\
1090 \\
992\end{array}$ & $\begin{array}{r}16 \\
6 \\
3 \\
9 \\
13\end{array}$ & $\begin{array}{r}571 \\
1190 \\
1260 \\
1020 \\
923\end{array}$ & $\begin{array}{r}15 \\
6 \\
4 \\
7 \\
9\end{array}$ & $\begin{array}{r}521 \\
939 \\
1100 \\
856 \\
733\end{array}$ & $\begin{array}{r}15 \\
6 \\
1 \\
8 \\
11\end{array}$ & $\begin{array}{l}381 \\
759 \\
718 \\
636 \\
536\end{array}$ & $\begin{array}{r}15 \\
1 \\
4 \\
8 \\
11\end{array}$ & $\begin{array}{l}285 \\
571 \\
536 \\
478 \\
390\end{array}$ & $\begin{array}{r}15 \\
1 \\
5 \\
8 \\
11\end{array}$ & $\begin{array}{l}234 \\
449 \\
433 \\
382 \\
310\end{array}$ & $\begin{array}{r}15 \\
1 \\
3 \\
8 \\
11\end{array}$ & $\begin{array}{l}172 \\
308 \\
303 \\
268 \\
218\end{array}$ & $\begin{array}{r}13 \\
1 \\
3 \\
8 \\
10\end{array}$ & $\begin{array}{l}104 \\
170 \\
166 \\
151 \\
123\end{array}$ & $\begin{array}{r}13 \\
1 \\
3 \\
8 \\
11\end{array}$ \\
\hline $\begin{array}{l}1971 \\
1972 \\
1973 \\
1974 \\
1975\end{array}$ & $\begin{array}{l}1970 \\
1700 \\
1260 \\
1490 \\
1580\end{array}$ & $\begin{array}{r}1 \\
2 \\
10 \\
8 \\
6\end{array}$ & $\begin{array}{l}1900 \\
1620 \\
1190 \\
1350 \\
1500\end{array}$ & $\begin{array}{r}1 \\
2 \\
11 \\
9 \\
6\end{array}$ & $\begin{array}{l}1810 \\
1510 \\
1060 \\
1160 \\
1160\end{array}$ & $\begin{array}{r}1 \\
2 \\
10 \\
7 \\
8\end{array}$ & $\begin{array}{r}1520 \\
1410 \\
864 \\
903 \\
1020\end{array}$ & $\begin{array}{r}1 \\
2 \\
12 \\
10 \\
8\end{array}$ & $\begin{array}{r}1080 \\
1090 \\
818 \\
738 \\
933\end{array}$ & $\begin{array}{r}3 \\
2 \\
9 \\
10 \\
7\end{array}$ & $\begin{array}{l}740 \\
710 \\
577 \\
536 \\
727\end{array}$ & $\begin{array}{r}2 \\
6 \\
9 \\
10 \\
3\end{array}$ & $\begin{array}{l}552 \\
512 \\
448 \\
394 \\
546\end{array}$ & $\begin{array}{r}2 \\
6 \\
9 \\
10 \\
3\end{array}$ & $\begin{array}{l}437 \\
399 \\
359 \\
310 \\
430\end{array}$ & $\begin{array}{r}2 \\
7 \\
9 \\
10 \\
4\end{array}$ & $\begin{array}{l}306 \\
277 \\
254 \\
215 \\
293\end{array}$ & $\begin{array}{r}2 \\
7 \\
9 \\
11 \\
5\end{array}$ & $\begin{array}{l}169 \\
157 \\
146 \\
123 \\
158\end{array}$ & $\begin{array}{r}2 \\
6 \\
9 \\
10 \\
4\end{array}$ \\
\hline $\begin{array}{l}1976 \\
1977 \\
1978 \\
1979 \\
1980\end{array}$ & $\begin{array}{r}790 \\
767 \\
1570 \\
1630 \\
1670\end{array}$ & $\begin{array}{r}14 \\
15 \\
7 \\
5 \\
4\end{array}$ & $\begin{array}{r}781 \\
729 \\
1510 \\
1370 \\
1600\end{array}$ & $\begin{array}{r}14 \\
15 \\
5 \\
7 \\
4\end{array}$ & $\begin{array}{r}757 \\
656 \\
1410 \\
1060 \\
1410\end{array}$ & $\begin{array}{r}14 \\
15 \\
4 \\
11 \\
5\end{array}$ & $\begin{array}{r}687 \\
481 \\
1240 \\
887 \\
1290\end{array}$ & $\begin{array}{r}14 \\
16 \\
5 \\
11 \\
3\end{array}$ & $\begin{array}{r}599 \\
296 \\
998 \\
730 \\
1030\end{array}$ & $\begin{array}{r}13 \\
16 \\
5 \\
12 \\
4\end{array}$ & $\begin{array}{l}400 \\
199 \\
695 \\
477 \\
712\end{array}$ & $\begin{array}{r}13 \\
16 \\
7 \\
12 \\
5\end{array}$ & $\begin{array}{l}296 \\
156 \\
510 \\
348 \\
539\end{array}$ & $\begin{array}{r}14 \\
16 \\
7 \\
12 \\
4\end{array}$ & $\begin{array}{l}235 \\
131 \\
401 \\
277 \\
426\end{array}$ & $\begin{array}{r}14 \\
16 \\
6 \\
12 \\
5\end{array}$ & $\begin{array}{l}165 \\
96.0 \\
278 \\
193 \\
294\end{array}$ & $\begin{array}{r}15 \\
16 \\
6 \\
12 \\
4\end{array}$ & $\begin{array}{l}95.0 \\
55.0 \\
151 \\
107 \\
157\end{array}$ & $\begin{array}{r}15 \\
16 \\
7 \\
12 \\
5\end{array}$ \\
\hline
\end{tabular}

DURATION OF DISCHARGE FOR EACH WATER YEAR

$\begin{array}{lllllllllllllllllllllllllllllllllllllllll}\text { CLASS } & 0 & 1 & 2 & 3 & 4 & 5 & 6 & 7 & 8 & 9 & 10 & 11 & 12 & 13 & 14 & 15 & 16 & 17 & 18 & 19 & 20 & 21 & 22 & 23 & 24 & 25 & 26 & 27 & 28 & 29 & 30 & 31 & 32 & 33 & 34\end{array}$ YEAR

NUMBER OF DAYS IN CJASS

CUBIC FEET PER SECOND

1966
1967
1968
1969
1970
1971
1972
1973
1974
1975
1976
1977
1978
1979
1980

$\begin{array}{lllllllllllllllllllllll}13 & 59 & 6 & 16 & 17 & 31 & 46 & 29 & 33 & 33 & 15 & 6 & 5 & 4 & 4 & 3 & 6 & 10 & 6 & 4 & 8 & 10 & 1\end{array}$

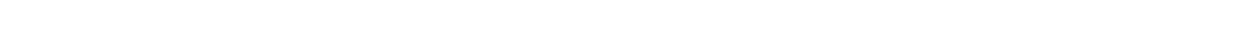

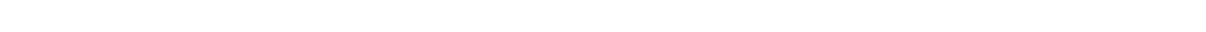

$\begin{array}{llllllllllllllllllllllllllll}27 & 54 & 58 & 56 & 32 & 18 & 38 & 26 & 14 & 12 & 12 & 10 & 9 & 7 & 4 & 4 & 5 & 3 & 10 & 7 & 5 & 6 & 11 & 4 & 9 & 1 & 55090.0 \\ & & & 17 & 20 & 21 & 12 & 16 & 11 & 11 & 6 & 2 & 2 & 6 & 3 & 2 & 5 & 6 & 8 & 7 & 5 & 5 & 6 & & 44772.0\end{array}$

$\begin{array}{llllllllllllllllllllllllllllll}40 & 41 & 15 & 46 & 47 & 22 & 11 & 19 & 17 & 11 & 14 & 5 & 5 & 7 & 8 & 6 & 3 & 9 & 4 & 5 & 7 & 7 & 2 & 3 & 1 & 2 & 6 & 2 & 61623.0\end{array}$

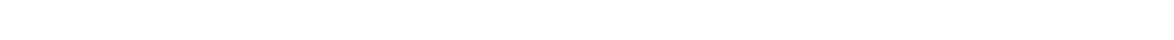

$\begin{array}{lllllllllllllllllllllllll}41 & 36 & 21 & 28 & 29 & 29 & 28 & 22 & 20 & 15 & 10 & 5 & 8 & 9 & 7 & 4 & 8 & 9 & 5 & 6 & 5 & 4 & 9 & 5 & 2\end{array}$

$\begin{array}{rrrrrrrrrrrrrrrrrrrrrrrrrrrrrrrr}60 & 77 & 64 & 32 & 24 & 7 & 9 & 7 & 10 & 10 & 5 & 3 & 2 & 4 & 2 & 5 & 6 & 14 & 6 & 3 & 6 & 2 & 4 & 2 & 1 & & 45076.0 \\ 9 & 21 & 43 & 13 & 11 & 6 & 15 & 7 & 4 & 8 & 3 & 6 & 11 & 6 & 3 & 7 & 4 & 4 & 6 & 5 & 8 & 7 & 10 & 8 & 2 & 3 & & 57644.0\end{array}$

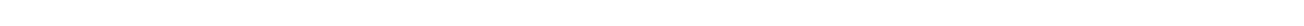

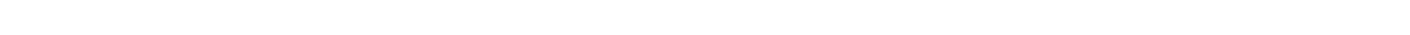

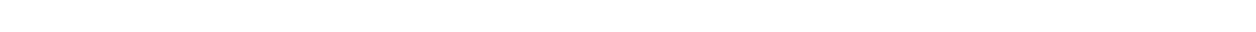

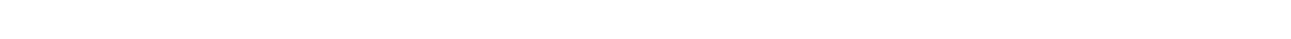

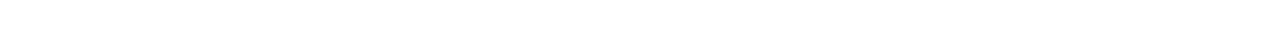

$\begin{array}{lllllllllllllllllllllllllll}61 & 40 & 18 & 30 & 50 & 36 & 21 & 13 & 8 & 6 & 5 & 8 & 15 & 12 & 6 & 4 & 7 & 3 & 4 & 2 & 2 & 2 & 4 & 4 & 4 & & \end{array}$ 
GREEN RIVER BASIN

09277800 ROCK CREEK ABOVE SOU'HH FORK, NEAR HANNA, UT--Continued

DURATTON TABLE OF DISCHARGE FOR WATER YEARS 1966-81

$\begin{array}{ccc}\text { OBBIC } & \text { ACO- } \\ \text { FEET } & \text { MJ- } & \text { PER- } \\ \text { PER TOTAL LAIED } & \text { CENT } \\ \text { CLASS SECOND DAYS DAYS } & \text { DAYS }\end{array}$

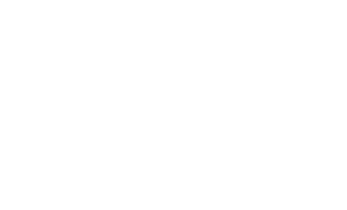

ABBIC ACOJ- GIBIC FEET MU- PERPER TOTAL LAIED CENT
CLASS SECOND DAYS DAYS DAYS

$\begin{array}{lll}\text { FEET } & \text { MU- } & \\ \text { FER- } & \text { PER- } \\ \text { PER TOTAL LATED } & \text { CENT }\end{array}$ PER TOTAL LATED CENT
CLASS SECOND DAYS DAYS DAYS

ABIC ACOUFEET MJ- PERPER TOTAL LATED CENT
CLASS SECOND DAYS DAYS DAYS

$\begin{array}{rrrrr}9 & 27.00 & 513 & 3987 & 68.2 \\ 10 & 32.00 & 505 & 3474 & 59.4 \\ 11 & 38.00 & 450 & 2969 & 50.8 \\ 12 & 45.00 & 373 & 2519 & 43.1 \\ 13 & 54.00 & 259 & 2146 & 36.7 \\ 14 & 64.00 & 216 & 1887 & 32.3 \\ 15 & 76.00 & 218 & 1671 & 28.6 \\ 16 & 90.00 & 176 & 1453 & 24.9 \\ 17 & 110.00 & 116 & 1277 & 21.9\end{array}$

$\begin{array}{rrrrr}27 & 580.0 & 99 & 396 & 6.8 \\ 28 & 690.0 & 91 & 297 & 5.1 \\ 29 & 820.0 & 59 & 206 & 3.5 \\ 30 & 970.0 & 71 & 147 & 2.5 \\ 31 & 1200.0 & 36 & 76 & 1.3 \\ 32 & 1400.0 & 25 & 40 & 0.7 \\ 33 & 1600.0 & 13 & 15 & 0.3 \\ 34 & 1900.0 & 2 & 2 & 0.0\end{array}$

MONIHLY MEAN DISCHARGES, IN CUBIC FEET PER SECOND, FOR EACH WATER YEAR

\begin{tabular}{|c|c|c|c|c|c|c|c|c|c|c|c|c|}
\hline YEAR & $\infty T$ & NOV & DEC & JAN & FEB & MAR & APR & MAY & JUNE & JUY & AUG & SEP \\
\hline $\begin{array}{l}1966 \\
1967 \\
1968 \\
1969 \\
1970\end{array}$ & $\begin{array}{l}70.9 \\
46.9 \\
41.7 \\
53.3 \\
41.6\end{array}$ & $\begin{array}{l}48.6 \\
36.1 \\
28.7 \\
36.6 \\
33.9\end{array}$ & $\begin{array}{l}35.2 \\
30.9 \\
26.6 \\
29.2 \\
24.5\end{array}$ & $\begin{array}{l}22.7 \\
25.2 \\
23.5 \\
26.6 \\
23.6\end{array}$ & $\begin{array}{l}19.0 \\
22.9 \\
22.8 \\
26.3 \\
19.8\end{array}$ & $\begin{array}{l}22.3 \\
20.4 \\
23.8 \\
24.9 \\
18.4\end{array}$ & $\begin{array}{l}71.4 \\
28.4 \\
31.7 \\
71.0 \\
23.0\end{array}$ & $\begin{array}{l}486 \\
305 \\
174 \\
741 \\
363\end{array}$ & $\begin{array}{r}264 \\
879 \\
1097 \\
504 \\
629\end{array}$ & $\begin{array}{l}86.7 \\
462 \\
288 \\
164 \\
157\end{array}$ & $\begin{array}{l}65.5 \\
117 \\
160 \\
76.9 \\
66.9\end{array}$ & $\begin{array}{l}54.1 \\
59.0 \\
77.4 \\
47.0 \\
70.4\end{array}$ \\
\hline $\begin{array}{l}1971 \\
1972 \\
1973 \\
1974 \\
1975\end{array}$ & $\begin{array}{l}42.2 \\
46.6 \\
60.5 \\
41.8 \\
30.6\end{array}$ & $\begin{array}{l}36.6 \\
40.0 \\
49.6 \\
36.7 \\
26.8\end{array}$ & $\begin{array}{l}32.1 \\
37.5 \\
40.1 \\
32.1 \\
20.0\end{array}$ & $\begin{array}{l}25.2 \\
33.6 \\
29.4 \\
29.8 \\
18.0\end{array}$ & $\begin{array}{l}22.3 \\
27.6 \\
24.3 \\
25.2 \\
18.0\end{array}$ & $\begin{array}{l}23.8 \\
31.4 \\
20.9 \\
25.8 \\
18.0\end{array}$ & $\begin{array}{l}67.2 \\
49.5 \\
34.6 \\
31.6 \\
21.5\end{array}$ & $\begin{array}{l}289 \\
459 \\
478 \\
491 \\
122\end{array}$ & $\begin{array}{r}1056 \\
920 \\
627 \\
555 \\
775\end{array}$ & $\begin{array}{l}297 \\
141 \\
218 \\
120 \\
667\end{array}$ & $\begin{array}{r}87.3 \\
55.6 \\
92.6 \\
55.2 \\
122\end{array}$ & $\begin{array}{l}50.6 \\
43.0 \\
71.0 \\
33.7 \\
50.9\end{array}$ \\
\hline $\begin{array}{l}1976 \\
1977 \\
1978 \\
1979 \\
1980\end{array}$ & $\begin{array}{l}38.3 \\
28.3 \\
27.5 \\
25.8 \\
27.2\end{array}$ & $\begin{array}{l}29.5 \\
18.6 \\
21.7 \\
23.5 \\
21.1\end{array}$ & $\begin{array}{l}22.9 \\
10.2 \\
25.0 \\
23.6 \\
17.8\end{array}$ & $\begin{array}{c}19.9 \\
8.08 \\
22.8 \\
19.7 \\
20.1\end{array}$ & $\begin{array}{c}16.4 \\
8.40 \\
18.3 \\
17.0 \\
20.1\end{array}$ & $\begin{array}{c}14.4 \\
9.00 \\
21.9 \\
15.2 \\
16.2\end{array}$ & $\begin{array}{l}27.5 \\
34.6 \\
56.1 \\
36.4 \\
56.3\end{array}$ & $\begin{array}{c}352 \\
99.2 \\
248 \\
415 \\
296\end{array}$ & $\begin{array}{c}420 \\
291 \\
998 \\
496 \\
1015\end{array}$ & $\begin{array}{l}103 \\
71.3 \\
269 \\
118 \\
287\end{array}$ & $\begin{array}{l}51.7 \\
49.6 \\
68.3 \\
60.2 \\
66.5\end{array}$ & $\begin{array}{l}38.3 \\
34.3 \\
38.3 \\
33.3 \\
50.7\end{array}$ \\
\hline 1988 & 38.3 & 31.6 & 25.6 & 19.1 & 17.9 & 18.1 & 59.6 & 252 & 520 & 93.0 & 43.5 & 40.2 \\
\hline
\end{tabular}

ANNUAL PEAK DISCHARGE, IN GBIC FEET PER SECOND, AND CORRESPONDING GAGE HEIGHT, IN FEET, FOR EAOH WAIER YEAR

\begin{tabular}{|c|c|c|c|c|c|c|c|c|c|c|c|}
\hline $\begin{array}{l}\text { WATER } \\
\text { YEAR }\end{array}$ & DATE & $\begin{array}{c}\text { GAGE } \\
\text { HEIGHT }\end{array}$ & $\begin{array}{c}\text { PEAK } \\
\text { DISOHARGE }\end{array}$ & $\begin{array}{l}\text { WATER } \\
\text { YEAR }\end{array}$ & DATE & $\begin{array}{c}\text { GAGE } \\
\text { HEIGHT }\end{array}$ & $\begin{array}{c}\text { PEAK } \\
\text { DISOHARGE }\end{array}$ & $\begin{array}{l}\text { WATERR } \\
\text { YEAR }\end{array}$ & DATE & $\begin{array}{c}\text { GAGE } \\
\text { HEIGHT }\end{array}$ & $\begin{array}{c}\text { PEAK } \\
\text { DISCHARGE }\end{array}$ \\
\hline $\begin{array}{l}1966 \\
1967 \\
1968 \\
1969 \\
1970 \\
1971\end{array}$ & $\begin{array}{l}\text { MAY } 09,1966 \\
\text { JUNE } 20,1967 \\
\text { JUNE } 19,1968 \\
\text { MAY } 27,1969 \\
\text { JUNE } 03,1970 \\
\text { JUNE } 17,1971\end{array}$ & $\begin{array}{l}3.50 \\
4.70 \\
4.77 \\
4.22 \\
4.06 \\
4.95\end{array}$ & $\begin{array}{r}840 \\
1890 \\
2110 \\
1510 \\
1320 \\
2760\end{array}$ & $\begin{array}{l}1972 \\
1973 \\
1974 \\
1975 \\
1976\end{array}$ & $\begin{array}{lll}\text { MAY } & 31,1972 \\
\text { JUNE } 09, & 1973 \\
\text { MAY } 28,1974 \\
\text { JUNE } 15,1975 \\
\text { JUNE } 03,1976\end{array}$ & $\begin{array}{l}4.70 \\
4.36 \\
4.54 \\
4.96 \\
3.62\end{array}$ & $\begin{array}{r}2160 \\
1700 \\
1880 \\
2030 \\
909\end{array}$ & $\begin{array}{l}1977 \\
1978 \\
1979 \\
1980 \\
1981\end{array}$ & $\begin{array}{l}\text { JUNE } 03,1977 \\
\text { JUNE } 13,1978 \\
\text { MAY } 28,1979 \\
\text { JUNE } 11,1980 \\
\text { JUNE } 08,1981\end{array}$ & $\begin{array}{l}3.78 \\
4.65 \\
4.67 \\
4.76 \\
4.45\end{array}$ & $\begin{array}{l}1030 \\
1820 \\
1820 \\
1930 \\
1470\end{array}$ \\
\hline
\end{tabular}

MAGNITUDE AND PRCBABILITY OF ANNUAL LOWEST MEAN DISGHARGE BASED ON CLIMATIC YEARS 1967-8

\begin{tabular}{|c|c|c|c|c|c|c|}
\hline \multirow{2}{*}{$\begin{array}{l}\text { PERIOD } \\
\text { (CON- } \\
\text { SECH- } \\
\text { TTVE } \\
\text { DAYS) }\end{array}$} & \multicolumn{6}{|c|}{$\begin{array}{l}\text { DISCHARGE, IN CUBIC FEET PER SECOND, FOR } \\
\text { INDICATED REQURREANCE INIERNAL, IN YEARS, AND } \\
\text { ANNUAL NONEXCEEDANCE PRCBABILITY, IN PERCENT }\end{array}$} \\
\hline & $\begin{array}{c}2 \\
508\end{array}$ & $\begin{array}{c}5 \\
208\end{array}$ & $\begin{array}{l}10 \\
108\end{array}$ & $\begin{array}{l}20 \\
58\end{array}$ & $\begin{array}{l}50 \\
28\end{array}$ & $\begin{array}{r}100 \\
18\end{array}$ \\
\hline
\end{tabular}

$\begin{array}{rrrrrrr}1 & 17 & 12 & 10 & 8.4 & - & = \\ 7 & 17 & 13 & 11 & 8.9 & - & = \\ 14 & 19 & 14 & 11 & 9.5 & - & = \\ 30 & 20 & 15 & 12 & 10 & = & = \\ 60 & 21 & 16 & 13 & 10 & = & = \\ 90 & 22 & 17 & 14 & 11 & - & \end{array}$

MAGNITUDE AND PRCBABILITY OF ANNUAL HIGHEST MEAN DISOHARGE BASED ON WATER YEARS 1966-81

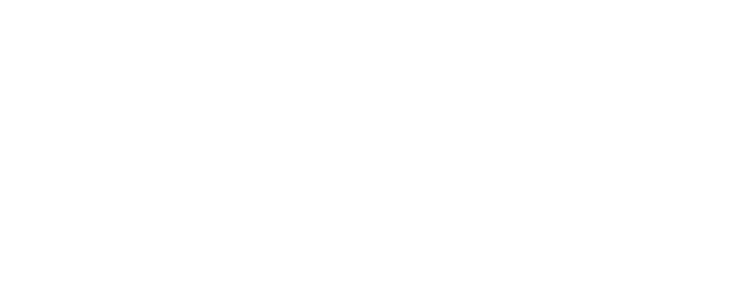


GREEN RIVER BASIN

09278000 SOUTH FORK ROCK CREEK NEAR HANNA, UT

LOCATION.--Lat $40^{\circ} 32^{\prime} 54^{\prime \prime}$, long $110^{\circ} 41^{\prime} 37^{\prime \prime}$, in SW $\mathrm{W}_{4}^{2} \mathrm{~W}_{\frac{1}{2}} \mathrm{SW}^{\frac{1}{4}}$ sec.21, T.2 N., R.7 W., Uintah Meridian, Duchesne County, Hydrologic Unit 14060003, Ashley National Forest, on right bank $175 \mathrm{ft}$ upstream from road bridge, $0.5 \mathrm{mi}$ upstream from mouth, and $10.6 \mathrm{mi}$ northeast of Hanna.

DRAINAGE AREA. $--15.7 \mathrm{mi}^{2}$.

MEAN BASIN ELEVATION. - $10,000 \mathrm{ft}$.

PERIOD OF RECORD AVAIIABLE.-August 1953 to September 1981.

REVISED RECORDS. -WDR UT-77-1: Drainage area.

GAGE.--Water-stage recorder. Altitude of gage is 7,860 ft fram river-profile map. Prior to July 23, 1974, at site 75 ft downstream at different gage datum.

REMARKS.--Pipeline capacity approximately $1.5 \mathrm{ft}^{3} / \mathrm{s}$ that provides water for small hydroelectric plant and irrigation for dude ranch lying below station, diverts water fram creek a short distance above station at times in summer months.

AVERAGE DISCHARGE. -28 years, $12.9 \mathrm{ft}^{3} / \mathrm{s}, 9,350$ acre-ft/yr.

EXIREMES FOR PERIOD OF REOORD. - Maximum discharge, $189 \mathrm{ft}^{3} / \mathrm{s}$ June 16,1975 , gage height, $2.43 \mathrm{ft}$; maximum gage height, $2.91 \mathrm{ft}$ NOw. 20, 1959 (backwater fram ice); minimum not determined, occurred during winter period of no gage-height record.

LOWEST MEAN DISCHARGE, IN CUBIC FEET PER SECOND, AND RANKING FOR THE INDICATED NURABR OF CONSECUTIVE DAYS FOR EACH CLIMATIC YEAR, APRIL 1-MARCH 31

IEAR

1955

1956

1957

1958
1959

1960

196

1963

1963
1964
1965

1966

1967

1968

1970

197

1972

1974

1975

1976

1977
1978

1978
1979

1980

1981

YEAR

195

1955

1956

1957
1958

1959

1960

$\begin{array}{lcccc}1961 & 34.0 & 27 & 26.0 & 27 \\ 1962 & 101 & 10 & 98.0 & 10\end{array}$

1963

1964

1965

2.5014

2.5015

2.5016

2.5017

$\begin{array}{rr}2.00 & 8 \\ 2.50 & 18\end{array}$

2.5019

2.3012

2.5020

3.0023

3.0024

2.209

2.6021

$\begin{array}{ll}3.20 & 26 \\ 2.40 & 13\end{array}$

2.2010

3.1025

3.0022

$\begin{array}{rr}3.00 & 22 \\ 1.90 & 5\end{array}$

1.906

$\begin{array}{ll}1.10 & 1 \\ 1.30 & 2\end{array}$

2.007

1.704

2.5014

2.5015

2.5016

2.50 17

$\begin{array}{rr}2.00 & 7 \\ 2.50 & 18\end{array}$

2.5019

1.503

2.5020

3.0024

2.2010
2.6021

2.6021
3.2025

3.2025
2.4013

1.101

$\begin{array}{ll}1.30 & 2 \\ 2.00 & 6\end{array}$

$\begin{array}{lll}1 & 3 & 7\end{array}$

2.50

14

2.5011

2.5013

2.5014

2.5015

$\begin{array}{lr}2.00 & 7 \\ 2.50 & 16\end{array}$

2.5012

2.5013

2.5014

$\begin{array}{lr}2.00 & 7 \\ 2.50 & 15\end{array}$

2.5017

2.5018

1.503

2.5019
3.0023

2.5016

2.5017

$\begin{array}{ll}1.50 & 3 \\ 2.50 & 18\end{array}$

$\begin{array}{ll}2.50 & 18 \\ 3.00 & 23\end{array}$

3.1024

2.3010

2.6020

$\begin{array}{ll}3.30 & 27 \\ 2.50 & 11\end{array}$

3.1024

$\begin{array}{rr}2.30 & 9 \\ 2.60 & 20\end{array}$

2.6020
3.4026

2.5019

CONSECUTIVE DAYS

$\begin{array}{llll}2.50 \quad 10 & 2.70 \quad 17\end{array}$

2.5011

2.5012

2.6018

$\begin{array}{rr}2.00 & 6 \\ 2.50 & 13\end{array}$

2.6013

2.509

3.2021

$\begin{array}{rr}2.00 & 3 \\ 2.50 & 10\end{array}$

2.5014

2.8020

1.602

$\begin{array}{ll}2.50 & 15 \\ 3.30 & 25\end{array}$

2.5011

$\begin{array}{rr}3.40 & 23 \\ 2.00 & 4\end{array}$

$\begin{array}{rr}2.00 & 4 \\ 2.70 & 14\end{array}$

$\begin{array}{ll}2.70 & 14 \\ 3.40 & 24\end{array}$

3.2023

$2.30 \quad 9$

$2.70 \quad 19$

3.5027
2.6016

$\begin{array}{rr}3.40 & 25 \\ 2.40 \quad 8\end{array}$

$\begin{array}{ll}3.80 & 27 \\ 2.80 & 18\end{array}$

3.0021

2.6021

3.2025

2.9021

3.4027
3.3025

3.0022

3.4026

3.3024

3.1019

3.6026

3.3022

3.2020

$\begin{array}{rr}3.00 & 22 \\ 2.00 & 8\end{array}$

$2.00 \quad 8$

2.007

2.005

1.905

1.90
1.10

$\begin{array}{ll}1.10 & 1 \\ 1.40 & 2\end{array}$

1.101

$\begin{array}{ll}1.50 & 2 \\ 2.00 & 6\end{array}$

$2.10 \quad 8$

$\begin{array}{ll}1.19 & 1 \\ 1.90 & 3\end{array}$

$\begin{array}{ll}1.90 & 3 \\ 2.00 & 4\end{array}$

$\begin{array}{rr}2.60 & 12 \\ 1.30 & 1 \\ 2.00 & 2\end{array}$

$\begin{array}{ll}2.10 & 6 \\ 2.20 & 7\end{array}$

\begin{tabular}{l}
1.704 \\
\hline
\end{tabular}

1.804

2.005

2.4010

2.6017

2.7016

$2.20 \quad 9$ $\begin{array}{ll}2.70 & 15 \\ 3.80 & 27\end{array}$

$\begin{array}{lr}90 & \\ 2.80 & 15 \\ 2.80 & 16 \\ 2.70 & 12 \\ 3.30 & 20 \\ 2.20 & 4 \\ 2.50 & 9 \\ 2.70 & 10 \\ 3.50 & 23 \\ 2.20 & 5 \\ 3.00 & 18 \\ 3.60 & 24 \\ 3.60 & 25 \\ 2.40 & 8 \\ 2.80 & 13 \\ 3.80 & 26 \\ 2.90 & 17 \\ 3.20 & 19 \\ 3.80 & 27 \\ 3.40 & 21 \\ 3.40 & 22 \\ 2.20 & 6 \\ 2.70 & 11 \\ 1.40 & 1 \\ 2.10 & 2 \\ 2.10 & 3 \\ 2.30 & 7 \\ 2.80 & 14 \\ 2.80 & 14\end{array}$

2.9013

2.9014

$\begin{array}{ll}2.90 & 14 \\ 3.00 & 15\end{array}$

3.5020

2.405

2.708

2. 8011

3.8024

$\begin{array}{rr}2.70 & 9\end{array}$

$\begin{array}{ll}3.40 & 18 \\ 3.70 & 23\end{array}$

$4.20 \quad 27$

$\begin{array}{ll}4.20 & 27 \\ 2.60 & 7\end{array}$

2.9012

4.1026

3.1016

3.4019

4.0025

3.6021

3.6022

2.406

2.8010

$\begin{array}{lr}2.80 & 10 \\ 1.60 & 1\end{array}$

2.102

$\begin{array}{ll}2.30 & 3 \\ 2.30 & 4\end{array}$

3.1017 $(83$

83 ALL

$\begin{array}{llll}3.10 & 7 & 7.80 & 3\end{array}$

$\begin{array}{llll}3.30 & 10 & 10.0 & 9\end{array}$

$3.4011 \quad 15,0 \quad 18$

$\begin{array}{llll}4.10 & 20 & 13.0 & 15\end{array}$

$\begin{array}{cccr}3.00 & 6 & 14.0 & 16 \\ 3.80 & 17 & 9.40 & 5\end{array}$

$3.4012 \quad 9.00 \quad 4$

$\begin{array}{lll}5.6027 & 6.80 \quad 2\end{array}$

$\begin{array}{llll}3.70 & 14 & 19.0 & 26 \\ 4.70 & 24 & 12.0 & 12\end{array}$

$\begin{array}{lll}3.8015 & 16.0 & 21\end{array}$

$\begin{array}{llll}5.40 & 26 & 23.0 & 27\end{array}$

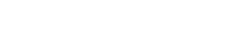

$\begin{array}{llll}3.5013 & 16.0 & 22\end{array}$

$\begin{array}{llll}5.10 & 25 & 16.0 & 23\end{array}$

$3.8016 \quad 15.0 \quad 19$

$\begin{array}{llll}3.90 & 18 & 10.0 & 7\end{array}$

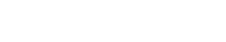

$4.6023 \quad 16.020$

$4.3021 \quad 13.0 \quad 13$

$\begin{array}{llll}3.30 & 9 & 18.0 & 25\end{array}$

$2.201 \quad 10.0 \quad 8$

$2.20204 .20 \quad 1$

$\begin{array}{llll}2.70 & 4 & 11.0 & 11 \\ 2.50 & 3 & 13.0 & 14\end{array}$

HIGHEST MEAN DISCHARGE, IN CUBIC FEET PER SECOND, AND RANKING FOR THE INDICATED NUMBER OF CONSEOUTIVE DAYS FOR EACH WATER YEAR, OCTOBER I-SEPTEMBER 30

$\begin{array}{crrr}1 & & 3 & \\ 44.0 & 26 & 43.0 & 26 \\ 61.0 & 19 & 60.0 & 19 \\ 110 & 8 & 105 & 8 \\ 104 & 9 & 100 & 9 \\ 125 & 5 & 122 & 4 \\ 52.0 & 24 & 52.0 & 22 \\ 51.0 & 25 & 50.0 & 24 \\ 34.0 & 27 & 26.0 & 27 \\ 101 & 10 & 98.0 & 10 \\ 53.0 & 23 & 51.0 & 23 \\ 100 & 11 & 95.0 & 12 \\ 160 & 1 & 147 & 1\end{array}$

$\begin{array}{cr}7 & \\ 40.0 & 26 \\ 58.0 & 19 \\ 104 & 7 \\ 94.0 & 10 \\ 114 & 4 \\ 51.0 & 22 \\ 49.0 & 24 \\ 22.0 & 28 \\ 94.0 & 11 \\ 50.0 & 23 \\ 86.0 & 12 \\ 136 & 1\end{array}$

15

CONSECUTIVE DAYS$$
30
$$

$\begin{array}{llll}31.0 & 26 & 24.0 & 26\end{array}$

$31.0 \quad 26$

$43.0 \quad 22$

36.021

$\begin{array}{rrrr}88.0 & 4 & 63.0 & 8\end{array}$

$\begin{array}{rrrr}61.0 & 14 & 48.0 & 13\end{array}$

$\begin{array}{rr}85.0 & 6 \\ 41.0 & 24\end{array}$

41.024

$\begin{array}{rr}59.0 & 9 \\ 30.0 & 25\end{array}$

$\begin{array}{ll}30.0 & 25 \\ 32.0 & 24\end{array}$

$45.0 \quad 25$

39.025

$19.0 \quad 28$

$90.0 \quad 8$

$\begin{array}{lr}83.0 & 7 \\ 44.0 & 20\end{array}$

$\begin{array}{ll}44.0 & 20 \\ 72.0 & 11\end{array}$

$\begin{array}{rr}12.0 & 27 \\ 65.0 & 5 \\ 38.0 & 19 \\ 65.0 & 6\end{array}$

79.0
117

$\begin{array}{cr}90 & \\ & \\ 20.0 & 26 \\ 28.0 & 23 \\ & \\ 48.0 & 8 \\ 36.0 & 14 \\ 44.0 & 11 \\ 24.0 & 24 \\ 24.0 & 25 \\ & \\ 9.70 & 27 \\ 57.0 & 3 \\ 30.0 & 20 \\ 50.0 & 6 \\ 69.0 & 1\end{array}$

183

ALL

$\begin{array}{rrrrrr}17.0 & 26 & 12.0 & 26 & 8.10 & 26\end{array}$

$\begin{array}{llll}23.0 & 23 & 17.0 & 22\end{array}$

$\begin{array}{cc}8.10 & 26 \\ 10.0 & 23\end{array}$

$\begin{array}{rrrrrr}39.0 & 8 & 27.0 & 9 & 15.0 & 9\end{array}$

$\begin{array}{llllll}30.0 & 14 & 21.0 & 15 & 12.0 & 15 \\ 35.0 & 11 & 25.0 & 11 & 14.0 & 11\end{array}$

$\begin{array}{llllll}32.0 & 24 & 15.0 & 24 & 8.90 & 25\end{array}$

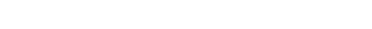

$\begin{array}{lllll}8.50 & 27 & 7.90 & 27 & 5.7027\end{array}$

$\begin{array}{llllll}47.0 & 3 & 33.0 & 3 & 19.0 & 2\end{array}$

$\begin{array}{rrrrrr}25.0 & 17 & 18.0 & 18 & 11.0 & 21\end{array}$

$\begin{array}{llllll}40.0 & 6 & 28.0 & 6 & 16.0 & 5 \\ 57.0 & 1 & 40.0 & 1 & 22.0 & 1\end{array}$ 
HIGHEST MEAN DISCHARGE, IN OABIC FEET PER SECOND, AND RANKING FOR THE INDICATED NUMBER OF CONSECUTTVE DAYS FOR EACH WATER YEAR, OCTOBER 1-SEPTEMBER 30--Continued

YEAR

$\begin{array}{rrrrrrr} & 1 & & 3 & & 7 & \\ 1966 & 54.0 & 22 & 49.0 & 25 & 48.0 & 25 \\ 1967 & 97.0 & 13 & 96.0 & 11 & 95.0 & 9 \\ 1968 & 112 & 7 & 111 & 7 & 99.0 & 8 \\ 1969 & 83.0 & 15 & 78.0 & 15 & 76.0 & 14 \\ 1970 & 61.0 & 20 & 60.0 & 20 & 58.0 & 20 \\ 1971 & 96.0 & 14 & 79.0 & 14 & 76.0 & 15 \\ 1972 & 114 & 6 & 114 & 6 & 108 & 6 \\ 1973 & 69.0 & 18 & 66.0 & 18 & 62.0 & 18 \\ 1974 & 54.0 & 21 & 53.0 & 21 & 51.0 & 21 \\ 1975 & 144 & 2 & 136 & 2 & 117 & 2 \\ 1976 & 79.0 & 16 & 77.0 & 16 & 74.0 & 16 \\ 1977 & 24.0 & 28 & 23.0 & 28 & 23.0 & 27 \\ 1978 & 100 & 12 & 94.0 & 13 & 83.0 & 13 \\ 1979 & 126 & 4 & 120 & 5 & 112 & 5 \\ 1980 & 138 & 3 & 131 & 3 & 117 & 3\end{array}$

1981

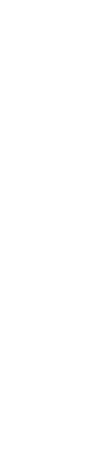

$60.0 \quad 17$ $\begin{array}{ll}\text { CONSECUTIVE DAYS } \\ 30 & 60\end{array}$

\section{$\begin{array}{llll}42.0 & 23 & 35.0 & 22\end{array}$}

$\begin{array}{lllr}78.0 & 9 & 68.0 & 3\end{array}$

$\begin{array}{llll}79.0 & 8 & 58.0 & 10\end{array}$

$\begin{array}{llll}66.0 & 12 & 56.0 & 11 \\ 43.0 & 21 & 35.0 & 23\end{array}$

$\begin{array}{llll}58.0 & 16 & 44.0 & 15\end{array}$

$\begin{array}{rrrr}86.0 & 5 & 64.0 & 7\end{array}$

$\begin{array}{llll}54.0 & 17 & 42.0 & 16\end{array}$

$\begin{array}{rrrr}46.0 & 19 & 39.0 & 18 \\ 95.0 & 2 & 77.0 & 2\end{array}$

$59.0 \quad 15$

$\begin{array}{ll}59.0 & 15 \\ 15.0 & 28\end{array}$

$\begin{array}{ll}15.0 & 28 \\ 61.0 & 13\end{array}$

$77.0 \quad 10$

88.03

$41.0 \quad 17$

$\begin{array}{ll}45.0 & 14 \\ 56.0 & 12\end{array}$

$\begin{array}{llll}41.0 & 17 & 31.0 & 18\end{array}$

$120 \quad 183$

183

$\begin{array}{lrll}18.0 & 19 & 12.0 & 16\end{array}$

$\begin{array}{lllllll}53.0 & 4 & 42.0 & 5 & 29.0 & 5 & 16.0\end{array}$

$\begin{array}{lrrrrrrr}45.0 & 9 & 37.0 & 9 & 27.0 & 7 & 15.0 & 10\end{array}$

$\begin{array}{rrrrrrrr}45.0 & 10 & 36.0 & 10 & 26.0 & 10 & 16.0 & 7\end{array}$

$\begin{array}{llllllll}28.0 & 22 & 23.0 & 22 & 17.0 & 23 & 10.0 & 22\end{array}$

$\begin{array}{llllllll}37.0 & 13 & 31.0 & 13 & 23.0 & 13 & 13.0 & 12\end{array}$

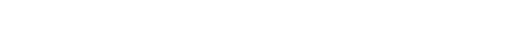

$\begin{array}{llllllll}34.0 & 15 & 29.0 & 15 & 21.0 & 14 & 13.0 & 13\end{array}$

$\begin{array}{rrrrrrrr}31.0 & 17 & 25.0 & 18 & 18.0 & 20 & 11.0 & 17\end{array}$

9.0028

$\begin{array}{llll}34.0 & 16 & 7.90 & 28\end{array}$

$\begin{array}{rr}42.0 & 12 \\ 52.0 & 5\end{array}$

28.016

$\begin{array}{cc}6.2028 \\ 20.0 & 16\end{array}$

$\begin{array}{rr}34.0 & 12 \\ 43.0 & 4\end{array}$

4.2028
11.0

$\begin{array}{llll}4.0 & 12 & 13.0 & 19\end{array}$

$\begin{array}{llll}36.0 & 20 & 30.0 \quad 19\end{array}$

$24.0 \quad 20$

$18.0 \quad 17$

DURATION OF DISCHARGE FOR EACH WATER YEAR

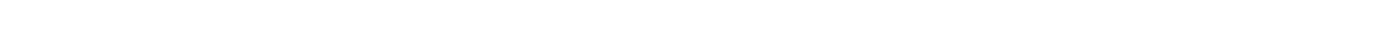
YE

NUMBER OF DAYS IN CLASS

वBIC FEET PER SECOND

1954

1955

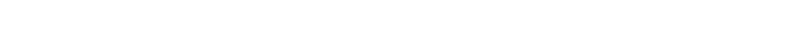

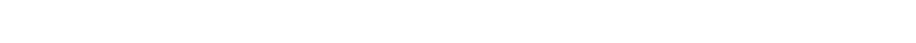

2971.9

1956

$\begin{array}{llllllllllllllllllllllllllll}49 & 55 & 33 & 46 & 23 & 14 & 11 & 7 & 18 & 4 & 2 & 12 & 10 & 6 & 6 & 6 & 8 & 7 & 4 & 5 & 6 & 3 & 3 & 4 & 13 & 9 & 2\end{array}$

5622.4

$\begin{array}{rrrrrrrrrrrrrrrrrrrrrrrrrr}43 & 11 & 45 & 35 & 11 & 5 & 2 & 15 & 19 & 14 & 8 & 11 & 8 & 5 & 4 & 3 & 6 & 3 & 8 & 11 & 10 & & 4 & 3 & 4 & \\ 36 & 65 & 43 & 31 & 32 & 35 & 14 & 14 & 5 & 6 & 4 & 12 & 2 & 5 & 8 & 6 & 5 & 2 & 3 & 4 & 6 & 7 & 2 & 8 & 5 & 5\end{array}$

1958
1959

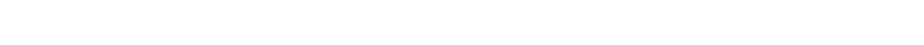

1960

$\begin{array}{llllllllllllllllll}72 & 59 & 62 & 25 & 17 & 24 & 15 & 18 & 12 & 15 & 6 & 3 & 15 & 8 & 7 & 5 & 1 & 1\end{array}$

1961
1962
1963
1964
1965

25

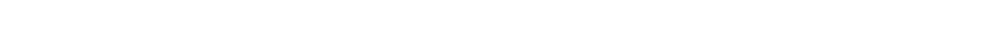

$\begin{array}{llllllllllllllllllllll}24 & 36 & 37 & 4 & 4 & 16 & 46 & 17 & 3 & 16 & 32 & 15 & 10 & 10 & 7 & 4 & 5 & 7 & 6 & 7 & 12 & 17\end{array}$

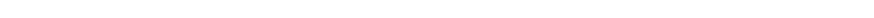

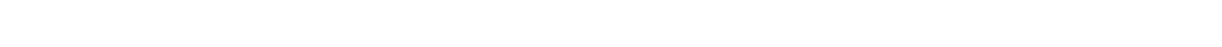

1966

1967

$\begin{array}{lllllllllllllllllllll}6 & 45 & 20 & 32 & 35 & 29 & 27 & 35 & 18 & 25 & 12 & 13 & 5 & 5 & 7 & 3 & 15 & 12 & 9 & 11 & 1\end{array}$

$\begin{array}{rrrrrrrrrrrrrrrrrrrrrrrrrrrrr}2 & 93 & 25 & 36 & 26 & 16 & 15 & 5 & 4 & 17 & 14 & 14 & 5 & 5 & 5 & 9 & 6 & 1 & 6 & 4 & 2 & 7 & 7 & 14 & 9 & 12 & 6\end{array}$

$\begin{array}{llllllllllllllllllllllllllll}19 & 63 & 28 & 27 & 30 & 24 & 41 & 18 & 14 & 6 & 7 & 8 & 4 & 8 & 2 & 6 & 5 & 5 & 12 & 15 & 11 & 11 & 1 & & \end{array}$

1970

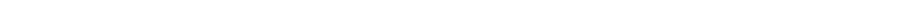

1971

1973

1974
1975

$\begin{array}{lllllllllllllllllllllllll}39 & 44 & 44 & 24 & 34 & 7 & 8 & 17 & 17 & 18 & 11 & 7 & 8 & 9 & 17 & 7 & 11 & 12 & 8 & 7 & 4 & 3 & 7 & 1 & 1\end{array}$

$\begin{array}{lllllllllllllllllllllllll}30 & 41 & 61 & 50 & 41 & 19 & 16 & 5 & 7 & 10 & 4 & 2 & 12 & 9 & 2 & 5 & 2 & 5 & 9 & 7 & 3 & 7 & 8 & 8 & 3\end{array}$

$\begin{array}{lllllllllllllllllllllll}90 & 24 & 42 & 14 & 23 & 9 & 17 & 14 & 14 & 25 & 7 & 10 & 13 & 7 & 5 & 11 & 6 & 2 & 11 & 14 & 6 & 1\end{array}$

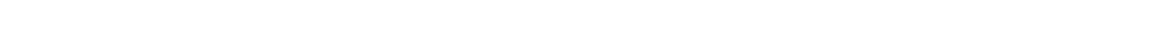

4926.7

5862.3

4712.6

6531.5

1976

1977
1978

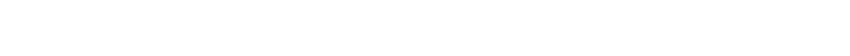

$\begin{array}{llllllllllllllllllllllllllllllll}1 & 4 & 47 & 41 & 68 & 5 & 14 & 9 & 17 & 20 & 32 & 8 & 4 & 10 & 4 & 5 & 7 & 4 & 7 & 5 & 5 & 11 & 8 & 5 & 5 & 6 & 3 & 5 & 3 & 2 & 4\end{array}$

$\begin{array}{lllllllllllllllllllllllllllll}85 & 25 & 38 & 22 & 36 & 15 & 11 & 13 & 6 & 9 & 11 & 5 & 10 & 5 & 5 & 8 & 6 & 3 & 4 & 4 & 9 & 6 & 6 & 6 & 4 & 5 & 4 & 4\end{array}$

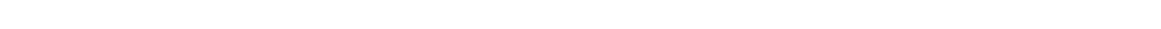

3867.9

1518.4

1980

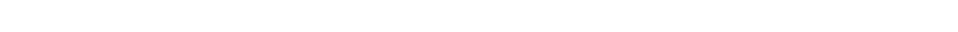

4866.6

6009.9

1981

3957.8

DURATION TABLE OF DISCHARGE FOR WATER YEARS 1954-81

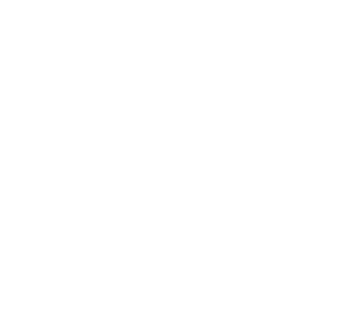

\begin{tabular}{rrrrrr}
\multicolumn{4}{c}{$\begin{array}{c}\text { CUBIC } \\
\text { FEET }\end{array}$} & $\begin{array}{c}\text { ACOU- } \\
\text { MU- }\end{array}$ & PER- \\
PER & TOTAL & LATED & CENT \\
CLASS SECOND & DAYS & DAYS & DAYS \\
9 & 3.60 & 855 & 6762 & 66.1 \\
10 & 4.20 & 760 & 5907 & 57.8 \\
11 & 4.80 & 669 & 5147 & 50.3 \\
12 & 5.60 & 544 & 4478 & 43.8 \\
13 & 6.50 & 356 & 3934 & 38.5 \\
14 & 7.50 & 417 & 3578 & 35.0 \\
15 & 8.70 & 347 & 3161 & 30.9 \\
16 & 10.00 & 285 & 2814 & 27.5 \\
17 & 12.00 & 240 & 2529 & 24.7
\end{tabular}

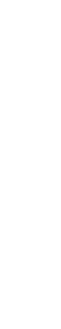

CUBIC ACOU-

PER TOTAL LATED CENT

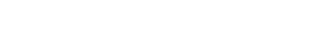

$\begin{array}{llll}14.0 & 218 & 2289 & 22.4 \\ 16.0 & 171 & 2071 & 20.3\end{array}$

$16.0171 \quad 2071$ 20.3

$\begin{array}{llll}18.0 & 199 & 1900 & 18.6\end{array}$

$\begin{array}{llll}21.0 & 209 & 1701 & 16.6 \\ 25.0 & 127 & 1492 & 14.6\end{array}$

$\begin{array}{llll}25.0 & 127 & 1492 & 14.6\end{array}$

$\begin{array}{llll}28.0 & 204 & 1365 & 13.3\end{array}$

$\begin{array}{rrrr}33.0 & 156 & 1161 & 11.4 \\ 38.0 & 175 & 1005 & 9.8\end{array}$

$\begin{array}{rrrr}38.0 & 175 & 1005 & 9.8 \\ 44.0 & 186 & 830 & 8.1\end{array}$ $\begin{array}{ccc}\text { OUBIC } & \text { ACOU- } \\ \text { FEET } & \text { MU- } & \text { PER- } \\ \text { PER } & \text { TOTAL LATED } & \text { CENT } \\ \text { CLASS SEOOND DAYS DAYS } & \text { DAYS }\end{array}$

$\begin{array}{rrrrr}27 & 51.0 & 180 & 644 & 6.3 \\ 28 & 60.0 & 123 & 464 & 4.5 \\ 29 & 69.0 & 110 & 341 & 3.3 \\ 30 & 80.0 & 104 & 231 & 2.3 \\ 31 & 93.0 & 85 & 127 & 1.2 \\ 32 & 110.0 & 34 & 42 & 0.4 \\ 33 & 130.0 & 7 & 8 & 0.1 \\ 34 & 150.0 & 1 & 1 & 0.0\end{array}$


GREEN RIVER BASTN

09278000 SCUTH FORK ROCK CREEK NEAR HANNA, UT--Continued

MONTHLY MEAN DISGHARGES, IN OUBIC FEET PER SECOND, FOR EACH WATER YEAR

\begin{tabular}{|c|c|c|c|c|c|c|c|c|c|c|c|c|}
\hline YEAR & $\infty C T$ & NOV & DEC & JAN & FEB & MAR & APR & MAY & JUNE & JULY & AUG & SEP \\
\hline $\begin{array}{l}1954 \\
1955\end{array}$ & $\begin{array}{l}4.63 \\
3.67\end{array}$ & $\begin{array}{l}4.58 \\
3.34\end{array}$ & $\begin{array}{l}3.85 \\
3.00\end{array}$ & $\begin{array}{l}3.50 \\
3.00\end{array}$ & $\begin{array}{l}3.30 \\
3.00\end{array}$ & $\begin{array}{l}3.30 \\
2.50\end{array}$ & $\begin{array}{l}6.52 \\
2.83\end{array}$ & $\begin{array}{l}29.2 \\
25.0\end{array}$ & $\begin{array}{l}18.5 \\
42.6\end{array}$ & $\begin{array}{l}10.4 \\
15.9\end{array}$ & $\begin{array}{l}5.29 \\
8.89\end{array}$ & $\begin{array}{l}4.18 \\
5.71\end{array}$ \\
\hline $\begin{array}{l}1956 \\
1957 \\
1958 \\
1959 \\
1960\end{array}$ & $\begin{array}{l}4.38 \\
4.62 \\
5.83 \\
4.21 \\
6.75\end{array}$ & $\begin{array}{l}3.42 \\
4.09 \\
4.59 \\
4.08 \\
5.24\end{array}$ & $\begin{array}{l}3.35 \\
3.82 \\
4.00 \\
3.08 \\
3.16\end{array}$ & $\begin{array}{l}3.00 \\
3.00 \\
3.50 \\
2.50 \\
2.50\end{array}$ & $\begin{array}{l}2.50 \\
2.50 \\
3.50 \\
2.00 \\
2.50\end{array}$ & $\begin{array}{l}2.95 \\
2.50 \\
3.00 \\
2.00 \\
2.77\end{array}$ & $\begin{array}{l}8.22 \\
2.61 \\
5.25 \\
4.96 \\
7.19\end{array}$ & $\begin{array}{l}50.3 \\
11.9 \\
52.5 \\
15.5 \\
24.3\end{array}$ & $\begin{array}{l}72.9 \\
60.6 \\
62.2 \\
40.6 \\
36.4\end{array}$ & $\begin{array}{l}20.7 \\
33.9 \\
15.7 \\
16.1 \\
11.0\end{array}$ & $\begin{array}{c}8.26 \\
11.9 \\
6.86 \\
7.15 \\
5.32\end{array}$ & $\begin{array}{l}4.38 \\
6.97 \\
5.14 \\
5.12 \\
3.93\end{array}$ \\
\hline $\begin{array}{l}1961 \\
1962 \\
1963 \\
1964 \\
1965\end{array}$ & $\begin{array}{c}4.87 \\
10.9 \\
6.09 \\
8.15 \\
4.20\end{array}$ & $\begin{array}{l}3.91 \\
7.33 \\
5.18 \\
6.45 \\
4.09\end{array}$ & $\begin{array}{l}3.23 \\
4.58 \\
4.21 \\
4.50 \\
3.91\end{array}$ & $\begin{array}{l}3.00 \\
3.66 \\
2.66 \\
3.50 \\
4.00\end{array}$ & $\begin{array}{l}2.50 \\
3.68 \\
2.36 \\
3.00 \\
3.50\end{array}$ & $\begin{array}{l}2.50 \\
3.28 \\
1.60 \\
2.50 \\
3.32\end{array}$ & $\begin{array}{c}3.18 \\
17.1 \\
2.79 \\
4.23 \\
5.79\end{array}$ & $\begin{array}{l}11.3 \\
44.2 \\
26.2 \\
37.4 \\
22.7\end{array}$ & $\begin{array}{r}12.7 \\
79.6 \\
42.8 \\
69.9 \\
102\end{array}$ & $\begin{array}{c}4.73 \\
41.5 \\
19.5 \\
38.0 \\
72.2\end{array}$ & $\begin{array}{c}3.84 \\
10.9 \\
9.87 \\
10.9 \\
24.9\end{array}$ & $\begin{array}{c}12.0 \\
6.21 \\
9.42 \\
5.20 \\
13.2\end{array}$ \\
\hline $\begin{array}{l}1966 \\
1967 \\
1968 \\
1969 \\
1970\end{array}$ & $\begin{array}{l}8.17 \\
4.86 \\
5.55 \\
8.02 \\
5.65\end{array}$ & $\begin{array}{l}6.86 \\
3.89 \\
3.59 \\
5.99 \\
4.69\end{array}$ & $\begin{array}{l}5.49 \\
2.90 \\
3.14 \\
4.78 \\
3.55\end{array}$ & $\begin{array}{l}3.62 \\
2.49 \\
2.83 \\
3.95 \\
3.16\end{array}$ & $\begin{array}{l}3.29 \\
2.33 \\
2.75 \\
3.99 \\
2.96\end{array}$ & $\begin{array}{l}4.39 \\
2.54 \\
2.92 \\
3.55 \\
2.56\end{array}$ & $\begin{array}{c}11.8 \\
3.11 \\
4.08 \\
6.28 \\
2.99\end{array}$ & $\begin{array}{l}38.1 \\
32.8 \\
19.8 \\
58.9 \\
23.8\end{array}$ & $\begin{array}{l}30.9 \\
73.4 \\
79.0 \\
49.9 \\
38.2\end{array}$ & $\begin{array}{l}13.2 \\
44.5 \\
31.0 \\
23.1 \\
20.2\end{array}$ & $\begin{array}{c}6.65 \\
14.5 \\
16.5 \\
11.0 \\
9.77\end{array}$ & $\begin{array}{c}5.21 \\
8.39 \\
10.0 \\
7.79 \\
7.23\end{array}$ \\
\hline $\begin{array}{l}1971 \\
1972 \\
1973 \\
1974 \\
1975\end{array}$ & $\begin{array}{l}5.30 \\
6.40 \\
7.74 \\
6.33 \\
3.91\end{array}$ & $\begin{array}{l}4.51 \\
4.83 \\
5.24 \\
4.56 \\
3.92\end{array}$ & $\begin{array}{l}3.64 \\
4.30 \\
4.32 \\
3.79 \\
2.98\end{array}$ & $\begin{array}{l}3.49 \\
3.79 \\
3.53 \\
3.35 \\
2.46\end{array}$ & $\begin{array}{l}3.04 \\
3.50 \\
3.30 \\
3.05 \\
2.03\end{array}$ & $\begin{array}{l}3.26 \\
4.61 \\
3.32 \\
4.54 \\
1.99\end{array}$ & $\begin{array}{l}8.36 \\
6.59 \\
4.22 \\
6.91 \\
2.12\end{array}$ & $\begin{array}{l}25.3 \\
42.5 \\
35.9 \\
35.5 \\
18.5\end{array}$ & $\begin{array}{l}52.0 \\
78.4 \\
43.4 \\
41.2 \\
78.8\end{array}$ & $\begin{array}{l}31.7 \\
23.8 \\
20.4 \\
15.7 \\
73.1\end{array}$ & $\begin{array}{c}12.7 \\
8.27 \\
13.2 \\
6.26 \\
16.2\end{array}$ & $\begin{array}{l}8.18 \\
5.43 \\
9.75 \\
3.55 \\
7.86\end{array}$ \\
\hline $\begin{array}{l}1976 \\
1977 \\
1978 \\
1979 \\
1980\end{array}$ & $\begin{array}{l}5.35 \\
3.64 \\
2.39 \\
3.76 \\
3.53\end{array}$ & $\begin{array}{l}3.45 \\
2.66 \\
2.37 \\
3.23 \\
2.16\end{array}$ & $\begin{array}{l}3.00 \\
2.18 \\
2.31 \\
2.82 \\
2.42\end{array}$ & $\begin{array}{l}3.00 \\
1.81 \\
2.21 \\
2.31 \\
2.49\end{array}$ & $\begin{array}{l}2.64 \\
1.32 \\
1.94 \\
2.10 \\
2.37\end{array}$ & $\begin{array}{l}2.51 \\
1.19 \\
2.38 \\
2.03 \\
2.30\end{array}$ & $\begin{array}{l}3.61 \\
2.37 \\
4.71 \\
3.84 \\
6.46\end{array}$ & $\begin{array}{c}36.3 \\
4.72 \\
18.2 \\
52.7 \\
34.8\end{array}$ & $\begin{array}{l}42.6 \\
14.4 \\
60.2 \\
51.7 \\
86.7\end{array}$ & $\begin{array}{c}12.9 \\
6.66 \\
22.2 \\
20.7 \\
33.8\end{array}$ & $\begin{array}{r}6.55 \\
5.50 \\
8.29 \\
9.50 \\
11.9\end{array}$ & $\begin{array}{l}4.78 \\
3.39 \\
5.57 \\
4.57 \\
8.57\end{array}$ \\
\hline 1981 & 6.57 & 4.98 & 3.97 & 3.12 & 2.71 & 2.65 & 8.40 & 24.3 & 46.9 & 15.7 & 5.68 & 5.06 \\
\hline
\end{tabular}

ANNUAL PEAK DISCHARGE, IN CUBIC FEET PER SECOND, AND CORRESPONDING GAGE HEIGHT, IN FEET, FOR EACH WATER YEAR

\begin{tabular}{|c|c|c|c|c|c|c|c|c|c|c|c|}
\hline $\begin{array}{l}\text { WATER } \\
\text { YEAR }\end{array}$ & DATE & $\begin{array}{c}\text { GAGE } \\
\text { HEIGHT }\end{array}$ & $\begin{array}{c}\text { PEAK } \\
\text { DISCHARGE }\end{array}$ & $\begin{array}{l}\text { WATER } \\
\text { YEAR }\end{array}$ & DATE & $\begin{array}{c}\text { GAGE } \\
\text { HEIGHT }\end{array}$ & $\begin{array}{c}\text { PEAK } \\
\text { DISOHARGE }\end{array}$ & $\begin{array}{l}\text { WAIER } \\
\text { YEAR }\end{array}$ & DATE & $\begin{array}{c}\text { GAGE } \\
\text { HEIGHT }\end{array}$ & $\begin{array}{c}\text { PEAK } \\
\text { DISQHARGE }\end{array}$ \\
\hline $\begin{array}{l}1954 \\
1955 \\
1956 \\
1957 \\
1958 \\
1959 \\
1960 \\
1961 \\
1962\end{array}$ & $\begin{array}{lll}\text { MAY } & 22,1954 \\
\text { JUNE } 08,1955 \\
\text { JUNE } 01,1956 \\
\text { JUNE } 06,1957 \\
\text { MAY } 29,1958 \\
\text { JUNE } 07,1959 \\
\text { JUNE } 03,1960 \\
\text { SEPT. 18, } 1961 \\
\text { JUNE 25, } 1962\end{array}$ & $\begin{array}{l}2.10 \\
2.28 \\
2.52 \\
2.42 \\
2.42 \\
1.86 \\
1.88 \\
1.88 \\
2.32\end{array}$ & $\begin{array}{r}51 \\
75 \\
127 \\
118 \\
139 \\
59 \\
59 \\
52 \\
109\end{array}$ & $\begin{array}{l}1963 \\
1964 \\
1965 \\
1966 \\
1967 \\
1968 \\
1969 \\
1970 \\
1971\end{array}$ & $\begin{array}{l}\text { JUNE } 03,1963 \\
\text { JUNE } 06,1964 \\
\text { JUNE } 12,1965 \\
\text { MAY } 09,1966 \\
\text { JUNE } 25,1967 \\
\text { JUNE } 05,1968 \\
\text { MAY } 20,1969 \\
\text { MAY } 28,1970 \\
\text { JUNE } 17,1971\end{array}$ & $\begin{array}{l}2.02 \\
2.36 \\
2.49 \\
1.90 \\
2.23 \\
2.47 \\
2.36 \\
2.28 \\
2.60\end{array}$ & $\begin{array}{r}63 \\
124 \\
183 \\
74 \\
106 \\
131 \\
100 \\
68 \\
160\end{array}$ & $\begin{array}{l}1972 \\
1973 \\
1974 \\
1975 \\
1976 \\
1977 \\
1978 \\
1980 \\
1981\end{array}$ & $\begin{array}{lll}\text { JUNE } & 02, & 1972 \\
\text { MAY } 19, & 1973 \\
\text { MAY } 28, & 1974 \\
\text { JUNE } 16, & 1975 \\
\text { JUNE } 03, & 1976 \\
\text { JUNE } 02, & 1977 \\
\text { JUNE } 14, & 1978 \\
\text { JUNE } 12, & 1980 \\
\text { JUNE } 09, & 1981\end{array}$ & $\begin{array}{l}2.43 \\
2.06 \\
1.95 \\
2.43 \\
1.60 \\
1.48 \\
2.17 \\
2.68 \\
2.36\end{array}$ & $\begin{array}{r}147 \\
79 \\
58 \\
189 \\
86 \\
32 \\
123 \\
163 \\
80\end{array}$ \\
\hline
\end{tabular}

MAGNITUDE AND PRCBABILITY OF ANNUAL LONEST MEAN DISGHARGE BASED ON CIMATIC YEARS 1955-81

\begin{tabular}{|c|c|c|c|c|c|c|}
\hline \multirow{2}{*}{$\begin{array}{l}\text { PERIOD } \\
\text { (CON- } \\
\text { SEOJ- } \\
\text { TIVE } \\
\text { DAYS) }\end{array}$} & \multicolumn{6}{|c|}{$\begin{array}{l}\text { DISGHARGE, IN GBIC FEET PER SECOND, FOR } \\
\text { INDICATED RECURRENCE INTERNAL, IN YEARS, AND } \\
\text { ANNUAL NONEXCEEDANCE PRCBABILITY, IN PERCENT }\end{array}$} \\
\hline & $\begin{array}{c}2 \\
508\end{array}$ & $\begin{array}{c}5 \\
208\end{array}$ & $\begin{array}{l}10 \\
108\end{array}$ & $\begin{array}{l}20 \\
58\end{array}$ & $\begin{array}{l}50 \\
28\end{array}$ & $\begin{array}{r}100 \\
18\end{array}$ \\
\hline $\begin{array}{r}1 \\
7 \\
14 \\
30 \\
60 \\
90\end{array}$ & $\begin{array}{l}2.4 \\
2.4 \\
2.5 \\
2.6 \\
2.7 \\
2.8\end{array}$ & $\begin{array}{l}1.9 \\
1.9 \\
1.9 \\
2.0 \\
2.2 \\
2.3\end{array}$ & $\begin{array}{l}1.6 \\
1.6 \\
1.6 \\
1.8 \\
1.9 \\
2.0\end{array}$ & $\begin{array}{l}1.4 \\
1.4 \\
1.4 \\
1.6 \\
1.7 \\
1.8\end{array}$ & $\begin{array}{l}1.1 \\
1.2 \\
1.2 \\
1.3 \\
1.5 \\
1.6\end{array}$ & 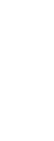 \\
\hline
\end{tabular}

MAGNITUDE AND PRCBABILITY OF ANNAL HIGHEST MEAN DISOHARGE BASED ON WATER YEARS 1954-81

\begin{tabular}{|c|c|c|c|c|c|c|}
\hline \multirow{2}{*}{$\begin{array}{l}\text { PERIOD } \\
\text { (CON- } \\
\text { SEOU- } \\
\text { TIVE } \\
\text { DAYS ) }\end{array}$} & \multicolumn{6}{|c|}{$\begin{array}{l}\text { DISQHARGE, IN OUBIC FEET PER SECOND, FOR } \\
\text { INDICATED RECJRRENCE INTERNAL, IN YEARS, AND } \\
\text { ANNUAL EXCEEDANCE PRCBABILITY, IN PERCENT }\end{array}$} \\
\hline & $\begin{array}{c}2 \\
508\end{array}$ & $\begin{array}{c}5 \\
208\end{array}$ & $\begin{array}{l}10 \\
108\end{array}$ & $\begin{array}{l}25 \\
48\end{array}$ & $\begin{array}{l}50 \\
28\end{array}$ & $\begin{array}{r}100 \\
18\end{array}$ \\
\hline $\begin{array}{r}1 \\
3 \\
7 \\
15\end{array}$ & $\begin{array}{l}83 \\
80 \\
76 \\
70\end{array}$ & $\begin{array}{r}117 \\
112 \\
105 \\
94\end{array}$ & $\begin{array}{l}136 \\
130 \\
120 \\
106\end{array}$ & $\begin{array}{l}157 \\
149 \\
134 \\
116\end{array}$ & $\begin{array}{l}171 \\
160 \\
143 \\
122\end{array}$ & $\overline{-}$ \\
\hline
\end{tabular}




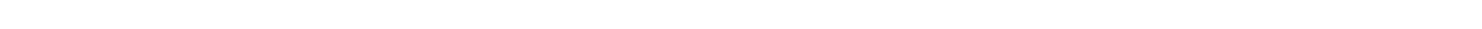
14060003, Ashley National Forest, on right bank $1.2 \mathrm{mi}$ downstream from South Fork and 11.5 mi northeast of Hanna.

DRAINAGE AREA. $--122 \mathrm{mi}^{2}$.

NEAN BASIN ELEVATION. $--10,200 \mathrm{ft}$.

PERIOD OF RECORD AVAIIABLE.--July 1949 to September 1969, August 1974 September 1981.

REVISED RECORDS. --WDR UT-77-1: Drainage area.

GAGE.--Water-stage recorder. Altitude of gage is 7,620 ft from river-profile map.

AVERAGE DISCHARGE.--27 years (water years 1950-69, 1975-81), $149 \mathrm{ft}^{3} / \mathrm{s}, 108,00$ acre-ft/yr.

EXIREMES FOR PERIOD OF RECORD.--Maximum discharge, 2,540 $\mathrm{ft}^{3} / \mathrm{s}$ June 13, 1953, gage height, $8.60 \mathrm{ft}$; minimum recorded, $4.4 \mathrm{ft}^{3} / \mathrm{s} \mathrm{Feb}^{2}$ 7,1977 , result of freezeup.

LONEST MEAN DISCHARGE, IN CUBIC FEET PER SECOND, AND RANKING FOR THE INDICATED NUMBER OF CONSECUTIVE DAYS FOR EACH CLIMATIC YEAR, APRIL 1-MARCH 31

YEAR

\begin{tabular}{|c|c|c|c|c|c|c|c|c|c|c|c|c|c|c|c|c|c|c|}
\hline 1 & & 3 & & 7 & & 14 & & $\begin{array}{l}\text { CONSE } \\
30\end{array}$ & ECU & $\begin{array}{l}\text { DAYS } \\
60\end{array}$ & & 90 & & 120 & & 183 & & ALL \\
\hline $\begin{array}{l}27.0 \\
26.0 \\
23.0 \\
22.0 \\
20.0\end{array}$ & $\begin{array}{r}24 \\
22 \\
18 \\
15 \\
9\end{array}$ & $\begin{array}{l}27.0 \\
28.0 \\
23.0 \\
22.0 \\
21.0\end{array}$ & $\begin{array}{l}22 \\
23 \\
18 \\
15 \\
12\end{array}$ & $\begin{array}{l}27.0 \\
29.0 \\
24.0 \\
23.0 \\
23.0\end{array}$ & $\begin{array}{l}22 \\
23 \\
18 \\
14 \\
15\end{array}$ & $\begin{array}{l}27.0 \\
29.0 \\
24.0 \\
24.0 \\
23.0\end{array}$ & $\begin{array}{l}21 \\
23 \\
15 \\
16 \\
13\end{array}$ & $\begin{array}{l}27.0 \\
29.0 \\
24.0 \\
25.0 \\
23.0\end{array}$ & $\begin{array}{l}20 \\
23 \\
14 \\
15 \\
12\end{array}$ & $\begin{array}{l}28.0 \\
30.0 \\
26.0 \\
25.0 \\
24.0\end{array}$ & $\begin{array}{l}19 \\
22 \\
16 \\
13 \\
11\end{array}$ & $\begin{array}{l}28.0 \\
31.0 \\
28.0 \\
25.0 \\
24.0\end{array}$ & $\begin{array}{r}16 \\
22 \\
17 \\
13 \\
8\end{array}$ & $\begin{array}{l}30.0 \\
32.0 \\
28.0 \\
25.0 \\
24.0\end{array}$ & $\begin{array}{r}16 \\
22 \\
14 \\
10 \\
6\end{array}$ & $\begin{array}{l}35.0 \\
39.0 \\
34.0 \\
29.0 \\
27.0\end{array}$ & $\begin{array}{r}16 \\
20 \\
15 \\
10 \\
6\end{array}$ & $\begin{array}{c}181 \\
173 \\
221 \\
127 \\
96.0\end{array}$ \\
\hline $\begin{array}{l}22.0 \\
21.0 \\
24.0 \\
17.0 \\
24.0\end{array}$ & $\begin{array}{r}16 \\
13 \\
19 \\
4 \\
20\end{array}$ & $\begin{array}{l}23.0 \\
21.0 \\
25.0 \\
19.0 \\
25.0\end{array}$ & $\begin{array}{r}16 \\
13 \\
19 \\
6 \\
20\end{array}$ & $\begin{array}{l}23.0 \\
21.0 \\
26.0 \\
20.0 \\
25.0\end{array}$ & $\begin{array}{r}16 \\
11 \\
20 \\
6 \\
19\end{array}$ & $\begin{array}{l}24.0 \\
21.0 \\
26.0 \\
20.0 \\
25.0\end{array}$ & $\begin{array}{r}17 \\
11 \\
20 \\
5 \\
18\end{array}$ & $\begin{array}{l}25.0 \\
21.0 \\
27.0 \\
20.0 \\
25.0\end{array}$ & $\begin{array}{r}16 \\
9 \\
21 \\
4 \\
17\end{array}$ & $\begin{array}{l}26.0 \\
23.0 \\
29.0 \\
20.0 \\
25.0\end{array}$ & $\begin{array}{r}17 \\
8 \\
20 \\
3 \\
14\end{array}$ & $\begin{array}{l}28.0 \\
24.0 \\
29.0 \\
21.0 \\
26.0\end{array}$ & $\begin{array}{r}18 \\
9 \\
19 \\
3 \\
14\end{array}$ & $\begin{array}{l}30.0 \\
25.0 \\
31.0 \\
22.0 \\
28.0\end{array}$ & $\begin{array}{r}17 \\
7 \\
18 \\
4 \\
15\end{array}$ & $\begin{array}{l}33.0 \\
27.0 \\
37.0 \\
26.0 \\
40.0\end{array}$ & $\begin{array}{r}14 \\
7 \\
17 \\
3 \\
21\end{array}$ & $\begin{array}{l}118 \\
155 \\
172 \\
139 \\
119\end{array}$ \\
\hline $\begin{array}{l}20.0 \\
21.0 \\
15.0 \\
23.0 \\
20.0\end{array}$ & $\begin{array}{r}10 \\
14 \\
3 \\
17 \\
11\end{array}$ & $\begin{array}{l}20.0 \\
21.0 \\
15.0 \\
23.0 \\
20.0\end{array}$ & $\begin{array}{r}9 \\
14 \\
3 \\
17 \\
10\end{array}$ & $\begin{array}{l}20.0 \\
22.0 \\
15.0 \\
24.0 \\
20.0\end{array}$ & $\begin{array}{r}7 \\
13 \\
3 \\
17 \\
8\end{array}$ & $\begin{array}{l}20.0 \\
23.0 \\
16.0 \\
26.0 \\
20.0\end{array}$ & $\begin{array}{r}6 \\
14 \\
2 \\
19 \\
7\end{array}$ & $\begin{array}{l}20.0 \\
27.0 \\
16.0 \\
27.0 \\
21.0\end{array}$ & $\begin{array}{r}5 \\
18 \\
2 \\
19 \\
6\end{array}$ & $\begin{array}{l}21.0 \\
38.0 \\
17.0 \\
28.0 \\
23.0\end{array}$ & $\begin{array}{r}4 \\
25 \\
2 \\
18 \\
9\end{array}$ & $\begin{array}{l}22.0 \\
40.0 \\
17.0 \\
30.0 \\
24.0\end{array}$ & $\begin{array}{r}4 \\
25 \\
2 \\
20 \\
10\end{array}$ & $\begin{array}{l}24.0 \\
43.0 \\
19.0 \\
31.0 \\
25.0\end{array}$ & $\begin{array}{r}5 \\
25 \\
2 \\
19 \\
8\end{array}$ & $\begin{array}{l}31.0 \\
64.0 \\
27.0 \\
41.0 \\
27.0\end{array}$ & $\begin{array}{r}11 \\
25 \\
4 \\
22 \\
5\end{array}$ & $\begin{array}{c}114 \\
96.0 \\
183 \\
139 \\
165\end{array}$ \\
\hline $\begin{array}{l}21.0 \\
25.0 \\
27.0 \\
28.0\end{array}$ & $\begin{array}{l}12 \\
21 \\
23 \\
25\end{array}$ & $\begin{array}{l}21.0 \\
27.0 \\
29.0 \\
28.0\end{array}$ & $\begin{array}{l}11 \\
21 \\
25 \\
24\end{array}$ & $\begin{array}{l}21.0 \\
27.0 \\
31.0 \\
29.0\end{array}$ & $\begin{array}{l}12 \\
21 \\
25 \\
24\end{array}$ & $\begin{array}{l}22.0 \\
28.0 \\
31.0 \\
30.0\end{array}$ & $\begin{array}{l}12 \\
22 \\
25 \\
24\end{array}$ & $\begin{array}{l}24.0 \\
28.0 \\
32.0 \\
31.0\end{array}$ & $\begin{array}{l}13 \\
22 \\
25 \\
24\end{array}$ & $\begin{array}{l}25.0 \\
30.0 \\
33.0 \\
32.0\end{array}$ & $\begin{array}{l}15 \\
21 \\
24 \\
23\end{array}$ & $\begin{array}{l}27.0 \\
30.0 \\
33.0 \\
33.0\end{array}$ & $\begin{array}{l}15 \\
21 \\
23 \\
24\end{array}$ & $\begin{array}{l}31.0 \\
32.0 \\
34.0 \\
33.0\end{array}$ & $\begin{array}{l}20 \\
21 \\
24 \\
23\end{array}$ & $\begin{array}{l}46.0 \\
38.0 \\
38.0 \\
41.0\end{array}$ & $\begin{array}{l}24 \\
18 \\
19 \\
23\end{array}$ & $\begin{array}{l}233 \\
115 \\
191 \\
184\end{array}$ \\
\hline $\begin{array}{c}19.0 \\
8.20 \\
11.0 \\
18.0 \\
18.0\end{array}$ & $\begin{array}{l}8 \\
1 \\
2 \\
5 \\
6\end{array}$ & $\begin{array}{c}19.0 \\
8.20 \\
12.0 \\
19.0 \\
18.0\end{array}$ & $\begin{array}{l}7 \\
1 \\
2 \\
8 \\
4\end{array}$ & $\begin{array}{c}20.0 \\
8.20 \\
14.0 \\
20.0 \\
19.0\end{array}$ & $\begin{array}{r}9 \\
1 \\
2 \\
10 \\
4\end{array}$ & $\begin{array}{c}20.0 \\
8.20 \\
20.0 \\
20.0 \\
19.0\end{array}$ & $\begin{array}{r}8 \\
1 \\
9 \\
10 \\
3\end{array}$ & $\begin{array}{c}23.0 \\
8.60 \\
21.0 \\
21.0 \\
20.0\end{array}$ & $\begin{array}{r}10 \\
1 \\
7 \\
8 \\
3\end{array}$ & $\begin{array}{c}24.0 \\
9.10 \\
23.0 \\
22.0 \\
22.0\end{array}$ & $\begin{array}{r}12 \\
1 \\
10 \\
5 \\
6\end{array}$ & $\begin{array}{c}24.0 \\
9.40 \\
24.0 \\
23.0 \\
22.0\end{array}$ & $\begin{array}{r}11 \\
11 \\
12 \\
6 \\
5\end{array}$ & $\begin{array}{l}26.0 \\
11.0 \\
26.0 \\
25.0 \\
22.0\end{array}$ & $\begin{array}{r}11 \\
1 \\
12 \\
9 \\
3\end{array}$ & $\begin{array}{l}32.0 \\
18.0 \\
28.0 \\
28.0 \\
25.0\end{array}$ & $\begin{array}{r}12 \\
1 \\
8 \\
9 \\
2\end{array}$ & $\begin{array}{c}190 \\
102 \\
66.0 \\
163 \\
119\end{array}$ \\
\hline 8.0 & 7 & 18.0 & 5 & 19.0 & 5 & 20.0 & 4 & 23.0 & 11 & 23.0 & 7 & 24.0 & 7 & 26.0 & 13 & 32.0 & 13 & 167 \\
\hline
\end{tabular}

HIGHEST MEAN DISCHARGE, IN CUBIC FEET PER SECOND, AND RANKING FOR THE INDICATED NUMBER OF CONSECUTIVE DAYS FOR EACH WATER YEAR, OCTOBER 1-SEPTEMBER 30

\begin{tabular}{|c|c|c|c|c|c|c|c|c|c|c|c|c|c|c|c|c|c|c|c|c|}
\hline YEAR & \multicolumn{20}{|c|}{ CONSECUTIVE DAYS } \\
\hline $\begin{array}{l}1961 \\
1962 \\
1963 \\
1964 \\
1965\end{array}$ & $\begin{array}{r}635 \\
1410 \\
1320 \\
1600 \\
2060\end{array}$ & $\begin{array}{r}27 \\
16 \\
18 \\
12 \\
2\end{array}$ & $\begin{array}{r}597 \\
1360 \\
1030 \\
1430 \\
1880\end{array}$ & $\begin{array}{r}27 \\
16 \\
22 \\
14 \\
2\end{array}$ & $\begin{array}{r}521 \\
1240 \\
919 \\
1110 \\
1590\end{array}$ & $\begin{array}{r}27 \\
14 \\
22 \\
16 \\
4\end{array}$ & $\begin{array}{r}440 \\
1140 \\
804 \\
1010 \\
1290\end{array}$ & $\begin{array}{r}27 \\
13 \\
20 \\
16 \\
5\end{array}$ & $\begin{array}{r}346 \\
959 \\
748 \\
900 \\
1210\end{array}$ & $\begin{array}{r}26 \\
13 \\
18 \\
15 \\
1\end{array}$ & $\begin{array}{l}240 \\
730 \\
551 \\
756 \\
943\end{array}$ & $\begin{array}{r}26 \\
9 \\
16 \\
8 \\
1\end{array}$ & $\begin{array}{l}180 \\
592 \\
409 \\
562 \\
729\end{array}$ & $\begin{array}{r}26 \\
5 \\
16 \\
8 \\
1\end{array}$ & $\begin{array}{l}148 \\
484 \\
331 \\
440 \\
594\end{array}$ & $\begin{array}{r}26 \\
5 \\
16 \\
9 \\
1\end{array}$ & $\begin{array}{l}127 \\
338 \\
238 \\
302 \\
420\end{array}$ & $\begin{array}{r}26 \\
5 \\
16 \\
11 \\
1\end{array}$ & $\begin{array}{l}79.0 \\
201 \\
133 \\
172 \\
224\end{array}$ & 16 \\
\hline
\end{tabular}


GREEN RIVER BASIN

09278500 ROCK CREER NEAR HANNA, UT-Continued

HIGHEST MEAN DISOHARGE, IN OBIC FEET PER SECOND, AND RANKING FOR THE INDICATED NUMBER OF CONSEQITTVE DAYS FOR EAOH WATER YEAR, OCTCBER 1-SEPTEMBER 30--Continued

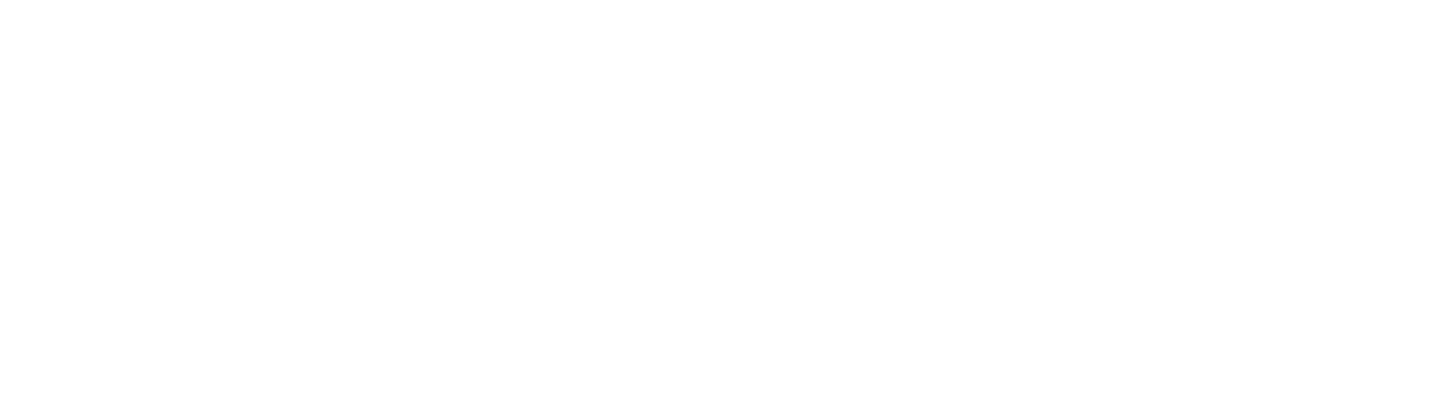

DURATION OF DISOHARGE FOR EACH WATER YEAR

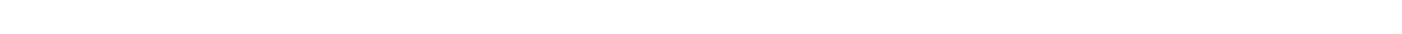
YEAR NUMBER OF DAYS IN CLASS

वBIC FEET -DAR

67046.0

1950

1951

1952

1953

1955

1956

1957

1958

1959
1960

1961

1962

1963

1964

1965

1966

1967

1968

1969

1975

1976

1977

1978

1979
1980

1981

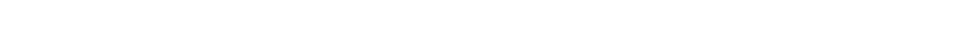

$\begin{array}{lllllllllllllllllllllllll}110 & 6 & 55 & 19 & 23 & 22 & 8 & 3 & 11 & 9 & 14 & 13 & 9 & 6 & 5 & 6 & 6 & 8 & 4 & 5 & 5 & 7 & 9 & 2\end{array}$ $\begin{array}{lllllllllllllllllllllllllll}33 & 76 & 48 & 11 & 14 & 15 & 10 & 7 & 26 & 5 & 13 & 10 & 5 & 13 & 9 & 3 & 9 & 11 & 9 & 12 & 5 & 5 & 3 & 5 & 3 & 6\end{array}$

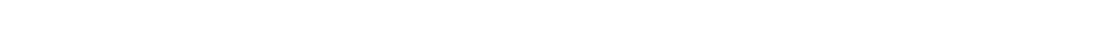
$\begin{array}{lllllllllllllllllllllll}121 & 13 & 14 & 49 & 45 & 11 & 10 & 8 & 8 & 15 & 12 & 5 & 12 & 10 & 4 & 6 & 3 & 2 & 3 & 4 & 4 & 4 & 2\end{array}$

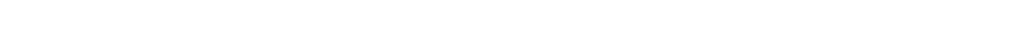

$\begin{array}{lllllllllllllllllllllllllll}27 & 46 & 80 & 43 & 29 & 15 & 15 & 6 & 3 & 21 & 8 & 7 & 4 & 6 & 6 & 7 & 7 & 2 & 4 & 2 & 1 & 5 & 7 & 7 & 5 & 2 & 1\end{array}$

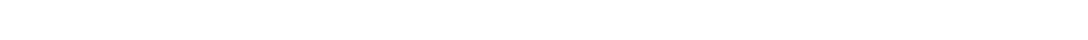

$\begin{array}{llllllllllllllllllllllllll}5 & 84 & 38 & 28 & 46 & 45 & 23 & 8 & 12 & 7 & 3 & 5 & 8 & 5 & 7 & 2 & 4 & 2 & 9 & 2 & 1 & 3 & 8 & 1 & 6 & 3\end{array}$

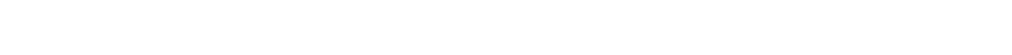

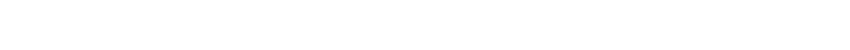

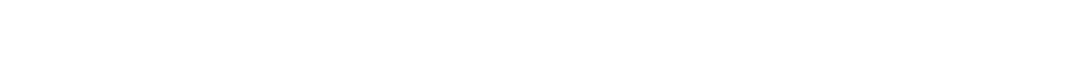

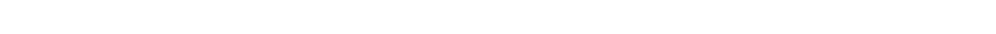

$\begin{array}{rrrrrrrrrrrrrrrrrrrrrrrrrrrrr}20 & 84 & 56 & 35 & 5 & 2 & & 1 & 7 & 5 & 6 & 20 & 15 & 9 & 12 & 8 & 6 & 10 & 9 & 5 & 7 & 4 & 9 & 9 & 4 & 14 & 3\end{array}$

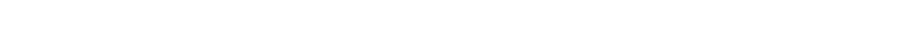

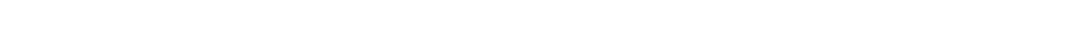

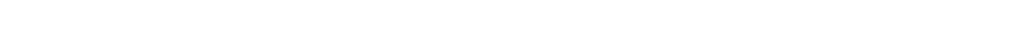

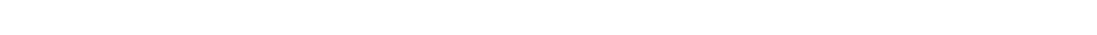

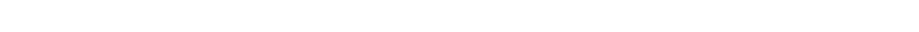

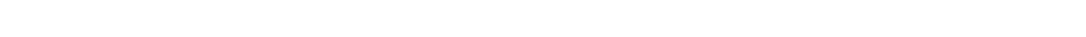

$\begin{array}{lllllllllllllllllllllllllllll}21 & 54 & 56 & 36 & 20 & 13 & 27 & 20 & 14 & 13 & 11 & 6 & 3 & 3 & 5 & 7 & 7 & 5 & 8 & 1 & 6 & 8 & 2 & 7 & 2 & 5 & 4 & 1\end{array}$

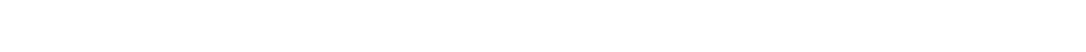

$\begin{array}{llllllllllllllllllllllllll}176 & 36 & 33 & 20 & 46 & 28 & 21 & 14 & 3 & 6 & 8 & 17 & 13 & 5 & 6 & 7 & 5 & 3 & 2 & 2 & 1 & 5 & 3 & 2 & 2\end{array}$
62369.0

81561.0

47360.0

42058.0

57709.0

61093.0

52719.0

40707.0

43384.0

28868.0

73481.0

48441.0

62772.0

81760.0

43131.0

6978.0

66847.0

63701.0

68712.0

39721.0

22153.1

53970.0

43970.0

40397.0

DURATION TABLE OF DISOHARGE FOR WATER YEARS 1950-69, 1975-81

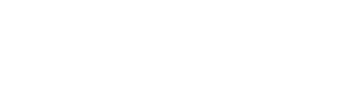

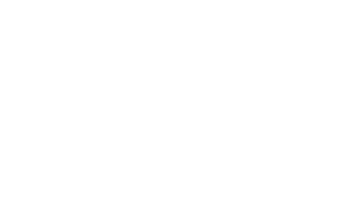

\begin{tabular}{|c|c|c|c|c|}
\hline & $\begin{array}{c}\text { वBIC } \\
\text { FEET } \\
\text { PER }\end{array}$ & TOTAL & $\begin{array}{c}\text { ACOU- } \\
\text { M- } \\
\text { LATED }\end{array}$ & $\begin{array}{l}\text { PER- } \\
\text { CENT }\end{array}$ \\
\hline C.ASS & SECOND & DAYS & DAYS & DAYS \\
\hline $\begin{array}{l}9 \\
10 \\
11 \\
12 \\
13 \\
14 \\
15 \\
16 \\
17\end{array}$ & $\begin{array}{r}31.00 \\
37.00 \\
44.00 \\
52.00 \\
61.00 \\
72.00 \\
86.00 \\
100.00\end{array}$ & $\begin{array}{r}1129 \\
871 \\
634 \\
512 \\
443 \\
420 \\
323 \\
380 \\
229\end{array}$ & $\begin{array}{l}7046 \\
5917 \\
5046 \\
4412 \\
3900 \\
3457 \\
3037 \\
2714 \\
2334\end{array}$ & $\begin{array}{l}71.4 \\
60.0 \\
51.2 \\
44.7 \\
39.5 \\
35.1 \\
30.8 \\
27.5\end{array}$ \\
\hline
\end{tabular}

$\begin{array}{lllll}17 & 120.00 & 229 & 2334 & 23.7\end{array}$

\begin{tabular}{ccccc}
\multicolumn{4}{c}{ CUBIC } & \multicolumn{2}{c}{ ACOU- } \\
FEET & MU- & PER- \\
PER & TOTAL & LAIED & CENT \\
CLASS & SECOND & DAYS & DAYS & DAYS \\
& & & & \\
18 & 140.0 & 248 & 2105 & 21.3 \\
19 & 170.0 & 196 & 1857 & 18.8 \\
20 & 200.0 & 152 & 1661 & 16.8 \\
21 & 230.0 & 170 & 1509 & 15.3 \\
22 & 280.0 & 154 & 1339 & 13.6 \\
23 & 330.0 & 145 & 1185 & 12.0 \\
24 & 390.0 & 134 & 1040 & 10.5 \\
25 & 460.0 & 129 & 906 & 9.2 \\
26 & 540.0 & 133 & 777 & 7.9
\end{tabular}

ABIC ACOU-

FEET M- PERGASS SECOMD DAYS LATED CENT

$\begin{array}{rrrrr}27 & 640.0 & 133 & 644 & 6.5 \\ 28 & 750.0 & 153 & 511 & 5.2 \\ 29 & 890.0 & 134 & 358 & 3.6 \\ 30 & 1100.0 & 53 & 224 & 2.3 \\ 31 & 1200.0 & 118 & 171 & 1.7 \\ 32 & 1500.0 & 34 & 53 & 0.5 \\ 33 & 1700.0 & 18 & 19 & 0.2 \\ 34 & 2100.0 & 1 & 1 & 0.0\end{array}$


GREEN RIVER BASIN

09278500 ROCK CREEK NEAR HANNA, UT-Continued

MONIHLY MEAN DISCHARGES, IN OUBIC FEET PER SECOND, FOR EACH WATER YEAR

\begin{tabular}{|c|c|c|c|c|c|c|c|c|c|c|c|c|}
\hline YEAR & $\propto C T$ & NOV & $\mathrm{DEC}$ & JAN & FEB & MAR & APR & MAY & JUNE & JULY & AUG & SEP \\
\hline 1950 & 52.2 & 43.3 & 35.4 & 39.8 & 35.7 & 29.3 & 85.0 & 350 & 1109 & 291 & 78.8 & 58.2 \\
\hline $\begin{array}{l}1951 \\
1952 \\
1953 \\
1954 \\
1955\end{array}$ & $\begin{array}{l}46.1 \\
61.2 \\
53.1 \\
39.9 \\
35.3\end{array}$ & $\begin{array}{l}41.7 \\
41.9 \\
32.8 \\
33.9 \\
29.3\end{array}$ & $\begin{array}{l}34.6 \\
37.2 \\
30.3 \\
25.0 \\
25.7\end{array}$ & $\begin{array}{l}29.0 \\
32.0 \\
30.7 \\
25.0 \\
25.0\end{array}$ & $\begin{array}{l}29.0 \\
32.0 \\
26.3 \\
25.0 \\
24.0\end{array}$ & $\begin{array}{l}27.0 \\
29.0 \\
27.6 \\
25.0 \\
23.0\end{array}$ & $\begin{array}{l}51.5 \\
76.0 \\
45.3 \\
62.2 \\
27.7\end{array}$ & $\begin{array}{l}420 \\
590 \\
111 \\
497 \\
385\end{array}$ & $\begin{array}{r}837 \\
1152 \\
842 \\
211 \\
522\end{array}$ & $\begin{array}{l}303 \\
351 \\
208 \\
108 \\
129\end{array}$ & $\begin{array}{l}160 \\
177 \\
103 \\
56.8 \\
95.5\end{array}$ & $\begin{array}{l}67.7 \\
96.9 \\
50.4 \\
45.0 \\
58.5\end{array}$ \\
\hline $\begin{array}{l}1956 \\
1957 \\
1958 \\
1959 \\
1960\end{array}$ & $\begin{array}{l}42.9 \\
34.4 \\
52.8 \\
38.3 \\
76.8\end{array}$ & $\begin{array}{l}34.6 \\
27.1 \\
45.3 \\
29.8 \\
53.3\end{array}$ & $\begin{array}{l}36.8 \\
27.0 \\
34.6 \\
24.2 \\
28.1\end{array}$ & $\begin{array}{l}30.5 \\
24.0 \\
30.5 \\
20.1 \\
26.0\end{array}$ & $\begin{array}{l}26.1 \\
21.3 \\
30.0 \\
20.0 \\
25.0\end{array}$ & $\begin{array}{l}27.8 \\
25.6 \\
27.4 \\
22.0 \\
32.7\end{array}$ & $\begin{array}{l}67.2 \\
28.8 \\
48.0 \\
40.3 \\
74.2\end{array}$ & $\begin{array}{l}586 \\
144 \\
584 \\
206 \\
364\end{array}$ & $\begin{array}{r}784 \\
1115 \\
649 \\
659 \\
539\end{array}$ & $\begin{array}{l}150 \\
391 \\
118 \\
158 \\
106\end{array}$ & $\begin{array}{l}67.5 \\
111 \\
59.4 \\
69.7 \\
50.2\end{array}$ & $\begin{array}{l}40.2 \\
62.5 \\
50.3 \\
53.5 \\
48.7\end{array}$ \\
\hline $\begin{array}{l}1961 \\
1962 \\
1963 \\
1964 \\
1965\end{array}$ & $\begin{array}{c}49.7 \\
128 \\
54.0 \\
68.8 \\
32.2\end{array}$ & $\begin{array}{l}40.0 \\
79.4 \\
32.9 \\
51.0 \\
27.1\end{array}$ & $\begin{array}{l}29.5 \\
55.1 \\
22.9 \\
35.9 \\
28.5\end{array}$ & $\begin{array}{l}23.2 \\
42.2 \\
16.4 \\
32.5 \\
26.6\end{array}$ & $\begin{array}{l}20.2 \\
41.3 \\
17.7 \\
28.8 \\
23.0\end{array}$ & $\begin{array}{l}22.0 \\
35.5 \\
18.5 \\
27.4 \\
22.1\end{array}$ & $\begin{array}{c}26.9 \\
151 \\
29.1 \\
36.2 \\
44.4\end{array}$ & $\begin{array}{l}261 \\
459 \\
401 \\
428 \\
248\end{array}$ & $\begin{array}{r}212 \\
948 \\
640 \\
845 \\
1111\end{array}$ & $\begin{array}{l}58.5 \\
324 \\
168 \\
362 \\
745\end{array}$ & $\begin{array}{c}56.1 \\
97.9 \\
98.7 \\
98.1 \\
232\end{array}$ & $\begin{array}{c}148 \\
52.9 \\
91.6 \\
44.7 \\
143\end{array}$ \\
\hline $\begin{array}{l}1966 \\
1967 \\
1968 \\
1969\end{array}$ & $\begin{array}{l}89.2 \\
60.9 \\
56.3 \\
64.7\end{array}$ & $\begin{array}{l}56.3 \\
41.7 \\
37.8 \\
46.6\end{array}$ & $\begin{array}{l}41.8 \\
36.2 \\
35.8 \\
35.6\end{array}$ & $\begin{array}{l}28.0 \\
30.9 \\
33.8 \\
34.2\end{array}$ & $\begin{array}{l}23.5 \\
29.2 \\
33.5 \\
32.7\end{array}$ & $\begin{array}{l}31.8 \\
30.0 \\
32.6 \\
30.9\end{array}$ & $\begin{array}{l}90.5 \\
37.5 \\
41.0 \\
86.8\end{array}$ & $\begin{array}{l}499 \\
335 \\
189 \\
831\end{array}$ & $\begin{array}{r}288 \\
953 \\
1159 \\
574\end{array}$ & $\begin{array}{l}116 \\
515 \\
314 \\
193\end{array}$ & $\begin{array}{l}77.6 \\
142 \\
178 \\
92.9\end{array}$ & $\begin{array}{l}67.5 \\
76.3 \\
91.0 \\
61.0\end{array}$ \\
\hline 1975 & 38.5 & 31.6 & 25.1 & 22.0 & 21.0 & 20.5 & 23.1 & 153 & 900 & 789 & 158 & 69.2 \\
\hline $\begin{array}{l}1976 \\
1977 \\
1978 \\
1979 \\
1980\end{array}$ & $\begin{array}{l}49.6 \\
37.4 \\
33.5 \\
34.0 \\
35.5\end{array}$ & $\begin{array}{l}37.3 \\
25.2 \\
29.4 \\
31.9 \\
26.5\end{array}$ & $\begin{array}{l}30.9 \\
14.7 \\
29.6 \\
32.0 \\
21.5\end{array}$ & $\begin{array}{c}25.5 \\
9.39 \\
26.0 \\
26.1 \\
23.3\end{array}$ & $\begin{array}{c}24.6 \\
8.86 \\
22.4 \\
22.7 \\
22.4\end{array}$ & $\begin{array}{l}22.9 \\
10.4 \\
25.3 \\
20.7 \\
20.9\end{array}$ & $\begin{array}{l}35.0 \\
37.7 \\
60.8 \\
48.2 \\
65.0\end{array}$ & $\begin{array}{l}382 \\
104 \\
258 \\
432 \\
291\end{array}$ & $\begin{array}{r}455 \\
298 \\
1067 \\
537 \\
1008\end{array}$ & $\begin{array}{l}126 \\
82.8 \\
272 \\
142 \\
299\end{array}$ & $\begin{array}{l}64.7 \\
59.3 \\
82.1 \\
74.7 \\
88.9\end{array}$ & $\begin{array}{l}48.1 \\
41.0 \\
51.5 \\
40.9 \\
66.4\end{array}$ \\
\hline 1981 & 49.5 & 39.7 & 31.3 & 24.7 & 23.3 & 24.0 & 75.6 & 269 & 570 & 114 & 57.1 & 51.0 \\
\hline
\end{tabular}

ANNUAL PEAK DISGHARGE, IN OBIC FEET PER SECOND, AND CORRESPONDING GAGE HEIGHT, IN FEET, FOR EACH WATER YEAR

\begin{tabular}{|c|c|c|c|c|c|c|c|c|c|c|c|}
\hline $\begin{array}{l}\text { WATERR } \\
\text { YEAR }\end{array}$ & DATE & $\begin{array}{c}\text { GAGE } \\
\text { HEIGHT }\end{array}$ & $\begin{array}{c}\text { PEAK } \\
\text { DISOHARGE }\end{array}$ & $\begin{array}{l}\text { WATER } \\
\text { YEAR }\end{array}$ & DATE & $\begin{array}{c}\text { GAGE } \\
\text { HEIGHT }\end{array}$ & $\begin{array}{c}\text { PEAK } \\
\text { DISCHARGE }\end{array}$ & $\begin{array}{l}\text { WATER } \\
\text { YEAR }\end{array}$ & DATE & $\begin{array}{c}\text { GAGE } \\
\text { HEIGHT }\end{array}$ & $\begin{array}{c}\text { PEAR } \\
\text { DISCHARGE }\end{array}$ \\
\hline $\begin{array}{l}1950 \\
1951 \\
1952 \\
1953 \\
1954 \\
1955 \\
1956 \\
1957 \\
1958\end{array}$ & $\begin{array}{l}\text { JUNE } 06,1950 \\
\text { JUNE 16, } 1951 \\
\text { JUNE } 09,1952 \\
\text { JUNE } 13,1953 \\
\text { MAY 19, } 1954 \\
\text { JUNE } 08,1955 \\
\text { JUNE 01, } 1956 \\
\text { JUNE 07, } 1957 \\
\text { MAY 27, } 1958\end{array}$ & $\begin{array}{l}7.32 \\
7.67 \\
8.16 \\
8.60 \\
6.42 \\
7.34 \\
7.77 \\
7.94 \\
7.38\end{array}$ & $\begin{array}{l}1780 \\
1970 \\
2240 \\
2540 \\
1230 \\
1800 \\
2030 \\
2200 \\
1850\end{array}$ & $\begin{array}{l}1959 \\
1960 \\
1961 \\
1962 \\
1963 \\
1964 \\
1965 \\
1966 \\
1967\end{array}$ & $\begin{array}{l}\text { JUNE 08, } 1959 \\
\text { JUNE 02, } 1960 \\
\text { MAY 27, } 1961 \\
\text { JUNE 20, } 1962 \\
\text { JUNE 14, } 1963 \\
\text { JUNE 06, } 1964 \\
\text { JUNE 13, } 1965 \\
\text { MAY 09, } 1966 \\
\text { JUNE } 20,1967\end{array}$ & $\begin{array}{l}6.65 \\
6.62 \\
5.32 \\
7.25 \\
6.85 \\
7.32 \\
8.08 \\
5.62 \\
7.46\end{array}$ & $\begin{array}{r}1410 \\
1450 \\
775 \\
1810 \\
1540 \\
1840 \\
2300 \\
874 \\
1870\end{array}$ & $\begin{array}{l}1968 \\
1969 \\
1975 \\
1976 \\
1977 \\
1978 \\
1979 \\
1980 \\
1981\end{array}$ & $\begin{array}{l}\text { JUNE } 20,1968 \\
\text { MAY } 27,1969 \\
\text { JUNE } 16,1975 \\
\text { JUNE } 03,1976 \\
\text { JUNE } 03,1977 \\
\text { JUNE } 14,1978 \\
\text { MAY } 29,1979 \\
\text { JUNE } 11,1980 \\
\text { JUNE } 07,1981\end{array}$ & $\begin{array}{l}7.68 \\
6.90 \\
7.48 \\
5.59 \\
-. .21 \\
7.21 \\
7.07 \\
7.31\end{array}$ & $\begin{array}{l}2050 \\
1640 \\
2120 \\
1010 \\
1070 \\
2040 \\
1890 \\
2010 \\
1280\end{array}$ \\
\hline
\end{tabular}

\begin{tabular}{|c|c|c|c|c|c|c|}
\hline \multirow{2}{*}{$\begin{array}{l}\text { ERIO } \\
\text { CON- } \\
\text { EQU- } \\
\text { IVE } \\
\text { AUS ) }\end{array}$} & \multicolumn{6}{|c|}{$\begin{array}{l}\text { DISCHARGE, IN CUBIC FEET PER SEOOND, FOR } \\
\text { INDICATED RECURRENCE INTERNAL, IN YEARS, AND } \\
\text { ANNUAL NONEXCEEDANCE PRCBABIIITY, IN PERCENT }\end{array}$} \\
\hline & $\begin{array}{c}2 \\
508\end{array}$ & $\begin{array}{c}5 \\
208\end{array}$ & $\begin{array}{l}10 \\
108\end{array}$ & $\begin{array}{l}20 \\
58\end{array}$ & $\begin{array}{l}50 \\
28\end{array}$ & $\begin{array}{r}100 \\
18\end{array}$ \\
\hline $\begin{array}{r}1 \\
7 \\
14 \\
30 \\
60 \\
90\end{array}$ & $\begin{array}{l}22 \\
23 \\
24 \\
25 \\
26 \\
27\end{array}$ & $\begin{array}{l}17 \\
18 \\
19 \\
20 \\
21 \\
21\end{array}$ & $\begin{array}{l}14 \\
15 \\
16 \\
16 \\
17 \\
18\end{array}$ & $\begin{array}{l}12 \\
12 \\
13 \\
14 \\
14 \\
15\end{array}$ & $\begin{array}{l}9.1 \\
9.7 \\
10 \\
11 \\
11 \\
11\end{array}$ & $\overline{-}$ \\
\hline
\end{tabular}

MAGNITUDE AND PRCBABILITY OF ANNUAL HIGHEST MEAN DISCHARGE BASED ON WATER YEARS 1950-69 AND 1975-81

\begin{tabular}{|c|c|c|c|c|c|c|}
\hline \multirow{2}{*}{$\begin{array}{l}\text { PERIOD } \\
\text { (CON- } \\
\text { SEOU- } \\
\text { TTVE } \\
\text { DAYS) }\end{array}$} & \multicolumn{6}{|c|}{$\begin{array}{l}\text { DISCHARGE, IN CUBIC FEET PER SECOND, FOR } \\
\text { INDICATED RECURRENCE INTTERVAL, IN YEARS, AND } \\
\text { ANNUAL EXCEEDANCE PRCBABIIITY, IN PERCENT }\end{array}$} \\
\hline & $\begin{array}{c}2 \\
50 \%\end{array}$ & $\begin{array}{c}5 \\
208\end{array}$ & $\begin{array}{l}10 \\
108\end{array}$ & $\begin{array}{l}25 \\
48\end{array}$ & $\begin{array}{l}50 \\
28\end{array}$ & $\begin{array}{r}100 \\
18\end{array}$ \\
\hline $\begin{array}{r}1 \\
3 \\
7 \\
15\end{array}$ & $\begin{array}{l}1450 \\
1360 \\
1210 \\
1050\end{array}$ & $\begin{array}{l}1810 \\
1700 \\
1510 \\
1310\end{array}$ & $\begin{array}{l}1980 \\
1860 \\
1660 \\
1430\end{array}$ & $\begin{array}{l}2140 \\
2020 \\
1810 \\
1550\end{array}$ & $\begin{array}{l}2230 \\
2110 \\
1900 \\
1610\end{array}$ & $\overline{-}$ \\
\hline
\end{tabular}


GREEN RIVER BASIN

09278700 ROCK CREEK BELCW MINERS GULCH, NEAR HANNA, UT

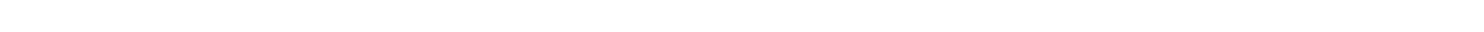
14060003 , on left bank $500 \mathrm{ft}$ below Miners Gulch, $2.5 \mathrm{mi}$ upstream from Peterson Gulch, and $11.0 \mathrm{mi}$ northeast of Hanna.

DRAINAGE AREA. --133 $\mathrm{mi}^{2}$.

PERIOD OF RECORD AVAIIABLE.--August 1974 to September 1981.

REVISED RECORDS.--WDR UT-77-1: Drainage area.

GAGE.-Water-stage recorder. Datum of gage is 7,470 ft fram topographic map.

AVERAGE DISQHARGE. -7 years, $121 \mathrm{ft}^{3} / \mathrm{s}, 87,660$ acre- $\mathrm{ft} / \mathrm{yr}$.

EXTREMES FOR PERIOD OF RECORD.--Maximum discharge, 2,090 $\mathrm{ft}^{3} / \mathrm{s}$ June 15,1975 , gage height, $5.45 \mathrm{ft}$, result of discharge measurement; minimum observed, $5.3 \mathrm{ft}^{3} / \mathrm{s}$ Dec, 23,1976 , result of discharge measurement.

LONEST MEAN DISQHARGE, IN OUBIC FEET PER SECOND, AND RANKING FOR THE INDICATED NUMBER OF CONSECUTIVE DAYS FOR EAOH CLIMATIC YEAR, APRIL 1-MARGH 31

\begin{tabular}{|c|c|c|c|c|c|c|c|c|c|c|c|c|c|c|c|c|c|c|c|}
\hline YEAR & 1 & & 3 & & 7 & & 14 & & cons & & E DAYS & & 90 & & 120 & & 183 & & ALL \\
\hline $\begin{array}{l}1976 \\
1977 \\
1978 \\
1979 \\
1980\end{array}$ & $\begin{array}{c}14.0 \\
4.70 \\
9.00 \\
17.0 \\
14.0\end{array}$ & $\begin{array}{l}5 \\
1 \\
2 \\
6 \\
3\end{array}$ & $\begin{array}{c}14.0 \\
4.70 \\
9.00 \\
17.0 \\
14.0\end{array}$ & $\begin{array}{l}5 \\
1 \\
2 \\
6 \\
3\end{array}$ & $\begin{array}{r}14.0 \\
4.90 \\
9.90 \\
17.0 \\
14.0\end{array}$ & $\begin{array}{l}5 \\
1 \\
2 \\
6 \\
3\end{array}$ & $\begin{array}{c}15.0 \\
5.10 \\
13.0 \\
17.0 \\
15.0\end{array}$ & $\begin{array}{l}5 \\
1 \\
2 \\
6 \\
3\end{array}$ & $\begin{array}{c}16.0 \\
5.20 \\
14.0 \\
17.0 \\
16.0\end{array}$ & $\begin{array}{l}4 \\
1 \\
2 \\
5 \\
3\end{array}$ & $\begin{array}{c}18.0 \\
5.40 \\
16.0 \\
18.0 \\
17.0\end{array}$ & $\begin{array}{l}4 \\
1 \\
2 \\
5 \\
3\end{array}$ & $\begin{array}{c}20.0 \\
5.80 \\
17.0 \\
20.0 \\
17.0\end{array}$ & $\begin{array}{l}4 \\
1 \\
2 \\
5 \\
3\end{array}$ & $\begin{array}{c}22.0 \\
7.50 \\
18.0 \\
22.0 \\
18.0\end{array}$ & $\begin{array}{l}4 \\
1 \\
2 \\
5 \\
3\end{array}$ & $\begin{array}{l}28.0 \\
15.0 \\
20.0 \\
25.0 \\
22.0\end{array}$ & $\begin{array}{l}5 \\
1 \\
2 \\
4 \\
3\end{array}$ & $\begin{array}{c}187 \\
94.0 \\
55.0 \\
134 \\
110\end{array}$ \\
\hline 99 & 14.0 & 4 & 14.0 & 4 & 14.0 & 4 & 15.0 & 4 & 20.0 & 6 & 20.0 & 6 & 21.0 & 6 & 23.0 & 6 & 30.0 & 6 & 161 \\
\hline
\end{tabular}

HIGHEST MEAN DISQHARGE, IN OBBIC FEE'T PER SECOND, AND RANKING FOR THE INDICATED NUMBER OF CONSEQUTTVE DAYS FOR EAOH WATER YEAR, OCIOBER I-SEPTEMBER 30

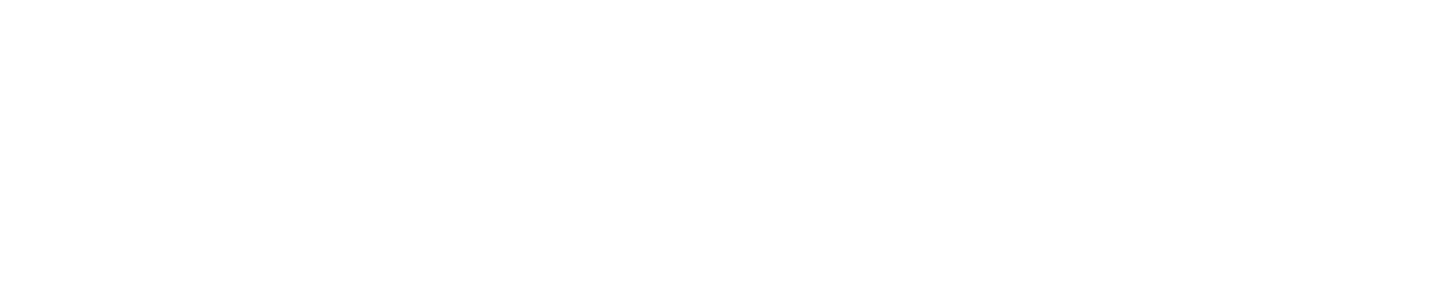

DURATION OF DISGHARGE FOR EAQH WATER YEAR

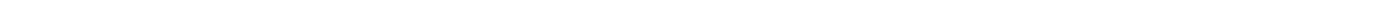

\begin{tabular}{|c|c|c|c|c|c|c|c|c|c|c|c|c|c|c|c|c|c|c|c|c|c|c|c|c|}
\hline YEAR & & & & & & UMBE & $R$ OF & DAY & $S \mathrm{IN}$ & $\alpha A$ & & & & & & & & & & & & & & $\begin{array}{l}\text { PER SECOND } \\
\text {-DAYS }\end{array}$ \\
\hline 1975 & & $\begin{array}{llll}35 & 44 & 72 & 29\end{array}$ & 26 & 13 & 3 & 5 & 8 & 6 & 14 & 6 & 7 & 4 & 8 & 71 & & 76 & 3 & 5 & 71 & & 97 & 710 & 3 & 67285.0 \\
\hline $\begin{array}{l}1976 \\
1977 \\
1978 \\
1979 \\
1980\end{array}$ & 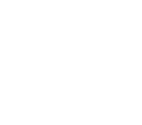 & $\begin{array}{rrrrr} & 5 & 31 & 39 & 44 \\
6 & 9 & 15 & 14 & 22 \\
15 & 14 & 40 & 56 & 46 \\
2 & 42 & 40 & 29 \\
17 & 70 & 49 & 31\end{array}$ & $\begin{array}{r}27 \\
27 \\
7 \\
84 \\
19\end{array}$ & $\begin{array}{l}39 \\
29 \\
12 \\
22 \\
12\end{array}$ & $\begin{array}{r}42 \\
16 \\
24 \\
8 \\
3\end{array}$ & $\begin{array}{r}32 \\
23 \\
22 \\
10 \\
8\end{array}$ & $\begin{array}{r}10 \\
14 \\
12 \\
5 \\
17\end{array}$ & $\begin{array}{r}4 \\
18 \\
11 \\
25 \\
7\end{array}$ & $\begin{array}{l}16 \\
17 \\
16 \\
15 \\
11\end{array}$ & $\begin{array}{r}6 \\
14 \\
10 \\
8 \\
9\end{array}$ & $\begin{array}{r}10 \\
10 \\
6 \\
13 \\
18\end{array}$ & $\begin{array}{l}5 \\
3 \\
2 \\
6 \\
7\end{array}$ & $\begin{array}{r}6 \\
3 \\
6 \\
6 \\
18\end{array}$ & $\begin{array}{l}6 \\
1 \\
5 \\
4 \\
6\end{array}$ & $\begin{array}{l}6 \\
2 \\
8 \\
6 \\
8\end{array}$ & $\begin{array}{lr}8 & 3 \\
2 & 2 \\
5 & 9 \\
0 & 1 \\
5 & 10\end{array}$ & $\begin{array}{l}3 \\
1 \\
4 \\
2 \\
9\end{array}$ & $\begin{array}{l}6 \\
2 \\
6 \\
5 \\
3\end{array}$ & $\begin{array}{l}9 \\
3 \\
8 \\
8 \\
7\end{array}$ & $\begin{array}{lr}9 \\
1 \\
6 & 10 \\
8 & 3 \\
3 & 5\end{array}$ & $\begin{array}{ll}0 & 5 \\
3 & 1 \\
5 & 7\end{array}$ & $\begin{array}{ll}5 & \\
1 & \\
7 & 4\end{array}$ & $\begin{array}{l}2 \\
3\end{array}$ & $\begin{array}{l}36883.0 \\
19173.1 \\
48241.0 \\
40989.0 \\
57349.0\end{array}$ \\
\hline
\end{tabular}
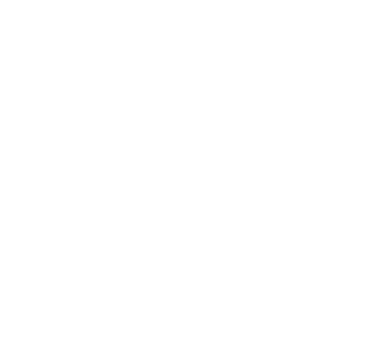

DURATION TABLE OF DISOHARGE FOR WATER YEARS 1975-81

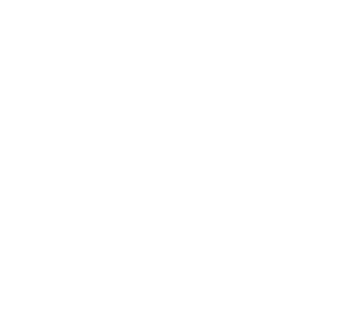

C
$\begin{array}{ccc}\text { OUBIC } & \text { ACOU- } \\ \text { FEET } & \text { MU- } & \text { PER- } \\ \text { PER TOTAL LAIED } & \text { CENT } \\ \text { CLASS SECOND DAYS DAYS DAYS } & \end{array}$

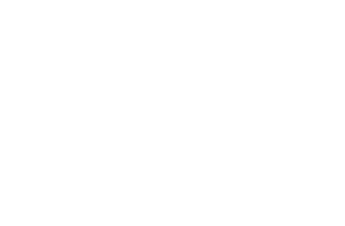

\begin{tabular}{|c|c|c|c|c|}
\hline CASS & $\begin{array}{c}\text { OBIC } \\
\text { FEET } \\
\text { PER } \\
\text { SECOND }\end{array}$ & $\begin{array}{l}\text { TOTAL } \\
\text { DAYS }\end{array}$ & $\begin{array}{l}\text { ACOJ- } \\
\text { MU- } \\
\text { LATED } \\
\text { DAYS }\end{array}$ & $\begin{array}{l}\text { PER- } \\
\text { CENT } \\
\text { DAYS }\end{array}$ \\
\hline $\begin{array}{l}27 \\
28 \\
29 \\
30 \\
31 \\
32 \\
33 \\
34\end{array}$ & $\begin{array}{r}480.0 \\
570.0 \\
680.0 \\
810.0 \\
970.0 \\
1200.0 \\
1400.0 \\
1700.0\end{array}$ & $\begin{array}{r}29 \\
44 \\
41 \\
32 \\
22 \\
16 \\
8 \\
0\end{array}$ & $\begin{array}{r}192 \\
163 \\
119 \\
78 \\
46 \\
24 \\
8 \\
0\end{array}$ & $\begin{array}{l}7.5 \\
6.4 \\
4.7 \\
3.1 \\
1.8 \\
0.9 \\
0.3 \\
0.0\end{array}$ \\
\hline
\end{tabular}


GREEN RIVER BASIN

09278700 ROCK CREEK BELOW MINERS GULOH, NEAR HANNA, UT-Continued

MONTHLY MEAN DISOHARGES, IN OBBIC FEET PER SECOND, FOR EAOH WATER YEAR

\begin{tabular}{|c|c|c|c|c|c|c|c|c|c|c|c|c|}
\hline YEAR & $\propto C T$ & NON & DEC & JAN & FEB & MAR & APR & MAY & JUNE & JULY & AUG & SEP \\
\hline 1975 & 32.0 & 27.1 & 21.9 & 20.0 & 17.0 & 15.5 & 17.8 & 152 & 866 & 790 & 172 & 72.1 \\
\hline $\begin{array}{l}1976 \\
1977 \\
1978 \\
1979 \\
1980\end{array}$ & $\begin{array}{l}46.4 \\
33.9 \\
25.7 \\
30.7 \\
31.1\end{array}$ & $\begin{array}{l}34.4 \\
23.3 \\
20.4 \\
29.5 \\
26.1\end{array}$ & $\begin{array}{l}29.9 \\
11.5 \\
21.0 \\
29.1 \\
20.5\end{array}$ & $\begin{array}{c}23.0 \\
5.35 \\
18.0 \\
23.2 \\
17.6\end{array}$ & $\begin{array}{c}20.1 \\
5.60 \\
14.3 \\
18.7 \\
18.0\end{array}$ & $\begin{array}{l}16.3 \\
7.72 \\
21.3 \\
17.3 \\
16.3\end{array}$ & $\begin{array}{l}29.3 \\
26.1 \\
55.6 \\
42.5 \\
58.1\end{array}$ & $\begin{array}{l}349 \\
89.7 \\
226 \\
395 \\
266\end{array}$ & $\begin{array}{l}430 \\
269 \\
795 \\
505 \\
969\end{array}$ & $\begin{array}{l}128 \\
71.8 \\
270 \\
142 \\
301\end{array}$ & $\begin{array}{l}59.7 \\
52.6 \\
76.5 \\
73.3 \\
97.9\end{array}$ & $\begin{array}{l}42.6 \\
33.9 \\
43.7 \\
37.1 \\
65.9\end{array}$ \\
\hline 1981 & 47.9 & 38.4 & 28.5 & 21.5 & 20.0 & 20.1 & 68.3 & 262 & 561 & 111 & 54.3 & 48.8 \\
\hline
\end{tabular}

ANNUAL PEAK DISCHARGE, IN OBBIC FEET PER SECOND, AND CORRESPONDING GAGE HEIGHT, IN FEET, FOR EAOH WATER YEAR

\begin{tabular}{|c|c|c|c|c|c|c|c|c|c|c|c|}
\hline $\begin{array}{l}\text { WATER } \\
\text { YEAR }\end{array}$ & DATE & $\begin{array}{c}\text { GAGE } \\
\text { HEIGTT }\end{array}$ & $\begin{array}{c}\text { PEAK } \\
\text { DISCHARGE }\end{array}$ & $\begin{array}{l}\text { WAIERR } \\
\text { YEAR }\end{array}$ & DATE & $\begin{array}{c}\text { GAGE } \\
\text { HEIGHT }\end{array}$ & $\begin{array}{c}\text { PEAK } \\
\text { DISCHARGE }\end{array}$ & $\begin{array}{l}\text { WATER } \\
\text { YEAR }\end{array}$ & DATE & $\begin{array}{c}\text { GAGE } \\
\text { HEIGHT }\end{array}$ & $\begin{array}{c}\text { PEAK } \\
\text { DISQHARGE }\end{array}$ \\
\hline $\begin{array}{l}1975 \\
1976\end{array}$ & $\begin{array}{l}\text { JUNE } 15,1975 \\
\text { MAY } 28,1976\end{array}$ & $\begin{array}{l}5.45 \\
4.72\end{array}$ & $\begin{array}{r}2090 \\
862\end{array}$ & $\begin{array}{l}1978 \\
1979\end{array}$ & $\begin{array}{l}\text { JUNE } 14,1978 \\
\text { MAY } 28,1979\end{array}$ & $\overline{-}$ & $\begin{array}{l}1140 \\
1540\end{array}$ & $\begin{array}{l}1980 \\
1981\end{array}$ & $\begin{array}{l}\text { JUNE } 11,1980 \\
\text { JUNE 07, } 1981\end{array}$ & 5.03 & $\begin{array}{l}2000 \\
1270\end{array}$ \\
\hline
\end{tabular}

09279000 ROCK CREEK NEAR MOUNTAIN HOME, UT

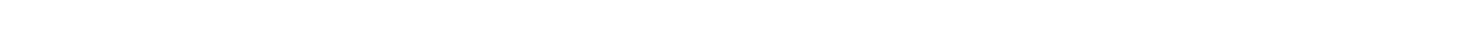
14060003 , Uintah and Ouray Indian Reservation, on right bank at Lower Stillwater damsite "B", 0.1 mi upstream from Corral Creek, $6.8 \mathrm{mi}$ downstream from South Fork, and $11.9 \mathrm{mi}$ northwest of Mountain Hame.

DRAINAGE AREA. $--147 \mathrm{mi}^{2}$.

MEAN BASIN ELEVATION. - $10,000 \mathrm{ft}$.

PERIOD OF RECORD AVAILABLE. - October 1937 to September 1981.

REVISED RECORDS.-WDR UT-77-1: Drainage area.

GAGE. -Water-stage recorder. Altitude of gage is 7,250 ft from river-profile map. Prior to Apr. 12, 1939, nonrecording gage at site $300 \mathrm{ft}$ upstream at different datum.

AVERAGE DISQHARGE. --44 years, $128 \mathrm{ft}^{3} / \mathrm{s}, 121,700$ acre-ft/yr.

EXIREMES FOR PERIOD OF RECORD.--Maximum discharge, 2,920 ft $\mathrm{ft}^{3} / \mathrm{s}$ June 18,1971 , gage height, $5.98 \mathrm{ft}$; maximum gage height, $6.02 \mathrm{ft}$ June 14, 1953; minimum recorded, $7 \mathrm{ft}^{3} / \mathrm{s}$ Mar. 13, 1940, Mar. 20, 1942 (probably caused by ice jams above station).

LCWEST MEAN DISCHARGE, IN OBBIC FEET PER SECOND, AND RANKING FOR THE INDICATED NUMBER OF CONSECUTIVE DAYS FOR EAOH CLIMATIC YEAR, APRIL 1-MAROH 31

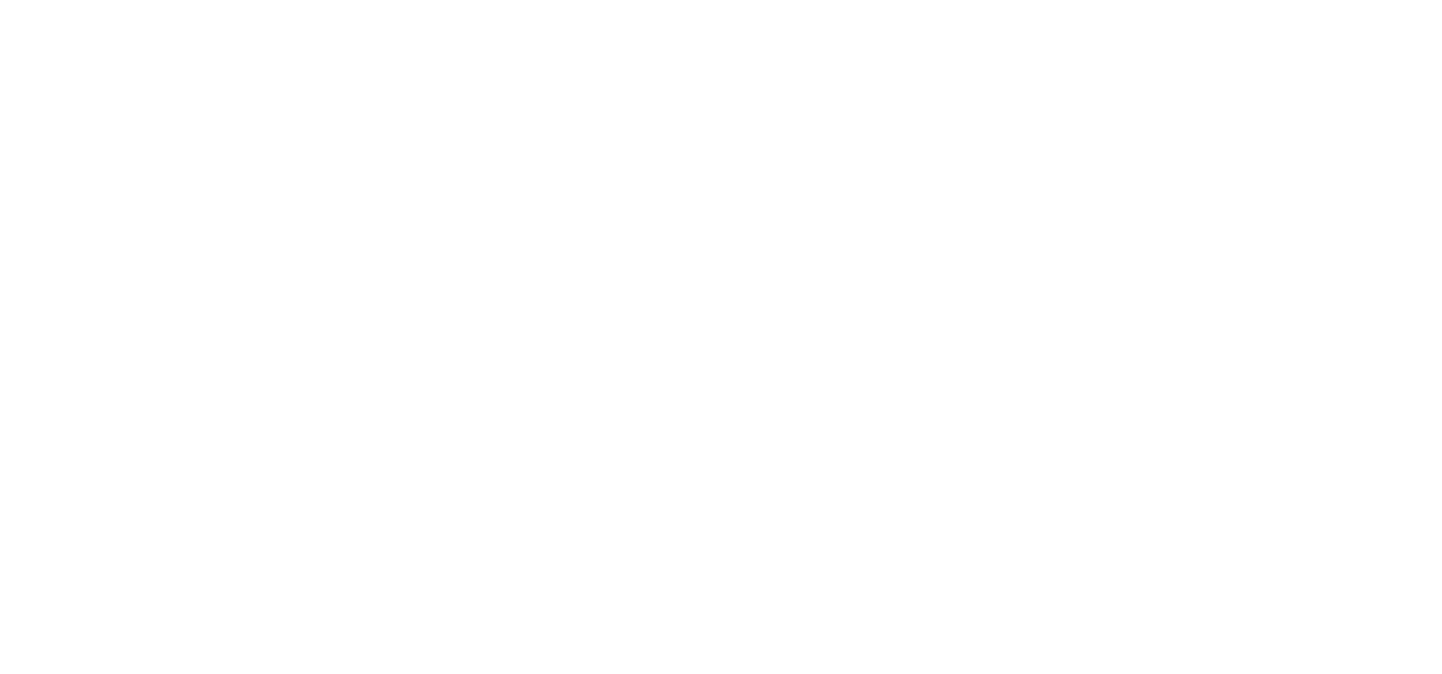


GREEN RIVER BASIN

09279000 ROCK CREEK NEAR MOUNTAIN HOME, UTh-Continued

LOWEST MEAN DISCHARGE, IN OUBIC FEET PER SECOND, AND RANKING FOR THE INDICATED NUMBER OF CONSBOUTIVE DAYS FOR EACH CLIMATIC YEAR, APRIL 1-MARCH 31-Continued

\begin{tabular}{|c|c|c|c|c|c|c|c|c|c|c|c|c|c|c|c|c|c|c|c|c|}
\hline YEAR & & & & & & & & & CONS & J. & DAYS & & & & & & & & & \\
\hline & 1 & & 3 & & 7 & & 14 & & 30 & & 60 & & 90 & & 120 & & 183 & & ALL & \\
\hline $\begin{array}{l}1961 \\
1962 \\
1963 \\
1964 \\
1965\end{array}$ & $\begin{array}{r}32.0 \\
.38 .0 \\
25.0 \\
36.0 \\
35.0\end{array}$ & $\begin{array}{r}8 \\
29 \\
4 \\
22 \\
16\end{array}$ & $\begin{array}{l}32.0 \\
39.0 \\
25.0 \\
37.0 \\
35.0\end{array}$ & $\begin{array}{r}6 \\
30 \\
2 \\
19 \\
11\end{array}$ & $\begin{array}{l}33.0 \\
39.0 \\
26.0 \\
39.0 \\
35.0\end{array}$ & $\begin{array}{r}6 \\
22 \\
2 \\
23 \\
8\end{array}$ & $\begin{array}{l}34.0 \\
41.0 \\
26.0 \\
39.0 \\
35.0\end{array}$ & $\begin{array}{r}6 \\
29 \\
2 \\
21 \\
8\end{array}$ & $\begin{array}{l}34.0 \\
45.0 \\
27.0 \\
39.0 \\
38.0\end{array}$ & $\begin{array}{r}6 \\
37 \\
2 \\
15 \\
11\end{array}$ & $\begin{array}{l}35.0 \\
51.0 \\
31.0 \\
40.0 \\
40.0\end{array}$ & $\begin{array}{r}5 \\
41 \\
3 \\
14 \\
15\end{array}$ & $\begin{array}{l}36.0 \\
53.0 \\
31.0 \\
42.0 \\
44.0\end{array}$ & $\begin{array}{r}5 \\
41 \\
2 \\
15 \\
23\end{array}$ & $\begin{array}{l}37.0 \\
57.0 \\
33.0 \\
44.0 \\
46.0\end{array}$ & $\begin{array}{r}5 \\
43 \\
2 \\
19 \\
23\end{array}$ & $\begin{array}{l}45.0 \\
80.0 \\
43.0 \\
56.0 \\
47.0\end{array}$ & $\begin{array}{r}11 \\
43 \\
7 \\
31 \\
12\end{array}$ & $\begin{array}{l}128 \\
112 \\
202 \\
156 \\
186\end{array}$ & $\begin{array}{r}8 \\
2 \\
34 \\
17 \\
27\end{array}$ \\
\hline $\begin{array}{l}1966 \\
1967 \\
1968 \\
1969 \\
1970\end{array}$ & $\begin{array}{l}37.0 \\
42.0 \\
35.0 \\
41.0 \\
37.0\end{array}$ & $\begin{array}{l}23 \\
42 \\
17 \\
40 \\
24\end{array}$ & $\begin{array}{l}37.0 \\
42.0 \\
38.0 \\
41.0 \\
37.0\end{array}$ & $\begin{array}{l}20 \\
39 \\
25 \\
35 \\
21\end{array}$ & $\begin{array}{l}38.0 \\
42.0 \\
40.0 \\
42.0 \\
39.0\end{array}$ & $\begin{array}{l}16 \\
36 \\
28 \\
37 \\
24\end{array}$ & $\begin{array}{l}38.0 \\
43.0 \\
41.0 \\
43.0 \\
40.0\end{array}$ & $\begin{array}{l}18 \\
35 \\
30 \\
36 \\
22\end{array}$ & $\begin{array}{l}41.0 \\
44.0 \\
43.0 \\
44.0 \\
40.0\end{array}$ & $\begin{array}{l}23 \\
33 \\
30 \\
34 \\
21\end{array}$ & $\begin{array}{l}44.0 \\
47.0 \\
44.0 \\
46.0 \\
42.0\end{array}$ & $\begin{array}{l}28 \\
38 \\
29 \\
33 \\
20\end{array}$ & $\begin{array}{l}48.0 \\
49.0 \\
44.0 \\
47.0 \\
42.0\end{array}$ & $\begin{array}{l}37 \\
38 \\
24 \\
33 \\
16\end{array}$ & & $\begin{array}{l}39 \\
38 \\
20 \\
33 \\
14\end{array}$ & $\begin{array}{l}66.0 \\
58.0 \\
51.0 \\
56.0 \\
51.0\end{array}$ & $\begin{array}{l}39 \\
36 \\
21 \\
32 \\
22\end{array}$ & $\begin{array}{l}259 \\
136 \\
210 \\
203 \\
190\end{array}$ & $\begin{array}{l}43 \\
11 \\
40 \\
35 \\
28\end{array}$ \\
\hline $\begin{array}{l}1971 \\
1972 \\
1973 \\
1974 \\
1975\end{array}$ & $\begin{array}{l}37.0 \\
45.0 \\
40.0 \\
37.0 \\
33.0\end{array}$ & $\begin{array}{l}25 \\
43 \\
38 \\
26 \\
11\end{array}$ & $\begin{array}{l}37.0 \\
45.0 \\
41.0 \\
38.0 \\
35.0\end{array}$ & $\begin{array}{l}22 \\
43 \\
36 \\
23 \\
12\end{array}$ & $\begin{array}{l}38.0 \\
46.0 \\
41.0 \\
38.0 \\
38.0\end{array}$ & $\begin{array}{l}17 \\
43 \\
29 \\
18 \\
19\end{array}$ & $\begin{array}{l}38.0 \\
47.0 \\
42.0 \\
38.0 \\
40.0\end{array}$ & $\begin{array}{l}19 \\
42 \\
31 \\
20 \\
23\end{array}$ & $\begin{array}{l}39.0 \\
48.0 \\
43.0 \\
40.0 \\
40.0\end{array}$ & $\begin{array}{l}16 \\
42 \\
31 \\
17 \\
18\end{array}$ & $\begin{array}{l}42.0 \\
51.0 \\
44.0 \\
42.0 \\
40.0\end{array}$ & $\begin{array}{l}21 \\
42 \\
30 \\
22 \\
16\end{array}$ & $\begin{array}{l}45.0 \\
54.0 \\
46.0 \\
44.0 \\
40.0\end{array}$ & $\begin{array}{l}27 \\
42 \\
28 \\
25 \\
12\end{array}$ & $\begin{array}{l}47.0 \\
56.0 \\
50.0 \\
46.0 \\
40.0\end{array}$ & $\begin{array}{r}29 \\
40 \\
36 \\
24 \\
9\end{array}$ & $\begin{array}{l}53.0 \\
60.0 \\
63.0 \\
54.0 \\
44.0\end{array}$ & $\begin{array}{r}28 \\
37 \\
38 \\
29 \\
9\end{array}$ & $\begin{array}{l}152 \\
203 \\
195 \\
176 \\
151\end{array}$ & $\begin{array}{l}16 \\
36 \\
30 \\
23 \\
15\end{array}$ \\
\hline 90 & 35.0 & 14 & 36.0 & 14 & 36.0 & 13 & 38.0 & 13 & 40.0 & 19 & 41.0 & 17 & 41.0 & 13 & 43.0 & 15 & 50.0 & 18 & 177 & 24 \\
\hline
\end{tabular}

HIGHEST MEAN DISCHARGE, IN CUBIC FEET PER SECOND, AND RANKING FOR THE INDICATED NUMBER OF CONSECUTIVE DAYS FOR EACH WATER YEAR, $O$ CIOBER 1-SEPTEMBER 30

YEAR

$\begin{array}{rrrrrr} & & & 3 & & \\ 1938 & 1790 & 9 & 1570 & 11 & 1440 \\ 1939 & 673 & 44 & 647 & 43 & 60 \\ 1940 & 1070 & 37 & 1010 & 38 & 91 \\ 1941 & 1300 & 27 & 1190 & 27 & 1080 \\ 1942 & 1490 & 20 & 1390 & 20 & 1300 \\ 1943 & 1190 & 32 & 1160 & 28 & 1050 \\ 1944 & 1390 & 24 & 1090 & 33 & 1060 \\ 1945 & 1050 & 38 & 1030 & 37 & 952 \\ 1946 & 1140 & 35 & 1070 & 36 & 953 \\ 1947 & 1260 & 28 & 1120 & 30 & 987 \\ 1948 & 1170 & 33 & 1110 & 31 & 1030 \\ 1949 & 1850 & 7 & 1650 & 8 & 1560 \\ 1950 & 1510 & 19 & 1460 & 15 & 1390 \\ 1951 & 1520 & 16 & 1460 & 16 & 1330 \\ 1952 & 1940 & 5 & 1900 & 1 & 1850 \\ 1953 & 2130 & 1 & 1850 & 4 & 1640 \\ 1954 & 1020 & 39 & 993 & 39 & 906 \\ 1955 & 1220 & 30 & 1140 & 29 & 981 \\ & & & & & \\ 1956 & 1650 & 11 & 1580 & 10 & 1450 \\ 1957 & 1950 & 4 & 1890 & 2 & 1680 \\ 1958 & 1550 & 14 & 1530 & 12 & 1420 \\ 1959 & 1210 & 31 & 1200 & 26 & 1100 \\ 1960 & 1140 & 36 & 1090 & 34 & 976 \\ 1961 & 698 & 43 & 644 & 44 & 567 \\ 1962 & 1400 & 22 & 1340 & 24 & 1240 \\ 1963 & 1230 & 29 & 1070 & 35 & 967 \\ 1964 & 1480 & 21 & 1350 & 21 & 1140 \\ 1965 & 2100 & 2 & 1890 & 3 & 1610 \\ & & & & & \\ 1966 & 835 & 40 & 787 & 41 & 729 \\ 1967 & 1520 & 17 & 1440 & 17 & 1400 \\ 1968 & 1810 & 8 & 1720 & 7 & 1610 \\ 1969 & 1370 & 25 & 1340 & 22 & 1260 \\ 1970 & 1160 & 34 & 1110 & 32 & 1040 \\ 1971 & 2000 & 3 & 1820 & 5 & 1740 \\ 1972 & 1700 & 10 & 1640 & 9 & 1560 \\ 1973 & 1330 & 26 & 1250 & 25 & 1140 \\ 1974 & 1520 & 18 & 1400 & 19 & 1220 \\ 1975 & 1900 & 6 & 1760 & 6 & 1440 \\ & & & & & \end{array}$

CONSECUTTVE DAYS

15

13963

$\begin{array}{rrrr} & 60 & & 90 \\ 18 & 668 & 21 & 506\end{array}$

$22 \quad 412$

120

$\begin{array}{ll} & 183 \\ 22 & 296\end{array}$

296
190
175

\begin{tabular}{ll} 
& ALL \\
\hline & \\
23 & 174 \\
40 & 129
\end{tabular}

$\begin{array}{lll}40 & 129 & 37 \\ 42 & 110 & 42\end{array}$

$\begin{array}{rrrrrr}27 & 922 & 29 & 876 & 22 & 750 \\ 18 & 1080 & 20 & 928 & 19 & 633\end{array}$

$\begin{array}{rr}18 & 1080 \\ 29 & 834\end{array}$

$28 \quad 944$

$33 \quad 781$

$\begin{array}{ll}27 & 861 \\ 36 & 639\end{array}$

$36 \quad 759$

$\begin{array}{ll}32 & 879 \\ 31 & 972\end{array}$

$8 \quad 1390$

$15 \quad 1270$

$\begin{array}{ll}38 & 611\end{array}$

$\begin{array}{rr}31 & 852 \\ 24 & 759 \\ 4 & 1040\end{array}$

$\begin{array}{rr}4 & 1040 \\ 14 & 1180\end{array}$

$\begin{array}{rr}17 & 1130 \\ 1 & 1680\end{array}$

$19 \quad 1000$

$\begin{array}{rr}1 & 1330 \\ 11 & 893 \\ 37 & 574\end{array}$

$\begin{array}{rr}4 & 1300 \\ 39 & 774\end{array}$

$33 \quad 754$

$39 \quad 664$

91320

$\begin{array}{rr}3 & 1340 \\ 13 & 1290\end{array}$

$\begin{array}{ll}9 & 1130 \\ 6 & 1230\end{array}$

$\begin{array}{rrrr}25 & 960 & 25 & 711\end{array}$

$34 \quad 815$

$34 \quad 661$

$\begin{array}{rr}44 & 477 \\ 20 & 1150\end{array}$

$43 \quad 375$

$\begin{array}{ll}18 & 981 \\ 32 & 788\end{array}$

$23 \quad 1020$

$\begin{array}{rr}71 & 925 \\ & 1250\end{array}$

$41 \quad 654$

$\begin{array}{cc}14 & 1330 \\ 6 & 1380\end{array}$

$\begin{array}{rr}6 & 1380 \\ 19 & 1160\end{array}$

$\begin{array}{rr}41 & 589 \\ 8 & 1070\end{array}$

$\begin{array}{rr}8 & 1070 \\ 5 & 1210\end{array}$

$\begin{array}{rrrr}19 & 1160 & 17 & 985 \\ & 987 & 22 & 789\end{array}$

$\begin{array}{ll}2 & 1510 \\ 7 & 1510\end{array}$

$\begin{array}{rr}2 & 1120 \\ 3 & 1200 \\ 28 & 872 \\ 23 & 813 \\ 10 & 1190\end{array}$

$\begin{array}{rrrr}21 & 983 & 23 & 813 \\ 10 & 1300 & 10 & 1190\end{array}$ $\begin{array}{ll}29 & 658 \\ 24 & 712\end{array}$

$\begin{array}{ll}24 & 712 \\ 37 & 538\end{array}$

$\begin{array}{llll}38 & 518 & 31 & 409 \\ 25 & 745 & 15 & 601\end{array}$

$\begin{array}{rrrr}30 & 478 & 36 & 350 \\ 11 & 799 & 8 & 623\end{array}$

7847

$\begin{array}{rr}13 & 764 \\ 1 & 992\end{array}$

$\begin{array}{rr}1 & 992 \\ 21 & 570\end{array}$

$\begin{array}{ll}41 & 390 \\ & 485\end{array}$

$\begin{array}{ll}8 & 739 \\ 3 & 830\end{array}$

$\begin{array}{rr}3 & 830 \\ 12 & 65 \\ 32 & 492\end{array}$

$\begin{array}{llll}34 & 485 & 33 & 371\end{array}$

$\begin{array}{llll}43 & 259 & 43 & 196 \\ 16 & 753 & 13 & 616\end{array}$

$\begin{array}{rrrr}28 & 579 & 28 & 432 \\ 20 & 788 & 10 & 588\end{array}$

\section{6}

$\begin{array}{rrrr}40 & 436 & 39 & 337 \\ 10 & 869 & 4 & 660\end{array}$

$\begin{array}{rr}10 & 869 \\ 4 & 802 \\ 15 & 737\end{array}$

$\begin{array}{rrrrrr}4 & 802 & 7 & 604 & 9 & 493 \\ 15 & 737 & 17 & 561 & 16 & 456 \\ 27 & 580 & 27 & 433 & 28 & 350\end{array}$

$\begin{array}{rrrr}9 & 777 & 11 & 592 \\ 5 & 793 & 9 & 583 \\ 23 & 634 & 24 & 503 \\ 26 & 609 & 26 & 456 \\ 6 & 945 & 3 & 715\end{array}$

$\begin{array}{ll}31 & 333 \\ 10 & 48 \\ 36 & 28\end{array}$

$\begin{array}{rr}13 & 475 \\ 1 & 654 \\ 30 & 348\end{array}$ $\begin{array}{llll}15 & 468 & 13 & 334 \\ 25 & 386 & 24 & 280\end{array}$

$\begin{array}{llll}17 & 461 & 16 & 335\end{array}$

$\begin{array}{ll}18 & 438 \\ 27 & 372\end{array}$

$\begin{array}{llll}31 & 333 & 31 & 241\end{array}$

$\begin{array}{ll}6 & 503 \\ 5 & 502\end{array}$

$\begin{array}{ll}41 & 252 \\ 34 & 304\end{array}$

$\begin{array}{llll}19 & 434 & 19 & 306\end{array}$

$\begin{array}{rrrr}8 & 487 & 10 & 342 \\ 24 & 382 & 25 & 273 \\ 33 & 302 & 34 & 220\end{array}$

$\begin{array}{llll}33 & 302 & 34 & 220 \\ 35 & 290 & 35 & 210\end{array}$

$\begin{array}{rr}43 & 164 \\ 7 & 507\end{array}$

$\begin{array}{rrrr}7 & 507 & 5 & 144\end{array}$

$\begin{array}{rr}12 & 464 \\ 2 & 627\end{array}$

$\begin{array}{ll}14 & 202 \\ 24 & 176\end{array}$

$\begin{array}{lll}13 & 194 & 14\end{array}$

$\begin{array}{lll}18 & 178 \quad 19\end{array}$

6159

$31 \quad 146 \quad 31$

$\begin{array}{lll}9 & 200 & 10 \\ 8 & 128 & 38\end{array}$

$\begin{array}{rrr}7 & 202 & 8 \\ 6 & 208 & 6\end{array}$

$\begin{array}{lll}2 & 196 & 12 \\ 1 & 261 & 1\end{array}$

$\begin{array}{lll}30 & 152 & 28 \\ 41 & 117 & 41\end{array}$

$32 \quad 131 \quad 35$

$\begin{array}{lll}11 & 192 & 16 \\ 25 & 165 & 25\end{array}$

$\begin{array}{lll}33 & 131 & 36 \\ 36 & 132 & 33\end{array}$

$\begin{array}{lrr}43 & 94.0 \quad 43\end{array}$

$\begin{array}{rlr}5 & 221 & 3 \\ 28 & 150 & 30\end{array}$

$\begin{array}{rrrrrrr}11 & 478 & 11 & 345 & 10 & 199 & 11 \\ 14 & 461 & 15 & 327 & 16 & 194 & 13 \\ 23 & 409 & 23 & 298 & 21 & 181 & 18 \\ 26 & 363 & 27 & 256 & 27 & 155 & 27 \\ 3 & 568 & 3 & 394 & 3 & 220 & 4\end{array}$ $\begin{array}{lll}19 & 178 & 20\end{array}$

$\begin{array}{rrr}17 & 190 & 17\end{array}$

$\begin{array}{lllll}29 & 251 & 29 & 151 & 29\end{array}$ 
09279000 ROCK CREEK NEAR MOUNTAIN HOME, UT-CONTInUEd

HIGHEST MEAN DISCHARGE, IN OUBIC FEET PER SECOND, AND RANKING FOR THE INDICATED NUMBER OF CONSECUTTVE DAYS FOR EACH WATER YEAR, $O$ CIOBER 1-SEPTEMBER 30-Continued

YEAR

$\begin{array}{rrrr} & 1 & & 3 \\ 1976 & 826 & 41 & 810 \\ 1977 & 720 & 42 & 698 \\ 1978 & 1550 & 15 & 1470 \\ 1979 & 1600 & 12 & 1410 \\ 1980 & 1550 & 13 & 1510 \\ 1981 & 1390 & 23 & 1340\end{array}$

CONSECUTIVE DAYS
30

$\begin{array}{rr} & 7 \\ 40 & 805 \\ 42 & 628 \\ 14 & 1430 \\ 18 & 1080 \\ 13 & 1340 \\ 23 & 1150\end{array}$

$\begin{array}{lr} & 15 \\ 40 & 736 \\ 42 & 466 \\ 12 & 1240 \\ 26 & 893 \\ 16 & 1200 \\ 22 & 954\end{array}$

$\begin{array}{ll}40 & 641 \\ 44 & 303 \\ 15 & 996 \\ 30 & 758 \\ 16 & 968\end{array}$

$\begin{array}{llll}36 & 445 & 37 & 340 \\ 44 & 211 & 44 & 175 \\ 14 & 695 & 19 & 520 \\ 31 & 502 & 32 & 373 \\ 17 & 678 & 20 & 523\end{array}$

$\begin{array}{ll} & 120 \\ 38 & 276 \\ 44 & 150 \\ 21 & 417 \\ 32 & 303 \\ 20 & 423 \\ 37 & 278\end{array}$

$\begin{array}{ll} & 183 \\ 39 & 201 \\ 44 & 117 \\ 21 & 298 \\ 33 & 219 \\ 20 & 303\end{array}$

DURATION OF DISCHARGE FOR EACH WATER YEAR

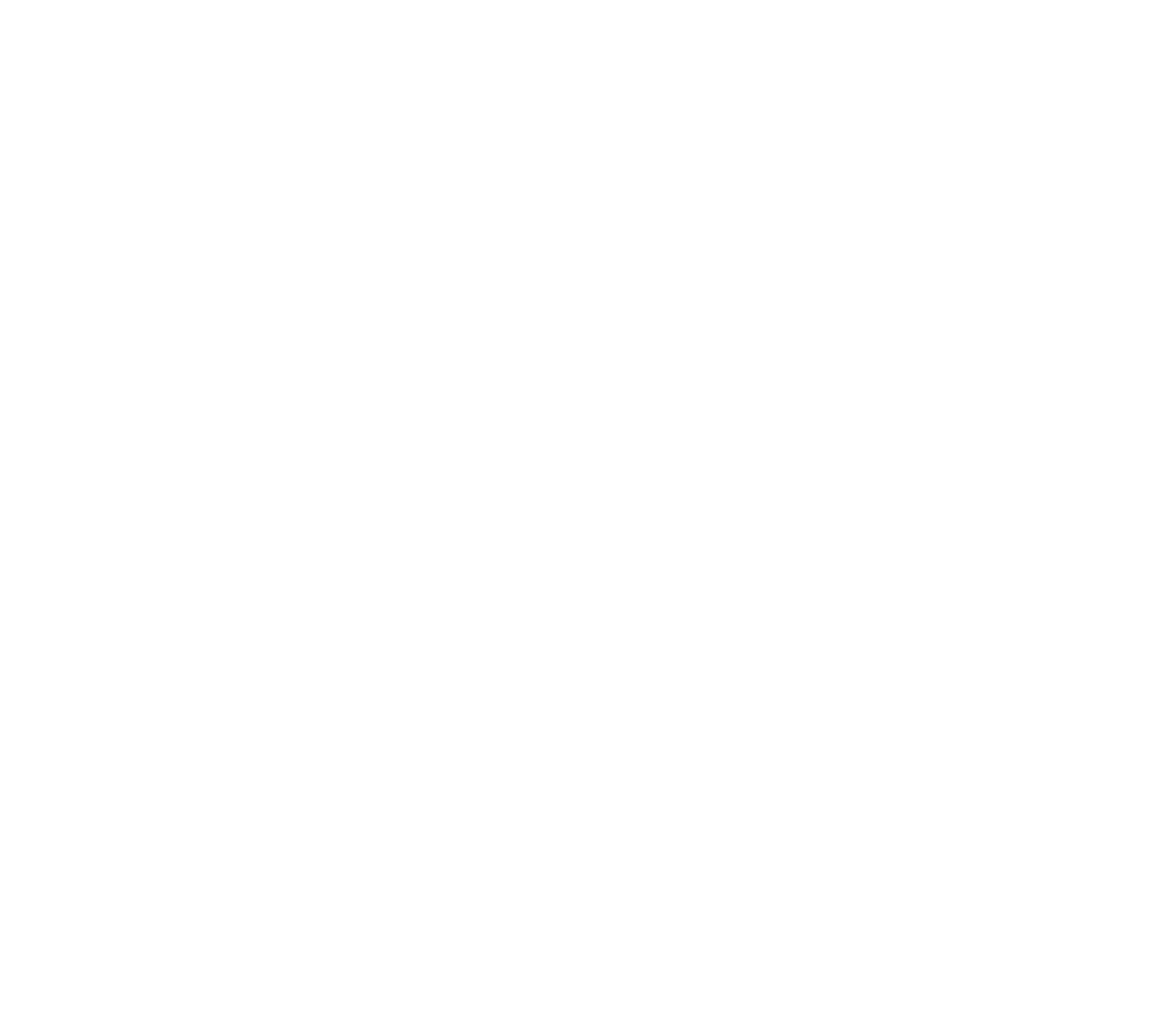


GREEN RTVER BASTN

09279000 ROCK CREEK NEAR MOUNTAIN HOME, UT-Continued

DURATION TABLE OF DISCHARGE FOR WATER YEARS 1938-81

\begin{tabular}{|c|c|c|c|c|c|c|c|c|c|c|c|c|c|c|c|c|c|c|c|}
\hline CLASS & $\begin{array}{c}\text { OBBIC } \\
\text { FEET } \\
\text { PER } \\
\text { SECOND }\end{array}$ & TOTAL & $\begin{array}{c}\text { ACOU- } \\
\text { LATED } \\
\text { DAYS }\end{array}$ & $\begin{array}{l}\text { PER- } \\
\text { CENT } \\
\text { DAYS }\end{array}$ & CLASS & $\begin{array}{c}\text { OUBIC } \\
\text { FEET } \\
\text { PER } \\
\text { SECOND }\end{array}$ & TOTAL & $\begin{array}{c}\text { ACOU- } \\
\text { MU- } \\
\text { LATED } \\
\text { DAYS }\end{array}$ & $\begin{array}{l}\text { PER- } \\
\text { CENT } \\
\text { DAYS }\end{array}$ & CLASS & $\begin{array}{c}\text { OUBIC } \\
\text { FEET } \\
\text { PER } \\
\text { SEOOND }\end{array}$ & $\begin{array}{l}\text { TOTAL } \\
\text { DAYS }\end{array}$ & $\begin{array}{c}\text { ACOJ- } \\
\text { MU- } \\
\text { LATED } \\
\text { DAYS }\end{array}$ & $\begin{array}{l}\text { PER- } \\
\text { CENT } \\
\text { DAYS }\end{array}$ & & $\begin{array}{c}\text { AJBIC } \\
\text { FEET } \\
\text { PER } \\
\text { SECOND }\end{array}$ & $\begin{array}{r}\text { TOTAL } \\
\text { DAYS }\end{array}$ & $\begin{array}{c}\text { ACOJ- } \\
\text { MU- } \\
\text { LATED } \\
\text { DAYS }\end{array}$ & $\begin{array}{l}\text { PER- } \\
\text { CENT } \\
\text { DAYS }\end{array}$ \\
\hline $\begin{array}{l}0 \\
1 \\
2 \\
3 \\
4 \\
5 \\
6 \\
7 \\
8\end{array}$ & $\begin{array}{r}0.00 \\
22.00 \\
25.00 \\
29.00 \\
33.00 \\
38.00 \\
44.00 \\
50.00 \\
58.00\end{array}$ & $\begin{array}{r}0 \\
23 \\
106 \\
113 \\
635 \\
1944 \\
2052 \\
2036 \\
1285\end{array}$ & $\begin{array}{r}16071 \\
16071 \\
16048 \\
15942 \\
15829 \\
15194 \\
13250 \\
11198 \\
9162\end{array}$ & $\begin{array}{r}100.0 \\
100.0 \\
99.9 \\
99.2 \\
98.5 \\
94.5 \\
82.4 \\
69.7 \\
57.0\end{array}$ & $\begin{array}{r}9 \\
10 \\
11 \\
12 \\
13 \\
14 \\
15 \\
16 \\
17\end{array}$ & $\begin{array}{r}66.00 \\
76.00 \\
88.00 \\
100.00 \\
120.00 \\
130.00 \\
150.00 \\
170.00 \\
200.00\end{array}$ & $\begin{array}{r}1071 \\
995 \\
669 \\
746 \\
295 \\
424 \\
326 \\
384 \\
279\end{array}$ & $\begin{array}{l}7877 \\
6806 \\
5811 \\
5142 \\
4396 \\
4101 \\
3677 \\
3351 \\
2967\end{array}$ & $\begin{array}{l}49.0 \\
42.3 \\
36.2 \\
32.0 \\
27.4 \\
25.5 \\
22.9 \\
20.9 \\
18.5\end{array}$ & $\begin{array}{l}18 \\
19 \\
20 \\
21 \\
22 \\
23 \\
24 \\
25 \\
26\end{array}$ & $\begin{array}{l}230.0 \\
260.0 \\
300.0 \\
350.0 \\
400.0 \\
460.0 \\
530.0 \\
610.0 \\
700.0\end{array}$ & $\begin{array}{l}197 \\
222 \\
234 \\
189 \\
216 \\
208 \\
240 \\
217 \\
205\end{array}$ & $\begin{array}{r}2688 \\
2491 \\
2269 \\
2035 \\
1846 \\
1630 \\
1422 \\
1182 \\
965\end{array}$ & $\begin{array}{r}16.7 \\
15.5 \\
14.1 \\
12.7 \\
11.5 \\
.1 \\
8.8 \\
7.4 \\
6.0\end{array}$ & $\begin{array}{l}27 \\
28 \\
29 \\
30 \\
31 \\
32 \\
33 \\
34\end{array}$ & $\begin{array}{r}800.0 \\
920.0 \\
1100.0 \\
1200.0 \\
1400.0 \\
1600.0 \\
1800.0 \\
2100.0\end{array}$ & $\begin{array}{r}198 \\
222 \\
84 \\
121 \\
94 \\
23 \\
16 \\
2\end{array}$ & $\begin{array}{r}760 \\
562 \\
340 \\
256 \\
135 \\
41 \\
18 \\
2\end{array}$ & $\begin{array}{l}4.7 \\
3.5 \\
2.1 \\
1.6 \\
0.8 \\
0.3 \\
0.1 \\
0.0\end{array}$ \\
\hline
\end{tabular}

MONIHLY MEAN DISCHARGES, IN OUBIC FEET PER SECOND, FOR EACH WATER YEAR

\begin{tabular}{|c|c|c|c|c|c|c|c|c|c|c|c|c|}
\hline YEAR & $\infty T$ & NON & $\mathrm{DEC}$ & JAN & FEB & MAR & AP1. & MAY & JUNE & JLY & AUG & SEP \\
\hline $\begin{array}{l}1938 \\
1939 \\
1940\end{array}$ & $\begin{array}{c}65.0 \\
102 \\
80.0\end{array}$ & $\begin{array}{l}59.6 \\
81.3 \\
52.3\end{array}$ & $\begin{array}{l}54.3 \\
60.6 \\
35.7\end{array}$ & $\begin{array}{l}44.1 \\
57.0 \\
31.5\end{array}$ & $\begin{array}{l}43.8 \\
55.0 \\
33.8\end{array}$ & $\begin{array}{l}44.1 \\
56.9 \\
38.0\end{array}$ & $\begin{array}{c}97.6 \\
112 \\
64.4\end{array}$ & $\begin{array}{l}489 \\
517 \\
549\end{array}$ & $\begin{array}{l}799 \\
263 \\
208\end{array}$ & $\begin{array}{c}206 \\
105 \\
73.4\end{array}$ & $\begin{array}{c}105 \\
63.0 \\
46.3\end{array}$ & $\begin{array}{l}83.7 \\
75.4 \\
103\end{array}$ \\
\hline $\begin{array}{l}1941 \\
1942 \\
1943 \\
1944 \\
1945\end{array}$ & $\begin{array}{c}138 \\
104 \\
=1.8 \\
66.9 \\
65.0\end{array}$ & $\begin{array}{l}79.8 \\
95.3 \\
54.6 \\
52.3 \\
54.1\end{array}$ & $\begin{array}{l}53.0 \\
71.9 \\
51.9 \\
43.6 \\
43.7\end{array}$ & $\begin{array}{l}45.0 \\
60.0 \\
45.5 \\
43.5 \\
43.1\end{array}$ & $\begin{array}{l}47.3 \\
50.0 \\
46.9 \\
41.9 \\
43.1\end{array}$ & $\begin{array}{l}49.6 \\
46.7 \\
48.4 \\
42.3 \\
43.4\end{array}$ & $\begin{array}{c}61.6 \\
103 \\
167 \\
51.9 \\
54.3\end{array}$ & $\begin{array}{l}621 \\
345 \\
589 \\
415 \\
367\end{array}$ & $\begin{array}{l}797 \\
824 \\
726 \\
835 \\
636\end{array}$ & $\begin{array}{l}284 \\
237 \\
304 \\
365 \\
306\end{array}$ & $\begin{array}{l}146 \\
103 \\
146 \\
110 \\
160\end{array}$ & $\begin{array}{l}95.0 \\
75.3 \\
78.2 \\
66.2 \\
89.5\end{array}$ \\
\hline $\begin{array}{l}1946 \\
1947 \\
1948 \\
1949 \\
1950\end{array}$ & $\begin{array}{l}57.9 \\
65.7 \\
71.7 \\
53.0 \\
72.4\end{array}$ & $\begin{array}{l}60.7 \\
58.8 \\
62.3 \\
48.4 \\
62.1\end{array}$ & $\begin{array}{l}48.3 \\
50.2 \\
54.3 \\
47.4 \\
53.2\end{array}$ & $\begin{array}{l}45.7 \\
43.9 \\
46.7 \\
47.2 \\
55.0\end{array}$ & $\begin{array}{l}44.0 \\
42.7 \\
40.8 \\
43.4 \\
47.8\end{array}$ & $\begin{array}{l}48.1 \\
49.2 \\
40.2 \\
41.9 \\
47.6\end{array}$ & $\begin{array}{c}159 \\
72.1 \\
55.9 \\
107 \\
105\end{array}$ & $\begin{array}{l}463 \\
690 \\
479 \\
486 \\
365\end{array}$ & $\begin{array}{r}534 \\
755 \\
438 \\
1020 \\
1149\end{array}$ & $\begin{array}{l}144 \\
334 \\
114 \\
339 \\
338\end{array}$ & $\begin{array}{c}87.6 \\
145 \\
79.7 \\
114 \\
112\end{array}$ & $\begin{array}{l}58.4 \\
90.4 \\
53.3 \\
70.2 \\
86.7\end{array}$ \\
\hline $\begin{array}{l}1951 \\
1952 \\
1953 \\
1954 \\
1955\end{array}$ & $\begin{array}{l}65.1 \\
83.5 \\
69.5 \\
58.7 \\
54.0\end{array}$ & $\begin{array}{l}59.1 \\
62.6 \\
55.5 \\
53.1 \\
46.9\end{array}$ & $\begin{array}{l}53.5 \\
58.9 \\
52.3 \\
45.2 \\
39.7\end{array}$ & $\begin{array}{l}47.9 \\
50.0 \\
50.0 \\
42.6 \\
40.5\end{array}$ & $\begin{array}{l}47.2 \\
50.0 \\
43.7 \\
41.5 \\
38.0\end{array}$ & $\begin{array}{l}45.3 \\
43.4 \\
44.1 \\
42.4 \\
37.0\end{array}$ & $\begin{array}{c}68.2 \\
105 \\
60.7 \\
79.9 \\
44.9\end{array}$ & $\begin{array}{l}426 \\
685 \\
131 \\
533 \\
393\end{array}$ & $\begin{array}{r}924 \\
1266 \\
887 \\
230 \\
545\end{array}$ & $\begin{array}{l}344 \\
413 \\
235 \\
126 \\
149\end{array}$ & $\begin{array}{c}181 \\
210 \\
129 \\
79.4 \\
113\end{array}$ & $\begin{array}{c}85.1 \\
112 \\
70.0 \\
65.6 \\
73.4\end{array}$ \\
\hline $\begin{array}{l}1956 \\
1957 \\
1958 \\
1959 \\
1960\end{array}$ & $\begin{array}{l}57.1 \\
49.6 \\
82.3 \\
52.5 \\
90.6\end{array}$ & $\begin{array}{l}53.4 \\
43.1 \\
67.7 \\
46.9 \\
65.8\end{array}$ & $\begin{array}{l}57.5 \\
42.3 \\
52.9 \\
39.6 \\
43.5\end{array}$ & $\begin{array}{l}49.3 \\
37.2 \\
46.1 \\
34.2 \\
41.3\end{array}$ & $\begin{array}{l}42.8 \\
33.5 \\
45.3 \\
35.0 \\
39.9\end{array}$ & $\begin{array}{l}45.7 \\
39.9 \\
42.0 \\
38.2 \\
46.1\end{array}$ & $\begin{array}{l}86.5 \\
44.0 \\
66.6 \\
57.5 \\
85.5\end{array}$ & $\begin{array}{l}630 \\
147 \\
595 \\
213 \\
382\end{array}$ & $\begin{array}{r}820 \\
1195 \\
685 \\
711 \\
559\end{array}$ & $\begin{array}{l}163 \\
447 \\
144 \\
180 \\
119\end{array}$ & $\begin{array}{c}80.9 \\
140 \\
80.8 \\
93.2 \\
60.1\end{array}$ & $\begin{array}{l}53.9 \\
88.2 \\
68.3 \\
72.1 \\
57.7\end{array}$ \\
\hline $\begin{array}{l}1961 \\
1962 \\
1963 \\
1964 \\
1965\end{array}$ & $\begin{array}{c}63.7 \\
152 \\
72.1 \\
87.4 \\
52.1\end{array}$ & $\begin{array}{l}53.7 \\
98.2 \\
51.6 \\
71.8 \\
48.2\end{array}$ & $\begin{array}{l}41.6 \\
69.5 \\
38.0 \\
52.0 \\
52.4\end{array}$ & $\begin{array}{l}35.9 \\
55.2 \\
27.7 \\
45.8 \\
50.8\end{array}$ & $\begin{array}{l}34.6 \\
54.1 \\
35.6 \\
40.3 \\
40.0\end{array}$ & $\begin{array}{l}37.6 \\
48.9 \\
33.3 \\
40.4 \\
39.5\end{array}$ & $\begin{array}{c}44.6 \\
177 \\
47.8 \\
50.7 \\
77.5\end{array}$ & $\begin{array}{l}274 \\
484 \\
414 \\
448 \\
262\end{array}$ & $\begin{array}{r}238 \\
965 \\
684 \\
870 \\
1143\end{array}$ & $\begin{array}{l}69.4 \\
352 \\
178 \\
395 \\
799\end{array}$ & $\begin{array}{l}68.9 \\
117 \\
108 \\
117 \\
258\end{array}$ & $\begin{array}{c}168 \\
72.8 \\
103 \\
66.7 \\
163\end{array}$ \\
\hline $\begin{array}{l}1966 \\
1967 \\
1968 \\
1969 \\
1970\end{array}$ & $\begin{array}{c}108 \\
79.4 \\
75.3 \\
77.8 \\
71.8\end{array}$ & $\begin{array}{l}76.8 \\
61.3 \\
50.8 \\
59.1 \\
58.7\end{array}$ & $\begin{array}{l}65.8 \\
58.1 \\
47.5 \\
52.7 \\
46.9\end{array}$ & $\begin{array}{l}48.9 \\
52.3 \\
44.8 \\
49.2 \\
42.4\end{array}$ & $\begin{array}{l}40.9 \\
47.2 \\
44.6 \\
48.5 \\
43.3\end{array}$ & $\begin{array}{l}54.1 \\
47.6 \\
43.8 \\
44.7 \\
40.4\end{array}$ & $\begin{array}{c}108 \\
55.2 \\
52.0 \\
106 \\
41.8\end{array}$ & $\begin{array}{l}547 \\
349 \\
203 \\
831 \\
370\end{array}$ & $\begin{array}{r}312 \\
988 \\
1209 \\
612 \\
690\end{array}$ & $\begin{array}{l}130 \\
560 \\
346 \\
217 \\
209\end{array}$ & $\begin{array}{l}93.5 \\
164 \\
196 \\
121 \\
100\end{array}$ & $\begin{array}{l}85.8 \\
102 \\
104 \\
82.7 \\
99.7\end{array}$ \\
\hline $\begin{array}{l}1971 \\
1972 \\
1973 \\
1974 \\
1975\end{array}$ & $\begin{array}{c}68.2 \\
75.4 \\
101 \\
72.6 \\
56.3\end{array}$ & $\begin{array}{l}58.8 \\
61.8 \\
76.6 \\
63.8 \\
48.4\end{array}$ & $\begin{array}{l}51.3 \\
61.6 \\
61.7 \\
51.7 \\
40.6\end{array}$ & $\begin{array}{l}52.1 \\
55.5 \\
50.1 \\
47.5 \\
40.0\end{array}$ & $\begin{array}{l}41.6 \\
47.6 \\
44.8 \\
39.8 \\
40.0\end{array}$ & $\begin{array}{l}42.4 \\
59.9 \\
43.5 \\
43.6 \\
40.0\end{array}$ & $\begin{array}{l}97.5 \\
73.7 \\
65.7 \\
56.6 \\
45.7\end{array}$ & $\begin{array}{l}325 \\
465 \\
489 \\
556 \\
169\end{array}$ & $\begin{array}{r}1081 \\
1059 \\
708 \\
634 \\
994\end{array}$ & $\begin{array}{l}356 \\
209 \\
280 \\
160 \\
880\end{array}$ & $\begin{array}{c}136 \\
93.1 \\
136 \\
77.7 \\
183\end{array}$ & $\begin{array}{c}81.6 \\
69.7 \\
108 \\
52.6 \\
89.6\end{array}$ \\
\hline $\begin{array}{l}1976 \\
1977 \\
1978 \\
1979 \\
1980\end{array}$ & $\begin{array}{l}68.1 \\
52.1 \\
52.1 \\
48.5 \\
50.3\end{array}$ & $\begin{array}{l}51.7 \\
36.8 \\
42.5 \\
49.0 \\
42.5\end{array}$ & $\begin{array}{l}47.8 \\
26.7 \\
40.0 \\
44.0 \\
38.8\end{array}$ & $\begin{array}{l}41.0 \\
25.5 \\
36.7 \\
43.0 \\
42.0\end{array}$ & $\begin{array}{l}39.9 \\
26.3 \\
35.4 \\
37.9 \\
41.5\end{array}$ & $\begin{array}{l}36.4 \\
28.7 \\
41.1 \\
37.6 \\
37.5\end{array}$ & $\begin{array}{l}52.6 \\
54.1 \\
77.4 \\
60.9 \\
84.8\end{array}$ & $\begin{array}{l}382 \\
118 \\
249 \\
421 \\
295\end{array}$ & $\begin{array}{l}474 \\
300 \\
993 \\
532 \\
944\end{array}$ & $\begin{array}{l}149 \\
101 \\
302 \\
153 \\
314\end{array}$ & $\begin{array}{c}83.5 \\
73.3 \\
108 \\
90.2 \\
101\end{array}$ & $\begin{array}{l}64.4 \\
58.3 \\
65.6 \\
55.5 \\
84.7\end{array}$ \\
\hline 1981 & 68.3 & 57.0 & 48.2 & 41.7 & 42.0 & 40.9 & 85.3 & 277 & 596 & 132 & 74.9 & 69.0 \\
\hline
\end{tabular}


GREEN RIVER BASIN

09279000 ROCK CREEK NEAR WOUNTAIN HONE, UT-Continued

ANNUAL PEAK DISCHARGE, IN CUBIC FEET PER SECOND, AND CORRESPONDING GAGE HEICHT, IN FEET, FOR EACH WATER YEAR

\begin{tabular}{|c|c|c|c|c|c|c|c|c|c|c|c|}
\hline $\begin{array}{l}\text { WATER } \\
\text { YEAR }\end{array}$ & DATE & $\begin{array}{c}\text { GAGE } \\
\text { HEIGHT }\end{array}$ & $\begin{array}{c}\text { PEAK } \\
\text { DISCHARGE }\end{array}$ & $\begin{array}{l}\text { WATER } \\
\text { YEAR }\end{array}$ & DATE & $\begin{array}{c}\text { GAGE } \\
\text { HEIGHT }\end{array}$ & $\begin{array}{c}\text { PEAK } \\
\text { DISCHARGE }\end{array}$ & $\begin{array}{l}\text { WATER } \\
\text { YEAR }\end{array}$ & DATE & $\begin{array}{c}\text { GAGE } \\
\text { HEIGHT }\end{array}$ & $\begin{array}{c}\text { PEAK } \\
\text { DISCHARGE }\end{array}$ \\
\hline $\begin{array}{l}1938 \\
1939 \\
1940 \\
1941 \\
1942 \\
1943 \\
1944 \\
1945 \\
1946 \\
1947 \\
1948 \\
1949 \\
1950 \\
1951 \\
1952\end{array}$ & $\begin{array}{l}\text { JUNE } 04,1938 \\
\text { MAY } 16,1939 \\
\text { MAY } 16,1940 \\
\text { JUNE } 18,1941 \\
\text { JUNE } 08,1942 \\
\text { MAY } 30,1943 \\
\text { JUNE } 26,1944 \\
\text { JUNE } 22,1945 \\
\text { JUNE 06, } 1946 \\
\text { JUNE } 08,1947 \\
\text { MAY 24, } 1948 \\
\text { JUNE 19, } 1949 \\
\text { JUNE } 07,1950 \\
\text { JUNE } 17,1951 \\
\text { JUNE } 10,1952\end{array}$ & $\begin{array}{r}11.19 \\
4.09 \\
4.71 \\
5.06 \\
5.25 \\
4.94 \\
5.32 \\
4.59 \\
4.68 \\
4.71 \\
4.81 \\
5.73 \\
5.13 \\
5.34 \\
5.81\end{array}$ & $\begin{array}{r}1790 \\
745 \\
1200 \\
1690 \\
1730 \\
1340 \\
1630 \\
1230 \\
1330 \\
1330 \\
1310 \\
2170 \\
1670 \\
1810 \\
2350\end{array}$ & $\begin{array}{l}1953 \\
1954 \\
1955 \\
1956 \\
1957 \\
1958 \\
1959 \\
1960 \\
1961 \\
1962 \\
1963 \\
1964 \\
1965 \\
1966 \\
1967\end{array}$ & $\begin{array}{l}\text { JUNE } 14,1953 \\
\text { MAY } 20,1954 \\
\text { JUNE } 09,1955 \\
\text { JUNE } 02,1956 \\
\text { JUNE } 08,1957 \\
\text { MAY } 28,1958 \\
\text { JUNE } 08,1959 \\
\text { JUNE } 03,1960 \\
\text { MAY } 28,1961 \\
\text { JUNE } 21,1962 \\
\text { JUNE } 15,1963 \\
\text { JUNE } 07,1964 \\
\text { JUNE } 13,1965 \\
\text { MAY } 09,1966 \\
\text { JUNE } 21,1967\end{array}$ & $\begin{array}{l}6.02 \\
4.66 \\
4.96 \\
5.49 \\
5.72 \\
5.15 \\
4.74 \\
4.75 \\
3.97 \\
5.00 \\
4.72 \\
5.02 \\
5.75 \\
4.17 \\
5.24\end{array}$ & $\begin{array}{r}2390 \\
1230 \\
1460 \\
1990 \\
2360 \\
1710 \\
1400 \\
1380 \\
830 \\
1610 \\
1430 \\
1700 \\
2330 \\
925 \\
1770\end{array}$ & $\begin{array}{l}1968 \\
1969 \\
1970 \\
1971 \\
1972 \\
1973 \\
1974 \\
1975 \\
1976 \\
1977 \\
1978 \\
1979 \\
1980 \\
1981\end{array}$ & $\begin{array}{lll}\text { JUNE } & 21, & 1968 \\
\text { MAY } & 28,1969 \\
\text { JUNE } 04, & 1970 \\
\text { JUNE } 18, & 1971 \\
\text { JUNE } 01, & 1972 \\
\text { JUNE } & 10, & 1973 \\
\text { MAY } & 29, & 1974 \\
\text { JUNE } & 16, & 1975 \\
\text { MAY } & 29, & 1976 \\
\text { JUNE } 03, & 1977 \\
\text { JUNE } 14, & 1978 \\
\text { MAY } & 29,1979 \\
\text { JUNE } & 11, & 1980 \\
\text { JUNE } & 07, & 1981\end{array}$ & $\begin{array}{l}5.60 \\
4.95 \\
4.75 \\
5.98 \\
5.29 \\
4.94 \\
5.13 \\
5.54 \\
4.22 \\
4.22 \\
5.23 \\
5.05 \\
4.76\end{array}$ & $\begin{array}{r}2150 \\
1550 \\
1360 \\
2920 \\
1940 \\
1520 \\
1720 \\
2260 \\
917 \\
924 \\
1550 \\
1880 \\
1790 \\
1570\end{array}$ \\
\hline
\end{tabular}

MAGNITUDE AND PRCBABILITY OF ANNUAL LOWEST MEAN DISOHARGE BASEDD ON OIMATIC YEARS 1939-81

\begin{tabular}{|c|c|c|c|c|c|c|}
\hline \multirow{2}{*}{$\begin{array}{l}\text { PERIOD } \\
\text { (CON- } \\
\text { SEQJ- } \\
\text { TTVE } \\
\text { DAYS) }\end{array}$} & \multicolumn{6}{|c|}{$\begin{array}{l}\text { DISGHARGE, IN OSBIC FEET PER SECOND, FOR } \\
\text { INDICATED RECURRENCE INTERNAL, IN YEARS, AND } \\
\text { ANNUAL NONEXCEEDANCE PROBABIIITY, IN PERCENT }\end{array}$} \\
\hline & $\begin{array}{c}2 \\
50 \%\end{array}$ & $\begin{array}{c}5 \\
208\end{array}$ & $\begin{array}{l}10 \\
108\end{array}$ & $\begin{array}{l}20 \\
58\end{array}$ & $\begin{array}{l}50 \\
28\end{array}$ & $\begin{array}{r}100 \\
18\end{array}$ \\
\hline
\end{tabular}

$\begin{array}{rllllll}1 & 36 & 31 & 29 & 26 & 23 & 21 \\ 7 & 39 & 34 & 31 & 28 & 25 & 23 \\ 14 & 40 & 35 & 32 & 29 & 26 & 24 \\ 30 & 41 & 36 & 33 & 30 & 27 & 25 \\ 60 & 43 & 37 & 34 & 31 & 28 & 26 \\ 90 & 44 & 38 & 35 & 32 & 29 & 27\end{array}$

MAGNITUDE AND PRCBABILITY OF ANNUAL HIGHEST MEAN DISGHARGE BASED ON WATER YEARS 1938-81

\begin{tabular}{|c|c|c|c|c|c|c|}
\hline \multirow{2}{*}{$\begin{array}{l}\text { PERIOD } \\
\text { (CON- } \\
\text { SEOU- } \\
\text { TIVE } \\
\text { DAYS) }\end{array}$} & \multicolumn{6}{|c|}{$\begin{array}{l}\text { DISCHARGE, IN GUBIC FEET PER SECOND, FOR } \\
\text { INDICATED RECURRENCE INTERNAL, IN YEARS, AND } \\
\text { ANNUAL EXCEEDANCE PROBABIIITY, IN PERCENT }\end{array}$} \\
\hline & $\begin{array}{c}2 \\
508\end{array}$ & $\begin{array}{c}5 \\
208\end{array}$ & $\begin{array}{l}10 \\
108\end{array}$ & $\begin{array}{l}25 \\
48\end{array}$ & $\begin{array}{l}50 \\
2.8\end{array}$ & $\begin{array}{r}100 \\
18\end{array}$ \\
\hline $\begin{array}{r}1 \\
3 \\
7 \\
15\end{array}$ & $\begin{array}{l}1400 \\
1310 \\
1190 \\
1030\end{array}$ & $\begin{array}{l}1730 \\
1620 \\
1470 \\
1290\end{array}$ & $\begin{array}{l}1910 \\
1770 \\
1620 \\
1430\end{array}$ & $\begin{array}{l}2080 \\
1920 \\
1770 \\
1570\end{array}$ & $\begin{array}{l}2190 \\
2020 \\
1860 \\
1660\end{array}$ & $\begin{array}{l}2280 \\
2100 \\
1940 \\
1730\end{array}$ \\
\hline
\end{tabular}

09279100 ROCK CREEK NEAR TALMAGE, UT

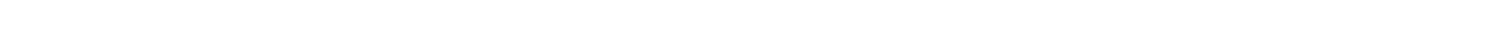
14060003 , Uintah and Ouray Indian Reservation, on left bank $1.5 \mathrm{mi}$ upstream fram mouth, 4.1 mi southwest of Talmage, and $11.1 \mathrm{mi}$ northwest of Duchesne.

DRAINAGE AREA. $--238 \mathrm{mi}^{2}$.

MEAN BASIN ELEVATION. $--9,400 \mathrm{ft}$.

PERIOD OF RECORD AVAILABLE.-October 1963 to September 1981.

REVISED RECORDS. -WDR UT-77-1: Drainage area.

GAGE.-Water-stage recorder. Datum of gage is 6,119.3 ft NGVD OF 1929.

REMARKS.--Small diversions for irrigation above station.

AVERAGE DISCHARGE. --18 years, $177 \mathrm{ft}^{3} / \mathrm{s}, 128,200$ acre-ft/yr.

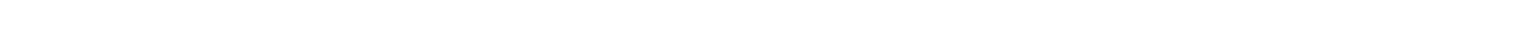
28,1976 , result of freezeup.

LONEST MEAN DISCHARGE, IN OBIC FEET PER SECOND, AND RANKING FOR THE INDICATED NUMBER OF CONSEQUTTVE DAYS FOR EACH CLIMATIC YEAR, APRII 1-MARQH 31

\begin{tabular}{|c|c|c|c|c|c|c|c|c|c|c|c|c|c|c|c|c|c|c|c|c|}
\hline \multirow[t]{2}{*}{ YEAR } & \multicolumn{20}{|c|}{ CONSEOTTVE DAYS } \\
\hline & 1 & & 3 & & 7 & & 14 & & 30 & & 60 & & 90 & & 120 & & 183 & & ALL & \\
\hline
\end{tabular}


09279100 ROCK CREEK NEAR TALMAGE, UT-Continued

LOWEST MEAN DISCHARGE, IN OUBIC FEET PER SECOND, AND RANKING FOR THE INDICATED NUMBER OF CONSECUTIVE DAYS FOR EACH CLIMATIC YFAR, APRIL 1-MARCH 31 -Continued

$\begin{array}{rrrrrrrrr} & 1 & & 3 & & 7 & & 14 & \\ 1976 & 44.0 & 12 & 46.0 & 12 & 48.0 & 14 & 49.0 & 12 \\ 1977 & 14.0 & 1 & 26.0 & 1 & 26.0 & 1 & 26.0 & 1 \\ 1978 & 32.0 & 2 & 34.0 & 2 & 36.0 & 2 & 41.0 & 3 \\ 1979 & 42.0 & 10 & 43.0 & 9 & 44.0 & 9 & 44.0 & 7 \\ 1980 & 37.0 & 3 & 38.0 & 3 & 42.0 & 5 & 44.0 & 8 \\ 1981 & 44.0 & 11 & 46.0 & 13 & 47.0 & 11 & 47.0 & 11\end{array}$

CONSECUTIVE DAYS
30

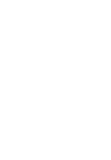

90

\section{$52.0 \quad 11$}

$120 \quad 183 \quad$ ALL

HIGHEST MEAN DISCHARGE, IN OUBIC FEET PER SECOND, AND RANKING FOR THE INDICATED MUMBER OF CONSECUTIVE DAYS FOR EACH WATER YEAR, OCTOBER I-SEPTEMBER 30

YEAR

$\begin{array}{rrrrrr}53.0 & 9 & 59.0 & 10 & 214 & 15\end{array}$

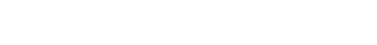

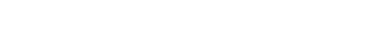

$\begin{array}{llllllll}51.0 & 8 & 54.0 & 12 & 61.0 & 12 & 192 & 10\end{array}$

\section{CONSEOUTIVE DAYS}

90

$120 \quad 183$

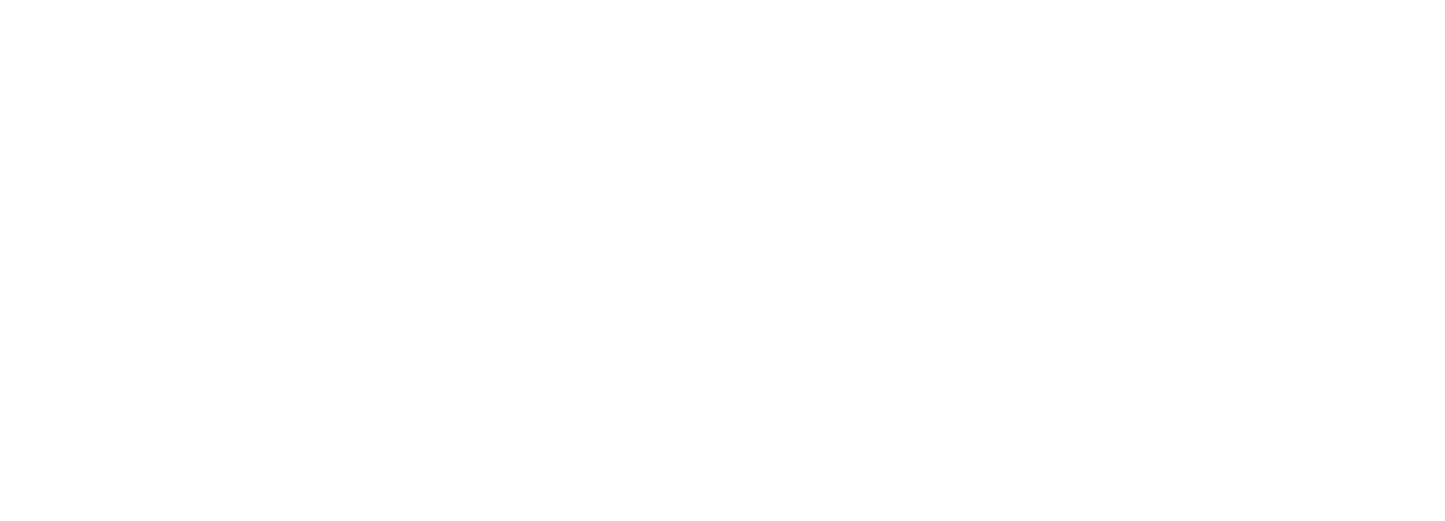

DURATION OF DISCHARGE FOR EACH WATER YEAR

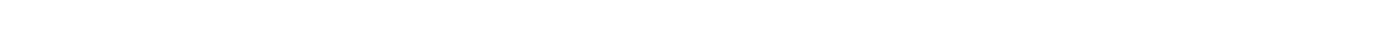
YEAR

MUMBER OF DAYS IN CLASS

OUBIC FEET -DAYS

1965

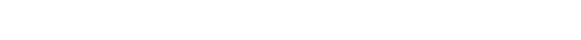

$\begin{array}{llllllllllll}2 & 5 & 4 & 2 & 4 & 11 & 7 & 8 & 9 & 4 & 3 & 2\end{array}$

69663.0

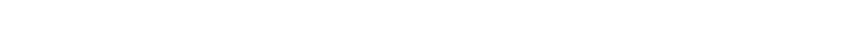

55804.0

$\begin{array}{llllllllllllllllllllllllll}1 & 50 & 95 & 46 & 35 & 19 & 20 & 9 & 3 & 8 & 7 & 3 & 4 & 4 & 3 & 3 & 8 & 6 & 8 & 10 & 8 & 2 & 8 & 5 & & 81110.0\end{array}$

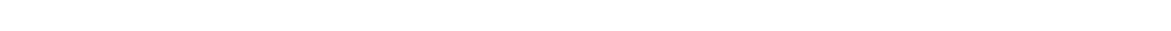

$\begin{array}{llllllllllllllllllllllllll} & 101 & 89 & 34 & 17 & 11 & 9 & 11 & 6 & 10 & 8 & 3 & 6 & 6 & 3 & 9 & 7 & 5 & 13 & 6 & 3 & 6 & 2 & 4 & 78486.0\end{array}$

$\begin{array}{llllllllllllllllllllllllllllll}1 & 24 & 45 & 45 & 61 & 33 & 21 & 13 & 11 & 15 & 10 & 5 & 9 & 6 & 12 & 5 & 8 & 6 & 3 & 5 & 7 & 5 & 2 & 1 & 3 & 6 & 3 & & 71137.0\end{array}$

$\begin{array}{lllllllllllllllllllllllllllllllll}16 & 37 & 58 & 78 & 55 & 22 & 8 & 7 & 5 & 8 & 6 & 9 & 5 & 3 & 3 & 5 & 6 & 5 & 4 & 1 & 4 & 4 & 2 & 5 & 8 & 2 & 69924.0\end{array}$

$\begin{array}{llllllllllllllllllllllllll}20 & 68 & 22 & 41 & 27 & 26 & 22 & 24 & 13 & 11 & 8 & 6 & 9 & 11 & 5 & 6 & 12 & 6 & 6 & 4 & 4 & 9 & 2 & 3 & & 67303.0\end{array}$

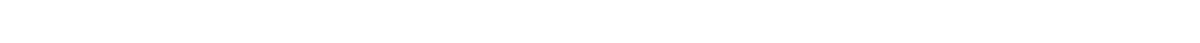

$\begin{array}{llllllllllllllllll}44116 & 53 & 50 & 8 & 11 & 11 & 10 & 8 & 4 & 8 & 3 & 6 & 6 & 2 & 1 & 8 & 5 & 9\end{array}$

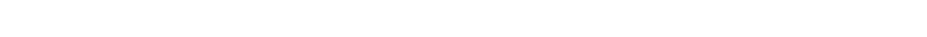

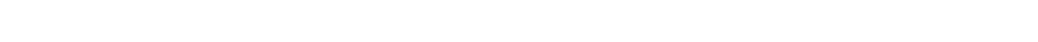

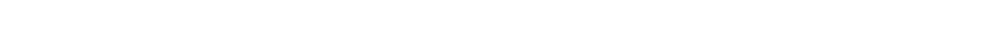

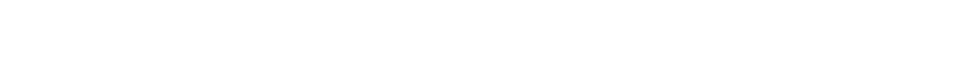

46758.0

27137.0

63284.0

48739.0

68307.0

1981

53535.0 
DURATION TABLE OF DISCHARGE FOR WATER YEARS 1964-81

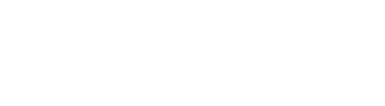

\begin{tabular}{|c|c|c|c|c|c|c|c|c|c|}
\hline CLASS & $\begin{array}{c}\text { CUBIC } \\
\text { FEET } \\
\text { PER } \\
\text { SECOND }\end{array}$ & $\begin{array}{l}\text { TOTAL } \\
\text { DAYS }\end{array}$ & $\begin{array}{l}\text { ACOU- } \\
\text { NIJ- } \\
\text { LATED } \\
\text { DAYS }\end{array}$ & $\begin{array}{l}\text { PER- } \\
\text { CENT } \\
\text { DAYS }\end{array}$ & & $\begin{array}{c}\text { OUBIC } \\
\text { FEET } \\
\text { PER } \\
\text { SECOND }\end{array}$ & $\begin{array}{l}\text { TOTAL } \\
\text { DAYS }\end{array}$ & $\begin{array}{l}\text { ACOU- } \\
\text { M- } \\
\text { LATED } \\
\text { DAYS }\end{array}$ & $\begin{array}{l}\text { PER- } \\
\text { CENT } \\
\text { DAYS }\end{array}$ \\
\hline $\begin{array}{r}9 \\
10 \\
11 \\
12 \\
13 \\
14 \\
15 \\
16 \\
17\end{array}$ & $\begin{array}{r}46.00 \\
54.00 \\
62.00 \\
72.00 \\
84.00 \\
97.00 \\
110.00 \\
130.00 \\
150.00\end{array}$ & $\begin{array}{r}1177 \\
877 \\
809 \\
598 \\
380 \\
245 \\
301 \\
181 \\
172\end{array}$ & $\begin{array}{l}6107 \\
4930 \\
4053 \\
3244 \\
2646 \\
2266 \\
2021 \\
1720 \\
1539\end{array}$ & $\begin{array}{l}92.9 \\
75.0 \\
61.6 \\
49.3 \\
40.2 \\
34.5 \\
30.7 \\
26.2 \\
23.4\end{array}$ & $\begin{array}{l}18 \\
19 \\
20 \\
21 \\
22 \\
23 \\
24 \\
25 \\
26\end{array}$ & $\begin{array}{l}180.0 \\
200.0 \\
240.0 \\
280.0 \\
320.0 \\
370.0 \\
430.0 \\
500.0 \\
580.0\end{array}$ & $\begin{array}{r}96 \\
163 \\
110 \\
96 \\
80 \\
100 \\
92 \\
98 \\
84\end{array}$ & $\begin{array}{r}1367 \\
1271 \\
1108 \\
998 \\
902 \\
822 \\
722 \\
630 \\
532\end{array}$ & $\begin{array}{r}20.8 \\
19.3 \\
16.9 \\
15.2 \\
13.7 \\
12.5 \\
11.0 \\
9.6 \\
8.1\end{array}$ \\
\hline
\end{tabular}

\begin{tabular}{rrrrr}
\multicolumn{4}{c}{ CUBIC } & \multicolumn{2}{c}{ ACQU- } \\
FEET & MU- & PER- \\
PER & TOTAL & \multicolumn{1}{c}{ LATED } & CENT \\
CIASS & SECOND & DAYS & DAYS & DAYS \\
27 & 670.0 & 104 & 448 & 6.8 \\
28 & 780.0 & 87 & 344 & 5.2 \\
29 & 910.0 & 99 & 257 & 3.9 \\
30 & 1100.0 & 32 & 158 & 2.4 \\
31 & 1200.0 & 66 & 126 & 1.9 \\
32 & 1400.0 & 46 & 60 & 0.9 \\
33 & 1600.0 & 12 & 14 & 0.2 \\
34 & 1900.0 & 2 & 2 & 0.0
\end{tabular}

MONTHLY MEAN DISCHARGES, IN CUBIC FEET PER SECOND, FOR EACH WATER YEAR

$\begin{array}{rllllllllllrr}\text { YEAR } & \text { OCT } & \text { NOV } & \text { DEC } & \text { JAN } & \text { FEB } & \text { MAR } & \text { APR } & \text { MAY } & \text { JUNE } & \text { JULY } & \text { AUG } & \text { SEP } \\ 1964 & 97.9 & 81.1 & 61.8 & 51.9 & 45.0 & 48.9 & 64.0 & 445 & 842 & 360 & 118 & 68.5 \\ 1965 & 60.8 & 61.6 & 65.7 & 65.8 & 55.0 & 51.5 & 91.7 & 277 & 1172 & 831 & 282 & 167 \\ 1966 & 121 & 92.4 & 78.2 & 58.5 & 48.3 & 64.0 & 119 & 574 & 335 & 137 & 102 & 96.3 \\ 1967 & 90.1 & 75.3 & 71.6 & 64.4 & 58.2 & 60.0 & 64.1 & 359 & 987 & 566 & 162 & 103 \\ 1968 & 77.1 & 56.0 & 54.5 & 51.8 & 53.7 & 52.5 & 62.2 & 210 & 1171 & 342 & 208 & 111 \\ 1969 & 79.2 & 77.7 & 74.5 & 67.0 & 67.8 & 66.7 & 135 & 875 & 679 & 252 & 114 & 81.5 \\ 1970 & 74.6 & 62.8 & 50.5 & 44.8 & 46.2 & 46.8 & 48.7 & 368 & 697 & 210 & 100 & 98.2 \\ 1971 & 67.3 & 70.1 & 59.7 & 60.3 & 48.0 & 45.9 & 104 & 338 & 1011 & 341 & 114 & 80.9 \\ 1972 & 77.4 & 71.0 & 62.4 & 52.4 & 46.9 & 58.5 & 70.1 & 478 & 1015 & 206 & 89.4 & 71.2 \\ 1973 & 95.3 & 81.1 & 63.5 & 51.6 & 46.4 & 47.7 & 70.2 & 480 & 713 & 300 & 145 & 112 \\ 1974 & 75.5 & 69.8 & 54.0 & 49.3 & 41.2 & 46.6 & 61.8 & 521 & 607 & 167 & 79.1 & 53.2 \\ 1975 & 62.5 & 58.4 & 52.5 & 52.0 & 52.0 & 52.8 & 53.1 & 173 & 880 & 823 & 186 & 96.3 \\ 1976 & 79.4 & 63.3 & 54.3 & 52.6 & 50.3 & 55.2 & 67.0 & 380 & 451 & 142 & 76.8 & 60.7 \\ 1977 & 55.0 & 43.3 & 32.3 & 26.0 & 29.4 & 34.9 & 54.6 & 120 & 284 & 89.5 & 67.8 & 55.8 \\ 1978 & 54.0 & 48.9 & 47.8 & 47.8 & 45.9 & 50.1 & 84.9 & 260 & 999 & 287 & 98.1 & 60.6 \\ 1979 & 52.1 & 51.3 & 50.0 & 48.6 & 46.0 & 45.7 & 71.6 & 405 & 510 & 168 & 94.2 & 56.5 \\ 1980 & 49.5 & 45.5 & 48.2 & 52.0 & 52.7 & 59.0 & 122 & 333 & 956 & 332 & 108 & 88.7 \\ 1981 & 78.4 & 70.3 & 62.8 & 52.4 & 52.6 & 49.0 & 99.7 & 309 & 648 & 160 & 95.7 & 83.3\end{array}$

ANNUAL PEAK DISCHARGE, IN CUBIC FEET PER SECOND, AND CORRESPONDING GAGE HEIGHT, IN FEET, FOR EACH WATER YEAR

$\begin{array}{lcccccccccc}\begin{array}{l}\text { WATER } \\ \text { YEAR }\end{array} & \text { DATE } & \begin{array}{c}\text { GAGE } \\ \text { HEIGHT }\end{array} & \begin{array}{c}\text { PEAK } \\ \text { DISCHARGE }\end{array} & \begin{array}{l}\text { WATER } \\ \text { YEAR }\end{array} & \text { DATE } & \begin{array}{c}\text { GAGE } \\ \text { HEIGHT }\end{array} & \begin{array}{c}\text { PEAK } \\ \text { DISCHARGE }\end{array} & \begin{array}{l}\text { WATER } \\ \text { YEAR }\end{array} & \text { DATE } & \begin{array}{c}\text { GAGE } \\ \text { HEIGHT }\end{array} \\ \text { DISCHARGE }\end{array}$

MAGNITUDE AND PROBABILITY OF ANNUAL LOWEST MEAN DISCHARGE BASED ON CIIMATIC YEARS 1965-81

\begin{tabular}{|c|c|c|c|c|c|c|}
\hline \multirow{2}{*}{$\begin{array}{l}\text { PERIOD } \\
\text { (CON- } \\
\text { SECU- } \\
\text { TIVE } \\
\text { DAYS) }\end{array}$} & \multicolumn{6}{|c|}{$\begin{array}{l}\text { DISCHARGE, IN CUBIC FEET PER SECOND, FOR } \\
\text { INDICATED RECURRENCE INTERVAL, IN YEARS, AND } \\
\text { ANNUAL NONEXCEEDANCE PROBABILITY, IN PERCENT }\end{array}$} \\
\hline & $\begin{array}{c}2 \\
508\end{array}$ & $\begin{array}{c}5 \\
20 \%\end{array}$ & $\begin{array}{l}10 \\
10 \%\end{array}$ & $\begin{array}{l}20 \\
58\end{array}$ & $\begin{array}{l}50 \\
28\end{array}$ & $\begin{array}{r}100 \\
18\end{array}$ \\
\hline
\end{tabular}

$\begin{array}{rrrrrrr}1 & 44 & 35 & 28 & 22 & - & - \\ 7 & 46 & 39 & 35 & 31 & - & - \\ 14 & 47 & 40 & 36 & 32 & - & - \\ 30 & 49 & 42 & 37 & 32 & - & - \\ 60 & 51 & 43 & 38 & 33 & - & - \\ 90 & 53 & 45 & 40 & 35 & - & -\end{array}$

MAGNITUDE AND PROBABILITY OF ANNUAL HIGHEST MEAN DISCHARGE BASED ON WATER YEARS 1964-81

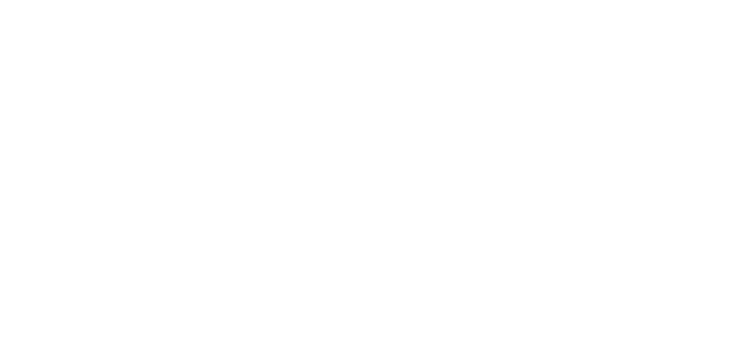


LOCATION.--Lat $40^{\circ} 16^{\prime} 14^{\prime \prime}$, Iong $110^{\circ} 26^{\prime} 31^{\prime \prime}$, in NE $\mathrm{NE}_{4}^{2} \mathrm{NW}_{2}^{2} \mathrm{NW}_{4}^{\frac{1}{4}}$ sec.34, T.2 S., R.5 W., Uintah Meridian, Duchesne County, Hydrologic Unit 14060003, on left bank $50 \mathrm{ft}$ downstream from bridge on State Highway 35, $1.7 \mathrm{mi}$ upstream from Knight diversion dam, $3.9 \mathrm{mi}$ downstream from Rock Creek, and $7.7 \mathrm{mi}$ north-northwest of Duchesne.

DRAINAGE AREA. $-623 \mathrm{mi}^{2}$.

PERTOD OF RECORD AVAULABLE.--April 1970 September 1981.

REVISED RECORDS. - WDR UM-77-1: Drainage area.

GAGE.--Water-stage recorder. Altitude of gage is 5,840 ft from topographic map. Prior to Apr. 25, 1973, at site 150 ft upstream at aifferent datum.

REMARKS.--Several diversions above station for irrigation, including a transmountain diversion to the Great Basin through Duchesne tunnel.

AVERAGE DISCHARGE. --11 years, $331 \mathrm{ft}^{3} / \mathrm{s}, 239,810$ acre-ft/yr.

EXIREMES FOR PERIOD OF RECORD.--Maximum discharge, 4,150 ft $\mathrm{ft}^{3} / \mathrm{s}$ June 16,1975 , gage height, $6.99 \mathrm{ft} ; \mathrm{minimum} 37 \mathrm{ft}{ }^{3} / \mathrm{s} \mathrm{Jan} .31,1980$.

LOWEST MEAN DISCHARGE, IN CUBIC FEET PER SECOND, AND RANKING FOR THE INDICATED NUMBER OF CONSECUTIVE DAYS FOR EACH CLIMATIC YEAR, APRIL 1-MARCH 31

\begin{tabular}{|c|c|c|c|c|c|c|c|c|c|c|c|c|c|c|c|c|c|c|c|c|}
\hline YEAR & 1 & & 3 & & 7 & & 14 & & $\begin{array}{l}\text { CNN } \\
30\end{array}$ & EOrT & 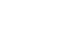 & & 90 & & 120 & & 183 & & ALL & \\
\hline $\begin{array}{l}1971 \\
1972 \\
1973 \\
1974 \\
1975\end{array}$ & $\begin{array}{c}107 \\
145 \\
142 \\
155 \\
72.0\end{array}$ & $\begin{array}{r}6 \\
10 \\
9 \\
11 \\
2\end{array}$ & $\begin{array}{c}111 \\
146 \\
143 \\
161 \\
73.0\end{array}$ & $\begin{array}{r}6 \\
10 \\
9 \\
11 \\
2\end{array}$ & $\begin{array}{c}124 \\
149 \\
146 \\
163 \\
74.0\end{array}$ & $\begin{array}{r}6 \\
10 \\
9 \\
11 \\
2\end{array}$ & $\begin{array}{c}128 \\
157 \\
155 \\
164 \\
79.0\end{array}$ & $\begin{array}{r}6 \\
10 \\
9 \\
11 \\
2\end{array}$ & $\begin{array}{c}139 \\
164 \\
161 \\
167 \\
90.0\end{array}$ & $\begin{array}{r}6 \\
10 \\
9 \\
11 \\
2\end{array}$ & $\begin{array}{l}152 \\
175 \\
165 \\
175 \\
106\end{array}$ & $\begin{array}{r}8 \\
11 \\
9 \\
10 \\
2\end{array}$ & $\begin{array}{l}158 \\
181 \\
170 \\
180 \\
127\end{array}$ & $\begin{array}{r}8 \\
11 \\
9 \\
10 \\
4\end{array}$ & $\begin{array}{l}161 \\
187 \\
177 \\
185 \\
138\end{array}$ & $\begin{array}{r}7 \\
11 \\
9 \\
10 \\
4\end{array}$ & $\begin{array}{l}170 \\
185 \\
197 \\
191 \\
144\end{array}$ & $\begin{array}{r}7 \\
9 \\
11 \\
10 \\
4\end{array}$ & $\begin{array}{l}297 \\
416 \\
379 \\
387 \\
358\end{array}$ & $\begin{array}{r}4 \\
10 \\
7 \\
8 \\
6\end{array}$ \\
\hline $\begin{array}{l}1976 \\
1977 \\
1978 \\
1979 \\
1980\end{array}$ & $\begin{array}{c}127 \\
79.0 \\
65.0 \\
102 \\
79.0\end{array}$ & $\begin{array}{l}8 \\
3 \\
1 \\
5 \\
4\end{array}$ & $\begin{array}{r}133 \\
85.0 \\
68.0 \\
104 \\
84.0\end{array}$ & $\begin{array}{l}8 \\
4 \\
1 \\
5 \\
3\end{array}$ & $\begin{array}{c}135 \\
88.0 \\
72.0 \\
105 \\
86.0\end{array}$ & $\begin{array}{l}8 \\
4 \\
1 \\
5 \\
3\end{array}$ & $\begin{array}{c}140 \\
93.0 \\
74.0 \\
107 \\
93.0\end{array}$ & $\begin{array}{l}8 \\
3 \\
1 \\
5 \\
4\end{array}$ & $\begin{array}{c}149 \\
103 \\
86.0 \\
120 \\
95.0\end{array}$ & $\begin{array}{l}8 \\
4 \\
1 \\
5 \\
3\end{array}$ & $\begin{array}{c}150 \\
109 \\
97.0 \\
125 \\
111\end{array}$ & $\begin{array}{l}7 \\
3 \\
1 \\
5 \\
4\end{array}$ & $\begin{array}{c}154 \\
112 \\
98.0 \\
135 \\
124\end{array}$ & $\begin{array}{l}6 \\
2 \\
1 \\
5 \\
3\end{array}$ & $\begin{array}{l}160 \\
118 \\
102 \\
144 \\
130\end{array}$ & $\begin{array}{l}6 \\
2 \\
1 \\
5 \\
3\end{array}$ & $\begin{array}{l}169 \\
129 \\
113 \\
145 \\
130\end{array}$ & $\begin{array}{l}6 \\
2 \\
1 \\
5 \\
3\end{array}$ & $\begin{array}{l}444 \\
247 \\
145 \\
344 \\
258\end{array}$ & $\begin{array}{r}11 \\
2 \\
1 \\
5 \\
3\end{array}$ \\
\hline & 110 & 7 & 116 & 7 & 125 & 7 & 138 & 7 & 144 & 7 & 150 & 6 & 155 & 7 & 164 & 8 & 177 & 8 & 408 & \\
\hline
\end{tabular}

HIGHEST MEAN DISCHARGE, IN CUBIC FEET PER SECOND, AND RANKING FOR THE INDICATFD NUMBER OF CONSEOUTIVE DAYS FOR EACH WATER YEAR, OCTOBER 1-SEPTEMBER 30

\begin{tabular}{|c|c|c|c|c|c|c|c|c|c|c|c|c|c|c|c|c|c|c|c|c|}
\hline YEAR & 1 & & 3 & & 7 & & & & & EQT & IVE DA & & & & 120 & & 983 & & $\lambda \mathrm{T}$ & \\
\hline $\begin{array}{l}1971 \\
1972 \\
1973 \\
1974 \\
1975\end{array}$ & $\begin{array}{l}3040 \\
2720 \\
2480 \\
2860 \\
3840\end{array}$ & $\begin{array}{l}3 \\
6 \\
8 \\
4 \\
1\end{array}$ & $\begin{array}{l}2950 \\
2650 \\
2420 \\
2630 \\
3430\end{array}$ & $\begin{array}{l}2 \\
5 \\
7 \\
6 \\
1\end{array}$ & $\begin{array}{l}2820 \\
2560 \\
2260 \\
2390 \\
2840\end{array}$ & $\begin{array}{l}2 \\
5 \\
7 \\
6 \\
1\end{array}$ & $\begin{array}{l}2500 \\
2400 \\
1810 \\
1980 \\
2330\end{array}$ & $\begin{array}{l}1 \\
2 \\
7 \\
6 \\
4\end{array}$ & $\begin{array}{l}1960 \\
1860 \\
1730 \\
1870 \\
2220\end{array}$ & $\begin{array}{l}2 \\
4 \\
7 \\
3 \\
1\end{array}$ & $\begin{array}{l}1400 \\
1230 \\
1230 \\
1350 \\
1700\end{array}$ & $\begin{array}{l}2 \\
6 \\
7 \\
4 \\
1\end{array}$ & $\begin{array}{r}1060 \\
925 \\
958 \\
977 \\
1290\end{array}$ & $\begin{array}{l}3 \\
6 \\
5 \\
4 \\
1\end{array}$ & $\begin{array}{r}872 \\
756 \\
778 \\
784 \\
1010\end{array}$ & $\begin{array}{l}3 \\
6 \\
5 \\
4 \\
1\end{array}$ & $\begin{array}{l}639 \\
566 \\
583 \\
577 \\
720\end{array}$ & $\begin{array}{l}2 \\
6 \\
4 \\
5 \\
1\end{array}$ & $\begin{array}{l}406 \\
375 \\
392 \\
373 \\
441\end{array}$ & $\begin{array}{l}2 \\
5 \\
3 \\
6 \\
1\end{array}$ \\
\hline $\begin{array}{l}1976 \\
1977 \\
1978 \\
1979 \\
1980\end{array}$ & $\begin{array}{r}1590 \\
953 \\
2850 \\
2600 \\
3070\end{array}$ & $\begin{array}{r}10 \\
11 \\
5 \\
7 \\
2\end{array}$ & $\begin{array}{r}1560 \\
879 \\
2730 \\
2330 \\
2940\end{array}$ & $\begin{array}{r}10 \\
11 \\
4 \\
8 \\
3\end{array}$ & $\begin{array}{r}1440 \\
743 \\
2670 \\
1830 \\
2590\end{array}$ & $\begin{array}{r}10 \\
11 \\
3 \\
8 \\
4\end{array}$ & $\begin{array}{r}1230 \\
555 \\
2360 \\
1520 \\
2270\end{array}$ & $\begin{array}{r}10 \\
11 \\
3 \\
8 \\
5\end{array}$ & $\begin{array}{r}1110 \\
397 \\
1830 \\
1220 \\
1810\end{array}$ & $\begin{array}{r}9 \\
11 \\
5 \\
8 \\
6\end{array}$ & $\begin{array}{r}759 \\
294 \\
1230 \\
802 \\
1380\end{array}$ & $\begin{array}{r}9 \\
11 \\
5 \\
8 \\
3\end{array}$ & $\begin{array}{r}581 \\
241 \\
920 \\
622 \\
1100\end{array}$ & $\begin{array}{r}9 \\
11 \\
7 \\
8 \\
2\end{array}$ & $\begin{array}{l}485 \\
205 \\
743 \\
512 \\
881\end{array}$ & $\begin{array}{r}9 \\
11 \\
7 \\
8 \\
2\end{array}$ & $\begin{array}{l}375 \\
170 \\
540 \\
386 \\
636\end{array}$ & $\begin{array}{r}9 \\
11 \\
7 \\
8 \\
3\end{array}$ & $\begin{array}{l}267 \\
147 \\
331 \\
264 \\
387\end{array}$ & $\begin{array}{r}8 \\
11 \\
7 \\
9 \\
4\end{array}$ \\
\hline 981 & 1710 & 9 & 1670 & 9 & 1580 & 9 & 1380 & 9 & 916 & 10 & 629 & 10 & 513 & 10 & 428 & 10 & 332 & 10 & 253 & \\
\hline
\end{tabular}

DURATION OF DISCHARGE FOR EACH WATER YEAR

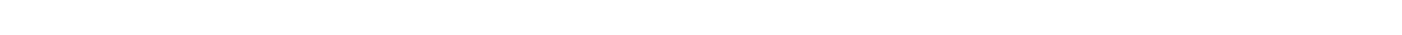
YEAR

NUMBER OF DAYS IN CuASS

OBIC FEET -DAYS

\begin{tabular}{|c|c|c|c|c|c|c|c|c|c|c|c|c|c|c|c|c|c|c|c|c|c|c|c|c|c|c|c|c|c|c|c|}
\hline $\begin{array}{l}1971 \\
1972 \\
1973 \\
1974 \\
1975\end{array}$ & 2 & 8 & 6 & $\begin{array}{r}915 \\
3\end{array}$ & $\begin{array}{l}33 \\
10 \\
9 \\
9 \\
76\end{array}$ & $\begin{array}{l}3379 \\
1032 \\
2554 \\
2527 \\
427 \\
51120\end{array}$ & $\begin{array}{ll}48 & 39 \\
91 & 57 \\
61 & 47 \\
75 & 97 \\
48 & 16\end{array}$ & $\begin{array}{l}31 \\
62 \\
57 \\
39 \\
13\end{array}$ & $\begin{array}{r}16 \\
18 \\
34 \\
11 \\
7\end{array}$ & $\begin{array}{r}15 \\
18 \\
17 \\
5 \\
4\end{array}$ & $\begin{array}{r}11 \\
13 \\
10 \\
3 \\
4\end{array}$ & $\begin{array}{r}11 \\
5 \\
4 \\
1 \\
2\end{array}$ & $\begin{array}{l}9 \\
8 \\
6\end{array}$ & $\begin{array}{l}9 \\
4 \\
9 \\
1 \\
5\end{array}$ & $\begin{array}{r}6 \\
3 \\
8 \\
2 \\
11\end{array}$ & $\begin{array}{l}3 \\
3 \\
4 \\
2 \\
4\end{array}$ & $\begin{array}{l}5 \\
1 \\
8 \\
1 \\
3\end{array}$ & $\begin{array}{l}3 \\
6 \\
7 \\
2 \\
2\end{array}$ & $\begin{array}{l}3 \\
4 \\
2 \\
2\end{array}$ & $\begin{array}{l}1 \\
4 \\
1 \\
5 \\
3\end{array}$ & $\begin{array}{l}5 \\
1 \\
2 \\
2 \\
2\end{array}$ & $\begin{array}{l}5 \\
2 \\
7 \\
8 \\
3\end{array}$ & $\begin{array}{l}2 \\
3 \\
2 \\
2 \\
2\end{array}$ & $\begin{array}{l}8 \\
3 \\
6 \\
6 \\
8\end{array}$ & $\begin{array}{l}2 \\
2 \\
5 \\
3 \\
7\end{array}$ & $\begin{array}{l}5 \\
2 \\
4 \\
2 \\
6\end{array}$ & $\begin{array}{l}1 \\
4 \\
5 \\
9 \\
5\end{array}$ & $\begin{array}{ll}2 & 7 \\
7 & 3 \\
3 & \\
6 & 1 \\
8 & 3\end{array}$ & $\begin{array}{l}1 \\
3\end{array}$ & 1 & $\begin{array}{l}148024.0 \\
137347.0 \\
142980.0 \\
136097.0 \\
160877.0\end{array}$ \\
\hline $\begin{array}{l}1976 \\
1977 \\
1978 \\
1979 \\
1980\end{array}$ & & $\begin{array}{ll}1 & \\
24 & 3 \\
1 & 1\end{array}$ & $\begin{array}{cc}2 \\
31 & 1 \\
8 \\
10 \\
1\end{array}$ & $\begin{array}{rr}7 & 10 \\
13 & 98 \\
8 & 84 \\
7 & 22 \\
& 16\end{array}$ & $\begin{array}{rr}6 & 4 \\
32 & 6 \\
45 & 4 \\
1712\end{array}$ & $\begin{array}{ll}10 & 92 \\
57 & 33 \\
49 & 37 \\
23 & 42 \\
8 & 62\end{array}$ & $\begin{array}{rr}63 & 51 \\
12 & 8 \\
13 & 16 \\
36 & 11 \\
19 & 12\end{array}$ & $\begin{array}{l}24 \\
16 \\
11 \\
11 \\
10\end{array}$ & $\begin{array}{r}8 \\
5 \\
13 \\
16 \\
5\end{array}$ & $\begin{array}{r}5 \\
3 \\
11 \\
15 \\
7\end{array}$ & $\begin{array}{l}9 \\
4 \\
4 \\
7 \\
2\end{array}$ & $\begin{array}{l}4 \\
1 \\
4 \\
5 \\
5\end{array}$ & 5 & $\begin{array}{l}4 \\
2 \\
4\end{array}$ & $\begin{array}{l}2 \\
3 \\
5 \\
3 \\
4\end{array}$ & $\begin{array}{l}3 \\
1 \\
3 \\
2 \\
8\end{array}$ & $\begin{array}{l}1 \\
2 \\
5 \\
1 \\
9\end{array}$ & $\begin{array}{l}6 \\
2 \\
5\end{array}$ & $\begin{array}{l}3 \\
2 \\
3 \\
2 \\
4\end{array}$ & $\begin{array}{l}4 \\
1 \\
3 \\
4 \\
8\end{array}$ & $\begin{array}{l}1 \\
5 \\
8\end{array}$ & $\begin{array}{l}7 \\
4 \\
4 \\
5\end{array}$ & $\begin{array}{l}2 \\
3 \\
2\end{array}$ & $\begin{array}{l}3 \\
4 \\
3\end{array}$ & $\begin{array}{l}2 \\
1 \\
5\end{array}$ & $\begin{array}{l}6 \\
1 \\
7\end{array}$ & $\begin{array}{l}23 \\
4\end{array}$ & $\begin{array}{l}3 \\
2\end{array}$ & $\begin{array}{l}5 \\
2 \\
2\end{array}$ & 1 & $\begin{array}{r}97657.0 \\
53808.0 \\
120817.0 \\
96237.0 \\
141740.0\end{array}$ \\
\hline 981 & & & 5 & 4111 & 125 & 678 & 3440 & 26 & 24 & 17 & 20 & & & 4 & 3 & & & & & 1 & & 3 & 1 & 5 & 4 & & & & & & 92298.0 \\
\hline
\end{tabular}


GREEN RIVER BASIN

09279150 DUCHESNE RIVER ABOVE KNIGHT DIVERSION, NEAR DUCHESNE, UT--Continued

DURATION TABLE OF DISCHARGE FOR WATER YEARS 1971-81

$\begin{array}{ccc}\text { CUBIC } & \text { ACOU- } \\ \text { FEET } & \text { MU- } & \text { PER- } \\ \text { PER TOTAL LATED } & \text { OENT } \\ \text { CLASS SECOND DAYS DAYS } & \text { DAYS }\end{array}$

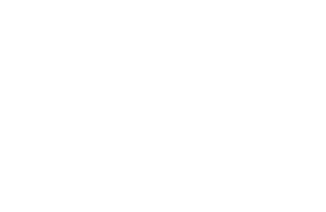

OUBIC ACOJ- OBBIC ACOU-

FEET MU- PER- FEET MU- PER-

$\begin{array}{rrrrr}\text { PER TOTAL LATED } & \text { CENT } & \text { PER TOTPL LATED } & \text { OENT } \\ \text { CIAASS SECOND DAYS DAYS DAYS } & \text { CLASS SECOND DAYS DAYS DAYS }\end{array}$

$\begin{array}{rrrrr}9 & 170.00 & 500 & 2228 & 55.5 \\ 10 & 190.00 & 394 & 1728 & 43.0 \\ 11 & 210.00 & 300 & 1334 & 33.2 \\ 12 & 240.00 & 157 & 1034 & 25.7 \\ 13 & 270.00 & 117 & 877 & 21.8 \\ 14 & 310.00 & 87 & 760 & 18.9 \\ 15 & 350.00 & 49 & 673 & 16.7 \\ 16 & 390.00 & 51 & 624 & 15.5 \\ 17 & 440.00 & 48 & 573 & 14.3\end{array}$

$\begin{array}{rrrrr}18 & 490.0 & 50 & 525 & 13.1 \\ 19 & 560.0 & 35 & 475 & 11.8 \\ 20 & 630.0 & 38 & 440 & 11.0 \\ 21 & 710.0 & 35 & 402 & 10.0 \\ 22 & 800.0 & 25 & 367 & 9.1 \\ 23 & 900.0 & 35 & 342 & 8.5 \\ 24 & 1000.0 & 34 & 307 & 7.6 \\ 25 & 1100.0 & 49 & 273 & 6.8 \\ 26 & 1300.0 & 21 & 224 & 5.6\end{array}$

OBIC ACOU-

FEET MU- PERCLASS SECOND DAYS DAYS DAYS

$\begin{array}{rrrrr}27 & 1400.0 & 50 & 203 & 5.1 \\ 28 & 1600.0 & 31 & 153 & 3.8 \\ 29 & 1800.0 & 33 & 122 & 3.0 \\ 30 & 2100.0 & 30 & 89 & 2.2 \\ 31 & 2300.0 & 31 & 59 & 1.5 \\ 32 & 2600.0 & 23 & 28 & 0.7 \\ 33 & 3000.0 & 3 & 5 & 0.1 \\ 34 & 3300.0 & 2 & 2 & 0.0\end{array}$

MONIHLY MEAN DISCHARGES, IN OBBIC FEET PER SBCOND, FOR EACH WATER YEAR

\begin{tabular}{|c|c|c|c|c|c|c|c|c|c|c|c|c|}
\hline YEAR & OCT & NOV & DEC & JAN & FEB & MAR & APR & MAY & JUNE & JULY & AUG & SEP \\
\hline $\begin{array}{l}1971 \\
1972 \\
1973 \\
1974 \\
1975\end{array}$ & $\begin{array}{l}181 \\
190 \\
249 \\
182 \\
162\end{array}$ & $\begin{array}{l}201 \\
211 \\
236 \\
219 \\
171\end{array}$ & $\begin{array}{l}165 \\
185 \\
195 \\
196 \\
154\end{array}$ & $\begin{array}{l}173 \\
182 \\
173 \\
184 \\
158\end{array}$ & $\begin{array}{l}161 \\
178 \\
165 \\
167 \\
150\end{array}$ & $\begin{array}{l}147 \\
213 \\
175 \\
193 \\
166\end{array}$ & $\begin{array}{l}269 \\
242 \\
225 \\
207 \\
149\end{array}$ & $\begin{array}{r}656 \\
814 \\
1122 \\
1442 \\
371\end{array}$ & $\begin{array}{l}1945 \\
1607 \\
1262 \\
1217 \\
1924\end{array}$ & $\begin{array}{r}556 \\
333 \\
456 \\
226 \\
1447\end{array}$ & $\begin{array}{l}256 \\
185 \\
210 \\
122 \\
258\end{array}$ & $\begin{array}{l}164 \\
175 \\
224 \\
106 \\
172\end{array}$ \\
\hline $\begin{array}{l}1976 \\
1977 \\
1978 \\
1979 \\
1980\end{array}$ & $\begin{array}{l}181 \\
153 \\
100 \\
128 \\
131\end{array}$ & $\begin{array}{l}191 \\
147 \\
124 \\
176 \\
154\end{array}$ & $\begin{array}{l}176 \\
136 \\
142 \\
160 \\
141\end{array}$ & $\begin{array}{l}150 \\
119 \\
117 \\
145 \\
130\end{array}$ & $\begin{array}{l}152 \\
116 \\
120 \\
141 \\
133\end{array}$ & $\begin{array}{l}165 \\
103 \\
139 \\
144 \\
140\end{array}$ & $\begin{array}{l}195 \\
86.3 \\
218 \\
219 \\
270\end{array}$ & $\begin{array}{l}829 \\
198 \\
462 \\
771 \\
900\end{array}$ & $\begin{array}{r}661 \\
388 \\
1834 \\
816 \\
1813\end{array}$ & $\begin{array}{l}230 \\
131 \\
444 \\
218 \\
490\end{array}$ & $\begin{array}{c}141 \\
93.3 \\
159 \\
146 \\
167\end{array}$ & $\begin{array}{c}126 \\
101 \\
124 \\
96.2 \\
191\end{array}$ \\
\hline 1981 & 197 & 210 & 192 & 162 & 156 & 145 & 198 & 426 & 828 & 246 & 120 & 157 \\
\hline
\end{tabular}

ANNUAL PEAK DISGHARGE, IN OUBIC FEET PER SECOND, AND CORRESPONDING GAGE HEIGHT, IN FEET, FOR EACH WATER YEAR

\begin{tabular}{|c|c|c|c|c|c|c|c|c|c|c|c|}
\hline $\begin{array}{l}\text { WATERR } \\
\text { YEAR }\end{array}$ & DATE & $\begin{array}{c}\text { GAGE } \\
\text { HEIGHT }\end{array}$ & $\begin{array}{c}\text { PEAK } \\
\text { DISCHARGE }\end{array}$ & $\begin{array}{l}\text { WATER } \\
\text { YEAR }\end{array}$ & DATE & $\begin{array}{c}\text { GAGE } \\
\text { HEIGHT }\end{array}$ & $\begin{array}{c}\text { PEAK } \\
\text { DISCHARGE }\end{array}$ & $\begin{array}{l}\text { WATERR } \\
\text { YEAR }\end{array}$ & DATE & $\begin{array}{c}\text { GAGE } \\
\text { HEIGHT }\end{array}$ & $\begin{array}{c}\text { PEAK } \\
\text { DISCHARGE }\end{array}$ \\
\hline $\begin{array}{l}1970 \\
1971 \\
1972 \\
1973\end{array}$ & $\begin{array}{l}\text { JUNE } 05,1970 \\
\text { JUNE } 18,1971 \\
\text { JUNE 04, } 1972 \\
\text { MAY } 20,1973\end{array}$ & $\begin{array}{l}4.10 \\
5.33 \\
5.53 \\
6.75\end{array}$ & $\begin{array}{l}1860 \\
3430 \\
3740 \\
2950\end{array}$ & $\begin{array}{l}1974 \\
1975 \\
1976 \\
1977\end{array}$ & $\begin{array}{lll}\text { MAY } & 29,1974 \\
\text { JUNE } & 16,1975 \\
\text { MAY } & 20,1976 \\
\text { JUNE } & 04,1977\end{array}$ & $\begin{array}{l}7.10 \\
6.99 \\
5.97 \\
5.54\end{array}$ & $\begin{array}{l}3160 \\
4150 \\
1710 \\
1170\end{array}$ & $\begin{array}{l}1978 \\
1979 \\
1980 \\
1981\end{array}$ & $\begin{array}{l}\text { JUNE }--, 1978 \\
\text { MAY 28, } 1979 \\
\text { JUNE } 11,1980 \\
\text { JUNE } 08,1981\end{array}$ & $\begin{array}{l}-- \\
6.97 \\
6.07\end{array}$ & $\begin{array}{l}3000 \\
2600 \\
3510 \\
2090\end{array}$ \\
\hline
\end{tabular}

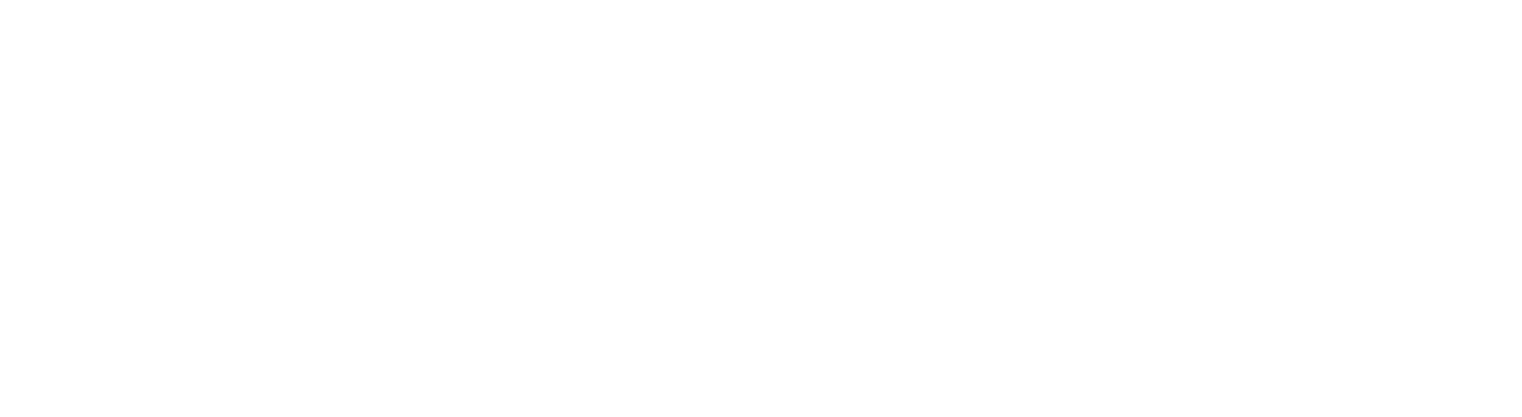

09279200 BENSON CREEK NEAR DUCHESNE, UT

LOCATION.--Lat $40^{\circ} 15^{\prime} 30^{\prime \prime}$, long $110^{\circ} 24^{\prime} 25^{\prime \prime}$, in SW $\frac{1}{4}$ sec. 36, T.2 S., R. 5 W., Uintah Special Meridian, Duchesne County, Hydrologic Unit $14060003,7.5 \mathrm{mi}$ northwest of Duchesne on State Highway 35.

DRAINAGE AREA. - $-11 \mathrm{mi}^{2}$.

PERIOD OF RECORD AVAIIABLE.--Water years 1960-68, annual peak discharge only.

GAGE.--Crest-stage gage. Altitude of gage is 5,850 ft from topographic map.

ANNUAL PEAK DISCHARGE, IN OBBIC FEET PER SECOND, AND CORRESPONDING GAGE HEIGHT, IN FEET, FOR EACH WATER YEAR

\begin{tabular}{|c|c|c|c|c|c|c|c|c|c|c|c|c|c|}
\hline $\begin{array}{l}\text { WATER } \\
\text { YEAR }\end{array}$ & DATE & $\begin{array}{c}\text { GAGE } \\
\text { HEIGHT }\end{array}$ & $\begin{array}{c}\text { PEAK } \\
\text { DISCHARGE }\end{array}$ & $\begin{array}{l}\text { WA' } \\
\mathrm{YE}\end{array}$ & & DATE & $\begin{array}{l}\text { GAGE } \\
\text { HEIGHT }\end{array}$ & $\begin{array}{c}\text { PEAK } \\
\text { DISCHARGE }\end{array}$ & & $\begin{array}{l}\text { ATtER } \\
\text { EAR }\end{array}$ & DA'T: & $\begin{array}{c}\text { GAGE } \\
\text { HEIGHT }\end{array}$ & $\begin{array}{c}\text { PEAK } \\
\text { DISCHARGE }\end{array}$ \\
\hline $\begin{array}{l}1960 \\
1961 \\
1962\end{array}$ & $\begin{array}{ll}\text { SEPT.02, } 1960 \\
\text { SEPT.09, } 1961 \\
\text { SEPT.21， } 1962\end{array}$ & $\begin{array}{l}15.40 \\
14.70 \\
13.67\end{array}$ & $\begin{array}{l}488 \\
390 \\
250\end{array}$ & $\begin{array}{l}1963 \\
1964 \\
1965\end{array}$ & $\begin{array}{l}\text { AUG. } \\
\text { AUG. } \\
\text { AUG. }\end{array}$ & $\begin{array}{l}26,1963 \\
01,1964 \\
21,1965\end{array}$ & $\begin{array}{l}16.30 \\
15.75 \\
15.80\end{array}$ & $\begin{array}{r}1800 \\
508 \\
290\end{array}$ & $\begin{array}{l}1966 \\
1967 \\
1968\end{array}$ & $\begin{array}{l}\text { MAR. 02, } \\
\text { SEPT.01, } \\
\text { JUNE 08, }\end{array}$ & $\begin{array}{l}1966 \\
1967 \\
1968\end{array}$ & $\begin{array}{l}11.05 \\
14.85 \\
14.77\end{array}$ & $\begin{array}{r}45 \\
195 \\
803\end{array}$ \\
\hline
\end{tabular}


GREEN RIVER BASIN

O9R79500 DUGHESNE RIVER AT DUGHESNE, UT

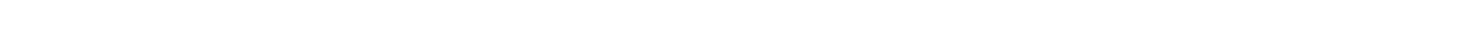
14060003, an left bank at Duchesne, $0.2 \mathrm{mi}$ upstrean fram Strawberry River.

DRAINAGE AREA $-660 \mathrm{mi}^{2}$, approximately.

MEAN BASIN ELEVATION. $-8,770 \mathrm{ft}$.

PERIOD OF RECORD AVAIIABLE. -OCtcber 1917 to April 1970.

GAGE.--Water-stage recorder. Datum of gage is 5,494.4 ft, NGVD of 1929. Prior to Oct. 18, 1934, nonrecording gage at site 2,200 ft upstream at different datum. Oct. 18, 1934, to Sept. 11, 1952, water-stage recorder at site 1,000 ft upstream at datum 4.6 ft higher.

AVERAGE DISGHARGE. --52 years $(1917-69), 360 \mathrm{ft}^{3} / \mathrm{s}, 260,800 \mathrm{acre}-\mathrm{ft} / \mathrm{yr}$.

REMARKS.--Several diversians above station for irrigation, including a transmountain diversion to the Great Basin through Duchesne tunnel. Sane diversion to Starvation Reservoir through Knight diversion tunnel began December 1969.

EXIREMES FOR PERIOD OF RECORD.--Maximum discharge cbserved, 4,420 $\mathrm{ft}^{3} / \mathrm{s}$ June 10, 1922, gage height, $8.65 \mathrm{ft}$, site and datum then in use; mininum daily, $4.0 \mathrm{ft}^{3} / \mathrm{s}$ Feb. 28 to Mar. $3,1970$.

LOWEST MEAN DISGHARGE, IN GBIC FEET PER SECOND, AND RANKING FOR THE INDICATED NUMBER OF CONSEQUTIVE DAYS FOR EAOH OLIMATIC YEAR, APRIL 1-MAROH 31

YEAR

\section{9}

1920

192

192

1924
1925

192

1927

1928
1929

1930

1931

1932
1933

1933
1934
1935

1935

1936
1937

1938

1939

1940

1941

1942
1943

1943
1944
1945

1946

1946
1947

1947
1948
1949

1949
1950

1951

1952
1953
1954

1954
1955

1956

1957

1958

1959
1960

1961

1961
1962
1963

1963
1964

1965

\begin{tabular}{|c|c|c|c|c|c|c|c|c|c|c|c|c|c|c|c|c|c|c|c|}
\hline \multicolumn{20}{|c|}{$\begin{array}{l}\text { CONSEQUTIVE DAUS } \\
30\end{array}$} \\
\hline $\begin{array}{l}100 \\
53.0\end{array}$ & $\begin{array}{r}34 \\
7\end{array}$ & $\begin{array}{l}109 \\
53.0\end{array}$ & $\begin{array}{r}37 \\
7\end{array}$ & $\begin{array}{l}121 \\
58.0\end{array}$ & $\begin{array}{r}40 \\
6\end{array}$ & $\begin{array}{r}134 \\
67.0\end{array}$ & $\begin{array}{r}41 \\
8\end{array}$ & $\begin{array}{r}145 \\
94.0\end{array}$ & $\begin{array}{l}40 \\
16\end{array}$ & $\begin{array}{l}185 \\
111\end{array}$ & $\begin{array}{l}46 \\
17\end{array}$ & $\begin{array}{l}192 \\
143\end{array}$ & $\begin{array}{l}47 \\
26\end{array}$ & $\begin{array}{l}204 \\
170\end{array}$ & $\begin{array}{l}47 \\
34\end{array}$ & $\begin{array}{l}228 \\
180\end{array}$ & $\begin{array}{l}48 \\
35\end{array}$ & $\begin{array}{l}391 \\
331\end{array}$ & $\begin{array}{l}32 \\
22\end{array}$ \\
\hline $\begin{array}{l}154 \\
160 \\
175 \\
150 \\
50.0\end{array}$ & $\begin{array}{r}49 \\
50 \\
51 \\
47 \\
5\end{array}$ & $\begin{array}{c}160 \\
160 \\
175 \\
150 \\
50.0\end{array}$ & $\begin{array}{r}49 \\
50 \\
51 \\
46 \\
5\end{array}$ & $\begin{array}{c}160 \\
160 \\
175 \\
156 \\
50.0\end{array}$ & $\begin{array}{r}49 \\
50 \\
51 \\
47 \\
4\end{array}$ & $\begin{array}{c}160 \\
160 \\
175 \\
166 \\
53.0\end{array}$ & $\begin{array}{r}46 \\
47 \\
51 \\
49 \\
4\end{array}$ & $\begin{array}{c}163 \\
179 \\
176 \\
169 \\
56.0\end{array}$ & $\begin{array}{r}44 \\
50 \\
49 \\
46 \\
4\end{array}$ & $\begin{array}{l}170 \\
197 \\
188 \\
187 \\
63.0\end{array}$ & $\begin{array}{r}41 \\
51 \\
48 \\
47 \\
2\end{array}$ & $\begin{array}{c}184 \\
213 \\
194 \\
191 \\
86.0\end{array}$ & & $\begin{array}{c}203 \\
224 \\
205 \\
202 \\
99.0\end{array}$ & $\begin{array}{r}46 \\
51 \\
48 \\
44 \\
5\end{array}$ & & $\begin{array}{r}46 \\
50 \\
5\end{array}$ & $\begin{array}{l}473 \\
596 \\
739 \\
571 \\
246\end{array}$ & 1 \\
\hline $\begin{array}{c}92.0 \\
70.0 \\
130 \\
64.0 \\
122\end{array}$ & $\begin{array}{l}29 \\
14 \\
43 \\
12 \\
41\end{array}$ & $\begin{array}{c}94.0 \\
73.0 \\
136 \\
64.0 \\
122\end{array}$ & $\begin{array}{l}26 \\
14 \\
43 \\
11 \\
41\end{array}$ & $\begin{array}{c}107 \\
78.0 \\
139 \\
66.0 \\
122\end{array}$ & $\begin{array}{r}32 \\
16 \\
43 \\
9 \\
41\end{array}$ & $\begin{array}{c}124 \\
82.0 \\
143 \\
68.0 \\
128\end{array}$ & $\begin{array}{r}38 \\
14 \\
42 \\
9 \\
39\end{array}$ & $\begin{array}{c}132 \\
85.0 \\
149 \\
73.0 \\
134\end{array}$ & $\begin{array}{c}33 \\
11 \\
42 \\
6 \\
38\end{array}$ & $\begin{array}{c}176 \\
101 \\
169 \\
82.0 \\
146\end{array}$ & $\begin{array}{r}45 \\
12 \\
40 \\
6 \\
31\end{array}$ & $\begin{array}{l}187 \\
109 \\
188 \\
106 \\
151\end{array}$ & $\begin{array}{r}43 \\
11 \\
44 \\
9 \\
29\end{array}$ & $\begin{array}{l}192 \\
118 \\
213 \\
123\end{array}$ & $\begin{array}{r}42 \\
8 \\
50 \\
11 \\
29\end{array}$ & $\begin{array}{l}196 \\
128 \\
268 \\
142 \\
183\end{array}$ & $\begin{array}{r}40 \\
6 \\
51 \\
13 \\
37\end{array}$ & $\begin{array}{l}342 \\
308 \\
508 \\
418 \\
421\end{array}$ & 5 \\
\hline $\begin{array}{c}92.0 \\
15.0 \\
100 \\
42.0 \\
40.0\end{array}$ & $\begin{array}{r}30 \\
1 \\
35 \\
3 \\
2\end{array}$ & $\begin{array}{c}96.0 \\
16.0 \\
112 \\
42.0 \\
41.0\end{array}$ & $\begin{array}{r}31 \\
1 \\
38 \\
3 \\
2\end{array}$ & $\begin{array}{r}115 \\
18.0 \\
116 \\
43.0 \\
42.0\end{array}$ & $\begin{array}{r}36 \\
1 \\
37 \\
3 \\
2\end{array}$ & $\begin{array}{c}151 \\
31.0 \\
122 \\
44.0 \\
43.0\end{array}$ & $\begin{array}{r}43 \\
1 \\
36 \\
3 \\
2\end{array}$ & $\begin{array}{c}161 \\
55.0 \\
133 \\
52.0 \\
46.0\end{array}$ & $\begin{array}{r}43 \\
3 \\
37 \\
2 \\
1\end{array}$ & $\begin{array}{c}166 \\
72.0 \\
147 \\
64.0 \\
50.0\end{array}$ & $\begin{array}{r}39 \\
4 \\
32 \\
3 \\
1\end{array}$ & $\begin{array}{c}171 \\
74.0 \\
155 \\
70.0 \\
54.0\end{array}$ & $\begin{array}{r}39 \\
3 \\
31 \\
2 \\
1\end{array}$ & $\begin{array}{c}175 \\
78.0 \\
153 \\
81.0 \\
58.0\end{array}$ & $\begin{array}{r}37 \\
2 \\
27 \\
3 \\
1\end{array}$ & $\begin{array}{c}205 \\
103 \\
157 \\
101 \\
64.0\end{array}$ & $\begin{array}{r}43 \\
3 \\
21 \\
2 \\
1\end{array}$ & $\begin{array}{l}353 \\
173 \\
419 \\
234 \\
103\end{array}$ & $\begin{array}{r}26 \\
2\end{array}$ \\
\hline $\begin{array}{c}58.0 \\
103 \\
83.0 \\
89.0 \\
53.0\end{array}$ & $\begin{array}{r}10 \\
37 \\
22 \\
25 \\
8\end{array}$ & $\begin{array}{c}60.0 \\
105 \\
83.0 \\
91.0 \\
57.0\end{array}$ & $\begin{array}{r}10 \\
35 \\
20 \\
23 \\
8\end{array}$ & $\begin{array}{c}67.0 \\
108 \\
89.0 \\
97.0 \\
72.0\end{array}$ & $\begin{array}{l}10 \\
33 \\
21 \\
27 \\
12\end{array}$ & $\begin{array}{l}75.0 \\
120 \\
102 \\
112 \\
82.0\end{array}$ & $\begin{array}{l}11 \\
33 \\
26 \\
30 \\
15\end{array}$ & $\begin{array}{l}80.0 \\
147 \\
120 \\
132 \\
85.0\end{array}$ & $\begin{array}{c}8 \\
41 \\
28 \\
34\end{array}$ & $\begin{array}{l}84.0 \\
152 \\
147 \\
173 \\
106\end{array}$ & $\begin{array}{r}7 \\
35 \\
33 \\
42 \\
15\end{array}$ & $\begin{array}{l}92.0 \\
155 \\
156 \\
177 \\
123\end{array}$ & $\begin{array}{r}5 \\
32 \\
33 \\
40 \\
15\end{array}$ & $\begin{array}{l}160 \\
161 \\
189 \\
134\end{array}$ & $\begin{array}{r}4 \\
28 \\
30 \\
41\end{array}$ & $\begin{array}{l}106 \\
157 \\
163 \\
200 \\
135\end{array}$ & $\begin{array}{r}4 \\
22 \\
26 \\
42 \\
11\end{array}$ & $\begin{array}{l}268 \\
421 \\
359 \\
383 \\
239\end{array}$ & $\begin{array}{l}14 \\
41 \\
27 \\
29\end{array}$ \\
\hline $\begin{array}{r}51.0 \\
141 \\
76.0 \\
96.0 \\
91.0\end{array}$ & $\begin{array}{r}6 \\
45 \\
17 \\
32 \\
26\end{array}$ & $\begin{array}{c}52.0 \\
147 \\
94.0 \\
97.0 \\
94.0\end{array}$ & $\begin{array}{r}6 \\
45 \\
27 \\
32 \\
28\end{array}$ & $\begin{array}{c}59.0 \\
155 \\
96.0 \\
100 \\
97.0\end{array}$ & $\begin{array}{r}7 \\
46 \\
25 \\
29 \\
26\end{array}$ & $\begin{array}{l}65.0 \\
161 \\
100 \\
102 \\
105\end{array}$ & $\begin{array}{r}6 \\
48 \\
24 \\
25 \\
28\end{array}$ & $\begin{array}{l}67.0 \\
172 \\
103 \\
111 \\
110\end{array}$ & $\begin{array}{r}5 \\
47 \\
22 \\
26 \\
25\end{array}$ & $\begin{array}{l}77.0 \\
175 \\
120 \\
140 \\
120\end{array}$ & $\begin{array}{r}5 \\
44 \\
21 \\
28 \\
22\end{array}$ & $\begin{array}{l}95.0 \\
178 \\
134 \\
170 \\
138\end{array}$ & $\begin{array}{r}6 \\
41 \\
20 \\
38 \\
21\end{array}$ & . & & & & & $\begin{array}{l}33 \\
21 \\
42 \\
30\end{array}$ \\
\hline $\begin{array}{c}130 \\
74.0 \\
104 \\
70.0 \\
111\end{array}$ & $\begin{array}{l}42 \\
15 \\
38 \\
13 \\
39\end{array}$ & $\begin{array}{c}130 \\
74.0 \\
105 \\
71.0 \\
115\end{array}$ & $\begin{array}{l}42 \\
15 \\
36 \\
13 \\
39\end{array}$ & $\begin{array}{c}130 \\
77.0 \\
110 \\
72.0 \\
118\end{array}$ & $\begin{array}{l}42 \\
15 \\
34 \\
13 \\
38\end{array}$ & $\begin{array}{c}130 \\
86.0 \\
117 \\
74.0 \\
120\end{array}$ & $\begin{array}{l}40 \\
17 \\
31 \\
10 \\
34\end{array}$ & $\begin{array}{c}132 \\
91.0 \\
132 \\
83.0 \\
125\end{array}$ & $\begin{array}{r}35 \\
14 \\
36 \\
9 \\
30\end{array}$ & $\begin{array}{c}137 \\
110 \\
156 \\
92.0 \\
135\end{array}$ & $\begin{array}{r}27 \\
16 \\
38 \\
8 \\
26\end{array}$ & $\begin{array}{l}144 \\
125 \\
161 \\
100 \\
156\end{array}$ & $\begin{array}{r}27 \\
16 \\
35 \\
7 \\
34\end{array}$ & & $\begin{array}{r}24 \\
18 \\
32 \\
6 \\
35\end{array}$ & & & & $\begin{array}{l}23 \\
20 \\
37 \\
13 \\
43\end{array}$ \\
\hline $\begin{array}{r}48.0 \\
91.0 \\
148 \\
85.0 \\
64.0\end{array}$ & $\begin{array}{r}4 \\
27 \\
46 \\
23 \\
11\end{array}$ & $\begin{array}{r}49.0 \\
94.0 \\
151 \\
86.0 \\
65.0\end{array}$ & $\begin{array}{r}4 \\
29 \\
47 \\
22 \\
12\end{array}$ & $\begin{array}{c}51.0 \\
99.0 \\
152 \\
88.0 \\
69.0\end{array}$ & $\begin{array}{r}5 \\
28 \\
45 \\
19 \\
11\end{array}$ & $\begin{array}{c}62.0 \\
104 \\
157 \\
88.0 \\
81.0\end{array}$ & $\begin{array}{r}5 \\
27 \\
44 \\
18 \\
13\end{array}$ & $\begin{array}{c}93.0 \\
128 \\
165 \\
98.0 \\
83.0\end{array}$ & $\begin{array}{l}32 \\
45 \\
20 \\
10\end{array}$ & $\begin{array}{l}155 \\
145 \\
174 \\
116 \\
92.0\end{array}$ & $\begin{array}{l}36 \\
29 \\
43 \\
20\end{array}$ & $\begin{array}{l}146 \\
191 \\
141\end{array}$ & $\begin{array}{l}3 \\
2 \\
4 \\
2\end{array}$ & 122 & $\begin{array}{r}26 \\
9\end{array}$ & & & & $\begin{array}{l}44 \\
34 \\
49\end{array}$ \\
\hline $\begin{array}{l}81.0 \\
80.0 \\
82.0 \\
86.0 \\
76.0\end{array}$ & $\begin{array}{l}20 \\
19 \\
21 \\
24 \\
16\end{array}$ & $\begin{array}{l}84.0 \\
80.0 \\
82.0 \\
92.0 \\
76.0\end{array}$ & $\begin{array}{l}21 \\
17 \\
18 \\
24 \\
16\end{array}$ & $\begin{array}{l}91.0 \\
82.0 \\
88.0 \\
93.0 \\
77.0\end{array}$ & $\begin{array}{l}22 \\
17 \\
20 \\
23 \\
14\end{array}$ & & $\begin{array}{l}22 \\
16 \\
23 \\
20 \\
12\end{array}$ & $\begin{array}{c}106 \\
86.0 \\
109 \\
95.0 \\
97.0\end{array}$ & $\begin{array}{l}23 \\
13 \\
24 \\
17 \\
19\end{array}$ & $\begin{array}{l}115 \\
94.0 \\
147 \\
101 \\
122\end{array}$ & $\begin{array}{l}18 \\
10 \\
34 \\
11 \\
23\end{array}$ & 16 & $\begin{array}{r}17 \\
10 \\
37 \\
8 \\
18\end{array}$ & 143 & $\begin{array}{l}17 \\
10 \\
39 \\
7\end{array}$ & & $\begin{array}{r}17 \\
8 \\
33 \\
9 \\
14\end{array}$ & & $\begin{array}{r}10 \\
19 \\
28 \\
18 \\
6\end{array}$ \\
\hline $\begin{array}{c}79.0 \\
56.0 \\
100 \\
117 \\
92.0\end{array}$ & $\begin{array}{r}18 \\
9 \\
33 \\
40 \\
28\end{array}$ & $\begin{array}{c}83.0 \\
57.0 \\
100 \\
119 \\
93.0\end{array}$ & $\begin{array}{r}19 \\
9 \\
33 \\
40 \\
25\end{array}$ & $\begin{array}{l}87.0 \\
61.0 \\
103 \\
120 \\
95.0\end{array}$ & $\begin{array}{r}18 \\
8 \\
31 \\
39 \\
24\end{array}$ & $\begin{array}{c}90.0 \\
67.0 \\
123 \\
120 \\
95.0\end{array}$ & $\begin{array}{r}19 \\
7 \\
37 \\
35 \\
21\end{array}$ & $\begin{array}{c}95.0 \\
78.0 \\
127 \\
122 \\
99.0\end{array}$ & $\begin{array}{r}18 \\
7 \\
31 \\
29 \\
21\end{array}$ & $\begin{array}{l}115 \\
145 \\
128 \\
104\end{array}$ & $\begin{array}{l}19 \\
30 \\
24 \\
14\end{array}$ & 114 & $\begin{array}{l}14 \\
22 \\
25 \\
19 \\
13\end{array}$ & $\begin{array}{l}126 \\
164 \\
146 \\
146 \\
131\end{array}$ & & $\begin{array}{l}136 \\
188 \\
155 \\
156 \\
151\end{array}$ & $\begin{array}{l}12 \\
38 \\
18 \\
20 \\
15\end{array}$ & $\begin{array}{l}194 \\
385 \\
270 \\
337\end{array}$ & $\begin{array}{r}5 \\
4 \\
31 \\
15 \\
24\end{array}$ \\
\hline
\end{tabular}


09279500 DUCHESNE RIVER AT DUCHESNE, UT-Continued

LOWEST MEAN DISCHARGE, IN OUBIC FEET PER SECOND, AND RANKING FOR THE INDICATED NUMBER OF CONSEOUTIVE DAYS FOR EACH CIIMATIC YEAR, APRIL 1-MARCH 31-Continued

YEAR

\begin{tabular}{|c|c|c|c|c|c|c|c|c|c|c|c|c|c|c|c|c|c|c|c|c|}
\hline YEAR & 1 & & 3 & & 7 & & 14 & & $\begin{array}{l}\infty \\
30\end{array}$ & $\mathrm{ECU} T$ & VE & & 90 & & 120 & & 183 & & ALI & \\
\hline
\end{tabular}

HIGHEST MEAN DISCHARGE, IN CUBIC FEET PER SECOND, AND RANKING FOR THE INDICATED NUMBER OF CONSECUTIVE DAYS FOR EACH WATER YEAR, OCTOBER 1-SEPTEMBER 30

YEAR

\begin{tabular}{|c|c|c|c|c|c|c|c|c|c|c|c|c|c|c|c|c|c|c|c|c|}
\hline & 1 & & 3 & & 7 & & 15 & & 30 & & 60 & & 90 & & 120 & & 183 & & ALL & \\
\hline $\begin{array}{l}1918 \\
1919 \\
1920\end{array}$ & $\begin{array}{l}2740 \\
2140 \\
2820\end{array}$ & $\begin{array}{l}22 \\
35 \\
20\end{array}$ & $\begin{array}{l}2620 \\
2110 \\
2730\end{array}$ & $\begin{array}{l}22 \\
35 \\
19\end{array}$ & $\begin{array}{l}2490 \\
2040 \\
2570\end{array}$ & $\begin{array}{l}21 \\
30 \\
18\end{array}$ & $\begin{array}{l}2220 \\
18.0 \\
2540\end{array}$ & $\begin{array}{r}21 \\
28 \\
8\end{array}$ & $\begin{array}{l}1660 \\
1460 \\
2260\end{array}$ & $\begin{array}{r}24 \\
35 \\
8\end{array}$ & $\begin{array}{l}1160 \\
1040 \\
1660\end{array}$ & $\begin{array}{r}29 \\
34 \\
8\end{array}$ & $\begin{array}{r}911 \\
785 \\
1240\end{array}$ & $\begin{array}{r}26 \\
35 \\
7\end{array}$ & $\begin{array}{l}733 \\
647 \\
989\end{array}$ & $\begin{array}{r}26 \\
34 \\
7\end{array}$ & $\begin{array}{l}545 \\
491 \\
723\end{array}$ & $\begin{array}{r}26 \\
34 \\
8\end{array}$ & $\begin{array}{l}363 \\
349 \\
462\end{array}$ & $\begin{array}{r}23 \\
28 \\
7\end{array}$ \\
\hline $\begin{array}{l}1931 \\
1932 \\
1933 \\
1934 \\
1935\end{array}$ & $\begin{array}{r}978 \\
3460 \\
2210 \\
573 \\
3070\end{array}$ & $\begin{array}{r}50 \\
5 \\
33 \\
52 \\
11\end{array}$ & $\begin{array}{r}902 \\
3220 \\
2140 \\
547 \\
3050\end{array}$ & $\begin{array}{r}50 \\
9 \\
34 \\
52 \\
11\end{array}$ & $\begin{array}{r}754 \\
2950 \\
1980 \\
508 \\
2950\end{array}$ & $\begin{array}{r}50 \\
9 \\
34 \\
52 \\
10\end{array}$ & $\begin{array}{r}670 \\
2660 \\
1890 \\
396 \\
2370\end{array}$ & $\begin{array}{r}50 \\
5 \\
27 \\
52 \\
16\end{array}$ & $\begin{array}{r}621 \\
1960 \\
1410 \\
327 \\
1660\end{array}$ & $\begin{array}{l}50 \\
14 \\
36 \\
52 \\
25\end{array}$ & $\begin{array}{r}414 \\
1520 \\
857 \\
217 \\
1030\end{array}$ & $\begin{array}{l}50 \\
11 \\
40 \\
52 \\
35\end{array}$ & $\begin{array}{r}320 \\
1140 \\
622 \\
180 \\
749\end{array}$ & $\begin{array}{l}50 \\
13 \\
40 \\
52 \\
38\end{array}$ & $\begin{array}{l}282 \\
924 \\
500 \\
166 \\
596\end{array}$ & $\begin{array}{l}50 \\
15 \\
41 \\
52 \\
38\end{array}$ & $\begin{array}{l}247 \\
682 \\
380 \\
157 \\
429\end{array}$ & $\begin{array}{l}50 \\
13 \\
42 \\
52 \\
38\end{array}$ & $\begin{array}{l}200 \\
415 \\
254 \\
117 \\
257\end{array}$ & $\begin{array}{l}49 \\
17 \\
44 \\
52 \\
43\end{array}$ \\
\hline $\begin{array}{l}1941 \\
1942 \\
1943 \\
1944 \\
1945\end{array}$ & $\begin{array}{l}2370 \\
2270 \\
2270 \\
2340 \\
1660\end{array}$ & $\begin{array}{l}29 \\
31 \\
32 \\
30 \\
42\end{array}$ & $\begin{array}{l}2220 \\
2180 \\
2190 \\
2210 \\
1620\end{array}$ & $\begin{array}{l}29 \\
33 \\
31 \\
30 \\
42\end{array}$ & $\begin{array}{l}2030 \\
2080 \\
2090 \\
1980 \\
1500\end{array}$ & $\begin{array}{l}32 \\
29 \\
28 \\
33 \\
42\end{array}$ & $\begin{array}{l}1710 \\
1810 \\
1640 \\
1740 \\
1290\end{array}$ & $\begin{array}{l}34 \\
31 \\
38 \\
32 \\
42\end{array}$ & $\begin{array}{l}1610 \\
1610 \\
1530 \\
1690 \\
1170\end{array}$ & $\begin{array}{l}26 \\
27 \\
31 \\
22 \\
40\end{array}$ & $\begin{array}{r}1320 \\
1050 \\
1320 \\
1410 \\
993\end{array}$ & $\begin{array}{l}21 \\
33 \\
22 \\
18 \\
37\end{array}$ & $\begin{array}{r}994 \\
820 \\
1120 \\
1050 \\
793\end{array}$ & $\begin{array}{l}23 \\
32 \\
15 \\
20 \\
34\end{array}$ & $\begin{array}{l}799 \\
680 \\
927 \\
850 \\
673\end{array}$ & $\begin{array}{l}23 \\
30 \\
12 \\
20 \\
31\end{array}$ & $\begin{array}{l}586 \\
507 \\
682 \\
619 \\
499\end{array}$ & $\begin{array}{l}22 \\
29 \\
12 \\
21 \\
33\end{array}$ & $\begin{array}{l}384 \\
349 \\
421 \\
393 \\
333\end{array}$ & $\begin{array}{l}22 \\
27 \\
13 \\
21 \\
32\end{array}$ \\
\hline $\begin{array}{l}1946 \\
1947 \\
1948 \\
1949 \\
1950\end{array}$ & $\begin{array}{l}2060 \\
2110 \\
2130 \\
2810 \\
2950\end{array}$ & $\begin{array}{l}38 \\
37 \\
36 \\
21 \\
16\end{array}$ & $\begin{array}{l}1930 \\
2010 \\
2100 \\
2790 \\
2700\end{array}$ & $\begin{array}{l}39 \\
37 \\
36 \\
16 \\
21\end{array}$ & $\begin{array}{l}1740 \\
1910 \\
1970 \\
2760 \\
2560\end{array}$ & $\begin{array}{l}39 \\
37 \\
35 \\
14 \\
19\end{array}$ & $\begin{array}{l}1350 \\
1700 \\
1830 \\
2430 \\
2430\end{array}$ & $\begin{array}{l}41 \\
35 \\
29 \\
11 \\
12\end{array}$ & $\begin{array}{l}1160 \\
1590 \\
1410 \\
1940 \\
2290\end{array}$ & $\begin{array}{r}41 \\
30 \\
37 \\
15 \\
6\end{array}$ & $\begin{array}{r}1060 \\
1450 \\
867 \\
1550 \\
1660\end{array}$ & $\begin{array}{r}31 \\
16 \\
39 \\
10 \\
7\end{array}$ & $\begin{array}{r}825 \\
1130 \\
644 \\
1230 \\
1260\end{array}$ & $\begin{array}{r}30 \\
14 \\
39 \\
9 \\
6\end{array}$ & $\begin{array}{r}664 \\
916 \\
524 \\
988 \\
1020\end{array}$ & $\begin{array}{r}33 \\
16 \\
39 \\
8 \\
6\end{array}$ & $\begin{array}{l}485 \\
672 \\
399 \\
707 \\
733\end{array}$ & $\begin{array}{r}35 \\
14 \\
40 \\
9 \\
7\end{array}$ & $\begin{array}{l}321 \\
425 \\
273 \\
429 \\
459\end{array}$ & $\begin{array}{r}36 \\
12 \\
40 \\
11 \\
8\end{array}$ \\
\hline $\begin{array}{l}1961 \\
1962 \\
1963 \\
1964 \\
1965\end{array}$ & $\begin{array}{r}691 \\
1950 \\
1490 \\
2730 \\
3400\end{array}$ & $\begin{array}{r}51 \\
40 \\
44 \\
24 \\
8\end{array}$ & $\begin{array}{r}662 \\
1850 \\
1450 \\
2370 \\
3260\end{array}$ & $\begin{array}{r}51 \\
40 \\
44 \\
26 \\
6\end{array}$ & $\begin{array}{r}581 \\
1720 \\
1300 \\
1920 \\
3010\end{array}$ & $\begin{array}{r}51 \\
40 \\
43 \\
36 \\
6\end{array}$ & $\begin{array}{r}485 \\
1670 \\
1170 \\
1740 \\
2620\end{array}$ & $\begin{array}{r}51 \\
37 \\
43 \\
33 \\
6\end{array}$ & $\begin{array}{r}417 \\
1460 \\
1090 \\
1510 \\
2320\end{array}$ & $\begin{array}{r}51 \\
34 \\
42 \\
32 \\
4\end{array}$ & $\begin{array}{r}309 \\
1220 \\
792 \\
1220 \\
1790\end{array}$ & $\begin{array}{r}51 \\
23 \\
42 \\
24 \\
5\end{array}$ & $\begin{array}{r}246 \\
1020 \\
593 \\
900 \\
1410\end{array}$ & $\begin{array}{r}51 \\
21 \\
42 \\
27 \\
5\end{array}$ & $\begin{array}{r}212 \\
850 \\
495 \\
716 \\
1150\end{array}$ & $\begin{array}{r}51 \\
21 \\
42 \\
27 \\
5\end{array}$ & $\begin{array}{l}197 \\
630 \\
383 \\
519 \\
851\end{array}$ & $\begin{array}{r}51 \\
20 \\
41 \\
27 \\
5\end{array}$ & $\begin{array}{l}168 \\
403 \\
269 \\
336 \\
505\end{array}$ & 41 \\
\hline $\begin{array}{l}1966 \\
1967 \\
1968 \\
1969\end{array}$ & $\begin{array}{l}1420 \\
3050 \\
3360 \\
2600\end{array}$ & $\begin{array}{r}45 \\
13 \\
9 \\
25\end{array}$ & $\begin{array}{l}1310 \\
2970 \\
3120 \\
2550\end{array}$ & $\begin{array}{l}45 \\
13 \\
10 \\
24\end{array}$ & $\begin{array}{l}1140 \\
2850 \\
2950 \\
2420\end{array}$ & $\begin{array}{r}46 \\
12 \\
8 \\
23\end{array}$ & $\begin{array}{r}925 \\
2610 \\
2490 \\
2240\end{array}$ & $\begin{array}{r}47 \\
7 \\
9 \\
20\end{array}$ & $\begin{array}{r}889 \\
2160 \\
2290 \\
1960\end{array}$ & $\begin{array}{r}46 \\
9 \\
7 \\
13\end{array}$ & $\begin{array}{r}637 \\
1600 \\
1450 \\
1480\end{array}$ & $\begin{array}{r}46 \\
9 \\
15 \\
13\end{array}$ & $\begin{array}{r}534 \\
1180 \\
1070 \\
1150\end{array}$ & $\begin{array}{l}44 \\
11 \\
19 \\
12\end{array}$ & $\begin{array}{l}459 \\
925 \\
880 \\
925\end{array}$ & $\begin{array}{l}43 \\
13 \\
18 \\
14\end{array}$ & $\begin{array}{l}368 \\
662 \\
641 \\
672\end{array}$ & $\begin{array}{l}43 \\
16 \\
19 \\
15\end{array}$ & $\begin{array}{l}286 \\
419 \\
409 \\
432\end{array}$ & \\
\hline
\end{tabular}


GREEN RIVER BASIN

09279500 DUCHESNE RIVER AT DUGHESNE, UT-CONtinued

DURATION OF DISCHARGE FOR EAOH WATER YEAR

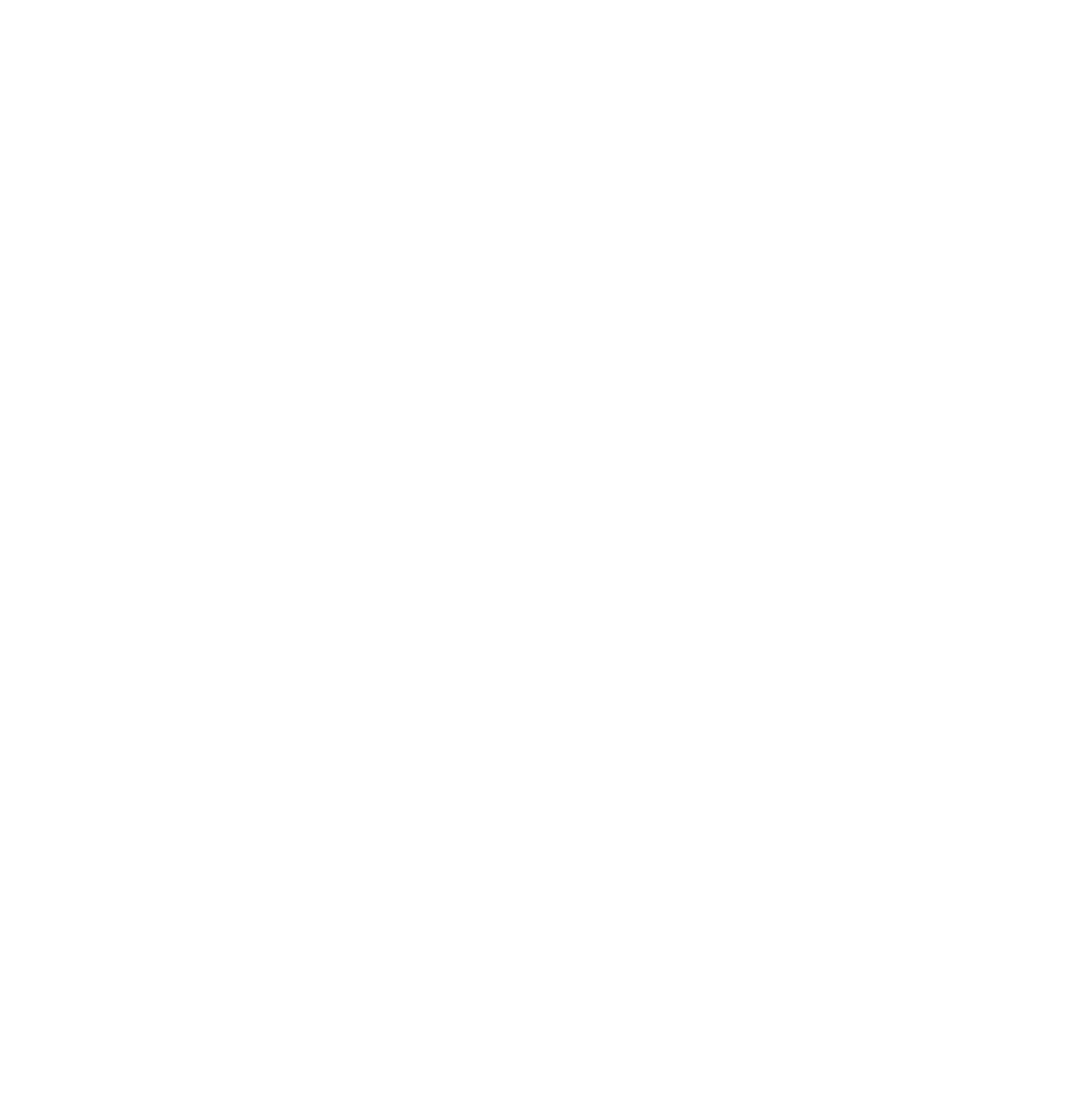


GREEN RTVER BASIN

09279500 WUCHESNE RIVER AT DUCHESNE, UT-COntinUEd

DURATION TRBLE OF DISOAARGE POR WAIER YEARS $1918-69$

\begin{tabular}{|c|c|c|c|c|c|c|c|c|c|c|c|c|c|c|c|c|c|c|c|}
\hline CLASS & $\begin{array}{c}\text { QBBIC } \\
\text { FEET } \\
\text { FER } \\
\text { SECOND }\end{array}$ & $\begin{array}{l}\text { TOTAL } \\
\text { DALS }\end{array}$ & $\begin{array}{l}\text { AODI- } \\
\text { MD- } \\
\text { LAIED } \\
\text { DALS }\end{array}$ & $\begin{array}{l}\text { PER } \\
\text { CENT } \\
\text { DAYS }\end{array}$ & OASS & $\begin{array}{c}\text { CBIC } \\
\text { EEET } \\
\text { PER } \\
\text { SECOND }\end{array}$ & $\begin{array}{l}\text { TOTAL } \\
\text { DAYS }\end{array}$ & $\begin{array}{l}\text { ACOJ- } \\
\text { LU- } \\
\text { LATED } \\
\text { DAYS }\end{array}$ & $\begin{array}{l}\text { PERR } \\
\text { CENT } \\
\text { DAYS }\end{array}$ & Q.ASS & $\begin{array}{c}\text { OBBIC } \\
\text { FEET } \\
\text { PER } \\
\text { SEOOND }\end{array}$ & TOTAL & $\begin{array}{l}\text { ACON- } \\
\text { WU- } \\
\text { LATED } \\
\text { DAYS }\end{array}$ & $\begin{array}{l}\text { PER } \\
\text { CENT } \\
\text { DAYS }\end{array}$ & QASS & $\begin{array}{c}\text { CUBIC } \\
\text { FEET } \\
\text { PER } \\
\text { SECOND }\end{array}$ & $\begin{array}{r}\text { TOTAL } \\
\text { DAYS }\end{array}$ & $\begin{array}{c}\text { ACOJ- } \\
\text { WU- } \\
\text { LATED } \\
\text { DAYS }\end{array}$ & $\begin{array}{l}\text { PER- } \\
\text { OENT } \\
\text { DAYS }\end{array}$ \\
\hline $\begin{array}{l}0 \\
1 \\
2 \\
3 \\
4 \\
5 \\
6 \\
7 \\
8\end{array}$ & $\begin{array}{r}0.00 \\
15.00 \\
18.00 \\
21.00 \\
25.00 \\
30.00 \\
35.00 \\
42.00 \\
50.00\end{array}$ & $\begin{array}{r}0 \\
5 \\
1 \\
0 \\
1 \\
0 \\
5 \\
56 \\
105\end{array}$ & $\begin{array}{l}18993 \\
18993 \\
18988 \\
18987 \\
18987 \\
18986 \\
18986 \\
18981 \\
18925\end{array}$ & $\begin{array}{r}100.0 \\
100.0 \\
100.0 \\
100.0 \\
100.0 \\
100.0 \\
100.0 \\
99.9 \\
99.6\end{array}$ & $\begin{array}{r}9 \\
10 \\
11 \\
12 \\
13 \\
14 \\
15 \\
16 \\
17\end{array}$ & $\begin{array}{r}59.00 \\
70.00 \\
83.00 \\
99.00 \\
120.00 \\
140.00 \\
170.00 \\
200.00 \\
230.00\end{array}$ & $\begin{array}{r}164 \\
277 \\
612 \\
960 \\
1532 \\
3775 \\
3270 \\
2056 \\
1424\end{array}$ & $\begin{array}{r}18820 \\
18656 \\
18379 \\
17767 \\
16807 \\
15275 \\
11500 \\
8230 \\
6174\end{array}$ & $\begin{array}{l}99.1 \\
98.2 \\
96.8 \\
93.5 \\
88.5 \\
80.4 \\
60.5 \\
43.3 \\
32.5\end{array}$ & $\begin{array}{l}18 \\
19 \\
20 \\
21 \\
22 \\
23 \\
24 \\
25 \\
26\end{array}$ & $\begin{array}{r}280.0 \\
330.0 \\
390.0 \\
460.0 \\
550.0 \\
650.0 \\
770.0 \\
920.0 \\
1100.0\end{array}$ & $\begin{array}{l}666 \\
600 \\
413 \\
354 \\
309 \\
302 \\
316 \\
299 \\
302\end{array}$ & $\begin{array}{l}4750 \\
4084 \\
3484 \\
3071 \\
2717 \\
2408 \\
2106 \\
1790 \\
1491\end{array}$ & $\begin{array}{r}25.0 \\
21.5 \\
18.3 \\
16.2 \\
14.3 \\
12.7 \\
11.1 \\
9.4 \\
7.9\end{array}$ & $\begin{array}{l}27 \\
28 \\
29 \\
30 \\
31 \\
32 \\
33 \\
34\end{array}$ & $\begin{array}{l}1300.0 \\
1500.0 \\
1800.0 \\
2200.0 \\
2600.0 \\
3000.0 \\
3600.0 \\
4300.0\end{array}$ & $\begin{array}{r}243 \\
313 \\
281 \\
162 \\
104 \\
52 \\
33 \\
1\end{array}$ & $\begin{array}{r}1189 \\
946 \\
633 \\
352 \\
190 \\
86 \\
34 \\
1\end{array}$ & $\begin{array}{l}6.3 \\
5.0 \\
3.3 \\
1.9 \\
1.0 \\
0.5 \\
0.2 \\
0.0\end{array}$ \\
\hline
\end{tabular}

MONIHLY MEAN DISOHARGES, IN OIBIC FEET PER SECOND, FOR EAOH WATER YEAR

\begin{tabular}{|c|c|c|c|c|c|c|c|c|c|c|c|c|}
\hline YEAR & $\infty T$ & NOV & DEC & JAN & FEB & MAR & APR & MAY & JUNE & JULY & AUG & SEP \\
\hline $\begin{array}{l}1918 \\
1919 \\
1920\end{array}$ & $\begin{array}{l}200 \\
322 \\
249\end{array}$ & $\begin{array}{l}200 \\
267 \\
218\end{array}$ & $\begin{array}{l}198 \\
217 \\
184\end{array}$ & $\begin{array}{l}141 \\
186 \\
170\end{array}$ & $\begin{array}{l}140 \\
200 \\
200\end{array}$ & $\begin{array}{l}195 \\
224 \\
187\end{array}$ & $\begin{array}{l}200 \\
256 \\
222\end{array}$ & $\begin{array}{r}610 \\
1313 \\
1146\end{array}$ & $\begin{array}{r}1653 \\
710 \\
2000\end{array}$ & $\begin{array}{l}447 \\
137 \\
531\end{array}$ & $\begin{array}{l}147 \\
103 \\
231\end{array}$ & $\begin{array}{l}229 \\
201 \\
215\end{array}$ \\
\hline $\begin{array}{l}1921 \\
1922 \\
1923 \\
1924 \\
1925\end{array}$ & $\begin{array}{l}250 \\
249 \\
210 \\
353 \\
135\end{array}$ & $\begin{array}{l}256 \\
248 \\
268 \\
274 \\
157\end{array}$ & $\begin{array}{l}179 \\
257 \\
242 \\
236 \\
148\end{array}$ & $\begin{array}{l}170 \\
196 \\
200 \\
200 \\
131\end{array}$ & $\begin{array}{l}209 \\
209 \\
175 \\
207 \\
140\end{array}$ & $\begin{array}{l}272 \\
233 \\
204 \\
169 \\
130\end{array}$ & $\begin{array}{l}290 \\
310 \\
284 \\
242 \\
166\end{array}$ & $\begin{array}{l}1093 \\
2256 \\
1293 \\
1132 \\
1085\end{array}$ & $\begin{array}{r}2783 \\
3557 \\
2065 \\
449 \\
937\end{array}$ & $\begin{array}{r}910 \\
827 \\
1096 \\
121 \\
323\end{array}$ & $\begin{array}{c}364 \\
366 \\
408 \\
57.6 \\
158\end{array}$ & $\begin{array}{l}320 \\
247 \\
263 \\
94.0 \\
208\end{array}$ \\
\hline $\begin{array}{l}1926 \\
1927 \\
1928 \\
1929 \\
1930\end{array}$ & $\begin{array}{l}237 \\
119 \\
413 \\
151 \\
240\end{array}$ & $\begin{array}{l}213 \\
143 \\
335 \\
181 \\
209\end{array}$ & $\begin{array}{l}198 \\
153 \\
290 \\
181 \\
188\end{array}$ & $\begin{array}{l}160 \\
140 \\
225 \\
175 \\
160\end{array}$ & $\begin{array}{l}218 \\
146 \\
168 \\
180 \\
158\end{array}$ & $\begin{array}{l}193 \\
162 \\
170 \\
199 \\
136\end{array}$ & $\begin{array}{l}283 \\
254 \\
195 \\
192 \\
324\end{array}$ & $\begin{array}{r}1219 \\
1127 \\
1705 \\
877 \\
693\end{array}$ & $\begin{array}{r}888 \\
1824 \\
1605 \\
1688 \\
1272\end{array}$ & $\begin{array}{l}206 \\
589 \\
266 \\
583 \\
215\end{array}$ & $\begin{array}{c}141 \\
179 \\
99.1 \\
307 \\
310\end{array}$ & $\begin{array}{l}87.6 \\
533 \\
73.4 \\
312 \\
194\end{array}$ \\
\hline $\begin{array}{l}1931 \\
1932 \\
1933 \\
1934 \\
1935\end{array}$ & $\begin{array}{c}306 \\
92.1 \\
160 \\
79.7 \\
47.3\end{array}$ & $\begin{array}{c}220 \\
149 \\
176 \\
124 \\
74.4\end{array}$ & $\begin{array}{l}190 \\
170 \\
151 \\
145 \\
105\end{array}$ & $\begin{array}{l}180 \\
170 \\
170 \\
129 \\
95.0\end{array}$ & $\begin{array}{l}170 \\
165 \\
150 \\
125 \\
106\end{array}$ & $\begin{array}{l}162 \\
167 \\
143 \\
101 \\
115\end{array}$ & $\begin{array}{l}142 \\
244 \\
140 \\
168 \\
158\end{array}$ & $\begin{array}{l}458 \\
924 \\
258 \\
261 \\
362\end{array}$ & $\begin{array}{c}344 \\
1950 \\
1360 \\
73.6 \\
1623\end{array}$ & $\begin{array}{l}61.6 \\
523 \\
220 \\
64.2 \\
227\end{array}$ & $\begin{array}{c}85.1 \\
267 \\
65.7 \\
70.5 \\
107\end{array}$ & $\begin{array}{c}76.3 \\
170 \\
70.1 \\
58.6 \\
83.3\end{array}$ \\
\hline $\begin{array}{l}1936 \\
1937 \\
1938 \\
1939 \\
1940\end{array}$ & $\begin{array}{l}85.6 \\
147 \\
174 \\
233 \\
175\end{array}$ & $\begin{array}{l}126 \\
158 \\
173 \\
240 \\
129\end{array}$ & $\begin{array}{l}118 \\
174 \\
179 \\
204 \\
137\end{array}$ & $\begin{array}{l}120 \\
160 \\
154 \\
180 \\
161\end{array}$ & $\begin{array}{l}115 \\
150 \\
160 \\
170 \\
160\end{array}$ & $\begin{array}{l}110 \\
155 \\
158 \\
220 \\
143\end{array}$ & $\begin{array}{l}249 \\
246 \\
289 \\
306 \\
142\end{array}$ & $\begin{array}{r}1694 \\
1524 \\
1073 \\
896 \\
967\end{array}$ & $\begin{array}{r}1077 \\
870 \\
1363 \\
387 \\
299\end{array}$ & $\begin{array}{l}479 \\
361 \\
278 \\
141 \\
102\end{array}$ & $\begin{array}{r}363 \\
133 \\
133 \\
96.0 \\
69.1\end{array}$ & $\begin{array}{l}225 \\
163 \\
214 \\
137 \\
168\end{array}$ \\
\hline $\begin{array}{l}1941 \\
1942 \\
1943 \\
1944 \\
1945\end{array}$ & $\begin{array}{l}259 \\
275 \\
167 \\
197 \\
173\end{array}$ & $\begin{array}{l}206 \\
243 \\
188 \\
209 \\
187\end{array}$ & $\begin{array}{l}168 \\
203 \\
162 \\
185 \\
168\end{array}$ & $\begin{array}{l}155 \\
184 \\
157 \\
170 \\
162\end{array}$ & $\begin{array}{l}157 \\
176 \\
169 \\
160 \\
155\end{array}$ & $\begin{array}{l}142 \\
173 \\
181 \\
196 \\
155\end{array}$ & $\begin{array}{l}179 \\
324 \\
500 \\
238 \\
165\end{array}$ & $\begin{array}{r}1175 \\
716 \\
1233 \\
935 \\
781\end{array}$ & $\begin{array}{l}1376 \\
1341 \\
1413 \\
1640 \\
1149\end{array}$ & $\begin{array}{l}396 \\
315 \\
517 \\
549 \\
425\end{array}$ & $\begin{array}{l}204 \\
109 \\
249 \\
132 \\
306\end{array}$ & $\begin{array}{l}186 \\
134 \\
111 \\
110 \\
161\end{array}$ \\
\hline $\begin{array}{l}1946 \\
1947 \\
1948 \\
1949 \\
1950\end{array}$ & $\begin{array}{l}186 \\
190 \\
161 \\
116 \\
186\end{array}$ & $\begin{array}{l}212 \\
213 \\
201 \\
169 \\
212\end{array}$ & $\begin{array}{l}172 \\
176 \\
175 \\
174 \\
191\end{array}$ & $\begin{array}{l}145 \\
165 \\
163 \\
155 \\
209\end{array}$ & $\begin{array}{l}131 \\
169 \\
160 \\
155 \\
190\end{array}$ & $\begin{array}{l}163 \\
184 \\
163 \\
179 \\
184\end{array}$ & $\begin{array}{l}463 \\
221 \\
186 \\
343 \\
345\end{array}$ & $\begin{array}{r}1017 \\
1447 \\
955 \\
1114 \\
846\end{array}$ & $\begin{array}{r}944 \\
1384 \\
750 \\
1868 \\
2208\end{array}$ & $\begin{array}{l}192 \\
517 \\
162 \\
582 \\
630\end{array}$ & $\begin{array}{l}126 \\
264 \\
106 \\
157 \\
146\end{array}$ & $\begin{array}{c}94.3 \\
154 \\
86.9 \\
130 \\
175\end{array}$ \\
\hline $\begin{array}{l}1951 \\
1952 \\
1953 \\
1954 \\
1955\end{array}$ & $\begin{array}{l}160 \\
197 \\
168 \\
132 \\
154\end{array}$ & $\begin{array}{l}204 \\
196 \\
206 \\
196 \\
153\end{array}$ & $\begin{array}{l}210 \\
176 \\
234 \\
177 \\
139\end{array}$ & $\begin{array}{l}182 \\
147 \\
222 \\
171 \\
150\end{array}$ & $\begin{array}{l}179 \\
150 \\
180 \\
161 \\
140\end{array}$ & $\begin{array}{l}162 \\
144 \\
168 \\
145 \\
150\end{array}$ & $\begin{array}{l}195 \\
389 \\
153 \\
173 \\
154\end{array}$ & $\begin{array}{r}946 \\
1625 \\
220 \\
644 \\
644\end{array}$ & $\begin{array}{c}1719 \\
2417 \\
1592 \\
228 \\
696\end{array}$ & $\begin{array}{l}569 \\
774 \\
376 \\
150 \\
196\end{array}$ & $\begin{array}{c}328 \\
433 \\
236 \\
89.7 \\
18\end{array}$ & $\begin{array}{c}142 \\
246 \\
114 \\
99.3 \\
123\end{array}$ \\
\hline $\begin{array}{l}1956 \\
1957 \\
1958 \\
1959 \\
1960\end{array}$ & $\begin{array}{c}107 \\
98.1 \\
153 \\
95.7 \\
181\end{array}$ & $\begin{array}{l}171 \\
165 \\
227 \\
164 \\
184\end{array}$ & $\begin{array}{l}192 \\
158 \\
202 \\
178 \\
148\end{array}$ & $\begin{array}{l}168 \\
148 \\
173 \\
146 \\
131\end{array}$ & $\begin{array}{l}156 \\
148 \\
167 \\
139 \\
125\end{array}$ & $\begin{array}{l}166 \\
143 \\
158 \\
134 \\
174\end{array}$ & $\begin{array}{l}220 \\
128 \\
200 \\
123 \\
176\end{array}$ & $\begin{array}{r}1013 \\
317 \\
1222 \\
267 \\
463\end{array}$ & $\begin{array}{r}1300 \\
2038 \\
1078 \\
799 \\
600\end{array}$ & $\begin{array}{l}228 \\
612 \\
184 \\
237 \\
178\end{array}$ & $\begin{array}{l}137 \\
217 \\
111 \\
140 \\
102\end{array}$ & $\begin{array}{l}93.9 \\
146 \\
106 \\
106 \\
110\end{array}$ \\
\hline $\begin{array}{l}1961 \\
1962 \\
1963 \\
1964 \\
1965\end{array}$ & $\begin{array}{c}141 \\
253 \\
191 \\
156 \\
99.5\end{array}$ & $\begin{array}{l}170 \\
222 \\
150 \\
191 \\
168\end{array}$ & $\begin{array}{l}156 \\
157 \\
151 \\
186 \\
181\end{array}$ & $\begin{array}{l}137 \\
128 \\
140 \\
142 \\
190\end{array}$ & $\begin{array}{l}120 \\
197 \\
167 \\
123 \\
164\end{array}$ & $\begin{array}{l}103 \\
192 \\
129 \\
136 \\
146\end{array}$ & $\begin{array}{l}77.7 \\
495 \\
134 \\
161 \\
214\end{array}$ & $\begin{array}{l}307 \\
944 \\
582 \\
816 \\
590\end{array}$ & $\begin{array}{r}299 \\
1452 \\
938 \\
1329 \\
2201\end{array}$ & $\begin{array}{r}123 \\
476 \\
241 \\
504 \\
1332\end{array}$ & $\begin{array}{l}111 \\
183 \\
191 \\
168 \\
429\end{array}$ & $\begin{array}{l}267 \\
139 \\
219 \\
114 \\
348\end{array}$ \\
\hline $\begin{array}{l}1966 \\
1967 \\
1968 \\
1969\end{array}$ & $\begin{array}{l}262 \\
161 \\
156 \\
202\end{array}$ & $\begin{array}{l}246 \\
152 \\
188 \\
203\end{array}$ & $\begin{array}{l}232 \\
195 \\
195 \\
189\end{array}$ & $\begin{array}{l}207 \\
207 \\
176 \\
205\end{array}$ & $\begin{array}{l}187 \\
176 \\
179 \\
196\end{array}$ & $\begin{array}{l}220 \\
179 \\
170 \\
193\end{array}$ & $\begin{array}{l}336 \\
160 \\
186 \\
397\end{array}$ & $\begin{array}{r}845 \\
563 \\
411 \\
1760\end{array}$ & $\begin{array}{r}398 \\
1999 \\
2282 \\
1171\end{array}$ & $\begin{array}{l}209 \\
866 \\
477 \\
308\end{array}$ & $\begin{array}{l}136 \\
217 \\
333 \\
177\end{array}$ & $\begin{array}{l}142 \\
155 \\
181 \\
173\end{array}$ \\
\hline
\end{tabular}


GREEN RIVER BASIN

O9279500 DUCHESNE RIVER AT DUCHESNE, UT-Continued

ANNUAL PEAK DISCAARGE, IN CUBIC FEET PER SECOND, AND CORRESPCNDING GAGE HEIGHT, IN FEET, FOR EACH WATMR YEAR

\begin{tabular}{|c|c|c|c|c|c|c|c|c|c|c|c|c|c|}
\hline $\begin{array}{l}\text { WATER } \\
\text { YEAR }\end{array}$ & DATE & $\begin{array}{c}\text { GAGE } \\
\text { HEIGHT }\end{array}$ & $\begin{array}{c}\text { PEAK } \\
\text { DISCHARGE }\end{array}$ & $\begin{array}{l}\text { WATER } \\
\text { YEAR }\end{array}$ & & DATE & $\begin{array}{c}\text { GAGE } \\
\text { HEIGHT }\end{array}$ & $\begin{array}{c}\text { PEAR } \\
\text { DISCHARGE }\end{array}$ & $\begin{array}{l}\text { WATER } \\
\text { YEAR }\end{array}$ & DATE & & $\begin{array}{c}\text { GAGE } \\
\text { HEIGHT }\end{array}$ & $\begin{array}{c}\text { PEAK } \\
\text { DISCHARGE }\end{array}$ \\
\hline $\begin{array}{l}1918 \\
1919 \\
1920 \\
1921 \\
1922 \\
1923 \\
1924 \\
1925 \\
1926 \\
1927 \\
1928 \\
1929 \\
1930 \\
1931 \\
1932 \\
1933 \\
1934 \\
1935\end{array}$ & 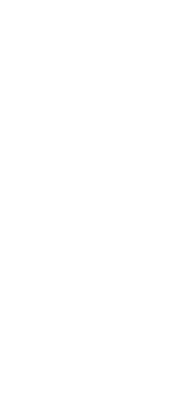 & $\begin{array}{l}7.40 \\
6.85 \\
7.40 \\
8.40 \\
8.65 \\
8.42 \\
2.65 \\
2.45 \\
2.80 \\
3.08 \\
3.50 \\
3.25 \\
3.15 \\
2.28 \\
3.60 \\
3.40 \\
2.42 \\
5.37\end{array}$ & $\begin{array}{r}2740 \\
2180 \\
2820 \\
4060 \\
4420 \\
3530 \\
2180 \\
1840 \\
2430 \\
2910 \\
3450 \\
2600 \\
2420 \\
978 \\
3460 \\
2210 \\
573 \\
3580\end{array}$ & $\begin{array}{l}1936 \\
1937 \\
1938 \\
1939 \\
1940 \\
1941 \\
1942 \\
1943 \\
1944 \\
1945 \\
1946 \\
1947 \\
1948 \\
1949 \\
1950 \\
1951 \\
1952\end{array}$ & $\begin{array}{l}\text { MAY } \\
\text { MAY } \\
\text { JUNE } \\
\text { MAY } \\
\text { MAY } \\
\text { MAY } \\
\text { JUNE } \\
\text { MAY } \\
\text { JUNE } \\
\text { JUNE } \\
\text { JUNE } \\
\text { MAY } \\
\text { MAY } \\
\text { JUNE } \\
\text { JUNE } \\
\text { MAY } \\
\text { JUNE }\end{array}$ & $\begin{array}{l}31,1936 \\
18,1937 \\
04,1938 \\
11,1939 \\
16,1940 \\
24,1941 \\
11,1942 \\
30,1943 \\
26,1944 \\
22,1945 \\
06,1946 \\
27,1947 \\
24,1948 \\
20,1949 \\
02,1950 \\
28,1951 \\
07,1952\end{array}$ & $\begin{array}{l}5.20 \\
5.05 \\
5.17 \\
3.87 \\
4.35 \\
5.05 \\
4.89 \\
4.88 \\
5.11 \\
4.53 \\
4.72 \\
4.88 \\
5.08 \\
5.63 \\
6.13 \\
6.08 \\
6.30\end{array}$ & $\begin{array}{l}3270 \\
3040 \\
3400 \\
1310 \\
2330 \\
3160 \\
2580 \\
2570 \\
3000 \\
1910 \\
2390 \\
2270 \\
2400 \\
3060 \\
3170 \\
3130 \\
4240\end{array}$ & $\begin{array}{l}1953 \\
1954 \\
1955 \\
1956 \\
1957 \\
1958 \\
1959 \\
1960 \\
1961 \\
1962 \\
1963 \\
1964 \\
1965 \\
1966 \\
1967 \\
1968 \\
1969\end{array}$ & $\begin{array}{l}\text { JUNE } 14 \text {, } \\
\text { MAY } 20, \\
\text { JUNE } 09, \\
\text { JUNE } 02 \text {, } \\
\text { JUNE } 08 \text {, } \\
\text { MAY 28, } \\
\text { JULY 14, } 14 \text { JUNE 04, } \\
\text { AUG. 26, } \\
\text { JUNE 21, } \\
\text { JUNE 16, } \\
\text { JUNE } 07 \text {, } \\
\text { JUNE 13, } \\
\text { MAY } 10, \\
\text { JUNE 21, } \\
\text { JUNE 20, } \\
\text { MAY 28, }\end{array}$ & $\begin{array}{l}1953 \\
1954 \\
1955 \\
1956 \\
1957 \\
1958 \\
1959 \\
1960 \\
1961 \\
1962 \\
1963 \\
1964 \\
1965 \\
1966 \\
1967 \\
1968 \\
1969\end{array}$ & $\begin{array}{l}5.13 \\
3.47 \\
4.10 \\
4.82 \\
4.92 \\
4.84 \\
3.90 \\
3.27 \\
2.72 \\
3.89 \\
4.68 \\
4.79 \\
4.49 \\
2.62 \\
4.33 \\
4.38 \\
4.02\end{array}$ & $\begin{array}{r}4020 \\
1270 \\
2080 \\
3140 \\
3620 \\
3340 \\
2090 \\
1430 \\
940 \\
2180 \\
2980 \\
3000 \\
3660 \\
1430 \\
3360 \\
3550 \\
2960\end{array}$ \\
\hline
\end{tabular}

MAGNITUDE AND PROBABILITY OF AMNUAL LOWEST MEAN DISCHARGE BASED ON CLIMATIC YEARS $1919-69$

\begin{tabular}{|c|c|c|c|c|c|c|}
\hline \multirow{2}{*}{$\begin{array}{l}\text { PERTOD } \\
\text { (CON- } \\
\text { SEQJ- } \\
\text { TIVE } \\
\text { DAYS) }\end{array}$} & \multicolumn{6}{|c|}{$\begin{array}{l}\text { DISCHARGE, IN OUIC FEET PER SECOND, FOR } \\
\text { INDICATED RECURRENCE INTERNAL, IN YEARS, AND } \\
\text { ANNUAL NONEXCEEDANCE ERCBABILITY, IN PERCENI }\end{array}$} \\
\hline & $\begin{array}{c}2 \\
50 \%\end{array}$ & $\begin{array}{c}5 \\
208\end{array}$ & $\begin{array}{l}10 \\
108\end{array}$ & $\begin{array}{l}20 \\
58\end{array}$ & $\begin{array}{l}50 \\
28\end{array}$ & $\begin{array}{r}100 \\
18\end{array}$ \\
\hline
\end{tabular}

$\begin{array}{rrrrrrr}1 & 93 & 62 & 47 & 37 & 27 & 21 \\ 7 & 100 & 68 & 52 & 41 & 30 & 24 \\ 14 & 104 & 74 & 60 & 49 & 39 & 33 \\ 30 & 113 & 83 & 70 & 59 & 49 & 43 \\ 60 & 131 & 98 & 82 & 69 & 57 & 49 \\ 90 & 144 & 110 & 93 & 79 & 65 & 57\end{array}$

MAGNITUDE AND PROBABIILIY OF ANNLAL HIGHEST MEAN DISCHARGE BASED ON WATER YEARS $1918-69$

\begin{tabular}{|c|c|c|c|c|c|c|}
\hline \multirow{2}{*}{$\begin{array}{l}\text { PERIOD } \\
\text { (CON- } \\
\text { SEOU- } \\
\text { TIVE } \\
\text { DAYS) }\end{array}$} & \multicolumn{6}{|c|}{$\begin{array}{l}\text { DISCHARGE, IN ONBIC FEET PER SECOND, FOR } \\
\text { NWICATED RECIRRENCE INTERNAL, IN YEARS, AND } \\
\text { ANNUAL EXCEEDANCE PROBABILITY, IN PERCENT }\end{array}$} \\
\hline & $\begin{array}{c}2 \\
508\end{array}$ & $\begin{array}{c}5 \\
208\end{array}$ & $\begin{array}{l}10 \\
108\end{array}$ & $\begin{array}{l}25 \\
48\end{array}$ & $\begin{array}{l}50 \\
28\end{array}$ & $\begin{array}{r}100 \\
18\end{array}$ \\
\hline $\begin{array}{r}1 \\
3 \\
7 \\
15\end{array}$ & $\begin{array}{l}2490 \\
2390 \\
2200 \\
1930\end{array}$ & $\begin{array}{l}3270 \\
3150 \\
2960 \\
2610\end{array}$ & $\begin{array}{l}3620 \\
3490 \\
3300 \\
2910\end{array}$ & $\begin{array}{l}3910 \\
3790 \\
3610 \\
3180\end{array}$ & $\begin{array}{l}4060 \\
3940 \\
3780 \\
3320\end{array}$ & $\begin{array}{l}4180 \\
4060 \\
3900 \\
3430\end{array}$ \\
\hline
\end{tabular}

09280400 HOBBLE CREEK AT DANIELS SUMMIT, NEAR WALLSBURG, UT

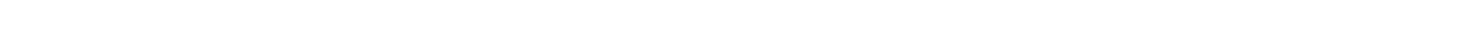
14060004, on left bank about 1,000 ft upstream from crossing of Hobble Creek ditch, $0.5 \mathrm{mi}$ west of Daniels Sumit on U.S. Highway 40 , and $10.5 \mathrm{mi}$ southeast of wallsburg.

DRAINAGE AREA. $--2.89 \mathrm{mi}^{2}$.

MEAN BASIN ELEVATION. $-9,060 \mathrm{ft}$.

PERIOD OF RECORD AVAIIABLE.-OCtober 1963 to September 1981.

REVISED RECORDS.-WOR UT-77-1: Drainage area.

GAGE.-Water-stage recorder. Altitude of gage is $8,200 \mathrm{ft}$ from topographic map.

AVERAGE DISCHARGE.--18 years, $2.75 \mathrm{ft}^{3} / \mathrm{s}, 1,990$ acre- $\mathrm{ft} / \mathrm{yr}$.

EXIREMES FOR PERIOD OF REOORD. - Maximum discharge, $145 \mathrm{ft}^{3} / \mathrm{s}$ June 7,1975 , gage height, $2.89 \mathrm{ft}$; no flow at times during February to April 1964, January to March 1966, Sept. 4, 1967, Aug. 10-17, 1970, on several days in Aug. 1977. 
GREEN RIVER BASIN

09280400 HOBBLE CREEK AT DANIETS SUMMIT, NEAR WALISBURG, UT-Continued

LOWEST MEAN DISCHARGE, IN CUBIC FEET PER SECOND, AND RANKING FOR THE INDICATED NUMBER OF CONSECUTIVE DAYS FOR EACH CLIMATIC YEAR, APRIL I-MARCH 31

YEAR

1965

1966

1967

1970

1971

1972

1974

1975

1976

1977

1979
1980

1981
0.00

0.002

0.1017

0.014

$\begin{array}{rr}0.06 & 14 \\ 0.02 & 7\end{array}$

0.015

0.0412

0.0310

0.028

0.0513

0.016

0.003

$\begin{array}{lr}0.08 & 15 \\ 0.03 & 9\end{array}$

0.1016

\begin{tabular}{lr}
\multicolumn{1}{l}{3} & \\
& \\
0.00 & 1 \\
& 1 \\
0.00 & 2 \\
0.10 & 16 \\
0.02 & 5 \\
0.07 & 14 \\
0.02 & 6 \\
0.02 & 7 \\
0.04 & 9 \\
0.04 & 10 \\
0.05 & 11 \\
0.05 & 12 \\
0.06 & 13 \\
0.01 & 4 \\
0.00 & 3 \\
0.08 & 15 \\
0.03 & 8
\end{tabular}

0.1117

$\begin{array}{lr}7 & \\ 0.00 & 1 \\ & \\ 0.00 & 2 \\ 0.10 & 16 \\ 0.02 & 5 \\ 0.08 & 14 \\ 0.02 & 6 \\ 0.02 & 7 \\ 0.05 & 9 \\ 0.05 & 10 \\ 0.08 & 15 \\ 0.05 & 11 \\ 0.06 & 12 \\ 0.01 & 3 \\ 0.02 & 4 \\ 0.08 & 13 \\ 0.04 & 8\end{array}$

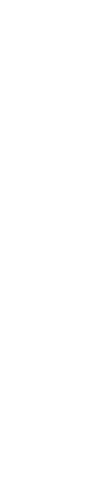

0.1117

0.1117
CONSECOTIVE DAYS

30

0.0911

0.1010

0.001

$\begin{array}{ll}0.1012 \\ 0.02 & 3\end{array}$

$\begin{array}{ll}0.02 & 3 \\ 0.17 & 17\end{array}$

0.024

0.057

0.1013

$\begin{array}{ll}0.07 & 10 \\ 0.13 & 15\end{array}$

$\begin{array}{rr}0.13 & 15 \\ 0.06 & 8\end{array}$

0.079

$\begin{array}{ll}0.07 & 9 \\ 0.01 & 2\end{array}$

0.045

$\begin{array}{rr}0.10 & 14 \\ 0.05 & 6\end{array}$

0.1416
0.055

$\begin{array}{ll}0.10 & 11 \\ 0.03 & 2\end{array}$

$\begin{array}{ll}0.03 & 2 \\ 0.18 & 17\end{array}$

$\begin{array}{ll}0.18 & 17 \\ 0.03 & 3\end{array}$

0.1113

0.1012

0.098

0.1515

0.099

$\begin{array}{ll}0.09 & 9 \\ 0.01 & 1\end{array}$

0.054

0.1716
0.1214

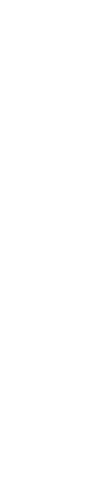

.

$\begin{array}{lr}120 & \\ 0.11 & 5 \\ 0.17 & 11 \\ 0.13 & 9 \\ 0.05 & 2 \\ 0.19 & 14 \\ 0.06 & 3 \\ 0.21 & 16 \\ 0.18 & 12 \\ 0.20 & 15 \\ 0.19 & 13 \\ 0.12 & 6 \\ 0.12 & 7 \\ 0.04 & 1 \\ 0.08 & 4 \\ 0.15 & 10 \\ 0.13 & 8\end{array}$

183

ALL

HIGHEST MEAN DISCHARGE, IN CUBIC FEET PER SEOOND, AND RANKING FOR THE INDICATED NUMBER OF CONSECUTIVE DAYS FOR EACH WATER YEAR, OCTOBER 1-SEPTEMBER 30

YEAR

196

1965

1966
1967

1967

1969

1970

1971

1972
1973

1973
1974

1975

1976

1977

1978
1979

1979
1980

1981

$\begin{array}{lllll}1 & & & & \\ 1 & 3 & 15 & 30 & 60\end{array}$

$\begin{array}{ll}49.0 & 8 \\ 47.0 & 9\end{array}$

$\begin{array}{rr}41.0 & 9 \\ 39.0 & 10\end{array}$

35.0

$26.0 \quad 12$

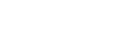

0.2217

0.158

2.106

$0.1912 \quad 3.2011$

0.1352 .004

0.11333 .8013

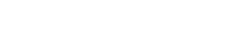

$\begin{array}{lll}0.2415 & 2.10 \quad 5\end{array}$

$\begin{array}{lll}0.1710 & 2.70 \quad 8\end{array}$

$\begin{array}{llll}0.31 & 17 & 1.90 & 2\end{array}$

$\begin{array}{llll}0.20 & 13 & 3.80 & 14\end{array}$

$0.156 \quad 4.0016$

0.081130

$0.102 \quad 0.301$

$0.1711 \quad 3.7012$

$\begin{array}{lll}0.15 & 7 & 2.60 \\ 0.2416 & 4.6017\end{array}$

\section{$\begin{array}{llllllllllll}33.0 & 15 & 31.0 & 15 & 28.0 & 15 & 21.0 & 15 & 16.0 & 15 & 10.0 & 15\end{array}$}

$\begin{array}{rrrrrrrrrrrr}33.0 & 15 & 31.0 & 15 & 28.0 & 15 & 21.0 & 15 & 16.0 & 15 & 10.0 & 15 \\ 61.0 & 4 & 50.0 & 6 & 44.0 & 6 & 41.0 & 4 & 35.0 & 3 & 22.0 & 3\end{array}$

$\begin{array}{lrrr}72.0 & 3 & 56.0 & 4\end{array}$

$\begin{array}{rrrr}46.0 & 10 & 44.0 & 8 \\ 39.0 & 11 & 38.0 & 11\end{array}$

47.04

37.07

$\begin{array}{llllllll}42.0 & 7 & 40.0 & 5 & 33.0 & 5 & 16.0 & 8 \\ 34.0 & 11 & 27.0 & 1 & 19.0 & 13 & 11.0 & 14\end{array}$

$\begin{array}{rrrrrrrr}42.0 & 7 & 40.0 & 5 & 33.0 & 5 & 21.0 & 4 \\ 34.0 & 11 & 27.0 & 11 & 19.0 & 13 & 11.0 & 14\end{array}$

$\begin{array}{llll}39.0 & 12 & 36.0 & 13\end{array}$

$\begin{array}{rrrr}25.0 & 16 & 24.0 & 16 \\ 77.0 & 2 & 71.0 & 2\end{array}$

$\begin{array}{rrrr}38.0 & 13 & 37.0 & 12 \\ 81.0 & 1 & 73.0 & 1\end{array}$

$\begin{array}{llll}29.0 & 14 & 24.0 & 14\end{array}$

$\begin{array}{rrrrrrrr}29.0 & 14 & 24.0 & 14 & 21.0 & 11 & 14.0 & 11 \\ 20.0 & 16 & 17.0 & 16 & 14.0 & 16 & 9.20 & 16 \\ 61.0 & 1 & 47.0 & 2 & 34.0 & 4 & 21.0 & 5\end{array}$

$\begin{array}{llllll}32.0 & 12 & 29.0 & 10 & 34.0 & 4\end{array}$

$\begin{array}{llll}37.0 & 14 & 34.0 & 14\end{array}$

$\begin{array}{rrr}2.90 & 18 & 2.6018\end{array}$

52.06

$\begin{array}{rr}2.60 & 18 \\ 50.0 & 5\end{array}$

59.02

51.01

$\begin{array}{llll}32.0 & 13 & 25.0 & 13\end{array}$

$\begin{array}{rrrr}2.00 & 18 & 1.50 & 18 \\ 46.0 & 5 & 40.0 & 6\end{array}$

$\begin{array}{cc}14.0 & 18 \\ 10.0 & 10\end{array}$

$\begin{array}{ll}36.0 & 8 \\ 45.0 & 3\end{array}$
60

90

$\begin{array}{ll}26.0 & 9 \\ 36.0 & 1\end{array}$

21.05

$\begin{array}{lll}14.0 & 11.7016 \\ 16.0 & 9 & 14.0\end{array}$

$\begin{array}{ll}14.0 & 5 \\ 11.0 & 9 \\ 16.0 & 2\end{array}$

$\begin{array}{llll}18.0 \quad 14 & 11.0 \quad 12\end{array}$

7.4015

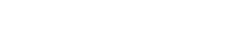

$\begin{array}{llll}32.0 & 6 & 20.0 & 6\end{array}$

0.8018

14.0
10.0
18.0

$\begin{array}{rr}24.0 & 10 \\ 35.0 & 2\end{array}$

$\begin{array}{ll}14.0 & 10 \\ 25.0 & 1\end{array}$

18.01

$8.6017 \quad 7.6017$

6.5017

4.8017

120

3.9012

ALL

DURATION OF DISCHARGE FOR EACH WATER YEAR

$\begin{array}{lllllllllllllllllllllllllllllllllllll}\text { CLASS } & 0 & 1 & 2 & 3 & 4 & 5 & 6 & 7 & 8 & 9 & 10 & 11 & 12 & 13 & 14 & 15 & 16 & 17 & 18 & 19 & 20 & 21 & 22 & 23 & 24 & 25 & 26 & 27 & 28 & 29 & 30 & 31 & 32 & 33 & 34\end{array}$

YEAR

NUMBER OF DAYS IN CLASS

ABIC FEET

$1964 \quad 72$

1965

$1966 \quad 44$

1967
1968
1969

1969

1971

1972

1973
1974

1974
1975

1976

1976
1977
1978
1979

1980

1981

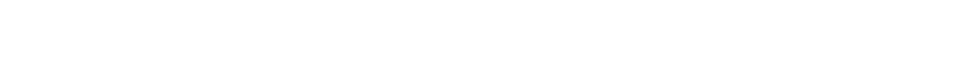

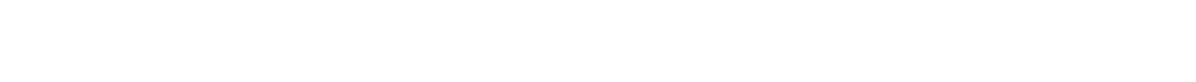

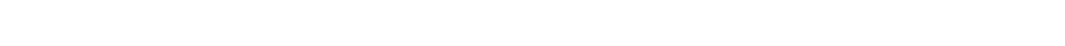

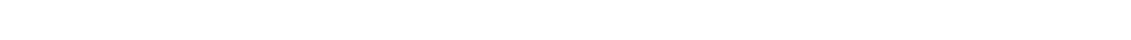

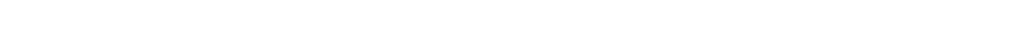

$\begin{array}{lllllllllllllllllllllllll}1 & 4 & 13 & 20 & 72 & 25 & 13 & 28 & 45 & 14 & 9 & 10 & 11 & 9 & 15 & 9 & 10 & 10 & 7 & 6 & 8 & 9 & 8 & 6 & 4\end{array}$

$\begin{array}{lllllllllllllllllllllllllllll}2 & 2 & 2 & 12 & 7 & 11102 & 33 & 19 & 23 & 32 & 25 & 9 & 7 & 10 & 5 & 5 & 6 & 2 & 3 & 3 & 8 & 4 & 8 & 8 & 6 & 5 & 2 & 3 & 1\end{array}$

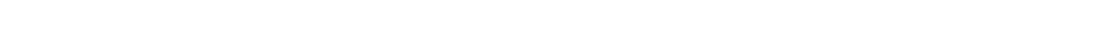

$\begin{array}{rrrrrrrrrrrrr}1 & 4 & 5 & 6 & 6 & 8 & 10 & 5 & & & \\ 5 & 3 & 7 & 6 & 12 & 3 & 5 & 3 & 7 & 3 & 1\end{array}$

$\begin{array}{llllllllllllllllllllllllllll}258 & 9 & 8 & 6 & 28 & 32 & 8 & 34 & 41123 & 4 & 7 & 6 & 9 & 3 & 7 & 4 & 8 & 9 & 5 & 2 & 2 & 2 & 8 & 6 & 7 & 2 & 4 & 3\end{array}$

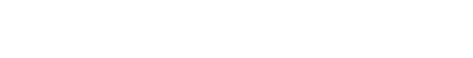

$\begin{array}{rrr}9 & 11 & 5 \\ 4 & 4 & 11\end{array}$

$\begin{array}{rrrrrrrrrrr}9 & 5 & 2 & 2 & 2 & 8 & 6 & 7 & 2 & 4 & 3 \\ 2 & 10 & 13 & 7 & 5 & 4 & 3 & 4 & 4 & 11 & 7\end{array}$

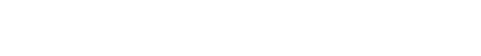

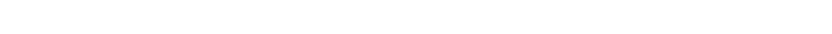

PER SECOND

-DAYS

733.6

1144.5

742.0

1402.1

1029.6

1430.2
750.4

964.8

679.8

1394.9

1394.9

1064.4
1475.3

713.8

92.2

1337.6

967.2
1677.3

496.6 
GREEN RIVER BASIN

09280400 HOBBLE CREEK AT DANIELS SUMMIT, NEAR WALLSBURG, UT-Continued

DURATION TABLE OF DISCHARGE FOR WATER YEARS 1964-81

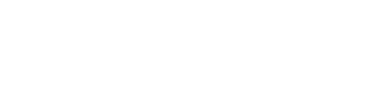

$\begin{array}{lllll}0 & 0.00 & 118 & 6575 & 100.0\end{array}$ $\begin{array}{rrrr}0.01 & 61 & 6457 & 98.2\end{array}$ $\begin{array}{llll}0.02 & 110 & 6396 & 97.3\end{array}$ $\begin{array}{llll}0.03 & 17 & 6286 & 95.6\end{array}$ $\begin{array}{llll}0.04 & 39 & 6269 & 95.3\end{array}$ $\begin{array}{llll}0.05 & 275 & 6230 & 94.8\end{array}$ $\begin{array}{llll}0.07 & 165 & 5955 & 90.6\end{array}$ $\begin{array}{llll}0.09 & 737 & 5790 & 88.1\end{array}$

$\begin{array}{cccc}\begin{array}{c}\text { CUBIC } \\ \text { FEET }\end{array} & \begin{array}{c}\text { ACOU } \\ \text { MU- }\end{array} & \text { PER- } \\ \text { PER } & \text { TOTAL } & \text { LATED } & \text { CENT } \\ \text { SECOND } & \text { DAYS } & \text { DAYS } & \text { DAYS } \\ & & & \\ 0.15 & 861 & 4649 & 70.7 \\ 0.20 & 915 & 3788 & 57.6 \\ 0.26 & 522 & 2873 & 43.7 \\ 0.34 & 353 & 2351 & 35.8 \\ 0.45 & 220 & 1998 & 30.4 \\ 0.58 & 197 & 1778 & 27.0 \\ 0.77 & 113 & 1581 & 24.0 \\ 1.00 & 118 & 1468 & 22.3 \\ 1.30 & 111 & 1350 & 20.5\end{array}$

CLASS
18
19
20
21
22
23
24
25
26

$\begin{array}{lll}\text { CUBIC } & \text { ACON- } \\ \text { FEET } & \text { MU- } & \\ \text { PER TER- } & \end{array}$ CLASS SECOND DAYS DAYS DAYS

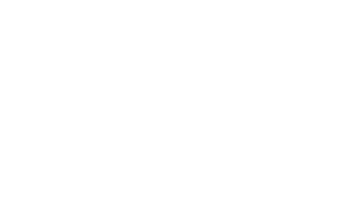

CUBIC ACQU-

FEET MU- PERGIASS SBCOND DAYS DAYS DAYS

$\begin{array}{rrrrr}27 & 20.0 & 76 & 296 & 4.5 \\ 28 & 26.0 & 96 & 220 & 3.3 \\ 29 & 34.0 & 79 & 124 & 1.9 \\ 30 & 45.0 & 35 & 45 & 0.7 \\ 31 & 59.0 & 8 & 10 & 0.2 \\ 32 & 77.0 & 2 & 2 & 0.0 \\ 33 & & & & \\ 34 & & & & \end{array}$

MONTHLY MEAN DISCHARGES, IN OUBIC FEET PER SEOOND, FOR EACH WATER YEAR

$\begin{array}{lllllllllllll}\text { YEAR } & \text { OCT } & \text { NOV } & \text { DEC } & \text { JAN } & \text { FEB } & \text { MAR } & \text { APR } & \text { MAY } & \text { JUNE } & \text { JULY } & \text { AUG } & \text { SEP } \\ 1964 & 0.10 & 0.27 & 0.14 & 0.10 & 0.00 & 0.00 & 0.42 & 14.7 & 7.02 & 0.89 & 0.21 & 0.10 \\ 1965 & 0.10 & 0.13 & 0.26 & 0.21 & 0.20 & 0.22 & 1.48 & 13.8 & 19.4 & 1.34 & 0.25 & 0.20 \\ 1966 & 0.24 & 0.29 & 0.29 & 0.15 & 0.00 & 0.48 & 5.61 & 14.8 & 1.90 & 0.27 & 0.11 & 0.10 \\ 1967 & 0.14 & 0.24 & 0.10 & 0.11 & 0.14 & 0.21 & 0.62 & 16.9 & 25.6 & 1.69 & 0.19 & 0.10 \\ 1968 & 0.24 & 0.25 & 0.05 & 0.03 & 0.02 & 0.15 & 0.63 & 10.6 & 20.5 & 0.83 & 0.34 & 0.29 \\ 1969 & 0.28 & 0.30 & 0.18 & 0.18 & 0.20 & 0.25 & 4.97 & 32.3 & 6.22 & 1.32 & 0.15 & 0.16 \\ 1970 & 0.40 & 0.31 & 0.08 & 0.02 & 0.04 & 0.11 & 0.69 & 15.0 & 6.97 & 0.59 & 0.05 & 0.19 \\ 1971 & 0.36 & 0.43 & 0.31 & 0.12 & 0.10 & 0.33 & 1.21 & 17.3 & 10.5 & 0.60 & 0.12 & 0.14 \\ 1972 & 0.25 & 0.30 & 0.16 & 0.10 & 0.17 & 0.95 & 3.63 & 13.5 & 2.56 & 0.35 & 0.11 & 0.09 \\ 1973 & 0.71 & 0.58 & 0.26 & 0.18 & 0.18 & 0.18 & 1.90 & 30.1 & 10.3 & 0.57 & 0.31 & 0.17 \\ 1974 & 0.25 & 0.32 & 0.19 & 0.15 & 0.15 & 0.48 & 2.13 & 24.9 & 5.58 & 0.34 & 0.08 & 0.07 \\ 1975 & 0.18 & 0.17 & 0.16 & 0.15 & 0.15 & 0.20 & 0.30 & 8.83 & 35.2 & 3.09 & 0.22 & 0.07 \\ 1976 & 0.16 & 0.15 & 0.17 & 0.20 & 0.20 & 0.22 & 1.06 & 18.0 & 2.58 & 0.26 & 0.08 & 0.08 \\ 1977 & 0.14 & 0.16 & 0.01 & 0.02 & 0.05 & 0.09 & 0.88 & 1.02 & 0.45 & 0.08 & 0.05 & 0.08 \\ 1978 & 0.13 & 0.13 & 0.15 & 0.15 & 0.16 & 0.34 & 2.50 & 15.5 & 23.8 & 0.90 & 0.10 & 0.13 \\ 1979 & 0.13 & 0.23 & 0.20 & 0.33 & 0.40 & 0.40 & 1.91 & 20.4 & 6.79 & 0.52 & 0.12 & 0.05 \\ 1980 & 0.18 & 0.19 & 0.17 & 0.17 & 0.16 & 0.17 & 3.64 & 19.1 & 29.3 & 1.65 & 0.23 & 0.16 \\ 1981 & 0.24 & 0.26 & 0.29 & 0.26 & 0.25 & 0.25 & 3.22 & 7.67 & 3.12 & 0.36 & 0.13 & 0.20\end{array}$

ANNUAL PEAK DISCHARGE, IN CUBIC FEET PER SECOND, AND CORRESPONDING GAGE HEIGHT, IN FEET, FOR EACH WATER YEAR

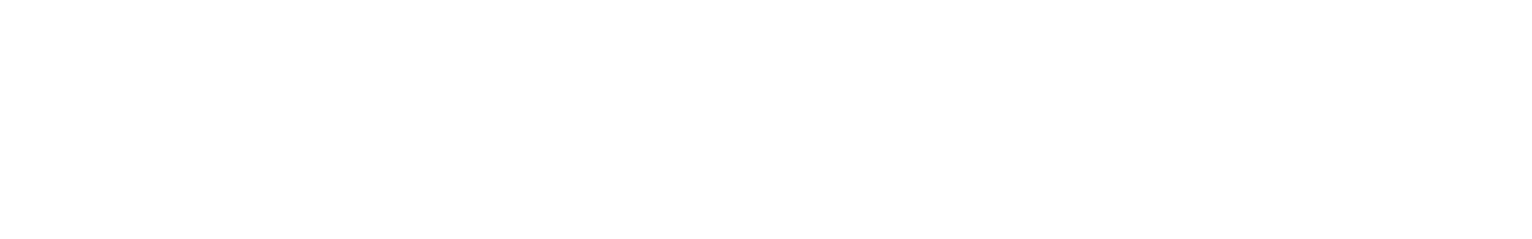

MAGNITUDE AND PRCBABILITY OF ANNUAL LOWEST MEAN DISCHARGE BASED ON OLIMATIC YEARS 1965-81

\begin{tabular}{|c|c|c|c|c|c|c|}
\hline \multirow{2}{*}{$\begin{array}{l}\text { PERIOD } \\
\text { (CON- } \\
\text { SEOU- } \\
\text { TIVE } \\
\text { DAYS) }\end{array}$} & \multicolumn{6}{|c|}{$\begin{array}{l}\text { DISCHARGE, IN OUBIC FEET PER SECOND, FOR } \\
\text { INDICATED RECURRENCE INTERNAL, IN YEARS, AND } \\
\text { ANNUAL NONEXCEEDANCE PROBABILITY, IN PERCENT }\end{array}$} \\
\hline & $\begin{array}{c}2 \\
50 \%\end{array}$ & $\begin{array}{c}5 \\
208\end{array}$ & $\begin{array}{l}10 \\
108\end{array}$ & $\begin{array}{l}20 \\
58\end{array}$ & $\begin{array}{l}50 \\
28\end{array}$ & $\begin{array}{r}100 \\
18\end{array}$ \\
\hline $\begin{array}{r}1 \\
7 \\
14 \\
30 \\
60 \\
90\end{array}$ & $\begin{array}{l}0.03 \\
0.04 \\
0.05 \\
0.06 \\
0.09 \\
0.11\end{array}$ & $\begin{array}{l}0.01 \\
0.02 \\
0.02 \\
0.03 \\
0.04 \\
0.06\end{array}$ & $\begin{array}{l}0.00 \\
0.00 \\
0.01 \\
0.01 \\
0.03 \\
0.05\end{array}$ & $\begin{array}{l}0.00 \\
0.00 \\
0.00 \\
0.00 \\
0.02 \\
0.03\end{array}$ & $\overline{-}$ & $\begin{array}{l}\bar{z} \\
\bar{z} \\
\overline{-}\end{array}$ \\
\hline
\end{tabular}


GREEN RIVER BASIN

09285000 STRFWERRY RIVER NEAR SOTDIER SPRINGS, UT

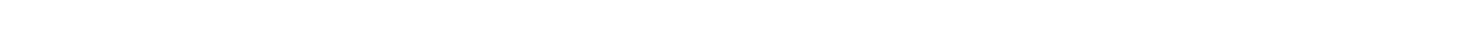
14060004 , on left bank $300 \mathrm{ft}$ below Soldier Creek Dam, $1.5 \mathrm{mi}$ upstrean fram Willow Creek, and $3.4 \mathrm{mi}$ south of Soldier Springs.

DRAINAGE AREA.--213 $\mathrm{mi}^{2}$, approximately (includes approximately $170 \mathrm{mi}^{2}$ tributary to Strawberry Reservoir, which includes area above diversion dams on Indian and Trail Hollow Creeks).

PERICD OF RECORD AVAIIABLE.-OCtober 1942 to September 1956, october 1963 to September 1981.

REVISED RECORDS. -WDR UT-77-1: Drainage area.

GAGE. -Water-stage recorder. Altitude of gage is $7,360 \mathrm{ft}$ from topographic map. Prior to June 1, 1971, water-stage recorder at site about $0.2 \mathrm{mi}$ upstream at different datum. From June 1, 1971 to Aug. 8, 1974, at site about $0.8 \mathrm{mi}$ downstream at different datum.

REMARRS.-FIow regulated by Stramberry Reservoir since July 14, 1912, capacity, 283,000 acre-ft prior to June 30, 1973 . New earthfilled dam (capacity, 1,106,500 acre-ft, which includes the old reservoir capacity), located $7 \mathrm{mi}$ below old dam, was completed in September 1972, and storage began June 30,1973. When elevation of the new reservoir reaches the elevation of the old reservoir, the old dan will be destroyed by explosives. Water Hollow tunnel will divert $600 \mathrm{ft}^{3} / \mathrm{s}$ to the reservoir during spring runoff when series of tunnels and small reservoirs are completed on Rock Creek, West Fork Duchesne River, and Currant creek. Several old trangmountain diversions upstream to the reservoir. Transmountain diversions fram the reservoir and upstrean tributaries to the Great Basin.

AVERAGE DISGHARGE. -23 years (water years 1943-56, 1964-72), $31.0 \mathrm{ft}^{3} / \mathrm{s}, 22,500$ acre-ft/yr, prior to campletion of Soldier Creek Dam.

EXIREMES FOR PERIOD OF RECORD.-Maximum discharge, 1,020 ft $3 / \mathrm{s}$ May 4, 1952, gage height, $3.84 \mathrm{ft}$, from rating curve extended above $550 \mathrm{ft}^{3} / \mathrm{s}$; minimum daily, $0.23 \mathrm{ft}^{3} / \mathrm{s} \mathrm{July}$ and August 1973.

DATA BELOW BASED ON PERICD OF RECORD PRIOR TO ENLARGING STRAWBERRY RESERVOIR

LONEST MEAN DISGHARGE, IN OBBIC FEET PER SECOND, AND RANKING FOR THE INDICATED NUMBE OF CONSECUTIVE DAYS FOR EACH OIMATIC YEAR, APRII 1-MARCH 31

YEAR

1944
1945

1946

194

1948

1950

1951

1951
1952
1953

1954

1955

1956

1965

1966

1967

1968

1969
1970

1971

1972

1

$\begin{array}{llll}13.0 & 13 & 13.0 & 13\end{array}$

$\begin{array}{llll}13.0 & 14 & 13.0 & 14\end{array}$

$\begin{array}{rr}12.0 & 9 \\ 11.0 & 6 \\ 11.0 & 7 \\ 11.0 & 8 \\ 14.0 & 15\end{array}$

$14.0 \quad 16$

$13.0 \quad 10$

$\begin{array}{ll}13.0 & 11 \\ 14.0 & 17\end{array}$

$9.60 \quad 2$

10.03

9.401

$\begin{array}{ll}10.0 & 4 \\ 11.0 & 5\end{array}$

$14.0 \quad 18$

$\begin{array}{ll}14.0 & 18 \\ 13.0 & 12\end{array}$

16.021

$15.0 \quad 19$

16.020

13.0 18

16.021
CONSEOUTTVE DAYS
30
60

$7 \quad 14$

$\begin{array}{llll}13.0 & 12 & 13.0 & 11\end{array}$

$13.0 \quad 13$

$\begin{array}{ll}12.0 & 8 \\ 12.0 & 9\end{array}$

11.06

11.07

15.018

$14.0 \quad 14$

13.010

$\begin{array}{ll}13.0 & 10 \\ 14.0 & 15 \\ 15.0 & 19\end{array}$

$\begin{array}{cr}15.0 & 19 \\ 9.60 \quad 2\end{array}$

10.03

9.501

$11.0 \quad 4$

$11.0 \quad 5$

$14.0 \quad 16$

$\begin{array}{ll}13.0 & 11 \\ 16.0 & 20\end{array}$

$15.0 \quad 17$

$\begin{array}{ll}15.0 & 17 \\ 16.0 & 21\end{array}$
60

$13.0 \quad 10$

$\begin{array}{ll}12.0 & 8 \\ 12.0 & 9\end{array}$

$\begin{array}{ll}12.0 & 9 \\ 11.0 & 6\end{array}$

11.07

15.018

$\begin{array}{ll}14.0 & 13 \\ 14.0 & 14\end{array}$

$\begin{array}{ll}14.0 & 14 \\ 14.0 & 15 \\ 15.0 & 16\end{array}$

$\begin{array}{r}15.702 \\ \hline\end{array}$

11.03

9.601

$11.0 \quad 4$

11.05

$\begin{array}{ll}16.0 & 19 \\ 13.0 & 10\end{array}$

$\begin{array}{ll}13.0 & 10 \\ 16.0 & 20\end{array}$

$\begin{array}{ll}15.0 & 17\end{array}$

$\begin{array}{ll}15.0 & 17 \\ 16.0 & 21\end{array}$ $\begin{array}{ll}12.0 & 7 \\ 12.0 & 8\end{array}$

$\begin{array}{ll}12.0 & 8 \\ 11.0 & 5 \\ 11.0 & 6\end{array}$

$15.0 \quad 16$

$15.0 \quad 17$

$14.0 \quad 12$

22.021

$\begin{array}{rr}15.0 & 13 \\ 10.0 & 2\end{array}$

11.03

9.701

$15.0 \quad 14$

$11.0 \quad 4$

16.018

$\begin{array}{rr}13.0 & 9 \\ 16.0 \quad 19\end{array}$

$15.0 \quad 15$

$\begin{array}{ll}15.0 & 15 \\ 16.0 & 20\end{array}$

31

HIGHEST MEAN DISGHARGE, IN OBIC FEET PER SECOND, AND RANKING FOR THE INDICATED NUMBER OF CONSEOUTIVE DAYS FORT PER SECOND, AND RANKING FOR THE INDICAT
FAOH WATER YEAR, OCTOBER I-SEPTEMBER 30

YEAR

1943
1944
1945
1946
1947
1948
1949
1950
1951
1952
1953
1954
1955

$\begin{array}{rrcrr}1 & & 3 & & \\ 172 & 12 & 158 & 12 & 1 \\ 228 & 6 & 206 & 6 & 1 \\ 190 & 10 & 162 & 11 & 1 \\ 238 & 5 & 201 & 8 & 150 \\ 105 & 20 & 99.0 & 19 & \\ 106 & 19 & 97.0 & 20 & \\ 222 & 8 & 209 & 5 & 1 \\ 273 & 2 & 238 & 2 & 1 \\ & & & & \\ 137 & 15 & 128 & 14 & 1 \\ 682 & 1 & 672 & 1 & 6 \\ 126 & 16 & 122 & 16 & \\ 120 & 18 & 107 & 18 & \\ 163 & 14 & 127 & 15 & \end{array}$

7

15

CONSBOUTIVE DAYS

$\begin{array}{rrrr}134 & 11 & 104 & 10 \\ 163 & 6 & 126 & 7\end{array}$

30

$\begin{array}{rr}60 & \\ 67.0 & 9 \\ 78.0 & 7 \\ 52.0 & 16 \\ & \\ 64.0 & 11 \\ 53.0 & 14 \\ 41.0 & 21 \\ 98.0 & 3 \\ 95.0 & 4\end{array}$

\begin{abstract}
9
\end{abstract}
$99.0-11$

$62.0 \quad 16$

84.09

$\begin{array}{rr}150 & 8 \\ 96.0 & 16 \\ 79.0 & 20\end{array}$

$\begin{array}{cc}79.0 & 20 \\ 182 & 4 \\ 187 & 3\end{array}$

$\begin{array}{cr}110 & 8 \\ 76.0 & 15 \\ 62.0 & 20 \\ 143 & 4 \\ 144 & 3\end{array}$

$\begin{array}{ll}63.0 & 14 \\ 49.0 & 21\end{array}$

$117 \quad 3$

$111 \quad 14$

$\begin{array}{cr}111 & 14 \\ 612 & 1 \\ 98.0 & 15\end{array}$

$\begin{array}{ll}98.0 & 15 \\ 91.0 & 19\end{array}$

$\begin{array}{ll}93.0 & 17\end{array}$

$89.0 \quad 13$

$\begin{array}{cc}516 & 1 \\ 69.0 & 18\end{array}$

$75.0 \quad 12$

$\begin{array}{cc}75.0 & 12 \\ 398 & 1\end{array}$

$\begin{array}{ll}55.0 & 18 \\ 47.0 & 22\end{array}$

$\begin{array}{ll}65.0 & 19 \\ 72.0 & 17\end{array}$

$\begin{array}{ll}53.0 & 20\end{array}$

$\begin{array}{rr}66.0 & 10 \\ 271 & 1 \\ 44.0 & 19 \\ 37.0 & 23\end{array}$

$\begin{array}{rrrr}90 & & 120 & \\ 59.0 & 9 & 53.0 & 9 \\ 66.0 & 8 & 58.0 & 8 \\ 46.0 & 18 & 41.0 & 18 \\ 53.0 & 11 & 46.0 & 11 \\ 47.0 & 15 & 42.0 & 17 \\ 36.0 & 21 & 33.0 & 21 \\ 81.0 & 3 & 70.0 & 3 \\ 80.0 & 4 & 69.0 & 4 \\ 58.0 & 10 & 52.0 & 10 \\ 211 & 1 & 176 & 1 \\ 40.0 & 19 & 38.0 & 19 \\ 35.0 & 23 & 33.0 & 22 \\ 36.0 & 22 & 32.0 & 23\end{array}$

183

$\begin{array}{ll}44.0 & 9 \\ 47.0 & 8\end{array}$

$34.0 \quad 19$

$\begin{array}{lll}38.0 & 12\end{array}$

$35.0 \quad 17$

27.02

$\begin{array}{ll}56.0 & 3 \\ 55.0 & 4\end{array}$

$43.0 \quad 10$

$\begin{array}{rr}43.0 & 10 \\ 133 & 1\end{array}$

$34.0 \quad 18$

$\begin{array}{ll}29.0 & 21 \\ 27.0 & 22\end{array}$

ALL

$30.0 \quad 12$

$31.0 \quad 9$

$25.0 \quad 19$

$27.0 \quad 15$

25.016

21.022

35.05

$31.0 \quad 10$

$\begin{array}{rr}31.0 & 10 \\ 73.0 & 1\end{array}$

33.06

$\begin{array}{ll}23.0 & 20 \\ 20.0 & 23\end{array}$ 
GREEN RIVER BASDN

09285000 STPEWERRY RIVER NEAR SQDIER SPRANGS, OT-Continued

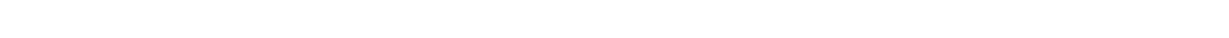

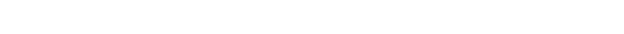

\begin{tabular}{|c|c|c|c|c|c|c|c|c|c|c|c|c|c|c|c|c|c|c|c|c|}
\hline YEAR & 1 & & 3 & & 7 & & 15 & & $\begin{array}{l}\text { cons } \\
30\end{array}$ & $\mathrm{EC}$ & $\begin{array}{l}\text { DAVS } \\
60\end{array}$ & & 90 & & 120 & & 183 & & ALd & \\
\hline 956 & 125 & 17 & 111 & 17 & 93.0 & 18 & 74.0 & 16 & 62.0 & 15 & 53.0 & 15 & 47.0 & 16 & 43.0 & 16 & 36.0 & 15 & 25.0 & 17 \\
\hline $\begin{array}{l}966 \\
967 \\
968 \\
969 \\
970\end{array}$ & $\begin{array}{l}101 \\
166 \\
190 \\
256 \\
213\end{array}$ & $\begin{array}{r}21 \\
13 \\
11 \\
3 \\
9\end{array}$ & $\begin{array}{l}91.0 \\
155 \\
173 \\
224 \\
196\end{array}$ & $\begin{array}{r}21 \\
13 \\
10 \\
4 \\
9\end{array}$ & $\begin{array}{l}71.0 \\
124 \\
159 \\
189 \\
143\end{array}$ & $\begin{array}{r}22 \\
12 \\
7 \\
2 \\
9\end{array}$ & $\begin{array}{c}52.0 \\
92.0 \\
131 \\
175 \\
\mathbf{5 . 0}\end{array}$ & $\begin{array}{r}23 \\
12 \\
5 \\
2 \\
11\end{array}$ & $\begin{array}{c}42.0 \\
82.0 \\
106 \\
146 \\
71.0\end{array}$ & $\begin{array}{r}23 \\
10 \\
5 \\
2 \\
13\end{array}$ & $\begin{array}{r}39.0 \\
74.0 \\
84.0 \\
109 \\
56.0\end{array}$ & $\begin{array}{r}22 \\
8 \\
5 \\
2 \\
13\end{array}$ & $\begin{array}{l}37.0 \\
67.0 \\
70.0 \\
93.0 \\
48.0\end{array}$ & $\begin{array}{r}20 \\
7 \\
6 \\
2 \\
13\end{array}$ & $\begin{array}{l}35.0 \\
61.0 \\
62.0 \\
81.0 \\
44.0\end{array}$ & $\begin{array}{r}20 \\
7 \\
6 \\
2 \\
14\end{array}$ & $\begin{array}{l}30.0 \\
51.0 \\
50.0 \\
64.0 \\
38.0\end{array}$ & $\begin{array}{r}20 \\
6 \\
7 \\
2 \\
13\end{array}$ & $\begin{array}{l}25.0 \\
32.0 \\
35.0 \\
41.0 \\
29.0\end{array}$ & $\begin{array}{r}18 \\
8 \\
4 \\
2 \\
13\end{array}$ \\
\hline $\begin{array}{l}971 \\
972\end{array}$ & $\begin{array}{l}98.0 \\
85.0\end{array}$ & $\begin{array}{l}22 \\
23\end{array}$ & $\begin{array}{l}87.0 \\
78.0\end{array}$ & $\begin{array}{l}22 \\
23\end{array}$ & $\begin{array}{l}72.0 \\
68.0\end{array}$ & $\begin{array}{l}21 \\
23\end{array}$ & $\begin{array}{l}60.0 \\
60.0\end{array}$ & $\begin{array}{l}21 \\
22\end{array}$ & $\begin{array}{l}54.0 \\
56.0\end{array}$ & $\begin{array}{l}19 \\
17\end{array}$ & $\begin{array}{l}50.0 \\
49.0\end{array}$ & $\begin{array}{l}17 \\
18\end{array}$ & $\begin{array}{l}46.0 \\
47.0\end{array}$ & $\begin{array}{l}17 \\
14\end{array}$ & $\begin{array}{l}43.0 \\
45.0\end{array}$ & $\begin{array}{l}15 \\
12\end{array}$ & $\begin{array}{l}38.0 \\
39.0\end{array}$ & $\begin{array}{l}14 \\
11\end{array}$ & $\begin{array}{l}29.0 \\
30.0\end{array}$ & $\begin{array}{l}14 \\
11\end{array}$ \\
\hline
\end{tabular}

DURATTON OF DISGHAFGE FOR EACH WATER YEAR

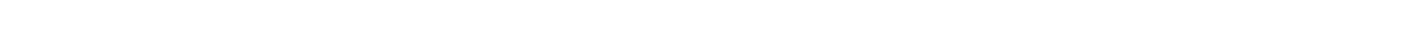

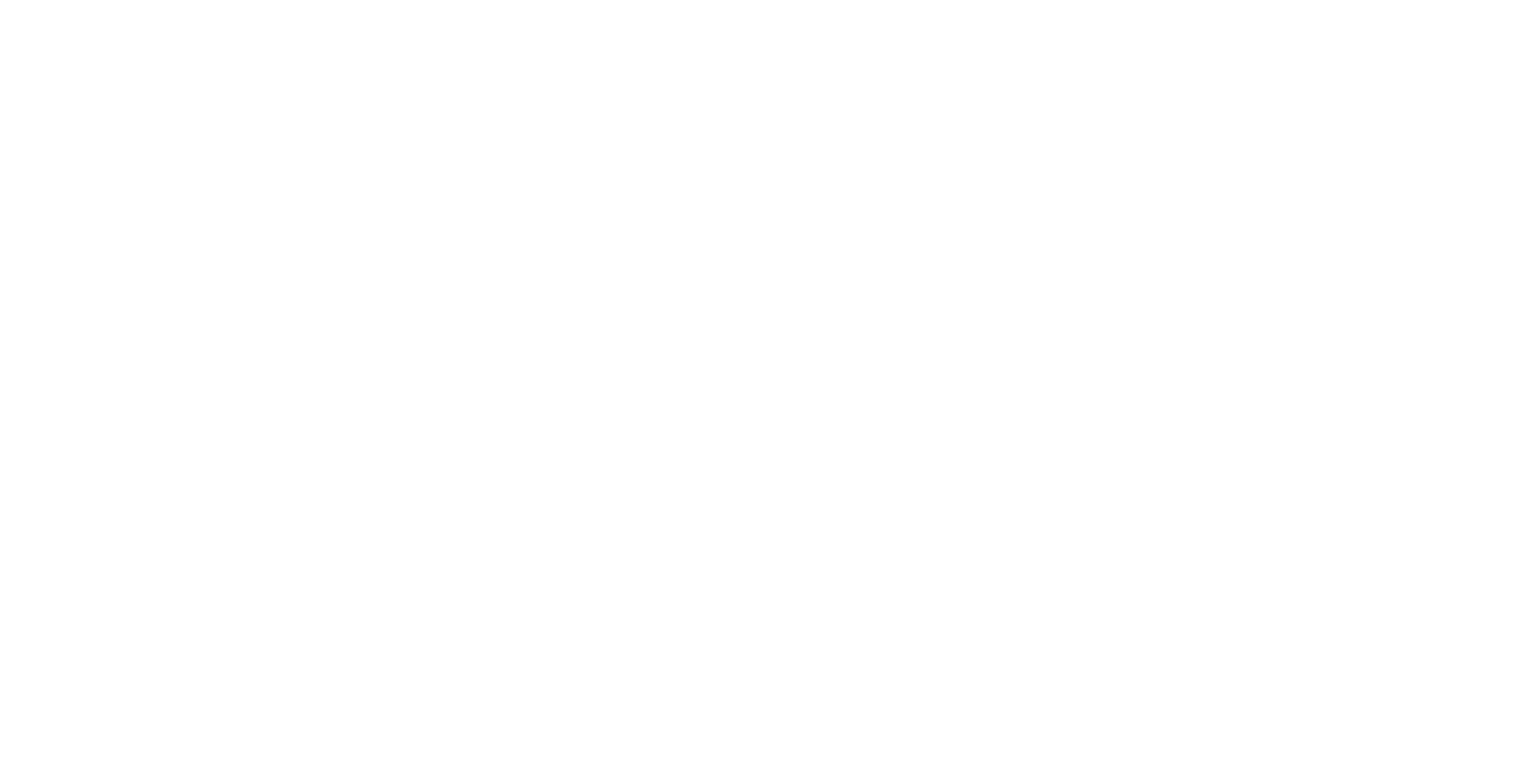

DURATION TABLE $\boldsymbol{O}$ DISCHARGE FOR WATER YEARS 1943-56, $1964-72$

\begin{tabular}{|c|c|c|c|c|c|c|c|c|c|c|c|c|c|c|c|c|c|c|c|}
\hline I.ASS & $\begin{array}{c}\text { arBIC } \\
\text { FEET } \\
\text { PER } \\
\text { SECOND }\end{array}$ & $\begin{array}{l}\text { TOTAL } \\
\text { DAYS }\end{array}$ & $\begin{array}{l}\text { AOCU- } \\
\text { MU- } \\
\text { LATED } \\
\text { DAYS }\end{array}$ & $\begin{array}{l}\text { PER- } \\
\text { EENT } \\
\text { DAYS }\end{array}$ & C.ASS & $\begin{array}{c}\text { OBIC } \\
\text { FEET } \\
\text { PER } \\
\text { SECOND }\end{array}$ & $\begin{array}{l}\text { TOTPL } \\
\text { DAYS }\end{array}$ & $\begin{array}{l}\text { ACOJ- } \\
\text { MU- } \\
\text { LATED } \\
\text { DAYS }\end{array}$ & $\begin{array}{l}\text { PER- } \\
\text { CENT } \\
\text { DAYS }\end{array}$ & CLASS & $\begin{array}{c}\text { OBIC } \\
\text { FEET } \\
\text { PER } \\
\text { SECOND }\end{array}$ & $\begin{array}{l}\text { TOTAL } \\
\text { DAYS }\end{array}$ & $\begin{array}{c}\text { ACOJ- } \\
\text { MU- } \\
\text { LAIED } \\
\text { DAYS }\end{array}$ & $\begin{array}{l}\text { PER } \\
\text { CENT } \\
\text { DAYS }\end{array}$ & C.ASS & $\begin{array}{c}\text { OUBIC } \\
\text { FEET } \\
\text { PER } \\
\text { SEOOND }\end{array}$ & $\begin{array}{l}\text { TOTAL } \\
\text { DAYS }\end{array}$ & $\begin{array}{l}\text { ACOU- } \\
\text { MU- } \\
\text { LAMED } \\
\text { DAYS }\end{array}$ & $\begin{array}{l}\text { PER- } \\
\text { CENT } \\
\text { DAYS }\end{array}$ \\
\hline $\begin{array}{l}0 \\
1 \\
2 \\
3 \\
4 \\
5 \\
6 \\
7 \\
8\end{array}$ & $\begin{array}{r}0.00 \\
6.90 \\
7.90 \\
9.10 \\
10.00 \\
12.00 \\
14.00 \\
16.00 \\
18.00\end{array}$ & $\begin{array}{r}0 \\
54 \\
53 \\
59 \\
264 \\
694 \\
869 \\
932 \\
847\end{array}$ & $\begin{array}{l}8402 \\
8402 \\
8348 \\
8295 \\
8236 \\
7972 \\
7278 \\
6409 \\
5477\end{array}$ & $\begin{array}{r}100.0 \\
100.0 \\
99.4 \\
98.7 \\
98.0 \\
94.9 \\
86.6 \\
76.3 \\
65.2\end{array}$ & $\begin{array}{r}9 \\
10 \\
11 \\
12 \\
13 \\
14 \\
15 \\
16 \\
17\end{array}$ & $\begin{array}{l}21.00 \\
24.00 \\
28.00 \\
32.00 \\
37.00 \\
42.00 \\
48.00 \\
55.00 \\
64.00\end{array}$ & $\begin{array}{l}686 \\
851 \\
617 \\
609 \\
376 \\
386 \\
244 \\
223 \\
188\end{array}$ & $\begin{array}{r}4630 \\
3944 \\
3093 \\
2476 \\
1867 \\
1491 \\
1105 \\
861 \\
638\end{array}$ & $\begin{array}{r}55.1 \\
46.9 \\
36.8 \\
29.5 \\
22.2 \\
17.7 \\
13.2 \\
10.2 \\
7.6\end{array}$ & $\begin{array}{l}18 \\
19 \\
20 \\
21 \\
22 \\
23 \\
24 \\
25 \\
26\end{array}$ & $\begin{array}{r}73.0 \\
84.0 \\
97.0 \\
110.0 \\
130.0 \\
150.0 \\
170.0 \\
190.0 \\
220.0\end{array}$ & $\begin{array}{r}127 \\
105 \\
42 \\
45 \\
38 \\
21 \\
16 \\
19 \\
14\end{array}$ & $\begin{array}{r}450 \\
323 \\
218 \\
176 \\
131 \\
93 \\
72 \\
56 \\
37\end{array}$ & $\begin{array}{l}5.4 \\
3.8 \\
2.6 \\
2.1 \\
1.6 \\
1.1 \\
0.9 \\
0.7 \\
0.4\end{array}$ & $\begin{array}{l}27 \\
28 \\
29 \\
30 \\
31 \\
32 \\
33 \\
34\end{array}$ & $\begin{array}{l}260.0 \\
290.0 \\
340.0 \\
390.0 \\
440.0 \\
510.0 \\
590.0 \\
680.0\end{array}$ & $\begin{array}{l}3 \\
1 \\
2 \\
7 \\
4 \\
1 \\
4 \\
1\end{array}$ & $\begin{array}{r}23 \\
20 \\
19 \\
17 \\
10 \\
6 \\
5 \\
1\end{array}$ & $\begin{array}{l}0.3 \\
0.2 \\
0.2 \\
0.2 \\
0.1 \\
0.1 \\
0.1 \\
0.0\end{array}$ \\
\hline
\end{tabular}


GREEN RIVER BASIN

09285000 STRAFBERRY RIVER NEAR SCLDIER SPRINCS, UT-Continued

MONTHLY MEAN DISOHARGES, IN OBIC FEET PER SECOND, FOR EACH WATER YEAR

\begin{tabular}{|c|c|c|c|c|c|c|c|c|c|c|c|c|}
\hline YEAR & $\infty \mathrm{CT}$ & $\mathrm{NOV}$ & DEC & JAN & FEBB & MAR & APR & MAY & JUNE & JULY & AUG & SEP \\
\hline $\begin{array}{l}1943 \\
1944 \\
1945\end{array}$ & $\begin{array}{l}20.7 \\
21.7 \\
21.4\end{array}$ & $\begin{array}{l}18.2 \\
18.2 \\
18.5\end{array}$ & $\begin{array}{l}16.0 \\
14.6 \\
15.5\end{array}$ & $\begin{array}{l}14.0 \\
13.3 \\
14.0\end{array}$ & $\begin{array}{l}15.0 \\
13.0 \\
13.0\end{array}$ & $\begin{array}{l}16.0 \\
13.7 \\
13.5\end{array}$ & $\begin{array}{l}72.0 \\
27.5 \\
17.3\end{array}$ & $\begin{array}{l}51.3 \\
97.3 \\
61.7\end{array}$ & $\begin{array}{l}49.9 \\
56.3 \\
41.2\end{array}$ & $\begin{array}{l}35.9 \\
42.6 \\
32.5\end{array}$ & $\begin{array}{l}30.4 \\
31.8 \\
28.4\end{array}$ & $\begin{array}{l}22.9 \\
25.1 \\
22.4\end{array}$ \\
\hline $\begin{array}{l}1946 \\
1947 \\
1948 \\
1949 \\
1950\end{array}$ & $\begin{array}{l}20.8 \\
18.4 \\
18.0 \\
16.0 \\
25.5\end{array}$ & $\begin{array}{l}19.1 \\
16.6 \\
16.7 \\
14.2 \\
20.4\end{array}$ & $\begin{array}{l}16.4 \\
14.6 \\
14.9 \\
12.4 \\
18.2\end{array}$ & $\begin{array}{l}14.0 \\
12.7 \\
13.5 \\
11.0 \\
16.0\end{array}$ & $\begin{array}{l}13.0 \\
12.0 \\
12.2 \\
11.6 \\
14.9\end{array}$ & $\begin{array}{l}12.9 \\
14.4 \\
11.4 \\
16.8 \\
15.5\end{array}$ & $\begin{array}{l}68.3 \\
50.8 \\
29.3 \\
93.0 \\
85.7\end{array}$ & $\begin{array}{l}51.8 \\
45.6 \\
41.2 \\
86.8 \\
84.7\end{array}$ & $\begin{array}{l}36.2 \\
40.2 \\
31.3 \\
57.4 \\
58.6\end{array}$ & $\begin{array}{l}26.8 \\
29.0 \\
24.2 \\
39.8 \\
40.7\end{array}$ & $\begin{array}{l}24.4 \\
23.6 \\
19.7 \\
32.0 \\
31.6\end{array}$ & $\begin{array}{l}20.3 \\
19.9 \\
16.0 \\
26.5 \\
26.5\end{array}$ \\
\hline $\begin{array}{l}1951 \\
1952 \\
1953 \\
1954 \\
1955\end{array}$ & $\begin{array}{l}22.8 \\
21.6 \\
54.6 \\
22.2 \\
15.7\end{array}$ & $\begin{array}{l}21.3 \\
19.2 \\
33.4 \\
19.4 \\
15.4\end{array}$ & $\begin{array}{l}19.4 \\
18.0 \\
26.8 \\
17.0 \\
12.0\end{array}$ & $\begin{array}{l}17.1 \\
16.0 \\
24.3 \\
15.0 \\
11.0\end{array}$ & $\begin{array}{l}16.1 \\
14.7 \\
23.1 \\
15.0 \\
10.7\end{array}$ & $\begin{array}{l}14.8 \\
13.8 \\
23.1 \\
18.4 \\
10.1\end{array}$ & $\begin{array}{l}62.1 \\
67.0 \\
46.2 \\
45.7 \\
39.0\end{array}$ & $\begin{array}{c}59.0 \\
373 \\
35.0 \\
26.3 \\
34.9\end{array}$ & $\begin{array}{c}48.0 \\
132 \\
35.5 \\
30.9 \\
27.9\end{array}$ & $\begin{array}{l}35.2 \\
83.7 \\
32.5 \\
27.5 \\
22.5\end{array}$ & $\begin{array}{l}30.6 \\
69.3 \\
29.5 \\
22.7 \\
19.9\end{array}$ & $\begin{array}{l}26.1 \\
69.6 \\
25.5 \\
18.4 \\
16.0\end{array}$ \\
\hline 1956 & 13.4 & 13.4 & 13.7 & 13.8 & 12.0 & 12.7 & 52.0 & 48.0 & 37.4 & 33.1 & 27.1 & 20.9 \\
\hline $\begin{array}{l}1964 \\
1965\end{array}$ & $\begin{array}{l}14.9 \\
15.6\end{array}$ & $\begin{array}{l}12.8 \\
13.5\end{array}$ & $\begin{array}{l}9.10 \\
13.1\end{array}$ & $\begin{array}{c}8.51 \\
12.4\end{array}$ & $\begin{array}{c}7.66 \\
10.6\end{array}$ & $\begin{array}{l}7.68 \\
9.72\end{array}$ & $\begin{array}{l}41.3 \\
40.7\end{array}$ & $\begin{array}{l}70.5 \\
88.4\end{array}$ & $\begin{array}{l}33.0 \\
57.9\end{array}$ & $\begin{array}{l}25.9 \\
43.1\end{array}$ & $\begin{array}{l}21.4 \\
38.9\end{array}$ & $\begin{array}{l}18.8 \\
35.0\end{array}$ \\
\hline $\begin{array}{l}1966 \\
1967 \\
1968 \\
1969 \\
1970\end{array}$ & $\begin{array}{l}28.1 \\
16.3 \\
26.1 \\
25.5 \\
29.6\end{array}$ & $\begin{array}{l}25.3 \\
15.8 \\
23.2 \\
21.1 \\
24.2\end{array}$ & $\begin{array}{l}20.0 \\
13.8 \\
19.4 \\
16.9 \\
20.0\end{array}$ & $\begin{array}{l}17.0 \\
12.0 \\
17.7 \\
14.8 \\
18.0\end{array}$ & $\begin{array}{l}15.9 \\
11.1 \\
16.9 \\
13.4 \\
16.9\end{array}$ & $\begin{array}{l}16.2 \\
11.9 \\
16.0 \\
13.5 \\
16.1\end{array}$ & $\begin{array}{l}41.5 \\
28.8 \\
22.4 \\
90.2 \\
29.5\end{array}$ & $\begin{array}{c}36.8 \\
76.7 \\
103 \\
110 \\
68.9\end{array}$ & $\begin{array}{l}32.1 \\
68.0 \\
62.1 \\
65.9 \\
39.0\end{array}$ & $\begin{array}{l}27.3 \\
54.5 \\
43.5 \\
49.7 \\
32.8\end{array}$ & $\begin{array}{l}22.3 \\
44.1 \\
36.4 \\
39.4 \\
28.9\end{array}$ & $\begin{array}{l}17.8 \\
34.0 \\
28.5 \\
30.0 \\
25.6\end{array}$ \\
\hline $\begin{array}{l}1971 \\
1972\end{array}$ & $\begin{array}{l}22.5 \\
24.0\end{array}$ & $\begin{array}{l}20.7 \\
21.0\end{array}$ & $\begin{array}{l}17.6 \\
17.6\end{array}$ & $\begin{array}{l}16.2 \\
16.5\end{array}$ & $\begin{array}{l}15.1 \\
16.9\end{array}$ & $\begin{array}{l}27.3 \\
38.4\end{array}$ & $\begin{array}{l}53.1 \\
51.2\end{array}$ & $\begin{array}{l}45.0 \\
42.0\end{array}$ & $\begin{array}{l}39.1 \\
44.3\end{array}$ & $\begin{array}{l}32.9 \\
30.1\end{array}$ & $\begin{array}{l}30.2 \\
28.2\end{array}$ & $\begin{array}{l}25.7 \\
24.6\end{array}$ \\
\hline
\end{tabular}

ANNUAL PEAK DISGHARGE, IN OBIC FEET PER SECOND, AND CORRESPONDING GAGE HEIGHT, IN FEET, FOR EAOH WAIER YEAR

\begin{tabular}{|c|c|c|c|c|c|c|c|c|c|c|c|}
\hline $\begin{array}{l}\text { WATER } \\
\text { YEAR }\end{array}$ & DATE & $\begin{array}{l}\text { GAGE } \\
\text { HEIGTT }\end{array}$ & $\begin{array}{c}\text { PEAK } \\
\text { DISOHARGE }\end{array}$ & $\begin{array}{l}\text { WATER } \\
\text { YEAR }\end{array}$ & DATE & $\begin{array}{c}\text { GAGE } \\
\text { HEIGT }\end{array}$ & $\begin{array}{c}\text { PEAR } \\
\text { DISOHARGE }\end{array}$ & $\begin{array}{l}\text { WATER } \\
\text { YEAR }\end{array}$ & DAIE & $\begin{array}{c}\text { GAGE } \\
\text { HEIGHT }\end{array}$ & $\begin{array}{c}\text { PEAK } \\
\text { DISQHARGE }\end{array}$ \\
\hline $\begin{array}{l}1943 \\
1944 \\
1945 \\
1946 \\
1947 \\
1948 \\
1949 \\
1950\end{array}$ & $\begin{array}{l}\text { APR. } 18,1943 \\
\text { MAY } 07,1944 \\
\text { MAY } 05,1945 \\
\text { APR. } 20,1946 \\
\text { APR. } 20,1947 \\
\text { APR. 29, } 1948 \\
\text { APR. 24, } 1949 \\
\text { APR. } 22,1950\end{array}$ & $\begin{array}{l}2.91 \\
3.18 \\
3.10 \\
3.42 \\
2.48 \\
2.52 \\
2.95 \\
3.22\end{array}$ & $\begin{array}{l}279 \\
370 \\
335 \\
453 \\
165 \\
165 \\
356 \\
458\end{array}$ & $\begin{array}{l}1951 \\
1952 \\
1953 \\
1954 \\
1955 \\
1956 \\
1964 \\
1965\end{array}$ & $\begin{array}{l}\text { APR. } 15,1951 \\
\text { MAY } 04,1952 \\
\text { APR. } 23,1953 \\
\text { APR. } 17,1954 \\
\text { APR. } 25,1955 \\
\text { APR. } 19,1956 \\
\text { MAY } 13,1964 \\
\text { MAY } 01,1965\end{array}$ & $\begin{array}{l}2.59 \\
3.84 \\
2.75 \\
2.58 \\
2.93 \\
2.60 \\
3.17 \\
3.04\end{array}$ & $\begin{array}{r}243 \\
1020 \\
302 \\
246 \\
368 \\
243 \\
486 \\
411\end{array}$ & $\begin{array}{l}1966 \\
1967 \\
1968 \\
1969 \\
1970 \\
1971 \\
1972\end{array}$ & $\begin{array}{l}\text { APR. } 09,1966 \\
\text { MAY } 08,1967 \\
\text { MAY } 09,1968 \\
\text { APR. } 29,1969 \\
\text { MAY } 07,1970 \\
\text { APR. 11, } 1971 \\
\text { MAR. 21, } 1972\end{array}$ & $\begin{array}{l}2.27 \\
2.85 \\
2.59 \\
2.98 \\
3.09 \\
2.28 \\
3.87\end{array}$ & $\begin{array}{l}169 \\
340 \\
240 \\
432 \\
464 \\
153 \\
163\end{array}$ \\
\hline
\end{tabular}

MAGNITUDE AND PRCBABILITY OF ANNOAL LONEST MEAN DISOHARGE BASED ON CLIMATTC YEARS 1944-56 AND 1965-72

\begin{tabular}{|c|c|c|c|c|c|c|}
\hline \multirow{2}{*}{$\begin{array}{l}\text { PERIOD } \\
\text { (CON- } \\
\text { SEQU- } \\
\text { TTVE } \\
\text { DAYS) }\end{array}$} & \multicolumn{6}{|c|}{$\begin{array}{l}\text { DISOHARGE, IN GBIC FEET PER SECOND, FOR } \\
\text { INDICATED REOJRRENCE INTERNAL, IN YEARS, AND } \\
\text { ANNUAL NONEXCEEDANCE PRCBABILITY, IN PERCENT }\end{array}$} \\
\hline & $\begin{array}{c}2 \\
508\end{array}$ & $\begin{array}{c}5 \\
208\end{array}$ & $\begin{array}{l}10 \\
108\end{array}$ & $\begin{array}{l}20 \\
58\end{array}$ & $\begin{array}{l}50 \\
28\end{array}$ & $\begin{array}{r}100 \\
18\end{array}$ \\
\hline
\end{tabular}

$\begin{array}{rrrrrrr}1 & 12 & 11 & 10 & 9.4 & - & - \\ 7 & 13 & 11 & 10 & 9.5 & - & - \\ 14 & 13 & 11 & 10 & 9.7 & - & - \\ 30 & 13 & 11 & 10 & 9.9 & - & - \\ 60 & 14 & 12 & 11 & 10 & - & - \\ 90 & 14 & 12 & 12 & 11 & - & -\end{array}$

MAGNITUDE AND PRCBABILITY OF ANNUAL HIGHEST MEAN DISCHARGE BASED ON WATER YEARS $1943-56$ AND $1964-72$

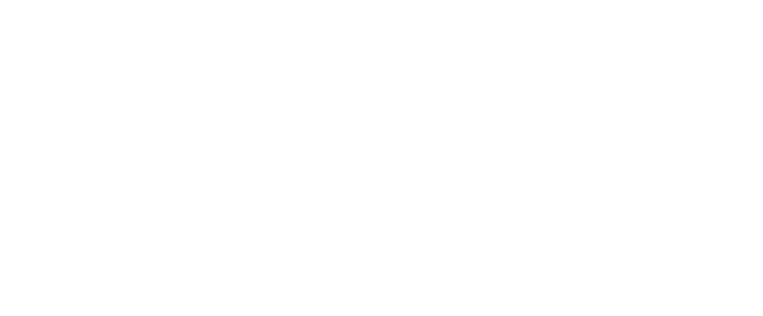

DATA BELCW BASED ON PERIOD OF RECORD AFTER ENLARGING STRAWBERRY RESERVOIR

LOWEST MEAN DISCHARGE, IN OBIC FEET PER SECOND, AND RANKING FOR THE INDICATED NUMBER OF CONSECUTIVE DAUS FOR EAOH CLIMATIC YEAR, APRIL I-MAROH 31

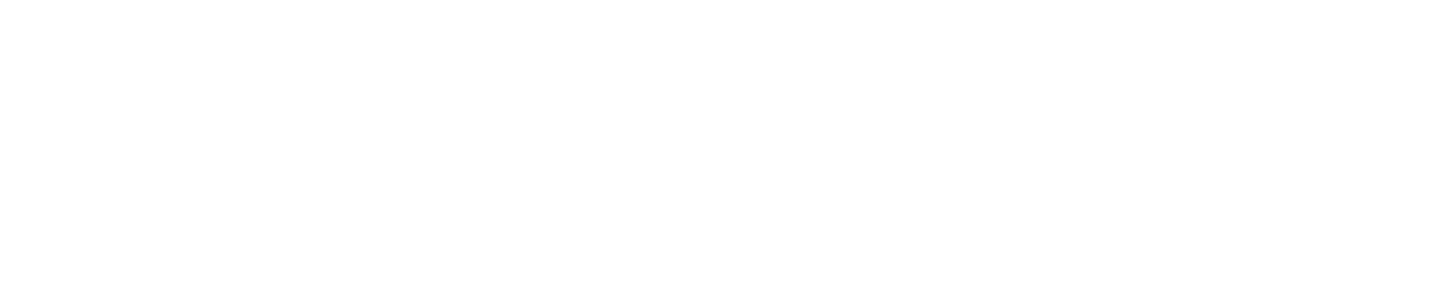


GREEN RIVER BASIN

09285000 STRAWBERY RIVER NEAR SQDIER SPRINGS, UT-Continued

HIGHEST MEAN DISGHARGE, IN OBIC FEET PER SECOND, AND RANKING FOR THE INDICATED NUMBER OF CONSEOUTIVE DAVS FOR EACH WATER YEAR, OCTCBER I-SEPTEMBER 30

\begin{tabular}{|c|c|c|c|c|c|c|c|c|c|c|c|c|c|c|c|c|c|c|}
\hline YEAR & & 3 & & 7 & & 15 & & $\begin{array}{l}\text { canst } \\
30\end{array}$ & & $\begin{array}{c}\text { E DAYS } \\
60\end{array}$ & & 90 & & 120 & & 183 & & ALL \\
\hline $\begin{array}{l}14.0 \\
46.0\end{array}$ & $\begin{array}{l}4 \\
1\end{array}$ & $\begin{array}{l}14.0 \\
46.0\end{array}$ & $\begin{array}{l}4 \\
1\end{array}$ & $\begin{array}{l}14.0 \\
38.0\end{array}$ & $\begin{array}{l}4 \\
1\end{array}$ & $\begin{array}{l}14.0 \\
26.0\end{array}$ & $\begin{array}{l}4 \\
1\end{array}$ & $\begin{array}{l}14.0 \\
22.0\end{array}$ & $\begin{array}{l}4 \\
3\end{array}$ & $\begin{array}{l}14.0 \\
17.0\end{array}$ & & $\begin{array}{l}13.0 \\
15.0\end{array}$ & $\begin{array}{l}5 \\
3\end{array}$ & $\begin{array}{l}13.0 \\
14.0\end{array}$ & $\begin{array}{l}4 \\
2\end{array}$ & $\begin{array}{l}13.0 \\
14.0\end{array}$ & $\begin{array}{l}4 \\
2\end{array}$ & $\begin{array}{l}12.0 \\
13.0\end{array}$ \\
\hline $\begin{array}{c}14.0 \\
12.0 \\
8.90 \\
8.70 \\
26.0\end{array}$ & $\begin{array}{l}5 \\
6 \\
7 \\
8 \\
2\end{array}$ & $\begin{array}{c}14.0 \\
12.0 \\
8.80 \\
8.60 \\
26.0\end{array}$ & $\begin{array}{l}5 \\
6 \\
7 \\
8 \\
2\end{array}$ & $\begin{array}{c}14.0 \\
12.0 \\
8.70 \\
8.40 \\
26.0\end{array}$ & $\begin{array}{l}5 \\
6 \\
7 \\
8 \\
2\end{array}$ & $\begin{array}{c}13.0 \\
10.0 \\
8.70 \\
8.30 \\
25.0\end{array}$ & $\begin{array}{l}5 \\
6 \\
7 \\
8 \\
2\end{array}$ & $\begin{array}{c}13.0 \\
9.20 \\
8.70 \\
8.20 \\
25.0\end{array}$ & $\begin{array}{l}5 \\
6 \\
7 \\
8 \\
1\end{array}$ & $\begin{array}{c}13.0 \\
8.80 \\
8.70 \\
8.10 \\
22.0\end{array}$ & $\begin{array}{l}5 \\
6 \\
7 \\
8 \\
2\end{array}$ & $\begin{array}{r}13.0 \\
8.60 \\
8.60 \\
8.10 \\
18.0\end{array}$ & $\begin{array}{l}4 \\
6 \\
7 \\
8 \\
2\end{array}$ & $\begin{array}{r}13.0 \\
8.50 \\
8.60 \\
8.10 \\
14.0\end{array}$ & $\begin{array}{l}5 \\
7 \\
6 \\
8 \\
3\end{array}$ & $\begin{array}{r}13.0 \\
8.40 \\
8.50 \\
8.00 \\
12.0\end{array}$ & $\begin{array}{l}3 \\
7 \\
6 \\
8 \\
5\end{array}$ & $\begin{array}{r}12.0 \\
7.80 \\
7.70 \\
7.30 \\
9.40\end{array}$ \\
\hline 25.0 & 3 & 25.0 & 3 & 24.0 & 3 & 24.0 & 3 & 23.0 & 2 & 23.0 & 1 & 23.0 & 1 & 22.0 & 1 & 21.0 & 1 & 18.0 \\
\hline
\end{tabular}

DURATION OF DISQHARGE FOR EAOH WATER YEAR

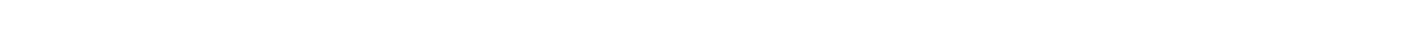

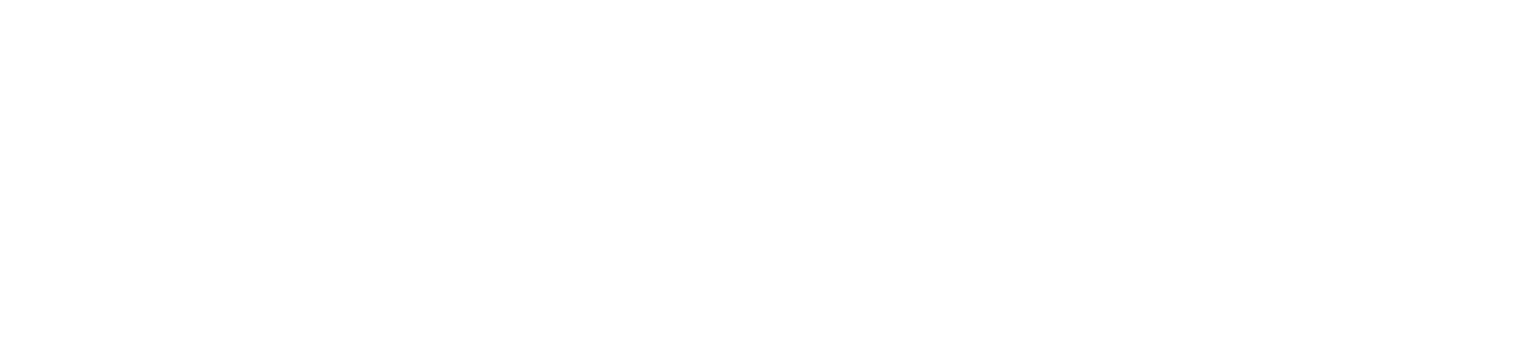

DURATION TABLE OF DISCHARGE FOR WATER YEARS 1974-8I

\begin{tabular}{|c|c|c|c|c|c|c|c|c|c|c|c|c|c|c|c|c|c|c|c|}
\hline CLASS & $\begin{array}{c}\text { CUBIC } \\
\text { FEET } \\
\text { PER } \\
\text { SECOND }\end{array}$ & $\begin{array}{l}\text { TOTAL } \\
\text { DAYS }\end{array}$ & $\begin{array}{l}\text { ACOJ- } \\
\text { MU- } \\
\text { LATED } \\
\text { DAYS }\end{array}$ & $\begin{array}{l}\text { PER- } \\
\text { CENT } \\
\text { DAYS }\end{array}$ & CLASS & $\begin{array}{c}\text { OBBIC } \\
\text { FEET } \\
\text { PER } \\
\text { SEOOND }\end{array}$ & $\begin{array}{r}\text { TOTAL } \\
\text { DAYS }\end{array}$ & $\begin{array}{c}\text { ACOJ- } \\
\text { MJ- } \\
\text { LATED } \\
\text { DAYS }\end{array}$ & $\begin{array}{l}\text { PER- } \\
\text { CENT } \\
\text { DALS }\end{array}$ & CLASS & $\begin{array}{c}\text { QUBIC } \\
\text { FEET } \\
\text { PER } \\
\text { SECOND }\end{array}$ & $\begin{array}{r}\text { TOTAL } \\
\text { DAYS }\end{array}$ & $\begin{array}{c}\text { ACOU- } \\
\text { MU- } \\
\text { LATED } \\
\text { DAYS }\end{array}$ & $\begin{array}{l}\text { PER- } \\
\text { CENT } \\
\text { DAIS }\end{array}$ & CAASS & $\begin{array}{c}\text { OBBIC } \\
\text { FEET } \\
\text { PER } \\
\text { SECOND }\end{array}$ & $\begin{array}{l}\text { TOTAL } \\
\text { DAYS }\end{array}$ & $\begin{array}{c}\text { ACOU- } \\
\text { MU- } \\
\text { LATED } \\
\text { DAYS }\end{array}$ & $\begin{array}{l}\text { PER- } \\
\text { CENT } \\
\text { DAYS }\end{array}$ \\
\hline $\begin{array}{l}0 \\
1 \\
2 \\
3 \\
4 \\
5 \\
6 \\
7 \\
8\end{array}$ & $\begin{array}{l}0.00 \\
3.20 \\
3.50 \\
3.70 \\
4.00 \\
4.40 \\
4.70 \\
5.10 \\
5.50\end{array}$ & $\begin{array}{r}0 \\
43 \\
45 \\
60 \\
31 \\
1 \\
25 \\
19 \\
1\end{array}$ & $\begin{array}{l}2922 \\
2922 \\
2879 \\
2834 \\
2774 \\
2743 \\
2742 \\
2717 \\
2698\end{array}$ & $\begin{array}{r}100.0 \\
100.0 \\
98.5 \\
97.0 \\
94.9 \\
93.9 \\
93.8 \\
93.0 \\
92.3\end{array}$ & $\begin{array}{l}9 \\
10 \\
11 \\
12 \\
13 \\
14 \\
15 \\
16 \\
17\end{array}$ & $\begin{array}{r}5.90 \\
6.40 \\
6.90 \\
7.40 \\
8.00 \\
8.70 \\
9.30 \\
10.00 \\
11.00\end{array}$ & $\begin{array}{r}4 \\
4 \\
69 \\
403 \\
657 \\
54 \\
11 \\
9 \\
58\end{array}$ & $\begin{array}{l}2697 \\
2693 \\
2689 \\
2620 \\
2217 \\
1560 \\
1506 \\
1495 \\
1486\end{array}$ & $\begin{array}{l}92.3 \\
92.2 \\
92.0 \\
89.7 \\
75.9 \\
53.4 \\
51.5 \\
51.2 \\
50.9\end{array}$ & $\begin{array}{l}18 \\
19 \\
20 \\
21 \\
22 \\
23 \\
24 \\
25 \\
26\end{array}$ & $\begin{array}{l}12.0 \\
13.0 \\
14.0 \\
15.0 \\
16.0 \\
17.0 \\
19.0 \\
20.0 \\
22.0\end{array}$ & $\begin{array}{r}790 \\
255 \\
46 \\
3 \\
0 \\
58 \\
100 \\
28 \\
4\end{array}$ & $\begin{array}{r}1428 \\
638 \\
383 \\
337 \\
334 \\
334 \\
276 \\
176 \\
148\end{array}$ & $\begin{array}{r}48.9 \\
21.8 \\
13.1 \\
11.5 \\
11.4 \\
11.4 \\
9.4 \\
6.0 \\
5.1\end{array}$ & $\begin{array}{l}27 \\
28 \\
29 \\
30 \\
31 \\
32 \\
33 \\
34\end{array}$ & $\begin{array}{l}23.0 \\
25.0 \\
27.0 \\
29.0 \\
32.0 \\
34.0 \\
37.0 \\
40.0\end{array}$ & $\begin{array}{r}73 \\
65 \\
0 \\
1 \\
0 \\
0 \\
0 \\
5\end{array}$ & $\begin{array}{r}144 \\
71 \\
6 \\
6 \\
5 \\
5 \\
5 \\
5\end{array}$ & $\begin{array}{l}4.9 \\
2.4 \\
0.2 \\
0.2 \\
0.2 \\
0.2 \\
0.2 \\
0.2\end{array}$ \\
\hline
\end{tabular}

MONTHLY MEAN DISCHARGES, IN GBIC FEET PER SECOND, FOR EAOH WATER YEAR

$\begin{array}{lcccccccccccc}\text { YEAR } & \text { OCT } & \text { NOV } & \text { DEC } & \text { JAN } & \text { FEB } & \text { MAR } & \text { APR } & \text { MAY } & \text { JUNE } & \text { JULY } & \text { AUG } & \text { SEP } \\ 1974 & 10.2 & 11.5 & 12.0 & 12.0 & 12.0 & 12.0 & 12.3 & 12.8 & 14.0 & 12.5 & 12.0 & 12.3 \\ 1975 & 12.0 & 12.5 & 12.3 & 12.2 & 13.0 & 13.0 & 13.0 & 12.0 & 12.3 & 11.7 & 21.2 & 8.21 \\ 1976 & 12.0 & 12.0 & 12.0 & 11.8 & 11.9 & 12.0 & 12.0 & 13.2 & 13.0 & 12.7 & 12.2 & 12.0 \\ 1977 & 9.19 & 8.37 & 8.18 & 8.42 & 8.19 & 8.21 & 8.56 & 4.70 & 5.06 & 8.16 & 8.13 & 7.99 \\ 1978 & 8.05 & 8.14 & 8.38 & 8.55 & 8.70 & 8.56 & 8.36 & 6.05 & 3.78 & 7.56 & 7.92 & 8.04 \\ 1979 & 8.03 & 7.79 & 7.99 & 7.99 & 7.96 & 8.06 & 8.11 & 5.52 & 3.47 & 7.45 & 7.67 & 7.60 \\ 1980 & 7.40 & 7.42 & 7.13 & 7.32 & 7.35 & 7.42 & 7.94 & 4.74 & 4.12 & 9.17 & 25.2 & 18.0 \\ 1981 & 14.3 & 12.0 & 15.5 & 19.0 & 19.0 & 12.7 & 18.6 & 17.8 & 19.4 & 22.4 & 23.1 & 22.7\end{array}$

ANNUAL PEAK DISGHARGE, IN OBBIC FEET PER SECOND, AND CORRESPONDING GAGE HEIGHT, IN FEET, FOR EAOH WATER YEAR

\begin{tabular}{|c|c|c|c|c|c|c|c|c|c|c|c|}
\hline $\begin{array}{l}\text { WATER } \\
\text { YEAR }\end{array}$ & DATE & $\begin{array}{c}\text { GAGE } \\
\text { HEIGHT }\end{array}$ & $\begin{array}{c}\text { PEAK } \\
\text { DISQHARGE }\end{array}$ & $\begin{array}{l}\text { WATER } \\
\text { YEAR }\end{array}$ & DATE & $\begin{array}{c}\text { GAGE } \\
\text { HEIGHT }\end{array}$ & $\begin{array}{c}\text { PEAK } \\
\text { DISOHARGE }\end{array}$ & $\begin{array}{l}\text { WATER } \\
\text { YEAR }\end{array}$ & DATE & $\begin{array}{c}\text { GAGE } \\
\text { HEIGHT }\end{array}$ & $\begin{array}{c}\text { PEAK } \\
\text { DISCHARGE }\end{array}$ \\
\hline 1973 & NOV. 08,1972 & 4.44 & $1_{332}$ & 1977 & OCT. - , 1976 & - & 12 & 1980 & AUG.,- 1980 & - & 26 \\
\hline $\begin{array}{l}1974 \\
1975 \\
1976\end{array}$ & $\begin{array}{lll}\text { MAY } & 26,1974 \\
\text { AUG. } & 19,1975 \\
\text { MAY } & -, 1976\end{array}$ & $\bar{z}$ & $\begin{array}{l}14 \\
46 \\
14\end{array}$ & $\begin{array}{l}1978 \\
1979\end{array}$ & $\begin{array}{l}\text { APR. } 01,1978 \\
\text { APR. } 17,1979\end{array}$ & $\overline{-}$ & $\begin{array}{l}8.9 \\
8.7\end{array}$ & 1981 & ळT. ${ }^{2}, 1980$ & - & 25 \\
\hline
\end{tabular}

${ }^{1}$ Peak discharge occurred during first year of storage in enlarged strawberry Reservoir.

${ }^{2}$ Peak discharge occurred octcober 1-5. 
GREEN RIVER BASIN

09285500 WIILON CRETR NEAR SCLDIER SPRINGS, UT

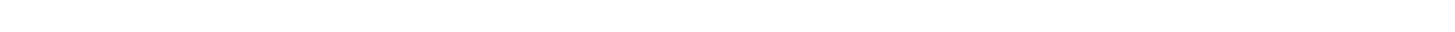
$14060004,700 \mathrm{ft}$ upstrean from mouth and $4.5 \mathrm{mi}$ southeast of soldier Springs.

DRATNAGE AREA. $-44 \mathrm{mi}^{2}$.

PERICD OF RECOFD AVACHABLE. - MaY 1943 to Septenber 1947.

GAGE.-Water-stage recorder. Altitude of gage is $7,300 \mathrm{ft}$ from topographic map.

EXIREMES FOR PERIOD OF RECORD.-Waximum discharge, $192 \mathrm{ft}^{3} / \mathrm{s}$ July 30, 1943, gage height, $2.35 \mathrm{ft}$, fram rating curve extended above $65 \mathrm{ft}^{3} / \mathrm{s}$; no flow during several months of each year.

LOWEST MEAN DISCHARGE, IN OBIC FEET PER SECOND, AND RANRING FOR THE INDICATED NUMBER OF CONSEOUTTVE DAYS FOR EAOB CIMATIC YEAR, APRII 1-MARCH 31

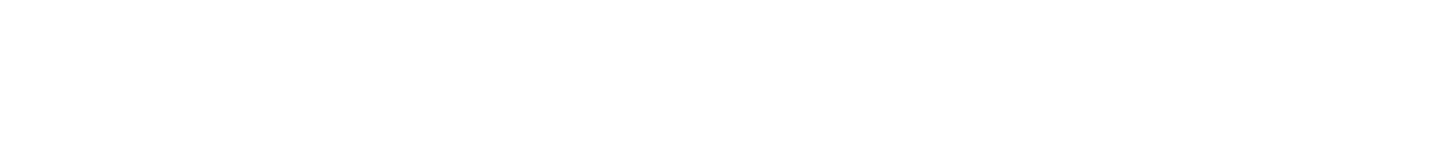

HIGHEST MEAN DISCHARGE, IN OBIC PEET PER SECOND, AND RANKING FOR THE INDICATED NUMBER OF CONSECUTTVE DALS FOR EAOA WATER YEAR, OCTCBER I-SEPTEMBER 30

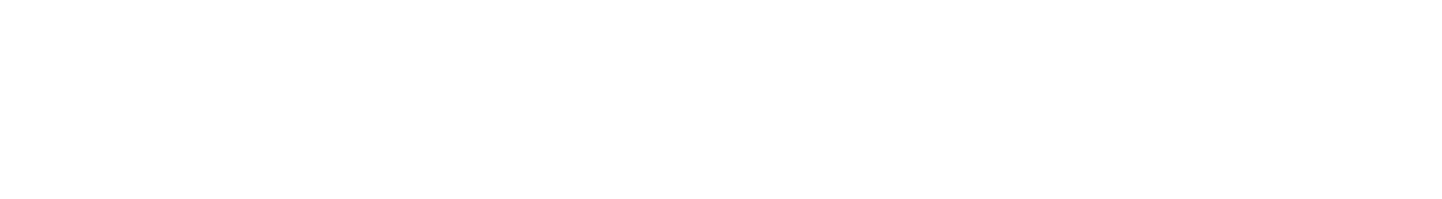

DURATION O DISOHARGE FOR EACH WATER YEAR

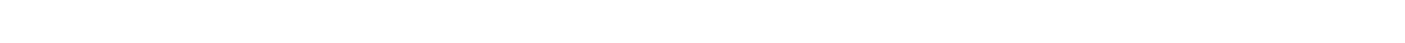
YEAR

NUMBER OF DAYS IN OLASS OBBIC FEET
PER SECOND
-DAYS

$\begin{array}{llllllllllllllllllllllllllllllllllllllllllllll}1944245 & 1 & 2 & 3 & 2 & 1 & 1 & 1 & 2 & 2 & 2 & 1 & 5 & 2 & 3 & 3 & 3 & 8 & 3 & 4 & 4 & 4 & 8 & 4 & 6 & 6 & 6 & 5 & 10 & 16 & 1 & 2 & 2903.1\end{array}$

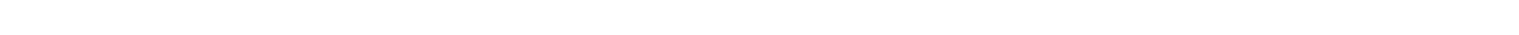

$\begin{array}{llllllllllllllllllllllllllllllllllll}1946224 & 3 & 4 & 4 & 2 & 1 & 3 & 1 & 5 & 3 & 4 & 9 & 6 & 7 & 6 & 4 & 6 & 6 & 6 & 7 & 7 & 8 & 7 & 7 & 4 & 5 & 6 & 6 & 4 & & & & & \end{array}$ $\begin{array}{lllllllllllllllllllllllllllll}1947244 & 4 & 2 & 3 & 1 & 1 & 1 & 3 & 1 & 7 & 7 & 6 & 5 & 3 & 3 & 11 & 4 & 5 & 3 & 9 & 3 & 7 & 6 & 7 & 13 & 3 & 3 & & \end{array}$

DURATION TFBLE OF DISOHARGE FOR WATER YEARS 1944-47
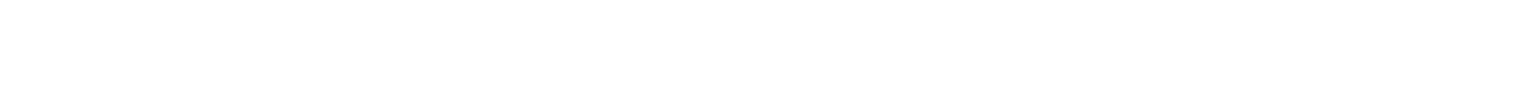

$\begin{array}{rrrrr}0 & 0.00 & 932 & 1461 & 100.0 \\ 1 & 0.10 & 9 & 529 & 36.2 \\ 2 & 0.12 & 0 & 520 & 35.6 \\ 3 & 0.15 & 0 & 520 & 35.6 \\ 4 & 0.19 & 11 & 520 & 35.6 \\ 5 & 0.23 & 0 & 509 & 34.8 \\ 6 & 0.28 & 9 & 509 & 34.8 \\ 7 & 0.34 & 8 & 500 & 34.2 \\ 8 & 0.42 & 5 & 492 & 33.7\end{array}$

$\begin{array}{rrrrr}9 & 0.52 & 5 & 487 & 33.3 \\ 10 & 0.63 & 5 & 482 & 33.0 \\ 11 & 0.78 & 9 & 477 & 32.6 \\ 12 & 0.95 & 11 & 468 & 32.0 \\ 13 & 1.20 & 8 & 457 & 31.3 \\ 14 & 1.40 & 20 & 449 & 30.7 \\ 15 & 1.80 & 22 & 429 & 29.4 \\ 16 & 2.20 & 24 & 407 & 27.9 \\ 17 & 2.70 & 22 & 383 & 26.2\end{array}$

$\begin{array}{lrlll}18 & 3.3 & 17 & 361 & 24.7 \\ 19 & 4.0 & 20 & 344 & 23.5 \\ 20 & 4.9 & 32 & 324 & 22.2 \\ 21 & 6.0 & 18 & 292 & 20.0 \\ 22 & 7.4 & 23 & 274 & 18.8 \\ 23 & 9.0 & 24 & 251 & 17.2 \\ 24 & 11.0 & 30 & 227 & 15.5 \\ 25 & 14.0 & 27 & 197 & 13.5 \\ 26 & 17.0 & 26 & 170 & 11.6\end{array}$

$\begin{array}{rrrrr}27 & 21.0 & 25 & 144 & 9.9 \\ 28 & 25.0 & 29 & 119 & 8.1 \\ 29 & 31.0 & 30 & 90 & 6.2 \\ 30 & 38.0 & 24 & 60 & 4.1 \\ 31 & 47.0 & 17 & 36 & 2.5 \\ 32 & 57.0 & 16 & 19 & 1.3 \\ 33 & 70.0 & 1 & 3 & 0.2 \\ 34 & 86.0 & 2 & 2 & 0.1\end{array}$

MONTHLY MEAN DISOHARGES, IN OUBIC FEET PER SECOND, FOR EACH WATER YEAR

\begin{tabular}{|c|c|c|c|c|c|c|c|c|c|c|c|c|}
\hline YEAR & $\propto T$ & NOV & DEC & JAN & FEB & MAR & APR & MAY & JUNE & JULY & AUG & SEP \\
\hline $\begin{array}{l}1944 \\
1945\end{array}$ & $\begin{array}{l}0.00 \\
0.00\end{array}$ & $\begin{array}{l}0.00 \\
0.00\end{array}$ & $\begin{array}{l}0.00 \\
0.00\end{array}$ & $\begin{array}{l}0.00 \\
0.00\end{array}$ & $\begin{array}{l}0.00 \\
0.00\end{array}$ & $\begin{array}{l}0.00 \\
0.00\end{array}$ & $\begin{array}{l}0.00 \\
0.00\end{array}$ & $\begin{array}{l}40.2 \\
25.9\end{array}$ & $\begin{array}{l}40.4 \\
19.3\end{array}$ & $\begin{array}{c}11.9 \\
6.67\end{array}$ & $\begin{array}{l}2.41 \\
6.07\end{array}$ & $\begin{array}{l}0.05 \\
1.15\end{array}$ \\
\hline $\begin{array}{l}1946 \\
1947\end{array}$ & $\begin{array}{l}0.00 \\
0.00\end{array}$ & $\begin{array}{l}0.00 \\
0.00\end{array}$ & $\begin{array}{l}0.00 \\
0.00\end{array}$ & $\begin{array}{l}0.00 \\
0.00\end{array}$ & $\begin{array}{l}0.00 \\
0.00\end{array}$ & $\begin{array}{l}0.00 \\
0.00\end{array}$ & $\begin{array}{l}7.25 \\
0.00\end{array}$ & $\begin{array}{l}29.2 \\
29.9\end{array}$ & $\begin{array}{r}9.04 \\
14.8\end{array}$ & $\begin{array}{l}3.08 \\
4.56\end{array}$ & $\begin{array}{l}1.06 \\
1.18\end{array}$ & $\begin{array}{l}0.07 \\
0.00\end{array}$ \\
\hline
\end{tabular}


LOCATION.--Lat $40^{\circ} 07^{\prime} 01^{\prime \prime}$, long $110^{\circ} 48^{\prime} 27^{\prime \prime}$, in NE $\mathrm{NEW}_{4}^{1} \mathrm{SEE}_{4}^{\frac{1}{4}}$ sec.20, T.4 S., R. 8 W., Uintah Heridian, Duchesne County, Hydrologic Unit 14060004 , on left bank $0.25 \mathrm{mi}$ downstream from Timber Canyon, $3.6 \mathrm{mi}$ upstream from Avintaquin Canyon, $3.8 \mathrm{mi}$ upstream from Bed Creek, and $7 \mathrm{mi}$ southeast of Fruitland.

DRAINAGE AREA.--363 $\mathrm{mi}^{2}$ (includes approximately $170 \mathrm{mi}^{2}$ tributary to strawberry Reservoir).

PERICO OF RECORD AVAIILABLE.--October 1963 to September 1981.

REVISED RECORDS.--WDR UT-77-1: Drainage area.

GAGE.--Water-stage recorder. Altitude of gage is 6,360 ft from topographic map. Prior to Apr. 7, 1971, at site $0.3 \mathrm{mi}$ downstream at different datum.

REMARKS.--Flow regulated by Strawberry Reservoir since July 14, 1912. Capacity, 1,106,500 acre-ft since Jume 30, 1973; 283,000 acre-ft prior to June 30, 1973 . New earthfilled dam located $7 \mathrm{mi}$ bel ow dam was campleted in September 1972 and storage began June 30,1973 . When elevation of new reservoir reaches the elevation of the ald reservoir, the old dam will be destroyed by explosives. Water Hollow tunnel will divert $600 \mathrm{ft}^{3} / \mathrm{s}$ to the reservoir during spring runoff when series of tunnels and gmall reservoirs are completed on Rock Creek, West Fork Duchesne River, and Currant Creek. Several old transmountain diversions upstream to the reservoir. Tranmountain diversions from the reservoir and upstream tributaries to the Great Basin.

AVERAGE DISQHARGE. -18 years, $51.1 \mathrm{ft}^{3} / \mathrm{s}, 37,020$ acre-ft/yr.

EXIREMES FOR PERIOD OF RECORD.-Maximum discharge, $610 \mathrm{ft} / \mathrm{s}$ May 14, 1964 , gage height, $3.80 \mathrm{ft}$ from floodnarks, from rating curve extended above $330 \mathrm{ft}^{3} / \mathrm{s}$; maximum gage height, $5.10 \mathrm{ft} \mathrm{July} \mathrm{9,} 1970$ (backwater from debris, $0.2 \mathrm{mi}$ below station); minimum recorded, $9.7 \mathrm{ft}^{3} / \mathrm{s}$ Dec. 8,1963 , result of freezeup.

DATA BELCW BASED ON PERICD OF REDOFO PRIOR TO ENLARGING STRAWBERRY RESERNOIR

LONEST MEAN DISQHARGE, IN OUBIC FEET PER SECOND, AND RANKING FOR THE INDICAIED NUMBER OF CONSECUTIVE DAYS FOR EAQA CIIMATIC YEAR, APRIL 1-MARG 31

\begin{tabular}{|c|c|c|c|c|c|c|c|c|c|c|c|c|c|c|c|c|c|c|c|}
\hline YEAR & & & & & & & & & cans & & $E$ DAYS & & & & & & & & \\
\hline & 1 & & 3 & & 7 & & 14 & & 30 & & 60 & & 90 & & 120 & & 183 & & ALL \\
\hline 1965 & 19.0 & 2 & 19.0 & 2 & 20.0 & 2 & 20.0 & 1 & 21.0 & 1 & 22.0 & 1 & 23.0 & 1 & 24.0 & 1 & 26.0 & 1 & 47.0 \\
\hline
\end{tabular}

HIGHEST MEAN DISCHARGE, IN OUBIC FEET PER SECOND, AND RANKING FOR THE INDICATED NUMBR $\propto$ CONSEOUTIVE DAYS FOR EAOH WATER YEAR, OCTCBER 1 -SEPTEMBER 30

\begin{tabular}{|c|c|c|c|c|c|c|c|c|c|c|c|c|c|c|c|c|c|c|c|}
\hline YEAR & 1 & & 3 & & 7 & & 15 & & $\begin{array}{l}\cos x \\
30\end{array}$ & ${ }^{\prime} T^{\circ}$ & $\begin{array}{c}\text { VE DAY } \\
60\end{array}$ & & 90 & & 120 & & 183 & & ALL \\
\hline $\begin{array}{l}1964 \\
1965\end{array}$ & $\begin{array}{l}290 \\
352\end{array}$ & $\begin{array}{l}3 \\
2\end{array}$ & $\begin{array}{l}233 \\
342\end{array}$ & $\begin{array}{l}5 \\
2\end{array}$ & $\begin{array}{l}207 \\
303\end{array}$ & 5 & $\begin{array}{l}199 \\
250\end{array}$ & $\begin{array}{l}5 \\
3\end{array}$ & $\begin{array}{l}161 \\
230\end{array}$ & $\begin{array}{l}5 \\
2\end{array}$ & $\begin{array}{l}127 \\
201\end{array}$ & $\begin{array}{l}5 \\
2\end{array}$ & $\begin{array}{l}103 \\
172\end{array}$ & $\begin{array}{l}5 \\
2\end{array}$ & $\begin{array}{l}87.0 \\
150\end{array}$ & $\begin{array}{l}7 \\
2\end{array}$ & $\begin{array}{l}67.0 \\
115\end{array}$ & $\begin{array}{l}8 \\
2\end{array}$ & $\begin{array}{l}44.0 \\
71.0\end{array}$ \\
\hline $\begin{array}{l}1966 \\
1967 \\
1968 \\
1969 \\
1970\end{array}$ & $\begin{array}{l}121 \\
269 \\
287 \\
386 \\
214\end{array}$ & $\begin{array}{l}9 \\
5 \\
4 \\
1 \\
6\end{array}$ & $\begin{array}{l}115 \\
266 \\
277 \\
382 \\
199\end{array}$ & $\begin{array}{l}9 \\
4 \\
3 \\
1 \\
6\end{array}$ & $\begin{array}{l}109 \\
260 \\
271 \\
379 \\
156\end{array}$ & $\begin{array}{l}9 \\
4 \\
3 \\
1\end{array}$ & $\begin{array}{l}100 \\
238 \\
255 \\
362 \\
137\end{array}$ & $\begin{array}{l}9 \\
4 \\
2 \\
1 \\
6\end{array}$ & $\begin{array}{l}91.0 \\
224 \\
222 \\
320 \\
127\end{array}$ & $\begin{array}{l}9 \\
3 \\
4 \\
1 \\
6\end{array}$ & $\begin{array}{l}79.0 \\
189 \\
183 \\
249 \\
107\end{array}$ & $\begin{array}{l}9 \\
3 \\
4 \\
1 \\
6\end{array}$ & $\begin{array}{l}74.0 \\
162 \\
152 \\
205 \\
94.0\end{array}$ & $\begin{array}{l}9 \\
3 \\
4 \\
1 \\
8\end{array}$ & $\begin{array}{l}67.0 \\
140 \\
132 \\
174 \\
83.0\end{array}$ & $\begin{array}{l}9 \\
3 \\
4 \\
1 \\
8\end{array}$ & $\begin{array}{c}58.0 \\
110 \\
102 \\
134 \\
69.0\end{array}$ & $\begin{array}{l}9 \\
3 \\
4 \\
1 \\
7\end{array}$ & $\begin{array}{l}49.0 \\
70.0 \\
72.0 \\
86.0 \\
54.0\end{array}$ \\
\hline
\end{tabular}

DURATION OF DISQHARGE FOR EACH WATER YEAR

CLASS $00 \begin{array}{llllllllllllllllllllllllllllllllll} & 1 & 3 & 4 & 5 & 6 & 7 & 8 & 9 & 10 & 11 & 12 & 13 & 14 & 15 & 16 & 17 & 18 & 19 & 20 & 21 & 22 & 23 & 24 & 25 & 26 & 27 & 28 & 29 & 30 & 31 & 32 & 33 & 34\end{array}$ YEAR

NUMBER OF DAYS IN OLASS CBBIC FEET PER SECOND

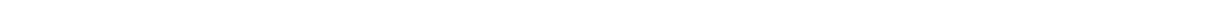

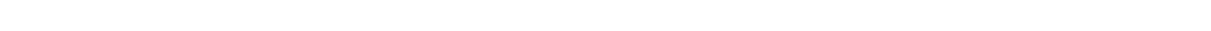
$1966 \quad \begin{array}{llllllllllllll}29 & 55 & 57 & 38 & 56 & 34 & 23 & 20 & 17 & 6 & 11 & 10 & 5 & 3\end{array}$

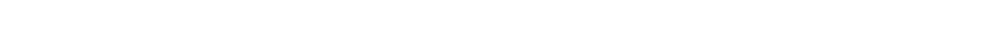

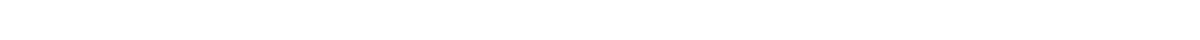

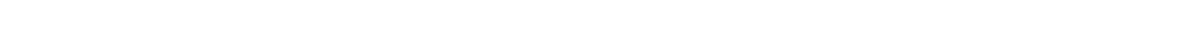

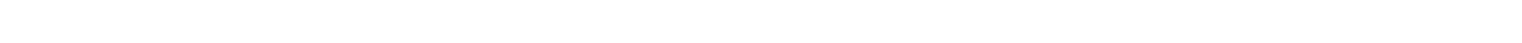

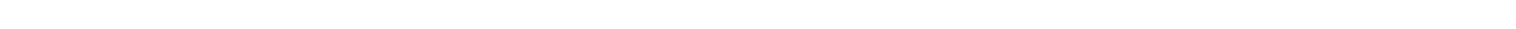


DURATION TABLE OF DISCHARGE FOR WATER YEARS 1964-72

\begin{tabular}{|c|c|c|c|c|c|c|c|c|c|c|c|c|c|c|c|c|c|c|c|}
\hline CLASS & $\begin{array}{c}\text { CUBIC } \\
\text { FEET } \\
\text { PER } \\
\text { SECOND }\end{array}$ & $\begin{array}{r}\text { TOTAL } \\
\text { DAYS }\end{array}$ & $\begin{array}{l}\text { ACOU- } \\
\text { MU- } \\
\text { LATED } \\
\text { DAYS }\end{array}$ & $\begin{array}{l}\text { PER- } \\
\text { CENT } \\
\text { DAYS }\end{array}$ & & $\begin{array}{c}\text { CUBIC } \\
\text { FEET } \\
\text { PER } \\
\text { SECOND }\end{array}$ & $\begin{array}{r}\text { TOTAL } \\
\text { DAYS }\end{array}$ & $\begin{array}{l}\text { ACCU- } \\
\text { MU- } \\
\text { LAATED } \\
\text { DAYS }\end{array}$ & $\begin{array}{l}\text { PER- } \\
\text { CENT } \\
\text { DAYS }\end{array}$ & & $\begin{array}{c}\text { CUBIC } \\
\text { FEET } \\
\text { PER } \\
\text { SECOND }\end{array}$ & $\begin{array}{l}\text { TOTAL } \\
\text { DAYS }\end{array}$ & $\begin{array}{l}\text { ACQU- } \\
\text { MU- } \\
\text { LATED } \\
\text { DAYS }\end{array}$ & $\begin{array}{l}\text { PER- } \\
\text { CENT } \\
\text { DAYS }\end{array}$ & & $\begin{array}{c}\text { CUBIC } \\
\text { FEET } \\
\text { PER } \\
\text { SECOND }\end{array}$ & $\begin{array}{r}\text { TOTAL, } \\
\text { DAYS }\end{array}$ & $\begin{array}{l}\text { ACOH- } \\
\text { MU- } \\
\text { LATED } \\
\text { DAYS }\end{array}$ & $\begin{array}{l}\text { PER- } \\
\text { CENT } \\
\text { DAYS }\end{array}$ \\
\hline $\begin{array}{l}0 \\
1 \\
2 \\
3 \\
4 \\
5 \\
6 \\
7 \\
8\end{array}$ & $\begin{array}{r}0.00 \\
15.00 \\
17.00 \\
18.00 \\
20.00 \\
22.00 \\
25.00 \\
27.00 \\
30.00\end{array}$ & $\begin{array}{r}0 \\
52 \\
11 \\
26 \\
79 \\
123 \\
120 \\
134 \\
319\end{array}$ & $\begin{array}{l}3288 \\
3288 \\
3236 \\
3225 \\
3199 \\
3120 \\
2997 \\
2877 \\
2743\end{array}$ & $\begin{array}{r}100.0 \\
100.0 \\
98.4 \\
98.1 \\
97.3 \\
94.9 \\
91.1 \\
87.5 \\
83.4\end{array}$ & $\begin{array}{l}9 \\
10 \\
11 \\
12 \\
13 \\
14 \\
15 \\
16 \\
17\end{array}$ & $\begin{array}{l}33.00 \\
36.00 \\
40.00 \\
44.00 \\
49.00 \\
54.00 \\
59.00 \\
66.00 \\
72.00\end{array}$ & $\begin{array}{l}257 \\
331 \\
244 \\
247 \\
162 \\
146 \\
145 \\
114 \\
125\end{array}$ & $\begin{array}{r}2424 \\
2167 \\
1836 \\
1592 \\
1345 \\
1183 \\
1037 \\
892 \\
778\end{array}$ & $\begin{array}{l}73.7 \\
65.9 \\
55.8 \\
48.4 \\
40.9 \\
36.0 \\
31.5 \\
27.1 \\
23.7\end{array}$ & $\begin{array}{l}18 \\
19 \\
20 \\
21 \\
22 \\
23 \\
24 \\
25 \\
26\end{array}$ & $\begin{array}{r}80.0 \\
88.0 \\
97.0 \\
110.0 \\
120.0 \\
130.0 \\
140.0 \\
160.0 \\
180.0\end{array}$ & $\begin{array}{r}106 \\
65 \\
98 \\
41 \\
52 \\
36 \\
64 \\
32 \\
12\end{array}$ & $\begin{array}{l}653 \\
547 \\
482 \\
384 \\
343 \\
291 \\
255 \\
191 \\
159\end{array}$ & $\begin{array}{r}19.9 \\
16.6 \\
14.7 \\
11.7 \\
10.4 \\
8.9 \\
7.8 \\
5.8 \\
4.8\end{array}$ & $\begin{array}{l}27 \\
28 \\
29 \\
30 \\
31 \\
32 \\
33 \\
34\end{array}$ & $\begin{array}{l}190.0 \\
210.0 \\
240.0 \\
260.0 \\
290.0 \\
320.0 \\
350.0 \\
390.0\end{array}$ & $\begin{array}{r}41 \\
41 \\
16 \\
19 \\
13 \\
5 \\
12 \\
0\end{array}$ & $\begin{array}{r}147 \\
106 \\
65 \\
49 \\
30 \\
17 \\
12 \\
0\end{array}$ & $\begin{array}{l}4.5 \\
3.2 \\
2.0 \\
1.5 \\
0.9 \\
0.5 \\
0.4 \\
0.0\end{array}$ \\
\hline
\end{tabular}

MONTHLY MEAN DISCHARGES, IN CUBIC FEET PER SECOND, FOR EACH WATER YEAR

\begin{tabular}{|c|c|c|c|c|c|c|c|c|c|c|c|}
\hline YEAR & OCT & NOV & $\mathrm{DEC}$ & JAN & FEB & MAR & APR & MAY & JUNE & JULY & AUG \\
\hline $\begin{array}{l}1964 \\
1965\end{array}$ & $\begin{array}{l}28.8 \\
30.3\end{array}$ & $\begin{array}{l}23.3 \\
29.7\end{array}$ & $\begin{array}{l}17.2 \\
26.3\end{array}$ & $\begin{array}{l}15.5 \\
24.7\end{array}$ & $\begin{array}{l}19.2 \\
23.4\end{array}$ & $\begin{array}{l}20.2 \\
20.7\end{array}$ & $\begin{array}{l}53.5 \\
59.9\end{array}$ & $\begin{array}{l}156 \\
211\end{array}$ & $\begin{array}{c}82.4 \\
179\end{array}$ & $\begin{array}{c}44.7 \\
106\end{array}$ & $\begin{array}{l}35.7 \\
73.8\end{array}$ \\
\hline $\begin{array}{l}1966 \\
1967 \\
1968 \\
1969 \\
1970\end{array}$ & $\begin{array}{l}50.2 \\
36.4 \\
52.7 \\
46.6 \\
54.1\end{array}$ & $\begin{array}{l}46.2 \\
33.0 \\
45.9 \\
40.9 \\
46.4\end{array}$ & $\begin{array}{l}39.2 \\
28.4 \\
39.3 \\
37.3 \\
38.8\end{array}$ & $\begin{array}{l}32.5 \\
29.3 \\
39.0 \\
35.9 \\
36.0\end{array}$ & $\begin{array}{l}33.0 \\
27.2 \\
34.7 \\
31.9 \\
31.8\end{array}$ & $\begin{array}{l}34.7 \\
26.9 \\
33.2 \\
29.5 \\
30.7\end{array}$ & $\begin{array}{r}64.0 \\
43.9 \\
39.5 \\
121 \\
42.9\end{array}$ & $\begin{array}{l}87.6 \\
157 \\
180 \\
312 \\
121\end{array}$ & $\begin{array}{l}68.6 \\
202 \\
180 \\
149 \\
89.6\end{array}$ & $\begin{array}{c}48.2 \\
118 \\
91.2 \\
93.7 \\
67.9\end{array}$ & $\begin{array}{l}41.5 \\
77.6 \\
72.0 \\
69.9 \\
48.9\end{array}$ \\
\hline $\begin{array}{l}1971 \\
1972\end{array}$ & $\begin{array}{l}42.4 \\
40.2\end{array}$ & $\begin{array}{l}37.3 \\
36.7\end{array}$ & $\begin{array}{l}27.5 \\
24.7\end{array}$ & $\begin{array}{l}28.4 \\
29.8\end{array}$ & $\begin{array}{l}21.6 \\
32.3\end{array}$ & $\begin{array}{l}42.5 \\
56.6\end{array}$ & $\begin{array}{l}77.3 \\
80.0\end{array}$ & $\begin{array}{l}116 \\
109\end{array}$ & $\begin{array}{l}95.9 \\
91.2\end{array}$ & $\begin{array}{l}61.3 \\
57.0\end{array}$ & $\begin{array}{l}49.9 \\
43.4\end{array}$ \\
\hline
\end{tabular}

ANNUAL PEAK DISCHARGE, IN CUBIC FEET PER SECOND, AND CORRESPONDING GAGE HEIGHT, IN FEET, FOR EACH WATER YEAR

\begin{tabular}{|c|c|c|c|c|c|c|c|c|c|c|c|c|c|c|}
\hline $\begin{array}{l}\text { WATER } \\
\text { YEAR }\end{array}$ & & DATE & $\begin{array}{c}\text { GAGE } \\
\text { HEIGHT }\end{array}$ & $\begin{array}{c}\text { PEAK } \\
\text { DISCHARGE }\end{array}$ & $\begin{array}{l}\text { WATER } \\
\text { YEAR }\end{array}$ & & DATE & $\begin{array}{c}\text { GAGE } \\
\text { HEIGHT }\end{array}$ & $\begin{array}{c}\text { PEAK } \\
\text { DISCHARGE }\end{array}$ & $\begin{array}{l}\text { WATER } \\
\text { YEAR }\end{array}$ & & DATE & $\begin{array}{l}\text { GAGE } \\
\text { HEIGHT }\end{array}$ & $\begin{array}{c}\text { PEAK } \\
\text { DISCHARGE }\end{array}$ \\
\hline $\begin{array}{l}1964 \\
1965 \\
1966\end{array}$ & $\begin{array}{l}\text { MAY } \\
\text { MAY } \\
\text { APR. }\end{array}$ & $\begin{array}{r}14,1964 \\
23,1965 \\
10,1966\end{array}$ & $\begin{array}{l}3.80 \\
3.35 \\
2.59\end{array}$ & $\begin{array}{l}610 \\
376 \\
159\end{array}$ & $\begin{array}{l}1967 \\
1968 \\
1969\end{array}$ & $\begin{array}{l}\text { MAY } \\
\text { MAY } \\
\text { MAY }\end{array}$ & $\begin{array}{ll}24, & 1967 \\
31, & 1968 \\
14, & 1969\end{array}$ & $\begin{array}{l}3.14 \\
3.20 \\
3.56\end{array}$ & $\begin{array}{l}288 \\
310 \\
416\end{array}$ & $\begin{array}{l}1970 \\
1971 \\
1972\end{array}$ & $\begin{array}{l}\text { MAY } \\
\text { MAY } \\
\text { MAY }\end{array}$ & $\begin{array}{ll}07, & 1970 \\
16, & 1971 \\
20, & 1972\end{array}$ & $\begin{array}{l}3.30 \\
3.00 \\
2.91\end{array}$ & $\begin{array}{l}352 \\
158 \\
135\end{array}$ \\
\hline
\end{tabular}

DATA BELOW BASED ON PERIOD OF RECORD AFTER ENLARGING STRAWBERRY RESERNOIR

LOWEST MEAN DISCHARGE, IN OUBIC FEET PER SECOND, AND RANKING FOR THE INDICATED NUMBER OF CONSECUTIVE DAYS FOR EACH OLIMATIC YEAR, APRIL 1-MARCH 31

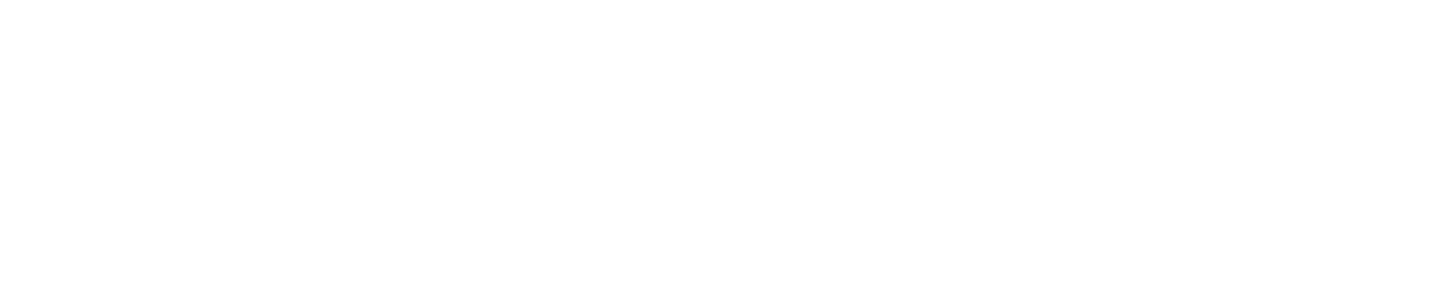

HIGHEST MEAN DISCHARGE, IN OUBIC FEET PER SECOND, AND RANKING FOR THE INDICATED NUMBER OF CONSECUTIVE DAYS FOR EACH WATER YEAR, OCTOBER 1-SEPTEMBER 30

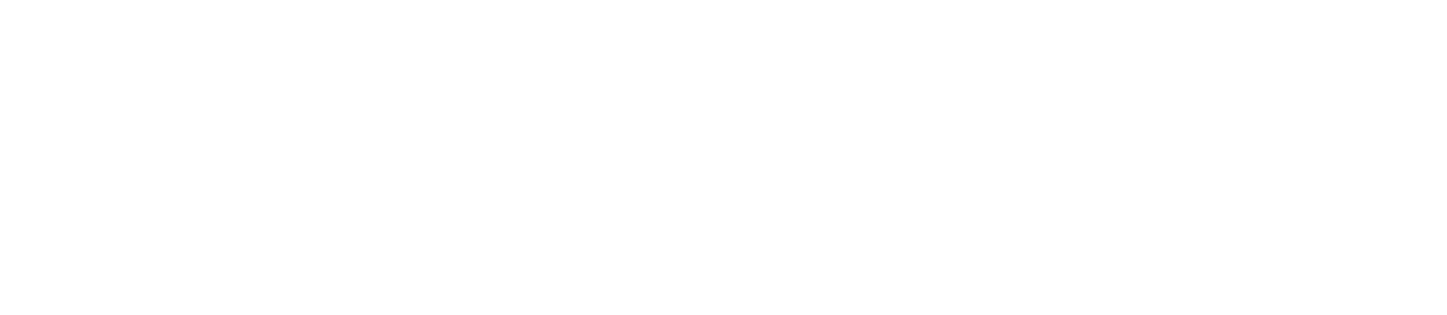


GREEN RIVER BASIN

09285700 STRANBERRY RIVER FBOVE RED CREEK, NEAR FRUITLAND, UT--Continued

DURATTON OF DISGHARGE FOR EAGH WATER YEAR

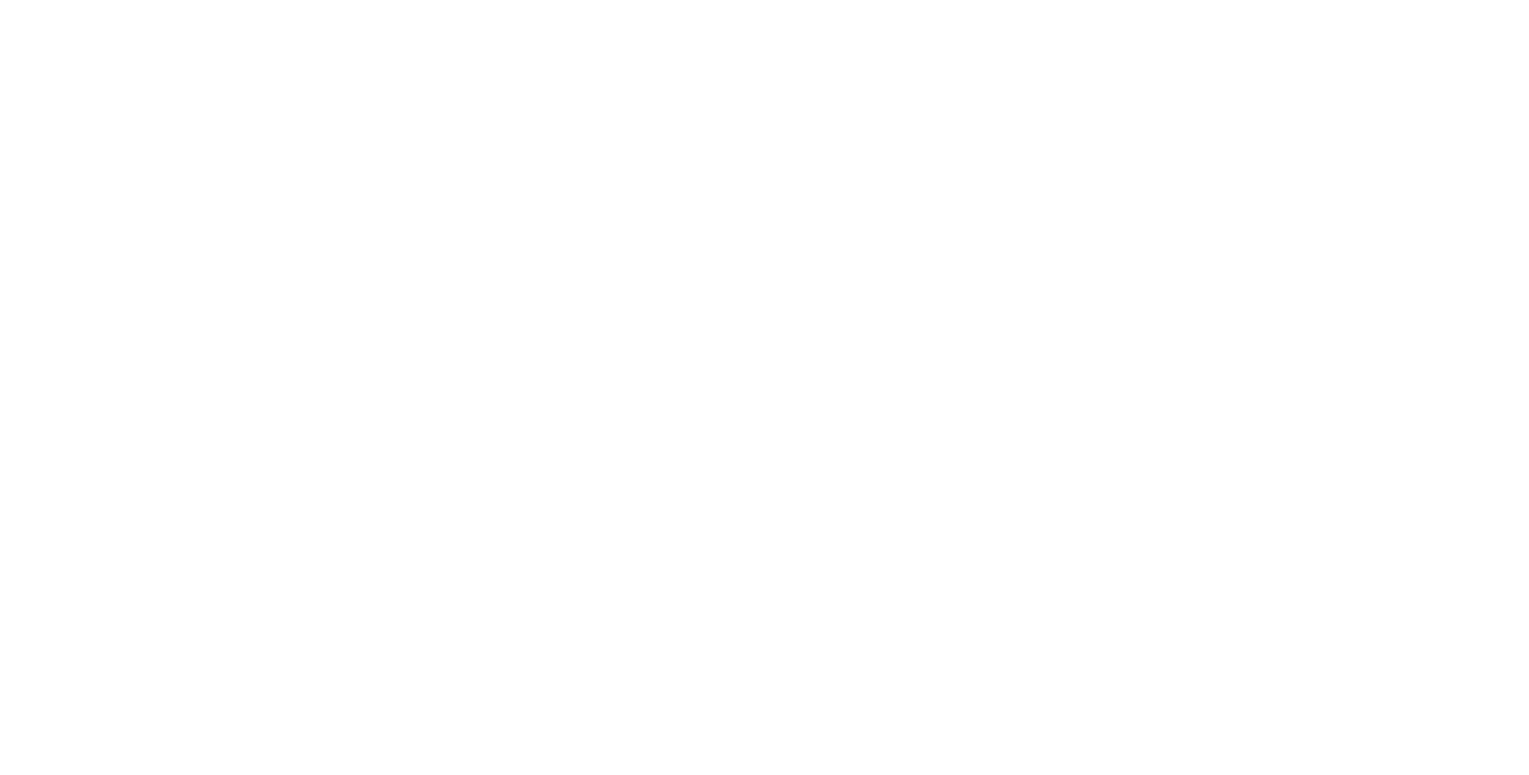

MONTHLY MEAN DISGHARGES, IN OBBIC FEET PER SECOND, FOR EAOH WAIER YEAR

\begin{tabular}{|c|c|c|c|c|c|c|c|c|c|c|c|c|}
\hline YEAR & OCT & $\mathrm{NON}$ & DEC & JAN & FEBB & MAR & APR & MAY & JUNE & JULY & AUG & SEP \\
\hline $\begin{array}{l}1974 \\
1975\end{array}$ & $\begin{array}{l}29.2 \\
30.7\end{array}$ & $\begin{array}{l}32.6 \\
30.5\end{array}$ & $\begin{array}{l}31.2 \\
25.8\end{array}$ & $\begin{array}{l}30.2 \\
27.1\end{array}$ & $\begin{array}{l}30.4 \\
27.4\end{array}$ & $\begin{array}{l}30.2 \\
27.0\end{array}$ & $\begin{array}{l}28.1 \\
26.7\end{array}$ & $\begin{array}{l}80.5 \\
49.7\end{array}$ & $\begin{array}{l}51.4 \\
143\end{array}$ & $\begin{array}{l}37.3 \\
67.1\end{array}$ & $\begin{array}{l}30.0 \\
54.4\end{array}$ & $\begin{array}{l}26.8 \\
34.8\end{array}$ \\
\hline $\begin{array}{l}1976 \\
1977 \\
1978 \\
1979 \\
1980\end{array}$ & $\begin{array}{l}35.3 \\
30.3 \\
24.8 \\
26.1 \\
29.8\end{array}$ & $\begin{array}{l}35.5 \\
28.6 \\
25.4 \\
27.3 \\
26.9\end{array}$ & $\begin{array}{l}32.8 \\
25.7 \\
23.3 \\
23.0 \\
26.3\end{array}$ & $\begin{array}{l}31.4 \\
25.5 \\
24.9 \\
22.8 \\
25.7\end{array}$ & $\begin{array}{l}33.9 \\
26.3 \\
25.1 \\
25.5 \\
25.6\end{array}$ & $\begin{array}{l}32.0 \\
26.0 \\
26.1 \\
26.7 \\
26.6\end{array}$ & $\begin{array}{l}32.4 \\
25.5 \\
29.7 \\
29.3 \\
38.4\end{array}$ & $\begin{array}{l}70.0 \\
20.0 \\
91.4 \\
105 \\
194\end{array}$ & $\begin{array}{r}46.5 \\
18.4 \\
81.3 \\
78.8 \\
155\end{array}$ & $\begin{array}{l}34.8 \\
20.9 \\
37.9 \\
41.3 \\
70.0\end{array}$ & $\begin{array}{l}31.1 \\
23.3 \\
28.3 \\
33.8 \\
60.5\end{array}$ & $\begin{array}{l}31.8 \\
23.6 \\
25.2 \\
27.4 \\
48.7\end{array}$ \\
\hline 1981 & 44.1 & 39.5 & 40.6 & 43.7 & 42.9 & 36.4 & 40.2 & 52.6 & 45.1 & 41.5 & 43.6 & 43.2 \\
\hline
\end{tabular}

ANNUAC PEAK DISCHARGE, IN OBIC FEET PER SECOND, AND CORRESPONDING GAGE HEIGHT, IN FEET, FOR EAQH WATER YEAR

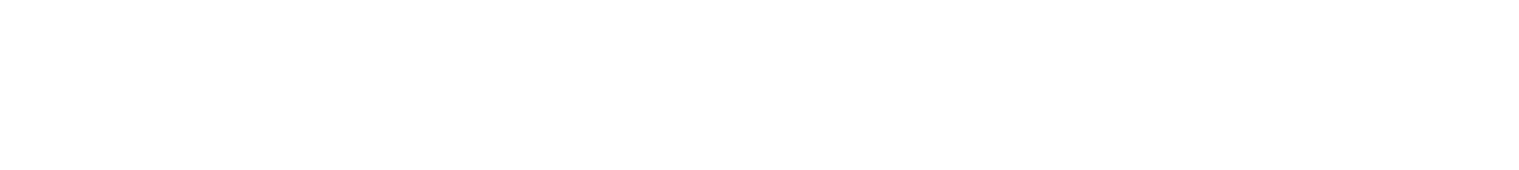

${ }^{1}$ Peak discharge occurred before storage began in enlarged Strawberry Reservoir.

09286500 RED CREEK NEAR FRUITLAND, UT

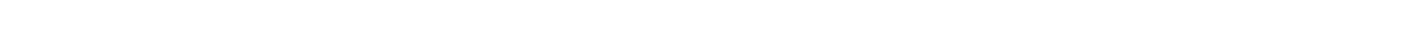
14060004 , on right bank $250 \mathrm{ft}$ upstream from bridge on U.S. Highway $40,1.5 \mathrm{mi}$ upstream from Currant Creek, and $4 \mathrm{mi}$ southeast of Fruitland.

DRAINAGE AREA-- $-89 \mathrm{mi}^{2}$, approximately.

PERIOD OF RECORD AVAII ABLE. - November 1917 to September 1922, September 1955 to September 1961.

GAGE.--Water-stage recorder. Prior to Sept. 1, 1955, staff gage at different datum.

REMARKS.--Diversions above station for irrigation. Flow regulated by Red Creek Reservoir beginning July 1960 (capacity, 6,500 acreft.)

AVERAGE DISGHARGE. -8 years (water years $1919-22,1955-59), 12.9 \mathrm{ft}^{3} / \mathrm{s}, 9,350$ acre-ft/yr.

EXTREMES FOR PERIOD OF RECORD. - Maximum discharge not determined; maximum gage height, 8.95 ft between July 31 and Aug. 3 , 1919 (but may have been higher at other times), from floodmarks, datum then in use; no flow at times in most years. 
GREEN RIVER BASIN

09286500 RED CREEK NEAR FRDITH.AND, UT-Continued

DATA BELOW BASED ON FERIOD OF RECORD PRIOR TO REGUIATIION BY RED CREEK RESERNOIR

LOWEST MEAN DISCHARGE, IN CUBIC FEET PER SECOND, AND RANKTNG FOR THE INDICATED NUMBER OF CONSECUTIVE DAYS FOR EACH CLIMATIC YEAR, APRIL I-MARCH 31

\begin{tabular}{|c|c|c|c|c|c|c|c|c|c|c|c|c|c|c|c|c|c|c|c|}
\hline YEAR & & & & & & & & & CONSE & & DAYS & & & & & & & & \\
\hline $\begin{array}{l}1919 \\
1920\end{array}$ & $\begin{array}{l}0.10 \\
0.00\end{array}$ & $\begin{array}{l}4 \\
1\end{array}$ & $\begin{array}{l}0.17 \\
0.00\end{array}$ & $\begin{array}{l}5 \\
1\end{array}$ & $\begin{array}{l}0.19 \\
0.00\end{array}$ & $\begin{array}{l}5 \\
1\end{array}$ & $\begin{array}{l}0.21 \\
0.00\end{array}$ & $\begin{array}{l}4 \\
1\end{array}$ & $\begin{array}{l}2.20 \\
0.20\end{array}$ & $\begin{array}{l}5 \\
1\end{array}$ & $\begin{array}{l}3.30 \\
2.20\end{array}$ & $\begin{array}{l}5 \\
4\end{array}$ & $\begin{array}{l}4.10 \\
5.90\end{array}$ & $\begin{array}{l}4 \\
5\end{array}$ & $\begin{array}{l}5.40 \\
6.20\end{array}$ & $\begin{array}{l}4 \\
5\end{array}$ & $\begin{array}{l}7.00 \\
7.30\end{array}$ & $\begin{array}{l}4 \\
5\end{array}$ & $\begin{array}{r}9.40 \\
13.0\end{array}$ \\
\hline $\begin{array}{l}1921 \\
1922\end{array}$ & $\begin{array}{l}1.00 \\
0.00\end{array}$ & $\begin{array}{l}7 \\
2\end{array}$ & $\begin{array}{l}1.30 \\
0.00\end{array}$ & $\begin{array}{l}7 \\
2\end{array}$ & $\begin{array}{l}1.70 \\
0.07\end{array}$ & $\begin{array}{l}7 \\
3\end{array}$ & $\begin{array}{l}2.00 \\
2.10\end{array}$ & $\begin{array}{l}6 \\
7\end{array}$ & $\begin{array}{l}2.60 \\
3.50\end{array}$ & $\begin{array}{l}6 \\
7\end{array}$ & $\begin{array}{l}7.20 \\
5.10\end{array}$ & $\begin{array}{l}7 \\
6\end{array}$ & $\begin{array}{l}7.90 \\
6.40\end{array}$ & $\begin{array}{l}7 \\
6\end{array}$ & $\begin{array}{l}8.60 \\
7.80\end{array}$ & $\begin{array}{l}7 \\
6\end{array}$ & $\begin{array}{c}10.0 \\
9.70\end{array}$ & $\begin{array}{l}7 \\
6\end{array}$ & $\begin{array}{l}17.0 \\
19.0\end{array}$ \\
\hline $\begin{array}{l}1957 \\
1958 \\
1959\end{array}$ & $\begin{array}{l}0.10 \\
0.50 \\
0.00\end{array}$ & $\begin{array}{l}5 \\
6 \\
3\end{array}$ & $\begin{array}{l}0.10 \\
0.57 \\
0.00\end{array}$ & $\begin{array}{l}4 \\
6 \\
3\end{array}$ & $\begin{array}{l}0.13 \\
0.79 \\
0.00\end{array}$ & $\begin{array}{l}4 \\
6 \\
2\end{array}$ & $\begin{array}{l}0.20 \\
1.19 \\
0.04\end{array}$ & $\begin{array}{l}3 \\
5 \\
2\end{array}$ & $\begin{array}{l}0.28 \\
1.40 \\
0.23\end{array}$ & $\begin{array}{l}3 \\
4 \\
2\end{array}$ & $\begin{array}{l}0.52 \\
2.20 \\
0.51\end{array}$ & $\begin{array}{l}2 \\
3 \\
1\end{array}$ & $\begin{array}{l}0.72 \\
2.90 \\
0.67\end{array}$ & $\begin{array}{l}2 \\
3 \\
1\end{array}$ & $\begin{array}{l}0.97 \\
2.80 \\
0.75\end{array}$ & $\begin{array}{l}2 \\
3 \\
1\end{array}$ & $\begin{array}{l}2.30 \\
4.50 \\
1.30\end{array}$ & $\begin{array}{l}2 \\
3 \\
1\end{array}$ & $\begin{array}{l}7.60 \\
8.20 \\
7.80\end{array}$ \\
\hline
\end{tabular}

HIGHEST MEAN DISCHARGE, IN GBIC FEET PER SECOND, AND RANKING FOR THE INDICATED NUMEER OF CONSECUTIVE DAYS FOR EACH WATER YEAR, OTCBER 1-SEPTEMBER 30

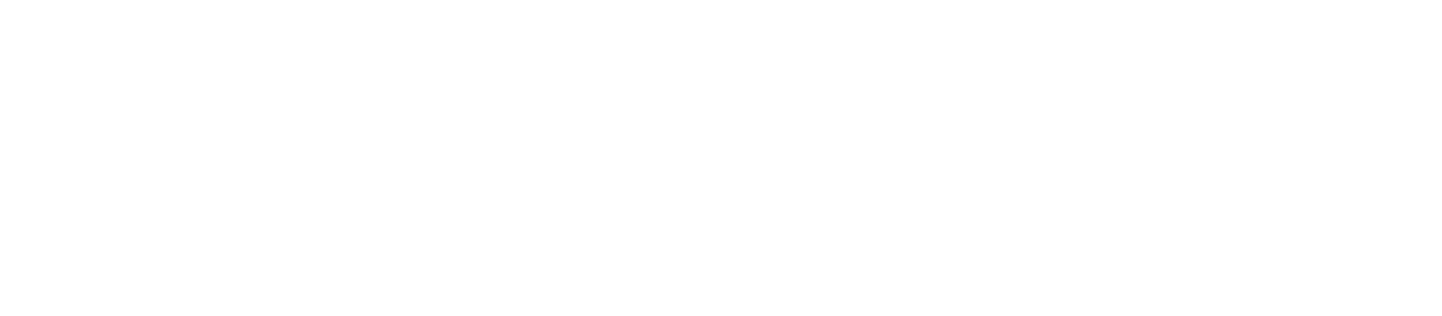

DURATION OF DISCHARGE FOR EACH WATER YEAR

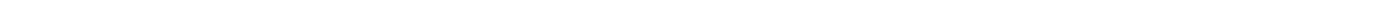

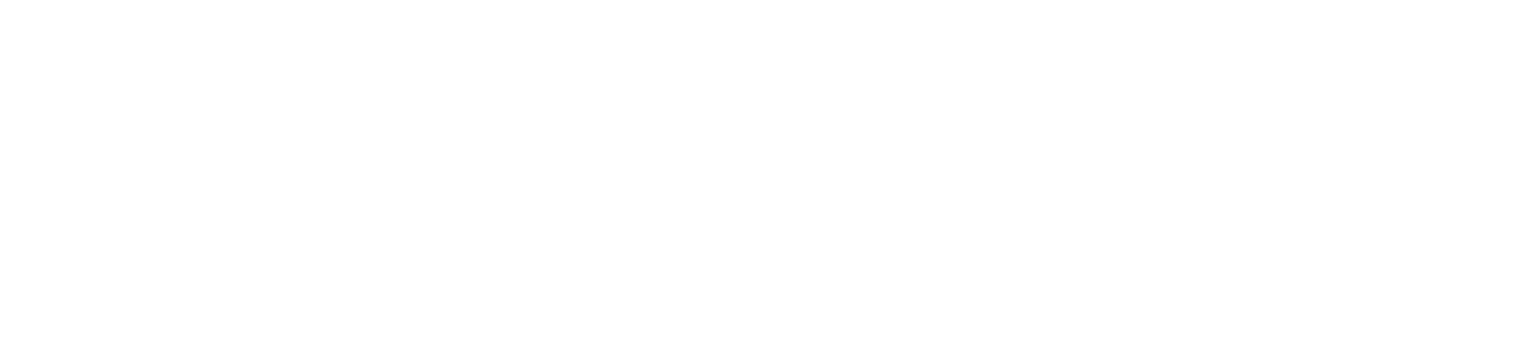

DURATION TABLE OF DISCHARGE FOR WATER YEARS 1919-22, 1956-59

\begin{tabular}{|c|c|c|c|c|c|c|c|c|c|c|c|c|c|c|c|c|c|c|c|}
\hline & $\begin{array}{c}\text { CBBIC } \\
\text { FEET } \\
\text { PER } \\
\text { SECOND }\end{array}$ & $\begin{array}{r}\text { TOTAL } \\
\text { DAYS }\end{array}$ & $\begin{array}{l}\text { ACOU- } \\
\text { MU- } \\
\text { LATED } \\
\text { DAYS }\end{array}$ & $\begin{array}{l}\text { PER- } \\
\text { CENT } \\
\text { DAYS }\end{array}$ & & $\begin{array}{c}\text { CUBIC } \\
\text { FEET } \\
\text { PER } \\
\text { SECOND }\end{array}$ & $\begin{array}{r}\text { TOTAL, } \\
\text { DAYS }\end{array}$ & $\begin{array}{c}\text { ACQU- } \\
\text { MU- } \\
\text { LATED } \\
\text { DAYS }\end{array}$ & $\begin{array}{l}\text { PER- } \\
\text { CENT } \\
\text { DAYS }\end{array}$ & CLASS & $\begin{array}{c}\text { CUBIC } \\
\text { FEET } \\
\text { PER } \\
\text { SECOND }\end{array}$ & $\begin{array}{r}\text { TOTAL } \\
\text { DAYS }\end{array}$ & $\begin{array}{c}\text { ACOU- } \\
\text { MU- } \\
\text { LATED } \\
\text { DAYS }\end{array}$ & $\begin{array}{l}\text { PER- } \\
\text { CENT } \\
\text { DAYS }\end{array}$ & & $\begin{array}{c}\text { CUB IC } \\
\text { FEET } \\
\text { PER } \\
\text { SECOND }\end{array}$ & $\begin{array}{r}\text { TOTAL } \\
\text { DAYS }\end{array}$ & $\begin{array}{l}\text { ACO- } \\
\text { MU- } \\
\text { LATED } \\
\text { DAYS }\end{array}$ & $\begin{array}{l}\text { PER- } \\
\text { CENT } \\
\text { DAXS }\end{array}$ \\
\hline $\begin{array}{l}0 \\
1 \\
2 \\
3 \\
4 \\
5 \\
6 \\
7 \\
8\end{array}$ & $\begin{array}{l}0.00 \\
0.10 \\
0.13 \\
0.16 \\
0.20 \\
0.25 \\
0.32 \\
0.40 \\
0.50\end{array}$ & $\begin{array}{r}70 \\
38 \\
0 \\
0 \\
67 \\
30 \\
0 \\
18 \\
87\end{array}$ & $\begin{array}{l}2922 \\
2852 \\
2814 \\
2814 \\
2814 \\
2747 \\
2717 \\
2717 \\
2699\end{array}$ & $\begin{array}{r}100.0 \\
97.6 \\
96.3 \\
96.3 \\
96.3 \\
94.0 \\
93.0 \\
93.0 \\
92.4\end{array}$ & $\begin{array}{r}9 \\
10 \\
11 \\
12 \\
13 \\
14 \\
15 \\
16 \\
17\end{array}$ & $\begin{array}{l}0.63 \\
0.80 \\
1.00 \\
1.30 \\
1.60 \\
2.00 \\
2.50 \\
3.20 \\
4.00\end{array}$ & $\begin{array}{r}6 \\
47 \\
139 \\
47 \\
38 \\
85 \\
82 \\
27 \\
69\end{array}$ & $\begin{array}{l}2612 \\
2606 \\
2559 \\
2420 \\
2373 \\
2335 \\
2250 \\
2168 \\
2141\end{array}$ & $\begin{array}{l}89.4 \\
89.2 \\
87.6 \\
82.8 \\
81.2 \\
79.9 \\
77.0 \\
74.2 \\
73.3\end{array}$ & $\begin{array}{l}18 \\
19 \\
20 \\
21 \\
22 \\
23 \\
24 \\
25 \\
26\end{array}$ & $\begin{array}{r}5.0 \\
6.3 \\
8.0 \\
10.0 \\
13.0 \\
16.0 \\
20.0 \\
25.0 \\
32.0\end{array}$ & $\begin{array}{r}400 \\
154 \\
476 \\
270 \\
253 \\
126 \\
82 \\
66 \\
40\end{array}$ & $\begin{array}{r}2072 \\
1672 \\
1518 \\
1042 \\
772 \\
519 \\
393 \\
311 \\
245\end{array}$ & $\begin{array}{r}70.9 \\
57.2 \\
52.0 \\
35.7 \\
26.4 \\
17.8 \\
13.4 \\
10.6 \\
8.4\end{array}$ & $\begin{array}{l}27 \\
28 \\
29 \\
30 \\
31 \\
32 \\
33 \\
34\end{array}$ & $\begin{array}{r}40.0 \\
50.0 \\
63.0 \\
80.0 \\
100.0 \\
130.0 \\
160.0 \\
200.0\end{array}$ & $\begin{array}{r}64 \\
48 \\
32 \\
18 \\
29 \\
3 \\
4 \\
7\end{array}$ & $\begin{array}{r}205 \\
141 \\
93 \\
61 \\
43 \\
14 \\
11 \\
7\end{array}$ & $\begin{array}{l}7.0 \\
4.8 \\
3.2 \\
2.1 \\
1.5 \\
0.5 \\
0.4 \\
0.2\end{array}$ \\
\hline
\end{tabular}

MONTHLY MEAN DISCHARGES, IN OBIC FEET PER SECOND, FOR EACH WATER YEAR

\begin{tabular}{|c|c|c|c|c|c|c|c|c|c|c|c|c|}
\hline YEAR & OCT & NOV & DEC & JAN & FEB & MAR & APR & MAY & JUNE & JULY & AUG & SEP \\
\hline $\begin{array}{l}1919 \\
1920\end{array}$ & $\begin{array}{c}10.9 \\
7.23\end{array}$ & $\begin{array}{l}9.50 \\
12.0\end{array}$ & $\begin{array}{l}8.00 \\
6.55\end{array}$ & $\begin{array}{l}6.48 \\
8.06\end{array}$ & $\begin{array}{l}5.57 \\
5.00\end{array}$ & $\begin{array}{c}13.4 \\
5.10\end{array}$ & $\begin{array}{l}27.2 \\
11.3\end{array}$ & $\begin{array}{l}42.9 \\
69.0\end{array}$ & $\begin{array}{l}3.33 \\
21.3\end{array}$ & $\begin{array}{l}9.03 \\
2.61\end{array}$ & $\begin{array}{l}24.5 \\
14.1\end{array}$ & $\begin{array}{l}6.79 \\
7.47\end{array}$ \\
\hline $\begin{array}{l}1921 \\
1922\end{array}$ & $\begin{array}{l}14.1 \\
13.8\end{array}$ & $\begin{array}{l}15.5 \\
12.7\end{array}$ & $\begin{array}{l}10.0 \\
11.0\end{array}$ & $\begin{array}{l}8.00 \\
8.00\end{array}$ & $\begin{array}{c}14.3 \\
5.46\end{array}$ & $\begin{array}{c}21.4 \\
8.65\end{array}$ & $\begin{array}{l}16.6 \\
24.7\end{array}$ & $\begin{array}{l}59.7 \\
96.8\end{array}$ & $\begin{array}{l}41.9 \\
64.4\end{array}$ & $\begin{array}{l}8.06 \\
14.8\end{array}$ & $\begin{array}{l}21.5 \\
27.4\end{array}$ & $\begin{array}{l}14.9 \\
18.0\end{array}$ \\
\hline $\begin{array}{l}1956 \\
1957 \\
1958 \\
1959\end{array}$ & $\begin{array}{l}1.50 \\
4.00 \\
2.21 \\
0.24\end{array}$ & $\begin{array}{l}4.78 \\
3.91 \\
8.61 \\
2.36\end{array}$ & $\begin{array}{c}10.2 \\
7.68 \\
8.00 \\
4.30\end{array}$ & $\begin{array}{l}8.81 \\
9.00 \\
8.00 \\
5.50\end{array}$ & $\begin{array}{l}7.93 \\
9.15 \\
9.79 \\
5.00\end{array}$ & $\begin{array}{c}16.3 \\
8.74 \\
12.1 \\
7.13\end{array}$ & $\begin{array}{c}19.4 \\
6.98 \\
17.0 \\
1.99\end{array}$ & $\begin{array}{c}22.1 \\
11.2 \\
44.7 \\
1.25\end{array}$ & $\begin{array}{c}3.60 \\
22.9 \\
3.79 \\
1.14\end{array}$ & $\begin{array}{l}2.08 \\
1.70 \\
1.00 \\
0.71\end{array}$ & $\begin{array}{l}0.62 \\
2.96 \\
0.26 \\
0.32\end{array}$ & $\begin{array}{l}0.50 \\
4.26 \\
1.80 \\
0.21\end{array}$ \\
\hline
\end{tabular}


LOCATION.--Lat $40^{\circ} 19^{\prime} 27^{\prime \prime}$, long $111^{\circ} 02 \cdot 43^{\prime \prime}$, in $\mathrm{NW}_{4}^{\frac{1}{4} \mathrm{SW}_{4} \mathrm{NW}}$ Unit 14060004 , on right bank $0.3 \mathrm{mi}$ below Red Ledge Hollow and $13.5 \mathrm{mi}$ northwest of Fruitland.

DRAINAGE AREA. $-50.1 \mathrm{mi}^{2}$.

MEAN BASIN ELEVATION. $-8,880 \mathrm{ft}$.

PERIOD OF RECORD.-OCtober 1945 to September 1968, August 1974 to September 1981.

REVISED RECORDS.--WDR UT-77-1: Drainage area.

GAGE.--Water-stage recorder. Altitude of gage is 7,520 ft from topographic map. Prior to october 1968 , at site $0.2 \mathrm{mi}$ upstream at different datum.

REMARKS.--Currant Creek feeder canal, constructed by the Bureau of Reclamation in 1936, diverts water fram headwaters to Strawberry Reservoir fram which water is then diverted through Strawberry tunnel to the Great Basin for irrigation in Strawberry valley project.

AVERAGE DISCHARGE.--30 years (water years 1946-68, 1975-81), $25.5 \mathrm{ft}^{3} / \mathrm{s}, 18,470 \mathrm{acre}-\mathrm{ft} / \mathrm{yr}$.

EXIREMES FOR PERTOD OF RECORD.--Maximum discharge, $946 \mathrm{ft}^{3} / \mathrm{s}$ May 21, 1975, gage height, $5.58 \mathrm{ft} ; \mathrm{minimum}, 0.7 \mathrm{ft}{ }^{3} / \mathrm{s}$ Sept. $8,1959$.

LOWEST MEAN DISCHARGE, IN OBBIC FEET PER SBCOND, AND RANRING FOR THE INDICATED NUMBER OF CONSECUTIVE DAYS FOR EACH CLIMATIC YEAR, APRII I-MARCH 31

\begin{tabular}{|c|c|c|c|c|c|c|c|c|c|c|c|c|c|c|c|c|c|}
\hline YEAR & 1 & 3 & 7 & 14 & & $\begin{array}{l}\text { CONSE } \\
30\end{array}$ & ECUT & $\begin{array}{l}\text { DAYS } \\
60\end{array}$ & & 90 & & 120 & & 183 & & ALL & \\
\hline $\begin{array}{l}1947 \\
1948 \\
1949 \\
1950\end{array}$ & $\begin{array}{rr}3.10 & 10 \\
6.80 & 23 \\
2.80 & 6 \\
4.50 & 14\end{array}$ & $\begin{array}{rr}3.10 & 9 \\
6.90 & 23 \\
2.80 & 6 \\
4.50 & 14\end{array}$ & $\begin{array}{rr}3.20 & 8 \\
7.00 & 23 \\
2.90 & 6 \\
4.70 & 15\end{array}$ & $\begin{array}{l}3.30 \\
7.00 \\
3.00 \\
4.70\end{array}$ & $\begin{array}{r}8 \\
23 \\
6 \\
13\end{array}$ & $\begin{array}{l}3.50 \\
7.00 \\
3.40 \\
5.20\end{array}$ & $\begin{array}{r}8 \\
23 \\
6 \\
17\end{array}$ & $\begin{array}{l}4.10 \\
7.10 \\
3.80 \\
6.20\end{array}$ & $\begin{array}{r}9 \\
22 \\
5 \\
19\end{array}$ & $\begin{array}{l}4.70 \\
7.30 \\
4.40 \\
6.90\end{array}$ & $\begin{array}{r}9 \\
21 \\
8 \\
20\end{array}$ & $\begin{array}{l}5.60 \\
7.50 \\
5.10 \\
7.20\end{array}$ & $\left\{\begin{array}{r}11 \\
21 \\
8 \\
20\end{array}\right.$ & $\begin{array}{l}7.30 \\
7.80 \\
5.50 \\
7.60\end{array}$ & $\begin{array}{r}14 \\
19 \\
8 \\
17\end{array}$ & $\begin{array}{l}23.0 \\
26.0 \\
18.0 \\
32.0\end{array}$ & $\begin{array}{r}13 \\
18 \\
7 \\
21\end{array}$ \\
\hline $\begin{array}{l}1951 \\
1952 \\
1953 \\
1954 \\
1955\end{array}$ & $\begin{array}{rr}5.00 & 20 \\
4.80 & 18 \\
7.50 & 26 \\
4.50 & 15 \\
2.80 & 7\end{array}$ & $\begin{array}{rr}5.00 & 21 \\
4.80 & 18 \\
7.50 & 26 \\
4.60 & 17 \\
3.10 & 7\end{array}$ & $\begin{array}{rr}5.20 & 21 \\
4.90 & 17 \\
7.50 & 24 \\
4.60 & 13 \\
3.40 & 9\end{array}$ & $\begin{array}{l}5.50 \\
5.10 \\
7.50 \\
4.80 \\
3.50\end{array}$ & $\begin{array}{r}21 \\
18 \\
24 \\
14 \\
9\end{array}$ & $\begin{array}{l}6.50 \\
5.60 \\
7.50 \\
4.90 \\
3.60\end{array}$ & $\begin{array}{r}22 \\
19 \\
24 \\
13 \\
9\end{array}$ & $\begin{array}{l}7.80 \\
6.30 \\
7.80 \\
5.90 \\
4.00\end{array}$ & $\begin{array}{r}23 \\
20 \\
24 \\
15 \\
7\end{array}$ & $\begin{array}{l}8.10 \\
6.80 \\
8.00 \\
6.80 \\
4.20\end{array}$ & $\begin{array}{r}24 \\
18 \\
23 \\
19 \\
5\end{array}$ & $\begin{array}{l}8.90 \\
7.10 \\
8.20 \\
7.10 \\
4.70\end{array}$ & $\begin{array}{r}25 \\
17 \\
23 \\
0 \\
18 \\
5\end{array}$ & $\begin{array}{l}9.20 \\
7.20 \\
8.80 \\
7.40 \\
5.20\end{array}$ & $\begin{array}{r}25 \\
12 \\
23 \\
15 \\
6\end{array}$ & $\begin{array}{l}43.0 \\
24.0 \\
62.0 \\
18.0 \\
13.0\end{array}$ & $\begin{array}{r}26 \\
14 \\
28 \\
8 \\
5\end{array}$ \\
\hline $\begin{array}{l}1956 \\
1957 \\
1958 \\
1959 \\
1960\end{array}$ & $\begin{array}{rr}4.50 & 16 \\
2.20 & 4 \\
4.50 & 17 \\
3.20 & 11 \\
1.00 & 1\end{array}$ & $\begin{array}{rr}4.50 & 15 \\
2.20 & 4 \\
4.50 & 16 \\
3.40 & 11 \\
1.19 & 1\end{array}$ & $\begin{array}{rr}4.60 & 14 \\
2.40 & 4 \\
4.80 & 16 \\
3.60 & 11 \\
1.40 & 1\end{array}$ & $\begin{array}{l}4.90 \\
2.70 \\
4.90 \\
3.70 \\
1.40\end{array}$ & $\begin{array}{r}15 \\
5 \\
16 \\
10 \\
1\end{array}$ & $\begin{array}{l}5.10 \\
3.20 \\
5.00 \\
3.90 \\
2.00\end{array}$ & $\begin{array}{r}16 \\
5 \\
14 \\
10 \\
2\end{array}$ & $\begin{array}{l}5.30 \\
3.80 \\
5.90 \\
4.20 \\
2.70\end{array}$ & $\begin{array}{r}13 \\
6 \\
16 \\
10 \\
1\end{array}$ & $\begin{array}{l}5.50 \\
4.30 \\
6.60 \\
4.40 \\
3.50\end{array}$ & $\begin{array}{r}13 \\
6 \\
16 \\
7 \\
3\end{array}$ & $\begin{array}{l}6.10 \\
4.80 \\
7.20 \\
5.10 \\
3.90\end{array}$ & $\begin{array}{r}13 \\
0 \\
0 \\
0 \\
0 \\
0 \\
0 \\
0 \\
7\end{array}$ & $\begin{array}{l}7.80 \\
5.00 \\
7.40 \\
5.50 \\
4.30\end{array}$ & $\begin{array}{r}20 \\
5 \\
16 \\
7 \\
1\end{array}$ & $\begin{array}{l}20.0 \\
22.0 \\
24.0 \\
27.0 \\
10.0\end{array}$ & $\begin{array}{r}10 \\
11 \\
15 \\
19 \\
3\end{array}$ \\
\hline $\begin{array}{l}1966 \\
1967 \\
1968\end{array}$ & $\begin{array}{ll}8.00 & 27 \\
3.60 & 12 \\
7.10 & 25\end{array}$ & $\begin{array}{ll}8.00 & 27 \\
3.80 & 12 \\
7.40 & 24\end{array}$ & $\begin{array}{ll}8.00 & 26 \\
4.10 & 12 \\
7.70 & 25\end{array}$ & $\begin{array}{l}8.10 \\
4.60 \\
7.90\end{array}$ & $\begin{array}{l}26 \\
12 \\
25\end{array}$ & $\begin{array}{l}8.30 \\
4.80 \\
8.20\end{array}$ & $\begin{array}{l}26 \\
12 \\
25\end{array}$ & $\begin{array}{l}8.70 \\
6.10 \\
8.50\end{array}$ & $\begin{array}{l}26 \\
17 \\
25\end{array}$ & $\begin{array}{l}9.00 \\
6.30 \\
8.70\end{array}$ & $\begin{array}{l}26 \\
15 \\
25\end{array}$ & $\begin{array}{l}9.90 \\
7.10 \\
8.90\end{array}$ & $\begin{array}{ll}0 & 26 \\
0 & 15 \\
0 & 24\end{array}$ & $\begin{array}{c}11.0 \\
7.70 \\
9.00\end{array}$ & $\begin{array}{l}27 \\
18 \\
24\end{array}$ & $\begin{array}{l}36.0 \\
22.0 \\
38.0\end{array}$ & $\begin{array}{l}24 \\
12 \\
25\end{array}$ \\
\hline $\begin{array}{l}1976 \\
1977 \\
1978 \\
1979 \\
1980\end{array}$ & $\begin{array}{rr}7.00 & 24 \\
2.80 & 8 \\
2.30 & 5 \\
4.10 & 13 \\
5.70 & 22\end{array}$ & $\begin{array}{rr}7.50 & 25 \\
3.20 & 10 \\
2.40 & 5 \\
4.50 & 13 \\
5.80 & 22\end{array}$ & $\begin{array}{rr}8.30 & 27 \\
3.40 & 10 \\
2.50 & 5 \\
5.00 & 19 \\
6.00 & 22\end{array}$ & $\begin{array}{l}8.40 \\
4.40 \\
2.50 \\
5.20 \\
6.10\end{array}$ & $\begin{array}{r}27 \\
11 \\
4 \\
19 \\
22\end{array}$ & $\begin{array}{l}9.60 \\
4.40 \\
3.10 \\
5.80 \\
6.20\end{array}$ & $\begin{array}{r}27 \\
11 \\
4 \\
20 \\
21\end{array}$ & $\begin{array}{l}9.70 \\
4.70 \\
3.10 \\
6.20 \\
7.10\end{array}$ & $\begin{array}{r}27 \\
11 \\
3 \\
18 \\
21\end{array}$ & $\begin{array}{l}9.80 \\
4.90 \\
3.50 \\
6.70 \\
7.90\end{array}$ & $\begin{array}{r}27 \\
11 \\
2 \\
17 \\
22\end{array}$ & $\begin{array}{l}9.90 \\
5.20 \\
3.90 \\
7.10 \\
7.60\end{array}$ & $\begin{array}{rr}0 & 27 \\
0 & 9 \\
0 & 3 \\
0 & 16 \\
0 & 22\end{array}$ & $\begin{array}{c}10.0 \\
5.90 \\
4.60 \\
7.90 \\
8.00\end{array}$ & $\begin{array}{r}26 \\
9 \\
2 \\
21 \\
22\end{array}$ & $\begin{array}{c}34.0 \\
19.0 \\
8.50 \\
29.0 \\
25.0\end{array}$ & $\begin{array}{r}23 \\
9 \\
2 \\
20 \\
17\end{array}$ \\
\hline 1981 & $8.60 \quad 28$ & 9.0028 & $9.40 \quad 28$ & 9.70 & 28 & 9.90 & 28 & 10.0 & 28 & 11.0 & 28 & 11.0 & 28 & 12.0 & 28 & 53.0 & 27 \\
\hline
\end{tabular}

HIGHEST MEAN DISCHARGE, IN OBIC FEET PER SBCOND, AND RANKING FOR THE INDICATED NUMBER OF CONSECUTIVE DAYS FOR EACH WATER YEAR, OCTCBER 1-SEPTEMBER 30

Yeap

1946
1947
1948
1949
1950
1951
1952
1953
1954
1955
1956
1957
1958
1959
1960

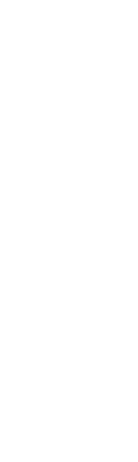

\section{CONSECUTIVE DAYS}

$$
\begin{array}{rrrr}
7 & & 15 & \\
192 & 12 & 170 & 12 \\
219 & 10 & 186 & 10 \\
145 & 21 & 117 & 21 \\
202 & 11 & 184 & 11 \\
339 & 3 & 316 &
\end{array}
$$$$
\begin{array}{rr}
136 & 20 \\
470 & \\
88.0 & 24 \\
71.0 & 26
\end{array}
$$$$
\begin{array}{cccc} 
& & 60 \\
136 & 13 & 93.0 & 17 \\
144 & 11 & 104 & 12 \\
99.0 & 21 & 72.0 & 22 \\
183 & 8 & 139 & 7
\end{array}
$$$$
225
$$$$
\begin{array}{rlrrr}
20 & 113 & 18 & 89.0 & 18 \\
1 & 397 & 1 & 300 & 1 \\
24 & 78.0 & 24 & 64.0 & 24 \\
26 & 66.0 & 25 & 49.0 & 25 \\
18 & 109 & 20 & 76.0 & 20
\end{array}
$$$$
178
$$

$\begin{array}{lll}192 & 14 \quad 178\end{array}$

$172 \quad 17$

$\begin{array}{rrr}172 & 17 & 163 \\ 234 & 9 & 227\end{array}$

$\begin{array}{rrr}178 & 14 & 142 \\ 227 & 17 & 1 \\ 51.0 & 28 & 208 \\ 92 & 25 & \end{array}$ $\begin{array}{cccc}143 & 18 & 109 & 20\end{array}$

$\begin{array}{rrr}142 & 19 & 125 \\ 147 & 16 & 1 \\ 208 & 8 & 188\end{array}$

$\begin{array}{ll}45.0 & 28 \\ 73.0 & 25\end{array}$ $\begin{array}{crrrrr}125 & 16 & 98.0 & 14 & 73.0 & 15 \\ 121 & 17 & 97.0 & 15 & 73.0 & 16 \\ 188 & 7 & 124 & 9 & 90.0 & 9 \\ 39.0 & 28 & 31.0 & 28 & 26.0 & 28 \\ 58.0 & 26 & 47.0 & 26 & 37.0 & 26\end{array}$

90

$\begin{array}{rr}90 & \\ 69.0 & 18 \\ 79.0 & 12 \\ 54.0 & 22 \\ 104 & 8 \\ 143 & 3 \\ 72.0 & 17 \\ 217 & 1 \\ 50.0 & 24 \\ 37.0 & 25 \\ 56.0 & 21 \\ 73.0 & 15 \\ 73.0 & 16 \\ 90.0 & 9 \\ 26.0 & 28 \\ 37.0 & 26\end{array}$

$54.0 \quad 18$

63.012

$43.0 \quad 22$

$\begin{array}{cc}82.0 & 8 \\ 113 & 3\end{array}$

$58.0 \quad 15$

168 1

$\begin{array}{ll}41.0 & 24 \\ 30.0 & 25\end{array}$

44.021

$58.0 \quad 16$

$\begin{array}{lll}58.0 & 17\end{array}$

69.010

$21.0 \quad 28$
183

$38.0 \quad 18$

$45.0 \quad 12$

31.021

56.08

$42.0 \quad 14$

1151

$\begin{array}{ll}30.0 & 24 \\ 22.0 & 25\end{array}$

$\begin{array}{ll}19.0 & 22\end{array}$

$\begin{array}{llll}42.0 & 15 & 24.0 & 15\end{array}$

$\begin{array}{lllll}40.0 & 17 & 23.0 & 18\end{array}$

$\begin{array}{llll}48.0 & 10 & 27.0 & 12\end{array}$

$\begin{array}{llll}16.0 & 28 & 10.0 & 28\end{array}$ 
HIGHEST MEAN DISCHARGE, IN OBIC FEET PER SECOND, AND RANKING FOR THE INDICATED NUMBER OF CONSEOUTIVE DAYS FOR EACH WATER YEAR, OCTCBER 1-SEPTEMBER 30--Continued

\begin{tabular}{rrrrrrrr} 
YEAR & \multicolumn{1}{c}{3} & & 7 & \\
1961 & 38.0 & 29 & 35.0 & 29 & 30.0 & 29 & \\
1962 & 303 & 6 & 291 & 5 & 276 & 5 & 2 \\
1963 & 130 & 23 & 129 & 22 & 122 & 22 & 1 \\
1964 & 292 & 7 & 284 & 6 & 264 & 7 & 224 \\
1965 & 263 & 8 & 250 & 8 & 230 & 8 & 1 \\
1966 & 131 & 22 & 123 & 23 & 111 & 23 & 1 \\
1967 & 376 & 3 & 363 & 3 & 329 & 4 & 2 \\
1968 & 184 & 17 & 169 & 19 & 155 & 20 & 1 \\
1975 & 319 & 5 & 272 & 7 & 265 & 6 & 2 \\
& & & & & & & \\
1976 & 190 & 16 & 183 & 15 & 170 & 15 & 1 \\
1977 & 29.0 & 30 & 26.0 & 30 & 23.0 & 30 & \\
1978 & 207 & 12 & 198 & 13 & 162 & 18 & 1 \\
1979 & 173 & 19 & 170 & 18 & 166 & 16 & 1 \\
1980 & 414 & 2 & 404 & 2 & 370 & 2 & 292 \\
1981 & 62.0 & 27 & 58.0 & 27 & 56.0 & 27 &
\end{tabular}

\section{CONSEOUTTVE DAYS
30}
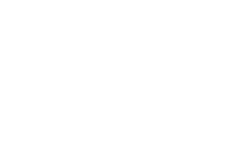

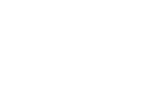

90

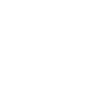

$\begin{array}{rr}76.0 & 13 \\ 106 & 6\end{array}$

$\begin{array}{llllllll}104 & 23 & 98.0 & 22 & 83.0 & 19 & 64.0 & 19\end{array}$

$\begin{array}{rrrrrrrr}281 & 4 & 227 & 4 & 160 & 4 & 120 & 4 \\ 149 & 15 & 135 & 14 & 106 & 11 & 80.0 & 11\end{array}$

$\begin{array}{llllllll}227 & 5 & 198 & 6 & 142 & 6 & 105 & 7\end{array}$

$\begin{array}{cccccccc}146 & 17 & 110 & 19 & 72.0 & 21 & 56.0 & 20 \\ 20.0 & 30 & 17.0 & 30 & 16.0 & 30 & 14.0 & 30\end{array}$

$\begin{array}{llllllll}158 & 13 & 137 & 12 & 111 & 10 & 87.0 & 10\end{array}$

$\begin{array}{rrrrrrrr}158 & 14 & 129 & 15 & 97.0 & 16 & 75.0 & 14 \\ 292 & 3 & 277 & 2 & 234 & 2 & 177 & 2\end{array}$

$50.0 \quad 27$

$\begin{array}{llllll}43.0 & 27 & 39.0 & 27 & 32.0 & 27\end{array}$

DURATION OF DISQHARGE FOR EACH WATER YEAR

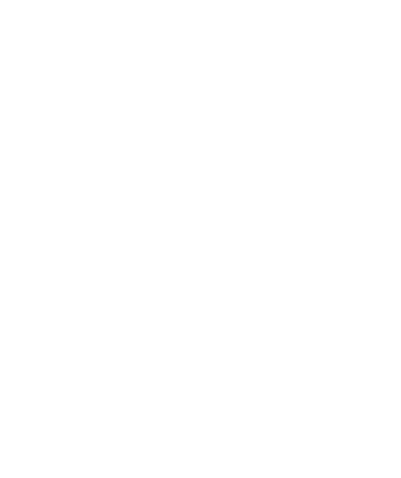

$27.0 \quad 27$

$\begin{array}{llll}21.0 & 27 & 16.0 & 25\end{array}$

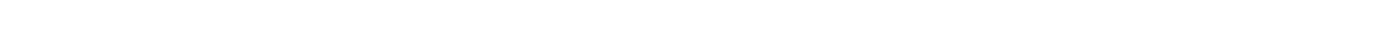
YEAR

NUMBER OF DAVS IN CLASS

OUBIC FEET PER SECOND

8016.6

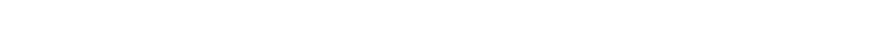

$\begin{array}{rrrrrrrrrrrrrrrrrrrrrrr} & 18 & 4 & 9 & 33 & 74 & 109 & 18 & 23 & 11 & 7 & 3 & 8 & 4 & 10 & 9 & 8 & 12 & 5 & 5 & 3 & 4 & 6\end{array}$

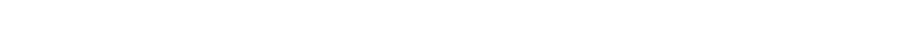

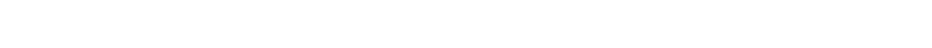

9893.5

6839.7

11404.6

15501.6

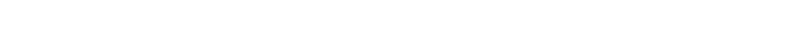

$\begin{array}{rrrrrrrrrrrrrrrrrrrrrrrrrr}19 & 16 & 137 & 22 & 20 & 33 & 3 & 3 & 5 & 15 & 8 & 8 & 8 & 21 & 9 & 8 & 1 & 9 & & & & 9175.0 \\ 11 & 155 & 14 & 6 & 30 & 39 & 13 & 10 & 6 & 5 & 2 & 2 & 4 & 5 & 2 & 2 & 2 & 13 & 1 & 6 & 15 & 6 & 6 & 8 & 3 & 22401.7\end{array}$

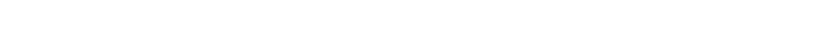

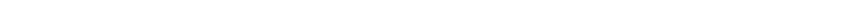

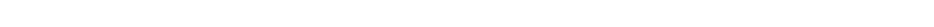

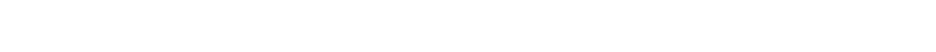

$\begin{array}{rrrrrrrrrrrrrrrrrrrrrrrrrr}2 & 8 & 5 & 11 & 7 & 10 & 16 & 18 & 20132 & 34 & 11 & 5 & 6 & 13 & 14 & 16 & 12 & 10 & 5 & 8 & 2 & & & \\ 1 & 11 & 9 & 7 & 12 & 8 & 31 & 31 & 95 & 10 & 47 & 3 & 11 & 4 & 10 & 4 & 11 & 9 & 18 & 10 & 10 & 5 & 4 & 2 & 3\end{array}$

$\begin{array}{llllllllllllllllll}6 & 7 & 3 & 10 & 29 & 38 & 99 & 38 & 52 & 16 & 15 & 17 & 13 & 11 & 6 & 1 & 3 & 1\end{array}$

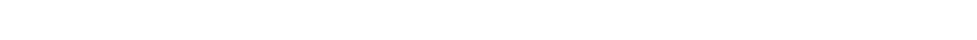

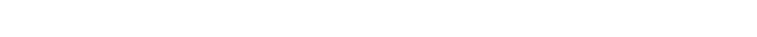

$\begin{array}{rrrrrrrrrrrrrrrrrrrrrr}92 & 69 & 45 & 37 & 17 & 9 & 2 & 18 & 10 & 5 & 6 & 9 & 10 & 6 & 7 & 4 & 3 & 2 & 2 & 3 & 5 & 5 \\ 17 & 19 & 60 & 22 & 66 & 27 & 26 & 23 & 16 & 7 & 3 & 6 & 3 & 6 & 15 & 4 & 9 & 5 & 18 & 8 & 3 & 2\end{array}$

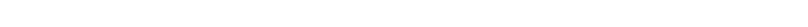

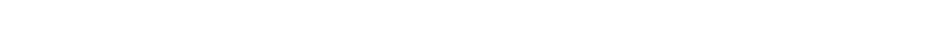

$\begin{array}{llllllllllllllllllllll}40 & 122 & 45 & 34 & 15 & 15 & 8 & 9 & 2 & 7 & 5 & 7 & 6 & 4 & 6 & 7 & 5 & 11 & 6 & 2 & 8 & 1\end{array}$

5233.8

6757.2

8928.3

8387.6

9994.2

3800.5

4706.4

2661.6

11861.8

6797.5

8811.8

8418.5

13800.6

11863.3

$\begin{array}{lllllllllllllllllllllll}1 & 4 & 2 & 4 & 12 & 31 & 54 & 116 & 27 & 22 & 13 & 17 & 13 & 12 & 6 & 3 & 5 & 3 & 4 & 6 & 2 & 6 & 3\end{array}$

$\begin{array}{lllllllllllll}36 & 47 & 66 & 46 & 44 & 18 & 21 & 17 & 17 & 17 & 6 & 3\end{array}$

$\begin{array}{lllllllllllllllllllll}17 & 51 & 29 & 90 & 22 & 15 & 13 & 8 & 14 & 12 & 6 & 8 & 7 & 12 & 7 & 6 & 6 & 22 & 7 & 7 & 5\end{array}$

$\begin{array}{lllllllllllllllllllll}1 & 2 & 30 & 75 & 26 & 105 & 23 & 7 & 7 & 7 & 6 & 6 & 10 & 7 & 14 & 8 & 6 & 7 & 2 & 13 & 3\end{array}$

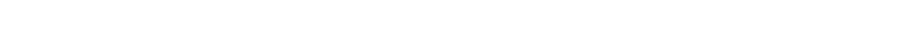

7754.3

2719.8

10312.4

9363.5

18907.1

$\begin{array}{llllllllllllll}6 & 19 & 30 & 31 & 84 & 86 & 28 & 7 & 14 & 10 & 25 & 13 & 5 & 7\end{array}$

5803.5

DURATION TABLE OF DISCHARGE FOR WATER YEARS 1946-68, 1975-81
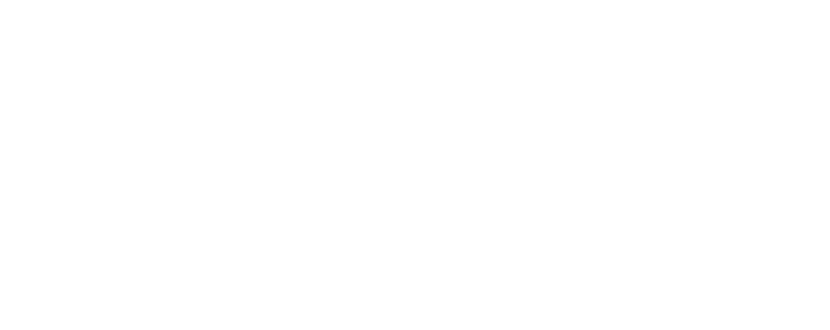

$\begin{array}{ccc}\text { OBIIC } & \text { ACO- } \\ \text { FEET } & \text { MU- } & \\ \text { PER- } & \end{array}$

PER TOTAL LATED CEN

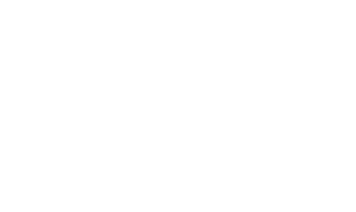

\begin{tabular}{crrrr}
\multicolumn{4}{c}{ CHBIC } & \multicolumn{2}{c}{ ACQU- } \\
FEET & & MU- & PER- \\
PER & TOTAL LATED & CENT \\
CLASS & SECOND & DAYS & DAYS & DAYS \\
& & & & \\
27 & 140.0 & 149 & 455 & 4.2 \\
28 & 170.0 & 134 & 306 & 2.8 \\
29 & 210.0 & 69 & 172 & 1.6 \\
30 & 250.0 & 54 & 103 & 0.9 \\
31 & 310.0 & 24 & 49 & 0.4 \\
32 & 370.0 & 14 & 25 & 0.2 \\
33 & 450.0 & 8 & 11 & 0.1 \\
34 & 540.0 & 3 & 3 & 0.0
\end{tabular} 
GREEN RIVER BASIN

09287000 ORRANT CREEK BELOW RED LEDGE HOLLOW, NEAR FRUITLAND, UT-Continued

MONTHLY MEAN DISCHARGES, IN OUIC FEET PER SECOND, FOR EACH WATER YEAR

\begin{tabular}{|c|c|c|c|c|c|c|c|c|c|c|c|c|}
\hline YEAR & $\infty T$ & NOW & $\mathrm{DEC}$ & JAN & FEB & MAR & APR & MAY & JUNE & JULY & AUG & SEP \\
\hline $\begin{array}{l}1946 \\
1947 \\
1948 \\
1949 \\
1950\end{array}$ & $\begin{array}{l}7.17 \\
7.48 \\
8.32 \\
5.10 \\
8.99\end{array}$ & $\begin{array}{l}7.82 \\
9.18 \\
8.76 \\
6.98 \\
9.75\end{array}$ & $\begin{array}{c}6.00 \\
11.0 \\
8.00 \\
6.39 \\
7.97\end{array}$ & $\begin{array}{c}6.00 \\
10.0 \\
7.40 \\
6.05 \\
7.00\end{array}$ & $\begin{array}{l}7.00 \\
9.54 \\
7.00 \\
7.05 \\
6.00\end{array}$ & $\begin{array}{c}10.0 \\
11.5 \\
7.52 \\
8.71 \\
8.06\end{array}$ & $\begin{array}{l}98.2 \\
49.9 \\
31.8 \\
84.4 \\
97.8\end{array}$ & $\begin{array}{c}80.4 \\
139 \\
95.5 \\
164 \\
223\end{array}$ & $\begin{array}{r}24.7 \\
43.3 \\
31.6 \\
56.6 \\
100\end{array}$ & $\begin{array}{c}8.05 \\
14.6 \\
9.34 \\
15.8 \\
22.5\end{array}$ & $\begin{array}{l}4.73 \\
9.97 \\
4.87 \\
6.22 \\
8.35\end{array}$ & $\begin{array}{l}3.55 \\
8.53 \\
3.40 \\
6.44 \\
8.08\end{array}$ \\
\hline $\begin{array}{l}1951 \\
1952 \\
1953 \\
1954 \\
1955\end{array}$ & $\begin{array}{c}8.84 \\
7.83 \\
10.2 \\
6.49 \\
4.89\end{array}$ & $\begin{array}{c}10.6 \\
7.93 \\
9.35 \\
8.39 \\
6.55\end{array}$ & $\begin{array}{c}10.7 \\
8.00 \\
8.50 \\
7.87 \\
5.96\end{array}$ & $\begin{array}{l}9.00 \\
7.00 \\
8.00 \\
8.00 \\
6.00\end{array}$ & $\begin{array}{l}9.00 \\
8.00 \\
7.50 \\
8.00 \\
5.50\end{array}$ & $\begin{array}{c}11.6 \\
8.00 \\
9.18 \\
8.00 \\
6.52\end{array}$ & $\begin{array}{c}54.6 \\
129 \\
26.5 \\
47.7 \\
23.3\end{array}$ & $\begin{array}{c}110 \\
369 \\
61.1 \\
47.3 \\
107\end{array}$ & $\begin{array}{c}48.6 \\
135 \\
57.8 \\
16.0 \\
35.2\end{array}$ & $\begin{array}{c}14.2 \\
24.2 \\
14.2 \\
6.01 \\
9.04\end{array}$ & $\begin{array}{c}7.68 \\
15.0 \\
9.59 \\
3.64 \\
5.78\end{array}$ & $\begin{array}{c}5.59 \\
12.9 \\
5.54 \\
4.70 \\
5.50\end{array}$ \\
\hline $\begin{array}{l}1956 \\
1957 \\
1958 \\
1959 \\
1960\end{array}$ & $\begin{array}{l}5.51 \\
5.25 \\
7.71 \\
4.82 \\
4.90\end{array}$ & $\begin{array}{l}8.86 \\
6.41 \\
8.71 \\
7.07 \\
6.77\end{array}$ & $\begin{array}{c}12.5 \\
5.58 \\
8.42 \\
6.74 \\
3.77\end{array}$ & $\begin{array}{l}9.81 \\
5.00 \\
7.74 \\
6.00 \\
5.00\end{array}$ & $\begin{array}{l}9.00 \\
5.00 \\
7.00 \\
6.00 \\
5.00\end{array}$ & $\begin{array}{c}13.4 \\
6.55 \\
6.73 \\
6.10 \\
10.8\end{array}$ & $\begin{array}{l}57.4 \\
21.6 \\
27.9 \\
24.2 \\
36.6\end{array}$ & $\begin{array}{l}121 \\
100 \\
184 \\
37.5 \\
54.6\end{array}$ & $\begin{array}{l}37.2 \\
90.9 \\
49.2 \\
14.7 \\
16.4\end{array}$ & $\begin{array}{c}9.20 \\
16.2 \\
9.66 \\
5.11 \\
4.54\end{array}$ & $\begin{array}{l}4.43 \\
7.28 \\
4.26 \\
2.98 \\
1.82\end{array}$ & $\begin{array}{l}3.54 \\
5.06 \\
4.42 \\
3.57 \\
3.99\end{array}$ \\
\hline $\begin{array}{l}1961 \\
1962 \\
1963 \\
1964 \\
1965\end{array}$ & $\begin{array}{l}5.62 \\
5.60 \\
6.34 \\
6.78 \\
5.56\end{array}$ & $\begin{array}{l}6.82 \\
6.46 \\
7.34 \\
9.06 \\
7.47\end{array}$ & $\begin{array}{l}5.96 \\
4.97 \\
7.37 \\
6.69 \\
9.13\end{array}$ & $\begin{array}{l}4.60 \\
4.16 \\
6.68 \\
5.32 \\
9.39\end{array}$ & $\begin{array}{l}4.93 \\
6.18 \\
7.36 \\
5.00 \\
8.11\end{array}$ & $\begin{array}{c}6.71 \\
7.48 \\
8.58 \\
6.42 \\
10.7\end{array}$ & $\begin{array}{c}16.0 \\
102 \\
17.7 \\
21.3 \\
36.4\end{array}$ & $\begin{array}{l}16.3 \\
167 \\
92.7 \\
141 \\
155\end{array}$ & $\begin{array}{l}7.16 \\
60.6 \\
41.4 \\
57.7 \\
111\end{array}$ & $\begin{array}{l}3.08 \\
15.5 \\
11.8 \\
16.0 \\
28.5\end{array}$ & $\begin{array}{c}4.00 \\
4.60 \\
7.69 \\
6.83 \\
16.5\end{array}$ & $\begin{array}{l}6.28 \\
4.07 \\
7.45 \\
5.58 \\
15.1\end{array}$ \\
\hline $\begin{array}{l}1966 \\
1967 \\
1968\end{array}$ & $\begin{array}{c}11.2 \\
7.27 \\
8.32\end{array}$ & $\begin{array}{r}11.7 \\
9.18 \\
9.09\end{array}$ & $\begin{array}{r}10.9 \\
9.41 \\
9.61\end{array}$ & $\begin{array}{l}8.95 \\
8.70 \\
9.02\end{array}$ & $\begin{array}{l}8.61 \\
8.26 \\
9.36\end{array}$ & $\begin{array}{l}16.9 \\
12.8 \\
11.4\end{array}$ & $\begin{array}{l}84.8 \\
32.0 \\
27.3\end{array}$ & $\begin{array}{l}78.2 \\
173 \\
125\end{array}$ & $\begin{array}{c}23.1 \\
140 \\
82.7\end{array}$ & $\begin{array}{l}9.82 \\
31.0 \\
18.4\end{array}$ & $\begin{array}{l}5.97 \\
11.5 \\
11.9\end{array}$ & $\begin{array}{l}6.39 \\
8.75 \\
7.91\end{array}$ \\
\hline 1975 & 7.65 & 7.51 & 6.73 & 6.61 & 7.06 & 8.48 & 11.3 & 118 & 155 & 38.4 & 12.6 & 10.1 \\
\hline $\begin{array}{l}1976 \\
1977 \\
1978 \\
1979 \\
1980\end{array}$ & $\begin{array}{c}12.6 \\
7.45 \\
4.79 \\
7.16 \\
8.81\end{array}$ & $\begin{array}{l}9.70 \\
6.81 \\
5.06 \\
8.33 \\
8.70\end{array}$ & $\begin{array}{l}9.98 \\
5.01 \\
7.13 \\
8.84 \\
6.57\end{array}$ & $\begin{array}{c}9.84 \\
4.76 \\
7.25 \\
10.5 \\
9.11\end{array}$ & $\begin{array}{c}9.92 \\
5.00 \\
8.89 \\
11.1 \\
9.00\end{array}$ & $\begin{array}{c}11.5 \\
8.19 \\
16.4 \\
10.4 \\
9.89\end{array}$ & $\begin{array}{l}26.5 \\
17.5 \\
52.7 \\
39.3 \\
69.1\end{array}$ & $\begin{array}{l}108 \\
14.8 \\
132 \\
128 \\
272\end{array}$ & $\begin{array}{c}28.9 \\
8.88 \\
74.0 \\
52.3 \\
167\end{array}$ & $\begin{array}{c}11.9 \\
4.73 \\
16.4 \\
15.8 \\
30.2\end{array}$ & $\begin{array}{c}7.29 \\
3.05 \\
7.06 \\
8.75 \\
14.1\end{array}$ & $\begin{array}{c}6.58 \\
3.22 \\
6.03 \\
6.41 \\
14.1\end{array}$ \\
\hline 1981 & 13.3 & 11.2 & 12.1 & 10.6 & 10.3 & 11.7 & 31.3 & 39.6 & 25.1 & 9.81 & 6.85 & 8.84 \\
\hline
\end{tabular}

ANNUAL PEAK DISCHARGE, IN OBBIC FEET PER SECOND, AND CORRESPONDING GAGE HEIGHT, IN FEET, FOR EACH WAIER YEAR

\begin{tabular}{|c|c|c|c|c|c|c|c|c|c|c|c|}
\hline $\begin{array}{l}\text { WATER } \\
\text { YEAR }\end{array}$ & DATE & $\begin{array}{c}\text { GAGE } \\
\text { HEIGHT }\end{array}$ & $\begin{array}{c}\text { PEAR } \\
\text { DISCHARGE }\end{array}$ & $\begin{array}{l}\text { WATER } \\
\text { YEAR }\end{array}$ & DATE & $\begin{array}{c}\text { GAGE } \\
\text { HEIGHT }\end{array}$ & $\begin{array}{c}\text { PEAK } \\
\text { DISOHARGE }\end{array}$ & $\begin{array}{l}\text { WATER } \\
\text { YEAR }\end{array}$ & DATE & $\begin{array}{c}\text { GAGE } \\
\text { HEIGAT }\end{array}$ & $\begin{array}{c}\text { PEAK } \\
\text { DISOHARGE }\end{array}$ \\
\hline $\begin{array}{l}1946 \\
1947 \\
1948 \\
1949 \\
1950 \\
1951 \\
1952 \\
1953 \\
1954 \\
1955\end{array}$ & $\begin{array}{ll}\text { APR. } & 24,1946 \\
\text { MAY } & 03,1947 \\
\text { MAY } & 17,1948 \\
\text { APR. } 27,1949 \\
\text { MAY } & 16,1950 \\
\text { MAY } & 20,1951 \\
\text { MAY } & 02,1952 \\
\text { MAY } & 28,1953 \\
\text { APR. } 24,1954 \\
\text { MAY } & 06,1955\end{array}$ & $\begin{array}{l}3.29 \\
3.65 \\
3.05 \\
3.23 \\
3.68 \\
2.88 \\
3.93 \\
2.10 \\
1.79 \\
2.67\end{array}$ & $\begin{array}{l}252 \\
326 \\
207 \\
307 \\
520 \\
242 \\
688 \\
150 \\
108 \\
286\end{array}$ & $\begin{array}{l}1956 \\
1957 \\
1958 \\
1959 \\
1960 \\
1961 \\
1962 \\
1963 \\
1964 \\
1965\end{array}$ & $\begin{array}{ll}\text { MAY } & 06,1956 \\
\text { JUNE } & 01,1957 \\
\text { MAY } & 11,1958 \\
\text { MAY } & 12,1959 \\
\text { MAY } & 10,1960 \\
\text { MAY } & 01,1961 \\
\text { MAY } & 05,1962 \\
\text { MAY } & 18,1963 \\
\text { MAY } & 21,1964 \\
\text { MAY } & 20,1965\end{array}$ & $\begin{array}{l}2.66 \\
2.49 \\
2.87 \\
1.50 \\
2.07 \\
1.29 \\
3.12 \\
2.08 \\
2.84 \\
2.63\end{array}$ & $\begin{array}{r}261 \\
254 \\
342 \\
72 \\
158 \\
50 \\
410 \\
174 \\
372 \\
313\end{array}$ & $\begin{array}{l}1966 \\
1967 \\
1968 \\
1975 \\
1976 \\
1977 \\
1978 \\
1979 \\
1980 \\
1981\end{array}$ & $\begin{array}{lll}\text { MAY } & 09,1966 \\
\text { MAY } & 22,1967 \\
\text { JUNE } & 05,1968 \\
\text { MAY } & 21,1975 \\
\text { MAY } & 14,1976 \\
\text { MAY } & 27,1977 \\
\text { MAY } & 16,1978 \\
\text { MAY } & 20,1979 \\
\text { MAY } & 21,1980 \\
\text { APR. } & 25,1981\end{array}$ & $\begin{array}{l}2.15 \\
3.08 \\
2.36 \\
5.58 \\
4.21 \\
3.55 \\
4.19 \\
3.92 \\
4.77 \\
3.18\end{array}$ & $\begin{array}{r}184 \\
524 \\
255 \\
946 \\
276 \\
52 \\
288 \\
199 \\
518 \\
79\end{array}$ \\
\hline
\end{tabular}

MAGNITUDE AND PROBABIIITY OF ANNUAL LONEST MEAN DISCHARGE BASED ON OIMATTC YEARS 1947-68 AND 1976-81

\begin{tabular}{|c|c|c|c|c|c|c|}
\hline \multirow{2}{*}{$\begin{array}{l}\text { PERIOD } \\
\text { (CON- } \\
\text { SEOU- } \\
\text { TIVE } \\
\text { DAYS) }\end{array}$} & \multicolumn{6}{|c|}{$\begin{array}{l}\text { DISGHARGE, IN OUBIC FEET PER SECOND, FOR } \\
\text { INDICATED REGURRENCE INTERNAL, IN YEARS, AND } \\
\text { ANNUAL NONEXCBEDANCE PRCBABIIITY, IN PEBCENT }\end{array}$} \\
\hline & $\begin{array}{c}2 \\
508\end{array}$ & $\stackrel{5}{208}$ & $\begin{array}{l}10 \\
108\end{array}$ & $\begin{array}{l}20 \\
58\end{array}$ & $\begin{array}{l}50 \\
28\end{array}$ & $\begin{array}{r}100 \\
18\end{array}$ \\
\hline $\begin{array}{r}1 \\
7 \\
14 \\
30 \\
60 \\
90\end{array}$ & $\begin{array}{l}4.1 \\
4.4 \\
4.6 \\
4.9 \\
5.4 \\
5.8\end{array}$ & $\begin{array}{l}2.5 \\
2.8 \\
3.0 \\
3.3 \\
3.9 \\
4.4\end{array}$ & $\begin{array}{l}1.8 \\
2.1 \\
2.3 \\
2.7 \\
3.3 \\
3.8\end{array}$ & $\begin{array}{l}1.4 \\
1.7 \\
1.8 \\
2.2 \\
2.8 \\
3.4\end{array}$ & $\begin{array}{l}0.98 \\
1.3 \\
1.3 \\
1.8 \\
2.4 \\
2.9\end{array}$ & $\begin{array}{l}- \\
\overline{-} \\
-\end{array}$ \\
\hline
\end{tabular}

MAGNITUDE AND PROBABIIITY OF ANNUAL HIGHEST MEAN DISOHARGE BASED ON WATER YEARS $1946-68$ AND 1975-8

\begin{tabular}{|c|c|c|c|c|c|c|}
\hline \multirow{2}{*}{$\begin{array}{l}\text { PERIOD } \\
\text { (CON- } \\
\text { SEOU- } \\
\text { TIVE } \\
\text { DAYS) }\end{array}$} & \multicolumn{6}{|c|}{$\begin{array}{l}\text { DISCHARGE, IN CUBIC FEET PER SEOOND, FOR } \\
\text { INDICATED REOURRENCE INTERNAL, IN YEARS, AND } \\
\text { ANNUAL EXCEEDANCE PRCBABIIITY, IN PERCENT }\end{array}$} \\
\hline & $\begin{array}{c}2 \\
508\end{array}$ & $\begin{array}{c}5 \\
208\end{array}$ & $\begin{array}{l}10 \\
108\end{array}$ & $\begin{array}{l}25 \\
48\end{array}$ & $\begin{array}{l}50 \\
28\end{array}$ & $\begin{array}{r}100 \\
18\end{array}$ \\
\hline $\begin{array}{r}1 \\
3 \\
7 \\
15\end{array}$ & $\begin{array}{l}190 \\
182 \\
170 \\
150\end{array}$ & $\begin{array}{l}307 \\
296 \\
279 \\
244\end{array}$ & $\begin{array}{l}374 \\
361 \\
340 \\
295\end{array}$ & $\begin{array}{l}444 \\
430 \\
405 \\
348\end{array}$ & $\begin{array}{l}488 \\
472 \\
444 \\
379\end{array}$ & $=$ \\
\hline
\end{tabular}


GREEN RIVER BASIN

09287500 WATER HOLLOW NEAR FRUITLAND, UT

LOCATION. --Lat $40^{\circ} 14^{\prime} 30^{\prime \prime}$, long $110^{\circ} 58^{\prime} 48^{\prime \prime}$, in $\mathrm{SW}^{3} \mathrm{SW}+\mathrm{SE}^{\frac{1}{4}} \mathrm{sec} .2, \mathrm{~T} .3$ S., R.10 W., Uintah Meridian, wasatch County, Hydrologic Unit 14060004 , on left bank $1.5 \mathrm{mi}$ upstream fram mouth and $7.7 \mathrm{mi}$ northwest of Fruitland.

DRAINAGE AREA. $--13.8 \mathrm{mi}^{2}$.

MEAN BASTN ELEVATION. $--8,380 \mathrm{ft}$.

PERIOD OF RECORD AVAILABLE.-April 1946 to September 1981.

GAGE.--Water-stage recorder. Altitude of gage is 7,110 ft from topographic map.

REMARKS.--Diversion into water Hollow tunnel for storage in Strawberry Reservoir began Dec. 9, 1971. Diversion 3.5 mi upstream from gage; all flows up to $20 \mathrm{ft}^{3} / \mathrm{s}$ diverted at this point except for $0.5 \mathrm{ft}^{3} / \mathrm{s}$, which is usually bypassed.

AVERAGE DISCHARGE.--25 years (water years 1947-71), $5.71 \mathrm{ft}^{3} / \mathrm{s}, 4,140$ acre-ft/yr prior to diversion to water Hollow tunnel. Nine years (water years 1973-81), $1.36 \mathrm{ft}^{3} / \mathrm{s}, 985$ acre-ft/yr, since completion of Water Hollow tunnel.

EXTREMES FOR PERIOD OF RECORD.--Maximum discharge, $133 \mathrm{ft}^{3} / \mathrm{s}$ July 18, 1954 , gage height, $3.24 \mathrm{ft}$, from rating curve extended above $56 \mathrm{ft}^{3} / \mathrm{s}$ on basis of slope-area measurement of peak flow; maximum gage height $3.59 \mathrm{ft}$ Now. 25, 1969 (backwater from ice); minimum recorded, no flow Jan. 6,1973 , result of freezeup.

DATA BELCW BASED ON PERIOD OF RECORD PRIOR TO DIVERSION TO WATER HOLLON TUNNEL

LOWEST MEAN DISGHARGE, IN OUBIC FEET PER SECOND, AND RANKING FOR THE INDICATED NUMBER OF CONSEQUTIVE DAYS FOR EAOH CLIMATIC YEAR, APRIL 1-MAROH 31

YEAR

1948
1949
1950
1951
1952
1950
1954
1955
1956
1957
1958
1959
1960
1961
1962
1963
1964
1965
1966
1967
1968
1969
1970

1971
3.2016 3.3017 4.3021

5.0023

3.6018

5.4024

3.6019

2.207

$2.10 \quad 5$

2.5010

2.8014

2.8015

1.402

1.001

$\begin{array}{rr}2.50 & 11 \\ 2.30 \quad 8\end{array}$

$\begin{array}{rr}2.30 & 8 \\ 2.50 \quad 12\end{array}$

$2.10 \quad 4$

2.8013

4.3022

4.0020
$2.40 \quad 9$

2.206

3

3.4017
3.3016
4.3022

4.3022

5.0023

4.0020

5.4024

3.40
3.6018

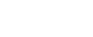

2.207

$\begin{array}{ll}2.50 & 11 \\ 2.80 & 14\end{array}$

$\begin{array}{rr}2.90 & 15 \\ 1.90 & 3\end{array}$

$1.40 \quad 2$

1.001

2.5012

$\begin{array}{ll}2.40 & 8 \\ 2.50 & 9\end{array}$

$2.20 \quad 4$

2.8013

4.3021

4.0019

$2.20 \quad 5$

7

3.5017

3.3016

5.0023

4.0019

5.4024

3.6018

$2.20 \quad 4$

$2.20 \quad 5$

2.507

2.90 14

$\begin{array}{rr}3.00 & 15 \\ 1.90 & 3\end{array}$

1.502

1.001

2.508

$\begin{array}{ll}2.50 & 9 \\ 2.50 & 10\end{array}$

2.5011

2.8013

4.4022

4.1020
2.7012

$2.30 \quad 6$

$\begin{array}{lr}14 & \\ 3.60 & 18 \\ 3.40 & 16 \\ 4.30 & 21 \\ 5.00 & 23 \\ 4.00 & 19 \\ 5.40 & 24 \\ 3.60 & 17 \\ 2.20 & 4 \\ 2.20 & 5 \\ 2.80 & 12 \\ 2.90 & 13 \\ 3.00 & 14 \\ 2.00 & 3 \\ & \\ 1.50 & 2 \\ 1.10 & 1 \\ 2.50 & 7 \\ 2.50 & 8 \\ 2.50 & 9 \\ 3.00 & 15 \\ 2.80 & 10 \\ 4.40 & 22 \\ 4.20 & 20 \\ 2.80 & 11 \\ 2.40 & 6 \\ 2.40 & 6\end{array}$

14

$\begin{array}{ll}\text { CONSEQUTIVE DAYS } \\ 30 & 60\end{array}$

3.7017

3.5015

3.8017

3.5015
$4.40 \quad 21$

5.0023

4.0019

5.4024

5.4014
3.8018

5.0023

4.2019

5.6024

3.9018

3.90
2.405

$2.20 \quad 5$

$\begin{array}{rr}2.20 & 5 \\ 3.00 & 12\end{array}$

3.0013

3.0014
2.10

$2.30 \quad 4$

3.0012
3.0013

3.0013

$\begin{array}{rr}3.00 & 14 \\ 2.20 & 3\end{array}$

$1.50 \quad 2$

1.191

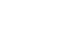

$1.60 \quad 2$

1.191

2.808

2.506

$\begin{array}{ll}2.50 & 6 \\ 2.90 & 9\end{array}$

3.7016

3.8016

3.7016
2.9010

2.9010
4.5022

4.4021

3.0010

4.6022

4.4020
3.0011

2.901

2.607
90

3.8016

3.5015
4.5020

5.0023

4.3019

5.8024

3.9017

$2.40 \quad 4$

3.1014
3.0011

$\begin{array}{rr}3.00 & 12 \\ 2.30 & 3\end{array}$

1.602

1.301

2.80

$\begin{array}{ll}2.50 & 5 \\ 3.00 & 9\end{array}$

4.0018

3.1013

4.6021

4.6022
3.0010

$2.70 \quad 7$
3.9016

3.6015
4.5020

5.1023

4.4019

6.1024

4.0017

2.606

$\begin{array}{ll}2.50 & 4 \\ 3.20 & 11\end{array}$

$\begin{array}{ll}3.20 & 11 \\ 3.30 & 14\end{array}$

$\begin{array}{lll}3.20 & 12 \\ 2.30 & 3\end{array}$

1.702

1.501

$\begin{array}{ll}2.80 & 7 \\ 2.60 & 5\end{array}$

$\begin{array}{ll}2.60 & 5 \\ 3.10 & 9\end{array}$

4.1018

3.3013

4.7022

4.6021
3.2010

$2.80 \quad 8$
4.0015

3.6013

4.9021

5.5023

.6018

.4024

4.3017

$2.50 \quad 4$

3.4010

3.8014

3.5011
2.30

1.902

1.601

$\begin{array}{ll}2.90 & 6 \\ 2.90 & 7\end{array}$

3.309

4.7019

3.6012

5.2022

4.8020
4.2016

$2.90 \quad 8$
ALL

5.6015

$\begin{array}{ll}4.50 & 8 \\ 7.70 & 21\end{array}$

8.4022

6.7018

5.5014

$\begin{array}{rr}5.50 & 14 \\ 3.70 & 5\end{array}$

3.204

4.709

5.1012

$\begin{array}{rr}6.10 & 16 \\ 2.70 & 3\end{array}$

2.302

1.901

5.0011

4.006

7.2019

5.2013

7.4020

6.2017
8.7023

4.7010

HIGHEST MEAN DISCHARGE, IN OUBIC FEET PER SECOND, AND RANKING FOR THE TNDICATED NUMBER OF CONSEGUTIVE DAYS FOR EACH WATER YEAR, OCTOBER I-SEPTEMER 30

EAR

$$
1
$$

$16.0 \quad 12$

$10.0 \quad 19$

$\begin{array}{ll}23.0 & 5 \\ 26.0 & 3\end{array}$

22.0

$\begin{array}{ll}60.0 & 1 \\ 13.0 & 15\end{array}$

$\begin{array}{cc}13.0 & 15 \\ 7.60 & 22\end{array}$

8.0021

$13.0 \quad 16$

$16.0 \quad 13$

$4.70 \quad 23$
4.70

4.7024
4

3

$16.0 \quad 12$

$10.0 \quad 19$

$\begin{array}{ll}23.0 & 5 \\ 25.0 & 3\end{array}$

21.06

59.01

$\begin{array}{cc}12.0 & 17 \\ 7.50 & 22\end{array}$

7.5022
8.0021

$13.0 \quad 16$

$15.0 \quad 13$

25.04

4.6024
4.7023

$\begin{array}{cr}7 & \\ 15.0 & 12 \\ 10.0 & 19 \\ 21.0 & 5 \\ 24.0 & 3 \\ & \\ 20.0 & 6 \\ 56.0 & 1 \\ 12.0 & 15 \\ 7.40 & 22 \\ 7.50 & 21 \\ 12.0 & 16 \\ 15.0 & 13 \\ 24.0 & 4 \\ 4.50 & 23 \\ 4.40 & 24\end{array}$

$\begin{array}{ll}4.50 & 23 \\ 4.40 & 24\end{array}$
15

$14.0 \quad 10$

9.6018
90.0

$\begin{array}{ll}20.0 & 5 \\ 23.0 & 3\end{array}$

19.06

$\begin{array}{ll}19.0 & 6 \\ 53.0 & 1\end{array}$

$\begin{array}{cc}53.0 & 1 \\ 12.0 & 15\end{array}$

7.2021
6.8022

$11.0 \quad 16$

$13.0 \quad 13$

$\begin{array}{rr}22.0 & 4 \\ 4.50 & 23\end{array}$

$\begin{array}{ll}4.50 & 23 \\ 4.20 & 24\end{array}$ $\begin{array}{ll}\text { CONSEOUT'IVE DAYS } \\ 30 & 60\end{array}$

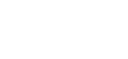

8.5019

$\begin{array}{ll}19.0 & 3 \\ 19.0 & 4\end{array}$

15.08

$50.0 \quad 1$

$\begin{array}{cc}11.0 & 13 \\ 6.60 & 21\end{array}$

$\begin{array}{ll}6.60 & 21 \\ 6.20 & 22\end{array}$

$10.0 \quad 16$

$\begin{array}{rr}11.0 & 14 \\ 19.0 & 5\end{array}$

4.4023
3.9024

90

9.5011 
GREEN RIVER BASIN

09287500 WATER HOLLOW NEAR FRUITLAND, UT-CONtinued

HIGHEST MEAN DISOHARGE, IN OUIC FEET PER SECOND, AND RANKING FOR THE INDICATED NUMBER OF CONSEOUTIVE DAYS

FOR EACH WATER YEAR, OCTOBER 1-SEPTEMBER 30-Continued

\begin{tabular}{|c|c|c|c|c|c|c|c|c|c|c|c|c|c|c|c|c|}
\hline YEAR & \multicolumn{16}{|c|}{ CONSECJTIVE DAYS } \\
\hline $\begin{array}{l}1961 \\
1962 \\
1963 \\
1964 \\
1965\end{array}$ & $\begin{array}{c}3.70 \\
17.0 \\
9.30 \\
13.0 \\
20.0\end{array}$ & $\begin{array}{l}25 \\
11 \\
20 \\
17 \\
9\end{array}$ & $\begin{array}{c}3.20 \\
17.0 \\
9.10 \\
13.0 \\
19.0\end{array}$ & $\begin{array}{r}25 \\
10 \\
20 \\
14 \\
9\end{array}$ & $\begin{array}{c}3.20 \\
16.0 \\
8.90 \\
12.0 \\
18.0\end{array}$ & $\begin{array}{r}25 \\
11 \\
20 \\
17 \\
9\end{array}$ & $\begin{array}{c}3.20 \\
14.0 \\
8.70 \\
11.0 \\
17.0\end{array}$ & $\begin{array}{r}25 \\
11 \\
20 \\
17 \\
8\end{array}$ & $\begin{array}{c}2.90 \\
12.0 \\
8.00 \\
10.0 \\
16.0\end{array}$ & $\begin{array}{r}25 \\
11 \\
20 \\
17 \\
7\end{array}$ & $\begin{array}{c}2.40 \\
11.0 \\
6.80 \\
8.40 \\
14.0\end{array}$ & $\begin{array}{r}25 \\
9 \\
20 \\
18 \\
7\end{array}$ & $\begin{array}{rr}2.20 & 25 \\
9.80 & 9 \\
6.10 & 20 \\
7.30 & 18 \\
13.0 & 5\end{array}$ & $\begin{array}{rr}2.00 & 25 \\
8.80 & 9 \\
5.70 & 20 \\
6.50 & 18 \\
12.0 & 5\end{array}$ & $\begin{array}{rr}2.00 & 25 \\
7.10 & 12 \\
5.00 & 20 \\
5.60 & 18 \\
9.70 & 5\end{array}$ & $\begin{array}{rr}1.80 & 25 \\
4.60 & 15 \\
4.00 & 21 \\
4.20 & 20 \\
6.50 & 8\end{array}$ \\
\hline $\begin{array}{l}1966 \\
1967 \\
1968 \\
1969 \\
1970\end{array}$ & $\begin{array}{l}14.0 \\
21.0 \\
17.0 \\
33.0 \\
21.0\end{array}$ & $\begin{array}{r}14 \\
7 \\
10 \\
2 \\
8\end{array}$ & $\begin{array}{l}13.0 \\
20.0 \\
16.0 \\
32.0 \\
20.0\end{array}$ & $\begin{array}{r}15 \\
7 \\
11 \\
2 \\
8\end{array}$ & $\begin{array}{l}13.0 \\
20.0 \\
16.0 \\
30.0 \\
18.0\end{array}$ & $\begin{array}{r}14 \\
7 \\
10 \\
2 \\
8\end{array}$ & $\begin{array}{l}12.0 \\
18.0 \\
14.0 \\
27.0 \\
16.0\end{array}$ & $\begin{array}{r}14 \\
7 \\
12 \\
2 \\
9\end{array}$ & $\begin{array}{l}11.0 \\
17.0 \\
12.0 \\
24.0 \\
13.0\end{array}$ & $\begin{array}{r}15 \\
6 \\
12 \\
2 \\
9\end{array}$ & $\begin{array}{c}9.30 \\
15.0 \\
10.0 \\
20.0 \\
9.90\end{array}$ & $\begin{array}{r}15 \\
6 \\
11 \\
2 \\
12\end{array}$ & $\begin{array}{rr}8.2015 \\
13.0 & 6 \\
9.50 & 10 \\
18.0 & 2 \\
8.70 & 13\end{array}$ & $\begin{array}{rr}7.60 & 15 \\
12.0 & 6 \\
8.80 & 10 \\
16.0 & 2 \\
7.70 & 13\end{array}$ & $\begin{array}{rr}6.70 & 13 \\
9.60 & 6 \\
7.60 & 9 \\
13.0 & 2 \\
6.60 & 14\end{array}$ & $\begin{array}{rr}5.70 & 11 \\
6.60 & 7 \\
6.40 & 9 \\
9.10 & 2 \\
5.40 & 13\end{array}$ \\
\hline 1971 & 11.0 & 18 & 11.0 & 18 & 10.0 & 18 & 9.50 & 19 & 9.30 & 018 & 8.60 & 17 & 7.9017 & 7.3016 & 6.3016 & 4.6016 \\
\hline
\end{tabular}

DURATION OF DISOHARGE FOR EACH WATER YEAR

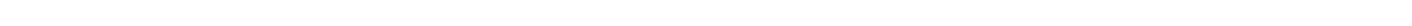

YEAR

NUMBER OF DAYS IN CLASS

CIBIC FEET

$\begin{array}{llllllllllllll}30 & 70 & 74 & 53 & 25 & 25 & 24 & 10 & 3 & 9 & 16 & 16 & 4 & 6\end{array}$ -DAYS

1947
1948
1949

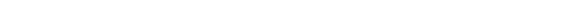

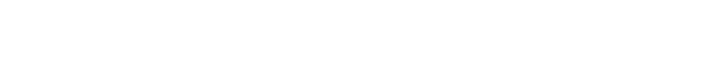

2013.5

1675.4

2621.7

1950

$\begin{array}{lllllllllllll}147 & 60 & 57 & 28 & 14 & 11 & 17 & 12 & 4 & 3 & 4 & 7 & 1\end{array}$

1952

1953

$\begin{array}{llllllllllllll}5 & 16 & 17 & 18 & 32 & 11 & 7 & 4 & 13 & 5 & 10 & 15 & 11 & 4\end{array}$

2576.4

$\begin{array}{llllllllll}70 & 114 & 69 & 30 & 30 & 19 & 26 & 6 & 1 & 17\end{array}$

$\begin{array}{llllllllll}36 & 39106 & 61 & 45 & 107 & 59 & 67 & 27 & 7 & 12\end{array}$

1633.2

1216.7

1955

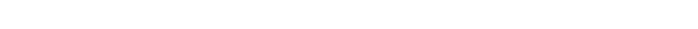

$\begin{array}{lllllllllllll}90 & 76 & 50 & 22 & 23 & 26 & 19 & 14 & 13 & 4 & 16 & 5 & 2\end{array}$

1956

1957

1959

1960

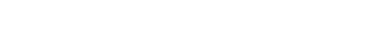

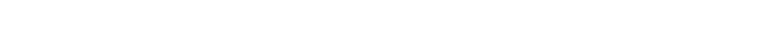

$\begin{array}{llllllllll}1961 & 13 & 331963 & 76 & 74 & 47 & 13 & 817 & 2\end{array}$

1962

1964

1966

1967

1968

1969

1970

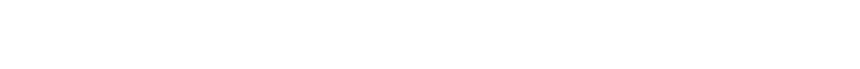

$\begin{array}{lllllllllllllll}79 & 33 & 38 & 71 & 36 & 36 & 7 & 15 & 10 & 12 & 7 & 8 & 8 & 4 & 2\end{array}$

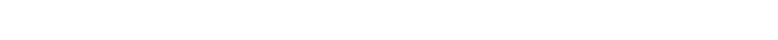

$\begin{array}{llllllllllll}41 & 41 & 66 & 46 & 101 & 17 & 12 & 6 & 14 & 11 & 5 & 5\end{array}$

$\begin{array}{rrrrrrrrrrrrrrrr}28 & 56 & 41 & 41 & 66 & 46 & 101 & 17 & 12 & 6 & 14 & 11 & 5 & 5 & & \\ & 30 & 44 & 55 & 6 & 10 & 11 & 19 & 23 & 19 & 15 & 4 & 9 & 23 & 7 & 6\end{array}$

$\begin{array}{rrrrlllllllll}10 & 95 & 45 & 96 & 32 & 25 & 23 & 15 & 13 & 3 & 2 & 5 & 2\end{array}$

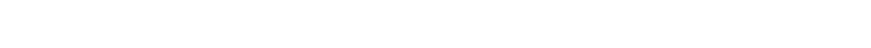

1573.1

1797.0
2278.5

1171.8

960.2

1971

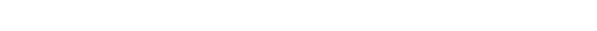

665.5

1667.8

1454.1

1554.0

2088.1

2421.3

2337.2

3308.3

1960.9

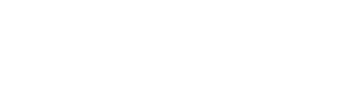

$0.00 \quad 0 \quad 9131100.0$

$\begin{array}{rrrr}0.00 & 0 & 9131 & 100.0 \\ 1.00 & 13 & 9131 & 100.0\end{array}$

$\begin{array}{llll}1.10 & 33 & 9118 & 99.9\end{array}$

$\begin{array}{llll}1.30 & 19 & 9085 & 99.5\end{array}$

$\begin{array}{llll}1.50 & 99 & 9066 & 99.3\end{array}$

$\begin{array}{llll}1.60 & 154 & 8967 & 98.2\end{array}$

$\begin{array}{llll}1.90 & 131 & 8813 & 96.5\end{array}$

$\begin{array}{llll}2.10 & 331 & 8682 & 95.1 \\ 2.40 & 486 & 8351 & 91.5\end{array}$
DURATION TABLE OF DISOHARGE FOR WATER YEARS 1947-71

\begin{tabular}{rrrrr}
\multicolumn{4}{c}{ GBIC } & ACO- \\
FEET & MU- & PER- \\
PER & TOTAL & LATED & CENT \\
CLASS SECOND & DAYS & DAYS & DAYS \\
& & & & \\
9 & 2.70 & 404 & 7865 & 86.1 \\
10 & 3.00 & 864 & 7461 & 81.7 \\
11 & 3.40 & 937 & 6597 & 72.2 \\
12 & 3.90 & 894 & 5660 & 62.0 \\
13 & 4.40 & 981 & 4766 & 52.2 \\
14 & 5.00 & 755 & 3785 & 41.5 \\
15 & 5.60 & 745 & 3030 & 33.2 \\
16 & 6.30 & 514 & 2285 & 25.0 \\
17 & 7.20 & 332 & 1771 & 19.4
\end{tabular}

$\begin{array}{lll}\text { OBIC } & \text { ACOU- } \\ \text { FEET } & \text { MU- } & \text { PER- } \\ \text { PER TOTAL LATED } & \text { CENT }\end{array}$ CLASS SECOND DAYS DAYS DAYS

$\begin{array}{rrrrr}18 & 8.1 & 288 & 1439 & 15.8 \\ 19 & 9.2 & 197 & 1151 & 12.6 \\ 20 & 10.0 & 274 & 954 & 10.4 \\ 21 & 12.0 & 130 & 680 & 7.4 \\ 22 & 13.0 & 133 & 550 & 6.0 \\ 23 & 15.0 & 129 & 417 & 4.6 \\ 24 & 17.0 & 74 & 288 & 3.2 \\ 25 & 19.0 & 94 & 214 & 2.3 \\ 26 & 22.0 & 33 & 120 & 1.3\end{array}$

$\begin{array}{lll}\text { ORIC } & \text { ACOU- } \\ \text { FEET } & \text { MU- PER- }\end{array}$ PER TOTAL LATED CENT
CLASS SECOND DAYS DAYS DAYS

$\begin{array}{rrrrr}27 & 25.0 & 19 & 87 & 1.0 \\ 28 & 28.0 & 7 & 68 & 0.7 \\ 29 & 31.0 & 16 & 61 & 0.7 \\ 30 & 35.0 & 5 & 45 & 0.5 \\ 31 & 40.0 & 10 & 40 & 0.4 \\ 32 & 45.0 & 15 & 30 & 0.3 \\ 33 & 51.0 & 11 & 15 & 0.2 \\ 34 & 58.0 & 4 & 4 & 0.0\end{array}$


GREEN RIVER BASIN

09287500 WATER HOLLOW NEAR FRUITIAND, UT-Continued

MONTHLY MEAN DISCHARGES, IN CUBIC FEET PER SECOND, FOR EACH WATER YEAR

\begin{tabular}{|c|c|c|c|c|c|c|c|c|c|c|c|c|}
\hline YEAR & $\infty C T$ & NOV & $\mathrm{DEC}$ & JAN & FEB & MAR & APR & MAY & JUNE & JULY & AUG & SEP \\
\hline $\begin{array}{l}1947 \\
1948 \\
1949 \\
1950\end{array}$ & $\begin{array}{l}4.64 \\
4.41 \\
3.60 \\
5.72\end{array}$ & $\begin{array}{l}4.18 \\
4.01 \\
3.76 \\
5.09\end{array}$ & $\begin{array}{l}4.00 \\
4.00 \\
3.60 \\
4.70\end{array}$ & $\begin{array}{l}3.50 \\
3.80 \\
3.50 \\
4.50\end{array}$ & $\begin{array}{l}3.27 \\
3.70 \\
3.50 \\
4.30\end{array}$ & $\begin{array}{l}3.29 \\
3.90 \\
4.52 \\
4.97\end{array}$ & $\begin{array}{l}4.47 \\
4.38 \\
7.45 \\
9.19\end{array}$ & $\begin{array}{c}12.3 \\
6.99 \\
16.9 \\
15.0\end{array}$ & $\begin{array}{c}9.54 \\
6.77 \\
15.0 \\
16.1\end{array}$ & $\begin{array}{c}6.59 \\
5.11 \\
10.1 \\
11.3\end{array}$ & $\begin{array}{l}5.73 \\
4.28 \\
7.72 \\
9.00\end{array}$ & $\begin{array}{l}4.53 \\
3.53 \\
6.37 \\
7.13\end{array}$ \\
\hline $\begin{array}{l}1951 \\
1952 \\
1953 \\
1954 \\
1955\end{array}$ & $\begin{array}{c}6.30 \\
5.75 \\
11.1 \\
5.15 \\
2.79\end{array}$ & $\begin{array}{l}5.86 \\
4.62 \\
8.72 \\
4.68 \\
2.96\end{array}$ & $\begin{array}{l}5.50 \\
4.50 \\
7.00 \\
4.00 \\
2.77\end{array}$ & $\begin{array}{l}5.00 \\
4.00 \\
6.00 \\
4.00 \\
2.79\end{array}$ & $\begin{array}{l}5.00 \\
4.50 \\
5.61 \\
4.01 \\
2.20\end{array}$ & $\begin{array}{l}5.00 \\
4.50 \\
5.65 \\
3.85 \\
2.70\end{array}$ & $\begin{array}{c}5.49 \\
13.5 \\
5.51 \\
4.65 \\
3.45\end{array}$ & $\begin{array}{c}11.6 \\
48.9 \\
6.61 \\
6.46 \\
5.94\end{array}$ & $\begin{array}{c}12.4 \\
37.9 \\
9.04 \\
5.45 \\
5.00\end{array}$ & $\begin{array}{c}8.64 \\
22.6 \\
7.01 \\
4.79 \\
3.66\end{array}$ & $\begin{array}{c}7.56 \\
17.7 \\
6.26 \\
3.56 \\
3.15\end{array}$ & $\begin{array}{c}6.25 \\
13.5 \\
5.29 \\
3.05 \\
2.50\end{array}$ \\
\hline $\begin{array}{l}1956 \\
1957 \\
1958 \\
1959 \\
1960\end{array}$ & $\begin{array}{l}2.51 \\
3.97 \\
4.91 \\
4.35 \\
2.37\end{array}$ & $\begin{array}{l}2.58 \\
3.50 \\
4.64 \\
4.05 \\
2.34\end{array}$ & $\begin{array}{l}2.83 \\
3.19 \\
4.13 \\
3.47 \\
2.29\end{array}$ & $\begin{array}{l}2.44 \\
3.00 \\
3.08 \\
3.02 \\
2.47\end{array}$ & $\begin{array}{l}2.20 \\
3.00 \\
3.00 \\
3.00 \\
2.40\end{array}$ & $\begin{array}{l}2.43 \\
3.50 \\
2.97 \\
3.12 \\
3.03\end{array}$ & $\begin{array}{l}3.57 \\
3.91 \\
5.40 \\
3.43 \\
3.12\end{array}$ & $\begin{array}{c}8.92 \\
5.59 \\
16.2 \\
3.43 \\
3.82\end{array}$ & $\begin{array}{c}8.82 \\
11.4 \\
12.4 \\
3.45 \\
3.12\end{array}$ & $\begin{array}{l}6.20 \\
7.32 \\
7.58 \\
2.66 \\
2.68\end{array}$ & $\begin{array}{l}5.08 \\
5.82 \\
5.83 \\
2.26 \\
1.70\end{array}$ & $\begin{array}{l}3.91 \\
4.80 \\
4.57 \\
2.28 \\
2.14\end{array}$ \\
\hline $\begin{array}{l}1961 \\
1962 \\
1963 \\
1964 \\
1965\end{array}$ & $\begin{array}{l}2.22 \\
1.97 \\
3.35 \\
3.65 \\
3.64\end{array}$ & $\begin{array}{l}2.08 \\
1.78 \\
2.95 \\
3.23 \\
3.90\end{array}$ & $\begin{array}{l}2.00 \\
1.88 \\
2.81 \\
2.80 \\
3.26\end{array}$ & $\begin{array}{l}1.66 \\
1.57 \\
2.72 \\
2.64 \\
3.19\end{array}$ & $\begin{array}{l}1.50 \\
2.09 \\
3.09 \\
2.50 \\
3.09\end{array}$ & $\begin{array}{l}1.63 \\
2.61 \\
2.68 \\
2.50 \\
2.94\end{array}$ & $\begin{array}{l}2.34 \\
6.94 \\
3.40 \\
3.84 \\
4.57\end{array}$ & $\begin{array}{c}2.52 \\
11.9 \\
6.64 \\
6.91 \\
10.6\end{array}$ & $\begin{array}{c}1.27 \\
9.58 \\
6.96 \\
8.80 \\
15.2\end{array}$ & $\begin{array}{c}1.20 \\
6.16 \\
4.68 \\
5.84 \\
11.6\end{array}$ & $\begin{array}{l}1.55 \\
4.61 \\
4.50 \\
4.42 \\
9.53\end{array}$ & $\begin{array}{l}1.89 \\
3.60 \\
3.98 \\
3.81 \\
6.49\end{array}$ \\
\hline $\begin{array}{l}1966 \\
1967 \\
1968 \\
1969 \\
1970\end{array}$ & $\begin{array}{l}6.09 \\
4.63 \\
6.16 \\
5.49 \\
6.90\end{array}$ & $\begin{array}{l}5.66 \\
3.99 \\
5.74 \\
4.94 \\
5.26\end{array}$ & $\begin{array}{l}4.48 \\
3.31 \\
5.17 \\
4.70 \\
3.89\end{array}$ & $\begin{array}{l}4.05 \\
2.89 \\
4.59 \\
4.79 \\
2.94\end{array}$ & $\begin{array}{l}3.82 \\
3.21 \\
4.53 \\
4.46 \\
3.14\end{array}$ & $\begin{array}{l}4.19 \\
3.80 \\
4.74 \\
4.54 \\
2.92\end{array}$ & $\begin{array}{c}5.95 \\
4.55 \\
4.93 \\
10.8 \\
4.32\end{array}$ & $\begin{array}{c}10.3 \\
9.68 \\
7.05 \\
22.8 \\
9.73\end{array}$ & $\begin{array}{c}8.15 \\
15.8 \\
11.8 \\
17.4 \\
8.52\end{array}$ & $\begin{array}{c}5.89 \\
11.0 \\
8.74 \\
11.9 \\
6.94\end{array}$ & $\begin{array}{l}4.88 \\
9.17 \\
7.17 \\
9.08 \\
5.44\end{array}$ & $\begin{array}{l}5.06 \\
7.44 \\
5.94 \\
7.52 \\
4.29\end{array}$ \\
\hline 1971 & 3.08 & 3.28 & 2.91 & 2.53 & 2.57 & 3.20 & 4,11 & 7.80 & 8.50 & 6.94 & 5.80 & 4.80 \\
\hline
\end{tabular}

ANNUAL PEAK DISCHARGE, IN CUBIC FEET PER SECOND, AND CORRESPONDING GAGE HEIGHT, IN FEET, FOR EACH WATER YEAR

\begin{tabular}{|c|c|c|c|c|c|c|c|c|c|c|c|}
\hline $\begin{array}{l}\text { WATER } \\
\text { YEAR }\end{array}$ & DATE & $\begin{array}{c}\text { GAGE } \\
\text { HEIGHT }\end{array}$ & $\begin{array}{c}\text { PEAK } \\
\text { DISCHARGE }\end{array}$ & $\begin{array}{l}\text { WATER } \\
\text { YEAR }\end{array}$ & DATE & $\begin{array}{l}\text { GAGE } \\
\text { HEIGHT }\end{array}$ & $\begin{array}{c}\text { PEAK } \\
\text { DISCHARGE }\end{array}$ & $\begin{array}{l}\text { WATER } \\
\text { YEAR }\end{array}$ & DATE & $\begin{array}{c}\text { GAGE } \\
\text { HEIGHT }\end{array}$ & $\begin{array}{c}\text { PEAK } \\
\text { DISCHARGE }\end{array}$ \\
\hline $\begin{array}{l}1946 \\
1947 \\
1948 \\
1949 \\
1950 \\
1951 \\
1952 \\
1953 \\
1954\end{array}$ & 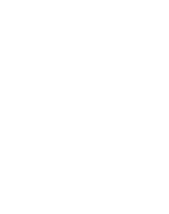 & $\begin{array}{l}1.61 \\
1.69 \\
1.52 \\
1.66 \\
1.77 \\
2.15 \\
2.59 \\
2.54 \\
3.24\end{array}$ & $\begin{array}{r}13 \\
18 \\
13 \\
25 \\
27 \\
65 \\
104 \\
100 \\
133\end{array}$ & $\begin{array}{l}1955 \\
1956 \\
1957 \\
1958 \\
1959 \\
1960 \\
1961 \\
1962 \\
1963\end{array}$ & $\begin{array}{lll}\text { MAY } & 16,1955 \\
\text { MAY } & 30,1956 \\
\text { AUG. } & 05,1957 \\
\text { MAY } & 23,1958 \\
\text { APR. } 09,1959 \\
\text { SEPT. 03, } 1960 \\
\text { SEPT.18, } 1961 \\
\text { MAY } 13,1962 \\
\text { ALG. } 04,1963\end{array}$ & $\begin{array}{l}-\overline{1} \\
1.54 \\
1.83 \\
1.61 \\
1.32 \\
1.27 \\
1.40 \\
1.62 \\
1.94\end{array}$ & $\begin{array}{l}8.3 \\
16 \\
32 \\
28 \\
10 \\
6.0 \\
10 \\
19 \\
40\end{array}$ & $\begin{array}{l}1964 \\
1965 \\
1966 \\
1967 \\
1968 \\
1969 \\
1970 \\
1971\end{array}$ & $\begin{array}{l}\text { JULY } 13,1964 \\
\text { AUG. } 21,1965 \\
\text { JULY } 24,1966 \\
\text { JUNE } 10,1967 \\
\text { JUNE } 05,1968 \\
\text { JUNE } 15,1969 \\
\text { JULY } 06,1970 \\
\text { AUG. } 06,1971\end{array}$ & $\begin{array}{l}1.57 \\
2.60 \\
2.80 \\
1.61 \\
1.56 \\
1.93 \\
2.67 \\
1.94\end{array}$ & $\begin{array}{l}21 \\
83 \\
96 \\
23 \\
19 \\
54 \\
99 \\
23\end{array}$ \\
\hline
\end{tabular}

MAGNITUDE AND PRCBABILITY OF ANNUAL LONEST MEAN DISCHARGE BASED ON CLIMATIC YEARS 1948-71

\begin{tabular}{|c|c|c|c|c|c|c|}
\hline \multirow{2}{*}{$\begin{array}{l}\text { PERIOD } \\
\text { (CON- } \\
\text { SECU- } \\
\text { TIVE } \\
\text { DAYS) }\end{array}$} & \multicolumn{6}{|c|}{$\begin{array}{l}\text { DISCHARGE, IN OUIC FEET PER SECOND, FOR } \\
\text { INDICATED RECURRENCE INTERNAL, IN YEARS, AND } \\
\text { ANNUAL NONEXCEEDANCE PROBABILITY, IN PERCENT }\end{array}$} \\
\hline & $\begin{array}{c}2 \\
508\end{array}$ & $\begin{array}{c}5 \\
20 \%\end{array}$ & $\begin{array}{l}10 \\
108\end{array}$ & $\begin{array}{l}20 \\
58\end{array}$ & $\begin{array}{l}50 \\
28\end{array}$ & $\begin{array}{r}100 \\
18\end{array}$ \\
\hline
\end{tabular}

$\begin{array}{rrrrrrr}1 & 2.8 & 2.0 & 1.6 & 1.4 & - & - \\ 7 & 3.0 & 2.1 & 1.7 & 1.4 & - & = \\ 14 & 3.0 & 2.2 & 1.8 & 1.5 & - & = \\ 30 & 3.1 & 2.3 & 1.9 & 1.6 & - & - \\ 60 & 3.2 & 2.3 & 1.9 & 1.6 & - & - \\ 90 & 3.3 & 2.4 & 2.0 & 1.7 & - & -\end{array}$

DATA BELOW BASED ON PERIOD OF RECORD AFTER DIVERSION TO WATER HOLLW TUNNEI

LOWEST MEAN DISCHARGE, IN OBBIC FEET PER SECOND, AND RANKING FOR THE INDICATFD NUMBER OF CONSECUTIVE DAYS FOR EACH CLIMATIC YEAR, APRII 1-MARCH 31

$\begin{array}{ccccc} & 1 & & 3 & \\ 1973 & 0.19 & 6 & 0.54 & 8 \\ 1974 & 0.27 & 8 & 0.29 & 7\end{array}$

\section{CONSECUTIVE DAYS}

14

$\begin{array}{llll}0.69 & 9 & 0.69 & 9 \\ 0.33 & 7 & 0.35 & 6\end{array}$

$\begin{array}{llll}0.33 & 7 & 0.35 & 6 \\ 0.21 & 5 & 0.32 & 5\end{array}$
$30 \quad 60$

$\begin{array}{llll}0.75 & 9 & 0.89 & 9\end{array}$

$\begin{array}{llll}0.47 & 6 & 0.86 & 8\end{array}$
90

0.968

$\begin{array}{llll}0.63 & 4 & 0.67 & 5\end{array}$
183

1.197

$\begin{array}{llll}2.10 & 9 & 2.20 & 7 \\ 0.97 & 6 & 1.50 & 5\end{array}$ 
GREEN RIVER BASIN

09287500 WATER HOLLOW NEAR FRUITLAND, UT-Continued

LOWEST MEAN DISCHARGE, IN OUBIC FEET PER SECOND, AND RANKING FOR THE INDICATED NUMBER CF CONSECUTIVE DAYS FOR EACH CLIMATIC YEAR, APRII 1-MARCH 31--Continued

YEAR
1976
1977
1978
1979
1980
1981

\begin{tabular}{|c|c|c|c|c|c|c|c|c|c|c|c|c|c|c|c|c|c|c|}
\hline 1 & & 3 & & 7 & & 14 & & $\begin{array}{l}\text { CONSEC } \\
30\end{array}$ & QTIVE & $\begin{array}{l}\text { DAYS } \\
60\end{array}$ & & 90 & & 120 & & 183 & & ALL \\
\hline $\begin{array}{l}0.24 \\
0.05 \\
0.15 \\
0.06 \\
0.05\end{array}$ & $\begin{array}{l}7 \\
1 \\
5 \\
3 \\
2\end{array}$ & $\begin{array}{l}0.26 \\
0.05 \\
0.16 \\
0.07 \\
0.06\end{array}$ & $\begin{array}{l}6 \\
1 \\
5 \\
3 \\
2\end{array}$ & $\begin{array}{l}0.32 \\
0.06 \\
0.18 \\
0.07 \\
0.07\end{array}$ & $\begin{array}{l}6 \\
1 \\
4 \\
2 \\
3\end{array}$ & $\begin{array}{l}0.39 \\
0.08 \\
0.22 \\
0.08 \\
0.18\end{array}$ & $\begin{array}{l}7 \\
1 \\
4 \\
2 \\
3\end{array}$ & $\begin{array}{l}0.45 \\
0.34 \\
0.28 \\
0.30 \\
0.38\end{array}$ & $\begin{array}{l}5 \\
3 \\
1 \\
2 \\
4\end{array}$ & $\begin{array}{l}0.74 \\
0.57 \\
0.33 \\
0.42 \\
0.43\end{array}$ & $\begin{array}{l}7 \\
5 \\
1 \\
2 \\
3\end{array}$ & $\begin{array}{l}0.93 \\
0.63 \\
0.35 \\
0.46 \\
0.44\end{array}$ & $\begin{array}{l}7 \\
5 \\
1 \\
3 \\
2\end{array}$ & $\begin{array}{l}1.10 \\
0.66 \\
0.39 \\
0.47 \\
0.45\end{array}$ & $\begin{array}{l}8 \\
4 \\
1 \\
3 \\
2\end{array}$ & $\begin{array}{l}1.40 \\
0.79 \\
0.59 \\
0.56 \\
0.55\end{array}$ & $\begin{array}{l}8 \\
4 \\
3 \\
2 \\
1\end{array}$ & $\begin{array}{l}2.40 \\
0.98 \\
0.93 \\
0.78 \\
0.73\end{array}$ \\
\hline .56 & 9 & 0.57 & 9 & 0.64 & 8 & 0.66 & 8 & 0.67 & 8 & 0.72 & 6 & 0.74 & 6 & 0.77 & 6 & 0.85 & 5 & 1.80 \\
\hline
\end{tabular}

HIGHEST MEAN DISCHARGE, IN CUBIC FEET PER SECOND, AND RANKING FOR THE INDICATED NUMBER OF CONSECUTIVE DAYS FOR EACH WATER YEAR, OCTCBER 1-SEPTEMBER 30

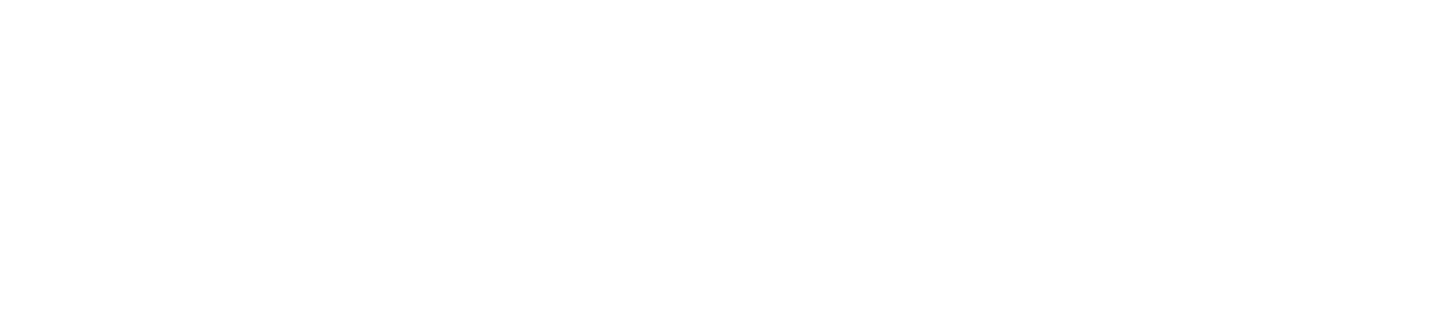

DURATION OF DISCHARGE FOR EACH WATER YEAR

CJASS $0 \begin{array}{llllllllllllllllllllllllllllllllllllll}1 & 2 & 3 & 4 & 5 & 6 & 7 & 8 & 9 & 10 & 11 & 12 & 13 & 14 & 15 & 16 & 17 & 18 & 19 & 20 & 21 & 22 & 23 & 24 & 25 & 26 & 27 & 28 & 29 & 30 & 31 & 32 & 33 & 34\end{array}$ $\begin{array}{llllllllllllll} & \\ \text { YEAR } & \text { NUMER OF DAYS IN CLASS } & \text { CIBIC FEET } \\ \text { PER SECOND }\end{array}$

\begin{tabular}{|c|c|c|c|c|c|c|c|c|c|c|c|c|c|c|c|c|c|c|c|c|c|c|c|c|c|c|c|c|c|c|c|c|}
\hline $\begin{array}{l}1973 \\
1974 \\
1975\end{array}$ & & & & & & 2 & $\begin{array}{l}1 \\
4\end{array}$ & $\begin{array}{l}4 \\
3\end{array}$ & $\begin{array}{l}3 \\
5 \\
6\end{array}$ & $\begin{array}{r}7 \\
6 \\
11\end{array}$ & $\begin{array}{l}5 \\
5 \\
6\end{array}$ & $\begin{array}{r}7 \\
15 \\
17\end{array}$ & $\begin{array}{l}20 \\
17 \\
11\end{array}$ & $\begin{array}{r}27 \\
6 \\
7\end{array}$ & $\begin{array}{l}30 \\
22 \\
31\end{array}$ & $\begin{array}{r}59 \\
6 \\
9\end{array}$ & $\begin{array}{l}\text { 81 } \\
11 \\
12\end{array}$ & $\begin{array}{r}9 \\
37 \\
5\end{array}$ & $\begin{array}{r}15 \\
54 \\
109\end{array}$ & $\begin{array}{l}15 \\
58 \\
44\end{array}$ & $\begin{array}{ll}34 & 1 \\
57 & 1 \\
45 & 1\end{array}$ & $\begin{array}{l}16 \\
141 \\
16\end{array}$ & $\begin{array}{c}9 \\
182 \\
9\end{array}$ & $\begin{array}{c}61 \\
23 \\
8\end{array}$ & & $\begin{array}{ll}7 & 1 \\
1 & \end{array}$ & 1 & 1 & 7 & 4 & 2 & $\begin{array}{l}598.0 \\
686.8 \\
840.7\end{array}$ \\
\hline $\begin{array}{l}1976 \\
1977 \\
1978 \\
1979 \\
1980\end{array}$ & 2 & $\begin{array}{rr}1 & 5 \\
1 & 10 \\
& 7\end{array}$ & $\begin{array}{l}5 \\
1\end{array}$ & $\begin{array}{l}2 \\
3\end{array}$ & $\begin{array}{l}3 \\
1\end{array}$ & $\begin{array}{l}3 \\
2\end{array}$ & $\begin{array}{l}5 \\
4\end{array}$ & $\begin{array}{l}2 \\
81 \\
1\end{array}$ & 3 & $\begin{array}{r}45 \\
7 \\
9\end{array}$ & $\begin{array}{r}6 \\
4 \\
31 \\
54 \\
40\end{array}$ & $\begin{array}{r}9 \\
31 \\
32 \\
89 \\
76\end{array}$ & $\begin{array}{l}10 \\
54 \\
25 \\
46 \\
38\end{array}$ & $\begin{array}{r}10 \\
59 \\
19 \\
45 \\
8\end{array}$ & $\begin{array}{r}24 \\
31 \\
48 \\
34 \\
2\end{array}$ & $\begin{array}{l}16 \\
56 \\
27 \\
19 \\
24\end{array}$ & $\begin{array}{l}44 \\
61 \\
41 \\
21 \\
26\end{array}$ & $\begin{array}{c}21 \\
27 \\
16 \\
1 \\
20\end{array}$ & $\begin{array}{r}129 \\
28 \\
7 \\
16 \\
23\end{array}$ & $\begin{array}{r}55 \\
7 \\
9 \\
1 \\
13\end{array}$ & $\begin{array}{r}7 \\
6 \\
12 \\
9\end{array}$ & $\begin{array}{c}3 \\
1 \\
10 \\
213\end{array}$ & $\begin{array}{c}1 \\
1 \\
39\end{array}$ & 3 & 3 & 1 & 1 & 8 & & & & $\begin{array}{l}534.5 \\
369.3 \\
297.8 \\
268.7 \\
586.7\end{array}$ \\
\hline 1981 & & & & & & & 1 & 6 & 6 & 15 & 14 & 27 & 27 & 92 & 72 & 59 & 23 & 12 & 4 & & 2 & 5 & & & & & & & & & & 298.4 \\
\hline
\end{tabular}

DURATION TABLE OF DISCHARGE FOR WATER YEARS 1973-81

\begin{tabular}{|c|c|c|c|c|c|c|c|c|c|c|c|c|c|c|c|c|c|c|c|}
\hline & $\begin{array}{r}\text { OBBIC } \\
\text { FEET }\end{array}$ & & $\begin{array}{c}\mathrm{ACO}- \\
\mathbf{M U}-\end{array}$ & PER- & & $\begin{array}{c}\text { OBIC } \\
\text { FEET }\end{array}$ & & $\begin{array}{c}\mathrm{ACO}- \\
\mathbf{M}-\end{array}$ & PER- & & $\begin{array}{c}\text { CUBIC } \\
\text { FEET }\end{array}$ & & $\begin{array}{c}\mathrm{ACOU}- \\
\mathbf{M}-\end{array}$ & PER- & & $\begin{array}{r}\text { OBBIC } \\
\text { FEET }\end{array}$ & & $\begin{array}{c}\mathrm{ACOU}- \\
\mathrm{MU}-\end{array}$ & PER- \\
\hline & PER & TOTAL & LATED & CENT & & PER & TOTAL & LATED & CENT & & PER & TOTAL & LATED & CENT & & PER & TOTAL & LATED & CENT \\
\hline CLASS & SECOND & DAYS & DAYS & DAYS & CLASS & SECOND & DAYS & DAYS & DAYS & CLASS & SECOND & DAYS & DAYS & DAYS & CLASS & SECOND & DAYS & DAYS & DAYS \\
\hline $\begin{array}{l}0 \\
1 \\
2 \\
3 \\
4 \\
5 \\
6 \\
7 \\
8\end{array}$ & $\begin{array}{l}0.00 \\
0.05 \\
0.06 \\
0.07 \\
0.09 \\
0.10 \\
0.13 \\
0.15 \\
0.18\end{array}$ & $\begin{array}{r}0 \\
6 \\
2 \\
22 \\
6 \\
8 \\
4 \\
8 \\
16\end{array}$ & $\begin{array}{l}3287 \\
3287 \\
3281 \\
3279 \\
3257 \\
3251 \\
3243 \\
3239 \\
3231\end{array}$ & $\begin{array}{r}100.0 \\
100.0 \\
99.8 \\
99.8 \\
99.1 \\
98.9 \\
98.7 \\
98.5 \\
98.3\end{array}$ & $\begin{array}{r}9 \\
10 \\
11 \\
12 \\
13 \\
14 \\
15 \\
16 \\
17\end{array}$ & $\begin{array}{l}0.22 \\
0.26 \\
0.31 \\
0.37 \\
0.45 \\
0.54 \\
0.65 \\
0.78 \\
0.94\end{array}$ & $\begin{array}{r}24 \\
36 \\
106 \\
165 \\
303 \\
248 \\
273 \\
294 \\
275\end{array}$ & $\begin{array}{l}3215 \\
3191 \\
3155 \\
3049 \\
2884 \\
2581 \\
2333 \\
2060 \\
1766\end{array}$ & $\begin{array}{l}97.8 \\
97.1 \\
96.0 \\
92.8 \\
87.7 \\
78.5 \\
71.0 \\
62.7 \\
53.7\end{array}$ & $\begin{array}{l}18 \\
19 \\
20 \\
21 \\
22 \\
23 \\
24 \\
25 \\
26\end{array}$ & $\begin{array}{l}1.1 \\
1.4 \\
1.6 \\
2.0 \\
2.3 \\
2.8 \\
3.4 \\
4.0 \\
4.9\end{array}$ & $\begin{array}{r}320 \\
148 \\
385 \\
202 \\
172 \\
86 \\
77 \\
50 \\
17\end{array}$ & $\begin{array}{r}1491 \\
1171 \\
1023 \\
638 \\
436 \\
264 \\
178 \\
101 \\
51\end{array}$ & $\begin{array}{r}45.4 \\
35.6 \\
31.1 \\
19.4 \\
13.3 \\
8.0 \\
5.4 \\
3.1 \\
1.6\end{array}$ & $\begin{array}{l}27 \\
28 \\
29 \\
30 \\
31 \\
32 \\
33 \\
34\end{array}$ & $\begin{array}{r}5.8 \\
7.0 \\
8.4 \\
10.0 \\
12.0 \\
15.0 \\
17.0 \\
21.0\end{array}$ & $\begin{array}{l}8 \\
2 \\
2 \\
8 \\
1 \\
7 \\
4 \\
2\end{array}$ & $\begin{array}{r}34 \\
26 \\
24 \\
22 \\
14 \\
13 \\
6 \\
2\end{array}$ & $\begin{array}{l}1.0 \\
0.8 \\
0.7 \\
0.7 \\
0.4 \\
0.4 \\
0.2 \\
0.1\end{array}$ \\
\hline
\end{tabular}

MONIHLY MEAN DISCHARGES, IN CUBIC FEET PER SECOND, FOR EACH WATER YEAR

\begin{tabular}{|c|c|c|c|c|c|c|c|c|c|c|c|c|}
\hline YEAR & $\propto C T$ & NOV & $\mathrm{DEC}$ & JAN & F安B & MAR & APR & MAY & JUNE & JLY & ALG & SEP \\
\hline $\begin{array}{l}1973 \\
1974 \\
1975\end{array}$ & $\begin{array}{l}2.11 \\
4.01 \\
0.95\end{array}$ & $\begin{array}{l}0.77 \\
2.07 \\
1.25\end{array}$ & $\begin{array}{l}1.07 \\
1.45 \\
1.92\end{array}$ & $\begin{array}{l}1.07 \\
1.87 \\
1.77\end{array}$ & $\begin{array}{l}1.00 \\
1.98 \\
1.80\end{array}$ & $\begin{array}{l}1.03 \\
2.73 \\
1.88\end{array}$ & $\begin{array}{l}2.23 \\
2.48 \\
2.36\end{array}$ & $\begin{array}{l}2.36 \\
2.12 \\
2.49\end{array}$ & $\begin{array}{l}1.30 \\
1.89 \\
9.26\end{array}$ & $\begin{array}{l}1.11 \\
0.84 \\
2.00\end{array}$ & $\begin{array}{l}0.60 \\
0.49 \\
1.10\end{array}$ & $\begin{array}{l}5.03 \\
0.65 \\
0.94\end{array}$ \\
\hline $\begin{array}{l}1976 \\
1977 \\
1978 \\
1979 \\
1980\end{array}$ & $\begin{array}{l}1.12 \\
1.12 \\
1.05 \\
0.75 \\
0.89\end{array}$ & $\begin{array}{l}2.05 \\
0.88 \\
0.55 \\
0.54 \\
0.50\end{array}$ & $\begin{array}{l}1.92 \\
0.60 \\
0.33 \\
0.42 \\
0.44\end{array}$ & $\begin{array}{l}1.86 \\
0.61 \\
0.42 \\
0.52 \\
0.46\end{array}$ & $\begin{array}{l}1.77 \\
0.71 \\
0.39 \\
0.50 \\
0.42\end{array}$ & $\begin{array}{l}1.82 \\
0.77 \\
0.96 \\
0.60 \\
0.55\end{array}$ & $\begin{array}{l}1.50 \\
0.68 \\
1.30 \\
1.17 \\
2.49\end{array}$ & $\begin{array}{l}1.04 \\
1.54 \\
0.92 \\
0.93 \\
3.65\end{array}$ & $\begin{array}{l}0.46 \\
1.55 \\
0.66 \\
0.60 \\
2.88\end{array}$ & $\begin{array}{l}1.29 \\
1.49 \\
1.33 \\
0.44 \\
1.73\end{array}$ & $\begin{array}{l}1.21 \\
1.05 \\
0.34 \\
0.55 \\
4.02\end{array}$ & $\begin{array}{l}1.51 \\
1.12 \\
1.52 \\
1.83 \\
1.14\end{array}$ \\
\hline 1981 & 1.09 & 0.92 & 0.86 & 0.70 & 0.76 & 0.78 & 0.90 & 0.66 & 1.02 & 0.93 & 0.60 & 0.61 \\
\hline
\end{tabular}


GREEN RIVER BASIN

09287500 WATER HOLLW NEAR FRUITHAND, UT--Continued

ANNUAL PEAK DISCHARGE, IN OUBIC FEET PER SECOND, AND CORRESPONDING GAGE HEIGHT, IN FEET, FOR EACH WATER YEAR

$\begin{array}{lccccccrrrr}\begin{array}{l}\text { WATER } \\ \text { YEAR }\end{array} & \text { DATE } & \begin{array}{c}\text { GAGE } \\ \text { HEIGHT }\end{array} & \begin{array}{c}\text { PEAK } \\ \text { DISCHARGE }\end{array} & \begin{array}{l}\text { WATER } \\ \text { YEAR }\end{array} & \text { DATE } & \begin{array}{c}\text { GAGE } \\ \text { HEIGHT }\end{array} & \begin{array}{r}\text { PEAK } \\ \text { DISCHARGE }\end{array} & \begin{array}{l}\text { WATER } \\ \text { YEAR }\end{array} & \begin{array}{c}\text { GAGE } \\ \text { DATE }\end{array} & \begin{array}{l}\text { PEAK } \\ \text { HEIGHT }\end{array} \\ \text { DISCHARGE }\end{array}$

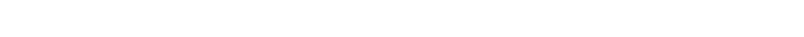

09288000 OURRANT CREEK NEAR FRUITLAND, UT

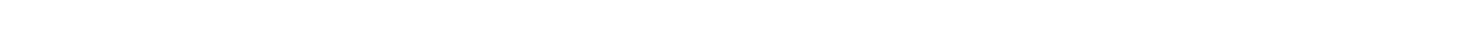
14060004 , on left bank $150 \mathrm{ft}$ downstream from Deep Creek, $150 \mathrm{ft}$ upstream from bridge on U.S. Highway 40, and $3.5 \mathrm{mi}$ southwest of Fruitland.

DRAINAGE AREA. $--140 \mathrm{mi}^{2}$.

MEAN BASIN ELEVATION. $--8,360 \mathrm{ft}$

PERIOD OF RECORD AVAILABLE.--October 1934 to September 1981.

GAGE.-Water-stage recorder. Altitude of gage is 6,670 ft from topographic map. Aug. 6, 1952 to Nov. 8, 1966 , water-stage recorder at site $150 \mathrm{ft}$ downstream at datum $1.30 \mathrm{ft}$ lower. See WSP 1733 for history of changes prior to Aug. 6,1952 .

REMARKS.--Currant Creek feeder canal, constructed by the Bureau of Reclamation in 1936, diverts water from headwaters of Currant Creek to Strawberry Reservoir, from which water is then diverted through Strawberry tunnel to the Great Basin for irrigation in Strawberry valley project. Since 1962, Deep Creek has been diverted intermittently into private fish ponds and enters Currant Creek $400 \mathrm{ft}$ below gage. Construction of Currant Creek dam began August 1974.

AVERAGE DISCHARGE. -47 years, $45.4 \mathrm{ft}^{3} / \mathrm{s}, 31,890$ acre- $\mathrm{ft} / \mathrm{yr}$.

EXTREMES FOR PERICD OF RECORD.--Maximum discharge, 1,260 ft $3 / \mathrm{s}$ May 4, 1952, gage height, $2.72 \mathrm{ft}$, site and datum then in use; maximum gage height, $5.92 \mathrm{ft}$, Jan. 27, 1974, backwater from Ice; minimum recorded, $3.6 \mathrm{ft}^{3} / \mathrm{s}$ Aug. 9, 10,1961 .

LOWEST MEAN DISCHARGE, IN CUBIC FEET PER SECOND, AND RANKING FOR THE INDICATED NUMBER OF CONSECUTIVE DAYS FOR EACH CIIMATIC YEAR, APRII 1-MARCH 31

\begin{tabular}{|c|c|c|c|c|c|c|c|c|c|c|c|c|c|c|c|c|c|c|c|}
\hline YEAR & \multicolumn{19}{|c|}{ CONSECTTIVE DAYS } \\
\hline $\begin{array}{l}1937 \\
1938 \\
1939 \\
1940\end{array}$ & $\begin{array}{rr}7.00 & 5 \\
13.0 & 17 \\
16.0 & 29 \\
10.0 & 12\end{array}$ & $\begin{array}{l}7.00 \\
19.0 \\
19.0 \\
10.0\end{array}$ & $\begin{array}{r}5 \\
32 \\
33 \\
10\end{array}$ & $\begin{array}{l}7.10 \\
19.0 \\
20.0 \\
10.0\end{array}$ & $\begin{array}{r}5 \\
31 \\
32 \\
9\end{array}$ & $\begin{array}{l}7.30 \\
20.0 \\
21.0 \\
12.0\end{array}$ & $\begin{array}{r}5 \\
30 \\
32 \\
13\end{array}$ & $\begin{array}{l}9.10 \\
21.0 \\
23.0 \\
13.0\end{array}$ & $\begin{array}{r}5 \\
29 \\
35 \\
13\end{array}$ & $\begin{array}{l}11.0 \\
21.0 \\
24.0 \\
16.0\end{array}$ & $\begin{array}{r}5 \\
26 \\
33 \\
14\end{array}$ & $\begin{array}{l}13.0 \\
22.0 \\
24.0 \\
17.0\end{array}$ & $\begin{array}{r}5 \\
28 \\
30 \\
14\end{array}$ & $\begin{array}{l}15.0 \\
24.0 \\
25.0 \\
18.0\end{array}$ & $\begin{array}{r}7 \\
29 \\
30 \\
14\end{array}$ & $\begin{array}{l}16.0 \\
24.0 \\
26.0 \\
18.0\end{array}$ & $\begin{array}{r}9 \\
28 \\
31 \\
13\end{array}$ & $\begin{array}{l}47.0 \\
56.0 \\
56.0 \\
34.0\end{array}$ & $\begin{array}{r}27 \\
36 \\
37 \\
9\end{array}$ \\
\hline $\begin{array}{l}1941 \\
1942 \\
1943 \\
1944 \\
1945\end{array}$ & $\begin{array}{rr}5.00 & 2 \\
14.0 & 25 \\
16.0 & 30 \\
21.0 & 36 \\
24.0 & 42\end{array}$ & $\begin{array}{l}6.00 \\
14.0 \\
16.0 \\
22.0 \\
25.0\end{array}$ & $\begin{array}{r}3 \\
16 \\
24 \\
36 \\
42\end{array}$ & $\begin{array}{l}6.90 \\
14.0 \\
17.0 \\
22.0 \\
25.0\end{array}$ & $\begin{array}{r}4 \\
15 \\
23 \\
36 \\
41\end{array}$ & $\begin{array}{l}7.20 \\
15.0 \\
17.0 \\
22.0 \\
25.0\end{array}$ & $\begin{array}{r}4 \\
16 \\
20 \\
35 \\
39\end{array}$ & $\begin{array}{l}7.80 \\
17.0 \\
18.0 \\
22.0 \\
26.0\end{array}$ & $\begin{array}{r}3 \\
18 \\
23 \\
30 \\
40\end{array}$ & $\begin{array}{l}9.00 \\
19.0 \\
18.0 \\
25.0 \\
27.0\end{array}$ & $\begin{array}{r}3 \\
24 \\
19 \\
35 \\
39\end{array}$ & $\begin{array}{l}11.0 \\
20.0 \\
19.0 \\
25.0 \\
28.0\end{array}$ & $\begin{array}{r}3 \\
22 \\
17 \\
33 \\
40\end{array}$ & $\begin{array}{l}13.0 \\
22.0 \\
19.0 \\
26.0 \\
29.0\end{array}$ & $\begin{array}{r}3 \\
24 \\
15 \\
33 \\
41\end{array}$ & $\begin{array}{l}14.0 \\
22.0 \\
20.0 \\
26.0 \\
30.0\end{array}$ & $\begin{array}{r}3 \\
23 \\
15 \\
32 \\
41\end{array}$ & $\begin{array}{l}22.0 \\
41.0 \\
40.0 \\
57.0 \\
60.0\end{array}$ & $\begin{array}{r}3 \\
19 \\
18 \\
38 \\
39\end{array}$ \\
\hline $\begin{array}{l}1946 \\
1947 \\
1948 \\
1949 \\
1950\end{array}$ & $\begin{array}{rr}23.0 & 39 \\
17.0 & 33 \\
15.0 & 26 \\
9.30 & 7 \\
23.0 & 40\end{array}$ & $\begin{array}{c}23.0 \\
17.0 \\
16.0 \\
9.50 \\
23.0\end{array}$ & $\begin{array}{r}37 \\
29 \\
25 \\
7 \\
38\end{array}$ & $\begin{array}{c}24.0 \\
17.0 \\
18.0 \\
9.80 \\
25.0\end{array}$ & $\begin{array}{r}39 \\
24 \\
28 \\
7 \\
42\end{array}$ & $\begin{array}{l}25.0 \\
17.0 \\
21.0 \\
10.0 \\
25.0\end{array}$ & $\begin{array}{r}40 \\
21 \\
33 \\
7 \\
41\end{array}$ & $\begin{array}{l}26.0 \\
18.0 \\
22.0 \\
12.0 \\
26.0\end{array}$ & $\begin{array}{r}41 \\
24 \\
31 \\
8 \\
42\end{array}$ & $\begin{array}{l}27.0 \\
19.0 \\
23.0 \\
14.0 \\
26.0\end{array}$ & $\begin{array}{l}40 \\
20 \\
30 \\
10 \\
36\end{array}$ & $\begin{array}{l}28.0 \\
20.0 \\
24.0 \\
15.0 \\
28.0\end{array}$ & $\begin{array}{l}41 \\
23 \\
31 \\
10 \\
42\end{array}$ & $\begin{array}{l}28.0 \\
22.0 \\
25.0 \\
17.0 \\
29.0\end{array}$ & $\begin{array}{l}37 \\
25 \\
31 \\
11 \\
42\end{array}$ & $\begin{array}{l}28.0 \\
24.0 \\
26.0 \\
17.0 \\
30.0\end{array}$ & $\begin{array}{l}35 \\
29 \\
30 \\
10 \\
42\end{array}$ & $\begin{array}{l}49.0 \\
45.0 \\
49.0 \\
34.0 \\
62.0\end{array}$ & $\begin{array}{l}30 \\
23 \\
31 \\
10 \\
40\end{array}$ \\
\hline $\begin{array}{l}1956 \\
1957 \\
1958 \\
1959 \\
1960\end{array}$ & $\begin{array}{cr}13.0 & 18 \\
13.0 & 19 \\
19.0 & 35 \\
15.0 & 27 \\
9.50 & 8\end{array}$ & $\begin{array}{c}14.0 \\
14.0 \\
20.0 \\
16.0 \\
9.80\end{array}$ & $\begin{array}{r}17 \\
18 \\
35 \\
27 \\
8\end{array}$ & $\begin{array}{l}14.0 \\
15.0 \\
21.0 \\
17.0 \\
10.0\end{array}$ & $\begin{array}{r}16 \\
19 \\
35 \\
26 \\
8\end{array}$ & $\begin{array}{l}15.0 \\
16.0 \\
22.0 \\
17.0 \\
11.0\end{array}$ & $\begin{array}{r}17 \\
18 \\
34 \\
23 \\
8\end{array}$ & $\begin{array}{l}16.0 \\
17.0 \\
22.0 \\
20.0 \\
11.0\end{array}$ & $\begin{array}{r}15 \\
19 \\
32 \\
26 \\
6\end{array}$ & $\begin{array}{l}17.0 \\
18.0 \\
24.0 \\
21.0 \\
11.0\end{array}$ & $\begin{array}{r}15 \\
16 \\
34 \\
27 \\
6\end{array}$ & $\begin{array}{l}18.0 \\
19.0 \\
26.0 \\
22.0 \\
13.0\end{array}$ & $\begin{array}{r}15 \\
18 \\
34 \\
25 \\
6\end{array}$ & $\begin{array}{l}19.0 \\
20.0 \\
26.0 \\
22.0 \\
15.0\end{array}$ & $\begin{array}{r}16 \\
20 \\
32 \\
23 \\
8\end{array}$ & $\begin{array}{l}21.0 \\
21.0 \\
27.0 \\
22.0 \\
15.0\end{array}$ & $\begin{array}{r}17 \\
18 \\
33 \\
19 \\
5\end{array}$ & $\begin{array}{l}37.0 \\
43.0 \\
46.0 \\
50.0 \\
23.0\end{array}$ & $\begin{array}{r}13 \\
22 \\
24 \\
32 \\
4\end{array}$ \\
\hline $\begin{array}{l}1961 \\
1962 \\
1963 \\
1964 \\
1965\end{array}$ & $\begin{array}{rr}5.50 & 3 \\
4.00 & 1 \\
9.50 & 9 \\
12.0 & 13 \\
8.60 & 6\end{array}$ & $\begin{array}{c}5.80 \\
4.10 \\
10.0 \\
12.0 \\
8.90\end{array}$ & $\begin{array}{r}2 \\
1 \\
9 \\
13 \\
6\end{array}$ & $\begin{array}{c}6.30 \\
4.60 \\
11.0 \\
12.0 \\
9.10\end{array}$ & $\begin{array}{r}2 \\
1 \\
10 \\
12 \\
6\end{array}$ & $\begin{array}{c}6.70 \\
5.10 \\
12.0 \\
12.0 \\
9.50\end{array}$ & $\begin{array}{r}2 \\
1 \\
9 \\
10 \\
6\end{array}$ & $\begin{array}{l}7.60 \\
5.30 \\
12.0 \\
13.0 \\
11.0\end{array}$ & $\begin{array}{r}2 \\
1 \\
9 \\
10 \\
7\end{array}$ & $\begin{array}{l}9.80 \\
6.60 \\
14.0 \\
13.0 \\
13.0\end{array}$ & $\begin{array}{r}4 \\
1 \\
11 \\
7 \\
8\end{array}$ & $\begin{array}{c}11.0 \\
7.90 \\
15.0 \\
14.0 \\
14.0\end{array}$ & $\begin{array}{r}4 \\
1 \\
11 \\
7 \\
8\end{array}$ & $\begin{array}{l}13.0 \\
9.80 \\
16.0 \\
15.0 \\
15.0\end{array}$ & $\begin{array}{l}4 \\
1 \\
9 \\
5 \\
6\end{array}$ & $\begin{array}{l}14.0 \\
12.0 \\
17.0 \\
16.0 \\
16.0\end{array}$ & $\begin{array}{r}4 \\
1 \\
11 \\
6 \\
7\end{array}$ & $\begin{array}{l}24.0 \\
16.0 \\
51.0 \\
31.0 \\
38.0\end{array}$ & $\begin{array}{r}5 \\
1 \\
34 \\
7 \\
14\end{array}$ \\
\hline
\end{tabular}


GREEN RIVER BASIN

09288000 CURRANT CREEX NEAR FRUITHAND, UT-Continued

LOWEST MEAN DISCHARGE, IN CBIC FEET PER SECOND, AND RANKING FOR THE INDICATED NUNBER OF CONSECUTIVE DAYS FOR EACH CIMATIC YEAR, APRII, 1-MARCH 31--Continued

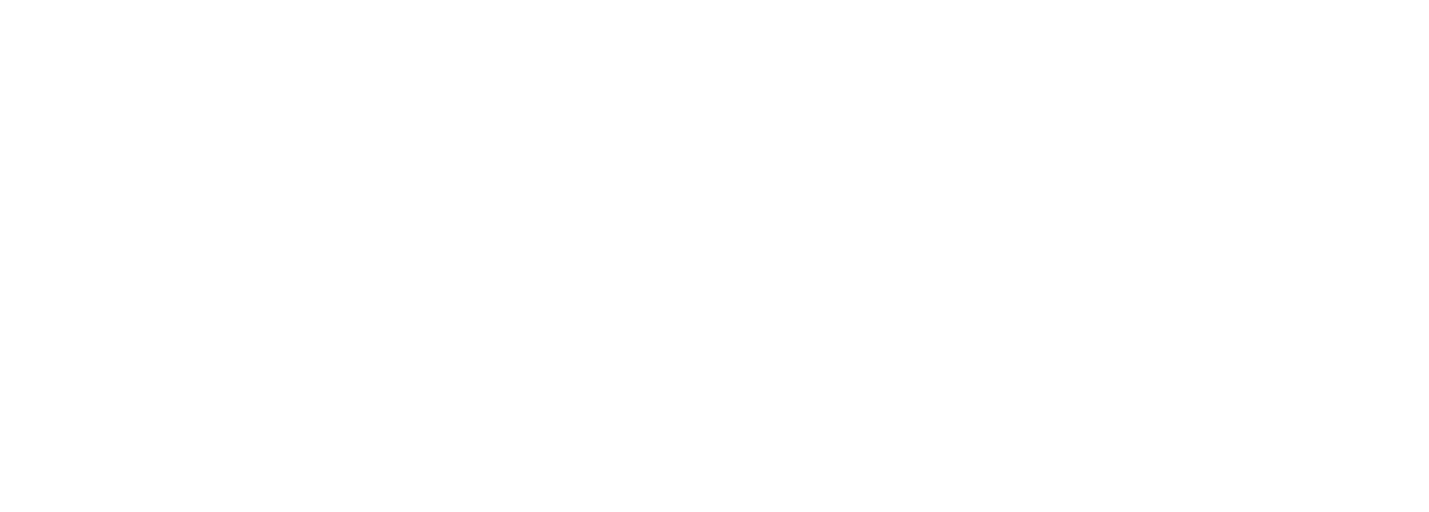

HIGHEST MEAN DISCHARGE, IN CUBIC FEET PER SEOOND, AND RANKING FOR THE INDICATED NUMBER CF CONSECUTIVE DAYS FOR EACH WATER YEAR, OCTCBER 1-SEPTEYBER 30

YEAR $\begin{array}{ll}15 & \text { CONSECUTIVE DAYS }\end{array}$

\begin{tabular}{|c|c|c|c|c|c|c|c|c|c|c|c|c|c|c|c|c|c|c|c|c|}
\hline & 1 & & 3 & & 7 & & 15 & & 30 & & 60 & & 90 & & 120 & & 180 & & ALLL & \\
\hline $\begin{array}{l}1936 \\
1937 \\
1938 \\
1939 \\
1940\end{array}$ & $\begin{array}{c}366 \\
337 \\
370 \\
144 \\
77.0\end{array}$ & $\begin{array}{l}11 \\
14 \\
10 \\
39 \\
43\end{array}$ & $\begin{array}{c}336 \\
332 \\
316 \\
142 \\
75.0\end{array}$ & $\begin{array}{l}10 \\
11 \\
14 \\
38 \\
43\end{array}$ & $\begin{array}{c}309 \\
322 \\
272 \\
136 \\
71.0\end{array}$ & $\begin{array}{l}12 \\
10 \\
17 \\
36 \\
43\end{array}$ & $\begin{array}{l}299 \\
292 \\
2 \\
122 \\
69.0\end{array}$ & $\begin{array}{r}7 \\
10 \\
17 \\
38 \\
43\end{array}$ & $\begin{array}{c}248 \\
241 \\
205 \\
111 \\
63.0\end{array}$ & $\begin{array}{l}8 \\
10 \\
15 \\
38 \\
43\end{array}$ & $\begin{array}{l}192 \\
184 \\
183 \\
93.0 \\
51.0\end{array}$ & $\begin{array}{r}6 \\
10 \\
11 \\
37 \\
43\end{array}$ & $\begin{array}{l}141 \\
146 \\
140 \\
83.0 \\
44.0\end{array}$ & $\begin{array}{r}11 \\
7 \\
12 \\
34 \\
43\end{array}$ & $\begin{array}{l}110 \\
119 \\
114 \\
70.0 \\
38.0\end{array}$ & & & $\begin{array}{r}15 \\
9 \\
10 \\
33 \\
44\end{array}$ & $\begin{array}{l}45.0 \\
53.0 \\
54.0 \\
39.0 \\
24.0\end{array}$ & $\begin{array}{r}22 \\
10 \\
9 \\
30 \\
44\end{array}$ \\
\hline $\begin{array}{l}941 \\
942 \\
943 \\
944 \\
945\end{array}$ & $\begin{array}{l}308 \\
176 \\
358 \\
390 \\
249\end{array}$ & $\begin{array}{r}17 \\
34 \\
12 \\
7 \\
25\end{array}$ & $\begin{array}{l}284 \\
160 \\
348 \\
372 \\
240\end{array}$ & $\begin{array}{r}19 \\
34 \\
9 \\
6 \\
24\end{array}$ & $\begin{array}{l}250 \\
133 \\
326 \\
349 \\
233\end{array}$ & $\begin{array}{r}19 \\
38 \\
9 \\
5 \\
22\end{array}$ & $\begin{array}{l}200 \\
124 \\
305 \\
295 \\
207\end{array}$ & $\begin{array}{r}22 \\
37 \\
6 \\
8 \\
20\end{array}$ & $\begin{array}{l}158 \\
113 \\
237 \\
254 \\
161\end{array}$ & $\begin{array}{r}26 \\
36 \\
11 \\
6 \\
24\end{array}$ & $\begin{array}{l}120 \\
107 \\
177 \\
185 \\
130\end{array}$ & $\begin{array}{r}27 \\
31 \\
12 \\
9 \\
20\end{array}$ & $\begin{array}{l}93.0 \\
90.0 \\
143 \\
144 \\
105\end{array}$ & $\begin{array}{r}27 \\
29 \\
10 \\
8 \\
19\end{array}$ & $\begin{array}{c}78.0 \\
76.0 \\
118 \\
120 \\
88.0\end{array}$ & $\begin{array}{r}28 \\
9 \\
7 \\
19\end{array}$ & & $\begin{array}{r}28 \\
29 \\
8 \\
7 \\
18\end{array}$ & & 16 \\
\hline $\begin{array}{l}946 \\
947 \\
948 \\
949 \\
950\end{array}$ & $\begin{array}{l}264 \\
332 \\
221 \\
303 \\
451\end{array}$ & $\begin{array}{r}21 \\
15 \\
28 \\
18 \\
3\end{array}$ & $\begin{array}{l}263 \\
313 \\
202 \\
292 \\
418\end{array}$ & $\begin{array}{r}20 \\
15 \\
30 \\
17 \\
5\end{array}$ & $\begin{array}{l}249 \\
297 \\
178 \\
273 \\
343\end{array}$ & $\begin{array}{r}20 \\
13 \\
32 \\
16 \\
6\end{array}$ & $\begin{array}{l}152 \\
243 \\
326\end{array}$ & $\begin{array}{r}18 \\
14 \\
32 \\
15 \\
4\end{array}$ & $\begin{array}{l}176 \\
193 \\
128 \\
242 \\
294\end{array}$ & $\begin{array}{r}18 \\
16 \\
33 \\
9 \\
4\end{array}$ & $\begin{array}{c}128 \\
143 \\
99.0 \\
191 \\
237\end{array}$ & $\begin{array}{r}23 \\
18 \\
34 \\
7 \\
4\end{array}$ & $\begin{array}{l}101 \\
113 \\
78.0 \\
152 \\
187\end{array}$ & $\begin{array}{r}23 \\
18 \\
37 \\
6 \\
4\end{array}$ & $\begin{array}{r}84.0 \\
96.0 \\
66.0 \\
124 \\
153\end{array}$ & $\begin{array}{r}37 \\
6 \\
4\end{array}$ & $\begin{array}{r}65.0 \\
73.0 \\
52.0 \\
91.0 \\
113\end{array}$ & $\begin{array}{r}37 \\
6 \\
4\end{array}$ & & 17 \\
\hline $\begin{array}{l}956 \\
957 \\
958 \\
959 \\
960\end{array}$ & $\begin{array}{c}232 \\
217 \\
302 \\
73.0 \\
126\end{array}$ & $\begin{array}{l}27 \\
29 \\
19 \\
44 \\
40\end{array}$ & $\begin{array}{c}227 \\
213 \\
292 \\
70.0 \\
115\end{array}$ & $\begin{array}{l}25 \\
28 \\
18 \\
44 \\
40\end{array}$ & $\begin{array}{l}215 \\
203 \\
281 \\
65.0 \\
99.0\end{array}$ & $\begin{array}{l}24 \\
27 \\
15 \\
44 \\
41\end{array}$ & $\begin{array}{r}180 \\
186 \\
261 \\
60.0 \\
81.0\end{array}$ & $\begin{array}{l}27 \\
24 \\
13 \\
44 \\
41\end{array}$ & $\begin{array}{l}162 \\
159 \\
237 \\
54.0 \\
67.0\end{array}$ & $\begin{array}{l}22 \\
25 \\
12 \\
44 \\
41\end{array}$ & $\begin{array}{r}130 \\
131 \\
169 \\
47.0 \\
59.0\end{array}$ & $\begin{array}{l}21 \\
19 \\
13 \\
44 \\
41\end{array}$ & $\begin{array}{r}103 \\
102 \\
129 \\
41.0 \\
50.0\end{array}$ & $\begin{array}{l}20 \\
21 \\
13 \\
44 \\
42\end{array}$ & $\begin{array}{r}86.0 \\
86.0 \\
105 \\
37.0 \\
43.0\end{array}$ & $\begin{array}{l}22 \\
13 \\
44 \\
42\end{array}$ & & $\begin{array}{l}24 \\
22 \\
14 \\
43 \\
42\end{array}$ & & $\begin{array}{l}24 \\
11 \\
42 \\
43\end{array}$ \\
\hline $\begin{array}{l}961 \\
962 \\
963 \\
964 \\
965\end{array}$ & $\begin{array}{l}58.0 \\
378 \\
144 \\
331 \\
264\end{array}$ & $\begin{array}{r}45 \\
9 \\
38 \\
16 \\
22\end{array}$ & $\begin{array}{l}49.0 \\
356 \\
144 \\
312 \\
254\end{array}$ & $\begin{array}{r}45 \\
8 \\
37 \\
16 \\
21\end{array}$ & $\begin{array}{l}44.0 \\
338 \\
138 \\
282 \\
238\end{array}$ & $\begin{array}{r}45 \\
8 \\
35 \\
14 \\
21\end{array}$ & $\begin{array}{l}36.0 \\
277 \\
131 \\
239 \\
202\end{array}$ & $\begin{array}{l}45 \\
11 \\
35 \\
16 \\
21\end{array}$ & $\begin{array}{l}32.0 \\
248 \\
113 \\
175 \\
180\end{array}$ & $\begin{array}{r}45 \\
7 \\
37 \\
19 \\
17\end{array}$ & $\begin{array}{c}29.0 \\
187 \\
87.0 \\
121 \\
150\end{array}$ & $\begin{array}{r}45 \\
8 \\
38 \\
25 \\
17\end{array}$ & $\begin{array}{c}26.0 \\
144 \\
71.0 \\
96.0 \\
123\end{array}$ & $\begin{array}{r}45 \\
9 \\
38 \\
26 \\
15\end{array}$ & $\begin{array}{c}24.0 \\
116 \\
60.0 \\
79.0 \\
103\end{array}$ & $\begin{array}{l}10 \\
3 \\
26\end{array}$ & & $\begin{array}{l}45 \\
11 \\
39 \\
30 \\
12\end{array}$ & & $\begin{array}{l}45 \\
18 \\
41 \\
37 \\
15\end{array}$ \\
\hline $\begin{array}{l}966 \\
967\end{array}$ & $\begin{array}{l}167 \\
451 \\
216 \\
436 \\
259\end{array}$ & $\begin{array}{r}35 \\
4 \\
30 \\
5 \\
23\end{array}$ & $\begin{array}{l}153 \\
420 \\
207 \\
423 \\
253\end{array}$ & $\begin{array}{r}36 \\
4 \\
29 \\
3 \\
22\end{array}$ & $\begin{array}{l}134 \\
377 \\
187 \\
409 \\
226\end{array}$ & $\begin{array}{r}37 \\
4 \\
29 \\
3 \\
23\end{array}$ & $\begin{array}{l}125 \\
322 \\
180 \\
379 \\
195\end{array}$ & $\begin{array}{r}36 \\
5 \\
28 \\
2 \\
23\end{array}$ & $\begin{array}{l}120 \\
278 \\
161 \\
323 \\
156\end{array}$ & $\begin{array}{r}34 \\
5 \\
23 \\
2 \\
28\end{array}$ & & $\begin{array}{r}32 \\
5 \\
22 \\
3 \\
28\end{array}$ & $\begin{array}{l}84.0 \\
157 \\
102 \\
191 \\
91.0\end{array}$ & $\begin{array}{r}33 \\
5 \\
22 \\
3 \\
28\end{array}$ & $\begin{array}{c}71.0 \\
129 \\
86.0 \\
157 \\
76.0\end{array}$ & $\begin{array}{r}33 \\
5 \\
23 \\
3 \\
29\end{array}$ & & $\begin{array}{r}34 \\
5 \\
21 \\
3 \\
26\end{array}$ & & 7 \\
\hline $\begin{array}{l}1976 \\
1977 \\
1978 \\
1979 \\
1980\end{array}$ & $\begin{array}{c}183 \\
45.0 \\
249 \\
199 \\
467\end{array}$ & $\begin{array}{r}33 \\
46 \\
24 \\
32 \\
2\end{array}$ & $\begin{array}{l}174 \\
43.0 \\
223 \\
191 \\
452\end{array}$ & $\begin{array}{r}33 \\
46 \\
26 \\
32 \\
2\end{array}$ & $\begin{array}{l}164 \\
37.0 \\
184 \\
183 \\
412\end{array}$ & $\begin{array}{r}33 \\
46 \\
30 \\
31 \\
2\end{array}$ & $\begin{array}{c}147 \\
35.0 \\
175 \\
171 \\
326\end{array}$ & $\begin{array}{r}33 \\
46 \\
29 \\
30 \\
3\end{array}$ & $\begin{array}{l}119 \\
30.0 \\
147 \\
136 \\
306\end{array}$ & $\begin{array}{r}35 \\
46 \\
29 \\
30 \\
3\end{array}$ & $\begin{array}{l}86.0 \\
27.0 \\
120 \\
107 \\
260\end{array}$ & $\begin{array}{r}39 \\
46 \\
26 \\
30 \\
2\end{array}$ & $\begin{array}{r}71.0 \\
25.0 \\
98.0 \\
86.0 \\
203\end{array}$ & $\begin{array}{r}39 \\
46 \\
25 \\
31 \\
2\end{array}$ & $\begin{array}{r}61.0 \\
23.0 \\
82.0 \\
72.0 \\
162\end{array}$ & $\begin{array}{r}38 \\
46 \\
25 \\
31 \\
2\end{array}$ & $\begin{array}{r}48.0 \\
20.0 \\
60.0 \\
54.0 \\
119\end{array}$ & $\begin{array}{r}38 \\
46 \\
27 \\
35 \\
2\end{array}$ & $\begin{array}{l}35.0 \\
17.0 \\
38.0 \\
36.0 \\
73.0\end{array}$ & $\begin{array}{l}33 \\
38\end{array}$ \\
\hline
\end{tabular}


09288000 CURRANI CREEK NEAR FRUITLAND, UT-Continued

DURATION OF DISCHARGE FOR EACH WATER YEAR

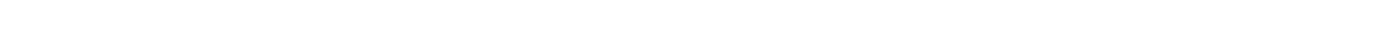

CUBIC FEET

-DAYS

16469.0

19214.0

19214.0

19616.0

8604.0

\begin{tabular}{lllllrlllllllllllllll}
1 & 1 & 7 & 33 & 10 & 10 & 10 & 26 & 23 & 62 & 85 & 34 & 13 & 14 & 10 & 16 & 18 & 10 & 16 & 12 & 28 \\
\hline
\end{tabular}

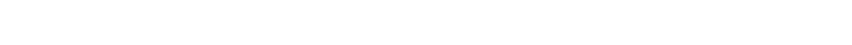

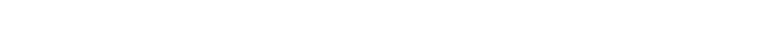

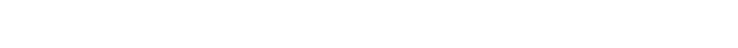

13734.0

14477.0

20271.0

21190.0

18244.0

$\begin{array}{lllllllllllllllll}15 & 38 & 25 & 112 & 71 & 15 & 17 & 16 & 5 & 5 & 12 & 4 & 8 & 9 & 1 & 6 & 6\end{array}$

$\begin{array}{lllllllllllllllllll}4 & 7 & 41 & 141 & 37 & 26 & 29 & 10 & 5 & 11 & 14 & 6 & 13 & 4 & 5 & 3 & 2 & 5 & 2\end{array}$

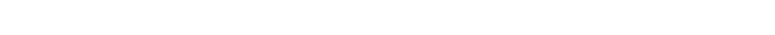

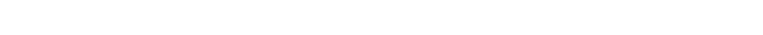

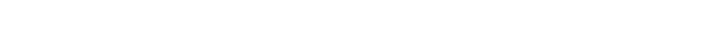

16467.0

18186.0

13536.6

20379.0

26631.0

$\begin{array}{lllllllllllllll}8 & 36 & 89 & 122 & 25 & 10 & 8 & 14 & 19 & 6 & 11 & 6 & 2 & 8 & 1\end{array}$ $\begin{array}{lllllllllllll}18 & 27 & 25 & 46 & 147 & 38 & 10 & 13 & 15 & 14 & 9 & 3\end{array}$

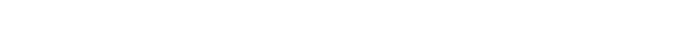

$\begin{array}{llllllllllllllllll}3 & 41 & 41 & 87 & 71 & 15 & 24 & 7 & 16 & 5 & 6 & 7 & 3 & 16 & 13 & 5 & 5 & 1\end{array}$

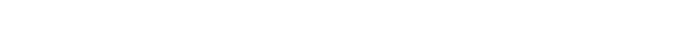

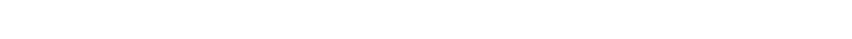

$\begin{array}{rrrrrrrrrrrrrrrrrrr}15 & 7 & 72 & 7 & 12 & 39 & 32 & 64 & 20 & 125 & 70 & 5 & 20 & 18 & 11 & 6 & 4 & & \\ 1 & 72 & 8 & 10 & 14 & 17 & 20 & 11 & 3 & 3 & 2 & 2\end{array}$

18146.0

12935.0

13640.0

15904.0

16222.0

19029.0

8831.6

$\begin{array}{llllllllllllllll}11 & 10 & 15 & 16 & 17 & 7 & 18 & 43 & 82 & 58 & 45 & 21 & 9 & 6 & 5 & 2\end{array}$

$\begin{array}{llllllrrrrrrrrrrrrrrrrr}2 & 51 & 71 & 98 & 12 & 16 & 9 & 9 & 6 & 9 & 11 & 3 & 7 & 5 & 3 & 15 & 8 & 6 & 8 & 4 & 6 & 5 & 1\end{array}$

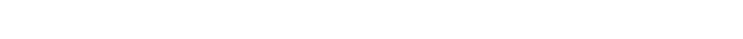

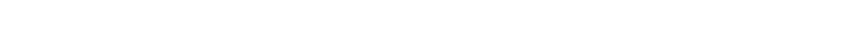

$\begin{array}{lllllllllllllllll}2 & 9 & 22 & 40 & 47 & 55 & 61 & 49 & 13 & 6 & 7 & 8 & 12 & 10 & 19 & 4 & 1\end{array}$

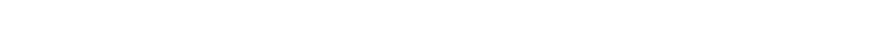

$\begin{array}{rrrrrrrrrrrrrrr}4 & 13 & 110 & 107 & 37 & 20 & 15 & 6 & 5 & 3 & 7 & 14 & 10 & 9 & 6\end{array}$

$\begin{array}{rrrrrrrrrrrrrrrrrrrrrrrr}1 & 1 & 3 & 8 & 23 & 95 & 80 & 33 & 13 & 8 & 7 & 8 & 12 & 12 & 17 & 3 & 6 & 6 & 7 & 5 & 7 & 10\end{array}$

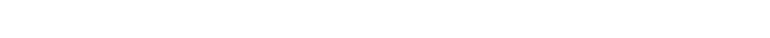

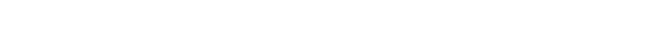

$\begin{array}{lllllllllllllllllllll}5 & 5 & 98 & 71 & 77 & 18 & 15 & 10 & 10 & 7 & 9 & 8 & 5 & 8 & 4 & 5 & 1 & 3 & 2 & 7 & 1\end{array}$

$\begin{array}{rrrrrrrrrrrrrrrrrrr}26 & 31 & 93 & 75 & 26 & 16 & 6 & 3 & 8 & 3 & 4 & 9 & 8 & 3 & 4 & 3 & 2 & 1 & 2 \\ 5140 & 38 & 65 & 25 & 14 & 7 & 6 & 7 & 7 & 5 & 6 & 15 & 6 & 5 & 2 & 1 & 4 & 6 & 1\end{array}$

$\begin{array}{lllllllllllllllll}1 & 21 & 32 & 31 & 55 & 84 & 48 & 21 & 11 & 18 & 7 & 8 & 3 & 3 & 8 & 5 & 4\end{array}$

$\begin{array}{llllllllllll}3 & 16 & 27 & 20 & 23 & 25125 & 64 & 25 & 20 & 11 & 2 & 4\end{array}$

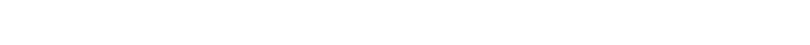

$\begin{array}{llllllllllllllll}488 & 75 & 48 & 42 & 7 & 13 & 7 & 13 & 5 & 18 & 8 & 7 & 6 & 2 & 11 & 1\end{array}$

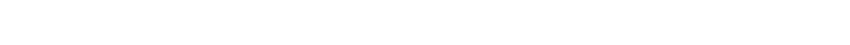

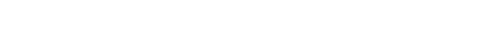

6172.3

17535.5

11872.0

13376.6

18409.0

14775.0

21084.0

17649.0

25937.0

16115.0

18498.0

14270.0

16872.0

13766.0

17033.0

12782.0

6054.3

13304.0

26598.0

1981

DURATION TABLE OF DISCHARGE FOR WATER YEARS 1936-81

\begin{tabular}{|c|c|c|c|c|c|c|c|c|c|}
\hline ASS & $\begin{array}{c}\text { CUBIC } \\
\text { FEET } \\
\text { PER } \\
\text { SECOND }\end{array}$ & $\begin{array}{l}\text { TOTAL } \\
\text { DAYS }\end{array}$ & $\begin{array}{l}\text { ACOU- } \\
\text { MU- } \\
\text { LATED } \\
\text { DAYS }\end{array}$ & $\begin{array}{l}\text { PER- } \\
\text { CENT } \\
\text { DAYS }\end{array}$ & & $\begin{array}{c}\text { CUBIC } \\
\text { FEET } \\
\text { PER } \\
\text { SECOND }\end{array}$ & $\begin{array}{l}\text { TOTAL } \\
\text { DAYS }\end{array}$ & $\begin{array}{l}\text { ACQU- } \\
\text { MU- } \\
\text { LATED } \\
\text { DAYS }\end{array}$ & $\begin{array}{l}\text { PER- } \\
\text { CENT } \\
\text { DAYS }\end{array}$ \\
\hline $\begin{array}{l}0 \\
1 \\
2 \\
3 \\
4 \\
5 \\
6 \\
7 \\
8\end{array}$ & $\begin{array}{r}0.00 \\
4.00 \\
4.70 \\
5.60 \\
6.60 \\
7.80 \\
9.30 \\
11.00 \\
13.00\end{array}$ & $\begin{array}{r}0 \\
11 \\
12 \\
26 \\
67 \\
106 \\
100 \\
285 \\
608\end{array}$ & $\begin{array}{l}16802 \\
16802 \\
16791 \\
16779 \\
16753 \\
16686 \\
16580 \\
16480 \\
16195\end{array}$ & $\begin{array}{r}100.0 \\
100.0 \\
99.9 \\
99.9 \\
99.7 \\
99.3 \\
98.7 \\
98.1 \\
96.4\end{array}$ & $\begin{array}{r}9 \\
10 \\
11 \\
12 \\
13 \\
14 \\
15 \\
16 \\
17\end{array}$ & $\begin{array}{l}15.00 \\
18.00 \\
21.00 \\
25.00 \\
30.00 \\
35.00 \\
42.00 \\
50.00 \\
59.00\end{array}$ & $\begin{array}{r}1452 \\
1796 \\
2367 \\
2771 \\
1855 \\
1256 \\
719 \\
511 \\
359\end{array}$ & $\begin{array}{r}15587 \\
14135 \\
12339 \\
9972 \\
7201 \\
5346 \\
4090 \\
3371 \\
2860\end{array}$ & $\begin{array}{l}92.8 \\
84.1 \\
73.4 \\
59.4 \\
42.9 \\
31.8 \\
24.3 \\
20.1 \\
17.0\end{array}$ \\
\hline
\end{tabular}

\begin{tabular}{crrrr}
\multicolumn{4}{c}{ CBBIC } & \multicolumn{2}{c}{ ACQU- } \\
FEET & MU- & PER- \\
PER & TOTAL LATED & CENT \\
CLASS SECOND & DAYS & DAYS & DAYS \\
18 & 69.0 & 418 & 2501 & 14.9 \\
19 & 82.0 & 339 & 2083 & 12.4 \\
20 & 97.0 & 273 & 1744 & 10.4 \\
21 & 110.0 & 464 & 1471 & 8.8 \\
22 & 140.0 & 215 & 1007 & 6.0 \\
23 & 160.0 & 226 & 792 & 4.7 \\
24 & 190.0 & 191 & 566 & 3.4 \\
25 & 230.0 & 146 & 375 & 2.2 \\
26 & 270.0 & 74 & 229 & 1.4
\end{tabular}

\begin{tabular}{|c|c|c|c|c|}
\hline & $\begin{array}{c}\text { CUBIC } \\
\text { FEET } \\
\text { PER }\end{array}$ & TOTAL & $\begin{array}{l}\text { ACQU- } \\
\text { NU- } \\
\text { LATED }\end{array}$ & $\begin{array}{l}\text { PER- } \\
\text { CENT }\end{array}$ \\
\hline IASS & SECOND & DAYS & DAYS & DAYS \\
\hline 27 & 310.0 & 82 & 155 & 0.9 \\
\hline & 370.0 & 35 & 73 & 0.4 \\
\hline 29 & 440.0 & 20 & 38 & 0.2 \\
\hline 30 & 520.0 & 4 & 18 & 0.1 \\
\hline 31 & 620.0 & 9 & 14 & 0.1 \\
\hline 32 & 730.0 & 0 & 5 & 0.0 \\
\hline 33 & & & 5 & 0.0 \\
\hline 34 & 1000 & 3 & 3 & 0.0 \\
\hline
\end{tabular}


GREEN RTVER BASIN

09288000 CURRANT CREEK NEAR FRUITI.AND, UT-Continued

MONTHLY MEAN DISCHARGES, IN OBBIC FEET PER SEOOND, FOR EACH WATER YEAR

\begin{tabular}{|c|c|c|c|c|c|c|c|c|c|c|c|c|}
\hline YEAR & OCT & NON & $\mathrm{DEC}$ & JAN & FEB & MAR & APR & MAY & JUNE & JULY & AUG & SEP \\
\hline 1935 & 16 & 16 & 15 & 14.7 & 13.5 & 15.3 & 33.7 & 108 & 109 & 21.5 & 14.5 & 11.0 \\
\hline $\begin{array}{l}1936 \\
1937 \\
1938 \\
1939 \\
1940\end{array}$ & $\begin{array}{l}12.7 \\
22.2 \\
25.7 \\
32.7 \\
22.1\end{array}$ & $\begin{array}{l}14.0 \\
19.5 \\
27.2 \\
27.7 \\
20.2\end{array}$ & $\begin{array}{l}13.1 \\
17.8 \\
25.7 \\
25.1 \\
18.1\end{array}$ & $\begin{array}{l}14.0 \\
14.5 \\
21.7 \\
24.3 \\
17.8\end{array}$ & $\begin{array}{r}13.9 \\
16.0 \\
20.5 \\
23.7 \\
-20.3\end{array}$ & $\begin{array}{l}15.0 \\
19.8 \\
27.0 \\
46.3 \\
25.6\end{array}$ & $\begin{array}{l}88.6 \\
68.0 \\
88.2 \\
82.4 \\
42.6\end{array}$ & $\begin{array}{c}240 \\
232 \\
200 \\
101 \\
57.7\end{array}$ & $\begin{array}{c}87.7 \\
117 \\
120 \\
47.8 \\
22.8\end{array}$ & $\begin{array}{l}9.45 \\
50.6 \\
40.2 \\
23.6 \\
11.3\end{array}$ & $\begin{array}{c}12.4 \\
27.4 \\
23.4 \\
14.2 \\
8.03\end{array}$ & $\begin{array}{l}17.6 \\
24.6 \\
23.9 \\
17.3 \\
15.6\end{array}$ \\
\hline $\begin{array}{l}1941 \\
1942 \\
1943 \\
1944 \\
1945\end{array}$ & $\begin{array}{l}17.3 \\
26.2 \\
21.1 \\
29.6 \\
28.3\end{array}$ & $\begin{array}{l}17.1 \\
26.0 \\
21.4 \\
27.7 \\
30.2\end{array}$ & $\begin{array}{l}15.2 \\
23.2 \\
22.5 \\
24.8 \\
32.0\end{array}$ & $\begin{array}{l}16.5 \\
19.5 \\
23.2 \\
24.8 \\
31.8\end{array}$ & $\begin{array}{l}18.3 \\
21.9 \\
26.3 \\
25.7 \\
33.2\end{array}$ & $\begin{array}{l}22.8 \\
30.2 \\
34.2 \\
30.5 \\
36.3\end{array}$ & $\begin{array}{c}38.7 \\
95.2 \\
162 \\
54.5 \\
49.8\end{array}$ & $\begin{array}{l}156 \\
109 \\
163 \\
230 \\
159\end{array}$ & $\begin{array}{c}76.1 \\
62.2 \\
100 \\
135 \\
97.8\end{array}$ & $\begin{array}{l}34.0 \\
26.8 \\
40.6 \\
54.0 \\
41.2\end{array}$ & $\begin{array}{l}19.5 \\
18.1 \\
29.3 \\
30.4 \\
31.2\end{array}$ & $\begin{array}{l}17.8 \\
17.5 \\
22.8 \\
25.9 \\
27.7\end{array}$ \\
\hline $\begin{array}{l}1946 \\
1947 \\
1948 \\
1949 \\
1950\end{array}$ & $\begin{array}{l}29.0 \\
25.5 \\
27.6 \\
18.7 \\
31.1\end{array}$ & $\begin{array}{l}30.5 \\
28.4 \\
29.8 \\
21.3 \\
34.1\end{array}$ & $\begin{array}{l}27.3 \\
28.7 \\
27.1 \\
19.7 \\
31.1\end{array}$ & $\begin{array}{l}27.0 \\
27.5 \\
22.7 \\
17.6 \\
33.7\end{array}$ & $\begin{array}{l}30.3 \\
27.1 \\
24.8 \\
21.2 \\
31.1\end{array}$ & $\begin{array}{l}36.2 \\
35.6 \\
28.2 \\
28.7 \\
36.2\end{array}$ & $\begin{array}{c}134 \\
75.8 \\
55.3 \\
125 \\
136\end{array}$ & $\begin{array}{l}115 \\
189 \\
126 \\
217 \\
255\end{array}$ & $\begin{array}{c}49.3 \\
71.1 \\
50.2 \\
103 \\
159\end{array}$ & $\begin{array}{l}25.6 \\
35.3 \\
23.6 \\
41.2 \\
55.4\end{array}$ & $\begin{array}{l}20.3 \\
26.8 \\
15.7 \\
28.8 \\
36.7\end{array}$ & $\begin{array}{l}17.7 \\
25.5 \\
11.9 \\
25.8 \\
33.3\end{array}$ \\
\hline $\begin{array}{l}1951 \\
1952 \\
1953 \\
1954 \\
1955\end{array}$ & $\begin{array}{l}34.4 \\
29.3 \\
50.0 \\
28.8 \\
21.8\end{array}$ & $\begin{array}{l}36.0 \\
28.9 \\
45.7 \\
31.6 \\
26.1\end{array}$ & $\begin{array}{l}34.1 \\
30.4 \\
42.5 \\
28.8 \\
24.3\end{array}$ & $\begin{array}{l}35.3 \\
29.4 \\
42.7 \\
28.9 \\
25.8\end{array}$ & $\begin{array}{l}39.6 \\
31.9 \\
40.6 \\
30.3 \\
25.4\end{array}$ & $\begin{array}{l}37.0 \\
31.1 \\
44.5 \\
33.9 \\
30.2\end{array}$ & $\begin{array}{c}71.1 \\
179 \\
59.4 \\
73.7 \\
47.9\end{array}$ & $\begin{array}{c}151 \\
600 \\
90.9 \\
71.8 \\
128\end{array}$ & $\begin{array}{c}78.3 \\
253 \\
85.3 \\
35.5 \\
56.2\end{array}$ & $\begin{array}{l}36.6 \\
98.5 \\
37.9 \\
23.5 \\
24.5\end{array}$ & $\begin{array}{l}30.4 \\
73.6 \\
32.4 \\
18.9 \\
20.4\end{array}$ & $\begin{array}{l}24.9 \\
57.3 \\
24.3 \\
19.7 \\
16.2\end{array}$ \\
\hline $\begin{array}{l}1956 \\
1957 \\
1958 \\
1959 \\
1960\end{array}$ & $\begin{array}{l}18.3 \\
21.0 \\
27.7 \\
23.5 \\
18.7\end{array}$ & $\begin{array}{l}22.1 \\
22.8 \\
28.2 \\
23.4 \\
18.8\end{array}$ & $\begin{array}{l}29.0 \\
23.5 \\
30.1 \\
22.3 \\
14.6\end{array}$ & $\begin{array}{l}25.8 \\
23.7 \\
26.8 \\
23.3 \\
17.1\end{array}$ & $\begin{array}{l}24.6 \\
25.4 \\
29.1 \\
25.3 \\
17.7\end{array}$ & $\begin{array}{l}33.0 \\
28.8 \\
27.9 \\
25.6 \\
26.6\end{array}$ & $\begin{array}{l}84.8 \\
42.6 \\
60.0 \\
42.4 \\
49.9\end{array}$ & $\begin{array}{l}156 \\
130 \\
231 \\
51.6 \\
64.7\end{array}$ & $\begin{array}{c}62.8 \\
129 \\
87.3 \\
25.2 \\
27.4\end{array}$ & $\begin{array}{l}27.4 \\
36.6 \\
32.7 \\
14.5 \\
14.2\end{array}$ & $\begin{array}{c}19.4 \\
26.7 \\
21.8 \\
11.6 \\
7.86\end{array}$ & $\begin{array}{l}17.8 \\
22.5 \\
20.3 \\
15.1 \\
11.9\end{array}$ \\
\hline $\begin{array}{l}1961 \\
1962 \\
1963 \\
1964 \\
1965\end{array}$ & $\begin{array}{l}18.3 \\
14.0 \\
17.3 \\
16.9 \\
15.5\end{array}$ & $\begin{array}{l}18.8 \\
15.4 \\
18.8 \\
21.7 \\
15.1\end{array}$ & $\begin{array}{l}16.5 \\
13.9 \\
18.5 \\
14.1 \\
17.8\end{array}$ & $\begin{array}{l}15.1 \\
13.8 \\
18.1 \\
13.0 \\
19.9\end{array}$ & $\begin{array}{l}17.9 \\
16.4 \\
26.0 \\
15.5 \\
21.4\end{array}$ & $\begin{array}{l}20.2 \\
17.1 \\
25.0 \\
18.3 \\
29.8\end{array}$ & $\begin{array}{c}29.5 \\
135 \\
39.4 \\
45.2 \\
57.8\end{array}$ & $\begin{array}{l}26.8 \\
210 \\
111 \\
156 \\
168\end{array}$ & $\begin{array}{r}11.5 \\
82.4 \\
57.2 \\
80.5 \\
128\end{array}$ & $\begin{array}{c}6.88 \\
29.4 \\
20.5 \\
28.3 \\
54.5\end{array}$ & $\begin{array}{c}6.86 \\
14.9 \\
19.9 \\
14.6 \\
40.3\end{array}$ & $\begin{array}{l}14.9 \\
12.9 \\
17.7 \\
13.7 \\
36.0\end{array}$ \\
\hline $\begin{array}{l}1966 \\
1967 \\
1968 \\
1969 \\
1970\end{array}$ & $\begin{array}{l}32.6 \\
22.6 \\
28.1 \\
27.0 \\
38.2\end{array}$ & $\begin{array}{l}34.7 \\
23.2 \\
29.8 \\
27.2 \\
34.5\end{array}$ & $\begin{array}{l}30.6 \\
18.6 \\
27.0 \\
28.5 \\
26.1\end{array}$ & $\begin{array}{l}22.3 \\
19.9 \\
29.3 \\
26.4 \\
22.7\end{array}$ & $\begin{array}{l}25.7 \\
18.9 \\
30.8 \\
26.3 \\
28.5\end{array}$ & $\begin{array}{l}34.8 \\
22.2 \\
34.7 \\
30.7 \\
30.2\end{array}$ & $\begin{array}{c}106 \\
43.1 \\
48.2 \\
145 \\
40.5\end{array}$ & $\begin{array}{l}97.8 \\
200 \\
147 \\
313 \\
149\end{array}$ & $\begin{array}{l}40.4 \\
198 \\
108 \\
107 \\
77.8\end{array}$ & $\begin{array}{l}24.8 \\
66.2 \\
36.1 \\
51.4 \\
34.0\end{array}$ & $\begin{array}{l}16.8 \\
33.4 \\
34.4 \\
36.3 \\
23.1\end{array}$ & $\begin{array}{l}19.1 \\
25.8 \\
25.4 \\
31.1 \\
23.5\end{array}$ \\
\hline $\begin{array}{l}1971 \\
1972 \\
1973 \\
1974 \\
1975\end{array}$ & $\begin{array}{l}25.8 \\
26.5 \\
28.0 \\
25.0 \\
22.1\end{array}$ & $\begin{array}{l}27.0 \\
23.8 \\
23.8 \\
26.8 \\
24.4\end{array}$ & $\begin{array}{l}19.4 \\
18.0 \\
20.5 \\
23.4 \\
19.5\end{array}$ & $\begin{array}{l}24.2 \\
19.2 \\
20.0 \\
22.4 \\
18.0\end{array}$ & $\begin{array}{l}24.0 \\
20.0 \\
21.4 \\
23.0 \\
18.4\end{array}$ & $\begin{array}{l}30.1 \\
40.2 \\
23.7 \\
31.1 \\
27.8\end{array}$ & $\begin{array}{c}115 \\
83.1 \\
51.9 \\
42.5 \\
30.4\end{array}$ & $\begin{array}{l}170 \\
117 \\
213 \\
162 \\
127\end{array}$ & $\begin{array}{r}93.1 \\
55.7 \\
71.1 \\
44.9 \\
175\end{array}$ & $\begin{array}{l}31.9 \\
25.9 \\
33.3 \\
21.3 \\
54.5\end{array}$ & $\begin{array}{l}25.3 \\
19.4 \\
20.5 \\
14.8 \\
21.9\end{array}$ & $\begin{array}{l}21.7 \\
18.9 \\
24.9 \\
13.8 \\
20.3\end{array}$ \\
\hline $\begin{array}{l}1976 \\
1977 \\
1978 \\
1979 \\
1980\end{array}$ & $\begin{array}{l}24.8 \\
16.3 \\
15.8 \\
17.8 \\
22.6\end{array}$ & $\begin{array}{l}28.4 \\
17.2 \\
18.2 \\
21.3 \\
24.9\end{array}$ & $\begin{array}{l}28.7 \\
15.2 \\
16.0 \\
17.0 \\
26.2\end{array}$ & $\begin{array}{l}21.8 \\
15.6 \\
16.7 \\
17.5 \\
25.9\end{array}$ & $\begin{array}{l}26.6 \\
17.1 \\
17.4 \\
21.9 \\
28.6\end{array}$ & $\begin{array}{l}31.1 \\
20.2 \\
27.3 \\
26.2 \\
29.1\end{array}$ & $\begin{array}{l}52.3 \\
30.0 \\
66.4 \\
56.6 \\
98.6\end{array}$ & $\begin{array}{l}117 \\
23.3 \\
145 \\
135 \\
303\end{array}$ & $\begin{array}{c}38.8 \\
14.9 \\
78.7 \\
62.1 \\
183\end{array}$ & $\begin{array}{l}19.1 \\
11.5 \\
24.7 \\
24.4 \\
52.5\end{array}$ & $\begin{array}{c}14.6 \\
8.75 \\
14.3 \\
18.5 \\
37.8\end{array}$ & $\begin{array}{c}15.3 \\
9.27 \\
17.7 \\
18.1 \\
38.6\end{array}$ \\
\hline 1981. & 40.6 & 38.4 & 37.5 & 35.1 & 36.9 & 35.2 & 53.6 & 57.5 & 40.1 & 23.5 & 21.0 & 22.9 \\
\hline
\end{tabular}

ANNUAL PEAK DISCHARGE, IN GBIC FEET PER SECOND, AND CORRESPONDING GAGE HEIGHT, IN FEET, FOR EAOH WATER YEAR

\begin{tabular}{|c|c|c|c|c|c|c|c|c|c|c|c|c|c|c|}
\hline $\begin{array}{l}\text { WATER } \\
\text { YEAR }\end{array}$ & & DATE & $\begin{array}{c}\text { GAGE } \\
\text { HEIGHT }\end{array}$ & $\begin{array}{c}\text { PEAK } \\
\text { DISCHARGE }\end{array}$ & $\begin{array}{l}\text { WATER } \\
\text { YEAR }\end{array}$ & & DATE & $\begin{array}{c}\text { GAGE } \\
\text { HEIGHT }\end{array}$ & $\begin{array}{c}\text { PEAK } \\
\text { DISCHARGE }\end{array}$ & $\begin{array}{l}\text { WATER } \\
\text { YEAR }\end{array}$ & & DATE & $\begin{array}{c}\text { GAGE } \\
\text { HEIGHT }\end{array}$ & $\begin{array}{c}\text { PEAR } \\
\text { DISOAARGE }\end{array}$ \\
\hline $\begin{array}{l}1935 \\
1936 \\
1937 \\
1938 \\
1939 \\
1940 \\
1941 \\
1942 \\
1943 \\
1944 \\
1945 \\
1946 \\
1947 \\
1948 \\
1949 \\
1950\end{array}$ & $\begin{array}{l}\text { MAY } \\
\text { MAY } \\
\text { MAY } \\
\text { MAY } \\
\text { OCT. } \\
\text { SEPT. } \\
\text { JULY } \\
\text { APR. } \\
\text { APR. } \\
\text { MAY } \\
\text { JULY } \\
\text { APR. } \\
\text { MAY } \\
\text { MAY } \\
\text { MAY } \\
\text { MAY }\end{array}$ & $\begin{array}{ll}26, & 1935 \\
07, & 1936 \\
15, & 1937 \\
16, & 1938 \\
05,1938 \\
20,1940 \\
26,1941 \\
23,1942 \\
24,1943 \\
15,1944 \\
19,1945 \\
25,1946 \\
04,1947 \\
21,1948 \\
04,1949 \\
17,1950\end{array}$ & $\begin{array}{l}-\overline{2} \\
2.88 \\
2.84 \\
3.15 \\
2.65 \\
2.22 \\
5.85 \\
2.30 \\
3.47 \\
3.94 \\
3.90 \\
2.90 \\
3.39 \\
2.55 \\
2.91 \\
3.57\end{array}$ & $\begin{array}{c}198 \\
366 \\
337 \\
370 \\
283 \\
189 \\
1040 \\
208 \\
441 \\
504 \\
512 \\
328 \\
446 \\
254 \\
378 \\
795\end{array}$ & $\begin{array}{l}1951 \\
1952 \\
1953 \\
1954 \\
1955 \\
1956 \\
1957 \\
1958 \\
1959 \\
1960 \\
1961 \\
1962 \\
1963 \\
1964 \\
1965 \\
1966\end{array}$ & $\begin{array}{l}\text { MAY } \\
\text { MAY } \\
\text { AUG. } \\
\text { APR. } \\
\text { MAY } \\
\text { MAY } \\
\text { JUNE } \\
\text { MAY } \\
\text { MAY } \\
\text { MAY } \\
\text { SEPT. } \\
\text { MAY } \\
\text { MAY } \\
\text { MAY } \\
\text { MAY } \\
\text { MAY }\end{array}$ & 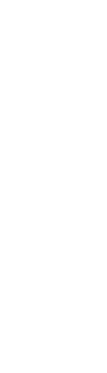 & $\begin{array}{l}1.85 \\
2.72 \\
2.18 \\
1.68 \\
2.15 \\
2.20 \\
2.13 \\
2.38 \\
1.47 \\
1.84 \\
2.12 \\
2.68 \\
1.85 \\
2.62 \\
2.49 \\
2.10\end{array}$ & $\begin{array}{r}304 \\
1260 \\
242 \\
128 \\
250 \\
267 \\
264 \\
354 \\
87 \\
164 \\
251 \\
469 \\
170 \\
472 \\
321 \\
208\end{array}$ & $\begin{array}{l}1967 \\
1968 \\
1969 \\
1970 \\
1971 \\
1972 \\
1973 \\
1974 \\
1975 \\
1976 \\
1977 \\
1978 \\
1979 \\
1980 \\
1981\end{array}$ & $\begin{array}{l}\text { MAY } \\
\text { MAY } \\
\text { MAY } \\
\text { MAY } \\
\text { MAY } \\
\text { MAY } \\
\text { MAY } \\
\text { MAY } \\
\text { MAY } \\
\text { MAY } \\
\text { JULY } \\
\text { MAY } \\
\text { MAY } \\
\text { MAY } \\
\text { JUNE }\end{array}$ & $\begin{array}{ll}24, & 1967 \\
22, & 1968 \\
10,1969 \\
18,1970 \\
16,11971 \\
07,1972 \\
19,1973 \\
10,1974 \\
20,1975 \\
15,1976 \\
24,1977 \\
16,1978 \\
19,1979 \\
07,1980 \\
20,1981\end{array}$ & $\begin{array}{l}2.67 \\
1.80 \\
2.39 \\
1.84 \\
1.80 \\
1.38 \\
2.20 \\
2.26 \\
3.80 \\
2.68 \\
2.20 \\
2.95 \\
2.69 \\
3.40 \\
2.33\end{array}$ & $\begin{array}{l}635 \\
276 \\
536 \\
340 \\
316 \\
200 \\
426 \\
444 \\
685 \\
234 \\
125 \\
324 \\
240 \\
589 \\
151\end{array}$ \\
\hline
\end{tabular}


GREEN RIVER BASIN

09288000 CURRANT CREEK NEAR FRUITLAND, UT-Continued

MAGNITUDE AND PRCBABIITTY OF ANNUAL LONEST MEAN DISCHARGF BASED ON CLIMATIC YEARS 1937-81

\begin{tabular}{|c|c|c|c|c|c|c|}
\hline \multirow{2}{*}{$\begin{array}{l}\text { PERIOD } \\
\text { (OON- } \\
\text { SEOU- } \\
\text { TIVE } \\
\text { DAYS) }\end{array}$} & \multicolumn{6}{|c|}{$\begin{array}{l}\text { DISCHARGE, IN ONBIC FEET PER SECOND, FOR } \\
\text { INDICATED RECIRRENCE INTERNAL, IN YEARS, AND } \\
\text { ANNUAL NONEXCEEDANCE PRCBABILITY, IN PERCENT }\end{array}$} \\
\hline & $\underset{508}{2}$ & $\begin{array}{c}5 \\
208\end{array}$ & $\begin{array}{l}10 \\
108\end{array}$ & $\begin{array}{l}20 \\
58\end{array}$ & $\begin{array}{l}50 \\
28\end{array}$ & $\begin{array}{r}100 \\
18\end{array}$ \\
\hline
\end{tabular}

$\begin{array}{rll}1 & 14 & 9.4 \\ 7 & 16 & 11 \\ 14 & 17 & 12 \\ 30 & 18 & 12 \\ 60 & 19 & 14 \\ 90 & 20 & 15\end{array}$

$\begin{array}{rrrr}7.4 & 5.9 & 4.6 & 3.8 \\ 8.4 & 6.8 & 5.2 & 4.3 \\ 8.8 & 7.2 & 5.6 & 4.7 \\ 9.9 & 8.1 & 6.4 & 5.4 \\ 11 & 9.4 & 7.7 & 6.6 \\ 13 & 11 & 9.0 & 7.9\end{array}$

MAGNITUDE AND PRCBABIIITY OF ANNUAL HIGHEST MEAN DISCHARGE BASED ON WATER YEARS 1936-81

\begin{tabular}{|c|c|c|c|c|c|c|}
\hline \multirow{2}{*}{$\begin{array}{l}\text { PERIOD } \\
\text { CON- } \\
\text { SEO- } \\
\text { TIVE } \\
\text { DAYS) }\end{array}$} & \multicolumn{4}{|c|}{$\begin{array}{l}\text { DISCHARGE, IN OBIC FEET PER } \\
\text { INDICATED REOJRRENCE INTERNAL, } \\
\text { ANNUAL EXCEEDANCE PRCBABILITY, }\end{array}$} & \multicolumn{2}{|c|}{$\begin{array}{l}\text { SECOND, FOR } \\
\text { IN YEARS, AND } \\
\text { IN PERCENT }\end{array}$} \\
\hline & $\begin{array}{c}2 \\
508\end{array}$ & $\begin{array}{c}5 \\
208\end{array}$ & $\begin{array}{l}10 \\
108\end{array}$ & $\begin{array}{l}25 \\
48\end{array}$ & $\begin{array}{l}50 \\
28\end{array}$ & $\begin{array}{r}100 \\
18\end{array}$ \\
\hline $\begin{array}{r}1 \\
3 \\
7 \\
15\end{array}$ & $\begin{array}{l}247 \\
233 \\
216 \\
192\end{array}$ & $\begin{array}{l}389 \\
369 \\
339 \\
295\end{array}$ & $\begin{array}{l}477 \\
452 \\
412 \\
356\end{array}$ & $\begin{array}{l}579 \\
549 \\
495 \\
422\end{array}$ & $\begin{array}{l}647 \\
614 \\
549 \\
464\end{array}$ & $\begin{array}{l}710 \\
674 \\
597 \\
502\end{array}$ \\
\hline
\end{tabular}

09288100 RED CREEK BELOW CURRANT CREEK, NEAR FRUITYAND, UT

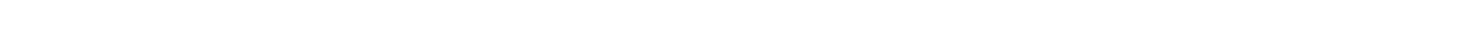
14060004 , on right bank $700 \mathrm{ft}$ upstream from bridge, $1.6 \mathrm{mi}$ upstream from mouth, $3.2 \mathrm{mi}$ downstream from Currant Creek, and 6.5 mi southeast of Fruitland.

DRAINAGE AREA. $-297 \mathrm{mi}^{2}$.

PERIOD OF RECORD AVAIIABLE.--October 1963 to september 1981.

REVISED RECORDS. -WDR UT-77-1: Drainage area.

GAGE.-Water-stage recorder. Altitude of gage is 6,130 ft from topographic map.

REMARKS. --Several diversions above station for irrigation, including transmountain diversion to the Great Basin through Strawberry tunnel. Flow slightly regulated by Red Creek Reservoir, $13 \mathrm{mi}$ upstream, beginning July 1960 , capacity, 5,700 acre-ft.

AVERAGE DISCHARGE. -18 years, $54.1 \mathrm{ft}^{3} / \mathrm{s}, 39,200 \mathrm{acre}-\mathrm{ft} / \mathrm{Yr}$.

EXTREMES FOR PERTOD OF REOORD.--Naximm discharge, 1,460 $\mathrm{ft}^{3} / \mathrm{s}$ July 16, 1975, gage height, $4.45 \mathrm{ft}$ in gage well, $4.50 \mathrm{ft}$ fram floodmarks, from rating curve extended above $540 \mathrm{ft}^{3} / \mathrm{s}$ on basis of slope-area measurement of peak flow; minimum, $3.9 \mathrm{ft} \mathrm{f}^{3} / \mathrm{s}$ Dec. 9, 1978.

LONEST MEAN DISCHARGE, IN CUBIC FEET PER SECOND, AND RANKING FOR THE INDICATED NUMBER OF CONSECUTIVE DAYS FOR EACH CLIMATIC YEAR, APRIL I-MARCH 31

YEAR

$\begin{array}{rrrrrrrrrrrrr} & 1 & & 3 & & 7 & & 14 & & 30 & & 60 & \\ 1965 & 12.0 & 4 & 15.0 & 5 & 15.0 & 5 & 16.0 & 5 & 17.0 & 4 & 19.0 & 6 \\ 1966 & 17.0 & 8 & 21.0 & 8 & 22.0 & 9 & 23.0 & 9 & 27.0 & 9 & 28.0 & 10 \\ 1967 & 14.0 & 6 & 16.0 & 6 & 17.0 & 7 & 19.0 & 7 & 20.0 & 7 & 24.0 & 7 \\ 1968 & 26.0 & 16 & 29.0 & 16 & 32.0 & 15 & 34.0 & 15 & 35.0 & 15 & 36.0 & 15 \\ 1969 & 24.0 & 15 & 280 & 15 & 32.0 & 16 & 35.0 & 16 & 36.0 & 16 & 37.0 & 16 \\ 1970 & 22.0 & 12 & 23.0 & 11 & 24.0 & 12 & 25.0 & 12 & 30.0 & 13 & 32.0 & 13 \\ 1971 & 23.0 & 13 & 23.0 & 12 & 23.0 & 10 & 24.0 & 10 & 27.0 & 10 & 32.0 & 14 \\ 1972 & 24.0 & 14 & 24.0 & 13 & 24.0 & 11 & 25.0 & 11 & 28.0 & 11 & 31.0 & 11 \\ 1973 & 21.0 & 9 & 22.0 & 9 & 22.0 & 8 & 23.0 & 8 & 25.0 & 8 & 26.0 & 8 \\ 1974 & 21.0 & 10 & 24.0 & 14 & 29.0 & 14 & 31.0 & 14 & 31.0 & 14 & 32.0 & 12 \\ 1975 & 6.80 & 2 & 8.60 & 2 & 9.40 & 2 & 11.0 & 2 & 15.0 & 2 & 17.0 & 2 \\ 1976 & 22.0 & 11 & 23.0 & 10 & 26.0 & 13 & 27.0 & 13 & 28.0 & 12 & 28.0 & 9 \\ 1977 & 16.0 & 7 & 16.0 & 7 & 16.0 & 6 & 16.0 & 6 & 17.0 & 3 & 18.0 & 3 \\ 1978 & 5.00 & 1 & 5.20 & 1 & 5.80 & 1 & 7.20 & 1 & 11.0 & 1 & 12.0 & 1 \\ 1979 & 12.0 & 3 & 12.0 & 3 & 13.0 & 3 & 15.0 & 3 & 18.0 & 5 & 19.0 & 4 \\ 1980 & 13.0 & 5 & 13.0 & 4 & 15.0 & 4 & 15.0 & 4 & 18.0 & 6 & 19.0 & 5 \\ 1981 & 28.0 & 17 & 35.0 & 17 & 37.0 & 17 & 38.0 & 17 & 38.0 & 17 & 39.0 & 17\end{array}$

90

$20.0 \quad 5$

$30.0 \quad 10$

25.07

$37.0 \quad 15$

38.016

$34.0 \quad 14$

$32.0 \quad 11$

$32.0 \quad 12$

27.08

$\begin{array}{lr}32.0 & 13 \\ 20.0 & 6\end{array}$

28.09

19.0

13.0
20.0

20.0
19.0

$39.0 \quad 17$

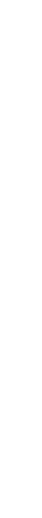

120

183

23.03

$36.0 \quad 13$

27.07

$38.0 \quad 14$

$44.0 \quad 17$

$39.0 \quad 15$

35.011

33.010

31.09

$\begin{array}{rr}36.0 & 12 \\ 24.0 & 6\end{array}$

30.0

30.0

23.0
16.0

24.05

23.02

$41.0 \quad 16$
ALL

$47.0 \quad 6$

$68.0 \quad 14$

48.07

$75.0 \quad 15$

$\begin{array}{ll}66.0 & 13 \\ 86.0 & 16\end{array}$

53.09

$58.0 \quad 11$

$48.0 \quad 8$

41.0

$55.0 \quad 10$

37.02

$22.0 \quad 1$

45.05

43.04

$88.0 \quad 17$ 
GREEN RIVER BASIN

09288100 RED CREEK BELON CURRANT CREEK, NEAR FPUITHAND, UT-Continued

HIGHEST MEAN DISCHARGE, IN OBIC FEET PER SEOOND, AND RANKING FOR THE INDICATED NUABER OF CONSECUTIVE DAYS FOR EACH WATER YEAR, OCTCBER 1-SEPTEBBER 30

\begin{tabular}{|c|c|c|c|c|c|c|c|c|c|c|c|c|c|c|c|c|c|c|c|c|}
\hline IEAR & 1 & & 3 & & 7 & & 15 & & $\begin{array}{l}\infty O N \\
30\end{array}$ & & $\begin{array}{l}\text { E DAYS } \\
60\end{array}$ & & 90 & & 120 & & 183 & & ALL & \\
\hline $\begin{array}{l}964 \\
665\end{array}$ & $\begin{array}{l}354 \\
376\end{array}$ & $\begin{array}{l}7 \\
5\end{array}$ & $\begin{array}{l}339 \\
357\end{array}$ & $\begin{array}{l}6 \\
5\end{array}$ & $\begin{array}{l}307 \\
324\end{array}$ & $\begin{array}{l}6 \\
5\end{array}$ & & $\begin{array}{l}6 \\
5\end{array}$ & $\begin{array}{l}195 \\
229\end{array}$ & $\begin{array}{l}7 \\
5\end{array}$ & $\begin{array}{l}135 \\
183\end{array}$ & $\begin{array}{l}9 \\
4\end{array}$ & & $\begin{array}{l}9 \\
4\end{array}$ & & $\begin{array}{r}10 \\
4\end{array}$ & & $\begin{array}{r}12 \\
4\end{array}$ & $\begin{array}{l}46.0 \\
64.0\end{array}$ & $\begin{array}{r}12 \\
4\end{array}$ \\
\hline $\begin{array}{l}666 \\
667 \\
268 \\
669 \\
970\end{array}$ & $\begin{array}{l}184 \\
454 \\
272 \\
522 \\
274\end{array}$ & $\begin{array}{r}15 \\
3 \\
10 \\
1 \\
9\end{array}$ & $\begin{array}{l}179 \\
446 \\
245 \\
465 \\
265\end{array}$ & $\begin{array}{r}15 \\
3 \\
10 \\
2 \\
9\end{array}$ & $\begin{array}{l}158 \\
406 \\
219 \\
456 \\
239\end{array}$ & $\begin{array}{r}16 \\
3 \\
10 \\
1 \\
9\end{array}$ & $\begin{array}{l}149 \\
363 \\
214 \\
421 \\
209\end{array}$ & $\begin{array}{r}16 \\
2 \\
8 \\
1 \\
9\end{array}$ & $\begin{array}{l}149 \\
319 \\
190 \\
357 \\
170\end{array}$ & $\begin{array}{r}13 \\
3 \\
8 \\
1 \\
9\end{array}$ & $\begin{array}{l}132 \\
232 \\
151 \\
261 \\
125\end{array}$ & $\begin{array}{r}10 \\
3 \\
7 \\
2 \\
11\end{array}$ & $\begin{array}{l}109 \\
175 \\
121 \\
213 \\
102\end{array}$ & $\begin{array}{r}10 \\
3 \\
8 \\
2 \\
11\end{array}$ & $\begin{array}{c}92.0 \\
146 \\
104 \\
177 \\
87.0\end{array}$ & $\begin{array}{r}9 \\
3 \\
7 \\
2 \\
11\end{array}$ & $\begin{array}{c}71.0 \\
111 \\
87.0 \\
134 \\
71.0\end{array}$ & $\begin{array}{r}9 \\
3 \\
6 \\
1 \\
10\end{array}$ & & $\begin{array}{r}10 \\
3 \\
5 \\
1 \\
8\end{array}$ \\
\hline $\begin{array}{l}976 \\
977 \\
978 \\
979\end{array}$ & $\begin{array}{l}213 \\
53.0 \\
262 \\
195 \\
517\end{array}$ & $\begin{array}{r}13 \\
18 \\
11 \\
14 \\
2\end{array}$ & $\begin{array}{l}191 \\
45.0 \\
234 \\
193 \\
488\end{array}$ & $\begin{array}{c}14 \\
18 \\
12 \\
13 \\
1\end{array}$ & $\begin{array}{c}187 \\
41.0 \\
189 \\
188 \\
428\end{array}$ & $\begin{array}{r}14 \\
18 \\
12 \\
13 \\
2\end{array}$ & $\begin{array}{l}164 \\
38.0 \\
178 \\
176 \\
352\end{array}$ & $\begin{array}{r}14 \\
18 \\
11 \\
13 \\
3\end{array}$ & $\begin{array}{l}130 \\
33.0 \\
153 \\
146 \\
349\end{array}$ & $\begin{array}{r}16 \\
18 \\
12 \\
14 \\
2\end{array}$ & $\begin{array}{l}94.0 \\
30.0 \\
120 \\
114 \\
290\end{array}$ & $\begin{array}{r}16 \\
18 \\
12 \\
13 \\
1\end{array}$ & $\begin{array}{c}78.0 \\
28.0 \\
100 \\
93.0 \\
225\end{array}$ & $\begin{array}{c}16 \\
18 \\
12 \\
14 \\
1\end{array}$ & $\begin{array}{r}67.0 \\
27.0 \\
85.0 \\
80.0 \\
181\end{array}$ & $\begin{array}{c}16 \\
18 \\
13 \\
14 \\
1\end{array}$ & $\begin{array}{r}54.0 \\
24.0 \\
64.0 \\
62.0 \\
134\end{array}$ & $\begin{array}{r}16 \\
18 \\
13 \\
14 \\
2\end{array}$ & $\begin{array}{l}41.0 \\
21.0 \\
42.0 \\
43.0 \\
82.0\end{array}$ & $\begin{array}{r}16 \\
18 \\
15 \\
14 \\
2\end{array}$ \\
\hline
\end{tabular}

DURATION OF DISCHARGE FOR EACH WATER YEAR

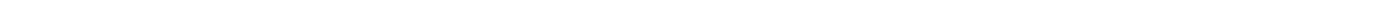

YEAR

MUBER OF DAYS IN CIASS

CUBIC FEET

PER SEOOND -DAYS

1964
1965

1966

1967

1968

1970

16723.0

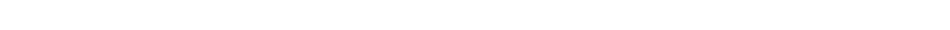
23185.0

$\begin{array}{rrrrrrrrrrrrrrrrrrrrrrrrrrr}1 & 7 & 13 & 20 & 43 & 44 & 40 & 53 & 47 & 14 & 10 & 2 & 12 & 4 & 9 & 13 & 18 & 10 & 5 & & & & & & \\ & 1 & 5 & 7 & 19 & 48 & 84 & 38 & 25 & 44 & 15 & 8 & 8 & 8 & 6 & 3 & 4 & 2 & 2 & 4 & 9 & 6 & 9 & 6 & 2 & 2 & 2589.0\end{array}$

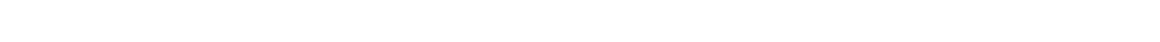

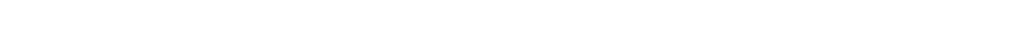
$\begin{array}{llllllllllllllllllllllll}1 & 9 & 15 & 39 & 104 & 51 & 18 & 12 & 9 & 16 & 13 & 23 & 9 & 5 & 4 & 2 & 9 & 4 & 3 & 8 & 8 & 2 & 1 & 32533.0\end{array}$ $\begin{array}{lllllllllllllllllllllll}1 & 11 & 25 & 66 & 64 & 67 & 52 & 15 & 15 & 3 & 10 & 4 & 10 & 6 & 4 & 2 & 5 & 3 & 2 & & & & \end{array}$ 32533.0

1971 $\begin{array}{lllllllllllllllll}26 & 62 & 68 & 68 & 31 & 22 & 9 & 6 & 3 & 9 & 13 & 8 & 14 & 12 & 4 & 5 & 5\end{array}$

$\begin{array}{llllllllllllllll}6 & 50 & 59 & 63 & 56 & 9 & 16 & 32 & 8 & 18 & 8 & 9 & 12 & 13 & 4 & 3\end{array}$

$\begin{array}{rrrrrrrrrrrrrrrrrrrrrrr}50 & 59 & 63 & 56 & 9 & 16 & 32 & 8 & 18 & 8 & 9 & 12 & 13 & 4 & 3 & & & & & & \\ 5 & 84 & 47 & 74 & 39 & 25 & 10 & 9 & 9 & 13 & 8 & 8 & 9 & 5 & 1 & 5 & 2 & 1 & 6 & 4 & 1\end{array}$

1973

1975

$1 \quad 2 \quad 5 \quad 2 \quad 224 \frac{11}{3}$ $\begin{array}{rrrr}5 & 23 & 33 \\ 4 & 25 & 153\end{array}$ $\begin{array}{lllll}79 & 61 & 48 & 16 & 10 \\ 40 & 37 & 20 & 12 & 8\end{array}$

$\begin{array}{rrrrrrrrrrrrr}9 & 9 & 13 & 8 & 8 & 9 & 5 & 1 & 5 & 2 & 1 & 6 & 4\end{array}$

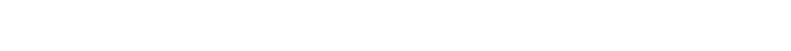

$\begin{array}{llllllllllllllrrr}4 & 5 & 2 & 6 & 14 & 14 & 15 & 22 & 49 & 23 & 49 & 75 & 47 & 24 & 9 & 5 & 2\end{array}$

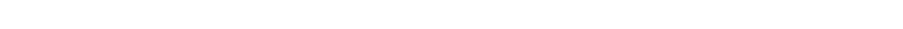

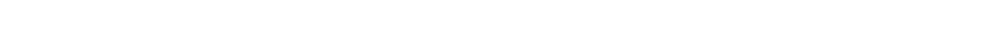

20729.0

18226.0

22345.0

16311.0

19822.0

1977

1980

7743.9

15344.0

15570.0

29882.0

1981

$\begin{array}{llllllllllllll}1 & 4 & 5 & 1 & 26 & 29 & 22 & 21 & 87 & 97 & 21 & 28 & 13 & 10\end{array}$

14570.0

\begin{tabular}{|c|c|c|c|c|c|c|c|c|c|c|c|c|c|c|c|c|c|c|c|}
\hline CJASS & $\begin{array}{c}\text { OBBIC } \\
\text { FEET } \\
\text { PER } \\
\text { SEOOND }\end{array}$ & TOIAL & $\begin{array}{c}\text { ACOJ- } \\
\text { MU- } \\
\text { LATED } \\
\text { DAYS }\end{array}$ & $\begin{array}{l}\text { PER- } \\
\text { GENT } \\
\text { DAYS }\end{array}$ & CJASS & $\begin{array}{c}\text { OBIC } \\
\text { FEET } \\
\text { PER } \\
\text { SECOND }\end{array}$ & $\begin{array}{r}\text { TOTAL } \\
\text { DAYS }\end{array}$ & $\begin{array}{c}\text { ACOU- } \\
\text { MU- } \\
\text { LATIED } \\
\text { DAYS }\end{array}$ & $\begin{array}{l}\text { PER- } \\
\text { CENI } \\
\text { DAYS }\end{array}$ & & $\begin{array}{c}\text { OBBIC } \\
\text { FEET } \\
\text { PER } \\
\text { SECOND }\end{array}$ & TOTAL & $\begin{array}{c}\text { ACOU- } \\
\text { MU- } \\
\text { LATED } \\
\text { DAYS }\end{array}$ & $\begin{array}{l}\text { PER- } \\
\text { CENT } \\
\text { DAYS }\end{array}$ & & $\begin{array}{c}\text { OBIC } \\
\text { FEET } \\
\text { PER } \\
\text { SECOND }\end{array}$ & TOTAL & $\begin{array}{c}\text { ACCU- } \\
\text { MU- } \\
\text { LATED } \\
\text { DAYS }\end{array}$ & $\begin{array}{l}\text { PER- } \\
\text { CENI } \\
\text { DAYS }\end{array}$ \\
\hline $\begin{array}{l}0 \\
1 \\
2 \\
3 \\
4 \\
5 \\
6 \\
7 \\
8\end{array}$ & $\begin{array}{r}0.00 \\
5.00 \\
5.80 \\
6.60 \\
7.60 \\
8.80 \\
10.00 \\
12.00 \\
13.00\end{array}$ & $\begin{array}{r}0 \\
4 \\
5 \\
3 \\
6 \\
16 \\
19 \\
23 \\
52\end{array}$ & $\begin{array}{l}6575 \\
6575 \\
6571 \\
6566 \\
6563 \\
6557 \\
6541 \\
6522 \\
6499\end{array}$ & $\begin{array}{r}100.0 \\
100.0 \\
99.9 \\
99.9 \\
99.8 \\
99.7 \\
99.5 \\
99.2 \\
98.8\end{array}$ & $\begin{array}{l}9 \\
10 \\
11 \\
12 \\
13 \\
14 \\
15 \\
16 \\
17\end{array}$ & $\begin{array}{l}15.00 \\
18.00 \\
20.00 \\
23.00 \\
27.00 \\
31.00 \\
36.00 \\
41.00 \\
47.00\end{array}$ & $\begin{array}{l}187 \\
163 \\
338 \\
670 \\
928 \\
741 \\
785 \\
685 \\
441\end{array}$ & $\begin{array}{l}6447 \\
6260 \\
6097 \\
5759 \\
5089 \\
4161 \\
3420 \\
2635 \\
1950\end{array}$ & $\begin{array}{l}98.1 \\
95.2 \\
92.7 \\
87.6 \\
77.4 \\
63.3 \\
52.0 \\
40.1 \\
29.7\end{array}$ & $\begin{array}{l}18 \\
19 \\
20 \\
21 \\
22 \\
23 \\
24 \\
25 \\
26\end{array}$ & $\begin{array}{r}55.0 \\
63.0 \\
72.0 \\
83.0 \\
96.0 \\
110.0 \\
130.0 \\
150.0 \\
170.0\end{array}$ & $\begin{array}{r}302 \\
163 \\
143 \\
127 \\
110 \\
136 \\
121 \\
79 \\
76\end{array}$ & $\begin{array}{r}1509 \\
1207 \\
1044 \\
901 \\
774 \\
664 \\
528 \\
407 \\
328\end{array}$ & $\begin{array}{r}23.0 \\
18.4 \\
15.9 \\
13.7 \\
11.8 \\
10.1 \\
80 \\
6.2 \\
5.0\end{array}$ & $\begin{array}{l}27 \\
28 \\
29 \\
30 \\
31 \\
32 \\
33 \\
34\end{array}$ & $\begin{array}{l}190.0 \\
220.0 \\
260.0 \\
290.0 \\
340.0 \\
390.0 \\
450.0 \\
520.0\end{array}$ & $\begin{array}{r}56 \\
65 \\
40 \\
37 \\
28 \\
18 \\
7 \\
1\end{array}$ & $\begin{array}{r}252 \\
196 \\
131 \\
91 \\
54 \\
26 \\
8 \\
1\end{array}$ & $\begin{array}{l}3.8 \\
3.0 \\
2.0 \\
1.4 \\
0.8 \\
0.4 \\
0.1 \\
0.0\end{array}$ \\
\hline
\end{tabular}


GREEN RIVER BASIN

09288100 RED CREEK BEICW OURRANT CREEK, NEAR FRUITLAND, UT--Continued

MONIHLY MEAN DISQHARGES, IN OUBIC FEET PER SECOND, FOR EACH WATER YEAR

\begin{tabular}{|c|c|c|c|c|c|c|c|c|c|c|c|c|}
\hline YEAR & OCT & $\mathrm{NOV}$ & $\mathrm{DEC}$ & JAN & FEB & MAR & APR & MAY & JUNE & JULY & AUG & SEP \\
\hline $\begin{array}{l}1964 \\
1965\end{array}$ & $\begin{array}{l}27.2 \\
21.2\end{array}$ & $\begin{array}{l}30.4 \\
26.1\end{array}$ & $\begin{array}{l}20.2 \\
27.5\end{array}$ & $\begin{array}{l}20.6 \\
28.3\end{array}$ & $\begin{array}{l}23.3 \\
28.3\end{array}$ & $\begin{array}{l}29.0 \\
37.5\end{array}$ & $\begin{array}{l}55.4 \\
64.2\end{array}$ & $\begin{array}{l}175 \\
211\end{array}$ & $\begin{array}{r}91.4 \\
148\end{array}$ & $\begin{array}{l}34.9 \\
61.6\end{array}$ & $\begin{array}{l}19.9 \\
56.4\end{array}$ & $\begin{array}{l}19.7 \\
49.6\end{array}$ \\
\hline $\begin{array}{l}1966 \\
1967 \\
1968 \\
1969 \\
1970\end{array}$ & $\begin{array}{l}41.1 \\
31.5 \\
36.5 \\
63.9 \\
51.3\end{array}$ & $\begin{array}{l}39.3 \\
30.1 \\
39.4 \\
40.2 \\
42.6\end{array}$ & $\begin{array}{l}33.2 \\
24.2 \\
37.2 \\
37.7 \\
33.4\end{array}$ & $\begin{array}{l}27.3 \\
29.5 \\
38.3 \\
38.1 \\
30.4\end{array}$ & $\begin{array}{l}31.5 \\
33.5 \\
45.2 \\
41.3 \\
41.5\end{array}$ & $\begin{array}{l}53.5 \\
42.6 \\
49.9 \\
55.6 \\
35.9\end{array}$ & $\begin{array}{c}138 \\
51.4 \\
57.7 \\
161 \\
51.8\end{array}$ & $\begin{array}{l}121 \\
212 \\
165 \\
348 \\
163\end{array}$ & $\begin{array}{l}51.3 \\
239 \\
133 \\
120 \\
80.4\end{array}$ & $\begin{array}{l}27.0 \\
68.2 \\
53.7 \\
62.1 \\
47.3\end{array}$ & $\begin{array}{l}21.4 \\
49.4 \\
59.7 \\
52.3 \\
36.5\end{array}$ & $\begin{array}{l}29.0 \\
38.0 \\
44.9 \\
45.4 \\
39.7\end{array}$ \\
\hline $\begin{array}{l}1971 \\
1972 \\
1973 \\
1974 \\
1975\end{array}$ & $\begin{array}{l}39.4 \\
34.9 \\
39.5 \\
40.2 \\
26.8\end{array}$ & $\begin{array}{l}36.1 \\
35.6 \\
36.8 \\
35.8 \\
28.3\end{array}$ & $\begin{array}{l}32.5 \\
28.0 \\
29.9 \\
32.8 \\
27.0\end{array}$ & $\begin{array}{l}33.1 \\
34.7 \\
27.0 \\
32.1 \\
27.0\end{array}$ & $\begin{array}{l}31.5 \\
38.8 \\
28.5 \\
32.4 \\
27.4\end{array}$ & $\begin{array}{l}39.5 \\
57.4 \\
40.6 \\
45.6 \\
36.9\end{array}$ & $\begin{array}{c}113 \\
99.8 \\
91.3 \\
52.5 \\
35.1\end{array}$ & $\begin{array}{l}163 \\
125 \\
233 \\
151 \\
120\end{array}$ & $\begin{array}{l}89.8 \\
61.0 \\
79.6 \\
46.8 \\
191\end{array}$ & $\begin{array}{l}37.5 \\
28.9 \\
46.7 \\
29.4 \\
68.9\end{array}$ & $\begin{array}{l}32.6 \\
25.5 \\
37.7 \\
21.3 \\
31.8\end{array}$ & $\begin{array}{l}32.0 \\
28.2 \\
40.8 \\
14.8 \\
31.4\end{array}$ \\
\hline $\begin{array}{l}1976 \\
1977 \\
1978 \\
1979 \\
1980\end{array}$ & $\begin{array}{l}32.9 \\
29.6 \\
19.2 \\
24.3 \\
25.1\end{array}$ & $\begin{array}{l}30.5 \\
24.9 \\
21.3 \\
30.8 \\
26.0\end{array}$ & $\begin{array}{l}29.6 \\
18.1 \\
19.5 \\
25.6 \\
26.6\end{array}$ & $\begin{array}{l}27.7 \\
17.7 \\
21.0 \\
24.4 \\
28.1\end{array}$ & $\begin{array}{l}28.0 \\
22.1 \\
23.2 \\
28.5 \\
32.1\end{array}$ & $\begin{array}{l}34.5 \\
25.0 \\
37.7 \\
43.2 \\
38.2\end{array}$ & $\begin{array}{r}54.2 \\
32.7 \\
64.7 \\
65.5 \\
114\end{array}$ & $\begin{array}{l}128 \\
26.4 \\
145 \\
145 \\
341\end{array}$ & $\begin{array}{r}46.8 \\
17.8 \\
86.2 \\
61.1 \\
204\end{array}$ & $\begin{array}{l}25.8 \\
15.9 \\
25.4 \\
22.9 \\
55.5\end{array}$ & $\begin{array}{l}21.7 \\
12.0 \\
18.6 \\
20.5 \\
43.5\end{array}$ & $\begin{array}{l}27.0 \\
12.7 \\
21.8 \\
18.6 \\
44.3\end{array}$ \\
\hline 1981 & 43.8 & 42.2 & 42.0 & 40.3 & 39.5 & 38.5 & 56.1 & 61.8 & 41.1 & 25.4 & 21.6 & 27.0 \\
\hline
\end{tabular}

ANNUAL PEAK DISGHARGE, IN GBIC FEET PER SECOND, AND CORRESPONDING GAGE HEIGHT, IN FEET, FOR EACH WATER YEAR

\begin{tabular}{|c|c|c|c|c|c|c|c|c|c|c|c|}
\hline $\begin{array}{l}\text { WATER } \\
\text { YEAR }\end{array}$ & DATE & $\begin{array}{c}\text { GAGE } \\
\text { HEIGHT }\end{array}$ & $\begin{array}{c}\text { PEAK } \\
\text { DISOHARGE }\end{array}$ & $\begin{array}{l}\text { WATER } \\
\text { YEAR }\end{array}$ & DATE & $\begin{array}{c}\text { GAGE } \\
\text { HEIGHT }\end{array}$ & $\begin{array}{c}\text { PEAR } \\
\text { DISAHARGE }\end{array}$ & $\begin{array}{l}\text { WATER } \\
\text { YEAR }\end{array}$ & DATE & $\begin{array}{c}\text { GAGE } \\
\text { HEIGHT }\end{array}$ & $\begin{array}{c}\text { PEAK } \\
\text { DISOHARGE }\end{array}$ \\
\hline $\begin{array}{l}1964 \\
1965 \\
1966 \\
1967 \\
1968 \\
1969\end{array}$ & $\begin{array}{l}\text { MAY } 21,1964 \\
\text { AUG. } 14,1965 \\
\text { MAY } 10,1966 \\
\text { AUG. } 31,1967 \\
\text { MAY } 22,1968 \\
\text { AUG. } 16,1969\end{array}$ & $\begin{array}{l}3.51 \\
3.58 \\
2.78 \\
4.74 \\
3.05 \\
4.08\end{array}$ & $\begin{array}{r}449 \\
485 \\
212 \\
1340 \\
318 \\
870\end{array}$ & $\begin{array}{l}1970 \\
1971 \\
1972 \\
1973 \\
1974 \\
1975\end{array}$ & $\begin{array}{l}\text { AUG. } 31,1970 \\
\text { AUG. } 30,1971 \\
\text { MAY } 07,1972 \\
\text { AUG. } 21,1973 \\
\text { AUG. } 27,1974 \\
\text { JULY } 16,1975\end{array}$ & $\begin{array}{l}3.40 \\
3.72 \\
2.63 \\
3.70 \\
3.90 \\
4.50\end{array}$ & $\begin{array}{r}461 \\
617 \\
206 \\
605 \\
865 \\
1460\end{array}$ & $\begin{array}{l}1976 \\
1977 \\
1978 \\
1979 \\
1980 \\
1981\end{array}$ & $\begin{array}{l}\text { SEPT.11, } 1976 \\
\text { JULY 04, } 1977 \\
\text { MAY 16, } 1978 \\
\text { MAY } 19,1979 \\
\text { MAY 07, } 1980 \\
\text { SEPT.08, } 1981\end{array}$ & $\begin{array}{l}3.50 \\
4.22 \\
2.95 \\
2.65 \\
3.70 \\
2.40\end{array}$ & $\begin{array}{r}619 \\
1210 \\
327 \\
219 \\
648 \\
135\end{array}$ \\
\hline
\end{tabular}

NAGNITUDE AND PROBABIIITY OF ANNUAL LONEST MEAN DISCHARGE BASED ON CLIMATIC YEARS $1965-81$

\begin{tabular}{|c|c|c|c|c|c|c|}
\hline \multicolumn{7}{|c|}{ BASED ON CLIMATIC YEARS 1965-81 } \\
\hline \multirow{2}{*}{$\begin{array}{l}\text { PERIOD } \\
\text { (CON- } \\
\text { SEQI- } \\
\text { TIVE } \\
\text { DAYS) }\end{array}$} & \multicolumn{6}{|c|}{$\begin{array}{l}\text { DISCHARGE, IN OUBIC FEET PER SECOND, FOR } \\
\text { INDICATED RECURRENCE INTERVAL, IN YEARS, AND } \\
\text { ANNUAL NONEXCEEDANCE PROBABILITY, IN PERCENT }\end{array}$} \\
\hline & $\begin{array}{c}2 \\
508\end{array}$ & $\begin{array}{c}5 \\
20 \%\end{array}$ & $\begin{array}{l}10 \\
10 z\end{array}$ & $\begin{array}{l}20 \\
58\end{array}$ & $\begin{array}{l}50 \\
28\end{array}$ & $\begin{array}{r}100 \\
18\end{array}$ \\
\hline
\end{tabular}

$\begin{array}{rllllll}1 & 18 & 12 & 8.7 & 6.6 & - & - \\ 7 & 21 & 14 & 10 & 7.9 & - & = \\ 14 & 22 & 15 & 12 & 9.2 & - & - \\ 30 & 24 & 18 & 15 & 13 & - & - \\ 60 & 26 & 19 & 16 & 14 & - & - \\ 90 & 27 & 20 & 17 & 15 & - & -\end{array}$

MAGNITUDE AND PROBABILITY OF ANNUAL HIGHEST MEAN DISCHARGE BASED ON WATER YEARS 1964-81

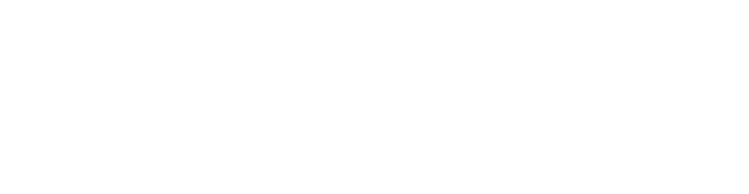

$\begin{array}{rrrrrrr}1 & 290 & 421 & 482 & 534 & - & - \\ 3 & 273 & 393 & 445 & 488 & - & - \\ 7 & 248 & 359 & 407 & 448 & - & - \\ 15 & 223 & 315 & 354 & 385 & - & -\end{array}$

09288150 WEST FORK AVINTAQUIN CREEK NEAR FRUITLAND, UT

(Formerly published as Cottonwood Creek near Fruitland)

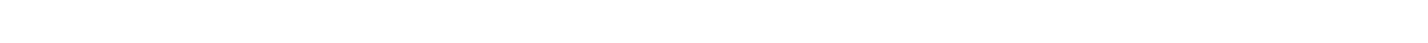

$14060004,0.2 \mathrm{mi}$ upstream from mouth and $15.2 \mathrm{mi}$ south of Fruitland.

DRAINAGE AREA. $--56.1 \mathrm{mi}^{2}$.

MEAN BASIN ELEVATION. $--8,310 \mathrm{ft}$.

PERIOD OF RECORD AVAILABLE.--June 1964 to September 1981.

REVISED RECORD.--WDR UT-77-1: Drainage area.

GAGE. -Water-stage recorder. Altitude of gage is 6,790 ft from topographic map.

RENARKS.--One small diversion above station, constructed in 1976 for irrigation, may divert small amounts of water intermittentiy auring the sumer months.

AVERAGE DISCHARGE. --17 years, $14.4 \mathrm{ft}^{3} / \mathrm{s}, 10,430$ acre-ft/yr.

EXTREMES FOR PERIOD OF RECORD.--Maximum discharge, 1,830 ft $3 / \mathrm{s}$ Aug. 22, 1971 , gage height, $5.40 \mathrm{ft}$, from rating curve extended above $320 \mathrm{ft}^{3} / \mathrm{s}$; minimum recorded, $0.2 \mathrm{ft}^{3} / \mathrm{s}$ Jan. 24,1965 , result of freezeup. 
GREEN RIVER BASIN

09288150 WEST FORK AVINTAQUIN CREEK NEAR FRUITHAND, UT--Continued

(Formerly published as cottorwood Creek near Fruitland)

LOWEST MEAN DISCHARGE, IN CUBIC FEET PER SECOND, AND RANKING FOR THE INDICATED NUMBER OF CONSECUTIVE DAYS FOR EACH CLIMATIC YEAR, APRII 1-MARCH 31

\begin{tabular}{|c|c|c|c|c|c|c|c|c|c|c|c|}
\hline YEAR & 1 & 3 & 7 & 14 & $\begin{array}{l}\text { CONSECUTIV } \\
30\end{array}$ & $\begin{array}{l}\text { DAYS } \\
60\end{array}$ & 90 & 120 & 183 & ALL & \\
\hline $\begin{array}{l}1971 \\
1972 \\
1973 \\
1974 \\
1975\end{array}$ & $\begin{array}{rr}1.80 & 12 \\
1.19 & 5 \\
2.50 & 16 \\
1.80 & 13 \\
1.10 & 4\end{array}$ & $\begin{array}{rr}1.80 & 12 \\
1.30 & 7 \\
2.50 & 16 \\
1.80 & 13 \\
1.10 & 4\end{array}$ & $\begin{array}{rr}1.80 & 12 \\
1.40 & 7 \\
2.50 & 16 \\
1.80 & 13 \\
1.10 & 4\end{array}$ & $\begin{array}{rr}1.90 & 12 \\
1.50 & 7 \\
2.50 & 16 \\
1.90 & 13 \\
1.10 & 4\end{array}$ & $\begin{array}{rr}1.90 & 12 \\
1.80 & 10 \\
2.50 & 16 \\
2.00 & 14 \\
1.10 & 3\end{array}$ & $\begin{array}{rr}2.00 & 14 \\
1.90 & 11 \\
2.50 & 16 \\
2.00 & 12 \\
1.10 & 3\end{array}$ & $\begin{array}{rr}2.30 & 14 \\
1.90 & 9 \\
2.60 & 16 \\
2.00 & 12 \\
1.19 & 3\end{array}$ & $\begin{array}{rr}2.60 & 15 \\
2.00 & 9 \\
2.70 & 16 \\
2.10 & 13 \\
1.30 & 3\end{array}$ & $\begin{array}{rr}3.10 & 14 \\
2.10 & 6 \\
3.10 & 15 \\
2.50 & 11 \\
1.70 & 3\end{array}$ & $\begin{array}{l}9.70 \\
15.0 \\
11.0 \\
27.0 \\
7.30\end{array}$ & $\begin{array}{r}5 \\
7 \\
6 \\
16 \\
3\end{array}$ \\
\hline $\begin{array}{l}1976 \\
1977 \\
1978 \\
1979 \\
1980\end{array}$ & $\begin{array}{rr}1.80 & 14 \\
0.49 & 2 \\
0.26 & 1 \\
1.30 & 6 \\
1.70 & 11\end{array}$ & $\begin{array}{rr}1.80 & 14 \\
0.51 & 2 \\
0.26 & 1 \\
1.30 & 5 \\
1.70 & 11\end{array}$ & $\begin{array}{rr}1.90 & 14 \\
0.52 & 2 \\
0.26 & 1 \\
1.30 & 5 \\
1.70 & 11\end{array}$ & $\begin{array}{rr}1.90 & 14 \\
0.53 & 2 \\
0.26 & 1 \\
1.30 & 5 \\
1.70 & 11\end{array}$ & $\begin{array}{rr}1.90 & 13 \\
0.55 & 2 \\
0.26 & 1 \\
1.50 & 5 \\
1.80 & 11\end{array}$ & $\begin{array}{rr}2.00 & 13 \\
0.60 & 2 \\
0.29 & 1 \\
1.50 & 4 \\
1.80 & 10\end{array}$ & $\begin{array}{rr}2.00 & 13 \\
0.65 & 2 \\
0.31 & 1 \\
1.60 & 4 \\
1.90 & 10\end{array}$ & $\begin{array}{rr}2.00 & 10 \\
0.71 & 2 \\
0.37 & 1 \\
1.60 & 4 \\
2.00 & 11\end{array}$ & $\begin{array}{rr}2.30 & 9 \\
1.10 & 2 \\
0.56 & 1 \\
1.90 & 4 \\
2.40 & 10\end{array}$ & $\begin{array}{c}16.0 \\
5.30 \\
1.00 \\
17.0 \\
20.0\end{array}$ & $\begin{array}{r}8 \\
2 \\
1 \\
11 \\
13\end{array}$ \\
\hline
\end{tabular}

HIGHEST MEAN DISCHARGE, IN CUBIC FEET PER SECOND, AND RANKING FOR THE INDICATED NUMBER OF OONSEOUTIVE DAYS FOR EACH WATER YEAR, OCTCBER 1-SEPTEMBER 30

\begin{tabular}{|c|c|c|c|c|c|c|c|c|c|c|c|c|c|c|c|c|c|c|c|c|}
\hline YEAR & 1 & & 3 & & 7 & & 15 & & $\begin{array}{l}\text { CONS } \\
30\end{array}$ & EOUT & $\begin{array}{l}\text { E DAYS } \\
60\end{array}$ & & 90 & & 120 & & 183 & & ALL & \\
\hline 1965 & 206 & 5 & 190 & 4 & 170 & 4 & 144 & 4 & 127 & 4 & 97.0 & 3 & 78.0 & 3 & 63.0 & 3 & 45.0 & 3 & 24.0 & 3 \\
\hline $\begin{array}{l}1976 \\
1977 \\
1978 \\
1979 \\
1980\end{array}$ & $\begin{array}{c}60.0 \\
7.50 \\
152 \\
225 \\
314\end{array}$ & $\begin{array}{r}15 \\
17 \\
8 \\
4 \\
2\end{array}$ & $\begin{array}{c}59.0 \\
3.70 \\
149 \\
207 \\
270\end{array}$ & $\begin{array}{r}15 \\
17 \\
7 \\
3 \\
2\end{array}$ & $\begin{array}{c}57.0 \\
2.40 \\
144 \\
200 \\
219\end{array}$ & $\begin{array}{r}15 \\
17 \\
7 \\
3 \\
2\end{array}$ & $\begin{array}{c}47.0 \\
2.40 \\
138 \\
176 \\
167\end{array}$ & $\begin{array}{r}15 \\
17 \\
6 \\
2 \\
3\end{array}$ & $\begin{array}{l}35.0 \\
2.20 \\
120 \\
130 \\
157\end{array}$ & $\begin{array}{r}15 \\
17 \\
5 \\
3 \\
2\end{array}$ & $\begin{array}{c}23.0 \\
2.00 \\
83.0 \\
92.0 \\
115\end{array}$ & $\begin{array}{r}15 \\
17 \\
5 \\
4 \\
2\end{array}$ & $\begin{array}{c}17.0 \\
1.60 \\
60.0 \\
70.0 \\
85.0\end{array}$ & $\begin{array}{r}15 \\
17 \\
6 \\
4 \\
2\end{array}$ & $\begin{array}{c}13.0 \\
1.30 \\
47.0 \\
55.0 \\
67.0\end{array}$ & $\begin{array}{r}15 \\
17 \\
6 \\
4 \\
2\end{array}$ & $\begin{array}{c}9.50 \\
1.10 \\
33.0 \\
38.0 \\
46.0\end{array}$ & $\begin{array}{r}15 \\
17 \\
6 \\
4 \\
2\end{array}$ & $\begin{array}{l}5.90 \\
1.10 \\
17.0 \\
20.0 \\
24.0\end{array}$ & $\begin{array}{r}15 \\
17 \\
7 \\
4 \\
2\end{array}$ \\
\hline
\end{tabular}

DURATION OF DISCHARGE FOR EACH WATER YEAR

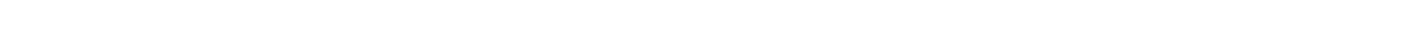

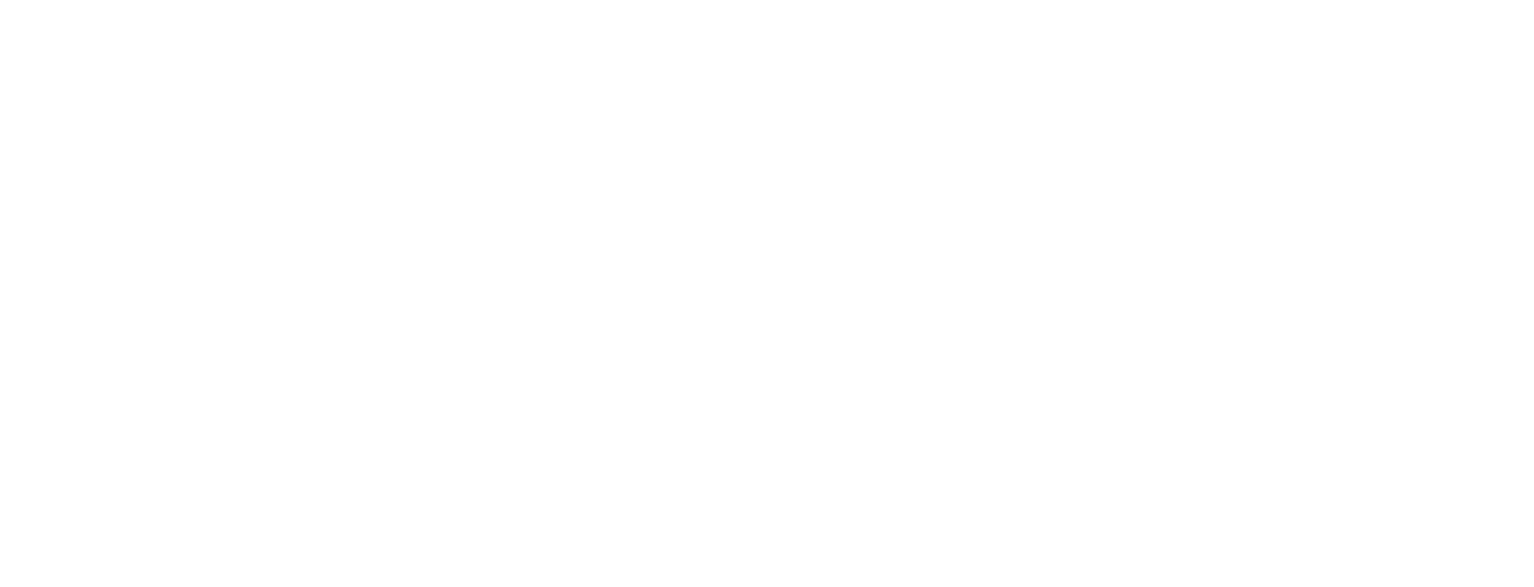


GREEN RIVER BASIN

09288150 WEST FORK AVINTAQUIN CREEK NEAR ERUITLAND, UT-Continued

(Formerly published as cottorwood Creek near Fruitland)

DURATION TABLE OF DISCHARGE FOR WATER YEARS 1965-81

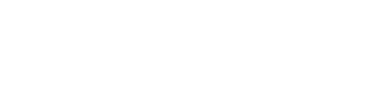

CUBIC ACOI- OUBIC ACOU-

FEET MU- PERPER TOTAL LATED CENT
CJASS SECOND DAYS DAYS DAYS

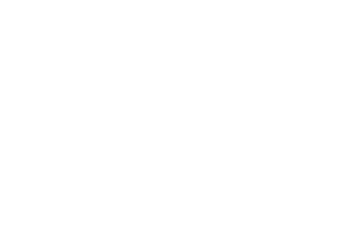

QUBIC
FEET
MUPER TOTAL LATED CENI CIJASS SECOND DAYS DAYS DAYS

$\begin{array}{rrrrr}18 & 10.0 & 216 & 1688 & 27.2 \\ 19 & 13.0 & 215 & 1472 & 23.7 \\ 20 & 16.0 & 170 & 1257 & 20.2 \\ 21 & 20.0 & 173 & 1087 & 17.5 \\ 22 & 25.0 & 158 & 914 & 14.7 \\ 23 & 31.0 & 134 & 756 & 12.2 \\ 24 & 39.0 & 106 & 622 & 10.0 \\ 25 & 48.0 & 130 & 516 & 8.3 \\ 26 & 60.0 & 89 & 386 & 6.2\end{array}$

CUBIC ACOJFEET MU- PERCLASS SECOND DAYS DAYS DAYS

$\begin{array}{rrrrr}27 & 74.0 & 82 & 297 & 4.8 \\ 28 & 92.0 & 55 & 215 & 3.5 \\ 29 & 110.0 & 80 & 160 & 2.6 \\ 30 & 140.0 & 46 & 80 & 1.3 \\ 31 & 180.0 & 18 & 34 & 0.5 \\ 32 & 220.0 & 5 & 16 & 0.3 \\ 33 & 270.0 & 9 & 11 & 0.2 \\ 34 & 340.0 & 2 & 2 & 0.0\end{array}$

MONIYLY MEAN DISCHARGES, IN CUBIC FEET PER SECOND, FOR EACH WATER YEAR

$\begin{array}{lllllllllllrr}\text { YEAR } & \text { OCT } & \text { NOV } & \text { DEC } & \text { JAN } & \text { FEB } & \text { MAR } & \text { APR } & \text { MAY } & \text { JUNE } & \text { JULY } & \text { AUG } & \text { SEP } \\ 1965 & 2.07 & 1.25 & 0.75 & 0.98 & 1.83 & 4.73 & 27.2 & 98.4 & 94.0 & 29.1 & 11.9 & 9.18 \\ 1966 & 5.50 & 3.11 & 2.53 & 2.06 & 2.54 & 4.09 & 23.0 & 38.9 & 12.6 & 6.33 & 2.74 & 2.14 \\ 1967 & 2.02 & 1.71 & 1.54 & 1.96 & 2.39 & 4.49 & 10.8 & 60.9 & 67.5 & 22.9 & 9.98 & 5.46 \\ 1968 & 3.16 & 2.22 & 1.77 & 1.57 & 2.09 & 7.05 & 15.0 & 79.7 & 67.3 & 17.7 & 9.89 & 3.76 \\ 1969 & 3.03 & 2.52 & 1.75 & 1.75 & 1.88 & 4.09 & 43.1 & 112 & 28.5 & 12.4 & 12.2 & 4.50 \\ 1970 & 3.67 & 3.08 & 1.95 & 1.33 & 2.41 & 3.42 & 5.04 & 37.6 & 28.8 & 12.9 & 5.22 & 4.05 \\ & & & & & & & & & & & & \\ 1971 & 4.19 & 2.81 & 1.95 & 2.52 & 3.46 & 7.55 & 18.4 & 61.1 & 35.5 & 17.5 & 17.2 & 3.26 \\ 1972 & 1.84 & 2.14 & 1.78 & 2.05 & 1.99 & 12.9 & 21.1 & 47.5 & 25.1 & 8.25 & 3.75 & 3.23 \\ 1973 & 3.92 & 3.68 & 2.65 & 2.50 & 2.56 & 3.30 & 29.7 & 191 & 57.1 & 14.8 & 6.19 & 3.73 \\ 1974 & 3.27 & 2.55 & 2.21 & 2.01 & 1.96 & 2.87 & 6.18 & 40.4 & 15.4 & 6.78 & 5.70 & 2.70 \\ 1975 & 2.74 & 2.11 & 1.17 & 1.10 & 1.30 & 1.76 & 4.67 & 42.1 & 91.0 & 31.4 & 8.82 & 4.78 \\ 1976 & 3.07 & 2.31 & 2.00 & 1.93 & 2.01 & 2.18 & 3.55 & 32.2 & 12.3 & 3.65 & 2.52 & 2.39 \\ 1977 & 2.18 & 1.71 & 0.85 & 0.58 & 0.68 & 0.76 & 0.86 & 0.99 & 1.23 & 1.37 & 0.84 & 1.39 \\ 1978 & 0.82 & 0.44 & 0.26 & 0.33 & 0.45 & 3.08 & 14.0 & 103 & 58.2 & 10.8 & 4.90 & 2.95 \\ 1979 & 2.56 & 1.81 & 1.61 & 1.67 & 1.52 & 2.39 & 27.1 & 127 & 47.6 & 13.6 & 5.75 & 3.23 \\ 1980 & 2.76 & 2.28 & 1.95 & 1.76 & 2.20 & 5.52 & 29.1 & 154 & 62.8 & 15.2 & 6.04 & 4.97 \\ 1981 & 3.66 & 2.30 & 1.84 & 2.11 & 1.75 & 1.70 & 5.05 & 18.9 & 20.3 & 6.16 & 4.06 & 2.68\end{array}$

ANNUAL PEAK DISCHARGE, IN CUBIC FEET PER SECOND, AND CORRESPONDING GAGE HEIGHT, IN FEET, FOR EACH WATER YEAR

\begin{tabular}{|c|c|c|c|c|c|c|c|c|c|c|c|}
\hline $\begin{array}{l}\text { WATER } \\
\text { YEAR }\end{array}$ & DATE & $\begin{array}{c}\text { GAGE } \\
\text { HEIGHT }\end{array}$ & $\begin{array}{c}\text { PEAK } \\
\text { DISCHARGE }\end{array}$ & $\begin{array}{l}\text { WATER } \\
\text { YEAR }\end{array}$ & DATE & $\begin{array}{c}\text { GAGE } \\
\text { HEIGHT }\end{array}$ & $\begin{array}{c}\text { PEAK } \\
\text { DISCHARGE }\end{array}$ & $\begin{array}{l}\text { WATER } \\
\text { YEAR }\end{array}$ & DATE & $\begin{array}{c}\text { GAGE } \\
\text { HEIGHT }\end{array}$ & $\begin{array}{c}\text { PEAK } \\
\text { DISCHARGE }\end{array}$ \\
\hline $\begin{array}{l}1965 \\
1966 \\
1967 \\
1968 \\
1969 \\
1970\end{array}$ & $\begin{array}{l}\text { JULY } 30,1965 \\
\text { JULY } 17,1966 \\
\text { AUG. } 31,1967 \\
\text { MAY } 31,1968 \\
\text { AUG. } 16,1969 \\
\text { MAY } 20,1970\end{array}$ & $\begin{array}{l}3.17 \\
1.77 \\
3.07 \\
1.94 \\
2.42 \\
1.75\end{array}$ & $\begin{array}{l}354 \\
139 \\
320 \\
200 \\
330 \\
106\end{array}$ & $\begin{array}{l}1971 \\
1972 \\
1973 \\
1974 \\
1975 \\
1976\end{array}$ & $\begin{array}{l}\text { AUG. } 22,1971 \\
\text { MAY } 20,1972 \\
\text { MAY } 19,1973 \\
\text { JULY } 31,1974 \\
\text { JULY } 31,1975 \\
\text { MAY } 18,1976\end{array}$ & $\begin{array}{l}5.40 \\
1.61 \\
2.65 \\
2.00 \\
4.20 \\
1.79\end{array}$ & $\begin{array}{r}1830 \\
67 \\
401 \\
197 \\
1160 \\
62\end{array}$ & $\begin{array}{l}1977 \\
1978 \\
1979 \\
1980 \\
1981\end{array}$ & 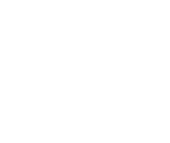 & $\begin{array}{l}2.00 \\
2.55 \\
2.92 \\
2.97 \\
2.75\end{array}$ & $\begin{array}{l}77 \\
181 \\
272 \\
489 \\
487\end{array}$ \\
\hline
\end{tabular}


GREEN RIVER BASIN

09288180 STREFBERRY RIVER NEAR DUCHESNE, UT

LOCATION. --Lat $40^{\circ} 09^{\prime} 17^{\prime \prime}$, long $110^{\circ} 33^{\prime} 15^{\prime \prime}$, in SE $\frac{1}{4} \mathrm{SW}_{4}^{1} \mathrm{SW} \frac{1}{4} \mathrm{sec} .3$, T.4 S., R.6 W., Uintah Meridian, Duchesne County, Hydrologic Unit 14060004 , on right bank $150 \mathrm{ft}$ downstream from County Road bridge, 2,000 ft upstream from maximm high-water line of Starvation Reservoir, and $7.9 \mathrm{mi}$ west of Duchesne.

DRAINAGE AREA.--917 $\mathrm{mi}^{2}$ (includes approximately $170 \mathrm{mi}^{2}$ tributary to Strawberry Reservoir).

PERIOD OF RECORD AVAIIABLE.--May 1968 to September 1981.

REVISED RECORDS. -WDR UT-77-1: Drainage area.

GAGE.-Water-stage recorder. Altitude of gage is 5,722 ft (Rabbit Gulch Quadrangle which gives bridge elevation).

REMARKS.-Flow regulated by Strawberry Reservoir since July 14, 1912 . Capacity, 1,106,500 acre-ft since June 30, 1973; 283,000 acre-ft prior to June 30,1973. New earthfilled dam located $7 \mathrm{mi}$ below old dam was completed in September 1972 and storage began June 30,1973 . When elevation of new reservoir reaches the elevation of the old reservoir, the old dam will be destroyed by explosives. Water Hollow tunnel will divert $600 \mathrm{ft}^{3} / \mathrm{s}$ to the reservoir during spring runoff when series of tunnels and small reservoirs are completed on Rock Creek, West Fork Duchesne River, and Currant Creek. Several old transmountain diversions

upstream to the reservoir. Transmountain diversions from the reservoir and upstream tributaries to the Great Basin.

AVERAGE DISCHARGE. --13 years, $125 \mathrm{ft}^{3} / \mathrm{s}, 90,560$ acre-ft/yr.

EXIREMES FOR PERIOD OF RECORD. - Maximum discharge, 1,310 $\mathrm{ft}^{3} / \mathrm{s}$ May 18, 1973, gage height, $6.30 \mathrm{ft}$; minimum recorded, $17 \mathrm{ft}{ }^{3} / \mathrm{s} \mathrm{June}$ 20,1977 .

DATA BELOW BASED ON PERIOD OF RECORD PRIOR TO ENLARGING STRAWBERRY RESERVOIR

LOWEST MEAN DISCHARGE, IN OUBIC FEET PER SECOND, AND RANKING FOR THE INDICATED NUMBER OF CONSECUTIVE DAYS FOR EACH OLIMATIC YEAR, APRIL 1-MARCH 31

\begin{tabular}{|c|c|c|c|c|c|c|c|c|c|c|c|c|c|c|c|c|c|c|c|}
\hline YEAR & 1 & & 3 & & 7 & & 14 & & $\begin{array}{l}\text { CONS } \\
30\end{array}$ & arm & $\begin{array}{l}\text { E DAYS } \\
60\end{array}$ & & 90 & & 120 & & 183 & & ALL \\
\hline 1970 & 51.0 & 3 & 52.0 & 3 & 54.0 & 3 & 55.0 & 3 & 61.0 & 3 & 66.0 & 3 & 70.0 & 3 & 76.0 & 3 & 87.0 & 3 & 203 \\
\hline
\end{tabular}

HIGHEST MEAN DISCHARGE, IN CUBIC FEET PER SECOND, AND RANKING FOR THE INDICATED NURBER OF CONSECUTIVE DAYS FOR EACH WATER YEAR, OCTCBER 1-SEPTEMBER 30

\begin{tabular}{|c|c|c|c|c|c|c|c|c|c|c|c|c|c|c|c|c|c|c|c|}
\hline YEAR & 1 & & 3 & & 7 & & 15 & & $\begin{array}{l}\infty \\
30\end{array}$ & & $\begin{array}{r}\text { VE DA } \\
60\end{array}$ & & 90 & & 12 & & 183 & & ALL \\
\hline $\begin{array}{l}1969 \\
1970\end{array}$ & $\begin{array}{r}1070 \\
544\end{array}$ & $\begin{array}{l}1 \\
3\end{array}$ & $\begin{array}{r}1060 \\
530\end{array}$ & $\begin{array}{l}1 \\
3\end{array}$ & $\begin{array}{r}1050 \\
493\end{array}$ & $\begin{array}{l}1 \\
2\end{array}$ & $\begin{array}{l}985 \\
444\end{array}$ & $\begin{array}{l}1 \\
2\end{array}$ & $\begin{array}{l}843 \\
378\end{array}$ & $\begin{array}{l}1 \\
2\end{array}$ & $\begin{array}{l}637 \\
292\end{array}$ & $\begin{array}{l}1 \\
3\end{array}$ & $\begin{array}{l}512 \\
236\end{array}$ & $\begin{array}{l}1 \\
4\end{array}$ & $\begin{array}{l}422 \\
201\end{array}$ & $\begin{array}{l}1 \\
4\end{array}$ & $\begin{array}{l}319 \\
160\end{array}$ & $\begin{array}{l}1 \\
4\end{array}$ & $\begin{array}{l}207 \\
124\end{array}$ \\
\hline $\begin{array}{l}1971 \\
1972\end{array}$ & $\begin{array}{l}566 \\
395\end{array}$ & $\begin{array}{l}2 \\
4\end{array}$ & $\begin{array}{l}547 \\
391\end{array}$ & $\begin{array}{l}2 \\
4\end{array}$ & $\begin{array}{l}480 \\
377\end{array}$ & $\begin{array}{l}3 \\
4\end{array}$ & $\begin{array}{l}411 \\
362\end{array}$ & $\begin{array}{l}3 \\
4\end{array}$ & $\begin{array}{l}374 \\
330\end{array}$ & $\begin{array}{l}3 \\
4\end{array}$ & $\begin{array}{l}299 \\
283\end{array}$ & $\begin{array}{l}2 \\
4\end{array}$ & $\begin{array}{l}255 \\
245\end{array}$ & $\begin{array}{l}2 \\
3\end{array}$ & $\begin{array}{l}218 \\
219\end{array}$ & $\begin{array}{l}3 \\
2\end{array}$ & $\begin{array}{l}172 \\
173\end{array}$ & $\begin{array}{l}3 \\
2\end{array}$ & $\begin{array}{l}121 \\
121\end{array}$ \\
\hline
\end{tabular}

DURATION OF DISCHARGE FOR EACH WATER YEAR

$\begin{array}{llllllllllllllllllllllllllllllllllll}\text { CLASS } & 0 & 1 & 2 & 3 & 4 & 5 & 6 & 7 & 8 & 9 & 10 & 11 & 12 & 13 & 14 & 15 & 16 & 17 & 18 & 19 & 20 & 21 & 22 & 23 & 24 & 25 & 26 & 27 & 28 & 29 & 30 & 31 & 32 & 33 & 34\end{array}$ YEAR NUMBER OF DAYS IN CIASS CUBIC FEET
PER SECOND -DAYS

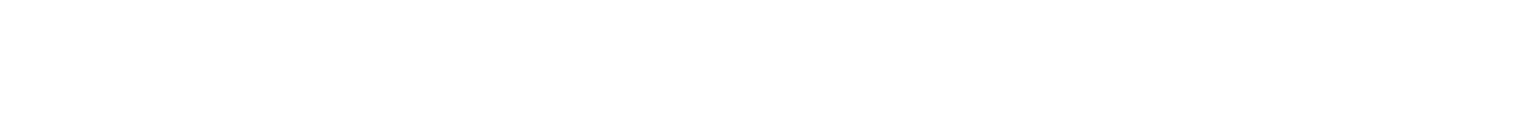

\begin{tabular}{crrrr}
\multicolumn{4}{c}{ CUBIC } & \multicolumn{2}{c}{ ACCU- } \\
FEET & MU- & PER- \\
PEER & TOTAL & LATED & CENT \\
CLASS SECOND & DAYS & DAYS & DAYS \\
& & & & \\
0 & 0.00 & 0 & 1461 & 100.0 \\
1 & 40.00 & 9 & 1461 & 100.0 \\
2 & 44.00 & 22 & 1452 & 99.4 \\
3 & 49.00 & 21 & 1430 & 97.9 \\
4 & 54.00 & 36 & 1409 & 96.4 \\
5 & 59.00 & 81 & 1373 & 94.0 \\
6 & 66.00 & 120 & 1292 & 88.4 \\
7 & 72.00 & 172 & 1172 & 80.2 \\
8 & 80.00 & 187 & 1000 & 68.4
\end{tabular}

DURATION TABLE OF DISCHARGE FOR WATER YEARS $1969-72$

$\begin{array}{ccc}\text { OUBIC } & \text { ACQJ- } \\ \text { FEET } & \text { MU- } & \text { PER- } \\ \text { PER } & \text { TOTAL LATED } & \text { CENT } \\ \text { CIASS SECOND } & \text { DAYS DAYS } & \text { DAYS }\end{array}$

$\begin{array}{rrrrr}9 & 88.00 & 148 & 81.3 & 55.6 \\ 10 & 98.00 & 127 & 665 & 45.5 \\ 11 & 110.00 & 71 & 538 & 36.8 \\ 12 & 120.00 & 55 & 467 & 32.0 \\ 13 & 130.00 & 33 & 412 & 28.2 \\ 14 & 140.00 & 60 & 379 & 25.9 \\ 15 & 160.00 & 35 & 319 & 21.8 \\ 16 & 180.00 & 32 & 284 & 19.4 \\ 17 & 200.00 & 23 & 252 & 17.2\end{array}$

\begin{tabular}{ccccc}
\multicolumn{4}{c}{ CUBIC } & \multicolumn{2}{c}{$\begin{array}{c}\text { ACOU- } \\
\text { FEET }\end{array}$} & $\begin{array}{c}\text { LV- } \\
\text { PER }\end{array}$ & TOTAL & PER- \\
CATED & CENT \\
CI.ASS SECOND & DAYS & DAYS & DAYS \\
18 & 220.0 & 24 & 229 & 15.7 \\
19 & 240.0 & 28 & 205 & 14.0 \\
20 & 260.0 & 27 & 177 & 12.1 \\
21 & 290.0 & 31 & 150 & 10.3 \\
22 & 320.0 & 25 & 119 & 8.1 \\
23 & 350.0 & 24 & 94 & 6.4 \\
24 & 390.0 & 15 & 70 & 4.8 \\
25 & 430.0 & 8 & 55 & 3.8 \\
26 & 480.0 & 8 & 47 & 3.2
\end{tabular}

\begin{tabular}{|c|c|c|c|c|}
\hline CLASS & $\begin{array}{r}\text { CUBIC } \\
\text { FEET } \\
\text { PER } \\
\text { SECOND }\end{array}$ & $\begin{array}{r}\text { TOTAL } \\
\text { DAYS }\end{array}$ & $\begin{array}{l}\text { ACOJ- } \\
\text { MU- } \\
\text { LATED } \\
\text { DAYS }\end{array}$ & $\begin{array}{l}\text { PER- } \\
\text { CENT } \\
\text { DAYS }\end{array}$ \\
\hline $\begin{array}{l}27 \\
28 \\
29 \\
30 \\
31 \\
32 \\
33 \\
34\end{array}$ & $\begin{array}{r}530.0 \\
580.0 \\
640.0 \\
710.0 \\
780.0 \\
860.0 \\
950.0 \\
1100.0\end{array}$ & $\begin{array}{r}6 \\
4 \\
6 \\
5 \\
5 \\
3 \\
10 \\
0\end{array}$ & $\begin{array}{r}39 \\
33 \\
29 \\
23 \\
18 \\
13 \\
10 \\
0\end{array}$ & $\begin{array}{l}2.7 \\
2.3 \\
2.0 \\
1.6 \\
1.2 \\
0.9 \\
0.7 \\
0.0\end{array}$ \\
\hline
\end{tabular}


GREEN RIVER BASIN

092881 80 STRAWBERRY RIVER NEAR DUCHESNE, UT-Continued

MONIHLY MEAN DISCHARGES, IN CUBIC FEET PER SECOND, FOR EACH WATER YEAR

\begin{tabular}{|c|c|c|c|c|c|c|c|c|c|c|c|c|}
\hline YEAR & $\infty \Gamma$ & $\mathrm{NON}$ & $\mathrm{DEC}$ & JAN & FEBB & MAR & APR & MAY & JUNE & JULY & AUG & SEP \\
\hline $\begin{array}{l}1969 \\
1970\end{array}$ & $\begin{array}{l}114 \\
118\end{array}$ & $\begin{array}{c}91.7 \\
101\end{array}$ & $\begin{array}{l}87.6 \\
88.3\end{array}$ & $\begin{array}{l}97.4 \\
62.5\end{array}$ & $\begin{array}{l}88.9 \\
72.9\end{array}$ & $\begin{array}{l}84.3 \\
79.8\end{array}$ & $\begin{array}{l}325 \\
107\end{array}$ & $\begin{array}{l}827 \\
357\end{array}$ & $\begin{array}{l}335 \\
219\end{array}$ & $\begin{array}{l}178 \\
108\end{array}$ & $\begin{array}{l}130 \\
81.5\end{array}$ & $\begin{array}{l}110 \\
86.4\end{array}$ \\
\hline $\begin{array}{l}1971 \\
1972\end{array}$ & $\begin{array}{l}84.8 \\
78.9\end{array}$ & $\begin{array}{l}80.3 \\
80.7\end{array}$ & $\begin{array}{l}65.6 \\
54.1\end{array}$ & $\begin{array}{l}72.1 \\
68.2\end{array}$ & $\begin{array}{l}48.5 \\
80.3\end{array}$ & $\begin{array}{r}82.2 \\
138\end{array}$ & $\begin{array}{l}173 \\
208\end{array}$ & $\begin{array}{l}361 \\
327\end{array}$ & $\begin{array}{l}220 \\
193\end{array}$ & $\begin{array}{l}103 \\
86.9\end{array}$ & $\begin{array}{l}82.2 \\
67.3\end{array}$ & $\begin{array}{l}74.8 \\
73.1\end{array}$ \\
\hline
\end{tabular}

ANNUAL PEAK DISCHARGE, IN CUBIC FEET PER SECOND, AND CORRESPONDING GAGE HEIGHT, IN FEET, FOR EACH WATER YEAR

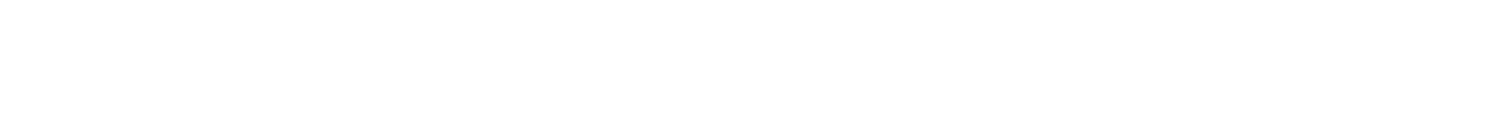

DATA BELOW BASED ON PERIOD OF RECORD AFTER ENLARGING STRAWBERRY RESERVOIR

LOWEST MEAN DISCHARGE, IN OUBIC FEET PER SECOND, AND RANKING FOR THE INDICATED NUMBER OF CONSECUTIVE DAYS FOR EACH CLIMATIC YEAR, APRIL 1-MARCH 31

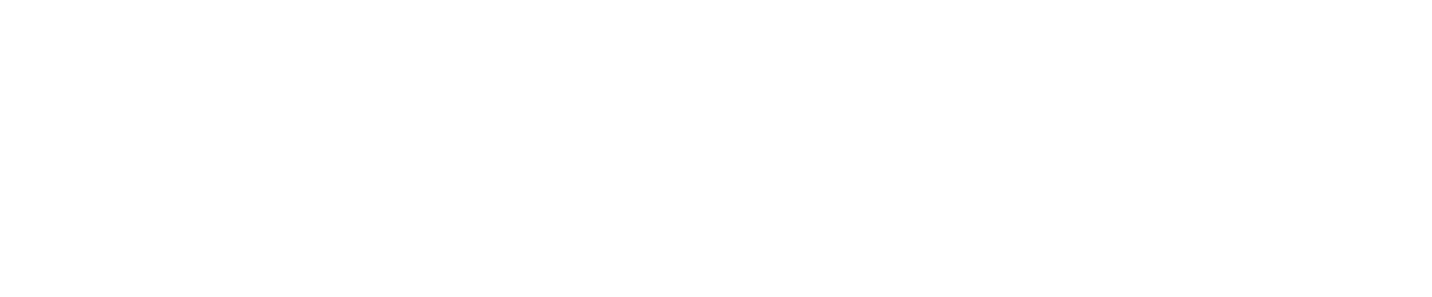

HIGHEST MEAN DISCHARGE, IN CUBIC FEET PER SECOND, AND RANKING FOR THE INDICATED NUMBER OF OONSECUTTVE DAYS FOR EACH WATER YEAR, OCTCBER 1-SEPTEMBER 30

\begin{tabular}{|c|c|c|c|c|c|c|c|c|c|c|c|c|c|c|c|c|c|c|c|}
\hline YEAR & 1 & & 3 & & 7 & & 15 & & $\begin{array}{l}\text { CON } \\
30\end{array}$ & Ba' & $\begin{array}{c}\text { VE DAYS } \\
60\end{array}$ & & 90 & & 120 & & 183 & & ALL \\
\hline $\begin{array}{l}1974 \\
1975\end{array}$ & $\begin{array}{l}494 \\
830\end{array}$ & $\begin{array}{l}5 \\
2\end{array}$ & $\begin{array}{l}476 \\
768\end{array}$ & $\begin{array}{l}5 \\
2\end{array}$ & $\begin{array}{l}437 \\
724\end{array}$ & $\begin{array}{l}5 \\
2\end{array}$ & & $\begin{array}{l}5 \\
2\end{array}$ & $\begin{array}{l}288 \\
581\end{array}$ & $\begin{array}{l}5 \\
2\end{array}$ & $\begin{array}{l}207 \\
432\end{array}$ & $\begin{array}{l}5 \\
2\end{array}$ & $\begin{array}{l}169 \\
324\end{array}$ & $\begin{array}{l}5 \\
2\end{array}$ & & $\begin{array}{l}5 \\
2\end{array}$ & $\begin{array}{l}122 \\
202\end{array}$ & $\begin{array}{l}5 \\
2\end{array}$ & $\begin{array}{c}93.0 \\
132\end{array}$ \\
\hline $\begin{array}{l}1976 \\
1977 \\
1978 \\
1979 \\
1980\end{array}$ & $\begin{array}{r}396 \\
137 \\
624 \\
744 \\
1160\end{array}$ & $\begin{array}{l}6 \\
8 \\
4 \\
3 \\
1\end{array}$ & $\begin{array}{c}379 \\
80.0 \\
579 \\
726 \\
1130\end{array}$ & $\begin{array}{l}6 \\
8 \\
4 \\
3 \\
1\end{array}$ & $\begin{array}{l}357 \\
70.0 \\
497 \\
707 \\
995\end{array}$ & $\begin{array}{l}6 \\
8 \\
4 \\
3 \\
1\end{array}$ & $\begin{array}{c}315 \\
68.0 \\
489 \\
653 \\
857\end{array}$ & $\begin{array}{l}6 \\
8 \\
4 \\
3 \\
1\end{array}$ & $\begin{array}{l}251 \\
68.0 \\
424 \\
517 \\
824\end{array}$ & $\begin{array}{l}6 \\
8 \\
4 \\
3 \\
1\end{array}$ & $\begin{array}{l}100 \\
65.0 \\
329 \\
392 \\
669\end{array}$ & $\begin{array}{l}6 \\
8 \\
4 \\
3 \\
1\end{array}$ & $\begin{array}{l}1.51 \\
60.0 \\
266 \\
310 \\
518\end{array}$ & $\begin{array}{l}6 \\
8 \\
4 \\
3 \\
1\end{array}$ & $\begin{array}{c}132 \\
56.0 \\
222 \\
259 \\
417\end{array}$ & $\begin{array}{l}6 \\
8 \\
4 \\
3 \\
1\end{array}$ & $\begin{array}{l}110 \\
56.0 \\
165 \\
193 \\
310\end{array}$ & $\begin{array}{l}6 \\
8 \\
4 \\
3 \\
1\end{array}$ & $\begin{array}{l}87.0 \\
48.0 \\
106 \\
125 \\
190\end{array}$ \\
\hline
\end{tabular}

DURATION OF DISCHARGE FOR EACH WATER YEAR

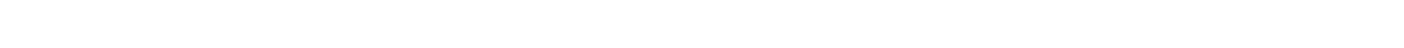
YEAR NUMBER OF DAYS IN CLASS OUBIC FEET PER SECOND

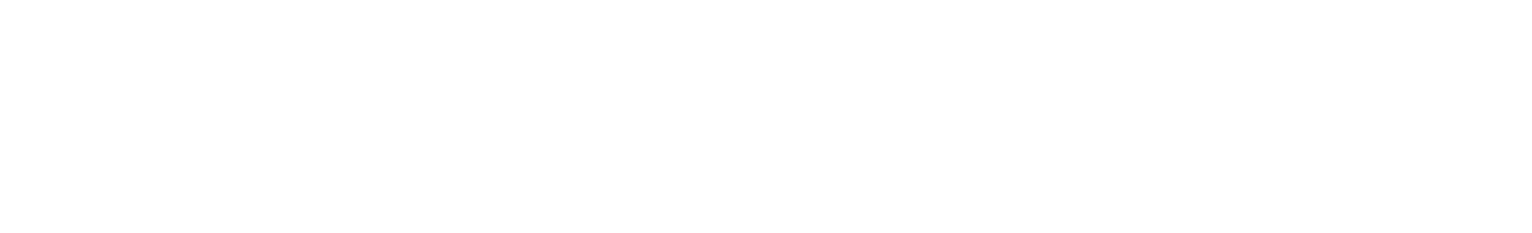


GREEN RIVER BASIN

09288180 STRAWBERRY RIVER NEAR DUCHESNE, UT--Continued

DURATION TABLE OF DISCHARGE FOR WATER YEARS 1974-81

$\begin{array}{ccc}\text { CUBIC } & \text { ACOU- } \\ \text { FEET } & \text { MU- } & \text { PER- } \\ \text { PER TOTAL LATED } & \text { CENT } \\ \text { CAASS SECOND DAYS DAYS DAYS } & \text { DAYS }\end{array}$

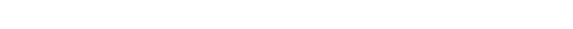

FEET ACON-

$\begin{array}{rrrr}\text { PER TOTAL LATED } & \text { CENT } \\ \text { CLASS SECOND DAYS DAYS DAYS OLASS SBCOND DAYS DAYS DAYS }\end{array}$

FEET MU- PER-

$\begin{array}{ccc}\text { CUBIC } & \text { ACOU- } \\ \text { FEET } & \text { MU- } & \text { PER- } \\ \text { PER TOIAL LATED } & \text { CENT } \\ \text { CIASS SECOND DAYS DAYS } & \text { DAYS }\end{array}$

$\begin{array}{rrrrr}0 & 0.00 & 0 & 2922 & 100.0 \\ 1 & 18.00 & 3 & 2922 & 100.0 \\ 2 & 20.00 & 14 & 2919 & 99.9 \\ 3 & 23.00 & 18 & 2905 & 99.4 \\ 4 & 26.00 & 26 & 2887 & 98.8 \\ 5 & 30.00 & 45 & 2861 & 97.9 \\ 6 & 34.00 & 49 & 2816 & 96.4 \\ 7 & 38.00 & 122 & 2767 & 94.7 \\ 8 & 43.00 & 133 & 2645 & 90.5\end{array}$

$\begin{array}{rrrrr}9 & 49.00 & 377 & 2512 & 86.0 \\ 10 & 56.00 & 222 & 2135 & 73.1 \\ 11 & 63.00 & 518 & 1913 & 65.5 \\ 12 & 72.00 & 264 & 1395 & 47.7 \\ 13 & 81.00 & 268 & 1131 & 38.7 \\ 14 & 92.00 & 159 & 863 & 29.5 \\ 15 & 100.00 & 221 & 704 & 24.1 \\ 16 & 120.00 & 44 & 483 & 16.5 \\ 17 & 130.00 & 55 & 439 & 15.0\end{array}$

$\begin{array}{llllr}18 & 150.0 & 45 & 384 & 13.1 \\ 19 & 170.0 & 56 & 339 & 11.6 \\ 20 & 200.0 & 21 & 283 & 9.7 \\ 21 & 220.0 & 29 & 262 & 9.0 \\ 22 & 250.0 & 28 & 233 & 8.0 \\ 23 & 290.0 & 29 & 205 & 7.0 \\ 24 & 320.0 & 29 & 176 & 6.0 \\ 25 & 370.0 & 22 & 147 & 5.0 \\ 26 & 420.0 & 28 & 125 & 4.3\end{array}$

$\begin{array}{rrrrr}27 & 470.0 & 18 & 97 & 3.3 \\ 28 & 540.0 & 19 & 79 & 2.7 \\ 29 & 610.0 & 27 & 60 & 2.1 \\ 30 & 690.0 & 17 & 33 & 1.1 \\ 31 & 780.0 & 7 & 16 & 0.5 \\ 32 & 890.0 & 5 & 9 & 0.3 \\ 33 & 1000.0 & 1 & 4 & 0.1 \\ 34 & 1100.0 & 3 & 3 & 0.1\end{array}$

MONIHLY MEAN DISCHARGES, IN CIBIC FEET PER SECOND, FOR EACH WATER YEAR

\begin{tabular}{|c|c|c|c|c|c|c|c|c|c|c|c|c|}
\hline YEAR & $\infty \mathrm{CT}$ & $\mathrm{NON}$ & DEC & JAN & FEB & MAR & APR & MAY & JUNE & JULY & AUG & SEP \\
\hline $\begin{array}{l}1974 \\
1975\end{array}$ & $\begin{array}{l}82.2 \\
67.0\end{array}$ & $\begin{array}{l}73.1 \\
72.6\end{array}$ & $\begin{array}{l}68.0 \\
58.3\end{array}$ & $\begin{array}{l}66.8 \\
55.0\end{array}$ & $\begin{array}{l}69.4 \\
56.5\end{array}$ & $\begin{array}{l}99.1 \\
91.4\end{array}$ & $\begin{array}{l}98.2 \\
75.6\end{array}$ & $\begin{array}{l}284 \\
322\end{array}$ & $\begin{array}{l}109 \\
491\end{array}$ & $\begin{array}{l}67.7 \\
147\end{array}$ & $\begin{array}{l}54.0 \\
87.3\end{array}$ & $\begin{array}{l}41.9 \\
62.4\end{array}$ \\
\hline $\begin{array}{l}1976 \\
1977 \\
1978 \\
1979 \\
1980\end{array}$ & $\begin{array}{l}71.6 \\
67.4 \\
37.1 \\
57.3 \\
66.7\end{array}$ & $\begin{array}{l}76.8 \\
62.5 \\
57.0 \\
66.6 \\
66.1\end{array}$ & $\begin{array}{l}74.7 \\
50.0 \\
47.9 \\
53.4 \\
64.8\end{array}$ & $\begin{array}{l}66.2 \\
40.8 \\
50.0 \\
53.8 \\
66.8\end{array}$ & $\begin{array}{l}70.0 \\
55.5 \\
54.1 \\
59.4 \\
70.3\end{array}$ & $\begin{array}{l}75.1 \\
59.6 \\
77.6 \\
95.0 \\
83.5\end{array}$ & $\begin{array}{l}96.4 \\
57.5 \\
161 \\
187 \\
221\end{array}$ & $\begin{array}{c}245 \\
44.2 \\
393 \\
502 \\
805\end{array}$ & $\begin{array}{c}104 \\
32.9 \\
235 \\
228 \\
471\end{array}$ & $\begin{array}{r}57.8 \\
36.9 \\
64.5 \\
78.3 \\
142\end{array}$ & $\begin{array}{r}49.7 \\
29.9 \\
39.8 \\
64.6 \\
110\end{array}$ & $\begin{array}{r}54.2 \\
33.8 \\
47.0 \\
45.7 \\
107\end{array}$ \\
\hline 1981 & 99.2 & 95.6 & 92.5 & 92.2 & 86.8 & 87.0 & 116 & 147 & 106 & 71.0 & 67.1 & 80.3 \\
\hline
\end{tabular}

ANNUAL PEAK DISCHARGE, IN OUBIC FEET PER SBCOND, AND CORRESPONDING GAGE HEIGHT, IN FEET, FOR EACH WATER YEAR

\begin{tabular}{|c|c|c|c|c|c|c|c|c|c|c|c|c|c|c|}
\hline $\begin{array}{l}\text { WATER } \\
\text { YEAR }\end{array}$ & & DATE & $\begin{array}{c}\text { GAGE } \\
\text { HEIGHT }\end{array}$ & $\begin{array}{c}\text { PEAK } \\
\text { DISCHARGE }\end{array}$ & $\begin{array}{l}\text { WATER } \\
\text { YEAR }\end{array}$ & & DATE & $\begin{array}{c}\text { GAGE } \\
\text { HEIGHT }\end{array}$ & $\begin{array}{c}\text { PEAK } \\
\text { DISCHARGE }\end{array}$ & $\begin{array}{l}\text { WATER } \\
\text { YEAR }\end{array}$ & & DATE & $\begin{array}{c}\text { GAGE } \\
\text { HEIGHT }\end{array}$ & $\begin{array}{c}\text { PEAK } \\
\text { DISCHARGE }\end{array}$ \\
\hline $\begin{array}{l}1973 \\
1974 \\
1975\end{array}$ & $\begin{array}{l}\text { MAY } \\
\text { MAY } \\
\text { JUNE }\end{array}$ & $\begin{array}{rl}18, & 1973 \\
10, & 1974 \\
\mathrm{E} & 03,1975\end{array}$ & $\begin{array}{l}6.30 \\
4.61 \\
5.71\end{array}$ & $\begin{array}{r}1310 \\
579 \\
965\end{array}$ & $\begin{array}{l}1976 \\
1977 \\
1978\end{array}$ & $\begin{array}{ll}\text { MAY } & 1 \\
\text { JULY } & 1 \\
\text { MAY } 1\end{array}$ & $\begin{array}{ll}18, & 1976 \\
19, & 1977 \\
16, & 1978\end{array}$ & $\begin{array}{l}4.24 \\
4.90 \\
4.87\end{array}$ & $\begin{array}{l}459 \\
716 \\
708\end{array}$ & $\begin{array}{l}1979 \\
1980 \\
1981\end{array}$ & $\begin{array}{l}\text { MAY } \\
\text { MAY } \\
\text { SEPT. }\end{array}$ & $\begin{array}{r}23,1979 \\
23,1980 \\
\Gamma .08,1981\end{array}$ & $\begin{array}{l}5.29 \\
6.39 \\
4.28\end{array}$ & $\begin{array}{r}786 \\
1220 \\
350\end{array}$ \\
\hline
\end{tabular}

${ }^{1}$ Peak discharge occurred before storage began in enlarged Strawberry Reservoir.

09288200 STRAWBERRY RIVER TRIBUTARY NEAR DUCHESNE, UT

LOCATION.--Lat $40^{\circ} 10^{\prime} 25^{\prime \prime}$, long $110^{\circ} 28^{\prime} 37^{\prime \prime}$, in SWl sec.32, T.3 S., R.5 W., Uintah Special Meridian, Duchesne County, Hydrologic

Unit 14060004 , on unimproved road $1 \mathrm{mi}$ south of U.S. Highway 40 and $4 \mathrm{mi}$ west of Duchesne.

DRATNAGE AREA. $--1.7 \mathrm{mi}^{2}$.

PERICD OF RECORD AVAILABLE.--Water years 1960-68, annual peak discharge only.

GAGE.--Crest-stage gage. Altitude of gage is 5,700 ft from topographic map.

ANNUAL PEAK DISCHARGE, IN CIBIC FEET PER SECOND, AND CORRESPONDING GAGE HEIGHT, IN FEET, FOR EACH WATER YEAR

\begin{tabular}{|c|c|c|c|c|c|c|c|c|c|c|c|c|}
\hline $\begin{array}{l}\text { WATERR } \\
\text { YEAR }\end{array}$ & DATE & $\begin{array}{c}\text { GAGE } \\
\text { HEIGHT }\end{array}$ & $\begin{array}{c}\text { PEAK } \\
\text { DISCHARGE }\end{array}$ & $\begin{array}{l}\text { WATE] } \\
\text { YEAR }\end{array}$ & DATE & $\begin{array}{c}\text { GAGE } \\
\text { HEIGHI }\end{array}$ & $\begin{array}{c}\text { PEAK } \\
\text { DISCHARGE }\end{array}$ & $\begin{array}{l}\text { WAT } \\
\text { YEA }\end{array}$ & & DATE & $\begin{array}{l}\text { GAGE } \\
\text { HEIGHT }\end{array}$ & $\begin{array}{c}\text { PEAK } \\
\text { DISCHARGE }\end{array}$ \\
\hline $\begin{array}{l}1960 \\
1961 \\
1962\end{array}$ & $\begin{array}{l}\text { SEPT.06, } 1960 \\
\text { SEPT.18, } 1961 \\
\text { MAR. } 23,1962\end{array}$ & $\begin{array}{l}10.15 \\
10.60 \\
10.60\end{array}$ & $\begin{array}{l}3.0 \\
15 \\
70\end{array}$ & $\begin{array}{l}1963 \\
1964 \\
1965\end{array}$ & $\begin{array}{lll}\text { AUG. } & 20, & 1963 \\
\text { AUG. } & 16, & 1964 \\
\text { JULY } 22, & 1965\end{array}$ & $\begin{array}{l}11.36 \\
11.00 \\
16.52\end{array}$ & $\begin{array}{r}177 \\
50 \\
2560\end{array}$ & $\begin{array}{l}1966 \\
1967 \\
1968\end{array}$ & $\begin{array}{l}\text { JULY } \\
\text { JULY } \\
-\end{array}$ & $\begin{array}{cc}25, & 1966 \\
03, & 1967 \\
- & --\end{array}$ & $\begin{array}{l}8.80 \\
8.45 \\
--\end{array}$ & $\begin{array}{r}40 \\
43 \\
0\end{array}$ \\
\hline
\end{tabular}


GREEN RIVER BASIN

09288300 TRATL HOLIOW NEAR TABIONA, UT

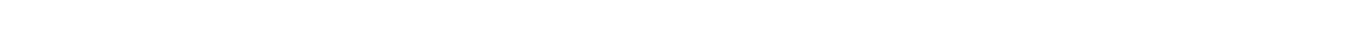

Hydrologic Unit $14060004,4.1 \mathrm{mi}$ south on State Highway 208 fram junction of State Highways 35 and 208 and $4.5 \mathrm{mi}$ southeast of Tabiona.

DRAINAGE AREA. $--6.8 \mathrm{mi}^{2}$.

PERIOD OF RECORD AVAILABLE.--Water years 1961-63, 1965-67, annual peak discharge only.

GAGE.-Crest-stage gage. Altitude of gage is 6,740 ft from topographic map.

ANNUAL PEAK DISCHARGE, IN OBBIC FEET PER SECOND, AND CORRESPONDING GAGE HEIGHT, IN FEET, FOR EACH WATER YEAR

\begin{tabular}{|c|c|c|c|c|c|c|c|c|c|c|c|}
\hline $\begin{array}{l}\text { WATER } \\
\text { YEAR }\end{array}$ & DATE & $\begin{array}{l}\text { GAGE } \\
\text { HEIGHT }\end{array}$ & $\begin{array}{c}\text { PEAK } \\
\text { DISCHARGE }\end{array}$ & $\begin{array}{l}\text { WATER } \\
\text { YEAR }\end{array}$ & DATE & $\begin{array}{c}\text { GAGE } \\
\text { HEIGHT }\end{array}$ & $\begin{array}{c}\text { PEAK } \\
\text { DISCHARGEE }\end{array}$ & $\begin{array}{l}\text { WATER } \\
\text { YEAR }\end{array}$ & DATE & $\begin{array}{l}\text { GAGE } \\
\text { HETGHT }\end{array}$ & $\begin{array}{c}\text { PEAR } \\
\text { DISCHARGE }\end{array}$ \\
\hline $\begin{array}{l}1961 \\
1962\end{array}$ & $\begin{array}{l}\text { AUG. } 31,1961 \\
\text { AUG. } 21,1962\end{array}$ & $\begin{array}{l}16.58 \\
11.35\end{array}$ & $\begin{array}{r}542 \\
11\end{array}$ & $\begin{array}{l}1963 \\
1965\end{array}$ & $\begin{array}{l}\text { SEPT.20, } 1963 \\
\text { JULY 23, } 1965\end{array}$ & $\begin{array}{l}12.49 \\
12.41\end{array}$ & $\begin{array}{l}50 \\
40\end{array}$ & $\begin{array}{l}1966 \\
1967\end{array}$ & $\begin{array}{l}\text { JULY 01, } 1966 \\
\text { AUG. 06, } 1967\end{array}$ & $\begin{array}{l}12.50 \\
12.75\end{array}$ & $\begin{array}{l}40 \\
56\end{array}$ \\
\hline
\end{tabular}

09288500 STRAWBERRI RIVER AT DUCHESNE, UT

LOCATION.--Lat $40^{\circ} 09^{\prime} 40^{\prime \prime}$, long $110^{\circ} 24^{\prime} 40^{\prime \prime}$, in SWliters sec.2, T.4 S., R.5 W., Uintah Meridian, Duchesne County, Hydrologic Unit 14060004 , on right bank $0.8 \mathrm{mi}$ west of Duchesne and $1.5 \mathrm{mi}$ upstream from mouth.

DRAINAGE AREA.--950 $\mathrm{mi}^{2}$, approximately (includes approximately $170 \mathrm{mi}^{2}$ tributary to Strawberry Reservoir).

MEAN BASIN ELEVATION. $-7,660 \mathrm{ft}$.

PERIOD OF RECORD AVAIIABLE.--June 1908 to November 1910 (no winter records; published as "at Theodore"). March 1914 to September 1968.

GAGE.-Water-stage recorder. Datum of gage 5,512.4 ft NGVD of 1929 . Prior to October 26, 1948, nonrecording gages near present site at various datums. Since October 26, 1948, water-stage recorder near present site at various datums.

REMARKS.--Several diversions above station for irrigation, including transmountain diversion to the Great Basin.

AVERAGE DISCHARGE. --54 years (water years 1915-68), $151 \mathrm{ft}^{3} / \mathrm{s}, 109,300 \mathrm{acre}-\mathrm{ft} / \mathrm{yr}$.

EXIREMES FOR PERIOD OF RECORD.--Maximum discharge, 3,490 $\mathrm{ft}^{3} / \mathrm{s}$ May 7, 1952, gage height, $5.34 \mathrm{ft}$; minimum discharge observed, $1 \mathrm{ft}^{3} / \mathrm{s}$, several days in July 1931.

LOWEST MEAN DISCHARGE, IN OBIC FEET PER SECOND, AND RANRING FOR THE INDICATED NUMBER OF CONSECITIVE DAYS FOR EACH CIIMATIC YEAR, APRII 1-MARCH 3I

\begin{tabular}{|c|c|c|c|c|c|c|c|c|c|c|c|c|c|c|c|c|c|c|c|c|}
\hline YEAR & 1 & & 3 & & 7 & & 14 & & $\begin{array}{l}\text { CONS } \\
30\end{array}$ & & $\begin{array}{l}\text { E DAYS } \\
60\end{array}$ & & 90 & & 120 & & 183 & & ALL & \\
\hline $\begin{array}{l}.921 \\
.922 \\
.923 \\
.924 \\
.925\end{array}$ & $\begin{array}{l}.0 \\
.0 \\
.0 \\
.0 \\
.0\end{array}$ & $\begin{array}{l}50 \\
32 \\
52 \\
51 \\
25\end{array}$ & $\begin{array}{l}78.0 \\
63.0 \\
90.0 \\
88.0 \\
37.0\end{array}$ & $\begin{array}{l}50 \\
43 \\
52 \\
51 \\
22\end{array}$ & $\begin{array}{l}5.0 \\
8.0 \\
0.0 \\
5.0 \\
7.0\end{array}$ & $\begin{array}{l}50 \\
46 \\
51 \\
52 \\
19\end{array}$ & $\begin{array}{c}85.0 \\
75.0 \\
90.0 \\
100 \\
39.0\end{array}$ & $\begin{array}{l}50 \\
49 \\
51 \\
53 \\
19\end{array}$ & $\begin{array}{c}87.0 \\
78.0 \\
90.0 \\
100 \\
42.0\end{array}$ & $\begin{array}{l}50 \\
48 \\
51 \\
53 \\
16\end{array}$ & $\begin{array}{r}88.0 \\
92.0 \\
92.0 \\
101 \\
44.0\end{array}$ & $\begin{array}{l}49 \\
50 \\
51 \\
53 \\
13\end{array}$ & $\begin{array}{c}92.0 \\
103 \\
97.0 \\
104 \\
46.0\end{array}$ & $\begin{array}{l}48 \\
52 \\
49 \\
53 \\
13\end{array}$ & $\begin{array}{l}99.0 \\
108 \\
104 \\
106 \\
50.0\end{array}$ & $\begin{array}{l}48 \\
52 \\
49 \\
51 \\
13\end{array}$ & $\begin{array}{l}109 \\
118 \\
121 \\
116 \\
55.0\end{array}$ & $\begin{array}{l}48 \\
50 \\
53 \\
49 \\
15\end{array}$ & $\begin{array}{c}249 \\
313 \\
399 \\
298 \\
85.0\end{array}$ & $\begin{array}{l}49 \\
10\end{array}$ \\
\hline $\begin{array}{l}1926 \\
1927 \\
1928 \\
1929 \\
1930\end{array}$ & $\begin{array}{l}37.0 \\
35.0 \\
64.0 \\
36.0 \\
61.0\end{array}$ & $\begin{array}{l}26 \\
22 \\
48 \\
23 \\
45\end{array}$ & $\begin{array}{l}38.0 \\
35.0 \\
64.0 \\
37.0 \\
63.0\end{array}$ & $\begin{array}{l}23 \\
19 \\
46 \\
20 \\
44\end{array}$ & $\begin{array}{l}39.0 \\
35.0 \\
64.0 \\
41.0 \\
68.0\end{array}$ & $\begin{array}{l}20 \\
18 \\
43 \\
22 \\
47\end{array}$ & $\begin{array}{l}42.0 \\
35.0 \\
67.0 \\
46.0 \\
70.0\end{array}$ & $\begin{array}{l}20 \\
13 \\
42 \\
23 \\
45\end{array}$ & $\begin{array}{l}45.0 \\
35.0 \\
70.0 \\
52.0 \\
70.0\end{array}$ & $\begin{array}{r}20 \\
9 \\
42 \\
27 \\
43\end{array}$ & $\begin{array}{l}62.0 \\
35.0 \\
70.0 \\
63.0 \\
72.0\end{array}$ & $\begin{array}{r}31 \\
9 \\
40 \\
32 \\
41\end{array}$ & $\begin{array}{l}65.0 \\
38.0 \\
77.0 \\
75.0 \\
77.0\end{array}$ & $\begin{array}{r}29 \\
9 \\
40 \\
38 \\
41\end{array}$ & & $\begin{array}{r}26 \\
8 \\
41 \\
39 \\
36\end{array}$ & $\begin{array}{c}67.0 \\
43.0 \\
100 \\
80.0 \\
81.0\end{array}$ & $\begin{array}{r}22 \\
7 \\
47 \\
38 \\
39\end{array}$ & $\begin{array}{l}92.0 \\
92.0 \\
196 \\
220 \\
173\end{array}$ & $\begin{array}{l}3 \\
4 \\
3 \\
6 \\
9\end{array}$ \\
\hline $\begin{array}{l}1936 \\
1937 \\
1938 \\
1939 \\
1940\end{array}$ & $\begin{array}{l}15.0 \\
54.0 \\
60.0 \\
54.0 \\
20.0\end{array}$ & $\begin{array}{r}7 \\
38 \\
44 \\
39 \\
8\end{array}$ & $\begin{array}{l}16.0 \\
55.0 \\
63.0 \\
54.0 \\
21.0\end{array}$ & $\begin{array}{r}7 \\
39 \\
45 \\
35 \\
9\end{array}$ & $\begin{array}{l}17.0 \\
55.0 \\
66.0 \\
55.0 \\
22.0\end{array}$ & $\begin{array}{r}7 \\
36 \\
44 \\
37 \\
8\end{array}$ & $\begin{array}{l}18.0 \\
57.0 \\
67.0 \\
55.0 \\
25.0\end{array}$ & $\begin{array}{r}7 \\
38 \\
43 \\
31 \\
9\end{array}$ & $\begin{array}{l}22.0 \\
58.0 \\
70.0 \\
55.0 \\
36.0\end{array}$ & $\begin{array}{r}7 \\
33 \\
44 \\
29 \\
11\end{array}$ & $\begin{array}{l}27.0 \\
67.0 \\
81.0 \\
59.0 \\
40.0\end{array}$ & $\begin{array}{r}6 \\
36 \\
46 \\
26 \\
11\end{array}$ & $\begin{array}{l}32.0 \\
72.0 \\
86.0 \\
64.0 \\
45.0\end{array}$ & $\begin{array}{r}6 \\
34 \\
44 \\
27 \\
12\end{array}$ & $\begin{array}{l}36.0 \\
75.0 \\
88.0 \\
69.0 \\
48.0\end{array}$ & $\begin{array}{r}6 \\
33 \\
44 \\
28 \\
12\end{array}$ & $\begin{array}{l}40.0 \\
78.0 \\
91.0 \\
74.0 \\
54.0\end{array}$ & $\begin{array}{r}6 \\
32 \\
41 \\
30 \\
13\end{array}$ & $\begin{array}{c}75.0 \\
163 \\
210 \\
160 \\
85.0\end{array}$ & $\begin{array}{r}7 \\
35 \\
45 \\
34\end{array}$ \\
\hline
\end{tabular}


GREEN RIVER BASIN

09288500 STRANBERRY RIVER AT DUCHESNE, UT-Continued

LOWEST MEAN DISCHARGE, IN OUBIC FEET PER SECOND, AND RANKING FOR THE INDICATED NUMBER OF CONSECUTIVE DAYS FOR EACH CLIMATIC YEAR, APRIL l-MARCH 31-Continued

\begin{tabular}{|c|c|c|c|c|c|c|c|c|c|c|c|c|c|c|c|c|c|c|c|c|}
\hline YEAR & 1 & & 3 & & 7 & & 14 & & $\begin{array}{l}\text { CONS } \\
30\end{array}$ & $\mathrm{ECO}$ & $\begin{array}{l}\text { E DAYS } \\
60\end{array}$ & & 90 & & 120 & & 183 & & ALL & \\
\hline $\begin{array}{l}1941 \\
1942 \\
1943 \\
1944 \\
1945\end{array}$ & $\begin{array}{l}14.0 \\
51.0 \\
35.0 \\
41.0 \\
62.0\end{array}$ & $\begin{array}{r}6 \\
35 \\
18 \\
29 \\
46\end{array}$ & $\begin{array}{l}15.0 \\
51.0 \\
43.0 \\
42.0 \\
62.0\end{array}$ & $\begin{array}{r}6 \\
32 \\
29 \\
28 \\
42\end{array}$ & $\begin{array}{l}16.0 \\
52.0 \\
53.0 \\
43.0 \\
63.0\end{array}$ & $\begin{array}{r}6 \\
30 \\
31 \\
23 \\
42\end{array}$ & $\begin{array}{l}17.0 \\
56.0 \\
54.0 \\
45.0 \\
64.0\end{array}$ & $\begin{array}{r}6 \\
35 \\
29 \\
21 \\
41\end{array}$ & $\begin{array}{l}19.0 \\
60.0 \\
56.0 \\
50.0 \\
65.0\end{array}$ & $\begin{array}{r}5 \\
34 \\
30 \\
24 \\
41\end{array}$ & $\begin{array}{l}23.0 \\
68.0 \\
60.0 \\
58.0 \\
67.0\end{array}$ & $\begin{array}{r}4 \\
38 \\
27 \\
24 \\
37\end{array}$ & $\begin{array}{l}29.0 \\
87.0 \\
63.0 \\
68.0 \\
73.0\end{array}$ & $\begin{array}{r}4 \\
45 \\
25 \\
31 \\
35\end{array}$ & $\begin{array}{l}43.0 \\
94.0 \\
65.0 \\
70.0 \\
78.0\end{array}$ & $\begin{array}{l}10 \\
47 \\
24 \\
30 \\
38\end{array}$ & $\begin{array}{l}49.0 \\
92.0 \\
68.0 \\
69.0 \\
79.0\end{array}$ & $\begin{array}{l}10 \\
42 \\
25 \\
26 \\
35\end{array}$ & $\begin{array}{l}63.0 \\
169 \\
137 \\
141 \\
164\end{array}$ & $\begin{array}{r}6 \\
38 \\
28 \\
30 \\
36\end{array}$ \\
\hline $\begin{array}{l}1946 \\
1947 \\
1948 \\
1949 \\
1950\end{array}$ & $\begin{array}{l}52.0 \\
41.0 \\
53.0 \\
20.0 \\
55.0\end{array}$ & $\begin{array}{r}36 \\
30 \\
37 \\
9 \\
40\end{array}$ & $\begin{array}{l}53.0 \\
41.0 \\
55.0 \\
20.0 \\
55.0\end{array}$ & $\begin{array}{r}33 \\
25 \\
36 \\
8 \\
37\end{array}$ & $\begin{array}{l}54.0 \\
44.0 \\
56.0 \\
23.0 \\
55.0\end{array}$ & $\begin{array}{r}32 \\
27 \\
38 \\
9 \\
33\end{array}$ & $\begin{array}{l}55.0 \\
46.0 \\
57.0 \\
24.0 \\
55.0\end{array}$ & $\begin{array}{r}32 \\
24 \\
36 \\
8 \\
33\end{array}$ & & $\begin{array}{r}31 \\
25 \\
39 \\
8 \\
32\end{array}$ & $\begin{array}{l}60.0 \\
59.0 \\
65.0 \\
29.0 \\
60.0\end{array}$ & $\begin{array}{r}28 \\
25 \\
33 \\
7 \\
29\end{array}$ & $\begin{array}{l}64.0 \\
62.0 \\
67.0 \\
34.0 \\
65.0\end{array}$ & $\begin{array}{r}26 \\
24 \\
30 \\
8 \\
28\end{array}$ & $\begin{array}{l}66.0 \\
64.0 \\
69.0 \\
40.0 \\
73.0\end{array}$ & $\begin{array}{r}25 \\
23 \\
29 \\
7 \\
31\end{array}$ & $\begin{array}{l}67.0 \\
69.0 \\
69.0 \\
46.0 \\
78.0\end{array}$ & $\begin{array}{r}23 \\
27 \\
28 \\
9 \\
33\end{array}$ & $\begin{array}{c}115 \\
114 \\
129 \\
85.0 \\
195\end{array}$ & $\begin{array}{l}23 \\
22 \\
26 \\
12 \\
42\end{array}$ \\
\hline $\begin{array}{l}1951 \\
1952 \\
1953 \\
1954 \\
1955\end{array}$ & $\begin{array}{l}62.0 \\
50.0 \\
95.0 \\
58.0 \\
30.0\end{array}$ & $\begin{array}{l}47 \\
33 \\
53 \\
43 \\
12\end{array}$ & $\begin{array}{l}67.0 \\
53.0 \\
95.0 \\
58.0 \\
30.0\end{array}$ & $\begin{array}{l}48 \\
34 \\
53 \\
41 \\
12\end{array}$ & $\begin{array}{l}68.0 \\
55.0 \\
95.0 \\
59.0 \\
32.0\end{array}$ & $\begin{array}{l}48 \\
34 \\
53 \\
41 \\
12\end{array}$ & $\begin{array}{l}70.0 \\
57.0 \\
95.0 \\
60.0 \\
37.0\end{array}$ & $\begin{array}{l}46 \\
37 \\
52 \\
39 \\
17\end{array}$ & & $\begin{array}{l}49 \\
36 \\
52 \\
35 \\
21\end{array}$ & $\begin{array}{l}85.0 \\
72.0 \\
98.0 \\
66.0 \\
57.0\end{array}$ & $\begin{array}{l}48 \\
42 \\
52 \\
34 \\
23\end{array}$ & $\begin{array}{c}87.0 \\
76.0 \\
101 \\
73.0 \\
58.0\end{array}$ & $\begin{array}{l}46 \\
39 \\
51 \\
36 \\
22\end{array}$ & $\begin{array}{c}89.0 \\
77.0 \\
104 \\
76.0 \\
59.0\end{array}$ & $\begin{array}{l}45 \\
37 \\
50 \\
34 \\
19\end{array}$ & $\begin{array}{c}89.0 \\
79.0 \\
120 \\
77.0 \\
64.0\end{array}$ & $\begin{array}{l}40 \\
34 \\
51 \\
31 \\
19\end{array}$ & $\begin{array}{c}183 \\
137 \\
422 \\
106 \\
80.0\end{array}$ & $\begin{array}{r}40 \\
27 \\
53 \\
17 \\
8\end{array}$ \\
\hline $\begin{array}{l}1961 \\
1962 \\
1963 \\
1964 \\
1965\end{array}$ & $\begin{array}{c}6.60 \\
2.10 \\
35.0 \\
22.0 \\
32.0\end{array}$ & $\begin{array}{l}4 \\
3 \\
19 \\
10 \\
15\end{array}$ & $\begin{array}{c}7.80 \\
2.40 \\
35.0 \\
23.0 \\
32.0\end{array}$ & $\begin{array}{r}4 \\
3 \\
17 \\
10 \\
14\end{array}$ & $\begin{array}{c}9.00 \\
2.60 \\
35.0 \\
24.0 \\
34.0\end{array}$ & $\begin{array}{r}4 \\
3 \\
16 \\
10 \\
14\end{array}$ & $\begin{array}{c}9.80 \\
3.50 \\
38.0 \\
30.0 \\
36.0\end{array}$ & $\begin{array}{r}4 \\
2 \\
18 \\
11 \\
15\end{array}$ & $\begin{array}{c}11.0 \\
5.90 \\
38.0 \\
38.0 \\
44.0\end{array}$ & $\begin{array}{r}4 \\
2 \\
14 \\
15 \\
18\end{array}$ & $\begin{array}{c}16.0 \\
8.90 \\
48.0 \\
41.0 \\
47.0\end{array}$ & $\begin{array}{r}3 \\
2 \\
17 \\
12 \\
15\end{array}$ & $\begin{array}{l}17.0 \\
13.0 \\
54.0 \\
44.0 \\
51.0\end{array}$ & $\begin{array}{r}3 \\
2 \\
18 \\
11 \\
16\end{array}$ & $\begin{array}{l}21.0 \\
21.0 \\
57.0 \\
47.0 \\
52.0\end{array}$ & $\begin{array}{r}2 \\
3 \\
18 \\
11 \\
15\end{array}$ & $\begin{array}{l}31.0 \\
33.0 \\
64.0 \\
51.0 \\
54.0\end{array}$ & $\begin{array}{r}2 \\
3 \\
18 \\
11 \\
14\end{array}$ & $\begin{array}{c}50.0 \\
49.0 \\
165 \\
84.0 \\
111\end{array}$ & $\begin{array}{r}4 \\
3 \\
37 \\
9 \\
19\end{array}$ \\
\hline $\begin{array}{l}1966 \\
1967 \\
1968\end{array}$ & $\begin{array}{l}65.0 \\
35.0 \\
41.0\end{array}$ & $\begin{array}{l}49 \\
20 \\
28\end{array}$ & $\begin{array}{l}66.0 \\
42.0 \\
50.0\end{array}$ & $\begin{array}{l}47 \\
27 \\
31\end{array}$ & $\begin{array}{l}67.0 \\
44.0 \\
58.0\end{array}$ & $\begin{array}{l}45 \\
26 \\
39\end{array}$ & $\begin{array}{l}71.0 \\
50.0 \\
68.0\end{array}$ & $\begin{array}{l}47 \\
27 \\
44\end{array}$ & $\begin{array}{l}74.0 \\
53.0 \\
77.0\end{array}$ & $\begin{array}{l}46 \\
28 \\
47\end{array}$ & $\begin{array}{l}74.0 \\
57.0 \\
80.0\end{array}$ & $\begin{array}{l}43 \\
22 \\
45\end{array}$ & $\begin{array}{l}78.0 \\
62.0 \\
82.0\end{array}$ & $\begin{array}{l}42 \\
23 \\
43\end{array}$ & & $\begin{array}{l}42 \\
27 \\
43\end{array}$ & $\begin{array}{l}96.0 \\
67.0 \\
93.0\end{array}$ & $\begin{array}{l}45 \\
21 \\
44\end{array}$ & $\begin{array}{l}205 \\
111 \\
183\end{array}$ & $\begin{array}{l}44 \\
20 \\
41\end{array}$ \\
\hline
\end{tabular}

HIGHEST MEAN DISCHARGE, IN GUBIC FEET PER SECOND, AND RANKING FOR THE INDICATED NUMBER OF CONSECUTIVE DAYS FOR EACH WATER YEAR, OCTOBER I-SEPTEMBER 30

\begin{tabular}{|c|c|c|c|c|c|c|c|c|c|c|c|c|c|c|c|c|c|c|c|c|}
\hline YEAR & 1 & & 3 & & 7 & & 15 & & $\begin{array}{l}C O N \\
30\end{array}$ & & $\begin{array}{l}\text { DAY } \\
60\end{array}$ & & 90 & & 120 & & 183 & & ALL & \\
\hline 915 & 367 & 47 & 350 & 44 & 336 & 43 & 328 & 38 & 322 & 35 & 293 & 33 & 255 & 32 & 221 & 31 & 176 & 31 & 133 & 30 \\
\hline $\begin{array}{l}926 \\
927 \\
928 \\
929 \\
930\end{array}$ & $\begin{array}{r}855 \\
1690 \\
1600 \\
892 \\
466\end{array}$ & $\begin{array}{r}20 \\
3 \\
6 \\
17 \\
40\end{array}$ & $\begin{array}{r}584 \\
1170 \\
1550 \\
866 \\
420\end{array}$ & $\begin{array}{r}31 \\
9 \\
5 \\
17 \\
39\end{array}$ & $\begin{array}{r}389 \\
1050 \\
1480 \\
860 \\
365\end{array}$ & $\begin{array}{r}36 \\
10 \\
5 \\
17 \\
40\end{array}$ & $\begin{array}{r}360 \\
864 \\
1420 \\
812 \\
316\end{array}$ & $\begin{array}{r}36 \\
11 \\
4 \\
16 \\
42\end{array}$ & $\begin{array}{r}301 \\
732 \\
1200 \\
657 \\
282\end{array}$ & $\begin{array}{r}38 \\
14 \\
6 \\
19 \\
39\end{array}$ & $\begin{array}{l}248 \\
521 \\
837 \\
475 \\
244\end{array}$ & $\begin{array}{r}37 \\
16 \\
7 \\
20 \\
38\end{array}$ & $\begin{array}{l}202 \\
415 \\
619 \\
382 \\
196\end{array}$ & $\begin{array}{r}38 \\
15 \\
7 \\
19 \\
41\end{array}$ & $\begin{array}{l}173 \\
344 \\
509 \\
331 \\
165\end{array}$ & $\begin{array}{r}38 \\
15 \\
7 \\
17 \\
41\end{array}$ & & $\begin{array}{r}38 \\
12 \\
8 \\
16 \\
40\end{array}$ & $\begin{array}{l}105 \\
168 \\
227 \\
177 \\
108\end{array}$ & $\begin{array}{r}40 \\
16 \\
8 \\
13 \\
37\end{array}$ \\
\hline $\begin{array}{l}1936 \\
1937 \\
1938 \\
1939 \\
1940\end{array}$ & $\begin{array}{r}768 \\
1220 \\
860 \\
800 \\
364\end{array}$ & $\begin{array}{l}27 \\
10 \\
19 \\
23 \\
48\end{array}$ & $\begin{array}{r}731 \\
1110 \\
809 \\
555 \\
209\end{array}$ & $\begin{array}{l}25 \\
12 \\
21 \\
33 \\
51\end{array}$ & $\begin{array}{r}699 \\
1070 \\
713 \\
371 \\
177\end{array}$ & $\begin{array}{r}25 \\
9 \\
23 \\
39 \\
50\end{array}$ & $\begin{array}{r}678 \\
1020 \\
584 \\
265 \\
149\end{array}$ & $\begin{array}{r}23 \\
9 \\
27 \\
45 \\
50\end{array}$ & $\begin{array}{l}604 \\
860 \\
550 \\
232 \\
138\end{array}$ & $\begin{array}{r}21 \\
9 \\
23 \\
45 \\
49\end{array}$ & $\begin{array}{l}466 \\
642 \\
469 \\
225 \\
115\end{array}$ & $\begin{array}{l}22 \\
10 \\
21 \\
41 \\
49\end{array}$ & $\begin{array}{l}372 \\
504 \\
363 \\
199 \\
103\end{array}$ & $\begin{array}{l}21 \\
10 \\
22 \\
39 \\
49\end{array}$ & $\begin{array}{c}325 \\
413 \\
298 \\
168 \\
93.0\end{array}$ & $\begin{array}{l}19 \\
10 \\
22 \\
39 \\
49\end{array}$ & $\begin{array}{r}243 \\
328 \\
232 \\
131 \\
83.0\end{array}$ & $\begin{array}{r}20 \\
9 \\
22 \\
43 \\
49\end{array}$ & $\begin{array}{r}147 \\
205 \\
161 \\
97.0 \\
67.0\end{array}$ & $\begin{array}{r}23 \\
9 \\
19 \\
43 \\
49\end{array}$ \\
\hline $\begin{array}{l}94 \\
94 \\
94 \\
94 \\
94\end{array}$ & $\begin{array}{r}1190 \\
560 \\
840 \\
1040 \\
508\end{array}$ & $\begin{array}{l}11 \\
36 \\
22 \\
13 \\
38\end{array}$ & $\begin{array}{r}1130 \\
515 \\
828 \\
1010 \\
486\end{array}$ & $\begin{array}{l}1 C \\
35 \\
20 \\
13 \\
38\end{array}$ & $\begin{array}{r}1020 \\
492 \\
748 \\
926 \\
482\end{array}$ & $\begin{array}{l}11 \\
33 \\
21 \\
15 \\
34\end{array}$ & $\begin{array}{l}831 \\
445 \\
719 \\
805 \\
432\end{array}$ & $\begin{array}{l}14 \\
33 \\
20 \\
17 \\
34\end{array}$ & $\begin{array}{l}658 \\
407 \\
571 \\
698 \\
334\end{array}$ & $\begin{array}{l}18 \\
32 \\
22 \\
15 \\
34\end{array}$ & $\begin{array}{l}505 \\
387 \\
409 \\
509 \\
264\end{array}$ & $\begin{array}{l}18 \\
26 \\
24 \\
17 \\
36\end{array}$ & $\begin{array}{l}387 \\
321 \\
327 \\
398 \\
215\end{array}$ & $\begin{array}{l}18 \\
25 \\
24 \\
17 \\
36\end{array}$ & $\begin{array}{l}323 \\
268 \\
271 \\
332 \\
197\end{array}$ & $\begin{array}{l}20 \\
25 \\
24 \\
16 \\
35\end{array}$ & $\begin{array}{l}240 \\
208 \\
215 \\
247 \\
161\end{array}$ & $\begin{array}{l}21 \\
25 \\
24 \\
18 \\
34\end{array}$ & $\begin{array}{l}147 \\
148 \\
142 \\
159 \\
122\end{array}$ & $\begin{array}{l}24 \\
22 \\
25 \\
20 \\
35\end{array}$ \\
\hline
\end{tabular}


HIGHEST MEAN DISCHARGE, IN OBBIC FEET PER SECOND, AND RANKING FOR THE INDICATED NUMBER OF CONSEOUTIVE DAYS FOR EACH WATER YEAR, OCTCBER 1-SEPTEMBER 30-Continued

YEAR

$\begin{array}{rrrrrr} & 1 & & 3 & & 7 \\ 1946 & 546 & 37 & 526 & 34 & 516 \\ 1947 & 755 & 28 & 729 & 26 & 710 \\ 1948 & 428 & 42 & 409 & 40 & 379 \\ 1949 & 1020 & 14 & 974 & 15 & 908 \\ 1950 & 863 & 18 & 852 & 18 & 835 \\ 1951 & 690 & 32 & 674 & 29 & 644 \\ 1952 & 3420 & 1 & 3260 & 1 & 2990 \\ 1953 & 308 & 50 & 298 & 46 & 290 \\ 1954 & 429 & 41 & 233 & 49 & 186 \\ 1955 & 501 & 39 & 494 & 37 & 477 \\ 1956 & 569 & 35 & 561 & 32 & 532 \\ 1957 & 721 & 29 & 714 & 27 & 694 \\ 1958 & 980 & 16 & 966 & 16 & 929 \\ 1959 & 162 & 53 & 105 & 53 & 97.0 \\ 1960 & 230 & 52 & 224 & 50 & 205 \\ & & & & & \\ 1961 & 415 & 44 & 190 & 52 & 108 \\ 1962 & 1020 & 15 & 1010 & 14 & 964 \\ 1963 & 368 & 46 & 362 & 42 & 342 \\ 1964 & 774 & 26 & 744 & 24 & 689 \\ 1965 & 1180 & 12 & 1130 & 11 & 1020 \\ 1966 & 422 & 43 & 408 & 41 & 374 \\ 1967 & 854 & 21 & 838 & 19 & 793 \\ 1968 & 791 & 24 & 764 & 23 & 718\end{array}$

CONSECUTIVE DAYS

$\begin{array}{rr} & 15 \\ 32 & 474 \\ 24 & 614 \\ 37 & 323 \\ 16 & 833 \\ 18 & 792 \\ 28 & 577 \\ 1 & 2680 \\ 44 & 276 \\ 49 & 181 \\ 35 & 400\end{array}$

15

$\begin{array}{llll}31 & 399 & 33 & 286 \\ 25 & 488 & 27 & 366 \\ 39 & 277 & 40 & 214\end{array}$

00

120

$\begin{array}{llll}39 & 277 & 40 & 214 \\ 13 & 784 & 10 & 646 \\ 18 & 667 & 16 & 560\end{array}$

$\begin{array}{rrrr}1 & 463 & 29 & 345 \\ 1 & 2180 & 1 & 1610\end{array}$

$\begin{array}{rrrr}1 & 2180 & 1 & 1610 \\ 43 & 237 & 44 & 203\end{array}$

$\begin{array}{llll}48 & 176 & 47 & 151 \\ 35 & 317 & 36 & 243\end{array}$

458

$\begin{array}{lll}635 & 24 & 431 \\ 647 & 31\end{array}$

$\begin{array}{cccccccc}635 & 24 & 547 & 24 & 447 & 23 & 345 & 23 \\ 850 & 12 & 764 & 11 & 529 & 14 & 400 & 16 \\ 89.0 & 53 & 82.0 & 52 & 82.0 & 52 & 79.0 & 52 \\ 174 & 49 & 138 & 50 & 114 & 50 & 100 & 50\end{array}$

$\begin{array}{llllllllllllll}91.0 & 52 & 69.0 & 53 & 61.0 & 53 & 56.0 & 53 & 53.0 & 53 & 50.0 & 53 & 41.0 & 53 \\ 820 & 15 & 738 & 13 & 564 & 12 & 466 & 12 & 379 & 12 & 275 & 14 & 161 & 18 \\ 316 & 41 & 267 & 42 & 197 & 46 & 166 & 45 & 139 & 45 & 120 & 45 & 93.0 & 44 \\ 606 & 26 & 471 & 28 & 334 & 31 & 266 & 31 & 220 & 32 & 163 & 32 & 106 & 39 \\ 874 & 10 & 747 & 12 & 607 & 11 & 489 & 11 & 412 & 11 & 313 & 10 & 187 & 10 \\ & & & & & & & & & & & & & \\ 334 & 37 & 312 & 37 & 274 & 35 & 231 & 34 & 202 & 33 & 159 & 35 & 122 & 34 \\ 725 & 19 & 662 & 17 & 524 & 15 & 419 & 14 & 353 & 14 & 272 & 15 & 174 & 14 \\ 688 & 21 & 611 & 20 & 476 & 19 & 374 & 20 & 319 & 21 & 253 & 17 & 172 & 15\end{array}$

DURATION OF DISCHARGE FOR EACH WATER YEAR

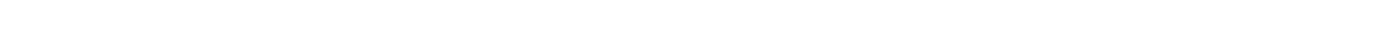
YEAR

NUMBER OF DAYS IN CTASS

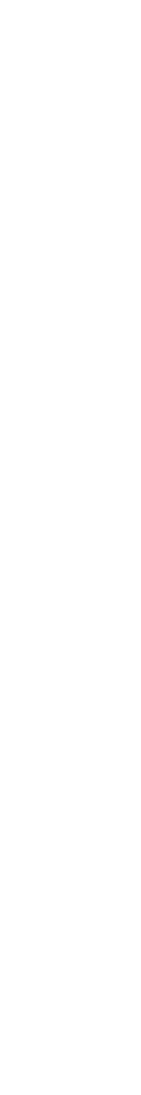


GREEN RIVER BASIN

09288500 STRANBERRY RIVER AT DUCHESNE, UT-Continued

DURATION OF DISCHARGE FOR EACH WATER YEAR--Continued

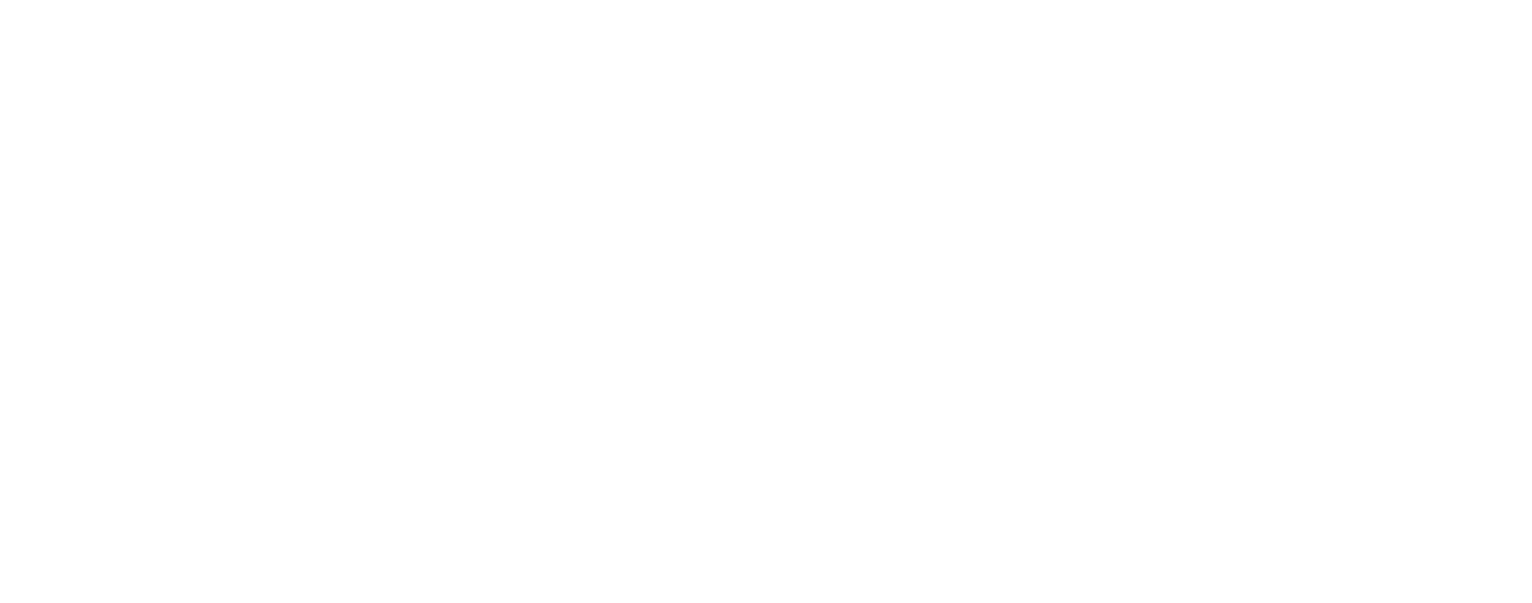

DURATION TABIE OF DISCHARGE FOR WATER YEARS 1915-68

\begin{tabular}{|c|c|c|c|c|c|c|c|c|c|c|c|c|c|c|c|c|c|c|c|}
\hline & $\begin{array}{l}\text { OBBIC } \\
\text { FEET } \\
\text { PER }\end{array}$ & TOTAL, & $\begin{array}{l}\text { ACOJ- } \\
\text { MU- } \\
\text { LATED }\end{array}$ & $\begin{array}{l}\text { PER- } \\
\text { CENT }\end{array}$ & & $\begin{array}{c}\text { CUBIC } \\
\text { FEET } \\
\text { PER }\end{array}$ & TOTAL & $\begin{array}{c}\text { ACOI- } \\
\text { MU- } \\
\text { LATED }\end{array}$ & $\begin{array}{l}\text { PER- } \\
\text { CENT }\end{array}$ & & $\begin{array}{c}\text { CUBIC } \\
\text { FEET } \\
\text { PER } \\
\text { SEOOND }\end{array}$ & TOTAL & $\begin{array}{r}\text { ACOU- } \\
\text { MU- } \\
\text { IATED }\end{array}$ & $\begin{array}{l}\text { PER- } \\
\text { CENT }\end{array}$ & & $\begin{array}{c}\text { OBBIC } \\
\text { FEET } \\
\text { PER }\end{array}$ & TOTAL & $\begin{array}{l}\text { ACOU- } \\
\text { MU- } \\
\text { LATED }\end{array}$ & $\begin{array}{l}\text { PER- } \\
\text { CENT } \\
\text { DAYS }\end{array}$ \\
\hline & SEUNV & Denive & DAYS & DAIS & & SEUTा & DAYS & DAIS & $\operatorname{Lent}$ & & SEDTW & DAIS & DAID & DSTS & & SELUND & DEIS & DMis & DESS \\
\hline $\begin{array}{l}0 \\
1 \\
2 \\
3 \\
4 \\
5 \\
6 \\
7 \\
8\end{array}$ & $\begin{array}{l}0.00 \\
1.00 \\
1.30 \\
1.60 \\
2.10 \\
2.70 \\
3.40 \\
4.40 \\
5.60\end{array}$ & $\begin{array}{r}0 \\
7 \\
0 \\
7 \\
3 \\
22 \\
24 \\
17 \\
39\end{array}$ & $\begin{array}{l}19724 \\
19724 \\
19717 \\
19717 \\
19710 \\
19707 \\
19685 \\
19661 \\
19644\end{array}$ & $\begin{array}{r}100.0 \\
100.0 \\
100.0 \\
100.0 \\
99.9 \\
99.9 \\
99.8 \\
99.7 \\
99.6\end{array}$ & $\begin{array}{l}9 \\
10 \\
11 \\
12 \\
13 \\
14 \\
15 \\
16 \\
17\end{array}$ & $\begin{array}{r}7.10 \\
9.10 \\
12.00 \\
15.00 \\
19.00 \\
24.00 \\
31.00 \\
40.00 \\
51.00\end{array}$ & $\begin{array}{r}42 \\
50 \\
51 \\
106 \\
137 \\
250 \\
668 \\
1679 \\
2498\end{array}$ & $\begin{array}{l}19605 \\
19563 \\
19513 \\
19462 \\
19356 \\
19219 \\
18969 \\
18301 \\
16622\end{array}$ & $\begin{array}{l}99.4 \\
99.2 \\
98.9 \\
98.7 \\
98.1 \\
97.4 \\
96.2 \\
92.8 \\
84.3\end{array}$ & $\begin{array}{l}18 \\
19 \\
20 \\
21 \\
22 \\
23 \\
24 \\
25 \\
26\end{array}$ & $\begin{array}{r}65.0 \\
83.0 \\
110.0 \\
140.0 \\
170.0 \\
220.0 \\
280.0 \\
360.0 \\
460.0\end{array}$ & $\begin{array}{r}3586 \\
3716 \\
1877 \\
1040 \\
921 \\
765 \\
609 \\
435 \\
370\end{array}$ & $\begin{array}{r}14124 \\
10538 \\
6822 \\
4945 \\
3905 \\
2984 \\
2219 \\
1610 \\
1175\end{array}$ & $\begin{array}{r}71.6 \\
53.4 \\
34.6 \\
25.1 \\
19.8 \\
15.1 \\
11.3 \\
8.2 \\
6.0\end{array}$ & $\begin{array}{l}27 \\
28 \\
29 \\
30 \\
31 \\
32 \\
33 \\
34\end{array}$ & $\begin{array}{r}590.0 \\
750.0 \\
960.0 \\
1200.0 \\
1600.0 \\
2000.0 \\
2600.0 \\
3300.0\end{array}$ & $\begin{array}{r}301 \\
211 \\
98 \\
135 \\
28 \\
21 \\
10 \\
1\end{array}$ & $\begin{array}{r}805 \\
504 \\
293 \\
195 \\
60 \\
32 \\
11 \\
1\end{array}$ & $\begin{array}{l}4.1 \\
2.6 \\
1.5 \\
1.0 \\
0.3 \\
0.2 \\
0.1 \\
0.0\end{array}$ \\
\hline
\end{tabular}

MONTHLY MEAN DISCHARGES, IN CUBIC FEET PER SECOND, FOR EACH WATER YEAR

\begin{tabular}{|c|c|c|c|c|c|c|c|c|c|c|c|c|}
\hline YEAR & $\infty C T$ & NON & DEC & JAN & FEB & MAR & APR & MAY & JUNE & JULY & AUG & SEP \\
\hline 1915 & 138 & 93.5 & 76.5 & 77.0 & 83.0 & 112 & 209 & 305 & 244 & 102 & 68.5 & 83.2 \\
\hline $\begin{array}{l}1916 \\
1917 \\
1918 \\
1919 \\
1920\end{array}$ & $\begin{array}{l}86.2 \\
172 \\
146 \\
104 \\
91.7\end{array}$ & $\begin{array}{l}103 \\
90.7 \\
135 \\
78.5 \\
83.8\end{array}$ & $\begin{array}{c}71.7 \\
88.5 \\
137 \\
49.7 \\
63.6\end{array}$ & $\begin{array}{l}66.0 \\
45.0 \\
70.3 \\
46.0 \\
75.0\end{array}$ & $\begin{array}{l}85.0 \\
85.0 \\
95.0 \\
70.0 \\
80.0\end{array}$ & $\begin{array}{c}305 \\
175 \\
132 \\
130 \\
98.9\end{array}$ & $\begin{array}{l}463 \\
301 \\
156 \\
219 \\
146\end{array}$ & $\begin{array}{r}1112 \\
886 \\
248 \\
495 \\
926\end{array}$ & $\begin{array}{c}521 \\
1204 \\
211 \\
176 \\
584\end{array}$ & $\begin{array}{c}239 \\
359 \\
132 \\
82.7 \\
198\end{array}$ & $\begin{array}{l}182 \\
176 \\
63.5 \\
97.2 \\
248\end{array}$ & $\begin{array}{l}102 \\
170 \\
80.0 \\
107 \\
128\end{array}$ \\
\hline $\begin{array}{l}1921 \\
1922 \\
1923 \\
1924 \\
1925\end{array}$ & $\begin{array}{c}113 \\
133 \\
148 \\
142 \\
60.2\end{array}$ & $\begin{array}{l}109 \\
121 \\
149 \\
128 \\
70.5\end{array}$ & $\begin{array}{l}87.5 \\
126 \\
120 \\
104 \\
54.7\end{array}$ & $\begin{array}{l}90.0 \\
84.4 \\
100 \\
100 \\
60.0\end{array}$ & $\begin{array}{c}137 \\
99.3 \\
90.0 \\
110 \\
65.0\end{array}$ & $\begin{array}{c}212 \\
202 \\
118 \\
111 \\
93.2\end{array}$ & $\begin{array}{l}277 \\
227 \\
298 \\
189 \\
136\end{array}$ & $\begin{array}{r}962 \\
1786 \\
1193 \\
206 \\
142\end{array}$ & $\begin{array}{c}970 \\
1277 \\
742 \\
80.4 \\
116\end{array}$ & $\begin{array}{c}271 \\
317 \\
298 \\
55.8 \\
123\end{array}$ & $\begin{array}{l}332 \\
261 \\
202 \\
44.1 \\
81.8\end{array}$ & $\begin{array}{c}167 \\
169 \\
144 \\
44.1 \\
56.1\end{array}$ \\
\hline $\begin{array}{l}1926 \\
1927 \\
1928 \\
1929 \\
1930\end{array}$ & $\begin{array}{l}79.1 \\
46.5 \\
111 \\
110 \\
91.6\end{array}$ & $\begin{array}{c}72.5 \\
55.8 \\
133 \\
92.6 \\
87.2\end{array}$ & $\begin{array}{l}65.4 \\
44.7 \\
93.8 \\
75.7 \\
75.0\end{array}$ & $\begin{array}{l}60.0 \\
35.0 \\
70.0 \\
75.0 \\
70.0\end{array}$ & $\begin{array}{l}70.0 \\
38.1 \\
70.0 \\
75.0 \\
90.0\end{array}$ & $\begin{array}{l}100 \\
72.2 \\
150 \\
109 \\
74.6\end{array}$ & $\begin{array}{l}215 \\
140 \\
340 \\
138 \\
206\end{array}$ & $\begin{array}{r}268 \\
715 \\
1143 \\
615 \\
252\end{array}$ & $\begin{array}{l}96.7 \\
292 \\
339 \\
319 \\
121\end{array}$ & $\begin{array}{l}73.5 \\
204 \\
123 \\
196 \\
70.9\end{array}$ & $\begin{array}{c}121 \\
116 \\
89.4 \\
168 \\
91.0\end{array}$ & $\begin{array}{c}38.5 \\
247 \\
53.6 \\
139 \\
69.7\end{array}$ \\
\hline $\begin{array}{l}1931 \\
1932 \\
1933 \\
1934 \\
1935\end{array}$ & $\begin{array}{l}70.7 \\
36.5 \\
53.8 \\
36.5 \\
21.5\end{array}$ & $\begin{array}{l}60.4 \\
49.7 \\
57.0 \\
48.4 \\
35.9\end{array}$ & $\begin{array}{l}50.0 \\
60.0 \\
47.6 \\
48.1 \\
35.0\end{array}$ & $\begin{array}{l}50.0 \\
70.0 \\
55.0 \\
50.0 \\
35.0\end{array}$ & $\begin{array}{l}60.0 \\
80.0 \\
50.0 \\
52.1 \\
35.0\end{array}$ & $\begin{array}{l}69.4 \\
91.4 \\
67.3 \\
46.3 \\
55.5\end{array}$ & $\begin{array}{c}84.9 \\
147 \\
85.1 \\
35.4 \\
75.3\end{array}$ & $\begin{array}{l}90.7 \\
503 \\
250 \\
16.5 \\
202\end{array}$ & $\begin{array}{c}44.8 \\
260 \\
343 \\
7.63 \\
201\end{array}$ & $\begin{array}{l}34.5 \\
87.8 \\
99.8 \\
11.3 \\
46.2\end{array}$ & $\begin{array}{l}41.6 \\
97.6 \\
57.1 \\
18.0 \\
49.3\end{array}$ & $\begin{array}{c}23.7 \\
56.1 \\
45.6 \\
8.03 \\
22.1\end{array}$ \\
\hline $\begin{array}{l}1936 \\
1937 \\
1938 \\
1939 \\
1940\end{array}$ & $\begin{array}{l}32.5 \\
63.5 \\
95.1 \\
83.6 \\
56.3\end{array}$ & $\begin{array}{l}41.8 \\
83.3 \\
94.5 \\
76.1 \\
61.0\end{array}$ & $\begin{array}{l}48.9 \\
85.0 \\
94.2 \\
84.9 \\
69.8\end{array}$ & $\begin{array}{l}55.0 \\
80.0 \\
70.2 \\
65.0 \\
60.0\end{array}$ & $\begin{array}{c}60.0 \\
80.0 \\
102 \\
55.0 \\
60.0\end{array}$ & $\begin{array}{l}64.3 \\
100 \\
103 \\
169 \\
81.2\end{array}$ & $\begin{array}{l}232 \\
221 \\
304 \\
192 \\
101\end{array}$ & $\begin{array}{l}567 \\
838 \\
521 \\
209 \\
127\end{array}$ & $\begin{array}{r}248 \\
369 \\
242 \\
93.6 \\
47.9\end{array}$ & $\begin{array}{r}189 \\
196 \\
104 \\
42.7 \\
27.5\end{array}$ & $\begin{array}{c}124 \\
163 \\
69.1 \\
39.2 \\
20.9\end{array}$ & $\begin{array}{c}92.3 \\
169 \\
136 \\
54.9 \\
97.0\end{array}$ \\
\hline
\end{tabular}


GREEN RIVER BASIN

09288500 STRANERRY RIVER AT DUGESNE, UT-ContinUed

MONTHLY MEAN DISCHARGES, IN QRBIC FEET PER SECOND, FOR EACH WATER YEAR-Continued

\begin{tabular}{|c|c|c|c|c|c|c|c|c|c|c|c|c|}
\hline YEAR & $\infty \mathrm{CT}$ & NOV & DEC & JAN & FEB & MAR & APR & MAY & JUNE & JULY & AUG & SEP \\
\hline $\begin{array}{l}1941 \\
1942 \\
1943 \\
1944 \\
1945\end{array}$ & $\begin{array}{c}50.8 \\
104 \\
67.1 \\
77.4 \\
85.1\end{array}$ & $\begin{array}{c}52.9 \\
123 \\
80.1 \\
77.1 \\
90.9\end{array}$ & $\begin{array}{l}55.6 \\
99.3 \\
74.2 \\
74.9 \\
79.4\end{array}$ & $\begin{array}{l}45.0 \\
85.0 \\
66.1 \\
60.0 \\
85.2\end{array}$ & $\begin{array}{l}55.0 \\
86.4 \\
92.7 \\
70.0 \\
91.8\end{array}$ & $\begin{array}{c}76.2 \\
107 \\
96.3 \\
99.6 \\
92.9\end{array}$ & $\begin{array}{l}123 \\
344 \\
382 \\
166 \\
102\end{array}$ & $\begin{array}{l}648 \\
397 \\
372 \\
643 \\
328\end{array}$ & $\begin{array}{l}337 \\
210 \\
219 \\
360 \\
192\end{array}$ & $\begin{array}{c}140 \\
99.8 \\
96.0 \\
137 \\
108\end{array}$ & $\begin{array}{c}108 \\
62.4 \\
110 \\
70.2 \\
136\end{array}$ & $\begin{array}{l}61.9 \\
59.6 \\
51.7 \\
65.0 \\
66.7\end{array}$ \\
\hline $\begin{array}{l}1946 \\
1947 \\
1948 \\
1949 \\
1950\end{array}$ & $\begin{array}{c}71.3 \\
69.5 \\
68.2 \\
52.8 \\
102\end{array}$ & $\begin{array}{l}72.8 \\
81.1 \\
74.6 \\
61.6 \\
97.2\end{array}$ & $\begin{array}{l}60.2 \\
75.5 \\
69.1 \\
56.0 \\
69.7\end{array}$ & $\begin{array}{l}60.0 \\
66.8 \\
65.0 \\
50.0 \\
60.0\end{array}$ & $\begin{array}{c}75.0 \\
107 \\
69.4 \\
56.4 \\
65.9\end{array}$ & $\begin{array}{l}103 \\
119 \\
106 \\
117 \\
112\end{array}$ & $\begin{array}{l}279 \\
206 \\
124 \\
374 \\
340\end{array}$ & $\begin{array}{l}279 \\
480 \\
274 \\
763 \\
604\end{array}$ & $\begin{array}{l}105 \\
176 \\
118 \\
366 \\
373\end{array}$ & $\begin{array}{c}71.0 \\
78.5 \\
50.6 \\
161 \\
153\end{array}$ & $\begin{array}{l}67.4 \\
83.7 \\
29.5 \\
86.7 \\
88.4\end{array}$ & $\begin{array}{l}52.2 \\
68.3 \\
29.2 \\
72.3 \\
88.4\end{array}$ \\
\hline $\begin{array}{l}1951 \\
1952 \\
1953 \\
1954 \\
1955\end{array}$ & $\begin{array}{c}90.8 \\
84.0 \\
163 \\
77.4 \\
72.6\end{array}$ & $\begin{array}{r}97.7 \\
81.6 \\
132 \\
86.1 \\
72.8\end{array}$ & $\begin{array}{c}91.0 \\
78.5 \\
110 \\
79.7 \\
63.0\end{array}$ & $\begin{array}{c}84.0 \\
80.0 \\
100 \\
75.0 \\
58.0\end{array}$ & $\begin{array}{l}91.7 \\
85.0 \\
95.0 \\
84.9 \\
55.0\end{array}$ & $\begin{array}{r}91.6 \\
97.6 \\
114 \\
93.2 \\
62.6\end{array}$ & $\begin{array}{l}172 \\
565 \\
141 \\
148 \\
138\end{array}$ & $\begin{array}{r}415 \\
2155 \\
1818 \\
150 \\
313\end{array}$ & $\begin{array}{c}246 \\
827 \\
199 \\
77.1 \\
131\end{array}$ & $\begin{array}{l}111 \\
305 \\
94.8 \\
61.9 \\
65.0\end{array}$ & $\begin{array}{c}124 \\
264 \\
97.7 \\
55.2 \\
104\end{array}$ & $\begin{array}{c}63.4 \\
200 \\
61.1 \\
82.9 \\
56.7\end{array}$ \\
\hline $\begin{array}{l}1956 \\
1957 \\
1958 \\
1959 \\
1960\end{array}$ & $\begin{array}{l}52.0 \\
62.5 \\
82.7 \\
61.2 \\
52.9\end{array}$ & $\begin{array}{r}59.6 \\
71.5 \\
102 \\
65.4 \\
51.0\end{array}$ & $\begin{array}{c}77.0 \\
84.4 \\
104 \\
61.9 \\
44.2\end{array}$ & $\begin{array}{l}76.4 \\
85.0 \\
87.9 \\
52.6 \\
44.2\end{array}$ & $\begin{array}{r}91.4 \\
84.6 \\
100 \\
60.9 \\
45.0\end{array}$ & $\begin{array}{c}124 \\
90.0 \\
103 \\
74.0 \\
62.6\end{array}$ & $\begin{array}{r}198 \\
104 \\
182 \\
81.1 \\
89.6\end{array}$ & $\begin{array}{c}425 \\
429 \\
740 \\
78.4 \\
136\end{array}$ & $\begin{array}{l}179 \\
454 \\
256 \\
41.5 \\
49.9\end{array}$ & $\begin{array}{c}80.1 \\
140 \\
89.5 \\
29.3 \\
19.8\end{array}$ & $\begin{array}{c}56.7 \\
105 \\
60.0 \\
31.9 \\
12.1\end{array}$ & $\begin{array}{l}39.2 \\
78.1 \\
77.5 \\
31.2 \\
21.3\end{array}$ \\
\hline $\begin{array}{l}1961 \\
1962 \\
1963 \\
1964 \\
1965\end{array}$ & $\begin{array}{l}42.6 \\
47.2 \\
99.7 \\
51.9 \\
51.0\end{array}$ & $\begin{array}{l}49.6 \\
49.7 \\
75.9 \\
65.9 \\
60.4\end{array}$ & $\begin{array}{l}43.6 \\
39.0 \\
57.2 \\
42.4 \\
53.5\end{array}$ & $\begin{array}{l}40.0 \\
36.1 \\
40.2 \\
40.2 \\
59.4\end{array}$ & $\begin{array}{l}45.0 \\
78.9 \\
80.3 \\
50.0 \\
60.7\end{array}$ & $\begin{array}{r}55.2 \\
117 \\
65.7 \\
59.7 \\
75.0\end{array}$ & $\begin{array}{l}66.5 \\
454 \\
101 \\
118 \\
172\end{array}$ & $\begin{array}{l}43.0 \\
638 \\
263 \\
426 \\
672\end{array}$ & $\begin{array}{l}13.2 \\
253 \\
117 \\
228 \\
527\end{array}$ & $\begin{array}{c}5.89 \\
101 \\
39.6 \\
85.4 \\
218\end{array}$ & $\begin{array}{r}25.1 \\
54.9 \\
97.0 \\
58.5 \\
158\end{array}$ & $\begin{array}{r}67.5 \\
54.9 \\
81.2 \\
45.4 \\
127\end{array}$ \\
\hline $\begin{array}{l}1966 \\
1967 \\
1968\end{array}$ & $\begin{array}{c}109 \\
81.4 \\
101\end{array}$ & $\begin{array}{r}114 \\
77.6 \\
92.9\end{array}$ & $\begin{array}{l}86.1 \\
62.3 \\
78.5\end{array}$ & $\begin{array}{l}74.1 \\
57.4 \\
83.4\end{array}$ & $\begin{array}{l}77.7 \\
71.0 \\
90.6\end{array}$ & $\begin{array}{l}122 \\
100 \\
114\end{array}$ & $\begin{array}{l}261 \\
128 \\
141\end{array}$ & $\begin{array}{l}284 \\
449 \\
506\end{array}$ & $\begin{array}{l}129 \\
559 \\
436\end{array}$ & $\begin{array}{l}73.6 \\
234 \\
159\end{array}$ & $\begin{array}{l}54.5 \\
143 \\
157\end{array}$ & $\begin{array}{l}73.7 \\
118 \\
103\end{array}$ \\
\hline
\end{tabular}

ANNUAL PEAK DISCHARGE, IN ORIC FEET PER SECOND, AND CORRESPONDING GAGE HEIGHT, IN FEET, FOR EAQH WATER YEAR

\begin{tabular}{|c|c|c|c|c|c|c|c|c|c|c|c|}
\hline $\begin{array}{l}\text { WATER } \\
\text { YEAR }\end{array}$ & DATE & $\begin{array}{c}\text { GAGE } \\
\text { HEIGHT }\end{array}$ & $\begin{array}{c}\text { PEAK } \\
\text { DISGHARGE }\end{array}$ & $\begin{array}{l}\text { WATER } \\
\text { YEAR }\end{array}$ & DATE & $\begin{array}{c}\text { GAGE } \\
\text { HEIGHT }\end{array}$ & $\begin{array}{c}\text { PEAK } \\
\text { DISCHARGE }\end{array}$ & $\begin{array}{l}\text { WATER } \\
\text { YEAR }\end{array}$ & DATE & $\begin{array}{c}\text { GAGE } \\
\text { HEIGHT }\end{array}$ & $\begin{array}{c}\text { PEAK } \\
\text { DISOHARG }\end{array}$ \\
\hline $\begin{array}{l}1909 \\
1910 \\
1914 \\
1915 \\
1916 \\
1917 \\
1918 \\
1919 \\
1920 \\
1921 \\
1922 \\
1923 \\
1924 \\
1925 \\
1926 \\
1927 \\
1928 \\
1929 \\
1930\end{array}$ & 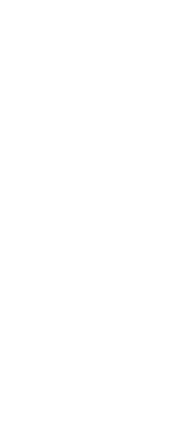 & $\begin{array}{l}8.30 \\
7.00 \\
4.00 \\
0.95 \\
5.12 \\
5.20 \\
2.80 \\
4.05 \\
6.00 \\
5.85 \\
7.70 \\
8.50 \\
7.90 \\
7.70 \\
7.00 \\
9.30 \\
8.35 \\
8.30 \\
6.90\end{array}$ & $\begin{array}{r}2950 \\
1860 \\
1340 \\
380 \\
1700 \\
1580 \\
613 \\
760 \\
1570 \\
1440 \\
3230 \\
1670 \\
1310 \\
1200 \\
1270 \\
2600 \\
1660 \\
1340 \\
561\end{array}$ & $\begin{array}{l}1931 \\
1932 \\
1933 \\
1934 \\
1935 \\
1936 \\
1937 \\
1938 \\
1939 \\
1940 \\
1941 \\
1942 \\
1943 \\
1944 \\
1945 \\
1946 \\
1947 \\
1948 \\
1949\end{array}$ & $\begin{array}{l}\text { JULY } 30,1931 \\
\text { AUG. } 22,1932 \\
\text { SEPT. } 09,1933 \\
\text { AUG. } 10,1934 \\
\text { AUG. } 16,1935 \\
\text { SEPT.03, } 1936 \\
\text { SEPT.02, } 1937 \\
\text { SEPT.09, } 1938 \\
\text { MAR. } 18,1939 \\
\text { SEPT.15, } 1940 \\
\text { MAY } 13,1941 \\
\text { APR. } 23,1942 \\
\text { AUG. } 07,1943 \\
\text { MAY } 16,1944 \\
\text { AUG. } 07,1945 \\
\text { JULY } 25,1946 \\
\text { MAY } 05,1947 \\
\text { JULY } 19,1948 \\
\text { MAY } 19,1949\end{array}$ & $\begin{array}{l}8.30 \\
8.70 \\
8.25 \\
6.70 \\
8.30 \\
9.70 \\
7.50 \\
8.20 \\
6.80 \\
6.30 \\
7.30 \\
6.00 \\
7.20 \\
4.98 \\
4.90 \\
3.84 \\
3.84 \\
3.24 \\
4.09\end{array}$ & $\begin{array}{r}1340 \\
1030 \\
812 \\
276 \\
780 \\
1300 \\
1690 \\
2540 \\
1140 \\
810 \\
1520 \\
599 \\
1500 \\
1060 \\
1300 \\
823 \\
812 \\
876 \\
1050\end{array}$ & $\begin{array}{l}1950 \\
1951 \\
1952 \\
1953 \\
1954 \\
1955 \\
1956 \\
1957 \\
1958 \\
1959 \\
1960 \\
1961 \\
1962 \\
1963 \\
1964 \\
1965 \\
1966 \\
1967 \\
1968\end{array}$ & $\begin{array}{l}\text { SEPT. } 19,1950 \\
\text { JULY } 21,1951 \\
\text { MAY } 07,1952 \\
\text { JULY } 31,1953 \\
\text { SEPT. } 26,1954 \\
\text { MAY } 12,1955 \\
\text { MAY } 10,1956 \\
\text { JUNE } 04,1957 \\
\text { MAY } 23,1958 \\
\text { AUG. } 20,1959 \\
\text { MAY } 14,1960 \\
\text { SEPT.09, } 1961 \\
\text { MAY } 11,1962 \\
\text { AUG. } 31,1963 \\
\text { MAY } 22,1964 \\
\text { JUNE } 12,1965 \\
\text { MAY } 11,1966 \\
\text { MAY } 24,1967 \\
\text { MAY } 31,1968\end{array}$ & $\begin{array}{l}3.77 \\
\overline{5.34} \\
3.04 \\
3.40 \\
2.25 \\
2.59 \\
3.24 \\
3.72 \\
3.80 \\
1.62 \\
4.40 \\
4.89 \\
6.80 \\
4.74 \\
5.60 \\
3.51 \\
4.95 \\
4.42\end{array}$ & $\begin{array}{r}898 \\
840 \\
3490 \\
826 \\
1000 \\
534 \\
607 \\
754 \\
997 \\
1070 \\
260 \\
900 \\
1080 \\
2130 \\
850 \\
1260 \\
437 \\
923 \\
808\end{array}$ \\
\hline
\end{tabular}

\begin{tabular}{|c|c|c|c|c|c|c|}
\hline \multirow{2}{*}{$\begin{array}{l}\text { PERIO } \\
\text { (CON- } \\
\text { SEOU- } \\
\text { IIVE } \\
\text { DAYS) }\end{array}$} & \multicolumn{6}{|c|}{$\begin{array}{l}\text { DISCHARGE, IN OUBIC FEET PER SECOND, FOR } \\
\text { INDICATED REOURENCE INIERVAL, IN YEARS, AND } \\
\text { ANNUAL EXCEEDANCE PRCBABILITY, IN PERCENT }\end{array}$} \\
\hline & $\begin{array}{c}2 \\
508\end{array}$ & $\begin{array}{c}5 \\
208\end{array}$ & $\begin{array}{l}10 \\
108\end{array}$ & $\begin{array}{l}25 \\
48\end{array}$ & $\begin{array}{l}50 \\
28\end{array}$ & $\begin{array}{r}100 \\
18\end{array}$ \\
\hline $\begin{array}{r}1 \\
3 \\
7 \\
15\end{array}$ & $\begin{array}{l}716 \\
652 \\
597 \\
532\end{array}$ & $\begin{array}{l}1230 \\
1170 \\
1110 \\
1010\end{array}$ & $\begin{array}{l}1630 \\
1560 \\
1490 \\
1360\end{array}$ & $\begin{array}{l}2180 \\
2080 \\
1970 \\
1830\end{array}$ & $\begin{array}{l}2630 \\
2480 \\
2340 \\
2180\end{array}$ & $\begin{array}{l}3100 \\
2890 \\
2700 \\
2540\end{array}$ \\
\hline
\end{tabular}


GREEN RIVER BASIN

09288900 SOWERS CREEK NEAR DUCHESNE, UT

LOCATION.-Lat $39^{\circ} 59^{\prime} 22^{\prime \prime}$, long $110^{\circ} 27^{\prime} 33^{\prime \prime}$, in SN ${ }^{3}$ SW $^{3} \mathrm{NW}^{\frac{1}{4}}$ sec.4, T.6 S., R.5 W., Uintah Meridian, Duchesne County, Hydrologic Unit 14060003, Ashley National Forest, on left bank $0.5 \mathrm{mi}$ upstream from Ashley National Forest boundary, $5.7 \mathrm{mi}$ upstream from mouth of Tabby Canyon, and $12.4 \mathrm{mi}$ south of Duchesme.

DRAINAGE AREA. $-40.6 \mathrm{mi}^{2}$.

MEAN BASIN ELEVATION. $-8,120 \mathrm{ft}$.

PERIOD OF RECORD AVAIIABLE.--May 1964 to September 1981.

REVISED RECORDS.-WTR UT-77-1: Drainage area.

GAGE.-Water-stage recorder. Altitude of gage is 6,800 ft fram topographic map.

AVERAGE DISCHARGE. -17 years, $3.80 \mathrm{ft}^{3} / \mathrm{s}, 2,750$ acre-ft/yr.

EXIREMES FOR PERIOD OF RECORD. - Maximum discharge, $350 \mathrm{ft}^{3} / \mathrm{s}$ July 24, 1974, gage height, $6.59 \mathrm{ft}$, fram rating curve extended above $42 \mathrm{ft}^{3} / \mathrm{s}$ on basis of slope-area measurement of peak flow; no flow for part of winter period 1964, 1965, Feb. 18-21, 1975.

LONEST MEAN DISCHARGE, IN CUBIC FEET PER SECOND, AND RANKING FOR THE INDICATED NUMBER OF CONSECUTIVE DAYS FOR EACH CLIMATIC YEAR, APRII I-MARCH 31

YEAR

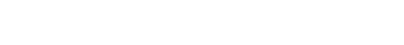

1.

CONSEOUTIVE DAYS

\begin{tabular}{|c|c|c|c|c|c|c|}
\hline & 1 & 3 & 7 & 14 & 30 & 60 \\
\hline $\begin{array}{l}1966 \\
1967 \\
1968 \\
1969 \\
1970\end{array}$ & $\begin{array}{rr}1.30 & 13 \\
0.60 & 9 \\
0.70 & 10 \\
1.70 & 16 \\
1.40 & 14\end{array}$ & $\begin{array}{rr}1.90 & 16 \\
0.60 & 9 \\
0.70 & 10 \\
1.70 & 15 \\
1.50 & 12\end{array}$ & $\begin{array}{rrr}2.00 & 16 \\
0.63 & 8 \\
0.80 & 10 \\
1.80 & 15 \\
1.50 & 11\end{array}$ & $\begin{array}{rr}2.20 & 16 \\
0.70 & 8 \\
0.96 & 10 \\
1.80 & 14 \\
1.60 & 11\end{array}$ & $\begin{array}{rr}3.50 & 16 \\
0.86 & 8 \\
1.19 & 10 \\
1.90 & 14 \\
1.70 & 12\end{array}$ & $\begin{array}{rr}3.60 & 16 \\
1.10 & 7 \\
1.30 & 8 \\
2.00 & 12 \\
2.00 & 13\end{array}$ \\
\hline $\begin{array}{l}1971 \\
1972 \\
1973 \\
1974 \\
1975\end{array}$ & $\begin{array}{lr}0.42 & 7 \\
0.51 & 8 \\
0.38 & 6 \\
1.19 & 11 \\
0.00 & 1\end{array}$ & $\begin{array}{rr}0.43 & 6 \\
0.56 & 8 \\
0.44 & 7 \\
1.60 & 13 \\
0.00 & 1\end{array}$ & $\begin{array}{rr}0.44 & 5 \\
0.59 & 7 \\
0.47 & 6 \\
1.60 & 12 \\
0.00 & 1\end{array}$ & $\begin{array}{lr}0.45 & 5 \\
0.61 & 7 \\
0.49 & 6 \\
1.60 & 12 \\
0.02 & 1\end{array}$ & $\begin{array}{lr}0.49 & 4 \\
0.72 & 6 \\
0.55 & 5 \\
1.60 & 11 \\
0.04 & 1\end{array}$ & $\begin{array}{lr}0.56 & 4 \\
0.86 & 6 \\
0.65 & 5 \\
1.60 & 11 \\
0.06 & 1\end{array}$ \\
\hline $\begin{array}{l}1976 \\
1977 \\
1978 \\
1979 \\
1980\end{array}$ & $\begin{array}{lr}0.01 & 2 \\
0.25 & 4 \\
0.15 & 3 \\
0.29 & 5 \\
1.19 & 12\end{array}$ & $\begin{array}{ll}0.12 & 2 \\
0.25 & 4 \\
0.18 & 3 \\
0.42 & 5 \\
1.30 & 11\end{array}$ & $\begin{array}{lr}0.31 & 4 \\
0.25 & 3 \\
0.18 & 2 \\
0.72 & 9 \\
1.70 & 13\end{array}$ & $\begin{array}{rr}0.43 & 4 \\
0.26 & 3 \\
0.18 & 2 \\
0.88 & 9 \\
1.90 & 15\end{array}$ & $\begin{array}{lr}0.85 & 7 \\
0.28 & 3 \\
0.20 & 2 \\
1.10 & 9 \\
2.20 & 15\end{array}$ & $\begin{array}{rr}1.50 & 10 \\
0.30 & 3 \\
0.21 & 2 \\
1.30 & 9 \\
2.40 & 15\end{array}$ \\
\hline 1981 & 1.6015 & 1.7014 & 1.8014 & 1.8013 & 1.9013 & 2.3014 \\
\hline
\end{tabular}

\begin{tabular}{|c|c|c|c|}
\hline 90 & 120 & 183 & ALC \\
\hline $\begin{array}{rr}3.90 & 16 \\
1.10 & 7 \\
1.40 & 8 \\
2.20 & 12 \\
2.30 & 13\end{array}$ & $\begin{array}{rr}4.30 & 16 \\
1.30 & 7 \\
1.60 & 10 \\
2.30 & 12 \\
2.40 & 13\end{array}$ & $\begin{array}{rr}5.10 & 16 \\
1.80 & 8 \\
1.80 & 9 \\
2.70 & 11 \\
2.90 & 13\end{array}$ & $\begin{array}{rr}9.30 & 16 \\
4.00 & 9 \\
2.70 & 8 \\
4.70 & 11 \\
7.10 & 13\end{array}$ \\
\hline $\begin{array}{rr}0.66 & 5 \\
0.91 & 6 \\
0.64 & 4 \\
1.60 & 11 \\
0.11 & 1\end{array}$ & $\begin{array}{lr}0.66 & 4 \\
0.92 & 6 \\
0.69 & 5 \\
2.00 & 11 \\
0.14 & 1\end{array}$ & $\begin{array}{rr}0.77 & 4 \\
0.94 & 5 \\
0.97 & 6 \\
2.80 & 12 \\
0.27 & 1\end{array}$ & $\begin{array}{rr}1.30 & 6 \\
1.19 & 4 \\
1.30 & 5 \\
8.30 & 15 \\
0.82 & 2\end{array}$ \\
\hline $\begin{array}{rr}1.50 & 10 \\
0.35 & 3 \\
0.21 & 2 \\
1.40 & 9 \\
2.50 & 14\end{array}$ & $\begin{array}{rr}1.50 & 8 \\
0.44 & 3 \\
0.23 & 2 \\
1.50 & 9 \\
2.70 & 14\end{array}$ & $\begin{array}{rr}2.10 & 10 \\
0.71 & 3 \\
0.33 & 2 \\
1.70 & 7 \\
3.00 & 14\end{array}$ & $\begin{array}{rr}4.40 & 10 \\
1.10 & 3 \\
0.48 & 1 \\
2.30 & 7 \\
6.40 & 12\end{array}$ \\
\hline
\end{tabular}

HIGHEST MEAN DISCHARGE, IN CIBIC FEET PER SECOND, AND RANKING FOR THE INDICATED NUMBER OF CONSEOUTIVE DAYS FOR EACH WATER YEAR, OCTCBER 1-SEPTEMBER 30

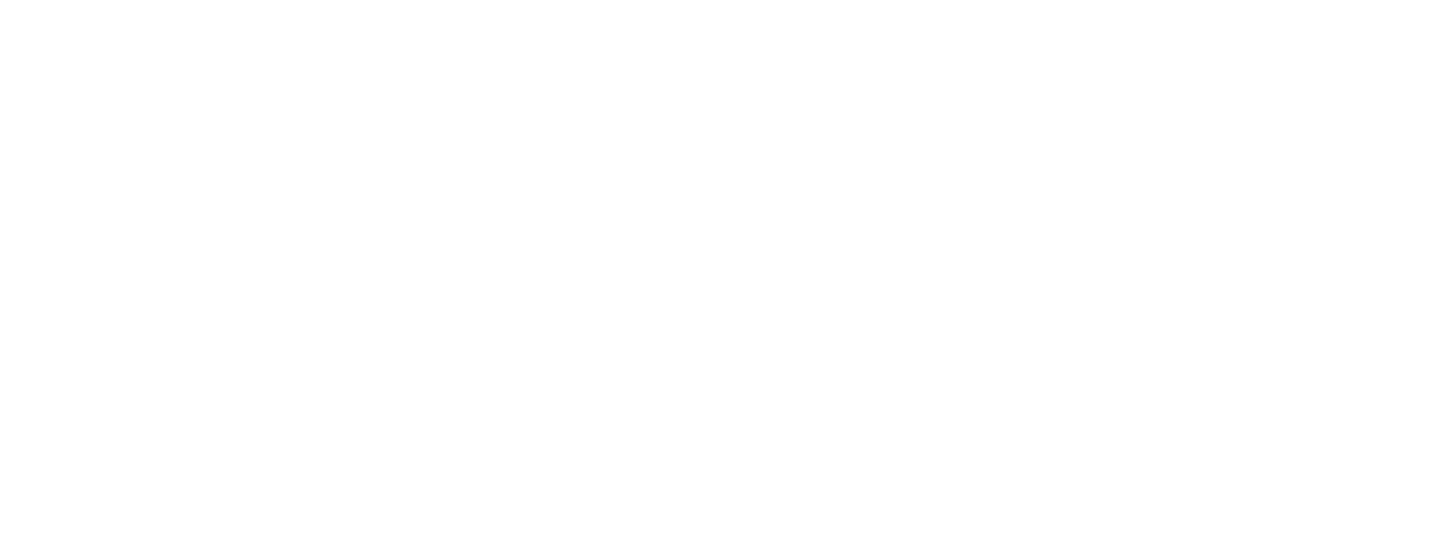


09288900 SCWERS CREEK NEAR DUCHESNE, UT-Continued

DURATION OF DISCHARGE FOR EACH WATER YEAR

$\begin{array}{llllllllllllllllllllllllllllllllllllllllll}\text { CLASS } & 0 & 1 & 2 & 3 & 4 & 5 & 6 & 7 & 8 & 9 & 10 & 11 & 12 & 13 & 14 & 15 & 16 & 17 & 18 & 19 & 20 & 21 & 22 & 23 & 24 & 25 & 26 & 27 & 28 & 29 & 30 & 31 & 32 & 33 & 34\end{array}$

YEAR

NUMBER OF DAYS IN CIASS

OBBIC FEET

-DAYS

$1965 \quad 40$

80

$\begin{array}{llll}14 & 19 & 11 & 12\end{array}$

$\begin{array}{llllllllllllll}1 & 1 & 15 & 5 & 4 & 1 & 1 & 30 & 18 & 50 & 30 & 13 & 20\end{array}$

2527.9

1966

1967

1969

1970

1971

1973

1974

$\begin{array}{llllllllll}23 & 98 & 74 & 88 & 76 & 5 & 1\end{array}$

$\begin{array}{rrrrrrrrrrrrrr}10 & 6 & 27 & 48 & 18 & 42 & 100 & 62 & 47 & 5 & & & \\ 3 & 3 & 11 & 39 & 48 & 64 & 29 & 29 & 30 & 37 & 33 & 36 & 3 & 1\end{array}$

$\begin{array}{lllllllllllllll}3 & 11 & 39 & 48 & 64 & 29 & 29 & 30 & 37 & 33 & 36 & 3 & 1 & & \\ & & & 31 & 49 & 58 & 38 & 21 & 54 & 28 & 19 & 15 & 32 & 15 & 5 \\ 2 & 22 & 46 & 79 & 78 & 79 & 46 & 13 & & & & \end{array}$

$\begin{array}{llllllll}3 & 36 & 72 & 55 & 86 & 77 & 33 & 3\end{array}$

$\begin{array}{rrrrrrrrrr}4 & 22 & 43 & 56 & 119 & 105 & 13 & 2 & 1\end{array}$

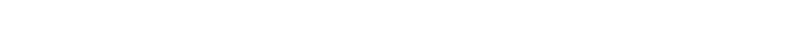

1976

1976
1977
1978

1978
1979

1980

1981

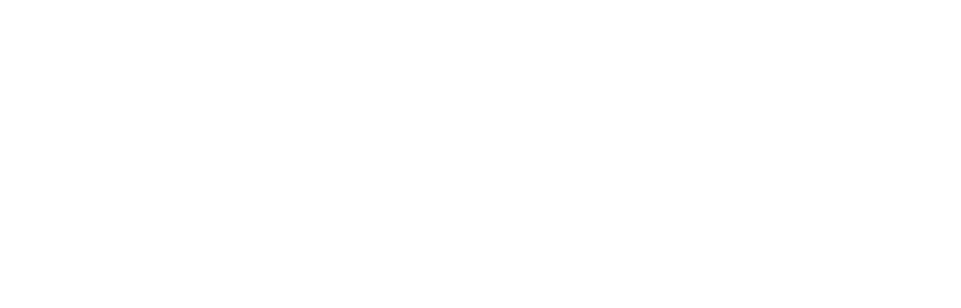

2031.7

1003.8

1547.9
2549.9

2549.9
865.3

362.1

499.0

2687.6
762.1

1254.4

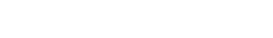

DURATION TABLE OF DISCHARGE FOR WATER YEARS 1965-81

$\begin{array}{crl}\text { CUBIC } & \text { ACOU- } \\ \text { FEET } & \text { MU- } & \text { PER- } \\ \text { PER } & \text { TOTAL LATED } & \text { CENT } \\ \text { OLASS SECOND DAYS DAYS } & \text { DAYS }\end{array}$

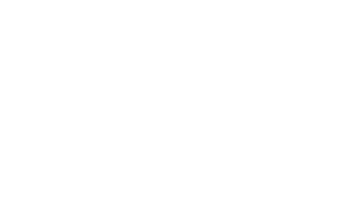

\section{CBBIC ACOU- GUIC}

FEET ACOU- PERPER TOTAL LATED CEN
CLASS SEDOND DAYS DAYS DAYS

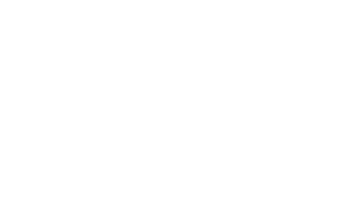

$\begin{array}{lll}\text { GBIC } & \text { ACOU- } \\ \text { FEET } & \text { MU- } & \\ \text { PER- } & \end{array}$ CLASS SECOND DAYS DAYS DAYS

MONTHLY MEAN DISCHARGES, IN GBIC FEET PER SECOND, FOR EACH WATER YEAR

$\begin{array}{lllllllllllll}\text { YEAR } & \text { OCT } & \text { NOV } & \text { DEC } & \text { JAN } & \text { FEB } & \text { MAR } & \text { APR } & \text { MAY } & \text { JUNE } & \text { JULY } & \text { ALG } & \text { SEP } \\ 1965 & 0.46 & 0.24 & 0.05 & 0.02 & 0.10 & 0.73 & 4.46 & 22.0 & 20.2 & 13.5 & 11.8 & 9.03 \\ 1966 & 6.90 & 6.12 & 4.85 & 3.59 & 3.70 & 4.98 & 6.71 & 8.12 & 7.89 & 5.14 & 5.09 & 3.60 \\ 1967 & 2.91 & 2.45 & 1.19 & 1.21 & 1.19 & 2.01 & 2.31 & 3.01 & 4.51 & 4.47 & 4.36 & 3.27 \\ 1968 & 2.50 & 2.00 & 1.66 & 1.18 & 1.58 & 2.09 & 3.68 & 10.2 & 8.81 & 7.03 & 5.85 & 4.01 \\ 1969 & 3.83 & 3.11 & 2.07 & 2.02 & 2.55 & 3.07 & 9.55 & 21.4 & 14.4 & 9.04 & 6.63 & 5.87 \\ 1970 & 4.25 & 3.60 & 1.97 & 2.06 & 2.91 & 2.79 & 2.70 & 1.91 & 2.25 & 1.54 & 1.40 & 1.12 \\ 1971 & 1.08 & 0.89 & 0.54 & 0.70 & 0.75 & 0.66 & 1.24 & 1.51 & 1.29 & 1.21 & 1.14 & 0.87 \\ 1972 & 1.01 & 0.88 & 0.92 & 1.10 & 0.83 & 1.92 & 1.69 & 1.78 & 1.70 & 1.41 & 1.51 & 1.61 \\ 1973 & 1.63 & 1.10 & 0.65 & 0.70 & 0.60 & 1.28 & 4.83 & 30.4 & 20.3 & 12.2 & 7.55 & 6.54 \\ 1974 & 4.87 & 3.75 & 1.65 & 1.60 & 1.68 & 3.25 & 2.01 & 1.49 & 1.08 & 2.58 & 0.61 & 0.40 \\ 1975 & 0.43 & 0.62 & 0.21 & 0.15 & 0.04 & 0.17 & 0.85 & 5.35 & 14.9 & 8.53 & 5.46 & 4.40 \\ 1976 & 3.79 & 2.80 & 1.48 & 1.50 & 1.50 & 1.68 & 1.71 & 1.62 & 1.45 & 1.37 & 1.53 & 1.27 \\ 1977 & 1.24 & 1.16 & 0.61 & 0.30 & 0.29 & 0.59 & 0.75 & 0.70 & 0.51 & 0.81 & 0.54 & 0.36 \\ 1978 & 0.66 & 0.39 & 0.24 & 0.21 & 0.20 & 0.38 & 1.67 & 5.42 & 3.61 & 2.53 & 2.14 & 2.07 \\ 1979 & 2.06 & 1.35 & 1.46 & 1.66 & 1.72 & 2.02 & 6.68 & 20.2 & 12.5 & 8.60 & 6.32 & 4.59 \\ 1980 & 3.77 & 3.01 & 2.64 & 2.45 & 2.88 & 3.52 & 4.75 & 21.8 & 18.1 & 12.5 & 9.95 & 7.76 \\ 1981 & 6.13 & 4.51 & 3.98 & 2.29 & 2.47 & 2.82 & 2.86 & 2.56 & 2.03 & 1.27 & 1.23 & 1.16\end{array}$

ANNUAL PEAK DISCHARGE, IN CUBIC FEET PER SECOND, AND CORRESPONDING GAGE HEIGHT, IN FEET, FOR EACH WATER YEAR

\begin{tabular}{|c|c|c|c|c|c|c|c|c|c|c|c|}
\hline $\begin{array}{l}\text { WATERR } \\
\text { YEAR }\end{array}$ & DATE & $\begin{array}{c}\text { GAGE } \\
\text { HEIGHT }\end{array}$ & $\begin{array}{c}\text { PEAK } \\
\text { DISCHARGE }\end{array}$ & $\begin{array}{l}\text { WATER } \\
\text { YEAR }\end{array}$ & DAIE & $\begin{array}{c}\text { GAGE } \\
\text { HEIGHT }\end{array}$ & $\begin{array}{c}\text { PEAK } \\
\text { DISCHARGE }\end{array}$ & $\begin{array}{l}\text { WATER } \\
\text { YEAR }\end{array}$ & DATE & $\begin{array}{c}\text { GAGE } \\
\text { HEIGHT }\end{array}$ & $\begin{array}{c}\text { PEAK } \\
\text { DISCHARGE }\end{array}$ \\
\hline $\begin{array}{l}1965 \\
1966 \\
1967 \\
1968 \\
1969 \\
1970\end{array}$ & $\begin{array}{l}\text { JULY } 26,1965 \\
\text { AUG. } 03,1966 \\
\text { AUG. } 08,1967 \\
\text { JULY } 30,1968 \\
\text { MAY } 14,1969 \\
\text { AUG. } 06,1970\end{array}$ & $\begin{array}{l}4.80 \\
5.41 \\
2.30 \\
5.21 \\
1.46 \\
0.99\end{array}$ & $\begin{array}{r}167 \\
202 \\
53 \\
187 \\
30 \\
11\end{array}$ & $\begin{array}{l}1971 \\
1972 \\
1973 \\
1974 \\
1975 \\
1976\end{array}$ & $\begin{array}{lll}\text { MAY } & 08,1971 \\
\text { MAR. } & 03,1972 \\
\text { MAY } & 10,1973 \\
\text { JULY } & 24,1974 \\
\text { JUNE } & 02,1975 \\
\text { JULY } & 30,1976\end{array}$ & $\begin{array}{l}0.56 \\
1.42 \\
2.09 \\
6.59 \\
1.71 \\
3.57\end{array}$ & $\begin{array}{l}4.0 \\
24 \\
45 \\
350 \\
27 \\
25\end{array}$ & $\begin{array}{l}1977 \\
1978 \\
1979 \\
1980 \\
1981\end{array}$ & $\begin{array}{l}\text { JULY } 21,1977 \\
\text { OCT. } 06,1977 \\
\text { MAY } 25,1979 \\
\text { MAY } 22,1980 \\
\text { AUG. } 12,1981\end{array}$ & $\begin{array}{l}6.00 \\
2.01 \\
3.12 \\
3.92 \\
3.41\end{array}$ & $\begin{array}{r}275 \\
12 \\
32 \\
66 \\
59\end{array}$ \\
\hline
\end{tabular}


GREEN RIVER BASIN

09288900 SCWERS OREER NEAR DUCHESNE, UT--Continued

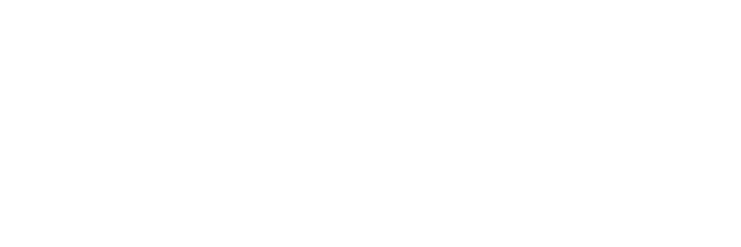

$\begin{array}{lllllll}1 & 0.69 & 0.15 & 0.03 & 0.00 & -\end{array}$

MAGNITUDE AND PRCBABILITY OF ANNUAL HIGHEST MEAN DISCHARGE BASED ON WATER YEARS 1965-81

\begin{tabular}{|c|c|c|c|c|c|c|}
\hline \multirow{2}{*}{$\begin{array}{l}\text { PERICD } \\
\text { (CON- } \\
\text { SECU- } \\
\text { TIVE } \\
\text { DAYS) }\end{array}$} & \multicolumn{6}{|c|}{$\begin{array}{l}\text { DISCAARGE, IN OIBIC FEET PER SEOOND, FOR } \\
\text { INDICATED RECURREANCE INTERNAL, IN YEARS, AND } \\
\text { ANNUAL EXCEEDANCE PRCBABIIITY, IN PERCENI }\end{array}$} \\
\hline & $\begin{array}{c}2 \\
508\end{array}$ & $\begin{array}{c}5 \\
208\end{array}$ & $\begin{array}{l}10 \\
108\end{array}$ & $\begin{array}{l}25 \\
48\end{array}$ & $\begin{array}{l}50 \\
28\end{array}$ & $\begin{array}{r}100 \\
18\end{array}$ \\
\hline $\begin{array}{r}7 \\
15\end{array}$ & $\begin{array}{l}9.1 \\
8.2\end{array}$ & $\begin{array}{l}21 \\
20\end{array}$ & $\begin{array}{l}33 \\
30\end{array}$ & $\begin{array}{l}52 \\
48\end{array}$ & 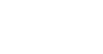 & $=$ \\
\hline
\end{tabular}

09289000 ANTELOPE CREEX NEAR MYTON, UT

LOCATION.--Lat $40^{\circ} 08^{\prime} 10^{\prime \prime}$, long $110^{\circ} 12^{\prime} 30^{\prime \prime}$, in S.r. sec.10, T.4 S., R.3 W., Uintah Meridian, Duchesne County, Hydrologic Unit 14060003, at crossing of Gray Mountain Canal, 1.2 miles upstream from mouth and 10 miles west of Myton.

DRAINAGE AREA. $--198 \mathrm{mi}^{2}$.

PERICD OF RBCORD AVAIIABLE. --December 1917 to March 1918 and June 1918 to July 1921 (monthly mean discharge for same periods, publ ished in WSP 1313).

GAGE.--Nonrecording gage. Altitude of gage is 5,310 ft from topographic map.

REMARRS.--Numerous small diversions above station.

MONIHLY MEAN DISCHARGES, IN OBBIC FEET PER SECOND, FOR EAOH WATER YEAR

\begin{tabular}{|c|c|c|c|c|c|c|c|c|c|c|c|c|}
\hline YEAR & $\infty C T$ & $\mathrm{NOV}$ & $\mathrm{DEC}$ & JAN & FEB & MAR & APR & MAY & JUNE & JULY & AUG & SEP \\
\hline $\begin{array}{l}1919 \\
1920\end{array}$ & $\begin{array}{l}0.91 \\
0\end{array}$ & $\begin{array}{l}3.67 \\
2.00\end{array}$ & $\begin{array}{l}3.22 \\
1.5\end{array}$ & $\begin{array}{l}2.16 \\
1.5\end{array}$ & $\begin{array}{l}1.70 \\
1.5\end{array}$ & $\begin{array}{l}2.52 \\
1.51\end{array}$ & $\begin{array}{l}0.40 \\
0.08\end{array}$ & $\begin{array}{l}0.10 \\
0\end{array}$ & $\begin{array}{l}0.20 \\
0\end{array}$ & $\begin{array}{l}0 \\
0\end{array}$ & $\begin{array}{l}0 \\
2.86\end{array}$ & $\begin{array}{l}0 \\
3.36\end{array}$ \\
\hline
\end{tabular}

09289500 LAKE FOFK RIVER ABOVE MOON LAKE, NEAR MOUNTAIN HOME, UT

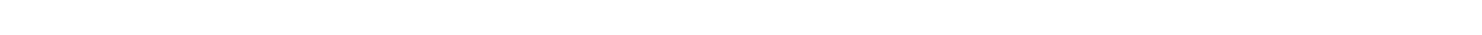
14060003 , Ashley National Forest, on right bank 2,000 ft upstream from head of Moon Lake at maximum stage, $2 \mathrm{mi}$ upstream fram Brown Duck Creek, and $16 \mathrm{mi}$ northeast of Mountain Hame.

DRAINAGE AREA. $--77.9 \mathrm{mi}^{2}$.

MEAN BASIN ELEVATION. $-10,800 \mathrm{ft}$.

PERICD OF RECORD AVAIIABLE.--April 1933 to September 1934 (published as, "West Fork of Lake Fork above Moon Lake, near Mountain Home"), July 1942 to September 1955 and Octcber 1963 to September 1965 (published as "Lake Fork above Moon Lake, near Mountain Home"), Octaber 1965 to September 1981.

REVISED RECORDS. -WDR UT-78-1: Drainage area.

GAGE.-Water-stage recorder. Altitude of gage is 8,180 ft from topographic map. April 1933 to September 1934 , at site $2.5 \mathrm{mi}$ upstream at different datum. July 13,1942 to July 26, 1949, at datum $1.00 \mathrm{ft}$ higher.

AVERAGE DISCHARGE. --31 years (water years 1943-55, 1964-81), $110 \mathrm{ft}^{3} / \mathrm{s}, 79,700 \mathrm{acre}-\mathrm{ft} / \mathrm{yr}$

EXTREMES FOR PERICD OF RECORD.--Maximum discharge, 2,700 ft 3 /s June 26, 1944, gage height, 5.21 ft, present datum, fran rating curve extended above $700 \mathrm{ft}^{3} / \mathrm{s}$; minimum daily recorded, $13 \mathrm{ft}^{3} / \mathrm{s} \mathrm{Apr} .14,1933$. 
GREEN RIVER BASIN

09289500 LAAKE FORK RIVER FBOVE MOON LAKE, NEAR MOUNTAIN HOME, UT-Continued

LOWEST MEAN DISCHARGE, IN CIBIC FEET PER SECOND, AND RANKING FOR THE INDICATED NUMBER OF CONSEOUTIVE DAYS FOR EAOH CLIMATIC YEAR, APRUL 1-MARCH 31

\begin{tabular}{|c|c|c|c|c|c|c|c|c|c|c|c|c|c|c|c|c|c|c|c|c|}
\hline YEAR & 1 & & 3 & & 7 & & 14 & & $\begin{array}{l}\text { cons } \\
30\end{array}$ & EOUT & $\begin{array}{l}\text { E DAYS } \\
60\end{array}$ & & 90 & & 120 & & 183 & & ALL & \\
\hline $\begin{array}{l}1944 \\
1945\end{array}$ & $\begin{array}{l}25.0 \\
24.0\end{array}$ & $\begin{array}{l}27 \\
25\end{array}$ & $\begin{array}{l}25.0 \\
24.0\end{array}$ & $\begin{array}{l}27 \\
25\end{array}$ & $\begin{array}{l}25.0 \\
24.0\end{array}$ & $\begin{array}{l}26 \\
23\end{array}$ & $\begin{array}{l}25.0 \\
24.0\end{array}$ & $\begin{array}{l}26 \\
23\end{array}$ & $\begin{array}{l}25.0 \\
24.0\end{array}$ & $\begin{array}{l}25 \\
22\end{array}$ & $\begin{array}{l}25.0 \\
24.0\end{array}$ & $\begin{array}{l}21 \\
17\end{array}$ & $\begin{array}{l}26.0 \\
25.0\end{array}$ & $\begin{array}{l}22 \\
19\end{array}$ & $\begin{array}{l}27.0 \\
2 \epsilon .0\end{array}$ & $\begin{array}{l}23 \\
19\end{array}$ & $\begin{array}{l}31.0 \\
31.0\end{array}$ & $\begin{array}{l}18 \\
19\end{array}$ & $\begin{array}{l}114 \\
134\end{array}$ & $\begin{array}{l}15 \\
24\end{array}$ \\
\hline $\begin{array}{l}1946 \\
1947 \\
1948 \\
1949 \\
1950\end{array}$ & $\begin{array}{l}23.0 \\
24.0 \\
23.0 \\
20.0 \\
23.0\end{array}$ & $\begin{array}{l}20 \\
26 \\
21 \\
13 \\
22\end{array}$ & $\begin{array}{l}23.0 \\
24.0 \\
23.0 \\
21.0 \\
23.0\end{array}$ & $\begin{array}{l}18 \\
26 \\
19 \\
14 \\
20\end{array}$ & $\begin{array}{l}23.0 \\
24.0 \\
23.0 \\
22.0 \\
25.0\end{array}$ & $\begin{array}{l}17 \\
24 \\
18 \\
14 \\
27\end{array}$ & $\begin{array}{l}23.0 \\
26.0 \\
23.0 \\
23.0 \\
25.0\end{array}$ & $\begin{array}{l}19 \\
27 \\
20 \\
21 \\
24\end{array}$ & $\begin{array}{l}23.0 \\
26.0 \\
23.0 \\
23.0 \\
25.0\end{array}$ & $\begin{array}{l}15 \\
26 \\
16 \\
17 \\
23\end{array}$ & $\begin{array}{l}24.0 \\
27.0 \\
23.0 \\
23.0 \\
26.0\end{array}$ & $\begin{array}{l}18 \\
26 \\
13 \\
14 \\
22\end{array}$ & $\begin{array}{l}24.0 \\
27.0 \\
24.0 \\
24.0 \\
27.0\end{array}$ & $\begin{array}{l}11 \\
23 \\
12 \\
13 \\
24\end{array}$ & $\begin{array}{l}25.0 \\
29.0 \\
25.0 \\
25.0 \\
27.0\end{array}$ & $\begin{array}{l}11 \\
24 \\
12 \\
13 \\
20\end{array}$ & $\begin{array}{l}30.0 \\
32.0 \\
30.0 \\
27.0 \\
32.0\end{array}$ & $\begin{array}{r}14 \\
20 \\
15 \\
8 \\
21\end{array}$ & $\begin{array}{c}105 \\
86.0 \\
122 \\
76.0 \\
130\end{array}$ & $\begin{array}{r}12 \\
6 \\
19 \\
3 \\
22\end{array}$ \\
\hline $\begin{array}{l}1951 \\
1952 \\
1953 \\
1954 \\
1955\end{array}$ & $\begin{array}{l}21.0 \\
22.0 \\
16.0 \\
14.0 \\
20.0\end{array}$ & $\begin{array}{r}15 \\
16 \\
6 \\
1 \\
14\end{array}$ & $\begin{array}{l}23.0 \\
22.0 \\
16.0 \\
14.0 \\
20.0\end{array}$ & $\begin{array}{r}21 \\
15 \\
4 \\
1 \\
12\end{array}$ & $\begin{array}{l}23.0 \\
22.0 \\
16.0 \\
14.0 \\
20.0\end{array}$ & $\begin{array}{r}19 \\
15 \\
4 \\
1 \\
11\end{array}$ & $\begin{array}{l}23.0 \\
22.0 \\
16.0 \\
14.0 \\
20.0\end{array}$ & $\begin{array}{r}22 \\
15 \\
4 \\
1 \\
10\end{array}$ & $\begin{array}{l}23.0 \\
22.0 \\
16.0 \\
24.0 \\
20.0\end{array}$ & $\begin{array}{r}18 \\
12 \\
3 \\
19 \\
7\end{array}$ & $\begin{array}{l}24.0 \\
23.0 \\
17.0 \\
26.0 \\
20.0\end{array}$ & $\begin{array}{r}19 \\
15 \\
3 \\
23 \\
6\end{array}$ & $\begin{array}{l}24.0 \\
24.0 \\
18.0 \\
26.0 \\
21.0\end{array}$ & $\begin{array}{r}14 \\
15 \\
3 \\
20 \\
7\end{array}$ & $\begin{array}{l}25.0 \\
25.0 \\
19.0 \\
26.0 \\
22.0\end{array}$ & $\begin{array}{r}14 \\
15 \\
3 \\
16 \\
6\end{array}$ & $\begin{array}{l}28.0 \\
31.0 \\
25.0 \\
29.0 \\
25.0\end{array}$ & $\begin{array}{r}9 \\
16 \\
5 \\
11 \\
6\end{array}$ & $\begin{array}{r}120 \\
110 \\
148 \\
90.0 \\
71.0\end{array}$ & $\begin{array}{r}17 \\
13 \\
28 \\
8 \\
2\end{array}$ \\
\hline 1965 & 17.0 & 7 & 17.0 & 5 & 17.0 & 5 & 17.0 & 5 & 17.0 & 4 & 19.0 & 4 & 20.0 & 5 & 22.0 & 7 & 25.0 & 7 & 114 & 14 \\
\hline $\begin{array}{l}1966 \\
1967 \\
1968 \\
1969 \\
1970\end{array}$ & $\begin{array}{l}19.0 \\
22.0 \\
20.0 \\
23.0 \\
22.0\end{array}$ & $\begin{array}{l}10 \\
17 \\
11 \\
23 \\
18\end{array}$ & $\begin{array}{l}19.0 \\
23.0 \\
20.0 \\
23.0 \\
22.0\end{array}$ & $\begin{array}{r}9 \\
22 \\
13 \\
23 \\
16\end{array}$ & $\begin{array}{l}19.0 \\
23.0 \\
20.0 \\
24.0 \\
23.0\end{array}$ & $\begin{array}{r}8 \\
20 \\
12 \\
25 \\
21\end{array}$ & $\begin{array}{l}19.0 \\
23.0 \\
21.0 \\
25.0 \\
23.0\end{array}$ & $\begin{array}{r}7 \\
16 \\
13 \\
25 \\
17\end{array}$ & $\begin{array}{l}20.0 \\
24.0 \\
22.0 \\
27.0 \\
24.0\end{array}$ & $\begin{array}{r}8 \\
20 \\
13 \\
27 \\
21\end{array}$ & $\begin{array}{l}22.0 \\
26.0 \\
22.0 \\
28.0 \\
24.0\end{array}$ & $\begin{array}{r}8 \\
24 \\
9 \\
27 \\
16\end{array}$ & $\begin{array}{l}24.0 \\
28.0 \\
24.0 \\
30.0 \\
24.0\end{array}$ & $\begin{array}{l}16 \\
25 \\
17 \\
27 \\
18\end{array}$ & $\begin{array}{l}27.0 \\
29.0 \\
26.0 \\
31.0 \\
25.0\end{array}$ & $\begin{array}{r}21 \\
25 \\
17 \\
27 \\
8\end{array}$ & $\begin{array}{l}39.0 \\
36.0 \\
33.0 \\
36.0 \\
29.0\end{array}$ & $\begin{array}{l}28 \\
26 \\
23 \\
27 \\
12\end{array}$ & $\begin{array}{l}170 \\
95.0 \\
140 \\
147 \\
120\end{array}$ & $\begin{array}{r}29 \\
9 \\
26 \\
27 \\
18\end{array}$ \\
\hline $\begin{array}{l}1971 \\
1972 \\
1973 \\
1974 \\
1975\end{array}$ & $\begin{array}{l}18.0 \\
28.0 \\
28.0 \\
23.0 \\
22.0\end{array}$ & $\begin{array}{r}8 \\
28 \\
29 \\
24 \\
19\end{array}$ & $\begin{array}{l}19.0 \\
29.0 \\
28.0 \\
23.0 \\
22.0\end{array}$ & $\begin{array}{l}10 \\
29 \\
28 \\
24 \\
17\end{array}$ & $\begin{array}{l}19.0 \\
29.0 \\
28.0 \\
23.0 \\
22.0\end{array}$ & $\begin{array}{r}9 \\
29 \\
28 \\
22 \\
16\end{array}$ & $\begin{array}{l}20.0 \\
29.0 \\
29.0 \\
23.0 \\
22.0\end{array}$ & $\begin{array}{l}11 \\
28 \\
29 \\
18 \\
14\end{array}$ & $\begin{array}{l}21.0 \\
29.0 \\
29.0 \\
23.0 \\
22.0\end{array}$ & $\begin{array}{r}9 \\
28 \\
29 \\
14 \\
10\end{array}$ & $\begin{array}{l}22.0 \\
30.0 \\
31.0 \\
23.0 \\
23.0\end{array}$ & $\begin{array}{l}10 \\
28 \\
29 \\
11 \\
12\end{array}$ & $\begin{array}{l}23.0 \\
31.0 \\
32.0 \\
24.0 \\
24.0\end{array}$ & $\begin{array}{r}8 \\
28 \\
29 \\
9 \\
10\end{array}$ & $\begin{array}{l}25.0 \\
31.0 \\
34.0 \\
26.0 \\
25.0\end{array}$ & $\begin{array}{r}9 \\
28 \\
29 \\
18 \\
10\end{array}$ & $\begin{array}{l}30.0 \\
34.0 \\
42.0 \\
33.0 \\
28.0\end{array}$ & $\begin{array}{l}13 \\
25 \\
29 \\
24 \\
10\end{array}$ & $\begin{array}{c}101 \\
133 \\
123 \\
116 \\
89.0\end{array}$ & $\begin{array}{r}10 \\
23 \\
20 \\
16 \\
7\end{array}$ \\
\hline $\begin{array}{l}1976 \\
1977 \\
1978 \\
1979 \\
1980\end{array}$ & $\begin{array}{l}20.0 \\
15.0 \\
15.0 \\
15.0 \\
16.0\end{array}$ & $\begin{array}{r}12 \\
2 \\
3 \\
4 \\
5\end{array}$ & $\begin{array}{l}20.0 \\
15.0 \\
15.0 \\
17.0 \\
18.0\end{array}$ & $\begin{array}{r}11 \\
2 \\
3 \\
6 \\
7\end{array}$ & $\begin{array}{l}20.0 \\
15.0 \\
15.0 \\
19.0 \\
18.0\end{array}$ & $\begin{array}{r}13 \\
2 \\
3 \\
10 \\
6\end{array}$ & $\begin{array}{l}20.0 \\
15.0 \\
15.0 \\
19.0 \\
18.0\end{array}$ & $\begin{array}{r}12 \\
2 \\
3 \\
8 \\
6\end{array}$ & $\begin{array}{l}22.0 \\
15.0 \\
16.0 \\
19.0 \\
18.0\end{array}$ & $\begin{array}{r}11 \\
1 \\
2 \\
6 \\
5\end{array}$ & $\begin{array}{l}25.0 \\
15.0 \\
16.0 \\
20.0 \\
19.0\end{array}$ & $\begin{array}{r}20 \\
1 \\
2 \\
7 \\
5\end{array}$ & $\begin{array}{l}26.0 \\
15.0 \\
17.0 \\
20.0 \\
19.0\end{array}$ & $\begin{array}{r}21 \\
1 \\
2 \\
6 \\
4\end{array}$ & $\begin{array}{l}27.0 \\
16.0 \\
18.0 \\
20.0 \\
20.0\end{array}$ & $\begin{array}{r}22 \\
1 \\
2 \\
4 \\
5\end{array}$ & $\begin{array}{l}31.0 \\
22.0 \\
21.0 \\
23.0 \\
23.0\end{array}$ & $\begin{array}{r}17 \\
2 \\
1 \\
3 \\
4\end{array}$ & $\begin{array}{r}137 \\
81.0 \\
60.0 \\
105 \\
85.0\end{array}$ & $\begin{array}{r}25 \\
4 \\
1 \\
11 \\
5\end{array}$ \\
\hline 1981 & 19.0 & 9 & 19.0 & 8 & 19.0 & 7 & 20.0 & 9 & 25.0 & 24 & 27.0 & 25 & 28.0 & 26 & 30.0 & 26 & 32.0 & 22 & 123 & 21 \\
\hline
\end{tabular}

HIGHEST MEAN DISQHARGE, IN CUBIC FEET PER SEOOND, AND RANKING FOR THE INDICATED NUMBER OF CONSEOUTTVE DAYS FOR EAOH WATER YEAR, OCTCBER 1-SEPTEMBER 30

YEAR

\begin{tabular}{|c|c|c|c|c|c|c|c|c|c|c|c|c|c|c|c|c|c|c|c|c|}
\hline IDATK & 1 & & 3 & & 7 & & 15 & & 30 & & 60 & & 90 & & 120 & & 183 & & ALL & \\
\hline $\begin{array}{l}1943 \\
1944 \\
1945\end{array}$ & $\begin{array}{r}717 \\
1610 \\
807\end{array}$ & $\begin{array}{r}28 \\
2 \\
25\end{array}$ & $\begin{array}{r}667 \\
1230 \\
786\end{array}$ & $\begin{array}{r}28 \\
7 \\
22\end{array}$ & $\begin{array}{r}604 \\
1050 \\
698\end{array}$ & $\begin{array}{r}27 \\
7 \\
21\end{array}$ & $\begin{array}{l}501 \\
910 \\
554\end{array}$ & $\begin{array}{r}27 \\
8 \\
24\end{array}$ & $\begin{array}{l}425 \\
720 \\
432\end{array}$ & $\begin{array}{l}26 \\
10 \\
25\end{array}$ & $\begin{array}{l}370 \\
561 \\
341\end{array}$ & $\begin{array}{r}19 \\
6 \\
22\end{array}$ & $\begin{array}{l}318 \\
427 \\
290\end{array}$ & $\begin{array}{r}18 \\
6 \\
19\end{array}$ & $\begin{array}{l}269 \\
340 \\
248\end{array}$ & $\begin{array}{r}16 \\
6 \\
19\end{array}$ & $\begin{array}{l}197 \\
236 \\
180\end{array}$ & $\begin{array}{r}16 \\
6 \\
19\end{array}$ & $\begin{array}{l}116 \\
133 \\
106\end{array}$ & $\begin{array}{r}16 \\
6 \\
18\end{array}$ \\
\hline $\begin{array}{l}1946 \\
1947 \\
1948 \\
1949 \\
1950\end{array}$ & $\begin{array}{r}865 \\
828 \\
761 \\
1710 \\
928\end{array}$ & $\begin{array}{r}21 \\
23 \\
26 \\
1 \\
17\end{array}$ & $\begin{array}{r}772 \\
702 \\
734 \\
1360 \\
850\end{array}$ & $\begin{array}{r}23 \\
26 \\
24 \\
3 \\
17\end{array}$ & $\begin{array}{r}656 \\
614 \\
683 \\
1270 \\
802\end{array}$ & $\begin{array}{r}23 \\
26 \\
22 \\
3 \\
16\end{array}$ & $\begin{array}{r}495 \\
512 \\
611 \\
1060 \\
732\end{array}$ & $\begin{array}{r}28 \\
26 \\
17 \\
3 \\
14\end{array}$ & $\begin{array}{l}358 \\
493 \\
475 \\
736 \\
675\end{array}$ & $\begin{array}{r}29 \\
18 \\
21 \\
8 \\
12\end{array}$ & $\begin{array}{l}294 \\
432 \\
294 \\
520 \\
488\end{array}$ & $\begin{array}{r}27 \\
16 \\
28 \\
8 \\
10\end{array}$ & $\begin{array}{l}235 \\
358 \\
216 \\
400 \\
366\end{array}$ & $\begin{array}{r}27 \\
12 \\
28 \\
8 \\
10\end{array}$ & $\begin{array}{l}191 \\
296 \\
174 \\
324 \\
293\end{array}$ & $\begin{array}{r}27 \\
10 \\
29 \\
7 \\
11\end{array}$ & $\begin{array}{l}139 \\
214 \\
125 \\
228 \\
210\end{array}$ & $\begin{array}{r}27 \\
9 \\
29 \\
8 \\
11\end{array}$ & $\begin{array}{c}85.0 \\
124 \\
78.0 \\
128 \\
122\end{array}$ & $\begin{array}{r}27 \\
9 \\
28 \\
8 \\
11\end{array}$ \\
\hline $\begin{array}{l}1951 \\
1952 \\
1953 \\
1954 \\
1955\end{array}$ & $\begin{array}{r}1110 \\
1320 \\
1520 \\
626 \\
826\end{array}$ & $\begin{array}{r}12 \\
9 \\
5 \\
29 \\
24\end{array}$ & $\begin{array}{r}1000 \\
1200 \\
1360 \\
582 \\
718\end{array}$ & $\begin{array}{r}13 \\
9 \\
4 \\
30 \\
25\end{array}$ & $\begin{array}{r}874 \\
1150 \\
1110 \\
526 \\
587\end{array}$ & $\begin{array}{r}13 \\
4 \\
6 \\
30 \\
28\end{array}$ & $\begin{array}{l}684 \\
979 \\
808 \\
445 \\
439\end{array}$ & $\begin{array}{r}16 \\
6 \\
12 \\
29 \\
30\end{array}$ & $\begin{array}{l}573 \\
755 \\
540 \\
331 \\
372\end{array}$ & $\begin{array}{r}14 \\
7 \\
16 \\
31 \\
27\end{array}$ & $\begin{array}{l}433 \\
566 \\
348 \\
238 \\
278\end{array}$ & $\begin{array}{r}15 \\
5 \\
20 \\
30 \\
29\end{array}$ & $\begin{array}{l}329 \\
454 \\
266 \\
189 \\
213\end{array}$ & $\begin{array}{r}16 \\
3 \\
21 \\
30 \\
29\end{array}$ & $\begin{array}{l}266 \\
376 \\
212 \\
157 \\
176\end{array}$ & $\begin{array}{r}17 \\
2 \\
21 \\
30 \\
28\end{array}$ & $\begin{array}{l}189 \\
270 \\
150 \\
117 \\
127\end{array}$ & $\begin{array}{r}17 \\
2 \\
23 \\
30 \\
28\end{array}$ & $\begin{array}{c}109 \\
150 \\
88.0 \\
73.0 \\
76.0\end{array}$ & $\begin{array}{r}17 \\
2 \\
24 \\
30 \\
29\end{array}$ \\
\hline $\begin{array}{l}1971 \\
1972 \\
1973 \\
1974 \\
1975\end{array}$ & $\begin{array}{r}1520 \\
1320 \\
839 \\
877 \\
1160\end{array}$ & $\begin{array}{r}4 \\
7 \\
22 \\
20 \\
10\end{array}$ & $\begin{array}{r}1460 \\
1240 \\
799 \\
832 \\
1090\end{array}$ & $\begin{array}{r}1 \\
6 \\
21 \\
19 \\
10\end{array}$ & $\begin{array}{r}1380 \\
1150 \\
740 \\
704 \\
980\end{array}$ & $\begin{array}{r}1 \\
5 \\
19 \\
20 \\
11\end{array}$ & $\begin{array}{r}1150 \\
1030 \\
571 \\
558 \\
874\end{array}$ & $\begin{array}{r}1 \\
4 \\
20 \\
22 \\
9\end{array}$ & $\begin{array}{l}816 \\
772 \\
515 \\
450 \\
765\end{array}$ & $\begin{array}{r}3 \\
5 \\
17 \\
24 \\
6\end{array}$ & $\begin{array}{l}533 \\
482 \\
388 \\
346 \\
593\end{array}$ & $\begin{array}{r}7 \\
12 \\
17 \\
21 \\
3\end{array}$ & $\begin{array}{l}401 \\
357 \\
322 \\
262 \\
444\end{array}$ & $\begin{array}{r}7 \\
13 \\
17 \\
22 \\
4\end{array}$ & $\begin{array}{l}324 \\
284 \\
272 \\
210 \\
353\end{array}$ & $\begin{array}{r}8 \\
14 \\
15 \\
22 \\
5\end{array}$ & $\begin{array}{l}232 \\
203 \\
199 \\
150 \\
243\end{array}$ & $\begin{array}{r}7 \\
13 \\
15 \\
22 \\
5\end{array}$ & $\begin{array}{c}131 \\
119 \\
121 \\
91.0 \\
136\end{array}$ & $\begin{array}{r}7 \\
14 \\
12 \\
22 \\
5\end{array}$ \\
\hline $\begin{array}{l}1976 \\
1977 \\
1978 \\
1979 \\
1980\end{array}$ & $\begin{array}{r}626 \\
888 \\
1080 \\
938 \\
1320\end{array}$ & $\begin{array}{r}30 \\
19 \\
13 \\
16 \\
8\end{array}$ & $\begin{array}{r}616 \\
844 \\
1050 \\
813 \\
1210\end{array}$ & $\begin{array}{r}29 \\
18 \\
11 \\
20 \\
8\end{array}$ & $\begin{array}{r}582 \\
761 \\
969 \\
647 \\
1040\end{array}$ & $\begin{array}{r}29 \\
18 \\
12 \\
24 \\
9\end{array}$ & $\begin{array}{l}530 \\
554 \\
844 \\
560 \\
986\end{array}$ & $\begin{array}{r}25 \\
23 \\
10 \\
21 \\
5\end{array}$ & $\begin{array}{l}453 \\
341 \\
680 \\
477 \\
800\end{array}$ & $\begin{array}{r}23 \\
30 \\
11 \\
20 \\
4\end{array}$ & $\begin{array}{l}311 \\
206 \\
457 \\
331 \\
509\end{array}$ & $\begin{array}{r}25 \\
31 \\
13 \\
23 \\
9\end{array}$ & $\begin{array}{l}241 \\
160 \\
336 \\
247 \\
376\end{array}$ & $\begin{array}{r}25 \\
31 \\
15 \\
23 \\
9\end{array}$ & $\begin{array}{l}195 \\
134 \\
265 \\
204 \\
301\end{array}$ & $\begin{array}{c}26 \\
31 \\
18 \\
23 \\
9\end{array}$ & $\begin{array}{c}141 \\
99.0 \\
186 \\
146 \\
213\end{array}$ & $\begin{array}{l}26 \\
31 \\
18 \\
25 \\
10\end{array}$ & $\begin{array}{c}86.0 \\
60.0 \\
104 \\
85.0 \\
118\end{array}$ & $\begin{array}{l}25 \\
31 \\
19 \\
26 \\
15\end{array}$ \\
\hline
\end{tabular}


GREEN RIVER BASIN

09289500 LAAKE FORK RIVER ABOVE MOON LAKE, NEAR MOUNTAIN HONE, UT-Continued

\section{DURATTON OF DISCHARGE FOR EACH WATER YEAR}

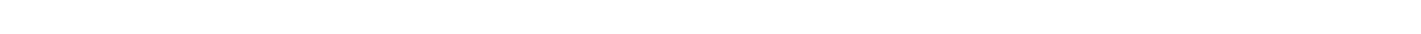

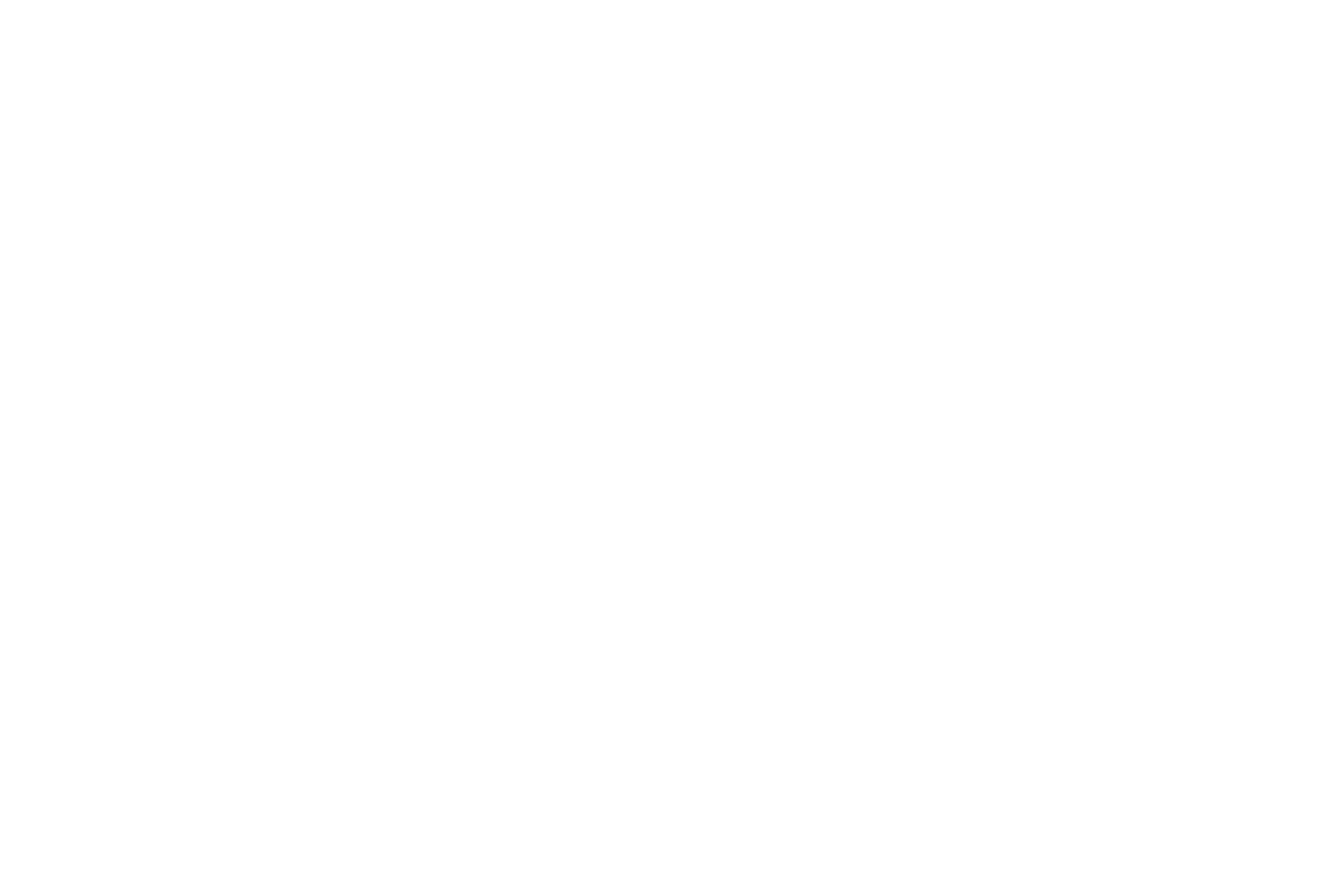

DURATION TABLE OF DISCHARGE' FOR WATER YEARS 1934, 1943-55, 1964-81

\begin{tabular}{|c|c|c|c|c|c|c|c|c|c|c|c|c|c|c|c|c|c|c|c|}
\hline OLASS & $\begin{array}{c}\text { CUBIC } \\
\text { FEET } \\
\text { PER } \\
\text { SECOND }\end{array}$ & $\begin{array}{l}\text { TOTAL } \\
\text { DAYS }\end{array}$ & $\begin{array}{l}\text { ACOU- } \\
\text { MU- } \\
\text { LATED } \\
\text { DAYS }\end{array}$ & $\begin{array}{l}\text { PER- } \\
\text { CENT } \\
\text { DAYS }\end{array}$ & C.ASS & $\begin{array}{c}\text { OUBIC } \\
\text { FEET } \\
\text { PER } \\
\text { SECOND }\end{array}$ & $\begin{array}{l}\text { TOTAL } \\
\text { DAYS }\end{array}$ & $\begin{array}{r}\text { ACOU- } \\
\text { MU- } \\
\text { LATEDD } \\
\text { DAYS }\end{array}$ & $\begin{array}{l}\text { PER- } \\
\text { CENT } \\
\text { DAYS }\end{array}$ & & $\begin{array}{c}\text { AJBIC } \\
\text { FEET } \\
\text { PER } \\
\text { SECOND }\end{array}$ & $\begin{array}{l}\text { TOTAL } \\
\text { DAYS }\end{array}$ & $\begin{array}{l}\text { ACOU- } \\
\text { MU- } \\
\text { LATED } \\
\text { DALS }\end{array}$ & $\begin{array}{l}\text { PER- } \\
\text { CENT } \\
\text { DAYS }\end{array}$ & CLASS & $\begin{array}{c}\text { AUIIC } \\
\text { FEET } \\
\text { PER } \\
\text { SECOND }\end{array}$ & $\begin{array}{c}\text { TOTAL } \\
\text { DAYS }\end{array}$ & $\begin{array}{r}\text { ACOU- } \\
\text { MU- } \\
\text { LATED } \\
\text { DAYS }\end{array}$ & $\begin{array}{l}\text { PER- } \\
\text { CENT } \\
\text { DAYS }\end{array}$ \\
\hline $\begin{array}{l}0 \\
1 \\
2 \\
3 \\
4 \\
5 \\
6 \\
7 \\
8\end{array}$ & $\begin{array}{r}0.00 \\
14.00 \\
16.00 \\
19.00 \\
22.00 \\
25.00 \\
29.00 \\
33.00 \\
38.00\end{array}$ & $\begin{array}{r}0 \\
126 \\
214 \\
623 \\
1070 \\
1637 \\
993 \\
912 \\
893\end{array}$ & $\begin{array}{r}11688 \\
11688 \\
11562 \\
11348 \\
10725 \\
9655 \\
8018 \\
7025 \\
6113\end{array}$ & $\begin{array}{r}100.0 \\
100.0 \\
98.9 \\
97.1 \\
91.8 \\
82.6 \\
68.6 \\
60.1 \\
52.3\end{array}$ & $\begin{array}{l}9 \\
10 \\
11 \\
12 \\
13 \\
14 \\
15 \\
16 \\
17\end{array}$ & $\begin{array}{r}44.00 \\
51.00 \\
59.00 \\
68.00 \\
79.00 \\
91.00 \\
100.00 \\
120.00 \\
140.00\end{array}$ & $\begin{array}{l}681 \\
523 \\
389 \\
354 \\
300 \\
163 \\
384 \\
252 \\
208\end{array}$ & $\begin{array}{l}5220 \\
4539 \\
4016 \\
3627 \\
3273 \\
2973 \\
2810 \\
2426 \\
2174\end{array}$ & $\begin{array}{l}44.7 \\
38.8 \\
34.4 \\
31.0 \\
28.0 \\
25.4 \\
24.0 \\
20.8 \\
18.6\end{array}$ & $\begin{array}{l}18 \\
19 \\
20 \\
21 \\
22 \\
23 \\
24 \\
25 \\
26\end{array}$ & $\begin{array}{l}160.0 \\
190.0 \\
220.0 \\
250.0 \\
290.0 \\
330.0 \\
380.0 \\
440.0 \\
510.0\end{array}$ & $\begin{array}{l}264 \\
200 \\
173 \\
185 \\
157 \\
155 \\
162 \\
129 \\
133\end{array}$ & $\begin{array}{r}1966 \\
1702 \\
1502 \\
1329 \\
1144 \\
987 \\
832 \\
670 \\
541\end{array}$ & $\begin{array}{r}16.8 \\
14.6 \\
12.9 \\
11.4 \\
9.8 \\
8.4 \\
7.1 \\
5.7 \\
4.6\end{array}$ & $\begin{array}{l}27 \\
28 \\
29 \\
30 \\
31 \\
32 \\
33 \\
34\end{array}$ & $\begin{array}{r}590.0 \\
680.0 \\
780.0 \\
910.0 \\
1000.0 \\
1200.0 \\
1400.0 \\
1600.0\end{array}$ & $\begin{array}{r}109 \\
81 \\
97 \\
42 \\
47 \\
22 \\
8 \\
2\end{array}$ & $\begin{array}{r}408 \\
299 \\
218 \\
121 \\
79 \\
32 \\
10 \\
2\end{array}$ & $\begin{array}{l}3.5 \\
2.6 \\
1.9 \\
1.0 \\
0.7 \\
0.3 \\
0.1 \\
0.0\end{array}$ \\
\hline
\end{tabular}

MON'THLY MEAN DISGHARGES, IN CUBIC FEET PER SECOND, FOR EACH WATER YEAR

$\begin{array}{llllllllllrrr}\text { YEAR } & \text { OCT } & \text { NOV } & \text { DEC } & \text { JAN } & \text { FEB } & \text { MAR } & \text { APR } & \text { MAY } & \text { JUNE } & \text { JULY } & \text { AUG } & \text { SEP } \\ 1934 & 28.0 & 24.0 & 22.0 & 20.0 & 20.0 & 20.1 & 89.3 & 165 & 66.9 & 31.1 & 39.1 & 26.5 \\ 1943 & 47.6 & 39.3 & 32.4 & 28.0 & 26.6 & 27.6 & 104 & 342 & 398 & 182 & 106 & 48.7 \\ 1944 & 41.2 & 36.3 & 30.0 & 25.0 & 25.0 & 27.0 & 30.0 & 259 & 675 & 323 & 85.5 & 45.8 \\ 1945 & 46.3 & 37.6 & 30.0 & 25.0 & 25.0 & 24.0 & 30.0 & 226 & 405 & 225 & 125 & 68.9 \\ 1946 & 41.9 & 35.0 & 28.0 & 26.0 & 24.0 & 23.0 & 85.0 & 231 & 335 & 91.0 & 53.3 & 43.0 \\ 1947 & 42.1 & 36.9 & 33.0 & 28.0 & 26.0 & 27.0 & 46.3 & 416 & 421 & 224 & 111 & 64.4 \\ 1948 & 43.6 & 36.4 & 29.0 & 25.0 & 23.0 & 23.0 & 27.2 & 315 & 249 & 71.8 & 49.6 & 36.7 \\ 1949 & 32.4 & 30.0 & 27.0 & 25.0 & 23.0 & 23.0 & 55.6 & 258 & 721 & 207 & 84.5 & 45.1 \\ 1950 & 44.1 & 40.1 & 30.2 & 28.5 & 26.1 & 25.0 & 57.3 & 211 & 656 & 205 & 83.3 & 55.3 \\ & & & & & & & & & & & & \\ 1951 & 37.6 & 32.4 & 27.4 & 25.5 & 24.0 & 23.0 & 36.0 & 226 & 526 & 195 & 103 & 52.1 \\ 1952 & 46.9 & 34.1 & 29.9 & 25.0 & 25.0 & 22.0 & 50.5 & 358 & 727 & 269 & 139 & 77.3 \\ 1953 & 46.8 & 27.4 & 22.2 & 20.1 & 17.0 & 16.9 & 23.8 & 57.5 & 529 & 164 & 89.1 & 40.4 \\ 1954 & 34.1 & 32.6 & 28.7 & 26.0 & 25.0 & 26.0 & 49.3 & 309 & 153 & 92.0 & 49.5 & 43.2 \\ 1955 & 35.8 & 28.6 & 24.5 & 23.0 & 20.0 & 20.0 & 24.7 & 221 & 315 & 90.2 & 67.8 & 43.8\end{array}$


GREEN RIVER BASIN

09289500 LAKE FORK RIVER ABOVE MOON LAKE, NEAR MOUNTAIN HOME, UT-Continued

NONTHLY MEAN DISGHARGES, IN GBIC FEET PER SECOND, FOR EACH WATER YEAR--Continued

\begin{tabular}{|c|c|c|c|c|c|c|c|c|c|c|c|c|}
\hline YEAR & $\infty C T$ & NOV & DEC & JAN & FEB & MAR & APR & MAY & JUNE & JULY & AUG & SEP \\
\hline $\begin{array}{l}1964 \\
1965\end{array}$ & $\begin{array}{l}60.2 \\
32.4\end{array}$ & $\begin{array}{l}43.0 \\
30.5\end{array}$ & $\begin{array}{l}35.8 \\
27.1\end{array}$ & $\begin{array}{l}27.0 \\
24.0\end{array}$ & $\begin{array}{l}20.0 \\
19.0\end{array}$ & $\begin{array}{l}23.2 \\
18.1\end{array}$ & $\begin{array}{l}26.3 \\
41.9\end{array}$ & $\begin{array}{l}291 \\
128\end{array}$ & $\begin{array}{l}510 \\
681\end{array}$ & $\begin{array}{l}253 \\
598\end{array}$ & $\begin{array}{l}84.8 \\
212\end{array}$ & $\begin{array}{c}49.1 \\
137\end{array}$ \\
\hline $\begin{array}{l}1966 \\
1967 \\
1968 \\
1969 \\
1970\end{array}$ & $\begin{array}{l}71.1 \\
58.7 \\
52.3 \\
50.1 \\
42.3\end{array}$ & $\begin{array}{l}53.9 \\
39.1 \\
40.8 \\
38.9 \\
33.0\end{array}$ & $\begin{array}{l}37.1 \\
33.6 \\
32.8 \\
34.2 \\
27.4\end{array}$ & $\begin{array}{l}26.5 \\
30.9 \\
25.6 \\
32.4 \\
24.4\end{array}$ & $\begin{array}{l}23.3 \\
27.6 \\
22.8 \\
27.6 \\
25.0\end{array}$ & $\begin{array}{l}21.0 \\
24.2 \\
22.3 \\
30.4 \\
23.6\end{array}$ & $\begin{array}{l}57.4 \\
28.7 \\
27.7 \\
89.5 \\
24.3\end{array}$ & $\begin{array}{l}338 \\
252 \\
117 \\
578 \\
251\end{array}$ & $\begin{array}{l}252 \\
670 \\
917 \\
309 \\
440\end{array}$ & $\begin{array}{l}118 \\
337 \\
262 \\
132 \\
154\end{array}$ & $\begin{array}{l}81.5 \\
131 \\
161 \\
86.3 \\
71.5\end{array}$ & $\begin{array}{l}77.4 \\
67.6 \\
74.5 \\
60.6 \\
92.9\end{array}$ \\
\hline $\begin{array}{l}1971 \\
1972 \\
1973 \\
1974 \\
1975\end{array}$ & $\begin{array}{l}45.5 \\
40.4 \\
64.2 \\
52.2 \\
37.8\end{array}$ & $\begin{array}{l}33.5 \\
35.2 \\
50.4 \\
38.8 \\
31.5\end{array}$ & $\begin{array}{l}28.5 \\
32.5 \\
40.4 \\
29.9 \\
27.1\end{array}$ & $\begin{array}{l}25.8 \\
30.5 \\
35.1 \\
26.0 \\
25.0\end{array}$ & $\begin{array}{l}23.3 \\
29.0 \\
32.1 \\
23.0 \\
23.5\end{array}$ & $\begin{array}{l}21.4 \\
35.5 \\
29.1 \\
23.6 \\
22.5\end{array}$ & $\begin{array}{l}55.9 \\
50.2 \\
30.1 \\
29.6 \\
21.7\end{array}$ & $\begin{array}{c}178 \\
288 \\
273 \\
337 \\
78.5\end{array}$ & $\begin{array}{l}768 \\
647 \\
432 \\
337 \\
593\end{array}$ & $\begin{array}{l}248 \\
126 \\
223 \\
101 \\
579\end{array}$ & $\begin{array}{c}92.1 \\
61.9 \\
131 \\
53.9 \\
128\end{array}$ & $\begin{array}{r}55.6 \\
51.1 \\
103 \\
40.7 \\
52.8\end{array}$ \\
\hline $\begin{array}{l}1976 \\
1977 \\
1978 \\
1979 \\
1980\end{array}$ & $\begin{array}{l}41.7 \\
39.3 \\
29.3 \\
28.7 \\
35.6\end{array}$ & $\begin{array}{l}34.4 \\
27.3 \\
22.9 \\
26.4 \\
22.9\end{array}$ & $\begin{array}{l}29.9 \\
17.5 \\
20.3 \\
21.3 \\
18.9\end{array}$ & $\begin{array}{l}27.9 \\
15.2 \\
18.2 \\
19.9 \\
19.9\end{array}$ & $\begin{array}{l}25.9 \\
15.0 \\
16.0 \\
20.0 \\
19.9\end{array}$ & $\begin{array}{l}23.7 \\
15.0 \\
17.5 \\
19.4 \\
19.8\end{array}$ & $\begin{array}{l}26.0 \\
28.9 \\
35.0 \\
29.1 \\
38.4\end{array}$ & $\begin{array}{l}264 \\
65.9 \\
104 \\
254 \\
142\end{array}$ & $\begin{array}{l}324 \\
339 \\
670 \\
355 \\
757\end{array}$ & $\begin{array}{l}118 \\
70.2 \\
213 \\
122 \\
222\end{array}$ & $\begin{array}{l}62.6 \\
55.4 \\
64.0 \\
73.8 \\
74.6\end{array}$ & $\begin{array}{l}50.8 \\
37.7 \\
36.6 \\
43.0 \\
53.6\end{array}$ \\
\hline 1981 & 36.4 & 34.3 & 34.7 & 30.5 & 28.1 & 25.1 & 53.2 & 192 & 429 & 91.6 & 66.5 & 51.7 \\
\hline
\end{tabular}

ANNUAL PEAK DISGAARGE, IN AJBIC FEET PER SECOND, AND CORRESPONDING GAGE HEIGHT, IN FEET, FOR EACH WATER YEAR

\begin{tabular}{|c|c|c|c|c|c|c|c|c|c|c|c|}
\hline $\begin{array}{l}\text { WATER } \\
\text { YEAR }\end{array}$ & DATE & $\begin{array}{c}\text { GAGE } \\
\text { HEIGHT }\end{array}$ & $\begin{array}{c}\text { PEAK } \\
\text { DISCHARGE }\end{array}$ & $\begin{array}{l}\text { WATER } \\
\text { YEAR }\end{array}$ & DATE & $\begin{array}{c}\text { GAGE } \\
\text { HEIGHT }\end{array}$ & $\begin{array}{c}\text { PEAK } \\
\text { DISCHARGE }\end{array}$ & $\begin{array}{l}\text { WATER } \\
\text { YEAR }\end{array}$ & DATE & $\begin{array}{c}\text { GAGE } \\
\text { HEIGHT }\end{array}$ & $\begin{array}{c}\text { PEAK } \\
\text { DISOHARGE }\end{array}$ \\
\hline $\begin{array}{l}1933 \\
1934 \\
1943 \\
1944 \\
1945 \\
1946 \\
1947 \\
1948 \\
1949 \\
1950 \\
1951\end{array}$ & $\begin{array}{l}\text { JUNE } 03,1933 \\
\text { APR. } 24,1934 \\
\text { JUNE } 25,1943 \\
\text { JUNE } 26,1944 \\
\text { JUNE } 21,1945 \\
\text { JUNE } 05,1946 \\
\text { JUNE } 07,1947 \\
\text { MAY } 23,1948 \\
\text { JUNE } 16,1949 \\
\text { JUNE 06, } 1950 \\
\text { JUNE } 16,1951\end{array}$ & $\begin{array}{l}-- \\
-- \\
2.83 \\
5.27 \\
3.02 \\
2.89 \\
2.74 \\
2.97 \\
3.85 \\
3.84 \\
4.09\end{array}$ & $\begin{array}{r}403 \\
295 \\
934 \\
2700 \\
1100 \\
1210 \\
1040 \\
1200 \\
1820 \\
1230 \\
1550\end{array}$ & $\begin{array}{l}1952 \\
1953 \\
1954 \\
1955 \\
1964 \\
1965 \\
1966 \\
1967 \\
1968 \\
1969 \\
1970\end{array}$ & $\begin{array}{ll}\text { JUNE } 06,1952 \\
\text { JUNE } 13,1953 \\
\text { MAY } 19,1954 \\
\text { JUNE } 08,1955 \\
\text { JUNE } 06,1964 \\
\text { JUNE } 13,1965 \\
\text { MAY } 29,1966 \\
\text { JUNE } 25,1967 \\
\text { JUNE } 20,1968 \\
\text { MAY } 26,1969 \\
\text { JUNE } 03,1970\end{array}$ & $\begin{array}{l}4.27 \\
4.90 \\
3.12 \\
3.85 \\
3.81 \\
4.67 \\
3.04 \\
4.08 \\
4.79 \\
4.07 \\
3.46\end{array}$ & $\begin{array}{r}1600 \\
2380 \\
892 \\
1290 \\
1160 \\
1850 \\
647 \\
1410 \\
2060 \\
1340 \\
960\end{array}$ & $\begin{array}{l}1971 \\
1972 \\
1973 \\
1974 \\
1975 \\
1976 \\
1977 \\
1978 \\
1979 \\
1980 \\
1981\end{array}$ & $\begin{array}{l}\text { JUNE } 17,1971 \\
\text { MAY } 31,1972 \\
\text { JUNE } 09,1973 \\
\text { MAY } 28,1974 \\
\text { JULY } 01,1975 \\
\text { JUNE } 03,1976 \\
\text { JUNE } 04,1977 \\
\text { JUNE } 13,1978 \\
\text { MAY } 28,1979 \\
\text { JUNE } 11,1980 \\
\text { JUNE } 08,1981\end{array}$ & $\begin{array}{l}4.73 \\
4.00 \\
3.80 \\
3.58 \\
3.94 \\
2.87 \\
3.45 \\
3.68 \\
3.41 \\
3.97 \\
4.14\end{array}$ & $\begin{array}{r}2070 \\
1500 \\
1150 \\
1100 \\
1490 \\
767 \\
1310 \\
1400 \\
1040 \\
1610 \\
1560\end{array}$ \\
\hline
\end{tabular}

MAGITUDE AND PROBBTHIT OP AMNUAL LOMEST \begin{tabular}{l} 
BASED ON QRIMATIC YEARS $1944-55$ AND $1965-81$ \\
\hline
\end{tabular}

\begin{tabular}{|c|c|c|c|c|c|c|}
\hline \multirow{2}{*}{$\begin{array}{l}\text { PERIOD } \\
\text { (CON- } \\
\text { SEQI- } \\
\text { TTVE } \\
\text { DAYS) }\end{array}$} & \multicolumn{6}{|c|}{$\begin{array}{l}\text { DISQHARGE, IN CUBIC FEET PER SECOND, FOR } \\
\text { INDICATED REOURRENCE INTERVAL, IN YEARS, AND } \\
\text { ANNUAL NONEXCEEDANCE PRCBABIIITY, IN PERCENT }\end{array}$} \\
\hline & $\begin{array}{c}2 \\
50 \%\end{array}$ & $\begin{array}{c}5 \\
208\end{array}$ & $\begin{array}{l}10 \\
108\end{array}$ & $\begin{array}{l}20 \\
58\end{array}$ & $\begin{array}{l}50 \\
28\end{array}$ & $\begin{array}{r}100 \\
18\end{array}$ \\
\hline
\end{tabular}

\begin{tabular}{|c|c|c|c|c|c|c|}
\hline \multirow{2}{*}{$\begin{array}{l}\text { PERTOD } \\
\text { (CON- } \\
\text { SEQI- } \\
\text { TTVE } \\
\text { DAYS) }\end{array}$} & \multicolumn{6}{|c|}{$\begin{array}{l}\text { DIS HARGE, IN CUBIC FEET PER SECOND, FOR } \\
\text { INDICATED REOURRENCE INTERNAL, IN YEARS, AND } \\
\text { ANNUAL EXCEEDANCE PRCBAB ILITY, IN PERCENT }\end{array}$} \\
\hline & $\begin{array}{c}2 \\
50 \%\end{array}$ & $\begin{array}{c}5 \\
208\end{array}$ & $\begin{array}{l}10 \\
108\end{array}$ & $\begin{array}{l}25 \\
48\end{array}$ & $\begin{array}{l}50 \\
28\end{array}$ & $\begin{array}{r}100 \\
18\end{array}$ \\
\hline $\begin{array}{r}1 \\
3 \\
7 \\
15\end{array}$ & $\begin{array}{r}1020 \\
953 \\
841 \\
701\end{array}$ & $\begin{array}{c}1320 \\
1200 \\
1070 \\
911\end{array}$ & $\begin{array}{l}1470 \\
1310 \\
1180 \\
1020\end{array}$ & $\begin{array}{l}1620 \\
1390 \\
1280 \\
1120\end{array}$ & $\begin{array}{l}1710 \\
1440 \\
1330 \\
1190\end{array}$ & $\overline{-}$ \\
\hline
\end{tabular}

09290000 BROWN DUCK CREEK NEAR MOUNTAIN HOME, UT

LOCATION.--Lat $40^{\circ} 34^{\prime} 30^{\prime \prime}$, long $110^{\circ} 31^{\prime} 00^{\prime \prime}$, in NE'sec.13, T.2 N., R.6 W., Uintah Beridian, Duchesne County, Hydrol ogic Unit 14060003, on right bank $0.25 \mathrm{mi}$ upstream fram mouth and $1.5 \mathrm{mi}$ northwest of Mountain Hame.

DRAINAGE AREA. $--15 \mathrm{mi}^{2}$.

PERIOD OF RECORD AVAILABLE.--April 1933 to September 1934, October 1942 to september 1955.

GAGE.-Water-stage recorder and parshall flume. Altitude of gage is 8,200 ft by barameter. Prior to October 1942 , at different datum.

REMARKS.--Flow regulated by Brown Duck Lake, usable contents, 3,720 acre-ft. Since July 1946, about $0.7 \mathrm{ft} / \mathrm{s}$ diverted above station for power purposes.

AVERAGE DISCHARGE. --14 years, $9.43 \mathrm{ft}^{3} / \mathrm{s}, 6,830$ acre-ft/yr.

EXTREMES FOR PERIOD OF RECORD.--Naximum discharge recorded, $148 \mathrm{ft}^{3} / \mathrm{s}$ Jume 4, 1952 , gage height, $2.75 \mathrm{ft}$, fram rating curve extended above $80 \mathrm{ft}^{3} / \mathrm{s}$; minimum recorded, $0.9 \mathrm{ft}^{3} / \mathrm{s}$ oct. 29,1942 . 
LONEST IEAN DISGHARGE, IN OBBIC FEET PER SEOOND, AND RANKING FOR THE INDICATED NUMBER OF CONSECUTTVE DAYS FOR EACH CLIMATIC YEAR, APRIL I-MARG 31

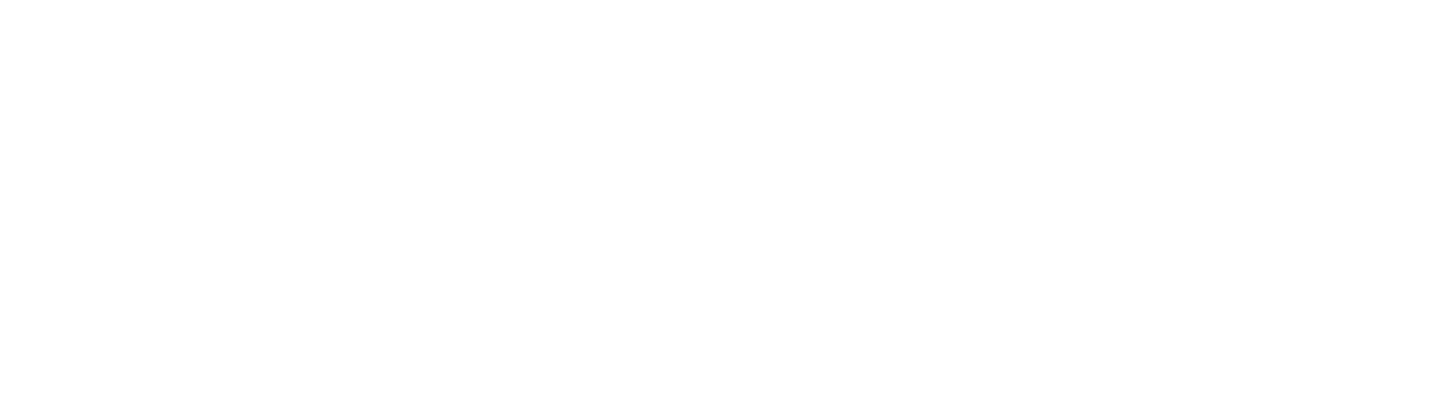

HIGHEST MEAN DISCHARGE, IN GBIC FEET PER SECOND, AND RANKING FOR THE INDICATED NUMBER OF CONSEQUTIVE DAYS FOR EACH WATER YEAR, OCTOBER I-SEPTEMBER 30

YEAR
1
1
1
1
1944
1
1
1
1
1
1
1
1
1
1

\begin{tabular}{|c|c|c|c|c|c|c|c|c|c|c|c|c|c|c|c|c|c|c|}
\hline \multicolumn{19}{|c|}{ CONSECUTTVE DAYS } \\
\hline & 3 & & 7 & & 15 & & 30 & & 60 & & 90 & & 120 & & 183 & & ALL & \\
\hline 14 & 37.0 & 14 & 26.0 & 14 & 15.0 & 14 & 9.20 & 14 & 5.30 & 14 & 4.60 & 14 & 3.90 & 14 & 2.90 & 14 & 2.10 & 14 \\
\hline $\begin{array}{r}4 \\
8 \\
11\end{array}$ & $\begin{array}{l}65.0 \\
60.0 \\
43.0\end{array}$ & $\begin{array}{r}4 \\
6 \\
11\end{array}$ & $\begin{array}{l}64.0 \\
55.0 \\
42.0\end{array}$ & $\begin{array}{r}3 \\
6 \\
10\end{array}$ & $\begin{array}{l}62.0 \\
53.0 \\
40.0\end{array}$ & $\begin{array}{l}2 \\
4 \\
9\end{array}$ & $\begin{array}{l}47.0 \\
45.0 \\
24.0\end{array}$ & $\begin{array}{r}2 \\
3 \\
13\end{array}$ & $\begin{array}{l}31.0 \\
40.0 \\
15.0\end{array}$ & $\begin{array}{r}7 \\
2 \\
13\end{array}$ & $\begin{array}{l}28.0 \\
34.0 \\
13.0\end{array}$ & $\begin{array}{r}4 \\
2 \\
13\end{array}$ & $\begin{array}{l}27.0 \\
34.0 \\
13.0\end{array}$ & $\begin{array}{r}4 \\
2 \\
13\end{array}$ & $\begin{array}{l}20.0 \\
23.0 \\
12.0\end{array}$ & $\begin{array}{r}4 \\
2 \\
12\end{array}$ & $\begin{array}{c}11.0 \\
12.0 \\
6.80\end{array}$ & $\begin{array}{r}4 \\
2 \\
12\end{array}$ \\
\hline $\begin{array}{r}10 \\
6 \\
9 \\
3 \\
7\end{array}$ & $\begin{array}{l}44.0 \\
51.0 \\
44.0 \\
70.0 \\
61.0\end{array}$ & $\begin{array}{r}10 \\
8 \\
9 \\
3 \\
5\end{array}$ & $\begin{array}{l}44.0 \\
42.0 \\
43.0 \\
61.0 \\
55.0\end{array}$ & $\begin{array}{r}8 \\
11 \\
9 \\
4 \\
5\end{array}$ & $\begin{array}{l}42.0 \\
37.0 \\
43.0 \\
53.0 \\
51.0\end{array}$ & $\begin{array}{r}8 \\
11 \\
7 \\
5 \\
6\end{array}$ & $\begin{array}{l}38.0 \\
36.0 \\
40.0 \\
45.0 \\
42.0\end{array}$ & $\begin{array}{l}8 \\
9 \\
7 \\
4 \\
6\end{array}$ & $\begin{array}{l}25.0 \\
28.0 \\
33.0 \\
35.0 \\
31.0\end{array}$ & $\begin{array}{l}9 \\
8 \\
5 \\
4 \\
6\end{array}$ & $\begin{array}{l}21.0 \\
22.0 \\
24.0 \\
28.0 \\
28.0\end{array}$ & $\begin{array}{r}10 \\
9 \\
8 \\
5 \\
6\end{array}$ & $\begin{array}{l}20.0 \\
21.0 \\
23.0 \\
27.0 \\
27.0\end{array}$ & $\begin{array}{r}10 \\
8 \\
7 \\
5 \\
6\end{array}$ & $\begin{array}{l}14.0 \\
16.0 \\
16.0 \\
20.0 \\
20.0\end{array}$ & $\begin{array}{r}10 \\
7 \\
8 \\
5 \\
6\end{array}$ & $\begin{array}{r}9.60 \\
8.70 \\
8.80 \\
11.0 \\
11.0\end{array}$ & $\begin{array}{l}7 \\
9 \\
8 \\
5 \\
6\end{array}$ \\
\hline $\begin{array}{r}1 \\
2 \\
5 \\
12 \\
13\end{array}$ & $\begin{array}{l}93.0 \\
93.0 \\
58.0 \\
40.0 \\
39.0\end{array}$ & $\begin{array}{r}1 \\
2 \\
7 \\
12 \\
13\end{array}$ & $\begin{array}{l}78.0 \\
85.0 \\
46.0 \\
39.0 \\
36.0\end{array}$ & $\begin{array}{r}2 \\
1 \\
7 \\
12 \\
13\end{array}$ & $\begin{array}{l}56.0 \\
81.0 \\
36.0 \\
38.0 \\
34.0\end{array}$ & $\begin{array}{r}3 \\
1 \\
12 \\
10 \\
13\end{array}$ & $\begin{array}{l}44.0 \\
66.0 \\
27.0 \\
33.0 \\
28.0\end{array}$ & $\begin{array}{l}5 \\
1 \\
12 \\
10 \\
11\end{array}$ & $\begin{array}{l}36.0 \\
51.0 \\
23.0 \\
24.0 \\
20.0\end{array}$ & $\begin{array}{r}3 \\
1 \\
11 \\
10 \\
12\end{array}$ & $\begin{array}{l}34.0 \\
41.0 \\
19.0 \\
24.0 \\
20.0\end{array}$ & $\begin{array}{r}3 \\
1 \\
12 \\
7 \\
11\end{array}$ & $\begin{array}{l}30.0 \\
41.0 \\
15.0 \\
20.0 \\
17.0\end{array}$ & $\begin{array}{r}3 \\
1 \\
12 \\
9 \\
11\end{array}$ & $\begin{array}{l}21.0 \\
30.0 \\
11.0 \\
14.0 \\
12.0\end{array}$ & $\begin{array}{r}3 \\
1 \\
13 \\
9 \\
11\end{array}$ & $\begin{array}{c}12.0 \\
17.0 \\
7.40 \\
8.30 \\
6.60\end{array}$ & $\begin{array}{l}3 \\
1 \\
11 \\
10 \\
13\end{array}$ \\
\hline
\end{tabular}

DURATION OF DISCHARGE FOR EACH WATER YEAR

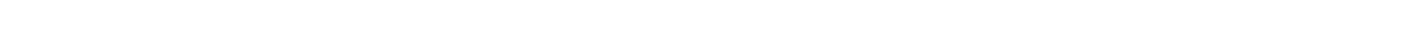
YEAR NUMBER OF DAYS IN OLASS

WBIC FEET PER SECOND -DAYS

\begin{tabular}{|c|c|c|c|c|c|c|c|c|c|c|c|c|c|c|c|c|c|c|c|c|c|c|c|c|c|c|c|c|c|c|c|c|}
\hline 1934 & 244 & & 66 & & 21 & & & 17 & 3 & 6 & & 2 & & & & 1 & & & & 1 & 2 & & 2 & & & & & & & & & 749.0 \\
\hline $\begin{array}{l}1943 \\
1944 \\
1945\end{array}$ & $\begin{array}{l}59 \\
60\end{array}$ & $\begin{array}{r}80 \\
61 \\
109\end{array}$ & $\begin{array}{r}436 \\
1104 \\
453\end{array}$ & $\begin{array}{rr}6 & 12 \\
4 & 7 \\
7 & 2\end{array}$ & $\begin{array}{r}14 \\
5 \\
20\end{array}$ & $\begin{array}{l}3 \\
2\end{array}$ & $\begin{array}{l}3 \\
1 \\
2\end{array}$ & $\begin{array}{r}5 \\
1 \\
14\end{array}$ & $\begin{array}{r}2 \\
2 \\
11\end{array}$ & $\begin{array}{r}2 \\
14\end{array}$ & $\begin{array}{l}2 \\
6\end{array}$ & $\begin{array}{r}4 \\
7 \\
10\end{array}$ & $\begin{array}{l}2 \\
3 \\
5\end{array}$ & $\begin{array}{r}14 \\
4 \\
8\end{array}$ & $\begin{array}{l}2 \\
1 \\
4\end{array}$ & $\begin{array}{r}11 \\
5 \\
21\end{array}$ & $\begin{array}{r}10 \\
5 \\
10\end{array}$ & $\begin{array}{r}26 \\
6 \\
17\end{array}$ & $\begin{array}{r}21 \\
2 \\
2\end{array}$ & $\begin{array}{r}12 \\
6 \\
7\end{array}$ & $\begin{array}{rr}5 & 11 \\
5 & 10 \\
4 & 1\end{array}$ & $\begin{array}{l}2 \\
9 \\
2\end{array}$ & $\begin{array}{r}4 \\
13 \\
8\end{array}$ & $\begin{array}{r}1 \\
17 \\
4\end{array}$ & $\begin{array}{r}5 \\
25\end{array}$ & 511 & 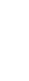 & 4 & & & & $\begin{array}{l}3918.4 \\
4534.6 \\
2466.7\end{array}$ \\
\hline $\begin{array}{l}1546 \\
1947 \\
1948 \\
1949\end{array}$ & $\begin{array}{r}5933 \\
91 \\
\end{array}$ & $\begin{array}{rr}7159 \\
71 \quad 7 \\
72 & 1 \\
1130\end{array}$ & $\begin{array}{l}2011 \\
\quad 12 \\
37 \quad 25 \\
64\end{array}$ & $\begin{array}{rr} & 3 \\
4 & 6 \\
2 & 19 \\
5 & 6 \\
4 & 67\end{array}$ & $\begin{array}{r}7 \\
11 \\
14 \\
8 \\
39\end{array}$ & $\begin{array}{r}1 \\
6 \\
19 \\
2 \\
6\end{array}$ & $\begin{array}{r}4 \\
8 \\
12 \\
3 \\
15\end{array}$ & $\begin{array}{r}2 \\
3 \\
11 \\
8 \\
13\end{array}$ & $\begin{array}{r}11 \\
5 \\
8 \\
11 \\
6\end{array}$ & $\begin{array}{r}8 \\
17 \\
3 \\
7 \\
7\end{array}$ & $\begin{array}{l}5 \\
9 \\
7 \\
7 \\
9\end{array}$ & $\begin{array}{r}6 \\
14 \\
6 \\
4 \\
14\end{array}$ & $\begin{array}{l}7 \\
6 \\
3 \\
4 \\
9\end{array}$ & $\begin{array}{r}5 \\
12 \\
4 \\
8 \\
8\end{array}$ & $\begin{array}{l}6 \\
6 \\
2 \\
1 \\
7\end{array}$ & $\begin{array}{r}18 \\
8 \\
6 \\
5 \\
7\end{array}$ & $\begin{array}{l}9 \\
7 \\
3 \\
6 \\
9\end{array}$ & $\begin{array}{r}11 \\
13 \\
6 \\
10 \\
7\end{array}$ & $\begin{array}{l}4 \\
6 \\
5 \\
3 \\
3\end{array}$ & $\begin{array}{r}8 \\
8 \\
6 \\
10 \\
7\end{array}$ & $\begin{array}{rr}6 & 7 \\
9 & 13 \\
3 & 10 \\
9 & 14 \\
9 & 11\end{array}$ & $\begin{array}{r}7 \\
7 \\
14 \\
12 \\
16\end{array}$ & $\begin{array}{l}21 \\
11 \\
16 \\
13 \\
17\end{array}$ & $\begin{array}{r}12 \\
4 \\
12 \\
10 \\
5\end{array}$ & $\begin{array}{l}1 \\
1 \\
7 \\
7\end{array}$ & 7 & 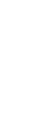 & 1 & 1 & & & $\begin{array}{l}3507.1 \\
3169.9 \\
3227.4 \\
3968.4 \\
4112.0\end{array}$ \\
\hline $\begin{array}{l}951 \\
952 \\
953 \\
954 \\
955\end{array}$ & 28 & 8280 & 1420 & 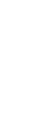 & $\begin{array}{r}55 \\
31 \\
61 \\
35 \\
5\end{array}$ & $\begin{array}{r}20 \\
3 \\
9 \\
9 \\
3\end{array}$ & $\begin{array}{r}6 \\
57 \\
35 \\
6 \\
5\end{array}$ & $\begin{array}{r}6 \\
16 \\
52 \\
40 \\
4\end{array}$ & $\begin{array}{r}38 \\
4 \\
2\end{array}$ & $\begin{array}{r}8 \\
16 \\
4 \\
3\end{array}$ & $\begin{array}{r}4 \\
8 \\
9 \\
1 \\
11\end{array}$ & $\begin{array}{l}1 \\
2 \\
8 \\
8 \\
8\end{array}$ & $\begin{array}{r}4 \\
1 \\
9 \\
20 \\
7\end{array}$ & $\begin{array}{r}4 \\
1 \\
10 \\
6 \\
6\end{array}$ & $\begin{array}{l}1 \\
6 \\
4 \\
4\end{array}$ & $\begin{array}{r}6 \\
15 \\
5 \\
6 \\
8\end{array}$ & $\begin{array}{l}2 \\
6 \\
5 \\
3 \\
7\end{array}$ & $\begin{array}{r}4 \\
7 \\
8 \\
4 \\
16\end{array}$ & $\begin{array}{c}4 \\
10 \\
2 \\
4 \\
9\end{array}$ & $\begin{array}{r}53 \\
10 \\
5 \\
10 \\
9\end{array}$ & $\begin{array}{rl}30 & 16 \\
7 & 16 \\
9 & 10 \\
7 & 20 \\
4 & 10\end{array}$ & $\begin{array}{r}21 \\
9 \\
3 \\
7 \\
9\end{array}$ & $\begin{array}{r}12 \\
23 \\
1 \\
13 \\
3\end{array}$ & $\begin{array}{r}3 \\
16 \\
2\end{array}$ & $\begin{array}{l}1 \\
6 \\
1\end{array}$ & 1 & & $\begin{array}{l}7 \\
1\end{array}$ & & & 1 & $\begin{array}{l}4277.4 \\
6080.5 \\
2696.7 \\
3045.5 \\
2420.6\end{array}$ \\
\hline
\end{tabular}

DURATION TABLE OF DISCHARGE FOR WATER YEARS 1934, 1943-55

\begin{tabular}{|c|c|c|c|c|}
\hline & $\begin{array}{c}\text { OBIIC } \\
\text { FEET } \\
\text { PER } \\
\text { SECODD }\end{array}$ & TOTAL & $\begin{array}{c}\text { ACOU- } \\
\text { MU- } \\
\text { LATED } \\
\text { DAYS }\end{array}$ & $\begin{array}{l}\text { PER- } \\
\text { CENT } \\
\text { DAYS }\end{array}$ \\
\hline CLASS & SECOND & DAYS & DAYS & DAYS \\
\hline 0 & 0.00 & 0 & 5113 & 100.0 \\
\hline 1 & 1.00 & 422 & $5] 13$ & 100.0 \\
\hline 2 & 1.20 & 152 & 4691 & 91 \\
\hline 3 & 1.30 & 233 & 4539 & 88.8 \\
\hline 4 & 1.50 & 627 & 4306 & \\
\hline 5 & 1.80 & 121 & 3679 & 72.0 \\
\hline & 2.00 & 561 & 3558 & 69.6 \\
\hline & 2. & 406 & 2997 & 58 \\
\hline & & 326 & 2591 & 50.7 \\
\hline
\end{tabular}

\begin{tabular}{rrrrr}
\multicolumn{4}{c}{ OBIIC } & \multicolumn{1}{c}{ ACOU- } \\
FEET & MU- & PER- \\
PER & TOTAL LATED & CENT \\
CLASS SECOND & DAYS & DAYS & DAYS \\
9 & 3.10 & 83 & 2265 & 44.3 \\
10 & 3.50 & 157 & 2182 & 42.7 \\
11 & 4.00 & 192 & 2025 & 39.6 \\
12 & 4.60 & 104 & 1833 & 35.8 \\
13 & 5.30 & 95 & 1729 & 33.8 \\
14 & 6.10 & 78 & 1634 & 32.0 \\
15 & 7.00 & 94 & 1556 & 30.4 \\
16 & 8.10 & 80 & 1462 & 28.6 \\
17 & 9.30 & 90 & 1382 & 27.0
\end{tabular}

\begin{tabular}{|c|c|c|c|c|}
\hline & $\begin{array}{c}\text { OUBIC } \\
\text { FEET } \\
\text { PER }\end{array}$ & TOTAL & $\begin{array}{l}\text { ACU- } \\
\text { MU- } \\
\text { LATED }\end{array}$ & $\begin{array}{l}\text { PER- } \\
\text { CENT }\end{array}$ \\
\hline ¿ASS & SECOND & DAYS & DAYS & DAYS \\
\hline $\begin{array}{l}27 \\
28 \\
29 \\
30 \\
31 \\
32 \\
33 \\
34\end{array}$ & $\begin{array}{l}37.0 \\
43.0 \\
49.0 \\
57.0 \\
65.0 \\
75.0 \\
86.0 \\
99.0\end{array}$ & $\begin{array}{r}157 \\
86 \\
54 \\
28 \\
13 \\
9 \\
5 \\
2\end{array}$ & $\begin{array}{r}354 \\
197 \\
111 \\
57 \\
29 \\
16 \\
7 \\
2\end{array}$ & $\begin{array}{l}6.9 \\
3.9 \\
2.2 \\
1.1 \\
0.6 \\
0.3 \\
0.1 \\
0.0\end{array}$ \\
\hline
\end{tabular}


GRFEN RIVER BASIN

09290000 BRONN DUCK CREEX NEAR MOUNTAIN HONE, UT--Continued

MONIYLY MEAN DISOAARGES, IN OBIC FEET PER SECOND, FOR EACH WATER YEAR

$\begin{array}{lcccccccccccc}\text { YEAR } & \text { NCT } & \text { NO } & \text { DEC } & \text { JAN } & \text { FEB } & \text { MAR } & \text { APR } & \text { MAY } & \text { JUNE } & \text { JULY } & \text { ALG } & \text { SEP } \\ 1934 & 2.00 & 1.00 & 1.00 & 1.00 & 1.00 & 1.00 & 2.50 & 2.52 & 6.20 & 4.26 & 1.13 & 1.00 \\ & & & & & & & & & & & & \\ 1943 & 1.84 & 1.50 & 1.50 & 1.00 & 1.00 & 2.39 & 12.5 & 25.1 & 19.7 & 17.0 & 41.7 & 2.57 \\ 1944 & 2.05 & 2.00 & 2.00 & 1.50 & 1.00 & 1.00 & 1.50 & 24.7 & 42.8 & 23.8 & 36.8 & 8.91 \\ 1945 & 2.19 & 1.70 & 1.60 & 1.50 & 1.60 & 1.80 & 2.50 & 15.0 & 15.4 & 7.79 & 6.09 & 24.0 \\ 1946 & 22.2 & 1.61 & 1.50 & 1.50 & 1.60 & 1.70 & 7.70 & 16.5 & 9.67 & 31.0 & 17.0 & 2.01 \\ 1947 & 1.94 & 1.30 & 1.30 & 1.20 & 1.00 & 1.00 & 4.72 & 34.5 & 19.7 & 9.90 & 17.6 & 9.28 \\ 1948 & 3.01 & 1.58 & 1.30 & 1.20 & 1.20 & 1.20 & 2.03 & 16.6 & 10.3 & 30.3 & 31.7 & 4.35 \\ 1949 & 1.88 & 1.86 & 1.70 & 1.60 & 1.60 & 1.60 & 5.78 & 27.0 & 41.5 & 12.1 & 27.9 & 5.45 \\ 1950 & 3.14 & 3.00 & 2.50 & 2.50 & 2.00 & 2.00 & 6.55 & 25.8 & 32.4 & 10.7 & 34.0 & 10.0 \\ & & & & & & & & & & & & \\ 1951 & 2.94 & 2.49 & 2.50 & 2.50 & 2.00 & 2.00 & 3.00 & 26.4 & 31.3 & 29.3 & 28.4 & 6.68 \\ 1952 & 3.63 & 3.50 & 3.00 & 2.50 & 2.50 & 2.00 & 8.00 & 52.0 & 49.2 & 21.9 & 38.5 & 11.9 \\ 1953 & 4.79 & 4.25 & 3.40 & 3.00 & 2.50 & 2.50 & 3.83 & 8.20 & 26.3 & 18.9 & 7.24 & 3.50 \\ 1954 & 2.85 & 2.50 & 2.50 & 2.00 & 2.00 & 2.00 & 4.94 & 21.9 & 14.0 & 32.2 & 8.59 & 3.80 \\ 1955 & 1.88 & 1.60 & 1.50 & 1.40 & 1.20 & 1.30 & 1.53 & 14.9 & 14.5 & 25.0 & 11.3 & 2.73\end{array}$

ANNUAL PEAK DISCHARGE, IN OUBIC FEET PER SECOND, AND CORRESPONDING GAGE HEIGHT, IN FEET, FOR EACH WATER YEAR

\begin{tabular}{|c|c|c|c|c|c|c|c|c|c|c|c|c|c|}
\hline $\begin{array}{l}\text { WATERR } \\
\text { YEAR }\end{array}$ & DATE & $\begin{array}{l}\text { GAGE } \\
\text { HEIGHY }\end{array}$ & $\begin{array}{c}\text { PEAK } \\
\text { DISCHARGE }\end{array}$ & $\begin{array}{l}\text { WATER } \\
\text { YEAR }\end{array}$ & & DATE & $\begin{array}{c}\text { GAGE } \\
\text { HEIGETT }\end{array}$ & $\begin{array}{c}\text { PEAK } \\
\text { DISCHARGE }\end{array}$ & $\begin{array}{l}\text { WATER } \\
\text { YEAR }\end{array}$ & & DATE & $\begin{array}{c}\text { GAGE } \\
\text { HEIGHT }\end{array}$ & $\begin{array}{c}\text { PEAR } \\
\text { DISCHARGE }\end{array}$ \\
\hline 1933 & 1 & - & $2_{55}$ & 1946 & OCT. & 12,1945 & 1.73 & 48 & 1951 & MAY & 27,1951 & 2.52 & 140 \\
\hline 1934 & JUNE $29,30,1934$ & - & 240 & 1947 & MAY & 08,1947 & 2.26 & 85 & 1952 & JURE & 04,1952 & 2.75 & 148 \\
\hline 1943 & AUG. 08,1943 & 2.27 & 86 & 1948 & MAY & 19,1948 & 2.14 & 71 & 1953 & JUNE & 13,1953 & - & $2_{66}$ \\
\hline $\begin{array}{l}1944 \\
1945\end{array}$ & $\begin{array}{l}\text { JUNE } 26,1944 \\
\text { SEPT.27, } 1945\end{array}$ & $\begin{array}{l}2.20 \\
1.65\end{array}$ & $\begin{array}{l}77 \\
44\end{array}$ & $\begin{array}{l}1949 \\
1950\end{array}$ & $\begin{array}{l}\text { JUNE } \\
\text { MAY }\end{array}$ & $\begin{array}{l}19,1949 \\
30,1950\end{array}$ & - & $\begin{array}{l}280 \\
106\end{array}$ & $\begin{array}{l}1954 \\
1955\end{array}$ & $\begin{array}{l}\text { JULY } \\
\text { AUG. }\end{array}$ & $\begin{array}{l}10,18,1954 \\
06,1955\end{array}$ & $\begin{array}{l}1.48 \\
1.60\end{array}$ & $\begin{array}{l}43 \\
46\end{array}$ \\
\hline
\end{tabular}

MAGNITUDE AND PROBABILITY OF ANNUAL LONEST MEAN DISOHAFGE BASED ON CLIMATIC YEARS 1944-55

\begin{tabular}{|c|c|c|c|c|c|c|}
\hline \multirow{2}{*}{$\begin{array}{l}\text { PERIOD } \\
\text { (CON- } \\
\text { SECU- } \\
\text { TIVE } \\
\text { DAYS) }\end{array}$} & \multicolumn{6}{|c|}{$\begin{array}{l}\text { DISCHARGE, IN OUBIC FEET PER SECOND, FOR } \\
\text { INDICATED REOURRENCE INTERNAL, IN YEARS, AND } \\
\text { ANNUAL NONEXCEEDANCE PRCBABILITY, IN PEERCENT }\end{array}$} \\
\hline & $\begin{array}{c}2 \\
508\end{array}$ & $\begin{array}{c}5 \\
208\end{array}$ & $\begin{array}{l}10 \\
108\end{array}$ & $\begin{array}{l}20 \\
58\end{array}$ & $\begin{array}{l}50 \\
28\end{array}$ & $\begin{array}{r}100 \\
18\end{array}$ \\
\hline
\end{tabular}

$\begin{array}{rrrllll}1 & 1.5 & 1.2 & 1.0 & 0.93 & - & - \\ 7 & 1.5 & 1.2 & 1.0 & 0.93 & - & - \\ 14 & 1.5 & 1.2 & 1.0 & 0.93 & - & - \\ 30 & 1.6 & 1.2 & 1.1 & 0.93 & - & - \\ 60 & 1.6 & 1.2 & 1.1 & 0.94 & = & - \\ 90 & 1.7 & 1.3 & 1.1 & 1.0 & - & -\end{array}$

${ }^{1}$ July 20-24, 27-29, 1933.

${ }^{2}$ Maximum daily discharge.
MAGNITUDE AND PRCBABIIITY OF ANNUAL HIGHEST MEAN DISCHARGE BASED ON WATER YEARS 1934 AND 1943-55

\begin{tabular}{|c|c|c|c|c|c|c|}
\hline \multirow{2}{*}{$\begin{array}{l}\text { PERIOD } \\
\text { SOON- } \\
\text { SEOU- } \\
\text { TIVE } \\
\text { DAYS }\end{array}$} & \multicolumn{6}{|c|}{$\begin{array}{l}\text { DISCHARGE, IN OUBIC FEET PER SECOND, FOR } \\
\text { INDICATED RECURRENCE INIERNAL, IN YEARS, AND } \\
\text { ANNUAL EXCEEDANCE PROBABILITY, IN PERCENT }\end{array}$} \\
\hline & $\begin{array}{c}2 \\
508\end{array}$ & $\begin{array}{c}5 \\
208\end{array}$ & $\begin{array}{l}10 \\
108\end{array}$ & $\begin{array}{l}25 \\
48\end{array}$ & $\begin{array}{l}50 \\
28\end{array}$ & $\begin{array}{r}100 \\
18\end{array}$ \\
\hline
\end{tabular}

$\begin{array}{rrrrrrr}1 & 57 & 76 & 89 & 107 & - & - \\ 3 & 53 & 70 & 82 & 98 & - & - \\ 7 & 49 & 64 & 73 & 85 & - & - \\ 15 & 47 & 60 & 65 & 70 & - & -\end{array}$

09291000 LAKE FORR RIVER BELOW MOQN LARE, NEAR MOUNTAIN HOME, UT

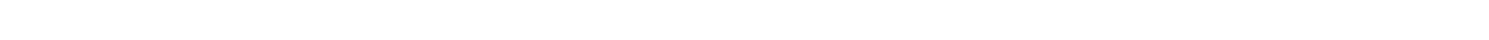
14060003, Ashley National Forest, on right bank 2,000 ft downstream from Moon Lake Dam, 2 mi downstream from Brown Duck Creek, and $12 \mathrm{mi}$ northwest of Mountain Home.

DRAINAGE AREA.--112 $\mathrm{mi}^{2}$.

PERIOD OF RECORD AVAIIABLE.--September 1921 to Septenber 1934, April 1942 to September 1981 (monthly mean discharge for same periods prior to October 1943, published in WSP 1313). Published as "West Fork near Mountain Home", 1921-34, and "Lake Fork below Moon Lake, near Mountain Home", 1942-65.

REVISED RECORDS. -WSP 1313: 1930 (M). WDR UT-77-1: Drainage area.

GAGE.--Water-stage recorder. Altitude of gage is 7,970 ft by barameter. Prior to April 1942 , at damsite $2,000 \mathrm{ft}$ upstream at different datum.

REMARRS.--Flow regulated by Moon Lake Reservoir since Dec. 9, 1937. No diversions above station.

AVERAGE DISCHARGE.--39 years (water years 1943-1981), $125 \mathrm{ft}^{3} / \mathrm{s}, 90,560$ acre-ft/yr.

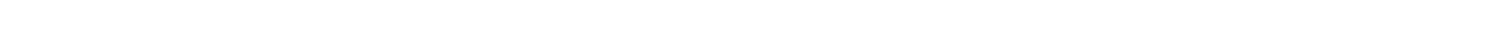
maximum gage height, $5.46 \mathrm{ft}$ June 26, 1944; no flow at times when reservoir gates are closed. 
GREEN RIVER BASIN

09291000 LAKE FORK RIVER BELOW MOON LAKE, NEAR MOUNTAIN HONE, UT-Continued

LONEST MEAN DISOHARGE, IN OBIC FEET PER SECOND, AND RANKING FOR THE INDICATED NUMBER OF CONSEOUTTVE DAYS FOR EAOH OLIMATIC YEAR, APRIL 1-MARQH 31

\begin{tabular}{|c|c|c|c|c|c|c|c|c|c|c|c|c|c|c|c|c|c|c|c|c|}
\hline YEAR & 1 & & 3 & & 7 & & 14 & & $\begin{array}{l}\text { CONSE } \\
30\end{array}$ & EQTT & $\begin{array}{l}\text { DAYS } \\
60\end{array}$ & & 90 & & 120 & & 183 & & ALL & \\
\hline $\begin{array}{l}1943 \\
1944 \\
1945\end{array}$ & $\begin{array}{l}0.00 \\
0.00 \\
0.00\end{array}$ & $\begin{array}{l}1 \\
2 \\
3\end{array}$ & $\begin{array}{l}0.00 \\
0.00 \\
0.00\end{array}$ & $\begin{array}{l}1 \\
2 \\
3\end{array}$ & $\begin{array}{l}0.00 \\
0.00 \\
0.00\end{array}$ & $\begin{array}{l}1 \\
2 \\
3\end{array}$ & $\begin{array}{l}0.00 \\
0.00 \\
0.00\end{array}$ & $\begin{array}{l}1 \\
2 \\
3\end{array}$ & $\begin{array}{l}0.00 \\
0.00 \\
0.00\end{array}$ & $\begin{array}{l}1 \\
2 \\
3\end{array}$ & $\begin{array}{l}0.00 \\
0.00 \\
0.00\end{array}$ & $\begin{array}{l}1 \\
2 \\
3\end{array}$ & $\begin{array}{l}0.00 \\
0.00 \\
0.00\end{array}$ & $\begin{array}{l}1 \\
2 \\
3\end{array}$ & $\begin{array}{l}0.00 \\
0.00 \\
0.00\end{array}$ & $\begin{array}{l}1 \\
2 \\
3\end{array}$ & $\begin{array}{c}10.0 \\
19.0 \\
9.60\end{array}$ & $\begin{array}{l}25 \\
37 \\
23\end{array}$ & $\begin{array}{l}145 \\
142 \\
161\end{array}$ & $\begin{array}{l}31 \\
29 \\
36\end{array}$ \\
\hline $\begin{array}{l}1946 \\
1947 \\
1948 \\
1949 \\
1950\end{array}$ & $\begin{array}{l}0.00 \\
0.00 \\
0.00 \\
0.00 \\
0.00\end{array}$ & $\begin{array}{l}4 \\
5 \\
6 \\
7 \\
8\end{array}$ & $\begin{array}{l}0.00 \\
0.00 \\
0.00 \\
0.00 \\
0.00\end{array}$ & $\begin{array}{l}4 \\
5 \\
6 \\
7 \\
8\end{array}$ & $\begin{array}{l}0.00 \\
0.00 \\
0.00 \\
0.00 \\
0.00\end{array}$ & $\begin{array}{l}4 \\
5 \\
6 \\
7 \\
8\end{array}$ & $\begin{array}{l}0.00 \\
0.00 \\
0.00 \\
0.00 \\
0.00\end{array}$ & $\begin{array}{l}4 \\
5 \\
6 \\
7 \\
8\end{array}$ & $\begin{array}{l}0.00 \\
0.00 \\
0.00 \\
0.00 \\
0.00\end{array}$ & $\begin{array}{l}4 \\
5 \\
6 \\
7 \\
8\end{array}$ & $\begin{array}{l}0.00 \\
0.00 \\
0.00 \\
0.00 \\
0.00\end{array}$ & $\begin{array}{l}4 \\
5 \\
6 \\
7 \\
8\end{array}$ & $\begin{array}{l}0.00 \\
0.00 \\
0.00 \\
0.00 \\
0.00\end{array}$ & $\begin{array}{l}4 \\
5 \\
6 \\
7 \\
8\end{array}$ & $\begin{array}{l}0.00 \\
0.00 \\
0.00 \\
0.00 \\
0.00\end{array}$ & $\begin{array}{l}4 \\
5 \\
6 \\
7 \\
8\end{array}$ & $\begin{array}{c}15.0 \\
10.0 \\
16.0 \\
4.80 \\
9.50\end{array}$ & $\begin{array}{r}32 \\
24 \\
34 \\
8 \\
22\end{array}$ & $\begin{array}{c}117 \\
114 \\
137 \\
94.0 \\
137\end{array}$ & $\begin{array}{r}15 \\
13 \\
25 \\
5 \\
26\end{array}$ \\
\hline $\begin{array}{l}1951 \\
1952 \\
1953 \\
1954 \\
1955\end{array}$ & $\begin{array}{l}0.00 \\
0.00 \\
0.00 \\
0.00 \\
0.00\end{array}$ & $\begin{array}{r}9 \\
10 \\
11 \\
12 \\
13\end{array}$ & $\begin{array}{l}0.00 \\
0.00 \\
0.00 \\
0.00 \\
0.00\end{array}$ & $\begin{array}{l}9 \\
10 \\
11 \\
12 \\
13\end{array}$ & $\begin{array}{l}0.00 \\
0.00 \\
0.00 \\
0.00 \\
0.00\end{array}$ & $\begin{array}{r}9 \\
10 \\
11 \\
12 \\
13\end{array}$ & $\begin{array}{l}0.00 \\
0.00 \\
0.00 \\
0.00 \\
0.00\end{array}$ & $\begin{array}{r}9 \\
10 \\
11 \\
12 \\
13\end{array}$ & $\begin{array}{l}0.00 \\
0.00 \\
0.00 \\
0.00 \\
0.00\end{array}$ & $\begin{array}{r}9 \\
10 \\
11 \\
12 \\
12\end{array}$ & $\begin{array}{l}0.00 \\
0.00 \\
0.00 \\
0.00 \\
0.00\end{array}$ & $\begin{array}{r}9 \\
10 \\
11 \\
12 \\
13\end{array}$ & $\begin{array}{l}0.00 \\
0.00 \\
0.00 \\
0.00 \\
0.00\end{array}$ & $\begin{array}{r}9 \\
10 \\
11 \\
12 \\
13\end{array}$ & $\begin{array}{l}0.00 \\
0.00 \\
0.00 \\
0.00 \\
0.00\end{array}$ & $\begin{array}{r}9 \\
10 \\
11 \\
12 \\
13\end{array}$ & $\begin{array}{c}5.80 \\
7.60 \\
32.0 \\
3.50 \\
2.80\end{array}$ & $\begin{array}{r}11 \\
17 \\
38 \\
5 \\
4\end{array}$ & $\begin{array}{c}141 \\
121 \\
191 \\
111 \\
84.0\end{array}$ & $\begin{array}{r}27 \\
17 \\
39 \\
11 \\
3\end{array}$ \\
\hline $\begin{array}{l}1956 \\
1957 \\
1958 \\
1959 \\
1960\end{array}$ & $\begin{array}{l}0.00 \\
0.00 \\
0.00 \\
0.00 \\
0.00\end{array}$ & $\begin{array}{l}14 \\
15 \\
16 \\
17 \\
18\end{array}$ & $\begin{array}{l}0.00 \\
0.00 \\
0.00 \\
0.00 \\
0.00\end{array}$ & $\begin{array}{l}14 \\
15 \\
16 \\
17 \\
18\end{array}$ & $\begin{array}{l}0.00 \\
0.00 \\
0.00 \\
0.00 \\
0.00\end{array}$ & $\begin{array}{l}14 \\
15 \\
16 \\
17 \\
18\end{array}$ & $\begin{array}{l}0.00 \\
0.00 \\
0.00 \\
0.00 \\
0.00\end{array}$ & $\begin{array}{l}14 \\
15 \\
16 \\
17 \\
18\end{array}$ & $\begin{array}{l}0.00 \\
0.00 \\
0.00 \\
0.00 \\
0.00\end{array}$ & $\begin{array}{l}14 \\
15 \\
16 \\
17 \\
18\end{array}$ & $\begin{array}{l}0.00 \\
0.00 \\
0.00 \\
0.00 \\
0.00\end{array}$ & $\begin{array}{l}14 \\
15 \\
16 \\
17 \\
18\end{array}$ & $\begin{array}{l}0.00 \\
0.00 \\
0.00 \\
0.00 \\
0.00\end{array}$ & $\begin{array}{l}14 \\
15 \\
16 \\
17 \\
18\end{array}$ & $\begin{array}{l}0.00 \\
0.00 \\
0.00 \\
0.00 \\
0.00\end{array}$ & $\begin{array}{l}14 \\
15 \\
16 \\
17 \\
18\end{array}$ & $\begin{array}{c}7.20 \\
5.30 \\
11.0 \\
11.0 \\
9.20\end{array}$ & $\begin{array}{r}14 \\
9 \\
26 \\
27 \\
20\end{array}$ & $\begin{array}{c}97.0 \\
129 \\
107 \\
142 \\
95.0\end{array}$ & $\begin{array}{r}7 \\
20 \\
9 \\
28 \\
6\end{array}$ \\
\hline $\begin{array}{l}1961 \\
1962 \\
1963 \\
1964 \\
1965\end{array}$ & $\begin{array}{l}0.00 \\
0.00 \\
0.00 \\
0.00 \\
0.00\end{array}$ & $\begin{array}{l}19 \\
20 \\
21 \\
22 \\
23\end{array}$ & $\begin{array}{l}0.00 \\
0.00 \\
0.00 \\
0.00 \\
0.00\end{array}$ & $\begin{array}{l}19 \\
20 \\
21 \\
22 \\
23\end{array}$ & $\begin{array}{l}0.00 \\
0.00 \\
0.00 \\
0.00 \\
0.00\end{array}$ & $\begin{array}{l}19 \\
20 \\
21 \\
22 \\
23\end{array}$ & $\begin{array}{l}0.00 \\
0.00 \\
0.00 \\
0.00 \\
0.00\end{array}$ & $\begin{array}{l}19 \\
20 \\
21 \\
22 \\
23\end{array}$ & $\begin{array}{l}0.00 \\
0.00 \\
0.00 \\
0.00 \\
0.00\end{array}$ & $\begin{array}{l}19 \\
20 \\
21 \\
22 \\
23\end{array}$ & $\begin{array}{l}0.00 \\
0.00 \\
0.00 \\
0.00 \\
0.00\end{array}$ & $\begin{array}{l}19 \\
20 \\
21 \\
22 \\
23\end{array}$ & $\begin{array}{l}0.00 \\
0.00 \\
0.00 \\
0.00 \\
0.00\end{array}$ & $\begin{array}{l}19 \\
20 \\
21 \\
22 \\
23\end{array}$ & $\begin{array}{l}0.00 \\
0.17 \\
0.00 \\
0.00 \\
0.00\end{array}$ & $\begin{array}{l}19 \\
38 \\
20 \\
21 \\
22\end{array}$ & $\begin{array}{r}6.20 \\
3.60 \\
5.70 \\
15.0 \\
7.30\end{array}$ & $\begin{array}{r}13 \\
6 \\
10 \\
33 \\
15\end{array}$ & $\begin{array}{l}92.0 \\
61.0 \\
165 \\
113 \\
146\end{array}$ & $\begin{array}{r}4 \\
2 \\
37 \\
12 \\
32\end{array}$ \\
\hline $\begin{array}{l}1966 \\
1967 \\
1968 \\
1969 \\
1970\end{array}$ & $\begin{array}{l}0.00 \\
0.00 \\
0.00 \\
0.00 \\
0.00\end{array}$ & $\begin{array}{l}24 \\
25 \\
26 \\
27 \\
28\end{array}$ & $\begin{array}{l}0.00 \\
0.00 \\
0.00 \\
0.00 \\
0.00\end{array}$ & $\begin{array}{l}24 \\
25 \\
26 \\
27 \\
28\end{array}$ & $\begin{array}{l}0.00 \\
0.00 \\
0.00 \\
0.00 \\
0.00\end{array}$ & $\begin{array}{l}24 \\
25 \\
26 \\
27 \\
28\end{array}$ & $\begin{array}{l}0.00 \\
0.00 \\
0.00 \\
0.00 \\
0.00\end{array}$ & $\begin{array}{l}24 \\
25 \\
26 \\
27 \\
28\end{array}$ & $\begin{array}{l}7.10 \\
0.00 \\
0.00 \\
0.00 \\
0.00\end{array}$ & $\begin{array}{l}39 \\
24 \\
25 \\
26 \\
27\end{array}$ & $\begin{array}{l}8.20 \\
0.00 \\
0.00 \\
0.00 \\
0.00\end{array}$ & $\begin{array}{l}39 \\
24 \\
25 \\
26 \\
27\end{array}$ & $\begin{array}{c}14.0 \\
0.00 \\
0.00 \\
0.00 \\
0.00\end{array}$ & $\begin{array}{l}39 \\
24 \\
25 \\
26 \\
27\end{array}$ & $\begin{array}{c}31.0 \\
0.00 \\
0.00 \\
0.00 \\
0.00\end{array}$ & $\begin{array}{l}39 \\
23 \\
24 \\
25 \\
26\end{array}$ & $\begin{array}{c}66.0 \\
13.0 \\
9.40 \\
18.0 \\
5.90\end{array}$ & $\begin{array}{l}39 \\
30 \\
21 \\
35 \\
12\end{array}$ & $\begin{array}{l}177 \\
132 \\
154 \\
157 \\
161\end{array}$ & $\begin{array}{l}38 \\
23 \\
33 \\
34 \\
35\end{array}$ \\
\hline $\begin{array}{l}1971 \\
1972 \\
1973 \\
1974 \\
1975\end{array}$ & $\begin{array}{l}0.00 \\
0.00 \\
0.00 \\
0.00 \\
0.00\end{array}$ & $\begin{array}{l}29 \\
30 \\
31 \\
32 \\
33\end{array}$ & $\begin{array}{l}0.00 \\
0.00 \\
0.00 \\
0.00 \\
0.00\end{array}$ & $\begin{array}{l}29 \\
30 \\
31 \\
32 \\
33\end{array}$ & $\begin{array}{l}0.00 \\
0.00 \\
0.00 \\
0.00 \\
0.00\end{array}$ & $\begin{array}{l}29 \\
30 \\
31 \\
32 \\
33\end{array}$ & $\begin{array}{l}0.00 \\
0.00 \\
0.00 \\
0.00 \\
0.00\end{array}$ & $\begin{array}{l}29 \\
30 \\
31 \\
32 \\
33\end{array}$ & $\begin{array}{l}0.00 \\
0.00 \\
0.00 \\
0.00 \\
0.00\end{array}$ & $\begin{array}{l}28 \\
29 \\
30 \\
31 \\
32\end{array}$ & $\begin{array}{l}0.00 \\
0.00 \\
0.00 \\
0.00 \\
0.00\end{array}$ & $\begin{array}{l}28 \\
29 \\
30 \\
31 \\
32\end{array}$ & $\begin{array}{l}0.00 \\
0.00 \\
0.00 \\
0.00 \\
0.00\end{array}$ & $\begin{array}{l}28 \\
29 \\
30 \\
31 \\
32\end{array}$ & $\begin{array}{l}0.00 \\
0.00 \\
0.00 \\
0.03 \\
0.00\end{array}$ & $\begin{array}{l}27 \\
28 \\
29 \\
37 \\
30\end{array}$ & $\begin{array}{c}11.0 \\
8.70 \\
2.10 \\
19.0 \\
4.60\end{array}$ & $\begin{array}{r}28 \\
18 \\
1 \\
36 \\
7\end{array}$ & $\begin{array}{l}115 \\
137 \\
129 \\
128 \\
119\end{array}$ & $\begin{array}{l}14 \\
24 \\
21 \\
18 \\
16\end{array}$ \\
\hline
\end{tabular}

HIGHEST MEAN DISQHARGE, IN CUBIC FEET PER SECOND, AND RANKING FOR THE INDICATED NUMBER OF CONSEQUTTVE DAYS FOR EAOH WATER YEAR, OCTOBER 1-SEPTEMBER 30

YEAR

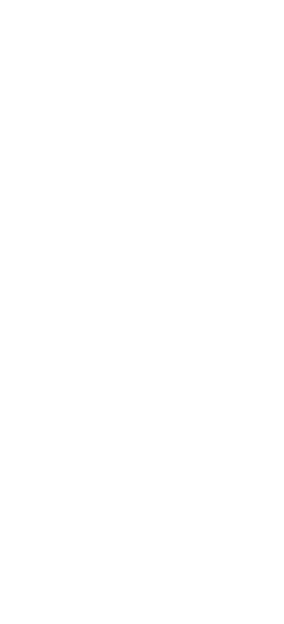

CONSEOTTIVE DAYS

15

$23 \quad 434$

7

$27 \quad 368$

$35 \quad 395$

$\begin{array}{rr}33 & 420 \\ 28 & 429 \\ 36 & 384\end{array}$

$\begin{array}{rr}1 & 1010 \\ 13 \quad 789\end{array}$

$32 \quad 406$

$\begin{array}{rr}3 & 1020 \\ 24 & 458\end{array}$

$\begin{array}{ll}38 & 353 \\ 31 & 431\end{array}$

$17 \quad 548$

$\begin{array}{rr}18 & 511 \\ 6 & 854\end{array}$

$34 \quad 403$

$37 \quad 369$

$\begin{array}{rr}2 & 1030 \\ 25 & 461\end{array}$

$\begin{array}{ll}25 & 461 \\ 15 & 738\end{array}$

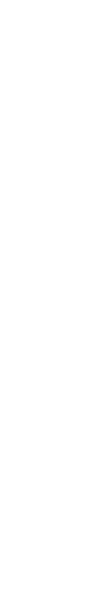

$35 \quad 362$

90

120

$\begin{array}{rr}30 & 32 \\ 2 & 565\end{array}$

$29 \quad 297$

2
33

$\begin{array}{ll}30 & 372 \\ 27 & 389\end{array}$

$\begin{array}{ll}27 & 389 \\ 36 & 335\end{array}$

9
11 467

$34 \quad 374$

$\begin{array}{rr}4 & 676 \\ 21 & 417 \\ 37 & 31\end{array}$

$\begin{array}{ll}37 & 319 \\ 26 & 355\end{array}$

$18 \quad 44$

$28 \quad 35$

$\begin{array}{llllll}31 & 341 & 12 & 440 & 10 & 41 \\ 34 & 272 & 37 & 263\end{array}$

233

$\begin{array}{rr}38 & 274 \\ 5 & 576 \\ 22 & 400\end{array}$

$\begin{array}{rr}5 & 576 \\ 22 & 400 \\ 13 & 503 \\ 3 & 720\end{array}$
$38 \quad 26$

$\begin{array}{rrrr}7 & 484 & 6 & 204\end{array}$

$\begin{array}{rr}38 & 204 \\ 6 & 427 \\ 19 & 341 \\ 8 & 41\end{array}$
90
28

$\begin{array}{rr}2 & 44 \\ 34 & 27 \\ 21 & 295\end{array}$
20

$\begin{array}{rrrrr}23 & 264 & 13 & 137 & 14 \\ 2 & 312 & 4 & 166 & 3\end{array}$

$25 \quad 114 \quad 26$

$\begin{array}{lllll}4 & 218 & 26 & 116 & 25\end{array}$

$\begin{array}{lllll}21 & 258 & 15 & 134 & 16 \\ 33 & 184 & 34 & 100 & 33\end{array}$

$\begin{array}{rrrrr}5 & 264 & 14 & 135 & 15 \\ 0 & 276 & 9 & 142 & 10\end{array}$

$\begin{array}{rrrrr}1 & 349 & 1 & 178 & 1 \\ 25 & 218 & 27 & 125 & 21\end{array}$

$\begin{array}{rlrrr}34 & 164 & 37 & 84.0 & 37 \\ & 186 & 33 & 95.0 & 35\end{array}$

$\begin{array}{lllll}12 & 252 & 18 & 129 & 18\end{array}$

$\begin{array}{rllll}32 & 204 & 30 & 105 & 30 \\ 7 & 273 & 10 & 142 & 11\end{array}$

$\begin{array}{lllrl}36 & 181 & 35 & 96.0 & 34 \\ 35 & 176 & 36 & 93.0 & 36\end{array}$

$38 \quad 117$

$\begin{array}{llll}117 & 38 & 62.0 & 38\end{array}$

$\begin{array}{rrrlr}4 & 323 & 2 & 164 & 4\end{array}$ 
09291000 LAKE FORK RIVER BELW NDON LAKE, NEAR NWUNTAIN HONE, UT-Continued

HIGHEST MEAN DISCHARGE, IN OUBIC FEET PER SECOND, AND RANKING FOR THE INDICATED NUMBER OF CONSEQUTIVE DAYS FOR EAOH WATER YEAR, OCTCBER 1-SEPTEYBER 30--Continued

YEAR

\begin{tabular}{rrrrrrrr} 
YEAR & \multicolumn{1}{c}{3} & & 7 & \\
1966 & 634 & 19 & 611 & 19 & 557 & 17 & 449 \\
1967 & 1270 & 5 & 1170 & 4 & 1140 & 1 & 980 \\
1968 & 1090 & 9 & 1000 & 9 & 870 & 9 & 735 \\
1969 & 967 & 13 & 953 & 10 & 850 & 11 & 758 \\
1970 & 499 & 24 & 494 & 22 & 435 & 26 & 4 \\
1971 & 989 & 12 & 849 & 14 & 702 & 15 & 541 \\
1972 & 895 & 14 & 777 & 16 & 671 & 16 & 552 \\
1973 & 1070 & 10 & 869 & 12 & 814 & 12 & 579 \\
1974 & 540 & 20 & 537 & 20 & 510 & 20 & 4 \\
1975 & 1190 & 6 & 1130 & 5 & 985 & 6 & 787 \\
1976 & 454 & 28 & 451 & 27 & 447 & 25 & \\
1977 & 319 & 39 & 319 & 39 & 315 & 39 & 279 \\
1978 & 529 & 22 & 499 & 21 & 481 & 21 & 465 \\
1979 & 440 & 30 & 437 & 30 & 433 & 28 & 424 \\
1980 & 1120 & 8 & 1030 & 8 & 918 & 8 & 725 \\
1981 & 446 & 29 & 441 & 29 & 429 & 30 & 393
\end{tabular}

CONSEOTTTE DAUS

$\begin{array}{lrrr}30 & & 60 \\ 394 & 25 & 352 & 23 \\ 680 & 3 & 459 & 7 \\ 614 & 6 & 498 & 4 \\ 634 & 5 & 491 & 5 \\ 400 & 22 & 339 & 24\end{array}$

400
90 \begin{tabular}{ll}
7 & 3 \\
5 & 3 \\
3 & 429 \\
\hline
\end{tabular} $\begin{array}{rrr}183 & & \text { ALL } \\ 251 & 19 & 159 \\ 298 & 5 & 155 \\ 296 & 6 & 152 \\ 316 & 3 & 167 \\ 220 & 24 & 113\end{array}$ 11327

$\begin{array}{ll}12 & 138 \\ 16 & 132\end{array}$

$\begin{array}{ll}16 & 132 \\ 21 & 120\end{array}$

$23 \quad 126$

1138

$\begin{array}{llllll}24 & 394 & 23 & 326 & 27 & 301\end{array}$

$\begin{array}{llll}24 & 394 & 23 & 326 \\ 39 & 254 & 39 & 21\end{array}$

$279 \quad 39 \quad 254$

$\begin{array}{ll}424 & 25 \\ 725 & 10\end{array}$

DURATION OF DISCHARGE FOR EAOH WATER YEAR

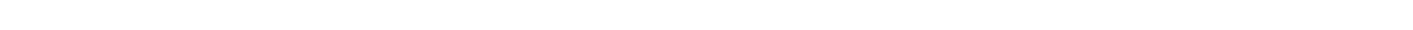
YEAR

NUMBER OF DAYS IN OLASS

1943159

1944184

1945155

1946152

1948196

1948167

1949167

1951162

1952182

1953169

1954203

1955208

1956179

1957177

1958191

1959153

1960161

1961188

1962139

1963198

1964187

1965196

1966

1967172

1968194

1969161

$1970174 \quad 1$

$\begin{array}{ll}1 & \\ 1 & 8\end{array}$

$\begin{array}{lllllllllll}8 & 3 & 8 & 1 & 6 & 9 & 59 & 44 & 65 & 2\end{array}$

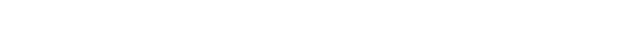

1971178

1972165

1973191

1974118

1976197

1977207

1978201

1979197

1980201

1981209

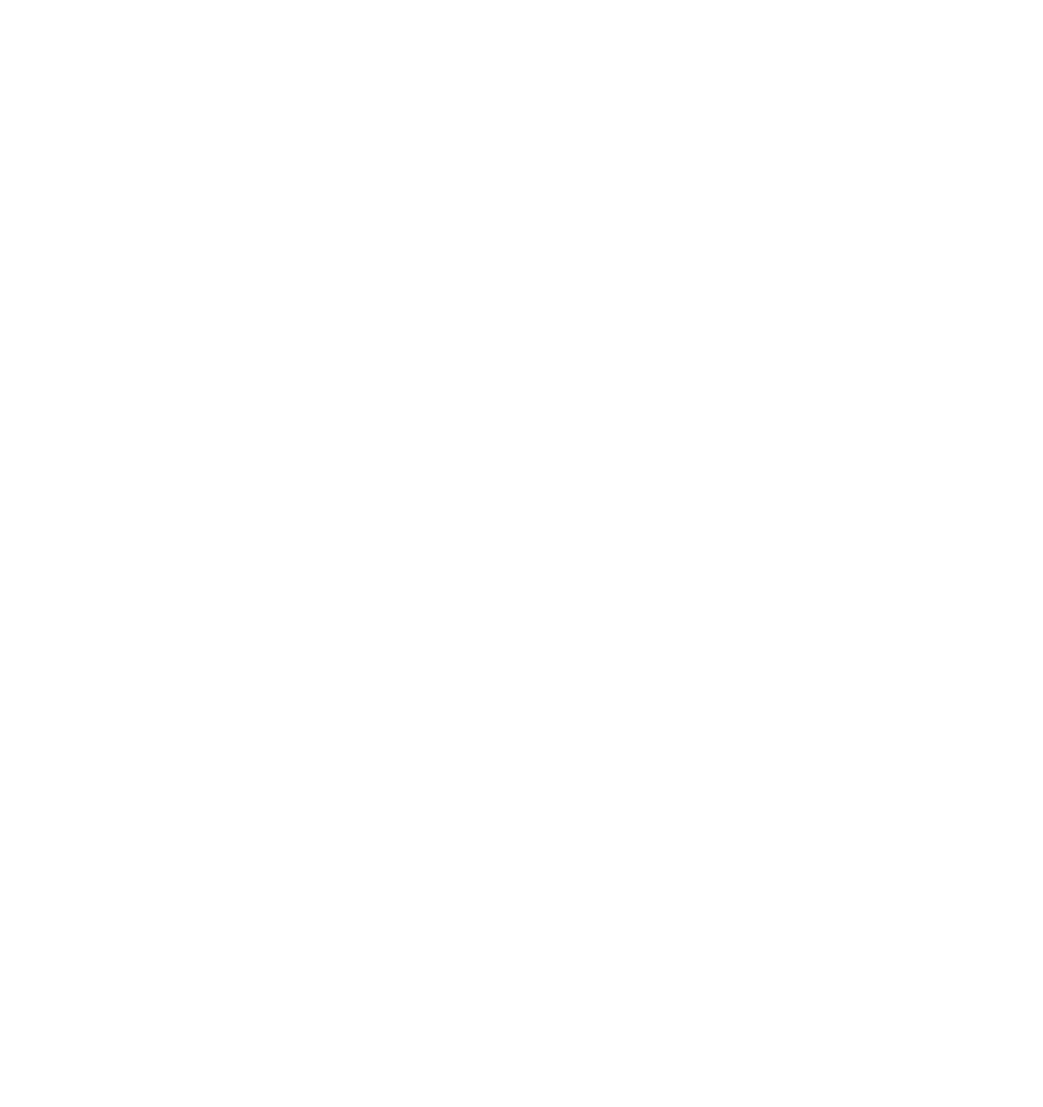


GREEN RIVER BASIN

09291000 LAKE FORK RIVER BELOW MOON LAKE, NEAR MOUNTAIN HONE, UT-Continued

DURATION TABLE OF DISCHARGE FOR WATER YEARS 1943-81

\begin{tabular}{|c|c|c|c|c|c|c|c|c|c|c|c|c|c|c|c|c|c|c|c|}
\hline CLASS & $\begin{array}{c}\text { OUBIC } \\
\text { FEET } \\
\text { PER } \\
\text { SECOND }\end{array}$ & $\begin{array}{l}\text { TOTAL } \\
\text { DAYS }\end{array}$ & $\begin{array}{c}\text { ACOJ- } \\
\text { MU- } \\
\text { LATED } \\
\text { DAYS }\end{array}$ & $\begin{array}{l}\text { PER- } \\
\text { CENT } \\
\text { DAYS }\end{array}$ & CLASS & $\begin{array}{c}\text { OBIIC } \\
\text { FEET } \\
\text { PER } \\
\text { SECOND }\end{array}$ & $\begin{array}{l}\text { TOTAL } \\
\text { DAYS }\end{array}$ & $\begin{array}{c}\text { ACOJ- } \\
\text { MU- } \\
\text { LATED } \\
\text { DAYS }\end{array}$ & $\begin{array}{l}\text { PER- } \\
\text { CENT } \\
\text { DAYS }\end{array}$ & CLASS & $\begin{array}{c}\text { OIBIC } \\
\text { FEET } \\
\text { PER } \\
\text { SECOND }\end{array}$ & $\begin{array}{l}\text { TOTAL } \\
\text { DAYS }\end{array}$ & $\begin{array}{c}\text { ACOJ- } \\
\text { MU- } \\
\text { LATED } \\
\text { DAYS }\end{array}$ & $\begin{array}{l}\text { PER- } \\
\text { CENT } \\
\text { DAYS }\end{array}$ & & $\begin{array}{c}\text { GBIC } \\
\text { FEET } \\
\text { PER } \\
\text { SECOND }\end{array}$ & $\begin{array}{r}\text { TOTAL } \\
\text { DAYS }\end{array}$ & $\begin{array}{c}\text { ACOJ- } \\
\text { MU- } \\
\text { LATED } \\
\text { DAYS }\end{array}$ & $\begin{array}{l}\text { PER- } \\
\text { CENT } \\
\text { DAYS }\end{array}$ \\
\hline $\begin{array}{l}0 \\
1 \\
2 \\
3 \\
4 \\
5 \\
6 \\
7 \\
8\end{array}$ & $\begin{array}{l}0.00 \\
0.01 \\
0.02 \\
0.03 \\
0.04 \\
0.06 \\
0.09 \\
0.12 \\
0.18\end{array}$ & $\begin{array}{r}6776 \\
1 \\
0 \\
0 \\
0 \\
0 \\
1 \\
0 \\
0\end{array}$ & $\begin{array}{r}14245 \\
7469 \\
7468 \\
7468 \\
7468 \\
7468 \\
7468 \\
7467 \\
7467\end{array}$ & $\begin{array}{r}100.0 \\
52.4 \\
52.4 \\
52.4 \\
52.4 \\
52.4 \\
52.4 \\
52.4 \\
52.4\end{array}$ & $\begin{array}{l}9 \\
10 \\
11 \\
12 \\
13 \\
14 \\
15 \\
16 \\
17\end{array}$ & $\begin{array}{l}0.25 \\
0.36 \\
0.51 \\
0.73 \\
1.10 \\
1.50 \\
2.20 \\
3.10 \\
4.40\end{array}$ & $\begin{array}{r}0 \\
0 \\
0 \\
11 \\
1 \\
16 \\
7 \\
23 \\
29\end{array}$ & $\begin{array}{l}7467 \\
7467 \\
7467 \\
7467 \\
7456 \\
7455 \\
7439 \\
7432 \\
7409\end{array}$ & $\begin{array}{l}52.4 \\
52.4 \\
52.4 \\
52.4 \\
52.3 \\
52.3 \\
52.2 \\
52.2 \\
52.0\end{array}$ & $\begin{array}{l}18 \\
19 \\
20 \\
21 \\
22 \\
23 \\
24 \\
25 \\
26\end{array}$ & $\begin{array}{r}6.3 \\
9.0 \\
13.0 \\
18.0 \\
26.0 \\
38.0 \\
54.0 \\
77.0 \\
110.0\end{array}$ & $\begin{array}{r}72 \\
88 \\
60 \\
155 \\
280 \\
247 \\
333 \\
492 \\
639\end{array}$ & $\begin{array}{l}7380 \\
7308 \\
7220 \\
7160 \\
7005 \\
6725 \\
6478 \\
6145 \\
5653\end{array}$ & $\begin{array}{l}51.8 \\
51.3 \\
50.7 \\
50.3 \\
49.2 \\
47.2 \\
45.5 \\
43.1 \\
39.7\end{array}$ & $\begin{array}{l}27 \\
28 \\
29 \\
30 \\
31 \\
32 \\
33 \\
34\end{array}$ & $\begin{array}{r}160.0 \\
230.0 \\
320.0 \\
460.0 \\
660.0 \\
940.0 \\
1400.0\end{array}$ & $\begin{array}{r}1316 \\
1647 \\
1612 \\
281 \\
112 \\
45 \\
1\end{array}$ & $\begin{array}{r}5014 \\
3698 \\
2051 \\
439 \\
158 \\
46 \\
1\end{array}$ & $\begin{array}{r}35.2 \\
26.0 \\
14.4 \\
3.1 \\
1.1 \\
0.3 \\
0.0\end{array}$ \\
\hline
\end{tabular}

MONIHLY MEAN DISCHARGES, IN OBIC FEET PER SECOND, FOR EAOH WATER YEAR

\begin{tabular}{|c|c|c|c|c|c|c|c|c|c|c|c|c|}
\hline YEAR & OCT & NOV & DEC & JAN & FEB & MAR & APR & MAY & JUNE & JULY & AUG & SEP \\
\hline 1934 & 32 & 28 & 24 & 22 & 22 & 22 & 107 & 202 & 66.9 & 45.8 & 45.1 & 34.1 \\
\hline $\begin{array}{l}1943 \\
1944 \\
1945\end{array}$ & $\begin{array}{c}51.4 \\
110 \\
35.8\end{array}$ & $\begin{array}{c}4.77 \\
0.47 \\
18.1\end{array}$ & $\begin{array}{l}0.00 \\
0.00 \\
0.00\end{array}$ & $\begin{array}{l}0.00 \\
0.00 \\
0.00\end{array}$ & $\begin{array}{l}0.00 \\
0.00 \\
0.00\end{array}$ & $\begin{array}{l}0.00 \\
0.00 \\
0.00\end{array}$ & $\begin{array}{r}202 \\
0.00 \\
0.83\end{array}$ & $\begin{array}{l}320 \\
200 \\
310\end{array}$ & $\begin{array}{l}227 \\
622 \\
144\end{array}$ & $\begin{array}{l}342 \\
470 \\
323\end{array}$ & $\begin{array}{l}253 \\
410 \\
298\end{array}$ & $\begin{array}{l}239 \\
168 \\
222\end{array}$ \\
\hline $\begin{array}{l}1946 \\
1947 \\
1948 \\
1949 \\
1950\end{array}$ & $\begin{array}{l}78.3 \\
35.2 \\
96.9 \\
25.7 \\
44.6\end{array}$ & $\begin{array}{c}7.33 \\
24.6 \\
0.00 \\
1.00 \\
5.73\end{array}$ & $\begin{array}{l}0.00 \\
0.00 \\
0.00 \\
0.00 \\
0.00\end{array}$ & $\begin{array}{l}0.00 \\
0.00 \\
0.00 \\
0.00 \\
0.00\end{array}$ & $\begin{array}{l}0.00 \\
0.00 \\
0.00 \\
0.00 \\
0.00\end{array}$ & $\begin{array}{l}0.00 \\
0.00 \\
0.00 \\
0.00 \\
0.00\end{array}$ & $\begin{array}{c}93.2 \\
106 \\
1.27 \\
92.6 \\
125\end{array}$ & $\begin{array}{l}351 \\
228 \\
258 \\
250 \\
303\end{array}$ & $\begin{array}{l}276 \\
304 \\
296 \\
423 \\
411\end{array}$ & $\begin{array}{l}331 \\
384 \\
329 \\
344 \\
342\end{array}$ & $\begin{array}{l}175 \\
243 \\
142 \\
326 \\
345\end{array}$ & $\begin{array}{c}73.1 \\
281 \\
69.5 \\
148 \\
122\end{array}$ \\
\hline $\begin{array}{l}1951 \\
1952 \\
1953 \\
1954 \\
1955\end{array}$ & $\begin{array}{c}33.5 \\
44.9 \\
177 \\
18.4 \\
16.5\end{array}$ & $\begin{array}{l}0.00 \\
0.00 \\
6.37 \\
0.00 \\
0.00\end{array}$ & $\begin{array}{l}0.00 \\
0.00 \\
0.00 \\
0.00 \\
0.00\end{array}$ & $\begin{array}{l}0.00 \\
0.00 \\
0.00 \\
0.00 \\
0.00\end{array}$ & $\begin{array}{l}0.00 \\
0.00 \\
0.00 \\
0.00 \\
0.00\end{array}$ & $\begin{array}{l}0.00 \\
0.00 \\
0.00 \\
0.00 \\
0.00\end{array}$ & $\begin{array}{c}121 \\
5.63 \\
17.5 \\
47.9 \\
1.40\end{array}$ & $\begin{array}{l}293 \\
536 \\
244 \\
265 \\
276\end{array}$ & $\begin{array}{l}208 \\
662 \\
181 \\
310 \\
208\end{array}$ & $\begin{array}{l}371 \\
382 \\
413 \\
221 \\
352\end{array}$ & $\begin{array}{l}220 \\
280 \\
321 \\
116 \\
173\end{array}$ & $\begin{array}{l}190 \\
224 \\
122 \\
19.0 \\
99.5\end{array}$ \\
\hline $\begin{array}{l}1956 \\
1957 \\
1958 \\
1959 \\
1960\end{array}$ & $\begin{array}{l}39.0 \\
28.0 \\
60.0 \\
51.9 \\
42.8\end{array}$ & $\begin{array}{l}3.43 \\
0.00 \\
0.00 \\
12.0 \\
11.7\end{array}$ & $\begin{array}{l}0.00 \\
0.00 \\
0.00 \\
0.00 \\
0.00\end{array}$ & $\begin{array}{l}0.00 \\
0.00 \\
0.00 \\
0.00 \\
0.00\end{array}$ & $\begin{array}{l}0.00 \\
0.00 \\
0.00 \\
0.00 \\
0.00\end{array}$ & $\begin{array}{l}0.00 \\
0.00 \\
0.00 \\
0.00 \\
0.00\end{array}$ & $\begin{array}{l}41.1 \\
22.4 \\
14.1 \\
72.1 \\
26.9\end{array}$ & $\begin{array}{l}247 \\
207 \\
447 \\
232 \\
239\end{array}$ & $\begin{array}{l}355 \\
201 \\
402 \\
202 \\
268\end{array}$ & $\begin{array}{l}437 \\
349 \\
393 \\
333 \\
366\end{array}$ & $\begin{array}{l}311 \\
289 \\
260 \\
184 \\
137\end{array}$ & $\begin{array}{l}113 \\
146 \\
114 \\
55.8 \\
15.7\end{array}$ \\
\hline $\begin{array}{l}1961 \\
1962 \\
1963 \\
1964 \\
1965\end{array}$ & $\begin{array}{l}36.4 \\
11.9 \\
18.1 \\
85.0 \\
36.6\end{array}$ & $\begin{array}{c}0.00 \\
8.10 \\
15.0 \\
6.60 \\
0.00\end{array}$ & $\begin{array}{l}0.00 \\
0.00 \\
0.00 \\
0.00 \\
0.00\end{array}$ & $\begin{array}{l}0.00 \\
0.00 \\
0.00 \\
0.00 \\
0.00\end{array}$ & $\begin{array}{l}0.00 \\
0.00 \\
0.00 \\
0.00 \\
0.00\end{array}$ & $\begin{array}{l}0.00 \\
2.39 \\
0.00 \\
0.00 \\
0.00\end{array}$ & $\begin{array}{c}20.1 \\
104 \\
0.00 \\
15.0 \\
19.6\end{array}$ & $\begin{array}{l}164 \\
412 \\
235 \\
292 \\
290\end{array}$ & $\begin{array}{l}269 \\
501 \\
280 \\
401 \\
420\end{array}$ & $\begin{array}{l}155 \\
366 \\
378 \\
415 \\
584\end{array}$ & $\begin{array}{l}65.9 \\
376 \\
322 \\
390 \\
239\end{array}$ & $\begin{array}{c}29.5 \\
173 \\
44.2 \\
189 \\
160\end{array}$ \\
\hline $\begin{array}{l}1966 \\
1967 \\
1968 \\
1969 \\
1970\end{array}$ & $\begin{array}{c}142 \\
68.4 \\
55.5 \\
103 \\
14.6\end{array}$ & $\begin{array}{c}120 \\
0.00 \\
0.00 \\
0.00 \\
20.5\end{array}$ & $\begin{array}{l}7.65 \\
0.00 \\
0.00 \\
0.00 \\
0.00\end{array}$ & $\begin{array}{l}9.84 \\
0.00 \\
0.00 \\
0.00 \\
0.00\end{array}$ & $\begin{array}{c}44.4 \\
0.00 \\
0.00 \\
0.00 \\
0.00\end{array}$ & $\begin{array}{l}72.3 \\
0.00 \\
0.00 \\
0.00 \\
0.00\end{array}$ & $\begin{array}{c}74.0 \\
117 \\
15.6 \\
26.0 \\
99.7\end{array}$ & $\begin{array}{l}320 \\
259 \\
299 \\
555 \\
230\end{array}$ & $\begin{array}{l}321 \\
420 \\
613 \\
403 \\
166\end{array}$ & $\begin{array}{l}337 \\
415 \\
336 \\
373 \\
324\end{array}$ & $\begin{array}{l}294 \\
259 \\
224 \\
357 \\
339\end{array}$ & $\begin{array}{l}155 \\
315 \\
286 \\
171 \\
151\end{array}$ \\
\hline $\begin{array}{l}1971 \\
1972 \\
1973 \\
1974 \\
1975\end{array}$ & $\begin{array}{c}45.1 \\
40.6 \\
9.81 \\
102 \\
26.0\end{array}$ & $\begin{array}{c}13.9 \\
0.00 \\
0.97 \\
0.22 \\
0.00\end{array}$ & $\begin{array}{l}0.00 \\
0.00 \\
0.00 \\
0.00 \\
0.00\end{array}$ & $\begin{array}{l}0.00 \\
0.00 \\
0.00 \\
0.00 \\
0.00\end{array}$ & $\begin{array}{l}0.00 \\
0.00 \\
0.00 \\
0.04 \\
0.00\end{array}$ & $\begin{array}{c}0.00 \\
10.7 \\
0.00 \\
4.58 \\
0.00\end{array}$ & $\begin{array}{c}69.7 \\
111 \\
12.9 \\
24.3 \\
0.87\end{array}$ & $\begin{array}{l}299 \\
273 \\
228 \\
318 \\
288\end{array}$ & $\begin{array}{l}336 \\
369 \\
459 \\
400 \\
217\end{array}$ & $\begin{array}{l}353 \\
287 \\
226 \\
377 \\
556\end{array}$ & $\begin{array}{l}303 \\
303 \\
251 \\
238 \\
298\end{array}$ & $\begin{array}{l}226 \\
182 \\
245 \\
34.8 \\
254\end{array}$ \\
\hline $\begin{array}{l}1976 \\
1977 \\
1978 \\
1979 \\
1980\end{array}$ & $\begin{array}{l}78.2 \\
51.4 \\
13.4 \\
44.1 \\
11.7\end{array}$ & $\begin{array}{l}5.93 \\
0.00 \\
0.90 \\
0.00 \\
2.87\end{array}$ & $\begin{array}{l}0.00 \\
0.00 \\
0.00 \\
0.00 \\
0.00\end{array}$ & $\begin{array}{l}0.00 \\
0.00 \\
0.00 \\
0.00 \\
0.00\end{array}$ & $\begin{array}{l}0.00 \\
0.00 \\
0.00 \\
0.00 \\
0.00\end{array}$ & $\begin{array}{l}0.00 \\
0.00 \\
0.00 \\
0.00 \\
0.00\end{array}$ & $\begin{array}{l}31.4 \\
0.00 \\
32.5 \\
51.4 \\
16.9\end{array}$ & $\begin{array}{l}249 \\
130 \\
350 \\
264 \\
224\end{array}$ & $\begin{array}{l}262 \\
213 \\
238 \\
237 \\
411\end{array}$ & $\begin{array}{l}383 \\
170 \\
395 \\
365 \\
361\end{array}$ & $\begin{array}{l}219 \\
93.3 \\
364 \\
183 \\
312\end{array}$ & $\begin{array}{c}74.2 \\
68.8 \\
133 \\
56.3 \\
143\end{array}$ \\
\hline 1981 & 60.7 & 0.00 & 0.00 & 0.00 & 0.00 & 0.00 & 67.5 & 329 & 203 & 330 & 225 & 22.5 \\
\hline
\end{tabular}


GREEN RIVER BASIN

09291000 LAKE FORK RIVER BELCW MOON LAKE, NEAR MOUNTAIN HONE, UT-Continued

ANNAL PEAK DISOHARGE, IN OJBIC FEET PER SECOND, AND CORRESPONDING GAGE HEIGHT, IN FEET, FOR EACH WATER YEAR

\begin{tabular}{|c|c|c|c|c|c|c|c|c|c|c|c|}
\hline $\begin{array}{l}\text { WATER } \\
\text { YEAR }\end{array}$ & DATE & $\begin{array}{c}\text { GAGE } \\
\text { HEIGHT }\end{array}$ & $\begin{array}{c}\text { PEAK } \\
\text { DISOHARGE }\end{array}$ & $\begin{array}{l}\text { WATER } \\
\text { YEAR }\end{array}$ & DATE & $\begin{array}{c}\text { GAGE } \\
\text { HEIGHT }\end{array}$ & $\begin{array}{c}\text { PEAK } \\
\text { DISOHARGE }\end{array}$ & $\begin{array}{l}\text { WATER } \\
\text { YEAR }\end{array}$ & DATE & $\begin{array}{c}\text { GAGE } \\
\text { HEIGHT }\end{array}$ & $\begin{array}{c}\text { PEAK } \\
\text { DISOHARGE }\end{array}$ \\
\hline $\begin{array}{l}1922 \\
1923 \\
1924 \\
1925 \\
1926 \\
1927 \\
1930 \\
1931 \\
1932 \\
1942 \\
1943 \\
1944 \\
1945 \\
1946 \\
1947 \\
1948 \\
1949\end{array}$ & $\begin{array}{l}\text { JUNE } 21,1922 \\
\text { JUNE } 13,1923 \\
\text { MAY } 17,1924 \\
\text { MAY } 21,1925 \\
\text { MAY } 21,1926 \\
\text { SEPT. } 09,1927 \\
\text { MAY } 29,1930 \\
\text { MAY } 17,1931 \\
\text { JUNE } 24,1932 \\
\text { JUNE } 10,1942 \\
\text { JUNE } 26,1943 \\
\text { JUNE } 26,1944 \\
\text { JULY } 18,1945 \\
\text { MAY } 28,1946 \\
\text { JUNE } 26,1947 \\
\text { JUNE } 09,1948 \\
\text { JUNE } 19,1949\end{array}$ & $\begin{array}{l}3.47 \\
3.50 \\
2.56 \\
2.44 \\
2.70 \\
3.85 \\
= \\
= \\
4.56 \\
3.55 \\
5.46 \\
2.74 \\
2.72 \\
3.32 \\
3.11 \\
4.83\end{array}$ & $\begin{array}{r}1910 \\
2120 \\
974 \\
804 \\
1080 \\
2000 \\
1200 \\
591 \\
1280 \\
1070 \\
744 \\
2070 \\
428 \\
435 \\
801 \\
460 \\
2180\end{array}$ & $\begin{array}{l}1950 \\
1951 \\
1952 \\
1953 \\
1954 \\
1955 \\
1956 \\
1957 \\
1958 \\
1959 \\
1960 \\
1961 \\
1962 \\
1963 \\
1964 \\
1965\end{array}$ & $\begin{array}{l}\text { JUNE } 17,1950 \\
\text { JUNE } 30,1951 \\
\text { JUNE } 10,1952 \\
\text { JULY } 02,1953 \\
\text { JUNE 01, } 1954 \\
\text { JULY } 04,1955 \\
\text { JUNE } 12,1956 \\
\text { JULY } 02,1957 \\
\text { JUNE } 16,1958 \\
\text { JULY } 20,1959 \\
\text { JUNE } 29,1960 \\
\text { JULY 03, } 1961 \\
\text { JUNE } 21,1962 \\
\text { MAY } 26,1963 \\
\text { JUNE } 28,1964 \\
\text { JULY } 12,1965\end{array}$ & $\begin{array}{l}3.69 \\
3.20 \\
4.39 \\
3.25 \\
2.70 \\
2.80 \\
3.63 \\
3.56 \\
4.21 \\
2.83 \\
2.93 \\
2.81 \\
4.70 \\
2.98 \\
4.28 \\
3.97\end{array}$ & $\begin{array}{r}960 \\
642 \\
1520 \\
701 \\
392 \\
436 \\
917 \\
853 \\
1250 \\
420 \\
470 \\
412 \\
1780 \\
513 \\
1370 \\
1180\end{array}$ & $\begin{array}{l}1966 \\
1967 \\
1968 \\
1969 \\
1970 \\
1971 \\
1972 \\
1973 \\
1974 \\
1975 \\
1976 \\
1977 \\
1978 \\
1979 \\
1980 \\
1981\end{array}$ & $\begin{array}{l}\text { JULY } 13,1966 \\
\text { JUNE } 23,1967 \\
\text { JUNE } 23,1968 \\
\text { JUNE } 01,1969 \\
\text { AUG. } 14,1970 \\
\text { JUNE } 26,1971 \\
\text { JUNE } 12,1972 \\
\text { JUNE } 10,1973 \\
\text { MAY } 21,1974 \\
\text { JULY } 05,1975 \\
\text { JULY } 15,1976 \\
\text { JUNE } 23,1977 \\
\text { JULY } 27,1978 \\
\text { JUNE } 19,1979 \\
\text { JUNE } 20,1980 \\
\text { MAY } 13,1981\end{array}$ & $\begin{array}{l}3.78 \\
4.46 \\
4.25 \\
3.87 \\
2.88 \\
4.42 \\
4.09 \\
4.57 \\
3.00 \\
4.58 \\
2.84 \\
2.53 \\
2.93 \\
2.80 \\
4.06 \\
2.17\end{array}$ & $\begin{array}{r}1170 \\
1510 \\
1280 \\
1100 \\
510 \\
1460 \\
1210 \\
1520 \\
555 \\
1560 \\
470 \\
332 \\
545 \\
470 \\
1220 \\
455\end{array}$ \\
\hline
\end{tabular}

MAGNITUDE AND PRGBABILITY OF ANNUAL LOWEST MEAN DISGHARGE BASED ON OIMATIC YEARS 1943-81

\begin{tabular}{|c|c|c|c|c|c|c|}
\hline \multirow{2}{*}{$\begin{array}{l}\text { PERICD } \\
\text { (CON- } \\
\text { SEOU- } \\
\text { TTVE } \\
\text { DAYS) }\end{array}$} & \multicolumn{6}{|c|}{$\begin{array}{l}\text { DISOHARGE, IN OBIC FEET PER SECOND, FOR } \\
\text { INDICATED REGRRENCE INNERNAL, IN YEARS, AND } \\
\text { ANNUAL NONEXCEEDANCE PRCBABILITY, IN PERCENT }\end{array}$} \\
\hline & $\begin{array}{c}2 \\
50 \AA\end{array}$ & $\begin{array}{c}5 \\
20 \%\end{array}$ & $\begin{array}{l}10 \\
108\end{array}$ & $\begin{array}{l}20 \\
58\end{array}$ & $\begin{array}{l}50 \\
28\end{array}$ & $\begin{array}{r}100 \\
18\end{array}$ \\
\hline
\end{tabular}

$\begin{array}{rllllll}1 & 0.00 & - & - & - & - & = \\ 7 & 0.00 & = & - & - & - & = \\ 14 & 0.00 & = & - & - & - & = \\ 30 & 0.00 & - & - & - & - & = \\ 60 & 0.00 & - & - & - & - & =\end{array} 9$

MAGNITUDE AND PRGBABILITY OF ANNUAL HIGHEST MEAN DISGARGE BASED ON WATER YEARS 1943-81

\begin{tabular}{|c|c|c|c|c|c|c|}
\hline \multirow{2}{*}{$\begin{array}{l}\text { PERIOD } \\
\text { (CON- } \\
\text { SEQU- } \\
\text { TIVE } \\
\text { DAYS) }\end{array}$} & \multicolumn{6}{|c|}{$\begin{array}{l}\text { DISGHARGE, IN GBIC FEET PER SECOND, FOR } \\
\text { INDICATED RECURRENCE INTERVAL, IN YEARS, AND } \\
\text { ANNUAL EXCEEDANCE PRCBABIIITY, IN PERCENT }\end{array}$} \\
\hline & $\begin{array}{c}2 \\
508\end{array}$ & $\begin{array}{c}5 \\
20 \%\end{array}$ & $\begin{array}{l}10 \\
108\end{array}$ & $\begin{array}{l}25 \\
48\end{array}$ & $\begin{array}{l}50 \\
28\end{array}$ & $\begin{array}{r}100 \\
18\end{array}$ \\
\hline $\begin{array}{r}1 \\
3 \\
7 \\
15\end{array}$ & $\begin{array}{l}652 \\
618 \\
569 \\
497\end{array}$ & $\begin{array}{l}994 \\
896 \\
796 \\
665\end{array}$ & $\begin{array}{r}1260 \\
1100 \\
960 \\
784\end{array}$ & $\begin{array}{r}1650 \\
1380 \\
1180 \\
944\end{array}$ & $\begin{array}{l}1980 \\
1610 \\
1360 \\
1070\end{array}$ & $\overline{-}$ \\
\hline
\end{tabular}

09291200 LAKE FORK RIVER BELOW TASKEEOH DAM SITE, NEAR MOUNTAIN HOME, UT

LOCATION, --Lat $40^{\circ} 30^{\prime} 05^{\prime \prime}$, long $110^{\circ} 24^{\prime} 17^{\prime \prime}$, in NE $\mathrm{NE}_{4}^{1} \mathrm{NW}_{4}^{\frac{1}{4}}$ sec.12, T.1 N., R.5 w., Uintah Meridian, Duchesne County, Hydrologic Unit 14060003 , on left bank $4.5 \mathrm{mi}$ north of Mountain Home, $4.9 \mathrm{mi}$ upstream fram Yellowstone River, and $6.8 \mathrm{mi}$ below Moon Lake Reservoir.

DRAINAGE AREA. $--138 \mathrm{mi}^{2}$.

PERIOD OF RECORD AVAII.ABLE.--October 1976 to September 1981.

GAGE.-Water-stage recorder. Al titude of gage is 7,375 ft fram topographic map.

REMARKS.-Flow regulated by Moon Lake Reservoir.

AVERAGE DISGHARGE. --5 years, $78.2 \mathrm{ft}^{3} / \mathrm{s}, 56,700$ acre-ft/yr.

EXTREMES FOR PERIOD OF RECORD.--Maximum discharge, 1,220 $\mathrm{ft}^{3} / \mathrm{s}$ June 22, 1980, gage height, $5.02 \mathrm{ft}$; minimum daily, $3.1 \mathrm{ft} t^{3} / \mathrm{s} \mathrm{Jan.} 1$, 1979.

LOWEST MEAN DISOHARGE, IN OUBIC FEET PER SECOND, AND RANKING FOR THE INDICATED NUMBER OF CONSEOITVE DAYS FOR EAOH OIMATIC YEAR, APRII I-MAROH 31

\begin{tabular}{|c|c|c|c|c|c|c|c|c|c|c|c|c|c|c|c|c|c|c|c|}
\hline YEAR & 1 & & 3 & & 7 & & 14 & & $\begin{array}{l}\text { Const } \\
30\end{array}$ & ФTTVE & $\begin{array}{l}\text { DAYS } \\
60\end{array}$ & & 90 & & 120 & & 183 & & ALL \\
\hline $\begin{array}{l}1978 \\
1979 \\
1980\end{array}$ & $\begin{array}{l}7.00 \\
3.10 \\
7.00\end{array}$ & $\begin{array}{l}3 \\
1 \\
4\end{array}$ & $\begin{array}{l}7.00 \\
3.90 \\
7.10\end{array}$ & $\begin{array}{l}3 \\
1 \\
4\end{array}$ & $\begin{array}{l}7.00 \\
6.50 \\
7.20\end{array}$ & $\begin{array}{l}3 \\
2 \\
4\end{array}$ & $\begin{array}{l}7.00 \\
6.90 \\
7.30\end{array}$ & $\begin{array}{l}3 \\
2 \\
4\end{array}$ & $\begin{array}{l}7.00 \\
8.90 \\
7.50\end{array}$ & $\begin{array}{l}2 \\
4 \\
3\end{array}$ & $\begin{array}{l}7.00 \\
9.00 \\
7.90\end{array}$ & $\begin{array}{l}2 \\
4 \\
3\end{array}$ & $\begin{array}{l}7.20 \\
9.20 \\
8.40\end{array}$ & $\begin{array}{l}2 \\
4 \\
3\end{array}$ & $\begin{array}{l}7.40 \\
9.50 \\
8.60\end{array}$ & $\begin{array}{l}1 \\
4 \\
3\end{array}$ & $\begin{array}{c}8.10 \\
15.0 \\
9.00\end{array}$ & $\begin{array}{l}1 \\
4 \\
2\end{array}$ & $\begin{array}{l}46.0 \\
99.0 \\
70.0\end{array}$ \\
\hline 981 & 4.50 & 2 & 4.80 & 2 & 4.80 & 1 & 4.90 & 1 & 5.10 & 1 & 6.20 & 1 & 7.00 & 1 & 7.80 & 2 & 15.0 & 3 & 95.0 \\
\hline
\end{tabular}


GREEN RIVER BASIN

09291200 LAKE FORR RIVER BELOW TASKEBCH DAM SITE, NEAR MOUNTADN HQME, UT-Continued

HIGHEST MEAN DISCHARGE, IN OUBIC FEET PER SECOND, AND RANKING FOR THE INDICATED NUMBER OF CONSECUTIVE DAYS FOR EACH WATER YEAR, $\propto$ TCBER 1-SEPTEMBER 30

\begin{tabular}{|c|c|c|c|c|c|c|c|c|c|c|c|c|c|c|c|c|c|c|c|}
\hline YEAR & & & & & & & & & & & VE D & & & & & & & & \\
\hline $\begin{array}{l}1977 \\
1978 \\
1979 \\
1980\end{array}$ & $\begin{array}{l}266 \\
516 \\
396 \\
948\end{array}$ & $\begin{array}{l}5 \\
2 \\
4 \\
1\end{array}$ & $\begin{array}{l}248 \\
510 \\
395 \\
894\end{array}$ & $\begin{array}{l}5 \\
2 \\
4 \\
1\end{array}$ & $\begin{array}{l}236 \\
493 \\
388 \\
782\end{array}$ & $\begin{array}{l}5 \\
2 \\
4 \\
1\end{array}$ & $\begin{array}{l}213 \\
456 \\
364 \\
606\end{array}$ & $\begin{array}{l}5 \\
2 \\
3 \\
1\end{array}$ & $\begin{array}{l}192 \\
428 \\
327 \\
425\end{array}$ & $\begin{array}{l}5 \\
1 \\
3 \\
2\end{array}$ & $\begin{array}{l}164 \\
361 \\
281 \\
346\end{array}$ & $\begin{array}{l}5 \\
1 \\
4\end{array}$ & $\begin{array}{l}139 \\
285 \\
216 \\
294\end{array}$ & $\begin{array}{l}5 \\
2 \\
4 \\
1\end{array}$ & $\begin{array}{l}116 \\
254 \\
182 \\
237\end{array}$ & $\begin{array}{l}5 \\
1 \\
4 \\
2\end{array}$ & $\begin{array}{l}83.0 \\
183 \\
130 \\
175\end{array}$ & 2 & $\begin{array}{l}49.0 \\
96.0 \\
73.0 \\
92.0\end{array}$ \\
\hline 1981 & 432 & 3 & 408 & 3 & 389 & 3 & 364 & 4 & 320 & 4 & 284 & 3 & 226 & 3 & 214 & 3 & 150 & 3 & 82.0 \\
\hline
\end{tabular}

DURATION OF DISCHARGE FOR EACH WATER YEAR

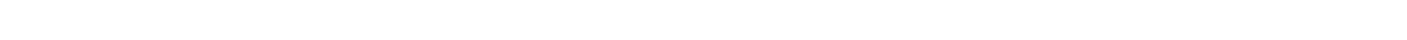
YEAR NUMBER OF DAYS IN CIASS
PER SECOND

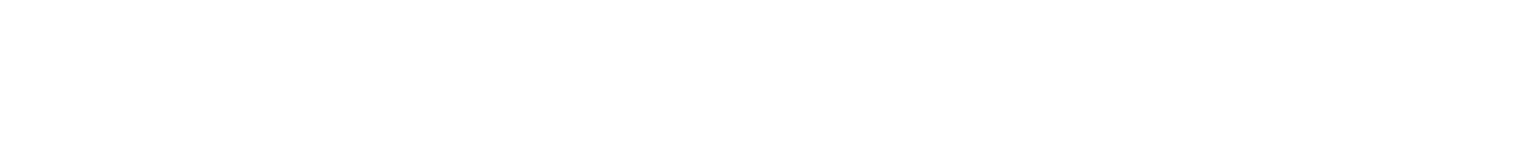

$\begin{array}{ccc} & \\ \text { CIBIC } & \text { ACOU- } \\ \text { FEET } & \text { MU- } & \text { PER- } \\ \text { PER TOTAL LATED } & \text { CENT } \\ \text { CLASS SECOND DAYS DAYS } & \text { DAYS }\end{array}$

DURATION TABLE OF DISCHARGE FOR WATER YEARS 1977-81

$\begin{array}{ccc}\text { OUBIC } & \text { ACQU- } \\ \text { FEET } & \text { MU- } & \text { PER- } \\ \text { PER TOTAL LATED } & \text { CENT } \\ \text { CIASS SECOND DAYS DAYS } & \text { DAYS }\end{array}$

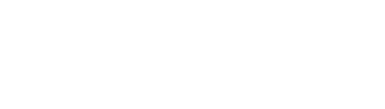

$\begin{array}{ccc}\text { CUBIC } & \text { ACOU- } \\ \text { FEET } & \text { MU- } & \text { PER- } \\ \text { PER TOTAL LATED } & \text { CENT } \\ \text { CLASS SEOOND DAYS DAYS } & \text { DAYS }\end{array}$

$\begin{array}{rrrrr}0 & 0.00 & 0 & 1826 & 100.0 \\ 1 & 3.10 & 1 & 1826 & 100.0 \\ 2 & 3.70 & 1 & 1825 & 99.9 \\ 3 & 4.40 & 20 & 1824 & 99.9 \\ 4 & 5.20 & 29 & 1804 & 98.8 \\ 5 & 6.20 & 173 & 1775 & 97.2 \\ 6 & 7.30 & 285 & 1602 & 87.7 \\ 7 & 8.70 & 265 & 1317 & 72.1 \\ 8 & 10.00 & 176 & 1052 & 57.6\end{array}$

$\begin{array}{rllll}9 & 12.00 & 64 & 876 & 48.0 \\ 10 & 14.00 & 45 & 812 & 44.5 \\ 11 & 17.00 & 25 & 767 & 42.0 \\ 12 & 20.00 & 29 & 742 & 40.6 \\ 13 & 24.00 & 14 & 713 & 39.0 \\ 14 & 29.00 & 15 & 699 & 38.3 \\ 15 & 34.00 & 16 & 684 & 37.5 \\ 16 & 40.00 & 34 & 668 & 36.6 \\ 17 & 48.00 & 35 & 634 & 34.7\end{array}$

$\begin{array}{rrrrr}18 & 57.0 & 34 & 599 & 32.8 \\ 19 & 67.0 & 27 & 565 & 30.9 \\ 20 & 80.0 & 66 & 538 & 29.5 \\ 21 & 95.0 & 21 & 472 & 25.8 \\ 22 & 110.0 & 32 & 451 & 24.7 \\ 23 & 130.0 & 35 & 419 & 22.9 \\ 24 & 160.0 & 47 & 384 & 21.0 \\ 25 & 190.0 & 71 & 337 & 18.5 \\ 26 & 220.0 & 122 & 266 & 14.6\end{array}$

$\begin{array}{rrrrr}27 & 270.0 & 44 & 144 & 7.9 \\ 28 & 310.0 & 39 & 100 & 5.5 \\ 29 & 370.0 & 42 & 61 & 3.3 \\ 30 & 440.0 & 12 & 19 & 1.0 \\ 31 & 530.0 & 1 & 7 & 0.4 \\ 32 & 620.0 & 2 & 6 & 0.3 \\ 33 & 740.0 & 3 & 4 & 0.2 \\ 34 & 880.0 & 1 & 1 & 0.1\end{array}$

MONTHLY MEAN DISCHARGES, IN OBBIC FEET PER SBCOND, FOR EACH WATER YEAR

$\begin{array}{llccccccccccc}\text { YEAR } & \text { OCT } & \text { NOV } & \text { DEC } & \text { JAN } & \text { FEB } & \text { MAR } & \text { APR } & \text { MAY } & \text { JUNE } & \text { JULY } & \text { AUG } & \text { SEP } \\ 1977 & 46.3 & 9.40 & 7.84 & 6.42 & 6.44 & 6.66 & 8.29 & 126 & 140 & 124 & 58.3 & 38.7 \\ 1978 & 9.79 & 8.57 & 7.94 & 7.06 & 7.00 & 8.18 & 11.4 & 176 & 75.2 & 357 & 341 & 125 \\ 1979 & 36.8 & 12.1 & 9.33 & 8.91 & 9.40 & 10.6 & 9.24 & 102 & 115 & 311 & 187 & 51.4 \\ 1980 & 10.1 & 9.73 & 9.06 & 9.48 & 8.24 & 7.56 & 18.3 & 90.6 & 278 & 290 & 237 & 131 \\ 1981 & 42.0 & 11.1 & 9.95 & 8.60 & 5.06 & 7.27 & 26.8 & 192 & 108 & 278 & 256 & 32.4\end{array}$

ANNUAL PEAK DISCHAPGE, IN CUBIC FEET PER SECOND, AND CORRESPONDING GAGE HEIGHT, IN FEET, FOR EACH WATER YEAR

\begin{tabular}{|c|c|c|c|c|c|c|c|c|c|c|c|}
\hline $\begin{array}{l}\text { WATER } \\
\text { YEAR }\end{array}$ & DATE & $\begin{array}{l}\text { GAGE } \\
\text { HEIGHT }\end{array}$ & $\begin{array}{c}\text { PEAK } \\
\text { DISCHAPGE }\end{array}$ & $\begin{array}{l}\text { WATERR } \\
\text { YEAR }\end{array}$ & DATE & $\begin{array}{l}\text { GAGE } \\
\text { HEIGHT }\end{array}$ & $\begin{array}{c}\text { PEAK } \\
\text { DISCHAPGE }\end{array}$ & $\begin{array}{l}\text { WATER } \\
\text { YEAR }\end{array}$ & DATE & $\begin{array}{c}\text { GAGE } \\
\text { HEIGHT }\end{array}$ & $\begin{array}{c}\text { PEAK } \\
\text { DISCHARGE }\end{array}$ \\
\hline $\begin{array}{l}1977 \\
1978\end{array}$ & $\begin{array}{l}\text { JUNE } 24,1977 \\
\text { JULY } 27,1978\end{array}$ & $\begin{array}{l}3.92 \\
4.41\end{array}$ & $\begin{array}{l}292 \\
552\end{array}$ & $\begin{array}{l}1979 \\
1980\end{array}$ & $\begin{array}{l}\text { JULY } 09,1979 \\
\text { JUNE } 22,1980\end{array}$ & $\begin{array}{l}4.35 \\
5.02\end{array}$ & $\begin{array}{r}402 \\
1220\end{array}$ & 1981 & AUG. 08,1981 & 4.28 & 584 \\
\hline
\end{tabular}




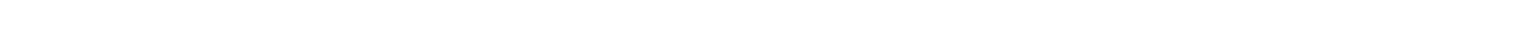
on left bank $0.25 \mathrm{mi}$ downstream from Swift Creek and $13.5 \mathrm{mi}$ north of Altmah.

DRAINAGE AREA. $-99 \mathrm{mi}^{2}$, approximately.

MEAN BASIN ELEVATION. $-10,810 \mathrm{ft}$.

PERIOD OF RECORD AVAIHABLE.--August 1949 to September 1955.

GAGE. -Water-stage recorder. Altitude of gage is 7,990 ft from river-profile map.

AVERAGE DISCHARGE. -6 years, $120 \mathrm{ft}^{3} / \mathrm{s}, 86,880$ acre-ft/yr.

EXIREMES FOR PERICD OF RECORD.--Maximum discharge, 1,400 ft $\mathrm{ft}^{3} / \mathrm{s}$ June 6, 1952; maximum gage height, $5.38 \mathrm{ft}$ June 13, 1953 ; minimum discharge recorded, $27 \mathrm{ft}^{3} / \mathrm{s} \mathrm{Apr.} \mathrm{28,} \mathrm{1955,} \mathrm{but} \mathrm{may} \mathrm{have} \mathrm{been} \mathrm{less} \mathrm{during} \mathrm{other} \mathrm{periods} \mathrm{of} \mathrm{ice} \mathrm{effect.}$

LOWEST MEAN DISGHARGE, IN CUBIC FEET PER SECOND, AND RANKING FOR THE INDICATED NUMBER OF CONSEQUTIVE DAYS FOR EACH OIMATIC YEAR, APRIL 1-MARCH 31

$\begin{array}{ccccccc}\text { YEAR } & & & & & & \\ & 1 & & 3 & & 7 & \\ 1951 & 42.0 & 4 & 42.0 & 4 & 43.0 & 4 \\ 1952 & 42.0 & 5 & 42.0 & 5 & 43.0 & 5 \\ 1953 & 40.0 & 3 & 40.0 & 3 & 40.0 & 3 \\ 1954 & 30.0 & 1 & 30.0 & 1 & 30.0 & 1 \\ 1955 & 30.0 & 2 & 30.0 & 2 & 30.0 & 2\end{array}$

$$
\text { CONSECUTTVE DAYS }
$$

$\begin{array}{cc}14 & \\ 44.0 & 4 \\ 44.0 & 5 \\ 40.0 & 3 \\ 30.0 & 1 \\ 30.0 & 2\end{array}$

30

$\begin{array}{llll}44.0 & 4 & 45.0 & 4 \\ 44.0 & 5 & 47.0 & 5 \\ 40.0 & 3 & 40.0 & 3 \\ 31.0 & 2 & 31.0 & 2 \\ 30.0 & 1 & 30.0 & 1\end{array}$

90

$120 \quad 183$

ALL

HIGHEST MEAN DISCHARGE, IN OBIC FEET PER SECOND, AND RANKING FOR THE INDICATED NUMBER OF CONSEOUTIVE DAVS FOR EACH WATER YEAR, OCTOBER 1-SEPTEMBER 30

\begin{tabular}{|c|c|c|c|c|c|c|c|c|c|c|c|c|c|c|c|c|c|c|c|c|}
\hline YEAR & & & & & & & & & & t & VE D? & & & & & & & & & \\
\hline 1950 & 844 & 3 & 804 & 3 & 694 & 3 & 651 & 2 & 599 & 2 & 448 & 2 & 348 & 2 & 287 & 2 & 216 & 2 & 137 & 2 \\
\hline
\end{tabular}

DURATION OF DISGAARE FOR EACH WATER YEAR

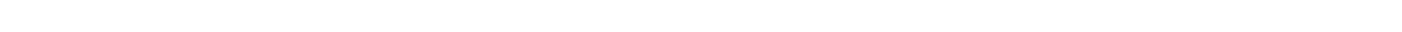

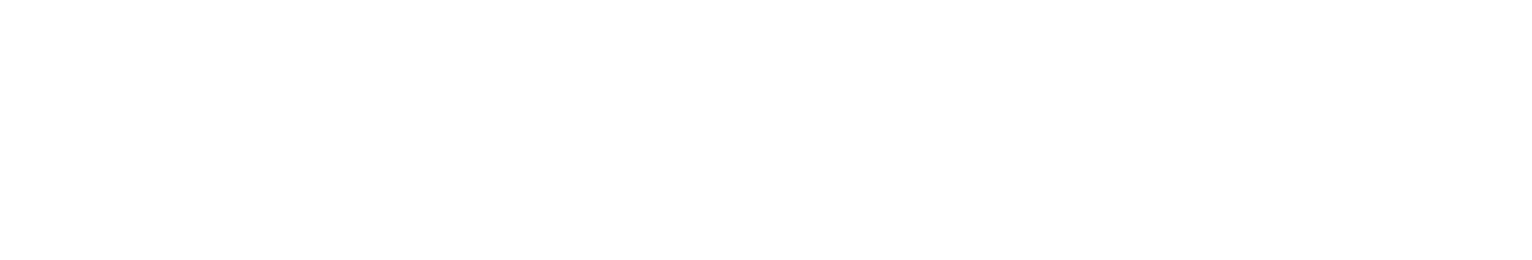

DURATION TABLE OF DISOHARGE FOR WATER YEARS 1950-55
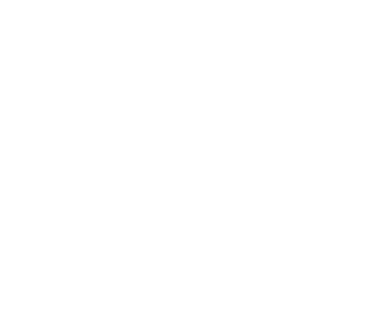

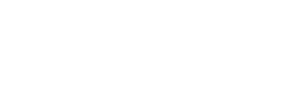

CLASS SECOND DAYS DAYS DAYS

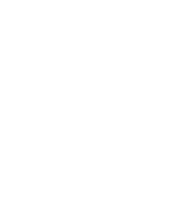

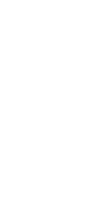

CLAS
18
19
20
21
22
23
24
25
26

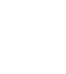

FEET $\stackrel{\text { ACON- }}{\text { MU- }}$ PER-

OLASS SECOND DAYS DAYS DAYS

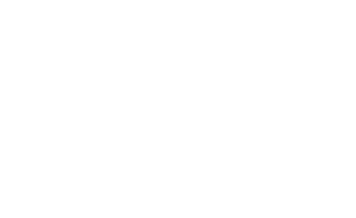

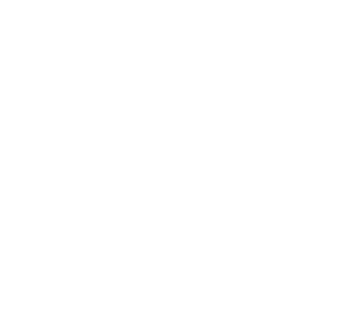


GREEN RIVER BASIN

09291500 YELLOWSTONE RIVER (YETLOWSTONE CREEK) BELOW SWIFT CREEK, NEAR ALTONAH, UT-CONtinUed

MONIHLY MEAN DISCHARGES, IN ABIC FEET PER SECOND, FOR EAOH WATER YEAR

\begin{tabular}{|c|c|c|c|c|c|c|c|c|c|c|c|c|}
\hline YEAR & $\infty \mathrm{OT}$ & NON & DEC & JAN & FEB & MAR & APR & MAY & JUNE & JULY & AUG & SEP \\
\hline 1950 & 83.4 & 70.5 & 56.1 & 48.3 & 45.3 & 43.5 & 77.5 & 240 & 555 & 221 & 108 & 95.6 \\
\hline $\begin{array}{l}1951 \\
1952 \\
1953 \\
1954 \\
1955\end{array}$ & $\begin{array}{l}61.9 \\
75.5 \\
91.6 \\
53.5 \\
60.7\end{array}$ & $\begin{array}{l}51.6 \\
60.1 \\
60.2 \\
48.5 \\
48.2\end{array}$ & $\begin{array}{l}46.5 \\
52.1 \\
50.1 \\
39.8 \\
41.1\end{array}$ & $\begin{array}{l}44.6 \\
50.0 \\
45.0 \\
33.1 \\
35.0\end{array}$ & $\begin{array}{l}45.0 \\
50.0 \\
40.0 \\
31.4 \\
30.0\end{array}$ & $\begin{array}{l}46.0 \\
45.0 \\
40.0 \\
30.7 \\
30.0\end{array}$ & $\begin{array}{l}44.0 \\
81.0 \\
46.5 \\
49.1 \\
36.1\end{array}$ & $\begin{array}{c}178 \\
359 \\
64.0 \\
279 \\
224\end{array}$ & $\begin{array}{l}390 \\
713 \\
408 \\
158 \\
305\end{array}$ & $\begin{array}{l}178 \\
340 \\
162 \\
121 \\
118\end{array}$ & $\begin{array}{l}162 \\
215 \\
124 \\
110 \\
140\end{array}$ & $\begin{array}{c}89.4 \\
155 \\
95.3 \\
73.3 \\
95.7\end{array}$ \\
\hline
\end{tabular}

ANNUAL PEAK DISCHARGE, IN CUBIC FEET PER SECOND, AND CORRESPONDING GAGE HEIGHT, IN FEET, FOR EAOH WATER YEAR

\begin{tabular}{|c|c|c|c|c|c|c|c|c|c|c|c|}
\hline $\begin{array}{l}\text { WATERR } \\
\text { YEAR }\end{array}$ & DATE & $\begin{array}{c}\text { GAGE } \\
\text { HEIGHT }\end{array}$ & $\begin{array}{c}\text { PEAR } \\
\text { DISCHARGE }\end{array}$ & $\begin{array}{l}\text { WATER } \\
\text { YEAR }\end{array}$ & DATE & $\begin{array}{c}\text { GAGE } \\
\text { HEIGHT }\end{array}$ & $\begin{array}{c}\text { PEAK } \\
\text { DISCHARGE }\end{array}$ & $\begin{array}{l}\text { WATER } \\
\text { YEAR }\end{array}$ & DATE & $\begin{array}{c}\text { GAGE } \\
\text { HEIGHT }\end{array}$ & $\begin{array}{c}\text { PEAK } \\
\text { DISCHARGE }\end{array}$ \\
\hline $\begin{array}{l}950 \\
951\end{array}$ & $\begin{array}{l}\text { JUNE } 06,1950 \\
\text { JUNE } 16,1951\end{array}$ & $\begin{array}{l}4.64 \\
4.74\end{array}$ & $\begin{array}{l}1030 \\
1130\end{array}$ & $\begin{array}{l}1952 \\
1953\end{array}$ & $\begin{array}{l}\text { JUNE } 06,1952 \\
\text { JUNE } 13,1953\end{array}$ & $\begin{array}{l}5.21 \\
5.38\end{array}$ & $\begin{array}{l}1400 \\
1310\end{array}$ & $\begin{array}{l}1954 \\
1955\end{array}$ & $\begin{array}{lll}\text { MAY } & 22,1954 \\
\text { JUNE } & 08,1955\end{array}$ & $\begin{array}{l}4.32 \\
4.77\end{array}$ & $\begin{array}{l}630 \\
939\end{array}$ \\
\hline
\end{tabular}

09292500 YELLOWSTONE RIVER NEAR ALTONAH, UT

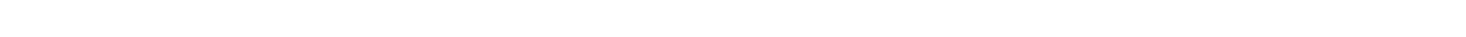

14060003, Uintah and Ouray Indian Reservation, on left bank $1.5 \mathrm{mi}$ downstream from powerplant of Moon Lake Electric Association, Inc., $2 \mathrm{mi}$ downstream from Hell Canyon, $8.2 \mathrm{mi}$ northwest of Altonah.

DRATNAGE AREA. $-132 \mathrm{mi}^{2}$.

MEAN BASIN ELEVATION. - $10,440 \mathrm{ft}$.

PERIOD OF RECORD AVAIIABIE. - October 1944 to September 1981. Prior to Octaber 1965, published as Yellowstone Creek near Altonah.

REVISED RECORDS. -WDR UT-77-1: Drainage area.

GAGE. -Water-stage recorder. Altitude of gage is 7,430 ft from river-prof ile map.

REMARKS.-Some diurnal fluctuation caused by powerplant $1.5 \mathrm{mi}$ upstream.

AVERAGE DISCHARGE. -37 years, $136 \mathrm{ft}^{3} / \mathrm{s}, 98,530$ acre-ft/yr.

EXIREMES FOR PERIOD OF RECORD.-Maximum discharge, $1,880 \mathrm{ft}^{3} / \mathrm{s}$ June 19, 1949 , gage height, $4.55 \mathrm{ft}$; minimum daily, $25 \mathrm{ft}{ }^{3} / \mathrm{s} \mathrm{NOv.} 28$, 1976.

LONEST MEAN DISCHARGE, IN OUBIC FEET PER SECOND, AND RANKING FOR THE INDICATED NUMBER OF CONSEQUTIVE DAYS FOR EACH OLIMATIC YEAR, APRII 1-MARGH 3 I

$\begin{array}{rrrrrrr} & 1 & & 3 & & 7 & \\ 1946 & 40.0 & 13 & 40.0 & 13 & 41.0 & 16 \\ 1947 & 47.0 & 34 & 49.0 & 36 & 50.0 & 36 \\ 1948 & 48.0 & 35 & 48.0 & 34 & 48.0 & 32 \\ 1949 & 46.0 & 31 & 46.0 & 28 & 47.0 & 28 \\ 1950 & 45.0 & 28 & 46.0 & 29 & 49.0 & 33 \\ 1951 & 48.0 & 36 & 49.0 & 35 & 49.0 & 34 \\ 1952 & 45.0 & 29 & 47.0 & 30 & 48.0 & 29 \\ 1953 & 45.0 & 30 & 48.0 & 31 & 49.0 & 35 \\ 1954 & 42.0 & 25 & 42.0 & 21 & 43.0 & 24 \\ 1955 & 40.0 & 14 & 40.0 & 14 & 40.0 & 10 \\ & & & & & & \\ 1956 & 40.0 & 15 & 40.0 & 15 & 40.0 & 11 \\ 1957 & 41.0 & 20 & 42.0 & 22 & 42.0 & 18 \\ 1958 & 41.0 & 21 & 42.0 & 23 & 42.0 & 19 \\ 1959 & 40.0 & 16 & 40.0 & 16 & 40.0 & 12 \\ 1960 & 43.0 & 26 & 43.0 & 27 & 43.0 & 25 \\ 1961 & 40.0 & 17 & 40.0 & 17 & 40.0 & 13 \\ 1962 & 42.0 & 22 & 42.0 & 24 & 42.0 & 20 \\ 1963 & 35.0 & 5 & 35.0 & 5 & 36.0 & 5 \\ 1964 & 39.0 & 10 & 40.0 & 18 & 40.0 & 14 \\ 1965 & 42.0 & 23 & 42.0 & 19 & 43.0 & 26 \\ & & & & & & \\ 1966 & 37.0 & 6 & 38.0 & 9 & 38.0 & 6 \\ 1967 & 47.0 & 32 & 48.0 & 32 & 48.0 & 30 \\ 1968 & 47.0 & 33 & 48.0 & 33 & 48.0 & 31 \\ 1969 & 40.0 & 18 & 40.0 & 10 & 42.0 & 21 \\ 1970 & 39.0 & 11 & 40.0 & 11 & 41.0 & 17\end{array}$

\begin{tabular}{|c|c|c|c|c|c|c|c|}
\hline 14 & & $\begin{array}{l}\text { cons } \\
30\end{array}$ & & $\begin{array}{l}\text { DAIS } \\
60\end{array}$ & & 90 & \\
\hline $\begin{array}{l}.0 \\
.0 \\
3.0 \\
3.0 \\
9.0\end{array}$ & $\begin{array}{l}21 \\
36 \\
28 \\
29 \\
33\end{array}$ & $\begin{array}{l}44.0 \\
51.0 \\
48.0 \\
49.0 \\
50.0\end{array}$ & $\begin{array}{l}20 \\
36 \\
27 \\
29 \\
30\end{array}$ & $\begin{array}{l}45.0 \\
53.0 \\
49.0 \\
49.0 \\
51.0\end{array}$ & $\begin{array}{l}15 \\
36 \\
24 \\
25 \\
28\end{array}$ & $\begin{array}{l}47.0 \\
54.0 \\
50.0 \\
50.0 \\
53.0\end{array}$ & $\begin{array}{l}18 \\
34\end{array}$ \\
\hline $\begin{array}{l}0 \\
.0 \\
.0\end{array}$ & $\begin{array}{r}34 \\
30 \\
35 \\
22 \\
9\end{array}$ & $\begin{array}{l}50.0 \\
50.0 \\
50.0 \\
45.0 \\
40.0\end{array}$ & $\begin{array}{r}31 \\
32 \\
33 \\
21 \\
7\end{array}$ & $\begin{array}{l}51.0 \\
52.0 \\
52.0 \\
45.0 \\
40.0\end{array}$ & $\begin{array}{r}29 \\
33 \\
34 \\
16 \\
5\end{array}$ & $\begin{array}{l}52.0 \\
53.0 \\
54.0 \\
47.0 \\
42.0\end{array}$ & \\
\hline $\begin{array}{l}0 \\
0\end{array}$ & $\begin{array}{l}10 \\
16 \\
23 \\
11 \\
17\end{array}$ & $\begin{array}{l}43.0 \\
44.0 \\
46.0 \\
42.0 \\
44.0\end{array}$ & $\begin{array}{l}16 \\
17 \\
24 \\
13 \\
18\end{array}$ & $\begin{array}{l}45.0 \\
45.0 \\
49.0 \\
44.0 \\
45.0\end{array}$ & $\begin{array}{l}17 \\
18 \\
26 \\
11 \\
19\end{array}$ & $\begin{array}{l}47.0 \\
46.0 \\
50.0 \\
44.0 \\
45.0\end{array}$ & 12 \\
\hline . & $\begin{array}{r}12 \\
18 \\
5 \\
13 \\
19\end{array}$ & $\begin{array}{l}40.0 \\
45.0 \\
38.0 \\
41.0 \\
43.0\end{array}$ & $\begin{array}{r}8 \\
22 \\
5 \\
9 \\
14\end{array}$ & $\begin{array}{l}40.0 \\
48.0 \\
40.0 \\
42.0 \\
45.0\end{array}$ & $\begin{array}{r}6 \\
23 \\
7 \\
8 \\
20\end{array}$ & $\begin{array}{l}40.0 \\
49.0 \\
40.0 \\
44.0 \\
45.0\end{array}$ & $\begin{array}{l}10 \\
13\end{array}$ \\
\hline . & $\begin{array}{r}7 \\
31 \\
32 \\
26 \\
20\end{array}$ & $\begin{array}{l}40.0 \\
50.0 \\
50.0 \\
48.0 \\
44.0\end{array}$ & $\begin{array}{r}6 \\
34 \\
35 \\
28 \\
19\end{array}$ & $\begin{array}{l}44.0 \\
53.0 \\
51.0 \\
51.0 \\
45.0\end{array}$ & $\begin{array}{l}12 \\
35 \\
30 \\
31 \\
13\end{array}$ & $\begin{array}{l}47.0 \\
56.0 \\
53.0 \\
55.0 \\
46.0\end{array}$ & $\begin{array}{l}16 \\
36 \\
29 \\
35 \\
14\end{array}$ \\
\hline
\end{tabular}

$\begin{array}{rrrrrr}120 & & 183 & & \text { ALL } & \\ 49.0 & 17 & 59.0 & 20 & 135 & 20 \\ 56.0 & 30 & 62.0 & 23 & 107 & 9 \\ 53.0 & 24 & 64.0 & 26 & 165 & 28 \\ 52.0 & 21 & 56.0 & 15 & 102 & 6 \\ 56.0 & 31 & 66.0 & 29 & 167 & 29 \\ & & & & & \\ 53.0 & 25 & 57.0 & 18 & 148 & 23 \\ 56.0 & 32 & 63.0 & 24 & 132 & 18 \\ 58.0 & 34 & 70.0 & 32 & 209 & 35 \\ 49.0 & 18 & 56.0 & 16 & 108 & 10 \\ 44.0 & 8 & 51.0 & 7 & 99.0 & 5 \\ 49.0 & 19 & 55.0 & 12 & 109 & 11 \\ 48.0 & 15 & 53.0 & 9 & 130 & 16 \\ 54.0 & 26 & 67.0 & 30 & 149 & 24 \\ 45.0 & 9 & 56.0 & 13 & 135 & 19 \\ 47.0 & 13 & 57.0 & 17 & 104 & 7 \\ 42.0 & 5 & 49.0 & 5 & 96.0 & 2 \\ 52.0 & 22 & 75.0 & 35 & 99.0 & 3 \\ 43.0 & 6 & 54.0 & 11 & 164 & 27 \\ 46.0 & 11 & 60.0 & 21 & 131 & 17 \\ 47.0 & 12 & 53.0 & 10 & 149 & 25 \\ & & & & & \\ 54.0 & 27 & 75.0 & 36 & 226 & 36 \\ 59.0 & 35 & 71.0 & 34 & 139 & 21 \\ 55.0 & 28 & 63.0 & 25 & 174 & 33 \\ 59.0 & 36 & 70.0 & 33 & 179 & 34 \\ 48.0 & 14 & 60.0 & 22 & 167 & 30\end{array}$


GREEN RIVER BASTN

09292500 YETLOWSTONE RIVER NEAR ALTONAF, UT-Continued

LOWEST MEAN DISGHARGE, IN OUBIC FEET PER SECOND, AND RANKING FOR THE INDICATED NUMBER OF CONSEQUTIVE DAYS FOR EACH CLIMATIC YEAR, APRII I-MARCH 3I-Continued

\begin{tabular}{|c|c|c|c|c|c|c|c|c|c|c|c|c|c|c|c|c|c|c|c|c|}
\hline YEAR & 1 & & 3 & & 7 & & 14 & & $\begin{array}{l}\text { Cons } \\
30\end{array}$ & EQTT & $\begin{array}{l}\text { E DAYS } \\
60\end{array}$ & & 90 & & 120 & & 183 & & ALL & \\
\hline $\begin{array}{l}1976 \\
1977 \\
1978 \\
1979 \\
1980\end{array}$ & $\begin{array}{l}38.0 \\
25.0 \\
28.0 \\
22.0 \\
34.0\end{array}$ & $\begin{array}{l}9 \\
2 \\
3 \\
1 \\
4\end{array}$ & $\begin{array}{l}38.0 \\
29.0 \\
29.0 \\
24.0 \\
34.0\end{array}$ & $\begin{array}{l}7 \\
2 \\
3 \\
1 \\
4\end{array}$ & $\begin{array}{l}38.0 \\
29.0 \\
30.0 \\
26.0 \\
34.0\end{array}$ & $\begin{array}{l}8 \\
2 \\
3 \\
1 \\
4\end{array}$ & $\begin{array}{l}38.0 \\
30.0 \\
32.0 \\
26.0 \\
36.0\end{array}$ & $\begin{array}{l}6 \\
2 \\
3 \\
1 \\
4\end{array}$ & $\begin{array}{l}42.0 \\
30.0 \\
33.0 \\
27.0 \\
38.0\end{array}$ & $\begin{array}{r}12 \\
2 \\
3 \\
1 \\
4\end{array}$ & $\begin{array}{l}45.0 \\
31.0 \\
36.0 \\
28.0 \\
39.0\end{array}$ & $\begin{array}{r}14 \\
2 \\
3 \\
1 \\
4\end{array}$ & $\begin{array}{l}47.0 \\
33.0 \\
38.0 \\
31.0 \\
39.0\end{array}$ & $\begin{array}{r}17 \\
2 \\
3 \\
1 \\
4\end{array}$ & & $\begin{array}{r}16 \\
2 \\
3 \\
1 \\
4\end{array}$ & & $\begin{array}{r}14 \\
2 \\
3 \\
1 \\
4\end{array}$ & $\begin{array}{l}167 \\
109 \\
77.0 \\
111 \\
107\end{array}$ & $\begin{array}{r}31 \\
12 \\
1 \\
13 \\
8\end{array}$ \\
\hline 1981 & 37.0 & 8 & 38.0 & 8 & 39.0 & 9 & 40.0 & 8 & 43.0 & 15 & 43.0 & 10 & 43.0 & 8 & 44.0 & 7 & 52.0 & 8 & 147 & 22 \\
\hline
\end{tabular}

HIGHEST MEAN DISGHARGE, IN OUBIC FEET PER SEOOND, AND RANKING FOR THE INDICATED NUMBER OF CONSEQUTIVE DAYS FOR EACH WATER YEAR, OCTCBER 1-SEPTEMBER 30

YEAR

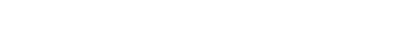

$\begin{array}{lllllllllllllllllllll}1945 & 736 & 25 & 718 & 24 & 651 & 24 & 525 & 26 & 436 & 26 & 349 & 23 & 309 & 19 & 276 & 18 & 211 & 17 & 136 & 18\end{array}$

$\begin{array}{llllllllllllllllllllll}1946 & 565 & 32 & 521 & 33 & 446 & 35 & 349 & 36 & 286 & 35 & 263 & 33 & 217 & 33 & 191 & 33 & 151 & 31 & 105 & 31 \\ 1947 & 820 & 22 & 737 & 23 & 689 & 22 & 593 & 22 & 558 & 18 & 491 & 13 & 414 & 10 & 353 & 10 & 266 & 10 & 164\end{array}$

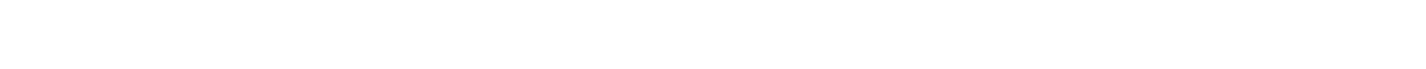

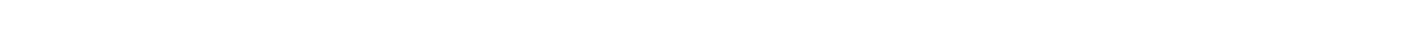

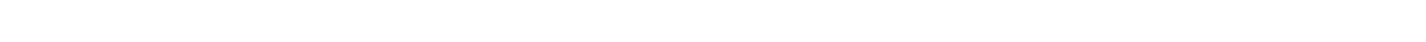

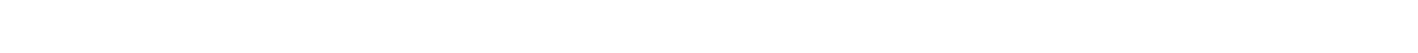

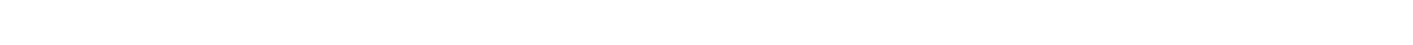

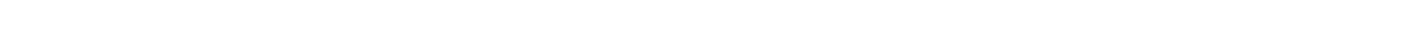

$\begin{array}{lllllllllllllllllllllll}1955 & 624 & 27 & 580 & 27 & 504 & 30 & 430 & 32 & 361 & 31 & 297 & 29 & 235 & 29 & 213 & 27 & 164 & 27 & 108 & 27\end{array}$

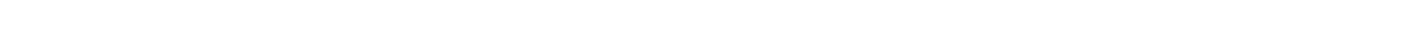

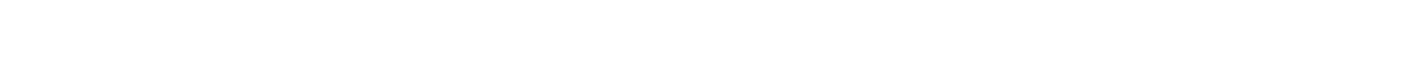

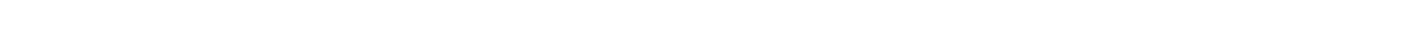

$\begin{array}{rrrrrrrrrrrrrrrrrrrrrr}1961 & 421 & 37 & 354 & 37 & 295 & 37 & 233 & 37 & 210 & 37 & 168 & 37 & 142 & 37 & 138 & 36 & 124 & 36 & 87.0 & 36\end{array}$

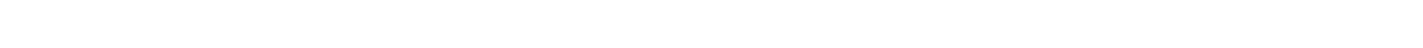

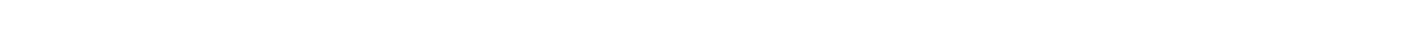

$\begin{array}{rrrrrrrrrrrrrrrrrrrrr}1966 & 559 & 34 & 521 & 32 & 476 & 33 & 437 & 31 & 398 & 29 & 342 & 25 & 285 & 23 & 253 & 22 & 207 & 19 & 141 & 17 \\ 1967 & 931 & 14 & 925 & 12 & 893 & 9 & 842 & 8 & 674 & 10 & 586 & 5 & 474 & 5 & 395 & 4 & 285 & 4 & 178 & 3 \\ 1968 & 1460 & 2 & 1380 & 1 & 1280 & 1 & 1070 & 1 & 883 & 2 & 600 & 4 & 481 & 3 & 398 & 3 & 288 & 3 & 176 & 4 \\ 1969 & 900 & 17 & 880 & 17 & 839 & 14 & 809 & 10 & 679 & 9 & 534 & 7 & 424 & 8 & 356 & 9 & 274 & 7 & 172 & 6\end{array}$

$\begin{array}{rrrrrrrrrrrrrrrrrrrrr}1969 & 900 & 17 & 880 & 17 & 839 & 14 & 809 & 10 & 679 & 9 & 534 & 7 & 424 & 8 & 356 & 9 & 274 & 7 & 172 & 6 \\ 1970 & 598 & 28 & 578 & 28 & 539 & 28 & 514 & 27 & 430 & 27 & 347 & 24 & 284 & 24 & 250 & 23 & 186 & 23 & 123 & 23\end{array}$

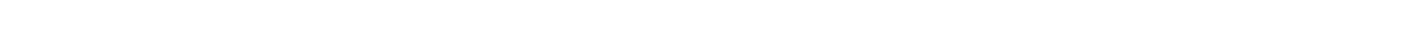

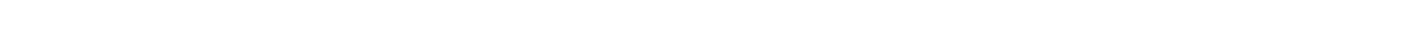

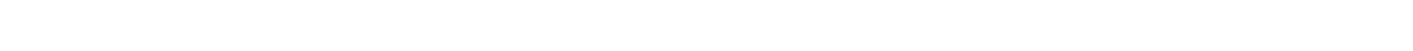

$\begin{array}{lllllllllllllllllllll}1976 & 749 & 24 & 713 & 25 & 672 & 23 & 602 & 21 & 497 & 21 & 353 & 22 & 277 & 25 & 233 & 25 & 175 & 25 & 116 & 24\end{array}$

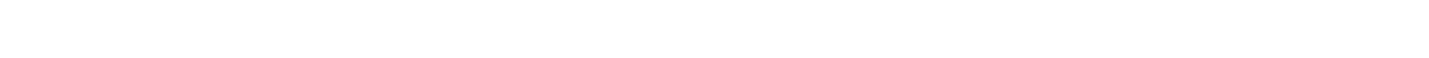

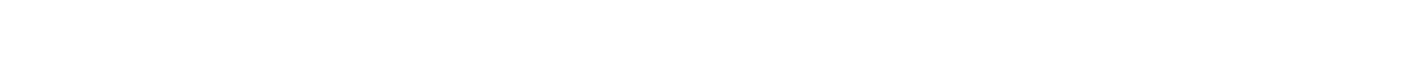

$\begin{array}{llllllllllllllllllllll}1981 & 926 & 15 & 914 & 15 & 787 & 17 & 658 & 17 & 456 & 24 & 300 & 28 & 240 & 28 & 206 & 29 & 161 & 28 & 106 & 30\end{array}$

DURATION OF DISGHARGE FOR EACH WATER YEAR

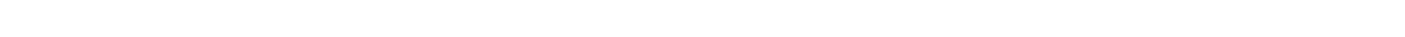

NUMBER OF' DAYS IN CLASS PER SECOND

1945

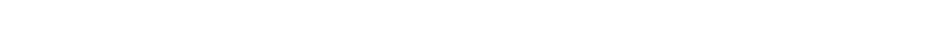

49685.0

1946

1947

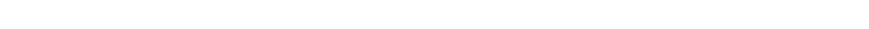

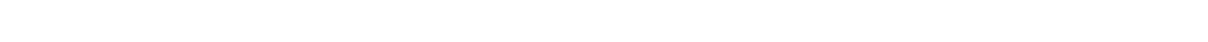

38288.0

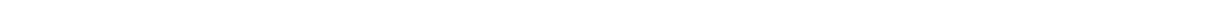

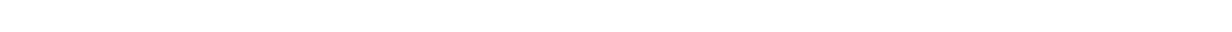


GREEN RIVER BASIN

09292500 YELLOWSTONE RIVER NEAR ALTONAH, UT-Continued

DURATION OF DISCHARGE FOR EAOH WATER YEAR.--Continued

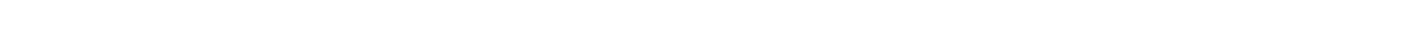

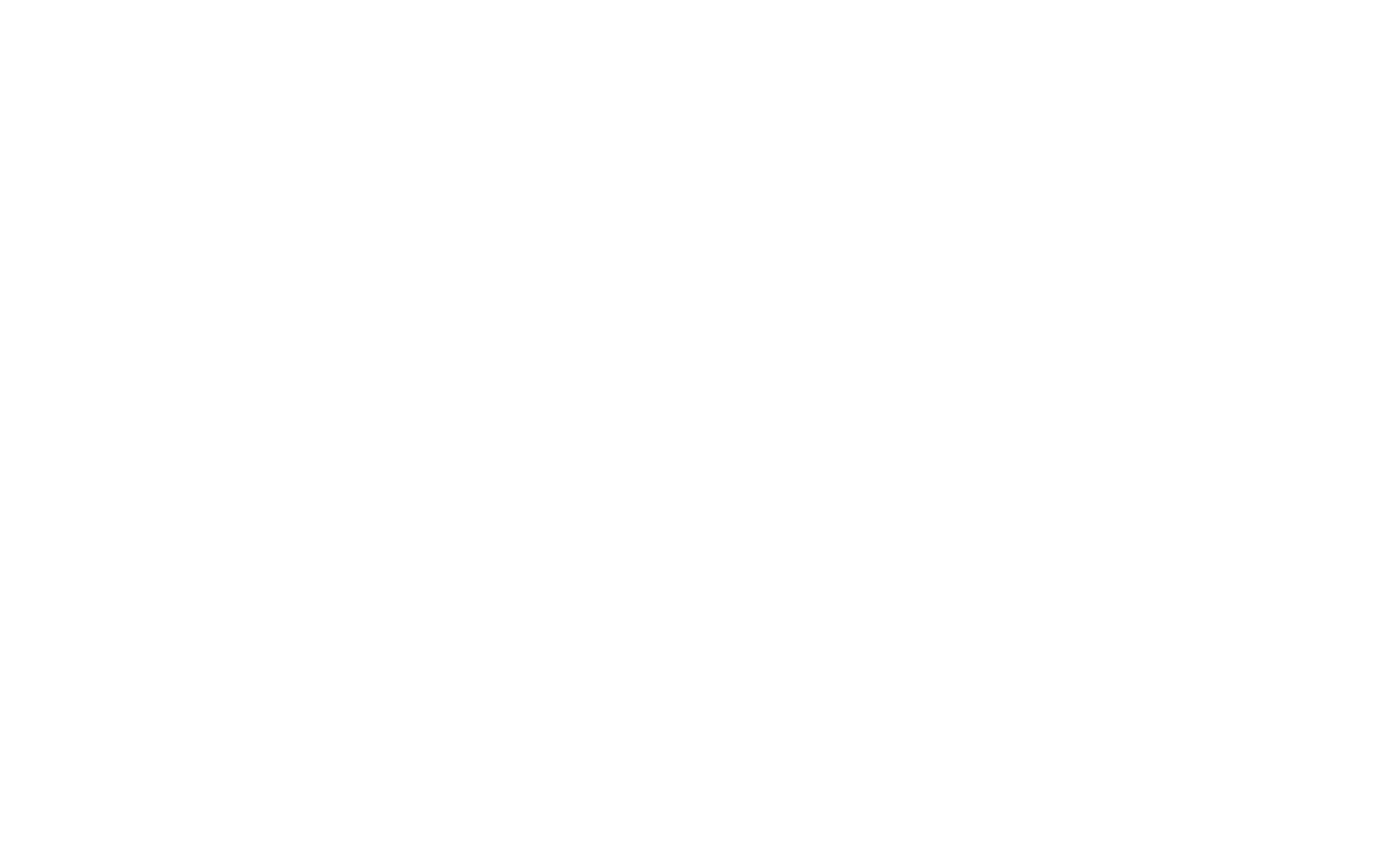

DURATION TABLE OF DISGHARGE FOR WATER YEARS 1945-81

$\begin{array}{rrr}\text { CUBIC } & \text { ACO- } & \\ \text { FEET } & \text { MU- } & \text { PER- } \\ \text { PER TOTAL, LATED } & \text { CENT } \\ \text { CLASS SECOND } & \text { LAYS LAYS } & \text { CAYS }\end{array}$

$0.00 \quad 0 \quad 13514 \quad 100.0$

$22.00 \quad 5 \quad 13514100.0$

$25.00 \quad 39 \quad 13509100.0$

$\begin{array}{llll}28.00 & 66 & 13470 & 99.7\end{array}$

$\begin{array}{llll}32.00 & 129 & 13404 & 99.2\end{array}$

$\begin{array}{llll}32.00 & 129 & 13404 & 99.2 \\ 37.00 & 583 & 13275 & 98.2\end{array}$

$42.001231 \quad 12692 \quad 93.9$

$47.001857 \quad 1146184.8$

$\begin{array}{rrrr}54.00 & 1506 & 9604 & 71.1\end{array}$ $\begin{array}{ccc}\text { OUBIC } & \text { ACO- } & \\ \text { FEET } & \text { MU- } & \text { PER- } \\ \text { PER TOTAL LATED } & \text { CENT }\end{array}$ OLASS SECOND DAYS LAYS DAYS

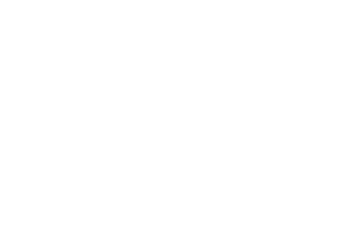

$\begin{array}{lll}\text { OUBIC } & \text { ACOI- } & \\ \text { FEET } & \text { MU- } & \text { PER- } \\ \text { PER TOTAL LATED } & \text { CENT }\end{array}$

CLASS SECOND DAYS LAYS DAYS

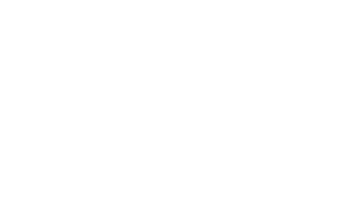

MONTHLY MEAN DISCHARGES, IN CUBIC FEET PER SECOND, FOR EACH WATER YEAR

$\begin{array}{lllllllllllrr}\text { YEAR } & \text { NCT } & \text { NON } & \text { LEC } & \text { JAN } & \text { FEB } & \text { MAR } & \text { APR } & \text { MAY } & \text { JUNE } & \text { JULY } & \text { AUG } & \text { SEP } \\ 1945 & 93.0 & 85.2 & 54.8 & 45.0 & 42.0 & 45.4 & 51.7 & 225 & 400 & 279 & 187 & 119 \\ 1946 & 86.3 & 67.1 & 55.0 & 51.0 & 45.0 & 44.0 & 114 & 239 & 256 & 122 & 103 & 73.3 \\ 1947 & 78.4 & 70.9 & 63.3 & 56.0 & 52.8 & 53.0 & 70.7 & 469 & 476 & 278 & 169 & 128 \\ 1948 & 94.5 & 75.6 & 63.0 & 54.0 & 48.0 & 49.0 & 54.1 & 266 & 280 & 112 & 108 & 71.4 \\ 1949 & 64.9 & 61.2 & 56.0 & 52.0 & 50.0 & 48.8 & 79.8 & 281 & 717 & 276 & 138 & 111 \\ 1950 & 94.4 & 78.1 & 64.5 & 56.4 & 52.1 & 50.4 & 94.1 & 274 & 618 & 234 & 107 & 107 \\ 1951 & 71.6 & 59.6 & 56.9 & 52.0 & 51.2 & 52.3 & 50.1 & 212 & 457 & 197 & 186 & 99.9 \\ 1952 & 85.6 & 70.0 & 65.0 & 55.0 & 55.0 & 50.0 & 93.9 & 443 & 751 & 371 & 250 & 177 \\ 1953 & 107 & 78.6 & 67.6 & 60.0 & 52.4 & 50.8 & 55.7 & 72.2 & 431 & 173 & 136 & 101 \\ 1954 & 71.2 & 64.5 & 56.7 & 49.7 & 45.2 & 45.5 & 65.0 & 308 & 161 & 124 & 126 & 86.7 \\ 1955 & 70.3 & 59.2 & 51.8 & 45.0 & 40.0 & 40.0 & 49.9 & 234 & 337 & 122 & 142 & 99.1 \\ & & & & & & & & & & & \\ 1956 & 72.5 & 60.0 & 54.5 & 50.9 & 45.0 & 45.8 & 64.2 & 351 & 499 & 149 & 101 & 77.3 \\ 1957 & 63.8 & 58.6 & 54.5 & 50.0 & 45.0 & 44.2 & 45.9 & 84.9 & 616 & 312 & 175 & 154 \\ 1958 & 102 & 84.6 & 65.4 & 51.6 & 50.0 & 48.0 & 58.3 & 381 & 480 & 148 & 104 & 118 \\ 1959 & 91.6 & 58.2 & 49.2 & 45.0 & 45.0 & 42.1 & 50.1 & 111 & 374 & 141 & 139 \\ 1960 & 84.9 & 65.7 & 50.9 & 45.5 & 44.7 & 48.2 & 64.0 & 222 & 294 & 116 & 84.4 & 77.0\end{array}$


09292500 YETLOWSTONE RIVER NEAR ALTONAH, UT-CONTinued

MONIHLY MEAN DISCHARGES, IN CABIC FEET PER SBCOND, FOR EACH WATER YEAR--Continued

\begin{tabular}{|c|c|c|c|c|c|c|c|c|c|c|c|c|}
\hline YEAR & $\infty \mathrm{CT}$ & NOV & DEC & JAN & FEB & MAR & APR & MAY & JUNE & JULY & AUG & SEPP \\
\hline $\begin{array}{l}1961 \\
1962 \\
1963 \\
1964 \\
1965\end{array}$ & $\begin{array}{c}70.0 \\
145 \\
86.4 \\
98.4 \\
71.5\end{array}$ & $\begin{array}{l}57.3 \\
89.1 \\
63.1 \\
75.2 \\
54.3\end{array}$ & $\begin{array}{l}47.7 \\
63.8 \\
50.8 \\
52.4 \\
52.4\end{array}$ & $\begin{array}{l}40.8 \\
50.7 \\
38.4 \\
46.2 \\
46.6\end{array}$ & $\begin{array}{l}40.0 \\
49.6 \\
42.1 \\
41.0 \\
45.3\end{array}$ & $\begin{array}{l}40.0 \\
45.6 \\
40.0 \\
43.8 \\
43.7\end{array}$ & $\begin{array}{c}46.5 \\
120 \\
42.6 \\
51.9 \\
55.1\end{array}$ & $\begin{array}{l}154 \\
287 \\
275 \\
309 \\
130\end{array}$ & $\begin{array}{l}163 \\
694 \\
427 \\
550 \\
741\end{array}$ & $\begin{array}{l}101 \\
303 \\
182 \\
301 \\
744\end{array}$ & $\begin{array}{l}95.0 \\
141 \\
134 \\
150 \\
366\end{array}$ & $\begin{array}{l}183 \\
106 \\
152 \\
106 \\
219\end{array}$ \\
\hline $\begin{array}{l}1966 \\
1967 \\
1968 \\
1969 \\
1970\end{array}$ & $\begin{array}{c}133 \\
107 \\
91.1 \\
104 \\
93.3\end{array}$ & $\begin{array}{l}94.7 \\
79.0 \\
69.8 \\
75.0 \\
71.4\end{array}$ & $\begin{array}{l}71.5 \\
68.6 \\
61.1 \\
71.9 \\
54.9\end{array}$ & $\begin{array}{l}49.3 \\
62.7 \\
55.1 \\
60.9 \\
47.8\end{array}$ & $\begin{array}{l}45.4 \\
56.4 \\
52.9 \\
49.9 \\
46.6\end{array}$ & $\begin{array}{l}49.2 \\
50.1 \\
50.4 \\
56.1 \\
43.8\end{array}$ & $\begin{array}{r}92.6 \\
54.0 \\
57.3 \\
128 \\
41.1\end{array}$ & $\begin{array}{l}369 \\
265 \\
125 \\
599 \\
210\end{array}$ & $\begin{array}{l}290 \\
615 \\
882 \\
448 \\
396\end{array}$ & $\begin{array}{l}185 \\
449 \\
303 \\
199 \\
192\end{array}$ & $\begin{array}{l}156 \\
199 \\
236 \\
147 \\
131\end{array}$ & $\begin{array}{l}143 \\
127 \\
133 \\
121 \\
145\end{array}$ \\
\hline $\begin{array}{l}1971 \\
1972 \\
1973 \\
1974 \\
1975\end{array}$ & $\begin{array}{l}84.3 \\
84.5 \\
96.8 \\
98.3 \\
63.2\end{array}$ & $\begin{array}{l}62.4 \\
75.2 \\
77.9 \\
78.5 \\
54.8\end{array}$ & $\begin{array}{l}58.7 \\
64.3 \\
64.4 \\
63.1 \\
49.4\end{array}$ & $\begin{array}{l}51.4 \\
55.7 \\
53.4 \\
54.6 \\
46.5\end{array}$ & $\begin{array}{l}47.6 \\
47.1 \\
49.0 \\
48.3 \\
43.6\end{array}$ & $\begin{array}{l}47.0 \\
59.8 \\
45.2 \\
54.3 \\
41.2\end{array}$ & $\begin{array}{l}62.1 \\
60.2 \\
49.6 \\
73.4 \\
41.9\end{array}$ & $\begin{array}{l}165 \\
219 \\
343 \\
304 \\
103\end{array}$ & $\begin{array}{l}676 \\
514 \\
564 \\
211 \\
637\end{array}$ & $\begin{array}{l}270 \\
150 \\
311 \\
143 \\
601\end{array}$ & $\begin{array}{c}157 \\
118 \\
203 \\
90.3 \\
176\end{array}$ & $\begin{array}{c}106 \\
85.6 \\
159 \\
61.8 \\
110\end{array}$ \\
\hline $\begin{array}{l}1976 \\
1977 \\
1978 \\
1979 \\
1980\end{array}$ & $\begin{array}{l}74.5 \\
67.5 \\
59.4 \\
57.9 \\
58.3\end{array}$ & $\begin{array}{l}63.2 \\
49.8 \\
49.8 \\
51.4 \\
50.4\end{array}$ & $\begin{array}{l}57.6 \\
40.7 \\
43.8 \\
38.6 \\
43.6\end{array}$ & $\begin{array}{l}50.0 \\
37.6 \\
33.0 \\
26.5 \\
38.3\end{array}$ & $\begin{array}{l}45.0 \\
29.9 \\
38.4 \\
31.5 \\
40.3\end{array}$ & $\begin{array}{l}45.0 \\
31.0 \\
45.2 \\
36.8 \\
40.4\end{array}$ & $\begin{array}{l}49.0 \\
41.5 \\
57.5 \\
48.4 \\
60.7\end{array}$ & $\begin{array}{l}246 \\
72.0 \\
134 \\
236 \\
169\end{array}$ & $\begin{array}{l}420 \\
250 \\
533 \\
372 \\
740\end{array}$ & $\begin{array}{l}145 \\
125 \\
185 \\
148 \\
257\end{array}$ & $\begin{array}{l}106 \\
96.9 \\
106 \\
133 \\
124\end{array}$ & $\begin{array}{r}88.5 \\
69.1 \\
74.8 \\
72.0 \\
103\end{array}$ \\
\hline 1981 & 75.0 & 58.5 & 46.5 & 42.7 & 44.4 & 43.5 & 52.8 & 172 & 419 & 127 & 105 & 91.0 \\
\hline
\end{tabular}

ANNUAL PEAR DISCHARGE, IN CUBIC FEET PER SECOND, AND CORRESPONDING GAGE HEIGHT, IN FEET, FOR EACH WATER YEAR

\begin{tabular}{|c|c|c|c|c|c|c|c|c|c|c|c|}
\hline $\begin{array}{l}\text { WATER } \\
\text { YEAR }\end{array}$ & DATE & $\begin{array}{c}\text { GAGE } \\
\text { HEIGHT }\end{array}$ & $\begin{array}{c}\text { PEAK } \\
\text { DISCHARGE }\end{array}$ & $\begin{array}{l}\text { WATER } \\
\text { YEAR }\end{array}$ & DATE & $\begin{array}{c}\text { GAGE } \\
\text { HEIGHI }\end{array}$ & $\begin{array}{c}\text { PEAK } \\
\text { DISCHARGE }\end{array}$ & $\begin{array}{l}\text { WATERR } \\
\text { YEAR }\end{array}$ & DATE & $\begin{array}{c}\text { GAGE } \\
\text { HEIGHT }\end{array}$ & $\begin{array}{c}\text { PEAAK } \\
\text { DISCHARGE }\end{array}$ \\
\hline $\begin{array}{l}1945 \\
1946 \\
1947 \\
1948 \\
1949 \\
1950 \\
1951 \\
1952 \\
1953 \\
1954 \\
1955 \\
1956 \\
1957\end{array}$ & $\begin{array}{ll}\text { JUNE } 22, & 1945 \\
\text { JUNE } 05,1946 \\
\text { JUNE } 08,1947 \\
\text { MAY } 19,1948 \\
\text { JUNE } 19,1949 \\
\text { JUNE } 02,1950 \\
\text { JUNE } 16,1951 \\
\text { JUNE } 06,1952 \\
\text { JUNE } 13,1953 \\
\text { MAY } 22,1954 \\
\text { JUNE 08, } 1955 \\
\text { JUNE 01, } 1956 \\
\text { JUNE } 06,1957\end{array}$ & $\begin{array}{l}3.38 \\
3.17 \\
3.41 \\
3.17 \\
4.55 \\
3.71 \\
3.76 \\
3.97 \\
3.82 \\
2.97 \\
3.18 \\
3.47 \\
3.65\end{array}$ & $\begin{array}{r}867 \\
739 \\
882 \\
720 \\
1880 \\
1070 \\
1110 \\
1440 \\
1360 \\
652 \\
799 \\
1170 \\
1240\end{array}$ & $\begin{array}{l}1958 \\
1959 \\
1960 \\
1961 \\
1962 \\
1963 \\
1964 \\
1965 \\
1966 \\
1967 \\
1968 \\
1969\end{array}$ & $\begin{array}{ll}\text { JUNE } 07,1958 \\
\text { JUNE } 08,1959 \\
\text { JUNE 02, } 1960 \\
\text { SEPT. 18, } 1961 \\
\text { JUNE } 20,1962 \\
\text { JUNE } 14,1963 \\
\text { JUNE } 07,1964 \\
\text { JUNE } 12,1965 \\
\text { MAY 07, } 1966 \\
\text { JUNE } 26,1967 \\
\text { JUNE } 20,1968 \\
\text { MAY 26, } 1969\end{array}$ & $\begin{array}{l}3.50 \\
2.73 \\
2.75 \\
2.59 \\
3.41 \\
3.01 \\
3.24 \\
3.56 \\
2.59 \\
3.19 \\
3.58 \\
3.08\end{array}$ & $\begin{array}{r}1140 \\
658 \\
664 \\
549 \\
1180 \\
792 \\
977 \\
1350 \\
674 \\
1110 \\
1790 \\
1100\end{array}$ & $\begin{array}{l}1970 \\
1971 \\
1972 \\
1973 \\
1974 \\
1975 \\
1976 \\
1977 \\
1978 \\
1979 \\
1980 \\
1981\end{array}$ & $\begin{array}{l}\text { JUNE } 04,1970 \\
\text { JUNE } 18,1971 \\
\text { JUNE } 01,1972 \\
\text { JUNE } 10,1973 \\
\text { MAY } 26,1974 \\
\text { JUNE } 16,1975 \\
\text { JUNE 03, } 1976 \\
\text { JUNE 03, } 1977 \\
\text { JUNE 14, } 1978 \\
\text { MAY 29, } 1979 \\
\text { JUNE 10, } 1980 \\
\text { JUNE } 08,1981\end{array}$ & $\begin{array}{l}2.55 \\
3.40 \\
3.02 \\
3.08 \\
2.45 \\
3.34 \\
2.73 \\
2.70 \\
2.71 \\
2.72 \\
3.37 \\
3.08\end{array}$ & $\begin{array}{r}714 \\
1440 \\
1060 \\
1170 \\
655 \\
1410 \\
907 \\
883 \\
928 \\
1060 \\
1590 \\
1260\end{array}$ \\
\hline
\end{tabular}

MAGNITUDE AND PRCBABIIITY OF ANNUAL HIGHEST MEAN DISCHARGE BASED ON WATER YEARS 1945-81

\begin{tabular}{lcccccc}
\hline & \multicolumn{5}{c}{$\begin{array}{c}\text { DISCHARGB, IN CUBIC FEET PER SBCOND, FOR } \\
\text { PERIOD } \\
\text { (CON- }\end{array}$} & $\begin{array}{c}\text { INDICATED RECURRENCE INTERNAL, IN YEARS, AND } \\
\text { ANNUAL EXCEEDANCE PRCBABILITY, IN PERCENT }\end{array}$ \\
$\begin{array}{l}\text { SEOU- } \\
\text { TIVE }\end{array}$ & 2 & 5 & 10 & 25 & 50 & 100 \\
DAYS) & 508 & 208 & 108 & 48 & 28 & 18 \\
\hline 1 & 833 & 1090 & 1250 & 1450 & 1590 & - \\
3 & 797 & 1040 & 1190 & 1350 & 1470 & - \\
7 & 726 & 948 & 1080 & 1230 & 1330 & - \\
15 & 635 & 835 & 948 & 1070 & 1150 & -
\end{tabular}

09293000 YELLOWSTONE RIVER AT MOUTH, NEAR MOUNTAIN HOME, UT

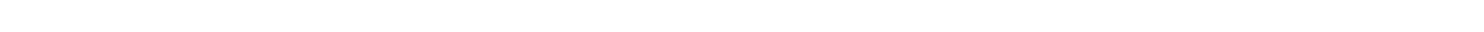
14060003 , on left bank on downstream side of county road bridge, 0.1 mi upstream from mouth, and 3.4 mi northeast of Mountain Hame.

DRAINAGE AREA.- $-142 \mathrm{mi}^{2}$.

PERIOD OF RECORD AVAIIABLE.--May 1943 to September 1944, October 1976 to September 1981.

GAGE.-Water-stage recorder. Altitude of gage is 6,915 ft from topographic map. Prior to July 18, 1980, at datum $1.02 \mathrm{ft} 10 \mathrm{wer}$. REMARKS.-Slight regulation caused by powerplant $6.7 \mathrm{mi}$ upstream and one diversion above station for irrigation below.

AVERAGE DISCHARGE.- -6 years (water years 1944, 1977-81), $88.7 \mathrm{ft}^{3} / \mathrm{s}, 64,260$ acre-ft/yr.

EXTREMES FOR PERIOD OF RECORD.-Maximum discharge, 2,130 ft $\mathrm{ft}^{3} / \mathrm{s}$ June 26,1944 , gage height, $3.92 \mathrm{ft}$; minimum daily, $2.9 \mathrm{ft}{ }^{3} / \mathrm{s}$ May 11 , 1978. 
LOWEST MEAN DISCHARGE, IN CUBIC FEET PER SECOND, AND RANKING FOR THE INDICATED NUMBER OF CONSECUTTVE DAYS FOR EACH CIIMATIC YEAR, APRIL 1-MARCH 31

\begin{tabular}{|c|c|c|c|c|c|c|c|c|c|c|c|c|c|c|c|c|c|c|c|}
\hline YEAR & & & & & & & & & CONSE & U & E DAYS & & & & & & & & \\
\hline $\begin{array}{l}1978 \\
1979 \\
1980\end{array}$ & $\begin{array}{l}5.10 \\
2.90 \\
4.60\end{array}$ & $\begin{array}{l}3 \\
1 \\
2\end{array}$ & $\begin{array}{l}5.40 \\
3.10 \\
4.90\end{array}$ & $\begin{array}{l}3 \\
1 \\
2\end{array}$ & $\begin{array}{l}6.40 \\
4.10 \\
5.10\end{array}$ & $\begin{array}{l}4 \\
1 \\
2\end{array}$ & $\begin{array}{l}8.60 \\
4.20 \\
6.10\end{array}$ & $\begin{array}{l}4 \\
1 \\
2\end{array}$ & $\begin{array}{c}24.0 \\
4.50 \\
13.0\end{array}$ & $\begin{array}{l}4 \\
1 \\
3\end{array}$ & $\begin{array}{c}35.0 \\
7.00 \\
37.0\end{array}$ & $\begin{array}{l}3 \\
1 \\
4\end{array}$ & $\begin{array}{l}39.0 \\
24.0 \\
44.0\end{array}$ & $\begin{array}{l}3 \\
2 \\
4\end{array}$ & $\begin{array}{l}42.0 \\
33.0 \\
45.0\end{array}$ & $\begin{array}{l}3 \\
2 \\
4\end{array}$ & $\begin{array}{l}47.0 \\
37.0 \\
50.0\end{array}$ & $\begin{array}{l}3 \\
1 \\
4\end{array}$ & $\begin{array}{l}62.0 \\
70.0 \\
79.0\end{array}$ \\
\hline 981 & 5.90 & 4 & 6.00 & 4 & 6.00 & 3 & 6.10 & 3 & 10.0 & 2 & 16.0 & 2 & 19.0 & 1 & 30.0 & $i$ & 38.0 & 2 & 105 \\
\hline
\end{tabular}

HIGHEST MEAN DISCHARGE, IN CIBIC FEET PER SECOND, AND RANKING FOR THE INDICATED NUMBER OF CONSECUTIVE DAYS FOR EACH WATER YEAR, OCTOBER 1-SEPTEMBER 30

\begin{tabular}{|c|c|c|c|c|c|c|c|c|c|c|c|c|c|c|c|c|c|c|c|}
\hline YEAR & 1 & & 3 & & 7 & & 15 & & $\begin{array}{l}\infty \\
30\end{array}$ & & $7 \mathrm{E}$ & & 9 & & 120 & & 183 & & ALL \\
\hline 1944 & 1320 & 1 & 1010 & 2 & 932 & 1 & 900 & 1 & 758 & 1 & 572 & 1 & 436 & 1 & 342 & 1 & 241 & 1 & 146 \\
\hline
\end{tabular}

DURATION OF DISCHARGE FOR EACH WATER YEAR

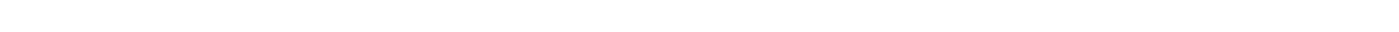
YEAR NUMBER OF DAYS IN CLASS
-DAYS

\begin{tabular}{|c|c|c|c|c|c|c|c|c|c|c|c|c|c|c|c|c|c|c|c|c|c|c|c|c|c|c|c|c|c|c|c|}
\hline 1944 & & & & & & & 1 & 3 & 6 & 7 & 7 & & 117 & 80 & 42 & 13 & 3 & 1 & 14 & 4 & 8 & & 8 & 710 & 3 & 41 & 12 & 8 & 4 & 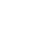 & 53479.0 \\
\hline $\begin{array}{l}1977 \\
1978 \\
1979 \\
1980\end{array}$ & 3 & $\begin{array}{r}524 \\
2\end{array}$ & $\begin{array}{l}3 \\
9 \\
7\end{array}$ & $\begin{array}{l}3 \\
5 \\
4\end{array}$ & $\begin{array}{ll}4 & 7 \\
3 & 5 \\
1 & 8 \\
17\end{array}$ & $\begin{array}{rr}5 & 10 \\
2 & 7 \\
7 & 8 \\
22 & 15\end{array}$ & $\begin{array}{l}6 \\
8 \\
2 \\
7\end{array}$ & $\begin{array}{l}3 \\
2\end{array}$ & $\begin{array}{l}3 \\
1 \\
2 \\
1\end{array}$ & $\begin{array}{l}4 \\
1 \\
7 \\
1\end{array}$ & $\begin{array}{r}73 \\
14 \\
50 \\
3\end{array}$ & $\begin{array}{l}73 \\
95 \\
64 \\
59\end{array}$ & $\begin{array}{l}30 \\
59 \\
25 \\
76\end{array}$ & $\begin{array}{l}22 \\
53 \\
72 \\
60\end{array}$ & $\begin{array}{l}39 \\
19 \\
48 \\
21\end{array}$ & $\begin{array}{r}32 \\
10 \\
4 \\
10\end{array}$ & $\begin{array}{r}21 \\
3 \\
7 \\
11\end{array}$ & $\begin{array}{r}7 \\
1 \\
11 \\
1\end{array}$ & $\begin{array}{lr}5 & 5 \\
2 & 3 \\
4 & \\
1 & 12\end{array}$ & $\begin{array}{l}5 \\
3 \\
12\end{array}$ & $\begin{array}{lr}1 & 3 \\
3 & 10 \\
2 & \\
6 & 6\end{array}$ & $\begin{array}{l}2 \\
3 \\
4 \\
5\end{array}$ & $\begin{array}{l}1 \\
2 \\
7 \\
3\end{array}$ & $\begin{array}{l}4 \\
6 \\
9 \\
5\end{array}$ & $\begin{array}{l}6 \\
3 \\
4\end{array}$ & $\begin{array}{l}3 \\
3 \\
3\end{array}$ & $\begin{array}{l}1 \\
7\end{array}$ & 4 & 3 & 1 & $\begin{array}{l}21717.0 \\
25779.0 \\
28044.0 \\
39536.5\end{array}$ \\
\hline 48 & & & 122 & 22 & 415 & 210 & 6 & 3 & 6 & 6 & 5 & 30 & 47 & 74 & 34 & 27 & 25 & 15 & 13 & 3 & 1 & 2 & 3 & 5 & & 1 & 2 & & & & 25928.1 \\
\hline
\end{tabular}
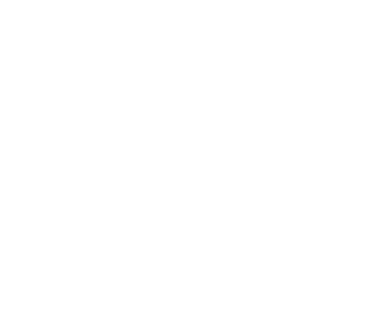

DURATION TABLE OF DISCHARGE FOR WATER YEARS 1944, 1977-81

\begin{tabular}{|c|c|c|c|c|c|c|c|c|c|c|c|c|c|c|}
\hline CLASS & $\begin{array}{c}\text { OUBIC } \\
\text { FEET } \\
\text { PER } \\
\text { SECOND }\end{array}$ & $\begin{array}{r}\text { TOTAL } \\
\text { DAYS }\end{array}$ & $\begin{array}{l}\text { ACO- } \\
\text { MU- } \\
\text { IATED } \\
\text { DAYS }\end{array}$ & $\begin{array}{l}\text { PER- } \\
\text { CENT } \\
\text { DAYS }\end{array}$ & & $\begin{array}{c}\text { CUBIC } \\
\text { FEET } \\
\text { PER } \\
\text { SECOND }\end{array}$ & $\begin{array}{r}\text { TOTAL } \\
\text { DAYS }\end{array}$ & $\begin{array}{l}\text { ACOU- } \\
\text { MU- } \\
\text { LATED } \\
\text { DAYS }\end{array}$ & $\begin{array}{l}\text { PER- } \\
\text { CENT } \\
\text { DAYS }\end{array}$ & CASS & $\begin{array}{c}\text { GBIC } \\
\text { FEET } \\
\text { PER } \\
\text { SECOND }\end{array}$ & $\begin{array}{r}\text { TOTAL } \\
\text { DAYS }\end{array}$ & $\begin{array}{l}\text { ACO- } \\
\text { MU- } \\
\text { LATED } \\
\text { DAYS }\end{array}$ & $\begin{array}{l}\text { PER } \\
\text { CENT } \\
\text { DAYS }\end{array}$ \\
\hline $\begin{array}{r}9 \\
10 \\
11 \\
12 \\
13 \\
14 \\
15 \\
16 \\
17\end{array}$ & $\begin{array}{l}12.00 \\
15.00 \\
18.00 \\
21.00 \\
25.00 \\
30.00 \\
36.00 \\
44.00 \\
52.00\end{array}$ & $\begin{array}{r}50 \\
30 \\
13 \\
19 \\
26 \\
152 \\
328 \\
354 \\
361\end{array}$ & $\begin{array}{l}1991 \\
1941 \\
1911 \\
1898 \\
1879 \\
1853 \\
1701 \\
1373 \\
1019\end{array}$ & $\begin{array}{l}90.8 \\
88.5 \\
87.2 \\
86.6 \\
85.7 \\
84.5 \\
77.6 \\
62.6 \\
46.5\end{array}$ & $\begin{array}{l}18 \\
19 \\
20 \\
21 \\
22 \\
23 \\
24 \\
25 \\
26\end{array}$ & $\begin{array}{r}63.0 \\
75.0 \\
90.0 \\
110.0 \\
130.0 \\
150.0 \\
190.0 \\
220.0 \\
270.0\end{array}$ & $\begin{array}{r}203 \\
96 \\
70 \\
36 \\
14 \\
27 \\
21 \\
30 \\
22\end{array}$ & $\begin{array}{l}658 \\
455 \\
359 \\
289 \\
253 \\
239 \\
212 \\
191 \\
161\end{array}$ & $\begin{array}{r}30.0 \\
20.8 \\
16.4 \\
13.2 \\
11.5 \\
10.9 \\
9.7 \\
8.7\end{array}$ & $\begin{array}{l}27 \\
28 \\
29 \\
30 \\
31 \\
32 \\
33 \\
34\end{array}$ & $\begin{array}{r}320.0 \\
380.0 \\
460.0 \\
550.0 \\
660.0 \\
790.0 \\
940.0 \\
1100.0\end{array}$ & $\begin{array}{r}23 \\
39 \\
20 \\
14 \\
22 \\
12 \\
7 \\
2\end{array}$ & $\begin{array}{r}139 \\
116 \\
77 \\
57 \\
43 \\
21 \\
9 \\
2\end{array}$ & $\begin{array}{l}6.3 \\
5.3 \\
3.5 \\
2.6 \\
2.0 \\
1.0 \\
0.4 \\
0.1\end{array}$ \\
\hline
\end{tabular}

MONIHLY MEAN DISCHARGES, IN CUBIC FEET PER SECOND, FOR EACH WATER YEAR

\begin{tabular}{|c|c|c|c|c|c|c|c|c|c|c|c|c|}
\hline YEAR & OCT & NOV & $\mathrm{DEC}$ & JAN & FEB & MAR & APR & MAY & JUNE & JULY & AUG & SEP \\
\hline 1944 & 30.2 & 67.7 & 62.6 & 51.5 & 46.9 & 47.3 & 57.0 & 266 & 694 & 333 & 48.5 & 51.2 \\
\hline $\begin{array}{l}1977 \\
1978 \\
1979 \\
1980\end{array}$ & $\begin{array}{l}66.8 \\
63.9 \\
62.5 \\
62.6\end{array}$ & $\begin{array}{l}47.2 \\
51.4 \\
58.8 \\
57.3\end{array}$ & $\begin{array}{l}40.4 \\
48.2 \\
45.3 \\
50.0\end{array}$ & $\begin{array}{l}36.9 \\
37.2 \\
32.5 \\
43.9\end{array}$ & $\begin{array}{l}30.0 \\
41.6 \\
37.5 \\
43.1\end{array}$ & $\begin{array}{l}34.3 \\
39.9 \\
42.5 \\
43.8\end{array}$ & $\begin{array}{l}43.5 \\
42.0 \\
50.7 \\
59.6\end{array}$ & $\begin{array}{l}26.7 \\
50.7 \\
168 \\
132\end{array}$ & $\begin{array}{l}140 \\
378 \\
280 \\
622\end{array}$ & $\begin{array}{c}80.5 \\
70.1 \\
36.2 \\
156\end{array}$ & $\begin{array}{c}95.4 \\
6.71 \\
47.4 \\
10.6\end{array}$ & $\begin{array}{l}71.4 \\
22.1 \\
61.1 \\
21.7\end{array}$ \\
\hline 1981 & 45.2 & 57.1 & 54.4 & 49.8 & 43.8 & 18.0 & 27.4 & 93.3 & 275 & 29.0 & 74.4 & 87.8 \\
\hline
\end{tabular}

ANNUAL PEAK DISCHARGE, IN CIBIC FEET PER SECOND, AND CORRESPONDING GAGE HEIGHT, IN FEET, FOR EACH WATER YEAR

\begin{tabular}{|c|c|c|c|c|c|c|c|c|c|c|c|}
\hline $\begin{array}{l}\text { WATERR } \\
\text { YEAR }\end{array}$ & DATE & $\begin{array}{c}\text { GAGE } \\
\text { HEIGHT }\end{array}$ & $\begin{array}{c}\text { PEAK } \\
\text { DISCHARGE }\end{array}$ & $\begin{array}{l}\text { WATER } \\
\text { YEAR }\end{array}$ & DATE & $\begin{array}{c}\text { GAGE } \\
\text { HEIGHT }\end{array}$ & $\begin{array}{c}\text { PEAK } \\
\text { DISCHARGE }\end{array}$ & $\begin{array}{l}\text { WATER } \\
\text { YEAR }\end{array}$ & DATE & $\begin{array}{c}\text { GAGE } \\
\text { HEIGHT }\end{array}$ & $\begin{array}{c}\text { PEAK } \\
\text { DISCHARGE }\end{array}$ \\
\hline $\begin{array}{l}1943 \\
1944 \\
1977\end{array}$ & $\begin{array}{lll}\text { MAY } & 29,1943 \\
\text { JUNE } & 26,1944 \\
\text { JUNE } & 04, & 1977\end{array}$ & $\begin{array}{l}2.40 \\
3.92 \\
3.36\end{array}$ & $\begin{array}{r}660 \\
2130 \\
788\end{array}$ & $\begin{array}{l}1978 \\
1979\end{array}$ & $\begin{array}{lll}\text { JUNE } & 14, & 1978 \\
\text { MAY } & 29, & 1979\end{array}$ & $\begin{array}{l}3.34 \\
3.21\end{array}$ & $\begin{array}{l}844 \\
828\end{array}$ & $\begin{array}{l}1980 \\
1981\end{array}$ & $\begin{array}{l}\text { JUNE 11, } 1980 \\
\text { JUNE 09, } 1981\end{array}$ & $\begin{array}{l}3.81 \\
3.31\end{array}$ & $\begin{array}{r}1560 \\
989\end{array}$ \\
\hline
\end{tabular}


GREEN RIVER BASIN

09293500 IAKE FORK RIVER NEAR ALTONAH, UT

LOCATION.--Lat $40^{\circ} 26^{\prime} 13^{\prime \prime}$, long $110^{\circ} 21^{\prime} 49^{\prime \prime}$, in SE ${ }_{4}^{1} \mathrm{NE}_{4}^{\prime} \mathrm{SW}^{\frac{1}{4}}$ sec.32, T.1 N., R.4 W., Uintah Meridian, Duchesne County, Hydrologic Unit 14060003, Uintah and Ouray Indian Reservation, on right bank $0.1 \mathrm{mi}$ downstream fran U.S. Lake Fork Canal, $0.5 \mathrm{mi}$ downstream 14060003 , Uintah and Ouray Indian Reservation, on right

DRAINAGE AREA. $--304 \mathrm{mi}^{2}$.

PERIOD OF RECORD AVAIIABLE.--May 1907 to November 1910 and June 1917 to september 1920 (monthly mean discharge for same periods, published in WSP 1313), October 1976 to September 1981. published as "below forks, near Whiterocks", 1907-10, and "below forks, near Altonah", 1917.

GAGE.--Water-stage recorder. Altitude of gage is 6,855 ft fram topographic map. Prior to october 16, 1917, chain gage or staff gage at several sites within $0.4 \mathrm{mi}$ of present site at various datums. May 10, 1907 to November 30, 1910, chain gages 500 $\mathrm{ft}$ upstream at an unknown datum prior to August 31, 1907, and at a different datum after that. June 4 to September 18, 1917, staff gage $0.4 \mathrm{mi}$ upstream and above heading of U.S. Lake Fork Canal at different datum.

REMARRS.--Several diversions above gage for irrigation. Flow affected by storage in Moon Lake Reservoir, usable capacity, 35,760 acre-ft, since December 9, 1937. Prior to October 1920, records show combined flow of Lake Fork River and of Farnsworth, Payne, and U.S. Lake Fork Canals for those periods during which the station was located below the heading of any of these canals.

AVERAGE DISCHARGE.--8 years (water years 1909, 1918-19, 1977-81), $198 \mathrm{ft}^{3} / \mathrm{s}, 143,450 \mathrm{acre}-\mathrm{ft} / \mathrm{yr}$

EXIREMES FOR PERIOD OF RECORD.-Maximum discharge observed, 9,300 $\mathrm{ft}^{3} / \mathrm{s}$ July 4, 1907, gage height, $5.25 \mathrm{ft}$, site and datum then in use, from rating curve extended above $2,900 \mathrm{ft}^{3} / \mathrm{s}$; minimum probably less than $1 \mathrm{ft} / \mathrm{s}$ October 12-20, 1920. Maximum discharge $1976-81,2,870 \mathrm{ft}^{3} / \mathrm{s}$ June 21,1980 , gage height, $5.01 \mathrm{ft}$.

LOWEST MEAN DISCHARGE, IN CUBIC FEET PER SECOND, AND RANRING FOR THE INDICAIED NUMBER OF CONSECITIVE DAYS FOR EACH CLIMATIC YEAR, APRII 1-MARCH 31

\begin{tabular}{|c|c|c|c|c|c|c|c|c|c|c|c|c|c|c|c|c|c|c|}
\hline YEAR & & 3 & & 7 & & 14 & & $\begin{array}{l}\text { CONSE } \\
30\end{array}$ & arI & $\begin{array}{l}\text { E DAYS } \\
60\end{array}$ & & 90 & & 120 & & 183 & & ALL \\
\hline $\begin{array}{l}1.80 \\
4.10 \\
7.90\end{array}$ & $\begin{array}{l}1 \\
2 \\
3\end{array}$ & $\begin{array}{r}1.80 \\
4.50 \\
12.0\end{array}$ & $\begin{array}{l}1 \\
2 \\
4\end{array}$ & $\begin{array}{c}2.20 \\
8.90 \\
19.0\end{array}$ & $\begin{array}{l}1 \\
2 \\
4\end{array}$ & $\begin{array}{l}3.50 \\
19.0 \\
34.0\end{array}$ & $\begin{array}{l}1 \\
3 \\
4\end{array}$ & $\begin{array}{l}6.80 \\
36.0 \\
42.0\end{array}$ & $\begin{array}{l}1 \\
3 \\
4\end{array}$ & $\begin{array}{l}33.0 \\
48.0 \\
50.0\end{array}$ & $\begin{array}{l}2 \\
3 \\
4\end{array}$ & $\begin{array}{l}50.0 \\
48.0 \\
53.0\end{array}$ & $\begin{array}{l}3 \\
2 \\
4\end{array}$ & $\begin{array}{l}50.0 \\
49.0 \\
54.0\end{array}$ & & $\begin{array}{l}52.0 \\
55.0 \\
54.0\end{array}$ & $\begin{array}{l}1 \\
4 \\
2\end{array}$ & $\begin{array}{l}69.0 \\
135 \\
104\end{array}$ \\
\hline 11.0 & 4 & 11.0 & 3 & 12.0 & 3 & 12.0 & 2 & 23.0 & 2 & 32.0 & 1 & 38.0 & 1 & 46.0 & 1 & 54.0 & 3 & 161 \\
\hline
\end{tabular}

HIGHEST MEAN DISCHARGE, IN CUBIC FEET PER SECOND, AND RANKING FOR THE INDICATED NUMBER OF CONSEOUTIVE DAYS FOR EACH WATER YEAR, OTTOBER 1-SEPTTMBER 30

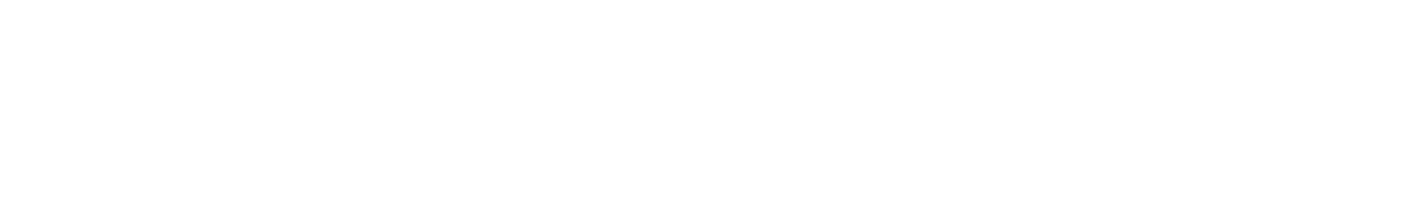

DURATION OF DISCHARGE FOR EAGH WATER YEAR

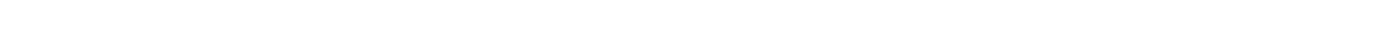
YEAR NUMBER OF DAYS IN CIASS OUBIC FEET PER SECON

1977

5

$\begin{array}{lllllllll}2 & 8 & 6 & 4 & 2 & 4 & & 4 & 1 \\ 1 & 3 & & & & 1 & 1 & & 1 \\ & & & 1 & & 1 & 1 & 2 & 1 \\ & & & & & & & & 1\end{array}$

$\begin{array}{lllllllllllll}2 & 6 & 81 & 81 & 38 & 29 & 25 & 30 & 15 & 12 & 3 & 1 & 5\end{array}$

24539.8

1978

1980

925

$\begin{array}{llllllllllllllllll}1 & 6 & 7 & 30 & 56 & 33 & 62 & 4 & 13 & 38 & 27 & 22 & 17 & 7 & 4 & 1 & 1 & 2\end{array}$

38178.9

38178.9

1981

DURATION TABLE OF DISCAARGE FOR WATER YEARS 1977-81

$\begin{array}{lll}\text { OABIC } & \text { ACOU- } \\ \text { FEET } & \text { MU- } & \text { PER- } \\ \text { PER TOTAL LATED } & \text { CENT }\end{array}$

CIASS SECOND DAYS DAYS DAYS

$\begin{array}{llll}0.00 & 0 & 1826 & 100.0\end{array}$

$\begin{array}{llll}1.80 & 5 & 1826 & 100.0\end{array}$

$2.20 \quad 1 \quad 1821 \quad 99.7$

$2.80 \quad 0 \quad 1820 \quad 99.7$

$\begin{array}{llll}3.40 & 3 & 1820 & 99.7\end{array}$

$4.20 \quad 11 \quad 1817 \quad 99$.

$5.20 \quad 6 \quad 1806 \quad 98.9$

$\begin{array}{llll}6.50 & 5 & 1800 & 98.6\end{array}$

$\begin{array}{llll}8.00 & 2 & 1795 & 98.3\end{array}$ $\begin{array}{lll}\text { OBBIC } & \text { ACOU- } \\ \text { FEET MET- } & \\ \text { PER TOTAL } & \text { MATED } & \text { CENT }\end{array}$

C.ASS SECOND DAYS DAYS DAYS

$\begin{array}{rrrrr}9 & 10.00 & 15 & 1793 & 98.2 \\ 10 & 12.00 & 27 & 1778 & 97.4 \\ 11 & 15.00 & 6 & 1751 & 95.9 \\ 12 & 19.00 & 5 & 1745 & 95.6 \\ 13 & 23.00 & 31 & 1740 & 95.3 \\ 14 & 29.00 & 49 & 1709 & 93.6 \\ 15 & 36.00 & 177 & 1660 & 90.9 \\ 16 & 45.00 & 447 & 1483 & 81.2\end{array}$

CUBIC ACQU

FEET MU- PER-

CLASS SECOND DAYS DAYS DAYS

$\begin{array}{rrrrr}18 & 68.0 & 128 & 756 & 41.4 \\ 19 & 85.0 & 54 & 628 & 34.4 \\ 20 & 100.0 & 77 & 574 & 31.4 \\ 21 & 130.0 & 95 & 497 & 27.2 \\ 22 & 160.0 & 124 & 402 & 22.0 \\ 23 & 200.0 & 95 & 278 & 15.2 \\ 24 & 250.0 & 69 & 183 & 10.0 \\ 25 & 300.0 & 56 & 114 & 6.2 \\ 26 & 380.0 & 16 & 58 & 3.2\end{array}$

CUBIC ACOI-

FEET MU- PER-

GASS SECOND DAYS DAYS DAYS

$\begin{array}{rrrrr}27 & 470.0 & 8 & 42 & 2.3 \\ 28 & 580.0 & 14 & 34 & 1.9 \\ 29 & 720.0 & 9 & 20 & 1.1 \\ 30 & 890.0 & 2 & 11 & 0.6 \\ 31 & 1100.0 & 5 & 9 & 0.5 \\ 32 & 1400.0 & 1 & 4 & 0.2 \\ 33 & 1700.0 & 2 & 3 & 0.2 \\ 34 & 2100.0 & 1 & 1 & 0.1\end{array}$


GREFN RTVER BASIN

09293500 LAAKE FORR RIVER NEAR RTTANA, UT-Continued

MONTHLY NEAN DISGAARGES, IN OBIC FEET PER SECOND, FOR EACB WATER YEAR

$\begin{array}{lcccccccccccc}\text { YEAR } & \text { OCT } & \text { NOV } & \text { DEC } & \text { JAN } & \text { FEB } & \text { MAR } & \text { ARR } & \text { MAY } & \text { JUNE } & \text { JULY } & \text { AUG } & \text { SEP } \\ 1909 & 377 & 280 & 251 & 182 & 165 & 168 & 212 & 393 & 2350 & 1030 & 634 & 668 \\ 1918 & 143 & 147 & 146 & 110 & 90.0 & 95.0 & 95.0 & 349 & 1050 & 336 & 209 & 174 \\ 1919 & 155 & 108 & 87.2 & 76.3 & 60.0 & 58.8 & 115 & 78 & 498 & 216 & 171 & 131 \\ 1977 & 69.9 & 55.0 & 47.0 & 43.5 & 38.5 & 41.6 & 9.50 & 56.6 & 166 & 113 & 98.4 & 66.0 \\ 1978 & 48.3 & 58.0 & 47.3 & 50.0 & 58.2 & 55.5 & 39.8 & 154 & 429 & 295 & 255 & 102 \\ 1979 & 70.1 & 06.5 & 50.7 & 48.7 & 48.0 & 49.5 & 43.4 & 201 & 247 & 225 & 135 & 64.4 \\ 1980 & 51.0 & 57.8 & 56.8 & 56.5 & 52.4 & 52.5 & 51.3 & 135 & 859 & 295 & 178 & 97.9 \\ 1981 & 58.5 & 80.2 & 69.5 & 49.6 & 41.4 & 23.8 & 28.4 & 180 & 285 & 201 & 212 & 85.0\end{array}$

ANNUAL PEAK DISGARGE, IN OBIC FEET PER SECOND, AND CORRESPONDIMG GAGE HEIGTT, IN FEET, FOR EAOH WATER YEAR

$\begin{array}{lcccccccccc}\begin{array}{l}\text { WATER } \\ \text { YEAR }\end{array} & \text { DATE } & \begin{array}{c}\text { GAGE } \\ \text { HEIGHT }\end{array} & \begin{array}{c}\text { PEAK } \\ \text { DLSGHARGE }\end{array} & \begin{array}{c}\text { WATER } \\ \text { YEAR }\end{array} & \text { DATE } & \begin{array}{c}\text { GAGE } \\ \text { HEIGH' }\end{array} & \begin{array}{c}\text { PEAK } \\ \text { DISCHARGE }\end{array} & \begin{array}{l}\text { WATER } \\ \text { YEAR }\end{array} & \begin{array}{c}\text { GAGE } \\ \text { DATE }\end{array} & \begin{array}{c}\text { PEAK } \\ \text { HEIGHT }\end{array} \\ \text { DISGHARGE }\end{array}$

09293600 LAKE FORK RIVER NEAR ALTAMONT, UT

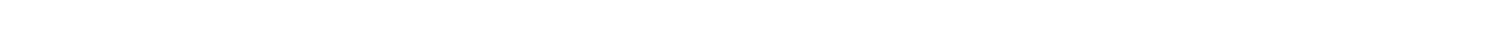
$14060003,1.7 \mathrm{mi}$ west of Al tamont.

DRAINAGE AREA. $--318 \mathrm{mi}^{2}$.

PERIOD OF RECORD.--Septenber 1976 to September 1981.

REVISED RECORDS. --WDR UT-80-1 : 1978 [M] .

GAGE.-Water-stage recorder. Altitude of gage is 6,270 ft from topographic map.

REMARKS.--Many diversions for irrigation above station.

AVERAGE DISGHARGE. --5 years, $31.3 \mathrm{ft}^{3} / \mathrm{s}, 22,680$ acre-ft/yr.

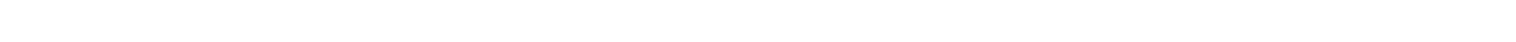
Dec. 11-19, 1976, Dec. 12, 1979.

LOWEST MEAN DISCHARGE, IN OUBIC FEET PER SECOND, AND RANKING FOR THE INDICATED NUMBER OF OONSECUTIVE DAUS FOR EACH OIMATIC YEAR, APRIL 1-MARQ 31

\begin{tabular}{|c|c|c|c|c|c|c|c|c|c|c|c|c|c|c|c|c|c|c|c|}
\hline YEAR & 1 & & 3 & & 7 & & 14 & & $\begin{array}{l}\text { CONSE } \\
30\end{array}$ & WTTV & $\begin{array}{l}\text { DAuS } \\
60\end{array}$ & & 90 & & 120 & & 183 & & ALL \\
\hline $\begin{array}{l}978 \\
979 \\
980\end{array}$ & $\begin{array}{l}2.10 \\
2.40 \\
1.00\end{array}$ & $\begin{array}{l}3 \\
4 \\
1\end{array}$ & $\begin{array}{l}2.10 \\
2.50 \\
1.90\end{array}$ & $\begin{array}{l}3 \\
4 \\
1\end{array}$ & $\begin{array}{l}2.20 \\
2.50 \\
2.20\end{array}$ & $\begin{array}{l}1 \\
4 \\
2\end{array}$ & $\begin{array}{l}2.40 \\
3.10 \\
2.30\end{array}$ & $\begin{array}{l}2 \\
4 \\
1\end{array}$ & $\begin{array}{l}2.60 \\
3.50 \\
2.40\end{array}$ & $\begin{array}{l}2 \\
3 \\
1\end{array}$ & $\begin{array}{l}2.80 \\
4.80 \\
5.20\end{array}$ & $\begin{array}{l}1 \\
2 \\
3\end{array}$ & $\begin{array}{l}5.10 \\
7.10 \\
8.90\end{array}$ & $\begin{array}{l}1 \\
3 \\
4\end{array}$ & $\begin{array}{l}7.30 \\
11.0 \\
11.0\end{array}$ & $\begin{array}{l}1 \\
3 \\
4\end{array}$ & $\begin{array}{l}13.0 \\
20.0 \\
19.0\end{array}$ & $\begin{array}{l}1 \\
3 \\
2\end{array}$ & $\begin{array}{l}21.0 \\
33.0 \\
29.0\end{array}$ \\
\hline & 1.60 & 2 & 1.90 & 2 & 2.40 & 3 & 2.90 & 3 & 3.50 & 4 & 5.50 & 4 & 6.70 & 2 & 10.0 & 2 & 23.0 & 4 & 53.0 \\
\hline
\end{tabular}

HIGHEST MEAN DISCHARGE, IN OUBIC FEET PER SECOND, AND RANKING FOR THE INDICATED NUMBER OF OONSECTTIVE DAYS FOR EACH WATER YEAR, OCTCBER I-SEPTEMBER 30

\begin{tabular}{|c|c|c|c|c|c|c|c|c|c|c|c|c|c|c|c|c|c|c|c|}
\hline YEAR & 1 & & 3 & & 7 & & 15 & & $\begin{array}{l}\text { Cons } \\
30\end{array}$ & & $\begin{array}{c}\text { VE DAYS } \\
60\end{array}$ & & 90 & & 120 & & 183 & & ALL \\
\hline $\begin{array}{l}1977 \\
1978 \\
1979 \\
1980\end{array}$ & $\begin{array}{c}59.0 \\
270 \\
320 \\
1280\end{array}$ & $\begin{array}{l}5 \\
3 \\
2 \\
2\end{array}$ & $\begin{array}{c}45.0 \\
223 \\
239 \\
1230\end{array}$ & $\begin{array}{l}5 \\
3 \\
2 \\
1\end{array}$ & $\begin{array}{l}40.0 \\
197 \\
137 \\
920\end{array}$ & $\begin{array}{l}5 \\
2 \\
3 \\
1\end{array}$ & $\begin{array}{c}40.0 \\
123 \\
88.0 \\
614\end{array}$ & $\begin{array}{l}5 \\
2 \\
3 \\
2\end{array}$ & $\begin{array}{l}40.0 \\
87.0 \\
66.0 \\
393\end{array}$ & $\begin{array}{l}5 \\
2 \\
4 \\
1\end{array}$ & $\begin{array}{r}29.0 \\
61.0 \\
54.0 \\
212\end{array}$ & $\begin{array}{l}5 \\
2 \\
4 \\
1\end{array}$ & $\begin{array}{r}27.0 \\
52.0 \\
52.0 \\
150\end{array}$ & $\begin{array}{l}5 \\
2 \\
3 \\
1\end{array}$ & $\begin{array}{r}24.0 \\
44.0 \\
52.0 \\
116\end{array}$ & $\begin{array}{l}5 \\
3 \\
2 \\
1\end{array}$ & $\begin{array}{l}19.0 \\
39.0 \\
47.0 \\
87.0\end{array}$ & $\begin{array}{l}5 \\
3 \\
2 \\
1\end{array}$ & $\begin{array}{l}16.0 \\
28.0 \\
34.0 \\
51.0\end{array}$ \\
\hline 1981 & 234 & 4 & 202 & 4 & 122 & 4 & 81.0 & 4 & 68.0 & 3 & 60.0 & 3 & 47.0 & 4 & 38.0 & 4 & 35.0 & 4 & 27.0 \\
\hline
\end{tabular}


GREEN RIVER BASTN

09293600 LAKE FORK RTVER NEAR ALTAMONT, UT-Continued

DURATION OF DISOHARGE FOR EACH WATER YEAR

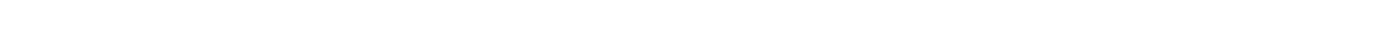
YEAR

NUMBR OF DAYS IN OAASS

OBBIC FEET PER SECOND

-DAYS

5950.5

10209.3

10209.3

12494.7
18675.5

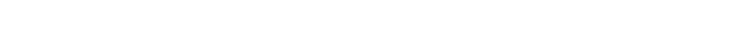

$\begin{array}{lllllll}2 & 2 & 2 & 2 & 1 & 1 & 3\end{array}$

9897.8

DURATTON TABLE OF DISCHARGE FOR WATER YEARS 1977-81

\begin{tabular}{|c|c|c|c|c|c|c|c|c|c|c|c|c|c|c|c|c|c|c|c|}
\hline C.ASS & $\begin{array}{c}\text { OBIC } \\
\text { FEET } \\
\text { PER } \\
\text { SEOOND }\end{array}$ & $\begin{array}{l}\text { TOTAL } \\
\text { DAYS }\end{array}$ & $\begin{array}{l}\text { ACOU- } \\
\text { MU- } \\
\text { LATED } \\
\text { DAVS }\end{array}$ & $\begin{array}{l}\text { PER- } \\
\text { CENT } \\
\text { DAYS }\end{array}$ & CLASS & $\begin{array}{c}\text { GBIC } \\
\text { FEET } \\
\text { PER } \\
\text { SEOOND }\end{array}$ & $\begin{array}{l}\text { TOTAL } \\
\text { DALS }\end{array}$ & $\begin{array}{l}\text { ACOU- } \\
\text { MU- } \\
\text { LAIED } \\
\text { DAUS }\end{array}$ & $\begin{array}{l}\text { PER- } \\
\text { CANT } \\
\text { DAYS }\end{array}$ & C.ASS & $\begin{array}{c}\text { GBIC } \\
\text { FEET } \\
\text { PER } \\
\text { SEOOND }\end{array}$ & $\begin{array}{l}\text { TOTAL } \\
\text { DAYS }\end{array}$ & $\begin{array}{l}\text { ACOU- } \\
\text { MU- } \\
\text { LATED } \\
\text { DAYS }\end{array}$ & $\begin{array}{l}\text { PER- } \\
\text { CDNT } \\
\text { DAYS }\end{array}$ & CASS & $\begin{array}{c}\text { वBIC } \\
\text { FEET } \\
\text { PER } \\
\text { SECOND }\end{array}$ & $\begin{array}{l}\text { TOTAL } \\
\text { DALS }\end{array}$ & $\begin{array}{c}\text { ACOU- } \\
\text { MU- } \\
\text { LATYED } \\
\text { DAYS }\end{array}$ & $\begin{array}{l}\text { PER- } \\
\text { CENT } \\
\text { DAYS }\end{array}$ \\
\hline $\begin{array}{l}0 \\
1 \\
2 \\
3 \\
4 \\
5 \\
6 \\
7 \\
8\end{array}$ & $\begin{array}{l}0.00 \\
1.00 \\
1.20 \\
1.50 \\
1.90 \\
2.40 \\
3.00 \\
3.70 \\
4.50\end{array}$ & $\begin{array}{r}0 \\
10 \\
15 \\
4 \\
55 \\
76 \\
78 \\
71 \\
81\end{array}$ & $\begin{array}{l}1826 \\
1826 \\
1816 \\
1801 \\
1797 \\
1742 \\
1666 \\
1588 \\
1517\end{array}$ & $\begin{array}{r}100.0 \\
100.0 \\
99.5 \\
98.6 \\
98.4 \\
95.4 \\
91.2 \\
87.0 \\
83.1\end{array}$ & $\begin{array}{l}99 \\
10 \\
11 \\
12 \\
13 \\
14 \\
15 \\
16 \\
17\end{array}$ & $\begin{array}{r}5.60 \\
7.00 \\
8.70 \\
11.00 \\
13.00 \\
17.00 \\
21.00 \\
26.00 \\
32.00\end{array}$ & $\begin{array}{r}63 \\
68 \\
51 \\
100 \\
137 \\
103 \\
109 \\
124 \\
165\end{array}$ & $\begin{array}{r}1436 \\
1373 \\
1305 \\
1254 \\
1154 \\
1017 \\
914 \\
805 \\
681\end{array}$ & $\begin{array}{l}78.6 \\
75.2 \\
71.5 \\
68.7 \\
63.2 \\
55.7 \\
50.1 \\
44.1 \\
37.3\end{array}$ & $\begin{array}{l}18 \\
19 \\
20 \\
21 \\
22 \\
23 \\
24 \\
25 \\
26\end{array}$ & $\begin{array}{r}39.0 \\
49.0 \\
61.0 \\
75.0 \\
93.0 \\
120.0 \\
140.0 \\
180.0 \\
220.0\end{array}$ & $\begin{array}{r}295 \\
150 \\
18 \\
9 \\
8 \\
3 \\
8 \\
4 \\
6\end{array}$ & $\begin{array}{r}516 \\
221 \\
71 \\
53 \\
44 \\
36 \\
33 \\
25 \\
21\end{array}$ & $\begin{array}{r}28.3 \\
12.1 \\
3.9 \\
2.9 \\
2.4 \\
2.0 \\
1.8 \\
1.4 \\
1.2\end{array}$ & $\begin{array}{l}27 \\
28 \\
29 \\
30 \\
31 \\
32 \\
33 \\
34\end{array}$ & $\begin{array}{r}280.0 \\
340.0 \\
420.0 \\
530.0 \\
650.0 \\
810.0 \\
1000.0 \\
1300.0\end{array}$ & $\begin{array}{l}2 \\
3 \\
1 \\
2 \\
3 \\
1 \\
3 \\
0\end{array}$ & $\begin{array}{r}15 \\
13 \\
10 \\
9 \\
7 \\
4 \\
3 \\
0\end{array}$ & $\begin{array}{l}0.8 \\
0.7 \\
0.5 \\
0.5 \\
0.4 \\
0.2 \\
0.2 \\
0.0\end{array}$ \\
\hline
\end{tabular}

MONIHLY MEAN DISCHARGES, IN OBBIC FEET PER SECOND, FOR EAOH WATER YEAR

\begin{tabular}{|c|c|c|c|c|c|c|c|c|c|c|c|c|}
\hline YEAR & $\infty C T$ & NOV & $\mathrm{DEC}$ & JAN & FEB & MAR & APR & MAY & JUNE & JULY & AUG & SEP \\
\hline $\begin{array}{l}1977 \\
1978 \\
1979 \\
1980\end{array}$ & $\begin{array}{c}11.0 \\
7.05 \\
7.50 \\
7.50\end{array}$ & $\begin{array}{l}2.04 \\
2.91 \\
3.73 \\
4.18\end{array}$ & $\begin{array}{l}15.3 \\
17.6 \\
36.0 \\
16.4\end{array}$ & $\begin{array}{l}35.5 \\
45.0 \\
53.4 \\
43.5\end{array}$ & $\begin{array}{l}10.5 \\
45.0 \\
51.3 \\
45.7\end{array}$ & $\begin{array}{l}4.92 \\
21.0 \\
47.5 \\
22.9\end{array}$ & $\begin{array}{c}7.05 \\
9.24 \\
36.7 \\
5.92\end{array}$ & $\begin{array}{l}18.6 \\
27.6 \\
44.0 \\
15.4\end{array}$ & $\begin{array}{r}33.2 \\
83.2 \\
44.0 \\
375\end{array}$ & $\begin{array}{l}25.1 \\
35.1 \\
39.4 \\
48.5\end{array}$ & $\begin{array}{l}18.9 \\
28.2 \\
31.4 \\
23.3\end{array}$ & $\begin{array}{c}12.7 \\
15.4 \\
16.5 \\
9.68\end{array}$ \\
\hline 1981 & 8.70 & 4.91 & 53.6 & 53.1 & 32.1 & 4.24 & 8.30 & 30.9 & 53.3 & 35.8 & 29.5 & 10.5 \\
\hline
\end{tabular}

ANNUAL PEAK DISCHARGE, IN GUIC FEET PER SECOND, AND CORRESPONDING GAGE HETGHT, IN FEET, FOR EACH WATER YEAR

\begin{tabular}{|c|c|c|c|c|c|c|c|c|c|c|c|}
\hline $\begin{array}{l}\text { WATER } \\
\text { YEAR }\end{array}$ & DATE & $\begin{array}{c}\text { GAGE } \\
\text { HEIGHT }\end{array}$ & $\begin{array}{c}\text { PEAK } \\
\text { DISCHARGE }\end{array}$ & $\begin{array}{l}\text { WATER } \\
\text { YEAR }\end{array}$ & DATE & $\begin{array}{c}\text { GAGE } \\
\text { HEIGHT }\end{array}$ & $\begin{array}{c}\text { PEAR } \\
\text { DISCGARGE }\end{array}$ & $\begin{array}{l}\text { WATERR } \\
\text { YEAR }\end{array}$ & DATE & $\begin{array}{c}\text { GAGE } \\
\text { HEIGHT }\end{array}$ & $\begin{array}{c}\text { PEAK } \\
\text { DISQHARGE }\end{array}$ \\
\hline $\begin{array}{l}1977 \\
1978\end{array}$ & $\begin{array}{l}\text { JUNE 03, } 1977 \\
\text { JUNE } 10,1978\end{array}$ & $\overline{4.83}$ & $\begin{array}{l}311 \\
534\end{array}$ & $\begin{array}{l}1979 \\
1980\end{array}$ & $\begin{array}{ll}\text { MAY } & 29,1979 \\
\text { JUNE } & 20-22,1980\end{array}$ & $\begin{array}{l}4.75 \\
5.96\end{array}$ & $\begin{array}{r}412 \\
1580\end{array}$ & 1981 & JUNE 09,1981 & 4.81 & 567 \\
\hline
\end{tabular}

09293700 PIGEON WATER CREEK NEAR ALTAMONT, UT

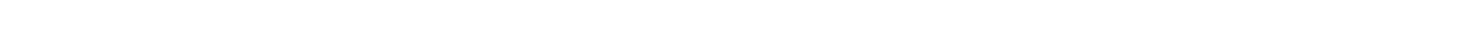
14060003 , on right bank $0.9 \mathrm{mi}$ upstream from mouth and $3.4 \mathrm{mi}$ south of Altamont.

DRAINAGE AREA. $-95.5 \mathrm{mi}^{2}$.

PERIOD OF RECORD AVAIIABLE.--Septenber 1976 to September 1979.

GAGE.-Water-stage recorder. Altitude of gage is 5,970 ft from topographic map.

REMARRS.--Many diversions for irrigation above station.

EXTREMES FOR PERICD OF RECORD.-Maximum discharge, $31 \mathrm{ft}^{3} / \mathrm{s} \mathrm{Apr.} \mathrm{7,} \mathrm{1979,} \mathrm{gage} \mathrm{height,} 2.03 \mathrm{ft}$; minimum $0.09 \mathrm{ft} / \mathrm{s}$ June 3-5, 1977 .

LOWEST MEAN DISCHARGE, IN OIBIC FEET PER SECOND, AND RANKING FOR THE INDICATED NUMBER OF CONSEOUTIVE DAYS FOR EACH CLIMATIC YEAR, APRI 1-MAROH 31

YEAR

$\begin{array}{lllll}\text { CONSECUTIVE DAYS } & & & & \\ 30 & 60 & 90 & 120 & 183\end{array}$

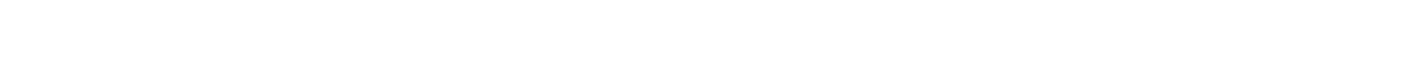


09293700 PIGEON WATER CREEK NEAR ALTAMONT, UT-Continued

HIGHEST MEAN DISCHARGE, IN GUBIC FEET PER SECOND, AND RANKING FOR THE INDICATED NUMBER OF CONSECUTIVE DAYS FOR EAOH WATER YEAR, $O C T C B E R$ 1-SEPTEMBER 30

\begin{tabular}{|c|c|c|c|c|c|c|c|c|c|c|c|c|c|c|c|c|c|c|c|}
\hline \multirow[t]{2}{*}{ YEAR } & \multicolumn{19}{|c|}{ CONSEQUTIVE DAYS } \\
\hline & 1 & & 3 & & 7 & & 15 & & 30 & & 60 & & 90 & & 120 & & 183 & & ALL \\
\hline $\begin{array}{l}1977 \\
1978 \\
1979\end{array}$ & $\begin{array}{l}5.90 \\
13.0 \\
23.0\end{array}$ & $\begin{array}{l}3 \\
2 \\
1\end{array}$ & $\begin{array}{r}4.60 \\
8.90 \\
22.0\end{array}$ & $\begin{array}{l}3 \\
2 \\
1\end{array}$ & $\begin{array}{r}4.00 \\
6.70 \\
20.0\end{array}$ & $\begin{array}{l}3 \\
2 \\
1\end{array}$ & $\begin{array}{r}3.50 \\
6.40 \\
17.0\end{array}$ & $\begin{array}{l}3 \\
2 \\
1\end{array}$ & $\begin{array}{r}3.40 \\
5.20 \\
13.0\end{array}$ & $\begin{array}{l}3 \\
2 \\
1\end{array}$ & $\begin{array}{l}3.40 \\
4.80 \\
9.20\end{array}$ & $\begin{array}{l}3 \\
2 \\
1\end{array}$ & $\begin{array}{l}3.10 \\
3.80 \\
7.70\end{array}$ & $\begin{array}{l}3 \\
2 \\
1\end{array}$ & $\begin{array}{l}2.90 \\
3.50 \\
6.70\end{array}$ & $\begin{array}{l}3 \\
2 \\
1\end{array}$ & $\begin{array}{l}2.70 \\
3.20 \\
6.20\end{array}$ & $\begin{array}{l}3 \\
2 \\
1\end{array}$ & $\begin{array}{l}1.90 \\
2.40 \\
4.10\end{array}$ \\
\hline
\end{tabular}

DURATTON OF DISQHARGE FOR EAGH WATER YEAR

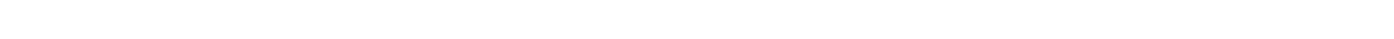
YEAR NUMBER OF DAYS IN OLASS

OUBIC FEET PER SECON -DAVS

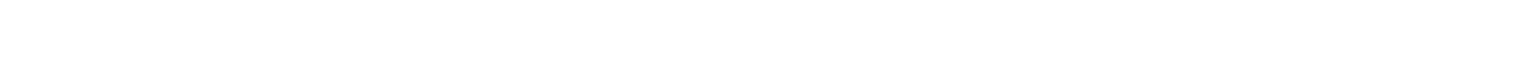

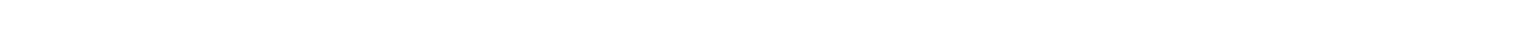

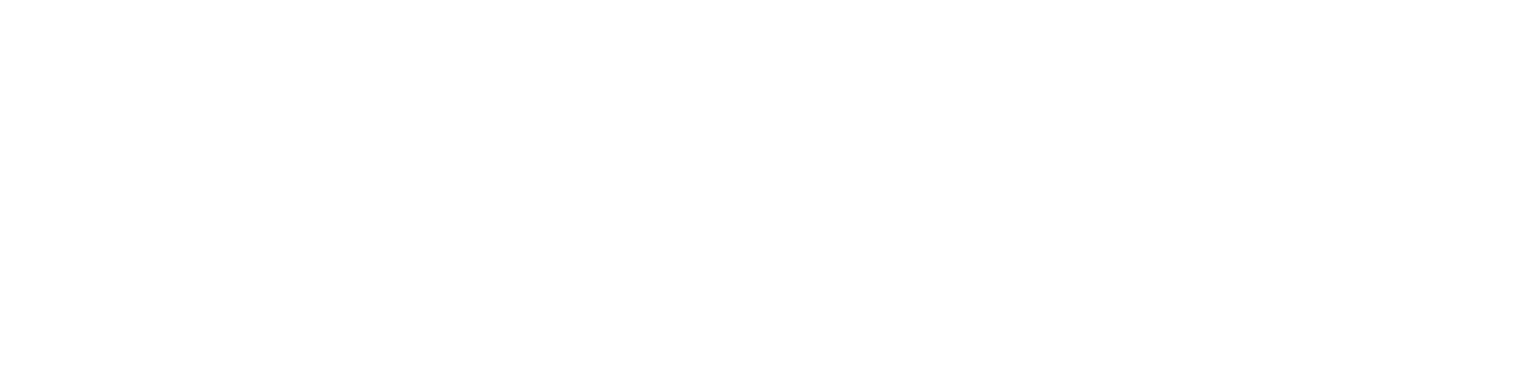

MONTHLY MEAN DISQHARGES, IN ABIC FEET PER SEOOND, FOR EACH WATER YEAR

$\begin{array}{lllllllllllll}\text { IEAR } & \text { OCT } & \text { NOV } & \text { DEC } & \text { JAN } & \text { FEB } & \text { MAR } & \text { APR } & \text { MAY } & \text { JUNE } & \text { JULY } & \text { AUG } & \text { SEP } \\ 1977 & 2.43 & 2.53 & 2.16 & 2.02 & 3.15 & 3.34 & 2.86 & 1.53 & 0.81 & 0.75 & 0.70 & 0.87 \\ 1978 & 1.04 & 0.81 & 1.70 & 1.78 & 2.25 & 3.69 & 2.45 & 1.57 & 4.72 & 4.57 & 1.97 & 1.69 \\ 1979 & 4.62 & 5.93 & 3.23 & 3.63 & 5.00 & 9.73 & 7.99 & 3.06 & 2.66 & 1.81 & 0.88 & 0.64\end{array}$

09294000 LAKE FORR RIVER NEAR UPALCO, UT

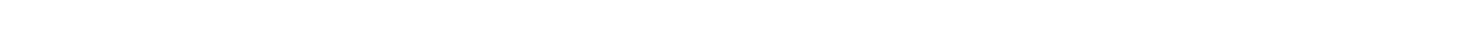
14060003 , on right bank $100 \mathrm{ft}$ upstrean from bridge on State Highway $86,1.5 \mathrm{mi}$ south of Upalco, $9 \mathrm{mi}$ northwest of Hyton, and 10 mi upstrean fram mouth.

DRAINAGE AREA $-427 \mathrm{mi}^{2}$.

PERICD OF RECORD AVALIBLE. - Octcher 1942 to September 1955, September 1976 to September 1981.

REVISED RECORDS. - WDR UT-77-1: Drainage area.

GAGE.-Water-stage recorder. Altitude of gage is 5,480 ft from topographic map. Prior to Sept. 30, 1955 , at site $0.2 \mathrm{mi}$ upstream. REMARRS.--Diversions above station diverts all water above station during summer.

AVERAGE DISQHARGE, -18 years (water years 1943-55, 1977-81), $48.0 \mathrm{ft}^{3} / \mathrm{s}, 34,780$ acre-ft/yr.

EXTREMES FOR PERIOD OF RECORD.--Maximum discharge, 4,520 ft $3 / \mathrm{s}$ June 26, 1944, gage height, $6.05 \mathrm{ft}$, site and datum then in use, from rating curve extended above $1,400 \mathrm{ft}^{3} / \mathrm{s}$; no flow for several days during each year 1955, 1977-80, 1981 .

LOWEST MEAN DISGHARGE, IN OUBIC FEET PER SECOND, AND RANKING FOR THE INDICATED NUMBER OF CONSEOUTIVE DAVS FOR EAOH CLIMATIC YE R, APRIL 1-MAROH 31

YEAR

13

1944
1

0.10
.17 5.5016
0.207 9.6016
14

0.206 9.9016

\section{CONSECI'TIVE DAYS}$$
30
$$$$
60
$$$$
0.20 \quad 5
$$

0.26
90

2.6010 $20.0 \quad 16$

$\begin{array}{lrlrcr}120 & & 183 & & \text { ALI } \\ & & & & \\ 2.80 & 9 & 11.0 & 8 & 43.0 & 11 \\ 26.0 & 16 & 40.0 & 16 & 137 & 15\end{array}$


GREEN RIVER BASIN

09294000 LAKE FORR RIVER NEAR UPALOO, UT-Continued

LONEST MEAN DISQHARGE, IN OTBIC FEET PER SECOND, AND RANKTNG FOR THE INDICATED NUMBER OP CONSEOUTVE DAYS FOR EAOH CLIMATIC YEAR, APRII 1-MAROB 31-Continued

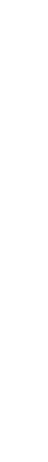

\begin{tabular}{lrlll}
1 & & \multicolumn{2}{c}{3} \\
0.60 & 14 & & 0.60 & 14 \\
0.80 & 15 & & 0.80 & 15 \\
0.50 & 13 & & 0.53 & 13 \\
0.20 & 9 & & 0.30 & 10 \\
0.10 & 5 & & 0.10 & 4 \\
0.20 & 10 & & 0.20 & 9 \\
0.40 & 11 & & 2.40 & 11 \\
0.40 & 12 & & 0.43 & 12 \\
0.10 & 6 & & 0.10 & 5 \\
0.10 & 7 & & 0.10 & 6 \\
0.00 & 1 & & 0.00 & 1 \\
0.03 & 3 & & 0.03 & 3 \\
0.00 & 2 & & 0.00 & 2 \\
0.12 & 8 & & 0.12 & 7
\end{tabular}

\begin{tabular}{|c|c|}
\hline 7 & 14 \\
\hline $\begin{array}{l}0.7013 \\
0.9315 \\
0.7914 \\
0.3310 \\
0.24 \quad 9\end{array}$ & $\begin{array}{rrr}1.19 & 15 \\
0.97 & 13 \\
1.19 & 14 \\
0.34 & 8 \\
0.36 & 10\end{array}$ \\
\hline $\begin{array}{lr}0.20 & 8 \\
0.411 & 11 \\
0.49 & 12 \\
0.10 & 4 \\
0.10 & 5\end{array}$ & $\begin{array}{rr}0.20 & -7 \\
0.49 & 11 \\
0.69 & 12 \\
0.12 & 5 \\
0.10 & 4\end{array}$ \\
\hline $\begin{array}{ll}0.00 & 1 \\
0.05 & 3 \\
0.00 & 2\end{array}$ & $\begin{array}{ll}0.00 & 1 \\
0.05 & 3 \\
0.00 & 2\end{array}$ \\
\hline
\end{tabular}

CONSEOTTIVE DAYS

YEA
1946
1947
1948
1949
1950
1951
1952
1953
1954
1955
1978
1979
1980
198

HIGAST MEAN DISCHARGE, IN OUBIC FEET PER SEOND, AND RANKING FOR THE INDICATED NUMBER OF CONSECUTTVE DAYS FOR EACH WATER YEAR, OCTCBER I-SEPTEMBER 30

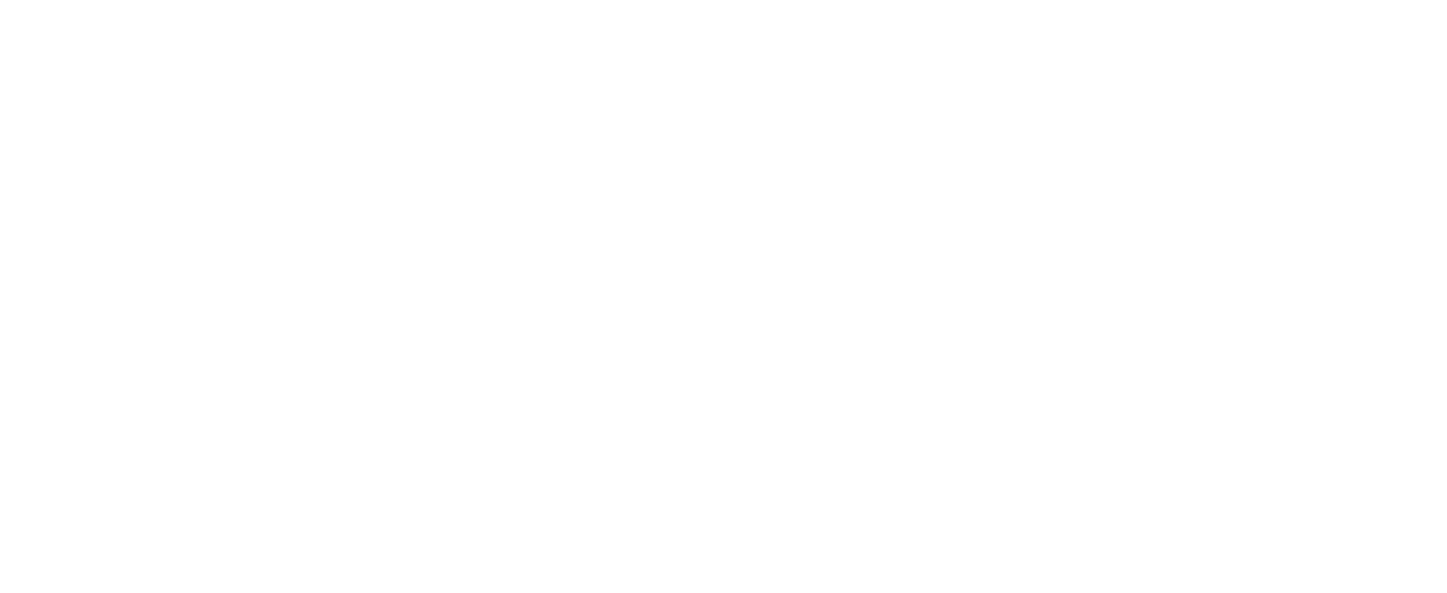

DURATION OF DISQHARGE FOR EACH WATER YEAR

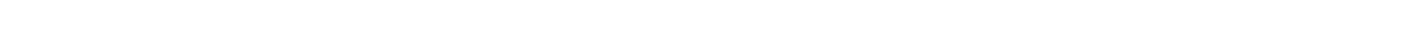
YEAR

$\begin{array}{llllllllllllllllllll}15 & 37 & 54 & 13 & 11 & 16 & 21 & 9 & 9 & 7 & 11 & 7 & 4 & 12 & 81 & 43 & 8 & 4 & 2 & 1\end{array}$

1951

$\begin{array}{rrrrrrrrrrrrrrrrrrrrrrr}11 & 3 & 4 & 12 & 6 & 10 & 4 & 7 & 8 & 13 & 6 & 8 & 12 & 21 & 6 & 10141 & 24 & 12 & 10 & 11 & 17 & 9\end{array}$

$\begin{array}{rlrrrrrrrrrrrrrrrrrr}1954 & & 30 & 31 & 74 & 33 & 10 & 10 & 7 & 14 & 14 & 29 & 10 & 21 & 8 & 12 & 5 & 7 & 45 & 75 \\ 1955 & 28 & 37 & 6 & 57 & 14 & 23 & 6 & 4 & 6 & 14 & 9 & 14 & 6 & 13 & 20 & 18 & 70 & 35 & 5\end{array}$

$\begin{array}{llllllllllllllllllllllll}1977 & 28 & 4 & 5 & 12 & 8 & 23 & 25 & 50 & 15 & 26 & 23 & 18 & 19 & 11 & 13 & 4 & 5 & 3 & 19 & 6 & 6 & 11 & 31\end{array}$

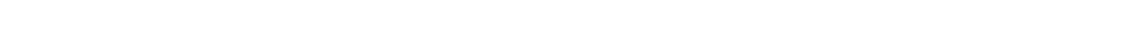

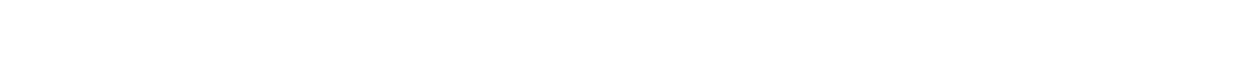

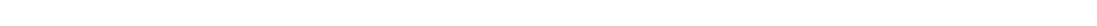


GREEN RIVER BASIN

09294000 LAKE FORK RIVER NEAR UPALCO, UT—Continued

DURATION TABLE OF DISGHARGE FOR WATER YEARS 1943-55, 1977-81

$\begin{array}{ccc}\text { CIBIC } & \text { ACO- } \\ \text { FEET } & \text { MU- } & \text { PER- } \\ \text { PER } & \text { TOTAL LAIED } & \text { CENT } \\ \text { GLASS SECOND DAYS DAYS } & \text { DAYS }\end{array}$

$0.00 \quad 88 \quad 6574 \quad 100.0$

$\begin{array}{rrrr}0.00 & 88 & 6574 & 100.0 \\ 0.01 & 7 & 6486 & 98.7\end{array}$

$\begin{array}{llll}0.02 & 28 & 6479 & 98.6\end{array}$

$\begin{array}{llll}0.03 & 85 & 6451 & 98.1\end{array}$

$\begin{array}{llll}0.05 & 47 & 6366 & 96.8\end{array}$

$\begin{array}{rrrr}0.05 & 47 & 6366 & 96.8\end{array}$

$0.10 \quad 190 \quad 6206 \quad 94.4$

$0.14 \quad 253 \quad 6016 \quad 91.5$ $\begin{array}{lll}\text { CBIC } & \text { ACOU- } \\ \text { FEET } & \text { MU- } & \text { PER- } \\ \text { PER TOTAL LLATED } & \text { CEN' }\end{array}$

CLASS SECOND DAYS DAYS DALS

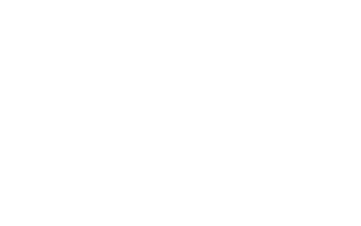

OUBIC ACOJ-

FEET MU- PER-

Q.ASS SECOND DAYS DAYS DAYS

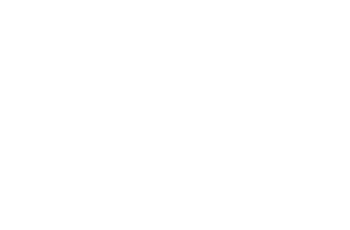

$\begin{array}{lll}\text { CUBIC } & \text { ACOU- } \\ \text { FEET } & \text { MU- } & \text { PER- } \\ \text { PER TOTAL LATED } & \text { CENT }\end{array}$ CLASS SECOND DAYS DAYS DAYS

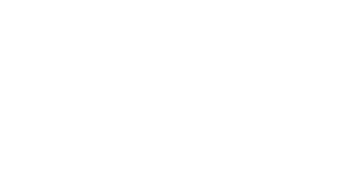

MONTHLY MEAN DISOHARGES, IN OUBIC FEET PER SECOND, FOR EAOH WATER YEAR

$\begin{array}{lcccccccccccc}\text { YEAR } & \text { NCT } & \text { NOV } & \text { DEC } & \text { JAN } & \text { FEB } & \text { MAR } & \text { APR } & \text { MAY } & \text { JUNE } & \text { JULY } & \text { AUG } & \text { SEP } \\ 1943 & 11.6 & 43.0 & 87.6 & 82.9 & 83.0 & 72.3 & 16.3 & 28.2 & 40.3 & 3.27 & 7.13 & 0.41 \\ 1944 & 0.20 & 46.8 & 97.4 & 90.0 & 90.0 & 98.6 & 95.2 & 71.5 & 778 & 320 & 36.9 & 23.9 \\ 1945 & 13.9 & 32.7 & 70.0 & 65.0 & 60.0 & 82.0 & 41.9 & 15.0 & 46.7 & 17.4 & 16.5 & 3.05 \\ 1946 & 4.12 & 37.3 & 60.0 & 58.0 & 60.8 & 50.8 & 11.8 & 8.32 & 10.7 & 1.18 & 6.06 & 2.32 \\ 1947 & 11.1 & 79.5 & 90.0 & 77.0 & 93.8 & 81.5 & 13.0 & 53.8 & 193 & 17.5 & 23.1 & 4.41 \\ 1948 & 5.22 & 48.4 & 82.5 & 75.0 & 70.0 & 92.3 & 71.0 & 11.2 & 8.59 & 0.51 & 0.62 & 0.64 \\ 1949 & 0.60 & 17.1 & 51.0 & 45.0 & 54.6 & 100 & 57.0 & 26.8 & 688 & 92.6 & 3.63 & 0.45 \\ 1950 & 13.3 & 38.7 & 61.4 & 65.0 & 76.4 & 89.8 & 25.5 & 21.7 & 245 & 9.28 & 0.74 & 1.11 \\ 1951 & 0.28 & 35.3 & 69.2 & 60.0 & 64.1 & 40.8 & 0.86 & 27.1 & 44.1 & 4.67 & 6.82 & 0.98 \\ 1952 & 10.4 & 50.2 & 80.0 & 80.0 & 80.0 & 80.1 & 113 & 381 & 889 & 122 & 31.9 & 3.51 \\ 1953 & 6.86 & 35.2 & 95.0 & 95.0 & 80.0 & 68.5 & 1.77 & 2.57 & 61.2 & 5.17 & 1.75 & 0.38 \\ 1954 & 0.45 & 23.3 & 62.6 & 58.6 & 52.1 & 13.5 & 0.85 & 4.10 & 1.35 & 0.22 & 0.28 & 1.17 \\ 1955 & 3.55 & 8.75 & 30.3 & 55.0 & 55.0 & 75.0 & 34.6 & 4.07 & 7.91 & 0.03 & 3.56 & 0.40 \\ 1977 & 2.16 & 1.64 & 15.4 & 38.5 & 14.6 & 0.60 & 0.52 & 0.88 & 1.32 & 0.10 & 0.07 & 0.00 \\ 1978 & 0.03 & 0.53 & 19.6 & 52.0 & 52.2 & 28.5 & 4.14 & 2.42 & 39.6 & 0.18 & 0.08 & 0.07 \\ 1979 & 0.08 & 5.35 & 39.8 & 60.0 & 66.4 & 86.2 & 48.3 & 21.7 & 1.65 & 0.76 & 0.45 & 0.09 \\ 1980 & 0.05 & 0.16 & 16.9 & 48.8 & 55.1 & 31.4 & 5.33 & 1.49 & 270 & 16.0 & 0.60 & 1.41 \\ 1981 & 0.59 & 4.31 & 55.7 & 61.4 & 37.5 & 1.53 & 0.36 & 1.46 & 14.7 & 0.13 & 0.07 & 0.18\end{array}$

ANNUAL PEAK DISQHARGE, IN CUBIC FEET PER SECOND, AND CORRESPONDING GAGE HEIGHT, IN FEET, FOR EACH WATER YEAR

\begin{tabular}{|c|c|c|c|c|c|c|c|c|c|c|c|}
\hline $\begin{array}{l}\text { WATER } \\
\text { YEAR }\end{array}$ & DATE & $\begin{array}{c}\text { GAGE } \\
\text { HEIGHT }\end{array}$ & $\begin{array}{c}\text { PEAK } \\
\text { DISQHARGE }\end{array}$ & $\begin{array}{l}\text { WATER } \\
\text { YEAR }\end{array}$ & DATE & $\begin{array}{c}\text { GAGE } \\
\text { HEIGHT }\end{array}$ & $\begin{array}{c}\text { PEAK } \\
\text { DISQHARGE }\end{array}$ & $\begin{array}{l}\text { WATER } \\
\text { YEAR }\end{array}$ & DATE & $\begin{array}{c}\text { GAGE } \\
\text { HEIGHT }\end{array}$ & $\begin{array}{c}\text { PEAK } \\
\text { DISCHARGE }\end{array}$ \\
\hline $\begin{array}{l}1943 \\
1944 \\
1945 \\
1946 \\
1947 \\
1948\end{array}$ & $\begin{array}{l}\text { JUNE } 27,1943 \\
\text { JUNE } 26,1944 \\
\text { AUG. 13, } 1945 \\
\text { AUG. 13, } 1946 \\
\text { JUNE 09, } 1947 \\
\text { APR. 01, } 1948\end{array}$ & $\begin{array}{l}3.43 \\
6.05 \\
3.09 \\
3.62 \\
3.33 \\
2.80\end{array}$ & $\begin{array}{r}548 \\
4520 \\
368 \\
669 \\
465 \\
254\end{array}$ & $\begin{array}{l}1949 \\
1950 \\
1951 \\
1952 \\
1953 \\
1955\end{array}$ & $\begin{array}{l}\text { JUNE 19, } 1949 \\
\text { JUNE 17, } 1950 \\
\text { JUNE 21, } 1951 \\
\text { JUNE 10, } 1952 \\
\text { JUNE 14, } 1953 \\
\text { AUG. 17, } 1955\end{array}$ & $\begin{array}{l}5.80 \\
3.58 \\
3.12 \\
4.75 \\
3.64 \\
2.80\end{array}$ & $\begin{array}{r}4000 \\
924 \\
605 \\
2260 \\
1100 \\
420\end{array}$ & $\begin{array}{l}1977 \\
1978 \\
1979 \\
1980 \\
1981\end{array}$ & $\begin{array}{l}\text { JUNE } 03,1977 \\
\text { JUNE } 10,1978 \\
\text { MAY } 29,1979 \\
\text { JUNE 21, } 1980 \\
\text { JUNE 09, } 1981\end{array}$ & $\begin{array}{l}4.07 \\
5.24 \\
5.19 \\
6.64 \\
5.36\end{array}$ & $\begin{array}{r}78 \\
652 \\
480 \\
903 \\
2290\end{array}$ \\
\hline
\end{tabular}

MAGNITUDE AND PRGBABILITY OF ANNUAL LONEST MEAN DISQHARGE BASED ON OLIMATIC YEARS $1944-55$ AND 1978-81

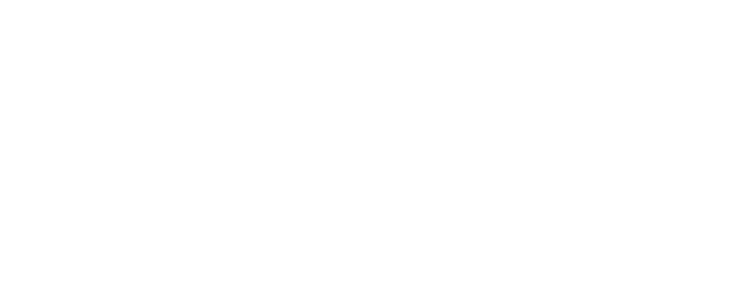

MAGNITUDE AND PRCBABILITY OF ANNUAL HIGHEST MEAN DISOHARGE BASED ON WATER YEARS $1943-55$ AND $1977-81$

\begin{tabular}{|c|c|c|c|c|c|c|}
\hline \multirow{2}{*}{$\begin{array}{l}\text { PERIOD } \\
\text { (CON- } \\
\text { SEQU- } \\
\text { TTVE } \\
\text { DAYS) }\end{array}$} & \multicolumn{6}{|c|}{$\begin{array}{l}\text { DISGHARGE, IN OUBIC FEET PER SECOND, FOR } \\
\text { INDICATED REQURRENCE INTERNAL, IN YEARS, AND } \\
\text { ANNUAL EXCEEDANCE PROBABIIIIT, IN PERCENT }\end{array}$} \\
\hline & $\begin{array}{c}2 \\
50 \%\end{array}$ & $\begin{array}{c}5 \\
20 \% 8\end{array}$ & $\begin{array}{l}10 \\
108\end{array}$ & $\begin{array}{l}25 \\
48\end{array}$ & $\begin{array}{l}50 \\
28\end{array}$ & $\begin{array}{r}100 \\
18\end{array}$ \\
\hline $\begin{array}{r}1 \\
3 \\
7 \\
15\end{array}$ & $\begin{array}{l}306 \\
243 \\
182 \\
137\end{array}$ & $\begin{array}{l}898 \\
690 \\
518 \\
380\end{array}$ & $\begin{array}{r}1660 \\
1270 \\
980 \\
729\end{array}$ & $\begin{array}{l}3330 \\
2580 \\
2080 \\
1600\end{array}$ & $\begin{array}{l}- \\
-- \\
--\end{array}$ & $\begin{array}{l}- \\
- \\
-\end{array}$ \\
\hline
\end{tabular}




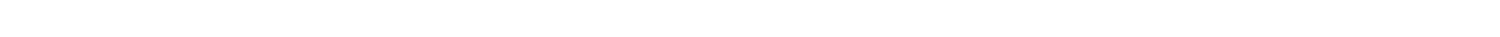
14060003 , on left bank at highway bridge on county road $3.0 \mathrm{mi}$ west of Myton.

DRAINAGE AREA. $--484 \mathrm{mi}^{2}$.

PERIOD OF REOORD AVAILABLE.--July 1900 to Decenber 1902, April to November 1903, September to November 1907 , April 1908 to November 1910, August 1911 to September 1936, October 1976 to September 1981. Monthly mean discharge for same periods prior to October 1911, published in WSP 1313.

REVISED RECORDS. - -WDR UT-77-1: Drainage area.

GAGE.--Water-stage recorder. Altitude of gage is 5,120 ft fran topographic map. July 1900 to December 1903 , June 1907 to May 6 ,

1919, nonrecording gages, May 7, 1919 to Sept. 3, 1929, water-stage recorder at site 500 ft downstream at different datum, Sept. 4, 1929 to Sept. 30, 1936, nonrecording gage at present site at different datum.

REMARKS.--Station below all diversions.

AVERAGE DISCHARGE.--34 years (water years 1901-02, 1909-10, 1912-36, 1977-81), $143 \mathrm{ft} 3 / \mathrm{s}, 103,600 \mathrm{acre}-\mathrm{ft} / \mathrm{yr}$.

EXTREMES FOR PERIOD OF RECORD.--Maximum discharge, 5,600 ft ${ }^{3} / \mathrm{s}$ Nov. 24, 1927, gage height, $11.5 \mathrm{ft}$, site and datum then in use, caused by failure of Farnsworth Reservoir. No flow during periods in 1916, 1931, and 1934.

LONEST MEAN DISCHARGE, IN OUBIC FEET PER SECOND, AND RANKING FOR THE INDICATED NUMBER OF CONSECUTIVE DAYS FOR EAGH CLIMATIC YEAR, APRIL 1-MARCH 31

\begin{tabular}{|c|c|c|c|c|c|c|c|c|c|c|c|c|c|c|c|c|c|c|c|c|}
\hline YEAR & 1 & & 3 & & 7 & & 14 & & $\begin{array}{l}\text { CONSE } \\
30\end{array}$ & EOT & $\begin{array}{l}\text { DAYS } \\
60\end{array}$ & & 90 & & 120 & & 183 & & ALL & \\
\hline $\begin{array}{l}1913 \\
1914 \\
1915\end{array}$ & $\begin{array}{c}1.19 \\
12.0 \\
5.00\end{array}$ & $\begin{array}{r}5 \\
24 \\
16\end{array}$ & $\begin{array}{c}1.50 \\
12.0 \\
6.30\end{array}$ & $\begin{array}{r}4 \\
24 \\
17\end{array}$ & $\begin{array}{c}1.80 \\
14.0 \\
8.70\end{array}$ & $\begin{array}{r}4 \\
24 \\
17\end{array}$ & $\begin{array}{l}1.90 \\
20.0 \\
11.0\end{array}$ & $\begin{array}{r}3 \\
26 \\
17\end{array}$ & $\begin{array}{l}3.40 \\
22.0 \\
17.0\end{array}$ & $\begin{array}{r}3 \\
25 \\
20\end{array}$ & $\begin{array}{l}6.20 \\
77.0 \\
29.0\end{array}$ & $\begin{array}{r}3 \\
28 \\
21\end{array}$ & $\begin{array}{c}31.0 \\
148 \\
45.0\end{array}$ & $\begin{array}{l}16 \\
28 \\
22\end{array}$ & $\begin{array}{c}66.0 \\
153 \\
59.0\end{array}$ & $\begin{array}{l}24 \\
28 \\
22\end{array}$ & $\begin{array}{c}70.0 \\
160 \\
72.0\end{array}$ & $\begin{array}{l}21 \\
28 \\
22\end{array}$ & $\begin{array}{l}212 \\
238 \\
287\end{array}$ & $\begin{array}{l}23 \\
24 \\
28\end{array}$ \\
\hline $\begin{array}{l}1916 \\
1917 \\
1918 \\
1919 \\
1920\end{array}$ & $\begin{array}{l}2.50 \\
0.00 \\
9.00 \\
2.00 \\
9.00\end{array}$ & $\begin{array}{r}10 \\
1 \\
20 \\
6 \\
21\end{array}$ & $\begin{array}{l}2.50 \\
0.20 \\
9.00 \\
3.00 \\
9.70\end{array}$ & $\begin{array}{r}8 \\
2 \\
19 \\
10 \\
21\end{array}$ & $\begin{array}{c}3.30 \\
1.00 \\
11.0 \\
3.90 \\
11.0\end{array}$ & $\begin{array}{r}8 \\
3 \\
19 \\
9 \\
20\end{array}$ & $\begin{array}{c}3.70 \\
2.10 \\
12.0 \\
6.10 \\
11.0\end{array}$ & $\begin{array}{r}8 \\
4 \\
19 \\
12 \\
18\end{array}$ & $\begin{array}{c}4.30 \\
8.30 \\
16.0 \\
10.0 \\
13.0\end{array}$ & $\begin{array}{r}6 \\
11 \\
17 \\
13 \\
16\end{array}$ & $\begin{array}{l}12.0 \\
17.0 \\
26.0 \\
25.0 \\
17.0\end{array}$ & $\begin{array}{r}9 \\
11 \\
19 \\
18 \\
12\end{array}$ & $\begin{array}{l}39.0 \\
15.0 \\
27.0 \\
59.0 \\
20.0\end{array}$ & $\begin{array}{r}20 \\
8 \\
14 \\
25 \\
11\end{array}$ & $\begin{array}{l}58.0 \\
33.0 \\
40.0 \\
63.0 \\
24.0\end{array}$ & $\begin{array}{l}21 \\
14 \\
17 \\
23 \\
11\end{array}$ & $\begin{array}{l}80.0 \\
52.0 \\
48.0 \\
73.0 \\
33.0\end{array}$ & $\begin{array}{l}24 \\
16 \\
14 \\
23 \\
11\end{array}$ & $\begin{array}{c}191 \\
139 \\
270 \\
125 \\
78.0\end{array}$ & $\begin{array}{l}20 \\
18 \\
27 \\
17 \\
11\end{array}$ \\
\hline $\begin{array}{l}1921 \\
1922 \\
1923 \\
1924 \\
1925\end{array}$ & $\begin{array}{c}13.0 \\
9.00 \\
13.0 \\
14.0 \\
4.00\end{array}$ & $\begin{array}{l}25 \\
22 \\
26 \\
27 \\
12\end{array}$ & $\begin{array}{c}13.0 \\
11.0 \\
14.0 \\
15.0 \\
4.00\end{array}$ & $\begin{array}{l}25 \\
23 \\
26 \\
27 \\
12\end{array}$ & $\begin{array}{c}16.0 \\
13.0 \\
15.0 \\
20.0 \\
4.10\end{array}$ & $\begin{array}{l}26 \\
23 \\
25 \\
28 \\
11\end{array}$ & $\begin{array}{c}20.0 \\
16.0 \\
16.0 \\
27.0 \\
4.50\end{array}$ & $\begin{array}{r}27 \\
21 \\
22 \\
28 \\
9\end{array}$ & $\begin{array}{c}30.0 \\
17.0 \\
19.0 \\
33.0 \\
5.70\end{array}$ & $\begin{array}{r}26 \\
18 \\
22 \\
28 \\
7\end{array}$ & $\begin{array}{c}44.0 \\
19.0 \\
29.0 \\
38.0 \\
6.40\end{array}$ & $\begin{array}{r}26 \\
14 \\
22 \\
24 \\
5\end{array}$ & $\begin{array}{c}50.0 \\
35.0 \\
32.0 \\
73.0 \\
7.30\end{array}$ & $\begin{array}{r}23 \\
19 \\
17 \\
26 \\
4\end{array}$ & $\begin{array}{c}54.0 \\
52.0 \\
36.0 \\
86.0 \\
8.40\end{array}$ & $\begin{array}{r}20 \\
19 \\
15 \\
26 \\
4\end{array}$ & $\begin{array}{l}64.0 \\
69.0 \\
62.0 \\
85.0 \\
18.0\end{array}$ & $\begin{array}{r}19 \\
20 \\
18 \\
25 \\
6\end{array}$ & $\begin{array}{c}153 \\
267 \\
263 \\
202 \\
54.0\end{array}$ & $\begin{array}{r}19 \\
26 \\
25 \\
21 \\
7\end{array}$ \\
\hline $\begin{array}{l}1926 \\
1927 \\
1928 \\
1929 \\
1930\end{array}$ & $\begin{array}{l}5.00 \\
3.00 \\
9.00 \\
2.00 \\
7.00\end{array}$ & $\begin{array}{r}13 \\
11 \\
23 \\
7 \\
18\end{array}$ & $\begin{array}{l}6.00 \\
3.00 \\
9.30 \\
2.30 \\
8.30\end{array}$ & $\begin{array}{r}16 \\
11 \\
20 \\
7 \\
18\end{array}$ & $\begin{array}{c}6.30 \\
3.90 \\
11.0 \\
2.40 \\
9.40\end{array}$ & $\begin{array}{r}14 \\
10 \\
21 \\
5 \\
18\end{array}$ & $\begin{array}{c}6.60 \\
5.70 \\
17.0 \\
3.60 \\
16.0\end{array}$ & $\begin{array}{r}14 \\
10 \\
24 \\
7 \\
23\end{array}$ & $\begin{array}{l}6.80 \\
12.0 \\
31.0 \\
17.0 \\
21.0\end{array}$ & $\begin{array}{r}9 \\
14 \\
27 \\
19 \\
23\end{array}$ & $\begin{array}{l}42.0 \\
14.0 \\
47.0 \\
27.0 \\
24.0\end{array}$ & $\begin{array}{l}25 \\
10 \\
27 \\
20 \\
17\end{array}$ & $\begin{array}{l}57.0 \\
14.0 \\
83.0 \\
29.0 \\
44.0\end{array}$ & $\begin{array}{r}24 \\
7 \\
27 \\
15 \\
21\end{array}$ & $\begin{array}{c}82.0 \\
16.0 \\
101 \\
31.0 \\
43.0\end{array}$ & $\begin{array}{r}25 \\
7 \\
27 \\
13 \\
18\end{array}$ & $\begin{array}{c}86.0 \\
22.0 \\
143 \\
48.0 \\
56.0\end{array}$ & $\begin{array}{r}26 \\
7 \\
27 \\
15 \\
17\end{array}$ & $\begin{array}{l}104 \\
68.0 \\
204 \\
102 \\
110\end{array}$ & $\begin{array}{l}14 \\
10 \\
22 \\
13 \\
16\end{array}$ \\
\hline $\begin{array}{l}1931 \\
1932 \\
1933 \\
1934\end{array}$ & $\begin{array}{c}14.0 \\
0.00 \\
5.00 \\
2.00 \\
0.00\end{array}$ & $\begin{array}{r}28 \\
2 \\
14 \\
8 \\
3\end{array}$ & $\begin{array}{c}17.0 \\
0.67 \\
5.70 \\
2.00 \\
0.00\end{array}$ & $\begin{array}{r}28 \\
3 \\
14 \\
6 \\
1\end{array}$ & $\begin{array}{c}18.0 \\
0.86 \\
6.60 \\
2.40 \\
0.00\end{array}$ & $\begin{array}{r}27 \\
2 \\
15 \\
6 \\
1\end{array}$ & $\begin{array}{c}20.0 \\
1.40 \\
8.40 \\
2.90 \\
0.00\end{array}$ & $\begin{array}{r}25 \\
2 \\
15 \\
5 \\
1\end{array}$ & $\begin{array}{c}21.0 \\
2.10 \\
9.50 \\
3.70 \\
0.00\end{array}$ & $\begin{array}{r}24 \\
2 \\
12 \\
4 \\
1\end{array}$ & $\begin{array}{c}33.0 \\
2.20 \\
18.0 \\
6.30 \\
0.43\end{array}$ & $\begin{array}{r}23 \\
2 \\
13 \\
4 \\
1\end{array}$ & $\begin{array}{c}34.0 \\
2.50 \\
18.0 \\
6.90 \\
1.19\end{array}$ & $\begin{array}{r}18 \\
2 \\
10 \\
3 \\
1\end{array}$ & $\begin{array}{c}38.0 \\
3.40 \\
19.0 \\
8.30 \\
1.30\end{array}$ & $\begin{array}{r}16 \\
2 \\
8 \\
3 \\
1\end{array}$ & $\begin{array}{c}40.0 \\
9.20 \\
24.0 \\
12.0 \\
3.30\end{array}$ & $\begin{array}{r}13 \\
2 \\
8 \\
3 \\
1\end{array}$ & $\begin{array}{r}108 \\
43.0 \\
79.0 \\
39.0 \\
12.0\end{array}$ & $\begin{array}{r}15 \\
6 \\
12 \\
4 \\
1\end{array}$ \\
\hline 1936 & 1.00 & 4 & 1.70 & 5 & 2.70 & 7 & 3.10 & 6 & 3.80 & 5 & 7.50 & 6 & 9.20 & 5 & 11.0 & 5 & 14.0 & 5 & 55.0 & 0 \\
\hline $\begin{array}{l}1978 \\
1979 \\
1980\end{array}$ & $\begin{array}{l}5.50 \\
7.70 \\
2.50\end{array}$ & $\begin{array}{r}17 \\
19 \\
9\end{array}$ & $\begin{array}{c}5.80 \\
10.0 \\
2.80\end{array}$ & $\begin{array}{r}15 \\
22 \\
9\end{array}$ & $\begin{array}{c}6.00 \\
13.0 \\
4.40\end{array}$ & $\begin{array}{l}13 \\
22 \\
12\end{array}$ & $\begin{array}{c}6.40 \\
15.0 \\
5.80\end{array}$ & $\begin{array}{l}13 \\
20 \\
11\end{array}$ & $\begin{array}{c}6.50 \\
18.0 \\
7.40\end{array}$ & $\begin{array}{r}8 \\
21 \\
10\end{array}$ & $\begin{array}{c}7.60 \\
20.0 \\
9.10\end{array}$ & $\begin{array}{r}7 \\
15 \\
8\end{array}$ & $\begin{array}{l}10.0 \\
22.0 \\
17.0\end{array}$ & $\begin{array}{r}6 \\
12 \\
9\end{array}$ & $\begin{array}{l}12.0 \\
22.0 \\
21.0\end{array}$ & $\begin{array}{r}6 \\
10 \\
9\end{array}$ & $\begin{array}{l}13.0 \\
24.0 \\
26.0\end{array}$ & $\begin{array}{r}4 \\
9 \\
10\end{array}$ & $\begin{array}{l}25.0 \\
41.0 \\
38.0\end{array}$ & 3 \\
\hline & 5.00 & 15 & 5.50 & 13 & 7.00 & 16 & 9.60 & 16 & 13.0 & 15 & 2.0 & 16 & 24.0 & 13 & 29.0 & 12 & 37.0 & 12 & 57.0 & \\
\hline
\end{tabular}

HIGHEST MEAN DISCHARGE, IN CUBIC FEET PER SECOND, AND RANKING FOR THE INDICATED NUMBER OF CONSECUTIVE DAYS FOR EACH WATER YEAR, OCTCBER I-SEPTEMBER 30.

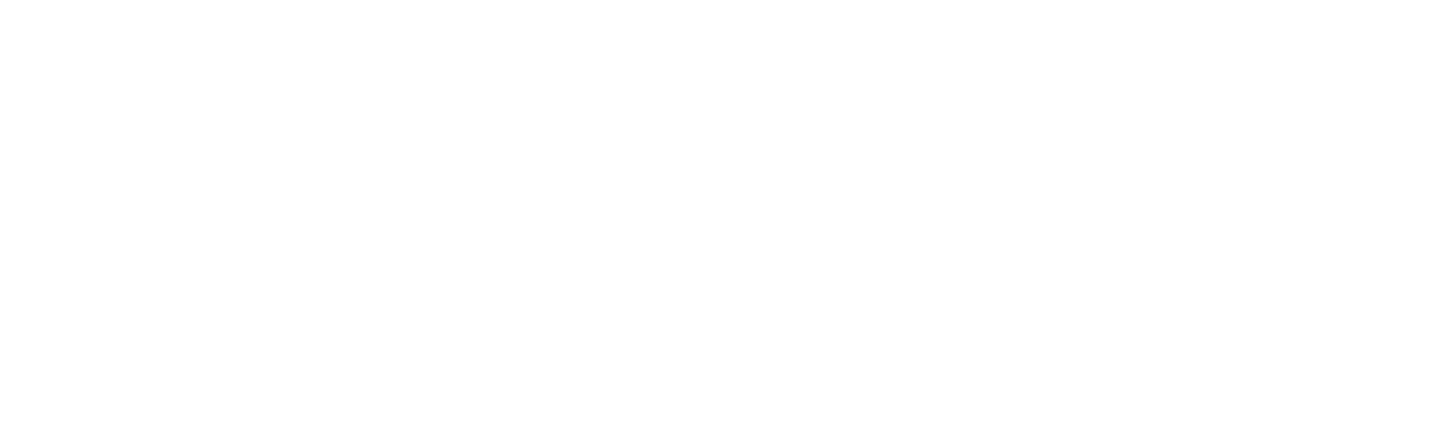


HIGHEST MEAN DISGHARGE, IN OUBIC FEET PER SECOND, AND RANKING FOR THE INDICATED NUMBER OF CONSEQJTTVE DAYS FOR EACH WATER YEAR, OCTOBER 1-SEPTEMBER 30--Continued

\begin{tabular}{|c|c|c|c|c|c|c|c|c|c|c|c|c|c|c|c|c|c|c|c|c|}
\hline YEAR & 1 & & 3 & & 7 & & 15 & & $\begin{array}{l}\text { CONs } \\
30\end{array}$ & EQT & $\begin{array}{l}\text { VE DAYS } \\
50\end{array}$ & & 90 & & 120 & & 183 & & ALL & \\
\hline $\begin{array}{l}1931 \\
1932 \\
1933 \\
1934 \\
1935\end{array}$ & $\begin{array}{c}191 \\
1070 \\
1070 \\
30.0 \\
1950\end{array}$ & $\begin{array}{l}27 \\
17 \\
18 \\
30 \\
10\end{array}$ & $\begin{array}{c}177 \\
995 \\
919 \\
30.0 \\
1760\end{array}$ & $\begin{array}{l}27 \\
17 \\
18 \\
30 \\
10\end{array}$ & $\begin{array}{c}132 \\
815 \\
724 \\
30.0 \\
1500\end{array}$ & $\begin{array}{r}27 \\
16 \\
19 \\
30 \\
9\end{array}$ & $\begin{array}{l}83.0 \\
761 \\
548 \\
30.0 \\
935\end{array}$ & $\begin{array}{l}28 \\
16 \\
19 \\
30 \\
14\end{array}$ & $\begin{array}{c}58.0 \\
466 \\
301 \\
30.0 \\
505\end{array}$ & $\begin{array}{l}28 \\
17 \\
21 \\
30 \\
16\end{array}$ & $\begin{array}{c}50.0 \\
329 \\
163 \\
25.0 \\
263\end{array}$ & $\begin{array}{l}28 \\
15 \\
23 \\
30 \\
17\end{array}$ & $\begin{array}{c}48.0 \\
225 \\
118 \\
23.0 \\
181\end{array}$ & $\begin{array}{l}28 \\
16 \\
24 \\
30 \\
18\end{array}$ & $\begin{array}{c}46.0 \\
187 \\
100 \\
21.0 \\
141\end{array}$ & $\begin{array}{l}28 \\
17 \\
24 \\
30 \\
18\end{array}$ & $\begin{array}{c}44.0 \\
157 \\
79.0 \\
16.0 \\
98.0\end{array}$ & $\begin{array}{l}28 \\
16 \\
24 \\
30 \\
20\end{array}$ & $\begin{array}{l}32.0 \\
94.0 \\
48.0 \\
10.0 \\
57.0\end{array}$ & $\begin{array}{l}28 \\
18 \\
24 \\
30 \\
21\end{array}$ \\
\hline 1936 & 815 & 22 & 700 & 22 & 575 & 22 & 415 & 21 & 320 & 19 & 202 & 19 & 160 & 19 & 132 & 20 & 91.0 & 21 & 54.0 & 23 \\
\hline $\begin{array}{l}1977 \\
1978 \\
1979 \\
1980\end{array}$ & $\begin{array}{l}53.0 \\
248 \\
279 \\
914\end{array}$ & $\begin{array}{l}29 \\
26 \\
25 \\
20\end{array}$ & $\begin{array}{l}53.0 \\
206 \\
203 \\
806\end{array}$ & $\begin{array}{l}29 \\
25 \\
26 \\
21\end{array}$ & $\begin{array}{l}53.0 \\
183 \\
141 \\
649\end{array}$ & $\begin{array}{l}29 \\
25 \\
26 \\
20\end{array}$ & $\begin{array}{l}53.0 \\
109 \\
118 \\
449\end{array}$ & $\begin{array}{l}29 \\
26 \\
25 \\
20\end{array}$ & $\begin{array}{l}53.0 \\
71.0 \\
105 \\
301\end{array}$ & $\begin{array}{l}29 \\
27 \\
25 \\
20\end{array}$ & $\begin{array}{r}42.0 \\
60.0 \\
88.0 \\
169\end{array}$ & $\begin{array}{l}29 \\
27 \\
25 \\
21\end{array}$ & $\begin{array}{r}32.0 \\
58.0 \\
79.0 \\
124\end{array}$ & $\begin{array}{l}29 \\
27 \\
25 \\
23\end{array}$ & $\begin{array}{r}28.0 \\
51.0 \\
71.0 \\
102\end{array}$ & $\begin{array}{l}29 \\
26 \\
25 \\
23\end{array}$ & $\begin{array}{l}24.0 \\
50.0 \\
60.0 \\
84.0\end{array}$ & $\begin{array}{l}29 \\
26 \\
25 \\
23\end{array}$ & $\begin{array}{l}20.0 \\
34.0 \\
45.0 \\
55.0\end{array}$ & $\begin{array}{l}29 \\
27 \\
25 \\
22\end{array}$ \\
\hline
\end{tabular}

DURATION OF DISQHARGE FOR EACH WATER YEAR

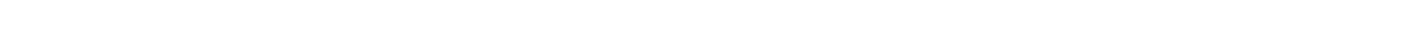

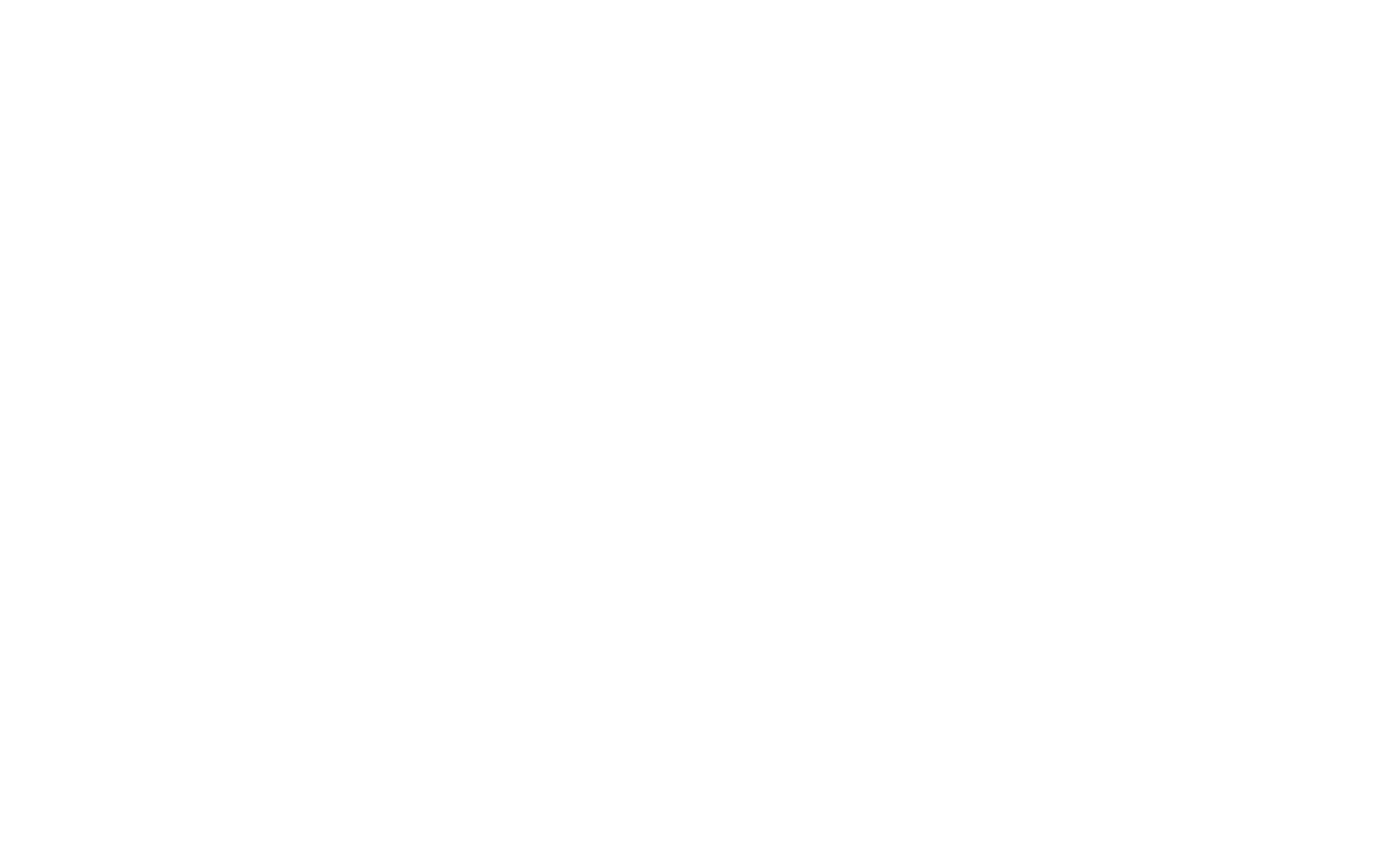

DURATTON TABLE OF DISGHARGE FOR WATER YEARS 1912-36, 1977-81

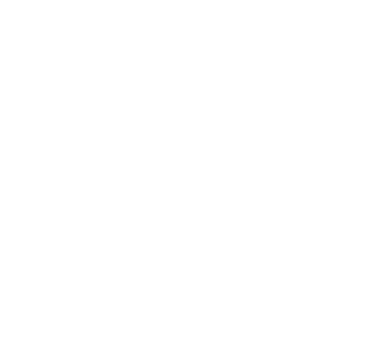

$\begin{array}{lcl}\text { CUBIC } & \text { ACOH- } & \\ \text { FEET } & \text { MU- } & \text { PER- } \\ \text { PER TOTAL LATED } & \text { CENT }\end{array}$

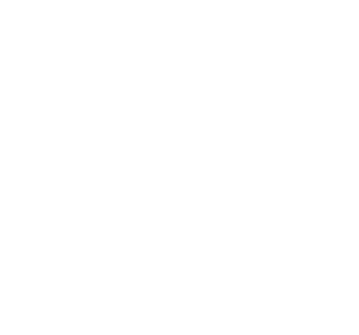

$\begin{array}{lll}\text { OBIC } & \text { ACOU- } \\ \text { FEET } & \text { M- } & \\ \text { PER- }\end{array}$ PER TOTAL LATED CENT
CLASS SECOND DAYS DAYS DAYS

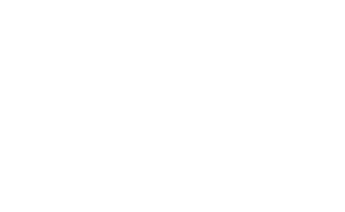

$\begin{array}{lll}\text { OBIC } & \text { ACOJ- } \\ \text { FEET } & \text { MU- } & \\ \text { PER- } & \end{array}$ PER TOTAL LATED CENT
GLASS SECOND DAYS DAYS DAYS

$\begin{array}{rrrrr}27 & 630.0 & 100 & 411 & 3.8 \\ 28 & 820.0 & 107 & 311 & 2.8 \\ 29 & 1100.0 & 62 & 204 & 1.9 \\ 30 & 1400.0 & 58 & 142 & 1.3 \\ 31 & 1800.0 & 33 & 84 & 0.8 \\ 32 & 2400.0 & 39 & 51 & 0.5 \\ 33 & 3100.0 & 10 & 12 & 0.1 \\ 34 & 4100.0 & 2 & 2 & 0.0\end{array}$


GREEN RIVER BASIN

09294500 LAKE FORK RIVER NEAR MYTON, UTL-Continued

MONTHLY MEAN DISOHARGES, IN OUBIC FEET PER SECOND, FOR EACH WATER YEAR

\begin{tabular}{|c|c|c|c|c|c|c|c|c|c|c|c|c|}
\hline YEAR & OCT & NOV & DEC & JAN & FEB & MAR & APR & MAY & JUNE & ЛயY & AUG & SEP \\
\hline $\begin{array}{l}1901 \\
1902\end{array}$ & $\begin{array}{l}117 \\
132\end{array}$ & $\begin{array}{l}115 \\
112\end{array}$ & $\begin{array}{l}124 \\
110\end{array}$ & $\begin{array}{l}95.0 \\
90.0\end{array}$ & $\begin{array}{l}95.0 \\
90.0\end{array}$ & $\begin{array}{l}100 \\
97.0\end{array}$ & $\begin{array}{l}132 \\
109\end{array}$ & $\begin{array}{r}1272 \\
718\end{array}$ & $\begin{array}{r}556 \\
1238\end{array}$ & $\begin{array}{l}250 \\
220\end{array}$ & $\begin{array}{l}255 \\
108\end{array}$ & $\begin{array}{r}144 \\
88.0\end{array}$ \\
\hline $\begin{array}{l}1909 \\
1910\end{array}$ & $\begin{array}{l}237 \\
177\end{array}$ & $\begin{array}{l}173 \\
151\end{array}$ & $\begin{array}{l}147 \\
171\end{array}$ & $\begin{array}{l}189 \\
144\end{array}$ & $\begin{array}{l}168 \\
146\end{array}$ & $\begin{array}{l}169 \\
154\end{array}$ & $\begin{array}{l}149 \\
262\end{array}$ & $\begin{array}{l}264 \\
762\end{array}$ & $\begin{array}{r}2070 \\
421\end{array}$ & $\begin{array}{l}709 \\
73.9\end{array}$ & $\begin{array}{l}383 \\
45.2\end{array}$ & $\begin{array}{c}507 \\
80.1\end{array}$ \\
\hline $\begin{array}{l}1912 \\
1913 \\
1914 \\
1915\end{array}$ & $\begin{array}{l}70.6 \\
145 \\
220 \\
97.2\end{array}$ & $\begin{array}{c}63.1 \\
97.2 \\
163 \\
88.4\end{array}$ & $\begin{array}{c}70.0 \\
82.5 \\
146 \\
93.5\end{array}$ & $\begin{array}{l}65.0 \\
70.0 \\
156 \\
100\end{array}$ & $\begin{array}{l}70.0 \\
70.0 \\
160 \\
125\end{array}$ & $\begin{array}{l}79.5 \\
95.4 \\
160 \\
138\end{array}$ & $\begin{array}{l}69.9 \\
115 \\
176 \\
85.6\end{array}$ & $\begin{array}{l}144 \\
649 \\
961 \\
198\end{array}$ & $\begin{array}{r}1493 \\
546 \\
1397 \\
1033\end{array}$ & $\begin{array}{l}266 \\
237 \\
204 \\
81.5\end{array}$ & $\begin{array}{c}17.4 \\
22.4 \\
32.5 \\
4.34\end{array}$ & $\begin{array}{c}7.92 \\
275 \\
27.4 \\
60.3\end{array}$ \\
\hline $\begin{array}{l}1916 \\
1917 \\
1918 \\
1919 \\
1920\end{array}$ & $\begin{array}{l}140 \\
110 \\
30.2 \\
88.5 \\
33.8\end{array}$ & $\begin{array}{c}108 \\
80.3 \\
78.5 \\
77.6 \\
61.5\end{array}$ & $\begin{array}{r}120 \\
85.0 \\
77.5 \\
97.1 \\
60.2\end{array}$ & $\begin{array}{l}120 \\
65.0 \\
50.0 \\
89.1 \\
60.0\end{array}$ & $\begin{array}{l}110 \\
100 \\
80.0 \\
110 \\
70.0\end{array}$ & $\begin{array}{l}245 \\
132 \\
54.9 \\
219 \\
111\end{array}$ & $\begin{array}{l}186 \\
135 \\
23.3 \\
111 \\
117\end{array}$ & $\begin{array}{l}235 \\
185 \\
26.2 \\
315 \\
325\end{array}$ & $\begin{array}{c}640 \\
1941 \\
595 \\
32.4 \\
686\end{array}$ & $\begin{array}{c}8.61 \\
564 \\
67.8 \\
13.4 \\
31.5\end{array}$ & $\begin{array}{l}26.2 \\
25.8 \\
10.4 \\
21.5 \\
84.5\end{array}$ & $\begin{array}{c}11.4 \\
32.8 \\
101 \\
38.9 \\
39.3\end{array}$ \\
\hline $\begin{array}{l}1921 \\
1922 \\
1923 \\
1924 \\
1925\end{array}$ & $\begin{array}{c}65.4 \\
19.5 \\
27.5 \\
156 \\
11.9\end{array}$ & $\begin{array}{r}91.3 \\
44.7 \\
99.0 \\
116 \\
44.8\end{array}$ & $\begin{array}{r}70.0 \\
89.0 \\
117 \\
80.0 \\
65.0\end{array}$ & $\begin{array}{l}75.0 \\
115 \\
110 \\
75.0 \\
71.5\end{array}$ & $\begin{array}{c}126 \\
130 \\
110 \\
100 \\
75.0\end{array}$ & $\begin{array}{l}128 \\
143 \\
123 \\
89.2 \\
34.9\end{array}$ & $\begin{array}{c}37.4 \\
130 \\
147 \\
78.5 \\
6.80\end{array}$ & $\begin{array}{l}109 \\
407 \\
387 \\
206 \\
152\end{array}$ & $\begin{array}{c}2085 \\
1858 \\
874 \\
32.0 \\
174\end{array}$ & $\begin{array}{c}294 \\
127 \\
317 \\
7.58 \\
49.2\end{array}$ & $\begin{array}{c}72.8 \\
36.8 \\
36.3 \\
6.45 \\
51.6\end{array}$ & $\begin{array}{c}85.1 \\
34.8 \\
51.3 \\
9.37 \\
84.5\end{array}$ \\
\hline $\begin{array}{l}1926 \\
1927 \\
1928 \\
1929 \\
1930\end{array}$ & $\begin{array}{l}163 \\
16.5 \\
269 \\
66.0 \\
40.9\end{array}$ & $\begin{array}{l}147 \\
21.0 \\
181 \\
75.4 \\
83.7\end{array}$ & $\begin{array}{c}128 \\
53.4 \\
133 \\
90.0 \\
80.0\end{array}$ & $\begin{array}{r}100 \\
70.0 \\
75.0 \\
75.0 \\
70.0\end{array}$ & $\begin{array}{c}125 \\
78.5 \\
74.0 \\
75.0 \\
90.0\end{array}$ & $\begin{array}{l}64.1 \\
150 \\
125 \\
112 \\
59.9\end{array}$ & $\begin{array}{c}62.2 \\
61.3 \\
28.7 \\
106 \\
35.6\end{array}$ & $\begin{array}{l}216 \\
156 \\
434 \\
149 \\
225\end{array}$ & $\begin{array}{l}95.4 \\
437 \\
173 \\
505 \\
682\end{array}$ & $\begin{array}{c}18.2 \\
117 \\
24.1 \\
41.6 \\
21.0\end{array}$ & $\begin{array}{l}23.3 \\
37.5 \\
33.8 \\
21.2 \\
55.4\end{array}$ & $\begin{array}{c}13.7 \\
799 \\
29.1 \\
83.5 \\
25.1\end{array}$ \\
\hline $\begin{array}{l}1931 \\
1932 \\
1933 \\
1934 \\
1935\end{array}$ & $\begin{array}{c}55.5 \\
9.61 \\
18.3 \\
9.52 \\
0.74\end{array}$ & $\begin{array}{c}43.9 \\
13.6 \\
27.4 \\
15.0 \\
6.93\end{array}$ & $\begin{array}{l}42.0 \\
75.0 \\
35.0 \\
20.0 \\
35.0\end{array}$ & $\begin{array}{l}40.0 \\
90.0 \\
40.0 \\
30.0 \\
30.0\end{array}$ & $\begin{array}{c}38.0 \\
105 \\
40.0 \\
17.4 \\
25.0\end{array}$ & $\begin{array}{c}39.2 \\
105 \\
52.3 \\
3.77 \\
15.5\end{array}$ & $\begin{array}{c}34.5 \\
29.3 \\
19.9 \\
6.23 \\
4.60\end{array}$ & $\begin{array}{r}52.9 \\
132 \\
34.5 \\
10.6 \\
13.0\end{array}$ & $\begin{array}{l}24.0 \\
466 \\
288 \\
7.80 \\
504\end{array}$ & $\begin{array}{c}3.29 \\
67.0 \\
16.0 \\
2.19 \\
19.9\end{array}$ & $\begin{array}{c}2.58 \\
20.7 \\
6.55 \\
2.94 \\
20.0\end{array}$ & $\begin{array}{c}2.40 \\
19.6 \\
6.83 \\
0.20 \\
12.9\end{array}$ \\
\hline 1936 & 6.77 & 12.2 & 14.0 & 25.0 & 30.0 & 10.7 & 8.67 & 216 & 139 & 80.8 & 59.1 & 39.7 \\
\hline $\begin{array}{l}1977 \\
1978 \\
1979 \\
1980\end{array}$ & $\begin{array}{l}20.3 \\
14.0 \\
22.0 \\
25.8\end{array}$ & $\begin{array}{c}14.7 \\
6.63 \\
21.4 \\
8.02\end{array}$ & $\begin{array}{l}27.3 \\
24.3 \\
33.8 \\
17.8\end{array}$ & $\begin{array}{l}47.5 \\
60.0 \\
57.0 \\
58.4\end{array}$ & $\begin{array}{l}21.4 \\
60.0 \\
64.4 \\
65.7\end{array}$ & $\begin{array}{l}13.4 \\
47.1 \\
95.1 \\
37.1\end{array}$ & $\begin{array}{l}11.8 \\
27.5 \\
60.4 \\
14.1\end{array}$ & $\begin{array}{l}15.0 \\
26.8 \\
40.8 \\
33.4\end{array}$ & $\begin{array}{l}16.6 \\
70.3 \\
38.4 \\
284\end{array}$ & $\begin{array}{l}14.7 \\
26.0 \\
37.6 \\
48.7\end{array}$ & $\begin{array}{l}13.7 \\
21.7 \\
30.3 \\
33.4\end{array}$ & $\begin{array}{l}18.2 \\
24.6 \\
35.2 \\
32.9\end{array}$ \\
\hline 1981 & 35.0 & 16.0 & 64.9 & 63.5 & 41.6 & 23.5 & 20.8 & 32.5 & 48.4 & 26.5 & 23.9 & 27.2 \\
\hline
\end{tabular}

ANNUAL PEAK DISOHARGE, IN OBBIC FEET PER SECOND, AND CORRESPONDING GAGE HEIGHT, IN FEET, FOR EACH WATER YEAR

\begin{tabular}{|c|c|c|c|c|c|c|c|c|c|c|c|}
\hline $\begin{array}{l}\text { WATERR } \\
\text { YEAR }\end{array}$ & DATE & $\begin{array}{c}\text { GAGE } \\
\text { HEIGHT }\end{array}$ & $\begin{array}{c}\text { PEAK } \\
\text { DISOH ARGE }\end{array}$ & $\begin{array}{l}\text { WATER } \\
\text { YEAR }\end{array}$ & DATE & $\begin{array}{c}\text { GAGE } \\
\text { HEIGHT }\end{array}$ & $\begin{array}{c}\text { PEAK } \\
\text { DISOHARGE }\end{array}$ & $\begin{array}{l}\text { WATER } \\
\text { YEAR }\end{array}$ & DATE & $\begin{array}{c}\text { GAGE } \\
\text { HEIGHT }\end{array}$ & $\begin{array}{c}\text { PEAK } \\
\text { DISCHARGE }\end{array}$ \\
\hline $\begin{array}{l}1910 \\
1912 \\
1913 \\
1914 \\
1915 \\
1916 \\
1917 \\
1918 \\
1919 \\
1920\end{array}$ & $\begin{array}{l}\text { MAY } 12,1910 \\
\text { JUNE } 07,1912 \\
\text { JUNE } 28,1913 \\
\text { JUNE } 03,1914 \\
\text { JUNE } 02,1915 \\
\text { JUNE } 10,1916 \\
\text { JUNE } 22,1917 \\
\text { JUNE } 11,1918 \\
\text { MAY } 21,1919 \\
\text { AUG. } 01,1920\end{array}$ & $\begin{array}{l}-- \\
-- \\
-- \\
6.00 \\
5.20 \\
9.40 \\
6.05 \\
4.75 \\
6.50 \\
9.10\end{array}$ & $\begin{array}{l}1440 \\
3050 \\
2710 \\
2880 \\
1840 \\
1300 \\
4350 \\
1740 \\
1080 \\
2200 \\
4010\end{array}$ & $\begin{array}{l}1922 \\
1923 \\
1924 \\
1925 \\
1926 \\
1927 \\
1928 \\
1929 \\
1930 \\
1931\end{array}$ & $\begin{array}{l}\text { JUNE } 21,1922 \\
\text { JUNE } 13,1923 \\
\text { MAY } 18,1924 \\
\text { MAY } 21,1925 \\
\text { MAY } 21,1926 \\
\text { SEPT.10, } 1927 \\
\text { NOW. } 24,1927 \\
\text { JUNE } 15,1929 \\
\text { JUNE } 12,1930 \\
\text { MAY } 18,1931\end{array}$ & $\begin{array}{r}7.56 \\
7.10 \\
4.03 \\
3.82 \\
4.56 \\
9.70 \\
11.50 \\
5.36 \\
7.12 \\
2.52\end{array}$ & $\begin{array}{r}3110 \\
2790 \\
875 \\
775 \\
1180 \\
4600 \\
5600 \\
1440 \\
2480 \\
191\end{array}$ & $\begin{array}{l}1932 \\
1933 \\
1934 \\
1935 \\
1936 \\
1977 \\
1978 \\
1979 \\
1980 \\
1981\end{array}$ & $\begin{array}{l}\text { JUNE } 16,1932 \\
\text { JUNE 04, } 1933 \\
\text { JULY 04, } 1934 \\
\text { JUNE 14, } 1935 \\
\text { SEPT.03, } 1936 \\
\text { JUNE 03, } 1977 \\
\text { JUNE 10, } 1978 \\
\text { MAY 29, } 1979 \\
\text { JUNE 21, } 1980 \\
\text { JUNE 09, } 1981\end{array}$ & $\begin{array}{l}4.82 \\
4.90 \\
2.00 \\
6.52 \\
4.56 \\
2.89 \\
4.43 \\
3.98 \\
6.75 \\
4.07\end{array}$ & $\begin{array}{r}1070 \\
1070 \\
85 \\
1950 \\
940 \\
70 \\
420 \\
342 \\
1020 \\
354\end{array}$ \\
\hline
\end{tabular}

\begin{tabular}{|c|c|c|c|c|c|c|c|c|c|c|c|c|c|}
\hline \multicolumn{7}{|c|}{$\begin{array}{l}\text { MAGNITUDE AND PRGBABILITY OF ANNUAL LWEST MEAN DISOHARGE } \\
\text { BASED OT CIMATIC YEARS 1913-36 AND 1978-81 }\end{array}$} & \multicolumn{7}{|c|}{$\begin{array}{l}\text { MAGNITUDE AND PRCBABIIIITY OF ANNUAL HIGHEST MEAN DISGARGE } \\
\text { BASED ON WATER YEARS } 1912-36 \text { AND } 1977-8 \mathrm{D}\end{array}$} \\
\hline \multirow{2}{*}{$\begin{array}{l}\text { PERIOD } \\
\text { (CON- } \\
\text { SEQU- } \\
\text { TIVE } \\
\text { DAYS) }\end{array}$} & \multicolumn{6}{|c|}{$\begin{array}{l}\text { DISCHARGE, IN OBBIC FEET PER SECOND, FOR } \\
\text { INDICAIED REOURRENCE INTERVAL, IN YEARS, AND } \\
\text { ANNUAL NONEXCEEDANCE PRCBABIIITY, IN PERCENT }\end{array}$} & \multirow{2}{*}{$\begin{array}{l}\text { PERIOD } \\
\text { (OON- } \\
\text { SEQ- } \\
\text { TTVE } \\
\text { DAYS) }\end{array}$} & \multicolumn{6}{|c|}{$\begin{array}{l}\text { DISGHARGE, IN GBIC FEET PER SECOND, FOR } \\
\text { INDICAIED REQURRENCE INTERNAL, IN YEARS, AND } \\
\text { ANNUAL EXCEEDANCE PRCBABIITY, IN PERCENT }\end{array}$} \\
\hline & $\begin{array}{c}2 \\
508\end{array}$ & $\begin{array}{c}5 \\
20 \%\end{array}$ & $\begin{array}{l}10 \\
10 \%\end{array}$ & $\begin{array}{l}20 \\
5 \%\end{array}$ & $\begin{array}{l}50 \\
28\end{array}$ & $\begin{array}{r}100 \\
18\end{array}$ & & $\begin{array}{c}2 \\
508\end{array}$ & $\begin{array}{c}5 \\
20 \%\end{array}$ & $\begin{array}{l}10 \\
108\end{array}$ & $\begin{array}{l}25 \\
48\end{array}$ & $\begin{array}{l}50 \\
28\end{array}$ & $\begin{array}{r}100 \\
18\end{array}$ \\
\hline 60 & 21 & 7.7 & 3.9 & 2.0 & 0.83 & - & $\begin{array}{r}1 \\
3 \\
7 \\
15\end{array}$ & $\begin{array}{r}1270 \\
1120 \\
907 \\
679\end{array}$ & $\begin{array}{l}2720 \\
2450 \\
2070 \\
1620\end{array}$ & $\begin{array}{l}3550 \\
3270 \\
2850 \\
2340\end{array}$ & $\begin{array}{l}4360 \\
4120 \\
3740 \\
3250\end{array}$ & $\begin{array}{l}4810 \\
4600 \\
4300 \\
3900\end{array}$ & -- \\
\hline
\end{tabular}


GREEN RIVER BASIN

09295000 DUCHESNE RIVER AT MYTON, UT

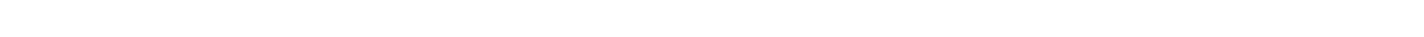
Unit 14060003, on left bank at Myton and $3 \mathrm{mi}$ downstream from Lake Fork.

DRAINAGE AREA. $-2,643 \mathrm{mi}^{2}$.

PERIOD OF RECORD AVAILABLE.--October 1899 to December 1902, April to December 1903, March to December 1904, March to July and September to November 1905, April to July 1906, April to December 1907, March to Decenber 1908, April to Decenber 1909, March to November 1910, July 1911 to September 1981. Monthly mean discharge only for same periods prior to October 1911, published in WSP 1313. Published as "at Price road bridge", 1899-1902.

REVISED RECORDS. -WDR UT-77-1: Drainage area.

GAGE.--Water-stage recorder. Datum of gage is $5,061.40 \mathrm{ft}$, NGVD of 1929 . Prior to Oct. 14, 1933, nonrecording gages at several sites within $0.5 \mathrm{mi}$ of present site at various datums.

AVERAGE DISCHARGE. -73 years (water years 1900-1902, 1912-1981), $503 \mathrm{ft}^{3} / \mathrm{s}, 364,400$ acre-ft/yr.

REMARKS. - Flow regulated by several reservoirs. Large diversions above station for irrigation, including transmountain diversions to the Great Basin through Duchesne and Strawberry tunnels, Hobble Creek ditch, Strawberry River, and willow creek ditch.

EXTREMES FOR PERIOD OF RECORD.-Maximum discharge observed, 12,800 $\mathrm{ft}^{3} / \mathrm{s}$ June 10, 1922, gage height, $7.94 \mathrm{ft}$, site and datum then in use, fram rating curve extended above $8,000 \mathrm{ft}^{3} / \mathrm{s}$; minimum, less than $1 \mathrm{ft}^{3} / \mathrm{s}$ July 16 , 1931, and for several days in August and September 1934.

LOWEST MEAN DISCHARGE, IN CUBIC FEET PER SECOND, AND RANKING FOR THE INDICATED NUMBER OF CONSECUTIVE DAYS FOR EACH CLIMATIC YEAR, APRIL I-MARCH 31

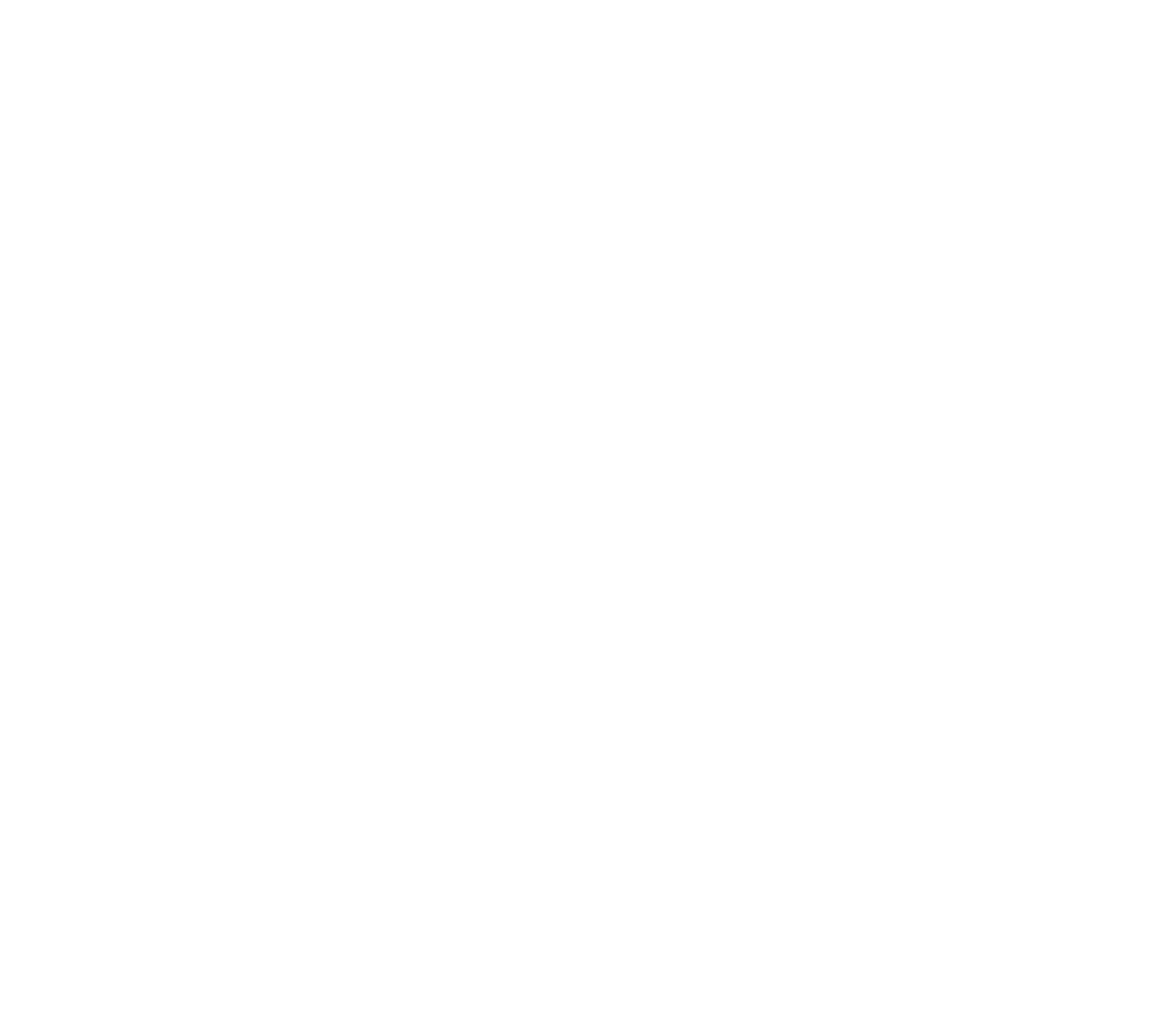


LOWEST MEAN DISCHARGE, IN OUBIC FEET PER SECOND, AND RANKING FOR THE INDICATED NUMBER OF CONSEGUTIVE DAYS FOR EAOH CLIMATIC YEAR, APRIL I-MARQH 31 -Continued

YEAR

\begin{tabular}{|c|c|c|c|c|}
\hline & 1 & & 3 & \\
\hline $\begin{array}{l}1956 \\
1957 \\
1958 \\
1959 \\
1960\end{array}$ & $\begin{array}{c}12.0 \\
7.60 \\
36.0 \\
7.40 \\
6.20\end{array}$ & $\begin{array}{l}27 \\
15 \\
44 \\
14 \\
12\end{array}$ & $\begin{array}{c}14.0 \\
8.80 \\
37.0 \\
8.90 \\
6.90\end{array}$ & $\begin{array}{l}27 \\
16 \\
44 \\
17 \\
12\end{array}$ \\
\hline $\begin{array}{l}1961 \\
1962 \\
1963 \\
1964 \\
1965\end{array}$ & $\begin{array}{l}2.50 \\
1.90 \\
5.10 \\
9.40 \\
9.40\end{array}$ & $\begin{array}{r}5 \\
4 \\
9 \\
19 \\
20\end{array}$ & $\begin{array}{l}2.90 \\
1.90 \\
6.40 \\
9.80 \\
9.40\end{array}$ & $\begin{array}{r}4 \\
3 \\
10 \\
20 \\
19\end{array}$ \\
\hline $\begin{array}{l}1966 \\
1967 \\
1968 \\
1969 \\
1970\end{array}$ & $\begin{array}{c}138 \\
6.00 \\
14.0 \\
21.0 \\
12.0\end{array}$ & $\begin{array}{l}57 \\
10 \\
31 \\
36 \\
28\end{array}$ & $\begin{array}{c}165 \\
6.90 \\
16.0 \\
23.0 \\
14.0\end{array}$ & $\begin{array}{l}58 \\
11 \\
30 \\
36 \\
28\end{array}$ \\
\hline $\begin{array}{l}1971 \\
1972 \\
1973 \\
1974 \\
1975\end{array}$ & $\begin{array}{c}4.30 \\
29.0 \\
9.50 \\
39.0 \\
17.0\end{array}$ & $\begin{array}{r}8 \\
42 \\
21 \\
45 \\
33\end{array}$ & $\begin{array}{l}4.60 \\
30.0 \\
12.0 \\
45.0 \\
22.0\end{array}$ & $\begin{array}{r}7 \\
41 \\
23 \\
46 \\
34\end{array}$ \\
\hline $\begin{array}{l}1976 \\
1977 \\
1978 \\
1979 \\
1980\end{array}$ & $\begin{array}{c}8.60 \\
19.0 \\
8.20 \\
14.0 \\
50.0\end{array}$ & $\begin{array}{l}17 \\
34 \\
16 \\
32 \\
49\end{array}$ & $\begin{array}{c}8.60 \\
24.0 \\
8.90 \\
17.0 \\
50.0\end{array}$ & $\begin{array}{l}14 \\
37 \\
18 \\
31 \\
47\end{array}$ \\
\hline 1981 & 23.0 & 38 & 25.0 & 38 \\
\hline
\end{tabular}

CONSECITTVE DAYS

$\begin{array}{llllll}30 & 60 & 90 & 120 & 183 & \text { ALL }\end{array}$

7

15.024

$17.0 \quad 22$

$26.0 \quad 23$

\section{$27.0 \quad 19$}

$42.0 \quad 20$

42.0

98.0

$\begin{array}{cccc}9.80 & 14 & 12.0 & 15 \\ 43.0 & 44 & 59.0 & 46\end{array}$

$9.3013 \quad 59.0 \quad 46$

$\begin{array}{llll}9.30 & 13 & 10.0 & 11 \\ 9.10 & 12 & 11.0 & 13\end{array}$

$\begin{array}{rr}13.0 & 9 \\ 63.0 & 42\end{array}$

$\begin{array}{llllllllll}99.0 & 41 & 116 & 38 & 172 & 42 & 234 & 46 & 433\end{array}$

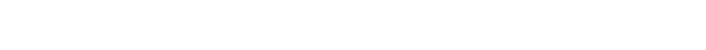

$\begin{array}{lll}11.0 & 13 & 14.0 \quad 10\end{array}$

$\begin{array}{llll}3.60 & 4 & 3.90 \quad 4\end{array}$

$4.60 \quad 4$

28.020

$\begin{array}{ccc}91.0 & 11 & 393 \\ 111 & 17 & 179\end{array}$

$\begin{array}{rrrr}2.20 & 3 & 2.80 & 3 \\ 7.20 & 10 & 8.20 & 7\end{array}$

$\begin{array}{rr}7.20 & 10 \\ 11.0 & 17\end{array}$

$\begin{array}{llll}11.0 & 17 & 13.0 & 16 \\ 10.0 & 15 & 11.0 & 14\end{array}$

$\begin{array}{rr}3.90 & 3 \\ 8.50 & 6\end{array}$

$\begin{array}{llll}8.50 & 6 & 12.0 & 7\end{array}$

$14.0 \quad 11 \quad 32.0 \quad 22$

$8.40 \quad 2$

$\begin{array}{lllll}11.0 & 2 & 49.0 & 4 & 137 \\ 22.0 & 5 & 41.0 & 3 & 182\end{array}$ $\begin{array}{lrlllrr}31.0 & 14 & 53.0 & 16 & 120 & 20 & 442\end{array}$ $\begin{array}{lllllll}63.0 & 29 & 57.0 & 20 & 112 & 18 & 222\end{array}$ $\begin{array}{rrrrrrr}20.0 & 8 & 35.0 & 9 & 122 & 22 & 352\end{array}$

31365

$14.0 \quad 12 \quad 14.0$

$\begin{array}{rrrr}184 & 59 & 313 & 65 \\ 12.0 & 19 & 14.0 & 17\end{array}$

$22.0 \quad 31$

$\begin{array}{llll}27.0 & 36 & 34.0 & 38\end{array}$

$392.69 \quad 400$

$39.0 \quad 32 \quad 52.0 \quad 16$

$\begin{array}{lllllllllll}58.0 & 39 & 106 & 43 & 120 & 39 & 145 & 39 & 220 & 43 & 530\end{array}$

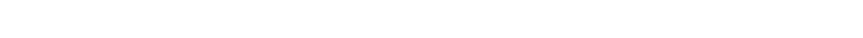

$\begin{array}{llll}6.80 \quad 9 & 10.0 \quad 12\end{array}$

$31.0 \quad 39$

$\begin{array}{llll}17.0 & 26 & 21.0 & 26\end{array}$

$\begin{array}{llll}49.0 & 46 & 56.0 & 45\end{array}$

$\begin{array}{lllllllllll}16.0 & 16 & 32.0 & 23 & 35.0 & 17 & 49.0 & 14 & 51.0 & 5 & 158\end{array}$

$\begin{array}{rllllllllll}32.0 & 27 & 34.0 & 25 & 55.0 & 27 & 99.0 & 29 & 168 & 30 & 404\end{array}$

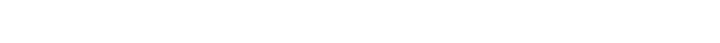

$\begin{array}{ccccccccccc}97.0 & 48 & 106 & 44 & 128 & 43 & 142 & 37 & 192 & 36 & 492 \\ 36.0 & 30 & 41.0 & 26 & 44.0 & 21 & 53.0 & 17 & 74.0 & 7 & 246\end{array}$

$\begin{array}{llll}14.0 & 21 \quad 19.0 \quad 25\end{array}$

$31.0 \quad 25$

$64.0 \quad 33$

$\begin{array}{llll}8.0 & 37 & 32.0 & 35\end{array}$

$\begin{array}{llll}11.0 & 18 & 16.0 & 20\end{array}$

36.031

19.020

31.026

$\begin{array}{ll}48.0 & 27\end{array}$

$\begin{array}{ccccccc}77.0 & 31 & 108 & 32 & 147 & 27 & 457\end{array}$

26.027

$21.0 \quad 14$

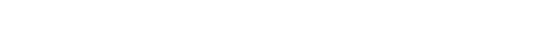

$\begin{array}{llll}50.0 & 47 & 51.0 & 42\end{array}$

$47.0 \quad 37$

HIGHEST MEAN DISCHARGE, IN OBIC FEET PER SECOND, AND RANKING FOR THE INDICATED NUMBER OF CONSECITIVE DAYS FOR EACH WATER YEAR, OCTCBER 1 -SEPTEMBER 30

YEAR

$\begin{array}{rrrr} & 1 & & 3 \\ 1912 & 6320 & 6 & 6250 \\ 1913 & 4160 & 21 & 3700 \\ 1914 & 6240 & 7 & 5890 \\ 1915 & 3770 & 28 & 3410 \\ 1916 & 4570 & 15 & 4410 \\ 1917 & 9690 & 1 & 9540 \\ 1918 & 4590 & 14 & 4530 \\ 1919 & 3380 & 38 & 3320 \\ 1920 & 5570 & 11 & 5430 \\ 1921 & 9350 & 2 & 9190 \\ 1922 & 8770 & 3 & 8560 \\ 1923 & 7120 & 4 & 6480 \\ 1924 & 3030 & 42 & 2840 \\ 1925 & 2250 & 52 & 2100 \\ 1926 & 3570 & 34 & 3310 \\ 1927 & 5700 & 9 & 3970 \\ 1928 & 4780 & 13 & 4480 \\ 1929 & 3750 & 29 & 3520 \\ 1930 & 4270 & 19 & 3930 \\ 1931 & 1180 & 63 & 1060 \\ 1932 & 3750 & 30 & 3530 \\ 1933 & 2480 & 51 & 2470 \\ 1934 & 451 & 69 & 425 \\ 1935 & 4300 & 17 & 4130 \\ 1936 & 3750 & 31 & 3310 \\ 1937 & 4040 & 24 & 3920 \\ 1938 & 3380 & 39 & 3350 \\ 1939 & 1200 & 62 & 1170 \\ 1940 & 1700 & 57 & 1650 \\ 1941 & 3930 & 26 & 3670 \\ 1942 & 3430 & 37 & 3140 \\ 1943 & 2700 & 46 & 2320 \\ 1944 & 4280 & 18 & 3900 \\ 1945 & 1720 & 55 & 1700 \\ & & & \end{array}$

CONSEOUTTVE DAVS

15

56010

$\begin{array}{rr}26 & 3540 \\ 7 & 5700\end{array}$

$33 \quad 3020$

$\begin{array}{rr}5 & 5100\end{array}$

$\begin{array}{rr}22 & 2970 \\ 6 & 5340\end{array}$

$\begin{array}{rr}6 & 5340 \\ 34 & 2920\end{array}$

30

144200

19260

133810

$\begin{array}{rr}13 & 8230\end{array}$ $12 \quad 3730$

$\begin{array}{llll}35 & 3090 & 33 & 2830\end{array}$

28870

38160

94650

$\begin{array}{ll}2 & 7520 \\ 3 & 7540 \\ 7 & 4410\end{array}$

5560

$\begin{array}{ll}43 & 2570 \\ 53 & 2010\end{array}$

$\begin{array}{rr}7 & 4410 \\ 43 & 2040\end{array}$

$\begin{array}{ll}43 & 2040 \\ 52 & 1830\end{array}$

$\begin{array}{ll}6 & 2880 \\ 8 & 3110\end{array}$

$18 \quad 3110$

134000

$37 \quad 2340$

$31 \quad 2820$

$14 \quad 3340$

$20 \quad 2780$

$63 \quad 812$

292970

$\begin{array}{rr}48 & 2370 \\ 69 & 386\end{array}$

$65 \quad 639$

$\begin{array}{ll}35 & 2640\end{array}$

$\begin{array}{ll}35 & 2640 \\ 45 & 2250\end{array}$

$\begin{array}{rr}45 & 2250 \\ 68 & 301\end{array}$

$\begin{array}{lr}68 & 301 \\ 17 & 2890\end{array}$

$37 \quad 3140$

$30 \quad 2960$

183140

$28 \quad 2910$

$\begin{array}{llll}62 & 1090 & 61 & 1050 \\ 57 & 1510 & 56 & 1250\end{array}$

$27 \quad 3430$

$38 \quad 2930$

$\begin{array}{ll}38 & 2930 \\ 49 & 2250\end{array}$

$25 \quad 3020$

$\begin{array}{ll}36 & 2460 \\ 47 & 1880\end{array}$

$\begin{array}{ll}47 & 1880 \\ 23 & 3110\end{array}$

$\begin{array}{ll}23 & 3110 \\ 55 & 1340\end{array}$ $\begin{array}{rr}6 & 4210 \\ 21 & 2400\end{array}$

$\begin{array}{lll}5 & 4650\end{array}$

$23 \quad 2540$

63050

$25 \quad 1910$

43620

13010

$\begin{array}{rr}1 & 6320 \\ 13 & 2740\end{array}$

$27 \quad 2120$

$11 \quad 2580$

2
18

$\begin{array}{ll}18 & 1850 \\ 35 & 1530\end{array}$

3990

82840

$\begin{array}{ll}3 & 6170 \\ 2 & 7030\end{array}$

$\begin{array}{ll}2 & 7030 \\ 9 & 4210\end{array}$

34210

\begin{tabular}{rr}
3 & 4210 \\
1 & 5230 \\
7 & 3420 \\
\hline 9 & 986
\end{tabular}

$\begin{array}{ll}46 & 1440 \\ 50 & 1390\end{array}$

$\begin{array}{rr}49 & 986 \\ 50 & 1170\end{array}$

$39 \quad 1760$

$\begin{array}{ll}28 & 2230 \\ 15 & 2790\end{array}$

$34 \quad 2240$

$41 \quad 1260$

$\begin{array}{ll}41 & 1260 \\ 29 & 1920\end{array}$

161970

$28 \quad 1770$

$65 \quad 529$

$\begin{array}{rr}65 & 529 \\ 33 & 2150\end{array}$

$\begin{array}{ll}33 & 2150 \\ 40 & 1660\end{array}$

$\begin{array}{lr}68 & 299 \\ 25 & 2010\end{array}$

$65 \quad 379$

$\begin{array}{rr}34 & 1900 \\ 46 & 993\end{array}$

$\begin{array}{ll}46 & 993 \\ 68 & 283\end{array}$

$\begin{array}{lr}68 & 283 \\ 36 & 1200\end{array}$

$\begin{array}{ll}26 & 2490 \\ 18 & 2590\end{array}$

$\begin{array}{ll}18 & 2590 \\ 24 & 2190\end{array}$

59
57

$\begin{array}{ll}23 & 1810 \\ 20 & 1870\end{array}$

$\begin{array}{ll}20 & 1870 \\ 32 & 1570\end{array}$

$\begin{array}{rr}32 & 1570 \\ 57 & 725\end{array}$

$20 \quad 2820$

$37 \quad 2190$

$\begin{array}{ll}48 & 1740 \\ 19 & 2650\end{array}$

$\begin{array}{ll}19 & 2650 \\ 54 & 1230\end{array}$

$15 \quad 2310$

$\begin{array}{ll}33 & 1440\end{array}$

$42 \quad 1570$

$\begin{array}{ll}19 & 2290 \\ 54 & 1090\end{array}$
90
$7 \quad 2260$

$\begin{array}{rr}7 & 2260 \\ 19 & 1520\end{array}$

$\begin{array}{rr}19 & 1520 \\ 5 & 2820\end{array}$

$23 \quad 1460$

$10 \quad 2050$

$\begin{array}{rr}2 & 3320 \\ 22 & 1430\end{array}$

331240

$\begin{array}{rr}33 & 1240 \\ 8 & 2080\end{array}$

33220

13850

$\begin{array}{rr}6 & 2720 \\ 51 & \end{array}$

$\begin{array}{ll}51 & 812 \\ 44 & 885\end{array}$

$\begin{array}{rr}40 & 968 \\ 18 & 1530\end{array}$

$\begin{array}{ll}18 & 1530 \\ 17 & 1440\end{array}$

$26 \quad 1350$

$\begin{array}{ll}26 & 1350 \\ 1120\end{array}$

$\begin{array}{ll}64 & 351 \\ 20 & 1450\end{array}$

$\begin{array}{rr}20 & 1450 \\ 49 & 750\end{array}$

$68 \quad 269$

$43 \quad 873$

$\begin{array}{ll}24 & 1400 \\ 21 & 1480\end{array}$

$\begin{array}{ll}21 & 1480 \\ 30 & 1270\end{array}$

$56 \quad 662$
$13 \quad 1700$

$\begin{array}{ll}36 & 1220 \\ 31 & 1330\end{array}$

$\begin{array}{ll}31 & 1330 \\ 14 & 1720\end{array}$

$\begin{array}{rr}14 & 1720 \\ 47 & 858\end{array}$
120

$7 \quad 1800$

$18 \quad 1300$

$\begin{array}{rr}5 & 2300 \\ 20 & 1190\end{array}$

9 1760

$\begin{array}{rr}3 & 2700 \\ 23 & 1160\end{array}$

$32 \quad 1050$

81690

$4 \quad 2590$

$\begin{array}{ll}1 & 3040 \\ 6 & 2220\end{array}$

$6 \quad 2220$

$\begin{array}{ll}48 & 727 \\ 41 & 729\end{array}$

$\begin{array}{rr}39 & 823 \\ 17 & 1240\end{array}$

$17 \quad 1240$

$\begin{array}{ll}22 & 1190 \\ 25 & 1130\end{array}$

$37 \quad 914$

$61 \quad 335$

$\begin{array}{ll}21 & 1180 \\ 50 & 628\end{array}$

$\begin{array}{ll}50 & 628 \\ 68 & 249\end{array}$

$43 \quad 702$

$\begin{array}{ll}24 & 1210 \\ 19 & 1230\end{array}$

$\begin{array}{ll}19 & 1230 \\ 30 & 1020\end{array}$

$\begin{array}{lr}56 & 573\end{array}$

59388

$\begin{array}{ll}14 & 1340 \\ 33 & 1020\end{array}$

$\begin{array}{ll}33 & 1020 \\ 26 & 1080\end{array}$

$\begin{array}{rr}26 & 1080 \\ 13 & 1420 \\ 45 & 732\end{array}$
183

$7 \quad 1300$

$\begin{array}{rr}16 & 1010 \\ 5 & 1670\end{array}$

81350

$\begin{array}{rr}2 & 2020 \\ 24 & 895 \\ 30 & 789\end{array}$

$\begin{array}{rr}30 & 789 \\ 9 & 1280\end{array}$

41910

12210

$\begin{array}{rr}44 & 622 \\ 43 & 574\end{array}$

$\begin{array}{rr}39 & 655 \\ 18 & 1110 \\ 22 & 896\end{array}$

$\begin{array}{ll}25 & 877 \\ 37 & 705\end{array}$

61 317

$\begin{array}{ll}23 & 894 \\ 52 & 501\end{array}$

$68 \quad 225$

$46 \quad 525$

$\begin{array}{lllll}20 & 876 & 25 & 522 & 29 \\ 19 & 929 & 19 & 589 & 22\end{array}$

$\begin{array}{lllll}19 & 929 & 19 & 589 & 22 \\ 31 & 772 & 33 & 507 & 30\end{array}$

$\begin{array}{lllll}56 & 489 & 55 & 343 & 51 \\ 59 & 335 & 59 & 231 & 60\end{array}$

$\begin{array}{lllll}14 & 972 & 17 & 625 & 16\end{array}$

$\begin{array}{lllll}32 & 816 & 30 & 556 & 25 \\ 27 & 833 & 27 & 523 & 28\end{array}$

$\begin{array}{rrrrr}27 & 833 & 27 & 523 & 28 \\ 12 & 1040 & 14 & 617 & 18\end{array}$ 
GREEN RIVER BASIN

09295000 DUGESNE RIVER AT MY'TON, UT--Continued

HIGHEST MEAN DISGHARGE, IN ABIC FEET PER SECOND, AND RANKING FOR THE INDICATED NUMBER OF CONSEQUTIVE DALS FOR EACH WATER YEAR, OCTCBER 1-SEPTEMBER 30--Continued

YEAR

$\begin{array}{rrrrrr}1946 & 1710 & 56 & 1650 & 56 & 1470 \\ 1947 & 2620 & 48 & 2580 & 45 & 2320 \\ 1948 & 2140 & 53 & 2140 & 52 & 2030 \\ 1949 & 5970 & 8 & 5320 & 9 & 4510 \\ 1950 & 3640 & 32 & 3470 & 31 & 3100 \\ 1951 & 3630 & 33 & 3570 & 28 & 3140 \\ 1952 & 6330 & 5 & 6220 & 6 & 6030 \\ 1953 & 4130 & 22 & 3900 & 23 & 3340 \\ 1954 & 974 & 65 & 944 & 65 & 859 \\ 1955 & 1600 & 58 & 1500 & 58 & 1180 \\ 1956 & 2990 & 43 & 2880 & 42 & 2570 \\ 1957 & 4040 & 23 & 3930 & 20 & 3540 \\ 1958 & 4490 & 16 & 4280 & 15 & 3870 \\ 1959 & 1060 & 64 & 1030 & 64 & 913 \\ 1960 & 884 & 67 & 833 & 67 & 716 \\ 1961 & 568 & 68 & 464 & 68 & 344 \\ 1962 & 3080 & 41 & 2990 & 40 & 2640 \\ 1963 & 1440 & 59 & 1260 & 60 & 1110 \\ 1964 & 2990 & 44 & 2580 & 46 & 2230 \\ 1965 & 5640 & 10 & 5220 & 11 & 4520 \\ 1966 & 1290 & 61 & 1230 & 61 & 992 \\ 1967 & 5490 & 12 & 5260 & 10 & 5110 \\ 1968 & 4250 & 20 & 4100 & 17 & 3880 \\ 1969 & 3940 & 25 & 3750 & 25 & 3580 \\ 1970 & 1400 & 60 & 1310 & 59 & 1140 \\ 1971 & 3530 & 35 & 3470 & 32 & 3300 \\ 1972 & 2650 & 47 & 2300 & 50 & 2240 \\ 1973 & 3450 & 36 & 2950 & 41 & 2710 \\ 1974 & 2600 & 50 & 2520 & 47 & 2180 \\ 1975 & 3870 & 27 & 3780 & 24 & 3450 \\ 1976 & 915 & 66 & 881 & 66 & 744 \\ 1977 & 205 & 70 & 182 & 70 & 160 \\ 1978 & 2940 & 45 & 2810 & 44 & 2670 \\ 1979 & 2610 & 49 & 2180 & 51 & 1770 \\ 1980 & 3240 & 40 & 3070 & 39 & 2700 \\ 1981 & 1910 & 54 & 1870 & 54 & 1610 \\ 190\end{array}$

CONSEQITIVE DAUS
30
60

15

$57 \quad 1380$
46

$46 \quad 1890$

$51 \quad 1830$

$32 \quad 2800$

$29 \quad 2420$

$\begin{array}{rr}4 & 5440 \\ 26 & 2510\end{array}$

$64 \quad 810$

$\begin{array}{ll}64 & 810 \\ 58 & 908\end{array}$

$44 \quad 2240$

$\begin{array}{ll}21 & 2810 \\ 16 & 3290\end{array}$

$\begin{array}{rr}16 & 3290 \\ 63 & 765\end{array}$

$\begin{array}{ll}67 & 567\end{array}$

$\begin{array}{lr}69 & 259\end{array}$

$60 \quad 962$

$\begin{array}{rr}60 & 962 \\ 49 & 1850\end{array}$

$\begin{array}{ll}49 & 1850 \\ 10 & 3910\end{array}$

62751

$\begin{array}{rr}8 & 4510 \\ 25 & 3200\end{array}$

$\begin{array}{ll}15 & 3200 \\ 19 & 3380\end{array}$

$\begin{array}{ll}19 & 3380 \\ 59 & 1090\end{array}$

$\begin{array}{ll}27 & 2790 \\ 48 & 2170\end{array}$

$\begin{array}{ll}48 & 2170 \\ 39 & 2240\end{array}$

$\begin{array}{ll}39 & 2240 \\ 50 & 1730\end{array}$

$\begin{array}{ll}50 & 1730 \\ 24 & 2950\end{array}$

$\begin{array}{ll}66 & 522 \\ 70 & 156\end{array}$

$\begin{array}{rr}70 & 156 \\ 41 & 2250 \\ 53 & 1320\end{array}$

$\begin{array}{ll}53 & 1320 \\ 40 & 2490\end{array}$

$54 \quad 1330$

$\begin{array}{ll}53 & 1250 \\ 47 & 1880 \\ 51 & 1390 \\ 12 & 2920 \\ 30 & 2780\end{array}$

$\begin{array}{rr}53 & 1110 \\ 39 & 1710 \\ 51 & 859 \\ 12 & 2330 \\ 17 & 1990\end{array}$

$38 \quad 2220$

$\begin{array}{rr}4 & 4490 \\ 35 & 1730\end{array}$

$\begin{array}{lr}62 & 534 \\ 61 & 788\end{array}$

$\begin{array}{rr}30 & 1630 \\ 5 & 4210 \\ 43 & 993\end{array}$

$\begin{array}{rr}43 & 4210 \\ 64 & 355\end{array}$

$\begin{array}{ll}64 & 355 \\ 60 & 617\end{array}$

$\begin{array}{ll}42 & 1900 \\ 29 & 2300\end{array}$

$\begin{array}{ll}29 & 2300 \\ 16 & 2470\end{array}$

$\begin{array}{rr}16 & 2470 \\ 63 & 543 \\ 66 & 483\end{array}$

$\begin{array}{ll}38 & 1210 \\ 26 & 1500\end{array}$

$\begin{array}{rr}24 & 1550 \\ 63 & 322 \\ 67 & 293\end{array}$

$\begin{array}{rrrr}69 & 249 & 69 & 242 \\ 45 & 1700 & 44 & 1400\end{array}$

$\begin{array}{rr}45 & 1700 \\ 60 & 894\end{array}$

$\begin{array}{rr}69 & 894 \\ 4630\end{array}$

$\begin{array}{ll}49 & 1630 \\ 10 & 3540\end{array}$

$\begin{array}{rr}44 & 1400 \\ 58 & 589\end{array}$

$\begin{array}{rr}58 & 589 \\ 47 & 1300\end{array}$

$\begin{array}{rr}47 & 1300 \\ 9 & 2610\end{array}$

$\begin{array}{rr}64 & 687 \\ 8 & 3480 \\ 17 & 2820 \\ 14 & 2820 \\ 58 & 835\end{array}$

$\begin{array}{lr}62 & 573 \\ 10 & 2380\end{array}$

$\begin{array}{ll}10 & 2380 \\ 13 & 1730\end{array}$

$\begin{array}{rr}13 & 1730 \\ 14 & 2160 \\ 59 & 487\end{array}$

$\begin{array}{ll}37 & 1250\end{array}$

31 1960

$43 \quad 2190$

$\begin{array}{ll}43 & 2190 \\ 52 & 1340\end{array}$

$\begin{array}{rr}45 & 992 \\ 31 & 1420\end{array}$

$\begin{array}{rr}31 & 1420 \\ 52 & 940\end{array}$

$\begin{array}{rr}52 & 940 \\ 21 & 1800\end{array}$

$\begin{array}{llll}67 & 513 & 66 & 417\end{array}$

$\begin{array}{rr}70 & 136 \\ 41 & 1570 \\ 56 & 994\end{array}$

$\begin{array}{ll}70 & 120 \\ 48 & 888\end{array}$

$\begin{array}{lr}48 & 888 \\ 55 & 819\end{array}$ $\begin{array}{ll}26 & 1500 \\ 24 & 1550\end{array}$

$\begin{array}{rr} & 90 \\ 46 & 847 \\ 28 & 1300 \\ 54 & 720 \\ 12 & 1880 \\ 16 & 1570\end{array}$

90

$\begin{array}{rr} & 120 \\ 47 & 719 \\ 27 & 1060 \\ 52 & 624 \\ 11 & 1540 \\ 16 & 1280\end{array}$

$\begin{array}{rrrrr} & 183 & & \text { ALL } \\ & & & & \\ 45 & 566 & 47 & 353 & 48 \\ 28 & 819 & 29 & 529 & 27 \\ 53 & 520 & 52 & 324 & 52 \\ 11 & 1120 & 11 & 630 & 13 \\ 17 & 963 & 18 & 596 & 21\end{array}$

$29 \quad 1200$
$4 \quad 3360$

$\begin{array}{rr}48 & 3360 \\ 48 & 712\end{array}$

$\begin{array}{ll}48 & 712 \\ 65 & 335\end{array}$

$34 \quad 957$

$\begin{array}{rr}2 & 2680 \\ 55 & 611\end{array}$

64333

$\begin{array}{ll}58 & 468\end{array}$

$42 \quad 882$

$\begin{array}{rr}34 & 1100 \\ 32 & 1150 \\ 66 & 283\end{array}$

$42 \quad 742$

$\begin{array}{ll}38 & 860 \\ 36 & 946 \\ 66 & 281\end{array}$

$\begin{array}{ll}66 & 281 \\ 67 & 275\end{array}$

$67 \quad 279$

$\begin{array}{rr}69 & 233 \\ 38 & 1280 \\ 58 & 401\end{array}$

$\begin{array}{ll}59 & 401 \\ 9\end{array}$

$\begin{array}{rr}69 & 220 \\ 28 & 1130\end{array}$

\begin{tabular}{rr}
60 & 326 \\
\hline
\end{tabular}

$\begin{array}{rr}40 & 755 \\ 10 & 1660\end{array}$

$\begin{array}{lr}59 & 574 \\ 11 & 1650\end{array}$

$\begin{array}{ll}27 & 1270\end{array}$

151740

$\begin{array}{rr}57 & 545 \\ 15 & 1310\end{array}$

$\begin{array}{ll}15 & 1310 \\ 31 & 1050\end{array}$

$\begin{array}{rr}31 & 1050 \\ 12 & 1410 \\ 63 & 261\end{array}$

$\begin{array}{rr}41 & 865 \\ 50 & 714 \\ 37 & 1160 \\ 52 & 729\end{array}$

$\begin{array}{rr}52 & 729 \\ 25 & 1280\end{array}$

$\begin{array}{rr}44 & 697 \\ 54 & 675\end{array}$

$35 \quad 1010$

$\begin{array}{lr}51 & 683 \\ 29 & 981\end{array}$

$\begin{array}{ll}62 & 346 \\ 70 & 111 \\ 53 & 715 \\ 55 & 778\end{array}$

$\begin{array}{ll}62 & 356 \\ 70 & 102\end{array}$

\begin{tabular}{ll}
70 & 102 \\
53 & 592 \\
\hline & 683
\end{tabular}

$\begin{array}{ll}49 & 683 \\ 46 & 661\end{array}$

61 405 $\begin{array}{rrrrr}35 & 723 & 35 & 482 & 35\end{array}$

$\begin{array}{rrrrr}54 & 543 & 49 & 376 & 44\end{array}$

$\begin{array}{lllll}62 & 332 & 60 & 205 & 63 \\ 58 & 392 & 58 & 256 & 57\end{array}$

$\begin{array}{lllll}41 & 602 & 41 & 347 & 50 \\ 38 & 650 & 39 & 409 & 41\end{array}$

$\begin{array}{lllll}64 & 238 & 66 & 169 & 67 \\ 65 & 266 & 64 & 173 & 66\end{array}$

$\begin{array}{lllll}69 & 156 & 69 & 98.0 & 69\end{array}$

$\begin{array}{lllll}26 & 861 & 26 & 500 & 33\end{array}$

$\begin{array}{lllll}40 & 582 & 42 & 218 & 61\end{array}$

$\begin{array}{rrrrr}40 & 582 & 44 & 349 & 49 \\ 10 & 1250 & 10 & 738 & 10\end{array}$

$\begin{array}{lllll}57 & 497 & 54 & 355 & 47\end{array}$

$\begin{array}{rrrrr}13 & 1070 & 13 & 626 & 15 \\ 67 & 211 & 68 & 174 & 65\end{array}$

$\begin{array}{lllll}47 \quad 536 & 50 & 296 & 55\end{array}$

$\begin{array}{lllll}50 & 577 & 45 & 362 & 46 \\ 33 & 790 & 31 & 504 & 32\end{array}$

$\begin{array}{lllll}48 & 588 & 42 & 381 & 43\end{array}$

$\begin{array}{lllll}60 & 309 & 63 & 206 & 62\end{array}$

$\begin{array}{ccccc}70 & 84.0 & 70 & 57.0 & 70 \\ 55 & 449 & 57 & 246 & 58\end{array}$

$\begin{array}{lllll}66 & 251 & 65 & 189 & 64\end{array}$ $\begin{array}{lllll}38 & 650 & 39 & 409 & 41 \\ 36 & 739 & 34 & 450 & 36\end{array}$

$\begin{array}{lllll}15 & 988 & 16 & 578 & 23 \\ 29 & 830 & 28 & 505 & 31\end{array}$

$\begin{array}{lllll}49 & 560 & 48 & 390 & 42 \\ 51 & 479 & 56 & 290 & 56\end{array}$

DURATION OF DISCHARGE FOR EAOH WATER YEAR

$\begin{array}{llllllllllllllllllllllllllllllllllll}\text { CLASS } & 0 & 1 & 2 & 3 & 4 & 5 & 6 & 7 & 8 & 9 & 10 & 11 & 12 & 13 & 14 & 15 & 16 & 17 & 18 & 19 & 20 & 21 & 22 & 23 & 24 & 25 & 26 & 27 & 28 & 29 & 30 & 31 & 32 & 33 & 34\end{array}$ YEAR

NUMBER OF DAYS IN CLASS

ABIC FEET PER SECOND

1912

1915

298133.0

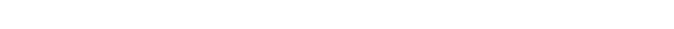
$\begin{array}{lllllllllllllll}11 & 67 & 82 & 72 & 36 & 7 & 16 & 21 & 4 & 12 & 15 & 17\end{array}$
376099.0

1916

1917
1918

$\begin{array}{llllllllllllll}19 & 45 & 102 & 52 & 42 & 23 & 17 & 23 & 13 & 11 & 14 & 5 & & \\ 513710.0\end{array}$

$\begin{array}{lllllllllllllllll}54 & 4 & 43 & 87 & 33 & 56 & 14 & 12 & 10 & 18 & 9 & 10 & 3 & 9 & 3 & 446780.0\end{array}$

1919

1920

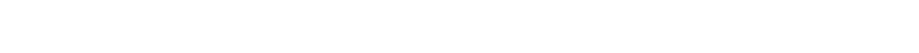

$\begin{array}{rrrrrrrrrrrrrrr}36 & 49 & 54 & 85 & 26 & 16 & 22 & 10 & 2 & 7 & 6 & & & 203404.0 \\ 1 & 103 & 99 & 86 & 11 & 6 & 6 & 12 & 6 & 9 & 16 & 8 & 3 & & 296041.0\end{array}$

229129.0

$\begin{array}{lllllllllllllll}43 & 81 & 82 & 49 & 15 & 22 & 23 & 8 & 7 & 7 & 13 & 5 & 10 & 429763.0\end{array}$

$2910370701411 \quad 8 \quad 5 \quad 7 \quad 9 \quad 8 \quad 2011$

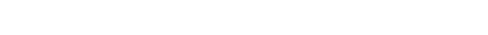

480975.0

$\begin{array}{lllllllllllllllllllllll}6 & 17 & 5 & 5 & 5 & 9 & 5 & 5 & 6 & 11 & 6 & 12 & 8 & 3 & 2 & 97106 & 31 & 10 & 4 & 5 & 3 & 5\end{array}$

1923

1925

$\begin{array}{llllllllllllllll}3 & 1 & 5 & 11 & 36 & 52 & 162 & 21 & 10 & 13 & 23 & 11 & 3 & 14\end{array}$

151225.0

1926

1927
1928

1929

$\begin{array}{lllllllllllllllllllll}2 & 3 & 3 & 11 & 25 & 2 & 7 & 6 & 13 & 9 & 22 & 81 & 72 & 56 & 11 & 11 & 8 & 12 & 4 & 5 & 2\end{array}$

$\begin{array}{rrrrrrrrrrrrrrr}5 & 42 & 23 & 97 & 54 & 21 & 23 & 3 & 8 & 30 & 22 & 8 & 22 & 6 & \\ 31 & 33 & 12 & 13 & 72 & 52 & 61 & 25 & 16 & 9 & 12 & 10 & 11 & 7 & 2\end{array}$

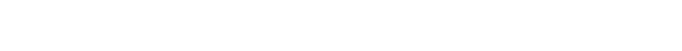

$\begin{array}{lllllllllllllllllllllll}1931 & 38 & 24 & 4 & 5 & 4 & 7 & 1 & 2 & 5 & 1 & 6 & 2 & 3 & 8 & 25 & 166 & 43 & 11 & 5 & 3 & 2\end{array}$

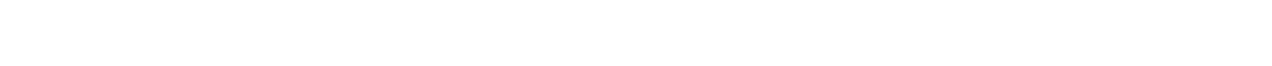

$\begin{array}{lllllllllllllllllllll}23 & 19 & 2 & 21 & 2 & 27 & 5 & 6 & 5 & 12 & 19 & 6 & 17 & 8 & 10 & 14 & 43 & 54 & 66 & 5 & 1\end{array}$

$\begin{array}{lllllllllllllllllll}6 & 8 & 4 & 8 & 6 & 9 & 9 & 15 & 13 & 12 & 7 & 7 & 15 & 15 & 59 & 105 & 14 & 5\end{array}$

163502.0

246070.0

227666.0

220744.0

179733.0

86051.0

198101.0

117047.0 
GREEN RIVER BASIN

09295000 DUOHESNE RIVER AT MYTON, UT-Continued

DURATION OF DISCHARGE FOR EAG WATER YEAR--Continued

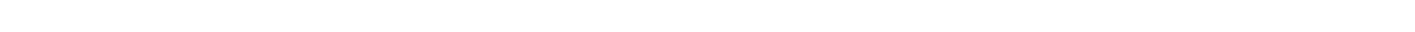
YEAR
1936
1937
1938
1939
1940
1941
1942
1943
1944
1945
1946
1947
1948
1949
1950
1951
1952
1953
1954
1955
1956
1957
1958
1959
1960
1961
1962
1963
1964
1965
1966
1967
1968
1969
1970
1971
1972
1973
1974
1975
1976
1977
1978
1979
1980
1981 MUMBER OF DAYS IN GLASS

बIBIC FEET

$\begin{array}{llllllllllllllllll}6 & 1 & 1 & 9 & 4 & 13 & 41 & 143 & 12 & 14 & 16 & 15 & 18 & 15 & 19 & 6 & 13 & 4\end{array}$ PER SECOND $\begin{array}{rrrrrrrrrrrrrrrrrr}5 & 6 & 2 & 2 & 6 & 21 & 19 & 50 & 72 & 78 & 15 & 20 & 13 & 17 & 12 & 10 & 11 & 6 \\ 5 & 2 & 5 & 7 & 11 & 4 & 20 & 77 & 115 & 32 & 11 & 11 & 18 & 18 & 11 & 6 & 5 & 7\end{array}$

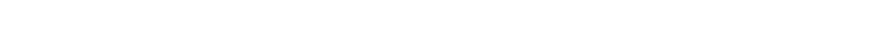

$\begin{array}{lllllllllllllllll}3 & 5 & 5 & 8 & 10 & 18 & 58 & 133 & 45 & 14 & 10 & 5 & 7 & 5 & 12 & 21 & 11\end{array}$

$\begin{array}{lllllllllllllllllll}11 & 15 & 4 & 14 & 7 & 11 & 10 & 3 & 6 & 12 & 111 & 70 & 36 & 16 & 10 & 6 & 12 & 10 & 1\end{array}$

$\begin{array}{llrrrrrrrrrrrrrrr}12 & 9 & 8 & 5 & 12 & 56 & 94 & 57 & 13 & 6 & 11 & 21 & 28 & 14 & 3\end{array}$

$\begin{array}{lrrrrrrrrrrrrrrrr}35 & 28 & 13 & 2 & 5 & 19 & 122 & 35 & 31 & 10 & 3 & 3 & 16 & 17 & 21 & 4 & 2\end{array}$

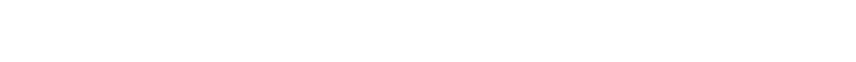

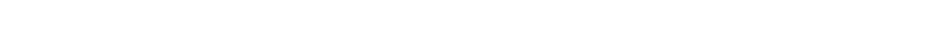

$\begin{array}{lllllllllllllllllllll}4 & 10 & 3 & 4 & 5 & 7 & 8 & 3 & 11 & 6 & 26 & 85 & 91 & 22 & 20 & 9 & 8 & 9 & 5 & 21 & 8\end{array}$

$\begin{array}{lllllllllllllllllll}9 & 8 & 3 & 1 & 6 & 6 & 30 & 30 & 63 & 62 & 67 & 26 & 6 & 3 & 5 & 19 & 7 & 9 & 5\end{array}$

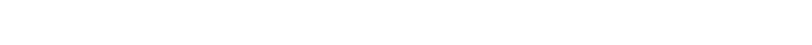

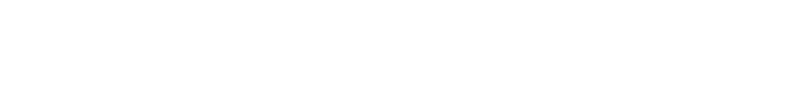

$\begin{array}{llllllllllllllllllllll}5 & 5 & 19 & 34 & 27 & 23 & 7 & 7 & 5 & 5 & 6 & 10 & 24 & 86 & 48 & 14 & 9 & 4 & 2 & 7 & 14 & 5\end{array}$

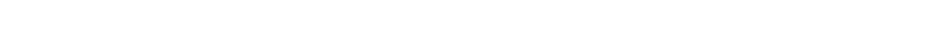

$\begin{array}{llllllllllllllllllll}3 & 6 & 18 & 31 & 28 & 32 & 13 & 10 & 12 & 21 & 11 & 14 & 9 & 44 & 82 & 14 & 3 & 8 & 3 & 3\end{array}$

$\begin{array}{lllllllllllllllllllllll}2 & 10 & 22 & 12 & 6 & 17 & 22 & 15 & 5 & 5 & 3 & 1 & 7 & 22 & 29 & 21 & 86 & 41 & 22 & 8 & 7 & 3\end{array}$

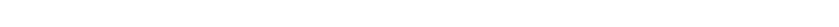

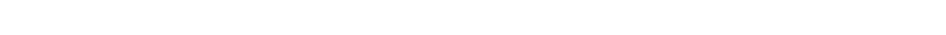

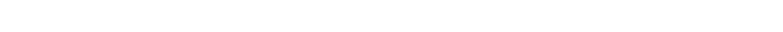

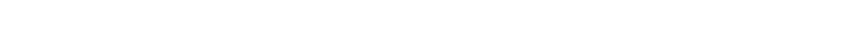

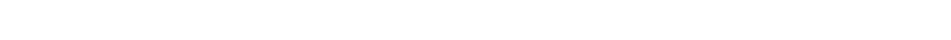

$\begin{array}{llllllllllllllllllll}1 & 2 & 5 & 5 & 20 & 19 & 23 & 9 & 6 & 6 & 5 & 3 & 7 & 7 & 15 & 92 & 94 & 32 & 11 & 3\end{array}$

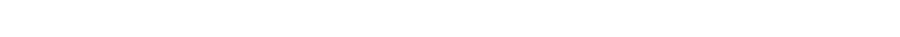

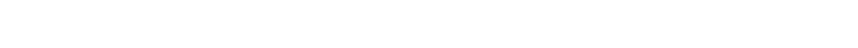

$\begin{array}{llllllllllllllllllllll}6 & 2 & 2 & 4 & 7 & 14 & 33 & 43 & 27 & 13 & 7 & 14 & 76 & 25 & 19 & 27 & 21 & 5 & 4 & 5 & 8 & 3\end{array}$

$\begin{array}{lllllllllllllllllll}5 & 67 & 58 & 25 & 27 & 22 & 13 & 16 & 44 & 29 & 14 & 5 & 9 & 4 & 5 & 8 & 2 & 5 & 7\end{array}$

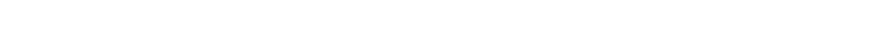

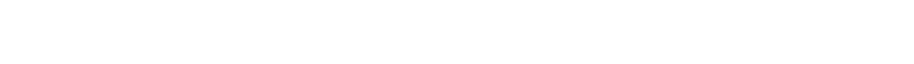

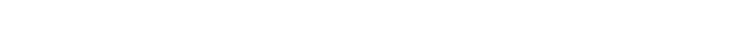

$\begin{array}{rrrrrrrrrrr}24 & 40 & 55 & 40 & 30 & 27 & 36 & 55 & 33 & 15 & 1 \\ 1 & 8 & 27 & 49 & 49 & 25 & 9 & 35 & 4 & 3 & 80\end{array}$

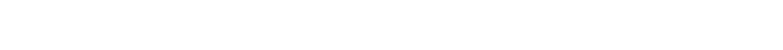

$\begin{array}{rlllllllllllllllll}8 & 15 & 60 & 33 & 64 & 41 & 41 & 32 & 16 & 9 & 10 & 4 & 5 & 8 & 6 & 5 & 8 & 1\end{array}$

$\begin{array}{llllllllllllllll}7 & 44 & 49 & 49 & 14 & 19 & 26 & 36 & 38 & 45 & 23 & 1 & 2 & 3 & 7 & 2\end{array}$

191132.0

214846.0

185104.0
125175.0

84658.0

227991.0

202960.0

190788.0

225941.0

128725.0

192971.0

118418.4

230011.8

217479.0

176060.0

401928.0

137110.0

74774.6

126989.2

149293.0

164339.2

61633.6

35930.3

182407.1
79727.8

79727.8
127872.0

269482.8

129519.8

211107.0

184682.0

228627.0

107896.0

132608.5

183947.0

138975.0

135261.8

DURATION TABLE OF DISCHARGE FOR WATER YEARS 1912-81

$\begin{array}{lcc}\text { OBBIC } & \text { ACOU- } \\ \text { FEET } & \text { MU- } & \text { PER- } \\ \text { PER TOTAL LATED } & \text { CENT }\end{array}$ CIASS SECOND DAYS DAYS DAYS

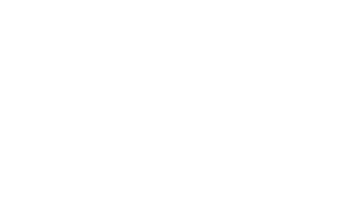

$\begin{array}{lcc}\text { AJBIC } & \text { ACOJ- } \\ \text { FEET } & \text { MU- } & \text { PER- } \\ \text { PER TOTAL LATED } & \text { CENT }\end{array}$

CLASS SECOND DAYS DAYS DAYS

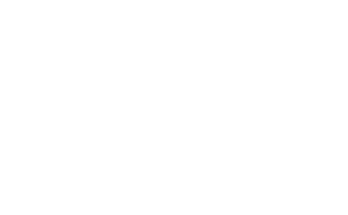

$\begin{array}{lll}\text { OUBIC } & \text { ACOU- } \\ \text { FEET } & \text { MU- } & \text { PER- } \\ \text { PER TOTAL L LATED } & \text { CENT }\end{array}$ GLASS SECOND DAYS DAYS DAYS

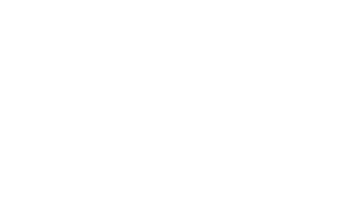

75218.0

20979.1

89966.0

142225.0

106272.0

68950.0 
GREEN RIVER BASIN

09295000 DUQHESNE RIVER AT MYTON, UT-Continued

MONTHLY MEAN DISCHARGES, IN OBIC FEET PER SECOND, FOR EAOH WATER YEAR

\begin{tabular}{|c|c|c|c|c|c|c|c|c|c|c|c|c|}
\hline YEAR & OCT & NOV & $\mathrm{DEC}$ & JAN & FEB & MAR & APR & MAY & JUNE & JULY & AUG & SEP \\
\hline $\begin{array}{l}1900 \\
1901 \\
1902\end{array}$ & $\begin{array}{l}403 \\
313 \\
322\end{array}$ & $\begin{array}{l}398 \\
305 \\
316\end{array}$ & $\begin{array}{l}323 \\
320 \\
300\end{array}$ & $\begin{array}{l}340 \\
280 \\
280\end{array}$ & $\begin{array}{l}340 \\
280 \\
280\end{array}$ & $\begin{array}{l}390 \\
299 \\
300\end{array}$ & $\begin{array}{l}467 \\
498 \\
656\end{array}$ & $\begin{array}{l}2327 \\
3169 \\
1969\end{array}$ & $\begin{array}{l}1702 \\
1485 \\
2239\end{array}$ & $\begin{array}{l}377 \\
597 \\
555\end{array}$ & $\begin{array}{l}271 \\
453 \\
273\end{array}$ & $\begin{array}{l}296 \\
307 \\
258\end{array}$ \\
\hline $\begin{array}{l}1912 \\
1913 \\
1914 \\
1915\end{array}$ & $\begin{array}{l}423 \\
489 \\
525 \\
479\end{array}$ & $\begin{array}{l}360 \\
456 \\
445 \\
379\end{array}$ & $\begin{array}{l}343 \\
338 \\
321 \\
317\end{array}$ & $\begin{array}{l}300 \\
280 \\
395 \\
310\end{array}$ & $\begin{array}{l}280 \\
300 \\
380 \\
320\end{array}$ & $\begin{array}{l}354 \\
408 \\
491 \\
356\end{array}$ & $\begin{array}{l}423 \\
662 \\
947 \\
554\end{array}$ & $\begin{array}{l}1469 \\
2023 \\
3345 \\
1093\end{array}$ & $\begin{array}{l}4154 \\
1656 \\
3778 \\
2508\end{array}$ & $\begin{array}{r}1087 \\
745 \\
1028 \\
507\end{array}$ & $\begin{array}{l}313 \\
253 \\
397 \\
133\end{array}$ & $\begin{array}{l}299 \\
657 \\
292 \\
379\end{array}$ \\
\hline $\begin{array}{l}1916 \\
1917 \\
1918 \\
1919 \\
1920\end{array}$ & $\begin{array}{l}471 \\
659 \\
475 \\
537 \\
372\end{array}$ & $\begin{array}{l}373 \\
410 \\
497 \\
456 \\
379\end{array}$ & $\begin{array}{l}376 \\
278 \\
466 \\
415 \\
303\end{array}$ & $\begin{array}{l}370 \\
245 \\
331 \\
260 \\
290\end{array}$ & $\begin{array}{l}400 \\
565 \\
390 \\
350 \\
375\end{array}$ & $\begin{array}{l}879 \\
852 \\
398 \\
632 \\
522\end{array}$ & $\begin{array}{r}1042 \\
800 \\
341 \\
650 \\
456\end{array}$ & $\begin{array}{r}2151 \\
1708 \\
830 \\
2056 \\
2213\end{array}$ & $\begin{array}{r}2874 \\
5767 \\
2735 \\
770 \\
3288\end{array}$ & $\begin{array}{r}627 \\
2372 \\
680 \\
109 \\
653\end{array}$ & $\begin{array}{l}459 \\
528 \\
129 \\
139 \\
545\end{array}$ & $\begin{array}{l}269 \\
525 \\
280 \\
292 \\
322\end{array}$ \\
\hline $\begin{array}{l}1921 \\
1922 \\
1923 \\
1924 \\
1925\end{array}$ & $\begin{array}{l}427 \\
360 \\
408 \\
579 \\
178\end{array}$ & $\begin{array}{l}497 \\
352 \\
542 \\
502 \\
268\end{array}$ & $\begin{array}{l}350 \\
518 \\
508 \\
443 \\
276\end{array}$ & $\begin{array}{l}325 \\
400 \\
425 \\
400 \\
262\end{array}$ & $\begin{array}{l}486 \\
425 \\
400 \\
480 \\
280\end{array}$ & $\begin{array}{l}688 \\
660 \\
468 \\
433 \\
278\end{array}$ & $\begin{array}{l}559 \\
692 \\
755 \\
528 \\
251\end{array}$ & $\begin{array}{l}1925 \\
3941 \\
2868 \\
1351 \\
1157\end{array}$ & $\begin{array}{r}6154 \\
6356 \\
3681 \\
407 \\
1051\end{array}$ & $\begin{array}{c}1504 \\
1006 \\
1489 \\
56.8 \\
387\end{array}$ & $\begin{array}{l}695 \\
619 \\
527 \\
27.6 \\
233\end{array}$ & $\begin{array}{c}551 \\
481 \\
379 \\
73.5 \\
346\end{array}$ \\
\hline $\begin{array}{l}1926 \\
1927 \\
1928 \\
1929 \\
1930\end{array}$ & $\begin{array}{l}430 \\
118 \\
761 \\
317 \\
284\end{array}$ & $\begin{array}{l}347 \\
173 \\
522 \\
324 \\
302\end{array}$ & $\begin{array}{l}343 \\
231 \\
383 \\
309 \\
290\end{array}$ & $\begin{array}{l}298 \\
250 \\
325 \\
325 \\
300\end{array}$ & $\begin{array}{l}422 \\
273 \\
334 \\
325 \\
325\end{array}$ & $\begin{array}{l}334 \\
375 \\
455 \\
400 \\
291\end{array}$ & $\begin{array}{l}498 \\
380 \\
390 \\
403 \\
493\end{array}$ & $\begin{array}{r}1490 \\
1591 \\
2506 \\
1286 \\
958\end{array}$ & $\begin{array}{r}854 \\
2149 \\
1337 \\
2139 \\
1886\end{array}$ & $\begin{array}{l}142 \\
747 \\
187 \\
580 \\
161\end{array}$ & $\begin{array}{l}170 \\
218 \\
144 \\
374 \\
399\end{array}$ & $\begin{array}{c}43.8 \\
1597 \\
96.3 \\
480 \\
235\end{array}$ \\
\hline $\begin{array}{l}1931 \\
1932 \\
1933 \\
1934 \\
1935\end{array}$ & $\begin{array}{c}379 \\
38.0 \\
177 \\
39.6 \\
4.81\end{array}$ & $\begin{array}{c}308 \\
178 \\
217 \\
174 \\
58.8\end{array}$ & $\begin{array}{l}290 \\
300 \\
221 \\
254 \\
206\end{array}$ & $\begin{array}{l}280 \\
330 \\
250 \\
275 \\
190\end{array}$ & $\begin{array}{l}280 \\
350 \\
250 \\
274 \\
171\end{array}$ & $\begin{array}{l}298 \\
372 \\
297 \\
177 \\
203\end{array}$ & $\begin{array}{l}247 \\
364 \\
231 \\
140 \\
198\end{array}$ & $\begin{array}{r}451 \\
1553 \\
410 \\
163 \\
441\end{array}$ & $\begin{array}{c}245 \\
2125 \\
1569 \\
17.8 \\
1924\end{array}$ & $\begin{array}{c}33.2 \\
572 \\
160 \\
8.65 \\
148\end{array}$ & $\begin{array}{c}10.9 \\
187 \\
68.7 \\
11.7 \\
87.2\end{array}$ & $\begin{array}{c}6.43 \\
133 \\
14.5 \\
1.37 \\
25.7\end{array}$ \\
\hline $\begin{array}{l}1936 \\
1937 \\
1938 \\
1939 \\
1940\end{array}$ & $\begin{array}{l}38.9 \\
168 \\
217 \\
357 \\
217\end{array}$ & $\begin{array}{l}176 \\
250 \\
255 \\
401 \\
178\end{array}$ & $\begin{array}{l}196 \\
300 \\
317 \\
367 \\
217\end{array}$ & $\begin{array}{l}210 \\
325 \\
258 \\
320 \\
240\end{array}$ & $\begin{array}{l}210 \\
350 \\
314 \\
300 \\
250\end{array}$ & $\begin{array}{l}190 \\
400 \\
302 \\
486 \\
267\end{array}$ & $\begin{array}{l}490 \\
578 \\
553 \\
513 \\
141\end{array}$ & $\begin{array}{r}2166 \\
2380 \\
1401 \\
895 \\
818\end{array}$ & $\begin{array}{r}1312 \\
1271 \\
1706 \\
258 \\
225\end{array}$ & $\begin{array}{c}545 \\
562 \\
314 \\
22.7 \\
7.65\end{array}$ & $\begin{array}{c}422 \\
179 \\
82.2 \\
17.3 \\
5.13\end{array}$ & $\begin{array}{l}297 \\
278 \\
376 \\
174 \\
206\end{array}$ \\
\hline $\begin{array}{l}1941 \\
1942 \\
1943 \\
1944 \\
1945\end{array}$ & $\begin{array}{l}355 \\
498 \\
158 \\
184 \\
217\end{array}$ & $\begin{array}{l}317 \\
509 \\
252 \\
269 \\
265\end{array}$ & $\begin{array}{l}326 \\
448 \\
321 \\
298 \\
344\end{array}$ & $\begin{array}{l}265 \\
424 \\
311 \\
272 \\
351\end{array}$ & $\begin{array}{l}292 \\
410 \\
356 \\
300 \\
350\end{array}$ & $\begin{array}{l}233 \\
422 \\
350 \\
447 \\
329\end{array}$ & $\begin{array}{l}305 \\
841 \\
682 \\
493 \\
260\end{array}$ & $\begin{array}{c}2003 \\
1049 \\
1516 \\
1539 \\
911\end{array}$ & $\begin{array}{l}2556 \\
1763 \\
1624 \\
2614 \\
1216\end{array}$ & $\begin{array}{l}436 \\
218 \\
417 \\
855 \\
411\end{array}$ & $\begin{array}{l}223 \\
55.1 \\
235 \\
71.0 \\
341\end{array}$ & $\begin{array}{c}180 \\
52.0 \\
49.5 \\
66.5 \\
96.2\end{array}$ \\
\hline $\begin{array}{l}1946 \\
1947 \\
1948 \\
1949 \\
1950\end{array}$ & $\begin{array}{l}151 \\
173 \\
113 \\
34.0 \\
216\end{array}$ & $\begin{array}{l}273 \\
385 \\
319 \\
172 \\
321\end{array}$ & $\begin{array}{l}282 \\
368 \\
337 \\
292 \\
294\end{array}$ & $\begin{array}{l}276 \\
305 \\
326 \\
270 \\
350\end{array}$ & $\begin{array}{l}265 \\
394 \\
325 \\
285 \\
324\end{array}$ & $\begin{array}{l}331 \\
389 \\
402 \\
445 \\
408\end{array}$ & $\begin{array}{l}637 \\
331 \\
377 \\
714 \\
632\end{array}$ & $\begin{array}{r}1107 \\
1758 \\
982 \\
1770 \\
1302\end{array}$ & $\begin{array}{r}753 \\
1604 \\
657 \\
2819 \\
2581\end{array}$ & $\begin{array}{c}62.3 \\
366 \\
25.0 \\
659 \\
528\end{array}$ & $\begin{array}{l}60.6 \\
180 \\
11.5 \\
51.4 \\
63.3\end{array}$ & $\begin{array}{c}34.6 \\
88.0 \\
10.9 \\
58.2 \\
146\end{array}$ \\
\hline $\begin{array}{l}1951 \\
1952 \\
1953 \\
1954 \\
1955\end{array}$ & $\begin{array}{l}170 \\
207 \\
187 \\
71.9 \\
165\end{array}$ & $\begin{array}{l}330 \\
349 \\
314 \\
255 \\
209\end{array}$ & $\begin{array}{l}390 \\
348 \\
430 \\
334 \\
229\end{array}$ & $\begin{array}{l}290 \\
280 \\
440 \\
320 \\
252\end{array}$ & $\begin{array}{l}341 \\
290 \\
390 \\
340 \\
250\end{array}$ & $\begin{array}{l}284 \\
300 \\
388 \\
282 \\
368\end{array}$ & $\begin{array}{r}191 \\
1293 \\
166 \\
185 \\
279\end{array}$ & $\begin{array}{r}1102 \\
4185 \\
182 \\
513 \\
671\end{array}$ & $\begin{array}{c}1922 \\
4154 \\
1707 \\
54.7 \\
508\end{array}$ & $\begin{array}{l}452 \\
955 \\
176 \\
23.5 \\
30.5\end{array}$ & $\begin{array}{c}265 \\
492 \\
127 \\
19.9 \\
84.1\end{array}$ & $\begin{array}{c}56.3 \\
328 \\
24.2 \\
64.3 \\
28.0\end{array}$ \\
\hline $\begin{array}{l}1956 \\
1957 \\
1958 \\
1959 \\
1960\end{array}$ & $\begin{array}{l}26.0 \\
42.6 \\
142 \\
22.8 \\
114\end{array}$ & $\begin{array}{l}152 \\
219 \\
416 \\
170 \\
161\end{array}$ & $\begin{array}{l}355 \\
257 \\
344 \\
278 \\
262\end{array}$ & $\begin{array}{l}335 \\
280 \\
329 \\
271 \\
252\end{array}$ & $\begin{array}{l}295 \\
271 \\
381 \\
300 \\
250\end{array}$ & $\begin{array}{l}314 \\
244 \\
327 \\
212 \\
332\end{array}$ & $\begin{array}{c}249 \\
116 \\
341 \\
55.2 \\
105\end{array}$ & $\begin{array}{c}1089 \\
521 \\
1769 \\
59.3 \\
257\end{array}$ & $\begin{array}{r}1271 \\
2262 \\
1274 \\
540 \\
316\end{array}$ & $\begin{array}{l}49.9 \\
485 \\
40.0 \\
62.5 \\
15.0\end{array}$ & $\begin{array}{c}20.9 \\
128 \\
11.5 \\
43.0 \\
5.15\end{array}$ & $\begin{array}{c}13.1 \\
105 \\
28.8 \\
28.9 \\
7.49\end{array}$ \\
\hline $\begin{array}{l}1961 \\
1962 \\
1963 \\
1964 \\
1965\end{array}$ & $\begin{array}{l}19.5 \\
137 \\
118 \\
38.0 \\
26.4\end{array}$ & $\begin{array}{l}118 \\
260 \\
179 \\
179 \\
196\end{array}$ & $\begin{array}{l}211 \\
272 \\
268 \\
296 \\
301\end{array}$ & $\begin{array}{l}241 \\
249 \\
245 \\
244 \\
272\end{array}$ & $\begin{array}{l}241 \\
456 \\
346 \\
240 \\
246\end{array}$ & $\begin{array}{l}113 \\
581 \\
103 \\
294 \\
274\end{array}$ & $\begin{array}{c}9.43 \\
1028 \\
25.7 \\
199 \\
400\end{array}$ & $\begin{array}{c}53.8 \\
1101 \\
459 \\
882 \\
994\end{array}$ & $\begin{array}{r}23.1 \\
1662 \\
705 \\
1451 \\
3207\end{array}$ & $\begin{array}{c}5.01 \\
250 \\
18.5 \\
334 \\
1799\end{array}$ & $\begin{array}{r}13.6 \\
11.2 \\
53.8 \\
27.7 \\
542\end{array}$ & $\begin{array}{l}142 \\
17.5 \\
117 \\
14.4 \\
600\end{array}$ \\
\hline $\begin{array}{l}1966 \\
1967 \\
1968 \\
1969 \\
1970\end{array}$ & $\begin{array}{l}492 \\
64.9 \\
76.6 \\
158 \\
192\end{array}$ & $\begin{array}{l}519 \\
226 \\
189 \\
308 \\
270\end{array}$ & $\begin{array}{l}403 \\
301 \\
343 \\
379 \\
211\end{array}$ & $\begin{array}{l}405 \\
326 \\
387 \\
428 \\
143\end{array}$ & $\begin{array}{l}455 \\
366 \\
408 \\
407 \\
132\end{array}$ & $\begin{array}{c}563 \\
415 \\
414 \\
433 \\
62.5\end{array}$ & $\begin{array}{l}488 \\
259 \\
346 \\
902 \\
15.6\end{array}$ & $\begin{array}{r}657 \\
688 \\
607 \\
2703 \\
259\end{array}$ & $\begin{array}{r}193 \\
3154 \\
2808 \\
1536 \\
658\end{array}$ & $\begin{array}{c}36.1 \\
1044 \\
244 \\
140 \\
84.7\end{array}$ & $\begin{array}{c}18.2 \\
72.9 \\
211 \\
46.2 \\
33.0\end{array}$ & $\begin{array}{l}31.9 \\
47.1 \\
59.4 \\
66.3 \\
32.1\end{array}$ \\
\hline $\begin{array}{l}1971 \\
1972 \\
1973 \\
1974 \\
1975\end{array}$ & $\begin{array}{l}69.5 \\
167 \\
203 \\
164 \\
39.8\end{array}$ & $\begin{array}{c}94.1 \\
313 \\
326 \\
230 \\
56.3\end{array}$ & $\begin{array}{l}34.3 \\
300 \\
369 \\
349 \\
81.5\end{array}$ & $\begin{array}{l}136 \\
314 \\
371 \\
393 \\
133\end{array}$ & $\begin{array}{c}256 \\
495 \\
386 \\
437 \\
98.8\end{array}$ & $\begin{array}{l}237 \\
539 \\
593 \\
531 \\
70.0\end{array}$ & $\begin{array}{l}121 \\
169 \\
576 \\
274 \\
34.8\end{array}$ & $\begin{array}{r}393 \\
472 \\
1375 \\
980 \\
186\end{array}$ & $\begin{array}{r}1927 \\
1495 \\
1438 \\
864 \\
1740\end{array}$ & $\begin{array}{c}237 \\
56.0 \\
195 \\
151 \\
1807\end{array}$ & $\begin{array}{l}32.7 \\
27.2 \\
98.1 \\
155 \\
116\end{array}$ & $\begin{array}{c}38.4 \\
27.5 \\
121 \\
42.6 \\
71.3\end{array}$ \\
\hline
\end{tabular}


MONTHLY MEAN DISCHARGES, IN OUBIC FEET PER SECOND, FOR EACH WATER YEAR--Continued

\begin{tabular}{|c|c|c|c|c|c|c|c|c|c|c|c|c|}
\hline YEAR & $\infty T$ & $\mathrm{NON}$ & DEC & JAN & FEB & MAR & APR & MAY & JUNE & JULY & AUG & SEP \\
\hline $\begin{array}{l}1976 \\
1977 \\
1978 \\
1979 \\
1980\end{array}$ & $\begin{array}{r}77.2 \\
38.5 \\
26.3 \\
35.6 \\
125\end{array}$ & $\begin{array}{c}186 \\
64.0 \\
35.6 \\
192 \\
131\end{array}$ & $\begin{array}{l}247 \\
83.5 \\
63.6 \\
221 \\
103\end{array}$ & $\begin{array}{l}200 \\
100 \\
134 \\
219 \\
105\end{array}$ & $\begin{array}{l}336 \\
121 \\
200 \\
276 \\
144\end{array}$ & $\begin{array}{l}484 \\
102 \\
217 \\
573 \\
118\end{array}$ & $\begin{array}{c}133 \\
23.7 \\
354 \\
743 \\
174\end{array}$ & $\begin{array}{l}344 \\
42.7 \\
220 \\
847 \\
378\end{array}$ & $\begin{array}{c}303 \\
47.0 \\
1562 \\
498 \\
1787\end{array}$ & $\begin{array}{l}51.7 \\
24.2 \\
100 \\
266 \\
276\end{array}$ & $\begin{array}{c}45.0 \\
23.0 \\
36.7 \\
427 \\
49.1\end{array}$ & $\begin{array}{r}62.9 \\
23.1 \\
36.0 \\
375 \\
118\end{array}$ \\
\hline 1981 & 153 & 259 & 357 & 203 & 148 & 130 & 63.5 & 118 & 686 & 50.4 & 46.8 & 57.4 \\
\hline
\end{tabular}

ANNUAL PEAK DISCHARGE, IN OBBIC FEET PER SECOND, AND CORRESPONDING GAGE HEIGHT, IN FEET, FOR EACH WATER YEAR

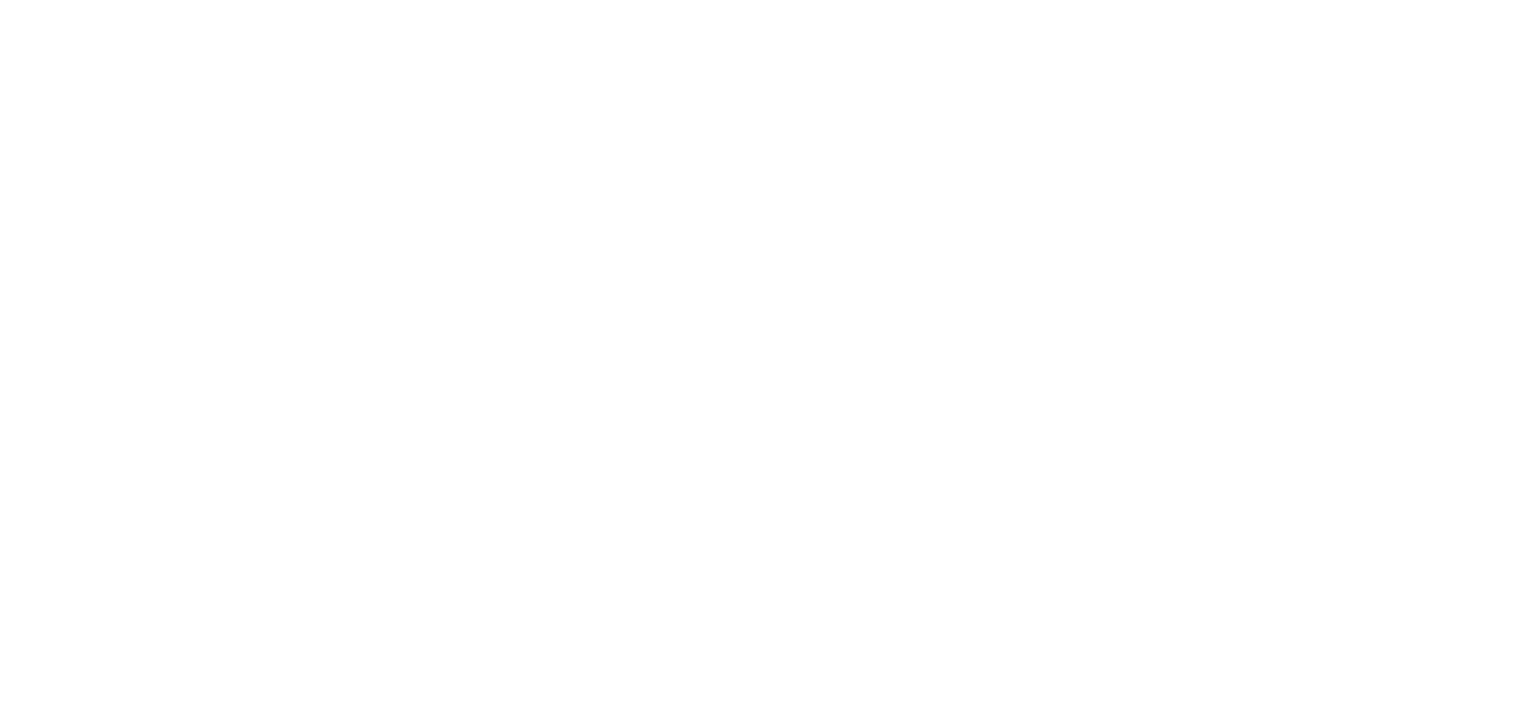

\begin{tabular}{|c|c|c|c|c|c|c|}
\hline \multirow{2}{*}{$\begin{array}{l}\text { PERIOD } \\
\text { (CON- } \\
\text { SECU- } \\
\text { PIVE } \\
\text { DAYS) }\end{array}$} & \multicolumn{6}{|c|}{$\begin{array}{l}\text { DISCHARGE, IN OUBIC FEET PER SECOND, FOR } \\
\text { INDICATED RECURRENCE INTERNAL, IN YEARS, AND } \\
\text { ANNUAL NONEXCEEDANCE PRCBABILITY, IN PERCENT }\end{array}$} \\
\hline & $\begin{array}{c}2 \\
50 z\end{array}$ & $\begin{array}{c}5 \\
208\end{array}$ & $\begin{array}{l}10 \\
108\end{array}$ & $\begin{array}{l}20 \\
58\end{array}$ & $\begin{array}{l}50 \\
28\end{array}$ & $\begin{array}{r}100 \\
18\end{array}$ \\
\hline $\begin{array}{r}1 \\
7 \\
14 \\
30 \\
60 \\
90\end{array}$ & $\begin{array}{l}23 \\
30 \\
38 \\
50 \\
70 \\
92\end{array}$ & $\begin{array}{l}6.6 \\
9.2 \\
11 \\
16 \\
23 \\
34\end{array}$ & $\begin{array}{l}3.5 \\
4.9 \\
6.0 \\
8.3 \\
12 \\
19\end{array}$ & $\begin{array}{c}2.1 \\
2.9 \\
3.4 \\
4.8 \\
6.8 \\
12\end{array}$ & $\begin{array}{l}1 . \\
1 . \\
1 . \\
2 . \\
3 . \\
6 .\end{array}$ & $\begin{array}{l}0.7 \\
1.1 \\
1.2 \\
1.6 \\
2.2 \\
4.4\end{array}$ \\
\hline
\end{tabular}

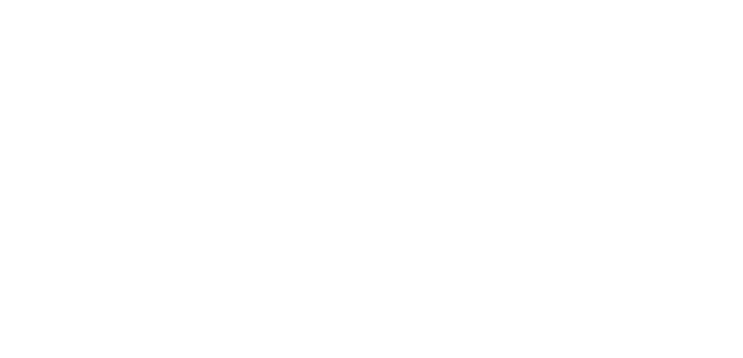

09295500 UINTA RIVER BELOW GILBERT CREER, NEAR NEOLA, UT

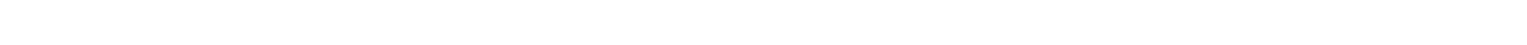
on left bank $27 \mathrm{mi}$ northwest of Neola.

DRATNAGE AREA. ---33 $\mathrm{mi}^{2}$, approximately.

PERIOD OF RECORD AVAILABLE.--August 1950 to September 1955.

GAGE.-Water-stage recorder. Altitude of gage is 9,950 ft fron topographic map.

AVERAGE DISCHARGE. -5 years, $39.8 \mathrm{ft}^{3} / \mathrm{s}, 28,810$ acre-ft/yr.

EXIREMES FOR PERIOD OF RECORD.--Maximum discharge recorded, $971 \mathrm{ft}^{3} / \mathrm{s}$ June 13, 1953, gage height, 4.88 ft, fram rating curve extended above $260 \mathrm{ft}^{3} / \mathrm{s}$ on basis of slope-area measurements at gage heights $4.03 \mathrm{ft}$ and $4.88 \mathrm{ft}$; minimum not determined. 
GREEN RIVER BASIN

09295500 UINTA RIVER BELOW GIIBERT CREEK, NEAR NEOLA, UT-Continued

LOWEST MEAN DISCHARGE, IN OUBIC FEET PER SECOND, AND RANKING FOR THE INDICATED NUMBER OF CONSECUTIVE DAYS FOR EACH CLIMATIC YEAR, APRIL 1-MARCH 31

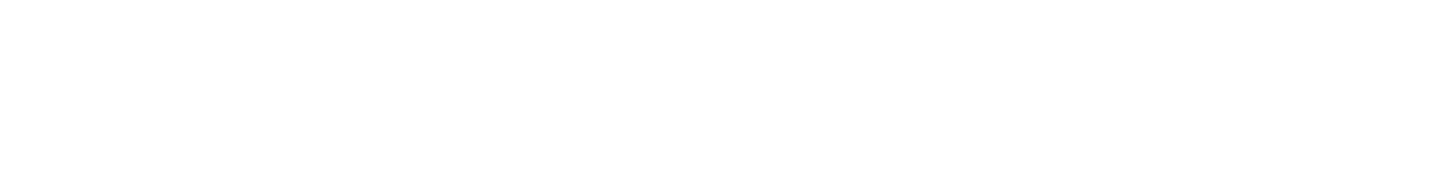

HIGHEST MEAN DISCHARGE, IN OUBIC FEET PER SECOND, AND RANKING FOR THE INDICATED NUMBER OF CONSECUTIVE DAYS FOR EACH WATER YEAR, OCTCBER 1-SEPTEMBER 30

\begin{tabular}{llllllll} 
YEAR & \multicolumn{1}{c}{3} & & 7 & & & & \\
& 1 & & \multicolumn{2}{c}{3} & & & \\
1951 & 515 & 2 & 497 & 2 & 381 & 3 & 225 \\
1952 & 500 & 3 & 467 & 3 & 416 & 2 & 3 \\
1953 & 757 & 1 & 621 & 1 & 467 & 1 & 336 \\
1954 & 340 & 4 & 273 & 4 & 229 & 4 & 220 \\
1955 & 299 & 5 & 260 & 5 & 203 & 5 & 156
\end{tabular}

\begin{tabular}{|c|c|c|c|c|c|c|c|c|c|c|c|}
\hline 15 & $\begin{array}{l}\infty \\
30\end{array}$ & & $\begin{array}{l}\text { VE DAYS } \\
60\end{array}$ & & 90 & & 120 & & 183 & & ALL \\
\hline $\begin{array}{l}3 \\
1 \\
2 \\
4 \\
5\end{array}$ & $\begin{array}{l}205 \\
273 \\
222 \\
144 \\
119\end{array}$ & $\begin{array}{l}3 \\
1 \\
2 \\
4 \\
5\end{array}$ & $\begin{array}{c}148 \\
219 \\
148 \\
99.0 \\
99.0\end{array}$ & $\begin{array}{l}3 \\
1 \\
2 \\
4 \\
5\end{array}$ & $\begin{array}{r}122 \\
188 \\
117 \\
80.0 \\
78.0\end{array}$ & $\begin{array}{l}2 \\
1 \\
3 \\
4 \\
5\end{array}$ & $\begin{array}{c}101 \\
162 \\
94.0 \\
67.0 \\
68.0\end{array}$ & $\begin{array}{l}2 \\
1 \\
3 \\
5 \\
4\end{array}$ & $\begin{array}{r}70.0 \\
117 \\
66.0 \\
50.0 \\
50.0\end{array}$ & $\begin{array}{l}2 \\
1 \\
3 \\
4 \\
5\end{array}$ & $\begin{array}{l}38.0 \\
64.0 \\
38.0 \\
29.0 \\
30.0\end{array}$ \\
\hline
\end{tabular}

DURATION OF DISCHARGE FOR EACH WATER YEAR

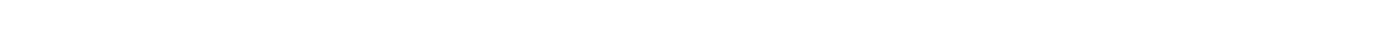
YEAR

NUMBER OF DAYS IN CLAASS

CABIC FEET PER SEOOND -DAYS

$\begin{array}{llllllllllllllllllllllllllllllllllllllll}1951 & 105 & 46 & 30 & 19 & 26 & 4 & 6 & 4 & 5 & 6 & 2 & 5 & 2 & 12 & 5 & 9 & 22 & 8 & 5 & 4 & 13 & 8 & 3 & 2 & 3 & 2 & 1 & 3 & 1 & 1 & 1 & 2 & & 140 & 41.0\end{array}$

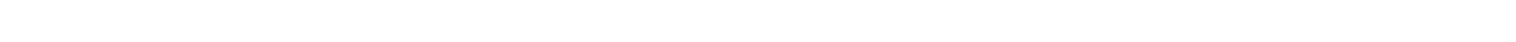
$\begin{array}{lllllllllllllllllllllllllllllll}1953 & 59 & 41 & 76 & 17 & 20 & 17 & 15 & 12 & 8 & 8 & 7 & 10 & 3 & 7 & 6 & 15 & 9 & 7 & 11 & 1 & 3 & 3 & 2 & 3 & 1 & 1 & 1 & 2 & 13948.0\end{array}$

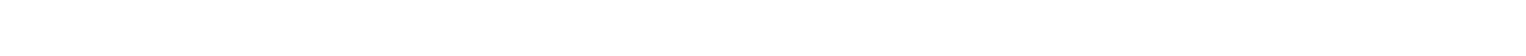

DURATION TABLE OF DISCHARGE FOR WATER YEARS 1 951-55

\begin{tabular}{|c|c|c|c|c|c|c|c|c|c|c|c|c|c|c|c|c|c|c|c|}
\hline CLASS & $\begin{array}{c}\text { OBIC } \\
\text { FEET } \\
\text { PER } \\
\text { SECOND }\end{array}$ & $\begin{array}{l}\text { TOTAL } \\
\text { DAYS }\end{array}$ & $\begin{array}{l}\text { ACOU- } \\
\text { MU- } \\
\text { LATED } \\
\text { DAYS }\end{array}$ & $\begin{array}{l}\text { PER- } \\
\text { CENT } \\
\text { DAYS }\end{array}$ & CLASS & $\begin{array}{c}\text { वBIC } \\
\text { FEET } \\
\text { PER } \\
\text { SECOND }\end{array}$ & $\begin{array}{l}\text { TOTAL } \\
\text { DAYS }\end{array}$ & $\begin{array}{l}\text { ACOU- } \\
\mathbf{M}- \\
\text { LATED } \\
\text { DAYS }\end{array}$ & $\begin{array}{l}\text { PER- } \\
\text { CENT } \\
\text { DAYS }\end{array}$ & CLASS & $\begin{array}{c}\text { OBIC } \\
\text { FEET } \\
\text { PER } \\
\text { SECOND }\end{array}$ & $\begin{array}{r}\text { TOTAL } \\
\text { DAYS }\end{array}$ & $\begin{array}{c}\text { ACCU- } \\
\text { NU- } \\
\text { LATED } \\
\text { DAYS }\end{array}$ & $\begin{array}{l}\text { PER- } \\
\text { CENT } \\
\text { DAYS }\end{array}$ & GIASS & $\begin{array}{c}\text { OBIC } \\
\text { FEET } \\
\text { PER } \\
\text { SECOND }\end{array}$ & $\begin{array}{r}\text { TOTAL } \\
\text { DAYS }\end{array}$ & $\begin{array}{c}\text { ACCU- } \\
\text { MU- } \\
\text { LATED } \\
\text { DAYS }\end{array}$ & $\begin{array}{l}\text { PER- } \\
\text { CENT } \\
\text { DAYS }\end{array}$ \\
\hline $\begin{array}{l}0 \\
1 \\
2 \\
3 \\
4 \\
5 \\
6 \\
7 \\
8\end{array}$ & $\begin{array}{r}0.00 \\
5.00 \\
5.80 \\
6.70 \\
7.70 \\
8.90 \\
10.00 \\
12.00 \\
14.00\end{array}$ & $\begin{array}{r}0 \\
91 \\
134 \\
132 \\
189 \\
140 \\
246 \\
43 \\
52\end{array}$ & $\begin{array}{r}1826 \\
1826 \\
1735 \\
1601 \\
1469 \\
1280 \\
1140 \\
894 \\
851\end{array}$ & $\begin{array}{r}100.0 \\
100.0 \\
95.0 \\
87.7 \\
80.4 \\
70.1 \\
62.4 \\
49.0 \\
46.6\end{array}$ & $\begin{array}{r}9 \\
10 \\
11 \\
12 \\
13 \\
14 \\
15 \\
16 \\
17\end{array}$ & $\begin{array}{l}16.00 \\
18.00 \\
21.00 \\
25.00 \\
28.00 \\
33.00 \\
38.00 \\
44.00 \\
51.00\end{array}$ & $\begin{array}{l}42 \\
61 \\
71 \\
38 \\
57 \\
49 \\
43 \\
41 \\
40\end{array}$ & $\begin{array}{l}799 \\
757 \\
696 \\
625 \\
587 \\
530 \\
481 \\
438 \\
397\end{array}$ & $\begin{array}{l}43.8 \\
41.5 \\
38.1 \\
34.2 \\
32.1 \\
29.0 \\
26.3 \\
24.0 \\
21.7\end{array}$ & $\begin{array}{l}18 \\
19 \\
20 \\
21 \\
22 \\
23 \\
24 \\
25 \\
26\end{array}$ & $\begin{array}{r}58.0 \\
68.0 \\
78.0 \\
90.0 \\
100.0 \\
120.0 \\
140.0 \\
160.0 \\
190.0\end{array}$ & $\begin{array}{l}59 \\
39 \\
31 \\
25 \\
55 \\
28 \\
20 \\
20 \\
24\end{array}$ & $\begin{array}{r}357 \\
298 \\
259 \\
228 \\
203 \\
148 \\
120 \\
100 \\
80\end{array}$ & $\begin{array}{r}19.6 \\
16.3 \\
14.2 \\
12.5 \\
11.1 \\
8.1 \\
6.6 \\
5.5 \\
4.4\end{array}$ & $\begin{array}{l}27 \\
28 \\
29 \\
30 \\
31 \\
32 \\
33 \\
34\end{array}$ & $\begin{array}{l}220.0 \\
250.0 \\
290.0 \\
330.0 \\
380.0 \\
440.0 \\
510.0 \\
590.0\end{array}$ & $\begin{array}{r}19 \\
8 \\
11 \\
5 \\
4 \\
4 \\
3\end{array}$ & $\begin{array}{r}56 \\
37 \\
29 \\
18 \\
13 \\
9 \\
5 \\
2\end{array}$ & $\begin{array}{l}3.1 \\
2.0 \\
1.6 \\
1.0 \\
0.7 \\
0.5 \\
0.3 \\
0.1\end{array}$ \\
\hline
\end{tabular}

MONIHLY MEAN DISCHARGES, IN OBIC FEET PER SECOND, FOR EACH WATER YEAR

\begin{tabular}{|c|c|c|c|c|c|c|c|c|c|c|c|c|}
\hline YEAR & $\propto C T$ & $\mathrm{NOV}$ & DEC & JAN & FEB & MAR & APR & MAY & JUNE & JULY & AUG & SEP \\
\hline $\begin{array}{l}1951 \\
1952 \\
1953 \\
1954 \\
1955\end{array}$ & $\begin{array}{l}10.0 \\
17.2 \\
17.0 \\
10.9 \\
16.3\end{array}$ & $\begin{array}{c}8.00 \\
11.4 \\
10.4 \\
8.87 \\
10.4\end{array}$ & $\begin{array}{c}7.00 \\
10.0 \\
10.0 \\
6.29 \\
9.00\end{array}$ & $\begin{array}{l}6.00 \\
9.00 \\
9.00 \\
5.50 \\
8.00\end{array}$ & $\begin{array}{l}6.00 \\
8.00 \\
8.00 \\
5.50 \\
8.00\end{array}$ & $\begin{array}{l}6.00 \\
7.39 \\
8.00 \\
5.00 \\
7.00\end{array}$ & $\begin{array}{c}6.50 \\
22.9 \\
10.1 \\
17.0 \\
8.00\end{array}$ & $\begin{array}{c}95.5 \\
142 \\
30.1 \\
139 \\
74.5\end{array}$ & $\begin{array}{c}150 \\
263 \\
220 \\
52.2 \\
117\end{array}$ & $\begin{array}{c}73.9 \\
153 \\
75.3 \\
43.3 \\
39.4\end{array}$ & $\begin{array}{l}67.7 \\
83.6 \\
44.1 \\
23.4 \\
37.8\end{array}$ & $\begin{array}{l}23.5 \\
37.6 \\
17.4 \\
22.8 \\
22.5\end{array}$ \\
\hline
\end{tabular}


GREEN RIVER BASIN

09296000 UINTA RIVER ABOVE GOVER CREEK, NEAR NEQAA, UT

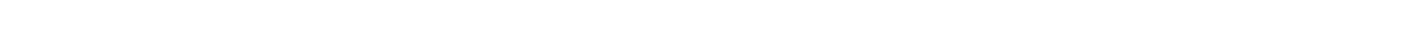
14060003 , on left bank $2 \mathrm{mi}$ usstream from Clover Creek and $15 \mathrm{mi}$ northwest of Neola.

DRAINAGE AREA, $-132 \mathrm{mi}^{2}$.

MEAN BASIN ELEVATION. $--10,960 \mathrm{ft}$.

PERIOD OF RECORD AVAILABLE. -October 1945 to September 1955.

GAGE.-Water-stage recorder. Altitude of gage is 7,750 ft from river-profile map. Prior to June 27, 1952, at a different datum.

REMARKS. -Flow partly regulated by several small mountain lakes and reservoirs including Fox Lake, Crescent Lake, Atwood Lake, and Chain Lake, total capacity, about 3,600 acre-ft. No diversions above station.

AVERAGE DISOHARGE. - -10 years, $142 \mathrm{ft}^{3} / \mathrm{s}, 102,800$ acre-ft/yr.

EXTREMES FOR PERIOD OF RECORD.--Maximum discharge, 2,300 $\mathrm{ft}^{3} / \mathrm{s}$ June 18, 1949, gage height, $5.10 \mathrm{ft}$, datum then in use; minimum recorded, $22 \mathrm{ft}^{3} / \mathrm{s}$ Jan. $2,1951$.

LOWEST NEAN DISCHARGE, IN OUBIC FEET PER SECOND, AND RANKING FOR THE INDICATED NUMBER OF CONSEQUTIVE DAYS FOR EAQH CIIMATIC YEAR, APRIL 1-MARGH 31

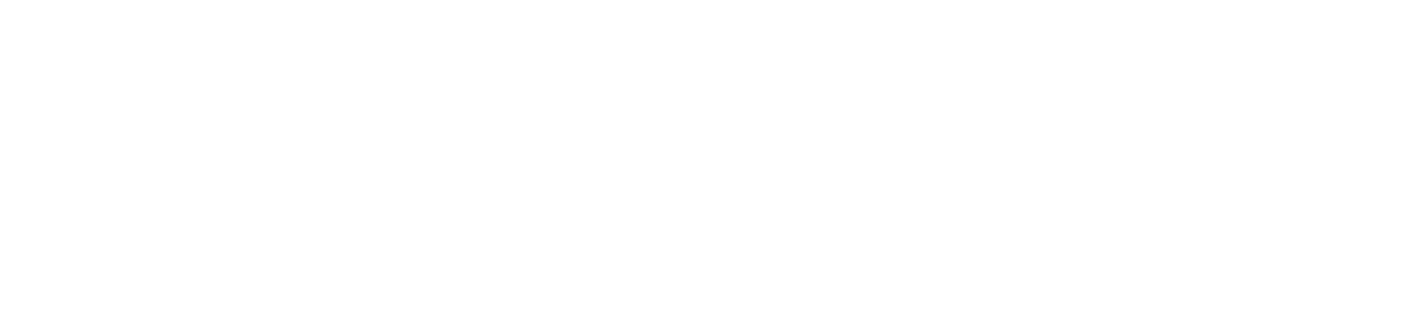

HIGHEST MEAN DISCHARGE, IN OUIC FEET PER SECOND, AND RANKING FOR THE INDICATED NUMBER OF CONSECUTIVE DAYS FOR EACH WATER YEAR, $O C T C B E R$ I-SEPTEMBER 30

\begin{tabular}{|c|c|c|c|c|c|c|c|c|c|c|c|c|c|c|c|c|c|c|c|}
\hline YEAR & & 3 & & 7 & & 15 & & $\begin{array}{l}0 \\
30\end{array}$ & EQT & $\begin{array}{l}\text { VE DA } \\
60\end{array}$ & & 90 & & 120 & & 183 & & ALL & \\
\hline $\begin{array}{rr}1946 & 486 \\
1947 & 868 \\
1948 & 759 \\
1949 & 1660 \\
1950 & 1050\end{array}$ & $\begin{array}{r}10 \\
6 \\
7 \\
1 \\
5\end{array}$ & $\begin{array}{r}443 \\
828 \\
673 \\
1430 \\
1010\end{array}$ & $\begin{array}{r}10 \\
6 \\
7 \\
2 \\
5\end{array}$ & $\begin{array}{r}392 \\
702 \\
615 \\
1230 \\
820\end{array}$ & $\begin{array}{r}10 \\
6 \\
7 \\
2 \\
4\end{array}$ & $\begin{array}{r}350 \\
617 \\
522 \\
1040 \\
751\end{array}$ & $\begin{array}{r}10 \\
5 \\
6 \\
2 \\
3\end{array}$ & $\begin{array}{l}274 \\
589 \\
480 \\
787 \\
667\end{array}$ & $\begin{array}{r}10 \\
4 \\
7 \\
2 \\
3\end{array}$ & $\begin{array}{l}256 \\
548 \\
338 \\
600 \\
518\end{array}$ & $\begin{array}{r}10 \\
3 \\
7 \\
2 \\
4\end{array}$ & $\begin{array}{l}226 \\
481 \\
278 \\
482 \\
411\end{array}$ & $\begin{array}{r}10 \\
3 \\
7 \\
2 \\
4\end{array}$ & $\begin{array}{l}202 \\
417 \\
235 \\
406 \\
343\end{array}$ & $\begin{array}{r}10 \\
2 \\
7 \\
3 \\
4\end{array}$ & $\begin{array}{l}162 \\
311 \\
175 \\
298 \\
255\end{array}$ & $\begin{array}{r}10 \\
2 \\
8 \\
3 \\
4\end{array}$ & $\begin{array}{l}110 \\
185 \\
118 \\
171 \\
158\end{array}$ & $\begin{array}{l}9 \\
2 \\
7 \\
3 \\
4\end{array}$ \\
\hline $\begin{array}{r}1130 \\
1600 \\
1590 \\
683 \\
711\end{array}$ & $\begin{array}{l}4 \\
2 \\
3 \\
9 \\
8\end{array}$ & $\begin{array}{r}1030 \\
1520 \\
1400 \\
560 \\
599\end{array}$ & $\begin{array}{l}4 \\
1 \\
3 \\
9 \\
8\end{array}$ & $\begin{array}{r}800 \\
1410 \\
1040 \\
474 \\
486\end{array}$ & $\begin{array}{l}5 \\
1 \\
3 \\
9 \\
8\end{array}$ & $\begin{array}{r}502 \\
1180 \\
724 \\
451 \\
419\end{array}$ & $\begin{array}{l}7 \\
1 \\
4 \\
8 \\
9\end{array}$ & $\begin{array}{l}487 \\
858 \\
496 \\
334 \\
353\end{array}$ & $\begin{array}{l}6 \\
1 \\
5 \\
9 \\
8\end{array}$ & $\begin{array}{l}365 \\
660 \\
347 \\
259 \\
297\end{array}$ & $\begin{array}{l}5 \\
1 \\
6 \\
9 \\
8\end{array}$ & $\begin{array}{l}324 \\
559 \\
291 \\
235 \\
250\end{array}$ & $\begin{array}{l}5 \\
1 \\
6 \\
9 \\
8\end{array}$ & $\begin{array}{l}281 \\
492 \\
248 \\
206 \\
232\end{array}$ & $\begin{array}{l}5 \\
1 \\
6 \\
9 \\
8\end{array}$ & $\begin{array}{l}203 \\
371 \\
181 \\
165 \\
175\end{array}$ & $\begin{array}{l}5 \\
1 \\
6 \\
9 \\
7\end{array}$ & $\begin{array}{l}124 \\
211 \\
121 \\
105 \\
112\end{array}$ & $\begin{array}{r}5 \\
1 \\
6 \\
10 \\
8\end{array}$ \\
\hline
\end{tabular}

DURATION OF DISCHARGE FOR EAOH WATER YEAR

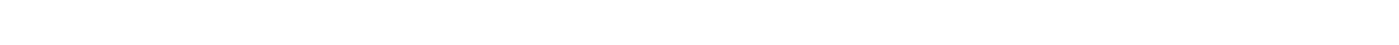
YEAR

NUMBER OF DAYS IN CLASS OIBIC FEET PER SECON

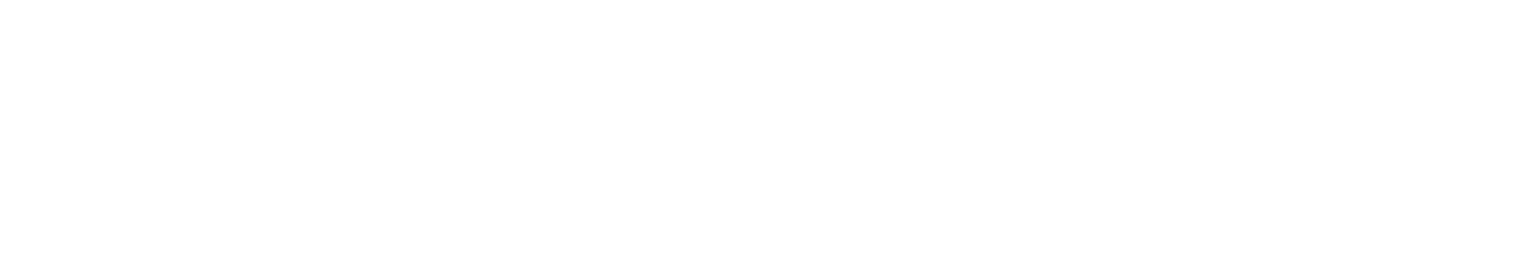


GREEN RIVER BASIN

0929000 UINTA RIVER ABOVE CLOVER CREEK, NEAR NEOAA, UT--Continued

DURATTON TFLE OF DISCHARGE FOR WATER YEARS 1946-55

$\begin{array}{ccc}\text { OBIC } & \text { ACOU- } \\ \text { FEET } & \text { MJ- } & \text { PER- } \\ \text { PER } & \text { TOTAL LATED } & \text { CENT } \\ \text { CLASS SECOND DAYS DAYS } & \text { DAYS }\end{array}$

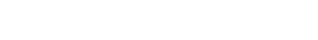

$\begin{array}{rrrrr}0 & 0.00 & 0 & 3652 & 100.0\end{array}$

$\begin{array}{lrrr}27.00 & 17 & 3649 & 99.9\end{array}$

$\begin{array}{llll}31.00 & 208 & 3632 & 99.5\end{array}$

$\begin{array}{llll}35.00 & 356 & 3424 & 93.8\end{array}$

$\begin{array}{llll}35.00 & 356 & 3424 & 93.8 \\ 40.00 & 368 & 3068 & 84.0\end{array}$

$\begin{array}{llll}40.00 & 368 & 3068 & 84.0 \\ 45.00 & 388 & 2700 & 73.9\end{array}$

$\begin{array}{llll}45.00 & 388 & 2700 & 73.9\end{array}$

$\begin{array}{llll}58.00 & 186 & 2312 & 63.3 \\ 588 & 2126 & 58.2\end{array}$ $\begin{array}{ccc}\text { OBIC } & \text { ACOH- } \\ \text { FEET } & \text { MU- } & \text { PER- } \\ \text { PER TOTAL LATED } & \text { CENT }\end{array}$

CASS SECOND DAYS DAYS DAYS

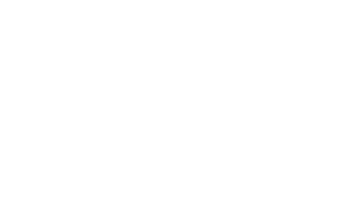

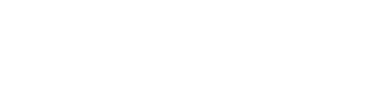

$\begin{array}{rrrrr}18 & 210.0 & 105 & 662 & 18.1 \\ 19 & 240.0 & 69 & 557 & 15.3\end{array}$

$\begin{array}{lllll}10 & 270.0 & 71 & 488 & 13.4\end{array}$

$\begin{array}{lllll}21 & 310.0 & 59 & 417 & 11.4\end{array}$

$\begin{array}{lllll}22 & 350.0 & 56 & 358 & 9.8\end{array}$

$\begin{array}{lllll}23 & 390.0 & 78 & 302 & 8.3\end{array}$

$\begin{array}{lllll}24 & 450.0 & 64 & 224 & 6.1\end{array}$

$\begin{array}{lllll}25 & 510.0 & 49 & 160 & 4.4 \\ 26 & 580.0 & 36 & 111 & 3.0\end{array}$ $\begin{array}{ccc}\text { OBIIC } & \text { ACQU- } \\ \text { FEET } & \text { MJ- } & \text { PER- } \\ \text { PER TOTAL LATED } & \text { CENT } \\ \text { CLASS SECOND } & \text { DAYS DAYS } & \text { DAYS }\end{array}$

$\begin{array}{rrrrr}27 & 660.0 & 20 & 75 & 2.1 \\ 28 & 750.0 & 16 & 55 & 1.5 \\ 29 & 850.0 & 9 & 39 & 1.1 \\ 30 & 960.0 & 11 & 30 & 0.8 \\ 31 & 1100.0 & 7 & 19 & 0.5 \\ 32 & 1200.0 & 4 & 12 & 0.3 \\ 33 & 1400.0 & 6 & 8 & 0.2 \\ 34 & 1600.0 & 2 & 2 & 0.1\end{array}$

MONTHLY MEAN DISGHARGES, IN OUBIC FEET PER SECOND, FOR EAOH WATER YEAR

\begin{tabular}{|c|c|c|c|c|c|c|c|c|c|c|c|c|}
\hline YEAR & OCT & NOV & $\mathrm{DEC}$ & JAN & FEB & MAR & APR & MAY & JUNE & JULY & AUG & SEP \\
\hline $\begin{array}{l}1946 \\
1947 \\
1948 \\
1949 \\
1950\end{array}$ & $\begin{array}{c}108 \\
92.8 \\
106 \\
57.9 \\
90.2\end{array}$ & $\begin{array}{l}61.0 \\
70.5 \\
69.4 \\
48.8 \\
75.9\end{array}$ & $\begin{array}{l}49.6 \\
56.5 \\
58.6 \\
42.3 \\
59.4\end{array}$ & $\begin{array}{l}45.4 \\
45.6 \\
49.3 \\
39.3 \\
49.5\end{array}$ & $\begin{array}{l}39.3 \\
41.1 \\
41.9 \\
35.4 \\
44.7\end{array}$ & $\begin{array}{l}38.7 \\
43.2 \\
38.6 \\
34.0 \\
41.8\end{array}$ & $\begin{array}{r}135 \\
64.5 \\
44.6 \\
68.6 \\
83.1\end{array}$ & $\begin{array}{l}221 \\
534 \\
293 \\
336 \\
338\end{array}$ & $\begin{array}{l}242 \\
527 \\
327 \\
743 \\
579\end{array}$ & $\begin{array}{l}158 \\
360 \\
167 \\
338 \\
266\end{array}$ & $\begin{array}{l}124 \\
226 \\
133 \\
192 \\
162\end{array}$ & $\begin{array}{c}88.5 \\
146 \\
82.1 \\
111 \\
102\end{array}$ \\
\hline $\begin{array}{l}1951 \\
1952 \\
1953 \\
1954 \\
1955\end{array}$ & $\begin{array}{r}68.1 \\
83.4 \\
118 \\
67.0 \\
84.1\end{array}$ & $\begin{array}{l}52.4 \\
62.1 \\
73.7 \\
53.8 \\
55.2\end{array}$ & $\begin{array}{l}44.8 \\
47.1 \\
54.2 \\
43.4 \\
46.1\end{array}$ & $\begin{array}{l}33.2 \\
41.0 \\
44.9 \\
33.9 \\
42.2\end{array}$ & $\begin{array}{l}35.0 \\
40.0 \\
40.4 \\
36.0 \\
35.0\end{array}$ & $\begin{array}{l}33.5 \\
38.1 \\
36.5 \\
32.5 \\
32.8\end{array}$ & $\begin{array}{l}35.0 \\
73.7 \\
36.1 \\
62.6 \\
37.4\end{array}$ & $\begin{array}{c}230 \\
487 \\
82.3 \\
316 \\
245\end{array}$ & $\begin{array}{l}384 \\
808 \\
496 \\
179 \\
325\end{array}$ & $\begin{array}{l}212 \\
368 \\
199 \\
194 \\
158\end{array}$ & $\begin{array}{l}241 \\
291 \\
171 \\
119 \\
180\end{array}$ & $\begin{array}{l}113 \\
195 \\
104 \\
113 \\
103\end{array}$ \\
\hline
\end{tabular}

ANNAL PEAK DISGHARGE, IN OBIC FEET PER SECOND, AND CORRESPONDING GAGE HEIGHT, IN FEET, FOR EACH WATER YEAR

\begin{tabular}{|c|c|c|c|c|c|c|c|c|c|c|c|}
\hline $\begin{array}{l}\text { WATER } \\
\text { YEAR }\end{array}$ & DATE & $\begin{array}{c}\text { GAGE } \\
\text { HEIGHT }\end{array}$ & $\begin{array}{c}\text { PEAK } \\
\text { DISCHARGE }\end{array}$ & $\begin{array}{l}\text { WATER } \\
\text { YEAR }\end{array}$ & DATE & $\begin{array}{c}\text { GAGE } \\
\text { HEIGHT }\end{array}$ & $\begin{array}{c}\text { PEAK } \\
\text { DISCHARGE }\end{array}$ & $\begin{array}{l}\text { WATER } \\
\text { YEAR }\end{array}$ & DATE & $\begin{array}{c}\text { GAGE } \\
\text { HEIGHT }\end{array}$ & $\begin{array}{c}\text { PEAK } \\
\text { DISOHARGE }\end{array}$ \\
\hline $\begin{array}{l}1946 \\
1947 \\
1948 \\
1949\end{array}$ & $\begin{array}{lll}\text { APR. } & 26,1946 \\
\text { MAY } & 08,1947 \\
\text { MAY } & 19,1948 \\
\text { JUNE } 18,1949\end{array}$ & $\begin{array}{l}3.40 \\
4.25 \\
4.10 \\
5.10\end{array}$ & $\begin{array}{r}638 \\
1040 \\
944 \\
2300\end{array}$ & $\begin{array}{l}1950 \\
1951 \\
1952\end{array}$ & $\begin{array}{ll}\text { JUNE } 01, & 1950 \\
\text { MAY } 27, & 1951 \\
\text { JUNE 06, } 1952\end{array}$ & $\begin{array}{l}3.57 \\
3.95 \\
4.65\end{array}$ & $\begin{array}{l}1310 \\
1530 \\
2060\end{array}$ & $\begin{array}{l}1953 \\
1954 \\
1955\end{array}$ & $\begin{array}{lll}\text { JUNE } & 12, & 1953 \\
\text { MAY } 22, & 1954 \\
\text { JUNE } 08, & 1955\end{array}$ & & $\begin{array}{r}2070 \\
928 \\
1080\end{array}$ \\
\hline
\end{tabular}

09296500 CLOVER CREEK NEAR NECLA, UT

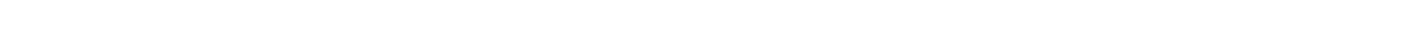

14060003 , on right bank $0.75 \mathrm{mi}$ upstream from mouth and $14 \mathrm{mi}$ nor thwest of Neola.

DRATNAGE AREA. $-9.5 \mathrm{mi}^{2}$, approximately.

MEAN BASIN ELEVITION. $-10,300 \mathrm{ft}$.

PERIOD OF RECORD AVAILABL.E. --August 1950 to September 1955.

GAGE.--Water-stage recorder. Altitude of gage is 7,900 ft fram topographic map.

REMARKS.--Small diversion for irrigation above station.

AVERAGE DISGHARGE. --5 years, $1.92 \mathrm{ft}^{3} / \mathrm{s}, 1,390$ acre-ft/yr.

EXTREMES FOR PERIOD OF RECORD.--Maximum discharge, $120 \mathrm{ft}^{3} / \mathrm{s}$ May 27,1951 , gage height, $2.68 \mathrm{ft}$, from rating curve extended above 58 $\mathrm{ft}^{3} / \mathrm{s} ;$ no flow at times.

LOWEST MEAN DISGARGE, IN CUBIC FEET PER SECOND, AND RANKING FOR THE INDICATED NUMBER OF CONSEOUTIVE DAYS FOR EAG CLIMATIC YEAR, APRIL 1-MAROH 31

YEAR

$\begin{array}{ccccc} & 1 & & 3 & \\ 1952 & 0.00 & 1 & 0.00 & 1 \\ 1953 & 0.00 & 2 & 0.00 & 2 \\ 1954 & 0.00 & 3 & 0.00 & 3 \\ 1955 & 0.00 & 4 & 0.00 & 4\end{array}$

$\begin{array}{llll}7 & & 14 & \\ 0.00 & 1 & 0.00 & 1 \\ 0.00 & 2 & 0.00 & 2 \\ 0.00 & 3 & 0.00 & 3 \\ 0.00 & 4 & 0.00 & 4\end{array}$

CONSEOTTIVE DAYS

0.001

$\begin{array}{llll}0.00 & 2 & 0.00 & 2\end{array}$

$\begin{array}{llll}0.00 & 4 & 0.00 & 4\end{array}$
90

0.001

$\begin{array}{lll}0.00 & 2 & 0.00\end{array}$

$\begin{array}{llll}0.00 & 4 & 0.00 & 4\end{array}$

\begin{tabular}{llll}
183 & \multicolumn{3}{l}{ ALL } \\
& & \\
0.00 & 1 & 1.80 & 3 \\
0.00 & 2 & 5.00 & 4 \\
0.00 & 3 & 0.67 & 1 \\
0.00 & 4 & 1.00 & 2
\end{tabular}


GREDN RIVER BASIN

09296500 CLOVER CREEK NEAR NECA, UT--Continued

HIGHEST MEAN DISCHARGE, IN OBBIC FEET PER SECOND, AND RANKING FOR THE INDICATED NUMBER OF CONSECUTIVE DAYS FOR EACH WATER YEAR, OCTCBER 1-SEPTEMBER 30

\begin{tabular}{|c|c|c|c|c|c|c|c|c|c|c|c|c|c|c|c|c|c|c|c|}
\hline YEAR & & & & & & & & & CONSE & ar & E DAYS & & & & & & & & \\
\hline $\begin{array}{l}1951 \\
1952 \\
1953 \\
1954 \\
1955\end{array}$ & $\begin{array}{l}69.0 \\
60.0 \\
15.0 \\
28.0 \\
30.0\end{array}$ & $\begin{array}{l}1 \\
2 \\
5 \\
4 \\
3\end{array}$ & $\begin{array}{l}58.0 \\
55.0 \\
14.0 \\
27.0 \\
27.0\end{array}$ & $\begin{array}{l}1 \\
2 \\
5 \\
3 \\
4\end{array}$ & $\begin{array}{l}47.0 \\
50.0 \\
12.0 \\
25.0 \\
22.0\end{array}$ & $\begin{array}{l}2 \\
1 \\
5 \\
3 \\
4\end{array}$ & $\begin{array}{l}27.0 \\
44.0 \\
11.0 \\
19.0 \\
16.0\end{array}$ & $\begin{array}{l}2 \\
1 \\
5 \\
3 \\
4\end{array}$ & $\begin{array}{c}18.0 \\
39.0 \\
7.40 \\
12.0 \\
11.0\end{array}$ & $\begin{array}{l}2 \\
1 \\
5 \\
3 \\
4\end{array}$ & $\begin{array}{c}9.70 \\
27.0 \\
4.00 \\
6.10 \\
6.80\end{array}$ & $\begin{array}{l}2 \\
1 \\
5 \\
4 \\
3\end{array}$ & $\begin{array}{c}6.90 \\
20.0 \\
2.70 \\
4.10 \\
4.60\end{array}$ & $\begin{array}{l}2 \\
1 \\
5 \\
4 \\
3\end{array}$ & $\begin{array}{c}5.40 \\
15.0 \\
2.00 \\
3.10 \\
3.50\end{array}$ & $\begin{array}{l}2 \\
1 \\
5 \\
4 \\
3\end{array}$ & $\begin{array}{l}3.60 \\
9.90 \\
1.30 \\
2.00 \\
2.30\end{array}$ & $\begin{array}{l}2 \\
1 \\
5 \\
4 \\
3\end{array}$ & $\begin{array}{l}1.80 \\
5.00 \\
0.67 \\
1.00 \\
1.10\end{array}$ \\
\hline
\end{tabular}

DURATION CF DISCHARGE FOR EACH WATER YEAR

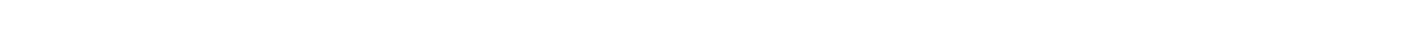
YEAR NUMBER OF DAYS IN CLASS

$$
\begin{aligned}
& \text { CUBIC FEET } \\
& \text { PER SECOND } \\
& \text {-DAYS }
\end{aligned}
$$

\begin{tabular}{|c|c|c|c|c|c|c|c|c|c|c|c|c|c|c|c|c|c|c|c|}
\hline CLASS & $\begin{array}{c}\text { OBIC } \\
\text { FEET } \\
\text { PER } \\
\text { SECOND }\end{array}$ & $\begin{array}{l}\text { TOTAL } \\
\text { DAYS }\end{array}$ & $\begin{array}{l}\text { ACOU- } \\
\text { MU- } \\
\text { LATED } \\
\text { DAYS }\end{array}$ & $\begin{array}{l}\text { PER- } \\
\text { CENT } \\
\text { DAYS }\end{array}$ & & $\begin{array}{c}\text { CBIC } \\
\text { FEET } \\
\text { PER } \\
\text { SECOND }\end{array}$ & $\begin{array}{l}\text { TOTAL } \\
\text { DAYS }\end{array}$ & $\begin{array}{l}\text { ACOU- } \\
\text { MU- } \\
\text { LATED } \\
\text { DAYS }\end{array}$ & $\begin{array}{l}\text { PER- } \\
\text { CENT } \\
\text { DAYS }\end{array}$ & & $\begin{array}{c}\text { OBIC } \\
\text { FEET } \\
\text { PER } \\
\text { SECOND }\end{array}$ & $\begin{array}{r}\text { TOTAL } \\
\text { DAYS }\end{array}$ & $\begin{array}{l}\text { ACOU- } \\
\text { MU- } \\
\text { LATED } \\
\text { DAYS }\end{array}$ & $\begin{array}{l}\text { PER- } \\
\text { CENT } \\
\text { DAYS }\end{array}$ & & $\begin{array}{c}\text { OBIC } \\
\text { FEET } \\
\text { PER } \\
\text { SECOND }\end{array}$ & $\begin{array}{r}\text { TOTAL } \\
\text { DAYS }\end{array}$ & $\begin{array}{l}\text { ACQ- } \\
\text { MU- } \\
\text { LATED } \\
\text { DAYS }\end{array}$ & $\begin{array}{l}\text { PER- } \\
\text { CENI } \\
\text { DAYS }\end{array}$ \\
\hline $\begin{array}{l}0 \\
1 \\
2 \\
3 \\
4 \\
5 \\
6 \\
7 \\
8\end{array}$ & $\begin{array}{l}0.00 \\
0.10 \\
0.12 \\
0.15 \\
0.18 \\
0.22 \\
0.26 \\
0.32 \\
0.39\end{array}$ & $\begin{array}{r}1398 \\
25 \\
0 \\
0 \\
19 \\
0 \\
14 \\
0 \\
25\end{array}$ & $\begin{array}{r}1826 \\
428 \\
403 \\
403 \\
403 \\
384 \\
384 \\
370 \\
370\end{array}$ & $\begin{array}{r}100.0 \\
23.4 \\
22.1 \\
22.1 \\
22.1 \\
21.0 \\
21.0 \\
20.3 \\
20.3\end{array}$ & $\begin{array}{r}9 \\
10 \\
11 \\
12 \\
13 \\
14 \\
15 \\
16 \\
17\end{array}$ & $\begin{array}{l}0.47 \\
0.57 \\
0.70 \\
0.84 \\
1.00 \\
1.20 \\
1.50 \\
1.80 \\
2.20\end{array}$ & $\begin{array}{r}16 \\
11 \\
15 \\
3 \\
16 \\
19 \\
9 \\
16 \\
14\end{array}$ & $\begin{array}{l}345 \\
329 \\
318 \\
303 \\
300 \\
284 \\
265 \\
256 \\
240\end{array}$ & $\begin{array}{l}18.9 \\
18.0 \\
17.4 \\
16.6 \\
16.4 \\
15.6 \\
14.5 \\
14.0 \\
13.1\end{array}$ & $\begin{array}{l}18 \\
19 \\
20 \\
21 \\
22 \\
23 \\
24 \\
25 \\
26\end{array}$ & $\begin{array}{r}2.7 \\
3.3 \\
4.0 \\
4.8 \\
5.9 \\
7.1 \\
8.6 \\
10.0 \\
13.0\end{array}$ & $\begin{array}{l}10 \\
24 \\
17 \\
21 \\
19 \\
19 \\
17 \\
13 \\
15\end{array}$ & $\begin{array}{r}226 \\
216 \\
192 \\
175 \\
154 \\
135 \\
116 \\
99 \\
86\end{array}$ & $\begin{array}{r}12.4 \\
11.8 \\
10.5 \\
9.6 \\
8.4 \\
7.4 \\
6.4 \\
5.4 \\
4.7\end{array}$ & $\begin{array}{l}27 \\
28 \\
29 \\
30 \\
31 \\
32 \\
33 \\
34\end{array}$ & $\begin{array}{l}15.0 \\
19.0 \\
23.0 \\
28.0 \\
34.0 \\
41.0 \\
49.0 \\
60.0\end{array}$ & $\begin{array}{r}14 \\
7 \\
11 \\
11 \\
9 \\
11 \\
6 \\
2\end{array}$ & $\begin{array}{r}71 \\
57 \\
50 \\
39 \\
28 \\
19 \\
8 \\
2\end{array}$ & $\begin{array}{l}3.9 \\
3.1 \\
2.7 \\
2.1 \\
1.5 \\
1.0 \\
0.4 \\
0.1\end{array}$ \\
\hline
\end{tabular}

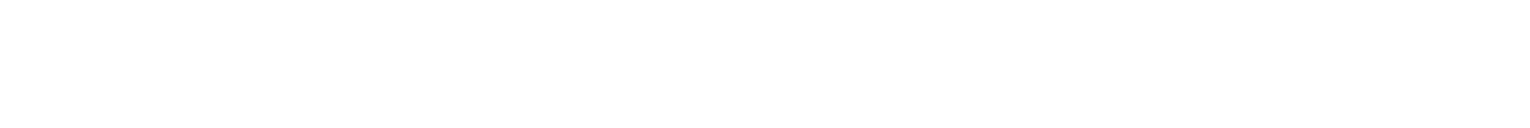

DURATION TABLE OF DISCHARGE FOR WATER YEARS 1951-55

MONIHLY MEAN DISCHARGES, IN CBBIC FEET PER SECOND, FOR EACH WATER YEAR

\begin{tabular}{|c|c|c|c|c|c|c|c|c|c|c|c|c|c|}
\hline $\begin{array}{l}\text { WATER } \\
\text { YEAR }\end{array}$ & & DATE & $\begin{array}{c}\text { GAGE } \\
\text { HEIGHT }\end{array}$ & $\begin{array}{c}\text { PEAK } \\
\text { DISCHARGE }\end{array}$ & $\begin{array}{l}\text { WATER } \\
\text { YEAR }\end{array}$ & DATE & $\begin{array}{l}\text { GAGE } \\
\text { HEIGHT }\end{array}$ & $\begin{array}{c}\text { PEAK } \\
\text { DISCHARGE }\end{array}$ & $\begin{array}{l}\text { WATER } \\
\text { YEAR }\end{array}$ & & DATE & $\begin{array}{c}\text { GAGE } \\
\text { HEIGHT }\end{array}$ & $\begin{array}{c}\text { FEAK } \\
\text { DISCHARGE }\end{array}$ \\
\hline $\begin{array}{l}1951 \\
1952\end{array}$ & $\begin{array}{l}\text { MAY } \\
\text { MAY }\end{array}$ & $\begin{array}{l}27,1951 \\
29,1952\end{array}$ & $\begin{array}{l}2.68 \\
2.51\end{array}$ & $\begin{array}{r}120 \\
75\end{array}$ & $\begin{array}{l}1953 \\
1954\end{array}$ & $\begin{array}{l}\text { JUNE } 12,1953 \\
\text { MAY 09, } 1954\end{array}$ & $\begin{array}{l}2.32 \\
2.44\end{array}$ & $\begin{array}{l}21 \\
45\end{array}$ & 1955 & MAY & 11,1955 & 2.40 & 39 \\
\hline
\end{tabular}

$\begin{array}{lcccccccccccc}\text { YEAR } & \text { OCT } & \text { NOV } & \text { DEC } & \text { JAN } & \text { FEB } & \text { MAR } & \text { APR } & \text { MAY } & \text { JUNE } & \text { JULY } & \text { AUG } & \text { SEP } \\ 1951 & 0.00 & 0.00 & 0.00 & 0.00 & 0.00 & 0.00 & 0.00 & 11.4 & 7.30 & 0.51 & 1.71 & 0.34 \\ 1952 & 0.00 & 0.00 & 0.00 & 0.00 & 0.00 & 0.00 & 0.07 & 33.3 & 19.8 & 4.69 & 1.35 & 0.12 \\ 1953 & 0.00 & 0.00 & 0.00 & 0.00 & 0.00 & 0.00 & 0.00 & 1.56 & 6.40 & 0.08 & 0.03 & 0.00 \\ 1954 & 0.00 & 0.00 & 0.00 & 0.00 & 0.00 & 0.00 & 0.30 & 11.3 & 0.32 & 0.02 & 0.00 & 0.00 \\ 1955 & 0.00 & 0.00 & 0.00 & 0.00 & 0.00 & 0.00 & 0.00 & 10.3 & 2.95 & 0.13 & 0.11 & 0.00\end{array}$

ANNUAL PEAK DISCHARGE, IN CABIC FEET PER SECOND, AND CORRESPONDING GAGE HEIGHT, IN FEET, FOR EACH WATER YEAR 
LOCATION.-Lat $40^{\circ} 32^{\prime} 08^{\prime \prime}$, long $110^{\circ} 03^{\prime} 46^{\prime \prime}$, in SE $\mathrm{SW}_{\frac{1}{4}} \mathrm{SW}_{\frac{1}{4}}$ sec.25, T.2 N., R.2 W., Uintah Meridian, Duchesne County, Hydrologic Unit 14060003, Uintah and Ouray Indian Reservation, on left bank 1,000 ft downstream from Moon Lake Electric Association, Inc. hydroelectric plant, $0.8 \mathrm{mi}$ upstream from Pole Creek, and $7 \mathrm{mi}$ north of Neola.

DRAINAGE AREA. $-163 \mathrm{mi}^{2}$.

MEAN BASIN ELEVATION. $-10,710 \mathrm{ft}$.

PERIOD OF RECORD AVAIIABLE.--July 1921 to September 1927 (no winter records 1922-25, 1927), September 1929 to September 1981. Monthly mean discharge for some periods prior to October 1925, published in WSP 1313.

REVISED RECORDS.--WDR UT-77-1: Drainage area.

GAGE. - Water-stage recorder. Altitude of gage is 6,910 ft from river-profile map. Prior to Aug. 4, 1951, water-stage recorder or nonrecording gages at several sites within 2,000 ft of present site at various datums. Aug. 4, 1951 to June 11, 1965 , waterstage recorder at site $50 \mathrm{ft}$ upstream at various datums.

REMARRS.--Flow regulated by powerplant. Summer flow slightly regulated by storage in several small lakes and reservoirs. Water from Pole Creek diverted into forebay. Uinta power canal enlargement completed in August 1944, and flow increased oct. 12, 13 , 1944 , which has held fairly constant since. Prior to Nov. 18, 1948, spill from forebay entered river $0.5 \mathrm{mi}$ below station.

AVERAGE DISCHARGE. --53 years (water years $1926,1930-81$ ) $, 177 \mathrm{ft}^{3} / \mathrm{s}, 128,200$ acre-ft/yr.

EXTREMES FOR PERTOD OF RECORD.-Maximim discharge, about 5,000 ft $3 / \mathrm{s}$ June 11, 1965, gage height, $7.00 \mathrm{ft}$ from floodmarks, site and datum then in use, from rating curve extended above $1,200 \mathrm{ft}^{3} / \mathrm{s} ;$ minimum recorded, $14 \mathrm{ft}^{3} / \mathrm{s} \mathrm{Jan} .14,1974$.

LOWEST MEAN DISCHARGE, IN COBIC FEET PER SECOND, AND RANKING FOR THE INDICATED NUMBER OF CONSECUTIVE DAYS FOR EACH OLIMATIC YEAR, APRIL 1-MARCH 31

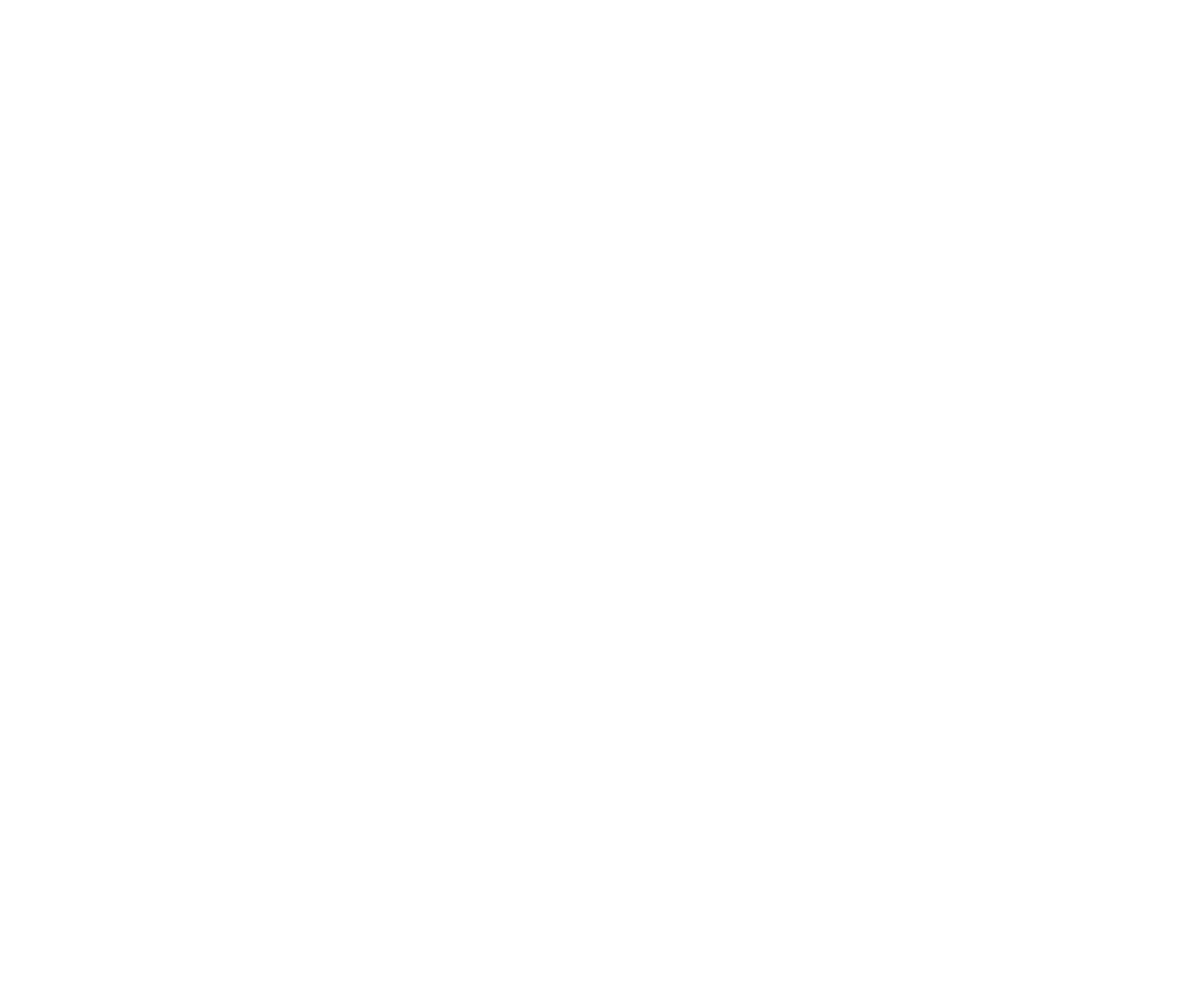


GREEN RIVER BASIN

09297000 UINTA RIVER NEAR NECLA, UT-Continued

LOWEST MEAN DISGHARGE, IN OBBIC FEET PER SECOND, AND RANKING FOR THE INDICATED NUMBER OF CONSECUTIVE DAVS FOR EAOH CLIMATIC YEAR, APRIL 1-MAROH 31--Continued

\begin{tabular}{|c|c|c|c|c|c|c|c|c|c|c|c|c|c|c|c|c|c|c|c|c|}
\hline YEAR & & & & & & & & & CONS & $\omega$ & E DAYS & & & & & & & & & \\
\hline $\begin{array}{l}1971 \\
1972 \\
1973 \\
1974 \\
1975\end{array}$ & $\begin{array}{l}28.0 \\
45.0 \\
52.0 \\
50.0 \\
41.0\end{array}$ & $\begin{array}{l}1 \\
21 \\
43 \\
36 \\
13\end{array}$ & $\begin{array}{l}30.0 \\
48.0 \\
53.0 \\
53.0 \\
43.0\end{array}$ & $\begin{array}{r}1 \\
27 \\
42 \\
43 \\
12\end{array}$ & $\begin{array}{l}34.0 \\
49.0 \\
54.0 \\
55.0 \\
44.0\end{array}$ & $\begin{array}{r}1 \\
25 \\
38 \\
41 \\
12\end{array}$ & $\begin{array}{l}41.0 \\
51.0 \\
54.0 \\
57.0 \\
45.0\end{array}$ & $\begin{array}{r}4 \\
26 \\
37 \\
45 \\
11\end{array}$ & $\begin{array}{l}46.0 \\
53.0 \\
58.0 \\
60.0 \\
46.0\end{array}$ & $\begin{array}{l}12 \\
29 \\
44 \\
47 \\
13\end{array}$ & $\begin{array}{l}49.0 \\
56.0 \\
60.0 \\
60.0 \\
46.0\end{array}$ & $\begin{array}{l}14 \\
31 \\
40 \\
41 \\
12\end{array}$ & $\begin{array}{l}53.0 \\
58.0 \\
65.0 \\
62.0 \\
47.0\end{array}$ & $\begin{array}{l}17 \\
31 \\
46 \\
39 \\
10\end{array}$ & $\begin{array}{l}56.0 \\
61.0 \\
71.0 \\
65.0 \\
47.0\end{array}$ & $\begin{array}{r}17 \\
30 \\
46 \\
39 \\
4\end{array}$ & $\begin{array}{l}73.0 \\
78.0 \\
76.0 \\
80.0 \\
56.0\end{array}$ & $\begin{array}{r}29 \\
36 \\
32 \\
37 \\
3\end{array}$ & $\begin{array}{l}179 \\
194 \\
159 \\
228 \\
110\end{array}$ & $\begin{array}{r}28 \\
34 \\
22 \\
45 \\
3\end{array}$ \\
\hline $\begin{array}{l}1976 \\
1977 \\
1978 \\
1979 \\
1980\end{array}$ & $\begin{array}{l}38.0 \\
30.0 \\
43.0 \\
30.0 \\
44.0\end{array}$ & $\begin{array}{r}5 \\
2 \\
14 \\
3 \\
15\end{array}$ & $\begin{array}{l}39.0 \\
32.0 \\
43.0 \\
46.0 \\
44.0\end{array}$ & $\begin{array}{r}4 \\
2 \\
13 \\
21 \\
14\end{array}$ & $\begin{array}{l}41.0 \\
36.0 \\
46.0 \\
50.0 \\
45.0\end{array}$ & $\begin{array}{r}8 \\
2 \\
18 \\
27 \\
13\end{array}$ & $\begin{array}{l}42.0 \\
38.0 \\
50.0 \\
51.0 \\
48.0\end{array}$ & $\begin{array}{r}5 \\
1 \\
22 \\
27 \\
18\end{array}$ & $\begin{array}{l}49.0 \\
44.0 \\
52.0 \\
51.0 \\
51.0\end{array}$ & $\begin{array}{r}15 \\
6 \\
25 \\
21 \\
22\end{array}$ & $\begin{array}{l}56.0 \\
45.0 \\
53.0 \\
52.0 \\
53.0\end{array}$ & $\begin{array}{r}32 \\
5 \\
22 \\
18 \\
19\end{array}$ & $\begin{array}{l}58.0 \\
45.0 \\
53.0 \\
53.0 \\
54.0\end{array}$ & $\begin{array}{r}32 \\
3 \\
18 \\
19 \\
20\end{array}$ & $\begin{array}{l}61.0 \\
48.0 \\
54.0 \\
55.0 \\
56.0\end{array}$ & $\begin{array}{r}31 \\
5 \\
12 \\
14 \\
18\end{array}$ & $\begin{array}{l}68.0 \\
59.0 \\
61.0 \\
62.0 \\
62.0\end{array}$ & $\begin{array}{r}18 \\
5 \\
10 \\
12 \\
13\end{array}$ & $\begin{array}{l}224 \\
134 \\
114 \\
150 \\
136\end{array}$ & $\begin{array}{r}43 \\
10 \\
4 \\
17 \\
15\end{array}$ \\
\hline 1981 & 45.0 & 22 & 46.0 & 22 & 48.0 & 22 & 48.0 & 19 & 49.0 & 16 & 50.0 & 15 & 52.0 & 15 & 57.0 & 22 & 70.0 & 23 & 192 & 33 \\
\hline
\end{tabular}

HIGHEST MEAN DISCHARGE, IN CUBIC FEET PER SECOND, AND RANKING FOR THE INDICATED INMBER OF CONSEQJTTVE DAYS FOR EACH WATER YEAR, OCTCBER 1-SEPTEMBER 30

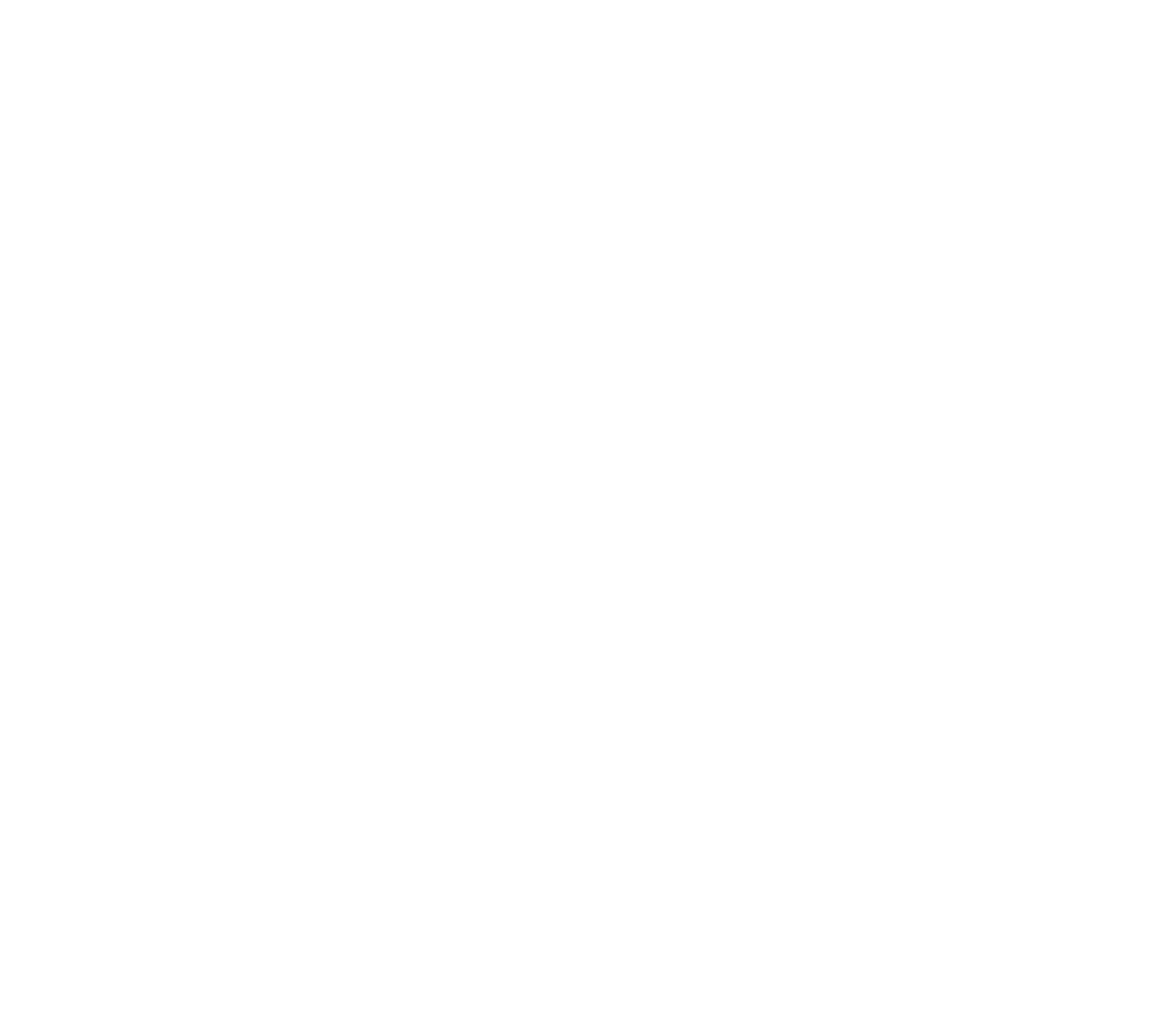


HIGHEST MEAN DISOHARGE, IN OBIC FEET PER SECOND, AND RANKING FOR THE INDICATED NUNBER OF CONSECUTIVE DAYS FOR EAOH WATER YEAR, OCTCBER 1-SEPTEMBER 30--Continued

\begin{tabular}{|c|c|c|c|c|c|c|c|c|c|c|c|c|c|c|c|c|c|c|c|c|}
\hline YEAR & 1 & & 3 & & 7 & & 15 & & $\begin{array}{l}\infty \\
30\end{array}$ & Q & $\begin{array}{r}\text { E DA } \\
60\end{array}$ & & 90 & & 120 & & 183 & & ALL & \\
\hline $\begin{array}{l}1971 \\
1972 \\
1973 \\
1974 \\
1975\end{array}$ & $\begin{array}{r}1750 \\
934 \\
1640 \\
446 \\
2670\end{array}$ & $\begin{array}{r}8 \\
34 \\
12 \\
52 \\
2\end{array}$ & $\begin{array}{r}1500 \\
881 \\
1490 \\
417 \\
2130\end{array}$ & $\begin{array}{r}12 \\
36 \\
13 \\
52 \\
2\end{array}$ & $\begin{array}{r}1320 \\
843 \\
1250 \\
372 \\
1530\end{array}$ & $\begin{array}{c}13 \\
33 \\
14 \\
51 \\
3\end{array}$ & $\begin{array}{r}1100 \\
720 \\
1010 \\
314 \\
1130\end{array}$ & $\begin{array}{l}12 \\
30 \\
16 \\
51 \\
10\end{array}$ & $\begin{array}{r}804 \\
582 \\
926 \\
312 \\
1080\end{array}$ & $\begin{array}{r}18 \\
29 \\
9 \\
50 \\
4\end{array}$ & $\begin{array}{l}582 \\
450 \\
684 \\
268 \\
830\end{array}$ & $\begin{array}{r}19 \\
29 \\
13 \\
49 \\
4\end{array}$ & $\begin{array}{l}478 \\
367 \\
578 \\
241 \\
647\end{array}$ & $\begin{array}{r}17 \\
30 \\
10 \\
48 \\
6\end{array}$ & $\begin{array}{l}417 \\
315 \\
506 \\
212 \\
540\end{array}$ & $\begin{array}{r}17 \\
33 \\
8 \\
49 \\
7\end{array}$ & $\begin{array}{l}311 \\
242 \\
375 \\
163 \\
380\end{array}$ & $\begin{array}{r}18 \\
34 \\
9 \\
50 \\
8\end{array}$ & $\begin{array}{l}192 \\
160 \\
226 \\
122 \\
218\end{array}$ & $\begin{array}{l}18 \\
31 \\
10 \\
50 \\
12\end{array}$ \\
\hline $\begin{array}{l}1976 \\
1977 \\
1978 \\
1979 \\
1980\end{array}$ & $\begin{array}{r}985 \\
1160 \\
1480 \\
1120 \\
1960\end{array}$ & $\begin{array}{r}33 \\
23 \\
16 \\
25 \\
4\end{array}$ & $\begin{array}{r}934 \\
1030 \\
1320 \\
1030 \\
1790\end{array}$ & $\begin{array}{r}32 \\
26 \\
17 \\
27 \\
3\end{array}$ & $\begin{array}{r}804 \\
869 \\
1220 \\
856 \\
1470\end{array}$ & $\begin{array}{r}34 \\
28 \\
15 \\
29 \\
8\end{array}$ & $\begin{array}{r}697 \\
601 \\
571 \\
687 \\
1200\end{array}$ & $\begin{array}{r}31 \\
38 \\
18 \\
33 \\
7\end{array}$ & $\begin{array}{l}558 \\
398 \\
749 \\
562 \\
938\end{array}$ & $\begin{array}{r}35 \\
43 \\
19 \\
33 \\
8\end{array}$ & $\begin{array}{l}397 \\
290 \\
502 \\
395 \\
648\end{array}$ & $\begin{array}{l}35 \\
47 \\
24 \\
36 \\
15\end{array}$ & $\begin{array}{l}324 \\
241 \\
387 \\
320 \\
502\end{array}$ & $\begin{array}{l}37 \\
49 \\
27 \\
39 \\
16\end{array}$ & $\begin{array}{l}274 \\
211 \\
320 \\
276 \\
419\end{array}$ & $\begin{array}{l}39 \\
50 \\
31 \\
30\end{array}$ & $\begin{array}{l}209 \\
167 \\
238 \\
210 \\
314\end{array}$ & $\begin{array}{l}39 \\
49 \\
35 \\
38 \\
17\end{array}$ & $\begin{array}{l}139 \\
113 \\
150 \\
136 \\
188\end{array}$ & $\begin{array}{l}39 \\
52 \\
35 \\
42 \\
21\end{array}$ \\
\hline 1981 & 1020 & 30 & 1010 & 28 & 918 & 24 & 854 & 22 & 608 & 27 & 431 & 30 & 363 & 31 & 312 & 34 & 243 & 32 & 156 & 33 \\
\hline
\end{tabular}

DURATION OF DISGHARGE FOR EAOH WATER YEAR

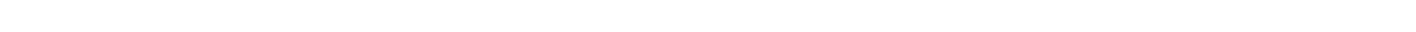

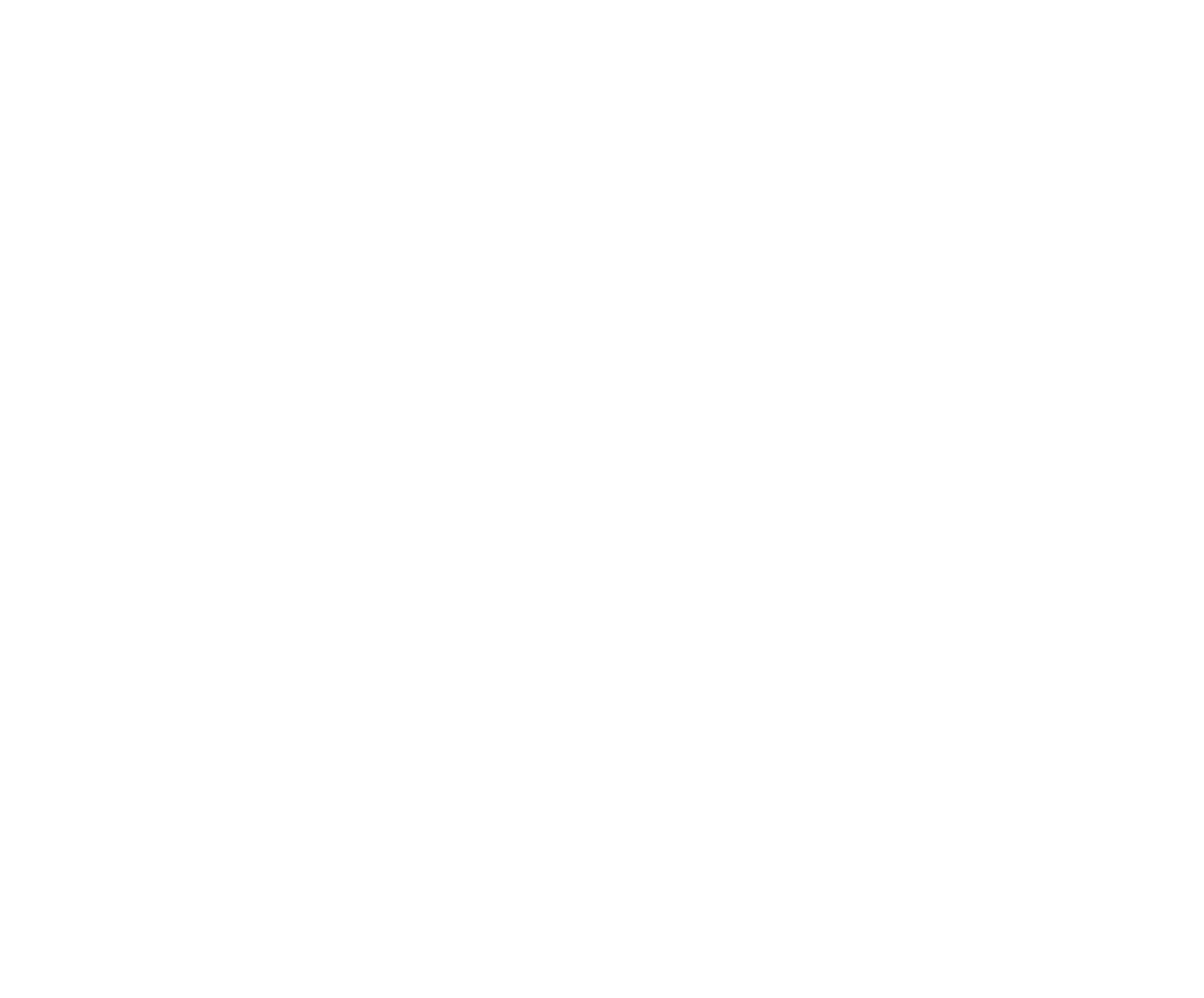


GREEN RIVER BASIN

09297000 UINTA RIVER NEAR NECLA, UT--Continued

DURATION OF DISCHARGE FOR EAGH WATER YEAR--Continued

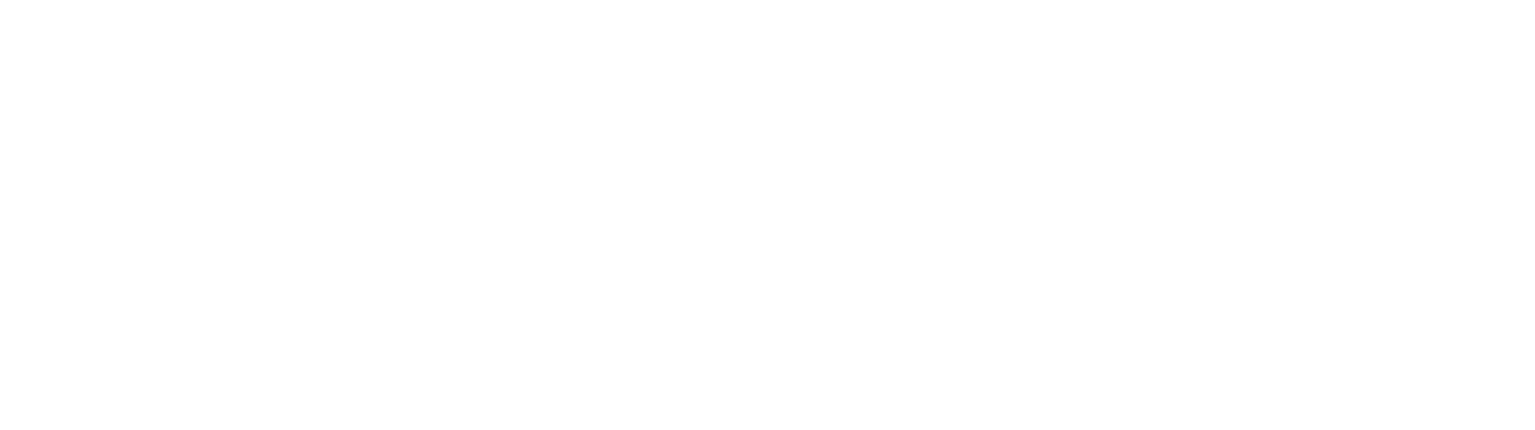

DURATION THBLE OF DISCHARGE FOR WATER YEARS 1926, 1930-81

$\begin{array}{ccc}\text { GBIC } & \text { ACU- } & \\ \text { FEET } & \text { MU- } & \text { PER- } \\ \text { PER } & \text { TOTAL LATED } & \text { CENT } \\ \text { CLASS SECOND DAYS } & \text { DAYS } & \text { DAYS }\end{array}$

$\begin{array}{lllll}0 & 0.00 & 0 & 19358 & 100.0\end{array}$

$28.00 \quad 4 \quad 19358100.0$

$32.00 \quad 7 \quad 19354100.0$

$37.00 \quad 155 \quad 19347 \quad 99.9$

$42.00 \quad 955 \quad 19192 \quad 99.1$

$\begin{array}{llll}49.00 & 1940 & 18237 & 94.2\end{array}$

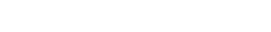

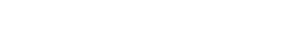

\section{DURATTON TFBLE OF DISCHARE}

\begin{tabular}{|c|c|c|c|c|c|c|c|c|c|c|c|c|c|c|}
\hline CASS & $\begin{array}{l}\text { OUBIC } \\
\text { FEET } \\
\text { PER } \\
\text { SECOND }\end{array}$ & $\begin{array}{l}\text { TOTAL } \\
\text { DAYS }\end{array}$ & $\begin{array}{c}\text { ACQU- } \\
\text { MU- } \\
\text { LATED } \\
\text { DAYS }\end{array}$ & $\begin{array}{l}\text { PER- } \\
\text { CENT } \\
\text { DAYS }\end{array}$ & & $\begin{array}{c}\text { GBIC } \\
\text { FEET } \\
\text { PER } \\
\text { SECOND }\end{array}$ & $\begin{array}{l}\text { TOTAL } \\
\text { DAYS }\end{array}$ & $\begin{array}{c}\text { ACOU- } \\
\text { MU- } \\
\text { LATED } \\
\text { DAYS }\end{array}$ & $\begin{array}{l}\text { PER- } \\
\text { CENT } \\
\text { DAYS }\end{array}$ & QASS & $\begin{array}{c}\text { OBBIC } \\
\text { FEET } \\
\text { PER } \\
\text { SECOND }\end{array}$ & $\begin{array}{l}\text { TOTAL } \\
\text { DAYS }\end{array}$ & $\begin{array}{c}\text { ACU- } \\
\text { M- } \\
\text { LATED } \\
\text { DAYS }\end{array}$ & $\begin{array}{l}\text { PER- } \\
\text { CENT } \\
\text { DAYS }\end{array}$ \\
\hline $\begin{array}{l}9 \\
10 \\
11 \\
12 \\
13 \\
14 \\
15 \\
16\end{array}$ & $\begin{array}{r}85.00 \\
97.00 \\
110.00 \\
130.00 \\
150.00 \\
170.00 \\
190.00 \\
220.00\end{array}$ & $\begin{array}{r}1032 \\
940 \\
1004 \\
830 \\
740 \\
632 \\
780 \\
1007\end{array}$ & $\begin{array}{r}10426 \\
9394 \\
8454 \\
7450 \\
6620 \\
5880 \\
5248 \\
4468\end{array}$ & $\begin{array}{l}53.9 \\
48.5 \\
43.7 \\
38.5 \\
34.2 \\
30.4 \\
27.1 \\
23.1\end{array}$ & $\begin{array}{l}18 \\
19 \\
20 \\
21 \\
22 \\
23 \\
24 \\
25\end{array}$ & $\begin{array}{l}290.0 \\
340.0 \\
390.0 \\
450.0 \\
510.0 \\
590.0 \\
680.0 \\
780.0\end{array}$ & $\begin{array}{l}577 \\
426 \\
364 \\
285 \\
307 \\
237 \\
185 \\
170\end{array}$ & $\begin{array}{r}2943 \\
2366 \\
1940 \\
1576 \\
1291 \\
984 \\
747 \\
562\end{array}$ & $\begin{array}{r}15.2 \\
12.2 \\
10.0 \\
8.1 \\
6.7 \\
5.1 \\
3.9 \\
2.9\end{array}$ & $\begin{array}{l}27 \\
28 \\
29 \\
30 \\
31 \\
32 \\
33 \\
34\end{array}$ & $\begin{array}{l}1000.0 \\
1200.0 \\
1400.0 \\
1600.0 \\
1800.0 \\
2000.0 \\
2400.0 \\
2700.0\end{array}$ & $\begin{array}{r}147 \\
73 \\
44 \\
13 \\
10 \\
3 \\
2 \\
2\end{array}$ & $\begin{array}{r}294 \\
147 \\
74 \\
30 \\
17 \\
7 \\
4 \\
2\end{array}$ & $\begin{array}{l}1.5 \\
0.8 \\
0.4 \\
0.2 \\
0.1 \\
0.0 \\
0.0 \\
0.0\end{array}$ \\
\hline
\end{tabular}

MONTHLY MEAN DISCHAPGES, IN OUBIC FEET PER SECOND, FOR EFOH WATER YEAR

\begin{tabular}{|c|c|c|c|c|c|c|c|c|c|c|c|c|}
\hline YEAR & $\mathrm{OCT}$ & NON & $\mathrm{DEC}$ & JAN & FEB & MAR & APR & MAY & JUNE & JULY & AUG & SEP \\
\hline 1926 & 208 & 119 & 92.6 & 74.2 & 64.3 & 64.3 & 94.9 & 516 & 446 & 285 & 177 & 96.9 \\
\hline 1930 & 150 & 71.1 & 60.0 & 50.0 & 60.0 & 40.0 & 92.1 & 339 & 583 & 302 & 324 & 191 \\
\hline $\begin{array}{l}1931 \\
1932 \\
1933 \\
1934 \\
1935\end{array}$ & $\begin{array}{c}155 \\
79.6 \\
110 \\
66.5 \\
59.0\end{array}$ & $\begin{array}{l}107 \\
67.5 \\
71.9 \\
62.6 \\
52.7\end{array}$ & $\begin{array}{l}80.0 \\
50.0 \\
45.0 \\
60.0 \\
50.0\end{array}$ & $\begin{array}{l}70.0 \\
45.0 \\
50.0 \\
60.0 \\
45.0\end{array}$ & $\begin{array}{l}6 c .0 \\
45.0 \\
45.0 \\
55.0 \\
45.0\end{array}$ & $\begin{array}{l}66.1 \\
65.0 \\
45.5 \\
50.0 \\
50.0\end{array}$ & $\begin{array}{l}71.7 \\
98.4 \\
55.9 \\
75.6 \\
55.0\end{array}$ & $\begin{array}{l}211 \\
475 \\
137 \\
123 \\
138\end{array}$ & $\begin{array}{c}267 \\
559 \\
515 \\
75.6 \\
640\end{array}$ & $\begin{array}{l}113 \\
322 \\
240 \\
71.7 \\
257\end{array}$ & $\begin{array}{c}107 \\
232 \\
118 \\
98.3 \\
156\end{array}$ & $\begin{array}{c}87.8 \\
142 \\
56.7 \\
73.8 \\
98.2\end{array}$ \\
\hline $\begin{array}{l}1936 \\
1937 \\
1938 \\
1939 \\
1940\end{array}$ & $\begin{array}{l}65.0 \\
122 \\
129 \\
202 \\
162\end{array}$ & $\begin{array}{r}50.0 \\
85.0 \\
92.4 \\
146 \\
95.5\end{array}$ & $\begin{array}{c}45.0 \\
60.0 \\
70.0 \\
105 \\
70.4\end{array}$ & $\begin{array}{l}45.0 \\
50.0 \\
58.4 \\
75.0 \\
62.4\end{array}$ & $\begin{array}{l}40.0 \\
45.0 \\
58.8 \\
60.0 \\
59.5\end{array}$ & $\begin{array}{l}40.0 \\
45.0 \\
69.1 \\
59.5 \\
61.0\end{array}$ & $\begin{array}{c}72.6 \\
70.0 \\
107 \\
99.1 \\
94.6\end{array}$ & $\begin{array}{l}338 \\
524 \\
401 \\
386 \\
328\end{array}$ & $\begin{array}{l}291 \\
446 \\
874 \\
251 \\
172\end{array}$ & $\begin{array}{l}293 \\
323 \\
348 \\
187 \\
116\end{array}$ & $\begin{array}{c}258 \\
280 \\
224 \\
111 \\
83.3\end{array}$ & $\begin{array}{l}199 \\
255 \\
217 \\
252 \\
169\end{array}$ \\
\hline $\begin{array}{l}1941 \\
1942 \\
1943 \\
1944 \\
1945\end{array}$ & $\begin{array}{c}227 \\
192 \\
116 \\
125 \\
98.8\end{array}$ & $\begin{array}{c}127 \\
148 \\
87.0 \\
93.0 \\
68.5\end{array}$ & $\begin{array}{c}87.2 \\
110 \\
74.5 \\
73.3 \\
49.4\end{array}$ & $\begin{array}{l}70.0 \\
84.8 \\
67.0 \\
60.1 \\
42.7\end{array}$ & $\begin{array}{l}64.0 \\
72.5 \\
62.7 \\
57.0 \\
45.8\end{array}$ & $\begin{array}{l}65.4 \\
70.7 \\
60.8 \\
57.4 \\
48.8\end{array}$ & $\begin{array}{l}74.4 \\
111 \\
142 \\
72.8 \\
63.6\end{array}$ & $\begin{array}{l}613 \\
363 \\
388 \\
445 \\
319\end{array}$ & $\begin{array}{r}952 \\
809 \\
368 \\
1132 \\
449\end{array}$ & $\begin{array}{l}454 \\
373 \\
274 \\
683 \\
341\end{array}$ & $\begin{array}{l}290 \\
230 \\
256 \\
267 \\
251\end{array}$ & $\begin{array}{l}192 \\
167 \\
160 \\
139 \\
168\end{array}$ \\
\hline $\begin{array}{l}1946 \\
1947 \\
1948 \\
1949 \\
1950\end{array}$ & $\begin{array}{l}120 \\
104 \\
125 \\
72.5 \\
116\end{array}$ & $\begin{array}{c}72.4 \\
79.8 \\
74.2 \\
67.2 \\
101\end{array}$ & $\begin{array}{l}62.2 \\
69.0 \\
61.7 \\
65.6 \\
78.2\end{array}$ & $\begin{array}{l}62.6 \\
57.1 \\
54.0 \\
62.2 \\
64.0\end{array}$ & $\begin{array}{l}55.0 \\
45.5 \\
56.9 \\
56.7 \\
62.6\end{array}$ & $\begin{array}{l}54.5 \\
49.0 \\
56.4 \\
59.0 \\
66.9\end{array}$ & $\begin{array}{l}145 \\
74.4 \\
62.6 \\
100 \\
127\end{array}$ & $\begin{array}{l}248 \\
635 \\
355 \\
425 \\
399\end{array}$ & $\begin{array}{l}263 \\
606 \\
374 \\
859 \\
646\end{array}$ & $\begin{array}{l}183 \\
395 \\
176 \\
397 \\
320\end{array}$ & $\begin{array}{l}141 \\
258 \\
141 \\
220 \\
172\end{array}$ & $\begin{array}{c}98.9 \\
165 \\
84.1 \\
147 \\
127\end{array}$ \\
\hline $\begin{array}{l}1951 \\
1952 \\
1953 \\
1954 \\
1955\end{array}$ & $\begin{array}{l}97.3 \\
106 \\
143 \\
84.9 \\
106\end{array}$ & $\begin{array}{l}81.0 \\
79.9 \\
98.7 \\
75.8 \\
82.7\end{array}$ & $\begin{array}{l}66.5 \\
69.0 \\
80.0 \\
60.8 \\
63.1\end{array}$ & $\begin{array}{l}52.6 \\
58.1 \\
66.6 \\
53.0 \\
58.2\end{array}$ & $\begin{array}{l}54.5 \\
56.0 \\
58.5 \\
57.9 \\
52.6\end{array}$ & $\begin{array}{l}53.4 \\
56.9 \\
59.3 \\
51.7 \\
57.6\end{array}$ & $\begin{array}{c}56.8 \\
119 \\
57.8 \\
94.1 \\
62.3\end{array}$ & $\begin{array}{l}270 \\
575 \\
104 \\
386 \\
264\end{array}$ & $\begin{array}{l}466 \\
871 \\
538 \\
223 \\
380\end{array}$ & $\begin{array}{l}242 \\
422 \\
224 \\
217 \\
177\end{array}$ & $\begin{array}{l}309 \\
368 \\
202 \\
134 \\
180\end{array}$ & $\begin{array}{l}143 \\
243 \\
113 \\
132 \\
112\end{array}$ \\
\hline $\begin{array}{l}1956 \\
1957 \\
1958 \\
1959 \\
1960\end{array}$ & $\begin{array}{l}77.6 \\
70.8 \\
161 \\
103 \\
129\end{array}$ & $\begin{array}{r}60.2 \\
64.2 \\
110 \\
86.0 \\
91.6\end{array}$ & $\begin{array}{l}54.9 \\
53.9 \\
79.9 \\
70.3 \\
70.4\end{array}$ & $\begin{array}{l}56.4 \\
44.3 \\
60.6 \\
52.7 \\
58.1\end{array}$ & $\begin{array}{l}55.4 \\
44.2 \\
63.1 \\
52.5 \\
56.7\end{array}$ & $\begin{array}{l}58.6 \\
61.3 \\
65.3 \\
51.9 \\
63.7\end{array}$ & $\begin{array}{l}74.7 \\
58.4 \\
84.8 \\
64.0 \\
96.6\end{array}$ & $\begin{array}{l}465 \\
103 \\
628 \\
163 \\
286\end{array}$ & $\begin{array}{l}484 \\
800 \\
568 \\
448 \\
375\end{array}$ & $\begin{array}{l}211 \\
350 \\
179 \\
202 \\
194\end{array}$ & $\begin{array}{l}152 \\
205 \\
165 \\
222 \\
125\end{array}$ & $\begin{array}{l}95.7 \\
204 \\
157 \\
151 \\
104\end{array}$ \\
\hline
\end{tabular}


09297000 UINTA RIVER NEAR NEOLA, UT--Continued

MONIHLY MEAN DISCHARGES, IN CUBIC FEET PER SECOND, FOR EACH WAT'ER YEAR.--Continued

$\begin{array}{lcccccccccccc}\text { YEAR } & \text { OCT } & \text { NOV } & \text { DEC } & \text { JAN } & \text { FEB } & \text { MAR } & \text { APR } & \text { MAY } & \text { JUNE } & \text { JUL } & \text { AUG } & \text { SEP } \\ 1961 & 109 & 85.8 & 62.7 & 51.7 & 45.8 & 43.4 & 49.0 & 218 & 254 & 155 & 162 & 298 \\ 1962 & 237 & 163 & 98.7 & 66.6 & 65.9 & 56.8 & 165 & 441 & 884 & 379 & 210 & 155 \\ 1963 & 127 & 88.4 & 66.0 & 51.5 & 53.9 & 59.5 & 58.2 & 355 & 403 & 238 & 224 & 235 \\ 1964 & 147 & 87.7 & 70.2 & 51.5 & 46.6 & 47.5 & 62.1 & 499 & 711 & 439 & 236 & 135 \\ 1965 & 80.1 & 65.6 & 62.1 & 53.8 & 48.6 & 48.5 & 77.8 & 254 & 1427 & 835 & 458 & 275 \\ 1966 & 199 & 133 & 95.8 & 74.9 & 62.4 & 79.7 & 119 & 435 & 324 & 279 & 218 & 180 \\ 1967 & 140 & 95.3 & 77.9 & 59.2 & 55.3 & 64.4 & 69.0 & 363 & 871 & 608 & 284 & 197 \\ 1968 & 131 & 90.6 & 74.7 & 56.9 & 62.5 & 64.4 & 72.7 & 182 & 1182 & 430 & 348 & 217 \\ 1969 & 150 & 104 & 75.6 & 65.1 & 63.6 & 60.4 & 131 & 775 & 647 & 321 & 244 & 178 \\ 1970 & 113 & 82.7 & 67.6 & 57.9 & 58.1 & 53.8 & 52.1 & 337 & 524 & 320 & 230 & 248 \\ & & & & & & & & & & & & \\ 1971 & 122 & 84.7 & 66.8 & 57.7 & 51.9 & 48.3 & 69.6 & 251 & 792 & 322 & 264 & 169 \\ 1972 & 126 & 95.3 & 66.0 & 60.3 & 52.7 & 66.8 & 86.4 & 310 & 514 & 251 & 167 & 120 \\ 1973 & 85.4 & 84.5 & 88.6 & 75.3 & 62.8 & 57.8 & 70.5 & 496 & 755 & 402 & 315 & 212 \\ 1974 & 128 & 90.5 & 73.0 & 65.5 & 61.2 & 59.9 & 57.6 & 270 & 245 & 188 & 133 & 83.4 \\ 1975 & 79.7 & 64.8 & 49.1 & 47.8 & 46.4 & 46.0 & 49.0 & 160 & 940 & 706 & 271 & 151 \\ 1976 & 92.5 & 75.0 & 69.2 & 61.5 & 55.9 & 56.2 & 61.3 & 301 & 426 & 207 & 140 & 118 \\ 1977 & 92.4 & 69.1 & 54.5 & 44.5 & 46.4 & 45.9 & 62.1 & 115 & 398 & 181 & 143 & 106 \\ 1978 & 80.5 & 64.3 & 54.9 & 53.7 & 51.9 & 58.5 & 68.8 & 164 & 749 & 216 & 133 & 107 \\ 1979 & 82.1 & 68.9 & 60.9 & 53.3 & 51.8 & 53.9 & 74.3 & 355 & 373 & 194 & 166 & 97.1 \\ 1980 & 79.5 & 67.3 & 61.1 & 51.5 & 58.8 & 52.5 & 80.1 & 243 & 924 & 321 & 174 & 149 \\ 1981 & 107 & 81.3 & 72.2 & 55.1 & 48.6 & 51.3 & 81.5 & 316 & 538 & 224 & 156 & 143\end{array}$

ANNUAL PEAK DISCHARGE, IN CUBIC FEET PER SECOND, AND CORRESPONDING GAGE HEIGHT, IN FEET, FOR EACH WATER YEAR

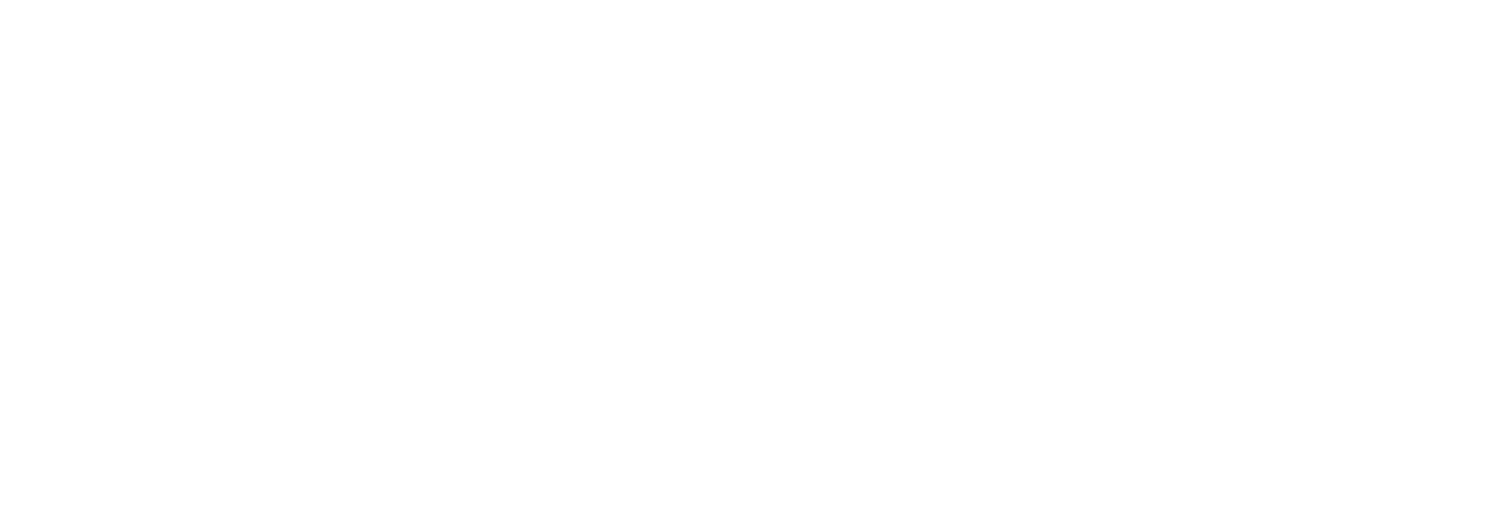

NAGNITUDE AND PRCBABIIITY OF ANNUAL LOWEST MEAN DISCHARGE BASED ON CLIMAT'IC YEARS 1926 AND 1931-81

\begin{tabular}{|c|c|c|c|c|c|c|}
\hline \multirow{2}{*}{$\begin{array}{l}\text { PERIOD } \\
\text { (CON- } \\
\text { SECU- } \\
\text { TIVE } \\
\text { DAYS) }\end{array}$} & \multicolumn{6}{|c|}{$\begin{array}{l}\text { DISCHARGE, IN CUBIC FEET PER SECOND, FOR } \\
\text { INDICATED RECURRENCE INTERNAL, IN YEARS, AND } \\
\text { ANNUAL NONEXCEEDANCE PRCBABILITY, IN PERCENT }\end{array}$} \\
\hline & $\begin{array}{c}2 \\
508\end{array}$ & $\begin{array}{c}5 \\
208\end{array}$ & $\begin{array}{l}10 \\
108\end{array}$ & $\begin{array}{l}20 \\
58\end{array}$ & $\begin{array}{l}50 \\
28\end{array}$ & $\begin{array}{r}100 \\
18\end{array}$ \\
\hline $\begin{array}{r}1 \\
7 \\
14 \\
30 \\
60 \\
90\end{array}$ & $\begin{array}{l}47 \\
49 \\
50 \\
52 \\
54 \\
56\end{array}$ & $\begin{array}{l}40 \\
43 \\
45 \\
47 \\
48 \\
50\end{array}$ & $\begin{array}{l}37 \\
41 \\
42 \\
44 \\
46 \\
47\end{array}$ & $\begin{array}{l}34 \\
38 \\
40 \\
42 \\
43 \\
45\end{array}$ & $\begin{array}{l}30 \\
36 \\
38 \\
40 \\
41 \\
43\end{array}$ & $\begin{array}{l}28 \\
34 \\
37 \\
39 \\
39 \\
41\end{array}$ \\
\hline
\end{tabular}


LOCATION.--Lat $40^{\circ} 31^{\prime} 15^{\prime \prime}$, long $110^{\circ} 02^{\prime} 25^{\prime \prime}$, in sec.31, T.2 N., R.1 W., Uintah Meridian, Uintah County, Hydrologic Unit 14060003, 220 ft downstream fram bridge on road to government sawmill, about i mi downstream fram Pole Creek, and 7 mi northwest of Whiterocks.

DRAINAGE AREA. $-218 \mathrm{mi}^{2}$.

PERIOD OF RECORD AVAIIABLE.--September 1899 to August 1904, August 1907 to November 1910, Novenber 1917 to September 1920. Monthly mean discharge for same periods prior to October 1918, published in wSP 1313.

GAGE.--Water-stage recorder after Nov. 5, 1917. Altitude of gage is 6,600 ft from topographic map. September 1899 to August 1904 , staff gage about $0.9 \mathrm{mi}$ upstream, and $600 \mathrm{ft}$ downstream from pole Creek at different datum. Aug. 13 to Oct. 9, 1907, staff gage about $1 \mathrm{mi}$ upstream, and $150 \mathrm{ft}$ downstream from Pole Creek at different datum. Oct. 22, 1907 to Nov. 30, 1910, chain gage 200 ft upstream at bridge at different datum.

REMARKS.--Station above all diversions except for Cedar View Canal which diverted 0.25 mi upstream 1917-20. Records of discharge herewith include canal flow for period 1917-20.

EXIREMES FOR PERIOD OF RECORD.--Maximum discharge (river and Cedar View Canal combined), 1,320 ft ${ }^{3} / \mathrm{s}$ May 29,1920 ; minimum recorded $45 \mathrm{ft}^{3} / \mathrm{s}$ Feb. 6, 1919.

LOWEST MEAN DISCHARGE, IN CUBIC FEET PER SECOND, AND RANKING FOR THE INDICATED NUMBER OF CONSECITIVE DAYS FOR EACH OLIMATIC YEAR, APRIL I-MARCH 31

\begin{tabular}{|c|c|c|c|c|c|c|c|c|c|c|c|c|c|c|c|c|c|c|c|c|}
\hline \multirow{2}{*}{ YEAR } & \multirow{2}{*}{\multicolumn{19}{|c|}{ CONSECUTIVE DAYS }} & \\
\hline & 1 & & & & & & & & 30 & & 60 & & 90 & & 120 & & 183 & & ALL & \\
\hline $\begin{array}{l}1919 \\
1920\end{array}$ & $\begin{array}{l}45.0 \\
50.0\end{array}$ & $\begin{array}{l}1 \\
2\end{array}$ & $\begin{array}{l}45.0 \\
50.0\end{array}$ & $\begin{array}{l}1 \\
2\end{array}$ & $\begin{array}{l}46.0 \\
50.0\end{array}$ & $\begin{array}{l}1 \\
2\end{array}$ & $\begin{array}{l}48.0 \\
50.0\end{array}$ & $\begin{array}{l}1 \\
2\end{array}$ & $\begin{array}{l}52.0 \\
50.0\end{array}$ & $\begin{array}{l}2 \\
1\end{array}$ & $\begin{array}{l}56.0 \\
50.0\end{array}$ & $\begin{array}{l}2 \\
1\end{array}$ & $\begin{array}{l}59.0 \\
53.0\end{array}$ & $\begin{array}{l}2 \\
1\end{array}$ & $\begin{array}{l}63.0 \\
57.0\end{array}$ & $\begin{array}{l}2 \\
1\end{array}$ & $\begin{array}{l}92.0 \\
79.0\end{array}$ & $\begin{array}{l}2 \\
1\end{array}$ & $\begin{array}{l}196 \\
154\end{array}$ & $\begin{array}{l}2 \\
1\end{array}$ \\
\hline
\end{tabular}

HIGHEST MEAN DISCHARGE, IN CUBIC FEET PER SECOND, AND RANKING FOR THE INDICATED NUMBER OF CONSECUTIVE DAYS FOR EACH WATER YEAR, OCTOBER 1-SEPTEMBER 30

YEAR

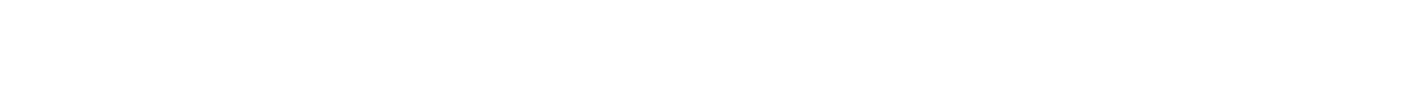

DURATION OF DISCHARGE FOR EACH WATER YEAR

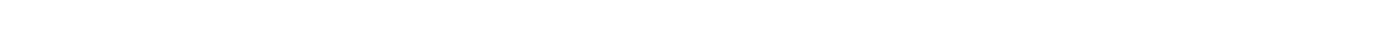
YEAR

NUMBER OF DAYS IN CLASS

CBBIC FEET PER SECOND

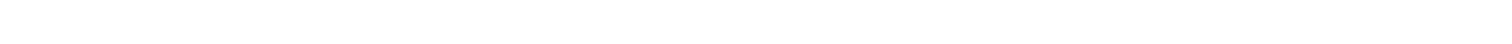

DURATION TABLE OF DISCHARGE FOR WATER YEARS 1919-20

$\begin{array}{ccc}\text { CUBIC } & \text { ACAJ- } \\ \text { FEET } & \text { MU- } & \text { PER- } \\ \text { PER TOTAL, LATED } & \text { CENT } \\ \text { CLASS SECOND DAYS DAYS } & \text { DAYS }\end{array}$
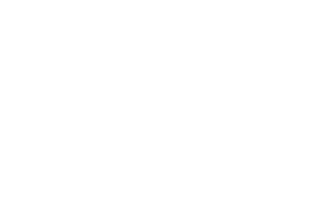

$\begin{array}{lcl}\text { OBIC } & \text { ACOU- } \\ \text { FEET } & \text { MU- } & \text { PER- } \\ \text { PER TOTAL IATED } & \text { CENT }\end{array}$

GLASS SECOND DAYS DAYS DAYS

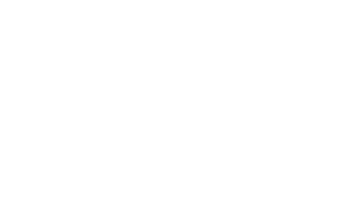

CUBIC ACOUFEET TOTAL LATED CENT CLASS SEOOND DAYS DAYS DAYS

$\begin{array}{rrrrr}18 & 240.0 & 20 & 156 & 21.3 \\ 19 & 260.0 & 15 & 136 & 18.6 \\ 20 & 290.0 & 21 & 121 & 16.6 \\ 21 & 320.0 & 19 & 100 & 13.7 \\ 22 & 350.0 & 11 & 81 & 11.1 \\ 23 & 390.0 & 6 & 70 & 9.6 \\ 24 & 430.0 & 9 & 64 & 8.8 \\ 25 & 470.0 & 10 & 55 & 7.5 \\ 26 & 520.0 & 5 & 45 & 6.2\end{array}$

$\begin{array}{lll}\text { FEET } & \text { MU- } & \\ \text { PER TOR- } & \text { POTAL LATED } & \text { CENT }\end{array}$ CLASS SECOND DAYS DAYS DAYS

$\begin{array}{rrrrr}27 & 570.0 & 17 & 40 & 5.5 \\ 28 & 630.0 & 4 & 23 & 3.2 \\ 29 & 690.0 & 4 & 19 & 2.6 \\ 30 & 760.0 & 2 & 15 & 2.0 \\ 31 & 840.0 & 5 & 13 & 1.8 \\ 32 & 930.0 & 4 & 8 & 1.1 \\ 33 & 1000.0 & 1 & 4 & 0.6 \\ 34 & 1100.0 & 3 & 3 & 0.4\end{array}$

MONTHLY MEAN DISCHARGES, IN CUBIC FEET PER SECOND, FOR EACH WATER YEAR

$\begin{array}{ccccccccccccc}\text { YEAR } & \text { OCT } & \text { NON } & \text { DEC } & \text { JAN } & \text { FEB } & \text { MAR } & \text { APR } & \text { MAY } & \text { JUNE } & \text { JULY } & \text { AUG } & \text { SEP } \\ 1900 & 162 & 130 & 120 & 112 & 112 & 125 & 138 & 650 & 597 & 223 & 184 & 157 \\ 1901 & 154 & 138 & 145 & 140 & 140 & 150 & 179 & 684 & 355 & 251 & 242 & 193 \\ 1902 & 163 & 142 & 147 & 136 & 127 & 144 & 154 & 555 & 655 & 262 & 181 & 167 \\ 1903 & 152 & 139 & 125 & 86.0 & 95.0 & 122 & 148 & 430 & 894 & 382 & 232 & 209 \\ & & & & & & & & & & & & \\ 1909 & 325 & 236 & 202 & 187 & 98.7 & 131 & 183 & 338 & 1430 & 667 & 494 & 546 \\ 1910 & 267 & 191 & 165 & 150 & 145 & 157 & 323 & 683 & 417 & 362 & 282 & 264 \\ 1919 & 184 & 111 & 75.0 & 60.4 & 54.6 & 61.9 & 84.1 & 452 & 313 & 183 & 173 & 162 \\ 1920 & 137 & 102 & 65.6 & 50.0 & 50.0 & 64.9 & 75.3 & 434 & 664 & 336 & 235 & 155\end{array}$


GREEN RIVER BASIN

09297600 WEST CHANNEJ UINTA RIVER BELOW DIVERSION WC', $h$ S, NEAR WHITEROCKS, UT

LOCATION. --Lat 40 $27^{\prime} 39^{\prime \prime}$, long $109^{\circ} 57^{\prime} 00^{\prime \prime}$, in NE ${ }_{4}^{1} \mathrm{NW}^{\frac{1}{3}} \mathrm{NW} \frac{1}{4}$ sec. 25, T.1 N., R.1 W., Uintah Meridian, Uintah County, Hydrologic Unit 14060003 , Uintah and Ouray Indian Reservation, on left bank $300 \mathrm{ft}$ downstream from Uinta No 1 canal diversion works, $1.2 \mathrm{mi}$ southwest of Whiterocks, $1.4 \mathrm{mi}$ downstream from East Channel diversion works.

DRAINAGE AREA. $--216 \mathrm{mi}^{2}$.

PERIOD OF RECORD AVAII.ABLE.--October 1976 to september 1981 .

GAGE.-Water-stage recorder. Altitude of gage is 5,990 ft, from topographic map.

REMARKS.--Flow regulated by several major diversions above gage for irrigation.

AVERAGE DISCHARGE. --5 years, $39.3 \mathrm{ft}^{3} / \mathrm{s}, 28,470 \mathrm{acre}-\mathrm{ft} / \mathrm{yr}$.

EXTREMES FOR PERIOD OF RECORD.--Maximum discharge, 2,810 ft $3 / \mathrm{s}$ June 11,1980 , gage height, $4.73 \mathrm{ft} ; \mathrm{minimum} \mathrm{daily,} 1.2 \mathrm{ft}{ }^{3} / \mathrm{s} \mathrm{Mar}$. $29,30,1978$.

LOWEST MEAN DISCHARGE, IN CUBIC FEET PER SECOND, AND RANKING FOR THE INDICATED NUMBER OF CONSECUTIVE DAYS FOR EACH CLIMAIIC YEAR, APRIL 1-MARCH 31

\begin{tabular}{|c|c|c|c|c|c|c|c|c|c|c|c|c|c|c|c|c|c|c|c|}
\hline YEAR & & & & & & & & & CONSE & OUTIV & JE DAYS & & & & & & & & \\
\hline & 1 & & 3 & & 7 & & 14 & & 30 & & 60 & & 90 & & 120 & & 183 & & ALL \\
\hline $\begin{array}{l}1978 \\
1979 \\
1980\end{array}$ & $\begin{array}{l}1.19 \\
2.60 \\
2.00\end{array}$ & $\begin{array}{l}1 \\
3 \\
2\end{array}$ & $\begin{array}{l}1.30 \\
2.90 \\
2.20\end{array}$ & $\begin{array}{l}1 \\
3 \\
2\end{array}$ & $\begin{array}{l}1.60 \\
2.90 \\
3.90\end{array}$ & $\begin{array}{l}1 \\
2 \\
3\end{array}$ & $\begin{array}{l}3.50 \\
2.90 \\
5.90\end{array}$ & $\begin{array}{l}2 \\
1 \\
3\end{array}$ & $\begin{array}{l}7.50 \\
2.90 \\
6.90\end{array}$ & $\begin{array}{l}3 \\
1 \\
2\end{array}$ & $\begin{array}{l}8.90 \\
3.50 \\
7.30\end{array}$ & $\begin{array}{l}3 \\
1 \\
2\end{array}$ & $\begin{array}{l}9.70 \\
3.80 \\
8.10\end{array}$ & $\begin{array}{l}3 \\
1 \\
2\end{array}$ & $\begin{array}{l}9.80 \\
4.70 \\
9.30\end{array}$ & $\begin{array}{l}3 \\
1 \\
2\end{array}$ & $\begin{array}{c}13.0 \\
9.20 \\
14.0\end{array}$ & $\begin{array}{l}2 \\
1 \\
3\end{array}$ & $\begin{array}{l}31.0 \\
37.0 \\
42.0\end{array}$ \\
\hline 1981 & 7.50 & 4 & 7.90 & 4 & 8.50 & 4 & 9.00 & 4 & 10.0 & 4 & 11.0 & 4 & 13.0 & 4 & 13.0 & 4 & 15.0 & 4 & 49.0 \\
\hline
\end{tabular}

HIGHEST MEAN DISCHARGE, IN CUBIC FEET PER SECOND, AND RANKING FOR THE INDICATED NUMBER OF CONSECUTIVE DAYS FOR EACH WATER YEAR, OCTCBER 1-SEPTEMBER 30

\begin{tabular}{|c|c|c|c|c|c|c|c|c|c|c|c|c|c|c|c|c|c|c|c|}
\hline YEAR & & & & & & & & & CONS & $\sigma_{\mathrm{T} T}$ & VE DAYS & & & & & & & & \\
\hline & 1 & & 3 & & 7 & & 15 & & 30 & & 60 & & 90 & & 120 & & 183 & & ALL \\
\hline $\begin{array}{l}1977 \\
1978 \\
1979 \\
1980\end{array}$ & $\begin{array}{l}210 \\
365 \\
343 \\
744\end{array}$ & $\begin{array}{l}4 \\
2 \\
3 \\
1\end{array}$ & $\begin{array}{l}173 \\
320 \\
291 \\
500\end{array}$ & $\begin{array}{l}4 \\
2 \\
3 \\
1\end{array}$ & $\begin{array}{l}138 \\
246 \\
226 \\
305\end{array}$ & $\begin{array}{l}5 \\
2 \\
3 \\
1\end{array}$ & $\begin{array}{l}102 \\
201 \\
178 \\
223\end{array}$ & $\begin{array}{l}5 \\
2 \\
3 \\
1\end{array}$ & $\begin{array}{l}82.0 \\
155 \\
140 \\
186\end{array}$ & $\begin{array}{l}5 \\
2 \\
3 \\
1\end{array}$ & $\begin{array}{l}72.0 \\
118 \\
118 \\
148\end{array}$ & $\begin{array}{l}5 \\
2 \\
3 \\
1\end{array}$ & $\begin{array}{r}65.0 \\
97.0 \\
102 \\
125\end{array}$ & $\begin{array}{l}5 \\
3 \\
2 \\
1\end{array}$ & $\begin{array}{r}60.0 \\
82.0 \\
91.0 \\
109\end{array}$ & $\begin{array}{l}5 \\
3 \\
2 \\
1\end{array}$ & $\begin{array}{l}49.0 \\
64.0 \\
71.0 \\
83.0\end{array}$ & $\begin{array}{l}5 \\
4 \\
2 \\
1\end{array}$ & $\begin{array}{l}30.0 \\
38.0 \\
40.0 \\
48.0\end{array}$ \\
\hline 981 & 169 & 5 & 165 & 5 & 144 & 4 & 134 & 4 & 124 & 4 & 103 & 4 & 91.0 & 4 & 81.0 & 4 & 65.0 & 3 & 40.0 \\
\hline
\end{tabular}

DURATION OF DISCHARGE FOR EACH WATER YEAR

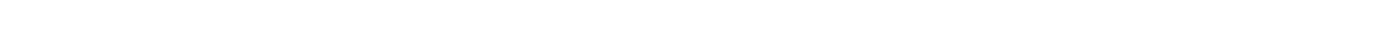
YEAR

NUMBER OF DAYS IN CLASS

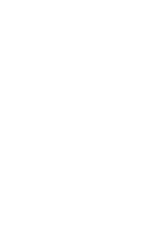

DURATION TABLE OF DISCHARGE FOR WATER YEARS 1977-8I

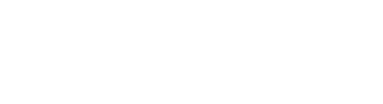

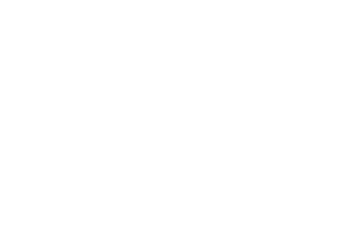

$\begin{array}{ccc}\text { OBIC } & \text { ACOU- } \\ \text { FEET } & \text { MU- } & \text { PER- } \\ \text { PER TOTAL } & \text { LATED } & \text { CENT }\end{array}$ CLASS SECOND DAYS DAYS DAYS $\begin{array}{ccc}\text { CUBIC } & \text { ACOU- } \\ \text { FEET } & \text { NU- } & \text { PER- } \\ \text { PER TOTAL IATED } & \text { CENT } \\ \text { CLASS SECOND DAYS } & \text { DAYS } & \text { DAYS }\end{array}$

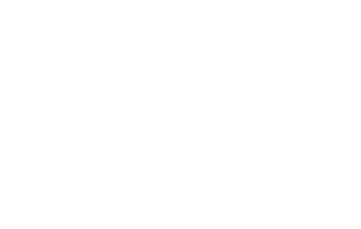

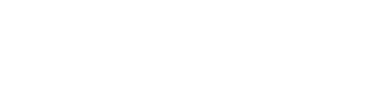

$\begin{array}{rrrrr}27 & 140.0 & 36 & 57 & 3.1 \\ 28 & 170.0 & 8 & 21 & 1.2 \\ 29 & 210.0 & 5 & 13 & 0.7 \\ 30 & 250.0 & 3 & 8 & 0.4 \\ 31 & 300.0 & 2 & 5 & 0.3 \\ 32 & 360.0 & 1 & 3 & 0.2 \\ 33 & 430.0 & 0 & 2 & 0.1 \\ 34 & 520.0 & 2 & 2 & 0.1\end{array}$

MONTHLY MEAN DISCHARGES, IN CUBIC FEET PER SECOND, FOR EACH WATER YEAR

\begin{tabular}{|c|c|c|c|c|c|c|c|c|c|c|c|c|}
\hline YEAR & $\infty \mathrm{CT}$ & NOV & DEC & JAN & FEB & MAR & APR & MAY & JUNE & JULY & AUG & SEP \\
\hline $\begin{array}{l}1977 \\
1978 \\
1979 \\
1980\end{array}$ & $\begin{array}{l}29.7 \\
24.6 \\
23.5 \\
27.1\end{array}$ & $\begin{array}{c}14.5 \\
11.6 \\
10.3 \\
9.36\end{array}$ & $\begin{array}{c}4.36 \\
10.3 \\
6.32 \\
7.06\end{array}$ & $\begin{array}{c}5.89 \\
11.2 \\
4.40 \\
8.23\end{array}$ & $\begin{array}{c}5.39 \\
10.0 \\
3.57 \\
14.1\end{array}$ & $\begin{array}{c}3.68 \\
7.73 \\
5.64 \\
16.2\end{array}$ & $\begin{array}{l}21.0 \\
19.8 \\
24.9 \\
16.0\end{array}$ & $\begin{array}{r}42.6 \\
65.5 \\
98.8 \\
77.5\end{array}$ & $\begin{array}{l}82.3 \\
151 \\
108 \\
181\end{array}$ & $\begin{array}{c}61.1 \\
66.9 \\
83.2 \\
107\end{array}$ & $\begin{array}{l}50.2 \\
42.8 \\
65.9 \\
67.2\end{array}$ & $\begin{array}{l}39.4 \\
38.0 \\
42.7 \\
46.4\end{array}$ \\
\hline 1982 & 23.8 & 13.6 & 14.9 & 15.7 & 9.92 & 12.5 & 28.0 & 79.6 & 120 & 71.2 & 48.7 & 39.6 \\
\hline
\end{tabular}


GREEN RIVER BASIN

09297600 WES'T OHANNEL UINTA RIVER BELCW DIVERSION WORKS, NEAR WHITEROCKS, UT-CONTINUEd

ANNUA PEAR DISOHARGE, IN OBBIC FEET PER SECOND, AND CORRFSPONDING GAGE HEIGHT, IN FEET, FOR EACH WATER YEAR

\begin{tabular}{|c|c|c|c|c|c|c|c|c|c|c|c|}
\hline $\begin{array}{l}\text { WATER } \\
\text { YEAR }\end{array}$ & DATE & $\begin{array}{c}\text { GAGE } \\
\text { HEIGHT }\end{array}$ & $\begin{array}{c}\text { PEAR } \\
\text { DISOHARGE }\end{array}$ & $\begin{array}{l}\text { WATER } \\
\text { YEAR }\end{array}$ & DATE & $\begin{array}{c}\text { GAGE } \\
\text { HEIGHT }\end{array}$ & $\begin{array}{c}\text { PEAR } \\
\text { DISQH ARGE }\end{array}$ & $\begin{array}{l}\text { WATER } \\
\text { YEAR }\end{array}$ & DATE & $\begin{array}{c}\text { GAGE } \\
\text { HEYGHT }\end{array}$ & $\begin{array}{c}\text { PEAR } \\
\text { DISAH ARGE }\end{array}$ \\
\hline $\begin{array}{l}1977 \\
1978\end{array}$ & $\begin{array}{l}\text { JUNE } 03,1977 \\
\text { JUNE } 10,1978\end{array}$ & $\overline{3.04}$ & $\begin{array}{l}342 \\
654\end{array}$ & $\begin{array}{l}1979 \\
1980\end{array}$ & $\begin{array}{lll}\text { MAY } & 28,1979 \\
\text { JUNE } 11, & 1980\end{array}$ & $\begin{array}{l}2.96 \\
4.73\end{array}$ & $\begin{array}{r}606 \\
2810\end{array}$ & 1981 & JUNE 09,1981 & 3.52 & 225 \\
\hline
\end{tabular}

09297700 EAST CH ANNEL UINTA RIVER BELCW DIVERSION WORKS, NEAR WHITEROCKS, UT

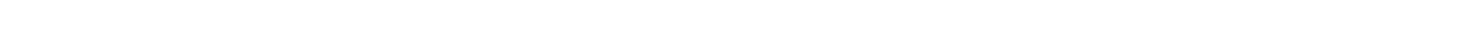
14060003 , Uintah and Ouray Indian Reservation, on right bank 0.7 mi downstream from diversion works, and $1.3 \mathrm{mi}$ west of Whiterocks.

DRAINAGE AREA. --215 $\mathrm{mi}^{2}$.

PERIOD OF RECORD AVAILABLE.--Octcber 1976 to September 1981.

GAGE.-Water-stage recorder. Altitude of gage is 6,075 ft from topographic map.

REMARKS.--Several major diversions above gage for irrigation.

AVERAGE DISGHARGE. --5 years, $23.3 \mathrm{ft}^{3} / \mathrm{s}, 16,880$ acre- $\mathrm{ft} / \mathrm{yr}$.

EXTREMES FOR PERIOD OF RECORD.--Maximum đischarge, 1,080 $\mathrm{ft}^{3} / \mathrm{s}$ June 11, 1980, gage height, $3.66 \mathrm{ft} ; \mathrm{minimum}$ daily, $0.16 \mathrm{ft} \mathrm{t}^{3} / \mathrm{s}$ Sept. 19, 1978.

LOWEST MEAN DISGHARGE, IN OUIC FEET PER SECOND, AND RANKING FOR THE INDICATED NUMBER OF CONSECUTIVE DAYS FOR EAG OLIMATIC YEAR, APRIL I-MAROH 31

\begin{tabular}{|c|c|c|c|c|c|c|c|c|c|c|c|c|c|c|c|c|c|c|c|}
\hline YEAR & 1 & & 3 & & 7 & & 14 & & $\begin{array}{l}\text { CONSE } \\
30\end{array}$ & QUTTVE & $\begin{array}{l}\text { DAYS } \\
60\end{array}$ & & 90 & & 120 & & 183 & & ALL \\
\hline $\begin{array}{l}1978 \\
1979 \\
1980\end{array}$ & $\begin{array}{l}0.54 \\
0.16 \\
0.60\end{array}$ & $\begin{array}{l}3 \\
1 \\
4\end{array}$ & $\begin{array}{l}0.55 \\
0.20 \\
0.65\end{array}$ & $\begin{array}{l}3 \\
1 \\
4\end{array}$ & $\begin{array}{l}0.58 \\
0.40 \\
0.70\end{array}$ & $\begin{array}{l}3 \\
2 \\
4\end{array}$ & $\begin{array}{l}0.72 \\
0.43 \\
0.75\end{array}$ & $\begin{array}{l}3 \\
2 \\
4\end{array}$ & $\begin{array}{l}0.87 \\
0.46 \\
1.70\end{array}$ & $\begin{array}{l}3 \\
2 \\
4\end{array}$ & $\begin{array}{l}1.19 \\
0.75 \\
1.90\end{array}$ & $\begin{array}{l}3 \\
2 \\
4\end{array}$ & $\begin{array}{l}3.70 \\
2.50 \\
4.20\end{array}$ & $\begin{array}{l}3 \\
2 \\
4\end{array}$ & $\begin{array}{l}6.50 \\
4.50 \\
4.40\end{array}$ & $\begin{array}{l}4 \\
3 \\
2\end{array}$ & $\begin{array}{c}8.80 \\
15.0 \\
13.0\end{array}$ & $\begin{array}{l}1 \\
4 \\
3\end{array}$ & $\begin{array}{l}16.0 \\
28.0 \\
26.0\end{array}$ \\
\hline 981 & 0.21 & 2 & 0.23 & 2 & 0.24 & 1 & 0.26 & 1 & 0.45 & 1 & 0.65 & 1 & 1.50 & 1 & 2.10 & 1 & 12.0 & 2 & 27.0 \\
\hline
\end{tabular}

HIGHEST MEAN DISCHARGE, IN OUBIC FEET PER SECOND, AND RANKING FOR THE INDICATED NUMBER OF CONSEQUTIVE DAVS FOR EAOH WATER YEAR, OCTCBER I-SEPIEMBER 30

\begin{tabular}{|c|c|c|c|c|c|c|c|c|c|c|c|c|c|c|c|c|c|c|c|}
\hline YEAR & 1 & & 3 & & 7 & & 15 & & $\begin{array}{l}\text { CONs } \\
30\end{array}$ & WT & $\begin{array}{l}\text { VE DAYS } \\
60\end{array}$ & & 90 & & 120 & & 183 & & ALL \\
\hline $\begin{array}{l}1977 \\
1978 \\
1979 \\
1980\end{array}$ & $\begin{array}{l}47.0 \\
610 \\
565 \\
820\end{array}$ & $\begin{array}{l}5 \\
2 \\
3 \\
1\end{array}$ & $\begin{array}{l}45.0 \\
513 \\
449 \\
638\end{array}$ & $\begin{array}{l}5 \\
2 \\
3 \\
1\end{array}$ & $\begin{array}{l}37.0 \\
461 \\
303 \\
394\end{array}$ & $\begin{array}{l}5 \\
1 \\
3 \\
2\end{array}$ & $\begin{array}{l}35.0 \\
275 \\
204 \\
365\end{array}$ & $\begin{array}{l}5 \\
2 \\
3 \\
1\end{array}$ & $\begin{array}{l}35.0 \\
155 \\
123 \\
206\end{array}$ & $\begin{array}{l}5 \\
2 \\
3 \\
1\end{array}$ & $\begin{array}{r}33.0 \\
83.0 \\
67.0 \\
105\end{array}$ & $\begin{array}{l}5 \\
2 \\
3 \\
1\end{array}$ & $\begin{array}{l}31.0 \\
58.0 \\
48.0 \\
71.0\end{array}$ & $\begin{array}{l}5 \\
2 \\
3 \\
1\end{array}$ & $\begin{array}{l}27.0 \\
46.0 \\
44.0 \\
56.0\end{array}$ & $\begin{array}{l}4 \\
2 \\
3 \\
1\end{array}$ & $\begin{array}{l}20.0 \\
43.0 \\
40.0 \\
48.0\end{array}$ & $\begin{array}{l}5 \\
2 \\
3 \\
1\end{array}$ & $\begin{array}{l}13.0 \\
26.0 \\
26.0 \\
32.0\end{array}$ \\
\hline 1981 & 280 & 4 & 256 & 4 & 183 & 4 & 155 & 4 & 83.0 & 4 & 45.0 & 4 & 31.0 & 4 & 26.0 & 5 & 26.0 & 4 & 19.0 \\
\hline
\end{tabular}

DURATION OF DISGHARGE FOR EACH WATER YEAR

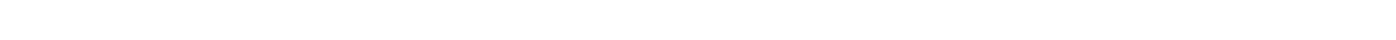
YEAR

NUMBER OF DAYS IN CLASS

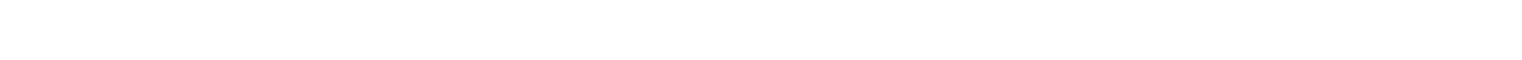

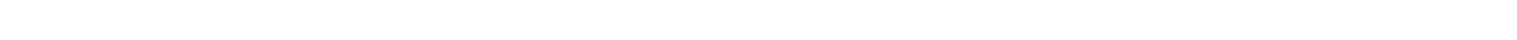

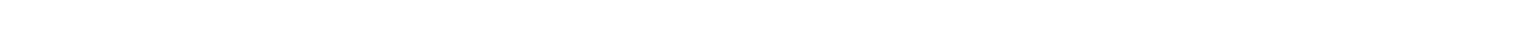

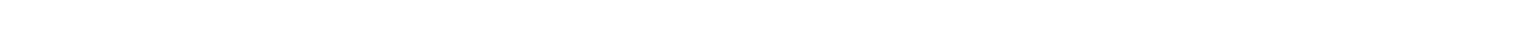


DURATION TABLE OF DISQHARGE FOR WATER YEARS 1977-81

\begin{tabular}{|c|c|c|c|c|c|c|c|c|c|c|c|c|c|c|c|c|c|c|c|}
\hline & $\begin{array}{c}\text { बBIC } \\
\text { FEET } \\
\text { PER } \\
\text { SECOND }\end{array}$ & $\begin{array}{l}\text { TOTAL } \\
\text { DAYS }\end{array}$ & $\begin{array}{c}\text { ACOU- } \\
\text { MU- } \\
\text { LATED } \\
\text { DAYS }\end{array}$ & $\begin{array}{l}\text { PER- } \\
\text { CENT } \\
\text { DAVS }\end{array}$ & CASS & $\begin{array}{c}\text { बBIC } \\
\text { FEET } \\
\text { PER } \\
\text { SEOOND }\end{array}$ & $\begin{array}{l}\text { TOTAL } \\
\text { DAYS }\end{array}$ & $\begin{array}{c}\text { ACON- } \\
\text { MI- } \\
\text { LATED } \\
\text { DAYS }\end{array}$ & $\begin{array}{l}\text { PER- } \\
\text { CENT } \\
\text { DAYS }\end{array}$ & & $\begin{array}{c}\text { UBIC } \\
\text { FEET } \\
\text { PER } \\
\text { SECOND }\end{array}$ & $\begin{array}{l}\text { TOTAL } \\
\text { DAYS }\end{array}$ & $\begin{array}{c}\text { ACOJ- } \\
\text { MU- } \\
\text { LAIED } \\
\text { DAYS }\end{array}$ & $\begin{array}{l}\text { PER- } \\
\text { CENT } \\
\text { DAYS }\end{array}$ & & $\begin{array}{c}\text { CUBIC } \\
\text { FEET } \\
\text { PER } \\
\text { SECOND }\end{array}$ & $\begin{array}{l}\text { TOTAL } \\
\text { DAYS }\end{array}$ & $\begin{array}{c}\text { ACOJ- } \\
\text { MJ- } \\
\text { LAIED } \\
\text { DAYS }\end{array}$ & $\begin{array}{l}\text { PER- } \\
\text { CENT } \\
\text { DAYS }\end{array}$ \\
\hline $\begin{array}{l}0 \\
1 \\
2 \\
3 \\
4 \\
5 \\
6 \\
7 \\
8\end{array}$ & $\begin{array}{l}0.00 \\
0.16 \\
0.21 \\
0.27 \\
0.34 \\
0.44 \\
0.57 \\
0.74 \\
0.95\end{array}$ & $\begin{array}{r}0 \\
2 \\
10 \\
41 \\
55 \\
69 \\
116 \\
104 \\
66\end{array}$ & $\begin{array}{l}1826 \\
1826 \\
1824 \\
1814 \\
1773 \\
1718 \\
1649 \\
1533 \\
1429\end{array}$ & $\begin{array}{r}100.0 \\
100.0 \\
99.9 \\
99.3 \\
97.1 \\
94.1 \\
90.3 \\
84.0 \\
78.3\end{array}$ & $\begin{array}{l}9 \\
10 \\
11 \\
12 \\
13 \\
14 \\
15 \\
16 \\
17\end{array}$ & $\begin{array}{l}1.20 \\
1.60 \\
2.00 \\
2.60 \\
3.40 \\
4.40 \\
5.60 \\
7.20 \\
9.30\end{array}$ & $\begin{array}{l}80 \\
71 \\
52 \\
26 \\
33 \\
41 \\
45 \\
54 \\
49\end{array}$ & $\begin{array}{r}1363 \\
1283 \\
1212 \\
1160 \\
1134 \\
1101 \\
1060 \\
1015 \\
961\end{array}$ & $\begin{array}{l}74.6 \\
70.3 \\
65.4 \\
63.5 \\
62.1 \\
60.3 \\
58.1 \\
55.6 \\
52.6\end{array}$ & $\begin{array}{l}18 \\
19 \\
20 \\
21 \\
22 \\
23 \\
24 \\
25 \\
26\end{array}$ & $\begin{array}{l}12.0 \\
16.0 \\
20.0 \\
26.0 \\
33.0 \\
43.0 \\
55.0 \\
71.0 \\
92.0\end{array}$ & $\begin{array}{r}97 \\
51 \\
151 \\
262 \\
218 \\
58 \\
10 \\
8 \\
12\end{array}$ & $\begin{array}{r}912 \\
815 \\
764 \\
613 \\
351 \\
133 \\
75 \\
65 \\
57\end{array}$ & $\begin{array}{r}49.9 \\
44.6 \\
41.8 \\
33.6 \\
19.2 \\
7.3 \\
4.1 \\
3.6 \\
3.1\end{array}$ & $\begin{array}{l}27 \\
28 \\
29 \\
30 \\
31 \\
32 \\
33 \\
34\end{array}$ & $\begin{array}{l}120.0 \\
150.0 \\
200.0 \\
250.0 \\
330.0 \\
420.0 \\
540.0 \\
700.0\end{array}$ & $\begin{array}{r}11 \\
8 \\
5 \\
5 \\
4 \\
4 \\
6 \\
2\end{array}$ & $\begin{array}{r}45 \\
34 \\
26 \\
21 \\
16 \\
12 \\
8 \\
2\end{array}$ & $\begin{array}{l}2.5 \\
1.9 \\
1.4 \\
1.2 \\
0.9 \\
0.7 \\
0.4 \\
0.1\end{array}$ \\
\hline
\end{tabular}

MONTHLY MEAN DISGHARGES, IN UBIC FEET PER SECOND, FOR EACH WATER YEAR

$\begin{array}{lllllllllllrr}\text { YEAR } & \text { OCT } & \text { NOV } & \text { DEC } & \text { JAN } & \text { FEB } & \text { MAR } & \text { APR } & \text { MAY } & \text { JUNE } & \text { JULY } & \text { AJG } & \text { SEP } \\ 1977 & 0.45 & 0.45 & 27.3 & 32.5 & 30.0 & 16.4 & 1.52 & 3.18 & 19.7 & 14.1 & 13.0 & 3.65 \\ 1978 & 0.88 & 11.2 & 23.2 & 36.9 & 41.7 & 28.0 & 0.56 & 2.32 & 154 & 11.2 & 6.35 & 1.07 \\ 1979 & 0.47 & 37.5 & 37.1 & 32.9 & 31.1 & 29.1 & 3.39 & 90.6 & 37.1 & 6.20 & 8.82 & 1.92 \\ 1980 & 1.95 & 40.0 & 39.8 & 34.5 & 34.7 & 13.8 & 0.61 & 4.04 & 204 & 5.80 & 3.00 & 0.76 \\ 1981 & 1.01 & 29.6 & 31.1 & 24.8 & 17.1 & 9.66 & 0.42 & 18.2 & 72.2 & 2.46 & 5.54 & 13.6\end{array}$

ANNUAL PEAK DISGHARGE, IN OBIC FEET PER SECOND, AND CORRESPONDING GAGE HEIGHT, IN FEET, FOR EACH WATER YEAR

\begin{tabular}{|c|c|c|c|c|c|c|c|c|c|c|c|}
\hline $\begin{array}{l}\text { WATER } \\
\text { YEAR }\end{array}$ & DAIE & $\begin{array}{c}\text { GEGE } \\
\text { HEIGHT }\end{array}$ & $\begin{array}{c}\text { PEAK } \\
\text { DISCH ARGE }\end{array}$ & $\begin{array}{l}\text { WATER } \\
\text { YEAR }\end{array}$ & DATE & $\begin{array}{c}\text { GAGE } \\
\text { HEIGHT }\end{array}$ & $\begin{array}{c}\text { PEAK } \\
\text { DISAH ARGE }\end{array}$ & $\begin{array}{l}\text { WATER } \\
\text { YEAR }\end{array}$ & DATE & $\begin{array}{c}\text { GAGE } \\
\text { HEIGHT }\end{array}$ & $\begin{array}{c}\text { PEAK } \\
\text { DISGARGE }\end{array}$ \\
\hline $\begin{array}{l}1977 \\
1978\end{array}$ & $\begin{array}{l}\text { JUNE 03, } 1977 \\
\text { JUNE 11, } 1978\end{array}$ & - & $\begin{array}{l}134 \\
610\end{array}$ & $\begin{array}{l}1979 \\
1980\end{array}$ & $\begin{array}{l}\text { MAY } 29,1979 \\
\text { JUNE } 11,1980\end{array}$ & $\begin{array}{l}3.68 \\
3.66\end{array}$ & $\begin{array}{r}830 \\
1080\end{array}$ & 1981 & JUNE 07, 1981 & 3.06 & 522 \\
\hline
\end{tabular}

09297800 EAST GHANNEL UINTA RIVER AT COUNTY ROAD BRIDGE, NEAR WHITEROCKS, UT

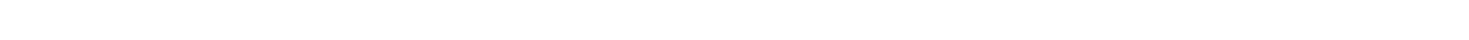
14060003, Uintah and ouray Indian Reservation, on right bank on downstream side of bridge on county road, $1.0 \mathrm{mi}$ south of Whiterocks.

DRAINAGE AREA, $-253 \mathrm{mi}^{2}$.

PERIOD OF RECORD AVAIL ABLE. - Oct cber 1976 to September 1981.

GAGE. -Water-stage recorder. Altitude of gage is 5,905 ft from topographic map.

REMARKS.-Several major irrigation diversions above gage.

AVERAGE DISGHARGE. --5 years, $36.3 \mathrm{ft}^{3} / \mathrm{s}, 26,300$ acre- $\mathrm{ft} / \mathrm{yr}$.

EXTREMES FOR PERIOD OF RECORD.--Maximum discharge, $1,290 \mathrm{ft}^{3} / \mathrm{s}$ June 10, 1980 , gage height, $3.92 \mathrm{ft} ; \mathrm{minimum} \mathrm{daily,} 3.2 \mathrm{ft}{ }^{3} / \mathrm{s} \mathrm{Apr.} 8$, $9,11,13,1980$.

LONEST MEAN DISGHARGE, IN OUBIC FEET PER SECOND, AND RANKING FOR THE INDICATED NUMBER OF CONSEQUTTVE DAVS FOR EACH CLIMATIC YEAR, APRII I-MARG 31

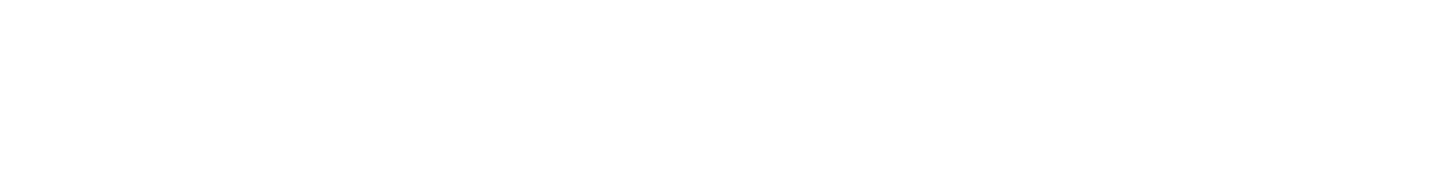

HIGHEST MEAN DISGHARGE, IN OBIC FEET PER SECOND, AND RANKING FOR THE INDICATED NUMBER OF OONSECUTTVE DAVS FOR EAOH WATER YEAR, OCTOBER 1-SEPTEMBER 30

\begin{tabular}{|c|c|c|c|c|c|c|c|c|c|c|c|c|c|c|c|c|c|c|c|c|}
\hline YEAR & 1 & & 3 & & 7 & & 15 & & $\begin{array}{l}\text { CONS } \\
30\end{array}$ & CUT & $\begin{array}{l}\text { VE DAYS } \\
60\end{array}$ & & 90 & & 120 & & 183 & & ALC & \\
\hline $\begin{array}{l}1977 \\
1978 \\
1979 \\
1980\end{array}$ & $\begin{array}{l}53.0 \\
738 \\
604 \\
965\end{array}$ & $\begin{array}{l}5 \\
2 \\
3 \\
1\end{array}$ & $\begin{array}{l}50.0 \\
623 \\
470 \\
814\end{array}$ & $\begin{array}{l}5 \\
2 \\
3 \\
1\end{array}$ & $\begin{array}{l}45.0 \\
599 \\
276 \\
610\end{array}$ & $\begin{array}{l}5 \\
2 \\
3 \\
1\end{array}$ & $\begin{array}{l}42.0 \\
366 \\
181 \\
498\end{array}$ & $\begin{array}{l}5 \\
2 \\
4\end{array}$ & $\begin{array}{l}41.0 \\
209 \\
116 \\
326\end{array}$ & $\begin{array}{l}5 \\
2 \\
4 \\
1\end{array}$ & $\begin{array}{c}39.0 \\
116 \\
68.0 \\
182\end{array}$ & $\begin{array}{l}5 \\
2 \\
4 \\
1\end{array}$ & $\begin{array}{r}37.0 \\
83.0 \\
51.0 \\
129\end{array}$ & $\begin{array}{l}5 \\
2 \\
4 \\
1\end{array}$ & $\begin{array}{c}33.0 \\
66.0 \\
50.0 \\
102\end{array}$ & $\begin{array}{l}5 \\
2 \\
4 \\
1\end{array}$ & $\begin{array}{l}25.0 \\
53.0 \\
46.0 \\
75.0\end{array}$ & $\begin{array}{l}5 \\
2 \\
3 \\
1\end{array}$ & $\begin{array}{l}19.0 \\
36.0 \\
35.0 \\
52.0\end{array}$ & $\begin{array}{l}5 \\
3 \\
4 \\
1\end{array}$ \\
\hline & 347 & 4 & 310 & $A$ & 259 & 4 & 211 & 3 & 34 & 3 & 86.0 & 3 & 66.0 & 3 & 56,0 & 3 & 44.0 & 4 & 38.0 & \\
\hline
\end{tabular}


GREEN RIVER BASIN

09297800 EAST CHANNEL UINTA RIVER AT COUNTY RCAD BRIDGE, NEAR WHITEROCKS, UT--Continued

DURATION OF DISCHARGE FOR EACH WATER YEAR

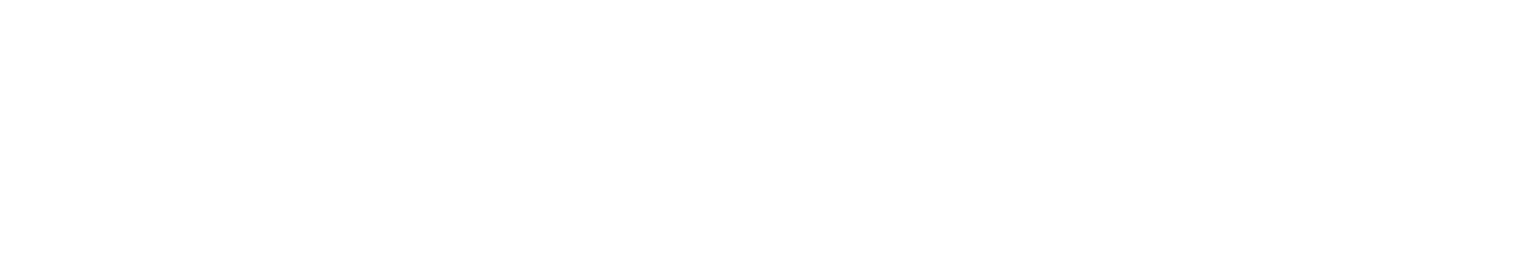

$\begin{array}{lcccccccccccc}\text { YEAR } & \text { OCT } & \text { NOV } & \text { DEC } & \text { JAN } & \text { FEB } & \text { MAR } & \text { APR } & \text { MAY } & \text { JUNE } & \text { JULY } & \text { ALG } & \text { SEP } \\ 1977 & 9.99 & 9.44 & 37.8 & 37.5 & 33.1 & 23.0 & 5.40 & 7.40 & 21.3 & 18.0 & 19.2 & 7.80 \\ 1978 & 5.47 & 18.2 & 31.4 & 35.0 & 32.3 & 29.1 & 5.79 & 9.52 & 206 & 25.7 & 17.7 & 13.0 \\ 1979 & 12.7 & 48.8 & 43.0 & 40.0 & 41.8 & 46.5 & 11.5 & 81.5 & 47.4 & 16.5 & 18.4 & 11.1 \\ 1980 & 11.6 & 46.0 & 44.2 & 34.7 & 43.1 & 16.8 & 4.38 & 29.5 & 324 & 27.9 & 23.7 & 20.5 \\ 1981 & 17.0 & 47.6 & 45.4 & 36.9 & 31.2 & 19.2 & 14.1 & 39.5 & 125 & 32.0 & 24.8 & 26.2\end{array}$

ANNUAL PEAK DISCHARGE, IN CUBIC FEET PER SECOND, AND CORRESPONDING GAGE HEIGHT, IN FEET, FOR EACH WATER YEAR

\begin{tabular}{|c|c|c|c|c|c|c|c|c|c|c|c|}
\hline $\begin{array}{l}\text { WATERR } \\
\text { YEAR }\end{array}$ & DATE & $\begin{array}{c}\text { GAGE } \\
\text { HEIGHT }\end{array}$ & $\begin{array}{c}\text { PEAK } \\
\text { DISCHARGE }\end{array}$ & $\begin{array}{l}\text { WATERR } \\
\text { YEAR }\end{array}$ & DATE & $\begin{array}{l}\text { GAGE } \\
\text { HEIGHT }\end{array}$ & $\begin{array}{c}\text { PEAK } \\
\text { DISCHARGE }\end{array}$ & $\begin{array}{l}\text { WATERR } \\
\text { YEAR }\end{array}$ & DATE & $\begin{array}{c}\text { GAGE } \\
\text { HEIGHT }\end{array}$ & $\begin{array}{c}\text { PEAK } \\
\text { DISCHARGE }\end{array}$ \\
\hline $\begin{array}{l}1977 \\
1978\end{array}$ & $\begin{array}{l}\text { JUNE 03, } 1977 \\
\text { JUNE 11, } 1978\end{array}$ & $\overline{3.49}$ & $\begin{array}{r}83 \\
858\end{array}$ & $\begin{array}{l}1979 \\
1980\end{array}$ & $\begin{array}{lll}\text { MAY } & 29,1979 \\
\text { JUNE } & 10,1980\end{array}$ & $\begin{array}{l}3.48 \\
3.92\end{array}$ & $\begin{array}{r}720 \\
1290\end{array}$ & 1981 & JUNE 09, 1989 & 3.09 & 497 \\
\hline
\end{tabular}

09297900 EAST CHANNEL UINTA RIVER AT LAPOINT ROAD, NEAR LAPOINT, UT

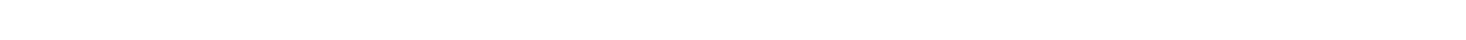
14060003, Uintah and Ouray Indian Reservation, on right bank on downstream side of bridge on State Highway 121 and 4.1 mi west of Lapoint.

DRAINAGE AREA. $--382 \mathrm{mi}^{2}$.

PERIOD OF RECORD AVAIIABLE.--OCtober 1976 to September 1981.

GAGE.--Water-stage recorder. Altitude of gage is 5,470 ft from topographic map.

REMARKS. --Several major irrigation diversions above gage.

AVERAGE DISCHARGE. -5 years, $47.4 \mathrm{ft}^{3} / \mathrm{s}, 34,340$ acre-ft/yr.

EXTREMES FOR PERIOD OF RECORD.--Maximum discharge, 1,320 ft ${ }^{3} / \mathrm{s}$ June 10, 1980, gage height, 4.51 ft; no flow Oct. 3-10, 1980.

LONEST MEAN DISCHARGE, IN CIBIC FEET PER SECOND, AND RANKING FOR THE INDICATED NUMBER OF CONSEOTTIVE DAYS FOR EACH CLIMATIC YEAR, APRIL 1-MARCH 31

\begin{tabular}{|c|c|c|c|c|c|c|c|c|c|c|c|c|c|c|c|c|c|c|c|}
\hline YEAR & & & & & & & & & CONSE & WTI & DAYS & & & & & & & & \\
\hline & 1 & & 3 & & 7 & & 14 & & 30 & & 60 & & 90 & & 120 & & 183 & & ALL \\
\hline $\begin{array}{l}1978 \\
1979 \\
1980\end{array}$ & $\begin{array}{l}0.56 \\
1.50 \\
2.00\end{array}$ & $\begin{array}{l}2 \\
3 \\
4\end{array}$ & $\begin{array}{l}0.59 \\
1.50 \\
2.30\end{array}$ & $\begin{array}{l}2 \\
3 \\
4\end{array}$ & $\begin{array}{l}0.63 \\
2.20 \\
2.70\end{array}$ & $\begin{array}{l}2 \\
3 \\
4\end{array}$ & $\begin{array}{l}0.71 \\
3.10 \\
3.70\end{array}$ & $\begin{array}{l}2 \\
3 \\
4\end{array}$ & $\begin{array}{l}3.10 \\
3.50 \\
5.70\end{array}$ & $\begin{array}{l}2 \\
3 \\
4\end{array}$ & $\begin{array}{l}4.50 \\
7.50 \\
7.20\end{array}$ & $\begin{array}{l}1 \\
3 \\
2\end{array}$ & $\begin{array}{l}10.0 \\
16.0 \\
12.0\end{array}$ & $\begin{array}{l}1 \\
4 \\
2\end{array}$ & $\begin{array}{l}15.0 \\
21.0 \\
19.0\end{array}$ & $\begin{array}{l}1 \\
4 \\
3\end{array}$ & $\begin{array}{l}19.0 \\
33.0 \\
26.0\end{array}$ & $\begin{array}{l}1 \\
4 \\
2\end{array}$ & $\begin{array}{l}27.0 \\
55.0 \\
42.0\end{array}$ \\
\hline 1981 & 0.00 & 1 & 0.00 & 1 & 0.00 & 1 & 0.25 & 1 & 2.70 & 1 & 8.90 & 4 & 13.0 & 3 & 16.0 & 2 & 32.0 & 3 & 77.0 \\
\hline
\end{tabular}


HIGHEST MEAN DISGHARGE, IN OUBIC FEET PER SECOND, AND RANKING FOR THE INDICATED NUMBER OF CONSEQUTIVE DAYS FOR EACH WATER YEAR, OCTOBER I-SEPTEMBER 30

\begin{tabular}{|c|c|c|c|c|c|c|c|c|c|c|c|c|c|c|c|c|c|c|c|c|}
\hline YEAR & 1 & & 3 & & 7 & & 15 & & $\begin{array}{l}\text { CONS } \\
30\end{array}$ & EUT & $\begin{array}{c}\text { IVE DAYS } \\
60\end{array}$ & & 90 & & 120 & & 183 & & ALL & \\
\hline $\begin{array}{l}1977 \\
1978 \\
1979 \\
1980\end{array}$ & $\begin{array}{r}200 \\
917 \\
908 \\
1140\end{array}$ & $\begin{array}{l}5 \\
2 \\
3 \\
1\end{array}$ & $\begin{array}{r}148 \\
803 \\
726 \\
1060\end{array}$ & $\begin{array}{l}5 \\
2 \\
3 \\
1\end{array}$ & $\begin{array}{l}95.0 \\
681 \\
506 \\
991\end{array}$ & $\begin{array}{l}5 \\
2 \\
3 \\
1\end{array}$ & $\begin{array}{l}64.0 \\
423 \\
328 \\
831\end{array}$ & $\begin{array}{l}5 \\
2 \\
3 \\
1\end{array}$ & $\begin{array}{l}45.0 \\
254 \\
197 \\
551\end{array}$ & $\begin{array}{l}5 \\
2 \\
3 \\
1\end{array}$ & $\begin{array}{l}44.0 \\
146 \\
112 \\
310\end{array}$ & $\begin{array}{l}5 \\
2 \\
3 \\
1\end{array}$ & $\begin{array}{c}42.0 \\
109 \\
87.0 \\
215\end{array}$ & $\begin{array}{l}5 \\
2 \\
3 \\
1\end{array}$ & $\begin{array}{r}37.0 \\
88.0 \\
79.0 \\
166\end{array}$ & $\begin{array}{l}5 \\
2 \\
3 \\
1\end{array}$ & $\begin{array}{r}30.0 \\
71.0 \\
70.0 \\
121\end{array}$ & $\begin{array}{l}5 \\
2 \\
3 \\
1\end{array}$ & $\begin{array}{l}24.0 \\
47.0 \\
50.0 \\
74.0\end{array}$ & $\begin{array}{l}5 \\
3 \\
2 \\
1\end{array}$ \\
\hline 1981 & 426 & 4 & 362 & 4 & 264 & 4 & 220 & 4 & 137 & 4 & 91.0 & 4 & 66.0 & 4 & 57.0 & 4 & 55.0 & 4 & 43.0 & 4 \\
\hline
\end{tabular}

$\begin{array}{llllllllllllllllllllllllllllllllllll}\text { CLASS } & 0 & 1 & 2 & 3 & 4 & 5 & 6 & 7 & 8 & 9 & 10 & 11 & 12 & 13 & 14 & 15 & 16 & 17 & 18 & 19 & 20 & 21 & 22 & 23 & 24 & 25 & 26 & 27 & 28 & 29 & 30 & 31 & 32 & 33 & 34\end{array}$ YEAR NUMBER OF DAYS IN OLASS PER SECOND -DAYS

DURATTON TABLE OF DISGHARGE FOR WATER YEARS 1977-81

\begin{tabular}{|c|c|c|c|c|c|c|c|c|c|c|c|c|c|c|c|c|c|c|c|}
\hline CLASS & $\begin{array}{c}\text { OBBIC } \\
\text { FEET } \\
\text { PER } \\
\text { SECOND }\end{array}$ & $\begin{array}{l}\text { TOTAL } \\
\text { DAYS }\end{array}$ & $\begin{array}{l}\text { ACOU- } \\
\text { MU- } \\
\text { LATED } \\
\text { DAYS }\end{array}$ & $\begin{array}{l}\text { PER- } \\
\text { CENT } \\
\text { DAYS }\end{array}$ & CASS & $\begin{array}{c}\text { OBIC } \\
\text { FEET } \\
\text { PER } \\
\text { SECOND }\end{array}$ & $\begin{array}{l}\text { TOTAL } \\
\text { DAYS }\end{array}$ & $\begin{array}{l}\text { ACOU- } \\
\text { NU- } \\
\text { LATED } \\
\text { DAYS }\end{array}$ & $\begin{array}{l}\text { PER- } \\
\text { CENT } \\
\text { DAYS }\end{array}$ & CLASS & $\begin{array}{c}\text { OUBIC } \\
\text { FEET } \\
\text { PER } \\
\text { SECOND }\end{array}$ & $\begin{array}{l}\text { TOTAL } \\
\text { DAYS }\end{array}$ & $\begin{array}{l}\text { ACOU- } \\
\text { MU- } \\
\text { LATED } \\
\text { DAYS }\end{array}$ & $\begin{array}{l}\text { PER- } \\
\text { CENT } \\
\text { DAYS }\end{array}$ & & $\begin{array}{c}\text { OUBIC } \\
\text { FEET } \\
\text { PER } \\
\text { SECOND }\end{array}$ & $\begin{array}{c}\text { TOTAL } \\
\text { DAYS }\end{array}$ & $\begin{array}{l}\text { ACO- } \\
\text { MU- } \\
\text { LAIED } \\
\text { DAYS }\end{array}$ & $\begin{array}{l}\text { PER- } \\
\text { CENT } \\
\text { DAYS }\end{array}$ \\
\hline $\begin{array}{l}0 \\
1 \\
2 \\
3 \\
4 \\
5 \\
6 \\
7 \\
8\end{array}$ & $\begin{array}{l}0.00 \\
0.10 \\
0.13 \\
0.18 \\
0.23 \\
0.31 \\
0.41 \\
0.54 \\
0.72\end{array}$ & $\begin{array}{r}8 \\
1 \\
0 \\
0 \\
1 \\
0 \\
1 \\
7 \\
10\end{array}$ & $\begin{array}{l}1826 \\
1818 \\
1817 \\
1817 \\
1817 \\
1816 \\
1816 \\
1815 \\
1808\end{array}$ & $\begin{array}{r}100.0 \\
99.6 \\
99.5 \\
99.5 \\
99.5 \\
99.5 \\
99.5 \\
99.4 \\
99.0\end{array}$ & $\begin{array}{r}9 \\
10 \\
11 \\
12 \\
13 \\
14 \\
15 \\
16 \\
17\end{array}$ & $\begin{array}{l}0.96 \\
1.30 \\
1.70 \\
2.20 \\
3.00 \\
3.90 \\
5.20 \\
6.90 \\
9.20\end{array}$ & $\begin{array}{r}11 \\
11 \\
9 \\
40 \\
66 \\
62 \\
63 \\
89 \\
93\end{array}$ & $\begin{array}{l}1798 \\
1787 \\
1776 \\
1767 \\
1727 \\
1661 \\
1599 \\
1536 \\
1447\end{array}$ & $\begin{array}{l}98.5 \\
97.9 \\
97.3 \\
96.8 \\
94.6 \\
91.0 \\
87.6 \\
84.1 \\
79.2\end{array}$ & $\begin{array}{l}18 \\
19 \\
20 \\
21 \\
22 \\
23 \\
24 \\
25 \\
26\end{array}$ & $\begin{array}{r}12.0 \\
16.0 \\
21.0 \\
28.0 \\
38.0 \\
50.0 \\
66.0 \\
88.0 \\
120.0\end{array}$ & $\begin{array}{r}91 \\
114 \\
136 \\
218 \\
344 \\
276 \\
85 \\
18 \\
7\end{array}$ & $\begin{array}{r}1354 \\
1263 \\
1149 \\
1013 \\
795 \\
451 \\
175 \\
90 \\
72\end{array}$ & $\begin{array}{r}74.2 \\
69.2 \\
62.9 \\
55.5 \\
43.5 \\
24.7 \\
9.6 \\
4.9 \\
3.9\end{array}$ & $\begin{array}{l}27 \\
28 \\
29 \\
30 \\
31 \\
32 \\
33 \\
34\end{array}$ & $\begin{array}{r}150.0 \\
200.0 \\
270.0 \\
360.0 \\
480.0 \\
630.0 \\
840.0 \\
1100.0\end{array}$ & $\begin{array}{r}10 \\
12 \\
7 \\
8 \\
10 \\
9 \\
7 \\
2\end{array}$ & $\begin{array}{r}65 \\
55 \\
43 \\
36 \\
28 \\
18 \\
9 \\
2\end{array}$ & $\begin{array}{l}3.6 \\
3.0 \\
2.4 \\
2.0 \\
1.5 \\
1.0 \\
0.5 \\
0.1\end{array}$ \\
\hline
\end{tabular}

MONTHLY NEAN DISCHARGES, IN OUBIC FEET PER SECOND, FOR EAG WATER YEAR

\begin{tabular}{|c|c|c|c|c|c|c|c|c|c|c|c|c|}
\hline YEAR & OCT & NOV & DEC & JAN & FEB & MAR & APR & MAY & JUNE & JULY & AUG & SEP \\
\hline $\begin{array}{l}1977 \\
1978 \\
1979 \\
1980\end{array}$ & $\begin{array}{c}10.3 \\
3.96 \\
8.30 \\
6.15\end{array}$ & $\begin{array}{l}8.94 \\
15.2 \\
60.0 \\
48.7\end{array}$ & $\begin{array}{l}39.8 \\
44.1 \\
59.2 \\
48.3\end{array}$ & $\begin{array}{l}42.5 \\
45.5 \\
50.4 \\
40.2\end{array}$ & $\begin{array}{l}40.2 \\
47.6 \\
60.0 \\
41.1\end{array}$ & $\begin{array}{l}24.7 \\
47.9 \\
64.7 \\
32.8\end{array}$ & $\begin{array}{c}4.64 \\
6.60 \\
13.7 \\
4.42\end{array}$ & $\begin{array}{c}8.14 \\
39.2 \\
161 \\
58.9\end{array}$ & $\begin{array}{c}40.3 \\
238 \\
47.0 \\
548\end{array}$ & $\begin{array}{l}25.3 \\
32.7 \\
36.1 \\
33.7\end{array}$ & $\begin{array}{l}32.5 \\
34.5 \\
24.8 \\
20.8\end{array}$ & $\begin{array}{r}13.4 \\
6.97 \\
8.34 \\
9.06\end{array}$ \\
\hline 1981 & 9.34 & 54.4 & 67.3 & 51.9 & 47.4 & 20.4 & 10.3 & 69.6 & 109 & 17.0 & 28.4 & 31.8 \\
\hline
\end{tabular}

ANNUAL PEAK DISGHARGE, IN OUBIC FEET PER SECOND, AND CORRESPONDING GAGE HEIGHT, IN FEET, FOR EACH WATER YEAR

\begin{tabular}{|c|c|c|c|c|c|c|c|c|c|c|c|}
\hline $\begin{array}{l}\text { WATER } \\
\text { YEAR }\end{array}$ & DATE & $\begin{array}{c}\text { GAGE } \\
\text { HEIGHT }\end{array}$ & $\begin{array}{c}\text { PEAK } \\
\text { DISCHARGE }\end{array}$ & $\begin{array}{l}\text { WATER } \\
\text { YEAR }\end{array}$ & DATE & $\begin{array}{c}\text { GAGE } \\
\text { HEIGHT }\end{array}$ & $\begin{array}{c}\text { PEAK } \\
\text { DISCHARGE }\end{array}$ & $\begin{array}{l}\text { WATER } \\
\text { YEAR }\end{array}$ & DATE & $\begin{array}{c}\text { GAGE } \\
\text { HEIGHT }\end{array}$ & $\begin{array}{c}\text { PEAK } \\
\text { DISCHARGE }\end{array}$ \\
\hline $\begin{array}{l}977 \\
978\end{array}$ & $\begin{array}{l}\text { JUNE 03, } 1977 \\
\text { JUNE 11, } 1978\end{array}$ & $\overline{4.14}$ & $\begin{array}{r}538 \\
1080\end{array}$ & $\begin{array}{l}1979 \\
1980\end{array}$ & $\begin{array}{lll}\text { MAY } & 29, & 1979 \\
\text { JUNE } & 10,1980\end{array}$ & $\begin{array}{l}4.07 \\
4.51\end{array}$ & $\begin{array}{l}1050 \\
1320\end{array}$ & 1981 & JUNE 09,1981 & 3.81 & 640 \\
\hline
\end{tabular}


LOCATION,--Lat 40 $34^{\prime} 03^{\prime \prime}$, long $109^{\circ} 57^{\prime} 39^{\prime \prime}$, in SE $\frac{1}{4} W^{3} \frac{1}{4} \mathrm{SE}_{4}^{\frac{1}{4}}$ sec.14, T.2 N., R.I W., Uintah Meridian, Uintah County, Hydrologic Unit

14060003, Ashley National Forest, on right bank $0.7 \mathrm{mi}$ upstream from Hominy Creek and $7 \mathrm{mi}$ northwest of Whiterocks.

DRAINAGE AREA. $--14.9 \mathrm{mi}^{2}$.

MEAN BASIN ELEVATION. $-9,180 \mathrm{ft}$.

PERIOD OF RECORD AVAILABLE.--July 1949 to Septenber 1981.

REVISED RECORDS. -WSP 21 25: Drainage area. WDR UT-76-1 : 1975.

GAGE.--Water-stage recorder and concrete control. Altitude of gage is 7,040 ft by barometer.

AVERAGE DISCHARGE. -32 years, $6.09 \mathrm{ft}^{3} / \mathrm{s}, 4,410$ acre $-\mathrm{ft} / \mathrm{yr}$.

EXIREMES FOR PERIOD OF RECORD.--Maximum discharge, $350 \mathrm{ft}^{3} / \mathrm{s}$ June 3, 1968, gage height, $3.95 \mathrm{ft}$, fram rating curve extended above $140 \mathrm{ft}^{3} / \mathrm{s} ;$ minimum, $1.2 \mathrm{ft}^{3} / \mathrm{s}$ Apr. 2,1965 , Mar. $29,1975$.

LOWEST MEAN DISCHARGE, IN OBIC FEET PER SECOND, AND RANKING FOR THE INDICATED NUMBER OF CONSECUTIVE DAYS FOR EACH CIIMATIC YEAR, APRIL 1-MARCH 31

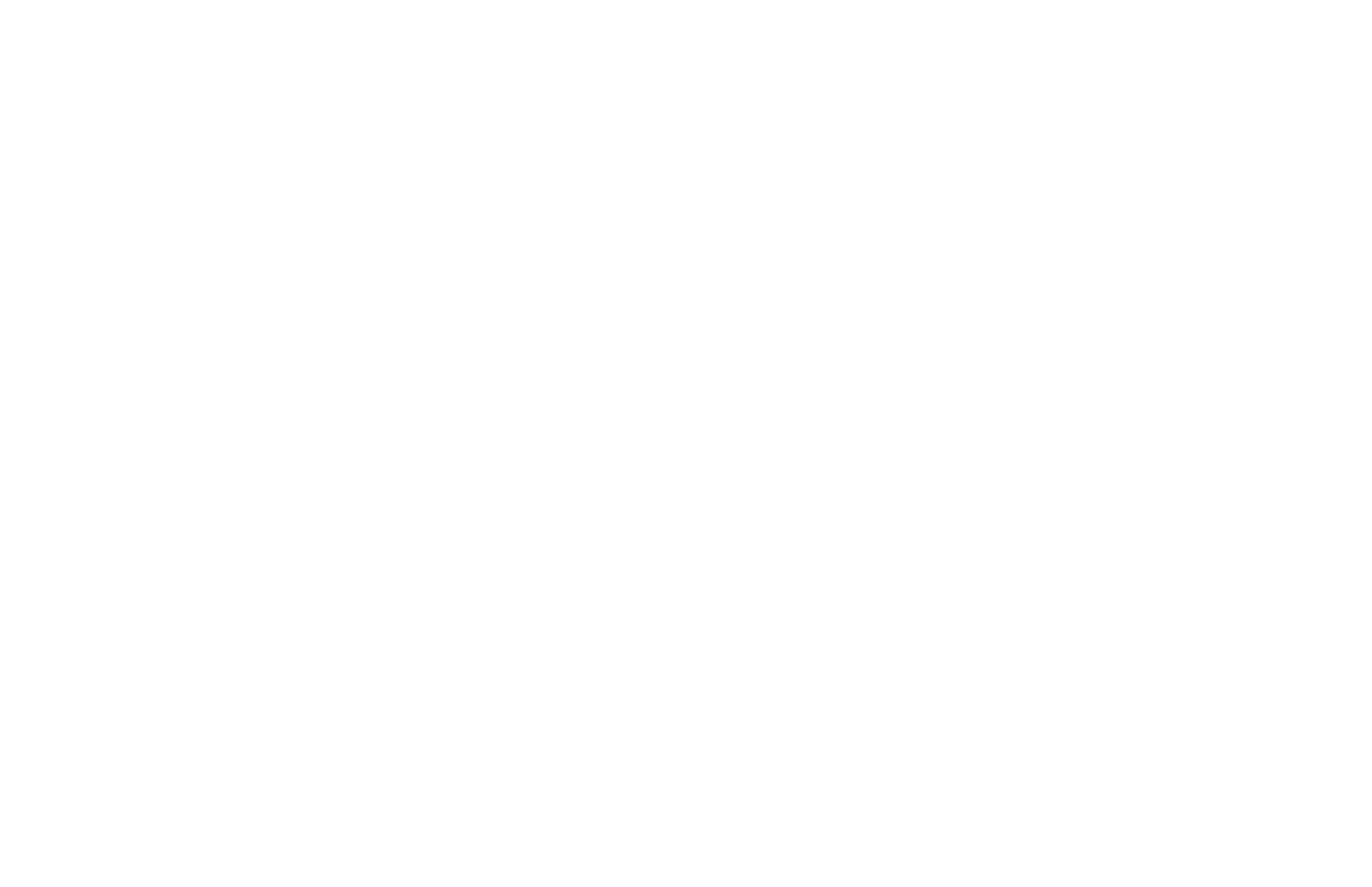

HIGHEST MEAN DISCHARGE, IN CUBIC FEET PER SECOND, AND RANKING FOR THE INDICATED NUMBER OF CONSECUTIVE DAYS FOR EACH WATER YEAR, $\propto$ CTCBER 1-SEPTEMBER 30

1950
1951
1952
1953
1954
1955
1956
1957
1958
1959
1960$$
1
$$

$\begin{array}{rrrr}92.0 & 9 & 85.0 & 8 \\ 93.0 & 8 & 85.0 & 9\end{array}$

$\begin{array}{llll}20.0 & 28 & 17.0 & 28 \\ 38.0 & 20 & 32.0 & 24\end{array}$

$\begin{array}{llll}38.0 & 20 & 32.0 & 24 \\ 27.0 & 27 & 26.0 & 27\end{array}$

$\begin{array}{llll}38.0 & 21 & 36.0 & 20\end{array}$

89.010

$\begin{array}{lll}109 & 4\end{array}$

$11.0 \quad 30$
$72.0 \quad 13$
107

9.7030

$\begin{array}{cr}7 & \\ 90.0 & 5 \\ & \\ 63.0 & 12 \\ 75.0 & 8 \\ 14.0 & 28 \\ 29.0 & 23 \\ 24.0 & 26 \\ 33.0 & 20 \\ 60.0 & 13 \\ 99.0 & 4 \\ 8.00 & 30 \\ 20.0 & 27\end{array}$

$\begin{array}{rr}8.00 & 30 \\ 20.0 \quad 27\end{array}$
15

$80.0 \quad 5$

$41.0 \quad 14$

69.07

$13.0 \quad 28$

$\begin{array}{ll}24.0 & 22 \\ 19.0 & 26\end{array}$

$27.0 \quad 20$

$46.0 \quad 12$

81.04

$\begin{array}{cc}7.20 & 30 \\ 14.0 \quad 27\end{array}$

\section{CONSECUTIVE DAYS}

30

$55.0 \quad 8$

$27.0 \quad 15$

59.03

$11.0 \quad 27$

$\begin{array}{ll}18.0 & 23 \\ 16.0 & 25\end{array}$

$20.0 \quad 21$

$31.0 \quad 12$

$\begin{array}{rr}57.0 & 6 \\ 6.00 & 30\end{array}$

$11.0 \quad 28$

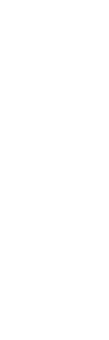

90

$28.0 \quad 5$

$13.0 \quad 18$

28.06

6.2028

$\begin{array}{ll}9.30 & 23 \\ 8.40 & 25\end{array}$

9.6022

$\begin{array}{rr}14.0 & 13 \\ 24.0 & 8\end{array}$

4.10
6.30
22.0

$10.0 \quad 18$

$\begin{array}{cccc}23.0 & 2 & 16.0 & 5 \\ 5.50 & 27 & 4.70 & 27\end{array}$

$\begin{array}{llll}7.80 & 23 & 6.70 & 27 \\ 7.20 & 22\end{array}$

$\begin{array}{lll}7.10 & 25 & 5.7025\end{array}$

$\begin{array}{lll}7.90 & 22 \quad 6.1023\end{array}$

$11.0 \quad 13 \quad 8.4013$

$\begin{array}{cccc}19.0 & 8 & 14.0 & 8 \\ 3.80 & 30 & 3.50 & 30\end{array}$

$\begin{array}{ll}5.5028 & 4.6028\end{array}$
ALL

9.703

6.0012

$9.70 \quad 4$

4.1027

$\begin{array}{ll}4.60 & 21 \\ 4.30 & 25\end{array}$

4. 4024

5.6015

8. 408

3.3030 
GREEN RIVER BASIN

09298000 FARM CREEK NEAR WHITEROCKS, UT-Continued

HIGHEST MEAN DISCHARGE, IN OUBIC FEET PER SECOND, AND RANKING FOR THE INDICATED NUMBER OF CONSECUTIVE DAYS FOR EACH WATER YEAR, OCTOBER 1-SEPTEMBER 30--Continued

YEAR

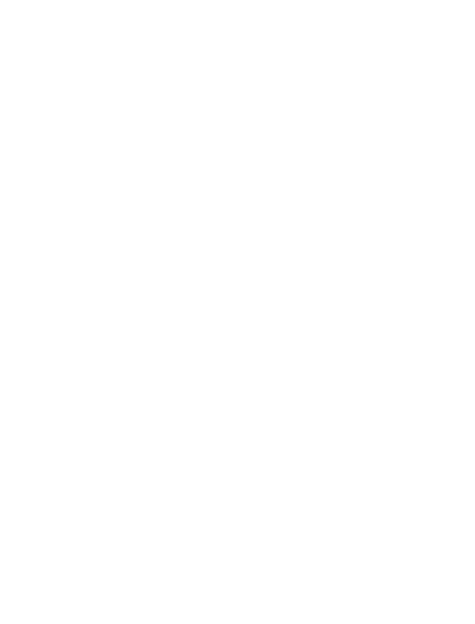

CONSECITIVE DAYS

\begin{tabular}{|c|c|c|c|c|c|c|c|c|c|c|c|c|}
\hline 15 & & 30 & & 60 & & 90 & & 120 & & 183 & & ALL \\
\hline $\begin{array}{l}6.40 \\
52.0 \\
20.0 \\
33.0 \\
67.0\end{array}$ & $\begin{array}{r}31 \\
11 \\
25 \\
17 \\
8\end{array}$ & $\begin{array}{l}5.00 \\
41.0 \\
14.0 \\
25.0 \\
48.0\end{array}$ & $\begin{array}{l}31 \\
11 \\
26 \\
19 \\
10\end{array}$ & $\begin{array}{c}4.00 \\
33.0 \\
9.90 \\
16.0 \\
33.0\end{array}$ & $\begin{array}{r}31 \\
9 \\
26 \\
19 \\
10\end{array}$ & $\begin{array}{c}3.50 \\
24.0 \\
7.70 \\
12.0 \\
24.0\end{array}$ & $\begin{array}{r}31 \\
9 \\
26 \\
19 \\
10\end{array}$ & $\begin{array}{c}3.20 \\
19.0 \\
6.50 \\
9.90 \\
19.0\end{array}$ & $\begin{array}{r}31 \\
9 \\
26 \\
19 \\
10\end{array}$ & $\begin{array}{c}2.90 \\
14.0 \\
5.40 \\
7.40 \\
14.0\end{array}$ & $\begin{array}{r}31 \\
9 \\
26 \\
19 \\
10\end{array}$ & $\begin{array}{l}2.60 \\
8.20 \\
4.20 \\
5.20 \\
8.20\end{array}$ \\
\hline $\begin{array}{l}32.0 \\
66.0 \\
87.0 \\
76.0 \\
22.0\end{array}$ & $\begin{array}{r}19 \\
9 \\
2 \\
6 \\
24\end{array}$ & $\begin{array}{l}26.0 \\
57.0 \\
59.0 \\
58.0 \\
17.0\end{array}$ & $\begin{array}{r}16 \\
7 \\
4 \\
5 \\
24\end{array}$ & $\begin{array}{l}18.0 \\
41.0 \\
36.0 \\
39.0 \\
11.0\end{array}$ & $\begin{array}{r}14 \\
2 \\
7 \\
3 \\
25\end{array}$ & $\begin{array}{c}13.0 \\
29.0 \\
26.0 \\
29.0 \\
8.70\end{array}$ & $\begin{array}{r}14 \\
2 \\
7 \\
3 \\
24\end{array}$ & $\begin{array}{c}11.0 \\
23.0 \\
21.0 \\
23.0 \\
7.30\end{array}$ & $\begin{array}{r}14 \\
3 \\
7 \\
4 \\
24\end{array}$ & $\begin{array}{c}8.30 \\
16.0 \\
15.0 \\
17.0 \\
5.80\end{array}$ & $\begin{array}{r}14 \\
6 \\
7 \\
2 \\
24\end{array}$ & $\begin{array}{c}5.60 \\
9.60 \\
9.00 \\
10.0 \\
4.60\end{array}$ \\
\hline $\begin{array}{c}33.0 \\
24.0 \\
96.0 \\
9.10 \\
58.0\end{array}$ & $\begin{array}{l}18 \\
21 \\
1 \\
29 \\
10\end{array}$ & $\begin{array}{c}26.0 \\
19.0 \\
65.0 \\
6.80 \\
49.0\end{array}$ & $\begin{array}{r}17 \\
22 \\
1 \\
29 \\
9\end{array}$ & $\begin{array}{c}17.0 \\
14.0 \\
39.0 \\
5.10 \\
32.0\end{array}$ & $\begin{array}{r}15 \\
21 \\
4 \\
29 \\
11\end{array}$ & $\begin{array}{c}13.0 \\
10.0 \\
28.0 \\
4.40 \\
23.0\end{array}$ & $\begin{array}{r}15 \\
21 \\
4 \\
29 \\
11\end{array}$ & $\begin{array}{c}10.0 \\
8.60 \\
22.0 \\
4.00 \\
18.0\end{array}$ & $\begin{array}{r}15 \\
21 \\
5 \\
29 \\
11\end{array}$ & $\begin{array}{c}7.70 \\
6.60 \\
16.0 \\
3.70 \\
13.0\end{array}$ & $\begin{array}{r}17 \\
21 \\
3 \\
29 \\
11\end{array}$ & $\begin{array}{l}5.30 \\
4.60 \\
9.20 \\
3.40 \\
7.30\end{array}$ \\
\hline $\begin{array}{c}41.0 \\
3.20 \\
33.0 \\
43.0 \\
81.0\end{array}$ & $\begin{array}{r}15 \\
32 \\
16 \\
13 \\
3\end{array}$ & $\begin{array}{c}30.0 \\
3.10 \\
26.0 \\
29.0 \\
65.0\end{array}$ & $\begin{array}{r}13 \\
32 \\
18 \\
14 \\
2\end{array}$ & $\begin{array}{c}19.0 \\
2.90 \\
16.0 \\
17.0 \\
44.0\end{array}$ & $\begin{array}{r}12 \\
32 \\
20 \\
16 \\
1\end{array}$ & $\begin{array}{c}14.0 \\
2.80 \\
12.0 \\
13.0 \\
32.0\end{array}$ & $\begin{array}{c}12 \\
32 \\
20 \\
16 \\
1\end{array}$ & $\begin{array}{c}11.0 \\
2.70 \\
9.80 \\
10.0 \\
25.0\end{array}$ & $\begin{array}{c}12 \\
32 \\
20 \\
16 \\
1\end{array}$ & $\begin{array}{r}8.50 \\
2.60 \\
7.40 \\
7.70 \\
18.0\end{array}$ & $\begin{array}{c}12 \\
32 \\
20 \\
18 \\
1\end{array}$ & $\begin{array}{r}5.70 \\
2.60 \\
4.90 \\
5.10 \\
10.0\end{array}$ \\
\hline 23.0 & 23 & 22.0 & 20 & 17.0 & 17 & 13.0 & 17 & 10.0 & 17 & 8.00 & 16 & 5.70 \\
\hline
\end{tabular}

DURATION OF DISCHARGE FOR EACH WATER YEAR

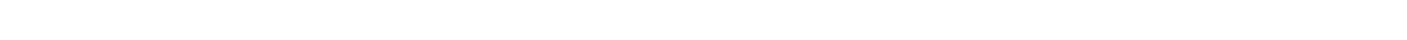

YEAR

1950

1951

1952

1954

1955

1956

1957

1959

1960

1961

1962

1964

1965

1966

1967

1968

1970

1971

1972

1973
1974

1975

1976

1976
1977
1978

1978

1980

1981

NUMBER OF DAYS IN CTASS

ABIC FEET

-DAYS

3548.7

2207.7

3561.6

1491.7

1683.2

1571.1

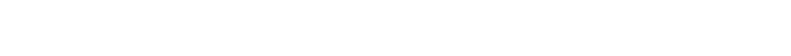

1625.5

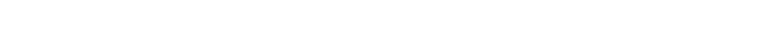

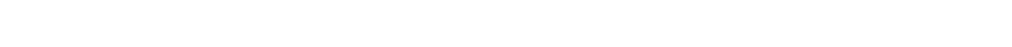

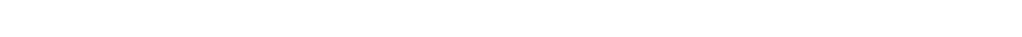

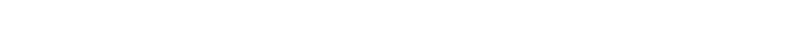

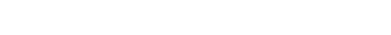

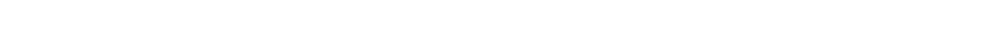

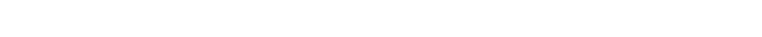

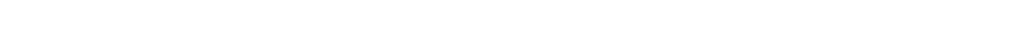

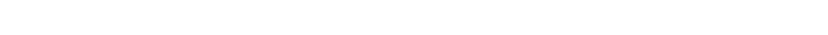

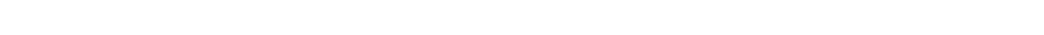

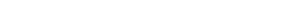

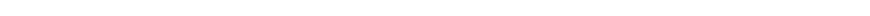

$\begin{array}{lllllllllllllllllll}32225 & 40 & 4 & 11 & 3 & 5 & 3 & 3 & 1 & 3 & 3 & 4 & 2 & 7 & 3 & 7 & 4 & 3 & 2\end{array}$

$\begin{array}{llllllllllllllllllllll}15 & 99145 & 37 & 6 & 6 & 4 & 6 & 5 & 4 & 1 & 2 & 11 & 6 & 5 & 6 & 2 & 3 & 1 & 2 & & & \\ 1689.4\end{array}$

$\begin{array}{lllllllllllllllllllllllllllllll}52 & 94 & 63 & 29 & 13 & 18 & 14 & 6 & 4 & 3 & 3 & 3 & 2 & 5 & 3 & 5 & 3 & 2 & 1 & 1 & 3 & 7 & 2 & 2 & 1 & 1 & 2 & 1 & 3358.4\end{array}$

$\begin{array}{lllllllllllllllllllllllllllllllll}12125 & 35 & 22 & 12 & 23 & 21 & 31 & 7 & 8 & 4 & 4 & 3 & 3 & 7 & 4 & 4 & 3 & 1 & 5 & 2 & 3 & 6 & 6 & 5 & 5 & 1 & 1 & 2 & & & & 2678.9\end{array}$

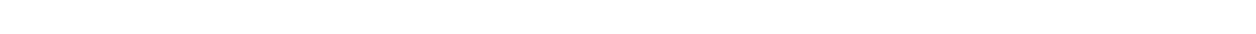

$\begin{array}{rrrrrrrrrrrrrrrrr}481 & 76132 & 9 & & & & & & & & & & & & & & \end{array}$

$\begin{array}{lllllllllllllllllllllllllll}91 & 74 & 79 & 47 & 22 & 5 & 5 & 5 & 5 & 3 & 1 & 3 & 2 & 3 & 1 & 2 & 4 & 1 & 2 & 1 & 1 & 5 & 3 & & & & \end{array}$

949.7

1797.2

1858.4

$\begin{array}{lllllllllllllllllll}8241 & 37 & 9 & 9 & 4 & 5 & 5 & 2 & 4 & 2 & 3 & 18 & 5 & 6 & 1 & 5 & 1 & 2080.3\end{array}$ 
09298000 FARM CREEK NEAR WHITEROCKS, UT--Continued

DURATION TABLE OF DISCHARGE FOR WATER YEARS 1950-81

\begin{tabular}{|c|c|c|c|c|c|c|c|c|c|c|c|c|c|c|c|c|c|c|c|}
\hline & $\begin{array}{c}\text { OBIC } \\
\text { FEET } \\
\text { PER }\end{array}$ & TOTAL & $\begin{array}{l}\text { ACOU- } \\
\text { MU- } \\
\text { LATED }\end{array}$ & $\begin{array}{l}\text { PER- } \\
\text { CENT }\end{array}$ & & $\begin{array}{c}\text { OBIC } \\
\text { FEET } \\
\text { PER }\end{array}$ & TOTAL & $\begin{array}{l}\text { ACOU- } \\
\text { MU- } \\
\text { LATED }\end{array}$ & $\begin{array}{l}\text { PER- } \\
\text { CENT }\end{array}$ & & $\begin{array}{c}\text { WBIC } \\
\text { FEET } \\
\text { PER }\end{array}$ & TOTAL & $\begin{array}{l}\text { ACOU- } \\
\text { MU- } \\
\text { LATED }\end{array}$ & $\begin{array}{l}\text { PER- } \\
\text { CENT }\end{array}$ & & $\begin{array}{c}\text { OBBIC } \\
\text { FEET } \\
\text { PER }\end{array}$ & TOTAL & $\begin{array}{l}\text { ACOU- } \\
\text { MU- } \\
\text { LATED }\end{array}$ & $\begin{array}{l}\text { PER- } \\
\text { CENT }\end{array}$ \\
\hline CLASS & SECOND & DAYS & DAYS & DAIS & CLASS & SECOND & DAYS & DAYS & DAYS & CLASS & SECOND & DAYS & DAYS & DAYS & CLASS & SECOND & DAYS & DAYS & DAYS \\
\hline $\begin{array}{l}0 \\
1 \\
2 \\
3 \\
4 \\
5 \\
6 \\
7 \\
8\end{array}$ & $\begin{array}{l}0.00 \\
1.30 \\
1.50 \\
1.80 \\
2.00 \\
2.40 \\
2.70 \\
3.20 \\
3.70\end{array}$ & $\begin{array}{r}0 \\
12 \\
125 \\
39 \\
657 \\
1429 \\
3458 \\
2521 \\
1042\end{array}$ & $\begin{array}{r}11688 \\
11688 \\
11676 \\
11551 \\
11512 \\
10855 \\
9426 \\
5968 \\
3447\end{array}$ & $\begin{array}{r}100.0 \\
100.0 \\
99.9 \\
98.8 \\
98.5 \\
92.9 \\
80.6 \\
51.1 \\
29.5\end{array}$ & $\begin{array}{r}9 \\
10 \\
11 \\
12 \\
13 \\
14 \\
15 \\
16 \\
17\end{array}$ & $\begin{array}{r}4.30 \\
5.00 \\
5.80 \\
6.70 \\
7.80 \\
9.00 \\
10.00 \\
12.00\end{array}$ & $\begin{array}{r}407 \\
239 \\
217 \\
187 \\
147 \\
98 \\
111 \\
93 \\
84\end{array}$ & $\begin{array}{r}2405 \\
1998 \\
1759 \\
1542 \\
1355 \\
1208 \\
1110 \\
999 \\
906\end{array}$ & $\begin{array}{r}20.6 \\
17.1 \\
15.0 \\
13.2 \\
11.6 \\
10.3 \\
9.5 \\
8.5 \\
7.8\end{array}$ & $\begin{array}{l}18 \\
19 \\
20 \\
21 \\
22 \\
23 \\
24 \\
25 \\
26\end{array}$ & $\begin{array}{l}16.0 \\
19.0 \\
22.0 \\
26.0 \\
30.0 \\
35.0 \\
40.0 \\
47.0 \\
54.0\end{array}$ & $\begin{array}{r}116 \\
89 \\
104 \\
89 \\
78 \\
67 \\
49 \\
60 \\
52\end{array}$ & $\begin{array}{l}822 \\
706 \\
617 \\
513 \\
424 \\
346 \\
279 \\
230 \\
170\end{array}$ & $\begin{array}{l}7.0 \\
6.0 \\
5.3 \\
4.4 \\
3.6 \\
3.0 \\
2.4 \\
2.0 \\
1.5\end{array}$ & $\begin{array}{l}27 \\
28 \\
29 \\
30 \\
31 \\
32 \\
33 \\
34\end{array}$ & $\begin{array}{r}63.0 \\
73.0 \\
84.0 \\
98.0 \\
110.0 \\
130.0 \\
150.0 \\
180.0\end{array}$ & $\begin{array}{r}33 \\
34 \\
30 \\
10 \\
6 \\
0 \\
4 \\
1\end{array}$ & $\begin{array}{r}118 \\
85 \\
51 \\
21 \\
11 \\
5 \\
5 \\
1\end{array}$ & $\begin{array}{l}1.0 \\
0.7 \\
0.4 \\
0.2 \\
0.1 \\
0.0 \\
0.0 \\
0.0\end{array}$ \\
\hline
\end{tabular}

MONTHLY MEAN DISCHARGES, IN OUIC FEET PER SECOND, FOR EAOH WATER YEAR

\begin{tabular}{|c|c|c|c|c|c|c|c|c|c|c|c|c|}
\hline YEAR & OCT & NOV & DEC & JAN & FEB & MAR & $\mathrm{APR}$ & MAY & JUNE & JULY & AUG & SEP \\
\hline 1950 & 3.85 & 3.67 & 3.45 & 3.34 & 3.14 & 3.41 & 14.5 & 49.1 & 17.7 & 6.19 & 3.90 & 3.81 \\
\hline $\begin{array}{l}1951 \\
1952 \\
1953 \\
1954 \\
1955\end{array}$ & $\begin{array}{l}4.32 \\
3.39 \\
4.01 \\
3.20 \\
2.97\end{array}$ & $\begin{array}{l}4.43 \\
3.19 \\
3.49 \\
3.23 \\
2.94\end{array}$ & $\begin{array}{l}4.31 \\
3.15 \\
3.45 \\
3.15 \\
2.98\end{array}$ & $\begin{array}{l}4.20 \\
3.05 \\
3.57 \\
2.84 \\
2.91\end{array}$ & $\begin{array}{l}3.91 \\
3.00 \\
3.24 \\
2.92 \\
2.70\end{array}$ & $\begin{array}{l}3.76 \\
3.39 \\
3.05 \\
3.28 \\
2.84\end{array}$ & $\begin{array}{l}3.81 \\
6.60 \\
3.24 \\
4.10 \\
3.44\end{array}$ & $\begin{array}{c}20.6 \\
57.1 \\
6.54 \\
17.2 \\
14.8\end{array}$ & $\begin{array}{c}11.9 \\
18.6 \\
8.18 \\
5.71 \\
6.25\end{array}$ & $\begin{array}{l}4.59 \\
5.93 \\
3.82 \\
3.59 \\
3.48\end{array}$ & $\begin{array}{l}3.32 \\
4.57 \\
3.40 \\
3.05 \\
3.12\end{array}$ & $\begin{array}{l}3.21 \\
4.18 \\
3.03 \\
2.77 \\
2.99\end{array}$ \\
\hline $\begin{array}{l}1956 \\
1957 \\
1958 \\
1959 \\
1960\end{array}$ & $\begin{array}{l}2.93 \\
2.91 \\
3.31 \\
3.36 \\
3.14\end{array}$ & $\begin{array}{l}2.92 \\
2.79 \\
3.39 \\
3.30 \\
2.68\end{array}$ & $\begin{array}{l}2.79 \\
2.66 \\
3.09 \\
3.15 \\
2.63\end{array}$ & $\begin{array}{l}2.73 \\
2.60 \\
2.79 \\
2.81 \\
2.70\end{array}$ & $\begin{array}{l}2.64 \\
2.66 \\
2.86 \\
2.72 \\
2.78\end{array}$ & $\begin{array}{l}2.69 \\
2.79 \\
2.73 \\
2.78 \\
3.01\end{array}$ & $\begin{array}{l}3.08 \\
3.04 \\
3.86 \\
3.10 \\
3.47\end{array}$ & $\begin{array}{c}18.6 \\
4.40 \\
52.4 \\
5.23 \\
9.75\end{array}$ & $\begin{array}{c}6.31 \\
30.4 \\
13.9 \\
3.96 \\
5.09\end{array}$ & $\begin{array}{l}3.16 \\
5.65 \\
4.85 \\
2.98 \\
3.21\end{array}$ & $\begin{array}{l}2.66 \\
3.79 \\
3.36 \\
3.07 \\
2.46\end{array}$ & $\begin{array}{l}2.56 \\
3.60 \\
3.23 \\
2.87 \\
2.45\end{array}$ \\
\hline $\begin{array}{l}1961 \\
1962 \\
1963 \\
1964 \\
1965\end{array}$ & $\begin{array}{l}2.57 \\
2.49 \\
3.37 \\
3.27 \\
2.90\end{array}$ & $\begin{array}{l}2.52 \\
2.69 \\
3.17 \\
3.20 \\
2.79\end{array}$ & $\begin{array}{l}2.50 \\
2.55 \\
2.99 \\
3.21 \\
2.69\end{array}$ & $\begin{array}{l}2.25 \\
2.29 \\
2.94 \\
3.05 \\
2.59\end{array}$ & $\begin{array}{l}2.11 \\
2.18 \\
2.91 \\
2.67 \\
2.42\end{array}$ & $\begin{array}{l}2.34 \\
2.37 \\
2.83 \\
2.32 \\
2.27\end{array}$ & $\begin{array}{c}2.43 \\
11.1 \\
2.85 \\
2.63 \\
2.74\end{array}$ & $\begin{array}{l}4.51 \\
39.4 \\
12.0 \\
17.4 \\
15.2\end{array}$ & $\begin{array}{c}3.37 \\
19.4 \\
7.27 \\
13.6 \\
45.4\end{array}$ & $\begin{array}{c}2.53 \\
5.77 \\
3.46 \\
4.68 \\
10.1\end{array}$ & $\begin{array}{l}2.11 \\
3.74 \\
3.13 \\
3.19 \\
5.11\end{array}$ & $\begin{array}{l}2.27 \\
3.43 \\
3.31 \\
2.90 \\
4.00\end{array}$ \\
\hline $\begin{array}{l}1966 \\
1967 \\
1968 \\
1969 \\
1970\end{array}$ & $\begin{array}{l}3.74 \\
3.20 \\
3.39 \\
4.00 \\
3.80\end{array}$ & $\begin{array}{l}3.47 \\
3.01 \\
2.99 \\
3.88 \\
3.54\end{array}$ & $\begin{array}{l}2.92 \\
2.79 \\
2.95 \\
3.41 \\
3.38\end{array}$ & $\begin{array}{l}2.56 \\
2.60 \\
2.93 \\
3.26 \\
3.37\end{array}$ & $\begin{array}{l}2.52 \\
2.48 \\
2.91 \\
2.91 \\
3.09\end{array}$ & $\begin{array}{l}2.66 \\
2.50 \\
2.80 \\
2.91 \\
3.00\end{array}$ & $\begin{array}{l}5.88 \\
2.95 \\
3.16 \\
6.41 \\
2.79\end{array}$ & $\begin{array}{l}25.8 \\
28.8 \\
15.6 \\
55.7 \\
12.1\end{array}$ & $\begin{array}{c}7.69 \\
47.3 \\
54.1 \\
21.5 \\
9.48\end{array}$ & $\begin{array}{c}3.92 \\
10.1 \\
8.05 \\
7.91 \\
4.10\end{array}$ & $\begin{array}{l}3.11 \\
5.09 \\
5.39 \\
4.29 \\
3.30\end{array}$ & $\begin{array}{l}3.09 \\
3.81 \\
3.98 \\
3.99 \\
3.14\end{array}$ \\
\hline $\begin{array}{l}1971 \\
1972 \\
1973 \\
1974 \\
1975\end{array}$ & $\begin{array}{l}3.07 \\
2.81 \\
3.11 \\
3.35 \\
2.77\end{array}$ & $\begin{array}{l}3.04 \\
2.80 \\
3.28 \\
3.33 \\
1.90\end{array}$ & $\begin{array}{l}3.01 \\
2.61 \\
3.05 \\
3.57 \\
1.89\end{array}$ & $\begin{array}{l}3.00 \\
2.50 \\
2.70 \\
3.27 \\
1.73\end{array}$ & $\begin{array}{l}2.95 \\
2.35 \\
2.34 \\
3.07 \\
1.49\end{array}$ & $\begin{array}{l}2.82 \\
2.74 \\
2.56 \\
3.07 \\
1.59\end{array}$ & $\begin{array}{l}2.86 \\
3.18 \\
2.87 \\
2.81 \\
1.59\end{array}$ & $\begin{array}{c}16.0 \\
17.9 \\
55.3 \\
6.50 \\
5.48\end{array}$ & $\begin{array}{c}17.8 \\
9.20 \\
20.1 \\
3.56 \\
49.1\end{array}$ & $\begin{array}{r}3.94 \\
3.53 \\
6.17 \\
3.02 \\
13.0\end{array}$ & $\begin{array}{l}2.79 \\
2.90 \\
4.47 \\
2.82 \\
4.26\end{array}$ & $\begin{array}{l}2.55 \\
2.69 \\
3.63 \\
2.69 \\
3.57\end{array}$ \\
\hline $\begin{array}{l}1976 \\
1977 \\
1978 \\
1979 \\
1980\end{array}$ & $\begin{array}{l}3.34 \\
2.86 \\
2.50 \\
2.69 \\
2.71\end{array}$ & $\begin{array}{l}3.00 \\
2.80 \\
2.50 \\
2.62 \\
2.49\end{array}$ & $\begin{array}{l}3.00 \\
2.62 \\
2.50 \\
2.46 \\
2.35\end{array}$ & $\begin{array}{l}3.00 \\
2.50 \\
2.50 \\
2.30 \\
2.32\end{array}$ & $\begin{array}{l}2.80 \\
2.46 \\
2.37 \\
2.21 \\
2.30\end{array}$ & $\begin{array}{l}2.80 \\
2.29 \\
2.39 \\
2.29 \\
2.30\end{array}$ & $\begin{array}{l}3.06 \\
2.44 \\
2.66 \\
3.02 \\
3.24\end{array}$ & $\begin{array}{c}22.6 \\
2.68 \\
12.1 \\
22.0 \\
31.4\end{array}$ & $\begin{array}{c}14.1 \\
3.02 \\
19.3 \\
11.5 \\
54.8\end{array}$ & $\begin{array}{l}4.62 \\
2.59 \\
4.37 \\
3.73 \\
8.20\end{array}$ & $\begin{array}{l}3.22 \\
2.46 \\
3.15 \\
3.20 \\
4.08\end{array}$ & $\begin{array}{l}3.12 \\
2.49 \\
2.71 \\
2.77 \\
3.78\end{array}$ \\
\hline 1981 & 3.66 & 3.60 & 3.36 & 3.17 & 3.27 & 3.27 & 4.53 & 21.7 & 10.6 & 4.31 & 3.44 & 3.25 \\
\hline
\end{tabular}

ANNUAL PEAK DISOHARGE, IN OUBIC FEET PER SECOND, AND CORRESPONDING GAGE HEIGHT, IN FEET, FOR EAOH WATER YEAR

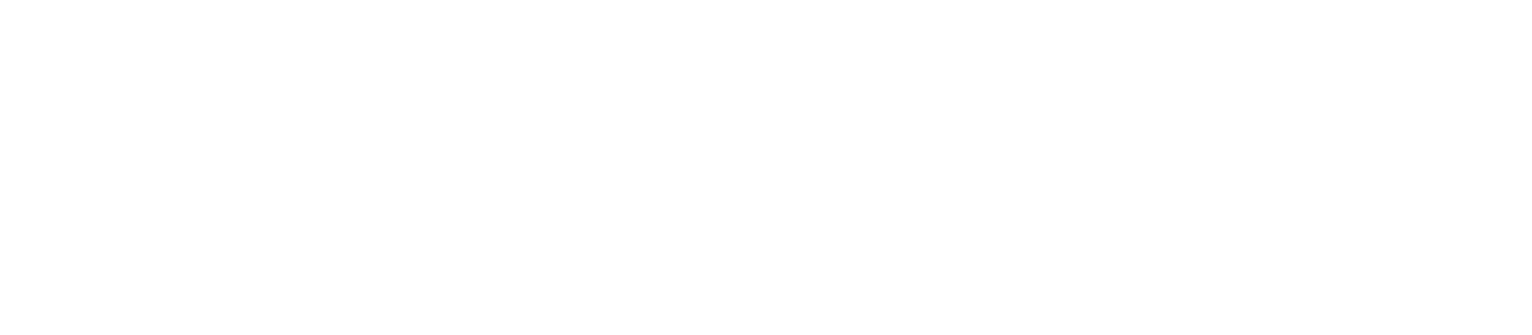


GREEN RIVER BASIN

09298000 FARM CREEK NEAR WHITEROCKS, UT-Continued

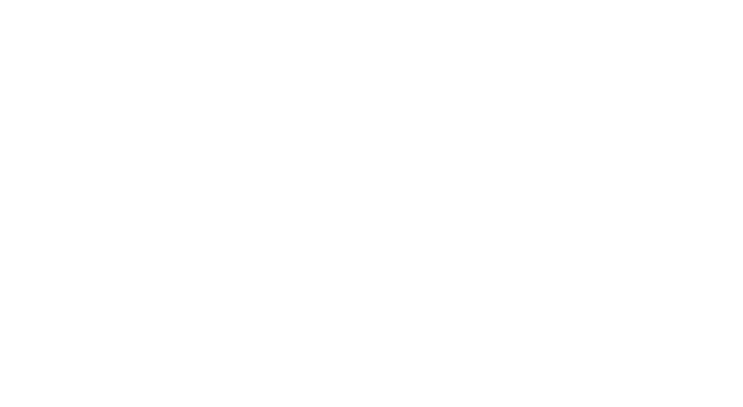

MAGNITUDE AND PRCBABILITY OF ANNUAL HIGHEST MEAN DISCHARGE BASED ON WATER YEARS 1950-8I

\begin{tabular}{|c|c|c|c|c|c|c|}
\hline \multirow{2}{*}{$\begin{array}{l}\text { PERICD } \\
\text { (CON- } \\
\text { SEQJ- } \\
\text { TIVE } \\
\text { DAYS) }\end{array}$} & \multicolumn{6}{|c|}{$\begin{array}{l}\text { DISCHARGE, IN CUBIC FEET PER SECOND, FOR } \\
\text { INDICATED RECURRENCE INIERVAL, IN YEARS, AND } \\
\text { ANNUAL EXCEEDANCE PROBABILITY, IN PERCENT }\end{array}$} \\
\hline & $\begin{array}{c}2 \\
508\end{array}$ & $\begin{array}{c}5 \\
208\end{array}$ & $\begin{array}{l}10 \\
108\end{array}$ & $\begin{array}{l}25 \\
48\end{array}$ & $\begin{array}{l}50 \\
28\end{array}$ & $\begin{array}{r}100 \\
18\end{array}$ \\
\hline $\begin{array}{r}7 \\
15\end{array}$ & $\begin{array}{l}44 \\
35\end{array}$ & $\begin{array}{l}80 \\
65\end{array}$ & $\begin{array}{r}103 \\
84\end{array}$ & $\begin{array}{l}128 \\
105\end{array}$ & $\begin{array}{l}144 \\
119\end{array}$ & -- \\
\hline
\end{tabular}

09298500 WHITEROCKS RIVER ABOVE PARADISE CREEK, NEAR WHITEROCKS, UT

LOCATION.--Lat 40 $38^{\prime} 10^{\prime \prime}$, long 109 $58^{\prime} 00^{\prime \prime}$, in $5 W^{\frac{1}{4}}$ sec. 23, T.3 N., R.1 W., Uintah Meridian, Uintah County, Hydrologic Unit 14060003, on right bank $2.75 \mathrm{mi}$ upstream from Paradise Creek and $12 \mathrm{mi}$ northwest of Whiterocks.

DRAINAGE AREA. $-90 \mathrm{mi}^{2}$, approximately.

MEAN BASIN ELLVVATION. $-10,700 \mathrm{ft}$.

PERICD OF RECORD AVALLABLE. --Octcber 1945 to September 1955.

REVISED RECORDS, - In WSP 1313, the runoff for May 1946 is listed in error; it should be 10,520 acre-ft.

GAGE. -Water-stage recorder. Altitude of gage is $7,800 \mathrm{ft}$ from river-profile map. Prior to oct. 1, 1950 , at datum $1.0 \mathrm{ft} 1$ ower.

REMARKS. -Flow slightly regulated by small mountain reservoirs.

AVERAGE DISCHARGE. -10 years, $98.3 \mathrm{ft}^{3} / \mathrm{s}, 71,170$ acre- $\mathrm{ft} / \mathrm{Yr}^{\mathrm{r}}$.

EXIREMES FOR PERIOD OF RECORD. - Maximum discharge, 1,780 $\mathrm{ft}^{3} / \mathrm{s}$ June 18, 1949, gage height, 4.42 ft present datum, from rating curve extended above $820 \mathrm{ft}^{3} / \mathrm{s}$; minimum not determined.

LOWEST MEAN DISGHARGE, IN OUBIC FEET PER SECOND, AND RANKING FOR THE INDICATED NUMBER OF CONSEQUTIVE DAYS FOR EAOH OIMATIC YEAR, APRIL I-MARCH 31

\begin{tabular}{|c|c|c|c|c|c|c|c|c|c|c|c|c|c|c|c|c|c|c|c|c|}
\hline YEA & & & & & & & & & CONS & OUT & E DAYS & & & & & & & & & \\
\hline $\begin{array}{l}94 \\
94\end{array}$ & $\begin{array}{l}23.0 \\
17.0 \\
20.0 \\
22.0\end{array}$ & $\begin{array}{l}9 \\
1 \\
3 \\
8\end{array}$ & $\begin{array}{l}23.0 \\
17.0 \\
21.0 \\
22.0\end{array}$ & $\begin{array}{l}9 \\
1 \\
4 \\
8\end{array}$ & $\begin{array}{l}24.0 \\
17.0 \\
22.0 \\
23.0\end{array}$ & $\begin{array}{l}9 \\
1 \\
7 \\
8\end{array}$ & $\begin{array}{l}25.0 \\
17.0 \\
22.0 \\
25.0\end{array}$ & $\begin{array}{l}8 \\
1 \\
6 \\
9\end{array}$ & $\begin{array}{l}31.0 \\
17.0 \\
22.0 \\
25.0\end{array}$ & $\begin{array}{l}9 \\
1 \\
5 \\
8\end{array}$ & $\begin{array}{l}33.0 \\
18.0 \\
22.0 \\
26.0\end{array}$ & $\begin{array}{l}9 \\
1 \\
5 \\
7\end{array}$ & $\begin{array}{l}34.0 \\
18.0 \\
23.0 \\
28.0\end{array}$ & $\begin{array}{l}9 \\
1 \\
4 \\
7\end{array}$ & $\begin{array}{l}36.0 \\
19.0 \\
24.0 \\
30.0\end{array}$ & $\begin{array}{l}9 \\
1 \\
3 \\
8\end{array}$ & & $\begin{array}{l}9 \\
5 \\
2 \\
8\end{array}$ & $\begin{array}{c}74.0 \\
132 \\
79.0 \\
124\end{array}$ & $\begin{array}{l}3 \\
8 \\
4 \\
7\end{array}$ \\
\hline 195 & $\begin{array}{l}21.0 \\
21.0 \\
21.0 \\
19.0 \\
21.0\end{array}$ & $\begin{array}{l}4 \\
5 \\
6 \\
2 \\
7\end{array}$ & $\begin{array}{l}21.0 \\
21.0 \\
23.0 \\
19.0 \\
21.0\end{array}$ & $\begin{array}{l}5 \\
6 \\
7 \\
2 \\
3\end{array}$ & $\begin{array}{l}21.0 \\
21.0 \\
21.0 \\
19.0 \\
22.0\end{array}$ & $\begin{array}{l}3 \\
4 \\
5 \\
2 \\
6\end{array}$ & $\begin{array}{l}21.0 \\
22.0 \\
21.0 \\
19.0 \\
22.0\end{array}$ & $\begin{array}{l}3 \\
7 \\
4 \\
2 \\
5\end{array}$ & $\begin{array}{l}22.0 \\
24.0 \\
21.0 \\
20.0 \\
22.0\end{array}$ & $\begin{array}{l}6 \\
7 \\
3 \\
2 \\
4\end{array}$ & $\begin{array}{l}23.0 \\
27.0 \\
21.0 \\
20.0 \\
22.0\end{array}$ & $\begin{array}{l}6 \\
8 \\
3 \\
2 \\
4\end{array}$ & $\begin{array}{l}24.0 \\
28.0 \\
22.0 \\
20.0 \\
24.0\end{array}$ & $\begin{array}{l}5 \\
8 \\
3 \\
2 \\
6\end{array}$ & $\begin{array}{l}24.0 \\
29.0 \\
24.0 \\
21.0 \\
25.0\end{array}$ & $\begin{array}{l}4 \\
7 \\
5 \\
2 \\
6\end{array}$ & $\begin{array}{l}29.0 \\
35.0 \\
31.0 \\
26.0 \\
32.0\end{array}$ & $\begin{array}{l}3 \\
7 \\
4 \\
1 \\
6\end{array}$ & $\begin{array}{r}107 \\
99.0 \\
146 \\
71.0 \\
73.0\end{array}$ & $\begin{array}{l}5 \\
9 \\
1 \\
2\end{array}$ \\
\hline
\end{tabular}

HIGHEST MEAN DISGHARGE, IN CUBIC FEET PER SECOND, AND RANKING FOR THE INDICATED NUMBER OF OONSECUTTVE DAYS FOR EACH WATER YEAR, OCTOBER 1-SEPIEMBER 30

YEAR

$\begin{array}{lr} & 1 \\ 1946 & 350 \\ 1947 & 900 \\ 1948 & 849 \\ 1949 & 1240 \\ 1950 & 956 \\ & \\ 1951 & 1150 \\ 1952 & 1260 \\ 1953 & 790 \\ 1954 & 624 \\ 1955 & 379\end{array}$

15 $\begin{array}{rr}10 & 320 \\ 5 & 833 \\ 6 & 774 \\ 2 & 1120 \\ 4 & 896 \\ 3 & 1070 \\ 1 & 1190 \\ 7 & 751 \\ 8 & 504 \\ 9 & 362\end{array}$
3

$10 \quad 286$

$\begin{array}{ll}5 & 672 \\ 6 & 665 \\ 2 & 969\end{array}$

$\begin{array}{ll}2 & 969 \\ 4 & 723\end{array}$

3821

$\begin{array}{rr}3 & 821 \\ 1 & 1040 \\ 7 & 642\end{array}$

$\begin{array}{ll}7 & 642 \\ 8 & 426\end{array}$
7

$10 \quad 261$

$\begin{array}{ll}0 & 261 \\ 5 & 581 \\ 6 & 560 \\ 2 & 856\end{array}$

$\begin{array}{ll}2 & 856 \\ 4 & 650\end{array}$

$\begin{array}{ll}3 & 504 \\ 1 & 862 \\ 7 & 466 \\ 8\end{array}$
CONSECUTTVE DAYS

$\begin{array}{ll}4 & 20 \\ 4 & 542 \\ 5 & 446 \\ 2 & 650 \\ 3 & 561 \\ 6 & 436 \\ 1 & 626 \\ 7 & 342 \\ 8 & 297\end{array}$

$\begin{array}{ll}8 & 205 \\ 9 & 211\end{array}$
$10 \quad 176$

$\begin{array}{rrrr}4 & 176 & 10 & 147 \\ 5 & 461 & 2 & 37 \\ & 290 & 6 & 220\end{array}$

$\begin{array}{llll}5 & 290 & 6 & 220 \\ 1 & 461 & 3 & 357\end{array}$

$\begin{array}{ll}1 & 461 \\ 3 & 404\end{array}$

$6 \quad 298$

$\begin{array}{ll}6 & 298 \\ 2 & 499 \\ 7 & 235\end{array}$

$\begin{array}{ll}7 & 235 \\ 8 & 205\end{array}$
$90 \quad 120$

$10 \quad 127$

$\begin{array}{ll}2 & 320 \\ 6 & 179\end{array}$

$\begin{array}{ll}6 & 179 \\ 3 & 295\end{array}$

$\begin{array}{ll}3 & 295 \\ 4 & 255\end{array}$

$\begin{array}{llll}5 & 261 & 5 & 227\end{array}$

$\begin{array}{lll}406 & 5 & 227 \\ 190 & 7 & 353\end{array}$

$\begin{array}{llll}9 & 190 & 7 & 159 \\ 9 & 172 & 9 & 147\end{array}$

$\begin{array}{rrrrr} & 183 & & \text { ALL } \\ 10 & 104 & 10 & 68.0 & 10 \\ 2 & 234 & 2 & 140 & 2 \\ 6 & 130 & 6 & 80.0 & 6 \\ 3 & 211 & 3 & 120 & 3 \\ 4 & 185 & 4 & 111 & 4 \\ 5 & 163 & 5 & 96.0 & 5 \\ 1 & 262 & 1 & 148 & 1 \\ 7 & 116 & 8 & 74.0 & 8 \\ 9 & 114 & 9 & 70.0 & 9 \\ 8 & 119 & 7 & 76.0 & 7\end{array}$


DURATION OF DISCHARGE FOR EACH WATER YEAR

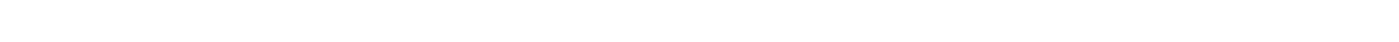

YEAR

MUMBER OF DAYS IN CLASS

OUBIC FEET -DAYS

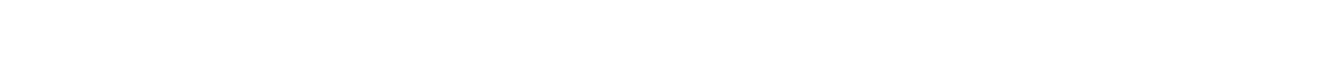

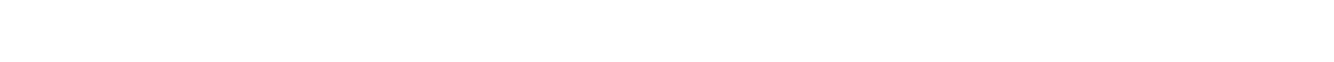
$\begin{array}{lllllllllllllllllllllllllllllllllllll}60 & 65 & 11 & 1 & 11 & 5 & 19 & 26 & 34 & 26 & 25 & 7 & 6 & 6 & 13 & 9 & 5 & 4 & 3 & 1 & 2 & 5 & 2 & 1 & 5 & 2 & 7 & 2 & 1 & 1 & 1 & & 29412.0 \\ & 65 & 70 & 27 & 24 & 14 & 3 & 12 & 6 & 19 & 9 & 7 & 2 & 7 & 14 & 10 & 11 & 5 & 9 & 9 & 5 & 8 & 3 & 4 & 2 & 4 & 3 & 2 & 3 & 3 & 2 & 1 & 2 & 43642.0\end{array}$ $\begin{array}{rrrrrrrrrrrrrrrrrrrrrrrrrrrrrrrrrrrrrrr}70 & 27 & 24 & 14 & 3 & 12 & 6 & 19 & 9 & 7 & 2 & 7 & 14 & 10 & 11 & 5 & 9 & 9 & 5 & 8 & 3 & 4 & 2 & 4 & 3 & 2 & 3 & 3 & 2 & 1 & 2 & 43642.0 \\ 44 & 28 & 19 & 24 & 34 & 21 & 20 & 15 & 6 & 5 & 20 & 11 & 3 & 8 & 1 & 7 & 8 & 3 & 4 & 4 & 4 & 10 & 4 & 3 & 4 & 2 & 2 & & & & 40677.0\end{array}$

$\begin{array}{lllllllllllllllllllllllllllllllllllll}31 & 46 & 78 & 14 & 23 & 17 & 13 & 5 & 6 & 6 & 7 & 6 & 2 & 8 & 30 & 8 & 14 & 14 & 12 & 2 & 3 & 1 & 1 & 7 & 2 & 1 & 2 & 1 & 2 & 1 & 2 & 34918.0\end{array}$ $\begin{array}{llllllllllllllllllllllllllllllllll}66 & 61 & 16 & 17 & 15 & 7 & 9 & 10 & 13 & 6 & 3 & 6 & 9 & 6 & 20 & 12 & 13 & 18 & 10 & 10 & 5 & 6 & 7 & 3 & 4 & 3 & 3 & 4 & 2 & 2 & 54331.0\end{array}$

$\begin{array}{rrrrrrrrrrrrrrrrrrrrrrrrrrrrrrrr}101 & 20 & 14 & 22 & 6 & 33 & 12 & 4 & 17 & 21 & 24 & 12 & 5 & 29 & 15 & 4 & 3 & 3 & 1 & 2 & 2 & & 6 & 6 & 1 & 1 & 1 & & & & 25506.0 \\ 70 & 40 & 40 & 14 & 17 & 12 & 12 & 15 & 18 & 13 & 12 & 5 & 29 & 13 & 5 & 15 & 6 & 7 & 7 & 5 & 6 & 4 & & & & & & \end{array}$

DURATION TABLE OF DISCHARGE FOR WATER YEARS 1946-55

$\begin{array}{rrr}\text { OBBIC } & \text { ACO- } \\ \text { FEET } & \text { MU- } & \text { PER- } \\ \text { PER TOTAL LATED } & \text { CENT } \\ \text { CLASS SECOND DAYS DAYS } & \text { DAYS }\end{array}$

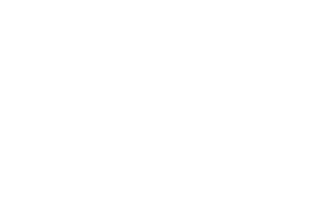

GBIC ABIC

FEET ACU- $M$ MER- $\quad$ FEET $M$ MU- PERPER TOTAL LATED CENT CIAASS SECOND DAYS DAYS DAYS

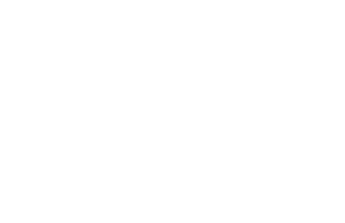

CLASS SECOND DAYS DAYS DAYS

$\begin{array}{rrrrr}18 & 150.0 & 112 & 606 & 16.6 \\ 19 & 180.0 & 61 & 494 & 13.5 \\ 20 & 200.0 & 61 & 433 & 11.9 \\ 21 & 230.0 & 59 & 372 & 10.2 \\ 22 & 260.0 & 52 & 313 & 8.6 \\ 23 & 300.0 & 49 & 261 & 7.1 \\ 24 & 340.0 & 30 & 212 & 5.8 \\ 25 & 380.0 & 45 & 182 & 5.0 \\ 26 & 440.0 & 33 & 137 & 3.8\end{array}$

MONIHLY MEAN DISCHARGES, IN CIBIC FEET PER SECOND, FOR EACH WATER YEAR

\begin{tabular}{|c|c|c|c|c|c|c|c|c|c|c|c|c|}
\hline YEAR & $\infty T$ & $\mathrm{NOV}$ & $\mathrm{DEC}$ & JAN & FEB & MAR & APR & MAY & JUNE & JULY & AUG & SEP \\
\hline $\begin{array}{l}1946 \\
1947 \\
1948 \\
1949 \\
1950\end{array}$ & $\begin{array}{l}57.5 \\
68.5 \\
65.5 \\
37.2 \\
58.1\end{array}$ & $\begin{array}{l}36.0 \\
53.3 \\
44.5 \\
31.1 \\
46.2\end{array}$ & $\begin{array}{l}28.9 \\
42.3 \\
20.0 \\
27.4 \\
35.9\end{array}$ & $\begin{array}{l}26.6 \\
37.3 \\
19.0 \\
25.0 \\
30.0\end{array}$ & $\begin{array}{l}23.4 \\
31.3 \\
17.0 \\
22.0 \\
27.7\end{array}$ & $\begin{array}{l}24.0 \\
34.8 \\
18.0 \\
22.0 \\
25.0\end{array}$ & $\begin{array}{l}95.4 \\
50.1 \\
31.1 \\
40.4 \\
59.7\end{array}$ & $\begin{array}{l}171 \\
505 \\
315 \\
283 \\
303\end{array}$ & $\begin{array}{l}132 \\
398 \\
230 \\
593 \\
436\end{array}$ & $\begin{array}{l}82.5 \\
209 \\
100 \\
182 \\
165\end{array}$ & $\begin{array}{c}75.1 \\
151 \\
58.1 \\
110 \\
94.9\end{array}$ & $\begin{array}{l}66.2 \\
86.6 \\
42.7 \\
60.1 \\
52.2\end{array}$ \\
\hline $\begin{array}{l}1951 \\
1952 \\
1953 \\
1954 \\
1955\end{array}$ & $\begin{array}{l}40.1 \\
58.3 \\
53.3 \\
38.6 \\
53.0\end{array}$ & $\begin{array}{l}32.5 \\
38.7 \\
35.4 \\
32.4 \\
36.5\end{array}$ & $\begin{array}{l}27.0 \\
31.5 \\
28.9 \\
22.6 \\
29.1\end{array}$ & $\begin{array}{l}25.0 \\
29.3 \\
23.9 \\
19.7 \\
27.4\end{array}$ & $\begin{array}{l}24.0 \\
27.0 \\
21.1 \\
20.0 \\
22.0\end{array}$ & $\begin{array}{l}21.6 \\
27.0 \\
21.0 \\
20.0 \\
22.0\end{array}$ & $\begin{array}{l}24.0 \\
58.4 \\
28.4 \\
49.0 \\
26.0\end{array}$ & $\begin{array}{c}239 \\
436 \\
71.9 \\
283 \\
212\end{array}$ & $\begin{array}{l}293 \\
549 \\
335 \\
116 \\
196\end{array}$ & $\begin{array}{l}134 \\
221 \\
125 \\
104 \\
101\end{array}$ & $\begin{array}{c}196 \\
196 \\
90.3 \\
63.0 \\
110\end{array}$ & $\begin{array}{c}86.3 \\
106 \\
48.3 \\
65.6 \\
68.1\end{array}$ \\
\hline
\end{tabular}

ANNUAL PEAK DISCHARGE, IN CUBIC FEET PER SEDOND, AND CORRESPONDING GAGE HEIGHT, IN FEET, FOR EACH WATER YEAR

\begin{tabular}{|c|c|c|c|c|c|c|c|c|c|c|c|c|}
\hline $\begin{array}{l}\text { WATER } \\
\text { YEAR }\end{array}$ & & DATE & $\begin{array}{c}\text { GAGE } \\
\text { HEIGHT }\end{array}$ & $\begin{array}{c}\text { PEAK } \\
\text { DISCHARGE }\end{array}$ & $\begin{array}{l}\text { WATER } \\
\text { YEAR }\end{array}$ & DATE & $\begin{array}{c}\text { GAGE } \\
\text { HEIGHT }\end{array}$ & $\begin{array}{c}\text { PEAK } \\
\text { DISCHARGE }\end{array}$ & $\begin{array}{l}\text { WATER } \\
\text { YEAR }\end{array}$ & DATE & $\begin{array}{l}\text { GAGE } \\
\text { HEIGET }\end{array}$ & $\begin{array}{c}\text { PEAK } \\
\text { DISCHARGE }\end{array}$ \\
\hline $\begin{array}{l}1946 \\
1947 \\
1948 \\
1949\end{array}$ & $\begin{array}{l}\text { MAY } \\
\text { MAY } \\
\text { MAY } \\
\text { JUNE }\end{array}$ & $\begin{array}{l}05,1946 \\
08,1947 \\
19,1948 \\
18,1949\end{array}$ & $\begin{array}{l}3.23 \\
3.95 \\
4.07 \\
4.42\end{array}$ & $\begin{array}{r}484 \\
1100 \\
1200 \\
1780\end{array}$ & $\begin{array}{l}1950 \\
1951 \\
1952\end{array}$ & $\begin{array}{lll}\text { MAY } & 31,1950 \\
\text { MAY } & 27,1951 \\
\text { JUNE } & 06,1952\end{array}$ & $\begin{array}{l}4.20 \\
3.48 \\
3.77\end{array}$ & $\begin{array}{l}1250 \\
1600 \\
1700\end{array}$ & $\begin{array}{l}1953 \\
1954 \\
1955\end{array}$ & $\begin{array}{lll}\text { JUNE } & 12,1953 \\
\text { MAY } & 22,1954 \\
\text { MAY } & 13,1955\end{array}$ & $\begin{array}{l}3.50 \\
2.72 \\
2.50\end{array}$ & $\begin{array}{r}1240 \\
667 \\
588\end{array}$ \\
\hline
\end{tabular}

MAGNITUDE AND PRCBABILITY OF ANNUAL HIGHEST MEAN DISCHARGE BASED ON PERIOD OF RECORD 1946-55

\begin{tabular}{|c|c|c|c|c|c|c|}
\hline \multirow{2}{*}{$\begin{array}{l}\text { PERIOD } \\
\text { (OON- } \\
\text { SEOU- } \\
\text { TIVE } \\
\text { DAYS) }\end{array}$} & \multicolumn{6}{|c|}{$\begin{array}{l}\text { DISCHARGE, IN OUBIC FEET PER SECOND, FOR } \\
\text { INDICATED RECURRENCE INTERNAL, IN YEARS, AND } \\
\text { ANNUAL EXCEEDANCE PROBABILITY, IN PERCENT }\end{array}$} \\
\hline & $\begin{array}{c}2 \\
508\end{array}$ & $\begin{array}{c}5 \\
20 \%\end{array}$ & $\begin{array}{l}10 \\
108\end{array}$ & $\begin{array}{l}25 \\
48\end{array}$ & $\begin{array}{l}50 \\
28\end{array}$ & $\begin{array}{r}100 \\
18\end{array}$ \\
\hline $\begin{array}{r}1 \\
3 \\
7 \\
15\end{array}$ & $\begin{array}{l}839 \\
764 \\
636 \\
518\end{array}$ & $\begin{array}{r}1160 \\
1070 \\
887 \\
717\end{array}$ & $\begin{array}{r}1320 \\
1230 \\
1030 \\
837\end{array}$ & $\begin{array}{l}- \\
- \\
-\end{array}$ & - & $\bar{z}$ \\
\hline
\end{tabular}


GREEN RIVER BASIN

09299000 PARADISE CREEK NEAR WHITEROCKS, UT

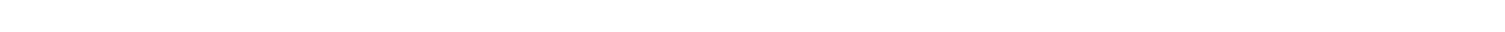
on right bank $1,000 \mathrm{ft}$ upstream from mouth and $10 \mathrm{mi}$ north of Whiterocks.

DRAINAGE AREA. - $10 \mathrm{mi}^{2}$, approximately.

PERIOD OF REOORD AVAIIABLE.--April 1946 to September 1955.

GAGE.-Water-stage recorder. Altitude of gage is $7,500 \mathrm{ft}$ from river-profile map.

REMARKS.-FIow regulated by Paradise Park Reservoir, capacity, 3,100 acre-ft.

AVERAGE DISGH ARGE. --9 years, $7.03 \mathrm{ft}^{3} / \mathrm{s}, 5,090$ acre-ft/yr.

EXIREMES FOR PERIOD OF RECORD. - Maximum discharge, $112 \mathrm{ft}^{3} / \mathrm{s}$ May 16,1948 ; maximun gage height, $2.56 \mathrm{ft}$ May 8 , 1947 ; no flow Aug. 17-20, I 946, Mar.1 to Apr. 30, 1951, Apr. 1-24, 1954, Apr. I to May 5, 1955.

LOWEST MEAN DISCHARGE, IN OUBIC FEET PER SEOOND, AND RANKING FOR THE INDICATED NUMBER OF CONSEQUTIVE DAYS FOR EAOH OLIMATIC YEAR, APRII 1-MARO 31

\begin{tabular}{|c|c|c|c|c|c|c|c|c|c|c|c|c|c|c|c|c|c|c|c|}
\hline YEAR & 1 & & 3 & & 7 & & 14 & & $\begin{array}{l}\text { CONSE } \\
30\end{array}$ & CUTTV & $\begin{array}{l}\text { DAYS } \\
60\end{array}$ & & 90 & & 120 & & 183 & & $\boldsymbol{A L L}$ \\
\hline $\begin{array}{l}1947 \\
1948 \\
1949 \\
1950\end{array}$ & $\begin{array}{l}0.00 \\
0.80 \\
0.60 \\
0.60\end{array}$ & $\begin{array}{l}1 \\
9 \\
7 \\
8\end{array}$ & $\begin{array}{l}0.00 \\
0.80 \\
0.60 \\
0.60\end{array}$ & $\begin{array}{l}1 \\
9 \\
7 \\
8\end{array}$ & $\begin{array}{l}0.09 \\
0.80 \\
0.60 \\
0.60\end{array}$ & $\begin{array}{l}4 \\
9 \\
7 \\
8\end{array}$ & $\begin{array}{l}0.90 \\
0.80 \\
0.60 \\
0.60\end{array}$ & $\begin{array}{l}9 \\
8 \\
6 \\
7\end{array}$ & $\begin{array}{l}0.90 \\
0.80 \\
0.60 \\
0.60\end{array}$ & $\begin{array}{l}9 \\
8 \\
6 \\
7\end{array}$ & $\begin{array}{l}0.93 \\
0.80 \\
0.60 \\
0.60\end{array}$ & $\begin{array}{l}9 \\
8 \\
6 \\
7\end{array}$ & $\begin{array}{l}0.95 \\
0.80 \\
0.63 \\
0.60\end{array}$ & $\begin{array}{l}9 \\
8 \\
7 \\
6\end{array}$ & $\begin{array}{l}0.99 \\
0.80 \\
0.68 \\
0.63\end{array}$ & $\begin{array}{l}9 \\
8 \\
7 \\
6\end{array}$ & $\begin{array}{l}1.10 \\
0.97 \\
0.81 \\
0.71\end{array}$ & $\begin{array}{l}8 \\
7 \\
5 \\
4\end{array}$ & $\begin{array}{l}5.80 \\
7.80 \\
9.60 \\
6.20\end{array}$ \\
\hline $\begin{array}{l}1951 \\
1952 \\
1953 \\
1954 \\
1955\end{array}$ & $\begin{array}{l}0.00 \\
0.00 \\
0.30 \\
0.10 \\
0.00\end{array}$ & $\begin{array}{l}2 \\
3 \\
6 \\
5 \\
4\end{array}$ & $\begin{array}{l}0.00 \\
0.00 \\
0.30 \\
0.10 \\
0.00\end{array}$ & $\begin{array}{l}2 \\
3 \\
6 \\
5 \\
4\end{array}$ & $\begin{array}{l}0.00 \\
0.00 \\
0.30 \\
0.10 \\
0.00\end{array}$ & $\begin{array}{l}1 \\
2 \\
6 \\
5 \\
3\end{array}$ & $\begin{array}{l}0.00 \\
0.00 \\
0.30 \\
0.10 \\
0.00\end{array}$ & $\begin{array}{l}1 \\
2 \\
5 \\
4 \\
3\end{array}$ & $\begin{array}{l}0.00 \\
0.00 \\
0.30 \\
0.10 \\
0.10\end{array}$ & $\begin{array}{l}1 \\
2 \\
5 \\
3 \\
4\end{array}$ & $\begin{array}{l}0.10 \\
0.14 \\
0.35 \\
0.15 \\
0.15\end{array}$ & $\begin{array}{l}1 \\
2 \\
5 \\
3 \\
4\end{array}$ & $\begin{array}{l}0.20 \\
0.16 \\
0.40 \\
0.20 \\
0.20\end{array}$ & $\begin{array}{l}4 \\
1 \\
5 \\
2 \\
3\end{array}$ & $\begin{array}{l}0.30 \\
0.20 \\
0.45 \\
0.25 \\
0.25\end{array}$ & $\begin{array}{l}4 \\
1 \\
5 \\
2 \\
3\end{array}$ & $\begin{array}{l}0.54 \\
0.48 \\
1.70 \\
0.44 \\
0.89\end{array}$ & $\begin{array}{l}3 \\
2 \\
9 \\
1 \\
6\end{array}$ & $\begin{array}{c}10.0 \\
4.70 \\
9.90 \\
6.40 \\
4.90\end{array}$ \\
\hline
\end{tabular}

HIGHEST MEAN DISCHARGE, IN QUBIC FEET PER SECOND, AND RANKING FOR THE INDICATED NUMBER OF CONSEQUTTVE DAYS FOR EACH WATER YEAR, OCTCBER 1-SEPTEMBER 30

\begin{tabular}{|c|c|c|c|c|c|c|c|c|c|c|c|c|c|c|c|c|c|c|c|}
\hline YEAR & \multicolumn{19}{|c|}{ CONSEQUTIVE DAYS } \\
\hline $\begin{array}{l}76.0 \\
79.0 \\
44.0 \\
73.0\end{array}$ & $\begin{array}{l}4 \\
3 \\
7 \\
5\end{array}$ & $\begin{array}{l}68.0 \\
73.0 \\
44.0 \\
72.0\end{array}$ & $\begin{array}{l}5 \\
3 \\
7 \\
4\end{array}$ & $\begin{array}{l}59.0 \\
62.0 \\
43.0 \\
65.0\end{array}$ & $\begin{array}{l}5 \\
4 \\
7 \\
2\end{array}$ & $\begin{array}{l}50.0 \\
55.0 \\
41.0 \\
61.0\end{array}$ & $\begin{array}{l}4 \\
3 \\
5 \\
2\end{array}$ & $\begin{array}{l}43.0 \\
42.0 \\
29.0 \\
51.0\end{array}$ & $\begin{array}{l}3 \\
4 \\
5 \\
1\end{array}$ & $\begin{array}{l}33.0 \\
33.0 \\
17.0 \\
34.0\end{array}$ & $\begin{array}{l}3 \\
4 \\
7 \\
2\end{array}$ & $\begin{array}{l}26.0 \\
29.0 \\
13.0 \\
29.0\end{array}$ & $\begin{array}{l}4 \\
2 \\
8 \\
3\end{array}$ & $\begin{array}{l}22.0 \\
26.0 \\
15.0 \\
27.0\end{array}$ & $\begin{array}{l}4 \\
2 \\
6 \\
1\end{array}$ & $\begin{array}{l}15.0 \\
18.0 \\
12.0 \\
20.0\end{array}$ & $\begin{array}{l}4 \\
3 \\
5 \\
1\end{array}$ & $\begin{array}{c}7.90 \\
9.60 \\
6.20 \\
10.0\end{array}$ & $\begin{array}{l}4 \\
2 \\
6 \\
1\end{array}$ \\
\hline $\begin{array}{l}57.0 \\
84.0 \\
83.0 \\
36.0 \\
27.0\end{array}$ & $\begin{array}{l}6 \\
1 \\
2 \\
8 \\
9\end{array}$ & $\begin{array}{l}55.0 \\
83.0 \\
74.0 \\
32.0 \\
26.0\end{array}$ & $\begin{array}{l}6 \\
1 \\
2 \\
8 \\
9\end{array}$ & $\begin{array}{l}50.0 \\
78.0 \\
64.0 \\
31.0 \\
22.0\end{array}$ & $\begin{array}{l}6 \\
1 \\
3 \\
8 \\
9\end{array}$ & $\begin{array}{l}40.0 \\
63.0 \\
40.0 \\
29.0 \\
19.0\end{array}$ & $\begin{array}{l}6 \\
1 \\
7 \\
8 \\
9\end{array}$ & $\begin{array}{l}26.0 \\
50.0 \\
26.0 \\
20.0 \\
15.0\end{array}$ & $\begin{array}{l}6 \\
2 \\
7 \\
8 \\
9\end{array}$ & $\begin{array}{c}17.0 \\
38.0 \\
25.0 \\
17.0 \\
9.80\end{array}$ & $\begin{array}{l}8 \\
1 \\
5 \\
6 \\
9\end{array}$ & $\begin{array}{c}17.0 \\
31.0 \\
20.0 \\
13.0 \\
9.10\end{array}$ & $\begin{array}{l}6 \\
1 \\
5 \\
7 \\
9\end{array}$ & $\begin{array}{c}13.0 \\
25.0 \\
18.0 \\
12.0 \\
7.70\end{array}$ & $\begin{array}{l}7 \\
3 \\
5 \\
8 \\
9\end{array}$ & $\begin{array}{r}9.00 \\
18.0 \\
12.0 \\
8.90 \\
6.30\end{array}$ & $\begin{array}{l}7 \\
2 \\
6 \\
8 \\
9\end{array}$ & $\begin{array}{l}4.80 \\
9.40 \\
6.90 \\
4.70 \\
3.60\end{array}$ & $\begin{array}{l}7 \\
3 \\
5 \\
8 \\
9\end{array}$ \\
\hline
\end{tabular}

DURATION OF DISQHARGE FOR EACH WATER YEAR

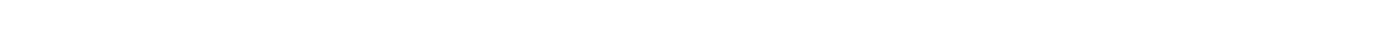
YEAR

NUMBER OF DAYS IN CLASS CUBIC FEET PER SECOND

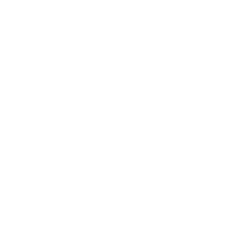

$\begin{array}{lllllllllllllllllllllllll}48 & 93 & 54 & 25 & 16 & 6 & 6 & 2 & 3 & 12 & 5 & 3 & 13 & 4 & 9 & 6 & 10 & 22 & 9 & 8 & 7 & 2 & 2 & & 2879.0\end{array}$ $\begin{array}{llllllllllllllllllllllll}122 & 48 & 4 & 22 & 14 & 4 & 3 & 2 & 2 & 6 & 8 & 20 & 28 & 18 & 3 & 6 & 10 & 9 & 25 & 7 & 2 & 3 & & 3523.9\end{array}$

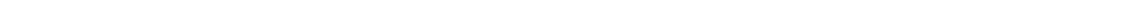

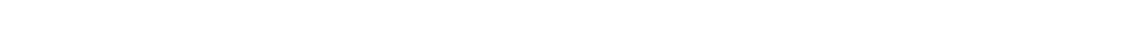
$\begin{array}{llllllllllllllllllllllllllll}31 & 2 & 33 & 33 & 17 & 17 & 34 & 2 & 2 & 6 & 4 & 2 & 2 & 6 & 15 & 6 & 5 & 6 & 5 & 7 & 7 & 17 & 2 & 3 & 4 & 2 & & 1740.8\end{array}$ $\begin{array}{llllllllllllllllllllllllllllllll}52 & 5 & 15 & 1 & 3 & 4 & 16 & 4 & 9 & 5 & 1 & 11 & 8 & 6 & 1 & 6 & 38 & 9 & 6 & 7 & 17 & 6 & 12 & 12 & 7 & 10 & 3 & 5 & 2 & 3423.9\end{array}$

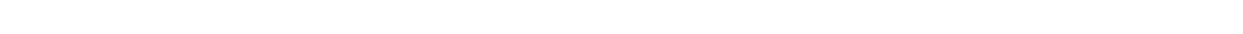

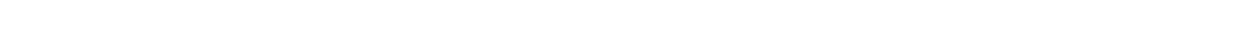


DURATION TABLE OF DISCHARGE FOR WATER YEARS 1947-55

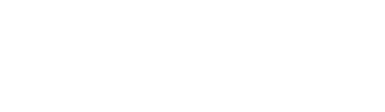

$\begin{array}{ccc}\text { OBBIC } & \text { ACOU- } \\ \text { FEET } & \text { MU- } & \text { PER- } \\ \text { PER TOTAL LATED } & \text { OENT } \\ \text { CLASS SECOND DAYS } & \text { DAYS } & \text { DAYS }\end{array}$

$\begin{array}{ccc}\text { OUBIC } & \text { ACOU- } \\ \text { FEET } & \text { MU- } & \text { PER } \\ \text { PER TOTAL LATED } & \text { CENT } \\ \text { CLASS SECOND DAYS DAYS } & \text { DAYS }\end{array}$

$\begin{array}{ccc}\text { OBBIC } & \text { ACQU- } \\ \text { FEET } & \text { NU- } & \text { PER } \\ \text { PER TOTAL LAIED } & \text { CENT } \\ \text { OLASS SECOND } & \text { DAYS DAYS } & \text { DAYS }\end{array}$

$\begin{array}{rrrrr}0 & 0.00 & 120 & 3287 & 100.0 \\ 1 & 0.10 & 102 & 3167 & 96.3 \\ 2 & 0.12 & 0 & 3065 & 93.2 \\ 3 & 0.15 & 0 & 3065 & 93.2 \\ 4 & 0.18 & 151 & 3065 & 93.2 \\ 5 & 0.23 & 0 & 2914 & 88.7 \\ 6 & 0.28 & 150 & 2914 & 88.7 \\ 7 & 0.34 & 153 & 2764 & 84.1 \\ 8 & 0.42 & 89 & 2611 & 79.4\end{array}$

$\begin{array}{rrrrr}9 & 0.51 & 244 & 2522 & 76.7 \\ 10 & 0.63 & 148 & 2278 & 69.3 \\ 11 & 0.77 & 318 & 2130 & 64.8 \\ 12 & 0.94 & 236 & 1812 & 55.1 \\ 13 & 1.20 & 142 & 1576 & 47.9 \\ 14 & 1.40 & 93 & 1434 & 43.6 \\ 15 & 1.70 & 78 & 1341 & 40.8 \\ 16 & 2.10 & 49 & 1263 & 38.4 \\ 17 & 2.60 & 49 & 1214 & 36.9\end{array}$

$\begin{array}{rrrrr}18 & 3.2 & 38 & 1165 & 35.4 \\ 19 & 3.9 & 65 & 1127 & 34.3 \\ 20 & 4.8 & 76 & 1062 & 32.3 \\ 21 & 5.9 & 86 & 986 & 30.0 \\ 22 & 7.2 & 79 & 900 & 27.4 \\ 23 & 8.8 & 140 & 821 & 25.0 \\ 24 & 11.0 & 92 & 681 & 20.7 \\ 25 & 13.0 & 91 & 589 & 17.9 \\ 26 & 16.0 & 99 & 498 & 15.2\end{array}$

$\begin{array}{rrrrr}27 & 20.0 & 74 & 399 & 12.1 \\ 28 & 24.0 & 106 & 325 & 9.9 \\ 29 & 30.0 & 70 & 219 & 6.7 \\ 30 & 37.0 & 66 & 149 & 4.5 \\ 31 & 45.0 & 45 & 83 & 2.5 \\ 32 & 55.0 & 18 & 38 & 1.2 \\ 33 & 68.0 & 17 & 20 & 0.6 \\ 34 & 83.0 & 3 & 3 & 0.1\end{array}$

MONTHLY MEAN DISCHARGES, IN OBIC FEET PER SECOND, FOR EAOH WATER YEAR

\begin{tabular}{|c|c|c|c|c|c|c|c|c|c|c|c|c|}
\hline YEAR & $O C T$ & $\mathrm{NOV}$ & DEC & JAN & FEE & MAR & APR & MAY & JUNE & JULY & AUG & SEP \\
\hline $\begin{array}{l}1947 \\
194 i ? \\
1949 \\
1950\end{array}$ & $\begin{array}{l}1.34 \\
1.60 \\
1.22 \\
0.98\end{array}$ & $\begin{array}{l}1.15 \\
1.00 \\
0.80 \\
0.72\end{array}$ & $\begin{array}{l}1.05 \\
0.80 \\
0.80 \\
0.70\end{array}$ & $\begin{array}{l}1.00 \\
0.80 \\
0.70 \\
0.60\end{array}$ & $\begin{array}{l}0.90 \\
0.80 \\
0.60 \\
0.60\end{array}$ & $\begin{array}{l}1.02 \\
0.80 \\
0.60 \\
0.60\end{array}$ & $\begin{array}{l}2.96 \\
1.34 \\
1.20 \\
4.96\end{array}$ & $\begin{array}{l}41.7 \\
36.1 \\
20.7 \\
34.4\end{array}$ & $\begin{array}{l}23.9 \\
27.2 \\
11.4 \\
30.7\end{array}$ & $\begin{array}{c}9.99 \\
17.1 \\
4.54 \\
17.9\end{array}$ & $\begin{array}{l}7.42 \\
19.8 \\
21.9 \\
16.7\end{array}$ & $\begin{array}{r}1.41 \\
7.65 \\
9.29 \\
13.3\end{array}$ \\
\hline $\begin{array}{l}1951 \\
1952 \\
1953 \\
1954 \\
1955\end{array}$ & $\begin{array}{l}1.21 \\
1.66 \\
6.84 \\
1.15 \\
3.67\end{array}$ & $\begin{array}{l}0.80 \\
0.38 \\
0.63 \\
0.43 \\
0.49\end{array}$ & $\begin{array}{l}0.60 \\
0.30 \\
0.60 \\
0.40 \\
0.40\end{array}$ & $\begin{array}{l}0.40 \\
0.20 \\
0.50 \\
0.30 \\
0.30\end{array}$ & $\begin{array}{l}0.20 \\
0.10 \\
0.40 \\
0.20 \\
0.20\end{array}$ & $\begin{array}{l}0.00 \\
0.19 \\
0.30 \\
0.10 \\
0.10\end{array}$ & $\begin{array}{l}0.00 \\
2.83 \\
0.40 \\
0.72 \\
0.00\end{array}$ & $\begin{array}{l}19.6 \\
36.7 \\
18.8 \\
18.9 \\
13.0\end{array}$ & $\begin{array}{c}8.82 \\
37.8 \\
13.6 \\
13.1 \\
4.46\end{array}$ & $\begin{array}{c}17.8 \\
15.8 \\
20.2 \\
6.68 \\
9.01\end{array}$ & $\begin{array}{c}4.15 \\
7.89 \\
14.6 \\
8.37 \\
3.21\end{array}$ & $\begin{array}{l}3.05 \\
8.21 \\
5.35 \\
5.38 \\
8.22\end{array}$ \\
\hline
\end{tabular}

ANNUAL PEAK DISGHARGE, IN OUBIC FEET PER SECOND, AND CORRESPONDING GAGE HEIGHT, IN FEET, FOR EAOH WATER YEAR

\begin{tabular}{|c|c|c|c|c|c|c|c|c|c|c|c|c|}
\hline $\begin{array}{l}\text { WAIER } \\
\text { YEAR }\end{array}$ & DATE & $\begin{array}{c}\text { GAGE } \\
\text { HEIGHT }\end{array}$ & $\begin{array}{c}\text { PEAK } \\
\text { DISOHARGE }\end{array}$ & $\begin{array}{l}\text { WAIER } \\
\text { YEAR }\end{array}$ & DATE & $\begin{array}{c}\text { GAGE } \\
\text { BEIGHT }\end{array}$ & $\begin{array}{c}\text { PEAK } \\
\text { DISQH ARGE }\end{array}$ & $\begin{array}{l}\text { WATER } \\
\text { YEAR }\end{array}$ & & DATE & $\begin{array}{c}\text { GAGE } \\
\text { HEIGHT }\end{array}$ & $\begin{array}{c}\text { PEAK } \\
\text { DISCH ARGE }\end{array}$ \\
\hline $\begin{array}{l}1946 \\
1947 \\
1948 \\
1949\end{array}$ & $\begin{array}{ll}\text { JUNE } & 13,1946 \\
\text { MAY } & 08,1947 \\
\text { MAY } & 16,1948 \\
\text { MAY } & 25,1949\end{array}$ & $\begin{array}{l}1.92 \\
2.56 \\
2.47 \\
2.01\end{array}$ & $\begin{array}{r}44 \\
109 \\
112 \\
51\end{array}$ & $\begin{array}{l}1950 \\
1951 \\
1952\end{array}$ & $\begin{array}{lll}\text { MAY } & 30,1950 \\
\text { MAY } & 25,1951 \\
\text { JUNE } & 03,1952\end{array}$ & $\begin{array}{l}2.41 \\
2.32 \\
2.41\end{array}$ & $\begin{array}{r}99 \\
87 \\
103\end{array}$ & $\begin{array}{l}1953 \\
1954 \\
1955\end{array}$ & $\begin{array}{l}\text { MAY } \\
\text { MAY } \\
\text { MAY }\end{array}$ & $\begin{array}{ll}28, & 1953 \\
09, & 1954 \\
13, & 1955\end{array}$ & $\begin{array}{l}2.16 \\
1.97 \\
1.85\end{array}$ & $\begin{array}{l}89 \\
50 \\
38\end{array}$ \\
\hline
\end{tabular}

09299400 WHITEROCKS RIVER BELCW DAM SITE, NEAR WHITEROCKS, UT

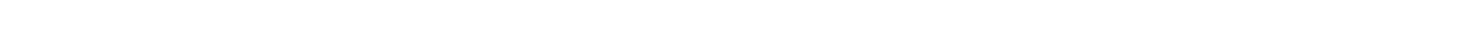

14060003 , Ashley National Forest, an left bank $3.2 \mathrm{mi}$ upstream from U.S. Forest Boundary and $9.6 \mathrm{mi}$ northeast of whiterocks.

DRAINAGE AREA - $110 \mathrm{mi}^{2}$.

PERIOD OF RECORD AVAILABLE.-OCtober 1976 to September 1981.

GAGE. -Water-stage recorder. Altitude of gage is 7,160 ft from topographic map.

REMARKS.-Flow slightly regulated by small mountain lakes. one small diversion $0.5 \mathrm{mi}$ above station for irrigation of about 100 acres below station.

AVERAGE DISCHARGE. -5 years, $90.6 \mathrm{ft}^{3} / \mathrm{s}, 65,640$ acre- $\mathrm{ft} / \mathrm{yr}$.

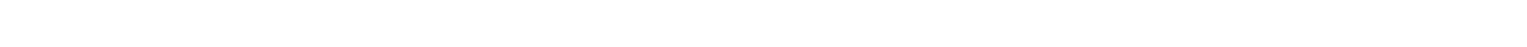

LOWEST MEAN DISCHARGE, IN GBIC FEET PER SECOND, AND RANKING FOR THE INDICATED NUMBER OF CONSEGUTTVE DAYS FOR EAOH CIMATIC YEAR, APRII, I-MARCH 31

\begin{tabular}{|c|c|c|c|c|c|c|c|c|c|c|c|c|c|c|c|c|c|c|c|}
\hline YEAR & 1 & & 3 & & 7 & & 14 & & $\begin{array}{l}\text { cons } \\
30\end{array}$ & CUT & $\begin{array}{c}\text { E DAUS } \\
60\end{array}$ & & 90 & & 120 & & 183 & & ALL \\
\hline $\begin{array}{l}1978 \\
1979 \\
1980\end{array}$ & $\begin{array}{l}16.0 \\
15.0 \\
18.0\end{array}$ & $\begin{array}{l}2 \\
1 \\
3\end{array}$ & $\begin{array}{l}18.0 \\
15.0 \\
18.0\end{array}$ & $\begin{array}{l}3 \\
1 \\
2\end{array}$ & $\begin{array}{l}19.0 \\
16.0 \\
18.0\end{array}$ & $\begin{array}{l}3 \\
1 \\
2\end{array}$ & $\begin{array}{l}20.0 \\
17.0 \\
19.0\end{array}$ & $\begin{array}{l}3 \\
1 \\
2\end{array}$ & $\begin{array}{l}20.0 \\
18.0 \\
19.0\end{array}$ & $\begin{array}{l}3 \\
1 \\
2\end{array}$ & $\begin{array}{l}21.0 \\
19.0 \\
20.0\end{array}$ & $\begin{array}{l}3 \\
1 \\
2\end{array}$ & $\begin{array}{l}21.0 \\
20.0 \\
20.0\end{array}$ & $\begin{array}{l}3 \\
1 \\
2\end{array}$ & $\begin{array}{l}22.0 \\
21.0 \\
22.0\end{array}$ & $\begin{array}{l}3 \\
1 \\
2\end{array}$ & $\begin{array}{l}28.0 \\
25.0 \\
28.0\end{array}$ & $\begin{array}{l}3 \\
1 \\
2\end{array}$ & $\begin{array}{l}62.0 \\
90.0 \\
88.0\end{array}$ \\
\hline 1981 & 19.0 & 4 & 19.0 & 4 & 20.0 & 4 & 21.0 & 4 & 23.0 & 4 & 24.0 & 4 & 25.0 & 4 & 27.0 & 4 & 37.0 & 4 & 130 \\
\hline
\end{tabular}


HIGHEST MEAN DISCHARGE, IN OUBIC FEET PER SECOND, AND RANKING FOR THE INDICATED NUMBER OF CONSECUTIVE DAYS FOR EACH WATER YEAR, OCTCBER 1-SEPTEMBER 30

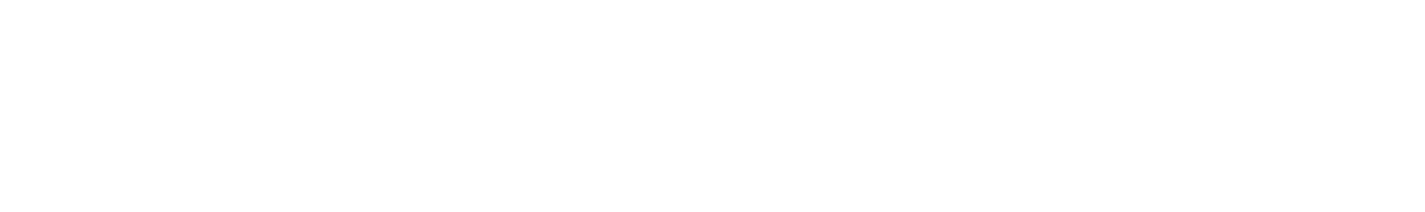

DURATION OF DISCHARGE FOR EACH WATER YEAR

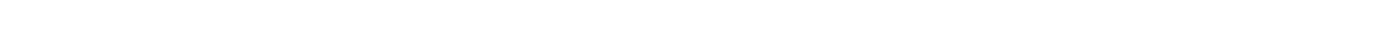
YEAR NUMBER OF DAYS IN CLASS

CBIC FEET PER SECOND -DAYS

$\begin{array}{llllllllllllllllllllllllllll}14 & 26 & 20 & 35 & 21 & 25 & 16 & 18 & 13 & 11 & 16 & 7 & 17 & 21 & 38 & 29 & 17 & 6 & 4 & 1 & 1 & 2 & 3 & 1 & 1 & 1 & 1\end{array}$ $\begin{array}{rrrrrrrrrrrrrrrrrrrrrrrrrrrrrrr}44 & 58 & 40 & 16 & 13 & 14 & 21 & 16 & 19 & 6 & 12 & 8 & 11 & 8 & 21 & 13 & 6 & 3 & 2 & 12 & 3 & 3 & 5 & 2 & 3 & 3 & 2 & 1 & & 33453.0 \\ 6 & 63 & 26 & 59 & 27 & 11 & 5 & 16 & 20 & 6 & 14 & 6 & 14 & 11 & 17 & 10 & 15 & 16 & 3 & 5 & 4 & 4 & 3 & 2 & 1 & 3 & 3 & 1 & 2 & & \\ 31808.0\end{array}$

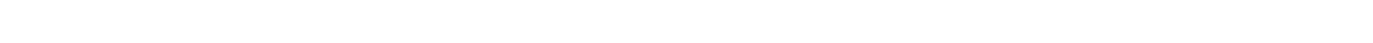
$\begin{array}{llllllllllllllllllllll}28 & 53 & 40 & 21 & 14 & 11 & 17 & 15 & 12 & 16 & 22 & 13 & 13 & 41 & 11 & 8 & 4 & 3 & 5 & 2 & 8 & 8\end{array}$

32523.0

DURATION TABLE OF DISCHARGE FOR WATER YEARS 1977-81

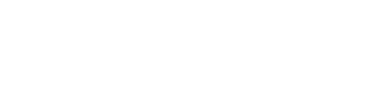
$\begin{array}{crl}\text { OBIIC } & \text { ACCJ- } \\ \text { FEET } & \text { MU- } & \text { PER- } \\ \text { PER TOTAL LATED } & \text { CENT } \\ \text { SECOND DAYS DAYS } & \text { DAYS }\end{array}$ OBIC ACAFEET MU- PER CIASS SECOND DAYS DAYS DAYS CLASS SECOND DAYS DAYS DAYS $\begin{array}{rrr}\text { CUBIC } & \text { ACOU- } \\ \text { FEET } & \text { MU- } & \text { PER- } \\ \text { PER } & \text { TOTAL LATED } & \text { CENT } \\ \text { CIAASS SECOND DAYS DAYS } & \text { DAYS }\end{array}$

$\begin{array}{rrrrr}0 & 0.00 & 0 & 1826 & 100.0 \\ 1 & 12.00 & 14 & 1826 & 100.0 \\ 2 & 14.00 & 28 & 1812 & 99.2 \\ 3 & 16.00 & 26 & 1784 & 97.7 \\ 4 & 18.00 & 203 & 1758 & 96.3 \\ 5 & 21.00 & 172 & 1555 & 85.2 \\ 6 & 24.00 & 195 & 1383 & 75.7 \\ 7 & 28.00 & 118 & 1188 & 65.1 \\ 8 & 32.00 & 84 & 1070 & 58.6\end{array}$

$\begin{array}{rrrrr}9 & 37.00 & 50 & 986 & 54.0 \\ 10 & 42.00 & 76 & 936 & 51.3 \\ 11 & 48.00 & 80 & 860 & 47.1 \\ 12 & 56.00 & 62 & 780 & 42.7 \\ 13 & 64.00 & 57 & 718 & 39.3 \\ 14 & 74.00 & 59 & 661 & 36.2 \\ 15 & 85.00 & 94 & 602 & 33.0 \\ 16 & 97.00 & 72 & 508 & 27.8 \\ 17 & 110.00 & 78 & 436 & 23.9\end{array}$

$\begin{array}{lll}18 & 130.0 & 99 \\ 19 & 150.0 & 5 \\ 20 & 170.0 & 36 \\ 21 & 200.0 & 15 \\ 22 & 220.0 & 22 \\ 23 & 260.0 & 29 \\ 24 & 300.0 & 16 \\ 25 & 340.0 & 19\end{array}$

99
56
36
15
22
29
16
19
21

$\begin{array}{rr}358 & 19.6 \\ 259 & 14.2 \\ 203 & 11.1 \\ 167 & 9.1 \\ 152 & 8.3 \\ 130 & 7.1 \\ 101 & 5.5 \\ 85 & 4.7\end{array}$

$\begin{array}{rrr}27 & 450.0 & 7 \\ 28 & 520.0 & 10 \\ 29 & 600.0 & 9 \\ 30 & 690.0 & 7 \\ 31 & 790.0 & 5 \\ 32 & 910.0 & 2 \\ 33 & 1000.0 & 3 \\ 34 & 1200.0 & 2\end{array}$

$\begin{array}{rr}45 & 2.5 \\ 38 & 2.1 \\ 28 & 1.5 \\ 19 & 1.0 \\ 12 & 0.7 \\ 7 & 0.4 \\ 5 & 0.3 \\ 2 & 0.1\end{array}$

MONIHLY MEAN DISCHARGES, IN OUBIC FEET PER SECOND, FOR EACH WATER YEAR

\begin{tabular}{|c|c|c|c|c|c|c|c|c|c|c|c|c|}
\hline YEAR & $\infty C T$ & NOV & DEC & JAN & FEB & MAR & APR & MAY & JUNE & JULY & AUG & SEP \\
\hline $\begin{array}{l}1977 \\
1978 \\
1979 \\
1980\end{array}$ & $\begin{array}{l}47.0 \\
49.8 \\
37.1 \\
47.4\end{array}$ & $\begin{array}{l}29.8 \\
29.3 \\
27.6 \\
32.2\end{array}$ & $\begin{array}{l}27.4 \\
23.9 \\
25.0 \\
26.8\end{array}$ & $\begin{array}{l}17.2 \\
23.0 \\
21.9 \\
20.9\end{array}$ & $\begin{array}{l}14.1 \\
20.0 \\
18.6 \\
19.9\end{array}$ & $\begin{array}{l}18.0 \\
22.4 \\
19.5 \\
19.3\end{array}$ & $\begin{array}{l}36.4 \\
31.7 \\
35.5 \\
43.2\end{array}$ & $\begin{array}{l}69.1 \\
164 \\
297 \\
202\end{array}$ & $\begin{array}{l}176 \\
421 \\
234 \\
679\end{array}$ & $\begin{array}{l}95.9 \\
150 \\
150 \\
207\end{array}$ & $\begin{array}{l}105 \\
103 \\
107 \\
122\end{array}$ & $\begin{array}{l}86.5 \\
62.1 \\
65.6 \\
82.2\end{array}$ \\
\hline 1981 & 73.7 & 41.3 & 31.4 & 26.9 & 25.3 & 23.5 & 59.0 & 240 & 238 & 114 & 122 & 69.8 \\
\hline
\end{tabular}

ANNUAL PEAK DISCHARGE, IN CUBIC FEET PER SECOND, AND CORRESPONDING GAGE HEIGHT, IN FEET, FOR EACH WATER YEAR

$\begin{array}{lccccccccccc}\begin{array}{l}\text { WATER } \\ \text { YEAR }\end{array} & \text { DATE } & \begin{array}{c}\text { GAGE } \\ \text { HEIGHT }\end{array} & \begin{array}{c}\text { PEAR } \\ \text { DISCHARGE }\end{array} & \begin{array}{l}\text { WATER } \\ \text { YEAR }\end{array} & \text { DATE } & \begin{array}{c}\text { GAGE } \\ \text { HEIGHT }\end{array} & \begin{array}{c}\text { PEAK } \\ \text { DISCHARGE }\end{array} & \begin{array}{l}\text { WATER } \\ \text { YEAR }\end{array} & \begin{array}{c}\text { GAGE } \\ \text { DATE }\end{array} & \begin{array}{c}\text { PEAK } \\ \text { HEIGHT }\end{array} \\ \text { DISCHARGE }\end{array}$




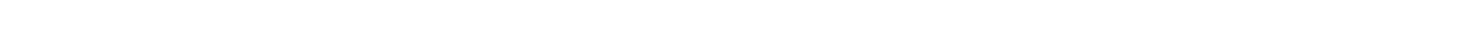
14060003 , on left bank $0.8 \mathrm{mi}$ upstream from heading of United States Whiterocks Canal, and $6.5 \mathrm{mi}$ north of Whiterocks.

DRAINAGE AREA. $--113 \mathrm{mi}^{2}$.

MEAN BASIN ELEVATION.-- $10,370 \mathrm{ft}$.

PERIOD OF RECORD AVAIlABLE.--September 1899 to December 1903, April to December 1907, March 1908 to November 1910 , October 1913 to September 1981. Monthly mean discharge for scme periods, published in WSP 1313. Published as "Whiterocks River in Canyon"

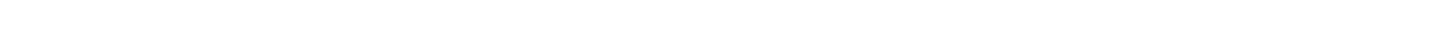
above station (records equivalent if flow of Whiterocks Canal is included).

GAGE.-Water-stage recorder. Altitude of gage is 6,980 ft fram river-profile map. Prior to oct. 16, 1930, nonrecording gages at several sites within $1 \mathrm{mi}$ of present site at various datums, Oct. 16, 1930 to Nov. 7, 1949, water-stage recorder at site $60 \mathrm{ft}$ downstream at different datum. Nov. 8, 1949 to June 14, 1975, water-stage recorder at site 40 ft upstream at different datum.

REMARKS. -Flow slightly regulated by small mountain lakes. One small diversion $2 \mathrm{mi}$ above station for irrigation of about 100 acres above and below station.

AVERAGE DISCHARGE.--74 years (water years 1900-03, 1909-10, 1914-81), $122 \mathrm{ft}^{3} / \mathrm{s}, 88,390$ acre-ft/yr.

EXTREMES FOR PERIOD OF RECORD.-Maximum discharge determined, 2,750 $\mathrm{ft}^{3} / \mathrm{s}$ June 20, 21, 1922, gage height, $5.40 \mathrm{ft}$, site and datum then in use, from rating curve extended above $1,700 \mathrm{ft}^{3} / \mathrm{s}$; minimum recorded, $9.2 \mathrm{ft} 3 / \mathrm{s} \mathrm{Apr.} \mathrm{3,} 1977$.

LOWEST MEAN DISOIARGE, IN OUBIC FEET PER SECOND, AND RANTING FOR THE INDICATED NUMBER OF CONSECOTIVE DAYS FOR EACH CLIMATIC YEAR, APRIL I-MARCH 31

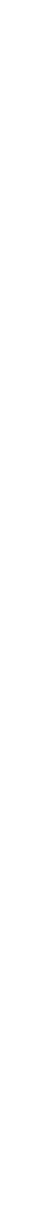

YEAR

1920

1931

1932

1934

1935

1936

1937

1939

1940

1941

1943

1944
1945

1946

1947
1948

1948
1949

1950

1951

1953

1954

1956

1957
1958

1958
1959

1960

1961

1963

1964

1966

1967
1968

1969

1970

\begin{tabular}{|c|c|c|c|c|c|c|c|c|c|c|c|c|c|c|c|c|c|c|c|}
\hline 1 & & 3 & & 7 & & 14 & & $\begin{array}{l}\text { CONS } \\
30\end{array}$ & & $\begin{array}{l}\text { DAYS } \\
60\end{array}$ & & 90 & & 120 & & 183 & & ALL & \\
\hline 21.0 & 16 & 21.0 & 15 & 21.0 & 16 & 22.0 & 13 & 23.0 & 14 & 24.0 & 14 & 26.0 & 15 & 31.0 & 32 & 41.0 & 41 & 59.0 & 3 \\
\hline $\begin{array}{l}30.0 \\
27.0 \\
19.0 \\
18.0 \\
17.0\end{array}$ & $\begin{array}{r}51 \\
43 \\
12 \\
8 \\
4\end{array}$ & $\begin{array}{l}30.0 \\
27.0 \\
20.0 \\
18.0 \\
18.0\end{array}$ & $\begin{array}{r}50 \\
43 \\
11 \\
6 \\
7\end{array}$ & $\begin{array}{l}30.0 \\
29.0 \\
21.0 \\
18.0 \\
19.0\end{array}$ & $\begin{array}{r}51 \\
47 \\
17 \\
4 \\
8\end{array}$ & $\begin{array}{l}30.0 \\
30.0 \\
22.0 \\
18.0 \\
20.0\end{array}$ & $\begin{array}{r}45 \\
46 \\
14 \\
3 \\
9\end{array}$ & $\begin{array}{l}30.0 \\
30.0 \\
23.0 \\
18.0 \\
21.0\end{array}$ & $\begin{array}{r}44 \\
45 \\
15 \\
3 \\
11\end{array}$ & $\begin{array}{l}32.0 \\
30.0 \\
24.0 \\
19.0 \\
27.0\end{array}$ & $\begin{array}{r}46 \\
39 \\
15 \\
3 \\
25\end{array}$ & $\begin{array}{l}33.0 \\
31.0 \\
26.0 \\
20.0 \\
31.0\end{array}$ & $\begin{array}{r}46 \\
39 \\
16 \\
2 \\
40\end{array}$ & $\begin{array}{l}36.0 \\
32.0 \\
26.0 \\
21.0 \\
31.0\end{array}$ & $\begin{array}{r}44 \\
37 \\
13 \\
2 \\
33\end{array}$ & $\begin{array}{l}49.0 \\
36.0 \\
32.0 \\
26.0 \\
33.0\end{array}$ & $\begin{array}{r}44 \\
22 \\
15 \\
1 \\
18\end{array}$ & $\begin{array}{c}139 \\
56.0 \\
129 \\
78.0 \\
46.0\end{array}$ & $\begin{array}{r}40 \\
2 \\
35 \\
8 \\
1\end{array}$ \\
\hline $\begin{array}{l}26.0 \\
25.0 \\
23.0 \\
27.0 \\
23.0\end{array}$ & $\begin{array}{l}41 \\
36 \\
27 \\
44 \\
28\end{array}$ & $\begin{array}{l}26.0 \\
25.0 \\
24.0 \\
28.0 \\
24.0\end{array}$ & $\begin{array}{l}41 \\
36 \\
26 \\
44 \\
27\end{array}$ & $\begin{array}{l}26.0 \\
25.0 \\
24.0 \\
29.0 \\
25.0\end{array}$ & $\begin{array}{l}39 \\
30 \\
24 \\
48 \\
31\end{array}$ & $\begin{array}{l}26.0 \\
25.0 \\
27.0 \\
31.0 \\
26.0\end{array}$ & $\begin{array}{l}35 \\
30 \\
40 \\
49 \\
36\end{array}$ & $\begin{array}{l}27.0 \\
25.0 \\
29.0 \\
35.0 \\
27.0\end{array}$ & $\begin{array}{l}36 \\
22 \\
41 \\
49 \\
37\end{array}$ & $\begin{array}{l}27.0 \\
25.0 \\
30.0 \\
35.0 \\
28.0\end{array}$ & $\begin{array}{l}26 \\
16 \\
40 \\
50 \\
34\end{array}$ & $\begin{array}{l}28.0 \\
27.0 \\
30.0 \\
37.0 \\
30.0\end{array}$ & $\begin{array}{l}28 \\
21 \\
33 \\
50 \\
34\end{array}$ & $\begin{array}{l}29.0 \\
29.0 \\
30.0 \\
40.0 \\
32.0\end{array}$ & $\begin{array}{l}24 \\
25 \\
26 \\
50 \\
38\end{array}$ & $\begin{array}{l}32.0 \\
40.0 \\
38.0 \\
69.0 \\
49.0\end{array}$ & $\begin{array}{l}16 \\
37 \\
32 \\
52 \\
45\end{array}$ & $\begin{array}{c}93.0 \\
93.0 \\
132 \\
155 \\
93.0\end{array}$ & $\begin{array}{l}18 \\
19 \\
38 \\
47 \\
20\end{array}$ \\
\hline $\begin{array}{l}28.0 \\
31.0 \\
22.0 \\
23.0 \\
29.0\end{array}$ & $\begin{array}{l}48 \\
52 \\
21 \\
29 \\
50\end{array}$ & $\begin{array}{l}28.0 \\
31.0 \\
24.0 \\
24.0 \\
30.0\end{array}$ & $\begin{array}{l}45 \\
52 \\
28 \\
29 \\
51\end{array}$ & $\begin{array}{l}30.0 \\
32.0 \\
27.0 \\
25.0 \\
30.0\end{array}$ & $\begin{array}{l}49 \\
52 \\
41 \\
32 \\
50\end{array}$ & $\begin{array}{l}31.0 \\
33.0 \\
28.0 \\
26.0 \\
30.0\end{array}$ & $\begin{array}{l}50 \\
52 \\
41 \\
37 \\
47\end{array}$ & $\begin{array}{l}32.0 \\
35.0 \\
29.0 \\
27.0 \\
30.0\end{array}$ & $\begin{array}{l}47 \\
50 \\
42 \\
38 \\
46\end{array}$ & $\begin{array}{l}33.0 \\
36.0 \\
30.0 \\
28.0 \\
31.0\end{array}$ & $\begin{array}{l}47 \\
51 \\
41 \\
35 \\
45\end{array}$ & $\begin{array}{l}34.0 \\
39.0 \\
30.0 \\
31.0 \\
32.0\end{array}$ & $\begin{array}{l}47 \\
52 \\
35 \\
41 \\
43\end{array}$ & $\begin{array}{l}37.0 \\
44.0 \\
32.0 \\
32.0 \\
33.0\end{array}$ & $\begin{array}{l}46 \\
52 \\
39 \\
40 \\
41\end{array}$ & $\begin{array}{l}64.0 \\
67.0 \\
37.0 \\
38.0 \\
38.0\end{array}$ & $\begin{array}{l}50 \\
51 \\
26 \\
33 \\
34\end{array}$ & $\begin{array}{c}77.0 \\
167 \\
129 \\
97.0 \\
166\end{array}$ & $\begin{array}{r}7 \\
51 \\
36 \\
23 \\
49\end{array}$ \\
\hline $\begin{array}{l}28.0 \\
27.0 \\
26.0 \\
23.0 \\
25.0\end{array}$ & $\begin{array}{l}49 \\
45 \\
42 \\
30 \\
37\end{array}$ & $\begin{array}{l}28.0 \\
28.0 \\
26.0 \\
24.0 \\
25.0\end{array}$ & $\begin{array}{l}46 \\
47 \\
42 \\
30 \\
37\end{array}$ & $\begin{array}{l}28.0 \\
28.0 \\
26.0 \\
24.0 \\
28.0\end{array}$ & $\begin{array}{l}42 \\
43 \\
40 \\
25 \\
44\end{array}$ & $\begin{array}{l}28.0 \\
30.0 \\
26.0 \\
24.0 \\
32.0\end{array}$ & $\begin{array}{l}42 \\
48 \\
38 \\
24 \\
51\end{array}$ & $\begin{array}{l}29.0 \\
35.0 \\
26.0 \\
25.0 \\
35.0\end{array}$ & $\begin{array}{l}43 \\
51 \\
30 \\
23 \\
52\end{array}$ & $\begin{array}{l}30.0 \\
37.0 \\
27.0 \\
25.0 \\
35.0\end{array}$ & $\begin{array}{l}42 \\
52 \\
27 \\
17 \\
48\end{array}$ & $\begin{array}{l}31.0 \\
38.0 \\
28.0 \\
26.0 \\
36.0\end{array}$ & $\begin{array}{l}42 \\
51 \\
22 \\
17 \\
48\end{array}$ & $\begin{array}{l}33.0 \\
41.0 \\
28.0 \\
27.0 \\
38.0\end{array}$ & $\begin{array}{l}42 \\
51 \\
20 \\
18 \\
47\end{array}$ & $\begin{array}{l}40.0 \\
49.0 \\
40.0 \\
31.0 \\
45.0\end{array}$ & $\begin{array}{l}38 \\
46 \\
39 \\
12 \\
42\end{array}$ & $\begin{array}{c}108 \\
81.0 \\
149 \\
91.0 \\
137\end{array}$ & $\begin{array}{r}27 \\
9 \\
46 \\
16 \\
39\end{array}$ \\
\hline $\begin{array}{l}25.0 \\
25.0 \\
28.0 \\
23.0 \\
23.0\end{array}$ & $\begin{array}{l}38 \\
39 \\
46 \\
31 \\
32\end{array}$ & $\begin{array}{l}25.0 \\
25.0 \\
28.0 \\
24.0 \\
24.0\end{array}$ & $\begin{array}{l}38 \\
39 \\
48 \\
31 \\
32\end{array}$ & $\begin{array}{l}25.0 \\
25.0 \\
28.0 \\
24.0 \\
25.0\end{array}$ & $\begin{array}{l}33 \\
34 \\
45 \\
26 \\
35\end{array}$ & $\begin{array}{l}25.0 \\
26.0 \\
28.0 \\
24.0 \\
25.0\end{array}$ & $\begin{array}{l}31 \\
32 \\
43 \\
25 \\
26\end{array}$ & $\begin{array}{l}26.0 \\
27.0 \\
28.0 \\
25.0 \\
26.0\end{array}$ & $\begin{array}{l}31 \\
39 \\
40 \\
24 \\
32\end{array}$ & $\begin{array}{l}27.0 \\
29.0 \\
28.0 \\
25.0 \\
26.0\end{array}$ & $\begin{array}{l}28 \\
38 \\
36 \\
18 \\
21\end{array}$ & $\begin{array}{l}28.0 \\
30.0 \\
29.0 \\
26.0 \\
28.0\end{array}$ & $\begin{array}{l}23 \\
36 \\
29 \\
18 \\
24\end{array}$ & $\begin{array}{l}29.0 \\
31.0 \\
30.0 \\
26.0 \\
30.0\end{array}$ & $\begin{array}{l}21 \\
34 \\
27 \\
14 \\
28\end{array}$ & $\begin{array}{l}34.0 \\
37.0 \\
39.0 \\
31.0 \\
37.0\end{array}$ & $\begin{array}{l}19 \\
27 \\
35 \\
13 \\
28\end{array}$ & $\begin{array}{r}123 \\
102 \\
167 \\
84.0 \\
83.0\end{array}$ & $\begin{array}{l}33 \\
26 \\
50 \\
12 \\
10\end{array}$ \\
\hline $\begin{array}{l}23.0 \\
20.0 \\
19.0 \\
20.0 \\
22.0\end{array}$ & $\begin{array}{r}33 \\
13 \\
9 \\
14 \\
22\end{array}$ & $\begin{array}{l}24.0 \\
20.0 \\
20.0 \\
21.0 \\
23.0\end{array}$ & $\begin{array}{l}33 \\
12 \\
13 \\
16 \\
22\end{array}$ & $\begin{array}{l}24.0 \\
20.0 \\
21.0 \\
21.0 \\
23.0\end{array}$ & $\begin{array}{l}27 \\
11 \\
12 \\
13 \\
18\end{array}$ & $\begin{array}{l}25.0 \\
20.0 \\
22.0 \\
22.0 \\
23.0\end{array}$ & $\begin{array}{l}27 \\
10 \\
15 \\
16 \\
19\end{array}$ & $\begin{array}{l}25.0 \\
20.0 \\
23.0 \\
22.0 \\
23.0\end{array}$ & $\begin{array}{r}25 \\
9 \\
16 \\
12 \\
13\end{array}$ & $\begin{array}{l}27.0 \\
23.0 \\
31.0 \\
22.0 \\
24.0\end{array}$ & $\begin{array}{l}29 \\
11 \\
43 \\
10 \\
12\end{array}$ & $\begin{array}{l}29.0 \\
24.0 \\
33.0 \\
23.0 \\
24.0\end{array}$ & $\begin{array}{l}30 \\
12 \\
44 \\
10 \\
11\end{array}$ & $\begin{array}{l}30.0 \\
25.0 \\
38.0 \\
24.0 \\
26.0\end{array}$ & $\begin{array}{l}29 \\
11 \\
48 \\
10 \\
12\end{array}$ & $\begin{array}{l}36.0 \\
29.0 \\
54.0 \\
29.0 \\
38.0\end{array}$ & $\begin{array}{r}23 \\
8 \\
48 \\
9 \\
29\end{array}$ & $\begin{array}{r}83.0 \\
89.0 \\
123 \\
115 \\
89.0\end{array}$ & $\begin{array}{l}11 \\
14 \\
34 \\
28 \\
15\end{array}$ \\
\hline $\begin{array}{l}16.0 \\
21.0 \\
18.0 \\
22.0 \\
24.0\end{array}$ & $\begin{array}{r}3 \\
17 \\
5 \\
18 \\
34\end{array}$ & $\begin{array}{l}16.0 \\
21.0 \\
18.0 \\
22.0 \\
25.0\end{array}$ & $\begin{array}{r}3 \\
17 \\
4 \\
18 \\
34\end{array}$ & $\begin{array}{l}16.0 \\
21.0 \\
18.0 \\
23.0 \\
25.0\end{array}$ & $\begin{array}{r}1 \\
14 \\
5 \\
19 \\
36\end{array}$ & $\begin{array}{l}16.0 \\
22.0 \\
19.0 \\
24.0 \\
26.0\end{array}$ & $\begin{array}{r}1 \\
17 \\
4 \\
20 \\
33\end{array}$ & $\begin{array}{l}17.0 \\
24.0 \\
19.0 \\
25.0 \\
26.0\end{array}$ & $\begin{array}{r}1 \\
17 \\
4 \\
26 \\
33\end{array}$ & $\begin{array}{l}18.0 \\
31.0 \\
19.0 \\
27.0 \\
27.0\end{array}$ & $\begin{array}{r}1 \\
44 \\
4 \\
30 \\
31\end{array}$ & $\begin{array}{l}20.0 \\
33.0 \\
20.0 \\
28.0 \\
28.0\end{array}$ & $\begin{array}{r}3 \\
45 \\
4 \\
25 \\
26\end{array}$ & $\begin{array}{l}22.0 \\
36.0 \\
21.0 \\
30.0 \\
29.0\end{array}$ & $\begin{array}{r}7 \\
45 \\
3 \\
30 \\
22\end{array}$ & $\begin{array}{l}30.0 \\
54.0 \\
30.0 \\
41.0 \\
33.0\end{array}$ & $\begin{array}{l}10 \\
49 \\
11 \\
40 \\
17\end{array}$ & $\begin{array}{c}75.0 \\
99.0 \\
141 \\
96.0 \\
117\end{array}$ & $\begin{array}{r}6 \\
24 \\
41 \\
22 \\
29\end{array}$ \\
\hline $\begin{array}{l}28.0 \\
25.0 \\
23.0 \\
22.0 \\
23.0\end{array}$ & $\begin{array}{l}47 \\
40 \\
23 \\
19 \\
24\end{array}$ & $\begin{array}{l}29.0 \\
25.0 \\
23.0 \\
22.0 \\
23.0\end{array}$ & $\begin{array}{l}49 \\
35 \\
23 \\
19 \\
24\end{array}$ & $\begin{array}{l}29.0 \\
26.0 \\
24.0 \\
23.0 \\
23.0\end{array}$ & $\begin{array}{l}46 \\
37 \\
28 \\
20 \\
21\end{array}$ & $\begin{array}{l}30.0 \\
26.0 \\
24.0 \\
24.0 \\
23.0\end{array}$ & $\begin{array}{l}44 \\
34 \\
21 \\
22 \\
18\end{array}$ & $\begin{array}{l}34.0 \\
27.0 \\
25.0 \\
24.0 \\
24.0\end{array}$ & $\begin{array}{l}48 \\
34 \\
27 \\
18 \\
19\end{array}$ & $\begin{array}{l}35.0 \\
28.0 \\
26.0 \\
25.0 \\
24.0\end{array}$ & $\begin{array}{l}49 \\
32 \\
22 \\
19 \\
13\end{array}$ & $\begin{array}{l}36.0 \\
29.0 \\
26.0 \\
26.0 \\
25.0\end{array}$ & $\begin{array}{l}49 \\
31 \\
19 \\
20 \\
13\end{array}$ & $\begin{array}{l}38.0 \\
31.0 \\
27.0 \\
27.0 \\
27.0\end{array}$ & $\begin{array}{l}49 \\
35 \\
15 \\
16 \\
17\end{array}$ & $\begin{array}{l}51.0 \\
37.0 \\
32.0 \\
35.0 \\
39.0\end{array}$ & $\begin{array}{l}47 \\
24 \\
14 \\
20 \\
36\end{array}$ & $\begin{array}{l}168 \\
101 \\
146 \\
147 \\
143\end{array}$ & $\begin{array}{l}52 \\
25 \\
43 \\
44 \\
42\end{array}$ \\
\hline
\end{tabular}


LOWEST MEAN DISGHARGE, IN OBIC FEET PER SECOND, AND RANKING FOR THE INDICATED NUMBER OF CONSEQUTIVE DAYS FOR EAOH OIMATIC YEAR, APRIL 1-MARG 31--Continued

\begin{tabular}{|c|c|c|c|c|c|c|c|c|c|c|c|c|c|c|c|c|c|c|c|c|}
\hline YEAR & 1 & & 3 & & 7 & & 14 & & $\begin{array}{l}\text { cons } \\
30\end{array}$ & EW' & $\begin{array}{l}\text { DAYS } \\
60\end{array}$ & & 90 & & 120 & & 183 & & FW & \\
\hline $\begin{array}{l}1971 \\
1972 \\
1973 \\
1974 \\
1975\end{array}$ & $\begin{array}{l}23.0 \\
22.0 \\
23.0 \\
24.0 \\
19.0\end{array}$ & $\begin{array}{l}25 \\
20 \\
26 \\
35 \\
10\end{array}$ & $\begin{array}{l}24.0 \\
22.0 \\
23.0 \\
26.0 \\
20.0\end{array}$ & $\begin{array}{l}25 \\
20 \\
21 \\
40 \\
14\end{array}$ & $\begin{array}{l}25.0 \\
23.0 \\
24.0 \\
26.0 \\
21.0\end{array}$ & $\begin{array}{l}29 \\
22 \\
23 \\
38 \\
15\end{array}$ & $\begin{array}{l}25.0 \\
24.0 \\
25.0 \\
27.0 \\
21.0\end{array}$ & $\begin{array}{l}28 \\
23 \\
29 \\
39 \\
11\end{array}$ & $\begin{array}{l}26.0 \\
25.0 \\
26.0 \\
27.0 \\
21.0\end{array}$ & $\begin{array}{l}28 \\
20 \\
29 \\
35 \\
10\end{array}$ & $\begin{array}{l}27.0 \\
27.0 \\
29.0 \\
28.0 \\
21.0\end{array}$ & $\begin{array}{r}23 \\
24 \\
37 \\
33 \\
8\end{array}$ & $\begin{array}{l}28.0 \\
30.0 \\
31.0 \\
29.0 \\
21.0\end{array}$ & $\begin{array}{r}27 \\
37 \\
38 \\
32 \\
5\end{array}$ & $\begin{array}{l}29.0 \\
32.0 \\
35.0 \\
30.0 \\
22.0\end{array}$ & $\begin{array}{r}23 \\
36 \\
43 \\
31 \\
4\end{array}$ & $\begin{array}{l}36.0 \\
37.0 \\
47.0 \\
38.0 \\
28.0\end{array}$ & $\begin{array}{r}21 \\
25 \\
43 \\
30 \\
3\end{array}$ & $\begin{array}{r}120 \\
122 \\
121 \\
148 \\
63.0\end{array}$ & $\begin{array}{r}30 \\
32 \\
31 \\
45 \\
4\end{array}$ \\
\hline $\begin{array}{l}1976 \\
1977 \\
1978 \\
979\end{array}$ & $\begin{array}{l}18.0 \\
14.0 \\
18.0 \\
16.0 \\
19.0\end{array}$ & $\begin{array}{r}6 \\
1 \\
7 \\
2 \\
11\end{array}$ & $\begin{array}{l}19.0 \\
14.0 \\
18.0 \\
16.0 \\
19.0\end{array}$ & $\begin{array}{l}8 \\
1 \\
5 \\
2 \\
9\end{array}$ & $\begin{array}{l}19.0 \\
16.0 \\
18.0 \\
17.0 \\
19.0\end{array}$ & $\begin{array}{l}9 \\
2 \\
6 \\
3 \\
7\end{array}$ & $\begin{array}{l}19.0 \\
17.0 \\
19.0 \\
19.0 \\
20.0\end{array}$ & $\begin{array}{l}5 \\
2 \\
6 \\
7 \\
8\end{array}$ & $\begin{array}{l}20.0 \\
17.0 \\
20.0 \\
20.0 \\
20.0\end{array}$ & $\begin{array}{l}5 \\
2 \\
6 \\
7 \\
8\end{array}$ & $\begin{array}{l}21.0 \\
18.0 \\
20.0 \\
20.0 \\
21.0\end{array}$ & $\begin{array}{l}9 \\
2 \\
5 \\
6 \\
7\end{array}$ & $\begin{array}{l}21.0 \\
18.0 \\
21.0 \\
21.0 \\
21.0\end{array}$ & $\begin{array}{l}6 \\
1 \\
7 \\
8 \\
9\end{array}$ & $\begin{array}{l}23.0 \\
20.0 \\
22.0 \\
22.0 \\
23.0\end{array}$ & $\begin{array}{l}8 \\
1 \\
5 \\
6 \\
9\end{array}$ & $\begin{array}{l}28.0 \\
28.0 \\
28.0 \\
26.0 \\
29.0\end{array}$ & $\begin{array}{l}4 \\
5 \\
6 \\
2 \\
7\end{array}$ & $\begin{array}{r}160 \\
93.0 \\
63.0 \\
95.0 \\
88.0\end{array}$ & $\begin{array}{r}48 \\
17 \\
5 \\
21 \\
13\end{array}$ \\
\hline You & 20.0 & 15 & 20.0 & 10 & 20.0 & 10 & 21.0 & 12 & 25.0 & 21 & 26.0 & 20 & 26.0 & 14 & 28.0 & 19 & 38.0 & 31 & 132 & \\
\hline
\end{tabular}

HIGHEST MEAN DISGHARGE, IN OBIC FEET PER SECOND, AND RANKING FOR THE INDICATED NUMBER OF CONSEQUTTVE DAYS FOR EACH WATER YEAR, OCTCBER 1-SEPTEMBER 30

\begin{tabular}{|c|c|c|c|c|c|c|c|c|c|c|c|c|c|c|c|c|c|c|c|c|}
\hline YEAR & 1 & & 3 & & 7 & & 15 & & $\begin{array}{l}\infty \\
30\end{array}$ & & $\begin{array}{l}\text { E DAY } \\
60\end{array}$ & & 90 & & 120 & & 183 & & ALL & \\
\hline 910 & 1040 & 22 & 987 & 21 & 754 & 26 & 508 & 36 & 430 & 34 & 350 & 28 & 276 & 27 & 242 & 27 & 199 & 24 & 138 & 15 \\
\hline 930 & 738 & 35 & 698 & 34 & 642 & 34 & 522 & 34 & 484 & 27 & 421 & 21 & 336 & 20 & 304 & 18 & 228 & 14 & 143 & 12 \\
\hline $\begin{array}{l}936 \\
937 \\
938 \\
939 \\
940\end{array}$ & $\begin{array}{r}553 \\
1210 \\
1310 \\
500 \\
344\end{array}$ & $\begin{array}{r}43 \\
16 \\
9 \\
45 \\
53\end{array}$ & $\begin{array}{r}516 \\
1130 \\
1250 \\
480 \\
309\end{array}$ & $\begin{array}{r}42 \\
14 \\
7 \\
44 \\
53\end{array}$ & $\begin{array}{r}427 \\
1010 \\
1150 \\
450 \\
281\end{array}$ & $\begin{array}{r}44 \\
12 \\
5 \\
41 \\
53\end{array}$ & $\begin{array}{l}322 \\
824 \\
989 \\
400 \\
266\end{array}$ & $\begin{array}{r}45 \\
16 \\
2 \\
40 \\
53\end{array}$ & $\begin{array}{l}271 \\
639 \\
708 \\
315 \\
204\end{array}$ & $\begin{array}{r}44 \\
14 \\
9 \\
41 \\
52\end{array}$ & $\begin{array}{l}205 \\
459 \\
501 \\
236 \\
157\end{array}$ & $\begin{array}{r}48 \\
17 \\
9 \\
42 \\
52\end{array}$ & $\begin{array}{l}187 \\
365 \\
382 \\
185 \\
125\end{array}$ & $\begin{array}{l}45 \\
17 \\
13 \\
46 \\
52\end{array}$ & $\begin{array}{l}178 \\
306 \\
318 \\
155 \\
104\end{array}$ & $\begin{array}{l}43 \\
16 \\
12 \\
48 \\
52\end{array}$ & $\begin{array}{c}145 \\
227 \\
241 \\
138 \\
92.0\end{array}$ & $\begin{array}{l}40 \\
16 \\
12 \\
43 \\
52\end{array}$ & $\begin{array}{c}88.0 \\
134 \\
139 \\
103 \\
70.0\end{array}$ & \\
\hline $\begin{array}{l}946 \\
947 \\
948 \\
949 \\
950\end{array}$ & $\begin{array}{r}388 \\
892 \\
799 \\
1390 \\
1060\end{array}$ & $\begin{array}{r}50 \\
26 \\
33 \\
6 \\
21\end{array}$ & $\begin{array}{r}352 \\
828 \\
754 \\
1210 \\
971\end{array}$ & $\begin{array}{l}52 \\
27 \\
33 \\
11 \\
22\end{array}$ & $\begin{array}{r}315 \\
681 \\
667 \\
1010 \\
796\end{array}$ & $\begin{array}{l}51 \\
32 \\
33 \\
13 \\
25\end{array}$ & $\begin{array}{l}280 \\
602 \\
568 \\
882 \\
711\end{array}$ & $\begin{array}{l}51 \\
27 \\
29 \\
10 \\
21\end{array}$ & $\begin{array}{l}220 \\
574 \\
469 \\
689 \\
610\end{array}$ & $\begin{array}{l}51 \\
20 \\
29 \\
12 \\
17\end{array}$ & $\begin{array}{l}190 \\
495 \\
316 \\
492 \\
439\end{array}$ & $\begin{array}{l}49 \\
10 \\
31 \\
11 \\
20\end{array}$ & $\begin{array}{l}164 \\
410 \\
247 \\
379 \\
343\end{array}$ & $\begin{array}{r}49 \\
9 \\
34 \\
14 \\
18\end{array}$ & $\begin{array}{l}140 \\
352 \\
205 \\
316 \\
285\end{array}$ & $\begin{array}{r}49 \\
9 \\
34 \\
13 \\
19\end{array}$ & $\begin{array}{l}113 \\
258 \\
151 \\
228 \\
212\end{array}$ & $\begin{array}{r}49 \\
9 \\
37 \\
13 \\
19\end{array}$ & $\begin{array}{c}76.0 \\
154 \\
96.0 \\
130 \\
129\end{array}$ & $\begin{array}{r}49 \\
6 \\
34 \\
18 \\
19\end{array}$ \\
\hline $\begin{array}{l}951 \\
952 \\
953 \\
954 \\
955\end{array}$ & $\begin{array}{r}1120 \\
1410 \\
861 \\
665 \\
368\end{array}$ & $\begin{array}{r}19 \\
5 \\
29 \\
37 \\
52\end{array}$ & $\begin{array}{r}1040 \\
1310 \\
812 \\
538 \\
359\end{array}$ & $\begin{array}{r}19 \\
5 \\
28 \\
40 \\
51\end{array}$ & $\begin{array}{r}834 \\
1160 \\
698 \\
463 \\
308\end{array}$ & $\begin{array}{r}22 \\
3 \\
30 \\
40 \\
52\end{array}$ & $\begin{array}{l}532 \\
958 \\
530 \\
437 \\
288\end{array}$ & $\begin{array}{r}31 \\
5 \\
33 \\
37 \\
50\end{array}$ & $\begin{array}{l}453 \\
690 \\
399 \\
325 \\
256\end{array}$ & $\begin{array}{l}31 \\
11 \\
36 \\
40 \\
47\end{array}$ & $\begin{array}{l}312 \\
555 \\
278 \\
228 \\
224\end{array}$ & $\begin{array}{r}32 \\
5 \\
38 \\
43 \\
44\end{array}$ & $\begin{array}{l}269 \\
453 \\
222 \\
191 \\
184\end{array}$ & $\begin{array}{r}29 \\
4 \\
40 \\
43 \\
47\end{array}$ & $\begin{array}{l}232 \\
395 \\
186 \\
166 \\
170\end{array}$ & $\begin{array}{r}29 \\
4 \\
40 \\
46 \\
44\end{array}$ & $\begin{array}{l}167 \\
294 \\
136 \\
128 \\
130\end{array}$ & $\begin{array}{r}29 \\
2 \\
44 \\
47 \\
45\end{array}$ & $\begin{array}{c}101 \\
166 \\
88.0 \\
80.0 \\
83.0\end{array}$ & $\begin{array}{r}31 \\
2 \\
41 \\
47 \\
45\end{array}$ \\
\hline $\begin{array}{l}1966 \\
1967 \\
1968 \\
1969 \\
1970\end{array}$ & $\begin{array}{r}558 \\
954 \\
1750 \\
873 \\
637\end{array}$ & $\begin{array}{r}41 \\
23 \\
2 \\
27 \\
38\end{array}$ & $\begin{array}{r}541 \\
906 \\
1420 \\
855 \\
599\end{array}$ & $\begin{array}{r}39 \\
23 \\
3 \\
26 \\
37\end{array}$ & $\begin{array}{r}486 \\
840 \\
1100 \\
805 \\
567\end{array}$ & $\begin{array}{c}38 \\
21 \\
8 \\
24 \\
36\end{array}$ & $\begin{array}{l}405 \\
737 \\
936 \\
748 \\
513\end{array}$ & $\begin{array}{r}39 \\
19 \\
6 \\
17 \\
35\end{array}$ & $\begin{array}{l}375 \\
628 \\
830 \\
605 \\
451\end{array}$ & $\begin{array}{r}37 \\
15 \\
3 \\
18 \\
32\end{array}$ & $\begin{array}{l}280 \\
552 \\
542 \\
469 \\
385\end{array}$ & $\begin{array}{r}37 \\
6 \\
7 \\
16 \\
25\end{array}$ & $\begin{array}{l}240 \\
437 \\
430 \\
384 \\
323\end{array}$ & $\begin{array}{r}35 \\
6 \\
7 \\
11 \\
24\end{array}$ & $\begin{array}{l}207 \\
366 \\
358 \\
329 \\
281\end{array}$ & $\begin{array}{r}33 \\
6 \\
7 \\
11 \\
22\end{array}$ & $\begin{array}{l}164 \\
260 \\
258 \\
246 \\
203\end{array}$ & $\begin{array}{r}30 \\
6 \\
7 \\
11 \\
21\end{array}$ & $\begin{array}{l}108 \\
149 \\
145 \\
141 \\
121\end{array}$ & $\begin{array}{r}28 \\
9 \\
10 \\
13 \\
23\end{array}$ \\
\hline $\begin{array}{l}971 \\
972 \\
973 \\
974 \\
975\end{array}$ & $\begin{array}{r}1260 \\
909 \\
1210 \\
761 \\
2200\end{array}$ & $\begin{array}{c}13 \\
25 \\
15 \\
34 \\
1\end{array}$ & $\begin{array}{r}1090 \\
863 \\
1140 \\
664 \\
1670\end{array}$ & $\begin{array}{c}16 \\
25 \\
13 \\
35 \\
1\end{array}$ & $\begin{array}{r}924 \\
826 \\
1030 \\
479 \\
1200\end{array}$ & $\begin{array}{r}18 \\
23 \\
11 \\
39 \\
2\end{array}$ & $\begin{array}{r}738 \\
721 \\
851 \\
326 \\
1020\end{array}$ & $\begin{array}{c}18 \\
20 \\
13 \\
44 \\
1\end{array}$ & $\begin{array}{l}557 \\
569 \\
774 \\
234 \\
896\end{array}$ & $\begin{array}{r}23 \\
22 \\
5 \\
50 \\
1\end{array}$ & $\begin{array}{l}405 \\
398 \\
526 \\
181 \\
682\end{array}$ & $\begin{array}{r}23 \\
24 \\
8 \\
50 \\
1\end{array}$ & $\begin{array}{l}332 \\
318 \\
424 \\
150 \\
514\end{array}$ & $\begin{array}{r}22 \\
25 \\
8 \\
50 \\
2\end{array}$ & $\begin{array}{l}283 \\
265 \\
357 \\
128 \\
421\end{array}$ & $\begin{array}{r}21 \\
25 \\
8 \\
50 \\
2\end{array}$ & $\begin{array}{c}206 \\
195 \\
258 \\
98.0 \\
291\end{array}$ & $\begin{array}{r}20 \\
25 \\
8 \\
50 \\
3\end{array}$ & $\begin{array}{c}121 \\
116 \\
153 \\
68.0 \\
160\end{array}$ & $\begin{array}{r}24 \\
25 \\
7 \\
51\end{array}$ \\
\hline
\end{tabular}


GREEN RIVER BASIN

09299500 WHITEROCKS RIVER NEAR WHITEROCKS, UT--Continued

HIGHEST MEAN DISCHARGE, IN GBIC FEET PER SECOND, AND RANKING FOR THE INDICATED NUMBER OF CONSECUTIVE DAVS FOR EACH WATER YEAR, OCTOBER 1-SEPTEMBER 30--continued

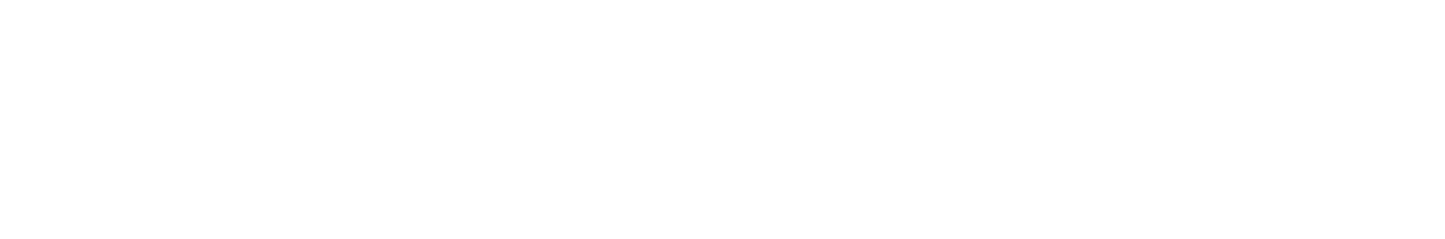

DURATION $Q F$ DISCHARGE FOR EACH WATER YEAR

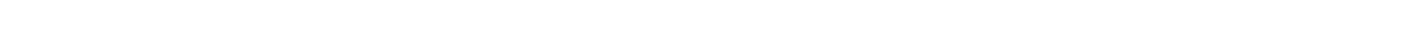

YEAR

1910

199

1920

1930

1931

1932

1933

1935

1936

1937

1938
1939

1940

1941

1942

1943
1944

1945

1946

1947

1948

1949
1950

1951

1952

1953
1954

1955

1956

1957

1958
1959

1960

1961

1962

1963

1965

1966

1967

1968

1969
1970

1971

1972

1973
1974

1975

1976

1977

1979
1980

1980

1981

NUMBER OF DAYS IN CLASS

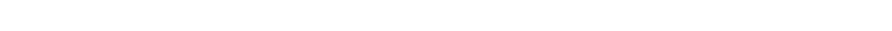

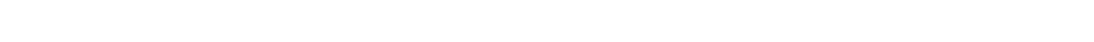

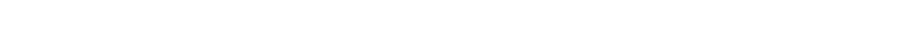

$\begin{array}{llllllllllllll}60 & 54 & 62 & 58 & 30 & 18 & 10 & 14 & 27 & 14 & 8 & 3 & 2 & 3\end{array}$

$\begin{array}{rrrrrrrrrrrrrrrrrrrrrrrrrrrrr}17 & 75 & 61 & 22 & 34 & 15 & 18 & 6 & 6 & 14 & 9 & 5 & 18 & 11 & 2 & 6 & 5 & 7 & 10 & 11 & 3 & 3 & 3 & 3 & 1 & 1\end{array}$

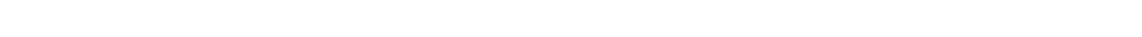

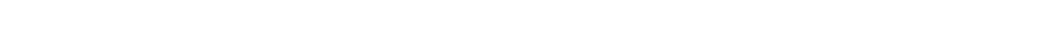

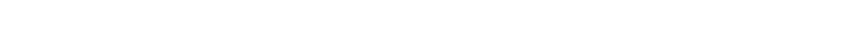

$\begin{array}{lllllllllllllllllllllllllll}68 & 3 & 32 & 32 & 3 & 9 & 32 & 22 & 26 & 9 & 16 & 13 & 14 & 17 & 10 & 9 & 6 & 9 & 8 & 6 & 4 & 4 & 6 & & 4 & 2 & 1\end{array}$

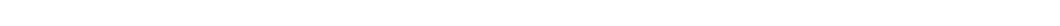

$\begin{array}{llllllllllllllllllll}11 & & 90 & 4 & 66 & 16 & 22 & 20 & 23 & 18 & 28 & 16 & 18 & 7 & 7 & 8 & 9 & 1 & 8 & 4\end{array}$

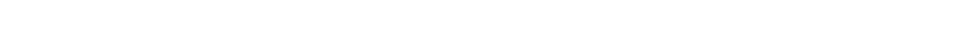

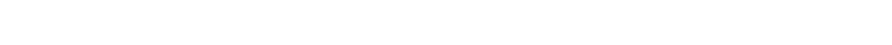

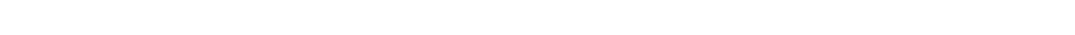

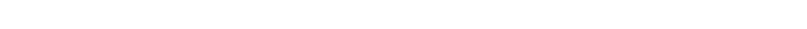

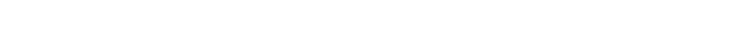

$\begin{array}{llllllllllllllllllllllll}961 & 40 & 33 & 30 & 26 & 20 & 14 & 9 & 7 & 6 & 15 & 16 & 7 & 4 & 9 & 16 & 14 & 9 & 9 & 7 & 2 & 2\end{array}$

$\begin{array}{lllllllllllllllllllllll}81 & 54 & 2 & 14 & 24 & 39 & 37 & 18 & 11 & 20 & 15 & 5 & 10 & 4 & 2 & 2 & 6 & 2 & 5 & 7 & 4 & 2 & 2\end{array}$

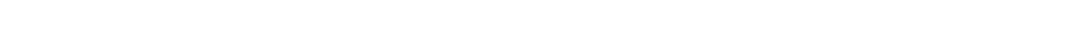

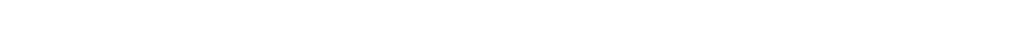

$\begin{array}{rrrrrrrrrrrrrrrrrrrrrrrrrrrrr}33 & 53 & 73 & 16 & 23 & 21 & 13 & 12 & 8 & 3 & 9 & 24 & 16 & 14 & 6 & 14 & 5 & 3 & 4 & 3 & 3 & 2 & 3 & & 2 & 2 & \\ 49 & 72 & 34 & 14 & 14 & 6 & 10 & 8 & 6 & 11 & 6 & 7 & 9 & 25 & 12 & 21 & 16 & 11 & 5 & 8 & 3 & 6 & 4 & 2 & 5 & 2\end{array}$

$\begin{array}{rrrrrrrrrrrrrrrrrrrrrrrrr}49 & 72 & 34 & 14 & 14 & 6 & 10 & 8 & 6 & 11 & 6 & 7 & 9 & 25 & 12 & 21 & 16 & 11 & 5 & 8 & 3 & 6 & 4 & 2 & 5 \\ 100 & 27 & 31 & 30 & 27 & 21 & 13 & 20 & 9 & 18 & 13 & 9 & 17 & 2 & 4 & 4 & 5 & 4 & 4 & 1 & 2 & 1 & 2 & 1\end{array}$

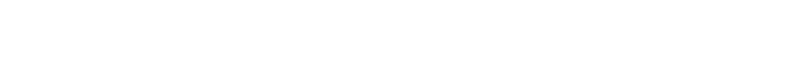

$\begin{array}{llllllllllllllllllllllll}12 & 53 & 59 & 40 & 32 & 28 & 35 & 15 & 3 & 13 & 6 & 25 & 6 & 3 & 4 & 4 & 5 & 2 & 2 & 1 & 6 & 4 & 4 & 4\end{array}$

$\begin{array}{lllllllllllllllllllllllllll}33 & 68 & 41 & 34 & 34 & 8 & 1 & 3 & 11 & 4 & 4 & 17 & 9 & 15 & 21 & 15 & 7 & 6 & 7 & 7 & 8 & 5 & & 1 & 1 & 2 & 3\end{array}$

$\begin{array}{lllllllllllllllllllllllllll}69 & 34 & 11 & 6 & 40 & 37 & 32 & 41 & 15 & 7 & 6 & 13 & 15 & 8 & 3 & 2 & 3 & 1 & 3 & 1 & 5 & 6 & 3 & 1 & 3\end{array}$

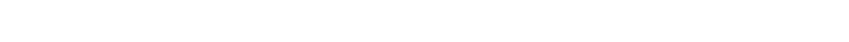

$\begin{array}{llllllllllllllllllllll}36 & 37 & 31 & 52 & 6 & 15 & 11 & 19 & 5 & 3 & 3 & 12 & 25 & 31 & 23 & 9 & 12 & 13 & 8 & 5 & 5 & 4\end{array}$

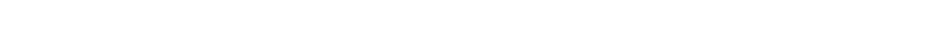

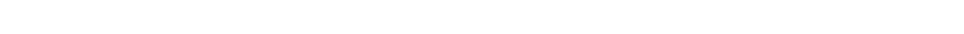

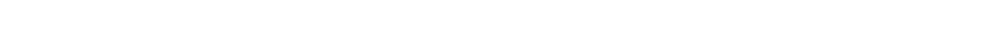

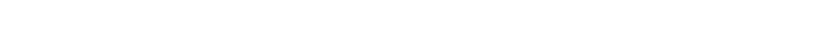

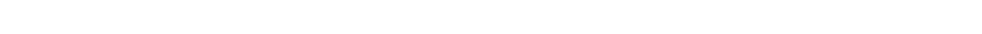

$\begin{array}{lllllllllllllllllllllllllllll}40 & 76 & 46 & 25 & 12 & 5 & 7 & 7 & 6 & 3 & 17 & 16 & 12 & 13 & 17 & 20 & 9 & 1 & 3 & 3 & 6 & 3 & 3 & 3 & 3 & 5 & 4 & 1\end{array}$

$\begin{array}{rrrrrrrrrrrrrrrrrrrrrrr}45 & 53 & 21 & 30 & 22 & 10 & 9 & 5 & 9 & 14 & 19 & 7 & 12 & 23 & 15 & 19 & 6 & 10 & 5 & 4 & 5 & 6 & 6 \\ 64 & 54 & 25 & 18 & 6 & 6 & 20 & 22 & 14 & 5 & 10 & 13 & 13 & 9 & 24 & 7 & 9 & 5 & 15 & 11 & 9 & 5 & 1\end{array}$

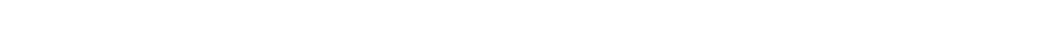

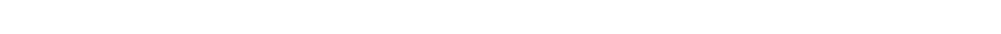

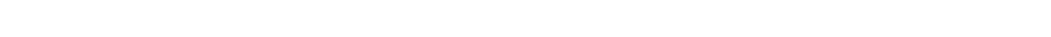

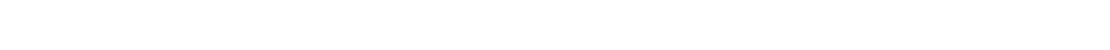

$\begin{array}{rrrrrrrrrrrrrrrrrrrrrrrrr}1 & 47 & 54 & 57 & 14 & 18 & 6 & 14 & 14 & 20 & 5 & 6 & 23 & 8 & 31 & 15 & 3 & 1 & 2 & 3 & 5 & 3 & 7 & 5 & 4\end{array}$

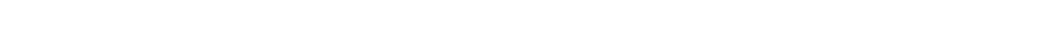

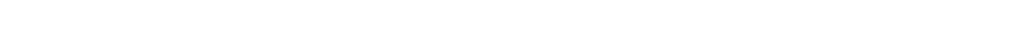

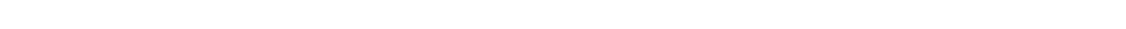

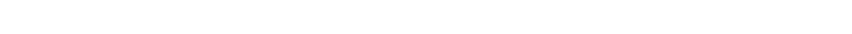

CIBIC FEET

PER SECON

50294.0

21452.0

52296.0

22667.0

48142.0

29489.0

15328.0
34118.0

32368.0

48750.0

50900.0

37653.0

25792.0

60025.0

52706.0

35144.0

60746.0

39315.0

27830.0

56034.0

34994.0

47306.0

46994.0

36798.0

60696.0

31956.0

29182.0

30422.0

33866.0

40436.0

46536.0

30870.0

29012.0

31844.0

55559.0

33192.0

44223.0

39306.0

54329.0

53040.0

53040.0

51301.0

44323.0

42479.0

55738.0

24739.0

58304.0

34063.0

22790.0

34891.0

31800.0

34672.0 
09299500 WHITEROCKS RIVER NEAR WHITEROCKS, UT-Continued

DURATION TABLE $O F$ DISCHARGE FOR WATER YEARS 1910, 1919-20, 1930-81

\begin{tabular}{|c|c|c|c|c|c|c|c|c|c|c|c|c|c|c|c|c|c|c|c|}
\hline CLASS & $\begin{array}{c}\text { GBIC } \\
\text { FEET } \\
\text { PER } \\
\text { SECOND }\end{array}$ & $\begin{array}{l}\text { TOTAL } \\
\text { DAYS }\end{array}$ & $\begin{array}{l}\text { ACOU- } \\
\text { MU- } \\
\text { LAIED } \\
\text { DAYS }\end{array}$ & $\begin{array}{l}\text { PER- } \\
\text { CENT } \\
\text { DAYS }\end{array}$ & C.ASS & $\begin{array}{c}\text { OBBIC } \\
\text { FEET } \\
\text { PER } \\
\text { SECOND }\end{array}$ & TOTAL & $\begin{array}{l}\text { ACOU- } \\
\text { MU- } \\
\text { LAIED } \\
\text { DAYS }\end{array}$ & $\begin{array}{l}\text { PER- } \\
\text { CENT } \\
\text { DAYS }\end{array}$ & CLASS & $\begin{array}{c}\text { OUBIC } \\
\text { FEET } \\
\text { PER } \\
\text { SECOND }\end{array}$ & $\begin{array}{l}\text { TOTAL } \\
\text { DAYS }\end{array}$ & $\begin{array}{c}\text { ACOU- } \\
\text { MU- } \\
\text { LATED } \\
\text { DAYS }\end{array}$ & $\begin{array}{l}\text { PER- } \\
\text { CENT } \\
\text { DAUS }\end{array}$ & व.ASS & $\begin{array}{c}\text { OUBIC } \\
\text { FEET } \\
\text { PER } \\
\text { SECOND }\end{array}$ & $\begin{array}{l}\text { TOTAL } \\
\text { DAYS }\end{array}$ & $\begin{array}{c}\text { ACOU- } \\
\text { MU- } \\
\text { LATED } \\
\text { DAYS }\end{array}$ & $\begin{array}{l}\text { PER- } \\
\text { CENT } \\
\text { DAYS }\end{array}$ \\
\hline $\begin{array}{l}0 \\
1 \\
2 \\
3 \\
4 \\
5 \\
6 \\
7 \\
8\end{array}$ & $\begin{array}{r}0.00 \\
14.00 \\
16.00 \\
19.00 \\
22.00 \\
26.00 \\
30.00 \\
35.00 \\
41.00\end{array}$ & $\begin{array}{r}0 \\
4 \\
147 \\
546 \\
1362 \\
1916 \\
2405 \\
1915 \\
1138\end{array}$ & $\begin{array}{l}20089 \\
20089 \\
20085 \\
19938 \\
19392 \\
18030 \\
16114 \\
13709 \\
11794\end{array}$ & $\begin{array}{r}100.0 \\
100.0 \\
100.0 \\
99.2 \\
96.5 \\
89.8 \\
80.2 \\
68.2 \\
58.7\end{array}$ & $\begin{array}{r}9 \\
10 \\
11 \\
12 \\
13 \\
14 \\
15 \\
16 \\
17\end{array}$ & $\begin{array}{r}47.00 \\
55.00 \\
64.00 \\
75.00 \\
87.00 \\
100.00 \\
120.00 \\
140.00 \\
160.00\end{array}$ & $\begin{array}{r}1165 \\
1016 \\
933 \\
669 \\
665 \\
992 \\
813 \\
764 \\
784\end{array}$ & $\begin{array}{r}10656 \\
9491 \\
8475 \\
7542 \\
6873 \\
6208 \\
5216 \\
4403 \\
3639\end{array}$ & $\begin{array}{l}53.0 \\
47.2 \\
42.2 \\
37.5 \\
34.2 \\
30.9 \\
26.0 \\
21.9 \\
18.1\end{array}$ & $\begin{array}{l}18 \\
19 \\
20 \\
21 \\
22 \\
23 \\
24 \\
25 \\
26\end{array}$ & $\begin{array}{l}190.0 \\
220.0 \\
250.0 \\
290.0 \\
340.0 \\
400.0 \\
460.0 \\
540.0 \\
630.0\end{array}$ & $\begin{array}{l}481 \\
363 \\
321 \\
327 \\
267 \\
254 \\
217 \\
152 \\
143\end{array}$ & $\begin{array}{r}2855 \\
2374 \\
2011 \\
1690 \\
1363 \\
1096 \\
842 \\
625 \\
473\end{array}$ & $\begin{array}{r}14.2 \\
11.8 \\
10.0 \\
8.4 \\
6.8 \\
5.5 \\
4.2 \\
3.1 \\
2.4\end{array}$ & $\begin{array}{l}27 \\
28 \\
29 \\
30 \\
31 \\
32 \\
33 \\
34\end{array}$ & $\begin{array}{r}730.0 \\
850.0 \\
990.0 \\
1200.0 \\
1300.0 \\
1600.0 \\
1800.0 \\
2100.0\end{array}$ & $\begin{array}{r}142 \\
81 \\
64 \\
27 \\
13 \\
2 \\
0 \\
1\end{array}$ & $\begin{array}{r}330 \\
188 \\
107 \\
43 \\
16 \\
3 \\
1 \\
1\end{array}$ & $\begin{array}{l}1.6 \\
0.9 \\
0.5 \\
0.2 \\
0.1 \\
0.0 \\
0.0 \\
0.0\end{array}$ \\
\hline
\end{tabular}

MONIHLY MEAN DISCHARGES, IN CUBIC FEET PER SECOND, FOR EACH WATER YEAR

\begin{tabular}{|c|c|c|c|c|c|c|c|c|c|c|c|c|}
\hline YEAR & OCT & NOV & DEC & JAN & FEB & MAR & APR & MAY & JUNE & JULY & AUG & SEP \\
\hline 1900 & 80 & 66 & 63 & 47 & 48 & 50 & 44 & 400 & 253 & 82 & 62 & 55 \\
\hline $\begin{array}{l}1901 \\
1902 \\
1903\end{array}$ & $\begin{array}{l}44 \\
75 \\
53\end{array}$ & $\begin{array}{l}59 \\
63 \\
48\end{array}$ & $\begin{array}{l}55 \\
61 \\
44\end{array}$ & $\begin{array}{l}50 \\
48 \\
34\end{array}$ & $\begin{array}{l}50 \\
41 \\
41\end{array}$ & $\begin{array}{l}50 \\
48 \\
43\end{array}$ & $\begin{array}{l}74 \\
57 \\
56\end{array}$ & $\begin{array}{l}507 \\
471 \\
260\end{array}$ & $\begin{array}{l}179 \\
348 \\
658\end{array}$ & $\begin{array}{l}101 \\
109 \\
198\end{array}$ & $\begin{array}{r}128 \\
67 \\
93\end{array}$ & $\begin{array}{l}95 \\
57 \\
89\end{array}$ \\
\hline $\begin{array}{l}1909 \\
1910\end{array}$ & $\begin{array}{l}187 \\
131\end{array}$ & $\begin{array}{l}95.8 \\
71.9\end{array}$ & $\begin{array}{l}72.6 \\
61.4\end{array}$ & $\begin{array}{l}56.9 \\
65.2\end{array}$ & $\begin{array}{l}52.4 \\
67.0\end{array}$ & $\begin{array}{l}556 \\
58.9\end{array}$ & $\begin{array}{c}75.1 \\
162\end{array}$ & $\begin{array}{l}217 \\
414\end{array}$ & $\begin{array}{l}908 \\
210\end{array}$ & $\begin{array}{l}269 \\
134\end{array}$ & $\begin{array}{l}249 \\
123\end{array}$ & $\begin{array}{l}434 \\
150\end{array}$ \\
\hline $\begin{array}{l}1914 \\
1915\end{array}$ & $\begin{array}{l}79.7 \\
92.7\end{array}$ & $\begin{array}{l}58.8 \\
70.6\end{array}$ & $\begin{array}{l}40.7 \\
43.9\end{array}$ & $\begin{array}{l}34.2 \\
39.0\end{array}$ & $\begin{array}{l}36.0 \\
34.2\end{array}$ & $\begin{array}{l}31.5 \\
39.0\end{array}$ & $\begin{array}{l}36.4 \\
50.4\end{array}$ & $\begin{array}{l}188 \\
659\end{array}$ & $\begin{array}{l}588 \\
605\end{array}$ & $\begin{array}{l}211 \\
211\end{array}$ & $\begin{array}{l}220 \\
114\end{array}$ & $\begin{array}{l}101 \\
113\end{array}$ \\
\hline $\begin{array}{l}1916 \\
1917 \\
1918 \\
1919 \\
1920\end{array}$ & $\begin{array}{l}96.0 \\
99.2 \\
99.2 \\
82.3 \\
65.4\end{array}$ & $\begin{array}{l}60.5 \\
65.5 \\
80.7 \\
49.8 \\
56.2\end{array}$ & $\begin{array}{l}43.9 \\
43.9 \\
37.5 \\
35.0 \\
40.0\end{array}$ & $\begin{array}{l}40.7 \\
37.4 \\
32.0 \\
30.0 \\
25.0\end{array}$ & $\begin{array}{l}34.8 \\
30.6 \\
34.0 \\
30.0 \\
30.0\end{array}$ & $\begin{array}{l}25.3 \\
43.9 \\
32.5 \\
32.0 \\
49.2\end{array}$ & $\begin{array}{l}80.7 \\
84.0 \\
40.3 \\
54.1 \\
37.8\end{array}$ & $\begin{array}{l}407 \\
374 \\
407 \\
256 \\
354\end{array}$ & $\begin{array}{c}387 \\
1176 \\
354 \\
39.7 \\
519\end{array}$ & $\begin{array}{l}171 \\
415 \\
229 \\
23.8 \\
89.2\end{array}$ & $\begin{array}{c}122 \\
166 \\
93.1 \\
25.1 \\
44.9\end{array}$ & $\begin{array}{c}77.3 \\
121 \\
70.9 \\
43.0 \\
30.0\end{array}$ \\
\hline $\begin{array}{l}1921 \\
1922 \\
1923 \\
1924 \\
1925\end{array}$ & $\begin{array}{l}25 \\
81.1 \\
87.8 \\
84.3 \\
42.5\end{array}$ & $\begin{array}{l}19 \\
63.9 \\
67.2 \\
57.5 \\
38.5\end{array}$ & $\begin{array}{l}14 \\
45.5 \\
50.4 \\
42.3 \\
35.8\end{array}$ & $\begin{array}{l}14 \\
43.9 \\
45.5 \\
39.0 \\
34.2\end{array}$ & $\begin{array}{l}15 \\
39.6 \\
39.6 \\
36.5 \\
30.6\end{array}$ & $\begin{array}{l}16 \\
39.0 \\
39.0 \\
37.4 \\
32.5\end{array}$ & $\begin{array}{l}18.0 \\
43.7 \\
45.4 \\
47.1 \\
40.2\end{array}$ & $\begin{array}{l}545 \\
544 \\
501 \\
293 \\
314\end{array}$ & $\begin{array}{r}1479 \\
1380 \\
923 \\
121 \\
262\end{array}$ & $\begin{array}{l}285 \\
309 \\
315 \\
72.9 \\
133\end{array}$ & $\begin{array}{c}173 \\
196 \\
138 \\
57.0 \\
114\end{array}$ & $\begin{array}{c}149 \\
121 \\
90.3 \\
50.1 \\
114\end{array}$ \\
\hline $\begin{array}{l}1926 \\
1927 \\
1928 \\
1929 \\
1930\end{array}$ & $\begin{array}{l}125 \\
48.1 \\
132 \\
60.2 \\
106\end{array}$ & $\begin{array}{l}82.3 \\
38.7 \\
95.8 \\
50.4 \\
73.1\end{array}$ & $\begin{array}{l}50.4 \\
35.8 \\
52.0 \\
37.4 \\
48.8\end{array}$ & $\begin{array}{l}40.7 \\
30.9 \\
47.2 \\
39.0 \\
47.2\end{array}$ & $\begin{array}{l}34.2 \\
28.8 \\
40.0 \\
34.2 \\
37.8\end{array}$ & $\begin{array}{l}30.9 \\
34.2 \\
37.4 \\
37.4 \\
32.5\end{array}$ & $\begin{array}{l}42.0 \\
77.3 \\
58.8 \\
80.7 \\
42.0\end{array}$ & $\begin{array}{l}431 \\
333 \\
561 \\
390 \\
447\end{array}$ & $\begin{array}{l}168 \\
402 \\
269 \\
823 \\
386\end{array}$ & $\begin{array}{l}138 \\
213 \\
150 \\
247 \\
167\end{array}$ & $\begin{array}{l}109 \\
142 \\
80.2 \\
146 \\
203\end{array}$ & $\begin{array}{c}67.2 \\
359 \\
68.3 \\
134 \\
120\end{array}$ \\
\hline $\begin{array}{l}1931 \\
1932 \\
1933 \\
1934 \\
1935\end{array}$ & $\begin{array}{l}96.4 \\
48.6 \\
48.9 \\
36.9 \\
40.5\end{array}$ & $\begin{array}{l}51.9 \\
40.2 \\
35.9 \\
33.3 \\
33.4\end{array}$ & $\begin{array}{l}45.0 \\
36.0 \\
25.0 \\
25.0 \\
32.0\end{array}$ & $\begin{array}{l}35.0 \\
32.0 \\
30.0 \\
22.0 \\
30.0\end{array}$ & $\begin{array}{l}30.0 \\
29.8 \\
25.0 \\
20.0 \\
30.0\end{array}$ & $\begin{array}{l}33.0 \\
30.6 \\
23.8 \\
18.0 \\
32.1\end{array}$ & $\begin{array}{l}40.7 \\
45.8 \\
25.8 \\
57.1 \\
38.6\end{array}$ & $\begin{array}{c}132 \\
485 \\
122 \\
102 \\
97.0\end{array}$ & $\begin{array}{c}114 \\
430 \\
378 \\
50.1 \\
562\end{array}$ & $\begin{array}{c}52.1 \\
193 \\
149 \\
22.4 \\
114\end{array}$ & $\begin{array}{c}64.6 \\
131 \\
63.1 \\
68.3 \\
64.5\end{array}$ & $\begin{array}{l}48.2 \\
71.9 \\
42.8 \\
47.8 \\
51.3\end{array}$ \\
\hline $\begin{array}{l}1936 \\
1937 \\
1938 \\
1939 \\
1940\end{array}$ & $\begin{array}{l}40.6 \\
68.7 \\
65.1 \\
155 \\
108\end{array}$ & $\begin{array}{l}33.3 \\
55.3 \\
37.8 \\
93.0 \\
54.9\end{array}$ & $\begin{array}{l}32.1 \\
35.0 \\
30.9 \\
50.0 \\
40.5\end{array}$ & $\begin{array}{l}30.4 \\
30.0 \\
30.5 \\
40.0 \\
32.2\end{array}$ & $\begin{array}{l}27.4 \\
25.0 \\
29.8 \\
35.0 \\
28.0\end{array}$ & $\begin{array}{l}26.5 \\
25.0 \\
30.3 \\
35.0 \\
29.9\end{array}$ & $\begin{array}{l}41.6 \\
49.0 \\
66.2 \\
76.1 \\
66.4\end{array}$ & $\begin{array}{l}235 \\
584 \\
353 \\
314 \\
199\end{array}$ & $\begin{array}{c}164 \\
313 \\
598 \\
140 \\
93.5\end{array}$ & $\begin{array}{c}128 \\
178 \\
181 \\
70.8 \\
48.6\end{array}$ & $\begin{array}{l}161 \\
131 \\
117 \\
62.3 \\
41.7\end{array}$ & $\begin{array}{l}138 \\
97.4 \\
131 \\
162 \\
101\end{array}$ \\
\hline $\begin{array}{l}1941 \\
1942 \\
1943 \\
1944 \\
1945\end{array}$ & $\begin{array}{c}147 \\
135 \\
53.7 \\
54.0 \\
54.1\end{array}$ & $\begin{array}{l}78.3 \\
90.5 \\
40.4 \\
44.4 \\
42.5\end{array}$ & $\begin{array}{l}46.8 \\
58.7 \\
35.7 \\
37.0 \\
35.7\end{array}$ & $\begin{array}{l}34.8 \\
43.4 \\
30.1 \\
36.0 \\
33.8\end{array}$ & $\begin{array}{l}31.5 \\
36.5 \\
30.0 \\
28.9 \\
30.6\end{array}$ & $\begin{array}{l}34.0 \\
35.7 \\
31.4 \\
27.3 \\
31.0\end{array}$ & $\begin{array}{c}41.4 \\
64.9 \\
110 \\
37.5 \\
38.6\end{array}$ & $\begin{array}{l}523 \\
305 \\
270 \\
358 \\
259\end{array}$ & $\begin{array}{l}596 \\
568 \\
211 \\
831 \\
347\end{array}$ & $\begin{array}{l}211 \\
203 \\
146 \\
339 \\
182\end{array}$ & $\begin{array}{l}123 \\
122 \\
128 \\
135 \\
151\end{array}$ & $\begin{array}{l}98.7 \\
65.7 \\
63.6 \\
64.0 \\
83.7\end{array}$ \\
\hline $\begin{array}{l}1946 \\
1947 \\
1948 \\
1949 \\
1950\end{array}$ & $\begin{array}{l}61.0 \\
69.6 \\
72.3 \\
40.9 \\
64.5\end{array}$ & $\begin{array}{l}43.9 \\
59.4 \\
56.1 \\
33.8 \\
52.1\end{array}$ & $\begin{array}{l}37.6 \\
47.3 \\
30.0 \\
31.5 \\
43.2\end{array}$ & $\begin{array}{l}34.6 \\
41.1 \\
28.0 \\
28.0 \\
37.4\end{array}$ & $\begin{array}{l}29.2 \\
35.3 \\
26.0 \\
25.1 \\
34.8\end{array}$ & $\begin{array}{l}30.0 \\
38.9 \\
28.6 \\
25.0 \\
35.5\end{array}$ & $\begin{array}{c}108 \\
60.1 \\
41.2 \\
49.3 \\
76.4\end{array}$ & $\begin{array}{l}176 \\
539 \\
334 \\
325 \\
339\end{array}$ & $\begin{array}{l}158 \\
432 \\
270 \\
618 \\
470\end{array}$ & $\begin{array}{l}96.8 \\
242 \\
119 \\
185 \\
190\end{array}$ & $\begin{array}{c}76.3 \\
174 \\
83.1 \\
124 \\
121\end{array}$ & $\begin{array}{l}61.5 \\
92.4 \\
55.3 \\
67.1 \\
78.3\end{array}$ \\
\hline $\begin{array}{l}1951 \\
1952 \\
1953 \\
1954 \\
1955\end{array}$ & $\begin{array}{l}48.6 \\
59.3 \\
68.4 \\
45.0 \\
58.7\end{array}$ & $\begin{array}{l}38.9 \\
40.4 \\
39.8 \\
36.5 \\
41.7\end{array}$ & $\begin{array}{l}32.1 \\
34.2 \\
34.8 \\
27.4 \\
34.2\end{array}$ & $\begin{array}{l}30.0 \\
31.0 \\
29.0 \\
25.3 \\
31.9\end{array}$ & $\begin{array}{l}28.9 \\
29.2 \\
28.3 \\
26.1 \\
26.4\end{array}$ & $\begin{array}{l}25.6 \\
28.9 \\
29.3 \\
26.5 \\
25.8\end{array}$ & $\begin{array}{l}26.8 \\
71.4 \\
35.7 \\
60.8 \\
31.3\end{array}$ & $\begin{array}{c}251 \\
493 \\
94.4 \\
311 \\
224\end{array}$ & $\begin{array}{l}312 \\
604 \\
390 \\
135 \\
207\end{array}$ & $\begin{array}{l}141 \\
250 \\
144 \\
112 \\
110\end{array}$ & $\begin{array}{c}189 \\
221 \\
104 \\
77.2 \\
123\end{array}$ & $\begin{array}{c}80.2 \\
124 \\
53.6 \\
71.1 \\
80.6\end{array}$ \\
\hline $\begin{array}{l}1956 \\
1957 \\
1958 \\
1959 \\
1960\end{array}$ & $\begin{array}{l}56.3 \\
39.1 \\
95.5 \\
42.9 \\
80.6\end{array}$ & $\begin{array}{l}38.7 \\
33.5 \\
74.6 \\
36.2 \\
41.0\end{array}$ & $\begin{array}{l}33.2 \\
28.7 \\
53.5 \\
27.8 \\
28.3\end{array}$ & $\begin{array}{l}30.7 \\
22.4 \\
37.2 \\
22.8 \\
24.9\end{array}$ & $\begin{array}{l}27.8 \\
22.8 \\
30.0 \\
22.1 \\
23.7\end{array}$ & $\begin{array}{l}27.8 \\
26.1 \\
31.0 \\
23.4 \\
26.5\end{array}$ & $\begin{array}{l}41.0 \\
23.1 \\
52.7 \\
30.5 \\
50.4\end{array}$ & $\begin{array}{l}381 \\
74.8 \\
490 \\
143 \\
193\end{array}$ & $\begin{array}{l}248 \\
534 \\
367 \\
245 \\
217\end{array}$ & $\begin{array}{l}110 \\
218 \\
146 \\
151 \\
135\end{array}$ & $\begin{array}{c}65.6 \\
180 \\
77.6 \\
154 \\
70.3\end{array}$ & $\begin{array}{c}45.8 \\
128 \\
66.8 \\
113 \\
58.8\end{array}$ \\
\hline
\end{tabular}


GREEN RIVER BASIN

09299500 WHITEROCKS RIVER NEAR WHITEROCKS, UT-Continued

MONIHLY MEAN DISGAARGE, IN OUBIC FEET PER SECOND, FOR EAOH WATER YEAR.--Continued

$\begin{array}{lcccccccccccr}\text { YEAR } & \text { OCT } & \text { NON } & \text { DEC } & \text { JAN } & \text { FEB } & \text { MAR } & \text { APR } & \text { MAY } & \text { JUNE } & \text { JULY } & \text { AUG } & \text { SEP } \\ 1961 & 52.0 & 36.7 & 27.0 & 23.1 & 19.2 & 17.8 & 24.2 & 194 & 215 & 119 & 126 & 190 \\ 1962 & 106 & 62.7 & 48.3 & 35.2 & 32.8 & 29.8 & 118 & 359 & 575 & 229 & 144 & 82.4 \\ 1963 & 58.4 & 32.5 & 24.6 & 19.7 & 19.6 & 21.0 & 25.2 & 266 & 245 & 149 & 104 & 121 \\ 1964 & 78.5 & 46.4 & 35.5 & 30.2 & 27.4 & 26.0 & 30.7 & 311 & 423 & 199 & 153 & 96.4 \\ 1965 & 46.7 & 34.0 & 33.5 & 29.1 & 25.9 & 28.4 & 39.3 & 158 & 789 & 388 & 198 & 140 \\ 1966 & 92.9 & 56.6 & 42.9 & 36.6 & 36.1 & 37.4 & 84.2 & 366 & 188 & 156 & 99.5 & 89.3 \\ 1967 & 61.3 & 36.6 & 36.8 & 30.4 & 28.2 & 28.9 & 36.4 & 294 & 614 & 308 & 187 & 121 \\ 1968 & 52.1 & 32.6 & 29.4 & 25.2 & 25.9 & 26.2 & 32.2 & 152 & 825 & 235 & 184 & 126 \\ 1969 & 60.3 & 38.4 & 30.9 & 26.8 & 25.3 & 25.2 & 65.4 & 575 & 347 & 215 & 163 & 103 \\ 1970 & 73.3 & 50.3 & 32.4 & 26.0 & 24.6 & 23.7 & 27.0 & 265 & 398 & 233 & 164 & 129 \\ & & & & & & & & & & \\ 1971 & 58.9 & 39.1 & 32.8 & 29.8 & 28.4 & 26.5 & 34.3 & 202 & 549 & 219 & 150 & 85.3 \\ 1972 & 53.8 & 41.0 & 36.5 & 29.4 & 25.3 & 37.2 & 42.8 & 328 & 436 & 174 & 109 & 78.8 \\ 1973 & 83.6 & 56.7 & 48.0 & 36.1 & 30.7 & 26.8 & 40.1 & 404 & 598 & 229 & 163 & 110 \\ 1974 & 58.5 & 44.2 & 34.4 & 30.5 & 28.5 & 26.9 & 27.3 & 225 & 132 & 87.2 & 61.1 & 53.4 \\ 1975 & 46.4 & 31.0 & 24.4 & 22.0 & 21.0 & 21.4 & 22.9 & 110 & 818 & 535 & 159 & 103 \\ 1976 & 48.0 & 31.6 & 27.1 & 22.2 & 21.0 & 20.5 & 26.3 & 307 & 280 & 154 & 109 & 66.7 \\ 1977 & 51.2 & 33.2 & 24.5 & 19.2 & 17.0 & 19.0 & 36.4 & 76.1 & 197 & 94.6 & 102 & 78.2 \\ 1978 & 46.8 & 28.6 & 24.2 & 21.1 & 20.0 & 25.9 & 35.9 & 169 & 448 & 160 & 102 & 64.1 \\ 1979 & 36.8 & 28.7 & 26.0 & 22.6 & 19.8 & 20.7 & 38.5 & 302 & 232 & 145 & 105 & 62.8 \\ 1980 & 47.3 & 33.4 & 28.1 & 22.1 & 21.0 & 20.4 & 43.9 & 202 & 690 & 211 & 124 & 82.6 \\ 1981 & \mathbf{7 2 . 8} & 42.6 & 33.6 & 27.5 & 26.6 & 25.0 & 72.6 & 274 & 251 & 121 & 119 & 68.6\end{array}$

ANNUAL PEAK DISGHARGE, IN OBIC FEET PER SECOND, AND CORRESPONDING GAGE HEIGHT, IN FEET, FOR EAOH WATER YEAR

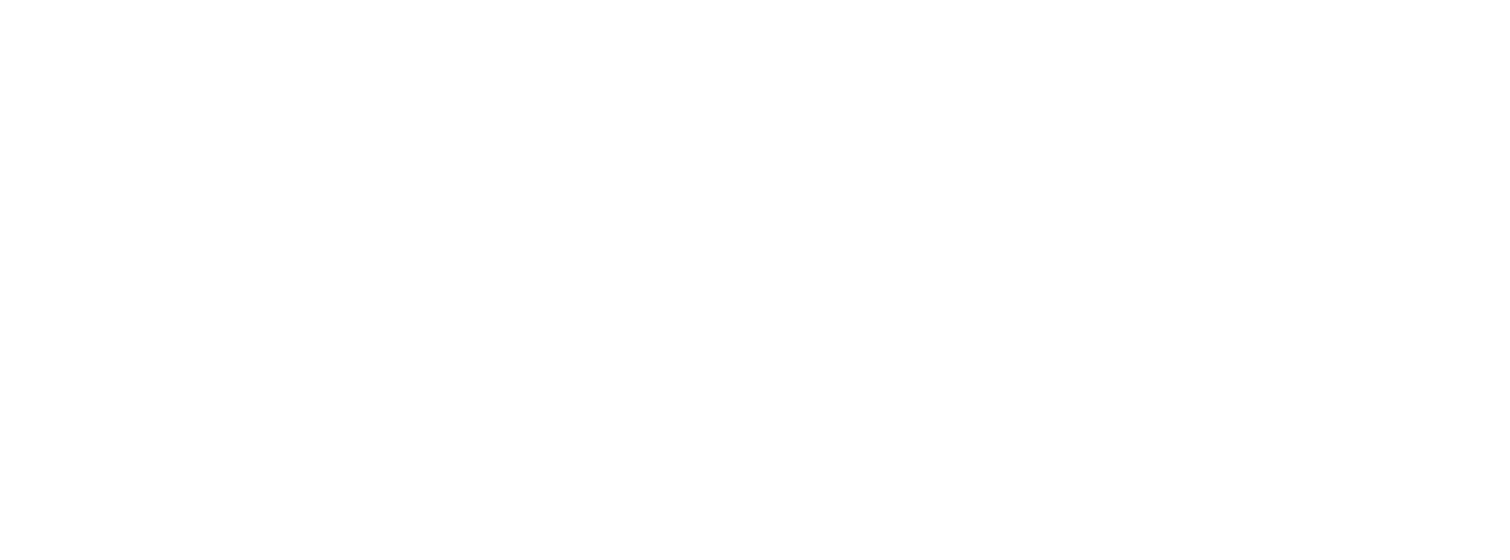

MAGNTIUDE AND PROBABILITY OF ANNUAT LOWEST MEAN DISCHARGE BASED ON CLIMATIC YEARS 1920 AND 1931-81

\begin{tabular}{|c|c|c|c|c|c|c|}
\hline \multirow{2}{*}{$\begin{array}{l}\text { PERIOD } \\
\text { (OON- } \\
\text { SEQU- } \\
\text { TIVE } \\
\text { DAUS ) }\end{array}$} & \multicolumn{6}{|c|}{$\begin{array}{l}\text { DISCHARGE, IN OUIC FEET PER SECOND, FOR } \\
\text { INDICATED REQURRENCE INTERNAL, IN YEARS, AND } \\
\text { ANNUAL NONEXCEEDANCE PRCBABILITY, IN PERCENT }\end{array}$} \\
\hline & $\begin{array}{c}2 \\
508\end{array}$ & $\begin{array}{c}5 \\
20 z\end{array}$ & $\begin{array}{l}10 \\
108\end{array}$ & $\begin{array}{l}20 \\
58\end{array}$ & $\begin{array}{l}50 \\
28\end{array}$ & $\begin{array}{r}100 \\
18\end{array}$ \\
\hline
\end{tabular}

$\begin{array}{rllllll}1 & 23 & 19 & 18 & 16 & 15 & 14 \\ 7 & 24 & 20 & 19 & 17 & 16 & 15 \\ 14 & 24 & 21 & 19 & 18 & 17 & 16 \\ 30 & 25 & 22 & 20 & 19 & 17 & 16 \\ 60 & 27 & 23 & 21 & 19 & 18 & 17 \\ 90 & 28 & 24 & 22 & 20 & 18 & 17\end{array}$

MAGNITUDE AND PRCBABILITY OF ANNUAT HIGHEST MEAN DISOHARGE BASED ON WATER YEARS $1910,1919-20$ AND 1930-81

\begin{tabular}{|c|c|c|c|c|c|c|}
\hline \multirow{2}{*}{$\begin{array}{l}\text { PERIOD } \\
\text { (CON- } \\
\text { SEQU- } \\
\text { TIVE } \\
\text { DAYS) }\end{array}$} & \multicolumn{6}{|c|}{$\begin{array}{l}\text { DISGH ARGE, IN OUIC FEET PER SECOND, FOR } \\
\text { INDICATED REQURRENCE INTERNA, IN YEARS, AND } \\
\text { ANNUAL EXCEEDANCE PRCBABILITY, IN PERCENT }\end{array}$} \\
\hline & $\begin{array}{c}2 \\
508\end{array}$ & $\begin{array}{c}5 \\
208\end{array}$ & $\begin{array}{l}10 \\
108\end{array}$ & $\begin{array}{l}25 \\
48\end{array}$ & $\begin{array}{l}50 \\
28\end{array}$ & $\begin{array}{r}100 \\
18\end{array}$ \\
\hline $\begin{array}{r}1 \\
3 \\
7 \\
15\end{array}$ & $\begin{array}{l}855 \\
799 \\
698 \\
576\end{array}$ & $\begin{array}{r}1260 \\
1150 \\
991 \\
820\end{array}$ & $\begin{array}{r}1500 \\
1340 \\
1150 \\
954\end{array}$ & $\begin{array}{l}1760 \\
1550 \\
1310 \\
1100\end{array}$ & $\begin{array}{l}1940 \\
1670 \\
1410 \\
1180\end{array}$ & $\begin{array}{l}2090 \\
1780 \\
1490 \\
1260\end{array}$ \\
\hline
\end{tabular}


GREEN RIVER BASIN

09299600 WHITEROCKS RIVER BELOW FARM CREEK CANAL, NEAR WHITEROCKS, UT

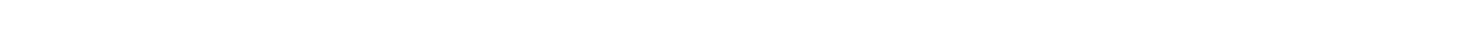
14060003, vintah and Ouray Indian Reservation, on left bank on downstream side of county road, $1.2 \mathrm{mi}$ downstrean from Ashley National Forest Boundary, and $6.6 \mathrm{mi}$ northeast of Whiterocks.

DRAINAGE AREA, $--120 \mathrm{mi}^{2}$.

PERIOD OF RECORD AVAILABLE. - Octcber 1976 to September 1981.

GAGE.--Water-stage recorder. Altitude of gage is 6,690 ft from topographic map.

REMARKS.-Several major irrigation diversions upstrean from station.

AVERAGE DISCHARGE. --5 years, $68.5 \mathrm{ft}^{3} / \mathrm{s}, 49,630$ acre-ft/yr.

EXIREMES FOR PERIOD OF RECORD.--Maximum discharge, 1,260 ft ${ }^{3} / \mathrm{s}$ May 28, 1979, gage height, $4.65 \mathrm{ft}$, probably exceeded by peak flow of June 12, 1980; minimum, $5.8 \mathrm{ft}^{3} / \mathrm{s}$ March 18,1981 .

LOWEST MEAN DISGHARG, IN OBIC FEET PER SECOND, AND RANRING FOR THE INDICATED NUMBER OF CONSEQUTTVE DAYS FOR EAOH CIMATIC YEAR, APRII 1-MARQH 31

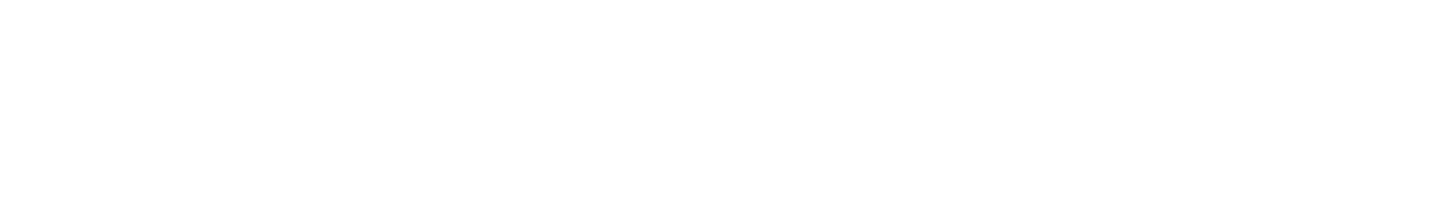

HIGHEST MEAN DISCHARGE, IN OUBIC FEET PER SECOND, AND RANKING FOR THE INDICATED NUMBER OF CONSEQUTIVE DAVS FOR EAOH WATER YEAR, OCTCBER I-SEPTEMBER 30

\begin{tabular}{|c|c|c|c|c|c|c|c|c|c|c|c|c|c|c|c|c|c|c|}
\hline YEAR & & 3 & & 7 & & 15 & & $\begin{array}{l}\infty \\
30\end{array}$ & & $\begin{array}{c}\text { VE DAYS } \\
60\end{array}$ & & 90 & & 120 & & 183 & & ALL \\
\hline $\begin{array}{rr}1977 & 419 \\
1978 & 915 \\
1979 & 760 \\
1980 & 1260\end{array}$ & $\begin{array}{l}4 \\
2 \\
3 \\
1\end{array}$ & $\begin{array}{r}333 \\
797 \\
725 \\
1180\end{array}$ & $\begin{array}{l}5 \\
2 \\
3 \\
1\end{array}$ & $\begin{array}{r}260 \\
677 \\
613 \\
1030\end{array}$ & $\begin{array}{l}5 \\
2 \\
3 \\
1\end{array}$ & $\begin{array}{l}176 \\
514 \\
484 \\
81\end{array}$ & $\begin{array}{l}5 \\
2 \\
3 \\
1\end{array}$ & $\begin{array}{l}116 \\
387 \\
357 \\
636\end{array}$ & $\begin{array}{l}5 \\
2 \\
3 \\
1\end{array}$ & $\begin{array}{l}93.0 \\
258 \\
237 \\
413\end{array}$ & $\begin{array}{l}5 \\
2 \\
3 \\
1\end{array}$ & $\begin{array}{l}88.0 \\
204 \\
189 \\
300\end{array}$ & $\begin{array}{l}5 \\
2 \\
3 \\
1\end{array}$ & $\begin{array}{l}79.0 \\
170 \\
157 \\
245\end{array}$ & $\begin{array}{l}5 \\
2 \\
3 \\
1\end{array}$ & $\begin{array}{l}61.0 \\
120 \\
114 \\
174\end{array}$ & $\begin{array}{l}5 \\
2 \\
3 \\
1\end{array}$ & $\begin{array}{l}41.0 \\
71.0 \\
67.0 \\
99.0\end{array}$ \\
\hline 358 & 5 & 352 & 4 & 338 & 4 & 305 & 4 & 226 & 4 & 182 & 4 & 148 & 4 & 133 & 4 & 101 & 4 & 64.0 \\
\hline
\end{tabular}

DURATION OF DISQHARGE FOR EACH WATER YEAR

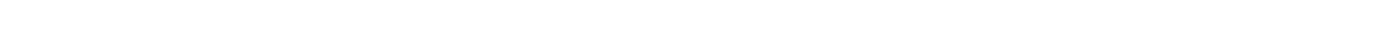
YEAR NUMBER OF DAUS IN CLASS OUBIC EEET PER SECON

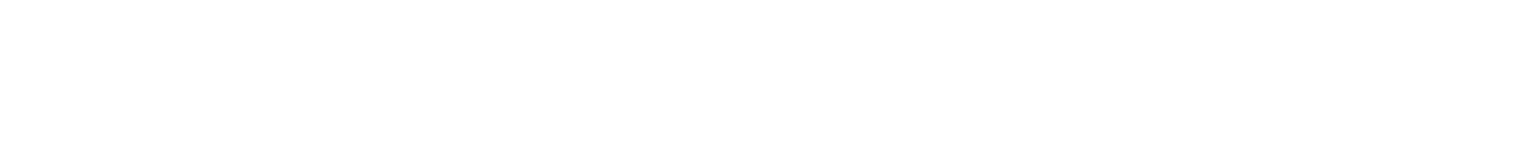

DURATION TFLE OF DISGAARE FOR WATER YEARS 1977-81

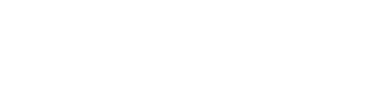

CLASS SECOND DAYS DAYS DAYS

$\begin{array}{rrrrr}0 & 0.00 & 0 & 1826 & 100.0 \\ 1 & 7.40 & 2 & 1826 & 100.0 \\ 2 & 8.60 & 3 & 1824 & 99.9 \\ 3 & 10.00 & 9 & 1821 & 99.7 \\ 4 & 12.00 & 48 & 1812 & 99.2 \\ 5 & 14.00 & 64 & 1764 & 96.6 \\ 6 & 16.00 & 298 & 1700 & 93.1 \\ 7 & 19.00 & 220 & 1402 & 76.8 \\ 8 & 22.00 & 123 & 1182 & 64.7\end{array}$

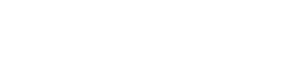

CASS SECOM DAS DAYS DAYS

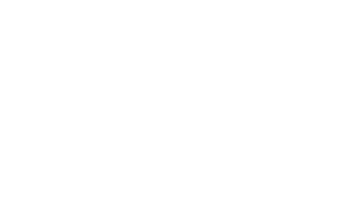

\begin{tabular}{ccc}
\multicolumn{4}{c}{ GBIC } \\
FEET \\
PER & TOT \\
CLAS SECOND & DAYS \\
18 & 100.0 & 78 \\
19 & 120.0 & 33 \\
20 & 140.0 & 16 \\
21 & 160.0 & \\
22 & 180.0 & 30 \\
23 & 220.0 & 14 \\
24 & 250.0 & 21 \\
25 & 290.0 & 22 \\
26 & 340.0 & 14
\end{tabular}

$\mathrm{ACOU}-$ MU- PERDAYS DAYS

\begin{tabular}{|c|c|c|c|c|}
\hline & $\begin{array}{l}\text { CUBIC } \\
\text { FEET } \\
\text { PER }\end{array}$ & TOTA & $\begin{array}{l}\text { ACOU- } \\
\text { MU- } \\
\text { LATED }\end{array}$ & $\begin{array}{l}\text { PER- } \\
\text { CENI }\end{array}$ \\
\hline CLASS & SECOND & DAYS & DAYS & DAYS \\
\hline 27 & 400.0 & 3 & 42 & \\
\hline 28 & 460 & 9 & 39 & \\
\hline 29 & 540.0 & 10 & 30 & \\
\hline 30 & 630.0 & 5 & 20 & \\
\hline 31 & 730.0 & 8 & 15 & \\
\hline 32 & 850.0 & 3 & 7 & \\
\hline 33 & & 3 & 4 & \\
\hline 34 & 1200.0 & 1 & $i$ & \\
\hline
\end{tabular}


GREEN RIVER BASIN

09299600 WHITEROCKS RIVER BELOW FARM CREEK CANAL, NEAR WHITEROCKS, UT-Continued

MONIULY MEAN DISCHARGES, IN CUBIC FEET PER SECOND, FOR EACH WATER YEAR

$\begin{array}{lllllllllllll}\text { YEAR } & \text { OCT } & \text { NOV } & \text { DEC } & \text { JAN } & \text { FEB } & \text { MAR } & \text { APR } & \text { MAY } & \text { JUNE } & \text { JULY } & \text { AUG } & \text { SEP } \\ 1977 & 29.5 & 21.3 & 22.0 & 17.4 & 18.8 & 16.8 & 19.9 & 34.2 & 116 & 69.2 & 77.7 & 49.1 \\ 1978 & 32.6 & 24.3 & 19.7 & 18.0 & 17.3 & 18.4 & 19.3 & 108 & 369 & 106 & 76.4 & 41.2 \\ 1979 & 26.5 & 23.6 & 21.0 & 17.6 & 17.1 & 16.8 & 24.8 & 248 & 177 & 113 & 73.1 & 44.2 \\ 1980 & 37.1 & 30.0 & 25.1 & 19.0 & 18.1 & 17.3 & 26.7 & 161 & 631 & 99.4 & 84.5 & 48.1 \\ 1981 & 49.2 & 29.0 & 30.3 & 21.4 & 18.5 & 12.5 & 38.3 & 179 & 175 & 72.5 & 91.6 & 49.2\end{array}$

ANNUAL PEAK DISCHARGE, IN GBIC FEET PER SECOND, AND OORRESPONDING GAGE HEIGHT, IN FEET, FOR EACH WATER YEAR

\begin{tabular}{|c|c|c|c|c|c|c|c|c|c|c|c|c|}
\hline $\begin{array}{l}\text { WATERR } \\
\text { YEAR }\end{array}$ & DATE & $\begin{array}{c}\text { GAGE } \\
\text { HEIGHT }\end{array}$ & $\begin{array}{c}\text { PEAK } \\
\text { DISCHARGE }\end{array}$ & $\begin{array}{l}\text { WATER } \\
\text { YEAR }\end{array}$ & DATE & $\begin{array}{c}\text { GAGE } \\
\text { HEIGHT }\end{array}$ & $\begin{array}{c}\text { PEAK } \\
\text { DISCHARGE }\end{array}$ & $\begin{array}{l}\text { WATER } \\
\text { YEAR }\end{array}$ & & DATE & $\begin{array}{c}\text { GAGE } \\
\text { HEIGHT }\end{array}$ & $\begin{array}{c}\text { PEAR } \\
\text { DISCHARGE }\end{array}$ \\
\hline 1977 & JUNE 02, 1977 & - & 698 & 1979 & 28,1979 & 4.65 & 1260 & 1981 & MAY & $27,28,1981$ & 2.63 & 455 \\
\hline 1978 & JUNE 10,1978 & 4.34 & 1240 & 1980 & JUNE 12, 1980 & - & $1_{1260}$ & & & & & \\
\hline
\end{tabular}

$1_{\text {Mean daily discharge. }}$

09299700 WHITEROCKS RIVER AT WHITEROCKS, UT

LOCATION. $-40^{\circ} 28^{\prime} 02^{\prime \prime}$, long $109^{\circ} 54^{\prime} 48^{\prime \prime}$, in $5 W_{4}^{\frac{1}{4}} \mathrm{NW}_{4}^{\prime} \mathrm{SW} / \frac{1}{4}$ sec. 20, T.1 N., R.1 E., Uintah Meridian, Uintah County, Hydrologic Unit

14060003, Uintah' and ouray Indian Reservation, on right bank on downstream side of county road $0.9 \mathrm{mi}$ east of Whiterocks.

DRAINAGE AREA. $-124 \mathrm{mi}^{2}$.

PERIOD OF RECORD AVAII.ABLE.--October 1976 to Septenber 1981.

GAGE.--Water-stage recorder. Altitude of gage is 6,020 ft from topographic map.

REMARKS.--Several major irrigation diversions above station.

AVERAGE DISCHARGE. -5 years, $35.3 \mathrm{ft}^{3} / \mathrm{s}, 25,570$ acre- $\mathrm{ft} / \mathrm{yr}$.

EXTREMES FOR PERIOD OF RECORD.--Maximum discharge, 1,660 ft $3 / \mathrm{s}$ June 11, 1980, gage height, $5.81 \mathrm{ft}$; no flow at times most years.

LOWEST MEAN DISCHARGE, IN OUBIC FEET PER SBCOND, AND RANKING FOR THE INDICATED NUMBER OF OONSECUTIVE DAYS FOR EACH CIIMATIC YEAR, APRIL 1-MARCH 31

\begin{tabular}{|c|c|c|c|c|c|c|c|c|c|c|c|c|c|c|c|c|c|c|c|}
\hline YEAR & 1 & & 3 & & 7 & & 14 & & $\begin{array}{l}\text { CONSE } \\
30\end{array}$ & arriv & $\begin{array}{l}\text { DAYS } \\
60\end{array}$ & & 90 & & 120 & & 183 & & ALL \\
\hline $\begin{array}{l}1978 \\
1979 \\
1980\end{array}$ & $\begin{array}{l}0.00 \\
0.00 \\
0.00\end{array}$ & $\begin{array}{l}1 \\
2 \\
3\end{array}$ & $\begin{array}{l}0.00 \\
0.00 \\
0.00\end{array}$ & $\begin{array}{l}1 \\
2 \\
3\end{array}$ & $\begin{array}{l}0.00 \\
0.04 \\
0.00\end{array}$ & $\begin{array}{l}1 \\
4 \\
2\end{array}$ & $\begin{array}{l}0.01 \\
0.11 \\
0.09\end{array}$ & $\begin{array}{l}2 \\
4 \\
3\end{array}$ & $\begin{array}{l}0.10 \\
0.16 \\
0.39\end{array}$ & $\begin{array}{l}1 \\
3 \\
4\end{array}$ & $\begin{array}{l}0.30 \\
0.21 \\
4.60\end{array}$ & $\begin{array}{l}2 \\
1 \\
4\end{array}$ & $\begin{array}{l}0.74 \\
0.57 \\
4.60\end{array}$ & $\begin{array}{l}2 \\
1 \\
3\end{array}$ & $\begin{array}{l}1.19 \\
0.95 \\
4.90\end{array}$ & $\begin{array}{l}2 \\
1 \\
3\end{array}$ & $\begin{array}{l}4.10 \\
2.20 \\
7.40\end{array}$ & $\begin{array}{l}2 \\
1 \\
3\end{array}$ & $\begin{array}{l}22.0 \\
31.0 \\
35.0\end{array}$ \\
\hline 1981 & 0.00 & 4 & 0.00 & 4 & 0.00 & 3 & 0.00 & 1 & 0.10 & 2 & 3.60 & 3 & 7.20 & 4 & 9.40 & 4 & 8.20 & 4 & 65.0 \\
\hline
\end{tabular}

HIGHEST MEAN DISCHARGE, IN OUBIC FEET PER SECOND, AND RANKING FOR THE INDICATED NUMBER OF CONSECOTIVE DAYS FOR EACH WATER YEAR, $O$ CTCBER 1-SEPTEMBER 30

\begin{tabular}{|c|c|c|c|c|c|c|c|c|c|c|c|c|c|c|c|c|c|c|c|}
\hline YEAR & 1 & & 3 & & 7 & & 10 & & Cons & UT & VE DAYS & & 90 & & 30 & & 783 & & T \\
\hline $\begin{array}{l}1977 \\
1978 \\
1979 \\
1980\end{array}$ & $\begin{array}{r}307 \\
668 \\
664 \\
1190\end{array}$ & $\begin{array}{l}4 \\
2 \\
3 \\
1\end{array}$ & $\begin{array}{r}250 \\
476 \\
596 \\
1100\end{array}$ & $\begin{array}{l}4 \\
3 \\
2 \\
1\end{array}$ & $\begin{array}{l}162 \\
440 \\
448 \\
917\end{array}$ & $\begin{array}{l}4 \\
3 \\
2 \\
1\end{array}$ & $\begin{array}{l}118 \\
321 \\
322 \\
719\end{array}$ & $\begin{array}{l}5 \\
3 \\
2 \\
1\end{array}$ & $\begin{array}{l}80.0 \\
222 \\
201 \\
503\end{array}$ & $\begin{array}{l}5 \\
2 \\
3 \\
1\end{array}$ & $\begin{array}{l}59.0 \\
136 \\
132 \\
301\end{array}$ & $\begin{array}{l}5 \\
2 \\
3 \\
1\end{array}$ & $\begin{array}{l}55.0 \\
105 \\
106 \\
219\end{array}$ & $\begin{array}{l}5 \\
3 \\
2 \\
1\end{array}$ & $\begin{array}{r}51.0 \\
86.0 \\
88.0 \\
177\end{array}$ & $\begin{array}{l}5 \\
3 \\
2 \\
1\end{array}$ & $\begin{array}{c}39.0 \\
60.0 \\
62.0 \\
122\end{array}$ & $\begin{array}{l}5 \\
3 \\
2 \\
1\end{array}$ & $\begin{array}{l}21.0 \\
32.0 \\
32.0 \\
65.0\end{array}$ \\
\hline 981 & 171 & 5 & 167 & 5 & 161 & 5 & 143 & 4 & 109 & 4 & 86.0 & 4 & 68.0 & 4 & 59.0 & 4 & 45.0 & 4 & 27.0 \\
\hline
\end{tabular}

DURATION OF DISCHARGE FOR EACA WATER YEAR

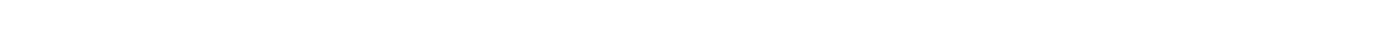
YEAR

NUMBER OF DAYS IN CLASS

$\begin{array}{lrlllllllllllllllllllllllllllllll}1977107 & & & & & & & & & & 1 & 10 & 21 & 7 & 19 & 18 & 1 & 1 & 13 & 20 & 18 & 35 & 47 & 27 & 11 & 6 & 2 & 1 & & \\ 1978 & 12 & 1 & 5 & 2 & 1 & 4 & 3 & 11 & 2 & 12 & 9 & 3 & 1 & 36 & 31 & 15 & 12 & 25 & 22 & 26 & 25 & 15 & 37 & 19 & 11 & 7 & 5 & 4 & 4 & 4 & 1 \\ 1979 & 5 & & & & & & & 10 & 37 & 1 & 3 & 4 & 14 & 18 & 23 & 29 & 34 & 15 & 11 & 9 & 1 & 22 & 21 & 25 & 48 & 18 & 5 & 1 & 2 & 5 & 2 & 2 \\ \end{array}$

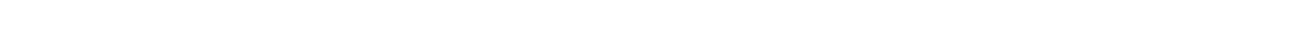

$\begin{array}{llllllllllllllllllll}1981 & 38 & 1 & 2 & 1 & 1 & 24 & 15 & 18 & 16 & 8 & 9 & 44 & 63 & 23 & 51 & 17 & 13 & 11 & 10\end{array}$ 
GREEN RIVER BASIN

09299700 WHITEROCKS RIVER AT WHITEROCKS, UT--Continued

DURATION TABLE OF DISCHARGE FOR WATER YEARS 1977-81
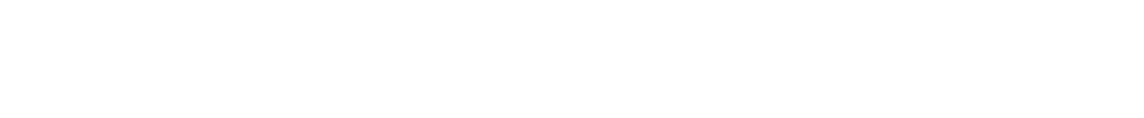

PER TOTAL LATED CEN

CLASS SECOND TOTAL LATED CENI

$\begin{array}{rcc}\text { CUBIC } & \text { ACOU- } \\ \text { FEET } & \text { MU- } & \text { PER- } \\ \text { PER TOTAL LATED } & \text { CENT } \\ \text { CLASS SBCOND DAYS DAYS } & \text { DAYS }\end{array}$

$\begin{array}{lllll}0 & 0.00 & 163 & 1826 & 100.0\end{array}$

$\begin{array}{rrrrr}1 & 0.01 & 13 & 1663 & 91.1 \\ 3 & 0.02 & 1 & 1650 & 90.4\end{array}$

$\begin{array}{lllll}3 & 0.03 & 1 & 1650 & 90.4 \\ 4 & 0.03 & 1649 & 90.3\end{array}$

$\begin{array}{lllll}4 & 0.04 & 4 & 1644 & 90.0 \\ 5 & 0.06 & 3 & 1640 & 89.8\end{array}$

$\begin{array}{lllll}6 & 0.08 & 5 & 1637 & 89.6\end{array}$

$\begin{array}{lllll}7 & 0.12 & 16 & 1632 & 89.4 \\ 8 & 0.17 & 49 & 1616 & 88.5\end{array}$

$\begin{array}{rrrrr}9 & 0.24 & 9 & 1567 & 85.8 \\ 10 & 0.34 & 17 & 1558 & 85.3 \\ 11 & 0.49 & 17 & 1541 & 84.4 \\ 12 & 0.69 & 32 & 1524 & 83.5 \\ 13 & 0.99 & 49 & 1492 & 81.7 \\ 14 & 1.40 & 94 & 1443 & 79.0 \\ 15 & 2.00 & 98 & 1349 & 73.9 \\ 16 & 2.80 & 89 & 1251 & 68.5 \\ 17 & 4.10 & 98 & 1162 & 63.6\end{array}$

$\begin{array}{rrrrr}18 & 5.8 & 57 & 1064 & 58.3 \\ 19 & 8.2 & 76 & 1007 & 55.1 \\ 20 & 12.0 & 164 & 931 & 51.0 \\ 21 & 17.0 & 131 & 767 & 42.0 \\ 22 & 24.0 & 110 & 636 & 34.8 \\ 23 & 34.0 & 194 & 526 & 28.8 \\ 24 & 48.0 & 142 & 332 & 18.2 \\ 25 & 68.0 & 74 & 190 & 10.4 \\ 26 & 97.0 & 40 & 116 & 6.4\end{array}$

$\begin{array}{rrrrr}27 & 140.0 & 25 & 76 & 4.2 \\ 28 & 200.0 & 10 & 51 & 2.8 \\ 29 & 280.0 & 13 & 41 & 2.2 \\ 30 & 400.0 & 15 & 28 & 1.5 \\ 31 & 570.0 & 9 & 13 & 0.7 \\ 32 & 810.0 & 4 & 4 & 0.2 \\ 33 & 1200.0 & 0 & 0 & 0.0 \\ 34 & & & & \end{array}$

MONIHLY MEAN DISCHARGES, IN CUBIC FEET PER SECOND, FOR EACH WATER YEAR

$\begin{array}{lcccccccccccc}\text { YEAR } & \text { OCT } & \text { NOV } & \text { DEC } & \text { JAN } & \text { FEB } & \text { MAR } & \text { APR } & \text { MAY } & \text { JUNE } & \text { JULY } & \text { AUG } & \text {. SEP } \\ 1977 & 9.38 & 1.67 & 0.92 & 0.00 & 0.86 & 0.00 & 9.19 & 27.5 & 75.4 & 40.7 & 49.1 & 33.9 \\ 1978 & 12.9 & 1.72 & 0.13 & 1.28 & 2.31 & 5.27 & 7.18 & 69.8 & 185 & 49.0 & 36.4 & 10.7 \\ 1979 & 4.33 & 0.18 & 0.55 & 1.62 & 3.16 & 3.04 & 3.38 & 167 & 75.1 & 60.5 & 42.4 & 23.3 \\ 1980 & 8.68 & 3.82 & 6.55 & 4.56 & 9.81 & 11.2 & 10.1 & 70.1 & 497 & 87.5 & 50.2 & 25.2 \\ 1981 & 5.01 & 2.10 & 16.7 & 14.6 & 10.6 & 0.15 & 8.58 & 87.1 & 82.3 & 28.6 & 33.1 & 28.7\end{array}$

ANNUAL PEAK DISCHARGE, IN CUBIC FEET FER SECOND, AND CORRESPONDING GAGE HEIGHT, IN FEET, FOR EACH WATER YEAR

\begin{tabular}{|c|c|c|c|c|c|c|c|c|c|c|c|c|}
\hline $\begin{array}{l}\text { WATER } \\
\text { YEAR }\end{array}$ & DATE & $\begin{array}{c}\text { GAGE } \\
\text { HEIGHT }\end{array}$ & $\begin{array}{l}\text { PEAK } \\
\text { DISCHARGE }\end{array}$ & $\begin{array}{l}\text { WATER } \\
\text { YEAR }\end{array}$ & DATE & $\begin{array}{c}\text { GAGE } \\
\text { HEIGHT }\end{array}$ & $\begin{array}{c}\text { PEAK } \\
\text { DISCHARGE }\end{array}$ & $\begin{array}{l}\text { WATER } \\
\text { YEAR }\end{array}$ & & DATE & $\begin{array}{c}\text { GAGE } \\
\text { HEIGHT }\end{array}$ & $\begin{array}{c}\text { PEAK } \\
\text { DISCHARGE }\end{array}$ \\
\hline $\begin{array}{l}1977 \\
1978\end{array}$ & $\begin{array}{ll}\text { JUNE } 02, & 1977 \\
\text { JUNE } 09, & 1978\end{array}$ & $\overrightarrow{3.89}$ & $\begin{array}{r}720 \\
1300\end{array}$ & $\begin{array}{l}1979 \\
1980\end{array}$ & $\begin{array}{ll}\text { MAY } & 29,1979 \\
\text { JUNE } & 11,1980\end{array}$ & $\begin{array}{l}4.44 \\
5.81\end{array}$ & $\begin{array}{l}1040 \\
1660\end{array}$ & 1981 & MAY & 28,1981 & 4.49 & 241 \\
\hline
\end{tabular}

09299900 DEEP CREEK AT STATE HIGHWAY 246, NEAR LAPOINT, UT

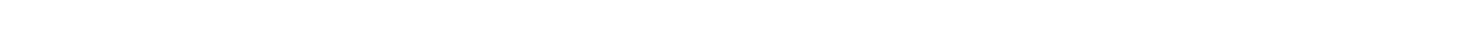

14060003, on right bank on upstream side of bridge on State Highway 246 and 2.2 mi southwest of Lapoint.

DRAINAGE AREA. $-72.2 \mathrm{mi}^{2}$.

PERIOD OF RECORD AVAILABLE.--October 1976 to September 1979.

GAGE.--Water-stage recorder. Altitude of gage is 5,350 ft from topographic map.

REMARKS.--Several major irrigation diversions upstream of gage.

EXIREMES FOR PERIOD OF RECORD.--Maximum discharge, 1,060 ft $3 / \mathrm{s}$ Sept. 7,1978 , gage height, 6.00 ft, on basis of slope area measurement; minimum daily, $0.31 \mathrm{ft}^{3} / \mathrm{s}$ May $24,1979$.

LOWEST MEAN DISCHARGE, IN CUBIC FEET PER SECOND, AND RANKING FOR THE INDICATED NUMBER OF CONSEOUTIVE DAYS FOR EACH CLIMATIC YEAR, APRIL 1-MARCH 31

\begin{tabular}{|c|c|c|c|c|c|c|c|c|c|c|c|c|c|c|c|c|c|c|c|}
\hline YEAR & 1 & & 3 & & 7 & & 14 & & $\begin{array}{l}\text { CONSE } \\
30\end{array}$ & OUTIVE & $\begin{array}{l}\text { DAYS } \\
60\end{array}$ & & 90 & & 120 & & 183 & & ALL \\
\hline $\begin{array}{l}1978 \\
1979\end{array}$ & $\begin{array}{l}2.10 \\
2.10\end{array}$ & $\begin{array}{l}1 \\
2\end{array}$ & $\begin{array}{l}2.20 \\
2.10\end{array}$ & $\begin{array}{l}2 \\
1\end{array}$ & $\begin{array}{l}2.30 \\
2.20\end{array}$ & $\begin{array}{l}2 \\
1\end{array}$ & $\begin{array}{l}2.40 \\
2.20\end{array}$ & 1 & $\begin{array}{l}2.70 \\
2.50\end{array}$ & $\begin{array}{l}2 \\
1\end{array}$ & $\begin{array}{l}2.80 \\
3.20\end{array}$ & $\begin{array}{l}1 \\
2\end{array}$ & $\begin{array}{l}3.10 \\
3.80\end{array}$ & $\begin{array}{l}1 \\
2\end{array}$ & $\begin{array}{l}3.10 \\
4.10\end{array}$ & $\frac{1}{2}$ & $\begin{array}{l}3.40 \\
4.20\end{array}$ & $\begin{array}{l}1 \\
2\end{array}$ & $\begin{array}{l}5.30 \\
6.10\end{array}$ \\
\hline
\end{tabular}

HIGHEST MEAN DISCHARGE, IN CUBIC FEET PER SECOND, AND RANKING FOR THE INDICATED NUMBER OF CONSEOUTIVE DAYS FOR EACH WATER YEAR, OCTOBER 1-SEPTEMBER 30

\begin{tabular}{|c|c|c|c|c|c|c|c|c|c|c|c|c|c|c|c|c|c|c|c|}
\hline YEAR & 1 & & 3 & & 7 & & 15 & & $\begin{array}{l}\text { CONS } \\
30\end{array}$ & aUT & $\begin{array}{l}\text { E DAYS } \\
60\end{array}$ & & 90 & & 120 & & 183 & & ALL \\
\hline $\begin{array}{l}1977 \\
1978 \\
1979\end{array}$ & $\begin{array}{l}14.0 \\
45.0\end{array}$ & $\begin{array}{l}3 \\
1\end{array}$ & $\begin{array}{l}13.0 \\
21.0\end{array}$ & $\begin{array}{l}3 \\
2\end{array}$ & $\begin{array}{l}12.0 \\
19.0\end{array}$ & $\begin{array}{l}3 \\
2\end{array}$ & $\begin{array}{l}12.0 \\
17.0\end{array}$ & $\begin{array}{l}3 \\
2\end{array}$ & $\begin{array}{l}11.0 \\
14.0\end{array}$ & $\begin{array}{l}3 \\
2\end{array}$ & $\begin{array}{l}9.60 \\
11.0\end{array}$ & $\begin{array}{l}3 \\
2\end{array}$ & $\begin{array}{r}9.00 \\
9.60\end{array}$ & $\begin{array}{l}3 \\
2\end{array}$ & $\begin{array}{l}8.00 \\
8.70\end{array}$ & $\begin{array}{l}3 \\
2\end{array}$ & $\begin{array}{l}6.70 \\
7.10\end{array}$ & $\begin{array}{l}3 \\
2\end{array}$ & $\begin{array}{l}5.10 \\
5.70\end{array}$ \\
\hline
\end{tabular}


DURATION OF DISCHARGE FOR EACH WAIER YEAR

GLASS $0 \begin{array}{llllllllllllllllllllllllllllllllllll} & 1 & 2 & 3 & 4 & 5 & 6 & 7 & 8 & 9 & 10 & 11 & 12 & 13 & 14 & 15 & 16 & 17 & 18 & 19 & 20 & 21 & 22 & 23 & 24 & 25 & 26 & 27 & 28 & 29 & 30 & 31 & 32 & 33 & 34\end{array}$ YEAR

NUMBER OF DAVS IN OLASS

$\begin{array}{lllllllllllllll}6 & 12 & 59 & 56 & 40 & 50 & 19 & 17 & 19 & 32 & 9 & 13 & 31 & 1 & 1\end{array}$ -DAUS

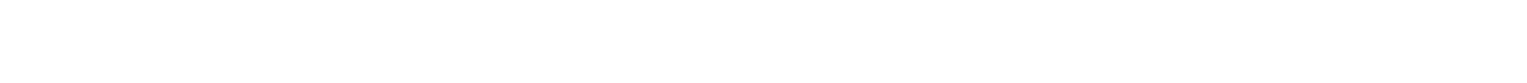

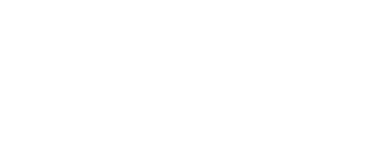

DURATION TABLE OF DISOHARGE FOR WATER YEARS 1977-79

CLASS SECOND DAYS DAYS DALS

$\begin{array}{ccc}\text { OUBIC } & \text { ACU- } \\ \text { FEET } & \text { MU- } & \text { PER } \\ \text { PER } & \text { TOTAL LATED } & \text { CENT } \\ \text { OLASS SECOND DAYS DAYS } & \text { DAYS }\end{array}$
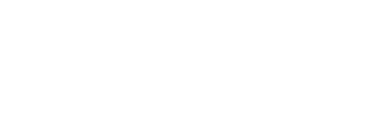

$\begin{array}{rrrrr}9 & 0.97 & 2 & 1080 & 98.6 \\ 10 & 1.10 & 1 & 1078 & 98.4 \\ 11 & 1.30 & 0 & 1077 & 98.4 \\ 12 & 1.50 & 1 & 1077 & 98.4 \\ 13 & 1.70 & 0 & 1076 & 98.3 \\ 14 & 2.00 & 17 & 1076 & 98.3 \\ 15 & 2.30 & 23 & 1059 & 96.7 \\ 16 & 2.60 & 97 & 1036 & 94.6 \\ 17 & 3.00 & 128 & 939 & 85.8\end{array}$

$\begin{array}{rrr}18 & 3.5 & 112 \\ 19 & 4.0 & 155 \\ 20 & 4.6 & 67 \\ 21 & 5.3 & 77 \\ 22 & 6.2 & 92 \\ 23 & 7.1 & 111 \\ 24 & 8.2 & 50 \\ 25 & 9.4 & 34 \\ 26 & 11.0 & 64\end{array}$

$\begin{array}{ll}811 & 74.1 \\ 699 & 63.8\end{array}$

$\begin{array}{ll}699 & 63.8 \\ 544 & 49.7\end{array}$ $\begin{array}{ll}477 & 43.6 \\ 400 & 36.5\end{array}$ $308 \quad 28.1$ 19718.0 $147 \quad 13.4$ $\begin{array}{ccc}\text { OBBIC } & \text { ACQU- } \\ \text { FEET } & \text { MU- } & \text { PER- } \\ \text { PER TOTAL LATED } & \text { CENT } \\ \text { G.ASS SECOND DAYS } & \text { DAYS } & \text { DAYS }\end{array}$

$\begin{array}{rrrrr}27 & 13.0 & 7 & 49 & 4.5 \\ 28 & 14.0 & 16 & 42 & 3.8 \\ 29 & 17.0 & 8 & 26 & 2.4 \\ 30 & 19.0 & 10 & 18 & 1.6 \\ 31 & 22.0 & 4 & 8 & 0.7 \\ 32 & 26.0 & 1 & 4 & 0.4 \\ 33 & 29.0 & 1 & 3 & 0.3 \\ 34 & 34.0 & 2 & 2 & 0.2\end{array}$

MONTHLY MEAN DISCHARGES, IN OJBIC FEET PER SECOND, FOR EACH WATER YEAR

\begin{tabular}{|c|c|c|c|c|c|c|c|c|c|c|c|c|}
\hline YEAR & OCT & NOV & DEC & JAN & FEB & MAR & APR & MAY & JUNE & JULY & AUG & SEP \\
\hline $\begin{array}{l}1977 \\
1978 \\
1979\end{array}$ & $\begin{array}{l}3.96 \\
2.86 \\
3.68\end{array}$ & $\begin{array}{l}3.36 \\
4.50 \\
9.96\end{array}$ & $\begin{array}{l}7.74 \\
5.63 \\
7.58\end{array}$ & $\begin{array}{l}7.52 \\
6.61 \\
7.29\end{array}$ & $\begin{array}{r}11.1 \\
8.49 \\
6.57\end{array}$ & $\begin{array}{l}5.67 \\
12.9 \\
11.4\end{array}$ & $\begin{array}{r}4.51 \\
4.25 \\
16.1\end{array}$ & $\begin{array}{l}4.08 \\
3.53 \\
2.36\end{array}$ & $\begin{array}{l}3.76 \\
5.16 \\
4.91\end{array}$ & $\begin{array}{l}3.77 \\
4.94 \\
4.13\end{array}$ & $\begin{array}{l}3.63 \\
3.98 \\
4.48\end{array}$ & $\begin{array}{l}2.91 \\
5.21 \\
4.10\end{array}$ \\
\hline
\end{tabular}

09300000 DEEP CREEK NEAR LAPOINT, UT

LOCATION. -Lat $40^{\circ} 20^{\prime} 00^{\prime \prime}$, lang $109^{\circ} 50^{\prime} 50^{\prime \prime}$, in $\mathrm{SE}_{4}^{3}$ sec. 2, T.2 s., R.1E., Uintah Meridian, Uintah County, Hydrol $\propto$ gic Unit 14060003, on right bank $0.75 \mathrm{mi}$ upstream from mouth and $5 \mathrm{mi}$ southwest of Lapoint.

DRATNAGE AREA.--75 $\mathrm{mi}^{2}$, approximately.

PERIOD OF RECORD AVAILABLE. - July 1942 to September 1945, July 1949 to September 1955.

GAGE.--Water-stage recorder. Altitude of gage is $5,150 \mathrm{ft}$ from topographic map. July 11,1942 to Sept. 30, 1945, staff gages at site about $3 \mathrm{mi}$ upstream at different datums.

REMARKS.--Many diversions above station for irrigation.

AVERAGE DISGHARGE. -9 years, $7.09 \mathrm{ft}^{3} / \mathrm{s}, 5,130$ acre $\mathrm{ft} / \mathrm{yr}$.

EXIREMES FOR PERIOD OF RECORD.--Maximum discharge, about $400 \mathrm{ft}^{3} / \mathrm{s}$ Oct. 4, 1954, gage height, $12.00 \mathrm{ft}$, fram floodmarks, from graph based on records for Uinta River at Fort Duchesne; no flow Apr. 17, 1950.

LOWEST MEAN DISOHARGE, IN OUBIC FEET PER SECOND, AND RANKING FOR THE INDICATED NUNBER OF DONSEUTTVE DAYS FOR EAOH OLIMATIC YEAR, APRIL I-MAROH 31

YEAR

\begin{tabular}{|c|c|c|c|c|c|c|c|c|c|c|c|c|}
\hline YEAR & 1 & & 3 & & 7 & & 14 & & $\begin{array}{l}\text { conse } \\
30\end{array}$ & $\sigma_{0}$ & & \\
\hline $\begin{array}{l}1944 \\
1945\end{array}$ & $\begin{array}{l}4.00 \\
4.50\end{array}$ & $\begin{array}{l}6 \\
7\end{array}$ & $\begin{array}{l}4.30 \\
4.80\end{array}$ & $\begin{array}{l}6 \\
7\end{array}$ & $\begin{array}{l}4.60 \\
5.40\end{array}$ & $\begin{array}{l}6 \\
7\end{array}$ & $\begin{array}{l}4.80 \\
5.90\end{array}$ & $\begin{array}{l}6 \\
7\end{array}$ & $\begin{array}{l}5.20 \\
6.00\end{array}$ & $\begin{array}{l}6 \\
7\end{array}$ & & \\
\hline $\begin{array}{l}1951 \\
1952 \\
1953 \\
1954 \\
1955\end{array}$ & $\begin{array}{l}1.50 \\
1.19 \\
0.90 \\
0.80 \\
0.80\end{array}$ & $\begin{array}{l}5 \\
4 \\
3 \\
1 \\
2\end{array}$ & $\begin{array}{l}1.50 \\
1.19 \\
1.19 \\
0.80 \\
0.80\end{array}$ & $\begin{array}{l}5 \\
3 \\
4 \\
1 \\
2\end{array}$ & $\begin{array}{l}1.60 \\
1.19 \\
1.30 \\
0.80 \\
1.60\end{array}$ & $\begin{array}{l}5 \\
2 \\
3 \\
1 \\
4\end{array}$ & $\begin{array}{l}1.80 \\
1.30 \\
1.40 \\
1.30 \\
1.60\end{array}$ & $\begin{array}{l}5 \\
1 \\
3 \\
2 \\
4\end{array}$ & $\begin{array}{l}2.20 \\
1.30 \\
2.10 \\
1.70 \\
1.70\end{array}$ & $\begin{array}{l}5 \\
1 \\
4 \\
2 \\
3\end{array}$ & & $\begin{array}{l}30 \\
70 \\
00 \\
80 \\
00\end{array}$ \\
\hline
\end{tabular}

$\begin{array}{ll}90 & \\ 5.90 & 6 \\ 6.30 & 7 \\ 2.40 & 3 \\ 2.10 & 2 \\ 3.80 & 5 \\ 1.90 & 1 \\ 2.60 & 4\end{array}$

120

183

ALL

1.604

$\begin{array}{ll}1.70 & 2 \\ 1.70 & 3\end{array}$

$\begin{array}{llll}1.00 & 2 & 1.90 & 1 \\ 2.00 & 3 & 2.60 & 4\end{array}$

$\begin{array}{rrrrrr}6.10 & 6 & 6.70 & 6 & 8.00 & 5\end{array}$

$\begin{array}{llllll}2.50 & 3 & 3.40 & 4 & 5.10 & 3\end{array}$

$\begin{array}{llllll}2.10 & 2 & 2.50 & 2 & 6.00 & 4\end{array}$

$\begin{array}{llllll}5.60 & 5 & 6.40 & 5 & 10.0 & 6\end{array}$

$\begin{array}{rrrrrr}2.00 & 1 & 2.10 & 1 & 3.10 & 1 \\ 3.00 & 4 & 3.00 & 3 & 4.70 & 2\end{array}$ 
GREEN RIVER BASIN

09300000 DEEP OREEK NEAR LAPOINT, UT--Continued

HIGHEST MEAN DISCHARGE, IN OUIC FEET PER SECOND, AND RANKING FOR THE INDICATED NUMBER OF CONSEQUTIVE DALS FOR EACH WATER YEAR, OCTOBER l-SEPTEMBER 30

\begin{tabular}{|c|c|c|c|c|c|c|c|c|c|c|c|c|c|c|c|c|c|c|}
\hline YEAR & & 3 & & 7 & & 15 & & $\begin{array}{l}\text { CONSE } \\
30\end{array}$ & बT' & $\begin{array}{c}\text { E DAYS } \\
60\end{array}$ & & 90 & & 120 & & 183 & & ALL \\
\hline $\begin{array}{l}38.0 \\
44.0 \\
15.0\end{array}$ & $\begin{array}{l}4 \\
2 \\
9\end{array}$ & $\begin{array}{l}33.0 \\
44.0 \\
15.0\end{array}$ & 9 & $\begin{array}{l}23.0 \\
43.0 \\
14.0\end{array}$ & $\begin{array}{l}3 \\
2 \\
8\end{array}$ & $\begin{array}{l}17.0 \\
42.0 \\
14.0\end{array}$ & $\begin{array}{l}4 \\
1 \\
6\end{array}$ & $\begin{array}{l}15.0 \\
37.0 \\
14.0\end{array}$ & $\begin{array}{l}5 \\
1 \\
6\end{array}$ & $\begin{array}{l}13.0 \\
29.0 \\
14.0\end{array}$ & $\begin{array}{l}6 \\
1 \\
4\end{array}$ & $\begin{array}{l}12.0 \\
24.0 \\
12.0\end{array}$ & $\begin{array}{l}4 \\
1 \\
5\end{array}$ & $\begin{array}{l}11.0 \\
20.0 \\
11.0\end{array}$ & $\begin{array}{l}4 \\
1 \\
5\end{array}$ & $\begin{array}{c}9.70 \\
16.0 \\
9.90\end{array}$ & $\begin{array}{l}5 \\
1 \\
4\end{array}$ & $\begin{array}{c}9.00 \\
11.0 \\
8.70\end{array}$ \\
\hline 26.0 & 5 & 23.0 & 4 & 21.0 & 4 & 19.0 & 3 & 17.0 & 3 & 14.0 & 5 & 12.0 & 6 & 12.0 & 3 & 10.0 & 3 & 7.30 \\
\hline $\begin{array}{l}18.0 \\
64.0 \\
17.0 \\
26.0 \\
39.0\end{array}$ & $\begin{array}{l}7 \\
1 \\
8 \\
6 \\
3\end{array}$ & $\begin{array}{l}17.0 \\
60.0 \\
17.0 \\
21.0 \\
21.0\end{array}$ & $\begin{array}{l}8 \\
5\end{array}$ & $\begin{array}{l}14.0 \\
50.0 \\
16.0 \\
15.0 \\
15.0\end{array}$ & $\begin{array}{l}9 \\
1 \\
5 \\
6 \\
7\end{array}$ & $\begin{array}{c}12.0 \\
38.0 \\
16.0 \\
9.80 \\
13.0\end{array}$ & $\begin{array}{l}8 \\
2 \\
5 \\
9 \\
7\end{array}$ & $\begin{array}{c}12.0 \\
30.0 \\
15.0 \\
8.10 \\
10.0\end{array}$ & $\begin{array}{l}7 \\
2 \\
4 \\
9 \\
8\end{array}$ & $\begin{array}{c}8.60 \\
22.0 \\
15.0 \\
7.20 \\
8.70\end{array}$ & $\begin{array}{l}8 \\
2 \\
3 \\
9 \\
7\end{array}$ & $\begin{array}{c}7.80 \\
19.0 \\
12.0 \\
5.90 \\
8.10\end{array}$ & $\begin{array}{l}8 \\
2 \\
3 \\
9 \\
7\end{array}$ & $\begin{array}{c}6.40 \\
17.0 \\
10.0 \\
5.20 \\
7.10\end{array}$ & $\begin{array}{l}8 \\
2 \\
6 \\
9 \\
7\end{array}$ & $\begin{array}{c}5.20 \\
15.0 \\
7.60 \\
4.20 \\
6.30\end{array}$ & $\begin{array}{l}8 \\
2 \\
6 \\
9 \\
7\end{array}$ & $\begin{array}{c}3.80 \\
11.0 \\
4.80 \\
3.60 \\
4.50\end{array}$ \\
\hline
\end{tabular}

LURATION OF DISCHARGE FOR EACH WATER YEAR

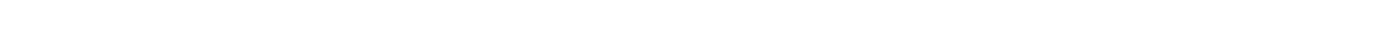

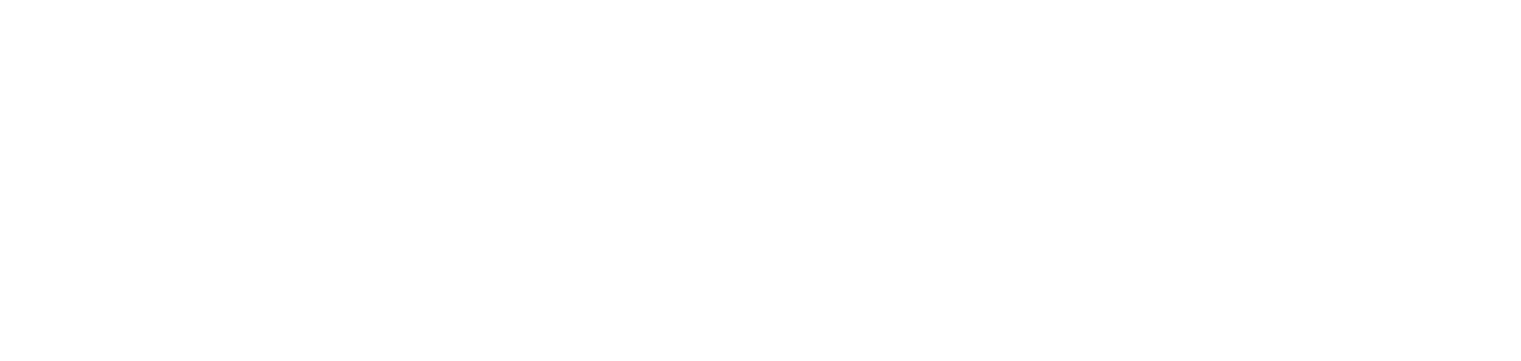

DURATION TABLE OF DISCHARGE FOR WATER YEARS 1943-45, $1950-55$

\begin{tabular}{|c|c|c|c|c|c|c|c|c|c|c|c|c|c|c|c|c|c|c|c|}
\hline CASS & $\begin{array}{c}\text { OBIC } \\
\text { FEET } \\
\text { PER } \\
\text { SECOND }\end{array}$ & $\begin{array}{r}\text { TOTAL } \\
\text { DAYS }\end{array}$ & $\begin{array}{l}\text { ACOU- } \\
\text { MU- } \\
\text { LATED } \\
\text { DAIS }\end{array}$ & $\begin{array}{l}\text { PER- } \\
\text { CENT } \\
\text { DAYS }\end{array}$ & CASS & $\begin{array}{c}\text { GBIC } \\
\text { FEET } \\
\text { PER } \\
\text { SECOND }\end{array}$ & $\begin{array}{r}\text { TOTAL } \\
\text { DAYS }\end{array}$ & $\begin{array}{l}\text { ACQU- } \\
\text { AU- } \\
\text { LATED } \\
\text { DAYS }\end{array}$ & $\begin{array}{l}\text { PER- } \\
\text { CENT } \\
\text { DAYS }\end{array}$ & CASS & $\begin{array}{c}\text { OUBIC } \\
\text { FEET } \\
\text { PER } \\
\text { SECOND }\end{array}$ & $\begin{array}{l}\text { TOTA } \\
\text { DAYS }\end{array}$ & $\begin{array}{l}\text { ACQU- } \\
\text { M- } \\
\text { LATED } \\
\text { DAYS }\end{array}$ & $\begin{array}{l}\text { PER- } \\
\text { CENT } \\
\text { DAYS }\end{array}$ & & $\begin{array}{c}\text { CBBIC } \\
\text { FEET } \\
\text { PER } \\
\text { SECOND }\end{array}$ & $\begin{array}{r}\text { TOTAL } \\
\text { DAYS }\end{array}$ & $\begin{array}{l}\text { ACQU- } \\
\text { MU- } \\
\text { LATED } \\
\text { DAYS }\end{array}$ & $\begin{array}{l}\text { PER- } \\
\text { CENT } \\
\text { DAYS }\end{array}$ \\
\hline $\begin{array}{l}0 \\
1 \\
2 \\
3 \\
4 \\
5 \\
6 \\
7 \\
8\end{array}$ & $\begin{array}{l}0.00 \\
0.80 \\
0.91 \\
1.00 \\
1.20 \\
1.40 \\
1.50 \\
1.80 \\
2.00\end{array}$ & $\begin{array}{r}0 \\
17 \\
0 \\
16 \\
55 \\
55 \\
251 \\
148 \\
269\end{array}$ & $\begin{array}{l}3287 \\
3287 \\
3270 \\
3270 \\
3254 \\
3199 \\
3144 \\
2893 \\
2745\end{array}$ & $\begin{array}{r}100.0 \\
100.0 \\
99.5 \\
99.5 \\
99.0 \\
97.3 \\
95.6 \\
88.0 \\
83.5\end{array}$ & $\begin{array}{l}9 \\
10 \\
11 \\
12 \\
13 \\
14 \\
15 \\
16 \\
17\end{array}$ & $\begin{array}{l}2.30 \\
2.60 \\
3.00 \\
3.40 \\
3.90 \\
4.40 \\
5.00 \\
5.70 \\
6.50\end{array}$ & $\begin{array}{r}200 \\
137 \\
72 \\
55 \\
69 \\
63 \\
148 \\
212 \\
264\end{array}$ & $\begin{array}{l}2476 \\
2276 \\
2139 \\
2067 \\
2012 \\
1943 \\
1880 \\
1732 \\
1520\end{array}$ & $\begin{array}{l}75.3 \\
69.2 \\
65.1 \\
62.9 \\
61.2 \\
59.1 \\
57.2 \\
52.7 \\
46.2\end{array}$ & $\begin{array}{l}18 \\
19 \\
20 \\
21 \\
22 \\
23 \\
24 \\
25 \\
26\end{array}$ & $\begin{array}{r}7.4 \\
8.4 \\
9.6 \\
11.0 \\
12.0 \\
14.0 \\
16.0 \\
18.0 \\
21.0\end{array}$ & $\begin{array}{r}206 \\
206 \\
185 \\
104 \\
223 \\
141 \\
50 \\
32 \\
30\end{array}$ & $\begin{array}{r}1256 \\
1050 \\
844 \\
659 \\
555 \\
332 \\
191 \\
141 \\
109\end{array}$ & $\begin{array}{r}38.2 \\
31.9 \\
25.7 \\
20.0 \\
16.9 \\
10.1 \\
5.8 \\
4.3 \\
3.3\end{array}$ & $\begin{array}{l}27 \\
28 \\
29 \\
30 \\
31 \\
32 \\
33 \\
34\end{array}$ & $\begin{array}{l}24.0 \\
27.0 \\
31.0 \\
36.0 \\
41.0 \\
46.0 \\
53.0 \\
60.0\end{array}$ & $\begin{array}{r}15 \\
12 \\
11 \\
19 \\
16 \\
3 \\
1 \\
2\end{array}$ & $\begin{array}{r}79 \\
64 \\
52 \\
41 \\
22 \\
6 \\
3 \\
2\end{array}$ & $\begin{array}{l}2.4 \\
1.9 \\
1.6 \\
1.2 \\
0.7 \\
0.2 \\
0.1 \\
0.1\end{array}$ \\
\hline
\end{tabular}

MONIHLY MEAN DISCHARGES, IN CBIC FEET PER SECOND, FOR EACH WATER YEAR

$\begin{array}{llccccccccccc}\text { YEAR } & \text { OCT } & \text { NON } & \text { DEC } & \text { JAN } & \text { FEB } & \text { MAR } & \text { APR } & \text { MAY } & \text { JULE } & \text { JULY } & \text { AUG } & \text { SEP } \\ 1943 & 6.42 & 9.10 & 10.2 & 7.97 & 8.79 & 10.2 & 6.27 & 7.00 & 15.0 & 10.2 & 9.42 & 7.13 \\ 1944 & 6.14 & 5.25 & 6.32 & 7.23 & 8.37 & 8.14 & 12.2 & 25.2 & 32.6 & 11.3 & 6.66 & 6.02 \\ 1945 & 6.51 & 6.64 & 12.6 & 13.3 & 11.3 & 8.01 & 7.47 & 5.48 & 10.8 & 8.29 & 7.79 & 5.80 \\ 1950 & 2.25 & 10.3 & 9.63 & 9.00 & 10.1 & 16.4 & 5.79 & 6.23 & 5.56 & 2.93 & 6.65 & 3.29 \\ 1951 & 2.54 & 2.20 & 2.50 & 10.8 & 6.12 & 6.06 & 1.46 & 1.99 & 4.97 & 1.61 & 2.57 & 2.27 \\ 1952 & 2.61 & 4.92 & 12.6 & 13.0 & 12.0 & 11.8 & 28.0 & 13.9 & 9.74 & 2.92 & 14.5 & 5.44 \\ 1953 & 3.55 & 2.50 & 14.1 & 14.0 & 8.58 & 2.88 & 1.85 & 2.09 & 2.94 & 1.95 & 2.03 & 1.66 \\ 1954 & 3.20 & 5.80 & 4.46 & 6.95 & 1.74 & 2.57 & 1.88 & 2.14 & 4.88 & 3.06 & 2.20 & 4.12 \\ 1955 & 5.97 & 4.06 & 3.56 & 7.00 & 7.00 & 10.1 & 1.97 & 2.49 & 1.71 & 1.68 & 3.75 & 4.29\end{array}$


ANNUAL PEAK DISCHARGE, IN CUBIC FEET PER SECOND, AND CORRESPONDNG GAGE HEIGHT, IN FEET, FOR EACH WATER YEAR

\begin{tabular}{|c|c|c|c|c|c|c|c|c|c|c|c|}
\hline $\begin{array}{l}\text { WATER } \\
\text { YEAR }\end{array}$ & DATE & $\begin{array}{c}\text { GAGE } \\
\text { HEIGHT }\end{array}$ & $\begin{array}{c}\text { PEAK } \\
\text { DISCHARGE }\end{array}$ & $\begin{array}{l}\text { WATER } \\
\text { YEAR }\end{array}$ & DATE & $\begin{array}{l}\text { GAGE } \\
\text { HEIGHT }\end{array}$ & $\begin{array}{c}\text { PEAK } \\
\text { DISCHARGE }\end{array}$ & $\begin{array}{l}\text { WATER } \\
\text { YEAR }\end{array}$ & DATE & $\begin{array}{l}\text { GAGE } \\
\text { HEIGHI }\end{array}$ & $\begin{array}{c}\text { PEAK } \\
\text { DISCHARGE }\end{array}$ \\
\hline $\begin{array}{l}1942 \\
1943\end{array}$ & $\begin{array}{l}\text { JULY 21, } 1942 \\
\text { AUG. } 29,1943\end{array}$ & $\begin{array}{l}6.00 \\
8.2\end{array}$ & $\begin{array}{l}1_{58} \\
200\end{array}$ & $\begin{array}{l}1950 \\
1951\end{array}$ & $\begin{array}{l}\text { NON. } 11,1949 \\
\text { MAY } 23,1951\end{array}$ & $\begin{array}{l}2.64 \\
3.08\end{array}$ & $\begin{array}{l}31 \\
22\end{array}$ & $\begin{array}{l}1953 \\
1954\end{array}$ & $\begin{array}{l}\text { JUNE 05, } 1953 \\
\text { SEPT. 27, } 1954\end{array}$ & $\begin{array}{l}3.73 \\
3.51\end{array}$ & $\begin{array}{l}26 \\
31\end{array}$ \\
\hline $\begin{array}{l}1944 \\
1945\end{array}$ & $\begin{array}{c}\text { JUNE } 5,6,1944 \\
3\end{array}$ & 5.64 & $\begin{array}{l}2_{44} \\
2_{15}\end{array}$ & 1952 & APR. 05, 1952 & 4.71 & 83 & 1955 & ОCT. 04, 1954 & 12.00 & ${ }^{4} 400$ \\
\hline
\end{tabular}

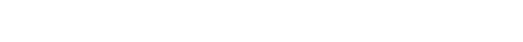

2 Maximum discharge observed.

${ }^{3}$ Dec. 19, 26, 28, 31, 1944, Feb. 3, 4, 1945.

4 Approximate.

09300500 UINTA RIVER AT FORT DUCHESNE, UT

LOCATTON.--Lat $40^{\circ} 18^{\prime} 07^{\prime \prime}$, long $109^{\circ} 51^{\prime} 09^{\prime \prime}$, in $\$ N_{\frac{1}{4}}^{1} \mathrm{SEl}_{4}^{\mathrm{L} S W_{4}^{2}}$ Sec.14, T.2 S., R.1 E., Uintah Meridian, Uintah County, Hydrologic Unit 14060003 , Uintah and ouray Indian Reservation, on left bank on upstream side of bridge on State Highway $40,6.3$ mi above Dry Gulch, and $0.9 \mathrm{mi}$ north of Fort Duchesne.

DRAINAGE AREA. $--557 \mathrm{mi}^{2}$.

REVISED RECORDS.--WDR UT-77-1: Drainage area.

PERIOD OF RECORD AVAILABLE.--SEptember 1899 to December 1904 (no winter records 1903-4), April to June 1906 (gage heights only) April to November 1907, April 1908 to November 1910, Mary to July and October to December 1917, March 1918 to September 1920 (no winter records 1918-19), October 1942 to September 1958, October 1976 to September 1981. Monthly mean discharge for same periods prior to October 1943, published in WSP 1313. Publ ished as "near Fort Duchesne", 1917-20.

GAGE. -Water-stage recorder. Altitude of gage is 5,020 ft from topographic map. Prior to Nov. 30, 1910, and June 27 to July 13 , 1917, staff or chain gages at site $1 \mathrm{mi}$ downstream at different datums. May 11 to June 11,1917 , staff gage and oct. 23, 1917, to Sept. 30 , 1920, water-stage recorder at site $2.8 \mathrm{mi}$ downstream at different datums. October 1942 to September 1958 , waterstage recorder at site $0.25 \mathrm{mi}$ downstream at different datum.

REMARKS.--Several major irrigation diversions above station.

AVERAGE DISCHARGE.--26 years (water years 1900-1902, 1909-10, 1943-58, 1977-81), $101 \mathrm{ft} / \mathrm{s}, 73,170 \mathrm{acre}-\mathrm{ft} / \mathrm{yr}$.

EXIREMES FOR PERIOD OF RECORD.--Maximum discharge, more than $7,500 \mathrm{ft}^{3} / \mathrm{s}$ between June 16 and 23,1917 , gage height, $6.52 \mathrm{ft}$ fram floodmarks, site and daturn then in use; no flow at times.

LOWEST MEAN DISCHARGE, IN OUBIC FEET PER SECOND, AND RANKING FOR THE INDICATED NUMBER OF CONSECOTIVE DAYS FEET PER SECOND, AND RANKING FOR THE INDIC
FOR EACH OLIMATIC YEAR, APRII 1-MARCH 31

YEAR

1944

1945

1946

1946
1947

1947
1948
1949

1949
1950

1951

1952

1953

1954

1956
1957

1958

197

1979
1980

1981
1

$\begin{array}{rr}0.90 & 8\end{array}$

7.0019

0.807

2.7017

0.406

1.009

1.9015

0.203

1.7014

0.304

0.001

0.002
$0.40 \quad 5$

$1.00 \quad 10$
0

1.4011

1.5012

2.6016

$1.50 \quad 13$$$
3
$$

1.00

$\begin{array}{rr}1.00 & 7 \\ 4.40 \quad 18\end{array}$

7.2019

$\begin{array}{rr}7.20 & 19 \\ 1.10 \quad 8\end{array}$

$3.20 \quad 17$

$\begin{array}{ll}0.40 & 5 \\ 1.10 & 9\end{array}$

2.1015

$\begin{array}{lr}2.10 & 15 \\ 0.30 & 3\end{array}$

.9014

$\begin{array}{ll}0.37 & 4 \\ 0.00 & 1\end{array}$

0.002

0.436

1.1010

1.4011

1.7013

3.1016

1.6012
7

1.4010
4.5018

4.5018

$10.0 \quad 19$

1.107

4.3017

0.465

1.309

2.3015

0.363

$\begin{array}{lll}0.90 & 13\end{array}$

0.394
0.004

0.112

$0.56 \quad 6$

0.56
1.198

1.5011

2.0014

3.5016

1.8012
14

2.5014

12.0018

$\begin{array}{rr}12.0 & 19 \\ 1.10 \quad 7\end{array}$

$1.10 \quad 7$
$5.20 \quad 17$

0.494

1.508

2.5015

0.495

2.3011

0.051

0.322

2.3012

1.509

2.1010

4.1016

2.4013 $\begin{array}{ll}\text { CONSECUTIVE DAYS } \\ 30 & 60\end{array}$

5.1016

5.1016
6.5017

$14.0 \quad 18$

$1.60 \quad 5$
14.05

$14.0 \quad 19$

0.694

1.706

3.3012
1.80

2.6010

0.583

0.391

3.7013

$1.80 \quad 8$

2.9011

4.3015

4.1014
6.7016

8.9017

$15.0 \quad 18$

$1.90 \quad 5$

$23.0 \quad 19$

$\begin{array}{ll}0.82 & 3 \\ 2.80 & 8\end{array}$

4.4011

4.7013

3.9010

0.812

1.60

2.507

4.6012

$2.40 \quad 6$

$3.80 \quad 9$

5.0014

6.5015
90

$11.0 \quad 16$

$16.0 \quad 18$

$2.30 \quad 4$

$22.0 \quad 19$

1.101

$4.70 \quad 9$

6.9012
8.3014

1.102

2.003

3.107

2.806

$11.0 \quad 15$

2.605

5.0010

5.2011

7.1013
120

$10.0 \quad 14$

$17.0 \quad 17$

2.804

$26.0 \quad 19$

1.701

4.909

$\begin{array}{rr}4.90 & 9\end{array}$

$18.0 \quad 18$

2.002

2.80

2.80
$3.20 \quad 5$

$\begin{array}{rr}3.20 & 5 \\ 12.0 \quad 15\end{array}$

$3.20 \quad 6$

$\begin{array}{rr}3.20 & 6 \\ 5.50 & 10\end{array}$

5.9011

8.8013
183

$\begin{array}{llll}15.0 & 11 & 40.0 & 9\end{array}$

$\begin{array}{llll}34.0 & 18 & 55.0 \quad 12\end{array}$

$\begin{array}{llll}6.60 & 4 & 39.0 & 8\end{array}$

$\begin{array}{llll}46.0 & 19 & 142 & 17\end{array}$

$\begin{array}{rrrr}7.00 & 7 & 46.0 & 10\end{array}$

$\begin{array}{llll}26.0 & 14 & 129 & 16\end{array}$

$\begin{array}{llll}16.0 & 12 & 73.0 & 13\end{array}$

$\begin{array}{llll}20.0 & 13 & 47.0 & 11\end{array}$

$\begin{array}{llll}33.0 & 16 & 165 & 18\end{array}$

$\begin{array}{llll}8.60 & 9 & 23.0 & 2 \\ 6.60 & 5 & 28.0 & 4\end{array}$

$\begin{array}{llll}5.30 & 3 & 26.0 & 3\end{array}$

$\begin{array}{llll}4.00 & 1 & 32.0 & 6\end{array}$

$\begin{array}{llll}27.0 & 15 & 91.0 & 15\end{array}$

$\begin{array}{llll}4.10 & 2 & 7.80 & 1\end{array}$

$\begin{array}{llll}7.40 & 8 & 30.0 & 5\end{array}$

$\begin{array}{llll}15.0 & 10 & 84.0 & 14\end{array}$ 
GREEN RIVER BASIN

09300500 UINTA RIVER AT FORT DUCHESNE, UT-Continued

HIGHEST MEAN DISCHARGE, IN OUBIC FEET PER SECOND, AND RANKING FOR THE INDICATED NUMBER OF CONSECUTIVE DAYS FOR EACH WATER YEAR, OCTOBER 1-SEPTEMBER 30

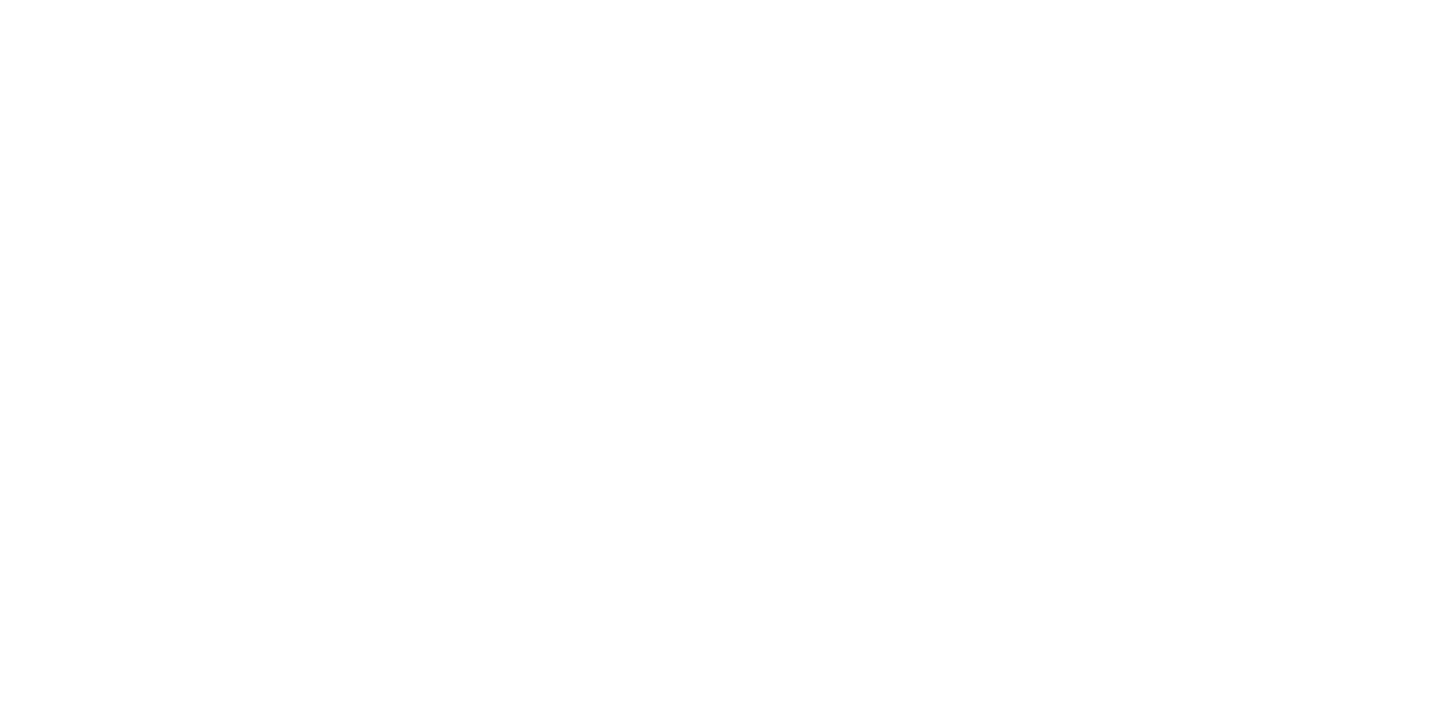

DURATION OF DISCHARGE FOR EACH WATER YEAR

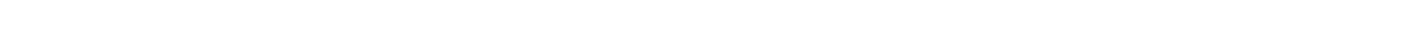
YEAR

NUMBER OF DAYS IN OLASS

CUBIC FEET PER SEDO

\begin{tabular}{|c|c|c|c|c|c|c|c|c|c|c|c|c|c|c|c|c|c|c|c|c|c|c|c|c|c|c|c|c|c|c|c|c|c|c|c|}
\hline 1910 & & & & & & & & 1 & & & & 1 & & 1 & & & 3 & 28 & 28 & 8 & 10 & 811 & 83 & & 5 & 67 & & 18 & 5 & 5 & 3 & & & & 68547.0 \\
\hline $\begin{array}{l}1943 \\
1944 \\
1945\end{array}$ & & & & & & & & 5 & 1 & 5 & 5 & $\begin{array}{l}4 \\
1\end{array}$ & $\begin{array}{l}19 \\
25\end{array}$ & $\begin{array}{r}20 \\
18 \\
2\end{array}$ & $\begin{array}{l}14 \\
22 \\
10\end{array}$ & $\begin{array}{l}22 \\
17 \\
30\end{array}$ & $\begin{array}{r}23 \\
8 \\
45\end{array}$ & $\begin{array}{l}57 \\
19 \\
56\end{array}$ & $\begin{array}{l}43 \\
13 \\
33\end{array}$ & $\begin{array}{l}19 \\
17 \\
13\end{array}$ & $\begin{array}{r}57 \\
7 \\
30\end{array}$ & $\begin{array}{ll}50 & 1 \\
86 & 5 \\
67 & 6\end{array}$ & 11 & & $\begin{array}{l}2 \\
7 \\
4\end{array}$ & $\begin{array}{l}2 \\
5 \\
7\end{array}$ & $\begin{array}{l}1 \\
9 \\
2\end{array}$ & 2 & 5 & & 151 & 14 & 2 & 1 & $\begin{array}{l}13853.8 \\
75355.8 \\
20360.0\end{array}$ \\
\hline $\begin{array}{l}1946 \\
1947 \\
1948 \\
1949 \\
1950\end{array}$ & & & & & & 12 & $\begin{array}{r}1 \\
18\end{array}$ & $\begin{array}{r}5 \\
27 \\
6\end{array}$ & $\begin{array}{l}19 \\
12\end{array}$ & $\begin{array}{r}3 \\
21 \\
2\end{array}$ & $\begin{array}{r}44 \\
6 \\
7 \\
27 \\
34\end{array}$ & $\begin{array}{r}18 \\
3 \\
11 \\
20 \\
21\end{array}$ & $\begin{array}{r}2 \\
5 \\
2 \\
24 \\
18\end{array}$ & $\begin{array}{r}15 \\
8 \\
2 \\
14 \\
25\end{array}$ & $\begin{array}{r}20 \\
9 \\
10 \\
15 \\
25\end{array}$ & $\begin{array}{r}22 \\
12 \\
9 \\
4 \\
16\end{array}$ & $\begin{array}{r}19 \\
41 \\
4 \\
13 \\
13\end{array}$ & $\begin{array}{r}35 \\
21 \\
15 \\
14 \\
7\end{array}$ & $\begin{array}{r}15 \\
36 \\
16 \\
7 \\
9\end{array}$ & $\begin{array}{l}10 \\
30 \\
24 \\
11 \\
11\end{array}$ & $\begin{array}{r}9 \\
14 \\
30 \\
31 \\
33\end{array}$ & $\begin{array}{lr}50 & 66 \\
29 & 96 \\
69 & 52 \\
91 & 9 \\
17 & 43\end{array}$ & $\begin{array}{l}2 \\
20 \\
12 \\
61\end{array}$ & & $\begin{array}{l}2 \\
2 \\
7 \\
4\end{array}$ & $\begin{array}{l}3 \\
4 \\
4 \\
2\end{array}$ & $\begin{array}{l}4 \\
2 \\
1 \\
6\end{array}$ & $\begin{array}{l}8 \\
2 \\
3 \\
6\end{array}$ & $\begin{array}{l}181 \\
1 \\
2 \\
6\end{array}$ & $\begin{array}{l}6 \\
3\end{array}$ & $\begin{array}{l}2 \\
1\end{array}$ & $\begin{array}{l}5 \\
2\end{array}$ & 3 & 1 & $\begin{array}{l}12986.5 \\
49920.3 \\
20970.1 \\
43101.9 \\
33648.8\end{array}$ \\
\hline $\begin{array}{l}1951 \\
1952 \\
1953 \\
1954 \\
1955\end{array}$ & $\begin{array}{r} \\
22 \\
4\end{array}$ & $\begin{array}{l}3 \\
2\end{array}$ & $\begin{array}{l}1 \\
\\
9 \\
4\end{array}$ & $\begin{array}{l}1 \\
2 \\
4 \\
3\end{array}$ & & $\begin{array}{r}6 \\
16 \\
6 \\
11\end{array}$ & $\begin{array}{r}4 \\
11 \\
7 \\
9\end{array}$ & $\begin{array}{r}11 \\
12 \\
10 \\
6\end{array}$ & $\begin{array}{r}10 \\
18 \\
9 \\
10 \\
10\end{array}$ & $\begin{array}{r}3 \\
2 \\
15 \\
15 \\
3\end{array}$ & $\begin{array}{r}12 \\
6 \\
16 \\
13 \\
3\end{array}$ & $\begin{array}{r}33 \\
5 \\
54 \\
34 \\
9\end{array}$ & $\begin{array}{r}45 \\
2 \\
17 \\
34 \\
37\end{array}$ & $\begin{array}{r}40 \\
1 \\
27 \\
62 \\
33\end{array}$ & $\begin{array}{r}20 \\
6 \\
23 \\
21 \\
31\end{array}$ & $\begin{array}{l}15 \\
26 \\
15 \\
15 \\
30\end{array}$ & $\begin{array}{r}8 \\
13 \\
8 \\
6 \\
18\end{array}$ & $\begin{array}{r}15 \\
14 \\
2 \\
11 \\
14\end{array}$ & $\begin{array}{r}9 \\
15 \\
3 \\
11 \\
12\end{array}$ & $\begin{array}{r}31 \\
12 \\
8 \\
16 \\
26\end{array}$ & $\begin{array}{r}27 \\
65 \\
2 \\
47 \\
3\end{array}$ & $\begin{array}{rr}39 & 16 \\
62 & 25 \\
66 & 37 \\
7 & \\
63 & 30\end{array}$ & & $\begin{array}{l}2 \\
72\end{array}$ & 41 & $\begin{array}{r}2 \\
17 \\
2 \\
1\end{array}$ & $\begin{array}{r}1 \\
14\end{array}$ & $\begin{array}{l}1 \\
6 \\
2\end{array}$ & $\begin{array}{l}2 \\
7\end{array}$ & $\begin{array}{l}1 \\
6 \\
2\end{array}$ & $\begin{array}{l}1 \\
3\end{array}$ & 5 & 5 & & $\begin{array}{r}14565.4 \\
60515.4 \\
13437.2 \\
5860.1 \\
10598.5\end{array}$ \\
\hline $\begin{array}{l}1956 \\
1957 \\
1958\end{array}$ & 1 & 1 & & & & $\begin{array}{l}2 \\
3 \\
1\end{array}$ & 8 & $\begin{array}{l}3 \\
5 \\
2\end{array}$ & $\begin{array}{r}11 \\
12 \\
2\end{array}$ & $\begin{array}{r}17 \\
8 \\
2\end{array}$ & $\begin{array}{r}25 \\
14 \\
1\end{array}$ & $\begin{array}{l}57 \\
29 \\
11\end{array}$ & $\begin{array}{l}67 \\
45 \\
22\end{array}$ & $\begin{array}{l}23 \\
34 \\
34\end{array}$ & $\begin{array}{r}8 \\
25 \\
28\end{array}$ & $\begin{array}{r}4 \\
21 \\
40\end{array}$ & $\begin{array}{r}6 \\
12 \\
12\end{array}$ & $\begin{array}{r}7 \\
10 \\
20\end{array}$ & $\begin{array}{l}13 \\
16 \\
10\end{array}$ & $\begin{array}{r}23 \\
2 \\
3\end{array}$ & $\begin{array}{l}16 \\
55 \\
49\end{array}$ & $\begin{array}{ll}50 & 17 \\
34 & 1 \\
40 & 61\end{array}$ & & 2 & 2 & $\begin{array}{l}6 \\
1 \\
2\end{array}$ & $\begin{array}{l}6 \\
4\end{array}$ & 8 & $\begin{array}{l}8 \\
5\end{array}$ & $\begin{array}{l}2 \\
3\end{array}$ & $\begin{array}{l}2 \\
5\end{array}$ & $\begin{array}{l}4 \\
5\end{array}$ & & & $\begin{array}{l}13311.1 \\
27686.3 \\
35665.5\end{array}$ \\
\hline $\begin{array}{l}1977 \\
1978 \\
1979 \\
1980\end{array}$ & & & & & & & & & $\begin{array}{r}12 \\
8 \\
2 \\
1\end{array}$ & $\begin{array}{r}17 \\
29 \\
10 \\
9\end{array}$ & $\begin{array}{r}45 \\
27 \\
8 \\
3\end{array}$ & $\begin{array}{r}40 \\
55 \\
21 \\
4\end{array}$ & $\begin{array}{l}63 \\
55 \\
36 \\
53\end{array}$ & $\begin{array}{l}63 \\
53 \\
52 \\
41\end{array}$ & $\begin{array}{l}48 \\
49 \\
50 \\
24\end{array}$ & $\begin{array}{l}19 \\
25 \\
40 \\
69\end{array}$ & $\begin{array}{r}8 \\
14 \\
13 \\
30\end{array}$ & $\begin{array}{r}9 \\
17 \\
35 \\
26\end{array}$ & $\begin{array}{r}3 \\
10 \\
33 \\
20\end{array}$ & $\begin{array}{r}5 \\
4 \\
10 \\
15\end{array}$ & $\begin{array}{r}28 \\
7 \\
11 \\
16\end{array}$ & $\begin{array}{rr}1 & 1 \\
1 & 1 \\
13 & 13 \\
20 & 7\end{array}$ & & $\begin{array}{l}9 \\
3\end{array}$ & $\begin{array}{l}1 \\
3 \\
3\end{array}$ & $\begin{array}{l}1 \\
3 \\
1\end{array}$ & $\begin{array}{l}1 \\
3\end{array}$ & $\begin{array}{l}1 \\
2\end{array}$ & $\begin{array}{l}4 \\
1 \\
3\end{array}$ & $\begin{array}{l}1 \\
5\end{array}$ & $\begin{array}{l}2 \\
1 \\
4\end{array}$ & 3 & 1 & & $\begin{array}{r}3914.4 \\
9237.6 \\
11390.6 \\
28055.7\end{array}$ \\
\hline 1981 & & & & & & & & & 1 & 3 & 3 & 13 & 42 & 40 & 33 & 37 & 51 & 26 & 26 & 28 & 4 & 1528 & e & 6 & 4 & 4 & 1 & & & & & & & & 11400.0 \\
\hline
\end{tabular}

DURATION TABLE OF DISCHARGE FOR WATER YEARS 1910, 1943-58, 1977-81

\begin{tabular}{|c|c|c|c|c|c|c|c|c|c|}
\hline CLASS & $\begin{array}{c}\text { OBIIC } \\
\text { FEET } \\
\text { PER } \\
\text { SECOND }\end{array}$ & $\begin{array}{c}\text { TOTAL } \\
\text { DAYS }\end{array}$ & $\begin{array}{l}\text { ACOU- } \\
\text { MU- } \\
\text { LATED } \\
\text { DAYS }\end{array}$ & $\begin{array}{l}\text { PER- } \\
\text { CENT } \\
\text { DAYS }\end{array}$ & CLASS & $\begin{array}{c}\text { OBBIC } \\
\text { FEET } \\
\text { PER } \\
\text { SECOND }\end{array}$ & $\begin{array}{l}\text { TOTAL } \\
\text { DAYS }\end{array}$ & $\begin{array}{l}\text { ACOU- } \\
\text { MU- } \\
\text { LATED } \\
\text { DAYS }\end{array}$ & $\begin{array}{l}\text { PER- } \\
\text { CENT } \\
\text { DAYS }\end{array}$ \\
\hline $\begin{array}{l}0 \\
1 \\
2 \\
3 \\
4 \\
5 \\
6 \\
7 \\
8\end{array}$ & $\begin{array}{l}0.00 \\
0.10 \\
0.14 \\
0.19 \\
0.25 \\
0.34 \\
0.46 \\
0.63 \\
0.86\end{array}$ & $\begin{array}{r}27 \\
6 \\
0 \\
14 \\
10 \\
33 \\
57 \\
58 \\
96\end{array}$ & $\begin{array}{l}8035 \\
8008 \\
8002 \\
8002 \\
7988 \\
7978 \\
7945 \\
7888 \\
7830\end{array}$ & $\begin{array}{r}100.0 \\
99.7 \\
99.6 \\
99.6 \\
99.4 \\
99.3 \\
98.9 \\
98.2 \\
97.4\end{array}$ & $\begin{array}{r}9 \\
10 \\
11 \\
12 \\
13 \\
14 \\
15 \\
16 \\
17\end{array}$ & $\begin{array}{r}1.20 \\
1.60 \\
2.20 \\
2.90 \\
4.00 \\
5.40 \\
7.30 \\
10.00 \\
14.00\end{array}$ & $\begin{array}{l}152 \\
184 \\
299 \\
444 \\
613 \\
608 \\
491 \\
488 \\
368\end{array}$ & $\begin{array}{l}7734 \\
7582 \\
7398 \\
7099 \\
6655 \\
6042 \\
5434 \\
4943 \\
4455\end{array}$ & $\begin{array}{l}96.3 \\
94.4 \\
92.1 \\
88.4 \\
82.8 \\
75.2 \\
67.6 \\
61.5 \\
55.4\end{array}$ \\
\hline
\end{tabular}

\begin{tabular}{crrrr}
\multicolumn{4}{c}{ OBIIC } & \multicolumn{3}{c}{ ACOU- } \\
FEET & & MU- & PER- \\
PER & TOTAL LATED & CENT \\
CIASS SECOND & DAYS & DAYS & DAYS \\
18 & 18.0 & 458 & 4087 & 50.9 \\
19 & 25.0 & 381 & 3629 & 45.2 \\
20 & 34.0 & 326 & 3248 & 40.4 \\
21 & 46.0 & 551 & 2922 & 36.4 \\
22 & 63.0 & 878 & 2371 & 29.5 \\
23 & 86.0 & 641 & 1493 & 18.6 \\
24 & 120.0 & 232 & 852 & 10.6 \\
25 & 160.0 & 143 & 620 & 7.7 \\
26 & 210.0 & 124 & 477 & 5.9
\end{tabular}

\begin{tabular}{|c|c|c|c|c|}
\hline & $\begin{array}{l}\text { OABIC } \\
\text { FEET } \\
\text { PER }\end{array}$ & TOTAL & $\begin{array}{c}\text { ACQU- } \\
\text { MU- } \\
\text { LATED }\end{array}$ & $\begin{array}{l}\text { PER- } \\
\text { CENT }\end{array}$ \\
\hline CASS & SECOND & DAYS & DAYS & DAY \\
\hline 27 & 290.0 & 76 & 353 & \\
\hline 28 & 400. & 63 & 277 & \\
\hline 29 & 540.0 & 67 & 214 & \\
\hline 30 & 730. & 54 & 147 & \\
\hline 31 & 1000 & 42 & 93 & \\
\hline 32 & 1400 & 38 & 5 & \\
\hline 33 & 1800. & 11 & 13 & \\
\hline 34 & 2500.0 & 2 & 2 & \\
\hline
\end{tabular}


09300500 UINTA RIVER AT FORT DUGESNE, UT-Continued

MONTHLY MEAN DISCHARGES, IN OBIC FEET PER SECOND, FOR EACH WATER YEAR

\begin{tabular}{|c|c|c|c|c|c|c|c|c|c|c|c|c|}
\hline YEAR & OCT & NOV & DEC & JAN & FEB & MAR & APR & MAY & JUNE & JULY & AUG & SEP \\
\hline 1900 & 88.0 & 111 & 114 & 125 & 125 & 125 & 99.0 & 924 & 431 & 67.0 & 36.0 & 66.0 \\
\hline $\begin{array}{l}1901 \\
1902\end{array}$ & $\begin{array}{l}98.0 \\
116\end{array}$ & $\begin{array}{l}105 \\
117\end{array}$ & 130.0 & $\begin{array}{l}135 \\
125\end{array}$ & $\begin{array}{l}135 \\
130\end{array}$ & $\begin{array}{l}132 \\
118\end{array}$ & $\begin{array}{l}117 \\
98.0\end{array}$ & $\begin{array}{r}1188 \\
662\end{array}$ & $\begin{array}{l}261 \\
622\end{array}$ & $\begin{array}{l}140 \\
158\end{array}$ & $\begin{array}{l}168 \\
43.0\end{array}$ & $\frac{121}{54.0}$ \\
\hline $\begin{array}{l}1909 \\
1910\end{array}$ & $\begin{array}{l}293 \\
246\end{array}$ & $\begin{array}{l}223 \\
201\end{array}$ & $\begin{array}{l}191 \\
168\end{array}$ & $\begin{array}{l}151 \\
151\end{array}$ & $\begin{array}{l}125 \\
149\end{array}$ & $\begin{array}{l}149 \\
195\end{array}$ & $\begin{array}{l}187 \\
295\end{array}$ & $\begin{array}{l}319 \\
541\end{array}$ & $\begin{array}{r}1936 \\
143\end{array}$ & $\begin{array}{l}430 \\
25.0\end{array}$ & $\begin{array}{l}272 \\
41.9\end{array}$ & $\begin{array}{l}740 \\
93.8\end{array}$ \\
\hline $\begin{array}{l}1943 \\
1944 \\
1945\end{array}$ & $\begin{array}{c}23.6 \\
6.42 \\
16.4\end{array}$ & $\begin{array}{l}38.7 \\
27.4 \\
30.7\end{array}$ & $\begin{array}{l}57.9 \\
62.8 \\
76.2\end{array}$ & $\begin{array}{l}66.8 \\
70.0 \\
100\end{array}$ & $\begin{array}{l}85.4 \\
80.0 \\
88.0\end{array}$ & $\begin{array}{l}44.3 \\
90.0 \\
75.2\end{array}$ & $\begin{array}{c}7.02 \\
109 \\
46.5\end{array}$ & $\begin{array}{c}60.0 \\
367 \\
34.9\end{array}$ & $\begin{array}{c}39.2 \\
1306 \\
154\end{array}$ & $\begin{array}{c}8.72 \\
345 \\
18.8\end{array}$ & $\begin{array}{l}18.8 \\
11.8 \\
17.9\end{array}$ & $\begin{array}{c}7.81 \\
6.52 \\
14.4\end{array}$ \\
\hline $\begin{array}{l}1946 \\
1947 \\
1948 \\
1949 \\
1950\end{array}$ & $\begin{array}{c}17.4 \\
14.6 \\
32.8 \\
3.58 \\
6.85\end{array}$ & $\begin{array}{l}53.7 \\
51.3 \\
70.1 \\
16.2 \\
38.1\end{array}$ & $\begin{array}{l}89.3 \\
87.1 \\
99.0 \\
64.8 \\
86.1\end{array}$ & $\begin{array}{l}86.0 \\
86.8 \\
85.0 \\
78.0 \\
120\end{array}$ & $\begin{array}{r}80.0 \\
98.3 \\
92.3 \\
81.1 \\
110\end{array}$ & $\begin{array}{l}55.1 \\
87.4 \\
105 \\
105 \\
115\end{array}$ & $\begin{array}{l}20.5 \\
15.8 \\
48.3 \\
23.4 \\
37.0\end{array}$ & $\begin{array}{l}12.2 \\
467 \\
122 \\
186 \\
222\end{array}$ & $\begin{array}{c}8.30 \\
663 \\
28.7 \\
833 \\
358\end{array}$ & $\begin{array}{c}2.42 \\
23.4 \\
1.76 \\
29.3 \\
5.30\end{array}$ & $\begin{array}{c}2.44 \\
30.8 \\
0.92 \\
3.03 \\
6.55\end{array}$ & $\begin{array}{c}1.98 \\
18.7 \\
0.72 \\
2.84 \\
5.25\end{array}$ \\
\hline $\begin{array}{l}1951 \\
1952 \\
1953 \\
1954 \\
1955\end{array}$ & $\begin{array}{r}3.61 \\
4.05 \\
3.11 \\
3.70 \\
15.7\end{array}$ & $\begin{array}{c}31.5 \\
28.1 \\
11.3 \\
13.8 \\
9.07\end{array}$ & $\begin{array}{l}53.5 \\
76.5 \\
80.0 \\
36.8 \\
24.0\end{array}$ & $\begin{array}{l}77.7 \\
64.8 \\
80.0 \\
61.0 \\
70.0\end{array}$ & $\begin{array}{l}58.6 \\
62.0 \\
90.0 \\
24.6 \\
80.0\end{array}$ & $\begin{array}{c}17.5 \\
86.3 \\
46.3 \\
4.71 \\
94.1\end{array}$ & $\begin{array}{c}4.50 \\
228 \\
5.16 \\
4.10 \\
17.0\end{array}$ & $\begin{array}{c}136 \\
462 \\
4.17 \\
28.2 \\
17.9\end{array}$ & $\begin{array}{c}70.7 \\
859 \\
121 \\
6.01 \\
13.7\end{array}$ & $\begin{array}{c}1.99 \\
63.2 \\
3.06 \\
0.64 \\
1.55\end{array}$ & $\begin{array}{c}16.8 \\
47.2 \\
1.70 \\
0.53 \\
2.92\end{array}$ & $\begin{array}{c}6.47 \\
11.7 \\
0.64 \\
8.31 \\
5.17\end{array}$ \\
\hline $\begin{array}{l}1956 \\
1957 \\
1958\end{array}$ & $\begin{array}{l}2.35 \\
1.83 \\
7.40\end{array}$ & $\begin{array}{c}15.3 \\
3.80 \\
56.1\end{array}$ & $\begin{array}{l}68.0 \\
28.4 \\
50.9\end{array}$ & $\begin{array}{l}65.7 \\
60.0 \\
85.2\end{array}$ & $\begin{array}{l}65.2 \\
68.2 \\
100\end{array}$ & $\begin{array}{l}32.5 \\
31.6 \\
77.2\end{array}$ & $\begin{array}{l}3.18 \\
6.16 \\
24.7\end{array}$ & $\begin{array}{l}105 \\
3.94 \\
455\end{array}$ & $\begin{array}{l}67.6 \\
649 \\
291\end{array}$ & $\begin{array}{l}4.02 \\
40.8 \\
12.4\end{array}$ & $\begin{array}{c}4.11 \\
18.3 \\
5.15\end{array}$ & $\begin{array}{l}3.60 \\
8.79 \\
7.38\end{array}$ \\
\hline $\begin{array}{l}1977 \\
1978 \\
1979 \\
1980\end{array}$ & $\begin{array}{l}4.71 \\
4.19 \\
3.28 \\
5.55\end{array}$ & $\begin{array}{l}3.35 \\
2.09 \\
6.29 \\
6.37\end{array}$ & $\begin{array}{c}4.05 \\
2.94 \\
6.52 \\
12.1\end{array}$ & $\begin{array}{l}37.3 \\
3.68 \\
15.3 \\
20.8\end{array}$ & $\begin{array}{c}33.0 \\
6.70 \\
28.8 \\
52.0\end{array}$ & $\begin{array}{l}3.09 \\
28.7 \\
95.7 \\
41.7\end{array}$ & $\begin{array}{l}3.39 \\
6.65 \\
41.7 \\
11.8\end{array}$ & $\begin{array}{r}6.40 \\
7.00 \\
130 \\
47.2\end{array}$ & $\begin{array}{c}15.1 \\
219 \\
24.0 \\
701\end{array}$ & $\begin{array}{c}7.20 \\
10.9 \\
8.96 \\
18.5\end{array}$ & $\begin{array}{l}7.29 \\
8.25 \\
7.88 \\
7.65\end{array}$ & $\begin{array}{l}5.53 \\
6.27 \\
4.55 \\
7.06\end{array}$ \\
\hline 1981 & 10.4 & 18.9 & 32.2 & 76.9 & 77.2 & 8.92 & 5.26 & 38.6 & 84.2 & 9.40 & 8.25 & 8.72 \\
\hline
\end{tabular}

ANNUAL PEAK DISCHARGE, IN GBIC FEET PER SECOND, AND CORRESPONDING GAGE HEIGAT, IN FEET, FOR EACH WATER YEAR

\begin{tabular}{|c|c|c|c|c|c|c|c|c|c|c|c|}
\hline $\begin{array}{l}\text { WATER } \\
\text { YEAR }\end{array}$ & DATE & $\begin{array}{c}\text { GAGE } \\
\text { HEIGHT }\end{array}$ & $\begin{array}{c}\text { PEAK } \\
\text { DISCHARGE }\end{array}$ & $\begin{array}{l}\text { WATER } \\
\text { YEAR }\end{array}$ & DATE & $\begin{array}{c}\text { GAGE } \\
\text { HEIGHT }\end{array}$ & $\begin{array}{c}\text { PEAK } \\
\text { DISCH ARGE }\end{array}$ & $\begin{array}{l}\text { WATER } \\
\text { YEAR }\end{array}$ & DAIE & $\begin{array}{c}\text { GAGE } \\
\text { HEIGHT }\end{array}$ & $\begin{array}{c}\text { PEAK } \\
\text { DISAHARGE }\end{array}$ \\
\hline $\begin{array}{l}1907 \\
1908 \\
1909\end{array}$ & $\begin{array}{l}\text { JULY 02, } 1907 \\
\text { JUNE } 12,1908 \\
\text { JUNE 06, } 1909\end{array}$ & $\overline{-}$ & $\begin{array}{l}3620 \\
2860 \\
5170\end{array}$ & $\begin{array}{l}1945 \\
1946 \\
1947\end{array}$ & $\begin{array}{l}\text { JUNE } 14,1945 \\
\text { DEC. } 05,1946 \\
\text { MAY } 09,1947\end{array}$ & $\begin{array}{l}2.58 \\
1.89 \\
3.39\end{array}$ & $\begin{array}{r}449 \\
127 \\
1390\end{array}$ & $\begin{array}{l}1955 \\
1956 \\
1957\end{array}$ & $\begin{array}{lll}\text { OCT. } & 04,1955 \\
\text { MAY } & 26,1956 \\
\text { JUNE } & 08,1957\end{array}$ & $\begin{array}{l}2.56 \\
3.16 \\
4.39\end{array}$ & $\begin{array}{r}374 \\
633 \\
1980\end{array}$ \\
\hline $\begin{array}{l}1910 \\
1917 \\
1918 \\
1919 \\
1920 \\
1943 \\
1944\end{array}$ & $\begin{array}{l}\text { MAY } 11,1910 \\
\text { JUNE }-1917 \\
\text { JULY } 14,1918 \\
\text { OCT. } 06,1919 \\
\text { MAY } 31,1920 \\
\text { MAY } 04,1943 \\
\text { JUNE 27, } 1944\end{array}$ & $\begin{array}{l}\overline{-} \\
\overline{5} \\
\overline{-} \\
\overline{-} \\
2.42 \\
4.34\end{array}$ & $\begin{array}{r}1_{1290} \\
7500 \\
1590 \\
523 \\
3100 \\
379 \\
3540\end{array}$ & $\begin{array}{l}1948 \\
1949 \\
1950 \\
1951 \\
1952 \\
1953 \\
1954\end{array}$ & $\begin{array}{l}\text { MAY } 20,1948 \\
\text { JUNE } 19,1949 \\
\text { JUNE } 01,1950 \\
\text { MAY 28, } 1951 \\
\text { JUNE } 07,1952 \\
\text { JUNE } 14,1953 \\
\text { MAY 22, } 1954\end{array}$ & $\begin{array}{l}3.10 \\
4.45 \\
3.85 \\
3.66 \\
4.77 \\
3.87 \\
2.70\end{array}$ & $\begin{array}{r}935 \\
3400 \\
1660 \\
1430 \\
2660 \\
1270 \\
385\end{array}$ & $\begin{array}{l}1958 \\
1977 \\
1978 \\
1979 \\
1980 \\
1981\end{array}$ & $\begin{array}{lll}\text { MAY } & 28, & 1958 \\
\text { JUNE } & 03, & 1977 \\
\text { JUNE } & 11, & 1978 \\
\text { MAY } & 29, & 1979 \\
\text { JUNE } & 12, & 1980 \\
\text { JUNE } & 09, & 1981\end{array}$ & $\begin{array}{l}4.34 \\
2.89 \\
4.26 \\
4.12 \\
4.69 \\
3.01\end{array}$ & $\begin{array}{r}1900 \\
256 \\
1470 \\
1450 \\
3480 \\
430\end{array}$ \\
\hline
\end{tabular}

MAGNITUDE AND PRCBABLITY OF ANNUAL LONEST MEAN DISOHARGE BASED ON OLIMATIC YEARS 1944-58 AND 1978-81

\begin{tabular}{|c|c|c|c|c|c|c|}
\hline \multirow{2}{*}{$\begin{array}{l}\text { PERIOD } \\
\text { (CON- } \\
\text { SEQJ- } \\
\text { TIVE } \\
\text { DAYS) }\end{array}$} & \multicolumn{6}{|c|}{$\begin{array}{l}\text { DISCHARGE, IN GBIC FEET PER SECOND, FOR } \\
\text { INDICATED RECURRENCE INTERNAL, IN YEARS, AND } \\
\text { ANNUAL NONEXCEEDANCE PRCBABIIITY, IN PERCENT }\end{array}$} \\
\hline & $\begin{array}{c}2 \\
508\end{array}$ & $\begin{array}{c}5 \\
208\end{array}$ & $\begin{array}{l}10 \\
108\end{array}$ & $\begin{array}{l}20 \\
58\end{array}$ & $\begin{array}{l}50 \\
28\end{array}$ & $\begin{array}{r}100 \\
18\end{array}$ \\
\hline $\begin{array}{r}1 \\
30 \\
60 \\
90\end{array}$ & $\begin{array}{l}1.1 \\
2.4 \\
3.5 \\
5.0\end{array}$ & $\begin{array}{l}0.34 \\
0.99 \\
1.5 \\
2.4\end{array}$ & $\begin{array}{l}0.00 \\
0.62 \\
0.97 \\
1.6\end{array}$ & $\begin{array}{l}0.00 \\
0.42 \\
0.67 \\
1.2\end{array}$ & $\begin{array}{l}-- \\
- \\
-\end{array}$ & $\begin{array}{l}- \\
-\end{array}$ \\
\hline
\end{tabular}

$1_{\text {Maximum daily discharge. }}$
MAGNITUDE AND PRCBABILITY OF ANNUAL HIGHEST MEAN DISCHARGE BASED ON WATER YEARS 1910, 1943-58 AND 1977-81

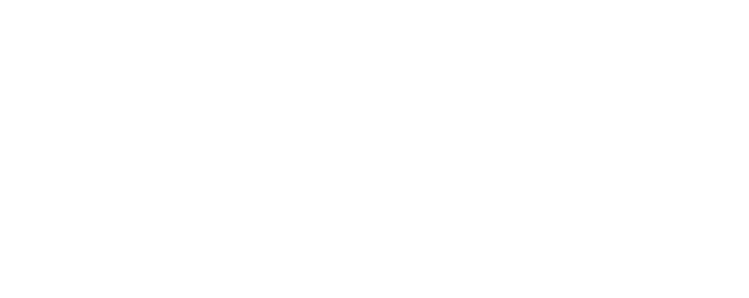


LOCATION.--Lat $40^{\circ} 27^{\prime} 50^{\prime \prime}$, long $110^{\circ} 09^{\prime} 40^{\prime \prime}$, in SWl sec.19, T.1 N., R.2 W., Uintah Meridian, Duchesne County, Hydrologic Unit 14060003 , on right bank $1.3 \mathrm{mi}$ above Highline Canal crossing, $7 \mathrm{mi}$ west northwest of Neola, and 8 mi northeast of Altonah.

DRAINAGE AREA. $-67 \mathrm{mi}^{2}$, approximately.

MEAN BASIN ELEVATION. --9,240 ft.

PERIOD OF RECORD AVAIIABLE.--October 1950 to september 1958.

GAGE.--Water-stage recorder. Altitude of gage is $6,800 \mathrm{ft}$ from topographic map.

AVERAGE DISCHARGE. --8 years, $3.11 \mathrm{ft}^{3} / \mathrm{s}, 2,250$ acre- $\mathrm{ft} / \mathrm{yr}$.

EXTREMES FOR PERIOD OF RECORD.--Maximum discharge, $381 \mathrm{ft} 3 / \mathrm{s}$ Apr. 29, 1952, gage height, $4.63 \mathrm{ft}$, from rating curve extended above $120 \mathrm{ft}^{3} / \mathrm{s}$ by logarithmic plotting; no flow during parts of each year.

LOWEST MEAN DISCHARGE, IN OBBIC FEET PER SECOND, AND RANKING FOR THE INDICATED NUMBER OF CONSECUTIVE DAYS FOR EACH CLIMATIC YEAR, APRIL 1-MARCH 31

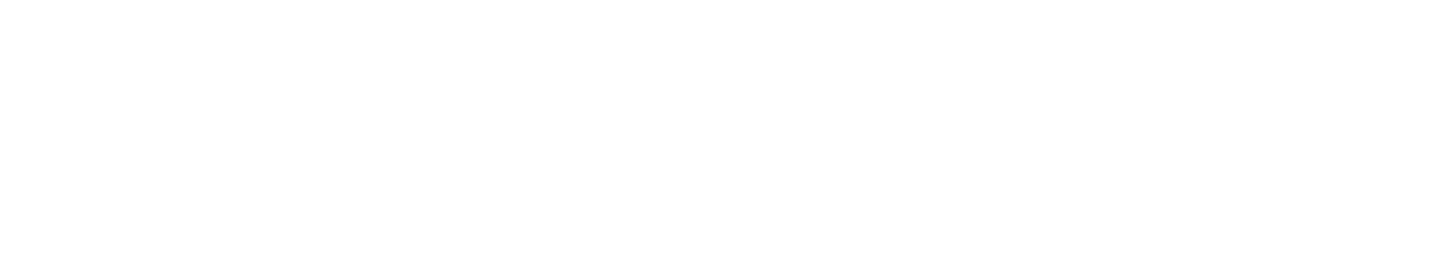

HIGHEST MEAN DISCHARGE, IN OUBIC FEET PER SECOND, AND RANKING FOR THE INDICATED NUMBER OF CONSECUTIVE DAYS FOR EACH WATER YEAR, OCTCBER 1-SEPTEYBER 30

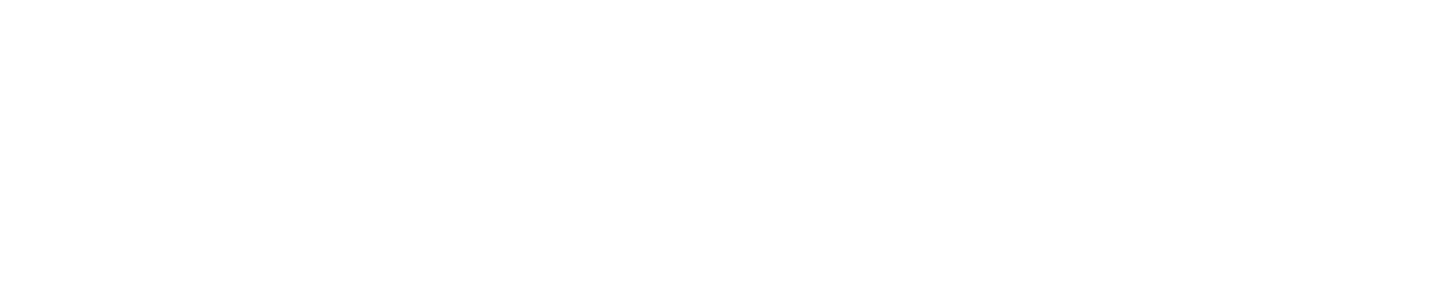

DURATION OF DISCHARGE FOR EACH WATER YEAR

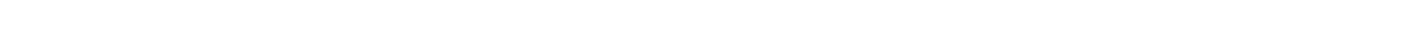
YEAR

OUBIC FEET PER SECON

\begin{tabular}{|c|c|c|c|c|c|c|c|c|c|c|c|c|c|c|c|c|c|c|c|c|c|c|c|c|c|c|c|c|c|c|}
\hline $\begin{array}{l}1951258 \\
1952267 \\
1953284 \\
1954291 \\
1955297\end{array}$ & $\begin{array}{r}39 \\
7 \\
63 \\
20 \\
14\end{array}$ & $\begin{array}{r}30 \\
2 \\
4 \\
9 \\
8\end{array}$ & $\begin{array}{l}5 \\
2\end{array}$ & $\begin{array}{l}1 \\
1\end{array}$ & $\begin{array}{l}2 \\
3\end{array}$ & $\begin{array}{l}1 \\
2\end{array}$ & $\begin{array}{l}1 \\
3\end{array}$ & $\begin{array}{l}2 \\
2 \\
1\end{array}$ & $\begin{array}{l}2 \\
1 \\
3 \\
4\end{array}$ & $\begin{array}{l}1 \\
2\end{array}$ & $\begin{array}{l}3 \\
3 \\
1 \\
1\end{array}$ & $\begin{array}{l}1 \\
1\end{array}$ & $\begin{array}{l}1 \\
1\end{array}$ & $\begin{array}{l}1 \\
3\end{array}$ & $\begin{array}{l}8 \\
3 \\
1 \\
2 \\
1\end{array}$ & $\begin{array}{l}4 \\
3 \\
3 \\
3\end{array}$ & $\begin{array}{l}4 \\
5 \\
2 \\
2 \\
5\end{array}$ & $\begin{array}{r}3 \\
4 \\
10 \\
2\end{array}$ & $\begin{array}{l}1 \\
3 \\
1 \\
5\end{array}$ & $\begin{array}{l}1 \\
1 \\
1 \\
5\end{array}$ & $\begin{array}{l}2 \\
2\end{array}$ & $\frac{1}{2}$ & $\begin{array}{l}1 \\
1\end{array}$ & $\begin{array}{l}1 \\
8\end{array}$ & $\begin{array}{lll}2 & 101\end{array}$ & 17 & 9 & 2 & 1 & $\begin{array}{r}378.4 \\
4194.6 \\
75.1 \\
189.7 \\
301.1\end{array}$ \\
\hline $\begin{array}{l}1956309 \\
1957315 \\
1958269\end{array}$ & $\begin{array}{l}1 \\
2 \\
2\end{array}$ & $\begin{array}{l}2 \\
1\end{array}$ & & & $\begin{array}{l}1 \\
2\end{array}$ & 1 & 1 & $\begin{array}{r}1 \\
1 \\
22\end{array}$ & $\begin{array}{l}3 \\
1 \\
1\end{array}$ & $\begin{array}{l}2 \\
2 \\
1\end{array}$ & $\begin{array}{l}3 \\
2 \\
1\end{array}$ & $\begin{array}{l}3 \\
2\end{array}$ & $\begin{array}{l}4 \\
3 \\
1\end{array}$ & $\begin{array}{r}12 \\
7\end{array}$ & 4 & $\begin{array}{l}2 \\
1 \\
1\end{array}$ & $\begin{array}{l}1 \\
1 \\
3\end{array}$ & 7 & $\begin{array}{l}2 \\
4 \\
1\end{array}$ & $\begin{array}{l}2 \\
9\end{array}$ & $\begin{array}{l}1 \\
3 \\
4\end{array}$ & $\begin{array}{l}5 \\
2 \\
5\end{array}$ & $\begin{array}{l}5 \\
4 \\
3\end{array}$ & $\begin{array}{l}5 \\
4 \\
7\end{array}$ & $\begin{array}{ll}2 & \\
1 & 1 \\
3 & 3\end{array}$ & $\begin{array}{l}2 \\
2\end{array}$ & $\begin{array}{l}1 \\
2\end{array}$ & 4 & 1 & $\begin{array}{r}757.0 \\
928.8 \\
2261.5\end{array}$ \\
\hline
\end{tabular}

DURATION TABLE OF DISCHARGE FOR WATER YEARS 1951-58

\begin{tabular}{crrrr}
\multicolumn{4}{c}{$\begin{array}{c}\text { OBBIC } \\
\text { FEET }\end{array}$} & \multicolumn{3}{c}{ ACOU- } \\
ME- & PER- \\
PER & TOTAL & LATED & CENT \\
CLASS SECOND & DAYS & DAYS & DAYS \\
& & & & \\
0 & 0.00 & 2290 & 2922 & 100.0 \\
1 & 0.10 & 148 & 632 & 21.6 \\
2 & 0.13 & 0 & 484 & 16.6 \\
3 & 0.16 & 0 & 484 & 16.6 \\
4 & 0.20 & 56 & 484 & 16.6 \\
5 & 0.25 & 9 & 428 & 14.6 \\
6 & 0.31 & 0 & 419 & 14.3 \\
7 & 0.39 & 13 & 419 & 14.3 \\
8 & 0.49 & 17 & 406 & 13.9
\end{tabular}

$\begin{array}{rrrrr} & \begin{array}{rrrr}\text { OBBIC } \\ \text { FEET }\end{array} & \begin{array}{r}\text { ACOJ- } \\ \text { MJ- }\end{array} & \text { PER- } \\ \text { PER } & \text { TOTAL } & \text { LATED } & \text { CENT } \\ \text { CLASS SECOND } & \text { DAYS } & \text { DAYS } & \text { DAYS } \\ & & & & \\ 9 & \mathbf{0 . 6 1} & 5 & 389 & 13.3 \\ 10 & 0.77 & 6 & 384 & 13.1 \\ 11 & 0.96 & 30 & 378 & 12.9 \\ 12 & 1.20 & 15 & 348 & 11.9 \\ 13 & 1.50 & 10 & 333 & 11.4 \\ 14 & 1.90 & 14 & 323 & 11.1 \\ 15 & 2.40 & 9 & 309 & 10.6 \\ 16 & 3.00 & 11 & 300 & 10.3 \\ 17 & 3.70 & 24 & 289 & 9.9\end{array}$

CLASS
18
19
20
21
22
23
24
25
26

CBBIC
FEET
PER TOR
SECOND
4.7
5.9
7.4
9.2
12.0
15.0
18.0
23.0
29.0

ACOUPER$\begin{array}{rrrr}\text { OUBIC } & \text { ACOU- } \\ \text { FEET } & \text { MU- } & \text { PER- } \\ \text { PER } & \text { TOTAL LAATED } & \text { CENT } \\ \text { CLASS SECOND DAYS DAYS } & \text { DAYS }\end{array}$ 
GREEN RIVER BASIN

09301000 DRY GULCH NEAR NEC.A, UT-Continued

MONTHLY MEAN DISCHARGES, IN ABIC FEET PER SECOND, FOR EAOH WATER YEAR

\begin{tabular}{|c|c|c|c|c|c|c|c|c|c|c|c|c|}
\hline YEAR & $\infty \mathrm{CT}$ & $\mathrm{NOV}$ & DEC & JAN & FEB & MAR & APR & MAY & JUNE & JULY & AUG & SEP \\
\hline $\begin{array}{l}1951 \\
1952 \\
1953 \\
1954 \\
1955\end{array}$ & $\begin{array}{l}0.00 \\
0.00 \\
0.00 \\
0.00 \\
0.00\end{array}$ & $\begin{array}{l}0.00 \\
0.00 \\
0.00 \\
0.00 \\
0.00\end{array}$ & $\begin{array}{l}0.00 \\
0.00 \\
0.00 \\
0.00 \\
0.00\end{array}$ & $\begin{array}{l}0.00 \\
0.00 \\
0.00 \\
0.00 \\
0.00\end{array}$ & $\begin{array}{l}0.00 \\
0.00 \\
0.00 \\
0.00 \\
0.00\end{array}$ & $\begin{array}{l}0.00 \\
0.00 \\
0.00 \\
0.04 \\
0.00\end{array}$ & $\begin{array}{c}0.08 \\
42.2 \\
0.10 \\
0.42 \\
0.24\end{array}$ & $\begin{array}{c}6.18 \\
66.4 \\
0.11 \\
5.66 \\
9.06\end{array}$ & $\begin{array}{c}5.99 \\
28.9 \\
2.29 \\
0.01 \\
0.44\end{array}$ & $\begin{array}{l}0.11 \\
0.05 \\
0.00 \\
0.00 \\
0.00\end{array}$ & $\begin{array}{l}0.03 \\
0.00 \\
0.00 \\
0.00 \\
0.00\end{array}$ & $\begin{array}{l}0.00 \\
0.00 \\
0.00 \\
0.00 \\
0.00\end{array}$ \\
\hline $\begin{array}{l}1956 \\
1957 \\
1958\end{array}$ & $\begin{array}{l}0.00 \\
0.00 \\
0.00\end{array}$ & $\begin{array}{l}0.00 \\
0.00 \\
0.00\end{array}$ & $\begin{array}{l}0.00 \\
0.00 \\
0.00\end{array}$ & $\begin{array}{l}0.00 \\
0.00 \\
0.00\end{array}$ & $\begin{array}{l}0.00 \\
0.00 \\
0.00\end{array}$ & $\begin{array}{l}0.00 \\
0.00 \\
0.39\end{array}$ & $\begin{array}{l}1.18 \\
0.00 \\
7.31\end{array}$ & $\begin{array}{c}16.3 \\
1.33 \\
51.1\end{array}$ & $\begin{array}{l}7.22 \\
29.4 \\
14.9\end{array}$ & $\begin{array}{l}0.00 \\
0.15 \\
0.00\end{array}$ & $\begin{array}{l}0.00 \\
0.00 \\
0.00\end{array}$ & $\begin{array}{l}0.00 \\
0.00 \\
0.00\end{array}$ \\
\hline
\end{tabular}

ANNUAL PEAK DISCHARGE, IN ABIC FEET PER SECOND, AND CORRESPONDING GAGE HEIGHT, IN FEET, FOR EACH WATER YEAR

\begin{tabular}{|c|c|c|c|c|c|c|c|c|c|c|c|c|}
\hline $\begin{array}{l}\text { WATER } \\
\text { YEAR }\end{array}$ & DAIE & $\begin{array}{c}\text { GAGE } \\
\text { HEIGHT }\end{array}$ & $\begin{array}{c}\text { PEAK } \\
\text { DISCHARGE }\end{array}$ & $\begin{array}{l}\text { WATER } \\
\text { YEAR }\end{array}$ & & DATE & $\begin{array}{c}\text { GAGE } \\
\text { HEIGHT }\end{array}$ & $\begin{array}{c}\text { PEAK } \\
\text { DISCH ARGE }\end{array}$ & $\begin{array}{l}\text { WAIER } \\
\text { YEAR }\end{array}$ & DATE & $\begin{array}{c}\text { GAGE } \\
\text { HEIGHT }\end{array}$ & $\begin{array}{c}\text { PEAR } \\
\text { DISGHARGE }\end{array}$ \\
\hline $\begin{array}{l}1951 \\
1952 \\
1953\end{array}$ & $\begin{array}{lll}\text { MAY } & 30,1951 \\
\text { APR. } & 29, & 1952 \\
\text { JUNE } & 14, & 1953\end{array}$ & $\begin{array}{l}2.23 \\
4.63 \\
1.66\end{array}$ & $\begin{array}{r}66 \\
381 \\
24\end{array}$ & $\begin{array}{l}1954 \\
1955 \\
1956\end{array}$ & $\begin{array}{l}\text { MAY } \\
\text { MAY } \\
\text { MAY }\end{array}$ & $\begin{array}{ll}23, & 1954 \\
15, & 1955 \\
26, & 1956\end{array}$ & $\begin{array}{l}1.68 \\
1.67 \\
2.06\end{array}$ & $\begin{array}{l}26 \\
23 \\
58\end{array}$ & $\begin{array}{l}1957 \\
1958\end{array}$ & $\begin{array}{lll}\text { JUNE } & 09, & 1957 \\
\text { MAY } & 29, & 1958\end{array}$ & $\begin{array}{l}2.68 \\
3.02\end{array}$ & $\begin{array}{l}124 \\
177\end{array}$ \\
\hline
\end{tabular}

09301200 DRY GULCH NEAR FORT DUCHESNE, UT

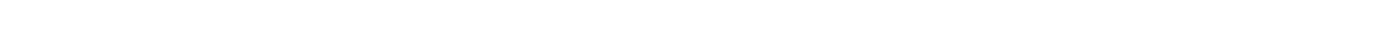
vintah and ouray Indian Reservation, on left bank $0.4 \mathrm{mi}$ downstream from bridge on county road, $1.1 \mathrm{mi}$ from mouth, and $3.5 \mathrm{mi}$ south of Fort Duchesne.

DRAINAGE AREA, $-469 \mathrm{mi}^{2}$.

FERIOD OF RECORD AVAIIABLE. - October 1976 to September 1981.

REVISED RECORDS. -WDR UT-79-1: 1978.

GAGE. - Water-stage recorder. Altitude of gage is 4,850 ft from topographic map.

REMARKS.-Flow slightly regulated by Montes Creek Reservoir, total capacity, I,000 acre-ft, about 11 mi above station, and several major diversions for irrigation above and below station.

AVERAGE DISCHARGE. --5 years, $34.1 \mathrm{ft}^{3} / \mathrm{s}, 24,710$ acre- $\mathrm{ft} / \mathrm{yr}$.

EXIREMES FOR FERICD OF RECORD.--Maximum discharge, $602 \mathrm{ft}^{3} / \mathrm{s}$ Mar. 30, 1979, gage height, $4.44 \mathrm{ft} ; \mathrm{minimum}$ daily, $5.0 \mathrm{ft}{ }^{3} / \mathrm{s} \mathrm{July} 19$, 1977.

LOWEST NEAN DISGHARGE, IN GBIC FEET PER SECOND, AND RANKING FOR THE INDICATED NUMBER OF CONSEOTTIVE DAVS FOR EACH OIMATIC YEAR, APRII I-MARQH 31

\begin{tabular}{|c|c|c|c|c|c|c|c|c|c|c|c|c|c|c|c|c|c|c|c|}
\hline YEAR & & & & & & & & & cons & 7 & E DAYS & & & & & & & & \\
\hline $\begin{array}{l}1978 \\
1979 \\
1980\end{array}$ & $\begin{array}{c}5.00 \\
10.0 \\
9.90\end{array}$ & $\begin{array}{l}1 \\
3 \\
2\end{array}$ & $\begin{array}{l}7.20 \\
10.0 \\
11.0\end{array}$ & $\begin{array}{l}1 \\
2 \\
3\end{array}$ & $\begin{array}{l}7.70 \\
11.0 \\
12.0\end{array}$ & $\begin{array}{l}1 \\
2 \\
3\end{array}$ & $\begin{array}{l}8.90 \\
14.0 \\
14.0\end{array}$ & $\begin{array}{l}1 \\
2 \\
3\end{array}$ & $\begin{array}{l}10.0 \\
15.0 \\
15.0\end{array}$ & $\begin{array}{l}1 \\
2 \\
3\end{array}$ & $\begin{array}{l}11.0 \\
18.0 \\
16.0\end{array}$ & $\begin{array}{l}1 \\
3 \\
2\end{array}$ & $\begin{array}{l}13.0 \\
21.0 \\
18.0\end{array}$ & $\begin{array}{l}1 \\
3 \\
2\end{array}$ & $\begin{array}{l}13.0 \\
22.0 \\
18.0\end{array}$ & $\begin{array}{l}1 \\
3 \\
2\end{array}$ & $\begin{array}{l}15.0 \\
22.0 \\
20.0\end{array}$ & $\begin{array}{l}1 \\
3 \\
2\end{array}$ & $\begin{array}{l}17.0 \\
35.0 \\
37.0\end{array}$ \\
\hline 98 & 12.0 & 4 & 14.0 & 4 & 16.0 & 4 & 20.0 & 4 & 24.0 & 4 & 29.0 & 4 & 30.0 & 4 & 35.0 & 4 & 43.0 & 4 & 56.0 \\
\hline
\end{tabular}

HIGHEST MEAN DISOHARGE, IN GBIC FEET PER SECOND, AND RANKING FOR THE INDICATED NUMBER OF CONSECITIVE DAYS FOR EACH WATER YEAR, OCTCBER 1-SEPTEMEER 30

\begin{tabular}{|c|c|c|c|c|c|c|c|c|c|c|c|c|c|c|c|c|c|c|c|c|}
\hline YEAR & & & & & & & & & cons & 0 & VE DAYS & & & & & & & & & \\
\hline & 1 & & 3 & & 7 & & 15 & & 30 & & 60 & & 90 & & 120 & & 183 & & FLL & \\
\hline $\begin{array}{l}1977 \\
1978 \\
1979 \\
1980\end{array}$ & $\begin{array}{l}40.0 \\
255 \\
432 \\
360\end{array}$ & $\begin{array}{l}5 \\
3 \\
1 \\
2\end{array}$ & $\begin{array}{l}39.0 \\
180 \\
356 \\
293\end{array}$ & $\begin{array}{l}5 \\
3 \\
1 \\
2\end{array}$ & $\begin{array}{l}36.0 \\
161 \\
241 \\
213\end{array}$ & $\begin{array}{l}5 \\
3 \\
1 \\
2\end{array}$ & $\begin{array}{l}33.0 \\
111 \\
187 \\
150\end{array}$ & $\begin{array}{l}5 \\
4 \\
1 \\
2\end{array}$ & $\begin{array}{l}27.0 \\
75.0 \\
152 \\
140\end{array}$ & $\begin{array}{l}5 \\
4 \\
1 \\
2\end{array}$ & $\begin{array}{r}22.0 \\
49.0 \\
99.0 \\
121\end{array}$ & $\begin{array}{l}5 \\
4 \\
2 \\
1\end{array}$ & $\begin{array}{l}21.0 \\
40.0 \\
84.0 \\
98.0\end{array}$ & $\begin{array}{l}5 \\
4 \\
2 \\
1\end{array}$ & $\begin{array}{l}19.0 \\
37.0 \\
75.0 \\
82.0\end{array}$ & $\begin{array}{l}5 \\
4 \\
2 \\
1\end{array}$ & $\begin{array}{l}18.0 \\
32.0 \\
59.0 \\
75.0\end{array}$ & $\begin{array}{l}5 \\
4 \\
2 \\
1\end{array}$ & $\begin{array}{l}16.0 \\
25.0 \\
41.0 \\
52.0\end{array}$ & $\begin{array}{l}5 \\
4 \\
3 \\
1\end{array}$ \\
\hline 981 & 217 & 4 & 163 & 4 & 148 & 4 & 127 & 3 & 94.0 & 3 & 69.0 & 3 & 58.0 & 3 & 51.0 & 3 & 43.0 & 3 & 41.0 & 2 \\
\hline
\end{tabular}


GREEN RIVER BASIN

09301200 DRY GULCH NEAR FORT DUCHESNE, UT-Continued

DURATION OF DISCHARGE FOR EAOH WATER YEAR

\begin{tabular}{|c|c|c|c|c|c|c|c|c|c|c|c|c|c|c|c|c|c|c|c|c|c|c|c|}
\hline $\begin{array}{l}\text { CLASS } \\
\text { YEAR }\end{array}$ & \multicolumn{21}{|c|}{ NUMBER OF DAYS IN CLASS } & \multicolumn{2}{|c|}{$\begin{array}{l}\text { CUBIC FEET } \\
\text { PER SBCOND } \\
\text {-DAYS }\end{array}$} \\
\hline $\begin{array}{l}1977 \\
1978 \\
1979 \\
1980\end{array}$ & 2 & 2 & $\begin{array}{llr}2 & 16 & 13 \\
& 12 \\
& & 1\end{array}$ & $\begin{array}{rr}13 & 23 \\
12 & 12 \\
1 & 2\end{array}$ & $\begin{array}{r}67 \\
23 \\
5 \\
4\end{array}$ & $\begin{array}{ll}41 & 79 \\
53 & 79 \\
32 & 18 \\
24 & 32\end{array}$ & $\begin{array}{l}14 \\
26 \\
31 \\
31\end{array}$ & $\begin{array}{ll}22 & 10 \\
28 & 27 \\
47 & 41 \\
20 & 19\end{array}$ & $\begin{array}{r}9 \\
12 \\
44 \\
22\end{array}$ & $\begin{array}{l}2 \\
11 \\
12 \\
24\end{array}$ & $\begin{array}{r}2 \\
6 \\
14 \\
17\end{array}$ & $\begin{array}{r}6 \\
6 \\
17\end{array}$ & $\begin{array}{r}2 \\
4 \\
14\end{array}$ & $\begin{array}{ll}5 & \\
9 & 1 \\
9 & 1\end{array}$ & 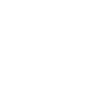 & $\begin{array}{rr}1 & 1 \\
8 & 7 \\
10 & 12\end{array}$ & $\begin{array}{rr}4 & 1 \\
4 & 4 \\
7 & 10\end{array}$ & $\begin{array}{l}7 \\
8\end{array}$ & $\begin{array}{ll}3 & \\
1 & 1 \\
2 & 3\end{array}$ & $\begin{array}{ll} & 1 \\
1 & \\
2 & 4\end{array}$ & $\begin{array}{l}1 \\
1\end{array}$ & \multicolumn{2}{|c|}{$\begin{array}{r}5990.3 \\
9052.8 \\
14797.9 \\
18937.0\end{array}$} \\
\hline 1981 & & & & & & 218 & $24 \quad 27$ & 3160 & 39 & 24 & 23 & 30 & 24 & 301 & 12 & 3 & 45 & 2 & 1 & 1 & & \multicolumn{2}{|c|}{15030.0} \\
\hline \multicolumn{24}{|c|}{ DURATION TABLE OF DISCHARGE FOR WATER YEARS 1977-81 } \\
\hline CIASS & $\begin{array}{c}\text { CABIC } \\
\text { FEET } \\
\text { PER } \\
\text { SECOND }\end{array}$ & $\begin{array}{r}\text { TOIAL } \\
\text { DAYS }\end{array}$ & $\begin{array}{c}\text { ACOU- } \\
\text { MU- } \\
\text { LATED } \\
\text { DAYS }\end{array}$ & $\begin{array}{l}\text { PER } \\
\text { CEN } \\
\text { DAY }\end{array}$ & & CIASS & $\begin{array}{c}\text { OBIC } \\
\text { FEET } \\
\text { PER } \\
\text { SECOND }\end{array}$ & TOTAL & $\begin{array}{l}\text { ACOU- } \\
\text { MU- } \\
\text { LATED } \\
\text { DAYS }\end{array}$ & $\begin{array}{l}\text { PEF } \\
\text { CEI } \\
\text { DAY }\end{array}$ & & a & & $\begin{array}{c}\text { OBIC } \\
\text { FEEI } \\
\text { PER } \\
\text { SECOND }\end{array}$ & $\begin{array}{l}\text { C } \\
\text { TOTAL } \\
\text { D DAYS }\end{array}$ & $\begin{array}{c}\text { ACOU- } \\
\text { MU- } \\
\text { LATED } \\
\text { DAYS }\end{array}$ & $\begin{array}{l}\text { PER- } \\
\text { CENT } \\
\text { DAYS }\end{array}$ & & CLASS & $\begin{array}{c}\text { QUBIC } \\
\text { FEET } \\
\text { PER } \\
\text { SECOND }\end{array}$ & TOTAL & $\begin{array}{c}\text { ACOU- } \\
\text { MU- } \\
\text { LATED } \\
\text { DAYS }\end{array}$ & $\begin{array}{l}\text { PER- } \\
\text { CENT } \\
\text { DAYS }\end{array}$ \\
\hline $\begin{array}{l}0 \\
1 \\
2 \\
3 \\
4 \\
5 \\
6 \\
7 \\
8\end{array}$ & $\begin{array}{r}0.00 \\
5.00 \\
5.70 \\
6.50 \\
7.40 \\
8.40 \\
9.60 \\
11.00 \\
12.00\end{array}$ & $\begin{array}{r}0 \\
2 \\
0 \\
2 \\
2 \\
16 \\
26 \\
37 \\
99\end{array}$ & $\begin{array}{l}1826 \\
1826 \\
1824 \\
1824 \\
1822 \\
1820 \\
1804 \\
1778 \\
1741\end{array}$ & $\begin{array}{rr}6 & 100 . \\
6 & 100 . \\
4 & 99 . \\
4 & 99 . \\
2 & 99 . \\
0 & 99 . \\
4 & 98 . \\
8 & 97 . \\
1 & 95 .\end{array}$ & & $\begin{array}{r}9 \\
10 \\
11 \\
12 \\
13 \\
14 \\
15 \\
16 \\
17\end{array}$ & $\begin{array}{l}14.00 \\
16.00 \\
18.00 \\
21.00 \\
24.00 \\
27.00 \\
31.00 \\
35.00 \\
40.00\end{array}$ & $\begin{array}{r}152 \\
226 \\
225 \\
129 \\
148 \\
157 \\
126 \\
73 \\
62\end{array}$ & $\begin{array}{r}1642 \\
1490 \\
1264 \\
1039 \\
910 \\
762 \\
605 \\
479 \\
406\end{array}$ & $\begin{array}{l}89 . \\
81 . \\
69 . \\
56 . \\
49 . \\
41 . \\
33 . \\
26 . \\
22 .\end{array}$ & & & $\begin{array}{l}18 \\
19 \\
20 \\
21 \\
22 \\
23 \\
24 \\
25 \\
26\end{array}$ & $\begin{array}{r}45.0 \\
52.0 \\
59.0 \\
67.0 \\
76.0 \\
87.0 \\
99.0 \\
110.0 \\
130.0\end{array}$ & $\begin{array}{l}59 \\
44 \\
53 \\
40 \\
22 \\
22 \\
23 \\
19 \\
20\end{array}$ & $\begin{array}{r}344 \\
285 \\
241 \\
188 \\
148 \\
126 \\
104 \\
81 \\
62\end{array}$ & $\begin{array}{r}18.8 \\
15.6 \\
13.2 \\
10.3 \\
8.1 \\
6.9 \\
5.7 \\
4.4 \\
3.4\end{array}$ & & $\begin{array}{l}27 \\
28 \\
29 \\
30 \\
31 \\
32 \\
33 \\
34\end{array}$ & $\begin{array}{l}150.0 \\
170.0 \\
190.0 \\
210.0 \\
240.0 \\
280.0 \\
320.0 \\
360.0\end{array}$ & $\begin{array}{r}17 \\
7 \\
4 \\
4 \\
5 \\
1 \\
2 \\
2\end{array}$ & $\begin{array}{r}42 \\
25 \\
18 \\
14 \\
10 \\
5 \\
4 \\
2\end{array}$ & $\begin{array}{l}2.3 \\
1.4 \\
1.0 \\
0.8 \\
0.5 \\
0.3 \\
0.2 \\
0.1\end{array}$ \\
\hline
\end{tabular}

MONIHLY MEAN DISCHARGES, IN OUBIC FEET PER SEOOND, FOR EACH WATER YEAR

$\begin{array}{lllllllllllll}\text { YEAR } & \text { OCT } & \text { NOV } & \text { DEC } & \text { JAN } & \text { FEB } & \text { MAR } & \text { APR } & \text { MAY } & \text { JUNE } & \text { JULY } & \text { AUG } & \text { SEP } \\ 1977 & 26.8 & 16.3 & 18.4 & 16.0 & 15.9 & 16.0 & 12.9 & 15.7 & 14.4 & 11.6 & 13.4 & 19.4 \\ 1978 & 17.1 & 13.5 & 19.8 & 15.3 & 17.0 & 36.9 & 18.2 & 19.0 & 73.6 & 23.2 & 23.2 & 21.2 \\ 1979 & 23.8 & 28.6 & 15.2 & 22.7 & 30.5 & 122 & 69.4 & 43.2 & 61.3 & 25.0 & 27.3 & 16.5 \\ 1980 & 23.0 & 17.8 & 15.8 & 21.0 & 82.6 & 50.3 & 29.9 & 87.6 & 118 & 82.5 & 35.1 & 60.3 \\ 1981 & 64.9 & 53.5 & 52.4 & 31.1 & 27.8 & 29.8 & 23.7 & 56.1 & 79.6 & 26.3 & 21.0 & 27.2\end{array}$

ANNUAL PEAK DISCHARGE, IN CUBIC FEET PER SECOND, AND CORRESPONDING GAGE HEIGHT, IN FEET, FOR EACH WATER YEAR

\begin{tabular}{|c|c|c|c|c|c|c|c|c|c|c|c|}
\hline $\begin{array}{l}\text { WATER } \\
\text { YEAR }\end{array}$ & DATE & $\begin{array}{c}\text { GAGE } \\
\text { HEIGHT }\end{array}$ & $\begin{array}{c}\text { PEAK } \\
\text { DISCHARGE }\end{array}$ & $\begin{array}{l}\text { WATER } \\
\text { YEAR }\end{array}$ & DATE & $\begin{array}{l}\text { GAGE } \\
\text { HEIGHT }\end{array}$ & $\begin{array}{l}\text { PEAK } \\
\text { DISCHARGE }\end{array}$ & $\begin{array}{l}\text { WATER } \\
\text { YEAR }\end{array}$ & DATE & $\begin{array}{c}\text { GAGE } \\
\text { HEIGHT }\end{array}$ & $\begin{array}{c}\text { PEAK } \\
\text { DISCHARGE }\end{array}$ \\
\hline $\begin{array}{l}1977 \\
1978\end{array}$ & $\begin{array}{l}\text { OCT. } 09,1976 \\
\text { MAR. } 12,1978\end{array}$ & $\overline{2.48}$ & $\begin{array}{r}49 \\
172\end{array}$ & $\begin{array}{l}1979 \\
1980\end{array}$ & $\begin{array}{ll}\text { MAR. } & 30,1979 \\
\text { MAY } & 12,1980\end{array}$ & $\begin{array}{l}4.44 \\
3.51\end{array}$ & $\begin{array}{l}602 \\
372\end{array}$ & 1981 & œCT. 16,1980 & 2.85 & 259 \\
\hline
\end{tabular}

09301500 UINTA RIVER AT RANDLETT, UT

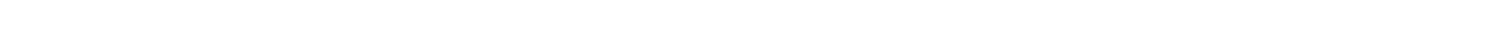
Ouray Indian Reservation, on right bank at Randlett, 0.1 mi upstream from bridge on State Highway 88 , and $2.8 \mathrm{mi}$ fram mouth. DRAINAGE AREA. $--1,064 \mathrm{mi}^{2}$.

PERIOD OF RECORD AVAILABLE.- - November 1899 to November 1904 (monthly mean discharge for same periods, published in WSP 1313), October 1976 to September 1981. November 1899 to November 1904, published as "at Ouray School".

GAGE.--Water-stage recorder. Altitude of gage is 4,790 ft from topographic map. Nov. 1899 to Nov. 1904, staff gage at different datum.

REMARKS.-Several irrigation diversions above station.

AVERAGE DISCHARGE. -5 years (water years 1977-81), $66.0 \mathrm{ft}^{3} / \mathrm{s}, 47,820$ acre-ft/yr.

EXIREMES FOR PERIOD OF RECORD.--Maximum discharge observed, 3;450 $\mathrm{ft}^{3} / \mathrm{s}$ May 19, 1901, gage height, $4.55 \mathrm{ft}$, at daturn then in use; minimum discharge, $3.6 \mathrm{ft}^{3} / \mathrm{s}$ July 15,1977 . 
GREEN RIVER BASIN

09301500 UINTA RIVER AT RANDLETT, UT-Continued

LOWEST MEAN DISGHARGE, IN OBBIC FEET PER SECOND, AND RANKING FOR THE INDICATED NUMBER OF CONSECITIVE DAYS FOR EACH OLIMATIC YEAR, APRIL 1-MARG 31

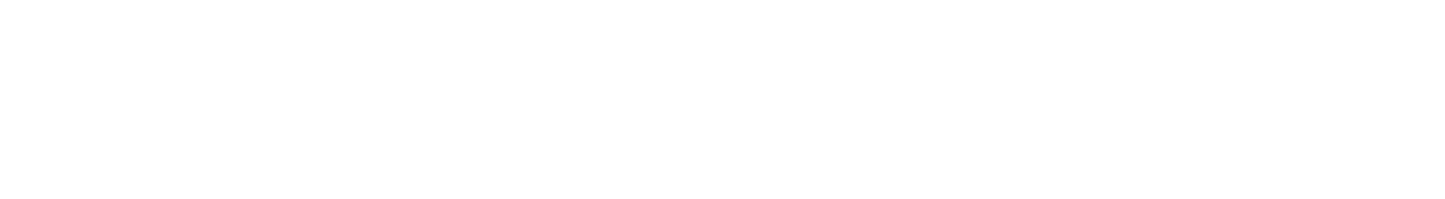

HIGHEST MEAN DISGHARE, IN OUIC FEET PER SECOND, AND RANRING FOR THE INDICATED NUMBER OF CONSEQUTTVE DAUS FOR EACH WATER YEAR, OCTCBER I-SEPTEMBER 30

\begin{tabular}{|c|c|c|c|c|c|c|c|c|c|c|c|c|c|c|c|c|c|c|c|}
\hline YEAR & & & & & & & & & CONS & 1 & VE DAYS & & & & & & & & \\
\hline $\begin{array}{l}1977 \\
1978 \\
1979 \\
1980\end{array}$ & $\begin{array}{c}78.0 \\
1270 \\
980 \\
2640\end{array}$ & $\begin{array}{l}5 \\
2 \\
3 \\
1\end{array}$ & $\begin{array}{c}66.0 \\
1070 \\
798 \\
2330\end{array}$ & $\begin{array}{l}5 \\
2 \\
3 \\
1\end{array}$ & $\begin{array}{c}66.0 \\
887 \\
495 \\
1830\end{array}$ & $\begin{array}{l}5 \\
2 \\
3 \\
1\end{array}$ & $\begin{array}{c}66.0 \\
530 \\
318 \\
1440\end{array}$ & $\begin{array}{l}5 \\
2 \\
3 \\
1\end{array}$ & $\begin{array}{l}65.0 \\
292 \\
241 \\
920\end{array}$ & $\begin{array}{l}5 \\
2 \\
3 \\
1\end{array}$ & $\begin{array}{l}46.0 \\
158 \\
170 \\
546\end{array}$ & $\begin{array}{l}5 \\
3 \\
2 \\
1\end{array}$ & $\begin{array}{l}38.0 \\
114 \\
168 \\
383\end{array}$ & $\begin{array}{l}5 \\
3 \\
2 \\
1\end{array}$ & $\begin{array}{l}34.0 \\
100 \\
146 \\
299\end{array}$ & $\begin{array}{l}5 \\
3 \\
2 \\
1\end{array}$ & $\begin{array}{l}31.0 \\
73.0 \\
110 \\
231\end{array}$ & $\begin{array}{l}5 \\
3 \\
2 \\
1\end{array}$ & $\begin{array}{l}24.0 \\
46.0 \\
69.0 \\
133\end{array}$ \\
\hline 1981 & 515 & 4 & 483 & 4 & 372 & 4 & 317 & 4 & 191 & 4 & 120 & 4 & 90.0 & 4 & 78.0 & 4 & 70.0 & 4 & 58.0 \\
\hline
\end{tabular}

DURATION OF DISCHARGE FOR EACH WATER YEAR

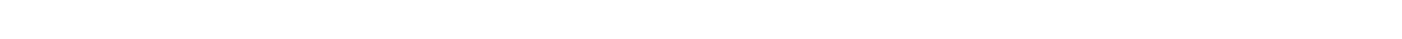

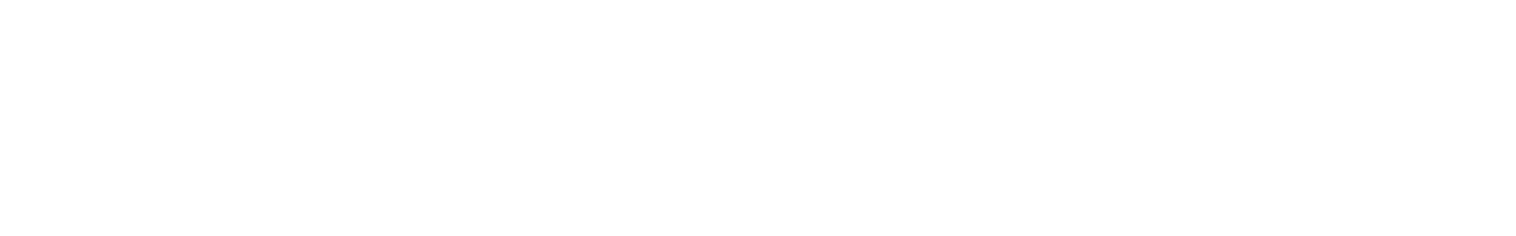

DURATION TABLE OF DISCHARGE FOR WATER YEARS 1977-81

\begin{tabular}{|c|c|c|c|c|c|c|c|c|c|c|c|c|c|c|c|c|c|c|c|}
\hline & $\begin{array}{c}\text { WBIC } \\
\text { FEET } \\
\text { PER }\end{array}$ & TOTAL & $\begin{array}{l}\text { ACOJ- } \\
\text { MU- } \\
\text { LATED }\end{array}$ & $\begin{array}{l}\text { PER- } \\
\text { CENT }\end{array}$ & & $\begin{array}{c}\text { WBIC } \\
\text { FEET } \\
\text { PER }\end{array}$ & TOTAL & $\begin{array}{c}\text { ACW- } \\
\text { MU- } \\
\text { LATED }\end{array}$ & $\begin{array}{l}\text { PER- } \\
\text { CENT }\end{array}$ & & $\begin{array}{c}\text { QUBIC } \\
\text { FEET } \\
\text { PER }\end{array}$ & TOTAL & $\begin{array}{c}\text { ACW- } \\
\text { MU- } \\
\text { LATED }\end{array}$ & $\begin{array}{l}\text { PER- } \\
\text { CENT }\end{array}$ & & $\begin{array}{l}\text { GBIC } \\
\text { FEET } \\
\text { PER }\end{array}$ & & $\begin{array}{l}\text { ACQU- } \\
\text { MU- } \\
\text { LATED }\end{array}$ & $\begin{array}{l}\text { PER- } \\
\text { CENT }\end{array}$ \\
\hline ASS & SECOND & DAYS & DAUS & DAYS & CLASS & SECOND & DAYS & DAYS & DAYS & CLASS & SECOND & DAYS & DAYS & DAYS & CLASS & SECOND & DAYS & DAYS & DAYS \\
\hline $\begin{array}{l}0 \\
1 \\
2 \\
3 \\
4 \\
5 \\
6 \\
7 \\
8\end{array}$ & $\begin{array}{r}0.00 \\
5.30 \\
6.40 \\
7.60 \\
9.20 \\
11.00 \\
13.00 \\
16.00 \\
19.00\end{array}$ & $\begin{array}{r}0 \\
1 \\
7 \\
31 \\
31 \\
72 \\
100 \\
144 \\
195\end{array}$ & $\begin{array}{l}1826 \\
1826 \\
1825 \\
1818 \\
1787 \\
1756 \\
1684 \\
1584 \\
1440\end{array}$ & $\begin{array}{r}100.0 \\
100.0 \\
99.9 \\
99.6 \\
97.9 \\
96.2 \\
92.2 \\
86.7 \\
78.9\end{array}$ & $\begin{array}{l}9 \\
10 \\
11 \\
12 \\
13 \\
14 \\
15 \\
16 \\
17\end{array}$ & $\begin{array}{l}23.00 \\
28.00 \\
33.00 \\
40.00 \\
48.00 \\
57.00 \\
69.00 \\
82.00 \\
99.00\end{array}$ & $\begin{array}{r}220 \\
212 \\
157 \\
136 \\
108 \\
123 \\
57 \\
49 \\
27\end{array}$ & $\begin{array}{r}1245 \\
1025 \\
813 \\
656 \\
520 \\
412 \\
289 \\
232 \\
183\end{array}$ & $\begin{array}{l}68.2 \\
56.1 \\
44.5 \\
35.9 \\
28.5 \\
22.6 \\
15.8 \\
12.7 \\
10.0\end{array}$ & $\begin{array}{l}18 \\
19 \\
20 \\
21 \\
22 \\
23 \\
24 \\
25 \\
26\end{array}$ & $\begin{array}{l}120.0 \\
140.0 \\
170.0 \\
210.0 \\
250.0 \\
300.0 \\
360.0 \\
430.0 \\
510.0\end{array}$ & $\begin{array}{r}26 \\
24 \\
17 \\
11 \\
18 \\
14 \\
7 \\
5 \\
6\end{array}$ & $\begin{array}{r}156 \\
130 \\
106 \\
89 \\
78 \\
60 \\
46 \\
39 \\
34\end{array}$ & $\begin{array}{l}8.5 \\
7.1 \\
5.8 \\
4.9 \\
4.3 \\
3.3 \\
2.5 \\
2.1 \\
1.9\end{array}$ & $\begin{array}{l}27 \\
28 \\
29 \\
30 \\
31 \\
32 \\
33 \\
34\end{array}$ & $\begin{array}{r}620.0 \\
740.0 \\
890.0 \\
1100.0 \\
1300.0 \\
1500.0 \\
1800.0 \\
2200.0\end{array}$ & $\begin{array}{l}7 \\
3 \\
6 \\
5 \\
2 \\
2 \\
1 \\
2\end{array}$ & $\begin{array}{r}28 \\
21 \\
18 \\
12 \\
7 \\
5 \\
3 \\
2\end{array}$ & $\begin{array}{l}0 \\
0\end{array}$ \\
\hline
\end{tabular}

MONHLY MEAN DIS GARGES, IN OUBIC FEET PER SECOND, FOR EACH WATER YEAR

\begin{tabular}{|c|c|c|c|c|c|c|c|c|c|c|c|c|}
\hline YEAR & OCT & NOV & $\mathrm{DEC}$ & JAN & FEB & MAR & APR & MAY & JUNE & JULY & AUG & SEP \\
\hline 1902 & 123 & 126 & 115 & 110 & 100 & 100 & 92 & 740 & 651 & 132 & 40 & 72 \\
\hline $\begin{array}{l}1977 \\
1978 \\
1979 \\
1980\end{array}$ & $\begin{array}{l}31.4 \\
16.8 \\
31.5 \\
22.6\end{array}$ & $\begin{array}{l}17.0 \\
13.6 \\
40.4 \\
20.1\end{array}$ & $\begin{array}{l}21.2 \\
20.6 \\
19.7 \\
28.8\end{array}$ & $\begin{array}{l}48.7 \\
16.5 \\
37.1 \\
41.5\end{array}$ & $\begin{array}{r}42.7 \\
20.5 \\
59.3 \\
127\end{array}$ & $\begin{array}{c}24.2 \\
59.0 \\
223 \\
87.5\end{array}$ & $\begin{array}{c}15.0 \\
22.3 \\
104 \\
39.1\end{array}$ & $\begin{array}{l}19.9 \\
25.3 \\
168 \\
142\end{array}$ & $\begin{array}{l}17.7 \\
291 \\
67.5 \\
901\end{array}$ & $\begin{array}{l}12.3 \\
22.7 \\
27.8 \\
100\end{array}$ & $\begin{array}{l}16.0 \\
23.5 \\
32.3 \\
41.1\end{array}$ & $\begin{array}{l}20.1 \\
24.4 \\
14.6 \\
62.0\end{array}$ \\
\hline 1981 & 71.5 & 71.1 & 73.7 & 50.7 & 53.5 & 38.5 & 24.6 & 75.5 & 164 & 28.2 & 21.5 & 27.1 \\
\hline
\end{tabular}

ANNUAL PEAR DISCHARGE, IN GBIC FEET PER SECOND, AND CORRESPONDING GAGE HEIGHT, IN FEET, FOR EACH WATER YEAR

$\begin{array}{lccccccccccc}\begin{array}{l}\text { WAIER } \\ \text { YEAR }\end{array} & \text { DATE } & \begin{array}{c}\text { GAGE } \\ \text { HEIGHT }\end{array} & \begin{array}{c}\text { PEAK } \\ \text { DISGHARGE }\end{array} & \begin{array}{l}\text { WATER } \\ \text { YEAR }\end{array} & \text { DATE } & \begin{array}{c}\text { GAGE } \\ \text { HEIGHT }\end{array} & \begin{array}{c}\text { PEAK } \\ \text { DISOHARGE }\end{array} & \begin{array}{l}\text { WATER } \\ \text { YEAR }\end{array} & \begin{array}{c}\text { GAGE } \\ \text { DATE }\end{array} & \begin{array}{c}\text { PEAK } \\ \text { HEIGHT }\end{array} \\ \text { DISGAARGE }\end{array}$

$1_{\text {Maximum discharge observed. }}$ 
GREEN RIVER BASIN

09302000 DUCHESNE RIVER NEAR RANDLETT, UT

LOCATION.--Lat $40^{\circ} 12^{\prime} 56^{\prime \prime}$, long $109^{\circ} 46^{\prime} 58^{\prime \prime}$, in SN ${ }^{\frac{1}{2}} \mathrm{SW}^{\frac{1}{4}} \mathrm{SW}^{\frac{1}{4}}$ sec.16, T.3 S., R.2 E., Uintah Meridian, Uintah County, Hydrologic Unit 14060003, Uintah and Ouray Indian Reservation, on left bank $0.25 \mathrm{mi}$ downstream fram Uinta River, $1.2 \mathrm{mi}$ southeast of Randlett, and $6.5 \mathrm{mi}$ southeast of Fort Duchesne.

DRAINAGE AREA. $-4,247 \mathrm{mi}^{2}$.

PERIOD OF RECORD AVAII.ABLE.--October 1942 to September 1981.

REVISED RECORDS. -WDR UT-78-1: Drainage area.

GAGE.-Water-stage recorder. Datum of gage is 4,756.1 ft NGVD of 1929. Prior to Aug. 23, 1944, at site $300 \mathrm{ft}$ downstream at different datum. Aug. 23, 1944 to Sept. 4, 1964, at site $200 \mathrm{ft}$ upstream at datum $1.87 \mathrm{ft}$ higher. Sept. 5, 1964 to June 6 , 1968 , at site $700 \mathrm{ft}$ upstream at datum $1.68 \mathrm{ft}$ higher. June 7,1968 to Aug. 31, 1970, at site $200 \mathrm{ft}$ upstream at datum $1.87 \mathrm{ft}$ 1968 , at site $700 \mathrm{ft}$ upstream at datum $1.68 \mathrm{ft}$ higher. June 7,1968 to Aug. 31 , 1970 , at
higher. Sept. 1, 1970 to June 7,1975 , at site $300 \mathrm{ft}$ upstream at datum $1.87 \mathrm{ft}$ higher.

REMARKS.-Flow regulated by several reservoirs. Large diversions above station for irrigation, including transmountain diversions to the Great Basin through Duchesne and Strawberry tunnels, Hobble Creek ditch, Strawberry River, and Willow Creek ditch.

AVERAGE DISGHARGE.--39 years, $550 \mathrm{ft}^{3} / \mathrm{s}, 398,500$ acre-ft/yr.

EXIREMES FOR PERIOD OF RECORD.--Maximum discharge, 10,300 $\mathrm{ft}^{3} / \mathrm{s}$ June 13, 1965, gage height, $8.33 \mathrm{ft}$, site and datum then in use; maximum gage height, $9.03 \mathrm{ft}$ Feb. 13, 1962 (backwater from ice); minimum discharge, $2.2 \mathrm{ft}^{3} / \mathrm{s} \mathrm{Aug.} 12,1961$.

LOWEST MEAN DISGHARGE, IN CUBIC FEET PER SECOND, AND RANKING FOR THE INDICATED NUMBER OF CONSECUTIVE DAYS FOR EACH CLIMATIC YEAR, APRII 1-MARCH 31

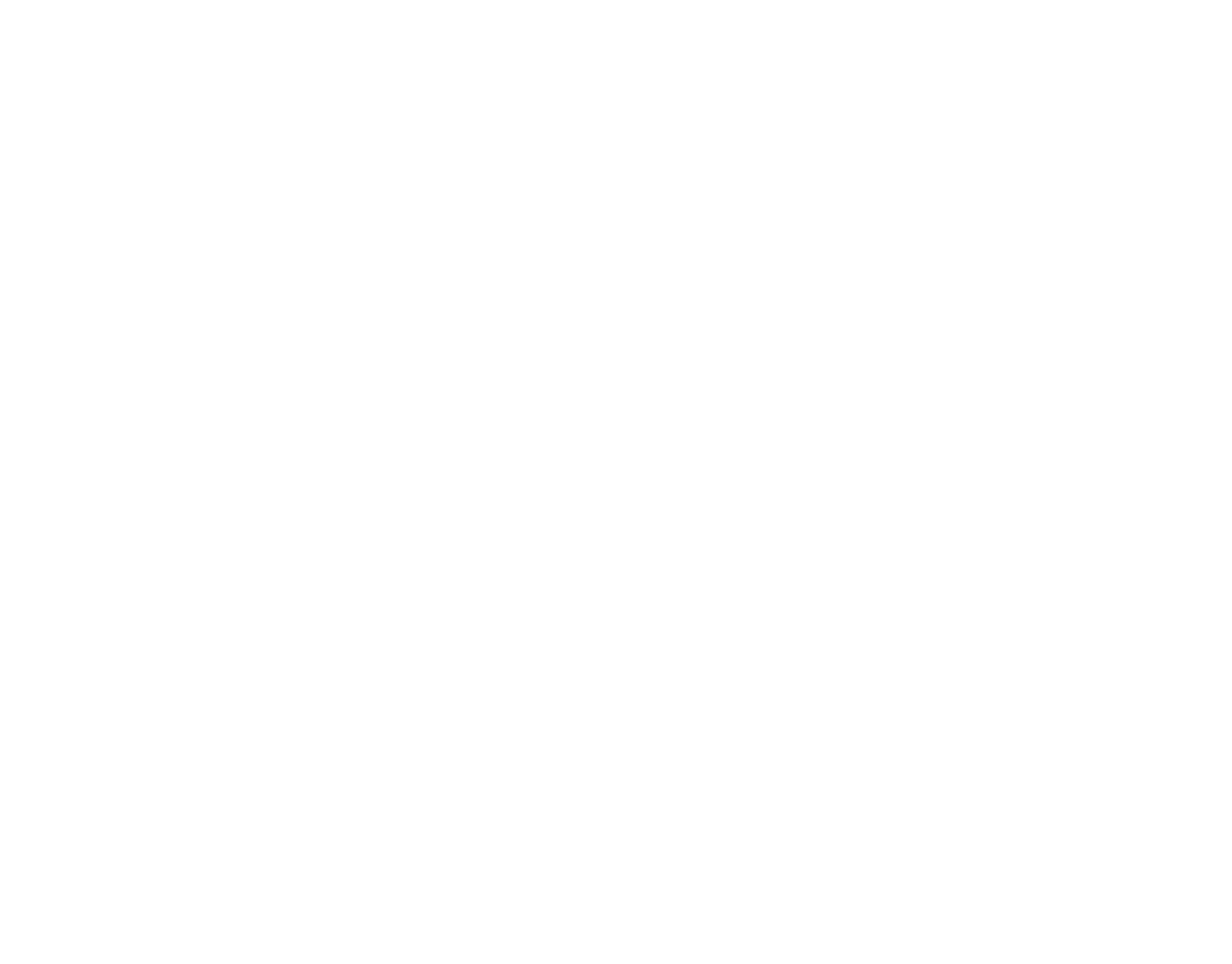


GREEN RIVER BASIN

09302000 DUGESNE RIVER NEAR RANDLETT, UT--Continued

HIGHEST MEAN DISCHARGE, IN QBIC FEET PER SECOND, AND RANKING FOR THE INDICATED NUMBER OF CONSEQUTIVE DAYS FOR EAOH WATER YEAR, OCTCBER 1-SEPTEMBER 30

\begin{tabular}{|c|c|c|c|c|c|c|c|c|c|c|c|c|c|c|c|c|c|c|c|c|}
\hline YEAR & \multicolumn{2}{|c|}{1} & \multicolumn{2}{|c|}{3} & \multicolumn{2}{|c|}{7} & \multicolumn{2}{|c|}{15} & a & ECH & IVE & & 90 & & \multicolumn{2}{|c|}{120} & 183 & & \multicolumn{2}{|l|}{ ALL } \\
\hline $\begin{array}{l}1946 \\
1947 \\
1948 \\
1949 \\
1950\end{array}$ & $\begin{array}{l}1650 \\
4150 \\
2540 \\
8230 \\
5170\end{array}$ & $\begin{array}{r}31 \\
19 \\
27 \\
3 \\
12\end{array}$ & $\begin{array}{l}1590 \\
3630 \\
2470 \\
7400 \\
4920\end{array}$ & $\begin{array}{r}31 \\
19 \\
27 \\
3 \\
12\end{array}$ & $\begin{array}{l}1470 \\
3220 \\
2410 \\
6320 \\
4250\end{array}$ & $\begin{array}{r}30 \\
19 \\
24 \\
4 \\
12\end{array}$ & $\begin{array}{l}1380 \\
2970 \\
2100 \\
5470 \\
3780\end{array}$ & $\begin{array}{r}30 \\
16 \\
24 \\
4 \\
12\end{array}$ & $\begin{array}{l}1260 \\
2880 \\
1670 \\
4050 \\
3550\end{array}$ & $\begin{array}{r}27 \\
13 \\
24 \\
6 \\
8\end{array}$ & $\begin{array}{l}1120 \\
2550 \\
1030 \\
3040 \\
2490\end{array}$ & $\begin{array}{r}23 \\
8 \\
26 \\
5 \\
9\end{array}$ & $\begin{array}{r}881 \\
1890 \\
918 \\
2380 \\
1940\end{array}$ & $\begin{array}{r}25 \\
9 \\
24 \\
4 \\
8\end{array}$ & $\begin{array}{r}785 \\
1530 \\
813 \\
1970 \\
1600\end{array}$ & $\begin{array}{r}25 \\
10 \\
24 \\
4 \\
7\end{array}$ & $\begin{array}{r}647 \\
1200 \\
691 \\
1450 \\
1240\end{array}$ & $\begin{array}{r}28 \\
10 \\
25 \\
4 \\
7\end{array}$ & $\begin{array}{l}437 \\
787 \\
456 \\
833 \\
803\end{array}$ & $\begin{array}{r}26 \\
9 \\
24 \\
5\end{array}$ \\
\hline $\begin{array}{l}1951 \\
1952 \\
1953 \\
1954 \\
1955\end{array}$ & $\begin{array}{l}4600 \\
8400 \\
4480 \\
1280 \\
1640\end{array}$ & $\begin{array}{r}14 \\
2 \\
15 \\
35 \\
32\end{array}$ & $\begin{array}{l}4470 \\
8240 \\
4110 \\
1190 \\
1590\end{array}$ & $\begin{array}{r}14 \\
2 \\
16 \\
35 \\
32\end{array}$ & $\begin{array}{r}3830 \\
7910 \\
3480 \\
995 \\
1280\end{array}$ & $\begin{array}{r}15 \\
1 \\
17 \\
35 \\
33\end{array}$ & $\begin{array}{r}2760 \\
7090 \\
2630 \\
903 \\
996\end{array}$ & $\begin{array}{c}18 \\
1 \\
22 \\
34 \\
33\end{array}$ & $\begin{array}{r}2520 \\
5740 \\
1820 \\
620 \\
851\end{array}$ & $\begin{array}{r}15 \\
2 \\
23 \\
35 \\
33\end{array}$ & $\begin{array}{r}1760 \\
5050 \\
1060 \\
451 \\
685\end{array}$ & $\begin{array}{r}17 \\
1 \\
24 \\
35 \\
30\end{array}$ & $\begin{array}{r}1350 \\
4030 \\
774 \\
448 \\
603\end{array}$ & $\begin{array}{r}16 \\
1 \\
28 \\
34 \\
30\end{array}$ & $\begin{array}{r}1090 \\
3300 \\
701 \\
423 \\
575\end{array}$ & $\begin{array}{r}16 \\
1 \\
29 \\
32 \\
30\end{array}$ & $\begin{array}{r}838 \\
2400 \\
673 \\
415 \\
505\end{array}$ & $\begin{array}{r}16 \\
1 \\
26 \\
32 \\
30\end{array}$ & $\begin{array}{r}601 \\
1430 \\
490 \\
264 \\
342\end{array}$ & $\begin{array}{r}14 \\
1 \\
19 \\
35 \\
29\end{array}$ \\
\hline $\begin{array}{l}1956 \\
1957 \\
1958 \\
1959 \\
1960\end{array}$ & $\begin{array}{r}3560 \\
5820 \\
6160 \\
1120 \\
845\end{array}$ & $\begin{array}{r}21 \\
9 \\
7 \\
36 \\
38\end{array}$ & $\begin{array}{r}3440 \\
5750 \\
5910 \\
1060 \\
810\end{array}$ & $\begin{array}{r}20 \\
8 \\
7 \\
36 \\
37\end{array}$ & $\begin{array}{r}3160 \\
5140 \\
5410 \\
932 \\
735\end{array}$ & $\begin{array}{r}20 \\
8 \\
6 \\
36 \\
37\end{array}$ & $\begin{array}{r}2760 \\
3990 \\
4510 \\
787 \\
614\end{array}$ & $\begin{array}{r}19 \\
10 \\
7 \\
36 \\
37\end{array}$ & $\begin{array}{r}2270 \\
3140 \\
3360 \\
581 \\
525\end{array}$ & $\begin{array}{l}19 \\
12 \\
10 \\
36 \\
37\end{array}$ & $\begin{array}{r}1390 \\
1980 \\
2050 \\
404 \\
427\end{array}$ & $\begin{array}{l}20 \\
14 \\
12 \\
37 \\
36\end{array}$ & $\begin{array}{r}1010 \\
1440 \\
1550 \\
378 \\
405\end{array}$ & $\begin{array}{l}21 \\
14 \\
13 \\
37 \\
36\end{array}$ & $\begin{array}{r}868 \\
1170 \\
1300 \\
371 \\
393\end{array}$ & $\begin{array}{l}20 \\
15 \\
13 \\
36\end{array}$ & $\begin{array}{r}723 \\
865 \\
1020 \\
297 \\
354\end{array}$ & $\begin{array}{l}22 \\
15 \\
13 \\
37 \\
35\end{array}$ & $\begin{array}{l}432 \\
561 \\
643 \\
223 \\
236\end{array}$ & $\begin{array}{l}27 \\
17 \\
12 \\
37 \\
36\end{array}$ \\
\hline $\begin{array}{l}1961 \\
1962 \\
1963 \\
1964 \\
1965\end{array}$ & $\begin{array}{r}936 \\
4300 \\
1630 \\
4150 \\
9460\end{array}$ & $\begin{array}{c}37 \\
17 \\
33 \\
18 \\
1\end{array}$ & $\begin{array}{r}645 \\
4040 \\
1490 \\
3670 \\
8860\end{array}$ & $\begin{array}{c}38 \\
17 \\
33 \\
18 \\
1\end{array}$ & $\begin{array}{r}517 \\
3540 \\
1350 \\
3060 \\
7760\end{array}$ & $\begin{array}{r}38 \\
16 \\
32 \\
21 \\
2\end{array}$ & $\begin{array}{r}363 \\
3130 \\
1040 \\
2640 \\
6640\end{array}$ & $\begin{array}{r}38 \\
15 \\
32 \\
21 \\
2\end{array}$ & $\begin{array}{r}350 \\
2520 \\
1010 \\
2300 \\
5830\end{array}$ & $\begin{array}{c}38 \\
16 \\
30 \\
18 \\
1\end{array}$ & $\begin{array}{r}338 \\
1990 \\
682 \\
1780 \\
4000\end{array}$ & $\begin{array}{r}38 \\
13 \\
31 \\
15 \\
2\end{array}$ & $\begin{array}{r}319 \\
1710 \\
480 \\
1250 \\
3100\end{array}$ & $\begin{array}{r}38 \\
12 \\
32 \\
18 \\
2\end{array}$ & $\begin{array}{r}305 \\
1520 \\
399 \\
1020 \\
2530\end{array}$ & $\begin{array}{r}38 \\
11 \\
34 \\
17 \\
2\end{array}$ & $\begin{array}{r}232 \\
1190 \\
396 \\
781 \\
1920\end{array}$ & $\begin{array}{r}38 \\
11 \\
33 \\
17 \\
2\end{array}$ & $\begin{array}{r}147 \\
726 \\
300 \\
483 \\
1130\end{array}$ & $\begin{array}{c}38 \\
11 \\
32 \\
21 \\
2\end{array}$ \\
\hline $\begin{array}{l}1966 \\
1967 \\
1968 \\
1969 \\
1970\end{array}$ & $\begin{array}{l}2170 \\
7200 \\
6550 \\
5860 \\
3010\end{array}$ & $\begin{array}{r}30 \\
4 \\
6 \\
8 \\
25\end{array}$ & $\begin{array}{l}1860 \\
7010 \\
6240 \\
5150 \\
2500\end{array}$ & $\begin{array}{r}30 \\
4 \\
5 \\
10 \\
25\end{array}$ & $\begin{array}{l}1460 \\
6660 \\
5800 \\
4150 \\
1790\end{array}$ & $\begin{array}{r}31 \\
3 \\
5 \\
13 \\
29\end{array}$ & $\begin{array}{l}1120 \\
5680 \\
4840 \\
3840 \\
1430\end{array}$ & $\begin{array}{r}31 \\
3 \\
6 \\
11 \\
29\end{array}$ & $\begin{array}{l}1000 \\
4550 \\
4200 \\
3150 \\
1120\end{array}$ & $\begin{array}{r}31 \\
3 \\
5 \\
11 \\
29\end{array}$ & $\begin{array}{r}782 \\
3110 \\
2490 \\
2690 \\
673\end{array}$ & $\begin{array}{r}29 \\
4 \\
10 \\
7 \\
32\end{array}$ & $\begin{array}{r}776 \\
2170 \\
1850 \\
2180 \\
473\end{array}$ & $\begin{array}{r}27 \\
6 \\
10 \\
5 \\
33\end{array}$ & $\begin{array}{r}749 \\
1700 \\
1540 \\
1850 \\
367\end{array}$ & $\begin{array}{r}26 \\
6 \\
9 \\
5 \\
37\end{array}$ & $\begin{array}{r}721 \\
1320 \\
1210 \\
1450 \\
332\end{array}$ & $\begin{array}{r}23 \\
6 \\
8 \\
5 \\
36\end{array}$ & $\begin{array}{l}528 \\
814 \\
770 \\
889 \\
273\end{array}$ & $\begin{array}{r}18 \\
6 \\
10 \\
4 \\
34\end{array}$ \\
\hline $\begin{array}{l}1971 \\
1972 \\
1973 \\
1974 \\
1975\end{array}$ & $\begin{array}{l}4430 \\
3360 \\
4700 \\
2510 \\
5180\end{array}$ & $\begin{array}{l}16 \\
23 \\
13 \\
28 \\
11\end{array}$ & $\begin{array}{l}4310 \\
3040 \\
4540 \\
2420 \\
4960\end{array}$ & $\begin{array}{l}15 \\
23 \\
13 \\
28 \\
11\end{array}$ & $\begin{array}{l}4100 \\
2920 \\
4360 \\
2110 \\
4750\end{array}$ & $\begin{array}{r}14 \\
22 \\
11 \\
26 \\
9\end{array}$ & $\begin{array}{l}3450 \\
2770 \\
3560 \\
1710 \\
4190\end{array}$ & $\begin{array}{r}14 \\
17 \\
13 \\
26 \\
8\end{array}$ & $\begin{array}{l}2380 \\
2160 \\
3410 \\
1360 \\
3880\end{array}$ & $\begin{array}{r}17 \\
20 \\
9 \\
26 \\
7\end{array}$ & $\begin{array}{r}1500 \\
1280 \\
2210 \\
974 \\
2720\end{array}$ & $\begin{array}{c}19 \\
21 \\
11 \\
28 \\
6\end{array}$ & $\begin{array}{r}1060 \\
923 \\
1770 \\
772 \\
1940\end{array}$ & $\begin{array}{r}19 \\
23 \\
11 \\
29 \\
7\end{array}$ & $\begin{array}{r}861 \\
846 \\
1550 \\
748 \\
1500\end{array}$ & $\begin{array}{r}21 \\
23 \\
8 \\
27 \\
12\end{array}$ & $\begin{array}{r}731 \\
725 \\
1200 \\
652 \\
1020\end{array}$ & $\begin{array}{r}19 \\
21 \\
9 \\
27 \\
12\end{array}$ & $\begin{array}{l}431 \\
483 \\
806 \\
464 \\
578\end{array}$ & $\begin{array}{r}28 \\
22 \\
7 \\
23 \\
15\end{array}$ \\
\hline
\end{tabular}

DURATION OF DISCHARGE FOR EACH WATER YEAR

$\begin{array}{lllllllllllllllllllllllllllllllllllllll}\text { CASS } & 0 & 1 & 2 & 3 & 4 & 5 & 6 & 7 & 8 & 9 & 10 & 11 & 12 & 13 & 14 & 15 & 16 & 17 & 18 & 19 & 20 & 21 & 22 & 23 & 24 & 25 & 26 & 27 & 28 & 29 & 30 & 31 & 32 & 33 & 34\end{array}$ YEAR

NUMBER OF DAYS IN OLASS GBIC FEET

1943

1944

$$
\begin{array}{rrrrrrrrrrrrrrrrrrrr} 
& 12 & 14 & 14 & 8 & 21 & 58 & 110 & 42 & 12 & 8 & 21 & 21 & 11 & 8 & 4 & 1 & & & \\
10 & 31 & 9 & 10 & 10 & 15 & 48 & 83 & 31 & 28 & 19 & 7 & 5 & 9 & 9 & 9 & 15 & 16 & 1 & 1
\end{array}
$$$$
\begin{array}{rrrrrrrrrrrrr}
9 & 10 & 10 & 15 & 48 & 83 & 31 & 28 & 19 & 7 & 5 & 9 & 9 \\
7 & 6 & 15 & 19 & 51 & 125 & 67 & 18 & 13 & 19 & 15 & 7 & 3
\end{array}
$$

1946
1947

1947
1948

1949

1950

1951

1952

1953

1955 -DAYS

230314.0 348333.0 208714.0

159493.0 287393.0 166753.0 304146.0
293003.0

219206.0 524860.0 178937.0

96514.0

158075.0 204930.0 204930.0
234791.0 81354.0

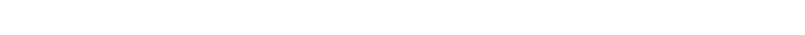

86354.2 
GREEN RIVER BASIN

09302000 DUCHESNE RIVER NEAR RANDLETT, UT-Continued

DURATION OF DISCHARGE FOR EACH WATER YEAR--Continued

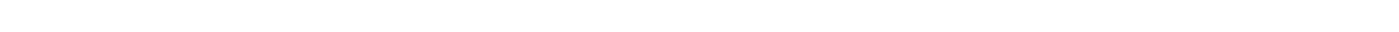

\begin{tabular}{|c|c|c|c|c|c|c|c|c|c|c|c|c|c|c|c|c|c|c|c|c|c|c|c|c|c|c|c|c|c|c|}
\hline YEAR & & & & & & & & & & L & No & DAYS & $S$ IN & QLAs & SS & & & & & & & & & & & & & & & $\begin{array}{l}\text { PER SECOND } \\
\text {-DAYS }\end{array}$ \\
\hline $\begin{array}{l}1961 \\
1962 \\
1963 \\
1964 \\
1965\end{array}$ & 6 & 71410181 & & 1112 & & 18 & $\begin{array}{r}13 \\
14 \\
13 \\
1\end{array}$ & $\begin{array}{r}14 \\
16 \\
12 \\
20 \\
4\end{array}$ & $\begin{array}{l}11 \\
15 \\
16 \\
19 \\
11\end{array}$ & $\begin{array}{l}25 \\
14 \\
29 \\
28 \\
10\end{array}$ & $\begin{array}{r}11 \\
8 \\
16 \\
22 \\
2\end{array}$ & $\begin{array}{r}11 \\
4 \\
12 \\
16 \\
8\end{array}$ & $\begin{array}{r}7 \\
6 \\
38 \\
26 \\
8\end{array}$ & $\begin{array}{r}16 \\
10 \\
40 \\
23 \\
2\end{array}$ & $\begin{array}{r}60 \\
12 \\
59 \\
44 \\
5\end{array}$ & $\begin{array}{l}57 \\
60 \\
24 \\
93 \\
39\end{array}$ & $\begin{array}{r}4 \\
49 \\
24 \\
20 \\
111\end{array}$ & $\begin{array}{rr}2 & \\
26 & 21 \\
25 & 12 \\
4 & 2 \\
34 & 15\end{array}$ & $\begin{array}{l}21 \\
2 \\
2 \\
2 \\
51\end{array}$ & $\begin{array}{rl}1 & \\
24 & 2 \\
8 & 1 \\
2 & \\
10 & 2\end{array}$ & $\begin{array}{r}21 \\
14 \\
4 \\
23\end{array}$ & $\begin{array}{cl}27 & 1 \\
4 & \\
10 & 1 \\
24 & 1\end{array}$ & $\begin{array}{l}12 \\
17\end{array}$ & $\begin{array}{l}9 \\
4\end{array}$ & $\begin{array}{l}8 \\
3\end{array}$ & $\begin{array}{l}3 \\
81\end{array}$ & 13 & 7 & 6 & $\begin{array}{r}53678.8 \\
264990.0 \\
109474.0 \\
176680.0 \\
413438.0\end{array}$ \\
\hline $\begin{array}{l}1966 \\
1967 \\
1968 \\
1969 \\
1970\end{array}$ & & & & 7 & 1 & 6 & 22 & 37 & $\begin{array}{r}13 \\
3\end{array}$ & $\begin{array}{r}14 \\
4\end{array}$ & $\begin{array}{r}11 \\
12 \\
5 \\
11 \\
16\end{array}$ & $\begin{array}{l}10 \\
24 \\
10 \\
18 \\
17\end{array}$ & $\begin{array}{r}3 \\
42 \\
22 \\
34 \\
8\end{array}$ & $\begin{array}{l}7 \\
25 \\
25 \\
18 \\
42\end{array}$ & $\begin{array}{r}5 \\
26 \\
40 \\
22 \\
43\end{array}$ & $\begin{array}{l}11 \\
29 \\
20 \\
11 \\
44\end{array}$ & $\begin{array}{l}9 \\
46 \\
351 \\
33 \\
36\end{array}$ & $\begin{array}{r}66109 \\
7228 \\
12937 \\
3673 \\
7 \quad 4\end{array}$ & $\begin{array}{l}93 \\
28 \\
37 \\
731 \\
4\end{array}$ & $\begin{array}{rl}32 & 1 \\
5 \\
9 \\
17 \\
6\end{array}$ & $\begin{array}{r}19 \\
1 \\
2 \\
25 \\
9\end{array}$ & $\begin{array}{r}4 \\
5 \\
1 \\
201 \\
3\end{array}$ & $\begin{array}{r}1 \\
3 \\
2 \\
12 \\
2\end{array}$ & $\begin{array}{l}1 \\
7 \\
5 \\
8 \\
1\end{array}$ & $\begin{array}{ll}10 & 1 \\
6 \\
91 \\
1\end{array}$ & $\begin{array}{r}11 \\
3 \\
13\end{array}$ & $\begin{array}{l}3 \\
9 \\
4\end{array}$ & $\begin{array}{l}7 \\
6 \\
1\end{array}$ & 2 & $\begin{array}{r}192635.0 \\
297144.0 \\
281846.0 \\
324601.0 \\
99595.0\end{array}$ \\
\hline $\begin{array}{l}1971 \\
1972 \\
1973 \\
1974 \\
1975\end{array}$ & & & & & & $\begin{array}{l}5 \\
2\end{array}$ & $\begin{array}{l}12 \\
14\end{array}$ & $\begin{array}{r}6 \\
25 \\
\\
2 \\
7\end{array}$ & $\begin{array}{r}8 \\
19 \\
16 \\
15\end{array}$ & $\begin{array}{r}13 \\
17 \\
2 \\
11 \\
36\end{array}$ & $\begin{array}{r}50 \\
11 \\
5 \\
4 \\
61\end{array}$ & $\begin{array}{r}41 \\
7 \\
13 \\
9 \\
43\end{array}$ & $\begin{array}{l}51 \\
17 \\
12 \\
21 \\
87\end{array}$ & $\begin{array}{l}26 \\
18 \\
21 \\
28 \\
27\end{array}$ & $\begin{array}{l}33 \\
22 \\
18 \\
40 \\
10\end{array}$ & $\begin{array}{r}32 \\
33 \\
17 \\
26 \\
5\end{array}$ & $\begin{array}{c}17 \\
76 \\
391 \\
98 \\
6\end{array}$ & $\begin{array}{rr}10 & 23 \\
43 & 29 \\
112 & 38 \\
47 & 20 \\
4 & 6\end{array}$ & $\begin{array}{l}23 \\
29 \\
382 \\
201 \\
6\end{array}$ & $\begin{array}{c}8 \\
3 \\
291 \\
191 \\
6\end{array}$ & $\begin{array}{r}5 \\
5 \\
14 \\
12 \\
2\end{array}$ & $\begin{array}{l}6 \\
6 \\
9 \\
5 \\
4\end{array}$ & $\begin{array}{l}4 \\
4 \\
4 \\
4 \\
3\end{array}$ & $\begin{array}{l}2 \\
6 \\
8 \\
3 \\
3 \\
5 \\
1\end{array}$ & $\begin{array}{c}4 \\
9 \\
101 \\
121\end{array}$ & $\begin{array}{c}8 \\
11 \\
121\end{array}$ & $\begin{array}{r}3 \\
10\end{array}$ & & & $\begin{array}{l}157196.0 \\
176773.0 \\
294062.0 \\
169446.0 \\
210924.0\end{array}$ \\
\hline $\begin{array}{l}1976 \\
1977 \\
1978 \\
1979 \\
1980\end{array}$ & & & 4 & 823 & $\begin{array}{r}23 \\
1\end{array}$ & $\begin{array}{r}25 \\
6\end{array}$ & $\begin{array}{l}13 \\
27 \\
24\end{array}$ & $\begin{array}{l}28 \\
31 \\
35\end{array}$ & $\begin{array}{r}22 \\
20 \\
43 \\
8 \\
7\end{array}$ & $\begin{array}{l}21 \\
25 \\
39 \\
11 \\
32\end{array}$ & $\begin{array}{l}15 \\
37 \\
21 \\
13 \\
42\end{array}$ & $\begin{array}{r}13 \\
50 \\
32 \\
2 \\
33\end{array}$ & $\begin{array}{r}14 \\
62 \\
4 \\
15 \\
60\end{array}$ & $\begin{array}{l}27 \\
16 \\
10 \\
37 \\
37\end{array}$ & $\begin{array}{l}33 \\
14 \\
64 \\
61 \\
46\end{array}$ & $\begin{array}{l}23 \\
42 \\
38\end{array}$ & $\begin{array}{r}16 \\
53 \\
6\end{array}$ & $\begin{array}{lr}18 & 6 \\
41 & 24 \\
10 & 7\end{array}$ & $\begin{array}{l}6 \\
24 \\
7\end{array}$ & $\begin{array}{r}1 \\
22 \\
5\end{array}$ & $\begin{array}{r}2 \\
23 \\
6\end{array}$ & $\begin{array}{l}3 \\
7 \\
6\end{array}$ & $\begin{array}{l}6 \\
3 \\
2\end{array}$ & $\begin{array}{l}3 \\
2 \\
3\end{array}$ & $\begin{array}{l}6 \\
1 \\
4\end{array}$ & 7 & 4 & 1 & & $\begin{array}{r}112046.0 \\
35044.0 \\
114936.0 \\
178617.0 \\
163017.0\end{array}$ \\
\hline 98 & & & & & & & 3 & 32 & 33 & 37 & 30 & 19 & 40 & 23 & 27 & 34 & 49 & 22 & 2 & 1 & 1 & 4 & 4 & 4 & & & & & & 103551.0 \\
\hline
\end{tabular}

DURATION TFBLE OF DISGHARGE FOR WATER YEARS 1943-81

\begin{tabular}{|c|c|c|c|c|c|c|c|c|c|c|c|c|c|c|c|c|c|c|c|}
\hline CASS & $\begin{array}{c}\text { CUBIC } \\
\text { FEET } \\
\text { PER } \\
\text { SECOND }\end{array}$ & $\begin{array}{l}\text { TOTAL } \\
\text { DALS }\end{array}$ & $\begin{array}{c}\text { ACOJ- } \\
\text { MU- } \\
\text { LATED } \\
\text { DAYS }\end{array}$ & $\begin{array}{l}\text { PER- } \\
\text { CENT } \\
\text { DAYS }\end{array}$ & & $\begin{array}{c}\text { CBIC } \\
\text { FEET } \\
\text { PER } \\
\text { SECOND }\end{array}$ & $\begin{array}{l}\text { TOTAL } \\
\text { DAYS }\end{array}$ & $\begin{array}{c}\text { ACU- } \\
\text { MU- } \\
\text { LATED } \\
\text { DAYS }\end{array}$ & $\begin{array}{l}\text { PER- } \\
\text { CENT } \\
\text { DAYS }\end{array}$ & & $\begin{array}{c}\text { OBIC } \\
\text { FEET } \\
\text { PER } \\
\text { SECOND }\end{array}$ & $\begin{array}{c}\text { TOTAL } \\
\text { DAYS }\end{array}$ & $\begin{array}{l}\text { ACU- } \\
\text { MU- } \\
\text { LATED } \\
\text { DAYS }\end{array}$ & $\begin{array}{l}\text { PER- } \\
\text { CENT } \\
\text { DAYS }\end{array}$ & CASS & $\begin{array}{c}\text { OBBIC } \\
\text { FEET } \\
\text { PER } \\
\text { SECOND }\end{array}$ & $\begin{array}{l}\text { TOTAL } \\
\text { DAYS }\end{array}$ & $\begin{array}{l}\text { ACQU- } \\
\text { MU- } \\
\text { LATED } \\
\text { DAYS }\end{array}$ & $\begin{array}{l}\text { PER- } \\
\text { CENT } \\
\text { DAYS }\end{array}$ \\
\hline $\begin{array}{l}0 \\
1 \\
2 \\
3 \\
4 \\
5 \\
6 \\
7 \\
8\end{array}$ & $\begin{array}{r}0.00 \\
3.20 \\
4.10 \\
5.20 \\
6.60 \\
8.40 \\
11.00 \\
14.00 \\
17.00\end{array}$ & $\begin{array}{r}0 \\
6 \\
7 \\
14 \\
10 \\
25 \\
60 \\
66 \\
167\end{array}$ & $\begin{array}{l}14245 \\
14245 \\
14239 \\
14232 \\
14218 \\
14208 \\
14183 \\
14123 \\
14057\end{array}$ & $\begin{array}{r}100.0 \\
100.0 \\
100.0 \\
99.9 \\
99.8 \\
99.7 \\
99.6 \\
99.1 \\
98.7\end{array}$ & $\begin{array}{r}9 \\
10 \\
11 \\
12 \\
13 \\
14 \\
15 \\
16 \\
17\end{array}$ & $\begin{array}{r}22.00 \\
28.00 \\
35.00 \\
45.00 \\
57.00 \\
73.00 \\
93.00 \\
120.00 \\
150.00\end{array}$ & $\begin{array}{l}158 \\
193 \\
294 \\
397 \\
409 \\
545 \\
552 \\
613 \\
822\end{array}$ & $\begin{array}{l}13890 \\
13732 \\
13539 \\
13245 \\
12848 \\
12439 \\
11894 \\
11342 \\
10729\end{array}$ & $\begin{array}{l}97.5 \\
96.4 \\
95.0 \\
93.0 \\
90.2 \\
87.3 \\
83.5 \\
79.6 \\
75.3\end{array}$ & $\begin{array}{l}18 \\
19 \\
20 \\
21 \\
22 \\
23 \\
24 \\
25 \\
26\end{array}$ & $\begin{array}{r}190.0 \\
240.0 \\
310.0 \\
390.0 \\
500.0 \\
640.0 \\
810.0 \\
1000.0 \\
1300.0\end{array}$ & $\begin{array}{r}791 \\
1147 \\
1572 \\
2164 \\
1551 \\
803 \\
356 \\
351 \\
284\end{array}$ & $\begin{array}{l}9907 \\
9116 \\
7969 \\
6397 \\
4233 \\
2682 \\
1879 \\
1523 \\
1172\end{array}$ & $\begin{array}{l}69.5 \\
64.0 \\
55.9 \\
44.9 \\
29.7 \\
18.8 \\
13.2 \\
10.7 \\
8.2\end{array}$ & $\begin{array}{l}27 \\
28 \\
29 \\
30 \\
31 \\
32 \\
33 \\
34\end{array}$ & $\begin{array}{l}1700.0 \\
2100.0 \\
2700.0 \\
3400.0 \\
4400.0 \\
5500.0 \\
7000.0 \\
9000.0\end{array}$ & $\begin{array}{r}188 \\
193 \\
191 \\
154 \\
90 \\
51 \\
20 \\
1\end{array}$ & $\begin{array}{r}888 \\
700 \\
507 \\
316 \\
162 \\
72 \\
21 \\
1\end{array}$ & $\begin{array}{l}6.2 \\
4.9 \\
3.6 \\
2.2 \\
1.1 \\
0.5 \\
0.1 \\
0.0\end{array}$ \\
\hline
\end{tabular}

MONTHLY MEAN DISCHARGES, IN OBIC FEET PER SECOND, FOR EACH WATER YEAR

\begin{tabular}{|c|c|c|c|c|c|c|c|c|c|c|c|c|}
\hline YEAR & OCr & NOV & $\mathrm{DEC}$ & JAN & FEB & MAR & APR & MAY & JUNE & JULY & AUG & SEP \\
\hline $\begin{array}{l}1943 \\
1944 \\
1945\end{array}$ & $\begin{array}{l}291 \\
361 \\
385\end{array}$ & $\begin{array}{l}367 \\
398 \\
439\end{array}$ & $\begin{array}{l}449 \\
406 \\
459\end{array}$ & $\begin{array}{l}428 \\
377 \\
493\end{array}$ & $\begin{array}{l}515 \\
450 \\
486\end{array}$ & $\begin{array}{l}477 \\
706 \\
523\end{array}$ & $\begin{array}{l}719 \\
811 \\
399\end{array}$ & $\begin{array}{r}1625 \\
2083 \\
963\end{array}$ & $\begin{array}{l}1728 \\
4285 \\
1523\end{array}$ & $\begin{array}{r}462 \\
1331 \\
496\end{array}$ & $\begin{array}{l}377 \\
122 \\
502\end{array}$ & $\begin{array}{l}137 \\
117 \\
195\end{array}$ \\
\hline $\begin{array}{l}1946 \\
1947 \\
1948 \\
1949 \\
1950\end{array}$ & $\begin{array}{l}337 \\
268 \\
281 \\
78.2 \\
398\end{array}$ & $\begin{array}{l}433 \\
541 \\
491 \\
234 \\
491\end{array}$ & $\begin{array}{l}389 \\
494 \\
503 \\
418 \\
454\end{array}$ & $\begin{array}{l}380 \\
416 \\
475 \\
390 \\
500\end{array}$ & $\begin{array}{l}379 \\
643 \\
450 \\
411 \\
474\end{array}$ & $\begin{array}{l}476 \\
577 \\
644 \\
715 \\
648\end{array}$ & $\begin{array}{l}670 \\
392 \\
528 \\
773 \\
744\end{array}$ & $\begin{array}{l}1145 \\
2333 \\
1140 \\
2071 \\
1586\end{array}$ & $\begin{array}{r}783 \\
2661 \\
850 \\
3873 \\
3248\end{array}$ & $\begin{array}{c}85.3 \\
531 \\
50.4 \\
809 \\
734\end{array}$ & $\begin{array}{c}98.8 \\
399 \\
33.6 \\
109 \\
147\end{array}$ & $\begin{array}{l}68.1 \\
199 \\
22.5 \\
133 \\
225\end{array}$ \\
\hline $\begin{array}{l}1951 \\
1952 \\
1953 \\
1954 \\
1955\end{array}$ & $\begin{array}{l}252 \\
406 \\
337 \\
146 \\
272\end{array}$ & $\begin{array}{l}451 \\
544 \\
434 \\
342 \\
307\end{array}$ & $\begin{array}{l}530 \\
529 \\
600 \\
421 \\
289\end{array}$ & $\begin{array}{l}425 \\
450 \\
640 \\
441 \\
400\end{array}$ & $\begin{array}{l}470 \\
460 \\
600 \\
446 \\
380\end{array}$ & $\begin{array}{l}371 \\
508 \\
559 \\
328 \\
550\end{array}$ & $\begin{array}{r}241 \\
1865 \\
212 \\
225 \\
377\end{array}$ & $\begin{array}{r}1288 \\
4938 \\
245 \\
592 \\
739\end{array}$ & $\begin{array}{c}2085 \\
5082 \\
1801 \\
85.1 \\
566\end{array}$ & $\begin{array}{c}509 \\
1137 \\
216 \\
30.3 \\
28.6\end{array}$ & $\begin{array}{l}427 \\
796 \\
190 \\
19.1 \\
133\end{array}$ & $\begin{array}{c}162 \\
504 \\
77.0 \\
105 \\
63.5\end{array}$ \\
\hline $\begin{array}{l}1956 \\
1957 \\
1958 \\
1959 \\
1960\end{array}$ & $\begin{array}{c}99.9 \\
70.3 \\
310 \\
77.0 \\
176\end{array}$ & $\begin{array}{l}248 \\
290 \\
683 \\
244 \\
225\end{array}$ & $\begin{array}{l}476 \\
302 \\
480 \\
347 \\
352\end{array}$ & $\begin{array}{l}444 \\
340 \\
469 \\
366 \\
367\end{array}$ & $\begin{array}{l}391 \\
368 \\
561 \\
425 \\
400\end{array}$ & $\begin{array}{l}403 \\
355 \\
573 \\
269 \\
443\end{array}$ & $\begin{array}{c}281 \\
196 \\
485 \\
89.6 \\
142\end{array}$ & $\begin{array}{c}1198 \\
638 \\
2300 \\
68.9 \\
297\end{array}$ & $\begin{array}{r}1520 \\
3095 \\
1725 \\
575 \\
380\end{array}$ & $\begin{array}{c}69.9 \\
563 \\
71.4 \\
102 \\
20.7\end{array}$ & $\begin{array}{c}39.8 \\
298 \\
18.3 \\
69.5 \\
13.8\end{array}$ & $\begin{array}{l}21.2 \\
255 \\
46.4 \\
64.8 \\
18.9\end{array}$ \\
\hline $\begin{array}{l}1961 \\
1962 \\
1963 \\
1964 \\
1965\end{array}$ & $\begin{array}{l}83.3 \\
315 \\
242 \\
122 \\
81.4\end{array}$ & $\begin{array}{l}202 \\
451 \\
250 \\
261 \\
298\end{array}$ & $\begin{array}{l}289 \\
430 \\
371 \\
352 \\
447\end{array}$ & $\begin{array}{l}336 \\
347 \\
297 \\
298 \\
434\end{array}$ & $\begin{array}{l}334 \\
775 \\
514 \\
317 \\
386\end{array}$ & $\begin{array}{l}164 \\
792 \\
162 \\
376 \\
429\end{array}$ & $\begin{array}{c}28.5 \\
1183 \\
77.3 \\
236 \\
540\end{array}$ & $\begin{array}{c}47.5 \\
1435 \\
505 \\
1166 \\
1157\end{array}$ & $\begin{array}{c}50.0 \\
2459 \\
840 \\
2051 \\
5083\end{array}$ & $\begin{array}{c}10.1 \\
432 \\
50.4 \\
467 \\
2840\end{array}$ & $\begin{array}{l}9.91 \\
62.0 \\
76.9 \\
94.8 \\
926\end{array}$ & $\begin{array}{c}226 \\
75.3 \\
241 \\
63.8 \\
975\end{array}$ \\
\hline $\begin{array}{l}1966 \\
1967 \\
1968 \\
1969 \\
1970\end{array}$ & $\begin{array}{l}772 \\
181 \\
196 \\
322 \\
319\end{array}$ & $\begin{array}{l}788 \\
317 \\
305 \\
459 \\
377\end{array}$ & $\begin{array}{l}680 \\
498 \\
526 \\
620 \\
323\end{array}$ & $\begin{array}{l}639 \\
537 \\
558 \\
683 \\
234\end{array}$ & $\begin{array}{l}680 \\
546 \\
582 \\
665 \\
297\end{array}$ & $\begin{array}{l}764 \\
657 \\
653 \\
846 \\
163\end{array}$ & $\begin{array}{c}592 \\
314 \\
528 \\
1155 \\
45.3\end{array}$ & $\begin{array}{r}946 \\
906 \\
731 \\
2981 \\
283\end{array}$ & $\begin{array}{r}276 \\
4256 \\
4199 \\
2342 \\
980\end{array}$ & $\begin{array}{c}51.8 \\
1240 \\
388 \\
279 \\
143\end{array}$ & $\begin{array}{c}47.0 \\
179 \\
422 \\
148 \\
46.9\end{array}$ & $\begin{array}{c}101 \\
169 \\
211 \\
168 \\
79.2\end{array}$ \\
\hline
\end{tabular}


GREEN RIVER BASIN

09302000 DUCHESNE RIVER NEAR RANDLETT, UT-Continued

MONTHLY MEAN DISCHARGES, IN OBIC FEET PER SECOND, FOR EACH WATER YEAR-Continued

$\begin{array}{lcccccccccccc}\text { YEAR } & \text { OCT } & \text { NOV } & \text { DEC } & \text { JAN } & \text { FEB } & \text { MAR } & \text { APR } & \text { MAY } & \text { JUNE } & \text { JULY } & \text { AUG } & \text { SEP } \\ 1971 & 145 & 177 & 115 & 370 & 552 & 331 & 198 & 450 & 2358 & 317 & 59.9 & 144 \\ 1972 & 328 & 477 & 424 & 398 & 608 & 609 & 218 & 595 & 1949 & 93.8 & 51.6 & 76.5 \\ 1973 & 367 & 520 & 598 & 517 & 517 & 947 & 823 & 2058 & 2320 & 503 & 212 & 282 \\ 1974 & 326 & 428 & 450 & 459 & 500 & 660 & 327 & 987 & 926 & 212 & 220 & 76.9 \\ 1975 & 99.6 & 119 & 132 & 180 & 179 & 118 & 73.9 & 271 & 2695 & 2656 & 242 & 154 \\ 1976 & 178 & 283 & 342 & 330 & 464 & 613 & 258 & 510 & 488 & 49.0 & 69.3 & 96.5 \\ 1977 & 115 & 125 & 127 & 150 & 187 & 171 & 37.1 & 49.2 & 65.2 & 45.7 & 37.8 & 47.3 \\ 1978 & 61.5 & 78.3 & 98.6 & 172 & 250 & 348 & 420 & 292 & 1846 & 131 & 48.5 & 63.1 \\ 1979 & 85.4 & 271 & 254 & 250 & 300 & 787 & 962 & 1005 & 601 & 349 & 522 & 479 \\ 1980 & 194 & 177 & 144 & 162 & 265 & 227 & 199 & 527 & 2777 & 382 & 84.4 & 246 \\ 1981 & 296 & 369 & 527 & 338 & 266 & 170 & 102 & 205 & 913 & 76.9 & 66.0 & 83.8\end{array}$

ANNUAL PEAK DISOHARGE, IN QUBIC FEET PER SECOND, AND CORRESPONDING GAGE HEIGHT, IN FEET, FOR EACH WATER YEAR

\begin{tabular}{|c|c|c|c|c|c|c|c|c|c|c|c|}
\hline $\begin{array}{l}\text { WATER } \\
\text { YEAR }\end{array}$ & DATE & $\begin{array}{c}\text { GAGE } \\
\text { HEIGHT }\end{array}$ & $\begin{array}{c}\text { PEAK } \\
\text { DISOH ARGE }\end{array}$ & $\begin{array}{l}\text { WATER } \\
\text { YEAR }\end{array}$ & DATE & $\begin{array}{c}\text { GAGE } \\
\text { HEIGHT }\end{array}$ & $\begin{array}{c}\text { PEAK } \\
\text { DISOH ARGE }\end{array}$ & $\begin{array}{l}\text { WATER } \\
\text { YEAR }\end{array}$ & DATE & $\begin{array}{c}\text { GAGE } \\
\text { HEIGHT }\end{array}$ & $\begin{array}{c}\text { PEAR } \\
\text { DISGHARG }\end{array}$ \\
\hline $\begin{array}{l}1943 \\
1944 \\
1945 \\
1946 \\
1947 \\
1948 \\
1949 \\
1950 \\
1951 \\
1952 \\
1953 \\
1954 \\
1955\end{array}$ & 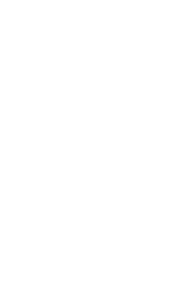 & $\begin{array}{l}5.04 \\
\overline{4.67} \\
4.07 \\
5.39 \\
4.51 \\
7.55 \\
5.88 \\
5.48 \\
7.87 \\
5.84 \\
3.76 \\
4.08\end{array}$ & $\begin{array}{l}4150 \\
7000 \\
2840 \\
1880 \\
4270 \\
2660 \\
8500 \\
5520 \\
4880 \\
8790 \\
4910 \\
1610 \\
1910\end{array}$ & $\begin{array}{l}1956 \\
1957 \\
1958 \\
1959 \\
1960 \\
1961 \\
1962 \\
1963 \\
1964 \\
1965 \\
1966 \\
1967 \\
1968\end{array}$ & $\begin{array}{l}\text { JUNE } 02,1956 \\
\text { JUNE } 08,1957 \\
\text { MAY } 30,1958 \\
\text { AUG. } 20,1959 \\
\text { JUNE } 04,1960 \\
\text { SEPT.19, } 1961 \\
\text { JUNE } 21,1962 \\
\text { JUNE } 17,1963 \\
\text { JUNE } 07,1964 \\
\text { JUNE } 13,1965 \\
\text { MAY } 12,1966 \\
\text { JUNE } 24,1967 \\
\text { JUNE } 20,1968\end{array}$ & $\begin{array}{l}5.22 \\
6.42 \\
6.68 \\
4.28 \\
3.54 \\
3.44 \\
5.49 \\
4.25 \\
5.57 \\
8.33 \\
4.80 \\
6.99 \\
7.11\end{array}$ & $\begin{array}{r}3860 \\
6240 \\
6480 \\
1780 \\
1010 \\
1100 \\
4920 \\
2500 \\
4690 \\
10300 \\
2830 \\
7480 \\
7020\end{array}$ & $\begin{array}{l}1969 \\
1970 \\
1971 \\
1972 \\
1973 \\
1974 \\
1975 \\
1976 \\
1977 \\
1978 \\
1979 \\
1980 \\
1981\end{array}$ & $\begin{array}{l}\text { JUNE } 18,1969 \\
\text { JUNE } 11,1970 \\
\text { JUNE } 18,1971 \\
\text { JUNE } 05,1972 \\
\text { MAY } 21,1973 \\
\text { MAY } 29,1974 \\
\text { JUNE } 16,1975 \\
\text { MAY } 20,1976 \\
\text { JULY } 24,1977 \\
\text { JUNE } 10,1978 \\
\text { MAY } 29,1979 \\
\text { JUNE } 12,1980 \\
\text { JUNE } 09,1981\end{array}$ & $\begin{array}{l}6.93 \\
5.14 \\
6.54 \\
5.94 \\
6.39 \\
5.79 \\
6.76 \\
3.26 \\
3.03 \\
6.30 \\
6.03 \\
7.69 \\
5.77\end{array}$ & $\begin{array}{l}6200 \\
3690 \\
4790 \\
3740 \\
4980 \\
2820 \\
5520 \\
1510 \\
744 \\
3890 \\
3420 \\
6060 \\
3040\end{array}$ \\
\hline
\end{tabular}

MAGNITUDE AND PROBABILITY OF ANNUAT LOWEST MEAN DISOHARGE BASED ON OLIMATIC YEARS 1944-81

\begin{tabular}{|c|c|c|c|c|c|c|}
\hline \multirow{2}{*}{$\begin{array}{l}\text { PERIOD } \\
\text { (CON- } \\
\text { SEQU- } \\
\text { TTVE } \\
\text { DAYS) }\end{array}$} & \multicolumn{6}{|c|}{$\begin{array}{l}\text { DISOHARGE, IN OUBIC FEET PER SECOND, FOR } \\
\text { INDICATED REQURRENCE INTERNAL, IN YEARS, AND } \\
\text { ANNUAL NONEXCEEDANCE PRCBABILITY, IN PERCENT }\end{array}$} \\
\hline & $\begin{array}{c}2 \\
508\end{array}$ & $\begin{array}{c}5 \\
208\end{array}$ & $\begin{array}{l}10 \\
108\end{array}$ & $\begin{array}{l}20 \\
58\end{array}$ & $\begin{array}{l}50 \\
28\end{array}$ & $\begin{array}{r}100 \\
18\end{array}$ \\
\hline
\end{tabular}

$\begin{array}{rrrr}1 & 40 & 20 & 11 \\ 7 & 47 & 20 & 13 \\ 14 & 52 & 23 & 1 \\ 30 & 65 & 28 & 18 \\ 60 & 91 & 40 & 25 \\ 90 & 113 & 52 & 34\end{array}$

$\begin{array}{llll}11 & 7.2 & 4.7 & - \\ 13 & 8.9 & 5.8 & - \\ 14 & 10 & 6.6 & = \\ 18 & 12 & 8.0 & - \\ 25 & 17 & 11 & = \\ 34 & 23 & 15 & -\end{array}$

MAGNITUDE AND PRCBABILITY OF ANNUAL HIGHEST MEAN DISOHARGE BASED ON WATER YEARS 1943-81

\begin{tabular}{|c|c|c|c|c|c|c|}
\hline \multirow{2}{*}{$\begin{array}{l}\text { PERIOD } \\
\text { (OON- } \\
\text { SEOU- } \\
\text { TTVE } \\
\text { DAYS) }\end{array}$} & \multicolumn{4}{|c|}{$\begin{array}{l}\text { DISOHARGE, IN OUBIC FEET PER } \\
\text { INDICATED REQURRENCE INTERNAL, } \\
\text { ANNUA EXCEEDANCE PRCBAEILITY, }\end{array}$} & \multicolumn{2}{|l|}{$\begin{array}{l}\text { SECOND, FOR } \\
\text { IN YEARS, AND } \\
\text { IN PERCENT }\end{array}$} \\
\hline & $\begin{array}{c}2 \\
508\end{array}$ & $\begin{array}{c}5 \\
208\end{array}$ & $\begin{array}{l}10 \\
108\end{array}$ & $\begin{array}{l}25 \\
48\end{array}$ & $\begin{array}{l}50 \\
28\end{array}$ & $\begin{array}{r}100 \\
18\end{array}$ \\
\hline
\end{tabular}

$\begin{array}{llllll}1 & 3720 & 6060 & 7260 & 8390 & 9000\end{array}$

$\begin{array}{llllll}3 & 3410 & 5650 & 6860 & 8040 & 8720\end{array}$

$\begin{array}{rrrrrr}7 & 2940 & 5030 & 6250 & 7550 & 8350 \\ 15 & 2440 & 4290 & 5440 & 6720 & 7560\end{array}$ 


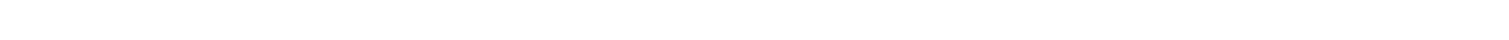
bank $900 \mathrm{ft}$ upstream from small right bank tributary, $2.7 \mathrm{mi}$ downstream from colorado-Utah state 1 ine, and $7.5 \mathrm{mi}$ upstream from Evacuation Creek.

DRAINAGE AREA $-3,680 \mathrm{mi}^{2}$, approximately.

MEAN BASIN ELEVATION. $-7,240 \mathrm{ft}$.

PERIOD OF RECORD AVAILABLE.--October 1976 to September 1981.

GAGE. - water-stage recorder. Altitude of gage is 5,030 ft from topographic map.

REMARKS.--Diversions for irrigation of about 31,900 acres above station.

AVERAGE DISCHARGE. -5 years, $602 \mathrm{ft}^{3} / \mathrm{s}, 436,100$ acre-ft/yr.

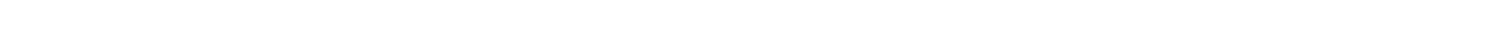
1977.

LONEST MEAN DISCHARGE, IN OUBIC FEET PER SECOND, AND RANKING FOR THE INDICATED NUMBER OF CONSEQUTTVE DAYS FOR EACH OLIMATTC YEAR, APRII 1-MARQH 31

\begin{tabular}{|c|c|c|c|c|c|c|c|c|c|c|c|c|c|c|c|c|c|c|c|c|}
\hline YEAR & \multicolumn{20}{|c|}{ CONSEQITTEE DAS } \\
\hline $\begin{array}{l}1978 \\
1979 \\
1980\end{array}$ & $\begin{array}{l}11.0 \\
170 \\
190\end{array}$ & $\begin{array}{l}1 \\
2 \\
3\end{array}$ & $\begin{array}{l}14.0 \\
216 \\
229\end{array}$ & $\begin{array}{l}1 \\
2 \\
3\end{array}$ & $\begin{array}{l}33.0 \\
238 \\
261\end{array}$ & $\begin{array}{l}1 \\
2 \\
3\end{array}$ & $\begin{array}{l}75.0 \\
271 \\
274\end{array}$ & $\begin{array}{l}1 \\
2 \\
3\end{array}$ & $\begin{array}{l}90.0 \\
283 \\
293\end{array}$ & $\begin{array}{l}1 \\
2 \\
3\end{array}$ & $\begin{array}{l}136 \\
295 \\
351\end{array}$ & $\begin{array}{l}1 \\
2 \\
3\end{array}$ & $\begin{array}{l}183 \\
319 \\
365\end{array}$ & 1 & $\begin{array}{l}197 \\
335 \\
371\end{array}$ & $\begin{array}{l}1 \\
2 \\
3\end{array}$ & $\begin{array}{l}234 \\
353 \\
382\end{array}$ & 1 & $\begin{array}{l}307 \\
757 \\
793\end{array}$ & $\begin{array}{l}1 \\
3 \\
4\end{array}$ \\
\hline 981 & 230 & 4 & 250 & 4 & 273 & 4 & 296 & 4 & 337 & 4 & 371 & 4 & 372 & 4 & 377 & 4 & 386 & 4 & 701 & 2 \\
\hline
\end{tabular}

HIGHEST MEAN DISCHARGE, IN QUBIC FEET PER SECOND, AND RANKING FOR THE INDICATED NUMBER OF CONSEQITIVE DAYS FOR EACH WATER YEAR, OCTOBER I-SEPIEMBER 30

\begin{tabular}{|c|c|c|c|c|c|c|c|c|c|c|c|c|c|c|c|c|c|c|c|c|}
\hline YEAR & & & & & & & & & & ד' & IVE D & & & & & & & & & \\
\hline $\begin{array}{l}1977 \\
1978 \\
1979 \\
1980\end{array}$ & $\begin{array}{r}635 \\
3850 \\
4230 \\
3110\end{array}$ & $\begin{array}{l}5 \\
2 \\
1 \\
3\end{array}$ & $\begin{array}{r}615 \\
3760 \\
4040 \\
2920\end{array}$ & $\begin{array}{l}5 \\
2 \\
1 \\
3\end{array}$ & $\begin{array}{r}563 \\
3600 \\
3740 \\
2810\end{array}$ & $\begin{array}{l}5 \\
2 \\
1 \\
3\end{array}$ & $\begin{array}{r}516 \\
3360 \\
3210 \\
2620\end{array}$ & $\begin{array}{l}5 \\
1 \\
2 \\
3\end{array}$ & $\begin{array}{r}481 \\
2880 \\
2960 \\
2530\end{array}$ & $\begin{array}{l}5 \\
2 \\
1 \\
3\end{array}$ & $\begin{array}{r}446 \\
2330 \\
2320 \\
2050\end{array}$ & $\begin{array}{l}5 \\
1 \\
2 \\
3\end{array}$ & $\begin{array}{r}432 \\
1830 \\
1840 \\
1650\end{array}$ & $\begin{array}{l}5 \\
2 \\
1 \\
3\end{array}$ & $\begin{array}{r}420 \\
1520 \\
1570 \\
1350\end{array}$ & $\begin{array}{l}5 \\
2 \\
1 \\
3\end{array}$ & $\begin{array}{r}383 \\
1150 \\
1190 \\
1070\end{array}$ & $\begin{array}{l}5 \\
2 \\
1 \\
3\end{array}$ & $\begin{array}{l}323 \\
731 \\
765 \\
725\end{array}$ & $\begin{array}{l}5 \\
2 \\
1 \\
3\end{array}$ \\
\hline 1981 & 1740 & 4 & 1680 & 4 & 1630 & 4 & 1530 & 4 & 1110 & 4 & 956 & 4 & 792 & 4 & 687 & 4 & 581 & 4 & 466 & \\
\hline
\end{tabular}

DURATION OF DISGHARGE FOR EACH WATER YEAR

$\begin{array}{llllllllllllllllllllllllllllllllllllll}\text { CASS } & 0 & 1 & 2 & 3 & 4 & 5 & 6 & 7 & 8 & 9 & 10 & 11 & 12 & 13 & 14 & 15 & 16 & 17 & 18 & 19 & 20 & 21 & 22 & 23 & 24 & 25 & 26 & 27 & 28 & 29 & 30 & 31 & 32 & 33 & 34\end{array}$

YEAR NUMBER $O F$ DAYS IN CLASS

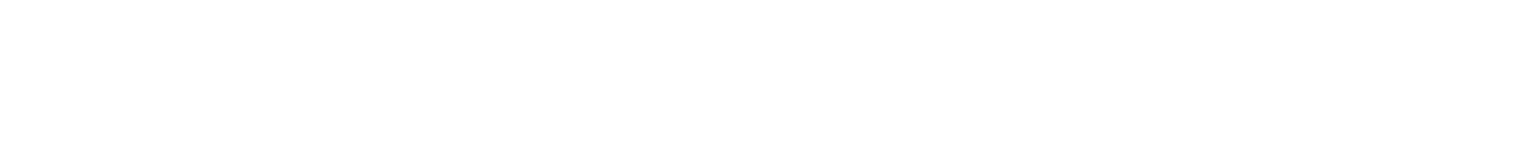

DURATION TABLE OF DISCHARGE FOR WATER YEARS 1977-81

$\begin{array}{ccc}\text { OBBIC } & \text { ACQU- } \\ \text { FEET } & \text { MU- } & \text { PER- } \\ \text { PER TOTAL LATED } & \text { CENT } \\ \text { CLASS SECOND DAYS } & \text { DAYS } & \text { DAYS }\end{array}$

$\begin{array}{llllr}0 & 0.00 & 0 & 1826 & 100.0 \\ 1 & 11.00 & 2 & 1826 & 100.0 \\ 2 & 13.00 & 0 & 1824 & 99.9 \\ 3 & 16.00 & 1 & 1824 & 99.9 \\ 4 & 19.00 & 0 & 1823 & 99.8 \\ 5 & 22.00 & 0 & 1823 & 99.8 \\ 6 & 27.00 & 3 & 1823 & 99.8 \\ 7 & 32.00 & 0 & 1820 & 99.7 \\ 8 & 38.00 & 2 & 1820 & 99.7\end{array}$

CUBIC ACQU-

$\begin{array}{lll}\text { FEET } & \text { MU- } & \text { PER- } \\ \text { PER TOTA, LATED } & \text { OENT }\end{array}$

CLASS SECOND DAYS DAYS DAYS

$\begin{array}{rr}9 & 46.00 \\ 10 & 55.00 \\ 11 & 65.00 \\ 12 & 78.00 \\ 13 & 94.00 \\ 14 & 110.00 \\ 15 & 130.00 \\ 16 & 160.00 \\ 17 & 190.00\end{array}$

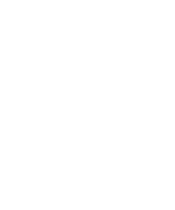

$$
\begin{array}{r}
\text { QLAS } \\
18 \\
19 \\
20 \\
21 \\
22 \\
23 \\
24 \\
25 \\
26
\end{array}
$$

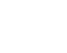

PER TOTAL LATED OENT

$\begin{array}{rrrrr}18 & 230.0 & 78 & 1710 & 93.6 \\ 19 & 270.0 & 294 & 1632 & 89.4 \\ 20 & 330.0 & 443 & 1338 & 73.3 \\ 21 & 390.0 & 333 & 895 & 49.0 \\ 22 & 470.0 & 146 & 562 & 30.8 \\ 23 & 560.0 & 76 & 416 & 22.8 \\ 24 & 670.0 & 51 & 340 & 18.6 \\ 25 & 800.0 & 53 & 289 & 15.8 \\ 26 & 950.0 & 37 & 236 & 12.9\end{array}$

$\begin{array}{ccc}\text { OBIC } & \text { ACQJ- } \\ \text { FEET } & \text { MU- } & \text { PER- } \\ \text { PER TOTAL LATED } & \text { CENT }\end{array}$ CLASS SECOND DAYS DAYS DAYS

$\begin{array}{lrrrr}27 & 1100.0 & 31 & 199 & 10.9 \\ 28 & 1400.0 & 19 & 168 & 9.2 \\ 29 & 1600.0 & 27 & 149 & 8.2 \\ 30 & 1900.0 & 45 & 122 & 6.7 \\ 31 & 2300.0 & 37 & 77 & 4.2 \\ 32 & 2800.0 & 22 & 40 & 2.2 \\ 33 & 3300.0 & 17 & 18 & 1.0 \\ 34 & 4000.0 & 1 & 1 & 0.1\end{array}$


GREEN RTVER BASTN

09306395 WHITE RIVER NEAR COLORADO-UTAH STATE LINE--Continued

MONIHLY MEAN DISCHARGES, IN OUIC FEET PER SECOND, FOR EACH WATER YEAR

$\begin{array}{rrrrrrrrrrrrr}\text { YEAR } & \text { OCT } & \text { NON } & \text { DEC } & \text { JAN } & \text { FEB } & \text { MAR } & \text { APR } & \text { MAY } & \text { JUNE } & \text { JULY } & \text { AUG } & \text { SEP } \\ 1977 & 398 & 353 & 299 & 327 & 355 & 413 & 438 & 406 & 279 & 151 & 227 & 236 \\ 1978 & 275 & 314 & 279 & 301 & 309 & 474 & 615 & 1487 & 2867 & 1057 & 397 & 399 \\ 1979 & 382 & 400 & 376 & 308 & 285 & 510 & 737 & 1893 & 2516 & 975 & 466 & 316 \\ 1980 & 398 & 425 & 356 & 347 & 600 & 507 & 618 & 1857 & 2196 & 668 & 363 & 384 \\ 1981 & 402 & 403 & 389 & 383 & 386 & 362 & 601 & 798 & 938 & 375 & 237 & 320\end{array}$

ANNAL FEAK DISCHARGE, IN OUBIC FEET PER SECOND, AND CORRESPONDING GAGE HEIGHT, IN FEET, FOR EACH WATER YEAR

\begin{tabular}{|c|c|c|c|c|c|c|c|c|c|c|c|c|}
\hline $\begin{array}{l}\text { WATER } \\
\text { YEAR }\end{array}$ & DATE & $\begin{array}{c}\text { GAGE } \\
\text { HEIGHT }\end{array}$ & $\begin{array}{c}\text { PEAK } \\
\text { DISOHARGE }\end{array}$ & $\begin{array}{l}\text { WATER } \\
\text { YEAR }\end{array}$ & & DATE & $\begin{array}{c}\text { GAGE } \\
\text { HEIGHT }\end{array}$ & $\begin{array}{c}\text { PEAK } \\
\text { DISQHARGE }\end{array}$ & $\begin{array}{l}\text { WATER } \\
\text { YEAR }\end{array}$ & DATE & $\begin{array}{c}\text { GAGE } \\
\text { HEIGHT }\end{array}$ & $\begin{array}{c}\text { PEAK } \\
\text { DISCHARGE }\end{array}$ \\
\hline $\begin{array}{l}1977 \\
1978\end{array}$ & $\begin{array}{l}\text { JULY } 25,1977 \\
\text { JUNE } 17,1978\end{array}$ & $\begin{array}{l}4.75 \\
7.00\end{array}$ & $\begin{array}{l}1700 \\
4000\end{array}$ & $\begin{array}{l}1979 \\
1980\end{array}$ & $\begin{array}{l}\text { MAY } \\
\text { MAY }\end{array}$ & $\begin{array}{l}30,1979 \\
25,1980\end{array}$ & $\begin{array}{l}7.20 \\
6.19\end{array}$ & $\begin{array}{l}4470 \\
3330\end{array}$ & 1981 & JUNE 09,1981 & 4.87 & 1920 \\
\hline
\end{tabular}

09306400 WHITE RIVER ABOVE HELIS HQLE CANYON, NEAR WATSON, UT

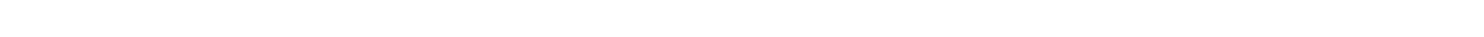
bank $0.1 \mathrm{mi}$ upstream fram Hells Hole Canyon, $1.4 \mathrm{mi}$ upstream fram Evacuation Creek, and $6.6 \mathrm{mi}$ north of watson.

DRAINAGE AREA. $--3,700 \mathrm{mi}^{2}$, approximately.

MEAN BASIN ELEVATION. $-7,230 \mathrm{ft}$.

PERIOD OF RECORD AVAILABLE.--October 1974 to September 1975, October 1975 to January 1976, and April to September 1976.

GAGE. -Water-stage recorder. Altitude of gage is $5,000 \mathrm{ft}$ from topographic map.

REMARKS.--Many diversions for irrigation above station.

EXTREMES FOR PERICD OF RECORD.--Maximum discharge, 3,870 ft 3 /s June 10, 1975; maximum gage height, $7.42 \mathrm{ft}$, June 9 , 1975 ; minimum, $66 \mathrm{ft}^{3} / \mathrm{s}$ Dec. 12,1975 but, may have been less during period of ice effect.

HIGHEST MEAN DISCHARGE, IN OBIC FEET PER SECOND, AND RANKING FOR THE INDICATED NUMBER OF CONSEOITIVE DAYS FOR EACH WATER YEAR, OCTCBER I-SEPTEMBER 30

\begin{tabular}{lllllllllll} 
YEAR & & & & & \multicolumn{1}{c}{ CONSEOUTTVE DAYS } & 90 & 120 & 183 & ALL
\end{tabular}

$\begin{array}{llllllllllllllllllllllllll}1975 & 3650.00 & 1 & 3430.00 & 1 & 3070.00 & 1 & 2960.00 & 1 & 2680.00 & 1 & 2280.00 & 1 & 1790.00 & 1 & 1470.00 & 1 & 1130.00 & 1 & 751 & 1\end{array}$

DURATION OF DISCHARGE FOR EACH WATER YEAR

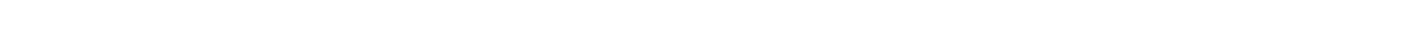
NUMBER OF DAYS IN CLASS PER SECOM

$\begin{array}{lllllllllllllllllllllllllllllllllllllll}1975 & 3 & 2 & 1 & 2 & 2 & 3 & 12 & 15 & 16 & 30 & 64 & 58 & 37 & 15 & 17 & 7 & 7 & 2 & 2 & 2 & 2 & 1 & 3 & 7 & 3 & 4 & 3 & 5 & 12 & 11 & 5 & 5 & 4 & 1 & 274266\end{array}$

DURATION TABLE OF DISQHARGE FOR WATER YEAR 1975

$\begin{array}{ccc}\text { OBBIC } & \text { ACQU- } \\ \text { FEET } & \text { MU- } & \text { PER- } \\ \text { PER } & \text { TOTAL LAIED } & \text { CENT } \\ \text { CLASS SECOND DAYS } & \text { DAYS } & \text { DAYS }\end{array}$

$\begin{array}{llll}0 & 0.0 & 0 & 365100.0\end{array}$

$\begin{array}{rrrr}0 & 0.0 & 0 & 365100.0 \\ 1 & 147.0 & 3 & 365100.0\end{array}$

2160.0

2160.0

$4 \quad 180.0$

4200.0

$\begin{array}{rrrrr}5 & 220.0 & 2 & 357 & 97.8 \\ 6 & 240.0 & 3 & 355 & 97.3 \\ 7 & 260.0 & 12 & 352 & 96.4\end{array}$

$\begin{array}{rrrrr}5 & 220.0 & 2 & 357 & 97.8 \\ 6 & 240.0 & 3 & 355 & 97.3 \\ 7 & 260.0 & 12 & 352 & 96.4\end{array}$

$\begin{array}{ll}7 & 260.0 \\ 8 & 290.0\end{array}$

$\begin{array}{rrr}2 & 357 & 97.8 \\ 3 & 355 & 97.3 \\ 12 & 352 & 96.4\end{array}$

$\begin{array}{lll}15 & 340 & 93.2\end{array}$
OBBIC ACQU-

$\begin{array}{lll}\text { FEET MN- } & \text { MER- } \\ \text { PER TOTAL LATED } & \text { CENT }\end{array}$

CLASS SECOND DAYS DAYS DAYS

$\begin{array}{rrrrr}9 & 320.0 & 16 & 325 & 89.0 \\ 10 & 350.0 & 30 & 309 & 84.7 \\ 11 & 380.0 & 64 & 279 & 76.4 \\ 12 & 420.0 & 58 & 215 & 58.9 \\ 13 & 460.0 & 37 & 157 & 43.0 \\ 14 & 510.0 & 15 & 120 & 32.9 \\ 15 & 560.0 & 17 & 105 & 28.8 \\ 16 & 620.0 & 7 & 88 & 24.1 \\ 17 & 680.0 & 7 & 81 & 22.2\end{array}$

\begin{tabular}{cr}
\multicolumn{3}{c}{ OBBIC } \\
\multicolumn{3}{c}{ FEET } \\
PER & TO \\
CIASS SECOND & DAY \\
18 & 750.0 \\
19 & 820.0 \\
20 & 900.0 \\
21 & 1000.0 \\
22 & 1100.0 \\
23 & 1200.0 \\
24 & 1300.0 \\
25 & 1500.0 \\
26 & 1600.0
\end{tabular}

ACOJ$\begin{array}{cc}\text { MU- } & \text { PER- } \\ \text { LATED } & \text { CENT }\end{array}$ DAYS DAYS DAYS

$\begin{array}{ll}74 & 20.3 \\ 72 & 19.7 \\ 70 & 19.2 \\ 66 & 18.1 \\ 64 & 17.5 \\ 63 & 17.3 \\ 60 & 16.4 \\ 53 & 14.5 \\ 50 & 13.7\end{array}$

\begin{tabular}{|c|c|c|c|c|}
\hline & $\begin{array}{c}\text { OBIIC } \\
\text { FEET } \\
\text { PER }\end{array}$ & TOTAL & $\begin{array}{l}\text { ACOU- } \\
\text { MU- } \\
\text { LATED }\end{array}$ & $\begin{array}{l}\text { PER- } \\
\text { CENT }\end{array}$ \\
\hline CLASS & SECOND & DAYS & DAYS & DAYS \\
\hline 27 & 1800.0 & 3 & 46 & 12.6 \\
\hline 28 & 1900.0 & 5 & 43 & 11.8 \\
\hline 29 & 2100.0 & 12 & 38 & 10.4 \\
\hline 30 & 2400.0 & 11 & 26 & 7.1 \\
\hline 31 & 2600.0 & 5 & 15 & 4.1 \\
\hline 32 & 2800.0 & 5 & 10 & 2.7 \\
\hline 33 & 3100.0 & & 5 & 1.4 \\
\hline 34 & 3500.0 & 1 & 1 & 0.3 \\
\hline
\end{tabular}

MONIHLY MEAN DISCHARGES, IN OBIC FEET PER SECOND, FOR EACH WATER YEAR

$\begin{array}{ccccccccccccc}\text { YEAR } & \text { OCT } & \text { NOV } & \text { DEC } & \text { JAN } & \text { FEB } & \text { MAR } & \text { APR } & \text { MAY } & \text { JUNE } & \text { JULY } & \text { AUG } & \text { SEP } \\ 1975 & 440 & 415 & 288 & 323 & 365 & 499 & 473 & 1211 & 2574 & 1510 & 487 & 423\end{array}$


GREEN RIVER BASIN

09306405 HELLS HOLE CANYON CREEK AT MOUTH, NEAR WATSON, UT

LOCATION. --Lat $39^{\circ} 58^{\prime} 24^{\prime}$, long $109^{\circ} 07^{\prime} 40^{\prime \prime}$, in NW $\frac{1}{4} \mathrm{SE}_{4}^{\frac{1}{4} S W^{\frac{1}{4}}}$ sec.5, T.10 S., R. 25 E., Uintah County, Hydrologic Unit 14050007, on right bank $0.1 \mathrm{mi}$ upstream from mouth and $6.5 \mathrm{mi}$ north of Watson.

DRAINAGE AREA. $-24.5 \mathrm{mi}^{2}$.

MEAN BASIN ELEVATION. $-6,610 \mathrm{ft}$.

PERIOD OF RECORD AVAIIABLE.--October 1974 to January 1976, February 1976 to September 1981.

GAGE.--Water-stage recorder. Altitude of gage is 5,040 ft from topographic map.

AVERAGE DISCHARGE. -6 years (water years 1975, 1977-81), $0.062 \mathrm{ft}^{3} / \mathrm{s}, 45$ acre-ft/yr.

EXTREMES FOR PERIOD OF RECORD.--Maximum discharge, $473 \mathrm{ft}^{3} / \mathrm{s}$ Aug. 12, 1975, gage height, $3.75 \mathrm{ft}$, fram rating curve extended above $88 \mathrm{ft}^{3} / \mathrm{s}$ on basis of slope-area measurement of peak flow; no flow most of time.

LONEST MEAN DISCHARGE, IN COBIC FEET PER SBCOND, AND RANKING FOR THE INDICATED NUMBER OF CONSECUTIVE DAYS FOR EACH CLIMATIC YEAR, APRIL 1-MARCH 31

\begin{tabular}{|c|c|c|c|c|c|c|c|c|c|c|c|c|c|c|c|c|c|c|c|}
\hline YEAR & & & & & & & & & CONSE & dנT & DAYS & & & & & & & & \\
\hline 1977 & 0.00 & 1 & 0.00 & 1 & 0.00 & 1 & 0.00 & 1 & 0.00 & I & 0.00 & 1 & 0.00 & I & 0.00 & I & 0.00 & 1 & 0.01 \\
\hline 1978 & 0.00 & 2 & 0.00 & 2 & 0.00 & 2 & 0.00 & 2 & 0.00 & 2 & 0.00 & 2 & 0.00 & 2 & 0.00 & 2 & 0.10 & 5 & 0.12 \\
\hline 1980 & 0.00 & 4 & 0.00 & 4 & 0.00 & 4 & 0.00 & 4 & 0.00 & 4 & 0.00 & 4 & 0.00 & 4 & 0.00 & 4 & 0.02 & 4 & 0.08 \\
\hline 1981 & 0.00 & 5 & 0.00 & 5 & 0.00 & 5 & 0.00 & 5 & 0.00 & 5 & 0.00 & 5 & 0.00 & 5 & 0.00 & 5 & 0.00 & 3 & 0.04 \\
\hline
\end{tabular}

HIGHEST MEAN DISCHARGE, IN CUBIC FEET PER SECOND, AND RANKING FOR THE INDICATED NUMBER OF CONSECUTIVE DAYS FOR EACH WATER YEAR, OCTOBER 1-SEPTTEMBER 30

\begin{tabular}{|c|c|c|c|c|c|c|c|c|c|c|c|c|c|c|c|c|c|c|c|}
\hline YEAR & 1 & & 3 & & 7 & & 15 & & $\begin{array}{l}\text { CONSEX } \\
30\end{array}$ & aTtive & $\begin{array}{l}\text { DAYS } \\
60\end{array}$ & & 90 & & 120 & & 183 & & ALL \\
\hline 1975 & 15.0 & 1 & 6.00 & 1 & 3.30 & 1 & 1.50 & 1 & 0.76 & 2 & 0.43 & 1 & 0.31 & 1 & 0.25 & 1 & 0.16 & I & 0.11 \\
\hline
\end{tabular}

DURATION OF LISCHARGE FOR EACH WATER YEAR

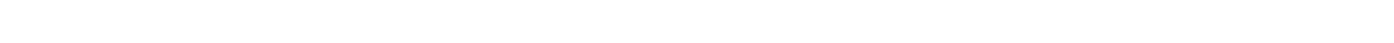
YEAR NUMBER OF DAYS IN CLASS

OBIC FEET PER SECOND -DAYS

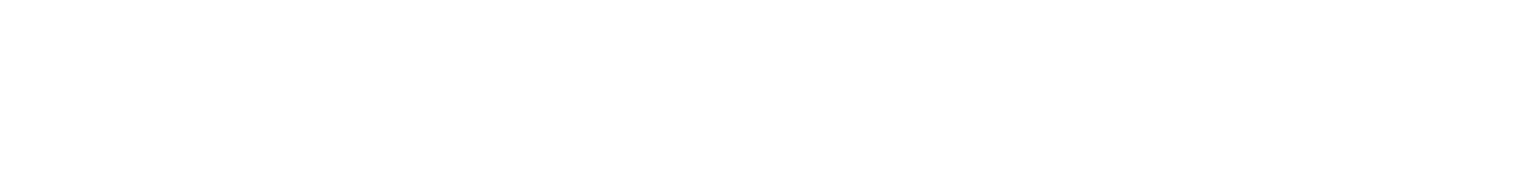

DURATION TABLE OF DISCHARGE FOR WATER YEARS 1975, 1977-81

\begin{tabular}{ccccc}
\multicolumn{4}{c}{ CUBIC } & \multicolumn{2}{c}{ ACG- } \\
FEET & MU- & PER- \\
PER & TOTAL LATED & \multicolumn{1}{c}{ CENT } \\
CIASS SECOND & DAYS & DAYS & DAYS \\
& & & & \\
0 & 0.00 & 2122 & 2191 & 100.0 \\
1 & 0.01 & 2 & 69 & 3.1 \\
2 & 0.02 & 6 & 67 & 3.1 \\
3 & 0.03 & 5 & 61 & 2.8 \\
4 & 0.04 & 8 & 56 & 2.6 \\
5 & 0.06 & 0 & 48 & 2.2 \\
6 & 0.07 & 4 & 48 & 2.2 \\
7 & 0.08 & 1 & 44 & 2.0 \\
8 & 0.10 & 0 & 43 & 2.0
\end{tabular}

$\begin{array}{ccc}\text { CBIC } & \text { ACOU- } \\ \text { FEET } & \text { MU- } & \text { PER- } \\ \text { PER TOTAL LATED } & \text { CENT }\end{array}$ CLASS SECOND DAYS DAYS DAYS PER TOTAL LATED CEN

\begin{tabular}{|c|c|c|c|}
\hline 9 & 0.13 & 1 & 43 \\
\hline 10 & 0.16 & 0 & 42 \\
\hline 11 & 0.20 & 2 & 42 \\
\hline 12 & 0.24 & 2 & 40 \\
\hline 13 & 0.30 & 1 & 38 \\
\hline 14 & 0.37 & 0 & 37 \\
\hline 15 & 0.46 & 5 & 37 \\
\hline 16 & 0.56 & 1 & 32 \\
\hline 17 & 0.70 & $\overline{2}$ & 31 \\
\hline
\end{tabular}

$\begin{array}{lll}18 & 0.9 & 1 \\ 19 & 1.1 & 0 \\ 20 & 1.3 & 5 \\ 21 & 1.6 & 0 \\ 22 & 2.0 & 5 \\ 23 & 2.5 & 3 \\ 24 & 3.1 & 2 \\ 25 & 3.8 & 1 \\ 26 & 4.7 & 4\end{array}$

OBIC
FEET
MUFEET TOTAL MU- PERCLASS SECOND DAYS DAYS DAYS

$\begin{array}{rrrrr}27 & 5.8 & 3 & 8 & 0.4 \\ 28 & 7.2 & 2 & 5 & 0.2 \\ 29 & 8.9 & 1 & 3 & 0.1 \\ 30 & 11.0 & 2 & 2 & 0.1\end{array}$


GREEN RIVER BASIN

09306405 HELLS HOLE CANYON CREEK AT MOUTH, NEAR WATSON, UT--Continued

MONIHLY MEAN DISCHARGES, IN OUBIC FEET PER SECOND, FOR EACH WATER YEAR

$\begin{array}{lllllllllllll}\text { YEAR } & \text { OCT } & \text { NOV } & \text { DEC } & \text { JAN } & \text { FEB } & \text { MAR } & \text { APR } & \text { MAY } & \text { JURE } & \text { JULY } & \text { AUG } & \text { SEP } \\ 1975 & 0.00 & 0.00 & 0.00 & 0.00 & 0.25 & 0.17 & 0.00 & 0.07 & 0.00 & 0.05 & 0.11 & 0.76 \\ 1976 & 0.00 & 0.00 & 0.00 & 0.00 & 0.11 & 0.00 & 0.00 & 0.03 & 0.03 & 0.02 & 0.01 & 0.06 \\ 1977 & 0.02 & 0.00 & 0.00 & 0.00 & 0.00 & 0.00 & 0.00 & 0.00 & 0.00 & 0.79 & 0.00 & 0.00 \\ 1978 & 0.35 & 0.26 & 0.00 & 0.00 & 0.00 & 0.00 & 0.00 & 0.00 & 0.00 & 0.00 & 0.00 & 0.00 \\ 1979 & 0.00 & 0.00 & 0.00 & 0.00 & 0.00 & 0.12 & 0.50 & 0.00 & 0.00 & 0.00 & 0.02 & 0.27 \\ 1980 & 0.00 & 0.00 & 0.00 & 0.00 & 0.14 & 0.00 & 0.00 & 0.00 & 0.00 & 0.05 & 0.40 & 0.00 \\ 1981 & 0.00 & 0.00 & 0.00 & 0.00 & 0.00 & 0.00 & 0.00 & 0.04 & 0.00 & 0.05 & 0.00 & 0.10\end{array}$

ANNUAL PEAK DISCHARGE, IN OUBIC FEET PER SECOND, AND CORRESPONDING GAGE HEIGHT, IN FEET, FOR EACH WATER YEAR

\begin{tabular}{|c|c|c|c|c|c|c|c|c|c|c|c|}
\hline $\begin{array}{l}\text { WATER } \\
\text { YEAR }\end{array}$ & DATE & $\begin{array}{l}\text { GAGE } \\
\text { HEIGHT }\end{array}$ & $\begin{array}{c}\text { PEAK } \\
\text { DISCHARGE }\end{array}$ & $\begin{array}{l}\text { WATER } \\
\text { YEAR }\end{array}$ & DATE & $\begin{array}{c}\text { GAGE } \\
\text { HEIGHT }\end{array}$ & $\begin{array}{c}\text { PEAK } \\
\text { DISCHARGE }\end{array}$ & $\begin{array}{l}\text { WATER } \\
\text { YEAR }\end{array}$ & DATE & $\begin{array}{c}\text { GAGE } \\
\text { HEIGHT }\end{array}$ & $\begin{array}{c}\text { PEAK } \\
\text { DISCHARGE }\end{array}$ \\
\hline $\begin{array}{l}1975 \\
1976 \\
1977\end{array}$ & $\begin{array}{lll}\text { AUG. } & 12,1975 \\
\text { MAY } & 10,1976 \\
\text { JULY } & 23,1977\end{array}$ & $\begin{array}{l}3.75 \\
2.04 \\
2.54\end{array}$ & $\begin{array}{l}473 \\
3.8 \\
171\end{array}$ & $\begin{array}{l}1978 \\
1979\end{array}$ & $\begin{array}{l}\text { OCT. 06, } 1977 \\
\text { SEPT. 26, } 1979\end{array}$ & $\begin{array}{l}2.54 \\
3.73\end{array}$ & $\begin{array}{l}171 \\
467\end{array}$ & $\begin{array}{l}1980 \\
1981\end{array}$ & $\begin{array}{l}\text { AUG. } 25,1980 \\
\text { SEPT.11, } 1981\end{array}$ & $\begin{array}{l}3.20 \\
2.55\end{array}$ & $\begin{array}{l}280 \\
122\end{array}$ \\
\hline
\end{tabular}

09306410 EVACUATION CREEK ABOVE MISSOURI CREEK, NEAR DRAGON, UT

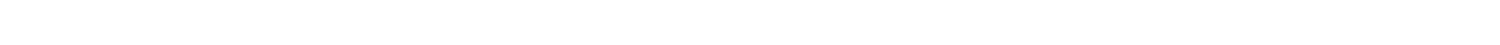
bank $0.5 \mathrm{mi}$ upstream from Missouri Creek and $0.8 \mathrm{mi}$ north of Dragon.

DRATNAGE AREA. $-100 \mathrm{mi}^{2}$.

MEAN BASIN ELEVATION. $--7,220 \mathrm{ft}$.

PERIOD OF RBCORD AVAILABLE.--OCtober 1974 to September 1981 .

GAGE.-Water-stage recorder. Altitude of gage is 5,680 ft from topographic map.

AVERAGE DISCHARGE. -7 years, $1.34 \mathrm{ft}^{3} / \mathrm{s}, 971$ acre-ft/yr.

EXIREMES FOR PERTOD OF RECORD.--Maximum discharge, $835 \mathrm{ft}^{3} / \mathrm{s}$ Aug. 13, 1978, gage height, $8.32 \mathrm{ft}$, from rating curve extended above $10 \mathrm{ft}^{3} / \mathrm{s}$ on basis of slope-area measurements of peak flow; minimu, $0.04 \mathrm{ft}^{3} / \mathrm{s} \mathrm{Feb.} 23,1979$.

LONEST MEAN DISCHARGE, IN OUBIC FEET PER SECOND, AND RANKING FOR THE INDICATED NUMBER OF CONSECUTIVE DAYS FOR EACH CLIMATIC YBAR, APRIL 1-MARCH 31

\begin{tabular}{|c|c|c|c|c|c|c|c|c|c|c|c|c|c|c|c|c|c|c|c|}
\hline YEAR & & & & & & & & & CONSE & OUTIVE & DAYS & & & & & & & & \\
\hline $\begin{array}{l}1976 \\
1977 \\
1978 \\
1979 \\
1980\end{array}$ & $\begin{array}{l}0.20 \\
0.07 \\
0.13 \\
0.13 \\
0.09\end{array}$ & $\begin{array}{l}5 \\
1 \\
3 \\
4 \\
2\end{array}$ & $\begin{array}{l}0.20 \\
0.13 \\
0.19 \\
0.13 \\
0.16\end{array}$ & $\begin{array}{l}5 \\
1 \\
4 \\
2 \\
3\end{array}$ & $\begin{array}{l}0.20 \\
0.19 \\
0.26 \\
0.14 \\
0.16\end{array}$ & $\begin{array}{l}4 \\
3 \\
5 \\
1 \\
2\end{array}$ & $\begin{array}{l}0.20 \\
0.21 \\
0.30 \\
0.14 \\
0.24\end{array}$ & $\begin{array}{l}2 \\
3 \\
5 \\
1 \\
4\end{array}$ & $\begin{array}{l}0.24 \\
0.23 \\
0.35 \\
0.17 \\
0.28\end{array}$ & $\begin{array}{l}3 \\
2 \\
5 \\
1 \\
4\end{array}$ & $\begin{array}{l}0.32 \\
0.28 \\
0.42 \\
0.20 \\
0.30\end{array}$ & $\begin{array}{l}4 \\
2 \\
5 \\
1 \\
3\end{array}$ & $\begin{array}{l}0.37 \\
0.40 \\
0.44 \\
0.29 \\
0.32\end{array}$ & $\begin{array}{l}3 \\
4 \\
5 \\
1 \\
2\end{array}$ & $\begin{array}{l}0.38 \\
0.41 \\
0.50 \\
0.31 \\
0.33\end{array}$ & $\begin{array}{l}3 \\
4 \\
5 \\
1 \\
2\end{array}$ & $\begin{array}{l}0.41 \\
0.42 \\
0.79 \\
0.34 \\
0.35\end{array}$ & $\begin{array}{l}3 \\
4 \\
6 \\
1 \\
2\end{array}$ & $\begin{array}{l}1.70 \\
0.79 \\
0.98 \\
0.77 \\
1.10\end{array}$ \\
\hline
\end{tabular}

HIGHEST MEAN DISCHARGE, IN GUIC FEET PER SECOND, AND RANKING FOR THE INDICATED NUMBER OF CONSECUTTVE DAYS FOR EACH WATER YEAR, OCTOBER I-SEPTEMBER 30

\begin{tabular}{|c|c|c|c|c|c|c|c|c|c|c|c|c|c|c|c|c|c|c|c|}
\hline & \multicolumn{19}{|c|}{ CONSECUTIVE DAYS } \\
\hline & 1 & & 3 & & 7 & & 15 & & 30 & & 60 & & 90 & & 120 & & 183 & & ALL \\
\hline 1975 & 31.0 & 4 & 25.0 & 3 & 16.0 & 3 & 8.40 & 3 & 5.10 & 4 & 3.50 & 3 & 2.80 & 4 & 2.60 & 4 & 1.80 & 5 & 1.10 \\
\hline
\end{tabular}


GREEN RIVER BASIN

09306410 EVAOUATION OREEK ABOVE MISSCURI QREEK, NEAR DRAGON, UT--Continued

DURATION OF DISGHARGE FOR EAGH WATER YEAR

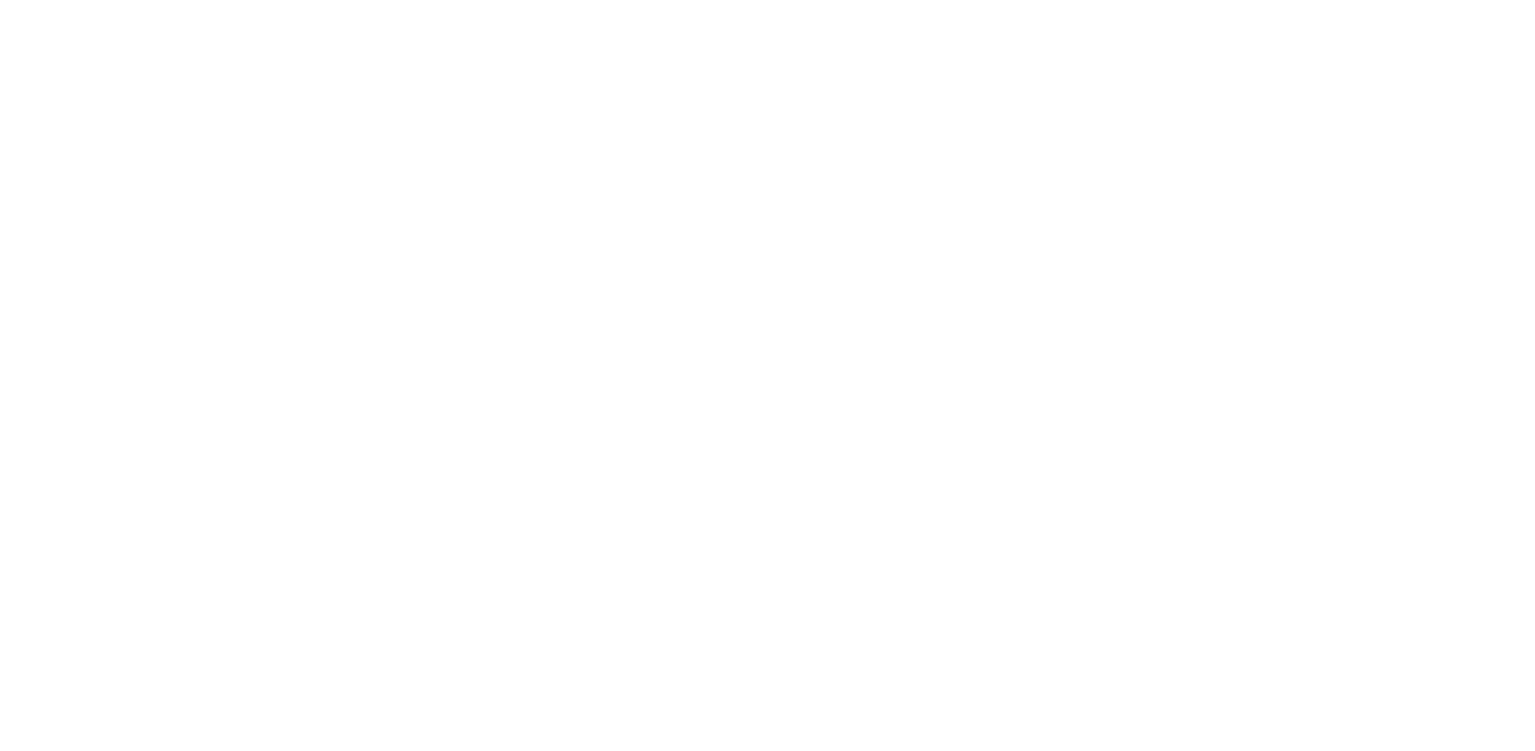

MONTHLY MEAN DISCHARGES, IN OUBIC FEET PER SECOND, FOR EAOH WATER YEAR

$\begin{array}{lllllllllllll}\text { YEAR } & \text { OCT } & \text { NOV } & \text { DEC } & \text { JAN } & \text { FEB } & \text { MAR } & \text { APR } & \text { MAY } & \text { JUNE } & \text { JULY } & \text { AUG } & \text { SEP } \\ 1975 & 0.26 & 0.28 & 0.26 & 0.29 & 0.30 & 0.78 & 1.92 & 4.35 & 2.12 & 1.41 & 0.28 & 0.51 \\ 1976 & 0.34 & 0.71 & 0.37 & 0.30 & 7.83 & 0.84 & 1.76 & 2.91 & 0.68 & 0.78 & 0.25 & 0.55 \\ 1977 & 0.45 & 0.46 & 0.45 & 0.39 & 0.40 & 0.42 & 0.48 & 0.48 & 0.36 & 0.97 & 2.70 & 0.98 \\ 1978 & 1.12 & 1.30 & 0.44 & 0.41 & 0.53 & 1.94 & 0.92 & 0.65 & 0.46 & 1.03 & 1.24 & 0.18 \\ 1979 & 0.39 & 0.39 & 0.38 & 0.40 & 0.38 & 2.71 & 1.52 & 4.78 & 1.46 & 0.37 & 0.43 & 0.35 \\ 1980 & 0.39 & 0.34 & 0.28 & 0.34 & 1.87 & 0.55 & 2.43 & 19.2 & 3.41 & 2.55 & 0.94 & 0.74 \\ 1981 & 0.90 & 0.62 & 0.72 & 0.70 & 1.27 & 3.02 & 2.29 & 0.71 & 0.47 & 0.80 & 3.05 & 2.84\end{array}$

ANNUAL PEAK DIS GAARE, IN GUBIC FEET PER SECOND, AND CORRESPONDING GAGE HEIGT, IN FEET, FOR EACH WATER YEAR

\begin{tabular}{|c|c|c|c|c|c|c|c|c|c|c|c|}
\hline $\begin{array}{l}\text { WATER } \\
\text { YEAR }\end{array}$ & DATE & $\begin{array}{c}\text { GAGE } \\
\text { HEIGIT }\end{array}$ & $\begin{array}{c}\text { PEAK } \\
\text { DISOHARGE }\end{array}$ & $\begin{array}{l}\text { WATER } \\
\text { YEAR }\end{array}$ & DATE & $\begin{array}{c}\text { GAGE } \\
\text { HEIGHT }\end{array}$ & $\begin{array}{c}\text { PEAK } \\
\text { DISOHARGE }\end{array}$ & $\begin{array}{l}\text { WATER } \\
\text { YEAR }\end{array}$ & DATE & $\begin{array}{c}\text { GAGE } \\
\text { HEIGHT }\end{array}$ & $\begin{array}{c}\text { PEAK } \\
\text { DISCHARGE }\end{array}$ \\
\hline $\begin{array}{l}1975 \\
1976 \\
1977\end{array}$ & $\begin{array}{l}\text { SEPT. 14, } 1975 \\
\text { MAY 09, } 1976 \\
\text { AUG. } 17,1977\end{array}$ & $\begin{array}{l}5.53 \\
6.16 \\
6.81\end{array}$ & $\begin{array}{l}207 \\
331 \\
503\end{array}$ & $\begin{array}{l}1978 \\
1979\end{array}$ & $\begin{array}{l}\text { AUG. } 13,1978 \\
\text { MAR. } 08,1979\end{array}$ & $\begin{array}{l}8.32 \\
4.65\end{array}$ & $\begin{array}{r}835 \\
47\end{array}$ & $\begin{array}{l}1980 \\
1981\end{array}$ & $\begin{array}{l}\text { JULY } 02,1980 \\
\text { AUG. 15, } 1981\end{array}$ & $\begin{array}{l}6.73 \\
7.55\end{array}$ & $\begin{array}{l}309 \\
562\end{array}$ \\
\hline
\end{tabular}

09306415 EVACUATTON CREEK BELOW PARK CANYON, NEAR WATSON, UT

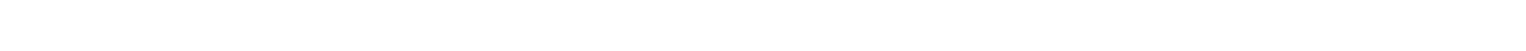

bank $0.4 \mathrm{mi}$ downstream from Park Canyon and $3.0 \mathrm{mi}$ southeast of Watson.

DRAINAGE AREA,- $-246 \mathrm{mi}^{2}$.

MEAN BASIN ELLVATION. $-6,790 \mathrm{ft}$.

PERIOD OF RECORD AVAILALE, - -October 1974 to Septenber 1975.

GAGE. -Water-stage recorder. Altitude of gage is 5,500 ft from topographic map.

REMARRS.--Small reservoir above station for irrigation of hay meadows.

EXTREMES FOR PERIOD OF RECORD.--Maximum discharge, $420 \mathrm{ft}^{3} / \mathrm{s} \mathrm{July} \mathrm{16,} \mathrm{1975,} \mathrm{gage} \mathrm{height,} 4.11$ ft; no flow for several days during August and September 1975. 
GREEN RIVER BASIN

09306415 EVACUATION CREEK BELOW PARK CANYON, NEAR WATSON, UT-Continued

HIGHEST MEAN DISCHARGE, IN OUBIC FEET PER SECOND, AND RANRING FOR THE INDICATED NUMBER OF CONSECUTIVE DAYS FOR EAOH WATER YEAR, OCTCBER 1-SEPTEMBER 30

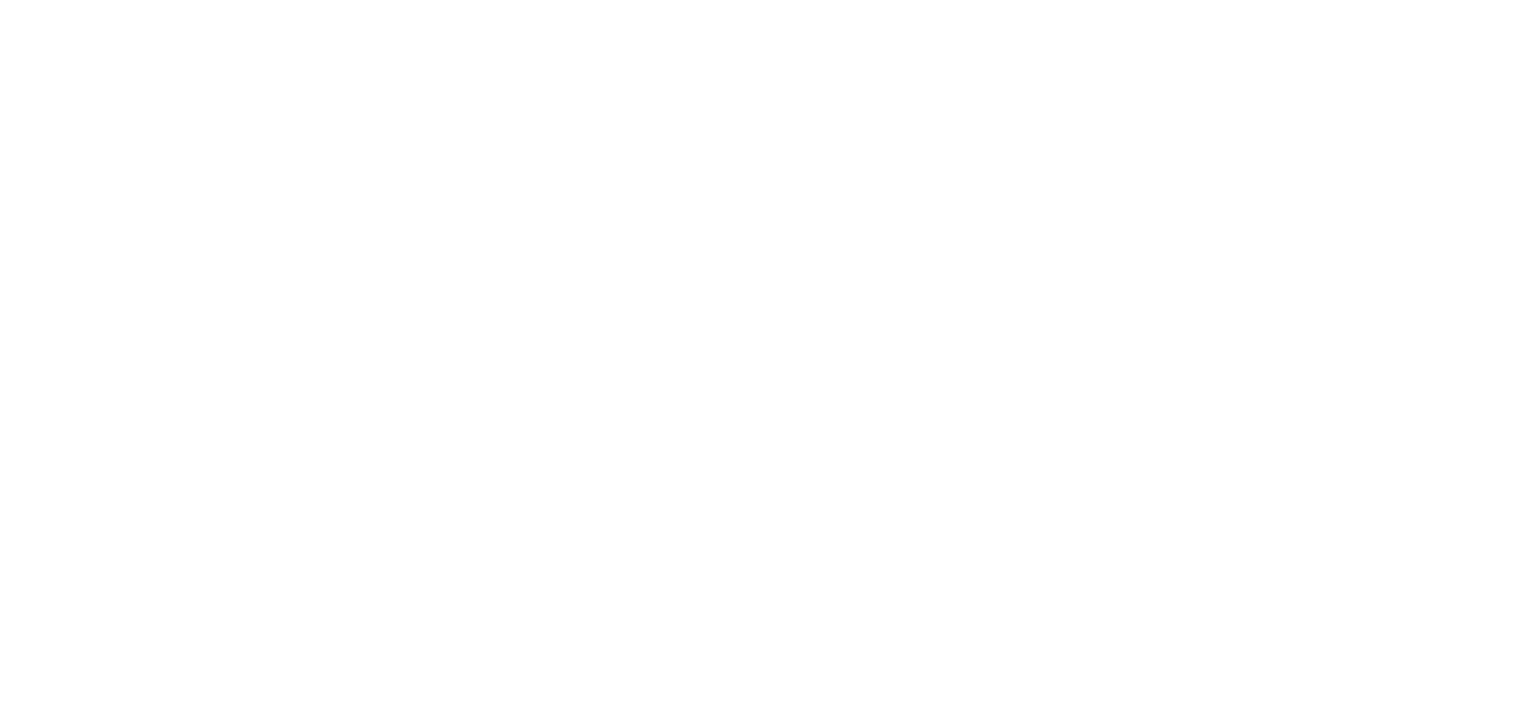

MONIHLY MEAN DISCHARGES, IN OUBIC FEET PER SECOND, FOR EACH WATER YEAR

$\begin{array}{lcccccccccccc}\text { YEAR } & \text { OCT } & \text { NOV } & \text { DEC } & \text { JAN } & \text { FEB } & \text { MAR } & \text { APR } & \text { MAY } & \text { JUNE } & \text { JULY } & \text { AUG } & \text { SEP } \\ 1975 & 0.20 & 0.20 & 0.20 & 0.20 & 0.10 & 2.31 & 2.25 & 6.12 & 1.24 & 0.83 & 0.17 & 0.91\end{array}$

09306417 THIMBLE ROCK CANYON CREER NEAR WATSON, UT

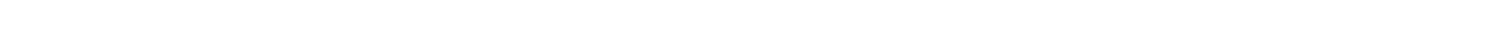
bank $3.1 \mathrm{mi}$ upstream from mouth and $4.3 \mathrm{mi}$ south of watson.

DRAINAGE AREA. $-1.7 \mathrm{mi}^{2}$.

MEAN BASIN ELEVATION. $-6,340 \mathrm{ft}$.

PERICD OF RECORD AVAIIABLE. - October 1974 to September 1975.

GAGE.-Water-stage recorder. Altitude of gage is 5,950 ft from topographic map.

NO FLOW FOR PERICO OF RECORD.

09306420 EVAOUATION CREEK AT WATSON, UT

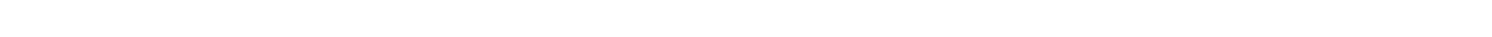
bank in the center of watson and 1.5 mi upstream from Evacuation Creek tributary.

DRAINAGE AREA. - -259 $\mathrm{mi}^{2}$.

MEAN BASIN ELEVATION. $-6,780 \mathrm{ft}$.

PERICD OF RECORD AVAIIABLE.--October 1974 to September 1976.

GAGE.--Water-stage recorder. Altitude of gage is 5,350 ft fram topographic map.

REMARRS. - Some minor diversions for irrigation above station.

EXIREMES FOR PERICD OF REOORD.-Maximum discharge, $650 \mathrm{ft}^{3} / \mathrm{s}$ May 9, 1976, gage height, $3.72 \mathrm{ft}$, based on slope-area measurement of peak flow; no flow for several days each year. 
GREEN RIVER BASIN

09306420 EVACUATION CREEK AT WATSON, UT--Continued

LOWEST MEAN DISCHARGE, IN GUBIC FEET PER SECOND, AND RANRING FOR THE INDICATED NUMBER OF CONSECUTIVE DAYS FOR EACH CIMATIC YEAR, APRII I-MARCH 31

\begin{tabular}{|c|c|c|c|c|c|c|c|c|c|c|c|c|c|c|c|c|c|c|c|}
\hline YEAR & \multicolumn{19}{|c|}{ CONSEOUTIVE DAYS } \\
\hline 1976 & 0.00 & 1 & 0.00 & 1 & 0.00 & 1 & 0.01 & 1 & 0.02 & 1 & 0.04 & 1 & 0.05 & 1 & 0.06 & 1 & 0.63 & 1 & 1.411 \\
\hline
\end{tabular}

HIGHEST MEAN DISCHARGE, IN OBIC FEET PER SECOND, AND RANKING FOR THE INDICATED NUMBER OF CONSECUTIVE DAYS FOR EACH WATER YEAR, OCTOBER 1-SEPTEMBER 30

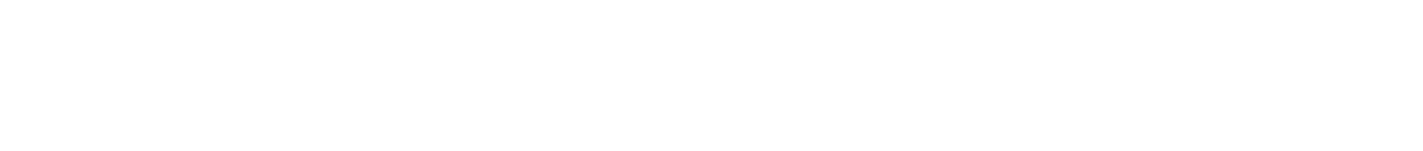

DURATION OF DISCHARGE FOR EACH WATER YEAR

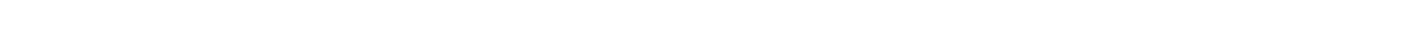
YEAR

NUMBER OF DAYS IN CLASS

OBIC FEET PER SECOND -DAYS

$\begin{array}{lllllllllllllllllllllllllllllllll}1975 & 7 & 72 & 8 & 7 & 3 & 1 & 7 & 59 & 7 & 8 & 10 & 6 & 33 & 12 & 16 & 6 & 7 & 21 & 14 & 10 & 15 & 6 & 5 & 3 & 7 & 3 & 7 & 2 & 1 & 1 & 1\end{array}$

516.0

$\begin{array}{llllllllllllllllllllllllll}1976 & 7 & 49 & 23 & 22 & 17 & 31 & 18 & 31 & 8 & 6 & 13 & 5 & 3 & 5 & 4 & 4 & 3 & 17 & 20 & 25 & 27 & 13 & 5 & 2 & 4\end{array}$

483.4

DURATION TABLE OF DISCHARGE FOR WATER YEARS 1975-76

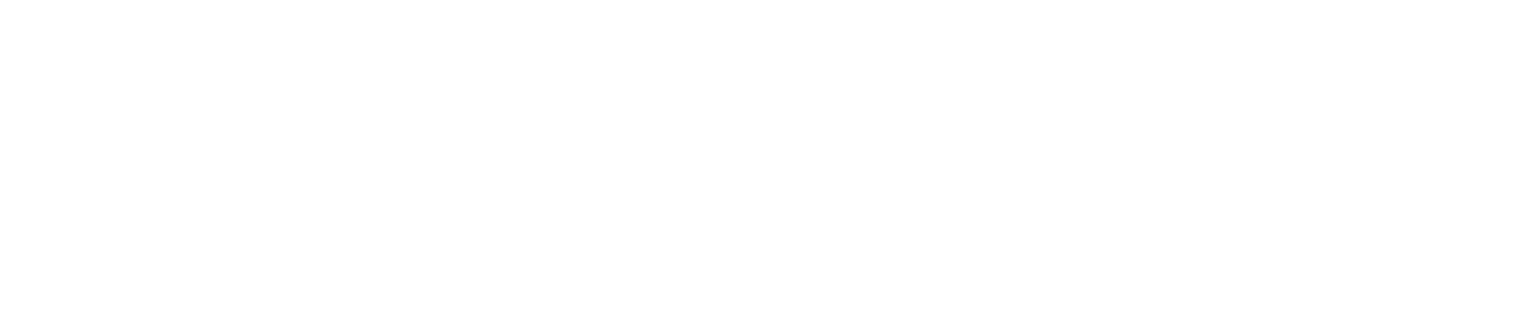

MONIHLY MEAN DISCHARGES, IN OUBIC FEET PER SECOND, FOR EACH WATER YEAR

\begin{tabular}{|c|c|c|c|c|c|c|c|c|c|c|c|c|}
\hline YEAR & OCT & NOV & $\mathrm{DEC}$ & JAN & FEB & MAR & APR & MAY & JUNE & JULY & AUG & SEP \\
\hline 1975 & 0.01 & 0.03 & 0.15 & 0.10 & 0.25 & 2.68 & 2.12 & 5.25 & 1.48 & 1.21 & 1.61 & 1.96 \\
\hline 1976 & 0.05 & 0.06 & 0.06 & 0.07 & 6.46 & 1.98 & 2.45 & 3.76 & 0.1 & 0.65 & 0.07 & 0.37 \\
\hline
\end{tabular}

09306425 EVACUATION CREEK TRIBUTARY NEAR WATSON, UT

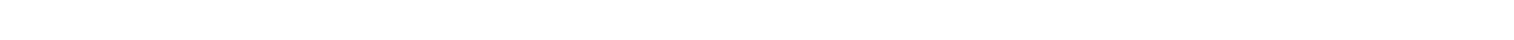
bank $0.3 \mathrm{mi}$ upstream from mouth and $1.2 \mathrm{mi}$ north of watson.

DRAINAGE AREA. $-12.4 \mathrm{mi}^{2}$.

MEAN BASIN ELEVATION. $-6,120 \mathrm{ft}$.

PERICD OF RECORD AVAILABLE.--October 1974 to September 1975.

GAGE.-Water-stage recorder. Altitude of gage is 5,320 ft from topographic map.

NO FLOW FOR PERIOD OF RECORD. 


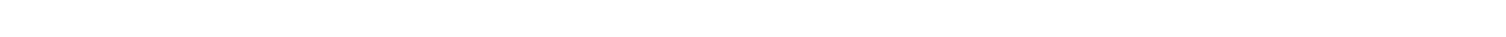
bank $2.2 \mathrm{mi}$ upstream from mouth and $4.8 \mathrm{mi}$ north of Watson.

DRADNAGE AREA $-284 \mathrm{mi}^{2}$.

MEAN BASIN ELEVATION. $-6,700 \mathrm{ft}$.

FERIOD OF RECORD AVAIJABLE.--OCtober 1974 to September 1981.

CAGE. -Water-stage recorder and artificial control. Altitude of gage is 5,050 ft fram topographic map.

REMARKS.--Some minor diversions for irrigation above station.

AVERAGE DISCHARGE. -7 years, $1.55 \mathrm{ft}^{3} / \mathrm{s}, 1,120$ acre-ft/yr.

EXIREMES FOR PERIOD OF RECORD.--Maximum discharge, 1,980 $\mathrm{ft}^{3} / \mathrm{s}$ Sept. 26,1979 , gage height, $7.48 \mathrm{ft}$, from rating curve extended

above $50 \mathrm{ft}^{3} / \mathrm{s}$ on basis of slope-area measurement of peak $\mathrm{flow}$.; no flow at times for some years.

LOWEST MEAN DIS CHARGE, IN OUBIC FEET PER SECOND, AND RANKING FOR THE INDICATED NUMBER OF CONSEGTTVE DAYS FOR EACH OLIMATTC YEAR, APRTL 1-MAROH 31

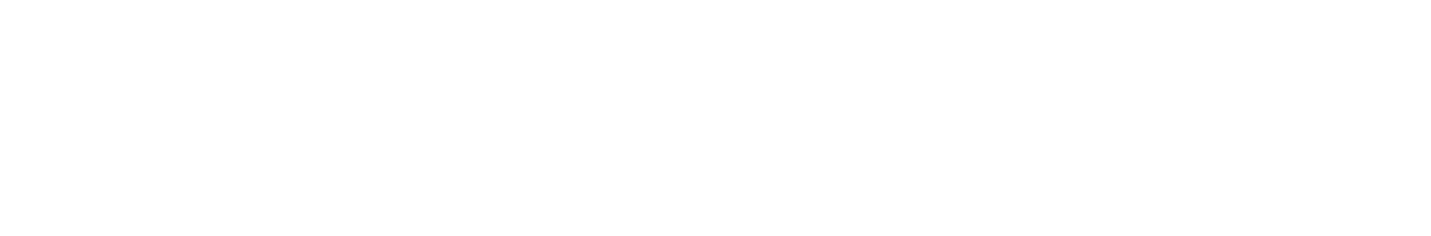

HIGHEST MEAN DISCHARGE, IN OUBIC FEET PER SECOND, AND RANKING FOR THE INDICATED NUMBER OF CONSEQUTIVE DAYS FOR EACH WATER YEAR, OCTOBER 1-SEPTEMBER 30

\begin{tabular}{|c|c|c|c|c|c|c|c|c|c|c|c|c|c|c|c|c|c|c|c|}
\hline YEAR & \multicolumn{19}{|c|}{ CONSEATTIVE DAYS } \\
\hline 1975 & 62.0 & 5 & 43.0 & 3 & 20.0 & 4 & 11.0 & 4 & 6.40 & 4 & 4.10 & 4 & 3.10 & 4 & 2.70 & 4 & 2.10 & 5 & 1.10 \\
\hline
\end{tabular}

DURATION OF DISOHARGE FOR EACH WATER YEAR

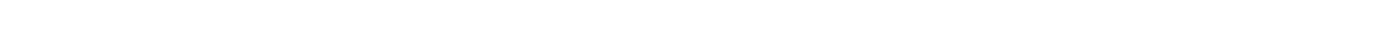

XEAR

NUMBE OF DAYS IN QLASS

OUBIC FEET PER SECOND

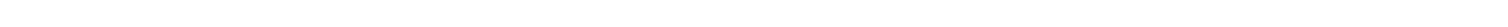

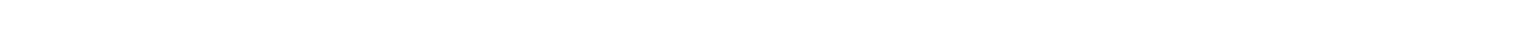

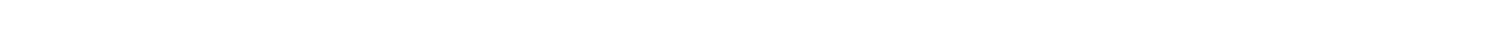

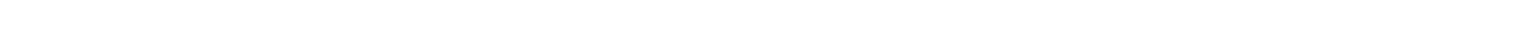

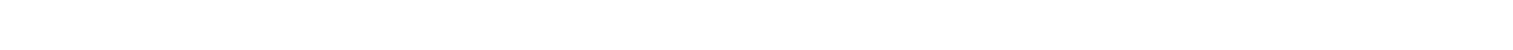

$\begin{array}{lllllllllllllllllllllllllll}1980 & 13 & 15 & 34 & 98 & 44 & 14 & 39 & 21 & 30 & 11 & 15 & 14 & 2 & 4 & & 1 & 4 & 2 & 2 & 1 & 1 & & & & \end{array}$

DURATION TABLE OF DISCHARGE FOR WATER YEARS $1975-81$

\begin{tabular}{|c|c|c|c|c|c|c|c|c|c|c|c|c|c|c|c|c|c|c|c|}
\hline & $\begin{array}{c}\text { OBBIC } \\
\text { FEET } \\
\text { PER } \\
\text { SECOND }\end{array}$ & $\begin{array}{l}\text { TOTAL } \\
\text { DAYS }\end{array}$ & $\begin{array}{l}\text { ACOU- } \\
\text { MU- } \\
\text { LATED } \\
\text { DAYS }\end{array}$ & $\begin{array}{l}\text { PER- } \\
\text { CENT } \\
\text { DAYS }\end{array}$ & CASS & $\begin{array}{c}\text { OUBIC } \\
\text { FEET } \\
\text { PER } \\
\text { SECOND }\end{array}$ & $\begin{array}{c}\text { TOTAL } \\
\text { DAYS }\end{array}$ & $\begin{array}{c}\text { ACOJ- } \\
\text { MU- } \\
\text { LATED } \\
\text { DAYS }\end{array}$ & $\begin{array}{l}\text { FER- } \\
\text { OENT } \\
\text { DAYS }\end{array}$ & QLASS & $\begin{array}{c}\text { OUBIC } \\
\text { FEET } \\
\text { PER } \\
\text { SECOND }\end{array}$ & $\begin{array}{l}\text { TOTAL } \\
\text { DAYS }\end{array}$ & $\begin{array}{c}\text { ACGU- } \\
\text { MUI- } \\
\text { LATED } \\
\text { DAYS }\end{array}$ & $\begin{array}{l}\text { FER- } \\
\text { EENT } \\
\text { DAYS }\end{array}$ & & $\begin{array}{c}\text { OJBIC } \\
\text { FEET } \\
\text { FER } \\
\text { SECOND }\end{array}$ & $\begin{array}{l}\text { TOTAL } \\
\text { DAYS }\end{array}$ & $\begin{array}{c}\text { ACUI- } \\
\text { NU- } \\
\text { LAIED } \\
\text { DAYS }\end{array}$ & $\begin{array}{l}\text { FER- } \\
\text { CENT } \\
\text { DAYS }\end{array}$ \\
\hline $\begin{array}{l}0 \\
1 \\
2 \\
3 \\
4 \\
5 \\
6 \\
7 \\
8\end{array}$ & $\begin{array}{l}0.00 \\
0.01 \\
0.02 \\
0.03 \\
0.05 \\
0.06 \\
0.08 \\
0.11 \\
0.15\end{array}$ & $\begin{array}{r}12 \\
36 \\
325 \\
465 \\
107 \\
140 \\
136 \\
93 \\
92\end{array}$ & $\begin{array}{l}2557 \\
2545 \\
2509 \\
2184 \\
1719 \\
1612 \\
1472 \\
1336\end{array}$ & $\begin{array}{r}100.0 \\
99.5 \\
98.1 \\
85.4 \\
67.2 \\
63.0 \\
57.6 \\
52.2 \\
48.6\end{array}$ & $\begin{array}{l}9 \\
10 \\
11 \\
12 \\
13 \\
14 \\
15 \\
16 \\
17\end{array}$ & $\begin{array}{l}0.20 \\
0.27 \\
0.36 \\
0.49 \\
0.66 \\
0.89 \\
1.20 \\
1.60\end{array}$ & $\begin{array}{r}196 \\
98 \\
94 \\
154 \\
102 \\
90 \\
91 \\
86 \\
65\end{array}$ & $\begin{array}{r}1151 \\
955 \\
857 \\
763 \\
609 \\
507 \\
417 \\
326 \\
240\end{array}$ & $\begin{array}{r}45.0 \\
37.3 \\
33.5 \\
29.8 \\
23.8 \\
19.8 \\
16.3 \\
12.7 \\
9.4\end{array}$ & $\begin{array}{l}18 \\
19 \\
20 \\
21 \\
22 \\
23 \\
24 \\
25 \\
26\end{array}$ & $\begin{array}{r}3.0 \\
4.0 \\
5.4 \\
7.3 \\
9.8 \\
13.0 \\
18.0 \\
24.0 \\
33.0\end{array}$ & $\begin{array}{r}32 \\
27 \\
16 \\
25 \\
14 \\
17 \\
13 \\
10 \\
8\end{array}$ & $\begin{array}{r}175 \\
143 \\
116 \\
100 \\
75 \\
61 \\
44 \\
31 \\
21\end{array}$ & $\begin{array}{l}6.8 \\
5.6 \\
4.5 \\
3.9 \\
2.9 \\
2.4 \\
1.7 \\
1.2 \\
0.8\end{array}$ & $\begin{array}{l}27 \\
28 \\
29 \\
30 \\
31 \\
32 \\
33 \\
34\end{array}$ & $\begin{array}{r}44.0 \\
59.0 \\
80.0 \\
110.0 \\
150.0 \\
200.0\end{array}$ & $\begin{array}{l}3 \\
6 \\
1 \\
0 \\
2 \\
1\end{array}$ & $\begin{array}{r}13 \\
10 \\
4 \\
3 \\
3 \\
1\end{array}$ & \\
\hline
\end{tabular}


GREEN RIVER BASIN

09306430 EVACUATION CREFK NEAR WATSON, UT-Continued

MONIHLY MEAN DISCHARGES, IN OBIC FEET PER SECOND, FOR EAGH WATER YEAR

$\begin{array}{lllllllllllll}\text { YEAR } & \text { OCT } & \text { NOV } & \text { DEC } & \text { JAN } & \text { FEB } & \text { MAR } & \text { APR } & \text { MAY } & \text { JUNE } & \text { JULY } & \text { AUG } & \text { SEP } \\ 1975 & 0.12 & 0.08 & 0.04 & 0.04 & 0.16 & 2.35 & 0.99 & 5.92 & 1.30 & 1.50 & 0.23 & 0.68 \\ 1976 & 0.04 & 0.06 & 0.04 & 0.04 & 10.1 & 1.23 & 1.67 & 3.74 & 0.35 & 0.48 & 0.20 & 0.92 \\ 1977 & 0.06 & 0.02 & 0.02 & 0.02 & 0.02 & 0.04 & 0.02 & 0.02 & 0.02 & 4.03 & 2.43 & 1.31 \\ 1978 & 1.13 & 1.01 & 0.05 & 0.03 & 0.04 & 0.97 & 0.85 & 0.57 & 0.17 & 0.14 & 2.19 & 0.04 \\ 1979 & 0.05 & 0.03 & 0.03 & 0.02 & 0.04 & 5.25 & 5.23 & 4.30 & 1.18 & 0.23 & 0.91 & 2.04 \\ 1980 & 0.12 & 0.05 & 0.05 & 1.76 & 25.7 & 0.62 & 1.78 & 12.0 & 1.95 & 2.01 & 2.50 & 0.47 \\ 1981 & 0.62 & 0.20 & 0.20 & 0.27 & 0.43 & 0.76 & 1.87 & 1.26 & 0.66 & 2.19 & 3.07 & 3.48\end{array}$

ANNUAL PEAK DISCHARGE, IN OUBIC FEET PER SECOND, AND CORRESPONDING GAGE HEIGHT, IN FEET, FOR EACH WATER YEAR

\begin{tabular}{|c|c|c|c|c|c|c|c|c|c|c|c|c|}
\hline $\begin{array}{l}\text { WATER } \\
\text { YEAR }\end{array}$ & & DATE & $\begin{array}{c}\text { GAGE } \\
\text { HEIGHT }\end{array}$ & $\begin{array}{c}\text { PEAK } \\
\text { DISCHARGE }\end{array}$ & $\begin{array}{l}\text { WATER } \\
\text { YEAR }\end{array}$ & DATE & $\begin{array}{c}\text { GAGE } \\
\text { HEIGHT }\end{array}$ & $\begin{array}{c}\text { PEAK } \\
\text { DISCHARGE }\end{array}$ & $\begin{array}{l}\text { WATER } \\
\text { YEAR }\end{array}$ & DATE & $\begin{array}{c}\text { GAGE } \\
\text { HEIGHT }\end{array}$ & $\begin{array}{c}\text { PEAK } \\
\text { DISCHARGE }\end{array}$ \\
\hline $\begin{array}{l}1975 \\
1976 \\
1977\end{array}$ & $\begin{array}{l}\text { MAY } \\
\text { MAY } \\
\text { JULY }\end{array}$ & $\begin{array}{l}28,1975 \\
10,1976 \\
05,1977\end{array}$ & $\begin{array}{l}3.09 \\
5.06 \\
5.25\end{array}$ & $\begin{array}{l}108 \\
679 \\
648\end{array}$ & $\begin{array}{l}1978 \\
1979\end{array}$ & $\begin{array}{l}\text { AUG. } 13,1978 \\
\text { SEPT. } 26,1979\end{array}$ & $\begin{array}{l}6.57 \\
7.48\end{array}$ & $\begin{array}{l}1300 \\
1980\end{array}$ & $\begin{array}{l}1980 \\
1981\end{array}$ & $\begin{array}{l}\text { FEB. } 19,1980 \\
\text { JULY } 24,1981\end{array}$ & $\begin{array}{l}4.99 \\
4.30\end{array}$ & $\begin{array}{l}676 \\
380\end{array}$ \\
\hline
\end{tabular}

09306500 WHITE RIVER NEAR WATSON, UT

LOCATION.--Lat $39^{\circ} 58^{\prime} 46^{\prime \prime}$, long $109^{\circ} 10^{\prime} 41^{\prime \prime}$, in SE $\frac{1}{4} \mathrm{SW}_{\frac{1}{4}} \mathrm{NE}_{\frac{1}{4}}$ sec.2, T.10 S., R.24 E., Uintah County, Hydrologic Unit 14050007, on right bank $350 \mathrm{ft}$ downstream from bridge on State Highway 45, $1 \mathrm{mi}$ downstream from Evacuation Creek, and $7 \mathrm{mi}$ north of Watson.

DRAINAGE AREA.--4,020 $\mathrm{mi}^{2}$, approximately.

MEAN BASIN ELEVATION. $-7,180 \mathrm{ft}$.

PERIOD OF RECORD AVAIIABLE.--April 1904 to October 1906 (no winter records), May to November 1918, April 1923 to September 1979.

Monthly mean discharge for some periods, published in WSP 1313. Published as "near Dragon", 1906, and "near Rangely, 00 ", 190405, 1918 .

GAGE.--Water-stage recorder. Datum of gage is 4,946.78 ft NGVD of 1929 . See WSP 1733 for history of changes prior to Oct. 27, 1959.

REMARKS.-Diversions for irrigation of about 31,900 acres above station.

AVERAGE DISCHARGE.--56 years $(1923-79), 695 \mathrm{ft}^{3} / \mathrm{s}, 503,500$ acre-ft/yr.

EXTREMES FOR PERIOD OF RECORD.--Maximum discharge, 8,160 ft ${ }^{3} / \mathrm{s}$ July 15, 1929; maximum gage height, $13.1 \mathrm{ft}$ Feb. 11, $1962, \mathrm{fram}$

floodmark in well (backwater from ice); minimum, $11 \mathrm{ft}^{3} / \mathrm{s} \mathrm{Dec.} \mathrm{6,} \mathrm{1972,} \mathrm{result} \mathrm{of} \mathrm{freezeup.}$

LOWEST MEAN DISCHARGE, IN OUBIC FEET PER SECOND, AND RANKING FOR THE INDICATED NUMBER OF CONSEOUTIVE DAYS FOR EAQH CIIMATIC YEAR, APRII 1-MARCH 31

YEAR

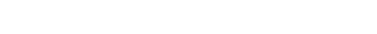

\begin{tabular}{|c|c|c|c|c|c|c|c|c|c|c|c|c|c|c|c|c|c|c|c|c|}
\hline & 1 & & 3 & & 7 & & 14 & & 30 & & 60 & & 90 & & 120 & & 183 & & ALL & \\
\hline $\begin{array}{l}1924 \\
1925\end{array}$ & $\begin{array}{l}373 \\
288\end{array}$ & $\begin{array}{l}51 \\
46\end{array}$ & $\begin{array}{l}386 \\
289\end{array}$ & $\begin{array}{l}52 \\
45\end{array}$ & $\begin{array}{l}405 \\
295\end{array}$ & $\begin{array}{l}55 \\
44\end{array}$ & $\begin{array}{l}420 \\
301\end{array}$ & $\begin{array}{l}54 \\
40\end{array}$ & $\begin{array}{l}421 \\
332\end{array}$ & $\begin{array}{l}55 \\
40\end{array}$ & $\begin{array}{l}430 \\
349\end{array}$ & $\begin{array}{l}54 \\
37\end{array}$ & $\begin{array}{l}440 \\
359\end{array}$ & $\begin{array}{l}54 \\
37\end{array}$ & $\begin{array}{l}449 \\
367\end{array}$ & $\begin{array}{l}51 \\
33\end{array}$ & $\begin{array}{l}479 \\
365\end{array}$ & $\begin{array}{l}51 \\
25\end{array}$ & $\begin{array}{l}804 \\
621\end{array}$ & $\begin{array}{l}42 \\
24\end{array}$ \\
\hline $\begin{array}{l}1936 \\
1937 \\
1938 \\
1939 \\
1940\end{array}$ & $\begin{array}{l}216 \\
160 \\
166 \\
164 \\
164\end{array}$ & $\begin{array}{l}35 \\
20 \\
25 \\
23 \\
24\end{array}$ & $\begin{array}{l}227 \\
160 \\
179 \\
173 \\
165\end{array}$ & $\begin{array}{l}33 \\
12 \\
20 \\
18 \\
15\end{array}$ & $\begin{array}{l}255 \\
160 \\
187 \\
187 \\
168\end{array}$ & $\begin{array}{r}36 \\
7 \\
15 \\
16 \\
11\end{array}$ & $\begin{array}{l}263 \\
160 \\
221 \\
225 \\
196\end{array}$ & $\begin{array}{r}29 \\
4 \\
17 \\
19 \\
11\end{array}$ & $\begin{array}{l}293 \\
160 \\
256 \\
278 \\
276\end{array}$ & $\begin{array}{r}33 \\
4 \\
17 \\
28 \\
26\end{array}$ & $\begin{array}{l}323 \\
219 \\
278 \\
299 \\
280\end{array}$ & $\begin{array}{r}32 \\
4 \\
17 \\
25 \\
18\end{array}$ & $\begin{array}{l}323 \\
244 \\
290 \\
309 \\
342\end{array}$ & $\begin{array}{r}23 \\
4 \\
11 \\
19 \\
32\end{array}$ & $\begin{array}{l}334 \\
265 \\
312 \\
326 \\
352\end{array}$ & $\begin{array}{r}21 \\
4 \\
13 \\
17 \\
27\end{array}$ & $\begin{array}{l}338 \\
302 \\
375 \\
394 \\
362\end{array}$ & $\begin{array}{r}13 \\
5 \\
28 \\
37 \\
22\end{array}$ & $\begin{array}{l}568 \\
635 \\
578 \\
877 \\
558\end{array}$ & $\begin{array}{l}15 \\
27 \\
18 \\
51 \\
13\end{array}$ \\
\hline
\end{tabular}


GREEN RIVER BASIN

09306500 WHITE RIVER NEAR WATSON, UT-Continued

LOWEST MEAN DISQHARGE, IN OUBIC FEET PER SECOND, AND RANKING FOR THE INDICATED NUNBER OF CONSEQUTTVE DAYS FOR EACH OLIMATIC YEAR, APRIL 1-MARG 31--Continued

\begin{tabular}{|c|c|c|c|c|c|c|c|c|c|c|c|c|c|c|c|c|c|c|c|c|}
\hline YEAR & \multicolumn{20}{|c|}{ CONSECUTTVE DAYS } \\
\hline $\begin{array}{l}1946 \\
1947 \\
1948 \\
1949 \\
1950\end{array}$ & $\begin{array}{l}160 \\
245 \\
230 \\
150 \\
225\end{array}$ & $\begin{array}{l}21 \\
42 \\
38 \\
17 \\
36\end{array}$ & $\begin{array}{l}187 \\
257 \\
243 \\
160 \\
232\end{array}$ & $\begin{array}{l}24 \\
42 \\
39 \\
13 \\
35\end{array}$ & $\begin{array}{l}208 \\
259 \\
253 \\
167 \\
259\end{array}$ & $\begin{array}{l}22 \\
37 \\
35 \\
10 \\
38\end{array}$ & $\begin{array}{l}241 \\
268 \\
258 \\
169 \\
268\end{array}$ & $\begin{array}{r}24 \\
31 \\
28 \\
7 \\
32\end{array}$ & $\begin{array}{l}327 \\
270 \\
278 \\
194 \\
296\end{array}$ & $\begin{array}{r}39 \\
24 \\
29 \\
7 \\
34\end{array}$ & $\begin{array}{l}342 \\
294 \\
365 \\
226 \\
307\end{array}$ & $\begin{array}{r}36 \\
21 \\
41 \\
5 \\
27\end{array}$ & $\begin{array}{l}354 \\
330 \\
382 \\
260 \\
328\end{array}$ & $\begin{array}{r}34 \\
27 \\
42 \\
6 \\
25\end{array}$ & $\begin{array}{l}378 \\
350 \\
409 \\
293 \\
355\end{array}$ & $\begin{array}{r}36 \\
26 \\
45 \\
8 \\
28\end{array}$ & $\begin{array}{l}386 \\
368 \\
438 \\
313 \\
408\end{array}$ & $\begin{array}{l}32 \\
26 \\
44 \\
10 \\
39\end{array}$ & $\begin{array}{l}699 \\
557 \\
809 \\
676 \\
813\end{array}$ & $\begin{array}{l}32 \\
12 \\
43 \\
28 \\
44\end{array}$ \\
\hline $\begin{array}{l}1951 \\
1952 \\
1953 \\
1954 \\
1955\end{array}$ & $\begin{array}{l}160 \\
245 \\
180 \\
246 \\
146\end{array}$ & $\begin{array}{l}18 \\
43 \\
29 \\
44 \\
14\end{array}$ & $\begin{array}{l}213 \\
272 \\
190 \\
248 \\
155\end{array}$ & $\begin{array}{l}32 \\
43 \\
25 \\
41 \\
11\end{array}$ & $\begin{array}{l}261 \\
287 \\
249 \\
251 \\
162\end{array}$ & $\begin{array}{r}39 \\
42 \\
30 \\
32 \\
8\end{array}$ & $\begin{array}{l}276 \\
300 \\
321 \\
257 \\
179\end{array}$ & $\begin{array}{r}35 \\
39 \\
43 \\
27 \\
8\end{array}$ & $\begin{array}{l}287 \\
324 \\
366 \\
275 \\
217\end{array}$ & $\begin{array}{l}31 \\
36 \\
46 \\
25 \\
10\end{array}$ & $\begin{array}{l}322 \\
330 \\
391 \\
303 \\
252\end{array}$ & $\begin{array}{r}31 \\
33 \\
46 \\
26 \\
9\end{array}$ & $\begin{array}{l}342 \\
331 \\
396 \\
340 \\
292\end{array}$ & $\begin{array}{l}33 \\
28 \\
45 \\
31 \\
13\end{array}$ & $\begin{array}{l}355 \\
334 \\
399 \\
347 \\
305\end{array}$ & $\begin{array}{l}29 \\
20 \\
41 \\
24 \\
11\end{array}$ & $\begin{array}{l}362 \\
352 \\
431 \\
357 \\
350\end{array}$ & $\begin{array}{l}23 \\
19 \\
42 \\
20 \\
17\end{array}$ & $\begin{array}{l}605 \\
630 \\
998 \\
632 \\
479\end{array}$ & $\begin{array}{r}22 \\
25 \\
53 \\
26 \\
5\end{array}$ \\
\hline $\begin{array}{l}1956 \\
1957 \\
1958 \\
1959 \\
1960\end{array}$ & $\begin{array}{c}138 \\
163 \\
290 \\
85.0 \\
190\end{array}$ & $\begin{array}{r}13 \\
22 \\
47 \\
6 \\
32\end{array}$ & $\begin{array}{l}142 \\
178 \\
317 \\
198 \\
207\end{array}$ & $\begin{array}{r}8 \\
19 \\
48 \\
27 \\
31\end{array}$ & $\begin{array}{l}160 \\
186 \\
334 \\
229 \\
225\end{array}$ & $\begin{array}{r}6 \\
14 \\
48 \\
26 \\
23\end{array}$ & $\begin{array}{l}180 \\
197 \\
365 \\
292 \\
242\end{array}$ & $\begin{array}{r}9 \\
12 \\
49 \\
38 \\
25\end{array}$ & $\begin{array}{l}204 \\
216 \\
374 \\
335 \\
260\end{array}$ & $\begin{array}{r}8 \\
9 \\
48 \\
41 \\
19\end{array}$ & $\begin{array}{l}262 \\
250 \\
404 \\
359 \\
296\end{array}$ & $\begin{array}{r}11 \\
8 \\
49 \\
40 \\
23\end{array}$ & $\begin{array}{l}258 \\
280 \\
431 \\
369 \\
312\end{array}$ & $\begin{array}{r}5 \\
8 \\
52 \\
38 \\
20\end{array}$ & $\begin{array}{l}279 \\
291 \\
469 \\
371 \\
328\end{array}$ & $\begin{array}{r}6 \\
7 \\
53 \\
35 \\
18\end{array}$ & $\begin{array}{l}302 \\
304 \\
511 \\
393 \\
364\end{array}$ & $\begin{array}{r}6 \\
7 \\
53 \\
36 \\
24\end{array}$ & $\begin{array}{r}535 \\
559 \\
1080 \\
756 \\
574\end{array}$ & $\begin{array}{r}9 \\
14 \\
55 \\
36 \\
17\end{array}$ \\
\hline $\begin{array}{l}1966 \\
1967 \\
1968 \\
1969 \\
1970\end{array}$ & $\begin{array}{c}178 \\
78.0 \\
149 \\
293 \\
100\end{array}$ & $\begin{array}{r}27 \\
5 \\
15 \\
48 \\
7\end{array}$ & $\begin{array}{l}202 \\
81.0 \\
151 \\
304 \\
133\end{array}$ & $\begin{array}{r}28 \\
3 \\
9 \\
46 \\
6\end{array}$ & $\begin{array}{c}280 \\
96.0 \\
167 \\
309 \\
235\end{array}$ & $\begin{array}{r}41 \\
3 \\
9 \\
46 \\
28\end{array}$ & $\begin{array}{l}357 \\
113 \\
187 \\
322 \\
329\end{array}$ & $\begin{array}{r}48 \\
3 \\
10 \\
44 \\
46\end{array}$ & $\begin{array}{l}367 \\
153 \\
232 \\
347 \\
378\end{array}$ & $\begin{array}{r}47 \\
3 \\
14 \\
44 \\
49\end{array}$ & $\begin{array}{l}377 \\
212 \\
288 \\
355 \\
406\end{array}$ & $\begin{array}{r}44 \\
3 \\
19 \\
39 \\
50\end{array}$ & $\begin{array}{l}397 \\
218 \\
301 \\
373 \\
411\end{array}$ & $\begin{array}{r}46 \\
3 \\
15 \\
39 \\
49\end{array}$ & $\begin{array}{l}415 \\
241 \\
313 \\
382 \\
418\end{array}$ & $\begin{array}{r}46 \\
3 \\
14 \\
37 \\
47\end{array}$ & $\begin{array}{l}457 \\
266 \\
311 \\
387 \\
444\end{array}$ & $\begin{array}{r}49 \\
3 \\
9 \\
34 \\
46\end{array}$ & $\begin{array}{l}856 \\
405 \\
530 \\
693 \\
678\end{array}$ & $\begin{array}{r}48 \\
3 \\
8 \\
31 \\
29\end{array}$ \\
\hline $\begin{array}{l}1971 \\
1972 \\
1973 \\
1974 \\
1975\end{array}$ & $\begin{array}{c}297 \\
242 \\
45.0 \\
238 \\
170\end{array}$ & $\begin{array}{r}49 \\
41 \\
2 \\
39 \\
26\end{array}$ & $\begin{array}{c}338 \\
245 \\
83.0 \\
315 \\
170\end{array}$ & $\begin{array}{r}49 \\
40 \\
4 \\
47 \\
17\end{array}$ & $\begin{array}{l}347 \\
252 \\
183 \\
316 \\
194\end{array}$ & $\begin{array}{l}50 \\
33 \\
13 \\
47 \\
17\end{array}$ & $\begin{array}{l}373 \\
276 \\
208 \\
323 \\
211\end{array}$ & $\begin{array}{l}50 \\
36 \\
15 \\
45 \\
16\end{array}$ & $\begin{array}{l}385 \\
324 \\
247 \\
337 \\
267\end{array}$ & $\begin{array}{l}51 \\
37 \\
15 \\
42 \\
23\end{array}$ & $\begin{array}{l}403 \\
388 \\
275 \\
368 \\
317\end{array}$ & $\begin{array}{l}48 \\
45 \\
15 \\
42 \\
29\end{array}$ & $\begin{array}{l}409 \\
391 \\
308 \\
378 \\
339\end{array}$ & $\begin{array}{l}48 \\
44 \\
18 \\
41 \\
30\end{array}$ & $\begin{array}{l}418 \\
400 \\
358 \\
396 \\
361\end{array}$ & $\begin{array}{l}48 \\
42 \\
31 \\
40 \\
32\end{array}$ & $\begin{array}{l}447 \\
422 \\
379 \\
418 \\
362\end{array}$ & $\begin{array}{l}48 \\
41 \\
29 \\
40 \\
21\end{array}$ & $\begin{array}{l}793 \\
708 \\
596 \\
788 \\
682\end{array}$ & $\begin{array}{l}41 \\
33 \\
20 \\
40 \\
30\end{array}$ \\
\hline $\begin{array}{l}1976 \\
1977 \\
1978 \\
1579\end{array}$ & $\begin{array}{c}205 \\
134 \\
13.0 \\
190\end{array}$ & $\begin{array}{r}33 \\
12 \\
1 \\
31\end{array}$ & $\begin{array}{c}205 \\
187 \\
18.0 \\
233\end{array}$ & $\begin{array}{r}30 \\
22 \\
1 \\
36\end{array}$ & $\begin{array}{c}205 \\
229 \\
33.0 \\
250\end{array}$ & $\begin{array}{r}20 \\
25 \\
1 \\
31\end{array}$ & $\begin{array}{c}205 \\
237 \\
66.0 \\
271\end{array}$ & $\begin{array}{c}14 \\
23 \\
1 \\
34\end{array}$ & $\begin{array}{c}219 \\
261 \\
86.0 \\
282\end{array}$ & $\begin{array}{r}11 \\
20 \\
1 \\
30\end{array}$ & $\begin{array}{l}268 \\
298 \\
124 \\
295\end{array}$ & $\begin{array}{r}13 \\
24 \\
2 \\
22\end{array}$ & $\begin{array}{l}306 \\
312 \\
167 \\
319\end{array}$ & $\begin{array}{r}16 \\
21 \\
2 \\
22\end{array}$ & $\begin{array}{l}348 \\
325 \\
181 \\
336\end{array}$ & $\begin{array}{r}25 \\
16 \\
1 \\
22\end{array}$ & $\begin{array}{l}379 \\
323 \\
222 \\
352\end{array}$ & $\begin{array}{r}30 \\
11 \\
1 \\
18\end{array}$ & $\begin{array}{l}772 \\
519 \\
295 \\
764\end{array}$ & $\begin{array}{r}39 \\
6 \\
1 \\
38\end{array}$ \\
\hline
\end{tabular}

HIGHEST MEAN DISQHARGE, IN CUBIC FEET PER SECOND, AND RANKING FOR THE INDICATED NUMBER OF CONSEQUTTVE DAYS FCR EACH WATER YEAR, OCTOBER 1-SEPTEMBER 30

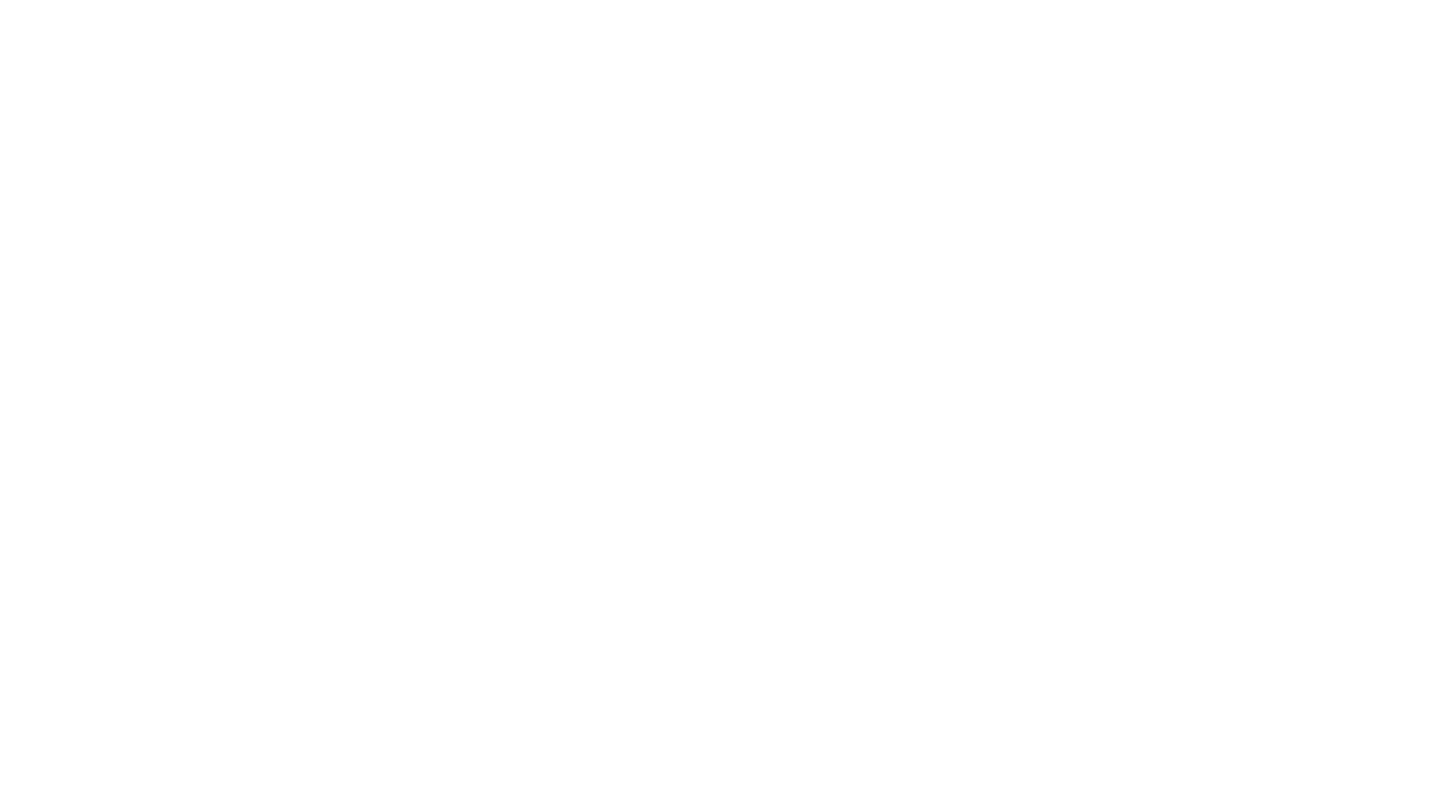


GREEN RIVER BASIN

09306500 WHITE RIVER NEAR WAISON, UT-Continued

HIGHEST MEAN DISCHARGE, IN OUBIC FEET PER SECOND, AND RANKING FOR THE INDICATED NUMBER OF CONSECUTIVE DAYS FOR EACH WATER YEAR, OCTCBER 1-SEPTEMBER 30--continued

\begin{tabular}{|c|c|c|c|c|c|c|c|c|c|c|c|c|c|c|c|c|c|c|c|}
\hline YEAR & & 3 & & 7 & & 15 & & $\begin{array}{l}00 \\
30\end{array}$ & SEOU' & IVE D & & 90 & & 120 & & 183 & & ALL & \\
\hline $\begin{array}{ll}956 & 2620 \\
957 & 4980 \\
958 & 3900 \\
959 & 2440 \\
960 & 2330\end{array}$ & $\begin{array}{r}42 \\
4 \\
13 \\
45 \\
46\end{array}$ & $\begin{array}{l}2590 \\
4830 \\
3820 \\
2390 \\
2310\end{array}$ & $\begin{array}{r}37 \\
3 \\
10 \\
41 \\
42\end{array}$ & $\begin{array}{l}2500 \\
4630 \\
3710 \\
2260 \\
2240\end{array}$ & $\begin{array}{r}35 \\
3 \\
6 \\
41 \\
42\end{array}$ & $\begin{array}{l}2420 \\
4230 \\
3580 \\
2000 \\
2030\end{array}$ & $\begin{array}{r}30 \\
3 \\
4 \\
40 \\
39\end{array}$ & $\begin{array}{l}2090 \\
3960 \\
3160 \\
1630 \\
1760\end{array}$ & $\begin{array}{r}30 \\
2 \\
4 \\
44 \\
41\end{array}$ & $\begin{array}{l}1580 \\
3260 \\
2340 \\
1350 \\
1370\end{array}$ & $\begin{array}{r}36 \\
2 \\
7 \\
45 \\
43\end{array}$ & $\begin{array}{l}1210 \\
2610 \\
1820 \\
1100 \\
1140\end{array}$ & $\begin{array}{r}38 \\
2 \\
13 \\
43 \\
41\end{array}$ & $\begin{array}{r}1090 \\
2220 \\
1530 \\
936 \\
1000\end{array}$ & $\begin{array}{r}35 \\
2 \\
12 \\
44 \\
41\end{array}$ & $\begin{array}{r}843 \\
1640 \\
1190 \\
755 \\
776\end{array}$ & $\begin{array}{r}36 \\
2 \\
12 \\
46 \\
42\end{array}$ & $\begin{array}{r}577 \\
1010 \\
821 \\
574 \\
552\end{array}$ & $\begin{array}{r}39 \\
2 \\
10 \\
40 \\
42\end{array}$ \\
\hline $\begin{array}{ll}61 & 2490 \\
62 & 5010 \\
63 & 1720 \\
64 & 2700 \\
65 & 4010\end{array}$ & $\begin{array}{r}44 \\
3 \\
52 \\
39 \\
9\end{array}$ & $\begin{array}{l}1830 \\
4030 \\
1650 \\
2610 \\
3630\end{array}$ & $\begin{array}{r}50 \\
6 \\
53 \\
36 \\
15\end{array}$ & $\begin{array}{l}1750 \\
3310 \\
1540 \\
2580 \\
3440\end{array}$ & $\begin{array}{l}49 \\
14 \\
53 \\
33 \\
11\end{array}$ & $\begin{array}{l}1620 \\
2780 \\
1460 \\
2290 \\
3150\end{array}$ & $\begin{array}{l}49 \\
19 \\
52 \\
33 \\
10\end{array}$ & $\begin{array}{l}1470 \\
2410 \\
1220 \\
2120 \\
2650\end{array}$ & $\begin{array}{l}49 \\
21 \\
52 \\
28 \\
16\end{array}$ & $\begin{array}{r}1080 \\
2220 \\
880 \\
1580 \\
2180\end{array}$ & $\begin{array}{l}50 \\
15 \\
54 \\
37 \\
16\end{array}$ & $\begin{array}{r}844 \\
2040 \\
744 \\
1210 \\
1800\end{array}$ & $\begin{array}{r}52 \\
6 \\
54 \\
39 \\
14\end{array}$ & $\begin{array}{r}725 \\
1870 \\
650 \\
1040 \\
1520\end{array}$ & $\begin{array}{r}52 \\
5 \\
54 \\
38 \\
13\end{array}$ & $\begin{array}{r}616 \\
1430 \\
550 \\
811 \\
1190\end{array}$ & $\begin{array}{r}52 \\
5 \\
54 \\
38 \\
13\end{array}$ & $\begin{array}{l}478 \\
922 \\
466 \\
546 \\
782\end{array}$ & $\begin{array}{r}52 \\
7 \\
54 \\
43 \\
14\end{array}$ \\
\hline $\begin{array}{l}2890 \\
3310 \\
3960 \\
3030 \\
3910\end{array}$ & $\begin{array}{l}34 \\
24 \\
10 \\
31 \\
12\end{array}$ & $\begin{array}{l}2860 \\
3080 \\
3850 \\
2910 \\
3640\end{array}$ & $\begin{array}{r}29 \\
25 \\
8 \\
28 \\
14\end{array}$ & $\begin{array}{l}2810 \\
2790 \\
3540 \\
2720 \\
3180\end{array}$ & $\begin{array}{l}25 \\
26 \\
10 \\
27 \\
17\end{array}$ & $\begin{array}{l}2640 \\
2510 \\
3030 \\
2490 \\
3060\end{array}$ & $\begin{array}{l}24 \\
26 \\
15 \\
27 \\
12\end{array}$ & $\begin{array}{l}2280 \\
2050 \\
2780 \\
2260 \\
2780\end{array}$ & $\begin{array}{l}23 \\
31 \\
11 \\
24 \\
12\end{array}$ & $\begin{array}{l}1880 \\
1500 \\
2270 \\
1900 \\
2340\end{array}$ & $\begin{array}{r}23 \\
39 \\
12 \\
21 \\
8\end{array}$ & $\begin{array}{l}1560 \\
1190 \\
1790 \\
1510 \\
1830\end{array}$ & $\begin{array}{l}21 \\
40 \\
15 \\
23 \\
12\end{array}$ & $\begin{array}{r}1330 \\
992 \\
1470 \\
1320 \\
1510\end{array}$ & $\begin{array}{l}22 \\
42 \\
16 \\
23 \\
14\end{array}$ & $\begin{array}{r}1020 \\
789 \\
1130 \\
1030 \\
1160\end{array}$ & $\begin{array}{l}26 \\
41 \\
18 \\
24 \\
15\end{array}$ & $\begin{array}{l}733 \\
582 \\
781 \\
712 \\
772\end{array}$ & $\begin{array}{l}24 \\
38 \\
15 \\
26 \\
17\end{array}$ \\
\hline $\begin{array}{r}2050 \\
602 \\
3800 \\
3820\end{array}$ & $\begin{array}{l}50 \\
56 \\
16 \\
15\end{array}$ & $\begin{array}{r}2040 \\
583 \\
3720 \\
3760\end{array}$ & $\begin{array}{l}47 \\
56 \\
13 \\
11\end{array}$ & $\begin{array}{r}1950 \\
529 \\
3590 \\
3570\end{array}$ & $\begin{array}{r}45 \\
56 \\
7 \\
9\end{array}$ & $\begin{array}{r}1770 \\
490 \\
3400 \\
3120\end{array}$ & $\begin{array}{r}44 \\
56 \\
6 \\
11\end{array}$ & $\begin{array}{r}1680 \\
456 \\
2950 \\
2910\end{array}$ & $\begin{array}{r}43 \\
56 \\
7 \\
8\end{array}$ & $\begin{array}{r}1320 \\
421 \\
2390 \\
2320\end{array}$ & $\begin{array}{r}46 \\
56 \\
6 \\
9\end{array}$ & $\begin{array}{r}1060 \\
408 \\
1870 \\
1840\end{array}$ & $\begin{array}{r}47 \\
56 \\
9 \\
11\end{array}$ & $\begin{array}{r}928 \\
399 \\
1550 \\
1570\end{array}$ & $\begin{array}{l}46 \\
56 \\
11 \\
10\end{array}$ & $\begin{array}{r}754 \\
368 \\
1160 \\
1190\end{array}$ & $\begin{array}{l}47 \\
56 \\
16 \\
14\end{array}$ & $\begin{array}{l}546 \\
308 \\
735 \\
767\end{array}$ & $\begin{array}{l}44 \\
56 \\
23 \\
18\end{array}$ \\
\hline
\end{tabular}

DURATION OF DISCHARGE FOR EACH WATER YEAR

CLASS $0 \begin{array}{llllllllllllllllllllllllllllllllllll} & 1 & 2 & 3 & 4 & 5 & 6 & 7 & 8 & 9 & 10 & 11 & 12 & 13 & 14 & 15 & 16 & 17 & 18 & 19 & 20 & 21 & 22 & 23 & 24 & 25 & 26 & 27 & 28 & 29 & 30 & 31 & 32 & 33 & 34\end{array}$ YEAR

NUMBER OF DAYS IN CLASS

OUBIC FEET PER SECON
-DAYS

192

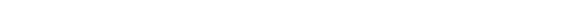

239120.0

925

$\begin{array}{llllllllll}149 & 4 & 75 & 28 & 13 & 12 & 21 & 22 & 32 & 9\end{array}$

272079.0

1927

1928

$\begin{array}{llllllllllllll}4 & 31 & 4 & 125 & 81 & 25 & 12 & 11 & 17 & 17 & 12 & 13 & 13\end{array}$

$\begin{array}{lllllllllll}89 & 54 & 71 & 38 & 17 & 29 & 9 & 30 & 7 & 12 & 9\end{array}$

$\begin{array}{lllllllllllll}91 & 61 & 57 & 67 & 13 & 3 & 13 & 18 & 6 & 19 & 12 & 4 & 2\end{array}$

$\begin{array}{rrrrrrrrrrrrrrrrrr}31 & 60 & 26 & 20 & 12 & 7 & 39 & 19 & 23 & 20 & 25 & 23 & 34 & 14 & 5 & 6 & 1 \\ 38 & 33 & 114 & 37 & 36 & 28 & 21 & 20 & 20 & 10 & 7 & 1 & & & & & \end{array}$

337160.0

278106.0

351022.0

1930

$\begin{array}{lllllllllllll}4 & 4 & 62 & 46 & 81 & 34 & 46 & 35 & 12 & 13 & 8 & 15 & 5\end{array}$

$\begin{array}{lllllllllllll}40 & 136 & 32 & 46 & 17 & 20 & 9 & 15 & 17 & 18 & 11 & 5\end{array}$

1932

1934

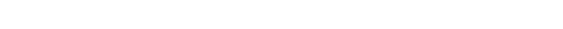

$\begin{array}{llllllllllllllll}2 & 7 & 13 & 13 & 7 & 6 & 9 & 21 & 16 & 17 & 85 & 114 & 16 & 15 & 19 & 5\end{array}$

$\begin{array}{llllllll}6 & 7 & 8 & 11 & 8 & 3\end{array}$

$\begin{array}{lllllllllllllll}5 & 59 & 165 & 30 & 12 & 13 & 12 & 7 & 12 & 16 & 13 & 7 & 15\end{array}$

1936
1937

1937

1939

$\begin{array}{rrrrrrrrrrrrrrrrrr}32 & 6 & 24 & 87 & 66 & 41 & 23 & 13 & 23 & 9 & 7 & 12 & 17 & 3 & 1 & 1 & \\ 4 & 4 & 26 & 76 & 42 & 46 & 40 & 16 & 21 & 12 & 10 & 8 & 9 & 17 & 12 & 20 & 2\end{array}$

$\begin{array}{rrrrrrrrrrrrrrrrrr} & 4 & 4 & 26 & 76 & 42 & 46 & 40 & 16 & 21 & 12 & 10 & 8 & 9 & 17 & 12 & 20 & 2 \\ & 13 & 14 & 32 & 42 & 84 & 42 & 30 & 23 & 15 & 6 & 13 & 33 & 13 & 1 & 2 & 2 \\ 7 & 15 & 11 & 21 & 38 & 144 & 47 & 17 & 6 & 7 & 12 & 6 & 11 & 15 & 9 & & & \end{array}$

1941

1942

1943

1944

$\begin{array}{llllllllllllllll}2 & 12 & 56 & 84 & 52 & 57 & 18 & 8 & 7 & 6 & 6 & 14 & 14 & 14 & 10 & 3\end{array}$

$\begin{array}{llllllllllllllllll}1 & 1 & 2 & 20 & 36 & 62 & 89 & 49 & 27 & 16 & 20 & 12 & 24 & 4 & 1 & 1\end{array}$

$\begin{array}{llllllllllllll}50 & 51 & 106 & 55 & 27 & 11 & 5 & 4 & 4 & 5 & 22 & 13 & 10\end{array}$

1946

1947

1948

1950

$\begin{array}{llllllllllll}9 & 56 & 89 & 97 & 33 & 8 & 12 & 20 & 12 & 17 & 6\end{array}$

$\begin{array}{lllllllllllllll}27 & 24 & 63 & 79 & 47 & 26 & 16 & 10 & 4 & 11 & 15 & 28 & 6 & 9\end{array}$

$\begin{array}{lllllllllllllll}20 & 46 & 41 & 87 & 50 & 19 & 21 & 27 & 5 & 15 & 9 & 8 & 12 & 6\end{array}$

$\begin{array}{rrrrrrrrrrrrrrrrrr}2 & 13 & 19 & 22 & 21 & 65 & 61 & 31 & 28 & 14 & 11 & 7 & 14 & 15 & 21 & 8 & 8 & 5\end{array}$

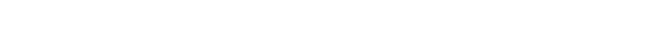

$\begin{array}{llllllllllllllllll}1 & 71 & 92 & 30 & 22 & 35 & 13 & 13 & 14 & 14 & 7 & 10 & 10 & 18 & 5 & 10 & 1\end{array}$

304842.0

952

1952
1953
1954

1954

$\begin{array}{llllllllllllllll}1 & 3 & 11 & 24 & 78 & 323 & 36 & 32 & 14 & 4 & 2 & 5 & 5 & 5 & 14 & 6\end{array}$

$\begin{array}{llllllllllllllll}5 & 14 & 14 & 26 & 46 & 113 & 59 & 24 & 15 & 14 & 13 & 12 & 7 & 3\end{array}$

$\begin{array}{rllllllllllllllll}5 & 12 & 30 & 45 & 72 & 72 & 27 & 24 & 12 & 7 & 10 & 10 & 20 & 9 & 9\end{array}$

141550.0

202878.0

237784.0

197637.0

302206.0

226072.0

195430.0

278078.0

346825.0

219766.0

224729.0

198809.0

286954.0

266167.0

289118.0

225246.0

235855.0

350073.0

239923.0

171734.0

195595.0 
GREEN RIVER BASIN

09306500 WHITE RIVER NEAR WATSON, UT--Continued

DURATION OF DISCHARGE FOR EACH WATER YEAR--Continued

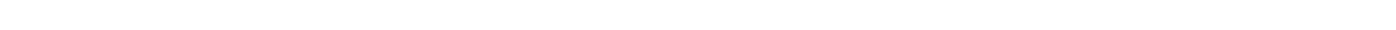
YEAR

CUBIC FEET PER SECOND

211325.0 367086.0 299842.0 209665.0 202152.0

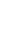

$\begin{array}{llllllllllllllll}1 & 5 & 20 & 44 & 60 & 103 & 38 & 13 & 11 & 16 & 10 & 6 & 10 & 8 & 7 & 14\end{array}$ $\begin{array}{rrrrrrrrrrrrrrrrr}4 & 7 & 65 & 64 & 39 & 50 & 13 & 13 & 16 & 16 & 14 & 11 & 6 & 4 & 12 & 13 & 17 \\ & & 24 & 60 & 80 & 74 & 33 & 16 & 24 & 6 & 5 & 5 & 8 & 8 & 7 & 15\end{array}$

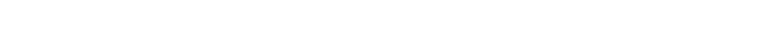

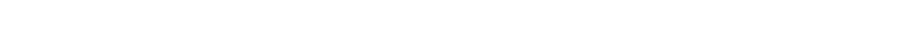

$\begin{array}{llllllllllllllllllllll}1 & 1 & & 5 & 3 & 25 & 92 & 48 & 46 & 12 & 16 & 14 & 8 & 10 & 24 & 37 & 12 & 7 & 3 & 1 & 336585.0\end{array}$ $\begin{array}{lllllllllllllll}3 & 10 & 13 & 15 & 16 & 25 & 92 & 110 & 37 & 8 & 7 & 8 & 6 & 13 & 2\end{array}$

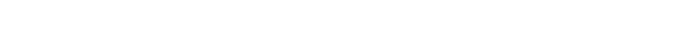

$\begin{array}{lllllllllllllllll}2 & 5 & 37 & 122 & 42 & 34 & 23 & 16 & 18 & 8 & 11 & 10 & 10 & 13 & 10 & 4\end{array}$

$\begin{array}{llllllllllllllllllll}3 & 5 & 9 & 10 & 11 & 25 & 30 & 21 & 56 & 85 & 41 & 19 & 8 & 17 & 7 & 6 & 5 & 3 & 2 & 2\end{array}$

$\begin{array}{rrrrrrrrrrrrrr}24 & 120 & 68 & 32 & 27 & 12 & 7 & 6 & 3 & 10 & 9 & 10 & 5 & 2 \\ 3 & 112 & 95 & 44 & 22 & 15 & 13 & 15 & 6 & 8 & 4 & 6 & 15 & 7\end{array}$

$\begin{array}{rrrrrrrrrrrrr}112 & 95 & 44 & 22 & 15 & 13 & 15 & 6 & 8 & 4 & 6 & 15 \\ 15 & 130 & 90 & 19 & 17 & 17 & 16 & 16 & 11 & 15 & 19\end{array}$

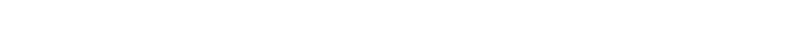

$\begin{array}{llllllllllllll}8 & 9 & 76 & 105 & 56 & 12 & 18 & 17 & 11 & 16 & 8 & 15 & 10 & 4\end{array}$

$\begin{array}{lllllllllllllllll}4 & 13 & 17 & 28 & 101 & 109 & 25 & 11 & 10 & 12 & 4 & 10 & 5 & 6 & 9 & 2\end{array}$

$\begin{array}{llllllllllllllll}1 & 1 & 3 & 75 & 133 & 46 & 17 & 17 & 11 & 5 & 2 & 17 & 11 & 7 & 9 & 7\end{array}$

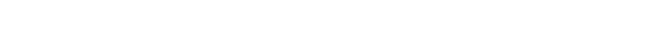

$\begin{array}{lllllllllllllll}1 & 29 & 30 & 57 & 47 & 82 & 53 & 6 & 11 & 11 & 7 & 10 & 17 & 5\end{array}$

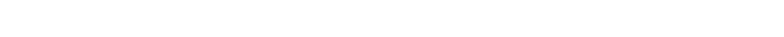

$\begin{array}{llllllllllllllll}6 & 25 & 109 & 54 & 32 & 28 & 12 & 16 & 13 & 3 & 6 & 3 & 15 & 13 & 11 & 7\end{array}$

169913.0

285255.0

183892.0

194689.0

238449.0

242849.0

284591.0

267693.0

213127.0

285107.0

259874.0

287737.0

200014.0

112507.0
268367.0

279803.0

DURATION TABLE OF DISCHARGE FOR WATER YEARS 1924-79

$\begin{array}{ccc}\text { CUBIC } & \text { ACCU- } \\ \text { FEET } & \text { MU- } & \text { PER- } \\ \text { PER TOTAL LATED } & \text { CENT } \\ \text { CLASS SECOND DAYS DAYS } & \text { DAYS }\end{array}$

$\begin{array}{llll}0.00 & 0 & 20454 & 100.0\end{array}$ $\begin{array}{rlll}0.00 & 0 & 20454 & 100.0 \\ 13.00 & 1 & 20454 & 100.0\end{array}$ $16.00 \quad 1 \quad 20453100.0$ $19.00 \quad 0 \quad 20452100.0$ $23.00 \quad 3 \quad 20452100.0$ $28.00+20449100.0$ $34.00+120448100.0$

$41.00 \quad 3 \quad 20447100.0$
CUBIC ACOU-

FEET MUI- PERPER TOTAL LATED CENI

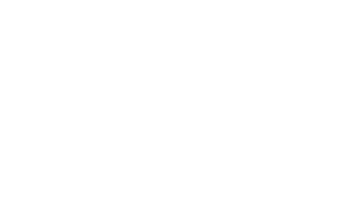

OBIC ACCJ-

FEET MU- PERPER TOTAL LATED
CLANS SECOND DAYS DAYS DAYS

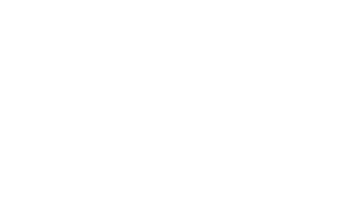

\begin{tabular}{|c|c|c|c|c|}
\hline & $\begin{array}{c}\text { CUBIC } \\
\text { FEET } \\
\text { PER }\end{array}$ & TOTAL & $\begin{array}{l}\text { ACOU- } \\
\text { MU- } \\
\text { LAIEED }\end{array}$ & $\begin{array}{l}\text { PER- } \\
\text { CENI }\end{array}$ \\
\hline CLASS & SECOND & DAYS & DAYS & DAYS \\
\hline 27 & 1900.0 & 563 & 1458 & 7.1 \\
\hline 28 & 2300.0 & 426 & 895 & \\
\hline 29 & 2800.0 & 278 & 469 & 2.3 \\
\hline 30 & 3400.0 & 131 & 191 & 0.9 \\
\hline 31 & 4100.0 & 46 & 60 & \\
\hline 32 & 5000.0 & 7 & 14 & 0.1 \\
\hline 33 & 6100.0 & 6 & 7 & \\
\hline 34 & 7400.0 & 1 & 1 & 0.0 \\
\hline
\end{tabular}

MONIHLY MEAN DISCHARGES, IN CUBIC FEET PER SECOND, FOR EACH WATER YEAR

\begin{tabular}{|c|c|c|c|c|c|c|c|c|c|c|c|c|}
\hline YEAR & $\infty \mathrm{CT}$ & $\mathrm{NOV}$ & DEC & JAN & FEB & MAR & APR & MAY & JUNE & JULY & AUG & SEP \\
\hline $\begin{array}{l}1924 \\
1925\end{array}$ & $\begin{array}{l}572 \\
395\end{array}$ & $\begin{array}{l}508 \\
381\end{array}$ & $\begin{array}{l}478 \\
365\end{array}$ & $\begin{array}{l}440 \\
350\end{array}$ & $\begin{array}{l}420 \\
405\end{array}$ & $\begin{array}{l}460 \\
590\end{array}$ & $\begin{array}{l}530 \\
957\end{array}$ & $\begin{array}{l}1434 \\
1634\end{array}$ & $\begin{array}{l}1860 \\
1533\end{array}$ & $\begin{array}{l}437 \\
965\end{array}$ & $\begin{array}{l}348 \\
633\end{array}$ & $\begin{array}{l}359 \\
724\end{array}$ \\
\hline $\begin{array}{l}1926 \\
1927 \\
1928 \\
1929 \\
1930\end{array}$ & $\begin{array}{r}771 \\
581 \\
548 \\
892 \\
1029\end{array}$ & $\begin{array}{l}625 \\
406 \\
549 \\
659 \\
713\end{array}$ & $\begin{array}{l}600 \\
405 \\
450 \\
400 \\
500\end{array}$ & $\begin{array}{l}580 \\
400 \\
420 \\
450 \\
380\end{array}$ & $\begin{array}{l}580 \\
550 \\
420 \\
450 \\
560\end{array}$ & $\begin{array}{r}660 \\
859 \\
750 \\
1150 \\
600\end{array}$ & $\begin{array}{r}1056 \\
521 \\
792 \\
2466 \\
1249\end{array}$ & $\begin{array}{l}1975 \\
1584 \\
3009 \\
3537 \\
1200\end{array}$ & $\begin{array}{l}2268 \\
1779 \\
1993 \\
4018 \\
1814\end{array}$ & $\begin{array}{r}972 \\
864 \\
1105 \\
2923 \\
586\end{array}$ & $\begin{array}{r}630 \\
565 \\
803 \\
1915 \\
894\end{array}$ & $\begin{array}{r}354 \\
618 \\
640 \\
1917 \\
502\end{array}$ \\
\hline $\begin{array}{l}1931 \\
1932 \\
1933 \\
1934 \\
1935\end{array}$ & $\begin{array}{l}487 \\
418 \\
450 \\
386 \\
281\end{array}$ & $\begin{array}{l}390 \\
392 \\
428 \\
441 \\
287\end{array}$ & $\begin{array}{l}230 \\
425 \\
425 \\
412 \\
325\end{array}$ & $\begin{array}{l}290 \\
420 \\
405 \\
400 \\
339\end{array}$ & $\begin{array}{l}375 \\
460 \\
485 \\
539 \\
372\end{array}$ & $\begin{array}{l}525 \\
710 \\
685 \\
418 \\
388\end{array}$ & $\begin{array}{l}677 \\
796 \\
840 \\
573 \\
392\end{array}$ & $\begin{array}{r}1045 \\
2105 \\
1156 \\
688 \\
1027\end{array}$ & $\begin{array}{r}1031 \\
1898 \\
2694 \\
227 \\
2080\end{array}$ & $\begin{array}{l}284 \\
980 \\
552 \\
109 \\
526\end{array}$ & $\begin{array}{l}351 \\
745 \\
453 \\
197 \\
298\end{array}$ & $\begin{array}{l}378 \\
466 \\
370 \\
277 \\
367\end{array}$ \\
\hline $\begin{array}{l}1936 \\
1937 \\
1938 \\
1939 \\
1940\end{array}$ & $\begin{array}{l}326 \\
376 \\
460 \\
472 \\
431\end{array}$ & $\begin{array}{l}374 \\
328 \\
325 \\
338 \\
375\end{array}$ & $\begin{array}{l}331 \\
287 \\
275 \\
294 \\
332\end{array}$ & $\begin{array}{l}364 \\
160 \\
285 \\
327 \\
341\end{array}$ & $\begin{array}{l}368 \\
290 \\
373 \\
360 \\
368\end{array}$ & $\begin{array}{r}388 \\
516 \\
679 \\
1180 \\
406\end{array}$ & $\begin{array}{l}671 \\
370 \\
727 \\
679 \\
621\end{array}$ & $\begin{array}{l}1976 \\
1344 \\
2024 \\
1513 \\
1634\end{array}$ & $\begin{array}{r}1540 \\
998 \\
2607 \\
1175 \\
966\end{array}$ & $\begin{array}{l}602 \\
888 \\
804 \\
311 \\
283\end{array}$ & $\begin{array}{l}479 \\
378 \\
510 \\
307 \\
237\end{array}$ & $\begin{array}{l}372 \\
541 \\
861 \\
456 \\
410\end{array}$ \\
\hline $\begin{array}{l}1941 \\
1942 \\
1943 \\
1944 \\
1945\end{array}$ & $\begin{array}{l}495 \\
716 \\
471 \\
346 \\
314\end{array}$ & $\begin{array}{l}370 \\
482 \\
461 \\
387 \\
338\end{array}$ & $\begin{array}{l}296 \\
388 \\
368 \\
347 \\
325\end{array}$ & $\begin{array}{l}296 \\
369 \\
346 \\
306 \\
415\end{array}$ & $\begin{array}{l}400 \\
398 \\
433 \\
372 \\
461\end{array}$ & $\begin{array}{l}511 \\
706 \\
538 \\
523 \\
457\end{array}$ & $\begin{array}{r}564 \\
1799 \\
675 \\
479 \\
497\end{array}$ & $\begin{array}{r}2539 \\
2577 \\
911 \\
1533 \\
1759\end{array}$ & $\begin{array}{l}1977 \\
2416 \\
1465 \\
1876 \\
1768\end{array}$ & $\begin{array}{l}656 \\
723 \\
504 \\
647 \\
925\end{array}$ & $\begin{array}{l}533 \\
433 \\
720 \\
299 \\
611\end{array}$ & $\begin{array}{l}482 \\
385 \\
334 \\
255 \\
395\end{array}$ \\
\hline
\end{tabular}


GREEN RIVER BASIN

09306500 WHITE RIVER NEAR WAISON, UT-Continued

MONIHLY MEAN DISCHARGES, IN OUBIC FEET PER SECOND, FOR EACH WATER YEAR--Continued

\begin{tabular}{|c|c|c|c|c|c|c|c|c|c|c|c|c|}
\hline YEAR & OCT & NOV & DEC & JAN & FEB & MAR & APR & MAY & JUNE & JLY & AUG & SEP \\
\hline $\begin{array}{l}1946 \\
1947 \\
1948 \\
1949 \\
1950\end{array}$ & $\begin{array}{l}403 \\
449 \\
548 \\
387 \\
548\end{array}$ & $\begin{array}{l}447 \\
411 \\
469 \\
378 \\
438\end{array}$ & $\begin{array}{l}333 \\
373 \\
440 \\
314 \\
340\end{array}$ & $\begin{array}{l}359 \\
270 \\
381 \\
244 \\
332\end{array}$ & $\begin{array}{l}373 \\
350 \\
369 \\
246 \\
313\end{array}$ & $\begin{array}{l}493 \\
693 \\
620 \\
632 \\
486\end{array}$ & $\begin{array}{l}730 \\
591 \\
989 \\
746 \\
560\end{array}$ & $\begin{array}{l}1107 \\
2276 \\
2086 \\
1723 \\
1027\end{array}$ & $\begin{array}{l}1121 \\
1950 \\
1537 \\
2664 \\
2016\end{array}$ & $\begin{array}{r}341 \\
990 \\
511 \\
1184 \\
615\end{array}$ & $\begin{array}{l}477 \\
607 \\
452 \\
496 \\
330\end{array}$ & $\begin{array}{l}350 \\
442 \\
316 \\
473 \\
403\end{array}$ \\
\hline $\begin{array}{l}1951 \\
1952 \\
1953 \\
1954 \\
1955\end{array}$ & $\begin{array}{l}402 \\
408 \\
420 \\
344 \\
431\end{array}$ & $\begin{array}{l}394 \\
382 \\
367 \\
406 \\
336\end{array}$ & $\begin{array}{l}366 \\
341 \\
427 \\
347 \\
292\end{array}$ & $\begin{array}{l}295 \\
327 \\
402 \\
369 \\
259\end{array}$ & $\begin{array}{l}423 \\
336 \\
419 \\
460 \\
338\end{array}$ & $\begin{array}{l}436 \\
336 \\
577 \\
398 \\
758\end{array}$ & $\begin{array}{r}439 \\
1295 \\
499 \\
580 \\
522\end{array}$ & $\begin{array}{l}1286 \\
2419 \\
1141 \\
1119 \\
1415\end{array}$ & $\begin{array}{r}1889 \\
3528 \\
2258 \\
536 \\
1271\end{array}$ & $\begin{array}{l}831 \\
818 \\
533 \\
297 \\
252\end{array}$ & $\begin{array}{l}629 \\
751 \\
559 \\
217 \\
334\end{array}$ & $\begin{array}{l}357 \\
558 \\
288 \\
580 \\
208\end{array}$ \\
\hline $\begin{array}{l}1956 \\
1957 \\
1958 \\
1959 \\
1960\end{array}$ & $\begin{array}{l}331 \\
314 \\
534 \\
445 \\
459\end{array}$ & $\begin{array}{l}362 \\
345 \\
558 \\
412 \\
381\end{array}$ & $\begin{array}{l}346 \\
295 \\
461 \\
358 \\
329\end{array}$ & $\begin{array}{l}328 \\
349 \\
389 \\
382 \\
272\end{array}$ & $\begin{array}{l}338 \\
399 \\
637 \\
375 \\
338\end{array}$ & $\begin{array}{l}709 \\
497 \\
573 \\
383 \\
571\end{array}$ & $\begin{array}{l}558 \\
493 \\
759 \\
510 \\
680\end{array}$ & $\begin{array}{l}1604 \\
1242 \\
2411 \\
1039 \\
1124\end{array}$ & $\begin{array}{l}1427 \\
3661 \\
2210 \\
1619 \\
1592\end{array}$ & $\begin{array}{r}357 \\
2746 \\
546 \\
486 \\
348\end{array}$ & $\begin{array}{r}345 \\
1090 \\
355 \\
479 \\
227\end{array}$ & $\begin{array}{l}217 \\
613 \\
428 \\
405 \\
317\end{array}$ \\
\hline $\begin{array}{l}1961 \\
1962 \\
1963 \\
1964 \\
1965\end{array}$ & $\begin{array}{l}345 \\
622 \\
454 \\
243 \\
326\end{array}$ & $\begin{array}{l}358 \\
433 \\
424 \\
324 \\
342\end{array}$ & $\begin{array}{l}307 \\
375 \\
347 \\
253 \\
350\end{array}$ & $\begin{array}{l}303 \\
337 \\
331 \\
277 \\
380\end{array}$ & $\begin{array}{l}348 \\
670 \\
428 \\
326 \\
403\end{array}$ & $\begin{array}{r}371 \\
1079 \\
389 \\
423 \\
544\end{array}$ & $\begin{array}{r}368 \\
1427 \\
487 \\
509 \\
590\end{array}$ & $\begin{array}{l}1052 \\
2250 \\
1158 \\
1370 \\
1595\end{array}$ & $\begin{array}{r}1087 \\
2147 \\
514 \\
1670 \\
2650\end{array}$ & $\begin{array}{c}260 \\
957 \\
190 \\
491 \\
1128\end{array}$ & $\begin{array}{l}300 \\
412 \\
413 \\
401 \\
519\end{array}$ & $\begin{array}{l}638 \\
353 \\
450 \\
264 \\
546\end{array}$ \\
\hline $\begin{array}{l}1966 \\
1967 \\
1968 \\
1969 \\
1970\end{array}$ & $\begin{array}{l}546 \\
376 \\
356 \\
420 \\
535\end{array}$ & $\begin{array}{l}467 \\
296 \\
332 \\
399 \\
455\end{array}$ & $\begin{array}{l}432 \\
303 \\
296 \\
422 \\
398\end{array}$ & $\begin{array}{l}396 \\
294 \\
291 \\
382 \\
422\end{array}$ & $\begin{array}{l}373 \\
318 \\
352 \\
349 \\
443\end{array}$ & $\begin{array}{r}1014 \\
467 \\
399 \\
533 \\
410\end{array}$ & $\begin{array}{l}541 \\
408 \\
480 \\
881 \\
454\end{array}$ & $\begin{array}{l}1164 \\
1129 \\
1162 \\
1884 \\
2007\end{array}$ & $\begin{array}{r}430 \\
1711 \\
2510 \\
1254 \\
2373\end{array}$ & $\begin{array}{l}161 \\
497 \\
601 \\
543 \\
844\end{array}$ & $\begin{array}{l}266 \\
273 \\
693 \\
402 \\
517\end{array}$ & $\begin{array}{l}232 \\
327 \\
362 \\
498 \\
487\end{array}$ \\
\hline $\begin{array}{l}1971 \\
1972 \\
1973 \\
1974 \\
1975\end{array}$ & $\begin{array}{l}529 \\
450 \\
481 \\
477 \\
438\end{array}$ & $\begin{array}{l}470 \\
481 \\
433 \\
453 \\
424\end{array}$ & $\begin{array}{l}419 \\
396 \\
413 \\
406 \\
304\end{array}$ & $\begin{array}{l}430 \\
395 \\
435 \\
398 \\
338\end{array}$ & $\begin{array}{l}389 \\
385 \\
384 \\
335 \\
380\end{array}$ & $\begin{array}{l}582 \\
425 \\
534 \\
687 \\
522\end{array}$ & $\begin{array}{l}722 \\
508 \\
473 \\
736 \\
487\end{array}$ & $\begin{array}{l}1399 \\
1166 \\
2092 \\
2076 \\
1235\end{array}$ & $\begin{array}{l}2272 \\
1816 \\
2301 \\
1672 \\
2671\end{array}$ & $\begin{array}{r}768 \\
364 \\
912 \\
594 \\
1524\end{array}$ & $\begin{array}{l}328 \\
254 \\
457 \\
373 \\
497\end{array}$ & $\begin{array}{l}491 \\
362 \\
436 \\
311 \\
434\end{array}$ \\
\hline $\begin{array}{l}1976 \\
1977 \\
1978 \\
1979\end{array}$ & $\begin{array}{l}452 \\
384 \\
269 \\
377\end{array}$ & $\begin{array}{l}420 \\
344 \\
311 \\
394\end{array}$ & $\begin{array}{l}296 \\
292 \\
277 \\
389\end{array}$ & $\begin{array}{l}267 \\
320 \\
300 \\
308\end{array}$ & $\begin{array}{l}448 \\
350 \\
306 \\
283\end{array}$ & $\begin{array}{l}547 \\
396 \\
457 \\
513\end{array}$ & $\begin{array}{l}520 \\
412 \\
604 \\
727\end{array}$ & $\begin{array}{r}1418 \\
384 \\
1514 \\
1903\end{array}$ & $\begin{array}{r}1203 \\
263 \\
2934 \\
2500\end{array}$ & $\begin{array}{r}364 \\
139 \\
1076 \\
995\end{array}$ & $\begin{array}{l}336 \\
206 \\
381 \\
474\end{array}$ & $\begin{array}{l}289 \\
211 \\
395 \\
316\end{array}$ \\
\hline
\end{tabular}

ANNUAL PEAK DISCHARGE, IN OBIC FEET PER SECOND, AND CORRESPONDING GAGE HEIGHT, IN FEET, FOR EACH WATER YEAR

\begin{tabular}{|c|c|c|c|c|c|c|c|c|c|c|c|}
\hline $\begin{array}{l}\text { WATER } \\
\text { YEAR }\end{array}$ & DATE & $\begin{array}{c}\text { GAGE } \\
\text { HEIGHT }\end{array}$ & $\begin{array}{c}\text { PEAK } \\
\text { DISCHARGE }\end{array}$ & $\begin{array}{l}\text { WATER } \\
\text { YEAR }\end{array}$ & DATE & $\begin{array}{c}\text { GAGE } \\
\text { HEIGHT }\end{array}$ & $\begin{array}{c}\text { PEAK } \\
\text { DISCHARGE }\end{array}$ & $\begin{array}{l}\text { WATER } \\
\text { YEAR }\end{array}$ & DATE & $\begin{array}{c}\text { GAGE } \\
\text { HEIGHT }\end{array}$ & $\begin{array}{c}\text { PEAK } \\
\text { DISCHARG }\end{array}$ \\
\hline $\begin{array}{l}1904 \\
1905 \\
1923 \\
1924 \\
1925 \\
1926 \\
1927 \\
1928 \\
1929 \\
1930 \\
1931 \\
1932 \\
1933 \\
1934 \\
1935 \\
1936 \\
1937 \\
1938 \\
1939 \\
1940\end{array}$ & $\begin{array}{lll}\text { MAY } & 26,1904 \\
\text { JUNE } 12,1905 \\
\text { MAY } 28,1923 \\
\text { AUG. } 14,1924 \\
\text { JULY } 21,1925 \\
\text { AUG. } 10,1926 \\
\text { SEPT. } 13,1927 \\
\text { MAY } 11,1928 \\
\text { JULY } 15,1929 \\
\text { OCT. } 09,1929 \\
\text { JUNE } 09,1931 \\
\text { MAY } 18,1932 \\
\text { AUG. } 28,1933 \\
\text { SEPT. 08, } 1934 \\
\text { SEPT. } 08,1935 \\
\text { AUG. } 11,1936 \\
\text { JUI.Y } 09,1937 \\
\text { SEPT. 02, } 1938 \\
\text { MAR. } 19,1939 \\
\text { MAY } 14,1940\end{array}$ & $\begin{array}{l}- \\
-- \\
4.13 \\
6.60 \\
4.51 \\
4.56 \\
4.49 \\
5.93 \\
-- \\
5.10 \\
3.63 \\
4.55 \\
4.31 \\
4.80 \\
4.08 \\
4.50 \\
5.86 \\
5.69 \\
5.67 \\
3.44\end{array}$ & $\begin{array}{l}2370 \\
4870 \\
3220 \\
7800 \\
4040 \\
3640 \\
3840 \\
6280 \\
8160 \\
5700 \\
1860 \\
3170 \\
4620 \\
5000 \\
3370 \\
3980 \\
6380 \\
5480 \\
4490 \\
2270\end{array}$ & $\begin{array}{l}1941 \\
1942 \\
1943 \\
1944 \\
1945 \\
1946 \\
1947 \\
1948 \\
1949 \\
1950 \\
1951 \\
1952 \\
1953 \\
1955 \\
1956 \\
1957 \\
1958 \\
1959 \\
1960\end{array}$ & $\begin{array}{lll}\text { MAY } & 15,1941 \\
\text { MAY } & 29,1942 \\
\text { AUG. } 03,1943 \\
\text { MAY } 18,1944 \\
\text { MAY } 13,1945 \\
\text { AUG. } 13,1946 \\
\text { AUG. } 12,1947 \\
\text { MAY } 23,1948 \\
\text { JUNE } 17,1949 \\
\text { OCT. } 09,1949 \\
\text { AUG. } 29,1951 \\
\text { JUNE } 12,1952 \\
\text { AUG. } 01,1953 \\
\text { MAR. } 12,1955 \\
\text { MAR. } 05,1956 \\
\text { AUG. } 06,1957 \\
\text { MAY } 31,1958 \\
\text { JUNE } 10,1959 \\
\text { JUNE } 08,1960\end{array}$ & $\begin{array}{l}4.63 \\
4.73 \\
6.50 \\
3.55 \\
3.40 \\
4.01 \\
5.67 \\
\overline{4.39} \\
- \\
5.45 \\
5.26 \\
4.68 \\
9.00 \\
4.28 \\
5.00 \\
3.57 \\
2.73 \\
5.50\end{array}$ & $\begin{array}{l}4210 \\
4620 \\
8010 \\
2880 \\
2820 \\
3650 \\
6200 \\
3180 \\
4150 \\
3740 \\
5820 \\
5200 \\
4600 \\
7650 \\
4040 \\
5350 \\
4000 \\
2670 \\
2600\end{array}$ & $\begin{array}{l}1961 \\
1962 \\
1963 \\
1964 \\
1965 \\
1966 \\
1967 \\
1968 \\
1969 \\
1970 \\
1971 \\
1972 \\
1973 \\
1974 \\
1975 \\
1976 \\
1977 \\
1978 \\
1979\end{array}$ & $\begin{array}{l}\text { SEPT. } 22,1961 \\
\text { MAR. } 28,1962 \\
\text { SEPT. 06, } 1963 \\
\text { MAY } 24,1964 \\
\text { JULY } 25,1965 \\
\text { MAR. } 11,1966 \\
\text { MAY } 26,1967 \\
\text { AUG. } 13,1968 \\
\text { MAY } 19,1969 \\
\text { JUNE } 11,1970 \\
\text { JUNE } 19,1971 \\
\text { JUNE } 09,1972 \\
\text { MAY } 22,1973 \\
\text { MAY } 11,1974 \\
\text { JUNE } 09,1975 \\
\text { MAY } 21,1976 \\
\text { JULY } 25,1977 \\
\text { JUNE } 17,1978 \\
\text { MAY } 31,1979\end{array}$ & $\begin{array}{l}6.86 \\
9.06 \\
6.05 \\
5.71 \\
9.22 \\
8.12 \\
5.89 \\
6.06 \\
5.12 \\
6.45 \\
5.50 \\
6.21 \\
6.64 \\
5.91 \\
6.60 \\
4.63 \\
3.79 \\
6.31 \\
6.29\end{array}$ & $\begin{array}{l}4180 \\
6760 \\
3380 \\
2880 \\
6830 \\
5650 \\
3340 \\
3770 \\
2560 \\
3940 \\
3010 \\
3820 \\
4200 \\
3230 \\
4150 \\
2150 \\
1310 \\
3910 \\
3900\end{array}$ \\
\hline
\end{tabular}

MAGNITUDE AND PRCBABILITY OF ANNUAL LONEST MEAN DISCHARGE BASED ON CLIMATIC YEARS 1924-79

\begin{tabular}{|c|c|c|c|c|c|c|}
\hline \multirow{2}{*}{$\begin{array}{l}\text { PERIOD } \\
\text { (CON- } \\
\text { SECU- } \\
\text { TIVE } \\
\text { DAYS) }\end{array}$} & \multicolumn{6}{|c|}{$\begin{array}{l}\text { DISCHARGE, IN OBBIC FEET PER SECOND, FOR } \\
\text { INDICATED RECURRENCE INTERNAL, IN YEARS, AND } \\
\text { ANNUAL NONEXCEEDANCE PRCBABILITY, IN PERCENT }\end{array}$} \\
\hline & $\begin{array}{c}2 \\
50 \%\end{array}$ & $\begin{array}{c}5 \\
208\end{array}$ & $\begin{array}{l}10 \\
108\end{array}$ & $\begin{array}{l}20 \\
58\end{array}$ & $\begin{array}{l}50 \\
28\end{array}$ & $\begin{array}{r}100 \\
18\end{array}$ \\
\hline 1 & 207 & 119 & 80 & 54 & 33 & 22 \\
\hline
\end{tabular}




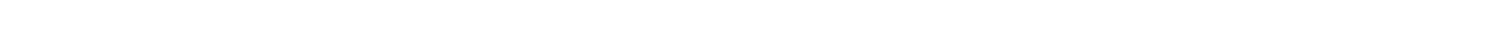
bank $2.2 \mathrm{mi}$ upstream from Southam Canyon and $5.2 \mathrm{mi}$ northwest of Watson.

DRAINAGE AREA. $-4,030 \mathrm{mi}^{2}$, approximately.

MEAN BASIN ELEVATION. $-7,180 \mathrm{ft}$.

PERIOD OF RECORD AVAIIABLE. - October 1974 to January 1976, April to July 1976.

GAGE.-Water-stage recorder. Altitude of gage is 4,900 ft from topographic map.

EXTREMES FOR PERIOD OF RECORD.--Maximum discharge, 2,200 $\mathrm{ft}^{3} / \mathrm{s}$ May 22, 1976, gage height, $6.70 \mathrm{ft} ; \mathrm{minimum} \mathrm{daily,} 180 \mathrm{ft} / \mathrm{s}$ Dec. 26 , $27,1974$.

HIGHEST MEAN DISCHARGE, IN CUBIC FEET PER SECOND, AND RANKING FOR THE INDICATED NUMBER OF OONSEOTTIVE DAYS FOR EACH WATER YEAR, OCTCBER 1-SEPTEMBER 30

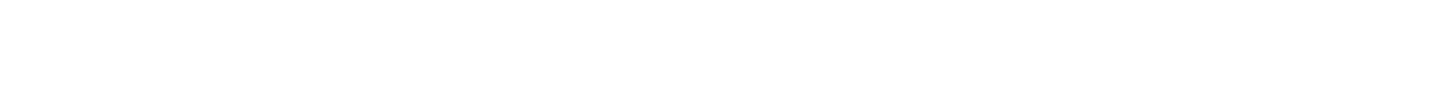

DURATION OF DISCHARGE FOR EACH WATER YEAR

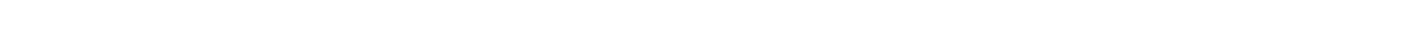
NUMBER OF DAYS IN CLASS PER SECOND -DAYS

DURATION TABLE OF DISOHARGE FOR WATER YEAR 1975

$\begin{array}{crc}\text { OHBIC } & \text { ACOU- } \\ \text { FEET } & \text { MU- } & \text { PER- } \\ \text { PER TOTAL LATED } & \text { CENT } \\ \text { GLASS SBCOND DAYS DAYS } & \text { DAYS }\end{array}$

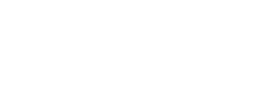

C.ASS SECOND DAYS DAYS DAYS

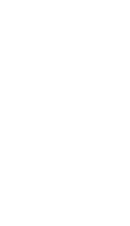

$\begin{array}{rrr}38 & 293 & 80.3 \\ 69 & 255 & 69.9 \\ 69 & 186 & 51.0 \\ 15 & 117 & 32.0 \\ 14 & 102 & 28.0 \\ 10 & 88 & 24.1 \\ 5 & 78 & 21.4 \\ 2 & 73 & 20.0 \\ 1 & 71 & 19.4\end{array}$

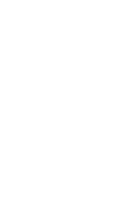

\begin{tabular}{cr}
\multicolumn{3}{c}{ OBBIC } \\
\multicolumn{3}{c}{ FEET } \\
PER & TO \\
C.ASS SECOND & D \\
& \\
18 & 870.0 \\
19 & 950.0 \\
20 & 1000.0 \\
21 & 1100.0 \\
22 & 1300.0 \\
23 & 1400.0 \\
24 & 1500.0 \\
25 & 1700.0 \\
26 & 1800.0
\end{tabular}

ACOULATED CENT DAYS DAYS DAYS $\begin{array}{crc}\text { OBBIC } & \text { ACOU- } \\ \text { FEET } & \text { MU- } & \text { PER- } \\ \text { PER TOTAL LATED } & \text { CENT } \\ \text { CLASS SECOND DAYS DAYS DAYS }\end{array}$ $27 \quad 2000.0 \quad 7 \quad 40-11.0$ $\begin{array}{lllll}28 & 2200.0 & 13 & 33 & 9.0\end{array}$ $\begin{array}{llrlr}29 & 2400.0 & 9 & 20 & 5.5\end{array}$ $\begin{array}{lllll}30 & 2600.0 & 3 & 11 & 3.0\end{array}$ $\begin{array}{rrrrr}31 & 2900.0 & 4 & 8 & 2.2\end{array}$ 333500.0 343800.0

$\begin{array}{ll}70 & 19.2 \\ 69 & 18.9 \\ 69 & 18.9 \\ 68 & 18.6 \\ 61 & 16.7 \\ 57 & 15.6 \\ 56 & 15.3 \\ 49 & 13.4 \\ 48 & 13.2\end{array}$

MONIHLY MEAN DISCHARGES, IN CUBIC FEET PER SBCOND, FOR EACH WATER YEAR

\begin{tabular}{|c|c|c|c|c|c|c|c|c|c|c|c|}
\hline YEAR & $\propto C T$ & NON & DEC & JAN & FEB & MAR & APR & MAY & JUNE & JULY & AIJG \\
\hline 975 & 430 & 443 & 305 & 343 & 381 & 506 & 441 & 1202 & 2443 & 1509 & 461 \\
\hline
\end{tabular}

09306605 SOUTHAM CANYON WASH NEAR WATSON, UT

LOCATION.-Lat $39^{\circ} 51^{\prime} 00^{\prime \prime}$, long $109^{\circ} 13^{\prime} 56^{\prime \prime}$, in SE ${ }_{4}^{3} \mathrm{SW}_{4}^{3} \mathrm{NW}_{\frac{1}{4}}$ sec.34, T.10 S., R.24 E., Uintah County, Hydrologic Unit 14050007, on right bank $3.0 \mathrm{mi}$ northwest of watson and $4.5 \mathrm{mi}$ upstream $\mathrm{frcm}$ mouth

DRAINAGE AREA. $-2.5 \mathrm{mi}^{2}$.

MEAN BASIN ELEVATION. $-5,930 \mathrm{ft}$.

PERIOD OF RECORD AVAIIABLE.--October 1974 to September 1976.

GAGE. -Water-stage recorder. Altitude of gage is 5,500 ft from topographic map.

EXTREMES FOR PERIOD OF RECORD.--Maximum discharge, $4.4 \mathrm{ft}^{3} / \mathrm{s}$ Dec. 17,1975 , gage height, 0.87 ft; no flow most of the year.

LOWEST MEAN DISCHARGE, IN OBIC FEET PER SECOND, AND RANKING FOR THE INDICATED NUMBER OF CONSECUTIVE DAYS FOR EACH CLIMATIC YEAR, APRIL 1-MAROH 31

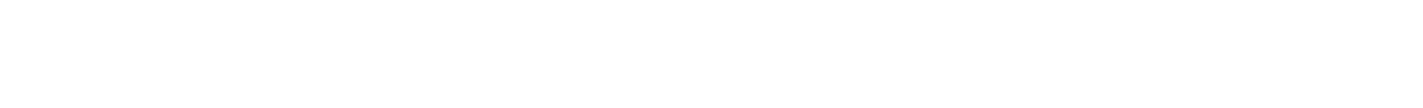


GREEN RIVER BASIN

09306605 SOUTHAM CANYON WASH NEAR WATSON, UT-Continued

HIGHEST MEAN DISCHARGE, IN OUBIC FEET PER SECOND, AND RANKING FOR THE INDICATED NUMBER OF CONSECUTIVE DAYS FOR EACH WATER YEAR, OCTCBER 1-SEPTEMBER 30

\begin{tabular}{|c|c|c|c|c|c|c|c|c|c|c|c|c|c|c|c|c|c|c|c|}
\hline YEAR & 1 & & 3 & & 7 & & 15 & & $\begin{array}{l}\text { CONSE } \\
30\end{array}$ & OTIVE & $\begin{array}{l}\text { DAYS } \\
60\end{array}$ & & 90 & & 120 & & 183 & & ALL \\
\hline $\begin{array}{l}1975 \\
1976\end{array}$ & $\begin{array}{l}0.49 \\
0.20\end{array}$ & $\begin{array}{l}1 \\
2\end{array}$ & $\begin{array}{l}0.26 \\
0.07\end{array}$ & $\begin{array}{l}1 \\
2\end{array}$ & $\begin{array}{l}0.11 \\
0.03\end{array}$ & $\begin{array}{l}1 \\
2\end{array}$ & $\begin{array}{l}0.05 \\
0.01\end{array}$ & $\begin{array}{l}1 \\
2\end{array}$ & $\begin{array}{l}0.03 \\
0.00\end{array}$ & $\begin{array}{l}1 \\
2\end{array}$ & $\begin{array}{l}0.01 \\
0.00\end{array}$ & $\begin{array}{l}1 \\
2\end{array}$ & $\begin{array}{l}0.00 \\
0.00\end{array}$ & $\begin{array}{l}1 \\
2\end{array}$ & $\begin{array}{l}0.00 \\
0.00\end{array}$ & $\begin{array}{l}1 \\
2\end{array}$ & $\begin{array}{l}0.00 \\
0.00\end{array}$ & $\begin{array}{l}1 \\
2\end{array}$ & $\begin{array}{l}0.00 \\
0.00\end{array}$ \\
\hline
\end{tabular}

DURATION OF DISCHARGE FOR EACH WATER YEAR

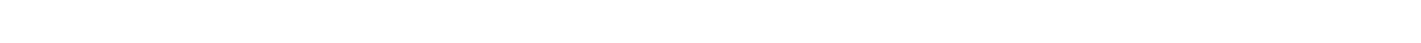
YEAR

NUMBER OF DAYS IN CLASS

ABIC FEEI PER SECOND -DAYS

1975363

$1976362 \quad 3$
2

0.8
0.2

DURATION TABLE OF DISCHARGE FOR WATER YEARS 1975-76
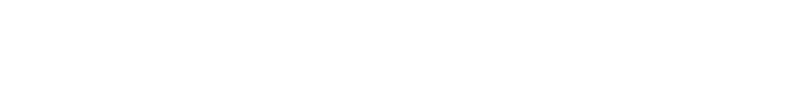

$\begin{array}{ccc}\text { CUBIC } & \text { ACOU- } \\ \text { FEET } & \text { MU- } & \text { PER- } \\ \text { PER TOTAL LATED } & \text { CENT } \\ \text { CLASS SECOND DAYS DAYS } & \text { DAYS }\end{array}$

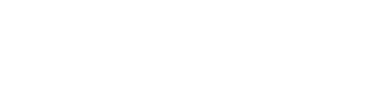

$\begin{array}{rrrrr}0 & 0.00 & 725 & 731 & 100.0 \\ 1 & 0.01 & 3 & 6 & 0.8 \\ 2 & 0.02 & 0 & 3 & 0.4 \\ 3 & 0.03 & 0 & 3 & 0.4 \\ 4 & 0.04 & 0 & 3 & 0.4 \\ 5 & 0.05 & 0 & 3 & 0.4 \\ 6 & 0.06 & 0 & 3 & 0.4 \\ 7 & 0.07 & 0 & 3 & 0.4 \\ 8 & 0.08 & 0 & 3 & 0.4\end{array}$

$\begin{array}{rll}9 & 0.09 & 0 \\ 10 & 0.10 & 0 \\ 11 & 0.11 & 0 \\ 12 & 0.13 & 0 \\ 13 & 0.14 & 0 \\ 14 & 0.15 & 0 \\ 15 & 0.17 & 0 \\ 16 & 0.19 & 1 \\ 17 & 0.21 & 0\end{array}$

$\begin{array}{ll}3 & 0.4 \\ 3 & 0.4 \\ 3 & 0.4 \\ 3 & 0.4 \\ 3 & 0.4 \\ 3 & 0.4 \\ 3 & 0.4 \\ 3 & 0.4 \\ 2 & 0.3\end{array}$

$\begin{array}{lllll}18 & 0.23 & 0 & 2 & 0.3 \\ 19 & 0.25 & 0 & 2 & 0.3 \\ 20 & 0.28 & 2 & 2 & 0.3 \\ 21 & & & & \\ 22 & & & & \\ 23 & & & & \\ 24 & & & & \\ 25 & & & & \\ 26 & & & & \end{array}$

CIASS SECOND DAYS DAYS DAYS

MONIHLY MEAN DISCHARGES, IN CUBIC FEET PER SECOND, FOR EACH WATER YEAR

$\begin{array}{lllllllllllll}\text { YEAR } & \text { OCT } & \text { NOV } & \text { DEC } & \text { JAN } & \text { FEB } & \text { MAR } & \text { APR } & \text { MAY } & \text { JUNE } & \text { JULY } & \text { AUG } & \text { SEP } \\ 1975 & 0.00 & 0.00 & 0.00 & 0.00 & 0.03 & 0.00 & 0.00 & 0.00 & 0.00 & 0.00 & 0.00 & 0.00 \\ 1976 & 0.00 & 0.00 & 0.01 & 0.00 & 0.00 & 0.00 & 0.00 & 0.00 & 0.00 & 0.00 & 0.00 & 0.00\end{array}$

09306610 SCUTHAM CANYON WASH AT MOUTH, NEAR WATSON, UT

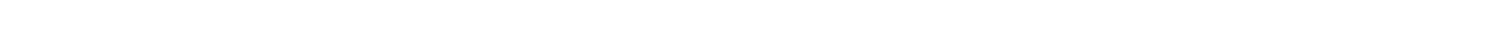
bank 0.1 mi upstream from mouth and 6.2 mi northwest of watson.

DRAINAGE AREA. $--8.3 \mathrm{mi}^{2}$.

MEAN BASIN ELEVATION. $--5,580 \mathrm{ft}$.

PERIOD OF RECORD AVAILABLE.--October 1974 to September 1976.

GAGE.--Water-stage recorder. Altitude of gage is 4,920 ft from topographic map.

EXIREYES FOR PERIOD OF RECORD.--Maximum discharge, $30 \mathrm{ft}^{3} / \mathrm{s}$ Nov. 10, 1974, gage height, $0.98 \mathrm{ft}$; no flow most of the year.

LOWEST MEAN DISCHARGE, IN OUBIC FEET PER SECOND, AND RANKING FOR THE INDICATED NUMBER OF CONSECUTIVE DAYS FOR EACH CIMATIC YEAR, APRIL 1-MARCH 31

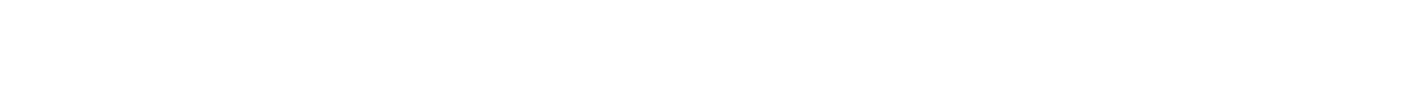

HIGHEST MEAN DISCHARGE, IN CUBIC FEET PER SECOND, AND RANRING FOR THE INDICATED NUMBER OF CONSECUTIVE DAYS FOR EACH WATER YEAR, OCTCBER 1-SEPTEMBER 30

\begin{tabular}{|c|c|c|c|c|c|c|c|c|c|c|c|c|c|c|c|c|c|c|c|}
\hline YEAR & 1 & & 3 & & 7 & & 15 & & $\begin{array}{l}\text { CONS } \\
30\end{array}$ & COTT & $\begin{array}{c}\text { E DAYS } \\
60\end{array}$ & & 90 & & 120 & & 183 & & ALL \\
\hline $\begin{array}{l}1975 \\
1976\end{array}$ & $\begin{array}{l}4.70 \\
1.80\end{array}$ & $\frac{1}{2}$ & $\begin{array}{l}3.50 \\
0.60\end{array}$ & $\begin{array}{l}1 \\
2\end{array}$ & $\begin{array}{l}1.50 \\
0.26\end{array}$ & $\frac{1}{2}$ & $\begin{array}{l}0.70 \\
0.12\end{array}$ & $\begin{array}{l}1 \\
2\end{array}$ & $\begin{array}{l}0.35 \\
0.60\end{array}$ & $\begin{array}{l}1 \\
2\end{array}$ & $\begin{array}{l}0.19 \\
0.03\end{array}$ & $\begin{array}{l}1 \\
2\end{array}$ & $\begin{array}{l}0.13 \\
0.02\end{array}$ & $\begin{array}{l}1 \\
2\end{array}$ & $\begin{array}{l}0.13 \\
0.02\end{array}$ & $\frac{1}{2}$ & $\begin{array}{l}0.12 \\
0.01\end{array}$ & $\begin{array}{l}1 \\
2\end{array}$ & $\begin{array}{l}0.06 \\
0.01\end{array}$ \\
\hline
\end{tabular}


$\begin{array}{llllllllllllllllllllllllllllllllllll}\text { CLASS } & 0 & 1 & 2 & 3 & 4 & 5 & 6 & 7 & 8 & 9 & 10 & 11 & 12 & 13 & 14 & 15 & 16 & 17 & 18 & 19 & 20 & 21 & 22 & 23 & 2 & 25 & 26 & 27 & 28 & 29 & 30 & 31 & 32 & 33 & 34\end{array}$ YEAR

CUBIC FEET PER SECOND -DAYS

1975356

$1976360 \quad 1 \quad 1$

$$
\begin{array}{llllllll}
1 & 1 & 2 & 1 & 1 & 1 & 2 & 21.1
\end{array}
$$

2.6

DURATION TABLE OF DISCHARGE FOR WATER YEARS 1975-76

\begin{tabular}{|c|c|c|c|c|c|c|c|c|c|c|c|c|c|c|c|c|c|c|c|}
\hline CLASS & $\begin{array}{c}\text { CUBIC } \\
\text { FEET } \\
\text { PER } \\
\text { SECOND }\end{array}$ & TOTAL & $\begin{array}{l}\text { ACOU- } \\
\text { MU- } \\
\text { LATED } \\
\text { DAYS }\end{array}$ & $\begin{array}{l}\text { PER- } \\
\text { CENT } \\
\text { DAYS }\end{array}$ & CLASS & $\begin{array}{c}\text { OBIC } \\
\text { FEET } \\
\text { PER } \\
\text { SECOND }\end{array}$ & TOTAL & $\begin{array}{c}\text { ACOJ- } \\
\text { MU- } \\
\text { LATED } \\
\text { DAYS }\end{array}$ & $\begin{array}{l}\text { PER- } \\
\text { CENT } \\
\text { DAYS }\end{array}$ & & $\begin{array}{c}\text { OBIC } \\
\text { FEET } \\
\text { PER } \\
\text { SEOOND }\end{array}$ & $\begin{array}{l}\text { TOTAL } \\
\text { DAYS }\end{array}$ & $\begin{array}{c}\text { ACCU- } \\
\text { MU- } \\
\text { LATED } \\
\text { DAYS }\end{array}$ & $\begin{array}{l}\text { PER- } \\
\text { CENT } \\
\text { DAYS }\end{array}$ & & $\begin{array}{c}\text { CBIIC } \\
\text { FEET } \\
\text { PER } \\
\text { SECOND }\end{array}$ & TOTAL & $\begin{array}{c}\text { ACOU- } \\
\text { MU- } \\
\text { LATED } \\
\text { DAYS }\end{array}$ & $\begin{array}{l}\text { PER- } \\
\text { CENT } \\
\text { DAYS }\end{array}$ \\
\hline $\begin{array}{l}0 \\
1 \\
2 \\
3 \\
4 \\
5 \\
6 \\
7 \\
8\end{array}$ & $\begin{array}{l}0.00 \\
0.03 \\
0.04 \\
0.05 \\
0.06 \\
0.07 \\
0.09 \\
0.10 \\
0.11\end{array}$ & $\begin{array}{r}716 \\
1 \\
0 \\
1 \\
0 \\
0 \\
0 \\
1 \\
0\end{array}$ & $\begin{array}{r}731 \\
15 \\
14 \\
14 \\
13 \\
13 \\
13 \\
13 \\
12\end{array}$ & $\begin{array}{r}100.0 \\
2.0 \\
1.9 \\
1.9 \\
1.8 \\
1.8 \\
1.8 \\
1.8 \\
1.6\end{array}$ & $\begin{array}{r}9 \\
10 \\
11 \\
12 \\
13 \\
14 \\
15 \\
16 \\
17\end{array}$ & $\begin{array}{l}0.13 \\
0.15 \\
0.18 \\
0.21 \\
0.24 \\
0.28 \\
0.32 \\
0.37 \\
0.43\end{array}$ & $\begin{array}{l}0 \\
1 \\
0 \\
0 \\
0 \\
0 \\
0 \\
1 \\
0\end{array}$ & $\begin{array}{l}12 \\
12 \\
11 \\
11 \\
11 \\
11 \\
11 \\
11 \\
10\end{array}$ & $\begin{array}{l}1.6 \\
1.6 \\
1.5 \\
1.5 \\
1.5 \\
1.5 \\
1.5 \\
1.5 \\
1.4\end{array}$ & $\begin{array}{l}18 \\
19 \\
20 \\
21 \\
22 \\
23 \\
24 \\
25 \\
26\end{array}$ & $\begin{array}{l}0.50 \\
0.58 \\
0.68 \\
0.78 \\
0.91 \\
1.1 \\
1.2 \\
1.4 \\
1.6\end{array}$ & $\begin{array}{l}0 \\
0 \\
0 \\
0 \\
1 \\
1 \\
0 \\
2 \\
2\end{array}$ & $\begin{array}{r}10 \\
10 \\
10 \\
10 \\
10 \\
9 \\
8 \\
8 \\
6\end{array}$ & $\begin{array}{l}1.4 \\
1.4 \\
1.4 \\
1.4 \\
1.4 \\
1.2 \\
1.1 \\
1.1 \\
0.8\end{array}$ & $\begin{array}{l}27 \\
28 \\
29 \\
30 \\
31 \\
32 \\
33 \\
34\end{array}$ & $\begin{array}{l}1.2 \\
2.2 \\
2.6 \\
3.0 \\
3.5 \\
4.0\end{array}$ & $\begin{array}{l}0 \\
1 \\
0 \\
1 \\
0 \\
2\end{array}$ & $\begin{array}{l}4 \\
4 \\
3 \\
3 \\
2 \\
2\end{array}$ & $\begin{array}{l}0.6 \\
0.6 \\
0.4 \\
0.4 \\
0.3 \\
0.3\end{array}$ \\
\hline
\end{tabular}

MONIHLY MEAN DISCHARGES, IN OUBIC FEET PER SECOND, FOR EACH WATER YEAR

$\begin{array}{lllllllllllll}\text { YEAR } & \text { OCT } & \text { NOV } & \text { DEC } & \text { JAN } & \text { FEB } & \text { MAR } & \text { APR } & \text { MAY } & \text { JUNE } & \text { JULY } & \text { AUG } & \text { SEP } \\ 1975 & 0.08 & 0.23 & 0.00 & 0.00 & 0.31 & 0.06 & 0.03 & 0.00 & 0.00 & 0.00 & 0.00 & 0.00 \\ 1976 & 0.00 & 0.00 & 0.00 & 0.00 & 0.02 & 0.00 & 0.00 & 0.00 & 0.06 & 0.00 & 0.00 & 0.00\end{array}$

09306620 ASPHALT WASH BELOW CENTER FOFK, NEAR WATSON, UT

LOCATTON.--Lat $39^{\circ} 54^{\prime} 42^{\prime \prime}$, long $109^{\circ} 15^{\prime} 53^{\prime \prime}$, in $\mathrm{NW}_{\frac{1}{4}}^{-1} W^{-1} \mathrm{WW}_{4}^{-\frac{1}{4}}$ sec.31, T.10 S., R.24 E., Uintah County, Hydrologic Unit 14050007 , on right bank $3.4 \mathrm{mi}$ upstream from mouth and $6.0 \mathrm{mi}$ northwest of Watson.

DRATNAGE AREA. $--94.4 \mathrm{mi}^{2}$.

MEAN BASIN ELEVATION. $-6,120 \mathrm{ft}$.

PERIOD OF RBCORD AVAIIABLE.--OCtaber 1974 to September 1976.

GAGE.-Water-stage recorder. Altitude of gage is 5,080 ft from topographic map.

EXTREMES FOR PERIOD $O$ F RBCORD.--Maximum discharge, $135 \mathrm{ft}^{3} / \mathrm{s}$ July 15, 1975, gage height, $2.33 \mathrm{ft}, \mathrm{trom}$ slope-area measurement of peak flow; no flow most of the year.

LOWEST MEAN DISCHARGE, IN CUBIC FEET PER SECOND, AND RANKING FOR THE INDICATED NUMBER $O F$ CONSECUTIVE DAYS FOR EACH OLIMATIC YEAR, APRIL I-MARCH 31

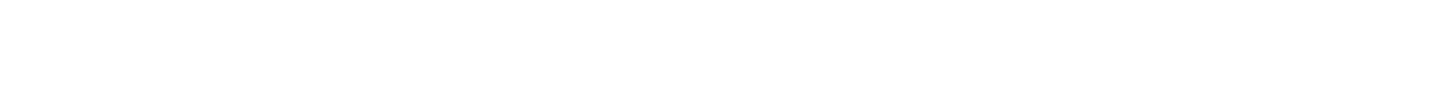

HIGHEST MEAN DISCHARGE, IN OUBIC FEET PER SECOND, AND RANKING FOR THE INDICATED NUMBER OF CONSECUTIVE DAYS FOR EACH WATER YEAR, OCTOBER I-SEPTEMBER 30

\begin{tabular}{|c|c|c|c|c|c|c|c|c|c|c|c|c|c|c|c|c|c|c|c|}
\hline YEAR & & & & & & & & & CONSE & DTTVE & DAYS & & & & & & & & \\
\hline & 1 & & 3 & & 7 & & 15 & & 30 & & 60 & & 90 & & 120 & & 183 & & ALL \\
\hline 1975 & 2.50 & 2 & 1.00 & 2 & 0.44 & 2 & 0.21 & 2 & 0.10 & 2 & 0.05 & 2 & 0.03 & 2 & 0.03 & 2 & 0.03 & 2 & .015 \\
\hline
\end{tabular}

DURATION OF DISCHARGE FOR EAOH WATER YEAR

CLASS $\begin{array}{llllllllllllllllllllllllllllllllllll}0 & 1 & 2 & 3 & 4 & 5 & 6 & 7 & 8 & 9 & 10 & 11 & 12 & 13 & 14 & 15 & 16 & 17 & 18 & 19 & 20 & 21 & 22 & 23 & 24 & 25 & 26 & 27 & 28 & 29 & 30 & 31 & 32 & 33 & 34\end{array}$ YEAR PER SECOND -DAYS

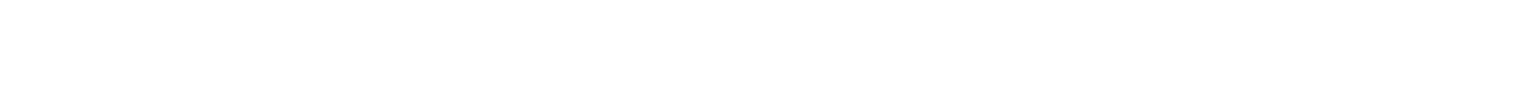


GREEN RIVER BASIN

09306620 ASPHALT WASH BELOW CENTER FORR, NEAR WATSON, UT-Continued

DURATION TABLE OF DISCHARGE FOR WATER YEARS 1975-76

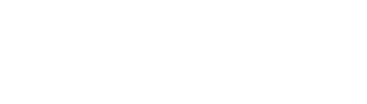
CLASS SECOND DAYS DAYS DAYS

$\begin{array}{rrrrr}0 & 0.00 & 717 & 731 & 100.0 \\ 1 & 0.03 & 1 & 14 & 1.9 \\ 2 & 0.04 & 0 & 13 & 1.8 \\ 3 & 0.05 & 0 & 13 & 1.8 \\ 4 & 0.06 & 0 & 13 & 1.8 \\ 5 & 0.07 & 0 & 13 & 1.8 \\ 6 & 0.08 & 1 & 13 & 1.8 \\ 7 & 0.09 & 1 & 12 & 1.6 \\ 8 & 0.10 & 1 & 11 & 1.5\end{array}$

OIBIC ACOU-

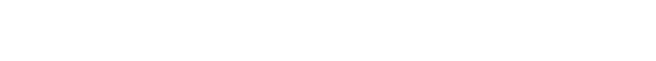
CLASS SECOND DAYS DAYS DAYS CLASS SECOND DAYS DAYS DAYS $\begin{array}{rrr}\text { OBBIC } & \text { ACOU- } \\ \text { FEET } & \text { MU- } & \text { PER- } \\ \text { PER } & \text { TOTAL LATTD } & \text { CENT } \\ \text { CLASS SECOND DAYS DAYS } & \text { DAYS }\end{array}$

$\begin{array}{rrrrr}9 & 0.12 & 0 & 10 & 1.4 \\ 10 & 0.13 & 0 & 10 & 1.4 \\ 11 & 0.15 & 1 & 10 & 1.4 \\ 12 & 0.17 & 0 & 9 & 1.2 \\ 13 & 0.20 & 2 & 9 & 1.2 \\ 14 & 0.22 & 0 & 7 & 1.0 \\ 15 & 0.26 & 0 & 7 & 1.0 \\ 16 & 0.29 & 0 & 7 & 1.0 \\ 17 & 0.34 & 0 & 7 & 1.0\end{array}$

$\begin{array}{lllll}27 & 1.3 & 0 & 5 & 0.7 \\ 28 & 1.5 & 1 & 5 & 0.7 \\ 29 & 1.7 & 1 & 4 & 0.6 \\ 30 & 1.9 & 1 & 3 & 0.4 \\ 31 & 2.2 & 0 & 2 & 0.3 \\ 32 & 2.5 & 2 & 2 & 0.3 \\ 33 & & & & \end{array}$

MONTHLY MEAN DISCHARGES, IN OBIC FEET PER SECOND, FOR EACH WATER YEAR

$\begin{array}{lllllllllllll}\text { YEAR } & \text { OCT } & \text { NOU } & \text { DEC } & \text { JAN } & \text { FEB } & \text { MAR } & \text { APR } & \text { MAY } & \text { JUNE } & \text { JULY } & \text { AUG } & \text { SEP } \\ 1975 & 0.00 & 0.00 & 0.00 & 0.00 & 0.11 & 0.00 & 0.00 & 0.00 & 0.00 & 0.06 & 0.01 & 0.00 \\ 1976 & 0.00 & 0.00 & 0.00 & 0.00 & 0.25 & 0.00 & 0.00 & 0.00 & 0.00 & 0.00 & 0.00 & 0.06\end{array}$

09306625 ASPHALT WASH NEAR MOUTH, NEAR WATSON, UT

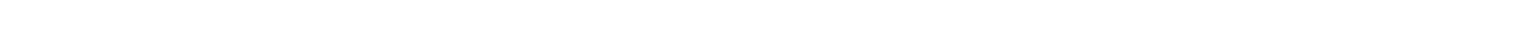
bank $1.3 \mathrm{mi}$ upstream fram mouth and $6.7 \mathrm{mi}$ northwest of Watson.

DRATNAGE AREA. $-97.5 \mathrm{mi}^{2}$.

MEAN BASTN ELEVATION. $-6,100 \mathrm{ft}$.

PERIOD OF RECORD AVAIlABLE.--October 1974 to September 1981.

GAGE.-Water-stage recorder. Altitude of gage is 4,950 ft fran topographic map.

AVERAGE DISCHARGE.--7 years, $0.18 \mathrm{ft}^{3} / \mathrm{s}, 130 \mathrm{acre}-\mathrm{ft} / \mathrm{yr}$.

EXIREMES FOR PERIOD OF RECORD.-Maximum discharge, 3,200 $\mathrm{ft}^{3} / \mathrm{s}$ Aug. 25, 1980, gage height, $9.21 \mathrm{ft}$, fran rating curve extended above $2 \mathrm{ft}^{3} / \mathrm{s}$ on basis of slope-area measurements of peak flow; no flow most of the time.

LONEST MEAN DISCHARGE, IN OUBIC FEET PER SEOOND, AND RANRING FOR THE INDICATED NUMBER OF CONSECOTIVE DAYS

\begin{tabular}{|c|c|c|c|c|c|c|c|c|c|c|c|c|c|c|c|c|c|c|c|}
\hline YEAR & 1 & & 3 & & 7 & & 14 & & $\begin{array}{l}\text { CONSE } \\
30\end{array}$ & aUTIVE & $\begin{array}{l}\text { DAYS } \\
60\end{array}$ & & 90 & & 120 & & 183 & & ALL \\
\hline 1981 & 0.00 & 6 & 0.00 & 6 & 0.00 & 6 & 0.00 & 6 & 0.00 & 6 & 0.00 & 6 & 0.00 & 6 & 0.00 & 6 & 0.00 & 4 & 0.45 \\
\hline
\end{tabular}

HIGHEST MEAN DISCHARGE, IN OUBIC FEET PER SECOND, AND RANRING FOR THE INDICATED NUMBER OF CONSEOUTIVE DAYS FOR EAOH WATER YEAR, OCTOBER 1-SEPTEMBER 30

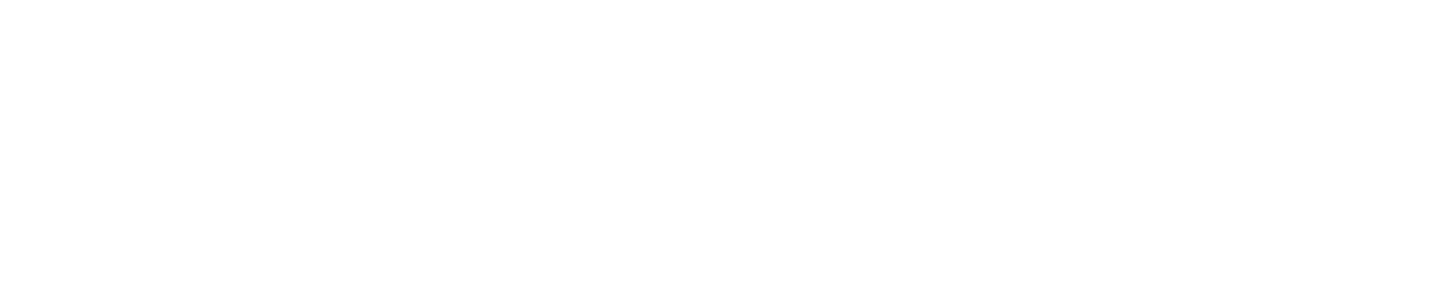


DURATION OF DISGHARGE FOR EACH WATER YEAR

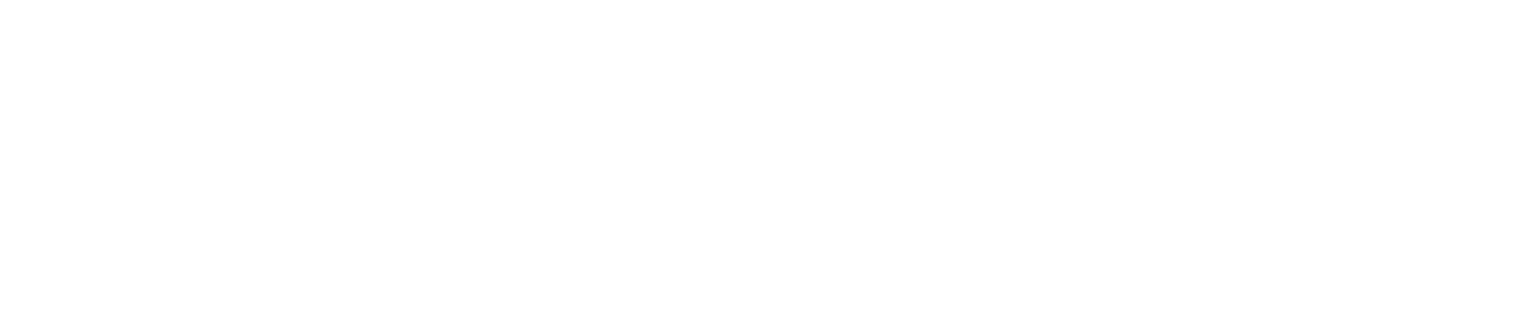

DURATION TABLE OF DISCHARGE FOR WATER YEARS 1975-81

\begin{tabular}{|c|c|c|c|c|c|c|c|c|c|c|c|c|c|c|c|c|c|c|c|}
\hline LASS & $\begin{array}{c}\text { OBIC } \\
\text { FEET } \\
\text { PER } \\
\text { SECOND }\end{array}$ & $\begin{array}{r}\text { TOTAL } \\
\text { DAYS }\end{array}$ & $\begin{array}{l}\text { ACOU- } \\
\text { MU- } \\
\text { LAIED } \\
\text { DAYS }\end{array}$ & $\begin{array}{l}\text { PER- } \\
\text { CENT } \\
\text { DAYS }\end{array}$ & CLASS & $\begin{array}{c}\text { GJBIC } \\
\text { FEET } \\
\text { PER } \\
\text { SECOND }\end{array}$ & $\begin{array}{r}\text { TOTAL } \\
\text { DAYS }\end{array}$ & $\begin{array}{c}\text { ACWJ- } \\
\text { MU- } \\
\text { LATED } \\
\text { DAYS }\end{array}$ & $\begin{array}{l}\text { PER- } \\
\text { GENT } \\
\text { DAYS }\end{array}$ & QLASS & $\begin{array}{c}\text { CUBIC } \\
\text { FEET } \\
\text { PER } \\
\text { SECOND }\end{array}$ & $\begin{array}{l}\text { TOTAL } \\
\text { DAYS }\end{array}$ & $\begin{array}{c}\text { ACOJ- } \\
\text { MU- } \\
\text { LATED } \\
\text { DAYS }\end{array}$ & $\begin{array}{l}\text { PER- } \\
\text { OENT } \\
\text { DAYS }\end{array}$ & QuASS & $\begin{array}{c}\text { OBBIC } \\
\text { FEET } \\
\text { PER } \\
\text { SECOND }\end{array}$ & TOTAL & $\begin{array}{c}\text { ACU- } \\
\text { MU- } \\
\text { LATED } \\
\text { DAYS }\end{array}$ & $\begin{array}{l}\text { FER- } \\
\text { OENT } \\
\text { DAYS }\end{array}$ \\
\hline $\begin{array}{l}0 \\
1 \\
2 \\
3 \\
4 \\
5 \\
6 \\
7 \\
8\end{array}$ & $\begin{array}{l}0.00 \\
0.01 \\
0.02 \\
0.03 \\
0.04 \\
0.05 \\
0.07 \\
0.09 \\
0.12\end{array}$ & $\begin{array}{r}2506 \\
3 \\
0 \\
2 \\
1 \\
0 \\
2 \\
1 \\
0\end{array}$ & $\begin{array}{r}2557 \\
51 \\
48 \\
48 \\
46 \\
45 \\
45 \\
43 \\
42\end{array}$ & $\begin{array}{r}100.0 \\
2.0 \\
1.9 \\
1.9 \\
1.8 \\
1.8 \\
1.8 \\
1.7 \\
1.6\end{array}$ & $\begin{array}{r}9 \\
10 \\
11 \\
12 \\
13 \\
14 \\
15 \\
16 \\
17\end{array}$ & $\begin{array}{l}0.15 \\
0.20 \\
0.27 \\
0.35 \\
0.46 \\
0.61 \\
0.80 \\
1.10 \\
1.40\end{array}$ & $\begin{array}{l}2 \\
2 \\
3 \\
0 \\
1 \\
6 \\
2 \\
0 \\
0\end{array}$ & $\begin{array}{l}42 \\
40 \\
38 \\
35 \\
35 \\
34 \\
28 \\
26 \\
26\end{array}$ & $\begin{array}{l}1.6 \\
1.6 \\
1.5 \\
1.4 \\
1.4 \\
1.3 \\
1.1 \\
1.0 \\
1.0\end{array}$ & $\begin{array}{l}18 \\
19 \\
20 \\
21 \\
22 \\
23 \\
24 \\
25 \\
26\end{array}$ & $\begin{array}{r}1.8 \\
2.4 \\
3.1 \\
4.1 \\
5.4 \\
7.1 \\
9.3 \\
12.0 \\
16.0\end{array}$ & $\begin{array}{l}6 \\
3 \\
1 \\
4 \\
1 \\
0 \\
1 \\
3 \\
3\end{array}$ & $\begin{array}{r}26 \\
20 \\
17 \\
16 \\
12 \\
11 \\
11 \\
10 \\
7\end{array}$ & $\begin{array}{l}1.0 \\
0.8 \\
0.7 \\
0.6 \\
0.5 \\
0.4 \\
0.4 \\
0.4 \\
0.3\end{array}$ & $\begin{array}{l}27 \\
28 \\
29 \\
30 \\
31 \\
32 \\
33 \\
34\end{array}$ & $\begin{array}{l}21.0 \\
28.0 \\
37.0 \\
48.0 \\
63.0 \\
83.0\end{array}$ & $\begin{array}{l}1 \\
0 \\
0 \\
1 \\
0\end{array}$ & $\begin{array}{l}4 \\
3 \\
3 \\
3 \\
2 \\
2\end{array}$ & \\
\hline
\end{tabular}

MONTHLY MEAN DISCHARGES, IN OBIC FEET PER SECOND, FOR EACH WATER YEAR

$\begin{array}{lllllllllllll}\text { YEAR } & \text { OCT } & \text { NOV } & \text { DEC } & \text { JAN } & \text { FEB } & \text { MAR } & \text { APR } & \text { MAY } & \text { JUNE } & \text { JULY } & \text { AUG } & \text { SEP } \\ 1975 & 0.00 & 0.00 & 0.00 & 0.00 & 0.00 & 0.01 & 0.03 & 0.00 & 0.00 & 0.16 & 0.08 & 0.03 \\ 1976 & 0.00 & 0.00 & 0.00 & 0.00 & 0.24 & 0.00 & 0.00 & 0.00 & 0.15 & 0.00 & 0.00 & 0.07 \\ 1977 & 0.01 & 0.00 & 0.00 & 0.00 & 0.00 & 0.00 & 0.00 & 0.00 & 0.00 & 0.00 & 0.12 & 0.01 \\ 1978 & 0.03 & 0.00 & 0.00 & 0.00 & 0.00 & 0.00 & 0.00 & 0.00 & 0.00 & 0.00 & 0.00 & 0.00 \\ 1979 & 0.00 & 0.00 & 0.00 & 0.00 & 0.00 & 1.70 & 0.42 & 0.00 & 0.00 & 0.00 & 0.00 & 0.09 \\ 1980 & 0.00 & 0.00 & 0.00 & 0.00 & 6.07 & 0.00 & 0.00 & 0.00 & 0.00 & 0.00 & 4.71 & 0.67 \\ 1981 & 0.00 & 0.00 & 0.00 & 0.00 & 0.00 & 0.00 & 0.00 & 0.00 & 0.00 & 0.00 & 0.45 & 0.00\end{array}$

ANNUAL PEAK DISCHARGE, IN OBBIC FEET FER SECOND, AND CORRESPONDING GAGE HEIGHT, IN FEET, FOR EAOH WATER YEAR

\begin{tabular}{|c|c|c|c|c|c|c|c|c|c|c|c|}
\hline $\begin{array}{l}\text { WATER } \\
\text { YEAR }\end{array}$ & DATE & $\begin{array}{c}\text { GAGE } \\
\text { HEIGHT }\end{array}$ & $\begin{array}{c}\text { FEAK } \\
\text { DISQH ARGE }\end{array}$ & $\begin{array}{l}\text { WATER } \\
\text { YEAR }\end{array}$ & DATE & $\begin{array}{c}\text { GAGE } \\
\text { HEIGT }\end{array}$ & $\begin{array}{c}\text { PEAK } \\
\text { DISCHARGE }\end{array}$ & $\begin{array}{l}\text { WATER } \\
\text { YEAR }\end{array}$ & DATE & $\begin{array}{c}\text { GAGE } \\
\text { HEIGHT }\end{array}$ & $\begin{array}{c}\text { PEAK } \\
\text { DISAHARGE }\end{array}$ \\
\hline $\begin{array}{l}1975 \\
1976 \\
1977\end{array}$ & $\begin{array}{l}\text { JULY } 15,1975 \\
\text { JUNE 22, } 1976 \\
\text { AUG. } 17,1977\end{array}$ & $\begin{array}{l}2.80 \\
2.47 \\
2.41\end{array}$ & $\begin{array}{r}123 \\
95 \\
65\end{array}$ & $\begin{array}{l}1978 \\
1979\end{array}$ & $\begin{array}{l}\text { OCT. 06, } 1977 \\
\text { SEPT. 26, } 1979\end{array}$ & $\begin{array}{l}1.44 \\
2.75\end{array}$ & $101^{4.8}$ & $\begin{array}{l}1980 \\
1981\end{array}$ & $\begin{array}{l}\text { AUG. } 25,1980 \\
\text { AUG. } 30,1981\end{array}$ & $\begin{array}{l}9.21 \\
3.39\end{array}$ & $\begin{array}{r}3200 \\
458\end{array}$ \\
\hline
\end{tabular}




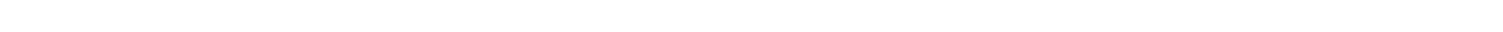
bank $1.3 \mathrm{mi}$ downstream from Asphalt Wash and $7.8 \mathrm{mi}$ northwest of Watson.

DRAINAGE AREA. $-4,130 \mathrm{mi}^{2}$, approximately.

MEAN BASIN ELEVATION. - -7,140 ft.

PERIOD OF RECORD AVAIIABLE.--Octcber 1974 to September 1977.

GAGE.-Water-stage recorder. Al titude of gage is 4,880 ft from topographic map.

REMARKS.--Many diversions for irrigation above station.

EXTREMES FOR PERICD OF RECORD.--Maximum discharge, 4,540 ft ${ }^{3} / \mathrm{s}$ June 9,1975 , gage height, $8.58 \mathrm{ft} ; \mathrm{minimum}$ daily, $17 \mathrm{ft}{ }^{3} / \mathrm{s} \mathrm{July} 3$, 1977.

LOWEST MEAN DISCHARGE, IN CUBIC FEET PER SECOND, AND RANKING FOR THE INDICATED NUMBER OF CONSEQUTIVE DAUS FOR EACH OLIMATIC YEAR, APRIL 1-MAROH 31

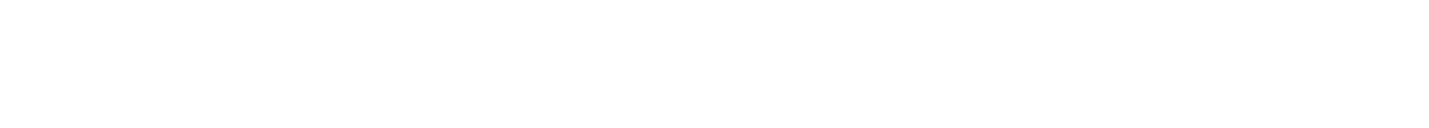

HIGHEST MEAN DISCHARGE, IN UIBIC FEET PER SECOND, AND RANKING FOR THE INDICATED NUMBER OF OONSEUTTVE DAUS FOR EACH WATER YEAR, OCTCBER 1-SEPTEMBER 30

\begin{tabular}{|c|c|c|c|c|c|c|c|c|c|c|c|c|c|c|c|c|c|c|c|}
\hline YEAR & 1 & & 3 & & 7 & & 15 & & $\begin{array}{l}\infty \\
30\end{array}$ & đT & $\begin{array}{c}\text { PIVE DAYS } \\
60\end{array}$ & & 90 & & 120 & & 183 & & ALL \\
\hline 1975 & 4380 & 1 & 3960 & 1 & 3410 & 1 & 3250 & 1 & 2900 & 1 & 2430 & 1 & 1890 & 1 & 1550 & 1 & 1180 & 1 & 780 \\
\hline
\end{tabular}

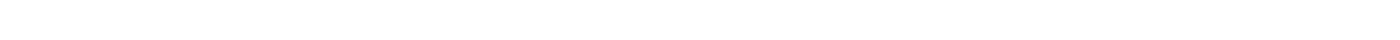
NUMBER OF DAYS IN CLASS

1975

$\begin{array}{lllllllllllllllllllll}3 & 6 & 8 & 17 & 56 & 120 & 41 & 28 & 13 & 3 & 5 & 2 & 7 & 4 & 10 & 12 & 17 & 7 & 5 & 1 & 284612.0\end{array}$

1976

201690.0

1977

$\begin{array}{lllllllllllllllllllll}1 & 1 & 3 & 1 & 1 & 2 & 3 & 5 & 6 & 5 & 6 & 13 & 10 & 13 & 27 & 28 & 31 & 143 & 37 & 18 & 11\end{array}$

DURATION TABLE OF DISCHARGE FOR WATER YEARS 1975-77

\begin{tabular}{crrrrr}
\multicolumn{4}{c}{ CUBIC } & \multicolumn{3}{c}{ ACCU- } \\
\multicolumn{4}{c}{ FEET } & MU- & PER- \\
PER & TOTAL & LATED & \multicolumn{1}{c}{ CENT } \\
CLASS SECOND & DAYS & DAYS & DAYS \\
0 & 0.00 & 0 & 1096 & 100.0 \\
1 & 17.00 & 1 & 1096 & 100.0 \\
2 & 20.00 & 1 & 1095 & 99.9 \\
3 & 24.00 & 3 & 1094 & 99.8 \\
4 & 28.00 & 1 & 1091 & 99.5 \\
5 & 33.00 & 1 & 1090 & 99.5 \\
6 & 39.00 & 2 & 1089 & 99.4 \\
7 & 46.00 & 3 & 1087 & 99.2 \\
8 & 54.00 & 0 & 1084 & 98.9
\end{tabular}

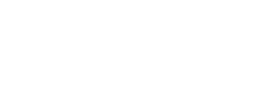

PER TOTEL LATED CENT

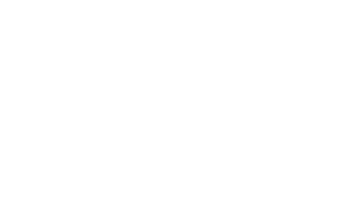

बBBIC $\mathrm{ACQ}-$

FEET MU- PER-

PER TOTAL LATED CENT

$\begin{array}{rrrrr}18 & 280.0 & 93 & 889 & 81.1 \\ 19 & 330.0 & 225 & 796 & 72.6 \\ 20 & 390.0 & 228 & 571 & 52.1 \\ 21 & 460.0 & 117 & 343 & 31.3 \\ 22 & 540.0 & 71 & 226 & 20.6 \\ 23 & 640.0 & 23 & 155 & 14.1 \\ 24 & 760.0 & 12 & 132 & 12.0 \\ 25 & 890.0 & 15 & 120 & 10.9 \\ 26 & 1100.0 & 7 & 105 & 9.6\end{array}$

ABIC ACQI-

FEET MU- PER-

GASS SECOR TOTAL LATED CENT

$\begin{array}{lllll}27 & 1200.0 & 16 & 98 & 8.9 \\ 28 & 1500.0 & 19 & 82 & 7.5\end{array}$

$\begin{array}{lllll}29 & 1700.0 & 19 & 82 & 7.5 \\ & 17 & 63 & 5.7\end{array}$

$\begin{array}{lllll}30 & 2000.0 & 16 & 63 & 5.7 \\ 31 & 2400.0 & 17 & 30 & 2.7\end{array}$

$\begin{array}{lllll}31 & 2400.0 & 17 & 30 & 2.7\end{array}$

$\begin{array}{lllll}32 & 2800.0 & 7 & 13 & 1.2\end{array}$

$\begin{array}{lllll}33 & 3300.0 & 5 & 6 & 0.5 \\ 34 & 4000.0 & 1 & 1 & 0.1\end{array}$

MONIHLY MEAN DISCHARGES, IN OBIC FEET PER SECOND, FOR EACH WATER YEAR

$\begin{array}{rrrrrrrrrrrrr}\text { YEAR } & \text { OCT } & \text { NOV } & \text { DEC } & \text { JAN } & \text { FEB } & \text { MAR } & \text { APR } & \text { MAY } & \text { JUNE } & \text { JULY } & \text { AUG } & \text { SEP } \\ 1975 & 429 & 434 & 301 & 343 & 381 & 516 & 482 & 1264 & 2780 & 1556 & 456 & 409 \\ 1976 & 455 & 429 & 299 & 270 & 466 & 585 & 520 & 1448 & 1190 & 347 & 326 & 280 \\ 1977 & 370 & 329 & 286 & 315 & 344 & 391 & 425 & 395 & 267 & 131 & 213 & 216\end{array}$


GREEN RIVER BASIN

09306740 BITTER CREEK ABOVE DICK CANYON, NEAR WATSON, UT

LOCATION. --Lat $39^{\circ} 31^{\prime} 04^{\prime \prime}$, long 109 $04^{\prime} 16^{\prime \prime}$, in SE bank $1.2 \mathrm{mi}$ downstream from Colorado-Utah State line, $2.0 \mathrm{mi}$ upstream fram Dick Canyon, and 26 mi southeast of Watson.

DRAINAGE AREA. $--11.7 \mathrm{mi}^{2}$.

PERIOD OF RECORD AVAILABLE,--October 1974 to September 1978.

GAGE. -Water-stage recorder and concrete control. Altitude of gage is 7,040 ft fram topographic map.

REMARKS. - Many diversions for irrigation above station.

EXTREMES FOR PERIOD OF RECORD.--Maximum discharge, $11 \mathrm{ft}^{3} / \mathrm{s}$ Apr. 25, 1975, Aug. 8, 1976; maximum gage height, $4.06 \mathrm{ft}$ Aug. 8, 1976 ; no flow Sept. 8-11, 1977, result of irrigation diversion.

LOWEST MEAN DISCHARGE, IN OUBIC FEET PER SECOND, AND RANKING FOR THE INDICATED NUMBER OF CONSECITIVE DAYS FOR EACH CLIMATIC YEAR, APRIL 1-MARCH 31

\begin{tabular}{|c|c|c|c|c|c|c|c|c|c|c|c|c|c|c|c|c|c|c|c|}
\hline YEAR & 1 & & 3 & & 7 & & 14 & & $\begin{array}{l}\text { CNSE } \\
30\end{array}$ & OUTIVE & $\begin{array}{l}\text { DAYS } \\
60\end{array}$ & & 90 & & 120 & & 183 & & ALL \\
\hline $\begin{array}{l}1976 \\
1977 \\
1978\end{array}$ & $\begin{array}{l}0.47 \\
0.03 \\
0.00\end{array}$ & $\begin{array}{l}3 \\
2 \\
1\end{array}$ & $\begin{array}{l}0.57 \\
0.03 \\
0.00\end{array}$ & $\begin{array}{l}3 \\
2 \\
1\end{array}$ & $\begin{array}{l}0.74 \\
0.03 \\
0.20\end{array}$ & $\begin{array}{l}3 \\
1 \\
2\end{array}$ & $\begin{array}{l}0.88 \\
0.05 \\
0.27\end{array}$ & $\begin{array}{l}3 \\
1 \\
2\end{array}$ & $\begin{array}{l}0.98 \\
0.10 \\
0.32\end{array}$ & $\begin{array}{l}3 \\
1 \\
2\end{array}$ & $\begin{array}{l}1.00 \\
0.18 \\
0.36\end{array}$ & $\begin{array}{l}3 \\
1 \\
2\end{array}$ & $\begin{array}{l}1.10 \\
0.32 \\
0.39\end{array}$ & $\begin{array}{l}3 \\
1 \\
2\end{array}$ & $\begin{array}{l}1.10 \\
0.46 \\
0.40\end{array}$ & $\begin{array}{l}3 \\
2 \\
1\end{array}$ & $\begin{array}{l}1.19 \\
0.68 \\
0.41\end{array}$ & $\begin{array}{l}3 \\
2 \\
1\end{array}$ & $\begin{array}{l}2.40 \\
2.00 \\
0.56\end{array}$ \\
\hline
\end{tabular}

HIGHEST MEAN DISCHARGE, IN OUBIC FEET PER SECOND, AND RANKING FOR THE INDICATED NUMBER OF CONSECITIVE DAYS FOR EACH WATER YEAR, $\propto$ CTOBER 1-SEPTEMBER 30

\begin{tabular}{|c|c|c|c|c|c|c|c|c|c|c|c|c|c|c|c|c|c|c|c|}
\hline YEAR & & & & & & & & & CONSE & & DAYS & & & & & & & & \\
\hline 1975 & 9.80 & 2 & 8.90 & 2 & 8.40 & 2 & 8.20 & 2 & 7.80 & 2 & 6.30 & 1 & 5.20 & 1 & 4.60 & 1 & 3.60 & 1 & 2.10 \\
\hline
\end{tabular}

DURATION OF DISCHARGE FOR EACH WATER YEAR

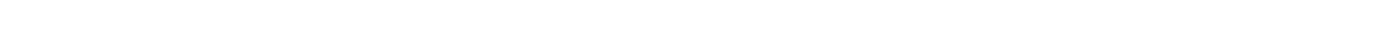
YEAR NUMBER OF DAYS IN CLASS

OBIC FEET PER SECOND -DAYS

$\begin{array}{llllllllllllllllllll}1975 & 66 & 76 & 34 & 10 & 4 & 3 & 9 & 27 & 24 & 33 & 11 & 12 & 12 & 7 & 11 & 18 & 8 & 772.7\end{array}$

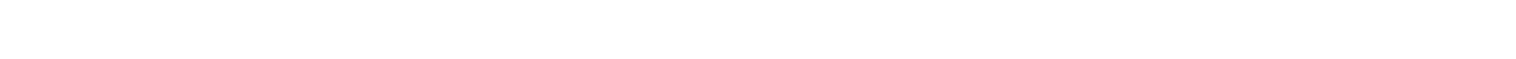
$\begin{array}{llllllllllllllllllllllllllll}1977 & 4 & 9 & 1 & 3 & 6 & 7 & 13 & 5 & 10 & 14 & 38 & 45 & 30 & 20 & 42 & 49 & 40 & 19 & 7 & 3 & & & & & & 236.0 \\ 1978 & & & & & & & & 2 & 13 & 14 & 52 & 36 & 42 & 66 & 25 & 14 & 14 & 18 & 36 & 30 & 2 & 1 & & & & & \end{array}$

DURATION TABLE OF DISCHARGE FOR WATER YEARS $1975-78$

\begin{tabular}{|c|c|c|c|c|c|c|c|c|c|c|c|c|c|c|c|c|c|c|c|}
\hline LASS & $\begin{array}{c}\text { OBIC } \\
\text { FEET } \\
\text { PER } \\
\text { SECOND }\end{array}$ & TOTAL & $\begin{array}{l}\text { ACCU- } \\
\text { MU- } \\
\text { LATED } \\
\text { DAYS }\end{array}$ & $\begin{array}{l}\text { PER- } \\
\text { CENT } \\
\text { DAYS }\end{array}$ & CASS & $\begin{array}{c}\text { OUBIC } \\
\text { FEET } \\
\text { PER } \\
\text { SECOND }\end{array}$ & TOTAL & $\begin{array}{c}\text { ACOU- } \\
\text { MU- } \\
\text { LATED } \\
\text { DAYS }\end{array}$ & $\begin{array}{l}\text { PER- } \\
\text { CENT } \\
\text { DAYS }\end{array}$ & & $\begin{array}{c}\text { OBIC } \\
\text { FEET } \\
\text { PER } \\
\text { SECOND }\end{array}$ & $\begin{array}{l}\text { TOTAL } \\
\text { DAYS }\end{array}$ & $\begin{array}{l}\text { ACOU- } \\
\text { NU- } \\
\text { LATED } \\
\text { DAYS }\end{array}$ & $\begin{array}{l}\text { PER- } \\
\text { CENT } \\
\text { DAYS }\end{array}$ & CLASS & $\begin{array}{c}\text { OUBIC } \\
\text { FEET } \\
\text { PER } \\
\text { SECOND }\end{array}$ & $\begin{array}{l}\text { TOTAL } \\
\text { DAYS }\end{array}$ & $\begin{array}{l}\text { ACQU- } \\
\text { MU- } \\
\text { LATED } \\
\text { DAYS }\end{array}$ & $\begin{array}{l}\text { PER- } \\
\text { CENI } \\
\text { DAYS }\end{array}$ \\
\hline $\begin{array}{l}0 \\
1 \\
2 \\
3 \\
4 \\
5 \\
6 \\
7 \\
8\end{array}$ & $\begin{array}{l}0.00 \\
0.03 \\
0.04 \\
0.05 \\
0.06 \\
0.07 \\
0.09 \\
0.10 \\
0.12\end{array}$ & $\begin{array}{l}4 \\
9 \\
0 \\
1 \\
0 \\
3 \\
0 \\
6 \\
7\end{array}$ & $\begin{array}{l}1461 \\
1457 \\
1448 \\
1448 \\
1447 \\
1447 \\
1444 \\
1444 \\
1438\end{array}$ & $\begin{array}{r}100.0 \\
99.7 \\
99.1 \\
99.1 \\
99.0 \\
99.0 \\
98.8 \\
98.8 \\
98.4\end{array}$ & $\begin{array}{l}9 \\
10 \\
11 \\
12 \\
13 \\
14 \\
15 \\
16 \\
17\end{array}$ & $\begin{array}{l}0.15 \\
0.17 \\
0.21 \\
0.25 \\
0.30 \\
0.35 \\
0.42 \\
0.50 \\
0.60\end{array}$ & $\begin{array}{r}0 \\
13 \\
7 \\
23 \\
28 \\
90 \\
82 \\
139 \\
165\end{array}$ & $\begin{array}{l}1431 \\
1431 \\
1418 \\
1411 \\
1388 \\
1360 \\
1270 \\
1188 \\
1049\end{array}$ & $\begin{array}{l}97.9 \\
97.9 \\
97.1 \\
96.6 \\
95.0 \\
93.1 \\
86.9 \\
81.3 \\
71.8\end{array}$ & $\begin{array}{l}18 \\
19 \\
20 \\
21 \\
22 \\
23 \\
24 \\
25 \\
26\end{array}$ & $\begin{array}{l}0.7 \\
0.8 \\
1.0 \\
1.2 \\
1.4 \\
1.7 \\
2.0 \\
2.4 \\
2.9\end{array}$ & $\begin{array}{r}108 \\
107 \\
92 \\
95 \\
163 \\
89 \\
43 \\
36 \\
30\end{array}$ & $\begin{array}{l}884 \\
776 \\
669 \\
577 \\
482 \\
319 \\
230 \\
187 \\
151\end{array}$ & $\begin{array}{l}60.5 \\
53.1 \\
45.8 \\
39.5 \\
33.0 \\
21.8 \\
15.7 \\
12.8 \\
10.3\end{array}$ & $\begin{array}{l}27 \\
28 \\
29 \\
30 \\
31 \\
32 \\
33 \\
34\end{array}$ & $\begin{array}{l}3.5 \\
4.1 \\
4.9 \\
5.8 \\
7.0 \\
8.3 \\
9.9\end{array}$ & $\begin{array}{l}22 \\
19 \\
14 \\
17 \\
23 \\
14 \\
12\end{array}$ & $\begin{array}{r}121 \\
99 \\
80 \\
66 \\
49 \\
26 \\
12\end{array}$ & $\begin{array}{l}5 \\
4 \\
3 \\
1 \\
0\end{array}$ \\
\hline
\end{tabular}

MONTHLY MEAN DISCHARGES, IN OUIC FEET PER SECOND, FOR EACH WATER YEAR

$\begin{array}{llccccccccccc}\text { YEAR } & \text { OCT } & \text { NOV } & \text { DEC } & \text { JAN } & \text { FEB } & \text { MAR } & \text { APR } & \text { MAY } & \text { JUNE } & \text { JULY } & \text { AUG } & \text { SEP } \\ 1975 & 0.67 & 0.76 & 0.64 & 0.50 & 0.50 & 0.67 & 1.89 & 5.37 & 6.82 & 3.17 & 2.43 & 1.91 \\ 1976 & 1.44 & 1.02 & 1.27 & 1.05 & 1.02 & 1.33 & 1.61 & 6.24 & 5.67 & 2.78 & 1.80 & 1.43 \\ 1977 & 1.23 & 0.91 & 0.91 & 0.46 & 0.10 & 0.37 & 1.10 & 0.83 & 0.50 & 0.48 & 0.50 & 0.32 \\ 1978 & 0.42 & 0.46 & 0.41 & 0.34 & 0.49 & 0.84 & 1.64 & 1.54 & 1.37 & 0.79 & 0.71 & 0.66\end{array}$


GREEN RIVER BASIN

09306760 SWEETWATER CANYON CREER BELOW SOUTH CANYON, NEAR WATSON, UT

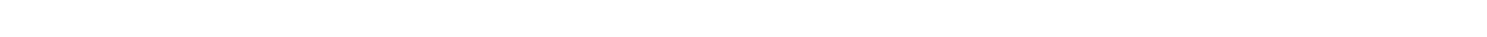
bank $0.6 \mathrm{mi}$ downstream fram South Canyon, and $24 \mathrm{mi}$ southwest of watson.

DRAINAGE AREA. $-22.6 \mathrm{mi}^{2}$.

MEAN BASIN ELEVATION. $-7,790 \mathrm{ft}$.

PERIOD OF RECORD AVAILABIE. - October 1974 to September 1978.

GAGE. -Water-stage recorder and concrete control. Altitude of gage is 6,810 ft from topographic map.

EXIREMES FOR PERTOD OF RECORD.--Maximum discharge, $68 \mathrm{ft}^{3} / \mathrm{s}$ Aug. 8,1976 , gage height, $2.82 \mathrm{ft}$, fram slope-area measurement of peak flow; minimum, $0.02 \mathrm{ft}^{3} / \mathrm{s}$ Nov. 20,1977 , result of freezeup.

LOWEST MEAN DISCHARGE, IN COBIC FEET PER SECOND, AND RANKING FOR THE INDICATED NUMBER OF CONSECUTIVE DAYS FOR EACH CLIMATIC YEAR, APRIL 1-MARCH 31

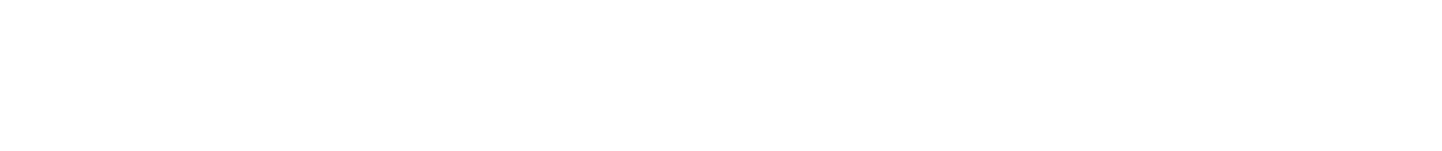

HIGHEST MEAN DISCHARGE, IN OUBIC FEET PER SECOND, AND RANKING FOR THE INDICATED NUMBER OF CONSEOUTIVE DAYS FOR EACH WATER YEAR, OCTCBER 1-SEPTEMBER 30

\begin{tabular}{|c|c|c|c|c|c|c|c|c|c|c|c|c|c|c|c|c|c|c|c|c|}
\hline YEAR & & & & & & & & & CONSE & CuTtv & DAYS & & & & & & & & & \\
\hline 1975 & 8.90 & 1 & 5.40 & 1 & 3.60 & 1 & 2.50 & 1 & 2.10 & 1 & 1.50 & 1 & 1.19 & 1 & 0.98 & 1 & 0.83 & 1 & 0.59 & 1 \\
\hline
\end{tabular}

DURATION OF DISCHARGE FOR EACH WATER YEAR

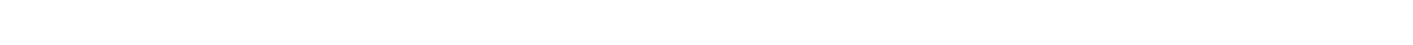
YEAR

NUMBER OF DAYS IN CLASS OBIC FEET -DAYS

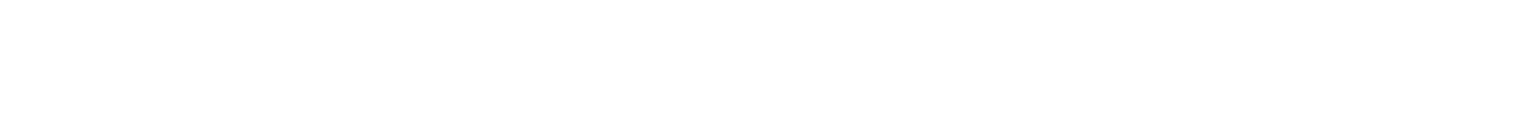

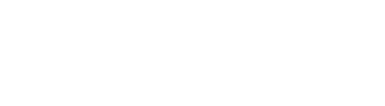

$$
\begin{array}{ll}
0 & 0.00 \\
1 & 0.09 \\
2 & 0.10 \\
3 & 0.12 \\
4 & 0.13 \\
5 & 0.15 \\
6 & 0.17 \\
7 & 0.19 \\
8 & 0.21
\end{array}
$$

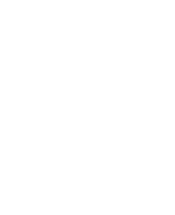
$\begin{array}{ccc}\text { CUBIC } & \text { ACQU- } \\ \text { FEET } & \text { MU- } & \text { PER- } \\ \text { PER TOTAL LATED } & \text { CENT } \\ \text { CLASS SECOND DAYS DAYS } & \text { DAYS }\end{array}$

\begin{tabular}{ccc}
\multicolumn{4}{c}{ CIBIC } \\
FEET \\
PER & TOTAL \\
CLASS SECOND & DAYS \\
18 & 0.7 & 10 \\
19 & 0.8 & 1 \\
20 & 0.9 & 2 \\
21 & 1.1 & 2 \\
22 & 1.2 & 1 \\
23 & 1.4 & 2 \\
24 & 1.5 & 3 \\
25 & 1.7 & 1 \\
26 & 2.0 & 2
\end{tabular}

$\begin{array}{rrrrr}9 & 0.24 & 15 & 1428 & 97.7 \\ 10 & 0.27 & 193 & 1413 & 96.7 \\ 11 & 0.31 & 278 & 1220 & 83.5 \\ 12 & 0.35 & 178 & 942 & 64.5 \\ 13 & 0.39 & 546 & 764 & 52.3 \\ 14 & 0.45 & 118 & 218 & 14.9 \\ 15 & 0.50 & 21 & 100 & 6.8 \\ 16 & 0.57 & 34 & 79 & 5.4 \\ 17 & 0.64 & 3 & 45 & 3.1\end{array}$

MONIHLY MEAN DISCHARGES, IN OBBIC FEET PER SECOND, FOR EACH WATER YEAR

\begin{tabular}{|c|c|c|c|c|c|c|c|c|c|c|c|c|}
\hline YEAR & $\infty \mathrm{CT}$ & $\mathrm{NOV}$ & DEC & JAN & FEB & MAR & APR & MAY & UUNE & JULY & AUG & SEP \\
\hline 1975 & 0.34 & 0.43 & 0.63 & 0.45 & 0.45 & 1.26 & 1.58 & 0.60 & 0.34 & 0.34 & 0.31 & 0.31 \\
\hline $\begin{array}{l}1976 \\
1977 \\
1978\end{array}$ & $\begin{array}{l}0.34 \\
0.45 \\
0.39\end{array}$ & $\begin{array}{l}0.40 \\
0.44 \\
0.35\end{array}$ & $\begin{array}{l}0.30 \\
0.43 \\
0.38\end{array}$ & $\begin{array}{l}0.30 \\
0.43 \\
0.39\end{array}$ & $\begin{array}{l}0.30 \\
0.42 \\
0.36\end{array}$ & $\begin{array}{l}0.40 \\
0.40 \\
0.43\end{array}$ & $\begin{array}{l}0.42 \\
0.41 \\
0.43\end{array}$ & $\begin{array}{l}0.40 \\
0.40 \\
0.34\end{array}$ & $\begin{array}{l}0.39 \\
0.40 \\
0.36\end{array}$ & $\begin{array}{l}0.39 \\
0.34 \\
0.31\end{array}$ & $\begin{array}{l}0.45 \\
0.41 \\
0.31\end{array}$ & $\begin{array}{l}0.39 \\
0.30 \\
0.33\end{array}$ \\
\hline
\end{tabular}




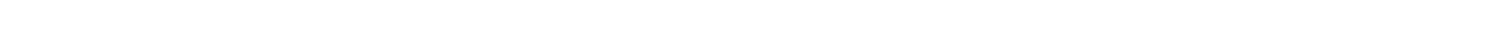
bank $0.6 \mathrm{mi}$ upstream from Park Canyon and $18 \mathrm{mi}$ southwest of Watson.

DRAINAGE ARÈA.--124 $\mathrm{mi}^{2}$.

MEAN BASIN ELEVATION.--7,300 ft.

PERIOD OF RECORD AVAIIABLE.--October 1974 to September 1978.

GAGE.--Water-stage recorder. Altitude of gage is $6,000 \mathrm{ft}$ from topographic map.

REMARKS.--Some diversions for irrigation above station.

EXTREMES FOR PERIOD OF RECORD.--Maximum discharge, $59 \mathrm{ft}^{3} / \mathrm{s}$ July 25,1976 , gage height, $2.70 \mathrm{ft}$, from slope-area measurement of peak flow; no flow most of the time.

LOWEST MEAN DISCHARGE, IN OBBIC FEET PER SECOND, AND RANKING FOR THE INDICATED NUMBER OF CONSEOUTIVE DAYS FOR EACH OLIMATIC YEAR, APRII 1-MARCH 31

\begin{tabular}{|c|c|c|c|c|c|c|c|c|c|c|c|c|c|c|c|c|c|c|c|}
\hline \multirow[t]{2}{*}{ YEAR } & \multicolumn{19}{|c|}{ CONSEOUTIVE DAYS } \\
\hline & 1 & & 3 & & 7 & & 14 & & 30 & & 60 & & 90 & & 120 & & 183 & & ALL \\
\hline $\begin{array}{l}1976 \\
1977 \\
1978\end{array}$ & $\begin{array}{l}0.00 \\
0.00 \\
0.00\end{array}$ & $\begin{array}{l}1 \\
2 \\
3\end{array}$ & $\begin{array}{l}0.00 \\
0.00 \\
0.00\end{array}$ & $\begin{array}{l}1 \\
2 \\
3\end{array}$ & $\begin{array}{l}0.00 \\
0.00 \\
0.00\end{array}$ & $\begin{array}{l}1 \\
2 \\
3\end{array}$ & $\begin{array}{l}0.00 \\
0.00 \\
0.00\end{array}$ & $\begin{array}{l}1 \\
2 \\
3\end{array}$ & $\begin{array}{l}0.00 \\
0.00 \\
0.00\end{array}$ & $\begin{array}{l}1 \\
2 \\
3\end{array}$ & $\begin{array}{l}0.00 \\
0.00 \\
0.00\end{array}$ & $\begin{array}{l}1 \\
2 \\
3\end{array}$ & $\begin{array}{l}0.00 \\
0.00 \\
0.00\end{array}$ & $\begin{array}{l}1 \\
2 \\
3\end{array}$ & $\begin{array}{l}0.00 \\
0.00 \\
0.00\end{array}$ & $\begin{array}{l}1 \\
2 \\
3\end{array}$ & $\begin{array}{l}0.00 \\
0.00 \\
0.00\end{array}$ & $\begin{array}{l}1 \\
2 \\
3\end{array}$ & $\begin{array}{l}0.07 \\
0.19 \\
0.05\end{array}$ \\
\hline
\end{tabular}

HIGHEST MEAN DISCHARGE, IN OUBIC FEET PER SECOND, AND RANKING FOR THE INDICATED NUMBER OF CONSEOTTIVE DAYS FOR EAGH WATER YEAR, OCTOBER I-SEPTEMBER 30

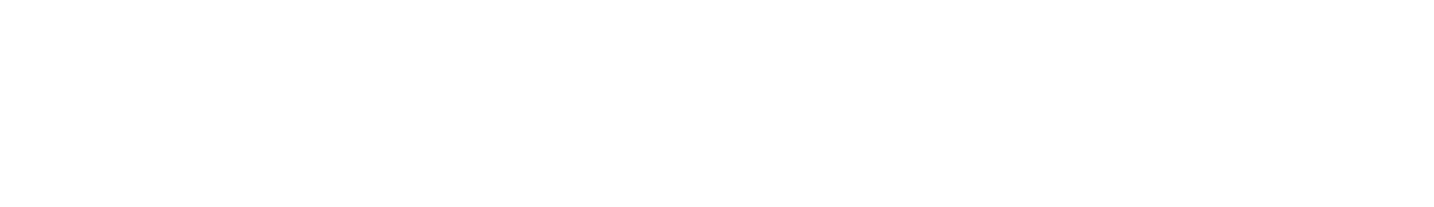

DURATION OF DISCHARGE FOR EACH WATER YEAR

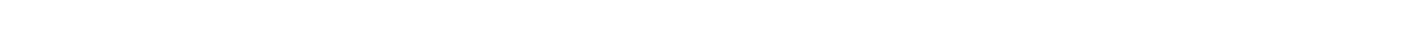
YEAR NUMBER OF DAYS IN OLASS

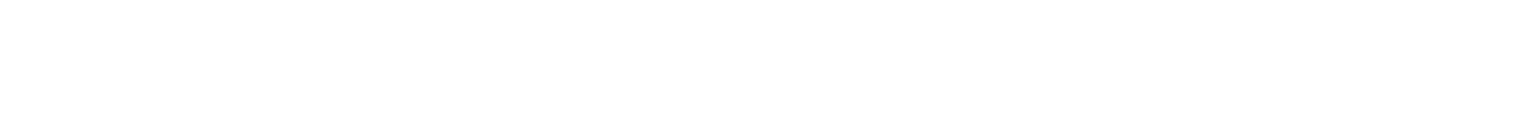

\section{DURATION TABLE OF DISCHARGE FOR WATER YEARS 1975-78}

\begin{tabular}{|c|c|c|c|c|c|c|c|c|c|c|c|c|c|c|c|c|c|c|c|}
\hline CLASS & $\begin{array}{r}\text { OABIC } \\
\text { FEET } \\
\text { PER } \\
\text { SECOND }\end{array}$ & $\begin{array}{r}\text { TOTAL } \\
\text { DAYS }\end{array}$ & $\begin{array}{l}\text { ACCJ- } \\
\text { MU- } \\
\text { LATED } \\
\text { DAYS }\end{array}$ & $\begin{array}{l}\text { PER- } \\
\text { CENT } \\
\text { DAYS }\end{array}$ & & $\begin{array}{c}\text { OBBIC } \\
\text { FEET } \\
\text { PER } \\
\text { SECOND }\end{array}$ & $\begin{array}{r}\text { TOTAL } \\
\text { DAYS }\end{array}$ & $\begin{array}{l}\text { ACOH- } \\
\text { MU- } \\
\text { LATED } \\
\text { DAYS }\end{array}$ & $\begin{array}{l}\text { PER- } \\
\text { CENT } \\
\text { DAYS }\end{array}$ & CLASS & $\begin{array}{c}\text { OBBIC } \\
\text { FEET } \\
\text { PER } \\
\text { SECOND }\end{array}$ & $\begin{array}{c}\text { TOTAL } \\
\text { DAYS }\end{array}$ & $\begin{array}{c}\text { ACCU- } \\
\text { MU- } \\
\text { LATED } \\
\text { DAYS }\end{array}$ & $\begin{array}{l}\text { PER- } \\
\text { CENT } \\
\text { DAYS }\end{array}$ & CLASS & $\begin{array}{c}\text { OBBIC } \\
\text { FEET } \\
\text { PER } \\
\text { SECOND }\end{array}$ & $\begin{array}{r}\text { TOTAL } \\
\text { DAYS }\end{array}$ & $\begin{array}{c}\text { ACCU- } \\
\text { MU- } \\
\text { LATED } \\
\text { DAYS }\end{array}$ & $\begin{array}{l}\text { PER- } \\
\text { CENT } \\
\text { DAYS }\end{array}$ \\
\hline $\begin{array}{l}0 \\
1 \\
2 \\
3 \\
4 \\
5 \\
6 \\
7 \\
8\end{array}$ & $\begin{array}{l}0.00 \\
0.01 \\
0.02 \\
0.03 \\
0.04 \\
0.05 \\
0.07 \\
0.08 \\
0.09\end{array}$ & $\begin{array}{r}1191 \\
3 \\
4 \\
6 \\
4 \\
17 \\
1 \\
2 \\
23\end{array}$ & $\begin{array}{r}1461 \\
270 \\
267 \\
263 \\
257 \\
253 \\
236 \\
235 \\
233\end{array}$ & $\begin{array}{r}100.0 \\
18.5 \\
18.3 \\
18.0 \\
17.6 \\
17.3 \\
16.2 \\
16.1 \\
15.9\end{array}$ & $\begin{array}{r}9 \\
10 \\
11 \\
12 \\
13 \\
14 \\
15 \\
16 \\
17\end{array}$ & $\begin{array}{l}0.11 \\
0.14 \\
0.17 \\
0.20 \\
0.24 \\
0.29 \\
0.35 \\
0.42 \\
0.51\end{array}$ & $\begin{array}{r}12 \\
9 \\
3 \\
13 \\
19 \\
29 \\
35 \\
34 \\
6\end{array}$ & $\begin{array}{r}210 \\
198 \\
189 \\
186 \\
173 \\
154 \\
125 \\
90 \\
56\end{array}$ & $\begin{array}{r}14.4 \\
13.6 \\
12.9 \\
12.7 \\
11.8 \\
10.5 \\
8.6 \\
6.2 \\
3.8\end{array}$ & $\begin{array}{l}18 \\
19 \\
20 \\
21 \\
22 \\
23 \\
24 \\
25 \\
26\end{array}$ & $\begin{array}{l}0.6 \\
0.7 \\
0.9 \\
1.1 \\
1.3 \\
1.6 \\
1.9 \\
2.3 \\
2.7\end{array}$ & $\begin{array}{r}15 \\
5 \\
5 \\
4 \\
5 \\
9 \\
2 \\
1 \\
1\end{array}$ & $\begin{array}{r}50 \\
35 \\
30 \\
25 \\
21 \\
16 \\
7 \\
5 \\
4\end{array}$ & $\begin{array}{l}3.4 \\
2.4 \\
2.1 \\
1.7 \\
1.4 \\
1.1 \\
0.5 \\
0.3 \\
0.3\end{array}$ & $\begin{array}{l}27 \\
28 \\
29 \\
30 \\
31 \\
32 \\
33 \\
34\end{array}$ & $\begin{array}{l}3.3 \\
4.0 \\
4.8\end{array}$ & $\begin{array}{l}0 \\
1 \\
2\end{array}$ & $\begin{array}{l}3 \\
3 \\
2\end{array}$ & $\begin{array}{l}0.2 \\
0.2 \\
0.1\end{array}$ \\
\hline
\end{tabular}

MONIHLY MEAN DISCHARGES, IN OUBIC FEET PER SECOND, FOR EACH WATER YEAR

$\begin{array}{lcccccccccccc}\text { YEAR } & \text { OCT } & \text { NOV } & \text { DEC } & \text { JAN } & \text { FEB } & \text { MAR } & \text { APR } & \text { MAY } & \text { JUNE } & \text { JULY } & \text { AJG } & \text { SEP } \\ 1975 & 0.00 & 0.00 & 0.00 & 0.00 & 0.02 & 0.48 & 0.09 & 0.03 & 0.00 & 0.00 & 0.00 & 0.00 \\ 1976 & 0.00 & 0.00 & 0.00 & 0.03 & 0.33 & 0.31 & 0.37 & 0.00 & 0.00 & 0.54 & 0.00 & 0.00 \\ 1977 & 0.00 & 0.00 & 0.01 & 0.00 & 0.81 & 0.57 & 0.32 & 0.00 & 0.00 & 0.00 & 0.00 & 0.01 \\ 1978 & 0.00 & 0.00 & 0.00 & 0.00 & 0.11 & 0.18 & 0.08 & 0.01 & 0.01 & 0.01 & 0.00 & 0.00\end{array}$




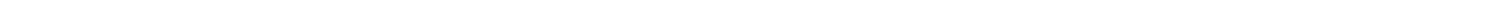
bank $150 \mathrm{ft}$ upstream from road bridge, $3 \mathrm{mi}$ downstream from Sweetwater canyon Creek, $17 \mathrm{mi}$ upstream from mouth, and $18 \mathrm{mi}$ southsouthwest of Bonanza.

DRAINAGE AREA $--324 \mathrm{mi}^{2}$.

MEAN BASIN ELEVATION. $--7,300 \mathrm{ft}$.

PERTOD OF RECORD AVAILABLE. -Octcber 1970 to September 1981.

GAGE.-Water-stage recorder. Altitude of gage is 5,570 ft fram topographic map.

REMARKS. - -Small reservoirs on tributaries above station.

AVERAGE DISGHARGE. --11 years, $1.57 \mathrm{ft}^{3} / \mathrm{s}, 1,140$ acre-ft/yr.

EXTREMES FOR PERTOD OF RECORD.--Maximum discharge, 1,660 ft ${ }^{3} / \mathrm{s}$ July 17, 1974, gage height, $13.55 \mathrm{ft}$ fram floodnarks, rating curve extended above $6 \mathrm{ft}^{3} / \mathrm{s}$ on basis of slope-area measurement of peak flow; no flow for many days most years.

LOWEST MEAN DISGHARGE, IN QUBIC FEET PER SECOND, AND RANKING FOR THE INDICATED NUMBER OF CONSEQUTIVE DAYS FOR EAOH OLIMATIC YEAR, APRIL 1-MARCH 31

YEAR

13

$\begin{array}{lllll}0.00 & 1 & 0.00 & 1\end{array}$

$\begin{array}{lll}0.00 & 2 & 0.00\end{array}$

$\begin{array}{llll}0.00 & 3 & 0.06 & 9 \\ 0.00 & 4 & 0.00 & 3\end{array}$

0.00

0.006

0.00

0.004

0.005

0.006

0.007

$\begin{array}{ll}0.00 & 7 \\ 0.008 & 8\end{array}$

0.6310

0.6310

$\begin{array}{cc}7 & \\ 0.00 & 1 \\ 0.00 & 2 \\ 0.17 & 9 \\ 0.00 & 3\end{array}$

0.004

0.005

0.00

$\begin{array}{ll}0.00 & 7 \\ 0.00 & 8\end{array}$

0.6910
14 CONSECUTIVE DAYS

0.001

0.002

0.269

$$
30
$$

0.001

0.002
0.42

0.429
0.00

60
0.01

$\begin{array}{ll}0.01 & 5 \\ 0.00 & 1 \\ 0.73 & 9\end{array}$

$\begin{array}{ll}0.73 & 9 \\ 0.00 & 2\end{array}$

0.004

0.027

0.004

0.088

0.005

0.047

0.003

0.178

0.004

0.007

0.006

0.036

0.9410

1.3010

2.5010
90
0.08
1
0.102
0
0.09
0.19
0

0.08

0.001

1.199
0.02

0.097

0.065

0.198

$\begin{array}{ll}0.00 & 2 \\ 0.05 & 4\end{array}$

2.6010
120

0.115

0.01
1.40
0.05

0.268

0.237

0.226

0.001

0.084

3.0010
183 ALL

$0.16 \quad 5$

0.052

$\begin{array}{llll}1.60 & 9 & 2.50 & 9 \\ 0.05 & 3 & 1.40 & 6\end{array}$

$\begin{array}{llll}0.37 & 7 & 2.00 & 8\end{array}$

$\begin{array}{llll}0.46 & 8 & 1.70 & 7\end{array}$

$\begin{array}{llll}0.26 & 6 & 0.63 & 3\end{array}$

$\begin{array}{llll}0.00 & 1 & 0.12 & 1 \\ 0.09 & 4 & 0.86 & 5\end{array}$

$3.4010 \quad 4.8010$

HIGHEST MEAN DISCHARGE, IN OBBIC FEET PER SECOND, AND RANKING FOR THE INDICATED NUMBER OF CONSEQUTIVE DAYS FOR EACH WATER YEAR, OCTOBER 1-SEPTEMBER 30

YEAR
1971
1972
1973
1974
1975
1976
1977
1978
1979
1980
1981

\begin{tabular}{crcr}
1 & & \multicolumn{2}{c}{3} \\
& & & \\
30.0 & 2 & 10.0 & 5 \\
3.10 & 10 & 1.40 & 11 \\
19.0 & 5 & 11.0 & 4 \\
92.0 & 1 & 58.0 & 1 \\
9.30 & 6 & 7.90 & 6 \\
& & & \\
6.60 & 7 & 6.20 & 7 \\
5.00 & 8 & 3.40 & 9 \\
2.70 & 11 & 1.40 & 10 \\
4.00 & 9 & 3.80 & 8 \\
20.0 & 4 & 15.0 & 2
\end{tabular}

$\begin{array}{cc}7 & \\ 5.60 & 7 \\ 1.30 & 10 \\ 6.00 & 5 \\ 28.0 & 1 \\ 7.10 & 3 \\ & \\ 5.80 & 6 \\ 3.30 & 8 \\ 0.65 & 11 \\ 3.30 & 9 \\ 12.0 & 2\end{array}$

15 CONSEQJTTVE DAYS

\section{$5.00 \quad 6$}

4.106

60

90

120

1.1910

3.807

$\begin{array}{rr}1.10 & 10 \\ 3.70 & 7\end{array}$

$\begin{array}{ll}.707 & 0.8810\end{array}$

$\begin{array}{llll}7.70 & 2 & 5.50 & 7 \\ 6.10 & 3 & 5.10 & 3\end{array}$

$\begin{array}{ll}5.10 & 3 \\ 5.20 & 2\end{array}$

3.007

$\begin{array}{ll}3.00 & 7 \\ 0.76 & 10\end{array}$

3.106

$\begin{array}{ll}4.40 & 5 \\ 4.50 & 4\end{array}$

2.707

$\begin{array}{rr}2.70 & 7 \\ 0.65 & 10\end{array}$

$\begin{array}{rr}0.65 & 10 \\ 2.906\end{array}$

$\begin{array}{ll}4.00 & 4 \\ 3.80 & 5\end{array}$

$2.40 \quad 6$

0.4910
2.40

$\begin{array}{ll}2.40 & 7 \\ 4.00 & 3\end{array}$

$\begin{array}{ll}4.00 & 3 \\ 2.60 & 5\end{array}$

$4.50 \quad 3$

$\begin{array}{ll}3.60 & 4 \\ 1.50 & 8\end{array}$

$\begin{array}{ll}1.50 & 8 \\ 0.4211\end{array}$

$0.4211 \quad 0.2811$

\begin{tabular}{|c|c|c|c|}
\hline $\begin{array}{rr}2.90 & 8 \\
0.48 & 11 \\
2.40 & 9\end{array}$ & $\begin{array}{rr}2.40 & 8 \\
0.43 & 11\end{array}$ & $\begin{array}{ll}2.00 & 8 \\
0.42 & 11\end{array}$ & $\begin{array}{ll}1.80 & 8 \\
0.42 & 11\end{array}$ \\
\hline
\end{tabular}

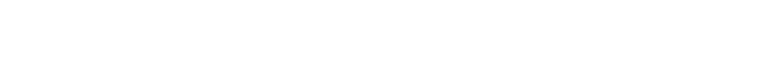

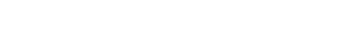

$\begin{array}{llll}4.50 & 2 & 3.40 \quad 1\end{array}$

DURATION OF DISGARGE FOR EACH WATER YEAR

$\begin{array}{lllllllllllllllllllllllllllllllllllllllll}\text { CASS } & 0 & 1 & 2 & 3 & 4 & 5 & 6 & 7 & 8 & 9 & 10 & 11 & 12 & 13 & 14 & 15 & 16 & 17 & 18 & 19 & 20 & 21 & 22 & 23 & 24 & 25 & 26 & 27 & 28 & 29 & 30 & 31 & 32 & 33 & 34\end{array}$

YEAR

NUMBER OF DAYS IN OLASS

OBBIC FEET -DAYS

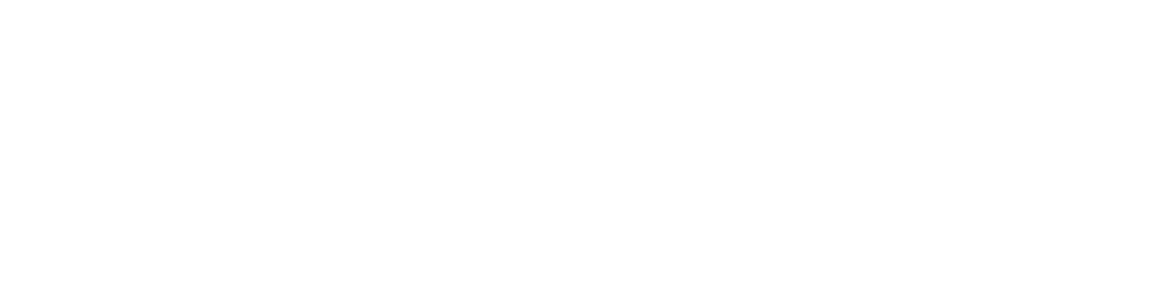

583.2

103.3

453.7

994.2
492.3

722.8

328.9

102.3

1150.3

$\begin{array}{lllllllllllllllllllllllllll}1981 & 10 & 1 & 1 & 2 & 1 & & 1 & 1 & 3 & 9 & 5 & 6 & 3 & 4 & 16 & 17 & 15 & 10 & 7 & 21 & 191 & 35 & 1 & 2 & 1 & 1\end{array}$

1232.5 
GREEN RIVER BASIN

09306800 BITTER CREER NEAR BONANZA, UT--Continued

DURATION TABLE OF DISCHARGE FOR WATER YEARS 1971-81
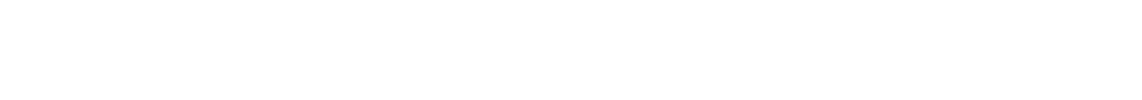

PER TOTAL LATED CEN

CIASS SECOR TOTAL LATED CENI

$\begin{array}{ccc}\text { CBBIC } & \text { ACOU- } \\ \text { FEET } & \text { MU- } & \text { PER- } \\ \text { PER TOTAL LATED } & \text { CENT } \\ \text { CLASS SECOND DAYS DAYS } & \text { DAYS }\end{array}$

CUASS SECOND DAYS DAYS DAYS

$\begin{array}{rrrrr}9 & 0.15 & 149 & 2695 & 67.1 \\ 10 & 0.19 & 82 & 2546 & 63.4 \\ 11 & 0.25 & 120 & 2464 & 61.3 \\ 12 & 0.33 & 234 & 2344 & 58.3 \\ 13 & 0.43 & 185 & 2110 & 52.5 \\ 14 & 0.56 & 78 & 1925 & 47.9 \\ 15 & 0.74 & 159 & 1847 & 46.0 \\ 16 & 0.96 & 182 & 1688 & 42.0\end{array}$

$\begin{array}{rrrrr}18 & 1.7 & 223 & 1337 & 33.3 \\ 19 & 2.2 & 232 & 1114 & 27.7 \\ 20 & 2.8 & 233 & 882 & 22.0 \\ 21 & 3.7 & 360 & 649 & 16.2 \\ 22 & 4.8 & 165 & 289 & 7.2 \\ 23 & 6.3 & 66 & 124 & 3.1 \\ 24 & 8.3 & 28 & 58 & 1.4 \\ 25 & 11.0 & 19 & 30 & 0.7 \\ 26 & 14.0 & 4 & 11 & 0.3\end{array}$

$\begin{array}{lllll}27 & 19.0 & 4 & 7 & 0.2 \\ 28 & 24.0 & 1 & 3 & 0.1 \\ 29 & 32.0 & 0 & 2 & 0.0 \\ 30 & 41.0 & 0 & 2 & 0.0 \\ 31 & 54.0 & 0 & 2 & 0.0 \\ 32 & 71.0 & 2 & 2 & 0.0\end{array}$

MONIHLY MEAN DISCHARGES, IN CUBIC FEET PER SECOND, FOR EACH WATER YEAR

\begin{tabular}{|c|c|c|c|c|c|c|c|c|c|c|c|c|}
\hline YEAR & $\infty T$ & $\mathrm{NOV}$ & DEC & JAN & FEB & MAR & APR & MAY & JUNE & JULY & AUG & SEP \\
\hline $\begin{array}{l}1971 \\
1972 \\
1973 \\
1974 \\
1975\end{array}$ & $\begin{array}{l}1.62 \\
0.03 \\
0.15 \\
1.72 \\
0.04\end{array}$ & $\begin{array}{l}1.87 \\
0.22 \\
0.11 \\
2.26 \\
0.11\end{array}$ & $\begin{array}{l}1.88 \\
0.18 \\
0.00 \\
2.08 \\
0.15\end{array}$ & $\begin{array}{l}1.77 \\
0.22 \\
0.00 \\
2.69 \\
0.02\end{array}$ & $\begin{array}{l}1.42 \\
0.31 \\
0.00 \\
2.98 \\
0.23\end{array}$ & $\begin{array}{l}3.92 \\
0.60 \\
1.38 \\
5.19 \\
0.44\end{array}$ & $\begin{array}{l}3.04 \\
0.78 \\
2.66 \\
4.96 \\
2.91\end{array}$ & $\begin{array}{l}1.91 \\
0.80 \\
3.64 \\
2.37 \\
3.49\end{array}$ & $\begin{array}{l}0.63 \\
0.17 \\
2.89 \\
0.96 \\
5.54\end{array}$ & $\begin{array}{l}0.02 \\
0.00 \\
1.53 \\
6.59 \\
3.13\end{array}$ & $\begin{array}{l}1.03 \\
0.05 \\
1.97 \\
0.83 \\
0.09\end{array}$ & $\begin{array}{l}0.00 \\
0.04 \\
0.51 \\
0.00 \\
0.02\end{array}$ \\
\hline $\begin{array}{l}1976 \\
1977 \\
1978 \\
1979 \\
1980\end{array}$ & $\begin{array}{l}0.20 \\
0.22 \\
0.13 \\
0.00 \\
0.17\end{array}$ & $\begin{array}{l}0.96 \\
0.77 \\
0.36 \\
0.00 \\
0.16\end{array}$ & $\begin{array}{l}0.54 \\
0.96 \\
0.40 \\
0.00 \\
0.08\end{array}$ & $\begin{array}{l}0.47 \\
0.87 \\
0.42 \\
0.00 \\
0.06\end{array}$ & $\begin{array}{l}2.74 \\
1.00 \\
0.45 \\
0.00 \\
2.28\end{array}$ & $\begin{array}{l}3.75 \\
1.60 \\
0.37 \\
0.19 \\
2.45\end{array}$ & $\begin{array}{l}4.69 \\
2.67 \\
0.44 \\
2.20 \\
6.27\end{array}$ & $\begin{array}{l}4.92 \\
1.65 \\
0.39 \\
1.63 \\
9.49\end{array}$ & $\begin{array}{l}4.07 \\
0.12 \\
0.23 \\
1.21 \\
8.14\end{array}$ & $\begin{array}{l}1.45 \\
0.48 \\
0.18 \\
0.08 \\
3.32\end{array}$ & $\begin{array}{l}0.02 \\
0.24 \\
0.00 \\
0.03 \\
2.82\end{array}$ & $\begin{array}{l}0.00 \\
0.24 \\
0.00 \\
0.06 \\
2.56\end{array}$ \\
\hline 1981 & 3.70 & 4.21 & 4.41 & 4.69 & 4.05 & 4.39 & 4.83 & 4.63 & 1.86 & 0.85 & 1.00 & 1.95 \\
\hline
\end{tabular}

ANNUAL PEAR DISCHARGE, IN CUBIC FEET PER SECOND, AND CORRESPONDING GAGE HEIGHT, IN FEET, FOR EACH WATER YEAR

\begin{tabular}{|c|c|c|c|c|c|c|c|c|c|c|c|}
\hline $\begin{array}{l}\text { WATER } \\
\text { YEAR }\end{array}$ & DATE & $\begin{array}{c}\text { GAGE } \\
\text { HEIGHT }\end{array}$ & $\begin{array}{c}\text { PEAR } \\
\text { DISCHARGE }\end{array}$ & $\begin{array}{l}\text { WATER } \\
\text { YEAR }\end{array}$ & DATE & $\begin{array}{c}\text { GAGE } \\
\text { HEIGHT }\end{array}$ & $\begin{array}{c}\text { PEAK } \\
\text { DISCHARGE }\end{array}$ & $\begin{array}{l}\text { WATER } \\
\text { YEAR }\end{array}$ & DATE & $\begin{array}{c}\text { GAGE } \\
\text { HEIGHT }\end{array}$ & $\begin{array}{c}\text { PEAR } \\
\text { DISCHARGE }\end{array}$ \\
\hline $\begin{array}{l}1971 \\
1972 \\
1973 \\
1974\end{array}$ & $\begin{array}{l}\text { AUG. } 30,1971 \\
\text { AUG. } 03,1972 \\
\text { AUG. 05, } 1973 \\
\text { JULY } 17,1974\end{array}$ & $\begin{array}{r}9.74 \\
5.12 \\
6.98 \\
13.55\end{array}$ & $\begin{array}{r}507 \\
27 \\
161 \\
1660\end{array}$ & $\begin{array}{l}1975 \\
1976 \\
1977 \\
1978\end{array}$ & $\begin{array}{l}\text { JULY } 17,1975 \\
\text { MAY 09, } 1976 \\
\text { SEPT. 16, } 1977 \\
\text { JULY 16, } 1978\end{array}$ & $\begin{array}{l}5.00 \\
4.50 \\
5.67 \\
5.03\end{array}$ & $\begin{array}{l}20 \\
6.9 \\
45 \\
23\end{array}$ & $\begin{array}{l}1979 \\
1980 \\
1981\end{array}$ & $\begin{array}{lrl}\text { MAY } & 24, & 1979 \\
\text { AUG. } & 23, & 1980 \\
\text { SEPT. } 10, & 1981\end{array}$ & $\begin{array}{l}4.42 \\
9.82 \\
8.88\end{array}$ & $\begin{array}{l}5.9 \\
534 \\
370\end{array}$ \\
\hline
\end{tabular}

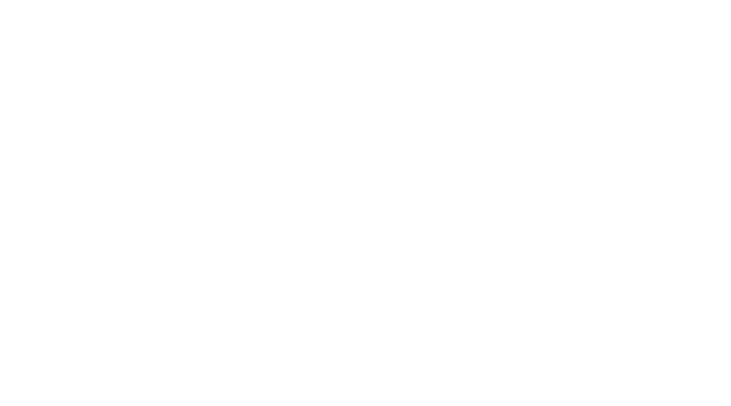

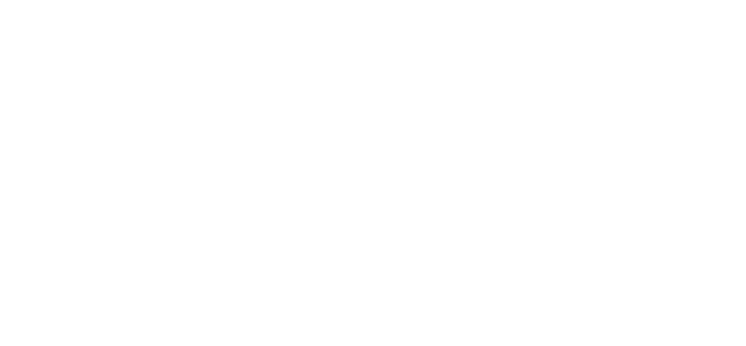




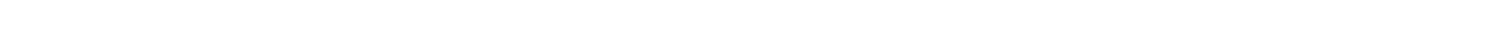
bank $0.6 \mathrm{mi}$ upstream fram mouth and $13 \mathrm{mi}$ southwest of Bonanza.

DRAINAGE AREA, $--398 \mathrm{mi}^{2}$.

MEAN BASIN ELEVATION. $-6,890 \mathrm{ft}$.

PERIOD OF RECORD AVAILABLE.--Octcher 1974 to September 1981.

GAGE.-Water-stage recorder and artificial control. Altitude of gage is 4,770 ft from topographic map.

REMARKS. - Sone diversions for irrigation above station.

AVERAGE DISGHARGE. -7 years, $1.08 \mathrm{ft}^{3} / \mathrm{s}, 782$ acre- $\mathrm{ft} / \mathrm{yr}$.

EXTREMES FOR PERIOD OF RECORD.--Maximum discharge, $188 \mathrm{ft}^{3} / \mathrm{s}$ Feb. 19, 1980, gage height, $3.26 \mathrm{ft}$, fram rating curve extended above 3 $\mathrm{ft}^{3} / \mathrm{s}$ on basis of indirect measurements at $117 \mathrm{ft}^{3} / \mathrm{s}$; minimum daily, $0.10 \mathrm{ft}^{3} / \mathrm{s}$ July $2,1975$.

LONEST MEAN DISGHARGE, IN OBBIC FEET PER SECOND, AND RANKING FOR THE INDICATED NUNBER OF CONSEQUTTVE DAVS FOR EAOH OLIMATIC YEAR, APRIL 1-MAROH 31 .

\begin{tabular}{|c|c|c|c|c|c|c|c|c|c|c|c|c|c|c|c|c|c|c|c|}
\hline YEAR & & & & & & & & & CONSE & QUTT & DAYS & & & & & & & & \\
\hline $\begin{array}{l}1976 \\
1977 \\
1978 \\
1979 \\
1980\end{array}$ & $\begin{array}{l}0.10 \\
0.26 \\
0.46 \\
0.39 \\
0.38\end{array}$ & $\begin{array}{l}1 \\
2 \\
5 \\
4 \\
3\end{array}$ & $\begin{array}{l}0.13 \\
0.28 \\
0.46 \\
0.40 \\
0.38\end{array}$ & $\begin{array}{l}1 \\
2 \\
5 \\
4 \\
3\end{array}$ & $\begin{array}{l}0.15 \\
0.29 \\
0.46 \\
0.40 \\
0.39\end{array}$ & $\begin{array}{l}1 \\
2 \\
5 \\
4 \\
3\end{array}$ & $\begin{array}{l}0.20 \\
0.30 \\
0.47 \\
0.41 \\
0.40\end{array}$ & $\begin{array}{l}1 \\
2 \\
5 \\
4 \\
3\end{array}$ & $\begin{array}{l}0.54 \\
0.30 \\
0.49 \\
0.42 \\
0.41\end{array}$ & $\begin{array}{l}6 \\
1 \\
4 \\
3 \\
2\end{array}$ & $\begin{array}{l}0.57 \\
0.32 \\
0.51 \\
0.43 \\
0.43\end{array}$ & $\begin{array}{l}6 \\
1 \\
4 \\
2 \\
3\end{array}$ & $\begin{array}{l}0.58 \\
0.40 \\
0.55 \\
0.45 \\
0.45\end{array}$ & $\begin{array}{l}6 \\
1 \\
4 \\
2 \\
3\end{array}$ & $\begin{array}{l}0.59 \\
0.45 \\
0.56 \\
0.46 \\
0.48\end{array}$ & $\begin{array}{l}5 \\
1 \\
4 \\
2 \\
3\end{array}$ & $\begin{array}{l}0.59 \\
0.52 \\
0.57 \\
0.49 \\
0.51\end{array}$ & $\begin{array}{l}5 \\
3 \\
4 \\
1 \\
2\end{array}$ & $\begin{array}{l}1.10 \\
0.97 \\
0.64 \\
0.69 \\
1.00\end{array}$ \\
\hline 981 & 0.48 & 6 & 0.48 & 6 & 0.49 & 6 & 0.51 & 6 & 0.52 & 5 & 0.57 & 5 & 0.57 & 5 & 0.98 & 6 & 1.70 & 6 & 1.90 \\
\hline
\end{tabular}

HIGHEST MEAN DISGHARGE, IN GBIC FEET PER SECOND, AND RANKING FOR 'HE INDICATED NUNBER OF CONSEQUTIVE DAVS FOR EAOH WATER YEAR, OCTOBER 1-SEPTEMBER 30

\begin{tabular}{|c|c|c|c|c|c|c|c|c|c|c|c|c|c|c|c|c|c|c|c|}
\hline YEAR & & & & & & & & & CONSE & OUTIVE & DAYS & & & & & & & & \\
\hline & 1 & & 3 & & 7 & & 15 & & 30 & & 60 & & 90 & & 120 & & 183 & & ALL \\
\hline 1975 & 5.80 & 6 & 4.90 & 6 & 3.80 & 5 & 3.50 & 5 & 3.10 & 4 & 2.30 & 4 & 1.90 & 4 & 1.60 & 4 & 1.30 & 4 & 0.95 \\
\hline
\end{tabular}

DURATION OF DISGHARGE FOR EACH WATER YEAR

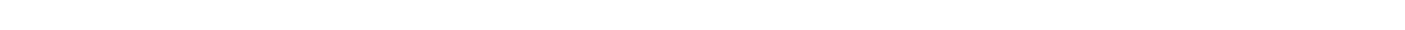

YEAR NUMBER OF DAYS IN $\triangle$ CASS

ABIC FEET

PER SECOND $-D A Y S$

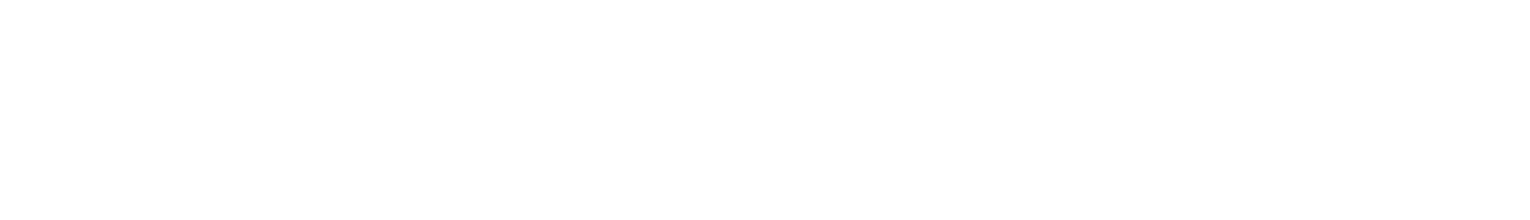

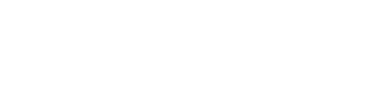

CLASS SECOND DAYS DAYS DAYS

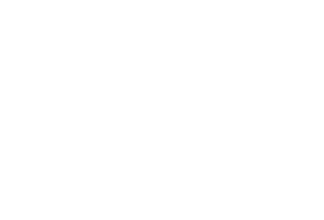

DURATION TABLE OF DISGHARGE FOR WATER YEARS 1975-8I

$\begin{array}{lll}\text { AUBIC } & \text { ACOU- } \\ \text { FEET } & \text { MU- } & \text { PER- } \\ \text { PER TOTA L LATED } & \text { CENT }\end{array}$

CLASS SECOND DAYS DAYS DAYS

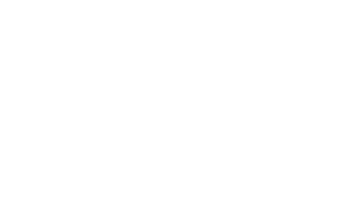

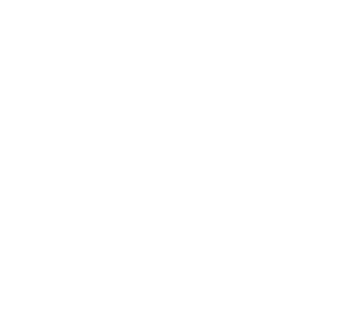

$\begin{array}{lll}\text { OUBIC } & \text { ACOU- } \\ \text { FEET } & \text { MU- } & \text { EER- } \\ \text { PER TOTA, LATED } & \text { CENT }\end{array}$ CLASS SECOND DAYS DAYS DAYS

$\begin{array}{lllll}27 & 15.0 & 1 & 6 & 0.2 \\ 28 & 18.0 & 1 & 5 & 0.2 \\ 29 & 22.0 & 2 & 4 & 0.2 \\ 30 & 27.0 & 0 & 2 & 0.1 \\ 31 & 33.0 & 0 & 2 & 0.1 \\ 32 & 39.0 & 0 & 2 & 0.1 \\ 33 & 48.0 & 0 & 2 & 0.1 \\ 34 & 58.0 & 2 & 2 & 0.1\end{array}$


GREEN RIVER BASIN

09306850 BITTER CREEK AT MDUTH, NEAR BONANZA, UT-Continued

MONTHLY MEAN DISCHARGES, IN GBIC FEET PER SECOND, FOR EACH WATER YEAR

$\begin{array}{llcccccccccrr}\text { YEAR } & \text { OCT } & \text { NOV } & \text { DEC } & \text { JAN } & \text { FEB } & \text { MAR } & \text { APR } & \text { MAY } & \text { JUNE } & \text { JULY } & \text { AUG } & \text { SEP } \\ 1975 & 0.57 & 0.65 & 0.49 & 0.58 & 0.76 & 0.82 & 1.42 & 1.60 & 2.51 & 0.82 & 0.60 & 0.59 \\ 1976 & 0.59 & 0.64 & 0.58 & 0.57 & 2.29 & 0.85 & 1.21 & 2.88 & 2.34 & 0.55 & 0.30 & 0.44 \\ 1977 & 0.60 & 0.63 & 0.66 & 0.75 & 0.64 & 0.61 & 0.63 & 0.62 & 0.50 & 0.69 & 0.94 & 0.58 \\ 1978 & 0.65 & 0.57 & 0.54 & 0.56 & 0.56 & 0.77 & 0.60 & 0.60 & 0.53 & 0.51 & 0.55 & 0.50 \\ 1979 & 0.46 & 0.42 & 0.49 & 0.51 & 0.57 & 2.48 & 1.15 & 0.63 & 0.47 & 0.42 & 0.71 & 0.42 \\ 1980 & 0.48 & 0.53 & 0.53 & 0.53 & 5.82 & 0.60 & 0.54 & 1.06 & 3.42 & 1.73 & 2.43 & 2.44 \\ 1981 & 3.25 & 2.65 & 0.58 & 0.59 & 1.33 & 2.83 & 3.82 & 4.12 & 1.41 & 0.88 & 0.48 & 1.23\end{array}$

ANNUAL FEAK DISCHARGE, IN GBIC FEET PER SECOND, AND CORRESFONDING GAGE HEIGGT, IN FEET, EOR EACH WATER YEAR

\begin{tabular}{|c|c|c|c|c|c|c|c|c|c|c|c|}
\hline $\begin{array}{l}\text { WATER } \\
\text { YEAR }\end{array}$ & DATE & $\begin{array}{c}\text { GAGE } \\
\text { HEIGHT T }\end{array}$ & $\begin{array}{c}\text { PEAK } \\
\text { DISCHARGE }\end{array}$ & $\begin{array}{l}\text { WATER } \\
\text { YEAR }\end{array}$ & DATE & $\begin{array}{c}\text { GAGE } \\
\text { HEIGHT }\end{array}$ & $\begin{array}{c}\text { PEAK } \\
\text { DISOHARGE }\end{array}$ & $\begin{array}{l}\text { WATER } \\
\text { YEAR }\end{array}$ & DATE & $\begin{array}{c}\text { GAGE } \\
\text { HEIGHT }\end{array}$ & $\begin{array}{c}\text { PEAK } \\
\text { DISOAARGE }\end{array}$ \\
\hline $\begin{array}{l}1975 \\
1976 \\
1977\end{array}$ & $\begin{array}{l}\text { JULY 17, } 1975 \\
\text { FEB. 10, } 1976 \\
\text { AUG. } 18,1977\end{array}$ & $\begin{array}{l}1.28 \\
1.58 \\
2.87\end{array}$ & $\begin{array}{r}29 \\
32 \\
117\end{array}$ & $\begin{array}{l}1978 \\
1979\end{array}$ & $\begin{array}{l}\text { MAR. 11, } 1978 \\
\text { AUG. } 20,1979\end{array}$ & $\begin{array}{l}2.03 \\
2.80\end{array}$ & $103^{7.2}$ & $\begin{array}{l}1980 \\
1981\end{array}$ & $\begin{array}{l}\text { FEB. } 19,1980 \\
\text { JULY } 09,1981\end{array}$ & $\begin{array}{l}3.26 \\
3.13\end{array}$ & $\begin{array}{l}188 \\
168\end{array}$ \\
\hline
\end{tabular}

09306870 SAND WASH NEAR OURAY, UT

LOCATION. - Lat $39^{\circ} 55^{\prime} 51 "$, long $109^{\circ} 29^{\prime} 45^{\prime \prime}$, in NE $\frac{1}{4} W_{4}^{1} \mathrm{SE}_{4}^{\frac{1}{4}}$ sec.24, T.10 S., R.21 E., Uintah County, Hydrologic Unit 14050007, on right bank $6.4 \mathrm{mi}$ south of mouth and $14 \mathrm{mi}$ southeast of ouray.

DRAINAGE AREA, $-59.7 \mathrm{mi}^{2}$.

MEAN BASIN ELEVATTON. $-5,980 \mathrm{ft}$.

FERIOD OF RECORD AVAILABLE. --October 1974 to Septenber 1981.

GAGE. --Water-stage recorder and artificial control. Altitude of gage is 5,140 ft from topographic map.

AVERAGE DISCHARGE. -7 years, $0.034 \mathrm{ft}^{3} / \mathrm{s}, 25$ acre- $\mathrm{ft} / \mathrm{Yr}$.

EXIREMES FOR PERIOD OF RECORD. --Maximum discharge, $162 \mathrm{ft}^{3} / \mathrm{s}$ Sept. 10, 1980, gage height, $3.24 \mathrm{ft}$; no flow most of the time.

LOWEST MEAN DISCAARGE, IN CUBIC FEET PER SECOND, AND RANKING FOR THE INDICATED NUMBER OF CONSECUTIVE DAYS FOR EACH CLIMATIC YEAR, APRIL 1-MARGH 31

\begin{tabular}{|c|c|c|c|c|c|c|c|c|c|c|c|c|c|c|c|c|c|c|c|}
\hline YEAR & & & & & & & & & CONSE & ¿ITI & DAYS & & & & & & & & \\
\hline $\begin{array}{l}1976 \\
1977 \\
1978 \\
1979 \\
1980\end{array}$ & $\begin{array}{l}0.00 \\
0.00 \\
0.00 \\
0.00 \\
0.00\end{array}$ & $\begin{array}{l}1 \\
2 \\
3 \\
4 \\
5\end{array}$ & $\begin{array}{l}0.00 \\
0.00 \\
0.00 \\
0.00 \\
0.00\end{array}$ & $\begin{array}{l}1 \\
2 \\
3 \\
4 \\
5\end{array}$ & $\begin{array}{l}0.00 \\
0.00 \\
0.00 \\
0.00 \\
0.00\end{array}$ & $\begin{array}{l}1 \\
2 \\
3 \\
4 \\
5\end{array}$ & $\begin{array}{l}0.00 \\
0.00 \\
0.00 \\
0.00 \\
0.00\end{array}$ & $\begin{array}{l}1 \\
2 \\
3 \\
4 \\
5\end{array}$ & $\begin{array}{l}0.00 \\
0.00 \\
0.00 \\
0.00 \\
0.00\end{array}$ & $\begin{array}{l}1 \\
2 \\
3 \\
4 \\
5\end{array}$ & $\begin{array}{l}0.00 \\
0.00 \\
0.00 \\
0.00 \\
0.00\end{array}$ & $\begin{array}{l}1 \\
2 \\
3 \\
4 \\
5\end{array}$ & $\begin{array}{l}0.00 \\
0.00 \\
0.00 \\
0.00 \\
0.00\end{array}$ & $\begin{array}{l}1 \\
2 \\
3 \\
4 \\
5\end{array}$ & $\begin{array}{l}0.00 \\
0.00 \\
0.00 \\
0.00 \\
0.00\end{array}$ & $\begin{array}{l}1 \\
2 \\
3 \\
4 \\
5\end{array}$ & $\begin{array}{l}0.00 \\
0.00 \\
0.00 \\
0.00 \\
0.00\end{array}$ & $\begin{array}{l}1 \\
2 \\
3 \\
4 \\
5\end{array}$ & $\begin{array}{l}0.00 \\
0.00 \\
0.02 \\
0.06 \\
0.11\end{array}$ \\
\hline 1981 & 0.00 & 6 & 0.00 & 6 & 0.00 & 6 & 0.00 & 6 & 0.00 & 6 & 0.00 & 6 & 0.00 & 6 & 0.00 & 6 & 0.00 & 6 & 0.03 \\
\hline
\end{tabular}

HIGHEST MEAN DISCHARGE, IN OBIC FEET PER SECOND, AND RANKING FOR THE INDICATED NUMBER OF CONSEQUTIVE DAYS FOR EAOH WATER YEAR, OCTOBER 1-SEPTEMBER 30

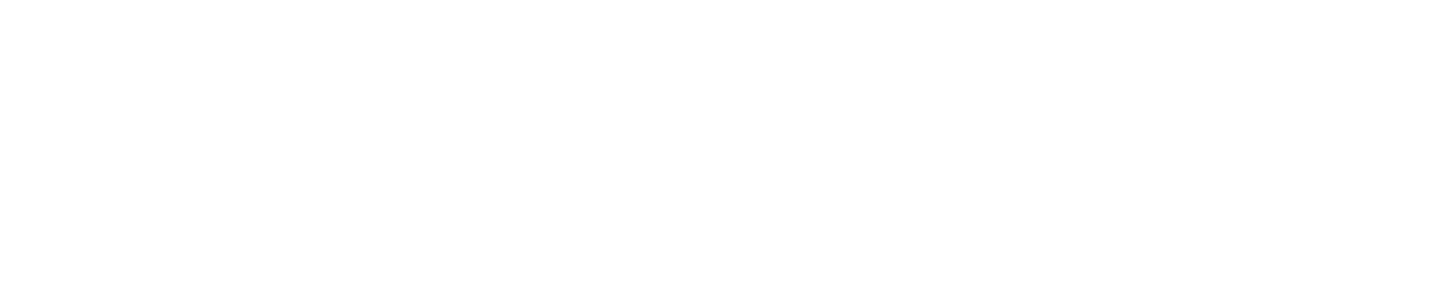


GREEN RIVER BASIN

09306870 SAND WASH NEAR OURAY, UT-Continued

DURATION OF DISCGARGE FOR EACH WATER YEAR

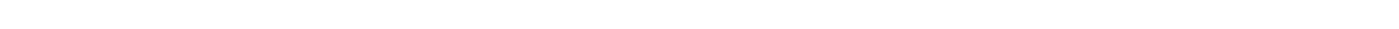
YEAR NUMBER OF DAYS IN CIASS

CUBIC FEET PER SECOND -DAYS

1975362

1

1976359

$\begin{array}{lll}1977 & 359 & 1\end{array}$

1978356

1979346

1980348

$\begin{array}{lllll}1981 & 358 & 1 & 3 & 1\end{array}$

DURATION TABLE OF DISCHARGE FOR WATER YEARS 1975-81

\begin{tabular}{|c|c|c|c|c|c|c|c|c|c|c|c|c|c|c|c|c|c|c|c|}
\hline CIASS & $\begin{array}{c}\text { CUBIC } \\
\text { FEET } \\
\text { PER } \\
\text { SECOND }\end{array}$ & $\begin{array}{l}\text { TOTAL } \\
\text { DAYS }\end{array}$ & $\begin{array}{c}\text { ACOJ- } \\
\text { MU- } \\
\text { LATED } \\
\text { DAYS }\end{array}$ & $\begin{array}{l}\text { PER- } \\
\text { CENT } \\
\text { DAYS }\end{array}$ & CLASS & $\begin{array}{c}\text { CBIC } \\
\text { FEET } \\
\text { PER } \\
\text { SECOND }\end{array}$ & $\begin{array}{r}\text { TOTAL } \\
\text { DAYS }\end{array}$ & $\begin{array}{c}\text { ACOU- } \\
\text { MU- } \\
\text { LATED } \\
\text { DAYS }\end{array}$ & $\begin{array}{l}\text { PER- } \\
\text { CENT } \\
\text { DAYS }\end{array}$ & CLASS & $\begin{array}{c}\text { OBIC } \\
\text { FEET } \\
\text { PER } \\
\text { SECOND }\end{array}$ & $\begin{array}{r}\text { TOTAL } \\
\text { DAYS }\end{array}$ & $\begin{array}{c}\text { ACOU- } \\
\mathbf{M}- \\
\text { LATED } \\
\text { DAYS }\end{array}$ & $\begin{array}{l}\text { PER- } \\
\text { CENT } \\
\text { DAYS }\end{array}$ & OASS & $\begin{array}{c}\text { CUBIC } \\
\text { FEET } \\
\text { PER } \\
\text { SFCOND }\end{array}$ & $\begin{array}{r}\text { TOTAL } \\
\text { DAYS }\end{array}$ & $\begin{array}{l}\text { ACOJ- } \\
\text { MJ- } \\
\text { LAFED } \\
\text { DAYS }\end{array}$ & $\begin{array}{l}\text { PER- } \\
\text { CENI } \\
\text { DAYS }\end{array}$ \\
\hline $\begin{array}{l}0 \\
1 \\
2 \\
3 \\
4 \\
5 \\
6 \\
7 \\
8\end{array}$ & $\begin{array}{l}0.00 \\
0.01 \\
0.02 \\
0.03 \\
0.04 \\
0.05 \\
0.06 \\
0.07 \\
0.09\end{array}$ & $\begin{array}{r}2488 \\
3 \\
3 \\
2 \\
1 \\
0 \\
1 \\
3 \\
2\end{array}$ & $\begin{array}{r}2557 \\
69 \\
66 \\
63 \\
61 \\
60 \\
60 \\
59 \\
56\end{array}$ & $\begin{array}{r}100.0 \\
2.7 \\
2.6 \\
2.5 \\
2.4 \\
2.3 \\
2.3 \\
2.3 \\
2.2\end{array}$ & $\begin{array}{r}9 \\
10 \\
11 \\
12 \\
13 \\
14 \\
15 \\
16 \\
17\end{array}$ & $\begin{array}{l}0.11 \\
0.14 \\
0.17 \\
0.21 \\
0.26 \\
0.32 \\
0.40 \\
0.50 \\
0.62\end{array}$ & $\begin{array}{l}2 \\
3 \\
2 \\
2 \\
4 \\
5 \\
4 \\
6 \\
5\end{array}$ & $\begin{array}{l}54 \\
52 \\
49 \\
47 \\
45 \\
41 \\
36 \\
32 \\
26\end{array}$ & $\begin{array}{l}2.1 \\
2.0 \\
1.9 \\
1.8 \\
1.8 \\
1.6 \\
1.4 \\
1.3 \\
1.0\end{array}$ & $\begin{array}{l}18 \\
19 \\
20 \\
21 \\
22 \\
23 \\
24 \\
25 \\
26\end{array}$ & $\begin{array}{l}0.8 \\
1.0 \\
1.2 \\
1.5 \\
1.8 \\
2.3 \\
2.8 \\
3.5 \\
4.4\end{array}$ & $\begin{array}{l}1 \\
6 \\
3 \\
2 \\
2 \\
1 \\
0 \\
2 \\
1\end{array}$ & $\begin{array}{r}21 \\
20 \\
14 \\
11 \\
9 \\
7 \\
6 \\
6 \\
4\end{array}$ & $\begin{array}{l}0.8 \\
0.8 \\
0.5 \\
0.4 \\
0.4 \\
0.3 \\
0.2 \\
0.2 \\
0.2\end{array}$ & $\begin{array}{l}27 \\
28 \\
29 \\
30 \\
31 \\
32 \\
33 \\
34\end{array}$ & $\begin{array}{r}5.5 \\
6.8 \\
8.4 \\
10.0 \\
13.0\end{array}$ & $\begin{array}{l}0 \\
1 \\
0 \\
0 \\
2\end{array}$ & $\begin{array}{l}3 \\
3 \\
2 \\
2 \\
2\end{array}$ & $\begin{array}{l}0.1 \\
0.1 \\
0.1 \\
0.1 \\
0.1\end{array}$ \\
\hline
\end{tabular}

MONTHLY MEAN DISCHARGES, IN OBIC FEET PER SECOND, FOR EACH WATER YEAR

$\begin{array}{lllllllllllll}\text { YEAR } & \text { OCT } & \text { NOV } & \text { DEC } & \text { JAN } & \text { FEB } & \text { MAR } & \text { APR } & \text { MAY } & \text { JUNE } & \text { JULY } & \text { AUG } & \text { SEP } \\ 1975 & 0.00 & 0.00 & 0.00 & 0.00 & 0.00 & 0.10 & 0.00 & 0.00 & 0.00 & 0.00 & 0.00 & 0.00 \\ 1976 & 0.00 & 0.00 & 0.00 & 0.00 & 0.05 & 0.01 & 0.00 & 0.00 & 0.00 & 0.04 & 0.00 & 0.02 \\ 1977 & 0.00 & 0.00 & 0.00 & 0.00 & 0.00 & 0.00 & 0.00 & 0.00 & 0.00 & 0.02 & 0.07 & 0.00 \\ 1978 & 0.03 & 0.00 & 0.00 & 0.00 & 0.00 & 0.07 & 0.00 & 0.00 & 0.00 & 0.00 & 0.00 & 0.00 \\ 1979 & 0.05 & 0.00 & 0.00 & 0.00 & 0.00 & 0.61 & 0.08 & 0.00 & 0.00 & 0.00 & 0.01 & 0.00 \\ 1980 & 0.00 & 0.00 & 0.00 & 0.02 & 1.29 & 0.01 & 0.00 & 0.00 & 0.00 & 0.00 & 0.00 & 0.38 \\ 1981 & 0.00 & 0.00 & 0.00 & 0.00 & 0.00 & 0.00 & 0.00 & 0.00 & 0.00 & 0.00 & 0.01 & 0.01\end{array}$

ANNUAL PEAK DISCHARGE, IN CUBIC FEET PER SECOND, AND CORRESPONDING GAGE HEIGHT, IN FEET, FOR EACH WATER YEAR

\begin{tabular}{|c|c|c|c|c|c|c|c|c|c|c|c|}
\hline $\begin{array}{l}\text { WATERR } \\
\text { YEAR }\end{array}$ & DATE & $\begin{array}{c}\text { GAGE } \\
\text { HEIGHT }\end{array}$ & $\begin{array}{c}\text { PEAK } \\
\text { DISCHARGE }\end{array}$ & $\begin{array}{l}\text { WATER } \\
\text { YEAR }\end{array}$ & DATE & $\begin{array}{c}\text { GAGE } \\
\text { HEIGHT }\end{array}$ & $\begin{array}{c}\text { PEAK } \\
\text { DISCHARGE }\end{array}$ & $\begin{array}{l}\text { WATER } \\
\text { YEAR }\end{array}$ & DATE & $\begin{array}{c}\text { GAGE } \\
\text { HEIGHT }\end{array}$ & $\begin{array}{c}\text { PEAR } \\
\text { DISCHARGE }\end{array}$ \\
\hline $\begin{array}{l}975 \\
976\end{array}$ & $\begin{array}{lll}\text { JULY } 29, & 1975 \\
\text { JULY } 30,1976\end{array}$ & $\begin{array}{l}1.98 \\
2.31\end{array}$ & $27^{4.0}$ & $\begin{array}{l}1978 \\
1979\end{array}$ & $\begin{array}{l}\text { OCT. } 07,1977 \\
\text { AUG. } 07,1979\end{array}$ & $\begin{array}{l}1.66 \\
2.54\end{array}$ & 43.2 & $\begin{array}{l}1980 \\
1981\end{array}$ & $\begin{array}{l}\text { SEPT. 10, } 1980 \\
\text { SEPT. 09, } 1981\end{array}$ & $\begin{array}{l}3.24 \\
2.59\end{array}$ & $\begin{array}{r}162 \\
47\end{array}$ \\
\hline
\end{tabular}

09306872 SAND WASH NEAR MOUTH, NEAR OURAY, UT

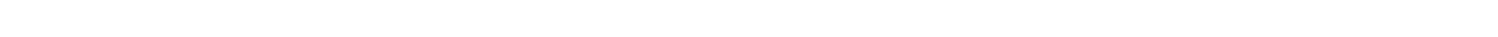
bank $3.0 \mathrm{mi}$ upstream from mouth and $7 \mathrm{mi}$ southeast of ouray.

DRAINAGE AREA. $--71.1 \mathrm{mi}^{2}$.

PERIOD OF RECORD AVAIIABLE. -October 1976 to September 1981.

GAGE.-Water-stage recorder and artificial control. Altitude of gage is 4,840 ft from topographic map.

AVERAGE DISCHARGE. --5 years, $0.415 \mathrm{ft}^{3} / \mathrm{s}, 301$ acre-ft $/ \mathrm{yr}$.

EXIREMES FOR PERIOD OF RECORD.-Maximum discharge, $267 \mathrm{ft}^{3} / \mathrm{s}$ Aug. 19, 1979, gage height, $3.10 \mathrm{ft}$; no flow most of the time. 
GREEN RIVER BASIN

09306872 SAND WASH NEAR MOUTH, NEAR OURAY, UT--Continued

LOWEST MEAN DISCHARGE, IN OUBIC FEET PER SECOND, AND RANKING FOR THE INDICATED NUMBER OF CONSECOTIVE DAYS FOR EACH CLIMAITIC YEAR, APRHI 1-MARCH 31

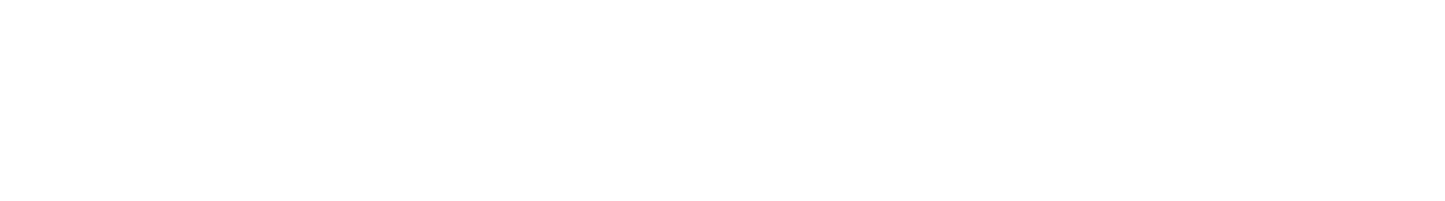

HIGHEST MEAN DISCHARGE, IN CUBIC FEET PER SBCOND, AND RANKING FOR THE INDICATED NUMBER OF CONSECUTIVE DAYS FOR EACH WATER YEAR, OCTOBER 1-SEPTEMBER 30

\begin{tabular}{|c|c|c|c|c|c|c|c|c|c|c|c|c|c|c|c|c|c|c|c|}
\hline YEAR & 1 & & 3 & & 7 & & 15 & & $\begin{array}{l}\text { CONSE } \\
30\end{array}$ & OUTIVE & $\begin{array}{l}\text { DAYS } \\
60\end{array}$ & & 90 & & 120 & & 183 & & ALL \\
\hline $\begin{array}{l}1977 \\
1978 \\
1979 \\
1980\end{array}$ & $\begin{array}{c}4.20 \\
9.00 \\
86.0 \\
85.0\end{array}$ & $\begin{array}{l}4 \\
3 \\
1 \\
2\end{array}$ & $\begin{array}{c}1.40 \\
7.40 \\
49.0 \\
52.0\end{array}$ & $\begin{array}{l}4 \\
3 \\
2 \\
1\end{array}$ & $\begin{array}{c}0.60 \\
5.20 \\
29.0 \\
25.0\end{array}$ & $\begin{array}{l}4 \\
3 \\
1 \\
2\end{array}$ & $\begin{array}{c}0.28 \\
2.70 \\
23.0 \\
12.0\end{array}$ & $\begin{array}{l}4 \\
3 \\
1 \\
2\end{array}$ & $\begin{array}{c}0.17 \\
1.30 \\
15.0 \\
6.20\end{array}$ & $\begin{array}{l}4 \\
3 \\
1 \\
2\end{array}$ & $\begin{array}{l}0.09 \\
0.68 \\
7.50 \\
3.20\end{array}$ & $\begin{array}{l}4 \\
3 \\
1 \\
2\end{array}$ & $\begin{array}{l}0.09 \\
0.46 \\
5.00 \\
2.10\end{array}$ & $\begin{array}{l}4 \\
3 \\
1 \\
2\end{array}$ & $\begin{array}{l}0.07 \\
0.34 \\
3.70 \\
1.60\end{array}$ & $\begin{array}{l}4 \\
3 \\
1 \\
2\end{array}$ & $\begin{array}{l}0.04 \\
0.22 \\
2.60 \\
1.10\end{array}$ & $\begin{array}{l}4 \\
3 \\
1 \\
2\end{array}$ & $\begin{array}{l}0.02 \\
0.11 \\
1.30 \\
0.61\end{array}$ \\
\hline 1981 & 1.50 & 5 & 0.64 & 5 & 0.27 & 5 & 0.13 & 5 & 0.06 & 5 & 0.03 & 5 & 0.02 & 5 & 0.02 & 5 & 0.01 & 5 & 0.01 \\
\hline
\end{tabular}

DURATION OF DISCHARGE FOR EACH WATER YEAR

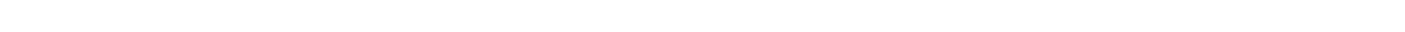
YEAR NUMBER OF DAYS IN CLASS

OUBIC FEET PER SECOND -DAYS

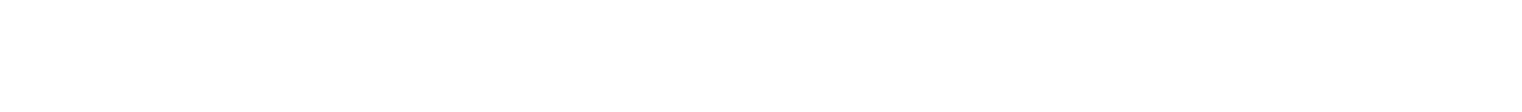
1981363

DURATION TABLE OF DISCHARGE FOR WATER YEARS 1977-81
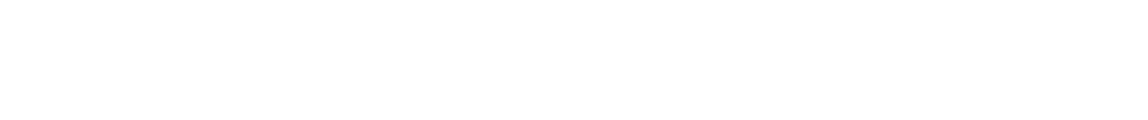
$\begin{array}{ccc}\text { OUBIC } & \text { ACOU- } \\ \text { FEET } & \text { MU- } & \text { PER- } \\ \text { PER TOTAL LATED } & \text { CENT } \\ \text { OASS SEOOND DAYS DAYS } & \text { DAYS }\end{array}$

$\begin{array}{lrrr}0.00 & 1727 & 1826 & 100.0 \\ 0.01 & 3 & 99 & 5.4 \\ 0.02 & 3 & 96 & 5.3 \\ 0.03 & 0 & 93 & 5.1 \\ 0.04 & 0 & 93 & 5.1 \\ 0.05 & 8 & 93 & 5.1 \\ 0.07 & 2 & 85 & 4.7 \\ 0.09 & 1 & 83 & 4.5 \\ 0.12 & 1 & 82 & 4.5\end{array}$

$\begin{array}{rll}9 & 0.16 & 3 \\ 10 & 0.20 & 5 \\ 11 & 0.27 & 1 \\ 12 & 0.35 & 3 \\ 13 & 0.47 & 7 \\ 14 & 0.61 & 4 \\ 15 & 0.80 & 3 \\ 16 & 1.10 & 1 \\ 17 & 1.40 & 4\end{array}$

$\begin{array}{ll}81 & 4.4 \\ 78 & 4.3 \\ 73 & 4.0 \\ 72 & 3.9 \\ 69 & 3.8 \\ 62 & 3.4 \\ 58 & 3.2 \\ 55 & 3.0 \\ 54 & 3.0\end{array}$

$\begin{array}{rr}18 & 1.8 \\ 19 & 2.4 \\ 20 & 3.2 \\ 21 & 4.2 \\ 22 & 5.5 \\ 23 & 7.2 \\ 24 & 9.5 \\ 25 & 12.0 \\ 26 & 16.0\end{array}$

$\begin{array}{ll}50 & 2.7 \\ 44 & 2.4 \\ 42 & 2.3 \\ 36 & 2.0 \\ 31 & 1.7 \\ 27 & 1.5 \\ 21 & 1.2 \\ 17 & 0.9 \\ 13 & 0.7\end{array}$

MONIFLY MEAN DISCHARGES, IN CUBIC FEET PER SBCOND, FOR EACH WATER YEAR

$\begin{array}{lllllllllllll}\text { YEAR } & \text { OCT } & \text { NOV } & \text { DEC } & \text { JAN } & \text { FEB } & \text { MAR } & \text { APR } & \text { MAY } & \text { JUNE } & \text { JULY } & \text { AUG } & \text { SEP } \\ 1977 & 0.00 & 0.00 & 0.00 & 0.00 & 0.00 & 0.00 & 0.00 & 0.00 & 0.14 & 0.03 & 0.10 & 0.00 \\ 1978 & 0.00 & 0.00 & 0.00 & 0.00 & 0.00 & 1.29 & 0.02 & 0.02 & 0.00 & 0.00 & 0.00 & 0.00 \\ 1979 & 0.39 & 0.00 & 0.00 & 0.00 & 0.00 & 12.0 & 2.62 & 0.01 & 0.00 & 0.00 & 0.79 & 0.00 \\ 1980 & 0.21 & 0.00 & 0.00 & 0.17 & 6.18 & 0.25 & 0.00 & 0.00 & 0.00 & 0.00 & 0.02 & 0.84 \\ 1981 & 0.00 & 0.00 & 0.00 & 0.00 & 0.00 & 0.00 & 0.00 & 0.00 & 0.00 & 0.00 & 0.00 & 0.06\end{array}$

ANNUAL PEAR DISCHARGE, IN CBBIC FEET PER SBCOND, AND OORRESPONDING GAGE HEIGET, IN FEET, FOR EACH WATER YEAR

\begin{tabular}{|c|c|c|c|c|c|c|c|c|c|c|c|}
\hline $\begin{array}{l}\text { WATER } \\
\text { YEAR }\end{array}$ & DATE & $\begin{array}{c}\text { GAGE } \\
\text { HEIGHT }\end{array}$ & $\begin{array}{c}\text { PEAK } \\
\text { DISCHARGE }\end{array}$ & $\begin{array}{l}\text { WATEER } \\
\text { YEAR }\end{array}$ & DATE & $\begin{array}{c}\text { GAGE } \\
\text { HEIGHT }\end{array}$ & $\begin{array}{c}\text { PEAK } \\
\text { DISCHARGE }\end{array}$ & $\begin{array}{l}\text { WATEER } \\
\text { YEAR }\end{array}$ & DATE & $\begin{array}{c}\text { GAGE } \\
\text { HEIGHT }\end{array}$ & $\begin{array}{c}\text { PEAR } \\
\text { DISCHARGE }\end{array}$ \\
\hline $\begin{array}{l}1977 \\
1978\end{array}$ & $\begin{array}{l}\text { JUNE } 08,1977 \\
\text { MAR. } 12,1978\end{array}$ & $\begin{array}{l}2.64 \\
2.10\end{array}$ & $\begin{array}{r}137 \\
38\end{array}$ & $\begin{array}{l}1979 \\
1980\end{array}$ & $\begin{array}{l}\text { AUG. } 19,1979 \\
\text { FEB. } 20,1980\end{array}$ & $\begin{array}{l}3.10 \\
3.13\end{array}$ & $\begin{array}{l}267 \\
247\end{array}$ & 1981 & SEPT. 05, 1980 & 2.26 & 24 \\
\hline
\end{tabular}


GREEN RIVER BASIN

09306878 COYOTE WASH NEAR MOUTH, NEAR OURAY, UT

LOCATION.--Lat $40^{\circ} 03^{\prime} 15^{\prime \prime}$, long $109^{\circ} 28^{\prime} 36^{\prime \prime}$, in SW $\mathrm{S}_{4}^{2} \mathrm{NE}_{4}^{3} \mathrm{NE}_{4}^{\frac{1}{4}}$ sec.7, T.9 S., R.22 E., Uintah County, Hydrologic Unit 14050007, on right bank $0.1 \mathrm{mi}$ upstream fram jeep trail, $1.1 \mathrm{mi}$ upstream fram mouth, and $11 \mathrm{mi}$ southeast of ouray.

DRATNAGE AREA. $--228 \mathrm{mi}^{2}$.

PERIOD OF RECORD AVAIIABLE.--October 1976 to September 1981.

GAGE.-Water-stage recorder and artificial control. Altitude of gage is 4,700 ft fram topographic map.

AVERAGE DISCHARGE. -5 years, $3.62 \mathrm{ft}^{3} / \mathrm{s}, 2,670$ acre-ft/yr.

EXIREMES FOR PERIOD OF RECORD.--Maximum discharge, $829 \mathrm{ft}^{3} / \mathrm{s}$ Feb. 20, 1980, gage height, $5.65 \mathrm{ft}$; no flow most of the time each year.

LONEST MEAN DISCHARGE, IN CUBIC FEET PER SECOND, AND RANKING FOR THE INDICATED NUMBER OF CONSECUTIVE DAYS FOR EACH CLIMATIC YEAR, APRIL 1-MARCH 31

\begin{tabular}{|c|c|c|c|c|c|c|c|c|c|c|c|c|c|c|c|c|c|c|c|}
\hline YEAR & 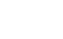 & & 3 & & 7 & & 14 & & CONSE & DUTIVE & DAYS & & On & & ח ברני & & 182 & & $\lambda \mathrm{T}$ \\
\hline $\begin{array}{l}1978 \\
1979 \\
1980\end{array}$ & $\begin{array}{l}0.00 \\
0.00 \\
0.00\end{array}$ & $\begin{array}{l}1 \\
2 \\
3\end{array}$ & $\begin{array}{l}0.00 \\
0.00 \\
0.00\end{array}$ & $\begin{array}{l}1 \\
2 \\
3\end{array}$ & $\begin{array}{l}0.00 \\
0.00 \\
0.00\end{array}$ & $\begin{array}{l}1 \\
2 \\
3\end{array}$ & $\begin{array}{l}0.00 \\
0.00 \\
0.00\end{array}$ & $\begin{array}{l}1 \\
2 \\
3\end{array}$ & $\begin{array}{l}0.00 \\
0.00 \\
0.00\end{array}$ & $\begin{array}{l}1 \\
2 \\
3\end{array}$ & $\begin{array}{l}0.00 \\
0.00 \\
0.00\end{array}$ & $\begin{array}{l}1 \\
2 \\
3\end{array}$ & $\begin{array}{l}0.00 \\
0.00 \\
0.08\end{array}$ & $\begin{array}{l}1 \\
2 \\
4\end{array}$ & $\begin{array}{l}0.96 \\
0.07 \\
0.18\end{array}$ & $\begin{array}{l}4 \\
2 \\
3\end{array}$ & $\begin{array}{l}1.10 \\
0.28 \\
0.31\end{array}$ & $\begin{array}{l}4 \\
1 \\
2\end{array}$ & $\begin{array}{l}4.10 \\
6.70 \\
5.40\end{array}$ \\
\hline & 0.00 & 4 & 0.00 & 4 & 0.00 & 4 & 0.00 & 4 & 0.00 & 4 & 0.00 & 4 & 0.00 & 3 & 0.00 & 1 & 0.70 & 3 & 1.00 \\
\hline
\end{tabular}

HIGHEST MEAN DISCHARGE, IN CUBIC FEET PER SECOND, AND RANKING FOR THE INDICATED NUMBER OF CONSEOUTIVE DAYS FOR EACH WATER YEAR, OCTCBER I-SEPTEMBER 30

\begin{tabular}{|c|c|c|c|c|c|c|c|c|c|c|c|c|c|c|c|c|c|c|c|}
\hline YEAR & 1 & & 3 & & 7 & & 15 & & $\begin{array}{l}\text { CONSE } \\
30\end{array}$ & & $\begin{array}{l}\text { DAYS } \\
60\end{array}$ & & 90 & & 120 & & 183 & & ALL \\
\hline $\begin{array}{l}1977 \\
1978 \\
1979 \\
1980\end{array}$ & $\begin{array}{l}114 \\
154 \\
477 \\
548\end{array}$ & $\begin{array}{l}4 \\
3 \\
2 \\
1\end{array}$ & $\begin{array}{l}43.0 \\
141 \\
336 \\
374\end{array}$ & $\begin{array}{l}4 \\
3 \\
2 \\
1\end{array}$ & $\begin{array}{l}27.0 \\
113 \\
197 \\
192\end{array}$ & $\begin{array}{l}4 \\
3 \\
1 \\
2\end{array}$ & $\begin{array}{c}13.0 \\
64.0 \\
158 \\
95.0\end{array}$ & $\begin{array}{l}4 \\
3 \\
1 \\
2\end{array}$ & $\begin{array}{l}7.90 \\
33.0 \\
85.0 \\
50.0\end{array}$ & $\begin{array}{l}4 \\
3 \\
1 \\
2\end{array}$ & $\begin{array}{l}5.00 \\
17.0 \\
43.0 \\
26.0\end{array}$ & $\begin{array}{l}4 \\
3 \\
1 \\
2\end{array}$ & $\begin{array}{l}3.60 \\
12.0 \\
28.0 \\
17.0\end{array}$ & $\begin{array}{l}4 \\
3 \\
1 \\
2\end{array}$ & $\begin{array}{c}2.70 \\
8.70 \\
21.0 \\
13.0\end{array}$ & $\begin{array}{l}4 \\
3 \\
1 \\
2\end{array}$ & $\begin{array}{c}1.80 \\
6.40 \\
14.0 \\
9.30\end{array}$ & $\begin{array}{l}4 \\
3 \\
1 \\
2\end{array}$ & $\begin{array}{l}0.93 \\
3.40 \\
7.30 \\
5.30\end{array}$ \\
\hline 9 & 107 & 5 & 42.0 & 5 & 18.0 & 5 & 9.40 & 5 & 5.20 & 5 & 2.70 & 5 & 1.80 & 5 & 1.30 & 5 & 1.50 & 5 & 1.10 \\
\hline
\end{tabular}

DURATION OF DISCHARGE FOR EACH WATER YEAR

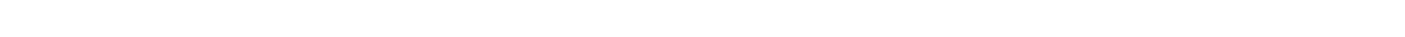
YEAR

NUMBER OF DAYS IN CLASS वBIC FEET PER SECON

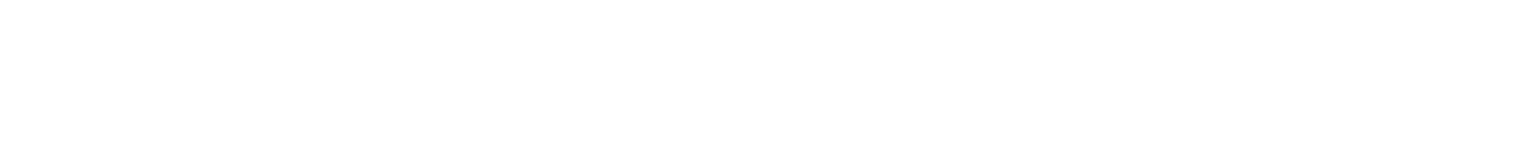

DURATION TABLE OF DISCHARGE FOR WATER YEARS 1977-81

\begin{tabular}{|c|c|c|c|c|c|c|c|c|c|c|c|c|c|c|c|c|c|c|c|}
\hline CLASS & $\begin{array}{c}\text { OBBIC } \\
\text { FEET } \\
\text { PER } \\
\text { SECOND }\end{array}$ & $\begin{array}{l}\text { TOTAL } \\
\text { DAYS }\end{array}$ & $\begin{array}{l}\text { ACOU- } \\
\text { MU- } \\
\text { LATED } \\
\text { DAYS }\end{array}$ & $\begin{array}{l}\text { PER- } \\
\text { CENT } \\
\text { DAYS }\end{array}$ & OASS & $\begin{array}{c}\text { वVIC } \\
\text { FEET } \\
\text { PER } \\
\text { SECOND }\end{array}$ & $\begin{array}{r}\text { TOTAL } \\
\text { DAYS }\end{array}$ & $\begin{array}{l}\text { ACOU- } \\
\text { MU- } \\
\text { L.ATED } \\
\text { DAYS }\end{array}$ & $\begin{array}{l}\text { PER- } \\
\text { CENT } \\
\text { DAYS }\end{array}$ & C.ASS & $\begin{array}{c}\text { CUBIC } \\
\text { FEET } \\
\text { PER } \\
\text { SECOND }\end{array}$ & $\begin{array}{l}\text { TOTAL } \\
\text { DAYS }\end{array}$ & $\begin{array}{c}\text { ACOU- } \\
\text { MJ- } \\
\text { LATED } \\
\text { DAYS }\end{array}$ & $\begin{array}{l}\text { PER- } \\
\text { CENT } \\
\text { DAYS }\end{array}$ & CLASS & $\begin{array}{c}\text { OABIC } \\
\text { FEET } \\
\text { PER } \\
\text { SECOND }\end{array}$ & $\begin{array}{l}\text { TOTAL } \\
\text { DAYS }\end{array}$ & $\begin{array}{c}\text { ACOU- } \\
\text { MU- } \\
\text { LATED } \\
\text { SAYS }\end{array}$ & $\begin{array}{l}\text { PER- } \\
\text { CENT } \\
\text { DAYS }\end{array}$ \\
\hline $\begin{array}{l}0 \\
1 \\
2 \\
3 \\
4 \\
5 \\
6 \\
7 \\
8\end{array}$ & $\begin{array}{l}0.00 \\
0.01 \\
0.02 \\
0.03 \\
0.04 \\
0.05 \\
0.07 \\
0.10 \\
0.14\end{array}$ & $\begin{array}{r}1621 \\
4 \\
0 \\
1 \\
3 \\
2 \\
1 \\
5 \\
6\end{array}$ & $\begin{array}{r}1826 \\
205 \\
201 \\
201 \\
200 \\
197 \\
195 \\
194 \\
189\end{array}$ & $\begin{array}{r}100.0 \\
11.2 \\
11.0 \\
11.0 \\
11.0 \\
10.8 \\
10.7 \\
10.6 \\
10.4\end{array}$ & $\begin{array}{r}9 \\
10 \\
11 \\
12 \\
13 \\
14 \\
15 \\
16 \\
17\end{array}$ & $\begin{array}{l}0.19 \\
0.26 \\
0.36 \\
0.50 \\
0.70 \\
0.97 \\
1.30 \\
1.90 \\
2.60\end{array}$ & $\begin{array}{r}4 \\
5 \\
8 \\
12 \\
13 \\
2 \\
5 \\
13 \\
13\end{array}$ & $\begin{array}{l}183 \\
179 \\
174 \\
166 \\
154 \\
141 \\
139 \\
134 \\
121\end{array}$ & $\begin{array}{r}10.0 \\
9.8 \\
9.5 \\
9.1 \\
8.4 \\
7.7 \\
7.6 \\
7.3 \\
6.6\end{array}$ & $\begin{array}{l}18 \\
19 \\
20 \\
21 \\
22 \\
23 \\
24 \\
25 \\
26\end{array}$ & $\begin{array}{r}3.6 \\
4.9 \\
6.9 \\
9.5 \\
13.0 \\
18.0 \\
25.0 \\
35.0 \\
49.0\end{array}$ & $\begin{array}{r}6 \\
12 \\
9 \\
12 \\
11 \\
8 \\
5 \\
7 \\
11\end{array}$ & $\begin{array}{r}108 \\
102 \\
90 \\
81 \\
69 \\
58 \\
50 \\
45 \\
38\end{array}$ & $\begin{array}{l}5.9 \\
5.6 \\
4.9 \\
4.4 \\
3.8 \\
3.2 \\
2.7 \\
2.5 \\
2.1\end{array}$ & $\begin{array}{l}27 \\
28 \\
29 \\
30 \\
31 \\
32 \\
33 \\
34\end{array}$ & $\begin{array}{r}67.0 \\
93.0 \\
130.0 \\
180.0 \\
250.0 \\
340.0 \\
480.0\end{array}$ & $\begin{array}{r}6 \\
10 \\
3 \\
3\end{array}$ & $\begin{array}{r}27 \\
21 \\
11 \\
8 \\
5 \\
5 \\
1\end{array}$ & \\
\hline
\end{tabular}

MONIHLY MEAN DISCHARGES, IN CUBIC FEET PER SECOND, FOR EACH WATER YEAR

$\begin{array}{lcccccccccccc}\text { YEAR } & \text { OCT } & \text { NOW } & \text { DEC } & \text { JAN } & \text { FEB } & \text { MAR } & \text { APR } & \text { MAY } & \text { JUNE } & \text { JULY } & \text { AUG } & \text { SEP } \\ & & & & & & & & & & & \\ 1977 & 0.00 & 0.00 & 0.00 & 0.00 & 0.09 & 0.13 & 0.35 & 0.05 & 0.07 & 7.66 & 2.02 & 0.67 \\ 1978 & 2.07 & 3.84 & 0.00 & 0.00 & 0.00 & 31.7 & 2.01 & 0.00 & 0.00 & 0.00 & 0.31 & 0.38 \\ 1979 & 1.41 & 0.27 & 0.00 & 0.00 & 0.00 & 74.9 & 7.48 & 0.47 & 0.00 & 0.22 & 1.16 & 0.00 \\ 1980 & 4.46 & 0.00 & 0.00 & 2.30 & 48.8 & 2.60 & 0.00 & 0.04 & 0.00 & 0.00 & 0.85 & 7.45 \\ 1981 & 4.11 & 0.00 & 0.00 & 0.00 & 0.00 & 0.00 & 1.64 & 2.36 & 0.01 & 0.17 & 1.12 & 4.03\end{array}$


ANNUAL PEAR DISCHARGE, IN OIBIC FEET PER SECOND, AND CORRESPONDING GAGE HEIGHT, IN FEET, FOR EACH WATER YEAR

$\begin{array}{lcccccccccc}\begin{array}{l}\text { WATER } \\ \text { YEAR }\end{array} & \text { DATE } & \begin{array}{c}\text { GAGE } \\ \text { HEIGHT }\end{array} & \begin{array}{c}\text { PEAK } \\ \text { DISCHARGE }\end{array} & \begin{array}{l}\text { WATER } \\ \text { YEAR }\end{array} & \text { DATE } & \begin{array}{c}\text { GAGE } \\ \text { HEIGHT }\end{array} & \begin{array}{c}\text { PEAK } \\ \text { DISCHARGE }\end{array} & \begin{array}{l}\text { WATER } \\ \text { YEAR }\end{array} & \begin{array}{c}\text { GAGE } \\ \text { DATE }\end{array} & \begin{array}{c}\text { PEAK } \\ \text { HEIGHT }\end{array} \\ \text { DISCHARGE }\end{array}$

09306880 NORTH WASH NEAR OURAY, UT

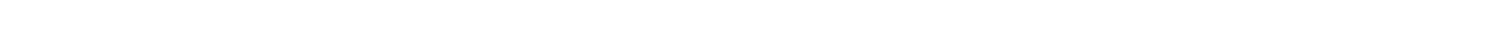
Ouray Indian Reservation, on right bank $2.9 \mathrm{mi}$ upstream from mouth, $5.4 \mathrm{mi}$ upstream tran cottorwood Creek, and $6.8 \mathrm{mi}$ southeast of ouray.

DRAINAGE AREA. $-11.0 \mathrm{mi}^{2}$.

PERIOD OF RECORD AVAILABLE.--October 1979 to September 1981.

GAGE. -Water-stage recorder and artificial control. Altitude of gage is 4,730 $\mathrm{ft}$ tran topographic map.

EXTREMES FOR PERIOD OF RECORD.--Maximum discharge, $212 \mathrm{ft} / \mathrm{s}$ May 28, 1981, gage height, $2.55 \mathrm{ft}$, fram rating curve extended above 15

$\mathrm{ft}^{3} / \mathrm{s}$ on basis of slope-area measurement of peak flow; no flow most of the time each year.

LONEST MEAN DISCHARGE, IN OUBIC FEET PER SECOND, AND RANKING FOR THE INDICATED NUMBER OF CONSECUTIVE DAYS FOR EACH CLIMATIC YEAR, APRII 1-MARCH 31

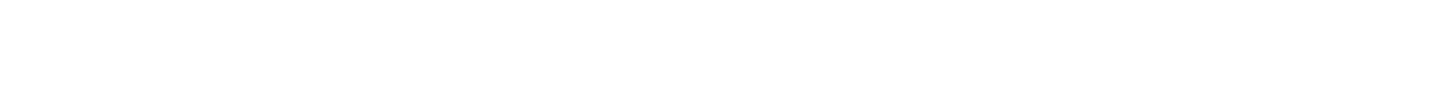

HIGHEST MEAN DISCHARGE, IN OUBIC FEET PER SECOND, AND RANKING FOR THE INDICATED NUMBER OF CONSECUTIVE DAYS FOR EACH WATER YEAR, OCTOBER 1-SEPTEMBER 30

\begin{tabular}{|c|c|c|c|c|c|c|c|c|c|c|c|c|c|c|c|c|c|c|c|}
\hline YEAR & & & & & & & & & CONSE & ar I & DAYS & & & & & & & & \\
\hline & 1 & & 3 & & 7 & & 15 & & 30 & & 60 & & 90 & & 120 & & 183 & & ALL \\
\hline 1980 & 33.0 & 1 & 23.0 & 1 & 12.0 & 1 & 5.60 & 1 & 3.00 & 1 & 1.70 & 1 & 1.10 & 1 & 0.85 & 1 & 0.62 & 1 & 0.33 \\
\hline
\end{tabular}

DURATION OF DISCHARGE FOR EACH WATER YEAR

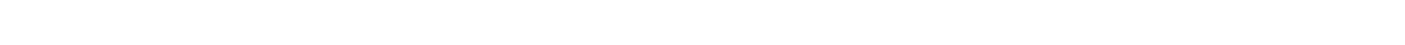
YEAR NUMBR OF DAYS IN CLASS OBBIC FEET PER SECON
-DAYS

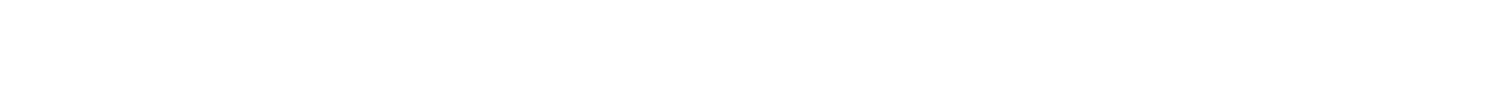

\begin{tabular}{|c|c|c|c|c|c|c|c|c|c|c|c|c|c|c|c|c|c|c|c|}
\hline & & & & & & DURATIO & N TABL & ${ }_{E} \propto F$ & SCHAR & OR WAI & TER YEAF & RS 198 & $30-81$ & & & & & & \\
\hline CLASS & $\begin{array}{c}\text { CBBIC } \\
\text { FEET } \\
\text { PER } \\
\text { SECOND }\end{array}$ & $\begin{array}{l}\text { TOTAL } \\
\text { DAYS }\end{array}$ & $\begin{array}{c}\text { ACOU- } \\
\text { MU- } \\
\text { LATED } \\
\text { DAYS }\end{array}$ & $\begin{array}{l}\text { PER- } \\
\text { CENT } \\
\text { DAYS }\end{array}$ & CLASS & $\begin{array}{c}\text { CUBIC } \\
\text { FEET } \\
\text { PER } \\
\text { SECOND }\end{array}$ & $\begin{array}{l}\text { TOTAL } \\
\text { DAYS }\end{array}$ & $\begin{array}{c}\text { ACOU- } \\
\text { MU- } \\
\text { LATED } \\
\text { DAYS }\end{array}$ & $\begin{array}{l}\text { PER- } \\
\text { CENT } \\
\text { DAYS }\end{array}$ & CLASS & $\begin{array}{c}\text { OUBIC } \\
\text { FEET } \\
\text { PER } \\
\text { SECOND }\end{array}$ & $\begin{array}{l}\text { TOIAL } \\
\text { DAYS }\end{array}$ & $\begin{array}{c}\text { ACOU- } \\
\text { MU- } \\
\text { LATED } \\
\text { DAYS }\end{array}$ & $\begin{array}{l}\text { PER- } \\
\text { CEN } \\
\text { DAYS }\end{array}$ & OLASS & $\begin{array}{c}\text { OUBIC } \\
\text { FEET } \\
\text { PER } \\
\text { SECOND }\end{array}$ & $\begin{array}{l}\text { TOTAL } \\
\text { DAYS }\end{array}$ & $\begin{array}{c}\text { ACOU- } \\
\text { MU- } \\
\text { LATED } \\
\text { DAYS }\end{array}$ & $\begin{array}{l}\text { PER- } \\
\text { CENI } \\
\text { DAYS }\end{array}$ \\
\hline $\begin{array}{l}0 \\
1 \\
2 \\
3 \\
4 \\
5 \\
6 \\
7 \\
8\end{array}$ & $\begin{array}{l}0.00 \\
0.01 \\
0.02 \\
0.03 \\
0.04 \\
0.05 \\
0.07 \\
0.09 \\
0.11\end{array}$ & $\begin{array}{r}690 \\
2 \\
1 \\
0 \\
3 \\
0 \\
1 \\
1 \\
1\end{array}$ & $\begin{array}{r}731 \\
41 \\
39 \\
38 \\
38 \\
35 \\
35 \\
34 \\
33\end{array}$ & $\begin{array}{r}100.0 \\
5.6 \\
5.3 \\
5.2 \\
5.2 \\
4.8 \\
4.8 \\
4.6 \\
4.5\end{array}$ & $\begin{array}{r}9 \\
10 \\
11 \\
12 \\
13 \\
14 \\
15 \\
16 \\
17\end{array}$ & $\begin{array}{l}0.14 \\
0.18 \\
0.22 \\
0.28 \\
0.36 \\
0.45 \\
0.57 \\
0.73 \\
0.93\end{array}$ & $\begin{array}{l}1 \\
0 \\
2 \\
0 \\
5 \\
3 \\
1 \\
2 \\
1\end{array}$ & $\begin{array}{l}32 \\
31 \\
31 \\
29 \\
29 \\
24 \\
21 \\
20 \\
18\end{array}$ & $\begin{array}{l}4.4 \\
4.2 \\
4.2 \\
4.0 \\
4.0 \\
3.3 \\
2.9 \\
2.7 \\
2.5\end{array}$ & $\begin{array}{l}18 \\
19 \\
20 \\
21 \\
22 \\
23 \\
24 \\
25 \\
26\end{array}$ & $\begin{array}{l}1.2 \\
1.5 \\
1.9 \\
2.4 \\
3.1 \\
3.9 \\
4.9 \\
6.2 \\
7.9\end{array}$ & $\begin{array}{l}0 \\
1 \\
2 \\
4 \\
2 \\
0 \\
0 \\
3 \\
1\end{array}$ & $\begin{array}{r}17 \\
17 \\
16 \\
14 \\
10 \\
8 \\
8 \\
8 \\
5\end{array}$ & $\begin{array}{l}2.3 \\
2.3 \\
2.2 \\
2.0 \\
1.4 \\
1.1 \\
1.1 \\
1.1 \\
0.7\end{array}$ & $\begin{array}{l}27 \\
28 \\
29 \\
30 \\
31 \\
32 \\
33 \\
34\end{array}$ & $\begin{array}{l}10.0 \\
13.0 \\
16.0 \\
20.0 \\
26.0\end{array}$ & $\begin{array}{l}2 \\
0 \\
0 \\
0 \\
2\end{array}$ & $\begin{array}{l}4 \\
2 \\
2 \\
2 \\
2\end{array}$ & $\begin{array}{l}0.6 \\
0.3 \\
0.3 \\
0.3 \\
0.3\end{array}$ \\
\hline
\end{tabular}

MONTHLY MEAN DISCHARGES, IN OBIC FEET PER SECOND, FOR EACH WATER YEAR

$\begin{array}{lllllllllllll}\text { YEAR } & \text { OCT } & \text { NOV } & \text { DEC } & \text { JAN } & \text { FEB } & \text { MAR } & \text { APR } & \text { MAY } & \text { JUNE } & \text { JULY } & \text { AUG } & \text { SEP } \\ 1980 & 0.39 & 0.00 & 0.00 & 0.33 & 2.91 & 0.22 & 0.00 & 0.00 & 0.00 & 0.00 & 0.02 & 0.23 \\ 1981 & 0.02 & 0.00 & 0.09 & 0.00 & 0.00 & 0.00 & 0.03 & 0.30 & 0.00 & 0.02 & 0.00 & 0.24\end{array}$


GREEN RIVER BASIN

09306885 COTTONOOD WASH AT MOUTH, NEAR OURAY, UT

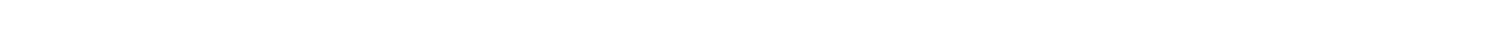
bank $0.9 \mathrm{mi}$ upstream from mouth and $4.1 \mathrm{mi}$ southeast of ouray.

DRAINAGE AREA. $-70.6 \mathrm{mi}^{2}$.

MEAN BASIN ELLVVATION. $-5,490 \mathrm{ft}$.

PERIOD OF RECORD AVAIIABLE.--October 1976 to September 1981.

GAGE.--Water-stage recorder and artificial control. Altitude of gage is 4,680 ft from topographic map.

AVERAGE DISQHARGE. -5 years, $1.39 \mathrm{ft}^{3} / \mathrm{s}, 1,010$ acre-ft/yr.

EXTREMES FOR PERIOD OF RECORD.--Maximum discharge, $840 \mathrm{ft}^{3} / \mathrm{s}$ Feb. 20, 1980, gage height, $3.28 \mathrm{ft}$; no flow most of time each year.

LOWEST MEAN DISQHARGE, IN OJBIC FEET PER SECOND, AND RANKING FOR THE INDICATED NUMBER OF CONSEOJTIVE DAYS FOR EAOH OIMATIC YEAR, APRIL 1-MARQH 31

\begin{tabular}{|c|c|c|c|c|c|c|c|c|c|c|c|c|c|c|c|c|c|c|c|}
\hline YEAR & 1 & & 3 & & 7 & & 14 & & $\begin{array}{l}\text { CONSE } \\
30\end{array}$ & QUTTE & $\begin{array}{l}\text { DAYS } \\
60\end{array}$ & & 90 & & 120 & & 183 & & ALL \\
\hline $\begin{array}{l}1978 \\
1979 \\
1980\end{array}$ & $\begin{array}{l}0.00 \\
0.00 \\
0.00\end{array}$ & $\begin{array}{l}1 \\
2 \\
3\end{array}$ & $\begin{array}{l}0.00 \\
0.00 \\
0.00\end{array}$ & $\begin{array}{l}1 \\
2 \\
3\end{array}$ & $\begin{array}{l}0.00 \\
0.00 \\
0.00\end{array}$ & $\begin{array}{l}1 \\
2 \\
3\end{array}$ & $\begin{array}{l}0.00 \\
0.00 \\
0.00\end{array}$ & $\begin{array}{l}1 \\
2 \\
3\end{array}$ & $\begin{array}{l}0.00 \\
0.00 \\
0.00\end{array}$ & $\begin{array}{l}1 \\
2 \\
3\end{array}$ & $\begin{array}{l}0.00 \\
0.00 \\
0.00\end{array}$ & $\begin{array}{l}1 \\
2 \\
3\end{array}$ & $\begin{array}{l}0.00 \\
0.00 \\
0.00\end{array}$ & $\begin{array}{l}1 \\
2 \\
3\end{array}$ & $\begin{array}{l}0.00 \\
0.00 \\
0.00\end{array}$ & $\begin{array}{l}1 \\
2 \\
3\end{array}$ & $\begin{array}{l}0.00 \\
0.00 \\
0.24\end{array}$ & $\begin{array}{l}1 \\
2 \\
4\end{array}$ & $\begin{array}{l}0.13 \\
3.90 \\
2.70\end{array}$ \\
\hline 1981 & 0.00 & 4 & 0.00 & 4 & 0.00 & 4 & 0.00 & 4 & 0.00 & 4 & 0.00 & 4 & 0.00 & 4 & 0.00 & 4 & 0.00 & 3 & 0.05 \\
\hline
\end{tabular}

HIGHEST MEAN DISOHARGE, IN ABIC FEET PER SECOND, AND RANKING FOR THE INDICATED NUMBER OF CONSECUTIVE DAYS FOR EAOH WATER YEAR, OCTOBER I-SEPTEMBER 30

\begin{tabular}{|c|c|c|c|c|c|c|c|c|c|c|c|c|c|c|c|c|c|c|c|}
\hline YEAR & & & & & & & & & CONSE & WTI & E DAYS & & & & & & & & \\
\hline & 1 & & 3 & & 7 & & 15 & & 30 & & 60 & & 90 & & 120 & & 183 & & ALL \\
\hline $\begin{array}{l}1977 \\
1978 \\
1979 \\
1980\end{array}$ & $\begin{array}{l}15.0 \\
8.10 \\
282 \\
180\end{array}$ & $\begin{array}{l}4 \\
5 \\
1 \\
2\end{array}$ & $\begin{array}{l}5.60 \\
6.50 \\
186 \\
141\end{array}$ & $\begin{array}{l}5 \\
4 \\
1 \\
2\end{array}$ & $\begin{array}{r}2.40 \\
3.60 \\
118 \\
76.0\end{array}$ & $\begin{array}{l}5 \\
4 \\
1 \\
2\end{array}$ & $\begin{array}{l}1.10 \\
1.70 \\
98.0 \\
35.0\end{array}$ & $\begin{array}{l}5 \\
4 \\
1 \\
2\end{array}$ & $\begin{array}{l}0.70 \\
0.85 \\
57.0 \\
19.0\end{array}$ & $\begin{array}{l}5 \\
4 \\
1 \\
2\end{array}$ & $\begin{array}{l}0.37 \\
0.43 \\
28.0 \\
10.0\end{array}$ & $\begin{array}{l}5 \\
4 \\
1 \\
2\end{array}$ & $\begin{array}{c}0.24 \\
0.28 \\
19.0 \\
6.70\end{array}$ & $\begin{array}{l}5 \\
4 \\
1 \\
2\end{array}$ & $\begin{array}{c}0.18 \\
0.21 \\
14.0 \\
5.10\end{array}$ & $\begin{array}{l}5 \\
4 \\
1 \\
2\end{array}$ & $\begin{array}{l}0.12 \\
0.14 \\
9.70 \\
3.40\end{array}$ & $\begin{array}{l}5 \\
4 \\
1 \\
2\end{array}$ & $\begin{array}{l}0.06 \\
0.07 \\
4.90 \\
1.80\end{array}$ \\
\hline 981 & 29.0 & 3 & 9.80 & 3 & 4.20 & 3 & 2.00 & 3 & 0.98 & 3 & 0.61 & 3 & 0.41 & 3 & 0.30 & 3 & 0.20 & 3 & 0.10 \\
\hline
\end{tabular}

DURATION OF DISGHARGE FOR EACH WATER YEAR

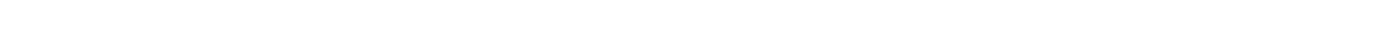
YEAR NUMBER OF DAYS IN GLASS

OBBIC FEET PER SECOND -DAYS

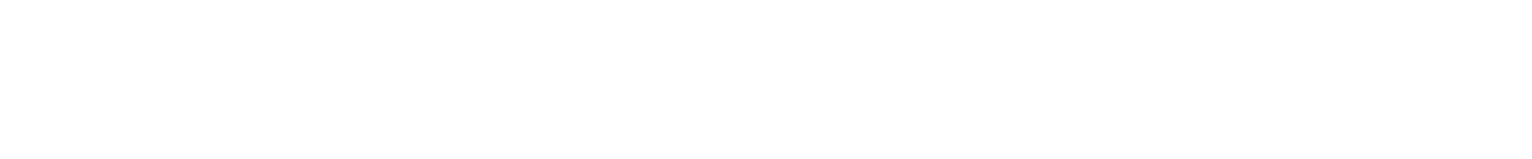

DURATION TABLE OF DISCHARGE FOR WATER YEARS $1977-81$

\begin{tabular}{|c|c|c|c|c|c|c|c|c|c|c|c|c|c|c|c|c|c|c|c|}
\hline CLASS & $\begin{array}{c}\text { ABBIC } \\
\text { FEET } \\
\text { PER } \\
\text { SECOND }\end{array}$ & $\begin{array}{l}\text { TOTAL } \\
\text { DAYS }\end{array}$ & $\begin{array}{c}\text { ACQU- } \\
\text { MU- } \\
\text { LATED } \\
\text { DAYS }\end{array}$ & $\begin{array}{l}\text { PER- } \\
\text { CENT } \\
\text { DAYS }\end{array}$ & & $\begin{array}{c}\text { CUBIC } \\
\text { FEET } \\
\text { PER } \\
\text { SECOND }\end{array}$ & $\begin{array}{c}\text { TOTAL } \\
\text { DAYS }\end{array}$ & $\begin{array}{c}\text { ACOH- } \\
\text { MU- } \\
\text { LATED } \\
\text { DAYS }\end{array}$ & $\begin{array}{l}\text { PER- } \\
\text { CENT } \\
\text { DAYS }\end{array}$ & GLASS & $\begin{array}{c}\text { QBBIC } \\
\text { FEET } \\
\text { PER } \\
\text { SECOND }\end{array}$ & $\begin{array}{r}\text { TOTAL } \\
\text { DAYS }\end{array}$ & $\begin{array}{l}\text { ACOU- } \\
\text { MU- } \\
\text { LATED } \\
\text { DAYS }\end{array}$ & $\begin{array}{l}\text { PER- } \\
\text { CENT } \\
\text { DAYS }\end{array}$ & G.ASS & $\begin{array}{c}\text { ABBIC } \\
\text { FEET } \\
\text { PER } \\
\text { SECOND }\end{array}$ & $\begin{array}{l}\text { TOTAL } \\
\text { DAYS }\end{array}$ & $\begin{array}{c}\text { ACd- } \\
\text { MU- } \\
\text { LATED } \\
\text { DAYS }\end{array}$ & $\begin{array}{l}\text { PER- } \\
\text { CENT } \\
\text { DAYS }\end{array}$ \\
\hline $\begin{array}{l}0 \\
1 \\
2 \\
3 \\
4 \\
5 \\
6 \\
7 \\
8\end{array}$ & $\begin{array}{l}0.00 \\
0.02 \\
0.03 \\
0.04 \\
0.05 \\
0.06 \\
0.08 \\
0.11 \\
0.15\end{array}$ & $\begin{array}{r}1758 \\
1 \\
1 \\
2 \\
0 \\
0 \\
2 \\
1 \\
0\end{array}$ & $\begin{array}{r}1826 \\
68 \\
67 \\
66 \\
64 \\
64 \\
64 \\
62 \\
61\end{array}$ & $\begin{array}{r}100.0 \\
3.7 \\
3.7 \\
3.6 \\
3.5 \\
3.5 \\
3.5 \\
3.4 \\
3.3\end{array}$ & $\begin{array}{r}9 \\
10 \\
11 \\
12 \\
13 \\
14 \\
15 \\
16 \\
17\end{array}$ & $\begin{array}{l}0.20 \\
0.26 \\
0.34 \\
0.46 \\
0.61 \\
0.81 \\
1.10 \\
1.40 \\
1.90\end{array}$ & $\begin{array}{l}2 \\
0 \\
0 \\
3 \\
0 \\
2 \\
1 \\
1 \\
8\end{array}$ & $\begin{array}{l}61 \\
59 \\
59 \\
59 \\
56 \\
56 \\
54 \\
53 \\
52\end{array}$ & $\begin{array}{l}3.3 \\
3.2 \\
3.2 \\
3.2 \\
3.1 \\
3.1 \\
3.0 \\
2.9 \\
2.8\end{array}$ & $\begin{array}{l}18 \\
19 \\
20 \\
21 \\
22 \\
23 \\
24 \\
25 \\
26\end{array}$ & $\begin{array}{r}2.5 \\
3.4 \\
4.5 \\
5.9 \\
7.9 \\
10.0 \\
14.0 \\
19.0 \\
25.0\end{array}$ & $\begin{array}{l}1 \\
2 \\
5 \\
3 \\
4 \\
2 \\
2 \\
4 \\
3\end{array}$ & $\begin{array}{l}44 \\
43 \\
41 \\
36 \\
33 \\
29 \\
27 \\
25 \\
21\end{array}$ & $\begin{array}{l}2.4 \\
2.4 \\
2.2 \\
2.0 \\
1.8 \\
1.6 \\
1.5 \\
1.4 \\
1.2\end{array}$ & $\begin{array}{l}27 \\
28 \\
29 \\
30 \\
31 \\
32 \\
33 \\
34\end{array}$ & $\begin{array}{r}33.0 \\
44.0 \\
58.0 \\
77.0 \\
100.0 \\
140.0 \\
180.0 \\
240.0\end{array}$ & $\begin{array}{l}0 \\
3 \\
6 \\
0 \\
2 \\
3 \\
2\end{array}$ & $\begin{array}{r}18 \\
18 \\
15 \\
9 \\
9 \\
7 \\
4 \\
2\end{array}$ & $\begin{array}{l}1.0 \\
1.0 \\
0.8 \\
0.5 \\
0.5 \\
0.4 \\
0.2 \\
0.1\end{array}$ \\
\hline
\end{tabular}

MONTHLY MEAN DISCHARGES, IN OBIC FEET PER SECOND, FOR EACH WATER YEAR

$\begin{array}{lllllllllllll}\text { YEAR } & \text { OCT } & \text { NOV } & \text { DEC } & \text { JAN } & \text { FEB } & \text { MAR } & \text { APR } & \text { MAY } & \text { JUNE } & \text { JULY } & \text { AUG } & \text { SEP } \\ 1977 & 0.00 & 0.00 & 0.00 & 0.00 & 0.00 & 0.00 & 0.00 & 0.00 & 0.00 & 0.68 & 0.03 & 0.00 \\ 1978 & 0.00 & 0.00 & 0.00 & 0.00 & 0.00 & 0.82 & 0.00 & 0.00 & 0.00 & 0.00 & 0.00 & 0.00 \\ 1979 & 0.71 & 0.00 & 0.00 & 0.00 & 0.00 & 45.7 & 9.43 & 0.00 & 0.00 & 0.00 & 2.58 & 0.00 \\ 1980 & 0.78 & 0.00 & 0.00 & 0.65 & 18.3 & 1.68 & 0.00 & 0.30 & 0.00 & 0.00 & 0.00 & 0.30 \\ 1981 & 0.00 & 0.00 & 0.00 & 0.00 & 0.00 & 0.00 & 0.00 & 0.00 & 0.00 & 0.22 & 0.00 & 0.98\end{array}$


GREEN RIVER BASIN

09306885 COTTOWOOD WASH AT MOUTH, NEAR OURAY, UT-Continued

ANNUA PEAK DISGHARGE, IN CUBIC FEET PER SECOND, AND CORRESFONDING GAGE HEIGHT, IN FEET, FOR EACH WATER YEAR

\begin{tabular}{|c|c|c|c|c|c|c|c|c|c|c|c|}
\hline $\begin{array}{l}\text { WATER } \\
\text { YEAR }\end{array}$ & DATE & $\begin{array}{c}\text { GAGE } \\
\text { HEIGHT }\end{array}$ & $\begin{array}{c}\text { PEAK } \\
\text { DISQHARGE }\end{array}$ & $\begin{array}{l}\text { WAIER } \\
\text { YEAR }\end{array}$ & DATE & $\begin{array}{c}\text { GAGE } \\
\text { HEIGHT }\end{array}$ & $\begin{array}{c}\text { PEAK } \\
\text { DISCHARGE }\end{array}$ & $\begin{array}{l}\text { WATER } \\
\text { YEAR }\end{array}$ & DATE & $\begin{array}{c}\text { GAGE } \\
\text { HEIGHT }\end{array}$ & $\begin{array}{c}\text { PEAK } \\
\text { DISCHARGE }\end{array}$ \\
\hline $\begin{array}{l}1977 \\
1978\end{array}$ & $\begin{array}{l}\text { JULY 24, } 1977 \\
\text { MAR. 07, } 1978\end{array}$ & $\begin{array}{l}3.07 \\
2.24\end{array}$ & $\begin{array}{r}286 \\
62\end{array}$ & $\begin{array}{l}1979 \\
1980\end{array}$ & 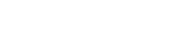 & $\begin{array}{l}3.56 \\
3.28\end{array}$ & $\begin{array}{l}780 \\
840\end{array}$ & 1981 & SEPT.05, 1981 & 1.42 & 232 \\
\hline
\end{tabular}

09306900 WHITE RIVER AT MOUTH, NEAR OURAY, UT

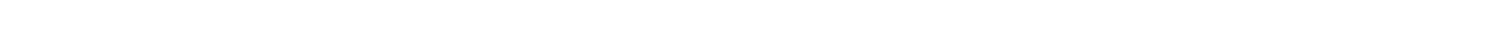
Ouray Indian Reservation, on left bank $2.8 \mathrm{mi}$ southeast of Ouray and $3.9 \mathrm{mi}$ upstream from mouth.

DRAINAGE AREA $--5,120 \mathrm{mi}^{2}$, approximately.

MEAN BASIN ELEVATION. $-6,910 \mathrm{ft}$.

PERIOD OF RECORD AVAILABLE.--Apr il 1974 to September 1981.

GAGE.--Water-stage recorder. Altitude of gage is 4,655 ft from topographic map.

REMARKS.--Diversions for irrigation of about 33,200 acres above station.

AVERAGE DISCHARGE. --7 years, $632 \mathrm{ft}^{3} / \mathrm{s}, 457,900$ acre-ft/yr

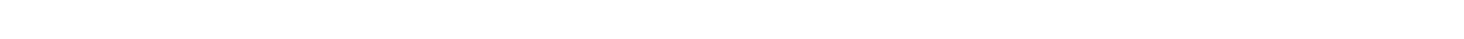
1977.

LONEST MEAN DISCHARGE, IN OBIC FEET PER SECOND, AND RANKING FOR THE INDICATED NUMBER OF CONSEQUTIVE DAYS FOR EAOH QLIMATIC YEAR, APRIL 1-MARQH 31

\begin{tabular}{|c|c|c|c|c|c|c|c|c|c|c|c|c|c|c|c|c|c|c|c|}
\hline YEAR & 1 & & 3 & & 7 & & 14 & & $\begin{array}{l}\text { CON } \\
30\end{array}$ & & $\begin{array}{r}V E D \\
60\end{array}$ & & 9 & & 120 & & 18 & & ALL \\
\hline 1975 & 177 & 3 & 180 & 3 & 190 & 2 & 197 & 2 & 242 & 3 & 307 & 4 & 350 & 5 & 372 & 6 & 360 & 3 & 704 \\
\hline
\end{tabular}

HIGHEST MEAN DISGHARGE, IN QUBIC FEET PER SECOND, AND RANKING FOR THE INDICATED NUMBER OF CONSEQUTIVE DAYS FOR EACH WATER YEAR, OCTOBER 1-SEPTEMBER 30

\begin{tabular}{|c|c|c|c|c|c|c|c|c|c|c|c|c|c|c|c|c|c|c|c|}
\hline YEAR & 1 & & 3 & & 7 & & 15 & & $\begin{array}{l}\alpha \\
30\end{array}$ & 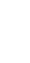 & IVE D & & 90 & & 120 & & 183 & & ALL \\
\hline 1975 & 3950 & 3 & 3750 & 3 & 3290 & 3 & 3150 & 3 & 2850 & 3 & 2410 & 1 & 1870 & 2 & 1540 & 2 & 1180 & 2 & 787 \\
\hline
\end{tabular}

DURATION OF DISGHARGE FOR EACH WATER YEAR

CLASS $0 \begin{array}{lllllllllllllllllllllllllllllllllllll} & 0 & 2 & 3 & 4 & 5 & 6 & 7 & 8 & 9 & 10 & 11 & 12 & 13 & 14 & 15 & 16 & 17 & 18 & 19 & 20 & 21 & 22 & 23 & 24 & 25 & 26 & 27 & 28 & 29 & 30 & 31 & 32 & 33 & 34\end{array}$ YEAR 
GREEN RIVER BASIN

09306900 WHITE RIVER AT MOUTH, NEAR OURAY, UT-Continued

DURATTON TABLE OF DISGHARGE FOR WATER YEARS 1975-81

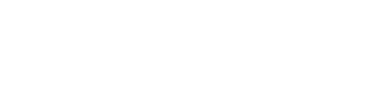

$\begin{array}{lll}\text { OBBIC } & \text { ACUI- } \\ \text { FEET } & \text { MU- } & \text { PER- } \\ \text { PER TOTAL LATED } & \text { CENT }\end{array}$ CASS SECOND DAYS DAYS DAYS

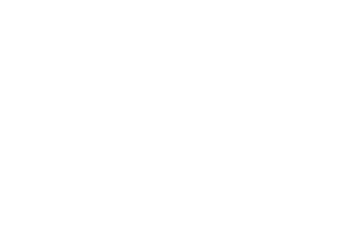

$\begin{array}{rrrr}\text { OBIC } & \text { ACOU- } \\ \text { FEET } & \text { MU- } & \text { PER- } \\ \text { FER } & \text { TOTAL LAIED } & \text { CENT } \\ \text { CLASS SECOND } & \text { DAYS DAYS } & \text { DAYS }\end{array}$

$\begin{array}{rrrrr}18 & 190.0 & 73 & 2459 & 96.2 \\ 19 & 230.0 & 162 & 2386 & 93.3 \\ 20 & 280.0 & 401 & 2224 & 87.0 \\ 21 & 340.0 & 553 & 1823 & 71.3 \\ 22 & 410.0 & 459 & 1270 & 49.7 \\ 23 & 500.0 & 212 & 811 & 31.7 \\ 24 & 600.0 & 120 & 599 & 23.4 \\ 25 & 730.0 & 75 & 479 & 18.7 \\ 26 & 880.0 & 71 & 404 & 15.8\end{array}$ $\begin{array}{ccc}\text { OUBIC } & \text { ACQU- } \\ \text { FEET } & \text { MU- } & \text { PER- } \\ \text { PER } & \text { TOTA LATED } & \text { CENT } \\ \text { CLASS SECOND } & \text { DAYS DAYS } & \text { DAYS }\end{array}$

$\begin{array}{rrrrr}27 & 1100.0 & 46 & 333 & 13.0 \\ 28 & 1300.0 & 40 & 287 & 11.2 \\ 29 & 1600.0 & 58 & 247 & 9.7 \\ 30 & 1900.0 & 72 & 189 & 7.4 \\ 31 & 2300.0 & 68 & 117 & 4.6 \\ 32 & 2800.0 & 28 & 49 & 1.9 \\ 33 & 3400.0 & 19 & 21 & 0.8 \\ 34 & 4100.0 & 2 & 2 & 0.1\end{array}$

MONTHLY MEAN DISCHARGES, IN OBIC FEET FER SECOND, FOR EACH WATER YEAR

\begin{tabular}{|c|c|c|c|c|c|c|c|c|c|c|c|c|}
\hline YEAR & OCT & NOV & DEC & JAN & FEB & MAR & APR & MAY & JUNE & JULY & AUG & SEP \\
\hline 1975 & 447 & 438 & 316 & 348 & 390 & 555 & 518 & 1264 & 2735 & 1537 & 481 & 412 \\
\hline $\begin{array}{l}1976 \\
1977 \\
1978 \\
1979 \\
1980\end{array}$ & $\begin{array}{l}459 \\
388 \\
267 \\
404 \\
405\end{array}$ & $\begin{array}{l}450 \\
348 \\
327 \\
411 \\
404\end{array}$ & $\begin{array}{l}308 \\
295 \\
290 \\
417 \\
359\end{array}$ & $\begin{array}{l}275 \\
321 \\
317 \\
332 \\
354\end{array}$ & $\begin{array}{r}477 \\
346 \\
317 \\
303 \\
1005\end{array}$ & $\begin{array}{l}613 \\
413 \\
528 \\
808 \\
617\end{array}$ & $\begin{array}{l}541 \\
425 \\
632 \\
793 \\
610\end{array}$ & $\begin{array}{r}1501 \\
409 \\
1511 \\
1893 \\
1825\end{array}$ & $\begin{array}{r}1288 \\
266 \\
2863 \\
2552 \\
2085\end{array}$ & $\begin{array}{r}335 \\
123 \\
1088 \\
1032 \\
645\end{array}$ & $\begin{array}{l}326 \\
188 \\
344 \\
447 \\
354\end{array}$ & $\begin{array}{l}289 \\
214 \\
393 \\
304 \\
402\end{array}$ \\
\hline 1981 & 454 & 428 & 403 & 382 & 376 & 364 & 571 & 722 & 894 & 330 & 192 & 296 \\
\hline
\end{tabular}

ANNAL FEAK DISCHARGE, IN CJBIC FEET FER SECOND, AND CORRESFONDING GAGE HEIGHT, IN FEET, FOR EACH WATER YEAR

\begin{tabular}{|c|c|c|c|c|c|c|c|c|c|c|c|}
\hline $\begin{array}{l}\text { WAIER } \\
\text { YEAR }\end{array}$ & DATE & $\begin{array}{c}\text { GAGE } \\
\text { HEIGHT }\end{array}$ & $\begin{array}{c}\text { PEAK } \\
\text { DISOH ARGE }\end{array}$ & $\begin{array}{l}\text { WATER } \\
\text { YEAR }\end{array}$ & DATE & $\begin{array}{c}\text { GAGE } \\
\text { HEIGHT }\end{array}$ & $\begin{array}{c}\text { FEAK } \\
\text { DISOHARGE }\end{array}$ & $\begin{array}{l}\text { WAIER } \\
\text { YEAR }\end{array}$ & DATE & $\begin{array}{c}\text { GAGE } \\
\text { HEIGHT }\end{array}$ & $\begin{array}{c}\text { FEAK } \\
\text { DISCH ARGE }\end{array}$ \\
\hline $\begin{array}{l}1975 \\
1976 \\
1977\end{array}$ & $\begin{array}{l}\text { JUNE } 10,1975 \\
\text { MAY 21, } 1976 \\
\text { AUG. 28, } 1977\end{array}$ & $\begin{array}{l}7.57 \\
5.79 \\
4.60\end{array}$ & $\begin{array}{r}3950 \\
2110 \\
840\end{array}$ & $\begin{array}{l}1978 \\
1979\end{array}$ & $\begin{array}{l}\text { JUNE 19, } 1978 \\
\text { MAR. 29, } 1979\end{array}$ & $\begin{array}{l}7.94 \\
7.71\end{array}$ & $\begin{array}{l}4080 \\
4260\end{array}$ & $\begin{array}{l}1980 \\
1981\end{array}$ & $\begin{array}{lll}\text { MAY } & 25,1980 \\
\text { JUNE } & 10,1981\end{array}$ & $\begin{array}{l}6.93 \\
6.29\end{array}$ & $\begin{array}{l}2840 \\
1920\end{array}$ \\
\hline
\end{tabular}

09307000 GREEN RIVER NEAR OURAY, UT

LOCATION.--Lat $40^{\circ} 04^{\prime} 20^{\prime \prime}$, lang $109^{\circ} 43^{\prime} 40^{\prime \prime}$, in NE $\frac{1}{4}$ sec.11, T.5 S., R. 2 E., Uintah Meridian, Uintah County, Hydrologic Unit 14060005 , on right bank $2.8 \mathrm{mi}$ upstream from willow Creek and $3 \mathrm{mi}$ southwest of Ouray.

DRAINAGE AREA. $--35,500 \mathrm{mi}^{2}$.

PERTOD OF RECORD AVAILABLE.--Octcber 1947 to September 1955, Octcber 1956 to September 1966.

GAGE. - Water-stage recorder. Datum of gage is 4,637 ft NGVD of 1929.

REMARKS.--Diversions for irrigation above station. Flow regulated by Flaming Gorge Reservoir since Nov. $1,1962$.

AVERAGE DISQHARGE. --1 8 years, $5,428 \mathrm{ft}^{3} / \mathrm{s}, 3,930,000$ acre-ft/yr, unadjusted.

EXTREMES FOR FERIOD OF RECORD.--Maximum discharge, 43,600 $\mathrm{ft}^{3} / \mathrm{s}$ June 11, 1952, gage height, $14.99 \mathrm{ft} ; \mathrm{minimum}$ daily, $470 \mathrm{ft} / \mathrm{s} \mathrm{July}$ 31, Aug. 1, 1963.

DATA BELOW BASED ON FERIOD OF RECORD PRIOR TO REGULATION BY FLAMING GORGE RESERVOIR

LONEST MEAN DISCHARGE, IN OBBIC FEET PER SECOND, AND RANKING FOR THE INDICATED NUMBER OF CONSECITIVE DAYS FOR EAG CLIMATIC YEAR, APRIL 1-MARCH 31

\begin{tabular}{|c|c|c|c|c|c|c|c|c|c|c|c|c|c|c|c|c|c|c|c|c|}
\hline YEAR & 1 & & 3 & & 7 & & 14 & & $\underset{30}{\infty}$ & SEW & TVE D & & 9 & & 120 & & 183 & & ALL & \\
\hline
\end{tabular}


LONEST MEAN DISCHARGE, IN OBIC FEET PER SECOND, AND RANKING FOR THE INDICATED NUMBER OF CONSEQUTIVE DAYS FOR EACH CLIMATIC YEAR, APRIL 1-MAROH 31--Continued

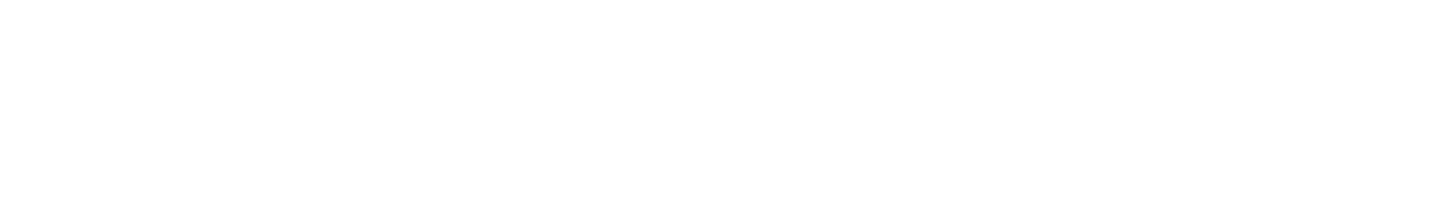

HIGHEST MEAN DISGHARGE, IN GBIC FEET PER SECOND, AND RANKING FOR THE INDICATED NUMBER OF OONSECUTIVE DAYS FOR EAOH WATER YEAR, OCTOBER 1-SEPTEMBER 30

YEAR

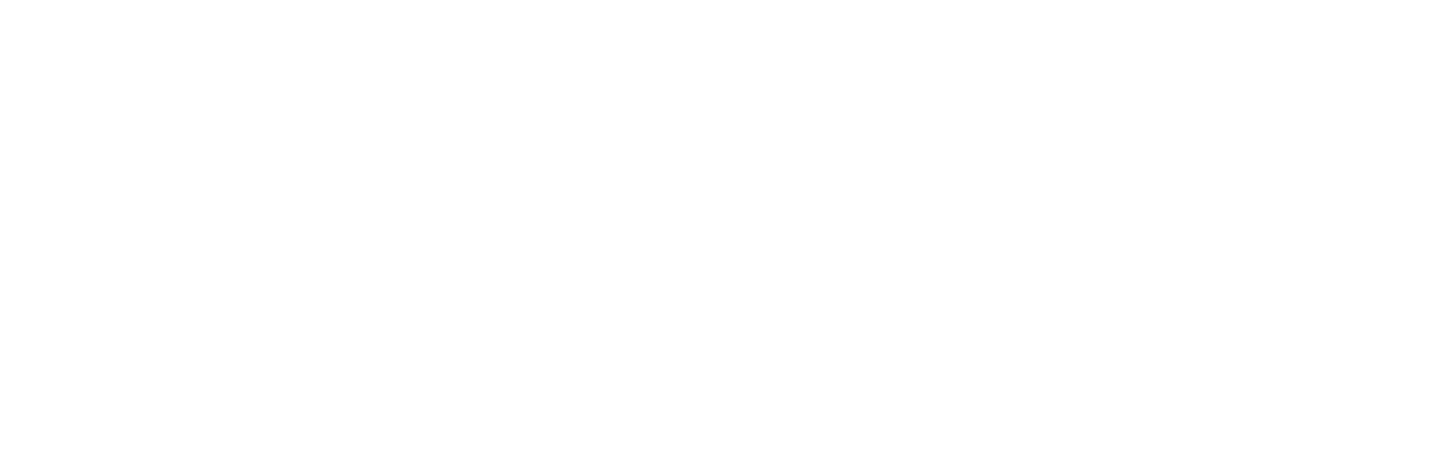

DURATION OF DISOHARGE FOR EACH WATER YEAR

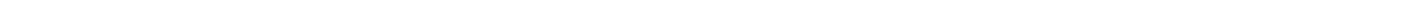
YEAR NUMBER OF DAYS IN CLASS

\begin{tabular}{|c|c|c|c|c|c|c|c|c|c|c|c|c|c|c|c|c|c|c|c|c|c|c|c|c|c|c|c|c|c|c|c|}
\hline $\begin{array}{l}1948 \\
1949 \\
1950\end{array}$ & & 3 & 1 & $\begin{array}{rr}4 & 14 \\
4 & 2 \\
1 & \end{array}$ & $\begin{array}{l}9 \\
6 \\
2\end{array}$ & $\begin{array}{c}10 \\
29 \\
1\end{array}$ & $\begin{array}{r}7 \\
59 \\
10\end{array}$ & & $\begin{array}{l}48 \\
30 \\
29\end{array}$ & $\begin{array}{l}41 \\
10 \\
41\end{array}$ & $\begin{array}{l}43 \\
12 \\
39\end{array}$ & $\begin{array}{r}32 \\
7 \\
31\end{array}$ & $\begin{array}{r}18 \\
8 \\
26\end{array}$ & $\begin{array}{r}9 \\
8 \\
15\end{array}$ & $\begin{array}{r}6 \\
6 \\
16\end{array}$ & $\begin{array}{r}6 \\
9 \\
11\end{array}$ & $\begin{array}{r}6 \\
10 \\
8\end{array}$ & $\begin{array}{l}5 \\
7 \\
6\end{array}$ & $\begin{array}{l}9 \\
5 \\
9\end{array}$ & $\begin{array}{l}9 \\
9 \\
8\end{array}$ & $\begin{array}{r}112 \\
4 \\
81\end{array}$ & & $\begin{array}{l}7 \\
7 \\
9\end{array}$ & & $\begin{array}{l}4 \\
8 \\
4\end{array}$ & & $\begin{array}{rr}16 & 3 \\
17 & 8 \\
10 & 24\end{array}$ & $\begin{array}{l}3 \\
8 \\
4\end{array}$ & $\begin{array}{l}9 \\
6\end{array}$ & 2 & $\begin{array}{l}2033248.0 \\
2432880.0 \\
2753230.0\end{array}$ \\
\hline $\begin{array}{l}951 \\
952 \\
953 \\
954\end{array}$ & & & 1 & $\begin{array}{rr}1 \quad 4 \\
& 9 \\
12 & 10\end{array}$ & $\begin{array}{l}8 \\
13 \\
11 \\
41\end{array}$ & $\begin{array}{r}4 \\
8 \\
11 \\
27 \\
35\end{array}$ & $\begin{array}{r}3 \\
6 \\
15 \\
25\end{array}$ & $\begin{array}{r}9 \\
5 \\
25 \\
33\end{array}$ & $\begin{array}{l}20 \\
17 \\
49 \\
62 \\
49\end{array}$ & $\begin{array}{l}65 \\
92 \\
52 \\
29 \\
19\end{array}$ & $\begin{array}{l}27 \\
46 \\
36 \\
21 \\
19\end{array}$ & $\begin{array}{l}29 \\
17 \\
22 \\
30 \\
15\end{array}$ & $\begin{array}{r}38 \\
15 \\
18 \\
7 \\
14\end{array}$ & $\begin{array}{r}14 \\
14 \\
18 \\
3 \\
7\end{array}$ & $\begin{array}{r}14 \\
22 \\
19 \\
28 \\
7\end{array}$ & $\begin{array}{r}10 \\
7 \\
11 \\
18 \\
6\end{array}$ & $\begin{array}{r}8 \\
6 \\
14 \\
13 \\
8\end{array}$ & $\begin{array}{r}13 \\
9 \\
7 \\
8 \\
10\end{array}$ & $\begin{array}{r}17 \\
4 \\
7 \\
11 \\
10\end{array}$ & $\begin{array}{r}20 \\
2 \\
2 \\
8 \\
7\end{array}$ & $\begin{array}{l}4 \\
2 \\
2 \\
5 \\
9\end{array}$ & $\begin{array}{r}9 \\
7 \\
7 \\
6 \\
18\end{array}$ & $\begin{array}{r}9 \\
8 \\
2 \\
3 \\
20\end{array}$ & $\begin{array}{l}9 \\
9 \\
2\end{array}$ & $\begin{array}{l}6 \\
9 \\
7 \\
3\end{array}$ & $\begin{array}{l}7 \\
6 \\
3 \\
2\end{array}$ & $\begin{array}{rr}7 & 10 \\
9 & 9 \\
4 & 7\end{array}$ & $\begin{array}{lr}0 & 3 \\
9 & 14 \\
7 & \end{array}$ & & 210 & $\begin{array}{r}2378870.0 \\
13239060.0 \\
1713550.0 \\
1343350.0 \\
1420641.0\end{array}$ \\
\hline $\begin{array}{l}957 \\
958 \\
959 \\
960\end{array}$ & & & & $\begin{array}{lr}4 & 6 \\
4 & 40\end{array}$ & $\begin{array}{r}22 \\
4 \\
10 \\
18\end{array}$ & $\begin{array}{l}69 \\
37 \\
48\end{array}$ & $\begin{array}{l}14 \\
15 \\
27\end{array}$ & $\begin{array}{l}23 \\
11 \\
38 \\
17\end{array}$ & $\begin{array}{r}6 \\
45 \\
34 \\
17\end{array}$ & $\begin{array}{l}1 \\
47 \\
39 \\
31\end{array}$ & $\begin{array}{l}25 \\
28 \\
22 \\
15\end{array}$ & $\begin{array}{l}16 \\
14 \\
22 \\
14\end{array}$ & $\begin{array}{l}17 \\
35 \\
24 \\
10\end{array}$ & $\begin{array}{r}14 \\
11 \\
10 \\
8\end{array}$ & $\begin{array}{r}21 \\
17 \\
7 \\
5\end{array}$ & $\begin{array}{r}10 \\
20 \\
7 \\
11\end{array}$ & $\begin{array}{l}6 \\
6 \\
3 \\
7\end{array}$ & $\begin{array}{l}7 \\
3 \\
8 \\
7\end{array}$ & $\begin{array}{r}13 \\
11 \\
13 \\
8\end{array}$ & $\begin{array}{r}5 \\
4 \\
10 \\
9\end{array}$ & $\begin{array}{c}1 \\
5 \\
21 \\
13\end{array}$ & $\begin{array}{r}4 \\
8 \\
13 \\
20\end{array}$ & $\begin{array}{r}3 \\
4 \\
5 \\
12\end{array}$ & $\begin{array}{r}12 \\
4 \\
9 \\
15\end{array}$ & $\begin{array}{r}14 \\
4 \\
4\end{array}$ & $\begin{array}{l}9 \\
4\end{array}$ & & $\begin{array}{rr}2 & 10 \\
9 & 5\end{array}$ & $\begin{array}{l}3 \\
8\end{array}$ & $\begin{array}{l}3 \\
8\end{array}$ & $\begin{array}{r}2819560.0 \\
2187310.0 \\
1417590.0 \\
1570920.0\end{array}$ \\
\hline $\begin{array}{l}961 \\
962\end{array}$ & 11 & 1 & $\begin{array}{l}2 \\
1\end{array}$ & $\begin{array}{rr}4 & 27 \\
1 & 1\end{array}$ & $\begin{array}{r}40 \\
4\end{array}$ & $\begin{array}{l}40 \\
17\end{array}$ & $\begin{array}{l}4 C \\
34\end{array}$ & & $\begin{array}{l}44 \\
36\end{array}$ & $\begin{array}{l}12 \\
10\end{array}$ & $\begin{array}{l}17 \\
32\end{array}$ & $\begin{array}{l}20 \\
28\end{array}$ & $\begin{array}{l}20 \\
16\end{array}$ & $\begin{array}{l}11 \\
14\end{array}$ & $\begin{array}{r}7 \\
12\end{array}$ & $\begin{array}{l}4 \\
7\end{array}$ & $\begin{array}{l}7 \\
8\end{array}$ & $\begin{array}{l}4 \\
4\end{array}$ & 9 & $\begin{array}{l}5 \\
4\end{array}$ & $\begin{array}{l}41 \\
5\end{array}$ & $\begin{array}{r}11 \\
6\end{array}$ & & & & & 913 & 3 & 7 & & $\begin{array}{l}1052737.0 \\
2917570.0\end{array}$ \\
\hline
\end{tabular}

DURATION TABLE OF DISCHARGE FOR WATER YEARS 1948-55, 1957-62

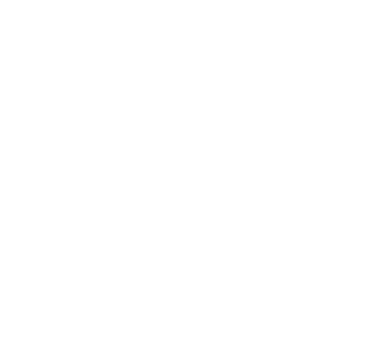

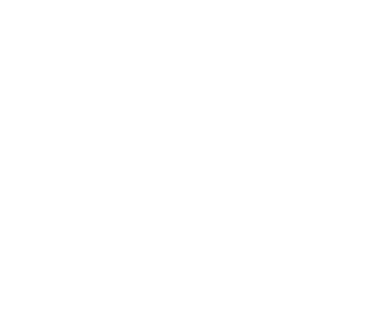

\begin{tabular}{|c|c|c|c|}
\hline $\begin{array}{c}\text { OUBIC } \\
\text { FEET } \\
\text { PER }\end{array}$ & TOTAL & $\begin{array}{l}\text { ACOJ- } \\
\text { MU- } \\
\text { LATED }\end{array}$ & $\begin{array}{l}\text { PER- } \\
\text { CENT }\end{array}$ \\
\hline CLASS SECOND & DAYS & DAYS & DAYS \\
\hline $\begin{array}{ll}27 & 17000.0 \\
28 & 19000.0 \\
29 & 22000.0 \\
30 & 25000.0 \\
31 & 29000.0 \\
32 & 33000.0 \\
33 & 38000.0 \\
34 & 43000.0\end{array}$ & $\begin{array}{l}77 \\
79 \\
85 \\
95 \\
54 \\
25 \\
17 \\
3\end{array}$ & $\begin{array}{r}435 \\
358 \\
279 \\
194 \\
99 \\
45 \\
20 \\
3\end{array}$ & $\begin{array}{l}8.5 \\
7.0 \\
5.5 \\
3.8 \\
1.9 \\
0.9 \\
0.4 \\
0.1\end{array}$ \\
\hline
\end{tabular}


GREEN RIVER BASIN

09307000 GREEN RIVER NEAR OURAY, UT-Continued

MONIHLY MEAN DISCHARGES, IN CUBIC FEET PER SECOND, FOR EACH WATER YEAR

\begin{tabular}{|c|c|c|c|c|c|c|c|c|c|c|c|c|}
\hline YEAR & $\propto T$ & $\mathrm{NOV}$ & DEC & JAN & FEB & MAR & APR & MAY & JUNE & JULY & AUG & SEP \\
\hline $\begin{array}{l}1948 \\
1949 \\
1950\end{array}$ & $\begin{array}{l}2778 \\
1464 \\
3135\end{array}$ & $\begin{array}{l}2742 \\
1622 \\
2944\end{array}$ & $\begin{array}{l}2461 \\
1518 \\
1861\end{array}$ & $\begin{array}{l}2111 \\
1577 \\
2039\end{array}$ & $\begin{array}{l}2420 \\
1870 \\
2438\end{array}$ & $\begin{array}{l}4497 \\
4270 \\
5233\end{array}$ & $\begin{array}{r}9140 \\
8233 \\
10900\end{array}$ & $\begin{array}{l}17720 \\
19990 \\
17390\end{array}$ & $\begin{array}{l}15780 \\
26010 \\
26830\end{array}$ & $\begin{array}{r}3931 \\
9076 \\
11560\end{array}$ & $\begin{array}{l}1998 \\
2495 \\
3669\end{array}$ & $\begin{array}{l}1101 \\
1752 \\
2436\end{array}$ \\
\hline $\begin{array}{l}1951 \\
1952 \\
1953 \\
1954 \\
1955\end{array}$ & $\begin{array}{l}2349 \\
3361 \\
1909 \\
1341 \\
2061\end{array}$ & $\begin{array}{l}2767 \\
2651 \\
1935 \\
1983 \\
1956\end{array}$ & $\begin{array}{l}2586 \\
2135 \\
1951 \\
1706 \\
1227\end{array}$ & $\begin{array}{l}1760 \\
2038 \\
2257 \\
1705 \\
1272\end{array}$ & $\begin{array}{l}2954 \\
2295 \\
2470 \\
2500 \\
1498\end{array}$ & $\begin{array}{l}3475 \\
2448 \\
3504 \\
2797 \\
3305\end{array}$ & $\begin{array}{r}6620 \\
16110 \\
3929 \\
4886 \\
5368\end{array}$ & $\begin{array}{r}15260 \\
30700 \\
8143 \\
11270 \\
11490\end{array}$ & $\begin{array}{r}21830 \\
29210 \\
19910 \\
6262 \\
11360\end{array}$ & $\begin{array}{r}10010 \\
7750 \\
5751 \\
5656 \\
3488\end{array}$ & $\begin{array}{l}5824 \\
4781 \\
3249 \\
1990 \\
2456\end{array}$ & $\begin{array}{l}2684 \\
2787 \\
1387 \\
1967 \\
1134\end{array}$ \\
\hline $\begin{array}{l}1957 \\
1958 \\
1959 \\
1960\end{array}$ & $\begin{array}{l}1216 \\
2949 \\
1382 \\
2762\end{array}$ & $\begin{array}{l}1609 \\
3465 \\
1662 \\
2444\end{array}$ & $\begin{array}{l}1300 \\
2277 \\
1794 \\
1678\end{array}$ & $\begin{array}{l}1350 \\
1979 \\
1626 \\
1416\end{array}$ & $\begin{array}{l}1838 \\
3206 \\
2107 \\
1497\end{array}$ & $\begin{array}{l}3748 \\
3995 \\
2602 \\
5612\end{array}$ & $\begin{array}{l}5324 \\
7099 \\
3942 \\
9679\end{array}$ & $\begin{array}{r}16050 \\
22080 \\
8262 \\
9358\end{array}$ & $\begin{array}{l}32180 \\
18730 \\
13660 \\
12250\end{array}$ & $\begin{array}{r}19270 \\
3075 \\
5134 \\
2689\end{array}$ & $\begin{array}{l}5604 \\
1607 \\
2741 \\
1157\end{array}$ & $\begin{array}{l}3001 \\
1401 \\
1701 \\
1047\end{array}$ \\
\hline $\begin{array}{l}1961 \\
1962\end{array}$ & $\begin{array}{l}1521 \\
3514\end{array}$ & $\begin{array}{l}1839 \\
2661\end{array}$ & $\begin{array}{l}1233 \\
1840\end{array}$ & $\begin{array}{l}1235 \\
1642\end{array}$ & $\begin{array}{l}1683 \\
6289\end{array}$ & $\begin{array}{l}2451 \\
7061\end{array}$ & $\begin{array}{r}3099 \\
18340\end{array}$ & $\begin{array}{r}6295 \\
22150\end{array}$ & $\begin{array}{r}9663 \\
18310\end{array}$ & $\begin{array}{l}1817 \\
9760\end{array}$ & $\begin{array}{l}1189 \\
2987\end{array}$ & $\begin{array}{l}2653 \\
1481\end{array}$ \\
\hline
\end{tabular}

ANNUAL, PEAK DISCHARGE, IN OUBIC FEET PER SECOND, AND CORRESPONDING GAGE HEIGHT, IN FEET, FOR EACH WAIER YEAR

\begin{tabular}{|c|c|c|c|c|c|c|c|c|c|c|c|}
\hline $\begin{array}{l}\text { WAIIER } \\
\text { YEAR }\end{array}$ & DATE & $\begin{array}{c}\text { GAGE } \\
\text { HEIGHT }\end{array}$ & $\begin{array}{c}\text { PEAK } \\
\text { DISCHARGE }\end{array}$ & $\begin{array}{l}\text { WATER } \\
\text { YEAR }\end{array}$ & DATE & $\begin{array}{c}\text { GAGE } \\
\text { HEIGHT }\end{array}$ & $\begin{array}{c}\text { PEAK } \\
\text { DISCHARGE }\end{array}$ & $\begin{array}{l}\text { WATER } \\
\text { YEAR }\end{array}$ & DAIE & $\begin{array}{c}\text { GAGE } \\
\text { HEIGHT }\end{array}$ & $\begin{array}{c}\text { PEAK } \\
\text { DISCHARGE }\end{array}$ \\
\hline $\begin{array}{l}1948 \\
1949 \\
1950 \\
1951 \\
1952\end{array}$ & $\begin{array}{ll}\text { MAY } & 25,1948 \\
\text { JUNE } 21,1949 \\
\text { JUNE } 07,1950 \\
\text { MAY } 31,1951 \\
\text { JUNE } 11,1952\end{array}$ & $\begin{array}{l}11.56 \\
12.62 \\
12.17 \\
12.27 \\
14.99\end{array}$ & $\begin{array}{l}26200 \\
33700 \\
31900 \\
30600 \\
43600\end{array}$ & $\begin{array}{l}1953 \\
1954 \\
1955 \\
1957 \\
1958\end{array}$ & 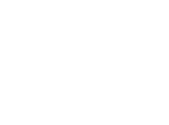 & $\begin{array}{r}12.36 \\
10.42 \\
9.55 \\
14.42 \\
13.53\end{array}$ & $\begin{array}{l}28400 \\
19700 \\
14700 \\
43300 \\
37600\end{array}$ & $\begin{array}{l}1959 \\
1960 \\
1961 \\
1962\end{array}$ & $\begin{array}{lll}\text { JUNE } & 23, & 1959 \\
\text { JUNE } & 10,1960 \\
\text { JUNE } & 02,1961 \\
\text { MAY } & 13, & 1962\end{array}$ & $\begin{array}{c}11.15 \\
10.59 \\
9.98 \\
--\end{array}$ & $\begin{array}{l}18500 \\
16900 \\
15000 \\
32500\end{array}$ \\
\hline
\end{tabular}

MAGNITUDE AND PRCBABILITY OF ANNUAL LOWEST MEAN DISCHARGE BASED ON CLIMATIC YEARS 1949-55 AND 1958-62

\begin{tabular}{|c|c|c|c|c|c|c|}
\hline \multirow{2}{*}{$\begin{array}{l}\text { PERIOD } \\
\text { (CON- } \\
\text { SEOU- } \\
\text { TIVE } \\
\text { DAYS) }\end{array}$} & \multicolumn{6}{|c|}{$\begin{array}{l}\text { DISCHARGE, IN OUBIC FEET PER SECOND, FOR } \\
\text { INDICATED RECURRENCE INTERNAL, IN YEARS, AND } \\
\text { ANNUAL NONEXCEEDANCE PRCBABIIITY, IN PERCENT }\end{array}$} \\
\hline & $\begin{array}{c}2 \\
50 \%\end{array}$ & $\begin{array}{c}5 \\
208\end{array}$ & $\begin{array}{l}10 \\
108\end{array}$ & $\begin{array}{l}20 \\
58\end{array}$ & $\begin{array}{l}50 \\
28\end{array}$ & $\begin{array}{r}100 \\
18\end{array}$ \\
\hline $\begin{array}{r}1 \\
7 \\
14 \\
30 \\
60 \\
90\end{array}$ & $\begin{array}{r}907 \\
1060 \\
1200 \\
1400 \\
1540 \\
1710\end{array}$ & $\begin{array}{r}705 \\
897 \\
1030 \\
1160 \\
1260 \\
1420\end{array}$ & $\begin{array}{r}615 \\
830 \\
958 \\
1050 \\
1140 \\
1280\end{array}$ & $\begin{array}{r}548 \\
783 \\
908 \\
971 \\
1050 \\
1180\end{array}$ & $\begin{array}{l}\bar{z} \\
\bar{z} \\
\overline{-}\end{array}$ & $\overline{-}$ \\
\hline
\end{tabular}

MAGNITUDE AND PRCBABILITY OF ANNAL HIGHEST MEAN DISCHARGE BASED ON WATER YEARS 1 948-55 AND 1957-62

\begin{tabular}{lcccccc}
\hline & \multicolumn{5}{c}{ DISCHARGE, IN CUBIC FEET PER SECOND, FOR } \\
$\begin{array}{l}\text { PERIOD } \\
\text { (CON- }\end{array}$ & $\begin{array}{c}\text { INDICATED RECURRENCE INTERNAL, IN YEARS, AND } \\
\text { ANNUAL EXCEEDANCE PRCBABILITY, IN PERCENT }\end{array}$ \\
$\begin{array}{l}\text { SECU- } \\
\text { TIVE }\end{array}$ & 2 & 5 & 10 & 25 & 50 & 100 \\
DAYS) & 508 & 208 & 108 & 48 & 28 & 18 \\
\hline & & & & & & \\
1 & 26500 & 36000 & 41800 & 48600 & - & - \\
3 & 26200 & 35600 & 41400 & 48200 & - & - \\
7 & 25300 & 34600 & 40300 & 47100 & - & - \\
15 & 23300 & 31700 & 36900 & 43000 & - & -
\end{tabular}

DATA BELOW BASED ON PERIOD OF RECORD AFTER COMPLETION OF FLAMING GORGE RESERVOIR

LOWEST MEAN DISCHARGE, IN CUBIC FEET PER SECOND, AND RANKING FOR THE INDICATED NUMBER OF CONSECUTIVE DAYS FOR EACH CLIMATIC YEAR, APRIL 1-MARCH 31

\begin{tabular}{|c|c|c|c|c|c|c|c|c|c|c|c|c|c|c|c|c|c|c|}
\hline YEAR & 1 & & 3 & & 7 & & 14 & & $\begin{array}{l}\alpha \\
30\end{array}$ & EOr? & $\begin{array}{l}\text { IVE } \\
60\end{array}$ & & 90 & & 120 & & 183 & ALI \\
\hline & 1870 & 1 & 1950 & 1 & 2000 & 1 & 2230 & 1 & 2510 & 1 & 2830 & 1 & 3150 & 1 & 3470 & 1 & 3480 & 6740 \\
\hline
\end{tabular}

HIGHEST MEAN DISCHARGE, IN OUBIC FEET PER SECOND, AND RANKING FOR THE INDICATED NUMBER OF CONSECUTIVE DAYS FOR EACH WAIER YEAR, OCTOBER 1-SEPTENBER 30

\begin{tabular}{|c|c|c|c|c|c|c|c|c|c|c|}
\hline YEAR & 3 & 7 & 15 & $\begin{array}{l}C O \\
30\end{array}$ & $\begin{array}{l}\text { SOUTIVE DAY } \\
60\end{array}$ & 90 & 320 & 183 & & ALL \\
\hline 196529900 & 129500 & 128300 & 125600 & 121100 & 117300 & 114700 & 112800 & 110300 & 1 & 6990 \\
\hline
\end{tabular}

DURATION OF DISCHARGE FOR EACH WATER YEAR

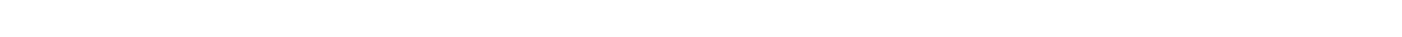
YEAR

MUMBER OF DAYS IN CIASS OUBIC FEET PER SECON
-DAYS

$\begin{array}{llllllllllllllllllllllllllllllllllllllll}1965 & 7 & 4 & 6 & 4 & 11 & 8 & 23 & 23 & 31 & 16 & 29 & 22 & 16 & 34 & 13 & 15 & 11 & 10 & 7 & 4 & 7 & 8 & 10 & 7 & 6 & 4 & 4 & 3 & 5 & 6 & 3 & 2 & 6 & 2550930.0\end{array}$

$\begin{array}{lllllllllllllllllllllllllllll}1966 & 1 & 6 & 34 & 31 & 29 & 22 & 44 & 24 & 14 & 10 & 32 & 17 & 14 & 12 & 15 & 7 & 10 & 9 & 13 & 6 & 2 & 5 & 3 & 1 & 3 & 1\end{array}$

1610850.0 
09307000 GREFAN RIVER NEAR OURAY, UT--Continued

DURATION TABLE OF DISCHARGE FOR WATER YEARS 1965-66
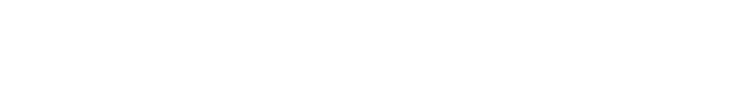

CUBIC ACOU-

FEET MU- PER-

CLASS SECOND DAYS DAYS DAYS

$\begin{array}{rcc}\text { OBBIC } & \text { ACOU- } \\ \text { FEET } & \text { MU- } & \text { PER- } \\ \text { PER } & \text { TOTAL LATED } & \text { CENT } \\ \text { CLASS SECOND DAYS } & \text { DAYS } & \text { DAYS }\end{array}$

$\begin{array}{rrrrr}0 & 0.0 & 0 & 730 & 100.0 \\ 1 & 1800.0 & 8 & 730 & 100.0 \\ 2 & 2000.0 & 10 & 722 & 98.9 \\ 3 & 2100.0 & 40 & 712 & 97.5 \\ 4 & 2300.0 & 35 & 672 & 92.0 \\ 5 & 2500.0 & 40 & 637 & 87.3 \\ 6 & 2800.0 & 30 & 597 & 81.8 \\ 7 & 3000.0 & 67 & 567 & 77.7 \\ 8 & 3300.0 & 47 & 500 & 68.5\end{array}$

$\begin{array}{rr}9 & 3600.0 \\ 10 & 3900.0 \\ 11 & 4200.0 \\ 12 & 4600.0 \\ 13 & 5000.0 \\ 14 & 5400.0 \\ 15 & 5900.0 \\ 16 & 6400.0 \\ 17 & 7000.0\end{array}$

$\begin{array}{lll}45 & 453 & 62.0 \\ 26 & 408 & 55.9 \\ 61 & 382 & 52.3 \\ 39 & 321 & 44.0 \\ 30 & 282 & 38.6 \\ 46 & 252 & 34.5 \\ 28 & 206 & 28.2 \\ 22 & 178 & 24.4 \\ 21 & 156 & 21.4\end{array}$

$\begin{array}{lrr}18 & 7600.0 & 19 \\ 19 & 8300.0 & 2 \\ 20 & 9000.0 & 1 \\ 21 & 9800.0 & \\ 22 & 11000.0 & 13 \\ 23 & 12000.0 & 13 \\ 24 & 13000.0 & \\ 25 & 14000.0 & \\ 26 & 15000.0 & \end{array}$

$\begin{array}{rr}135 & 18.5 \\ 116 & 15.9 \\ 96 & 13.2 \\ 86 & 11.8 \\ 77 & 10.6 \\ 64 & 8.8 \\ 51 & 7.0 \\ 43 & 5.9 \\ 34 & 4.7\end{array}$

$\begin{array}{ll}27 & 16000.0 \\ 28 & 18000.0 \\ 29 & 19000.0 \\ 30 & 21000.0 \\ 31 & 23000.0 \\ 32 & 25000.0 \\ 33 & 27000.0 \\ 34 & \end{array}$

$\begin{array}{rrr}4 & 29 & 4.0 \\ 3 & 25 & 3.4 \\ 5 & 22 & 3.0 \\ 6 & 17 & 2.3 \\ 3 & 11 & 1.5 \\ 2 & 8 & 1.1 \\ 6 & 6 & 0.8\end{array}$

MONTHLY MEAN DISCHARGES, IN OUIC FEET PER SBCOND, FOR EACH WATER YEAR

$\begin{array}{rrrrrrrrrrrrr}\text { YEAR } & \infty & \text { NOV } & \text { DEC } & \text { JAN } & \text { FEB } & \text { MAR } & \text { APR } & \text { MAY } & \text { JUNE } & \text { JULY } & \text { AUG } & \text { SEP } \\ 1965 & 3300 & 3526 & 4014 & 4906 & 5382 & 5802 & 8425 & 13210 & 20990 & 8080 & 3252 & 3084 \\ 1966 & 4030 & 4090 & 3973 & 2873 & 2918 & 5867 & 6522 & 9813 & 5455 & 2376 & 2353 & 2577\end{array}$

ANNUAL PEAK DISCHARGE, IN CUBIC FEET PER SECOND, AND CORRESPONDING GAGE HEIGHI, IN FEET, FOR EAGH WATER YEAR

\begin{tabular}{|c|c|c|c|c|c|c|c|c|c|c|c|c|c|}
\hline $\begin{array}{l}\text { WATERR } \\
\text { YEAR }\end{array}$ & & DATE & $\begin{array}{c}\text { GAGE } \\
\text { HEIGHT }\end{array}$ & $\begin{array}{c}\text { PEAK } \\
\text { DISCHARGE }\end{array}$ & $\begin{array}{l}\text { WATER } \\
\text { YEAR }\end{array}$ & DATE & $\begin{array}{c}\text { GAGE } \\
\text { HEIGHT }\end{array}$ & $\begin{array}{c}\text { PEAK } \\
\text { DISCHARGE }\end{array}$ & $\begin{array}{l}\text { WATER } \\
\text { YEAR }\end{array}$ & & DATE & $\begin{array}{c}\text { GAGE } \\
\text { HEIGHT }\end{array}$ & $\begin{array}{l}\text { PEAK } \\
\text { DISCHARGE }\end{array}$ \\
\hline 1963 & MAY & 14,1963 & 8.60 & $\mathrm{I}_{10400}$ & 1965 & JUNE 17,1965 & 12.92 & 30200 & 1966 & MAY & 12,1966 & 10.27 & 15500 \\
\hline 1964 & MAY & 22,1964 & 11.23 & $I_{21200}$ & & & & & & & & & \\
\hline
\end{tabular}

1 Peak discharge occurred during filling period for Flaming Gorge Reservoir.

09308200 PLEASANT VALLEY WASH TRIBUTARY NEAR MYTON, UT

LOCATION.--Lat $40^{\circ} 07^{\prime} 08^{\prime \prime}$, long $110^{\circ} 08^{\prime \prime} 00^{n}$, in center of sec.20, T.4 S., R.2 W., Uintah Special Meridian, Duchesne County, Hydrologic Unit $14060005,5.5 \mathrm{mi}$ southwest on State Highway 53 from junction of U.S. Highway 40 and State Highway 53 , and 7.3 mi southwest of Myton.

DRATNAGE AREA. $-15 \mathrm{mi}^{2}$.

MEAN BASIN ELEVATION. $-6,110 \mathrm{ft}$.

PERIOD OF RECORD AVAII.ABLE. - Water years 1960-70, annual peak discharge only.

GAGE.-Crest-stage gage. Altitude of gage is $5,400 \mathrm{ft}$ fram topographic map.

ANNUAL PEAK DISCHARGE, IN CUBIC FEET PER SECOND, AND CORRESPONDING GAGE HEIGHT, IN FEET, FOR EACH WATER YEAR

\begin{tabular}{|c|c|c|c|c|c|c|c|c|c|c|c|c|c|}
\hline $\begin{array}{l}\text { WATERR } \\
\text { YEAR }\end{array}$ & DATE & $\begin{array}{c}\text { GAGE } \\
\text { HEIGHT }\end{array}$ & $\begin{array}{c}\text { PEAR } \\
\text { DISCHARGE }\end{array}$ & $\begin{array}{l}\text { WAT } \\
\text { YEA }\end{array}$ & & DATE & $\begin{array}{c}\text { GAGE } \\
\text { HEIGEPT }\end{array}$ & $\begin{array}{c}\text { PEAK } \\
\text { DISCHARGE }\end{array}$ & $\begin{array}{l}\text { WAT } \\
\text { YEI }\end{array}$ & & DATE & $\begin{array}{c}\text { GAGE } \\
\text { HEIGHT }\end{array}$ & $\begin{array}{c}\text { PEAR } \\
\text { DISCHARGE }\end{array}$ \\
\hline $\begin{array}{l}1960 \\
1961 \\
1962 \\
1963\end{array}$ & $\begin{array}{l}\text { SEPT.17, } 1960 \\
\text { SEPT.09, } 1961 \\
\text { FEB. 13, } 1962 \\
\text { AUG. 06, } 1963\end{array}$ & $\begin{array}{l}10.02 \\
11.35 \\
11.45 \\
12.41\end{array}$ & $\begin{array}{r}3.5 \\
183 \\
230 \\
1060\end{array}$ & $\begin{array}{l}1964 \\
1965 \\
1966 \\
1967\end{array}$ & $\begin{array}{l}-\overline{\text { JUNE }} \\
\text { JULY } \\
\text { JUNE }\end{array}$ & $\begin{array}{l}\overline{12}, \overline{1965} \\
01,1966 \\
04,1967\end{array}$ & $\begin{array}{r}-\overline{12.95} \\
9.50 \\
7.75\end{array}$ & $\begin{array}{l}0 \\
350 \\
310 \\
0.40\end{array}$ & $\begin{array}{l}1968 \\
1969 \\
1970\end{array}$ & $\begin{array}{l}\text { JULY } \\
\text { JUNE } \\
\text { SEPT }\end{array}$ & $\begin{array}{r}09,1968 \\
17,1969 \\
06,1970\end{array}$ & $\begin{array}{r}15.50 \\
8.78 \\
8.39\end{array}$ & $\begin{array}{r}2590 \\
93 \\
31\end{array}$ \\
\hline
\end{tabular}


GREEN RIVER BASIN

09307200 PARIETTE DRAW NEAR OURAY, UT

LOCATION. --Lat $40^{\circ} 04^{\prime} 58^{\prime \prime}$, long $109^{\circ} 2^{\prime} 22^{\prime \prime}$, in SW ${ }^{1} \mathrm{SE}^{3} \mathrm{SE}_{\frac{1}{4}}^{\frac{1}{4}}$ sec. 27, T. 8 S., R.18 E., Uintah County, Hydrologic Unit 14060005, on right bank 1.2 mi upstream from Castle Peak Draw and $10.5 \mathrm{mi}$ west of Ouray.

DRAINAGE AREA, $-153 \mathrm{mi}^{2}$.

MEAN BASIN ELEVATTON. $-5,920 \mathrm{ft}$.

PERIOD OF RECORD AVAILABLE. - October 1975 to September 1981.

REVISED RECORDS. -WDR UT-77-1: Drainage area.

GAGE. -Water-stage recorder. Altitude of gage is 4,790 ft from topographic map.

REMARKS. -Scme small diversions above station for irrigation.

AVERAGE DISOHARGE. -6 years, $24.9 \mathrm{ft}^{3} / \mathrm{s}, 18,040$ acre- $\mathrm{ft} / \mathrm{yt}$.

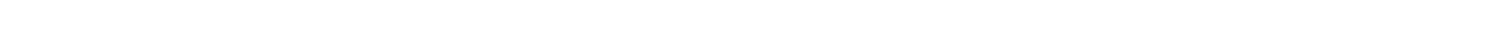
1976.

LOWEST NEAN DISOHARGE, IN GBIC FEET PER SECOND, AND RANKING FOR THE INDICATED -NUMBER OF CONSEQUTIVE DAYS FOR EACH OLIMATIC YEAR, APRIL 1-MAROH 31

\begin{tabular}{|c|c|c|c|c|c|c|c|c|c|c|c|c|c|c|c|c|c|c|c|}
\hline YEAR & 1 & & 3 & & 7 & & 14 & & $\begin{array}{l}\text { CONSE } \\
30\end{array}$ & UT & $\begin{array}{c}\text { E DAYS } \\
60\end{array}$ & & 90 & & 120 & & 183 & & ALL \\
\hline 1981 & 5.00 & 2 & 6.70 & 4 & 7.20 & 3 & 7.60 & 3 & 8.50 & 3 & 11.0 & 4 & 13.0 & 4 & 15.0 & 5 & 27.0 & 5 & 29.0 \\
\hline
\end{tabular}

HIGHEST MEAN DISGHARGE, IN OUIC FEET PER SECOND, AND RANKING FOR THE INDICATED NUMBER OF CONSEQUTIVE DAYS FOR EAOH WATER YEAR, OCTOBER 1-SEPTEMBER 30

\begin{tabular}{|c|c|c|c|c|c|c|c|c|c|c|c|c|c|c|c|c|c|c|c|}
\hline YEAR & & & & & & & & & CONS & QUT & E DAYS & & & & & & & & \\
\hline $\begin{array}{l}1976 \\
1977 \\
1978 \\
1979 \\
1980\end{array}$ & $\begin{array}{l}72.0 \\
97.0 \\
140 \\
331 \\
335\end{array}$ & $\begin{array}{l}6 \\
5 \\
3 \\
2 \\
1\end{array}$ & $\begin{array}{l}70.0 \\
81.0 \\
110 \\
172 \\
177\end{array}$ & $\begin{array}{l}6 \\
5 \\
3 \\
2 \\
1\end{array}$ & $\begin{array}{r}66.0 \\
64.0 \\
81.0 \\
104 \\
102\end{array}$ & $\begin{array}{l}5 \\
6 \\
4 \\
1 \\
2\end{array}$ & $\begin{array}{l}65.0 \\
55.0 \\
67.0 \\
98.0 \\
86.0\end{array}$ & $\begin{array}{l}5 \\
6 \\
4 \\
1 \\
2\end{array}$ & $\begin{array}{l}61.0 \\
52.0 \\
46.0 \\
62.0 \\
70.0\end{array}$ & $\begin{array}{l}4 \\
5 \\
6 \\
3 \\
1\end{array}$ & $\begin{array}{l}50.0 \\
36.0 \\
34.0 \\
47.0 \\
53.0\end{array}$ & $\begin{array}{l}2 \\
5 \\
6 \\
4 \\
1\end{array}$ & $\begin{array}{l}38.0 \\
32.0 \\
28.0 \\
38.0 \\
42.0\end{array}$ & $\begin{array}{l}3 \\
5 \\
6 \\
4 \\
1\end{array}$ & $\begin{array}{l}30.0 \\
28.0 \\
24.0 \\
34.0 \\
37.0\end{array}$ & $\begin{array}{l}4 \\
5 \\
6 \\
3 \\
1\end{array}$ & $\begin{array}{l}24.0 \\
24.0 \\
23.0 \\
31.0 \\
30.0\end{array}$ & $\begin{array}{l}4 \\
5 \\
6 \\
2 \\
3\end{array}$ & $\begin{array}{l}23.0 \\
21.0 \\
22.0 \\
27.0 \\
25.0\end{array}$ \\
\hline 1981 & 107 & 4 & 101 & 4 & 87.0 & 3 & 73.0 & 3 & 68.0 & 2 & 48.0 & 3 & 40.0 & 2 & 37.0 & 2 & 34.0 & 1 & 31.0 \\
\hline
\end{tabular}

DURATTON OF DISCHARGE FOR EACH WATER YEAR

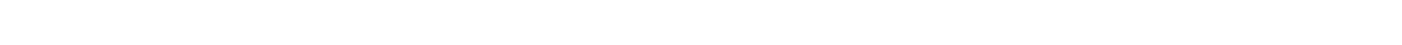

YEAR

NUMBER OF DAYS IN CLASS

OBBIC FEET
PER SECOND
-DAYS

$\begin{array}{lllllllllllllllllllllll}2 & 3 & 4 & 7 & 8 & 39 & 9 & 15 & 10 & 5 & 20 & 41 & 34 & 27 & 22 & 33 & 14 & 6 & 11 & 6 & 14 & 28 & 8\end{array}$

$\begin{array}{lllllllllllllllllllllll}24 & 32 & 9 & 7 & 9 & 16 & 37 & 27 & 30 & 23 & 28 & 18 & 17 & 20 & 17 & 13 & 16 & 15 & 3 & 1 & 2 & 1\end{array}$

$\begin{array}{llllllllllllllllll}11 & 6 & 13 & 12 & 61 & 88 & 30 & 28 & 20 & 14 & 28 & 13 & 9 & 9 & 6 & 4 & 5 & 6\end{array}$

$\begin{array}{lllllllllllllllllllllll}46 & 1 & 5 & 30 & 8 & 43 & 22 & 18 & 31 & 30 & 26 & 19 & 10 & 10 & 12 & 15 & 15 & 11 & 7 & 2 & 1 & 1 & 1\end{array}$

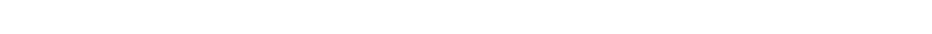

1979
1980

$\begin{array}{lllllllllllllll}1 & 2 & 17 & 16 & 30 & 36 & 42 & 44 & 12 & 19 & 15 & 18 & 35 & 23\end{array}$

DURATION TABLE OF DISCHARGE FOR WATER YEARS 1976-81.

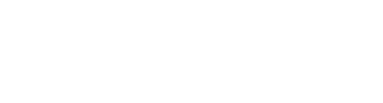

OLASS SECOND DAYS DAYS DAYS

$\begin{array}{rrrrr}0 & 0.00 & 0 & 2192 & 100.0 \\ 1 & 3.00 & 2 & 2192 & 100.0 \\ 2 & 3.50 & 3 & 2190 & 99.9 \\ 3 & 4.00 & 4 & 2187 & 99.8 \\ 4 & 4.60 & 32 & 2183 & 99.6 \\ 5 & 5.30 & 42 & 2151 & 98.1 \\ 6 & 6.10 & 96 & 2109 & 96.2 \\ 7 & 7.10 & 46 & 2013 & 91.8 \\ 8 & 8.10 & 60 & 1967 & 89.7\end{array}$

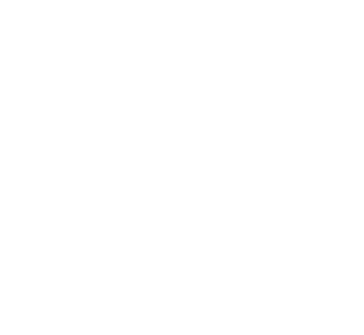

\begin{tabular}{crr}
\multicolumn{3}{c}{ OBBIC } \\
\multicolumn{3}{c}{ FEET } \\
CER & TOTR \\
CASS & SECOND & DAY \\
18 & 34.0 & 94 \\
19 & 39.0 & 82 \\
20 & 45.0 & 85 \\
21 & 52.0 & 79 \\
22 & 60.0 & 68 \\
23 & 69.0 & 35 \\
24 & 80.0 & 24 \\
25 & 92.0 & 15 \\
26 & 110.0 & 1
\end{tabular}

ACQJ-

MU- PERLATED CENT

$\begin{array}{rr}489 & 22.3 \\ 395 & 18.0 \\ 313 & 14.3 \\ 228 & 10.4 \\ 149 & 6.8 \\ 81 & 3.7 \\ 46 & 2.1 \\ 22 & 1.0 \\ 7 & 0.3\end{array}$

CUBIC ACQU-

FEET ND- PERCLASS SECOND DAYS DAYS DAYS

$\begin{array}{lllll}27 & 120.0 & 2 & 6 & 0.3 \\ 28 & 140.0 & 2 & 4 & 0.2 \\ 29 & 160.0 & 0 & 2 & 0.1 \\ 30 & 190.0 & 0 & 2 & 0.1 \\ 31 & 220.0 & 0 & 2 & 0.1 \\ 32 & 250.0 & 0 & 2 & 0.1 \\ 33 & 290.0 & 0 & 2 & 0.1 \\ 34 & 330.0 & 2 & 2 & 0.1\end{array}$


GREEN RIVER BASIN

09307200 PARIETTE DRAN NEAR GRAY, UT-Continued

MONTHLY MEAN DISGHARGES, IN OUBIC FEET PER SECOND, FOR EACH WATER YEAR

\begin{tabular}{|c|c|c|c|c|c|c|c|c|c|c|c|c|}
\hline YEAR & OCT & NON & $\mathrm{DEC}$ & JAN & FEB & MAR & APR & MAY & JUNE & JUY & AUG & SEP \\
\hline $\begin{array}{l}1976 \\
1977 \\
1978 \\
1979 \\
1980\end{array}$ & $\begin{array}{l}60.7 \\
52.0 \\
32.4 \\
50.5 \\
43.9\end{array}$ & $\begin{array}{l}38.1 \\
19.0 \\
29.0 \\
25.0 \\
23.5\end{array}$ & $\begin{array}{c}12.4 \\
7.77 \\
15.1 \\
9.66 \\
11.1\end{array}$ & $\begin{array}{c}6.16 \\
5.83 \\
13.3 \\
7.00 \\
11.5\end{array}$ & $\begin{array}{c}6.26 \\
8.61 \\
10.4 \\
11.3 \\
12.5\end{array}$ & $\begin{array}{l}12.0 \\
12.9 \\
28.8 \\
56.6 \\
12.0\end{array}$ & $\begin{array}{r}39.7 \\
14.5 \\
20.8 \\
15.8 \\
8.49\end{array}$ & $\begin{array}{l}22.6 \\
16.7 \\
22.4 \\
16.3 \\
28.4\end{array}$ & $\begin{array}{l}24.3 \\
17.3 \\
14.9 \\
20.1 \\
21.2\end{array}$ & $\begin{array}{l}16.0 \\
28.2 \\
14.3 \\
21.0 \\
19.7\end{array}$ & $\begin{array}{l}17.5 \\
29.2 \\
21.9 \\
42.7 \\
34.8\end{array}$ & $\begin{array}{l}26.2 \\
36.5 \\
46.1 \\
50.1 \\
70.4\end{array}$ \\
\hline 1981 & 51.6 & 43.9 & 14.0 & 10.5 & 15.8 & 27.0 & 24.8 & 31.7 & 29.6 & 24.4 & 26.5 & 67.6 \\
\hline
\end{tabular}

ANNUAL PEAK DISGARGE, IN OBIC FEET PER SECOND, AND CORRESPONDING GAGE HEIGHT, IN FEET, FOR EACH WATER YEAR

\begin{tabular}{|c|c|c|c|c|c|c|c|c|c|c|c|}
\hline $\begin{array}{l}\text { WATER } \\
\text { YEAR }\end{array}$ & DATE & $\begin{array}{c}\text { GAGE } \\
\text { HEIGHT }\end{array}$ & $\begin{array}{c}\text { PEAK } \\
\text { DISCHARGE }\end{array}$ & $\begin{array}{l}\text { WAIER } \\
\text { YEAR }\end{array}$ & DATE & $\begin{array}{c}\text { GAGE } \\
\text { HEIGHT }\end{array}$ & $\begin{array}{c}\text { PEAK } \\
\text { DISOHARGE }\end{array}$ & $\begin{array}{l}\text { WATER } \\
\text { YEAR }\end{array}$ & DATE & $\begin{array}{c}\text { GAGE } \\
\text { HEIGHT }\end{array}$ & $\begin{array}{c}\text { PEAK } \\
\text { DISCHARGE }\end{array}$ \\
\hline $\begin{array}{l}1976 \\
1977\end{array}$ & $\begin{array}{l}\text { APR. } 10,1976 \\
\text { JULY } 24,1977\end{array}$ & $\begin{array}{l}5.17 \\
9.23\end{array}$ & $\begin{array}{r}84 \\
449\end{array}$ & $\begin{array}{l}1978 \\
1979\end{array}$ & $\begin{array}{l}\text { MAR. } 12,1978 \\
\text { MAR. } 29,1979\end{array}$ & $\begin{array}{l}6.80 \\
9.20\end{array}$ & $\begin{array}{l}226 \\
562\end{array}$ & $\begin{array}{l}1980 \\
1981\end{array}$ & $\begin{array}{l}\text { SEPT.10, } 1980 \\
\text { OCT. } 15,1980\end{array}$ & $\begin{array}{l}9.76 \\
5.84\end{array}$ & $\begin{array}{l}626 \\
179\end{array}$ \\
\hline
\end{tabular}

09307300 PARIETTE DRA AT MOUTH, NEAR OURAY, UT

LOCATION. -Lat $40^{\circ} 01^{\prime} 48^{\prime \prime}$, long $109^{\circ} 45^{\prime} 23^{\prime \prime}$, in NW $\frac{1}{4} \mathrm{NW}^{1} \mathrm{3} \mathrm{SW}^{\frac{1}{4}}$ sec.14, T.9 S., R.19 E., Uintah County, Hydrologic Unit 14060005 , on right bank $120 \mathrm{ft}$ downstream from dike for waterfowl habitat area, $0.8 \mathrm{mi}$ upstream from mouth, and $5.8 \mathrm{mi}$ southwest of ouray.

DRATNAGE AREA, $-298 \mathrm{mi}^{2}$.

PERIOD OF RECORD AVAILABLE.,-OCtober 1975 to September 1981.

REVISED RECORDS. -WDR UT-77-1: Drainage area.

GAGE. - Water-stage recorder. Altitude of gage is 4,650 ft from topographic map.

REMARKS.--FIow regulated by waterfowl habitat area. Diversions above station for irrigation of about 250 acres above and 100 acres below.

AVERAGE DISCHARGE. -6 years, $20.4 \mathrm{ft}^{3} / \mathrm{s}, 14,780$ acre- $\mathrm{ft} / \mathrm{yr}$.

EXIREMES FOR PERTOD OF RECORD. --Maximum discharge, about $450 \mathrm{ft}^{3} / \mathrm{s}$ July 24, 1977 (may have been higher when the dam broke Mar. 29, 1979); no flow July 21-23, Aug. 16, 17, Dec. 25-27, 1976, Jan. 25-27, 1977, July 24-30, 1980.

LOWEST MEAN DISGARGE, IN OBBIC FEET PER SECOND, AND RANKING FOR THE INDICATED NUMBER OF CONSEGTTVE DAYS FOR EACH OLIMATIC YEAR, APRLL 1-MAROH 31

\begin{tabular}{|c|c|c|c|c|c|c|c|c|c|c|c|c|c|c|c|c|c|c|c|c|}
\hline $\mathrm{YEAR}$ & \multicolumn{20}{|c|}{ CONSEOITTE DAYS } \\
\hline $\begin{array}{l}1977 \\
1978 \\
1979 \\
1980\end{array}$ & $\begin{array}{l}0.00 \\
0.23 \\
0.33 \\
9.00\end{array}$ & $\begin{array}{l}1 \\
3 \\
4 \\
5\end{array}$ & $\begin{array}{l}0.00 \\
0.27 \\
0.37 \\
9.00\end{array}$ & $\begin{array}{l}1 \\
3 \\
4 \\
5\end{array}$ & $\begin{array}{l}0.03 \\
0.32 \\
0.56 \\
9.30\end{array}$ & $\begin{array}{l}2 \\
3 \\
4 \\
5\end{array}$ & $\begin{array}{l}0.04 \\
2.30 \\
1.30 \\
9.70\end{array}$ & $\begin{array}{l}1 \\
3 \\
2 \\
5\end{array}$ & $\begin{array}{r}0.05 \\
2.80 \\
2.90 \\
11.0\end{array}$ & $\begin{array}{l}1 \\
2 \\
3 \\
5\end{array}$ & $\begin{array}{r}0.16 \\
5.90 \\
3.60 \\
11.0\end{array}$ & $\begin{array}{l}1 \\
3 \\
2 \\
5\end{array}$ & $\begin{array}{r}0.92 \\
8.50 \\
4.40 \\
12.0\end{array}$ & $\begin{array}{l}1 \\
3 \\
2 \\
4\end{array}$ & $\begin{array}{c}2.80 \\
11.0 \\
5.20 \\
12.0\end{array}$ & $\begin{array}{l}1 \\
3 \\
2 \\
4\end{array}$ & $\begin{array}{l}10.0 \\
16.0 \\
12.0 \\
20.0\end{array}$ & $\begin{array}{l}1 \\
3 \\
2 \\
4\end{array}$ & $\begin{array}{l}12.0 \\
18.0 \\
22.0 \\
23.0\end{array}$ & $\begin{array}{l}1 \\
2 \\
3 \\
4\end{array}$ \\
\hline 1981 & 0.00 & 2 & 0.00 & 2 & 0.00 & 1 & 2.80 & 4 & 7.80 & 4 & 8.40 & 4 & 12.0 & 5 & 12.0 & 5 & 23.0 & 5 & 25.0 & 5 \\
\hline
\end{tabular}

HIGHEST MEAN DISGARGE, IN QUBIC FEET PER SECOND, AND RANKING FOR THE INDICATED NUMBER OF CONSEQTTVE DAYS FOR EACH WATER YEAR, OCTOBER 1-SEPTEMBER 30

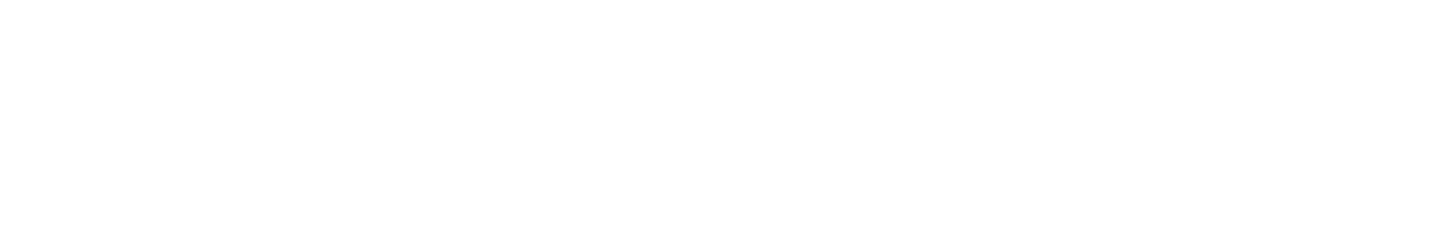


GREEN RIVER BASIN

09307300 PARIETTE DRFW AT MOUTH, NEAR OURAY, UT-Continued

DURATION OF DISCHARGE FOR EACH WATER YEAR

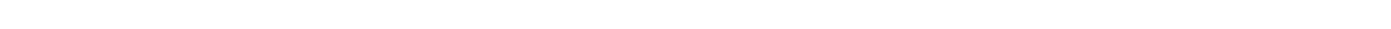
YEAR

GIBIC FEET PER SECOND -DAYS

$\begin{array}{llllllllllllllllllllllllll}1976 & 5 & 1 & 3 & 1 & 2 & 2 & 1 & 3 & 1 & 6 & 7 & 19 & 47 & 14 & 19 & 14 & 14 & 46 & 39 & 41 & 12 & 22 & 20 & 27\end{array}$

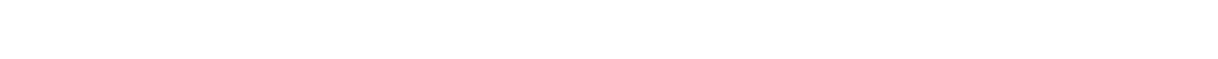

1979

1980 2

1981

$\begin{array}{lllllllllllllllllll}1 & 1 & 6 & 2 & 7 & 5 & 6 & 9 & 22 & 25 & 50 & 44 & 57 & 29 & 22 & 28 & 39 & 11 & 1\end{array}$

6306.8

4724.5

6108.8

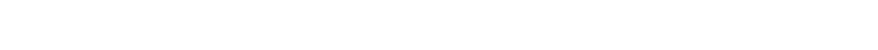

DURATION TABLE OF DISCHARGE FOR WAIER YEARS 1976-81

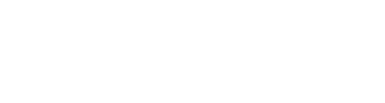

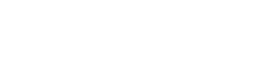

CIASS SECOND DAYS DAYS DAYS

$\begin{array}{lll}\text { CUBIC } & \text { ACOU- } \\ \text { FEET } & \text { MU- } & \text { PER- } \\ \text { PER TOTAL LATED } & \text { CENT }\end{array}$

CIASS SECOND DAYS DAYS DAYS

$\begin{array}{ccc}\text { CUBIC } & \text { ACOU- } \\ \text { FEET } & \text { MU- } & \text { PER- } \\ \text { PER TOTAL LATED } & \text { CENT } \\ \text { CLASS SECOND DAYS DAYS } & \text { DAYS }\end{array}$

$\begin{array}{lrrr}0.00 & 18 & 2192 & 100.0 \\ 0.05 & 31 & 2174 & 99.2 \\ 0.07 & 0 & 2143 & 97.8 \\ 0.08 & 5 & 2143 & 97.8 \\ 0.11 & 0 & 2138 & 97.5 \\ 0.14 & 2 & 2138 & 97.5 \\ 0.18 & 8 & 2136 & 97.4 \\ 0.24 & 4 & 2128 & 97.1 \\ 0.31 & 9 & 2124 & 96.9\end{array}$

$\begin{array}{rrrrr}9 & 0.39 & 13 & 2115 & 96.5 \\ 10 & 0.51 & 9 & 2102 & 95.9 \\ 11 & 0.66 & 23 & 2093 & 95.5 \\ 12 & 0.86 & 12 & 2070 & 94.4 \\ 13 & 1.10 & 9 & 2058 & 93.9 \\ 14 & 1.40 & 20 & 2049 & 93.5 \\ 15 & 1.90 & 25 & 2029 & 92.6 \\ 16 & 2.40 & 46 & 2004 & 91.4 \\ 17 & 3.10 & 71 & 1958 & 89.3\end{array}$

$\begin{array}{rrrrr}18 & 4.0 & 51 & 1887 & 86.1 \\ 19 & 5.2 & 73 & 1836 & 83.8 \\ 20 & 6.7 & 179 & 1763 & 80.4 \\ 21 & 8.7 & 162 & 1584 & 72.3 \\ 22 & 11.0 & 359 & 1422 & 64.9 \\ 23 & 15.0 & 230 & 1063 & 48.5 \\ 24 & 19.0 & 241 & 833 & 38.0 \\ 25 & 25.0 & 172 & 592 & 27.0 \\ 26 & 32.0 & 139 & 420 & 19.2\end{array}$

$\begin{array}{rrrrr}27 & 41.0 & 117 & 281 & 12.8 \\ 28 & 53.0 & 110 & 164 & 7.5 \\ 29 & 69.0 & 31 & 54 & 2.5 \\ 30 & 89.0 & 12 & 23 & 1.0 \\ 31 & 120.0 & 2 & 11 & 0.5 \\ 32 & 150.0 & 4 & 9 & 0.4 \\ 33 & 190.0 & 2 & 5 & 0.2 \\ 34 & 250.0 & 3 & 3 & 0.1\end{array}$

MONIHLY MEAN DISCHARGES, IN OBBIC FEET PER SECOND, FOR EACH WATER YEAR

\begin{tabular}{|c|c|c|c|c|c|c|c|c|c|c|c|c|}
\hline YEAR & $\infty T$ & NOV & $\mathrm{DEC}$ & JAN & FEB & MAR & APR & MAY & JUNE & JULY & AUG & SEP \\
\hline $\begin{array}{l}1976 \\
1977 \\
1978 \\
1979 \\
1980\end{array}$ & $\begin{array}{l}53.2 \\
38.6 \\
31.8 \\
45.3 \\
42.7\end{array}$ & $\begin{array}{c}33.3 \\
9.20 \\
29.5 \\
27.1 \\
32.3\end{array}$ & $\begin{array}{c}8.36 \\
0.43 \\
15.7 \\
10.8 \\
11.6\end{array}$ & $\begin{array}{c}2.97 \\
0.05 \\
10.7 \\
8.00 \\
11.5\end{array}$ & $\begin{array}{c}5.10 \\
4.31 \\
10.1 \\
14.3 \\
12.6\end{array}$ & $\begin{array}{c}18.3 \\
8.17 \\
28.5 \\
83.3 \\
12.1\end{array}$ & $\begin{array}{c}27.0 \\
8.27 \\
14.5 \\
18.9 \\
7.83\end{array}$ & $\begin{array}{c}10.8 \\
6.14 \\
14.1 \\
16.9 \\
19.9\end{array}$ & $\begin{array}{c}11.5 \\
12.8 \\
3.85 \\
20.1 \\
10.9\end{array}$ & $\begin{array}{c}3.89 \\
18.8 \\
3.68 \\
19.1 \\
7.67\end{array}$ & $\begin{array}{c}11.6 \\
21.1 \\
9.16 \\
41.0 \\
24.1\end{array}$ & $\begin{array}{l}20.8 \\
26.9 \\
28.9 \\
37.8 \\
67.1\end{array}$ \\
\hline 1981 & 51.2 & 48.4 & 15.9 & 10.5 & 12.8 & 23.0 & 21.5 & 22.3 & 15.0 & 12.4 & 14.6 & 54.3 \\
\hline
\end{tabular}

ANNUAL PEAK DISCHARGE, IN OUBIC FEET PER SECOND, AND CORRESPONDING GAGE HEIGHT, IN FEET, FOR EACH WATER YEAR

\begin{tabular}{|c|c|c|c|c|c|c|c|c|c|c|c|}
\hline $\begin{array}{l}\text { WATERR } \\
\text { YEAR }\end{array}$ & DATE & $\begin{array}{c}\text { GAGE } \\
\text { HEIGHT }\end{array}$ & $\begin{array}{c}\text { PEAK } \\
\text { DISCHARGE }\end{array}$ & $\begin{array}{l}\text { WATERR } \\
\text { YEAR }\end{array}$ & DATE & $\begin{array}{c}\text { GAGE } \\
\text { HEIGHT }\end{array}$ & $\begin{array}{c}\text { PEAR } \\
\text { DISCHARGE }\end{array}$ & $\begin{array}{l}\text { WAITER } \\
\text { YEAR }\end{array}$ & DATE & $\begin{array}{l}\text { GAGE } \\
\text { HEIGHT }\end{array}$ & $\begin{array}{c}\text { PEAK } \\
\text { DISCHARGE }\end{array}$ \\
\hline $\begin{array}{l}1976 \\
1977\end{array}$ & $\begin{array}{lll}\text { OCT. } & 06,1975 \\
\text { JULY } & 24,1977\end{array}$ & 1.93 & $\begin{array}{r}84 \\
450\end{array}$ & $\begin{array}{l}1978 \\
1979\end{array}$ & $\begin{array}{l}\text { MAR. } 10,1978 \\
\text { MAR. } 29,1979\end{array}$ & $=$ & $\begin{array}{l}190 \\
400\end{array}$ & $\begin{array}{l}1980 \\
1981\end{array}$ & $\begin{array}{l}\text { SEPT. 12, } 1980 \\
\text { APR. 01， } 1981\end{array}$ & $\begin{array}{l}3.32 \\
3.09\end{array}$ & $\begin{array}{l}158 \\
120\end{array}$ \\
\hline
\end{tabular}




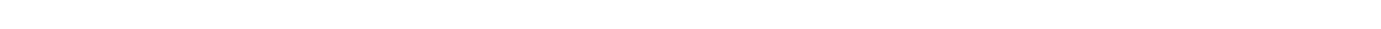
Reservation, Hydrologic Unit 14060006, on right bank $0.1 \mathrm{mi}$ downstream from Big Canyon and $36 \mathrm{mi}$ southeast of ouray.

DRAINAGE AREA, $-297 \mathrm{mi}^{2}$.

MEAN BASIN ELEVATTON. $-7,710 \mathrm{ft}$.

PERIOD OF RECORD AVALABLE.--August 1950 to September 1955, September 1957 to September 1970, and Octcher 1974 to Septenber 1981.

GAGE. -Water-stage recorder. Altitude of gage is 6,000 ft from topographic map. Prior to Nov. 7, 1952, at site $0.9 \mathrm{mi}$ downstream at different datum. Now. 7, 1952 to Sept. 30, 1970, at site 0.8 mi downstream at different datum, Oct. 1, 1974 to July 18,

1977 , at present site and datum $2.00 \mathrm{ft}$ higher.

AVERAGE DISCHARGE. --25 years (water years 1951-55, 1958-70, 1975-81), $20.6 \mathrm{ft}^{3} / \mathrm{s}, 14,920$ acre-ft/yr.

EXTREMES FOR PERTOD OF RECORD. - Maximum discharge, 2,240 ft ${ }^{3} / \mathrm{s}$ July 19, 1977, gage height, $9.55 \mathrm{ft}$, from rating curve extended above $100 \mathrm{ft}^{3} / \mathrm{s}$ on basis of slope-area measurements of peak flow; minimum, $0.3 \mathrm{ft}^{3} / \mathrm{s} \mathrm{Aug.} 21-23,1960$.

LOWEST MEAN DISOHARGE, IN GBIC FEET PER SECOND, AND RANKING FOR THE INDICATED NUMBER OF CONSEQUTTVE DAYS FOR EACH OLIMATIC YEAR, APRII 1-MARCH 31

YEAR

$\begin{array}{ccccc}\text { YEAR } & 1 & & 3 \\ & 1 & & & \\ 1952 & 4.50 & 9 & 4.60 & 8 \\ 1953 & 10.0 & 20 & 10.0 & 20 \\ 1954 & 8.00 & 17 & 8.00 & 14 \\ 1955 & 6.40 & 13 & 6.50 & 12\end{array}$

$6.1012 \quad 6.2011$

1960

196

1961

196

1964

1965

196

196

1969

1970

1976

1977
1978

1978
1979

1980

1981

$2.40 \quad 4$

0.301

0.402

5.1011

1.103

$\begin{array}{ll}1.10 & 3\end{array}$

9.6019

4.9010

7.8014

11.021

$11.0 \quad 22$

8.0015

4.407

3.706

4.508

2.604

0.371

0.402

$5.50 \quad 9$

$\begin{array}{ll}1.10 & 3 \\ 3.80 & 5\end{array}$

9.9019

6.2010

8.1015
8.8017

11.021

8.0016

$12.0 \quad 22$

8.7016

4.507

$\begin{array}{rr}3.80 & 6 \\ 6.80 & 13\end{array}$

9.5018

7

7

4.807

10.018

8.3013
6.8012

6.4010

3.004

0.532

0.49 I

5.909

$\begin{array}{ll}1.40 & 3 \\ 4.00 & 5\end{array}$

$10.0 \quad 19$

6.8011

8.8014

9.2015

$12.0 \quad 20$

$12.0 \quad 21$

9.3016

9.3016
4.008

4.006

$10.0 \quad 17$

$13.0 \quad 22$

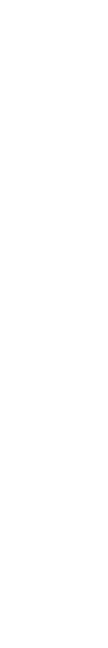

CONSECUTTVE DAYS

7.7010

10.016

8.6012
8.8013

$\begin{array}{cr}60 & \\ 8.00 & 8 \\ 11.0 & 17 \\ 9.30 & 12 \\ 9.10 & 11\end{array}$

90

8.807

$11.0 \quad 14$

$\begin{array}{rr}11.0 & 15 \\ 9.40 & 10\end{array}$

$\begin{array}{llll}7.60 & 9 & 10.0 & 13\end{array}$

11.011

$1.30 \quad 2$

1.191

6.307

3.403

4.906

2.001

3.002

7.807

$\begin{array}{ll}6.60 & 6 \\ 6.40 & 5\end{array}$

2.701

4.202

$\begin{array}{ll}9.10 & 9 \\ 8.20 & 6\end{array}$

6.805

$12.0 \quad 19$

8.0011

$\begin{array}{rr}13.0 & 18 \\ 8.50 & 9\end{array}$

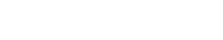

14.020

$11.0 \quad 15$

$\begin{array}{cc}14.0 & 19\end{array}$

8.908

$11.0 \quad 12$

$12.0 \quad 16$

$14.0 \quad 21$

15.021

9.9015

6.808

$4.70 \quad 5$

$11.0 \quad 16$

9.0010

$\begin{array}{rr}5.80 & 4 \\ 13.0 \quad 19\end{array}$

$\begin{array}{ll}16.0 & 21\end{array}$

$\begin{array}{ll}16.0 & 21 \\ 12.0 & 17\end{array}$

$\begin{array}{cc}11.0 & 13 \\ 6.60 & 4\end{array}$

$\begin{array}{rr}6.60 & 4 \\ 13.0 \quad 18\end{array}$

$15.0 \quad 22$

16.022

$17.0 \quad 22$

$9.80 \quad 8$

$13.0 \quad 17$

12.016

11.0

$15.0 \quad 19$

$\begin{array}{llll}11.0 & 10 & 18.0 & 12 \\ 18.0 & 13\end{array}$

$\begin{array}{rrrrrr}12.0 & 11 & 12.0 & 11 & 22.0 & 14 \\ 6.10 & 3 & 6.90 & 2 & 11.0 & 2\end{array}$

3.401

5.602

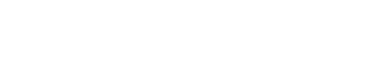

5.501

HIGHEST MEAN DISCHARGE, IN OUBIC FEET PER SECOND, AND RANKING FOR THE INDICATED NUMBER OF CONSEQUTIVE DAYS FOR EACH WATER YEAR, OCTOBER 1-SEPTEMBER 30

YE

195

13

$\begin{array}{cr}7 & \\ 33.0 & 23 \\ 205 & 1 \\ 45.0 & 20 \\ 63.0 & 15 \\ 78.0 & 12\end{array}$

15

CONSECUTTVE DAVS

$\begin{array}{crcr}41.0 & 25 & 34.0 & 24 \\ 222 & 2 & 218 & 2 \\ 109 & 10 & 76.0 & 14 \\ 70.0 & 18 & 65.0 & 17 \\ 120 & 9 & 109 & 9\end{array}$ 78.012

1955

$92.0 \quad 14$

$87.0 \quad 13$

$81.0 \quad 10$

$29.0 \quad 24$

$\begin{array}{llll}45.0 & 23 & 32.0 & 25 \\ 50.0 & 22 & 44.0 & 22\end{array}$

$\begin{array}{ll}43.0 & 22\end{array}$

$30.0 \quad 23$

$\begin{array}{cc}179 & 1 \\ 40.0 & 20\end{array}$

$149 \quad 1 \quad 113 \quad 1$

$\begin{array}{llllll}60.0 & 12 & 53.0 & 20 & 29.0 & 19 \\ 11 & 41.0 & 11\end{array}$

52.014

$39.0 \quad 17$

$38.0 \quad 12$

$77.0 \quad 9$

$\begin{array}{rrrr}72.0 & 7 & 61.0 & 7 \\ 23.0 & 25 & 21.0 & 25\end{array}$

24.025

1960

$\begin{array}{llll}80.0 & 16 & 67.0 & 16\end{array}$

1962

1962 259

$\begin{array}{lllll}1964 & 96.0 & 12 & 87.0 & 11\end{array}$

$\begin{array}{llll}46.0 & 19 & 37.0 & 27\end{array}$

$191 \quad 2 \quad 148$

$\begin{array}{ll}79.0 & 11 \\ 66.0 & 14\end{array}$

$\begin{array}{ll}66.0 & 14 \\ 54.0 & 16\end{array}$

\begin{tabular}{lr}
37.0 & 21 \\
\hline 48 & 2
\end{tabular}

65.010

36.018

$21.0 \quad 25$

$\begin{array}{llll}32.0 & 21 & 27.0 & 21\end{array}$

$\begin{array}{ll}53.0 & 13 \\ 45.0 & 18\end{array}$

147.0

$\begin{array}{ll}48.0 & 12 \\ 43.0 & 15\end{array}$

36.016

64.018

99.07

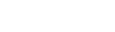

44.014

$38.0 \quad 13$

$\begin{array}{llll}63.0 & 9 & 47.0 & 10\end{array}$

$\begin{array}{rrr}1966 & 135 & 6 \\ 1967 & 44.0 & 24 \\ 1968 & 71.0 & 17\end{array}$

$\begin{array}{llll}34.0 & 23 & 28.0 & 25\end{array}$

$\begin{array}{ll}70.0 & 15\end{array}$

68.013

1969

1970

160445

$\begin{array}{lll}118 & 4 & 151\end{array}$

$\begin{array}{rr}79.0 & 24 \\ 65.0 & 11\end{array}$

$\begin{array}{llll}25.0 & 24 & 22.0 & 23\end{array}$

62.010

10

$\begin{array}{lll}87.0 \quad 12 \quad 82.0 & 9\end{array}$

$\begin{array}{cc}53.0 & 9 \\ 103 & 4 \\ 65.0 & 6\end{array}$

56.08

$\begin{array}{cr}90 & \\ 25.0 & 21 \\ 88.0 & 1 \\ 26.0 & 19 \\ 35.0 & 11 \\ 33.0 & 14\end{array}$

51.07

$\begin{array}{ll}19.0 & 24 \\ 25.0 & 20\end{array}$

$23.0 \quad 22$

83.04

$\begin{array}{ll}31.0 & 16 \\ 28.0 & 18\end{array}$

34.012

$40.0 \quad 10$

$\begin{array}{rr}21.0 & 23 \\ 45.0 & 9\end{array}$

88.02

52.06
120

$24.0 \quad 18$

74.01

$24.0 \quad 19$

29.014

45.06

$17.0 \quad 25$

21.021

$20.0 \quad 22$

67.05

$27.0 \quad 17$

$\begin{array}{rr}23.0 & 20 \\ 32.0 & 12\end{array}$

34.010

$20.0 \quad 23$

40.09

$\begin{array}{ll}72.0 & 2 \\ 44.0 & 7\end{array}$

42.0
183

$21.0 \quad 17$

55.01

$\begin{array}{ll}20.0 & 19 \\ 26.0 & 13\end{array}$

22.015

$36.0 \quad 6$

$\begin{array}{llll}15.0 & 25 & 12.0 & 23\end{array}$

$17.023 \quad 11.0 \quad 24$

$\begin{array}{llll}15.0 & 24 & 11.0 & 25\end{array}$

$\begin{array}{llll}48.0 \quad 5 & 28.0 \quad 5\end{array}$

$\begin{array}{llll}21.0 & 18 & 16.0 & 18\end{array}$

$\begin{array}{llll}18.0 & 21 & 13.0 & 22\end{array}$

$\begin{array}{llll}11 & 18.0 \quad 14\end{array}$

$\begin{array}{llll}27.0 & 12 & 20.0 & 12\end{array}$

$\begin{array}{rrrr}19.0 & 20 & 16.0 & 19\end{array}$

$\begin{array}{llll}54.0 & 2 & 34.0 & 1\end{array}$

$\begin{array}{llll}34.0 & 8 & 25.0 & 6\end{array}$

$\begin{array}{llll}35.0 & 7 & 25.0 \quad 7\end{array}$ 
GREEN RIVER BASIN

09307500 WIIIOW CREER ABOVE DIVERSIONS, NEAR OURAY, UT--Continued

HIGHEST MEAN DISCHARGE, IN ABIC FEET PER SECOND, AND RANKING FOR THE INDICATED NUMBER OF CONSECUTTVE DAYS FOR EAOH WATER YEAR, OCTCBER 1-SEPTEMBER 30--Continued

\begin{tabular}{|c|c|c|c|c|c|c|c|c|c|c|c|c|c|c|c|c|c|c|c|c|}
\hline YEAR & & & & & & & & & @NS & EOUT & VE DAYS & & & & & & & & & \\
\hline $\begin{array}{l}1976 \\
1977 \\
1978 \\
1979 \\
1980\end{array}$ & $\begin{array}{c}55.0 \\
155 \\
46.0 \\
166 \\
133\end{array}$ & $\begin{array}{r}20 \\
5 \\
22 \\
3 \\
7\end{array}$ & $\begin{array}{c}53.0 \\
120 \\
45.0 \\
164 \\
132\end{array}$ & $\begin{array}{r}20 \\
6 \\
21 \\
3 \\
5\end{array}$ & $\begin{array}{l}51.0 \\
84.0 \\
44.0 \\
161 \\
130\end{array}$ & $\begin{array}{r}17 \\
8 \\
21 \\
3 \\
5\end{array}$ & $\begin{array}{r}47.0 \\
49.0 \\
42.0 \\
147 \\
122\end{array}$ & $\begin{array}{r}16 \\
15 \\
19 \\
3 \\
5\end{array}$ & $\begin{array}{c}45.0 \\
30.0 \\
39.0 \\
130 \\
113\end{array}$ & $\begin{array}{r}13 \\
22 \\
16 \\
4 \\
5\end{array}$ & $\begin{array}{c}38.0 \\
22.0 \\
36.0 \\
105 \\
101\end{array}$ & $\begin{array}{r}14 \\
24 \\
15 \\
3 \\
5\end{array}$ & $\begin{array}{l}34.0 \\
18.0 \\
32.0 \\
83.0 \\
81.0\end{array}$ & $\begin{array}{r}13 \\
25 \\
15 \\
3 \\
5\end{array}$ & $\begin{array}{l}32.0 \\
18.0 \\
28.0 \\
69.0 \\
67.0\end{array}$ & $\begin{array}{r}11 \\
24 \\
15 \\
3 \\
4\end{array}$ & $\begin{array}{l}27.0 \\
17.0 \\
22.0 \\
51.0 \\
52.0\end{array}$ & $\begin{array}{r}10 \\
22 \\
16 \\
4 \\
3\end{array}$ & $\begin{array}{l}21.0 \\
15.0 \\
16.0 \\
31.0 \\
34.0\end{array}$ & $\begin{array}{r}10 \\
21 \\
20 \\
4 \\
2\end{array}$ \\
\hline 1981 & 67.0 & 19 & 61.0 & 19 & 51.0 & 18 & 45.0 & 17 & 36.0 & 19 & 33.0 & 18 & 30.0 & 17 & 27.0 & 16 & 24.0 & 14 & 19.0 & 13 \\
\hline
\end{tabular}

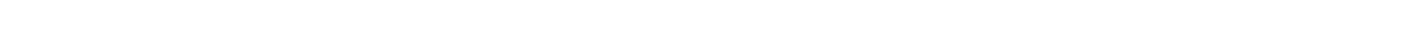
YEAR NUMBER OF DAYS IN CLASS

OBIC FEET PER SEOOND

1951
1952
1953
1954
1955

$\begin{array}{llllllllllll}7 & 16 & 12 & 31 & 15 & 20 & 78 & 60 & 73 & 35 & 17 & 1\end{array}$ $\begin{array}{rrrrrrrrrr} & 8 & 161 & 27 & 32 & 28 & 13 & 15 & 13 & 11 \\ 41 & 58 & 83 & 34 & 37 & 62 & 28 & 6 & 12 & \end{array}$ $\begin{array}{rrrrrrrrrrr} & 41 & 58 & 83 & 34 & 37 & 62 & 28 & 6 & 12 & 2 \\ 21 & 17 & 23 & 34 & 77 & 75 & 43 & 27 & 17 & 11 & 7\end{array}$ $1 \quad 1 \quad 6075.0$ $\begin{array}{lllllllllllllllll}48 & 21 & 64 & 41 & 25 & 60 & 11 & 34 & 17 & 19 & 15 & 5 & 2 & 1 & 1 & 1 & 7197.2\end{array}$

1958

1959

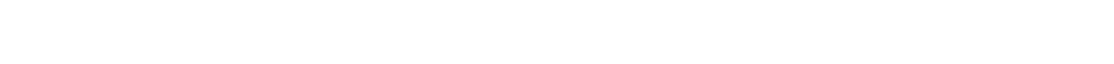

8580.0

1960

$\begin{array}{llllllllllllll}1 & 2 & 1 & 1 & 4 & 4 & 4 & 4 & 7 & 8 & 11 & 8 & 25\end{array}$

$\begin{array}{lllllllllllllllllllllllllll}6 & 1 & 2 & 4 & 2 & 4 & 5 & 6 & 7 & 12 & 7 & 18 & 39 & 21 & 77 & 29 & 30 & 22 & 28 & 24 & 5 & 5 & 5 & 2 & 2 & 2\end{array}$

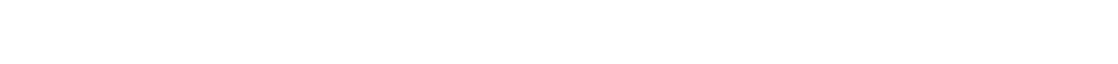

$\begin{array}{rrrrrrrrrrrrrr}52 & 11 & 104 & 36 & 68 & 9 & 7 & 25 & 12 & 7 & 4 & 8 & 3 & 3 \\ 6 & 58 & 50 & 20 & 62 & 32 & 18 & 33 & 20 & 19 & 24 & 16 & 6 & 1\end{array}$

$\begin{array}{lllllllllllllllll}1 & 17 & 47 & 11 & 61 & 94 & 29 & 26 & 27 & 18 & 11 & 9 & 6 & 2 & 3 & 1 & 2\end{array}$

$\begin{array}{llllllllll}1 & 6 & 27 & 155 & 61 & 33 & 60 & 13 & 7 & 2\end{array}$

$\begin{array}{lllllllllllll}16 & 42 & 92 & 47 & 23 & 37 & 33 & 24 & 7 & 15 & 26 & 4\end{array}$

$\begin{array}{lllllllllllllll}17 & 87 & 72 & 51 & 18 & 25 & 5 & 6 & 6 & 23 & 16 & 9 & 7 & 19 & 4\end{array}$

$\begin{array}{lllllllllllllll}7 & 17 & 59 & 102 & 46 & 37 & 23 & 21 & 8 & 3 & 21 & 7 & 7 & 5 & 2\end{array}$

$\begin{array}{llllllllllllllll}1 & 1 & 2 & 8 & 58 & 73 & 43 & 68 & 23 & 26 & 19 & 10 & 15 & 15 & 3\end{array}$

$\begin{array}{lllllllllll}29 & 36 & 93 & 47 & 66 & 31 & 33 & 17 & 12 & 2\end{array}$

$\begin{array}{rrrrrrrrrrrrrr} & 5 & 6 & 11 & 19 & 35 & 121 & 85 & 45 & 23 & 8 & 1 & 1 & 1 \\ 4 & 17 & 8 & 26 & 37 & 31 & 70 & 56 & 21 & 17 & 16 & 38 & 21 & 3\end{array}$

$\begin{array}{lllllllllllllllllll}1 & 3 & 19 & 64 & 87 & 27 & 34 & 20 & 22 & 9 & 10 & 7 & 15 & 4 & 11 & 13 & 12 & 7\end{array}$

$\begin{array}{lllllllllllll}2 & 9 & 11 & 26 & 58 & 44 & 46 & 97 & 35 & 22 & 9 & 3 & 3\end{array}$

4253.2

4063.5

0377.

5898.9

4908.7

6644.9

7176.2

5675.5

8173.3

91 24.5

9182.5

7663.8

5486.1

6017.5

11320.1

1980

1981

7034.9

DURATION TABLE OF DISCHARGE FOR WATER YEARS 1951-55, 1958-70, 1975-81

\begin{tabular}{|c|c|c|c|c|c|c|c|c|c|c|c|c|c|c|c|c|c|c|c|}
\hline IAASS & $\begin{array}{c}\text { OUBIC } \\
\text { FEET } \\
\text { PER } \\
\text { SECOND }\end{array}$ & $\begin{array}{l}\text { TOTAL } \\
\text { DAYS }\end{array}$ & $\begin{array}{r}\text { ACO- } \\
\mathbf{M U}- \\
\text { LATED } \\
\text { DAYS }\end{array}$ & $\begin{array}{l}\text { PER- } \\
\text { CENT } \\
\text { DAYS }\end{array}$ & CLASS & $\begin{array}{c}\text { QUBIC } \\
\text { FEET } \\
\text { PER } \\
\text { SECOND }\end{array}$ & $\begin{array}{l}\text { TOTAL } \\
\text { DAYS }\end{array}$ & $\begin{array}{r}\text { ACOU- } \\
\text { MU- } \\
\text { LATED } \\
\text { DAYS }\end{array}$ & $\begin{array}{l}\text { PER- } \\
\text { CENT } \\
\text { DAYS }\end{array}$ & CLASS & $\begin{array}{c}\text { OBIIC } \\
\text { FEET } \\
\text { PER } \\
\text { SECOND }\end{array}$ & $\begin{array}{l}\text { TOTAL } \\
\text { DAYS }\end{array}$ & $\begin{array}{r}\text { ACQU- } \\
\text { MU- } \\
\text { LATED } \\
\text { DAYS }\end{array}$ & $\begin{array}{l}\text { PER- } \\
\text { CENT } \\
\text { DAYS }\end{array}$ & CLASS & $\begin{array}{c}\text { OUBIC } \\
\text { FEET } \\
\text { PER } \\
\text { SECOND }\end{array}$ & $\begin{array}{l}\text { TOTAL } \\
\text { DAYS }\end{array}$ & $\begin{array}{r}\text { ACOH- } \\
\text { MU- } \\
\text { LAIED } \\
\text { DAYS }\end{array}$ & $\begin{array}{l}\text { PER- } \\
\text { CENT } \\
\text { DAYS }\end{array}$ \\
\hline $\begin{array}{l}0 \\
1 \\
2 \\
3 \\
4 \\
5 \\
6 \\
7 \\
8\end{array}$ & $\begin{array}{l}0.00 \\
0.30 \\
0.37 \\
0.45 \\
0.55 \\
0.67 \\
0.82 \\
1.00 \\
1.20\end{array}$ & $\begin{array}{r}0 \\
1 \\
8 \\
2 \\
3 \\
8 \\
4 \\
8 \\
10\end{array}$ & $\begin{array}{l}9131 \\
9131 \\
9130 \\
9122 \\
9120 \\
9117 \\
9109 \\
9105 \\
9097\end{array}$ & $\begin{array}{r}100.0 \\
100.0 \\
100.0 \\
99.9 \\
99.9 \\
99.8 \\
99.8 \\
99.7 \\
99.6\end{array}$ & $\begin{array}{r}9 \\
10 \\
11 \\
12 \\
13 \\
14 \\
15 \\
16 \\
17\end{array}$ & $\begin{array}{l}1.50 \\
1.80 \\
2.20 \\
2.70 \\
3.30 \\
4.10 \\
5.00 \\
6.10 \\
7.50\end{array}$ & $\begin{array}{r}14 \\
21 \\
21 \\
28 \\
74 \\
93 \\
259 \\
393 \\
764\end{array}$ & $\begin{array}{l}9087 \\
9073 \\
9052 \\
9031 \\
9003 \\
8929 \\
8836 \\
8577 \\
8184\end{array}$ & $\begin{array}{l}99.5 \\
99.4 \\
99.1 \\
98.9 \\
98.6 \\
97.8 \\
96.8 \\
93.9 \\
89.6\end{array}$ & $\begin{array}{l}18 \\
19 \\
20 \\
21 \\
22 \\
23 \\
24 \\
25 \\
26\end{array}$ & $\begin{array}{r}9.1 \\
11.0 \\
14.0 \\
17.0 \\
20.0 \\
25.0 \\
30.0 \\
37.0 \\
45.0\end{array}$ & $\begin{array}{r}702 \\
1726 \\
1307 \\
817 \\
1034 \\
534 \\
374 \\
240 \\
144\end{array}$ & $\begin{array}{r}7420 \\
6718 \\
4992 \\
3685 \\
2868 \\
1834 \\
1300 \\
926 \\
686\end{array}$ & $\begin{array}{r}81.3 \\
73.6 \\
54.7 \\
40.4 \\
31.4 \\
20.1 \\
14.2 \\
10.1 \\
7.5\end{array}$ & $\begin{array}{l}27 \\
28 \\
29 \\
30 \\
31 \\
32 \\
33 \\
34\end{array}$ & $\begin{array}{r}55.0 \\
68.0 \\
83.0 \\
100.0 \\
120.0 \\
150.0 \\
180.0 \\
230.0\end{array}$ & $\begin{array}{r}174 \\
118 \\
80 \\
67 \\
64 \\
22 \\
16 \\
1\end{array}$ & $\begin{array}{r}542 \\
368 \\
250 \\
170 \\
103 \\
39 \\
17 \\
1\end{array}$ & $\begin{array}{l}5.9 \\
4.0 \\
2.7 \\
1.9 \\
1.1 \\
0.4 \\
0.2 \\
0.0\end{array}$ \\
\hline
\end{tabular}

MONIHLY MEAN DISCHARGES, IN OUBIC FEET PER SECOND, FOR EACH WATER YEAR

$\begin{array}{llccccccccccc}\text { YEAR } & \text { OCT } & \text { NOV } & \text { DEC } & \text { JAN } & \text { FEB } & \text { MAR } & \text { APR } & \text { MAY } & \text { JUNE } & \text { JULY } & \text { AUG } & \text { SEP } \\ 1951 & 16.1 & 19.2 & 17.3 & 15.9 & 20.2 & 28.1 & 24.8 & 20.4 & 13.7 & 7.69 & 10.0 & 9.24 \\ 1952 & 14.1 & 12.6 & 12.0 & 10.8 & 11.0 & 12.8 & 63.1 & 139 & 53.6 & 31.6 & 19.3 & 19.2 \\ 1953 & 17.8 & 18.2 & 12.0 & 10.0 & 12.5 & 25.9 & 30.0 & 21.8 & 14.5 & 14.9 & 13.2 & 8.66 \\ 1954 & 14.9 & 16.8 & 17.0 & 16.0 & 18.8 & 30.0 & 49.2 & 26.1 & 14.6 & 12.6 & 8.80 & 12.2 \\ 1955 & 13.9 & 14.6 & 10.0 & 9.00 & 9.21 & 36.2 & 35.2 & 26.9 & 14.8 & 6.63 & 12.0 & 5.32 \\ & & & & & & & & & & & & \\ 1958 & 10.1 & 10.5 & 12.3 & 13.0 & 29.5 & 28.5 & 48.2 & 68.5 & 27.4 & 10.7 & 12.1 & 12.0 \\ 1959 & 12.7 & 12.1 & 10.7 & 11.8 & 12.1 & 20.4 & 20.8 & 14.5 & 6.61 & 4.26 & 8.61 \\ 1960 & 8.17 & 8.83 & 8.93 & 9.91 & 11.6 & 26.3 & 29.8 & 17.3 & 6.46 & 3.35 & 1.68 & 3.53\end{array}$


09307500 WIILOW CREEK ABOVE DIVERSIONS, NEAR OURAY, UT-CONtinued

MONItLY MEAN DISCHARGES, IN CUBIC FEET PER SECOND, FOR EACG WATER YEAR-Continued

$\begin{array}{lcccccccccccc}\text { YEAR } & \text { OCT } & \text { NOV } & \text { DEC } & \text { JAN } & \text { FEB } & \text { MAR } & \text { APR } & \text { MAY } & \text { JUNE } & \text { JULY } & \text { AUG } & \text { SEP } \\ 1961 & 8.95 & 9.18 & 8.48 & 5.48 & 10.4 & 19.4 & 32.0 & 15.9 & 4.80 & 1.31 & 7.89 & 10.1 \\ 1962 & 12.6 & 7.67 & 8.52 & 8.29 & 10.3 & 46.0 & 132 & 58.2 & 26.2 & 14.5 & 6.76 & 10.1 \\ 1963 & 13.8 & 11.6 & 7.45 & 8.65 & 20.8 & 39.1 & 29.8 & 16.9 & 10.6 & 3.86 & 17.4 & 14.5 \\ 1964 & 11.9 & 11.3 & 9.00 & 8.32 & 8.00 & 13.9 & 42.6 & 25.2 & 10.2 & 5.01 & 9.25 & 6.38 \\ 1965 & 7.31 & 7.51 & 9.15 & 10.8 & 8.89 & 16.6 & 30.2 & 43.5 & 24.3 & 26.4 & 20.9 & 12.1 \\ 1966 & 14.6 & 16.8 & 14.6 & 13.0 & 17.7 & 59.9 & 33.3 & 24.4 & 14.1 & 9.66 & 9.15 & 8.43 \\ 1967 & 11.9 & 11.5 & 12.7 & 12.5 & 13.0 & 20.1 & 22.6 & 16.4 & 21.7 & 14.8 & 16.2 & 13.1 \\ 1968 & 12.0 & 15.4 & 10.2 & 10.3 & 13.1 & 24.2 & 28.6 & 59.3 & 44.7 & 16.5 & 20.3 & 13.2 \\ 1969 & 15.1 & 11.0 & 11.6 & 13.4 & 14.1 & 16.9 & 84.6 & 117 & 57.6 & 25.6 & 19.2 & 17.2 \\ 1970 & 20.5 & 17.5 & 15.1 & 14.5 & 15.8 & 27.2 & 61.6 & 66.3 & 17.4 & 14.8 & 15.7 & 13.0 \\ 1975 & 15.6 & 19.1 & 12.1 & 16.3 & 17.4 & 22.5 & 27.8 & 65.5 & 45.6 & 28.4 & 15.1 & 15.9 \\ 1976 & 18.2 & 17.4 & 15.0 & 16.7 & 22.7 & 25.0 & 31.9 & 43.8 & 23.0 & 15.4 & 11.1 & 11.1 \\ 1977 & 13.1 & 14.2 & 11.7 & 12.0 & 14.4 & 16.9 & 22.0 & 13.7 & 8.70 & 27.2 & 10.8 & 15.6 \\ 1978 & 14.3 & 15.0 & 13.3 & 11.1 & 9.66 & 21.8 & 35.0 & 36.6 & 19.2 & 9.86 & 5.65 & 6.08 \\ 1979 & 9.33 & 11.1 & 9.81 & 10.0 & 11.1 & 17.0 & 41.8 & 126 & 74.0 & 28.7 & 18.5 & 13.5 \\ 1980 & 16.7 & 13.8 & 12.7 & 14.1 & 22.0 & 23.4 & 51.1 & 113 & 71.0 & 29.2 & 20.7 & 21.3 \\ 1981 & 22.0 & 20.9 & 19.3 & 15.1 & 21.9 & 29.5 & 35.0 & 20.1 & 12.9 & 11.5 & 11.1 & 12.3\end{array}$

ANNUAL PEAK DISCHARGE, IN CUBIC FEET PER SECOND, AND CORRESPONDING GAGE HEIGHT, IN FEET, FOR EACH WATER YEAR

\begin{tabular}{|c|c|c|c|c|c|c|c|c|c|c|c|}
\hline $\begin{array}{l}\text { WATERR } \\
\text { YEAR }\end{array}$ & DATE & $\begin{array}{c}\text { GAGE } \\
\text { HEIGHT }\end{array}$ & $\begin{array}{c}\text { PEAR } \\
\text { DISCHARGE }\end{array}$ & $\begin{array}{l}\text { WATER } \\
\text { YEAR }\end{array}$ & DATE & $\begin{array}{c}\text { GAGE } \\
\text { HEIGHT }\end{array}$ & $\begin{array}{c}\text { PEAR } \\
\text { DISCAARGE }\end{array}$ & $\begin{array}{l}\text { WATEER } \\
\text { YEAR }\end{array}$ & DATE & $\begin{array}{c}\text { GAGE } \\
\text { HEIGHT }\end{array}$ & $\begin{array}{c}\text { PEAR } \\
\text { DISCHARGE }\end{array}$ \\
\hline $\begin{array}{l}1951 \\
1952 \\
1953 \\
1954 \\
1955 \\
1958 \\
1959 \\
1960\end{array}$ & $\begin{array}{l}\text { JULY } 16,1951 \\
\text { JULY } 30,1952 \\
\text { JULY } 31,1953 \\
\text { JULY } 16,1954 \\
\text { MAR. 11, } 1955 \\
\text { MAR. 22, } 1958 \\
\text { AUG. 01, } 1959 \\
\text { MAR. 20, } 1960\end{array}$ & $\begin{array}{l}6.19 \\
8.17 \\
8.02 \\
7.07 \\
6.32 \\
7.90 \\
7.43 \\
5.41\end{array}$ & $\begin{array}{l}131 \\
386 \\
399 \\
282 \\
181 \\
398 \\
322 \\
100 \\
162\end{array}$ & $\begin{array}{l}1962 \\
1963 \\
1964 \\
1965 \\
1966 \\
1967 \\
1968 \\
1969\end{array}$ & $\begin{array}{l}\text { MAR. } 27,1962 \\
\text { AUG. } 06,1963 \\
\text { APR. } 17,1964 \\
\text { JULY } 16,1965 \\
\text { MAR. } 10,1966 \\
\text { AUG. } 08,1967 \\
\text { JULY } 30,1968 \\
\text { JUNE } 17,1969\end{array}$ & $\begin{array}{l}8.58 \\
8.62 \\
5.76 \\
6.39 \\
6.15 \\
6.14 \\
5.36 \\
5.76\end{array}$ & $\begin{array}{l}435 \\
668 \\
162 \\
306 \\
312 \\
171 \\
106 \\
170\end{array}$ & $\begin{array}{l}1970 \\
1975 \\
1976 \\
1977 \\
1978 \\
1979 \\
1980 \\
1981\end{array}$ & $\begin{array}{lll}\text { MAY } & 04,1970 \\
\text { JULY } & 13,1975 \\
\text { JULY } 25,1976 \\
\text { JULY } 19,1977 \\
\text { APR. } 27,1978 \\
\text { MAY } & 23,1979 \\
\text { MAY } & 12,1980 \\
\text { JULY } 18, & 1981\end{array}$ & $\begin{array}{l}4.58 \\
5.52 \\
2.93 \\
9.55 \\
2.87 \\
3.29 \\
3.21 \\
4.50\end{array}$ & $\begin{array}{r}160 \\
572 \\
78 \\
2240 \\
61 \\
179 \\
156 \\
282\end{array}$ \\
\hline
\end{tabular}

09307800 HILL CREEX ABOVE TOWAVE RESERNOIR, NEAR OURAY, UT

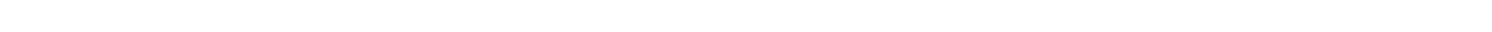
bank $0.5 \mathrm{mi}$ upstream from Lower Wagon Canyon, $3.5 \mathrm{mi}$ above Towave Reservoir, and $39 \mathrm{mi}$ south of ouray.

DRAINAGE AREA. $-89.7 \mathrm{mi}^{2}$.

MEAN BASIN ELEVATION. $-7,570 \mathrm{ft}$.

PERIOD OF RECORD AVAILABLE.-OCtaber 1974 to September 1981.

GAGE.--Water-stage recorder and concrete control. Altitude of gage is 6,470 ft fram topographic map.

AVERAGE DISCHARGE. -7 years, $9.39 \mathrm{ft}^{3} / \mathrm{s}, 6,800$ acre- $\mathrm{ft} / \mathrm{yr}$.

EXIREMES FOR PERIOD OF RECORD.-Maximum discharge, $106 \mathrm{ft}^{3} / \mathrm{s}$ May 28,1979 , gage height, $3.65 \mathrm{ft}$; maximum gage height, $4,73 \mathrm{ft}$ Feb.

21, 1978 (backwater fram ice); no flow part of each day, Aug. 7, 8, 1980, probably caused by bank caving in above station.

LOWEST MEAN DISCHARGE, IN OUBIC FEET PER SBCOND, AND RANKING FOR THE INDICATED NUMBER OF CONSEOUTIVE DAYS FOR EAOH OIIMATIC YEAR, APRIL I-MARCH 31

\begin{tabular}{|c|c|c|c|c|c|c|c|c|c|c|c|c|c|c|c|c|c|c|c|}
\hline YEAR & 1 & & 3 & & 7 & & 14 & & $\begin{array}{l}\text { CONSEX } \\
30\end{array}$ & GTIVE & $\begin{array}{l}\text { DAYS } \\
60\end{array}$ & & 90 & & 120 & & 183 & & ALL \\
\hline $\begin{array}{l}1976 \\
1977 \\
1978 \\
1979 \\
1980\end{array}$ & $\begin{array}{l}3.70 \\
3.00 \\
0.07 \\
0.66 \\
3.80\end{array}$ & $\begin{array}{l}5 \\
3 \\
1 \\
2 \\
6\end{array}$ & $\begin{array}{l}3.90 \\
3.00 \\
0.22 \\
0.68 \\
4.10\end{array}$ & $\begin{array}{l}4 \\
3 \\
1 \\
2 \\
5\end{array}$ & $\begin{array}{l}4.00 \\
3.00 \\
0.42 \\
0.75 \\
4.90\end{array}$ & $\begin{array}{l}4 \\
3 \\
1 \\
2 \\
5\end{array}$ & $\begin{array}{l}4.00 \\
3.00 \\
0.55 \\
0.80 \\
6.00\end{array}$ & $\begin{array}{l}4 \\
3 \\
1 \\
2 \\
6\end{array}$ & $\begin{array}{l}4.30 \\
3.10 \\
0.92 \\
1.10 \\
6.90\end{array}$ & $\begin{array}{l}4 \\
3 \\
1 \\
2 \\
6\end{array}$ & $\begin{array}{l}4.90 \\
4.10 \\
1.00 \\
1.50 \\
7.50\end{array}$ & $\begin{array}{l}4 \\
3 \\
1 \\
2 \\
6\end{array}$ & $\begin{array}{l}6.20 \\
4.50 \\
1.10 \\
2.00 \\
7.30\end{array}$ & $\begin{array}{l}4 \\
3 \\
1 \\
2 \\
5\end{array}$ & $\begin{array}{l}6.40 \\
4.60 \\
1.50 \\
2.50 \\
7.70\end{array}$ & $\begin{array}{l}4 \\
3 \\
1 \\
2 \\
5\end{array}$ & $\begin{array}{l}7.00 \\
4.90 \\
2.40 \\
3.30 \\
8.60\end{array}$ & $\begin{array}{l}4 \\
3 \\
1 \\
2 \\
6\end{array}$ & $\begin{array}{r}12.0 \\
6.90 \\
4.00 \\
5.30 \\
17.0\end{array}$ \\
\hline 981 & 3.60 & 4 & 4.40 & 6 & 5.60 & 6 & 5.80 & 5 & 6.00 & 5 & 7.00 & 5 & 7.50 & 6 & 7.80 & 6 & 8.50 & 5 & 15.0 \\
\hline
\end{tabular}


GREEN RIVER BASIN

09307800 HIIL CREEK ABOVE TOWAVE RESERVOIR, NEAR OURAY, UT-Continued

HIGHEST MEAN DISCHARGE, IN CUBIC FEET PER SECOND, AND RANKING FOR THE INDICATED NUMBER OF CONSEOUTIVE DAYS FOR EACH WATER YEAR, OCTCBER 1-SEPTEMBER 30

$\begin{array}{ccccc}\text { YEAR } & & & 3 & \\ & 1 & & & \\ 1975 & 45.0 & 3 & 42.0 & 3 \\ 1976 & 20.0 & 5 & 19.0 & 5 \\ 1977 & 9.60 & 7 & 9.00 & 7 \\ 1978 & 13.0 & 6 & 13.0 & 6 \\ 1979 & 98.0 & 1 & 97.0 & 1 \\ 1980 & 56.0 & 2 & 55.0 & 2 \\ 1981 & 29.0 & 4 & 27.0 & 4\end{array}$

$\begin{array}{cccc}7 & & 15 & \\ 41.0 & 3 & 39.0 & 3 \\ 18.0 & 5 & 16.0 & 5 \\ 8.40 & 7 & 7.90 & 7 \\ 13.0 & 6 & 12.0 & 6 \\ 96.0 & 1 & 86.0 & 1 \\ 52.0 & 2 & 48.0 & 2 \\ 21.0 & 4 & 18.0 & 4\end{array}$

\begin{tabular}{cccc}
\multicolumn{4}{c}{ CONSECUTIVE DAYS } \\
30 & & 60 \\
37.0 & 3 & 29.0 & 3 \\
& & & \\
15.0 & 4 & 14.0 & 4 \\
7.60 & 7 & 6.80 & 7 \\
12.0 & 6 & 10.0 & 6 \\
69.0 & 1 & 48.0 & 1 \\
44.0 & 2 & 36.0 & 2
\end{tabular}

$\begin{array}{cccccccc}90 & & 120 & & 183 & & \text { ALL } & \\ 24.0 & 3 & 21.0 & 3 & 17.0 & 3 & 11.0 & 3 \\ 13.0 & 4 & 12.0 & 4 & 9.50 & 4 & 8.00 & 4 \\ 5.90 & 7 & 5.50 & 7 & 5.30 & 7 & 4.20 & 7 \\ 9.80 & 6 & 9.00 & 6 & 7.20 & 6 & 5.10 & 6 \\ 38.0 & 1 & 32.0 & 1 & 24.0 & 1 & 14.0 & 2 \\ 31.0 & 2 & 26.0 & 2 & 21.0 & 2 & 15.0 & 1 \\ 11.0 & 5 & 11.0 & 5 & 9.50 & 5 & 7.80 & 5\end{array}$

DURATION OF DISCHARGE FOR EACH WATER YEAR

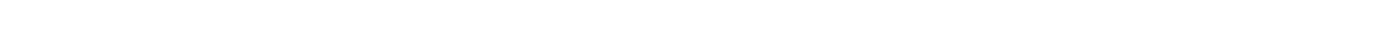

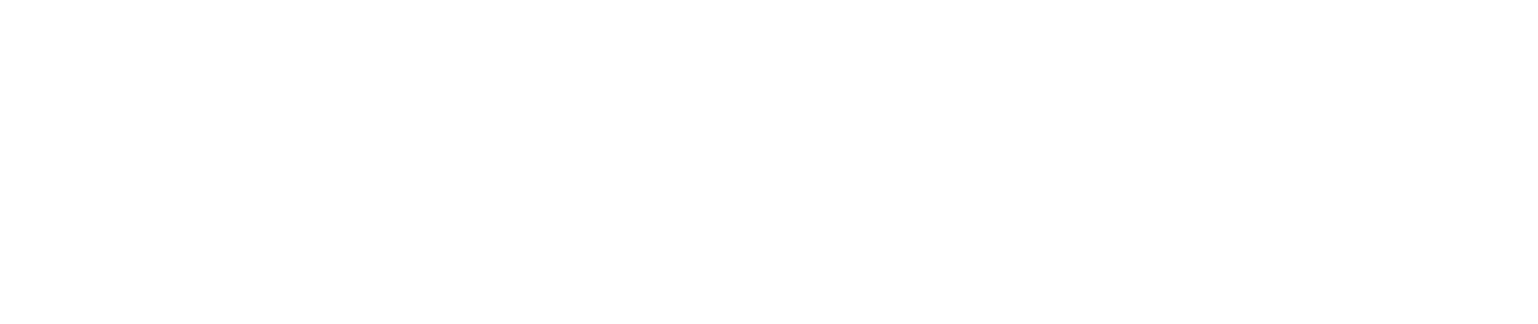

DURATION TABLE OF DISCHARGE FOR WATER YEARS 1975-81

\begin{tabular}{|c|c|c|c|c|c|c|c|c|c|c|c|c|c|c|c|c|c|c|c|}
\hline LASS & $\begin{array}{c}\text { CUBIC } \\
\text { FEET } \\
\text { PER } \\
\text { SECOND }\end{array}$ & $\begin{array}{l}\text { TOTAL } \\
\text { DAYS }\end{array}$ & $\begin{array}{l}\text { ACOJ- } \\
\text { MU- } \\
\text { LATED } \\
\text { DAYS }\end{array}$ & $\begin{array}{l}\text { PER- } \\
\text { CENT } \\
\text { DAYS }\end{array}$ & & $\begin{array}{c}\text { CUBIC } \\
\text { FEET } \\
\text { PER } \\
\text { SECOND }\end{array}$ & $\begin{array}{r}\text { TOTAL } \\
\text { DAYS }\end{array}$ & $\begin{array}{l}\text { ACCU- } \\
\text { MU- } \\
\text { LATEDD } \\
\text { DAYS }\end{array}$ & $\begin{array}{l}\text { PER- } \\
\text { CENT } \\
\text { DAYS }\end{array}$ & & $\begin{array}{c}\text { CUBIC } \\
\text { FEET } \\
\text { PER } \\
\text { SEXOND }\end{array}$ & $\begin{array}{l}\text { TOTAL } \\
\text { DAYS }\end{array}$ & $\begin{array}{l}\text { ACOU- } \\
\text { MU- } \\
\text { LA'TED } \\
\text { DAYS }\end{array}$ & $\begin{array}{l}\text { PER- } \\
\text { CENT } \\
\text { DAYS }\end{array}$ & CIASS & $\begin{array}{c}\text { CUBIC } \\
\text { FEET } \\
\text { PER } \\
\text { SECOND }\end{array}$ & $\begin{array}{l}\text { TOTAL } \\
\text { DAYS }\end{array}$ & $\begin{array}{l}\text { ACCU- } \\
\text { MU- } \\
\text { LA'TED } \\
\text { DAYS }\end{array}$ & $\begin{array}{l}\text { PER- } \\
\text { CENT } \\
\text { DAYS }\end{array}$ \\
\hline $\begin{array}{l}0 \\
1 \\
2 \\
3 \\
4 \\
5 \\
6 \\
7 \\
8\end{array}$ & $\begin{array}{l}0.00 \\
0.04 \\
0.05 \\
0.06 \\
0.08 \\
0.10 \\
0.13 \\
0.17 \\
0.21\end{array}$ & $\begin{array}{l}0 \\
1 \\
1 \\
1 \\
0 \\
0 \\
0 \\
0 \\
1\end{array}$ & $\begin{array}{l}2557 \\
2557 \\
2556 \\
2555 \\
2554 \\
2554 \\
2554 \\
2554 \\
2554\end{array}$ & $\begin{array}{r}100.0 \\
100.0 \\
100.0 \\
99.9 \\
99.9 \\
99.9 \\
99.9 \\
99.9 \\
99.9\end{array}$ & $\begin{array}{l}9 \\
10 \\
11 \\
12 \\
13 \\
14 \\
15 \\
16 \\
17\end{array}$ & $\begin{array}{l}0.26 \\
0.33 \\
0.42 \\
0.54 \\
0.68 \\
0.86 \\
1.10 \\
1.40 \\
1.70\end{array}$ & $\begin{array}{r}3 \\
2 \\
3 \\
12 \\
23 \\
35 \\
24 \\
22 \\
26\end{array}$ & $\begin{array}{l}2553 \\
2550 \\
2548 \\
2545 \\
2533 \\
2510 \\
2475 \\
2451 \\
2429\end{array}$ & $\begin{array}{l}99.8 \\
99.7 \\
99.6 \\
99.5 \\
99.1 \\
98.2 \\
96.8 \\
95.9 \\
95.0\end{array}$ & $\begin{array}{l}18 \\
19 \\
20 \\
21 \\
22 \\
23 \\
24 \\
25 \\
26\end{array}$ & $\begin{array}{r}2.2 \\
2.8 \\
3.5 \\
4.5 \\
5.7 \\
7.2 \\
9.1 \\
11.0 \\
15.0\end{array}$ & $\begin{array}{r}48 \\
140 \\
225 \\
470 \\
315 \\
345 \\
254 \\
296 \\
78\end{array}$ & $\begin{array}{r}2403 \\
2355 \\
2215 \\
1990 \\
1520 \\
1205 \\
860 \\
606 \\
310\end{array}$ & $\begin{array}{l}94.0 \\
92.1 \\
86.6 \\
77.8 \\
59.4 \\
47.1 \\
33.6 \\
23.7 \\
12.1\end{array}$ & $\begin{array}{l}27 \\
28 \\
29 \\
30 \\
31 \\
32 \\
33 \\
34\end{array}$ & $\begin{array}{l}18.0 \\
23.0 \\
30.0 \\
37.0 \\
47.0 \\
60.0 \\
76.0 \\
96.0\end{array}$ & $\begin{array}{r}60 \\
58 \\
34 \\
46 \\
15 \\
8 \\
7 \\
4\end{array}$ & $\begin{array}{r}232 \\
172 \\
114 \\
80 \\
34 \\
19 \\
11 \\
4\end{array}$ & $\begin{array}{l}9.1 \\
6.7 \\
4.5 \\
3.1 \\
1.3 \\
0.7 \\
0.4 \\
0.2\end{array}$ \\
\hline
\end{tabular}

MONTHLY MEAN DISCHARGES, IN OBBIC FEET PER SECOND, FOR EACH WATER IEAR

\begin{tabular}{|c|c|c|c|c|c|c|c|c|c|c|c|c|}
\hline YEAR & $\infty \mathrm{OCT}$ & $\mathrm{NOV}$ & DEC & JAN & FEB & MAR & APR & MAY & JUNE & JULY & AUG & SEP \\
\hline 1975 & 4.65 & 5.98 & 4.00 & 5.00 & 5.00 & 8.92 & 10.8 & 23.8 & 32.5 & 16.1 & 8.52 & 7.58 \\
\hline $\begin{array}{l}1976 \\
1977 \\
1978 \\
1979 \\
1980\end{array}$ & $\begin{array}{l}8.38 \\
5.56 \\
3.16 \\
3.36 \\
8.25\end{array}$ & $\begin{array}{l}7.21 \\
5.74 \\
4.00 \\
4.70 \\
6.93\end{array}$ & $\begin{array}{l}8.32 \\
5.00 \\
4.29 \\
5.00 \\
8.76\end{array}$ & $\begin{array}{l}7.71 \\
5.00 \\
3.51 \\
5.00 \\
9.88\end{array}$ & $\begin{array}{c}4.32 \\
5.28 \\
3.87 \\
5.04 \\
12.0\end{array}$ & $\begin{array}{r}6.60 \\
3.25 \\
8.31 \\
6.24 \\
11.8\end{array}$ & $\begin{array}{c}12.0 \\
7.39 \\
9.81 \\
10.4 \\
16.5\end{array}$ & $\begin{array}{c}15.3 \\
6.14 \\
10.9 \\
51.2 \\
38.9\end{array}$ & $\begin{array}{c}10.6 \\
3.70 \\
6.55 \\
44.0 \\
32.3\end{array}$ & $\begin{array}{c}6.85 \\
1.40 \\
3.33 \\
17.8 \\
16.7\end{array}$ & $\begin{array}{c}3.88 \\
0.97 \\
1.41 \\
11.1 \\
10.8\end{array}$ & $\begin{array}{c}4.60 \\
1.11 \\
1.94 \\
7.03 \\
10.5\end{array}$ \\
\hline 1981 & 9.83 & 8.93 & 8.92 & 6.55 & 7.59 & 9.73 & 14.3 & 9.78 & 5.89 & 4.29 & 3.36 & 4.25 \\
\hline
\end{tabular}

ANNUAL PEAK DISCHARGE, IN CUBIC FEET PER SECOND, AND CORRESPONDING GAGE HEIGHT, IN FEET, FOR EACH WATER YEAR

\begin{tabular}{|c|c|c|c|c|c|c|c|c|c|c|c|}
\hline $\begin{array}{l}\text { WATER } \\
\text { YEAR }\end{array}$ & DATE & $\begin{array}{l}\text { GAGE } \\
\text { HEIGHT }\end{array}$ & $\begin{array}{c}\text { PEAK } \\
\text { DISCHARGE }\end{array}$ & $\begin{array}{l}\text { WATER } \\
\text { YEAR }\end{array}$ & DATE & $\begin{array}{c}\text { GAGE } \\
\text { HEIGHT }\end{array}$ & $\begin{array}{c}\text { PEAR } \\
\text { DISCHARGE }\end{array}$ & $\begin{array}{l}\text { WATER } \\
\text { YEAR }\end{array}$ & DATE & $\begin{array}{l}\text { GAGE } \\
\text { HEIGETT }\end{array}$ & $\begin{array}{c}\text { PEAK } \\
\text { DISCHARGE }\end{array}$ \\
\hline $\begin{array}{l}1975 \\
1976 \\
1977\end{array}$ & $\begin{array}{lll}\text { MAY } & 28,1975 \\
\text { MAY } & 06,1976 \\
\text { JULY } & 19,1977\end{array}$ & $\begin{array}{l}2.56 \\
2.14 \\
2.45\end{array}$ & $\begin{array}{l}47 \\
23 \\
42\end{array}$ & $\begin{array}{l}1978 \\
1979\end{array}$ & $\begin{array}{l}\text { APR. } 27,1978 \\
\text { MAY } \\
28,1979\end{array}$ & $\begin{array}{l}1.84 \\
3.65\end{array}$ & $\begin{array}{r}15 \\
106\end{array}$ & $\begin{array}{l}1980 \\
1981\end{array}$ & $\begin{array}{l}\text { APR. } 29,1980 \\
\text { APR. } 11,1981\end{array}$ & $\begin{array}{l}2.85 \\
2.54\end{array}$ & $\begin{array}{l}65 \\
44\end{array}$ \\
\hline
\end{tabular}


GREEN RIVER BASIN

09307900 HILL CREEX NEAR MOUTH, NEAR OURAY, UT

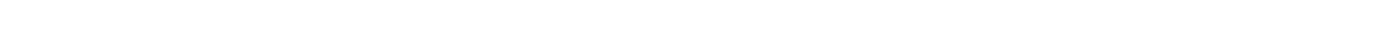
Reservation, Hydrologic Unit 14060006, on right bank $5.9 \mathrm{mi}$ upstream fram mouth and $15 \mathrm{mi}$ south of ouray.

DRAINAGE AREA. $--288 \mathrm{mi}^{2}$.

MEAN BASIN ELEVATION. $-6,780 \mathrm{ft}$.

PERIOD OF REOORD AVAIIABLE.--October 1974 to September 1981.

GAGE.--Water-stage recorder and concrete control. Altitude of gage is 5,080 ft from topographic map.

REMARKS.-Flow regulated by Towave Reservoir above station.

AVERAGE DISCHARGE. --7 years, $5.09 \mathrm{ft}^{3} / \mathrm{s}, 3,690$ acre- $\mathrm{ft} / \mathrm{yr}$

EXIREMES FOR FERIOD OF RECORD.--Maximum discharge, $201 \mathrm{ft}^{3} / \mathrm{s}$ Aug. 1, 1976, gage height, $4.4 \mathrm{ft}$, fram slope-area measurement of peak flow; maximum gage height, $4.84 \mathrm{ft}$ May 17,1975 ; no flow for many days each year.

LOWEST MEAN DISCHARGE, IN OBBIC FEET PER SECOND, AND RANIRING FOR THE INDICATED NUMBER OF CONSECUTIVE DAYS FOR EACH CLIMATIC YEAR, APRIL I-MARCH 31

\begin{tabular}{|c|c|c|c|c|c|c|c|c|c|c|c|c|c|c|c|c|c|c|c|}
\hline YEAR & 1 & & 3 & & 7 & & 14 & & $\begin{array}{l}\text { CONSE } \\
30\end{array}$ & CII & $\begin{array}{l}\text { DAYS } \\
60\end{array}$ & & 90 & & 120 & & 183 & & ALE \\
\hline $\begin{array}{l}1976 \\
1977 \\
1978 \\
1979 \\
1980\end{array}$ & $\begin{array}{l}0.00 \\
0.00 \\
0.00 \\
0.00 \\
0.00\end{array}$ & $\begin{array}{l}1 \\
2 \\
3 \\
4 \\
5\end{array}$ & $\begin{array}{l}0.00 \\
0.00 \\
0.00 \\
0.00 \\
0.00\end{array}$ & $\begin{array}{l}1 \\
2 \\
3 \\
4 \\
5\end{array}$ & $\begin{array}{l}0.00 \\
0.00 \\
0.00 \\
0.00 \\
0.00\end{array}$ & $\begin{array}{l}1 \\
2 \\
3 \\
4 \\
5\end{array}$ & $\begin{array}{l}0.00 \\
0.00 \\
0.00 \\
0.00 \\
0.00\end{array}$ & $\begin{array}{l}1 \\
2 \\
3 \\
4 \\
5\end{array}$ & $\begin{array}{l}0.00 \\
0.00 \\
0.00 \\
0.00 \\
0.00\end{array}$ & $\begin{array}{l}1 \\
2 \\
3 \\
4 \\
5\end{array}$ & $\begin{array}{l}0.06 \\
0.00 \\
0.00 \\
0.00 \\
0.63\end{array}$ & $\begin{array}{l}4 \\
1 \\
2 \\
3 \\
5\end{array}$ & $\begin{array}{l}0.16 \\
0.00 \\
0.00 \\
0.00 \\
1.30\end{array}$ & $\begin{array}{l}4 \\
1 \\
2 \\
3 \\
5\end{array}$ & $\begin{array}{l}0.70 \\
0.00 \\
0.00 \\
0.00 \\
1.19\end{array}$ & $\begin{array}{l}4 \\
1 \\
2 \\
3 \\
5\end{array}$ & $\begin{array}{l}0.58 \\
0.11 \\
0.01 \\
0.00 \\
1.80\end{array}$ & $\begin{array}{l}4 \\
3 \\
2 \\
1 \\
5\end{array}$ & $\begin{array}{c}6.80 \\
2.20 \\
0.56 \\
0.84 \\
12.0\end{array}$ \\
\hline 1981 & 0.00 & 6 & 0.00 & 6 & 0.11 & 6 & 1.50 & 6 & 2.20 & 6 & 3.30 & 6 & 3.50 & 6 & 4.20 & 6 & 4.60 & 6 & 11.0 \\
\hline
\end{tabular}

HIGHEST MEAN DISCHARGE, IN OBIC FEET PER SECOND, AND RANKING FOR THE INDICATED NUMBER OF CONSECUTIVE DAYS FOR EACH WATER YEAR, OCTCBER 1-SEPTEMBER 30

\begin{tabular}{|c|c|c|c|c|c|c|c|c|c|c|c|c|c|c|c|c|c|c|c|}
\hline YEAR & \multicolumn{19}{|c|}{ CONSECOTIVE DAYS } \\
\hline 1975 & 52.0 & 3 & 46.0 & 3 & 40.0 & 3 & 37.0 & 3 & 34.0 & 3 & 24.0 & 3 & 18.0 & 3 & 15.0 & 3 & 12.0 & 3 & 6.00 \\
\hline
\end{tabular}

DURATION OF DISCHARGE FOR EACH WATER YEAR

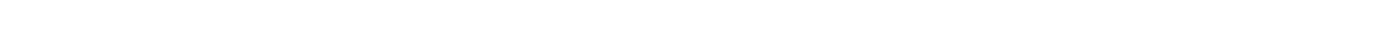
YEAR NUMBER OF DAYS IN CLASS OBIC FEET PER SECOND

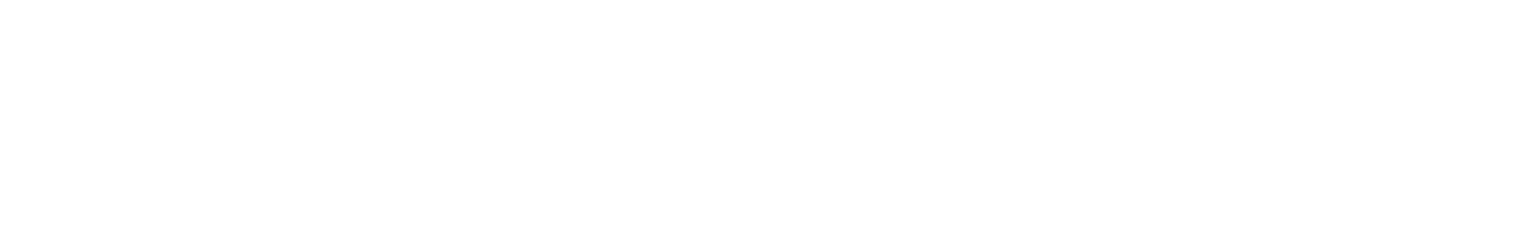

DURATION TABLE OF DISCHARGE FOR WATER YEARS 1975-81

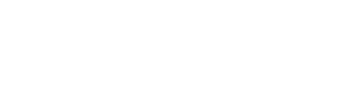

$\begin{array}{rrrrr}0 & 0.00 & 1179 & 2557 & 100.0 \\ 1 & 0.01 & 6 & 1378 & 53.9 \\ 2 & 0.02 & 3 & 1372 & 53.7 \\ 3 & 0.03 & 2 & 1369 & 53.5 \\ 4 & 0.04 & 2 & 1367 & 53.5 \\ 5 & 0.05 & 4 & 1365 & 53.4 \\ 6 & 0.07 & 8 & 1361 & 53.2 \\ 7 & 0.09 & 17 & 1353 & 52.9 \\ 8 & 0.12 & 5 & 1336 & 52.2\end{array}$

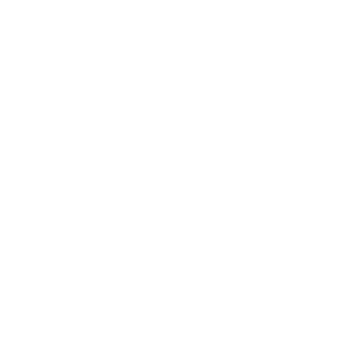

ABBIC

FEET ACOU- PER CLASS SEOOND TOTAL LATED CENI

$\begin{array}{rrrrr}18 & 1.9 & 59 & 1119 & 43.8 \\ 19 & 2.4 & 114 & 1060 & 41.5 \\ 20 & 3.2 & 136 & 946 & 37.0 \\ 21 & 4.2 & 121 & 810 & 31.7 \\ 22 & 5.6 & 153 & 689 & 26.9 \\ 23 & 7.3 & 165 & 536 & 21.0 \\ 24 & 9.7 & 108 & 371 & 14.5 \\ 25 & 13.0 & 77 & 263 & 10.3 \\ 26 & 17.0 & 51 & 186 & 7.3\end{array}$

$\begin{array}{lcl}\text { OABIC } & \text { ACCJ- } \\ \text { FEET } & \\ \text { PER TOTAL } & \text { PER- }\end{array}$ GLASS SECOND DAYS DAYS DAYS

$\begin{array}{rrrrr}27 & 22.0 & 22 & 135 & 5.3 \\ 28 & 29.0 & 51 & 113 & 4.4 \\ 29 & 38.0 & 27 & 62 & 2.4 \\ 30 & 50.0 & 20 & 35 & 1.4 \\ 31 & 66.0 & 11 & 15 & 0.6 \\ 32 & 87.0 & 4 & 4 & 0.2 \\ 33 & & & & \\ 34 & & & & \end{array}$


GREEN RIVER BASIN

09307900 HILL CREFK NEAR MOUTH, NEAR OURAY, UT-Continued

MONTHLY MEAN DISCHARGES, IN OBIC FEET PER SECOND, FOR EACH WATER YEAR

$\begin{array}{lllllllllllll}\text { YEAR } & \text { OCT } & \text { NOV } & \text { DEC } & \text { JAN } & \text { FEB } & \text { MAR } & \text { APR } & \text { MAY } & \text { JUNE } & \text { JULY } & \text { AUG } & \text { SEP } \\ 1975 & 0.00 & 0.09 & 0.00 & 0.00 & 1.68 & 7.02 & 6.55 & 18.8 & 27.4 & 7.43 & 3.13 & 0.12 \\ 1976 & 1.17 & 1.57 & 0.28 & 0.06 & 2.21 & 12.5 & 9.72 & 8.41 & 1.07 & 0.06 & 0.82 & 0.00 \\ 1977 & 0.03 & 0.00 & 0.00 & 0.48 & 2.46 & 3.28 & 4.05 & 0.07 & 0.00 & 1.31 & 1.08 & 0.00 \\ 1978 & 0.07 & 0.00 & 0.00 & 0.00 & 0.00 & 0.14 & 2.12 & 1.28 & 0.31 & 0.00 & 0.00 & 0.00 \\ 1979 & 0.00 & 0.00 & 0.00 & 0.00 & 0.00 & 6.30 & 9.90 & 42.3 & 41.4 & 7.82 & 3.81 & 0.09 \\ 1980 & 1.52 & 2.44 & 0.98 & 2.27 & 13.2 & 16.7 & 13.7 & 41.3 & 27.8 & 8.15 & 2.68 & 4.02 \\ 1981 & 4.72 & 5.60 & 5.54 & 5.24 & 6.91 & 9.55 & 10.2 & 4.96 & 0.93 & 0.00 & 0.00 & 0.43\end{array}$

ANNUAL PEAK DISCHARGE, IN CUBIC FEET PER SECOND, AND CORRESPONDING GAGE HEIGHT, IN FEET, FOR EACR WATER YEAR

\begin{tabular}{|c|c|c|c|c|c|c|c|c|c|c|c|}
\hline $\begin{array}{l}\text { WATER } \\
\text { YEAR }\end{array}$ & DATE & $\begin{array}{c}\text { GAGE } \\
\text { HEIGHT }\end{array}$ & $\begin{array}{c}\text { PEAK } \\
\text { DISCHARGE }\end{array}$ & $\begin{array}{l}\text { WATER } \\
\text { YEAR }\end{array}$ & DATE & $\begin{array}{l}\text { GAGE } \\
\text { HEIGHT }\end{array}$ & $\begin{array}{c}\text { PEAK } \\
\text { DISCHARGE }\end{array}$ & $\begin{array}{l}\text { WATER } \\
\text { YEAR }\end{array}$ & DATE & $\begin{array}{l}\text { GAGE } \\
\text { HEIGHT }\end{array}$ & $\begin{array}{c}\text { PEAK } \\
\text { DISCHARGE }\end{array}$ \\
\hline $\begin{array}{l}1975 \\
1976 \\
1977\end{array}$ & $\begin{array}{lll}\text { MAY } & 17,1975 \\
\text { AUG. } & 01, & 1976 \\
\text { JULY } 19, & 1977\end{array}$ & $\begin{array}{l}4.84 \\
4.40 \\
3.99\end{array}$ & $\begin{array}{r}82 \\
201 \\
134\end{array}$ & $\begin{array}{l}1978 \\
1979\end{array}$ & $\begin{array}{l}\text { OCT. } 07,1977 \\
\text { AUG. } 14,1979\end{array}$ & $\begin{array}{l}2.55 \\
3.66\end{array}$ & 103 & $\begin{array}{l}1980 \\
1981\end{array}$ & $\begin{array}{l}\text { SEPT. 10, } 1980 \\
\text { SEPT. 05, } 1981\end{array}$ & $\begin{array}{l}3.69 \\
2.97\end{array}$ & $\begin{array}{l}97 \\
29\end{array}$ \\
\hline
\end{tabular}

09308000 WILLOW CREEK NEAR OURAY, UT

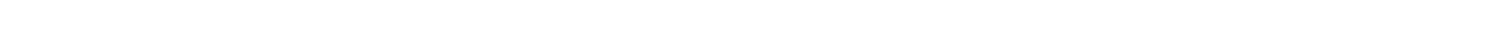
bank $0.3 \mathrm{mi}$ upstream from Black Bridge, $1.6 \mathrm{mi}$ downstream from Hill Creek, and $10 \mathrm{mi}$ south of ouray.

DRAINAGE AREA.--897 $\mathrm{mi}^{2}$.

MEAN BASIN ELEVATION. $--7,140 \mathrm{ft}$.

PERIOD OF RECORD AVAILABLE.-July 1947 to September 1955, October 1974 to September 1981, and annual peak discharge only, water years $1960-68$.

GAGE.--Water-stage recorder and concrete control. Altitude of gage is 4,860 ft from topographic map.

REMARKS.-Diversions for irrigation above station.

AVERAGE DISCHARGE. -15 years, $25.2 \mathrm{ft}^{3} / \mathrm{s}, 18,260$ acre- $\mathrm{ft} / \mathrm{yr}$.

EXIREMES FOR PERIOD OF RECORD.-Maximum discharge, about $11,000 \mathrm{ft}^{3} / \mathrm{s}$ February 1962 , gage height, $17.73 \mathrm{ft}$, site and datum then in use; no flow at times.

LOWEST MEAN DISCHARGE, IN OUBIC FEET PER SECOND, AND RANKING FOR THE INDICATED NUMBER OF CONSECITIVE DAYS FOR EACH CLIMATIC YEAR, APRIL I-MARCH 31

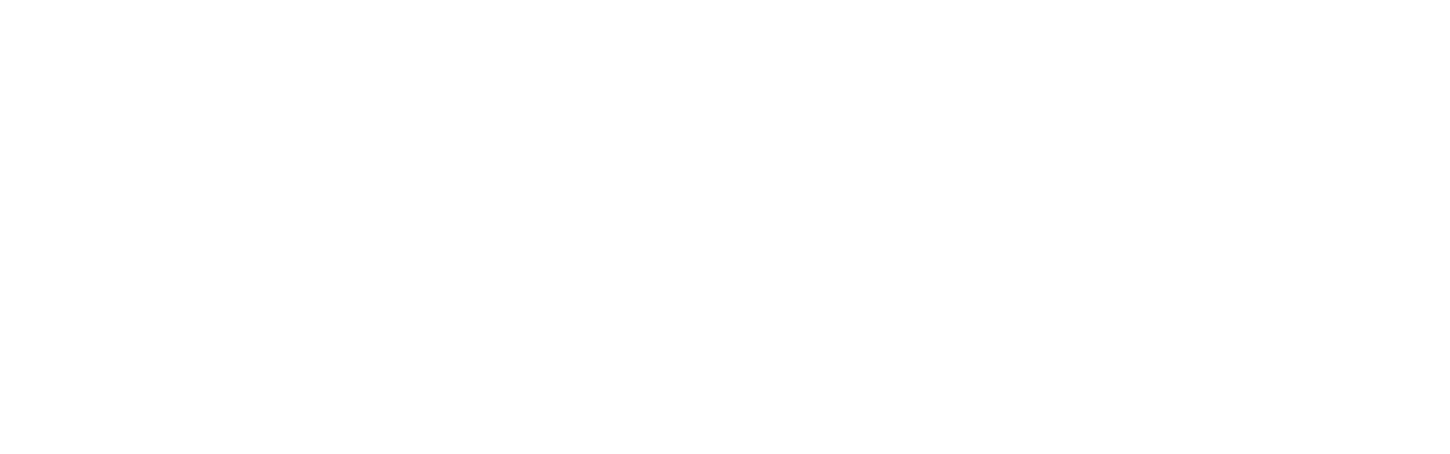


09308000 WILLOW CREEK NEAR OURAY, UTL-Continued

HIGHEST MEAN DISGHARGE, IN CUBIC FEET PER SECOND, AND RANKING FOR THE INDICATED NUMBER OF CONSEOITIVE DAYS FOR EACH WATER YEAR, OCTOBER 1-SEPTEMBER 30

\begin{tabular}{|c|c|c|c|c|c|c|c|c|c|c|c|c|c|c|c|c|c|c|c|c|}
\hline YEAR & 1 & & 3 & & 7 & & 15 & & $\begin{array}{l}\text { CONS } \\
30\end{array}$ & EQU? & $\begin{array}{c}\text { VE DAYS } \\
60\end{array}$ & & 90 & & 120 & & 183 & & ALL & \\
\hline $\begin{array}{l}948 \\
949 \\
950\end{array}$ & $\begin{array}{l}311 \\
260 \\
122\end{array}$ & $\begin{array}{l}3 \\
4 \\
9\end{array}$ & $\begin{array}{l}264 \\
186 \\
119\end{array}$ & $\begin{array}{l}3 \\
5 \\
8\end{array}$ & $\begin{array}{l}197 \\
140 \\
115\end{array}$ & $\begin{array}{l}4 \\
5 \\
6\end{array}$ & $\begin{array}{l}148 \\
130 \\
108\end{array}$ & $\begin{array}{l}4 \\
5 \\
6\end{array}$ & $\begin{array}{c}123 \\
125 \\
99.0\end{array}$ & $\begin{array}{l}5 \\
4 \\
6\end{array}$ & $\begin{array}{c}93.0 \\
109 \\
86.0\end{array}$ & $\begin{array}{l}5 \\
4\end{array}$ & & $\begin{array}{l}6 \\
2 \\
5\end{array}$ & & $\begin{array}{l}6 \\
3 \\
5\end{array}$ & & $\begin{array}{l}7 \\
3 \\
5\end{array}$ & $\begin{array}{l}22.0 \\
40.0 \\
37.0\end{array}$ & $\begin{array}{l}7 \\
3 \\
4\end{array}$ \\
\hline $\begin{array}{l}951 \\
952 \\
953 \\
954 \\
955\end{array}$ & $\begin{array}{c}59.0 \\
500 \\
74.0 \\
92.0 \\
167\end{array}$ & $\begin{array}{r}14 \\
1 \\
12 \\
10 \\
7\end{array}$ & $\begin{array}{c}53.0 \\
343 \\
64.0 \\
68.0 \\
120\end{array}$ & $\begin{array}{r}14 \\
2 \\
12 \\
11 \\
6\end{array}$ & $\begin{array}{r}51.0 \\
322 \\
47.0 \\
66.0 \\
96.0\end{array}$ & $\begin{array}{r}13 \\
1 \\
14 \\
11 \\
8\end{array}$ & $\begin{array}{c}47.0 \\
280 \\
46.0 \\
63.0 \\
64.0\end{array}$ & $\begin{array}{r}12 \\
1 \\
13 \\
9 \\
8\end{array}$ & $\begin{array}{c}45.0 \\
226 \\
45.0 \\
51.0 \\
48.0\end{array}$ & $\begin{array}{r}11 \\
1 \\
12 \\
8 \\
9\end{array}$ & $\begin{array}{c}41.0 \\
166 \\
40.0 \\
43.0 \\
46.0\end{array}$ & $\begin{array}{r}11 \\
1 \\
12 \\
10 \\
8\end{array}$ & $\begin{array}{c}34.0 \\
133 \\
35.0 \\
37.0 \\
36.0\end{array}$ & $\begin{array}{r}13 \\
1 \\
12 \\
9 \\
10\end{array}$ & $\begin{array}{c}30.0 \\
108 \\
31.0 \\
33.0 \\
30.0\end{array}$ & $\begin{array}{r}13 \\
1 \\
11 \\
10 \\
12\end{array}$ & & $\begin{array}{l}10 \\
1 \\
11 \\
12 \\
13\end{array}$ & $\begin{array}{l}18.0 \\
49.0 \\
19.0 \\
17.0 \\
15.0\end{array}$ & $\begin{array}{r}11 \\
1 \\
10 \\
12 \\
13\end{array}$ \\
\hline 975 & 129 & 8 & 119 & 7 & 104 & 7 & 99.0 & 7 & 88.0 & 7 & 67.0 & 7 & 56.0 & 7 & 49.0 & 7 & 39.0 & 6 & 24.0 & \\
\hline $\begin{array}{l}976 \\
977 \\
978 \\
979 \\
980\end{array}$ & $\begin{array}{c}60.0 \\
234 \\
39.0 \\
234 \\
500\end{array}$ & $\begin{array}{r}13 \\
5 \\
15 \\
6 \\
2\end{array}$ & $\begin{array}{c}59.0 \\
109 \\
38.0 \\
227 \\
377\end{array}$ & $\begin{array}{r}13 \\
9 \\
15 \\
4 \\
1\end{array}$ & $\begin{array}{r}55.0 \\
92.0 \\
36.0 \\
221 \\
256\end{array}$ & $\begin{array}{r}12 \\
9 \\
15 \\
3 \\
2\end{array}$ & $\begin{array}{l}49.0 \\
46.0 \\
33.0 \\
201 \\
157\end{array}$ & $\begin{array}{r}11 \\
14 \\
15 \\
2 \\
3\end{array}$ & $\begin{array}{r}45.0 \\
24.0 \\
31.0 \\
157 \\
149\end{array}$ & $\begin{array}{r}13 \\
15 \\
14 \\
2 \\
3\end{array}$ & $\begin{array}{r}44.0 \\
21.0 \\
28.0 \\
118 \\
118\end{array}$ & $\begin{array}{r}9 \\
15 \\
14 \\
2 \\
3\end{array}$ & $\begin{array}{l}41.0 \\
18.0 \\
24.0 \\
97.0 \\
94.0\end{array}$ & $\begin{array}{r}8 \\
15 \\
14 \\
3 \\
4\end{array}$ & $\begin{array}{l}38.0 \\
16.0 \\
21.0 \\
82.0 \\
95.0\end{array}$ & $\begin{array}{r}8 \\
15 \\
14 \\
4 \\
2\end{array}$ & & $\begin{array}{r}8 \\
15 \\
14 \\
4 \\
2\end{array}$ & $\begin{array}{l}21.0 \\
10.0 \\
11.0 \\
33.0 \\
44.0\end{array}$ & $\begin{array}{r}8 \\
15 \\
14 \\
5 \\
2\end{array}$ \\
\hline
\end{tabular}

DURATION OF DISCHARGE FOR EACH WATER YEAR

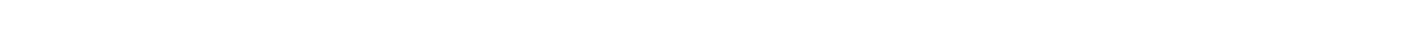

YEAR

NUMBER OF DAYS IN OLASS

UBIC FEET PER SECOND -DAVS

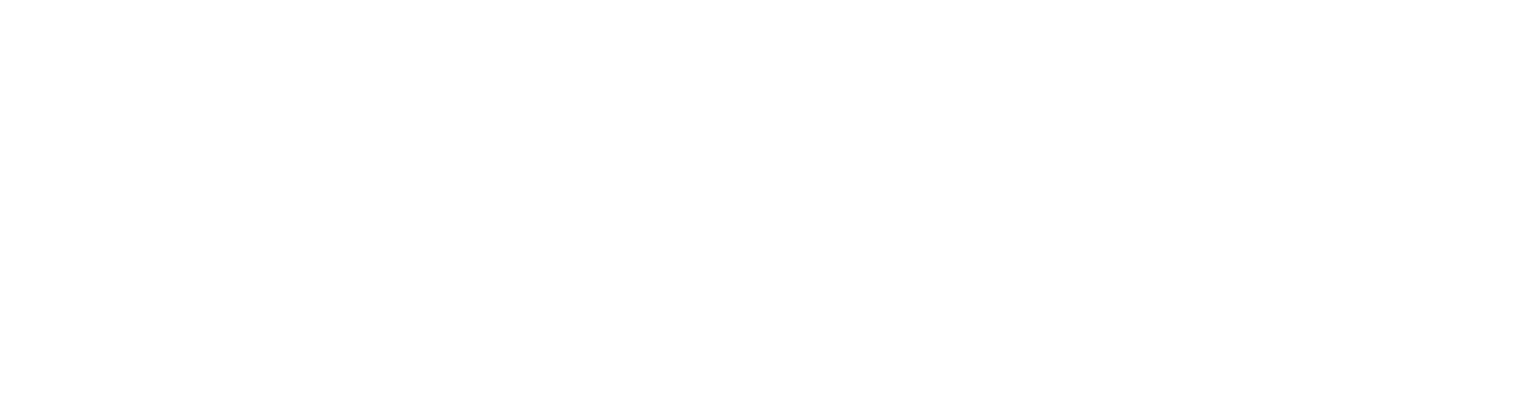

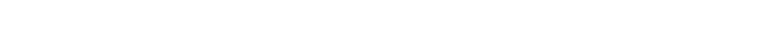

DURAITON TABLE OF DISCHARGE FOR WAIER YEARS 1948-55, 1975-81

$\begin{array}{rrr}\text { CUBIC } & \text { ACUI- } \\ \text { FEET } & \text { MU- } & \text { PER- } \\ \text { PER } & \text { TOTAL LATED } & \text { CENT } \\ \text { OLASS SECOND DAYS } & \text { DAYS } & \text { DAYS }\end{array}$

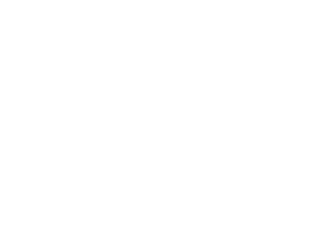

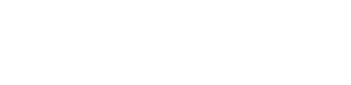
CLASS SECOND DAYS DAYS DAYS

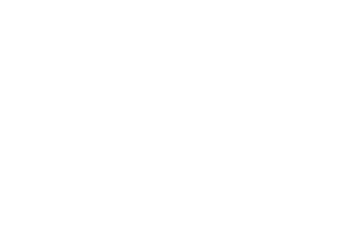

CBBIC ACOI-

FEET MU- PER PER TOTAL LATED
OENS SECOND DAYS DAYS DAYS

$\begin{array}{rrrrr}18 & 3.1 & 148 & 4492 & 82.0 \\ 19 & 4.3 & 216 & 4344 & 79.3 \\ 20 & 5.9 & 179 & 4128 & 75.3 \\ 21 & 8.1 & 490 & 3949 & 72.1 \\ 22 & 11.0 & 660 & 3459 & 63.1 \\ 23 & 15.0 & 702 & 2799 & 51.1 \\ 24 & 21.0 & 686 & 2097 & 38.3 \\ 25 & 29.0 & 465 & 1411 & 25.8 \\ 26 & 40.0 & 380 & 946 & 17.3\end{array}$

FBIC ACCNFEET TU- PER-
PER TOTA LATED CENT CLASS SECOND DAYS DAYS DAYS

$\begin{array}{rrrrr}27 & 55.0 & 191 & 566 & 10.3 \\ 28 & 75.0 & 151 & 375 & 6.8 \\ 29 & 100.0 & 130 & 224 & 4.1 \\ 30 & 140.0 & 54 & 94 & 1.7 \\ 31 & 200.0 & 26 & 40 & 0.7 \\ 32 & 270.0 & 11 & 14 & 0.3 \\ 33 & 370.0 & 3 & 3 & 0.1 \\ 34 & & & & \end{array}$


GREEN RIVER BASTN

09308000 WHLWW CREEK NEAR OURAY, UT--Continued

MONTHLY MEAN DISCHARGES, IN OBBIC FEET PER SECOND, FOR EACH WATER YEAR

\begin{tabular}{|c|c|c|c|c|c|c|c|c|c|c|c|c|}
\hline YEAR & $\infty T$ & NOV & DEC & JAN & FEB & MAR & APR & MAY & JUNE & JULY & AUG & SEP \\
\hline $\begin{array}{l}1948 \\
1949 \\
1950\end{array}$ & $\begin{array}{c}11.7 \\
9.19 \\
37.5\end{array}$ & $\begin{array}{l}11.4 \\
11.1 \\
39.2\end{array}$ & $\begin{array}{l}3.58 \\
10.0 \\
20.1\end{array}$ & $\begin{array}{c}4.35 \\
9.00 \\
17.4\end{array}$ & $\begin{array}{c}7.41 \\
10.4 \\
24.6\end{array}$ & $\begin{array}{l}34.3 \\
35.9 \\
50.7\end{array}$ & $\begin{array}{l}120 \\
61.9 \\
90.7\end{array}$ & $\begin{array}{c}51.2 \\
115 \\
80.4\end{array}$ & $\begin{array}{l}15.5 \\
94.9 \\
34.3\end{array}$ & $\begin{array}{c}9.88 \\
59.9 \\
23.9\end{array}$ & $\begin{array}{c}1.03 \\
32.0 \\
8.79\end{array}$ & $\begin{array}{c}0.94 \\
23.4 \\
16.6\end{array}$ \\
\hline $\begin{array}{l}1951 \\
1952 \\
1953 \\
1954 \\
1955\end{array}$ & $\begin{array}{l}21.5 \\
10.1 \\
27.3 \\
13.3 \\
11.7\end{array}$ & $\begin{array}{l}30.5 \\
13.0 \\
26.6 \\
16.9 \\
15.1\end{array}$ & $\begin{array}{l}27.7 \\
13.0 \\
21.0 \\
20.2 \\
11.0\end{array}$ & $\begin{array}{l}16.9 \\
11.8 \\
20.0 \\
20.0 \\
10.0\end{array}$ & $\begin{array}{l}23.2 \\
12.0 \\
23.5 \\
24.1 \\
10.4\end{array}$ & $\begin{array}{l}42.5 \\
16.9 \\
37.5 \\
37.2 \\
44.9\end{array}$ & $\begin{array}{l}35.7 \\
92.4 \\
42.5 \\
48.0 \\
44.0\end{array}$ & $\begin{array}{c}7.53 \\
222 \\
12.3 \\
9.05 \\
14.1\end{array}$ & $\begin{array}{c}3.14 \\
77.5 \\
3.03 \\
3.37 \\
0.51\end{array}$ & $\begin{array}{c}0.26 \\
33.5 \\
2.90 \\
4.45 \\
0.09\end{array}$ & $\begin{array}{c}2.22 \\
49.8 \\
6.67 \\
1.85 \\
14.1\end{array}$ & $\begin{array}{c}1.60 \\
28.9 \\
2.13 \\
11.2 \\
1.04\end{array}$ \\
\hline 1975 & 8.60 & 15.5 & 8.50 & 13.0 & 13.0 & 27.6 & 37.7 & 68.0 & 59.5 & 28.4 & 5.69 & 4.15 \\
\hline $\begin{array}{l}1976 \\
1977 \\
1978 \\
1979 \\
1980\end{array}$ & $\begin{array}{c}20.4 \\
7.20 \\
4.13 \\
0.09 \\
11.8\end{array}$ & $\begin{array}{c}25.1 \\
7.94 \\
12.9 \\
6.55 \\
17.8\end{array}$ & $\begin{array}{l}19.0 \\
10.2 \\
12.5 \\
10.0 \\
13.3\end{array}$ & $\begin{array}{l}19.4 \\
13.0 \\
11.2 \\
10.0 \\
15.1\end{array}$ & $\begin{array}{l}25.6 \\
19.1 \\
12.2 \\
12.1 \\
84.8\end{array}$ & $\begin{array}{l}38.4 \\
21.1 \\
17.3 \\
39.5 \\
45.4\end{array}$ & $\begin{array}{l}42.3 \\
10.3 \\
28.0 \\
51.1 \\
60.2\end{array}$ & $\begin{array}{c}41.7 \\
2.62 \\
26.2 \\
139 \\
147\end{array}$ & $\begin{array}{c}10.4 \\
0.44 \\
3.70 \\
89.6 \\
68.1\end{array}$ & $\begin{array}{c}2.61 \\
22.9 \\
0.01 \\
22.4 \\
17.7\end{array}$ & $\begin{array}{l}0.98 \\
2.30 \\
0.00 \\
9.54 \\
7.88\end{array}$ & $\begin{array}{c}2.56 \\
2.73 \\
0.00 \\
3.21 \\
39.8\end{array}$ \\
\hline 1981 & 18.9 & 22.9 & 27.6 & 22.9 & 31.8 & 32.5 & 42.5 & 10.8 & 3.75 & 4.32 & 4.08 & 8.74 \\
\hline
\end{tabular}

ANNUAL PEAK DISCHARGE, IN OABIC FEET PER SECOND, AND CORRESPONDING GAGE HEIGHT, IN FEET, FOR EACH WATER YEAR

\begin{tabular}{|c|c|c|c|c|c|c|c|c|c|c|c|}
\hline $\begin{array}{l}\text { WATER } \\
\text { YEAR }\end{array}$ & DATE & $\begin{array}{c}\text { GAGE } \\
\text { HEIGHT }\end{array}$ & $\begin{array}{c}\text { PEAR } \\
\text { DISCHARGE }\end{array}$ & $\begin{array}{l}\text { WATER } \\
\text { YEAR }\end{array}$ & DATE & $\begin{array}{c}\text { GAGE } \\
\text { HEIGHT }\end{array}$ & $\begin{array}{c}\text { PEAK } \\
\text { DISCHARGE }\end{array}$ & $\begin{array}{l}\text { WATER } \\
\text { YEAR }\end{array}$ & DATE & $\begin{array}{c}\text { GAGE } \\
\text { HEIGHT }\end{array}$ & $\begin{array}{c}\text { PEAK } \\
\text { DISCHARGE }\end{array}$ \\
\hline $\begin{array}{l}1947 \\
1948 \\
1949 \\
1950 \\
1951 \\
1952 \\
1953 \\
1954\end{array}$ & $\begin{array}{l}\text { AUG. } 06,1947 \\
\text { JULY } 25,1948 \\
\text { JULY } 05,1949 \\
\text { SEPT. } 07,1950 \\
\text { MAR. 26, } 1951 \\
\text { AUG. 27, } 1952 \\
\text { JULY 31, } 1953 \\
\text { SEPT.26, } 1954\end{array}$ & $\begin{array}{l}5.56 \\
4.02 \\
5.18 \\
2.66 \\
1.66 \\
9.68 \\
2.85 \\
3.60\end{array}$ & $\begin{array}{r}905 \\
424 \\
740 \\
214 \\
64 \\
2320 \\
206 \\
446\end{array}$ & $\begin{array}{l}1955 \\
1960 \\
1961 \\
1962 \\
1963 \\
1964 \\
1965 \\
1966\end{array}$ & $\begin{array}{l}\text { AUG. } 07,1955 \\
\text { JULY } 30,1960 \\
\text { SEPT. } 17,1961 \\
\text { FEB. --, } 1962 \\
\text { AUG. } 22,1963 \\
\text { JULY } 31,1964 \\
\text { MAY } 07,1965 \\
\text { JULY } 16,1966\end{array}$ & $\begin{array}{c}7.16 \\
7 \overline{7.87} \\
17.73 \\
11.11 \\
10.74 \\
11.90 \\
3.51\end{array}$ & $\begin{array}{r}1420 \\
690 \\
1510 \\
11000 \\
3200 \\
2600 \\
3500 \\
408\end{array}$ & $\begin{array}{l}1967 \\
1968 \\
1975 \\
1976 \\
1977 \\
1978 \\
1979 \\
1981\end{array}$ & $\begin{array}{lll}\text { JUNE } & 04,1967 \\
\text { MAY } & 08,1968 \\
\text { MAY } & 17,1975 \\
\text { MAY } & 07,1976 \\
\text { JULY } 20,1977 \\
\text { MAY } 01,1978 \\
\text { MAY } 24,1979 \\
\text { SEPT.11, } 1981\end{array}$ & $\begin{array}{l}4.61 \\
1.45 \\
4.49 \\
3.51 \\
4.67 \\
2.87 \\
3.94 \\
4.34\end{array}$ & $\begin{array}{r}520 \\
50 \\
673 \\
178 \\
816 \\
48 \\
270 \\
554\end{array}$ \\
\hline
\end{tabular}

09308500 MINNIE MAJD CREEK NEAR MYTON, UT

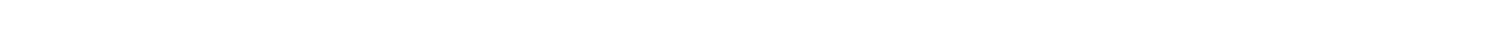
bank $38.4 \mathrm{mi}$ southwest of Myton.

DRATNAGE AREA. $-32.0 \mathrm{mi}^{2}$.

MEAN BASIN ELEVATION. $-8,460 \mathrm{ft}$.

PERIOD OF RECORD AVAILABLE.--August 1950 to September 1955, September 1957 to September 1981.

REVISED RECORDS.--WDR UT-77-1: Drainage area.

GAGE.--Water-stage recorder. Altitude of gage is 7,190 ft by barameter.

AVERAGE DISCHARGE. -29 years, $5.03 \mathrm{ft}^{3} / \mathrm{s}, 3,640$ acre-ft/yr.

EXTREMES FOR PERIOD OF RECORD.--Maximum discharge unknown, occurred oct. 13, 1975, gage height, $11.67 \mathrm{ft}$; maximum known discharge, $1,370 \mathrm{ft}^{3} / \mathrm{s}$ Aug. 25, 1961, gage height, $9.40 \mathrm{ft}$, from rating curve extended above $110 \mathrm{ft}^{3} / \mathrm{s}$ on basis of slope-area measurement of peak flow; no flow at times.

LOWEST MEAN DISCHARGE, IN OUBIC FEET PER SECOND, AND RANKING FOR THE INDICATED NUMBER OF CONSECUTIVE DAYS FOR EACH CLIMATIC YEAR, APRIL I-MAROH 31

\begin{tabular}{|c|c|c|c|c|c|c|c|c|c|c|c|}
\hline YEAR & & & & & CONSECUTIV & DAYS & & & & & \\
\hline & 1 & 3 & 7 & 14 & 30 & 60 & 90 & 120 & 183 & ALل & \\
\hline $\begin{array}{l}1952 \\
1953 \\
1954 \\
1955\end{array}$ & $\begin{array}{rr}0.20 & 15 \\
0.10 & 9 \\
0.10 & 10 \\
0.00 & 1\end{array}$ & $\begin{array}{rr}0.20 & 14 \\
0.10 & 9 \\
0.10 & 10 \\
0.00 & 1\end{array}$ & $\begin{array}{rr}0.20 & 14 \\
0.10 & 9 \\
0.10 & 10 \\
0.00 & 1\end{array}$ & $\begin{array}{rr}0.23 & 13 \\
0.10 & 9 \\
0.10 & 10 \\
0.00 & 1\end{array}$ & $\begin{array}{rr}0.27 & 13 \\
0.10 & 7 \\
0.10 & 8 \\
0.00 & 1\end{array}$ & $\begin{array}{rr}0.28 & 11 \\
0.10 & 7 \\
0.29 & 12 \\
0.00 & 1\end{array}$ & $\begin{array}{rr}0.29 & 11 \\
0.10 & 6 \\
0.41 & 14 \\
0.07 & 5\end{array}$ & $\begin{array}{rr}0.30 & 10 \\
0.21 & 8 \\
0.44 & 13 \\
0.18 & 6\end{array}$ & $\begin{array}{rr}0.43 & 8 \\
0.68 & 13 \\
0.52 & 10 \\
0.36 & 7\end{array}$ & $\begin{array}{c}1.70 \\
16.0 \\
1.40 \\
1.30\end{array}$ & $\begin{array}{r}8 \\
27 \\
6 \\
5\end{array}$ \\
\hline $\begin{array}{l}1959 \\
1960\end{array}$ & $\begin{array}{ll}0.70 & 23 \\
0.10 & 11\end{array}$ & $\begin{array}{ll}0.70 & 23 \\
0.10 & 11\end{array}$ & $\begin{array}{ll}0.70 & 23 \\
0.10 & 11\end{array}$ & $\begin{array}{ll}0.70 & 21 \\
0.10 & 11\end{array}$ & $\begin{array}{rr}0.70 & 21 \\
0.10 & 9\end{array}$ & $\begin{array}{rr}0.72 & 21 \\
0.10 & 8\end{array}$ & $\begin{array}{rr}0.75 & 21 \\
0.13 & 8\end{array}$ & $\begin{array}{rr}0.80 & 18 \\
0.19 & 7\end{array}$ & $\begin{array}{rr}0.89 & 15 \\
0.29 & 6\end{array}$ & $\begin{array}{l}9.40 \\
1.00\end{array}$ & $\begin{array}{r}20 \\
3\end{array}$ \\
\hline
\end{tabular}


GREEN RIVER BASIN

09308500 MINNIE MAUD CREEK NEAR MYTON, UT-Continued

IOWEST NEAN DISGHARGE, IN OBIC FEET PER SECOND, AND RANKING FOR THE INDICATED NUMBER OF CONSEQUTTVE DAYS FOR EACH OIMATIC YEAR, APRII 1-MAROH 31-Continued

YEAR

\begin{tabular}{|c|c|c|c|}
\hline & 1 & 3 & 7 \\
\hline $\begin{array}{l}1966 \\
1967 \\
1968 \\
1969 \\
1970\end{array}$ & $\begin{array}{ll}0.60 & 22 \\
0.40 & 21 \\
1.00 & 24 \\
1.40 & 25 \\
1.40 & 26\end{array}$ & $\begin{array}{ll}0.63 & 22 \\
0.40 & 21 \\
1.00 & 24 \\
1.40 & 25 \\
1.40 & 26\end{array}$ & 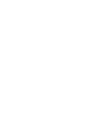 \\
\hline $\begin{array}{l}1971 \\
1972 \\
1973 \\
1974 \\
1975\end{array}$ & $\begin{array}{rr}0.20 & 14 \\
0.34 & 19 \\
0.23 & 16 \\
1.60 & 27 \\
0.00 & 5\end{array}$ & $\begin{array}{rr}0.21 & 15 \\
0.34 & 18 \\
0.24 & 16 \\
1.60 & 27 \\
0.00 & 5\end{array}$ & $\begin{array}{l}0.221 \\
0.351 \\
0.281 \\
1.602 \\
0.00\end{array}$ \\
\hline $\begin{array}{l}1976 \\
1977 \\
1978 \\
1979 \\
1980\end{array}$ & $\begin{array}{lr}0.32 & 18 \\
0.00 & 6 \\
0.00 & 7 \\
0.00 & 8 \\
0.35 & 20\end{array}$ & $\begin{array}{rr}0.34 & 19 \\
0.05 & 8 \\
0.00 & 6 \\
0.00 & 7 \\
0.37 & 20\end{array}$ & $\begin{array}{l}0.381 \\
0.07 \\
0.00 \\
0.00 \\
0.45\end{array}$ \\
\hline 1981 & 0.2517 & 0.2517 & 0.26 \\
\hline
\end{tabular}

$\begin{array}{lr}14 & \\ 0.79 & 23 \\ 0.40 & 19 \\ 1.00 & 24 \\ 1.50 & 25 \\ 1.50 & 26 \\ 0.25 & 14 \\ 0.37 & 17 \\ 0.37 & 18 \\ 1.60 & 27 \\ 0.00 & 4 \\ 0.71 & 22 \\ 0.07 & 7 \\ 0.00 & 5 \\ 0.00 & 6 \\ 0.48 & 20 \\ 0.27 & 16\end{array}$

CONSECUTTVE DAYS
30

0.9022

$1.0023 \quad 1.1024$

$\begin{array}{ll}1.5025 & 1.6025 \\ 1.6026 & 1.6026\end{array}$

$0.2814 \quad 0.3514$

$0.4518 \quad 0.7120$

$\begin{array}{lll}0.5019 & 0.5217\end{array}$

$1.6027 \quad 1.6027$

00.24

0.2011

0.026

$\begin{array}{lr}0.00 & 5 \\ 0.56 & 20\end{array}$

0.3215

0.003

0.3515

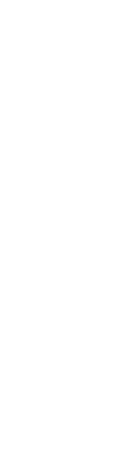

120

1.3023

1.3023
0.6916

$0.6916 \quad 0.9116$

$1.4024 \quad 1.6023$

$\begin{array}{ll}1.7025 & 2.0026\end{array}$

2.2027

0.5315

0.9521

0.9320

1.8027

$0.9417 \quad 2.5013$

$\begin{array}{llll}1.90 & 25 & 12.0 \quad 26\end{array}$

$0.1520 .77 \quad 1$

$\begin{array}{llllllll}1.0023 & 1.0022 & 1.10 & 22 & 1.5022 & 6.0018\end{array}$

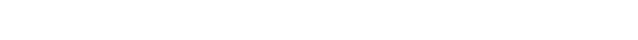

$\begin{array}{lllllllll}0.10 & 6 & 0.11 & 7 & 0.12 & 5 & 0.19 & 3 & 0.82\end{array}$

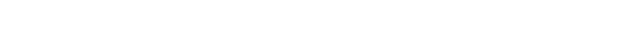

0.3713

0.4714

$1.4021 \quad 7.6019$

HIGHEST MEAN DISGHARGE, IN OUBIC FEET PER SECOND, AND RANKING FOR THE INDICATED NUMBER OF CONSEQITTVE DAYS FOR EACH WATER YEAR, OCTOBER 1-SEPTEYBER 30

YEAR

19

1951

1953

1955

$1958 \quad 109$

1959

1961

196

1964

1966

1967

1969

1969
1970

$\begin{array}{lllll}1971 & 13.0 & 22 & 12.0 & 20\end{array}$

1972
1973
1974

1975

$\begin{array}{lllllll}1978 & 27.0 & 15 & 25.0 & 13 & 21.0 & 13\end{array}$

$\begin{array}{ccccccc}1979 & 117 & 5 & 107 & 5 & 103 & 5 \\ 1980 & 80.0 & 7 & 78.0 & 7 & 69.0 & 8\end{array}$

1981

$\begin{array}{lllll}9.00 & 25 & 9.0025 \quad 9.0022\end{array}$

$\begin{array}{cccc}15 & 1 & 170 & 1 \\ 3.70 & 29 & 3.50 & 28\end{array}$

$6.2026 \quad 5.7026$

$\begin{array}{llllll}29.0 & 13 & 15.0 & 18 & 7.00 & 24\end{array}$

$\begin{array}{rrrrrr}27.0 & 14 & 26.0 & 11 & 24.0 & 11 \\ 139 & 3 & 129 & 3 & 107 & 3\end{array}$

$\begin{array}{llll}26.0 & 16 & 25.0 & 12\end{array}$

$\begin{array}{llll}8.0 & 18 & 17.0 & 16\end{array}$

$\begin{array}{llll}75.0 & 8 & 69.0 & 7\end{array}$

$\begin{array}{rr}17.0 & 15 \\ 69.0 & 7\end{array}$

$\begin{array}{cr}64.0 & 9 \\ 9.00 & 23\end{array}$

$12.0 \quad 19$

9.8021

$\begin{array}{ccc}160 & 1 \\ 3.90 & 27\end{array}$

164

4.0027

$31.0 \quad 10$ $\begin{array}{lllllll}1977 & 17.0 & 19 & 11.0 & 22 & 5.90 & 25\end{array}$

\begin{tabular}{lll}
15 & \multicolumn{1}{l}{ CONSEQUTTVE DAVS } \\
15 & 30 & 60
\end{tabular}

$\begin{array}{llll}6 & 104 \quad 6\end{array}$

$\begin{array}{rrr}3.50 & 29\end{array}$

$\begin{array}{rrrrrr}31.0 & 12 & 15.0 & 19 & 105 & 4 \\ 27.0 & 18\end{array}$

$$
30
$$

60

8.3022

$\begin{array}{rr}7.00 & 22 \\ 116 & 1 \\ 3.00 & 26\end{array}$

5.7022

80.01

3.0025

4.6024

$11.0 \quad 17$

7.7018

5.4024

48.06

2.8026

3.0027

$\begin{array}{ll}2.80 & 26 \\ 5.60 & 23\end{array}$

9.1021

6.9023

1.9029

3.8025

$\begin{array}{rr}92.0 & 3 \\ 10.0 & 18\end{array}$

$\begin{array}{ll}10.0 & 18 \\ 19.0 & 13\end{array}$

2.5028

$\begin{array}{cr}82.0 & 3 \\ 8.20 & 20\end{array}$

$\begin{array}{cc}8.20 & 20 \\ 14.0 & 13\end{array}$

$\begin{array}{cc}1.90 & 29 \\ 51.0 & 3\end{array}$

5.9020

8.3016

68.06

48.04

$22.0 \quad 11$

$\begin{array}{ll}22.0 & 1 . \\ 15.0 & 14\end{array}$

$\begin{array}{llll}14.0 & 14 & 12.0 & 113\end{array}$

$\begin{array}{llll}63.0 & 7 & 59.0 & 7\end{array}$

8.2023

$\begin{array}{ll}58.0 & 8 \\ 7.40 & 21\end{array}$

$\begin{array}{rr}12.0 & 13 \\ 45.0 & 8\end{array}$

45.0
46.07

$\begin{array}{cc}46.0 & 7 \\ 5.80 & 21\end{array}$

$\begin{array}{lll}10.0 \quad 19 & 9.0018\end{array}$

$\begin{array}{rrrr}9.20 & 20 & 8.70 & 19 \\ 138 & 2 & 96.0 & 2\end{array}$

$\begin{array}{llll}3.80 & 26 & 3.0 & 2\end{array}$

$\begin{array}{ll}7.1019 & 6.0018\end{array}$

$\begin{array}{ll}89.0 & 15\end{array}$

2.8027

$\begin{array}{cr}42.0 & 2 \\ 2.40 & 26\end{array}$

2.4026
19.010

$\begin{array}{ll}15.0 & 15\end{array}$

3.2028
21.0
12

$82.0 \quad 6 \quad 7.0 \quad 12$

59.09

$\begin{array}{ll}71.0 & 5 \\ 50.0 & 9\end{array}$

$\begin{array}{lll}8.2017 & 6.3017\end{array}$

2.0028

$17.0 \quad 12$

32.09

15.011

$\begin{array}{ll}35.0 & 7 \\ 24.0 & 9\end{array}$

$12.0 \quad 16$

9.0014

6.9015

DURATION OF DISCHARGE FOR EACH WATER YEAR

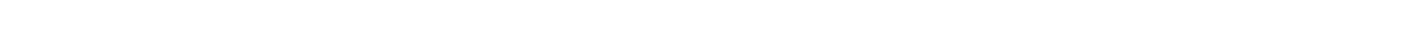

YEAR

NUMBER OF DAIS IN GLASS

OBBIC FEET DAYS

1951

1952

195455

100
31

$\begin{array}{rrrrrrrrrrrrrrrrrrrrrr}6 & 8 & 3 & 7 & 16 & 71 & 74 & 46 & 30 & 31 & 41 & 18 & 14 & & & & & & & & & \\ 10118 & 6 & 27 & 18 & 21 & & & 14 & 13 & 27 & 18 & 8 & 8 & 9 & 11 & 6 & 4 & 715 & 6 & 9 & 10 & 1\end{array}$

$\begin{array}{rrrrrrrrrrrr}10 & 30 & 6 & 88 & 31 & 36 & 19 & 12 & 20 & 34 & 32 & 16\end{array}$

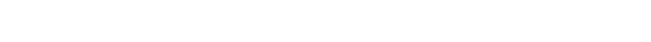

1958

$\begin{array}{lllllllllllllllllllll}1 & 1 & 1 & 41 & 60 & 100 & 41 & 12 & 12 & 14 & 7 & 9 & 5 & 9 & 9 & 8 & 5 & 6 & 6 & 14 & 4\end{array}$

$69 \quad \begin{array}{rrrrrrrrrrrrrrr}11 & 14 & 60 & 95 & 95 & 22 & 11 & 32 & 24 & 1 & & & & \\ 69 & 41 & 41 & 36 & 8 & 16 & 13 & 24 & 8 & 21 & 28 & 19 & 6 & 4 & 3\end{array}$

842.2

5649.3

460.4

677.3

3489.0

411.9
583.8 
GREEN RIVER BASIN

09308500 MINNIE MAUD CREEK NEAR MYTON, UT-Continued

DURATION OF DISCHARGE FOR EACH WATER YEAR-Continued

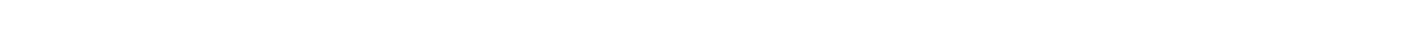
YEAR

NUMBER OF DAYS IN CIASS

CUBIC FEET

$1961 \quad 3$

1962
1963
1964106
196592

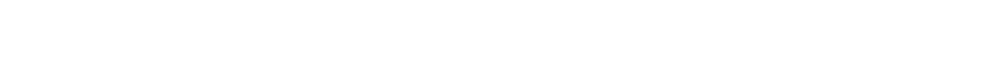

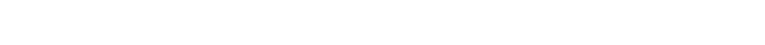

21

16

$\begin{array}{rrrrrrrrrrrrrrr}12 & 21 & 16 & 4 & 5 & 7 & 5 & 3 & 6 & 1 & & & & & \end{array}$

1966

1967

1969

$\begin{array}{llllllllllllll}3 & 10 & 41 & 57 & 26 & 81 & 31 & 17 & 16 & 15 & 12 & 17 & 27 & 12\end{array}$

$\begin{array}{llllllllllllll}22 & 48 & 16 & 26 & 52 & 14 & 8 & 29 & 42 & 21 & 21 & 32 & 26 & 8\end{array}$

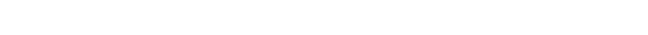

$\begin{array}{lllllllllllllll} & 17 & 97 & 69 & 38 & 22 & 13 & 21 & 5 & 14 & 5 & 13 & 16 & 12 & 23\end{array}$

$\begin{array}{lllllllllll}6 & 35 & 19 & 34 & 90 & 59 & 63 & 26 & 10 & 20 & 3\end{array}$

$\begin{array}{llllllllllllllll}1971 & 7 & 32 & 36 & 26 & 88 & 48 & 19 & 9 & 7 & 16 & 33 & 16 & 16 & 8 & 4\end{array}$

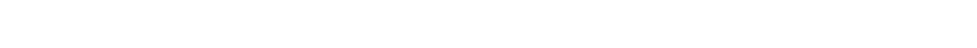

1973

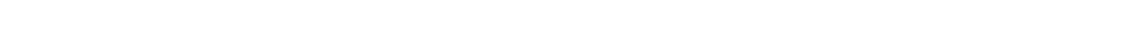

$\begin{array}{rrrrrrrrrr}19 & 28 & 19 & 33 & 79 & 24 & 11 & 28 & 29 & 25 \\ 7 & 7 & 174 & 51 & 19 & 8\end{array}$

$\begin{array}{llllllllllllllllllll}1976 & 3 & 10 & 17 & 7 & 126 & 67 & 43 & 25 & 18 & 11 & 8 & 7 & 4 & 15 & 4 & & 1\end{array}$

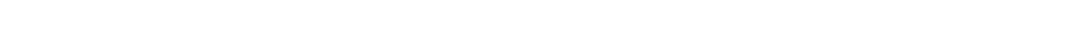

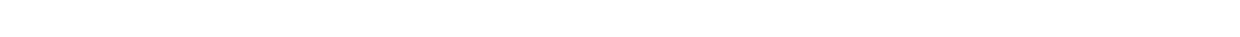

1980

$\begin{array}{rrrrrrrrrrrrrrrrrrr}6 & 16 & 93 & 25 & 46 & 20 & 3 & 30 & 19 & 25 & 16 & 13 & 13 & 11 & 6 & 2 & 10 & 8 & 4\end{array}$

1981

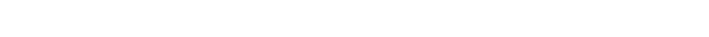

PER SECOND - DAYS

DURATION TABLE OF DISCHARGE FOR WATER YEARS 1951-55, 1958-81

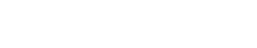 PER TOTAL LATED CENT CLASS SECOND DAYS DAYS DAYS}

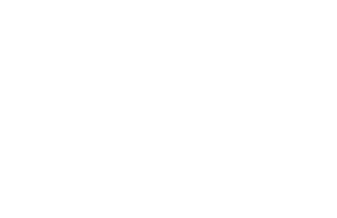

OBBIC ACOU-
FEET
PER TOTAL LATED
PER$\begin{aligned} & \text { PER TOTAL LATED } \text { CENT } \\ & \text { CLASS SECOND DAYS DAYS DAYS }\end{aligned}$

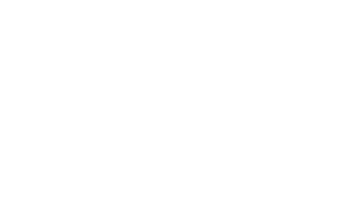

CBBIC ACON-
FEET CLASS SECOND DAYS DAYS DAYS

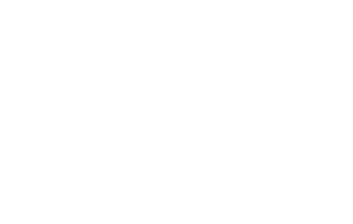

398.9

3660.5

711.0

3750.1

1888.9

1586.2

4062.4

4015.8
942.0

763.6

1131.2

4400.3

1957.9

948.4

260.1

1624.2

3454.5

2684.3

987.3

MONTHLY MEAN DISCHARGES, IN CUBIC FEET PER SECOND, FOR EACA WATER YEAR

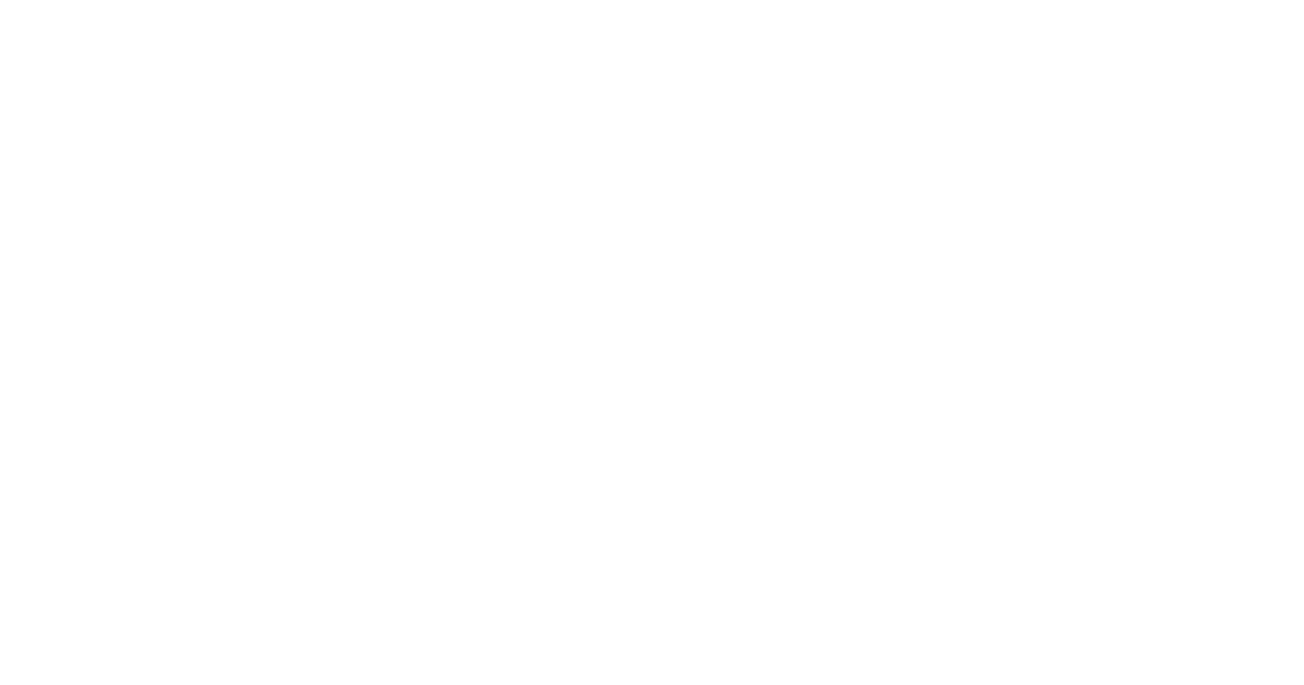


GREPN RIVER BASIN

09308500 MINNIE MAUD CREER NEAR MYTON, UT-Continued

MONIHLY MEAN DISCHARGES, IN OBBIC FEET PER SECOND, FOR EACH WATER YEAR--Continued

\begin{tabular}{|c|c|c|c|c|c|c|c|c|c|c|c|c|}
\hline YEAR & OCT & NOV & $\mathrm{DEC}$ & JAN & FEB & MAR & APR & MAY & JUNE & JULY & AUG & SEP \\
\hline $\begin{array}{l}1976 \\
1977 \\
1978 \\
1979 \\
1980\end{array}$ & $\begin{array}{l}3.17 \\
0.80 \\
0.26 \\
0.99 \\
1.47\end{array}$ & $\begin{array}{l}1.20 \\
0.85 \\
0.19 \\
0.55 \\
1.42\end{array}$ & $\begin{array}{l}1.10 \\
0.45 \\
0.11 \\
0.03 \\
0.83\end{array}$ & $\begin{array}{l}1.00 \\
0.25 \\
0.20 \\
0.00 \\
0.78\end{array}$ & $\begin{array}{l}1.00 \\
0.25 \\
0.04 \\
0.00 \\
0.56\end{array}$ & $\begin{array}{l}1.20 \\
0.20 \\
3.23 \\
0.13 \\
0.75\end{array}$ & $\begin{array}{c}2.81 \\
0.24 \\
14.3 \\
17.2 \\
3.23\end{array}$ & $\begin{array}{c}11.8 \\
0.64 \\
18.6 \\
67.1 \\
34.5\end{array}$ & $\begin{array}{c}3.88 \\
0.61 \\
11.0 \\
16.2 \\
29.2\end{array}$ & $\begin{array}{l}2.25 \\
2.06 \\
3.04 \\
4.79 \\
7.61\end{array}$ & $\begin{array}{l}0.93 \\
1.72 \\
1.15 \\
3.56 \\
4.01\end{array}$ & $\begin{array}{l}0.54 \\
0.40 \\
1.20 \\
2.05 \\
3.43\end{array}$ \\
\hline 1981 & 3.84 & 2.68 & 0.81 & 0.38 & 0.34 & 0.39 & 9.95 & 7.21 & 3.13 & 1.41 & 1.10 & 1.19 \\
\hline
\end{tabular}

ANNUAL PEAK DISCHARGE, IN OBBIC FEET PER SECOND, AND CORRESPONDING GAGE HEIGHT, IN FEET, FOR EACH WATER YEAR

\begin{tabular}{|c|c|c|c|c|c|c|c|c|c|c|c|}
\hline $\begin{array}{l}\text { WAITER } \\
\text { YEAR }\end{array}$ & DATE & $\begin{array}{l}\text { GAGE } \\
\text { HEIGHT }\end{array}$ & $\begin{array}{c}\text { PEAK } \\
\text { DISCHARGE }\end{array}$ & $\begin{array}{l}\text { WATER } \\
\text { YEAR }\end{array}$ & DATE & $\begin{array}{c}\text { GAGE } \\
\text { HEIGHT }\end{array}$ & $\begin{array}{c}\text { PEAR } \\
\text { DISCHARGE }\end{array}$ & $\begin{array}{l}\text { WATER } \\
\text { YEAR }\end{array}$ & DATE & $\begin{array}{c}\text { GAGE } \\
\text { HEIGHT }\end{array}$ & $\begin{array}{c}\text { PEAR } \\
\text { DISCHARGE }\end{array}$ \\
\hline $\begin{array}{l}1952 \\
1953 \\
1954 \\
1955 \\
1958 \\
1959 \\
1960 \\
1961 \\
1962\end{array}$ & $\begin{array}{lll}\text { MAY } & 05,1952 \\
\text { JULY } & 31, & 1953 \\
\text { JUNE } 27, & 1954 \\
\text { APR. } 25, & 1955 \\
\text { MAY } & 11, & 1958 \\
\text { AJG. } 20, & 1959 \\
\text { AUG. } 22, & 1960 \\
\text { AUG. } 25, & 1961 \\
\text { SEPT. } 21, & 1962\end{array}$ & $\begin{array}{l}6.07 \\
4.82 \\
5.60 \\
5.41 \\
6.92 \\
5.93 \\
6.83 \\
9.40 \\
7.78\end{array}$ & $\begin{array}{c}314 \\
53 \\
10 \\
22 \\
146 \\
7.0 \\
103 \\
1370 \\
798\end{array}$ & $\begin{array}{l}1964 \\
1965 \\
1966 \\
1967 \\
1968 \\
1969 \\
1970 \\
1971 \\
1972\end{array}$ & $\begin{array}{lll}\text { MAY } & 13,1964 \\
\text { JULY } & 07,1965 \\
\text { AUG. } 03,1966 \\
\text { AUG. } 08,1967 \\
\text { MAY } 30,1968 \\
\text { APR. } 22,1969 \\
\text { MAY } 06,1970 \\
\text { MAY } 16,1971 \\
\text { MAR. } 30,1972\end{array}$ & $\begin{array}{l}6.06 \\
8.02 \\
6.27 \\
8.02 \\
6.10 \\
6.32 \\
5.52 \\
5.69 \\
6.10\end{array}$ & $\begin{array}{r}48 \\
207 \\
172 \\
372 \\
81 \\
76 \\
12 \\
15 \\
33\end{array}$ & $\begin{array}{l}1973 \\
1974 \\
1975 \\
1976 \\
1977 \\
1978 \\
1979 \\
1980 \\
1981\end{array}$ & $\begin{array}{l}\text { MAY } 12,1973 \\
\text { APR. } 28,1974 \\
\text { AUG. } 11,1975 \\
\text { OCT. } 13,1975 \\
\text { AUG. } 19,1977 \\
\text { MAY } 14,1978 \\
\text { MAY } 22,1979 \\
\text { SEPT.10, } 1980 \\
\text { APR. 09, } 1981\end{array}$ & $\begin{array}{r}6.37 \\
4.79 \\
5.98 \\
11.67 \\
9.75 \\
7.69 \\
8.11 \\
8.25 \\
7.18\end{array}$ & $\begin{array}{l}208 \\
4.6 \\
114 \\
-\overline{425} \\
30 \\
197 \\
247 \\
36\end{array}$ \\
\hline
\end{tabular}

1963 JULY 22,1963

$6.85 \quad 386$

MAGNITUDE AND PRCBABILITY OF ANNUAL LOWEST MEAN DISCHARGE BASED ON CLIMATIC YEARS 1952-55 AND 1959-81

\begin{tabular}{|c|c|c|c|c|c|c|}
\hline \multirow{2}{*}{$\begin{array}{l}\text { PERIOD } \\
\text { (CON- } \\
\text { SECH- } \\
\text { TIVE } \\
\text { DAYS) }\end{array}$} & \multicolumn{6}{|c|}{$\begin{array}{l}\text { DISCHARGE, IN ONIC FEET PER SECOND, FOR } \\
\text { INDICATED RECURRENCE INITENAL, IN YEARS, AND } \\
\text { ANNUAL NONEXCEEDANCE PRCBABIIITY, IN PERCENT }\end{array}$} \\
\hline & $\begin{array}{c}2 \\
508\end{array}$ & $\begin{array}{c}5 \\
20 \%\end{array}$ & $\begin{array}{l}10 \\
108\end{array}$ & $\begin{array}{l}20 \\
58\end{array}$ & $\begin{array}{l}50 \\
28\end{array}$ & $\begin{array}{r}100 \\
18\end{array}$ \\
\hline 1 & 0.19 & 0.00 & 0.00 & - & - & - \\
\hline 7 & 0.21 & 0.00 & 0.00 & - & - & - \\
\hline 14 & 0.23 & 0.00 & 0.00 & - & - & - \\
\hline 30 & 0.30 & 0.02 & 0.00 & - & -- & - \\
\hline 60 & 0.40 & 0.05 & 0.00 & - & - & - \\
\hline 90 & 0.44 & 0.10 & 0.00 & - & - & - \\
\hline
\end{tabular}

MAGNITUDE AND PROBABILITY OF ANNUAL HIGHEST MEAN DISCHARGE BASED ON WRTER YEARS 1951-55 AND 1958-81

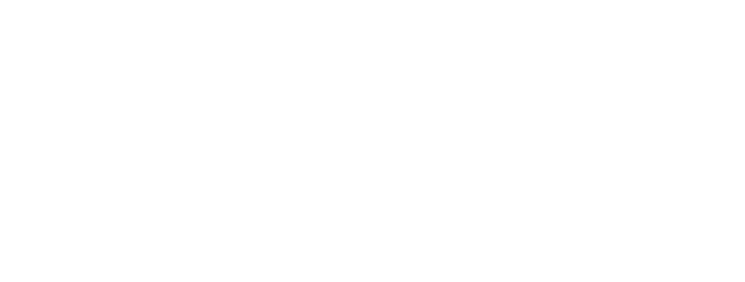

09309000 MINNIE MAUD CREEK AT NUTTER RANCH, NEAR MYTON, UT

LOCATION. - Lat $39^{\circ} 48^{\prime} 45^{\prime \prime}$, long $110^{\circ} 15^{\prime} 00^{\prime \prime}$, in SEl/ sec. 32, T.11 s., R.15 E., Carbon County, Hydrologic Unit 14060005, on left bank $0.75 \mathrm{mi}$ upstream from Gate Canyon, $18 \mathrm{mi}$ north of Sunnyside, $22 \mathrm{mi}$ upstream fron mouth, and $29 \mathrm{mi}$ south of Myton.

DRAINAGE AREA.--231 $\mathrm{mi}^{2}$.

MEAN BASIN EREVATION. $-7,880 \mathrm{ft}$.

PERIOD OF RECORD AVAILABLE.-July 1947 to September 1955, and annual peak discharge only, water years $1960-73$.

GAGE. -Water-stage recorder. Altitude of gage is 5,760 ft by barcaneter.

REMARKS.--Same diversions above station for irrigation.

AVERAGE DISCHARGE. -8 years, $20.4 \mathrm{ft}^{3} / \mathrm{s}, 14,770$ acre-ft/yr.

EXIREMES FOR PERIOD OF RBCORD.--Maximun discharge, 1,370 ft $3 / \mathrm{s}$ Aug. 25,1955 , gage height, $8.80 \mathrm{ft}$; no flow at times.

LOWEST MEAN DISCHARGE, IN OBBIC FEET PER SECOND, AND RANKING FOR THE INDICATED NUMBER OF CONSECUTIVE DAYS

\begin{tabular}{|c|c|c|c|c|c|c|c|c|c|c|c|c|c|c|c|c|c|c|c|}
\hline \multirow[t]{2}{*}{ YEAR } & \multicolumn{19}{|c|}{ CONSEOTIVE DAYS } \\
\hline & 1 & & 3 & & 7 & & 14 & & 30 & & 60 & & 90 & & 120 & & 183 & & ALLL \\
\hline $\begin{array}{l}1949 \\
1950\end{array}$ & $\begin{array}{l}1.10 \\
5.60\end{array}$ & $\begin{array}{l}4 \\
6\end{array}$ & $\begin{array}{l}1.30 \\
5.80\end{array}$ & $\begin{array}{l}4 \\
6\end{array}$ & $\begin{array}{l}1.90 \\
6.90\end{array}$ & & $\begin{array}{l}2.30 \\
7.90\end{array}$ & $\begin{array}{l}4 \\
7\end{array}$ & $\begin{array}{l}2.70 \\
11.0\end{array}$ & $\begin{array}{l}4 \\
7\end{array}$ & $\begin{array}{r}3.80 \\
11.0\end{array}$ & $\begin{array}{l}4 \\
7\end{array}$ & $\begin{array}{c}4.40 \\
12.0\end{array}$ & $\begin{array}{l}4 \\
7\end{array}$ & $\begin{array}{l}4.90 \\
13.0\end{array}$ & $\begin{array}{l}4 \\
7\end{array}$ & $\begin{array}{c}6.20 \\
14.0\end{array}$ & $\begin{array}{l}4 \\
7\end{array}$ & $\begin{array}{l}12.0 \\
38.0\end{array}$ \\
\hline
\end{tabular}


GREEN RIVER BASIN

09309000 MINNIE MAUD CREEK AT NUTTER RANG, NEAR MYTON, UT-Continued

HIGHEST MEAN DISCHARGE, IN OJBIC FEET PER SECOND, AND RANKING FOR THE INDICATED NUMBER OF CONSECTTIVE DAYS FOR EACH WAIER YEAR, OCTOBER 1-SEPTEMBER 30

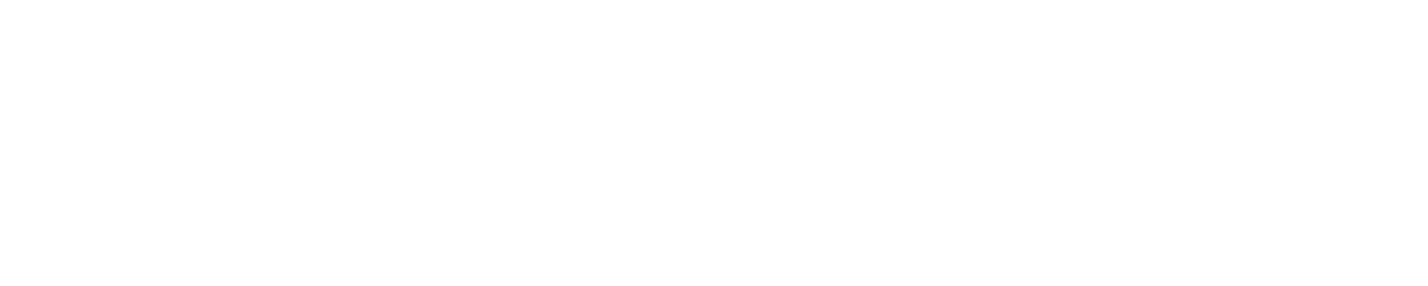

DURATION OF DISCHARGE FOR EACH WATER YEAR

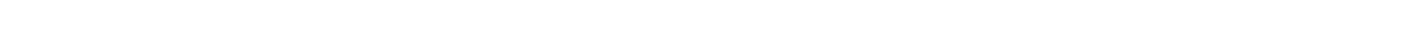

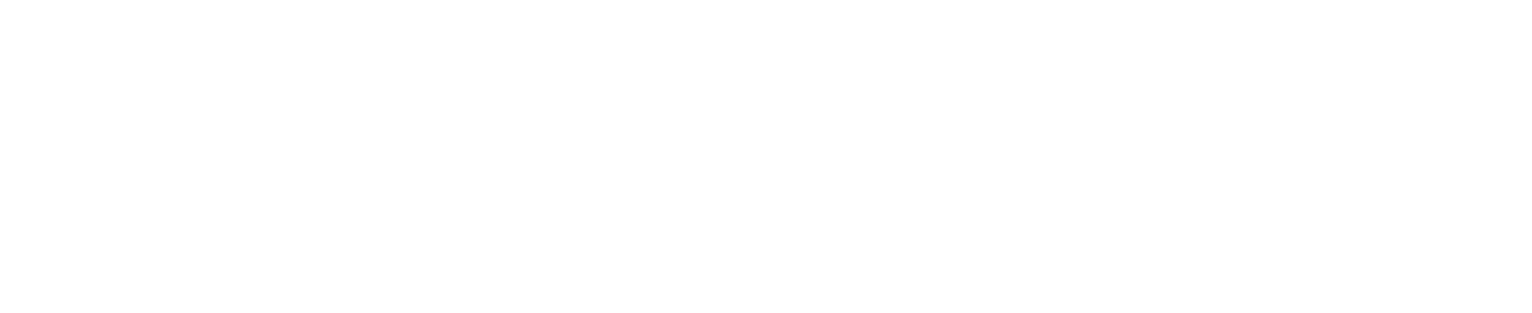

DURATTON TABLE OF DISCHARGE FOR WATER YEARS 1 948-55

\begin{tabular}{|c|c|c|c|c|c|c|c|c|c|c|c|c|c|c|c|c|c|c|c|}
\hline & $\begin{array}{c}\text { वJBIC } \\
\text { FEET } \\
\text { PER } \\
\text { SECOND }\end{array}$ & $\begin{array}{l}\text { TOTAL } \\
\text { DAYS }\end{array}$ & $\begin{array}{r}\text { ACOJ- } \\
\text { MU- } \\
\text { LATED } \\
\text { DAYS }\end{array}$ & $\begin{array}{l}\text { PER- } \\
\text { CENT } \\
\text { DAYS }\end{array}$ & GLASS & $\begin{array}{c}\text { CBBIC } \\
\text { FEET } \\
\text { PER } \\
\text { SECOND }\end{array}$ & $\begin{array}{l}\text { TOTAL } \\
\text { DAYS }\end{array}$ & $\begin{array}{c}\text { ACOH- } \\
\text { MU- } \\
\text { LATED } \\
\text { DAYS }\end{array}$ & $\begin{array}{l}\text { PER- } \\
\text { CENT } \\
\text { DAYS }\end{array}$ & & $\begin{array}{c}\text { GBIC } \\
\text { FEET } \\
\text { PER } \\
\text { SECOND }\end{array}$ & $\begin{array}{l}\text { TOTAL } \\
\text { DAYS }\end{array}$ & $\begin{array}{l}\text { ACOJ- } \\
\text { MU- } \\
\text { LAIED } \\
\text { DAYS }\end{array}$ & $\begin{array}{l}\text { PER- } \\
\text { CENT } \\
\text { DAYS }\end{array}$ & OLASS & $\begin{array}{c}\text { QBBIC } \\
\text { FEET } \\
\text { PER } \\
\text { SECOND }\end{array}$ & $\begin{array}{l}\text { TOTAL } \\
\text { DAYS }\end{array}$ & $\begin{array}{l}\text { ACQU- } \\
\text { MU- } \\
\text { LATED } \\
\text { DAYS }\end{array}$ & $\begin{array}{l}\text { PER- } \\
\text { CENT } \\
\text { DAYS }\end{array}$ \\
\hline $\begin{array}{l}0 \\
1 \\
2 \\
3 \\
4 \\
5 \\
6 \\
7 \\
8\end{array}$ & $\begin{array}{l}0.00 \\
0.10 \\
0.13 \\
0.17 \\
0.22 \\
0.28 \\
0.37 \\
0.47 \\
0.61\end{array}$ & $\begin{array}{r}38 \\
46 \\
0 \\
46 \\
0 \\
11 \\
16 \\
49 \\
14\end{array}$ & $\begin{array}{l}2922 \\
2884 \\
2838 \\
2838 \\
2792 \\
2792 \\
2781 \\
2765 \\
2716\end{array}$ & $\begin{array}{r}100.0 \\
98.7 \\
97.1 \\
97.1 \\
95.6 \\
95.6 \\
95.2 \\
94.6 \\
93.0\end{array}$ & $\begin{array}{l}9 \\
10 \\
11 \\
12 \\
13 \\
14 \\
15 \\
16 \\
17\end{array}$ & $\begin{array}{l}0.80 \\
1.00 \\
1.30 \\
1.70 \\
2.30 \\
2.90 \\
3.80 \\
4.90 \\
6.30\end{array}$ & $\begin{array}{r}22 \\
114 \\
46 \\
63 \\
64 \\
67 \\
203 \\
216 \\
450\end{array}$ & $\begin{array}{l}2702 \\
2680 \\
2566 \\
2520 \\
2457 \\
2393 \\
2326 \\
2123 \\
1907\end{array}$ & $\begin{array}{l}92.5 \\
91.7 \\
87.8 \\
86.2 \\
84.1 \\
81.9 \\
79.6 \\
72.7 \\
65.3\end{array}$ & $\begin{array}{l}18 \\
19 \\
20 \\
21 \\
22 \\
23 \\
24 \\
25 \\
26\end{array}$ & $\begin{array}{r}8.2 \\
11.0 \\
14.0 \\
18.0 \\
23.0 \\
30.0 \\
39.0 \\
50.0 \\
65.0\end{array}$ & $\begin{array}{r}304 \\
263 \\
245 \\
171 \\
107 \\
82 \\
50 \\
46 \\
34\end{array}$ & $\begin{array}{r}1457 \\
1153 \\
890 \\
645 \\
474 \\
367 \\
285 \\
235 \\
189\end{array}$ & $\begin{array}{r}49.9 \\
39.5 \\
30.5 \\
22.1 \\
16.2 \\
12.6 \\
9.8 \\
8.0\end{array}$ & $\begin{array}{l}27 \\
28 \\
29 \\
30 \\
31 \\
32 \\
33 \\
34\end{array}$ & $\begin{array}{r}85.0 \\
110.0 \\
140.0 \\
180.0 \\
240.0 \\
310.0 \\
400.0 \\
520.0\end{array}$ & $\begin{array}{r}44 \\
41 \\
22 \\
15 \\
12 \\
9 \\
9 \\
3\end{array}$ & $\begin{array}{r}155 \\
111 \\
70 \\
48 \\
33 \\
21 \\
12 \\
3\end{array}$ & $\begin{array}{l}5.3 \\
3.8 \\
2.4 \\
1.6 \\
1.1 \\
0.7 \\
0.4 \\
0.1\end{array}$ \\
\hline
\end{tabular}

MONTHLY MEAN DISCHARGES, IN OBBIC FEET PER SECOND, FOR EACH WATER YEAR

\begin{tabular}{|c|c|c|c|c|c|c|c|c|c|c|c|c|}
\hline YEAR & OCT & NOV & DEC & JAN & FEB & MAR & APR & MAY & JUNE & JULY & AUG & SEP \\
\hline $\begin{array}{l}1948 \\
1949 \\
1950\end{array}$ & $\begin{array}{c}7.98 \\
8.99 \\
18.6\end{array}$ & $\begin{array}{c}7.61 \\
8.26 \\
15.9\end{array}$ & $\begin{array}{r}5.00 \\
7.50 \\
13.0\end{array}$ & $\begin{array}{l}7.03 \\
7.20 \\
11.0\end{array}$ & $\begin{array}{c}10.4 \\
8.14 \\
12.0\end{array}$ & $\begin{array}{l}19.0 \\
16.7 \\
21.1\end{array}$ & $\begin{array}{l}37.1 \\
91.3 \\
83.0\end{array}$ & $\begin{array}{l}31.7 \\
149 \\
100\end{array}$ & $\begin{array}{l}6.45 \\
72.4 \\
34.3\end{array}$ & $\begin{array}{l}3.08 \\
25.9 \\
38.9\end{array}$ & $\begin{array}{l}5.81 \\
12.3 \\
10.1\end{array}$ & $\begin{array}{c}4.83 \\
14.9 \\
9.91\end{array}$ \\
\hline $\begin{array}{l}1951 \\
1952 \\
1953 \\
1954 \\
1955\end{array}$ & $\begin{array}{c}15.5 \\
2.81 \\
18.7 \\
5.24 \\
10.5\end{array}$ & $\begin{array}{c}14.4 \\
6.98 \\
11.5 \\
9.37 \\
7.22\end{array}$ & $\begin{array}{r}11.2 \\
5.66 \\
8.00 \\
7.07 \\
4.27\end{array}$ & $\begin{array}{l}9.00 \\
4.68 \\
8.00 \\
4.70 \\
4.00\end{array}$ & $\begin{array}{c}10.6 \\
5.00 \\
7.00 \\
8.47 \\
4.00\end{array}$ & $\begin{array}{c}12.5 \\
7.10 \\
12.5 \\
9.94 \\
8.57\end{array}$ & $\begin{array}{c}4.96 \\
113 \\
19.5 \\
14.5 \\
19.1\end{array}$ & $\begin{array}{c}10.0 \\
352 \\
2.30 \\
1.75 \\
14.3\end{array}$ & $\begin{array}{c}4.66 \\
91.7 \\
1.09 \\
1.57 \\
2.34\end{array}$ & $\begin{array}{c}0.62 \\
28.6 \\
2.59 \\
0.20 \\
0.30\end{array}$ & $\begin{array}{c}4.05 \\
26.2 \\
5.15 \\
0.77 \\
5.72\end{array}$ & $\begin{array}{c}3.73 \\
22.5 \\
0.67 \\
8.85 \\
1.62\end{array}$ \\
\hline
\end{tabular}

ANNUA PEAK DISCHARGE, IN OBIC FEET PER SECOND, AND CORRESPONDING GAGE HEIGT, IN FEET, FOR EACH WATER YEAR

\begin{tabular}{|c|c|c|c|c|c|c|c|c|c|c|c|}
\hline $\begin{array}{l}\text { WAIER } \\
\text { YEAR }\end{array}$ & DATE & $\begin{array}{c}\text { GAGE } \\
\text { HEICHT }\end{array}$ & $\begin{array}{c}\text { PEAK } \\
\text { DISCHARGE }\end{array}$ & $\begin{array}{l}\text { WATER } \\
\text { YEAR }\end{array}$ & DATE & $\begin{array}{c}\text { GAGE } \\
\text { HEIGT T }\end{array}$ & $\begin{array}{c}\text { PEAK } \\
\text { DISCH ARGE }\end{array}$ & $\begin{array}{l}\text { WAIER } \\
\text { YEAR }\end{array}$ & DATE & $\begin{array}{c}\text { GAGE } \\
\text { HEIGHT }\end{array}$ & $\begin{array}{c}\text { PEAK } \\
\text { DISCHARGE }\end{array}$ \\
\hline $\begin{array}{l}1947 \\
1948 \\
1949 \\
1950 \\
1951 \\
1952 \\
1953 \\
1954\end{array}$ & $\begin{array}{lll}\text { AUG. } 22,1947 \\
\text { AUG. } 24,1948 \\
\text { JUNE } 19,1949 \\
\text { JULY } 28,1950 \\
\text { MAY 21, } 1951 \\
\text { MAY } 06,1952 \\
\text { JULY } 31,1953 \\
\text { SEPT. 26, } 1954\end{array}$ & $\begin{array}{l}5.96 \\
2.88 \\
5.50 \\
4.56 \\
2.93 \\
4.85 \\
4.49 \\
3.58\end{array}$ & $\begin{array}{l}704 \\
158 \\
670 \\
467 \\
143 \\
596 \\
483 \\
321\end{array}$ & $\begin{array}{l}1955 \\
1960 \\
1961 \\
1962 \\
1963 \\
1964 \\
1965 \\
1966\end{array}$ & $\begin{array}{l}\text { AUG. } 25,1955 \\
\text { SEPT. 01, } 1960 \\
\text { SEPT.18, } 1961 \\
\text { SEPT. 22, } 1962 \\
\text { SEPT. 07, } 1963 \\
\text { JULY } 13,1964 \\
\text { AUG. } 16,1965 \\
\text { AUG. } 01,1966\end{array}$ & $\begin{array}{l}8.80 \\
4.20 \\
7.30 \\
5.62 \\
5.68 \\
3.31 \\
6.46 \\
5.31\end{array}$ & $\begin{array}{r}1370 \\
360 \\
1200 \\
670 \\
685 \\
190 \\
920 \\
590\end{array}$ & $\begin{array}{l}1967 \\
1968 \\
1969 \\
1970 \\
1971 \\
1972 \\
1973\end{array}$ & $\begin{array}{l}\text { AUG. } 03,1967 \\
\text { OCT. } 05,1967 \\
\text { SEPT. } 10,1969 \\
-\quad-, 1970 \\
\text { SEPP. 01, } 1971 \\
\text { JUNE 17, } 1972 \\
\text { JUNE --, } 1973\end{array}$ & $\begin{array}{l}5.20 \\
3.98 \\
4.77 \\
-0 \\
5.34 \\
2.95 \\
7.67\end{array}$ & $\begin{array}{r}555 \\
295 \\
460 \\
10 \\
591 \\
143 \\
1380\end{array}$ \\
\hline
\end{tabular}


GREEN RIVER BASIN

09309100 GATE CANYON NEAR MYTON, UT

LOCATTON.--Lat $39^{\circ} 50^{\prime} 00^{\prime \prime}$, long $110^{\circ} 5^{\prime} 00^{\prime \prime}$, in $\mathrm{NE}_{4}^{\frac{1}{4}}$ sec. 29 , T.11 S., R.15 E., Duchesne County, Hydrol 0 gic unit $14060005,1.4$ mi above mouth and $32.9 \mathrm{mi}$ on State Highway 53 south of Duchesne River bridge at Myton.

DRA NAGE AREA, $-5.4 \mathrm{mi}^{2}$.

MEAN BASTN ELLVVATION. $-6,860 \mathrm{ft}$.

PERIOD OF RECORD AVALIABLE. -- Water years 1960-63, 1965-72, annual peak discharge only.

GAGE. --Crest-stage gage. Altitude of gage is 6,200 ft from topographic map.

ANNUAT, FEAK DISGAAGE, IN OBIC FEET PER SECOND, AND CORRESRONDING GAGE HEIGHT, IN FEET, FOR EAOH WATER YEAR

\begin{tabular}{|c|c|c|c|c|c|c|c|c|c|c|c|}
\hline $\begin{array}{l}\text { WATER } \\
\text { YEAR }\end{array}$ & DATE & $\begin{array}{c}\text { GAGE } \\
\text { HEIGHT }\end{array}$ & $\begin{array}{c}\text { PEAK } \\
\text { DISGHARGE }\end{array}$ & $\begin{array}{l}\text { WATER } \\
\text { YEAR }\end{array}$ & DATE & $\begin{array}{l}\text { GAGE } \\
\text { HEIGHT }\end{array}$ & $\begin{array}{c}\text { PEAK } \\
\text { DISGAARGE }\end{array}$ & $\begin{array}{l}\text { WATER } \\
\text { YEAR }\end{array}$ & DATE & $\begin{array}{c}\text { GAGE } \\
\text { HEIGHT }\end{array}$ & $\begin{array}{c}\text { PEAK } \\
\text { DISOHARGE }\end{array}$ \\
\hline $\begin{array}{l}1960 \\
1961 \\
1962 \\
1963\end{array}$ & $\begin{array}{l}\text { SEPT.17, } 1960 \\
\text { AUG. 02, } 1961 \\
\text { MAR. 24, } 1962 \\
\text { SEPT. 06, } 1963\end{array}$ & $\begin{array}{r}9.80 \\
11.77 \\
9.30 \\
11.76\end{array}$ & $\begin{array}{c}23 \\
860 \\
5.0 \\
860\end{array}$ & $\begin{array}{l}1965 \\
1966 \\
1967 \\
1968\end{array}$ & $\begin{array}{l}\text { AUG. } 16,1965 \\
\text { AUG. } 03,1966 \\
\text { JUNE } 05,1967 \\
\text { MAY } 04,1968\end{array}$ & $\begin{array}{r}11.68 \\
10.77 \\
9.27 \\
9.75\end{array}$ & $\begin{array}{c}1000 \\
460 \\
8.2 \\
92\end{array}$ & $\begin{array}{l}1969 \\
1970 \\
1971 \\
1972\end{array}$ & $\begin{array}{ll}\text { SEPT.07, } 1969 \\
\text { SEPT.06, } 1970 \\
\text { SEPT.01, } 1971 \\
\text { JUNE 18, } 1972\end{array}$ & $\begin{array}{l}10.64 \\
10.35 \\
10.35 \\
10.07\end{array}$ & $\begin{array}{l}390 \\
280 \\
280 \\
180\end{array}$ \\
\hline
\end{tabular}

09309800 GOOSEBERRY CREEK NEAR FAIRVIEW, UT

LOCATION. --Lat $39^{\circ} 40^{\prime} 27^{\prime \prime}$, lang $1119^{1} 8^{\prime} 15^{\prime \prime}$, in SW $\frac{1}{4} W^{\frac{1}{4}} \mathrm{SW}^{\frac{1}{4}}$ sec.19, T.13 S., R.6 E., Sanpete County, Hydrol $\circ$ gic Unit 14060009, on left bank $0.5 \mathrm{mi}$ upstream from small tributary, $1.5 \mathrm{mi}$ southeast of Mamoth ranger station, and 8 mi northeast of Fairview.

DRAINAGE AREA, $--7.9 \mathrm{mi}^{2}$.

PERIOD OF RECORD AVAILABLE. --Octaber 1959 to September 1963 , October 1964 to June 199

GAGE. - Water-stage recorder. Altitude of gage is $8,600 \mathrm{ft}$ from topographic map.

REMARKS. - Transmountain diversion above station by Fairview ditch and Fairview tunnel for irrigation in Sevier River basin, part of which is water diverted into Gooseberry Creek from Boulger Creek. A small reservoir on Gooseberry Creek, about $2.5 \mathrm{mi}$ above station (capacity, about 1,900 acre-ft) is used.

AVERAGE DISQHARGE. -8 years (water years $1960-63,1965-68$ ), $9.38 \mathrm{ft}^{3} / \mathrm{s}, 6,790 \mathrm{acre}-\mathrm{ft} / \mathrm{yr}$

EXTREMES FOR PERIOD OF RECORD.--Maximum discharge, $263 \mathrm{ft}^{3} / \mathrm{s}$ June 2,1968 , gage height, $3.62 \mathrm{ft}$, from rating curve extended above $110 \mathrm{ft}^{3} / \mathrm{s}$; minimum recorded, $0.40 \mathrm{ft}^{3} / \mathrm{s}$ October $22,26,1961$, Nov. $16,1962$.

LOWEST MEAN DISCHARGE, IN CBIC FEET PER SECOND, AND RANKING FOR THE INDICATED NIMBER OF CONSEQUTIVE DAYS FOR EACH CLIMATIC YEAR, APRII I-MARG 31

\begin{tabular}{|c|c|c|c|c|c|c|c|c|c|c|c|c|c|c|c|c|c|c|c|}
\hline YEAR & & & & & & & & & CONSE & 47 & DAYS & & & & & & & & \\
\hline $\begin{array}{l}1961 \\
1962 \\
1963\end{array}$ & $\begin{array}{l}0.90 \\
1.00 \\
0.60\end{array}$ & $\begin{array}{l}2 \\
4 \\
1\end{array}$ & $\begin{array}{l}0.90 \\
1.00 \\
0.60\end{array}$ & $\begin{array}{l}2 \\
3 \\
1\end{array}$ & $\begin{array}{l}0.90 \\
1.00 \\
0.60\end{array}$ & $\begin{array}{l}2 \\
3 \\
1\end{array}$ & $\begin{array}{l}0.90 \\
1.00 \\
0.60\end{array}$ & $\begin{array}{l}2 \\
3 \\
1\end{array}$ & $\begin{array}{l}0.90 \\
1.00 \\
0.60\end{array}$ & $\begin{array}{l}2 \\
3 \\
1\end{array}$ & $\begin{array}{l}0.90 \\
1.00 \\
0.78\end{array}$ & $\begin{array}{l}2 \\
3 \\
1\end{array}$ & $\begin{array}{l}0.93 \\
1.19 \\
0.80\end{array}$ & $\begin{array}{l}2 \\
4 \\
1\end{array}$ & $\begin{array}{l}1.00 \\
1.30 \\
0.89\end{array}$ & $\begin{array}{l}2 \\
5 \\
1\end{array}$ & $\begin{array}{l}1.19 \\
1.30 \\
1.19\end{array}$ & $\begin{array}{l}1 \\
4 \\
2\end{array}$ & $\begin{array}{c}7.50 \\
4.40 \\
14.0\end{array}$ \\
\hline $\begin{array}{l}1966 \\
1967 \\
1968 \\
1969\end{array}$ & $\begin{array}{l}1.40 \\
0.99 \\
1.10 \\
1.50\end{array}$ & $\begin{array}{l}6 \\
3 \\
5 \\
7\end{array}$ & $\begin{array}{l}1.40 \\
1.00 \\
1.19 \\
1.50\end{array}$ & $\begin{array}{l}6 \\
4 \\
5 \\
7\end{array}$ & $\begin{array}{l}1.40 \\
1.00 \\
1.19 \\
1.50\end{array}$ & $\begin{array}{l}6 \\
4 \\
5 \\
7\end{array}$ & $\begin{array}{l}1.40 \\
1.10 \\
1.19 \\
1.50\end{array}$ & $\begin{array}{l}6 \\
4 \\
5 \\
7\end{array}$ & $\begin{array}{l}1.40 \\
1.10 \\
1.30 \\
1.60\end{array}$ & $\begin{array}{l}6 \\
4 \\
5 \\
7\end{array}$ & $\begin{array}{l}1.50 \\
1.10 \\
1.30 \\
1.60\end{array}$ & $\begin{array}{l}6 \\
4 \\
5 \\
7\end{array}$ & $\begin{array}{l}1.70 \\
1.10 \\
1.30 \\
1.70\end{array}$ & $\begin{array}{l}7 \\
3 \\
5 \\
6\end{array}$ & $\begin{array}{l}1.90 \\
1.19 \\
1.30 \\
1.70\end{array}$ & $\begin{array}{l}7 \\
3 \\
4 \\
6\end{array}$ & $\begin{array}{l}2.80 \\
1.30 \\
1.50 \\
1.90\end{array}$ & $\begin{array}{l}7 \\
3 \\
5 \\
6\end{array}$ & $\begin{array}{r}13.0 \\
7.00 \\
9.90 \\
11.0\end{array}$ \\
\hline
\end{tabular}

HIGHEST MEAN DISCHARGE, IN OBIC FEET PER SECOND, AND RANKING FOR THE INDICATED NUMBER OF CONSEQUTIVE DAYS FOR EAOH WATER YEAR, OCTOBER 1-SEPTEMBER 30

\begin{tabular}{|c|c|c|c|c|c|c|c|c|c|c|c|c|c|c|c|c|c|c|c|c|}
\hline YEAR & 1 & & 3 & & 7 & & 15 & & $\begin{array}{l}\text { CONS } \\
30\end{array}$ & & $\begin{array}{l}\text { E DAYS } \\
60\end{array}$ & & 90 & & 120 & & 183 & & $A L L$ & \\
\hline 1965 & 118 & 4 & 111 & 4 & 100 & 4 & 89.0 & 4 & 79.0 & 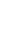 & 53.0 & 3 & 40.0 & 2 & 32.0 & 2 & 23.0 & 2 & 12.0 & 2 \\
\hline
\end{tabular}


GREEN RIVER BASIN

09309800 GOOSEBERRY CREEK NEAR FAIRVIEW, UT-Continued

DURATION OF DISCHARGE FOR EAOH WATER YEAR

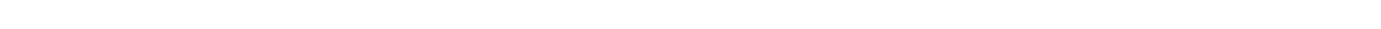

YEAR

NUMBER OF DAYS IN GLASS

GBIC FEET
PER SECOND PER SECOND

$\begin{array}{lllllllllllllllllllllllllllllllllll}76 & 5 & 7 & 9 & 41 & 10 & 33 & 39 & 8 & 11 & 4 & 19 & 16 & 15 & 14 & 11 & 3 & 5 & 5 & 2 & 3 & 4 & 4 & 4 & 3 & 6 & 3 & 2 & 4 & & & & & 2790.1\end{array}$

$\begin{array}{llllllllllllllllllllllllll}59 & 45 & 66 & 60 & 8 & 11 & 11 & 5 & 4 & 5 & 8 & 8 & 15 & 9 & 11 & 7 & 4 & 6 & 3 & 7 & 10 & 1 & 1 & 1 & & 1586.6\end{array}$

$\begin{array}{llllllllllllllllllllllllllllllllll}65 & 21 & 88 & 6 & 24 & 2 & 2 & 2 & 5 & 4 & 3 & 7 & 25 & 15 & 6 & 4 & 14 & 5 & 9 & 7 & 2 & 7 & 2 & 10 & 14 & 6 & 2 & 3 & 3 & 2 & 5078.6\end{array}$

$\begin{array}{lllllllllllllllllllllllllllllll}64 & 36 & 28 & 16 & 3 & 41 & 23 & 8 & 5 & 8 & 24 & 23 & 11 & 15 & 10 & 4 & 2 & 6 & 3 & 4 & 3 & 6 & 3 & 4 & 2 & 4 & 3 & 6 & & & \\ & & & \end{array}$

$\begin{array}{llllllllllllllllllllllllllllllllllllll}1 & 4 & 88 & 25 & 36 & 13 & 17 & 9 & 9 & 2 & 2 & 6 & 7 & 10 & 22 & 15 & 22 & 7 & 10 & 5 & 5 & 7 & 9 & 4 & 3 & 5 & 3 & 6 & 5 & 8 & & & \end{array}$

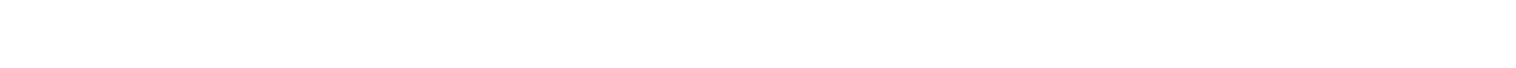

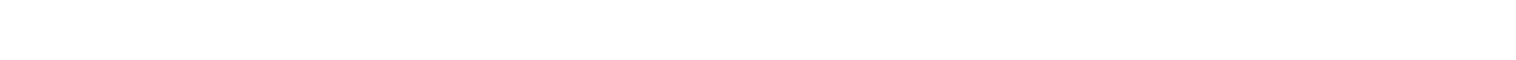

DURATION TABLE OF DISOHARGE FOR WATER YEARS $1960-63,1965-68$

\begin{tabular}{|c|c|c|c|c|c|c|c|c|c|c|c|c|c|c|c|c|c|c|c|}
\hline & $\begin{array}{c}\text { वBIC } \\
\text { FEET } \\
\text { PER }\end{array}$ & TOTAL & $\begin{array}{l}\text { ACOU- } \\
\text { MU- } \\
\text { LATED }\end{array}$ & $\begin{array}{l}\text { PER- } \\
\text { CENT }\end{array}$ & & $\begin{array}{c}\text { GBIC } \\
\text { FEET } \\
\text { PER }\end{array}$ & TOTAL & $\begin{array}{c}\text { ACOU- } \\
\text { MU- } \\
\text { LATED }\end{array}$ & $\begin{array}{l}\text { PER- } \\
\text { CENT }\end{array}$ & & $\begin{array}{c}\text { CUBIC } \\
\text { FEET } \\
\text { PER }\end{array}$ & TOTAL & $\begin{array}{l}\text { ACQU- } \\
\text { MU- } \\
\text { LATED }\end{array}$ & $\begin{array}{l}\text { PER- } \\
\text { CENT }\end{array}$ & & $\begin{array}{c}\text { ABIC } \\
\text { EEET } \\
\text { PER }\end{array}$ & TOTA & $\begin{array}{c}\text { ACQ- } \\
\text { MU- } \\
\text { LATED }\end{array}$ & $\begin{array}{l}\text { PER- } \\
\text { CENT }\end{array}$ \\
\hline ASS & SECOND & DAYS & DAYS & DAYS & CASS & SECOND & DAYS & DAYS & DAYS & QASS & SECOND & DAYS & DAYS & DAYS & CASS & SECOND & DAYS & DAYS & DAYS \\
\hline $\begin{array}{l}0 \\
1 \\
2 \\
3 \\
4 \\
5 \\
6 \\
7 \\
8\end{array}$ & $\begin{array}{l}0.00 \\
0.60 \\
0.71 \\
0.84 \\
1.00 \\
1.20 \\
1.40 \\
1.70\end{array}$ & $\begin{array}{r}0 \\
64 \\
77 \\
69 \\
293 \\
296 \\
454 \\
129\end{array}$ & $\begin{array}{l}2922 \\
2922 \\
2858 \\
2781 \\
2712 \\
2419 \\
2123 \\
1669 \\
1540\end{array}$ & $\begin{array}{r}100.0 \\
100.0 \\
97.8 \\
95.2 \\
92.8 \\
82.8 \\
72.7 \\
57.1\end{array}$ & $\begin{array}{r}9 \\
10 \\
11 \\
12 \\
13 \\
14 \\
15 \\
16 \\
17\end{array}$ & $\begin{array}{l}2.40 \\
2.80 \\
3.30 \\
3.90 \\
4.60 \\
5.50 \\
6.50 \\
7.70\end{array}$ & $\begin{array}{r}162 \\
96 \\
75 \\
45 \\
89 \\
94 \\
95 \\
114 \\
72\end{array}$ & $\begin{array}{r}1352 \\
1190 \\
1094 \\
1019 \\
974 \\
885 \\
791 \\
696 \\
582\end{array}$ & $\begin{array}{l}46.3 \\
40.7 \\
37.4 \\
34.9 \\
33.3 \\
30.3 \\
27.1 \\
23.8\end{array}$ & $\begin{array}{l}18 \\
19 \\
20 \\
21 \\
22 \\
23 \\
24 \\
25 \\
26\end{array}$ & $\begin{array}{l}11.0 \\
13.0 \\
15.0 \\
18.0 \\
21.0 \\
25.0 \\
30.0 \\
36.0 \\
42\end{array}$ & $\begin{array}{l}62 \\
32 \\
53 \\
35 \\
41 \\
43 \\
33 \\
34 \\
24\end{array}$ & $\begin{array}{l}510 \\
448 \\
416 \\
363 \\
328 \\
287 \\
244 \\
211\end{array}$ & $\begin{array}{r}17.5 \\
15.3 \\
14.2 \\
12.4 \\
11.2 \\
9.8 \\
8.4 \\
7.2\end{array}$ & $\begin{array}{l}27 \\
28 \\
29 \\
30 \\
31 \\
32 \\
33 \\
34\end{array}$ & $\begin{array}{r}50.0 \\
60.0 \\
71.0 \\
84.0 \\
100.0 \\
120.0 \\
140.0 \\
170.0\end{array}$ & $\begin{array}{r}35 \\
34 \\
24 \\
24 \\
18 \\
5 \\
12 \\
1\end{array}$ & $\begin{array}{r}153 \\
118 \\
84 \\
60 \\
36 \\
18 \\
13 \\
1\end{array}$ & $\begin{array}{l}5.2 \\
4.0 \\
2.9 \\
2.1 \\
1.2 \\
0.6 \\
0.4 \\
0.0\end{array}$ \\
\hline
\end{tabular}

MONTHLY MEAN DISQGARGES, IN GBIC FEET PER SECOND, FOR EACH WATER YEAR

\begin{tabular}{|c|c|c|c|c|c|c|c|c|c|c|c|c|}
\hline YEAR & OCT & NOV & DEC & JAN & FEB & MAR & APR & MAY & JUNE & JULY & AUG & SEP \\
\hline 1960 & 2.52 & 2.20 & 0.91 & 0.80 & 0.80 & 1.91 & 5.65 & 48.3 & 16.0 & 7.01 & 3.06 & 1.76 \\
\hline $\begin{array}{l}1961 \\
1962 \\
1963\end{array}$ & $\begin{array}{l}1.46 \\
1.54 \\
1.78\end{array}$ & $\begin{array}{l}1.49 \\
1.50 \\
1.34\end{array}$ & $\begin{array}{l}1.22 \\
1.08 \\
1.02\end{array}$ & $\begin{array}{l}0.95 \\
1.00 \\
0.60\end{array}$ & $\begin{array}{l}0.90 \\
1.68 \\
1.07\end{array}$ & $\begin{array}{l}0.95 \\
1.32 \\
1.19\end{array}$ & $\begin{array}{c}5.27 \\
11.4 \\
2.41\end{array}$ & $\begin{array}{l}22.4 \\
78.9 \\
50.2\end{array}$ & $\begin{array}{l}9.38 \\
40.4 \\
18.7\end{array}$ & $\begin{array}{c}4.27 \\
13.7 \\
7.48\end{array}$ & $\begin{array}{l}1.51 \\
8.75 \\
5.80\end{array}$ & $\begin{array}{l}2.09 \\
4.47 \\
4.03\end{array}$ \\
\hline 1965 & 1.93 & 1.56 & 1.19 & 1.00 & 1.06 & 1.04 & 3.18 & 49.9 & 55.5 & 12.2 & 10.0 & 8.92 \\
\hline $\begin{array}{l}1966 \\
1967 \\
1968\end{array}$ & $\begin{array}{l}5.25 \\
1.55 \\
2.00\end{array}$ & $\begin{array}{l}3.00 \\
1.56 \\
1.46\end{array}$ & $\begin{array}{l}2.44 \\
1.44 \\
1.45\end{array}$ & $\begin{array}{l}1.50 \\
1.17 \\
1.27\end{array}$ & $\begin{array}{l}1.54 \\
1.12 \\
1.29\end{array}$ & $\begin{array}{l}2.52 \\
1.25 \\
1.34\end{array}$ & $\begin{array}{c}19.3 \\
1.46 \\
3.53\end{array}$ & $\begin{array}{l}41.3 \\
49.2 \\
45.1\end{array}$ & $\begin{array}{l}9.02 \\
44.6 \\
61.7\end{array}$ & $\begin{array}{l}2.76 \\
8.49 \\
7.14\end{array}$ & $\begin{array}{l}1.59 \\
3.89 \\
4.89\end{array}$ & $\begin{array}{l}1.81 \\
2.43 \\
3.18\end{array}$ \\
\hline
\end{tabular}

ANNUAL PEAK DISOHARGE, IN OUBIC FEET PER SECOND, AND CORRESPONDING GAGE HEIGHT, IN FEET, FOR EACH WATER YEAR

\begin{tabular}{|c|c|c|c|c|c|c|c|c|c|c|c|c|c|}
\hline $\begin{array}{l}\text { WATER } \\
\text { YEAR }\end{array}$ & & DATE & $\begin{array}{c}\text { GAGE } \\
\text { HEIGHT }\end{array}$ & $\begin{array}{c}\text { PEAK } \\
\text { DISCHARGE }\end{array}$ & $\begin{array}{l}\text { WATER } \\
\text { YEAR }\end{array}$ & & DAIE & $\begin{array}{c}\text { GAGE } \\
\text { HEIGHT }\end{array}$ & $\begin{array}{c}\text { PEAK } \\
\text { DISCHARGE }\end{array}$ & $\begin{array}{l}\text { WATER } \\
\text { YEAR }\end{array}$ & DATE & $\begin{array}{c}\text { GAGE } \\
\text { HEIGHT }\end{array}$ & $\begin{array}{c}\text { PEAK } \\
\text { DISCHARGE }\end{array}$ \\
\hline $\begin{array}{l}1960 \\
1961 \\
1962\end{array}$ & $\begin{array}{l}\text { MAY } \\
\text { MAY } \\
\text { MAY }\end{array}$ & $\begin{array}{l}13,1960 \\
11,1961 \\
09,1962\end{array}$ & $\begin{array}{l}2.92 \\
2.31 \\
3.18\end{array}$ & $\begin{array}{r}155 \\
93 \\
190\end{array}$ & $\begin{array}{l}1963 \\
1965 \\
1966\end{array}$ & $\begin{array}{l}\text { MAY } \\
\text { MAY } \\
\text { MAY }\end{array}$ & $\begin{array}{ll}21, & 1963 \\
20, & 1965 \\
09, & 1966\end{array}$ & $\begin{array}{l}\overline{2.74} \\
2.10\end{array}$ & $\begin{array}{r}95 \\
164 \\
96\end{array}$ & $\begin{array}{l}1967 \\
1968 \\
1969\end{array}$ & $\begin{array}{lll}\text { MAY } & 27,1967 \\
\text { JUNE } & 02,1968 \\
\text { MAY } & 14,1969\end{array}$ & $\begin{array}{l}3.05 \\
3.62 \\
3.30\end{array}$ & $\begin{array}{l}198 \\
263 \\
235\end{array}$ \\
\hline
\end{tabular}


LOCATION.--Lat $39^{\circ} 42^{\prime} 57^{\prime \prime}$, long $111^{\circ} 17^{\prime} 58^{\prime \prime}$, in NW $W^{\frac{1}{4}} \mathrm{SE}_{\frac{1}{4}} \mathrm{SW}^{\frac{1}{4}}$ sec.6, T.13 S., R.6 E., Sanpete County, Hydrologic Unit 14060007 , on left bank $300 \mathrm{ft}$ downstream from old Manmoth Dam, $5.5 \mathrm{mi}$ upstream from mouth, and $7 \mathrm{mi}$ west of scofield.

DRAINAGE AREA. $-16.8 \mathrm{mi}^{2}$

PERIOD OF RECORD AVAIIABLE.- - October 1930 to September 1931 (winter months partly estimated), May 1940 to September 1981 , and annual peak discharge only, water year 1932.

REVISED RECORDS. -WDR UT-77-1: Drainage area.

GAGE.--Water-stage recorder. Altitude of gage is $8,400 \mathrm{ft}$ from topographic map. October 1930 to September 1931 , at different datum, May 1940 to September 1954, at datum $0.50 \mathrm{ft}$ higher.

REMARKS.--Transmountain diversion above station for irrigation in Sevier River basin, part of which is water diverted into Gooseberry Creek from Boulger Creek. A small reservoir on Gooseberry Creek $5 \mathrm{mi}$ above station, capacity, about 1,900 acre-ft, is used to regulate these diversions. Flow also affected by snall reservoir 1 mi above station.

AVERAGE DISCHARGE. -42 years, $18.2 \mathrm{ft}^{3} / \mathrm{s}, 13,190 \mathrm{acre}-\mathrm{ft} / \mathrm{yr}$.

EXIREMES FOR PERIOD OF RECORD.--Maximum discharge, $414 \mathrm{ft}^{3} / \mathrm{s}$ May 30, 1952; maximum gage height, $2.98 \mathrm{ft}$ June 6 , 1957 ; no flow NOW. 11 , 1964, Sept. 23-26, 1966.

LOWEST MEAN DISCHARGE, IN CUBIC FEET PER SECOND, AND RANKING FOR THE INDICATED NUMBER OF CONSECUTIVE DAYS FOR EACH OLIMATIC YEAR, APRI 1-MARCH 31

YEA

5.0040

2.0014

3.0028
3.0029

3.0030

2.0015

2.3021

2.3022

2.0016

2.0017

3.0031

2.5025

3.5036

2.3023

1.7011

1.607

3.0032

2.0018

1.403

1.7012

1.404

$1.40 \quad 5$

1.7013

2.3019

4.0038

0.00

3.2033

2.3020

4.0039

3.2034

3.5037

1.608

3.4035

1.609

2.4024

1.6010

I. 406

0.072

2.8027

2.7026

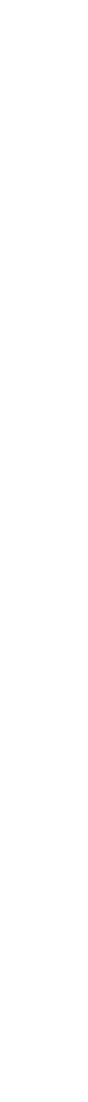

2.8026

$2.80 \quad 27$

\begin{tabular}{|c|c|c|}
\hline 7 & & 14 \\
\hline $\begin{array}{l}6.00 \\
2.00 \\
3.00 \\
3.00\end{array}$ & $\begin{array}{l}40 \\
13 \\
28 \\
29\end{array}$ & $\begin{array}{rr}6.00 & 40 \\
2.00 & 8 \\
3.00 & 26 \\
3.00 & 27\end{array}$ \\
\hline $\begin{array}{l}3.00 \\
2.30 \\
2.30 \\
2.50 \\
2.00\end{array}$ & $\begin{array}{l}30 \\
18 \\
19 \\
21 \\
14\end{array}$ & $\begin{array}{rr}3.00 & 28 \\
2.50 & 18 \\
2.30 & 14 \\
2.70 & 22 \\
2.00 & 9\end{array}$ \\
\hline $\begin{array}{l}2.10 \\
3.00 \\
2.50 \\
3.80 \\
2.50\end{array}$ & $\begin{array}{l}15 \\
31 \\
22 \\
36 \\
23\end{array}$ & $\begin{array}{ll}2.30 & 15 \\
3.00 & 29 \\
2.50 & 19 \\
4.00 & 36 \\
2.50 & 20\end{array}$ \\
\hline $\begin{array}{l}1.90 \\
1.80 \\
3.00 \\
2.20 \\
1.40\end{array}$ & $\begin{array}{r}11 \\
7 \\
32 \\
16 \\
3\end{array}$ & $\begin{array}{rr}1.90 & 7 \\
2.10 & 10 \\
3.00 & 30 \\
2.50 & 21 \\
1.40 & 3\end{array}$ \\
\hline $\begin{array}{l}2.00 \\
1.80 \\
1.40 \\
1.80 \\
2.30\end{array}$ & $\begin{array}{r}12 \\
8 \\
4 \\
9 \\
17\end{array}$ & $\begin{array}{rrr}2.10 & 11 \\
2.10 & 12 \\
1.40 & 4 \\
2.30 & 16 \\
2.40 & 17\end{array}$ \\
\hline $\begin{array}{l}4.10 \\
0.06 \\
3.40 \\
2.60 \\
4.00\end{array}$ & $\begin{array}{r}39 \\
1 \\
33 \\
24 \\
38\end{array}$ & $\begin{array}{rr}4.30 & 39 \\
0.36 & 2 \\
3.40 & 33 \\
2.80 & 23 \\
4.00 & 37\end{array}$ \\
\hline $\begin{array}{l}3.40 \\
3.80 \\
2.40 \\
3.60 \\
1.90\end{array}$ & $\begin{array}{l}34 \\
37 \\
20 \\
35 \\
10\end{array}$ & $\begin{array}{ll}3.50 & 34 \\
4.20 & 38 \\
3.00 & 24 \\
3.70 & 35 \\
2.20 & 13\end{array}$ \\
\hline $\begin{array}{l}2.90 \\
1.70 \\
1.40 \\
0.07 \\
2.80\end{array}$ & $\begin{array}{r}26 \\
6 \\
5 \\
2 \\
25\end{array}$ & $\begin{array}{rr}3.00 & 25 \\
1.80 & 6 \\
1.60 & 5 \\
0.07 & 1 \\
3.10 & 31\end{array}$ \\
\hline
\end{tabular}

2.8025

3.0027
CONSEOUTIVE DAYS

\begin{tabular}{|c|c|c|c|c|c|c|c|c|}
\hline 30 & 60 & 90 & 120 & & 183 & & ALL & \\
\hline $\begin{array}{rr}6.10 & 40 \\
2.00 & 7 \\
3.00 & 26 \\
3.00 & 27\end{array}$ & $\begin{array}{ll}6.60 & 40 \\
2.50 & 11 \\
3.00 & 23 \\
3.00 & 24\end{array}$ & $\begin{array}{ll}7.10 & 40 \\
2.60 & 12 \\
3.20 & 27 \\
3.10 & 23\end{array}$ & $\begin{array}{l}7.60 \\
2.70 \\
3.40 \\
3.20\end{array}$ & $\begin{array}{l}40 \\
12 \\
26 \\
21\end{array}$ & $\begin{array}{l}8.60 \\
3.10 \\
3.70 \\
3.70\end{array}$ & $\begin{array}{l}40 \\
13 \\
24 \\
25\end{array}$ & $\begin{array}{l}30.0 \\
26.0 \\
17.0 \\
23.0\end{array}$ & $\begin{array}{l}39 \\
36 \\
17 \\
31\end{array}$ \\
\hline $\begin{array}{rr}3.00 & 28 \\
2.50 & 19 \\
2.30 & 12 \\
2.90 & 23 \\
2.00 & 8\end{array}$ & $\begin{array}{rr}3.00 & 25 \\
2.50 & 12 \\
2.30 & 9 \\
2.90 & 21 \\
2.00 & 4\end{array}$ & $\begin{array}{rr}3.10 & 24 \\
2.60 & 13 \\
2.40 & 9 \\
3.00 & 20 \\
2.10 & 6\end{array}$ & $\begin{array}{l}3.20 \\
2.90 \\
2.60 \\
3.00 \\
2.30\end{array}$ & $\begin{array}{r}22 \\
17 \\
10 \\
20 \\
6\end{array}$ & $\begin{array}{l}3.70 \\
3.40 \\
3.30 \\
3.10 \\
2.70\end{array}$ & $\begin{array}{r}26 \\
18 \\
17 \\
14 \\
6\end{array}$ & $\begin{array}{l}22.0 \\
14.0 \\
19.0 \\
13.0 \\
22.0\end{array}$ & $\begin{array}{r}27 \\
11 \\
24 \\
8 \\
28\end{array}$ \\
\hline $\begin{array}{ll}2.40 & 13 \\
3.00 & 24 \\
2.50 & 14 \\
4.00 & 36 \\
2.50 & 15\end{array}$ & $\begin{array}{ll}2.50 & 13 \\
3.00 & 26 \\
2.60 & 16 \\
4.10 & 35 \\
2.50 & 14\end{array}$ & $\begin{array}{lll}2.60 & 14 \\
3.20 & 25 \\
2.70 & 18 \\
4.20 & 33 \\
2.60 & 15\end{array}$ & $\begin{array}{l}2.90 \\
3.30 \\
3.00 \\
4.30 \\
2.70\end{array}$ & $\begin{array}{l}18 \\
23 \\
19 \\
34 \\
11\end{array}$ & $\begin{array}{l}3.60 \\
3.80 \\
3.70 \\
4.50 \\
3.10\end{array}$ & $\begin{array}{l}21 \\
27 \\
22 \\
34 \\
15\end{array}$ & $\begin{array}{l}17.0 \\
18.0 \\
41.0 \\
17.0 \\
11.0\end{array}$ & $\begin{array}{r}18 \\
21 \\
40 \\
19 \\
4\end{array}$ \\
\hline $\begin{array}{rr}1.90 & 6 \\
2.20 & 10 \\
3.00 & 25 \\
2.50 & 16 \\
1.40 & 2\end{array}$ & $\begin{array}{rr}2.00 & 5 \\
2.20 & 7 \\
3.10 & 27 \\
2.60 & 17 \\
1.40 & 1\end{array}$ & $\begin{array}{rr}2.00 & 3 \\
2.30 & 7 \\
3.20 & 26 \\
2.60 & 16 \\
1.50 & 1\end{array}$ & $\begin{array}{l}2.00 \\
2.50 \\
3.50 \\
2.80 \\
1.80\end{array}$ & $\begin{array}{r}3 \\
7 \\
27 \\
13 \\
1\end{array}$ & $\begin{array}{l}2.30 \\
2.70 \\
4.30 \\
2.90 \\
2.30\end{array}$ & $\begin{array}{r}1 \\
7 \\
32 \\
11 \\
2\end{array}$ & $\begin{array}{c}13.0 \\
15.0 \\
26.0 \\
23.0 \\
9.80\end{array}$ & $\begin{array}{r}9 \\
12 \\
37 \\
29 \\
3\end{array}$ \\
\hline $\begin{array}{rr}2.20 & 11 \\
2.10 & 9 \\
1.40 & 3 \\
2.50 & 17 \\
2.80 & 21\end{array}$ & $\begin{array}{rr}2.20 & 8 \\
2.60 & 18 \\
1.70 & 2 \\
2.70 & 19 \\
3.30 & 28\end{array}$ & $\begin{array}{rr}2.30 & 8 \\
3.10 & 21 \\
1.70 & 2 \\
2.70 & 17 \\
3.50 & 28\end{array}$ & $\begin{array}{l}2.50 \\
3.30 \\
2.00 \\
2.80 \\
3.70\end{array}$ & $\begin{array}{r}8 \\
24 \\
2 \\
14 \\
29\end{array}$ & $\begin{array}{l}2.70 \\
3.20 \\
2.70 \\
2.90 \\
3.70\end{array}$ & $\begin{array}{r}8 \\
16 \\
9 \\
10 \\
23\end{array}$ & $\begin{array}{l}12.0 \\
7.90 \\
25.0 \\
15.0 \\
18.0\end{array}$ & $\begin{array}{r}5 \\
2 \\
34 \\
13 \\
20\end{array}$ \\
\hline $\begin{array}{ll}4.30 & 38 \\
2.50 & 18 \\
3.70 & 35 \\
2.90 & 22 \\
4.10 & 37\end{array}$ & $\begin{array}{ll}4.30 & 36 \\
2.50 & 15 \\
3.70 & 32 \\
2.90 & 22 \\
4.50 & 38\end{array}$ & $\begin{array}{ll}4.60 & 36 \\
2.50 & 10 \\
3.80 & 32 \\
3.10 & 22 \\
4.60 & 37\end{array}$ & $\begin{array}{l}4.90 \\
2.80 \\
3.90 \\
3.30 \\
4.70\end{array}$ & $\begin{array}{l}38 \\
15 \\
32 \\
25 \\
35\end{array}$ & $\begin{array}{l}6.20 \\
3.50 \\
4.00 \\
3.90 \\
5.20\end{array}$ & $\begin{array}{l}39 \\
19 \\
30 \\
28 \\
37\end{array}$ & $\begin{array}{l}24.0 \\
13.0 \\
19.0 \\
20.0 \\
27.0\end{array}$ & $\begin{array}{l}32 \\
10 \\
22 \\
25 \\
38\end{array}$ \\
\hline 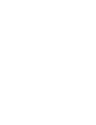 & 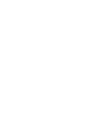 & 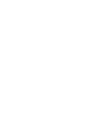 & $\begin{array}{l}5.20 \\
4.80 \\
3.80 \\
4.30 \\
2.90\end{array}$ & $\begin{array}{l}39 \\
37 \\
30 \\
33 \\
16\end{array}$ & $\begin{array}{l}5.30 \\
4.90 \\
3.90 \\
4.30 \\
3.00\end{array}$ & $\begin{array}{l}38 \\
35 \\
29 \\
33 \\
12\end{array}$ & $\begin{array}{l}19.0 \\
16.0 \\
12.0 \\
20.0 \\
15.0\end{array}$ & $\begin{array}{r}23 \\
15 \\
6 \\
26 \\
14\end{array}$ \\
\hline $\begin{array}{rr}3.40 & 31 \\
1.80 & 4 \\
1.90 & 5 \\
0.54 & 1 \\
3.30 & 30\end{array}$ & $\begin{array}{rr}4.30 & 37 \\
2.00 & 6 \\
1.90 & 3 \\
2.40 & 10 \\
3.40 & 29\end{array}$ & $\begin{array}{rr}4.50 & 35 \\
2.10 & 4 \\
2.10 & 5 \\
2.60 & 11 \\
3.50 & 29\end{array}$ & $\begin{array}{l}4.70 \\
2.20 \\
2.20 \\
2.60 \\
3.50\end{array}$ & $\begin{array}{r}36 \\
4 \\
5 \\
9 \\
28\end{array}$ & $\begin{array}{l}5.00 \\
2.40 \\
2.40 \\
2.70 \\
3.50\end{array}$ & $\begin{array}{r}36 \\
3 \\
4 \\
5 \\
20\end{array}$ & $\begin{array}{c}23.0 \\
12.0 \\
4.80 \\
24.0 \\
17.0\end{array}$ & $\begin{array}{r}30 \\
7 \\
1 \\
33 \\
16\end{array}$ \\
\hline .5032 & 3.6031 & 3.7031 & 3.90 & 31 & 4.20 & 31 & 26.0 & 35 \\
\hline
\end{tabular}


HIGHEST MEAN DISCHARGE, IN OUBIC FEET PER SECOND, AND RANKING FOR THE INDICATED NUMBER OF CONSECUTIVE DAYS FOR EACH WATER YEAR, OCTCBER 1-SEPTEMBER 30

\begin{tabular}{|c|c|c|c|c|c|c|c|c|c|c|c|c|c|c|c|c|c|c|c|c|}
\hline YEAR & 1 & & 3 & & 7 & & 15 & & $\begin{array}{l}\text { CONS } \\
30\end{array}$ & & $\begin{array}{l}\text { DAYS } \\
60\end{array}$ & & 90 & & 120 & & 183 & & ALL & \\
\hline $\begin{array}{l}1941 \\
1942 \\
1943 \\
1944 \\
1945\end{array}$ & $\begin{array}{l}268 \\
270 \\
117 \\
220 \\
240\end{array}$ & $\begin{array}{r}7 \\
6 \\
36 \\
17 \\
12\end{array}$ & $\begin{array}{l}254 \\
266 \\
115 \\
208 \\
230\end{array}$ & $\begin{array}{r}6 \\
5 \\
35 \\
17 \\
14\end{array}$ & $\begin{array}{l}240 \\
239 \\
110 \\
195 \\
213\end{array}$ & $\begin{array}{r}5 \\
6 \\
34 \\
16 \\
11\end{array}$ & $\begin{array}{l}234 \\
189 \\
104 \\
180 \\
180\end{array}$ & $\begin{array}{r}5 \\
8 \\
33 \\
13 \\
14\end{array}$ & $\begin{array}{c}193 \\
150 \\
79.0 \\
166 \\
136\end{array}$ & $\begin{array}{r}33 \\
11 \\
34 \\
8 \\
16\end{array}$ & $\begin{array}{l}128 \\
112 \\
65.0 \\
114 \\
100\end{array}$ & $\begin{array}{r}2 \\
9 \\
28 \\
7 \\
13\end{array}$ & $\begin{array}{l}93.0 \\
87.0 \\
50.0 \\
81.0 \\
73.0\end{array}$ & $\begin{array}{r}2 \\
6 \\
27 \\
9 \\
13\end{array}$ & $\begin{array}{l}74.0 \\
71.0 \\
42.0 \\
63.0 \\
57.0\end{array}$ & $\begin{array}{r}2 \\
3 \\
23 \\
9 \\
13\end{array}$ & $\begin{array}{l}51.0 \\
50.0 \\
29.0 \\
43.0 \\
40.0\end{array}$ & $\begin{array}{r}2 \\
3 \\
25 \\
9 \\
14\end{array}$ & $\begin{array}{l}28.0 \\
29.0 \\
16.0 \\
23.0 \\
22.0\end{array}$ & $\begin{array}{r}3 \\
2 \\
25 \\
9 \\
13\end{array}$ \\
\hline $\begin{array}{l}1946 \\
1947 \\
1948 \\
1949 \\
1950\end{array}$ & $\begin{array}{l}135 \\
235 \\
149 \\
290 \\
200\end{array}$ & $\begin{array}{r}32 \\
13 \\
29 \\
3 \\
22\end{array}$ & $\begin{array}{l}131 \\
233 \\
146 \\
244 \\
195\end{array}$ & $\begin{array}{r}32 \\
11 \\
29 \\
9 \\
20\end{array}$ & $\begin{array}{l}123 \\
220 \\
136 \\
205 \\
179\end{array}$ & $\begin{array}{r}32 \\
9 \\
29 \\
14 \\
22\end{array}$ & $\begin{array}{l}112 \\
172 \\
107 \\
174 \\
157\end{array}$ & $\begin{array}{l}28 \\
17 \\
31 \\
15 \\
22\end{array}$ & $\begin{array}{c}88.0 \\
125 \\
80.0 \\
139 \\
112\end{array}$ & $\begin{array}{l}29 \\
20 \\
32 \\
14 \\
23\end{array}$ & $\begin{array}{c}61.0 \\
82.0 \\
53.0 \\
103 \\
71.0\end{array}$ & $\begin{array}{l}30 \\
19 \\
35 \\
12 \\
23\end{array}$ & $\begin{array}{l}46.0 \\
61.0 \\
40.0 \\
77.0 \\
53.0\end{array}$ & $\begin{array}{l}30 \\
18 \\
32 \\
12 \\
23\end{array}$ & & $\begin{array}{l}30 \\
18 \\
31 \\
11 \\
24\end{array}$ & & $\begin{array}{l}30 \\
18 \\
35 \\
12 \\
23\end{array}$ & $\begin{array}{l}15.0 \\
19.0 \\
13.0 \\
22.0 \\
16.0\end{array}$ & $\begin{array}{l}31 \\
17 \\
32 \\
14 \\
26\end{array}$ \\
\hline $\begin{array}{l}1951 \\
1952 \\
1953 \\
1954 \\
1955\end{array}$ & $\begin{array}{c}165 \\
364 \\
184 \\
79.0 \\
135\end{array}$ & $\begin{array}{r}27 \\
1 \\
24 \\
39 \\
33\end{array}$ & $\begin{array}{c}163 \\
353 \\
162 \\
79.0 \\
130\end{array}$ & $\begin{array}{r}25 \\
1 \\
27 \\
39 \\
33\end{array}$ & $\begin{array}{c}155 \\
333 \\
147 \\
74.0 \\
117\end{array}$ & $\begin{array}{r}24 \\
1 \\
26 \\
39 \\
33\end{array}$ & $\begin{array}{l}140 \\
306 \\
133 \\
67.0 \\
96.0\end{array}$ & $\begin{array}{r}24 \\
1 \\
25 \\
39 \\
35\end{array}$ & $\begin{array}{l}108 \\
272 \\
111 \\
61.0 \\
80.0\end{array}$ & $\begin{array}{c}25 \\
1 \\
24 \\
38 \\
33\end{array}$ & $\begin{array}{c}73.0 \\
201 \\
70.0 \\
44.0 \\
54.0\end{array}$ & $\begin{array}{c}22 \\
1 \\
24 \\
38 \\
31\end{array}$ & $\begin{array}{c}57.0 \\
146 \\
53.0 \\
33.0 \\
40.0\end{array}$ & $\begin{array}{r}20 \\
1 \\
24 \\
38 \\
33\end{array}$ & $\begin{array}{c}46.0 \\
114 \\
42.0 \\
27.0 \\
32.0\end{array}$ & $\begin{array}{r}20 \\
1 \\
25 \\
38 \\
32\end{array}$ & & $\begin{array}{r}20 \\
1 \\
24 \\
38 \\
32\end{array}$ & & $\begin{array}{r}20 \\
1 \\
21 \\
37 \\
33\end{array}$ \\
\hline $\begin{array}{l}1961 \\
1962 \\
1963 \\
1964 \\
1965\end{array}$ & $\begin{array}{l}64.0 \\
248 \\
148 \\
224 \\
211\end{array}$ & $\begin{array}{l}40 \\
11 \\
30 \\
15 \\
20\end{array}$ & $\begin{array}{l}58.0 \\
245 \\
146 \\
219 \\
198\end{array}$ & $\begin{array}{r}40 \\
7 \\
28 \\
15 \\
19\end{array}$ & $\begin{array}{l}48.0 \\
230 \\
140 \\
210 \\
171\end{array}$ & $\begin{array}{r}40 \\
7 \\
28 \\
12 \\
23\end{array}$ & $\begin{array}{l}42.0 \\
188 \\
126 \\
174 \\
151\end{array}$ & $\begin{array}{r}40 \\
9 \\
26 \\
16 \\
23\end{array}$ & $\begin{array}{l}37.0 \\
151 \\
101 \\
129 \\
139\end{array}$ & $\begin{array}{l}40 \\
10 \\
26 \\
19 \\
15\end{array}$ & $\begin{array}{c}27.0 \\
113 \\
65.0 \\
80.0 \\
94.0\end{array}$ & $\begin{array}{r}40 \\
8 \\
27 \\
20 \\
14\end{array}$ & $\begin{array}{l}21.0 \\
85.0 \\
47.0 \\
57.0 \\
71.0\end{array}$ & $\begin{array}{r}40 \\
7 \\
28 \\
21 \\
14\end{array}$ & $\begin{array}{l}17.0 \\
67.0 \\
38.0 \\
45.0 \\
57.0\end{array}$ & $\begin{array}{r}40 \\
7 \\
28 \\
21 \\
14\end{array}$ & & $\begin{array}{r}40 \\
7 \\
27 \\
21 \\
11\end{array}$ & $\begin{array}{l}7.40 \\
25.0 \\
15.0 \\
17.0 \\
23.0\end{array}$ & $\begin{array}{r}40 \\
7 \\
28 \\
22 \\
11\end{array}$ \\
\hline $\begin{array}{l}1966 \\
1967 \\
1968 \\
1969 \\
1970\end{array}$ & $\begin{array}{l}129 \\
235 \\
214 \\
288 \\
253\end{array}$ & $\begin{array}{r}35 \\
14 \\
18 \\
4 \\
9\end{array}$ & $\begin{array}{l}118 \\
233 \\
191 \\
278 \\
232\end{array}$ & $\begin{array}{r}34 \\
12 \\
22 \\
4 \\
13\end{array}$ & $\begin{array}{l}107 \\
219 \\
187 \\
268 \\
210\end{array}$ & $\begin{array}{r}35 \\
10 \\
20 \\
4 \\
13\end{array}$ & $\begin{array}{l}98.0 \\
192 \\
165 \\
252 \\
188\end{array}$ & $\begin{array}{r}34 \\
6 \\
20 \\
2 \\
10\end{array}$ & $\begin{array}{l}78.0 \\
147 \\
135 \\
200 \\
133\end{array}$ & $\begin{array}{r}35 \\
12 \\
17 \\
2 \\
18\end{array}$ & $\begin{array}{r}54.0 \\
90.0 \\
88.0 \\
125 \\
83.0\end{array}$ & $\begin{array}{r}33 \\
15 \\
17 \\
3 \\
18\end{array}$ & $\begin{array}{l}41.0 \\
65.0 \\
63.0 \\
91.0 \\
60.0\end{array}$ & $\begin{array}{r}31 \\
15 \\
17 \\
3 \\
19\end{array}$ & & $\begin{array}{r}34 \\
15 \\
17 \\
4 \\
19\end{array}$ & & $\begin{array}{r}31 \\
15 \\
16 \\
4 \\
19\end{array}$ & $\begin{array}{l}15.0 \\
19.0 \\
20.0 \\
26.0 \\
19.0\end{array}$ & $\begin{array}{r}29 \\
18 \\
15 \\
5 \\
19\end{array}$ \\
\hline $\begin{array}{l}1971 \\
1972 \\
1973 \\
1974 \\
1975\end{array}$ & $\begin{array}{c}184 \\
88.0 \\
250 \\
222 \\
256\end{array}$ & $\begin{array}{r}25 \\
38 \\
10 \\
16 \\
8\end{array}$ & $\begin{array}{l}172 \\
85.0 \\
238 \\
211 \\
244\end{array}$ & $\begin{array}{r}24 \\
38 \\
10 \\
16 \\
8\end{array}$ & $\begin{array}{l}149 \\
80.0 \\
204 \\
191 \\
224\end{array}$ & $\begin{array}{r}25 \\
38 \\
15 \\
18 \\
8\end{array}$ & $\begin{array}{c}107 \\
71.0 \\
169 \\
159 \\
189\end{array}$ & $\begin{array}{r}30 \\
38 \\
18 \\
21 \\
7\end{array}$ & $\begin{array}{l}87.0 \\
62.0 \\
140 \\
114 \\
158\end{array}$ & $\begin{array}{r}30 \\
36 \\
13 \\
22 \\
9\end{array}$ & $\begin{array}{r}63.0 \\
46.0 \\
90.0 \\
70.0 \\
107\end{array}$ & $\begin{array}{l}29 \\
37 \\
16 \\
25 \\
11\end{array}$ & $\begin{array}{l}47.0 \\
35.0 \\
65.0 \\
50.0 \\
77.0\end{array}$ & $\begin{array}{l}29 \\
37 \\
16 \\
26 \\
11\end{array}$ & $\begin{array}{l}37.0 \\
29.0 \\
51.0 \\
39.0 \\
59.0\end{array}$ & $\begin{array}{l}29 \\
37 \\
16 \\
27 \\
12\end{array}$ & $\begin{array}{l}26.0 \\
21.0 \\
35.0 \\
27.0 \\
40.0\end{array}$ & $\begin{array}{l}29 \\
36 \\
17 \\
28 \\
13\end{array}$ & $\begin{array}{l}16.0 \\
13.0 \\
20.0 \\
15.0 \\
22.0\end{array}$ & $\begin{array}{l}23 \\
34 \\
16 \\
30 \\
12\end{array}$ \\
\hline 198 & 32 & 34 & 113 & 36 & 95.0 & 36 & 75.0 & 36 & 61.0 & 37 & 50.0 & 36 & 38.0 & 36 & 30.0 & 36 & 21.0 & 37 & 13.0 & \\
\hline
\end{tabular}

DURATION OF DISCHARGE FOR EACH WATER YEAR

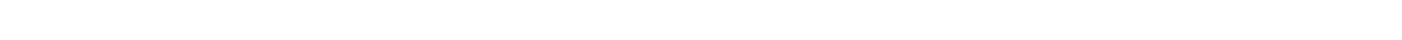

YEAR

1941

1942

1944

1945

1946

1947
1948

1949

1950

1951

1952

1954

1955

1956

1957
1958

1959
1960
NUMBER OF DAYS IN CJASS

$\begin{array}{llllllllllllllllll}70 & 83 & 29 & 28 & 20 & 16 & 12 & 22 & 21 & 9 & 5 & 6 & 5 & 4 & 8 & 7 & 6 & 14\end{array}$ $\begin{array}{llllllllllllllllllll}13 & 12 & 70 & 67 & 32 & 36 & 29 & 19 & 13 & 5 & 14 & 12 & 12 & 15 & 7 & 3 & 5 & 1\end{array}$

$\begin{array}{lllllllllllllllll}36 & 109 & 49 & 8 & 28 & 9 & 8 & 19 & 26 & 6 & 13 & 11 & 15 & 8 & 6 & 14\end{array}$

$\begin{array}{llllllllllllllllllll}60 & 103 & 74 & 21 & 14 & 8 & 14 & 7 & 6 & 5 & 7 & 5 & 2 & 4 & 8 & 10 & 14 & 4 & & 8507.9\end{array}$

$\begin{array}{llllllllllllllllllll}69 & 88 & 29 & 53 & 10 & 12 & 26 & 8 & 10 & 7 & 2 & 4 & 6 & 18 & 10 & 3 & 6 & 4 & 7943.1\end{array}$

$\begin{array}{lllllllllllllllll}4 & 97 & 71 & 59 & 13 & 30 & 14 & 7 & 5 & 10 & 11 & 13 & 8 & 4 & 8 & 8 & 3\end{array}$

$\begin{array}{llllllllllllllllllll}75 & 39 & 38 & 36 & 22 & 47 & 14 & 11 & 9 & 10 & 16 & 12 & 6 & 7 & 9 & 3 & 3 & 3 & 5\end{array}$

$\begin{array}{lrrrrrrrrrrrrrrrrrr}98 & 53 & 48 & 31 & 26 & 23 & 7 & 9 & 16 & 14 & 6 & 9 & 7 & 6 & 5 & 3 & 5 & & \\ 4 & 160 & 29 & 34 & 11 & 23 & 4 & 9 & 11 & 8 & 6 & 9 & 7 & 14 & 9 & 12 & 6 & 7 & 1\end{array}$

$\begin{array}{rrrrrrrrrrrrrrrrrrr}4 & 160 & 29 & 34 & 11 & 23 & 4 & 9 & 11 & 8 & 6 & 9 & 7 & 14 & 9 & 12 & 6 & 7 & 1 \\ 95 & 54 & 33 & 37 & 33 & 17 & 5 & 18 & 14 & 11 & 9 & 6 & 8 & 5 & 2 & 4 & 8 & 6 & \end{array}$

$\begin{array}{llllllllllllllllll}67 & 46 & 55 & 39 & 16 & 13 & 14 & 23 & 15 & 7 & 12 & 22 & 10 & 3 & 6 & 6 & 7 & 4\end{array}$ $\begin{array}{llllllllllllllllllll}60 & 70 & 51 & 27 & 14 & 8 & 26 & 23 & 7 & 7 & 5 & 5 & 8 & 7 & 6 & 2 & 11 & 13 & 15 & 1\end{array}$

$\begin{array}{llllllllllllllllll}24 & 75 & 17 & 75 & 40 & 18 & 15 & 20 & 18 & 16 & 9 & 5 & 4 & 3 & 6 & 13 & 6 & 1\end{array}$

$\begin{array}{llllllllllllllll}3 & 21 & 71 & 135 & 23 & 32 & 7 & 10 & 14 & 7 & 6 & 4 & 14 & 14 & 4\end{array}$

$\begin{array}{lllllllllllllllll}59 & 81 & 47 & 41 & 19 & 22 & 24 & 7 & 12 & 5 & 12 & 5 & 7 & 7 & 9 & 7 & 1\end{array}$

$\begin{array}{llllllllllllllllll}31 & 126 & 48 & 7 & 18 & 11 & 19 & 16 & 18 & 11 & 8 & 5 & 7 & 9 & 7 & 12 & 9 & 4\end{array}$

$\begin{array}{lllllllllllllllllll}68 & 63 & 37 & 26 & 22 & 13 & 25 & 21 & 8 & 5 & 9 & 4 & 10 & 9 & 12 & 7 & 5 & 5 & 4\end{array}$

$\begin{array}{lllllllllllllllllll}7 & 61 & 57 & 64 & 37 & 27 & 14 & 17 & 11 & 10 & 9 & 8 & 6 & 3 & 10 & 5 & 5 & 4 & 6\end{array}$

$\begin{array}{rrrrrrrrrrrrrrrrrrrr}75 & 10 & 58 & 121 & 60 & 13 & 11 & 8 & 10 & 8 & 12 & 11 & 13 & 10 & 9 & 5 & 4 & 2 & & \\ 75 & 57 & 60 & 22 & 18 & 11 & 18 & 25 & 18 & 12 & 5 & 6 & 6 & 6 & 7 & 6 & 6 & 2 & 1\end{array}$
CUBIC FEET PER SECOND

5297.9

6859.4

4655.9

8139.8

6539.2

14883.7

6145.6

4281.4

5507.4

9340.7

8548.0

3702.0

4489.6 
GREEN RIVER BASIN

09310000 GOOSEBERRY CREEK NEAR SCOFIELD, UT'-Continued

DURATION OF DISGHARGE FOR EACH WATER YEAR--Continued

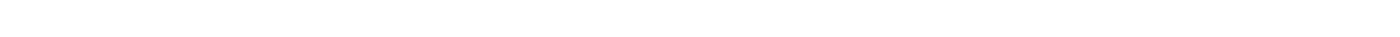

YEAR

NUMBER OF DAYS IN CLASS

OUBIC FEET

PER SECOND

-DAYS

\begin{tabular}{|c|c|c|c|c|c|}
\hline $\begin{array}{l}1961 \\
1962 \\
1963 \\
1964 \\
1965\end{array}$ & & & & & \\
\hline $\begin{array}{l}1966 \\
1967 \\
1968 \\
1969 \\
1970\end{array}$ & 4 & 2 & 12 & 7 & 13 \\
\hline $\begin{array}{l}1971 \\
1972 \\
1973 \\
1974 \\
1975\end{array}$ & & & & & \\
\hline $\begin{array}{l}1976 \\
1977 \\
1978 \\
1979 \\
1980\end{array}$ & 15 & & 8 & 1 & 1 \\
\hline
\end{tabular}

$\begin{array}{llllllllllllllll}3 & 11 & 112 & 84 & 27 & 19 & 28 & 12 & 13 & 7 & 11 & 9 & 15 & 10 & 2 & 2\end{array}$

$\begin{array}{rllllllllllrrrrrrrr}63 & 6 & 22 & 46 & 70 & 70 & 14 & 16 & 23 & 12 & 13 & 12 & 9 & 8 & 6 & 6 & 11 & 19 & 7 \\ 63 & & 41 & 41 & 12 & 13 & 13 & 6 & 7 & 5 & 5 & 5 & 8 & 9 & 6\end{array}$

$\begin{array}{lllllllllllllllllllll}6 & 22 & 46 & 70 & 15 & 13 & 41 & 12 & 13 & 13 & 6 & 7 & 5 & 5 & 5 & 8 & 9 & 6 & & & 9170.7\end{array}$ $\begin{array}{rrrrrrrrrrrrrrrrrrrr}22 & 46 & 70 & 15 & 13 & 41 & 12 & 13 & 13 & 6 & 7 & 5 & 5 & 5 & 8 & 9 & 6 & & \\ 40 & 122 & 27 & 5 & 38 & 33 & 10 & 20 & 15 & 4 & 7 & 7 & 7 & 3 & 5 & 8 & 2 & 6 & 3 & 5344.9 \\ 13 & 24 & 128 & 22 & 10 & 5 & 9 & 25 & 49 & 15 & 8 & 7 & 9 & 9 & 4 & 10 & 10 & 7 & 1 & 6373.0 \\ & & & & & & & & & & & & & \end{array}$

1981

$\begin{array}{rrrrrrrrrrrrrrrrrrrrr} & 8 & 43 & 87 & 48 & 27 & 24 & 22 & 8 & 14 & 18 & 8 & 7 & 7 & 6 & 9 & & & \\ 76 & 42 & 51 & 54 & 20 & 20 & 15 & 19 & 12 & 10 & 9 & 1 & 1 & 4 & 9 & 4 & 5 & 8 & 5 & & 7033.4\end{array}$

$\begin{array}{lllllllllllllllllllll}5 & 149 & 37 & 41 & 22 & 24 & 20 & 9 & 4 & 6 & 7 & 8 & 7 & 7 & 4 & 4 & 11 & 1 & 71 & \end{array}$

$\begin{array}{llllllllllllllllllll}3 & 64 & 65 & 35 & 64 & 12 & 16 & 20 & 10 & 11 & 912 & 7 & 3 & 3 & 7 & 4 & 5 & 10 & 5 & 9656.5\end{array}$

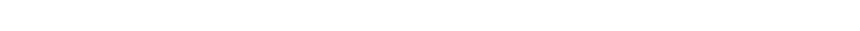

$\begin{array}{lllllllllllllllllll}2 & 62 & 94 & 89 & 9 & 19 & 22 & 9 & 7 & 5 & 4 & 13 & 17 & 6 & 2 & 3 & 2 & & \end{array}$

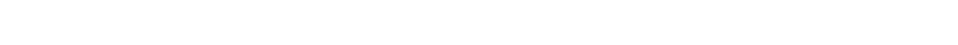

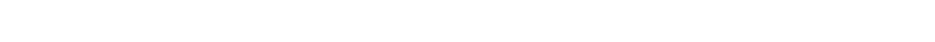

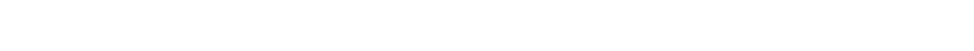

$\begin{array}{llllllllllllllllll}7 & 21 & 23 & 45 & 134 & 41 & 21 & 11 & 10 & 10 & 8 & 5 & 4 & 5 & 4 & 4 & 8 & 5\end{array}$

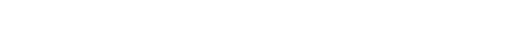

$\begin{array}{lllllllllllllllllll}24 & 100 & 36 & 37 & 21 & 20 & 14 & 9 & 9 & 17 & 12 & 12 & 7 & 5 & 2 & 5 & 5 & 9 & 21\end{array}$

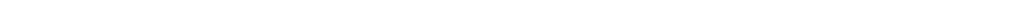

$\begin{array}{lllllllllllllllllll}26 & 168 & 15 & 35 & 17 & 7 & 9 & 8 & 10 & 7 & 6 & 6 & 11 & 3 & 11 & 7 & 19 & 1 & 9319.3\end{array}$

$\begin{array}{lllllllllllllllll}3 & 39 & 127 & 58 & 40 & 12 & 6 & 12 & 6 & 11 & 5 & 11 & 18 & 10 & 4 & 2 & 1\end{array}$

DURATION TABLE OF DISCHARGE FOR WATER YEARS 1941-81

$\begin{array}{ccc}\text { OBBIC } & \text { AOCU- } \\ \text { FEET } & \text { MU- } & \text { PER- } \\ \text { PER } & \text { TOTAL LATED } & \text { CENT } \\ \text { CLASS SECOND DAYS DAYS } & \text { DAYS }\end{array}$

\begin{tabular}{rrrrrr}
\multicolumn{4}{c}{$\begin{array}{c}\text { OUBIC } \\
\text { FEET }\end{array}$} & $\begin{array}{c}\text { ACCU- } \\
\text { MU- }\end{array}$ \\
$\begin{array}{c}\text { PER } \\
\text { TOTAL }\end{array}$ & $\begin{array}{c}\text { PER- } \\
\text { LATED }\end{array}$ & $\begin{array}{c}\text { CENT } \\
\text { CLASS SECOND }\end{array}$ & DAYS & DAYS & DAYS \\
9 & 0.55 & 2 & 14926 & 99.7 \\
10 & 0.72 & 3 & 14924 & 99.7 \\
11 & 0.93 & 0 & 14921 & 99.6 \\
12 & 1.20 & 149 & 14921 & 99.6 \\
13 & 1.60 & 180 & 14772 & 98.6 \\
14 & 2.00 & 1317 & 14592 & 97.4 \\
15 & 2.60 & 2398 & 13275 & 88.6 \\
16 & 3.40 & 2421 & 10877 & 72.6 \\
17 & 4.40 & 2037 & 8456 & 56.5
\end{tabular}

ABIC ACQU-

FEET TOTAL LATED CENT

OUIC
FEET
PER TOTAL MUI-
PEER-

CLASS SECOID DAYS DAYS DAYS

$\begin{array}{rrrr}0.00 & 4 & 14975 & 100.0 \\ 0.07 & 15 & 14971 & 100.0\end{array}$

$\begin{array}{rrrr}0.07 & 15 & 14971 & 100.0 \\ 0.09 & 2 & 14956 & 99.9\end{array}$

$\begin{array}{llll}0.12 & 0 & 14954 & 99.9\end{array}$

$\begin{array}{llll}0.15 & 8 & 14954 & 99.9\end{array}$

$\begin{array}{llll}0.20 & 12 & 14946 & 99.8\end{array}$

$\begin{array}{llll}0.26 & 0 & 14934 & 99.7\end{array}$

$\begin{array}{llll}0.33 & 8 & 14934 & 99.7 \\ 0.43 & 0 & 14926 & 99.7\end{array}$

CLASS SECOND DAYS DAYS DAYS

CLASS SECOND DAYS DAYS DAYS

MONTHLY MEAN DISCHARGES, IN OUBIC FEET PER SECOND, FOR EAOH WATER YEAR

\begin{tabular}{|c|c|c|c|c|c|c|c|c|c|c|c|c|}
\hline YEAR & $\propto C T$ & $\mathrm{NOV}$ & $\mathrm{DEC}$ & JAN & FEB & MAR & APR & MAY & JUNE & JULY & AUG & SEP \\
\hline 1931 & 4.5 & 6.7 & 4 & 3 & 3 & 3 & 17.8 & 40.8 & 12.6 & 4.3 & 2.7 & 2.0 \\
\hline $\begin{array}{l}1941 \\
1942 \\
1943 \\
1944 \\
1945\end{array}$ & $\begin{array}{c}4.52 \\
12.0 \\
4.26 \\
4.40 \\
4.56\end{array}$ & $\begin{array}{c}4.00 \\
10.0 \\
3.03 \\
4.00 \\
4.52\end{array}$ & $\begin{array}{l}3.65 \\
9.00 \\
3.03 \\
4.00 \\
3.00\end{array}$ & $\begin{array}{l}3.00 \\
7.00 \\
2.00 \\
3.00 \\
3.00\end{array}$ & $\begin{array}{l}3.00 \\
6.00 \\
3.00 \\
3.00 \\
3.50\end{array}$ & $\begin{array}{l}4.52 \\
8.35 \\
3.42 \\
3.50 \\
3.50\end{array}$ & $\begin{array}{c}8.23 \\
55.4 \\
42.8 \\
5.00 \\
6.77\end{array}$ & $\begin{array}{l}170 \\
134 \\
54.8 \\
129 \\
126\end{array}$ & $\begin{array}{l}82.1 \\
67.8 \\
49.0 \\
93.3 \\
70.1\end{array}$ & $\begin{array}{l}22.4 \\
21.7 \\
15.2 \\
16.9 \\
18.0\end{array}$ & $\begin{array}{c}13.2 \\
12.6 \\
10.6 \\
7.40 \\
10.7\end{array}$ & $\begin{array}{l}9.53 \\
5.07 \\
4.23 \\
4.95 \\
6.17\end{array}$ \\
\hline $\begin{array}{l}1946 \\
1947 \\
1948 \\
1949 \\
1950\end{array}$ & $\begin{array}{l}4.68 \\
5.09 \\
4.78 \\
3.30 \\
3.91\end{array}$ & $\begin{array}{l}4.33 \\
4.01 \\
4.25 \\
3.24 \\
2.91\end{array}$ & $\begin{array}{l}3.16 \\
3.35 \\
3.35 \\
3.10 \\
2.21\end{array}$ & $\begin{array}{l}3.00 \\
2.50 \\
2.50 \\
2.90 \\
2.00\end{array}$ & $\begin{array}{l}3.14 \\
2.50 \\
2.30 \\
2.89 \\
2.00\end{array}$ & $\begin{array}{l}3.77 \\
3.58 \\
2.37 \\
3.76 \\
3.02\end{array}$ & $\begin{array}{l}44.8 \\
22.9 \\
10.5 \\
38.0 \\
19.1\end{array}$ & $\begin{array}{c}65.0 \\
122 \\
78.2 \\
137 \\
92.1\end{array}$ & $\begin{array}{l}23.8 \\
31.7 \\
23.9 \\
48.7 \\
40.7\end{array}$ & $\begin{array}{l}9.10 \\
12.4 \\
10.1 \\
13.2 \\
12.4\end{array}$ & $\begin{array}{l}5.66 \\
8.45 \\
6.46 \\
6.45 \\
6.25\end{array}$ & $\begin{array}{l}3.16 \\
5.11 \\
3.08 \\
3.76 \\
5.76\end{array}$ \\
\hline $\begin{array}{l}1951 \\
1952 \\
1953 \\
1954 \\
1955\end{array}$ & $\begin{array}{l}3.62 \\
5.45 \\
5.34 \\
4.50 \\
3.83\end{array}$ & $\begin{array}{l}6.25 \\
4.42 \\
5.04 \\
4.97 \\
3.71\end{array}$ & $\begin{array}{l}3.30 \\
3.58 \\
3.35 \\
4.26 \\
2.72\end{array}$ & $\begin{array}{l}2.45 \\
3.00 \\
2.60 \\
4.00 \\
2.50\end{array}$ & $\begin{array}{l}2.45 \\
3.00 \\
2.54 \\
4.50 \\
2.50\end{array}$ & $\begin{array}{l}3.28 \\
3.66 \\
3.42 \\
4.76 \\
3.34\end{array}$ & $\begin{array}{c}24.8 \\
20.6 \\
10.3 \\
28.7 \\
8.95\end{array}$ & $\begin{array}{c}98.3 \\
239 \\
69.4 \\
52.5 \\
76.2\end{array}$ & $\begin{array}{c}42.0 \\
156 \\
68.7 \\
15.5 \\
30.4\end{array}$ & $\begin{array}{c}13.5 \\
26.1 \\
15.3 \\
8.16 \\
9.92\end{array}$ & $\begin{array}{c}9.12 \\
14.1 \\
9.65 \\
4.00 \\
7.38\end{array}$ & $\begin{array}{l}4.63 \\
8.04 \\
5.76 \\
4.31 \\
3.81\end{array}$ \\
\hline $\begin{array}{l}1956 \\
1957 \\
1958 \\
1959 \\
1960\end{array}$ & $\begin{array}{l}2.46 \\
3.61 \\
6.11 \\
3.26 \\
3.23\end{array}$ & $\begin{array}{l}2.16 \\
2.98 \\
5.66 \\
3.44 \\
2.90\end{array}$ & $\begin{array}{l}2.10 \\
2.20 \\
3.50 \\
2.89 \\
1.81\end{array}$ & $\begin{array}{l}2.00 \\
2.20 \\
3.00 \\
2.74 \\
1.40\end{array}$ & $\begin{array}{l}1.90 \\
2.66 \\
3.18 \\
2.50 \\
1.40\end{array}$ & $\begin{array}{l}3.27 \\
3.76 \\
4.27 \\
2.91 \\
3.40\end{array}$ & $\begin{array}{c}27.5 \\
9.01 \\
16.2 \\
8.55 \\
11.0\end{array}$ & $\begin{array}{c}94.5 \\
77.6 \\
153 \\
55.3 \\
78.8\end{array}$ & $\begin{array}{c}25.6 \\
164 \\
58.5 \\
23.1 \\
26.1\end{array}$ & $\begin{array}{c}10.0 \\
23.8 \\
13.3 \\
9.41 \\
9.99\end{array}$ & $\begin{array}{c}5.48 \\
10.2 \\
8.26 \\
3.92 \\
3.54\end{array}$ & $\begin{array}{l}2.67 \\
5.73 \\
3.88 \\
2.87 \\
2.75\end{array}$ \\
\hline $\begin{array}{l}1961 \\
1962 \\
1963 \\
1964 \\
1965\end{array}$ & $\begin{array}{l}3.16 \\
3.44 \\
4.30 \\
3.00 \\
3.65\end{array}$ & $\begin{array}{l}3.37 \\
3.82 \\
3.75 \\
2.92 \\
2.92\end{array}$ & $\begin{array}{l}3.05 \\
2.98 \\
2.34 \\
2.50 \\
4.08\end{array}$ & $\begin{array}{l}2.20 \\
3.00 \\
1.41 \\
3.00 \\
4.23\end{array}$ & $\begin{array}{l}2.20 \\
4.64 \\
1.97 \\
3.00 \\
3.95\end{array}$ & $\begin{array}{l}2.56 \\
4.50 \\
2.13 \\
3.00 \\
3.50\end{array}$ & $\begin{array}{c}10.4 \\
29.2 \\
3.92 \\
5.66 \\
9.96\end{array}$ & $\begin{array}{c}36.5 \\
145 \\
92.5 \\
92.6 \\
92.1\end{array}$ & $\begin{array}{l}13.2 \\
66.4 \\
35.2 \\
60.1 \\
94.9\end{array}$ & $\begin{array}{l}5.64 \\
19.5 \\
11.6 \\
16.5 \\
21.6\end{array}$ & $\begin{array}{c}2.32 \\
10.3 \\
8.84 \\
9.13 \\
16.7\end{array}$ & $\begin{array}{c}3.93 \\
6.56 \\
6.33 \\
6.79 \\
14.1\end{array}$ \\
\hline
\end{tabular}


GREEN RIVER BASIN

09310000 GOOSEBERRY CREEK NEAR SOOFIELD, UT-CONTInUed

MONIULY MEAN DISCHARGES, IN CABIC FEET PER SECOND, FOR EACH WATER YEAR--Continued

\begin{tabular}{|c|c|c|c|c|c|c|c|c|c|c|c|c|}
\hline YEAR & $O C T$ & $\mathrm{NOV}$ & DEC & JAN & FEB & MAR & APR & MAY & JUNE & JULY & AUG & SEP \\
\hline $\begin{array}{l}1966 \\
1967 \\
1968 \\
1969 \\
1970\end{array}$ & $\begin{array}{l}9.42 \\
5.86 \\
4.07 \\
5.73 \\
6.81\end{array}$ & $\begin{array}{l}6.86 \\
3.51 \\
3.76 \\
4.57 \\
5.77\end{array}$ & $\begin{array}{l}4.83 \\
3.26 \\
3.79 \\
3.42 \\
4.89\end{array}$ & $\begin{array}{l}4.31 \\
2.50 \\
3.97 \\
2.90 \\
4.80\end{array}$ & $\begin{array}{l}4.60 \\
2.50 \\
4.00 \\
2.98 \\
4.15\end{array}$ & $\begin{array}{l}6.54 \\
2.99 \\
4.23 \\
3.83 \\
4.93\end{array}$ & $\begin{array}{c}35.5 \\
5.70 \\
7.51 \\
22.4 \\
7.35\end{array}$ & $\begin{array}{l}69.0 \\
93.4 \\
82.0 \\
196 \\
110\end{array}$ & $\begin{array}{l}15.9 \\
80.3 \\
91.9 \\
43.6 \\
52.5\end{array}$ & $\begin{array}{l}6.04 \\
16.5 \\
12.8 \\
15.3 \\
13.6\end{array}$ & $\begin{array}{l}7.49 \\
8.32 \\
9.97 \\
7.46 \\
5.84\end{array}$ & $\begin{array}{l}4.12 \\
5.38 \\
6.39 \\
6.18 \\
4.94\end{array}$ \\
\hline $\begin{array}{l}1971 \\
1972 \\
1973 \\
1974 \\
1975\end{array}$ & $\begin{array}{l}5.28 \\
4.98 \\
4.77 \\
4.40 \\
3.38\end{array}$ & $\begin{array}{l}5.16 \\
4.60 \\
4.63 \\
4.22 \\
3.36\end{array}$ & $\begin{array}{l}6.53 \\
5.00 \\
3.79 \\
4.20 \\
2.67\end{array}$ & $\begin{array}{l}7.39 \\
5.35 \\
3.50 \\
4.80 \\
3.00\end{array}$ & $\begin{array}{l}3.63 \\
4.97 \\
3.50 \\
4.12 \\
3.00\end{array}$ & $\begin{array}{c}4.15 \\
10.6 \\
4.28 \\
4.01 \\
3.00\end{array}$ & $\begin{array}{c}12.5 \\
24.1 \\
8.36 \\
8.48 \\
3.37\end{array}$ & $\begin{array}{c}85.1 \\
60.4 \\
119 \\
111 \\
52.8\end{array}$ & $\begin{array}{c}38.2 \\
18.4 \\
57.6 \\
24.1 \\
149\end{array}$ & $\begin{array}{c}10.7 \\
5.72 \\
13.1 \\
7.35 \\
25.0\end{array}$ & $\begin{array}{l}5.58 \\
3.26 \\
5.73 \\
3.65 \\
8.76\end{array}$ & $\begin{array}{l}4.70 \\
3.91 \\
5.20 \\
2.66 \\
5.18\end{array}$ \\
\hline $\begin{array}{l}1976 \\
1977 \\
1978 \\
1979 \\
1980\end{array}$ & $\begin{array}{l}5.91 \\
3.05 \\
2.45 \\
0.65 \\
3.73\end{array}$ & $\begin{array}{l}5.27 \\
2.68 \\
2.73 \\
4.39 \\
3.38\end{array}$ & $\begin{array}{l}5.06 \\
1.90 \\
2.67 \\
2.82 \\
3.49\end{array}$ & $\begin{array}{l}5.00 \\
2.12 \\
2.50 \\
2.80 \\
3.50\end{array}$ & $\begin{array}{l}4.72 \\
2.38 \\
2.64 \\
2.80 \\
3.50\end{array}$ & $\begin{array}{l}3.95 \\
2.58 \\
3.11 \\
2.80 \\
3.50\end{array}$ & $\begin{array}{c}8.69 \\
10.9 \\
17.3 \\
8.00 \\
15.9\end{array}$ & $\begin{array}{l}85.0 \\
12.9 \\
105 \\
102 \\
108\end{array}$ & $\begin{array}{c}19.9 \\
9.80 \\
122 \\
51.2 \\
131\end{array}$ & $\begin{array}{c}7.27 \\
3.75 \\
14.9 \\
9.91 \\
17.2\end{array}$ & $\begin{array}{l}3.14 \\
1.96 \\
8.89 \\
5.33 \\
7.02\end{array}$ & $\begin{array}{l}2.39 \\
1.89 \\
4.30 \\
3.37 \\
5.81\end{array}$ \\
\hline 1981 & 5.02 & 4.74 & 3.86 & 3.68 & 3.70 & 5.15 & 25.4 & 59.3 & 26.7 & 7.10 & 3.86 & 3.59 \\
\hline
\end{tabular}

ANNUAL PEAK DISCHARGE, IN OUBIC FEET PER SECOND, AND OORRESPONDING GAGE HEIGHT, IN FEET, FOR EACH WATER YEAR

\begin{tabular}{|c|c|c|c|c|c|c|c|c|c|c|c|c|c|c|}
\hline $\begin{array}{l}\text { WATER } \\
\text { YEAR }\end{array}$ & & DATE & $\begin{array}{c}\text { GAGE } \\
\text { HEIGHT }\end{array}$ & $\begin{array}{c}\text { PEAK } \\
\text { DISCHARGE }\end{array}$ & $\begin{array}{l}\text { WATEER } \\
\text { YEAR }\end{array}$ & & DATE & $\begin{array}{c}\text { GAGE } \\
\text { HEIGHT }\end{array}$ & $\begin{array}{c}\text { PEAK } \\
\text { DISCHARGE }\end{array}$ & $\begin{array}{l}\text { WATERR } \\
\text { YEAR }\end{array}$ & & DATE & $\begin{array}{c}\text { GAGE } \\
\text { HEIGHT }\end{array}$ & $\begin{array}{c}\text { PEAR } \\
\text { DISCHARG }\end{array}$ \\
\hline $\begin{array}{l}1931 \\
1932 \\
1941 \\
1942 \\
1943 \\
1944 \\
1945 \\
1946 \\
1947 \\
1948 \\
1949 \\
1950 \\
1951 \\
1952 \\
1953\end{array}$ & $\begin{array}{l}\text { MAY } \\
- \\
\text { MAY } \\
\text { MAY } \\
\text { JUNE } \\
\text { MAY } \\
\text { MAY } \\
\text { APR. } \\
\text { MAY } \\
\text { MAY } \\
\text { MAY } \\
\text { MAY } \\
\text { MAY } \\
\text { MAY } \\
\text { MAY }\end{array}$ & \begin{tabular}{ll}
03 & 1931 \\
\hdashline & 1932 \\
18, & 1941 \\
25, & 1942 \\
01, & 1943 \\
15, & 1944 \\
12, & 1945 \\
29, & 1946 \\
04, & 1947 \\
16, & 1948 \\
17, & 1949 \\
22, & 1950 \\
20, & 1951 \\
30, & 1952 \\
27, & 1953
\end{tabular} & $\begin{array}{l}1.09 \\
2.04 \\
2.25 \\
2.05 \\
1.57 \\
1.95 \\
1.5 \\
1.55 \\
2.06 \\
1.54 \\
2.31 \\
1.82 \\
1.68 \\
2.36 \\
1.59\end{array}$ & $\begin{array}{l}98 \\
325 \\
366 \\
304 \\
178 \\
265 \\
240 \\
170 \\
292 \\
167 \\
360 \\
235 \\
189 \\
414 \\
218\end{array}$ & $\begin{array}{l}1954 \\
1955 \\
1956 \\
1957 \\
1958 \\
1959 \\
1960 \\
1961 \\
1962 \\
1963 \\
1964 \\
1965 \\
1966 \\
1967\end{array}$ & $\begin{array}{l}\text { MAY } \\
\text { MAY } \\
\text { MAY } \\
\text { JUNE } \\
\text { MAY } \\
\text { MAY } \\
\text { MAY } \\
\text { MAY } \\
\text { MAY } \\
\text { MAY } \\
\text { MAY } \\
\text { MAY } \\
\text { MAY } \\
\text { MAY }\end{array}$ & $\begin{array}{l}07,1954 \\
12,1955 \\
09,1956 \\
06,1957 \\
23,1958 \\
14,1959 \\
13,1960 \\
12,1961 \\
09,1962 \\
19,1963 \\
23,1964 \\
20,1965 \\
10,1966 \\
28,1967\end{array}$ & $\begin{array}{l}0.87 \\
1.99 \\
2.02 \\
2.98 \\
2.85 \\
1.79 \\
2.20 \\
1.42 \\
2.57 \\
2.05 \\
2.54 \\
2.42 \\
1.84 \\
2.48\end{array}$ & $\begin{array}{r}89 \\
161 \\
165 \\
369 \\
345 \\
122 \\
203 \\
74 \\
279 \\
173 \\
272 \\
230 \\
133 \\
252\end{array}$ & $\begin{array}{l}1968 \\
1969 \\
1970 \\
1971 \\
1972 \\
1973 \\
1974 \\
1975 \\
1976 \\
1977 \\
1978 \\
1979 \\
1980 \\
1981\end{array}$ & $\begin{array}{l}\text { MAY } \\
\text { MAY } \\
\text { MAY } \\
\text { MAY } \\
\text { MAY } \\
\text { MAY } \\
\text { MAY } \\
\text { JUNE } \\
\text { MAY } \\
\text { APR. } \\
\text { MAY } \\
\text { MAY } \\
\text { MAY } \\
\text { MAY }\end{array}$ & $\begin{array}{ll}22, & 1968 \\
14, & 1969 \\
19, & 1970 \\
15, & 1971 \\
07, & 1972 \\
21, & 1973 \\
09, & 1974 \\
06, & 1975 \\
14, & 1976 \\
17, & 1977 \\
30, & 1978 \\
28, & 1979 \\
23, & 1980 \\
03, & 1981\end{array}$ & $\begin{array}{l}2.41 \\
2.95 \\
2.71 \\
2.27 \\
1.76 \\
2.84 \\
2.61 \\
2.58 \\
2.31 \\
1.01 \\
2.62 \\
2.64 \\
2.77 \\
2.16\end{array}$ & $\begin{array}{l}239 \\
338 \\
281 \\
224 \\
101 \\
312 \\
251 \\
256 \\
184 \\
32 \\
205 \\
208 \\
230 \\
147\end{array}$ \\
\hline
\end{tabular}

MAGNITUDE AND PRCBABILITY OF ANNUAL LOWEST MEAN DISCHARGE BASED ON CIIMATIC YEARS 1942-81

\begin{tabular}{lcccccc}
\multicolumn{7}{c}{ BASED ON CLIMATIC YEARS 1942-81 } \\
\hline $\begin{array}{c}\text { PERIOD } \\
\text { (CON- }\end{array}$ & $\begin{array}{c}\text { DISCHARGE, IN OUBIC FEET PER SECOND, FOR } \\
\text { INDICATED RECURRENCE INTERNAL, IN YEARS, AND }\end{array}$ \\
$\begin{array}{c}\text { SEOU- } \\
\text { TIVN }\end{array}$ & 2 & 5 & 10 & 20 & 50 & 100 \\
DAYS) & 508 & 208 & 108 & 58 & 28 & 18 \\
\hline & & & & & & \\
\hline 60 & 2.8 & 2.2 & 2.0 & 1.8 & 1.6 & - \\
90 & 3.0 & 2.3 & 2.0 & 1.8 & 1.7 & -
\end{tabular}




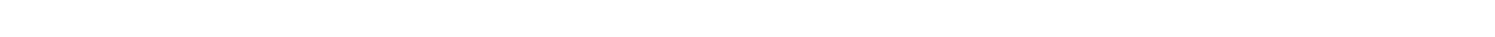
bank $0.8 \mathrm{mi}$ upstream fram bridge, $1.2 \mathrm{mi}$ dawnstream from French Creek, and $4.5 \mathrm{mi}$ north of Scof ield.

DRAINAGE AREA, $-60.1 \mathrm{mi}^{2}$.

MEAN BASIN ELEVATION, $-8,710 \mathrm{ft}$.

ZERIOD OF RECORD AVAILABLE. - June to October 1931 and April to September 1932 (monthly mean discharge only, published in wSP 1313 ), Octaber 1938 to September 1981. Published as "Price River above Scofield Reservoir, near Scofield", October 1938 to September 1967.

REVISED RECORDS. --WDR UT-77-1: Drainage area.

GAGE. -Water-stage recorder. Altitude of gage is 7,670 ft from topographic map. June 1931 to September 1932 and october 1938 to July 27, 1967, at various sites about 0.5 mi downstream at different datums.

REMARRS. --Small transmountain diversions in headwaters for irrigation in Sevier Lake basin and one diversion for irrigation above station.

AVERAGE DISCHARGE. -43 years (water years $1939-81$ ), $46.8 \mathrm{ft}^{3} / \mathrm{s}, 33,900 \mathrm{acre}-\mathrm{ft} / \mathrm{yr}$.

EXTREMES FOR PERIOD OF RECORD.--Maximum discharge, 1,160 ft $\mathrm{ft}^{3} / \mathrm{s}$ May 20,1973 , gage height, $4.87 \mathrm{ft}$; minimum recorded, $0.6 \mathrm{ft} / \mathrm{s}$ Oct. 31,1960 .

LOWEST MEAN DISCHARGE, IN CUBIC FEET PER SECOND, AND RANKING FOR THE INDICATED NUMBER OF CONSECJTTVE DAYS FOR EACH OIMATIC YEAR, APRII 1-MARQH 31

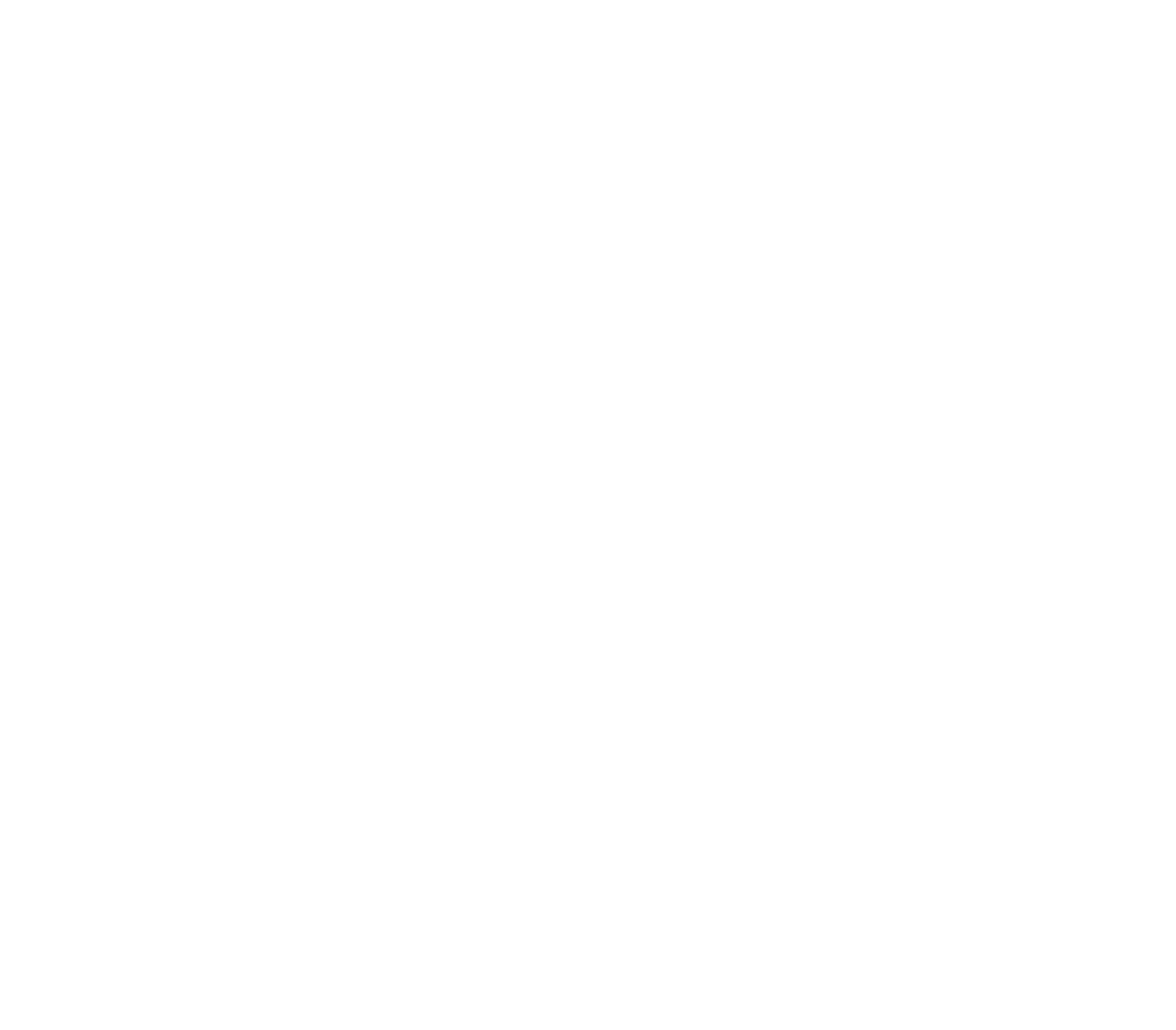


GREEN RIVER BASIN

09310500 FISH CREEK ABOVE RESERVOIR, NEAR SCOFIELD, UT-Continued

HIGHEST MEAN DISOHARGE, IN GUIC FEET PER SECOND, AND RANKING FOR THE INDICATFD NUMBER OF CONSEOUTIVE DAYS FOR EACH WATER YEAR, OCTCBER 1-SEPIEMBER 30

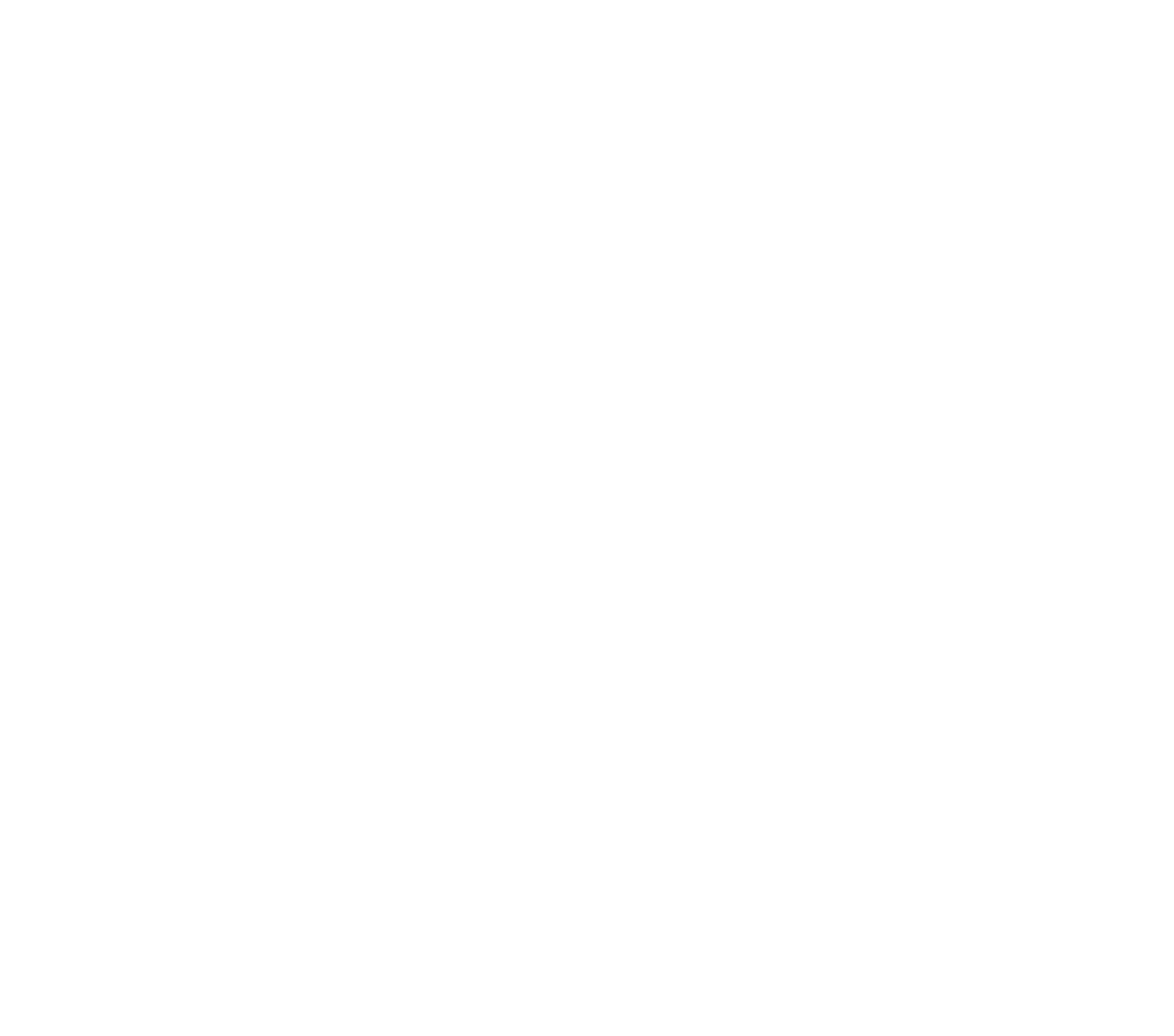

DURATION OF DISQHARGE FOR EACH WATER YEAR

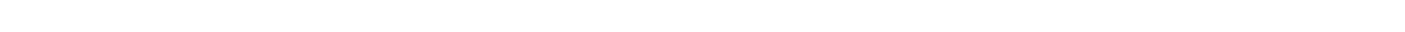
YEAR

NUMBER OF DAYS IN GLASS

CUBIC FEET

10973.0

14741.0

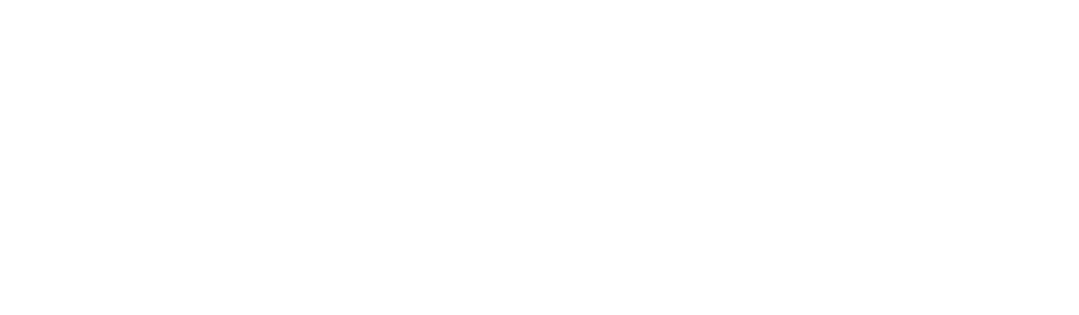

19576.0

21061.0

14249.0

19842.5

18638.6

13958.8

16737.5

11657.9 
GREEN RIVER BASIN

09310500 FISH CREEK ABOVE RESERNOIR, NEAR SCOFIELD, UT--Continued

DURATION OF DISCHARGE FOR EACH WATER YEAR--Continued

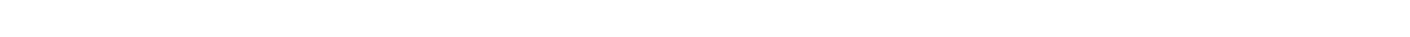

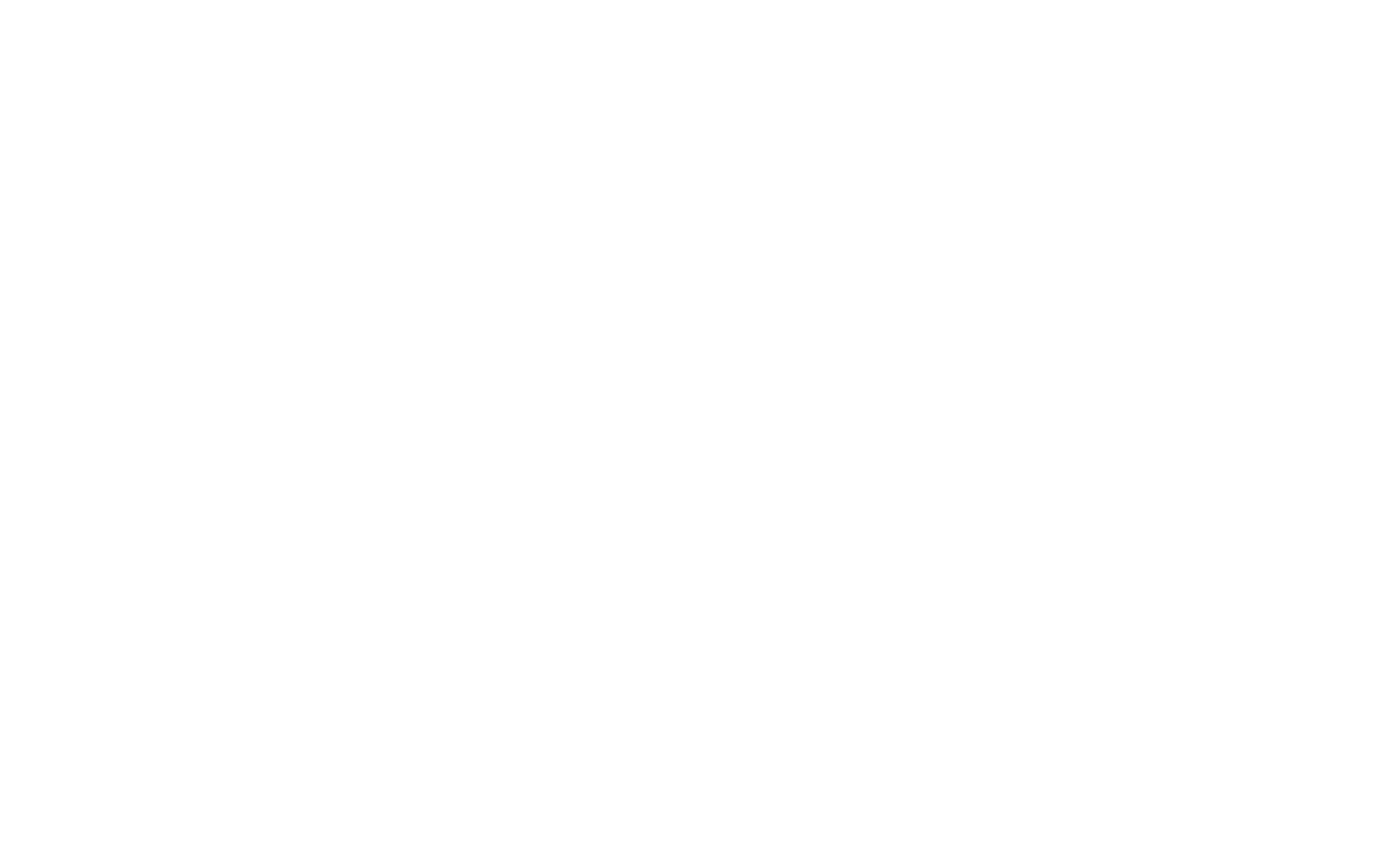

DURATION TABLE OF DISCHARGE FOR WATER YEARS 1939-81

\begin{tabular}{|c|c|c|c|c|c|c|c|c|c|c|c|c|c|c|c|c|c|c|c|}
\hline CASS & $\begin{array}{c}\text { CBIIC } \\
\text { FEET } \\
\text { PER } \\
\text { SECOND }\end{array}$ & $\begin{array}{l}\text { TOTAL } \\
\text { DAYS }\end{array}$ & $\begin{array}{l}\text { ACQJ- } \\
\text { MU- } \\
\text { LATED } \\
\text { DAYS }\end{array}$ & $\begin{array}{l}\text { PER- } \\
\text { CENT } \\
\text { DAYS }\end{array}$ & C.ASS & $\begin{array}{c}\text { QUBIC } \\
\text { FEET } \\
\text { PER } \\
\text { SECOND }\end{array}$ & TOTAL & $\begin{array}{c}\text { ACQU- } \\
\text { MU- } \\
\text { LATED } \\
\text { DAYS }\end{array}$ & $\begin{array}{l}\text { PER- } \\
\text { CENT } \\
\text { DAVS }\end{array}$ & OLASS & $\begin{array}{c}\text { QJBIC } \\
\text { FEET } \\
\text { PER } \\
\text { SECOND }\end{array}$ & TOTAL & $\begin{array}{c}\text { ACU- } \\
\text { MU- } \\
\text { LATED } \\
\text { DAYS }\end{array}$ & $\begin{array}{l}\text { PER- } \\
\text { CENT } \\
\text { DAYS }\end{array}$ & & $\begin{array}{c}\text { QUBIC } \\
\text { FEET } \\
\text { FER } \\
\text { SECOND }\end{array}$ & TOTAL & $\begin{array}{l}\text { ACQU- } \\
\text { MU- } \\
\text { LATED } \\
\text { DAYS }\end{array}$ & $\begin{array}{l}\text { PER- } \\
\text { CENT } \\
\text { DAYS }\end{array}$ \\
\hline $\begin{array}{l}0 \\
1 \\
2 \\
3 \\
4 \\
5 \\
6 \\
7 \\
8\end{array}$ & $\begin{array}{l}0.00 \\
2.60 \\
3.10 \\
3.70 \\
4.50 \\
5.40 \\
6.40 \\
7.70 \\
9.20\end{array}$ & $\begin{array}{r}0 \\
12 \\
64 \\
102 \\
397 \\
762 \\
1256 \\
2495 \\
1751\end{array}$ & $\begin{array}{l}15706 \\
15706 \\
15694 \\
15630 \\
15528 \\
15131 \\
14369 \\
13113 \\
10618\end{array}$ & $\begin{array}{r}100.0 \\
100.0 \\
99.9 \\
99.5 \\
98.9 \\
96.3 \\
91.5 \\
83.5 \\
67.6\end{array}$ & $\begin{array}{l}9 \\
10 \\
11 \\
12 \\
13 \\
14 \\
15 \\
16 \\
17\end{array}$ & $\begin{array}{l}11.00 \\
13.00 \\
16.00 \\
19.00 \\
23.00 \\
27.00 \\
33.00 \\
39.00 \\
47.00\end{array}$ & $\begin{array}{r}1495 \\
1546 \\
687 \\
690 \\
472 \\
472 \\
321 \\
301 \\
237\end{array}$ & $\begin{array}{l}8867 \\
7372 \\
5826 \\
5139 \\
4449 \\
3977 \\
3505 \\
3184 \\
2883\end{array}$ & $\begin{array}{l}56.5 \\
46.9 \\
37.1 \\
32.7 \\
28.3 \\
25.3 \\
22.3 \\
20.3 \\
18.4\end{array}$ & $\begin{array}{l}18 \\
19 \\
20 \\
21 \\
22 \\
23 \\
24 \\
25 \\
26\end{array}$ & $\begin{array}{r}56.0 \\
67.0 \\
81.0 \\
96.0 \\
120.0 \\
140.0 \\
170.0 \\
200.0 \\
240.0\end{array}$ & $\begin{array}{l}277 \\
246 \\
234 \\
271 \\
178 \\
240 \\
207 \\
202 \\
191\end{array}$ & $\begin{array}{r}2646 \\
2369 \\
2123 \\
1889 \\
1618 \\
1440 \\
1200 \\
993 \\
791\end{array}$ & $\begin{array}{r}16.8 \\
15.1 \\
13.5 \\
12.0 \\
10.3 \\
9.2 \\
7.6 \\
6.3 \\
5.0\end{array}$ & $\begin{array}{l}27 \\
28 \\
29 \\
30 \\
31 \\
32 \\
33 \\
34\end{array}$ & $\begin{array}{r}290.0 \\
340.0 \\
410.0 \\
490.0 \\
590.0 \\
700.0 \\
840.0 \\
1000.0\end{array}$ & $\begin{array}{r}128 \\
146 \\
111 \\
96 \\
72 \\
35 \\
10 \\
2\end{array}$ & $\begin{array}{r}600 \\
472 \\
326 \\
215 \\
119 \\
47 \\
12 \\
2\end{array}$ & $\begin{array}{l}3.8 \\
3.0 \\
2.1 \\
1.4 \\
0.8 \\
0.3 \\
0.1 \\
0.0\end{array}$ \\
\hline
\end{tabular}

MONTHLY MEAN DISCHARGES, IN CUBIC FEET FER SECOND, FOR EACH WATER YEAR

$\begin{array}{lcccccccccccc}\text { YEAR } & \text { OCT } & \text { NOV } & \text { DEC } & \text { JAN } & \text { FEB } & \text { MAR } & \text { AIR } & \text { MAY } & \text { JUNE } & \text { JULY } & \text { AUG } & \text { SEP } \\ 1939 & 11.5 & 11.0 & 10.0 & 10.0 & 9.00 & 12.0 & 102 & 132 & 34.5 & 12.9 & 8.23 & 7.27 \\ 1940 & 8.87 & 10.2 & 8.94 & 7.00 & 8.00 & 10.9 & 72.0 & 282 & 42.5 & 15.8 & 6.29 & 7.93 \\ & & & & & & & & & & & & \\ 1941 & 7.74 & 7.53 & 7.00 & 6.00 & 7.00 & 9.03 & 20.2 & 367 & 139 & 35.2 & 17.2 & 14.4 \\ 1942 & 19.0 & 15.8 & 14.4 & 12.0 & 10.0 & 14.1 & 119 & 294 & 135 & 33.6 & 15.1 & 7.40 \\ 1943 & 9.77 & 10.6 & 10.0 & 8.00 & 8.00 & 9.35 & 101 & 130 & 127 & 30.0 & 16.4 & 8.57 \\ 1944 & 11.8 & 10.0 & 9.00 & 8.00 & 8.00 & 10.0 & 22.7 & 313 & 196 & 36.5 & 13.1 & 9.17 \\ 1945 & 9.95 & 10.9 & 7.00 & 7.00 & 8.00 & 9.00 & 20.5 & 302 & 159 & 38.7 & 23.5 & 13.6 \\ 1946 & 12.1 & 12.8 & 9.29 & 8.00 & 8.29 & 9.39 & 141 & 168 & 50.4 & 20.8 & 12.0 & 6.31 \\ 1947 & 11.1 & 8.90 & 8.35 & 7.39 & 8.68 & 17.1 & 76.6 & 281 & 69.8 & 29.2 & 17.8 & 10.1 \\ 1948 & 10.6 & 10.8 & 8.66 & 7.50 & 6.72 & 8.68 & 35.2 & 204 & 54.0 & 19.9 & 8.01 & 6.26 \\ 1949 & 9.15 & 9.60 & 9.40 & 8.00 & 7.40 & 12.0 & 94.2 & 320 & 114 & 29.7 & 13.6 & 9.47 \\ 1950 & 12.4 & 11.3 & 9.00 & 8.00 & 8.00 & 9.00 & 68.3 & 237 & 110 & 31.1 & 14.8 & 12.5\end{array}$


GREEN RIVER BASIN

09310500 FISH CREEK ABOVE RESERVIR, NEAR SCOFIELD, UT--Continued

MONTHLY MEAN DISCHARGES, IN CUBIC FEET PER SECOND, FOR EAGH WATER YEAR-Continued

\begin{tabular}{|c|c|c|c|c|c|c|c|c|c|c|c|c|}
\hline YEAR & $\infty T$ & NOV & DEC & JAN & FEBB & MAR & APR & MAY & JUNE & JULY & AUG & SEP \\
\hline $\begin{array}{l}1951 \\
1952 \\
1953 \\
1954 \\
1955\end{array}$ & $\begin{array}{c}10.0 \\
12.4 \\
14.7 \\
10.7 \\
8.65\end{array}$ & $\begin{array}{c}11.2 \\
10.5 \\
17.3 \\
10.6 \\
9.40\end{array}$ & $\begin{array}{c}7.84 \\
9.16 \\
15.0 \\
9.65 \\
8.40\end{array}$ & $\begin{array}{c}5.84 \\
8.00 \\
13.0 \\
9.00 \\
8.00\end{array}$ & $\begin{array}{c}5.70 \\
8.00 \\
11.4 \\
10.0 \\
8.00\end{array}$ & $\begin{array}{c}7.87 \\
8.26 \\
15.3 \\
10.5 \\
10.4\end{array}$ & $\begin{array}{l}83.6 \\
75.9 \\
39.0 \\
74.4 \\
32.0\end{array}$ & $\begin{array}{l}259 \\
681 \\
182 \\
125 \\
219\end{array}$ & $\begin{array}{l}98.0 \\
360 \\
158 \\
34.5 \\
78.0\end{array}$ & $\begin{array}{l}29.6 \\
60.5 \\
35.4 \\
16.6 \\
23.3\end{array}$ & $\begin{array}{c}19.3 \\
32.2 \\
19.9 \\
8.03 \\
15.0\end{array}$ & $\begin{array}{c}10.1 \\
18.1 \\
11.0 \\
8.97 \\
8.38\end{array}$ \\
\hline $\begin{array}{l}1956 \\
1957 \\
1958 \\
1959 \\
1960\end{array}$ & $\begin{array}{c}8.51 \\
8.43 \\
15.8 \\
9.01 \\
7.20\end{array}$ & $\begin{array}{c}8.30 \\
8.15 \\
12.2 \\
8.35 \\
7.54\end{array}$ & $\begin{array}{l}8.00 \\
6.50 \\
7.00 \\
7.71 \\
6.32\end{array}$ & $\begin{array}{l}7.60 \\
6.00 \\
6.00 \\
7.48 \\
6.00\end{array}$ & $\begin{array}{l}7.40 \\
7.29 \\
6.64 \\
7.23 \\
6.00\end{array}$ & $\begin{array}{c}9.39 \\
10.6 \\
8.19 \\
8.35 \\
12.5\end{array}$ & $\begin{array}{l}74.6 \\
31.0 \\
41.7 \\
21.6 \\
47.4\end{array}$ & $\begin{array}{l}247 \\
217 \\
417 \\
112 \\
188\end{array}$ & $\begin{array}{c}60.7 \\
354 \\
132 \\
41.3 \\
56.8\end{array}$ & $\begin{array}{l}20.0 \\
53.9 \\
27.7 \\
12.9 \\
18.7\end{array}$ & $\begin{array}{c}11.6 \\
23.5 \\
14.1 \\
6.67 \\
7.52\end{array}$ & $\begin{array}{c}7.02 \\
14.4 \\
11.1 \\
7.24 \\
5.12\end{array}$ \\
\hline $\begin{array}{l}1961 \\
1962 \\
1963 \\
1964 \\
1965\end{array}$ & $\begin{array}{c}7.15 \\
6.18 \\
10.3 \\
7.75 \\
8.22\end{array}$ & $\begin{array}{c}10.4 \\
6.75 \\
10.1 \\
8.22 \\
6.01\end{array}$ & $\begin{array}{l}9.61 \\
5.16 \\
6.32 \\
6.16 \\
5.42\end{array}$ & $\begin{array}{l}7.00 \\
5.00 \\
6.29 \\
5.00 \\
5.00\end{array}$ & $\begin{array}{l}6.00 \\
6.89 \\
9.91 \\
5.00 \\
5.46\end{array}$ & $\begin{array}{c}6.19 \\
6.97 \\
10.1 \\
5.00 \\
10.2\end{array}$ & $\begin{array}{c}18.8 \\
167 \\
22.9 \\
17.6 \\
36.5\end{array}$ & $\begin{array}{l}68.5 \\
358 \\
209 \\
253 \\
294\end{array}$ & $\begin{array}{c}22.9 \\
131 \\
67.4 \\
126 \\
224\end{array}$ & $\begin{array}{l}8.97 \\
31.8 \\
19.6 \\
29.5 \\
48.7\end{array}$ & $\begin{array}{l}5.08 \\
15.2 \\
14.6 \\
14.2 \\
28.9\end{array}$ & $\begin{array}{l}7.66 \\
12.2 \\
11.4 \\
10.7 \\
22.0\end{array}$ \\
\hline $\begin{array}{l}1966 \\
1967 \\
1968 \\
1969 \\
1970\end{array}$ & $\begin{array}{l}17.2 \\
12.1 \\
10.6 \\
13.8 \\
14.8\end{array}$ & $\begin{array}{c}15.3 \\
9.59 \\
10.1 \\
13.4 \\
11.7\end{array}$ & $\begin{array}{c}9.94 \\
9.74 \\
9.05 \\
8.29 \\
10.5\end{array}$ & $\begin{array}{r}7.89 \\
9.00 \\
9.49 \\
7.40 \\
10.0\end{array}$ & $\begin{array}{c}8.00 \\
9.00 \\
10.7 \\
7.41 \\
10.0\end{array}$ & $\begin{array}{l}19.0 \\
11.4 \\
14.5 \\
11.4 \\
14.0\end{array}$ & $\begin{array}{c}103 \\
24.9 \\
20.7 \\
102 \\
21.8\end{array}$ & $\begin{array}{l}167 \\
245 \\
255 \\
452 \\
290\end{array}$ & $\begin{array}{l}38.8 \\
202 \\
230 \\
105 \\
145\end{array}$ & $\begin{array}{l}16.8 \\
42.8 \\
36.4 \\
36.4 \\
38.7\end{array}$ & $\begin{array}{l}12.1 \\
18.1 \\
22.0 \\
17.4 \\
14.9\end{array}$ & $\begin{array}{l}8.03 \\
11.9 \\
14.7 \\
13.1 \\
13.8\end{array}$ \\
\hline $\begin{array}{l}1971 \\
1972 \\
1973 \\
1974 \\
1975\end{array}$ & $\begin{array}{c}12.0 \\
11.4 \\
12.4 \\
11.6 \\
9.03\end{array}$ & $\begin{array}{l}13.2 \\
12.7 \\
12.0 \\
11.0 \\
11.8\end{array}$ & $\begin{array}{c}19.1 \\
10.3 \\
11.2 \\
10.0 \\
9.24\end{array}$ & $\begin{array}{c}20.3 \\
9.35 \\
12.7 \\
10.0 \\
9.65\end{array}$ & $\begin{array}{l}20.3 \\
10.2 \\
12.0 \\
10.0 \\
10.0\end{array}$ & $\begin{array}{l}24.1 \\
31.6 \\
12.1 \\
11.5 \\
10.0\end{array}$ & $\begin{array}{l}77.5 \\
65.1 \\
27.7 \\
31.0 \\
11.5\end{array}$ & $\begin{array}{l}276 \\
158 \\
475 \\
322 \\
175\end{array}$ & $\begin{array}{c}111 \\
45.2 \\
147 \\
60.3 \\
437\end{array}$ & $\begin{array}{l}28.3 \\
13.3 \\
30.8 \\
21.5 \\
51.8\end{array}$ & $\begin{array}{c}13.7 \\
8.46 \\
14.0 \\
10.5 \\
20.0\end{array}$ & $\begin{array}{c}10.1 \\
9.82 \\
11.0 \\
7.04 \\
15.0\end{array}$ \\
\hline $\begin{array}{l}1976 \\
1977 \\
1978 \\
1979 \\
1980\end{array}$ & $\begin{array}{c}14.9 \\
8.24 \\
5.34 \\
6.32 \\
8.20\end{array}$ & $\begin{array}{c}14.0 \\
8.36 \\
6.24 \\
9.49 \\
9.18\end{array}$ & $\begin{array}{c}14.0 \\
7.28 \\
7.89 \\
6.40 \\
9.67\end{array}$ & $\begin{array}{c}14.0 \\
5.58 \\
8.00 \\
3.34 \\
9.52\end{array}$ & $\begin{array}{r}14.0 \\
5.53 \\
8.57 \\
3.79 \\
9.85\end{array}$ & $\begin{array}{c}14.1 \\
5.68 \\
17.6 \\
6.84 \\
9.69\end{array}$ & $\begin{array}{l}26.4 \\
29.0 \\
51.4 \\
28.4 \\
77.0\end{array}$ & $\begin{array}{l}227 \\
23.5 \\
341 \\
335 \\
476\end{array}$ & $\begin{array}{l}48.6 \\
14.4 \\
278 \\
135 \\
332\end{array}$ & $\begin{array}{c}18.3 \\
6.83 \\
34.9 \\
27.1 \\
43.3\end{array}$ & $\begin{array}{c}9.98 \\
4.07 \\
15.6 \\
11.9 \\
17.6\end{array}$ & $\begin{array}{c}8.03 \\
3.49 \\
10.7 \\
7.55 \\
15.8\end{array}$ \\
\hline 1981 & 13.6 & 12.2 & 15.1 & 9.87 & 13.9 & 17.2 & 67.6 & 121 & 71.9 & 15.7 & 8.45 & 10.3 \\
\hline
\end{tabular}

ANNUAL PEAR DISCHARGE, IN CUBIC FEET PER SECOND, AND CORRESPONDING GAGE HEIGHT, IN FEET, FOR EACH WATER YEAR

\begin{tabular}{|c|c|c|c|c|c|c|c|c|c|c|c|c|c|c|}
\hline $\begin{array}{l}\text { WATERR } \\
\text { YEAR }\end{array}$ & & DATE & $\begin{array}{l}\text { GAGE } \\
\text { HEIGET }\end{array}$ & $\begin{array}{c}\text { PEAK } \\
\text { DISCHARGE }\end{array}$ & $\begin{array}{l}\text { WATER } \\
\text { YEAR }\end{array}$ & & DATE & $\begin{array}{c}\text { GAGE } \\
\text { HEIGHT }\end{array}$ & $\begin{array}{c}\text { PEAK } \\
\text { DISCHARGE }\end{array}$ & $\begin{array}{l}\text { WAIFER } \\
\text { YEAR }\end{array}$ & & DATE & $\begin{array}{c}\text { GAGE } \\
\text { HEIGHI }\end{array}$ & $\begin{array}{l}\text { PEAR } \\
\text { DISCHARGE }\end{array}$ \\
\hline $\begin{array}{l}1932 \\
1933 \\
1939 \\
1940 \\
1941 \\
1942 \\
1943 \\
1944 \\
1945 \\
1946\end{array}$ & $\begin{array}{l}\text { MAY } \\
\text { JUNE } \\
\text { APR. } \\
\text { MAY } \\
\text { MAY } \\
\text { MAY } \\
\text { JUNE } \\
\text { MAY } \\
\text { MAY } \\
\text { APR. }\end{array}$ & $\begin{array}{l}19,1932 \\
02,1933 \\
30,1939 \\
13,1940 \\
13,1941 \\
26,1942 \\
01,1943 \\
15,1944 \\
11,1945 \\
26,1946\end{array}$ & $\begin{array}{l}3.77 \\
4.10 \\
2.29 \\
3.00 \\
3.11 \\
3.10 \\
2.43 \\
3.00 \\
3.08 \\
2.48\end{array}$ & $\begin{array}{l}673 \\
261 \\
520 \\
645 \\
629 \\
342 \\
577 \\
629 \\
412\end{array}$ & $\begin{array}{l}1952 \\
1953 \\
1954 \\
1955 \\
1956 \\
1957 \\
1958 \\
1959 \\
1960 \\
1961\end{array}$ & $\begin{array}{l}\text { MAY } \\
\text { MAY } \\
\text { MAY } \\
\text { MAY } \\
\text { MAY } \\
\text { JUNE } \\
\text { MAY } \\
\text { MAY } \\
\text { MAY } \\
\text { MAY }\end{array}$ & $\begin{array}{ll}14, & 1952 \\
28, & 1953 \\
08, & 1954 \\
12, & 1955 \\
06, & 1956 \\
04, & 1957 \\
23, & 1958 \\
14, & 1959 \\
13, & 1960 \\
12, & 1961\end{array}$ & $\begin{array}{l}3.62 \\
2.52 \\
1.53 \\
2.48 \\
2.45 \\
3.65 \\
3.63 \\
1.98 \\
2.86 \\
1.43\end{array}$ & $\begin{array}{r}1070 \\
492 \\
213 \\
448 \\
448 \\
818 \\
868 \\
221 \\
479 \\
122\end{array}$ & $\begin{array}{l}1967 \\
1968 \\
1969 \\
1970 \\
1971 \\
1972 \\
1973 \\
1974 \\
1975 \\
1976\end{array}$ & $\begin{array}{l}\text { MAY } \\
\text { MAY } \\
\text { MAY } \\
\text { MAY } \\
\text { MAY } \\
\text { MAY } \\
\text { MAY } \\
\text { MAY } \\
\text { JUNE } \\
\text { MAY }\end{array}$ & $\begin{array}{ll}27 & 1967 \\
30, & 1968 \\
14, & 1969 \\
19,1970 \\
15,1971 \\
08,1972 \\
20,1973 \\
09,1974 \\
05,1975 \\
14,1976\end{array}$ & $\begin{array}{l}3.68 \\
4.60 \\
4.55 \\
4.20 \\
3.93 \\
2.78 \\
4.87 \\
4.35 \\
4.87 \\
3.51\end{array}$ & $\begin{array}{r}744 \\
756 \\
752 \\
639 \\
659 \\
229 \\
1160 \\
874 \\
1030 \\
457\end{array}$ \\
\hline $\begin{array}{l}1947 \\
1948 \\
1949 \\
1950 \\
1951\end{array}$ & $\begin{array}{l}\text { MAY } \\
\text { MAY } \\
\text { MAY } \\
\text { MAY } \\
\text { MAY }\end{array}$ & $\begin{array}{l}04,1947 \\
17,1948 \\
17,1949 \\
23,1950 \\
20,1951\end{array}$ & $\begin{array}{l}3.08 \\
2.55 \\
2.94 \\
2.66 \\
2.37\end{array}$ & $\begin{array}{l}622 \\
414 \\
594 \\
463 \\
433\end{array}$ & $\begin{array}{l}1962 \\
1963 \\
1964 \\
1965 \\
1966\end{array}$ & $\begin{array}{l}\text { MAY } \\
\text { MAY } \\
\text { MAY } \\
\text { MAY } \\
\text { MAY }\end{array}$ & $\begin{array}{l}07,1962 \\
19,1963 \\
23,1964 \\
21,1965 \\
10,1966\end{array}$ & $\begin{array}{l}- \\
2.64 \\
3.54 \\
3.58 \\
2.08\end{array}$ & $\begin{array}{r}1_{660} \\
382 \\
710 \\
717 \\
295\end{array}$ & $\begin{array}{l}1977 \\
1978 \\
1979 \\
1980 \\
1981\end{array}$ & $\begin{array}{l}\text { APR. } \\
\text { MAY } \\
\text { MAY } \\
\text { MAY } \\
\text { MAY }\end{array}$ & $\begin{array}{ll}17, & 1977 \\
23, & 1978 \\
22, & 1979 \\
23, & 1980 \\
03, & 1981\end{array}$ & $\begin{array}{l}\overline{4.12} \\
4.09 \\
4.58 \\
2.90\end{array}$ & $\begin{array}{l}174 \\
729 \\
715 \\
997 \\
282\end{array}$ \\
\hline
\end{tabular}

MAGNITUDE AND PRCBABILITY OF ANNUAL LOWEST MEAN DISCHARGE BASED ON CITMATIC YFARS 1940-81

\begin{tabular}{|c|c|c|c|c|c|c|}
\hline \multirow{2}{*}{$\begin{array}{l}\text { PERIOD } \\
\text { (CON- } \\
\text { SECU- } \\
\text { TIVE } \\
\text { DAYS) }\end{array}$} & \multicolumn{6}{|c|}{$\begin{array}{l}\text { DISCHARGE, IN CUBIC FEET PER SEOOND, FOR } \\
\text { INDICATED RECURRENCE INTERNAL, IN YEARS, AND } \\
\text { ANNUAL NONEXCEEDANCE PRCBABILITY, IN PERCENT }\end{array}$} \\
\hline & $\begin{array}{c}2 \\
508\end{array}$ & $\begin{array}{c}5 \\
208\end{array}$ & $\begin{array}{l}10 \\
108\end{array}$ & $\begin{array}{l}20 \\
58\end{array}$ & $\begin{array}{l}50 \\
28\end{array}$ & $\begin{array}{r}100 \\
18\end{array}$ \\
\hline $\begin{array}{r}1 \\
7 \\
14 \\
30 \\
90\end{array}$ & $\begin{array}{l}6.1 \\
6.5 \\
6.8 \\
7.2 \\
7.9\end{array}$ & $\begin{array}{l}4.5 \\
4.9 \\
5.2 \\
5.5 \\
6.2\end{array}$ & $\begin{array}{l}3.8 \\
4.1 \\
4.4 \\
4.7 \\
5.5\end{array}$ & $\begin{array}{l}3.2 \\
3.6 \\
3.8 \\
4.1 \\
4.9\end{array}$ & $\begin{array}{l}2.7 \\
3.0 \\
3.3 \\
3.5 \\
4.4\end{array}$ & $\begin{array}{l}2.3 \\
2.6 \\
2.9 \\
3.2 \\
4.0\end{array}$ \\
\hline
\end{tabular}

$1_{\text {Maximum daily discharge. }}$ 


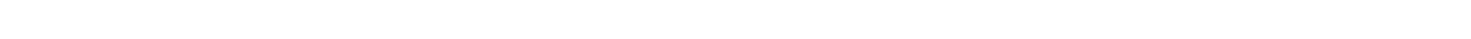
bank upstream from mouth and $4 \mathrm{mi}$ northwest of Scofield.

DRADNAGE AREA. $-78.6 \mathrm{mi}^{2}$.

PERIOD OF RECORD AVAIIABLE.-October 1979 to September 1980.

GAGE.-Water-stage recorder. Altitude of gage is $7,635 \mathrm{ft}$ from topographic map.

EXIREMES FOR PERICD OF RECORD.--Maximum discharge, $108 \mathrm{ft}^{3} / \mathrm{s}$ May 23,1980 , gage height, $2.73 \mathrm{ft}$; minimum recorded, $0.62 \mathrm{ft}{ }^{3} / \mathrm{s}$ November 14-16, 1979.

HIGHEST MEAN DISCHARGE, IN OUBIC FEET PER SECOND, AND RANRING FOR THE INDICATED NUMBER OF CONSECUTIVE DAYS FOR EACH WATER YEAR, OCTOBER 1-SEPTEYBER 30

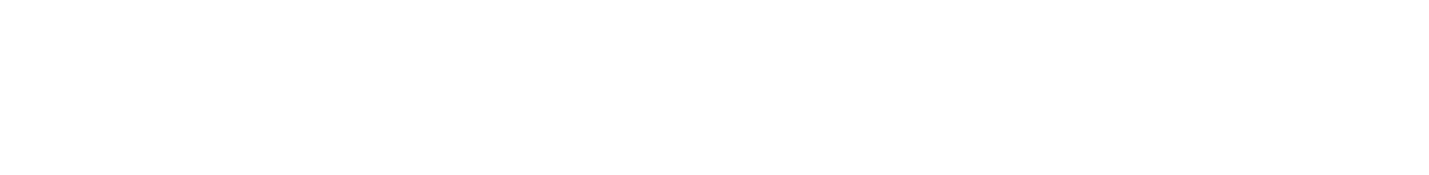

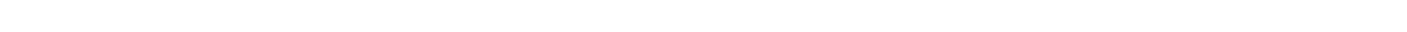

YEAR

NUMBER OF DAYS IN CLASS

OIBIC FEET

PER SECOND -DAYS

$\begin{array}{llllllllllllllllllllllllllllllllllllll}1980 & 32 & 39 & 71 & 23 & 16 & 25 & 40 & 15 & 6 & 5 & 4 & 6 & 6 & 3 & 2 & 3 & 1 & 2 & 4 & 5 & 5 & 3 & 4 & 4 & 2 & 8 & 5 & 2 & 9 & 10 & 1 & 2 & 1 & 2 & 2714.2\end{array}$

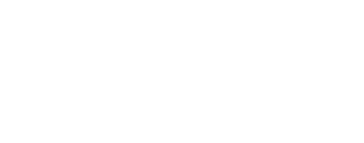

DURATION TABIE OF DISCHARGE FOR WATER YEAR 1980

CLASS SECOND DAYS DAYS DAYS

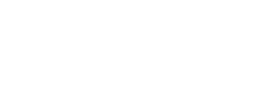

OIBIC ACCUFEET MU- PERGIASS SECOOD DAYS DAYS DAYS CIASS SECOND DAYS LATED CENI

$\begin{array}{rlrrr}0 & 0.00 & 0 & 366 & 100.0 \\ 1 & 0.62 & 32 & 366 & 100.0 \\ 2 & 0.72 & 39 & 334 & 91.3 \\ 3 & 0.84 & 71 & 295 & 80.6 \\ 4 & 0.97 & 23 & 224 & 61.2 \\ 5 & 1.1 & 16 & 201 & 54.9 \\ 6 & 1.3 & 25 & 185 & 50.6 \\ 7 & 1.5 & 40 & 160 & 43.7 \\ 8 & 1.8 & 15 & 120 & 32.8\end{array}$

$\begin{array}{rrrrr}9 & 2.1 & 6 & 105 & 28.7 \\ 10 & 2.4 & 5 & 99 & 27.0 \\ 11 & 2.8 & 4 & 94 & 25.7 \\ 12 & 3.3 & 6 & 90 & 24.6 \\ 13 & 3.8 & 6 & 84 & 23.0 \\ 14 & 4.4 & 3 & 78 & 21.3 \\ 15 & 5.1 & 2 & 75 & 20.5 \\ 16 & 5.9 & 3 & 73 & 20.0 \\ 17 & 6.9 & 1 & 70 & 19.1\end{array}$

$\begin{array}{rrr}18 & 8.0 & 2 \\ 19 & 9.3 & 4 \\ 20 & 11.0 & 5 \\ 21 & 13.0 & 5 \\ 22 & 15.0 & 3 \\ 23 & 17.0 & 4 \\ 24 & 20.0 & 4 \\ 25 & 23.0 & 2 \\ 26 & 27.0 & 8\end{array}$

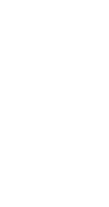

$\begin{array}{rrr}27 & 31.0 & 5 \\ 28 & 36.0 & 2 \\ 29 & 42.0 & 9 \\ 30 & 49.0 & 10 \\ 31 & 57.0 & 1 \\ 32 & 66.0 & 2 \\ 33 & 77.0 & 1 \\ 34 & 89.0 & 2\end{array}$
$\begin{array}{lll}\text { OBBIC } & \text { ACOU- } \\ \text { FEET } & \text { MU- } & \text { PER- } \\ \text { PER TOTAL ILATED } & \text { CENT }\end{array}$

MONIHLY MEAN DISCHARGES, IN OUBIC FEET PER SECOND, FOR EACH WATER YEAR

\begin{tabular}{|c|c|c|c|c|c|c|c|c|c|c|c|c|}
\hline YEAR & $\propto \Gamma$ & $\mathrm{NOV}$ & $\mathrm{DEC}$ & JAN & FEB & MAR & APR & MAY & JUNE & JULY & ADG & SEP \\
\hline 1980 & 1.17 & 0.68 & 0.73 & 0.88 & 0.90 & 1.01 & 6.98 & 44.81 & 25.41 & 2.93 & 1.58 & 1.65 \\
\hline
\end{tabular}

09310600 ECCLES CANYON NEAR SOOFIED, UT

LOCATION. $-39^{\circ} 41^{\prime} 07^{\prime \prime}$, long $111^{\circ} 09^{\prime} 22^{\prime \prime}$, in $\mathrm{NWH}_{4} \mathrm{SW}_{\frac{1}{4}} \mathrm{SEE}_{4}^{\frac{1}{4}}$ sec. 17, T.13 S., R.7 E., Carbon County, Hydrologic Unit 14060007 , on left bank about $0.4 \mathrm{mi}$ upstream fram State Highway $96,2.9 \mathrm{mi}$ south of Scofield.

DRAINAGE AREA. $--5.5 \mathrm{mi}^{2}$.

PERIOD OF RECORD AVAILABLE. - October 1979 to September 1981.

GAGE.-Water-stage recorder. Altitude of gage is $7,980 \mathrm{ft}$ fram topographic map.

EXIREMES FOR PERICD OF RECORD.--Maximum discharge, $46 \mathrm{ft}^{3} / \mathrm{s}$ June 11,1981 , gage height, $1.26 \mathrm{ft} ;$ minimum, $0.62 \mathrm{ft} t^{3} / \mathrm{s} \mathrm{Jan} .10,1980$. LOWEST MEAN DISCHARGE, IN OUBIC FEET PER SECOND, AND RANRING FOR THE INDICATED NUMBER OF CONSECUTIVE DAYS FOR EACH CLIMATIC YEAR, APRIL 1-MARCH 31

YEAR

$\begin{array}{lllll}1 & 3 & 7 & 14 & 30\end{array}$

$\begin{array}{lllllllllllllllllllll}1981 & 0.89 & 1 & 0.96 & 1 & 1.00 & 1 & 1.10 & 1 & 1.10 & 1 & 1.19 & 1 & 1.19 & 1 & 1.19 & 1 & 1.40 & 1 & 4.20 & 1\end{array}$ 
GREEN RIVER BASIN

09310600 EOCLES CANYON NEAR SCOFIETD, UT-Continued

HIGHEST MEAN DISOHARGE, IN OBIC FEET PER SECOND, AND RANKING FOR THE INDICATED NUNBER $O F$ CONSEOUTIVE DAYS FOR EACH WATER YEAR, OCTCBER 1-SEPTEMBER 30

\begin{tabular}{|c|c|c|c|c|c|c|c|c|c|c|c|c|c|c|c|c|c|c|c|}
\hline YEAR & 1 & & 3 & & 7 & & 15 & & $\begin{array}{l}\text { CONSE } \\
30\end{array}$ & גד] & $\begin{array}{l}\text { DAYS } \\
60\end{array}$ & & 90 & & 120 & & 183 & & ALL \\
\hline
\end{tabular}

DURAI ION OF DISCHARGE FOR EACH WATER YEAR

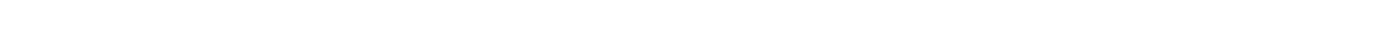

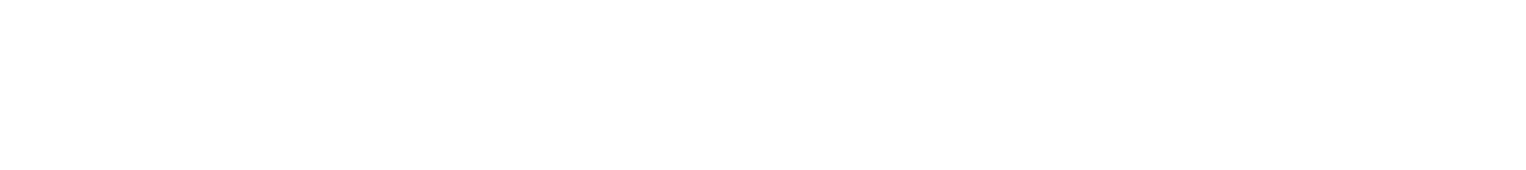
DURATION TABLE OF DISCHARGE FOR WATER YEARS 1980-81 $\begin{array}{ccc}\text { CUBIC } & \text { ACOU- } \\ \text { FEET } & \text { MU- } & \text { PER- } \\ \text { PER } & \text { TOTAL LATED } & \text { CENN } \\ \text { CLASS SEEOND DAYS DAYS } & \text { DAYS }\end{array}$ $\begin{array}{ccc}\text { CUBIC } & \text { ACOU- } \\ \text { FEET } & \text { MU- } & \text { PER- } \\ \text { PER TOTAL LATED } & \text { CENT }\end{array}$ ABIC ACOU CLASS SECOND DAYS DAYS DAYS $\begin{array}{ll}\text { FEET MU- } & \text { PER- } \\ \text { PER TOTAL LATED CENI } & \text { CATS }\end{array}$

$\begin{array}{rrrrr}9 & 1.60 & 53 & 279 & 38.2 \\ 10 & 1.80 & 58 & 226 & 30.9 \\ 11 & 2.10 & 12 & 168 & 23.1 \\ 12 & 2.30 & 18 & 156 & 21.3 \\ 13 & 2.60 & 18 & 138 & 18.9 \\ 14 & 2.90 & 9 & 120 & 16.4 \\ 15 & 3.30 & 18 & 111 & 15.2 \\ 16 & 3.70 & 9 & 93 & 12.7 \\ 17 & 4.20 & 11 & 84 & 11.5\end{array}$

$\begin{array}{crrrr}\text { CLASS SECOND } & \text { DAYS } & \text { DAYS } & \text { DAYS } \\ 18 & 4.7 & 4 & 73 & 10.0 \\ 19 & 5.3 & 7 & 69 & 9.4 \\ 20 & 6.0 & 9 & 62 & 8.5 \\ 21 & 6.8 & 5 & 53 & 7.3 \\ 22 & 7.6 & 4 & 48 & 6.6 \\ 23 & 8.6 & 4 & 44 & 6.0 \\ 24 & 9.7 & 1 & 40 & 5.5 \\ 25 & 11.0 & 3 & 39 & 5.3 \\ 26 & 12.0 & 3 & 36 & 4.9\end{array}$
$\begin{array}{ccc}\text { OBBIC } & \text { ACOJ- } \\ \text { FEET } & \text { MU- } & \text { PER- } \\ \text { PER } & \text { TOTAL LATED } & \text { CENI } \\ \text { CLASS SECOND DAYS } & \text { DAYS } & \text { DAYS }\end{array}$

$\begin{array}{llll}0.00 & 0 & 731 & 100.0\end{array}$ $0.62 \quad 1 \quad 731100.0$ $0.70 \quad 3 . \quad 730 \quad 99.9$ $\begin{array}{llll}0.79 & 15 & 727 & 99.5\end{array}$ $0.89 \quad 111 \quad 712 \quad 97.4$ $\begin{array}{lrll}1.00 & 40 & 601 & 82.2\end{array}$ $\begin{array}{llll}1.10 & 127 & 561 & 76.7\end{array}$ $\begin{array}{llll}1.30 & 60 & 434 & 59.4 \\ 1.40 & 95 & 374 & 51.2\end{array}$

MONTHLY MEAN DISCHARGES, IN OBBIC FEET PER SECOND, FOR EACH WATER YEAR

$\begin{array}{lllllllllllll}\text { YEAR } & \text { OCT } & \text { NOV } & \text { DEC } & \text { JAN } & \text { FEB } & \text { MAR } & \text { APR } & \text { MAY } & \text { JUNE } & \text { JULY } & \text { AUG } & \text { SEP } \\ 1980 & 1.13 & 0.99 & 0.92 & 0.83 & 0.91 & 1.00 & 3.01 & 11.5 & 21.2 & 3.22 & 1.85 & 1.82 \\ 1981 & 1.63 & 1.45 & 1.30 & 1.17 & 1.16 & 1.38 & 2.56 & 3.02 & 2.01 & 1.35 & 1.33 & 1.31\end{array}$

LOCATION.-Lat $39^{\circ} 43^{\prime} 18^{n}$, long $111^{\circ} 09^{\prime} 38^{n}$, in SW $W_{4}^{1}$ NE⿺辶 sec.5, T.13 S., R.7 E., Carbon County, Hydrologic Unit 14060007, on left bank

$1.3 \mathrm{mi}$ upstream from mouth, $0.1 \mathrm{mi}$ below Winter Quarters Canyon, and $0.2 \mathrm{mi}$ upstream from Scofield.

DRAINAGE AREA. $-29.1 \mathrm{mi}^{2}$.

PERIOD OF RECORD AVAILABLE. -Aungust 1978 to September 1981.

GAGE.--Water-stage recorder. Altitude of gage is 7,720 ft from topographic map.

EXTREMES FOR PERICD OF RECOFD.--Maximum discharge, $145 \mathrm{ft}^{3} / \mathrm{s}$ May 23, 1980; minimu, $1.4 \mathrm{ft}^{3} / \mathrm{s}$ Sept. $8,1979$.

LOWEST MEAN DISCHARGE, IN OBIC FEET PER SECOND, AND RANKING FOR THE INDICATED NUMBER OF CONSECUTIVE DAYS FOR EACH CIIMATIC YEAR, APRIL 1-MARCH 31

\begin{tabular}{|c|c|c|c|c|c|c|c|c|c|c|c|c|c|c|c|c|c|c|c|}
\hline YEAR & 1 & & 3 & & 7 & & 14 & & $\begin{array}{l}\text { CONSE } \\
30\end{array}$ & OTIVE & $\begin{array}{l}\text { DAYS } \\
60\end{array}$ & & 90 & & 120 & & 183 & & ALL \\
\hline 1981 & 3.30 & 2 & 3.30 & 2 & 3.30 & 2 & 3.40 & 2 & 3.50 & 2 & 3.60 & 2 & 3.80 & 2 & 4.00 & 2 & 4.50 & 2 & 19.0 \\
\hline
\end{tabular}

HIGHEST MEAN DISCHARGE, IN OBBIC FEET PER SECOND, AND RANKING FOR THE INDICATED NUMBER OF CONSECUTIVE DAYS FOR EACH WATER YEAR, OCTCBER 1-SEPTEMBER 30

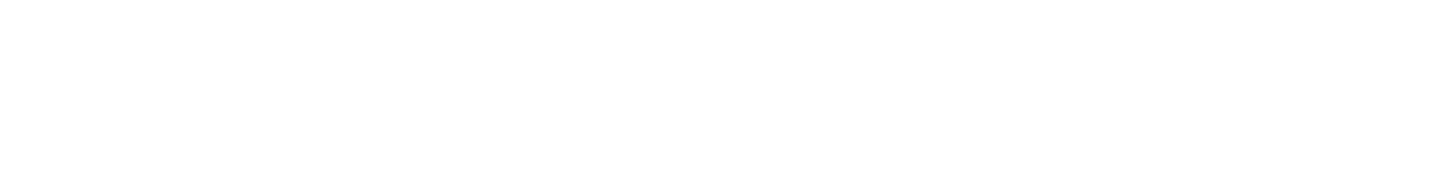


GREEN RTVER BASIN

09310700 MUD CREEK BELOW WINTER QUARTERS CANYON, AT SCOFIEID, UT-Continued

DURATION OF DISCHARGE FOR EACH WATER YEAR

\begin{tabular}{|c|c|c|c|c|c|c|c|c|c|c|c|c|c|c|c|c|c|c|c|c|c|c|c|c|c|c|c|c|c|c|c|}
\hline $\begin{array}{l}\text { CLASS } \\
\text { YEAR }\end{array}$ & 1 & 3 & 4 & 5 & 6 & 7 & 8 & 910 & 11 & 2 & 13 & $\begin{array}{l}14 \\
\mathrm{UMBE}\end{array}$ & & $\begin{array}{l}161 \\
\text { DAYS }\end{array}$ & IN & $\alpha A$ & & 20 & 21 & 23 & 2425 & 252 & 262 & 27 & 28 & 29 & 30 & 313 & & 333 & $\begin{array}{l}\text { CUBIC FEET } \\
\text { PER SECOND } \\
\text {-DAYS }\end{array}$ \\
\hline $\begin{array}{l}1979 \\
1980\end{array}$ & $\begin{array}{r}215 \\
1512\end{array}$ & $\begin{array}{r}12 \\
9\end{array}$ & $\begin{array}{l}41 \\
22\end{array}$ & $\begin{array}{l}87 \\
17\end{array}$ & $\begin{array}{l}44 \\
51\end{array}$ & $\begin{array}{l}22 \\
22\end{array}$ & $\begin{array}{l}15 \\
34\end{array}$ & $\begin{array}{ll}16 & 13 \\
21 & 33\end{array}$ & $\begin{array}{l}14 \\
10\end{array}$ & $\begin{array}{l}4 \\
8\end{array}$ & $\begin{array}{l}4 \\
7\end{array}$ & $\begin{array}{l}5 \\
9\end{array}$ & $\begin{array}{l}4 \\
2\end{array}$ & $\begin{array}{r}10 \\
3\end{array}$ & $\begin{array}{l}8 \\
4\end{array}$ & $\begin{array}{l}6 \\
4\end{array}$ & $\begin{array}{l}6 \\
5\end{array}$ & $\begin{array}{l}3 \\
3\end{array}$ & $\begin{array}{l}7 \\
5\end{array}$ & $\begin{array}{rr}5 & 1 \\
4 & 10\end{array}$ & $\begin{array}{l}8 \\
8\end{array}$ & $\begin{array}{l}3 \\
4\end{array}$ & $\begin{array}{l}2 \\
3\end{array}$ & $\begin{array}{l}2 \\
3\end{array}$ & $\begin{array}{l}2 \\
2\end{array}$ & $\begin{array}{l}3 \\
6\end{array}$ & $\begin{array}{l}1 \\
6\end{array}$ & 9 & 7 & 5 & $\begin{array}{l}3106.6 \\
6793.2\end{array}$ \\
\hline 1981 & & 4 & 13 & 27 & 41 & 55 & 66 & 4530 & 13 & 7 & 16 & 16 & 6 & 15 & 5 & 5 & 1 & & & & & & & & & & & & & & 2015.0 \\
\hline
\end{tabular}

DURATION TFBLE OF DISCHARGE FOR WATER YEARS 1979-81

\begin{tabular}{|c|c|c|c|c|c|c|c|c|c|c|c|c|c|c|c|c|c|c|c|}
\hline LASS & $\begin{array}{c}\text { OBBIC } \\
\text { FEET } \\
\text { PER } \\
\text { SEOND }\end{array}$ & $\begin{array}{c}\text { TOTAL } \\
\text { DAYS }\end{array}$ & $\begin{array}{l}\text { ACOU- } \\
\text { MU- } \\
\text { LATED } \\
\text { DAYS }\end{array}$ & $\begin{array}{l}\text { PER- } \\
\text { CENT } \\
\text { DAYS }\end{array}$ & đASS & $\begin{array}{c}\text { GBIC } \\
\text { FEET } \\
\text { PER } \\
\text { SECOND }\end{array}$ & $\begin{array}{c}\text { TOTAL } \\
\text { DAYS }\end{array}$ & $\begin{array}{l}\text { ACOJ- } \\
\text { MU- } \\
\text { LATED } \\
\text { DAYS }\end{array}$ & $\begin{array}{l}\text { PER- } \\
\text { GENT } \\
\text { DAYS }\end{array}$ & QASS & $\begin{array}{c}\text { OBBIC } \\
\text { FEET } \\
\text { PER } \\
\text { SECOND }\end{array}$ & $\begin{array}{c}\text { TOTAL } \\
\text { DAYS }\end{array}$ & $\begin{array}{l}\text { ACOU- } \\
\text { MU- } \\
\text { LATED } \\
\text { DAYS }\end{array}$ & $\begin{array}{l}\text { PER- } \\
\text { CENT } \\
\text { DAYS }\end{array}$ & QASS & $\begin{array}{c}\text { OBIC } \\
\text { FEET } \\
\text { PER } \\
\text { SECOND }\end{array}$ & $\begin{array}{r}\text { TOTAL } \\
\text { DAYS }\end{array}$ & $\begin{array}{l}\text { ACOU- } \\
\text { MU- } \\
\text { LATED } \\
\text { DAYS }\end{array}$ & $\begin{array}{l}\text { PER- } \\
\text { CENT } \\
\text { DAYS }\end{array}$ \\
\hline $\begin{array}{l}0 \\
1 \\
2 \\
3 \\
4 \\
5 \\
6 \\
7 \\
8\end{array}$ & $\begin{array}{l}0.00 \\
1.60 \\
1.80 \\
2.10 \\
2.40 \\
2.80 \\
3.20 \\
3.60 \\
4.10\end{array}$ & $\begin{array}{r}0 \\
17 \\
27 \\
25 \\
76 \\
131 \\
136 \\
99 \\
115\end{array}$ & $\begin{array}{r}1096 \\
1096 \\
1079 \\
1052 \\
1027 \\
951 \\
820 \\
684 \\
585\end{array}$ & $\begin{array}{r}100.0 \\
100.0 \\
98.4 \\
96.0 \\
93.7 \\
86.8 \\
74.8 \\
62.4 \\
53.4\end{array}$ & $\begin{array}{l}9 \\
10 \\
11 \\
12 \\
13 \\
14 \\
15 \\
16 \\
17\end{array}$ & $\begin{array}{r}4.80 \\
5.40 \\
6.20 \\
7.10 \\
8.20 \\
9.40 \\
11.00 \\
12.00 \\
14.00\end{array}$ & $\begin{array}{l}82 \\
76 \\
37 \\
19 \\
27 \\
30 \\
12 \\
28 \\
17\end{array}$ & $\begin{array}{l}470 \\
388 \\
312 \\
275 \\
256 \\
229 \\
199 \\
187 \\
159\end{array}$ & $\begin{array}{l}42.9 \\
35.4 \\
28.5 \\
25.1 \\
23.4 \\
20.9 \\
18.2 \\
17.1 \\
14.5\end{array}$ & $\begin{array}{l}18 \\
19 \\
20 \\
21 \\
22 \\
23 \\
24 \\
25 \\
26\end{array}$ & $\begin{array}{l}16.0 \\
18.0 \\
21.0 \\
24.0 \\
28.0 \\
32.0 \\
36.0 \\
42.0 \\
48.0\end{array}$ & $\begin{array}{r}15 \\
12 \\
6 \\
12 \\
9 \\
11 \\
16 \\
7 \\
5\end{array}$ & $\begin{array}{r}142 \\
127 \\
115 \\
109 \\
97 \\
88 \\
77 \\
61 \\
54\end{array}$ & $\begin{array}{r}13.0 \\
11.6 \\
10.5 \\
9.9 \\
8.9 \\
8.0 \\
7.0 \\
5.6 \\
4.9\end{array}$ & $\begin{array}{l}27 \\
28 \\
29 \\
30 \\
31 \\
32 \\
33 \\
34\end{array}$ & $\begin{array}{r}55.0 \\
63.0 \\
72.0 \\
82.0 \\
94.0 \\
110.0 \\
120.0 \\
140.0\end{array}$ & $\begin{array}{l}5 \\
4 \\
9 \\
7 \\
9 \\
7 \\
5 \\
3\end{array}$ & $\begin{array}{r}49 \\
44 \\
40 \\
31 \\
24 \\
15 \\
8 \\
3\end{array}$ & $\begin{array}{l}4.5 \\
4.0 \\
3.6 \\
2.8 \\
2.2 \\
1.4 \\
0.7 \\
0.3\end{array}$ \\
\hline
\end{tabular}

MONIHLY MEAN DISCHARGES, IN CUBIC FEET PER SECOND, FOR EAOH WATER YEAR

\begin{tabular}{llllllllllrrr} 
YEAR & OCT & \multicolumn{1}{l}{ NOV } & \multicolumn{1}{l}{ DEC } & JAN & FEB & MAR & APR & MAY & JUNE & JULY & AUG & SEP \\
1979 & 2.73 & 4.23 & 3.26 & 2.89 & 3.00 & 4.27 & 9.00 & 37.4 & 24.2 & 5.08 & 3.72 & 2.03 \\
1980 & 3.16 & 3.35 & 2.80 & 1.95 & 3.89 & 4.42 & 17.3 & 70.4 & 89.0 & 14.6 & 6.17 & 6.01 \\
1981 & 5.60 & 4.68 & 4.44 & 3.63 & 3.56 & 4.79 & 9.46 & 11.3 & 7.77 & 3.43 & 3.84 & 3.65
\end{tabular}

09311500 PRICE RIVER NEAR SCOFIELD, UT

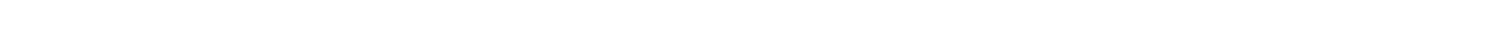
bank $800 \mathrm{ft}$ downstream from Scofield Reservoir Dam, $5 \mathrm{mi}$ northeast of Scofield, and $9 \mathrm{mi}$ upstream from white River.

DRAINAGE AREA - $-155 \mathrm{mi}^{2}$, approximately.

PERIOD OF RECORD AVAIIABLE.--November 1917 to October 1918, April to Novenber 1919, April to December 1920 , July to September 1921, June to September 1925, April to November 1926, December 1926 to April 1927, May to September 1927, October 1927 to March 1928 , Apr il 1928 to October 1930, Novenber 1930 to March 1931, Apr il to September 1931, October to November 1938 , December 1938 to February 1939. Monthly mean discharge only for sone periods, published in WSP 1313 . March 1939 to July 1969 , May to September 1979 (fragmentary), October 1979 to October 1980. Prior to October 1938, published as "Fish Creek near Scof ield".

GAGE. -Water-stage recorder and concrete control. Datum of gage is 7,570.13 ft NGVD of 1929, (levels by Bureau of Reclamation). Nov. 17, 1917, to Sept. 30, 1921, and Oct. 25, 1938, to Nov. 1, 1945, water-stage recorder; June 15 to Sept. 30, 1925, and Apr. 27,1926 , to sept. 30,1931 , nonrecording gage; all near present site at various datums.

REMARKS.--Flow completely regulated by Scofield Reservoir. Small diversions for irrigation above Scofield Reservoir.

AVERAGE DISGHARGE. - -36 years (water years $1927-31,1939-68,1980$ ), $60.8 \mathrm{ft}^{3} / \mathrm{s}, 44,050$ acre-ft/yr.

EXTREMES FOR PERIOD OF RECORD.--Maximum daily discharge, 1,060 $\mathrm{ft}^{3} / \mathrm{s}$ May 31, June 1, 1952; practically no flow at times in most winters when reservoir gates were closed.

LOWEST MEAN DISGHARGE, IN CUBIC FEET PER SECOND, AND RANKING FOR THE INDICATED NUMBER OF CONSECUTIVE DAVS FOR EACH CIIMATIC YEAR, APRIL 1-MARQH 31

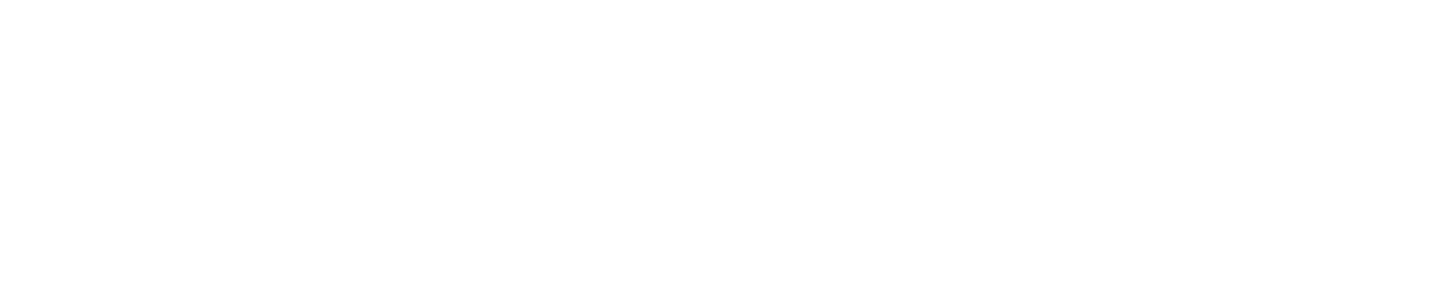


GREEN RIVER BASIN

09311500 PRICE RIVER NEAR SCOFIETD, UT--Continued

LOWEST MEAN DISGHARGE, IN GBIC FEET PER SECOND, AND RANKING FOR THE INDICATED NUMBER OF CONSEQUTIVE DAYS FOR EAOH CIMATIC YEAR, APRIL 1-MAROH 31--Continued

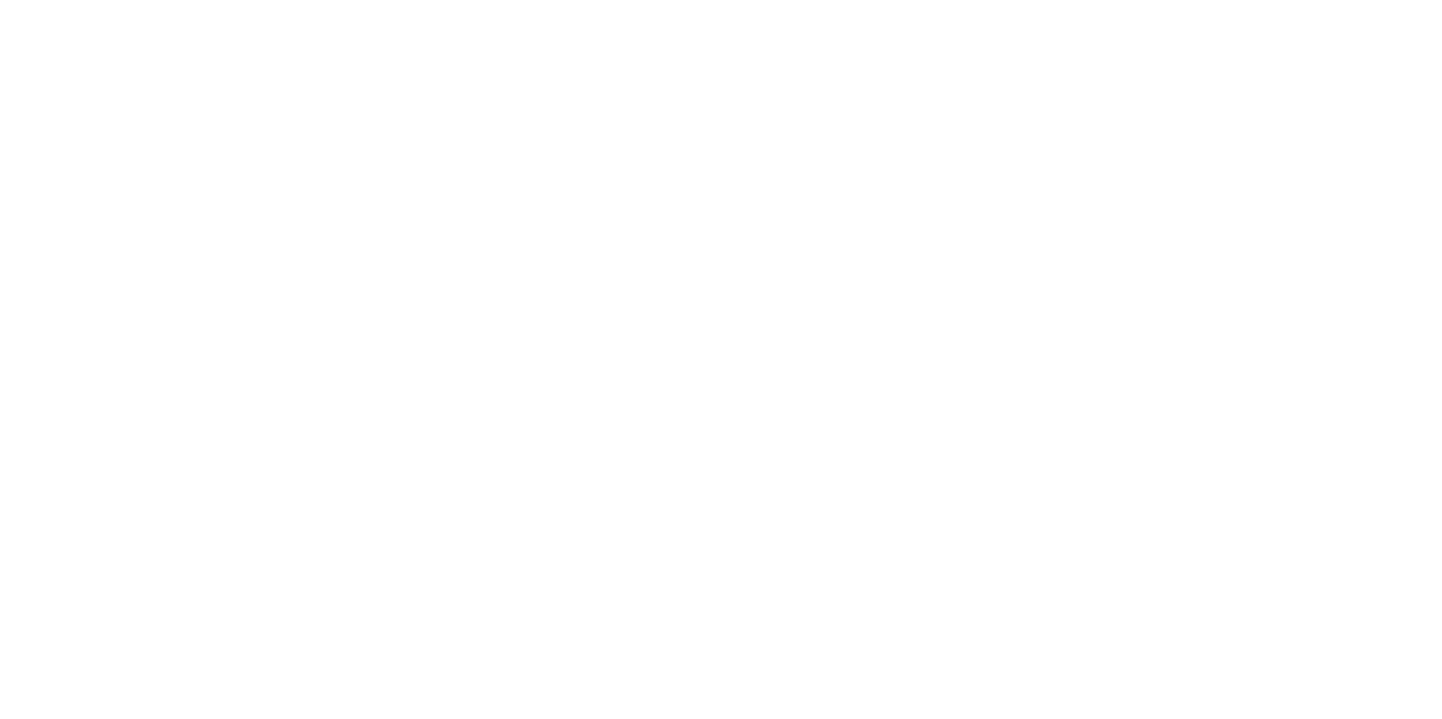

HIGHEST MEAN DISCHARGE, IN CUBIC FEET PER SECOND, AND RANKING FOR THE INDICATED NUMBER OF CONSECUTIVE DAYS FOR EACH WATER YEAR, OCTOBER 1-SEPTEMBER 30

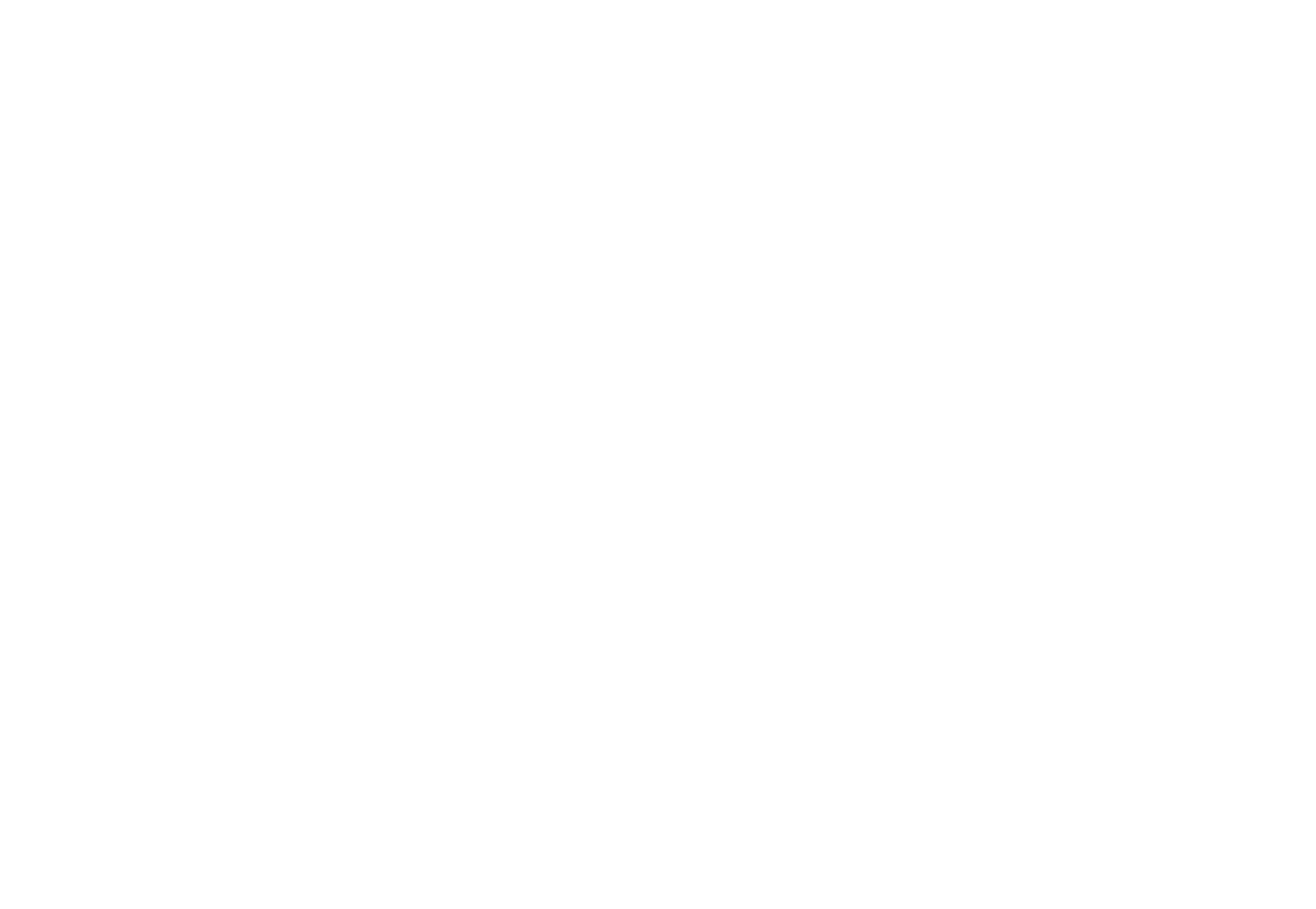


GREEN RIVER BASTN

09311500 PRICE RIVER NEAR SCOFIELD, UT-COntinued

DURATION OF DISCHARGE FOR EACH WATER YEAR

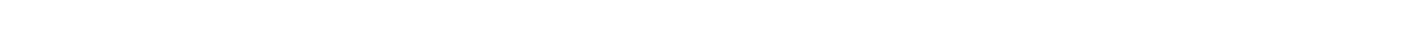

YEAR

NUMBER OF DAYS IN CIAASS

CUBIC FEET PER SEOOND

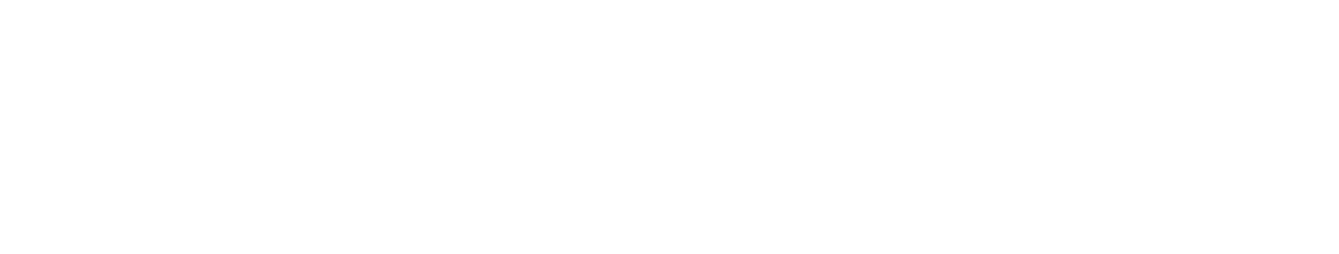

27077.0

16849.0

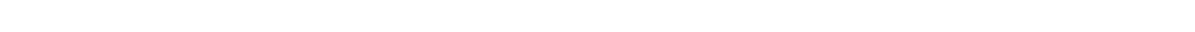

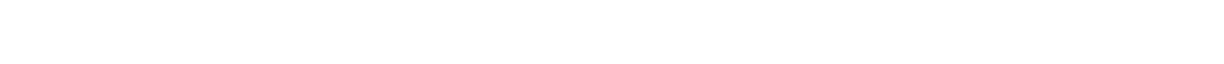

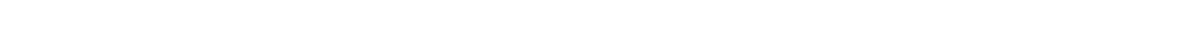

$\begin{array}{llllllllllll}1950 & 92105 & 9 & 9 & 3 & 5 & 17 & 11 & 17 & 37\end{array}$

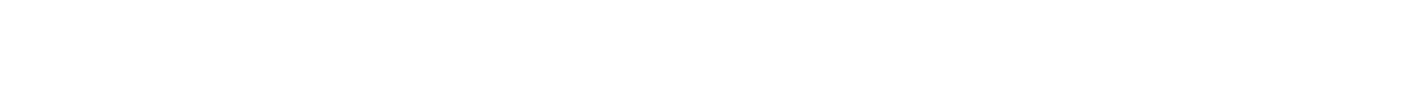

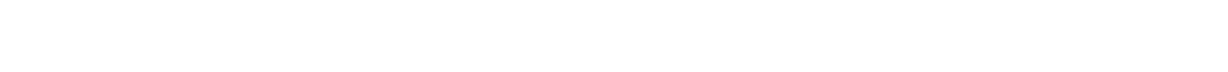

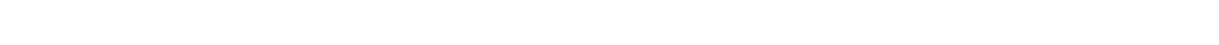

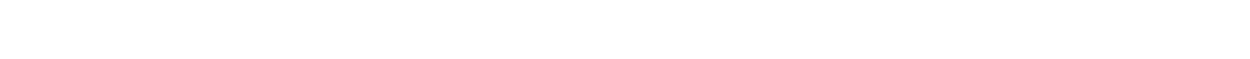

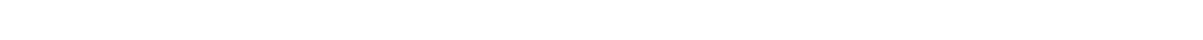

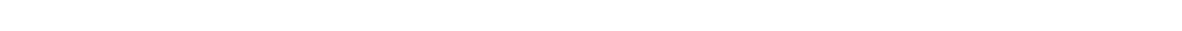

1961

1962

1963

1965

$\begin{array}{lllllllllllllllllll}1 & 7 & 4 & 33 & 43 & 7 & 11 & 90 & 12 & 22 & 24 & 40 & 18 & 22 & 22 & 17 & 12 & 17 & 14\end{array}$

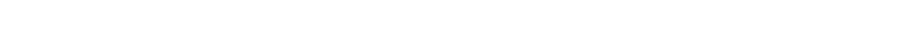

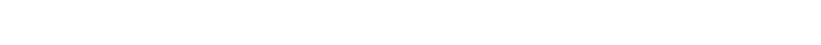

$\begin{array}{rrrrrrrrrrrrrrrrrr}2 & 1 & 64 & 15 & 63 & 14 & 8 & 24 & 8 & 5 & 8 & 2 & 7 & 15 & 22 & 26 & 29 & 42 \\ 94 & 25 & 2 & 25 & 24 & 8 & 3 & 22 & 15 & 10 & 17 & 13 & 11 & 18 & 19 & 10 & 31 & 18\end{array}$

1966

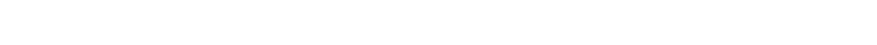

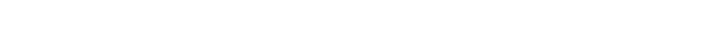

18286.0

22734.0

34376.0

22084.0

28514.6
23337.0

17022.5

1522.3

1988.5

22432.9

48733.7

29063.4

25466.7

18367.5

19201.0

13463.4

31804.6

23226.9

6938.1

19891.1

18187.7

19555.1
12863.4

19802.9

29631.0

1980

$\begin{array}{lllllllllllllllllllll}28 & 3 & 2 & 72 & 68 & 7 & 3 & 6 & 3 & 1 & 5 & 16 & 14 & 22 & 16 & 55 & 20 & 2 & 3 & 6 & 14\end{array}$

35958.0

DURATION TABLE OF DISCHARGE FOR WATER YEARS 1929-30, 1940-68, 1980

\begin{tabular}{|c|c|c|c|c|c|c|c|c|c|c|c|c|c|c|c|c|c|c|c|}
\hline CIASS & $\begin{array}{c}\text { OUBIC } \\
\text { FEET } \\
\text { PER } \\
\text { SECOND }\end{array}$ & $\begin{array}{l}\text { TOTAL } \\
\text { DAYS }\end{array}$ & $\begin{array}{c}\text { ACOU- } \\
\text { MU- } \\
\text { LATED } \\
\text { DAYS }\end{array}$ & $\begin{array}{l}\text { PER- } \\
\text { CENT } \\
\text { DAYS }\end{array}$ & CLASS & $\begin{array}{c}\text { CUBIC } \\
\text { FEET } \\
\text { PER } \\
\text { SECOND }\end{array}$ & $\begin{array}{l}\text { TOTAL } \\
\text { DAYS }\end{array}$ & $\begin{array}{c}\text { ACOU- } \\
\text { MU- } \\
\text { LATED } \\
\text { DAYS }\end{array}$ & $\begin{array}{l}\text { PER- } \\
\text { CENT } \\
\text { DAYS }\end{array}$ & CLASS & $\begin{array}{c}\text { OUBIC } \\
\text { FEET } \\
\text { PER } \\
\text { SECOND }\end{array}$ & $\begin{array}{r}\text { TOTAL } \\
\text { DAYS }\end{array}$ & $\begin{array}{c}\text { ACOU- } \\
\text { MU- } \\
\text { LATED } \\
\text { DAYS }\end{array}$ & $\begin{array}{l}\text { FER- } \\
\text { CENT } \\
\text { DAYS }\end{array}$ & OASS & $\begin{array}{c}\text { CUBIC } \\
\text { FEET } \\
\text { PER } \\
\text { SECOND }\end{array}$ & TOTAL & $\begin{array}{c}\text { ACOU- } \\
\text { MU- } \\
\text { LATED } \\
\text { DAYS }\end{array}$ & $\begin{array}{l}\text { PER- } \\
\text { CENT } \\
\text { DAYS }\end{array}$ \\
\hline $\begin{array}{l}0 \\
1 \\
2 \\
3 \\
4 \\
5 \\
6 \\
7 \\
8\end{array}$ & $\begin{array}{l}0.00 \\
0.10 \\
0.13 \\
0.18 \\
0.23 \\
0.31 \\
0.41 \\
0.54 \\
0.71\end{array}$ & $\begin{array}{r}23 \\
592 \\
0 \\
585 \\
425 \\
249 \\
78 \\
105 \\
48\end{array}$ & $\begin{array}{r}11689 \\
11666 \\
11074 \\
11074 \\
10489 \\
10064 \\
9815 \\
9737 \\
9632\end{array}$ & $\begin{array}{r}100.0 \\
99.8 \\
94.7 \\
94.7 \\
89.7 \\
86.1 \\
84.0 \\
83.3 \\
82.4\end{array}$ & $\begin{array}{r}9 \\
10 \\
11 \\
12 \\
13 \\
14 \\
15 \\
16 \\
17\end{array}$ & $\begin{array}{l}0.94 \\
1.30 \\
1.70 \\
2.20 \\
2.90 \\
3.80 \\
5.10 \\
6.70 \\
8.90\end{array}$ & $\begin{array}{r}526 \\
314 \\
1002 \\
240 \\
261 \\
575 \\
441 \\
290 \\
269\end{array}$ & $\begin{array}{l}9584 \\
9058 \\
8744 \\
7742 \\
7502 \\
7241 \\
6666 \\
6225 \\
5935\end{array}$ & $\begin{array}{l}82.0 \\
77.5 \\
74.8 \\
66.2 \\
64.2 \\
61.9 \\
57.0 \\
53.3 \\
50.8\end{array}$ & $\begin{array}{l}18 \\
19 \\
20 \\
21 \\
22 \\
23 \\
24 \\
25 \\
26\end{array}$ & $\begin{array}{r}12.0 \\
16.0 \\
21.0 \\
27.0 \\
36.0 \\
48.0 \\
63.0 \\
84.0 \\
110.0\end{array}$ & $\begin{array}{l}309 \\
306 \\
229 \\
215 \\
263 \\
358 \\
440 \\
610 \\
938\end{array}$ & $\begin{array}{l}5666 \\
5357 \\
5051 \\
4822 \\
4607 \\
4344 \\
3986 \\
3546 \\
2936\end{array}$ & $\begin{array}{l}48.5 \\
45.8 \\
43.2 \\
41.3 \\
39.4 \\
37.2 \\
34.1 \\
30.3 \\
25.1\end{array}$ & $\begin{array}{l}27 \\
28 \\
29 \\
30 \\
31 \\
32 \\
33 \\
34\end{array}$ & $\begin{array}{l}150.0 \\
200.0 \\
260.0 \\
340.0 \\
450.0 \\
600.0 \\
790.0\end{array}$ & $\begin{array}{r}1141 \\
633 \\
82 \\
51 \\
42 \\
28 \\
21\end{array}$ & $\begin{array}{r}1998 \\
857 \\
224 \\
142 \\
91 \\
49 \\
21\end{array}$ & $\begin{array}{r}17.1 \\
7.3 \\
1.9 \\
1.2 \\
0.8 \\
0.4 \\
0.2\end{array}$ \\
\hline
\end{tabular}

MONIHLY MEAN DISCHARGES, IN CUBIC FEET PER SECOND, FOR EACH WATER YEAR

$\begin{array}{lcccccccccccc}\text { YEAR } & \text { OCT } & \text { NOV } & \text { DEC } & \text { JAN } & \text { FEB } & \text { MAR } & \text { APR } & \text { MAY } & \text { JUNE } & \text { JULY } & \text { AUG } & \text { SEP } \\ & & & & & & & & & & & & \\ 1927 & 13.8 & 5.8 & 1.00 & 2.00 & 2.00 & 4.00 & 6.00 & 33.0 & 107 & 82.6 & 144 & 20.1 \\ 1928 & 2.00 & 2.00 & 2.00 & 2.00 & 2.00 & 2.00 & 5.8 & 261 & 301 & 225 & 230 & 177 \\ 1929 & 51.8 & 2.00 & 2.00 & 2.00 & 48.6 & 17.2 & 2.00 & 82.7 & 203 & 197 & 110 & 172 \\ 1930 & 47.1 & 16.6 & 8.87 & 5.00 & 5.00 & 5.00 & 5.00 & 73.4 & 177 & 121 & 41.0 & 46.2 \\ 1931 & 13.1 & 2.00 & 2.00 & 2.00 & 2.00 & 2.00 & 48.5 & 87.5 & 81.6 & 67.9 & 20.7 & 7.00 \\ 1939 & 22.1 & 14.8 & 1.00 & 1.00 & 1.00 & 3.7 & 6.6 & 178 & 173 & 125 & 75.5 & 16.7 \\ 1940 & 2.74 & 1.00 & 1.00 & 2.00 & 2.00 & 2.00 & 11.7 & 150 & 170 & 158 & 91.3 & 4.37\end{array}$


GREEN RIVER BASIN

09311500 PRICE RIVER NEAR SCOFIED, UT-Continued

MONIHLY MEAN DISCHARGES, IN CUBIC FEET PER SECOND, FOR EACH WATER YEAR-Continued

\begin{tabular}{|c|c|c|c|c|c|c|c|c|c|c|c|c|}
\hline YEAR & $\propto C T$ & NOV & DEC & JAN & FEB & MAR & APR & MAY & JUNE & JULY & AUG & SEPP \\
\hline $\begin{array}{l}1941 \\
1942 \\
1943 \\
1944 \\
1945\end{array}$ & $\begin{array}{c}2.00 \\
16.0 \\
58.3 \\
4.05 \\
20.6\end{array}$ & $\begin{array}{l}2.00 \\
4.13 \\
1.00 \\
1.00 \\
2.50\end{array}$ & $\begin{array}{l}2.00 \\
2.00 \\
1.00 \\
1.00 \\
2.00\end{array}$ & $\begin{array}{l}2.00 \\
2.00 \\
2.00 \\
1.00 \\
2.00\end{array}$ & $\begin{array}{l}2.00 \\
2.00 \\
2.00 \\
1.00 \\
2.00\end{array}$ & $\begin{array}{l}2.00 \\
2.35 \\
3.00 \\
1.00 \\
2.00\end{array}$ & $\begin{array}{c}3.00 \\
103 \\
7.40 \\
14.3 \\
2.00\end{array}$ & $\begin{array}{l}233 \\
334 \\
154 \\
257 \\
167\end{array}$ & $\begin{array}{l}163 \\
258 \\
101 \\
185 \\
133\end{array}$ & $\begin{array}{l}133 \\
176 \\
191 \\
190 \\
208\end{array}$ & $\begin{array}{l}116 \\
136 \\
117 \\
158 \\
118\end{array}$ & $\begin{array}{c}80.9 \\
85.9 \\
80.7 \\
116 \\
101\end{array}$ \\
\hline $\begin{array}{l}1946 \\
1947 \\
1948 \\
1949 \\
1950\end{array}$ & $\begin{array}{c}27.1 \\
3.35 \\
55.4 \\
7.28 \\
18.4\end{array}$ & $\begin{array}{l}4.44 \\
0.38 \\
2.01 \\
0.10 \\
0.20\end{array}$ & $\begin{array}{l}1.00 \\
0.20 \\
0.10 \\
0.15 \\
0.20\end{array}$ & $\begin{array}{l}1.10 \\
0.10 \\
0.10 \\
0.30 \\
0.20\end{array}$ & $\begin{array}{l}1.30 \\
0.10 \\
0.10 \\
0.30 \\
0.30\end{array}$ & $\begin{array}{l}1.50 \\
0.10 \\
0.10 \\
0.40 \\
0.30\end{array}$ & $\begin{array}{l}7.55 \\
0.11 \\
4.79 \\
0.39 \\
0.30\end{array}$ & $\begin{array}{c}140 \\
44.8 \\
121 \\
0.40 \\
14.0\end{array}$ & $\begin{array}{l}126 \\
119 \\
158 \\
45.1 \\
160\end{array}$ & $\begin{array}{l}151 \\
204 \\
195 \\
186 \\
172\end{array}$ & $\begin{array}{l}73.6 \\
80.3 \\
120 \\
190 \\
195\end{array}$ & $\begin{array}{c}58.3 \\
104 \\
43.5 \\
86.5 \\
88.8\end{array}$ \\
\hline $\begin{array}{l}1951 \\
1952 \\
1953 \\
1954 \\
1955\end{array}$ & $\begin{array}{l}27.3 \\
29.6 \\
70.5 \\
44.8 \\
23.1\end{array}$ & $\begin{array}{c}1.03 \\
10.8 \\
11.4 \\
5.80 \\
8.14\end{array}$ & $\begin{array}{l}0.20 \\
0.29 \\
2.03 \\
8.98 \\
0.42\end{array}$ & $\begin{array}{l}0.20 \\
0.20 \\
0.40 \\
0.65 \\
0.20\end{array}$ & $\begin{array}{l}0.20 \\
0.33 \\
0.40 \\
8.12 \\
0.20\end{array}$ & $\begin{array}{l}1.30 \\
0.70 \\
0.50 \\
0.30 \\
0.20\end{array}$ & $\begin{array}{c}25.8 \\
1.11 \\
13.4 \\
66.5 \\
0.10\end{array}$ & $\begin{array}{c}56.4 \\
439 \\
146 \\
205 \\
72.8\end{array}$ & $\begin{array}{l}162 \\
655 \\
219 \\
202 \\
154\end{array}$ & $\begin{array}{l}228 \\
230 \\
212 \\
125 \\
161\end{array}$ & $\begin{array}{c}100 \\
125 \\
135 \\
114 \\
84.7\end{array}$ & $\begin{array}{c}132 \\
105 \\
139 \\
51.9 \\
96.0\end{array}$ \\
\hline $\begin{array}{l}1956 \\
1957 \\
1958 \\
1959 \\
1960\end{array}$ & $\begin{array}{l}32.5 \\
24.9 \\
55.1 \\
44.3 \\
33.2\end{array}$ & $\begin{array}{c}7.02 \\
7.00 \\
7.90 \\
12.3 \\
16.8\end{array}$ & $\begin{array}{c}4.59 \\
0.11 \\
5.70 \\
11.3 \\
14.5\end{array}$ & $\begin{array}{c}0.20 \\
0.10 \\
4.52 \\
2.45 \\
13.1\end{array}$ & $\begin{array}{l}0.10 \\
0.10 \\
6.29 \\
0.47 \\
4.21\end{array}$ & $\begin{array}{l}0.14 \\
0.12 \\
7.08 \\
0.22 \\
4.05\end{array}$ & $\begin{array}{r}8.17 \\
9.99 \\
101 \\
85.7 \\
27.2\end{array}$ & $\begin{array}{c}55.0 \\
3.42 \\
81.5 \\
120 \\
87.1\end{array}$ & $\begin{array}{l}160 \\
66.3 \\
268 \\
147 \\
143\end{array}$ & $\begin{array}{l}175 \\
199 \\
235 \\
164 \\
139\end{array}$ & $\begin{array}{l}109 \\
62.6 \\
182 \\
81.6 \\
48.9\end{array}$ & $\begin{array}{l}76.4 \\
65.2 \\
87.0 \\
90.7 \\
11.2\end{array}$ \\
\hline $\begin{array}{l}1961 \\
1962 \\
1963 \\
1964 \\
1965\end{array}$ & $\begin{array}{c}6.96 \\
7.52 \\
9.05 \\
55.9 \\
44.0\end{array}$ & $\begin{array}{c}10.7 \\
10.8 \\
10.3 \\
6.47 \\
14.3\end{array}$ & $\begin{array}{c}11.2 \\
7.72 \\
15.7 \\
11.7 \\
9.20\end{array}$ & $\begin{array}{l}4.89 \\
4.89 \\
4.56 \\
8.19 \\
1.52\end{array}$ & $\begin{array}{l}4.37 \\
3.59 \\
1.72 \\
4.00 \\
1.60\end{array}$ & $\begin{array}{l}2.86 \\
6.10 \\
2.98 \\
3.94 \\
1.62\end{array}$ & $\begin{array}{c}7.56 \\
1.04 \\
21.5 \\
2.48 \\
2.95\end{array}$ & $\begin{array}{r}68.4 \\
19.5 \\
122 \\
2.50 \\
3.76\end{array}$ & $\begin{array}{l}52.3 \\
150 \\
117 \\
109 \\
22.1\end{array}$ & $\begin{array}{l}34.4 \\
183 \\
183 \\
181 \\
109\end{array}$ & $\begin{array}{c}14.7 \\
163 \\
74.2 \\
142 \\
91.9\end{array}$ & $\begin{array}{l}8.38 \\
92.8 \\
31.1 \\
111 \\
118\end{array}$ \\
\hline $\begin{array}{l}1966 \\
1967 \\
1968\end{array}$ & $\begin{array}{l}51.1 \\
31.3 \\
49.4\end{array}$ & $\begin{array}{l}13.9 \\
14.7 \\
13.8\end{array}$ & $\begin{array}{l}14.1 \\
12.9 \\
i 5.9\end{array}$ & $\begin{array}{l}3.89 \\
1.71 \\
5.42\end{array}$ & $\begin{array}{l}2.53 \\
1.12 \\
5.30\end{array}$ & $\begin{array}{l}2.27 \\
0.73 \\
5.09\end{array}$ & $\begin{array}{c}8.68 \\
13.5 \\
4.67\end{array}$ & $\begin{array}{r}135 \\
32.5 \\
29.0\end{array}$ & $\begin{array}{l}145 \\
133 \\
362\end{array}$ & $\begin{array}{l}156 \\
181 \\
212\end{array}$ & $\begin{array}{c}148 \\
142 \\
93.9\end{array}$ & $\begin{array}{r}89.9 \\
81.5 \\
177\end{array}$ \\
\hline 1980 & 35.5 & 7.07 & 7.14 & 6.61 & 6.47 & 37.7 & 112 & 89.4 & 466 & 186 & 162 & 63.9 \\
\hline
\end{tabular}

ANNUAL PEAK DISCHARGE, IN OUBIC FEET PER SECOND, AND CORRESPONDING GAGE HEIGHT, IN FEET, FOR EACH WATER YEAR ${ }^{1}$

\begin{tabular}{|c|c|c|c|c|c|c|c|c|c|c|c|c|c|c|}
\hline $\begin{array}{l}\text { WATERR } \\
\text { YEAR }\end{array}$ & & DATE & $\begin{array}{l}\text { GAGE } \\
\text { HEIGHI }\end{array}$ & $\begin{array}{c}\text { PEAR } \\
\text { DISCHARGE }\end{array}$ & $\begin{array}{l}\text { WATERR } \\
\text { YEAR }\end{array}$ & & DATE & $\begin{array}{c}\text { GAGE } \\
\text { HEIGHT }\end{array}$ & $\begin{array}{c}\text { PEAR } \\
\text { DISCHARGE }\end{array}$ & $\begin{array}{l}\text { WATER } \\
\text { YEAR }\end{array}$ & & DATE & $\begin{array}{c}\text { GAGE } \\
\text { HEIGHT }\end{array}$ & $\begin{array}{c}\text { PEAR } \\
\text { DISCHARGE }\end{array}$ \\
\hline $\begin{array}{l}1918 \\
1919\end{array}$ & $\begin{array}{l}\text { MAY } \\
\text { MAY }\end{array}$ & $\begin{array}{l}24,1918 \\
04,1919\end{array}$ & - & $\begin{array}{l}345 \\
494\end{array}$ & $\begin{array}{l}1944 \\
1946\end{array}$ & $\begin{array}{l}\text { MAY } \\
\text { MAY }\end{array}$ & $\begin{array}{ll}19, & 1944 \\
21, & 1946\end{array}$ & $\overline{-}$ & $\begin{array}{l}494 \\
413\end{array}$ & $\begin{array}{l}1958 \\
1959\end{array}$ & $\begin{array}{l}\text { JUNE } \\
\text { JULY }\end{array}$ & $\begin{array}{l}03,1958 \\
24,1959\end{array}$ & $\overline{--}$ & $\begin{array}{l}392 \\
217\end{array}$ \\
\hline 1920 & MAY & 24,1920 & - & 1000 & 1947 & & & -- & 228 & 1960 & & 12 & - & 195 \\
\hline 1926 & MAY & 21,1926 & - & 381 & 1948 & JULY & 17,1948 & - & 322 & 1961 & & 13 & 1.33 & 114 \\
\hline 1927 & & 2 & - & 200 & 1949 & JU.Y & 29,1949 & - & 273 & 1962 & & 14 & 2.72 & 230 \\
\hline 1929 & MAY & 26,1929 & - & 308 & 1950 & JULY & 31,1950 & -- & 257 & 1963 & & 15 & 2.65 & 210 \\
\hline 1930 & & 3 & - & 211 & 1951 & & & - & 284 & 1964 & JULY & 22,1964 & 2.84 & 212 \\
\hline 1931 & & 4 & - & 123 & 1952 & & 9 & - & 1060 & 1965 & SEPT. & c. 04,1965 & 2.59 & 184 \\
\hline 1939 & MAY & 26,1939 & - & 221 & 1953 & & 10 & - & 270 & 1966 & & & 3.72 & 189 \\
\hline $\begin{array}{l}1940 \\
1941 \\
1942\end{array}$ & $\begin{array}{l}\text { MAY } \\
\text { MAY }\end{array}$ & $\begin{array}{c}5 \\
25,1941 \\
28,1942\end{array}$ & $=$ & $\begin{array}{l}254 \\
585 \\
710\end{array}$ & $\begin{array}{l}1954 \\
1955 \\
1956\end{array}$ & $\begin{array}{l}\text { MAY } \\
\text { JULY } \\
\text { JULY }\end{array}$ & $\begin{array}{l}26,1954 \\
13,1955 \\
22,1956\end{array}$ & $\bar{m}$ & $\begin{array}{l}263 \\
224 \\
225\end{array}$ & $\begin{array}{l}1967 \\
1968 \\
1969\end{array}$ & $\begin{array}{l}\text { JUNE } \\
\text { MAY }\end{array}$ & $\begin{array}{l}17 \\
06,1968 \\
22,1969\end{array}$ & $\begin{array}{l}-\overline{4} \\
3.28\end{array}$ & $\begin{array}{l}212 \\
586 \\
456\end{array}$ \\
\hline 1943 & & 6 & - & 240 & 1957 & & 11 & - & 263 & 1980 & & & 3.66 & 700 \\
\hline
\end{tabular}

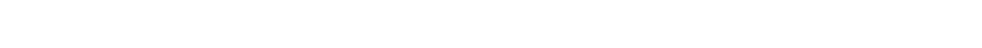

2 July 17-24, 1927

3 July 7,8, 1930

4 June 5,6, 1931

$5_{\text {June }} 27,28,1940$

6 July $11,12,1943$

7 July 12-18, 1947

$8_{\text {July 15,16, } 1951}$

9May 31, June 1, 1952

11 July 5,6, 1957

12 June 30, July 1, 1960

13 May 17,18, 1961

14 July 15-17, 1962

15 May 29, July 14-21, 1963

${ }^{16}$ May 25, July 10, 1966

17 June 18-21, July 10, 1967

${ }^{10}$ July 2-4,7, 1953
} 
LOCATION. -Lat $39^{\circ} 49^{\prime} 40^{\prime \prime}$, long $111^{\circ} 00^{\prime} 30^{\prime \prime}$, in NW' sec.35, T.11 S., R. 8 E., Carbon County, Hydrologic Unit 14060007 , on left bank 150 $\mathrm{ft}$ downstream from railroad bridge, $0.75 \mathrm{mi}$ upstream fram White River, $8 \mathrm{mi}$ southeast of soldier summit, and $11 \mathrm{mi}$ northeast of Scofield.

DRAINAGE AREA. $-180 \mathrm{mi}^{2}$.

PERIOD OF RECORD AVALIABLE. - Auxgust 1961 to September 1963.

GAGE. -Water-stage recorder. Altitude of gage is 7,200 ft from topographic map.

REMARKS.--Flow regulated by Scofield Reservoir.

EXTREMES FOR PERIOD OF RECORD.--Maximum discharge, $351 \mathrm{ft}^{3} / \mathrm{s}$ Aug. 4, 1963, gage height, $2.79 \mathrm{ft}$; minimum, $1.2 \mathrm{ft}^{3} / \mathrm{s}$ Apr. $2,1963$.

LONEST MEAN DISGHAFG, IN CUBIC FEET PER SECOND, AND RANKING FOR THE INDICATED NUMBER OF CONSEQUTIVE DAYS FOR EACH CLIMATIC YEAR, APRIL 1-MARCH 31

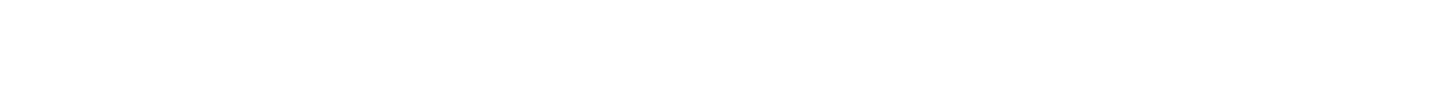

HIGHEST MEAN DISCHARGE, IN OUBIC FEET PER SECOND, AND RANRING FOR THE INDICATED NUMBER OF CONSEQUTTVE DAYS FOR EAOH WATER YEAR, OCTOBER 1-SEPTEMBER 30

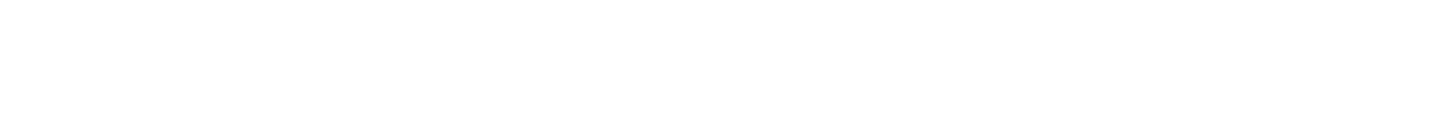

DURATION OF DISCHARGE FOR EACH WATER YEAR

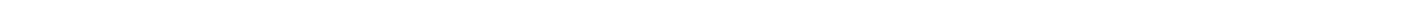

YEAR NUMBER OF DAYS IN CASS

QBBIC FEET PER SECOND

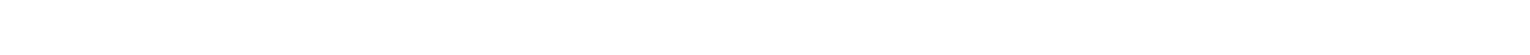

DURATION TABLE OF DISCHARGE FOR WATER YEARS $1962-63$

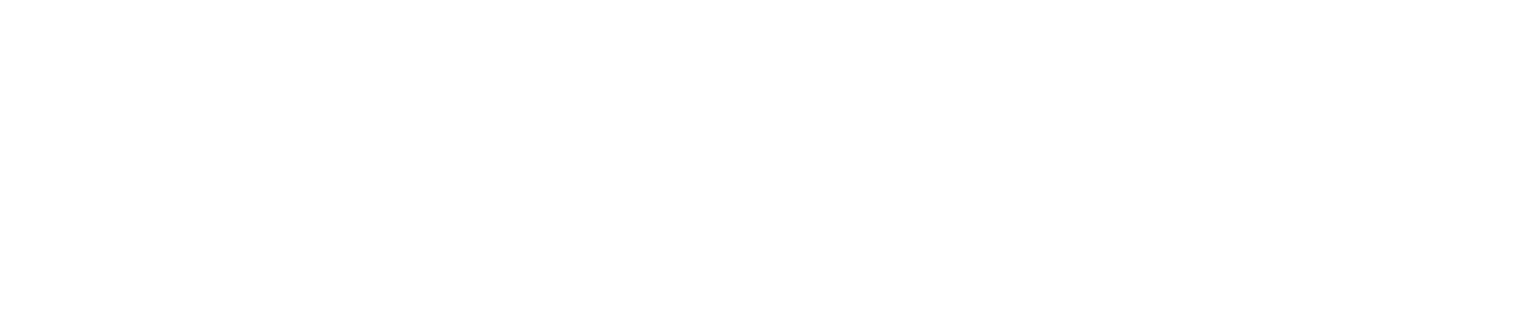

MONTHLY MEAN DISCHARGES, IN OBBIC FEET PER SECOND, FOR EACH WATER YEAR

$\begin{array}{lllllllllllll}\text { YEAR } & \text { OCT } & \text { NOV } & \text { DEC } & \text { JAN } & \text { FEB } & \text { MAR } & \text { APR } & \text { MAY } & \text { JUNE } & \text { JULY } & \text { AUG } & \text { SEP } \\ 1962 & 10.2 & 12.9 & 9.21 & 6.71 & 5.42 & 8.01 & 7.58 & 21.8 & 151 & 187 & 146 & 89.2 \\ 1963 & 10.3 & 10.0 & 15.7 & 4.71 & 3.22 & 4.74 & 21.8 & 121 & 115 & 180 & 66.2 & 28.8\end{array}$


LOCATION.--Lat $39^{\circ} 56^{\prime} 00^{\prime \prime}$, long $111^{\circ} 04^{\prime} 00^{\prime \prime}$, in NE $\}_{4}^{3}$ sec.30, T.10 S., R.8 E., wasatch County, Hydrologic Unit 14060007 , 500 ft upstream from mouth and $1 \mathrm{mi}$ southeast of Soldier sumit.

DRAINAGE AREA. $--23.3 \mathrm{mi}^{2}$.

MEAN BASIN ELEVAIION. $-8,000 \mathrm{ft}$.

PERIOD OF RECORD AVAIIABLE.--April 1938 to March 1942 (fragmentary record in files of Bureau of Reclamation), April 1942 to September 1947.

GAGE.--Water-stage recorder. Altitude of gage is 7,360 ft from topographic map. Prior to April 5, 1943, staff gage at same site and datum.

REMARKS.- - one small diversion above station for irrigation.

AVERAGE DISCHARGE. -5 years (water years $1943-47$ ) , $6.27 \mathrm{ft}^{3} / \mathrm{s}, 4,540 \mathrm{acre}-\mathrm{ft} / \mathrm{yr}$.

EXTREMES FOR PERIOD OF RECORD.--Maximum discharge, $121 \mathrm{ft}^{3} / \mathrm{s}$ May 9, 1944, gage height, $3.50 \mathrm{ft}$; no flow at times during $1942-43$.

LOWEST MEAN DISCHARGE, IN OBBIC FEET PER SECOND, AND RANKING FOR THE INDICATED NUMBER OF CONSECUTIVE DAYS FOR EACH CIIMATIC YEAR, APRII 1-MARCH 31

\begin{tabular}{|c|c|c|c|c|c|c|c|c|c|c|c|c|c|c|c|c|c|c|c|}
\hline YEAR & 1 & & 3 & & 7 & & 14 & & $\begin{array}{l}\text { CONS } \\
30\end{array}$ & ar & $\begin{array}{l}\text { DAYS } \\
60\end{array}$ & & 90 & & 120 & & 183 & & ALL \\
\hline $\begin{array}{l}1943 \\
1944 \\
1945\end{array}$ & $\begin{array}{l}0.00 \\
0.00 \\
0.40\end{array}$ & $\begin{array}{l}1 \\
2 \\
5\end{array}$ & $\begin{array}{l}0.00 \\
0.00 \\
0.40\end{array}$ & $\begin{array}{l}1 \\
2 \\
5\end{array}$ & $\begin{array}{l}0.00 \\
0.00 \\
0.49\end{array}$ & $\begin{array}{l}1 \\
2 \\
5\end{array}$ & $\begin{array}{l}0.00 \\
0.00 \\
0.54\end{array}$ & $\begin{array}{l}1 \\
2 \\
5\end{array}$ & $\begin{array}{l}0.00 \\
0.20 \\
0.59\end{array}$ & $\begin{array}{l}1 \\
2 \\
5\end{array}$ & $\begin{array}{l}0.48 \\
0.42 \\
0.70\end{array}$ & $\begin{array}{l}4 \\
2 \\
5\end{array}$ & $\begin{array}{l}0.66 \\
0.51 \\
0.74\end{array}$ & $\begin{array}{l}4 \\
3 \\
5\end{array}$ & $\begin{array}{l}0.64 \\
0.67 \\
0.82\end{array}$ & $\begin{array}{l}3 \\
4 \\
5\end{array}$ & $\begin{array}{l}0.72 \\
0.74 \\
0.82\end{array}$ & $\begin{array}{l}3 \\
4 \\
5\end{array}$ & $\begin{array}{r}11.0 \\
6.00 \\
7.80\end{array}$ \\
\hline $\begin{array}{l}1946 \\
1947\end{array}$ & $\begin{array}{l}0.20 \\
0.20\end{array}$ & $\begin{array}{l}3 \\
4\end{array}$ & $\begin{array}{l}0.23 \\
0.20\end{array}$ & $\begin{array}{l}4 \\
3\end{array}$ & $\begin{array}{l}0.27 \\
0.20\end{array}$ & $\begin{array}{l}4 \\
3\end{array}$ & $\begin{array}{l}0.29 \\
0.20\end{array}$ & $\begin{array}{l}4 \\
3\end{array}$ & $\begin{array}{l}0.30 \\
0.20\end{array}$ & $\begin{array}{l}4 \\
3\end{array}$ & $\begin{array}{l}0.43 \\
0.22\end{array}$ & $\begin{array}{l}3 \\
1\end{array}$ & $\begin{array}{l}0.45 \\
0.28\end{array}$ & $\begin{array}{l}2 \\
1\end{array}$ & $\begin{array}{l}0.46 \\
0.35\end{array}$ & $\begin{array}{l}2 \\
1\end{array}$ & $\begin{array}{l}0.46 \\
0.40\end{array}$ & $\begin{array}{l}2 \\
1\end{array}$ & $\begin{array}{l}5.50 \\
5.50\end{array}$ \\
\hline
\end{tabular}

HIGHEST MEAN DISCHARGE, IN OUBIC FEET PER SECOND, AND RANKING FOR THE INDICATED NUMBER OF CONSECITIVE DAYS FOR EACH WATER YEAR, OCTOBER 1-SEPTEMBER 30

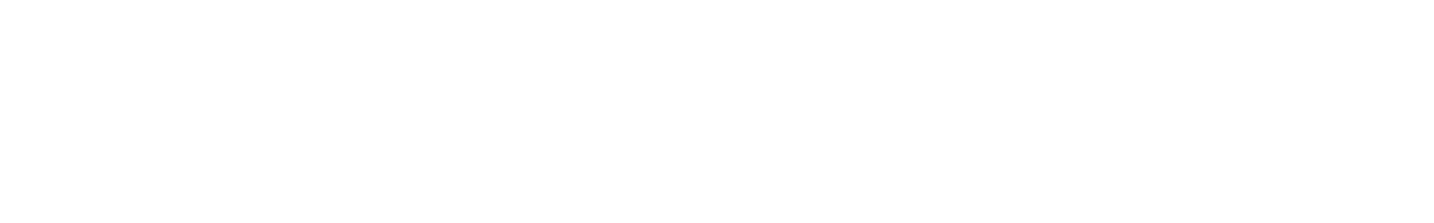

DURATION OF DISCHARGE FOR EACH WATTR YEAR

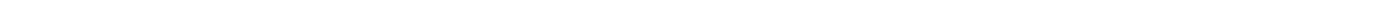
YEAR NUMBER OF DAYS IN CLASS OBIC FEET PER SECON -DAYS

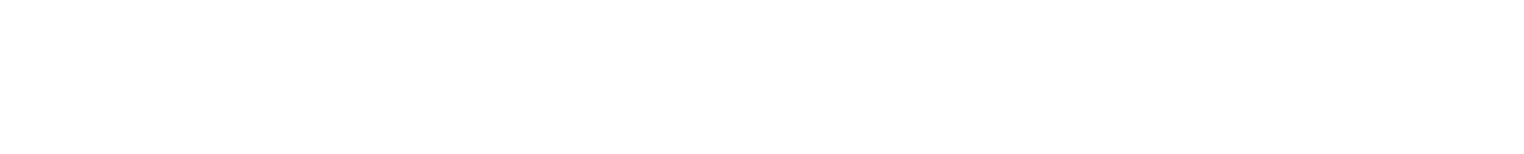

DURATION TABLE OF DISCHARGE FOR WATER YEARS 1943-47

$\begin{array}{crl}\text { CUBIC } & \text { ACCU- } \\ \text { FEET } & \text { MU- } & \text { PER- } \\ \text { PER } & \text { TOTAL LATYED } & \text { CENT } \\ \text { CLASS SECOND DAYS DAYS } & \text { DAYS }\end{array}$

$\begin{array}{lllll}0 & 0.00 & 68 & 1826 & 100.0\end{array}$

$\begin{array}{rrrr}0.00 & 68 & 1826 & 100.0 \\ 0.10 & 1 & 1758 & 96.3\end{array}$

$\begin{array}{llll}0.12 & 0 & 1757 & 96.2\end{array}$

$\begin{array}{llll}0.15 & 0 & 1757 & 96.2\end{array}$

$\begin{array}{llll}0.19 & 80 & 1757 & 96.2\end{array}$

$\begin{array}{llll}0.23 & 0 & 1677 & 91.8\end{array}$

$\begin{array}{lllll}0.28 & 76 & 1677 & 91.8\end{array}$

$\begin{array}{rrrr}0.28 & 76 & 1677 & 91.8 \\ 0.35 & 136 & 1601 & 87.7\end{array}$

$\begin{array}{llll}0.43 & 109 & 1465 & 80.2\end{array}$
AIBIC ACOJ- AJIC ACOJ-

$\begin{array}{lll}\text { OUBIC } & \text { ACCJ- } \\ \text { FEET } & \text { MU- } & \text { PER- } \\ \text { PER TOTAL LATED } & \text { CENT }\end{array}$

PER TOTAL LATED
CEAT
OLASS SECOND DAYS DAYS DAYS

$\begin{array}{rrrrr}9 & 0.53 & 88 & 1356 & 74.3 \\ 10 & 0.66 & 231 & 1268 & 69.4 \\ 11 & 0.81 & 126 & 1037 & 56.8 \\ 12 & 1.00 & 328 & 911 & 49.9 \\ 13 & 1.20 & 59 & 583 & 31.9 \\ 14 & 1.50 & 27 & 524 & 28.7 \\ 15 & 1.90 & 55 & 497 & 27.2 \\ 16 & 2.30 & 8 & 442 & 24.2 \\ 17 & 2.80 & 19 & 434 & 23.8\end{array}$

CUBIC ACCU-
FEET
MU- PERPER TOTAL LATED CENT OLASS SECOND DAYS DAYS DAYS

$\begin{array}{ccc}\text { CUBIC } & \text { ACCU- } \\ \text { FEET } & \text { MU- } & \text { PER- } \\ \text { PER TOTAL LATED } & \text { CENT } \\ \text { OAASS SECOND DAYS DAYS } & \text { DAYS }\end{array}$

$\begin{array}{rrrrr}18 & 3.5 & 13 & 415 & 22.7 \\ 19 & 4.3 & 17 & 402 & 22.0 \\ 20 & 5.3 & 19 & 385 & 21.1 \\ 21 & 6.5 & 23 & 366 & 20.0 \\ 22 & 8.1 & 30 & 343 & 18.8 \\ 23 & 9.9 & 44 & 313 & 17.1 \\ 24 & 12.0 & 41 & 269 & 14.7 \\ 25 & 15.0 & 39 & 228 & 12.5 \\ 26 & 19.0 & 38 & 189 & 10.4\end{array}$

$\begin{array}{rrrrr}27 & 23.0 & 24 & 151 & 8.3 \\ 28 & 28.0 & 27 & 127 & 7.0 \\ 29 & 35.0 & 26 & 100 & 5.5 \\ 30 & 43.0 & 21 & 74 & 4.1 \\ 31 & 53.0 & 24 & 53 & 2.9 \\ 32 & 65.0 & 15 & 29 & 1.6 \\ 33 & 80.0 & 12 & 14 & 0.8 \\ 34 & 99.0 & 2 & 2 & 0.1\end{array}$


MONTHLY MEAN DISCHARGES, IN GBIC FEET FER SECOND, FOR EACH WATER YEAR

$\begin{array}{llccccccccccc}\text { YEAR } & \text { OCT } & \text { NOV } & \text { DEC } & \text { JAN } & \text { FEB } & \text { MAR } & \text { AFR } & \text { MAY } & \text { JUNE } & \text { JULY } & \text { AUG } & \text { SEP } \\ 1943 & 1.00 & 1.00 & 0.00 & 1.00 & 1.00 & 4.52 & 38.6 & 13.1 & 13.0 & 1.32 & 0.58 & 0.43 \\ 1944 & 0.87 & 1.00 & 0.90 & 0.80 & 0.80 & 1.52 & 15.4 & 56.5 & 12.0 & 1.94 & 0.78 & 0.62 \\ 1945 & 0.83 & 1.08 & 0.80 & 0.80 & 0.90 & 0.90 & 9.45 & 41.0 & 9.15 & 1.30 & 1.01 & 0.30 \\ 1946 & 0.66 & 0.45 & 0.50 & 0.40 & 0.64 & 1.00 & 39.8 & 15.0 & 1.71 & 0.57 & 0.23 & 0.20 \\ 1947 & 0.44 & 0.55 & 0.57 & 0.43 & 0.65 & 6.11 & 26.8 & 36.2 & 4.27 & 0.94 & 0.39 & 0.22\end{array}$

ANNUAL FEAK DISCHARGE, IN CUBIC FEET PER SECOND, AND CORRESFONDING GAGE HEIGHT, IN FEET, FOR EAGH WATER YEAR

\begin{tabular}{|c|c|c|c|c|c|c|c|c|c|c|c|c|}
\hline $\begin{array}{l}\text { WATER } \\
\text { YEAR }\end{array}$ & DATE & $\begin{array}{c}\text { GAGE } \\
\text { HEIGHT }\end{array}$ & $\begin{array}{c}\text { PEAK } \\
\text { DISCHARGE }\end{array}$ & $\begin{array}{l}\text { WATER } \\
\text { YEAR }\end{array}$ & & DATE & $\begin{array}{c}\text { GAGE } \\
\text { HEIGHT }\end{array}$ & $\begin{array}{c}\text { PEAK } \\
\text { DISQHARGE }\end{array}$ & $\begin{array}{l}\text { WATER } \\
\text { IEAR }\end{array}$ & DATE & $\begin{array}{c}\text { GAGE } \\
\text { HEIGHT }\end{array}$ & $\begin{array}{c}\text { PEAK } \\
\text { DISCHARGE }\end{array}$ \\
\hline $\begin{array}{l}1942 \\
1943\end{array}$ & $\begin{array}{l}\text { APR. } 15,1942 \\
\text { APR. } 21,1943\end{array}$ & $\begin{array}{l}3.33 \\
2.18\end{array}$ & $\begin{array}{l}99 \\
58\end{array}$ & $\begin{array}{l}1944 \\
1945\end{array}$ & $\begin{array}{l}\text { MAY } \\
\text { MAY }\end{array}$ & $\begin{array}{ll}09, & 1944 \\
08, & 1945\end{array}$ & $\begin{array}{l}3.50 \\
2.84\end{array}$ & $\begin{array}{r}121 \\
86\end{array}$ & $\begin{array}{l}1946 \\
1947\end{array}$ & $\begin{array}{l}\text { APR. } 21,1946 \\
\text { MAY } 04,1947\end{array}$ & $\overline{2.61}$ & $\begin{array}{c}198 \\
86\end{array}$ \\
\hline
\end{tabular}

$1_{\text {Maximum daily discharge. }}$

09312500 WHITE RIVER NEAR SOLDIER SUMMIT, UT

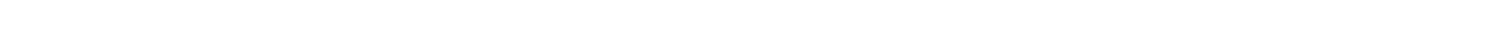
$600 \mathrm{ft}$ downstream from North Fork and $1 \mathrm{mi}$ southeast of Soldier Sumit.

DRATNAGE AREA.--53 $\mathrm{mi}^{2}$, approximately.

MEAN BASIN ELEVATION. - 8,360 ft.

PERIOD OF RECORD AVAHABLE.--April to October 1938, March 1939 to september 1967.

REVISED RECORDS. -WSP 1733: Drainage area.

GAGE.-Water-stage recorder. Altitude of gage is $7,340 \mathrm{ft}$ from topographic map.

REMARKS.--Two small diversions fram North Fork for irrigation.

AVERAGE DISCHARGE. -28 years, $19.4 \mathrm{ft}^{3} / \mathrm{s}, 14,050$ acre- $\mathrm{ft} / \mathrm{yr}$.

EXIREMES FOR PERIOD OF RECORD.--Maximum discharge, 1,120 ft ${ }^{3} / \mathrm{s}$ May 5, 1952, gage height, $4.53 \mathrm{ft}$; no flow at times July to Sept. 1939.

LWWEST MEAN DISQHARGE, IN OBIC FEET PER SECOND, AND RANKING FOR THE INDICATED NUMBER OF CONSECUTIVE DAYS FOR EAGH OLIMATIC YEAR, APRIL 1-MARQH 31

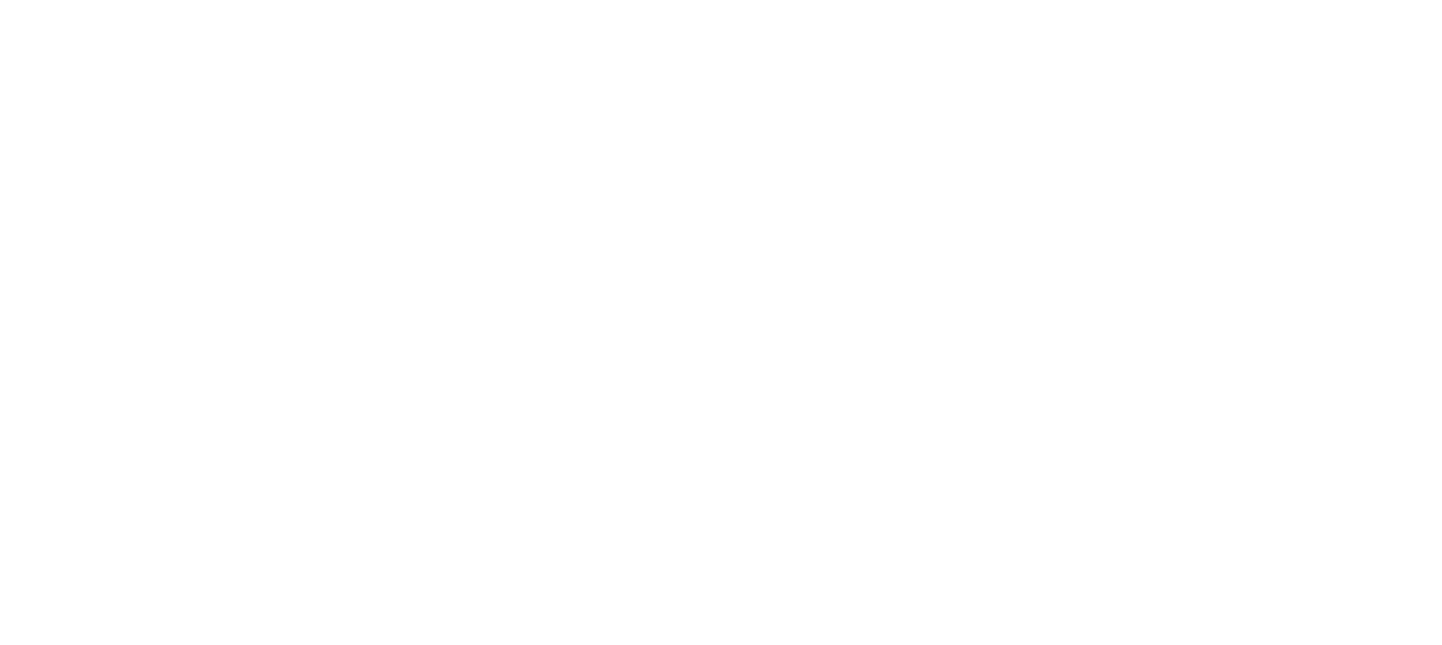


GREEN RIVER BASTN

09312500 WHITE RIVER NEAR SQLDIER SUMMIT, UT--Continued

LOWEST MEAN DISCHARGE, IN OBIC FEET PER SECOND, AND RANKING FOR THE INDICATED NUMBER OF CONSECUTTVE DAYS

FOR EAOH CLIMATIC YEAR, APRIL 1-MAROH 31-Continued

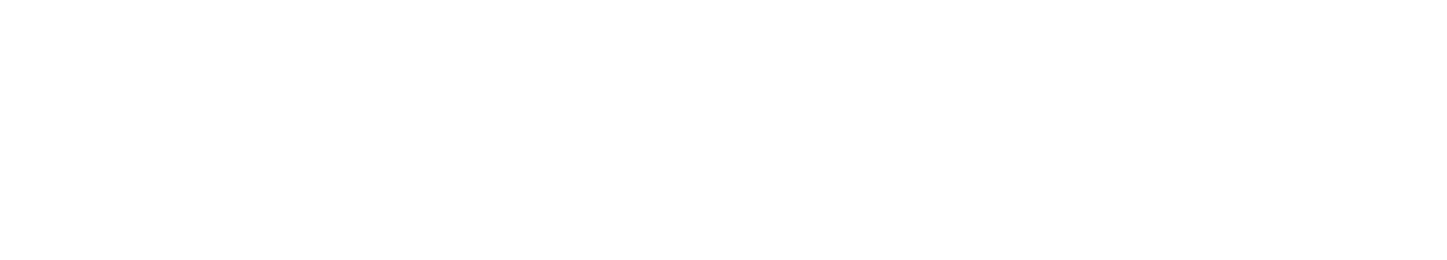

HIGHEST MEAN DISGHARGE, IN OBBIC FEET PER SECOND, AND RANKING FOR THE INDICATED NUMBER OF CONSEQUTTVE DAYS FOR EAOH WATER YEAR, OCTOBER I-SEPTEYBER 30

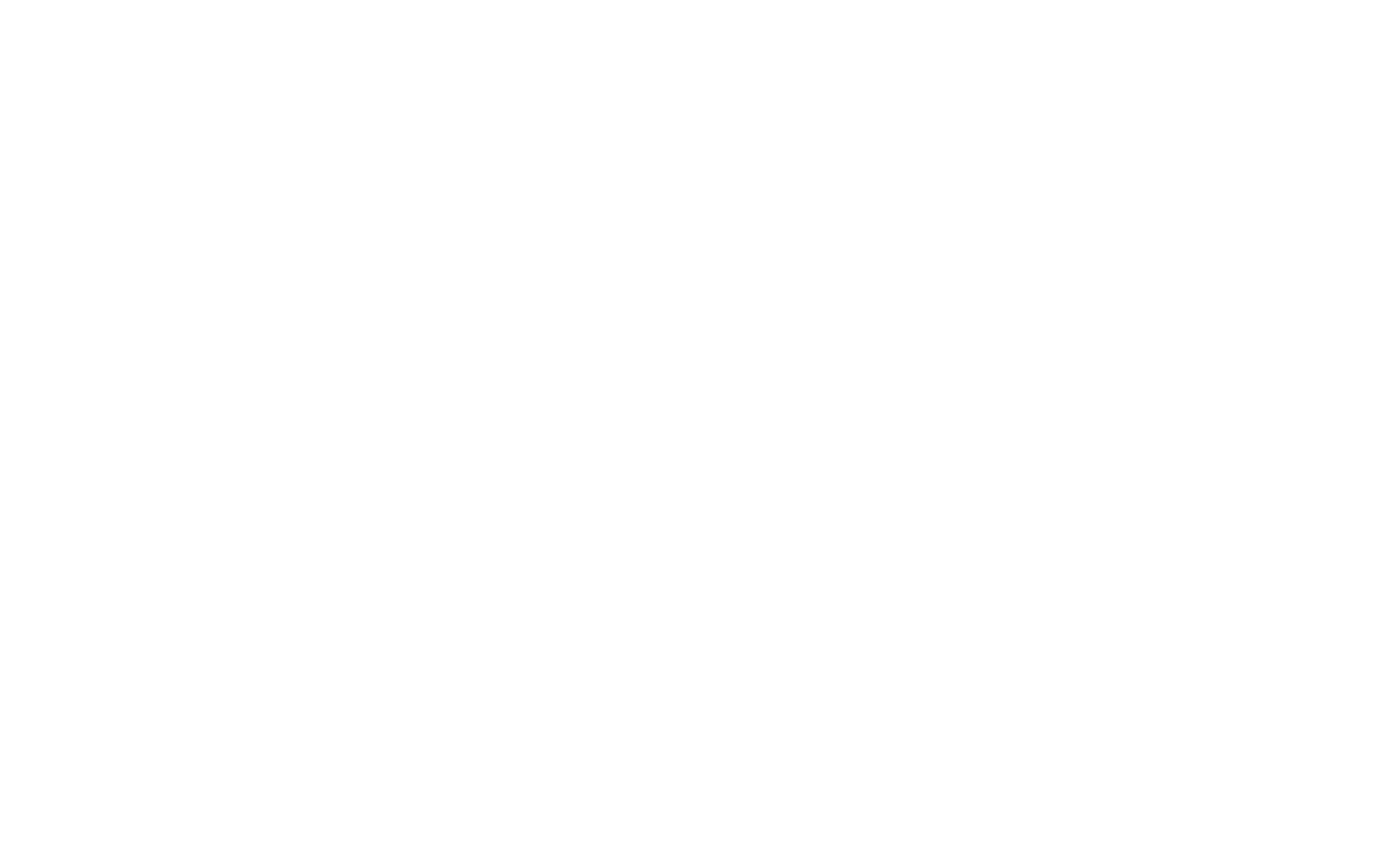

DURATION OF DISGHARGE FOR EAG WATER YEAR

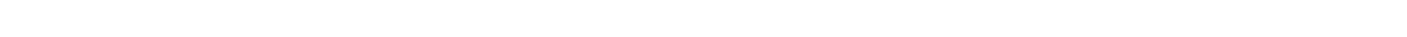

YEAR

NUMBER OF DAYS IN QLASS

OBIC FEET
PER SECOND
-DAYS
3818.8

9813.0
9033.0
5577.0
7072.8
4487.3
4782.8
5670.2
3799.4
11111.3
8324.3

6769.7
24209.3
5410.8
3059.5
5506.6


GREEN RIVER BASIN

09312500 WHITE RIVER NEAR SOLDIER SUMMIT, UT-Continued

DURATION OF DISCHARGE FOR EACH WATER YEAR--Continued

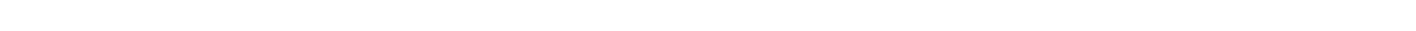
YEAR

NUMBER OF DAYS IN OLASS

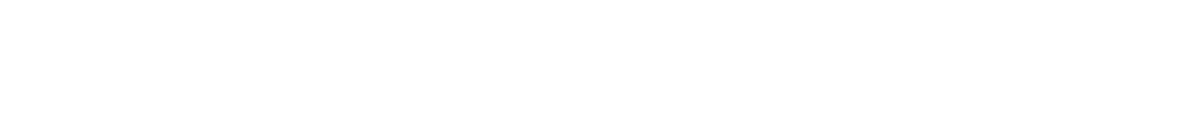

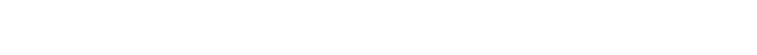

1962

1963

1964

$\begin{array}{lllllllllllllllllll}63114 & 36 & 31 & 4 & 11 & 14 & 4 & 7 & 5 & 13 & 9 & 8 & 5 & 6 & 3 & 4 & 8 & 11 & 9\end{array}$

$\begin{array}{llllllllllllllll}56 & 17112 & 32 & 15 & 17 & 17 & 25 & 29 & 8 & 5 & 4 & 6 & 5 & 5 & 7 & 5\end{array}$

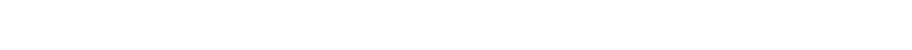

1966
1967

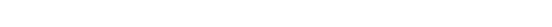

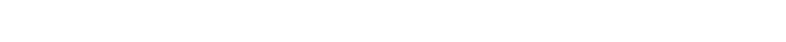

OUBIC FEET
PER SEOOND
-DAYS

DURATION TABLE OF DISCHARGE FOR WATER YEARS $1940-67$

$\begin{array}{rrr}\text { OUIC } & \text { ACO- } \\ \text { FEET } & \text { MU- } & \text { PER- } \\ \text { FER TOTAL LATED } & \text { CENT } \\ \text { G.ASS SECOND DAYS DAYS } & \text { DAYS }\end{array}$

$\begin{array}{llllll}0 & 0.00 & 0 & 10227 & 100.0\end{array}$

$\begin{array}{rrrrr}I & 0.30 & 11 & 10227 & 100.0 \\ 2 & 0.38 & 9 & 10216 & 99.9\end{array}$

$\begin{array}{lllll}3 & 0.49 & 27 & 10207 & 99.8\end{array}$

$\begin{array}{lllll}4 & 0.63 & 28 & 10180 & 99.5\end{array}$

$5 \quad, 0.81 \quad 16 \quad 10152 \quad 99.3$

$\begin{array}{llll}1.00 & 106 & 10136 & 99.1 \\ 1.30 & 113 & 10030 & 98.1\end{array}$

$\begin{array}{rrrr}1.70 & 606 & 9917 & 97.0\end{array}$ $\begin{array}{lll}\text { OBIC ACW- } & \\ \text { FEET } & \text { MN- } \\ \text { PER } & \text { PER- }\end{array}$ OLASS SECOND DAYS DAYS DAYS

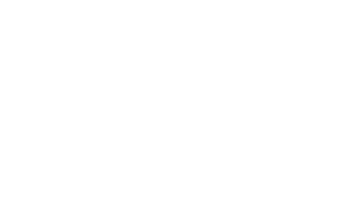

OBIC ACQUCLASS SECOND DAYS DAYS DAYS

$\begin{array}{rrrrr}18 & 20.0 & 326 & 2017 & 19.7 \\ 19 & 26.0 & 252 & 1691 & 16.5 \\ 20 & 33.0 & 224 & 1439 & 14.1 \\ 21 & 42.0 & 242 & 1215 & 11.9 \\ 22 & 54.0 & 213 & 973 & 9.5 \\ 23 & 69.0 & 194 & 760 & 7.4 \\ 24 & 88.0 & 151 & 566 & 5.5 \\ 25 & 110.0 & 135 & 415 & 4.1\end{array}$

8071.1

10038.5

9323.6

1602.7
3012.2

1510.1

10014.9

3795.7

6753.9

4414.6

10343.9

MONIHLY MEAN DISCHARGES, IN OUBIC FEET PER SECOND, FOR EACH WATER YEAR

\begin{tabular}{|c|c|c|c|c|c|c|c|c|c|c|c|c|}
\hline YEAR & OCT & NOV & $D E C$ & JAN & FEB & MAR & AFR & MAY & JUNE & JULY & AUG & SEP \\
\hline 1940 & 2.50 & 2.50 & 2.30 & 2.00 & 2.00 & 9.42 & 48.6 & 40.8 & 9.43 & 2.61 & 1.16 & 2.00 \\
\hline $\begin{array}{l}1941 \\
1942 \\
1943 \\
1944 \\
1945\end{array}$ & $\begin{array}{l}2.87 \\
5.00 \\
3.94 \\
3.80 \\
4.00\end{array}$ & $\begin{array}{l}3.00 \\
5.00 \\
3.50 \\
3.34 \\
3.50\end{array}$ & $\begin{array}{l}2.50 \\
4.00 \\
3.65 \\
3.00 \\
2.50\end{array}$ & $\begin{array}{l}2.50 \\
3.00 \\
3.00 \\
2.50 \\
2.50\end{array}$ & $\begin{array}{l}4.00 \\
3.00 \\
3.93 \\
2.50 \\
3.00\end{array}$ & $\begin{array}{c}13.1 \\
7.58 \\
12.0 \\
6.06 \\
3.00\end{array}$ & $\begin{array}{c}38.9 \\
122 \\
73.8 \\
33.7 \\
16.0\end{array}$ & $\begin{array}{c}159 \\
101 \\
34.6 \\
122 \\
73.7\end{array}$ & $\begin{array}{l}63.5 \\
31.4 \\
29.5 \\
33.5 \\
22.7\end{array}$ & $\begin{array}{c}18.8 \\
8.84 \\
8.26 \\
11.6 \\
7.22\end{array}$ & $\begin{array}{l}7.68 \\
3.45 \\
4.61 \\
5.05 \\
5.26\end{array}$ & $\begin{array}{l}4.70 \\
2.70 \\
3.00 \\
3.46 \\
3.03\end{array}$ \\
\hline $\begin{array}{l}1946 \\
1947 \\
1948 \\
1949 \\
1950\end{array}$ & $\begin{array}{l}3.53 \\
2.73 \\
3.01 \\
2.80 \\
5.18\end{array}$ & $\begin{array}{l}3.33 \\
2.69 \\
3.33 \\
2.94 \\
4.49\end{array}$ & $\begin{array}{l}2.61 \\
2.86 \\
2.55 \\
2.90 \\
3.40\end{array}$ & $\begin{array}{l}2.00 \\
2.61 \\
2.50 \\
2.80 \\
3.00\end{array}$ & $\begin{array}{l}2.46 \\
2.80 \\
2.50 \\
3.05 \\
3.46\end{array}$ & $\begin{array}{c}6.41 \\
13.0 \\
2.60 \\
13.2 \\
5.00\end{array}$ & $\begin{array}{c}79.3 \\
48.8 \\
25.7 \\
126 \\
93.1\end{array}$ & $\begin{array}{c}38.9 \\
78.9 \\
60.8 \\
142 \\
104\end{array}$ & $\begin{array}{l}11.4 \\
17.7 \\
12.0 \\
44.9 \\
33.4\end{array}$ & $\begin{array}{c}3.95 \\
7.15 \\
4.62 \\
13.4 \\
10.7\end{array}$ & $\begin{array}{l}2.35 \\
3.44 \\
2.52 \\
6.19 \\
4.26\end{array}$ & $\begin{array}{l}1.44 \\
2.78 \\
1.98 \\
4.41 \\
3.32\end{array}$ \\
\hline $\begin{array}{l}1951 \\
1952 \\
1953 \\
1954 \\
1955\end{array}$ & $\begin{array}{l}3.11 \\
3.28 \\
4.95 \\
3.81 \\
3.18\end{array}$ & $\begin{array}{l}3.79 \\
3.10 \\
5.03 \\
2.75 \\
2.64\end{array}$ & $\begin{array}{l}3.98 \\
3.10 \\
4.50 \\
2.39 \\
2.28\end{array}$ & $\begin{array}{l}3.45 \\
2.50 \\
4.10 \\
2.20 \\
2.10\end{array}$ & $\begin{array}{l}3.45 \\
2.50 \\
3.99 \\
2.64 \\
2.10\end{array}$ & $\begin{array}{l}5.45 \\
3.16 \\
6.44 \\
4.52 \\
2.84\end{array}$ & $\begin{array}{c}55.7 \\
148 \\
29.1 \\
32.4 \\
32.1\end{array}$ & $\begin{array}{c}94.0 \\
495 \\
67.0 \\
29.0 \\
90.5\end{array}$ & $\begin{array}{l}31.0 \\
85.5 \\
30.9 \\
10.2 \\
22.6\end{array}$ & $\begin{array}{c}9.45 \\
23.3 \\
10.7 \\
5.15 \\
9.14\end{array}$ & $\begin{array}{c}5.08 \\
12.4 \\
6.45 \\
2.42 \\
7.12\end{array}$ & $\begin{array}{l}3.24 \\
7.58 \\
4.01 \\
3.03 \\
3.21\end{array}$ \\
\hline $\begin{array}{l}1956 \\
1957 \\
1958 \\
1959 \\
1960\end{array}$ & $\begin{array}{l}3.83 \\
3.21 \\
8.75 \\
4.03 \\
1.71\end{array}$ & $\begin{array}{l}3.92 \\
3.06 \\
5.94 \\
3.12 \\
1.70\end{array}$ & $\begin{array}{l}3.81 \\
2.85 \\
4.00 \\
3.02 \\
0.95\end{array}$ & $\begin{array}{l}3.60 \\
2.80 \\
3.50 \\
2.50 \\
1.55\end{array}$ & $\begin{array}{l}3.50 \\
3.63 \\
3.91 \\
2.59 \\
2.17\end{array}$ & $\begin{array}{c}10.6 \\
6.27 \\
4.85 \\
3.55 \\
4.55\end{array}$ & $\begin{array}{l}77.7 \\
32.5 \\
41.7 \\
13.1 \\
24.5\end{array}$ & $\begin{array}{l}113 \\
164 \\
179 \\
13.0 \\
42.8\end{array}$ & $\begin{array}{c}26.8 \\
74.2 \\
31.9 \\
4.95 \\
10.5\end{array}$ & $\begin{array}{c}9.27 \\
18.3 \\
10.3 \\
1.18 \\
3.27\end{array}$ & $\begin{array}{l}4.62 \\
9.26 \\
5.44 \\
0.55 \\
1.95\end{array}$ & $\begin{array}{l}3.32 \\
8.15 \\
4.50 \\
1.06 \\
2.94\end{array}$ \\
\hline $\begin{array}{l}1961 \\
1962 \\
1963 \\
1964 \\
1965\end{array}$ & $\begin{array}{l}3.76 \\
3.29 \\
4.12 \\
3.23 \\
3.52\end{array}$ & $\begin{array}{l}3.80 \\
3.01 \\
3.23 \\
3.50 \\
3.00\end{array}$ & $\begin{array}{l}2.04 \\
2.58 \\
2.13 \\
2.00 \\
3.18\end{array}$ & $\begin{array}{l}1.80 \\
2.50 \\
2.00 \\
2.00 \\
3.50\end{array}$ & $\begin{array}{l}1.80 \\
4.00 \\
3.36 \\
2.00 \\
4.02\end{array}$ & $\begin{array}{l}3.48 \\
3.81 \\
4.84 \\
2.85 \\
6.94\end{array}$ & $\begin{array}{c}11.1 \\
127 \\
16.0 \\
16.1 \\
52.1\end{array}$ & $\begin{array}{c}11.9 \\
138 \\
59.5 \\
130 \\
188\end{array}$ & $\begin{array}{c}4.31 \\
28.8 \\
13.2 \\
36.0 \\
55.0\end{array}$ & $\begin{array}{c}2.53 \\
8.25 \\
7.66 \\
11.2 \\
20.9\end{array}$ & $\begin{array}{c}1.37 \\
3.82 \\
4.79 \\
5.72 \\
12.2\end{array}$ & $\begin{array}{l}1.70 \\
4.53 \\
3.07 \\
5.29 \\
8.20\end{array}$ \\
\hline $\begin{array}{l}1966 \\
1967\end{array}$ & $\begin{array}{l}4.37 \\
4.67\end{array}$ & $\begin{array}{l}5.13 \\
4.07\end{array}$ & $\begin{array}{l}4.27 \\
3.62\end{array}$ & $\begin{array}{l}4.11 \\
2.90\end{array}$ & $\begin{array}{l}4.00 \\
3.20\end{array}$ & $\begin{array}{c}7.56 \\
12.8\end{array}$ & $\begin{array}{l}46.7 \\
39.9\end{array}$ & $\begin{array}{l}37.3 \\
138\end{array}$ & $\begin{array}{l}15.4 \\
77.0\end{array}$ & $\begin{array}{r}7.19 \\
31.2\end{array}$ & $\begin{array}{c}4.56 \\
13.1\end{array}$ & $\begin{array}{l}4.55 \\
7.35\end{array}$ \\
\hline
\end{tabular}


GREEN RTVER BASIN

09312500 WHITE RIVER NEAR SQDDIER SUMMIT, UT—Continued

ANNUAL PEAR DISCHARGE, IN OBIC FEET PER SECOND, AND CORRESPONDING GAGE HEIGHT, IN FEET, FOR EACH WATER YEAR

\begin{tabular}{|c|c|c|c|c|c|c|c|c|c|c|c|}
\hline $\begin{array}{l}\text { WAIER } \\
\text { YEAR }\end{array}$ & DATE & $\begin{array}{c}\text { GAGE } \\
\text { HEIGHT }\end{array}$ & $\begin{array}{c}\text { PEAR } \\
\text { DISOHARGE }\end{array}$ & $\begin{array}{l}\text { WATER } \\
\text { YEAR }\end{array}$ & DATE & $\begin{array}{c}\text { GAGE } \\
\text { HEIGHT }\end{array}$ & $\begin{array}{c}\text { PEAK } \\
\text { DISQHARGE }\end{array}$ & $\begin{array}{l}\text { WATER } \\
\text { YEAR }\end{array}$ & DATE & $\begin{array}{c}\text { GAGE } \\
\text { HEIGHT }\end{array}$ & $\begin{array}{c}\text { PEAR } \\
\text { DISCHARGE }\end{array}$ \\
\hline $\begin{array}{l}1940 \\
1941 \\
1942 \\
1943 \\
1944 \\
1945 \\
1946 \\
1947 \\
1948 \\
1949\end{array}$ & $\begin{array}{l}\text { APR. } 04,1940 \\
\text { MAY } 10,1941 \\
\text { APR. } 14,1942 \\
\text { APR. } 24,1943 \\
\text { MAY } 09,1944 \\
\text { MAY } 08,1945 \\
\text { APR. } 22,1946 \\
\text { MAY } 05,1947 \\
\text { MAY } 07,1948 \\
\text { APR. } 29,1949\end{array}$ & $\begin{array}{l}1.65 \\
3.70 \\
3.13 \\
1.78 \\
2.96 \\
1.77 \\
1.77 \\
1.86 \\
1.41 \\
2.57\end{array}$ & $\begin{array}{r}87 \\
288 \\
216 \\
113 \\
241 \\
152 \\
160 \\
165 \\
96 \\
272\end{array}$ & $\begin{array}{l}1950 \\
1951 \\
1952 \\
1953 \\
1954 \\
1955 \\
1956 \\
1957 \\
1958\end{array}$ & $\begin{array}{ll}\text { APR. } & 22,1950 \\
\text { MAY } & 12,1951 \\
\text { MAY } & 05,1952 \\
\text { APR. } & 27,1953 \\
\text { JULY } 17,1954 \\
\text { AUG. } 18,1955 \\
\text { MAY } 07,1956 \\
\text { MAY } 09,1957 \\
\text { MAY } 11,1958\end{array}$ & $\begin{array}{l}2.00 \\
1.55 \\
4.53 \\
1.15 \\
1.32 \\
1.61 \\
1.80 \\
2.40 \\
2.73\end{array}$ & $\begin{array}{r}221 \\
130 \\
1120 \\
95 \\
115 \\
171 \\
188 \\
270 \\
318\end{array}$ & $\begin{array}{l}1959 \\
1960 \\
1961 \\
1962 \\
1963 \\
1964 \\
1965 \\
1966 \\
1967\end{array}$ & $\begin{array}{l}\text { APR. } 06,1959 \\
\text { MAY } 10,1960 \\
\text { MAY } 03,1961 \\
\text { APR. } 24,1962 \\
\text { MAY } 05,1963 \\
\text { MAY } 16,1964 \\
\text { MAY } 21,1965 \\
\text { JULY } 17,1966 \\
\text { MAY } 21,1967\end{array}$ & $\begin{array}{l}0.40 \\
1.14 \\
0.39 \\
2.72 \\
2.71 \\
2.09 \\
2.17 \\
2.32 \\
2.02\end{array}$ & $\begin{array}{r}34 \\
77 \\
20 \\
304 \\
132 \\
308 \\
310 \\
190 \\
286\end{array}$ \\
\hline
\end{tabular}

09312600 WHITE RIVER BELON TABBYNE CREER, NEAR SQ.DIER SUMMIT, UT

LOCATTON. -Lat $39^{\circ} 52^{\prime} 33^{\prime \prime}$, long $111^{\circ} 02{ }^{\prime} 12^{\prime \prime}$, in NE downstream from bridge on U.S. Highways $6-50,1.5 \mathrm{mi}$ downstream fram Tabbyune Creek, $2.5 \mathrm{mi}$ northwest of the Colton railroad siding, and $4.5 \mathrm{mi}$ southeast of Soldier sumit.

DRAINAGE AREA. $-75.6 \mathrm{mi}^{2}$.

MEAN BASIN ELLEVATION. $-8,150 \mathrm{ft}$.

PERIOD OF RECORD AVAIIABLE.--May 1967 to September 1981.

GAGE. -Water-stage recorder. Altitude of gage is 7,230 ft from topographic map.

AVERAGE DISCHARGE. -14 years, $27.3 \mathrm{ft}^{3} / \mathrm{s}, 19,780$ acre-ft/yr.

EXIREMES FOR PERIOD OF REOORD. - Maximum discharge, $458 \mathrm{ft}^{3} / \mathrm{s}$ May 14, 1973, gage height, $5.24 \mathrm{ft}$; no flow many days Aug. and Sept.

1977.

LOWEST MEAN DISOHARGE, IN OUBIC FEET PER SECOND, AND RANKING FOR THE INDICATED NUMBER OF CONSEOUTIVE DAYS FOR EACH CIIMATIC YEAR, AFRII I-WARC: 31

\begin{tabular}{|c|c|c|c|c|c|c|c|c|c|c|c|c|c|c|c|c|c|c|c|c|}
\hline YEAR & 1 & & 3 & & 7 & & 14 & & $\begin{array}{l}\text { CONSE } \\
30\end{array}$ & EOUTI & $\begin{array}{l}\text { DAYS } \\
60\end{array}$ & & 90 & & 120 & & 183 & & ALL & \\
\hline $\begin{array}{l}1969 \\
1970\end{array}$ & $\begin{array}{l}1.60 \\
3.00\end{array}$ & $\begin{array}{l}4 \\
8\end{array}$ & $\begin{array}{l}1.60 \\
3.00\end{array}$ & $\begin{array}{l}4 \\
8\end{array}$ & $\begin{array}{l}1.60 \\
3.10\end{array}$ & $\begin{array}{l}4 \\
8\end{array}$ & $\begin{array}{l}1.60 \\
3.30\end{array}$ & $\begin{array}{l}4 \\
8\end{array}$ & $\begin{array}{l}1.70 \\
3.60\end{array}$ & $\begin{array}{l}4 \\
7\end{array}$ & $\begin{array}{l}1.80 \\
4.40\end{array}$ & $\begin{array}{l}3 \\
9\end{array}$ & $\begin{array}{l}1.90 \\
4.70\end{array}$ & $\begin{array}{l}3 \\
9\end{array}$ & $\begin{array}{l}2.20 \\
5.00\end{array}$ & $\begin{array}{r}3 \\
10\end{array}$ & $\begin{array}{l}3.80 \\
5.50\end{array}$ & $\begin{array}{l}4 \\
9\end{array}$ & $\begin{array}{l}36.0 \\
37.0\end{array}$ & $\begin{array}{r}9 \\
10\end{array}$ \\
\hline $\begin{array}{l}1971 \\
1972 \\
1973 \\
1974 \\
1975\end{array}$ & $\begin{array}{l}4.40 \\
3.60 \\
3.20 \\
4.10 \\
2.00\end{array}$ & $\begin{array}{r}12 \\
10 \\
9 \\
11 \\
5\end{array}$ & $\begin{array}{l}4.60 \\
3.70 \\
3.20 \\
4.10 \\
2.10\end{array}$ & $\begin{array}{r}12 \\
10 \\
9 \\
11 \\
5\end{array}$ & $\begin{array}{l}4.90 \\
3.90 \\
3.30 \\
4.10 \\
2.20\end{array}$ & $\begin{array}{r}13 \\
10 \\
9 \\
11 \\
5\end{array}$ & $\begin{array}{l}4.90 \\
4.20 \\
3.60 \\
4.10 \\
2.30\end{array}$ & $\begin{array}{r}13 \\
11 \\
9 \\
10 \\
5\end{array}$ & $\begin{array}{l}5.20 \\
4.70 \\
3.90 \\
4.40 \\
2.70\end{array}$ & $\begin{array}{r}13 \\
11 \\
8 \\
10 \\
5\end{array}$ & $\begin{array}{l}5.30 \\
5.10 \\
4.20 \\
4.70 \\
3.20\end{array}$ & $\begin{array}{r}12 \\
11 \\
7 \\
10 \\
6\end{array}$ & $\begin{array}{l}5.40 \\
5.30 \\
4.40 \\
4.80 \\
3.90\end{array}$ & $\begin{array}{r}12 \\
11 \\
7 \\
10 \\
6\end{array}$ & $\begin{array}{l}5.70 \\
5.70 \\
4.40 \\
4.90 \\
4.10\end{array}$ & $\begin{array}{r}11 \\
12 \\
7 \\
8 \\
6\end{array}$ & $\begin{array}{l}5.80 \\
5.70 \\
4.50 \\
5.10 \\
4.00\end{array}$ & $\begin{array}{r}12 \\
10 \\
7 \\
8 \\
5\end{array}$ & $\begin{array}{l}21.0 \\
31.0 \\
17.0 \\
41.0 \\
28.0\end{array}$ & $\begin{array}{r}4 \\
8 \\
3 \\
12 \\
6\end{array}$ \\
\hline $\begin{array}{l}1976 \\
1977 \\
1978 \\
1979 \\
1980\end{array}$ & $\begin{array}{l}4.70 \\
0.30 \\
0.00 \\
1.40 \\
2.30\end{array}$ & $\begin{array}{r}13 \\
2 \\
1 \\
3 \\
6\end{array}$ & $\begin{array}{l}4.70 \\
0.30 \\
0.00 \\
1.40 \\
2.40\end{array}$ & $\begin{array}{r}13 \\
2 \\
1 \\
3 \\
6\end{array}$ & $\begin{array}{l}4.70 \\
0.30 \\
0.00 \\
1.50 \\
2.40\end{array}$ & $\begin{array}{r}12 \\
2 \\
1 \\
3 \\
6\end{array}$ & $\begin{array}{l}4.80 \\
0.33 \\
0.00 \\
1.50 \\
2.50\end{array}$ & $\begin{array}{r}12 \\
2 \\
1 \\
3 \\
6\end{array}$ & $\begin{array}{l}5.20 \\
0.51 \\
0.00 \\
1.60 \\
2.80\end{array}$ & $\begin{array}{r}12 \\
2 \\
1 \\
3 \\
6\end{array}$ & $\begin{array}{l}6.00 \\
1.00 \\
0.01 \\
2.60 \\
3.20\end{array}$ & $\begin{array}{r}13 \\
2 \\
1 \\
4 \\
5\end{array}$ & $\begin{array}{l}6.20 \\
1.30 \\
0.17 \\
3.30 \\
3.60\end{array}$ & $\begin{array}{r}13 \\
2 \\
1 \\
4 \\
5\end{array}$ & $\begin{array}{l}6.30 \\
1.80 \\
0.43 \\
3.60 \\
3.50\end{array}$ & $\begin{array}{r}13 \\
2 \\
1 \\
5 \\
4\end{array}$ & $\begin{array}{l}6.60 \\
2.10 \\
1.10 \\
3.50 \\
4.00\end{array}$ & $\begin{array}{r}13 \\
2 \\
1 \\
3 \\
6\end{array}$ & $\begin{array}{c}40.0 \\
14.0 \\
3.40 \\
31.0 \\
27.0\end{array}$ & $\begin{array}{r}11 \\
2 \\
1 \\
7 \\
5\end{array}$ \\
\hline 1981 & 2.70 & 7 & 2.70 & 7 & 2.90 & 7 & 3.20 & 7 & 3.90 & 9 & 4.30 & 8 & 4.60 & 8 & 5.00 & 9 & 5.80 & 11 & 44.0 & 13 \\
\hline
\end{tabular}

HIGHEST MEAN DISCHARGE, IN OBIC FEET PER SECOND, AND RANKING FOR THE INDICATED NUMBER OF CONSEOUTIVE DAYS FOR EAOH WATER YEAR, $O$ CTOBER I-SEPTEBBR 30

\begin{tabular}{|c|c|c|c|c|c|c|c|c|c|c|c|c|c|c|c|c|c|c|c|c|}
\hline YEAR & & & & & & & & & cons & EWTT & [VE DAYS & & & & & & & & & \\
\hline $\begin{array}{l}1968 \\
1969 \\
1970\end{array}$ & $\begin{array}{l}330 \\
331 \\
205\end{array}$ & $\begin{array}{l}5 \\
4 \\
9\end{array}$ & $\begin{array}{l}317 \\
323 \\
202\end{array}$ & $\begin{array}{l}5 \\
4 \\
9\end{array}$ & $\begin{array}{l}284 \\
307 \\
184\end{array}$ & $\begin{array}{l}5 \\
4 \\
9\end{array}$ & $\begin{array}{l}255 \\
281 \\
157\end{array}$ & $\begin{array}{r}5 \\
4 \\
10\end{array}$ & $\begin{array}{l}237 \\
239 \\
126\end{array}$ & $\begin{array}{r}5 \\
4 \\
10\end{array}$ & $\begin{array}{c}162 \\
170 \\
83.0\end{array}$ & $\begin{array}{r}5 \\
4 \\
10\end{array}$ & $\begin{array}{c}122 \\
128 \\
63.0\end{array}$ & $\begin{array}{r}5 \\
4 \\
10\end{array}$ & $\begin{array}{c}98.0 \\
101 \\
50.0\end{array}$ & $\begin{array}{r}5 \\
4 \\
11\end{array}$ & $\begin{array}{l}68.0 \\
69.0 \\
36.0\end{array}$ & $\begin{array}{r}5 \\
4 \\
10\end{array}$ & $\begin{array}{l}37.0 \\
36.0 \\
21.0\end{array}$ & $\begin{array}{r}4 \\
5 \\
10\end{array}$ \\
\hline $\begin{array}{l}1971 \\
1972 \\
1973 \\
1974 \\
1975\end{array}$ & $\begin{array}{c}187 \\
99.0 \\
453 \\
269 \\
371\end{array}$ & $\begin{array}{r}10 \\
12 \\
1 \\
7 \\
3\end{array}$ & $\begin{array}{c}178 \\
97.0 \\
446 \\
260 \\
351\end{array}$ & $\begin{array}{r}10 \\
12 \\
1 \\
7 \\
3\end{array}$ & $\begin{array}{c}167 \\
94.0 \\
431 \\
244 \\
349\end{array}$ & $\begin{array}{r}10 \\
12 \\
1 \\
6 \\
3\end{array}$ & $\begin{array}{c}163 \\
89.0 \\
387 \\
216 \\
323\end{array}$ & $\begin{array}{r}9 \\
12 \\
1 \\
6 \\
2\end{array}$ & $\begin{array}{c}139 \\
82.0 \\
295 \\
183 \\
275\end{array}$ & $\begin{array}{r}9 \\
12 \\
1 \\
6 \\
3\end{array}$ & $\begin{array}{l}116 \\
68.0 \\
199 \\
134 \\
179\end{array}$ & $\begin{array}{r}9 \\
11 \\
2 \\
7 \\
3\end{array}$ & $\begin{array}{c}93.0 \\
61.0 \\
145 \\
98.0 \\
133\end{array}$ & $\begin{array}{r}8 \\
12 \\
2 \\
7 \\
3\end{array}$ & $\begin{array}{c}74.0 \\
51.0 \\
113 \\
77.0 \\
106\end{array}$ & $\begin{array}{r}8 \\
10 \\
2 \\
7 \\
3\end{array}$ & $\begin{array}{l}51.0 \\
36.0 \\
77.0 \\
53.0 \\
73.0\end{array}$ & $\begin{array}{r}8 \\
11 \\
2 \\
7 \\
3\end{array}$ & $\begin{array}{l}28.0 \\
21.0 \\
41.0 \\
29.0 \\
39.0\end{array}$ & $\begin{array}{r}8 \\
11 \\
2 \\
7 \\
3\end{array}$ \\
\hline $\begin{array}{l}1976 \\
1977 \\
1978 \\
1979 \\
1980\end{array}$ & $\begin{array}{l}109 \\
16.0 \\
297 \\
257 \\
389\end{array}$ & $\begin{array}{r}11 \\
14 \\
6 \\
8 \\
2\end{array}$ & $\begin{array}{c}108 \\
14.0 \\
279 \\
244 \\
382\end{array}$ & $\begin{array}{r}11 \\
14 \\
6 \\
8 \\
2\end{array}$ & $\begin{array}{c}106 \\
10.0 \\
237 \\
230 \\
361\end{array}$ & $\begin{array}{r}11 \\
14 \\
7 \\
8 \\
2\end{array}$ & $\begin{array}{l}99.0 \\
7.40 \\
205 \\
194 \\
314\end{array}$ & $\begin{array}{r}11 \\
14 \\
7 \\
8 \\
3\end{array}$ & $\begin{array}{c}83.0 \\
5.90 \\
178 \\
162 \\
290\end{array}$ & $\begin{array}{r}11 \\
14 \\
7 \\
8 \\
2\end{array}$ & $\begin{array}{c}63.0 \\
5.00 \\
140 \\
121 \\
208\end{array}$ & $\begin{array}{r}12 \\
14 \\
6 \\
8 \\
1\end{array}$ & $\begin{array}{c}49.0 \\
4.50 \\
112 \\
91.0 \\
152\end{array}$ & $\begin{array}{r}12 \\
14 \\
6 \\
9 \\
1\end{array}$ & $\begin{array}{c}39.0 \\
4.20 \\
88.0 \\
72.0 \\
119\end{array}$ & $\begin{array}{r}12 \\
14 \\
6 \\
9 \\
1\end{array}$ & $\begin{array}{c}28.0 \\
3.10 \\
60.0 \\
50.0 \\
81.0\end{array}$ & $\begin{array}{r}12 \\
14 \\
6 \\
9 \\
1\end{array}$ & $\begin{array}{c}17.0 \\
2.20 \\
32.0 \\
27.0 \\
43.0\end{array}$ & $\begin{array}{r}12 \\
14 \\
6 \\
9 \\
1\end{array}$ \\
\hline
\end{tabular}


GREEN RIVER BASIN

09312600 WHITE RIVER BELOW TFBBYUNE OREEK, NEAR SOLDIER SUMMTT, UT-COntinued

DURATION OF DISGHARGE FOR EACH WATER YEAR

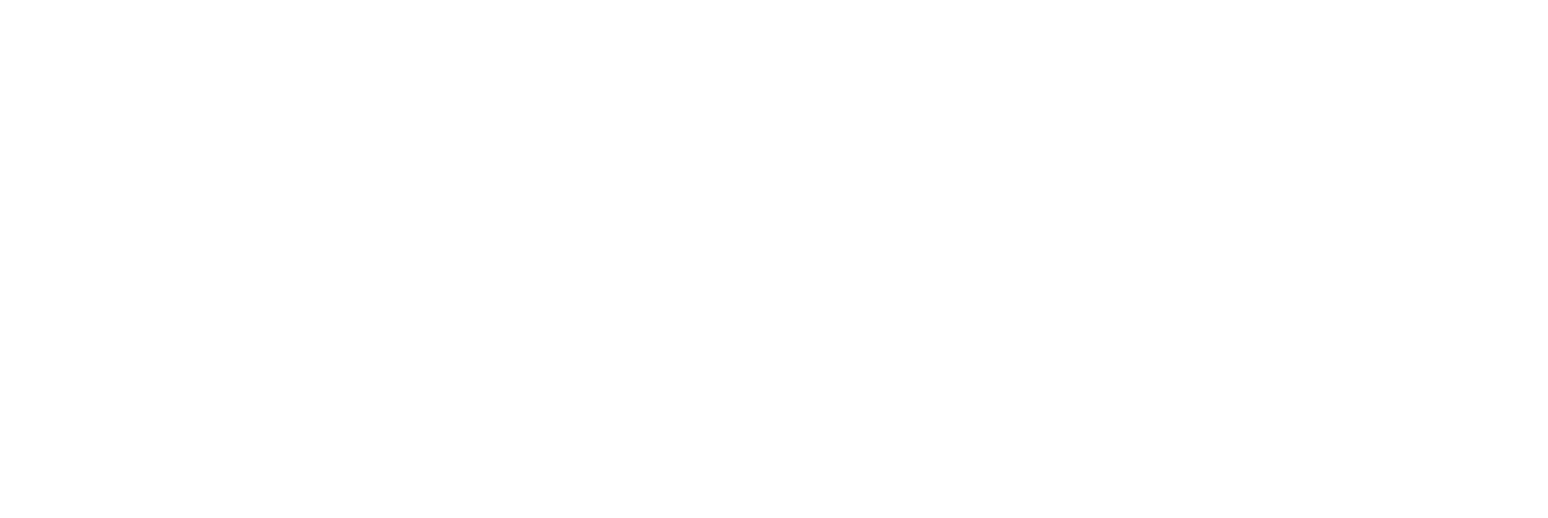

DURATTON TFBLE OF DISQHARGE FOR WATER YEARS 1968-81

\begin{tabular}{|c|c|c|c|c|c|c|c|c|c|c|c|c|c|c|c|c|c|c|c|}
\hline LASS & $\begin{array}{c}\text { OUBIC } \\
\text { FEET } \\
\text { PER } \\
\text { SECOND }\end{array}$ & $\begin{array}{c}\text { TOTAL } \\
\text { DAYS }\end{array}$ & $\begin{array}{c}\text { ACOU- } \\
\text { MU- } \\
\text { LAMED } \\
\text { DASS }\end{array}$ & $\begin{array}{l}\text { PER- } \\
\text { CENT } \\
\text { DAYS }\end{array}$ & CASS & $\begin{array}{l}\text { OBIC } \\
\text { FEET } \\
\text { PER } \\
\text { SECOND }\end{array}$ & $\begin{array}{l}\text { TOTAL } \\
\text { DAYS }\end{array}$ & $\begin{array}{c}\text { ACOU- } \\
\text { WU- } \\
\text { LAIED } \\
\text { DAYS }\end{array}$ & $\begin{array}{l}\text { PER- } \\
\text { GENT } \\
\text { DAYS }\end{array}$ & C.ASS & $\begin{array}{c}\text { CUBIC } \\
\text { FEET } \\
\text { PER } \\
\text { SECOND }\end{array}$ & $\begin{array}{l}\text { TOTAL } \\
\text { DAYS }\end{array}$ & $\begin{array}{c}\text { ACOU- } \\
\text { MU- } \\
\text { LATED } \\
\text { DAYS }\end{array}$ & $\begin{array}{l}\text { PER- } \\
\text { CENT } \\
\text { DAYS }\end{array}$ & C.ASS & $\begin{array}{l}\text { CBIC } \\
\text { FEET } \\
\text { PER } \\
\text { SECOND }\end{array}$ & $\begin{array}{l}\text { TOTAL } \\
\text { DAYS }\end{array}$ & $\begin{array}{c}\text { ACOU- } \\
\text { MU- } \\
\text { LAIED } \\
\text { DAYS }\end{array}$ & $\begin{array}{l}\text { PER- } \\
\text { CENT } \\
\text { DAYSS }\end{array}$ \\
\hline $\begin{array}{l}0 \\
1 \\
2 \\
3 \\
4 \\
5 \\
6 \\
7 \\
8\end{array}$ & $\begin{array}{l}0.00 \\
0.02 \\
0.03 \\
0.04 \\
0.05 \\
0.07 \\
0.09 \\
0.12 \\
0.17\end{array}$ & $\begin{array}{r}49 \\
5 \\
0 \\
6 \\
4 \\
0 \\
4 \\
2 \\
4\end{array}$ & $\begin{array}{l}5114 \\
5065 \\
5060 \\
5060 \\
5054 \\
5050 \\
5050 \\
5046 \\
5044\end{array}$ & $\begin{array}{r}100.0 \\
99.0 \\
98.9 \\
98.9 \\
98.8 \\
98.7 \\
98.7 \\
98.7 \\
98.6\end{array}$ & $\begin{array}{r}9 \\
10 \\
11 \\
12 \\
13 \\
14 \\
15 \\
16 \\
17\end{array}$ & $\begin{array}{l}0.23 \\
0.31 \\
0.42 \\
0.56 \\
0.76 \\
1.00 \\
1.40 \\
1.90 \\
2.60\end{array}$ & $\begin{array}{r}10 \\
12 \\
3 \\
20 \\
13 \\
45 \\
111 \\
202 \\
395\end{array}$ & $\begin{array}{l}5040 \\
5030 \\
5018 \\
5015 \\
4995 \\
4982 \\
4937 \\
4826 \\
4624\end{array}$ & $\begin{array}{l}98.6 \\
98.4 \\
98.1 \\
98.1 \\
97.7 \\
97.4 \\
96.5 \\
94.4 \\
90.4\end{array}$ & $\begin{array}{l}18 \\
19 \\
20 \\
21 \\
22 \\
23 \\
24 \\
25 \\
26\end{array}$ & $\begin{array}{r}3.5 \\
4.7 \\
6.4 \\
8.7 \\
12.0 \\
16.0 \\
22.0 \\
29.0 \\
40.0\end{array}$ & $\begin{array}{r}540 \\
1186 \\
728 \\
228 \\
178 \\
181 \\
149 \\
174 \\
175\end{array}$ & $\begin{array}{r}4229 \\
3689 \\
2503 \\
1775 \\
1547 \\
1369 \\
1188 \\
1039 \\
865\end{array}$ & $\begin{array}{l}82.7 \\
72.1 \\
48.9 \\
34.7 \\
30.3 \\
26.8 \\
23.2 \\
20.3 \\
16.9\end{array}$ & $\begin{array}{l}27 \\
28 \\
29 \\
30 \\
31 \\
32 \\
33 \\
34\end{array}$ & $\begin{array}{r}54.0 \\
73.0 \\
98.0 \\
130.0 \\
180.0 \\
240.0 \\
330.0 \\
450.0\end{array}$ & $\begin{array}{r}137 \\
142 \\
120 \\
108 \\
88 \\
62 \\
32 \\
1\end{array}$ & $\begin{array}{r}690 \\
553 \\
411 \\
291 \\
183 \\
95 \\
33 \\
1\end{array}$ & $\begin{array}{r}13.5 \\
10.8 \\
8.0 \\
5.7 \\
3.6 \\
1.9 \\
0.6 \\
0.0\end{array}$ \\
\hline
\end{tabular}

MONTHLY MEAN DISCHARGES, IN CUBIC FEET PER SECOND, FOR EACH WATER YEAR

\begin{tabular}{|c|c|c|c|c|c|c|c|c|c|c|c|c|}
\hline YEAR & $\infty C T$ & NOV & DEC & JAN & FEB & MAR & APR & MAY & JUNE & JULY & AUG & SEP \\
\hline $\begin{array}{l}1968 \\
1969 \\
1970\end{array}$ & $\begin{array}{l}7.49 \\
6.65 \\
7.22\end{array}$ & $\begin{array}{l}7.03 \\
6.34 \\
5.56\end{array}$ & $\begin{array}{l}5.18 \\
2.43 \\
5.36\end{array}$ & $\begin{array}{l}5.02 \\
2.00 \\
3.63\end{array}$ & $\begin{array}{l}5.74 \\
1.90 \\
5.40\end{array}$ & $\begin{array}{c}12.1 \\
7.95 \\
6.74\end{array}$ & $\begin{array}{c}41.0 \\
140 \\
18.7\end{array}$ & $\begin{array}{l}230 \\
195 \\
120\end{array}$ & $\begin{array}{l}85.7 \\
42.4 \\
43.0\end{array}$ & $\begin{array}{l}25.2 \\
14.8 \\
15.8\end{array}$ & $\begin{array}{c}12.1 \\
8.06 \\
7.55\end{array}$ & $\begin{array}{l}6.64 \\
5.53 \\
5.42\end{array}$ \\
\hline $\begin{array}{l}1971 \\
1972 \\
1973 \\
1974 \\
1975\end{array}$ & $\begin{array}{l}6.71 \\
6.84 \\
5.13 \\
5.73 \\
5.08\end{array}$ & $\begin{array}{l}5.87 \\
5.99 \\
4.02 \\
5.20 \\
5.18\end{array}$ & $\begin{array}{l}6.48 \\
6.15 \\
4.47 \\
5.20 \\
3.35\end{array}$ & $\begin{array}{l}5.33 \\
4.84 \\
5.02 \\
5.00 \\
3.87\end{array}$ & $\begin{array}{l}5.38 \\
5.88 \\
5.17 \\
4.35 \\
4.68\end{array}$ & $\begin{array}{c}15.0 \\
43.1 \\
8.23 \\
10.5 \\
6.65\end{array}$ & $\begin{array}{l}88.3 \\
61.7 \\
54.4 \\
61.5 \\
21.2\end{array}$ & $\begin{array}{l}137 \\
73.5 \\
288 \\
174 \\
189\end{array}$ & $\begin{array}{r}45.6 \\
23.8 \\
81.0 \\
53.7 \\
161\end{array}$ & $\begin{array}{c}12.6 \\
6.90 \\
19.2 \\
12.0 \\
40.6\end{array}$ & $\begin{array}{r}6.35 \\
4.00 \\
8.19 \\
5.18 \\
14.8\end{array}$ & $\begin{array}{l}4.71 \\
4.49 \\
5.35 \\
2.71 \\
7.72\end{array}$ \\
\hline $\begin{array}{l}1976 \\
1977 \\
1978 \\
1979 \\
1980\end{array}$ & $\begin{array}{l}6.83 \\
3.15 \\
1.60 \\
3.62 \\
3.57\end{array}$ & $\begin{array}{l}6.55 \\
2.85 \\
2.70 \\
4.78 \\
4.51\end{array}$ & $\begin{array}{l}6.80 \\
1.46 \\
2.95 \\
4.73 \\
3.16\end{array}$ & $\begin{array}{l}6.66 \\
0.64 \\
3.00 \\
1.75 \\
5.22\end{array}$ & $\begin{array}{l}5.25 \\
2.33 \\
3.00 \\
3.57 \\
5.08\end{array}$ & $\begin{array}{c}10.7 \\
3.50 \\
15.1 \\
7.33 \\
5.72\end{array}$ & $\begin{array}{l}42.8 \\
5.68 \\
94.9 \\
56.9 \\
84.2\end{array}$ & $\begin{array}{c}80.7 \\
4.37 \\
174 \\
160 \\
278\end{array}$ & $\begin{array}{l}21.0 \\
1.95 \\
58.8 \\
50.0 \\
77.2\end{array}$ & $\begin{array}{l}5.74 \\
0.48 \\
12.0 \\
16.0 \\
25.0\end{array}$ & $\begin{array}{l}2.80 \\
0.02 \\
4.93 \\
6.43 \\
8.81\end{array}$ & $\begin{array}{c}2.53 \\
0.12 \\
3.26 \\
2.87 \\
11.7\end{array}$ \\
\hline 1981 & 6.82 & 5.55 & 3.97 & 4.84 & 5.89 & 7.49 & 29.7 & 30.5 & 24.1 & 7.61 & 2.26 & 2.83 \\
\hline
\end{tabular}

ANNUAL PEAK DISCHARGE, IN OUBIC FEET PER SECOND, AND CORRESPONDING GAGE HEIGHT, IN FEET, FOR EACH WAIER YEAR

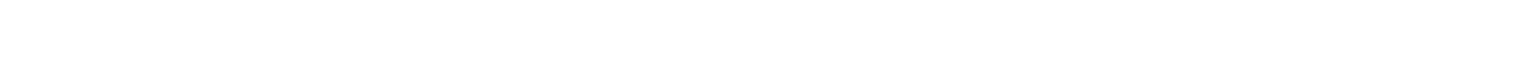

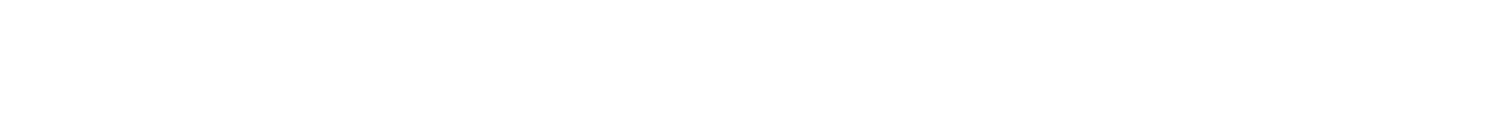


GREEN RTVER BASTN

09312700 BEAVER CREEK NEAR SOLDIER SUMMIT, UT

LOCATION. -Lat $39^{\circ} 49^{\prime} 50^{\prime \prime}$, long $110^{\circ} 58^{\prime} 07^{\prime \prime}$, in NW' bank $0.5 \mathrm{mi}$ upstream from mouth, $2.5 \mathrm{mi}$ southeast of Colton, and $9.1 \mathrm{mi}$ southeast of Soldier Sumit.

DRAINAGE AREA. $--26.1 \mathrm{mi}^{2}$.

MEAN BASIN ELEVATION. $--8,750 \mathrm{ft}$.

PERIOD OF RECORD AVAIIABLE.--October 1960 to Septenber 1981.

REVISED RECORDS. -WDR UT-77-1: Drainage area.

GAGE.-Water-stage recorder and concrete control. Altitude of gage is 7,200 ft from topographic map.

AVERAGE DISCHARGE. --21 years, $3.88 \mathrm{ft}^{3} / \mathrm{s}, 2,810 \mathrm{acre}-\mathrm{ft} / \mathrm{yr}$.

EXIREMES FOR PERIOD OF RECORD.--Maximum discharge, $135 \mathrm{ft}^{3} / \mathrm{s}$ May 19, 1973 and May 17, 1979, gage height, $2.71 \mathrm{ft}$; no flow for many days sane years.

LOWEST MEAN DISCHARGE, IN CUBIC FEET PER SEOOND, AND RANKING FOR THE INDICATED NUMBER OF CONSECUTIVE DAYS FOR EACH CLIMATIC YEAR, APRIL 1-MARCH 31

YE
196
196
1964
1965
1966
1967
1968
1969
1970
1971
1972
1973
1974
1975
1976
1977
1978
1979
1980
1981

\begin{tabular}{|c|c|c|c|}
\hline 1 & & 3 & 7 \\
\hline $\begin{array}{l}0.00 \\
0.00 \\
0.00 \\
0.00\end{array}$ & $\begin{array}{l}1 \\
2 \\
3 \\
4\end{array}$ & $\begin{array}{ll}0.00 & 1 \\
0.00 & 2 \\
0.00 & 3 \\
0.00 & 4\end{array}$ & $\begin{array}{ll}0.00 & 1 \\
0.00 & 2 \\
0.00 & 3 \\
0.00 & 4\end{array}$ \\
\hline $\begin{array}{l}1.19 \\
0.10 \\
0.50 \\
0.98 \\
1.00\end{array}$ & $\begin{array}{l}19 \\
13 \\
16 \\
17 \\
18\end{array}$ & $\begin{array}{ll}1.4019 \\
0.1013 \\
0.5316 \\
1.1917 \\
1.1918\end{array}$ & $\begin{array}{l}1.4019 \\
0.1613 \\
0.6316 \\
1.1917 \\
1.3018\end{array}$ \\
\hline $\begin{array}{l}0.44 \\
0.01 \\
0.00 \\
1.40 \\
0.01\end{array}$ & $\begin{array}{r}14 \\
9 \\
5 \\
20 \\
10\end{array}$ & $\begin{array}{rr}0.48 & 15 \\
0.01 & 9 \\
0.00 & 5 \\
1.50 & 20 \\
0.01 & 10\end{array}$ & $\begin{array}{ll}0.57 & 15 \\
0.04 & 10 \\
0.00 & 5 \\
1.50 & 20 \\
0.04 & 11\end{array}$ \\
\hline $\begin{array}{l}0.44 \\
0.00 \\
0.00 \\
0.01 \\
0.04\end{array}$ & $\begin{array}{r}15 \\
6 \\
7 \\
8 \\
12\end{array}$ & $\begin{array}{rr}0.47 & 14 \\
0.00 & 6 \\
0.00 & 7 \\
0.01 & 8 \\
0.04 & 12\end{array}$ & $\begin{array}{lr}0.55 & 14 \\
0.00 & 6 \\
0.00 & 7 \\
0.01 & 8 \\
0.04 & 12\end{array}$ \\
\hline
\end{tabular}

0.0311

0.039
14

0.001

0.002

0.003

0.004

1.5020

0.1913

0.7016

1.1917

0.6114

0.1312

$0.00 \quad 5$

1.5019

0.0511

0.6515

0.006

0.007

$\begin{array}{lr}0.01 & 8 \\ 0.04 & 10\end{array}$

0.039
CONSECUTTVE DAYS

$30 \quad 60$

$0.03 \quad 8$

0.003

0.001

$\begin{array}{ll}0.00 & 1 \\ 0.00 & 2\end{array}$

1.6020

$\begin{array}{lll}1.6020 & 1.7020 \\ 0.4913 & 0.5713\end{array}$

0.7314

1.1917
1.4018

0.9115
1.3017

1.5018

0.7515

0.2712

0.00

0.8514

0.2912

0.058

1.5019

0.1311

0.0711

1.1016

0.005

0.006

0.017

0.0410

0.003

0.014

$\begin{array}{lr}90 & \\ 0.05 & 8 \\ 0.16 & 10 \\ 0.00 & 1 \\ 0.00 & 2 \\ 1.70 & 20 \\ 0.65 & 13 \\ 1.00 & 15 \\ 1.30 & 17 \\ 1.60 & 19 \\ 0.91 & 14 \\ 0.36 & 12 \\ 0.10 & 9 \\ 1.50 & 18 \\ 0.23 & 11 \\ 1.19 & 16 \\ 0.03 & 5 \\ 0.00 & 3 \\ 0.01 & 4 \\ 0.05 & 6\end{array}$

120

183

ALL

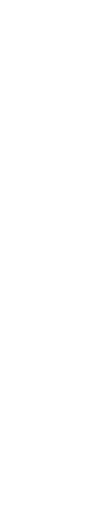

0.157

0.229

$\begin{array}{llll}0.08 & 4 & 1.10 & 3 \\ 0.02 & 3 & 2.50 & 8\end{array}$

$\begin{array}{ll}2.0020 & 9.2019\end{array}$

$0.8913 \quad 2.709$

$1.1915 \quad 4.2013$

$\begin{array}{ll}1.5017 & 5.7015 \\ 1.7019 & 7.7017\end{array}$

$1.1014 \quad 3.4012$

$0.7111 \quad 3.2010$

$\begin{array}{lll}0.7812 \quad 1.70 \quad 4 & 12\end{array}$

$\begin{array}{lll}1.6018 & 11.0 & 20\end{array}$

$\begin{array}{llll}0.44 \quad 10 & 2.20 \quad 7\end{array}$

I. 4016

0.218

6.2016

$\begin{array}{llll}0.00 & 1 & 1.80 & 6 \\ 0.02 & 0.28 & 1\end{array}$

$\begin{array}{llll}0.02 & 2 & 1.70 & 5\end{array}$

$\begin{array}{llll}0.10 & 6 & 3.4011\end{array}$

$\begin{array}{lllllllll}0.04 & 6 & 0.05 & 7 & 0.06 & 6 & 0.09 & 5 & 7.8018\end{array}$

HIGHEST MEAN DISCHARGE, IN OABIC FEET PER SECOND, AND RANKTNG FOR THE INDICATED NUMBER OF CONSECUTIVE DAYS FOR EACH WATER YEAR, OCTCBER I-SEPTEMBER 30

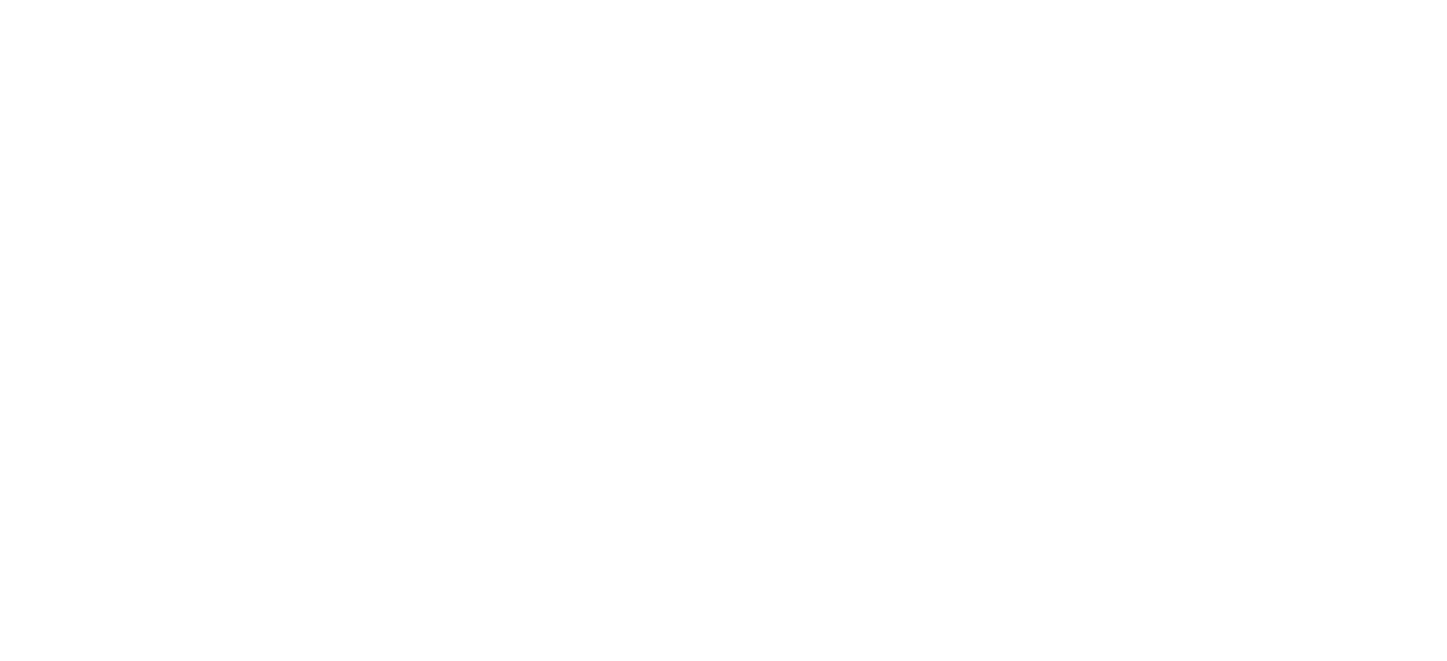


GREEN RIVER BASIN

09312700 BEAVER CREEK NEAR SOLDIER SUMMIT, UT-Continued

DURATION OF DISCHARGE FOR EACH WATER YEAR

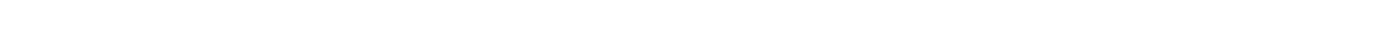

YEAR

NUMBER OF DAYS IN CLASS

CUBIC FEET

-DAYS

1961202

196271

196370

196592

$\begin{array}{llllllllllllllll}51 & 16 & 8 & 8 & 2 & 5 & 2 & 18 & 21 & 15 & 5 & 6 & 2 & 1 & 3\end{array}$

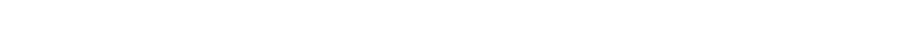

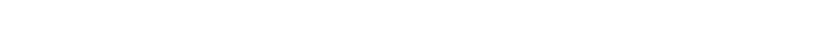

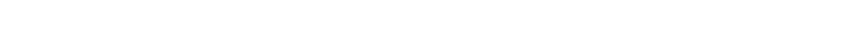

170.6

1861.6

496.0

843.1
3028.8

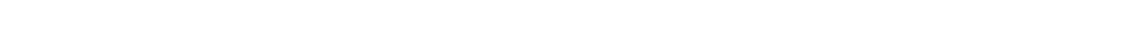

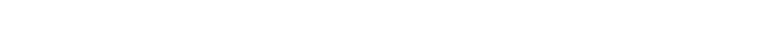

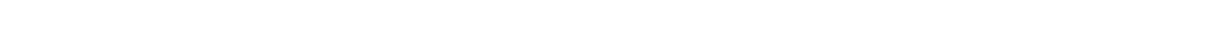

1169.4

1521.2

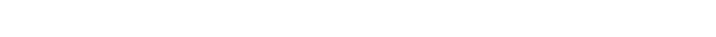

2016.9

2733.0

$\begin{array}{lllllllllllllllllllllllllllllll}1971 & 4 & 4 & 1 & & 4 & 3 & 3 & 14 & 14 & 5 & 11 & 7 & 46 & 30 & 101 & 22 & 11 & 7 & 23 & 14 & 5 & 13 & 9 & 13 & 5\end{array}$

$\begin{array}{lllllllllllllllllllllllll}1971 & & 4 & & & 1 & & 4 & 3 & 3 & 14 & 14 & 5 & 11 & 7 & 46 & 30 & 101 & 22 & 11 & 7 & 23 & 14 & 5 & 13 \\ 1972 & 44 & 3 & 1 & 1 & & 1 & 7 & 1 & 7 & 10 & 1 & 20 & 13 & 37 & 47 & 40 & 25 & 15 & 21 & 31 & 19 & 20 & 2 \\ 1973 & & & & & & & & & 1 & 2 & & 1 & 2 & 3 & 5 & 128 & 23 & 55 & 25 & 21 & 14 & 8 & 8\end{array}$

$\begin{array}{llll}19 & 20 & 208 \\ 564.0 & & \end{array}$

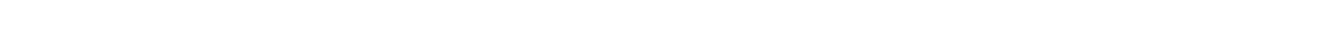

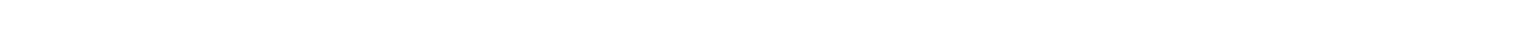

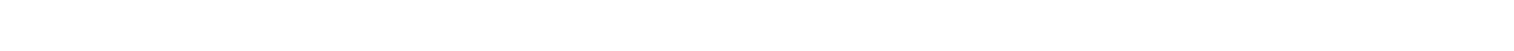

$\begin{array}{lllllllllllllllllllllllllllll}1977 & 81 & 33 & 26 & 14 & 47 & 31 & 5 & 4 & 5 & 4 & 51 & 18 & 10 & 12 & 5 & 5 & 4 & 8 & 2 & & & & & & & & & \end{array}$

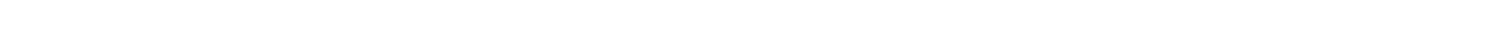

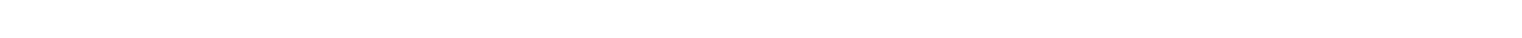

$\begin{array}{lllllllllllllllllllllll}1981 & 46 & 45 & 52 & 24 & 46 & 28 & 44 & 11 & 12 & 8 & 11 & 8 & 4 & & 2 & 6 & 5 & 4 & 7 & 1 & 1 & \end{array}$

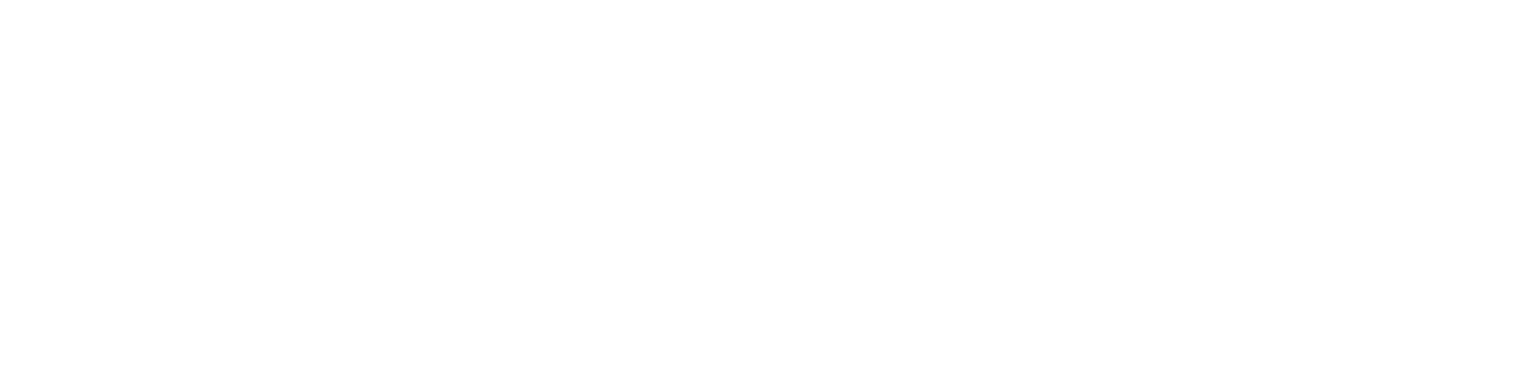

MONIHLY MEAN DISCHARGES, IN CUBIC FEET PER SECOND, FOR EACH WATER YEAR

\begin{tabular}{|c|c|c|c|c|c|c|c|c|c|c|c|c|}
\hline YEAR & $\propto T$ & NOW & DEC & JAN & FEB & MAR & APR & MAY & JUNE & JULY & AUG & SEP \\
\hline $\begin{array}{l}1961 \\
1962 \\
1963 \\
1964 \\
1965\end{array}$ & $\begin{array}{l}0.00 \\
0.04 \\
0.36 \\
0.25 \\
0.00\end{array}$ & $\begin{array}{l}0.00 \\
0.08 \\
0.37 \\
0.24 \\
0.00\end{array}$ & $\begin{array}{l}0.00 \\
0.04 \\
0.28 \\
0.01 \\
0.00\end{array}$ & $\begin{array}{l}0.00 \\
0.39 \\
0.03 \\
0.00 \\
0.30\end{array}$ & $\begin{array}{l}0.04 \\
0.64 \\
0.21 \\
0.00 \\
0.75\end{array}$ & $\begin{array}{l}0.69 \\
0.89 \\
1.89 \\
0.15 \\
1.33\end{array}$ & $\begin{array}{c}2.70 \\
14.6 \\
3.06 \\
5.13 \\
6.23\end{array}$ & $\begin{array}{c}1.28 \\
33.0 \\
8.14 \\
14.3 \\
35.5\end{array}$ & $\begin{array}{c}0.16 \\
9.22 \\
1.19 \\
7.20 \\
35.8\end{array}$ & $\begin{array}{c}0.07 \\
1.48 \\
0.11 \\
0.36 \\
12.9\end{array}$ & $\begin{array}{l}0.20 \\
0.29 \\
0.24 \\
0.00 \\
4.26\end{array}$ & $\begin{array}{l}0.47 \\
0.22 \\
0.31 \\
0.00 \\
2.14\end{array}$ \\
\hline $\begin{array}{l}1966 \\
1967 \\
1968 \\
1969 \\
1970\end{array}$ & $\begin{array}{l}2.19 \\
0.86 \\
1.09 \\
1.64 \\
2.04\end{array}$ & $\begin{array}{l}2.23 \\
0.74 \\
0.75 \\
1.65 \\
1.57\end{array}$ & $\begin{array}{l}1.81 \\
1.49 \\
1.56 \\
1.20 \\
1.50\end{array}$ & $\begin{array}{l}1.72 \\
1.08 \\
1.22 \\
1.42 \\
1.83\end{array}$ & $\begin{array}{l}1.75 \\
1.17 \\
1.17 \\
1.49 \\
1.77\end{array}$ & $\begin{array}{l}3.33 \\
1.72 \\
1.54 \\
1.66 \\
2.37\end{array}$ & $\begin{array}{c}8.11 \\
3.00 \\
3.47 \\
13.0 \\
3.21\end{array}$ & $\begin{array}{l}10.9 \\
12.5 \\
24.8 \\
45.0 \\
15.5\end{array}$ & $\begin{array}{c}3.87 \\
18.5 \\
21.3 \\
14.7 \\
9.27\end{array}$ & $\begin{array}{l}1.14 \\
5.94 \\
4.91 \\
4.23 \\
2.58\end{array}$ & $\begin{array}{l}0.52 \\
1.67 \\
2.70 \\
1.98 \\
0.92\end{array}$ & $\begin{array}{l}0.77 \\
1.28 \\
1.45 \\
1.39 \\
0.88\end{array}$ \\
\hline $\begin{array}{l}1971 \\
1972 \\
1973 \\
1974 \\
1975\end{array}$ & $\begin{array}{l}1.05 \\
0.75 \\
2.19 \\
1.64 \\
0.66\end{array}$ & $\begin{array}{l}0.93 \\
1.04 \\
1.07 \\
1.50 \\
0.81\end{array}$ & $\begin{array}{l}1.29 \\
1.20 \\
1.10 \\
1.50 \\
0.51\end{array}$ & $\begin{array}{l}2.39 \\
0.74 \\
1.10 \\
1.50 \\
0.40\end{array}$ & $\begin{array}{l}1.55 \\
0.71 \\
1.10 \\
1.55 \\
1.26\end{array}$ & $\begin{array}{l}2.15 \\
2.29 \\
1.61 \\
1.94 \\
1.30\end{array}$ & $\begin{array}{l}4.54 \\
3.20 \\
6.63 \\
4.65 \\
2.59\end{array}$ & $\begin{array}{c}16.8 \\
5.19 \\
75.1 \\
13.2 \\
19.7\end{array}$ & $\begin{array}{c}7.97 \\
2.99 \\
25.1 \\
2.42 \\
31.4\end{array}$ & $\begin{array}{l}1.28 \\
0.24 \\
5.61 \\
0.90 \\
8.27\end{array}$ & $\begin{array}{l}0.31 \\
0.05 \\
2.51 \\
0.18 \\
1.81\end{array}$ & $\begin{array}{l}0.27 \\
0.07 \\
1.83 \\
0.11 \\
1.07\end{array}$ \\
\hline $\begin{array}{l}1976 \\
1977 \\
1978 \\
1979 \\
1980\end{array}$ & $\begin{array}{l}1.34 \\
0.51 \\
0.01 \\
0.01 \\
0.16\end{array}$ & $\begin{array}{l}1.46 \\
0.53 \\
0.01 \\
0.02 \\
0.15\end{array}$ & $\begin{array}{l}1.50 \\
0.07 \\
0.01 \\
0.02 \\
0.13\end{array}$ & $\begin{array}{l}1.55 \\
0.01 \\
0.00 \\
0.01 \\
0.07\end{array}$ & $\begin{array}{l}1.96 \\
0.03 \\
0.01 \\
0.01 \\
0.05\end{array}$ & $\begin{array}{l}2.00 \\
0.09 \\
0.26 \\
0.07 \\
0.04\end{array}$ & $\begin{array}{l}3.53 \\
1.75 \\
2.86 \\
2.64 \\
6.48\end{array}$ & $\begin{array}{c}12.1 \\
1.18 \\
10.9 \\
23.2 \\
55.5\end{array}$ & $\begin{array}{c}3.41 \\
0.13 \\
5.72 \\
10.3 \\
25.5\end{array}$ & $\begin{array}{l}0.86 \\
0.03 \\
0.37 \\
2.23 \\
4.04\end{array}$ & $\begin{array}{l}0.42 \\
0.01 \\
0.11 \\
1.12 \\
0.46\end{array}$ & $\begin{array}{l}0.43 \\
0.00 \\
0.02 \\
0.30 \\
0.30\end{array}$ \\
\hline 1981 & 0.14 & 0.14 & 0.06 & 0.04 & 0.05 & 0.17 & 2.68 & 0.76 & 0.11 & 0.04 & 0.01 & 0.02 \\
\hline
\end{tabular}


GREEN RIVER BASIN

09312700 BEAVER CREEK NEAR SOTDIER SUMMIT, UT-Continued

ANNUAL, PEAK DISCHARGE, IN OBBIC FEET PER SECOND, AND CORRESPONDING GAGE HEIGHT, IN FEET, FOR EACH WATER YEAR

\begin{tabular}{|c|c|c|c|c|c|c|c|c|c|c|c|c|}
\hline $\begin{array}{l}\text { WATER } \\
\text { YEAR }\end{array}$ & DATE & $\begin{array}{c}\text { GAGE } \\
\text { HEIGHT }\end{array}$ & $\begin{array}{c}\text { PEAR } \\
\text { DISGHARGE }\end{array}$ & $\begin{array}{l}\text { WATER } \\
\text { YEAR }\end{array}$ & & DATE & $\begin{array}{c}\text { GAGE } \\
\text { HEIGHT }\end{array}$ & $\begin{array}{c}\text { PEAK } \\
\text { DISCHARGE }\end{array}$ & $\begin{array}{l}\text { WATER } \\
\text { YEAR }\end{array}$ & DATE & $\begin{array}{c}\text { GAGE } \\
\text { HEIGHT }\end{array}$ & $\begin{array}{c}\text { PEAK } \\
\text { DISCHARG }\end{array}$ \\
\hline 1961 & FUG. 02,1961 & 2.32 & 63 & 1968 & MAY & 22,1968 & 1.87 & 48 & 1975 & JUNE 04, 1975 & 1.83 & 57 \\
\hline 1962 & 06,1962 & 1.77 & 68 & 1969 & MAY & 14,1969 & - & $1_{62}$ & 1976 & MAY 22,1976 & 1.40 & 23 \\
\hline 1963 & APR. 08,1963 & 1.52 & 27 & 1970 & MAY & 18,1970 & - & ${ }^{I_{28}}$ & 1977 & APR. 10,1977 & -- & 14.0 \\
\hline $\begin{array}{l}1964 \\
1965 \\
1966 \\
1967\end{array}$ & $\begin{array}{ll}\text { MAY } & 19,1964 \\
\text { MAY } & 20,1965 \\
\text { MAY } & 10,1966 \\
\text { JULY } & 16,1967\end{array}$ & $\begin{array}{l}1.79 \\
1.81 \\
1.52 \\
1.81\end{array}$ & $\begin{array}{l}45 \\
58 \\
33 \\
86\end{array}$ & $\begin{array}{l}1971 \\
1972 \\
1973 \\
1974\end{array}$ & $\begin{array}{l}\text { MAY } \\
\text { MAY } \\
\text { MAY } \\
\text { MAY }\end{array}$ & $\begin{array}{ll}16, & 1971 \\
15, & 1972 \\
19, & 1973 \\
07, & 1974\end{array}$ & $\begin{array}{l}1.50 \\
1.26 \\
2.71 \\
1.44\end{array}$ & $\begin{array}{r}30 \\
11 \\
135 \\
25\end{array}$ & $\begin{array}{l}1978 \\
1979 \\
1980 \\
1981\end{array}$ & $\begin{array}{ll}\text { MAY } & 16,1978 \\
\text { MAY } & 17,1979 \\
\text { MAY } & 23,1980 \\
\text { APR. } & 19,1981\end{array}$ & $\begin{array}{l}1.43 \\
2.65 \\
2.23 \\
1.13\end{array}$ & $\begin{array}{r}125 \\
135 \\
93 \\
12\end{array}$ \\
\hline
\end{tabular}

MAGNITUDE AND PROBABIIITY OF ANNUAL, LOWEST MEAN DISGHARGE

\begin{tabular}{|c|c|c|c|c|c|c|}
\hline \multirow{2}{*}{$\begin{array}{l}\text { PERIOD } \\
\text { (CON- } \\
\text { SEQU- } \\
\text { TIVE } \\
\text { DAVS) }\end{array}$} & \multicolumn{6}{|c|}{$\begin{array}{l}\text { DISGHARGE, IN OUBIC FEET PER SECOND, FOR } \\
\text { INDICATED RECURRENCE INTERNAL, IN YEARS, AND } \\
\text { ANNUAL NONEXCEEDANCE PROBABIITY, IN PERCENT }\end{array}$} \\
\hline & $\begin{array}{c}2 \\
508\end{array}$ & $\begin{array}{c}5 \\
208\end{array}$ & $\begin{array}{l}10 \\
108\end{array}$ & $\begin{array}{l}20 \\
58\end{array}$ & $\begin{array}{l}50 \\
28\end{array}$ & $\begin{array}{r}100 \\
18\end{array}$ \\
\hline $\begin{array}{r}1 \\
7 \\
14 \\
30 \\
60 \\
90\end{array}$ & $\begin{array}{l}0.04 \\
0.06 \\
0.07 \\
0.12 \\
0.16 \\
0.21\end{array}$ & $\begin{array}{l}0.00 \\
0.00 \\
0.00 \\
0.00 \\
0.01 \\
0.02\end{array}$ & $\begin{array}{l}0.00 \\
0.00 \\
0.00 \\
0.00 \\
0.00 \\
0.00\end{array}$ & $\begin{array}{l}-- \\
-- \\
-- \\
- \\
-\end{array}$ & $\begin{array}{l}-- \\
- \\
-- \\
-- \\
--\end{array}$ & $\overline{-}$ \\
\hline
\end{tabular}

${ }^{1}$ Maximum daily discharge.

09312800 WIHLOW OREEK NEAR CASTIE GATE, UT

LOCATION.--Lat $39^{\circ} 46^{\prime} 37^{\prime \prime}$, long $110^{\circ} 47^{\prime} 30^{\prime \prime}$, in SW $\frac{1}{4} \mathrm{SE}_{4}^{1} \mathrm{SW}^{\frac{1}{4}}$ sec.15, T.12 S., R.10 E., Carbon County, Hydrologic Unit 14060007, on right bank $130 \mathrm{ft}$ upstream from Deep Canyon, $170 \mathrm{ft}$ east of State Highway $33,1.5 \mathrm{mi}$ downstream fram junction with two major tributaries, $5.1 \mathrm{mi}$ northeast of Castle Gate, $5.4 \mathrm{mi}$ upstream from mouth, and $12.3 \mathrm{mi}$ north of Price.

DRAINAGE AREA. $-62.8 \mathrm{mi}^{2}$.

MEAN BASIN ELEVATION. $-8,120 \mathrm{ft}$.

PERIOD OF RECORD AVALIABLE.--Octcber 1962 to September 1981.

GAGE. - Water-stage recorder and concrete control. Altitude of gage is 7,000 ft fram topographic map.

AVERAGE DISGHARGE. --1 9 years, $8.15 \mathrm{ft}^{3} / \mathrm{s}, 5,900 \mathrm{acre}-\mathrm{ft} / \mathrm{yr}$.

EXTREMES FOR PERIOD OF RECORD.--Maximum discharge, $836 \mathrm{ft}^{3} / \mathrm{s}$ Aug. 6,1973 , gage height, $6.47 \mathrm{ft}$ from floodnarks; no flow on many days.

LOWEST MEAN DISCHARGE, IN OBBIC FEET PER SECOND, AND RANKING FOR THE INDICATED NUMBER OF CONSEQUTTVE DAYS FOR EACH CLIMATIC YEAR, APRIL 1-MARCH 31

YEAR

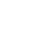

1965

1966

1967

1968
1969

1969
1970

1971

1972

1973
1974

1975

1976

1977

1978
1979

1979
1980

1981

$$
1
$$

0.001

0.002

1.5018

0.003

0.5013

0.00
0.20

0.028

0.2911

0.2810

0.00

0.6916

0.006

$\begin{array}{ll}0.00 & 6 \\ 0.00 & 7\end{array}$

0.4712

0.6014

0.6815

$$
3
$$

0.001

1.5018

1.5018
0.003

0.5013

0.038

0.209

0.027

0.3210

0.3211

1.1917
0.00

0.004

$\begin{array}{lr}0.80 & 16 \\ 0.00 & 5\end{array}$

0.006

0.4712

0.6014

0.6915

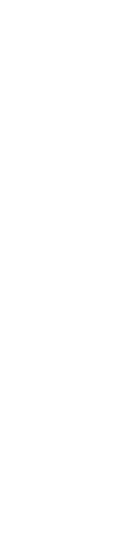

0.9116
14

0.001

1.8018

$\begin{array}{rr}1.80 & 18 \\ 0.07 \quad 6\end{array}$

$\begin{array}{lr}0.07 & 6 \\ 0.50 & 13\end{array}$

0.128

0.209

0.077

0.3510

0.3811

1.4017

0.8015

0.004

$\begin{array}{ll}0.00 & 4 \\ 0.00 & 5\end{array}$

0.4812

0.6014

1.3016 $\begin{array}{ll}\text { CONSECUTIVE DAYS } \\ 30 & 60\end{array}$

0.001

2.1018

2.1018
$0.17 \quad 8$

0.5012

0.167

0.24

$\begin{array}{ll}0.126 \\ 0.45 & 10\end{array}$

0.4510

1.5017

0.003

0.8015

$0.00 \quad 4$

0.005

0.5011

0.6214

1.4016

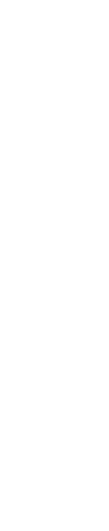

1.5016
90

0.001

2.3018

2.3018
0.426

$0.42 \quad 6$
0.6810

$\begin{array}{ll}0.681 & 10 \\ 0.447\end{array}$

0.468

0.469

0.7311

0.8613

1.7017

0.8312

$\begin{array}{lr}0.83 & 12 \\ 0.01 & 3\end{array}$

$\begin{array}{ll}0.01 & 4 \\ 0.87 & 14\end{array}$

$\begin{array}{ll}0.87 & 14 \\ 0.93 & 15\end{array}$

1.6016
120

0.001

2.8018

$\begin{array}{ll}2.80 & 18 \\ 0.64 & 7\end{array}$

0.8011

$\begin{array}{ll}0.72 & 8 \\ 0.73 & 9\end{array}$

0.546

0.7710

1.1015

1.7016
$0.20 \quad 5$

0.8712

0.094

$\begin{array}{ll}0.09 & 4 \\ 0.03 & 3\end{array}$

$0.91 \quad 13$

1.1014

1.8017
183

0.142

3.1018

3.1018
1.0010

$\begin{array}{rr}1.00 & 10 \\ 0.978\end{array}$

1.3013

1.3014

0.706

$0.82 \quad 7$

1. 8015

1.8016
0.345

$\begin{array}{ll}1.00 & 9 \\ 0.27 & 4\end{array}$

0.274

$\begin{array}{ll}1.10 & 11 \\ 1.3012\end{array}$

2.5017
A. L

$\begin{array}{rr}2.30 & 4 \\ 3.10 & 7\end{array}$

$19.0 \quad 17$

7.6011

5. $40 \quad 9$

$17.0 \quad 14$

$2.50 \quad 5$

3.708

2.906

$18.0 \quad 16$
1.80

8.6012

2.203

$\begin{array}{lll}1.20 & 1\end{array}$

7.6010
20.018

$17.0 \quad 15$ 
GREEN RIVER BASIN

09312800 WILLOW CREEK NEAR CASTLE GATE, UT-Continued

HIGHEST MEAN DISCHARGE, IN OBIC FEET PER SECOND, AND RANKING FOR THE INDICATED NUMBER OF CONSEOUTIVE DAYS FOR EACH WATER YEAR, OCTCBER 1-SEPTEYBER 30

\begin{tabular}{|c|c|c|c|c|c|c|c|c|c|c|c|c|c|c|c|c|c|c|c|}
\hline YEAR & 1 & & 3 & & 7 & & 15 & & $\begin{array}{l}\text { CONSE } \\
30\end{array}$ & & $\begin{array}{c}\text { VE DAYS } \\
60\end{array}$ & & 90 & & 120 & & 183 & & ALL \\
\hline $\begin{array}{l}1966 \\
1967 \\
1968 \\
1969 \\
1970\end{array}$ & $\begin{array}{c}62.0 \\
46.0 \\
83.0 \\
177 \\
31.0\end{array}$ & $\begin{array}{r}9 \\
10 \\
6 \\
5 \\
16\end{array}$ & $\begin{array}{c}60.0 \\
29.0 \\
77.0 \\
166 \\
15.0\end{array}$ & $\begin{array}{r}9 \\
12 \\
6 \\
5 \\
16\end{array}$ & $\begin{array}{c}46.0 \\
27.0 \\
68.0 \\
149 \\
13.0\end{array}$ & $\begin{array}{r}9 \\
12 \\
6 \\
4 \\
17\end{array}$ & $\begin{array}{r}38.0 \\
22.0 \\
65.0 \\
128 \\
11.0\end{array}$ & $\begin{array}{r}9 \\
11 \\
6 \\
3 \\
17\end{array}$ & $\begin{array}{r}37.0 \\
19.0 \\
57.0 \\
112 \\
9.30\end{array}$ & $\begin{array}{r}9 \\
11 \\
6 \\
3 \\
17\end{array}$ & $\begin{array}{c}34.0 \\
16.0 \\
46.0 \\
82.0 \\
7.40\end{array}$ & $\begin{array}{r}8 \\
10 \\
6 \\
3 \\
17\end{array}$ & $\begin{array}{c}29.0 \\
14.0 \\
36.0 \\
62.0 \\
6.70\end{array}$ & $\begin{array}{r}8 \\
10 \\
6 \\
2 \\
17\end{array}$ & $\begin{array}{c}24.0 \\
13.0 \\
29.0 \\
49.0 \\
5.70\end{array}$ & $\begin{array}{r}7 \\
10 \\
6 \\
2 \\
17\end{array}$ & $\begin{array}{c}17.0 \\
10.0 \\
21.0 \\
33.0 \\
4.30\end{array}$ & $\begin{array}{r}7 \\
10 \\
6 \\
3 \\
17\end{array}$ & $\begin{array}{c}9.80 \\
5.70 \\
11.0 \\
17.0 \\
2.70\end{array}$ \\
\hline $\begin{array}{l}1971 \\
1972 \\
1973 \\
1974 \\
1975\end{array}$ & $\begin{array}{c}22.0 \\
17.0 \\
209 \\
9.60 \\
75.0\end{array}$ & $\begin{array}{r}17 \\
18 \\
2 \\
19 \\
8\end{array}$ & $\begin{array}{c}21.0 \\
15.0 \\
206 \\
9.50 \\
69.0\end{array}$ & $\begin{array}{r}14 \\
17 \\
1 \\
19 \\
8\end{array}$ & $\begin{array}{c}18.0 \\
14.0 \\
193 \\
9.10 \\
59.0\end{array}$ & $\begin{array}{r}14 \\
16 \\
1 \\
18 \\
7\end{array}$ & $\begin{array}{c}16.0 \\
14.0 \\
172 \\
8.50 \\
50.0\end{array}$ & $\begin{array}{r}15 \\
16 \\
1 \\
18 \\
8\end{array}$ & $\begin{array}{c}14.0 \\
11.0 \\
143 \\
7.70 \\
46.0\end{array}$ & $\begin{array}{r}14 \\
16 \\
1 \\
18 \\
7\end{array}$ & $\begin{array}{c}11.0 \\
9.60 \\
88.0 \\
6.50 \\
35.0\end{array}$ & $\begin{array}{r}14 \\
15 \\
2 \\
18 \\
7\end{array}$ & $\begin{array}{c}9.10 \\
8.90 \\
62.0 \\
5.40 \\
29.0\end{array}$ & $\begin{array}{r}13 \\
14 \\
3 \\
18 \\
7\end{array}$ & $\begin{array}{c}7.60 \\
7.20 \\
49.0 \\
4.40 \\
23.0\end{array}$ & $\begin{array}{r}13 \\
14 \\
3 \\
18 \\
8\end{array}$ & $\begin{array}{c}5.50 \\
5.10 \\
33.0 \\
3.50 \\
16.0\end{array}$ & $\begin{array}{r}13 \\
14 \\
4 \\
18 \\
8\end{array}$ & $\begin{array}{c}3.10 \\
3.00 \\
18.0 \\
2.40 \\
8.50\end{array}$ \\
\hline $\begin{array}{l}1976 \\
1977 \\
1978 \\
1979 \\
1980\end{array}$ & $\begin{array}{l}33.0 \\
35.0 \\
80.0 \\
198 \\
200\end{array}$ & $\begin{array}{r}15 \\
14 \\
7 \\
4 \\
3\end{array}$ & $\begin{array}{l}18.0 \\
14.0 \\
70.0 \\
180 \\
173\end{array}$ & $\begin{array}{r}15 \\
18 \\
7 \\
3 \\
4\end{array}$ & $\begin{array}{c}18.0 \\
6.20 \\
59.0 \\
166 \\
140\end{array}$ & $\begin{array}{r}15 \\
19 \\
8 \\
2 \\
5\end{array}$ & $\begin{array}{c}17.0 \\
3.30 \\
52.0 \\
139 \\
111\end{array}$ & $\begin{array}{r}14 \\
19 \\
7 \\
2 \\
5\end{array}$ & $\begin{array}{c}13.0 \\
3.00 \\
40.0 \\
136 \\
102\end{array}$ & $\begin{array}{r}15 \\
19 \\
8 \\
2 \\
4\end{array}$ & $\begin{array}{c}9.20 \\
2.20 \\
33.0 \\
101 \\
75.0\end{array}$ & $\begin{array}{r}16 \\
19 \\
9 \\
1 \\
4\end{array}$ & $\begin{array}{l}7.20 \\
1.80 \\
26.0 \\
73.0 \\
56.0\end{array}$ & $\begin{array}{r}16 \\
19 \\
9 \\
1 \\
4\end{array}$ & $\begin{array}{c}6.00 \\
1.60 \\
21.0 \\
57.0 \\
44.0\end{array}$ & $\begin{array}{r}16 \\
19 \\
9 \\
1 \\
5\end{array}$ & $\begin{array}{c}4.40 \\
1.30 \\
14.0 \\
39.0 \\
31.0\end{array}$ & $\begin{array}{r}16 \\
19 \\
9 \\
1 \\
5\end{array}$ & $\begin{array}{c}2.60 \\
0.76 \\
7.30 \\
20.0 \\
16.0\end{array}$ \\
\hline 1981 & 40.0 & 13 & 33.0 & 11 & 28.0 & 11 & 22.0 & 12 & 17.0 & 12 & 12.0 & 12 & 9.70 & 12 & 8.10 & 12 & 6.00 & 11 & 4.10 \\
\hline
\end{tabular}

DURATION OF DISCHARGE FOR EACH WATER YEAR

CLASS $0 \begin{array}{llllllllllllllllllllllllllllllllllllll} & 1 & 2 & 3 & 4 & 5 & 6 & 7 & 8 & 9 & 10 & 11 & 12 & 13 & 14 & 15 & 16 & 17 & 18 & 19 & 20 & 21 & 22 & 23 & 24 & 25 & 26 & 27 & 28 & 29 & 30 & 31 & 32 & 33 & 34\end{array}$ YEAR

NMMBER OF DAYS IN CLASS OBBIC FEET
PER SEOOND

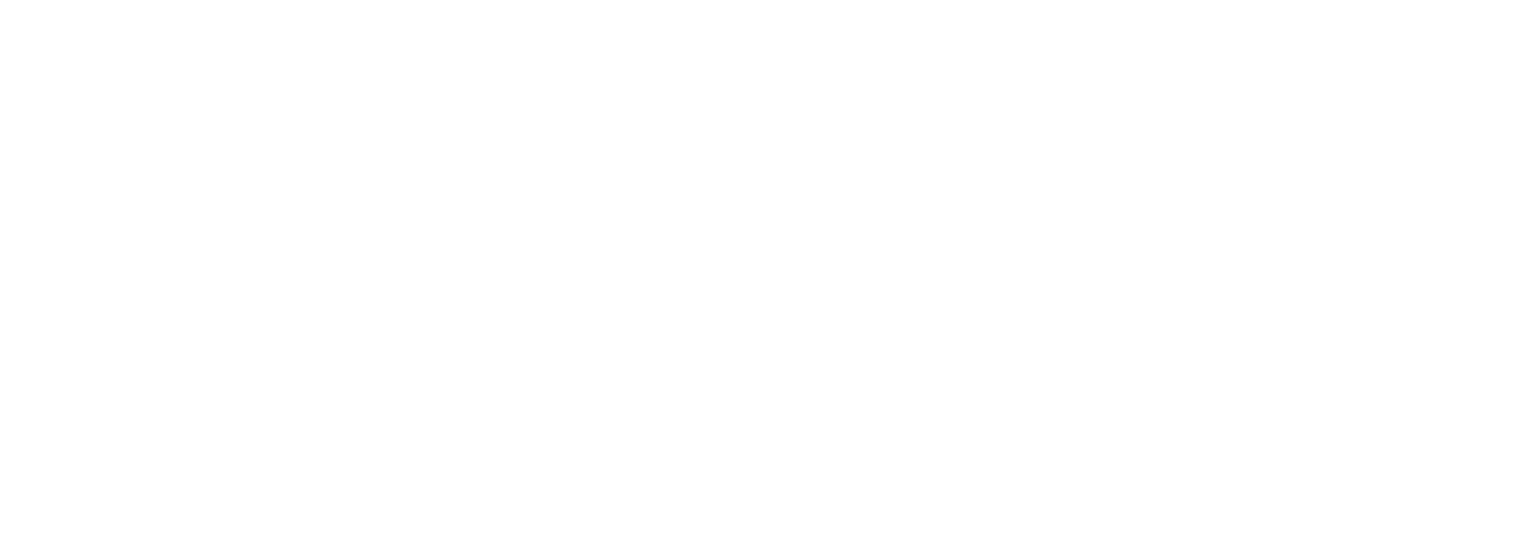

DURATION TABLE OF DISOHARGE FOR WATER YEARS 1963-81

$\begin{array}{crl}\text { CUBIC } & \text { ACOU- } \\ \text { FEET } & \text { MU- } & \text { PER- } \\ \text { PER } & \text { TOTAL LATED } & \text { CENT } \\ \text { CLASS SECOND DAYS DAYS } & \text { DAYS }\end{array}$

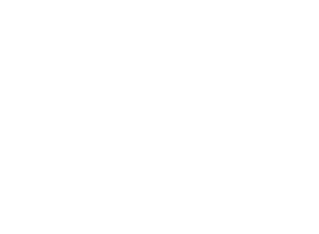

OUBIC AOCI-

PER TOTAL LATED CENT

OLASS SECOND DAYS DAYS DAYS

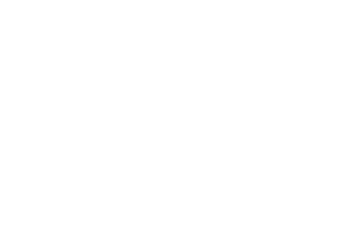

$\begin{array}{lll}\text { ABIC } & \text { ACOU- } \\ \text { FEET } & \text { MU- PER- }\end{array}$ PER TOTAL LATED CENT
CLASS SECOND DAYS DAYS DAYS

$\begin{array}{rrrrr}18 & 3.1 & 430 & 2478 & 35.7 \\ 19 & 4.2 & 334 & 2048 & 29.5 \\ 20 & 5.6 & 296 & 1714 & 24.7 \\ 21 & 7.6 & 284 & 1418 & 20.4 \\ 22 & 10.0 & 223 & 1134 & 16.3 \\ 23 & 14.0 & 184 & 911 & 13.1 \\ 24 & 19.0 & 165 & 727 & 10.5 \\ 25 & 25.0 & 130 & 562 & 8.1 \\ 26 & 34.0 & 140 & 432 & 6.2\end{array}$

ABIC ACOH-

FEET MU- PERPER TOTAL LATED
CEASS SECOND DAYS DAYS DAYS

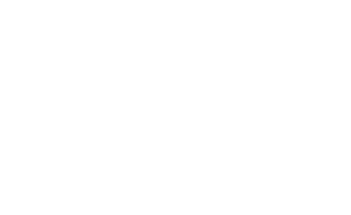


GREEN RIVER BASIN

09312800 WIILOW CREEK NEAR CASTLE GATE, UT-CONTInUed

MONTHLY MEAN DISCHARGES, IN OBIC FEET PER SECOND, FOR EACH WATER YEAR

\begin{tabular}{lllllllllllrr} 
YEAR & OCT & NOV & DEC & JAN & FEB & MAR & APR & MAY & JUNE & \multicolumn{1}{l}{ JULY } & \multicolumn{1}{l}{ AUG } & SEP \\
1963 & 2.54 & 0.46 & 0.23 & 0.09 & 2.19 & 4.72 & 5.16 & 14.3 & 2.71 & 0.37 & 1.64 & 1.98 \\
1964 & 0.51 & 0.13 & 0.00 & 0.00 & 0.00 & 0.94 & 5.87 & 21.1 & 6.10 & 0.88 & 0.48 & 0.30 \\
1965 & 0.05 & 0.00 & 0.01 & 0.21 & 0.66 & 1.80 & 26.3 & 90.4 & 39.3 & 24.3 & 10.9 & 5.39 \\
1966 & 3.39 & 4.18 & 2.07 & 2.35 & 2.46 & 20.9 & 33.9 & 28.1 & 9.90 & 4.84 & 2.41 & 3.18 \\
1967 & 1.17 & 1.19 & 0.62 & 0.34 & 0.40 & 5.56 & 10.1 & 13.9 & 17.8 & 8.89 & 5.04 & 2.68 \\
1968 & 1.36 & 1.24 & 0.65 & 0.50 & 0.95 & 1.18 & 15.1 & 57.0 & 30.8 & 9.37 & 7.64 & 3.00 \\
1969 & 2.58 & 1.90 & 0.17 & 0.52 & 0.81 & 3.55 & 86.2 & 76.2 & 20.6 & 8.91 & 3.80 & 2.97 \\
1970 & 2.38 & 0.75 & 0.57 & 0.27 & 1.39 & 3.87 & 5.17 & 9.05 & 4.56 & 1.50 & 0.82 & 1.95 \\
1971 & 0.47 & 0.19 & 0.77 & 0.94 & 1.00 & 3.05 & 7.10 & 13.8 & 5.54 & 1.16 & 2.08 & 0.49 \\
1972 & 0.72 & 0.99 & 0.90 & 0.90 & 0.90 & 9.37 & 7.68 & 8.36 & 2.92 & 1.11 & 0.61 & 0.98 \\
1973 & 6.20 & 0.98 & 0.92 & 1.20 & 1.27 & 2.32 & 41.1 & 123 & 16.0 & 7.58 & 7.55 & 2.10 \\
1974 & 1.82 & 1.86 & 1.80 & 1.72 & 1.45 & 3.03 & 5.96 & 6.59 & 1.92 & 1.41 & 0.61 & 0.31 \\
1975 & 0.73 & 0.76 & 0.02 & 0.04 & 0.18 & 3.45 & 15.8 & 37.5 & 29.6 & 8.23 & 3.01 & 2.34 \\
1976 & 1.27 & 0.92 & 0.80 & 0.80 & 1.03 & 1.82 & 5.06 & 12.9 & 2.87 & 2.62 & 0.72 & 0.59 \\
1977 & 0.71 & 0.41 & 0.00 & 0.00 & 0.05 & 0.43 & 0.83 & 1.33 & 0.72 & 2.96 & 1.11 & 0.45 \\
1978 & 0.28 & 0.08 & 0.01 & 0.00 & 0.03 & 5.97 & 21.0 & 39.2 & 14.9 & 3.01 & 1.15 & 1.08 \\
1979 & 1.02 & 1.26 & 0.51 & 1.51 & 3.37 & 3.60 & 49.8 & 133 & 30.5 & 8.77 & 6.17 & 2.29 \\
1980 & 1.70 & 1.22 & 0.62 & 1.04 & 1.51 & 2.43 & 29.9 & 99.9 & 33.0 & 10.2 & 4.51 & 4.68 \\
1981 & 4.11 & 2.63 & 1.70 & 1.53 & 1.63 & 3.55 & 16.1 & 8.01 & 4.21 & 1.99 & 2.08 & 1.99
\end{tabular}

ANNUA, PEAK DISOHARGE, IN OBIC FEET PER SECOND, AND CORRESPONDING GAGE HEIGHT, IN FEET, FOR EACH WATER YEAR

\begin{tabular}{|c|c|c|c|c|c|c|c|c|c|c|c|}
\hline $\begin{array}{l}\text { WATER } \\
\text { YEAR }\end{array}$ & DATE & $\begin{array}{c}\text { GAGE } \\
\text { HEIGHT }\end{array}$ & $\begin{array}{c}\text { PEAK } \\
\text { DISCHAFGE }\end{array}$ & $\begin{array}{l}\text { WATER } \\
\text { YEAR }\end{array}$ & DATE & $\begin{array}{c}\text { GAGE } \\
\text { HEIGHT }\end{array}$ & $\begin{array}{c}\text { PEAK } \\
\text { DISAHARGE }\end{array}$ & $\begin{array}{l}\text { WATER } \\
\text { YEAR }\end{array}$ & DATE & $\begin{array}{c}\text { GAGE } \\
\text { HEIGHT }\end{array}$ & $\begin{array}{c}\text { PEAK } \\
\text { DISGARGE }\end{array}$ \\
\hline $\begin{array}{l}1963 \\
1964 \\
1965 \\
1966 \\
1967 \\
1968 \\
1969\end{array}$ & $\begin{array}{l}\text { OCT. } 05,1962 \\
\text { JUNE } 28,1964 \\
\text { MAY } 21,1965 \\
\text { JULY } 01,1966 \\
\text { JULY } 15,1967 \\
\text { AUG. } 09,1968 \\
\text { APR. } 21,1969\end{array}$ & $\begin{array}{l}3.53 \\
2.73 \\
3.32 \\
4.14 \\
5.00 \\
3.30 \\
3.16\end{array}$ & $\begin{array}{l}292 \\
106 \\
262 \\
388 \\
550 \\
206 \\
214\end{array}$ & $\begin{array}{l}1970 \\
1971 \\
1972 \\
1973 \\
1974 \\
1975\end{array}$ & $\begin{array}{l}\text { SEPT. 05, } 1970 \\
\text { AUG. 16, } 1971 \\
\text { SEPT.19, } 1972 \\
\text { AUG. 06, } 1973 \\
\text { JULY 18, } 1974 \\
\text { APR. 22, } 1975\end{array}$ & $\begin{array}{l}3.03 \\
2.84 \\
2.65 \\
6.47 \\
2.13 \\
2.82\end{array}$ & $\begin{array}{r}152 \\
119 \\
91 \\
836 \\
28 \\
115\end{array}$ & $\begin{array}{l}1976 \\
1977 \\
1978 \\
1979 \\
1980 \\
1981\end{array}$ & $\begin{array}{l}\text { JULY } 25,1976 \\
\text { JULY } 19,1977 \\
\text { APR. } 11,1978 \\
\text { MAY } 05,1979 \\
\text { MAY } 23,1980 \\
\text { APR. } 09,1981\end{array}$ & $\begin{array}{l}6.21 \\
3.96 \\
2.99 \\
3.52 \\
3.39 \\
3.38\end{array}$ & $\begin{array}{l}808 \\
313 \\
124 \\
242 \\
188 \\
207\end{array}$ \\
\hline
\end{tabular}

\begin{tabular}{|c|c|c|c|c|c|c|}
\hline MAG & CTUDE & $\begin{array}{l}\text { ROBABI } \\
\text { ISED OA }\end{array}$ & $\begin{array}{l}\text { Y OF } \\
\text { IMAT }\end{array}$ & $\begin{array}{l}\text { LO } \\
51\end{array}$ & AN & RGE \\
\hline \multirow{2}{*}{$\begin{array}{l}\text { PERIOD } \\
\text { KCON- } \\
\text { SEQJ- } \\
\text { TTVE } \\
\text { DAYS! }\end{array}$} & \multicolumn{6}{|c|}{$\begin{array}{l}\text { DISCHARGE, IN GBIC FEET PER SECOND, FOR } \\
\text { INDICATED REQURRENCE INTERVAL, IN YEARS, AND } \\
\text { ANNUAL NONEXCEEDANCE PROBABIITTY, IN PERCENT }\end{array}$} \\
\hline & $\begin{array}{c}2 \\
50 \AA\end{array}$ & $\begin{array}{c}5 \\
208\end{array}$ & $\begin{array}{l}10 \\
108\end{array}$ & $\begin{array}{l}20 \\
58\end{array}$ & $\begin{array}{l}50 \\
28\end{array}$ & $\begin{array}{r}100 \\
18\end{array}$ \\
\hline 1 & 0.18 & 0.00 & -- & -- & -- & - \\
\hline 7 & 0.21 & 0.00 & -- & -- & -- & -- \\
\hline 14 & 0.24 & 0.00 & -- & -- & -- & -- \\
\hline 30 & 0.32 & 0.00 & - & -- & - & - \\
\hline 60 & 0.47 & 0.00 & - & -- & - & - \\
\hline
\end{tabular}


GREEN RIVER BASIN

09312900 WHLWW CREEK AT CASTLE GATE, UT

LOCATION. -Lat $39^{\circ} 43^{\prime} 37^{\prime \prime}$, lang $110^{\circ} 51^{\prime} 41^{\prime \prime}$, in $\mathrm{SN}_{4}^{3} \mathrm{SW}_{4} \mathrm{NE}_{4}$ sec.1, T.13 S., R. 9 E., Carbon County, Hydrologic Unit 14060007 , on right bank $0.1 \mathrm{mi}$ upstrearn fram Utah Power \& Light Co. electrical substation and $0.5 \mathrm{mi}$ upstream fram mouth.

DRAINAGE AREA. $-77.4 \mathrm{mi}^{2}$.

PERIOD OF RECORD AVAILFBLE.--October 1979 to September 1981.

GAGE. - water-stage recorder. Altitude of gage is $6,100 \mathrm{ft}$ from topographic map.

EXIREMES FOR PERIOD OF RECORD.--Maximun daily discharge, $210 \mathrm{ft}^{3} / \mathrm{s}$ May 23, 1980 ; minimum daily, 0.60 $\mathrm{ft}^{3} / \mathrm{s}$ Dec. $13-26,1979$.

LONEST MEAN DISCHARGE, IN GBIC FEET PER SECOND, AND RANKING FOR THE INDICATED NUMBER OF CONSECUTIVE DAYS FOR EAOH OIMATIC YEAR, APRIL 1-MARO 31

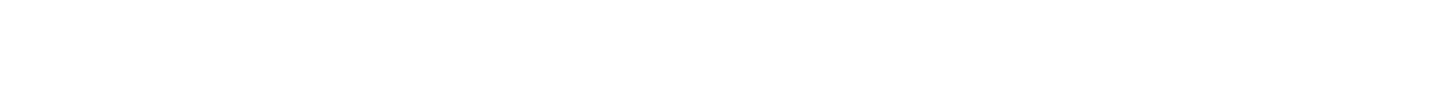

HIGHEST MEAN DISGHARGE, IN OBIC FEET PER SECOND, AND RANKING FOR THE INDICATED NUMBER OF CONSEQITIVE DAYS FOR EAOH WATER YEAR, OCTOBER 1-SEPTEMBER 30

\begin{tabular}{|c|c|c|c|c|c|c|c|c|c|c|c|c|c|c|c|c|c|c|c|}
\hline YEAR & & & & & & & & & CONs & & E DAYS & & & & & & & & \\
\hline 1980 & 210 & 1 & 180 & 1 & 146 & 1 & 115 & 1 & 108 & 1 & 82.0 & 1 & 61.0 & 1 & 48.0 & 1 & 33.0 & 1 & 17.0 \\
\hline
\end{tabular}

DURATION OF DISGHARGE FOR EACH WATER YEAR

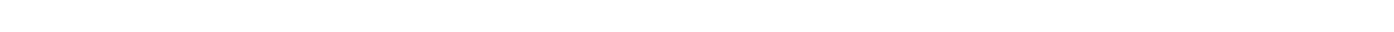

YEAR NUMBER OF DAVS IN GLASS COBIC FEET -DANS

$\begin{array}{llllllllllllllllllllllllllllllllllllllllll}1980 & 24 & 10 & 8 & 8 & 7 & 27 & 56 & 23 & 4 & 9 & 29 & 26 & 8 & 9 & 6 & 10 & 4 & 4 & 7 & 9 & 8 & 5 & 6 & 4 & 3 & 4 & 4 & 6 & 16 & 6 & 8 & 3 & 3 & 2 & 6342.7\end{array}$

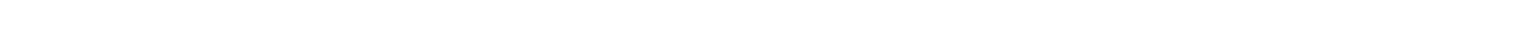

DURATION TABLE OF DISGHARGE FOR WATER YEARS 1980-8I

\begin{tabular}{|c|c|c|c|c|c|c|c|c|c|c|c|c|c|c|c|c|c|c|c|}
\hline & $\begin{array}{c}\text { CJBIC } \\
\text { FEET } \\
\text { PER } \\
\text { SECOND }\end{array}$ & $\begin{array}{l}\text { TOOTAL } \\
\text { DAYS }\end{array}$ & $\begin{array}{l}\text { ACOU- } \\
\text { MU- } \\
\text { LATED } \\
\text { DAYS }\end{array}$ & $\begin{array}{l}\text { PER } \\
\text { CENT } \\
\text { DAYS }\end{array}$ & Q.ASS & $\begin{array}{c}\text { CUBIC } \\
\text { FEET } \\
\text { PER } \\
\text { SECOND }\end{array}$ & $\begin{array}{l}\text { TOTAL } \\
\text { DAYS }\end{array}$ & $\begin{array}{c}\text { ACOU- } \\
\text { MU- } \\
\text { LATED } \\
\text { DAYS }\end{array}$ & $\begin{array}{l}\text { PER } \\
\text { CENT } \\
\text { DAYS }\end{array}$ & & $\begin{array}{c}\text { OIBIC } \\
\text { FEET } \\
\text { PER } \\
\text { SECOND }\end{array}$ & $\begin{array}{l}\text { TOTAL } \\
\text { DAYS }\end{array}$ & $\begin{array}{c}\text { ACOU- } \\
\text { MU- } \\
\text { LATED } \\
\text { DAYS }\end{array}$ & $\begin{array}{l}\text { PER } \\
\text { CENT } \\
\text { DAYS }\end{array}$ & Q.ASS & $\begin{array}{c}\text { CBIIC } \\
\text { FEET } \\
\text { PER } \\
\text { SECOND }\end{array}$ & $\begin{array}{l}\text { TOTAL } \\
\text { DAYS }\end{array}$ & $\begin{array}{l}\text { ACOU- } \\
\text { MU- } \\
\text { LATED } \\
\text { DAYS }\end{array}$ & $\begin{array}{l}\text { PER } \\
\text { CENT } \\
\text { DAYS }\end{array}$ \\
\hline $\begin{array}{l}0 \\
1 \\
2 \\
3 \\
4 \\
5 \\
6 \\
7 \\
8\end{array}$ & $\begin{array}{l}0.00 \\
0.60 \\
0.71 \\
0.85 \\
1.00 \\
1.20 \\
1.40 \\
1.70 \\
2.00\end{array}$ & $\begin{array}{r}0 \\
24 \\
10 \\
8 \\
8 \\
39 \\
109 \\
84 \\
56\end{array}$ & $\begin{array}{l}731 \\
731 \\
707 \\
697 \\
689 \\
681 \\
642 \\
533 \\
449\end{array}$ & $\begin{array}{r}100.0 \\
100.0 \\
96.7 \\
95.3 \\
94.3 \\
93.2 \\
87.8 \\
72.9 \\
61.4\end{array}$ & $\begin{array}{l}9 \\
10 \\
11 \\
12 \\
13 \\
14 \\
15 \\
16 \\
17\end{array}$ & $\begin{array}{l}2.40 \\
2.80 \\
3.30 \\
3.90 \\
4.70 \\
5.60 \\
6.60 \\
7.80 \\
9.30\end{array}$ & $\begin{array}{l}19 \\
35 \\
61 \\
44 \\
28 \\
15 \\
22 \\
28 \\
11\end{array}$ & $\begin{array}{l}393 \\
374 \\
339 \\
278 \\
234 \\
206 \\
191 \\
169 \\
141\end{array}$ & $\begin{array}{l}53.8 \\
51.2 \\
46.4 \\
38.0 \\
32.0 \\
28.2 \\
26.1 \\
23.1 \\
19.3\end{array}$ & $\begin{array}{l}18 \\
19 \\
20 \\
21 \\
22 \\
23 \\
24 \\
25 \\
26\end{array}$ & $\begin{array}{l}11.0 \\
13.0 \\
15.0 \\
18.0 \\
22.0 \\
26.0 \\
31.0 \\
36.0 \\
43.0\end{array}$ & $\begin{array}{r}9 \\
10 \\
20 \\
12 \\
8 \\
9 \\
6 \\
4 \\
4\end{array}$ & $\begin{array}{r}130 \\
121 \\
111 \\
91 \\
79 \\
71 \\
62 \\
56 \\
52\end{array}$ & $\begin{array}{r}17.8 \\
16.6 \\
15.2 \\
12.4 \\
10.8 \\
9.7 \\
8.5 \\
7.7 \\
7.1\end{array}$ & $\begin{array}{l}27 \\
28 \\
29 \\
30 \\
31 \\
32 \\
33 \\
34\end{array}$ & $\begin{array}{r}51.0 \\
61.0 \\
72.0 \\
86.0 \\
100.0 \\
120.0 \\
140.0 \\
170.0\end{array}$ & $\begin{array}{r}4 \\
6 \\
16 \\
6 \\
8 \\
3 \\
3 \\
2\end{array}$ & $\begin{array}{r}48 \\
44 \\
38 \\
22 \\
16 \\
8 \\
5 \\
2\end{array}$ & $\begin{array}{l}6.6 \\
6.0 \\
5.2 \\
3.0 \\
2.2 \\
1.1 \\
0.7 \\
0.3\end{array}$ \\
\hline
\end{tabular}

MONIHLY MEAN DISGAARGS, IN OBIC FEET PER SECOND, FOR EAOH WATER YEAR

\begin{tabular}{|c|c|c|c|c|c|c|c|c|c|c|c|c|}
\hline YEAR & $\mathrm{OCT}$ & NOV & DEC & JAN & FEB & MAR & APR & MAY & JUNE & JULY & AUG & SEP \\
\hline 1980 & 2.02 & 1.44 & 0.66 & 1.29 & 1.79 & 2.79 & 31.2 & 107 & 37.9 & 11.1 & 4.60 & 5.6 \\
\hline 98 & 4.19 & 2.62 & 1.34 & 1.50 & 1.84 & 4.03 & 18.2 & 9.51 & 4.89 & 2.25 & 2.48 & 2.2 \\
\hline
\end{tabular}


GREEN RIVER BASIN

09313000 PRICE RTVER NEAR HEINER, UT

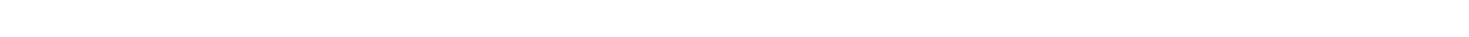
bank $0.8 \mathrm{mi}$ downstream from Willow Creek and $1.2 \mathrm{mi}$ upstream from Martin.

DRAINAGE AREA, $--415 \mathrm{mi}^{2}$.

MEAN BASTN ELEVATION. $-8,160 \mathrm{ft}$.

PERIOD OF RECORD AVAILABLE.--June 1934 to September 1969 , October 1979 to September 1981.

GAGE. -Water-stage recorder. Altitude of gage is 6,000 ft from topographic map. Prior to September 1969 , at site 400 ft upstream at different datum.

REMARKS.--Flow affected by regulation of scof ield Reservoir.

AVERAGE DISCHARGE. --37 years (water years 1935-69, 1980-81), $112 \mathrm{ft}^{3} / \mathrm{s}, 81,140$ acre-ft/yr.

EXTREMES FOR PERIOD OF RECORD.--Maximum discharge, 9,340 $\mathrm{ft}^{3} / \mathrm{s}$ Sept. 13, 1940, gage height, $7.98 \mathrm{ft}$, from rating curve extended above $750 \mathrm{ft}^{3} / \mathrm{s}$ on basis of slope-area measurements of peak flow; minimum recorded, $0.4 \mathrm{ft}^{3} / \mathrm{s} \mathrm{Aug.} 21,1961$.

LOWEST MEAN DISGARGE, IN đBIC FEET PER SECOND, AND RANKING FOR THE INDICATED NUMBER OF CONSEQUTIVE DAYS FOR EACH OLIMATIC YEAR, APRII 1-MARCH 31

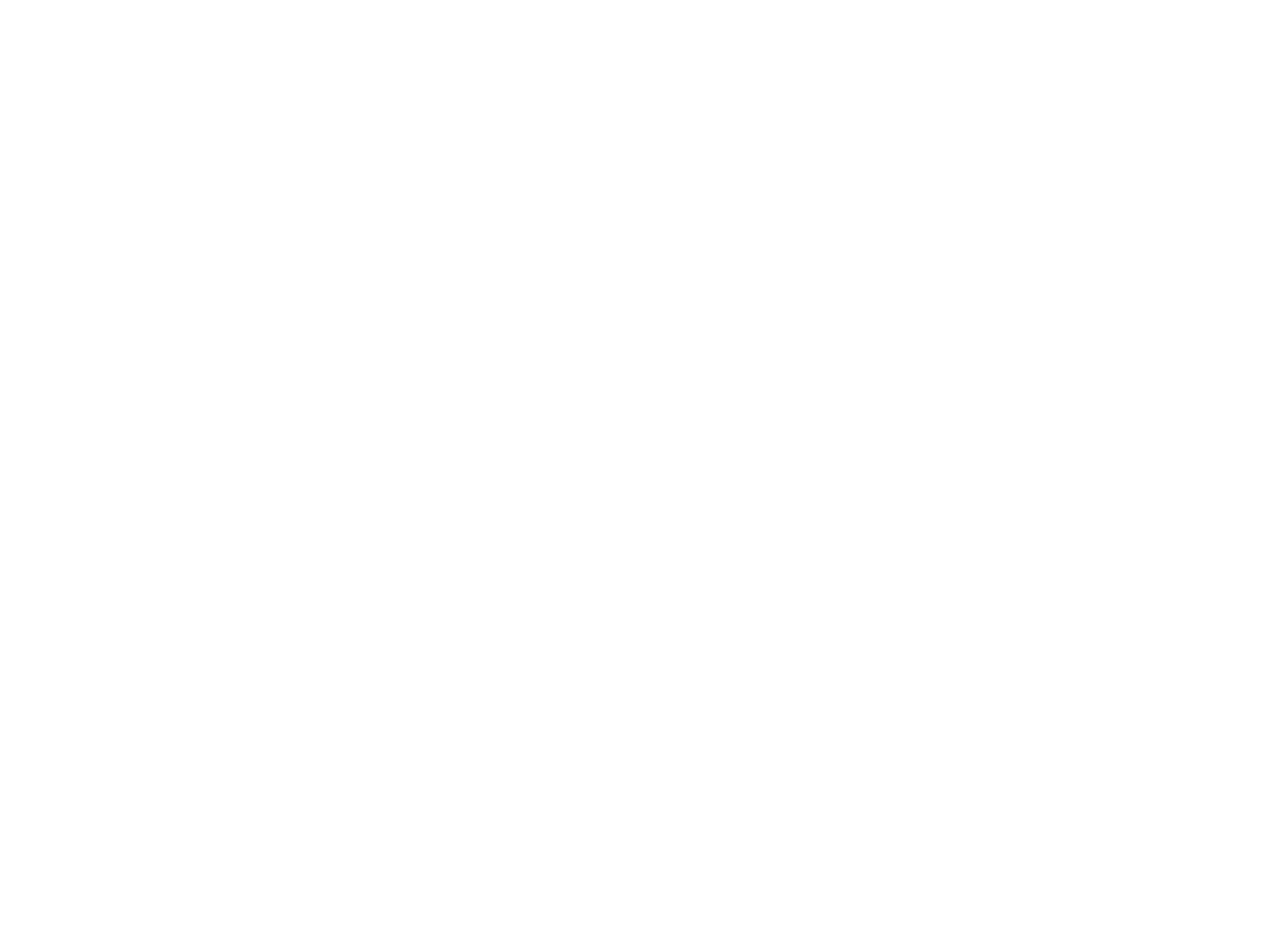


09313000 PRICE RIVER NEAR HEINER, UT-CONTInUEC

HIGHEST MEAN DISOHARGE, IN OBIC FEET PER SECOND, AND RANKING FOR THE INDICATED NUMBER OF CONSEQUTIVE DAVS FOR EAOH WATER YEAR, OCTOBER I-SEPIEMBER 30

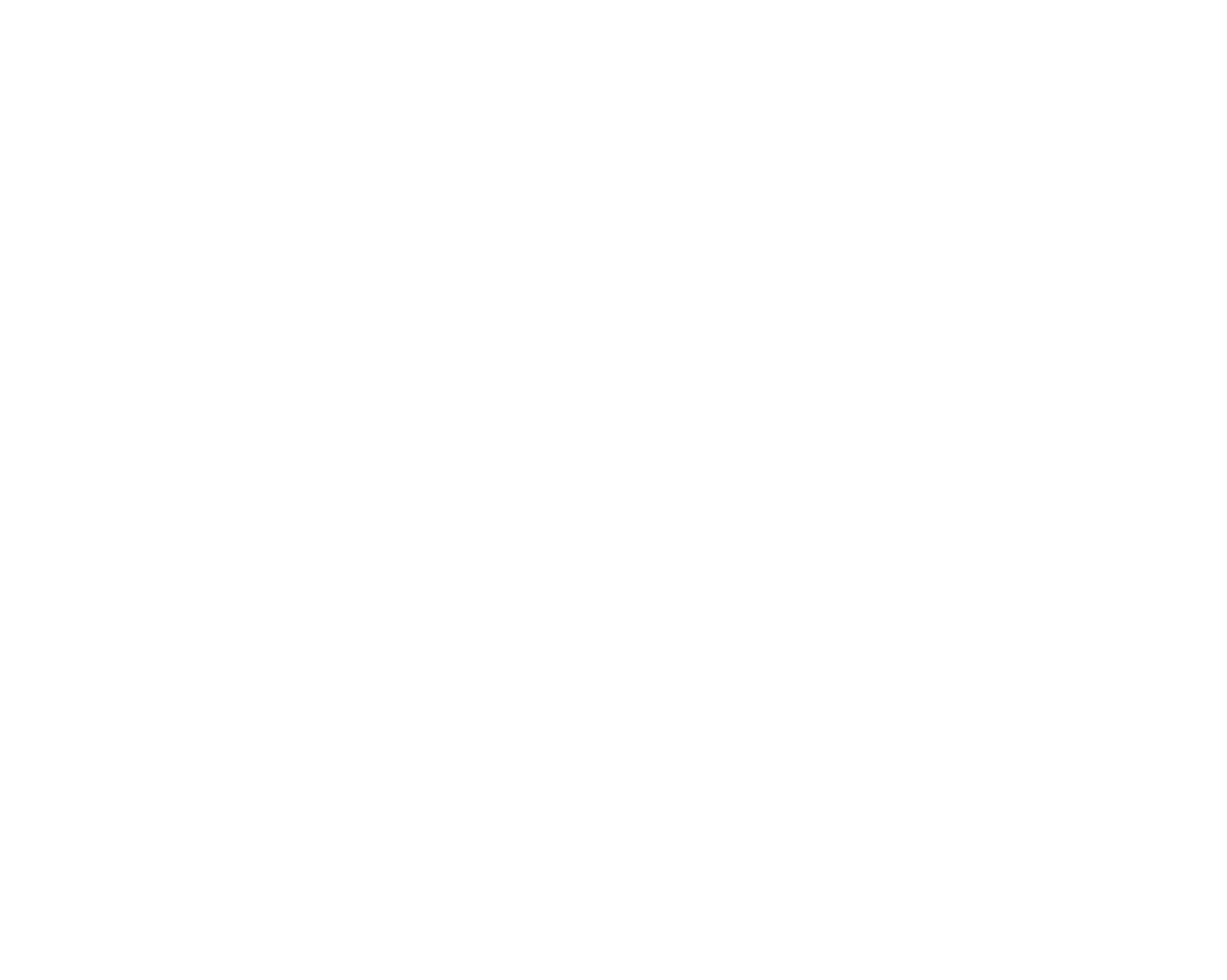

DURATION OF DISCHARGE FOR EACH WATER YEAR

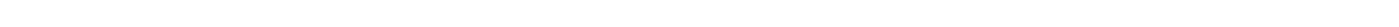

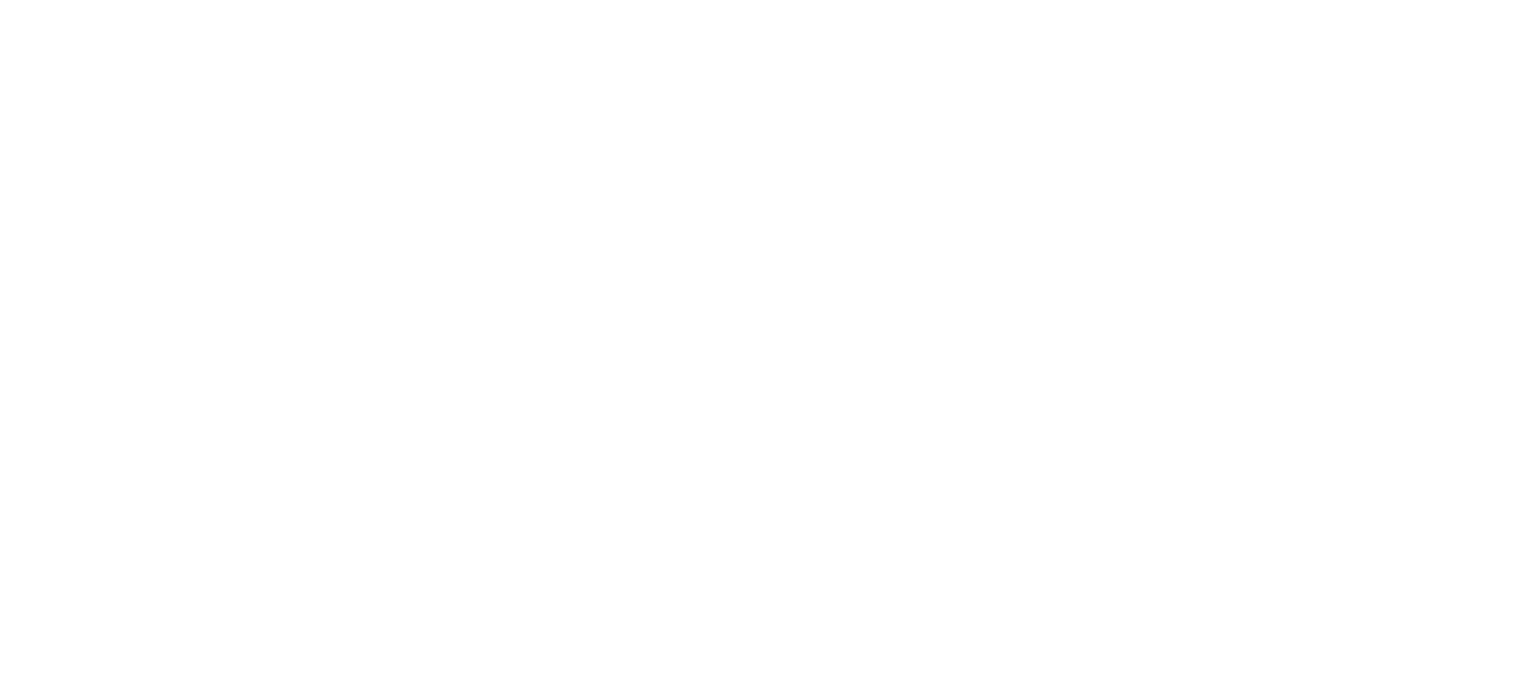


GREEN RIVER BASIN

09313000 PRICE RIVER NEAR HEINER, UT-Continued

DURATION OF DISQHARGE FOR EACH WATER YEAR--Continued

CLASS $\begin{array}{llllllllllllllllllllllllllllllllllllll} & 1 & 2 & 3 & 4 & 5 & 6 & 7 & 8 & 9 & 10 & 11 & 12 & 13 & 14 & 15 & 16 & 17 & 18 & 19 & 20 & 21 & 22 & 23 & 24 & 25 & 26 & 27 & 28 & 29 & 30 & 31 & 32 & 33 & 34\end{array}$

YEAR

NUMBER OF DAYS IN OLASS

OBIC FEET

PER SECOND

$\begin{array}{rrrrrrrrrrrrrrrrrrrrrrr}1956 & 1 & 1 & 4 & 7 & 77 & 18 & 16 & 6 & 4 & 11 & 13 & 11 & 16 & 23 & 21 & 8 & 28 & 42 & 54 & 5 & \\ 1957 & 2 & 15 & 24 & 47 & 16 & 19 & 21 & 11 & 19 & 11 & 11 & 8 & 9 & 14 & 9 & 12 & 17 & 16 & 26 & 43 & 14 & 1\end{array}$

1958

1959

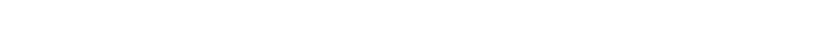
$\begin{array}{rrrrrrrrrrrrrrrr}1 & 13 & 50 & 21 & 12 & 23 & 37 & 14 & 8 & 12 & 23 & 8 & 11 & 40 & 69 & 37 \\ 12 & 26 & 58 & 14 & 22 & 16 & 28 & 17 & 12 & 11 & 20 & 32 & 43 & 2\end{array}$

30996.6

33351.4
63653.0

25551.2
21161.8

$\begin{array}{llllllllllllllllllllllll}1961 & 1 & 1 & & 2 & 1 & 7 & 53 & 49 & 20 & 25 & 27 & 37 & 25 & 18 & 21 & 19 & 16 & 14 & 18 & 8 & 1 & 1 & 1\end{array}$

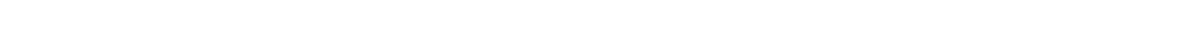

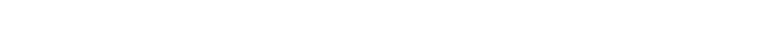

$\begin{array}{llllllllllllllllllll}35 & 42 & 31 & 25 & 20 & 12 & 2 & 18 & 12 & 20 & 5 & 5 & 29 & 26 & 19 & 30 & 13 & 12 & 4 & 5\end{array}$

9244.1

44440.3

23468.4

28982.0

41771.6

1965

$\begin{array}{lllllllllllllll}31 & 27 & 11 & 33 & 16 & 15 & 20 & 17 & 31 & 9 & 23 & 65 & 29 & 38\end{array}$

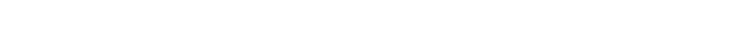

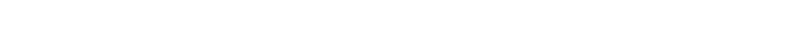

39104.0

40999.9
51534.0

69939.0

1969

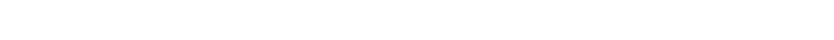

71648.9

1981

$\begin{array}{lllllllllllllll}13 & 15 & 68 & 44 & 17 & 17 & 9 & 9 & 15 & 15 & 9 & 14 & 28 & 77 & 15\end{array}$

26944.9

DURATION TPBLE OF DISCHARGE FOR WATER YEARS 1935-69, 1980-81

\begin{tabular}{|c|c|c|c|c|c|c|c|c|c|c|c|c|c|c|c|c|c|c|c|}
\hline & $\begin{array}{c}\text { CBBIC } \\
\text { FEET } \\
\text { PER }\end{array}$ & TOTAL & $\begin{array}{l}\text { ACU- } \\
\text { MU- } \\
\text { LATED }\end{array}$ & $\begin{array}{l}\text { PER- } \\
\text { CENT }\end{array}$ & & $\begin{array}{c}\text { OUBIC } \\
\text { FEET } \\
\text { PER }\end{array}$ & TOTAL & $\begin{array}{l}\text { ACOU- } \\
\text { MU- } \\
\text { LATED }\end{array}$ & $\begin{array}{l}\text { PER- } \\
\text { CENT }\end{array}$ & & $\begin{array}{c}\text { GBIC } \\
\text { FEET } \\
\text { PER } \\
\text { SECND }\end{array}$ & TOTAL & $\begin{array}{l}\text { ACOU- } \\
\text { MJ- } \\
\text { LATED }\end{array}$ & $\begin{array}{l}\text { PER- } \\
\text { CENT } \\
\text { DAYS }\end{array}$ & & $\begin{array}{c}\text { CUBIC } \\
\text { FEET } \\
\text { PER } \\
\text { SECOND }\end{array}$ & TOTAL & $\begin{array}{c}\text { ACOU- } \\
\text { MU- } \\
\text { LATED } \\
\text { DAYS }\end{array}$ & $\begin{array}{l}\text { PER- } \\
\text { CENT } \\
\text { DAYS }\end{array}$ \\
\hline CLASS & SECOND & DAYS & DAYS & DAYS & OASS & SECOND & DAYS & DAYS & DAYS & $\sigma$ ASS & SECOND & DAYS & DAYS & DAVS & O.ASS & SECOND & DAYS & DAVS & DAYS \\
\hline $\begin{array}{l}0 \\
1 \\
2 \\
3 \\
4 \\
5 \\
6 \\
7 \\
8\end{array}$ & $\begin{array}{l}0.00 \\
0.90 \\
1.10 \\
1.40 \\
1.80 \\
2.30 \\
2.90 \\
3.60 \\
4.60\end{array}$ & $\begin{array}{r}0 \\
1 \\
1 \\
0 \\
4 \\
2 \\
40 \\
132 \\
214\end{array}$ & $\begin{array}{l}13515 \\
13515 \\
13514 \\
13513 \\
13513 \\
13509 \\
13507 \\
13467 \\
13335\end{array}$ & $\begin{array}{r}100.0 \\
100.0 \\
100.0 \\
100.0 \\
100.0 \\
100.0 \\
99.9 \\
99.6 \\
98.7\end{array}$ & $\begin{array}{r}9 \\
10 \\
11 \\
12 \\
13 \\
14 \\
15 \\
16 \\
17\end{array}$ & $\begin{array}{r}5.80 \\
7.30 \\
9.30 \\
12.00 \\
15.00 \\
19.00 \\
24.00 \\
30.00 \\
37.00\end{array}$ & $\begin{array}{l}636 \\
862 \\
737 \\
938 \\
999 \\
649 \\
492 \\
406 \\
428\end{array}$ & $\begin{array}{r}13121 \\
12485 \\
11623 \\
10886 \\
9948 \\
8949 \\
8300 \\
7808 \\
7402\end{array}$ & $\begin{array}{l}97.1 \\
92.4 \\
86.0 \\
80.5 \\
73.6 \\
66.2 \\
61.4 \\
57.8 \\
54.8\end{array}$ & $\begin{array}{l}18 \\
19 \\
20 \\
21 \\
22 \\
23 \\
24 \\
25 \\
26\end{array}$ & $\begin{array}{r}47.0 \\
60.0 \\
75.0 \\
95.0 \\
120.0 \\
150.0 \\
190.0 \\
240.0 \\
310.0\end{array}$ & $\begin{array}{r}508 \\
540 \\
591 \\
637 \\
801 \\
1125 \\
1122 \\
874 \\
202\end{array}$ & $\begin{array}{r}6974 \\
6466 \\
5926 \\
5335 \\
4698 \\
3897 \\
2772 \\
1650 \\
776\end{array}$ & $\begin{array}{r}51.6 \\
47.8 \\
43.8 \\
39.5 \\
34.8 \\
28.8 \\
20.5 \\
12.2 \\
5.7\end{array}$ & $\begin{array}{l}27 \\
28 \\
29 \\
30 \\
31 \\
32 \\
33 \\
34\end{array}$ & $\begin{array}{r}390.0 \\
490.0 \\
610.0 \\
780.0 \\
980.0 \\
1200.0 \\
1600.0 \\
2000.0\end{array}$ & $\begin{array}{r}166 \\
139 \\
149 \\
59 \\
17 \\
31 \\
12 \\
1\end{array}$ & $\begin{array}{r}574 \\
408 \\
269 \\
120 \\
61 \\
44 \\
13 \\
1\end{array}$ & $\begin{array}{l}4.2 \\
3.0 \\
2.0 \\
0.9 \\
0.5 \\
0.3 \\
0.1 \\
0.0\end{array}$ \\
\hline
\end{tabular}

MONMHLY MEAN DISCHARGES, IN OUBIC FEET PER SECOND, FOR EAOH WATER YEAR

\begin{tabular}{|c|c|c|c|c|c|c|c|c|c|c|c|c|}
\hline YEAR & OCT & NOV & DEC & JAN & FEB & MAR & APR & MAY & JUNE & JULY & AUG & SEP \\
\hline 1935 & 3.84 & 3.23 & 4.00 & 4.00 & 11.6 & 28.4 & 51.0 & 143 & 205 & 183 & 80.3 & 78.6 \\
\hline $\begin{array}{l}1936 \\
1937 \\
1938 \\
1939 \\
1940\end{array}$ & $\begin{array}{r}28.3 \\
56.7 \\
143 \\
44.7 \\
11.3\end{array}$ & $\begin{array}{c}14.5 \\
11.7 \\
90.7 \\
25.5 \\
9.70\end{array}$ & $\begin{array}{c}6.00 \\
7.00 \\
19.5 \\
10.0 \\
9.87\end{array}$ & $\begin{array}{c}8.00 \\
6.00 \\
11.6 \\
10.0 \\
6.32\end{array}$ & $\begin{array}{c}9.00 \\
8.00 \\
15.9 \\
8.00 \\
9.55\end{array}$ & $\begin{array}{r}26.4 \\
35.9 \\
44.5 \\
123 \\
35.7\end{array}$ & $\begin{array}{c}419 \\
406 \\
154 \\
119 \\
90.0\end{array}$ & $\begin{array}{l}360 \\
597 \\
434 \\
242 \\
221\end{array}$ & $\begin{array}{l}202 \\
284 \\
238 \\
191 \\
183\end{array}$ & $\begin{array}{l}135 \\
171 \\
171 \\
126 \\
144\end{array}$ & $\begin{array}{l}121 \\
190 \\
151 \\
67.8 \\
85.8\end{array}$ & $\begin{array}{l}91.4 \\
90.4 \\
60.1 \\
37.6 \\
70.6\end{array}$ \\
\hline $\begin{array}{l}1941 \\
1942 \\
1943 \\
1944 \\
1945\end{array}$ & $\begin{array}{l}15.4 \\
47.3 \\
74.5 \\
16.8 \\
33.5\end{array}$ & $\begin{array}{c}11.2 \\
31.5 \\
13.5 \\
7.72 \\
14.5\end{array}$ & $\begin{array}{c}7.84 \\
17.9 \\
12.1 \\
6.00 \\
10.1\end{array}$ & $\begin{array}{c}7.16 \\
17.0 \\
11.2 \\
5.00 \\
10.0\end{array}$ & $\begin{array}{c}23.8 \\
15.6 \\
29.0 \\
7.00 \\
12.0\end{array}$ & $\begin{array}{l}63.3 \\
70.3 \\
54.2 \\
37.9 \\
47.6\end{array}$ & $\begin{array}{c}117 \\
428 \\
132 \\
107 \\
46.3\end{array}$ & $\begin{array}{l}685 \\
540 \\
223 \\
569 \\
282\end{array}$ & $\begin{array}{l}356 \\
363 \\
163 \\
310 \\
171\end{array}$ & $\begin{array}{l}203 \\
221 \\
215 \\
242 \\
224\end{array}$ & $\begin{array}{l}152 \\
160 \\
137 \\
169 \\
144\end{array}$ & $\begin{array}{c}120 \\
97.3 \\
89.9 \\
125 \\
113\end{array}$ \\
\hline $\begin{array}{l}1946 \\
1947 \\
1948 \\
1949 \\
1950\end{array}$ & $\begin{array}{l}35.7 \\
17.6 \\
73.1 \\
22.1 \\
35.1\end{array}$ & $\begin{array}{c}12.3 \\
7.45 \\
14.1 \\
10.1 \\
13.0\end{array}$ & $\begin{array}{c}7.33 \\
7.56 \\
9.12 \\
7.00 \\
10.3\end{array}$ & $\begin{array}{r}7.06 \\
6.31 \\
8.30 \\
7.00 \\
11.0\end{array}$ & $\begin{array}{c}9.64 \\
19.2 \\
13.8 \\
9.36 \\
17.4\end{array}$ & $\begin{array}{l}28.3 \\
46.8 \\
33.5 \\
53.5 \\
32.3\end{array}$ & $\begin{array}{c}120 \\
106 \\
68.3 \\
256 \\
212\end{array}$ & $\begin{array}{l}212 \\
236 \\
216 \\
332 \\
248\end{array}$ & $\begin{array}{l}143 \\
173 \\
193 \\
173 \\
260\end{array}$ & $\begin{array}{l}159 \\
233 \\
208 \\
242 \\
185\end{array}$ & $\begin{array}{l}93.9 \\
113 \\
148 \\
194 \\
207\end{array}$ & $\begin{array}{c}59.5 \\
101 \\
46.5 \\
104 \\
102\end{array}$ \\
\hline $\begin{array}{l}1951 \\
1952 \\
1953 \\
1954 \\
1955\end{array}$ & $\begin{array}{l}45.6 \\
45.5 \\
92.2 \\
57.8 \\
45.9\end{array}$ & $\begin{array}{l}17.6 \\
21.3 \\
29.4 \\
13.5 \\
16.8\end{array}$ & $\begin{array}{c}14.4 \\
13.2 \\
19.6 \\
15.2 \\
6.63\end{array}$ & $\begin{array}{r}11.5 \\
14.9 \\
18.4 \\
8.65 \\
5.45\end{array}$ & $\begin{array}{c}17.1 \\
17.0 \\
20.0 \\
28.3 \\
6.12\end{array}$ & $\begin{array}{l}41.3 \\
20.0 \\
32.1 \\
35.6 \\
13.8\end{array}$ & $\begin{array}{c}113 \\
523 \\
68.9 \\
118 \\
87.9\end{array}$ & $\begin{array}{r}209 \\
1538 \\
230 \\
237 \\
216\end{array}$ & $\begin{array}{l}232 \\
913 \\
258 \\
217 \\
182\end{array}$ & $\begin{array}{l}245 \\
297 \\
244 \\
132 \\
179\end{array}$ & $\begin{array}{l}118 \\
183 \\
161 \\
115 \\
108\end{array}$ & $\begin{array}{c}134 \\
131 \\
144 \\
70.6 \\
106\end{array}$ \\
\hline $\begin{array}{l}1956 \\
1957 \\
1958 \\
1959 \\
1960\end{array}$ & $\begin{array}{l}39.8 \\
30.6 \\
69.5 \\
51.8 \\
36.8\end{array}$ & $\begin{array}{l}12.9 \\
10.2 \\
23.2 \\
19.5 \\
18.9\end{array}$ & $\begin{array}{c}14.6 \\
4.52 \\
16.6 \\
16.6 \\
16.9\end{array}$ & $\begin{array}{c}8.38 \\
5.90 \\
17.2 \\
9.25 \\
14.9\end{array}$ & $\begin{array}{c}8.91 \\
6.79 \\
23.3 \\
8.68 \\
9.33\end{array}$ & $\begin{array}{l}34.5 \\
12.8 \\
31.6 \\
16.8 \\
21.6\end{array}$ & $\begin{array}{l}106 \\
71.5 \\
313 \\
108 \\
79.1\end{array}$ & $\begin{array}{l}214 \\
289 \\
621 \\
138 \\
154\end{array}$ & $\begin{array}{l}191 \\
229 \\
416 \\
147 \\
149\end{array}$ & $\begin{array}{l}181 \\
230 \\
270 \\
140 \\
135\end{array}$ & $\begin{array}{l}122 \\
121 \\
185 \\
89.3 \\
45.3\end{array}$ & $\begin{array}{c}79.9 \\
78.4 \\
97.0 \\
92.2 \\
10.8\end{array}$ \\
\hline $\begin{array}{l}1961 \\
1962 \\
1963 \\
1964 \\
1965\end{array}$ & $\begin{array}{l}15.6 \\
10.9 \\
18.1 \\
51.9 \\
36.1\end{array}$ & $\begin{array}{l}13.7 \\
12.3 \\
16.2 \\
10.6 \\
14.7\end{array}$ & $\begin{array}{c}13.8 \\
9.23 \\
16.4 \\
12.3 \\
15.0\end{array}$ & $\begin{array}{l}5.51 \\
8.82 \\
8.47 \\
8.23 \\
8.95\end{array}$ & $\begin{array}{c}5.46 \\
24.3 \\
16.8 \\
6.67 \\
10.6\end{array}$ & $\begin{array}{l}13.4 \\
31.4 \\
33.3 \\
14.7 \\
14.3\end{array}$ & $\begin{array}{c}29.0 \\
403 \\
63.6 \\
48.9 \\
126\end{array}$ & $\begin{array}{l}80.2 \\
310 \\
186 \\
182 \\
446\end{array}$ & $\begin{array}{l}52.3 \\
218 \\
123 \\
173 \\
249\end{array}$ & $\begin{array}{l}28.1 \\
187 \\
170 \\
205 \\
202\end{array}$ & $\begin{array}{c}19.3 \\
142 \\
77.5 \\
140 \\
123\end{array}$ & $\begin{array}{c}26.1 \\
104 \\
36.3 \\
93.0 \\
119\end{array}$ \\
\hline
\end{tabular}


GREEN RIVER BASIN

09313000 PRICE RIVER NEAR HEINER, UT-Continued

MONITLY MEAN DISCHARGES, IN ABIC FEET PER SECOND, FOR EACH WATER YEAR--Continued

\begin{tabular}{|c|c|c|c|c|c|c|c|c|c|c|c|c|}
\hline YEAR & OCT & NOV & DEC & JAN & FEB & MAR & APR & MAY & JUNE & JULY & AUG & SEP \\
\hline $\begin{array}{l}1966 \\
1967 \\
1968 \\
1969\end{array}$ & $\begin{array}{l}65.0 \\
40.1 \\
56.8 \\
60.5\end{array}$ & $\begin{array}{l}32.9 \\
20.0 \\
21.6 \\
33.0\end{array}$ & $\begin{array}{l}30.1 \\
17.5 \\
23.7 \\
18.7\end{array}$ & $\begin{array}{c}17.3 \\
9.83 \\
13.1 \\
17.0\end{array}$ & $\begin{array}{l}14.6 \\
11.8 \\
15.7 \\
16.6\end{array}$ & $\begin{array}{c}62.5 \\
33.8 \\
27.2 \\
181\end{array}$ & $\begin{array}{r}137 \\
83.4 \\
81.3 \\
418\end{array}$ & $\begin{array}{l}265 \\
253 \\
368 \\
673\end{array}$ & $\begin{array}{l}198 \\
310 \\
529 \\
350\end{array}$ & $\begin{array}{l}206 \\
257 \\
254 \\
247\end{array}$ & $\begin{array}{l}166 \\
194 \\
122 \\
180\end{array}$ & $\begin{array}{l}83.7 \\
110 \\
178 \\
91.4\end{array}$ \\
\hline 1980 & 38.4 & 14.7 & 12.2 & 16.9 & 17.5 & 39.7 & 290 & 737 & 698 & 232 & 174 & 75.4 \\
\hline 1981 & 42.3 & 9.91 & 14.1 & 13.2 & 14.9 & 22.3 & 69.7 & 181 & 158 & 155 & 148 & 51.0 \\
\hline
\end{tabular}

ANNUAL PEAK DISCHARGE, IN GUBIC FEET PER SECOND, AND CORRESPONDING GAGE HEIGHT, IN FEET, FOR EACH WATER YEAR

\begin{tabular}{|c|c|c|c|c|c|c|c|c|c|c|c|}
\hline $\begin{array}{l}\text { WATER } \\
\text { YEAR }\end{array}$ & DATE & $\begin{array}{l}\text { GAGE } \\
\text { HEIGHT }\end{array}$ & $\begin{array}{c}\text { PEAR } \\
\text { DISCHARGE }\end{array}$ & $\begin{array}{l}\text { WATERR } \\
\text { YEAR }\end{array}$ & DATE & $\begin{array}{l}\text { GAGE } \\
\text { HEIGHT }\end{array}$ & $\begin{array}{c}\text { PEAR } \\
\text { DISCHARGE }\end{array}$ & $\begin{array}{l}\text { WATERR } \\
\text { YEAR }\end{array}$ & DATE & $\begin{array}{c}\text { GAGE } \\
\text { HEIGHT }\end{array}$ & $\begin{array}{c}\text { PEAK } \\
\text { DISCHARGE }\end{array}$ \\
\hline $\begin{array}{l}1935 \\
1936 \\
1937 \\
1938 \\
1939 \\
1940 \\
1941 \\
1942 \\
1943 \\
1944 \\
1945\end{array}$ & $\begin{array}{l}\text { AUG. } 26,1935 \\
\text { SEPT. 02, } 1936 \\
\text { JULY } 29,1937 \\
\text { AUG. 08, } 1938 \\
\text { SEPT.12, } 1939 \\
\text { SEPT.13, } 1940 \\
\text { SEPT.13, } 1941 \\
\text { APR. 02, } 1942 \\
\text { AUG. 18, } 1943 \\
\text { MAY 18, } 1944 \\
\text { AUG. } 14,1945\end{array}$ & $\begin{array}{l}6.16 \\
5.70 \\
4.12 \\
3.58 \\
3.40 \\
7.98 \\
4.75 \\
3.40 \\
4.00 \\
3.44 \\
5.00\end{array}$ & $\begin{array}{r}4850 \\
4000 \\
1360 \\
1090 \\
1040 \\
9340 \\
2280 \\
975 \\
1200 \\
868 \\
2660\end{array}$ & $\begin{array}{l}1948 \\
1949 \\
1950 \\
1951 \\
1952 \\
1953 \\
1954 \\
1955 \\
1956 \\
1957 \\
1958\end{array}$ & $\begin{array}{l}\text { AUG. } 23,1948 \\
\text { JULY } 03,1949 \\
\text { JULY } 28,1950 \\
\text { AUG. } 04,1951 \\
\text { APR. } 28,1952 \\
\text { AUG. 28, } 1953 \\
\text { SEPT.26, } 1954 \\
\text { OCT. 07, } 1954 \\
\text { JULY } 02,1956 \\
\text { AUG. 07, } 1957 \\
\text { MAY } 11,1958\end{array}$ & $\begin{array}{l}3.25 \\
4.26 \\
2.62 \\
2.85 \\
4.87 \\
4.77 \\
3.00 \\
3.37 \\
2.29 \\
5.75 \\
3.90\end{array}$ & $\begin{array}{r}736 \\
1610 \\
417 \\
528 \\
2620 \\
2460 \\
1070 \\
1340 \\
622 \\
2320 \\
1010\end{array}$ & $\begin{array}{l}1960 \\
1961 \\
1962 \\
1963 \\
1964 \\
1965 \\
1966 \\
1967 \\
1968 \\
1969 \\
1980\end{array}$ & $\begin{array}{l}\text { JULY } 07,1960 \\
\text { AUG. } 25,1961 \\
\text { SEPT. } 21,1962 \\
\text { OCT. } 05,1962 \\
\text { JULY } 13,1964 \\
\text { MAY } 21,1965 \\
\text { JULY } 01,1966 \\
\text { JULY } 15,1967 \\
\text { JUNE } 06,1968 \\
\text { MAY } 21,1969 \\
\text { MAY } 31,1980\end{array}$ & $\begin{array}{l}2.61 \\
4.27 \\
4.40 \\
3.58 \\
3.03 \\
3.75 \\
3.60 \\
4.43 \\
4.31 \\
4.00 \\
4.65\end{array}$ & $\begin{array}{r}315 \\
1160 \\
1220 \\
729 \\
423 \\
708 \\
621 \\
1080 \\
891 \\
825 \\
1100\end{array}$ \\
\hline $\begin{array}{l}1946 \\
1947\end{array}$ & $\begin{array}{l}\text { AUG. } 13,1946 \\
\text { OCT. 01, } 1946\end{array}$ & $\begin{array}{l}5.24 \\
4.68\end{array}$ & $\begin{array}{l}2950 \\
2180\end{array}$ & 1959 & AJG. 25,1959 & 3.51 & 751 & 1981 & AUG. 23,1981 & ${ }^{1} 11.63$ & 516 \\
\hline
\end{tabular}

MAGNITUDE AND PRCBABILITY OF ANNUAL LONEST MEAN DISGHARGE BASED ON CIMATIC YEARS 1936-69 AND 1981

\begin{tabular}{|c|c|c|c|c|c|c|}
\hline \multirow{2}{*}{$\begin{array}{l}\text { PERIOD } \\
\text { (CON- } \\
\text { SEOU- } \\
\text { TIVE } \\
\text { DAYS) }\end{array}$} & \multicolumn{6}{|c|}{$\begin{array}{l}\text { DISCHARGE, IN CNIC FEET PER SECOND, FOR } \\
\text { INDICATED RECURRENCE INTEERNAL, IN YEARS, AND } \\
\text { ANNUAL NONEXCEEDANCE PRCBABILITY, IN PERCENT }\end{array}$} \\
\hline & $\begin{array}{c}2 \\
508\end{array}$ & $\begin{array}{c}5 \\
208\end{array}$ & $\begin{array}{l}10 \\
108\end{array}$ & $\begin{array}{l}20 \\
58\end{array}$ & $\begin{array}{l}50 \\
28\end{array}$ & $\begin{array}{r}100 \\
18\end{array}$ \\
\hline
\end{tabular}

$\begin{array}{rrrrrrr}1 & 6.7 & 4.0 & 2.9 & 2.2 & 1.5 & - \\ 7 & 7.3 & 5.0 & 4.1 & 3.5 & 3.0 & - \\ 14 & 8.0 & 5.9 & 5.1 & 4.5 & 4.0 & - \\ 30 & 8.5 & 6.2 & 5.4 & 4.8 & 4.2 & - \\ 60 & 9.5 & 7.0 & 6.0 & 5.3 & 4.6 & - \\ 90 & 10 & 7.8 & 6.7 & 5.9 & 5.1 & -\end{array}$

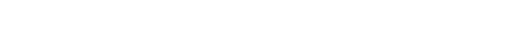

MAGNITUDE AND PRCBABIITTY OF ANNUAL HIGHEST MEAN DISCHARGE BASED ON WATER YEARS 1935-69 AND 1980-81

\begin{tabular}{|c|c|c|c|c|c|c|}
\hline \multirow{2}{*}{$\begin{array}{l}\text { PERIOD } \\
\text { (CON- } \\
\text { SEOU- } \\
\text { TIVE } \\
\text { DAYS) }\end{array}$} & \multicolumn{6}{|c|}{$\begin{array}{l}\text { DISCHARGE, IN OUBIC FEET PER SECOND, FOR } \\
\text { INDICATED RECORREANCE INTERNAL, IN YEARS, AND } \\
\text { ANNUAL EXCEEDANCE PRCBABLITY, IN PERCENT }\end{array}$} \\
\hline & $\begin{array}{c}2 \\
508\end{array}$ & $\begin{array}{c}5 \\
208\end{array}$ & $\begin{array}{l}10 \\
108\end{array}$ & $\begin{array}{l}25 \\
48\end{array}$ & $\begin{array}{l}50 \\
28\end{array}$ & $\begin{array}{r}100 \\
18\end{array}$ \\
\hline $\begin{array}{r}1 \\
3 \\
7 \\
15\end{array}$ & $\begin{array}{l}417 \\
393 \\
375 \\
350\end{array}$ & $\begin{array}{l}700 \\
676 \\
643 \\
599\end{array}$ & $\begin{array}{l}949 \\
921 \\
875 \\
812\end{array}$ & $\begin{array}{l}1350 \\
1310 \\
1240 \\
1140\end{array}$ & $\begin{array}{l}1720 \\
1660 \\
1570 \\
1440\end{array}$ & $\begin{array}{l}- \\
\overline{-}\end{array}$ \\
\hline
\end{tabular}

09313040 SPRING CANYON BELCW SOWBELLY GULCH, AT HEJ.PER, UT

LOCATION.--Lat $39^{\circ} 41^{\prime} 19^{\prime \prime}$, long $110^{\circ} 53^{\prime} 09^{\prime \prime}$, in NE $\frac{1}{4} W_{\frac{1}{4}} \mathrm{NW}_{\frac{1}{4}}$ sec. 23 , T.13 S., R.9 E., Carbon County, Aydrologic Unit 14060007, on left bank $1.2 \mathrm{mi}$ upstream from mouth, $0.4 \mathrm{mi}$ upstream from railroad trestle, and $1.4 \mathrm{mi}$ west of Helper.

DRATNAGE AREA. $--23.0 \mathrm{mi}^{2}$.

PERIOD OF RECORD AVAILABLE.--October 1978 to September 1981.

REVISED RECORDS. - WDR UT-81-1: 1980(P).

GAGE. -Water-stage recorder. Altitude of gage is $6,110 \mathrm{ft}$ from topographic map.

EXIRENES FOR PERIOD OF RECORD.- Waximum discharge, $271 \mathrm{ft}^{3} / \mathrm{s}$ July 12, 1981, gage height, $3.93 \mathrm{ft}$, result of slope-area measurement; minimam, $0.02 \mathrm{ft}^{3} / \mathrm{s}$ July $2,1979$.

LONEST MEAN DISCHARGE, IN OUBIC FEET PER SECOND, AND RANKING FOR THE INDICATED NUMBER OF CONSECUTIVE DAYS FOR EACH QLIMATIC YEAR, APRIL I-MARCH 31

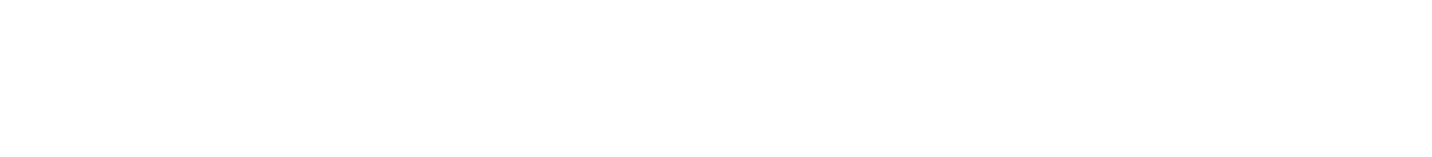


GREEN RIVER BASIN

09313040 SPRING CANYON BELOW SOWBELLYY GULCH, AT HELPER, UT-Continued

HIGHEST MEAN DISCHARGE, IN OUBIC FEET PER SECOND, AND RANKING FOR THE INDICATED NUMBER OF CONSEOUTIVE DAYS FOR EAOH WATER YEAR, OCTOBER I-SEPTEMBER 30

\begin{tabular}{|c|c|c|c|c|c|c|c|c|c|c|c|c|c|c|c|c|c|c|c|}
\hline YEAR & 1 & & 3 & & 7 & & 15 & & $\begin{array}{l}\text { CONSE } \\
30\end{array}$ & ATIV & $\begin{array}{l}\text { DAYS } \\
60\end{array}$ & & 90 & & 120 & & 183 & & ALL \\
\hline $\begin{array}{l}1979 \\
1980\end{array}$ & $\begin{array}{l}2.40 \\
6.30\end{array}$ & $\begin{array}{l}3 \\
1\end{array}$ & $\begin{array}{l}0.90 \\
2.50\end{array}$ & $\begin{array}{l}3 \\
1\end{array}$ & $\begin{array}{l}0.49 \\
1.40\end{array}$ & $\begin{array}{l}3 \\
2\end{array}$ & $\begin{array}{l}0.34 \\
0.91\end{array}$ & $\begin{array}{l}3 \\
2\end{array}$ & $\begin{array}{l}0.25 \\
0.77\end{array}$ & $\begin{array}{l}3 \\
2\end{array}$ & $\begin{array}{l}0.21 \\
0.65\end{array}$ & $\begin{array}{l}3 \\
2\end{array}$ & $\begin{array}{l}0.21 \\
0.54\end{array}$ & $\begin{array}{l}3 \\
2\end{array}$ & $\begin{array}{l}0.19 \\
0.49\end{array}$ & $\begin{array}{l}3 \\
2\end{array}$ & $\begin{array}{l}0.16 \\
0.43\end{array}$ & $\begin{array}{l}3 \\
2\end{array}$ & $\begin{array}{l}0.12 \\
0.35\end{array}$ \\
\hline
\end{tabular}

DURATION OF DISCHARGE FOR EACH WATER YEAR

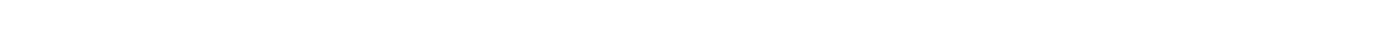
YEAR NUMBER OF DAYS IN CLASS OUBIC FEET -DAYS

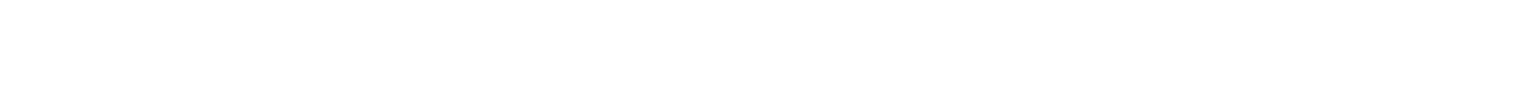

DURATION TABLE OF DISCHARGE FOR WATER YEARS 1979-81

$\begin{array}{crr}\text { OUBIC } & \text { ACOU- } \\ \text { FEET } & \text { MU- } & \text { PER- } \\ \text { PER } & \text { TOTIAL ILATED } & \text { CBNT } \\ \text { CLASS SECOND DAYS DAYS } & \text { DAYS }\end{array}$

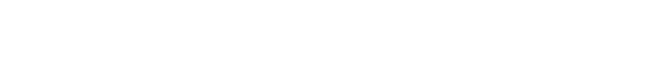

CLASS SECOND DAYS DAYS DAYS

$\begin{array}{lll}\text { CUBIC } & \text { ACOU- } \\ \text { FEET } & \text { MU- } & \text { PER- } \\ \text { PER TOTAL LATED } & \text { CENT }\end{array}$

CLASS SECOND DAYS DAYS DAYS

$\begin{array}{rrrrr}18 & 0.6 & 16 & 48 & 4.4 \\ 19 & 0.7 & 13 & 32 & 2.9 \\ 20 & 0.8 & 9 & 19 & 1.7 \\ 21 & 1.0 & 0 & 10 & 0.9 \\ 22 & 1.1 & 1 & 10 & 0.9 \\ 23 & 1.3 & 1 & 9 & 0.8 \\ 24 & 1.5 & 2 & 8 & 0.7 \\ 25 & 1.8 & 1 & 6 & 0.5 \\ 26 & 2.1 & 0 & 5 & 0.5\end{array}$

OLASS SECOND DAYS DAYS DAYS

$\begin{array}{lrrr}0.00 & 0 & 1096 & 100.0 \\ 0.04 & 5 & 1096 & 100.0 \\ 0.05 & 60 & 1091 & 99.5 \\ 0.06 & 0 & 1031 & 94.1 \\ 0.07 & 56 & 1031 & 94.1 \\ 0.09 & 40 & 975 & 89.0 \\ 0.10 & 46 & 935 & 85.3 \\ 0.12 & 82 & 889 & 81.1 \\ 0.14 & 41 & 807 & 73.6\end{array}$

$\begin{array}{rrrrr}9 & 0.16 & 69 & 766 & 69.9 \\ 10 & 0.18 & 76 & 697 & 63.6 \\ 11 & 0.21 & 79 & 621 & 56.7 \\ 12 & 0.25 & 86 & 542 & 49.5 \\ 13 & 0.29 & 107 & 456 & 41.6 \\ 14 & 0.34 & 65 & 349 & 31.8 \\ 15 & 0.39 & 81 & 284 & 25.9 \\ 16 & 0.45 & 83 & 203 & 18.5 \\ 17 & 0.53 & 72 & 120 & 10.9\end{array}$

MONTHLY MEAN DISCHARGES, IN OUBIC FEET PER SECOND, FOR EACH WATER YEAR

$\begin{array}{lllllllllllll}\text { YEAR } & \text { OCT } & \text { NOV } & \text { DEC } & \text { JAN } & \text { FEB } & \text { MAR } & \text { APR } & \text { MAY } & \text { JUNE } & \text { JULY } & \text { AUG } & \text { SEP } \\ 1979 & 0.15 & 0.22 & 0.20 & 0.19 & 0.12 & 0.07 & 0.15 & 0.09 & 0.06 & 0.05 & 0.07 & 0.12 \\ 1980 & 0.25 & 0.33 & 0.24 & 0.24 & 0.29 & 0.25 & 0.19 & 0.46 & 0.32 & 0.33 & 0.68 & 0.61 \\ 1981 & 0.87 & 0.48 & 0.53 & 0.52 & 0.39 & 0.41 & 0.39 & 0.33 & 0.24 & 0.33 & 0.20 & 0.27\end{array}$

09313500 PRICE RIVER NEAR HELPER, UT

LOCATION.-Lat $39^{\circ} 39^{\prime} 05^{\prime \prime}$, long $110^{\circ} 51^{\prime} 25^{\prime \prime}$, in SEl/ sec.36, T. 13 S., R. 9 E., Carbon County, Hydrologic Unit 14060007, at highway bridge $0.75 \mathrm{mi}$ upstream from diversion dam of Price River Irrigation Co. and $2 \mathrm{mi}$ south of Helper.

DRAINAGE AREA. $-530 \mathrm{mi}^{2}$.

MEAN BASIN ELEVATION. $-7,920 \mathrm{ft}$.

PERIOD OF RECORD AVAIIABLE.-February to May 1904, June 1904 to April 1907, June 1907 to December 1908 , January 1909 to August 1921, September 1921 to September 1934. Monthly mean discharge only for some periods prior to September 1921, published in WSP 1313 .

GAGE.--Chain gage after May 29, 1922. Altitude of gage is $5,700 \mathrm{ft}$ from topographic map. Prior to May 29, 1922, staff gages at ford near Spring Glenn $0.25 \mathrm{mi}$ upstream at different datums. Datum was raised $0.70 \mathrm{ft}$ on June 23 , 1907 , and raised $1.57 \mathrm{ft}$ on June 10, 1921.

REMARKS.-Main irrigation diversions are below station. Flow affected since May 1926 by storage in Scofield Reservoir on Price River and prior to June 24, 1917 (when dam failed) by Mammoth Reservoir on Gooseberry Creek.

AVERAGE DISCHARGE. - 29 years (water years $1905-06,1908-34$ ) $, 143 \mathrm{ft}^{3} / \mathrm{s}, 103,600$ acre-ft/year.

EXTREMES FOR PERIOD OF RECORD.--Maximum discharge, 12,000 ft 3 /s Sept. 8, 1919, gage height, $10.0 \mathrm{ft}$, from floodmark, site and datum then in use, from rating curve extended above $2,200 \mathrm{ft}^{3} / \mathrm{s}$; minimum, $2 \mathrm{ft}^{3} / \mathrm{s}$ Nov. 18, 1930, June 15, 16, Sept. 2-6, 1934. 
09313500 PRICE RIVER NEAR HELPER, UT-CONtinued

DATA BELOW BASED ON PERIOD OF RECORD FRIOR TO REGULATTON BY SCOFIELD RESERVOIR LOWEST MEAN DISGHARGE, IN OUBIC FEET PER SECOND, AND RANKING FOR THE INDICATED NUMBER OF CONSEOUTTVE DAYS FOR EAOH QLIMATIC YEAR, ARRIL 1-MARG 31

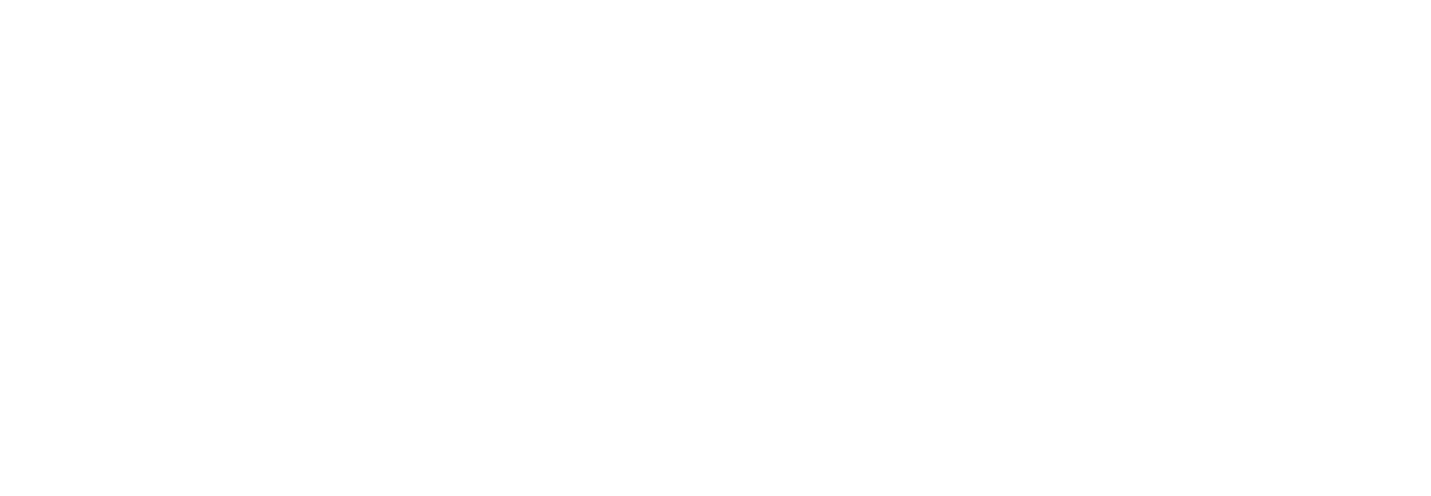

HIGHEST MEAN DISCHARGE, IN OUBIC FEET PER SECOND, AND RANKING FOR THE INDICATED NUMBER OF CONSECUTTVE DAYS FOR EACH WATER YEAR, OCTCBER 1-SEPI'EMBER 30

\begin{tabular}{|c|c|c|c|c|c|c|c|c|c|c|c|c|c|c|c|c|c|c|c|c|}
\hline YEAR & 1 & & 3 & & 7 & & 15 & & $\begin{array}{l}\infty \\
30\end{array}$ & EQJT & IVE DA & & 90 & & 120 & & 183 & & ALL & \\
\hline 1910 & 1470 & 8 & 1390 & 6 & 1320 & 6 & 1140 & 6 & 1030 & 6 & 848 & 5 & 675 & 5 & 522 & 5 & 375 & 5 & 214 & 5 \\
\hline $\begin{array}{l}1922 \\
1923 \\
1924 \\
1925\end{array}$ & $\begin{array}{r}3100 \\
1660 \\
564 \\
1300\end{array}$ & $\begin{array}{r}2 \\
6 \\
14 \\
11\end{array}$ & $\begin{array}{r}2470 \\
1630 \\
533 \\
767\end{array}$ & $\begin{array}{r}1 \\
5 \\
13 \\
12\end{array}$ & $\begin{array}{r}2270 \\
1560 \\
455 \\
348\end{array}$ & $\begin{array}{r}1 \\
4 \\
12 \\
14\end{array}$ & $\begin{array}{r}2170 \\
1490 \\
324 \\
247\end{array}$ & $\begin{array}{r}1 \\
3 \\
13 \\
15\end{array}$ & $\begin{array}{r}1780 \\
1340 \\
245 \\
201\end{array}$ & $\begin{array}{r}1 \\
2 \\
14 \\
15\end{array}$ & $\begin{array}{r}1280 \\
985 \\
206 \\
166\end{array}$ & $\begin{array}{r}1 \\
3 \\
14 \\
15\end{array}$ & $\begin{array}{l}913 \\
751 \\
155 \\
150\end{array}$ & $\begin{array}{r}1 \\
3 \\
14 \\
15\end{array}$ & $\begin{array}{l}716 \\
600 \\
129 \\
127\end{array}$ & $\begin{array}{r}1 \\
3 \\
14 \\
15\end{array}$ & $\begin{array}{c}501 \\
417 \\
96.0 \\
116\end{array}$ & $\begin{array}{r}1 \\
4 \\
15\end{array}$ & $\begin{array}{r}274 \\
230 \\
67.0 \\
73.0\end{array}$ & $\begin{array}{r}1 \\
4 \\
15 \\
14\end{array}$ \\
\hline
\end{tabular}

DURATION OF DISCHARGE FOR EAOH WATER YEAR

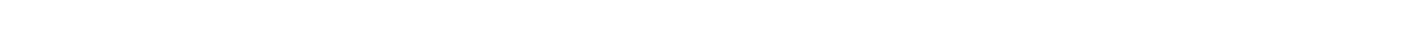

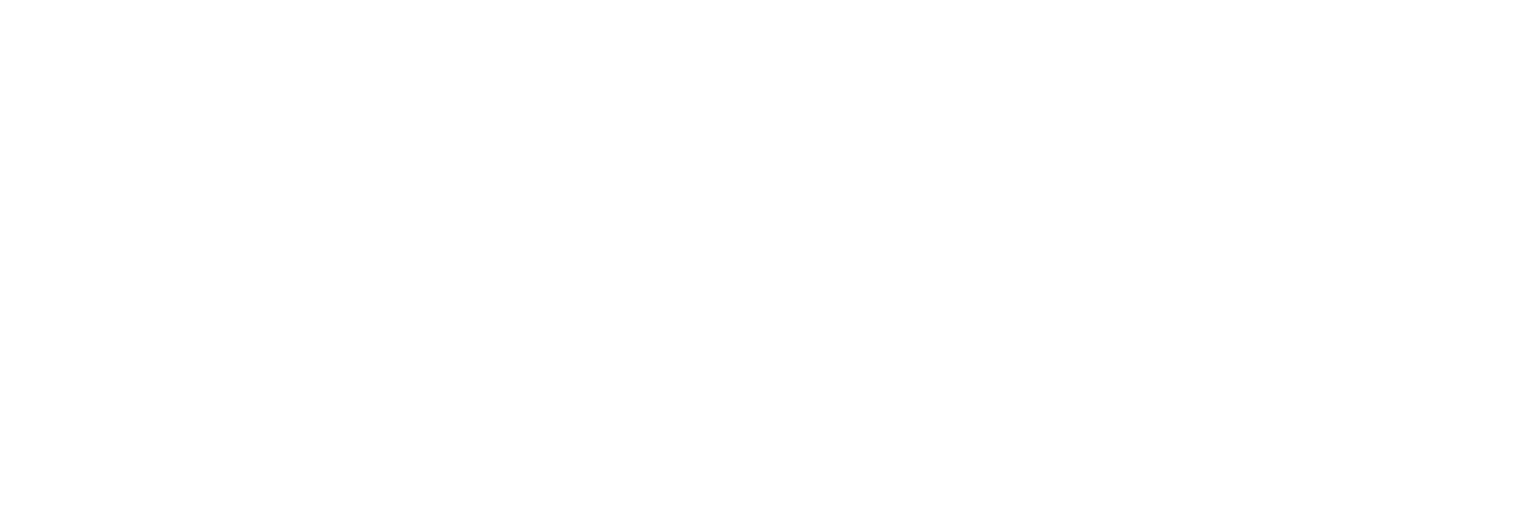


GREEN RIVER BASIN

09313500 PRICE RIVER NEAR HELPER, UT--Continued

DURATION TABLE OF DISGHARGE FOR WATER YEARS 1910-20, 1922-25

\begin{tabular}{|c|c|c|c|c|c|c|c|c|c|c|c|c|c|c|c|c|c|c|c|}
\hline QASS & $\begin{array}{c}\text { CBBIC } \\
\text { FEET } \\
\text { PER } \\
\text { SECOND }\end{array}$ & $\begin{array}{l}\text { TOTAL } \\
\text { DAYS }\end{array}$ & $\begin{array}{r}\text { ACOU- } \\
\text { MU- } \\
\text { LATED } \\
\text { DAYS }\end{array}$ & $\begin{array}{l}\text { PER- } \\
\text { CENT } \\
\text { DAYS }\end{array}$ & CLASS & $\begin{array}{c}\text { QUBIC } \\
\text { FEET } \\
\text { PER } \\
\text { SECOND }\end{array}$ & $\begin{array}{c}\text { TOTAL } \\
\text { DAYS }\end{array}$ & $\begin{array}{c}\text { ACOU- } \\
\text { MU- } \\
\text { LATED } \\
\text { DAYS }\end{array}$ & $\begin{array}{l}\text { PER- } \\
\text { CENT } \\
\text { DAYS }\end{array}$ & QASS & $\begin{array}{c}\text { QBIC } \\
\text { FEET } \\
\text { PER } \\
\text { SECOND }\end{array}$ & $\begin{array}{l}\text { TOTAL } \\
\text { DAYS }\end{array}$ & $\begin{array}{l}\text { ACOU- } \\
\text { MU- } \\
\text { LATED } \\
\text { DAISS }\end{array}$ & $\begin{array}{l}\text { PER- } \\
\text { CENT } \\
\text { DAYS }\end{array}$ & CAASS & $\begin{array}{c}\text { OBIIC } \\
\text { FEET } \\
\text { PER } \\
\text { SECOND }\end{array}$ & $\begin{array}{c}\text { TOTAL } \\
\text { DAYS }\end{array}$ & $\begin{array}{c}\text { ACQU- } \\
\text { MU- } \\
\text { LATED } \\
\text { DAYS }\end{array}$ & $\begin{array}{l}\text { PER- } \\
\text { CENT } \\
\text { DAYS }\end{array}$ \\
\hline $\begin{array}{l}0 \\
1 \\
2 \\
3 \\
4 \\
5 \\
6 \\
7 \\
8\end{array}$ & $\begin{array}{r}0.00 \\
4.00 \\
4.90 \\
6.00 \\
7.30 \\
9.00 \\
11.00 \\
13.00 \\
16.00\end{array}$ & $\begin{array}{r}0 \\
1 \\
0 \\
4 \\
7 \\
20 \\
28 \\
43 \\
85\end{array}$ & $\begin{array}{l}5479 \\
5479 \\
5478 \\
5478 \\
5474 \\
5467 \\
5447 \\
5419 \\
5376\end{array}$ & $\begin{array}{r}100.0 \\
100.0 \\
100.0 \\
100.0 \\
99.9 \\
99.8 \\
99.4 \\
98.9 \\
98.1\end{array}$ & $\begin{array}{l}9 \\
10 \\
11 \\
12 \\
13 \\
14 \\
15 \\
16 \\
17\end{array}$ & $\begin{array}{r}20.00 \\
25.00 \\
30.00 \\
37.00 \\
45.00 \\
55.00 \\
67.00 \\
82.00 \\
100.00\end{array}$ & $\begin{array}{l}279 \\
377 \\
618 \\
879 \\
595 \\
371 \\
232 \\
246 \\
160\end{array}$ & $\begin{array}{l}5291 \\
5012 \\
4635 \\
4017 \\
3138 \\
2543 \\
2172 \\
1940 \\
1694\end{array}$ & $\begin{array}{l}96.6 \\
91.5 \\
84.6 \\
73.3 \\
57.3 \\
46.4 \\
39.6 \\
35.4 \\
30.9\end{array}$ & $\begin{array}{l}18 \\
19 \\
20 \\
21 \\
22 \\
23 \\
24 \\
25 \\
26\end{array}$ & $\begin{array}{l}120.0 \\
150.0 \\
180.0 \\
230.0 \\
280.0 \\
340.0 \\
410.0 \\
510.0 \\
620.0\end{array}$ & $\begin{array}{r}226 \\
199 \\
177 \\
126 \\
115 \\
105 \\
102 \\
125 \\
78\end{array}$ & $\begin{array}{r}1534 \\
1308 \\
1109 \\
932 \\
806 \\
691 \\
586 \\
484 \\
359\end{array}$ & $\begin{array}{r}28.0 \\
23.9 \\
20.2 \\
17.0 \\
14.7 \\
12.6 \\
10.7 \\
8.8 \\
6.6\end{array}$ & $\begin{array}{l}27 \\
28 \\
29 \\
30 \\
31 \\
32 \\
33 \\
34\end{array}$ & $\begin{array}{r}760.0 \\
920.0 \\
1100.0 \\
1400.0 \\
1700.0 \\
2100.0 \\
2500.0 \\
3100.0\end{array}$ & $\begin{array}{r}82 \\
51 \\
76 \\
40 \\
22 \\
8 \\
0 \\
2\end{array}$ & $\begin{array}{r}281 \\
199 \\
148 \\
72 \\
32 \\
10 \\
2 \\
2\end{array}$ & $\begin{array}{l}5.1 \\
3.6 \\
2.7 \\
1.3 \\
0.6 \\
0.2 \\
0.0 \\
0.0\end{array}$ \\
\hline
\end{tabular}

MONTHLY MEAN DISOHARGES, IN OBIC FEET PER SECOND, FOR EACH WATER YEAR

\begin{tabular}{|c|c|c|c|c|c|c|c|c|c|c|c|c|}
\hline YEAR & $\mathrm{OCT}$ & $\mathrm{NOV}$ & DEC & JAN & FEB & MAR & APR & MAY & JUNE & JULY & AUG & SEP \\
\hline 1905 & 29.5 & 21.2 & 17.8 & 21.1 & 36.3 & 49.8 & 71.5 & 379 & 254 & 25.8 & 18.8 & 87.8 \\
\hline 1906 & 26.3 & 20.5 & 12.0 & 7.1 & 16.5 & 38.6 & 290 & 949 & 446 & 191 & 113 & 42.0 \\
\hline $\begin{array}{l}1908 \\
1909 \\
1910\end{array}$ & $\begin{array}{l}54 \\
33.6 \\
71.6\end{array}$ & $\begin{array}{l}46 \\
37.8 \\
53.0\end{array}$ & $\begin{array}{l}44.3 \\
29.2 \\
47.7\end{array}$ & $\begin{array}{l}40.3 \\
14.0 \\
155\end{array}$ & $\begin{array}{l}40.7 \\
13 \\
40.5\end{array}$ & $\begin{array}{c}248 \\
59.1 \\
318\end{array}$ & $\begin{array}{l}268 \\
364 \\
794\end{array}$ & $\begin{array}{r}256 \\
1030 \\
801\end{array}$ & $\begin{array}{l}169 \\
925 \\
136\end{array}$ & $\begin{array}{c}50.9 \\
167 \\
43.5\end{array}$ & $\begin{array}{c}56.8 \\
146 \\
33.8\end{array}$ & $\begin{array}{c}17.5 \\
142 \\
62.7\end{array}$ \\
\hline $\begin{array}{l}1911 \\
1912 \\
1913 \\
1914 \\
1915\end{array}$ & $\begin{array}{l}67.7 \\
89.5 \\
72.7 \\
46.8 \\
71.8\end{array}$ & $\begin{array}{l}38.8 \\
73.1 \\
29.5 \\
48.0 \\
39.5\end{array}$ & $\begin{array}{l}47.6 \\
64.2 \\
27.4 \\
29.0 \\
35.9\end{array}$ & $\begin{array}{l}42.5 \\
25.0 \\
17.2 \\
31.9 \\
29.1\end{array}$ & $\begin{array}{l}56.9 \\
30.0 \\
18.3 \\
40.0 \\
40.0\end{array}$ & $\begin{array}{r}202 \\
35.0 \\
72.8 \\
127 \\
73.7\end{array}$ & $\begin{array}{l}225 \\
121 \\
500 \\
471 \\
207\end{array}$ & $\begin{array}{r}558 \\
451 \\
480 \\
1161 \\
326\end{array}$ & $\begin{array}{l}236 \\
444 \\
238 \\
465 \\
209\end{array}$ & $\begin{array}{l}81.6 \\
120 \\
193 \\
208 \\
128\end{array}$ & $\begin{array}{r}36.7 \\
64.5 \\
65.0 \\
117 \\
57.2\end{array}$ & $\begin{array}{r}128 \\
49.9 \\
88.3 \\
50.6 \\
50.0\end{array}$ \\
\hline $\begin{array}{l}1916 \\
1917 \\
1918 \\
1919 \\
1920\end{array}$ & $\begin{array}{l}31.2 \\
84.0 \\
46.1 \\
58.9 \\
38.0\end{array}$ & $\begin{array}{l}38.1 \\
39.4 \\
37.4 \\
44.6 \\
27.3\end{array}$ & $\begin{array}{l}31.2 \\
34.8 \\
41.3 \\
50.2 \\
28.8\end{array}$ & $\begin{array}{l}33.5 \\
33.4 \\
40.3 \\
34.3 \\
27.7\end{array}$ & $\begin{array}{l}35.2 \\
54.1 \\
41.6 \\
34.9 \\
29.4\end{array}$ & $\begin{array}{r}175 \\
71.2 \\
85.7 \\
95.2 \\
36.9\end{array}$ & $\begin{array}{l}494 \\
363 \\
115 \\
313 \\
104\end{array}$ & $\begin{array}{r}851 \\
922 \\
286 \\
558 \\
1094\end{array}$ & $\begin{array}{r}371 \\
1069 \\
124 \\
103 \\
458\end{array}$ & $\begin{array}{c}195 \\
178 \\
93.5 \\
36.4 \\
77.1\end{array}$ & $\begin{array}{c}141 \\
54.7 \\
26.8 \\
45.5 \\
131\end{array}$ & $\begin{array}{r}66.0 \\
53.2 \\
56.6 \\
137 \\
63.1\end{array}$ \\
\hline $\begin{array}{l}1921 \\
1922 \\
1923 \\
1924 \\
1925\end{array}$ & $\begin{array}{l}46.8 \\
57.0 \\
37.9 \\
60.3 \\
20.6\end{array}$ & $\begin{array}{l}45.0 \\
48.8 \\
43.6 \\
45.1 \\
24.4\end{array}$ & $\begin{array}{l}25.0 \\
47.6 \\
43.1 \\
26.1 \\
22.7\end{array}$ & $\begin{array}{l}25.0 \\
40.0 \\
40.9 \\
30.0 \\
26.3\end{array}$ & $\begin{array}{l}33.1 \\
38.0 \\
45.1 \\
49.3 \\
37.5\end{array}$ & $\begin{array}{r}180 \\
68.6 \\
48.9 \\
43.3 \\
73.0\end{array}$ & $\begin{array}{l}260 \\
226 \\
414 \\
236 \\
127\end{array}$ & $\begin{array}{r}1283 \\
1636 \\
1280 \\
169 \\
195\end{array}$ & $\begin{array}{c}782 \\
814 \\
520 \\
46.7 \\
101\end{array}$ & $\begin{array}{r}104 \\
135 \\
144 \\
17.7 \\
44.6\end{array}$ & $\begin{array}{r}140 \\
95.1 \\
73.4 \\
39.2 \\
128\end{array}$ & $\begin{array}{r}107 \\
54.4 \\
59.2 \\
40.9 \\
66.8\end{array}$ \\
\hline
\end{tabular}

ANNUAL PEAK DISQHARGE, IN GBIC FEET PER SECOND, AND CORRESPONDING GAGE HEIGHT, IN FEET, FOR EACH WATER YEAR

\begin{tabular}{|c|c|c|c|c|c|c|c|c|c|c|c|}
\hline $\begin{array}{l}\text { WATER } \\
\text { YEAR }\end{array}$ & DATE & $\begin{array}{c}\text { GAGE } \\
\text { HEIGHT }\end{array}$ & $\begin{array}{c}\text { PEAK } \\
\text { DISCH ARGE }\end{array}$ & $\begin{array}{l}\text { WATER } \\
\text { YEAR }\end{array}$ & DATE & $\begin{array}{l}\text { GAGE } \\
\text { HEIGHT }\end{array}$ & $\begin{array}{c}\text { PEAK } \\
\text { DISQHARGE }\end{array}$ & $\begin{array}{l}\text { WATER } \\
\text { YEAR }\end{array}$ & DATE & $\begin{array}{c}\text { GAGE } \\
\text { HEIGHT }\end{array}$ & $\begin{array}{c}\text { PEAK } \\
\text { DISGH ARGE }\end{array}$ \\
\hline $\begin{array}{l}1904 \\
1905 \\
1906 \\
1908 \\
1909 \\
1910 \\
1911\end{array}$ & $\begin{array}{l}\text { AUG. } 27,1904 \\
\text { SEPT. 29, } 1905 \\
\text { MAY 21, } 1906 \\
\text { MAR. 15, } 1908 \\
\text { JUNE 06, } 1909 \\
\text { SEPT.17, } 1910 \\
\text { SEPT. 27, } 1911\end{array}$ & $\begin{array}{l}9.50 \\
6.80 \\
6.30 \\
4.80 \\
5.90 \\
4.80 \\
6.00\end{array}$ & $\begin{array}{r}1770 \\
1740 \\
1530 \\
910 \\
1660 \\
1580 \\
3500\end{array}$ & $\begin{array}{l}1912 \\
1913 \\
1914 \\
1915 \\
1916 \\
1917 \\
1918\end{array}$ & $\begin{array}{l}\text { JUNE } 04,1912 \\
\text { JULY } 19,1913 \\
\text { MAY } 18,1914 \\
\text { SEPT. 03, } 1915 \\
\text { JULY } 28,1916 \\
\text { JUNE } 25,1917 \\
\text { SEPT. 22, } 1918\end{array}$ & $\begin{array}{l}4.50 \\
8.00 \\
5.30 \\
4.40 \\
7.00 \\
8.43 \\
4.60\end{array}$ & $\begin{array}{r}990 \\
6000 \\
1790 \\
850 \\
3800 \\
7300 \\
1700\end{array}$ & $\begin{array}{l}1919 \\
1920 \\
1921 \\
1922 \\
1923 \\
1924 \\
1925\end{array}$ & $\begin{array}{l}\text { SEPT. } 08,1919 \\
\text { AUG. } 19,1920 \\
\text { MAY } 30,1921 \\
\text { JULY } 28,1922 \\
\text { MAY } 21,1923 \\
\text { AUG. } 13,1924 \\
\text { AUG. } 27,1925\end{array}$ & $\begin{array}{r}10.00 \\
8.00 \\
5.12 \\
5.10 \\
9.66 \\
10.40 \\
12.02\end{array}$ & $\begin{array}{r}12000 \\
6900 \\
1950 \\
3940 \\
1660 \\
2680 \\
4400\end{array}$ \\
\hline
\end{tabular}

MAGNITUDE AND PROBABILITY OF ANNUAL LONEST MEAN DISCHARGE BASED ON CIMATIC YEARS $1910-21$ AND 1 923-25

\begin{tabular}{|c|c|c|c|c|c|c|}
\hline \multirow{2}{*}{$\begin{array}{l}\text { PERIOD } \\
\text { (CON- } \\
\text { SEQU- } \\
\text { TIVE } \\
\text { DAYS ) }\end{array}$} & \multicolumn{6}{|c|}{$\begin{array}{l}\text { DISGARGE, IN OBIC FEET PER SECOND, FOR } \\
\text { INDICATED RECURRENCE INTERNAL, IN YEARS, AND } \\
\text { ANNUAL NONEXCEEDANCE PROBABILITY, IN PERCENT }\end{array}$} \\
\hline & $\begin{array}{c}2 \\
50 \%\end{array}$ & $\begin{array}{c}5 \\
20 z\end{array}$ & $\begin{array}{l}10 \\
108\end{array}$ & $\begin{array}{l}20 \\
58\end{array}$ & $\begin{array}{l}50 \\
28\end{array}$ & $\begin{array}{r}100 \\
18\end{array}$ \\
\hline $\begin{array}{r}1 \\
7 \\
14 \\
30 \\
60 \\
90\end{array}$ & $\begin{array}{l}19 \\
23 \\
25 \\
29 \\
30 \\
33\end{array}$ & $\begin{array}{l}13 \\
16 \\
18 \\
22 \\
24 \\
26\end{array}$ & $\begin{array}{l}10 \\
13 \\
14 \\
19 \\
21 \\
24\end{array}$ & $\begin{array}{l}8.3 \\
10 \\
11 \\
16 \\
19 \\
21\end{array}$ & $\begin{array}{l}- \\
-- \\
-- \\
-- \\
-\end{array}$ & $\begin{array}{l}- \\
- \\
- \\
-- \\
-\end{array}$ \\
\hline
\end{tabular}

MAGNITUDE AND PROBABIIITY OF ANNUAC HTGHEST MEAN DISOHARGE BASED ON WATER YEARS 1910-20 AND 1922-25

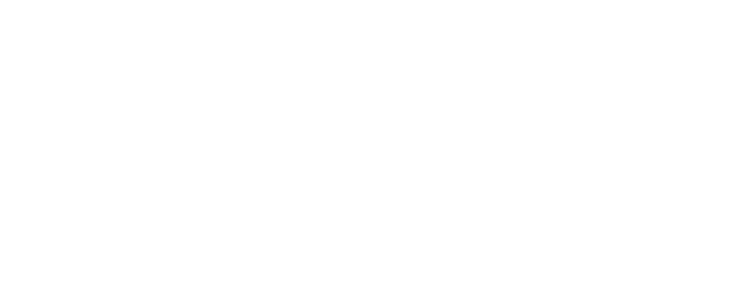


09313500 PRICE RIVER NEAR HELPER, UT-Continued

DATA BELOW BASED ON PERIOD OF RECORD AFTER COMPLETTON OF SCOFIELD RESERNOIR

LOWEST MEAN DISGARGE, IN OUIC FEET PER SECOND, AND RANKING FOR THE INDICATED NUMBER OF CONSECTTIVE DAYS FOR EAOH OLIMATIC YEAR, APRIL 1-MARCH 31

\begin{tabular}{|c|c|c|c|c|c|c|c|c|c|c|c|c|c|c|c|c|c|c|c|c|}
\hline YEAR & & & & & & & & & CONS: & & $E$ DAYS & & & & & & & & & \\
\hline $\begin{array}{l}1928 \\
1929 \\
1930\end{array}$ & $\begin{array}{l}9.00 \\
18.0 \\
13.0\end{array}$ & $\begin{array}{l}5 \\
7 \\
6\end{array}$ & $\begin{array}{l}13.0 \\
18.0 \\
14.0\end{array}$ & $\begin{array}{l}5 \\
7 \\
6\end{array}$ & $\begin{array}{l}16.0 \\
18.0 \\
17.0\end{array}$ & $\begin{array}{l}5 \\
7 \\
6\end{array}$ & $\begin{array}{l}18.0 \\
18.0 \\
19.0\end{array}$ & $\begin{array}{l}5 \\
6 \\
7\end{array}$ & $\begin{array}{l}18.0 \\
18.0 \\
20.0\end{array}$ & $\begin{array}{l}5 \\
6 \\
7\end{array}$ & $\begin{array}{l}19.0 \\
18.0 \\
21.0\end{array}$ & $\begin{array}{l}6 \\
5 \\
7\end{array}$ & $\begin{array}{l}20.0 \\
18.0 \\
21.0\end{array}$ & $\begin{array}{l}6 \\
5 \\
7\end{array}$ & $\begin{array}{l}21.0 \\
19.0 \\
22.0\end{array}$ & $\begin{array}{l}6 \\
5 \\
7\end{array}$ & $\begin{array}{l}27.0 \\
51.0 \\
29.0\end{array}$ & $\begin{array}{l}3 \\
7 \\
6\end{array}$ & $\begin{array}{l}113 \\
179 \\
119\end{array}$ & $\begin{array}{l}5 \\
7 \\
6\end{array}$ \\
\hline $\begin{array}{l}1931 \\
1932 \\
1933 \\
1934\end{array}$ & $\begin{array}{l}2.00 \\
3.00 \\
6.00 \\
9.00\end{array}$ & $\begin{array}{l}1 \\
2 \\
3 \\
4\end{array}$ & $\begin{array}{r}2.70 \\
4.00 \\
7.00 \\
11.0\end{array}$ & $\begin{array}{l}1 \\
2 \\
3 \\
4\end{array}$ & $\begin{array}{r}3.30 \\
4.00 \\
8.10 \\
12.0\end{array}$ & $\begin{array}{l}1 \\
2 \\
3 \\
4\end{array}$ & $\begin{array}{c}3.80 \\
5.00 \\
10.0 \\
12.0\end{array}$ & $\begin{array}{l}1 \\
2 \\
3 \\
4\end{array}$ & $\begin{array}{c}6.60 \\
6.60 \\
12.0 \\
14.0\end{array}$ & $\begin{array}{l}1 \\
2 \\
3 \\
4\end{array}$ & $\begin{array}{c}7.00 \\
7.40 \\
13.0 \\
15.0\end{array}$ & $\begin{array}{l}1 \\
2 \\
3 \\
4\end{array}$ & $\begin{array}{r}7.60 \\
9.80 \\
15.0 \\
17.0\end{array}$ & $\begin{array}{l}1 \\
2 \\
3 \\
4\end{array}$ & $\begin{array}{r}9.40 \\
9.70 \\
18.0 \\
18.0\end{array}$ & $\begin{array}{l}1 \\
2 \\
3 \\
4\end{array}$ & $\begin{array}{l}20.0 \\
11.0 \\
28.0 \\
29.0\end{array}$ & $\begin{array}{l}2 \\
1 \\
4 \\
5\end{array}$ & $\begin{array}{l}69.0 \\
39.0 \\
87.0 \\
90.0\end{array}$ & 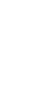 \\
\hline
\end{tabular}

HIGHEST MEAN DISGHARGE, IN CBIC FEET PER SECOND, AND RANKING FOR THE INDICATED NUNBER OF CONSECITIV DAYS FOR EAOH WATER YEAR, OCIOBER 1-SEPTEMBER 30

YEAR

\begin{tabular}{|c|c|c|c|c|c|c|c|c|c|c|c|c|c|c|c|c|c|c|c|}
\hline YEAR & 1 & & 3 & & 7 & & 15 & & $\begin{array}{l}c 0 \\
30\end{array}$ & & $\begin{array}{c}\text { VE DAYS } \\
60\end{array}$ & & 90 & & 120 & & 183 & & ALL \\
\hline $\begin{array}{l}1931 \\
1932 \\
1933 \\
1934\end{array}$ & $\begin{array}{l}403 \\
790 \\
324 \\
146\end{array}$ & $\begin{array}{l}6 \\
3 \\
7 \\
8\end{array}$ & $\begin{array}{l}245 \\
409 \\
313 \\
138\end{array}$ & $\begin{array}{l}7 \\
4 \\
6 \\
8\end{array}$ & $\begin{array}{l}133 \\
264 \\
295 \\
124\end{array}$ & $\begin{array}{l}7 \\
6 \\
4 \\
8\end{array}$ & $\begin{array}{l}130 \\
235 \\
274 \\
111\end{array}$ & $\begin{array}{l}7 \\
5 \\
4 \\
8\end{array}$ & $\begin{array}{l}121 \\
228 \\
251 \\
105\end{array}$ & $\begin{array}{l}7 \\
5 \\
4 \\
8\end{array}$ & $\begin{array}{r}103 \\
200 \\
217 \\
86.0\end{array}$ & $\begin{array}{l}7 \\
5 \\
4 \\
8\end{array}$ & $\begin{array}{l}97.0 \\
189 \\
199 \\
72.0\end{array}$ & $\begin{array}{l}7 \\
5 \\
4 \\
8\end{array}$ & $\begin{array}{c}87.0 \\
179 \\
188 \\
64.0\end{array}$ & $\begin{array}{l}7 \\
5\end{array}$ & $\begin{array}{l}68.0 \\
145 \\
151 \\
47.0\end{array}$ & $\begin{array}{l}7 \\
5 \\
4 \\
8\end{array}$ & $\begin{array}{l}42.0 \\
80.0 \\
90.0 \\
36.0\end{array}$ \\
\hline
\end{tabular}

DURATION OF DISCHARGE FOR EACH WATER YEAR

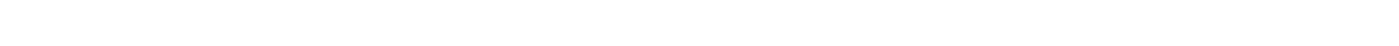
YEAR

NUMBER OF DAYS IN GLASS QBIC FEET PER SECON

1927

1928

1928

$\begin{array}{lllllllllllllllllllll}1 & 6 & 48 & 43 & 44 & 5 & 16 & 8 & 7 & 10 & 2 & 15 & 9 & 14 & 5 & 19 & 17 & 17 & 37 & 26 & 14\end{array}$

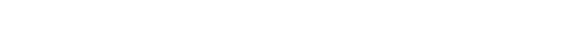
$\begin{array}{lllllllll}1 & 4 & 5 & 10 & 8 & 12 & 5 & 3 & 63163.0\end{array}$

1930 $\begin{array}{lllllllllllllllllllll}3 & 3 & 54 & 58 & 49 & 6 & 20 & 17 & 9 & 17 & 22 & 24 & 25 & 30 & 21 & 1 & 3 & 1 & 1 & 1\end{array}$ 26766.0

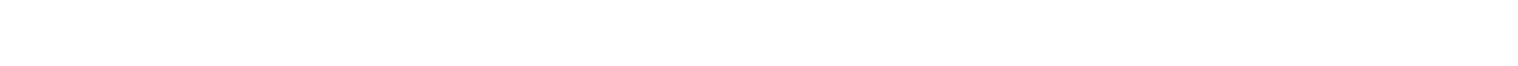

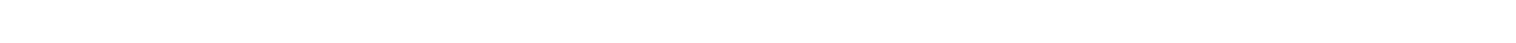

$\begin{array}{llllllllllllllllllllllllllll}1934 & 7 & 13 & 16 & 1 & 13 & 1 & 11 & 10 & 25 & 47 & 35 & 30 & 22 & 17 & 10 & 16 & 17 & 19 & 21 & 28 & 6 & & & & & \end{array}$

DURATTON TPBLE OF DISCHARGE FOR WATER YEARS $1927-34$

\begin{tabular}{|c|c|c|c|c|c|c|c|c|c|c|c|c|c|c|c|c|c|c|c|}
\hline CLASS & $\begin{array}{c}\text { OBIIC } \\
\text { FEET } \\
\text { PER } \\
\text { SECOND }\end{array}$ & $\begin{array}{c}\text { TOTAL } \\
\text { DAYS }\end{array}$ & $\begin{array}{l}\text { AOCJ- } \\
\text { MJ- } \\
\text { LATED } \\
\text { DAYS }\end{array}$ & $\begin{array}{l}\text { PER- } \\
\text { CENT } \\
\text { DAYS }\end{array}$ & OLASS & $\begin{array}{c}\text { UBIC } \\
\text { FEET } \\
\text { PER } \\
\text { SECOND }\end{array}$ & $\begin{array}{c}\text { TOTAL } \\
\text { DAYS }\end{array}$ & $\begin{array}{l}\text { ACOU- } \\
\text { MD- } \\
\text { LATED } \\
\text { DAYS }\end{array}$ & $\begin{array}{l}\text { PER } \\
\text { OENT } \\
\text { DAYS }\end{array}$ & OLASS & $\begin{array}{c}\text { OUBIC } \\
\text { FEET } \\
\text { PER } \\
\text { SECOND }\end{array}$ & $\begin{array}{l}\text { TOTAL } \\
\text { DAYS }\end{array}$ & $\begin{array}{c}\text { ACOJ- } \\
\text { MD- } \\
\text { LATED } \\
\text { DAYS }\end{array}$ & $\begin{array}{l}\text { PER- } \\
\text { OENT } \\
\text { DAYS }\end{array}$ & G.ASS & $\begin{array}{c}\text { UBIC } \\
\text { FEET } \\
\text { PER } \\
\text { SECOND }\end{array}$ & $\begin{array}{l}\text { TOTAL } \\
\text { DAYS }\end{array}$ & $\begin{array}{l}\text { ACOI- } \\
\text { MU- } \\
\text { LATED } \\
\text { DAYS }\end{array}$ & $\begin{array}{l}\text { PER- } \\
\text { CENT } \\
\text { DAYS }\end{array}$ \\
\hline $\begin{array}{l}0 \\
1 \\
2 \\
3 \\
4 \\
5 \\
6 \\
7 \\
8\end{array}$ & $\begin{array}{l}0.00 \\
2.00 \\
2.40 \\
3.00 \\
3.60 \\
4.40 \\
5.30 \\
6.50 \\
7.80\end{array}$ & $\begin{array}{r}0 \\
8 \\
0 \\
18 \\
38 \\
10 \\
37 \\
29 \\
95\end{array}$ & $\begin{array}{l}2922 \\
2922 \\
2914 \\
2914 \\
2896 \\
2858 \\
2848 \\
2811 \\
2782\end{array}$ & $\begin{array}{r}100.0 \\
100.0 \\
99.7 \\
99.7 \\
99.1 \\
97.8 \\
97.5 \\
96.2 \\
95.2\end{array}$ & $\begin{array}{l}9 \\
10 \\
11 \\
12 \\
13 \\
14 \\
15 \\
16 \\
17\end{array}$ & $\begin{array}{r}9.50 \\
12.00 \\
14.00 \\
17.00 \\
21.00 \\
25.00 \\
31.00 \\
37.00 \\
45.00\end{array}$ & $\begin{array}{r}110 \\
140 \\
174 \\
299 \\
220 \\
162 \\
83 \\
90 \\
116\end{array}$ & $\begin{array}{l}2687 \\
2577 \\
2437 \\
2263 \\
1964 \\
1744 \\
1582 \\
1499 \\
1409\end{array}$ & $\begin{array}{l}92.0 \\
88.2 \\
83.4 \\
77.4 \\
67.2 \\
59.7 \\
54.1 \\
51.3 \\
48.2\end{array}$ & $\begin{array}{l}18 \\
19 \\
20 \\
21 \\
22 \\
23 \\
24 \\
25 \\
26\end{array}$ & $\begin{array}{r}55.0 \\
67.0 \\
81.0 \\
99.0 \\
120.0 \\
150.0 \\
180.0 \\
220.0 \\
260.0\end{array}$ & $\begin{array}{r}108 \\
95 \\
117 \\
166 \\
171 \\
142 \\
164 \\
155 \\
80\end{array}$ & $\begin{array}{r}1293 \\
1185 \\
1090 \\
973 \\
807 \\
636 \\
494 \\
330 \\
175\end{array}$ & $\begin{array}{r}44.3 \\
40.6 \\
37.3 \\
33.3 \\
27.6 \\
21.8 \\
16.9 \\
11.3 \\
6.0\end{array}$ & $\begin{array}{l}27 \\
28 \\
29 \\
30 \\
31 \\
32 \\
33 \\
34\end{array}$ & $\begin{array}{r}320.0 \\
390.0 \\
470.0 \\
570.0 \\
700.0 \\
850.0 \\
1000.0 \\
1300.0\end{array}$ & $\begin{array}{r}29 \\
17 \\
17 \\
8 \\
15 \\
5 \\
3 \\
1\end{array}$ & $\begin{array}{r}95 \\
66 \\
49 \\
32 \\
24 \\
9 \\
4 \\
1\end{array}$ & $\begin{array}{l}3.3 \\
2.3 \\
1.7 \\
1.1 \\
0.8 \\
0.3 \\
0.1 \\
0.0\end{array}$ \\
\hline
\end{tabular}

MONTHLY MEAN DISCHARGES, IN CUBIC FEET PER SECOND, FOR EACH WATER YEAR

$\begin{array}{llccccccccccc}\text { YEAR } & \text { OCT } & \text { NOV } & \text { DEC } & \text { JAN } & \text { FEB } & \text { MAR } & \text { APR } & \text { MAY } & \text { JUNE } & \text { JULY } & \text { AUG } & \text { SEP } \\ 1926^{1} & 57.3 & 22.9 & 18.8 & 15.7 & 30.1 & 104 & 241 & 336 & 93.6 & 86.2 & 35.4 & 11.8 \\ 1927 & 14.1 & 12.3 & 10.3 & 12.0 & 17.1 & 38.5 & 106 & 215 & 221 & 206 & 230 & 145 \\ 1928 & 27.4 & 26.5 & 18.5 & 20.0 & 22.0 & 112 & 213 & 678 & 366 & 225 & 208 & 147 \\ 1929 & 57.1 & 21.2 & 18.0 & 18.0 & 85.8 & 104 & 93.3 & 28 & 307 & 234 & 156 & 176 \\ 1930 & 54.5 & 22.5 & 22.2 & 20.1 & 23.5 & 26.1 & 101 & 148 & 182 & 112 & 107 & 59.1 \\ 1931 & 49.3 & 7.97 & 7.52 & 7.77 & 15.1 & 27.5 & 65.4 & 113 & 92.3 & 72.7 & 33.4 & 11.3 \\ 1932 & 7.29 & 14.2 & 8.00 & 10.0 & 17.9 & 26.5 & 90.8 & 207 & 185 & 169 & 146 & 70.7 \\ 1933 & 53.4 & 27.2 & 13.5 & 14.2 & 18.8 & 37.1 & 51.7 & 192 & 224 & 143 & 184 & 111 \\ 1934 & 71.9 & 21.3 & 23.9 & 19.1 & 15.8 & 14.8 & 59.1 & 97.4 & 43.2 & 41.9 & 21.2 & 5.23\end{array}$


GREEN RIVER BASIN

09313500 PRICE RIVER NEAR HELPER, UT-Continued

ANNUAL PEAK DISGARGE, IN GUBIC FEET PER SECOND, AND CORRESPONDING GAGE HEIGHT, IN FEET, FOR EAGH WATER YEAR

\begin{tabular}{|c|c|c|c|c|c|c|c|c|c|c|c|}
\hline $\begin{array}{l}\text { WATER } \\
\text { YEAR }\end{array}$ & DATE & $\begin{array}{c}\text { GAGE } \\
\text { HEIGHT }\end{array}$ & $\begin{array}{c}\text { FEAK } \\
\text { DISQHARGE }\end{array}$ & $\begin{array}{l}\text { WATER } \\
\text { YEAR }\end{array}$ & DATE & $\begin{array}{c}\text { GAGE } \\
\text { HEIGHT }\end{array}$ & $\begin{array}{c}\text { PEAK } \\
\text { DISOHARGE }\end{array}$ & $\begin{array}{l}\text { WAIER } \\
\text { YEAR }\end{array}$ & DATE & $\begin{array}{c}\text { GAGE } \\
\text { HEIGHT }\end{array}$ & $\begin{array}{c}\text { PEAK } \\
\text { DISGHARG }\end{array}$ \\
\hline $\begin{array}{l}1926 \\
1927 \\
1928\end{array}$ & $\begin{array}{ll}\text { OCT. } 05,1925 \\
\text { SEPT.13, } 1927 \\
\text { MAY 25, } 1928\end{array}$ & $\begin{array}{r}9.40 \\
12.30 \\
10.36\end{array}$ & $\begin{array}{r}21400 \\
10000 \\
1440\end{array}$ & $\begin{array}{l}1929 \\
1930 \\
1931\end{array}$ & $\begin{array}{l}\text { AUG. } 03,1929 \\
\text { AUG. } 03,1930 \\
\text { AUG. } 06,1931\end{array}$ & $\begin{array}{r}12.00 \\
12.00 \\
9.70\end{array}$ & $\begin{array}{r}1500 \\
1500 \\
525\end{array}$ & $\begin{array}{l}1932 \\
1933 \\
1934\end{array}$ & $\begin{array}{lll}\text { AUG. } & 28,1932 \\
\text { MAY } & 29,1933 \\
\text { AUG. } & 12,1934\end{array}$ & $\begin{array}{r}11.81 \\
9.60 \\
9.89\end{array}$ & $\begin{array}{r}1570 \\
324 \\
318\end{array}$ \\
\hline
\end{tabular}

1 Water year in which monthly means were affected by storage in Scof ield Reservoir after April.

2 Peak discharge occurred prior to storage in Scof ield Reservoir.

09314000 PRICE RIVER NEAR WETLINGTON, UT

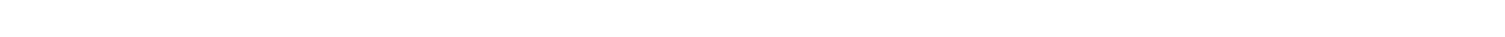
$0.3 \mathrm{mi}$ upstream from Miller Creek and $3.5 \mathrm{mi}$ southeast of Wellington.

DRATNAGE AREA. $--850 \mathrm{mi}^{2}$.

PERIOD OF RECORD AVAILABLE.- - October 1949 to September 1958.

GAGE.--Water-stage recorder. Altitude of gage is 5,300 $\mathrm{ft}$ by barameter.

REMARKS.--Many diversions for irrigation above and below station. Flow affected by storage in Scof ield Reservoir.

AVERAGE DISGHARGE. -9 years, $75.4 \mathrm{ft}^{3} / \mathrm{s}, 54,590$ acre-ft/yr.

EXTREMFS FOR PERIOD OF RECORD.--Maximum discharge, 4,190 ft ${ }^{3} / \mathrm{s} \mathrm{Aug.} \mathrm{28,} \mathrm{1953,} \mathrm{gage} \mathrm{height,} 10.22 \mathrm{ft}$, fron rating curve extended above $1,800 \mathrm{ft}^{3} / \mathrm{s}$ on basis of slope-area measurements at gage heights 8.87 and $10.22 \mathrm{ft}$; minimum, $2.4 \mathrm{ft} / \mathrm{s} \mathrm{Nov} .19,1956$.

LOWEST MEAN DISGHARGE, IN UBIC FEET FER SECOND, AND RANKING FOR THE INDICATED NUMBER OF CONSECITIVE DAYS FOR EACH OIMATIC YEAR, ARRIL 1-MARG 31

\begin{tabular}{|c|c|c|c|c|c|c|c|c|c|c|c|c|c|c|c|c|c|c|c|c|}
\hline YEAR & \multicolumn{20}{|c|}{ CNSEUTIVE DAUS } \\
\hline $\begin{array}{l}1951 \\
1952 \\
1953 \\
1954 \\
1955\end{array}$ & $\begin{array}{c}14.0 \\
13.0 \\
30.0 \\
18.0 \\
9.00\end{array}$ & $\begin{array}{l}6 \\
5 \\
8 \\
7 \\
2\end{array}$ & $\begin{array}{c}15.0 \\
14.0 \\
30.0 \\
18.0 \\
9.00\end{array}$ & $\begin{array}{l}6 \\
5 \\
8 \\
7 \\
2\end{array}$ & $\begin{array}{c}16.0 \\
17.0 \\
31.0 \\
18.0 \\
9.00\end{array}$ & $\begin{array}{l}6 \\
8 \\
7 \\
2\end{array}$ & $\begin{array}{c}18.0 \\
19.0 \\
31.0 \\
19.0 \\
9.00\end{array}$ & $\begin{array}{l}5 \\
6 \\
8 \\
7 \\
1\end{array}$ & $\begin{array}{c}18.0 \\
21.0 \\
32.0 \\
20.0 \\
9.00\end{array}$ & $\begin{array}{l}5 \\
7 \\
8 \\
6 \\
1\end{array}$ & $\begin{array}{c}19.0 \\
22.0 \\
36.0 \\
23.0 \\
9.80\end{array}$ & $\begin{array}{l}4 \\
5 \\
8 \\
6 \\
1\end{array}$ & $\begin{array}{l}20.0 \\
26.0 \\
38.0 \\
23.0 \\
11.0\end{array}$ & $\begin{array}{l}4 \\
6 \\
8 \\
5 \\
2\end{array}$ & $\begin{array}{l}21.0 \\
25.0 \\
39.0 \\
27.0 \\
13.0\end{array}$ & $\begin{array}{l}4 \\
5 \\
8 \\
6 \\
2\end{array}$ & $\begin{array}{l}24.0 \\
27.0 \\
41.0 \\
32.0 \\
24.0\end{array}$ & $\begin{array}{l}3 \\
5 \\
8 \\
6 \\
4\end{array}$ & $\begin{array}{r}50.0 \\
38.0 \\
293 \\
46.0 \\
33.0\end{array}$ & $\begin{array}{l}6 \\
4 \\
8 \\
5 \\
3\end{array}$ \\
\hline $\begin{array}{l}1956 \\
1957 \\
1958\end{array}$ & $\begin{array}{l}9.80 \\
8.10 \\
9.20\end{array}$ & $\begin{array}{l}4 \\
1 \\
3\end{array}$ & $\begin{array}{l}9.90 \\
8.50 \\
9.30\end{array}$ & $\begin{array}{l}4 \\
1 \\
3\end{array}$ & $\begin{array}{c}11.0 \\
8.90 \\
12.0\end{array}$ & $\begin{array}{l}3 \\
1 \\
4\end{array}$ & $\begin{array}{c}11.0 \\
9.40 \\
14.0\end{array}$ & $\begin{array}{l}3 \\
2 \\
4\end{array}$ & $\begin{array}{l}13.0 \\
10.0 \\
18.0\end{array}$ & $\begin{array}{l}3 \\
2 \\
4\end{array}$ & $\begin{array}{l}14.0 \\
10.0 \\
28.0\end{array}$ & $\begin{array}{l}3 \\
2 \\
7\end{array}$ & $\begin{array}{l}16.0 \\
10.0 \\
29.0\end{array}$ & $\begin{array}{l}3 \\
1 \\
7\end{array}$ & $\begin{array}{l}17.0 \\
12.0 \\
32.0\end{array}$ & $\begin{array}{l}3 \\
1 \\
7\end{array}$ & $\begin{array}{l}17.0 \\
12.0 \\
37.0\end{array}$ & $\begin{array}{l}2 \\
1 \\
7\end{array}$ & $\begin{array}{l}30.0 \\
18.0 \\
63.0\end{array}$ & $\begin{array}{l}2 \\
1 \\
7\end{array}$ \\
\hline
\end{tabular}

HIGHEST MEAN DISGHARGE, IN WBIC FEET PER SECOND, AND RANKING FOR THE INDICATED NUMBER OF CONSEOUTIVE DAYS FOR EAOH WAIER YEAR, OCTOBER 1-SEPTEMBER 30

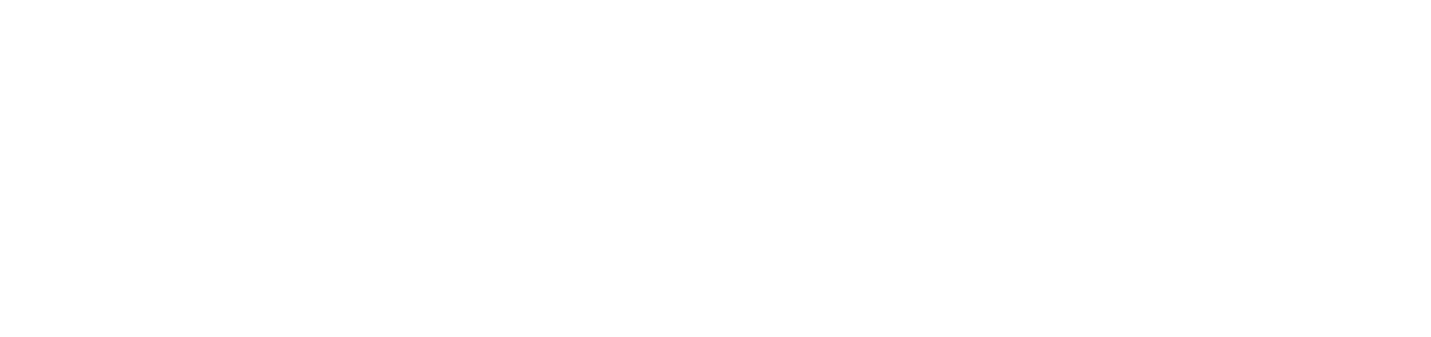


09314000 PRICE RIVER NEAR WELLINGTON, UT-Continued

$$
\text { DURATION OF DISCHARGE FOR EACH WATER YEAR }
$$

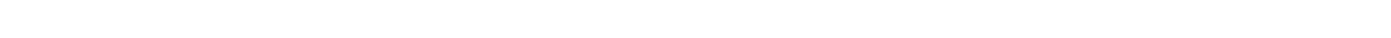

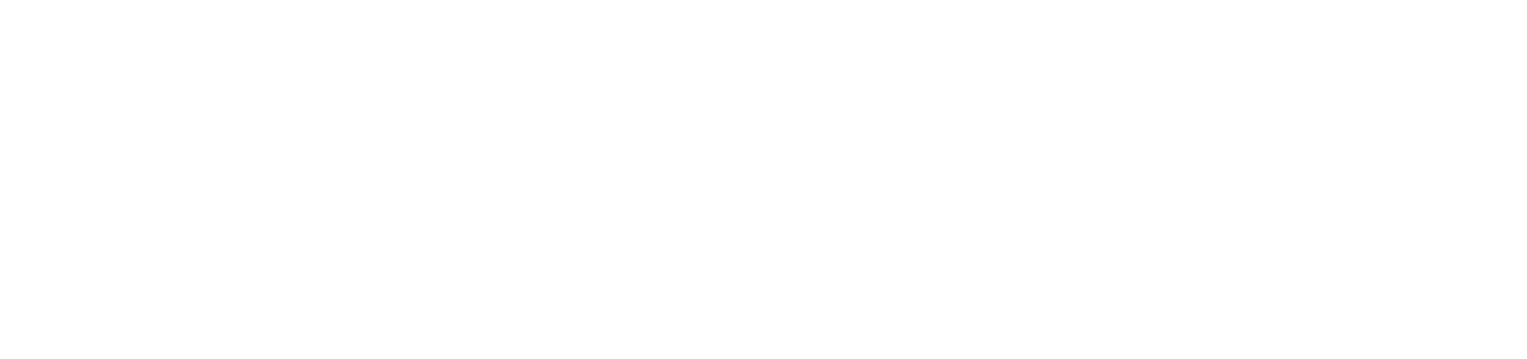

DURATION TABLE OF DISCHARGE FOR WATER YEARS 1950-58
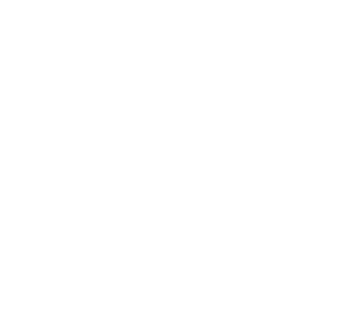

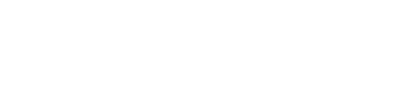

ABIC ACUIFEET TOTAL LATED PER OLASS SECOND DAYS DAYS DAYS

$\begin{array}{rrrrr}18 & 150.0 & 17 & 229 & 7.0 \\ 19 & 170.0 & 21 & 212 & 6.4 \\ 20 & 210.0 & 21 & 191 & 5.8 \\ 21 & 240.0 & 24 & 170 & 5.2 \\ 22 & 290.0 & 17 & 146 & 4.4 \\ 23 & 340.0 & 20 & 129 & 3.9 \\ 24 & 410.0 & 8 & 109 & 3.3 \\ 25 & 480.0 & 23 & 101 & 3.1 \\ 26 & 570.0 & 15 & 78 & 2.4\end{array}$

$\begin{array}{lcc}\text { OBBIC } & \text { ACOU- } \\ \text { FEET } & \text { M- } & \text { PER- } \\ \text { PER TOTAL LATED } & \text { CENT }\end{array}$ CIASS SECOND DAYS DAYS DAYS

$\begin{array}{rrrrr}27 & 670.0 & 8 & 63 & 1.9 \\ 28 & 800.0 & 5 & 55 & 1.7 \\ 29 & 950.0 & 3 & 50 & 1.5 \\ 30 & 1100.0 & 11 & 47 & 1.4 \\ 31 & 1300.0 & 18 & 36 & 1.1 \\ 32 & 1600.0 & 10 & 18 & 0.5 \\ 33 & 1900.0 & 5 & 8 & 0.2 \\ 34 & 2200.0 & 3 & 3 & 0.1\end{array}$

MONTHLY MEAN DISCHARGES, IN OUBIC FEET PER SECOND, FOR EACH WATER YEAR

\begin{tabular}{|c|c|c|c|c|c|c|c|c|c|c|c|c|}
\hline YEAR & OCT & NOV & DEC & JAN & FEB & MAR & APR & MAY & JUNE & JULY & AUG & SEP \\
\hline 1950 & 46.9 & 23.2 & 28.3 & 32.0 & 35.4 & 46.3 & 189 & 81.6 & 43.7 & 58.5 & 26.9 & 33.2 \\
\hline $\begin{array}{l}1951 \\
1952 \\
1953 \\
1954 \\
1955\end{array}$ & $\begin{array}{l}23.4 \\
24.4 \\
42.3 \\
38.1 \\
47.4\end{array}$ & $\begin{array}{l}24.1 \\
32.7 \\
33.2 \\
24.7 \\
19.5\end{array}$ & $\begin{array}{l}20.6 \\
22.7 \\
41.6 \\
24.3 \\
12.3\end{array}$ & $\begin{array}{c}18.7 \\
27.4 \\
40.0 \\
21.2 \\
9.32\end{array}$ & $\begin{array}{l}23.0 \\
35.0 \\
43.7 \\
45.8 \\
11.0\end{array}$ & $\begin{array}{l}51.7 \\
48.6 \\
44.1 \\
48.9 \\
43.1\end{array}$ & $\begin{array}{c}25.4 \\
609 \\
49.7 \\
35.7 \\
81.5\end{array}$ & $\begin{array}{c}38.1 \\
1618 \\
45.8 \\
44.1 \\
32.2\end{array}$ & $\begin{array}{c}48.2 \\
780 \\
51.6 \\
34.3 \\
26.6\end{array}$ & $\begin{array}{c}43.5 \\
100 \\
79.5 \\
34.9 \\
26.0\end{array}$ & $\begin{array}{l}86.7 \\
89.3 \\
81.9 \\
32.6 \\
42.7\end{array}$ & $\begin{array}{l}22.6 \\
58.7 \\
39.3 \\
68.4 \\
13.1\end{array}$ \\
\hline $\begin{array}{l}1956 \\
1957 \\
1958\end{array}$ & $\begin{array}{l}16.9 \\
15.2 \\
31.8\end{array}$ & $\begin{array}{l}19.5 \\
13.5 \\
63.1\end{array}$ & $\begin{array}{l}23.8 \\
10.0 \\
28.7\end{array}$ & $\begin{array}{l}15.7 \\
10.0 \\
28.0\end{array}$ & $\begin{array}{l}15.9 \\
19.1 \\
40.9\end{array}$ & $\begin{array}{l}44.9 \\
26.6 \\
29.7\end{array}$ & $\begin{array}{l}16.3 \\
18.8 \\
297\end{array}$ & $\begin{array}{l}25.0 \\
116 \\
509\end{array}$ & $\begin{array}{r}19.3 \\
92.2 \\
171\end{array}$ & $\begin{array}{l}33.5 \\
47.5 \\
42.0\end{array}$ & $\begin{array}{c}13.7 \\
219 \\
32.0\end{array}$ & $\begin{array}{l}10.4 \\
34.5 \\
46.0\end{array}$ \\
\hline
\end{tabular}

ANNUAL PEAK DISCHARGE, IN OBIC FEET PER SECOND, AND CORRESPONDING GAGE HEIGHT, IN FEET, FOR EAG WATER YEAR

\begin{tabular}{|c|c|c|c|c|c|c|c|c|c|c|c|}
\hline $\begin{array}{l}\text { WATER } \\
\text { YEAR }\end{array}$ & DATE & $\begin{array}{c}\text { GAGE } \\
\text { HEIGHT }\end{array}$ & $\begin{array}{c}\text { PEAR } \\
\text { DISCH ARGE }\end{array}$ & $\begin{array}{l}\text { WATER } \\
\text { YEAR }\end{array}$ & DATE & $\begin{array}{c}\text { GAGE } \\
\text { HEIGHT }\end{array}$ & $\begin{array}{c}\text { PEAK } \\
\text { DISOHARGE }\end{array}$ & $\begin{array}{l}\text { WATER } \\
\text { YEAR }\end{array}$ & DATE & $\begin{array}{c}\text { GAGE } \\
\text { HEIGHT }\end{array}$ & $\begin{array}{c}\text { PEAK } \\
\text { DISCHARGE }\end{array}$ \\
\hline $\begin{array}{l}1950 \\
1951 \\
1952\end{array}$ & $\begin{array}{lll}\text { JULY } 08,1950 \\
\text { AUG. } 04,1951 \\
\text { MAY } 05,1952\end{array}$ & $\begin{array}{l}5.12 \\
8.87 \\
7.18\end{array}$ & $\begin{array}{l}1170 \\
3250 \\
2370\end{array}$ & $\begin{array}{l}1953 \\
1954 \\
1955\end{array}$ & $\begin{array}{l}\text { AUG. 28, } 1953 \\
\text { SEPT. 04, } 1954 \\
\text { JULY 25, } 1955\end{array}$ & $\begin{array}{r}10.22 \\
7.05 \\
6.19\end{array}$ & $\begin{array}{l}4190 \\
2200 \\
1740\end{array}$ & $\begin{array}{l}1956 \\
1957 \\
1958\end{array}$ & $\begin{array}{l}\text { JULY } 13,1956 \\
\text { AUG. 30, } 1957 \\
\text { NOV. 03, } 1957\end{array}$ & $\begin{array}{l}4.62 \\
9.14 \\
6.22\end{array}$ & $\begin{array}{l}1020 \\
3430 \\
1650\end{array}$ \\
\hline
\end{tabular}




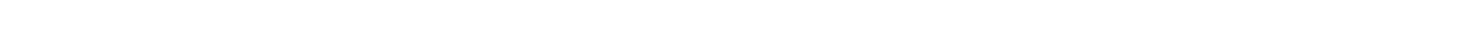
side of bridge on State Highway 10 and $5.5 \mathrm{mi}$ south of Price.

DRAINAGE AREA $-62 \mathrm{mi}^{2}$.

MEAN BASIN ELEVATION. $-7,040 \mathrm{ft}$.

PERIOD OF RECORD AVAJLABLE.-Water years 1960-71, 1973, annual peak discharge only.

GAGE.--Crest-stage gage. Altitude of gage is 5,600 ft from topographic map.

REMARKS.--Peak discharge not significantly affected by diversions above station.

ANNUAL PEAK DISCHARGE, IN CUBIC FEET PER SECOND, AND CORRESPONDING GAGE HEIGHT, IN FEET, FOR EACH WATER YEAR

\begin{tabular}{|c|c|c|c|c|c|c|c|c|c|c|c|}
\hline $\begin{array}{l}\text { WATER } \\
\text { YEAR }\end{array}$ & DATE & $\begin{array}{l}\text { GAGE } \\
\text { HEIGHT }\end{array}$ & $\begin{array}{c}\text { PEAK } \\
\text { DISCHARGE }\end{array}$ & $\begin{array}{l}\text { WATER } \\
\text { YEAR }\end{array}$ & DATE & $\begin{array}{c}\text { GAGE } \\
\text { HEIGHT }\end{array}$ & $\begin{array}{c}\text { PEAK } \\
\text { DISCHARGE }\end{array}$ & $\begin{array}{l}\text { WATER } \\
\text { YEAR }\end{array}$ & DATE & $\begin{array}{l}\text { GAGE } \\
\text { HEIGHT }\end{array}$ & $\begin{array}{c}\text { PEAK } \\
\text { DISCHARGE }\end{array}$ \\
\hline $\begin{array}{l}1960 \\
1961 \\
1962 \\
1963 \\
1964\end{array}$ & $\begin{array}{l}\text { SEPT.24, } 1960 \\
\text { SEPT.09, } 1961 \\
\text { AUG. 03, } 1962 \\
\text { AUG. 10, } 1963 \\
\text { JULY 14, } 1964\end{array}$ & $\begin{array}{l}10.39 \\
15.30 \\
12.90 \\
20.89 \\
15.46\end{array}$ & $\begin{array}{r}300 \\
2500 \\
400 \\
3610 \\
1410\end{array}$ & $\begin{array}{l}1965 \\
1966 \\
1967 \\
1968\end{array}$ & $\begin{array}{l}\text { AUG. } 18,1965 \\
\text { JULY } 17,1966 \\
\text { AUG. } 10,1967 \\
\text { JULY } 30,1968\end{array}$ & $\begin{array}{l}14.45 \\
17.30 \\
16.00 \\
22.87\end{array}$ & $\begin{array}{l}1080 \\
2100 \\
1650 \\
4600\end{array}$ & $\begin{array}{l}1969 \\
1970 \\
1971 \\
1973\end{array}$ & $\begin{array}{l}\text { SEPT. } 14,1969 \\
\text { SEPT.06, } 1970 \\
\text { ALG. 29, } 1971 \\
\text { AUG. 07, } 1973\end{array}$ & $\begin{array}{l}24.29 \\
13.38 \\
10.04 \\
20.34\end{array}$ & $\begin{array}{r}5000 \\
720 \\
175 \\
3300\end{array}$ \\
\hline
\end{tabular}

O9314250 PRICE RIVER BELOW MHLER CREEK, NEAR WEILINGTON, UT

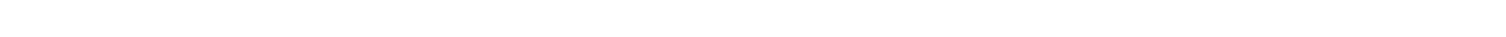

$100 \mathrm{ft}$ downstream from highway bridge and $8.5 \mathrm{mi}$ southeast of Wellington.

DRAINAGE AREA. $-956 \mathrm{mi}^{2}$

MEAN BASIN ELEVATION. $-7,5 j 0 \mathrm{ft}$.

PERIOD OF RECORD AVAIIABLE.--April 1972 to September 1981.

REVISED RECORDS.--WDR UT-77-1: Drainage area.

GAGE.--Water-stage recorder. Altitude of gage is 5,150 ft from topographic map.

REMARKS.--Diversions for irrigation above station. Flow affected by storage in scofield Reservoir.

AVERAGE DISCHARGE. -9 Years, $84.0 \mathrm{ft}^{3} / \mathrm{s}, 60,860$ acre- $\mathrm{ft} / \mathrm{yr}$.

EXTREMES FOR PERIOD OF RECORD.-Maximum discharge, 2,880 ft ${ }^{3} / \mathrm{s}$ September 11, 1975, gage height, $9.97 \mathrm{ft}$ from $\mathrm{floodmark;} \mathrm{minimum,}$ $0.68 \mathrm{ft}^{3} / \mathrm{s}$ June 30 , July $1,2,1977$.

LOWEST MEAN DISCHARGE, IN CUBIC FEET PER SECOND, AND RANKING FOR THE INDICATED NUMBER OF CONSECITIVE DAYS FOR EAOH CLIMATIC YEAR, APRII 1-MARQH 31

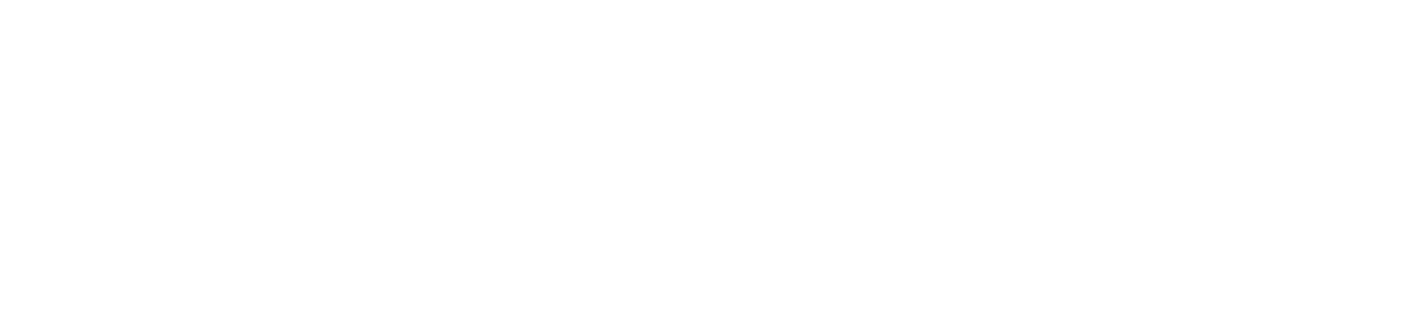


GREEN RIVER BASIN

09314250 PRICE RIVER BELOW MIILER CREER, NEAR WELLINGTON, UT-Continued

HIGHEST MEAN DISQHARGE, IN GBIC FEET PER SECOND, AND RANKING FOR THE INDICAIED NUMBER OF CONSEQUTIVE DAYS FOR EAOH WATER YEAR, OCIOBER 1-SEPTEMBER 30

\begin{tabular}{|c|c|c|c|c|c|c|c|c|c|c|c|c|c|c|c|c|c|c|c|c|}
\hline YEAR & 1 & & 3 & & 7 & & 15 & & $\begin{array}{l}\text { CONS } \\
30\end{array}$ & out' & $\begin{array}{c}\text { VE DAYS } \\
60\end{array}$ & & 90 & & 120 & & 183 & & ALL & \\
\hline $\begin{array}{l}1973 \\
1974 \\
1975\end{array}$ & $\begin{array}{r}1500 \\
318 \\
862\end{array}$ & $\begin{array}{l}2 \\
8 \\
4\end{array}$ & $\begin{array}{r}1100 \\
254 \\
672\end{array}$ & $\begin{array}{l}2 \\
8 \\
4\end{array}$ & $\begin{array}{r}1040 \\
154 \\
604\end{array}$ & $\begin{array}{l}1 \\
8 \\
3\end{array}$ & $\begin{array}{c}926 \\
87.0 \\
572\end{array}$ & $\begin{array}{l}2 \\
8 \\
3\end{array}$ & $\begin{array}{c}759 \\
65.0 \\
481\end{array}$ & $\begin{array}{l}2 \\
8 \\
3\end{array}$ & $\begin{array}{c}489 \\
58.0 \\
331\end{array}$ & $\begin{array}{l}2 \\
6 \\
4\end{array}$ & $\begin{array}{c}372 \\
58.0 \\
254\end{array}$ & $\begin{array}{l}2 \\
6 \\
4\end{array}$ & $\begin{array}{c}308 \\
55.0 \\
208\end{array}$ & $\begin{array}{l}2 \\
6 \\
4\end{array}$ & $\begin{array}{l}237 \\
51.0 \\
156\end{array}$ & $\begin{array}{l}2 \\
6 \\
4\end{array}$ & $\begin{array}{l}148 \\
41.0 \\
101\end{array}$ & $\begin{array}{l}2 \\
8 \\
4\end{array}$ \\
\hline $\begin{array}{l}1976 \\
1977 \\
1978 \\
1979 \\
1980\end{array}$ & $\begin{array}{r}531 \\
580 \\
294 \\
1370 \\
1900\end{array}$ & $\begin{array}{l}7 \\
6 \\
9 \\
3 \\
1\end{array}$ & $\begin{array}{r}212 \\
350 \\
268 \\
810 \\
1200\end{array}$ & $\begin{array}{l}9 \\
5 \\
7 \\
3 \\
1\end{array}$ & $\begin{array}{r}125 \\
277 \\
206 \\
500 \\
1010\end{array}$ & $\begin{array}{l}9 \\
5 \\
6 \\
4 \\
2\end{array}$ & $\begin{array}{l}77.0 \\
133 \\
179 \\
463 \\
957\end{array}$ & $\begin{array}{l}9 \\
6 \\
5 \\
4 \\
1\end{array}$ & $\begin{array}{l}53.0 \\
84.0 \\
174 \\
432 \\
855\end{array}$ & $\begin{array}{l}9 \\
6 \\
5 \\
4 \\
1\end{array}$ & $\begin{array}{l}49.0 \\
52.0 \\
152 \\
368 \\
791\end{array}$ & $\begin{array}{l}9 \\
8 \\
5 \\
3 \\
1\end{array}$ & $\begin{array}{l}49.0 \\
39.0 \\
117 \\
330 \\
604\end{array}$ & $\begin{array}{l}8 \\
9 \\
5 \\
3 \\
1\end{array}$ & $\begin{array}{c}48.0 \\
34.0 \\
99.0 \\
267 \\
479\end{array}$ & $\begin{array}{l}7 \\
9 \\
5 \\
3 \\
1\end{array}$ & $\begin{array}{l}47.0 \\
27.0 \\
76.0 \\
193 \\
357\end{array}$ & $\begin{array}{l}7 \\
9 \\
5 \\
3 \\
1\end{array}$ & $\begin{array}{l}42.0 \\
22.0 \\
44.0 \\
121 \\
202\end{array}$ & $\begin{array}{l}6 \\
9 \\
5 \\
3 \\
1\end{array}$ \\
\hline 1981 & 670 & 5 & 321 & 6 & 179 & 7 & 108 & 7 & 75.0 & 7 & 56.0 & 7 & 50.0 & 7 & 47.0 & 8 & 45.0 & 8 & 41.0 & 7 \\
\hline
\end{tabular}

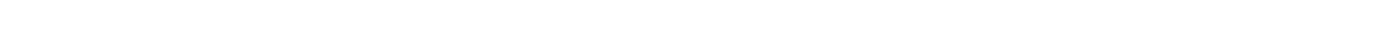
NUMBER OF DAYS IN CLASS

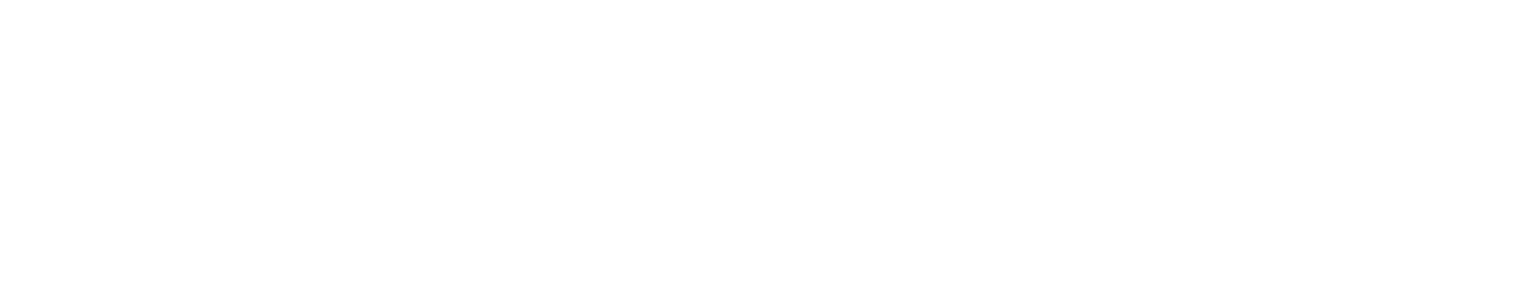

DURATION TABLE OF DISGHARGE FOR WATER YEARS 1973-81

\begin{tabular}{|c|c|c|c|c|c|c|c|c|c|c|c|c|c|c|c|c|c|c|c|}
\hline & $\begin{array}{c}\text { OBBIC } \\
\text { FEET } \\
\text { PER }\end{array}$ & TOTAL & $\begin{array}{l}\text { ACOI- } \\
\text { MU- } \\
\text { LAIED }\end{array}$ & $\begin{array}{l}\text { PER- } \\
\text { CENT }\end{array}$ & & $\begin{array}{c}\text { UBIC } \\
\text { FEET } \\
\text { PER }\end{array}$ & TOTAL & $\begin{array}{l}\text { ACOJ- } \\
\text { MU- } \\
\text { LATED }\end{array}$ & $\begin{array}{l}\text { PER- } \\
\text { CENT }\end{array}$ & & $\begin{array}{l}\text { OUBIC } \\
\text { FEET } \\
\text { PER }\end{array}$ & TOTAL & $\begin{array}{l}\text { ACOU- } \\
\text { MU- } \\
\text { LATED }\end{array}$ & $\begin{array}{l}\text { PER } \\
\text { CENT }\end{array}$ & & $\begin{array}{c}\text { OUBIC } \\
\text { FEET } \\
\text { PER }\end{array}$ & TOTAL & $\begin{array}{l}\text { ACO- } \\
\text { MU- } \\
\text { LATED }\end{array}$ & $\begin{array}{l}\text { PER } \\
\text { CENT }\end{array}$ \\
\hline CLASS & SECOND & DAYS & DAYS & DAYS & CLASS & SECOND & DAYS & DAYS & DAYS & CLASS & SECOND & DAYS & DAYS & DAYS & CLASS & SECOND & DAYS & DAYS & DAYS \\
\hline $\begin{array}{l}0 \\
1 \\
2 \\
3 \\
4 \\
5 \\
6 \\
7 \\
8\end{array}$ & $\begin{array}{l}0.00 \\
0.80 \\
1.00 \\
1.30 \\
1.60 \\
2.00 \\
2.50 \\
3.20 \\
4.00\end{array}$ & $\begin{array}{r}0 \\
4 \\
4 \\
5 \\
6 \\
10 \\
5 \\
6 \\
14\end{array}$ & $\begin{array}{l}3287 \\
3287 \\
3283 \\
3279 \\
3274 \\
3268 \\
3258 \\
3253 \\
3247\end{array}$ & $\begin{array}{r}100.0 \\
100.0 \\
99.9 \\
99.8 \\
99.6 \\
99.4 \\
99.1 \\
99.0 \\
98.8\end{array}$ & $\begin{array}{l}9 \\
10 \\
11 \\
12 \\
13 \\
14 \\
15 \\
16 \\
17\end{array}$ & $\begin{array}{r}5.00 \\
6.30 \\
7.90 \\
9.90 \\
12.00 \\
16.00 \\
20.00 \\
25.00 \\
31.00\end{array}$ & $\begin{array}{r}17 \\
9 \\
80 \\
128 \\
129 \\
220 \\
298 \\
393 \\
427\end{array}$ & $\begin{array}{l}3233 \\
3216 \\
3207 \\
3127 \\
2999 \\
2870 \\
2650 \\
2352 \\
1959\end{array}$ & $\begin{array}{l}98.4 \\
97.8 \\
97.6 \\
95.1 \\
91.2 \\
87.3 \\
80.6 \\
71.6 \\
59.6\end{array}$ & $\begin{array}{l}18 \\
19 \\
20 \\
21 \\
22 \\
23 \\
24 \\
25 \\
26\end{array}$ & $\begin{array}{r}39.0 \\
49.0 \\
61.0 \\
77.0 \\
97.0 \\
120.0 \\
150.0 \\
190.0 \\
240.0\end{array}$ & $\begin{array}{r}491 \\
273 \\
124 \\
104 \\
90 \\
75 \\
58 \\
54 \\
39\end{array}$ & $\begin{array}{r}1532 \\
1041 \\
768 \\
644 \\
540 \\
450 \\
375 \\
317 \\
263\end{array}$ & $\begin{array}{r}46.6 \\
31.7 \\
23.4 \\
19.6 \\
16.4 \\
13.7 \\
11.4 \\
9.6 \\
8.0\end{array}$ & $\begin{array}{l}27 \\
28 \\
29 \\
30 \\
31 \\
32 \\
33 \\
34\end{array}$ & $\begin{array}{r}300.0 \\
380.0 \\
480.0 \\
600.0 \\
760.0 \\
950.0 \\
1200.0 \\
1500.0\end{array}$ & $\begin{array}{r}54 \\
39 \\
37 \\
40 \\
27 \\
22 \\
3 \\
2\end{array}$ & $\begin{array}{r}224 \\
170 \\
131 \\
94 \\
54 \\
27 \\
5 \\
2\end{array}$ & $\begin{array}{l}6.8 \\
5.2 \\
4.0 \\
2.9 \\
1.6 \\
0.8 \\
0.2 \\
0.1\end{array}$ \\
\hline
\end{tabular}

MONTHLY MEAN DISCHARGES, IN QBBIC FEET PER SECOND, FOR EACH WATER YEAR

\begin{tabular}{|c|c|c|c|c|c|c|c|c|c|c|c|c|}
\hline YEAR & OCT & NON & DEC & JAN & FEB & MAR & APR & MAY & JUNE & JULY & AUG & SEP \\
\hline $\begin{array}{l}1973 \\
1974 \\
1975\end{array}$ & $\begin{array}{r}146 \\
45.7 \\
63.9\end{array}$ & $\begin{array}{l}38.3 \\
30.1 \\
42.8\end{array}$ & $\begin{array}{l}37.7 \\
40.0 \\
29.7\end{array}$ & $\begin{array}{l}35.0 \\
40.0 \\
32.7\end{array}$ & $\begin{array}{l}43.2 \\
40.0 \\
46.1\end{array}$ & $\begin{array}{r}116 \\
54.4 \\
62.4\end{array}$ & $\begin{array}{c}259 \\
40.6 \\
102\end{array}$ & $\begin{array}{c}676 \\
62.9 \\
171\end{array}$ & $\begin{array}{c}158 \\
48.4 \\
463\end{array}$ & $\begin{array}{l}111 \\
57.1 \\
90.7\end{array}$ & $\begin{array}{l}94.1 \\
17.1 \\
47.6\end{array}$ & $\begin{array}{l}43.0 \\
18.2 \\
60.7\end{array}$ \\
\hline $\begin{array}{l}1976 \\
1977 \\
1978 \\
1979 \\
1980\end{array}$ & $\begin{array}{l}36.6 \\
28.1 \\
15.4 \\
23.0 \\
22.7\end{array}$ & $\begin{array}{r}45.8 \\
21.0 \\
14.8 \\
185 \\
25.5\end{array}$ & $\begin{array}{c}25.4 \\
16.9 \\
9.42 \\
24.2 \\
20.4\end{array}$ & $\begin{array}{c}32.5 \\
10.0 \\
8.39 \\
19.1 \\
26.7\end{array}$ & $\begin{array}{c}47.9 \\
12.9 \\
10.0 \\
22.8 \\
103\end{array}$ & $\begin{array}{l}45.5 \\
16.7 \\
46.8 \\
271 \\
108\end{array}$ & $\begin{array}{l}47.7 \\
11.2 \\
158 \\
301 \\
370\end{array}$ & $\begin{array}{l}49.7 \\
24.0 \\
140 \\
391 \\
811\end{array}$ & $\begin{array}{c}44.8 \\
8.11 \\
42.5 \\
82.3 \\
595\end{array}$ & $\begin{array}{l}40.5 \\
81.5 \\
43.3 \\
46.1 \\
71.5\end{array}$ & $\begin{array}{l}34.7 \\
18.5 \\
23.8 \\
56.5 \\
65.7\end{array}$ & $\begin{array}{c}50.0 \\
9.90 \\
12.6 \\
25.7 \\
215\end{array}$ \\
\hline 1981 & 72.8 & 29.1 & 30.2 & 29.6 & 27.1 & 32.5 & 43.9 & 41.7 & 35.8 & 37.6 & 47.6 & 60.2 \\
\hline
\end{tabular}

ANNUA PEAK DISGAARE, IN OBBIC FEET PER SECOND, AND CORRESPONDING GAGE HEIGHT, IN FEET, FOR EACH WATER YEAR

\begin{tabular}{|c|c|c|c|c|c|c|c|c|c|c|c|}
\hline $\begin{array}{l}\text { WATER } \\
\text { YEAR }\end{array}$ & DATE & $\begin{array}{c}\text { GAGE } \\
\text { HEIGHT }\end{array}$ & $\begin{array}{c}\text { PEAK } \\
\text { DISCHARGE }\end{array}$ & $\begin{array}{l}\text { WATER } \\
\text { YEAR }\end{array}$ & DATE & $\begin{array}{c}\text { GAGE } \\
\text { HEIGHT }\end{array}$ & $\begin{array}{c}\text { PEAK } \\
\text { DISCHARGE }\end{array}$ & $\begin{array}{l}\text { WATER } \\
\text { YEAR }\end{array}$ & DATE & $\begin{array}{c}\text { GAGE } \\
\text { HEIGHT }\end{array}$ & $\begin{array}{c}\text { PEAK } \\
\text { DISOAARGE }\end{array}$ \\
\hline $\begin{array}{l}1973 \\
1974 \\
1975\end{array}$ & $\begin{array}{c}1 \\
\text { JULY 17, } 1974 \\
\text { SEPT.11, } 1975\end{array}$ & $\begin{array}{l}9.45 \\
5.26 \\
9.97\end{array}$ & $\begin{array}{r}2720 \\
858 \\
2880\end{array}$ & $\begin{array}{l}1976 \\
1977 \\
1978\end{array}$ & $\begin{array}{l}\text { SEPT.11, } 1976 \\
\text { JULY 19, } 1977 \\
\text { JULY } 18,1978\end{array}$ & $\begin{array}{l}7.31 \\
8.30 \\
6.26\end{array}$ & $\begin{array}{l}1640 \\
1700 \\
1020\end{array}$ & $\begin{array}{l}1979 \\
1980 \\
1981\end{array}$ & $\begin{array}{l}\text { NOV. } 03,1978 \\
\text { SEPT.10， } 1980 \\
\text { OCT. } 15,1980\end{array}$ & $\begin{array}{r}9.84 \\
10.00 \\
9.97\end{array}$ & $\begin{array}{l}2070 \\
2110 \\
1760\end{array}$ \\
\hline
\end{tabular}


GREEN RTVER BASIN

09314280 DESERT SEEP WASH NEAR WELLINGTON, UT

LOCATION.--Lat $39^{\circ} 25^{\prime} 16^{\prime \prime}$, long $110^{\circ} 38^{\prime} 44^{\prime \prime}$, in SW $W_{4}^{\frac{1}{4} W^{\frac{1}{4}}}$ sec.24, T.16 S., R.11 E., Emery County, Hydrol ogic Unit 14060007 , on left bank 2,000 ft above mouth and $9.5 \mathrm{mi}$ southeast of Wellington.

DRAINAGE AREA, $-191 \mathrm{mi}^{2}$.

MEAN BASTN ELLVITTON. $--5,810 \mathrm{ft}$.

PERIOD OF RECORD AVAIL ABLE. --May 1972 to September 1981.

REVISED RECORDS. -WDR UT-77-1: 1972-76, WDR UT-80-1: 1979, 1978-79(M).

GAGE. - Water-stage recorder. Altitude of gage is 5,235 ft fram topographic map.

REMARKS.--Diversions above station for irrigation.

AVERAGE DISCHARGE. --9 years, $22.6 \mathrm{ft}^{3} / \mathrm{s}, 16,370$ acre-ft/yr.

EXIREMES FOR PERIOD OF RECORD.--Maximum discharge, 2,060 ft ${ }^{3} / \mathrm{s}$ July 24, 1977, gage height, $10.00 \mathrm{ft}$ fran floodnarks, fram rating curve extended above $70 \mathrm{ft}^{3} / \mathrm{s}$ on basis of slope-area measurements; no flow July 15-17, 1977.

LONEST MEAN DISCHARGE, IN OBIC FEET PER SECOND, AND RANKING FOR THE INDICATED NUMBER OF CONSEQUTIVE DAYS FOR EACH CIMATIC YEAR, APRII I-MARQH 31

$\begin{array}{lllll}1 & 3 & 7 & 14 & 30\end{array}$

$\begin{array}{lllllll}8.00 & 8 & 8.00 & 8 & 8.00 & 6 & 8.00\end{array}$

$\begin{array}{llllll}5.00 & 4 & 5.00 & 4 & 5.00 \quad 4\end{array}$

8.005

$8.00 \quad 5$

$60-90$

120

183

ALL

1975

6.406

7.006

$\begin{array}{ll}8.40 & 7 \\ 2.00 & 2\end{array}$

2.002

$\begin{array}{ll}7.00 & 6 \\ 2.00 & 2\end{array}$

5.003

5.003

8.20

9.005

10.0

$\begin{array}{ll}9.00 & 6 \\ 2.00 & 2\end{array}$

10.06

0.711

$\begin{array}{ll}2.00 & 2 \\ 0.95 & 1\end{array}$

2.00

5.90

7.60

12.0

16.0

2.201

$\begin{array}{rr}2.60 & 2 \\ 6.50 & 4\end{array}$

12.06

13.0
5.20

$\begin{array}{ll}5.20 & 4 \\ 9.80 & 8\end{array}$

6.404

$\begin{array}{rr}6.50 & 4 \\ 13.0 & 8\end{array}$

3.00

7.203

3.101

8.503

21.07

$\begin{array}{llll}3.60 & 3 & 3.90 & 3 \\ 6.00 & 5 & 6.10 & 5\end{array}$

6.705

9.407

10.07

$11.0 \quad 7$

$14.0 \quad 8$

15.0

HIGHEST MEAN DISCHARGE, IN OUBIC FEET PER SECOND, AND RANKING FOR THE INDICATED NUMBER OF CONSEQUTIVE DAYS FOR EACH WATER YEAR, OCTOBER 1-SEPTEMBER 30

\begin{tabular}{|c|c|c|c|c|c|c|c|c|c|c|c|c|c|c|c|c|c|c|c|}
\hline YEAR & & & & & & & & & $\infty N$ & & DAYS & & & & & & & & \\
\hline $\begin{array}{l}1973 \\
1974 \\
1975\end{array}$ & $\begin{array}{l}250 \\
60.0 \\
213\end{array}$ & $\begin{array}{l}3 \\
8 \\
5\end{array}$ & $\begin{array}{l}150 \\
39.0 \\
161\end{array}$ & 4 & $\begin{array}{l}95.0 \\
36.0 \\
123\end{array}$ & $\begin{array}{l}5 \\
9 \\
3\end{array}$ & $\begin{array}{l}68.0 \\
31.0 \\
90.0\end{array}$ & $\begin{array}{l}5 \\
8\end{array}$ & $\begin{array}{l}61.0 \\
28.0 \\
75.0\end{array}$ & $\begin{array}{l}5 \\
7 \\
3\end{array}$ & $\begin{array}{l}51.0 \\
26.0 \\
61.0\end{array}$ & $\begin{array}{l}4 \\
7 \\
3\end{array}$ & $\begin{array}{l}46.0 \\
22.0 \\
54.0\end{array}$ & $\begin{array}{l}4 \\
7 \\
3\end{array}$ & $\begin{array}{l}41.0 \\
20.0 \\
52.0\end{array}$ & $\begin{array}{l}4 \\
8 \\
2\end{array}$ & $\begin{array}{l}37.0 \\
17.0 \\
42.0\end{array}$ & $\begin{array}{l}4 \\
7 \\
2\end{array}$ & $\begin{array}{l}29.0 \\
16.0 \\
31.0\end{array}$ \\
\hline $\begin{array}{l}1976 \\
1977 \\
1978 \\
1979 \\
1980\end{array}$ & $\begin{array}{c}66.0 \\
234 \\
48.0 \\
282 \\
390\end{array}$ & $\begin{array}{l}7 \\
4 \\
9 \\
2 \\
1\end{array}$ & $\begin{array}{c}61.0 \\
121 \\
42.0 \\
246 \\
260\end{array}$ & $\begin{array}{l}8 \\
2\end{array}$ & $\begin{array}{c}59.0 \\
78.0 \\
40.0 \\
211 \\
223\end{array}$ & $\begin{array}{l}7 \\
6 \\
8 \\
2 \\
1\end{array}$ & $\begin{array}{r}55.0 \\
40.0 \\
30.0 \\
169 \\
158\end{array}$ & $\begin{array}{l}7 \\
9\end{array}$ & $\begin{array}{r}46.0 \\
25.0 \\
25.0 \\
124 \\
107\end{array}$ & $\begin{array}{l}6 \\
8 \\
9 \\
1 \\
2\end{array}$ & $\begin{array}{l}39.0 \\
17.0 \\
23.0 \\
71.0 \\
74.0\end{array}$ & $\begin{array}{l}6 \\
9 \\
8 \\
2 \\
1\end{array}$ & $\begin{array}{l}30.0 \\
15.0 \\
20.0 \\
56.0 \\
61.0\end{array}$ & $\begin{array}{l}6 \\
9 \\
8 \\
2 \\
1\end{array}$ & $\begin{array}{l}25.0 \\
11.0 \\
20.0 \\
47.0 \\
58.0\end{array}$ & $\begin{array}{l}6 \\
9 \\
7 \\
3 \\
1\end{array}$ & $\begin{array}{c}21.0 \\
9.10 \\
16.0 \\
38.0 \\
50.0\end{array}$ & $\begin{array}{l}6 \\
9 \\
8 \\
3 \\
1\end{array}$ & $\begin{array}{c}21.0 \\
8.30 \\
10.0 \\
25.0 \\
38.0\end{array}$ \\
\hline 1981 & 154 & 6 & 119 & 6 & 99.0 & 4 & 81.0 & 4 & 66.0 & 4 & 46.0 & 5 & 37.0 & 5 & 32.0 & 5 & 25.0 & 5 & 25.0 \\
\hline
\end{tabular}

DURATION OF DISCHARGE FOR EACH WATER YEAR

CAASS $0 \begin{array}{llllllllllllllllllllllllllllllllll}1 & 2 & 3 & 4 & 5 & 6 & 7 & 8 & 9 & 10 & 11 & 12 & 13 & 14 & 15 & 16 & 17 & 18 & 19 & 20 & 21 & 22 & 23 & 24 & 25 & 26 & 27 & 28 & 29 & 30 & 31 & 32 & 33 & 34\end{array}$ YEAR

NUMBER OF DAYS IN CLASS

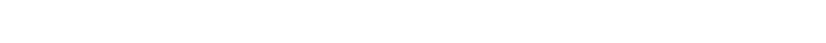
$\begin{array}{rrrllllllllllllllll}38 & 7 & 13 & 25 & 21 & 25 & 24 & 43 & 26 & 36 & 47 & 22 & 21 & 10 & 3 & 1 & 1 & 2 & \end{array}$

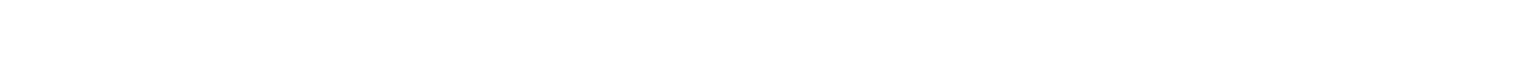

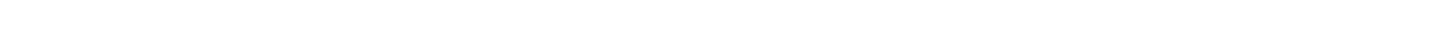

1981 
DURATION TABLE OF DISCHARGE FOR WATER YEARS 1973-81

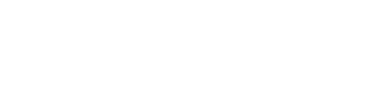

\begin{tabular}{|c|c|c|c|c|}
\hline & $\begin{array}{c}\text { CUBIC } \\
\text { FEET } \\
\text { PER }\end{array}$ & TOTAL & $\begin{array}{l}\text { ACOJ- } \\
\text { MU- } \\
\text { LATED }\end{array}$ & $\begin{array}{l}\text { PER- } \\
\text { CENT }\end{array}$ \\
\hline JASS & SECOND & DAYS & DAYS & DAYS \\
\hline $\begin{array}{r}9 \\
10 \\
11 \\
12 \\
13 \\
14 \\
15 \\
16\end{array}$ & $\begin{array}{l}1.30 \\
1.60 \\
1.90 \\
2.40 \\
3.00 \\
3.70 \\
4.60 \\
5.70\end{array}$ & $\begin{array}{r}10 \\
21 \\
84 \\
22 \\
62 \\
75 \\
142 \\
149 \\
233\end{array}$ & $\begin{array}{l}3243 \\
3233 \\
3212 \\
3128 \\
3106 \\
3044 \\
2969 \\
2827 \\
2678\end{array}$ & $\begin{array}{l}98.7 \\
98.4 \\
97.7 \\
95.2 \\
94.5 \\
92.6 \\
90.3 \\
86.0\end{array}$ \\
\hline
\end{tabular}

\begin{tabular}{crrrrr}
\multicolumn{4}{c}{ CUBIC } & \multicolumn{1}{c}{ ACCJ- } \\
FEET & MU- & PER- \\
PER & TOTAL LATED & CENT \\
CIASS SECOND & DAYS & DAYS & DAYS \\
18 & 8.8 & 203 & 2445 & 74.4 \\
19 & 11.0 & 344 & 2242 & 68.2 \\
19 & 14.0 & 296 & 1898 & 57.7 \\
21 & 17.0 & 351 & 1602 & 48.7 \\
22 & 21.0 & 315 & 1251 & 38.1 \\
23 & 26.0 & 327 & 936 & 28.5 \\
24 & 32.0 & 218 & 609 & 18.5 \\
25 & 40.0 & 140 & 391 & 11.9 \\
26 & 50.0 & 85 & 251 & 7.6
\end{tabular}

\begin{tabular}{crrrr}
\multicolumn{4}{c}{$\begin{array}{c}\text { CBBIC } \\
\text { FEET }\end{array}$} & $\begin{array}{c}\text { ACOU- } \\
\text { MUt }\end{array}$ \\
PER & TOIAL & PER- \\
CATED & CENT \\
CLASS & SECOND & DAYS & DAYS & DAYS \\
& & & & \\
27 & 62.0 & 71 & 166 & 5.1 \\
28 & 77.0 & 32 & 95 & 2.9 \\
29 & 95.0 & 19 & 63 & 1.9 \\
30 & 120.0 & 12 & 44 & 1.3 \\
31 & 150.0 & 5 & 32 & 1.0 \\
32 & 180.0 & 17 & 27 & 0.8 \\
33 & 230.0 & 8 & 10 & 0.3 \\
34 & 280.0 & 2 & 2 & 0.1
\end{tabular}

MONIHLY MEAN DISCHARGES, IN GIBIC FEET PER SECOND, FOR EACH WATER YEAR

\begin{tabular}{|c|c|c|c|c|c|c|c|c|c|c|c|c|}
\hline YEAR & OCT & $\mathrm{NOV}$ & DEC & JAN & FEB & MAR & APR & MAY & JUNE & JULY & AUG & SEP \\
\hline $\begin{array}{l}1973 \\
1974 \\
1975\end{array}$ & $\begin{array}{l}60.5 \\
27.6 \\
36.1\end{array}$ & $\begin{array}{l}23.8 \\
24.9 \\
29.0\end{array}$ & $\begin{array}{l}13.4 \\
13.8 \\
10.9\end{array}$ & $\begin{array}{l}7.74 \\
8.32 \\
6.13\end{array}$ & $\begin{array}{l}8.05 \\
8.00 \\
5.71\end{array}$ & $\begin{array}{l}20.2 \\
12.4 \\
27.5\end{array}$ & $\begin{array}{l}27.7 \\
16.9 \\
16.3\end{array}$ & $\begin{array}{l}36.1 \\
19.2 \\
27.3\end{array}$ & $\begin{array}{l}60.4 \\
21.5 \\
53.3\end{array}$ & $\begin{array}{l}43.8 \\
21.7 \\
79.7\end{array}$ & $\begin{array}{l}28.0 \\
11.8 \\
36.4\end{array}$ & $\begin{array}{c}29.5 \\
9.45 \\
51.0\end{array}$ \\
\hline $\begin{array}{l}1976 \\
1977 \\
1978 \\
1979 \\
1980\end{array}$ & $\begin{array}{c}45.8 \\
18.0 \\
2.76 \\
9.20 \\
17.5\end{array}$ & $\begin{array}{c}30.9 \\
15.5 \\
4.24 \\
35.0 \\
19.2\end{array}$ & $\begin{array}{c}13.0 \\
9.45 \\
3.25 \\
7.84 \\
13.0\end{array}$ & $\begin{array}{c}10.5 \\
2.00 \\
4.14 \\
6.85 \\
14.1\end{array}$ & $\begin{array}{c}12.1 \\
3.71 \\
5.21 \\
7.16 \\
61.1\end{array}$ & $\begin{array}{c}16.1 \\
5.77 \\
22.2 \\
115 \\
30.5\end{array}$ & $\begin{array}{c}26.7 \\
4.38 \\
11.1 \\
22.3 \\
24.2\end{array}$ & $\begin{array}{c}28.6 \\
6.82 \\
20.1 \\
25.0 \\
103\end{array}$ & $\begin{array}{c}16.5 \\
1.83 \\
24.7 \\
23.2 \\
40.1\end{array}$ & $\begin{array}{l}12.9 \\
21.0 \\
10.6 \\
18.3 \\
35.2\end{array}$ & $\begin{array}{c}13.8 \\
7.44 \\
7.15 \\
20.7 \\
26.5\end{array}$ & $\begin{array}{c}20.5 \\
2.98 \\
7.55 \\
13.6 \\
67.8\end{array}$ \\
\hline 1981 & 60.6 & 31.0 & 19.1 & 15.5 & 10.4 & 14.7 & 20.9 & 24.3 & 23.0 & 18.1 & 30.2 & 32.8 \\
\hline
\end{tabular}

ANNUAL PEAK DISCHARGE, IN CUBIC FEET PER SECOND, AND CORRESPONDING GAGE HEIGHT, IN FEET, FOR EAOH WATER YEAR

\begin{tabular}{|c|c|c|c|c|c|c|c|c|c|c|c|}
\hline $\begin{array}{l}\text { WATER } \\
\text { YEAR }\end{array}$ & DATE & $\begin{array}{c}\text { GAGE } \\
\text { HEIGH: }\end{array}$ & $\begin{array}{c}\text { PEAR } \\
\text { DISCHARGE }\end{array}$ & $\begin{array}{l}\text { WATER } \\
\text { YEAR }\end{array}$ & DATE & $\begin{array}{c}\text { GAGE } \\
\text { HEIGHT }\end{array}$ & $\begin{array}{c}\text { PEAR } \\
\text { DISCHARGE }\end{array}$ & $\begin{array}{l}\text { WATER } \\
\text { YEAR }\end{array}$ & DATE & $\begin{array}{l}\text { GAGE } \\
\text { HEIGHT }\end{array}$ & $\begin{array}{c}\text { PEAR } \\
\text { DISCHARGE }\end{array}$ \\
\hline $\begin{array}{l}1972 \\
1973 \\
1974 \\
1975\end{array}$ & $\begin{array}{l}\text { JUNE } 08,1972 \\
\text { OCT. } 18,1972 \\
\text { JULY } 20,1974 \\
\text { JULY } 16,1975\end{array}$ & $\begin{array}{l}3.92 \\
6.60 \\
6.50 \\
5.55\end{array}$ & $\begin{array}{l}160 \\
673 \\
645 \\
423\end{array}$ & $\begin{array}{l}1976 \\
1977 \\
1978\end{array}$ & $\begin{array}{l}\text { SEPT.12, } 1976 \\
\text { JULY 24，1977 } \\
\text { JULY } 18,1978\end{array}$ & $\begin{array}{r}3.87 \\
10.00 \\
5.71\end{array}$ & $\begin{array}{r}153 \\
2060 \\
456\end{array}$ & $\begin{array}{l}1979 \\
1980 \\
1981\end{array}$ & $\begin{array}{l}\text { MAR. } 13,1979 \\
\text { SEPT.11, } 1980 \\
\text { AUG. } 15,1981\end{array}$ & $\begin{array}{l}5.58 \\
7.36 \\
5.00\end{array}$ & $\begin{array}{l}429 \\
904 \\
318\end{array}$ \\
\hline
\end{tabular}

09314340 GRASSY TRAII CREEK AT SUNNYSIDE, UT

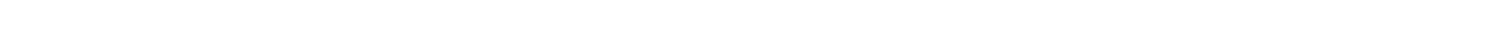
bank $13 \mathrm{mi}$ upstream from mouth and $0.1 \mathrm{mi}$ downstream from slaughter Caryon in sunnyside.

DRAINAGE AREA.- $-40.1 \mathrm{mi}^{2}$.

PERIOD OF RECORD AVAII.ABLE.--October 1978 to September 1981.

GAGE.-Water-stage recorder. Altitude of gage is 6,540 ft from topographic map.

REMARKS.--Flow regulated by small reservoir above station.

EXIREMES FOR PERIOD OF RECORD.--Maximum discharge, $138 \mathrm{ft}^{3} / \mathrm{s}$ May 23, 1980, gage height, $3.13 \mathrm{ft}$; minimum daily, $0.04 \mathrm{ft}^{3} / \mathrm{s}$ February 22,1981 .

LOWEST MEAN DISCHARGE, IN CUBIC FEET PER SECOND, AND RANKING FOR THE INDICATED NUMBER OF CONSECUTIVE DAYS FOR EACH CIIMATIC YEAR, APRII I-MARCH 31

\begin{tabular}{|c|c|c|c|c|c|c|c|c|c|c|c|c|c|c|c|c|c|c|c|}
\hline YEAR & 1 & & 3 & & 7 & & 14 & & $\begin{array}{l}\text { CONSE } \\
30\end{array}$ & arn & $\begin{array}{l}\text { DAYS } \\
60\end{array}$ & & 90 & & 120 & & 183 & & AL, L \\
\hline 1980 & 0.27 & 2 & 0.44 & 2 & 0.47 & 1 & 0.71 & 1 & 0.92 & 1 & 0.93 & 1 & 1.00 & 1 & 1.10 & 1 & 1.19 & 1 & 7.10 \\
\hline
\end{tabular}

HIGHEST MEAN DISCHARGE, IN OUBIC FEET PER SECOND, AND RANKING FOR THE INDICATED NUMBER OF CONSEOUTIVE DAYS FOR EACH WATER YEAR, OCTOBER 1-SEPTEMBER 30

\begin{tabular}{|c|c|c|c|c|c|c|c|c|c|c|c|c|c|c|c|c|c|c|c|}
\hline YEAR & 1 & & 3 & & 7 & & 15 & & $\begin{array}{l}\text { CONSS } \\
30\end{array}$ & Q & $\begin{array}{l}\text { E DAYS } \\
60\end{array}$ & & 90 & & 120 & & 183 & & ALL \\
\hline $\begin{array}{l}1979 \\
1980\end{array}$ & $\begin{array}{l}80.0 \\
134\end{array}$ & $\begin{array}{l}2 \\
1\end{array}$ & $\begin{array}{l}78.0 \\
122\end{array}$ & $\begin{array}{l}2 \\
1\end{array}$ & $\begin{array}{l}75.0 \\
99.0\end{array}$ & $\begin{array}{l}2 \\
1\end{array}$ & $\begin{array}{l}70.0 \\
86.0\end{array}$ & $\begin{array}{l}2 \\
1\end{array}$ & $\begin{array}{l}55.0 \\
73.0\end{array}$ & $\begin{array}{l}2 \\
1\end{array}$ & $\begin{array}{l}33.0 \\
55.0\end{array}$ & $\begin{array}{l}2 \\
1\end{array}$ & $\begin{array}{l}24.0 \\
41.0\end{array}$ & $\begin{array}{l}2 \\
1\end{array}$ & $\begin{array}{l}19.0 \\
31.0\end{array}$ & $\begin{array}{l}2 \\
1\end{array}$ & $\begin{array}{l}13.0 \\
21.0\end{array}$ & $\begin{array}{l}2 \\
1\end{array}$ & $\begin{array}{r}7.00 \\
11.0\end{array}$ \\
\hline 981 & 17.0 & 3 & 16.0 & 3 & 14.0 & 3 & 11.0 & 3 & 8.90 & 3 & 6.80 & 3 & 5.20 & 3 & 4.30 & 3 & 3.30 & 3 & 2.40 \\
\hline
\end{tabular}


GREEN RIVER BASTN

09314340 GRASSY TRAII, CREEK AT SUNNYSIDE, UT--Continued

DURATION OF DISCHARGE FOR EACH WATER YEAR

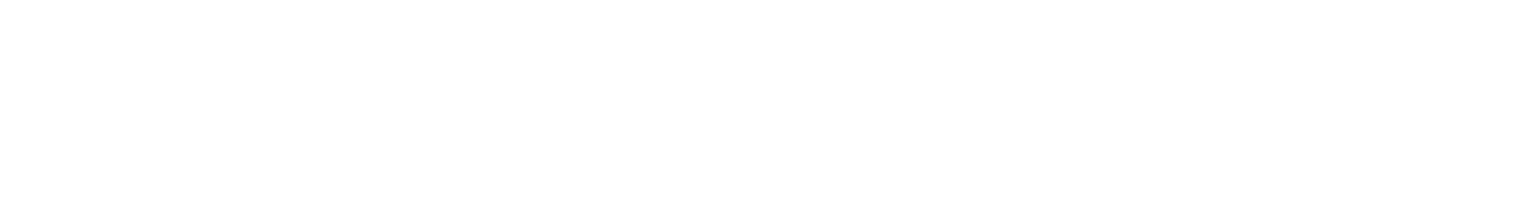

DURATION TABLE OF DISCHARGE FOR WATER YEARS 1979-81

\begin{tabular}{|c|c|c|c|c|c|c|c|c|c|c|c|c|c|c|c|c|c|c|c|}
\hline & $\begin{array}{c}\text { OBIC } \\
\text { FEET } \\
\text { PER }\end{array}$ & TOTAL & $\begin{array}{c}\text { ACOU- } \\
\text { MU- } \\
\text { LATED }\end{array}$ & $\begin{array}{l}\text { PER- } \\
\text { CENT }\end{array}$ & & $\begin{array}{c}\text { CUBIC } \\
\text { FEET } \\
\text { PER }\end{array}$ & TOTAL & $\begin{array}{c}\text { ACOU- } \\
\text { MU- } \\
\text { LATED }\end{array}$ & $\begin{array}{l}\text { PER- } \\
\text { CENT }\end{array}$ & & $\begin{array}{c}\text { CUBIC } \\
\text { FEET } \\
\text { PER }\end{array}$ & TOTAL & $\begin{array}{c}\mathrm{ACOU}- \\
\mathbf{M}- \\
\mathrm{LATED}\end{array}$ & $\begin{array}{l}\text { PER- } \\
\text { CENT }\end{array}$ & & $\begin{array}{c}\text { GEIC } \\
\text { FEET } \\
\text { PER }\end{array}$ & TOTA & $\underset{\text { MU- }}{\mathrm{ACO}-}$ & $\begin{array}{l}\text { PER } \\
\text { CENT }\end{array}$ \\
\hline CJASS & SECOND & DAYS & DAYS & DAYS & CAASS & SECOND & DAYS & DAYS & DAYS & CASS & SECOND & DAYS & DAYS & DAYS & CLASS & SECOND & DAYS & DAYS & DAYS \\
\hline $\begin{array}{l}0 \\
1 \\
2 \\
3 \\
4 \\
5 \\
6 \\
7 \\
8\end{array}$ & $\begin{array}{l}0.00 \\
0.04 \\
0.05 \\
0.07 \\
0.08 \\
0.11 \\
0.13 \\
0.17 \\
0.22\end{array}$ & $\begin{array}{l}0 \\
1 \\
0 \\
0 \\
0 \\
1 \\
4 \\
5 \\
6\end{array}$ & $\begin{array}{l}1096 \\
1096 \\
1095 \\
1095 \\
1095 \\
1095 \\
1094 \\
1090 \\
1085\end{array}$ & $\begin{array}{r}100.0 \\
100.0 \\
99.9 \\
99.9 \\
99.9 \\
99.9 \\
99.8 \\
99.5 \\
99.0\end{array}$ & $\begin{array}{r}9 \\
10 \\
11 \\
12 \\
13 \\
14 \\
15 \\
16 \\
17\end{array}$ & $\begin{array}{l}0.28 \\
0.35 \\
0.45 \\
0.58 \\
0.73 \\
0.93 \\
1.20 \\
1.50 \\
1.90\end{array}$ & $\begin{array}{r}14 \\
23 \\
43 \\
62 \\
82 \\
69 \\
92 \\
162 \\
180\end{array}$ & $\begin{array}{r}1079 \\
1065 \\
1042 \\
999 \\
937 \\
855 \\
786 \\
694 \\
532\end{array}$ & $\begin{array}{l}98.4 \\
97.2 \\
95.1 \\
91.1 \\
85.5 \\
78.0 \\
71.7 \\
63.3 \\
48.5\end{array}$ & $\begin{array}{l}18 \\
19 \\
20 \\
21 \\
22 \\
23 \\
24 \\
25 \\
26\end{array}$ & $\begin{array}{r}2.5 \\
3.1 \\
4.0 \\
5.1 \\
6.5 \\
8.3 \\
11.0 \\
13.0 \\
17.0\end{array}$ & $\begin{array}{l}85 \\
23 \\
19 \\
29 \\
43 \\
17 \\
19 \\
18 \\
15\end{array}$ & $\begin{array}{r}352 \\
267 \\
244 \\
225 \\
196 \\
153 \\
136 \\
117 \\
99\end{array}$ & $\begin{array}{r}32.1 \\
24.4 \\
22.3 \\
20.5 \\
17.9 \\
14.0 \\
12.4 \\
10.7 \\
9.0\end{array}$ & $\begin{array}{l}27 \\
28 \\
29 \\
30 \\
31 \\
32 \\
33 \\
34\end{array}$ & $\begin{array}{r}22.0 \\
28.0 \\
35.0 \\
45.0 \\
58.0 \\
73.0 \\
93.0 \\
120.0\end{array}$ & $\begin{array}{r}7 \\
9 \\
12 \\
13 \\
24 \\
16 \\
2 \\
1\end{array}$ & $\begin{array}{r}84 \\
77 \\
68 \\
56 \\
43 \\
19 \\
3 \\
1\end{array}$ & $\begin{array}{l}7.7 \\
7.0 \\
6.2 \\
5.1 \\
3.9 \\
1.7 \\
0.3 \\
0.1\end{array}$ \\
\hline
\end{tabular}

MONTHLY MEAN DISCHARGES, IN CUBIC FEET PER SECOND, FOR EAOH WATER YEAR

\begin{tabular}{|c|c|c|c|c|c|c|c|c|c|c|c|c|}
\hline YEAR & OCT & NOV & DEC & JAN & FEB & MAR & APR & MAY & JUNE & JULY & AUG & SEP \\
\hline $\begin{array}{l}1979 \\
1980\end{array}$ & $\begin{array}{l}0.81 \\
1.00\end{array}$ & $\begin{array}{l}1.59 \\
1.29\end{array}$ & $\begin{array}{l}0.80 \\
1.28\end{array}$ & $\begin{array}{l}1.05 \\
1.15\end{array}$ & $\begin{array}{l}1.15 \\
1.46\end{array}$ & $\begin{array}{l}1.44 \\
1.54\end{array}$ & $\begin{array}{l}5.18 \\
6.79\end{array}$ & $\begin{array}{l}39.8 \\
63.2\end{array}$ & $\begin{array}{l}24.3 \\
44.3\end{array}$ & $\begin{array}{l}4.05 \\
8.54\end{array}$ & $\begin{array}{l}2.47 \\
2.48\end{array}$ & $\begin{array}{l}1.07 \\
2.49\end{array}$ \\
\hline 1981 & 2.41 & 1.80 & 1.52 & 1.39 & 1.23 & 1.65 & 6.44 & 5.88 & 2.79 & 1.42 & 1.14 & 1.46 \\
\hline
\end{tabular}

09314374 HORSE CANYON NEAR SUNNYSIDE, UT

LOCATTON.--Lat $39^{\circ} 27^{\prime} 26^{\prime \prime}$, long $110^{\circ} 21^{\prime} 33^{\prime \prime}$, in NE $\frac{1}{4} \mathrm{SE}^{\frac{1}{4}}$ sec. 4, T.16 S., R.14 E., Emery County, Hydrologic Unit 14060007 , on right bank $6.8 \mathrm{mi}$ upstream from mouth, $0.5 \mathrm{mi}$ downstream from Geneva coal mine, and $9 \mathrm{mi}$ southeast of Sunnyside.

DRATNAGE AREA, $-12.5 \mathrm{mi}^{2}$.

PERIOD OF RECORD AVAIIFLE.--September 1978 to September 1981.

GAGE.--Water-stage recorder. Al titude of gage is $6,180 \mathrm{ft}$ from topographic map.

EXTREMES FOR PERIOD OF RECORD.-Maximum discharge, $93 \mathrm{ft} \mathrm{ft}^{3} / \mathrm{s}$ Sept. 5,1981 , gage height, $2.64 \mathrm{ft}$, estimated on basis of critical depth computation; no flow on many days in 1979,1980 , and 1981 .

LOWEST MEAN DISGHARGE, IN OUBIC FEET PER SECOND, AND RANKING FOR THE INDICATED NUMBER OF CONSEQITIVE DAYS FOR EAO GIMATIC YEAR, APRIL 1-MARCH 31

\begin{tabular}{|c|c|c|c|c|c|c|c|c|c|c|c|c|c|c|c|c|c|c|c|}
\hline YEAR & & & & & & & & & CONSE & נד & DAYS & & & & & & & & \\
\hline 1980 & 0.00 & 1 & 0.01 & 2 & 0.04 & 2 & 0.09 & 2 & 0.21 & 2 & 0.25 & 2 & 0.30 & 2 & 0.31 & 2 & 0.32 & 2 & 0.38 \\
\hline
\end{tabular}

HIGHEST MEAN DISCHARGE, IN OUBIC FEET PER SECOND, AND RANKING FOR THE INDICATED NUMBER OF CONSECTIVE DAYS FOR EAOH WATER YEAR, OCTOBER 1-SEPIEMBER 30

\begin{tabular}{|c|c|c|c|c|c|c|c|c|c|c|c|c|c|c|c|c|c|c|c|}
\hline YEAR & & & & & & & & & CONSE & बTा & DAYS & & & & & & & & \\
\hline $\begin{array}{l}1979 \\
1980\end{array}$ & $\begin{array}{l}2.10 \\
2.40\end{array}$ & $\begin{array}{l}2 \\
1\end{array}$ & $\begin{array}{l}1.60 \\
2.10\end{array}$ & $\begin{array}{l}2 \\
1\end{array}$ & $\begin{array}{l}1.50 \\
1.80\end{array}$ & $\begin{array}{l}2 \\
1\end{array}$ & $\begin{array}{l}1.19 \\
1.30\end{array}$ & $\begin{array}{l}2 \\
1\end{array}$ & $\begin{array}{l}0.93 \\
1.00\end{array}$ & $\begin{array}{l}2 \\
1\end{array}$ & $\begin{array}{l}0.61 \\
0.89\end{array}$ & $\begin{array}{l}2 \\
1\end{array}$ & $\begin{array}{l}0.55 \\
0.75\end{array}$ & $\begin{array}{l}2 \\
1\end{array}$ & $\begin{array}{l}0.53 \\
0.66\end{array}$ & $\begin{array}{l}2 \\
1\end{array}$ & $\begin{array}{l}0.43 \\
0.57\end{array}$ & $\begin{array}{l}2 \\
1\end{array}$ & $\begin{array}{l}0.40 \\
0.43\end{array}$ \\
\hline 1981 & 1.30 & 3 & 0.96 & 3 & 0.89 & 3 & 0.65 & 3 & 0.53 & 3 & 0.44 & 3 & 0.42 & 3 & 0.41 & 3 & 0.40 & 3 & 0.29 \\
\hline
\end{tabular}


GREEN RIVER BASIN

09314374 HORSE CANYON NEAR SUNNYSIDE, UT--Continued

DURATION OF DISCHARGE FOR EACH WATER YEAR

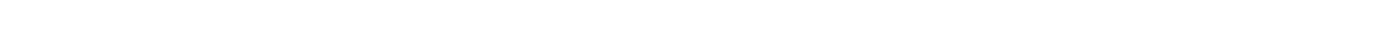
YEAR

OUBIC FEET PER SECON -DAYS

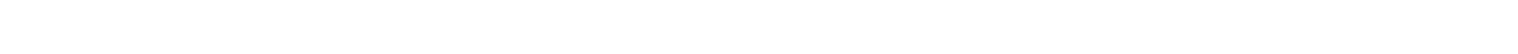
$\begin{array}{llllllllllllllllllllllllllllll}1981 & 66 & 13 & 9 & 4 & 4 & 1 & 1 & 1 & 4 & 5 & 6 & 13 & 23 & 39 & 60 & 34 & 24 & 19 & 10 & 18 & 5 & 2 & 3 & 1 & & & & & \end{array}$

\begin{tabular}{|c|c|c|c|c|c|c|c|c|c|c|c|c|c|c|c|c|c|c|c|}
\hline CLASS & $\begin{array}{c}\text { CUBIC } \\
\text { FEET } \\
\text { PER } \\
\text { SECOND }\end{array}$ & $\begin{array}{r}\text { TOTAL } \\
\text { DAYS }\end{array}$ & $\begin{array}{c}\text { ACOJ- } \\
\text { MU- } \\
\text { LATED } \\
\text { DAYS }\end{array}$ & $\begin{array}{l}\text { PER- } \\
\text { CENT } \\
\text { DAYS }\end{array}$ & CLASS & $\begin{array}{c}\text { OBBIC } \\
\text { FEET } \\
\text { PER } \\
\text { SECOND }\end{array}$ & $\begin{array}{l}\text { TOTAL } \\
\text { DAYS }\end{array}$ & $\begin{array}{c}\text { ACOU- } \\
\text { MU- } \\
\text { LATED } \\
\text { DAYS }\end{array}$ & $\begin{array}{l}\text { PER- } \\
\text { CENT } \\
\text { DAYS }\end{array}$ & CLASS & $\begin{array}{c}\text { OUBIC } \\
\text { FEET } \\
\text { PER } \\
\text { SEOOND }\end{array}$ & $\begin{array}{r}\text { TOTAL } \\
\text { DAYS }\end{array}$ & $\begin{array}{c}\text { ACCU- } \\
\text { MU- } \\
\text { LATED } \\
\text { DAYS }\end{array}$ & $\begin{array}{l}\text { PER- } \\
\text { CENT } \\
\text { DAYS }\end{array}$ & CLASS & $\begin{array}{c}\text { QUBIC } \\
\text { FEET } \\
\text { PER } \\
\text { SECOND }\end{array}$ & $\begin{array}{r}\text { TOTAL } \\
\text { DAYS }\end{array}$ & $\begin{array}{c}\text { ACOU- } \\
\text { MJ- } \\
\text { LATED } \\
\text { DAYS }\end{array}$ & $\begin{array}{l}\text { PER- } \\
\text { CENT } \\
\text { DAYS }\end{array}$ \\
\hline $\begin{array}{l}0 \\
1 \\
2 \\
3 \\
4 \\
5 \\
6 \\
7 \\
8\end{array}$ & $\begin{array}{l}0.00 \\
0.01 \\
0.02 \\
0.03 \\
0.04 \\
0.05 \\
0.06 \\
0.07 \\
0.08\end{array}$ & $\begin{array}{r}94 \\
33 \\
26 \\
20 \\
10 \\
5 \\
4 \\
9 \\
9\end{array}$ & $\begin{array}{r}1096 \\
1002 \\
969 \\
943 \\
923 \\
913 \\
908 \\
904 \\
895\end{array}$ & $\begin{array}{r}100.0 \\
91.4 \\
88.4 \\
86.0 \\
84.2 \\
83.3 \\
82.8 \\
82.5 \\
81.7\end{array}$ & $\begin{array}{l}9 \\
10 \\
11 \\
12 \\
13 \\
14 \\
15 \\
16 \\
17\end{array}$ & $\begin{array}{l}0.10 \\
0.11 \\
0.13 \\
0.16 \\
0.19 \\
0.22 \\
0.26 \\
0.30 \\
0.35\end{array}$ & $\begin{array}{r}4 \\
18 \\
15 \\
18 \\
40 \\
77 \\
98 \\
102 \\
107\end{array}$ & $\begin{array}{l}886 \\
882 \\
864 \\
849 \\
831 \\
791 \\
714 \\
616 \\
514\end{array}$ & $\begin{array}{l}80.8 \\
80.5 \\
78.8 \\
77.5 \\
75.8 \\
72.2 \\
65.1 \\
56.2 \\
46.9\end{array}$ & $\begin{array}{l}18 \\
19 \\
20 \\
21 \\
22 \\
23 \\
24 \\
25 \\
26\end{array}$ & $\begin{array}{l}0.4 \\
0.5 \\
0.6 \\
0.7 \\
0.8 \\
0.9 \\
1.1 \\
1.3 \\
1.5\end{array}$ & $\begin{array}{r}91 \\
111 \\
59 \\
49 \\
57 \\
14 \\
7 \\
9 \\
6\end{array}$ & $\begin{array}{r}407 \\
316 \\
205 \\
146 \\
97 \\
40 \\
26 \\
19 \\
10\end{array}$ & $\begin{array}{r}37.1 \\
28.8 \\
18.7 \\
13.3 \\
8.9 \\
3.6 \\
2.4 \\
1.7 \\
0.9\end{array}$ & $\begin{array}{l}27 \\
28 \\
29 \\
30 \\
31 \\
32 \\
33 \\
34\end{array}$ & $\begin{array}{l}1.8 \\
2.1\end{array}$ & $\begin{array}{l}1 \\
3\end{array}$ & $\begin{array}{l}4 \\
3\end{array}$ & $\begin{array}{l}0.4 \\
0.3\end{array}$ \\
\hline
\end{tabular}

MONTHLY MEAN DISCHARGES, IN OUBIC FEET PER SECOND, FOR EACH WATER YEAR

$\begin{array}{lllllllllllll}\text { YEAR } & \text { OCT } & \text { NOV } & \text { DEC } & \text { JAN } & \text { FEB } & \text { MAR } & \text { APR } & \text { MAY } & \text { JUNE } & \text { JULY } & \text { AUG } & \text { SEP } \\ 1979 & 0.53 & 0.58 & 0.49 & 0.53 & 0.07 & 0.06 & 0.43 & 0.68 & 0.24 & 0.48 & 0.38 & 0.34 \\ 1980 & 0.27 & 0.42 & 0.34 & 0.22 & 0.38 & 0.34 & 0.52 & 1.01 & 0.69 & 0.38 & 0.41 & 0.14 \\ 1981 & 0.12 & 0.00 & 0.00 & 0.33 & 0.38 & 0.35 & 0.45 & 0.32 & 0.44 & 0.35 & 0.34 & 0.38\end{array}$

09314400 COLEMAN WASH TRIBUTARY NEAR WOODSIDE, UT

LOCATION.-Lat $39^{\circ} 22^{\prime} 50^{\prime \prime}$, long $110^{\circ} 24^{\prime} 10^{\prime \prime}$, in SE $\frac{1}{4}$ Sec.36, T.16 S., R.13 E., Emery County, Hydrologic Unit 14060007, on U.S. Highway

6 and 50 and $8 \mathrm{mi}$ northwest of woodside.

DRAINAGE AREA. $--3.6 \mathrm{mi}^{2}$.

MEAN BASIN ELEVATION. $-5,540 \mathrm{ft}$.

PERIOD OF RECORD AVAIIABLE.--Water years 1959-68, annual peak discharge only.

GAGE.-Crest-stage gage. Altitude of gage is 5,010 ft from topographic map.

ANNUAL PEAK DISCHARGE, IN OABIC FEET PER SECOND, AND CORRESPONDING GAGE HEIGHT, IN FEET, FOR EACH WATER YEAR

\begin{tabular}{|c|c|c|c|c|c|c|c|c|c|c|c|}
\hline $\begin{array}{l}\text { WATER } \\
\text { YEAR }\end{array}$ & DATE & $\begin{array}{c}\text { GAGE } \\
\text { HEIGHT }\end{array}$ & $\begin{array}{c}\text { PEAK } \\
\text { DISCHARGE }\end{array}$ & $\begin{array}{l}\text { WATEER } \\
\text { YEAR }\end{array}$ & DATE & $\begin{array}{c}\text { GAGE } \\
\text { HEIGHT }\end{array}$ & $\begin{array}{c}\text { PEAR } \\
\text { DISCHARGE }\end{array}$ & $\begin{array}{l}\text { WATER } \\
\text { YEAR }\end{array}$ & DATE & $\begin{array}{c}\text { GAGE } \\
\text { HEIGHT }\end{array}$ & $\begin{array}{c}\text { PEAR } \\
\text { DISCHARGE }\end{array}$ \\
\hline $\begin{array}{l}1959 \\
1960 \\
1961 \\
1962\end{array}$ & $\begin{array}{l}\text { AUG. } 12,1959 \\
\text { OCT. } 28,1959 \\
\text { OCT. } 09,1960 \\
\text { SEPT. } 28,1962\end{array}$ & $\begin{array}{ll}9 & 19.87 \\
9 . & 10.96 \\
0 & 11.05 \\
2 & 15.54\end{array}$ & $\begin{array}{r}1040 \\
86 \\
93 \\
527\end{array}$ & $\begin{array}{l}1963 \\
1964 \\
1965\end{array}$ & $\begin{array}{l}\text { AUG. } 22,1963 \\
\text { JULY } 31,1964 \\
\text { JULY } 24,1965\end{array}$ & $\begin{array}{l}17.55 \\
15.08 \\
11.80\end{array}$ & $\begin{array}{r}637 \\
496 \\
51\end{array}$ & $\begin{array}{l}1966 \\
1967 \\
1968\end{array}$ & $\begin{array}{l}\text { JULY } 17,1966 \\
\text { SEPT. 09, } 1967 \\
\text { AUG. 01, } 1968\end{array}$ & $\begin{array}{l}14.53 \\
12.60 \\
14.62\end{array}$ & $\begin{array}{r}360 \\
96 \\
400\end{array}$ \\
\hline
\end{tabular}


GREEN RIVER BASIN

09314500 PRICE RIVER AT WOODSIDE, UT

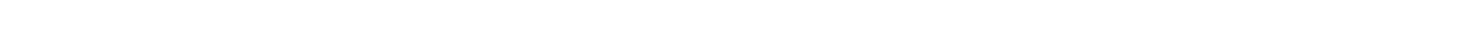
downstream wingwall of old highway bridge, $200 \mathrm{ft}$ downstream from railroad bridge at Woodside, and $16.3 \mathrm{mi}$ upstream fram mouth.

DRATNAGE AREA. $-1,540 \mathrm{mi}^{2}$.

MEAN BASTN ELEVATTON. $-6,490 \mathrm{ft}$.

PERTOD OF RECORD AVAIIABLE. - September 1909 to December 1910, January to August 1911 (gage heights only), November 1945 to September 1981. Monthly mean discharge only for sane periods, published in wSP 1313.

REVISED RECORDS,--WDR UT-77-1: Drainage area.

GAGE.-Water-stage recorder. Altitude of gage is 4,600 ft by barcmeter. September 1909 to August 1911 , reference point at site about $100 \mathrm{ft}$ upstream at different datum. Nov. 27, 1945 to Oct. 16, 1954 , water-stage recorder at site $15 \mathrm{ft}$ downstream at datum $1.85 \mathrm{ft}$ higher.

REMARKS.--Diversions above station for irrigation of about 18,000 acres. Flow affected by storage in Scof ield Reservoir, usable capacity, 65,780 acre-ft, since May 1926 .

AVERAGE DISGHARGE.--35 years (water years 1947-81), $103 \mathrm{ft}^{3} / \mathrm{s}, 74,620$ acre-ft/yr.

EXIREMES FOR PERIOD OF RECORD.--Maximum discharge, 9,720 ft $\mathrm{ft}^{3} / \mathrm{s}$ Sept. 11, 1980, gage height, $11.16 \mathrm{ft}$, from rating curve extended above 1,200 $\mathrm{ft}^{3} / \mathrm{s}$; no flow for several days in 1960, 1961, and part of July 8, 1963.

LOWEST MEAN DISGARGE, IN OUBIC FEET PER SECOND, AND RANKING FOR THE INDICAIED NUMBER OF CONSECUTIVE DAVS

YEAR

1948
1949
1950
1951
1952
1953
1954
1955
1956
1957
1958
1959
1960
1961
1962
1963
1964
1965
1966
1967
1968
1969
1970
1971
1972
1973
1974
1975
1976
1977
1978
1979
1980
1981

1

$16.0 \quad 14$

7.008

$22.0 \quad 22$

$\begin{array}{llll}9.0 & 20 & 22.0 & 21\end{array}$

$\begin{array}{llll}16.0 & 15 & 17.0 & 14\end{array}$

$\begin{array}{llll}35.0 & 32 & 36.0 & 34\end{array}$

$\begin{array}{llll}35.0 & 16 & 17.0 & 15\end{array}$

8.7010

6.407

$22.0 \quad 23$

$\begin{array}{cc}27.0 & 28 \\ 4.40 \quad 6\end{array}$

9. 3010

$\begin{array}{rr}9.30 & 10 \\ 6.807 \\ 23.0 \quad 22 \\ 28.0 & 28\end{array}$

$\begin{array}{cc}28.0 & 28 \\ 4.50 & 5\end{array}$

0.001

0.002

0.001

0.002

10.011

0.334

22.024

$16.0 \quad 17$

$\begin{array}{ll}26.0 & 27 \\ 30.0 & 30\end{array}$

$\begin{array}{ll}30.0 & 30 \\ 25.0 & 25\end{array}$

11.011

$27.0 \quad 26$

$\begin{array}{ll}27.0 & 26 \\ 17.0 & 16\end{array}$

$\begin{array}{ll}17.0 & 16 \\ 28.0 & 27\end{array}$

30.02

25.023

$\begin{array}{llll}18.0 & 18 & 25.0 & 24\end{array}$

$\begin{array}{llll}25.0 & 26 & 25.0 & 25\end{array}$

$\begin{array}{llll}18.0 & 19 & 19.0 & 18\end{array}$

$\begin{array}{llll}41.0 & 33 & 45.0 & 33\end{array}$

$11.0 \quad 12$

$33.0 \quad 31$

$14.0 \quad 13$

$\begin{array}{ll}0.14 & 4 \\ 8.30 & 9\end{array}$

20.021

$11.0 \quad 12$

$33.0 \quad 30$

$16.0 \quad 13$

0.153

8.80

$20.0 \quad 19$

$28.0 \quad 29$

$33.0 \quad 31$
7

$21.0 \quad 17$

$\begin{array}{rr}8.30 & 8 \\ 23.0 & 19\end{array}$

$24.0 \quad 17$

8.408

$27.0 \quad 22$

$27.0 \quad 24$

$31.0 \quad 26$

$24.0 \quad 18$

56.034

35.028

$19.0 \quad 14$

$10.0 \quad 10$

$6.90 \quad 6$

$30.0 \quad 27$

$\begin{array}{cc}35.0 & 31 \\ 5.50 & 5\end{array}$

10.09

$\begin{array}{cr}7.40 & 5 \\ 35.0 & 29\end{array}$

37.030

0.001

0.002

$0.84 \quad 4$

\subsection{2}

0.001

$\begin{array}{lll}0.84 & 4 & 1.70\end{array}$

$31.0 \quad 28$

$18.0 \quad 15$

29.025

$\begin{array}{ll}30.0 & 26 \\ 25.0 & 20\end{array}$

$25.0 \quad 21$

$25.0 \quad 22$

$25.0 \quad 23$

$46.0 \quad 33$

12.011

$33.0 \quad 29$

$17.0 \quad 13$

$\begin{array}{ll}0.27 & 3 \\ 9.80 & 9\end{array}$

$\begin{array}{rr}91.0 & 16\end{array}$

$17.0 \quad 12$

$40.0 \quad 31$

$19.0 \quad 13$

30.023

$\begin{array}{ll}30.0 & 24 \\ 26.0 & 20\end{array}$

$25.0 \quad 19$

27.027

$31.0 \quad 25$

50.033

13.011

$33.0 \quad 27$

$\begin{array}{ll}33.0 & 27 \\ 20.0 & 15\end{array}$

$0.66 \quad 3$

12.010

24.016

$38.0 \quad 32$

$41.0 \quad 32$
CONSECUTIVE DAYS

$30 \quad 60 \quad 90$

$25.0 \quad 16$

$\begin{array}{rr}10.0 & 8 \\ 28.0 & 20\end{array}$

$\begin{array}{ll}28.0 & 16 \\ 15.0 & 6\end{array}$

$\begin{array}{rr}15.0 & 6 \\ 28.0 & 17\end{array}$

$\begin{array}{ll}34.0 & 17 \\ 22.0 & 13 \\ 34.0 & 18\end{array}$

$\begin{array}{rr}120 & \\ 36.0 & 16 \\ 24.0 & 8\end{array}$

$\begin{array}{rr}24.0 & 8 \\ 39.0 & 17\end{array}$

183

$41.0 \quad 11$

$\begin{array}{lll}27.0 & 59.0 & 11\end{array}$

$\begin{array}{rrrr}27.0 & 5 & 53.0 & 8 \\ 58.0 & 25 & 123 & 24\end{array}$

$\begin{array}{llll}32.0 & 23 & 39.0 & 28\end{array}$

$25.0 \quad 17$

43.025

$36.0 \quad 20$

$56.0 \quad 34$

58.034

\begin{tabular}{ll}
$58.0 \quad 32$ \\
\hline 5.0
\end{tabular}

$44.0 \quad 22$

$\begin{array}{llll}49.0 & 17 & 86.0 & 18\end{array}$

$20.014 \quad 20.0 \quad 14$

$46.0 \quad 29$

62.032

$53.0 \quad 29$

$15.0 \quad 10$

$\begin{array}{cr}15.0 & 10 \\ 8.30 \quad 4\end{array}$

$36.0 \quad 29$

$39.0 \quad 30$

$18.0 \quad 10$

18.010

$51.0 \quad 31$

$\begin{array}{ll}41.0 & 29 \\ 16.0 & 7\end{array}$

$\begin{array}{rrrrrrrr}21.0 & 8 & 25.0 & 9 & 30.0 & 8 & 44.0 & 6\end{array}$

$28.0 \quad 13$

$51.0 \quad 18$

$\begin{array}{llll}68.0 & 31 & 342 & 34\end{array}$

$\begin{array}{rrrr}59.0 & 26 & 79.0 & 16\end{array}$

$60.0 \quad 27 \quad 79.0 \quad 16$

\begin{tabular}{lrrrrrrr}
52.0 & 30 & 62.0 & 4 & 16.0 & 1 & 28.0 & 1 \\
\hline & 112 & 34 & 149 & 28
\end{tabular}

43.026

$3.00 \quad 3$

8.902

19.0

44.021

21.06

1.19

$\begin{array}{ll}8.90 & 2 \\ 3.10 & 1\end{array}$

$\begin{array}{cc}12.0 & 2\end{array}$

$14.0 \quad 2$

26.011

10.06

18.011

18.012

$20.0 \quad 12$

12.010

45.031

$25.0 \quad 15$

$33.0 \quad 25$

$\begin{array}{llll}52.0 & 32 & 66.0 & 34\end{array}$

$\begin{array}{llll}52.0 & 32 & 66.0 & 34 \\ 27.0 & 15 & 39.0 & 22\end{array}$

35.023

$\begin{array}{llll}38.0 & 24 & 43.0 & 15 \\ & 44.0 & 27\end{array}$

32.024

$28.0 \quad 18$

$31.0 \quad 22$

$\begin{array}{ll}35.0 & 26 \\ 52.0 & 33\end{array}$

$\begin{array}{ll}52.0 & 33 \\ 15.0 & 11\end{array}$

$\begin{array}{ll}34.0 & 22 \\ 33.0 & 21\end{array}$

$39.0 \quad 27$

$55.0 \quad 33$

17.0

$35.0 \quad 27$

$20.0 \quad 13$

$\begin{array}{rr}2.50 & 2 \\ 14.0 & 9\end{array}$

$38.0 \quad 25$

$\begin{array}{ll}38.0 & 25 \\ 20.0 & 13\end{array}$

$28.0 \quad 17.09$

$30.0 \quad 19$

$42.0 \quad 23$

$35.0 \quad 19$

$43.0 \quad 24$

$59.0 \quad 33$

22.0 I1

$46.0 \quad 28$

$22.0 \quad 12$

13.03

$\begin{array}{rr}21.0 & 7 \\ 34.0 & 16\end{array}$

$45.0 \quad 32$

$49.0 \quad 30$

$52.0 \quad 31$

17.05

24.07

$71.0 \quad 34$

$\begin{array}{ll}48.0 & 25 \\ 39.0 & 18\end{array}$

$\begin{array}{ll}39.0 & 18 \\ 40.0 & 19\end{array}$

51.028

$48.0 \quad 26$

$\begin{array}{ll}45.0 & 23 \\ 45.0 & 24\end{array}$

59.031

$\begin{array}{ll}32.0 & 14\end{array}$

$\begin{array}{ll}50.0 & 27\end{array}$

$25.0 \quad 10$

$\begin{array}{rr}15.0 & 3 \\ 28.0 & 12\end{array}$

$34.0 \quad 15$

$45.0 \quad 12$

$\begin{array}{lrrr}36.0 & 9 & 146 & 27\end{array}$

$20.0 \quad 3 \quad 36.0$

$\begin{array}{llll}48.0 & 16 & 77.0 & 14\end{array}$

$\begin{array}{llll}52.0 & 20 & 121 & 23\end{array}$

$\begin{array}{llll}20.0 & 4 & 56.0 & 9 \\ 29.0 & 6 & 53.0 & 7\end{array}$

$\begin{array}{cccc}78.0 & 33 & 168 & 31 \\ 51.0 & 19 & 72.0 & 12\end{array}$

$\begin{array}{llll}45.0 & 13 & 102 & 22\end{array}$

$\begin{array}{llll}55.0 & 23 & 167 & 30 \\ 60.0 & 28 & 203 & 32\end{array}$

$\begin{array}{llll}53.0 & 21 & 86.0 & 17\end{array}$

$\begin{array}{lllll}58.0 & 24 & 79.0 & 15\end{array}$

$\begin{array}{rrrr}55.0 & 22 & 91.0 & 20\end{array}$

$\begin{array}{llll}61.0 & 29 & 160 & 29\end{array}$

$\begin{array}{rrrr}62.0 & 30 & 132 & 25 \\ 29.0 & 7 & 42.0 & 4\end{array}$

$\begin{array}{rrrr}17.0 & 2 & 36.0 & 3\end{array}$

$\begin{array}{cccc}48.0 & 15 & 96.0 & 21 \\ 39.0 & 10 & 135 & 26\end{array}$

$55.0 \quad 30$

$\begin{array}{llll}72.0 & 32 & 251 & 33\end{array}$ 
09314500 PRICE RIVER AT WOODSIDE, UT-Continued

HIGHEST MEAN DISCHARGE, IN OUBIC FEET PER SECOND, AND RANKING FOR THE INDICATED NUMBER OF CONSECUTIVE DAYS FOR EACH WATER YEAR, OCTCBER 1-SEPTEMBER 30

YEAR CONSECUTIVE DAYS

\begin{tabular}{|c|c|c|c|c|c|c|c|c|c|c|c|c|c|c|c|c|c|c|c|c|}
\hline 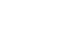 & 1 & & 3 & & 7 & & 15 & & 30 & . & 60 & & 90 & & 120 & & 183 & & ALL & \\
\hline $\begin{array}{l}951 \\
952 \\
953 \\
954 \\
955\end{array}$ & $\begin{array}{r}4220 \\
2460 \\
975 \\
1720 \\
1110\end{array}$ & $\begin{array}{r}4 \\
11 \\
25 \\
16 \\
22\end{array}$ & $\begin{array}{r}1970 \\
2420 \\
596 \\
948 \\
659\end{array}$ & $\begin{array}{r}7 \\
5 \\
24 \\
18 \\
23\end{array}$ & $\begin{array}{r}1000 \\
2300 \\
324 \\
447 \\
452\end{array}$ & $\begin{array}{r}6 \\
1 \\
25 \\
21 \\
20\end{array}$ & $\begin{array}{r}520 \\
1990 \\
201 \\
321 \\
284\end{array}$ & $\begin{array}{r}14 \\
1 \\
25 \\
19 \\
21\end{array}$ & $\begin{array}{r}323 \\
1800 \\
182 \\
200 \\
190\end{array}$ & $\begin{array}{r}16 \\
1 \\
24 \\
21 \\
23\end{array}$ & $\begin{array}{r}200 \\
1490 \\
141 \\
128 \\
146\end{array}$ & $\begin{array}{r}16 \\
1 \\
23 \\
24 \\
21\end{array}$ & $\begin{array}{r}165 \\
1120 \\
122 \\
105 \\
112\end{array}$ & $\begin{array}{r}15 \\
1 \\
21 \\
25 \\
24\end{array}$ & $\begin{array}{r}146 \\
890 \\
110 \\
92.0 \\
92.0\end{array}$ & $\begin{array}{r}15 \\
1 \\
22 \\
24 \\
25\end{array}$ & $\begin{array}{l}118 \\
628 \\
99.0 \\
82.0 \\
78.0\end{array}$ & $\begin{array}{r}15 \\
1 \\
21 \\
24 \\
26\end{array}$ & $\begin{array}{c}83.0 \\
341 \\
81.0 \\
72.0 \\
61.0\end{array}$ & $\begin{array}{r}17 \\
1 \\
18 \\
22 \\
26\end{array}$ \\
\hline $\begin{array}{l}1956 \\
1957 \\
1958 \\
1959 \\
1960\end{array}$ & $\begin{array}{r}219 \\
4310 \\
3980 \\
1000 \\
357\end{array}$ & $\begin{array}{r}35 \\
3 \\
5 \\
24 \\
32\end{array}$ & $\begin{array}{r}150 \\
2010 \\
2540 \\
486 \\
195\end{array}$ & $\begin{array}{r}35 \\
6 \\
2 \\
26 \\
34\end{array}$ & $\begin{array}{r}104 \\
950 \\
1200 \\
289 \\
169\end{array}$ & $\begin{array}{r}35 \\
7 \\
4 \\
28 \\
33\end{array}$ & $\begin{array}{l}86.0 \\
535 \\
755 \\
166 \\
140\end{array}$ & $\begin{array}{r}34 \\
12 \\
7 \\
30 \\
32\end{array}$ & $\begin{array}{l}62.0 \\
515 \\
654 \\
132 \\
110\end{array}$ & $\begin{array}{r}35 \\
8 \\
5 \\
28 \\
32\end{array}$ & $\begin{array}{c}53.0 \\
309 \\
553 \\
90.0 \\
73.0\end{array}$ & $\begin{array}{r}35 \\
11 \\
4 \\
29 \\
33\end{array}$ & $\begin{array}{l}46.0 \\
255 \\
416 \\
63.0 \\
59.0\end{array}$ & $\begin{array}{r}35 \\
12 \\
5 \\
32 \\
33\end{array}$ & $\begin{array}{l}46.0 \\
248 \\
335 \\
53.0 \\
51.0\end{array}$ & $\begin{array}{r}34 \\
10 \\
6 \\
32 \\
33\end{array}$ & $\begin{array}{l}42.0 \\
180 \\
252 \\
45.0 \\
44.0\end{array}$ & $\begin{array}{r}34 \\
12 \\
6 \\
32 \\
33\end{array}$ & $\begin{array}{c}34.0 \\
103 \\
182 \\
45.0 \\
32.0\end{array}$ & $\begin{array}{r}33 \\
13 \\
5 \\
32 \\
34\end{array}$ \\
\hline $\begin{array}{l}961 \\
962 \\
963 \\
964 \\
965\end{array}$ & $\begin{array}{l}4790 \\
2950 \\
2460 \\
1720 \\
1280\end{array}$ & $\begin{array}{r}2 \\
9 \\
10 \\
17 \\
21\end{array}$ & $\begin{array}{r}2530 \\
1800 \\
1060 \\
1040 \\
780\end{array}$ & $\begin{array}{r}3 \\
8 \\
13 \\
16 \\
19\end{array}$ & $\begin{array}{r}1110 \\
848 \\
637 \\
489 \\
684\end{array}$ & $\begin{array}{r}5 \\
10 \\
15 \\
19 \\
13\end{array}$ & $\begin{array}{l}853 \\
523 \\
472 \\
320 \\
561\end{array}$ & $\begin{array}{r}4 \\
13 \\
15 \\
20 \\
11\end{array}$ & $\begin{array}{l}506 \\
478 \\
378 \\
179 \\
468\end{array}$ & $\begin{array}{r}9 \\
11 \\
14 \\
25 \\
12\end{array}$ & $\begin{array}{l}280 \\
364 \\
231 \\
110 \\
393\end{array}$ & $\begin{array}{r}14 \\
10 \\
15 \\
27 \\
9\end{array}$ & $\begin{array}{l}190 \\
276 \\
162 \\
104 \\
354\end{array}$ & $\begin{array}{r}14 \\
10 \\
17 \\
26 \\
7\end{array}$ & $\begin{array}{c}143 \\
237 \\
128 \\
89.0 \\
314\end{array}$ & $\begin{array}{r}17 \\
11 \\
20 \\
26 \\
7\end{array}$ & $\begin{array}{l}97.0 \\
191 \\
106 \\
73.0 \\
241\end{array}$ & $\begin{array}{r}22 \\
10 \\
18 \\
27 \\
7\end{array}$ & $\begin{array}{c}73.0 \\
123 \\
72.0 \\
46.0 \\
138\end{array}$ & $\begin{array}{l}20 \\
10 \\
23 \\
31\end{array}$ \\
\hline $\begin{array}{l}966 \\
967 \\
968 \\
969 \\
970\end{array}$ & $\begin{array}{l}1710 \\
1380 \\
1340 \\
2960 \\
1790\end{array}$ & $\begin{array}{r}18 \\
19 \\
20 \\
8 \\
13\end{array}$ & $\begin{array}{r}747 \\
731 \\
1050 \\
1140 \\
964\end{array}$ & $\begin{array}{l}20 \\
21 \\
14 \\
12 \\
17\end{array}$ & $\begin{array}{l}412 \\
702 \\
919 \\
933 \\
582\end{array}$ & $\begin{array}{r}23 \\
12 \\
9 \\
8 \\
18\end{array}$ & $\begin{array}{l}234 \\
590 \\
779 \\
806 \\
383\end{array}$ & $\begin{array}{r}23 \\
10 \\
6 \\
5 \\
17\end{array}$ & $\begin{array}{l}204 \\
425 \\
592 \\
733 \\
267\end{array}$ & $\begin{array}{r}20 \\
13 \\
6 \\
4 \\
17\end{array}$ & $\begin{array}{l}180 \\
307 \\
408 \\
624 \\
183\end{array}$ & $\begin{array}{r}18 \\
12 \\
7 \\
3 \\
17\end{array}$ & $\begin{array}{l}153 \\
243 \\
350 \\
560 \\
156\end{array}$ & $\begin{array}{r}20 \\
13 \\
8 \\
3 \\
19\end{array}$ & $\begin{array}{l}130 \\
211 \\
309 \\
480 \\
144\end{array}$ & $\begin{array}{r}19 \\
13 \\
8 \\
3 \\
16\end{array}$ & $\begin{array}{l}112 \\
159 \\
232 \\
386 \\
117\end{array}$ & $\begin{array}{r}17 \\
13 \\
8 \\
3 \\
16\end{array}$ & $\begin{array}{l}92.0 \\
106 \\
139 \\
224 \\
88.0\end{array}$ & $\begin{array}{r}3 \\
16\end{array}$ \\
\hline $\begin{array}{l}971 \\
973 \\
974 \\
975\end{array}$ & $\begin{array}{r}295 \\
749 \\
5650 \\
300 \\
1730\end{array}$ & $\begin{array}{r}34 \\
27 \\
1 \\
33 \\
15\end{array}$ & $\begin{array}{r}241 \\
400 \\
2870 \\
210 \\
1040\end{array}$ & $\begin{array}{r}32 \\
29 \\
1 \\
33 \\
15\end{array}$ & $\begin{array}{r}193 \\
265 \\
1370 \\
137 \\
628\end{array}$ & $\begin{array}{r}31 \\
29 \\
2 \\
34 \\
16\end{array}$ & $\begin{array}{c}155 \\
185 \\
1010 \\
84.0 \\
593\end{array}$ & $\begin{array}{r}31 \\
28 \\
3 \\
35 \\
9\end{array}$ & $\begin{array}{l}146 \\
131 \\
784 \\
79.0 \\
498\end{array}$ & $\begin{array}{r}27 \\
29 \\
3 \\
34 \\
10\end{array}$ & $\begin{array}{l}125 \\
97.0 \\
528 \\
71.0 \\
394\end{array}$ & $\begin{array}{r}25 \\
28 \\
5 \\
34 \\
8\end{array}$ & $\begin{array}{l}119 \\
86.0 \\
415 \\
67.0 \\
307\end{array}$ & $\begin{array}{r}22 \\
28 \\
6 \\
31 \\
9\end{array}$ & $\begin{array}{c}108 \\
84.0 \\
355 \\
64.0 \\
260\end{array}$ & $\begin{array}{r}23 \\
28 \\
4 \\
30 \\
9\end{array}$ & $\begin{array}{c}96.0 \\
71.0 \\
277 \\
63.0 \\
202\end{array}$ & $\begin{array}{r}23 \\
28 \\
4 \\
30 \\
9\end{array}$ & $\begin{array}{c}73.0 \\
63.0 \\
192 \\
54.0 \\
135\end{array}$ & $\begin{array}{r}21 \\
25 \\
4 \\
29 \\
9\end{array}$ \\
\hline $\begin{array}{l}1976 \\
1977 \\
1978 \\
1979 \\
1980\end{array}$ & $\begin{array}{r}519 \\
685 \\
454 \\
2400 \\
3840\end{array}$ & $\begin{array}{r}30 \\
28 \\
31 \\
12 \\
6\end{array}$ & $\begin{array}{r}334 \\
500 \\
293 \\
1590 \\
2480\end{array}$ & $\begin{array}{r}30 \\
25 \\
31 \\
9 \\
4\end{array}$ & $\begin{array}{r}179 \\
401 \\
229 \\
833 \\
1270\end{array}$ & $\begin{array}{r}32 \\
24 \\
30 \\
11 \\
3\end{array}$ & $\begin{array}{r}117 \\
195 \\
204 \\
598 \\
1020\end{array}$ & $\begin{array}{r}33 \\
27 \\
24 \\
8 \\
2\end{array}$ & $\begin{array}{l}91.0 \\
125 \\
191 \\
565 \\
977\end{array}$ & $\begin{array}{r}33 \\
30 \\
22 \\
7 \\
2\end{array}$ & $\begin{array}{l}86.0 \\
77.0 \\
174 \\
514 \\
884\end{array}$ & $\begin{array}{r}30 \\
32 \\
20 \\
6 \\
2\end{array}$ & $\begin{array}{l}69.0 \\
54.0 \\
157 \\
442 \\
674\end{array}$ & $\begin{array}{r}30 \\
34 \\
18 \\
4 \\
2\end{array}$ & $\begin{array}{l}68.0 \\
45.0 \\
131 \\
352 \\
541\end{array}$ & $\begin{array}{r}29 \\
35 \\
18 \\
5 \\
2\end{array}$ & $\begin{array}{l}62.0 \\
37.0 \\
100 \\
252 \\
431\end{array}$ & $\begin{array}{r}31 \\
35 \\
19 \\
5 \\
2\end{array}$ & $\begin{array}{l}59.0 \\
31.0 \\
59.0 \\
152 \\
253\end{array}$ & $\begin{array}{r}27 \\
35 \\
28 \\
6\end{array}$ \\
\hline
\end{tabular}

DURATION OF DISCHARGE FOR EACH WATER YEAR

CLASS $\begin{array}{llllllllllllllllllllllllllllllllllll} & 0 & 1 & 2 & 3 & 4 & 5 & 6 & 7 & 8 & 9 & 10 & 11 & 12 & 13 & 14 & 15 & 16 & 17 & 18 & 19 & 20 & 21 & 22 & 23 & 24 & 25 & 26 & 27 & 28 & 29 & 30 & 31 & 32 & 33 & 34\end{array}$ YEAR

NUMBER OF DAYS IN CLASS OBIC FEE

1947

1948

1950

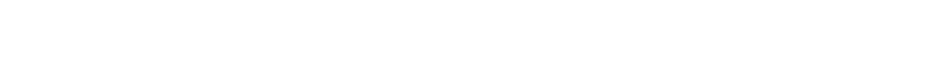

195

1952

1954

$\begin{array}{rrrrrrrrrrrrrrrrr}4 & 19 & 40 & 76 & 25 & 32 & 33 & 29 & 34 & 26 & 32 & 9 & 1 & 2 & 2 & 1 & 42398.0\end{array}$

$\begin{array}{llllllllllllll}12 & 58 & 84 & 92 & 60 & 34 & 12 & 5 & 3 & 2 & 2 & & 1 & 30288.0\end{array}$

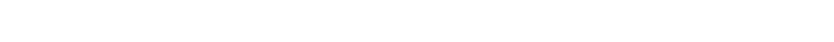

$\begin{array}{llllllllllllllll}1 & 1 & 22 & 151 & 147 & 31 & 5 & 2 & 2 & 2 & 1 & 1 & 29678.0\end{array}$

$\begin{array}{llllllllllllllllll}5 & 27 & 12 & 19 & 56 & 68 & 118 & 46 & 25 & 10 & 1 & 4 & 1 & 2 & 2 & 1 & 1 & 95 \\ 44 & 57 & 33 & 33 & 19 & 15 & 6 & 4 & 2 & 4 & 1 & 1 & & \end{array}$

1956

1957

1958

$\begin{array}{llllllllllllll}1960 & 22 & 2 & 1 & 2 & 2 & 2 & 2 & 3 & 1 & 4 & 6 & 4 & 10\end{array}$

$\begin{array}{llllllllllll}3 & 19 & 17 & 29 & 74 & 101 & 64 & 35 & 14 & 8 & 1 & 1\end{array}$

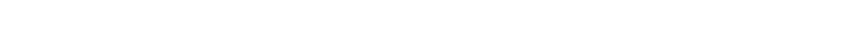

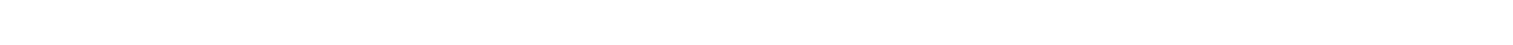

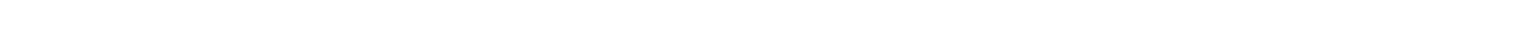
$\begin{array}{llllllllllllllllllllllllllllllllll}1963 & 1 & 1 & 1 & 1 & 3 & 3 & 3 & 4 & 5 & 4 & 4 & 15 & 28 & 56 & 82 & 44 & 33 & 32 & 9 & 4 & 3 & 9 & 3 & 7 & 5 & 1 & 2 & 1 & 2 & & 26342.9\end{array}$

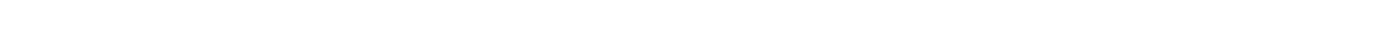

1966

1967

1968

1970

$\begin{array}{llllllllllll}9 & 23 & 37 & 35 & 90 & 71 & 28 & 35 & 23 & 7 & 5 & 1\end{array}$

$\begin{array}{llllllllllllll}40 & 60 & 63 & 65 & 51 & 17 & 21 & 13 & 11 & 10 & 6 & 6 & 1 & 1\end{array}$

$\begin{array}{lllll}11 & 3 & 1 & 50982.0\end{array}$

$\begin{array}{llllllllllllllllll}11 & 11 & 42 & 118 & 106 & 41 & 17 & 8 & 6 & 1 & 3 & & & 1 & & & & 32145.0\end{array}$ 
09314500 PRICE RIVER AT WOODSIDE, UT-Continued

DURATION OF DISGHARGE FOR EAOH WATER YEAR--Continued

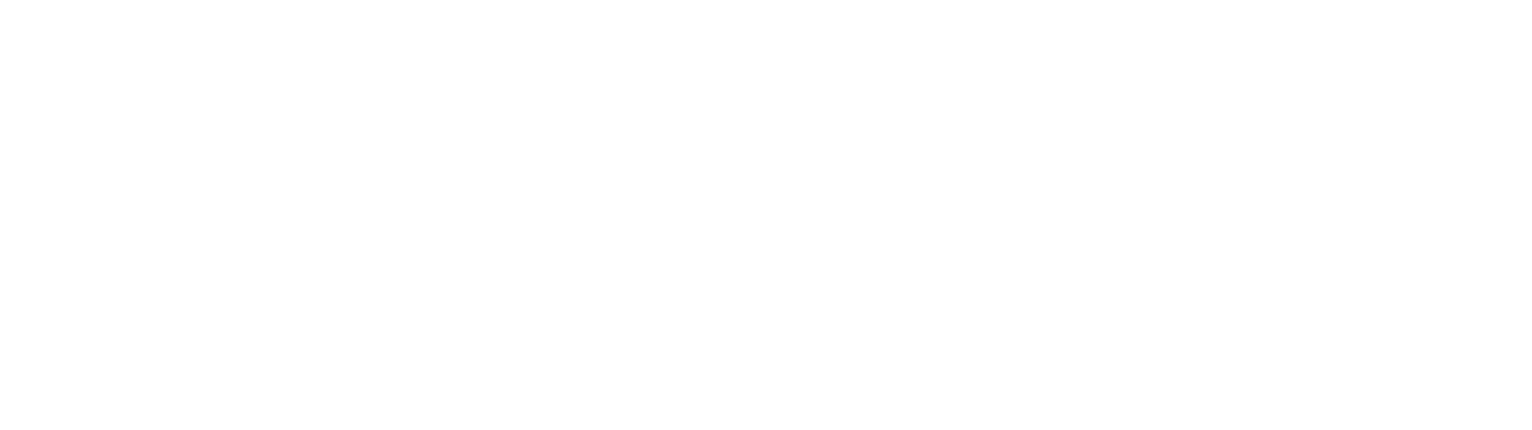

DURATION TABIE OF DISCHARGE FOR WATER YEARS 1 947-81

\begin{tabular}{|c|c|c|c|c|c|c|c|c|c|c|c|c|c|c|c|c|c|c|c|}
\hline CLASS & $\begin{array}{c}\text { OBIC } \\
\text { PEET } \\
\text { PER } \\
\text { SECOND }\end{array}$ & $\begin{array}{l}\text { TOTAL } \\
\text { DAYS }\end{array}$ & $\begin{array}{r}\text { ACQ- } \\
\text { N- } \\
\text { LATED } \\
\text { DAYS }\end{array}$ & $\begin{array}{l}\text { PER- } \\
\text { CENT } \\
\text { DAYS }\end{array}$ & CLASS & $\begin{array}{c}\text { QUBIC } \\
\text { FEET } \\
\text { PER } \\
\text { SECOND }\end{array}$ & $\begin{array}{l}\text { TOTAL } \\
\text { DAYS }\end{array}$ & $\begin{array}{l}\text { ACQU- } \\
\text { MU- } \\
\text { LATED } \\
\text { DAYS }\end{array}$ & $\begin{array}{l}\text { PER- } \\
\text { CENT } \\
\text { DAYS }\end{array}$ & CLASS & $\begin{array}{c}\text { CUBIC } \\
\text { FEET } \\
\text { PER } \\
\text { SECOND }\end{array}$ & $\begin{array}{c}\text { TOTAL } \\
\text { DAYS }\end{array}$ & $\begin{array}{r}\text { ACCU- } \\
M- \\
\text { LATED } \\
\text { DAYS }\end{array}$ & $\begin{array}{l}\text { PER- } \\
\text { CENT } \\
\text { DAYS }\end{array}$ & CLASS & $\begin{array}{c}\text { CBBIC } \\
\text { FEET } \\
\text { PER } \\
\text { SECOND }\end{array}$ & $\begin{array}{l}\text { TOTAL } \\
\text { DAYS }\end{array}$ & $\begin{array}{r}\text { ACOU- } \\
\text { MU- } \\
\text { LATED } \\
\text { DAYS }\end{array}$ & $\begin{array}{l}\text { PER- } \\
\text { CENT } \\
\text { DAYS }\end{array}$ \\
\hline $\begin{array}{l}0 \\
1 \\
2 \\
3 \\
4 \\
5 \\
6 \\
7 \\
8\end{array}$ & $\begin{array}{l}0.00 \\
0.10 \\
0.14 \\
0.19 \\
0.27 \\
0.37 \\
0.51 \\
0.71 \\
0.98\end{array}$ & $\begin{array}{r}58 \\
5 \\
3 \\
7 \\
8 \\
9 \\
10 \\
11 \\
16\end{array}$ & $\begin{array}{l}12784 \\
12726 \\
12721 \\
12718 \\
12711 \\
12703 \\
12694 \\
12684 \\
12673\end{array}$ & $\begin{array}{r}100.0 \\
99.5 \\
99.5 \\
99.5 \\
99.4 \\
99.4 \\
99.3 \\
99.2 \\
99.1\end{array}$ & $\begin{array}{r}9 \\
10 \\
11 \\
12 \\
13 \\
14 \\
15 \\
16 \\
17\end{array}$ & $\begin{array}{r}1.40 \\
1.90 \\
2.60 \\
3.60 \\
5.00 \\
7.00 \\
9.70 \\
13.00 \\
19.00\end{array}$ & $\begin{array}{r}19 \\
24 \\
31 \\
43 \\
67 \\
138 \\
243 \\
778 \\
1155\end{array}$ & $\begin{array}{l}12657 \\
12638 \\
12614 \\
12583 \\
12540 \\
12473 \\
12335 \\
12092 \\
11314\end{array}$ & $\begin{array}{l}99.0 \\
98.9 \\
98.7 \\
98.4 \\
98.1 \\
97.6 \\
96.5 \\
94.6 \\
88.5\end{array}$ & $\begin{array}{l}18 \\
19 \\
20 \\
21 \\
22 \\
23 \\
24 \\
25 \\
26\end{array}$ & $\begin{array}{r}26.0 \\
36.0 \\
50.0 \\
69.0 \\
95.0 \\
130.0 \\
180.0 \\
250.0 \\
350.0\end{array}$ & $\begin{array}{r}1728 \\
1849 \\
2326 \\
1527 \\
816 \\
521 \\
387 \\
295 \\
227\end{array}$ & $\begin{array}{c}10159 \\
8431 \\
6582 \\
4256 \\
2729 \\
1913 \\
1392 \\
1005 \\
710\end{array}$ & $\begin{array}{r}79.5 \\
65.9 \\
51.5 \\
33.3 \\
21.3 \\
15.0 \\
10.9 \\
7.9 \\
5.6\end{array}$ & $\begin{array}{l}27 \\
28 \\
29 \\
30 \\
31 \\
32 \\
33 \\
34\end{array}$ & $\begin{array}{r}490.0 \\
680.0 \\
940.0 \\
1300.0 \\
1800.0 \\
2500.0 \\
3500.0 \\
4800.0\end{array}$ & $\begin{array}{r}198 \\
133 \\
73 \\
42 \\
24 \\
7 \\
5 \\
1\end{array}$ & $\begin{array}{r}483 \\
285 \\
152 \\
79 \\
37 \\
13 \\
6 \\
1\end{array}$ & $\begin{array}{l}3.8 \\
2.2 \\
1.2 \\
0.6 \\
0.3 \\
0.1 \\
0.0 \\
0.0\end{array}$ \\
\hline
\end{tabular}

MONIHLY MEAN DISOHARGES, IN OBIC FEET PER SECOND, FOR EACH WATER YEAR

\begin{tabular}{|c|c|c|c|c|c|c|c|c|c|c|c|c|}
\hline YEAR & OCT & NOV & DEC & JAN & FEB & MAR & APR & MAY & JUNE & JULY & AUG & SEP \\
\hline 1910 & 74 & 80 & 73 & 70 & 70 & 792 & 918 & 1102 & 187 & 114 & 41 & 221 \\
\hline $\begin{array}{l}1947 \\
1948 \\
1949 \\
1950\end{array}$ & $\begin{array}{l}67.7 \\
51.7 \\
31.8 \\
95.1\end{array}$ & $\begin{array}{l}42.6 \\
37.3 \\
27.2 \\
48.0\end{array}$ & $\begin{array}{l}34.8 \\
41.4 \\
28.5 \\
35.6\end{array}$ & $\begin{array}{l}18.5 \\
28.3 \\
28.2 \\
28.0\end{array}$ & $\begin{array}{r}52.1 \\
49.6 \\
46.8 \\
103\end{array}$ & $\begin{array}{l}76.4 \\
69.0 \\
163 \\
102\end{array}$ & $\begin{array}{l}79.1 \\
74.1 \\
226 \\
223\end{array}$ & $\begin{array}{l}106 \\
47.9 \\
213 \\
132\end{array}$ & $\begin{array}{c}55.1 \\
43.1 \\
246 \\
71.7\end{array}$ & $\begin{array}{l}35.5 \\
42.9 \\
212 \\
164\end{array}$ & $\begin{array}{c}238 \\
94.9 \\
76.6 \\
52.2\end{array}$ & $\begin{array}{l}37.4 \\
10.2 \\
92.6 \\
69.4\end{array}$ \\
\hline $\begin{array}{l}1951 \\
1952 \\
1953 \\
1954 \\
1955\end{array}$ & $\begin{array}{r}48.9 \\
90.6 \\
75.6 \\
87.4 \\
134\end{array}$ & $\begin{array}{l}51.3 \\
52.4 \\
71.0 \\
63.3 \\
48.6\end{array}$ & $\begin{array}{l}48.2 \\
30.1 \\
59.2 \\
36.7 \\
24.2\end{array}$ & $\begin{array}{l}33.5 \\
31.1 \\
56.0 \\
40.6 \\
20.0\end{array}$ & $\begin{array}{l}52.0 \\
48.1 \\
63.2 \\
78.5 \\
23.0\end{array}$ & $\begin{array}{c}81.7 \\
152 \\
85.3 \\
76.8 \\
174\end{array}$ & $\begin{array}{l}51.0 \\
646 \\
69.8 \\
59.9 \\
101\end{array}$ & $\begin{array}{c}84.2 \\
1762 \\
75.5 \\
62.2 \\
53.0\end{array}$ & $\begin{array}{l}100 \\
888 \\
85.2 \\
52.9 \\
33.9\end{array}$ & $\begin{array}{l}70.0 \\
145 \\
101 \\
64.0 \\
25.5\end{array}$ & $\begin{array}{l}314 \\
151 \\
176 \\
50.3 \\
78.5\end{array}$ & $\begin{array}{c}54.7 \\
89.9 \\
55.0 \\
200 \\
15.8\end{array}$ \\
\hline $\begin{array}{l}1956 \\
1957 \\
1958 \\
1959 \\
1960\end{array}$ & $\begin{array}{l}22.1 \\
19.4 \\
97.6 \\
46.3 \\
33.1\end{array}$ & $\begin{array}{c}28.0 \\
18.6 \\
337 \\
44.3 \\
32.8\end{array}$ & $\begin{array}{l}44.0 \\
14.0 \\
51.0 \\
48.5 \\
26.2\end{array}$ & $\begin{array}{l}34.3 \\
16.7 \\
50.0 \\
40.2 \\
26.1\end{array}$ & $\begin{array}{l}38.8 \\
41.0 \\
81.9 \\
45.4 \\
30.0\end{array}$ & $\begin{array}{c}56.8 \\
43.6 \\
90.9 \\
45.4 \\
104\end{array}$ & $\begin{array}{c}38.7 \\
36.3 \\
356 \\
29.1 \\
37.4\end{array}$ & $\begin{array}{l}39.8 \\
197 \\
643 \\
26.4 \\
20.4\end{array}$ & $\begin{array}{l}25.6 \\
172 \\
221 \\
21.9 \\
14.8\end{array}$ & $\begin{array}{c}48.1 \\
104 \\
70.8 \\
9.95 \\
4.21\end{array}$ & $\begin{array}{c}22.1 \\
478 \\
78.8 \\
106 \\
17.6\end{array}$ & $\begin{array}{c}8.33 \\
82.6 \\
109 \\
71.5 \\
40.6\end{array}$ \\
\hline $\begin{array}{l}1961 \\
1962 \\
1963 \\
1964 \\
1965\end{array}$ & $\begin{array}{l}1 \text { N } \\
18.5 \\
95.8 \\
22.4 \\
18.3\end{array}$ & $\begin{array}{l}23.8 \\
26.2 \\
28.0 \\
23.2 \\
25.9\end{array}$ & $\begin{array}{l}19.6 \\
21.5 \\
23.4 \\
15.2 \\
25.7\end{array}$ & $\begin{array}{l}10.7 \\
15.2 \\
13.6 \\
11.3 \\
39.6\end{array}$ & $\begin{array}{c}22.6 \\
135 \\
45.7 \\
18.0 \\
52.6\end{array}$ & $\begin{array}{l}25.6 \\
134 \\
108 \\
31.0 \\
52.0\end{array}$ & $\begin{array}{c}15.0 \\
474 \\
25.7 \\
54.1 \\
162\end{array}$ & $\begin{array}{c}5.26 \\
198 \\
21.6 \\
94.2 \\
461\end{array}$ & $\begin{array}{c}1.51 \\
47.1 \\
25.5 \\
47.3 \\
309\end{array}$ & $\begin{array}{c}8.63 \\
162 \\
24.6 \\
31.5 \\
271\end{array}$ & $\begin{array}{l}99.6 \\
10.8 \\
251 \\
167 \\
137\end{array}$ & $\begin{array}{l}457 \\
251 \\
200 \\
32.0 \\
99.7\end{array}$ \\
\hline $\begin{array}{l}1966 \\
1967 \\
1968 \\
1969 \\
1970\end{array}$ & $\begin{array}{l}80.3 \\
38.7 \\
45.4 \\
95.1 \\
78.8\end{array}$ & $\begin{array}{l}90.8 \\
34.3 \\
38.8 \\
59.9 \\
63.4\end{array}$ & $\begin{array}{c}88.8 \\
101 \\
46.9 \\
31.6 \\
41.6\end{array}$ & $\begin{array}{l}54.6 \\
24.8 \\
33.0 \\
32.3 \\
35.4\end{array}$ & $\begin{array}{l}59.3 \\
53.4 \\
45.9 \\
36.0 \\
65.8\end{array}$ & $\begin{array}{c}188 \\
77.7 \\
71.8 \\
349 \\
75.6\end{array}$ & $\begin{array}{c}169 \\
61.0 \\
109 \\
535 \\
58.9\end{array}$ & $\begin{array}{l}88.2 \\
92.5 \\
299 \\
682 \\
78.1\end{array}$ & $\begin{array}{l}54.8 \\
425 \\
510 \\
324 \\
264\end{array}$ & $\begin{array}{l}61.8 \\
158 \\
105 \\
128 \\
98.7\end{array}$ & $\begin{array}{l}50.5 \\
96.4 \\
295 \\
214 \\
100\end{array}$ & $\begin{array}{c}117 \\
108 \\
71.2 \\
194 \\
98.7\end{array}$ \\
\hline $\begin{array}{l}1971 \\
1972 \\
1973 \\
1974 \\
1975\end{array}$ & $\begin{array}{l}58.6 \\
104 \\
365 \\
69.9 \\
94.9\end{array}$ & $\begin{array}{l}66.5 \\
80.9 \\
67.8 \\
54.0 \\
68.4\end{array}$ & $\begin{array}{l}45.7 \\
36.7 \\
48.5 \\
61.7 \\
41.6\end{array}$ & $\begin{array}{l}27.6 \\
34.1 \\
40.0 \\
60.6 \\
42.7\end{array}$ & $\begin{array}{l}55.4 \\
36.2 \\
50.4 \\
60.6 \\
58.6\end{array}$ & $\begin{array}{l}84.4 \\
125 \\
174 \\
60.7 \\
93.4\end{array}$ & $\begin{array}{c}93.9 \\
66.3 \\
260 \\
51.0 \\
125\end{array}$ & $\begin{array}{c}127 \\
64.7 \\
735 \\
74.9 \\
175\end{array}$ & $\begin{array}{c}117 \\
73.7 \\
226 \\
60.8 \\
492\end{array}$ & $\begin{array}{c}57.8 \\
40.9 \\
165 \\
58.5 \\
235\end{array}$ & $\begin{array}{r}84.1 \\
46.8 \\
93.5 \\
18.8 \\
77.9\end{array}$ & $\begin{array}{r}53.5 \\
42.6 \\
60.4 \\
16.2 \\
113\end{array}$ \\
\hline $\begin{array}{l}1976 \\
1977 \\
1978 \\
1979 \\
1980\end{array}$ & $\begin{array}{l}81.6 \\
39.4 \\
31.5 \\
20.3 \\
34.4\end{array}$ & $\begin{array}{c}89.5 \\
31.7 \\
18.7 \\
179 \\
38.8\end{array}$ & $\begin{array}{l}35.4 \\
34.2 \\
12.2 \\
25.1 \\
34.1\end{array}$ & $\begin{array}{l}41.5 \\
20.0 \\
13.1 \\
22.5 \\
44.3\end{array}$ & $\begin{array}{r}63.8 \\
20.0 \\
22.1 \\
39.9 \\
177\end{array}$ & $\begin{array}{l}62.5 \\
26.8 \\
124 \\
375 \\
135\end{array}$ & $\begin{array}{l}71.2 \\
16.8 \\
173 \\
368 \\
384\end{array}$ & $\begin{array}{l}70.9 \\
21.6 \\
169 \\
534 \\
930\end{array}$ & $\begin{array}{c}48.4 \\
3.85 \\
53.1 \\
104 \\
677\end{array}$ & $\begin{array}{c}39.3 \\
120 \\
48.7 \\
52.6 \\
103\end{array}$ & $\begin{array}{l}35.0 \\
29.6 \\
25.8 \\
69.1 \\
99.4\end{array}$ & $\begin{array}{c}67.5 \\
8.42 \\
17.7 \\
30.0 \\
387\end{array}$ \\
\hline 1981 & 140 & 71.7 & 62.1 & 53.1 & 45.0 & 59.9 & 76.1 & 65.9 & 57.2 & 70.1 & 99.1 & 113 \\
\hline
\end{tabular}


09314500 PRICE RIVER AT WOODSIDE, UT-Continued

ANNUAL PEAK DISCHARGE, IN CUBIC FEET PER SECOND, AND CORRESPONDING GAGE HEIGHT, IN FEET, FOR EACH WATER YEAR

\begin{tabular}{|c|c|c|c|c|c|c|c|c|c|c|c|}
\hline $\begin{array}{l}\text { WAIERR } \\
\text { YEAR }\end{array}$ & DATE & $\begin{array}{c}\text { GAGE } \\
\text { HEIGHT }\end{array}$ & $\begin{array}{c}\text { PEAK } \\
\text { DISCHARGE }\end{array}$ & $\begin{array}{l}\text { WATER } \\
\text { YEAR }\end{array}$ & DATE & $\begin{array}{c}\text { GAGE } \\
\text { HEIGHT }\end{array}$ & $\begin{array}{c}\text { PEAK } \\
\text { DISCHARGE }\end{array}$ & $\begin{array}{l}\text { WATER } \\
\text { YEAR }\end{array}$ & DATE & $\begin{array}{c}\text { GAGE } \\
\text { HEIGHT }\end{array}$ & $\begin{array}{c}\text { PEAK } \\
\text { DISCHARGE }\end{array}$ \\
\hline $\begin{array}{l}1909 \\
1910 \\
1946 \\
1947 \\
1948 \\
1949 \\
1950 \\
1951 \\
1952 \\
1953 \\
1954 \\
1955 \\
1956\end{array}$ & $\begin{array}{l}\text { SEPT. 01, } 1909 \\
\text { MAR. } 06,1910 \\
\text { AUG. } 24,1946 \\
\text { AUG. } 22,1947 \\
\text { AUG. } 05,1948 \\
\text { JULY } 04,1949 \\
\text { JULY } 08,1950 \\
\text { AUG. } 04,1951 \\
\text { AUG. } 27,1952 \\
\text { AUG. } 28,1953 \\
\text { SEPT. 04, } 1954 \\
\text { OCT. } 08,1954 \\
\text { JULY } 30,1956\end{array}$ & $\begin{array}{r}18.20 \\
12.40 \\
2.77 \\
6.55 \\
3.04 \\
4.33 \\
3.93 \\
7.34 \\
3.98 \\
5.11 \\
5.58 \\
7.55 \\
2.65\end{array}$ & $\begin{array}{r}8150 \\
2870 \\
967 \\
6820 \\
1150 \\
3570 \\
3260 \\
7720 \\
3460 \\
4650 \\
5420 \\
5020 \\
487\end{array}$ & $\begin{array}{l}1957 \\
1958 \\
1959 \\
1960 \\
1961 \\
1962 \\
1963 \\
1964 \\
1965 \\
1966 \\
1967 \\
1968 \\
1969\end{array}$ & $\begin{array}{l}\text { AUG. } 07,1957 \\
\text { NOV. } 03,1957 \\
\text { AUG. } 20,1959 \\
\text { SEPT. } 02,1960 \\
\text { SEPT. } 10,1961 \\
\text { SEPT. } 22,1962 \\
\text { AUG. } 18,1963 \\
\text { AUG. 01, } 1964 \\
\text { JULY } 19,1965 \\
\text { SEPT. } 01,1966 \\
\text { JULY } 17,1967 \\
\text { AUG. 11, } 1968 \\
\text { AUG. } 30,1969\end{array}$ & $\begin{array}{l}8.38 \\
8.70 \\
4.84 \\
4.15 \\
9.74 \\
8.84 \\
9.81 \\
8.68 \\
6.90 \\
7.87 \\
5.47 \\
7.20 \\
8.81\end{array}$ & $\begin{array}{l}6430 \\
6810 \\
2170 \\
1530 \\
8500 \\
5600 \\
7520 \\
6880 \\
4330 \\
5560 \\
2500 \\
4530 \\
6920\end{array}$ & $\begin{array}{l}1970 \\
1971 \\
1972 \\
1973 \\
1974 \\
1975 \\
1976 \\
1977 \\
1978 \\
1979 \\
1980 \\
1981\end{array}$ & $\begin{array}{l}\text { JUNE } 11,1970 \\
\text { AUG. } 27,1971 \\
\text { OCT. } 25,1971 \\
\text { OCT. } 20,1972 \\
\text { APR. 19, } 1974 \\
\text { JULY } 16,1975 \\
\text { SEPT.12, } 1976 \\
\text { JULY 24, } 1977 \\
\text { JULY 11, } 1978 \\
\text { NOT. 12, } 1978 \\
\text { SEPT.11, } 1980 \\
\text { AUG. 16, } 1981\end{array}$ & $\begin{array}{c}7.20 \\
4.68 \\
4.96 \\
8.68 \\
-. \\
6.77 \\
4.98 \\
6.30 \\
9.60 \\
6.93 \\
11.16 \\
8.30\end{array}$ & $\begin{array}{r}4210 \\
1310 \\
1580 \\
7290 \\
300 \\
3780 \\
1800 \\
3300 \\
8700 \\
4070 \\
9720 \\
3740\end{array}$ \\
\hline
\end{tabular}

MAGNITUDE AND PROBABILITY OF ANNUAL LOWEST MEAN DISCHARGE BASED ON CIMATIC YEARS 1948-81

\begin{tabular}{|c|c|c|c|c|c|c|}
\hline \multirow{2}{*}{$\begin{array}{l}\text { PERIOD } \\
\text { (CON- } \\
\text { SECU- } \\
\text { TIVE } \\
\text { DAYS) }\end{array}$} & \multicolumn{6}{|c|}{$\begin{array}{l}\text { DISCHARGE, IN CUBIC FEET PER SECOND, FOR } \\
\text { INDICATED RECURRENCE INTERNAL, IN YEARS, AND } \\
\text { ANNUAL NONEXCEEDANCE PROBABILITY, IN PERCENI }\end{array}$} \\
\hline & $\begin{array}{c}2 \\
508\end{array}$ & $\begin{array}{c}5 \\
208\end{array}$ & $\begin{array}{l}10 \\
108\end{array}$ & $\begin{array}{l}20 \\
58\end{array}$ & $\begin{array}{l}50 \\
28\end{array}$ & $\begin{array}{r}100 \\
18\end{array}$ \\
\hline
\end{tabular}

MAGNITUDE AND PRCBABILITY OF ANNUAL HIGHEST MEAN DISCHARGE BASED ON WATER YEARS $1947-81$

\begin{tabular}{|c|c|c|c|c|c|c|}
\hline \multirow{2}{*}{$\begin{array}{l}\text { PERIOD } \\
\text { (CON- } \\
\text { SEOU- } \\
\text { TIVE } \\
\text { DAYS) }\end{array}$} & \multicolumn{6}{|c|}{$\begin{array}{l}\text { DISCHARGE, IN GIBIC FEET PER SECOND, FOR } \\
\text { INDICATED REAURREANCE INTERNAL, IN YEARS, AND } \\
\text { ANNUAL EXCEEDANCE PRCBABILITY, IN PERCENT }\end{array}$} \\
\hline & $\begin{array}{c}2 \\
50 \text { z }\end{array}$ & $\begin{array}{c}5 \\
208\end{array}$ & $\begin{array}{l}10 \\
108\end{array}$ & $\begin{array}{l}25 \\
48\end{array}$ & $\begin{array}{l}50 \\
28\end{array}$ & $\begin{array}{r}100 \\
18\end{array}$ \\
\hline $\begin{array}{r}1 \\
3 \\
7 \\
15\end{array}$ & $\begin{array}{r}1470 \\
854 \\
520 \\
347\end{array}$ & $\begin{array}{r}2920 \\
1630 \\
933 \\
659\end{array}$ & $\begin{array}{r}4060 \\
2230 \\
1250 \\
924\end{array}$ & $\begin{array}{l}5650 \\
3060 \\
1680 \\
1330\end{array}$ & $\begin{array}{l}6900 \\
3730 \\
2020 \\
1680\end{array}$ & $\overline{-}$ \\
\hline
\end{tabular}

09315000 GREEN RIVER AT GREEN RIVER, UT

LOCATION.--Lat $38^{\circ} 59^{\prime} 10^{\prime \prime}$, long $110^{\circ} 09.02 "$, in $\mathrm{NW}_{4}^{\frac{1}{4}} \mathrm{NW}_{\frac{1}{4}}^{\frac{1}{4} S W^{\frac{1}{4}}} \mathrm{sec} .15$, T.21 S., R.16 E., Enery County, Hydrologic Unit 14060008 , on right bank $100 \mathrm{ft}$ upstream fram site of old highway bricige, $500 \mathrm{ft}$ upstream from San Rafael River, and at mile 117.4 upstream fram mouth.

DRAINAGE AREA.- -44,850 $\mathrm{mi}^{2}$, approximately, of which about 4,260 $\mathrm{mi}^{2}$, including $3,959 \mathrm{mi}^{2}$ in Great Divide basin in southern Wyaming, is noncontributing.

PERIOD OF RECORD AVAIIABLE.--October 1894 to October 1899, October 1904 to September 1981. Published as "at Blake", 1894-99, as "near Elgin", 1911, and as "at Little Valley, near Green River", 1910-23.

REVISED RECORDS. -WSP 918: 1895-1900. WDR UT-76-1: Drainage area.

GAGE. - Water-stage recorder. Datum of gage is 4,040.18 ft NGVD of 1929. Prior to Nov. 6, 1914, staff, wire-weight, or chain gages at several sites within $7 \mathrm{mi}$ of present site at various datums. Nov, 6, 1914 to June 20,1924 , water-stage recorder at site 7 mi downstream at different datum. June 21 to Sept. 18, 1924, chain gage, and Sept. 19, 1924 to May 7, 1947, water-stage recorder, at site $100 \mathrm{ft}$ downstream at present datum.

REMARKS.--Diversions for irrigation above station. Flow regulated by Flaming Gorge Reservoir since Nov. $1,1962$.

AVERAGE DISCHARGE.--82 years, $6,263 \mathrm{ft}^{3} / \mathrm{s}, 4,538,000$ acre-ft/yr, unadjusted.

EXTREMES FOR PERIOD OF RECORD.-Maximum discharge, $68,100 \mathrm{ft}^{3} / \mathrm{s}$ June 27,1917 , gage height, $14.53 \mathrm{ft}$, site and datum then in use; minimum, $255 \mathrm{ft}^{3} / \mathrm{s}$ Nov 26, 1931; minimum gage height, $4.08 \mathrm{ft}$ Aug. 1, Dec. 5, 1934. 
GREEN RIVER BASIN

09315000 GREEN RIVER AT GREEN RIVER, UT-Continued

DATA BELOW BASED ON PERIOD OF RECORD PRIOR TO REGULATION BY FLAMING GORGE RESERVOIR

LOWEST MEAN DISCHARGE, IN CUBIC FEET PER SECOND, AND RANKING FOR THE INDICATED NUMBER OF CONSEQUTIVE DAYS FOR EAG OLIMATIC YEAR, APRIL 1-MAROH 31

YEAR

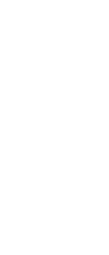

1911770

$1912 \quad 1430$

$\begin{array}{ll}1913 & 1290 \\ 1914 & 1120\end{array}$

19151100

$1916 \quad 875$

$1917 \quad 1070$

$1918 \quad 1200$

19191310

$1920 \quad 510$

$1921 \quad 1100$

$1922 \quad 955$

19241000

$1925 \quad 600$

$1926 \quad 1240$

$1927 \quad 875$

$1928 \quad 1350$

$\begin{array}{ll}1929 & 930 \\ 1930 & 754\end{array}$

$1931 \quad 1200$

$1932 \quad 400$

$1933 \quad 635$

$1935 \quad 380$

$1936 \quad 00$

1937
1938

$\begin{array}{rr}1938 & 742 \\ 1939 & 1220\end{array}$

$1940 \quad 539$

$\begin{array}{ll}1941 & 508 \\ 1942 & 720\end{array}$

$1942 \quad 720$

$1944 \quad 890$

19451060

$1946 \quad 1000$

$1947 \quad 1080$

19481130

$1950 \quad 854$

$1951 \quad 1290$

$1952 \quad 1090$

19531000

$\begin{array}{llll}954 & 850 & 17 & 883\end{array}$

$1955 \quad 980 \quad 30 \quad 1100$

$\begin{array}{llll}1956 & 914 & 26 & 922\end{array}$

$\begin{array}{llll}1957 \quad 986 & 31 & 994\end{array}$

$1958 \quad 1600 \quad 60 \quad 1650$

1959910

$1960 \quad 1000$

$\begin{array}{rrrrrr}1961 & 524 & 6 & 604 & 6 & 774 \\ 1962 & 850 & 18 & 933 & 22 & 1040\end{array}$

$5 \quad 600$

1100

$57 \quad 1680$

$\begin{array}{rr}27 & 1110 \\ 14 & 923\end{array}$

CONSECUTIVE DAYS

14

$\begin{array}{ll}31 & 1290 \\ 14 & 1000\end{array}$

151000

$\begin{array}{ll}28 & 1290\end{array}$

$10 \quad 1100$

$\begin{array}{ll}16 & 1270\end{array}$

191000

$42 \quad 1240$

$61 \quad 2110$

8800

9800

$34 \quad 1280$

$61 \quad 2330$

$\begin{array}{ll}37 & 1300\end{array}$

$26 \quad 1340$

61 2400

$\begin{array}{rr}29 & 1330 \\ 4 & 1210\end{array}$

$\begin{array}{rr}4 & 1210 \\ 5 & 951\end{array}$

$\begin{array}{ll}12 & 1270 \\ 50 & 1520\end{array}$

451510

$25 \quad 1680$

$43 \quad 1650$

$37 \quad 1750$

$\begin{array}{ll}29 & 1490 \\ 30 & 1330\end{array}$

311420

$\begin{array}{llll}43 & 1130 & 34 & 1160 \\ 44 & 1140 & 36 & 1170\end{array}$

$46 \quad 1590$

$21 \quad 1190$

$59 \quad 2030$

$\begin{array}{rr}42 & 1400 \\ 9 & 1200\end{array}$

$45 \quad 1730$

$17 \quad 1490$

592390

$\begin{array}{ll}33 & 1550 \\ 18 & 1340\end{array}$

$52 \quad 1720$

$51 \quad 1630$

$48 \quad 1920$

$46 \quad 1890$

552060

40
$4 \quad 1030$

$\begin{array}{ll}34 & 1610\end{array}$

$43 \quad 1380$

3781

51850

$52 \quad 1930$

$57 \quad 1760$

$59 \quad 1780$

$31 \quad 1280$

$\begin{array}{ll}31 & 1280 \\ 14 & 1040\end{array}$

$27 \quad 1330$

$56 \quad 2010$

$36 \quad 1490$

$18 \quad 1210$

$32 \quad 1600$

$\begin{array}{ll}58 & 2450\end{array}$

$\begin{array}{ll}38 & 1750\end{array}$

$21 \quad 1620$

$47 \quad 1520$

41 1650

$\begin{array}{lr}2 & 997 \\ 8 & 1290\end{array}$

$2 \quad 657$

$\begin{array}{rr}5 & 878\end{array}$

$\begin{array}{rr}6 & 1160 \\ 1 & 483\end{array}$

$\begin{array}{ll}7 & 973\end{array}$

$28 \quad 1200$

$19 \quad 1260$

$10 \quad 888$

$\begin{array}{lr}20 & 1000\end{array}$

$32 \quad 1330$

$\begin{array}{ll}54 & 1740 \\ 13 & 1020\end{array}$

$8 \quad 932$

$13 \quad 1000$

$\begin{array}{ll}38 & 1490\end{array}$

$54 \quad 1860$

61020

$\begin{array}{ll}9 & 1140\end{array}$

$39 \quad 1780$

531940

$\begin{array}{ll}53 & 1940 \\ 27 & 1370\end{array}$

$\begin{array}{rr}2 & 741 \\ 35 & 1720\end{array}$

$\begin{array}{rr}4 & 650 \\ 15 & 1240\end{array}$

$\begin{array}{ll}15 & 1240 \\ 52 & 1480\end{array}$

$\begin{array}{ll}35 & 1720 \\ 48 & 1520\end{array}$

$\begin{array}{rr}3 & 898 \\ 47 & 2000\end{array}$

$\begin{array}{ll}47 \quad 2000 \\ 42 & 1630\end{array}$

$\begin{array}{ll}42 & 1630 \\ 30 & 1570\end{array}$

$\begin{array}{ll}30 & 1570 \\ 22 & 1520\end{array}$

$\begin{array}{ll}22 & 1320 \\ 24 & 1220\end{array}$

351140

$41 \quad 1790$

$39 \quad 1450$

$51 \quad 1830$

$35 \quad 1750$

$\begin{array}{ll}39 & 1360\end{array}$

$50 \quad 1790$

$\begin{array}{ll}26 & 1050 \\ 33 & 1480\end{array}$

$19 \quad 1110$

572110

151300

$49 \quad 1780$

492120

$53 \quad 1450$

$\begin{array}{ll}48 & 1690 \\ 41 & 1440\end{array}$

$44 \quad 1780$

$53 \quad 1960$

$50 \quad 2150$

$56 \quad 2120$

$\begin{array}{ll}54 & 2000 \\ 20 & 1420\end{array}$

$24 \quad 1270$

$40 \quad 1200$

$\begin{array}{ll}23 & 1210 \\ 32 & 1250\end{array}$

$16 \quad 958$

$21 \quad 1010$

$\begin{array}{ll}11 & 1090 \\ 16 & 1050\end{array}$

$28 \quad 1240$

$25 \quad 1470$

$14 \quad 1190$

$13 \quad 1210$

$\begin{array}{ll}60 & 2240\end{array}$

$36 \quad 1530$

$44 \quad 1620$

$\begin{array}{rr}17 & 1320 \\ 8 & 1170\end{array}$

90

120

183

ALL

$\begin{array}{rr}6 & 1140 \\ 15 & 1380\end{array}$

$\begin{array}{ll}3 & 1440 \\ 4 & 1400\end{array}$

$\begin{array}{ll}8 & 1550 \\ 4 & 1570\end{array}$

$10 \quad 2350$

$\begin{array}{rr}8 & 5760 \\ 10 & 5510\end{array}$

$\begin{array}{rr}39 & 8300 \\ 7 & 5040\end{array}$

$22 \quad 1440$

$17 \quad 1590$

$18 \quad 1900$

$59 \quad 2730$

$20 \quad 1430$

$\begin{array}{rr}12 & 1480 \\ 3 & 1420\end{array}$

$\begin{array}{ll}22 & 1600 \\ 15 & 1900\end{array}$

$59 \quad 3290$

$23 \quad 2270$

192180

$39 \quad 1990$

$\begin{array}{ll}37 & 1710\end{array}$

$44 \quad 2230$

331800

$\begin{array}{ll}46 & 2010 \\ 43 & 1970\end{array}$

$\begin{array}{ll}45 & 2260 \\ 43 & 2300\end{array}$

$43 \quad 2300$

$43 \quad 2190$

$29 \quad 2190$

$45 \quad 2730$

$26 \quad 1590$

$25 \quad 1760$

$\begin{array}{ll}48 & 2760 \\ 27 & 2320\end{array}$

$40 \quad 1930$

$38 \quad 2140$

$27 \quad 1650$

$\begin{array}{ll}59 & 2500 \\ 30 & 1730\end{array}$

$21 \quad 1470$

$\begin{array}{ll}26 & 1980\end{array}$

$\begin{array}{lll}2560 & 58 & 2960\end{array}$

$34 \quad 1900 \quad 33 \quad 2420$

$21 \quad 1630$

$\begin{array}{ll}33 & 2420 \\ 21 & 1660\end{array}$

$24 \quad 5770$

$\begin{array}{ll}59 & 9120\end{array}$

3211600

$\begin{array}{lr}28 & 6280 \\ 60 & 12200\end{array}$

$29 \quad 6170$

$30 \quad 5400$

518710

$\begin{array}{ll}52 & 7610 \\ 37 & 9370\end{array}$

$47 \quad 5590$

$\begin{array}{lll}48 & 7480\end{array}$

5411800

$41 \quad 6930$

$48 \quad 2160$

$\begin{array}{ll}47 & 2070\end{array}$

$52 \quad 2440$

$54 \quad 2540$

$47 \quad 2140$

$50 \quad 2230$

$39 \quad 2310$

$18 \quad 1540$

$49 \quad 2160$

$32 \quad 1670$

61 2600

$41 \quad 1830$

341960

2400

$\begin{array}{ll}41 & 2310 \\ 44 & 2280\end{array}$

492780

$17 \quad 1560$

$44 \quad 8770$

$36 \quad 9720$

$33 \quad 8390$

$53 \quad 8920$

94970

$38 \quad 1700$

$\begin{array}{rr}4 & 1140 \\ 16 & 1460\end{array}$

13 1310

2400

$52 \quad 3150$

$58 \quad 6190$

612980

$36 \quad 2060$

$\begin{array}{ll}26 & 1750\end{array}$

613840

372350

195410

618120

$\begin{array}{ll}38 & 7640 \\ 56 & 8800\end{array}$

$31 \quad 1930$

$4 \quad 1190$

$35 \quad 2480$

$\begin{array}{ll}3 & 1240\end{array}$

$42 \quad 6040$

$3 \quad 2930$

$\begin{array}{rr}20 & 6720 \\ 6 & 4730\end{array}$

$\begin{array}{ll}6 & 4730 \\ 1 & 1560\end{array}$

$7 \quad 1100$

$\begin{array}{rr}9 & 1350 \\ 1 & 664\end{array}$

$\begin{array}{rr}7 & 1450 \\ 1 & 747\end{array}$

$2 \quad 1090$

$2 \quad 1200$

24030

$9 \quad 1330$

$44 \quad 1880$

$50 \quad 2070$

$11 \quad 1530$

$37 \quad 1910$ 
09315000 GREEN RIVER AT GREEN RIVER, UT--Continued

HIGHEST MEAN DISCHARGE, IN CUBIC FEET PER SECOND, AND RANKING FOR THE INDICATED NUMBER OF CONSECOTIVE DAYS FOR EACH WATER YEAR, OCTCBER 1-SEPTEMBER 30

YEAR

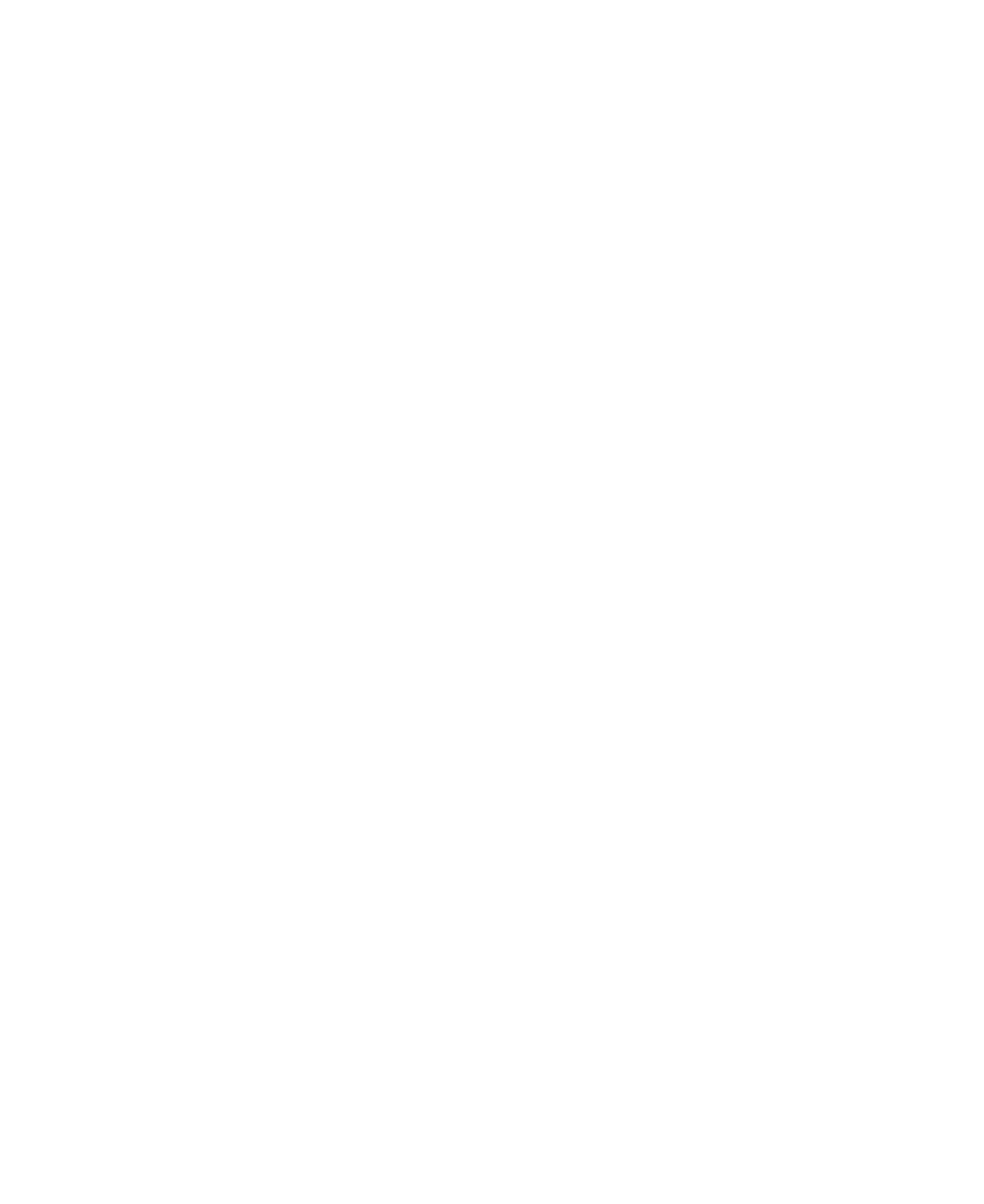


GREEN RIVER BASIN

09315000 GREEN RIVER AT GREEN RIVER, UT-Continued

DURATION OF DISCHARGE FOR EACH WATER YEAR

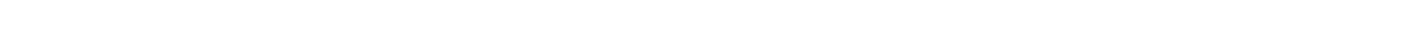

YEAR

1895

1896

1897

1898

1906

1907

1910

191

1912
1913

914

1915

1916

1917

1919

1920

1921

1922
1923

1924
1925

1926

1927

1928

1929
1930

1931

1932
1933

1934

1936

1937

1938

1939
1940

1941

1942

1943

1944
1945

1946

1946

1947
1948
1949

1949

1951

1952

1953
1954

1955

1956

1957

1958

1959

1961
1962
NUMBER OF DAYS IN CLASS

CUBIC FEET

PER SECOND

2301760.0

$\begin{array}{llllllllllllllllllll}3 & 18 & 18 & 95 & 14 & 64 & 10 & 9 & 22 & 9 & 9 & 3 & 4 & 17 & 13 & 21 & 12 & 6 & 16 & 2\end{array}$

$\begin{array}{lllllllllllllllllllllllll}2 & 3 & 27 & 62 & 51 & 25 & 23 & 12 & 20 & 12 & 16 & 17 & 15 & 13 & 7 & 7 & 8 & 8 & 6 & 4 & 5 & 6 & 6 & 6 & 5\end{array}$

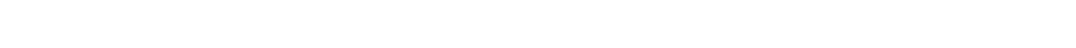

$\begin{array}{rrrrrrrrrrrrrrrrrrrrrrrrrrrr}1 & 60 & 18 & 7 & 15 & 35 & 27 & 23 & 27 & 12 & 18 & 9 & 9 & 8 & 13 & 4 & 5 & 39 & 17 & 10 & 6 & 2 & & & & \\ 13 & 25 & 33 & 76 & 19 & 15 & 9 & 9 & 14 & 17 & 7 & 6 & 5 & 11 & 13 & 12 & 7 & 6 & 12 & 16 & 10 & 9 & 5 & 7 & 8 & 1\end{array}$

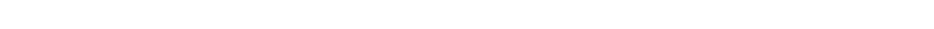

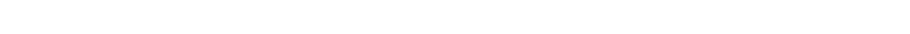

$\begin{array}{lllllllllllllllllllll}6 & 56 & 26 & 18 & 13 & 18 & 28 & 26 & 19 & 25 & 9 & 14 & 18 & 12 & 18 & 30 & 12 & 4 & 6 & 8\end{array}$

$\begin{array}{lllllllllllllllllllllllllllll}30 & 3 & 5 & 11 & 26 & 24 & 16 & 7 & 21 & 12 & 11 & 9 & 6 & 7 & 16 & 20 & 21 & 25 & 14 & 8 & 6 & 13 & 6 & 13 & 11 & 11 & 10 & 3\end{array}$

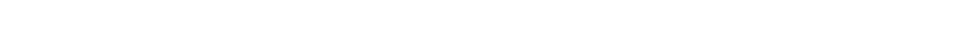

$\begin{array}{lllllllllllllllllllllll}3 & 6 & 11 & 2 & 27 & 49 & 41 & 27 & 20 & 7 & 21 & 22 & 25 & 14 & 10 & 13 & 16 & 15 & 12 & 10 & 5 & 5 & 4\end{array}$

$\begin{array}{lllllllllllllllllllllllll}14 & 53 & 33 & 21 & 19 & 22 & 16 & 21 & 22 & 27 & 12 & 11 & 12 & 13 & 10 & 8 & 4 & 1 & 11 & 14 & 6 & 4 & 4 & 8\end{array}$

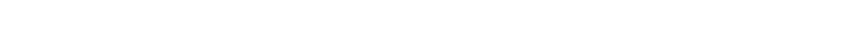

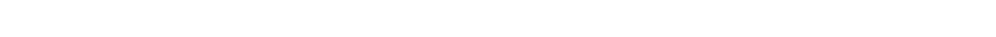

$\begin{array}{rlllllllllllllllllll}15 & 7 & 62 & 41 & 24 & 22 & 27 & 27 & 18 & 17 & 10 & 12 & 11 & 13 & 22 & 11 & 14 & 11 & 1\end{array}$

2036285.0

2879480.0

962690.0

2924050.0

3127890.0

4480400.0

2162750.0

2378585.0

2101730.0

3106020.0

2712730.0

3570720.0

1822700.0

$\begin{array}{llllllllllllllllllllllll}2 & 1 & 1 & 3 & 40 & 9 & 44 & 49 & 30 & 12 & 8 & 3 & 8 & 17 & 24 & 8 & 11 & 16 & 17 & 20 & 12 & 19 & 9 & 3\end{array}$

2895970.0

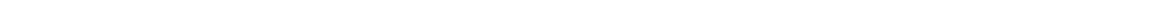

$\begin{array}{llllllllllllllllllllllllll}1 & 4 & 1 & 26 & 42 & 31 & 82 & 26 & 21 & 15 & 18 & 12 & 5 & 7 & 7 & 11 & 17 & 16 & 2 & 2 & 2 & 4 & 10 & 3 & & \end{array}$

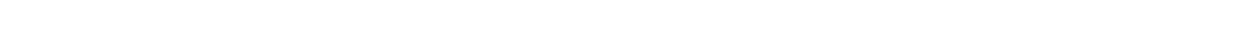

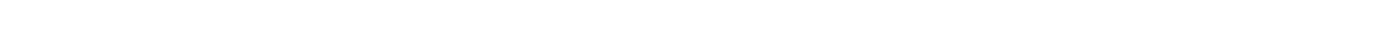

$\begin{array}{llllllllllllllllllllllllll}4 & 2 & 12 & 17 & 65 & 16 & 24 & 20 & 20 & 24 & 27 & 21 & 23 & 11 & 11 & 6 & 2 & 3 & 4 & 8 & 9 & 10 & 4 & 9 & 3 & 10\end{array}$

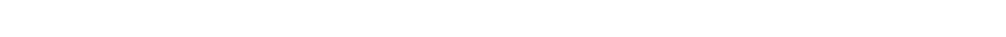

$\begin{array}{lllllllllllllllllllllll}11 & 55 & 53 & 46 & 23 & 19 & 9 & 9 & 5 & 7 & 3 & 17 & 18 & 14 & 12 & 12 & 7 & 8 & 10 & 11 & 13 & 3\end{array}$

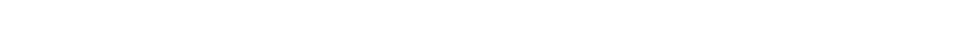

$\begin{array}{llllllllllllllllllll}6 & 10 & 28 & 30 & 38 & 35 & 25 & 27 & 26 & 20 & 18 & 12 & 10 & 10 & 12 & 10 & 9 & 18 & 9 & 12\end{array}$

$\begin{array}{llllllllllllllllllllllll}2 & 13 & 9 & 54 & 42 & 31 & 17 & 17 & 13 & 13 & 17 & 14 & 20 & 16 & 3 & 7 & 14 & 5 & 12 & 11 & 15 & 14 & 6\end{array}$

$\begin{array}{lllllllllllllllllllllll}2 & 11 & 22 & 25 & 41 & 24 & 22 & 47 & 34 & 32 & 18 & 9 & 6 & 19 & 2 & 4 & 5 & 7 & 7 & 7 & 7 & 9 & 6\end{array}$

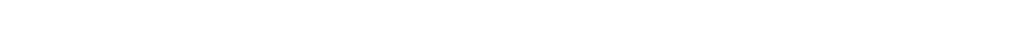

$5 \begin{array}{rrrrrrrrrrrrrrrrrrrrrrr}1 & 1 & 7 & 13 & 6 & 11 & 6 & 10 & 30 & 23 & 51 & 40 & 34 & 20 & 10 & 8 & 9 & 22 & 17 & 14 & 16 & 10 & 2\end{array}$

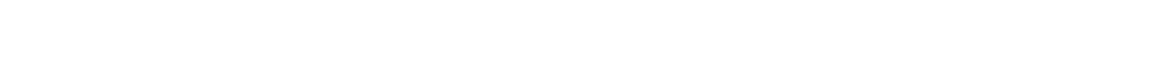

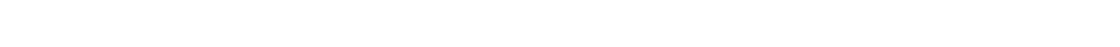

$\begin{array}{llllllllllllllllllllllll}6 & 41 & 16 & 41 & 32 & 12 & 33 & 35 & 11 & 8 & 13 & 7 & 8 & 10 & 5 & 6 & 9 & 6 & 6 & 13 & 12 & 10 & 19 & 7\end{array}$

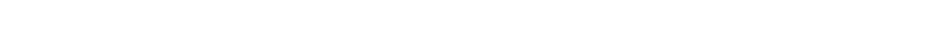

$\begin{array}{lllllllllllllllllll}2 & 4 & 8 & 22 & 62 & 55 & 11 & 29 & 23 & 26 & 13 & 8 & 6 & 6 & 9 & 7 & 5 & 16 & 17\end{array}$

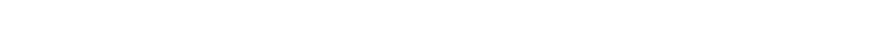

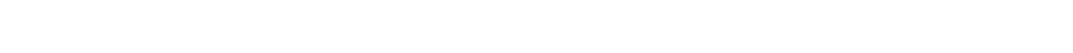

$\begin{array}{rrrrrrrrrrrrrrrrrrrrr}3 & 12 & 32 & 19 & 48 & 28 & 25 & 12 & 22 & 13 & 21 & 29 & 4 & 4 & 12 & 19 & 14 & 17 & 4 & 9 & 10 \\ 2 & 16 & 29 & 77 & 44 & 5 & 17 & 13 & 13 & 21 & 14 & 10 & 19 & 12 & 12 & 11 & 19 & 20 & 5 & 2 & 3\end{array}$

$\begin{array}{rrrrrrrrrrrrrrrrrrrrrrrr}3 & 1 & 2 & 16 & 29 & 77 & 44 & 5 & 17 & 13 & 13 & 21 & 14 & 10 & 19 & 12 & 12 & 11 & 19 & 20 & 5 & 2 & 3 \\ & 6 & 27 & 17 & 48 & 45 & 46 & 25 & 7 & 5 & 9 & 23 & 8 & 10 & 8 & 8 & 5 & 6 & 5 & 6 & 24 & 18 & 7\end{array}$

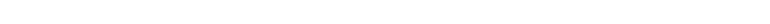

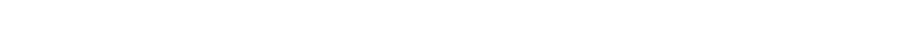

$\begin{array}{lllllllllllllllllllllll}15 & 13 & 6 & 12 & 32 & 58 & 38 & 46 & 22 & 12 & 9 & 5 & 10 & 7 & 14 & 17 & 12 & 10 & 7 & 3 & 15 & 4\end{array}$

$\begin{array}{rrrrrrrrrrrrrrrrrrrrrrr} & 4 & 13 & 23 & 62 & 69 & 23 & 14 & 12 & 6 & 11 & 8 & 11 & 10 & 10 & 9 & 5 & 4 & 12 & 14 & 9 & 20 & 7 \\ 3 & 1 & 1 & 1 & 6 & 29 & 35 & 48 & 42 & 30 & 19 & 16 & 14 & 9 & 5 & 16 & 13 & 8 & 16 & 10 & 4 & 15 & 24\end{array}$

$\begin{array}{llllllllllllllllllllll}1 & 10 & 7 & 15 & 49 & 53 & 35 & 34 & 20 & 14 & 9 & 14 & 21 & 18 & 10 & 7 & 12 & 10 & 7 & 9 & 7 & 3\end{array}$

$\begin{array}{rrrrrrrrrrrrrrrrrrrrrrrrrrr}1 & 2 & 3 & 7 & 13 & 63 & 75 & 23 & 15 & 23 & 17 & 9 & 9 & 7 & 2 & 7 & 5 & 8 & 13 & 6 & 11 & 10 & 12 & 14 & 11\end{array}$

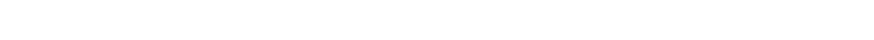

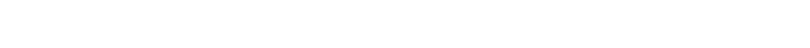

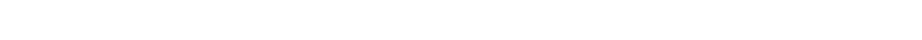

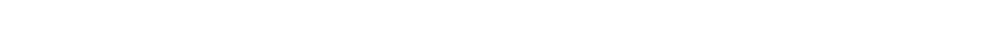

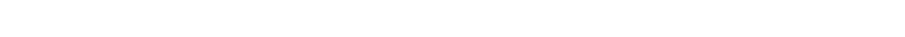

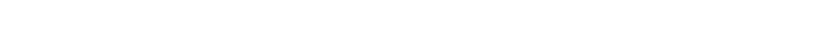

$\begin{array}{lllllllllllllllllll}2 & 3 & 30 & 35 & 45 & 62 & 55 & 13 & 18 & 21 & 19 & 11 & 9 & 9 & 5 & 7 & 4 & 12 & 5\end{array}$

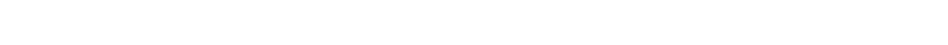

3633010.0

3150055.0

3198840.0

1928890.0

2042744.0

2209710.0

2634245.0

2903260.0

3258954.0

2296154.0

1205598.0

2431343.0

1776981.0

658706.0

1436756.0

2090772.0

2083966.0

2393274.0

17243290

1724329.0

2138858.0

2515812.0

2152590.0

2259130.0

2096850.0

1748700.0

2764370.0

2091130.0

2468730.0

2779397.0

2380580.0

3447270.0

1711600.0

1320060.0

1431336.0

2045186.0

2773028.0

2251700.0

389130.0

521866.0

1021528.0

2938440.0 
GREEN RIVER BASIN

09315000 GREEN RIVER AT GREEN RIVER, UT--Continued

DURATION TABLE OF DISQHARGE FOR WATER YEARS 1895-99, $1906-62$

\begin{tabular}{|c|c|c|c|c|}
\hline ASS & $\begin{array}{c}\text { OBBIC } \\
\text { FEET } \\
\text { PER } \\
\text { SEODND }\end{array}$ & TOTAL, & $\begin{array}{c}\text { ACOH- } \\
\text { MU- } \\
\text { LATED } \\
\text { LAYS }\end{array}$ & $\begin{array}{l}\text { PER- } \\
\text { CENT } \\
\text { DAYYS }\end{array}$ \\
\hline STSS & & DAYS & DAYS & DAYS \\
\hline $\begin{array}{l}0 \\
1 \\
2 \\
3 \\
4 \\
5 \\
6 \\
7 \\
8\end{array}$ & $\begin{array}{r}0.00 \\
380.00 \\
440.00 \\
520.00 \\
610.00 \\
710.00 \\
830.00 \\
970.00 \\
1100.00\end{array}$ & $\begin{array}{r}0 \\
7 \\
24 \\
48 \\
71 \\
142 \\
229 \\
431 \\
828\end{array}$ & $\begin{array}{l}22645 \\
22645 \\
22638 \\
22614 \\
22566 \\
22495 \\
22353 \\
22124 \\
21693\end{array}$ & $\begin{array}{r}100.0 \\
100.0 \\
100.0 \\
99.9 \\
99.7 \\
99.3 \\
98.7 \\
97.7 \\
95.8\end{array}$ \\
\hline
\end{tabular}

\begin{tabular}{lccccc} 
OBIC & ACOJ- & \multicolumn{3}{c}{ OUBIC } & ACOU- \\
FEET & MU- & PER- & FEET & MU- & PER- \\
PER TOTAL LATED & CENT & PER TOTAL LATED & CENT
\end{tabular} CLASS SECOND DAYS DAYS DAYS CLASS SECOND DAYS DAYS DAYS

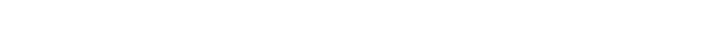

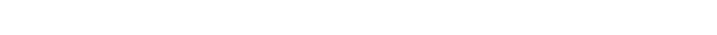
$\begin{array}{llllllllll}11 & 1800.00 & 2096 & 17791 & 78.6 & 20 & 7400.0 & 618 & 5665 & 25.0\end{array}$

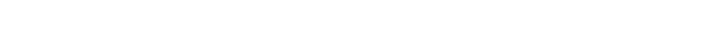

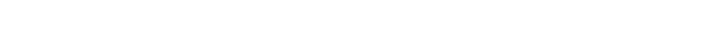
$\begin{array}{lllllllll}14 & 2900.001565 & 11839 & 52.3 & 23 & 12000.0 & 658 & 3780 & 16.7\end{array}$

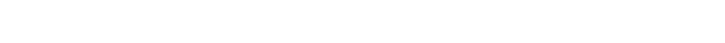

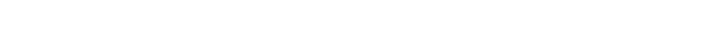

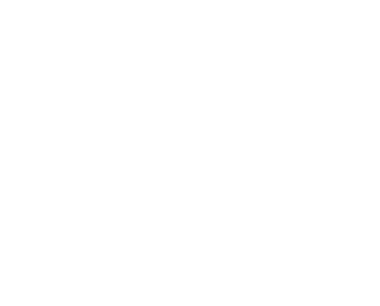

MONIHLY MEAN DISCHARGES, IN OBIC FEET PER SECOND, FOR EACH WATER YEAR

\begin{tabular}{|c|c|c|c|c|c|c|c|c|c|c|c|c|}
\hline YEAR & OCT & $\mathrm{NON}$ & $\mathrm{DEC}$ & JAN & FEB & MAR & APR & MAY & JUNE & JULY & AUG & SEP \\
\hline 1895 & 3250 & 2934 & 2237 & 2168 & 2136 & 3776 & 8276 & 21410 & 14610 & 9435 & 3343 & 1771 \\
\hline $\begin{array}{l}1896 \\
1897 \\
1898 \\
1899\end{array}$ & $\begin{array}{l}2024 \\
2109 \\
5262 \\
1505\end{array}$ & $\begin{array}{l}1586 \\
1725 \\
2941 \\
1376\end{array}$ & $\begin{array}{l}1305 \\
1300 \\
1398 \\
1297\end{array}$ & $\begin{array}{l}1332 \\
1000 \\
1000 \\
1597\end{array}$ & $\begin{array}{l}1385 \\
1200 \\
1050 \\
1721\end{array}$ & $\begin{array}{l}2462 \\
2000 \\
2576 \\
2797\end{array}$ & $\begin{array}{l}4843 \\
6434 \\
7699 \\
5618\end{array}$ & $\begin{array}{l}12640 \\
40990 \\
13390 \\
15480\end{array}$ & $\begin{array}{l}26340 \\
24800 \\
17020 \\
32440\end{array}$ & $\begin{array}{r}6721 \\
6126 \\
8030 \\
20980\end{array}$ & $\begin{array}{l}3237 \\
3256 \\
2251 \\
8185\end{array}$ & $\begin{array}{l}3062 \\
3232 \\
1745 \\
2858\end{array}$ \\
\hline 1905 & 2100 & 1600 & 1400 & 1300 & 1526 & 2988 & 4073 & 12940 & 24290 & 7641 & 2727 & 2507 \\
\hline $\begin{array}{l}1906 \\
1907 \\
1908 \\
1909 \\
1910\end{array}$ & $\begin{array}{l}2479 \\
3024 \\
3671 \\
3585 \\
3933\end{array}$ & $\begin{array}{l}2053 \\
3258 \\
2565 \\
2159 \\
2981\end{array}$ & $\begin{array}{r}1318 \\
2430 \\
1468 \\
801 \\
1291\end{array}$ & $\begin{array}{l}1400 \\
2440 \\
1300 \\
1979 \\
1000\end{array}$ & $\begin{array}{l}1616 \\
3794 \\
1534 \\
1717 \\
2501\end{array}$ & $\begin{array}{r}6106 \\
6755 \\
3573 \\
8124 \\
11430\end{array}$ & $\begin{array}{r}9579 \\
13980 \\
6580 \\
9292 \\
12520\end{array}$ & $\begin{array}{l}24780 \\
24670 \\
11640 \\
22410 \\
21230\end{array}$ & $\begin{array}{l}28500 \\
38840 \\
18070 \\
46310 \\
13660\end{array}$ & $\begin{array}{r}13430 \\
31630 \\
10260 \\
25230 \\
3228\end{array}$ & $\begin{array}{r}6173 \\
11220 \\
6814 \\
10280 \\
2158\end{array}$ & $\begin{array}{l}5079 \\
4822 \\
3381 \\
9960 \\
2036\end{array}$ \\
\hline $\begin{array}{l}1911 \\
1912 \\
1913 \\
1914 \\
1915\end{array}$ & $\begin{array}{l}3275 \\
3803 \\
3655 \\
3565 \\
3958\end{array}$ & $\begin{array}{l}2274 \\
2245 \\
3506 \\
3253 \\
2723\end{array}$ & $\begin{array}{l}1516 \\
1643 \\
1524 \\
1679 \\
1531\end{array}$ & $\begin{array}{l}2331 \\
1721 \\
2303 \\
1950 \\
1500\end{array}$ & $\begin{array}{l}3441 \\
1798 \\
2229 \\
2640 \\
1766\end{array}$ & $\begin{array}{l}6283 \\
3689 \\
4156 \\
6432 \\
3035\end{array}$ & $\begin{array}{r}5481 \\
6551 \\
12810 \\
12590 \\
7439\end{array}$ & $\begin{array}{l}11730 \\
16090 \\
16500 \\
28520 \\
10990\end{array}$ & $\begin{array}{l}19380 \\
37630 \\
19430 \\
35680 \\
15610\end{array}$ & $\begin{array}{r}8456 \\
16270 \\
14730 \\
13630 \\
6159\end{array}$ & $\begin{array}{l}2926 \\
6864 \\
4330 \\
4617 \\
2075\end{array}$ & $\begin{array}{l}1975 \\
3624 \\
3831 \\
2625 \\
3118\end{array}$ \\
\hline $\begin{array}{l}1916 \\
1917 \\
1918 \\
1919 \\
1920\end{array}$ & $\begin{array}{l}3937 \\
4994 \\
3256 \\
3685 \\
1994\end{array}$ & $\begin{array}{l}2834 \\
2565 \\
3096 \\
3013 \\
2102\end{array}$ & $\begin{array}{l}1879 \\
2055 \\
2723 \\
2116 \\
1473\end{array}$ & $\begin{array}{l}1715 \\
1294 \\
2352 \\
1420 \\
1748\end{array}$ & $\begin{array}{l}2238 \\
2089 \\
2450 \\
1750 \\
2431\end{array}$ & $\begin{array}{l}9075 \\
3351 \\
4082 \\
4496 \\
3965\end{array}$ & $\begin{array}{r}10520 \\
11930 \\
6475 \\
7975 \\
6534\end{array}$ & $\begin{array}{l}20960 \\
26220 \\
13770 \\
14850 \\
26720\end{array}$ & $\begin{array}{r}23000 \\
46300 \\
29050 \\
9286 \\
34060\end{array}$ & $\begin{array}{r}10340 \\
27990 \\
11480 \\
1755 \\
10220\end{array}$ & $\begin{array}{l}5748 \\
6655 \\
3276 \\
1203 \\
4534\end{array}$ & $\begin{array}{l}2571 \\
4011 \\
2572 \\
1788 \\
2537\end{array}$ \\
\hline $\begin{array}{l}1921 \\
1922 \\
1923 \\
1924 \\
1925\end{array}$ & $\begin{array}{l}2607 \\
2346 \\
2062 \\
3887 \\
1708\end{array}$ & $\begin{array}{l}3313 \\
2463 \\
2587 \\
3382 \\
2052\end{array}$ & $\begin{array}{l}1896 \\
2179 \\
2132 \\
2066 \\
1179\end{array}$ & $\begin{array}{l}1971 \\
1754 \\
2198 \\
1444 \\
1452\end{array}$ & $\begin{array}{l}3042 \\
2474 \\
2119 \\
2868 \\
2332\end{array}$ & $\begin{array}{l}7669 \\
6421 \\
3673 \\
3306 \\
4475\end{array}$ & $\begin{array}{r}7450 \\
6046 \\
11470 \\
11310 \\
7887\end{array}$ & $\begin{array}{l}25160 \\
26770 \\
25830 \\
15880 \\
13690\end{array}$ & $\begin{array}{l}46650 \\
37420 \\
30850 \\
12590 \\
14100\end{array}$ & $\begin{array}{r}10750 \\
8595 \\
12940 \\
3627 \\
9268\end{array}$ & $\begin{array}{l}5502 \\
4071 \\
5783 \\
1473 \\
4372\end{array}$ & $\begin{array}{l}3435 \\
2885 \\
3303 \\
1499 \\
4529\end{array}$ \\
\hline $\begin{array}{l}1926 \\
1927 \\
1928 \\
1929 \\
1930\end{array}$ & $\begin{array}{l}4847 \\
1924 \\
4935 \\
3567 \\
4157\end{array}$ & $\begin{array}{l}3222 \\
1729 \\
4320 \\
2849 \\
2792\end{array}$ & $\begin{array}{l}2373 \\
1685 \\
2335 \\
1586 \\
2137\end{array}$ & $\begin{array}{l}1897 \\
1656 \\
2802 \\
2007 \\
1253\end{array}$ & $\begin{array}{l}2275 \\
1996 \\
2725 \\
1971 \\
4164\end{array}$ & $\begin{array}{l}5602 \\
3545 \\
6432 \\
7858 \\
3982\end{array}$ & $\begin{array}{r}10270 \\
6466 \\
6637 \\
12240 \\
10250\end{array}$ & $\begin{array}{l}18240 \\
20750 \\
30560 \\
25060 \\
11830\end{array}$ & $\begin{array}{l}13120 \\
22070 \\
21160 \\
28270 \\
17480\end{array}$ & $\begin{array}{r}5766 \\
12330 \\
7240 \\
10400 \\
5513\end{array}$ & $\begin{array}{l}3228 \\
3755 \\
3693 \\
4769 \\
8228\end{array}$ & $\begin{array}{l}1575 \\
8515 \\
2095 \\
6346 \\
3795\end{array}$ \\
\hline $\begin{array}{l}1931 \\
1932 \\
1933 \\
1934 \\
1935\end{array}$ & $\begin{array}{r}3926 \\
1485 \\
1898 \\
1232 \\
718\end{array}$ & $\begin{array}{r}2481 \\
1498 \\
2275 \\
1486 \\
935\end{array}$ & $\begin{array}{r}1863 \\
869 \\
1265 \\
1392 \\
928\end{array}$ & $\begin{array}{l}1532 \\
1288 \\
1455 \\
1625 \\
1112\end{array}$ & $\begin{array}{l}1943 \\
1589 \\
1678 \\
2149 \\
1509\end{array}$ & $\begin{array}{l}3506 \\
4127 \\
3095 \\
2155 \\
1893\end{array}$ & $\begin{array}{l}4983 \\
8255 \\
4505 \\
2927 \\
2892\end{array}$ & $\begin{array}{r}7783 \\
22531 \\
10770 \\
4632 \\
7431\end{array}$ & $\begin{array}{r}7447 \\
20930 \\
23030 \\
2128 \\
21240\end{array}$ & $\begin{array}{r}1693 \\
10910 \\
5426 \\
645 \\
5394\end{array}$ & $\begin{array}{r}1489 \\
3864 \\
1742 \\
712 \\
2020\end{array}$ & $\begin{array}{r}943 \\
2254 \\
1345 \\
603 \\
1273\end{array}$ \\
\hline $\begin{array}{l}1936 \\
1937 \\
1938 \\
1939 \\
1940\end{array}$ & $\begin{array}{r}959 \\
1922 \\
1987 \\
3809 \\
2052\end{array}$ & $\begin{array}{l}1393 \\
2194 \\
2090 \\
2875 \\
1650\end{array}$ & $\begin{array}{r}987 \\
1317 \\
1953 \\
2499 \\
1442\end{array}$ & $\begin{array}{l}1084 \\
1000 \\
1643 \\
2083 \\
1327\end{array}$ & $\begin{array}{l}1576 \\
1700 \\
2254 \\
1864 \\
1679\end{array}$ & $\begin{array}{l}2288 \\
4575 \\
4277 \\
6343 \\
3232\end{array}$ & $\begin{array}{l}7520 \\
7583 \\
7862 \\
7499 \\
4260\end{array}$ & $\begin{array}{l}21370 \\
18810 \\
18250 \\
14350 \\
11440\end{array}$ & $\begin{array}{r}17660 \\
15100 \\
22600 \\
8804 \\
8272\end{array}$ & $\begin{array}{l}6181 \\
8995 \\
7910 \\
2639 \\
1736\end{array}$ & $\begin{array}{r}5160 \\
2594 \\
2821 \\
1609 \\
805\end{array}$ & $\begin{array}{l}2291 \\
2475 \\
4982 \\
2120 \\
1361\end{array}$ \\
\hline $\begin{array}{l}1941 \\
1942 \\
1943 \\
1944 \\
1945\end{array}$ & $\begin{array}{l}2464 \\
5169 \\
1913 \\
2015 \\
1867\end{array}$ & $\begin{array}{l}1903 \\
4029 \\
2077 \\
2452 \\
2001\end{array}$ & $\begin{array}{l}1556 \\
2736 \\
1895 \\
1823 \\
1438\end{array}$ & $\begin{array}{l}1630 \\
1823 \\
1816 \\
1367 \\
1770\end{array}$ & $\begin{array}{l}2270 \\
2206 \\
2336 \\
1936 \\
2303\end{array}$ & $\begin{array}{l}3514 \\
4299 \\
3835 \\
4105 \\
3014\end{array}$ & $\begin{array}{r}5268 \\
14410 \\
9568 \\
8885 \\
4889\end{array}$ & $\begin{array}{l}19060 \\
15930 \\
12410 \\
15030 \\
14780\end{array}$ & $\begin{array}{l}19260 \\
21350 \\
18050 \\
23380 \\
17070\end{array}$ & $\begin{array}{r}5830 \\
6744 \\
9955 \\
9617 \\
11400\end{array}$ & $\begin{array}{l}4350 \\
2473 \\
4880 \\
2323 \\
5455\end{array}$ & $\begin{array}{l}3057 \\
1524 \\
1951 \\
1224 \\
2734\end{array}$ \\
\hline $\begin{array}{l}1946 \\
1947 \\
1948 \\
1949 \\
1950\end{array}$ & $\begin{array}{l}2620 \\
2420 \\
2943 \\
1500 \\
3362\end{array}$ & $\begin{array}{l}2504 \\
282 \\
3006 \\
1740 \\
3201\end{array}$ & $\begin{array}{l}1835 \\
2504 \\
2478 \\
1577 \\
2079\end{array}$ & $\begin{array}{l}2000 \\
1487 \\
2291 \\
1633 \\
2290\end{array}$ & $\begin{array}{l}2105 \\
2718 \\
2373 \\
1977 \\
2680\end{array}$ & $\begin{array}{l}3833 \\
6687 \\
5097 \\
4495 \\
5795\end{array}$ & $\begin{array}{r}8876 \\
7090 \\
9374 \\
7963 \\
10420\end{array}$ & $\begin{array}{l}12610 \\
22770 \\
17250 \\
19860 \\
16690\end{array}$ & $\begin{array}{l}12540 \\
22650 \\
16000 \\
25990 \\
26330\end{array}$ & $\begin{array}{r}4288 \\
10670 \\
4358 \\
9630 \\
11940\end{array}$ & $\begin{array}{l}2472 \\
5942 \\
2230 \\
2798 \\
3998\end{array}$ & $\begin{array}{l}1759 \\
2787 \\
1159 \\
1872 \\
2503\end{array}$ \\
\hline $\begin{array}{l}1951 \\
1952 \\
1953 \\
1954 \\
1955\end{array}$ & $\begin{array}{l}2492 \\
3423 \\
2096 \\
1403 \\
2254\end{array}$ & $\begin{array}{l}2792 \\
2755 \\
2059 \\
2107 \\
2015\end{array}$ & $\begin{array}{l}2779 \\
2144 \\
2096 \\
1743 \\
1295\end{array}$ & $\begin{array}{l}1843 \\
2187 \\
2272 \\
1745 \\
1296\end{array}$ & $\begin{array}{l}3011 \\
2440 \\
2542 \\
2487 \\
1556\end{array}$ & $\begin{array}{l}3326 \\
2601 \\
3525 \\
2752 \\
3862\end{array}$ & $\begin{array}{r}6247 \\
16600 \\
3712 \\
4537 \\
5226\end{array}$ & $\begin{array}{r}14350 \\
33940 \\
7382 \\
10400 \\
11020\end{array}$ & $\begin{array}{r}22000 \\
30400 \\
19610 \\
6316 \\
11000\end{array}$ & $\begin{array}{r}10200 \\
8365 \\
6120 \\
5623 \\
3620\end{array}$ & $\begin{array}{l}6158 \\
5125 \\
3442 \\
1946 \\
2616\end{array}$ & $\begin{array}{l}2986 \\
3096 \\
1468 \\
2253 \\
1188\end{array}$ \\
\hline
\end{tabular}


GREEN RIVER BASIN

09315000 GREEN RIVER AT GREEN RIVER, UT--Continued

MONTHLY MEAN DISGAARGS, IN OBBIC FEET PER SECOND, FOR EAOH WATER YEAR--Continued

\begin{tabular}{|c|c|c|c|c|c|c|c|c|c|c|c|c|}
\hline YEAR & OCT & $\mathrm{NOV}$ & DEC & JAN & FEB & MAR & APR & MAY & JUNE & JULY & AUG & SEP \\
\hline $\begin{array}{l}1956 \\
1957 \\
1958 \\
1959 \\
1960\end{array}$ & $\begin{array}{l}1255 \\
1243 \\
3006 \\
1481 \\
2898\end{array}$ & $\begin{array}{l}1450 \\
1666 \\
3834 \\
1714 \\
2552\end{array}$ & $\begin{array}{l}2065 \\
1292 \\
2422 \\
1858 \\
1728\end{array}$ & $\begin{array}{l}2514 \\
1354 \\
2076 \\
1579 \\
1547\end{array}$ & $\begin{array}{l}1736 \\
1801 \\
3306 \\
2044 \\
1769\end{array}$ & $\begin{array}{l}5110 \\
3846 \\
4005 \\
2379 \\
5210\end{array}$ & $\begin{array}{l}7731 \\
4878 \\
7263 \\
3678 \\
8968\end{array}$ & $\begin{array}{r}16180 \\
14840 \\
21320 \\
7812 \\
8962\end{array}$ & $\begin{array}{l}20290 \\
31440 \\
19730 \\
12820 \\
11470\end{array}$ & $\begin{array}{r}4777 \\
18930 \\
3643 \\
5627 \\
2768\end{array}$ & $\begin{array}{l}2750 \\
6283 \\
1792 \\
2920 \\
1121\end{array}$ & $\begin{array}{r}1217 \\
3391 \\
1609 \\
1743 \\
987\end{array}$ \\
\hline $\begin{array}{l}1961 \\
1962\end{array}$ & $\begin{array}{l}1565 \\
3809\end{array}$ & $\begin{array}{l}1768 \\
2700\end{array}$ & $\begin{array}{l}1307 \\
2044\end{array}$ & $\begin{array}{l}1292 \\
1861\end{array}$ & $\begin{array}{l}1693 \\
7258\end{array}$ & $\begin{array}{l}2221 \\
6521\end{array}$ & $\begin{array}{r}3098 \\
18370\end{array}$ & $\begin{array}{r}5555 \\
21950\end{array}$ & $\begin{array}{r}9110 \\
18050\end{array}$ & $\begin{array}{l}1815 \\
9725\end{array}$ & $\begin{array}{l}1293 \\
2871\end{array}$ & $\begin{array}{l}2946 \\
1647\end{array}$ \\
\hline
\end{tabular}

ANNJAL PEAK DISCHARGE, IN OBIC FEET PER SECOND, AND CORRESPONDING GAGE HEIGHT, IN FEET, FOR EAOH WATER YEAR

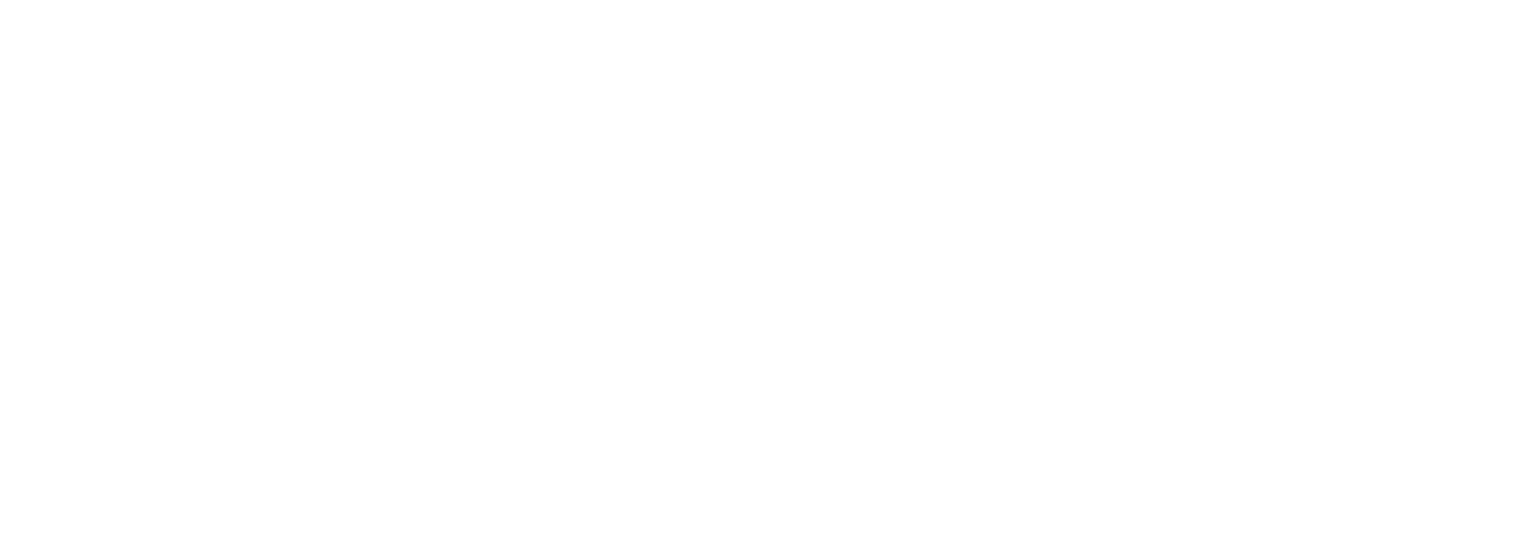

\begin{tabular}{|c|c|c|c|c|c|c|c|c|c|c|c|c|c|}
\hline \multicolumn{7}{|c|}{$\begin{array}{l}\text { MAGNITUDE AND PROBABILITY OF ANNUAL LOWEST MEAN DISCHARGE } \\
\text { BASED ON CIMATIC YEARS } 1896-99 \text { AND } 1906-62\end{array}$} & \multicolumn{7}{|c|}{$\begin{array}{l}\text { MAGNITUDE AND PROBABILITY OF ANNUAL HIGHEST MEAN DISCHARGE } \\
\text { BASED ON WATER YEARS } 1895-99 \text { AND } 1906-62\end{array}$} \\
\hline $\begin{array}{l}\text { ERIOD } \\
\text { CON- }\end{array}$ & \multicolumn{6}{|c|}{$\begin{array}{l}\text { DISCHARGE, IN OUBIC FEET PER SEOOND, FOR } \\
\text { INDICATED RECIRRENCE INTERVAL, IN YEARS, AND } \\
\text { ANNUAL NON-EXCEEDANCE PRCBABILITY, IN PERCENT }\end{array}$} & \multicolumn{7}{|c|}{$\begin{array}{l}\text { DISCHARGE, IN CUBIC FEET PER SECOND, FOR } \\
\text { INDICATED RECURRENCE INTERNA, IN YEARS, AND } \\
\text { ANNUAL EXCEEDANCE PROBAIILITY, IN PERCENT }\end{array}$} \\
\hline $\begin{array}{l}\text { IVE } \\
\text { AYS ) }\end{array}$ & $\begin{array}{c}2 \\
508\end{array}$ & $\begin{array}{c}5 \\
208\end{array}$ & $\begin{array}{l}10 \\
108\end{array}$ & $\begin{array}{l}20 \\
58\end{array}$ & $\begin{array}{l}50 \\
28\end{array}$ & $\begin{array}{r}100 \\
18\end{array}$ & $\begin{array}{l}\text { TIVE } \\
\text { DAYS ) }\end{array}$ & $\begin{array}{c}2 \\
508\end{array}$ & $\begin{array}{c}5 \\
208\end{array}$ & $\begin{array}{l}10 \\
108\end{array}$ & $\begin{array}{l}25 \\
48\end{array}$ & $\begin{array}{l}50 \\
28\end{array}$ & $\begin{array}{r}100 \\
18\end{array}$ \\
\hline $\begin{array}{r}1 \\
7 \\
14 \\
30 \\
60 \\
90\end{array}$ & $\begin{array}{r}967 \\
1120 \\
1230 \\
1370 \\
1550 \\
1740\end{array}$ & $\begin{array}{r}720 \\
864 \\
954 \\
1060 \\
1220 \\
1380\end{array}$ & $\begin{array}{r}601 \\
735 \\
822 \\
907 \\
1060 \\
1190\end{array}$ & $\begin{array}{r}510 \\
635 \\
720 \\
792 \\
933 \\
1040\end{array}$ & $\begin{array}{l}418 \\
530 \\
615 \\
673 \\
805 \\
887\end{array}$ & $\begin{array}{l}362 \\
465 \\
550 \\
601 \\
726 \\
790\end{array}$ & $\begin{array}{r}1 \\
3 \\
7 \\
15\end{array}$ & $\begin{array}{l}30600 \\
30100 \\
29000 \\
26800\end{array}$ & $\begin{array}{l}42900 \\
42300 \\
40800 \\
37600\end{array}$ & $\begin{array}{l}50100 \\
49300 \\
47600 \\
43800\end{array}$ & $\begin{array}{l}58000 \\
57000 \\
55000 \\
50600\end{array}$ & $\begin{array}{l}63200 \\
62000 \\
59900 \\
55000\end{array}$ & $\begin{array}{l}67900 \\
66600 \\
64200 \\
58900\end{array}$ \\
\hline
\end{tabular}

DATA BELOW BASED ON PERIOD OF RECORD AFTER COMFLETTON OF FLAMING GORGE RESERVOIR

LONEST MEAN DISOHARGE, IN OUBIC FEET PER SECOND, AND RANKING FOR THE INDICATED NUMBER OF CONSECUTIVE DAYS FEET PER SECOND, AND RANKING FOR THE IND
FOR EACH OIMATIC YEAR, APRI 1-MARCH 31

YEAR

3

14

$\begin{array}{ll}\text { CONSEUTIVE DAYS } \\ 30 & 60\end{array}$

90

120

183

ALL

\begin{tabular}{|c|c|c|c|c|c|c|c|c|c|c|c|c|c|c|c|c|c|c|c|}
\hline $\begin{array}{l}1966 \\
1967 \\
1968 \\
1969 \\
1970\end{array}$ & $\begin{array}{l}1920 \\
1450 \\
2260 \\
1640 \\
2180\end{array}$ & $\begin{array}{r}11 \\
2 \\
15 \\
5 \\
14\end{array}$ & $\begin{array}{l}2040 \\
1620 \\
2480 \\
1800 \\
2280\end{array}$ & $\begin{array}{r}10 \\
2 \\
14 \\
7 \\
12\end{array}$ & $\begin{array}{l}2210 \\
1960 \\
2710 \\
2490 \\
2330\end{array}$ & $\begin{array}{r}9 \\
7 \\
14 \\
12 \\
11\end{array}$ & $\begin{array}{l}2520 \\
2040 \\
3060 \\
3050 \\
2630\end{array}$ & $\begin{array}{r}10 \\
6 \\
15 \\
14 \\
11\end{array}$ & $\begin{array}{l}2800 \\
2220 \\
3170 \\
3320 \\
2960\end{array}$ & $\begin{array}{r}10 \\
5 \\
14 \\
16 \\
12\end{array}$ & $\begin{array}{l}2910 \\
2320 \\
3680 \\
3540 \\
3130\end{array}$ & $\begin{array}{r}9 \\
3 \\
16 \\
15 \\
11\end{array}$ & $\begin{array}{l}3250 \\
2420 \\
3700 \\
3600 \\
3130\end{array}$ & $\begin{array}{r}11 \\
2 \\
16 \\
15 \\
10\end{array}$ & $\begin{array}{l}3510 \\
2590 \\
3780 \\
3650 \\
3460\end{array}$ & $\begin{array}{r}11 \\
3 \\
16 \\
15 \\
10\end{array}$ & $\begin{array}{l}3540 \\
2570 \\
3850 \\
4120 \\
3670\end{array}$ & $\begin{array}{r}9 \\
2 \\
14 \\
16 \\
10\end{array}$ & $\begin{array}{l}6890 \\
3930 \\
5910 \\
6700 \\
6400\end{array}$ \\
\hline $\begin{array}{l}971 \\
972 \\
973 \\
974 \\
975\end{array}$ & $\begin{array}{l}1770 \\
2270 \\
1610 \\
2030 \\
1540\end{array}$ & $\begin{array}{r}9 \\
16 \\
4 \\
12 \\
3\end{array}$ & $\begin{array}{l}1790 \\
2510 \\
1640 \\
2510 \\
1720\end{array}$ & $\begin{array}{r}6 \\
15 \\
3 \\
16 \\
4\end{array}$ & $\begin{array}{l}1790 \\
2940 \\
1750 \\
2580 \\
2040\end{array}$ & $\begin{array}{r}3 \\
16 \\
2 \\
13 \\
8\end{array}$ & $\begin{array}{l}1830 \\
3100 \\
1850 \\
2660 \\
2430\end{array}$ & $\begin{array}{r}2 \\
16 \\
3 \\
12 \\
9\end{array}$ & $\begin{array}{l}2060 \\
3190 \\
2080 \\
2680 \\
2830\end{array}$ & $\begin{array}{r}2 \\
15 \\
3 \\
9 \\
11\end{array}$ & $\begin{array}{l}2370 \\
3360 \\
2650 \\
3190 \\
2940\end{array}$ & $\begin{array}{r}4 \\
14 \\
7 \\
13 \\
10\end{array}$ & $\begin{array}{l}2460 \\
3380 \\
2970 \\
3370 \\
3080\end{array}$ & $\begin{array}{r}4 \\
14 \\
8 \\
13 \\
9\end{array}$ & $\begin{array}{l}2570 \\
3550 \\
3520 \\
3620 \\
3390\end{array}$ & $\begin{array}{r}2 \\
13 \\
12 \\
14 \\
9\end{array}$ & $\begin{array}{l}2670 \\
3830 \\
4050 \\
3700 \\
3460\end{array}$ & $\begin{array}{r}3 \\
13 \\
15 \\
12 \\
7\end{array}$ & $\begin{array}{l}5450 \\
6470 \\
5740 \\
6910 \\
6200\end{array}$ \\
\hline $\begin{array}{l}1976 \\
1977 \\
1978 \\
1979 \\
1980\end{array}$ & $\begin{array}{l}2040 \\
1920 \\
1070 \\
1670 \\
1690\end{array}$ & $\begin{array}{r}13 \\
10 \\
1 \\
6 \\
7\end{array}$ & $\begin{array}{l}2080 \\
2290 \\
1200 \\
1830 \\
1780\end{array}$ & $\begin{array}{r}11 \\
13 \\
1 \\
9 \\
5\end{array}$ & $\begin{array}{l}2220 \\
2840 \\
1480 \\
1950 \\
1930\end{array}$ & $\begin{array}{c}10 \\
15 \\
1 \\
6 \\
5\end{array}$ & $\begin{array}{l}2390 \\
2910 \\
1740 \\
2030 \\
2170\end{array}$ & $\begin{array}{r}8 \\
13 \\
1 \\
4 \\
7\end{array}$ & $\begin{array}{l}2470 \\
3000 \\
1860 \\
2260 \\
2300\end{array}$ & $\begin{array}{r}8 \\
13 \\
1 \\
6 \\
7\end{array}$ & $\begin{array}{l}2680 \\
3170 \\
1900 \\
2310 \\
2470\end{array}$ & $\begin{array}{r}8 \\
12 \\
1 \\
2 \\
5\end{array}$ & $\begin{array}{l}2910 \\
3310 \\
1900 \\
2450 \\
2630\end{array}$ & $\begin{array}{r}7 \\
12 \\
1 \\
3 \\
6\end{array}$ & $\begin{array}{l}3310 \\
3380 \\
1950 \\
2620 \\
2670\end{array}$ & $\begin{array}{l}7 \\
8 \\
1 \\
4 \\
6\end{array}$ & $\begin{array}{l}3690 \\
3510 \\
2070 \\
2720 \\
2890\end{array}$ & $\begin{array}{r}11 \\
8 \\
1 \\
4 \\
6\end{array}$ & $\begin{array}{l}6850 \\
5230 \\
3070 \\
5700 \\
6130\end{array}$ \\
\hline & 1730 & 8 & 1820 & 8 & 1920 & 4 & 2040 & 5 & 2220 & 4 & 2490 & 6 & 2560 & 5 & 2630 & 5 & 2790 & 5 & 5610 \\
\hline
\end{tabular}


09315000 GREEN RIVER AT GREEN RIVER, UT--Continued

HIGHEST MEAN DISCHARGE, IN COBIC FEET PER SECOND, AND RANKING FOR THE INDICATED NUMBER OF CONSECUTIVE DAYS FOR EACH WATER YEAR, OCTCBER 1-SEPTEMBER 30

\begin{tabular}{|c|c|c|c|c|c|c|c|c|c|c|c|}
\hline 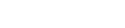 & 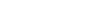 & 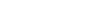 & 15 & 30 & 60 & 90 & 120 & & 183 & & ALI \\
\hline 196529800 & 229100 & 228300 & 225100 & 120500 & 417100 & 514700 & 312900 & & 10400 & 1 & 7090 \\
\hline $\begin{array}{ll}1966 & 13800 \\
1967 & 22300 \\
1968 & 28800 \\
1969 & 20500 \\
1970 & 23200\end{array}$ & $\begin{array}{rr}15 & 13400 \\
10 & 21700 \\
3 & 28700 \\
12 & 20300 \\
8 & 22800\end{array}$ & $\begin{array}{rl}15 & 12300 \\
11 & 20700 \\
3 & 27300 \\
12 & 19900 \\
9 & 21400\end{array}$ & $\begin{array}{rr}15 & 10500 \\
11 & 19500 \\
3 & 23900 \\
12 & 19500 \\
9 & 20600\end{array}$ & $\begin{array}{rr}16 & 9340 \\
11 & 19400 \\
5 & 21100 \\
12 & 18600 \\
7 & 19300\end{array}$ & $\begin{array}{rr}15 & 8060 \\
7 & 15500 \\
3 & 16700 \\
10 & 15100 \\
8 & 16300\end{array}$ & $\begin{array}{rr}15 & 7880 \\
9 & 12000 \\
6 & 13400 \\
11 & 13600 \\
7 & 12800\end{array}$ & $\begin{array}{rr}15 & 6980 \\
12 & 10000 \\
8 & 11400 \\
7 & 11800 \\
10 & 10700\end{array}$ & $\begin{array}{r}15 \\
12 \\
8 \\
5 \\
11\end{array}$ & $\begin{array}{l}5610 \\
8000 \\
8930 \\
9690 \\
8160\end{array}$ & $\begin{array}{r}15 \\
12 \\
7 \\
4 \\
11\end{array}$ & $\begin{array}{l}4440 \\
5520 \\
6410 \\
6800 \\
5900\end{array}$ \\
\hline $\begin{array}{ll}1971 & 21900 \\
1972 & 19700 \\
1973 & 30300 \\
1974 & 26800 \\
1975 & 27900\end{array}$ & $\begin{array}{rr}11 & 21800 \\
13 & 19500 \\
1 & 30100 \\
6 & 26400 \\
5 & 27100\end{array}$ & $\begin{array}{rr}10 & 21300 \\
13 & 18800 \\
1 & 28500 \\
6 & 24600 \\
5 & 24700\end{array}$ & $\begin{array}{rr}10 & 19600 \\
13 & 17800 \\
1 & 25000 \\
6 & 22300 \\
5 & 24100\end{array}$ & $\begin{array}{rr}10 & 17800 \\
13 & 15500 \\
2 & 22400 \\
6 & 20100 \\
3 & 21800\end{array}$ & $\begin{array}{rl}12 & 15100 \\
13 & 12200 \\
1 & 18800 \\
5 & 17500 \\
2 & 19500\end{array}$ & $\begin{array}{rl}12 & 13000 \\
13 & 10100 \\
2 & 15300 \\
3 & 13700 \\
1 & 15700\end{array}$ & $\begin{array}{rr}9 & 11200 \\
13 & 8800 \\
2 & 12800 \\
5 & 11600 \\
1 & 13100\end{array}$ & $\begin{array}{r}9 \\
13 \\
3 \\
6 \\
1\end{array}$ & $\begin{array}{r}8500 \\
7490 \\
10200 \\
8770 \\
9970\end{array}$ & $\begin{array}{r}9 \\
13 \\
2 \\
8 \\
3\end{array}$ & $\begin{array}{l}5600 \\
5510 \\
7440 \\
6170 \\
6830\end{array}$ \\
\hline $\begin{array}{lr}1976 & 18000 \\
1977 & 7600 \\
1978 & 23100 \\
1979 & 28800 \\
1980 & 23300\end{array}$ & $\begin{array}{rr}14 & 17100 \\
17 & 7370 \\
9 & 23000 \\
4 & 28400 \\
7 & 22900\end{array}$ & $\begin{array}{rr}14 & 16200 \\
17 & 6810 \\
7 & 22300 \\
4 & 27100 \\
8 & 21900\end{array}$ & $\begin{array}{rr}14 & 15100 \\
17 & 5890 \\
7 & 20300 \\
4 & 23900 \\
8 & 19600\end{array}$ & $\begin{array}{rr}14 & 14200 \\
17 & 5660 \\
8 & 18200 \\
4 & 20100 \\
9 & 19000\end{array}$ & $\begin{array}{rr}14 & 11800 \\
17 & 5450 \\
11 & 15200 \\
6 & 15800 \\
9 & 17100\end{array}$ & $\begin{array}{rr}14 & 9850 \\
17 & 5150 \\
10 & 12600 \\
8 & 13600 \\
4 & 14000\end{array}$ & $\begin{array}{rr}14 & 8490 \\
17 & 4930 \\
11 & 10900 \\
6 & 12200 \\
4 & 11400\end{array}$ & $\begin{array}{r}14 \\
17 \\
10 \\
4 \\
7\end{array}$ & $\begin{array}{l}7090 \\
4480 \\
8360 \\
9270 \\
9110\end{array}$ & $\begin{array}{r}14 \\
16 \\
10 \\
5 \\
6\end{array}$ & $\begin{array}{l}5320 \\
3800 \\
5220 \\
6040 \\
5950\end{array}$ \\
\hline
\end{tabular}

DURATION OF DISCHARGE FOR EACH WATER YEAR

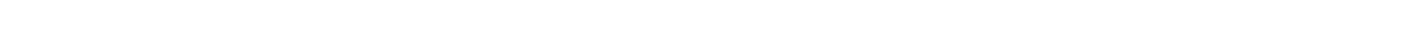
YEAR

NUMBER OF DAYS IN CLASS

OBIC FEET PER SECOND -DAYS

$\begin{array}{lllllllllllllllllllllllllllllllllllllll}1965 & 1 & 2 & 1 & 4 & 6 & 13 & 10 & 31 & 27 & 20 & 22 & 32 & 19 & 34 & 22 & 20 & 11 & 11 & 8 & 7 & 8 & 9 & 17 & 3 & 4 & 4 & 6 & 6 & 1 & 6 & 2588490.0\end{array}$

$\begin{array}{lllllllllllllllllllllllllllllllllll}1966 & 5 & 18 & 30 & 32 & 21 & 58 & 26 & 13 & 27 & 34 & 11 & 12 & 18 & 12 & 18 & 11 & 4 & 2 & 4 & 5 & 4 & & & & & \end{array}$

1967

1969

1970

$\begin{array}{llllllllllllllllllllllllllll}1 & 1 & 3 & 5 & 19 & 32 & 19 & 43 & 46 & 48 & 34 & 25 & 15 & 9 & 4 & 2 & 6 & 3 & 5 & 1 & 2 & 2 & 2 & 1 & 10 & 15 & 9 & 3\end{array}$

$\begin{array}{lllllllllllllllllllllllllllll}2 & 3 & 4 & 8 & 30 & 29 & 51 & 57 & 56 & 17 & 21 & 10 & 11 & 6 & 2 & 2 & 7 & 6 & 5 & 10 & 3 & 2 & 9 & 7 & 3 & 3 & 4 & \end{array}$ $\begin{array}{llllllllllllllllllllll}1 & 1 & 12 & 44 & 56 & 39 & 29 & 19 & 34 & 25 & 6 & 5 & 6 & 9 & 18 & 13 & 7 & 8 & 2 & 5 & 21 & 3\end{array}$

2344910.0

2151730.0

1971

1972

1973

1974
1975

1976

1977

1978

1980

1981

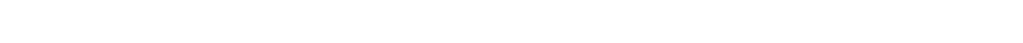

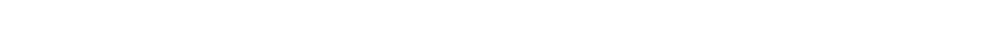$$
\begin{array}{lllllllllllllllllllllllllll}
5 & 5 & 2 & 8 & 8 & 10 & 45 & 76 & 39 & 48 & 27 & 13 & 13 & 3 & 1 & 4 & 7 & 9 & 4 & 3 & 8 & 9 & 5 & 12 & 4 & 2 & 2716580.0
\end{array}
$$$$
\begin{array}{rrrrrrrrrrrrrrrrrrrrrrrrrrrrr}
2 & 5 & 5 & 30 & 30 & 41 & 22 & 51 & 38 & 28 & 13 & 16 & 9 & 2 & 8 & 1 & 2 & 3 & 1 & 1 & 15 & 7 & 10 & 8 & 11 & 2 & 4 & & 2252650.0
\end{array}
$$$$
\begin{array}{lllllllllllllllllllllllllllllllllll}
1 & 1 & 3 & 1 & 7 & 4 & 12 & 44 & 31 & 39 & 57 & 44 & 14 & 16 & 6 & 5 & 6 & 6 & 2 & 2 & 2 & 1 & 9 & 4 & 9 & 12 & 14 & 7 & 3 & 3 & 24941 & 40.0
\end{array}
$$$$
\begin{array}{rllllllllllllll}
6 & 11 & 13 & 25 & 25 & 49 & 47 & 51 & 42 & 38 & 30 & 10 & 9 & 8 & 1
\end{array}
$$

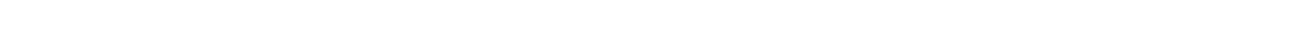$$
\begin{array}{rrrrrrrrrrrrrrrrrrrrrrrrrrrrrrr}
2 & 7 & 9 & 27 & 36 & 25 & 56 & 42 & 20 & 9 & 8 & 3 & 5 & 6 & 9 & 8 & 11 & 9 & 22 & 9 & 7 & 7 & 4 & 6 & 6 & 1 & 5 & 2 & 4 & 2204580.0 \\
6 & 6 & 9 & 35 & 31 & 51 & 37 & 28 & 21 & 20 & 17 & 5 & 8 & 8 & 3 & 2 & 5 & 6 & 1 & 5 & 7 & 11 & 8 & 15 & 6 & 10 & 5 & & & 2176600.0
\end{array}
$$$$
\begin{array}{llllllllllllllllllllll}
1 & 9 & 11 & 25 & 34 & 72 & 44 & 58 & 22 & 23 & 17 & 13 & 5 & 3 & 2 & 3 & 3 & 4 & 2 & 2 & 11 & 1
\end{array}
$$

1261090.0

DURATION TABLE OF DISCHARGE FOR WATER YEARS 1965-81

\begin{tabular}{|c|c|c|c|c|}
\hline & $\begin{array}{c}\text { CBBIC } \\
\text { FEET } \\
\text { PER }\end{array}$ & TOTAL & $\begin{array}{l}\text { ACOU- } \\
\text { MU- } \\
\text { LATED }\end{array}$ & $\begin{array}{l}\text { PER- } \\
\text { CENT }\end{array}$ \\
\hline ILASS & SECOND & DAYS & DAYS & DAYS \\
\hline $\begin{array}{l}0 \\
1 \\
2 \\
3 \\
4 \\
5 \\
5 \\
6 \\
7 \\
8 \\
8\end{array}$ & $\begin{array}{r}0.00 \\
1070.00 \\
1200.00 \\
1300.00 \\
1400.00 \\
1600.00 \\
1800.00 \\
2000.00 \\
2200.00\end{array}$ & $\begin{array}{r}0 \\
2 \\
0 \\
3 \\
5 \\
45 \\
132 \\
159 \\
234\end{array}$ & $\begin{array}{l}6209 \\
6209 \\
6207 \\
6207 \\
6204 \\
6199 \\
6154 \\
6022 \\
5863\end{array}$ & $\begin{array}{r}100.0 \\
100.0 \\
100.0 \\
100.0 \\
99.9 \\
99.8 \\
99.1 \\
97.0 \\
94.4\end{array}$ \\
\hline
\end{tabular}

\begin{tabular}{|c|c|c|c|}
\hline $\begin{array}{l}\text { CUBIC } \\
\text { FEET }\end{array}$ & & $\underset{\mathbf{M U}-}{\mathrm{ACOU}-}$ & PER- \\
\hline PER & TOTAL & LATED & CENT \\
\hline IASS SECOND & DAYS & DAYS & DAYS \\
\hline 2400.00 & 400 & 5629 & 90.7 \\
\hline & & 5229 & 84 \\
\hline 112900.00 & 671 & 4871 & 78.5 \\
\hline 123300.00 & 511 & 4200 & 67.6 \\
\hline 133600.00 & 547 & 3689 & 59.4 \\
\hline 144000.00 & 547 & 3142 & 50.6 \\
\hline 154400.00 & 53 & 2595 & 41.8 \\
\hline 00.0 & 28 & 2059 & 33.2 \\
\hline .00 & 285 & 1775 & 28.6 \\
\hline
\end{tabular}

(c)

\begin{tabular}{|c|c|c|c|}
\hline $\begin{array}{c}\text { GBIC } \\
\text { FEET } \\
\text { PER }\end{array}$ & TOTAL & $\begin{array}{l}\text { ACCU- } \\
\text { MU- } \\
\text { LATED }\end{array}$ & $\begin{array}{l}\text { PER- } \\
\text { CENT }\end{array}$ \\
\hline CLASS SECOND & DAYS & DAYS & DAYS \\
\hline $\begin{array}{ll}27 & 15000.0 \\
28 & 16000.0 \\
29 & 18000.0 \\
30 & 20000.0 \\
31 & 22000.0 \\
32 & 25000.0 \\
33 & 27000.0 \\
34 & 30000.0\end{array}$ & $\begin{array}{r}59 \\
108 \\
112 \\
90 \\
52 \\
13 \\
21 \\
2\end{array}$ & $\begin{array}{r}457 \\
398 \\
290 \\
178 \\
88 \\
36 \\
23 \\
2\end{array}$ & $\begin{array}{l}7.4 \\
6.4 \\
4.7 \\
2.9 \\
1.4 \\
0.6 \\
0.4 \\
0.0\end{array}$ \\
\hline
\end{tabular}


GREEN RIVER BASIN

09315000 GREEN RIVER AT GREEN RIVER, UT--Continued

MONTHLY MEAN DISCHARGES, IN OBIC EEET PER SECOND, FOR EAOH WATER YEAR

\begin{tabular}{|c|c|c|c|c|c|c|c|c|c|c|c|c|}
\hline YEAR & OCT & NOV & DEC & JAN & FEB & MAR & APR & MAY & JUNE & JULY & AUG & SEP \\
\hline 1965 & 3185 & 3365 & 4340 & 4883 & 5452 & 5878 & 8707 & 13310 & 20290 & 8879 & 3711 & 3173 \\
\hline $\begin{array}{l}1966 \\
1967 \\
1968 \\
1969 \\
1970\end{array}$ & $\begin{array}{l}4108 \\
3077 \\
4062 \\
3750 \\
4152\end{array}$ & $\begin{array}{l}4023 \\
2672 \\
4087 \\
3715 \\
3972\end{array}$ & $\begin{array}{l}4034 \\
2378 \\
3730 \\
3396 \\
4405\end{array}$ & $\begin{array}{l}2949 \\
3190 \\
4045 \\
4589 \\
3106\end{array}$ & $\begin{array}{l}2984 \\
3043 \\
3407 \\
5633 \\
3155\end{array}$ & $\begin{array}{l}6398 \\
4159 \\
3927 \\
5764 \\
3148\end{array}$ & $\begin{array}{r}6550 \\
4376 \\
4618 \\
11050 \\
4176\end{array}$ & $\begin{array}{r}9197 \\
8195 \\
11520 \\
17810 \\
14090\end{array}$ & $\begin{array}{r}5468 \\
19060 \\
20970 \\
11500 \\
17120\end{array}$ & $\begin{array}{l}2381 \\
8255 \\
6922 \\
5812 \\
6835\end{array}$ & $\begin{array}{l}2382 \\
4020 \\
5618 \\
4396 \\
3448\end{array}$ & $\begin{array}{l}2645 \\
3882 \\
4043 \\
4133 \\
3014\end{array}$ \\
\hline $\begin{array}{l}1971 \\
1972 \\
1973 \\
1974 \\
1975\end{array}$ & $\begin{array}{l}2836 \\
3433 \\
4919 \\
3755 \\
3720\end{array}$ & $\begin{array}{l}2675 \\
4413 \\
5722 \\
4292 \\
3916\end{array}$ & $\begin{array}{l}2354 \\
4344 \\
4508 \\
3881 \\
3331\end{array}$ & $\begin{array}{l}2512 \\
4426 \\
4297 \\
3757 \\
4160\end{array}$ & $\begin{array}{l}2969 \\
5264 \\
4779 \\
2706 \\
4654\end{array}$ & $\begin{array}{l}3280 \\
5246 \\
5562 \\
4881 \\
4056\end{array}$ & $\begin{array}{l}8053 \\
5439 \\
5092 \\
5991 \\
3768\end{array}$ & $\begin{array}{l}11620 \\
10330 \\
18990 \\
19170 \\
10610\end{array}$ & $\begin{array}{l}17820 \\
14010 \\
17970 \\
14990 \\
21060\end{array}$ & $\begin{array}{r}6456 \\
4009 \\
8469 \\
4370 \\
14610\end{array}$ & $\begin{array}{l}3204 \\
3277 \\
4933 \\
3129 \\
5173\end{array}$ & $\begin{array}{l}3521 \\
2076 \\
3908 \\
2909 \\
2872\end{array}$ \\
\hline $\begin{array}{l}1976 \\
1977 \\
1978 \\
1979 \\
1980\end{array}$ & $\begin{array}{l}2609 \\
3485 \\
1898 \\
2290 \\
2453\end{array}$ & $\begin{array}{l}3438 \\
3684 \\
1952 \\
3089 \\
3036\end{array}$ & $\begin{array}{l}4748 \\
3671 \\
1925 \\
2882 \\
2713\end{array}$ & $\begin{array}{l}4206 \\
3850 \\
2049 \\
2971 \\
3356\end{array}$ & $\begin{array}{l}4331 \\
3592 \\
2247 \\
3004 \\
5301\end{array}$ & $\begin{array}{l}4774 \\
4665 \\
4035 \\
5620 \\
4358\end{array}$ & $\begin{array}{l}5205 \\
4474 \\
6287 \\
8701 \\
5885\end{array}$ & $\begin{array}{r}12440 \\
5650 \\
11160 \\
15450 \\
16920\end{array}$ & $\begin{array}{r}11050 \\
4410 \\
18050 \\
15830 \\
17010\end{array}$ & $\begin{array}{l}4575 \\
2978 \\
7855 \\
6555 \\
5070\end{array}$ & $\begin{array}{l}3356 \\
2760 \\
2815 \\
3475 \\
2319\end{array}$ & $\begin{array}{l}3110 \\
2358 \\
2332 \\
2519 \\
3075\end{array}$ \\
\hline 1981 & 3036 & 3250 & 2836 & 2234 & 2829 & 2766 & 3593 & 5787 & 7697 & 2588 & 1975 & 2926 \\
\hline
\end{tabular}

ANNUAL PEAK DISCHARGE, IN CUBIC FEET PER SECOND, AND CORRFSPONDING GAGE HEIGHT, IN FEET, FOR EACH WATER YEAR

\begin{tabular}{|c|c|c|c|c|c|c|c|c|c|c|c|}
\hline $\begin{array}{l}\text { WATER } \\
\text { YEAR }\end{array}$ & DATE & $\begin{array}{c}\text { GAGE } \\
\text { HEIGHT }\end{array}$ & $\begin{array}{c}\text { PEAK } \\
\text { DISCHARGE }\end{array}$ & $\begin{array}{l}\text { WATER } \\
\text { YEAR }\end{array}$ & DATE & $\begin{array}{c}\text { GAGE } \\
\text { HEIGHT }\end{array}$ & $\begin{array}{c}\text { PEAK } \\
\text { DISCHARGE }\end{array}$ & $\begin{array}{l}\text { WATER } \\
\text { YEAR }\end{array}$ & DATE & $\begin{array}{c}\text { GAGE } \\
\text { HEIGHT }\end{array}$ & $\begin{array}{c}\text { PEAK } \\
\text { DISCHARGE }\end{array}$ \\
\hline 1963 & 15,1963 & 8.59 & ${ }^{1} 9450$ & 1970 & JUNE 12,1970 & 11.24 & 23600 & 1976 & 26,1976 & 10.15 & 18200 \\
\hline $\begin{array}{l}1964 \\
1965 \\
1966 \\
1967 \\
1968 \\
1969\end{array}$ & $\begin{array}{lll}\text { MAY } & 27, & 1964 \\
\text { JUNE } & 15,1 & 1965 \\
\text { MAR. } & 17,1966 \\
\text { MAY } & 30,1967 \\
\text { JUNE } 08,1968 \\
\text { MAY } 16,1969\end{array}$ & $\begin{array}{r}11.07 \\
12.60 \\
9.43 \\
11.14 \\
12.33 \\
10.68\end{array}$ & $\begin{array}{r}122300 \\
30000 \\
14400 \\
22600 \\
29480 \\
21020\end{array}$ & $\begin{array}{l}1971 \\
1972 \\
1973 \\
1974 \\
1975\end{array}$ & $\begin{array}{l}\text { JUNE } 21,1971 \\
\text { JUNE } 13,1972 \\
\text { MAY 24, } 1973 \\
\text { MAY 14, } 1974 \\
\text { JUNE 12, } 1975\end{array}$ & $\begin{array}{l}11.04 \\
10.52 \\
12.67 \\
11.99 \\
11.96\end{array}$ & $\begin{array}{l}22490 \\
20100 \\
30500 \\
27600 \\
28600\end{array}$ & $\begin{array}{l}1977 \\
1978 \\
1979 \\
1980 \\
1981\end{array}$ & $\begin{array}{ll}\text { JUNE } 10,1977 \\
\text { JUNE } 16,1978 \\
\text { MAY } 31,1979 \\
\text { MAY } 27,1980 \\
\text { JUNE } 08,1981\end{array}$ & $\begin{array}{r}8.02 \\
11.23 \\
11.95 \\
11.11 \\
8.88\end{array}$ & $\begin{array}{r}8680 \\
23600 \\
29200 \\
24200 \\
12300\end{array}$ \\
\hline
\end{tabular}

MAGNTTUDE AND PRCBABITITY OF ANNUAL IONEST MEAN DISCHARGE BASED ON OLIMATIC YEARS $1966-81$

\begin{tabular}{|c|c|c|c|c|c|c|}
\hline \multirow{3}{*}{$\begin{array}{l}\text { PERIOD } \\
\text { (CON- } \\
\text { SEQ- } \\
\text { TTVE } \\
\text { DAVS) }\end{array}$} & \multicolumn{6}{|c|}{$\begin{array}{l}\text { DISCHARGE, IN OUBIC FEET PER SECOND, FOR } \\
\text { INDICATED REQIRRENCE INTERNAL, IN YEARS, AND } \\
\text { ANNUAL NONEXOEEDANCE PROBAB ILITY, IN PERCENT }\end{array}$} \\
\hline & 2 & 5 & 10 & 20 & 50 & 100 \\
\hline & 508 & 208 & 108 & $5 \%$ & 28 & 18 \\
\hline 1 & 1830 & 1530 & 1370 & 1230 & -- & - \\
\hline 7 & 2160 & 1840 & 1690 & 1570 & $\ldots$ & - \\
\hline 14 & 2360 & 2000 & 1840 & 1710 & -- & - \\
\hline 30 & 2560 & 2190 & 2020 & 1880 & - & -- \\
\hline 60 & 2800 & 2390 & 2190 & 2030 & -- & - \\
\hline 90 & 2970 & 2520 & 2280 & 2090 & - & - \\
\hline
\end{tabular}

MAGNITUDE AND PROBABTITTY OF ANNUAL HTGHEST MEAN DISCHARGE BASED ON WATER YEARS $1965-81$

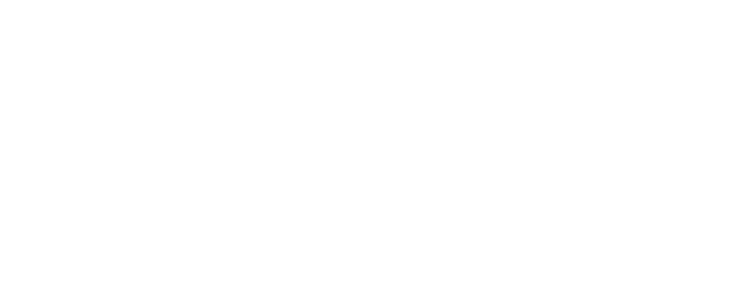

${ }^{I}$ Peak discharge occurred during filling period for Flaming Gorge Reservoir. 
LOCATION. $--39^{\circ} 07^{\prime} 40^{\prime \prime}$, long $110^{\circ} 20^{\prime} 00^{\prime \prime}$, in $\mathrm{NE}^{\frac{1}{4}} \sec 34, \mathrm{~T} .19$ S., R.14 E., Emery County, Hydrologic Unit 14060008 , on U.S. Highway 6 and $50,5.3 \mathrm{mi}$ south fram railroad underpass, and $10 \mathrm{mi}$ south of woodside.

DRAINAGE AREA.-- $10 \mathrm{mi}^{2}$.

MEAN BASIN ELEVATION. $--5,070 \mathrm{ft}$.

PERIOD OF RECORD AVAIABLE.--Water years 1959-71, 1973-74, annual peak discharge only.

GAGE.--Crest-stage gage. Altitude of gage is 4,650 ft from topographic map.

ANNUAL PEAK DISCHARGE, IN OBBIC FEET PER SECOND, AND CORRESPONDING GAGE HEIGHT, IN FEET, FOR EACH WATER YEAR

\begin{tabular}{|c|c|c|c|c|c|c|c|c|c|c|c|}
\hline $\begin{array}{l}\text { WATERR } \\
\text { YEAR }\end{array}$ & DATE & $\begin{array}{l}\text { GAGE } \\
\text { HEIGHT }\end{array}$ & $\begin{array}{c}\text { PEAK } \\
\text { DISCHARGE }\end{array}$ & $\begin{array}{l}\text { WATER } \\
\text { YEAR }\end{array}$ & DATE & $\begin{array}{l}\text { GAGE } \\
\text { HEIGHT }\end{array}$ & $\begin{array}{c}\text { PEAK } \\
\text { DISCHARGE }\end{array}$ & $\begin{array}{l}\text { WATER } \\
\text { YEAR }\end{array}$ & DATE & $\begin{array}{l}\text { GAGE } \\
\text { HEIGHT }\end{array}$ & $\begin{array}{c}\text { PEAR } \\
\text { DISCHARGE }\end{array}$ \\
\hline $\begin{array}{l}1959 \\
1960 \\
1961 \\
1962 \\
1963\end{array}$ & $\begin{array}{l}\text { AUG. } 24,1959 \\
\text { OCT. } 28,1959 \\
\text { SEPT. 08, } 1961 \\
\text { SEPT.21, } 1962 \\
\text { AJJG. 17, } 1963\end{array}$ & $\begin{array}{l}14.62 \\
11.61 \\
17.06 \\
20.00 \\
11.72\end{array}$ & $\begin{array}{r}1220 \\
237 \\
2600 \\
5340 \\
257\end{array}$ & $\begin{array}{l}1964 \\
1965 \\
1966 \\
1967 \\
1968\end{array}$ & $\begin{array}{lll}\text { OCT. } & 20,1963 \\
\text { JULY } 12,1965 \\
\text { OCT. } 16,1965 \\
\text { JULY } 17,1967 \\
\text { JULY } 28,1968\end{array}$ & $\begin{array}{l}19.40 \\
13.00 \\
11.76 \\
13.60 \\
13.67\end{array}$ & $\begin{array}{r}4500 \\
590 \\
262 \\
800 \\
820\end{array}$ & $\begin{array}{l}1969 \\
1970 \\
1971 \\
1973 \\
1974\end{array}$ & $\begin{array}{l}\text { AUG. } 29,1969 \\
\text { SEPT. 06, } 1970 \\
\text { AUG. 25, } 1971 \\
\text { OCT. 11, } 1972 \\
\text { FEB. 01, } 1974\end{array}$ & $\begin{array}{l}14.31 \\
12.37 \\
13.14 \\
18.50 \\
10.50\end{array}$ & $\begin{array}{r}1080 \\
405 \\
640 \\
3650 \\
72\end{array}$ \\
\hline
\end{tabular}

09315200 SALERATUS WASH TRIBUTARY NO. 2 NEAR WOCDSIDE, UT

LOCATION.--Lat $39^{\circ} 06^{\prime} 08^{\prime \prime}$, long $110^{\circ} 19^{\prime} 24^{n}$, in NW' sec. 11, T.20 S., R.13 E., Emery County, Hydrologic Unit 14060008, on U.S. Highway 6 and $50,7.3 \mathrm{mi}$ south from railroad underpass, and $12 \mathrm{mi}$ south of Woodside.

DRAINAGE AREA. $-4.4 \mathrm{mi}^{2}$.

MEAN BASTN ELEVATION. $--5,030 \mathrm{ft}$.

PERIDD OF RECORD AVAIIABLE.--Water years 1959-1971, 1973-74, annual peak discharge only.

GAGE.--Crest-stage gage. Altitude of gage is 4,520 ft fram topographic map.

ANNUAL PEAK DISGAARG, IN OBBIC FEET PER SECOND, AND CORRESPONDING GAGE HEIGHT, IN FEET, FOR EACH WATER YEAR

\begin{tabular}{|c|c|c|c|c|c|c|c|c|c|c|c|c|}
\hline $\begin{array}{l}\text { WATER } \\
\text { YEAR }\end{array}$ & DATE & $\begin{array}{l}\text { GAGE } \\
\text { HEIGHT }\end{array}$ & $\begin{array}{c}\text { PEAK } \\
\text { DISCHARGE }\end{array}$ & $\begin{array}{l}\text { WATER } \\
\text { YEAR }\end{array}$ & DATE & $\begin{array}{c}\text { GAGE } \\
\text { HEIGHT }\end{array}$ & $\begin{array}{c}\text { PEAK } \\
\text { DISCHARGE }\end{array}$ & $\begin{array}{l}\text { WATER } \\
\text { YEAR }\end{array}$ & DATE & & $\begin{array}{l}\text { GAGE } \\
\text { HEIGHT }\end{array}$ & $\begin{array}{c}\text { PEAR } \\
\text { DISCHARGE }\end{array}$ \\
\hline $\begin{array}{l}1959 \\
1960 \\
1961 \\
1962 \\
1963\end{array}$ & $\begin{array}{l}\text { AUG. } 24,1959 \\
\text { SEPT.16, } 1960 \\
\text { SEPT.08, } 1961 \\
\text { SEPT. 21, } 1962 \\
\text { AUG. } 17,1963\end{array}$ & $\begin{array}{l}15.15 \\
13.83 \\
13.37 \\
18.30 \\
11.92\end{array}$ & $\begin{array}{r}1320 \\
740 \\
580 \\
3720 \\
88\end{array}$ & $\begin{array}{l}1964 \\
1965 \\
1966 \\
1967 \\
1968\end{array}$ & $\begin{array}{lll}\text { OCT. } 20,1963 \\
\text { JULY } 12,1965 \\
\text { OCT. } 16,1965 \\
\text { JULY } 17,1967 \\
\text { AUG. 01, } 1968\end{array}$ & $\begin{array}{l}17.50 \\
17.30 \\
13.00 \\
15.40 \\
12.15\end{array}$ & $\begin{array}{r}3000 \\
2800 \\
480 \\
1470 \\
268\end{array}$ & $\begin{array}{l}1969 \\
1970 \\
1971 \\
1973 \\
1974\end{array}$ & $\begin{array}{l}\text { AUG. } 29 \text {, } \\
\text { SEPT.06, } \\
\text { JULY 20, } \\
\text { OCT. 11, } \\
\text { SEPT. } 18,\end{array}$ & $\begin{array}{l}1969 \\
1970 \\
1971 \\
1972 \\
1974\end{array}$ & $\begin{array}{l}17.34 \\
12.93 \\
17.04 \\
15.70 \\
10.50\end{array}$ & $\begin{array}{r}2850 \\
450 \\
2600 \\
1650 \\
20\end{array}$ \\
\hline
\end{tabular}

09315400 SALERATUS WASH ABOVE COTTONWOCD WASH, NEAR GREEN RIVER, UT

LOCATION,--Lat $39^{\circ} 01^{\prime} 08^{\prime \prime}$, long $110^{\circ} 18^{\prime} 20^{\prime \prime}$, in NE's sec.6, T.21 S., R.15 E., Emery County, Hydrologic unit 14060008 , 1,000 ft below road crossing, about $0.5 \mathrm{mi}$ southwest of U.S. Highway 6 and 50 , and about $8.5 \mathrm{mi}$ west of Green River.

DRAINAGE AREA. $-120 \mathrm{mi}^{2}$.

MEAN BASIN ELEVATION. $-5,430 \mathrm{ft}$.

PERIOD OF RECORD AVAII.ABLE.--Water years 1959-68, annual peak discharge only.

GAGE.--Crest-stage gage. Altitude of gage is $4,270 \mathrm{ft}$ from topographic map.

ANNUAL PEAK DISOHARGE, IN GBIC FEET PER SECOND, AND CORRESPONDING GAGE HEIGHT, IN FEET, FOR EACH WATER YEAR

\begin{tabular}{|c|c|c|c|c|c|c|c|c|c|c|c|}
\hline $\begin{array}{l}\text { WATER } \\
\text { YEAR }\end{array}$ & DATE & $\begin{array}{c}\text { GAGE } \\
\text { HEIGHT }\end{array}$ & $\begin{array}{c}\text { PEAK } \\
\text { DISCHARGE }\end{array}$ & $\begin{array}{l}\text { WATER } \\
\text { YEAR }\end{array}$ & DATE & $\begin{array}{l}\text { GAGE } \\
\text { HEIGHT }\end{array}$ & $\begin{array}{c}\text { PEAK } \\
\text { DISCHARGE }\end{array}$ & $\begin{array}{l}\text { WATER } \\
\text { YEAR }\end{array}$ & DATE & $\begin{array}{c}\text { GAGE } \\
\text { HEIGHT }\end{array}$ & $\begin{array}{c}\text { PEAK } \\
\text { DISCHARGE }\end{array}$ \\
\hline $\begin{array}{l}1959 \\
1960 \\
1961 \\
1962\end{array}$ & $\begin{array}{l}\text { AUG. } 19,1959 \\
\text { SEPT.16, } 1960 \\
\text { SEPT.09, } 1961 \\
\text { SEPT.21, } 1962\end{array}$ & $\begin{array}{l}15.97 \\
14.20 \\
15.95 \\
16.50\end{array}$ & $\begin{array}{r}2720 \\
1600 \\
2500 \\
19500\end{array}$ & $\begin{array}{l}1963 \\
1964 \\
1965\end{array}$ & $\begin{array}{l}\text { AUG. } 17,1963 \\
\text { OCT. } 20,1963 \\
\text { JULY } 12,1965\end{array}$ & $\begin{array}{l}13.20 \\
14.20 \\
14.80\end{array}$ & $\begin{array}{l}1900 \\
3800 \\
5800\end{array}$ & $\begin{array}{l}1966 \\
1967 \\
1968\end{array}$ & $\begin{array}{lll}\text { OCT. } 16,1965 \\
\text { JULY } 17,1967 \\
\text { JULY } 28,1968\end{array}$ & $\begin{array}{l}12.66 \\
14.00 \\
13.50\end{array}$ & $\begin{array}{l}1300 \\
3400 \\
2400\end{array}$ \\
\hline
\end{tabular}


GREEN RIVER BASIN

09315500 SALERATUS WASH AT GREEN RIVER, UT

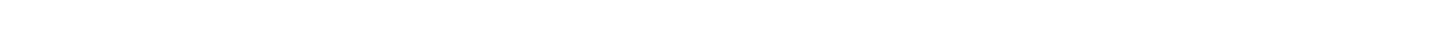
downstream end of pier of bridge on State Highway $24,4.5 \mathrm{mi}$ west of Green River, and $8 \mathrm{mi}$ upstream from mouth.

DRAINAGE AREA $-180 \mathrm{mi}^{2}$.

MEAN BASIN ELEVATTON. $--5,050 \mathrm{ft}$.

PERIOD OF RECORD AVAILABLE.--OCtaber 1948 to September 1970.

GAGE. - Water-stage recorder. Al titude of gage is $4,170 \mathrm{ft}$ from topographic map.

REMARKS.--Some diversions above station.

AVERAGE DISCHARGE. --22 years, $2.99 \mathrm{ft}^{3} / \mathrm{s}, 2,170$ acre- $\mathrm{ft} / \mathrm{yr}$.

EXTREMES FOR PERIOD OF RECORD.--Maximum discharge, 14,200 ft $\mathrm{ft}^{3} / \mathrm{s}$ Sept. 21,1962 , gage height, $11.60 \mathrm{ft}$, fram slope-area measurement of peak flow; no flow for many days in each year.

LOWEST MEAN DISCHARGE, IN GUBIC FEET PER SECOND, AND RANKING FOR THE INDICATED NUMBER OF CONSEQUTIVE DAYS FOR EACH CIMATIC YEAR, APRII I-MARCH 31

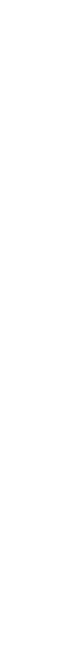

1969

\begin{tabular}{|c|c|c|c|c|c|c|}
\hline 1 & & 3 & & 7 & & 14 \\
\hline 0.00 & 1 & 0.03 & 21 & 0.06 & 21 & 0.0821 \\
\hline $\begin{array}{l}0.00 \\
0.00 \\
0.00 \\
0.00 \\
0.00\end{array}$ & $\begin{array}{l}2 \\
3 \\
4 \\
5 \\
6\end{array}$ & $\begin{array}{l}0.00 \\
0.00 \\
0.00 \\
0.00 \\
0.00\end{array}$ & $\begin{array}{l}1 \\
2 \\
3 \\
4 \\
5\end{array}$ & $\begin{array}{l}0.00 \\
0.03 \\
0.00 \\
0.00 \\
0.00\end{array}$ & $\begin{array}{r}1 \\
19 \\
2 \\
3 \\
4\end{array}$ & $\begin{array}{ll}0.03 & 18 \\
0.06 & 19 \\
0.00 & 1 \\
0.00 & 2 \\
0.00 & 3\end{array}$ \\
\hline $\begin{array}{l}0.00 \\
0.00 \\
0.00 \\
0.00 \\
0.00\end{array}$ & $\begin{array}{r}7 \\
8 \\
9 \\
10 \\
11\end{array}$ & $\begin{array}{l}0.00 \\
0.00 \\
0.00 \\
0.00 \\
0.00\end{array}$ & $\begin{array}{r}6 \\
7 \\
8 \\
9 \\
10\end{array}$ & $\begin{array}{l}0.00 \\
0.00 \\
0.00 \\
0.00 \\
0.00\end{array}$ & $\begin{array}{l}5 \\
6 \\
7 \\
8 \\
9\end{array}$ & $\begin{array}{l}0.00 \\
0.00 \\
0.00 \\
0.00 \\
0.00\end{array}$ \\
\hline $\begin{array}{l}0.00 \\
0.00 \\
0.00 \\
0.00 \\
0.00\end{array}$ & $\begin{array}{l}12 \\
13 \\
14 \\
15 \\
16\end{array}$ & $\begin{array}{l}0.00 \\
0.00 \\
0.00 \\
0.00 \\
0.00\end{array}$ & $\begin{array}{l}11 \\
12 \\
13 \\
14 \\
15\end{array}$ & $\begin{array}{l}0.00 \\
0.00 \\
0.00 \\
0.00 \\
0.00\end{array}$ & $\begin{array}{l}10 \\
11 \\
12 \\
13 \\
14\end{array}$ & $\begin{array}{l}0.00 \\
0.0010 \\
0.0011 \\
0.0012 \\
0.0013\end{array}$ \\
\hline $\begin{array}{l}0.00 \\
0.00 \\
0.00 \\
0.00 \\
0.00\end{array}$ & $\begin{array}{l}17 \\
18 \\
19 \\
20 \\
21\end{array}$ & $\begin{array}{l}0.00 \\
0.00 \\
0.00 \\
0.00 \\
0.00\end{array}$ & $\begin{array}{l}16 \\
17 \\
18 \\
19 \\
20\end{array}$ & $\begin{array}{l}0.04 \\
0.00 \\
0.00 \\
0.00 \\
0.00\end{array}$ & $\begin{array}{l}20 \\
15 \\
16 \\
17 \\
18\end{array}$ & $\begin{array}{l}0.0720 \\
0.0014 \\
0.0015 \\
0.0016 \\
0.0017\end{array}$ \\
\hline
\end{tabular}

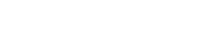

$0.0920 \quad 0.1018$

90

183

A.I

$0.0618 \quad 0.0917$

$0.1021 \quad 0.5621$

$0.0416 \quad 0.0615$

$\begin{array}{llll}0.00 & 1 & 0.02 & 13 \\ 0.00 & 2 & 0.00 & 1\end{array}$

0.1017

0.1015

1.8017

3.5015

$0.1018 \quad 0.1116$

0.9321

0.0614

0.0713

0.165

5.2020

0.144

$\begin{array}{llll}0.00 & 3 & 0.00 \quad 2\end{array}$

0.001

0.001

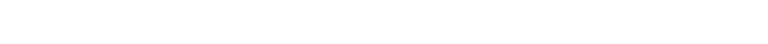

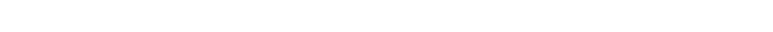

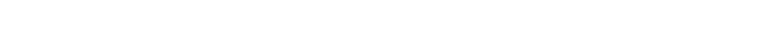

$\begin{array}{lllllllllll}0.00 & 8 & 0.00 & 7 & 0.00 & 7 & 0.00 & 5 & 0.7411 & 1.30 & 6\end{array}$

$\begin{array}{llllllllll}0.00 & 9 & 0.00 & 8 & 0.00 & 8 & 0.00 & 6 & 1.1014 & 2.3010\end{array}$

$\begin{array}{llllllll}0.0010 & 0.00 & 9 & 0.009 & 0.007 & 1.5015 & 4.3017\end{array}$

$\begin{array}{lllllll}0.0011 & 0.0010 & 0.0916 & 0.1218 & 0.8913 & 1.6017 \\ 0.0517 & 0.0716 & 0.0815 & 0.1117 & 0.17 & 7 & 3.4014\end{array}$

$\begin{array}{llllllll}0.0919 & 0.2020 & 0.2219 & 1.1020 & 3.9019 & 6.1019\end{array}$

$\begin{array}{llllllll}0.0012 & 0.0314 & 0.0412 & 0.0411 & 0.18 & 8 & 0.202\end{array}$

$0.0013 \quad 0.0011 \quad 0.0010 \quad 0.008 \quad 0.04330 .4018$

$\begin{array}{lllllll}0.0013 & 0.0011 & 0.0010 & 0.008 & 0.04 & 3 & 4.4018\end{array}$

$\begin{array}{lllllll}0.0014 & 0.0012 & 0.0011 & 0.0814 & 0.25 & 9 & 2.3011 \\ 0.0015 & 0.1619 & 0.2320 & 0.2619 & 0.3010 & 4.2016\end{array}$

HIGHEST MEAN DISCHARGE, IN QBIC FEET PER SECOND, AND RANKING FOR THE INDICATED NUMBER OF CONSEQUTIVE DAVS FOR EAOH WATER YEAR, OCTOBER 1-SEPTEMBER 30

YEAR

1949
1950
1951
1952
1953
1954
1955
1956
1957
1958
1959
1960
1961
1962
1963
1964
1965
1966
1967
1968
1969
1970

1970

$\begin{array}{crcrr}1 & & 3 & & \\ 249 & 15 & 102 & 16 & \\ 577 & 3 & 243 & 3 & 107 \\ 355 & 9 & 197 & 5 & \\ 388 & 8 & 146 & 11 & 63 . \\ 201 & 18 & 104 & 15 & 46 \\ 246 & 16 & 99.0 & 17 & \\ 86.0 & 21 & 51.0 & 20 & 28 . \\ & & & & \\ 24.0 & 22 & 8.40 & 22 & \\ 464 & 5 & 197 & 6 & \\ 748 & 2 & 367 & 1 & 160 \\ 310 & 12 & 122 & 13 & \\ 132 & 20 & 47.0 & 21 & \\ & & & & \\ 196 & 19 & 113 & 14 & \\ 885 & 1 & 298 & 2 & 1 \\ 237 & 17 & 82.0 & 19 & \\ 352 & 10 & 128 & 12 & \\ 265 & 14 & 96.0 & 18 & \\ & & & & \\ 437 & 6 & 147 & 10 & \\ 407 & 7 & 187 & 7 & \\ 284 & 13 & 168 & 9 & \\ 520 & 4 & 173 & 8 & \\ 352 & 11 & 199 & 4 & \\ & & & & \end{array}$

7

15

$\begin{array}{rr}37.0 & 12 \\ 50.0 & 5\end{array}$

$\begin{array}{rr}45.0 & 7 \\ 29.0 & 15 \\ 22.0 & 18 \\ 37.0 & 13\end{array}$

$\begin{array}{ll}37.0 & 13 \\ 13.0 & 20\end{array}$

42.018

28.020

$\begin{array}{lll}3.6022 \quad 1.7022 & 22\end{array}$

94.05

$\begin{array}{lll}64.0 & 13.0 & 3\end{array}$

$53.0 \quad 14$

$25.0 \quad 16$

$49.0 \quad 15$

$\begin{array}{ll}128 & 2 \\ 35.0 & 19\end{array}$

$\begin{array}{ll}35.0 & 19 \\ 55.0 & 13\end{array}$

72.010

$\begin{array}{ll}63.0 & 11 \\ 81.0 & \end{array}$

$77.0 \quad 8$

$\begin{array}{ll}75.0 & 9 \\ 98.0 & 4\end{array}$

\subsection{1}

$\begin{array}{ll}25.0 & 17 \\ 86.0 & 2\end{array}$

$\begin{array}{rr}86.0 & 2 \\ 19.0 & 19\end{array}$

$\begin{array}{lr}40.0 & 8 \\ 40.0 & 9\end{array}$

$29.0 \quad 14$

$\begin{array}{rr}29.0 & 14 \\ 55.0 & 4 \\ 38.0 & 10\end{array}$

$\begin{array}{ll}38.0 & 10 \\ 37.0 & 11\end{array}$
CONSEQUTIVE DAYS

$\begin{array}{llllll}30 & 60 & 90 & 120 & 183\end{array}$

$\begin{array}{llllllllll}20.0 & 14 & 11.0 & 16 & 8.5012 & 7.8010 & 5.1011 & 3.0011\end{array}$

$26.07 \quad 13.079$

9.0010

6.8012

4.6012

3.2010

$33.0 \quad 5 \quad 20.0 \quad 5$

14.05

11.06

$7.30 \quad 6$

5.2010

2.5019

3.4017

2.9018

3.609

1.3020

2.7013
2.0016

$\begin{array}{lllllll}19.0 & 15 & 9.7017 & 6.6017 & 5.1017 & 3.4017 & 2.7013 \\ 6.60 & 20 & 5.2020 & 4.5020 & 3.6019 & 2.9018 & 2.0016\end{array}$

\subsection{2}

39.03

0.6422

0.4322

0.3222

0.2122

0.1122

4.802

6.101

1.9018

$\begin{array}{llll}.0 & 12 & 11.0 \quad 11\end{array}$

$\begin{array}{ll}15.0 & 2 \\ 17.0 & 1\end{array}$

3.6015

0.7621

$13.0 \quad 18$

43.02

$13.0 \quad 19$

$\begin{array}{rr}21.0 & 13 \\ 30.0 & 6\end{array}$

$11.0 \quad 12$

1.6021

5.5015
1.1921

0.7821

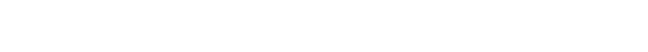

$\begin{array}{lllllll}7.0018 & 4.7019 & 3.5020 & 2.4020 & 1.9019\end{array}$

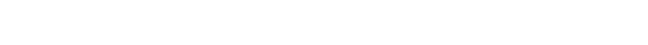

$\begin{array}{llllllllll}15.0 & 16 & 11.0 & 13 & 7.7014 & 5.8014 & 3.9014 & 2.0017\end{array}$

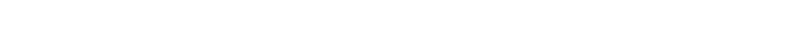

$\begin{array}{lllllllll}23.0 & 10 & 11.0 & 14 & 8.6011 & 6.5013 & 4.3013 & 2.2015\end{array}$

$\begin{array}{llllllllllll}24.0 & 8 & 15.0 & 8 & 16.0 & 4 & 12.0 & 4 & 8.10 & 5 & 4.20 & 4\end{array}$ 
09315500 SALERATUS WASH AT GREEN RIVER, UT-Continued

DURATION OF DISCHARGE FOR EACH WATER YEAR

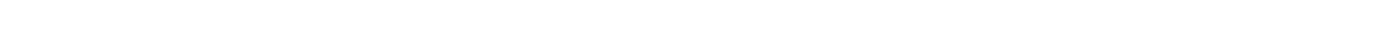
YEAR

NUMBER OF DAYS IN CIAASS

CUBIC FEET PER SECOND

DAYS

194910

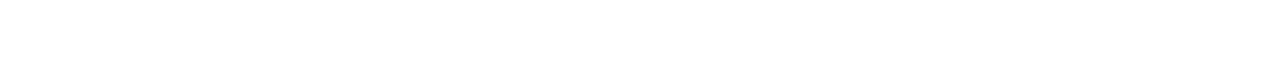

195033

$\begin{array}{rrrrrrrrrrrrr}144 & 84 & 40 & 13 & 3 & 6 & 5 & 5 & 2 & 4 & 4 & 2 \\ 145 & 46 & 28 & 15 & 13 & 24 & 3 & 11 & 11 & 4 & 4 & 4 & \\ 78 & 19 & 19 & 23 & 15 & 27 & 7 & 5 & 4 & 1 & 2 & 1 & 1 \\ 101 & 41 & 37 & 16 & 19 & 15 & 6 & 4 & 7 & 1 & 1 & 1 & \\ 84 & 14 & 5 & 5 & 3 & 12 & 4 & 17 & 6 & 12 & 6 & 13 & 11\end{array}$

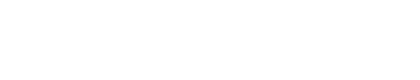

195240

1953160
1954107

1955164

1956360

1957334

1958340

1959347
1960361

1

11

$\begin{array}{lll}2 & 1 & 1 \\ 1 & 1 & 1 \\ & & 1\end{array}$

$\begin{array}{lllll}3 & 3 & 3 & & 1 \\ 2 & & 3 & 1 & 1 \\ & 1 & 1 & 1 & 1 \\ & & & & 1 \\ & 1 & 1 & & 1 \\ 1 & 1 & 1 & & 1 \\ 1 & & 2 & 1 & 3 \\ 3 & 4 & 2 & 3 & 2 \\ & & & & 4\end{array}$

$\begin{array}{lll}1 & 1 & \\ 2 & 2 & 2 \\ & & 5\end{array}$

31

1961345

1962341

196393

196415
196523

$\begin{array}{rrrrrrrrrrrrr}3 & & 2 & & 1 & 1 & & 1 & & 1 & 1 & & 1 \\ 17 & & 1 & & & & & 1 & & & 1 & & 1 \\ 116 & 135 & 1 & 2 & 1 & & & 3 & 1 & 1 & 2 & 1 & 3 \\ 210 & 92 & 21 & 1 & & 2 & 2 & 2 & 1 & & 2 & 3 & 2 \\ 179 & 48 & 80 & 5 & 3 & & & 2 & 3 & 4 & 2 & & 4\end{array}$

$\begin{array}{llllllllll} & & 2 & 2 & 1 & & 3 & 1 & & \\ & & & & & & & 1 & & 1 \\ 2 & & & & 1 & 2 & & 1 & & \\ 1 & 4 & 1 & 1 & & 4 & & 1 & 1 & \\ 1 & 1 & 2 & 3 & & & 1 & 4 & & \\ 1 & & & & 1 & 1 & & & & 1 \\ 1 & 1 & 2 & 1 & 1 & 1 & 2 & & & 2 \\ 3 & & & 1 & 1 & & & 1 & 1 & \\ 1 & & 2 & 1 & 1 & 1 & 1 & 2 & & 1 \\ 1 & & & 2 & 2 & 1 & & 1 & 1 & \end{array}$

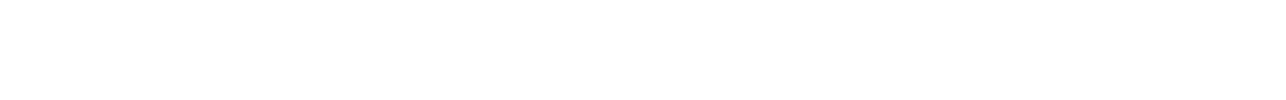

DURATION TABLE OF DISCHARGE FOR WATER YEARS 1949-70

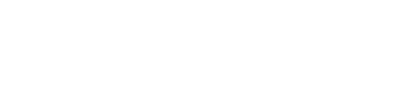

$\begin{array}{lcl}\text { OUBIC } & \text { ACOU- } \\ \text { FEET } & \text { MU- } & \\ \text { PER- } & \\ \text { PER TOTAL LATED } & \text { CENI }\end{array}$ CLASS SECOND DAYS DAYS DAYS

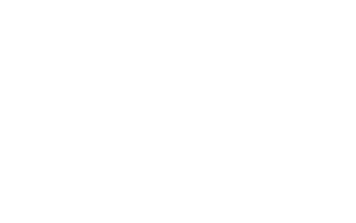

ABIC ACQU$\begin{array}{lcl}\text { FEET MUT MU- } & \text { PER- } \\ \text { PER TOTAL LATED } & \text { CENT }\end{array}$ CJASS SECOND DAYS DAYS DAYS

$\begin{array}{rrrrr}18 & 4.6 & 46 & 312 & 3.9 \\ 19 & 6.4 & 34 & 266 & 3.3 \\ 20 & 9.0 & 40 & 232 & 2.9 \\ 21 & 13.0 & 17 & 192 & 2.4 \\ 22 & 18.0 & 27 & 175 & 2.2 \\ 23 & 25.0 & 24 & 148 & 1.8 \\ 24 & 35.0 & 14 & 124 & 1.5 \\ 25 & 49.0 & 17 & 110 & 1.4 \\ 26 & 69.0 & 17 & 93 & 1.2\end{array}$

1359.2

1334.0

473.0

967.9
738.5

38.9

1753.6

2212.3

277.2

987.4

1497.1
709.4

709.4
1390.7

1390.7
1535.7

CIASS SECOND DAYS DAYS DAY

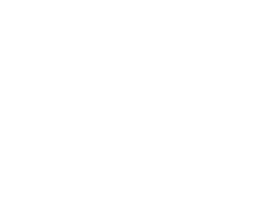

MONIHLY MEAN DISCHARGES, IN CUBIC FEET PER SECOND, FOR EACH WATER YEAR

$\begin{array}{lcccccccccccc}\text { YEAR } & \text { OCT } & \text { NOV } & \text { DEC } & \text { JAN } & \text { FEB } & \text { MAR } & \text { APR } & \text { MAY } & \text { JUNE } & \text { JULY } & \text { AUG } & \text { SEP } \\ 1949 & 2.37 & 0.24 & 0.14 & 0.15 & 2.21 & 0.31 & 0.12 & 0.18 & 18.5 & 2.50 & 4.32 & 5.43 \\ 1950 & 9.73 & 0.30 & 0.11 & 0.10 & 0.10 & 0.12 & 0.41 & 0.10 & 0.39 & 25.0 & 0.41 & 0.60 \\ & & & & & & & & & & & & \\ 1951 & 0.37 & 0.15 & 0.14 & 0.11 & 0.13 & 0.07 & 0.15 & 1.15 & 2.03 & 6.11 & 32.0 & 1.52 \\ 1952 & 21.8 & 1.24 & 0.13 & 4.60 & 3.14 & 0.30 & 0.14 & 0.37 & 0.68 & 0.38 & 8.50 & 2.12 \\ 1953 & 0.35 & 0.05 & 0.08 & 0.07 & 0.15 & 0.05 & 0.00 & 0.31 & 0.43 & 2.93 & 10.5 & 0.42 \\ 1954 & 7.06 & 3.86 & 0.10 & 0.10 & 0.00 & 0.07 & 0.14 & 0.39 & 0.41 & 0.38 & 0.36 & 19.1 \\ 1955 & 6.43 & 0.10 & 0.00 & 0.00 & 0.00 & 3.42 & 0.05 & 2.67 & 4.07 & 5.54 & 1.66 & 0.01 \\ & & & & & & & & & & & & \\ 1956 & 0.00 & 0.01 & 0.00 & 0.00 & 0.00 & 0.00 & 0.00 & 0.82 & 0.00 & 0.43 & 0.01 & 0.00 \\ 1957 & 0.11 & 0.00 & 0.00 & 0.00 & 0.00 & 0.00 & 0.00 & 1.42 & 12.0 & 5.37 & 38.1 & 0.00 \\ 1958 & 28.2 & 37.3 & 0.00 & 0.00 & 0.05 & 0.00 & 0.00 & 0.10 & 0.00 & 0.00 & 5.54 & 1.43 \\ 1959 & 0.00 & 1.06 & 0.00 & 0.00 & 0.00 & 0.00 & 0.00 & 0.00 & 0.00 & 0.35 & 9.14 & 12.3 \\ 1960 & 4.58 & 0.00 & 0.00 & 0.00 & 0.01 & 0.00 & 0.00 & 0.00 & 0.00 & 0.00 & 0.00 & 4.50 \\ 1961 & 11.0 & 0.00 & 0.00 & 0.00 & 0.00 & 0.00 & 0.00 & 0.04 & 0.00 & 2.13 & 6.70 & 12.4 \\ 1962 & 6.65 & 0.00 & 0.00 & 0.00 & 0.04 & 0.00 & 0.00 & 0.00 & 0.00 & 0.00 & 0.00 & 43.0 \\ 1963 & 8.09 & 0.29 & 0.18 & 0.13 & 0.21 & 0.20 & 0.29 & 0.03 & 0.00 & 0.42 & 12.2 & 0.93 \\ 1964 & 4.64 & 0.13 & 0.10 & 0.10 & 0.19 & 0.22 & 1.31 & 5.36 & 0.55 & 7.95 & 14.3 & 10.4 \\ 1965 & 0.05 & 0.10 & 0.10 & 0.25 & 0.32 & 0.32 & 0.27 & 8.35 & 3.82 & 27.9 & 7.71 & 0.48 \\ 1966 & 14.3 & 4.63 & 3.43 & 0.26 & 0.29 & 0.12 & 0.10 & 0.12 & 0.09 & 0.75 & 0.00 & 0.05 \\ 1967 & 0.88 & 0.02 & 0.08 & 0.03 & 0.10 & 0.11 & 0.13 & 2.23 & 27.5 & 19.3 & 1.91 & 1.17 \\ 1968 & 0.02 & 0.02 & 0.00 & 0.00 & 0.13 & 0.10 & 0.12 & 0.18 & 3.03 & 3.54 & 18.4 & 0.21 \\ 1969 & 0.79 & 0.02 & 0.00 & 0.24 & 0.31 & 0.23 & 0.14 & 1.73 & 18.7 & 0.06 & 23.0 & 5.19 \\ 1970 & 0.08 & 0.69 & 0.35 & 0.06 & 0.38 & 0.28 & 0.12 & 0.07 & 22.8 & 0.03 & 2.56 & 7.92\end{array}$


GREEN RIVER BASIN

09315500 SALERATUS WASH AT GREEN RIVER, UT--Continued

ANNUAL PEAK DISCHARGE, IN CUBIC FEET PER SECOND, AND CORRESPONDING GAGE HEIGHT, IN FEET, FOR EACH WATER YEAR

\begin{tabular}{|c|c|c|c|c|c|c|c|c|c|c|c|}
\hline $\begin{array}{l}\text { WA'TER } \\
\text { YEAR }\end{array}$ & DATE & $\begin{array}{c}\text { GAGE } \\
\text { HEIGHT }\end{array}$ & $\begin{array}{c}\text { PEAK } \\
\text { DISCHARGE }\end{array}$ & $\begin{array}{l}\text { WATER } \\
\text { YEAR }\end{array}$ & DATE & $\begin{array}{c}\text { GAGE } \\
\text { HEIGHT }\end{array}$ & $\begin{array}{c}\text { PEAK } \\
\text { DISCHARGE }\end{array}$ & $\begin{array}{l}\text { WATER } \\
\text { YEAR }\end{array}$ & DATE & $\begin{array}{c}\text { GAGE } \\
\text { HEIGHT }\end{array}$ & $\begin{array}{c}\text { PEAK } \\
\text { DISCHARGE }\end{array}$ \\
\hline $\begin{array}{l}1949 \\
1950 \\
1951 \\
1952 \\
1953 \\
1954 \\
1955 \\
1956\end{array}$ & $\begin{array}{ll}\text { JUNE } 06,1949 \\
\text { JULY } 08,1950 \\
\text { AUG. 04, } 1951 \\
\text { AUG. 09, } 1952 \\
\text { AUG. 01, } 1953 \\
\text { SEPT.13, } 1954 \\
\text { JULY 25, } 1955 \\
\text { MAY 24, } 1956\end{array}$ & $\begin{array}{l}6.60 \\
8.67 \\
6.10 \\
6.13 \\
5.78 \\
7.72 \\
4.03 \\
4.88\end{array}$ & $\begin{array}{r}2550 \\
4850 \\
1670 \\
1810 \\
1340 \\
2340 \\
700 \\
372\end{array}$ & $\begin{array}{l}1957 \\
1958 \\
1959 \\
1960 \\
1961 \\
1962 \\
1963\end{array}$ & $\begin{array}{l}\text { AUG. } 30,1957 \\
\text { NOV. } 02,1957 \\
\text { AUG. } 19,1959 \\
\text { OCT. } 28,1959 \\
\text { OCT. 09, } 1960 \\
\text { SEPT.21, } 1962 \\
\text { OCT. 05, } 1962\end{array}$ & $\begin{array}{r}9.70 \\
10.60 \\
8.86 \\
7.27 \\
5.43 \\
11.60 \\
4.10\end{array}$ & $\begin{array}{r}2250 \\
2700 \\
1510 \\
1170 \\
1410 \\
14200 \\
1550\end{array}$ & $\begin{array}{l}1964 \\
1965 \\
1966 \\
1967 \\
1968 \\
1969 \\
1970\end{array}$ & $\begin{array}{l}\text { AUG. } 14,1964 \\
\text { JULY } 31,1965 \\
\text { OCT. } 16,1965 \\
\text { JULY } 16,1967 \\
\text { AUG. 14, } 1968 \\
\text { JUNE } 24,1969 \\
\text { JUNE 07, } 1970\end{array}$ & $\begin{array}{l}4.63 \\
6.86 \\
4.53 \\
6.86 \\
5.08 \\
6.10 \\
6.66\end{array}$ & $\begin{array}{l}2920 \\
6290 \\
2800 \\
6290 \\
3480 \\
4980 \\
4740\end{array}$ \\
\hline
\end{tabular}

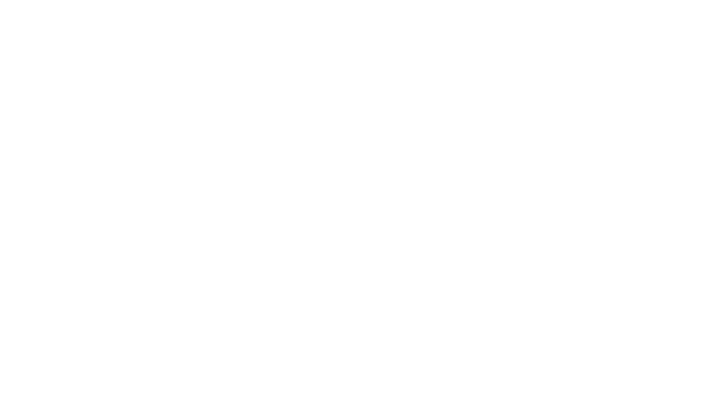

09315900 BRONNS WASH TRIBUTARY NEAR GREEN RIVER, UT

LOCATION.-Irat $38^{\circ} 59^{\prime} 10^{\prime \prime}$, long $110^{\circ} 05^{\prime} 50^{\prime \prime}$, in $\mathrm{NE}_{4}^{1} \mathrm{SE}_{4}^{\frac{3}{4}} \mathrm{sec}, 13, \mathrm{~T} .21 \mathrm{~S}$, , R.16 E., Grand County, Hydrologic Unit 14060008 , about 3.5 mi east of Green River and $15 \mathrm{mi}$ west of Crescent Junction.

DRAINAGE AREA. $--3.89 \mathrm{mi}^{2}$.

MEAN BASIN ELEVATION. $-4,300 \mathrm{ft}$.

PERIOD OF RECORD AVAILABLE. - Water years 1959-73, annual peak discharge only.

GAGE.-Crest-stage gage. Altitude of gage is 4,160 ft from topographic map.

ANNUAL PEAK DISCHARGE, IN CUBIC FEET PER SECOND, AND CORRESPONDING GAGE HEIGHT, IN FEET, FOR EACH WATER YEAR

\begin{tabular}{|c|c|c|c|c|c|c|c|c|c|c|c|}
\hline $\begin{array}{l}\text { WATER } \\
\text { YEAR }\end{array}$ & DATE & $\begin{array}{c}\text { GAGE } \\
\text { HEIGHI }\end{array}$ & $\begin{array}{c}\text { PEAK } \\
\text { DISCHARGE }\end{array}$ & $\begin{array}{l}\text { WATERR } \\
\text { YEAR }\end{array}$ & DATE & $\begin{array}{l}\text { GAGE } \\
\text { HEIGHT }\end{array}$ & $\begin{array}{c}\text { PEAK } \\
\text { DISCHARGE }\end{array}$ & $\begin{array}{l}\text { WATER } \\
\text { YEAR }\end{array}$ & DATE & $\begin{array}{c}\text { GAGE } \\
\text { HEIGHT }\end{array}$ & $\begin{array}{c}\text { PEAK } \\
\text { DISCHARGE }\end{array}$ \\
\hline $\begin{array}{l}1959 \\
1960 \\
1961 \\
1962 \\
1963\end{array}$ & $\begin{array}{l}\text { AUG. } 19,1959 \\
\text { SEPT.12, } 1960 \\
\text { SEPT.09, } 1961 \\
\text { OCT. 08, } 1961 \\
\text { AUG. 31, } 1963\end{array}$ & $\begin{array}{l}15.40 \\
10.64 \\
15.20 \\
10.32 \\
10.86\end{array}$ & $\begin{array}{r}1470 \\
105 \\
1310 \\
69 \\
127\end{array}$ & $\begin{array}{l}1964 \\
1965 \\
1966 \\
1967 \\
1968\end{array}$ & $\begin{array}{l}\text { AUG. } 14,1964 \\
\text { SEPT.18，1965 } \\
\text { SEPT.14, } 1966 \\
\text { AUG. 31, } 1967 \\
\text { AUG. 01, } 1968\end{array}$ & $\begin{array}{r}10.32 \\
9.96 \\
11.62 \\
12.97 \\
13.77\end{array}$ & $\begin{array}{r}69 \\
38 \\
240 \\
520 \\
760\end{array}$ & $\begin{array}{l}1969 \\
1970 \\
1971 \\
1972 \\
1973\end{array}$ & $\begin{array}{lll}\text { JUNE } 24,1969 \\
\text { OCT. } 04,1969 \\
\text { APR. } 23,1971 \\
\text { AUG. } 04,1972 \\
\text { OCT. } 06,1972\end{array}$ & $\begin{array}{r}10.26 \\
13.90 \\
9.26 \\
11.11 \\
12.56\end{array}$ & $\begin{array}{l}63 \\
800 \\
0.10 \\
160 \\
420\end{array}$ \\
\hline
\end{tabular}

09316000 BRONNS WASH NEAR GREEN RIVER, UT

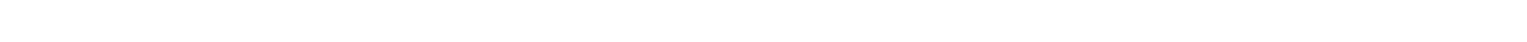
$0.2 \mathrm{mi}$ upstream from The Denver \& Rio Grande Western Railroad Co. bridge, $1.2 \mathrm{mi}$ upstream from mouth, and $1.8 \mathrm{mi}$ east of Green River.

DRAINAGE AREA. $-75 \mathrm{mi}^{2}$, approximately.

MEAN BASIN ELEVATION.--5,220 ft.

PERIOD OF RECORD AVAII.ABLE.-February 1949 to September 1968.

GAGE.-Water-stage recorder. Altitude of gage is 4,085 ft fram river-profile map.

AVERAGE DISChARGE. - 19 years, $0.95 \mathrm{ft}^{3} / \mathrm{s}, 688$ acre-ft/yr.

EXTREMES FOR PERIOD OF RECORD.--Maximum discharge, $5,620 \mathrm{ft}^{3} / \mathrm{s}$ Aug. 19, 1959, gage height, $13.50 \mathrm{ft}$, from slope-area measurement of peak flow; no flow for most of the time. 
GREEN RIVER BASIN

09316000 BRCWNS WASH NEAR GREEN RTVER, UT--Continued

LOWEST MEAN DISGHARGE, IN OUBIC FEET PER SECOND, AND RANKING FOR THE INDICATED NUMBER CF' CONSEQJTTVE DAYS FOR EACH CLIMATTC YEAR, APRIL 1-MAROH 31

YE
1951
1952
1953
1954
1955
1956
1957
1958
1959
1960
1961
1962
1963
1964
1965
1966
1967
1968

\begin{tabular}{|c|c|c|c|}
\hline 1 & & 3 & \\
\hline 0.00 & 1 & 0.00 & 1 \\
\hline 0.00 & 2 & 0.00 & 2 \\
\hline 0.00 & 3 & 0.00 & 3 \\
\hline 0.00 & 4 & 0.00 & 4 \\
\hline 0.00 & 5 & 0.00 & 5 \\
\hline 0.00 & 6 & 0.00 & 6 \\
\hline 0.00 & 7 & 0.00 & 7 \\
\hline 0.00 & 8 & 0.00 & 8 \\
\hline 0.00 & 9 & 0.00 & 9 \\
\hline 0.00 & 10 & 0.00 & 10 \\
\hline 0.00 & 11 & 0.00 & 11 \\
\hline 0.00 & 12 & 0.00 & 12 \\
\hline 0.00 & 13 & 0.00 & 13 \\
\hline 0.00 & 14 & 0.00 & \\
\hline 0.00 & & 0.00 & \\
\hline 0.00 & 16 & 0.00 & 16 \\
\hline 0.00 & 17 & 0.00 & 17 \\
\hline 0.00 & 18 & 0.00 & 18 \\
\hline
\end{tabular}

\begin{tabular}{|c|c|c|}
\hline 7 & & 14 \\
\hline $\begin{array}{l}0.00 \\
0.00 \\
0.00 \\
0.00 \\
0.00\end{array}$ & $\begin{array}{l}1 \\
2 \\
3 \\
4 \\
5\end{array}$ & $\begin{array}{l}0.00 \\
0.00 \\
0.00 \\
0.00 \\
0.00\end{array}$ \\
\hline $\begin{array}{l}0.00 \\
0.00 \\
0.00 \\
0.00 \\
0.00\end{array}$ & $\begin{array}{r}6 \\
7 \\
8 \\
9 \\
10\end{array}$ & $\begin{array}{l}0.00 \\
0.00 \\
0.00 \\
0.00 \\
0.001\end{array}$ \\
\hline $\begin{array}{l}0.00 \\
0.00 \\
0.00 \\
0.00 \\
0.00\end{array}$ & $\begin{array}{l}11 \\
12 \\
13 \\
14 \\
15\end{array}$ & $\begin{array}{ll}0.00 & 1 \\
0.00 & 1 \\
0.00 & 1 \\
0.00 & 1 \\
0.00 & 1\end{array}$ \\
\hline $\begin{array}{l}0.00 \\
0.00 \\
0.00\end{array}$ & $\begin{array}{l}16 \\
17 \\
18\end{array}$ & $\begin{array}{lll}0.001 \\
0.00 & 1 \\
0.00 & 1\end{array}$ \\
\hline
\end{tabular}

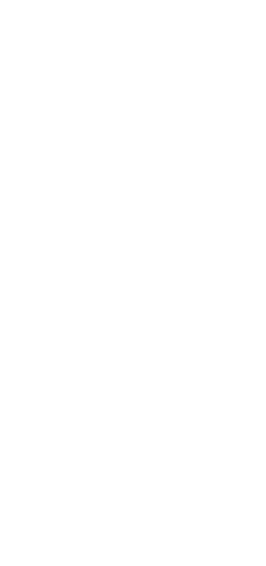

$\begin{array}{lr}90 & \\ & \\ 0.00 & 1 \\ 0.09 & 18 \\ 0.00 & 2 \\ 0.00 & 3 \\ 0.00 & 4 \\ 0.00 & 5 \\ 0.00 & 6 \\ 0.02 & 17 \\ 0.00 & 7 \\ 0.00 & 8 \\ 0.00 & 9 \\ 0.00 & 10 \\ 0.00 & 11 \\ 0.00 & 12 \\ 0.00 & 13 \\ 0.00 & 14 \\ 0.00 & 15 \\ 0.00 & 16\end{array}$

\begin{tabular}{|c|c|c|c|}
\hline 120 & & 183 & ALL \\
\hline $\begin{array}{l}0.00 \\
0.101 \\
0.00 \\
0.00 \\
0.00\end{array}$ & $\begin{array}{r}1 \\
18 \\
2 \\
3 \\
4\end{array}$ & $\begin{array}{rr}0.00 & 1 \\
1.80 & 16 \\
0.00 & 2 \\
0.48 & 13 \\
0.55 & 15\end{array}$ & $\begin{array}{ll}0.04 & 2 \\
2.30 & 16 \\
0.54 & 11 \\
0.56 & 12 \\
1.10 & 14\end{array}$ \\
\hline $\begin{array}{l}0.00 \\
0.00 \\
0.03 \\
0.00 \\
0.00\end{array}$ & $\begin{array}{r}5 \\
6 \\
16 \\
7 \\
8\end{array}$ & $\begin{array}{rr}0.00 & 3 \\
0.02 & 8 \\
3.60 & 18 \\
0.00 & 4 \\
0.36 & 12\end{array}$ & $\begin{array}{rr}0.03 & 1 \\
0.08 & 4 \\
3.80 & 17 \\
0.17 & 6 \\
1.60 & 15\end{array}$ \\
\hline 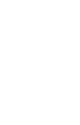 & $\begin{array}{l}9 \\
15 \\
10 \\
11 \\
12\end{array}$ & $\begin{array}{rr}0.00 & 5 \\
2.20 & 17 \\
0.04 & 9 \\
0.13 & 10 \\
0.00 & 6\end{array}$ & $\begin{array}{lr}0.06 & 3 \\
4.70 & 18 \\
0.18 & 7 \\
0.21 & 8 \\
0.14 & 5\end{array}$ \\
\hline $\begin{array}{ll}0.00 & 1 \\
0.04 & 1 \\
0.00 & 1\end{array}$ & $\begin{array}{l}13 \\
17 \\
14\end{array}$ & $\begin{array}{rr}0.24 & 11 \\
0.53 & 14 \\
0.00 & 7\end{array}$ & $\begin{array}{l}0.33 \quad 9 \\
0.8013 \\
0.3310\end{array}$ \\
\hline
\end{tabular}

HIGHEST MEAN DISGHARGE, IN OUBIC FEET PER SECOND, AND RANKING FOR THE INDICATED NUMBER OF CONSECUTIVE DAYS FOR EAOH WATER YEAR, OCTOBER 1-SEPTEMBER 30
FO

\begin{tabular}{|c|c|c|c|c|c|c|c|c|c|c|c|c|c|c|c|c|c|c|c|}
\hline YEAR & 1 & & 3 & & 7 & & 15 & & $\begin{array}{l}\text { CONSE } \\
30\end{array}$ & Eat & $\begin{array}{l}\text { E DAYS } \\
60\end{array}$ & & 90 & & 120 & & 183 & & ALL \\
\hline 1950 & 240 & 7 & 80.0 & 7 & 34.0 & 7 & 22.0 & 6 & 11.0 & 7 & 5.60 & 7 & 3.70 & 7 & 2.80 & 7 & 1.80 & 7 & 0.96 \\
\hline $\begin{array}{l}1961 \\
1962 \\
1963 \\
1964 \\
1965\end{array}$ & $\begin{array}{l}874 \\
315 \\
25.0 \\
32.0 \\
22.0\end{array}$ & $\begin{array}{r}1 \\
3 \\
17 \\
16 \\
18\end{array}$ & $\begin{array}{c}394 \\
134 \\
8.40 \\
11.0 \\
11.0\end{array}$ & $\begin{array}{r}1 \\
4 \\
18 \\
16 \\
17\end{array}$ & $\begin{array}{r}169 \\
58.0 \\
3.60 \\
4.60 \\
4.70\end{array}$ & $\begin{array}{r}1 \\
4 \\
18 \\
17 \\
16\end{array}$ & $\begin{array}{c}81.0 \\
27.0 \\
1.80 \\
2.90 \\
2.90\end{array}$ & $\begin{array}{r}1 \\
5 \\
18 \\
16 \\
17\end{array}$ & $\begin{array}{c}41.0 \\
13.0 \\
1.70 \\
1.50 \\
2.20\end{array}$ & $\begin{array}{r}1 \\
6 \\
17 \\
18 \\
16\end{array}$ & $\begin{array}{c}22.0 \\
6.70 \\
0.87 \\
0.73 \\
1.19\end{array}$ & $\begin{array}{r}1 \\
6 \\
17 \\
18 \\
15\end{array}$ & $\begin{array}{c}14.0 \\
4.50 \\
0.59 \\
0.49 \\
0.85\end{array}$ & $\begin{array}{l}1 \\
6 \\
17 \\
18 \\
15\end{array}$ & $\begin{array}{c}11.0 \\
3.40 \\
0.45 \\
0.37 \\
0.64\end{array}$ & $\begin{array}{r}1 \\
6 \\
17 \\
18 \\
15\end{array}$ & $\begin{array}{l}7.10 \\
2.20 \\
0.29 \\
0.29 \\
0.43\end{array}$ & $\begin{array}{r}1 \\
6 \\
17 \\
18 \\
14\end{array}$ & $\begin{array}{l}3.60 \\
1.30 \\
0.17 \\
0.21 \\
0.21 \\
1\end{array}$ \\
\hline
\end{tabular}

DURATION OF DISQHARGE FOR EACH WATER YEAR

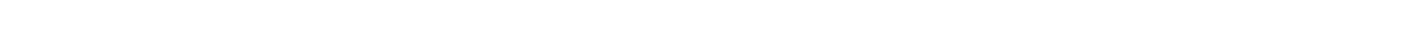
YEAR

OBIC FEET ER SECO -DAYS

\begin{tabular}{|c|c|c|c|c|c|c|c|c|c|c|c|c|c|c|c|c|c|c|c|c|c|c|c|c|}
\hline 1950355 & 1 & 1 & 2 & & 1 & 1 & & 1 & & & & & & & 1 & & & & & & 1 & & 1 & 348.9 \\
\hline $\begin{array}{l}1951351 \\
1952337 \\
1953353 \\
1954340 \\
1955343\end{array}$ & $\begin{array}{l}2 \\
2 \\
1 \\
2 \\
1\end{array}$ & $\begin{array}{l}1 \\
2 \\
4 \\
2 \\
1\end{array}$ & $\begin{array}{l}2 \\
1 \\
2 \\
1 \\
3\end{array}$ & $\begin{array}{l}1 \\
2\end{array}$ & 1 & $\begin{array}{l}1 \\
1\end{array}$ & $\begin{array}{l}1 \\
4 \\
1 \\
2\end{array}$ & $\begin{array}{l}1 \\
1\end{array}$ & $\begin{array}{l}2 \\
3 \\
1\end{array}$ & $\begin{array}{l}2 \\
1 \\
1 \\
1\end{array}$ & 5 & $\begin{array}{l}1 \\
2 \\
1\end{array}$ & 1 & $\begin{array}{l}1 \\
1\end{array}$ & $\begin{array}{l}1 \\
1 \\
1 \\
1\end{array}$ & $\begin{array}{l}1 \\
1\end{array}$ & 4 & $\begin{array}{l}1 \\
2 \\
2\end{array}$ & $\begin{array}{l}1 \\
1\end{array}$ & $\begin{array}{l}1 \\
1\end{array}$ & $\begin{array}{l}1 \\
1\end{array}$ & 1 & 1 & $\begin{array}{r}511.5 \\
527.9 \\
88.9 \\
218.3 \\
313.6\end{array}$ \\
\hline $\begin{array}{l}1956358 \\
1957340 \\
1958310 \\
1959356 \\
1960363\end{array}$ & $\begin{array}{r}1 \\
23\end{array}$ & 11 & $\begin{array}{l}1 \\
4 \\
1 \\
1\end{array}$ & $\begin{array}{l}3 \\
1\end{array}$ & 1 & 2 & $\begin{array}{l}1 \\
5 \\
1 \\
2\end{array}$ & 1 & $\begin{array}{l}1 \\
1 \\
3\end{array}$ & 1 & $\begin{array}{l}2 \\
2\end{array}$ & $\begin{array}{l}2 \\
3 \\
1\end{array}$ & 1 & $\begin{array}{l}1 \\
1 \\
3\end{array}$ & 1 & $\begin{array}{l}4 \\
3 \\
1\end{array}$ & & & I & 1 & 1 & $\begin{array}{l}1 \\
1\end{array}$ & $\begin{array}{ll}1 & \\
1 & \\
& 1\end{array}$ & $\begin{array}{r}26.3 \\
659.7 \\
787.9 \\
510.7 \\
65.3\end{array}$ \\
\hline $\begin{array}{l}1961321 \\
1962336 \\
1963352 \\
1964352 \\
1965351\end{array}$ & $\begin{array}{r}23 \\
20 \\
2 \\
5 \\
4\end{array}$ & $\begin{array}{l}4 \\
2\end{array}$ & $\begin{array}{l}1 \\
2 \\
1\end{array}$ & $\begin{array}{l}2 \\
2 \\
1\end{array}$ & $\begin{array}{l}1 \\
2\end{array}$ & 1 & 2 & 2 & $\begin{array}{l}2 \\
1 \\
1 \\
1\end{array}$ & 3 & 2 & $\begin{array}{l}2 \\
1 \\
1\end{array}$ & 1 & 1 & $\begin{array}{l}1 \\
1\end{array}$ & $\begin{array}{l}2 \\
1\end{array}$ & $\begin{array}{l}1 \\
2 \\
1 \\
2\end{array}$ & 2 & & & 1 & & $\frac{1}{1}$ & $\begin{array}{r}1321.3 \\
461.9 \\
61.4 \\
76.9 \\
77.9\end{array}$ \\
\hline $\begin{array}{l}1966355 \\
1967355 \\
1968363\end{array}$ & 1 & & 1 & $\begin{array}{l}3 \\
1\end{array}$ & & & & 1 & 1 & 1 & 2 & 1 & & 1 & 1 & & & 1 & $\begin{array}{l}1 \\
1\end{array}$ & 1 & $\frac{1}{1}$ & 1 & & $\begin{array}{r}237.0 \\
219.0 \\
79.0\end{array}$ \\
\hline
\end{tabular}


GREEN RIVER BASIN

09316000 BROWNS WASH NEAR GREEN RIVER, UT--Continued

DURATION TABLE OF DISCHARGE FOR WATER YEARS $1950-68$

\begin{tabular}{|c|c|c|c|c|c|c|c|c|c|c|c|c|c|c|c|c|c|c|c|}
\hline CIASS & $\begin{array}{c}\text { OBBIC } \\
\text { FEET } \\
\text { PER } \\
\text { SECOND }\end{array}$ & $\begin{array}{c}\text { TOTAL } \\
\text { DAYS }\end{array}$ & $\begin{array}{r}\text { ACO- } \\
\mathbf{M}- \\
\text { LATED } \\
\text { DAYS }\end{array}$ & $\begin{array}{l}\text { PER- } \\
\text { CENT } \\
\text { DAYS }\end{array}$ & CLASS & $\begin{array}{c}\text { CUBIC } \\
\text { FEET } \\
\text { PER } \\
\text { SECOND }\end{array}$ & $\begin{array}{l}\text { TOTAL } \\
\text { DAYS }\end{array}$ & $\begin{array}{r}\text { ACOU- } \\
\text { MU- } \\
\text { LATED } \\
\text { DAYS }\end{array}$ & $\begin{array}{l}\text { PER- } \\
\text { CENT } \\
\text { DAYS }\end{array}$ & & $\begin{array}{c}\text { CUBIC } \\
\text { FEET } \\
\text { PER } \\
\text { SECOND }\end{array}$ & $\begin{array}{r}\text { TOTAL } \\
\text { DAYS }\end{array}$ & $\begin{array}{r}\text { ACOU- } \\
\text { MU- } \\
\text { LATED } \\
\text { DAYS }\end{array}$ & $\begin{array}{l}\text { PER- } \\
\text { CENT } \\
\text { DAYS }\end{array}$ & CIASS & $\begin{array}{c}\text { CUBIC } \\
\text { FEET } \\
\text { PER } \\
\text { SECOND }\end{array}$ & $\begin{array}{r}\text { TOTAL } \\
\text { DAYS }\end{array}$ & $\begin{array}{r}\text { ACOH- } \\
\text { MU- } \\
\text { LATED } \\
\text { DAYS }\end{array}$ & $\begin{array}{l}\text { PER- } \\
\text { CENT } \\
\text { DAYS }\end{array}$ \\
\hline $\begin{array}{l}0 \\
1 \\
2 \\
3 \\
4 \\
5 \\
6 \\
7 \\
8\end{array}$ & $\begin{array}{l}0.00 \\
0.02 \\
0.03 \\
0.04 \\
0.05 \\
0.07 \\
0.09 \\
0.12 \\
0.17\end{array}$ & $\begin{array}{r}6591 \\
1 \\
0 \\
0 \\
0 \\
0 \\
88 \\
0 \\
28\end{array}$ & $\begin{array}{r}6940 \\
349 \\
348 \\
348 \\
348 \\
348 \\
348 \\
260 \\
260\end{array}$ & $\begin{array}{r}100.0 \\
5.0 \\
5.0 \\
5.0 \\
5.0 \\
5.0 \\
5.0 \\
3.7 \\
3.7\end{array}$ & $\begin{array}{r}9 \\
10 \\
11 \\
12 \\
13 \\
14 \\
15 \\
16 \\
17\end{array}$ & $\begin{array}{l}0.22 \\
0.30 \\
0.41 \\
0.56 \\
0.75 \\
1.00 \\
1.40 \\
1.90 \\
2.50\end{array}$ & $\begin{array}{r}0 \\
23 \\
20 \\
6 \\
6 \\
19 \\
8 \\
17 \\
10\end{array}$ & $\begin{array}{l}232 \\
232 \\
209 \\
189 \\
183 \\
177 \\
158 \\
150 \\
133\end{array}$ & $\begin{array}{l}3.3 \\
3.3 \\
3.0 \\
2.7 \\
2.6 \\
2.6 \\
2.3 \\
2.2 \\
1.9\end{array}$ & $\begin{array}{l}18 \\
19 \\
20 \\
21 \\
22 \\
23 \\
24 \\
25 \\
26\end{array}$ & $\begin{array}{r}3.4 \\
4.6 \\
6.2 \\
8.4 \\
11.0 \\
15.0 \\
21.0 \\
28.0 \\
38.0\end{array}$ & $\begin{array}{r}14 \\
15 \\
5 \\
14 \\
11 \\
13 \\
11 \\
9 \\
5\end{array}$ & $\begin{array}{r}123 \\
109 \\
94 \\
89 \\
75 \\
64 \\
51 \\
40 \\
31\end{array}$ & $\begin{array}{l}1.8 \\
1.6 \\
1.4 \\
1.3 \\
1.1 \\
0.9 \\
0.7 \\
0.6 \\
0.4\end{array}$ & $\begin{array}{l}27 \\
28 \\
29 \\
30 \\
31 \\
32 \\
33 \\
34\end{array}$ & $\begin{array}{r}52.0 \\
70.0 \\
95.0 \\
130.0 \\
170.0 \\
230.0 \\
320.0 \\
430.0\end{array}$ & $\begin{array}{l}4 \\
6 \\
3 \\
2 \\
3 \\
6 \\
1 \\
1\end{array}$ & $\begin{array}{r}26 \\
22 \\
16 \\
13 \\
11 \\
8 \\
2 \\
1\end{array}$ & $\begin{array}{l}0.4 \\
0.3 \\
0.2 \\
0.2 \\
0.2 \\
0.1 \\
0.0 \\
0.0\end{array}$ \\
\hline
\end{tabular}

MONTHLY MEAN DISCHARGES, IN CUBIC FEET PER SECOND, FOR EACH WATER YEAR

$\begin{array}{lcccccccccccc}\text { YEAR } & \text { OCT } & \text { NOV } & \text { DEC } & \text { JAN } & \text { FEB } & \text { MAR } & \text { APR } & \text { MAY } & \text { JUNE } & \text { JULY } & \text { AUG } & \text { SEP } \\ 1950 & 10.8 & 0.00 & 0.00 & 0.00 & 0.00 & 0.00 & 0.00 & 0.00 & 0.00 & 0.44 & 0.00 & 0.00 \\ 1951 & 0.00 & 0.00 & 0.00 & 0.00 & 0.00 & 0.00 & 0.00 & 0.18 & 0.18 & 0.05 & 16.1 & 0.00 \\ 1952 & 5.31 & 0.00 & 0.00 & 1.27 & 4.43 & 0.00 & 0.00 & 0.00 & 0.00 & 0.90 & 4.44 & 0.99 \\ 1953 & 0.00 & 0.00 & 0.00 & 0.01 & 0.03 & 0.00 & 0.01 & 0.00 & 0.00 & 2.36 & 0.46 & 0.00 \\ 1954 & 2.62 & 1.12 & 0.00 & 0.00 & 0.00 & 0.07 & 0.00 & 0.00 & 0.00 & 0.30 & 0.00 & 3.07 \\ 1955 & 7.62 & 0.00 & 0.00 & 0.00 & 0.00 & 2.16 & 0.00 & 0.00 & 0.00 & 0.00 & 0.31 & 0.03 \\ 1956 & 0.00 & 0.00 & 0.00 & 0.00 & 0.00 & 0.00 & 0.00 & 0.00 & 0.00 & 0.09 & 0.75 & 0.00 \\ 1957 & 0.12 & 0.00 & 0.00 & 0.00 & 0.00 & 0.00 & 0.00 & 0.17 & 0.31 & 0.48 & 19.9 & 0.37 \\ 1958 & 6.19 & 17.7 & 0.03 & 0.01 & 0.04 & 0.04 & 0.00 & 0.00 & 0.00 & 0.00 & 0.98 & 1.02 \\ 1959 & 0.00 & 0.00 & 0.00 & 0.00 & 0.00 & 0.00 & 0.00 & 0.00 & 0.06 & 0.00 & 15.7 & 0.70 \\ 1960 & 2.10 & 0.00 & 0.00 & 0.00 & 0.00 & 0.00 & 0.00 & 0.00 & 0.00 & 0.00 & 0.00 & 0.01 \\ & & & & & & & & & & & & \\ 1961 & 0.66 & 0.00 & 0.00 & 0.01 & 0.07 & 0.00 & 0.00 & 0.01 & 0.00 & 0.18 & 3.51 & 39.4 \\ 1962 & 13.0 & 0.00 & 0.00 & 0.03 & 0.04 & 0.00 & 0.00 & 0.00 & 0.00 & 0.00 & 0.00 & 1.90 \\ 1963 & 0.24 & 0.02 & 0.00 & 0.00 & 0.00 & 0.00 & 0.01 & 0.00 & 0.05 & 0.00 & 1.67 & 0.01 \\ 1964 & 0.79 & 0.00 & 0.00 & 0.00 & 0.00 & 0.00 & 0.27 & 0.01 & 0.00 & 1.03 & 0.38 & 0.00 \\ 1965 & 0.00 & 0.00 & 0.00 & 0.00 & 0.00 & 0.00 & 0.00 & 0.05 & 0.11 & 0.34 & 1.77 & 0.26 \\ 1966 & 1.00 & 0.40 & 0.01 & 0.00 & 0.00 & 0.00 & 0.00 & 0.00 & 0.00 & 0.15 & 1.61 & 4.63 \\ 1967 & 0.00 & 0.00 & 3.13 & 0.00 & 0.00 & 0.00 & 0.00 & 0.00 & 1.98 & 0.39 & 1.61 & 0.02 \\ 1968 & 0.00 & 0.00 & 0.00 & 0.00 & 0.00 & 0.00 & 0.00 & 0.05 & 0.02 & 2.48 & 0.00 & 0.00\end{array}$

ANNUAL PEAK DISCHARGE, IN CUBIC FEET PER SECOND, AND CORRESPONDING GAGE HEIGHT, IN FEET, FOR EACH WATER YEAR

\begin{tabular}{|c|c|c|c|c|c|c|c|c|c|c|c|}
\hline $\begin{array}{l}\text { WATER } \\
\text { YEAR }\end{array}$ & DATE & $\begin{array}{l}\text { GAGE } \\
\text { HEIGHT }\end{array}$ & $\begin{array}{c}\text { PEAK } \\
\text { DISCHARGE }\end{array}$ & $\begin{array}{l}\text { WATER } \\
\text { YEAR }\end{array}$ & DATE & $\begin{array}{c}\text { GAGE } \\
\text { HEIGHT }\end{array}$ & $\begin{array}{c}\text { PEAK } \\
\text { DISCHARGE }\end{array}$ & $\begin{array}{l}\text { WATER } \\
\text { YEAR }\end{array}$ & DATE & $\begin{array}{c}\text { GAGE } \\
\text { HEIGHT }\end{array}$ & $\begin{array}{c}\text { PEAK } \\
\text { DISCHARGE }\end{array}$ \\
\hline $\begin{array}{l}1949 \\
1950 \\
1951 \\
1952 \\
1953 \\
1954 \\
1955\end{array}$ & $\begin{array}{l}\text { AUG. } 09,1949 \\
\text { OCT. } 19,1949 \\
\text { AUG. } 29,1951 \\
\text { AUG. } 26,1952 \\
\text { JULY } 31,11953 \\
\text { SEPT.13, } 1954\end{array}$ & $\begin{array}{l}4.95 \\
3.33 \\
4.45 \\
4.54 \\
3.23 \\
5.34 \\
\end{array}$ & $\begin{array}{r}2400 \\
738 \\
2120 \\
2710 \\
816 \\
2880 \\
5100\end{array}$ & $\begin{array}{l}1956 \\
1957 \\
1958 \\
1959 \\
1961 \\
1962\end{array}$ & $\begin{array}{l}\text { AUG. } 01,1956 \\
\text { AUG. 21, } 1957 \\
\text { NOV. 04, } 1957 \\
\text { AUG. } 19,1959 \\
\text { SEPT. 09, } 1961 \\
\text { OCT. } 08,1961\end{array}$ & $\begin{array}{c}3.10 \\
-- \\
-- \\
13.50 \\
11.90 \\
7.30\end{array}$ & $\begin{array}{r}531 \\
5500 \\
352 \\
5620 \\
4460 \\
1700\end{array}$ & $\begin{array}{l}1963 \\
1964 \\
1965 \\
1966 \\
1967 \\
1968\end{array}$ & $\begin{array}{l}\text { AUG. } 09,1963 \\
\text { JULY } 31,1964 \\
\text { AUG. } 02,1965 \\
\text { SEPT.01, } 1966 \\
\text { JUNE 20, } 1967 \\
\text { JULY } 27,1968\end{array}$ & $\begin{array}{r}7.60 \\
9.40 \\
10.50 \\
12.30 \\
14.00 \\
13.50\end{array}$ & $\begin{array}{r}767 \\
1680 \\
470 \\
1160 \\
2070 \\
5500\end{array}$ \\
\hline
\end{tabular}

MAGNITUDE AND PRABABIITTY OF ANNUAL LOWEST MEAN DISCHARGE BASED ON CIIMATIC YEARS $1951-68$

\begin{tabular}{|c|c|c|c|c|c|c|}
\hline \multirow{2}{*}{$\begin{array}{l}\text { PERIOD } \\
\text { (CON- } \\
\text { SECU- } \\
\text { TIVE } \\
\text { DAYS) }\end{array}$} & \multicolumn{6}{|c|}{$\begin{array}{l}\text { DISCHARGE, IN OUBIC FEET PER SECOND, FOR } \\
\text { INDICATED REOURR NCE INTERNAL, IN YEARS, AND } \\
\text { ANNUAL NONEXCEEDANCE PRCBABIIITY, IN PERCENT }\end{array}$} \\
\hline & $\begin{array}{c}2 \\
508\end{array}$ & $\begin{array}{c}5 \\
208\end{array}$ & $\begin{array}{l}10 \\
108\end{array}$ & $\begin{array}{l}20 \\
58\end{array}$ & $\begin{array}{l}50 \\
28\end{array}$ & $\begin{array}{r}100 \\
18\end{array}$ \\
\hline 1 & 0.00 & - & - & - & - & - \\
\hline 7 & 0.00 & - & - & - & - & -- \\
\hline 14 & 0.00 & - & - & - & - & - \\
\hline 30 & 0.00 & - & - & - & - & -- \\
\hline 60 & 0.00 & - & - & - & - & - \\
\hline 90 & 0.00 & - & - & - & -- & - \\
\hline
\end{tabular}


GREEN RIVER BASIN

09317000 BQULGER CREEK NEAR FAIRVIEW, UT

LOCATION.--Lat 3993.00", long $111^{9} 9^{\prime} 00^{\prime \prime}$, in $\mathrm{NW}_{4}^{\frac{1}{4}}$ sec.4, T. 14 S., R. 6 E., Carbon County, Hydrologic Unit 14060009, 2 mi upstream from mouth and 9.5 mi east of Fairview.

DRAINAGE AREA $-1.9 \mathrm{mi}^{2}$.

PERIOD OF RECORD AVAILABLE. --June 1938 to September 1949. Records of discharge at about same site available in office of State Engineer of Utah for periods April to September 1928, May to September 1929, and April to August 1931. No winter record, water years 1939, 1942.

GAGE.--water-stage recorder. Al titude of gage is $8,900 \mathrm{ft}$ from topographic map.

REMARKS.--Diversion by Fairview ditch above station to Gooseberry Creek basin from which flow is rediverted to sevier River basin for irrigation.

AVERAGE DISCHARGE. --9 years (water years $1940-41,1943-49$ ), $3.86 \mathrm{ft}^{3} / \mathrm{s}, 2,790 \mathrm{acre}-\mathrm{ft} / \mathrm{yr}$.

EXTREMES FOR PERIOD OF RECORD.--Maximum discharge, $85 \mathrm{ft}^{3} / \mathrm{s}$ May 18, 1948, gage height, $2.42 \mathrm{ft}$; minimum not determined, $\propto$ ccurred during period of ice effect.

LOWEST MEAN DISCHARGE, IN CBBIC FEET PER SECOND, AND RANKING FOR THE INDICATED NUMBER OF CONSECITIVE DAYS FOR EACH OLIMATIC YEAR, APRIL 1-MAROH 31

\begin{tabular}{|c|c|c|c|c|c|c|c|c|c|c|c|c|c|c|c|c|c|c|c|}
\hline \multirow[t]{2}{*}{ YEAR } & \multirow{2}{*}{\multicolumn{2}{|c|}{1}} & \multirow{2}{*}{\multicolumn{2}{|c|}{3}} & \multirow{2}{*}{\multicolumn{2}{|c|}{7}} & \multirow{2}{*}{\multicolumn{2}{|c|}{14}} & \multicolumn{4}{|c|}{ CONSEQTTVE DAYS } & \multirow{2}{*}{\multicolumn{2}{|c|}{90}} & \multirow{2}{*}{\multicolumn{2}{|c|}{120}} & \multirow{2}{*}{\multicolumn{2}{|c|}{183}} & \multirow[b]{2}{*}{ ALL } \\
\hline & & & & & & & & & 30 & & 60 & & & & & & & & \\
\hline 1941 & 1.00 & 7 & 1.00 & 7 & 1.00 & 7 & 1.00 & 7 & 1.00 & 7 & 1.00 & 7 & 1.00 & 7 & 1.00 & 6 & 1.00 & 5 & 3.50 \\
\hline $\begin{array}{l}1946 \\
1947 \\
1948 \\
1949\end{array}$ & $\begin{array}{l}1.00 \\
0.40 \\
0.40 \\
0.50\end{array}$ & $\begin{array}{l}6 \\
1 \\
2 \\
3\end{array}$ & $\begin{array}{l}1.00 \\
0.40 \\
0.40 \\
0.50\end{array}$ & $\begin{array}{l}6 \\
1 \\
2 \\
3\end{array}$ & $\begin{array}{l}1.00 \\
0.40 \\
0.40 \\
0.50\end{array}$ & $\begin{array}{l}6 \\
1 \\
2 \\
3\end{array}$ & $\begin{array}{l}1.00 \\
0.40 \\
0.48 \\
0.50\end{array}$ & $\begin{array}{l}6 \\
1 \\
2 \\
3\end{array}$ & $\begin{array}{l}1.00 \\
0.40 \\
0.50 \\
0.50\end{array}$ & $\begin{array}{l}6 \\
1 \\
2 \\
3\end{array}$ & $\begin{array}{l}1.00 \\
0.40 \\
0.50 \\
0.50\end{array}$ & $\begin{array}{l}6 \\
1 \\
2 \\
3\end{array}$ & $\begin{array}{l}1.00 \\
0.43 \\
0.51 \\
0.53\end{array}$ & $\begin{array}{l}6 \\
1 \\
2 \\
3\end{array}$ & $\begin{array}{l}1.10 \\
0.48 \\
0.56 \\
0.56\end{array}$ & $\begin{array}{l}7 \\
1 \\
2 \\
3\end{array}$ & $\begin{array}{l}1.10 \\
0.74 \\
0.79 \\
0.70\end{array}$ & $\begin{array}{l}6 \\
2 \\
3 \\
1\end{array}$ & $\begin{array}{l}4.00 \\
3.30 \\
3.70 \\
2.90\end{array}$ \\
\hline
\end{tabular}

HIGHEST MEAN DISGHARGE, IN OUBIC FEET PER SECOND, AND RANKING FOR THE INDICATED NUMBER OF CONSECUTIVE DAYS FOR EACH WATER YEAR, OCTOBER 1-SEPTEMBER 30

\begin{tabular}{|c|c|c|c|c|c|c|c|c|c|c|c|c|c|c|c|c|c|c|c|}
\hline YEAR & & & & & & & & & cons & WT. & $E$ DAYS & & & & & & & & \\
\hline 1940 & 50.0 & 3 & 47.0 & 3 & 42.0 & 3 & 35.0 & 1 & 25,0 & 3 & 15.0 & 6 & 11.0 & 6 & 8.60 & 7 & 6.00 & 7 & 3.50 \\
\hline $\begin{array}{l}1943 \\
1944 \\
1945\end{array}$ & $\begin{array}{l}34.0 \\
48.0 \\
26.0\end{array}$ & $\begin{array}{l}6 \\
4 \\
8\end{array}$ & $\begin{array}{l}27.0 \\
46.0 \\
25.0\end{array}$ & $\begin{array}{l}7 \\
4 \\
8\end{array}$ & $\begin{array}{l}23.0 \\
39.0 \\
23.0\end{array}$ & $\begin{array}{l}7 \\
4 \\
8\end{array}$ & $\begin{array}{l}19.0 \\
32.0 \\
21.0\end{array}$ & $\begin{array}{l}9 \\
3 \\
7\end{array}$ & $\begin{array}{l}15.0 \\
27.0 \\
19.0\end{array}$ & $\begin{array}{l}9 \\
2 \\
7\end{array}$ & $\begin{array}{l}14.0 \\
18.0 \\
16.0\end{array}$ & $\begin{array}{l}7 \\
2 \\
3\end{array}$ & $\begin{array}{l}11.0 \\
13.0 \\
12.0\end{array}$ & $\begin{array}{l}7 \\
2 \\
3\end{array}$ & $\begin{array}{c}9.10 \\
10.0 \\
9.60\end{array}$ & 4 & $\begin{array}{l}6.50 \\
7.10 \\
6.80\end{array}$ & $\begin{array}{l}6 \\
2 \\
4\end{array}$ & $\begin{array}{l}3.80 \\
4.00 \\
4.00\end{array}$ \\
\hline
\end{tabular}

DURATION OF DISCHARGE FOR EACH WATER YEAR

\begin{tabular}{|c|c|c|c|c|c|c|c|c|c|c|c|c|c|c|c|c|c|c|c|c|c|c|c|c|c|c|c|c|c|c|c|c|c|c|c|c|}
\hline $\begin{array}{l}\text { C.ASS } \\
\text { YEAR }\end{array}$ & 1 & 2 & 3 & 4 & 5 & 7 & 8 & & 10 & 11 & 12 & 2 & 13 & $\begin{array}{l}14 \\
\text { UNBE }\end{array}$ & & & & IN & CAS & & 20 & 21 & 22 & 23 & 24 & 2526 & & & 28 & 29 & 30 & 31 & & & 34 & $\begin{array}{l}\text { CUBIC FEET } \\
\text { PER SECOND } \\
\text {-DAYS }\end{array}$ \\
\hline 1940 & & & & & & 250 & & & & 40 & & & & 14 & & 12 & & 7 & & 5 & 7 & 2 & 2 & 5 & 1 & 3 & 1 & 3 & 2 & 2 & 3 & 3 & 3 & 1 & & 1280.0 \\
\hline 1941 & & & & & & 216 & & & & 60 & & & & 7 & & 7 & & 4 & & 2 & 5 & & 3 & 3 & 3 & 2 & 4 & & 30 & 5 & 2 & 2 & 2 & & 1 & 2010.0 \\
\hline $\begin{array}{l}1943 \\
1944 \\
1945\end{array}$ & & & & 3952 & 23 & $\begin{array}{r}198 \\
662 \\
121\end{array}$ & $\begin{array}{r}3 \\
24\end{array}$ & $\begin{array}{r}68 \\
90\end{array}$ & $\begin{array}{r}5 \\
13\end{array}$ & 16 & & $\begin{array}{l}4 \\
7\end{array}$ & $\begin{array}{l}4 \\
7\end{array}$ & $\begin{array}{r}20 \\
2 \\
10\end{array}$ & $\begin{array}{l}9 \\
8\end{array}$ & $\begin{array}{r}15 \\
5 \\
5\end{array}$ & & $\begin{array}{l}5 \\
4 \\
3\end{array}$ & $\begin{array}{l}3 \\
4\end{array}$ & $\begin{array}{l}5 \\
1 \\
6\end{array}$ & $\begin{array}{r}12 \\
3 \\
5\end{array}$ & $\begin{array}{l}7 \\
3 \\
2\end{array}$ & $\begin{array}{l}4 \\
4 \\
2\end{array}$ & $\begin{array}{l}8 \\
7 \\
3 \\
3\end{array}$ & $\begin{array}{l}8 \\
4 \\
9\end{array}$ & $\begin{array}{l}9 \\
3 \\
8\end{array}$ & $\begin{array}{r}9 \\
5 \\
13\end{array}$ & $\begin{array}{l}2 \\
4 \\
8\end{array}$ & $\begin{array}{l}2 \\
8 \\
8\end{array}$ & $\begin{array}{l}3 \\
6\end{array}$ & $\begin{array}{l}1 \\
2\end{array}$ & 1 & 3 & & & $\begin{array}{l}1384.0 \\
1478.2 \\
1458.8\end{array}$ \\
\hline $\begin{array}{l}1946 \\
1947 \\
1948 \\
1949\end{array}$ & $\begin{array}{r}673 \\
9 \\
6\end{array}$ & $\begin{array}{ll}35 & 2 \\
91 & 2 \\
66 & 4\end{array}$ & & $\begin{array}{ll}1 & 10 \\
2 & 23 \\
23 & 8\end{array}$ & $\begin{array}{ll}0 & 1 \\
3 \\
8\end{array}$ & $\begin{array}{l}158 \\
4 \quad 27 \\
454 \\
360\end{array}$ & $\begin{array}{r}58 \\
13 \\
19 \\
2\end{array}$ & $\begin{array}{l}26 \\
41 \\
47 \\
29\end{array}$ & $\begin{array}{l}6 \\
5 \\
8 \\
6\end{array}$ & $\begin{array}{l}11 \\
14 \\
11 \\
10\end{array}$ & & $\begin{array}{r}13 \\
5 \\
4 \\
16\end{array}$ & $\begin{array}{r}6 \\
10 \\
6 \\
9\end{array}$ & $\begin{array}{r}10 \\
12 \\
4 \\
2\end{array}$ & $\begin{array}{l}6 \\
6 \\
6 \\
5\end{array}$ & 5 & & $\begin{array}{l}3 \\
7 \\
3 \\
9\end{array}$ & $\begin{array}{l}3 \\
3 \\
6 \\
6\end{array}$ & $\begin{array}{l}2 \\
4 \\
2 \\
5\end{array}$ & $\begin{array}{l}5 \\
6 \\
8 \\
7\end{array}$ & $\begin{array}{l}3 \\
9 \\
7 \\
4\end{array}$ & $\begin{array}{l}8 \\
6 \\
5 \\
3\end{array}$ & $\begin{array}{r}10 \\
3 \\
5 \\
3 \\
3\end{array}$ & $\begin{array}{r}13 \\
6 \\
1 \\
4\end{array}$ & $\begin{array}{ll}5 & 7 \\
2 & 7 \\
3 & 1 \\
4 & 13\end{array}$ & $\begin{array}{r}7 \\
7 \\
1 \\
13\end{array}$ & $\begin{array}{l}2 \\
4 \\
1 \\
9\end{array}$ & $\begin{array}{l}5 \\
6 \\
1 \\
7\end{array}$ & $\begin{array}{l}3 \\
1 \\
4\end{array}$ & $\begin{array}{l}2 \\
3\end{array}$ & $\begin{array}{l}2 \\
1\end{array}$ & 1 & 1 & 1 & $\begin{array}{l}1260.8 \\
1338.3 \\
1092.2 \\
1395.3\end{array}$ \\
\hline
\end{tabular}


GREEN RIVER BASIN

09317000 BOULGER CREEK NEAR FAIRVIEW, UT—Continued

DURATION TABLE OF DISGHARGE FOR WATER YEARS 1940-41, 1943-49

\begin{tabular}{|c|c|c|c|c|c|c|c|c|c|c|c|c|c|c|c|c|c|c|c|}
\hline LASS & $\begin{array}{c}\text { OBIIC } \\
\text { FEET } \\
\text { PER } \\
\text { SECOND }\end{array}$ & $\begin{array}{l}\text { TOTAL } \\
\text { DAYS }\end{array}$ & $\begin{array}{c}\text { ACQI- } \\
\text { MU- } \\
\text { LATED } \\
\text { DAYS }\end{array}$ & $\begin{array}{l}\text { PER- } \\
\text { CENT } \\
\text { DAYS }\end{array}$ & CASS & $\begin{array}{c}\text { GBIC } \\
\text { FEET } \\
\text { PER } \\
\text { SECOND }\end{array}$ & $\begin{array}{l}\text { TOTAL } \\
\text { DAYS }\end{array}$ & $\begin{array}{l}\text { ACU- } \\
\text { MU- } \\
\text { LATED } \\
\text { DAYS }\end{array}$ & $\begin{array}{l}\text { PER- } \\
\text { CENT } \\
\text { DAYS }\end{array}$ & CUASS & $\begin{array}{c}\text { CBIC } \\
\text { FEET } \\
\text { PER } \\
\text { SECOND }\end{array}$ & $\begin{array}{r}\text { TOTAL } \\
\text { DAYS }\end{array}$ & $\begin{array}{l}\text { ACU- } \\
\text { MU- } \\
\text { LATED } \\
\text { DAYS }\end{array}$ & $\begin{array}{l}\text { PER } \\
\text { CENT } \\
\text { DAYS }\end{array}$ & & $\begin{array}{c}\text { QBIC } \\
\text { FEET } \\
\text { PER } \\
\text { SECOND }\end{array}$ & $\begin{array}{l}\text { TOTAL } \\
\text { DAYS }\end{array}$ & $\begin{array}{l}\text { ACQU- } \\
\text { MU- } \\
\text { LATED } \\
\text { DAYS }\end{array}$ & $\begin{array}{l}\text { PER- } \\
\text { CENT } \\
\text { DAYS }\end{array}$ \\
\hline $\begin{array}{l}0 \\
1 \\
2 \\
3 \\
4 \\
5 \\
6 \\
7 \\
8\end{array}$ & $\begin{array}{l}0.00 \\
0.40 \\
0.47 \\
0.54 \\
0.63 \\
0.73 \\
0.85 \\
0.99 \\
1.20\end{array}$ & $\begin{array}{r}0 \\
67 \\
192 \\
95 \\
65 \\
93 \\
57 \\
1146 \\
119\end{array}$ & $\begin{array}{l}3288 \\
3288 \\
3221 \\
3029 \\
2934 \\
2869 \\
2776 \\
2719 \\
1573\end{array}$ & $\begin{array}{r}100.0 \\
100.0 \\
98.0 \\
92.1 \\
89.2 \\
87.3 \\
84.4 \\
82.7 \\
47.8\end{array}$ & $\begin{array}{l}9 \\
10 \\
11 \\
12 \\
13 \\
14 \\
15 \\
16 \\
17\end{array}$ & $\begin{array}{l}1.30 \\
1.60 \\
1.80 \\
2.10 \\
2.40 \\
2.80 \\
3.30 \\
3.80 \\
4.50\end{array}$ & $\begin{array}{r}301 \\
43 \\
228 \\
49 \\
42 \\
81 \\
40 \\
74 \\
45\end{array}$ & $\begin{array}{r}1454 \\
1153 \\
1110 \\
882 \\
833 \\
791 \\
710 \\
670 \\
596\end{array}$ & $\begin{array}{l}44.2 \\
35.1 \\
33.8 \\
26.8 \\
25.3 \\
24.1 \\
21.6 \\
20.4 \\
18.1\end{array}$ & $\begin{array}{l}18 \\
19 \\
20 \\
21 \\
22 \\
23 \\
24 \\
25 \\
26\end{array}$ & $\begin{array}{r}5.2 \\
6.0 \\
7.0 \\
8.2 \\
9.5 \\
11.0 \\
13.0 \\
15.0 \\
17.0\end{array}$ & $\begin{array}{l}25 \\
32 \\
58 \\
37 \\
37 \\
46 \\
49 \\
39 \\
60\end{array}$ & $\begin{array}{l}551 \\
526 \\
494 \\
436 \\
399 \\
362 \\
316 \\
267 \\
228\end{array}$ & $\begin{array}{r}16.8 \\
16.0 \\
15.0 \\
13.3 \\
12.1 \\
11.0 \\
9.6 \\
8.1 \\
6.9\end{array}$ & $\begin{array}{l}27 \\
28 \\
29 \\
30 \\
31 \\
32 \\
33 \\
34\end{array}$ & $\begin{array}{l}20.0 \\
23.0 \\
27.0 \\
32.0 \\
37.0 \\
43.0 \\
50.0 \\
58.0\end{array}$ & $\begin{array}{r}40 \\
69 \\
24 \\
13 \\
9 \\
9 \\
2 \\
2\end{array}$ & $\begin{array}{r}168 \\
128 \\
59 \\
35 \\
22 \\
13 \\
4 \\
2\end{array}$ & $\begin{array}{l}5.1 \\
3.9 \\
1.8 \\
1.1 \\
0.7 \\
0.4 \\
0.1 \\
0.1\end{array}$ \\
\hline
\end{tabular}

MONTHLY MEAN DISCHARGES, IN OBIC FEET PER SECOND, FOR EAOH WATER YEAR

\begin{tabular}{|c|c|c|c|c|c|c|c|c|c|c|c|c|}
\hline YEAR & $\mathrm{OCT}$ & NOV & DEC & JAN & FEB & MAR & APR & MAY & JUNE & JULY & AUG & SEP \\
\hline 1940 & 1.19 & 1.00 & 1.00 & 1.00 & 1.00 & 1.00 & 2.87 & 22.9 & 5.53 & 2.10 & 1.00 & 1.10 \\
\hline 1941 & 1.00 & 1.00 & 1.00 & 1.00 & 1.00 & 1.00 & 7.30 & 29.2 & 17.5 & 2.90 & 1.58 & 1.30 \\
\hline $\begin{array}{l}1943 \\
1944 \\
1945\end{array}$ & $\begin{array}{l}1.13 \\
1.38 \\
1.37\end{array}$ & $\begin{array}{l}1.00 \\
1.10 \\
1.44\end{array}$ & $\begin{array}{l}1.00 \\
1.00 \\
1.00\end{array}$ & $\begin{array}{l}1.00 \\
0.90 \\
1.00\end{array}$ & $\begin{array}{l}1.00 \\
0.80 \\
1.10\end{array}$ & $\begin{array}{l}1.16 \\
0.70 \\
1.10\end{array}$ & $\begin{array}{l}7.57 \\
0.77 \\
1.50\end{array}$ & $\begin{array}{l}13.4 \\
14.5 \\
15.2\end{array}$ & $\begin{array}{l}12.1 \\
20.1 \\
16.0\end{array}$ & $\begin{array}{l}2.90 \\
4.21 \\
4.51\end{array}$ & $\begin{array}{l}2.06 \\
1.70 \\
2.11\end{array}$ & $\begin{array}{l}1.17 \\
1.31 \\
1.48\end{array}$ \\
\hline $\begin{array}{l}1946 \\
1947 \\
1948 \\
1949\end{array}$ & $\begin{array}{l}1.30 \\
1.46 \\
1.44 \\
1.03\end{array}$ & $\begin{array}{l}1.20 \\
0.95 \\
1.03 \\
0.95\end{array}$ & $\begin{array}{l}1.10 \\
0.64 \\
0.71 \\
0.58\end{array}$ & $\begin{array}{l}1.00 \\
0.50 \\
0.53 \\
0.50\end{array}$ & $\begin{array}{l}1.00 \\
0.40 \\
0.50 \\
0.50\end{array}$ & $\begin{array}{l}1.10 \\
0.40 \\
0.50 \\
0.65\end{array}$ & $\begin{array}{l}5.68 \\
1.46 \\
2.04 \\
2.56\end{array}$ & $\begin{array}{l}16.2 \\
21.9 \\
19.5 \\
17.5\end{array}$ & $\begin{array}{c}7.61 \\
8.99 \\
5.44 \\
14.7\end{array}$ & $\begin{array}{l}2.36 \\
3.73 \\
1.73 \\
3.62\end{array}$ & $\begin{array}{l}1.45 \\
2.00 \\
1.15 \\
1.77\end{array}$ & $\begin{array}{l}1.33 \\
1.21 \\
1.01 \\
1.25\end{array}$ \\
\hline
\end{tabular}

ANNUA PEAK DISCHARCE, IN OUIC FEET PER SECOND, AND CORRESPONDING GAGE HEIGHT, IN FEET, FOR EACH WATER YEAR

\begin{tabular}{|c|c|c|c|c|c|c|c|c|c|c|c|c|c|c|}
\hline $\begin{array}{l}\text { WATER } \\
\text { YEAR }\end{array}$ & & ATE & $\begin{array}{c}\text { GAGE } \\
\text { HEIGHT }\end{array}$ & $\begin{array}{c}\text { PEAK } \\
\text { DISCH ARCE }\end{array}$ & $\begin{array}{l}\text { WATER } \\
\text { YEAR }\end{array}$ & & ATE & $\begin{array}{c}\text { GAGE } \\
\text { HEIGHT }\end{array}$ & $\begin{array}{c}\text { PEAK } \\
\text { DISCHARGE }\end{array}$ & $\begin{array}{l}\text { WATER } \\
\text { YEAR }\end{array}$ & & ATE & $\begin{array}{c}\text { GAGE } \\
\text { HEIGHT }\end{array}$ & $\begin{array}{c}\text { PEAK } \\
\text { DISCHARCE }\end{array}$ \\
\hline 1938 & MAY & 27,1938 & -- & $1_{47}$ & 1943 & JUNE & 01,1943 & 2.10 & 68 & 1947 & & 2 & - & 45 \\
\hline $\begin{array}{l}1939 \\
1940\end{array}$ & $\begin{array}{l}\text { MAY } \\
\text { MAY }\end{array}$ & $\begin{array}{ll}09, & 1939 \\
16, & 1940\end{array}$ & $\overline{2.11}$ & $\begin{array}{r}122 \\
69\end{array}$ & $\begin{array}{l}1944 \\
1945\end{array}$ & $\begin{array}{l}\text { MAY } \\
\text { MAY }\end{array}$ & $\begin{array}{ll}31, & 1944 \\
28, & 1945\end{array}$ & $\begin{array}{l}2.11 \\
1.86\end{array}$ & $\begin{array}{l}61 \\
36\end{array}$ & $\begin{array}{l}1948 \\
1949\end{array}$ & $\begin{array}{l}\text { MAY } \\
\text { MAY }\end{array}$ & $\begin{array}{l}18,1948 \\
17,1949\end{array}$ & $\begin{array}{l}2.42 \\
1.97\end{array}$ & $\begin{array}{l}85 \\
34\end{array}$ \\
\hline 1941 & MAY & 27,1941 & - & ${ }^{1} 60$ & 1946 & MAY & 08,1946 & 1.82 & 33 & & & & & \\
\hline
\end{tabular}

${ }^{1}$ Maximum daily discharge.

2 Between May 1 and $15,1947$.

09317919 CRANDALL CANYON AT MOUTH, NEAR HUNTTNGTON, UT

LOCATION,--Lat $39^{\circ} 27^{\prime} 48^{\prime \prime}$, lang $111^{\circ} 08^{\prime} 54^{\prime \prime}$, in SW $\frac{1}{4} W^{\frac{1}{4}}$ sec.4, T.16 S., R.7 E., Emery County, Hydrologic unit 14060009 , on right bank $0.1 \mathrm{mi}$ from Highway 31 and $15.5 \mathrm{mi}$ northwest of Huntington.

DRAINAGE AREA, $--5.7 \mathrm{mi}^{2}$.

PERIOD OF RECORD AVAILABLE.--October 1977 to September 1981. No winter record 1978, 1980-81 water years.

GAGE. -Water-stage recorder. Altitude of gage is 7,350 ft.

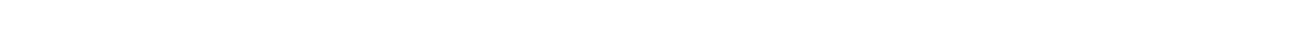

HIGHEST MEAN DISCHARGE, IN OUBIC FEET PER SECOND, AND RANKING FOR THE INDICATED NUMBER OF CONSEQUTIVE DAYS FOR EACH WATER YEAR, OCTOBER 1-SEPTEMBER 30

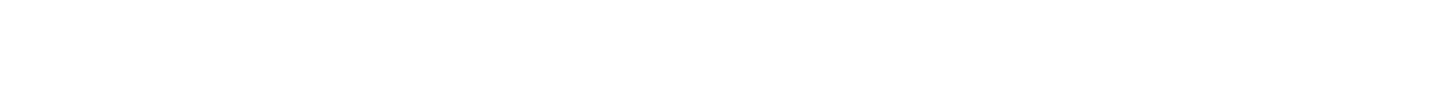

DURATION OF DISCHARCE FOR EACH WATER YEAR

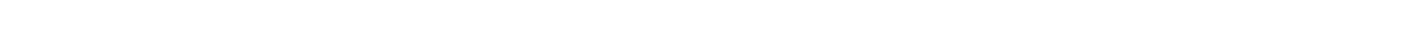
YEAR

NUMBER OF DAYS IN $O A S S$

ABIC FEET PER SECOND 
GREEN RIVER BASIN

09317919 CRANDALL CANYON AT MOUTH, NEAR HUNTINGTON, UT-Continued

DURATION TABLE OF DISCHARGE FOR WATER YEAR 1979

\begin{tabular}{|c|c|c|c|c|c|c|c|c|c|c|c|c|c|c|c|c|c|c|c|}
\hline C.ASS & $\begin{array}{c}\text { OUBIC } \\
\text { FEET } \\
\text { PER } \\
\text { SECOND }\end{array}$ & $\begin{array}{r}\text { TOTAL } \\
\text { DAYS }\end{array}$ & $\begin{array}{c}\text { ACOU- } \\
\text { MU- } \\
\text { LATED } \\
\text { DAYS }\end{array}$ & $\begin{array}{l}\text { PER- } \\
\text { CENT } \\
\text { DAYS }\end{array}$ & GASS & $\begin{array}{c}\text { OUBIC } \\
\text { FEET } \\
\text { PER } \\
\text { SECOND }\end{array}$ & $\begin{array}{r}\text { TOTAL } \\
\text { DAYS }\end{array}$ & $\begin{array}{c}\text { ACOJ- } \\
\text { MU- } \\
\text { LATED } \\
\text { DAYS }\end{array}$ & $\begin{array}{l}\text { PER- } \\
\text { CENT } \\
\text { DAYS }\end{array}$ & & $\begin{array}{c}\text { OUBIC } \\
\text { FEET } \\
\text { PER } \\
\text { SECOND }\end{array}$ & $\begin{array}{r}\text { TOTAL, } \\
\text { DAYS }\end{array}$ & $\begin{array}{c}\text { ACOU- } \\
\text { MU- } \\
\text { LATED } \\
\text { DAYS }\end{array}$ & $\begin{array}{l}\text { PER- } \\
\text { CENT } \\
\text { DAYS }\end{array}$ & CLASS & $\begin{array}{c}\text { OABIC } \\
\text { FEET } \\
\text { PER } \\
\text { SECOND }\end{array}$ & $\begin{array}{r}\text { TOTAL } \\
\text { DAYS }\end{array}$ & $\begin{array}{c}\text { ACOJ- } \\
\text { MU- } \\
\text { LATED } \\
\text { DAYS }\end{array}$ & $\begin{array}{l}\text { PER- } \\
\text { CENI } \\
\text { DAYS }\end{array}$ \\
\hline $\begin{array}{l}0 \\
1 \\
2 \\
3 \\
4 \\
5 \\
6 \\
7 \\
8\end{array}$ & $\begin{array}{l}0.00 \\
0.01 \\
0.02 \\
0.03 \\
0.04 \\
0.05 \\
0.07 \\
0.09 \\
0.11\end{array}$ & $\begin{array}{l}0 \\
0 \\
0 \\
0 \\
0 \\
0 \\
0 \\
0 \\
0\end{array}$ & $\begin{array}{l}365 \\
365 \\
365 \\
365 \\
365 \\
365 \\
365 \\
365 \\
365\end{array}$ & $\begin{array}{l}100.0 \\
100.0 \\
100.0 \\
100.0 \\
100.0 \\
100.0 \\
100.0 \\
100.0 \\
100.0\end{array}$ & $\begin{array}{r}9 \\
10 \\
11 \\
12 \\
13 \\
14 \\
15 \\
16 \\
17\end{array}$ & $\begin{array}{l}0.14 \\
0.2 \\
0.23 \\
0.29 \\
0.36 \\
0.46 \\
0.59 \\
0.74 \\
0.95\end{array}$ & $\begin{array}{r}2 \\
0 \\
0 \\
0 \\
33 \\
128 \\
35 \\
30 \\
23\end{array}$ & $\begin{array}{l}365 \\
365 \\
365 \\
365 \\
365 \\
332 \\
204 \\
169 \\
139\end{array}$ & $\begin{array}{r}100.0 \\
100.0 \\
100.0 \\
100.0 \\
100.0 \\
91.0 \\
55.9 \\
46.3 \\
38.1\end{array}$ & $\begin{array}{l}18 \\
19 \\
20 \\
21 \\
22 \\
23 \\
24 \\
25 \\
26\end{array}$ & $\begin{array}{l}1.2 \\
1.5 \\
1.9 \\
2.5 \\
3.1 \\
4.0 \\
5.1 \\
6.4 \\
8.2\end{array}$ & $\begin{array}{r}18 \\
19 \\
10 \\
12 \\
9 \\
5 \\
4 \\
5 \\
6\end{array}$ & $\begin{array}{r}116 \\
98 \\
79 \\
69 \\
57 \\
48 \\
43 \\
39 \\
34\end{array}$ & $\begin{array}{r}31.8 \\
26.8 \\
21.6 \\
18.9 \\
15.6 \\
13.2 \\
11.8 \\
10.7 \\
9.3\end{array}$ & $\begin{array}{l}27 \\
28 \\
29 \\
30 \\
31 \\
32 \\
33 \\
34\end{array}$ & $\begin{array}{l}10.0 \\
13.0 \\
17.0\end{array}$ & $\begin{array}{r}13 \\
11 \\
4\end{array}$ & $\begin{array}{r}28 \\
15 \\
4\end{array}$ & $\begin{array}{l}7.7 \\
4.1 \\
1.1\end{array}$ \\
\hline
\end{tabular}

MONIHLY MEAN DISCHARGES, IN CUBIC FEET PER SECOND, FOR EACH WATER YEAR

$\begin{array}{lllllllllllll}\text { YEAR } & \text { OCT } & \text { NOT } & \text { DEC } & \text { JAN } & \text { FEB } & \text { MAR } & \text { APR } & \text { MAY } & \text { JUNE } & \text { JULY } & \text { AUG } & \text { SEP } \\ 1979 & 0.41 & 0.50 & 0.50 & 0.55 & 0.54 & 0.63 & 1.35 & 8.19 & 9.71 & 2.19 & 1.05 & 0.66\end{array}$

09317920 TIE FORK CANYON NEAR HUNTINGTON, UT

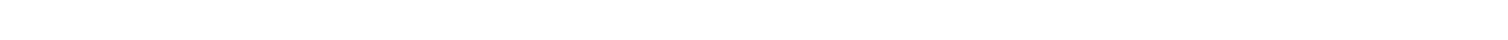
$0.4 \mathrm{mi}$ upstream from mouth, $0.4 \mathrm{mi}$ from State Highway 31 , and $15 \mathrm{mi}$ northwest of Huntington.

DRAINAGE AREA. $--11.7 \mathrm{mi}^{2}$.

PERIOD OF RECORD AVAILABLE.--October 1977 to September 1981. No winter record 1978, 1980-81 water years.

GAGE. - Water-stage recorder. Altitude of gage is 7,400 ft from topographic map.

EXIREMES FOR PERIOD OF RECORD.--Maximum daily discharge, $21 \mathrm{ft}^{3} / \mathrm{s}$ May $26,27,1979$; minimu, $0.17 \mathrm{ft}{ }^{3} / \mathrm{s} \mathrm{March} 10,1979$.

HIGHEST MEAN DISCHARGE, IN CUBIC FEET PER SECOND, AND RANKING FOR THE INDICATED NUMBER OF CONSECUTIVE DAYS FOR EACH WATER YEAR, OCTCBER 1-SEPTEMBER 30

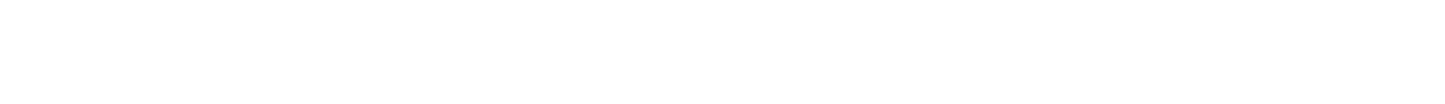

DURATION OF DISCHARGE FOR EACH WATER YEAR

CLASS $\begin{array}{llllllllllllllllllllllllllllllllllll} & 0 & 1 & 2 & 3 & 4 & 5 & 6 & 7 & 8 & 9 & 10 & 11 & 12 & 13 & 14 & 15 & 16 & 17 & 18 & 19 & 20 & 21 & 22 & 23 & 24 & 25 & 26 & 27 & 28 & 29 & 30 & 31 & 32 & 33 & 34\end{array}$ YEAR NUMBER OF DAYS IN CLASS GBIC FEET

1979

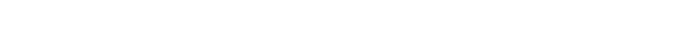
PER SECOND -DAYS DURATION TABLE OF DISCHARGE FOR WATER YEAR 1979

\begin{tabular}{|c|c|c|c|c|c|c|c|c|c|c|c|c|c|c|c|c|c|c|c|}
\hline CLASS & $\begin{array}{c}\text { OABIC } \\
\text { FEET } \\
\text { PER } \\
\text { SECOND }\end{array}$ & $\begin{array}{r}\text { TOTAL } \\
\text { DAYS }\end{array}$ & $\begin{array}{l}\text { ACOJ- } \\
\text { MU- } \\
\text { LATED } \\
\text { DAYS }\end{array}$ & $\begin{array}{l}\text { PER- } \\
\text { CENI } \\
\text { DAYS }\end{array}$ & C.ASS & $\begin{array}{c}\text { OUBIC } \\
\text { FEET } \\
\text { PER } \\
\text { SECOND }\end{array}$ & $\begin{array}{r}\text { TOTAL } \\
\text { DAYS }\end{array}$ & $\begin{array}{l}\text { ACOU- } \\
\text { MU- } \\
\text { LATED } \\
\text { DAYS }\end{array}$ & $\begin{array}{l}\text { PER- } \\
\text { CENI } \\
\text { DAYS }\end{array}$ & C.ASS & $\begin{array}{c}\text { QUBIC } \\
\text { FEET } \\
\text { PER } \\
\text { SECOND }\end{array}$ & $\begin{array}{l}\text { TOTAL } \\
\text { DAYS }\end{array}$ & $\begin{array}{c}\text { ACOU- } \\
\text { MU- } \\
\text { LATED } \\
\text { DAYS }\end{array}$ & $\begin{array}{l}\text { PER- } \\
\text { CENT } \\
\text { DAYS }\end{array}$ & & $\begin{array}{c}\text { OUBIC } \\
\text { FEET } \\
\text { PER } \\
\text { SECOND }\end{array}$ & $\begin{array}{r}\text { TOTAL } \\
\text { DAYS }\end{array}$ & $\begin{array}{c}\text { ACCJ- } \\
\text { MU- } \\
\text { LATED } \\
\text { DAYS }\end{array}$ & $\begin{array}{l}\text { PER- } \\
\text { CENT } \\
\text { DAYS }\end{array}$ \\
\hline $\begin{array}{l}0 \\
1 \\
2 \\
3 \\
4 \\
5 \\
6 \\
7 \\
8\end{array}$ & $\begin{array}{l}0.00 \\
0.01 \\
0.02 \\
0.03 \\
0.04 \\
0.05 \\
0.07 \\
0.09 \\
0.11\end{array}$ & $\begin{array}{l}0 \\
0 \\
0 \\
0 \\
0 \\
0 \\
0 \\
0 \\
0\end{array}$ & $\begin{array}{l}365 \\
365 \\
365 \\
365 \\
365 \\
365 \\
365 \\
365 \\
365\end{array}$ & $\begin{array}{l}100.0 \\
100.0 \\
100.0 \\
100.0 \\
100.0 \\
100.0 \\
100.0 \\
100.0 \\
100.0\end{array}$ & $\begin{array}{r}9 \\
10 \\
11 \\
12 \\
13 \\
14 \\
15 \\
16 \\
17\end{array}$ & $\begin{array}{l}0.14 \\
0.18 \\
0.23 \\
0.29 \\
0.37 \\
0.47 \\
0.60 \\
0.76 \\
0.97\end{array}$ & $\begin{array}{r}0 \\
0 \\
0 \\
0 \\
32 \\
106 \\
78 \\
25 \\
19\end{array}$ & $\begin{array}{l}365 \\
365 \\
365 \\
365 \\
365 \\
333 \\
227 \\
149 \\
124\end{array}$ & $\begin{array}{r}100.0 \\
100.0 \\
100.0 \\
100.0 \\
100.0 \\
91.2 \\
62.2 \\
40.8 \\
34.0\end{array}$ & $\begin{array}{l}18 \\
19 \\
20 \\
21 \\
22 \\
23 \\
24 \\
25 \\
26\end{array}$ & $\begin{array}{l}1.2 \\
1.6 \\
2.0 \\
2.5 \\
3.2 \\
4.1 \\
5.2 \\
6.6 \\
8.4\end{array}$ & $\begin{array}{r}9 \\
19 \\
11 \\
13 \\
11 \\
8 \\
5 \\
6 \\
4\end{array}$ & $\begin{array}{r}105 \\
96 \\
77 \\
66 \\
53 \\
42 \\
34 \\
29 \\
23\end{array}$ & $\begin{array}{r}28.8 \\
26.3 \\
21.1 \\
18.1 \\
14.5 \\
11.5 \\
9.3 \\
8.0 \\
6.3\end{array}$ & $\begin{array}{l}27 \\
28 \\
29 \\
30 \\
31 \\
32 \\
33 \\
34\end{array}$ & $\begin{array}{l}11.0 \\
14.0 \\
17.0\end{array}$ & $\begin{array}{l}8 \\
4 \\
7\end{array}$ & $\begin{array}{r}19 \\
11 \\
7\end{array}$ & $\begin{array}{l}5.2 \\
3.0 \\
1.9\end{array}$ \\
\hline
\end{tabular}

MONTHLY MEAN DISCHARGES, IN OUBIC FEET PER SECOND, FOR EACH WATER YEAR

$\begin{array}{ccccccccccccc}\text { YEAR } & \text { OCT } & \text { NOV } & \text { DEC } & \text { JAN } & \text { FEB } & \text { MAR } & \text { APR } & \text { MAY } & \text { JUNE } & \text { JULY } & \text { AUG } & \text { SEP } \\ 1979 & 0.44 & 0.62 & 0.54 & 0.54 & 0.58 & 0.70 & 1.31 & 9.62 & 6.74 & 1.81 & 0.93 & 0.56\end{array}$


GREEN RIVER BASIN

09317997 HUNTINGTON CREEK NEAR HUNTINGTON, UT (UPPER STATION)

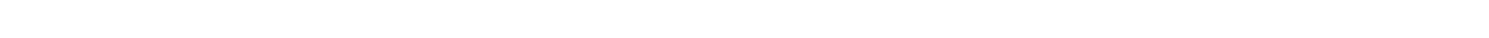
bank about $500 \mathrm{ft}$ upstream from bridge to Deer Creek Mine, $8 \mathrm{mi}$ northwest of Huntington.

DRAINAGE AREA, $-181 \mathrm{mi}^{2}$, approximately.

PERIOD OF RECORD AVAILABLE.--October 1979 to September 1981.

GAGE.-Water-stage recorder. Altitude of gage is 6,450 ft from topographic map.

REMARKS.--Small tranmountain diversions to tributaries of San Pitch River (Sevier Lake basin). Flow regulated by reservoirs above station.

COOPERATION. --Gage-height record was furnished by Utah Power \& Light Co., and reviewed by U.S. Geological Survey.

EXMREMES FOR PERIOD OF RECORD.--Maximum discharge, 1,020 ft ${ }^{3} / \mathrm{s}$ June 11, 1980, gage height, $4.43 \mathrm{ft} ; \mathrm{minimum,} 3.0 \mathrm{ft}{ }^{3} / \mathrm{sec}$ Feb. $2-5$, 1981 .

LOWEST MEAN DISCHAFGE, IN GBIC FEET PER SECOND, AND RANKING FOR THE INDICATED NUMBER OF CONSEQUTIVE DAYS FOR EAOH OIMATIC YEAR, APRIL 1-MARCH 31

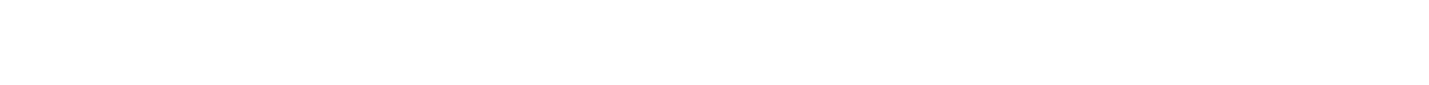

HIGHEST MEAN DISQHARGE, IN OUBIC FEET PER SECOND, AND RANKING FOR THE INDICAIED NUMBER OF CONSECUTIVE DAYS FOR EACH WATER YEAR, OCTOBER 1-SEPTEMBER 30

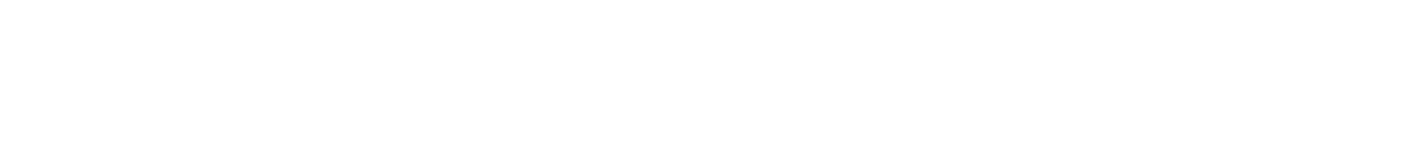

DURATION OF DISCHARGE FOR EAGH WATER YEAR

$\begin{array}{lllllllllllllllllllllllllllllllllll}\text { CASS } 0 & 1 & 2 & 3 & 4 & 5 & 6 & 7 & 8 & 9 & 10 & 11 & 12 & 13 & 14 & 15 & 16 & 17 & 18 & 19 & 20 & 21 & 22 & 23 & 24 & 25 & 26 & 27 & 28 & 29 & 30 & 31 & 32 & 33 & 34\end{array}$

NUMBER OF DAYS IN CLASS बBIC FEET YEAR PER SECON $\begin{array}{llllllllllllllllllllllllllllllllllllll}1980 & 1 & 2 & 9 & 9 & 23 & 24 & 22 & 30 & 15 & 26 & 8 & 5 & 23 & 31 & 15 & 8 & 9 & 21 & 7 & 15 & 10 & 3 & 4 & 3 & 5 & 6 & 5 & 5 & 4 & 5 & 8 & 3 & 2 & 41077.0\end{array}$

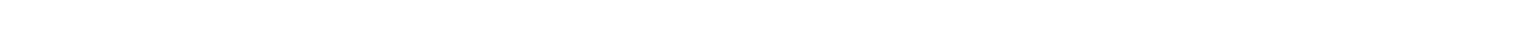

DURATION TABLE OF DISCHARGE FOR WATER YEARS 1980-81
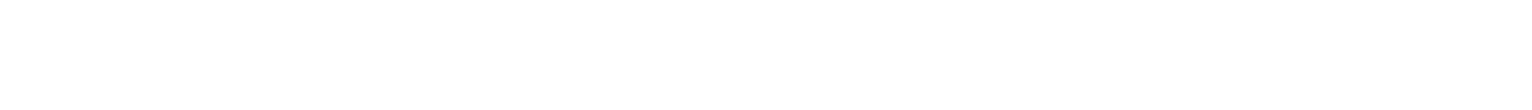

$\begin{array}{rrrrr}0 & 0.0 & 0 & 731 & 100.0 \\ 1 & 8.1 & 1 & 731 & 100.0 \\ 2 & 9.3 & 1 & 730 & 99.9 \\ 3 & 11.0 & 2 & 729 & 99.7 \\ 4 & 12.0 & 10 & 727 & 99.5 \\ 5 & 14.0 & 11 & 717 & 98.1 \\ 6 & 16.0 & 28 & 706 & 96.6 \\ 7 & 19.0 & 24 & 678 & 92.8 \\ 8 & 22.0 & 37 & 654 & 89.5\end{array}$

$\begin{array}{rrrrr}9 & 25.0 & 49 & 617 & 84.4 \\ 10 & 29.0 & 83 & 568 & 77.7 \\ 11 & 33.0 & 56 & 485 & 66.4 \\ 12 & 38.0 & 28 & 429 & 58.7 \\ 13 & 44.0 & 5 & 401 & 54.9 \\ 14 & 50.0 & 51 & 396 & 54.2 \\ 15 & 58.0 & 64 & 345 & 47.2 \\ 16 & 67.0 & 35 & 281 & 38.4 \\ 17 & 77.0 & 41 & 246 & 33.7\end{array}$

$\begin{array}{rrr}18 & 88.0 & 43 \\ 19 & 100.0 & 49 \\ 20 & 120.0 & 13 \\ 21 & 130.0 & 24 \\ 22 & 150.0 & 20 \\ 23 & 180.0 & \\ 24 & 200.0 \\ 25 & 240.0 \\ 26 & 270.0\end{array}$

$\begin{array}{rr}205 & 28.0 \\ 162 & 22.2 \\ 113 & 15.5 \\ 100 & 13.7 \\ 76 & 10.4 \\ 56 & 7.7 \\ 50 & 6.8 \\ 46 & 6.3 \\ 43 & 5.9\end{array}$

MONTHLY MEAN DISCHARGES, IN OBIC FEET PER SECOND, FOR EACH WATER YEAR

\begin{tabular}{|c|c|c|c|c|c|c|c|c|c|c|c|c|}
\hline YEAR & OCT & NOV & $\mathrm{DEC}$ & $J A N$ & FEBB & MAR & APR & MAY & JUNE & JULY & AUG & SEP \\
\hline 1980 & 57.7 & 29.7 & 24.6 & 16.0 & 25.6 & 20.5 & 65.5 & 235 & 583 & 126 & 107 & 61.8 \\
\hline 1981 & 71.8 & 40.0 & 30.1 & 26.9 & 28.9 & 28.1 & 61.9 & 100 & 85.5 & 135 & 87.8 & 56.8 \\
\hline
\end{tabular}


LOCATION.--Lat $39^{\circ} 22^{\prime} 17^{\prime \prime}$, long $111^{\circ} 03^{\prime} 47^{\prime \prime}$, in SW sec.6, T.17 S., R. 8 E., Enery County, Hydrologic Unit 14060009 , on left bank about $300 \mathrm{ft}$ downstream from fam-road bridge, $1 \mathrm{mi}$ upstream from Fish Creek, and $7 \mathrm{mi}$ northwest of Huntingtan.

DRAINAGE AREA. $-190 \mathrm{mi}^{2}$, approximately.

MEAN BASIN ELEVATION. $-9,000 \mathrm{ft}$.

FERIOD OF RECORD AVAILABLE.--May 1909 to September 1917 (irrigation seasons only, monthly mean discharge for most of the period), October 1917 to September 1918 (peak discharge only), Octcber 1918 to November 1920 (fragmentary), April 1921 to February 1939 (irrigation season only for some years), March 1939 to September 1973, Octcber 1973 to September 1977 (peak discharge only), October 1977 to September 1979.

GAGE. - Water-stage recorder. Altitude of gage is 6,210 ft from river profile map. Prior to Apr. 30, 1913, nanrecording gage $5 \mathrm{ft}$ downstream at different datum. Nay 1, 1913 to Sept. 10, 1917, water-stage recorder at site $95 \mathrm{ft}$ upstream, datum same as that of preceding gage. Sept. 11, 1917 to May 28, 1934, water-stage recorder at approximately same site and datum.

REMARKS.--Small diversion for irrigation above station, including transmountain diversions to tributaries of San Pitch River (Sevier Lake basin). Slight regulation by mall reservoirs above station.

AVERAGE DISGHARGE. -60 years (water years 1911-17, 1922-29, 1931-73, 1978-79), $96.3 \mathrm{ft}^{3} / \mathrm{s}, 69,770 \mathrm{acre}-\mathrm{ft} / \mathrm{yr}$.

EXTREMES FOR PERIOD OF RECORD.--Maximum discharge, 2,500 ft 3 /s Aug. 2 or 3, 1930, gage height, $7.5 \mathrm{ft}$, from floodmark, fram rating curve extended above $600 \mathrm{ft}^{3} / \mathrm{s} ;$ minimum, $0.87 \mathrm{ft}^{3} / \mathrm{s}$ Nov. 28,1978 , result of bridge construction upstream.

LONEST MEAN DISCHARGE, IN OBBIC FEET PER SECOND, AND RANKING FOR THE INDICATED NUMBER OF CONSEOUTIVE DAYS FOR EAOH CIIMATIC YEAR, APRIL 1-MARQH 31

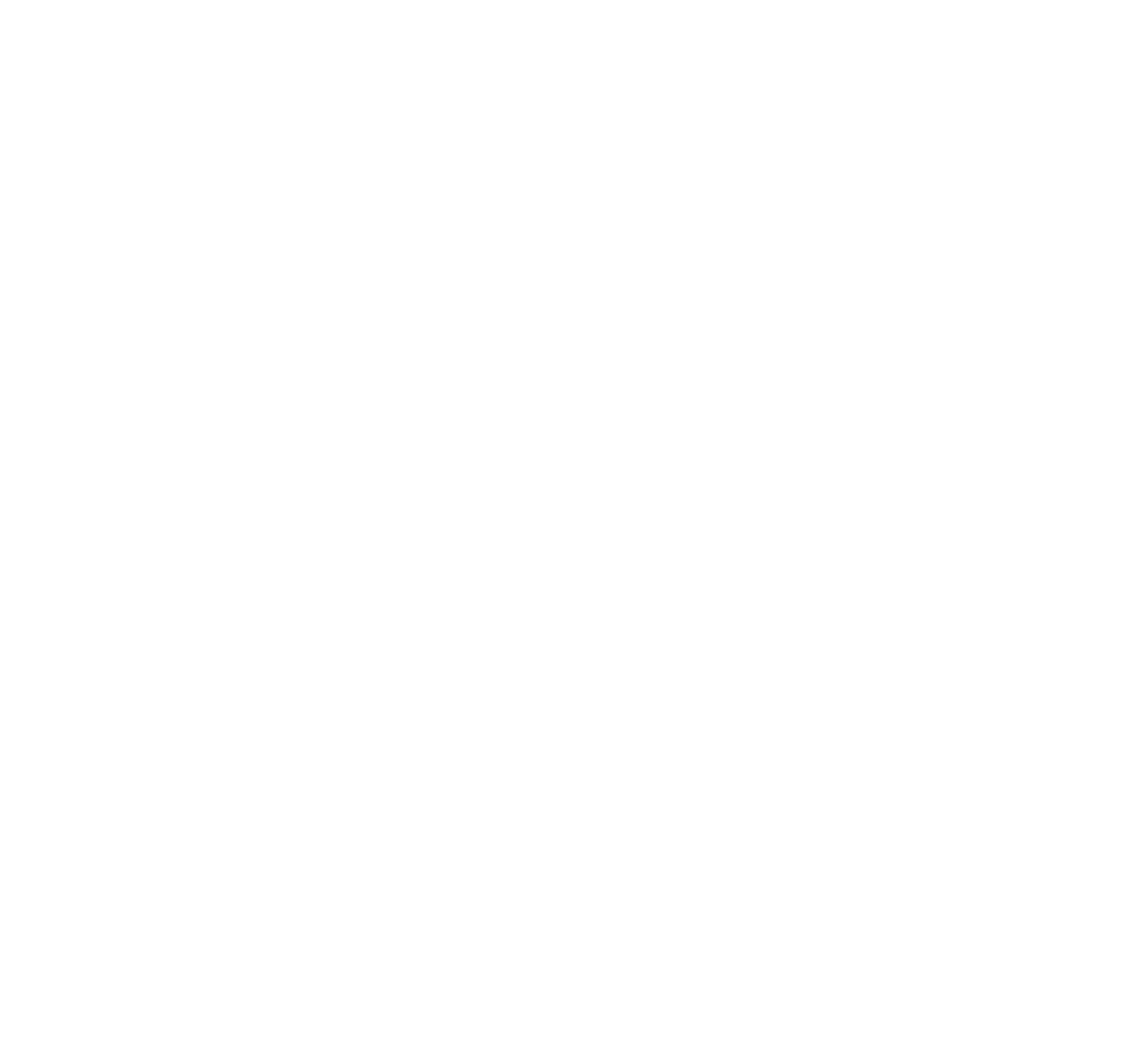


GREEN RIVER BASIN

09318000 HUNTINGTON CREEK NEAR HUNTTNGTON, UT (LOWER STATTON)-Continued

HIGHEST MEAN DISGHARGE, IN ABIC FEET PER SECOND, AND RANKING FOR THE INDICATED NUMBER OF CONSEQUTIVE DAVS FOR EAOH WATER YEAR, OCTCBER 1-SEPTEHBER 30

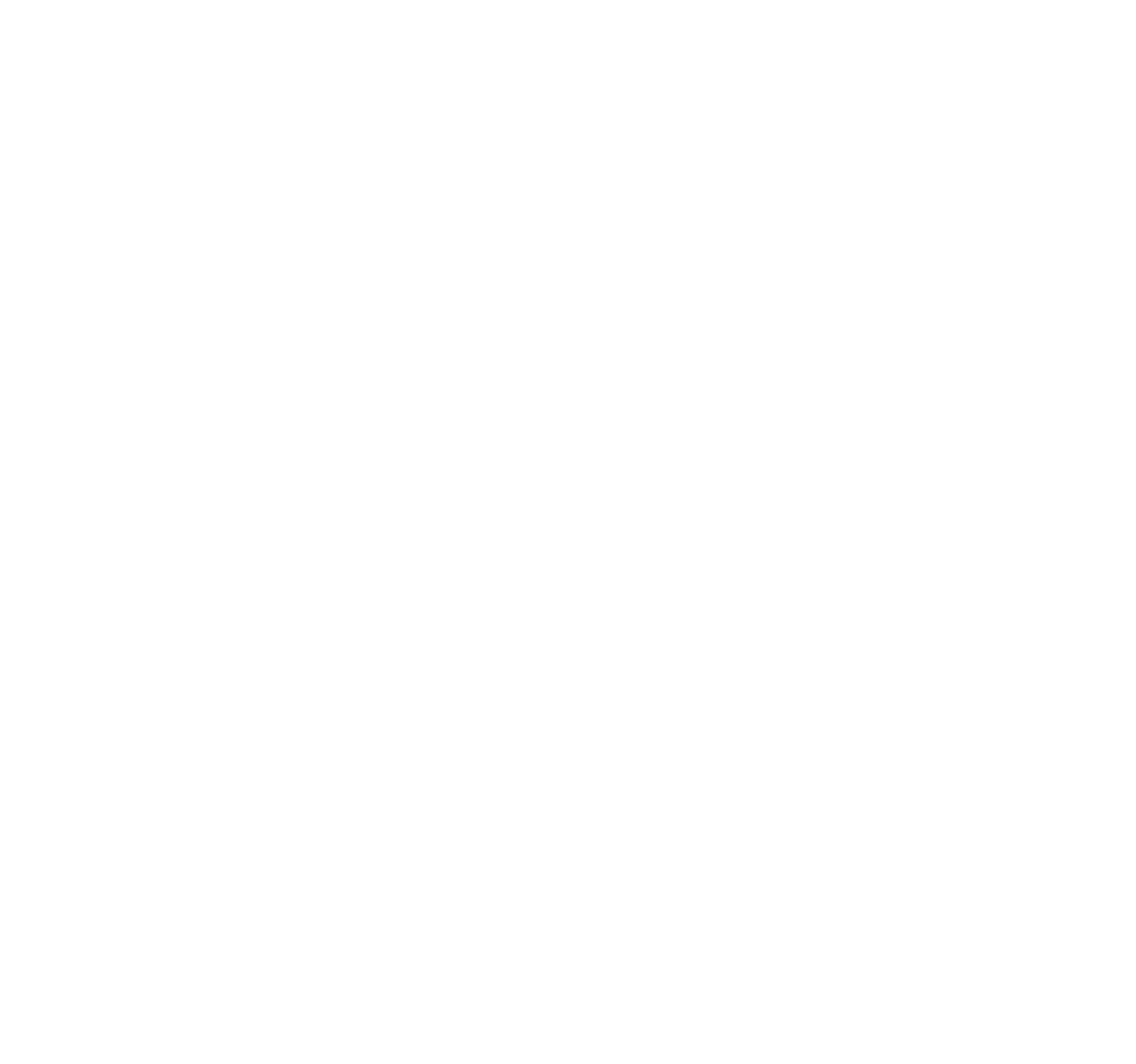

DURATION OF DISCHARGE FOR EACH WATER YEAR

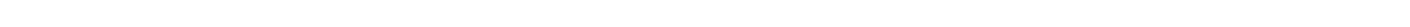

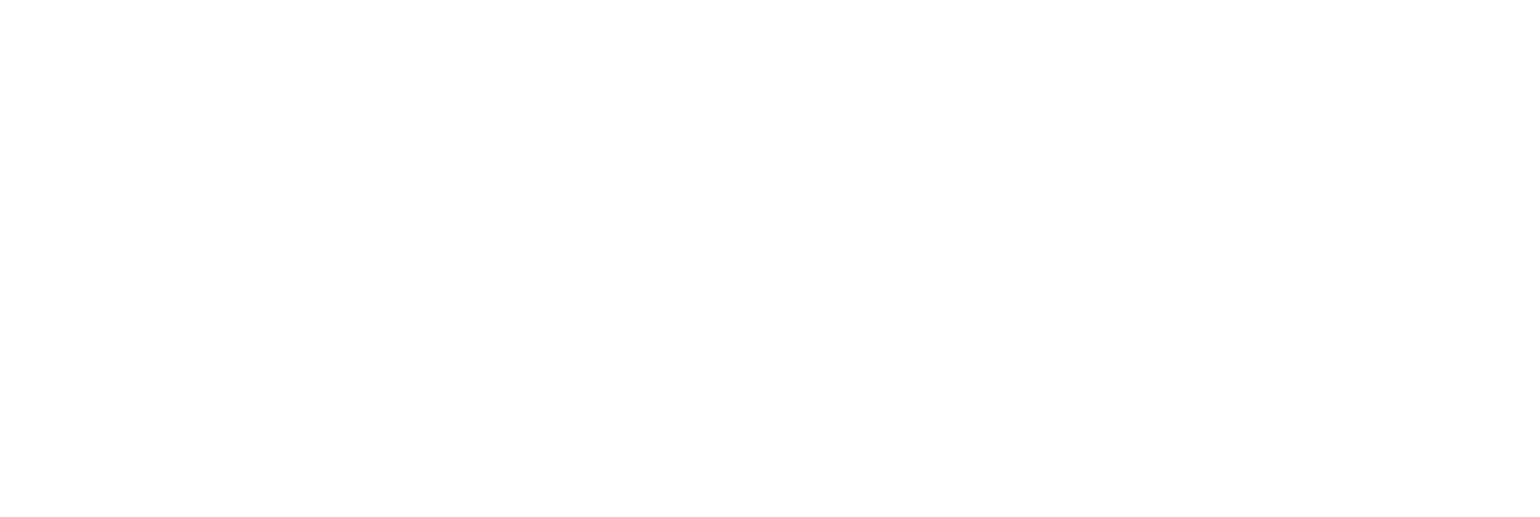


GREEN RIVER BASIN

09318000 HUNTINGTON CREEK NEAR HUNTINGTON, UT (LOWER STATION)--Continued

DURATION OF DISCHARGE FOR EACH WATER YEAR---Continued

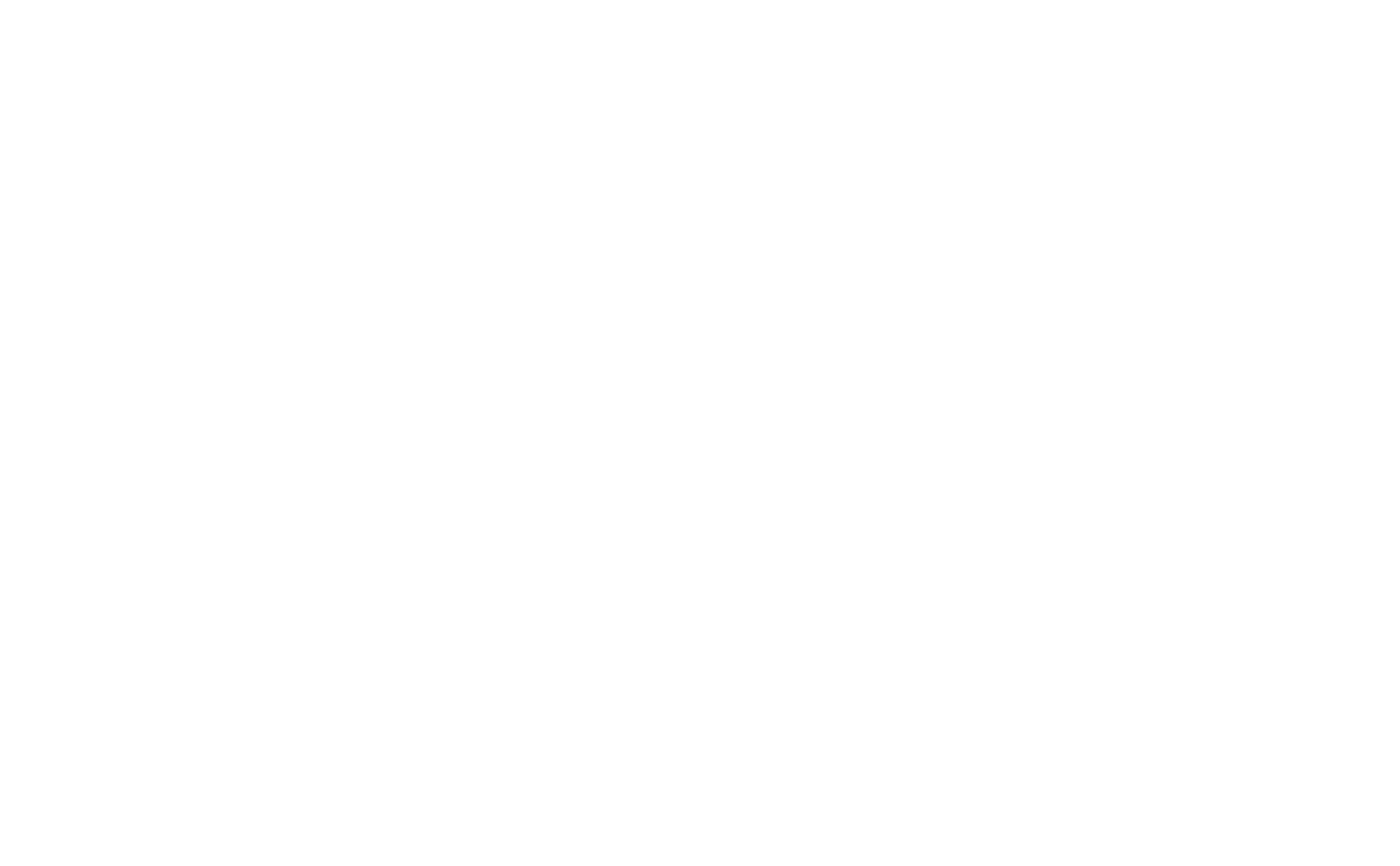

DURATION TABLE OF DISCHARGE FOR WATER YEARS 1922-23, 1925, 1927-29, 1938, 1940-73, 1978-79

$\begin{array}{rrr}\text { CJBIC } & \text { ACOU- } \\ \text { FEET } & \text { MU- } & \text { PER- } \\ \text { PER TOTAL LATED } & \text { CENT } \\ \text { CLASS SECOND DAYS DAYS } & \text { DAYS }\end{array}$

$\begin{array}{llll}0.00 & 0 & 15705 & 100.0 \\ 1.20 & 1 & 15705 & 100.0\end{array}$

$\begin{array}{lllll}1.20 & 1 & 15705 & 100.0 \\ 1.50 & 1 & 15704 & 100.0\end{array}$

$1.80 \quad 0 \quad 15703100.0$

$2.30 \quad 1 \quad 15703100.0$

$2.80 \quad 2 \quad 15702100.0$

$3.50 \quad 1 \quad 15700100.0$

$4.30 \quad 1 \quad 15699100.0$

$\begin{array}{llll}5.30 & 1 & 15698 & 100.0\end{array}$ $\begin{array}{rrr}\text { CUBIC } & \text { ACCU- } \\ \text { FEET } & \text { MU- } & \text { PER- } \\ \text { PER TOTAL LATED } & \text { CENT } \\ \text { CIAASS SECOND DAYS DAYS } & \text { DAYS }\end{array}$

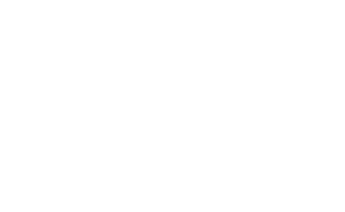

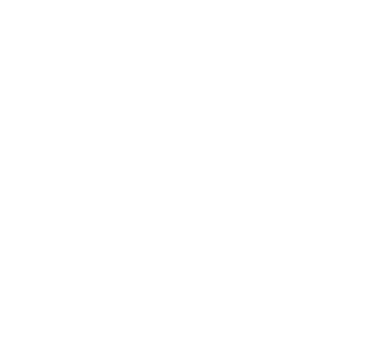

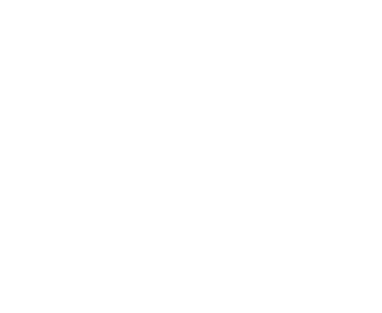

MONIHLY MEAN DISCHARGES, IN CUBIC FEET PER SBOOND, FOR EACH WATER YEAR

\begin{tabular}{|c|c|c|c|c|c|c|c|c|c|c|c|c|}
\hline YEAR & OCT & Nov & DEC & JAN & FEB & MAR & APR & MAY & JUNE & JULY & AUG & SEP \\
\hline $\begin{array}{l}1911 \\
1912 \\
1913 \\
1914 \\
1915\end{array}$ & $\begin{array}{l}39.9 \\
25 \\
36 \\
46.8 \\
56.7\end{array}$ & $\begin{array}{l}34.0 \\
25 \\
12 \\
43.2 \\
40.7\end{array}$ & $\begin{array}{l}32.9 \\
20 \\
10 \\
48.0 \\
30.5\end{array}$ & $\begin{array}{l}30 \\
18 \\
25 \\
52 \\
39.3\end{array}$ & $\begin{array}{l}40 \\
20 \\
30 \\
42.3 \\
31.8\end{array}$ & $\begin{array}{l}49.4 \\
24 \\
41.2 \\
52.8 \\
43.9\end{array}$ & $\begin{array}{l}79.3 \\
43 \\
157 \\
134 \\
125\end{array}$ & $\begin{array}{l}296 \\
269 \\
376 \\
764 \\
224\end{array}$ & $\begin{array}{l}275 \\
488 \\
218 \\
474 \\
236\end{array}$ & $\begin{array}{l}121 \\
127 \\
126 \\
145 \\
124\end{array}$ & $\begin{array}{c}62.5 \\
85 \\
70.9 \\
102 \\
63.4\end{array}$ & $\begin{array}{l}36.8 \\
48 \\
69.6 \\
55.7 \\
41.8\end{array}$ \\
\hline $\begin{array}{l}1916 \\
1917\end{array}$ & $\begin{array}{l}41 \\
56.2\end{array}$ & $\begin{array}{l}39.2 \\
35.9\end{array}$ & $\begin{array}{l}38.9 \\
35.4\end{array}$ & $\begin{array}{l}38.6 \\
25.0\end{array}$ & $\begin{array}{l}35.8 \\
30.0\end{array}$ & $\begin{array}{l}54.6 \\
44.8\end{array}$ & $\begin{array}{c}128 \\
92.6\end{array}$ & $\begin{array}{l}549 \\
418\end{array}$ & $\begin{array}{l}480 \\
779\end{array}$ & $\begin{array}{l}141 \\
227\end{array}$ & $\begin{array}{l}118 \\
101\end{array}$ & $\begin{array}{l}54.5 \\
67.7\end{array}$ \\
\hline $\begin{array}{l}1922 \\
1923 \\
1924 \\
1925\end{array}$ & $\begin{array}{l}62.8 \\
17.5 \\
47.1 \\
32.4\end{array}$ & $\begin{array}{l}51.3 \\
29.4 \\
42.0 \\
33.0\end{array}$ & $\begin{array}{l}40.0 \\
45.6 \\
40 \\
25.5\end{array}$ & $\begin{array}{l}45.0 \\
48.4 \\
35 \\
27.6\end{array}$ & $\begin{array}{l}45.0 \\
45.0 \\
30 \\
28.4\end{array}$ & $\begin{array}{l}50.9 \\
50.0 \\
30 \\
35.3\end{array}$ & $\begin{array}{r}77.5 \\
82.3 \\
75.1 \\
104\end{array}$ & $\begin{array}{l}520 \\
502 \\
192 \\
209\end{array}$ & $\begin{array}{c}553 \\
329 \\
98.6 \\
122\end{array}$ & $\begin{array}{l}173 \\
181 \\
64.0 \\
96.5\end{array}$ & $\begin{array}{r}123 \\
92.4 \\
35.2 \\
67.4\end{array}$ & $\begin{array}{l}51.8 \\
52.5 \\
40.3 \\
35.2\end{array}$ \\
\hline $\begin{array}{l}1926 \\
1927 \\
1928 \\
1929 \\
1930\end{array}$ & $\begin{array}{l}34.6 \\
32.9 \\
35.1 \\
37.9 \\
46.3\end{array}$ & $\begin{array}{l}30.8 \\
29.2 \\
34.9 \\
32.1 \\
38.0\end{array}$ & $\begin{array}{l}35 \\
30.1 \\
27.0 \\
27.0 \\
35.0\end{array}$ & $\begin{array}{l}35 \\
32.0 \\
27.0 \\
27.0 \\
30.0\end{array}$ & $\begin{array}{l}35 \\
34.0 \\
27.0 \\
30.0 \\
33.0\end{array}$ & $\begin{array}{l}41.7 \\
34.6 \\
37.0 \\
40.0 \\
41.8\end{array}$ & $\begin{array}{r}132 \\
68.6 \\
92.0 \\
45.3 \\
138\end{array}$ & $\begin{array}{l}327 \\
380 \\
550 \\
365 \\
235\end{array}$ & $\begin{array}{l}149 \\
260 \\
228 \\
368 \\
182\end{array}$ & $\begin{array}{l}91.5 \\
112 \\
125 \\
148 \\
114\end{array}$ & $\begin{array}{l}50.1 \\
88.9 \\
53.2 \\
90.4 \\
72.4\end{array}$ & $\begin{array}{l}32.0 \\
78.6 \\
34.6 \\
78.9 \\
57.4\end{array}$ \\
\hline
\end{tabular}


GREEN RTVER BASIN

09318000 HUNTINGTON CREEK NEAR HUNTINGTON, UT (LONER STATION)-Continued

MONTHLY MEAN DISCHARGES, IN UBIC FEET PER SECOND, FOR EAOH WATER YEAR--Continued

\begin{tabular}{|c|c|c|c|c|c|c|c|c|c|c|c|c|}
\hline YEAR & $\mathrm{OCT}$ & NON & $\mathrm{DEC}$ & JAN & FEB & MAR & APR & MAY & JUNE & JULY & AUG & SEP \\
\hline $\begin{array}{l}1931 \\
1932 \\
1933 \\
1934 \\
1935\end{array}$ & $\begin{array}{l}49.8 \\
23.3 \\
30 \\
27.4 \\
21.8\end{array}$ & $\begin{array}{l}35.9 \\
26.9 \\
32 \\
25.0 \\
21.9\end{array}$ & $\begin{array}{l}32.0 \\
30 \\
30 \\
30.0 \\
23.0\end{array}$ & $\begin{array}{l}30.0 \\
25 \\
35 \\
27.5 \\
25.7\end{array}$ & $\begin{array}{l}30.5 \\
30 \\
30 \\
29.0 \\
23.1\end{array}$ & $\begin{array}{l}34.4 \\
27.6 \\
32 \\
31.2 \\
26.4\end{array}$ & $\begin{array}{l}71.2 \\
81.3 \\
41.1 \\
81.6 \\
48.1\end{array}$ & $\begin{array}{c}137 \\
327 \\
174 \\
72.0 \\
224\end{array}$ & $\begin{array}{c}86.6 \\
260 \\
470 \\
51.1 \\
394\end{array}$ & $\begin{array}{c}69.9 \\
123 \\
126 \\
20.7 \\
129\end{array}$ & $\begin{array}{l}30.7 \\
66.2 \\
57.7 \\
19.3 \\
60.6\end{array}$ & $\begin{array}{l}25.6 \\
26.9 \\
30.3 \\
19.5 \\
26.2\end{array}$ \\
\hline $\begin{array}{l}1936 \\
1937 \\
1938 \\
1939 \\
1940\end{array}$ & $\begin{array}{l}23.3 \\
33.8 \\
42.0 \\
33.3 \\
28.9\end{array}$ & $\begin{array}{l}24.3 \\
26.9 \\
28.2 \\
32.0 \\
23.7\end{array}$ & $\begin{array}{l}22.3 \\
24.0 \\
31.5 \\
29.8 \\
20.5\end{array}$ & $\begin{array}{l}18.5 \\
22.0 \\
29.2 \\
35.5 \\
19.0\end{array}$ & $\begin{array}{l}27.1 \\
26.7 \\
29.3 \\
20.0 \\
23.0\end{array}$ & $\begin{array}{l}28.8 \\
28.5 \\
31.7 \\
38.8 \\
27.9\end{array}$ & $\begin{array}{l}131 \\
66.3 \\
115 \\
128 \\
72.3\end{array}$ & $\begin{array}{l}580 \\
472 \\
326 \\
213 \\
374\end{array}$ & $\begin{array}{l}279 \\
230 \\
258 \\
140 \\
158\end{array}$ & $\begin{array}{l}113 \\
113 \\
128 \\
103 \\
100\end{array}$ & $\begin{array}{l}80.3 \\
88.8 \\
73.1 \\
40.2 \\
35.6\end{array}$ & $\begin{array}{l}50.0 \\
51.6 \\
37.7 \\
31.9 \\
36.0\end{array}$ \\
\hline $\begin{array}{l}1941 \\
1942 \\
1943 \\
1944 \\
1945\end{array}$ & $\begin{array}{l}31.1 \\
62.3 \\
36.7 \\
36.0 \\
37.2\end{array}$ & $\begin{array}{l}25.7 \\
43.8 \\
35.4 \\
27.7 \\
34.9\end{array}$ & $\begin{array}{l}26.6 \\
35.5 \\
33.5 \\
28.2 \\
30.0\end{array}$ & $\begin{array}{l}24.0 \\
33.0 \\
32.0 \\
23.0 \\
28.0\end{array}$ & $\begin{array}{l}26.4 \\
30.0 \\
31.7 \\
25.0 \\
28.8\end{array}$ & $\begin{array}{l}30.0 \\
34.2 \\
33.3 \\
32.9 \\
35.4\end{array}$ & $\begin{array}{c}41.4 \\
140 \\
178 \\
45.0 \\
53.0\end{array}$ & $\begin{array}{l}525 \\
371 \\
211 \\
450 \\
305\end{array}$ & $\begin{array}{l}371 \\
378 \\
211 \\
480 \\
239\end{array}$ & $\begin{array}{l}160 \\
152 \\
122 \\
159 \\
146\end{array}$ & $\begin{array}{c}77.6 \\
80.9 \\
74.1 \\
102 \\
94.4\end{array}$ & $\begin{array}{l}69.9 \\
39.1 \\
33.3 \\
40.7 \\
47.6\end{array}$ \\
\hline $\begin{array}{l}1946 \\
1947 \\
1948 \\
1949 \\
1950\end{array}$ & $\begin{array}{l}36.5 \\
43.2 \\
39.4 \\
31.0 \\
40.8\end{array}$ & $\begin{array}{l}32.9 \\
32.5 \\
36.5 \\
28.4 \\
31.4\end{array}$ & $\begin{array}{l}28.0 \\
28.7 \\
37.6 \\
25.5 \\
24.1\end{array}$ & $\begin{array}{l}26.0 \\
27.7 \\
32.0 \\
24.0 \\
23.3\end{array}$ & $\begin{array}{l}25.0 \\
30.7 \\
32.0 \\
25.0 \\
27.8\end{array}$ & $\begin{array}{l}34.7 \\
35.8 \\
31.5 \\
31.3 \\
31.5\end{array}$ & $\begin{array}{r}173 \\
91.5 \\
51.9 \\
107 \\
98.8\end{array}$ & $\begin{array}{l}224 \\
354 \\
224 \\
348 \\
251\end{array}$ & $\begin{array}{l}167 \\
200 \\
132 \\
319 \\
194\end{array}$ & $\begin{array}{l}122 \\
154 \\
100 \\
177 \\
149\end{array}$ & $\begin{array}{l}52.2 \\
92.6 \\
52.5 \\
121 \\
105\end{array}$ & $\begin{array}{l}28.5 \\
39.9 \\
28.5 \\
56.7 \\
47.1\end{array}$ \\
\hline $\begin{array}{l}1951 \\
1952 \\
1953 \\
1954 \\
1955\end{array}$ & $\begin{array}{l}34.4 \\
38.2 \\
67.9 \\
41.9 \\
29.3\end{array}$ & $\begin{array}{l}31.3 \\
27.8 \\
43.0 \\
33.2 \\
23.7\end{array}$ & $\begin{array}{l}29.6 \\
25.4 \\
40.0 \\
29.3 \\
21.2\end{array}$ & $\begin{array}{l}27.0 \\
25.6 \\
37.0 \\
28.2 \\
19.1\end{array}$ & $\begin{array}{l}23.9 \\
32.4 \\
39.3 \\
35.3 \\
21.4\end{array}$ & $\begin{array}{l}29.6 \\
35.0 \\
46.5 \\
37.0 \\
24.3\end{array}$ & $\begin{array}{c}82.7 \\
124 \\
79.4 \\
91.7 \\
38.3\end{array}$ & $\begin{array}{l}266 \\
850 \\
185 \\
150 \\
168\end{array}$ & $\begin{array}{l}260 \\
776 \\
318 \\
122 \\
156\end{array}$ & $\begin{array}{c}172 \\
251 \\
187 \\
75.9 \\
138\end{array}$ & $\begin{array}{c}91.2 \\
169 \\
102 \\
46.5 \\
67.1\end{array}$ & $\begin{array}{c}64.4 \\
131 \\
73.0 \\
33.2 \\
28.3\end{array}$ \\
\hline $\begin{array}{l}1956 \\
1957 \\
1958 \\
1959 \\
1960\end{array}$ & $\begin{array}{l}26.6 \\
25.8 \\
77.5 \\
38.7 \\
26.0\end{array}$ & $\begin{array}{l}21.5 \\
19.6 \\
37.3 \\
25.8 \\
21.3\end{array}$ & $\begin{array}{l}24.5 \\
19.0 \\
32.8 \\
26.4 \\
20.0\end{array}$ & $\begin{array}{l}26.2 \\
19.0 \\
30.0 \\
25.3 \\
19.1\end{array}$ & $\begin{array}{l}24.7 \\
22.5 \\
31.9 \\
26.7 \\
21.2\end{array}$ & $\begin{array}{l}29.9 \\
23.7 \\
34.4 \\
28.9 \\
25.5\end{array}$ & $\begin{array}{l}87.7 \\
37.6 \\
95.2 \\
53.0 \\
57.6\end{array}$ & $\begin{array}{l}230 \\
226 \\
611 \\
107 \\
156\end{array}$ & $\begin{array}{c}160 \\
587 \\
412 \\
93.5 \\
130\end{array}$ & $\begin{array}{c}158 \\
206 \\
183 \\
93.4 \\
132\end{array}$ & $\begin{array}{c}58.7 \\
116 \\
150 \\
63.9 \\
64.1\end{array}$ & $\begin{array}{l}27.4 \\
92.4 \\
47.8 \\
26.2 \\
24.2\end{array}$ \\
\hline $\begin{array}{l}1961 \\
1962 \\
1963 \\
1964 \\
1965\end{array}$ & $\begin{array}{l}25.3 \\
23.5 \\
35.5 \\
32.6 \\
23.0\end{array}$ & $\begin{array}{l}21.7 \\
23.6 \\
28.2 \\
17.8 \\
21.4\end{array}$ & $\begin{array}{l}19.9 \\
17.1 \\
19.6 \\
14.5 \\
21.0\end{array}$ & $\begin{array}{l}18.0 \\
12.3 \\
12.7 \\
17.0 \\
22.8\end{array}$ & $\begin{array}{l}18.4 \\
23.6 \\
25.5 \\
19.0 \\
24.9\end{array}$ & $\begin{array}{l}21.2 \\
27.7 \\
26.3 \\
19.7 \\
26.0\end{array}$ & $\begin{array}{c}43.1 \\
123 \\
39.3 \\
34.0 \\
52.1\end{array}$ & $\begin{array}{l}103 \\
378 \\
202 \\
238 \\
300\end{array}$ & $\begin{array}{l}81.4 \\
309 \\
126 \\
178 \\
525\end{array}$ & $\begin{array}{l}86.9 \\
171 \\
147 \\
139 \\
229\end{array}$ & $\begin{array}{l}40.8 \\
161 \\
101 \\
135 \\
174\end{array}$ & $\begin{array}{r}33.9 \\
51.6 \\
36.6 \\
26.7 \\
125\end{array}$ \\
\hline $\begin{array}{l}1966 \\
1967 \\
1968 \\
1969 \\
1970\end{array}$ & $\begin{array}{l}60.8 \\
34.5 \\
46.2 \\
67.9 \\
61.8\end{array}$ & $\begin{array}{l}35.1 \\
25.0 \\
24.2 \\
31.8 \\
32.0\end{array}$ & $\begin{array}{l}36.1 \\
20.9 \\
21.1 \\
25.8 \\
30.3\end{array}$ & $\begin{array}{l}33.3 \\
20.2 \\
29.7 \\
26.0 \\
29.5\end{array}$ & $\begin{array}{l}28.0 \\
18.4 \\
23.4 \\
27.4 \\
34.4\end{array}$ & $\begin{array}{l}37.7 \\
31.0 \\
30.9 \\
32.6 \\
34.1\end{array}$ & $\begin{array}{c}115 \\
42.3 \\
51.1 \\
121 \\
70.8\end{array}$ & $\begin{array}{l}187 \\
245 \\
267 \\
552 \\
363\end{array}$ & $\begin{array}{l}142 \\
345 \\
435 \\
285 \\
378\end{array}$ & $\begin{array}{l}113 \\
162 \\
138 \\
133 \\
146\end{array}$ & $\begin{array}{c}76.0 \\
122 \\
70.2 \\
88.4 \\
97.3\end{array}$ & $\begin{array}{l}56.8 \\
72.6 \\
86.8 \\
58.6 \\
80.1\end{array}$ \\
\hline $\begin{array}{l}1971 \\
1972 \\
1973\end{array}$ & $\begin{array}{l}55.7 \\
49.9 \\
43.1\end{array}$ & $\begin{array}{l}36.7 \\
31.1 \\
28.2\end{array}$ & $\begin{array}{l}32.5 \\
28.0 \\
26.0\end{array}$ & $\begin{array}{l}30.0 \\
27.3 \\
22.3\end{array}$ & $\begin{array}{l}32.7 \\
31.8 \\
29.4\end{array}$ & $\begin{array}{l}38.5 \\
47.3 \\
31.7\end{array}$ & $\begin{array}{l}106 \\
94.6 \\
57.9\end{array}$ & $\begin{array}{l}240 \\
189 \\
563\end{array}$ & $\begin{array}{l}263 \\
141 \\
436\end{array}$ & $\begin{array}{l}139 \\
91.4 \\
117\end{array}$ & $\begin{array}{l}114 \\
69.5 \\
110\end{array}$ & $\begin{array}{l}62.9 \\
45.1 \\
82.1\end{array}$ \\
\hline $\begin{array}{l}1978 \\
1979\end{array}$ & $\begin{array}{l}16.9 \\
24.4\end{array}$ & $\begin{array}{l}19.8 \\
24.9\end{array}$ & $\begin{array}{l}16.3 \\
25.5\end{array}$ & $\begin{array}{l}19.5 \\
30.3\end{array}$ & $\begin{array}{l}22.1 \\
28.9\end{array}$ & $\begin{array}{l}23.5 \\
29.7\end{array}$ & $\begin{array}{l}39.4 \\
58.1\end{array}$ & $\begin{array}{l}172 \\
186\end{array}$ & $\begin{array}{l}379 \\
196\end{array}$ & $\begin{array}{l}134 \\
118\end{array}$ & $\begin{array}{l}120 \\
121\end{array}$ & $\begin{array}{l}60.1 \\
83.8\end{array}$ \\
\hline
\end{tabular}

ANNUAL PEAK DISGAARE, IN OBBIC FEET PER SECOND, AND CORRESPONDING GAGE HEIGHT, IN FEET, FOR EAOH WATER YEAR

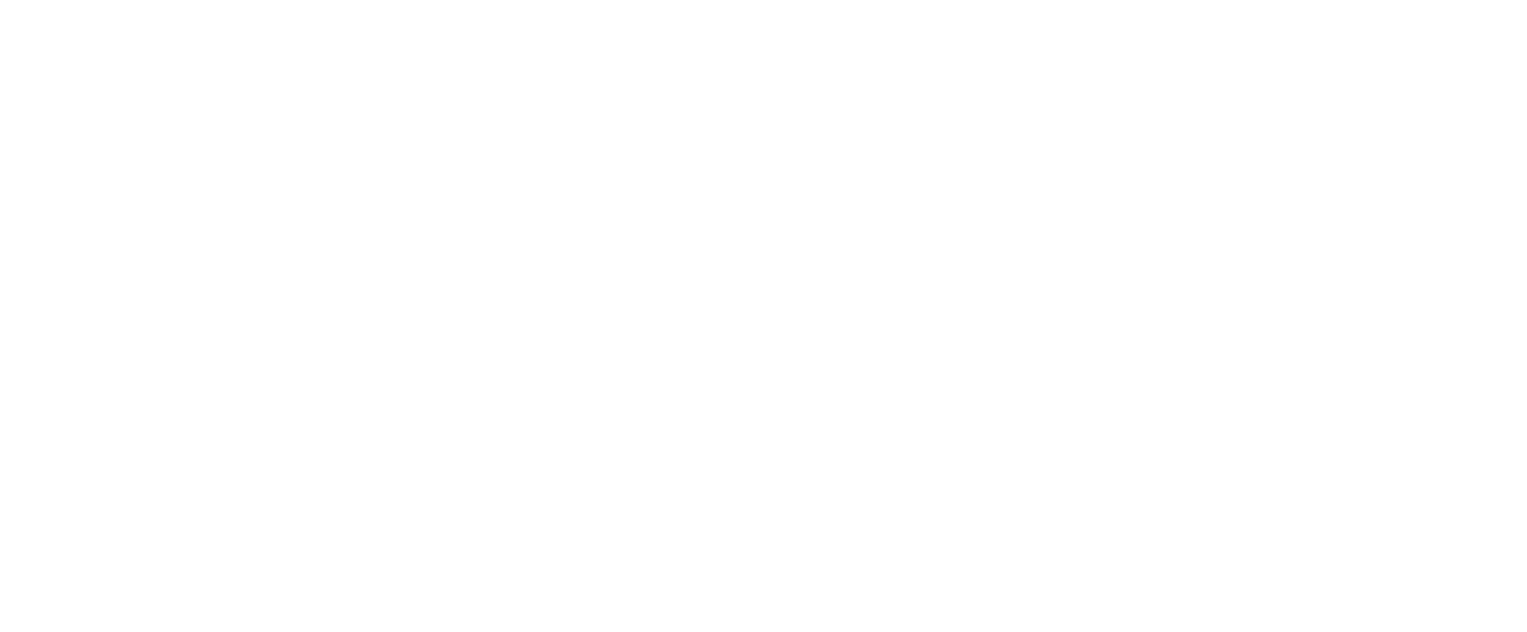


MAGNITUDE AND PROBABILITY OF ANNUAL LOWEST MEAN DISGHARGE BASED ON OLIMATIC YEARS 1922-23, 1925, 1927-29, 1938, 1940-73 AND 1979

\begin{tabular}{|c|c|c|c|c|c|c|}
\hline \multirow{2}{*}{$\begin{array}{l}\text { PERIOD } \\
\text { (CON- } \\
\text { SEQU- } \\
\text { TIVE } \\
\text { DAYS) }\end{array}$} & \multicolumn{6}{|c|}{$\begin{array}{l}\text { DISCH APGE, IN CUBIC FEET PER SECOND, FOR } \\
\text { INDICATED RECURRENCE INTERVAL, IN YEARS, AND } \\
\text { ANNUAL NONEXCEEDANCE PROBABIIITY, IN PERCENT }\end{array}$} \\
\hline & $\begin{array}{c}2 \\
508\end{array}$ & $\begin{array}{c}5 \\
208\end{array}$ & $\begin{array}{l}10 \\
108\end{array}$ & $\begin{array}{l}20 \\
58\end{array}$ & $\begin{array}{l}50 \\
28\end{array}$ & $\begin{array}{r}100 \\
18\end{array}$ \\
\hline $\begin{array}{r}1 \\
7 \\
14 \\
30 \\
60 \\
90\end{array}$ & $\begin{array}{l}19 \\
22 \\
23 \\
24 \\
25 \\
26\end{array}$ & $\begin{array}{l}14 \\
17 \\
18 \\
19 \\
20 \\
22\end{array}$ & $\begin{array}{l}12 \\
15 \\
15 \\
17 \\
18 \\
20\end{array}$ & $\begin{array}{l}11 \\
13 \\
13 \\
15 \\
16 \\
18\end{array}$ & $\begin{array}{l}8.8 \\
11 \\
11 \\
13 \\
14 \\
16\end{array}$ & $\begin{array}{l}7.7 \\
10 \\
10 \\
11 \\
13 \\
15\end{array}$ \\
\hline
\end{tabular}

MAGNITUDE AND PRCBABIIITY OF ANNUAL HIGHEST MEAN DISCHARGE BAGED ON WATER YEARS $1922-23,1925,1927-29,1938,1940-73$, AND 1978-79

\begin{tabular}{|c|c|c|c|c|c|c|}
\hline \multirow{2}{*}{$\begin{array}{l}\text { PERIOD } \\
\text { (CON- } \\
\text { SEQU- } \\
\text { TTVE } \\
\text { DAYS) }\end{array}$} & \multicolumn{6}{|c|}{$\begin{array}{l}\text { DISCHARGE, IN OBIC FEET PER SECOND, FOR } \\
\text { INDICATED REOURRENCE INTEERNAL, IN YEARS, AND } \\
\text { ANNUAL EXCEEDANCE PROBABILITY, IN FERCENT }\end{array}$} \\
\hline & $\begin{array}{c}2 \\
50 \%\end{array}$ & $\begin{array}{c}5 \\
208\end{array}$ & $\begin{array}{l}10 \\
108\end{array}$ & $\begin{array}{l}25 \\
48\end{array}$ & $\begin{array}{l}50 \\
28\end{array}$ & $\begin{array}{r}100 \\
18\end{array}$ \\
\hline $\begin{array}{r}1 \\
3 \\
7 \\
15\end{array}$ & $\begin{array}{l}515 \\
495 \\
460 \\
410\end{array}$ & $\begin{array}{l}777 \\
745 \\
695 \\
621\end{array}$ & $\begin{array}{l}943 \\
904 \\
844 \\
757\end{array}$ & $\begin{array}{r}1140 \\
1100 \\
1020 \\
921\end{array}$ & $\begin{array}{l}1280 \\
1230 \\
1150 \\
1040\end{array}$ & $\begin{array}{l}1420 \\
1360 \\
1260 \\
1150\end{array}$ \\
\hline
\end{tabular}

0931 8500 HUNTINGTON OREEK NEAR CAS'TLE DALE, UT

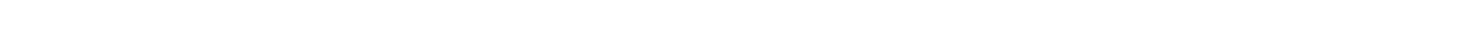
fram bridge on road to Green River, $5 \mathrm{mi}$ upstream fram mouth of Cottonwood Creek, and $6 \mathrm{mi}$ east of Castle Dale.

DRATNAGE AREA, $--325 \mathrm{mi}^{2}$.

FERIOD OF RECORD AVAILABLE.--July 1911 to August 1921 (fragmentary). Monthly mean discharge for scme periods, published in wSP 1313.

GAGE.--Water-stage recorder after May 2, 1913. Prior to May 2, 1913, staff gage at same site and datum.

REMARKS.--Diversions for irrigation above station.

EXIREMES FOR PERIOD OF RECORD.--Maximum discharge (caused by failure of dam upstream), 1,750 ft ${ }^{3} / \mathrm{s} \mathrm{Sept.} \mathrm{8,} \mathrm{1913,} \mathrm{gage} \mathrm{height,} \mathrm{11.3}$

$\mathrm{ft}$, from rating curve extended above $370 \mathrm{ft}^{3} / \mathrm{s}$; minimum recorded, $2.5 \mathrm{ft}^{3} / \mathrm{s}$ Sept. 10 , 1915.

LONEST MEAN DISGAAGE, IN OUBIC FEET PER SECOND, AND RANKING FOR THE INDICATED NUMBER OF CONSEQUTIVE DAYS FOR EAOH OIIMATIC YEAR, APRII I-MARO 31

\begin{tabular}{|c|c|c|c|c|c|c|c|c|c|c|c|c|c|c|c|c|c|c|c|}
\hline YEAR & & & & & & & & & CONSE & dT & E DAYS & & & & & & & & \\
\hline 1915 & 7.00 & 1 & 7.00 & 1 & 7.00 & 1 & 7.40 & 1 & 9.00 & 1 & 16.0 & 1 & 19.0 & 1 & 21.0 & 1 & 24.0 & 1 & 93.0 \\
\hline
\end{tabular}

HIGHEST MEAN DISGHARGE, IN CUBIC FEET PER SECOND, AND RANKING FOR THE INDICATED NUMBER OF CONSEQUTIVE DAYS FOR EACH WATER YEAR, OCTOBER 1-SEPTEMBER 30

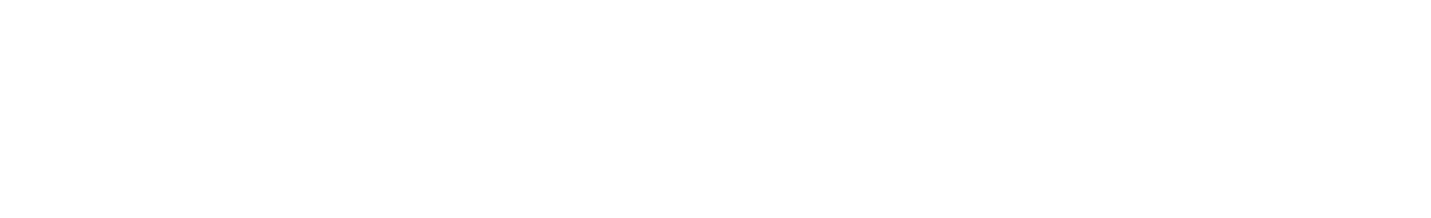

DURATION OF DISCHARGE FOR EAOH WATER YEAR

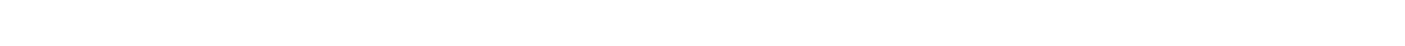
YEAR NUMBER OF DAYS IN CLASS OBIC FEET -DAYS

1912 $\begin{array}{llllllllllllllll}9 & 6 & 22 & 15 & 31 & 68 & 28 & 34 & 30 & 15 & 15 & 6 & 21 & 14 & 2 & 1\end{array}$ 
DURATION TABLE OF DISOHARGE FOR WATER YEARS 1912, $1914,1916-17$
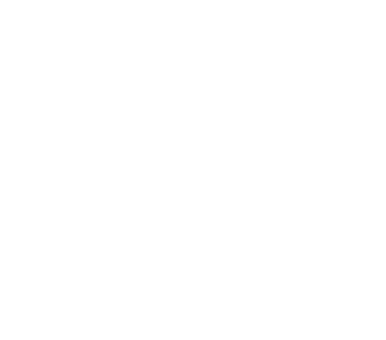

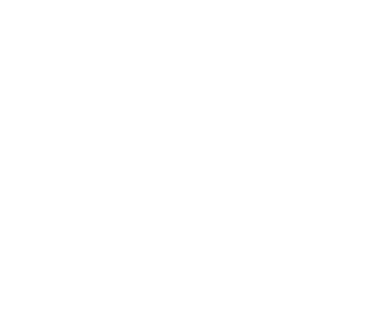

\begin{tabular}{crrrr}
\multicolumn{4}{c}{$\begin{array}{c}\text { CUBIC } \\
\text { FEET }\end{array}$} & $\begin{array}{c}\text { ACU- } \\
\text { PER }\end{array}$ \\
$\begin{array}{c}\text { POTAL } \\
\text { LATED }\end{array}$ & $\begin{array}{l}\text { PER- } \\
\text { CENT }\end{array}$ \\
CLASS SECOND & DAYS & DAYS & DAYS \\
18 & 52.0 & 34 & 360 & 24.6 \\
19 & 62.0 & 19 & 326 & 22.3 \\
20 & 74.0 & 27 & 307 & 21.0 \\
21 & 88.0 & 26 & 280 & 19.2 \\
22 & 100.0 & 46 & 254 & 17.4 \\
23 & 130.0 & 19 & 208 & 14.2 \\
24 & 150.0 & 22 & 189 & 12.9 \\
25 & 180.0 & 9 & 167 & 11.4 \\
26 & 210.0 & 14 & 158 & 10.8
\end{tabular}

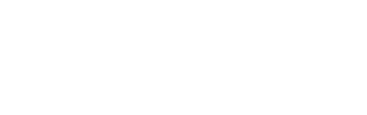

MONTHLY MEAN DISCHARGES, IN CUBIC FEET PER SECOND, FOR EACH WATER YEAR

\begin{tabular}{|c|c|c|c|c|c|c|c|c|c|c|c|c|}
\hline YEAR & $\mathrm{OCT}$ & NOV & $\mathrm{DEC}$ & JAN & FEB & MAR & APR & MAY & JUNE & JULY & AUG & SEP \\
\hline 1912 & 14.3 & 11.8 & 10.0 & 7.10 & 5.79 & 16.1 & 27.2 & 158 & 340 & 32.9 & 30.1 & 13.8 \\
\hline $\begin{array}{l}1914 \\
1915\end{array}$ & $\begin{array}{l}18.5 \\
26.0\end{array}$ & $\begin{array}{l}22.4 \\
23.2\end{array}$ & $\begin{array}{l}21.5 \\
28.0\end{array}$ & $\begin{array}{l}37.8 \\
32.0\end{array}$ & $\begin{array}{l}40.5 \\
30.0\end{array}$ & $\begin{array}{l}42.9 \\
35.0\end{array}$ & $\begin{array}{l}70.4 \\
92.7\end{array}$ & $\begin{array}{l}455 \\
71.2\end{array}$ & $\begin{array}{l}307 \\
55.1\end{array}$ & $\begin{array}{c}48.4 \\
7.68\end{array}$ & $\begin{array}{c}48.7 \\
3.70\end{array}$ & $\begin{array}{c}11.3 \\
5.33\end{array}$ \\
\hline $\begin{array}{l}1916 \\
1917\end{array}$ & $\begin{array}{c}8.13 \\
74.3\end{array}$ & $\begin{array}{l}30.7 \\
32.4\end{array}$ & $\begin{array}{l}27.0 \\
32.1\end{array}$ & $\begin{array}{l}27.0 \\
20.0\end{array}$ & $\begin{array}{l}40.0 \\
30.0\end{array}$ & $\begin{array}{l}78.9 \\
40.0\end{array}$ & $\begin{array}{r}105 \\
48.9\end{array}$ & $\begin{array}{l}250 \\
269\end{array}$ & $\begin{array}{l}206 \\
522\end{array}$ & $\begin{array}{l}16.1 \\
52.0\end{array}$ & $\begin{array}{l}47.2 \\
16.6\end{array}$ & $\begin{array}{l}13.7 \\
24.3\end{array}$ \\
\hline
\end{tabular}

ANNUAL PEAK DISCHARGE, IN OUBIC FEET PER SECOND, AND CORRESPONDING GAGE HEIGTT, IN FEET, FOR EACH WATER IEAR

\begin{tabular}{|c|c|c|c|c|c|c|c|c|c|c|c|}
\hline $\begin{array}{l}\text { WATER } \\
\text { YEAR }\end{array}$ & DATE & $\begin{array}{c}\text { GAGE } \\
\text { HEIGHT }\end{array}$ & $\begin{array}{c}\text { PEAK } \\
\text { DISCHARGE }\end{array}$ & $\begin{array}{l}\text { WATER } \\
\text { YEAR }\end{array}$ & DATE & $\begin{array}{c}\text { GAGE } \\
\text { HEIGHT }\end{array}$ & $\begin{array}{c}\text { PEAK } \\
\text { DISAHARGE }\end{array}$ & $\begin{array}{l}\text { WATER } \\
\text { YEAR }\end{array}$ & DATE & $\begin{array}{c}\text { GAGE } \\
\text { HEIGT T }\end{array}$ & $\begin{array}{c}\text { PEAK } \\
\text { DISGHARGE }\end{array}$ \\
\hline $\begin{array}{l}1911 \\
1912 \\
1913 \\
1914\end{array}$ & $\begin{array}{l}\text { SEPT. 29, } 1911 \\
\text { MAY 30, } 1912 \\
\text { SEPT.08, } 1913 \\
\text { MAY 24, } 1914\end{array}$ & $\begin{array}{r}4.20 \\
6.50 \\
11.30 \\
6.62\end{array}$ & $\begin{array}{r}301 \\
755 \\
1750 \\
823\end{array}$ & $\begin{array}{l}1915 \\
1916 \\
1917 \\
1918\end{array}$ & $\begin{array}{l}\text { APR. } 20,1915 \\
\text { AUG. } 12,1916 \\
\text { OCT. } 10,1916 \\
\text { JULY } 14,1918\end{array}$ & $\begin{array}{l}3.94 \\
7.20 \\
8.10 \\
7.00\end{array}$ & $\begin{array}{r}305 \\
1030 \\
1240 \\
954\end{array}$ & $\begin{array}{l}1919 \\
1920 \\
1921\end{array}$ & $\begin{array}{lll}\text { AUG. } & 02,1919 \\
\text { MAY } & 23, & 1920 \\
\text { JULY } & 30, & 1921\end{array}$ & $\begin{array}{l}7.42 \\
7.60 \\
8.50\end{array}$ & $\begin{array}{r}993 \\
1040 \\
1260\end{array}$ \\
\hline
\end{tabular}

09324000 SEELY CREEK NEAR ORANGEVIILE, UT

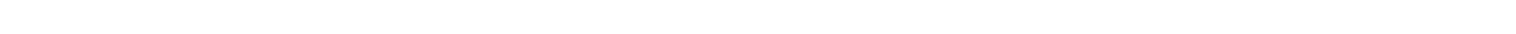
downstream from Lowry creek and $13 \mathrm{mi}$ west of Orangeville.

DRAINAGE AREA. --150 $\mathrm{mi}^{2}$.

PERTOD OF RECORD AVAILABLE.--September 1953 to September 1957.

GAGE.--Water-stage recorder. Altitude of gage is $6,800 \mathrm{ft}$ from topographic map.

REMARKS.--Sinall diversions for irrigation above station.

EXTREMES FOR PERTOD OF RECORD.--Maximum discharge, 2,110 ft $3 / \mathrm{s} \mathrm{Aug.} \mathrm{26,} \mathrm{1957,} \mathrm{gage} \mathrm{height,} 4.62 \mathrm{ft} ; \mathrm{minimum}^{3} 11 \mathrm{ft}{ }^{3} / \mathrm{s} \mathrm{Mar} .14,1957$, gage height, $0.62 \mathrm{ft}$.

LOWEST MEAN DISCHARGE, IN OBIC FEET PER SECOND, AND RANKING FOR THE INDICATED NUMBER OF CONSECUTIVE DAYS FOR EAOH OLIMATIC YEAR, APRIL 1-MAROH 31

\begin{tabular}{|c|c|c|c|c|c|c|c|c|c|c|c|c|c|c|c|c|c|c|c|c|}
\hline YEAR & & & & & & & & & CONS & (ब) & E DAYS & & & & & & & & & \\
\hline & 1 & & 3 & & 7 & & 14 & & 30 & & 60 & & 90 & & 120 & & 183 & & ALL & \\
\hline 1955 & 14.0 & 1 & 15.0 & 1 & 16.0 & 1 & 16.0 & 1 & 16.0 & 1 & 16.0 & 1 & 16.0 & 1 & 16.0 & 1 & 17.0 & 1 & 55.0 & 1 \\
\hline
\end{tabular}

HIGHEST MEAN DISGHARGE, IN OUBIC FEET PER SECOND, AND RANKING FOR THE INDICATED NUMBER OF CONSEUTIVE DAYS FOR EAOH WATER YEAR, OCTOBER 1-SEPTEMBER 30

\begin{tabular}{|c|c|c|c|c|c|c|c|c|c|c|c|c|c|c|c|c|c|c|c|}
\hline YEAR & & & & & & & & & 'W & CVE D & & & & & & & & & \\
\hline $\begin{array}{l}358 \\
412\end{array}$ & $\begin{array}{l}4 \\
3\end{array}$ & $\begin{array}{l}355 \\
387\end{array}$ & $\begin{array}{l}4 \\
3\end{array}$ & $\begin{array}{l}347 \\
333\end{array}$ & $\begin{array}{l}3 \\
4\end{array}$ & $\begin{array}{l}339 \\
275\end{array}$ & $\begin{array}{l}3 \\
4\end{array}$ & $\begin{array}{l}265 \\
258\end{array}$ & $\begin{array}{l}3 \\
4\end{array}$ & $\begin{array}{l}192 \\
203\end{array}$ & $\begin{array}{l}4 \\
3\end{array}$ & $\begin{array}{l}151 \\
160\end{array}$ & $\begin{array}{l}4 \\
3\end{array}$ & $\begin{array}{l}125 \\
134\end{array}$ & $\begin{array}{l}4 \\
3\end{array}$ & $\begin{array}{l}93.0 \\
98.0\end{array}$ & $\begin{array}{l}4 \\
3\end{array}$ & $\begin{array}{l}58.0 \\
58.0\end{array}$ & $\begin{array}{l}3 \\
4\end{array}$ \\
\hline $\begin{array}{rr}956 & 550 \\
957 & 1290\end{array}$ & $\begin{array}{l}2 \\
1\end{array}$ & $\begin{array}{r}537 \\
1240\end{array}$ & $\begin{array}{l}2 \\
1\end{array}$ & $\begin{array}{r}506 \\
1160\end{array}$ & $\begin{array}{l}2 \\
1\end{array}$ & $\begin{array}{r}449 \\
1010\end{array}$ & $\begin{array}{l}2 \\
1\end{array}$ & $\begin{array}{l}372 \\
969\end{array}$ & $\begin{array}{l}2 \\
1\end{array}$ & $\begin{array}{l}260 \\
634\end{array}$ & $\begin{array}{l}2 \\
1\end{array}$ & $\begin{array}{l}200 \\
462\end{array}$ & $\begin{array}{l}2 \\
1\end{array}$ & $\begin{array}{l}161 \\
363\end{array}$ & $\begin{array}{l}2 \\
1\end{array}$ & $\begin{array}{l}116 \\
250\end{array}$ & $\begin{array}{l}2 \\
1\end{array}$ & $\begin{array}{l}68.0 \\
134\end{array}$ & $\begin{array}{l}2 \\
1\end{array}$ \\
\hline
\end{tabular}


GREEN RIVER BASIN

09324000 SEELY CREEK NEAR ORANGEVILLE, UP--Continued

DURATION OF DISCHARGE FOR EACH WATER YEAR

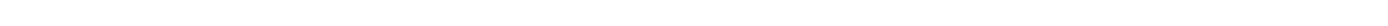

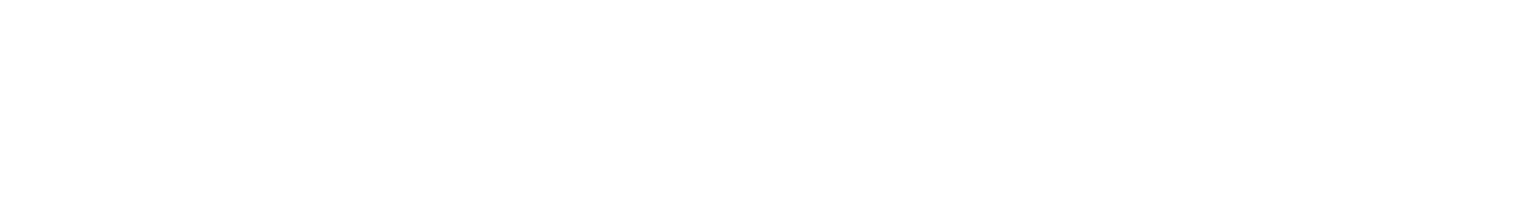

DURATION TABLE OF DISCHARGE FOR WATER YEARS 1954-57

\begin{tabular}{|c|c|c|c|c|c|c|c|c|c|c|c|c|c|c|c|c|c|c|c|}
\hline ASS & $\begin{array}{c}\text { CUBIC } \\
\text { FEET } \\
\text { PER } \\
\text { SECOND }\end{array}$ & $\begin{array}{r}\text { TOTAL } \\
\text { DAYS }\end{array}$ & $\begin{array}{l}\text { ACOU- } \\
\text { MU- } \\
\text { LATED } \\
\text { DAYS }\end{array}$ & $\begin{array}{l}\text { PER- } \\
\text { CENT } \\
\text { DAYS }\end{array}$ & CLASS & $\begin{array}{c}\text { OUBIC } \\
\text { FEET } \\
\text { PER } \\
\text { SECOND }\end{array}$ & $\begin{array}{r}\text { TOMAL } \\
\text { DAYS }\end{array}$ & $\begin{array}{c}\text { ACOU- } \\
\text { MU- } \\
\text { LATED } \\
\text { DAYS }\end{array}$ & $\begin{array}{l}\text { PER- } \\
\text { CENNT } \\
\text { DAYS }\end{array}$ & CLASS & $\begin{array}{c}\text { OBIIC } \\
\text { FEET } \\
\text { PER } \\
\text { SECOND }\end{array}$ & $\begin{array}{r}\text { TOTAL } \\
\text { DAYS }\end{array}$ & $\begin{array}{l}\text { ACCU- } \\
\text { MU- } \\
\text { LATED } \\
\text { DAYS }\end{array}$ & $\begin{array}{l}\text { PER- } \\
\text { CENT } \\
\text { DAYS }\end{array}$ & CLASS & $\begin{array}{c}\text { OABIC } \\
\text { FEET } \\
\text { PER } \\
\text { SECOND }\end{array}$ & $\begin{array}{r}\text { TOTAL } \\
\text { DAYS }\end{array}$ & $\begin{array}{l}\text { ACO- } \\
\text { MU- } \\
\text { LATED } \\
\text { DAYS }\end{array}$ & $\begin{array}{l}\text { PER- } \\
\text { CENT } \\
\text { DAYS }\end{array}$ \\
\hline $\begin{array}{l}0 \\
1 \\
2 \\
3 \\
4 \\
5 \\
6 \\
7 \\
8\end{array}$ & $\begin{array}{r}0.00 \\
14.00 \\
16.00 \\
18.00 \\
21.00 \\
24.00 \\
28.00 \\
32.00 \\
36.00\end{array}$ & $\begin{array}{r}0 \\
5 \\
243 \\
242 \\
172 \\
145 \\
74 \\
62 \\
52\end{array}$ & $\begin{array}{r}1461 \\
1461 \\
1456 \\
1213 \\
971 \\
799 \\
654 \\
580 \\
518\end{array}$ & $\begin{array}{r}100.0 \\
100.0 \\
99.7 \\
83.0 \\
66.5 \\
54.7 \\
44.8 \\
39.7 \\
35.5\end{array}$ & $\begin{array}{r}99 \\
10 \\
11 \\
12 \\
13 \\
14 \\
15 \\
16 \\
17\end{array}$ & $\begin{array}{r}42.00 \\
48.00 \\
55.00 \\
63.00 \\
72.00 \\
82.00 \\
94.00 \\
110.00 \\
120.00\end{array}$ & $\begin{array}{l}37 \\
43 \\
26 \\
25 \\
29 \\
49 \\
26 \\
10 \\
24\end{array}$ & $\begin{array}{l}466 \\
429 \\
386 \\
360 \\
335 \\
306 \\
257 \\
231 \\
221\end{array}$ & $\begin{array}{l}31.9 \\
29.4 \\
26.4 \\
24.6 \\
22.9 \\
20.9 \\
17.6 \\
15.8 \\
15.1\end{array}$ & $\begin{array}{l}18 \\
19 \\
20 \\
21 \\
22 \\
23 \\
24 \\
25 \\
26\end{array}$ & $\begin{array}{l}140.0 \\
160.0 \\
190.0 \\
210.0 \\
240.0 \\
280.0 \\
320.0 \\
370.0 \\
420.0\end{array}$ & $\begin{array}{r}26 \\
29 \\
14 \\
21 \\
16 \\
12 \\
23 \\
10 \\
4\end{array}$ & $\begin{array}{r}197 \\
171 \\
142 \\
128 \\
107 \\
91 \\
79 \\
56 \\
46\end{array}$ & $\begin{array}{r}13.5 \\
11.7 \\
9.7 \\
8.8 \\
7.3 \\
6.2 \\
5.4 \\
3.8 \\
3.1\end{array}$ & $\begin{array}{l}27 \\
28 \\
29 \\
30 \\
31 \\
32 \\
33 \\
34\end{array}$ & $\begin{array}{r}480.0 \\
550.0 \\
630.0 \\
730.0 \\
830.0 \\
950.0 \\
1100.0\end{array}$ & $\begin{array}{l}8 \\
2 \\
4 \\
5 \\
7 \\
9 \\
7\end{array}$ & $\begin{array}{r}42 \\
34 \\
32 \\
28 \\
23 \\
16 \\
7\end{array}$ & $\begin{array}{l}1 \\
0\end{array}$ \\
\hline
\end{tabular}

MONIHLY MEAN DISCHARGES, IN OABIC FEET PER SECOND, FOR EACH WATER YEAR

\begin{tabular}{|c|c|c|c|c|c|c|c|c|c|c|c|c|}
\hline YEAR & OCT & NOV & DEC & JAN & FEBB & MAR & APR & MAY & JUNE & JULY & AUG & SEP \\
\hline $\begin{array}{l}1954 \\
1955\end{array}$ & $\begin{array}{l}27.1 \\
20.7\end{array}$ & $\begin{array}{l}23.6 \\
17.5\end{array}$ & $\begin{array}{l}20.9 \\
16.1\end{array}$ & $\begin{array}{l}20.8 \\
16.0\end{array}$ & $\begin{array}{l}22.6 \\
16.6\end{array}$ & $\begin{array}{l}22.5 \\
17.5\end{array}$ & $\begin{array}{l}81.9 \\
28.8\end{array}$ & $\begin{array}{l}261 \\
184\end{array}$ & $\begin{array}{l}95.0 \\
217\end{array}$ & $\begin{array}{l}52.9 \\
74.4\end{array}$ & $\begin{array}{l}32.5 \\
52.4\end{array}$ & $\begin{array}{l}29.3 \\
28.3\end{array}$ \\
\hline $\begin{array}{l}1956 \\
1957\end{array}$ & $\begin{array}{l}21.8 \\
20.9\end{array}$ & $\begin{array}{l}18.6 \\
17.4\end{array}$ & $\begin{array}{l}21.0 \\
17.0\end{array}$ & $\begin{array}{l}20.2 \\
16.9\end{array}$ & $\begin{array}{l}18.6 \\
16.6\end{array}$ & $\begin{array}{l}25.4 \\
16.8\end{array}$ & $\begin{array}{l}49.1 \\
26.6\end{array}$ & $\begin{array}{l}299 \\
138\end{array}$ & $\begin{array}{l}213 \\
939\end{array}$ & $\begin{array}{l}67.0 \\
298\end{array}$ & $\begin{array}{l}36.9 \\
63.6\end{array}$ & $\begin{array}{l}26.0 \\
41.3\end{array}$ \\
\hline
\end{tabular}

09324200 COTYONWOOD CREEK ABONE STRAIGHT CANYON, NEAR ORANGEVILLE, UT

LOCATION.--Lat 39 $18^{\prime} 26^{\prime \prime}$, long $111^{\circ} 11^{\prime} 02^{\prime \prime}$, in $\mathrm{SE}_{4}^{\prime} \mathrm{NE}_{4}^{\prime}$ sec.36, T.17 S., R.6 E., Emery County, Hydrologic Unit 14060009, on left bank $2.5 \mathrm{mi}$ north from Ephraim-Castle Dale road and $10.6 \mathrm{mi}$ northwest of Orangeville.

DRAINAGE AREA. $-21.9 \mathrm{mi}^{2}$.

PERIOD OF RECORD AVAIIABLE.--October 1977 to September 1979, October 1979 to september 1981 (seasonal record).

GAGE.-Water-stage recorder. Altitude of gage is 6,940 ft fram topographic map.

EXTREMES FOR PERIOD OF RECORD.-Maximum daily discharge, $5.2 \mathrm{ft}^{3} / \mathrm{s}$ May $24,25,1979$, gage height, $1.42 \mathrm{ft} ; \mathrm{minimum}, 0.10 \mathrm{ft} / \mathrm{s}$ Mar. $10,1979$.

LOWEST MEAN DISCHARGE, IN OBBIC FEET PER SECOND, AND RANKING FOR THE INDICATED NUMBER OF CONSECUTIVE DAYS FOR EAGH CLIMATIC YEAR, APRII 1-MARCH 31

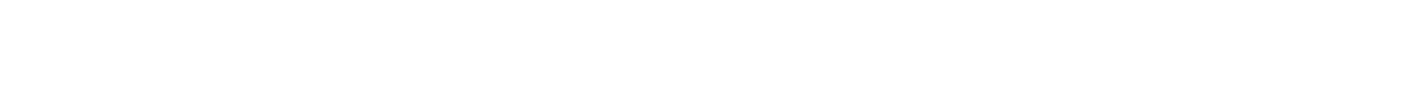

HIGHEST MEAN DISCHARGE, IN OUBIC FEET PER SECOND, AND RANKING FOR THE INDICATED NUMBER OF CONSECUTIVE DAYS FOR EACH WATER YEAR, OCTOBER 1-SEPTEMBER 30

YEAR

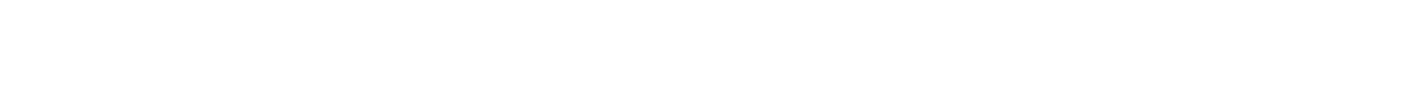


GREEN RIVER BASIN

09324200 COTTONWOOD CREEK ABOVE STRAIGHT CANYON, NEAR ORANGEVILLE, UT-COntinued

DURATION OF DISOHARGE FOR EACH WATER YEAR

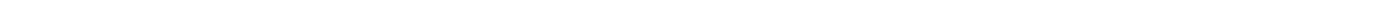

YEAR

NUMBER OF DAYS IN OLASS

OBBIC FEET PER SECOND -DAYS

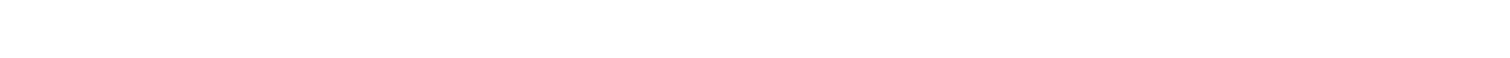

DURATION TABLE OF DISCHARGE FOR WATER YEARS 1978-79

\begin{tabular}{|c|c|c|c|c|c|c|c|c|c|c|c|c|c|c|c|}
\hline G.ASS & $\begin{array}{c}\text { CUBIC } \\
\text { FEET } \\
\text { PER } \\
\text { SECOND }\end{array}$ & $\begin{array}{l}\text { TOTAL } \\
\text { DAYS }\end{array}$ & $\begin{array}{l}\text { ACOU- } \\
\text { MU- } \\
\text { LATED } \\
\text { DAYS }\end{array}$ & $\begin{array}{l}\text { PER- } \\
\text { CENI } \\
\text { DAYS }\end{array}$ & & $\begin{array}{c}\text { CUBIC } \\
\text { FEET } \\
\text { PER } \\
\text { SECOND }\end{array}$ & $\begin{array}{r}\text { TOTAL } \\
\text { DAYS }\end{array}$ & $\begin{array}{c}\text { ACOS- } \\
\text { MU- } \\
\text { LATED } \\
\text { DAYS }\end{array}$ & $\begin{array}{l}\text { PER- } \\
\text { CENT } \\
\text { DAYS }\end{array}$ & & $\begin{array}{c}\text { OBIC } \\
\text { FEET } \\
\text { PER } \\
\text { SECOND }\end{array}$ & $\begin{array}{r}\text { TOTAL } \\
\text { DAYS }\end{array}$ & $\begin{array}{l}\text { ACOU- } \\
\text { MU- } \\
\text { LATED } \\
\text { DAYS }\end{array}$ & $\begin{array}{l}\text { PER- } \\
\text { CENT } \\
\text { DAYS }\end{array}$ & C.ASS \\
\hline $\begin{array}{l}0 \\
1 \\
2 \\
3 \\
4 \\
5 \\
6 \\
7 \\
8\end{array}$ & $\begin{array}{l}0.00 \\
0.14 \\
0.16 \\
0.19 \\
0.22 \\
0.25 \\
0.29 \\
0.34 \\
0.39\end{array}$ & $\begin{array}{r}0 \\
2 \\
12 \\
25 \\
45 \\
116 \\
61 \\
61 \\
103\end{array}$ & $\begin{array}{l}730 \\
730 \\
728 \\
716 \\
691 \\
646 \\
530 \\
469 \\
408\end{array}$ & $\begin{array}{r}100.0 \\
100.0 \\
99.7 \\
98.1 \\
94.7 \\
88.5 \\
72.6 \\
64.2 \\
55.9\end{array}$ & $\begin{array}{r}9 \\
10 \\
11 \\
12 \\
13 \\
14 \\
15 \\
16 \\
17\end{array}$ & $\begin{array}{l}0.45 \\
0.53 \\
0.61 \\
0.71 \\
0.82 \\
0.95 \\
1.10 \\
1.30 \\
1.50\end{array}$ & $\begin{array}{r}50 \\
43 \\
36 \\
21 \\
37 \\
15 \\
12 \\
10 \\
9\end{array}$ & $\begin{array}{r}305 \\
255 \\
212 \\
176 \\
155 \\
118 \\
103 \\
91 \\
81\end{array}$ & $\begin{array}{l}41.8 \\
34.9 \\
29.0 \\
24.1 \\
21.2 \\
16.2 \\
14.1 \\
12.5\end{array}$ & $\begin{array}{l}18 \\
19 \\
20 \\
21 \\
22 \\
23 \\
24 \\
25 \\
26\end{array}$ & $\begin{array}{l}1.7 \\
2.0 \\
2.3 \\
2.7 \\
3.1 \\
3.6 \\
4.1 \\
4.8\end{array}$ & $\begin{array}{r}7 \\
6 \\
8 \\
12 \\
13 \\
12 \\
8 \\
6\end{array}$ & $\begin{array}{r}72 \\
65 \\
59 \\
51 \\
39 \\
26 \\
14 \\
6\end{array}$ & $\begin{array}{l}9.9 \\
8.9 \\
8.1 \\
7.0 \\
5.3 \\
3.6 \\
1.9 \\
0.8\end{array}$ & $\begin{array}{l}27 \\
28 \\
29 \\
30 \\
31 \\
32 \\
33 \\
34\end{array}$ \\
\hline
\end{tabular}

MONTHLY MEAN DISCHARGES, IN OUBIC FEET PER SECOND, FOR EACH WATER YEAR

$\begin{array}{llcccccccrrrr}\text { YEAR } & \text { OCT } & \text { NOV } & \text { DEC } & \text { JAN } & \text { FEB } & \text { MAR } & \text { APR } & \text { MAY } & \text { JUNE } & \text { JULY } & \text { AUG } & \text { SEP } \\ & & & & & & & & & & & & \\ 1978 & 0.41 & 0.43 & 0.31 & 0.25 & 0.28 & 0.47 & 0.54 & 1.46 & 2.26 & 0.45 & 0.23 & 0.19 \\ 1979 & 0.28 & 0.42 & 0.32 & 0.26 & 0.33 & 0.60 & 0.87 & 2.40 & 3.00 & 1.06 & 0.58 & 0.35\end{array}$

09324500 COITIONWOCD CREEK NEAR ORANGEVILLE, UT

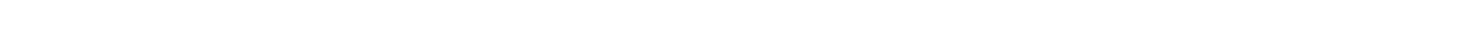

bank $2 \mathrm{mi}$ upstream from Grimes wash and $5 \mathrm{mi}$ northwest of orangeville.

DRAINAGE AREA. $-208 \mathrm{mi}^{2}$.

MEAN BASIN EIEVATION. $--8,940 \mathrm{ft}$.

PERIOD OF RECORD.--May 1909 to July 1921 and October 1921 to September 1927 and May 1932 to September 1970 (monthly mean discharge for same periods, published in WSP 1313), October 1975 to September 1981.

REVISED RECORDS. - WDR UT-77-1: Drainage area.

GAGE.--Water-stage recorder. Altitude of gage is 6,050 ft from topographic map. Prior to Aug. 11, 1921, staff gages, and Aug. 11, 1921 to Sept. 30, 1970, water-stage recorder, at several sites in vicinity of present gage at different datums.

REMARRS.--Flow regulated by Joes Valley Reservoir, $8 \mathrm{mi}$ upstream, constructed by Bureau of Reclamation in fall of 1965 . Small diversions for irrigation above station. Ephraim and Spring City tunnels constructed by Bureau of Reclamation in 1936 and 1938 , respectively, and several small tunnels and ditches divert from headwaters of cottonwood Creek to the Great Basin for irrigation in San Pitch River basin.

AVERAGE DISCHARGE. -61 years (water years 1910-20, 1922-27, 1933-70, 1976-81), $95.0 \mathrm{ft} 3 / \mathrm{s}, 68,800 \mathrm{acre}-\mathrm{ft} / \mathrm{Yr}$.

EXIREMES FOR PERIOD OF RECORD.--Maximum discharge, 7,220 ft 3 /s Aug. 1, 1964, gage height, $9.05 \mathrm{ft}$ tron high-water mark, at site then in use, fran slope-area measurement of peak flow; minirum observed, $1.2 \mathrm{ft}^{3} / \mathrm{s} \mathrm{Apr} .8,1966$.

DATA BEIOW BASED ON PERIOD OF RECORD PRIOR TO REGUTATION BY JOES VALLEY RESERVOIR

LOWEST MEAN DISCHARGE, IN CUBIC FEET PER SECOND, AND RANKING FOR THE INDICATED NUMBER OF CONSECUTIVE DAYS FOR EACH CIIMATIC YEAR, APRIL I-MARCH 31

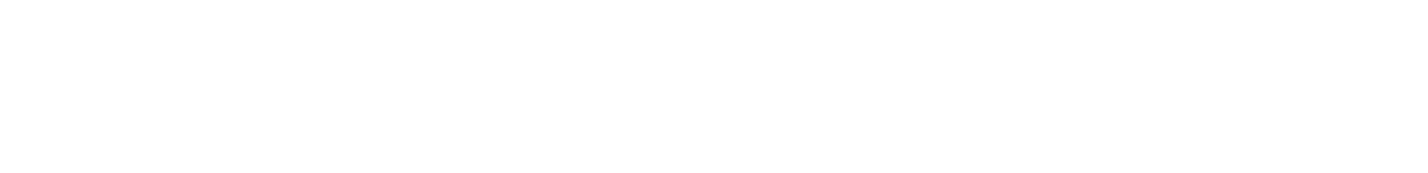


GREEN RIVER BASIN

09324500 COTTOWWOD CREEK NEAR ORANGEVILLE, UT--CONtinued

LOWEST MEAN DISGHARGE, IN OBIC FEET PER SECOND, AND RANKING FOR THE INDICATED NUMBER OF CONSEQUTIVE DAYS FOR EACH OIMATIC YEAR, APRII 1-MARCH 31--Continued

YEAR

$\begin{array}{lcccccccr} & & & & & 7 & & 14 & \\ 1916 & 18.0 & 40 & 18.0 & 36 & 22.0 & 43 & 24.0 & 44 \\ 1917 & 8.00 & 4 & 8.00 & 1 & 10.0 & 5 & 11.0 & 8 \\ 1918 & 8.00 & 5 & 8.70 & 5 & 11.0 & 10 & 15.0 & 17 \\ 1919 & 15.0 & 26 & 15.0 & 24 & 15.0 & 23 & 15.0 & 18 \\ 1920 & 8.00 & 6 & 10.0 & 6 & 10.0 & 6 & 10.0 & 4 \\ 1921 & 6.00 & 1 & 8.00 & 2 & 11.0 & 7 & 15.0 & 19 \\ 1923 & 14.0 & 20 & 15.0 & 25 & 15.0 & 24 & 15.0 & 20 \\ 1924 & 15.0 & 27 & 15.0 & 26 & 15.0 & 25 & 15.0 & 21 \\ 1925 & 8.00 & 2 & 8.00 & 3 & 8.00 & 1 & 8.00 & 1 \\ 1926 & 11.0 & 11 & 11.0 & 10 & 13.0 & 11 & 14.0 & 12 \\ 1927 & 8.00 & 3 & 8.70 & 4 & 8.90 & 2 & 8.90 & 2 \\ 1934 & 12.0 & 16 & 13.0 & 16 & 13.0 & 12 & 13.0 & 9 \\ 1935 & 11.0 & 12 & 11.0 & 11 & 11.0 & 8 & 11.0 & 5 \\ 1936 & 13.0 & 17 & 14.0 & 17 & 14.0 & 17 & 14.0 & 13 \\ 1937 & 14.0 & 21 & 14.0 & 18 & 15.0 & 18 & 16.0 & 22 \\ 1938 & 11.0 & 13 & 16.0 & 27 & 17.0 & 29 & 18.0 & 32 \\ 1939 & 16.0 & 32 & 16.0 & 28 & 16.0 & 26 & 16.0 & 23 \\ 1940 & 12.0 & 14 & 12.0 & 12 & 13.0 & 13 & 14.0 & 14 \\ 1941 & 14.0 & 22 & 14.0 & 19 & 15.0 & 19 & 16.0 & 24 \\ 1942 & 20.0 & 43 & 21.0 & 45 & 25.0 & 46 & 25.0 & 45 \\ 1943 & 16.0 & 33 & 18.0 & 37 & 20.0 & 39 & 20.0 & 37 \\ 1944 & 15.0 & 28 & 16.0 & 29 & 16.0 & 27 & 16.0 & 25 \\ 1945 & 16.0 & 34 & 16.0 & 30 & 17.0 & 30 & 18.0 & 33 \\ 1946 & 17.0 & 37 & 18.0 & 38 & 20.0 & 40 & 20.0 & 38 \\ 1947 & 10.0 & 7 & 12.0 & 13 & 13.0 & 14 & 14.0 & 15 \\ 1948 & 19.0 & 41 & 19.0 & 41 & 19.0 & 35 & 19.0 & 34 \\ 1949 & 20.0 & 44 & 20.0 & 42 & 20.0 & 36 & 20.0 & 39 \\ 1950 & 20.0 & 45 & 20.0 & 43 & 21.0 & 41 & 21.0 & 41 \\ 1951 & 15.0 & 29 & 18.0 & 39 & 20.0 & 37 & 20.0 & 40 \\ 1952 & 14.0 & 23 & 14.0 & 20 & 15.0 & 20 & 17.0 & 28 \\ 1953 & 25.0 & 47 & 25.0 & 47 & 25.0 & 47 & 26.0 & 47 \\ 1954 & 22.0 & 46 & 22.0 & 46 & 22.0 & 44 & 22.0 & 42 \\ 1955 & 16.0 & 35 & 16.0 & 31 & 17.0 & 31 & 17.0 & 29 \\ 1956 & 14.0 & 24 & 17.0 & 33 & 18.0 & 34 & 19.0 & 35 \\ 1957 & 16.0 & 36 & 16.0 & 32 & 17.0 & 32 & 17.0 & 30 \\ 1958 & 18.0 & 38 & 18.0 & 34 & 21.0 & 42 & 23.0 & 43 \\ 1959 & 12.0 & 15 & 14.0 & 21 & 16.0 & 28 & 16.0 & 26 \\ 1960 & 10.0 & 8 & 10.0 & 7 & 10.0 & 3 & 11.0 & 6 \\ 1961 & 15.0 & 30 & 15.0 & 22 & 15.0 & 21 & 16.0 & 27 \\ 1962 & 18.0 & 39 & 18.0 & 35 & 18.0 & 33 & 18.0 & 31 \\ 1964 & 10.0 & 9 & 10.0 & 8 & 10.0 & 4 & 10.0 & 3 \\ 1965 & 13.0 & 18 & 13.0 & 14 & 13.0 & 15 & 13.0 & 10 \\ & & & & & & & & \end{array}$

$\begin{array}{lll}\text { CONSECITIVE DAYS } & \\ 30 & 60 & 90\end{array}$

$\begin{array}{llll}25.0 & 43 & 25.0 & 43\end{array}$

12.07

$\begin{array}{llll}15.0 & 28 & 19.0 & 29\end{array}$

11.04

$15.0 \quad 16$

$17.0 \quad 17$

$\begin{array}{lll}18.0 & 25\end{array}$

$\begin{array}{llll}15.0 & 18 & 17.0 & 18\end{array}$

$15.0 \quad 19$

$\begin{array}{rr}15.0 & 19 \\ 9.00 & 1\end{array}$

$15.0 \quad 12$

9.101

$\begin{array}{rr}15.0 & 13 \\ 12.0 & 3\end{array}$

14.09

$17.0 \quad 19$

19.030

15.014

6.021

$17.0 \quad 25$

$25.0 \quad 44$

$25.0 \quad 21$

$\begin{array}{llll}21.0 & 39 & 22.0 & 41\end{array}$

$16.0 \quad 22 \quad 17.0 \quad 22$

$\begin{array}{llll}16.0 & 22 & 17.0 & 22 \\ 19.0 & 31 & 19.0 & 31\end{array}$

$20.0 \quad 36$

16.023

$19.0 \quad 32$

19.032

$21.0 \quad 41$

$20.0 \quad 38$

$28.0 \quad 47$

$22.0 \quad 42$

17.026

$19.0 \quad 33$

$\begin{array}{llll}18.0 & 30 & 18.0 & 27 \\ 27.0 & 46 & 28.0 & 46\end{array}$

$\begin{array}{llll}17.0 & 27 & 18.0 & 28\end{array}$

11.05

$16.0 \quad 24$

$20.0 \quad 34$

$\begin{array}{ll}10.0 & 3 \\ 13.0 & 9\end{array}$

$\begin{array}{rr}13.0 & 9 \\ 15.0 & 14\end{array}$

$22.0 \quad 38$

$20.0 \quad 34$

$\begin{array}{ll}29.0 & 47 \\ 23.0 & 42\end{array}$

$18.0 \quad 26$

12.04

$16.0 \quad 15$

$22.0 \quad 39$

13.05

$\begin{array}{ll}14.0 & 10 \\ 17.0 & 24\end{array}$
120

$27.0 \quad 44$

16.08

20.026

$\begin{array}{ll}16.0 & 9 \\ 14.0 & 5\end{array}$

$18.0 \quad 15$

$20.0 \quad 27$

$21.0 \quad 33$

11.01

$16.0 \quad 10$

12.02

$\begin{array}{rr}16.0 & 11 \\ 12.0 & 3\end{array}$

$15.0 \quad 6$

19.021

$20.0 \quad 29$

17.012

$19.0 \quad 22$

$29.0 \quad 45$

$23.0 \quad 34$

$\begin{array}{ll}19.0 & 23 \\ 20.0 & 30\end{array}$

$19.0 \quad 24$
$23.0 \quad 35$

$21.0 \quad 31$

$\begin{array}{ll}23.0 & 36 \\ 23.0 & 37\end{array}$

20.031

$21.0 \quad 34$

20.032

$21.0 \quad 35$

$22.0 \quad 37$

$\begin{array}{lll}37 & 23.0 & 38\end{array}$

$\begin{array}{llll}22.0 & 38 & 23.0 & 39\end{array}$

$\begin{array}{llll}29.0 & 46 & 29.0 & 46\end{array}$

$\begin{array}{llll}18.0 & 25 & 18.0 & 16\end{array}$

$\begin{array}{llll}20.0 & 33 & 21.0 & 32\end{array}$

$\begin{array}{llll}18.0 & 26 & 18.0 & 17\end{array}$

$\begin{array}{llll}30.0 & 47 & 31.0 & 47\end{array}$

$\begin{array}{rrrr}13.0 & 4 & 14.0 & 4\end{array}$

$\begin{array}{llll}17.0 & 16 & 19.0 & 18\end{array}$

$\begin{array}{llll}24.0 & 42 & 24.0 & 40\end{array}$

$\begin{array}{llll}15.0 & 10 & 17.0 & 13\end{array}$

$\begin{array}{rrrr}14.0 & 8 & 15.0 & 7 \\ 18.0 & 17 & 19.0 & 19\end{array}$

\begin{tabular}{|c|c|c|c|}
\hline 83 & & ALL & \\
\hline $\begin{array}{l}27.0 \\
25.0 \\
23.0 \\
22.0 \\
17.0\end{array}$ & $\begin{array}{r}42 \\
37 \\
31 \\
24 \\
7\end{array}$ & $\begin{array}{c}101 \\
129 \\
134 \\
92.0 \\
101\end{array}$ & $\begin{array}{l}28 \\
38 \\
39 \\
24 \\
29\end{array}$ \\
\hline 21.0 & 16 & 135 & 40 \\
\hline $\begin{array}{l}22.0 \\
25.0 \\
13.0\end{array}$ & $\begin{array}{c}25 \\
38 \\
1\end{array}$ & $\begin{array}{c}162 \\
148 \\
61.0\end{array}$ & $\begin{array}{r}45 \\
44 \\
6\end{array}$ \\
\hline $\begin{array}{l}19.0 \\
14.0\end{array}$ & $\begin{array}{l}9 \\
3\end{array}$ & $\begin{array}{l}73.0 \\
68.0\end{array}$ & $\begin{array}{l}15 \\
10\end{array}$ \\
\hline $\begin{array}{l}16.0 \\
13.0\end{array}$ & $\begin{array}{l}4 \\
2\end{array}$ & $\begin{array}{l}86.0 \\
31.0\end{array}$ & $\begin{array}{r}20 \\
1\end{array}$ \\
\hline $\begin{array}{l}17.0 \\
21.0 \\
22.0 \\
23.0 \\
19.0\end{array}$ & $\begin{array}{r}5 \\
17 \\
26 \\
32 \\
10\end{array}$ & $\begin{array}{l}104 \\
120 \\
97.0 \\
96.0 \\
76.0\end{array}$ & $\begin{array}{l}30 \\
34 \\
27 \\
26 \\
17\end{array}$ \\
\hline $\begin{array}{l}21.0 \\
34.0 \\
24.0 \\
21.0 \\
22.0\end{array}$ & $\begin{array}{l}18 \\
47 \\
33 \\
19 \\
27\end{array}$ & $\begin{array}{c}86.0 \\
123 \\
115 \\
71.0 \\
127\end{array}$ & $\begin{array}{l}21 \\
35 \\
32 \\
12 \\
36\end{array}$ \\
\hline $\begin{array}{l}25.0 \\
21.0 \\
23.0 \\
24.0 \\
25.0\end{array}$ & $\begin{array}{l}39 \\
20 \\
28 \\
34 \\
35\end{array}$ & $\begin{array}{r}88.0 \\
74.0 \\
95.0 \\
71.0 \\
115\end{array}$ & $\begin{array}{l}23 \\
16 \\
25 \\
13 \\
33\end{array}$ \\
\hline $\begin{array}{l}23.0 \\
25.0 \\
31.0 \\
27.0 \\
20.0\end{array}$ & $\begin{array}{l}29 \\
36 \\
45 \\
40 \\
13\end{array}$ & $\begin{array}{r}70.0 \\
80.0 \\
214 \\
83.0 \\
54.0\end{array}$ & $\begin{array}{r}11 \\
18 \\
47 \\
19 \\
4\end{array}$ \\
\hline $\begin{array}{l}22.0 \\
19.0 \\
34.0 \\
22.0 \\
17.0\end{array}$ & $\begin{array}{r}21 \\
11 \\
46 \\
22 \\
6\end{array}$ & $\begin{array}{r}61.0 \\
66.0 \\
144 \\
127 \\
40.0\end{array}$ & $\begin{array}{r}7 \\
9 \\
43 \\
37 \\
2\end{array}$ \\
\hline $\begin{array}{l}21.0 \\
29.0 \\
21.0 \\
18.0 \\
20.0\end{array}$ & $\begin{array}{r}14 \\
43 \\
15 \\
8 \\
12\end{array}$ & $\begin{array}{l}63.0 \\
54.0 \\
87.0 \\
51.0 \\
72.0\end{array}$ & $\begin{array}{r}8 \\
5 \\
22 \\
3 \\
14\end{array}$ \\
\hline
\end{tabular}


GREEN RIVER BASIN

09324500 COTTONWOOD CREEK NEAR ORANGEVIILL, UT--Continued

HIGHEST MEAN DISCHARGE, IN CUBIC FEET PER SECOND, AND RANKING FOR THE INDICATED NUNBER OF CONSECITIVE DAYS FOR EACH WATER YEAR, OCTOBER I-SEPTEMBER 30

YEAR

\begin{tabular}{|c|c|c|c|c|c|}
\hline $\begin{array}{l}1911 \\
1912 \\
1913 \\
1914 \\
1915\end{array}$ & $\begin{array}{r}700 \\
1880 \\
1980 \\
1440 \\
954\end{array}$ & $\begin{array}{r}28 \\
3 \\
1 \\
6 \\
16\end{array}$ & $\begin{array}{r}682 \\
1540 \\
1120 \\
1340 \\
785\end{array}$ & $\begin{array}{r}29 \\
3 \\
8 \\
5 \\
23\end{array}$ & $\begin{array}{r}654 \\
1470 \\
1100 \\
1200 \\
661\end{array}$ \\
\hline $\begin{array}{l}1916 \\
1917 \\
1918 \\
1919 \\
1920\end{array}$ & $\begin{array}{r}950 \\
1880 \\
770 \\
900 \\
1250\end{array}$ & $\begin{array}{r}17 \\
2 \\
26 \\
20 \\
7\end{array}$ & $\begin{array}{r}937 \\
1660 \\
729 \\
867 \\
1220\end{array}$ & $\begin{array}{r}14 \\
2 \\
25 \\
20 \\
6\end{array}$ & $\begin{array}{r}883 \\
1610 \\
682 \\
834 \\
1120\end{array}$ \\
\hline $\begin{array}{l}1922 \\
1923 \\
1924 \\
1925\end{array}$ & $\begin{array}{r}1100 \\
940 \\
504 \\
497\end{array}$ & $\begin{array}{l}10 \\
18 \\
37 \\
38\end{array}$ & $\begin{array}{r}1090 \\
920 \\
495 \\
476\end{array}$ & $\begin{array}{l}10 \\
17 \\
36 \\
40\end{array}$ & $\begin{array}{r}1030 \\
849 \\
464 \\
445\end{array}$ \\
\hline $\begin{array}{l}1926 \\
1927\end{array}$ & $\begin{array}{l}627 \\
800\end{array}$ & $\begin{array}{l}31 \\
24\end{array}$ & $\begin{array}{l}624 \\
717\end{array}$ & $\begin{array}{l}31 \\
26\end{array}$ & $\begin{array}{l}559 \\
593\end{array}$ \\
\hline $\begin{array}{l}1933 \\
1934 \\
1935\end{array}$ & $\begin{array}{r}780 \\
178 \\
1600\end{array}$ & $\begin{array}{r}25 \\
49 \\
5\end{array}$ & $\begin{array}{r}763 \\
174 \\
1530\end{array}$ & $\begin{array}{r}24 \\
49 \\
4\end{array}$ & $\begin{array}{r}744 \\
169 \\
1440\end{array}$ \\
\hline $\begin{array}{l}1936 \\
1937 \\
1938 \\
1939 \\
1940\end{array}$ & $\begin{array}{r}925 \\
898 \\
1010 \\
497 \\
1000\end{array}$ & $\begin{array}{l}19 \\
21 \\
12 \\
39 \\
13\end{array}$ & $\begin{array}{l}925 \\
878 \\
947 \\
465 \\
933\end{array}$ & $\begin{array}{l}16 \\
19 \\
12 \\
41 \\
15\end{array}$ & $\begin{array}{l}906 \\
796 \\
878 \\
442 \\
836\end{array}$ \\
\hline $\begin{array}{l}1941 \\
1942 \\
1943 \\
1944 \\
1945\end{array}$ & $\begin{array}{r}852 \\
1210 \\
464 \\
958 \\
490\end{array}$ & $\begin{array}{r}22 \\
8 \\
42 \\
15 \\
41\end{array}$ & $\begin{array}{r}826 \\
1110 \\
457 \\
941 \\
479\end{array}$ & $\begin{array}{r}21 \\
9 \\
42 \\
13 \\
37\end{array}$ & $\begin{array}{l}758 \\
-35 \\
399 \\
878 \\
457\end{array}$ \\
\hline $\begin{array}{l}1946 \\
1947 \\
1948 \\
1949 \\
1950\end{array}$ & $\begin{array}{l}441 \\
682 \\
555 \\
731 \\
550\end{array}$ & $\begin{array}{l}43 \\
30 \\
32 \\
27 \\
34\end{array}$ & $\begin{array}{l}432 \\
658 \\
530 \\
697 \\
530\end{array}$ & $\begin{array}{l}43 \\
30 \\
33 \\
27 \\
34\end{array}$ & $\begin{array}{l}411 \\
587 \\
507 \\
688 \\
509\end{array}$ \\
\hline $\begin{array}{l}1951 \\
1952 \\
1953 \\
1954 \\
1955\end{array}$ & $\begin{array}{r}844 \\
1720 \\
695 \\
322 \\
420\end{array}$ & $\begin{array}{r}23 \\
4 \\
29 \\
45 \\
44\end{array}$ & $\begin{array}{r}820 \\
1680 \\
685 \\
319 \\
388\end{array}$ & $\begin{array}{c}22 \\
1 \\
28 \\
45 \\
44\end{array}$ & $\begin{array}{r}740 \\
1610 \\
655 \\
317 \\
346\end{array}$ \\
\hline $\begin{array}{l}1956 \\
1957 \\
1958 \\
1959 \\
1960\end{array}$ & $\begin{array}{r}534 \\
1200 \\
1040 \\
249 \\
517\end{array}$ & $\begin{array}{r}35 \\
9 \\
11 \\
48 \\
36\end{array}$ & $\begin{array}{r}507 \\
1180 \\
1020 \\
244 \\
476\end{array}$ & $\begin{array}{r}35 \\
7 \\
11 \\
48 \\
38\end{array}$ & $\begin{array}{r}495 \\
1120 \\
947 \\
227 \\
430\end{array}$ \\
\hline $\begin{array}{l}1961 \\
1962 \\
1963 \\
1964 \\
1965\end{array}$ & $\begin{array}{l}312 \\
496 \\
286 \\
555 \\
975\end{array}$ & $\begin{array}{l}46 \\
40 \\
47 \\
33 \\
14\end{array}$ & $\begin{array}{l}307 \\
476 \\
279 \\
543 \\
883\end{array}$ & $\begin{array}{l}46 \\
39 \\
47 \\
32 \\
18\end{array}$ & $\begin{array}{l}291 \\
436 \\
272 \\
522 \\
831\end{array}$ \\
\hline
\end{tabular}

CONSEUTTVE DAYS

15

$28 \quad 622$

$\begin{array}{ll}3 & 1200 \\ 8 & 1000\end{array}$

$\begin{array}{ll}8 & 1000 \\ 5 & 1060\end{array}$

$13 \quad 820$

$\begin{array}{rr}1 & 1380 \\ 25 & 580\end{array}$

$\begin{array}{ll}25 & 580 \\ 18 & 797\end{array}$

$11 \quad 654$

$\begin{array}{rr}2 & 1020 \\ 27 & 476\end{array}$

$\begin{array}{rr}13 & 638 \\ 5 & 932\end{array}$

$\begin{array}{rr}9 & 991 \\ 16 & 764 \\ 36 & 410 \\ 38 & 402\end{array}$

$\begin{array}{rl}9 & 860 \\ 18 & 731 \\ 38 & 346 \\ 39 & 360\end{array}$

$\begin{array}{ll}31 & 459 \\ 29 & 481\end{array}$

$22 \quad 679$

$49 \quad 154$

$21 \quad 567$

$\begin{array}{rrr}21 & 480 & 17 \\ 5 & 592 & 8\end{array}$

90

120

183

$\begin{array}{rrrr}7 & 566 & 12 & 425 \\ 3 & 726 & 2 & 551 \\ 25 & 397 & 21 & 302\end{array}$

$\begin{array}{lll}19 & 291\end{array}$

$4 \quad 1170$

$\begin{array}{ll}12 & 792 \\ 20 & 671 \\ 14 & 772 \\ 39 & 429 \\ 17 & 804\end{array}$

$\begin{array}{rr}16 & 520 \\ 2 & 616 \\ 26 & 351 \\ 18 & 447\end{array}$

14405

$\begin{array}{rr}6 & 454 \\ 8 & 278\end{array}$

$\begin{array}{ll}40 & 328 \\ 4 & 463\end{array}$

8643

$\begin{array}{rrr}12 & 607 & 7 \\ 37 & 245 & 42\end{array}$

510
487
187
214

3432

$\begin{array}{rr}357 & 8 \\ 143 & 10\end{array}$

$\begin{array}{rrr}21 & 441 & 2 \\ 21 & 244 & 21\end{array}$

$\begin{array}{rrr}209 & 16 & 121 \\ 247 & 9 & 135\end{array}$

$21 \quad 14$ $\begin{array}{rrrr}247 & 9 & 135 & 8 \\ 252 & 7 & 140 & 6 \\ 306 & 2 & 168 & 3 \\ 172 & 22 & 97.0 & 21\end{array}$

$\begin{array}{llll}21 & 694 & 20 & 640 \\ 11 & 794 & 14 & 700\end{array}$

$\begin{array}{llll}43 & 316 & 43 & 252 \\ 15 & 771 & 17 & 733\end{array}$

$\begin{array}{llll}37 & 425 & 37 & 375\end{array}$

$\begin{array}{llll}42 & 369 & 41 & 330 \\ 30 & 461 & 32 & 445 \\ 34 & 487 & 29 & 407 \\ 24 & 611 & 25 & 550 \\ 33 & 466 & 31 & 367\end{array}$

330
445
407
550
367

23550

$28 \quad 452$

$\begin{array}{rrrrrrrrrr}2 & 1460 & 1 & 1200 & 1 & 936 & 1 & 721 & 1 & 568 \\ 27 & 583 & 26 & 471 & 27 & 314 & 30 & 237 & 31 & 193\end{array}$

$\begin{array}{llllllllll}45 & 302 & 44 & 237 & 45 & 170 & 46 & 137 & 45 & 115 \\ 44 & 285 & 45 & 260 & 43 & 207 & 44 & 163 & 44 & 137\end{array}$

$\begin{array}{llll}35 & 441 & 35 & 359\end{array}$

$\begin{array}{rrrrrrrrrrrrrrr}7 & 993 & 8 & 944 & 4 & 627 & 5 & 460 & 6 & 367 & 6 & 253 & 6 & 136 & 7 \\ 10 & 891 & 10 & 782 & 10 & 576 & 10 & 418 & 12 & 331 & 12 & 231 & 13 & 133 & 10 \\ 48 & 206 & 48 & 165 & 48 & 126 & 48 & 100 & 48 & 85.0 & 48 & 63.0 & 48 & 43.0 & 48 \\ 41 & 372 & 40 & 330 & 41 & 231 & 43 & 176 & 43 & 144 & 43 & 105 & 43 & 61.0 & 43\end{array}$

$38 \quad 249$

$\begin{array}{rrrrrrrrrrrrrrr}7 & 993 & 8 & 944 & 4 & 627 & 5 & 460 & 6 & 367 & 6 & 253 & 6 & 136 & 7 \\ 10 & 891 & 10 & 782 & 10 & 576 & 10 & 418 & 12 & 331 & 12 & 231 & 13 & 133 & 10 \\ 48 & 206 & 48 & 165 & 48 & 126 & 48 & 100 & 48 & 85.0 & 48 & 63.0 & 48 & 43.0 & 48 \\ 41 & 372 & 40 & 330 & 41 & 231 & 43 & 176 & 43 & 144 & 43 & 105 & 43 & 61.0 & 43\end{array}$

$\begin{array}{rrrr}40 & 192 & 41 & 157\end{array}$

$\begin{array}{lllll}13 & 234 & 11 & 131 & 12\end{array}$

$\begin{array}{lllll}26 & 162 & 26 & 93.0 & 26\end{array}$

$\begin{array}{llllll}58 & 20 & 185 & 20 & 104 & 19\end{array}$

$\begin{array}{ll}46 & 257 \\ 40 & 350 \\ 47 & 261 \\ 32 & 446\end{array}$

$\begin{array}{ll}47 & 208 \\ 42 & 310 \\ 46 & 228 \\ 34 & 394\end{array}$

$\begin{array}{lllll}47 & 118 & 47 & 100 & 47\end{array}$

$\begin{array}{llll}3 & 252 & 30 & 209\end{array}$

$\begin{array}{llll}133 & 46 & 112 \\ 4 & 220 & 34 & 175\end{array}$

$\begin{array}{lllll}47 & 78.0 & 47 & 50.0 & 47 \\ 30 & 155 & 28 & 92.0 & 27 \\ 46 & 85.0 & 46 & 53.0 & 46 \\ 35 & 124 & 36 & 71.0 & 38\end{array}$

DURATTON OF DISCHARGE FOR EACH WATER YEAR

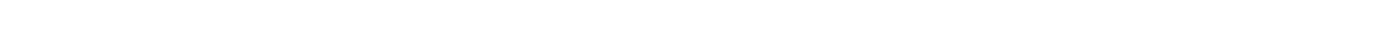
YEAR

NUMER OF DAUS IN OLASS

CBBIC FEET ER SECOND -DAYS

1911

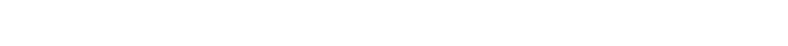

44147.0

912

1914

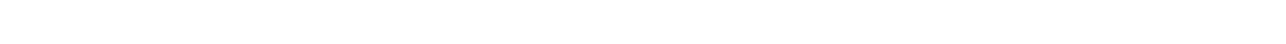
$\begin{array}{llrrrrrrrrrrrrrrrrrrrrrrrrrr}1 & 1 & 1 & 2127 & 34 & 37 & 25 & 7 & 7 & 13 & 3 & 16 & 10 & 7 & 8 & 4 & 7 & 3 & 3 & 1 & 10 & 12 & 10 & 10 & 4 & 2 & 1 & 61398.0\end{array}$

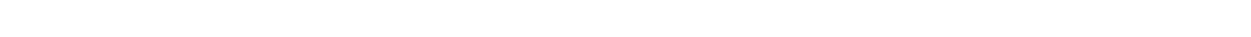

1916

1917

1918

1919

$\begin{array}{llllllllllllllllllllllll}4 & 2109 & 60 & 29 & 17 & 12 & 16 & 6 & 6 & 9 & 3 & 21 & 10 & 3 & 6 & 18 & 4 & 4 & 10 & 6 & 9 & 2\end{array}$

48010.0

$\begin{array}{lllllllllllllllllllllllllllllllll}6 & 3 & 75 & 12 & 46 & 3 & 43 & 4 & 33 & 19 & 12 & 14 & 6 & 6 & 8 & 10 & 9 & 11 & 6 & 4 & 2 & 2 & 4 & 3 & 5 & 5 & 1 & 5 & 6 & 2 & 49250.0\end{array}$

$\begin{array}{llllllllllllllllllllll}1100 & 24 & 33 & 44 & 22 & 21 & 21 & 5 & 7 & 9 & 2 & 8 & 11 & 8 & 13 & 5 & 8 & 10 & 3 & 6 & 2 & 2\end{array}$

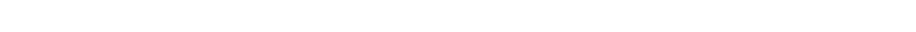

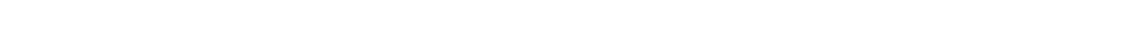

43814.0

48352.0 
GREEN RIVER BASIN

09324500 COTTONWOOD CREEK NEAR ORANGEVIILE, UT-CONTInUed

DURATION OF DISCHARGE FOR EACH WATER YEAR--Continued

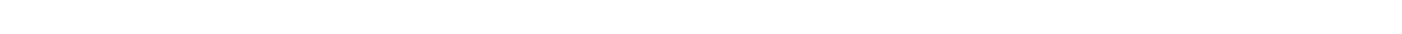

YEAR

NUMBER OF DAYS IN OLASS

OUBIC FEET

1922

1923
1924

1924
1925

$\begin{array}{rlllllllllllllllllllll}5 & 104 & 21 & 48 & 47 & 16 & 1 & 2 & 3 & 1 & 6 & 26 & 16 & 9 & 10 & 5 & 9 & 5 & 12 & 6 & 12 & 1\end{array}$

1926

1927

1933

1934
1935

1936

1937
1938

1938
1939

1940

1941

1942

1943
1944

1944
1945

1946

1947
1948

1949
1950

1951

1952

1953

1954
1955

1956

1957

1958
1959

1960

1961
1962

1963

1964
1965

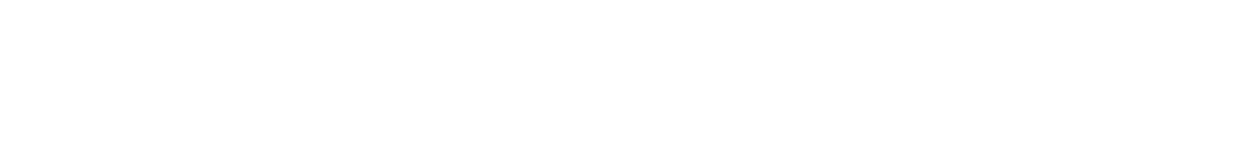

$\begin{array}{rrrrrrrrrrrrrrrrrrrrrrrrr}3 & 53 & 24 & 83 & 56 & 40 & 32 & 14 & 18 & 8 & 3 & 10 & 9 & 5 & 4 & 4 & 7 & 6 & 12 & 4 & 12 & 4 & 3 & 4 & \\ 17 & 46 & 6 & 13 & 13 & 22 & 12 & 9 & 10 & 18 & 12 & 12 & 9 & 7 & 8 & 8 & 13 & 9 & 15 & 15 & 5 & 2 & 1 & 1\end{array}$

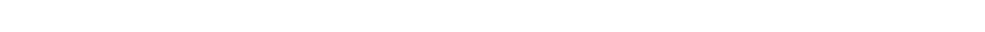

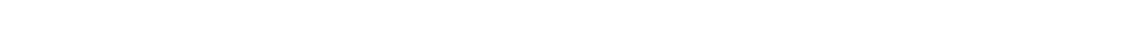

PER SECOND

-DAYS

62795.0

53425.0

24332.0

25676.0

25190.0

34757.0

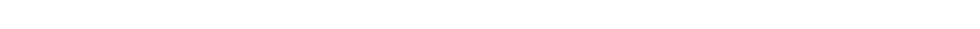

$\begin{array}{rrrrrrrrrrrrrrrrrrrrrrrrrrrr}31 & 72 & 37 & 57 & 20 & 11 & 18 & 9 & 13 & 14 & 7 & 7 & 4 & 9 & 8 & 2 & 16 & 7 & 3 & 5 & 5 & 6 & 4 & \\ 1 & 15 & 82 & 52 & 56 & 27 & 11 & 10 & 13 & 8 & 6 & 7 & 10 & 8 & 5 & 6 & 5 & 5 & 4 & 3 & 3 & 3 & 5 & 7 & 2\end{array}$

$\begin{array}{rrrrrrrrrrrrrrrrrrrrrrrrrrrrrrrrrr}1 & 1 & 15 & 82 & 52 & 56 & 27 & 11 & 10 & 13 & 8 & 6 & 7 & 10 & 8 & 15 & 6 & 5 & 5 & 4 & 3 & 3 & 3 & 5 & 7 & 2\end{array}$

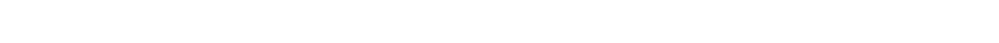

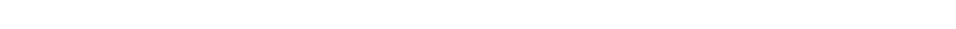

$\begin{array}{lllllllllllllllllllllll}1 & 2109 & 50 & 41 & 20 & 13 & 10 & 7 & 18 & 16 & 7 & 11 & 16 & 7 & 3 & 2 & 3 & 3 & 8 & 10 & 4 & 3 & 1\end{array}$

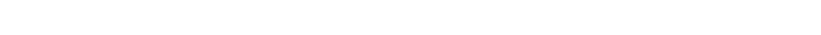

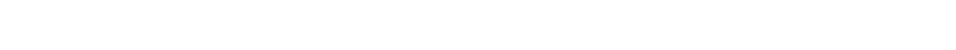

$\begin{array}{lllllllllllllllllll}1 & 31 & 97 & 54 & 31 & 29 & 18 & 8 & 11 & 7 & 8 & 7 & 3 & 4 & 10 & 11 & 14 & 14 & 7\end{array}$

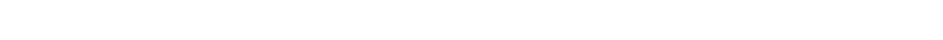

$\begin{array}{llllllllllllllllllll}79 & 34 & 85 & 34 & 20 & 12 & 19 & 18 & 7 & 6 & 9 & 5 & 6 & 1 & 4 & 4 & 4 & 5 & 12 & 2\end{array}$

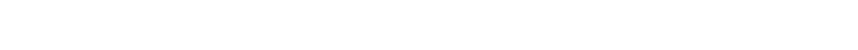

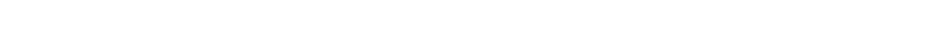

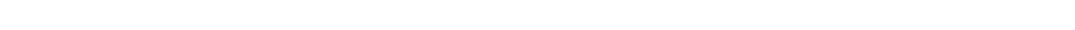
$\begin{array}{lllllllllllllllllll}78 & 102 & 47 & 13 & 24 & 18 & 16 & 8 & 6 & 8 & 7 & 3 & 5 & 5 & 3 & 7 & 4 & 6 & 5\end{array}$

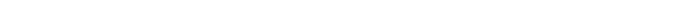

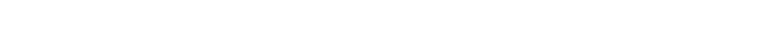

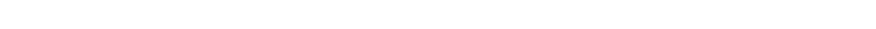

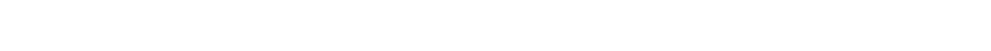

$\begin{array}{rrrrrrrrrrrrrrrrrrrrrrr}2 & 8 & 59 & 88 & 46 & 27 & 19 & 20 & 12 & 14 & 6 & 1 & 4 & 4 & 2 & 3 & 6 & 5 & 5 & 11 & 5 & 12 & 6\end{array}$

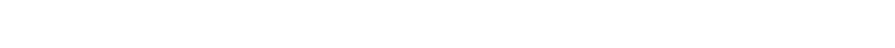

$\begin{array}{llllllllllllllllll}61 & 30 & 71 & 27 & 46 & 32 & 16 & 12 & 13 & 8 & 11 & 5 & 7 & 4 & 8 & 7 & 5 & 2\end{array}$

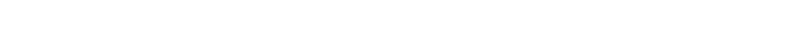

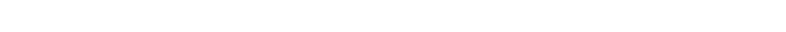

$\begin{array}{llllllllllllllllllllll}70 & 42 & 23 & 32 & 72 & 15 & 16 & 7 & 9 & 7 & 7 & 6 & 5 & 2 & 5 & 4 & 12 & 9 & 8 & 7 & 5 & 3\end{array}$

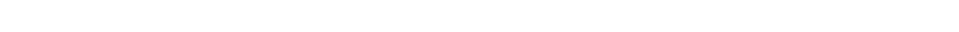

42996.0

35128.0

34336.0

28899.0

31034.0

42421.0

43657.0

26675.0

45997.0

31368.0

27559.0

34533.0

25838.0

41974.0

25740.0

29147.0

76968.0

31321.0

20838.0

21801.0

24582.0

49700.0

48491 . 0

15581.0

22328.0

18099.0

33461.0

19370.0
25863.0

DURATION TFLE OF DISCHARGE FOR WATER YEARS 1911-20, 1922-27, $1933-65$

$\begin{array}{ccc}\text { OBIIC } & \text { ACG- } \\ \text { FEET } & \text { MU- } & \text { PER- } \\ \text { PER TOTAL LATED } & \text { CENT } \\ \text { CAASS SECOND DAYS DAYS } & \text { DAYS }\end{array}$

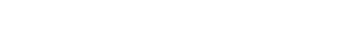

$\begin{array}{llll}5.00 & 0 & 17897 & 100.0\end{array}$

$\begin{array}{lllll}5.00 & 0 & 17897 & 100.0 \\ 6.00 & 0 & 17897 & 100.0\end{array}$

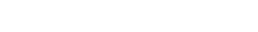

$\begin{array}{llll}7.20 & 23 & 17897 & 100.0\end{array}$

$\begin{array}{rrrr}8.60 & 53 & 17874 & 99.9\end{array}$

$\begin{array}{llll}10.00 & 287 & 17821 & 99.6\end{array}$

$\begin{array}{llll}12.00 & 661 & 17534 & 98.0\end{array}$

$\begin{array}{llll}15.00 & 1231 & 16873 & 94.3\end{array}$

$\begin{array}{ccc}\text { OJBIC } & \text { ACOJ- } \\ \text { FEET } & \text { MU- } & \text { PER- } \\ \text { PER TOTAL LAIED } & \text { CENT } \\ \text { GAASS SECOND DAYS DAYS DAYS } & & \end{array}$

$\begin{array}{rcc}\text { OJBIC } & \text { ACOJ- } \\ \text { FEET } & \text { MU- } & \text { PER- } \\ \text { PER TOTAL LAIED } & \text { CENT } \\ \text { GASS SECOND DAYS DAVS } & \text { DAYS }\end{array}$

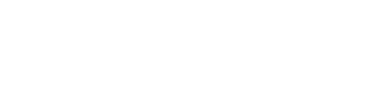

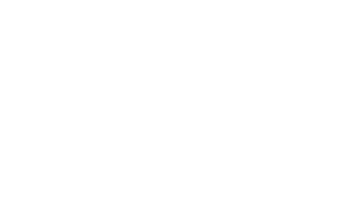

CLASS SECOND DAYS DAYS DAYS

$\begin{array}{rrrrr}18 & 110.0 & 340 & 3514 & 19.6 \\ 19 & 130.0 & 266 & 3174 & 17.7 \\ 20 & 150.0 & 328 & 2908 & 16.2 \\ 21 & 180.0 & 363 & 2580 & 14.4 \\ 22 & 220.0 & 326 & 2217 & 12.4 \\ 23 & 260.0 & 308 & 1891 & 10.6 \\ 24 & 310.0 & 324 & 1583 & 8.8 \\ 25 & 370.0 & 271 & 1259 & 7.0 \\ 26 & 450.0 & 211 & 988 & 5.5\end{array}$

$\begin{array}{lllll}27 & 530.0 & 236 & 777 & 4.3\end{array}$

$\begin{array}{lllll}28 & 640.0 & 207 & 541 & 3.0\end{array}$

$\begin{array}{rrrrr}29 & 770.0 & 167 & 334 & 1.9\end{array}$

$\begin{array}{rrrrr}31 & 1100.0 & 37 & 73 & 0.4\end{array}$

$\begin{array}{rrrrr}33 & 1600.0 & 11 & 12 & 0.1 \\ 34 & 1900.0 & 1 & 1 & 0.0\end{array}$ $\begin{array}{lllll}32 & 1300.0 & 24 & 36 & 0.2\end{array}$

MONTHLY MEAN DISCHARGES, IN OBIC FEET PER SECOND, FOR EACH WATER YEAR

\begin{tabular}{|c|c|c|c|c|c|c|c|c|c|c|c|c|}
\hline YEAR & OCT & NOV & DEC & JAN & FEB & MAR & APR & MAY & JUNE & JULY & AUG & SEP \\
\hline 1910 & 45.3 & 38.7 & 36.0 & 30.0 & 30.0 & 91.0 & 285 & 607 & 328 & 91.1 & 47.1 & 81.8 \\
\hline $\begin{array}{l}1911 \\
1912 \\
1913 \\
1914 \\
1915\end{array}$ & $\begin{array}{l}25.0 \\
28.1 \\
33.0 \\
29.0 \\
35.7\end{array}$ & $\begin{array}{l}32.0 \\
26.4 \\
30.1 \\
26.4 \\
25.6\end{array}$ & $\begin{array}{l}30.0 \\
25.0 \\
20.0 \\
28.5 \\
19.3\end{array}$ & $\begin{array}{l}30.0 \\
14.0 \\
25.0 \\
26.9 \\
16.0\end{array}$ & $\begin{array}{l}39.1 \\
11.6 \\
25.0 \\
28.1 \\
14.9\end{array}$ & $\begin{array}{l}96.3 \\
24.9 \\
29.9 \\
36.3 \\
21.0\end{array}$ & $\begin{array}{r}82.4 \\
41.8 \\
127 \\
98.6 \\
73.2\end{array}$ & $\begin{array}{l}492 \\
251 \\
711 \\
726 \\
269\end{array}$ & $\begin{array}{l}456 \\
881 \\
401 \\
694 \\
509\end{array}$ & $\begin{array}{l}83.2 \\
219 \\
111 \\
210 \\
109\end{array}$ & $\begin{array}{l}40.1 \\
60.0 \\
50.5 \\
63.8 \\
43.3\end{array}$ & $\begin{array}{c}41.4 \\
38.1 \\
104 \\
43.9 \\
30.8\end{array}$ \\
\hline
\end{tabular}


GREEN RIVER BASIN

09324500 COTTONOOD CREEK NEAR ORANGEVILLE, UT-COntinued

MONTHLY MEAN DISCHARGES, IN OJBIC FEET PER SECOND, FOR EACH WATER YEAR--Continued

\begin{tabular}{|c|c|c|c|c|c|c|c|c|c|c|c|c|}
\hline YEAR & $\mathrm{OCT}$ & MOV & DEC & JAN & FEB & MAR & APR & MAY & JUNE & JULY & AUG & SEP \\
\hline $\begin{array}{l}1916 \\
1917 \\
1918 \\
1919 \\
1920\end{array}$ & $\begin{array}{l}25.0 \\
65.8 \\
29.9 \\
39.4 \\
22.4\end{array}$ & $\begin{array}{l}25.8 \\
19.5 \\
21.5 \\
26.1 \\
19.6\end{array}$ & $\begin{array}{l}31.1 \\
24.0 \\
20.0 \\
15.0 \\
16.9\end{array}$ & $\begin{array}{l}27.0 \\
12.0 \\
18.0 \\
16.5 \\
10.9\end{array}$ & $\begin{array}{l}25.0 \\
13.1 \\
20.0 \\
15.0 \\
15.2\end{array}$ & $\begin{array}{l}49.0 \\
14.2 \\
29.3 \\
20.2 \\
15.2\end{array}$ & $\begin{array}{c}95.8 \\
27.7 \\
47.6 \\
101 \\
20.0\end{array}$ & $\begin{array}{l}405 \\
128 \\
267 \\
626 \\
507\end{array}$ & $\begin{array}{l}626 \\
921 \\
430 \\
221 \\
702\end{array}$ & $\begin{array}{c}164 \\
288 \\
126 \\
60.4 \\
152\end{array}$ & $\begin{array}{l}66.3 \\
67.6 \\
56.9 \\
35.9 \\
76.0\end{array}$ & $\begin{array}{l}36.2 \\
41.9 \\
44.7 \\
62.3 \\
29.4\end{array}$ \\
\hline $\begin{array}{l}1922 \\
1923 \\
1924 \\
1925\end{array}$ & $\begin{array}{l}56.9 \\
27.1 \\
36.3 \\
17.3\end{array}$ & $\begin{array}{l}45.7 \\
27.0 \\
32.8 \\
10.6\end{array}$ & $\begin{array}{c}35.0 \\
25.0 \\
25.0 \\
9.10\end{array}$ & $\begin{array}{l}30.0 \\
20.0 \\
20.0 \\
10.0\end{array}$ & $\begin{array}{l}35.0 \\
15.0 \\
15.0 \\
15.0\end{array}$ & $\begin{array}{l}51.2 \\
20.0 \\
22.8 \\
22.5\end{array}$ & $\begin{array}{l}78.8 \\
64.6 \\
65.7 \\
82.9\end{array}$ & $\begin{array}{l}457 \\
457 \\
315 \\
350\end{array}$ & $\begin{array}{l}779 \\
664 \\
166 \\
178\end{array}$ & $\begin{array}{c}275 \\
319 \\
50.1 \\
74.9\end{array}$ & $\begin{array}{r}177 \\
68.5 \\
23.0 \\
40.0\end{array}$ & $\begin{array}{l}38.8 \\
42.7 \\
23.7 \\
29.5\end{array}$ \\
\hline $\begin{array}{l}1926 \\
1927\end{array}$ & $\begin{array}{l}22.3 \\
18.4\end{array}$ & $\begin{array}{l}15.1 \\
17.3\end{array}$ & $\begin{array}{l}15.0 \\
10.9\end{array}$ & $\begin{array}{c}15.0 \\
9.00\end{array}$ & $\begin{array}{l}20.0 \\
10.0\end{array}$ & $\begin{array}{l}25.5 \\
30.3\end{array}$ & $\begin{array}{r}94.6 \\
68.8\end{array}$ & $\begin{array}{l}363 \\
382\end{array}$ & $\begin{array}{l}163 \\
328\end{array}$ & $\begin{array}{l}42.9 \\
134\end{array}$ & $\begin{array}{l}24.8 \\
72.8\end{array}$ & $\begin{array}{l}22.1 \\
56.2\end{array}$ \\
\hline $\begin{array}{l}1933 \\
1934 \\
1935\end{array}$ & $\begin{array}{l}21.7 \\
14.7 \\
12.3\end{array}$ & $\begin{array}{l}22.0 \\
17.1 \\
12.7\end{array}$ & $\begin{array}{l}15.0 \\
18.0 \\
13.0\end{array}$ & $\begin{array}{l}10.0 \\
15.0 \\
13.0\end{array}$ & $\begin{array}{l}10.0 \\
14.4 \\
14.0\end{array}$ & $\begin{array}{l}16.7 \\
19.4 \\
17.8\end{array}$ & $\begin{array}{l}32.1 \\
90.1 \\
36.5\end{array}$ & $\begin{array}{l}110 \\
110 \\
146\end{array}$ & $\begin{array}{c}552 \\
39.8 \\
815\end{array}$ & $\begin{array}{l}154 \\
20.8 \\
101\end{array}$ & $\begin{array}{l}63.0 \\
20.5 \\
38.7\end{array}$ & $\begin{array}{l}26.0 \\
11.5 \\
22.1\end{array}$ \\
\hline $\begin{array}{l}1936 \\
1937 \\
1938 \\
1939 \\
1940\end{array}$ & $\begin{array}{l}17.4 \\
24.3 \\
25.9 \\
24.4 \\
24.9\end{array}$ & $\begin{array}{l}20.3 \\
26.3 \\
20.3 \\
24.6 \\
19.1\end{array}$ & $\begin{array}{l}14.0 \\
20.0 \\
20.2 \\
20.0 \\
16.5\end{array}$ & $\begin{array}{l}14.0 \\
16.0 \\
18.9 \\
18.0 \\
15.0\end{array}$ & $\begin{array}{l}15.0 \\
18.0 \\
19.6 \\
16.0 \\
16.5\end{array}$ & $\begin{array}{l}18.4 \\
21.9 \\
24.8 \\
50.0 \\
21.4\end{array}$ & $\begin{array}{r}92.4 \\
58.3 \\
85.0 \\
111 \\
48.5\end{array}$ & $\begin{array}{l}655 \\
485 \\
385 \\
384 \\
530\end{array}$ & $\begin{array}{l}346 \\
279 \\
379 \\
184 \\
211\end{array}$ & $\begin{array}{c}116 \\
108 \\
71.1 \\
52.8 \\
50.1\end{array}$ & $\begin{array}{l}62.0 \\
48.5 \\
43.4 \\
30.4 \\
24.1\end{array}$ & $\begin{array}{l}33.6 \\
42.7 \\
33.5 \\
30.6 \\
34.6\end{array}$ \\
\hline $\begin{array}{l}1941 \\
1942 \\
1943 \\
1944 \\
1945\end{array}$ & $\begin{array}{l}23.6 \\
45.8 \\
26.2 \\
24.8 \\
26.7\end{array}$ & $\begin{array}{l}21.1 \\
38.8 \\
24.3 \\
22.0 \\
24.6\end{array}$ & $\begin{array}{l}20.0 \\
31.3 \\
24.0 \\
20.5 \\
22.5\end{array}$ & $\begin{array}{l}17.0 \\
27.0 \\
22.0 \\
16.0 \\
19.6\end{array}$ & $\begin{array}{l}17.5 \\
25.0 \\
22.3 \\
18.0 \\
19.8\end{array}$ & $\begin{array}{l}24.0 \\
37.7 \\
26.8 \\
22.6 \\
19.4\end{array}$ & $\begin{array}{l}36.7 \\
132 \\
122 \\
38.5 \\
31.0\end{array}$ & $\begin{array}{l}501 \\
401 \\
247 \\
416 \\
285\end{array}$ & $\begin{array}{l}517 \\
515 \\
218 \\
683 \\
362\end{array}$ & $\begin{array}{l}120 \\
109 \\
67.6 \\
172 \\
122\end{array}$ & $\begin{array}{l}55.7 \\
43.6 \\
50.2 \\
46.6 \\
62.4\end{array}$ & $\begin{array}{l}36.1 \\
29.2 \\
25.4 \\
29.9 \\
32.8\end{array}$ \\
\hline $\begin{array}{l}1946 \\
1947 \\
1948 \\
1949 \\
1950\end{array}$ & $\begin{array}{l}28.3 \\
24.4 \\
30.1 \\
26.9 \\
28.2\end{array}$ & $\begin{array}{l}28.9 \\
19.5 \\
27.2 \\
28.1 \\
26.1\end{array}$ & $\begin{array}{l}23.4 \\
16.9 \\
22.4 \\
25.4 \\
23.5\end{array}$ & $\begin{array}{l}21.0 \\
18.2 \\
20.0 \\
20.0 \\
21.0\end{array}$ & $\begin{array}{l}20.0 \\
22.7 \\
19.0 \\
20.5 \\
22.4\end{array}$ & $\begin{array}{l}30.2 \\
32.7 \\
21.2 \\
25.8 \\
26.4\end{array}$ & $\begin{array}{r}132 \\
65.8 \\
36.8 \\
98.8 \\
65.3\end{array}$ & $\begin{array}{l}306 \\
431 \\
293 \\
393 \\
240\end{array}$ & $\begin{array}{l}191 \\
282 \\
232 \\
505 \\
244\end{array}$ & $\begin{array}{c}62.6 \\
115 \\
73.0 \\
149 \\
77.3\end{array}$ & $\begin{array}{l}35.6 \\
62.6 \\
43.4 \\
54.2 \\
41.6\end{array}$ & $\begin{array}{l}23.4 \\
38.1 \\
27.2 \\
31.3 \\
29.1\end{array}$ \\
\hline $\begin{array}{l}1951 \\
1952 \\
1953 \\
1954 \\
1955\end{array}$ & $\begin{array}{l}24.3 \\
28.4 \\
39.9 \\
31.2 \\
23.9\end{array}$ & $\begin{array}{l}24.8 \\
22.2 \\
29.0 \\
26.7 \\
21.7\end{array}$ & $\begin{array}{l}23.2 \\
21.7 \\
30.0 \\
23.4 \\
19.1\end{array}$ & $\begin{array}{l}23.0 \\
21.2 \\
28.0 \\
22.9 \\
17.1\end{array}$ & $\begin{array}{l}21.1 \\
28.2 \\
29.6 \\
27.1 \\
18.0\end{array}$ & $\begin{array}{l}23.9 \\
28.5 \\
30.8 \\
28.0 \\
19.3\end{array}$ & $\begin{array}{c}35.5 \\
111 \\
43.0 \\
72.2 \\
26.9\end{array}$ & $\begin{array}{l}244 \\
776 \\
113 \\
231 \\
181\end{array}$ & $\begin{array}{c}340 \\
1070 \\
468 \\
95.1 \\
224\end{array}$ & $\begin{array}{c}101 \\
263 \\
119 \\
56.4 \\
79.2\end{array}$ & $\begin{array}{l}63.3 \\
93.3 \\
66.4 \\
34.4 \\
56.5\end{array}$ & $\begin{array}{l}32.2 \\
62.5 \\
35.3 \\
33.9 \\
28.7\end{array}$ \\
\hline $\begin{array}{l}1956 \\
1957 \\
1958 \\
1959 \\
1960\end{array}$ & $\begin{array}{l}23.7 \\
21.4 \\
40.7 \\
28.4 \\
22.0\end{array}$ & $\begin{array}{l}19.7 \\
18.9 \\
39.7 \\
22.5 \\
18.2\end{array}$ & $\begin{array}{l}21.5 \\
18.1 \\
29.1 \\
20.8 \\
13.1\end{array}$ & $\begin{array}{l}20.4 \\
17.9 \\
27.0 \\
18.4 \\
11.7\end{array}$ & $\begin{array}{l}20.5 \\
17.5 \\
37.9 \\
19.3 \\
14.0\end{array}$ & $\begin{array}{l}27.0 \\
17.8 \\
29.9 \\
21.3 \\
24.8\end{array}$ & $\begin{array}{l}47.4 \\
27.6 \\
64.3 \\
34.3 \\
56.3\end{array}$ & $\begin{array}{c}286 \\
137 \\
535 \\
97.8 \\
225\end{array}$ & $\begin{array}{l}206 \\
902 \\
590 \\
150 \\
227\end{array}$ & $\begin{array}{l}71.4 \\
325 \\
106 \\
48.9 \\
59.9\end{array}$ & $\begin{array}{l}37.2 \\
88.2 \\
52.0 \\
28.6 \\
30.0\end{array}$ & $\begin{array}{l}23.9 \\
45.0 \\
40.2 \\
21.4 \\
29.8\end{array}$ \\
\hline $\begin{array}{l}1961 \\
1962 \\
1963 \\
1964 \\
1965\end{array}$ & $\begin{array}{l}27.0 \\
37.6 \\
32.5 \\
26.2 \\
19.9\end{array}$ & $\begin{array}{l}22.6 \\
33.7 \\
25.9 \\
21.3 \\
20.3\end{array}$ & $\begin{array}{l}20.9 \\
25.5 \\
17.8 \\
15.5 \\
16.4\end{array}$ & $\begin{array}{l}16.9 \\
20.0 \\
10.7 \\
14.3 \\
18.2\end{array}$ & $\begin{array}{l}16.0 \\
27.5 \\
18.6 \\
14.6 \\
20.9\end{array}$ & $\begin{array}{l}22.6 \\
35.5 \\
20.8 \\
14.4 \\
23.0\end{array}$ & $\begin{array}{r}38.7 \\
118 \\
27.8 \\
25.7 \\
47.9\end{array}$ & $\begin{array}{l}171 \\
275 \\
154 \\
239 \\
189\end{array}$ & $\begin{array}{l}130 \\
310 \\
177 \\
299 \\
702\end{array}$ & $\begin{array}{c}45.0 \\
126 \\
61.8 \\
104 \\
422\end{array}$ & $\begin{array}{c}47.4 \\
54.3 \\
49.3 \\
48.0 \\
155\end{array}$ & $\begin{array}{l}35.2 \\
35.1 \\
39.1 \\
26.4 \\
72.0\end{array}$ \\
\hline
\end{tabular}

ANNUAL PEAK DISCHARGE, IN CUBIC FEET PER SECOND, AND CORRESPONDING GAGE HEIGHT, IN FEET, FOR EACH WATER YEAR

\begin{tabular}{|c|c|c|c|c|c|c|c|c|c|c|c|}
\hline $\begin{array}{l}\text { WATER } \\
\text { YEAR }\end{array}$ & DATE & $\begin{array}{c}\text { GAGE } \\
\text { HEIGHT }\end{array}$ & $\begin{array}{c}\text { PEAK } \\
\text { DISCHARGE }\end{array}$ & $\begin{array}{l}\text { WATER } \\
\text { YEAR }\end{array}$ & DATE & $\begin{array}{c}\text { GAGE } \\
\text { HEIGHT }\end{array}$ & $\begin{array}{c}\text { PEAK } \\
\text { DISOHARGE }\end{array}$ & $\begin{array}{l}\text { WATER } \\
\text { YEAR }\end{array}$ & DATE & $\begin{array}{c}\text { GAGE } \\
\text { HEIGHT }\end{array}$ & $\begin{array}{c}\text { PEAK } \\
\text { DISCHARGE }\end{array}$ \\
\hline $\begin{array}{l}1910 \\
1911 \\
1912 \\
1913 \\
1914 \\
1915 \\
1916 \\
1917 \\
1918 \\
1919 \\
1920 \\
1921 \\
1922 \\
1923 \\
1924 \\
1925 \\
1926 \\
1927\end{array}$ & $\begin{array}{l}\text { SEPT.16, } 1910 \\
\text { JUNE 08, } 1911 \\
\text { JULY } 30,1912 \\
\text { SEPT. 07, } 1913 \\
\text { JUNE 01, } 1914 \\
\text { JUNE 01, } 1915 \\
\text { JUNE 09, } 1916 \\
\text { JUNE 21, } 1917 \\
\text { JUNE } 12,1918 \\
\text { MAY } 19,1919 \\
\text { MAY } 30,1920 \\
\text { JUNE 09, } 1921 \\
\text { JUG. 22, } 1922 \\
\text { JULY 25, } 1923 \\
\text { MAY 17, } 1924 \\
\text { JULY 21, } 1925 \\
\text { SEPT.11, } 1926 \\
\text { SEPT.09, } 1927\end{array}$ & $\begin{array}{l}7.90 \\
6.50 \\
9.00 \\
9.20 \\
8.00 \\
7.00 \\
7.00 \\
9.00 \\
7.50 \\
5.80 \\
5.60 \\
6.30 \\
9.10 \\
8.35 \\
5.08 \\
6.80 \\
6.90 \\
9.20\end{array}$ & $\begin{array}{r}1140 \\
700 \\
1880 \\
1980 \\
1440 \\
954 \\
950 \\
1880 \\
770 \\
1750 \\
1520 \\
2200 \\
2500 \\
2140 \\
653 \\
1360 \\
1210 \\
2500\end{array}$ & $\begin{array}{l}1932 \\
1933 \\
1934 \\
1935 \\
1936 \\
1937 \\
1938 \\
1939 \\
1940 \\
1941 \\
1942 \\
1943 \\
1944 \\
1945 \\
1946 \\
1947 \\
1948\end{array}$ & $\begin{array}{l}\text { AUG. } 21,1932 \\
\text { JULY } 10,1933 \\
\text { AUG. } 06,1934 \\
\text { JUNE } 11,1935 \\
\text { SEPT. 01, } 1936 \\
\text { JULY } 08,1937 \\
\text { JULY } 26,1938 \\
\text { JULY } 27,1939 \\
\text { MAY } 13,1940 \\
\text { AUG. 09, } 1941 \\
\text { MAY } \\
\text { AUG. } 06,1942 \\
\text { JUNE } 13,1943 \\
\text { AUG. } 03,1944 \\
\text { JULY } 24,1946 \\
\text { MAY } 08,1947 \\
\text { MAY } 23,1948\end{array}$ & $\begin{array}{l}9.80 \\
8.65 \\
3.50 \\
4.95 \\
4.80 \\
5.10 \\
4.03 \\
4.25 \\
3.88 \\
6.38 \\
4.73 \\
6.18 \\
5.15 \\
5.30 \\
4.60 \\
4.22 \\
3.97\end{array}$ & $\begin{array}{r}2600 \\
1940 \\
450 \\
2060 \\
1580 \\
2110 \\
1640 \\
1990 \\
1290 \\
2870 \\
1660 \\
2670 \\
1140 \\
1280 \\
916 \\
824 \\
650\end{array}$ & $\begin{array}{l}1949 \\
1950 \\
1951 \\
1952 \\
1953 \\
1954 \\
1955 \\
1956 \\
1957 \\
1958 \\
1959 \\
1960 \\
1961 \\
1962 \\
1963 \\
1964 \\
1965\end{array}$ & $\begin{array}{l}\text { JULY } 04,1949 \\
\text { MAY } 30,1950 \\
\text { AUG. } 23,1951 \\
\text { JULY } 27,1952 \\
\text { AUG. } 01,1953 \\
\text { JULY } 25,1954 \\
\text { JUNE } 08,1955 \\
\text { JULY } 30,1956 \\
\text { AUG. } 26,1957 \\
\text { JUNE } 05,1958 \\
\text { JUNE } 07,1959 \\
\text { JUNE } 03,1960 \\
\text { AUG. } 05,1961 \\
\text { MAY } 08,1962 \\
\text { AUG. } 10,1963 \\
\text { AUG. } 01,1964 \\
\text { JUNE } 08,1965\end{array}$ & $\begin{array}{l}5.14 \\
4.35 \\
5.77 \\
4.72 \\
3.42 \\
2.82 \\
2.28 \\
2.61 \\
5.00 \\
4.35 \\
2.80 \\
3.73 \\
5.30 \\
3.42 \\
4.50 \\
9.05 \\
4.70\end{array}$ & $\begin{array}{r}1500 \\
850 \\
1420 \\
2170 \\
1040 \\
765 \\
535 \\
596 \\
1280 \\
1260 \\
300 \\
686 \\
1440 \\
534 \\
1030 \\
7220 \\
1130\end{array}$ \\
\hline
\end{tabular}


GREEN RTVER BASTN

09324500 COTIONWOOD CREEK NEAR ORANGEVHLLE, UT--Continued

\begin{tabular}{|c|c|c|c|c|c|c|}
\hline \multicolumn{7}{|c|}{$\begin{array}{l}\text { MAGNITUDE AND PROBABIIITY OF ANNUAL LONEST MEAN DISCHARGE } \\
\text { BASED ON CLIMATIC YEARS } 1912-21,1923-27 \text { AND 1934-65 }\end{array}$} \\
\hline \multirow{2}{*}{$\begin{array}{l}\text { PERIOD } \\
\text { (CON- } \\
\text { SEGJ- } \\
\text { TIVE } \\
\text { DAYS) }\end{array}$} & \multicolumn{6}{|c|}{$\begin{array}{l}\text { DISCHARGE, IN OUIC FEET PER SECOND, FOR } \\
\text { INDICAIED REOURRENCE INTERVAL, IN YEARS, AND } \\
\text { ANNUAL NONEXCEEDANCE PROBABILITY, IN PERCENT }\end{array}$} \\
\hline & $\begin{array}{c}2 \\
508\end{array}$ & $\begin{array}{c}5 \\
208\end{array}$ & $\begin{array}{l}10 \\
108\end{array}$ & $\begin{array}{l}20 \\
58\end{array}$ & $\begin{array}{l}50 \\
28\end{array}$ & $\begin{array}{r}100 \\
18\end{array}$ \\
\hline $\begin{array}{r}1 \\
7 \\
14 \\
30 \\
60 \\
90\end{array}$ & $\begin{array}{l}14 \\
15 \\
16 \\
17 \\
18 \\
19\end{array}$ & $\begin{array}{l}11 \\
12 \\
13 \\
13 \\
14 \\
15\end{array}$ & $\begin{array}{l}9.0 \\
11 \\
11 \\
12 \\
12 \\
13\end{array}$ & $\begin{array}{c}7.8 \\
9.4 \\
9.8 \\
10 \\
11 \\
12\end{array}$ & $\begin{array}{c}6.6 \\
8.2 \\
8.5 \\
9.1 \\
9.9 \\
10\end{array}$ & $\begin{array}{l}5.5 \\
7.5 \\
7.7 \\
8.4 \\
9.1 \\
9.6\end{array}$ \\
\hline
\end{tabular}

\begin{tabular}{|c|c|c|c|c|c|c|}
\hline \multirow{2}{*}{$\begin{array}{l}\text { PERIOD } \\
\text { (CON- } \\
\text { SEQJ- } \\
\text { TTVE } \\
\text { DAYS) }\end{array}$} & \multicolumn{6}{|c|}{$\begin{array}{l}\text { DISCHARGE, IN GBIC FEET PER SECOND, FOR } \\
\text { INDICATED RECURRENCE INTERNAL, IN YEARS, AND } \\
\text { ANNUAL EXCEEDANCE PRCBABILITY, IN PERCENT }\end{array}$} \\
\hline & $\begin{array}{c}2 \\
508\end{array}$ & $\begin{array}{c}5 \\
208\end{array}$ & $\begin{array}{l}10 \\
108\end{array}$ & $\begin{array}{l}25 \\
48\end{array}$ & $\begin{array}{l}50 \\
28\end{array}$ & $\begin{array}{r}100 \\
18\end{array}$ \\
\hline $\begin{array}{r}1 \\
3 \\
7 \\
15\end{array}$ & $\begin{array}{l}757 \\
723 \\
670 \\
592\end{array}$ & $\begin{array}{r}1160 \\
1070 \\
999 \\
885\end{array}$ & $\begin{array}{l}1430 \\
1290 \\
1210 \\
1070\end{array}$ & $\begin{array}{l}1770 \\
1550 \\
1460 \\
1300\end{array}$ & $\begin{array}{l}2010 \\
1730 \\
1640 \\
1470\end{array}$ & $\begin{array}{l}2260 \\
1900 \\
1820 \\
1630\end{array}$ \\
\hline
\end{tabular}

DATA BELOW BASED ON PERIOD OF RECORD AFTER COMELTTON OF JOES VALLEY RESERVOIR

LOWEST MEAN DISCHARGE, IN OBIC FEET PER SECOND, AND RANKING FOR THE INDICATED NUMBER OF CONSECUTTVE DAYS FOR EACH CLIMATIC YEAR, APRII 1-MARCH 31

YEAR

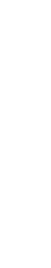

1981
CONSECUTIVE DAYS

14

7.007

$4.40 \quad 3$
6.00

6.005

6.006

4.002

4.604

3.501

.00

\subsection{7}

$\begin{array}{ll}7.40 & 7 \\ 5.10 & 4 \\ 6.00 & 5\end{array}$

$\begin{array}{ll}6.00 & 5 \\ 6.30 & 6\end{array}$

$4.10 \quad 2$

5.103

$\begin{array}{ll}3.70 & 1 \\ 8.40 & 8\end{array}$

22.0
60
7.907

$\begin{array}{ll}7.90 & 7 \\ 6.40 & 5\end{array}$

6.104

6.706

4.002

5.403

4.001

8.908
$90 \quad 120 \quad 183 \quad$ ALI

$\begin{array}{llllllll}8.50 & 7 & 9.50 & 7 & 13.0 & 2 & 48.0 & 2\end{array}$

$\begin{array}{llllllll}6.70 & 5 & 7.10 & 5 & 22.0 & 6 & 62.0 & 3\end{array}$

$\begin{array}{llllllll}6.30 & 4 & 6.70 & 4 & 17.0 & 3 & 75.0 & 6\end{array}$

$\begin{array}{llllllll}7.30 & 6 & 7.60 & 6 & 20.0 & 5 & 81.0 & 7\end{array}$

$\begin{array}{llllllll}5.40 & 2 & 6.40 & 2 & 11.0 & 1 & 67.0 & 4\end{array}$

$\begin{array}{llllllll}5.90 & 3 & 6.50 & 3 & 17.0 & 4 & 33.0 & 1\end{array}$

$\begin{array}{llllllll}4.50 & 1 & 5.40 & 1 & 26.0 & 7 & 71.0 & 5 \\ 9.10 & 8 & 9.60 & 8 & 26.0 & 8 & 97.0 & 8\end{array}$

$\begin{array}{llllllll}23.0 & 9 & 24.0 & 9 & 39.0 & 9 & 120 & 9\end{array}$

HIGHST MEAN DISCHARGE, IN OBIC FEET PER SECOND, AND RANKING FOR THE INDICATED NUMBER OF CONSECUTIVE DAYS FOR EACH WATER YEAR, OCTCBER 1-SEPTEMBER 30

\begin{tabular}{|c|c|c|c|c|c|c|c|c|c|c|c|c|c|c|c|c|c|c|c|c|}
\hline YEAR & 1 & & 3 & & 7 & & 15 & & $\begin{array}{l}\text { CONS } \\
30\end{array}$ & EWT & $\begin{array}{c}\text { IVE DAY } \\
60\end{array}$ & & 90 & & 120 & & 183 & & ALL & \\
\hline $\begin{array}{l}66 \\
67 \\
68 \\
689 \\
67\end{array}$ & $\begin{array}{l}158 \\
273 \\
250 \\
400 \\
665\end{array}$ & $\begin{array}{r}10 \\
6 \\
7 \\
4 \\
2\end{array}$ & $\begin{array}{l}156 \\
263 \\
246 \\
388 \\
654\end{array}$ & $\begin{array}{r}10 \\
6 \\
7 \\
4 \\
2\end{array}$ & $\begin{array}{l}154 \\
222 \\
238 \\
335 \\
643\end{array}$ & $\begin{array}{r}10 \\
8 \\
6 \\
5 \\
2\end{array}$ & $\begin{array}{l}150 \\
197 \\
232 \\
320 \\
568\end{array}$ & $\begin{array}{r}10 \\
8 \\
6 \\
5 \\
2\end{array}$ & $\begin{array}{l}142 \\
173 \\
229 \\
300 \\
502\end{array}$ & $\begin{array}{r}10 \\
8 \\
6 \\
4 \\
2\end{array}$ & $\begin{array}{l}124 \\
159 \\
211 \\
253 \\
374\end{array}$ & $\begin{array}{r}10 \\
8 \\
5 \\
4 \\
2\end{array}$ & $\begin{array}{l}124 \\
141 \\
189 \\
212 \\
311\end{array}$ & $\begin{array}{r}10 \\
8 \\
5 \\
4 \\
1\end{array}$ & $\begin{array}{l}114 \\
133 \\
176 \\
187 \\
270\end{array}$ & $\begin{array}{r}10 \\
8 \\
5 \\
4 \\
1\end{array}$ & $\begin{array}{l}84.0 \\
101 \\
134 \\
143 \\
200\end{array}$ & $\begin{array}{r}10 \\
8 \\
5 \\
4 \\
1\end{array}$ & $\begin{array}{r}52.0 \\
57.0 \\
78.0 \\
80.0 \\
110\end{array}$ & $\begin{array}{r}10 \\
9 \\
5 \\
4 \\
2\end{array}$ \\
\hline $\begin{array}{r}977 \\
978 \\
979\end{array}$ & $\begin{array}{l}224 \\
113 \\
389 \\
550 \\
820\end{array}$ & $\begin{array}{r}9 \\
11 \\
5 \\
3 \\
1\end{array}$ & $\begin{array}{c}224 \\
92.0 \\
383 \\
543 \\
788\end{array}$ & $\begin{array}{r}8 \\
11 \\
5 \\
3 \\
1\end{array}$ & $\begin{array}{l}222 \\
85.0 \\
367 \\
534 \\
780\end{array}$ & $\begin{array}{r}7 \\
11 \\
4 \\
3 \\
1\end{array}$ & $\begin{array}{l}216 \\
82.0 \\
324 \\
497 \\
764\end{array}$ & $\begin{array}{r}7 \\
11 \\
4 \\
3 \\
1\end{array}$ & $\begin{array}{c}200 \\
73.0 \\
247 \\
430 \\
580\end{array}$ & $\begin{array}{r}7 \\
11 \\
5 \\
3 \\
1\end{array}$ & $\begin{array}{l}184 \\
69.0 \\
191 \\
331 \\
379\end{array}$ & $\begin{array}{r}7 \\
11 \\
6 \\
3 \\
1\end{array}$ & $\begin{array}{l}170 \\
65.0 \\
167 \\
267 \\
307\end{array}$ & $\begin{array}{r}6 \\
11 \\
7 \\
3 \\
2\end{array}$ & $\begin{array}{l}158 \\
61.0 \\
152 \\
227 \\
267\end{array}$ & $\begin{array}{r}6 \\
11 \\
7 \\
3 \\
2\end{array}$ & $\begin{array}{l}123 \\
49.0 \\
116 \\
168 \\
200\end{array}$ & $\begin{array}{r}6 \\
11 \\
7 \\
3 \\
2\end{array}$ & $\begin{array}{r}74.0 \\
30.0 \\
66.0 \\
97.0 \\
113\end{array}$ & $\begin{array}{r}6 \\
11 \\
8 \\
3 \\
1\end{array}$ \\
\hline & 238 & 8 & 190 & 9 & 157 & 9 & 155 & 9 & 153 & 9 & 145 & 9 & 127 & 9 & 124 & 9 & 100 & 9 & 70.0 & \\
\hline
\end{tabular}

\section{DURATTON OF DISCHARGE FOR EACH WATER YEAR}

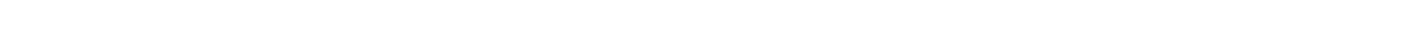

\begin{tabular}{|c|c|c|c|c|c|c|c|c|c|c|c|c|c|c|c|c|c|c|c|c|c|c|c|c|c|c|c|}
\hline \multirow{2}{*}{$\begin{array}{l}\text { YEAR } \\
\\
1966 \\
1967 \\
1968 \\
1969 \\
1970\end{array}$} & & \multirow[b]{2}{*}{4} & \multirow[b]{2}{*}{913} & \multirow[b]{2}{*}{$\begin{array}{rrr}1 & 39 & 28 \\
63 & 28 \\
21 & 55 & 56 \\
73 & 62 & 19 \\
36 & 41 & 76\end{array}$} & \multirow[b]{2}{*}{$\begin{array}{c}1 \\
15 \\
9 \\
8 \\
1\end{array}$} & \multirow[b]{2}{*}{$\begin{array}{rr}7 & 29 \\
50 & 9 \\
1 & \\
4 & 1\end{array}$} & \multirow[b]{2}{*}{$\begin{array}{r}17 \\
1 \\
1\end{array}$} & \multirow[b]{2}{*}{$\begin{array}{r}19 \\
2 \\
4 \\
5 \\
1\end{array}$} & \multicolumn{4}{|c|}{ NUMBER OF DAYS } & \multicolumn{5}{|c|}{ IN CASS } & \multirow{2}{*}{\multicolumn{2}{|c|}{$\begin{array}{rrr}28 & 34 & 9 \\
5 & 26 & 36 \\
31 & 20 & 25 \\
26 & 14 & 13 \\
10 & 24 & 27\end{array}$}} & \multirow{2}{*}{\multicolumn{2}{|c|}{$\begin{array}{rr}7 & 3 \\
31 & 27 \\
12 & 15 \\
6 & 26\end{array}$}} & \multirow{2}{*}{\multicolumn{2}{|c|}{$\begin{array}{rr}2 & \\
1 & \\
14 & 12 \\
3 & 6\end{array}$}} & \multirow[b]{2}{*}{$\begin{array}{l}3 \\
613\end{array}$} & \multirow[b]{2}{*}{2} & \multirow{2}{*}{\multicolumn{2}{|c|}{$\begin{array}{l}\text { PER SECOND } \\
\text {-DAYS } \\
18819.0 \\
20857.0 \\
28430.6 \\
29127.8 \\
40100.2\end{array}$}} \\
\hline & & & & & & & & & $\begin{array}{r}52 \\
32 \\
1 \\
1 \\
3\end{array}$ & $\begin{array}{r}5 \\
8 \\
6 \\
10 \\
8\end{array}$ & $\begin{array}{r}6 \\
8 \\
10 \\
1 \\
10\end{array}$ & $\begin{array}{r}23 \\
7 \\
1 \\
4\end{array}$ & $\begin{array}{r}12 \\
9 \\
1 \\
4 \\
3\end{array}$ & $\begin{array}{l}4 \\
8 \\
2 \\
3\end{array}$ & $\begin{array}{r}10 \\
9 \\
12 \\
15 \\
11\end{array}$ & $\begin{array}{r}25 \\
9 \\
11 \\
31 \\
19\end{array}$ & $\begin{array}{l}15 \\
28 \\
18 \\
19 \\
16\end{array}$ & & & & & & & & & & \\
\hline $\begin{array}{l}1976 \\
1977 \\
1978 \\
1979 \\
1980\end{array}$ & 10 & $\begin{array}{l}28 \\
29 \\
29\end{array}$ & $\begin{array}{ll}18 \\
20 & 33 \\
21\end{array}$ & $\begin{array}{rrrr}14 & 27 & 12 & \\
37 & 45 & 32 \\
22 & 35 & 25 \\
11 & 10 & 21 \\
4 & 26 & 58\end{array}$ & $\begin{array}{l}22 \\
141 \\
21 \\
16 \\
391\end{array}$ & $\begin{array}{rr}42 & 17 \\
10 & 2 \\
2 & 6 \\
8 & 10 \\
11 & 9\end{array}$ & $\begin{array}{r}17 \\
3 \\
6 \\
3 \\
7\end{array}$ & $\begin{array}{l}9 \\
9 \\
2 \\
2 \\
7\end{array}$ & $\begin{array}{r}9 \\
12 \\
3 \\
1\end{array}$ & $\begin{array}{r}11 \\
6 \\
8 \\
1 \\
2\end{array}$ & $\begin{array}{r}1 \\
15 \\
7 \\
6 \\
8\end{array}$ & $\begin{array}{r}4 \\
12 \\
7 \\
9 \\
4\end{array}$ & $\begin{array}{r}4 \\
29 \\
7 \\
9 \\
8\end{array}$ & $\begin{array}{r}5 \\
29 \\
5 \\
2 \\
9\end{array}$ & $\begin{array}{c}11 \\
38 \\
6 \\
\\
2\end{array}$ & $\begin{array}{r}22 \\
18 \\
8 \\
3\end{array}$ & $\begin{array}{r}37 \\
3 \\
36 \\
33 \\
12\end{array}$ & $\begin{array}{cc}31 & 18 \\
1 & \\
40 & 29 \\
31 & 26 \\
33 & 28\end{array}$ & $\begin{array}{r}44 \\
5 \\
14 \\
51\end{array}$ & $\begin{array}{l}211 \\
5 \\
9 \\
8\end{array}$ & $\begin{array}{l}3 \\
61 \\
7\end{array}$ & $\begin{array}{r}3 \\
10 \\
3\end{array}$ & $\begin{array}{l}5 \\
7 \\
1\end{array}$ & $\begin{array}{ll}6 & \\
8 & 9 \\
6 & 3\end{array}$ & $\begin{array}{l}9 \\
1\end{array}$ & 213 & $\begin{array}{l}27166.8 \\
10907.8 \\
24223.0 \\
35425.2 \\
41199.3\end{array}$ \\
\hline 1981 & & & & & & 2 & & 43 & 72 & 43 & 11 & 19 & 2 & 3 & 8 & 13 & 52 & 3331 & 31 & & 2 & & & & & & 25423.0 \\
\hline
\end{tabular}


GREEN RTVER BASIN

09324500 COTPIONOOD CREEK NEAR ORANGEVIILE, UT-Continued

DURATION TFBLE OF DISCHARGE FOR WATER YEARS 1966-70, 1976-81
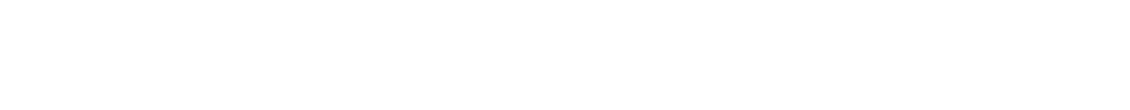

CLASS SECOND DAYS DAYS DAYS

CLASS SECOND DAYS DAYS DAYS

\begin{tabular}{|c|c|c|c|c|}
\hline & $\begin{array}{c}\text { GBIC } \\
\text { FEET } \\
\text { PER }\end{array}$ & TOTAL & $\begin{array}{c}\text { ACQU- } \\
\text { U- } \\
\text { LAIED }\end{array}$ & $\begin{array}{l}\text { PER- } \\
\text { CENT }\end{array}$ \\
\hline CLASS & SECOND & DAYS & DAYS & DAYS \\
\hline 27 & 250.0 & 36 & 158 & 3.9 \\
\hline 28 & 290.0 & 31 & 122 & 3.0 \\
\hline 29 & 350.0 & 29 & 91 & 2.3 \\
\hline 30 & 410.0 & 25 & 62 & 1.5 \\
\hline 31 & 490.0 & 12 & 37 & 0.9 \\
\hline 32 & 580.0 & 11 & 25 & 0.6 \\
\hline 33 & 680.0 & 13 & 14 & 0.3 \\
\hline 34 & 810.0 & 1 & 1 & 0.0 \\
\hline
\end{tabular}

MONTHLY MEAN DISGHARGES, IN OUBIC FEET PER SECOND, FOR EACH WAIER YEAR

\begin{tabular}{|c|c|c|c|c|c|c|c|c|c|c|c|c|}
\hline YEAR & OCT & NOV & $\mathrm{DEC}$ & JAN & FEB & MAR & APR & MAY & JUNE & JULY & AUG & SEP \\
\hline $\begin{array}{l}1966 \\
1967 \\
1968 \\
1969 \\
1970\end{array}$ & $\begin{array}{l}42.3 \\
24.9 \\
92.0 \\
60.5 \\
72.6\end{array}$ & $\begin{array}{c}21.4 \\
12.9 \\
7.03 \\
9.28 \\
12.0\end{array}$ & $\begin{array}{c}20.2 \\
12.6 \\
7.39 \\
6.94 \\
8.31\end{array}$ & $\begin{array}{c}10.3 \\
9.65 \\
5.64 \\
6.15 \\
6.29\end{array}$ & $\begin{array}{l}7.72 \\
7.54 \\
8.51 \\
6.00 \\
7.44\end{array}$ & $\begin{array}{c}11.1 \\
8.16 \\
8.97 \\
7.71 \\
8.50\end{array}$ & $\begin{array}{l}31.4 \\
22.1 \\
17.9 \\
34.1 \\
26.4\end{array}$ & $\begin{array}{l}135 \\
75.2 \\
90.0 \\
138 \\
179\end{array}$ & $\begin{array}{l}111 \\
87.3 \\
214 \\
284 \\
500\end{array}$ & $\begin{array}{l}122 \\
165 \\
207 \\
186 \\
228\end{array}$ & $\begin{array}{l}77.2 \\
149 \\
140 \\
127 \\
152\end{array}$ & $\begin{array}{l}24.2 \\
107 \\
132 \\
87.5 \\
114\end{array}$ \\
\hline $\begin{array}{l}1976 \\
1977 \\
1978 \\
1979 \\
1980\end{array}$ & $\begin{array}{l}94.6 \\
28.6 \\
62.9 \\
119 \\
101\end{array}$ & $\begin{array}{c}14.1 \\
7.95 \\
10.2 \\
13.0 \\
10.3\end{array}$ & $\begin{array}{r}10.8 \\
9.61 \\
6.75 \\
6.25 \\
8.58\end{array}$ & $\begin{array}{l}7.52 \\
6.35 \\
5.55 \\
4.36 \\
9.95\end{array}$ & $\begin{array}{c}13.4 \\
4.54 \\
5.37 \\
3.68 \\
10.9\end{array}$ & $\begin{array}{c}11.3 \\
5.13 \\
9.11 \\
7.17 \\
11.2\end{array}$ & $\begin{array}{l}26.4 \\
11.3 \\
17.5 \\
24.3 \\
43.9\end{array}$ & $\begin{array}{c}118 \\
42.4 \\
69.0 \\
90.3 \\
153\end{array}$ & $\begin{array}{l}159 \\
49.0 \\
209 \\
418 \\
545\end{array}$ & $\begin{array}{l}196 \\
71.5 \\
162 \\
239 \\
211\end{array}$ & $\begin{array}{l}148 \\
63.9 \\
129 \\
115 \\
152\end{array}$ & $\begin{array}{l}87.5 \\
56.1 \\
107 \\
121 \\
94.9\end{array}$ \\
\hline 1981 & 110 & 28.7 & 23.7 & 21.9 & 24.5 & 25.0 & 36.4 & 122 & 153 & 103 & 102 & 81.8 \\
\hline
\end{tabular}

ANNUAL PEAK DISCHARGE, IN OUBIC FEET PER SECOND, AND CORRESPONDING GAGE HEIGHT, IN FEET, FOR EAOH WATER YEAR

\begin{tabular}{|c|c|c|c|c|c|c|c|c|c|c|c|}
\hline $\begin{array}{l}\text { WATER } \\
\text { YEAR }\end{array}$ & DATE & $\begin{array}{c}\text { GAGE } \\
\text { HEIGHT }\end{array}$ & $\begin{array}{c}\text { PEAK } \\
\text { DISOHARGE }\end{array}$ & $\begin{array}{l}\text { WATER } \\
\text { YEAR }\end{array}$ & DATE & $\begin{array}{l}\text { GAGE } \\
\text { HEIGHT }\end{array}$ & $\begin{array}{c}\text { PEAK } \\
\text { DISOHARGE }\end{array}$ & $\begin{array}{l}\text { WATER } \\
\text { YEAR }\end{array}$ & DATE & $\begin{array}{c}\text { GAGE } \\
\text { HEIGHT }\end{array}$ & $\begin{array}{c}\text { PEAK } \\
\text { DISGAARGE }\end{array}$ \\
\hline $\begin{array}{l}1966 \\
1967 \\
1968 \\
1969\end{array}$ & $\begin{array}{l}\text { AUG. } 19,1966 \\
\text { SEPT. 09, } 1967 \\
\text { HUG. 01, } 1968 \\
\text { JULY } 19,1969\end{array}$ & $\begin{array}{l}3.00 \\
3.63 \\
2.43 \\
3.38\end{array}$ & $\begin{array}{l}507 \\
922 \\
321 \\
705\end{array}$ & $\begin{array}{l}1970 \\
1976 \\
1977 \\
1978\end{array}$ & $\begin{array}{lll}\text { JUNE } & 10, & 1970 \\
\text { JULY } & 03, & 1976 \\
\text { JULY } & 24, & 1977 \\
\text { JUNE } & 22, & 1978\end{array}$ & $\begin{array}{l}3.17 \\
2.89 \\
3.22 \\
3.56\end{array}$ & $\begin{array}{l}789 \\
224 \\
315 \\
395\end{array}$ & $\begin{array}{l}1979 \\
1980 \\
1981\end{array}$ & $\begin{array}{l}\text { JUNE } 08,1979 \\
\text { JUNE } 12,1980 \\
\text { SEPT.10, } 1981\end{array}$ & $\begin{array}{l}4.03 \\
5.34 \\
3.41\end{array}$ & $\begin{array}{r}588 \\
1260 \\
372\end{array}$ \\
\hline
\end{tabular}

MAGNITUDE AND PROBABILITY OF ANNUAL HIGHEST MEAN DISCHARGE BASED ON WATER YEARS 1966-70 AND 1976-81

\begin{tabular}{|c|c|c|c|c|c|c|}
\hline \multirow{2}{*}{$\begin{array}{l}\text { PERIOD } \\
\text { (CON- } \\
\text { SEQI- } \\
\text { TIVE } \\
\text { DAYS) }\end{array}$} & \multicolumn{6}{|c|}{$\begin{array}{l}\text { DISCH ARGE, IN OBIC FEET PER SECOND, FOR } \\
\text { INDICATED REOURRENCE INTERNAL, IN YEARS, AND } \\
\text { ANNUAL EXCEEDANCE PROBABILITY, IN PEROENT }\end{array}$} \\
\hline & $\begin{array}{c}2 \\
508\end{array}$ & $\begin{array}{c}5 \\
208\end{array}$ & $\begin{array}{l}10 \\
10 \%\end{array}$ & $\begin{array}{l}25 \\
48\end{array}$ & $\begin{array}{l}50 \\
28\end{array}$ & $\begin{array}{r}100 \\
18\end{array}$ \\
\hline $\begin{array}{r}1 \\
3 \\
7 \\
15\end{array}$ & $\begin{array}{l}315 \\
303 \\
281 \\
263\end{array}$ & $\begin{array}{l}525 \\
516 \\
492 \\
457\end{array}$ & $\begin{array}{l}686 \\
675 \\
657 \\
610\end{array}$ & - & $\begin{array}{l}\overline{-} \\
\overline{-}\end{array}$ & -- \\
\hline
\end{tabular}


LOCATION.--Lat $39^{\circ} 10^{\prime} 12^{n}$, long $110^{\circ} 56^{\prime} 15^{n}$, in sec.8, T.19 S., R.9 E., Emery County, Hydrologic Unit 14060009 , on right bank 0.5 mi upstream fram Rock Canyon and $6 \mathrm{mi}$ east of Castle Dale.

DRAINAGE AREA. $--261 \mathrm{mi}^{2}$.

PERIOD OF RECORD AVAIJABLE. -July 1947 to September 1958.

GAGE.--Water-stage recorder. Altitude of gage is 5,400 ft fram river-profile map.

REMARKS.--Many diversions above station for irrigation and several transmountain diversions from headwaters to the Great Basin for irrigation in San Pitch River basin

AVERAGE DISCHARGE. - 11 years, $54.7 \mathrm{ft}^{3} / \mathrm{s}, 39,630$ acre-ft/yr.

EXTREMES FOR PERIOD OF RECORD.--Maximum discharge, 1,660 ft ${ }^{3} / \mathrm{s}$ about June 3, 1952, gage height, $8.00 \mathrm{ft}$, fram $\mathrm{rloodmarks,} \mathrm{fram}$ rating curve extended above $820 \mathrm{ft}^{3} / \mathrm{s}$ by logarithmic plotting; no flow for part of Aug. 31, 1954, and for several days during August to September 1956.

LOWEST MEAN DISCHARGE, IN OUBIC FEET PER SECOND, AND RANKING FOR THE INDICATED NUMBER OF CONSECUTIVE DAYS FOR EACH OIMATIC YEAR, APRII 1-MARCH 31

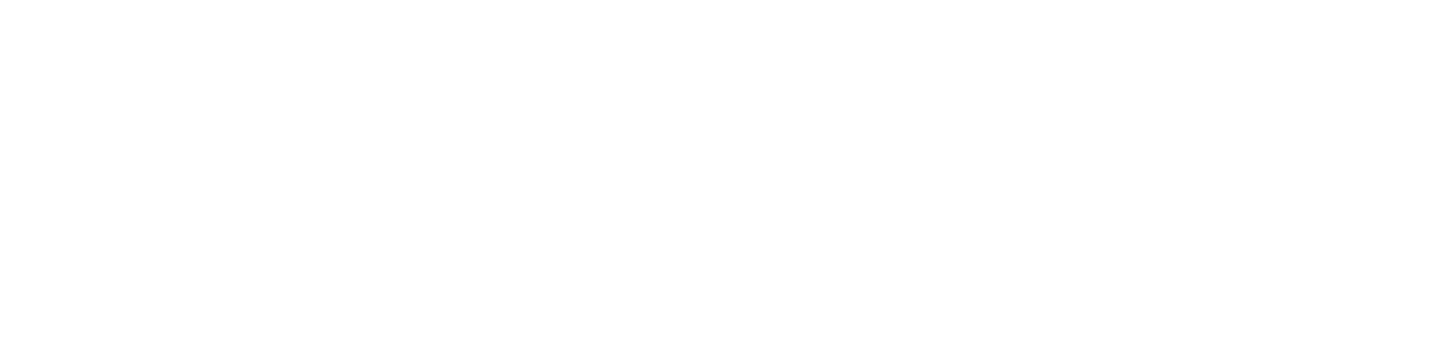

HIGHEST MEAN DISCHARGE, IN OUBIC FEET PER SECOND, AND RANRING FOR THE INDICATED NUMER OF CONSECUTIVE DAYS FOR EACH WATER YEAR, OCTOBER 1-SEPTEMBER 30

\begin{tabular}{|c|c|c|c|c|c|c|c|c|c|c|c|c|c|c|c|c|c|c|c|c|}
\hline YEAR & \multicolumn{20}{|c|}{ CONSEOTTIVE DAYS } \\
\hline $\begin{array}{l}1951 \\
1952 \\
1953 \\
1954 \\
1955\end{array}$ & $\begin{array}{r}620 \\
1450 \\
694 \\
182 \\
261\end{array}$ & $\begin{array}{r}5 \\
1 \\
4 \\
11 \\
10\end{array}$ & $\begin{array}{r}603 \\
1420 \\
673 \\
164 \\
220\end{array}$ & $\begin{array}{r}5 \\
1 \\
4 \\
11 \\
10\end{array}$ & $\begin{array}{r}535 \\
1390 \\
628 \\
153 \\
177\end{array}$ & $\begin{array}{r}6 \\
1 \\
4 \\
11 \\
10\end{array}$ & $\begin{array}{r}362 \\
1210 \\
511 \\
138 \\
111\end{array}$ & $\begin{array}{r}6 \\
1 \\
4 \\
10 \\
11\end{array}$ & $\begin{array}{r}275 \\
952 \\
351 \\
90.0 \\
86.0\end{array}$ & $\begin{array}{r}6 \\
1 \\
5 \\
10 \\
11\end{array}$ & $\begin{array}{c}158 \\
728 \\
189 \\
52.0 \\
54.0\end{array}$ & $\begin{array}{r}6 \\
1 \\
5 \\
11 \\
10\end{array}$ & $\begin{array}{r}119 \\
546 \\
135 \\
38.0 \\
38.0\end{array}$ & $\begin{array}{r}6 \\
1 \\
5 \\
10 \\
11\end{array}$ & $\begin{array}{c}93.0 \\
42.0 \\
105 \\
33.0 \\
34.0\end{array}$ & $\begin{array}{r}6 \\
1 \\
5 \\
11 \\
10\end{array}$ & $\begin{array}{c}63.0 \\
286 \\
72.0 \\
25.0 \\
29.0\end{array}$ & $\begin{array}{r}6 \\
1 \\
5 \\
11 \\
10\end{array}$ & $\begin{array}{r}36.0 \\
152 \\
45.0 \\
17.0 \\
19.0\end{array}$ & $\begin{array}{r}5 \\
11 \\
10\end{array}$ \\
\hline 95 & $\begin{array}{r}433 \\
1240 \\
1050\end{array}$ & $\begin{array}{l}7 \\
2 \\
3\end{array}$ & $\begin{array}{r}410 \\
1200 \\
1020\end{array}$ & $\begin{array}{l}7 \\
2 \\
3\end{array}$ & $\begin{array}{r}398 \\
1130 \\
950\end{array}$ & $\begin{array}{l}7 \\
2 \\
3\end{array}$ & $\begin{array}{l}337 \\
938 \\
891\end{array}$ & $\begin{array}{l}2 \\
3\end{array}$ & $\begin{array}{l}222 \\
808 \\
729\end{array}$ & $\begin{array}{l}8 \\
2 \\
3\end{array}$ & $\begin{array}{l}118 \\
492 \\
460\end{array}$ & $\begin{array}{l}8 \\
2\end{array}$ & $\begin{array}{l}81.0 \\
338 \\
331\end{array}$ & $\begin{array}{l}8 \\
2 \\
3\end{array}$ & $\begin{array}{l}64.0 \\
264 \\
254\end{array}$ & $\begin{array}{l}8 \\
2 \\
3\end{array}$ & $\begin{array}{l}50.0 \\
176 \\
175\end{array}$ & $\begin{array}{l}8 \\
2\end{array}$ & $\begin{array}{l}27.0 \\
92.0 \\
97.0\end{array}$ & \\
\hline
\end{tabular}

DURATION OF DISCHARGE FOR EACH WATER YEAR

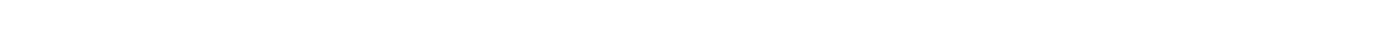
YEAR

NUMBER OF DAYS IN CLASS GBIC FEET PER SECOND

$\begin{array}{rrrrrrrrrrrrrrrrrrrrrr}3 & 5 & 7 & 9 & 16 & 20 & 52 & 36 & 118 & 15 & 12 & 39 & 1 & 2 & 2 & 1 & 6 & 2 & 6 & 9 & 5 & \\ & & & 1 & 11 & 18 & 36 & 80 & 73 & 19 & 29 & 15 & 3 & 3 & 5 & 4 & 12 & 10 & 17 & 9 & 9 & 9\end{array}$

10913.4

1948

1949

$\begin{array}{lllllllllllllllllll}1 & 3 & 6 & 13 & 18 & 42 & 57 & 72 & 50 & 33 & 32 & 7 & 6 & 3 & 4 & 1 & 4 & 8 & 3\end{array}$

22736.5

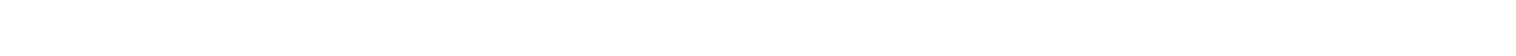

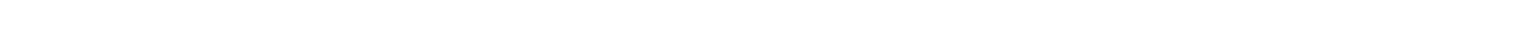

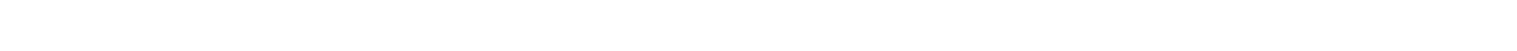

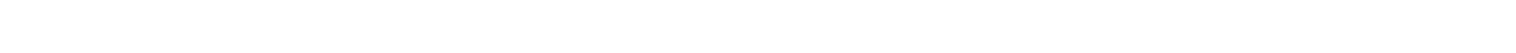

$\begin{array}{llllllllllllllllllllllllllllllll}1957 & 11 & 1 & 1 & 12 & 10 & 40 & 40 & 105 & 34 & 20 & 14 & 6 & 8 & 7 & 5 & 6 & 9 & 6 & 4 & 3 & 3 & 7 & 9 & 9 & 6 & & 33590.1\end{array}$

$\begin{array}{lllllllllllllllllllllllllllllllll}1958 & 1 & 3 & 11 & 20 & 9 & 10 & 30 & 13 & 17 & 105 & 46 & 18 & 7 & 5 & 5 & 4 & 9 & 12 & 8 & 6 & 4 & 10 & 8 & 4 & 3529.3\end{array}$ 
GREEN RIVER BASIN

09325000 COTTONWOOD CREEK NEAR CASTLE DALE, UT-COntinued

DURATION TABLE OF DISGHARGE FOR WATER YEARS 1948-58

\begin{tabular}{|c|c|c|c|c|}
\hline CLASS & $\begin{array}{c}\text { OBIC } \\
\text { FEET } \\
\text { PER } \\
\text { SECOND }\end{array}$ & $\begin{array}{l}\text { TOTAL } \\
\text { DAYS }\end{array}$ & $\begin{array}{c}\text { ACOU- } \\
\text { MU- } \\
\text { LATED } \\
\text { DAYS }\end{array}$ & $\begin{array}{l}\text { PER- } \\
\text { CENT } \\
\text { DAYS }\end{array}$ \\
\hline $\begin{array}{l}0 \\
1 \\
2 \\
3 \\
4 \\
5 \\
6 \\
7\end{array}$ & $\begin{array}{l}0.00 \\
0.10 \\
0.13 \\
0.18 \\
0.24 \\
0.32 \\
0.43 \\
0.57 \\
0.7\end{array}$ & $\begin{array}{r}9 \\
18 \\
0 \\
15 \\
12 \\
8 \\
2 \\
24\end{array}$ & $\begin{array}{l}4018 \\
4009 \\
3991 \\
3991 \\
3976 \\
3964 \\
3956 \\
3954 \\
3930\end{array}$ & $\begin{array}{r}100.0 \\
99.8 \\
99.3 \\
99.3 \\
99.0 \\
98.7 \\
98.5 \\
98.4\end{array}$ \\
\hline
\end{tabular}

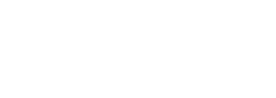

$\begin{array}{lll}\text { OBIC } & \text { ACOU- } \\ \text { FEET } & \text { MU- } & \text { PER- } \\ \text { PER TOTAL LATED } & \text { CENT }\end{array}$ CLASS SECOND DAYS DAYS DAYS CLASS SECOND DAYS DAYS DAYS

$\begin{array}{ccc}\text { CUBIC } & \text { ACOJ- } \\ \text { FEET } & \text { MU- } & \text { PER- } \\ \text { PER } & \text { TOTAL LATED } & \text { CENT } \\ \text { CLASS SECOND DAYS } & \text { DAYS } & \text { DAYS }\end{array}$

$\begin{array}{rrrrr}9 & 1.00 & 26 & 3924 & 97.7 \\ 10 & 1.40 & 35 & 3898 & 97.0 \\ 11 & 1.80 & 31 & 3863 & 96.1 \\ 12 & 2.40 & 68 & 3832 & 95.4 \\ 13 & 3.20 & 109 & 3764 & 93.7 \\ 14 & 4.30 & 202 & 3655 & 91.0 \\ 15 & 5.70 & 375 & 3453 & 85.9 \\ 16 & 7.70 & 637 & 3078 & 76.6 \\ 17 & 10.00 & 614 & 2441 & 60.8\end{array}$

$\begin{array}{rrrrr}18 & 14.0 & 362 & 1827 & 45.5 \\ 19 & 18.0 & 542 & 1465 & 36.5 \\ 20 & 24.0 & 271 & 923 & 23.0 \\ 21 & 33.0 & 76 & 652 & 16.2 \\ 22 & 44.0 & 54 & 576 & 14.3 \\ 23 & 58.0 & 49 & 522 & 13.0 \\ 24 & 78.0 & 37 & 473 & 11.8 \\ 25 & 100.0 & 59 & 436 & 10.9 \\ 26 & 140.0 & 65 & 377 & 9.4\end{array}$

$\begin{array}{rrrrr}27 & 180.0 & 74 & 312 & 7.8 \\ 28 & 250.0 & 55 & 238 & 5.9 \\ 29 & 330.0 & 46 & 183 & 4.6 \\ 30 & 440.0 & 50 & 137 & 3.4 \\ 31 & 590.0 & 40 & 87 & 2.2 \\ 32 & 780.0 & 25 & 47 & 1.2 \\ 33 & 1000.0 & 19 & 22 & 0.5 \\ 34 & 1400.0 & 3 & 3 & 0.1\end{array}$

MONTHLY MEAN DISGHARGES, IN OBBIC FEET PER SECOND, FOR EACH WATER YEAR

\begin{tabular}{|c|c|c|c|c|c|c|c|c|c|c|c|c|}
\hline YEAR & $\mathrm{OCT}$ & NOV & DEC & JAN & FEB & MAR & APR & MAY & JUNE & JULY & AUG & SEP \\
\hline $\begin{array}{l}1948 \\
1949 \\
1950\end{array}$ & $\begin{array}{r}9.39 \\
7.26 \\
11.8\end{array}$ & $\begin{array}{l}9.88 \\
10.2 \\
12.4\end{array}$ & $\begin{array}{c}13.0 \\
9.48 \\
9.10\end{array}$ & $\begin{array}{c}11.0 \\
8.50 \\
12.0\end{array}$ & $\begin{array}{l}20.2 \\
12.3 \\
20.4\end{array}$ & $\begin{array}{l}19.8 \\
20.9 \\
12.2\end{array}$ & $\begin{array}{l}8.16 \\
44.7 \\
12.3\end{array}$ & $\begin{array}{l}156 \\
266 \\
92.1\end{array}$ & $\begin{array}{c}92.0 \\
302 \\
84.4\end{array}$ & $\begin{array}{l}9.79 \\
49.6 \\
22.9\end{array}$ & $\begin{array}{c}4.49 \\
10.3 \\
6.16\end{array}$ & $\begin{array}{l}3.06 \\
5.66 \\
6.04\end{array}$ \\
\hline $\begin{array}{l}1951 \\
1952 \\
1953 \\
1954 \\
1955\end{array}$ & $\begin{array}{c}8.98 \\
14.1 \\
14.3 \\
13.5 \\
7.86\end{array}$ & $\begin{array}{c}11.8 \\
15.5 \\
13.3 \\
9.14 \\
10.1\end{array}$ & $\begin{array}{c}10.1 \\
15.7 \\
23.0 \\
9.63 \\
19.0\end{array}$ & $\begin{array}{l}9.00 \\
16.5 \\
21.0 \\
10.3 \\
20.1\end{array}$ & $\begin{array}{l}9.36 \\
22.2 \\
24.3 \\
17.6 \\
21.0\end{array}$ & $\begin{array}{l}7.19 \\
22.7 \\
12.7 \\
10.3 \\
21.7\end{array}$ & $\begin{array}{c}5.82 \\
76.9 \\
9.83 \\
13.0 \\
7.23\end{array}$ & $\begin{array}{l}124 \\
559 \\
15.7 \\
87.0 \\
38.6\end{array}$ & $\begin{array}{c}184 \\
881 \\
350 \\
9.90 \\
66.3\end{array}$ & $\begin{array}{c}16.1 \\
140 \\
21.1 \\
5.20 \\
4.53\end{array}$ & $\begin{array}{c}41.0 \\
38.2 \\
29.7 \\
2.23 \\
9.43\end{array}$ & $\begin{array}{c}7.38 \\
23.7 \\
7.83 \\
17.9 \\
1.22\end{array}$ \\
\hline $\begin{array}{l}1956 \\
1957 \\
1958\end{array}$ & $\begin{array}{c}5.57 \\
4.23 \\
23.8\end{array}$ & $\begin{array}{c}8.44 \\
6.98 \\
35.4\end{array}$ & $\begin{array}{c}12.4 \\
8.00 \\
21.1\end{array}$ & $\begin{array}{c}23.9 \\
8.00 \\
20.0\end{array}$ & $\begin{array}{l}21.6 \\
10.7 \\
27.5\end{array}$ & $\begin{array}{r}9.22 \\
7.55 \\
22.1\end{array}$ & $\begin{array}{c}8.67 \\
5.71 \\
73.8\end{array}$ & $\begin{array}{c}154 \\
45.6 \\
466\end{array}$ & $\begin{array}{l}75.7 \\
796 \\
439\end{array}$ & $\begin{array}{c}4.57 \\
157^{6.81}\end{array}$ & $\begin{array}{c}0.45 \\
45.7 \\
5.18\end{array}$ & $\begin{array}{l}0.38 \\
14.9 \\
18.7\end{array}$ \\
\hline
\end{tabular}

ANNUAL PEAK DISCHARGE, IN OBIC FEET PER SECOND, AND CORRESPONDING GAGE HEIGHT, IN FEET, FOR EACH WATER YEAR

\begin{tabular}{|c|c|c|c|c|c|c|c|c|c|c|c|}
\hline $\begin{array}{l}\text { WATER } \\
\text { YEAR }\end{array}$ & DATE & $\begin{array}{c}\text { GAGE } \\
\text { HEIGHT }\end{array}$ & $\begin{array}{c}\text { PEAK } \\
\text { DISCHARGE }\end{array}$ & $\begin{array}{l}\text { WATER } \\
\text { YEAR }\end{array}$ & DATE & $\begin{array}{c}\text { GAGE } \\
\text { HEIGHT }\end{array}$ & $\begin{array}{c}\text { PEAK } \\
\text { DISGARGE }\end{array}$ & $\begin{array}{l}\text { WATER } \\
\text { YEAR }\end{array}$ & DATE & $\begin{array}{c}\text { GAGE } \\
\text { HEIGHT }\end{array}$ & $\begin{array}{c}\text { PEAK } \\
\text { DISCHARGE }\end{array}$ \\
\hline $\begin{array}{l}1947 \\
1948 \\
1949 \\
1950\end{array}$ & $\begin{array}{lll}\text { AUG. } & 22,1947 \\
\text { MAY } & 18,1948 \\
\text { JUNE } 18,1949 \\
\text { JUNE } 01,1950\end{array}$ & $\begin{array}{l}6.14 \\
3.65 \\
4.58 \\
3.40\end{array}$ & $\begin{array}{r}1150 \\
468 \\
704 \\
409\end{array}$ & $\begin{array}{l}1951 \\
1952 \\
1953 \\
1954\end{array}$ & $\begin{array}{l}\text { AUG. } 04,1951 \\
\text { JUNE 03, } 1952 \\
\text { JUNE 14, } 1953 \\
\text { SEPT. 02, } 1954\end{array}$ & $\begin{array}{l}5.19 \\
8.00 \\
6.80 \\
5.98\end{array}$ & $\begin{array}{r}872 \\
1660 \\
800 \\
564\end{array}$ & $\begin{array}{l}1955 \\
1956 \\
1957 \\
1958\end{array}$ & $\begin{array}{l}\text { AUG. } 13,1955 \\
\text { MAY } 22,1956 \\
\text { AUG. 05, } 1957 \\
\text { JUNE } 07,1958\end{array}$ & $\begin{array}{l}6.13 \\
6.00 \\
8.08 \\
7.93\end{array}$ & $\begin{array}{r}636 \\
528 \\
1340 \\
1390\end{array}$ \\
\hline
\end{tabular}

MAGNITUDE AND PROBABIIITY OF ANNUAL LONEST MEAN DISCHARGE BASED ON OLIMATIC YEARS 1949-58

\begin{tabular}{|c|c|c|c|c|c|c|}
\hline \multirow{2}{*}{$\begin{array}{l}\text { PERIOD } \\
\text { (CON- } \\
\text { SEQJ- } \\
\text { TIVE } \\
\text { DAYS) }\end{array}$} & \multicolumn{6}{|c|}{$\begin{array}{l}\text { DISCHARGE, IN OBBIC FEET PER SECOND, FOR } \\
\text { INDICAIED REOURRENCE INTEIRNAL, IN YEARS, AND } \\
\text { ANNUAL NONEXCEEDANCEE PROBABILITY, IN PERCENT }\end{array}$} \\
\hline & $\begin{array}{c}2 \\
508\end{array}$ & $\begin{array}{c}5 \\
208\end{array}$ & $\begin{array}{l}10 \\
108\end{array}$ & $\begin{array}{l}20 \\
58\end{array}$ & $\begin{array}{l}50 \\
28\end{array}$ & $\begin{array}{r}100 \\
18\end{array}$ \\
\hline
\end{tabular}

$\begin{array}{lllllll}90 & 7.9 & 4.0 & 2.7 & 1.8 & - & -\end{array}$
MAGNITUDE AND PROBABILITY OF ANNUAL HIGHEST MEAN DISGARGE BASED ON WATER YEARS 1948-58

\begin{tabular}{|c|c|c|c|c|c|c|}
\hline \multirow{2}{*}{$\begin{array}{l}\text { PERIOD } \\
\text { (CON- } \\
\text { SEQU- } \\
\text { TIVE } \\
\text { DAYS) }\end{array}$} & \multicolumn{6}{|c|}{$\begin{array}{l}\text { DISGHARGE, IN ONBIC FEET PER SECOND, FOR } \\
\text { INDICATED RECURRENCE INTERVAL, IN YEARS, AND } \\
\text { ANNUAL EXCEEDANCE PROBABILITY, IN PERCENT }\end{array}$} \\
\hline & $\begin{array}{c}2 \\
508\end{array}$ & $\begin{array}{c}5 \\
208\end{array}$ & $\begin{array}{l}10 \\
108\end{array}$ & $\begin{array}{l}25 \\
48\end{array}$ & $\begin{array}{l}50 \\
28\end{array}$ & $\begin{array}{r}100 \\
18\end{array}$ \\
\hline $\begin{array}{r}1 \\
3 \\
7 \\
15\end{array}$ & $\begin{array}{l}556 \\
527 \\
484 \\
397\end{array}$ & $\begin{array}{l}955 \\
930 \\
876 \\
743\end{array}$ & $\begin{array}{l}1260 \\
1240 \\
1190 \\
1020\end{array}$ & $\overline{-}$ & $\bar{z}$ & $\overline{-}$ \\
\hline
\end{tabular}

09325100 SAN RAFAEL RIVER ABOVE FERRON CREER, NEAR CASTLE DALE, UT

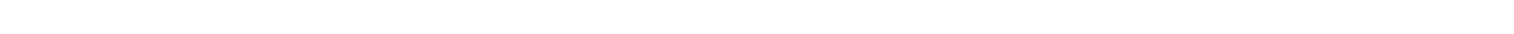
ft upstream from Ferron Creek and $7 \mathrm{mi}$ southeast of Castle Dale.

DRAINAGE AREA $-680 \mathrm{mi}^{2}$.

PERIOD OF RECORD AVAIIABLE. - Octcber 1964 to September 1970.

GAGE. - Water-stage recorder. Altitude of gage is 5,400 ft from topographic map. Prior to Apr. 12, 1967, at site $30 \mathrm{ft}$ upstream at $1.16 \mathrm{ft}$ higher gage datum.

REMARKS.--Diversions for irrigation above station, including transmountain diversions from tributaries for irrigation in Sevier Lake basin. Flow regulated by Joes valley Reservoir.

AVERAGE DISCHARGE. -6 years, $94.3 \mathrm{ft}^{3} / \mathrm{s}, 68,320$ acre-ft/yr.

EXTREMES FOR PERIOD OF RECORD.--Maximum discharge, 1,670 $\mathrm{ft}^{3} / \mathrm{s}$ June 25, 1965, gage height, $6.25 \mathrm{ft}$, site and datum then in use; minimum, $5.7 \mathrm{ft}^{3} / \mathrm{s}$ Oct. $1,8,1964$. 
LOWEST MEAN DISCHARGE, IN CUBIC FEET PER SECOND, AND RANKING FOR THE INDICATED NUMBER OF CONSECUTIVE DAYS FOR EACH CIIMATIC YEAR, APRIL I-MARCH 31

YEAR

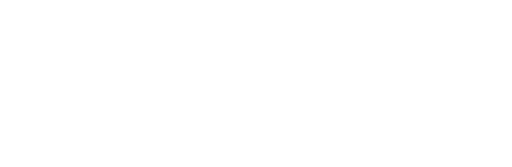

\section{CONSECITIVE DAYS}

$\begin{array}{cccccc}30 & & 60 & & 90 & \\ 35.0 & 5 & 43.0 & 5 & 51.0 & 5 \\ 11.0 & 1 & 16.0 & 1 & 17.0 & 1 \\ 12.0 & 2 & 20.0 & 2 & 23.0 & 2 \\ 25.0 & 3 & 34.0 & 3 & 35.0 & 3 \\ 28.0 & 4 & 34.0 & 4 & 35.0 & 4\end{array}$

$120 \quad 183$

$\begin{array}{llllll}51.0 & 5 & 55.0 & 5 & 194 & 5\end{array}$

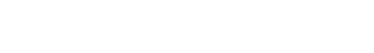

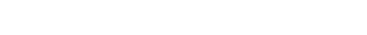

HIGHEST MEAN DISCHARGE, IN OUBIC FEET PER SECOND, AND RANKING FOR THE INDICATED NUMBER OF CONSEOUTIVE DAYS FOR EACH WATER YEAR, OCTOBER 1-SEPTEMBER 30

\begin{tabular}{|c|c|c|c|c|c|c|c|c|c|c|c|c|c|c|c|c|c|c|c|c|}
\hline YEAR & 1 & & 3 & & 7 & & 1 & & $\begin{array}{l}\text { CONS } \\
30\end{array}$ & ar & IE DAYS & & 90 & & 120 & & 183 & & ALL & \\
\hline $\begin{array}{l}1966 \\
1967 \\
1968 \\
1969 \\
1970\end{array}$ & $\begin{array}{r}402 \\
408 \\
503 \\
801 \\
1100\end{array}$ & $\begin{array}{l}6 \\
5 \\
4 \\
3 \\
2\end{array}$ & $\begin{array}{l}187 \\
340 \\
489 \\
702 \\
911\end{array}$ & $\begin{array}{l}6 \\
5 \\
4 \\
3 \\
2\end{array}$ & $\begin{array}{l}138 \\
298 \\
455 \\
569 \\
775\end{array}$ & $\begin{array}{l}6 \\
5 \\
4 \\
3 \\
2\end{array}$ & $\begin{array}{l}117 \\
261 \\
393 \\
493 \\
689\end{array}$ & $\begin{array}{l}6 \\
5 \\
4 \\
3 \\
2\end{array}$ & $\begin{array}{l}95.0 \\
212 \\
331 \\
467 \\
611\end{array}$ & $\begin{array}{l}6 \\
5 \\
4 \\
3 \\
2\end{array}$ & $\begin{array}{l}78.0 \\
151 \\
212 \\
383 \\
403\end{array}$ & $\begin{array}{l}6 \\
5 \\
4 \\
3 \\
2\end{array}$ & $\begin{array}{l}68.0 \\
113 \\
182 \\
300 \\
297\end{array}$ & $\begin{array}{l}5 \\
4\end{array}$ & $\begin{array}{l}64.0 \\
96.0 \\
153 \\
250 \\
239\end{array}$ & $\begin{array}{l}6 \\
5 \\
4\end{array}$ & $\begin{array}{l}61.0 \\
69.0 \\
113 \\
194 \\
172\end{array}$ & $\begin{array}{l}6 \\
5 \\
4 \\
2 \\
3\end{array}$ & $\begin{array}{c}48.0 \\
45.0 \\
70.0 \\
120 \\
110\end{array}$ & $\begin{array}{l}5 \\
6 \\
4 \\
2 \\
3\end{array}$ \\
\hline
\end{tabular}

DURATION OF DISCHARGE FOR EACH WATER YEAR

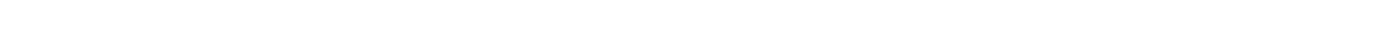
YEAR PER SECOND -DAYS

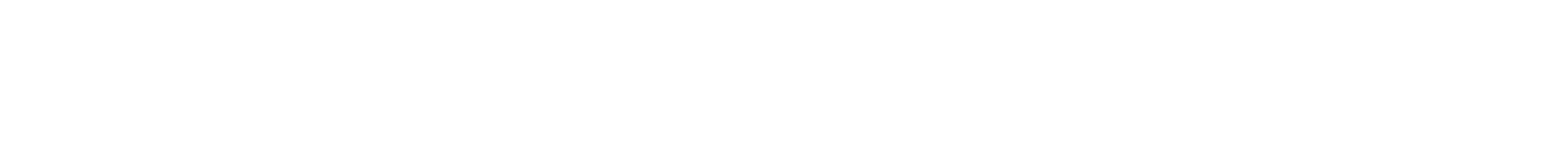

DURATION TABLE OF DISCHARGE FOR WATER YEARS 1965-70
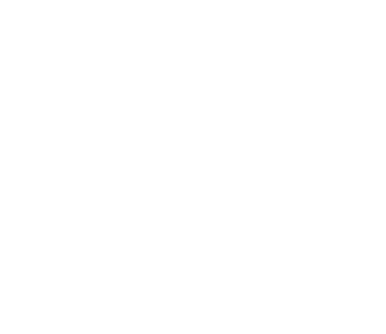

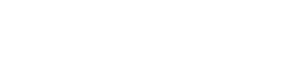

CI.ASS SECOND DAYS DAYS DAYS

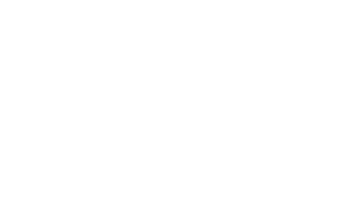

$\begin{array}{ccc}\text { CUBIC } & \text { ACOU- } \\ \text { FEET } & \text { MU- } & \text { PER- } \\ \text { PER TOTAL LATED } & \text { CENT }\end{array}$ CIASS SECOND DAYS DAYS DAYS

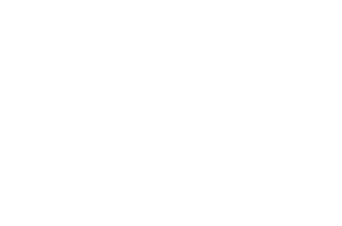

MONIHLY MEAN DISCHARGES, IN OUBIC FEET PER SECOND, FOR EACH WATER YEAR

$\begin{array}{rccccccccccrr}\text { YEAR } & \text { OCT } & \text { NOV } & \text { DEC } & \text { JAN } & \text { FEB } & \text { MAR } & \text { APR } & \text { MAY } & \text { JUNE } & \text { JULY } & \text { AUG } & \text { SEP } \\ 1965 & 8.03 & 20.0 & 41.6 & 50.4 & 48.8 & 43.5 & 69.2 & 227 & 1016 & 434 & 156 & 72.2 \\ 1966 & 50.3 & 54.6 & 67.5 & 42.4 & 44.6 & 94.4 & 50.4 & 50.5 & 33.4 & 38.2 & 31.5 & 16.3 \\ 1967 & 19.5 & 19.0 & 30.9 & 13.7 & 27.8 & 20.9 & 14.4 & 56.7 & 205 & 59.9 & 32.2 & 47.8 \\ 1968 & 38.2 & 29.5 & 22.6 & 19.1 & 29.0 & 26.1 & 25.0 & 95.1 & 309 & 78.3 & 119 & 55.6 \\ 1969 & 68.8 & 40.1 & 32.4 & 37.1 & 37.3 & 76.2 & 122 & 443 & 316 & 99.5 & 86.0 & 75.0 \\ 1970 & 68.2 & 60.1 & 54.6 & 35.8 & 40.9 & 28.1 & 35.1 & 163 & 609 & 106 & 66.9 & 57.5\end{array}$

ANNUAL PEAK DISCHARGE, IN CABIC FEET PER SECOND, AND OORRESPONDING GAGE HEIGHT, IN FEET, FOR EACH WATER YEAR

\begin{tabular}{|c|c|c|c|c|c|c|c|c|c|c|c|}
\hline $\begin{array}{l}\text { WATER } \\
\text { YEAR }\end{array}$ & DATE & $\begin{array}{c}\text { GAGE } \\
\text { HEIGHI }\end{array}$ & $\begin{array}{l}\text { PEAK } \\
\text { DISCHARGE }\end{array}$ & $\begin{array}{l}\text { WATER } \\
\text { YEAR }\end{array}$ & DATE & $\begin{array}{c}\text { GAGE } \\
\text { HEIGHT }\end{array}$ & $\begin{array}{c}\text { PEAR } \\
\text { DISCHARGE }\end{array}$ & $\begin{array}{l}\text { WATER } \\
\text { YEAR }\end{array}$ & DATE & $\begin{array}{l}\text { GAGE } \\
\text { HEIGHT }\end{array}$ & $\begin{array}{c}\text { PEAR } \\
\text { DISCHARGE }\end{array}$ \\
\hline $\begin{array}{l}1965 \\
1966\end{array}$ & $\begin{array}{l}\text { JUNE } 25,1965 \\
\text { AUG. } 31,1966\end{array}$ & $\begin{array}{l}6.25 \\
5.20\end{array}$ & $\begin{array}{l}1670 \\
1260\end{array}$ & $\begin{array}{l}1967 \\
1968\end{array}$ & $\begin{array}{l}\text { SEPT.09, } 1967 \\
\text { AUG. 01, } 1968\end{array}$ & $\begin{array}{l}5.68 \\
6.22\end{array}$ & $\begin{array}{l}1000 \\
1200\end{array}$ & $\begin{array}{l}1969 \\
1970\end{array}$ & $\begin{array}{ll}\text { AUG. } 29, & 1969 \\
\text { JUNE } 10,1970\end{array}$ & $\begin{array}{l}7.25 \\
7.04\end{array}$ & $\begin{array}{l}1640 \\
1540\end{array}$ \\
\hline
\end{tabular}




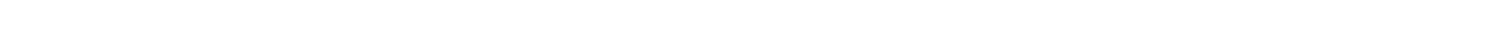
$1.8 \mathrm{mi}$ upstream from Dry Wash and $4.5 \mathrm{mi}$ west of Ferron.

DRAINAGE AREA, $-138 \mathrm{mi}^{2}$.

MEAN BASIN ELEVATION. $--8,800 \mathrm{ft}$.

PERIOD OF RECORD AVAIIABLE.--May 1911 to September 1923 (monthly mean discharge only in 1911 water year, published in wSP 1313), Octaber 1947 to September 1981. Records for station at site $2 \mathrm{mi}$ downstream published in WSP 1313 as "Ferron Creek nea Ferron", Apr. 1909 to Oct. 191 , not equivalent because of diversions $1.5 \mathrm{mi}$ downstream from present site.

REVISED RECORDS. -WSP 1243: 1951 (P). WSP 1313: $1920(\mathrm{M})$.

GAGE. -Water-stage recorder. Altitude of gage is 6,210 ft from topographic map. May 6, 1911 to Sept. 30, 1923, nonrecording gages in vicinity of present site at different datums. Dec. 19, 1947 to Sept. 30, 1966, at site 1.5 mi downstream at different datum.

REMARKS.--Slight regulation by small reservoir above station (capacity not known). Small diversions above station for irrigation, including a transmountain diversion to tributary of San Pitch River (Sevier Lake basin). Greater part of flow diverted during irrigation season by Upper North and Upper South Canals, $1.5 \mathrm{mi}$ bel ow station.

AVERAGE DISCHARGE. --46 years, $66.0 \mathrm{ft}^{3} / \mathrm{s}, 47,820$ acre-ft/yr.

EXTREMES FOR PERIOD OF RECORD.--Maximum discharge observed, 4,180 $\mathrm{ft}^{3} / \mathrm{s}$ Aug. 27, 1952, gage height, $9.71 \mathrm{ft}$, site and datum then in use, from rating table extended above $400 \mathrm{ft}^{3} / \mathrm{s}$ on basis of slope-area measurements at gage heights $8.70 \mathrm{ft}$ and $9.71 \mathrm{ft}$, site and datum then in use; no flow Oct. $1,1976$.

IOWEST MEAN DISCHARGE, IN OUBIC FEET PER SECOND, AND RANKING FOR THE INDICATED NUMBER OF CONSEQUTIVE DAYS FOR EAOH OLIMATIC YEAR, APRIL 1-MARCH 31

YE

1

1914
1915

1916

191

1918

1920

1921

1922

1923

1949
1950

195

1952

195

1956

1957

1958
1959

1960

19

1962

1964

1965

196

1967
1968
1969

1969
1970

197

1972

1974

1975

197

1978

1980

1981
$6.00 \quad 20$

5.0011

$11.0 \quad 44$

9.0037

$10.0 \quad 41$

0.042

5.0012

5.0013

6.0021

8.0032

$10.0 \quad 43$

7.0029

6.2023

5.0014

6.5025

8.6034

6.7026

2. 903

5.6017

8.7035

$\begin{array}{ll}3.90 & 7 \\ 2.10 & \end{array}$

4.7010

5.9018

$3.00 \quad 4$

6.0019

9.0038

5.6016

6.4024

7.0030

8.8036

7.0031

9.8039

6.1022

6.7027

$\begin{array}{ll}3.00 & 5 \\ 1.00 & 1\end{array}$

$1.00 \quad 1$
3.20

4.00

8.2033

7.0028
7

8.0029

8.0030

6.3017

9.0036

10.040

$10.0 \quad 41$

7.0023

8.7033

8.0031

10.042

7.0024

6.2016

5.7013

6.5018

8.9035
7.9029

5.0010

$4.30 \quad 6$

6.5019

8.7034

$\begin{array}{ll}4.50 & 7 \\ 2.20 & 1\end{array}$

5.0011

6.0014

$\begin{array}{lll}3.00 & 2\end{array}$

6.0015

9. 3037

6.7020

7. 8028

7.0025
9.5038

7.0026

$12.0 \quad 44$

$10.0 \quad 39$

6.9022

3.003

$\begin{array}{ll}3.00 & 4 \\ 3.20 & 5\end{array}$

$\begin{array}{ll}3.20 & 5 \\ 4.70 & 8\end{array}$

$\begin{array}{rr}4.70 & 8 \\ 8.50 & 32\end{array}$

$7.30 \quad 27$

11.043

9.0033

$10.0 \quad 37$

$10.0 \quad 38$

5.007
7.00

7.0021

8.9032

$10.0 \quad 40$

7.0022

6.5015

7.4024

6.8016
10.011

10.041

6.7030

5.4010

5.4010
7.0017

$10.0 \quad 42$

5.109
2.60

$5.00 \quad 8$

6.1013

3.002

6.0012

9.7034

9.7034
7.6025

8.0026

7.0018

10.035

7.0019

$\begin{array}{cc}12.0 & 44 \\ 8.00 & 27\end{array}$

$10.0 \quad 36$

7.0020

$\begin{array}{ll}3.00 & 3 \\ 3.30 & 4\end{array}$

3.505

5.006
8.9031

8.0028
14

8.0023

8.1025

$10.0 \quad 39$

9.0030

$10.0 \quad 33$

$10.0 \quad 34$

7.0018

$10.0 \quad 35$

9.4031

7.0019

6.5013

8.8028

7.1021

$\begin{array}{ll}12.0 & 44 \\ 10.0 & 37\end{array}$

6.6014

5.8011

7.0020
$11.0 \quad 42$

$\begin{array}{rr}11.0 & 42 \\ 5.50 & 8\end{array}$

3.001

5.006

6.6015

5.507

6.0012

$10.0 \quad 38$

8.5027

8.1026

$10.0 \quad 39$

7.0017

$\begin{array}{rr}12.0 & 43 \\ 8.00 & 24\end{array}$

8.00
$10.0 \quad 40$

7.4022

$3.00 \quad 3$

3.804

$4.00 \quad 5$

$\begin{array}{ll}5.70 & 10 \\ 9.40 & 32\end{array}$

8.9029

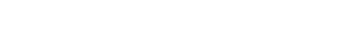

CONSEUTIVE DAYS$$
30
$$

8.0022

8.6027

$11.0 \quad 41$
9.0028

$10.0 \quad 37$

10.038

$6.20 \quad 9$

$11.0 \quad 39$

9.7031

$10.0 \quad 32$

7.0015

6.6011

9.0029

8.1023

$12.0 \quad 42$

7.9021

6.5010

7.0016

$\begin{array}{rr}7.00 & 16 \\ 12.0 \quad 43\end{array}$

$\begin{array}{rr}12.0 & 43 \\ 5.80 & 8\end{array}$

3.403

5.006

7.5019

3.001

5.707

6.7012

$11.0 \quad 40$

$\begin{array}{cc}11.0 & 40 \\ 8.50 & 26\end{array}$

8.5026
8.1024

7.2018

10.034

7.0017

$\begin{array}{rr}12.0 & 44 \\ 8.20 & 25\end{array}$

$10.0 \quad 35$

7.9020

3.402

3.40
$4.40 \quad 4$

4.505

6.9013
$10.0 \quad 36$

9.4030

90

8.1019

8.8025

$11.0 \quad 37$

9.1027

$\begin{array}{rr}13.0 & 43 \\ 11.0 & 38\end{array}$

6.408

8.0017

$12.0 \quad 39$

$14.0 \quad 44$

7.4013

6.9010

9. 2028

8. 2020

$12.0 \quad 40$

10.0
8.1018

6.9011

7.0012

$\begin{array}{cc}12.0 & 41 \\ 6.40 & 9\end{array}$

$\begin{array}{ll}6.90 & 2\end{array}$

5.205

9.9030

$\begin{array}{ll}3.600 & 1 \\ 6.007\end{array}$

8.3021

$11.0 \quad 34$

$\begin{array}{rr}11.0 & 34 \\ 8.80 & 26\end{array}$

8.4022

7.6014
$11.0 \quad 35$

7.7015

$\begin{array}{cc}12.0 & 42 \\ 8.70 & 24\end{array}$

10.031 
GREEN RIVER BASIN

09326500 FERRON CPEEK (UPPER STATION) NEAR FERRON, UT-Continued

HIGHEST MEAN DISGAARG, IN OBIC FEET PER SECOND, AND RANKING FOR THE INDICATED NUMBER OF CONSEOTTIVE DAVS FOR EACH WATER YEAR, OCTOBER 1-SEPTEMBER 30

\begin{tabular}{|c|c|c|c|c|c|c|c|c|c|c|c|c|c|c|c|c|c|c|c|c|}
\hline YEAR & & & & & & & & & & & IE DAY & & & & & & & & & \\
\hline $\begin{array}{l}1912 \\
1913 \\
1914 \\
915\end{array}$ & $\begin{array}{l}800 \\
650 \\
882 \\
605\end{array}$ & $\begin{array}{r}8 \\
15 \\
4 \\
16\end{array}$ & $\begin{array}{l}773 \\
365 \\
740 \\
512\end{array}$ & $\begin{array}{r}5 \\
31 \\
7 \\
19\end{array}$ & $\begin{array}{l}725 \\
356 \\
661 \\
412\end{array}$ & $\begin{array}{r}6 \\
31 \\
8 \\
25\end{array}$ & $\begin{array}{l}653 \\
335 \\
622 \\
398\end{array}$ & $\begin{array}{r}6 \\
29 \\
9 \\
22\end{array}$ & $\begin{array}{l}525 \\
301 \\
580 \\
321\end{array}$ & $\begin{array}{r}9 \\
26 \\
6 \\
24\end{array}$ & $\begin{array}{l}375 \\
235 \\
445 \\
240\end{array}$ & $\begin{array}{r}10 \\
25 \\
3 \\
23\end{array}$ & $\begin{array}{l}278 \\
188 \\
340 \\
185\end{array}$ & $\begin{array}{r}12 \\
22 \\
4 \\
24\end{array}$ & $\begin{array}{l}219 \\
153 \\
272 \\
150\end{array}$ & $\begin{array}{r}13 \\
22 \\
4 \\
24\end{array}$ & $\begin{array}{l}151 \\
111 \\
189 \\
106\end{array}$ & $\begin{array}{r}13 \\
22 \\
4 \\
23\end{array}$ & $\begin{array}{c}81.0 \\
62.0 \\
100 \\
60.0\end{array}$ & $\begin{array}{r}14 \\
22 \\
5 \\
23\end{array}$ \\
\hline $\begin{array}{l}1916 \\
1917 \\
1918 \\
1919 \\
1920\end{array}$ & $\begin{array}{l}540 \\
829 \\
510 \\
589 \\
900\end{array}$ & $\begin{array}{r}20 \\
5 \\
24 \\
17 \\
3\end{array}$ & $\begin{array}{l}531 \\
814 \\
435 \\
494 \\
647\end{array}$ & $\begin{array}{r}17 \\
3 \\
28 \\
21 \\
12\end{array}$ & $\begin{array}{l}520 \\
781 \\
396 \\
448 \\
613\end{array}$ & $\begin{array}{r}16 \\
3 \\
27 \\
22 \\
11\end{array}$ & $\begin{array}{l}480 \\
732 \\
338 \\
397 \\
582\end{array}$ & $\begin{array}{r}16 \\
3 \\
27 \\
23 \\
11\end{array}$ & $\begin{array}{l}394 \\
612 \\
281 \\
326 \\
508\end{array}$ & $\begin{array}{r}16 \\
3 \\
30 \\
23 \\
11\end{array}$ & $\begin{array}{l}304 \\
465 \\
212 \\
238 \\
336\end{array}$ & $\begin{array}{r}19 \\
2 \\
29 \\
24 \\
14\end{array}$ & $\begin{array}{l}243 \\
358 \\
165 \\
179 \\
248\end{array}$ & $\begin{array}{r}18 \\
2 \\
30 \\
26 \\
16\end{array}$ & $\begin{array}{l}211 \\
287 \\
136 \\
145 \\
195\end{array}$ & $\begin{array}{r}15 \\
2 \\
29 \\
26 \\
18\end{array}$ & $\begin{array}{l}151 \\
201 \\
101 \\
104 \\
138\end{array}$ & $\begin{array}{r}14 \\
2 \\
28 \\
27 \\
18\end{array}$ & $\begin{array}{c}81.0 \\
114 \\
58.0 \\
57.0 \\
74.0\end{array}$ & $\begin{array}{r}15 \\
2 \\
26 \\
28 \\
18\end{array}$ \\
\hline $\begin{array}{l}921 \\
922 \\
923\end{array}$ & $\begin{array}{r}1070 \\
692 \\
572\end{array}$ & $\begin{array}{r}2 \\
12 \\
19\end{array}$ & $\begin{array}{r}1030 \\
675 \\
545\end{array}$ & $\begin{array}{r}1 \\
11 \\
16\end{array}$ & $\begin{array}{l}997 \\
644 \\
489\end{array}$ & $\begin{array}{r}1 \\
10 \\
17\end{array}$ & $\begin{array}{l}846 \\
609 \\
416\end{array}$ & $\begin{array}{r}1 \\
10 \\
19\end{array}$ & $\begin{array}{l}645 \\
509 \\
392\end{array}$ & $\begin{array}{r}2 \\
10 \\
17\end{array}$ & $\begin{array}{l}444 \\
364 \\
307\end{array}$ & $\begin{array}{c}4 \\
11 \\
18\end{array}$ & $\begin{array}{l}342 \\
268 \\
241\end{array}$ & $\begin{array}{r}3 \\
14 \\
19\end{array}$ & $\begin{array}{l}274 \\
212 \\
198\end{array}$ & $\begin{array}{r}3 \\
14 \\
17\end{array}$ & $\begin{array}{l}192 \\
149 \\
141\end{array}$ & $\begin{array}{r}3 \\
15 \\
17\end{array}$ & $\begin{array}{c}104 \\
85.0 \\
79.0\end{array}$ & $\begin{array}{r}3 \\
12 \\
16\end{array}$ \\
\hline $\begin{array}{l}1948 \\
1949 \\
1950\end{array}$ & $\begin{array}{l}425 \\
675 \\
333\end{array}$ & $\begin{array}{l}30 \\
14 \\
36\end{array}$ & $\begin{array}{l}391 \\
604 \\
326\end{array}$ & $\begin{array}{l}29 \\
14 \\
36\end{array}$ & $\begin{array}{l}359 \\
561 \\
302\end{array}$ & $\begin{array}{l}29 \\
13 \\
37\end{array}$ & $\begin{array}{l}326 \\
515 \\
283\end{array}$ & $\begin{array}{l}30 \\
13 \\
35\end{array}$ & $\begin{array}{l}264 \\
453 \\
236\end{array}$ & $\begin{array}{l}33 \\
14 \\
37\end{array}$ & $\begin{array}{l}183 \\
346 \\
175\end{array}$ & $\begin{array}{l}35 \\
13 \\
37\end{array}$ & $\begin{array}{l}142 \\
279 \\
142\end{array}$ & $\begin{array}{l}35 \\
11 \\
36\end{array}$ & $\begin{array}{l}115 \\
229 \\
122\end{array}$ & $\begin{array}{l}37 \\
11 \\
35\end{array}$ & $\begin{array}{c}81.0 \\
162 \\
86.0\end{array}$ & $\begin{array}{l}37 \\
11 \\
35\end{array}$ & & $\begin{array}{l}36 \\
11 \\
32\end{array}$ \\
\hline $\begin{array}{l}1956 \\
1957 \\
1958 \\
1959 \\
1960\end{array}$ & $\begin{array}{l}386 \\
807 \\
823 \\
146 \\
341\end{array}$ & $\begin{array}{r}31 \\
7 \\
6 \\
45 \\
35\end{array}$ & $\begin{array}{l}367 \\
762 \\
806 \\
142 \\
330\end{array}$ & $\begin{array}{r}30 \\
6 \\
4 \\
45 \\
35\end{array}$ & $\begin{array}{l}334 \\
748 \\
754 \\
138 \\
306\end{array}$ & $\begin{array}{r}33 \\
5 \\
4 \\
45 \\
35\end{array}$ & $\begin{array}{l}301 \\
654 \\
707 \\
131 \\
269\end{array}$ & $\begin{array}{r}34 \\
5 \\
4 \\
45 \\
37\end{array}$ & $\begin{array}{l}255 \\
598 \\
608 \\
120 \\
238\end{array}$ & $\begin{array}{r}35 \\
5 \\
4 \\
45 \\
36\end{array}$ & $\begin{array}{c}185 \\
410 \\
431 \\
94.0 \\
178\end{array}$ & $\begin{array}{r}34 \\
7 \\
5 \\
45 \\
36\end{array}$ & $\begin{array}{c}152 \\
308 \\
324 \\
79.0 \\
142\end{array}$ & $\begin{array}{r}33 \\
7 \\
6 \\
45 \\
37\end{array}$ & $\begin{array}{l}124 \\
247 \\
261 \\
67.0 \\
118\end{array}$ & $\begin{array}{r}33 \\
8 \\
6 \\
45 \\
36\end{array}$ & $\begin{array}{l}87.0 \\
174 \\
181 \\
49.0 \\
84.0\end{array}$ & $\begin{array}{r}34 \\
8 \\
6 \\
45 \\
36\end{array}$ & $\begin{array}{c}48.0 \\
91.0 \\
100 \\
29.0 \\
45.0\end{array}$ & $\begin{array}{r}34 \\
8 \\
4 \\
45 \\
37\end{array}$ \\
\hline $\begin{array}{l}1961 \\
1962 \\
1963 \\
1964 \\
1965\end{array}$ & $\begin{array}{l}235 \\
463 \\
372 \\
368 \\
756\end{array}$ & $\begin{array}{l}43 \\
27 \\
32 \\
33 \\
10\end{array}$ & $\begin{array}{l}227 \\
461 \\
344 \\
362 \\
703\end{array}$ & $\begin{array}{r}42 \\
25 \\
34 \\
33 \\
9\end{array}$ & $\begin{array}{l}205 \\
452 \\
330 \\
357 \\
598\end{array}$ & $\begin{array}{l}44 \\
21 \\
34 \\
30 \\
12\end{array}$ & $\begin{array}{l}177 \\
415 \\
317 \\
311 \\
547\end{array}$ & $\begin{array}{l}44 \\
20 \\
31 \\
32 \\
12\end{array}$ & $\begin{array}{l}148 \\
376 \\
266 \\
286 \\
503\end{array}$ & $\begin{array}{l}44 \\
20 \\
31 \\
29 \\
12\end{array}$ & $\begin{array}{l}107 \\
335 \\
189 \\
208 \\
387\end{array}$ & $\begin{array}{r}44 \\
15 \\
33 \\
31 \\
9\end{array}$ & $\begin{array}{l}91.0 \\
281 \\
148 \\
160 \\
305\end{array}$ & $\begin{array}{r}44 \\
10 \\
34 \\
32 \\
8\end{array}$ & $\begin{array}{l}77.0 \\
231 \\
123 \\
129 \\
247\end{array}$ & $\begin{array}{r}44 \\
10 \\
34 \\
32 \\
7\end{array}$ & $\begin{array}{c}57.0 \\
165 \\
89.0 \\
90.0 \\
174\end{array}$ & $\begin{array}{r}44 \\
9 \\
33 \\
32 \\
7\end{array}$ & & $\begin{array}{r}44 \\
9 \\
35 \\
33 \\
7\end{array}$ \\
\hline $\begin{array}{l}1976 \\
1977 \\
1978 \\
1979 \\
1980\end{array}$ & $\begin{array}{l}228 \\
70.0 \\
478 \\
677 \\
698\end{array}$ & $\begin{array}{l}44 \\
46 \\
26 \\
13 \\
11\end{array}$ & $\begin{array}{c}223 \\
66.0 \\
461 \\
621 \\
689\end{array}$ & $\begin{array}{l}44 \\
46 \\
24 \\
13 \\
10\end{array}$ & $\begin{array}{c}213 \\
59.0 \\
430 \\
530 \\
669\end{array}$ & $\begin{array}{r}42 \\
46 \\
24 \\
15 \\
7\end{array}$ & $\begin{array}{l}207 \\
54.0 \\
413 \\
511 \\
628\end{array}$ & $\begin{array}{c}40 \\
46 \\
21 \\
14 \\
7\end{array}$ & $\begin{array}{c}192 \\
48.0 \\
385 \\
462 \\
542\end{array}$ & $\begin{array}{r}39 \\
46 \\
18 \\
13 \\
7\end{array}$ & $\begin{array}{c}141 \\
47.0 \\
283 \\
335 \\
418\end{array}$ & $\begin{array}{r}39 \\
46 \\
21 \\
16 \\
6\end{array}$ & $\begin{array}{c}107 \\
40.0 \\
213 \\
262 \\
336\end{array}$ & $\begin{array}{r}40 \\
46 \\
21 \\
15 \\
5\end{array}$ & $\begin{array}{l}86.0 \\
33.0 \\
170 \\
209 \\
269\end{array}$ & $\begin{array}{r}43 \\
46 \\
21 \\
16 \\
5\end{array}$ & $\begin{array}{l}61.0 \\
26.0 \\
119 \\
145 \\
186\end{array}$ & $\begin{array}{r}43 \\
46 \\
21 \\
16 \\
5\end{array}$ & $\begin{array}{l}36.0 \\
18.0 \\
63.0 \\
78.0 \\
99.0\end{array}$ & $\begin{array}{r}43 \\
46 \\
21 \\
17 \\
6\end{array}$ \\
\hline 1981 & 243 & 39 & 228 & 41 & 224 & 40 & 218 & 39 & 164 & 43 & 136 & 40 & 107 & 41 & 87.0 & 42 & 66.0 & 41 & 39.0 & 41 \\
\hline
\end{tabular}

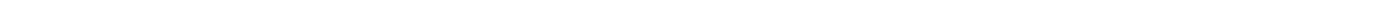

\begin{tabular}{|c|c|c|c|c|c|c|c|c|c|c|c|c|c|c|c|c|c|c|c|c|c|c|c|c|c|c|}
\hline YEAR & & & & & & & & & UABE & $\mathrm{R}$ OF & DAY & IS IN & $\alpha A$ & & & & & & & & & & & & & $\begin{array}{l}\text { PER SECOND } \\
\text {-DAYS }\end{array}$ \\
\hline $\begin{array}{l}1912 \\
1913 \\
1914 \\
1915\end{array}$ & 2 & 3 & 2 & 1 & $\begin{array}{r}575 \\
59 \\
312\end{array}$ & $\begin{array}{r}3 \\
89\end{array}$ & $\begin{array}{r}45 \\
68 \\
27 \\
103\end{array}$ & $\begin{array}{l}29 \\
25 \\
26 \\
58\end{array}$ & $\begin{array}{l}21 \\
23 \\
21 \\
13\end{array}$ & $\begin{array}{r}33 \\
46 \\
4 \\
32\end{array}$ & $\begin{array}{l}17 \\
17 \\
29 \\
23\end{array}$ & $\begin{array}{r}17 \\
6 \\
23 \\
18\end{array}$ & $\begin{array}{l}7 \\
10 \\
14 \\
11\end{array}$ & $\begin{array}{l}14 \\
13 \\
11 \\
19\end{array}$ & $\begin{array}{r}7 \\
14 \\
13 \\
11\end{array}$ & $\begin{array}{r}9 \\
6 \\
10 \\
9\end{array}$ & $\begin{array}{rrr}9 & 11 & 6 \\
5 & 11 & 14 \\
3 & 9 & 3 \\
7 & 12 & 11\end{array}$ & $\begin{array}{r}2 \\
14 \\
7 \\
6\end{array}$ & $\begin{array}{l}3 \\
61 \\
6 \\
6\end{array}$ & $\begin{array}{rr}9 & 13 \\
12 & 14 \\
6 & 7 \\
9 & 9\end{array}$ & 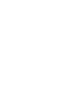 & $\begin{array}{r}5 \\
141 \\
3\end{array}$ & $\begin{array}{l}8 \\
1 \\
4 \\
1\end{array}$ & $\begin{array}{l}5 \\
1\end{array}$ & 1 & $\begin{array}{l}29674.0 \\
22634.0 \\
36526.0 \\
21965.0\end{array}$ \\
\hline $\begin{array}{l}1916 \\
1917 \\
1918 \\
1919 \\
1920\end{array}$ & & & & $\begin{array}{r}13 \\
1\end{array}$ & $\begin{array}{rr}1 & \\
43 & 74 \\
4 & 41\end{array}$ & $\begin{array}{r}1 \\
30\end{array}$ & $\begin{array}{l}50 \\
33 \\
99 \\
24 \\
71\end{array}$ & $\begin{array}{r}5 \\
4 \\
50 \\
22 \\
31\end{array}$ & $\begin{array}{l}29 \\
42 \\
24 \\
16 \\
22\end{array}$ & $\begin{array}{l}15 \\
77 \\
22 \\
25 \\
22\end{array}$ & $\begin{array}{r}6 \\
27 \\
16 \\
14 \\
9\end{array}$ & $\begin{array}{l}10 \\
30 \\
28 \\
19 \\
20\end{array}$ & $\begin{array}{l}14 \\
10 \\
18 \\
21 \\
26\end{array}$ & $\begin{array}{r}7 \\
21 \\
20 \\
12 \\
8\end{array}$ & $\begin{array}{r}19 \\
7 \\
16 \\
7 \\
9\end{array}$ & $\begin{array}{r}12 \\
6 \\
7 \\
7 \\
3\end{array}$ & $\begin{array}{rrr}7 & 9 & 10 \\
12 & 14 & 5 \\
6 & 4 & 10 \\
4 & 12 & 10 \\
5 & 12 & 6\end{array}$ & $\begin{array}{l}201 \\
11 \\
121 \\
10 \\
8\end{array}$ & $\begin{array}{r}101 \\
81 \\
11 \\
8 \\
4\end{array}$ & $\begin{array}{rr}13 & 11 \\
13 & 10 \\
9 & 7 \\
4 & 12 \\
4 & 5\end{array}$ & $\begin{array}{ll}1 & 6 \\
0 & 9 \\
7 & 4 \\
2 & 4 \\
5 & 3\end{array}$ & $\begin{array}{r}11 \\
6 \\
1 \\
2 \\
14\end{array}$ & $\begin{array}{l}812 \\
1 \\
61\end{array}$ & 2 & 1 & $\begin{array}{l}29639.0 \\
41606.0 \\
20991.0 \\
20635.0 \\
27087.0\end{array}$ \\
\hline $\begin{array}{l}1921 \\
1922 \\
1923\end{array}$ & & & & & $\begin{array}{l}2 \\
4\end{array}$ & & $\begin{array}{l}56 \\
27 \\
94\end{array}$ & $\begin{array}{r}60 \\
14 \\
5\end{array}$ & $\begin{array}{l}45 \\
16 \\
28\end{array}$ & $\begin{array}{l}28 \\
66 \\
35\end{array}$ & $\begin{array}{l}10 \\
76 \\
43\end{array}$ & $\begin{array}{r}18 \\
32 \\
6\end{array}$ & $\begin{array}{l}15 \\
26 \\
23\end{array}$ & $\begin{array}{l}14 \\
13 \\
13\end{array}$ & $\begin{array}{l}14 \\
14 \\
19\end{array}$ & $\begin{array}{r}8 \\
7 \\
16\end{array}$ & $\begin{array}{rrrr}4 & 12 & 13 \\
5 & 7 & 8 \\
5 & 9 & 10\end{array}$ & $\begin{array}{r}14 \\
4 \\
9\end{array}$ & & $\begin{array}{rr}5 & 6 \\
11 & 7 \\
13 & 12\end{array}$ & $\begin{array}{lr}6 & 12 \\
7 & 5 \\
2 & 8\end{array}$ & $\begin{array}{ll}5 \\
7 & 1 \\
7\end{array}$ & $\begin{array}{r}4 \\
3 \\
1\end{array}$ & 3 & 8 & $\begin{array}{l}37820.0 \\
31058.0 \\
28690.0\end{array}$ \\
\hline $\begin{array}{l}1948 \\
1949 \\
1950\end{array}$ & & & & & $\begin{array}{r}20 \\
76 \\
29 \quad 35\end{array}$ & $\begin{array}{r}7 \\
47 \\
6\end{array}$ & $\begin{array}{r}100 \\
31 \\
66\end{array}$ & $\begin{array}{l}88 \\
21 \\
49\end{array}$ & $\begin{array}{l}20 \\
18 \\
22\end{array}$ & $\begin{array}{l}11 \\
19 \\
28\end{array}$ & $\begin{array}{r}10 \\
3 \\
5\end{array}$ & $\begin{array}{r}11 \\
4 \\
2\end{array}$ & $\begin{array}{l}9 \\
5 \\
6\end{array}$ & $\begin{array}{r}8 \\
7 \\
14\end{array}$ & $\begin{array}{l}14 \\
16 \\
16\end{array}$ & $\begin{array}{l}14 \\
19 \\
19\end{array}$ & $\begin{array}{rrr}9 & 9 & 9 \\
12 & 7 & 12 \\
17 & 11 & 8\end{array}$ & $\begin{array}{r}5 \\
12 \\
14\end{array}$ & $\begin{array}{r}4 \\
101 \\
21\end{array}$ & $\begin{array}{rr}7 & 9 \\
12 & 11 \\
13 & 3\end{array}$ & $\begin{array}{c}9 \\
11 \\
3\end{array}$ & 8 & 4 & & & $\begin{array}{l}16913.6 \\
31463.9 \\
17782.8\end{array}$ \\
\hline
\end{tabular}


GREEN RIVER BASIN

09326500 FERRON CREEK (UPPER STATION) NEAR FERRON, UT--Continued

DURATION OF DISCHARGE FOR EAOH WATER YEAR---Continued

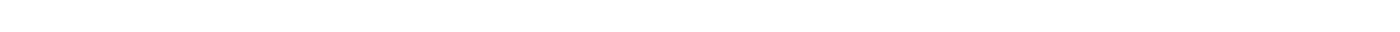
YEAR NUMBER OF DAYS IN CLASS OBIC FEET
PER SECOND -DAYS

\begin{tabular}{|c|c|c|c|c|c|c|c|c|c|c|c|c|c|c|c|c|c|c|c|c|c|c|c|c|c|c|c|c|c|c|}
\hline $\begin{array}{l}1951 \\
1952 \\
1953 \\
1954 \\
1955\end{array}$ & & & & & 4 & & $\begin{array}{r}1 \\
29\end{array}$ & $\begin{array}{r}64 \\
55 \\
3 \\
22 \\
71\end{array}$ & $\begin{array}{r}82 \\
59 \\
81 \\
122 \\
24\end{array}$ & $\begin{array}{l}23 \\
23 \\
53 \\
59 \\
26\end{array}$ & $\begin{array}{r}8 \\
8 \\
44 \\
12 \\
8\end{array}$ & $\begin{array}{r}13 \\
1 \\
23 \\
8 \\
10\end{array}$ & $\begin{array}{r}16 \\
2 \\
7 \\
7 \\
9\end{array}$ & $\begin{array}{r}27 \\
6 \\
18 \\
7 \\
4\end{array}$ & $\begin{array}{r}19 \\
14 \\
28 \\
19 \\
9\end{array}$ & $\begin{array}{r}14 \\
27 \\
21 \\
8 \\
10\end{array}$ & $\begin{array}{l}10 \\
13 \\
13 \\
36 \\
11\end{array}$ & $\begin{array}{r}11 \\
12 \\
9 \\
11 \\
14\end{array}$ & $\begin{array}{rr}9 & 15 \\
8 & 11 \\
8 & 11 \\
9 & 19 \\
19 & 15\end{array}$ & $\begin{array}{rl}7 & \\
12 & \\
11 & 1 \\
4 & 1 \\
17 & 1\end{array}$ & $\begin{array}{r}8 \\
6 \\
10 \\
10 \\
12\end{array}$ & $\begin{array}{l}71 \\
5 \\
5 \\
5 \\
4\end{array}$ & $\begin{array}{r}18 \\
9 \\
7 \\
2 \\
1\end{array}$ & $\begin{array}{l}4 \\
9 \\
9\end{array}$ & $\begin{array}{r}3 \\
18 \\
4\end{array}$ & $\begin{array}{c}3 \\
151\end{array}$ & 10 & 6 & 1 & $\begin{array}{l}21533.0 \\
48026.4 \\
20349.6 \\
14255.8 \\
14452.0\end{array}$ \\
\hline $\begin{array}{l}956 \\
957 \\
958 \\
959 \\
960\end{array}$ & & 1 & $\begin{array}{r}2 \\
4 \quad 14\end{array}$ & $\begin{array}{r}3 \\
24\end{array}$ & $\begin{array}{r}6 \\
65\end{array}$ & $\begin{array}{l}40 \\
23\end{array}$ & $\begin{array}{l}54 \\
19\end{array}$ & $\begin{array}{l}34 \\
13\end{array}$ & $\begin{array}{l}55 \\
35 \\
79 \\
64 \\
12\end{array}$ & $\begin{array}{r}12 \\
7 \\
38 \\
23 \\
26\end{array}$ & $\begin{array}{r}15 \\
4 \\
34 \\
11 \\
25\end{array}$ & $\begin{array}{r}16 \\
8 \\
36 \\
5 \\
10\end{array}$ & $\begin{array}{r}10 \\
3 \\
22 \\
9 \\
3\end{array}$ & $\begin{array}{r}8 \\
5 \\
8 \\
15 \\
17\end{array}$ & $\begin{array}{r}7 \\
21 \\
21 \\
17 \\
9\end{array}$ & $\begin{array}{r}5 \\
23 \\
10 \\
22 \\
9\end{array}$ & $\begin{array}{l}13 \\
15 \\
16 \\
18 \\
11\end{array}$ & $\begin{array}{r}11 \\
8 \\
10 \\
11 \\
20\end{array}$ & $\begin{array}{rr}11 & 20 \\
11 & 20 \\
5 & 15 \\
10 & 9 \\
13 & 9\end{array}$ & $\begin{array}{r}10 \\
5 \\
13 \\
14 \\
41\end{array}$ & $\begin{array}{r}6 \\
8 \\
3 \\
111\end{array}$ & $\begin{array}{ll}7 & 1 \\
4 \\
7 & 1 \\
10 & 1\end{array}$ & $\begin{array}{r}11 \\
4 \\
10 \\
10\end{array}$ & $\begin{array}{l}4 \\
5 \\
8 \\
\\
4\end{array}$ & $\begin{array}{l}2 \\
6 \\
5\end{array}$ & $\begin{array}{ll}7 & 1 \\
6 & 1\end{array}$ & $\begin{array}{l}13 \\
12\end{array}$ & $\begin{array}{l}6 \\
7\end{array}$ & & $\begin{array}{l}17445.0 \\
33313.2 \\
36377.0 \\
10630.8 \\
16507.8\end{array}$ \\
\hline $\begin{array}{l}961 \\
962 \\
963 \\
964 \\
965\end{array}$ & & & 48 & 35 & $\begin{array}{l}47 \\
13\end{array}$ & $\begin{array}{r}72 \\
8 \\
14 \\
93 \\
26\end{array}$ & $\begin{array}{l}17 \\
34 \\
22 \\
35\end{array}$ & $\begin{array}{r}15 \\
9 \\
9 \\
18 \\
6\end{array}$ & $\begin{array}{r}30 \\
57 \\
14 \\
47 \\
147\end{array}$ & $\begin{array}{r}17 \\
35 \\
36 \\
28 \\
9\end{array}$ & $\begin{array}{r}20 \\
31 \\
15 \\
15 \\
5\end{array}$ & $\begin{array}{r}23 \\
17 \\
17 \\
8 \\
1\end{array}$ & $\begin{array}{r}7 \\
6 \\
10 \\
7 \\
3\end{array}$ & $\begin{array}{r}10 \\
10 \\
8 \\
9 \\
10\end{array}$ & $\begin{array}{l}17 \\
19 \\
14 \\
10 \\
26\end{array}$ & $\begin{array}{r}17 \\
9 \\
13 \\
12 \\
15\end{array}$ & $\begin{array}{l}22 \\
13 \\
23 \\
17 \\
10\end{array}$ & $\begin{array}{l}15 \\
14 \\
19 \\
12 \\
17\end{array}$ & $\begin{array}{lr}6 & 9 \\
4 & 15 \\
8 & 7 \\
4 & 5 \\
2 & 12\end{array}$ & $\begin{array}{rl}12 & \\
6 & 1 \\
4 & 1 \\
6 & 1 \\
7 & \end{array}$ & $\begin{array}{l}5 \\
151 \\
12 \\
101 \\
91\end{array}$ & $\begin{array}{r}4 \\
14 \\
6 \\
10 \\
101\end{array}$ & $\begin{array}{rr}9 & 1 \\
6 & 1 \\
6 & 1 \\
11\end{array}$ & $\begin{array}{l}13 \\
11 \\
14 \\
7\end{array}$ & $\begin{array}{c}22 \\
1\end{array}$ & 5 & 7 & 1 & & $\begin{array}{l}11904.9 \\
32454.3 \\
17669.0 \\
17899.8 \\
33720.9\end{array}$ \\
\hline $\begin{array}{l}1966 \\
1967 \\
1968 \\
1969 \\
1970\end{array}$ & & & & & & & $\begin{array}{r}5 \\
35 \\
58\end{array}$ & $\begin{array}{r}25 \\
72 \\
76 \\
35 \\
4\end{array}$ & $\begin{array}{l}74 \\
74 \\
45 \\
28 \\
92\end{array}$ & $\begin{array}{l}25 \\
48 \\
31 \\
16 \\
74\end{array}$ & $\begin{array}{r}29 \\
13 \\
8 \\
23 \\
40\end{array}$ & $\begin{array}{l}42 \\
11 \\
21 \\
36 \\
23\end{array}$ & $\begin{array}{r}15 \\
18 \\
24 \\
13 \\
9\end{array}$ & $\begin{array}{r}20 \\
17 \\
16 \\
14 \\
9\end{array}$ & $\begin{array}{l}16 \\
12 \\
13 \\
19 \\
11\end{array}$ & $\begin{array}{r}31 \\
14 \\
5 \\
14 \\
9\end{array}$ & $\begin{array}{r}22 \\
16 \\
14 \\
13 \\
7\end{array}$ & $\begin{array}{r}20 \\
2 \\
14 \\
9 \\
7\end{array}$ & $\begin{array}{rr}11 & 8 \\
1 & 8 \\
9 & 10 \\
5 & 11 \\
11 & 14\end{array}$ & $\begin{array}{rl}111 & 1 \\
5 \\
5 \\
6 \\
7\end{array}$ & $\begin{array}{cl}11 \\
7 & 1 \\
5 \\
8 & 1 \\
3 & \end{array}$ & $\begin{array}{rl}4 & \\
13 & 1 \\
5 & \\
11 & 1 \\
5 & 1\end{array}$ & $\begin{array}{l}1 \\
19 \\
91 \\
10 \\
16\end{array}$ & $\begin{array}{r}8 \\
11 \\
7 \\
9\end{array}$ & $\begin{array}{r}5 \\
17 \\
11\end{array}$ & $\begin{array}{r}4 \\
11 \\
4\end{array}$ & 1 & & & $\begin{array}{l}15474.8 \\
19303.3 \\
21311.2 \\
30751.6 \\
24560.2\end{array}$ \\
\hline $\begin{array}{l}1971 \\
1972 \\
1973 \\
1974 \\
1975\end{array}$ & & & & & & 1 & 28 & $\begin{array}{r}4 \\
1 \\
33 \\
\\
45\end{array}$ & $\begin{array}{r}71 \\
122 \\
87 \\
139 \\
59\end{array}$ & $\begin{array}{l}28 \\
42 \\
31 \\
49 \\
49\end{array}$ & $\begin{array}{l}35 \\
26 \\
26 \\
39 \\
14\end{array}$ & $\begin{array}{l}18 \\
33 \\
19 \\
18 \\
20\end{array}$ & $\begin{array}{r}8 \\
18 \\
4 \\
10 \\
7\end{array}$ & $\begin{array}{l}11 \\
23 \\
19 \\
23 \\
18\end{array}$ & $\begin{array}{r}10 \\
16 \\
15 \\
5 \\
8\end{array}$ & $\begin{array}{r}20 \\
18 \\
8 \\
3 \\
6\end{array}$ & $\begin{array}{r}14 \\
9 \\
9 \\
9 \\
16\end{array}$ & $\begin{array}{r}20 \\
7 \\
7 \\
8 \\
6\end{array}$ & $\begin{array}{rr}15 & 13 \\
10 & 10 \\
9 & 3 \\
4 & 8 \\
3 & 7\end{array}$ & $\begin{array}{c}101 \\
101 \\
4 \\
7 \\
7\end{array}$ & $\begin{array}{l}101 \\
10 \\
7 \\
81 \\
5\end{array}$ & $\begin{array}{rl}12 & 1 \\
6 & \\
6 & 2 \\
13 & \\
7 & 1\end{array}$ & $\begin{array}{c}13 \\
5 \\
201 \\
8 \\
11\end{array}$ & $\begin{array}{r}7 \\
14 \\
8 \\
6\end{array}$ & $\begin{array}{r}9 \\
6 \\
13\end{array}$ & 6 & 6 & 5 & & $\begin{array}{l}21422.8 \\
14899.8 \\
26725.4 \\
19586.0 \\
31878.3\end{array}$ \\
\hline $\begin{array}{l}1976 \\
1977 \\
1978 \\
1979 \\
1980\end{array}$ & 1 & 1 & $\begin{array}{r}19 \\
5 \\
4\end{array}$ & $\begin{array}{r}17 \\
7 \\
9 \\
1\end{array}$ & $\begin{array}{r}1 \\
19 \\
28 \\
8\end{array}$ & $\begin{array}{l}22 \\
121 \\
36 \\
6\end{array}$ & $\begin{array}{c}30 \\
.01 \\
62 \\
28 \\
1\end{array}$ & $\begin{array}{r}5 \\
26 \\
22 \\
18 \\
23\end{array}$ & $\begin{array}{l}32 \\
22 \\
17 \\
53 \\
61\end{array}$ & $\begin{array}{r}55 \\
46 \\
6 \\
70 \\
82\end{array}$ & $\begin{array}{r}46 \\
18 \\
8 \\
26 \\
25\end{array}$ & $\begin{array}{l}33 \\
25 \\
28 \\
14 \\
18\end{array}$ & $\begin{array}{r}12 \\
8 \\
18 \\
6 \\
12\end{array}$ & $\begin{array}{r}18 \\
13 \\
15 \\
8 \\
10\end{array}$ & $\begin{array}{l}10 \\
28 \\
15 \\
16 \\
15\end{array}$ & $\begin{array}{r}5 \\
25 \\
11 \\
13 \\
8\end{array}$ & $\begin{array}{r}7 \\
7 \\
10 \\
5 \\
3\end{array}$ & $\begin{array}{r}5 \\
1 \\
9 \\
10 \\
9\end{array}$ & $\begin{array}{rr}8 & 11 \\
6 & 7 \\
3 & 12 \\
7 & 11\end{array}$ & $\begin{array}{r}5 \\
121 \\
81\end{array}$ & $\begin{array}{r}7 \\
10 \\
10\end{array}$ & $\begin{array}{l}8 \\
7 \\
8\end{array}$ & $\begin{array}{l}8 \\
7 \\
81\end{array}$ & $\begin{array}{r}6 \\
4 \\
11\end{array}$ & $\begin{array}{l}19 \\
16 \\
13\end{array}$ & $\begin{array}{c}1 \\
9 \\
111\end{array}$ & $\begin{array}{r}3 \\
12\end{array}$ & & & $\begin{array}{r}13145.0 \\
6411.5 \\
23077.7 \\
28493.1 \\
36394.4\end{array}$ \\
\hline 98 & & & & & & & 9 & 31 & 77 & 51 & 34 & 48 & 8 & 13 & 10 & 9 & 8 & 16 & 1213 & 5 & & & & & & & & & & 14358.7 \\
\hline
\end{tabular}

DURATION TABLE OF DISCHARGE FOR WATER YEARS 1912-23, 1948-81

\begin{tabular}{|c|c|c|c|c|c|c|c|c|c|c|c|c|c|c|c|c|c|c|c|}
\hline CLASS & $\begin{array}{c}\text { OBIC } \\
\text { FEET } \\
\text { PER } \\
\text { SECOND }\end{array}$ & $\begin{array}{l}\text { TOTAL } \\
\text { DAYS }\end{array}$ & $\begin{array}{l}\text { ACQU- } \\
\text { MU- } \\
\text { LATED } \\
\text { DAYS }\end{array}$ & $\begin{array}{l}\text { PER- } \\
\text { CENT } \\
\text { DAYS }\end{array}$ & CLASS & $\begin{array}{c}\text { वBBIC } \\
\text { FEET } \\
\text { PER } \\
\text { SECOND }\end{array}$ & $\begin{array}{l}\text { TOTAL } \\
\text { DAYS }\end{array}$ & $\begin{array}{c}\text { ACOU- } \\
\text { WU- } \\
\text { LATED } \\
\text { DAYS }\end{array}$ & $\begin{array}{l}\text { PER- } \\
\text { CENT } \\
\text { DAYS }\end{array}$ & & $\begin{array}{c}\text { OHBIC } \\
\text { FEET } \\
\text { PER } \\
\text { SECOND }\end{array}$ & $\begin{array}{l}\text { TOTAL } \\
\text { DAYS }\end{array}$ & $\begin{array}{l}\text { ACOU- } \\
\text { MU- } \\
\text { LATED } \\
\text { DAYS }\end{array}$ & $\begin{array}{l}\text { PER- } \\
\text { CENT } \\
\text { DAYS }\end{array}$ & & $\begin{array}{c}\text { बBIC } \\
\text { FEET } \\
\text { PER } \\
\text { SECOND }\end{array}$ & $\begin{array}{l}\text { TOTAL } \\
\text { DAYS }\end{array}$ & $\begin{array}{c}\text { ACOJ- } \\
\text { MU- } \\
\text { LATED } \\
\text { DAYS }\end{array}$ & $\begin{array}{l}\text { PER- } \\
\text { CENI } \\
\text { DAYS }\end{array}$ \\
\hline $\begin{array}{l}0 \\
1 \\
2 \\
3 \\
4 \\
5 \\
6 \\
7\end{array}$ & $\begin{array}{l}0.00 \\
1.00 \\
1.20 \\
1.50 \\
1.90 \\
2.30 \\
2.90 \\
3.60 \\
4.40\end{array}$ & $\begin{array}{r}0 \\
3 \\
0 \\
0 \\
5 \\
4 \\
94 \\
98\end{array}$ & $\begin{array}{l}16802 \\
16802 \\
16799 \\
16799 \\
16799 \\
16794 \\
16790 \\
16696 \\
16598\end{array}$ & $\begin{array}{r}100.0 \\
100.0 \\
100.0 \\
100.0 \\
100.0 \\
100.0 \\
99.9 \\
99.4\end{array}$ & $\begin{array}{l}9 \\
10 \\
11 \\
12 \\
13 \\
14 \\
15 \\
16\end{array}$ & $\begin{array}{r}5.40 \\
6.70 \\
8.30 \\
10.00 \\
13.00 \\
16.00 \\
19.00 \\
24.00 \\
29.00\end{array}$ & $\begin{array}{r}489 \\
1326 \\
1091 \\
2855 \\
1605 \\
1025 \\
1066 \\
616\end{array}$ & $\begin{array}{r}16388 \\
15899 \\
14573 \\
13482 \\
10627 \\
9022 \\
7997 \\
6931 \\
6315\end{array}$ & $\begin{array}{l}97.5 \\
94.6 \\
86.7 \\
80.2 \\
63.2 \\
53.7 \\
47.6 \\
41.3 \\
37.6\end{array}$ & $\begin{array}{l}18 \\
19 \\
20 \\
21 \\
22 \\
23 \\
24 \\
25\end{array}$ & $\begin{array}{r}36.0 \\
45.0 \\
55.0 \\
69.0 \\
85.0 \\
100.0 \\
130.0 \\
160.0\end{array}$ & $\begin{array}{l}684 \\
608 \\
606 \\
496 \\
351 \\
487 \\
374 \\
388 \\
333\end{array}$ & $\begin{array}{l}5662 \\
4978 \\
4370 \\
3764 \\
3268 \\
2917 \\
2430 \\
2056 \\
1668\end{array}$ & $\begin{array}{l}33.7 \\
29.6 \\
26.0 \\
22.4 \\
19.5 \\
17.4 \\
14.5 \\
12.2\end{array}$ & $\begin{array}{l}27 \\
28 \\
29 \\
30 \\
31 \\
32 \\
33 \\
34\end{array}$ & $\begin{array}{r}240.0 \\
300.0 \\
370.0 \\
460.0 \\
570.0 \\
700.0 \\
870.0 \\
1100.0\end{array}$ & $\begin{array}{r}380 \\
315 \\
271 \\
182 \\
125 \\
47 \\
14 \\
1\end{array}$ & $\begin{array}{r}1335 \\
955 \\
640 \\
369 \\
187 \\
62 \\
15 \\
1\end{array}$ & $\begin{array}{l}7.9 \\
5.7 \\
3.8 \\
2.2 \\
1.1 \\
0.4 \\
0.1 \\
0.0\end{array}$ \\
\hline
\end{tabular}


09326500 FERRON CREEK (UPPER STATION) NEAR FERRON, UT--Continued MONIHLY MEAN DISCHARGES, IN CUBIC FEET PER SECOND, FOR EACH WATER YEAR

\begin{tabular}{|c|c|c|c|c|c|c|c|c|c|c|c|c|}
\hline YEAR & $O C T$ & NOV & DEC & JAN & FEB & MAR & APR & MAY & JUNE & JULY & AUG & SEP \\
\hline $\begin{array}{l}1912 \\
1913 \\
1914 \\
1915\end{array}$ & $\begin{array}{l}14.4 \\
20.1 \\
13.4 \\
20.3\end{array}$ & $\begin{array}{l}18.3 \\
17.3 \\
11.0 \\
14.0\end{array}$ & $\begin{array}{c}11.7 \\
13.4 \\
9.00 \\
12.0\end{array}$ & $\begin{array}{r}8.00 \\
8.00 \\
9.00 \\
11.0\end{array}$ & $\begin{array}{r}7.00 \\
8.00 \\
8.71 \\
11.0\end{array}$ & $\begin{array}{l}9.94 \\
12.0 \\
14.6 \\
13.7\end{array}$ & $\begin{array}{l}21.8 \\
53.8 \\
51.0 \\
55.3\end{array}$ & $\begin{array}{l}238 \\
257 \\
469 \\
153\end{array}$ & $\begin{array}{l}468 \\
208 \\
393 \\
311\end{array}$ & $\begin{array}{c}116 \\
75.2 \\
137 \\
70.8\end{array}$ & $\begin{array}{l}40.7 \\
27.4 \\
51.9 \\
30.8\end{array}$ & $\begin{array}{l}20.7 \\
41.0 \\
26.7 \\
20.1\end{array}$ \\
\hline $\begin{array}{l}1916 \\
1917 \\
1918 \\
1919 \\
1920\end{array}$ & $\begin{array}{l}9.55 \\
70.2 \\
15.9 \\
15.9 \\
12.4\end{array}$ & $\begin{array}{c}9.00 \\
22.5 \\
13.6 \\
8.80 \\
12.5\end{array}$ & $\begin{array}{c}10.0 \\
20.1 \\
12.0 \\
7.00 \\
10.0\end{array}$ & $\begin{array}{c}9.32 \\
10.0 \\
11.0 \\
6.48 \\
7.00\end{array}$ & $\begin{array}{c}9.00 \\
16.0 \\
10.0 \\
8.00 \\
9.00\end{array}$ & $\begin{array}{c}17.5 \\
22.5 \\
19.9 \\
8.71 \\
12.1\end{array}$ & $\begin{array}{l}71.0 \\
91.9 \\
27.7 \\
81.7 \\
34.1\end{array}$ & $\begin{array}{l}215 \\
260 \\
173 \\
322 \\
335\end{array}$ & $\begin{array}{l}387 \\
598 \\
247 \\
117 \\
325\end{array}$ & $\begin{array}{l}112 \\
176 \\
69.4 \\
41.2 \\
70.8\end{array}$ & $\begin{array}{l}94.0 \\
47.9 \\
46.8 \\
34.2 \\
35.7\end{array}$ & $\begin{array}{l}29.6 \\
32.8 \\
42.2 \\
22.3 \\
23.0\end{array}$ \\
\hline $\begin{array}{l}1921 \\
1922 \\
1923\end{array}$ & $\begin{array}{l}15.4 \\
29.3 \\
23.4\end{array}$ & $\begin{array}{l}12.6 \\
20.8 \\
24.9\end{array}$ & $\begin{array}{l}11.0 \\
18.5 \\
13.0\end{array}$ & $\begin{array}{c}13.7 \\
9.74 \\
10.0\end{array}$ & $\begin{array}{l}16.7 \\
20.0 \\
10.0\end{array}$ & $\begin{array}{l}16.8 \\
25.6 \\
13.8\end{array}$ & $\begin{array}{l}31.7 \\
42.3 \\
22.9\end{array}$ & $\begin{array}{l}226 \\
339 \\
301\end{array}$ & $\begin{array}{l}639 \\
382 \\
296\end{array}$ & $\begin{array}{c}154 \\
61.0 \\
113\end{array}$ & $\begin{array}{l}71.0 \\
41.6 \\
67.8\end{array}$ & $\begin{array}{l}37.3 \\
29.9 \\
43.1\end{array}$ \\
\hline $\begin{array}{l}1948 \\
1949 \\
1950\end{array}$ & $\begin{array}{l}15.0 \\
12.5 \\
17.2\end{array}$ & $\begin{array}{c}14.0 \\
9.43 \\
12.0\end{array}$ & $\begin{array}{r}12.0 \\
8.52 \\
8.32\end{array}$ & $\begin{array}{c}10.0 \\
7.77 \\
6.68\end{array}$ & $\begin{array}{c}10.0 \\
7.00 \\
9.81\end{array}$ & $\begin{array}{l}9.93 \\
13.2 \\
12.1\end{array}$ & $\begin{array}{l}21.1 \\
94.5 \\
43.5\end{array}$ & $\begin{array}{l}191 \\
276 \\
165\end{array}$ & $\begin{array}{l}158 \\
412 \\
169\end{array}$ & $\begin{array}{c}69.3 \\
103 \\
84.5\end{array}$ & $\begin{array}{l}28.8 \\
66.5 \\
37.5\end{array}$ & $\begin{array}{l}13.8 \\
22.4 \\
16.9\end{array}$ \\
\hline $\begin{array}{l}1951 \\
1952 \\
1953 \\
1954 \\
1955\end{array}$ & $\begin{array}{l}12.0 \\
15.0 \\
25.3 \\
15.9 \\
10.0\end{array}$ & $\begin{array}{c}15.0 \\
9.35 \\
15.1 \\
11.6 \\
8.24\end{array}$ & $\begin{array}{c}11.3 \\
8.84 \\
13.3 \\
10.6 \\
8.50\end{array}$ & $\begin{array}{c}9.00 \\
8.13 \\
12.2 \\
10.4 \\
8.00\end{array}$ & $\begin{array}{c}9.50 \\
10.2 \\
12.5 \\
12.2 \\
8.25\end{array}$ & $\begin{array}{c}12.8 \\
14.1 \\
14.5 \\
12.4 \\
7.92\end{array}$ & $\begin{array}{c}33.3 \\
104 \\
25.0 \\
66.8 \\
18.6\end{array}$ & $\begin{array}{l}179 \\
486 \\
90.6 \\
164 \\
125\end{array}$ & $\begin{array}{c}250 \\
609 \\
283 \\
67.5 \\
140\end{array}$ & $\begin{array}{c}98.5 \\
184 \\
105 \\
57.7 \\
72.8\end{array}$ & $\begin{array}{l}46.1 \\
74.0 \\
41.3 \\
21.1 \\
50.9\end{array}$ & $\begin{array}{l}29.9 \\
51.0 \\
30.8 \\
16.2 \\
14.9\end{array}$ \\
\hline $\begin{array}{l}1956 \\
1957 \\
1958 \\
1959 \\
1960\end{array}$ & $\begin{array}{c}9.94 \\
11.4 \\
34.1 \\
12.5 \\
7.59\end{array}$ & $\begin{array}{c}6.53 \\
8.02 \\
20.6 \\
10.1 \\
6.62\end{array}$ & $\begin{array}{c}7.61 \\
7.00 \\
14.4 \\
7.48 \\
4.40\end{array}$ & $\begin{array}{c}6.64 \\
7.00 \\
12.0 \\
5.95 \\
3.53\end{array}$ & $\begin{array}{c}7.21 \\
7.99 \\
12.3 \\
7.79 \\
4.91\end{array}$ & $\begin{array}{c}14.4 \\
9.16 \\
14.7 \\
8.93 \\
14.7\end{array}$ & $\begin{array}{l}35.6 \\
22.8 \\
61.5 \\
31.7 \\
43.9\end{array}$ & $\begin{array}{c}202 \\
115 \\
443 \\
89.8 \\
167\end{array}$ & $\begin{array}{c}160 \\
591 \\
407 \\
92.2 \\
178\end{array}$ & $\begin{array}{l}84.8 \\
208 \\
102 \\
50.6 \\
75.7\end{array}$ & $\begin{array}{l}22.9 \\
65.1 \\
48.1 \\
19.8 \\
19.4\end{array}$ & $\begin{array}{l}12.2 \\
43.8 \\
21.1 \\
11.4 \\
15.2\end{array}$ \\
\hline $\begin{array}{l}1961 \\
1962 \\
1963 \\
1964 \\
1965\end{array}$ & $\begin{array}{l}13.3 \\
16.9 \\
17.3 \\
11.2 \\
11.3\end{array}$ & $\begin{array}{c}8.09 \\
14.8 \\
7.96 \\
9.38 \\
11.1\end{array}$ & $\begin{array}{c}5.79 \\
10.8 \\
4.27 \\
6.02 \\
10.0\end{array}$ & $\begin{array}{r}5.05 \\
9.35 \\
3.00 \\
5.95 \\
10.0\end{array}$ & $\begin{array}{c}5.50 \\
11.4 \\
5.50 \\
6.50 \\
10.0\end{array}$ & $\begin{array}{c}8.68 \\
16.0 \\
8.21 \\
8.22 \\
8.37\end{array}$ & $\begin{array}{c}20.7 \\
119 \\
16.2 \\
16.1 \\
34.9\end{array}$ & $\begin{array}{l}119 \\
287 \\
184 \\
164 \\
157\end{array}$ & $\begin{array}{l}90.8 \\
376 \\
187 \\
221 \\
494\end{array}$ & $\begin{array}{c}56.3 \\
126 \\
65.9 \\
76.2 \\
250\end{array}$ & $\begin{array}{l}34.3 \\
54.7 \\
50.5 \\
44.8 \\
72.6\end{array}$ & $\begin{array}{l}21.6 \\
22.8 \\
28.2 \\
16.9 \\
37.8\end{array}$ \\
\hline $\begin{array}{l}1966 \\
1967 \\
1968 \\
1969 \\
1970\end{array}$ & $\begin{array}{l}33.2 \\
11.7 \\
14.5 \\
19.3 \\
16.3\end{array}$ & $\begin{array}{c}18.4 \\
9.44 \\
10.0 \\
12.5 \\
14.4\end{array}$ & $\begin{array}{c}16.0 \\
11.3 \\
8.79 \\
8.52 \\
10.6\end{array}$ & $\begin{array}{c}10.8 \\
8.50 \\
8.15 \\
7.24 \\
11.9\end{array}$ & $\begin{array}{c}11.0 \\
10.3 \\
9.31 \\
8.29 \\
12.3\end{array}$ & $\begin{array}{l}25.2 \\
13.7 \\
10.3 \\
14.5 \\
11.2\end{array}$ & $\begin{array}{l}65.0 \\
13.7 \\
16.9 \\
53.0 \\
19.2\end{array}$ & $\begin{array}{l}169 \\
136 \\
142 \\
407 \\
240\end{array}$ & $\begin{array}{l}69.2 \\
248 \\
321 \\
292 \\
302\end{array}$ & $\begin{array}{c}51.5 \\
101 \\
93.5 \\
106 \\
103\end{array}$ & $\begin{array}{l}25.6 \\
43.2 \\
39.6 \\
52.3 \\
44.2\end{array}$ & $\begin{array}{l}10.3 \\
26.8 \\
26.1 \\
24.7 \\
20.4\end{array}$ \\
\hline $\begin{array}{l}1971 \\
1972 \\
1973 \\
1974 \\
1975\end{array}$ & $\begin{array}{l}17.2 \\
15.5 \\
17.6 \\
15.0 \\
15.0\end{array}$ & $\begin{array}{l}12.9 \\
12.9 \\
11.9 \\
12.3 \\
11.8\end{array}$ & $\begin{array}{c}8.77 \\
12.0 \\
11.0 \\
10.0 \\
9.94\end{array}$ & $\begin{array}{c}7.13 \\
12.0 \\
9.00 \\
10.0 \\
8.54\end{array}$ & $\begin{array}{c}10.7 \\
12.0 \\
8.21 \\
10.2 \\
8.36\end{array}$ & $\begin{array}{l}18.1 \\
21.4 \\
11.4 \\
12.1 \\
10.3\end{array}$ & $\begin{array}{l}51.6 \\
38.8 \\
35.1 \\
23.0 \\
16.7\end{array}$ & $\begin{array}{l}147 \\
145 \\
293 \\
223 \\
155\end{array}$ & $\begin{array}{l}261 \\
138 \\
312 \\
221 \\
530\end{array}$ & $\begin{array}{c}93.2 \\
40.7 \\
112 \\
63.6 \\
202\end{array}$ & $\begin{array}{l}56.6 \\
21.1 \\
35.1 \\
25.4 \\
54.1\end{array}$ & $\begin{array}{l}18.9 \\
19.3 \\
18.5 \\
16.1 \\
26.6\end{array}$ \\
\hline $\begin{array}{l}1976 \\
1977 \\
1978 \\
1979 \\
1980\end{array}$ & $\begin{array}{c}19.4 \\
12.2 \\
8.68 \\
14.3 \\
14.0\end{array}$ & $\begin{array}{c}16.6 \\
15.5 \\
8.05 \\
12.8 \\
14.0\end{array}$ & $\begin{array}{c}12.0 \\
7.97 \\
7.14 \\
10.3 \\
11.5\end{array}$ & $\begin{array}{c}7.74 \\
7.00 \\
5.27 \\
7.32 \\
11.8\end{array}$ & $\begin{array}{c}4.83 \\
6.32 \\
4.61 \\
8.82 \\
13.8\end{array}$ & $\begin{array}{c}5.94 \\
5.02 \\
10.4 \\
12.5 \\
13.4\end{array}$ & $\begin{array}{l}25.6 \\
29.6 \\
27.0 \\
49.9 \\
61.1\end{array}$ & $\begin{array}{c}164 \\
44.8 \\
128 \\
287 \\
272\end{array}$ & $\begin{array}{l}115 \\
40.3 \\
384 \\
373 \\
541\end{array}$ & $\begin{array}{l}32.5 \\
17.2 \\
116 \\
103 \\
173\end{array}$ & $\begin{array}{l}14.7 \\
12.0 \\
39.0 \\
37.9 \\
41.2\end{array}$ & $\begin{array}{l}11.5 \\
12.8 \\
20.2 \\
18.5 \\
29.4\end{array}$ \\
\hline 1981 & 20.9 & 14.7 & 12.2 & 9.58 & 9.64 & 11.0 & 56.1 & 126 & 130 & 29.6 & 19.4 & 32.8 \\
\hline
\end{tabular}

ANNUAL PEAK DISCHARGE, IN CUBIC FEET PER SECOND, AND CORRESPONDING GAGE HEIGHT, IN FEET, FOR EACH WATER YEAR

\begin{tabular}{|c|c|c|c|c|c|c|c|c|c|c|c|}
\hline $\begin{array}{l}\text { WATER } \\
\text { YEAR }\end{array}$ & DATE & $\begin{array}{c}\text { GAGE } \\
\text { HEIGHT }\end{array}$ & $\begin{array}{c}\text { PEAK } \\
\text { DISCHARGE }\end{array}$ & $\begin{array}{l}\text { WATER } \\
\text { YEAR }\end{array}$ & DATE & $\begin{array}{c}\text { GAGE } \\
\text { HEIGHT }\end{array}$ & $\begin{array}{c}\text { PEAK } \\
\text { DISCHARGE }\end{array}$ & $\begin{array}{l}\text { WATER } \\
\text { YEAR }\end{array}$ & DATE & $\begin{array}{c}\text { GAGE } \\
\text { HEIGHT }\end{array}$ & $\begin{array}{c}\text { PEAK } \\
\text { DISCHARGE }\end{array}$ \\
\hline $\begin{array}{l}1912 \\
1913 \\
1914 \\
1915 \\
1916 \\
1917 \\
1918 \\
1919 \\
1920 \\
1921 \\
1922 \\
1923 \\
1948 \\
1949 \\
1950 \\
1951\end{array}$ & $\begin{array}{l}\text { JUNE } 03,1912 \\
\text { SEPT.07, } 1913 \\
\text { JULY } 28,1914 \\
\text { JUNE 01, } 1915 \\
\text { JUNE 05, } 1916 \\
\text { JUNE } 17,1917 \\
\text { JUNE 08, } 1918 \\
\text { AUG. 02, } 1919 \\
\text { JULY 25, } 1920 \\
\text { JUNE 09, } 1921 \\
\text { AUG. 22, } 1922 \\
\text { AUG. 11, } 1923 \\
\text { AUG. 04, } 1948 \\
\text { SEPT. 28, } 1949 \\
\text { JULY 07, } 1950 \\
\text { AUG. 03, } 1951\end{array}$ & $\begin{array}{r}5.40 \\
7.01 \\
7.50 \\
4.05 \\
3.00 \\
6.30 \\
4.00 \\
6.80 \\
10.00 \\
6.60 \\
6.00 \\
4.00 \\
5.70 \\
5.98 \\
4.13 \\
6.82\end{array}$ & $\begin{array}{r}976 \\
1490 \\
1710 \\
640 \\
561 \\
980 \\
510 \\
900 \\
2100 \\
1300 \\
1110 \\
698 \\
1300 \\
1240 \\
561 \\
1520\end{array}$ & $\begin{array}{l}1952 \\
1953 \\
1954 \\
1955 \\
1956 \\
1957 \\
1958 \\
1959 \\
1960 \\
1961 \\
1962 \\
1963 \\
1964 \\
1965 \\
1966\end{array}$ & $\begin{array}{l}\text { AUG. } 27,1952 \\
\text { JULY } 31,1953 \\
\text { ALU. } 13,1954 \\
\text { AUG. } 05,1955 \\
\text { JULY } 29,1956 \\
\text { JUNE } 07,1957 \\
\text { MAY } 27,1958 \\
\text { ALG. } 04,1959 \\
\text { JULY } 30,1960 \\
\text { AUG. } 03,1961 \\
\text { MAY } 06,1962 \\
\text { AUG. } 10,1963 \\
\text { JULY } 31,1964 \\
\text { JULY } 31,1965 \\
\text { JULY } 17,1966\end{array}$ & $\begin{array}{l}9.71 \\
8.70 \\
4.85 \\
5.70 \\
5.02 \\
5.14 \\
4.85 \\
2.48 \\
4.81 \\
5.20 \\
4.32 \\
5.32 \\
5.08 \\
7.80 \\
7.03\end{array}$ & $\begin{array}{r}4180 \\
3180 \\
1020 \\
1160 \\
884 \\
1000 \\
1040 \\
214 \\
946 \\
1020 \\
629 \\
1090 \\
947 \\
2100 \\
1820\end{array}$ & $\begin{array}{l}1967 \\
1968 \\
1969 \\
1970 \\
1971 \\
1972 \\
1973 \\
1974 \\
1975 \\
1976 \\
1977 \\
1978 \\
1979 \\
1980 \\
1981\end{array}$ & $\begin{array}{lll}\text { MAY } 24, & 1967 \\
\text { JUNE } 03,1968 \\
\text { MAY } 07,1969 \\
\text { JULY } 17,1970 \\
\text { AUG. } 25,1971 \\
\text { MAY } 28,1972 \\
\text { JULY } 13,1973 \\
\text { JULY } 17,1974 \\
\text { JUNE } 06,1975 \\
\text { MAY } 28,1976 \\
\text { SEPT. I1, I977 } \\
\text { JUNE 21, } 1978 \\
\text { MAY } 28,1979 \\
\text { JUNE } 18,1980 \\
\text { AUG. } 15,1981\end{array}$ & $\begin{array}{l}3.18 \\
3.73 \\
4.15 \\
3.60 \\
3.31 \\
2.78 \\
8.80 \\
4.70 \\
5.00 \\
2.37 \\
3.54 \\
3.91 \\
5.39 \\
5.44 \\
3.97\end{array}$ & $\begin{array}{r}464 \\
620 \\
770 \\
683 \\
498 \\
355 \\
3040 \\
828 \\
1060 \\
278 \\
452 \\
525 \\
836 \\
858 \\
348\end{array}$ \\
\hline
\end{tabular}


GREEN RIVER BASIN

09326500 FERRON CREEK (UPPER STATION) NEAR FERRON, UT--Continued

\begin{tabular}{|c|c|c|c|c|c|c|}
\hline \multirow{2}{*}{$\begin{array}{l}\text { PERICD } \\
\text { (OON- } \\
\text { SEOU- } \\
\text { TIVE } \\
\text { DAYS) }\end{array}$} & \multicolumn{6}{|c|}{$\begin{array}{l}\text { DISCHARGE, IN OIBIC FEET PER SECOND, FOR } \\
\text { INDICATFD RECURRENCE INTERNAL, IN YEARS, AND } \\
\text { ANNUAL NONEXCEEDANCE PRCBABILITY, IN PERCENT }\end{array}$} \\
\hline & $\begin{array}{c}2 \\
50 \%\end{array}$ & $\begin{array}{c}5 \\
20 \%\end{array}$ & $\begin{array}{l}10 \\
10 \%\end{array}$ & $\begin{array}{l}20 \\
58\end{array}$ & $\begin{array}{l}50 \\
28\end{array}$ & $\begin{array}{r}100 \\
18\end{array}$ \\
\hline $\begin{array}{r}1 \\
7 \\
14 \\
30 \\
60 \\
90\end{array}$ & $\begin{array}{l}6.5 \\
7.3 \\
7.7 \\
8.1 \\
8.6 \\
9.0\end{array}$ & $\begin{array}{l}4.2 \\
5.2 \\
5.5 \\
5.9 \\
6.5 \\
6.9\end{array}$ & $\begin{array}{l}3.1 \\
4.2 \\
4.5 \\
4.8 \\
5.4 \\
5.9\end{array}$ & $\begin{array}{l}2.3 \\
3.4 \\
3.7 \\
4.0 \\
4.7 \\
5.1\end{array}$ & $\begin{array}{l}1.6 \\
2.7 \\
2.9 \\
3.2 \\
3.9 \\
4.3\end{array}$ & $\begin{array}{l}1.2 \\
2.2 \\
2.4 \\
2.7 \\
3.4 \\
3.8\end{array}$ \\
\hline
\end{tabular}

09327500 FERRON CREEK NEAR CASTLE DALE, UT

LOCATION.--Lat $39^{\circ} 06^{\prime} 20^{\prime \prime}$, long $111^{\circ} 01^{\prime} 25^{\prime \prime}$, in SE $\mathrm{E}_{4}^{\mathrm{l}}$ sec.4, T.20 S., R.8 E., Emery County, Hydrologic Unit 14060009 , on left bank 6 mi east of Ferron and $7 \mathrm{mi}$ south of Castle Dale.

DRAINAGE AREA. $--210 \mathrm{mi}^{2}$, approximately.

PERICD OF RECORD AVAIIABLE.--June 1911 to September 1914 and December 1947 to September 1958 (monthly mean discharge prior to October 1911 and for December 1947 to September 1948 published in WSP 1313).

GAGE.--Water-stage recorder. Altitude of gage is 5,550 ft from topographic map. June 9, 1911, to Sept. 30, 1914, staff gage at site $1.5 \mathrm{mi}$ downstream at different datum.

REMARKS.--Flow slightly regulated by small reservoir in mountains (capacity unknown). Many diversions for irrigation above station.

AVERAGE DISCHARGE.--13 years (water years 1912-14, 1949-58), $35.6 \mathrm{ft}^{3} / \mathrm{s}, 25,770 \mathrm{acre}-\mathrm{ft} / \mathrm{yr}$.

EXTREMES FOR PERIOD OF RECORD.--Maximum discharge, 1,630 ft $\mathrm{ft}^{3} / \mathrm{s}$ Aug. 3, 1951, gage neight, $6.52 \mathrm{ft}$, fram rating curve extended above $650 \mathrm{ft}^{3} / \mathrm{s}$ on basis of slope-area measurements at gage heights $3.90 \mathrm{ft}$ and $6.52 \mathrm{ft}$; no flow tor several days in september and October 1955.

LOWEST MEAN DISCHARGE, IN OBBIC FEET PER SECOND, AND RANKING FOR THE INDICATED NUMBER OF CONSECITIVE DAYS FOR EACH CIIMATIC YEAR, APRIL 1-MARCH 31

YEAR

\begin{tabular}{rrrlrlrr} 
& 1 & \multicolumn{1}{c}{3} & 7 & \\
1913 & 0.00 & 1 & 0.00 & 1 & 0.00 & 1 \\
1914 & 0.00 & 2 & 0.00 & 2 & 0.64 & 5 \\
1949 & 0.60 & 8 & 0.63 & 7 & 0.86 & 7 \\
1950 & 2.50 & 10 & 2.60 & 10 & 3.60 & 10 \\
1951 & 0.10 & 4 & 0.10 & 4 & 0.10 & 3 \\
1952 & 0.50 & 7 & 1.10 & 9 & 1.10 & 9 \\
1953 & 8.30 & 12 & 8.50 & 12 & 9.50 & 12 \\
1954 & 0.20 & 6 & 0.33 & 5 & 0.77 & 6 \\
1955 & 0.70 & 9 & 0.87 & 8 & 0.94 & 8 \\
1956 & 0.00 & 3 & 0.00 & 3 & 0.00 & 2 \\
1957 & 0.12 & 5 & 0.43 & 6 & 0.53 & 4 \\
1958 & 2.80 & 11 & 3.10 & 11 & 4.60 & 11
\end{tabular}

HIGHEST MEAN DISCHARGE, IN OBBIC FEET PER SECOND, AND RANRING FOR THE INDICATED NUMBER OF CONSBCUTIVE DAYS FOR EACH WATER YEAR, OCTOBER 1-SEPTEMBER 30

\begin{tabular}{|c|c|c|c|c|c|c|c|c|c|c|c|c|c|c|c|c|c|c|c|c|}
\hline YEAR & 1 & & 3 & & 7 & & 15 & & $\begin{array}{l}\text { CONS } \\
30\end{array}$ & & $\begin{array}{l}\text { E DAYS } \\
60\end{array}$ & & 90 & & 120 & & 183 & & ALL & \\
\hline $\begin{array}{l}945 \\
950\end{array}$ & $\begin{array}{l}420 \\
168\end{array}$ & $\begin{array}{r}7 \\
10\end{array}$ & & $\begin{array}{r}6 \\
10\end{array}$ & $\begin{array}{l}352 \\
124\end{array}$ & $\begin{array}{r}6 \\
11\end{array}$ & & $\begin{array}{r}6 \\
11\end{array}$ & $\begin{array}{l}243 \\
71.0\end{array}$ & $\begin{array}{r}6 \\
11\end{array}$ & $\begin{array}{r}182 \\
47.0\end{array}$ & $\begin{array}{r}6 \\
10\end{array}$ & $\begin{array}{r}144 \\
36.0\end{array}$ & $\begin{array}{r}6 \\
10\end{array}$ & $\begin{array}{l}113 \\
31.0\end{array}$ & $\begin{array}{r}6 \\
10\end{array}$ & & $\begin{array}{r}6 \\
10\end{array}$ & & $\begin{array}{r}6 \\
10\end{array}$ \\
\hline
\end{tabular}


HIGHEST MEAN DISCHARGE, IN OUBIC FEET PER SBCOND, AND RANKING FOR THE INDICATED NUMBER OF CONSECUTIVE DAYS FOR EACH WATER YEAR, OCTOBER 1-SEPTEMBER 30-Continued

\begin{tabular}{|c|c|c|c|c|c|c|c|c|c|c|c|c|c|c|c|c|c|c|}
\hline YEAR & & 3 & & 7 & & 15 & & $\begin{array}{l}\text { CONS } \\
30\end{array}$ & EOUT & $\begin{array}{c}\text { VE DAYS } \\
60\end{array}$ & & 90 & & 120 & & 183 & & ALL \\
\hline $\begin{array}{l}154 \\
526 \\
563\end{array}$ & $\begin{array}{r}11 \\
5 \\
4\end{array}$ & $\begin{array}{l}141 \\
476 \\
553\end{array}$ & $\begin{array}{r}11 \\
5 \\
3\end{array}$ & $\begin{array}{l}129 \\
472 \\
525\end{array}$ & $\begin{array}{r}10 \\
5 \\
3\end{array}$ & $\begin{array}{l}109 \\
403 \\
501\end{array}$ & $\begin{array}{r}10 \\
5 \\
2\end{array}$ & $\begin{array}{l}72.0 \\
361 \\
403\end{array}$ & $\begin{array}{r}10 \\
4 \\
3\end{array}$ & $\begin{array}{l}39.0 \\
225 \\
260\end{array}$ & $\begin{array}{r}11 \\
4 \\
3\end{array}$ & $\begin{array}{l}28.0 \\
161 \\
195\end{array}$ & $\begin{array}{r}11 \\
4 \\
3\end{array}$ & $\begin{array}{l}22.0 \\
126 \\
150\end{array}$ & $\begin{array}{r}11 \\
4 \\
3\end{array}$ & $\begin{array}{r}16.0 \\
86.0 \\
103\end{array}$ & $\begin{array}{r}11 \\
4 \\
3\end{array}$ & $\begin{array}{cc}9.50 & 12 \\
46.0 & 4 \\
58.0 & 3\end{array}$ \\
\hline
\end{tabular}

DURATION OF DISCHARGE FOR EACH WATER YEAR

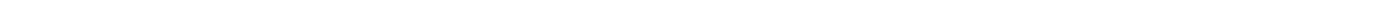

\begin{tabular}{|c|c|c|c|c|c|c|c|c|c|c|c|c|c|c|c|c|c|c|c|c|c|c|c|c|c|c|c|c|c|c|c|c|}
\hline YEAR & & & & & & & & & & & & UMBE & $\mathrm{R} O F$ & F DAYS & IS IN & J $\triangle A$ & ASS & & & & & & & & & & & & & & & $\begin{array}{l}\text { ER SECOND } \\
\text {-DAYS }\end{array}$ \\
\hline $\begin{array}{rr}1912 & 19 \\
1913 & 8 \\
1914 & \end{array}$ & & & & $\begin{array}{l}2 \\
1\end{array}$ & & & $\begin{array}{r}13 \\
18\end{array}$ & & $\begin{array}{l}8 \\
6\end{array}$ & & 1 & $\begin{array}{r}6 \\
10 \\
11\end{array}$ & $\begin{array}{r}87 \\
7 \\
44\end{array}$ & $\begin{array}{l}15 \\
341 \\
14\end{array}$ & $\begin{array}{r}43 \\
107 \\
50\end{array}$ & $\begin{array}{l}16 \\
41 \\
92\end{array}$ & $\begin{array}{l}41 \\
46 \\
36\end{array}$ & $\begin{array}{r}28 \\
9 \\
17\end{array}$ & $\begin{array}{r}8 \\
13 \\
16\end{array}$ & $\begin{array}{l}2 \\
2 \\
6\end{array}$ & $\begin{array}{rl}5 & \\
9 & 1 \\
16 & 1\end{array}$ & $\begin{array}{l}3 \\
101 \\
12\end{array}$ & $\begin{array}{r}8 \\
15\end{array}$ & $\begin{array}{rr}6 & 9 \\
5 & 13 \\
2 & 2\end{array}$ & $\begin{array}{ll}9 & 1 \\
3 & 6 \\
2 & 7\end{array}$ & $\begin{array}{r}7 \\
2 \\
10\end{array}$ & $\begin{array}{r}10 \\
2 \\
81\end{array}$ & $\begin{array}{r}7 \\
1 \\
11\end{array}$ & $\begin{array}{l}2 \\
5\end{array}$ & 6 & & $\begin{array}{l}15914.4 \\
10684.5 \\
25108.0\end{array}$ \\
\hline $\begin{array}{l}949 \\
950\end{array}$ & 8 & 9 & 1 & 1 & & 1 & 1 & $\begin{array}{l}1 \\
5\end{array}$ & $\begin{array}{r}2 \\
15\end{array}$ & $\begin{array}{l}13 \\
11\end{array}$ & $\begin{array}{r}9 \\
10\end{array}$ & $\begin{array}{r}17 \\
4\end{array}$ & $\begin{array}{r}90 \\
8\end{array}$ & $\begin{array}{l}43 \\
621\end{array}$ & $\begin{array}{r}26 \\
134\end{array}$ & $\begin{array}{l}18 \\
17\end{array}$ & $\begin{array}{l}26 \\
18\end{array}$ & $\begin{array}{l}18 \\
10\end{array}$ & $\begin{array}{r}9 \\
19\end{array}$ & $\begin{array}{l}12 \\
10\end{array}$ & $\begin{array}{r}11 \\
3\end{array}$ & $\begin{array}{l}7 \\
2\end{array}$ & $\begin{array}{l}9 \\
8\end{array}$ & $\begin{array}{lr}5 & 20 \\
5 & 3\end{array}$ & 14 & 7 & 7 & 1 & & & & $\begin{array}{r}15566.3 \\
5455.9\end{array}$ \\
\hline $\begin{array}{l}1951 \\
1952 \\
1953 \\
1954 \\
1955 \quad 27\end{array}$ & 16 & $\begin{array}{r}1 \\
12\end{array}$ & 5 & $\begin{array}{l}3 \\
7\end{array}$ & 3 & $\begin{array}{r}121 \\
4\end{array}$ & $\begin{array}{c}6 \\
102 \\
3\end{array}$ & $\begin{array}{r}5 \\
4 \\
21 \\
6\end{array}$ & $\begin{array}{r}9 \\
2 \\
24 \\
4\end{array}$ & $\begin{array}{r}13 \\
3 \\
17 \\
18\end{array}$ & $\begin{array}{r}19 \\
3 \\
19 \\
23\end{array}$ & $\begin{array}{r}19 \\
2 \\
14 \\
7 \\
29\end{array}$ & $\begin{array}{l}97 \\
10 \\
28 \\
11 \\
27\end{array}$ & $\begin{array}{r}79 \\
15 \\
21 \\
27 \\
117\end{array}$ & $\begin{array}{l}46 \\
23 \\
31 \\
34 \\
26\end{array}$ & $\begin{array}{r}13 \\
105 \\
138 \\
123 \\
16\end{array}$ & $\begin{array}{r}7 \\
65 \\
61 \\
19 \\
10\end{array}$ & $\begin{array}{r}4 \\
26 \\
7 \\
15 \\
6\end{array}$ & $\begin{array}{r}2 \\
13 \\
10 \\
7 \\
1\end{array}$ & $\begin{array}{r}3 \\
14 \\
9 \\
15 \\
2\end{array}$ & $\begin{array}{r}10 \\
4 \\
6 \\
3\end{array}$ & $\begin{array}{l}6 \\
8 \\
3 \\
1 \\
2\end{array}$ & $\begin{array}{l}5 \\
3 \\
6 \\
1\end{array}$ & $\begin{array}{ll}2 & 8 \\
7 & 6 \\
5 & 4\end{array}$ & $\begin{array}{rr}8 & 4 \\
5 & 10 \\
4 & 2\end{array}$ & $\begin{array}{c}3 \\
12 \\
3\end{array}$ & $\begin{array}{c}4 \\
191 \\
1\end{array}$ & 12 & 5 & 6 & 1 & $\begin{array}{r}8110.6 \\
32817.6 \\
7717.3 \\
3824.9 \\
2310.0\end{array}$ \\
\hline $\begin{array}{ll}195610 \\
1957 \\
1958\end{array}$ & 8 & 1 & 4 & 6 & & 192 & $\begin{array}{r}23 \\
5\end{array}$ & $\begin{array}{r}24 \\
8\end{array}$ & $\begin{array}{r}25 \\
9\end{array}$ & $\begin{array}{r}19 \\
7\end{array}$ & $\begin{array}{l}19 \\
12 \\
17\end{array}$ & $\begin{array}{l}45 \\
31 \\
11\end{array}$ & $\begin{array}{l}79 \\
23 \\
34\end{array}$ & $\begin{array}{r}20 \\
98 \\
6\end{array}$ & $\begin{array}{l}15 \\
23 \\
12\end{array}$ & $\begin{array}{r}5 \\
24 \\
35\end{array}$ & $\begin{array}{r}4 \\
26 \\
154\end{array}$ & $\begin{array}{r}8 \\
9 \\
15\end{array}$ & $\begin{array}{r}2 \\
12 \\
3\end{array}$ & $\begin{array}{l}4 \\
7 \\
3\end{array}$ & $\begin{array}{r}141 \\
8\end{array}$ & $\begin{array}{r}2 \\
14 \\
5\end{array}$ & $\begin{array}{l}6 \\
3 \\
6\end{array}$ & $\begin{array}{rr}8 & 2 \\
4 & 3 \\
9 & 10\end{array}$ & $\begin{array}{r}5 \\
10\end{array}$ & $\begin{array}{l}6 \\
3\end{array}$ & $\begin{array}{r}14 \\
71\end{array}$ & $\begin{array}{r}8 \\
11\end{array}$ & 6 & & & $\begin{array}{r}3471.7 \\
16862.8 \\
21021.1\end{array}$ \\
\hline
\end{tabular}

DURATION TABLE OF DISCHARGE FOR WATER YEARS 1912-14, 1949-58

\begin{tabular}{|c|c|c|c|c|c|c|c|c|c|c|c|c|c|c|c|c|c|c|c|}
\hline ASS & $\begin{array}{c}\text { CUBIC } \\
\text { FEET } \\
\text { PER } \\
\text { SECOND }\end{array}$ & $\begin{array}{r}\text { TOTAL } \\
\text { DAYS }\end{array}$ & $\begin{array}{l}\text { ACOU- } \\
\text { MU- } \\
\text { LATED } \\
\text { DAYS }\end{array}$ & $\begin{array}{l}\text { PER- } \\
\text { CENT } \\
\text { DAYS }\end{array}$ & CLASS & $\begin{array}{c}\text { CUBIC } \\
\text { FEET } \\
\text { PERR } \\
\text { SECOND }\end{array}$ & $\begin{array}{r}\text { TOTAL } \\
\text { DAYS }\end{array}$ & $\begin{array}{c}\text { ACCU- } \\
\text { MU- } \\
\text { LATED } \\
\text { DAYS }\end{array}$ & $\begin{array}{l}\text { PER- } \\
\text { CENT } \\
\text { DAYS }\end{array}$ & & $\begin{array}{c}\text { CUBIC } \\
\text { FEET } \\
\text { PER } \\
\text { SEOOND }\end{array}$ & $\begin{array}{l}\text { TOTAL } \\
\text { DAYS }\end{array}$ & $\begin{array}{l}\text { ACCU- } \\
\text { MU- } \\
\text { LATED } \\
\text { DAYS }\end{array}$ & $\begin{array}{l}\text { PER- } \\
\text { CENT } \\
\text { DAYS }\end{array}$ & CLASS & $\begin{array}{c}\text { CUBIC } \\
\text { FEET } \\
\text { PER } \\
\text { SECOND }\end{array}$ & $\begin{array}{l}\text { TOTAL } \\
\text { DAYS }\end{array}$ & $\begin{array}{l}\text { ACOU- } \\
\text { MU- } \\
\text { LATED } \\
\text { DAYS }\end{array}$ & $\begin{array}{l}\text { PER- } \\
\text { CENT } \\
\text { DAYS }\end{array}$ \\
\hline $\begin{array}{l}0 \\
1 \\
2 \\
3 \\
4 \\
5 \\
6 \\
7\end{array}$ & $\begin{array}{l}0.00 \\
0.10 \\
0.13 \\
0.17 \\
0.23 \\
0.30 \\
0.40 \\
0.53\end{array}$ & $\begin{array}{r}64 \\
32 \\
0 \\
23 \\
0 \\
10 \\
21 \\
11\end{array}$ & $\begin{array}{l}4748 \\
4684 \\
4652 \\
4652 \\
4629 \\
4629 \\
4619 \\
4598 \\
4587\end{array}$ & $\begin{array}{r}100.0 \\
98.7 \\
98.0 \\
98.0 \\
97.5 \\
97.5 \\
97.3 \\
96.8 \\
96.6\end{array}$ & $\begin{array}{r}9 \\
10 \\
11 \\
12 \\
13 \\
14 \\
15 \\
16\end{array}$ & $\begin{array}{l}0.91 \\
1.20 \\
1.60 \\
2.10 \\
2.80 \\
3.60 \\
4.80 \\
6.30 \\
8.30\end{array}$ & $\begin{array}{r}67 \\
105 \\
104 \\
101 \\
132 \\
206 \\
545 \\
551 \\
570\end{array}$ & $\begin{array}{l}4551 \\
4484 \\
4379 \\
4275 \\
4174 \\
4042 \\
3836 \\
3291 \\
2740\end{array}$ & $\begin{array}{l}95.9 \\
94.4 \\
92.2 \\
90.0 \\
87.9 \\
85.1 \\
80.8 \\
69.3 \\
57.7\end{array}$ & $\begin{array}{l}18 \\
19 \\
20 \\
21 \\
22 \\
23 \\
24 \\
25\end{array}$ & $\begin{array}{r}11.0 \\
14.0 \\
19.0 \\
25.0 \\
33.0 \\
44.0 \\
58.0 \\
76.0 \\
100.0\end{array}$ & $\begin{array}{r}643 \\
513 \\
172 \\
115 \\
89 \\
89 \\
75 \\
70 \\
58\end{array}$ & $\begin{array}{r}2170 \\
1527 \\
1014 \\
842 \\
727 \\
638 \\
549 \\
474 \\
404\end{array}$ & $\begin{array}{r}45.7 \\
32.2 \\
21.4 \\
17.7 \\
15.3 \\
13.4 \\
11.6 \\
10.0 \\
8.5\end{array}$ & $\begin{array}{l}27 \\
28 \\
29 \\
30 \\
31 \\
32 \\
33 \\
34\end{array}$ & $\begin{array}{l}130.0 \\
170.0 \\
230.0 \\
300.0 \\
400.0 \\
530.0 \\
690.0 \\
920.0\end{array}$ & $\begin{array}{r}80 \\
59 \\
53 \\
72 \\
51 \\
18 \\
12 \\
1\end{array}$ & $\begin{array}{r}346 \\
266 \\
207 \\
154 \\
82 \\
31 \\
13 \\
1\end{array}$ & \\
\hline
\end{tabular}

MONTHLY MEAN DISCHARGES, IN CUBIC FEET PER SEDOND, FOR EACH WATER YEAR

$\begin{array}{llccccccccccc}\text { YEAR } & \text { OCT } & \text { NOV } & \text { DEC } & \text { JAN } & \text { FEB } & \text { MAR } & \text { APR } & \text { MAY } & \text { JUNE } & \text { JULY } & \text { AUG } & \text { SEP } \\ 1912 & 12.4 & 12.7 & 1.50 & 5.00 & 5.00 & 13.1 & 11.2 & 138 & 280 & 33.6 & 4.61 & 6.57 \\ 1913 & 12.2 & 13.0 & 8.00 & 9.00 & 10.0 & 12.0 & 38.9 & 138 & 48.5 & 17.6 & 3.95 & 39.3 \\ 1914 & 14.0 & 9.47 & 8.16 & 12.0 & 12.0 & 14.4 & 28.8 & 272 & 313 & 121 & 8.74 & 8.80 \\ 1949 & 4.02 & 7.46 & 6.48 & 5.00 & 6.56 & 19.3 & 73.0 & 127 & 220 & 23.6 & 14.0 & 5.44 \\ 1950 & 8.90 & 8.30 & 7.99 & 8.85 & 9.91 & 9.04 & 18.6 & 38.7 & 40.3 & 24.4 & 2.08 & 2.00 \\ 1951 & 5.56 & 8.56 & 7.51 & 6.00 & 6.46 & 6.64 & 3.40 & 85.6 & 93.2 & 7.19 & 28.6 & 7.12 \\ 1952 & 11.3 & 12.0 & 11.9 & 10.1 & 13.2 & 14.1 & 77.4 & 322 & 497 & 61.8 & 27.8 & 20.3 \\ 1953 & 14.6 & 13.7 & 11.0 & 11.0 & 11.4 & 12.0 & 8.18 & 6.03 & 114 & 28.2 & 19.2 & 5.16 \\ 1954 & 13.6 & 12.7 & 11.6 & 11.4 & 11.0 & 10.4 & 16.2 & 23.0 & 4.90 & 3.28 & 1.68 & 5.86 \\ 1955 & 3.19 & 5.23 & 7.90 & 7.00 & 7.11 & 10.5 & 7.95 & 5.37 & 13.5 & 0.24 & 8.06 & 0.05 \\ 1956 & 0.55 & 3.18 & 5.11 & 4.74 & 5.65 & 7.32 & 2.26 & 47.0 & 29.3 & 5.24 & 1.97 & 1.25 \\ 1957 & 1.91 & 4.97 & 7.50 & 7.50 & 11.4 & 6.92 & 7.28 & 45.5 & 356 & 78.9 & 21.4 & 8.20 \\ 1958 & 16.6 & 14.9 & 16.5 & 14.0 & 14.5 & 15.6 & 67.4 & 268 & 241 & 8.23 & 5.80 & 7.45\end{array}$

ANNUA PEAK DISCHARGE, IN GBIC FEET PER SEOOND, AND CORRESPONDING GAGE HEIGHT, IN FEET, FOR EACH WATER YEAR

$\begin{array}{lcrcccccccc}\begin{array}{l}\text { WATER } \\ \text { YEAR }\end{array} & \text { DATE } & \begin{array}{c}\text { GAGE } \\ \text { HEIGHT }\end{array} & \begin{array}{c}\text { PEAK } \\ \text { DISCHARG }\end{array} & \begin{array}{l}\text { WATER } \\ \text { YEAR }\end{array} & \text { DATE } & \begin{array}{c}\text { GAGE } \\ \text { HEIGHT }\end{array} & \begin{array}{r}\text { PEAK } \\ \text { DISCHARGE }\end{array} & \begin{array}{l}\text { WAIER } \\ \text { YEAR }\end{array} & \begin{array}{c}\text { GAGE } \\ \text { DATE }\end{array} & \begin{array}{c}\text { PEAK } \\ \text { HEIGHT }\end{array} \\ \text { DISCHARGE }\end{array}$


GREEN RIVER BASIN

09327500 FERRON OREEK NEAR CASTLE DALE, UT--Continued

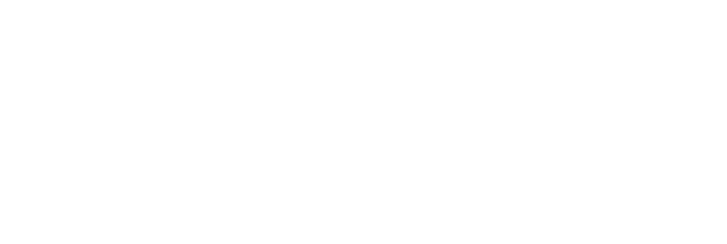

$10.34 \quad 0.00 \quad-5 \quad \ldots \quad \ldots+\ldots$
MAGNITUDE AND PROBAETITY OF ANNUAL HIGHEST MEAN DISGHARGE BASED ON WATER YEARS $1912-14$ AND 1949-58

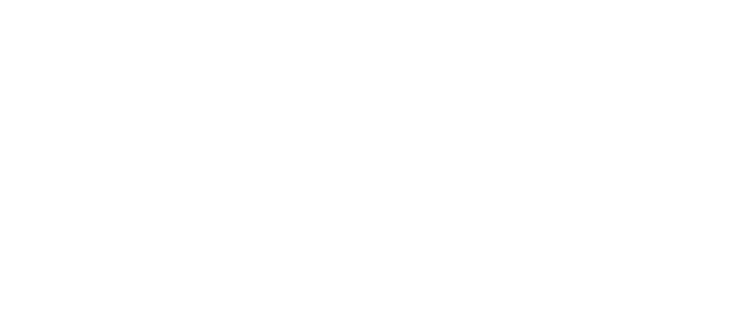

09327550 FERRON OREEK BELOW PARADISE RANCH, NEAR CLAWSON, UT

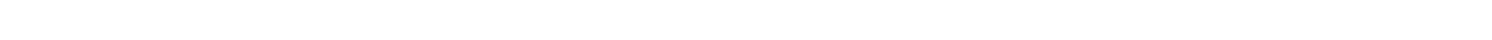
$5.5 \mathrm{mi}$ southeast of clawson.

DRAINAGE AREA, --221 $\mathrm{mi}^{2}$.

PERIOD OF RECORD AVAILABLE.--October 1975 to September 1981.

REVISED RECORDS, --WDR UT-77-1: 1976 (M).

GAGE. - Water-stage recorder. Altitude of gage is 5,600 ft from topographic map.

REMARKS.--Many diversions for irrigation above station.

AVERAGE DISCHARGE. -6 years, $39.5 \mathrm{ft}^{3} / \mathrm{s}, 28,620$ acre- $\mathrm{ft} / \mathrm{yr}$.

EXTREMES FOR PERIOD OF RECORD.--Maximum discharge, $1,980 \mathrm{ft}^{3} / \mathrm{s}$ June 20,1980 , gage height, $5.59 \mathrm{ft}$; no flow on many days.

LOWEST MEAN DISGHARGE, IN GBIC FEET PER SECOND, AND RANKING FOR THE INDICATED NUMBER OF CONSEQUTIVE DAYS FOR EAOH CLIMATIC YEAR, APRLI I-MAROH 31

\begin{tabular}{|c|c|c|c|c|c|c|c|c|c|c|c|c|c|c|c|c|c|c|c|}
\hline YEAR & 1 & & 3 & & 7 & & 14 & & $\begin{array}{l}\text { CONSE } \\
30\end{array}$ & CUTIVE & $\begin{array}{l}\text { DAYS } \\
60\end{array}$ & & 90 & & 120 & & 183 & & ALL \\
\hline $\begin{array}{l}1977 \\
1978 \\
1979 \\
1980\end{array}$ & $\begin{array}{l}2.30 \\
0.00 \\
2.60 \\
5.00\end{array}$ & $\begin{array}{l}2 \\
1 \\
3 \\
4\end{array}$ & $\begin{array}{l}2.40 \\
0.00 \\
2.70 \\
5.00\end{array}$ & $\begin{array}{l}2 \\
1 \\
3 \\
4\end{array}$ & $\begin{array}{l}2.70 \\
0.00 \\
2.70 \\
5.30\end{array}$ & $\begin{array}{l}3 \\
1 \\
2 \\
4\end{array}$ & $\begin{array}{l}3.20 \\
0.00 \\
2.80 \\
5.70\end{array}$ & $\begin{array}{l}3 \\
1 \\
2 \\
4\end{array}$ & $\begin{array}{l}4.00 \\
0.18 \\
3.40 \\
7.20\end{array}$ & $\begin{array}{l}3 \\
1 \\
2 \\
4\end{array}$ & $\begin{array}{l}5.30 \\
0.34 \\
4.70 \\
8.00\end{array}$ & $\begin{array}{l}3 \\
1 \\
2 \\
4\end{array}$ & $\begin{array}{l}5.50 \\
0.68 \\
6.80 \\
8.40\end{array}$ & $\begin{array}{l}2 \\
1 \\
3 \\
4\end{array}$ & $\begin{array}{l}5.90 \\
1.00 \\
7.70 \\
8.70\end{array}$ & $\begin{array}{l}2 \\
1 \\
3 \\
4\end{array}$ & $\begin{array}{r}6.20 \\
1.50 \\
9.60 \\
11.0\end{array}$ & $\begin{array}{l}2 \\
1 \\
3 \\
4\end{array}$ & $\begin{array}{c}8.30 \\
3.40 \\
20.0 \\
43.0\end{array}$ \\
\hline 1981 & 5.60 & 5 & 6.00 & 5 & 6.10 & 5 & 6.30 & 5 & 8.80 & 5 & 9.30 & 5 & 9.80 & 5 & 9.90 & 5 & 12.0 & 5 & 106 \\
\hline
\end{tabular}

HIGHEST MEAN DISCHARGE, IN OBIC FEET PER SECOND, AND RANKING FOR THE INDICATED NUMBER OF CONSEQUTTVE DAVS FOR EACH WATER YEAR, OCTOBER 1-SEPTEMBER 30

\begin{tabular}{|c|c|c|c|c|c|c|c|c|c|c|c|c|c|c|c|c|c|c|c|}
\hline YEAR & 1 & & 3 & & 7 & & 15 & & $\begin{array}{l}\text { CONS } \\
30\end{array}$ & OTT & $\begin{array}{l}\text { VE DAYS } \\
60\end{array}$ & & 90 & & 120 & & 183 & & ALL \\
\hline $\begin{array}{l}1976 \\
1977 \\
1978 \\
1979 \\
1980\end{array}$ & $\begin{array}{l}35.0 \\
116 \\
318 \\
722 \\
1700\end{array}$ & $\begin{array}{l}6 \\
5 \\
3 \\
2 \\
1\end{array}$ & $\begin{array}{r}23.0 \\
41.0 \\
301 \\
556 \\
1650\end{array}$ & $\begin{array}{l}6 \\
5 \\
3 \\
2 \\
1\end{array}$ & $\begin{array}{r}20.0 \\
20.0 \\
276 \\
429 \\
1520\end{array}$ & $\begin{array}{l}5 \\
6 \\
3 \\
2 \\
1\end{array}$ & $\begin{array}{c}20.0 \\
9.60 \\
205 \\
406 \\
1400\end{array}$ & $\begin{array}{l}5 \\
6 \\
3 \\
2\end{array}$ & $\begin{array}{l}19.0 \\
7.10 \\
126 \\
345 \\
986\end{array}$ & $\begin{array}{l}5 \\
6 \\
3 \\
2 \\
1\end{array}$ & $\begin{array}{c}17.0 \\
6.90 \\
73.0 \\
195 \\
565\end{array}$ & $\begin{array}{l}4 \\
6 \\
3 \\
2 \\
1\end{array}$ & $\begin{array}{c}16.0 \\
6.90 \\
54.0 \\
139 \\
387\end{array}$ & $\begin{array}{l}4 \\
6 \\
3 \\
2 \\
1\end{array}$ & $\begin{array}{c}14.0 \\
6.80 \\
44.0 \\
109 \\
296\end{array}$ & $\begin{array}{l}4 \\
6 \\
3 \\
2\end{array}$ & $\begin{array}{c}13.0 \\
6.20 \\
30.0 \\
75.0 \\
200\end{array}$ & $\begin{array}{l}4 \\
6 \\
3 \\
2 \\
1\end{array}$ & $\begin{array}{c}12.0 \\
4.00 \\
18.0 \\
42.0 \\
106\end{array}$ \\
\hline 8] & 123 & 4 & 63.0 & 4 & 46.0 & 4 & 27.0 & 4 & 20.0 & 4 & 15.0 & 5 & 14.0 & 5 & 13.0 & 5 & 12.0 & 5 & 10.0 \\
\hline
\end{tabular}

DURATION OF DISGHARGE FOR EACH WATER YEAR

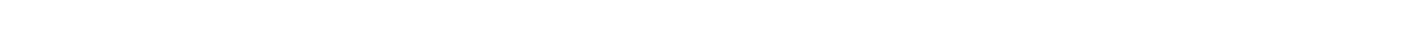
YEAR NUMBER OF DAYS IN CLASS 
GREEN RIVER BASTN

09327550 FERRON CREEK BELOW PARADISE RANCH, NEAR CLAWSON, UT-Continued

DURATION TABLE OF DISCHARGE FOR WATER YEARS 1976-81
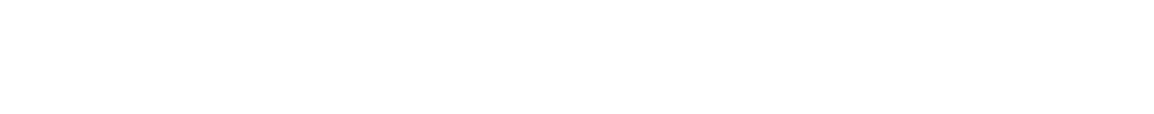

$\begin{array}{ccc}\text { CUBIC } & \text { ACOU- } \\ \text { FEET } & \text { MU- } & \text { PER- } \\ \text { PER } & \text { TOTAL LATED } & \text { CENT } \\ \text { C.ASS SECOND DAYS } & \text { DAYS } & \text { DAYS }\end{array}$

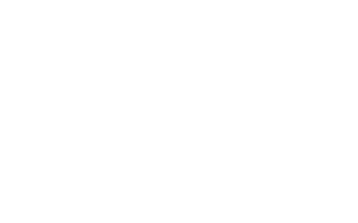

$\begin{array}{rrrrr}9 & 0.26 & 1 & 2097 & 95.7 \\ 10 & 0.38 & 4 & 2096 & 95.6 \\ 11 & 0.55 & 7 & 2092 & 95.4 \\ 12 & 0.79 & 20 & 2085 & 95.1 \\ 13 & 1.10 & 25 & 2065 & 94.2 \\ 14 & 1.60 & 34 & 2040 & 93.1 \\ 15 & 2.30 & 97 & 2006 & 91.5 \\ 16 & 3.40 & 136 & 1909 & 87.1 \\ 17 & 4.80 & 344 & 1773 & 80.9\end{array}$

$\begin{array}{rrrrr}18 & 7.0 & 414 & 1429 & 65.2 \\ 19 & 10.0 & 385 & 1015 & 46.3 \\ 20 & 14.0 & 337 & 630 & 28.7 \\ 21 & 21.0 & 109 & 293 & 13.4 \\ 22 & 30.0 & 49 & 184 & 8.4 \\ 23 & 43.0 & 22 & 135 & 6.2 \\ 24 & 62.0 & 12 & 113 & 5.2 \\ 25 & 89.0 & 12 & 101 & 4.6 \\ 26 & 130.0 & 13 & 89 & 4.1\end{array}$

$\begin{array}{rrrrr}27 & 180.0 & 19 & 76 & 3.5 \\ 28 & 260.0 & 22 & 57 & 2.6 \\ 29 & 380.0 & 10 & 35 & 1.6 \\ 30 & 550.0 & 7 & 25 & 1.1 \\ 31 & 790.0 & 4 & 18 & 0.8 \\ 32 & 1100.0 & 11 & 14 & 0.6 \\ 33 & 1600.0 & 3 & 3 & 0.1 \\ 34 & & & & \end{array}$

MONHLY MEAN DISCHARGES, IN CUBIC FEET PER SECOND, FOR EACH WATER YEAR

$\begin{array}{lcccccccccccc}\text { YEAR } & \text { CCT } & \text { NOV } & \text { DEC } & \text { JAN } & \text { FEB } & \text { MAR } & \text { APR } & \text { MAY } & \text { JUNE } & \text { JULY } & \text { AUG } & \text { SEP } \\ 1976 & 19.1 & 15.4 & 14.3 & 8.58 & 10.0 & 9.48 & 6.84 & 13.1 & 16.5 & 13.9 & 7.06 & 4.93 \\ 1977 & 6.78 & 6.83 & 7.00 & 6.03 & 6.64 & 4.03 & 2.71 & 1.86 & 0.27 & 4.65 & 0.92 & 0.22 \\ 1978 & 1.18 & 2.69 & 5.62 & 5.29 & 5.21 & 9.98 & 3.38 & 6.15 & 107 & 35.5 & 18.2 & 13.5 \\ 1979 & 10.9 & 15.9 & 7.42 & 5.35 & 7.95 & 10.2 & 7.62 & 73.0 & 292 & 33.9 & 28.3 & 15.5 \\ 1980 & 9.26 & 8.91 & 8.84 & 7.74 & 21.2 & 13.1 & 8.97 & 68.7 & 978 & 110 & 19.0 & 30.9 \\ 1981 & 17.3 & 12.8 & 10.1 & 10.8 & 9.82 & 8.78 & 4.27 & 4.51 & 6.56 & 8.90 & 10.5 & 17.2\end{array}$

ANNUAL PEAK DISCHARGE, IN OUBIC FEET PER SECOND, AND CORRESPONDING GAGE HEIGHT, IN FEET, FOR EACH WATER YEAR

\begin{tabular}{|c|c|c|c|c|c|c|c|c|c|c|c|c|}
\hline $\begin{array}{l}\text { WATER } \\
\text { YEAR }\end{array}$ & & DATE & $\begin{array}{l}\text { GAGE } \\
\text { HEIGHT }\end{array}$ & $\begin{array}{c}\text { PEAK } \\
\text { DISCHARGE }\end{array}$ & $\begin{array}{l}\text { WATERR } \\
\text { YEAR }\end{array}$ & DATE & $\begin{array}{c}\text { GAGE } \\
\text { HEIGHT }\end{array}$ & $\begin{array}{c}\text { PEAK } \\
\text { DISCHARGE }\end{array}$ & $\begin{array}{l}\text { WATER } \\
\text { YEAR }\end{array}$ & DATE & $\begin{array}{c}\text { GAGE } \\
\text { HEIGHT }\end{array}$ & $\begin{array}{c}\text { PEAK } \\
\text { DISCHARGE }\end{array}$ \\
\hline $\begin{array}{l}1976 \\
1977\end{array}$ & $\begin{array}{l}\text { MAY } \\
\text { JULY }\end{array}$ & $\begin{array}{r}09,1976 \\
\times 24,1977\end{array}$ & $\begin{array}{l}3.90 \\
5.50\end{array}$ & $\begin{array}{r}421 \\
1840\end{array}$ & $\begin{array}{l}1978 \\
1979\end{array}$ & $\begin{array}{l}\text { JUNE } 19,1978 \\
\text { MAY } 29,1979\end{array}$ & $\begin{array}{l}4.21 \\
5.05\end{array}$ & $\begin{array}{l}611 \\
986\end{array}$ & $\begin{array}{l}1980 \\
1981\end{array}$ & $\begin{array}{l}\text { JUNE 20， } 1980 \\
\text { SEPT.05， } 1981\end{array}$ & $\begin{array}{l}5.59 \\
4.56\end{array}$ & $\begin{array}{r}1980 \\
796\end{array}$ \\
\hline
\end{tabular}

09327600 FERRON CREEK TRIBUTARY NEAR FERRON, UT

LOCATION.--Lat $39^{\circ} 04^{\prime} 00^{\prime \prime}$, long $111^{\circ} 01^{\prime} 46^{\prime \prime}$, in NW' sec.21, T.20 S., R.8 E., Emery County, Hydrologic Unit 14060009 , 6.6 mi east of Ferron and $10 \mathrm{mi}$ south of Castle Dale.

DRATNAGE AREA.--0.96 $\mathrm{mi}^{2}$.

MEAN BASIN ELEVATION. $-6,300 \mathrm{ft}$.

PERIOD OF RECORD AVAIIABLE. - Water years 1959, 1961-71, annual peak discharge only.

GAGE.--Crest-stage gage. Altitude of gage is 5,900 ft tran topographic map.

ANNUAL PEAK DISCHARGE, IN OUBIC FEET PER SECOND, AND CORPESPONDING GAGE HEIGHT, IN FEET, FOR EACH WATER YEAR

\begin{tabular}{|c|c|c|c|c|c|c|c|c|c|c|c|}
\hline $\begin{array}{l}\text { WATER } \\
\text { YEAR }\end{array}$ & DATE & $\begin{array}{c}\text { GAGE } \\
\text { HEIGHT }\end{array}$ & $\begin{array}{c}\text { PEAK } \\
\text { DISCHARGE }\end{array}$ & $\begin{array}{l}\text { WATER } \\
\text { YEAR }\end{array}$ & DATE & $\begin{array}{c}\text { GAGE } \\
\text { HEIGHT }\end{array}$ & $\begin{array}{c}\text { PEAK } \\
\text { DISCHARGE }\end{array}$ & $\begin{array}{l}\text { WATERR } \\
\text { YEAR }\end{array}$ & DATE & $\begin{array}{c}\text { GAGE } \\
\text { HEIGHT }\end{array}$ & $\begin{array}{c}\text { PEAK } \\
\text { DISCHARGE }\end{array}$ \\
\hline $\begin{array}{l}1959 \\
1961 \\
1962 \\
1963\end{array}$ & $\begin{array}{l}\text { SEPT. } 15,1959 \\
\text { AUG. 05, } 1961 \\
\text { OCT. 07, } 1961 \\
\text { AUG. } 12,1963\end{array}$ & $\begin{array}{l}10.35 \\
11.92 \\
11.50 \\
10.30\end{array}$ & $\begin{array}{r}40 \\
314 \\
250 \\
25\end{array}$ & $\begin{array}{l}1964 \\
1965 \\
1966 \\
1967\end{array}$ & $\begin{array}{l}\text { AUG. } 15,1964 \\
\text { AUG. 18, } 1965 \\
\text { SEPT. 02, } 1966 \\
\text { SEPT.09, } 1967\end{array}$ & $\begin{array}{l}10.30 \\
12.73 \\
10.62 \\
13.00\end{array}$ & $\begin{array}{r}25 \\
515 \\
44 \\
600\end{array}$ & $\begin{array}{l}1968 \\
1969 \\
1970 \\
1971\end{array}$ & $\begin{array}{l}\text { JULY } 30,1968 \\
\text { SEPT.11, } 1969 \\
\text { SEPT.06, } 1970 \\
\text { AUG. } 25,1971\end{array}$ & $\begin{array}{r}10.70 \\
12.40 \\
12.19 \\
9.95\end{array}$ & $\begin{array}{r}88 \\
326 \\
280 \\
12\end{array}$ \\
\hline
\end{tabular}




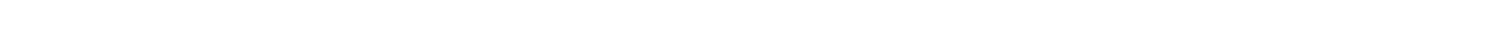
$1.7 \mathrm{mi}$ downstream from Ferron Creek and $8.3 \mathrm{mi}$ southeast of Castle Dale.

DRATNAGE AREA, $--930 \mathrm{mi}^{2}$.

PERIOD OF RECORD AVAILABLE. --October 1947 to September 1964 , August 1972 to september 1981.

GAGE. -Water-stage recorder. Altitude of gage is 5,320 ft fram topographic map. Prior to July 11,1956 , at site $0.7 \mathrm{mi}$ upstream at different datum. July 11,1956 to september 30,1964 , at site $0.6 \mathrm{mi}$ upstream at different datum.

REMARKS.--Diversions for irrigation above station, including transmountain diversions to sevier Lake basin.

AVERAGE DISGHARGE. -26 years, $104 \mathrm{ft}^{3} / \mathrm{s}, 75,300$ acre-ft/yr.

EXTREMES FOR PERIOD OF RECORD. - Maximum discharge, 4,510 $\mathrm{ft}^{3} / \mathrm{s}$ June 3, 1952 , gage height, $7.56 \mathrm{ft}$, site and datum then in use; no flow for several days in 1977 .

LOWEST MEAN DISGHARGE, IN OBIC FEET PER SECOND, AND RANKING FOR THE INDICATED NUMBER OF CONSEOTIVE DAVS FOR EACH CLIMATIC YEAR, APRIL 1-MARCH 31

\begin{tabular}{|c|c|c|c|c|c|c|c|c|c|c|c|c|c|c|c|c|c|c|c|c|}
\hline YEAR & & & & & & & & & CONSE & EW & DAYS & & & & & & & & & \\
\hline $\begin{array}{l}949 \\
950\end{array}$ & $\begin{array}{r}3.80 \\
16.0\end{array}$ & $\begin{array}{r}8 \\
16\end{array}$ & $\begin{array}{l}3.80 \\
16.0\end{array}$ & $\begin{array}{r}8 \\
15\end{array}$ & $\begin{array}{c}4.00 \\
17.0\end{array}$ & $\begin{array}{r}8 \\
15\end{array}$ & $\begin{array}{l}4.10 \\
18.0\end{array}$ & $\begin{array}{r}8 \\
15\end{array}$ & $\begin{array}{l}4.70 \\
19.0\end{array}$ & $\begin{array}{r}5 \\
14\end{array}$ & $\begin{array}{c}7.80 \\
26.0\end{array}$ & $\begin{array}{r}5 \\
15\end{array}$ & $\begin{array}{l}12.0 \\
32.0\end{array}$ & $\begin{array}{r}6 \\
15\end{array}$ & $\begin{array}{l}16.0 \\
36.0\end{array}$ & $\begin{array}{r}5 \\
16\end{array}$ & $\begin{array}{l}21.0 \\
36.0\end{array}$ & $\begin{array}{r}4 \\
13\end{array}$ & $\begin{array}{c}77.0 \\
165\end{array}$ & $\begin{array}{l}13 \\
20\end{array}$ \\
\hline $\begin{array}{l}951 \\
952 \\
953 \\
954 \\
955\end{array}$ & $\begin{array}{c}10.0 \\
18.0 \\
48.0 \\
18.0 \\
1.40\end{array}$ & $\begin{array}{r}11 \\
17 \\
24 \\
18 \\
2\end{array}$ & $\begin{array}{c}10.0 \\
18.0 \\
50.0 \\
19.0 \\
1.50\end{array}$ & $\begin{array}{r}11 \\
18 \\
24 \\
19 \\
2\end{array}$ & $\begin{array}{c}11.0 \\
19.0 \\
51.0 \\
20.0 \\
1.70\end{array}$ & $\begin{array}{c}12 \\
17 \\
24 \\
18 \\
3\end{array}$ & $\begin{array}{c}12.0 \\
21.0 \\
53.0 \\
21.0 \\
2.90\end{array}$ & $\begin{array}{r}12 \\
17 \\
24 \\
18 \\
6\end{array}$ & $\begin{array}{c}16.0 \\
22.0 \\
55.0 \\
25.0 \\
8.80\end{array}$ & $\begin{array}{r}11 \\
16 \\
24 \\
18 \\
8\end{array}$ & $\begin{array}{l}20.0 \\
33.0 \\
59.0 \\
42.0 \\
11.0\end{array}$ & $\begin{array}{r}10 \\
19 \\
23 \\
22 \\
7\end{array}$ & $\begin{array}{l}22.0 \\
44.0 \\
60.0 \\
48.0 \\
15.0\end{array}$ & $\begin{array}{r}9 \\
21 \\
23 \\
22 \\
7\end{array}$ & $\begin{array}{l}24.0 \\
46.0 \\
62.0 \\
47.0 \\
18.0\end{array}$ & $\begin{array}{r}10 \\
20 \\
23 \\
21 \\
6\end{array}$ & & $\begin{array}{r}10 \\
19 \\
23 \\
20 \\
5\end{array}$ & $\begin{array}{l}62.0 \\
111 \\
416 \\
101 \\
44.0\end{array}$ & $\begin{array}{r}11 \\
16 \\
24 \\
15 \\
5\end{array}$ \\
\hline $\begin{array}{l}1956 \\
1957 \\
1958 \\
1959 \\
1960\end{array}$ & $\begin{array}{c}2.10 \\
1.60 \\
15.0 \\
5.20 \\
2.50\end{array}$ & $\begin{array}{r}6 \\
4 \\
15 \\
9 \\
7\end{array}$ & $\begin{array}{c}2.10 \\
1.70 \\
16.0 \\
5.60 \\
2.50\end{array}$ & $\begin{array}{r}6 \\
4 \\
16 \\
9 \\
7\end{array}$ & $\begin{array}{c}2.90 \\
1.90 \\
20.0 \\
8.40 \\
2.50\end{array}$ & $\begin{array}{r}7 \\
4 \\
19 \\
9 \\
6\end{array}$ & $\begin{array}{c}3.10 \\
2.20 \\
22.0 \\
11.0 \\
2.50\end{array}$ & $\begin{array}{r}7 \\
3 \\
19 \\
11 \\
4\end{array}$ & $\begin{array}{c}5.50 \\
2.50 \\
25.0 \\
17.0 \\
2.70\end{array}$ & $\begin{array}{r}6 \\
3 \\
19 \\
12 \\
4\end{array}$ & $\begin{array}{c}8.10 \\
4.30 \\
63.0 \\
27.0 \\
5.60\end{array}$ & $\begin{array}{r}6 \\
3 \\
24 \\
16 \\
4\end{array}$ & $\begin{array}{c}11.0 \\
6.00 \\
73.0 \\
31.0 \\
8.10\end{array}$ & $\begin{array}{r}5 \\
3 \\
24 \\
14 \\
4\end{array}$ & $\begin{array}{c}14.0 \\
8.50 \\
83.0 \\
31.0 \\
8.90\end{array}$ & $\begin{array}{r}4 \\
2 \\
24 \\
11 \\
3\end{array}$ & $\begin{array}{c}22.0 \\
11.0 \\
101 \\
36.0 \\
14.0\end{array}$ & $\begin{array}{r}6 \\
2 \\
24 \\
14 \\
3\end{array}$ & $\begin{array}{l}39.0 \\
46.0 \\
231 \\
223 \\
28.0\end{array}$ & $\begin{array}{r}4 \\
6 \\
23 \\
22 \\
2\end{array}$ \\
\hline $\begin{array}{l}1961 \\
1962 \\
1963 \\
1964\end{array}$ & $\begin{array}{c}1.50 \\
2.00 \\
10.0 \\
9.00\end{array}$ & $\begin{array}{r}3 \\
5 \\
12 \\
10\end{array}$ & $\begin{array}{c}1.50 \\
2.00 \\
10.0 \\
9.00\end{array}$ & $\begin{array}{r}3 \\
5 \\
12 \\
10\end{array}$ & $\begin{array}{c}1.50 \\
2.00 \\
10.0 \\
9.30\end{array}$ & $\begin{array}{r}2 \\
5 \\
11 \\
10\end{array}$ & $\begin{array}{c}1.50 \\
2.60 \\
10.0 \\
10.0\end{array}$ & $\begin{array}{r}2 \\
5 \\
9 \\
10\end{array}$ & $\begin{array}{r}1.70 \\
5.70 \\
13.0 \\
12.0\end{array}$ & $\begin{array}{r}1 \\
7 \\
10 \\
9\end{array}$ & $\begin{array}{l}2.60 \\
17.0 \\
24.0 \\
22.0\end{array}$ & $\begin{array}{r}1 \\
8 \\
13 \\
12\end{array}$ & $\begin{array}{l}5.70 \\
26.0 \\
33.0 \\
23.0\end{array}$ & $\begin{array}{r}2 \\
12 \\
16 \\
10\end{array}$ & $\begin{array}{l}19.0 \\
31.0 \\
34.0 \\
23.0\end{array}$ & $\begin{array}{r}7 \\
12 \\
14 \\
8\end{array}$ & & $\begin{array}{r}7 \\
21 \\
12 \\
9\end{array}$ & $\begin{array}{c}49.0 \\
59.0 \\
141 \\
53.0\end{array}$ & $\begin{array}{r}7 \\
10 \\
18 \\
8\end{array}$ \\
\hline $\begin{array}{l}1976 \\
1977 \\
1978 \\
1979 \\
1980\end{array}$ & $\begin{array}{c}24.0 \\
13.0 \\
0.00 \\
12.0 \\
23.0\end{array}$ & $\begin{array}{r}21 \\
14 \\
1 \\
13 \\
20\end{array}$ & $\begin{array}{c}25.0 \\
14.0 \\
0.00 \\
13.0 \\
24.0\end{array}$ & $\begin{array}{c}21 \\
14 \\
1 \\
13 \\
20\end{array}$ & $\begin{array}{c}26.0 \\
16.0 \\
0.00 \\
14.0 \\
24.0\end{array}$ & $\begin{array}{r}21 \\
14 \\
1 \\
13 \\
20\end{array}$ & $\begin{array}{c}26.0 \\
17.0 \\
0.03 \\
16.0 \\
25.0\end{array}$ & $\begin{array}{c}21 \\
14 \\
1 \\
13 \\
20\end{array}$ & $\begin{array}{c}26.0 \\
19.0 \\
2.40 \\
17.0 \\
28.0\end{array}$ & $\begin{array}{r}20 \\
15 \\
2 \\
13 \\
21\end{array}$ & $\begin{array}{c}30.0 \\
20.0 \\
3.20 \\
21.0 \\
31.0\end{array}$ & $\begin{array}{r}17 \\
9 \\
2 \\
11 \\
18\end{array}$ & $\begin{array}{c}36.0 \\
22.0 \\
4.70 \\
26.0 \\
33.0\end{array}$ & $\begin{array}{r}19 \\
8 \\
1 \\
11 \\
17\end{array}$ & $\begin{array}{c}38.0 \\
23.0 \\
5.90 \\
31.0 \\
37.0\end{array}$ & $\begin{array}{r}19 \\
9 \\
1 \\
13 \\
17\end{array}$ & $\begin{array}{c}48.0 \\
26.0 \\
7.20 \\
32.0 \\
41.0\end{array}$ & $\begin{array}{r}18 \\
8 \\
1 \\
11 \\
15\end{array}$ & $\begin{array}{r}126 \\
33.0 \\
14.0 \\
70.0 \\
95.0\end{array}$ & $\begin{array}{r}17 \\
3 \\
1 \\
12 \\
14\end{array}$ \\
\hline 98 & 28.0 & 22 & 30.0 & 22 & 31.0 & 22 & 35.0 & 23 & 40.0 & 23 & 42.0 & 21 & 43.0 & 20 & 47.0 & 22 & 60.0 & 22 & 185 & $\Delta$ \\
\hline
\end{tabular}

HIGHEST MEAN DISGHARGE, IN OBBIC FEET PER SECOND, AND RANKING FOR THE INDICATED NUMBER OF CONSECUTIVE DAYS FOR EACH WATER YEAR, OCTOBER I-SEPTEMBER 30

YEAR

$\begin{array}{lr} & 1 \\ 1948 & 700 \\ 1949 & 1410 \\ 1950 & 560 \\ 1951 & 1240 \\ 1952 & 3840 \\ 1953 & 1150 \\ 1954 & 296 \\ 1955 & 329 \\ 1956 & 643 \\ 1957 & 2120 \\ 1958 & 2350 \\ 1959 & 106 \\ 1960 & 422 \\ 1961 & 2140 \\ 1962 & 964 \\ 1963 & 600 \\ 1964 & 979 \\ 1973 & 1200 \\ 1974 & 333 \\ 1975 & 1470\end{array}$

CONSEUTTIVE DAYS

$30 \quad 60$

$14 \quad 663$

$\begin{array}{ll}7 & 1270\end{array}$

$18 \quad 540$

$8 \quad 1060$

13810

$\begin{array}{rr}10 & 1100 \\ 22 & 253\end{array}$

$20 \quad 208$

$16 \quad 598$

$\begin{array}{rrrr}4 & 2090 & 3 & 1970 \\ 2 & 2220 & 2 & 2120\end{array}$

$\begin{array}{llll}25 & 96.0 & 25 & 87.0\end{array}$

7

13602

$\begin{array}{rr}5 & 1180 \\ 17 & 473\end{array}$

$8 \quad 924$

$16 \quad 423$

$9 \quad 635$

$\begin{array}{rr}1 & 3050 \\ 7 & 768 \\ 20 & 206\end{array}$

$\begin{array}{ll}20 & 206 \\ 21 & 152\end{array}$

$15 \quad 486$

$\begin{array}{rcrl}15 & 486 & 15 & 322 \\ 3 & 1710 & 3 & 1470 \\ 2 & 1940 & 2 & 1610 \\ 25 & 74.0 & 25 & 66.0\end{array}$

$\begin{array}{rrrr}3 & 919 & 11 & 410\end{array}$

$\begin{array}{ll}12 & 936 \\ 17 & 407\end{array}$

$\begin{array}{llll}11 & 791 & 18 & 358\end{array}$

$\begin{array}{rr}9 & 999 \\ 20 & 260\end{array}$

$\begin{array}{rr}20 & 1230\end{array}$
$9 \quad 968$

$\begin{array}{rr}9 & 968 \\ 21 & 192 \\ 6 & 1040\end{array}$
$17 \quad 29$

$\begin{array}{ll}10 & 711 \\ 19 & 323\end{array}$

11571

$\begin{array}{rr}8 & 846 \\ 22 & 131 \\ 6 & 944\end{array}$

19168

$\begin{array}{rr}9 & 641 \\ 17 & 255\end{array}$

$\begin{array}{rrrr}7 & 785 & 6 & 568 \\ 22 & 111 & 22 & 102 \\ 6 & 778 & 7 & 476\end{array}$ $\begin{array}{rr}8 & 555 \\ 17 & 150\end{array}$
$60 \quad 90$

$\begin{array}{rr}12 & 277 \\ 5 & 638 \\ 16 & 199\end{array}$

$\begin{array}{rr}10 & 332 \\ 1 & 1870 \\ 9 & 378\end{array}$

$\begin{array}{rrr}9 & 318 & 10\end{array}$

$\begin{array}{lll}21 & 98.0 & 21 \\ 21 & 83.0 & 23\end{array}$

$\begin{array}{rr}15 & 180 \\ 3 & 906\end{array}$

$\begin{array}{rrrrrr}15 & 180 & 16 & 127 & 17 & 108 \\ 3 & 906 & 3 & 650 & 3 & 515 \\ 2 & 1050 & 2 & 778 & 2 & 608\end{array}$

$\begin{array}{rrrr}77 & 3 & 519 & 17 \\ 78 & 2 & 608 & 2\end{array}$

$\begin{array}{cr}608 & 2 \\ 52.0 & 24\end{array}$

$119 \quad 15$

$\begin{array}{rr}69.0 & 23 \\ 361 & 6\end{array}$

$\begin{array}{cc}361 & 6 \\ 104 & 18\end{array}$

$\begin{array}{ll}104 & 18 \\ 167 & 13\end{array}$

$18 \quad 109$

$\begin{array}{rrrrr}6 & 427 & 7 & 341 & 7 \\ 20 & 93.0 & 19 & 84.0 & 19 \\ 8 & 349 & 8 & 287 & 8\end{array}$
$183 \quad$ ALL

$\begin{array}{llll}140 & 12 & 86.0 & 12\end{array}$

$\begin{array}{rrrr}294 & 5 & 161 & 5 \\ 107 & 14 & 70.0 & 14\end{array}$

$\begin{array}{llll}149 & 11 & 92.0 \quad 11\end{array}$ $\begin{array}{rrr}772 & 1 & 41 \\ 153 & 10 & 10\end{array}$ $\begin{array}{llll}70.0 & 19 & 52.0 & 18\end{array}$

$\begin{array}{llll}85.0 & 17 & 49.0 & 20\end{array}$ $\begin{array}{llll}353 & 3 & 189 & 3\end{array}$ $\begin{array}{rrrr}431 & 2 & 255 & 2 \\ 46.0 & 25 & 32.0 & 25\end{array}$ $\begin{array}{llll}46.0 & 25 & 32.0 & 25 \\ 86.0 & 16 & 50.0 & 19\end{array}$ $\begin{array}{llll}57.0 & 23 & 46.0 & 22\end{array}$ $\begin{array}{rrrr}264 & 6 & 151 & 6 \\ 77.0 & 18 & 58.0 & 15\end{array}$ $\begin{array}{llll}123 & 13 & 72.0 & 13\end{array}$ $\begin{array}{crrr}256 & 7 & 151 & 7 \\ 69.0 & 20 & 58.0 & 16\end{array}$ 
GREEN RIVER BASIN

09328000 SAN RAFAEL RIVER NEAR CASTLE DALE, UT-Continued

HIGHEST MEAN DISCHARGE, IN QUBIC FEET PER SECOND, AND RANKING FOR THE INDICATED NUMBER OF CONSECUTIVE DAYS FOR EACH WATER YEAR, OCTOBER 1-SEPTEMBER 30--Continued

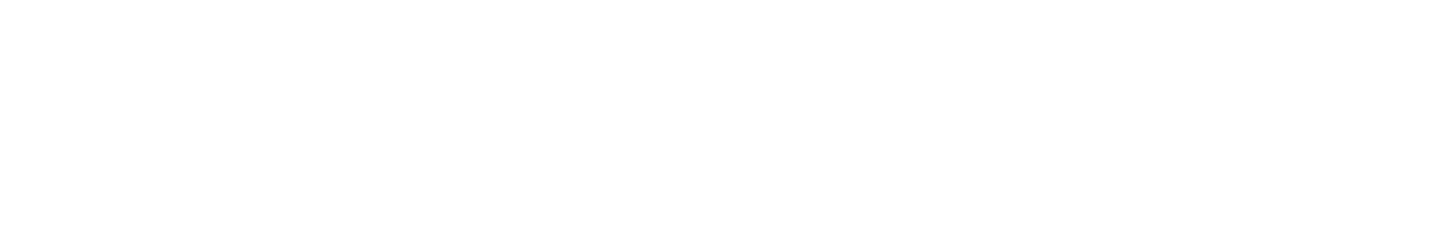

DURATION OF DISCHARGE FOR EACH WATER YEAR

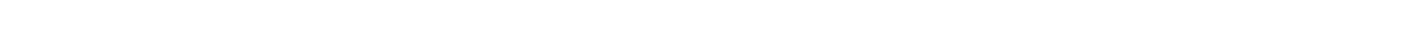

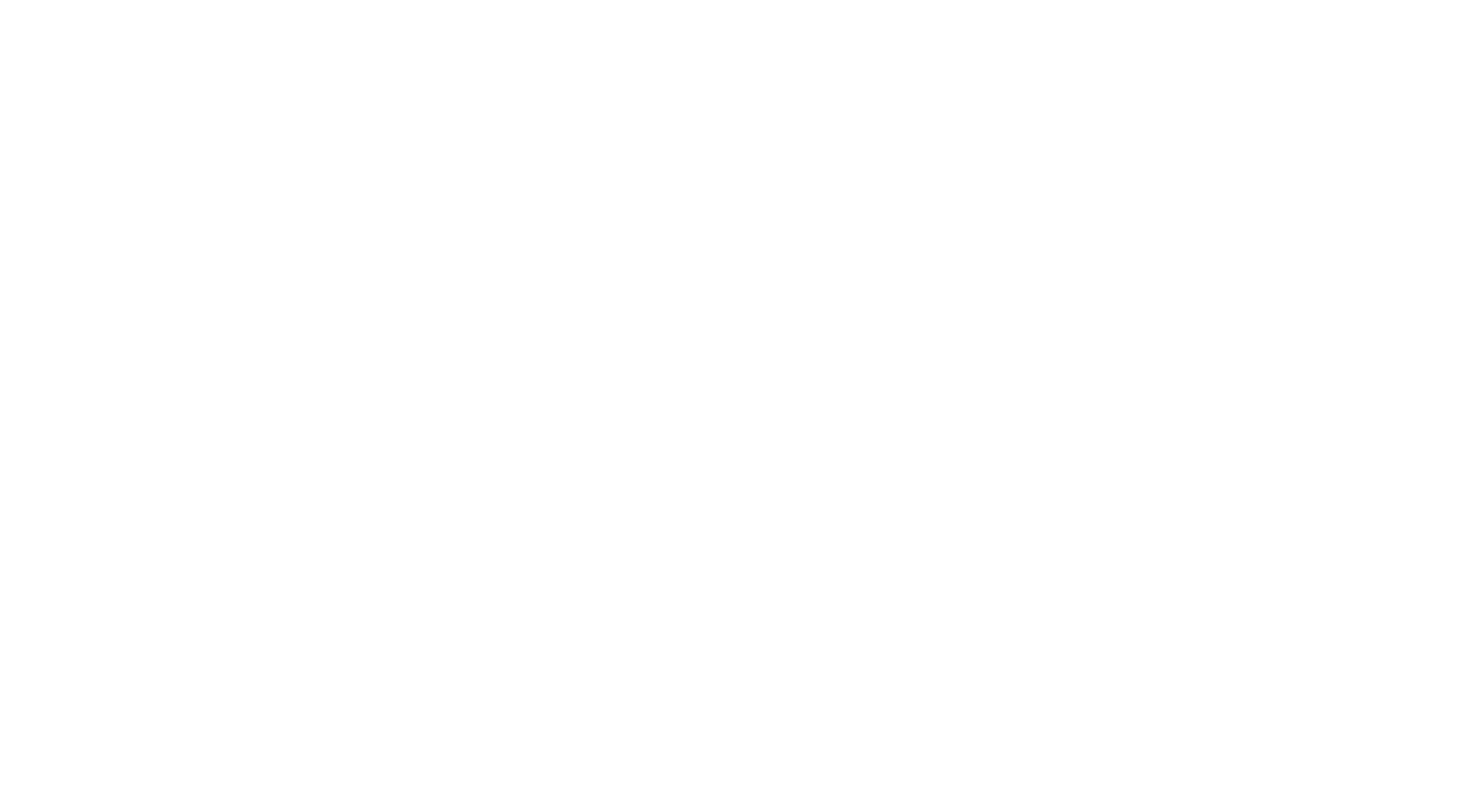

DURATION TABLE OF DISCHARGE FOR WATER YEARS 1 948-64, 1973-81

\begin{tabular}{|c|c|c|c|c|c|c|c|c|c|c|c|c|c|c|c|c|c|c|c|}
\hline CLASS & $\begin{array}{c}\text { OBIC } \\
\text { FEET } \\
\text { PER } \\
\text { SECOND }\end{array}$ & $\begin{array}{l}\text { TOTAL } \\
\text { DAYS }\end{array}$ & $\begin{array}{l}\text { AOCU- } \\
\text { MU- } \\
\text { LATED } \\
\text { DAYS }\end{array}$ & $\begin{array}{l}\text { PER- } \\
\text { CENT } \\
\text { DAYS }\end{array}$ & & $\begin{array}{c}\text { OUBIC } \\
\text { FEET } \\
\text { PER } \\
\text { SECOND }\end{array}$ & $\begin{array}{r}\text { TOTAL } \\
\text { DAYS }\end{array}$ & $\begin{array}{c}\text { ACOJ- } \\
\text { MU- } \\
\text { LATIED } \\
\text { DAYS }\end{array}$ & $\begin{array}{l}\text { PER- } \\
\text { CENI } \\
\text { DAYS }\end{array}$ & CASS & $\begin{array}{c}\text { OJBIC } \\
\text { FEET } \\
\text { PER } \\
\text { SECOND }\end{array}$ & $\begin{array}{l}\text { TOTAL } \\
\text { DAYS }\end{array}$ & $\begin{array}{r}\text { ACOU- } \\
\text { MU- } \\
\text { LATED } \\
\text { DAYS }\end{array}$ & $\begin{array}{l}\text { PER- } \\
\text { CENT } \\
\text { DAYS }\end{array}$ & CASS & $\begin{array}{c}\text { OJBIC } \\
\text { FEET } \\
\text { PER } \\
\text { SECOND }\end{array}$ & $\begin{array}{r}\text { TOTAL } \\
\text { DAYS }\end{array}$ & $\begin{array}{r}\text { ACQU- } \\
\text { MU- } \\
\text { LATED } \\
\text { DAYS }\end{array}$ & $\begin{array}{l}\text { PER- } \\
\text { CENT } \\
\text { DAYS }\end{array}$ \\
\hline $\begin{array}{l}0 \\
1 \\
2 \\
3 \\
4 \\
5 \\
6 \\
7 \\
8\end{array}$ & $\begin{array}{l}0.00 \\
0.02 \\
0.03 \\
0.04 \\
0.06 \\
0.09 \\
0.13 \\
0.18 \\
0.26\end{array}$ & $\begin{array}{r}20 \\
2 \\
2 \\
1 \\
2 \\
1 \\
1 \\
1 \\
3 \\
1\end{array}$ & $\begin{array}{l}9497 \\
9477 \\
9475 \\
9473 \\
9472 \\
9470 \\
9469 \\
9468 \\
9465\end{array}$ & $\begin{array}{r}100.0 \\
99.8 \\
99.8 \\
99.7 \\
99.7 \\
99.7 \\
99.7 \\
99.7 \\
99.7\end{array}$ & $\begin{array}{r}9 \\
10 \\
11 \\
12 \\
13 \\
14 \\
15 \\
16 \\
17\end{array}$ & $\begin{array}{l}0.38 \\
0.55 \\
0.80 \\
1.20 \\
1.70 \\
2.40 \\
3.50 \\
5.00 \\
7.30\end{array}$ & $\begin{array}{r}10 \\
9 \\
4 \\
28 \\
50 \\
126 \\
91 \\
147 \\
296\end{array}$ & $\begin{array}{l}9464 \\
9454 \\
9445 \\
9441 \\
9413 \\
9363 \\
9237 \\
9146 \\
8999\end{array}$ & $\begin{array}{l}99.7 \\
99.5 \\
99.5 \\
99.4 \\
99.1 \\
98.6 \\
97.3 \\
96.3 \\
94.8\end{array}$ & $\begin{array}{l}18 \\
19 \\
20 \\
21 \\
22 \\
23 \\
24 \\
25 \\
26\end{array}$ & $\begin{array}{r}11.0 \\
15.0 \\
22.0 \\
32.0 \\
46.0 \\
66.0 \\
96.0 \\
140.0 \\
200.0\end{array}$ & $\begin{array}{r}354 \\
820 \\
1674 \\
1829 \\
1453 \\
897 \\
490 \\
269 \\
217\end{array}$ & $\begin{array}{r}8703 \\
8349 \\
7529 \\
5855 \\
4026 \\
2573 \\
1676 \\
1186 \\
917\end{array}$ & $\begin{array}{r}91.6 \\
87.9 \\
79.3 \\
61.7 \\
42.4 \\
27.1 \\
17.6 \\
12.5 \\
9.7\end{array}$ & $\begin{array}{l}27 \\
28 \\
29 \\
30 \\
31 \\
32 \\
33 \\
34\end{array}$ & $\begin{array}{r}290.0 \\
420.0 \\
600.0 \\
870.0 \\
1300.0 \\
1800.0 \\
2600.0 \\
3800.0\end{array}$ & $\begin{array}{r}197 \\
163 \\
154 \\
85 \\
53 \\
38 \\
8 \\
2\end{array}$ & $\begin{array}{r}700 \\
503 \\
340 \\
186 \\
101 \\
48 \\
10 \\
2\end{array}$ & $\begin{array}{l}7.4 \\
5.3 \\
3.6 \\
2.0 \\
1.1 \\
0.5 \\
0.1 \\
0.0\end{array}$ \\
\hline
\end{tabular}

MONIHLY MEAN DISCHARGES, IN GUBIC FEET PER SECOND, FOR EAOH WATER YEAR

\begin{tabular}{|c|c|c|c|c|c|c|c|c|c|c|c|c|}
\hline YEAR & $\mathrm{OCT}$ & NOV & $\mathrm{DEC}$ & JAN & FEB & MAR & APR & MAY & JUNE & JULY & AUG & SEP \\
\hline $\begin{array}{l}1948 \\
1949 \\
1950\end{array}$ & $\begin{array}{l}26.7 \\
19.3 \\
37.0\end{array}$ & $\begin{array}{l}58.7 \\
30.8 \\
49.5\end{array}$ & $\begin{array}{l}58.8 \\
30.7 \\
35.4\end{array}$ & $\begin{array}{l}45.0 \\
27.7 \\
34.8\end{array}$ & $\begin{array}{l}98.1 \\
37.9 \\
87.5\end{array}$ & $\begin{array}{c}88.1 \\
120 \\
68.8\end{array}$ & $\begin{array}{c}59.9 \\
181 \\
51.4\end{array}$ & $\begin{array}{l}321 \\
500 \\
170\end{array}$ & $\begin{array}{l}222 \\
749 \\
179\end{array}$ & $\begin{array}{c}29.2 \\
143 \\
89.0\end{array}$ & $\begin{array}{l}16.5 \\
71.4 \\
19.6\end{array}$ & $\begin{array}{c}5.50 \\
22.6 \\
23.6\end{array}$ \\
\hline $\begin{array}{l}1951 \\
1952 \\
1953 \\
1954 \\
1955\end{array}$ & $\begin{array}{l}22.2 \\
61.4 \\
57.5 \\
53.0 \\
21.4\end{array}$ & $\begin{array}{l}37.8 \\
50.7 \\
61.1 \\
60.8 \\
29.1\end{array}$ & $\begin{array}{l}48.2 \\
41.3 \\
62.4 \\
44.1 \\
34.5\end{array}$ & $\begin{array}{l}35.0 \\
40.5 \\
84.2 \\
49.7 \\
30.0\end{array}$ & $\begin{array}{l}36.8 \\
79.8 \\
94.9 \\
84.9 \\
31.4\end{array}$ & $\begin{array}{c}31.3 \\
168 \\
83.4 \\
52.3 \\
108\end{array}$ & $\begin{array}{c}23.6 \\
353 \\
48.7 \\
52.7 \\
39.7\end{array}$ & $\begin{array}{c}252 \\
1600 \\
51.2 \\
140 \\
68.1\end{array}$ & $\begin{array}{r}387 \\
2116 \\
538 \\
31.3 \\
95.5\end{array}$ & $\begin{array}{c}55.1 \\
303 \\
89.3 \\
14.4 \\
12.8\end{array}$ & $\begin{array}{c}143 \\
101 \\
111 \\
8.79 \\
54.8\end{array}$ & $\begin{array}{c}31.2 \\
70.6 \\
30.8 \\
29.9 \\
5.61\end{array}$ \\
\hline
\end{tabular}


GREEN RIVER BASIN

09328000 SAN RAFAEL RIVER NEAR CASTLE DALE, UT-Continued

MONIHLY MEAN DISCHARGES, IN OABIC FEET PER SECOND, FOR EACH WATER YEAR---Continued

$\begin{array}{lcccccccccccc}\text { YEAR } & \text { OCT } & \text { NOW } & \text { DEC } & \text { JAN } & \text { FEB } & \text { MAR } & \text { APR } & \text { MAY } & \text { JUNE } & \text { JULY } & \text { AUG } & \text { SEP } \\ & & & & & & & & & & & & \\ 1956 & 11.6 & 17.3 & 32.6 & 44.4 & 43.7 & 39.3 & 22.1 & 225 & 126 & 18.7 & 7.12 & 2.87 \\ 1957 & 9.67 & 16.0 & 15.0 & 22.1 & 58.8 & 30.0 & 24.5 & 138 & 1450 & 316 & 148 & 58.1 \\ 1958 & 120 & 189 & 63.9 & 61.9 & 128 & 96.1 & 243 & 1127 & 929 & 38.2 & 28.3 & 41.5 \\ 1959 & 25.0 & 40.1 & 55.1 & 41.5 & 65.4 & 41.4 & 28.1 & 24.6 & 45.6 & 5.96 & 8.23 & 10.8 \\ 1960 & 12.2 & 23.0 & 22.0 & 22.0 & 28.6 & 104 & 53.1 & 147 & 165 & 7.56 & 1.94 & 10.3 \\ 1961 & 71.2 & 31.9 & 22.7 & 22.6 & 26.5 & 31.9 & 30.2 & 57.4 & 35.4 & 5.76 & 50.5 & 168 \\ 1962 & 43.0 & 56.4 & 40.5 & 39.8 & 101 & 81.5 & 212 & 447 & 635 & 115 & 26.1 & 25.4 \\ 1963 & 48.5 & 39.7 & 31.8 & 30.2 & 63.9 & 26.5 & 14.7 & 128 & 167 & 13.1 & 68.1 & 72.4 \\ 1964 & 22.1 & 25.9 & 23.9 & 20.2 & 36.6 & 44.7 & 20.5 & 253 & 313 & 48.4 & 43.6 & 7.37 \\ 1973 & 62.5 & 53.2 & 37.3 & 26.0 & 26.0 & 121 & 82.8 & 474 & 645 & 135 & 79.6 & 61.6 \\ 1974 & 73.5 & 47.6 & 38.9 & 32.6 & 33.6 & 52.4 & 35.0 & 77.2 & 98.4 & 95.3 & 55.8 & 49.1 \\ 1975 & 71.0 & 65.8 & 27.3 & 23.2 & 39.9 & 45.2 & 32.4 & 48.5 & 518 & 422 & 94.6 & 102 \\ & & & & & & & & & & & & \\ 1976 & 85.5 & 53.1 & 36.3 & 26.0 & 56.8 & 33.1 & 26.9 & 56.7 & 53.8 & 45.6 & 27.0 & 34.9 \\ 1977 & 35.5 & 28.2 & 23.5 & 20.0 & 22.6 & 25.3 & 9.92 & 10.2 & 4.64 & 15.3 & 3.70 & 2.59 \\ 1978 & 7.85 & 9.69 & 13.3 & 17.1 & 23.4 & 44.5 & 20.9 & 21.5 & 329 & 86.8 & 29.0 & 26.2 \\ 1979 & 32.3 & 53.5 & 30.0 & 28.9 & 23.8 & 161 & 55.2 & 147 & 425 & 85.8 & 64.8 & 42.1 \\ 1980 & 47.3 & 39.4 & 33.4 & 30.9 & 105 & 67.5 & 59.1 & 218 & 1179 & 230 & 60.3 & 127 \\ 1981 & 99.5 & 71.9 & 58.6 & 46.4 & 40.7 & 43.0 & 25.9 & 31.5 & 35.6 & 30.1 & 26.6 & 63.4\end{array}$

ANNUAL PEAK DISCHARGE, IN CUBIC FEET PER SECOND, AND CORRESPONDING GAGE HEIGHT, IN FEET, FOR EACH WATER YEAR

\begin{tabular}{|c|c|c|c|c|c|c|c|c|c|c|c|}
\hline $\begin{array}{l}\text { WATER } \\
\text { YEAR }\end{array}$ & DATE & $\begin{array}{c}\text { GAGE } \\
\text { HEIGHT' }\end{array}$ & $\begin{array}{c}\text { PEAK } \\
\text { DISCHARGE }\end{array}$ & $\begin{array}{l}\text { WATER } \\
\text { YEAR }\end{array}$ & DATE & $\begin{array}{c}\text { GAGE } \\
\text { HEIGHT }\end{array}$ & $\begin{array}{c}\text { PEAK } \\
\text { DISCHARGE }\end{array}$ & $\begin{array}{l}\text { WATER } \\
\text { YEAR }\end{array}$ & DATE & $\begin{array}{c}\text { GAGE } \\
\text { HEIGHT }\end{array}$ & $\begin{array}{c}\text { PEAK } \\
\text { DISCHARGE }\end{array}$ \\
\hline $\begin{array}{l}1948 \\
1949 \\
1950 \\
1951 \\
1952 \\
1953 \\
1954 \\
1955 \\
1956\end{array}$ & $\begin{array}{l}\text { JUNE } 02,1948 \\
\text { AUG. } 09,1949 \\
\text { JULY } 08,1950 \\
\text { AUG. } 04,1951 \\
\text { JUNE } 03,1952 \\
\text { JUNE } 14,1953 \\
\text { SEPT.12, } \\
\text { AUG. } 13,1954 \\
\text { MAY } 26,1955\end{array}$ & $\begin{array}{l}3.64 \\
5.30 \\
4.08 \\
5.53 \\
7.56 \\
4.13 \\
2.47 \\
5.08 \\
3.07\end{array}$ & $\begin{array}{r}782 \\
1890 \\
1100 \\
2020 \\
4510 \\
1440 \\
509 \\
2200 \\
783\end{array}$ & $\begin{array}{l}1957 \\
1958 \\
1959 \\
1960 \\
1961 \\
1962 \\
1963 \\
1964 \\
1973\end{array}$ & $\begin{array}{l}\text { JUNE } 10,1957 \\
\text { NOV. } 03,1957 \\
\text { AUG. } 20,1959 \\
\text { JUNE } 03,1960 \\
\text { SEPT.09, } 1961 \\
\text { SEPT.21, } 1962 \\
\text { AUG. } 30,1963 \\
\text { AUG. } 02,1964 \\
\text { MAY } 26,1973\end{array}$ & $\begin{array}{l}5.28 \\
6.08 \\
1.92 \\
2.68 \\
6.00 \\
3.28 \\
5.30 \\
3.70 \\
-\end{array}$ & $\begin{array}{r}2990 \\
4010 \\
216 \\
575 \\
3670 \\
1230 \\
2960 \\
1460 \\
1300\end{array}$ & $\begin{array}{l}1974 \\
1975 \\
1976 \\
1977 \\
1978 \\
1979 \\
1980 \\
1981\end{array}$ & $\begin{array}{lll}\text { JULY } 18,1974 \\
\text { JUNE } 19,1975 \\
\text { MAY } 06,1976 \\
\text { AUG. } 20,1977 \\
\text { JUNE } 24,1978 \\
\text { JUNE } 07,1979 \\
\text { JUNE 12, } 1980 \\
\text { SEPT.06, } 1981\end{array}$ & $\begin{array}{l}5.02 \\
5.80 \\
5.00 \\
4.56 \\
5.71 \\
5.56 \\
7.32 \\
4.95\end{array}$ & $\begin{array}{r}957 \\
1660 \\
965 \\
657 \\
1550 \\
815 \\
2090 \\
618\end{array}$ \\
\hline
\end{tabular}

MAGNITUDE AND PRCBABILITY OF ANNUAL HIGHEST MFAN DISCHARGE

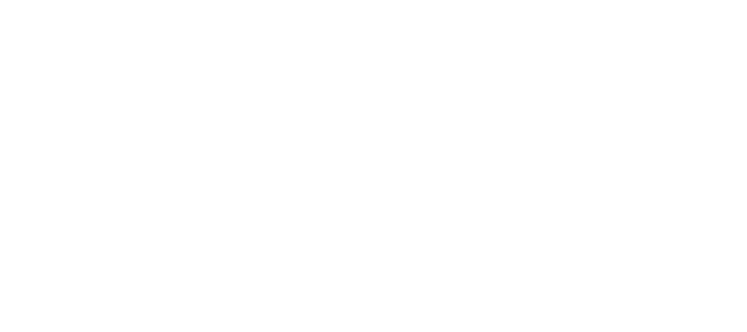

09328050 DRY WASH NEAR MDORE, UT

LOCATION.--Lat $38^{\circ} 56^{\prime} 28^{\prime \prime}$, long $111^{\circ} 04^{\prime} 21^{\prime \prime}$, in SW sec.31, T.21 S., R.8 E., Emery County, Hydrologic Unit 14060009, 5 mi southeast of Moore and about $9.5 \mathrm{mi}$ northeast of Emery.

DRAINAGE AREA.--14 $\mathrm{mi}^{2}$.

MEAN BASIN EIEVATION. $-6,320 \mathrm{ft}$.

PERIOD OF RECORD AVAIIABLE.--Water years 1959-73, annual peak discharge only.

GAGE.--Crest-stage gage. Altitude of gage is 5,940 ft from topographic map.

ANNUAL PEAK DISCHARGE, IN OUBIC FEET PER SECOND, AND CORRESPONDING GAGE HEIGHT, IN FEET, FOR EACH WATER YEAR

\begin{tabular}{|c|c|c|c|c|c|c|c|c|c|c|c|}
\hline $\begin{array}{l}\text { WATER } \\
\text { YEAR }\end{array}$ & DATE & $\begin{array}{l}\text { GAGE } \\
\text { HEIGHT }\end{array}$ & $\begin{array}{c}\text { PEAK } \\
\text { DISCHARGE }\end{array}$ & $\begin{array}{l}\text { WATER } \\
\text { YEAR }\end{array}$ & DATE & $\begin{array}{c}\text { GAGE } \\
\text { HEIGHT }\end{array}$ & $\begin{array}{c}\text { PEAK } \\
\text { DISCHARGE }\end{array}$ & $\begin{array}{l}\text { WATER } \\
\text { YEAR }\end{array}$ & DATE & $\begin{array}{c}\text { GAGE } \\
\text { HEIGHT }\end{array}$ & $\begin{array}{c}\text { PEAK } \\
\text { DISCHARGE }\end{array}$ \\
\hline $\begin{array}{l}1959 \\
1960 \\
1961 \\
1962 \\
1963\end{array}$ & $\begin{array}{l}\text { JULY } 14,1959 \\
\text { - } \bar{~} \\
\text { SEPT.09, } 1961 \\
\text { OCT. 09, } 1961 \\
\text { AUG. 31, } 1963\end{array}$ & $\begin{array}{l}12.64 \\
11.92 \\
12.82 \\
13.06 \\
16.28\end{array}$ & $\begin{array}{r}214 \\
105 \\
250 \\
300 \\
1630\end{array}$ & $\begin{array}{l}1964 \\
1965 \\
1966 \\
1967 \\
1968\end{array}$ & $\begin{array}{lll}\text { AUG. } & 12,1964 \\
\text { JULY } & 14,1965 \\
\text { JULY } 17,1966 \\
\text { AUG. } 08,1967 \\
\text { JULY } 30,1968\end{array}$ & $\begin{array}{l}13.28 \\
15.01 \\
13.40 \\
10.90 \\
15.11\end{array}$ & $\begin{array}{r}325 \\
830 \\
350 \\
26 \\
875\end{array}$ & $\begin{array}{l}1969 \\
1970 \\
1971 \\
1972 \\
1973\end{array}$ & $\begin{array}{l}\text { AUG. } 30,1969 \\
\text { SEPT. 06, } 1970 \\
\text { JULY 15, } 1971 \\
\text { AUG. } 03,1972 \\
\text { OCT. } 19,1972\end{array}$ & $\begin{array}{l}12.72 \\
15.07 \\
12.52 \\
12.96 \\
12.82\end{array}$ & $\begin{array}{l}240 \\
900 \\
190 \\
260 \\
250\end{array}$ \\
\hline
\end{tabular}


LOCATION.-Lat $39^{\circ} 04^{\prime} 51^{\prime \prime}$, long $110^{\circ} 39^{\prime} 56^{\prime \prime}$, in NE⿺辶大 $\mathrm{SE}^{\frac{1}{4}}$ sec.15, T.20 S., R.11 E., Emery County, Hydrologic Unit 14060009, on left bank $80 \mathrm{ft}$ downstream from San Rafael River bridge, $21 \mathrm{mi}$ southeast of Castle Dale, and $52 \mathrm{mi}$ northwest of Green River.

DRAINAGE AREA. $--1,284 \mathrm{mi}^{2}$.

PERIOD OF RECORD AVAIIABLE.-October 1975 to September 1981.

GAGE.-Water-stage recorder. Altitude of gage is 5,100 ft from topographic map.

REMARKS.--Many diversions above station.

AVERAGE DISCHARGE. -6 years, $76.8 \mathrm{ft}^{3} / \mathrm{s}, 55,640$ acre-ft/yr.

EXIREMES FOR PERIOD OF RECORD.-Maximum discharge, 4,630 ft ${ }^{3} / \mathrm{s}$ Sept. 10, 1980, gage height, $11.08 \mathrm{ft}$, from slope-area measurement of peak flow; no flow for several days in 1977-78.

LOWEST MEAN DISCHARGE, IN CUBIC FEET PER SECOND, AND RANKING FOR THE INDICATED NUMBER OF CONSECUTIVE DAYS FOR EACH CLIMATIC YEAR, APRIL I-MARCH 31

\begin{tabular}{|c|c|c|c|c|c|c|c|c|c|c|c|c|c|c|c|c|c|c|c|}
\hline YEAR & 1 & & 3 & & 7 & & 14 & & $\begin{array}{l}\text { CONSI } \\
30\end{array}$ & & $\begin{array}{l}\text { E DAYS } \\
60\end{array}$ & & 90 & & 120 & & 183 & & ALL \\
\hline $\begin{array}{l}1977 \\
1978 \\
1979 \\
1980\end{array}$ & $\begin{array}{c}5.00 \\
0.00 \\
12.0 \\
28.0\end{array}$ & $\begin{array}{l}2 \\
1 \\
3 \\
5\end{array}$ & $\begin{array}{c}5.30 \\
0.00 \\
12.0 \\
28.0\end{array}$ & $\begin{array}{l}2 \\
1 \\
3 \\
5\end{array}$ & $\begin{array}{c}6.70 \\
0.00 \\
14.0 \\
30.0\end{array}$ & $\begin{array}{l}2 \\
1 \\
3 \\
4\end{array}$ & $\begin{array}{c}8.90 \\
0.00 \\
16.0 \\
32.0\end{array}$ & $\begin{array}{l}2 \\
1 \\
3 \\
4\end{array}$ & $\begin{array}{c}12.0 \\
0.59 \\
18.0 \\
34.0\end{array}$ & $\begin{array}{l}2 \\
1 \\
3 \\
4\end{array}$ & $\begin{array}{c}19.0 \\
2.50 \\
22.0 \\
38.0\end{array}$ & $\begin{array}{l}2 \\
1 \\
3 \\
4\end{array}$ & $\begin{array}{c}20.0 \\
4.80 \\
27.0 \\
41.0\end{array}$ & $\begin{array}{l}2 \\
1 \\
3 \\
4\end{array}$ & $\begin{array}{l}22.0 \\
10.0 \\
33.0 \\
42.0\end{array}$ & $\begin{array}{l}2 \\
1 \\
3 \\
4\end{array}$ & $\begin{array}{l}25.0 \\
14.0 \\
42.0 \\
46.0\end{array}$ & $\begin{array}{l}2 \\
1 \\
3 \\
4\end{array}$ & $\begin{array}{l}34.0 \\
19.0 \\
69.0 \\
97.0\end{array}$ \\
\hline 981 & 24.0 & 4 & 27.0 & 4 & 31.0 & 5 & 34.0 & 5 & 39.0 & 5 & 43.0 & 5 & 46.0 & 5 & 48.0 & 5 & 59.0 & 5 & 197 \\
\hline
\end{tabular}

HIGHEST MEAN DISCHARGE, IN OUBIC FEET PER SECOND, AND RANKING FOR THE INDICATED NUMBER OF CONSEOUTIVE DAYS FOR EACH WATER YEAR, OCTOBER 1-SEPTEMBER 30

\begin{tabular}{|c|c|c|c|c|c|c|c|c|c|c|c|c|c|c|c|c|c|c|c|c|}
\hline YEAR & 1 & & 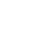 & & 7 & & 15 & & $\begin{array}{l}\text { CONs } \\
30\end{array}$ & CuT & $\begin{array}{c}\text { VE DAYs } \\
60\end{array}$ & & 90 & & 120 & & 183 & & ALL & \\
\hline $\begin{array}{l}1976 \\
1977 \\
1978 \\
1979 \\
1980\end{array}$ & $\begin{array}{r}203 \\
383 \\
549 \\
660 \\
2080\end{array}$ & $\begin{array}{l}6 \\
5 \\
4 \\
2 \\
1\end{array}$ & $\begin{array}{r}188 \\
185 \\
544 \\
603 \\
1920\end{array}$ & $\begin{array}{l}5 \\
6 \\
3 \\
2 \\
1\end{array}$ & $\begin{array}{r}149 \\
113 \\
523 \\
556 \\
1780\end{array}$ & $\begin{array}{l}5 \\
6 \\
3 \\
2 \\
1\end{array}$ & $\begin{array}{c}109 \\
56.0 \\
418 \\
537 \\
1630\end{array}$ & $\begin{array}{l}5 \\
6 \\
3 \\
2 \\
1\end{array}$ & $\begin{array}{r}88.0 \\
41.0 \\
303 \\
426 \\
1270\end{array}$ & $\begin{array}{l}5 \\
6 \\
3 \\
2 \\
1\end{array}$ & $\begin{array}{l}70.0 \\
34.0 \\
174 \\
271 \\
780\end{array}$ & $\begin{array}{l}5 \\
6 \\
3 \\
2 \\
1\end{array}$ & $\begin{array}{l}62.0 \\
28.0 \\
126 \\
208 \\
573\end{array}$ & $\begin{array}{l}5 \\
6 \\
3 \\
2 \\
1\end{array}$ & $\begin{array}{l}53.0 \\
26.0 \\
102 \\
196 \\
457\end{array}$ & $\begin{array}{l}5 \\
6 \\
3 \\
2 \\
1\end{array}$ & $\begin{array}{r}47.0 \\
25.0 \\
80.0 \\
150 \\
334\end{array}$ & $\begin{array}{l}5 \\
6 \\
3 \\
2 \\
1\end{array}$ & $\begin{array}{r}44.0 \\
20.0 \\
49.0 \\
97.0 \\
199\end{array}$ & $\begin{array}{l}5 \\
6 \\
4 \\
2 \\
1\end{array}$ \\
\hline 1981 & 599 & 3 & 270 & 4 & 253 & 4 & 159 & 4 & 111 & 4 & 81.0 & 4 & 73.0 & 4 & 65.0 & 4 & 59.0 & 4 & 52.0 & 3 \\
\hline
\end{tabular}

DURATION OF DISCEARGE FOR EACH WATER YEAR

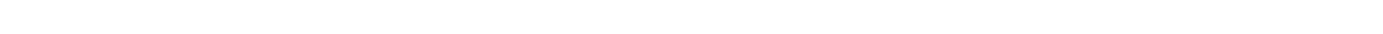
YEAR NUMBER OF DAYS IN CIASS

$$
\begin{aligned}
& \text { OBBIC FEET } \\
& \text { PER SECOND } \\
& \text {-DAYS }
\end{aligned}
$$

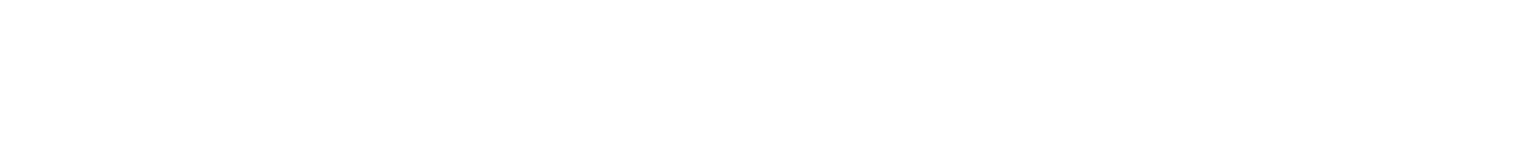

DURATION TABLE OF DISCHARGE FOR WATER YEARS 1976-81 $\begin{array}{ccc}\text { CUBIC } & \text { ACOU- } \\ \text { FEET } & \text { MU- } & \text { PER- } \\ \text { PER } & \text { TOTAL LATED } & \text { CENT } \\ \text { CLASS SECOND DAYS } & \text { DAYS } & \text { DAYS }\end{array}$

$\begin{array}{rrrrr}0 & 0.00 & 27 & 2192 & 100.0 \\ 1 & 0.08 & 3 & 2165 & 98.8 \\ 2 & 0.11 & 0 & 2162 & 98.6 \\ 3 & 0.15 & 3 & 2162 & 98.6 \\ 4 & 0.20 & 0 & 2159 & 98.5 \\ 5 & 0.27 & 3 & 2159 & 98.5 \\ 6 & 0.37 & 1 & 2156 & 98.4 \\ 7 & 0.50 & 8 & 2155 & 98.3 \\ 8 & 0.68 & 4 & 2147 & 97.9\end{array}$

OUBIC ACOU-
FEET PER TOTAL LATED CENT
CIASS SECOND DAYS DAYS DAYS

$\begin{array}{rrrrr}9 & 0.93 & 12 & 2143 & 97.8 \\ 10 & 1.30 & 5 & 2131 & 97.2 \\ 11 & 1.70 & 9 & 2126 & 97.0 \\ 12 & 2.30 & 11 & 2117 & 96.6 \\ 13 & 3.20 & 10 & 2106 & 96.1 \\ 14 & 4.30 & 17 & 2096 & 95.6 \\ 15 & 5.80 & 51 & 2079 & 94.8 \\ 16 & 7.90 & 74 & 2028 & 92.5 \\ 17 & 11.00 & 71 & 1954 & 89.1\end{array}$

AUBIC ACOUFEET MU- PER$\begin{array}{ccc}\text { PER TOTAL LATED } & \text { CENT } \\ \text { CLASS SECOND DAYS DAYS DAYS }\end{array}$

$\begin{array}{rrrrr}18 & 15.0 & 161 & 1883 & 85.9 \\ 19 & 20.0 & 279 & 1722 & 78.6 \\ 20 & 27.0 & 335 & 1443 & 65.8 \\ 21 & 36.0 & 368 & 1108 & 50.5 \\ 22 & 50.0 & 256 & 740 & 33.8 \\ 23 & 67.0 & 163 & 484 & 22.1 \\ 24 & 91.0 & 86 & 321 & 14.6 \\ 25 & 120.0 & 68 & 235 & 10.7 \\ 26 & 170.0 & 43 & 167 & 7.6\end{array}$

OBBIC ACOU$\begin{array}{lll}\text { FEET TOT- } & \text { PER- } \\ \text { PER TOTAL LATED } & \text { CENT }\end{array}$ CIASS SECOND DAYS DAYS DAYS

$\begin{array}{rrrrr}27 & 230.0 & 30 & 124 & 5.7 \\ 28 & 310.0 & 27 & 94 & 4.3 \\ 29 & 420.0 & 23 & 67 & 3.1 \\ 30 & 570.0 & 18 & 44 & 2.0 \\ 31 & 780.0 & 7 & 26 & 1.2 \\ 32 & 1100.0 & 4 & 19 & 0.9 \\ 33 & 1400.0 & 14 & 15 & 0.7 \\ 34 & 2000.0 & 1 & 1 & 0.0\end{array}$


GREEN RIVER BASIN

09328100 SAN RAFAEL RIVER AT SAN RAFAET BRIDGE CAMPGROND, NEAR CASTLE DALE, UT-Continued

MONTHLY MEAN DISCHARGES, IN OUBIC FEET PER SBCOND, FOR EACH WATER YEAR

$\begin{array}{rlcllllllrrrr}\text { YEAR } & \text { OCT } & \text { NOV } & \text { DEC } & \text { JAN } & \text { FEB } & \text { MAR } & \text { APR } & \text { MAY } & \text { JUNE } & \text { JULY } & \text { AUG } & \text { SEP } \\ 1976 & 82.2 & 55.8 & 34.0 & 25.0 & 53.8 & 25.7 & 20.4 & 79.0 & 49.5 & 43.4 & 26.9 & 37.6 \\ 1977 & 34.2 & 28.4 & 20.9 & 19.0 & 20.1 & 26.9 & 11.3 & 8.63 & 2.0 & 27.0 & 22.7 & 17.3 \\ 1978 & 11.8 & 9.28 & 13.2 & 18.3 & 25.4 & 58.9 & 24.0 & 20.9 & 285 & 61.0 & 31.0 & 29.9 \\ 1979 & 35.2 & 106 & 31.0 & 27.3 & 27.0 & 148 & 64.8 & 127 & 400 & 93.9 & 68.3 & 36.5 \\ 1980 & 47.0 & 45.5 & 38.7 & 39.6 & 137 & 75.6 & 56.7 & 226 & 1236 & 247 & 66.2 & 189 \\ 1981 & 98.4 & 61.7 & 55.8 & 42.4 & 45.2 & 50.2 & 25.3 & 32.1 & 40.3 & 30.7 & 42.3 & 93.8\end{array}$

ANNUAL PEAK DISCHARGE, IN OBBIC FEET PER SEOOND, AND CORRESPONDING GAGE HEIGHT, IN FEET, FOR EACH WATER YEAR

\begin{tabular}{|c|c|c|c|c|c|c|c|c|c|c|c|}
\hline $\begin{array}{l}\text { WATER } \\
\text { YEAR }\end{array}$ & DATE & $\begin{array}{l}\text { GAGE } \\
\text { HEIGHT }\end{array}$ & $\begin{array}{c}\text { PEAK } \\
\text { DISCHARGE }\end{array}$ & $\begin{array}{l}\text { WATER } \\
\text { YEAR }\end{array}$ & DATE & $\begin{array}{l}\text { GAGE } \\
\text { HEIGHT }\end{array}$ & $\begin{array}{c}\text { PEAK } \\
\text { DISCHARGE }\end{array}$ & $\begin{array}{l}\text { WATER } \\
\text { YEAR }\end{array}$ & DATE & $\begin{array}{l}\text { GAGE } \\
\text { HEIGHT }\end{array}$ & $\begin{array}{c}\text { PEAK } \\
\text { DISCHARGE }\end{array}$ \\
\hline $\begin{array}{l}1976 \\
1977\end{array}$ & $\begin{array}{l}\text { AUG. } 02,1976 \\
\text { AUG. } 17,1977\end{array}$ & $\begin{array}{l}3.92 \\
7.29\end{array}$ & $\begin{array}{r}257 \\
1250\end{array}$ & $\begin{array}{l}1978 \\
1979\end{array}$ & $\begin{array}{l}\text { JUNE } 24,1978 \\
\text { NOV. 03, } 1978\end{array}$ & $\begin{array}{l}5.38 \\
6.80\end{array}$ & $\begin{array}{r}621 \\
1070\end{array}$ & $\begin{array}{l}1980 \\
198 j\end{array}$ & $\begin{array}{l}\text { SEPT.10, } 1980 \\
\text { SEPT.06, } 1981\end{array}$ & $\begin{array}{r}11.08 \\
8.38\end{array}$ & $\begin{array}{l}4630 \\
2550\end{array}$ \\
\hline
\end{tabular}

09328200 BUCKHORN DRAW TRIBUTARY NEAR CASTLE DALE, UT

LOCATION.--Lat $39^{\circ} 10^{\prime} 38^{\prime \prime}$, long $110^{\circ} 42^{\prime} 53^{\prime \prime}$, in SW $\frac{1}{4}$ sec.8, T.19 S., R.1l E., Emery County, Hydrologic Unit 14060009, 60 ft above bridge, $14.5 \mathrm{mi}$ east of Castle Dale, and $22 \mathrm{mi}$ northeast of Ferron.

DRAINAGE AREA. $-5.7 \mathrm{mi}^{2}$.

PERIOD OF RECORD AVAILABLE.--Water years 1959-67, annual peak discharge only.

GAGE.--Crest-stage gage. Altitude of gage is 5,700 ft fram topographic map.

ANNUAL PEAK DISCHARGE, IN OUBIC FEET PER SECOND, AND CORRESPONDING GAGE HEIGHT, IN FEET, FOR EACH WATER YEAR

\begin{tabular}{|c|c|c|c|c|c|c|c|c|c|c|c|}
\hline $\begin{array}{l}\text { WATER } \\
\text { YEAR }\end{array}$ & DATE & $\begin{array}{c}\text { GAGE } \\
\text { HEIGHT }\end{array}$ & $\begin{array}{c}\text { PEAR } \\
\text { DISCHARGE }\end{array}$ & $\begin{array}{l}\text { WATEER } \\
\text { YEAR }\end{array}$ & DATE & $\begin{array}{c}\text { GAGE } \\
\text { HEIGHT }\end{array}$ & $\begin{array}{c}\text { PEAK } \\
\text { DISCHARGE }\end{array}$ & $\begin{array}{l}\text { WATER } \\
\text { YEAR }\end{array}$ & DATE & $\begin{array}{c}\text { GAGE } \\
\text { HEIGHT }\end{array}$ & $\begin{array}{c}\text { PEAK } \\
\text { DISCHARGE }\end{array}$ \\
\hline $\begin{array}{l}1959 \\
1960 \\
1961\end{array}$ & $\begin{array}{l}\text { AUG. } 04,1959 \\
\text { NON. 02, } 1959 \\
\text { SEPT. 08, } 1961\end{array}$ & $\begin{array}{r}12.05 \\
9.80 \\
10.46\end{array}$ & $\begin{array}{r}1190 \\
25 \\
80\end{array}$ & $\begin{array}{l}1962 \\
1963 \\
1964\end{array}$ & $\begin{array}{l}\text { SEPT. } 28,1962 \\
\text { AUG. } 17,1963 \\
\text { SEPT. } 15,1964\end{array}$ & $\begin{array}{ll}2 & 10.40 \\
3 & 18.50 \\
4 & 10.52\end{array}$ & $\begin{array}{r}84 \\
5880 \\
380\end{array}$ & $\begin{array}{l}1965 \\
1966 \\
1967\end{array}$ & $\begin{array}{l}\text { AUG. } 18,1965 \\
\text { OCT. 16, } 1965 \\
\text { SEPT.10, } 1967\end{array}$ & $\begin{array}{rr}5 & 10.05 \\
5 & 9.35 \\
7 & 10.20\end{array}$ & $\begin{array}{r}270 \\
50 \\
41\end{array}$ \\
\hline
\end{tabular}

09328300 SIDS DRAW NEAR CASTHE DALE, UT

LOCATION.--Lat $38^{\circ} 58^{\prime} 40^{\prime \prime}$, long $110^{\circ} 39^{\prime} 55^{\prime \prime}$, in $\mathrm{NW}^{\frac{1}{4}} \mathrm{sec} .23$, T.21 S., R.11 E. (unsurveyed), Emery County, Hydrologic Unit 14060009 , about $8.5 \mathrm{mi}$ south of San Rafael River bridge along the Castle Dale-Temple Junction road and 24 mi southeast of Castle Dale.

DRAINAGE AREA. $-17.6 \mathrm{mi}^{2}$

MEAN BASIN ELEVATION.--6,380 ft.

PERIOD OF RECORD AVAIIABLE.-Water years 1959-73, annual peak discharge only.

GAGE.--Crest-stage gage. Altitude of gage is 5,800 ft from topographic map.

REMARKS.--Small peak discharges slightly affected by Sids Reservoir 1 mi above station.

ANNUAL PEAK DISCHARGE, IN OUBIC FEET PER SECOND, AND CORRESPONDING GAGE HEIGHT, IN FEET, FOR EACH WATER YEAR

\begin{tabular}{|c|c|c|c|c|c|c|c|c|c|c|c|}
\hline $\begin{array}{l}\text { WATER } \\
\text { YEAR }\end{array}$ & DATE & $\begin{array}{l}\text { GAGE } \\
\text { HEIGHT }\end{array}$ & $\begin{array}{c}\text { PEAR } \\
\text { DISCHARGE }\end{array}$ & $\begin{array}{l}\text { WATER } \\
\text { YEAR }\end{array}$ & DATE & $\begin{array}{l}\text { GAGE } \\
\text { HEIGHT }\end{array}$ & $\begin{array}{c}\text { PEAR } \\
\text { DISCHARGE }\end{array}$ & $\begin{array}{l}\text { WATERR } \\
\text { YEAR }\end{array}$ & DATE & $\begin{array}{c}\text { GAGE } \\
\text { HEIGHT }\end{array}$ & $\begin{array}{c}\text { PEAK } \\
\text { DISGHARGE }\end{array}$ \\
\hline $\begin{array}{l}1959 \\
1960 \\
1961 \\
1962 \\
1963\end{array}$ & $\begin{array}{cc}\text { SEPT.16, } 1959 \\
--\overline{25} & \overline{-1961} \\
\text { AUG. } & 25, \\
\text { SEPT. } 28, & 1962 \\
\text { AUG. } 13,1963\end{array}$ & $\begin{array}{c}12.18 \\
-- \\
12.30 \\
12.07 \\
13.65\end{array}$ & $\begin{array}{c}888 \\
1.0 \\
1320 \\
820 \\
1940\end{array}$ & $\begin{array}{l}1964 \\
1965 \\
1966 \\
1967 \\
1968\end{array}$ & $\begin{array}{l}\text { JULY } 31,1964 \\
\text { AUG. } 18,1965 \\
\text { AUG. } 06,1966 \\
\text { AUG. } 08,1967 \\
\text { AUG. } 01,1968\end{array}$ & $\begin{array}{l}12.40 \\
11.32 \\
12.80 \\
13.90 \\
10.48\end{array}$ & $\begin{array}{r}1020 \\
440 \\
1260 \\
2150 \\
120\end{array}$ & $\begin{array}{l}1969 \\
1970 \\
1971 \\
1972 \\
1973\end{array}$ & $\begin{array}{l}\text { AUG. } 30,1969 \\
\text { SEPT. 06, } 1970 \\
\text { JULY } 16,1971 \\
\text { JULY } 14,1972 \\
\text { AUG. } 07,1973\end{array}$ & $\begin{array}{l}10.56 \\
10.70 \\
10.28 \\
10.60 \\
11.18\end{array}$ & $\begin{array}{r}145 \\
190 \\
60 \\
160 \\
420\end{array}$ \\
\hline
\end{tabular}


GREEN RIVER BASIN

09328500 SAN RAFAEI. RIVER NEAR GREEN RIVER, UT

LOCATION.--Lat $38^{\circ} 51^{\prime} 30^{\prime \prime}$, long $110^{\circ} 22^{\prime} 10^{\prime \prime}$, in SE $\frac{1}{4} \mathrm{SE}_{\frac{1}{4}} \mathrm{NW}_{\frac{1}{4}}$ sec.34, T.22 S., R.14 E., Emery County, Hydrologic Unit 14060009, on left bank $300 \mathrm{ft}$ upstream from bridge on State Highway $245,14.0 \mathrm{mi}$ southwest of Green River, and $34.3 \mathrm{mi}$ upstream from mouth.

DRAINAGE AREA. $-1,628 \mathrm{mi}^{2}$.

MEAN BASIN ELEVATION. $-6,910 \mathrm{ft}$.

PERIOD OF RECORD AVAIIABLE.--May 1909 to September 1918 (monthly mean discharge prior to October 1909 published in wSP 1313 ), September 1919 to July 1920 (gage heights only), October 1945 to September 1981.

REVISED RECORDS.--WDR UT-77-1: Drainage area.

GAGE.--Water-stage recorder. Altitude of gage is 4,190 ft from topographic map. May 5, 1909 to Sept. 10, 1918, staff gage, and Sept. 10, 1919 to July 10, 1920, tape-weight gage. Now. 29, 1945 to July 7, 1976, water-stage recorder at various sites and datums about $1 \mathrm{mi}$ upstream.

REMARKS.-Diversions above station for irrigation of about 42,000 acres. Several small transmountain diversions from tributaries for irrigation in Sevier Lake basin, and some storage since Nov. 3, 1965, in Joes Valley Reservoir.

AVERAGE DISCHARGE.--45 years (water years 1910-18, 1946-81), $145 \mathrm{ft}^{3} / \mathrm{s}, 105,100 \mathrm{acre}-\mathrm{ft} / \mathrm{yr}$.

EXIREMES FOR PERIOD OF RECORD.--Maximum discharge, 12,000 ft $3 / \mathrm{s}$ Sept. 2, 1909, gage height, $12.7 \mathrm{ft}$, site and datum then in use, fram rating curve extended above $3,100 \mathrm{ft} / \mathrm{s}$; no flow at times in some years.

LOWEST MEAN DISCHARGE, IN OBIC FEET PER SECOND, AND RANKING FOR THE INDICATED NUMBER OF CONSECUTIVE DAYS FOR EACH CLIMATIC YEAR, APRI I-MARCH 31

YEAR

1

0.00

$50.0 \quad 43$

$15.0 \quad 32$

2.0020
$16.0 \quad 33$

0.002

$14.0 \quad 29$

$27.0 \quad 39$

0.003

$15.0 \quad 30$

$\begin{array}{rr}15.0 & 30 \\ 0.00 \quad 4\end{array}$

$\begin{array}{lr}0.00 & 4 \\ 6.10 & 22\end{array}$

0.005

9.0024

0.4016

$12.0 \quad 27$

0.2013

0.006

$19.0 \quad 35$

3.0021

3.0021
0.1011

0.007

0.008

1.0018

0.3014

$27.0 \quad 40$

27.0
0.20

0.009

$17.0 \quad 34$

$\begin{array}{ll}17.0 & 34 \\ 15.0 & 31\end{array}$

$20.0 \quad 36$

$\begin{array}{ll}20.0 & 36 \\ 11.0 & 37\end{array}$

11.026

$\begin{array}{ll}32.0 & 42 \\ 20.0 & 38\end{array}$

$10.0 \quad 25$

7.0023

0.0010

0.0010
1.4019

1.4019
$14.0 \quad 28$

$31.0 \quad 41$
3

0.001

$50.0 \quad 43$

$15.0 \quad 28$

3.3019
$16.0 \quad 30$

0.002

$\begin{array}{ll}20.0 & 37 \\ 27.0 & 38\end{array}$

$\begin{array}{rr}0.00 & 3 \\ 15.0 & 29\end{array}$

$\begin{array}{ll}0.00 & 4 \\ 7.60 & 22\end{array}$

0.005

9.5023

$28.0 \quad 40$

$\begin{array}{cc}12.0 & 26 \\ 0.40 & 15\end{array}$

0.2012

0.006

$19.0 \quad 33$

3.3020
0.1011

0.007

0.008

1.0017

0.3013
0.4716

$27.0 \quad 39$

0.3014

0.009

$18.0 \quad 32$

$20.0 \quad 34$

$20.0 \quad 35$

11.025

$\begin{array}{ll}32.0 & 41 \\ 20.0 & 36\end{array}$

$10.0 \quad 24$

7.0021

0.0010

1.5018
$15.0 \quad 27$

$32.0 \quad 42$

$\begin{array}{cc}7 & \\ & \\ 4.60 & 18 \\ 50.0 & 43 \\ 15.0 & 27 \\ 8.10 & 20 \\ 16.0 & 28\end{array}$

14

$11.0 \quad 20$

50.043

$\begin{array}{ll}50.0 & 43 \\ 17.0 & 27\end{array}$

$\begin{array}{ll}14.0 & 24 \\ 17.0 & 28\end{array}$

0.001

$20.0 \quad 34$

1.3015

$\begin{array}{cc}1.30 & 15 \\ 17.0 \quad 30 & 0\end{array}$

$\begin{array}{rr}17.0 & 30 \\ 0.00 \quad 2\end{array}$

8.2021

0.003

$\begin{array}{cc}10.0 & 23 \\ 46.0 & 42\end{array}$

$\begin{array}{rr}46.0 & 42 \\ 13.0 & 26\end{array}$

0.4011

0.209

$0.00 \quad 4$
$21.0 \quad 35$

21.035

$\begin{array}{rr}5.40 & 19 \\ 0.10 & 8\end{array}$

0.005

$\begin{array}{ll}0.00 & 6 \\ 1.40 & 16\end{array}$

1.4016
0.3710

0.6413

$29.0 \quad 38$

0.4912

$0.83 \quad 14$
22.0

$\begin{array}{ll}22.0 & 36 \\ 25.0 & 37\end{array}$

$20.0 \quad 31$

$20.0 \quad 32$

$\begin{array}{ll}11.0 & 24 \\ 32.0 & 40\end{array}$

$20.0 \quad 33$

$12.0 \quad 25$

9.0022
0.007

2.2017

2.2017
$16.0 \quad 29$

$33.0 \quad 41$

$0.00 \quad 1$

$\begin{array}{ll}20.0 & 31 \\ 37.0 & 41\end{array}$

3.0015

$18.0 \quad 29$

0.002

$14.0 \quad 25$

$0.53 \quad 9$
$12.0 \quad 21$

$\begin{array}{ll}12.0 & 21 \\ 50.0 & 42\end{array}$

$\begin{array}{ll}50.0 & 42 \\ 14.0 & 26\end{array}$

0.7610

$0.20 \quad 8$

0.003
$22.0 \quad 35$

$\begin{array}{cc}22.0 & 35 \\ 7.10 & 18\end{array}$

$\begin{array}{ll}7.10 & 18 \\ 0.10 & 6\end{array}$

0.034

0.085

2.0014

1.8013
1.3012

$32.0 \quad 39$

3.4016

1.1911

$\begin{array}{ll}31.0 & 37 \\ 27.0 & 36\end{array}$

$20.0 \quad 32$

$21.0 \quad 33$

12.022

$\begin{array}{ll}32.0 & 38 \\ 21.0 & 34\end{array}$

$14.0 \quad 23$

11.0 19

0.137

3.6017

19.030

36.040

CONSECUTIVE DAYS

$30 \quad 60$

$40.0 \quad 37$

$\begin{array}{ll}40.0 & 37 \\ 50.0 & 42\end{array}$

$\begin{array}{ll}50.0 & 42 \\ 30.0 & 32\end{array}$

$\begin{array}{ll}46.0 & 41 \\ 23.0 & 25\end{array}$

$\begin{array}{lll}58.0 & 42\end{array}$

$\begin{array}{ll}55.0 & 39 \\ 43.0 & 35\end{array}$

$\begin{array}{ll}43.0 & 35 \\ 56.0 & 40\end{array}$

$\begin{array}{ll}56.0 & 40 \\ 35.0 & 29\end{array}$

$0.02 \quad 3$

$\begin{array}{ll}20.0 & 23 \\ 41.0 & 38\end{array}$

$7.10 \quad 8$

$\begin{array}{ll}37.0 & 30 \\ 54.0 & 38\end{array}$

5.3013

$26.0 \quad 29$

$0.00 \quad 1$

$31.0 \quad 33$

$24.0 \quad 18$

$34.0 \quad 28$

$4.00 \quad 5$
38.0

4.00
381

5.4014

16.021

56.043

17.022
3.7011

$13.0 \quad 11$

$28.0 \quad 23$

57.041

$\begin{array}{ll}42.0 & 34 \\ 13.0 & 12\end{array}$

0.215

0.002

$\begin{array}{rr}23.0 & 26 \\ 12.0 & 18\end{array}$

$\begin{array}{rr}12.0 & 18 \\ 1.40 & 8\end{array}$

0.104

$0.29 \quad 6$
$3.30 \quad 10$

3.3010
7.0016

2.309

$42.0 \quad 40$
4.00

9.0017

5.0012

$36.0 \quad 36$

$31.0 \quad 34$

$\begin{array}{ll}26.0 & 30 \\ 27.0 & 31\end{array}$

$\begin{array}{ll}27.0 & 31 \\ 13.0 & 19\end{array}$

$\begin{array}{ll}32.0 & 35 \\ 24.0 & 28\end{array}$

1.40

0.081

$76.0 \quad 43$

$\begin{array}{cr}28.0 & 24 \\ 6.20 & 6\end{array}$

0.722

$\begin{array}{ll}12.0 & 10 \\ 15.0 & 14\end{array}$

$23.0 \quad 17$

6.707

$53.0 \quad 37$

$16.0 \quad 15$

27.021

$39.0 \quad 32$

$41.0 \quad 33$

$31.0 \quad 26$

$30.0 \quad 25$

$14.0 \quad 13$

$\begin{array}{ll}33.0 & 27 \\ 27.0 & 22\end{array}$

$23.0 \quad 27$

$14.0 \quad 20$

$\begin{array}{lll}0.34 & 7\end{array}$

6.4015

$25.0 \quad 19$

$19.0 \quad 16$

1.193

10.0
27.0

$41.0 \quad 39$

$46.0 \quad 36$

90

$88.0 \quad 43$

$58.0 \quad 37$

45.030

$\begin{array}{ll}61.0 & 40 \\ 50.0 & 33\end{array}$

$14.0 \quad 8$

$\begin{array}{ll}52.0 & 36 \\ 59.0 & 38\end{array}$

$41.0 \quad 26$

$46.0 \quad 31$

$\begin{array}{rr}46.0 & 31 \\ 11.0 & 6\end{array}$

$43.0 \quad 27$

$\begin{array}{rr}14.0 & 9 \\ 51.0 & 34\end{array}$

$\begin{array}{rr}51.0 & 34 \\ 61.0 & 39\end{array}$

$\begin{array}{ll}61.0 & 39 \\ 51.0 & 35\end{array}$

$15.0 \quad 10$

6.103

2.102

$87.0 \quad 42$

$\begin{array}{cr}37.0 & 24 \\ 7.50 & 5\end{array}$

$7.00 \quad 4$

$27.0 \quad 16$

35.021

$\begin{array}{rr}24.0 & 15 \\ 13.0 & 7\end{array}$

$\begin{array}{ll}65.0 & 41\end{array}$

$18.0 \quad 13$

$30.0 \quad 17$

$43.0 \quad 28$

$45.0 \quad 29$

$\begin{array}{ll}35.0 & 22 \\ 37 & \end{array}$

$37.0 \quad 25$

$\begin{array}{ll}17.0 & 12 \\ 35.0 & 23\end{array}$

$32.0 \quad 19$

$\begin{array}{ll}31.0 & 18 \\ 20.0 & 14\end{array}$

2.001

$\begin{array}{cc}2.00 & 1 \\ 15.0 \quad 11\end{array}$

$\begin{array}{rr}15.0 & 11 \\ 34.0 & 20\end{array}$

$49.0 \quad 32$

$119 \quad 43$

$\begin{array}{llllll}61.0 & 36 & 117 & 39 & 192 & 32 \\ 55.0 & 34 & 127 & 40 & 273 & 37 \\ 68.0 & 41 & 75.0 & 36 & 231 & 35\end{array}$

$\begin{array}{llllll}49.0 & 30 & 63.0 & 32 & 373 & 42\end{array}$ 
GREEN RIVER BASIN

09328500 SAN RAFAEL RTVER NEAR GREEN RIVER, UT--Continued

HIGHEST MEAN DISCHARGE, IN OUBIC FEET PER SECOND, AND RANKING FOR THE INDICATED NUMBER OF CONSECUTIVE DAYS FOR EACH WATER YEAR, OCTOBER I-SEPTEMBER 30

\begin{tabular}{|c|c|c|c|c|c|c|c|c|c|c|c|c|c|c|c|c|c|c|c|c|}
\hline YEAR & 1 & & 3 & & 7 & & 15 & & $\begin{array}{l}\text { CONS } \\
30\end{array}$ & $\mathrm{E}$ & $\begin{array}{c}\text { VE DAYS } \\
60\end{array}$ & & 90 & & 120 & & 183 & & $A L L$ & \\
\hline 110 & 3040 & 9 & 2170 & 9 & 1910 & 8 & 1490 & 9 & 1380 & 7 & 1020 & 6 & 897 & 4 & 766 & 4 & 560 & 4 & 345 & \\
\hline $\begin{array}{l}946 \\
947 \\
948 \\
949 \\
950\end{array}$ & $\begin{array}{r}931 \\
3330 \\
1120 \\
1690 \\
892\end{array}$ & $\begin{array}{r}29 \\
6 \\
23 \\
17 \\
32\end{array}$ & $\begin{array}{r}522 \\
1810 \\
682 \\
1460 \\
651\end{array}$ & $\begin{array}{l}34 \\
11 \\
28 \\
16 \\
32\end{array}$ & $\begin{array}{r}482 \\
905 \\
537 \\
1320 \\
431\end{array}$ & $\begin{array}{l}32 \\
21 \\
30 \\
13 \\
34\end{array}$ & $\begin{array}{r}428 \\
608 \\
511 \\
1160 \\
378\end{array}$ & $\begin{array}{l}32 \\
23 \\
29 \\
12 \\
33\end{array}$ & $\begin{array}{l}371 \\
588 \\
419 \\
956 \\
270\end{array}$ & $\begin{array}{l}30 \\
20 \\
27 \\
12 \\
33\end{array}$ & $\begin{array}{l}287 \\
497 \\
250 \\
714 \\
204\end{array}$ & $\begin{array}{l}25 \\
19 \\
30 \\
12 \\
32\end{array}$ & $\begin{array}{l}216 \\
356 \\
196 \\
563 \\
156\end{array}$ & $\begin{array}{l}27 \\
20 \\
29 \\
12 \\
31\end{array}$ & $\begin{array}{l}192 \\
347 \\
181 \\
450 \\
130\end{array}$ & $\begin{array}{l}27 \\
18 \\
28 \\
12 \\
31\end{array}$ & $\begin{array}{l}147 \\
249 \\
146 \\
330 \\
118\end{array}$ & $\begin{array}{l}26 \\
18 \\
27 \\
12 \\
30\end{array}$ & $\begin{array}{c}92.0 \\
154 \\
92.0 \\
181 \\
76.0\end{array}$ & $\begin{array}{l}26 \\
18 \\
27 \\
14 \\
29\end{array}$ \\
\hline $\begin{array}{l}1956 \\
1957 \\
1958 \\
1959 \\
1960\end{array}$ & $\begin{array}{r}550 \\
2710 \\
4160 \\
266 \\
530\end{array}$ & $\begin{array}{r}37 \\
11 \\
2 \\
44 \\
38\end{array}$ & $\begin{array}{r}528 \\
2530 \\
2210 \\
159 \\
500\end{array}$ & $\begin{array}{r}33 \\
6 \\
8 \\
44 \\
35\end{array}$ & $\begin{array}{c}505 \\
2310 \\
2130 \\
97.0 \\
435\end{array}$ & $\begin{array}{r}31 \\
5 \\
6 \\
44 \\
33\end{array}$ & $\begin{array}{c}433 \\
1950 \\
1930 \\
88.0 \\
347\end{array}$ & $\begin{array}{r}31 \\
5 \\
6 \\
43 \\
34\end{array}$ & $\begin{array}{c}296 \\
1630 \\
1600 \\
73.0 \\
259\end{array}$ & $\begin{array}{r}32 \\
5 \\
6 \\
43 \\
34\end{array}$ & $\begin{array}{c}163 \\
1020 \\
1030 \\
60.0 \\
159\end{array}$ & $\begin{array}{r}33 \\
7 \\
5 \\
43 \\
34\end{array}$ & $\begin{array}{c}116 \\
725 \\
761 \\
58.0 \\
138\end{array}$ & $\begin{array}{r}35 \\
8 \\
6 \\
43 \\
33\end{array}$ & $\begin{array}{c}101 \\
592 \\
595 \\
56.0 \\
124\end{array}$ & $\begin{array}{r}35 \\
7 \\
6 \\
42 \\
33\end{array}$ & $\begin{array}{l}83.0 \\
401 \\
425 \\
48.0 \\
91.0\end{array}$ & $\begin{array}{r}36 \\
9 \\
7 \\
43 \\
33\end{array}$ & $\begin{array}{c}47.0 \\
214 \\
277 \\
33.0 \\
52.0\end{array}$ & $\begin{array}{r}40 \\
11 \\
5 \\
44 \\
38\end{array}$ \\
\hline $\begin{array}{l}1961 \\
1962 \\
1963 \\
1964 \\
1965\end{array}$ & $\begin{array}{l}3230 \\
1120 \\
1160 \\
1180 \\
1940\end{array}$ & $\begin{array}{r}7 \\
24 \\
22 \\
21 \\
15\end{array}$ & $\begin{array}{r}1750 \\
1070 \\
733 \\
909 \\
1760\end{array}$ & $\begin{array}{l}13 \\
21 \\
27 \\
25 \\
12\end{array}$ & $\begin{array}{r}804 \\
983 \\
368 \\
770 \\
1620\end{array}$ & $\begin{array}{l}22 \\
18 \\
35 \\
23 \\
11\end{array}$ & $\begin{array}{r}558 \\
724 \\
299 \\
606 \\
1510\end{array}$ & $\begin{array}{r}26 \\
20 \\
35 \\
24 \\
8\end{array}$ & $\begin{array}{r}337 \\
635 \\
237 \\
500 \\
1340\end{array}$ & $\begin{array}{r}31 \\
19 \\
35 \\
24 \\
8\end{array}$ & $\begin{array}{l}215 \\
561 \\
135 \\
320 \\
967\end{array}$ & $\begin{array}{r}31 \\
16 \\
35 \\
23 \\
8\end{array}$ & $\begin{array}{l}143 \\
448 \\
126 \\
248 \\
779\end{array}$ & $\begin{array}{r}32 \\
15 \\
34 \\
25 \\
5\end{array}$ & $\begin{array}{l}117 \\
360 \\
127 \\
192 \\
624\end{array}$ & $\begin{array}{r}34 \\
16 \\
32 \\
26 \\
5\end{array}$ & $\begin{array}{c}89.0 \\
269 \\
92.0 \\
139 \\
440\end{array}$ & $\begin{array}{r}34 \\
17 \\
32 \\
28 \\
5\end{array}$ & $\begin{array}{c}70.0 \\
156 \\
69.0 \\
82.0 \\
240\end{array}$ & $\begin{array}{r}31 \\
17 \\
32 \\
28 \\
9\end{array}$ \\
\hline $\begin{array}{l}1976 \\
1977 \\
1978 \\
1979 \\
1980\end{array}$ & $\begin{array}{c}82.0 \\
671 \\
688 \\
1060 \\
2500\end{array}$ & $\begin{array}{l}45 \\
36 \\
35 \\
27 \\
12\end{array}$ & $\begin{array}{c}81.0 \\
273 \\
681 \\
754 \\
1990\end{array}$ & $\begin{array}{l}45 \\
42 \\
29 \\
26 \\
10\end{array}$ & $\begin{array}{c}78.0 \\
152 \\
645 \\
643 \\
1830\end{array}$ & $\begin{array}{r}45 \\
43 \\
27 \\
28 \\
9\end{array}$ & $\begin{array}{c}74.0 \\
86.0 \\
554 \\
592 \\
1640\end{array}$ & $\begin{array}{r}45 \\
44 \\
27 \\
25 \\
7\end{array}$ & $\begin{array}{r}69.0 \\
67.0 \\
417 \\
435 \\
1240\end{array}$ & $\begin{array}{r}44 \\
45 \\
28 \\
26 \\
9\end{array}$ & $\begin{array}{l}60.0 \\
47.0 \\
257 \\
259 \\
763\end{array}$ & $\begin{array}{l}44 \\
45 \\
29 \\
28 \\
10\end{array}$ & $\begin{array}{l}50.0 \\
32.0 \\
178 \\
216 \\
567\end{array}$ & $\begin{array}{l}44 \\
45 \\
30 \\
26 \\
11\end{array}$ & $\begin{array}{l}44.0 \\
25.0 \\
138 \\
210 \\
455\end{array}$ & $\begin{array}{l}44 \\
45 \\
30 \\
23 \\
11\end{array}$ & $\begin{array}{l}40.0 \\
24.0 \\
108 \\
155 \\
336\end{array}$ & $\begin{array}{l}44 \\
45 \\
31 \\
22 \\
11\end{array}$ & $\begin{array}{l}34.0 \\
21.0 \\
59.0 \\
109 \\
201\end{array}$ & $\begin{array}{l}43 \\
45 \\
34 \\
23 \\
12\end{array}$ \\
\hline 98 & 900 & 31 & 387 & 37 & 323 & 36 & 209 & 36 & 147 & 36 & 109 & 37 & 90.0 & 37 & 78.0 & 39 & 69.0 & 39 & 59.0 & 35 \\
\hline
\end{tabular}

DURATION OF DISCHARGE FOR EAOH WATER YEAR

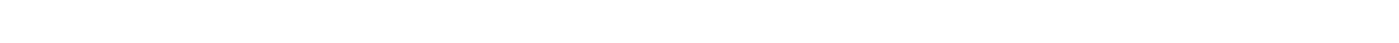

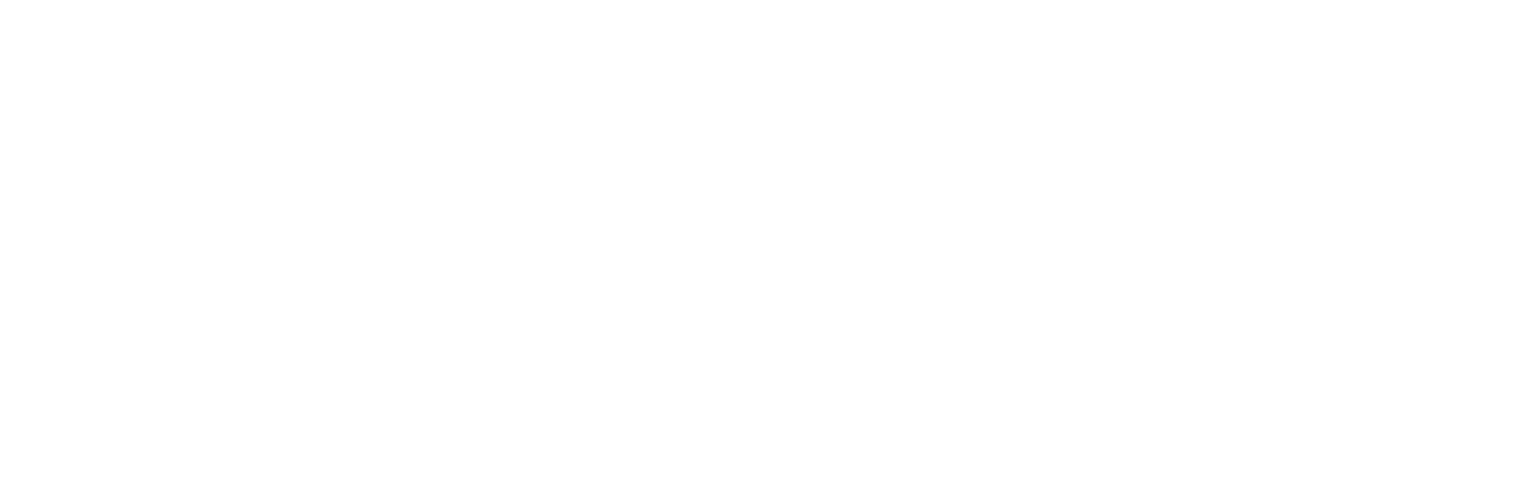


GREEN RIVER BASIN

09328500 SAN RAFAEL RIVER NEAR GREEN RIVER, UT--Continued

DURATION OF DISGAARGE FOR EACH WATER YEAR--ContinUEd

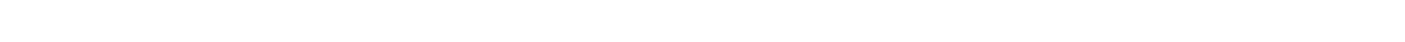

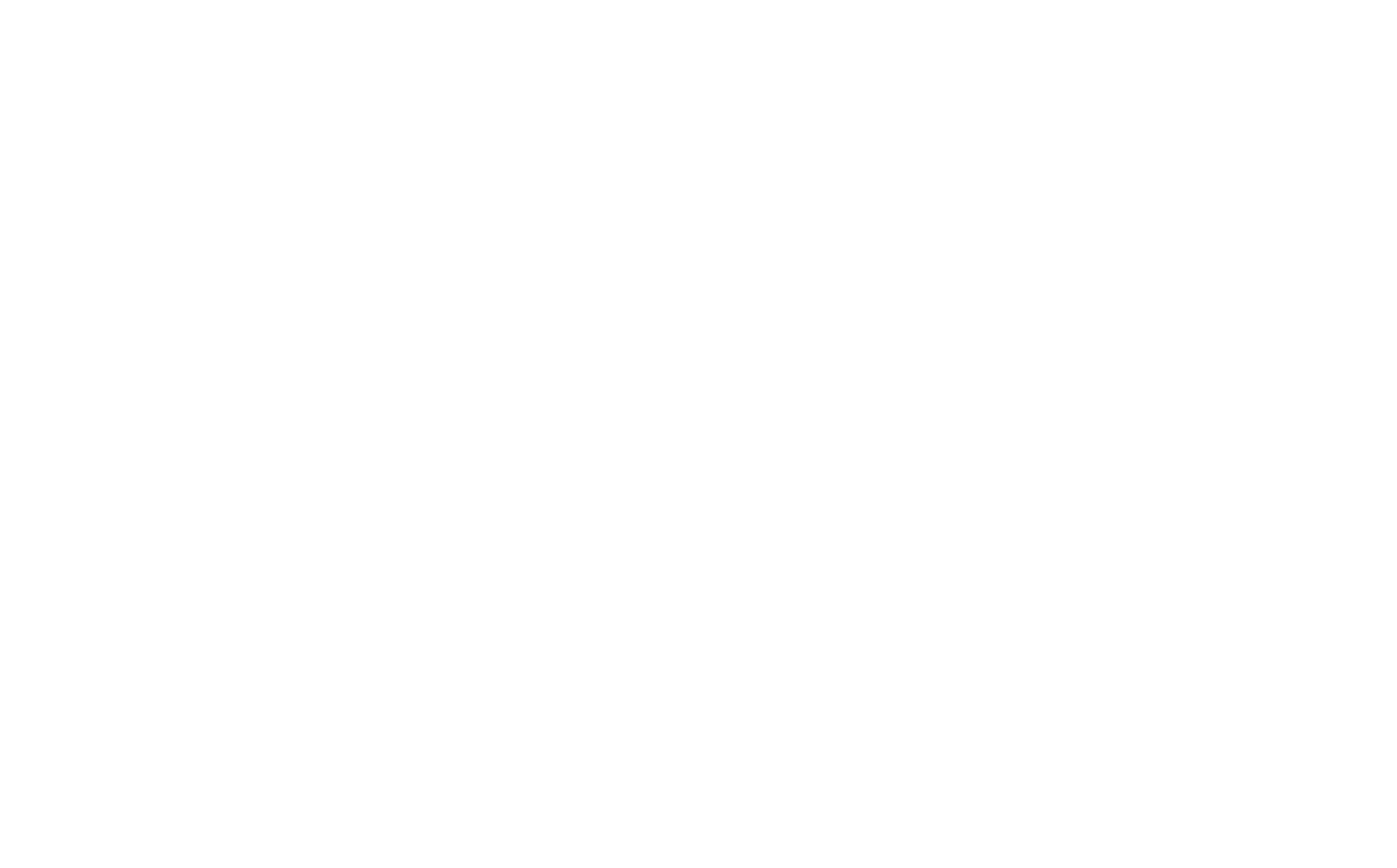

DURATION TABLE OF DISGHARGE FOR WATER YEARS $1910-18,1946-81$

\begin{tabular}{|c|c|c|c|c|c|c|c|c|c|c|c|c|c|c|c|c|c|c|c|}
\hline & $\begin{array}{c}\text { CUBIC } \\
\text { FEET } \\
\text { PER } \\
\text { SECOND }\end{array}$ & $\begin{array}{l}\text { TOTAL } \\
\text { DAYS }\end{array}$ & $\begin{array}{r}\text { ACOU- } \\
\text { MU- } \\
\text { LATED } \\
\text { DAYS }\end{array}$ & $\begin{array}{l}\text { PER- } \\
\text { CENT } \\
\text { DAYS }\end{array}$ & & $\begin{array}{c}\text { OUBIC } \\
\text { FEET } \\
\text { PER } \\
\text { SECOND }\end{array}$ & $\begin{array}{l}\text { TOTAL } \\
\text { DAYS }\end{array}$ & $\begin{array}{l}\text { ACOU- } \\
\text { MU- } \\
\text { LATED } \\
\text { DAXS }\end{array}$ & $\begin{array}{l}\text { PER- } \\
\text { CBNT } \\
\text { DAYS }\end{array}$ & & $\begin{array}{c}\text { CUBIC } \\
\text { FEET } \\
\text { PER } \\
\text { SECOND }\end{array}$ & $\begin{array}{l}\text { TOTAL } \\
\text { DAYS }\end{array}$ & $\begin{array}{r}\text { ACO- } \\
\text { MU- } \\
\text { LATED } \\
\text { DAYS }\end{array}$ & $\begin{array}{l}\text { PER- } \\
\text { CENT } \\
\text { DAYS }\end{array}$ & CLASS & $\begin{array}{c}\text { CUBIC } \\
\text { FEET } \\
\text { PER } \\
\text { SECOND }\end{array}$ & $\begin{array}{l}\text { TOTAL } \\
\text { DAYS }\end{array}$ & $\begin{array}{r}\text { ACQU- } \\
\text { MU- } \\
\text { LATED } \\
\text { DAYS }\end{array}$ & $\begin{array}{l}\text { PER- } \\
\text { CFNT } \\
\text { DAYS }\end{array}$ \\
\hline $\begin{array}{l}0 \\
1 \\
2 \\
3 \\
4 \\
5 \\
6 \\
7 \\
8\end{array}$ & $\begin{array}{l}0.00 \\
0.06 \\
0.09 \\
0.12 \\
0.17 \\
0.24 \\
0.34 \\
0.49 \\
0.69\end{array}$ & $\begin{array}{r}148 \\
3 \\
59 \\
2 \\
82 \\
31 \\
63 \\
75 \\
49\end{array}$ & $\begin{array}{l}16436 \\
16288 \\
16285 \\
16226 \\
16224 \\
16142 \\
16111 \\
16048 \\
15973\end{array}$ & $\begin{array}{r}100.0 \\
99.1 \\
99.1 \\
98.7 \\
98.7 \\
98.2 \\
98.0 \\
97.6 \\
97.2\end{array}$ & $\begin{array}{r}9 \\
10 \\
11 \\
12 \\
13 \\
14 \\
15 \\
16 \\
17\end{array}$ & $\begin{array}{r}0.97 \\
1.40 \\
2.00 \\
2.80 \\
3.90 \\
5.60 \\
7.90 \\
11.00 \\
16.00\end{array}$ & $\begin{array}{r}65 \\
61 \\
86 \\
108 \\
147 \\
160 \\
250 \\
645 \\
815\end{array}$ & $\begin{array}{l}15924 \\
15859 \\
15798 \\
15712 \\
15604 \\
15457 \\
15297 \\
15047 \\
14402\end{array}$ & $\begin{array}{l}96.9 \\
96.5 \\
96.1 \\
95.6 \\
94.9 \\
94.0 \\
93.1 \\
91.5 \\
87.6\end{array}$ & $\begin{array}{l}18 \\
19 \\
20 \\
21 \\
22 \\
23 \\
24 \\
25 \\
26\end{array}$ & $\begin{array}{r}22.0 \\
32.0 \\
45.0 \\
64.0 \\
90.0 \\
130.0 \\
180.0 \\
260.0 \\
360.0\end{array}$ & $\begin{array}{r}1786 \\
2384 \\
2814 \\
1903 \\
1332 \\
824 \\
583 \\
434 \\
448\end{array}$ & $\begin{array}{r}13587 \\
11801 \\
9417 \\
6603 \\
4700 \\
3368 \\
2544 \\
1961 \\
1527\end{array}$ & $\begin{array}{r}82.7 \\
71.8 \\
57.3 \\
40.2 \\
28.6 \\
20.5 \\
15.5 \\
11.9 \\
9.3\end{array}$ & $\begin{array}{l}27 \\
28 \\
29 \\
30 \\
31 \\
32 \\
33 \\
34\end{array}$ & $\begin{array}{r}510.0 \\
730.0 \\
1000.0 \\
1500.0 \\
2100.0 \\
2900.0 \\
4200.0 \\
5900.0\end{array}$ & $\begin{array}{r}386 \\
235 \\
240 \\
121 \\
63 \\
32 \\
0 \\
2\end{array}$ & $\begin{array}{r}1079 \\
693 \\
458 \\
218 \\
97 \\
34 \\
2 \\
2\end{array}$ & \\
\hline
\end{tabular}

MONTHLY MEAN DISGHARGES, IN CUBIC FEET PBR SECOND, FOR EACH WATER YEAR

$\begin{array}{lcccccccccccc}\text { YEAR } & \text { OCI } & \text { NOV } & \text { DEC } & \text { JAN } & \text { FEB } & \text { MAR } & \text { APR } & \text { MAY } & \text { JUNE } & \text { JULY } & \text { AUG } & \text { SEP } \\ 1910 & 128 & 162 & 125 & 150 & 200 & 729 & 748 & 1196 & 307 & 110 & 44.3 & 235 \\ & & & & & & & & & & & & \\ 1911 & 222 & 98.8 & 101 & 224 & 196 & 164 & 163 & 492 & 608 & 98.8 & 88.0 & 152 \\ 1912 & 356 & 64.2 & 60.0 & 50.0 & 70.0 & 100 & 95.7 & 406 & 1570 & 223 & 74.7 & 59.7 \\ 1913 & 384 & 199 & 46.6 & 40.0 & 50.0 & 136 & 338 & 1075 & 464 & 136 & 45.6 & 237 \\ 1914 & 72.5 & 125 & 65.1 & 55.0 & 65.0 & 90.0 & 251 & 1626 & 1650 & 294 & 45.1 & 25.2 \\ 1915 & 159 & 41.2 & 60.9 & 48.0 & 47.0 & 208 & 197 & 380 & 449 & 38.0 & 1.20 & 34.1 \\ 1916 & 7.52 & 120 & 68.6 & 58.0 & 80.9 & 379 & 207 & 542 & 932 & 196 & 344 & 71.3 \\ 1917 & 848 & 81.1 & 87.2 & 20.0 & 100.0 & 131 & 194 & 855 & 2245 & 370 & 109 & 219 \\ 1918 & 64.8 & 79.0 & 63.9 & 56.0 & 73.7 & 109 & 107 & 141 & 588 & 552 & 125 & 129 \\ 1946 & 48.7 & 48.1 & 33.4 & 29.3 & 70.5 & 97.0 & 183 & 321 & 133 & 17.5 & 113 & 6.36 \\ 1947 & 41.8 & 78.3 & 57.9 & 37.5 & 96.1 & 66.5 & 55.6 & 536 & 435 & 76.1 & 317 & 48.9 \\ 1948 & 32.2 & 58.6 & 64.7 & 50.0 & 111 & 116 & 64.3 & 269 & 223 & 29.9 & 88.9 & 0.13 \\ 1949 & 14.0 & 28.9 & 34.5 & 31.3 & 43.6 & 144 & 167 & 492 & 871 & 220 & 78.4 & 42.7 \\ 1950 & 47.0 & 53.4 & 40.4 & 39.2 & 112 & 86.6 & 55.9 & 141 & 176 & 139 & 9.85 & 17.3\end{array}$


GREEN RIVER BASIN

09328500 SAN RAFAEL RIVER NEAR GREEN RIVER, UT--Continued

MONIHLY MEAN DISOHARGES, IN GBBIC FEET PER SECOND, FOR EACH WATER YEAR--Continued

\begin{tabular}{|c|c|c|c|c|c|c|c|c|c|c|c|c|}
\hline YEAR & $\mathrm{OCT}$ & NOV & $\mathrm{DEC}$ & JAN & FEB & MAR & APR & MAY & JUNE & JULY & AUG & SEP \\
\hline $\begin{array}{l}1951 \\
1952 \\
1953 \\
1954 \\
1955\end{array}$ & $\begin{array}{l}17.2 \\
91.8 \\
56.2 \\
58.2 \\
36.9\end{array}$ & $\begin{array}{l}36.7 \\
62.4 \\
59.2 \\
69.0 \\
28.6\end{array}$ & $\begin{array}{l}45.5 \\
47.4 \\
66.8 \\
49.8 \\
37.8\end{array}$ & $\begin{array}{l}40.0 \\
46.0 \\
92.5 \\
58.6 \\
34.0\end{array}$ & $\begin{array}{c}51.3 \\
88.3 \\
119 \\
96.4 \\
36.3\end{array}$ & $\begin{array}{c}36.6 \\
223 \\
92.9 \\
57.8 \\
105\end{array}$ & $\begin{array}{c}20.3 \\
405 \\
57.0 \\
49.0 \\
42.5\end{array}$ & $\begin{array}{c}237 \\
1506 \\
36.0 \\
125 \\
57.4\end{array}$ & $\begin{array}{r}388 \\
2150 \\
522 \\
22.0 \\
93.1\end{array}$ & $\begin{array}{c}44.2 \\
317 \\
82.1 \\
19.2 \\
4.98\end{array}$ & $\begin{array}{l}193 \\
192 \\
140 \\
10.7 \\
48.4\end{array}$ & $\begin{array}{c}19.8 \\
81.7 \\
25.7 \\
63.5 \\
0.74\end{array}$ \\
\hline $\begin{array}{l}1956 \\
1957 \\
1958 \\
1959 \\
1960\end{array}$ & $\begin{array}{c}2.55 \\
0.85 \\
163 \\
22.3 \\
11.2\end{array}$ & $\begin{array}{c}17.1 \\
12.7 \\
358 \\
41.3 \\
29.6\end{array}$ & $\begin{array}{l}36.4 \\
16.2 \\
79.7 \\
60.5 \\
23.9\end{array}$ & $\begin{array}{l}48.7 \\
26.5 \\
72.9 \\
42.7 \\
22.9\end{array}$ & $\begin{array}{c}48.8 \\
65.7 \\
136 \\
69.8 \\
33.5\end{array}$ & $\begin{array}{c}44.0 \\
41.1 \\
95.0 \\
47.7 \\
124\end{array}$ & $\begin{array}{c}21.8 \\
23.3 \\
223 \\
27.4 \\
51.7\end{array}$ & $\begin{array}{c}188 \\
142 \\
1068 \\
16.7 \\
123\end{array}$ & $\begin{array}{c}132 \\
1588 \\
959 \\
36.5 \\
188\end{array}$ & $\begin{array}{c}14.7 \\
388 \\
34.2 \\
1.84 \\
2.35\end{array}$ & $\begin{array}{c}11.4 \\
208 \\
69.7 \\
11.7 \\
0.38\end{array}$ & $\begin{array}{l}0.11 \\
70.1 \\
70.7 \\
20.5 \\
20.0\end{array}$ \\
\hline $\begin{array}{l}1961 \\
1962 \\
1963 \\
1964 \\
1965\end{array}$ & $\begin{array}{c}124 \\
50.1 \\
67.3 \\
19.2 \\
2.28\end{array}$ & $\begin{array}{l}34.8 \\
61.5 \\
38.6 \\
26.8 \\
20.3\end{array}$ & $\begin{array}{l}29.7 \\
33.7 \\
36.0 \\
28.0 \\
50.5\end{array}$ & $\begin{array}{l}31.7 \\
39.4 \\
33.2 \\
23.2 \\
57.8\end{array}$ & $\begin{array}{c}46.1 \\
139 \\
71.9 \\
39.9 \\
55.9\end{array}$ & $\begin{array}{l}40.2 \\
90.0 \\
35.1 \\
50.0 \\
52.4\end{array}$ & $\begin{array}{c}32.0 \\
192 \\
15.5 \\
23.2 \\
92.8\end{array}$ & $\begin{array}{l}48.6 \\
465 \\
96.1 \\
249 \\
291\end{array}$ & $\begin{array}{c}32.2 \\
620 \\
171 \\
335 \\
1297\end{array}$ & $\begin{array}{c}0.31 \\
120 \\
8.80 \\
62.9 \\
621\end{array}$ & $\begin{array}{l}117 \\
13.1 \\
151 \\
101 \\
257\end{array}$ & $\begin{array}{c}309 \\
57.5 \\
109 \\
23.9 \\
85.5\end{array}$ \\
\hline $\begin{array}{l}1966 \\
1967 \\
1968 \\
1969 \\
1970\end{array}$ & $\begin{array}{l}65.1 \\
23.9 \\
34.9 \\
87.7 \\
68.5\end{array}$ & $\begin{array}{l}77.9 \\
22.1 \\
36.6 \\
45.4 \\
61.2\end{array}$ & $\begin{array}{l}83.4 \\
39.2 \\
29.9 \\
38.3 \\
59.6\end{array}$ & $\begin{array}{l}48.4 \\
18.9 \\
26.6 \\
52.3 \\
32.3\end{array}$ & $\begin{array}{l}62.9 \\
35.6 \\
42.6 \\
52.4 \\
68.2\end{array}$ & $\begin{array}{c}137 \\
34.5 \\
42.1 \\
140 \\
39.4\end{array}$ & $\begin{array}{r}75.0 \\
11.9 \\
40.2 \\
211 \\
32.2\end{array}$ & $\begin{array}{l}70.1 \\
86.2 \\
98.7 \\
613 \\
220\end{array}$ & $\begin{array}{l}28.1 \\
373 \\
426 \\
542 \\
806\end{array}$ & $\begin{array}{l}28.1 \\
109 \\
97.6 \\
125 \\
143\end{array}$ & $\begin{array}{c}8.99 \\
48.2 \\
179 \\
146 \\
60.7\end{array}$ & $\begin{array}{c}29.1 \\
84.9 \\
65.1 \\
108 \\
63.5\end{array}$ \\
\hline $\begin{array}{l}1971 \\
1972 \\
1973 \\
1974 \\
1975\end{array}$ & $\begin{array}{c}53.9 \\
87.0 \\
144 \\
76.8 \\
74.0\end{array}$ & $\begin{array}{l}51.0 \\
68.4 \\
62.2 \\
55.3 \\
72.6\end{array}$ & $\begin{array}{l}46.4 \\
30.6 \\
30.8 \\
40.5 \\
29.3\end{array}$ & $\begin{array}{l}25.8 \\
33.0 \\
26.0 \\
32.7 \\
25.2\end{array}$ & $\begin{array}{l}36.5 \\
52.7 \\
45.0 \\
33.6 \\
42.6\end{array}$ & $\begin{array}{c}53.0 \\
51.3 \\
287 \\
49.8 \\
49.6\end{array}$ & $\begin{array}{l}46.2 \\
26.6 \\
75.5 \\
34.2 \\
28.7\end{array}$ & $\begin{array}{c}66.9 \\
34.7 \\
464 \\
56.3 \\
46.8\end{array}$ & $\begin{array}{c}87.1 \\
53.1 \\
862 \\
73.3 \\
525\end{array}$ & $\begin{array}{c}88.7 \\
23.0 \\
160 \\
78.1 \\
451\end{array}$ & $\begin{array}{l}68.0 \\
16.3 \\
70.0 \\
41.6 \\
81.0\end{array}$ & $\begin{array}{l}40.0 \\
13.1 \\
67.1 \\
37.8 \\
90.3\end{array}$ \\
\hline $\begin{array}{l}1976 \\
1977 \\
1978 \\
1979 \\
1980\end{array}$ & $\begin{array}{c}64.2 \\
31.3 \\
4.95 \\
79.6 \\
38.7\end{array}$ & $\begin{array}{c}55.3 \\
28.6 \\
5.68 \\
200 \\
41.6\end{array}$ & $\begin{array}{l}29.9 \\
22.6 \\
11.8 \\
24.2 \\
29.5\end{array}$ & $\begin{array}{l}23.0 \\
19.0 \\
14.6 \\
18.9 \\
53.5\end{array}$ & $\begin{array}{r}47.7 \\
20.9 \\
22.2 \\
35.9 \\
148\end{array}$ & $\begin{array}{r}23.3 \\
24.5 \\
79.3 \\
232 \\
92.2\end{array}$ & $\begin{array}{c}15.2 \\
6.84 \\
16.8 \\
90.8 \\
55.7\end{array}$ & $\begin{array}{c}37.4 \\
3.72 \\
23.3 \\
85.7 \\
234\end{array}$ & $\begin{array}{c}37.4 \\
1.09 \\
369 \\
411 \\
1190\end{array}$ & $\begin{array}{c}29.9 \\
41.6 \\
138 \\
65.3 \\
268\end{array}$ & $\begin{array}{l}22.1 \\
35.3 \\
14.0 \\
45.4 \\
77.4\end{array}$ & $\begin{array}{c}27.4 \\
15.0 \\
7.24 \\
22.7 \\
206\end{array}$ \\
\hline 1981 & 129 & 81.3 & 53.1 & 43.1 & 51.7 & 54.0 & 28.8 & 22.5 & 24.3 & 38.8 & 38.8 & 137 \\
\hline
\end{tabular}

ANNUAL PEAK DISOHARGE, IN ABIC FEET PER SECOND, AND CORRESPONDING GAGE HEIGHT, IN FEET, FOR EACH WATER YEAR

\begin{tabular}{|c|c|c|c|c|c|c|c|c|c|c|c|}
\hline $\begin{array}{l}\text { WATER } \\
\text { YEAR }\end{array}$ & DATE & $\begin{array}{c}\text { GAGE } \\
\text { HEIGHT }\end{array}$ & $\begin{array}{c}\text { PEAK } \\
\text { DISOH ARGE }\end{array}$ & $\begin{array}{l}\text { WATER } \\
\text { YEAR }\end{array}$ & DATE & $\begin{array}{c}\text { GAGE } \\
\text { HEIGHT }\end{array}$ & $\begin{array}{c}\text { PEAK } \\
\text { DISOH ARGE }\end{array}$ & $\begin{array}{l}\text { WATER } \\
\text { YEAR }\end{array}$ & DATE & $\begin{array}{c}\text { GAGE } \\
\text { HEIGTT }\end{array}$ & $\begin{array}{c}\text { PEAK } \\
\text { DISCH ARGE }\end{array}$ \\
\hline $\begin{array}{l}1909 \\
1910 \\
1911 \\
1912 \\
1913 \\
1914 \\
1915 \\
1916 \\
1917 \\
1918 \\
1946 \\
1947 \\
1948 \\
1949 \\
1950\end{array}$ & $\begin{array}{l}\text { SEPT.02, } 1909 \\
\text { SEPT.17, } 1910 \\
\text { OCT. 17, } 1910 \\
\text { JUNE 05, } 1912 \\
\text { SEPT. 09, } 1913 \\
\text { JUNE 02, } 1914 \\
\text { JUNE 11, } 1915 \\
\text { AUG. 06, } 1916 \\
\text { OCT. 08, } 1916 \\
\text { JULY } 12,1918 \\
\text { AUG. } 12,1946 \\
\text { AUG. } 22,1947 \\
\text { AUG. } 04,1948 \\
\text { JULY } 06,1949 \\
\text { JULY } 08,1950\end{array}$ & $\begin{array}{r}12.70 \\
7.30 \\
7.10 \\
7.80 \\
8.00 \\
9.00 \\
5.30 \\
9.00 \\
12.60 \\
9.00 \\
5.94 \\
9.26 \\
6.15 \\
7.11 \\
6.56\end{array}$ & $\begin{array}{r}12000 \\
3120 \\
2960 \\
3660 \\
3800 \\
3760 \\
1300 \\
3750 \\
11500 \\
3200 \\
2410 \\
8640 \\
2580 \\
3200 \\
2230\end{array}$ & $\begin{array}{l}1951 \\
1952 \\
1953 \\
1954 \\
1955 \\
1956 \\
1957 \\
1958 \\
1959 \\
1960 \\
1961 \\
1962 \\
1963 \\
1964 \\
1965\end{array}$ & $\begin{array}{l}\text { AUG. } 04,1951 \\
\text { JUNE } 04,1952 \\
\text { JUNE } 14,1953 \\
\text { SEPT.13, } 1954 \\
\text { AUG. } 14,1955 \\
\text { MAY } 26,1956 \\
\text { JUNE 11, } 1957 \\
\text { NOV. 04, } 1957 \\
\text { SEPT.17, } 1959 \\
\text { SEPT.07, } 1960 \\
\text { SEPT.10, } 1961 \\
\text { SEPT. 22, } 1962 \\
\text { AUG. 31, } 1963 \\
\text { AUG. 03, } 1964 \\
\text { JUNE 26, } 1965\end{array}$ & $\begin{array}{r}7.78 \\
8.80 \\
4.57 \\
6.55 \\
2.84 \\
4.27 \\
8.59 \\
11.31 \\
5.44 \\
7.15 \\
12.88 \\
8.90 \\
10.72 \\
9.90 \\
11.34\end{array}$ & $\begin{array}{r}3740 \\
4480 \\
1220 \\
2500 \\
600 \\
634 \\
2970 \\
9660 \\
687 \\
1320 \\
4740 \\
1350 \\
1780 \\
1650 \\
2000\end{array}$ & $\begin{array}{l}1966 \\
1967 \\
1968 \\
1969 \\
1970 \\
1971 \\
1972 \\
1973 \\
1975 \\
1976 \\
1977 \\
1978 \\
1979 \\
1980 \\
1981\end{array}$ & $\begin{array}{l}\text { SEPT.01, } 1966 \\
\text { SEPT. 09, } 1967 \\
\text { AUG. 02, } 1968 \\
\text { APR. 23, } 1969 \\
\text { JUNE } 12,1970 \\
\text { JULY 22, } 1971 \\
\text { OCT. 25, } 1971 \\
\text { OCT. } 18,1972 \\
\text { JUNE 20, } 1975 \\
\text { SEPT.16, } 1976 \\
\text { AUG. } 18,1977 \\
\text { JUNE } 25,1978 \\
\text { MAR. 30, } 1979 \\
\text { SEPT. } 11,1980 \\
\text { SEPT.07, } 1981\end{array}$ & $\begin{array}{r}9.50 \\
9.77 \\
10.19 \\
12.00 \\
11.24 \\
9.16 \\
9.32 \\
11.70 \\
10.64 \\
5.66 \\
10.02 \\
7.84 \\
10.57 \\
13.60\end{array}$ & $\begin{array}{r}1360 \\
1410 \\
1560 \\
2360 \\
1940 \\
922 \\
1010 \\
2220 \\
1380 \\
107 \\
1250 \\
719 \\
1570 \\
3740 \\
900\end{array}$ \\
\hline
\end{tabular}

\begin{tabular}{|c|c|c|c|c|c|c|}
\hline \multirow{2}{*}{$\begin{array}{l}\text { PERIOD } \\
\text { CON- } \\
\text { SEQJ- } \\
\text { TIVE } \\
\text { DAYS) }\end{array}$} & \multicolumn{6}{|c|}{$\begin{array}{l}\text { DISOH ARGE, IN GBIC FEET PER SECOND, FOR } \\
\text { INDICATED REQURRENCE INTERNAL, IN YEARS, AND } \\
\text { ANNUAL EXCEEDANCE PROBABIIITY, IN PERENT }\end{array}$} \\
\hline & $\begin{array}{c}2 \\
508\end{array}$ & $\begin{array}{c}5 \\
208\end{array}$ & $\begin{array}{l}10 \\
108\end{array}$ & $\begin{array}{l}25 \\
48\end{array}$ & $\begin{array}{l}50 \\
28\end{array}$ & $\begin{array}{r}100 \\
18\end{array}$ \\
\hline $\begin{array}{r}3 \\
7 \\
15\end{array}$ & $\begin{array}{l}970 \\
755 \\
613\end{array}$ & $\begin{array}{l}1950 \\
1630 \\
1360\end{array}$ & $\begin{array}{l}2710 \\
2360 \\
1990\end{array}$ & $\begin{array}{l}3750 \\
3410 \\
2910\end{array}$ & $\begin{array}{l}4550 \\
4280 \\
3680\end{array}$ & $\begin{array}{l}5360 \\
5210 \\
4500\end{array}$ \\
\hline
\end{tabular}


LOCATION.--Lat $38^{\circ} 49^{\prime} 28^{\prime \prime}$, long $110^{\circ} 42^{\prime} 17^{\prime \prime}$, in SW $W_{4}^{1}$ SW ${ }^{\frac{1}{4}}$ sec.9, T.23 S., R.11 E., Emery County, Hydrologic Unit 14060009 , 25 mi south of San Rafael River bridge along the Castle Dale-Temple Junction road, and $31 \mathrm{mi}$ north of Hanksville.

DRATNAGE AREA. $-6.63 \mathrm{mi}^{2}$.

MEAN BASIN ELENATION. $--7,010 \mathrm{ft}$.

PERIOD OF RECORD AVAII.ABLE.--Water years 1959-67, 1969-73, annual peak discharge only.

GAGE.-Crest-stage gage. Altitude of gage is $6,700 \mathrm{ft}$ from topographic map.

ANNUAL PEAK DISCHARGE, IN OBIC FEET PER SECOND, AND CORRESPONDING GAGE HEIGHT, IN FEET, FOR EACH WATER YEAR

\begin{tabular}{|c|c|c|c|c|c|c|c|c|c|c|c|}
\hline $\begin{array}{l}\text { WATER } \\
\text { YEAR }\end{array}$ & DATE & $\begin{array}{c}\text { GAGE } \\
\text { HEIGHT }\end{array}$ & $\begin{array}{c}\text { PEAR } \\
\text { DISCHARGE }\end{array}$ & $\begin{array}{l}\text { WATER } \\
\text { YEAR }\end{array}$ & DATE & $\begin{array}{l}\text { GAGE } \\
\text { HEIGHT }\end{array}$ & $\begin{array}{c}\text { PEAR } \\
\text { DISCHARGE }\end{array}$ & $\begin{array}{l}\text { WATERR } \\
\text { YEAR }\end{array}$ & DATE & $\begin{array}{l}\text { GAGE } \\
\text { HEIGHT }\end{array}$ & $\begin{array}{c}\text { PEAR } \\
\text { DISCHARGE }\end{array}$ \\
\hline $\begin{array}{l}1959 \\
1960 \\
1961 \\
1962 \\
1963\end{array}$ & $\begin{array}{l}\text { AUG. } 25,1959 \\
\text { AUG. 01, } 1960 \\
\text { JULY 07, } 1961 \\
\text { SEPT. 21, } 1962 \\
\text { AUG. } 17,1963\end{array}$ & $\begin{array}{r}12.45 \\
9.65 \\
11.10 \\
9.50 \\
10.85\end{array}$ & $\begin{array}{r}1650 \\
80 \\
600 \\
57 \\
470\end{array}$ & $\begin{array}{l}1964 \\
1965 \\
1966 \\
1967 \\
1969\end{array}$ & $\begin{array}{l}\text { AUG. } 11,1964 \\
\text { JULY } 24,1965 \\
\text { AUG. } 18,1966 \\
\text { AUG. } 31,1967 \\
\text { AUU. } 30,1969\end{array}$ & $\begin{array}{rr}4 & 9.71 \\
10.58 \\
9.62 \\
10.37 \\
7 \\
11.94\end{array}$ & $\begin{array}{r}91 \\
350 \\
56 \\
215 \\
1200\end{array}$ & $\begin{array}{l}1970 \\
1971 \\
1972 \\
1973\end{array}$ & $\begin{array}{l}\text { SEPT.06, } 1970 \\
\text { AUG. 26, } 1971 \\
\text { MAY 26, } 1972 \\
\text { SEPT.11, } 1973\end{array}$ & $\begin{array}{r}11.09 \\
8.78 \\
10.08 \\
9.70\end{array}$ & $\begin{array}{l}590 \\
0.10 \\
180 \\
90\end{array}$ \\
\hline
\end{tabular}

09328700 TEMPLE WASH NEAR HANKSVILLE, UT

LOCATION.--Lat 38 ${ }^{\circ} 39^{\prime} 09^{\prime \prime}$, long $110^{\circ} 33^{\prime} 10^{\prime \prime}$, in SE $\mathrm{SEE}_{4}^{\frac{1}{4}}$ sec.11, T.25 S., R.12 E., Emery County, Hydrologic Unit 14060009, about 1.5 mi north of Temple Junction on State Highway 24 and $22 \mathrm{mi}$ north of Hanksville.

DRATNAGE AREA. $-38.2 \mathrm{mi}^{2}$.

MEAN BASIN ELEVATION. $-5,630 \mathrm{ft}$.

PERIOD OF RECORD AVAII.ABLE. --water years 1959-68, annual peak discharge only.

GAGE.--Crest-stage gage. Altitude of gage is 4,910 ft from topographic map.

ANNUAL PEAK DISCHARGE, IN GUBIC FEET PER SECOND, AND CORRESPONDING GAGE HEIGHT, IN FEET, FOR EACH WATER YEAR

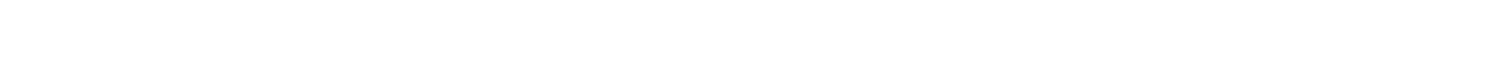

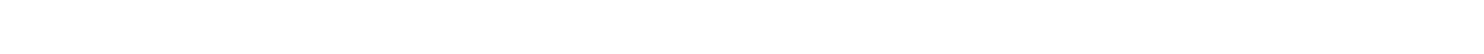

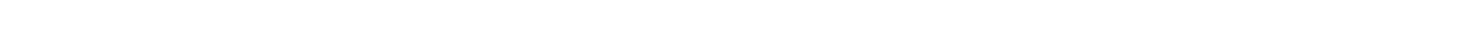

1962 SEPT.21, 1962

09328720 OWD WOMAN WASH NEAR HANKSVILLE, UT

LOCATION.--Lat $38^{\circ} 41^{\prime} 00^{\prime \prime}$, long $110^{\circ} 32^{\prime} 22^{\prime \prime}$, in SW $\mathrm{NE}_{4}^{\frac{1}{4}}$ sec.31, T.24 S., R.13 E., Emery County, Hydrologic Unit 14060009, 4 mi north of Temple Junction and $24 \mathrm{mi}$ north of Hanksville.

DRAINAGE AREA. $--17.6 \mathrm{mi}^{2}$.

MEAN BASIN ELEVATION. $-5,450 \mathrm{ft}$.

PERIOD OF RECORD AVAII.ABLE.--Water years 1959-68, annual peak discharge only.

GAGE.--Crest-stage gage. Altitude of gage is 4,820 ft from topographic map.

ANNUAL PEAK DISCHARGE, IN GBIC FEET PER SECOND, AND CORRESPONDING GAGE HEIGHT, IN FEET, FOR EACH WATER YEAR

\begin{tabular}{|c|c|c|c|c|c|c|c|c|c|c|c|}
\hline $\begin{array}{l}\text { WATER } \\
\text { YEAR }\end{array}$ & DATE & $\begin{array}{c}\text { GAGE } \\
\text { HEIGHI }\end{array}$ & $\begin{array}{c}\text { PEAR } \\
\text { DISCHARGE }\end{array}$ & $\begin{array}{l}\text { WATER } \\
\text { YEAR }\end{array}$ & DATE & $\begin{array}{l}\text { GAGE } \\
\text { HEIGHT }\end{array}$ & $\begin{array}{c}\text { PEAR } \\
\text { DISCHARGE }\end{array}$ & $\begin{array}{l}\text { WATERR } \\
\text { YEAR }\end{array}$ & DATE & $\begin{array}{l}\text { GAGE } \\
\text { HEIGHT }\end{array}$ & $\begin{array}{c}\text { PEAR } \\
\text { DISCHARGE }\end{array}$ \\
\hline $\begin{array}{l}1959 \\
1960\end{array}$ & $\begin{array}{l}\text { JULY 14, } 1959 \\
\text { SEPT.01, } 1960\end{array}$ & $\begin{array}{r}9.75 \\
10.22\end{array}$ & $\begin{array}{r}40 \\
140\end{array}$ & $\begin{array}{l}1963 \\
1964\end{array}$ & $\begin{array}{l}\text { SEPT. } 17,1963 \\
\text { OCT. } 20,1963\end{array}$ & $\begin{array}{l}10.72 \\
10.60\end{array}$ & $\begin{array}{l}560 \\
430\end{array}$ & $\begin{array}{l}1966 \\
1967\end{array}$ & $\begin{array}{l}\text { AUG. } 18,1966 \\
\text { JULY } 17,1967\end{array}$ & $\begin{array}{l}10.25 \\
10.20\end{array}$ & $\begin{array}{r}180 \\
10\end{array}$ \\
\hline $\begin{array}{l}1961 \\
1962\end{array}$ & $\begin{array}{ll}\text { OCT. } 09, & 1960 \\
\text { SEPT. } 21, & 1962\end{array}$ & $\begin{array}{ll}0 & 10.70 \\
2 & 11.99\end{array}$ & $\begin{array}{r}348 \\
2650\end{array}$ & 1965 & AUG. 18,1965 & 11.04 & 1030 & 1968 & & 10.49 & 280 \\
\hline
\end{tabular}

1962 SEPT. 21,1962 11. 2650

${ }^{1}$ some time between August 2 and 10. 
LOCATION.--Lat $38^{\circ} 56^{\prime} 32^{\prime \prime}$, long $109^{\circ} 49^{\prime} 15^{\prime \prime}$, in El/ sec.33, T.21 S., R.19 E., Grand County, Hydrologic unit 14060008 , about 0.2 mi west of Crescent Junction and $18 \mathrm{mi}$ east of Green River.

DRAINAGE AREA. $--23.3 \mathrm{mi}^{2}$.

MEAN BASIN ELEVATION. $-6,180 \mathrm{ft}$.

PERIOD OF RECORD AVALABLE.--Water years 1959-68, annual peak discharge only.

GAGE.--Crest-stage gage. Altitude of gage is 4,880 ft from topographic map.

ANNUAL PEAK DISCHARGE, IN OUBIC FEET PER SECOND, AND CORRESPONDING GAGE HEIGHT, IN FEET, FOR EACH WATER YEAR

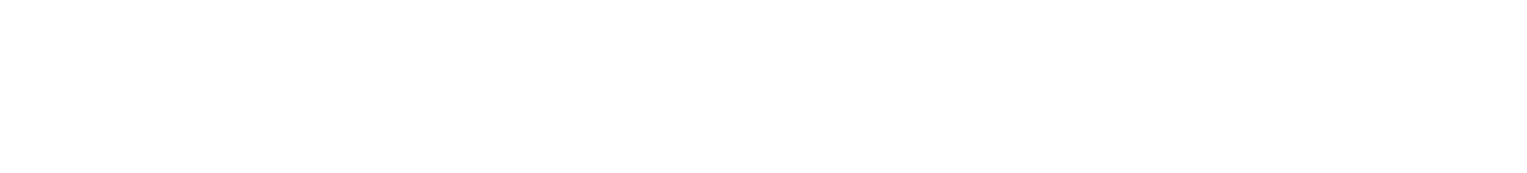

DIRTY DEVIL RIVER BASIN

09329000 FREMONT RIVER BESCW FISH LAKE, NEAR FREMONT, UT

LOCATION.-Lat $38^{\circ} 35^{\prime} 30^{\prime \prime}$, long $111^{\circ} 40^{\prime} 30^{\prime \prime}$, in NE光 sec.34, T.25 S., R.2 E., Sevier County, Hydrologic unit 14070003 , $0.5 \mathrm{mi}$

downstream from outlet gates of Fish Lake, $3.25 \mathrm{mi}$ northeast of Twin Creeks ranger station, and $10 \mathrm{mi}$ northwest of Fremont.

DRAINAGE AREA. $--27 \mathrm{mi}^{2}$.

PERIOD OF RECORD AVAIIABLE.---June 1938 to September 1945 (no winter record in 1939 water year).

GAGE.-Water-stage recorder. Altitude of gage is $8,700 \mathrm{ft}$ fran topographic map.

REMARRS.-Flow is completely regulated by Fish Lake. No diversions above station.

AVERAGE DISCHARGE. -6 years (water years 1940-45), $7.02 \mathrm{ft}^{3} / \mathrm{s}, 5,090$ acre-ft/yr.

EXITEMES FOR PERIOD OF RECORD.--Maximum discharge, $90 \mathrm{ft}^{3} / \mathrm{s}$ June 29, 1941; practically no flow at times when gates are closed

at outlet of Fish Lake.

LOWEST MEAN DISCHARGE, IN CUBIC FEET PER SECOND, AND RANKING FOR THE INDICATED NUMBER OF CONSEOUTIVE DAYS FOR EACH CLIMATIC YEAR, APRIL 1-MARCH 31

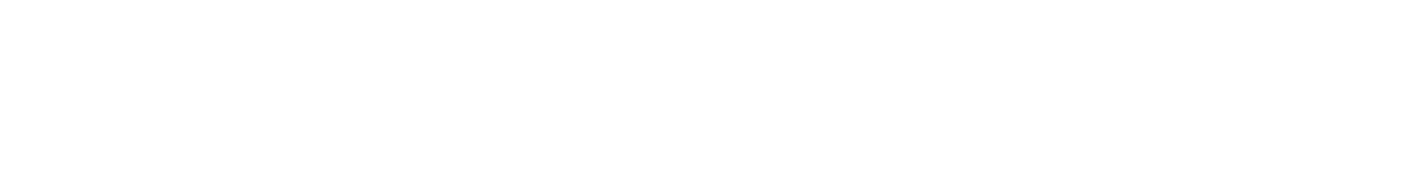

HIGHEST MEAN DISCHARGE, IN CUBIC FEET PER SECOND, AND RANKING FOR THE INDICATED NUMBER OF CONSECUTIVE DAYS FOR EACH WATER YEAR, OCTOBER I-SEPTEMBER 30

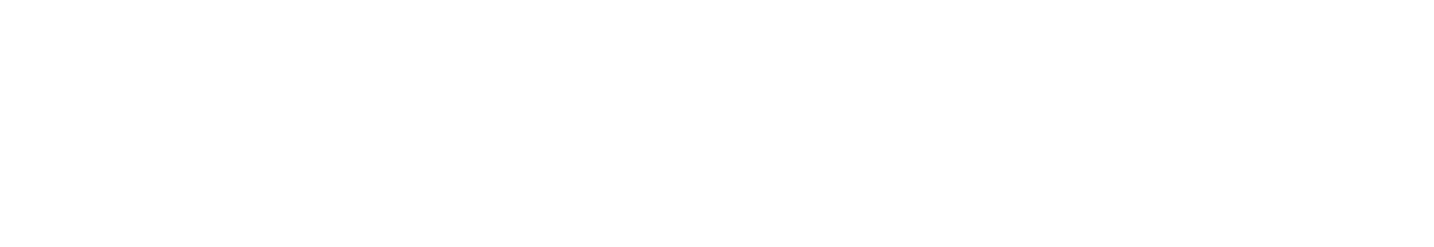


DIRTY DEVIL RIVER BASIN

09329000 FREMONT RIVER BELOW FISH LAKE, NEAR FREMONT, UI--Continued

DURATION OF DISCHARGE FOR EACH WATER YEAR

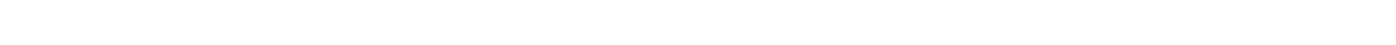

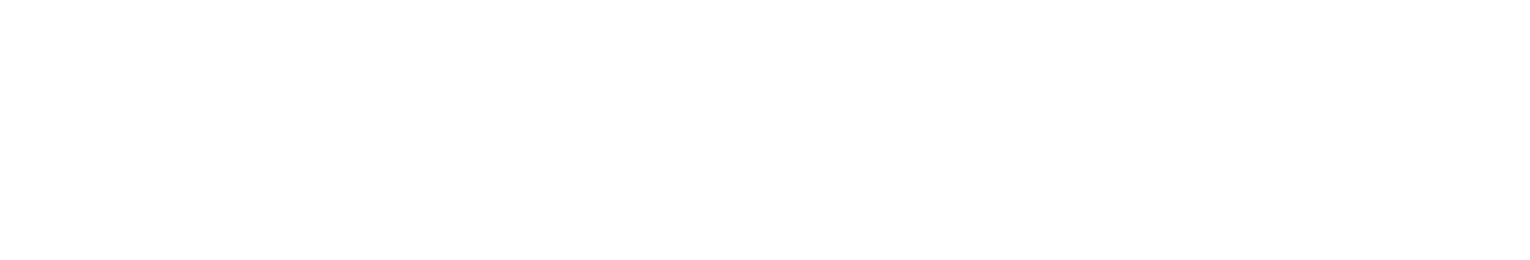

DURATION TABLE OF DISCHARGE FOR WATER YEARS 1940-45

\begin{tabular}{|c|c|c|c|c|c|c|c|c|c|c|c|c|c|c|c|c|c|c|c|}
\hline CLASS & $\begin{array}{c}\text { CUBIC } \\
\text { FEET } \\
\text { PER } \\
\text { SECOND }\end{array}$ & $\begin{array}{l}\text { TOTAL } \\
\text { DAYS }\end{array}$ & $\begin{array}{c}\text { ACOU- } \\
\text { MU- } \\
\text { LATED } \\
\text { DAYS }\end{array}$ & $\begin{array}{l}\text { PER- } \\
\text { CENT } \\
\text { DAYS }\end{array}$ & CLASS & $\begin{array}{c}\text { वUBIC } \\
\text { FEET } \\
\text { PER } \\
\text { SECOND }\end{array}$ & $\begin{array}{l}\text { TOTAL } \\
\text { DAYS }\end{array}$ & $\begin{array}{c}\text { ACOU- } \\
\text { MU- } \\
\text { LATED } \\
\text { DAYS }\end{array}$ & $\begin{array}{l}\text { PER- } \\
\text { CENT } \\
\text { DAYS }\end{array}$ & & $\begin{array}{c}\text { OBIC } \\
\text { FEET } \\
\text { PER } \\
\text { SECOND }\end{array}$ & $\begin{array}{l}\text { TOTAL } \\
\text { LAYS }\end{array}$ & $\begin{array}{l}\text { ACOU- } \\
\text { MU- } \\
\text { LATED } \\
\text { DAYS }\end{array}$ & $\begin{array}{l}\text { PER- } \\
\text { CENT } \\
\text { DAYS }\end{array}$ & & $\begin{array}{c}\text { CUBIC } \\
\text { FEET } \\
\text { PER } \\
\text { SECOND }\end{array}$ & $\begin{array}{l}\text { TOTAL } \\
\text { DAYS }\end{array}$ & $\begin{array}{l}\text { ACOU- } \\
\text { MU- } \\
\text { LATED } \\
\text { DAYS }\end{array}$ & $\begin{array}{l}\text { PER- } \\
\text { CENT } \\
\text { DAYS }\end{array}$ \\
\hline $\begin{array}{l}0 \\
1 \\
2 \\
3 \\
4 \\
5 \\
6 \\
7 \\
8\end{array}$ & $\begin{array}{l}0.00 \\
0.20 \\
0.24 \\
0.29 \\
0.35 \\
0.42 \\
0.50 \\
0.61 \\
0.73\end{array}$ & $\begin{array}{r}8 \\
504 \\
0 \\
73 \\
165 \\
0 \\
621 \\
37 \\
68\end{array}$ & $\begin{array}{r}2192 \\
2184 \\
1680 \\
1680 \\
1607 \\
1442 \\
1442 \\
821 \\
784\end{array}$ & $\begin{array}{r}100.0 \\
99.6 \\
76.6 \\
76.6 \\
73.3 \\
65.8 \\
65.8 \\
37.5 \\
35.8\end{array}$ & $\begin{array}{r}9 \\
10 \\
11 \\
12 \\
13 \\
14 \\
15 \\
16 \\
17\end{array}$ & $\begin{array}{l}0.88 \\
1.10 \\
1.30 \\
1.50 \\
1.80 \\
2.20 \\
2.70 \\
3.20 \\
3.80\end{array}$ & $\begin{array}{r}74 \\
5 \\
5 \\
4 \\
43 \\
33 \\
8 \\
34 \\
13 \\
43\end{array}$ & $\begin{array}{l}716 \\
642 \\
637 \\
632 \\
628 \\
595 \\
587 \\
553 \\
540\end{array}$ & $\begin{array}{l}32.7 \\
29.3 \\
29.1 \\
28.8 \\
28.6 \\
27.1 \\
26.8 \\
25.2 \\
24.6\end{array}$ & $\begin{array}{l}18 \\
19 \\
20 \\
21 \\
22 \\
23 \\
24 \\
25 \\
26\end{array}$ & $\begin{array}{r}4.6 \\
5.5 \\
6.7 \\
8.0 \\
9.6 \\
12.0 \\
14.0 \\
17.0 \\
20.0\end{array}$ & $\begin{array}{l}34 \\
18 \\
14 \\
22 \\
19 \\
33 \\
42 \\
23 \\
49\end{array}$ & $\begin{array}{l}497 \\
463 \\
445 \\
431 \\
409 \\
390 \\
357 \\
315 \\
292\end{array}$ & $\begin{array}{l}22.7 \\
21.1 \\
20.3 \\
19.7 \\
18.7 \\
17.8 \\
16.3 \\
14.4 \\
13.3\end{array}$ & $\begin{array}{l}27 \\
28 \\
29 \\
30 \\
31 \\
32 \\
33 \\
34\end{array}$ & $\begin{array}{l}24.0 \\
29.0 \\
35.0 \\
42.0 \\
51.0 \\
61.0 \\
73.0 \\
88.0\end{array}$ & $\begin{array}{r}31 \\
43 \\
45 \\
49 \\
32 \\
24 \\
17 \\
2\end{array}$ & $\begin{array}{r}243 \\
212 \\
169 \\
124 \\
75 \\
43 \\
19 \\
2\end{array}$ & $\begin{array}{r}11.1 \\
9.7 \\
7.7 \\
5.7 \\
3.4 \\
2.0 \\
0.9 \\
0.1\end{array}$ \\
\hline
\end{tabular}

MONTHLY MEAN DISCHARGES, IN CUBIC FEET PER SECOND, FOR EACH WATER YEAR

$\begin{array}{lcccccccccccr}\text { YEAR } & \text { OCT } & \text { NOV } & \text { DEC } & \text { JAN } & \text { FEB } & \text { MAR } & \text { APR } & \text { MAY } & \text { JUNE } & \text { JULY } & \text { AUG } & \text { SEP } \\ 1940 & 0.50 & 0.50 & 0.50 & 0.50 & 0.50 & 0.50 & 0.50 & 0.50 & 34.1 & 15.2 & 4.06 & 1.23 \\ & & & & & & & & & & & & \\ 1941 & 0.20 & 0.20 & 0.20 & 0.20 & 0.20 & 0.20 & 0.20 & 0.20 & 7.61 & 54.8 & 28.3 & 5.49 \\ 1942 & 0.50 & 0.50 & 0.20 & 0.20 & 0.20 & 0.20 & 0.20 & 0.20 & 36.7 & 39.3 & 17.8 & 3.28 \\ 1943 & 0.69 & 0.81 & 0.70 & 0.50 & 0.50 & 0.50 & 0.50 & 0.40 & 33.4 & 16.4 & 9.29 & 3.83 \\ 1944 & 2.56 & 0.80 & 0.60 & 0.40 & 0.40 & 0.40 & 0.40 & 0.50 & 20.1 & 44.0 & 7.38 & 3.19 \\ 1945 & 4.07 & 0.22 & 1.00 & 0.50 & 0.50 & 0.50 & 0.30 & 0.30 & 41.8 & 29.9 & 17.5 & 2.19\end{array}$

ANNUAL PEAK DISCHARGE, IN CBBIC FEET PER SECOND, AND CORRESPONDING GAGE HEIGHT, IN FEET, FOR EACH WATER YEAR

\begin{tabular}{|c|c|c|c|c|c|c|c|c|c|c|c|}
\hline $\begin{array}{l}\text { WATER } \\
\text { YEAR }\end{array}$ & DATE & $\begin{array}{c}\text { GAGE } \\
\text { HEIGHT }\end{array}$ & $\begin{array}{c}\text { PEAK } \\
\text { DISCHARGE }\end{array}$ & $\begin{array}{l}\text { WATER } \\
\text { YEAR }\end{array}$ & DATE & $\begin{array}{c}\text { GAGE } \\
\text { HEIGHT }\end{array}$ & $\begin{array}{c}\text { PEAK } \\
\text { DISCHARGE }\end{array}$ & $\begin{array}{l}\text { WATEER } \\
\text { YEAR }\end{array}$ & DATE & $\begin{array}{c}\text { GAGE } \\
\text { HEIGHT }\end{array}$ & $\begin{array}{l}\text { PEAK } \\
\text { DISCHARGE }\end{array}$ \\
\hline 1940 & JUNE 06, 1940 & $\cdots$ & $1_{58}$ & 1942 & JUNE 19,1942 & - & $1_{88}$ & 1944 & JUNE 24, 1944 & - & $1_{86}$ \\
\hline 1941 & JUNE 29,1941 & - & $1_{90}$ & 1943 & JUNE 06, 1943 & -- & $1_{61}$ & 1945 & JUNE 08,1945 & 9.32 & 78 \\
\hline
\end{tabular}

${ }^{1}$ Maximum daily discharge.

09329050 SEVEN MILE CREEK NEAR FISH LAKE, UT

LOCATION.--Lat $38^{\circ} 37^{\prime} 40^{\prime \prime}$, long $111^{\circ} 38^{\prime} 50^{\prime \prime}$, in SE $\mathrm{SWW}_{4}^{\frac{1}{4}} \mathrm{SW}_{\frac{1}{4}}$ sec.13, T.25 S., R.2 E., Sevier County, Hydrologic Unit 14070003 , on left bank $0.4 \mathrm{mi}$ upstream fram bridge on State Highway 25 , about $0.7 \mathrm{mi}$ upstream fram Johnson Valley Reservolr, and $3.5 \mathrm{mi}$ northeast of north end of Fish Lake.

DRAINAGE AREA. $--24.0 \mathrm{mi}^{2}$.

MEAN BASIN ELEVATION. $--10,000 \mathrm{ft}$.

PERIOD OF RECORD AVAI.ABLE.--October 1964 to September 1981.

REVISED RECORDS. --WDR UT-78-1: Drainage area.

GAGE.--Water-stage recorder. Altitude of gage is $9,200 \mathrm{ft}$ fran topographic map.

AVERAGE DISCHARGE.--17 years, $14.1 \mathrm{ft}^{3} / \mathrm{s}, 10,220$ acre-ft/yr.

EXIREMES FOR PERIOD OF RECORD.-Haximum discharge, $225 \mathrm{ft}^{3} / \mathrm{s}$ May 29,1979 , gage height, $3.30 \mathrm{ft}$; minimum, $1.9 \mathrm{ft} 3 / \mathrm{s}$ Nov. 16,17 , 1978. 
DIRTY DEVIL RIVER BASIN

09329050 SEVEN MILE CREEX NEAR FISH LAKE, UT-Continued

LONEST MEAN DISCHARGE, IN OBIC FEET PER SECOND, AND RANKING FOR THE INDICATED NUMBER OF CONSEOUTIVE DAYS FOR EAOH OLIMATIC YEAR, ARRIL I-MARCH 31

YEAP
196
1967
1968
1969
1970
1971
1972
1973
1974
1975
1976
1977
1978
1979
1980
19

1981

\begin{tabular}{|c|c|c|}
\hline 1 & & 3 \\
\hline $\begin{array}{l}5.00 \\
3.70 \\
4.00 \\
3.90 \\
6.20\end{array}$ & $\begin{array}{r}8 \\
2 \\
5 \\
3 \\
15\end{array}$ & $\begin{array}{l}5.30 \\
4.10 \\
4.10 \\
5.10 \\
6.40\end{array}$ \\
\hline $\begin{array}{l}6.10 \\
6.10 \\
4.80 \\
5.70 \\
5.00\end{array}$ & $\begin{array}{r}13 \\
14 \\
6 \\
11 \\
9\end{array}$ & $\begin{array}{l}7.1016 \\
6.601 \\
6.1011 \\
6.3012 \\
5.90\end{array}$ \\
\hline $\begin{array}{l}6.00 \\
4.80 \\
3.40 \\
4.00 \\
5.30\end{array}$ & $\begin{array}{r}12 \\
7 \\
1 \\
4 \\
10\end{array}$ & $\begin{array}{l}6.00 \\
4.80 \\
3.50 \\
4.80 \\
6.0010\end{array}$ \\
\hline
\end{tabular}

$\begin{array}{ll}7 & \\ 5.50 & 6 \\ 4.60 & 3 \\ 4.10 & 2 \\ 6.00 & 7 \\ 7.10 & 15\end{array}$

$\begin{array}{ll}14 & \\ 5.50 & 6 \\ 4.60 & 2 \\ 4.60 & 3 \\ 6.10 & 7 \\ 7.30 & 15\end{array}$

CONSEQTTIVE DAYS
30

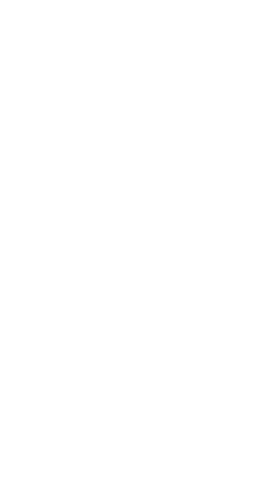

\subsection{6}

6.7013

6.2010

$\begin{array}{rr}6.60 & 12 \\ 6.10 & 8\end{array}$

7.4016

6.9013

6.208

$\begin{array}{rr}6.80 & 11 \\ 6.20 & 9\end{array}$

6.209

6.2010

3.501

$\begin{array}{ll}4.90 & 5 \\ 6.50 & 11\end{array}$

$\begin{array}{ll}4.90 & 4 \\ 3.60 & 1\end{array}$

5.005

7.2014

6.8014

6.9012

7.0011

.2011

6.909

$\begin{array}{ll}4.80 & 2 \\ 5.80 & 5\end{array}$

6.306

7.8014

8.3015

7.6012

6.50
8.9016

$\begin{array}{rr}8.90 & 16 \\ 6.50 & 8\end{array}$

120

$\begin{array}{rr}7.50 & 10 \\ 5.10 & 2 \\ 5.70 & 5 \\ 6.40 & 6\end{array}$

183

8.8012

5.302

$\begin{array}{lllll}8.0012 & 8.3010 & 16.0 & 9\end{array}$

8.7015

$\begin{array}{lllll}8.0013 & 8.9013 & 17.0 & 10 \\ 6.70 & 7 & 7.30 & 7 & 11.0\end{array}$

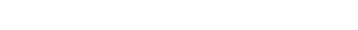

$\begin{array}{rrrrrr}8.90 & 16 & 9.40 & 14 & 20.0 & 16 \\ 6.70 & 8 & 7.50 & 8 & 17.0 & 11\end{array}$

7.5011

$\begin{array}{ll}5.40 & 4 \\ 3.90 & 1\end{array}$

$\begin{array}{lllll}8.0014 & 9.6015 \quad 17.0 \quad 12\end{array}$

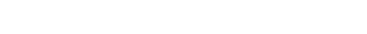

$\begin{array}{llllll}4.00 & 1 & 4.00 & 1 & 6.40 & 1\end{array}$

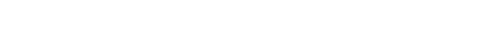

HIGHEST MEAN DISCHARGE, IN OUBIC FEET PER SECOND, AND RANKING FOR THE INDICATED NUMBER OF CONSEQUTIVE DAYS FOR EAOH WATER YEAR, OCTCBER I-SEPTEMBER 30

$\begin{array}{lcccccccc} & 1 & & 3 & & 7 & & 15 & \\ 1965 & 131 & 5 & 127 & 5 & 116 & 5 & 104 & 4 \\ 1966 & 39.0 & 17 & 38.0 & 16 & 35.0 & 16 & 31.0 & 16 \\ 1967 & 79.0 & 13 & 75.0 & 13 & 73.0 & 13 & 63.0 & 12 \\ 1968 & 137 & 3 & 132 & 3 & 129 & 1 & 106 & 3 \\ 1969 & 94.0 & 9 & 89.0 & 10 & 87.0 & 9 & 81.0 & 9 \\ 1970 & 122 & 7 & 115 & 7 & 107 & 7 & 103 & 5 \\ 1971 & 78.0 & 14 & 71.0 & 14 & 60.0 & 14 & 54.0 & 14 \\ 1972 & 41.0 & 15 & 40.0 & 15 & 38.0 & 15 & 34.0 & 15 \\ 1973 & 147 & 1 & 144 & 1 & 127 & 3 & 109 & 1 \\ 1974 & 144 & 2 & 139 & 2 & 129 & 2 & 107 & 2 \\ 1975 & 131 & 4 & 128 & 4 & 121 & 4 & 100 & 6\end{array}$

CONSEOUTIVE DAYS

82.03

58.02

$47.0 \quad 2$

120

183

ALL

$27.0 \quad 16$

$\begin{array}{llllll}64.0 & 6 & 49.0 & 7 & 37.0 & 7\end{array}$

$\begin{array}{rrrrrr}64.0 & 10 & 46.0 & 8 & 36.0 & 8 \\ 81.0 & 4 & 56.0 & 3 & 44.0 & 3\end{array}$

$\begin{array}{llll}50.0 & 12 & 42.0 & 10\end{array}$

$29.0 \quad 15 \quad 25.0 \quad 15$

$\begin{array}{rrrr}25.0 & 15 & 20.0 & 15 \\ 67.0 & 1 & 50.0 & 1\end{array}$

$\begin{array}{llll}83.0 & 2 & 56.0 & 4 \\ 78.0 & 7 & 55.0 & 5\end{array}$

$\begin{array}{ll}42.0 & 4 \\ 42.0 & 5\end{array}$

$67.0 \quad 11$

$47.0 \quad 13$

$31.0 \quad 14$

$23.0 \quad 14$

$\begin{array}{ll}13.0 & 17 \\ 31.0 & 10\end{array}$

$\begin{array}{rr}17.0 & 17 \\ 43.0 & 9\end{array}$

$\begin{array}{rrrr}65.0 & 9 & 43.0 & 9 \\ 66.0 & 8 & 41.0 & 11\end{array}$

$\begin{array}{ll}31.0 & 10 \\ 31.0 & 11\end{array}$

$\begin{array}{rrrrrrrrr}1977 & 39.0 & 16 & 35.0 & 17 & 33.0 & 17 & 30.0 & 17 \\ 1978 & 87.0 & 12 & 80.0 & 12 & 75.0 & 12 & 72.0 & 10 \\ 1979 & 110 & 8 & 98.0 & 8 & 94.0 & 8 & 85.0 & 8 \\ 1980 & 128 & 6 & 125 & 6 & 112 & 6 & 94.0 & 7\end{array}$

$\begin{array}{rr}31.0 & 11 \\ 40.0 & 6\end{array}$

40.0

$\begin{array}{ll}14.0 & 16 \\ 22.0 & 12\end{array}$

$\begin{array}{rrrr}22.0 & 12 & 17.0 & 12 \\ 30.0 & 7 & 22.0 & 9\end{array}$

$\begin{array}{rrrrr}122.0 & 9 & 14.0 & 9\end{array}$

$\begin{array}{llllll}37.0 & 3 & 28.0 & 8 & 15.0 & 8 \\ \end{array}$

$\begin{array}{rrrrrr}30.0 & 9 & 24.0 & 7 & 17.0 & 5\end{array}$

$\begin{array}{rrrrrr}18.0 & 15 & 14.0 & 15 & 11.0 & 15\end{array}$

$\begin{array}{llllll}35.0 & 4 & 26.0 & 2 & 19.0 & 1 \\ 34 & & 26.0 & 18.0 & 2\end{array}$

$\begin{array}{llllll}34.0 & 4 & 26.0 & 4 & 18.0 & 2 \\ & 5 & 25.0 & 5 & 16.0 & 7\end{array}$

1981

$92.0 \quad 11$

$\begin{array}{llll}84.0 & 11 & 77.0 & 11\end{array}$

$62.0 \quad 13$

$45.0 \quad 14$

$32.0 \quad 13$

$25.0 \quad 13$

$\begin{array}{llllll}20.0 & 13 & 15.0 & 14 & 12.0 & 12\end{array}$

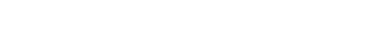

$\begin{array}{llllll}11.0 & 17 & 9.3017 & 7.3017\end{array}$

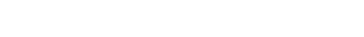

$\begin{array}{rrrrrr}33.0 & 6 & 25.0 & 6 & 17.0 & 6\end{array}$

DURATION OF DISCHARGE FOR EAOH WATER YEAR

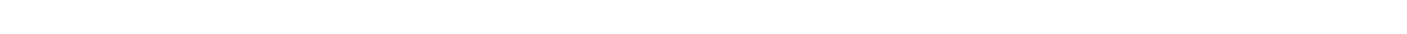

YEAR

NUMBER OF DAYS IN CLASS

ABIC FEET

PER SECOND

-DAYS

196
196
1967
196
1969
1970
197
197
1973
1974
1975
1976
1977
1978
1979
1980

$\begin{array}{lllllllllllll}17179 & 9 & 4 & 1 & 1 & 1 & 7 & 27 & 16 & 13 & 8 & 12\end{array}$

$\begin{array}{lllllllllllllll}10 & 2 & 6 & 3 & 5 & 6 & 4 & 4 & 3 & 2 & 4 & 3 & 6 & 2 & 1\end{array}$

6445.9

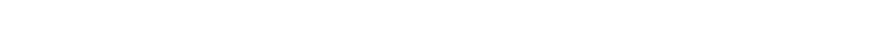

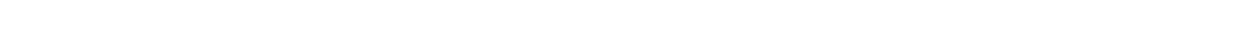

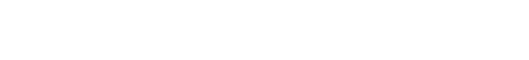

$3 \begin{array}{lrr}3 & 10 & 2 \\ 3 & 8 & 3\end{array}$

$\begin{array}{llllllllll}4 & 3 & 7 & 1 & 1 & 3 & 4 & 7 & 2 \\ 3 & 2 & 1 & 4 & 8 & 3 & & 3 & 2 & 9\end{array}$

$\begin{array}{lllllllllllllllllllllll}1 & 26 & 27 & 37 & 38 & 36 & 38 & 46 & 26 & 10 & 6 & 6 & 6 & 5 & 7 & 7 & 11 & 18 & 5 & 2 & 3 & 3 & 1\end{array}$

$\begin{array}{rlllllllllllllllr}21 & 85 & 64 & 51 & 35 & 21 & 12 & 13 & 7 & 10 & 7 & 13 & 4 & 6 & 6 & 6 & 5\end{array}$

$\begin{array}{lllllllllllllllllll}2 & 4 & 58 & 66 & 42 & 26 & 22 & 23 & 11 & 24 & 13 & 12 & 4 & 6\end{array}$

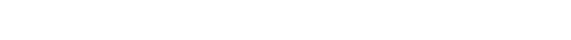

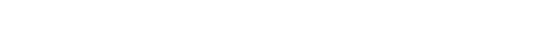

$\begin{array}{llllllllll}2 & 87 & 67 & 16 & 23 & 32 & 25 & 9 & 24 & 10\end{array}$

$\begin{array}{lllllllllllllllll}44 & 37 & 17 & 86 & 27 & 48 & 55 & 80 & 46 & 38 & 15 & 22 & 26 & 6 & 5 & 6 & 3\end{array}$

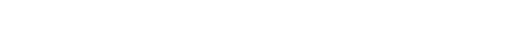

$\begin{array}{lllll}2 & 2 & 3 & 2 & 1 \\ 6 & 8 & 1 & 3 & 2 \\ 1 & 3 & 3 & 2 & 2\end{array}$

$\begin{array}{llllllllllll}6 & 3 & 3 & 6 & 3 & 1 & 5 & & 2 & 2 & 3 & 4 \\ 6 & 3 & 5 & 2 & & 6 & 2 & 4 & 2 & 2 & 4 & 1\end{array}$

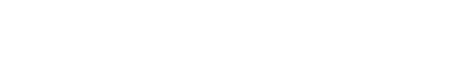

$\begin{array}{lll}3 & 1 & 2 \\ 1 & 2 & 3 \\ 6 & 9 & 6\end{array}$

$\begin{array}{lllllllllllllll}1 & 41 & 88 & 84 & 44 & 27 & 9 & 5 & 13 & 4 & 3 & 5 & 7 & 7 & 9\end{array}$

41

$\begin{array}{llllllll}3 & 1 & 2 & 3 & 2 & 1 & 2 & 2\end{array}$

$\begin{array}{lllllll}2 & 2 & 1 & 6 & 9 & 8 & 1\end{array}$

$\begin{array}{lllllllll}2 & 3 & 1 & 2 & 3 & 4 & 5 & 3 & 1 \\ 4 & 3 & 3 & 2 & 2 & 4 & 3 & 2 & 5\end{array}$

1981

$\begin{array}{lllll}1 & 1 & 4 & 4 & 1\end{array}$

3642.0

3984.2

5216.3

6640.3

6183.7

4156.6

6804.2

6472.0

6022.3

4549.5

2682.4

4140.9

4745.6
6067.3

4382.1 
DIRTY DEVII RIVER BASIN

09329050 SEVEN MILE CREEK NEAR FISH LAKE, UT--Continued

DURATION TABLE OF DISCHARGE FOR WATER YEARS $1965-81$
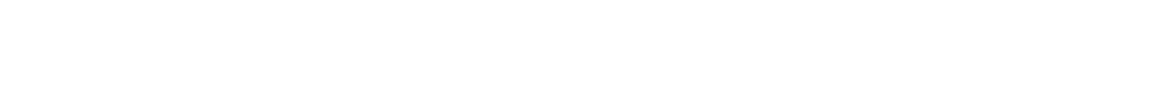

$\begin{array}{ccc}\text { GBIC } & \text { ACOU- } \\ \text { FEET } & \text { MU- } & \text { PER- } \\ \text { PER } & \text { TOTAL LATED } & \text { CENT } \\ \text { OLASS SECOND DAYS } & \text { DAYS } & \text { DAYS }\end{array}$

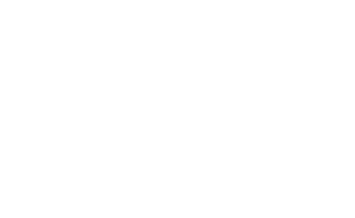

$\begin{array}{rrrrr}9 & 8.50 & 538 & 2999 & 48.3 \\ 10 & 9.50 & 435 & 2461 & 39.6 \\ 11 & 11.00 & 294 & 2026 & 32.6 \\ 12 & 12.00 & 237 & 1732 & 27.9 \\ 13 & 13.00 & 309 & 1495 & 24.1 \\ 14 & 15.00 & 155 & 1186 & 19.1 \\ 15 & 17.00 & 107 & 1031 & 16.6 \\ 16 & 19.00 & 80 & 924 & 14.9 \\ 17 & 21.00 & 104 & 844 & 13.6\end{array}$

$\begin{array}{llllr}18 & 24.0 & 62 & 740 & 11.9 \\ 19 & 26.0 & 99 & 678 & 10.9 \\ 20 & 30.0 & 58 & 579 & 9.3 \\ 21 & 33.0 & 62 & 521 & 8.4 \\ 22 & 37.0 & 62 & 459 & 7.4 \\ 23 & 42.0 & 56 & 397 & 6.4 \\ 24 & 47.0 & 47 & 341 & 5.5 \\ 25 & 52.0 & 34 & 294 & 4.7 \\ 26 & 58.0 & 40 & 260 & 4.2\end{array}$

$\begin{array}{rrrrr}27 & 65.0 & 53 & 220 & 3.5 \\ 28 & 73.0 & 40 & 167 & 2.7 \\ 29 & 82.0 & 36 & 127 & 2.0 \\ 30 & 92.0 & 27 & 91 & 1.5 \\ 31 & 100.0 & 33 & 64 & 1.0 \\ 32 & 120.0 & 19 & 31 & 0.5 \\ 33 & 130.0 & 12 & 12 & 0.2 \\ 34 & & & & \end{array}$

MONIHLY MEAN DISCHARGES, IN GBIC FEET PER SECOND, FOR EAOH WATER YEAR

\begin{tabular}{lcccccccccccc} 
YEAR & OCT & NOV & DEC & JAN & FEB & MAR & \multicolumn{1}{l}{ APR } & MAY & JUNE & JULY & AUG & SEP \\
1965 & 5.80 & 5.77 & 5.70 & 5.60 & 5.50 & 5.25 & 6.16 & 38.1 & 75.9 & 25.4 & 18.7 & 13.8 \\
1966 & 12.0 & 10.6 & 9.12 & 7.58 & 6.56 & 6.58 & 22.7 & 19.9 & 7.72 & 6.04 & 5.15 & 5.58 \\
1967 & 6.06 & 5.25 & 5.85 & 4.83 & 4.71 & 4.86 & 5.02 & 38.4 & 31.0 & 9.09 & 7.12 & 8.37 \\
1968 & 7.06 & 6.65 & 5.88 & 6.05 & 5.69 & 5.64 & 6.65 & 43.1 & 53.6 & 12.1 & 10.8 & 7.86 \\
1969 & 7.46 & 7.22 & 6.23 & 6.33 & 6.50 & 6.45 & 13.8 & 62.8 & 27.4 & 12.2 & 10.0 & 10.6 \\
1970 & 9.59 & 8.50 & 8.42 & 8.23 & 7.80 & 7.44 & 8.55 & 64.0 & 43.5 & 21.0 & 15.9 & 14.4 \\
1971 & 12.9 & 10.3 & 9.76 & 9.17 & 7.75 & 8.12 & 20.5 & 45.3 & 37.1 & 15.8 & 13.5 & 12.6 \\
1972 & 11.1 & 9.85 & 8.64 & 7.63 & 6.98 & 8.96 & 19.4 & 28.0 & 13.0 & 7.17 & 7.33 & 8.03 \\
1973 & 8.40 & 8.34 & 7.35 & 6.75 & 6.45 & 6.26 & 8.13 & 75.6 & 55.4 & 16.5 & 12.8 & 10.8 \\
1974 & 10.5 & 9.93 & 8.99 & 9.11 & 8.71 & 8.92 & 11.8 & 81.4 & 26.9 & 14.2 & 11.2 & 9.95 \\
1975 & 9.82 & 8.66 & 7.19 & 6.70 & 6.40 & 6.30 & 6.57 & 24.9 & 74.1 & 24.1 & 12.3 & 11.1 \\
1976 & 14.4 & 10.8 & 9.62 & 8.37 & 7.50 & 6.64 & 9.56 & 43.3 & 16.2 & 8.39 & 7.03 & 6.80 \\
1977 & 6.95 & 8.65 & 5.73 & 5.83 & 5.10 & 5.12 & 23.2 & 10.6 & 5.31 & 4.30 & 3.87 & 3.70 \\
1978 & 4.24 & 4.16 & 3.91 & 4.05 & 4.45 & 4.72 & 5.21 & 41.3 & 41.8 & 8.84 & 6.48 & 6.66 \\
1979 & 6.35 & 6.85 & 5.80 & 5.41 & 5.09 & 5.45 & 9.11 & 42.7 & 38.6 & 11.3 & 10.5 & 8.55 \\
1980 & 8.27 & 8.30 & 7.80 & 7.75 & 7.81 & 7.58 & 9.75 & 42.6 & 61.1 & 15.0 & 10.9 & 12.3 \\
1981 & 11.0 & 9.47 & 8.05 & 7.26 & 7.17 & 7.49 & 32.0 & 28.7 & 12.2 & 7.21 & 6.67 & 6.87
\end{tabular}

ANNUA PEAK DISCHARGE, IN GBIC FEET PER SECOND, AND CORRESPONDING GAGE HEIGHT, IN FEET, FOR EACH WATER YEAR

\begin{tabular}{|c|c|c|c|c|c|c|c|c|c|c|c|}
\hline $\begin{array}{l}\text { WATER } \\
\text { YEAR }\end{array}$ & DATE & $\begin{array}{c}\text { GAGE } \\
\text { HEIGATT }\end{array}$ & $\begin{array}{c}\text { PEAR } \\
\text { DISCH ARGE }\end{array}$ & $\begin{array}{l}\text { WATER } \\
\text { YEAR }\end{array}$ & DATE & $\begin{array}{c}\text { GAGE } \\
\text { HEIGIT }\end{array}$ & $\begin{array}{c}\text { PEAR } \\
\text { DISCH ARGE }\end{array}$ & $\begin{array}{l}\text { WATERR } \\
\text { YEAR }\end{array}$ & DATE & $\begin{array}{c}\text { GAGE } \\
\text { HEIGHT }\end{array}$ & $\begin{array}{c}\text { PEAK } \\
\text { DISCHARGE }\end{array}$ \\
\hline $\begin{array}{l}1965 \\
1966 \\
1967 \\
1968 \\
1969 \\
1970\end{array}$ & $\begin{array}{lll}\text { JUNE } & 05,1965 \\
\text { MAY } & 01,1966 \\
\text { MAY } & 22,1967 \\
\text { JUNE } 01,1968 \\
\text { JUNE } 24,196 \\
\text { MAY 28, } 1970\end{array}$ & $\begin{array}{l}3.45 \\
2.30 \\
2.82 \\
3.43 \\
3.26 \\
3.39\end{array}$ & $\begin{array}{r}206 \\
64 \\
126 \\
215 \\
187 \\
209\end{array}$ & $\begin{array}{l}1971 \\
1972 \\
1973 \\
1974 \\
1975 \\
1976\end{array}$ & $\begin{array}{lll}\text { MAY } & 27,1971 \\
\text { MAY } & 05,1972 \\
\text { MAY } & 18,1973 \\
\text { MAY } & 16,1974 \\
\text { JUNE } & 05,1975 \\
\text { MAY } & 18,1976\end{array}$ & $\begin{array}{l}2.71 \\
2.16 \\
3.25 \\
3.34 \\
3.26 \\
3.08\end{array}$ & $\begin{array}{r}115 \\
64 \\
190 \\
206 \\
187 \\
160\end{array}$ & $\begin{array}{l}1977 \\
1978 \\
1979 \\
1980 \\
1981\end{array}$ & $\begin{array}{lll}\text { APR. } & 17,1977 \\
\text { MAY } & 30,1978 \\
\text { MAY } & 29,1979 \\
\text { JUNE } 05,1980 \\
\text { APR. 03, } 1981\end{array}$ & $\begin{array}{l}2.15 \\
2.79 \\
3.30 \\
3.23 \\
2.95\end{array}$ & $\begin{array}{r}59 \\
128 \\
225 \\
214 \\
170\end{array}$ \\
\hline
\end{tabular}

MAGNITUDE AND PROBFIIT ITY OF ANNUAT LONEST MEAN DISCHARGE

\begin{tabular}{|c|c|c|c|c|c|c|}
\hline \multirow{2}{*}{$\begin{array}{l}\text { PERIOD } \\
\text { (OON- } \\
\text { SEAJ- } \\
\text { TIVE } \\
\text { DAVS) }\end{array}$} & \multicolumn{6}{|c|}{$\begin{array}{l}\text { DISCHARGE, IN CUBIC FEET PER SECOND, FOR } \\
\text { INDICATED REOURRENCE INTERNA, IN YEARS, AND } \\
\text { ANNUAC NONEXCEEDANCE PROBABII ITY, IN PERCENT }\end{array}$} \\
\hline & $\begin{array}{c}2 \\
508\end{array}$ & $\begin{array}{c}5 \\
208\end{array}$ & $\begin{array}{l}10 \\
108\end{array}$ & $\begin{array}{l}20 \\
58\end{array}$ & $\begin{array}{l}50 \\
28\end{array}$ & $\begin{array}{r}100 \\
18\end{array}$ \\
\hline $\begin{array}{r}1 \\
7 \\
14 \\
30 \\
60 \\
90\end{array}$ & $\begin{array}{l}5.0 \\
5.9 \\
6.0 \\
6.3 \\
6.5 \\
6.7\end{array}$ & $\begin{array}{l}4.2 \\
4.9 \\
5.0 \\
5.2 \\
5.3 \\
5.5\end{array}$ & $\begin{array}{l}3.7 \\
4.3 \\
4.4 \\
4.6 \\
4.7 \\
4.9\end{array}$ & $\begin{array}{l}3.4 \\
3.8 \\
4.0 \\
4.1 \\
4.2 \\
4.3\end{array}$ & 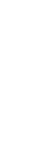 & $\bar{z}=$ \\
\hline
\end{tabular}

MAGNITUDE AND PROB BASED ON WATER YEARS $1965-81$

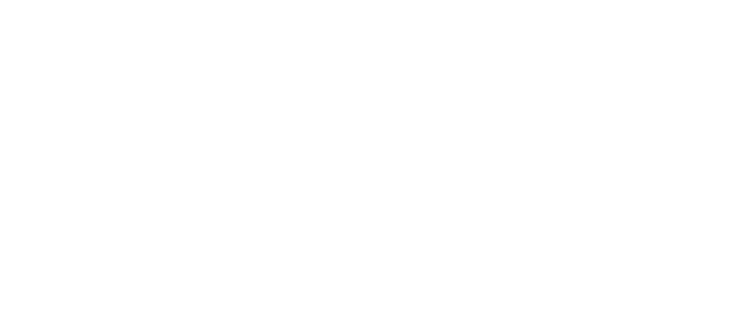


DIRTY DEVIL RIVER BASTN

09329500 FREMONT RTVER NEAR FREMONT, UT

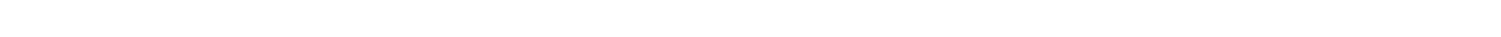
ft downstream from road bridge, $1.75 \mathrm{mi}$ downstream from East Fork, and $2.5 \mathrm{mi}$ northeast of Fremont.

DRAINAGE AREA. $-205 \mathrm{mi}^{2}$.

PERIOD OF RECORD AVAILABLE. - July 1949 to September 1958.

GAGE. - Water-stage recorder. Altitude of gage is $7,480 \mathrm{ft}$ by barcmeter.

REMARKS.--Flow regulated by Fish Lake and Johnson and Forsythe Reservoirs.

AVERAGE DISCHARGE. - -9 years, $41.2 \mathrm{ft}^{3} / \mathrm{s}, 29,830$ acre-ft.

EXTREMES FOR PERIOD OF RECORD.--Maximum discharge, $262 \mathrm{ft}^{3} / \mathrm{s} \mathrm{July} 29,1953$, gage height, $2.75 \mathrm{ft} ; \mathrm{minimum} \mathrm{cbserved}, 0.4 \mathrm{ft}{ }^{3} / \mathrm{s} \mathrm{Jan}$. 16. 1957 (discharge measurement).

LOWEST MEAN DISGHARGE, IN OUBIC FEET PER SECOND, AND RANKING FOR THE INDICATED NUMBER OF CONSEQUTIVE DAYS FOR EAOH OLIMRTIC YEAR, APRII 1-MARG 31

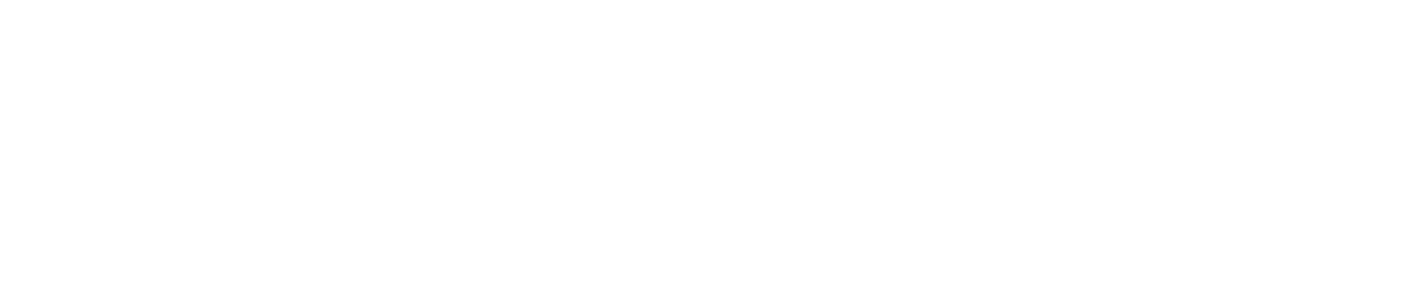

HIGHEST MEAN DISGHARGE, IN OUBIC FEET PER SECOND, AND RANKING FOR THE TNDICATED NUMBER OF CONSECUTIVE DAVS FOR EACH WATER YEAR, OCTOBER 1-SEPTEMBER 30

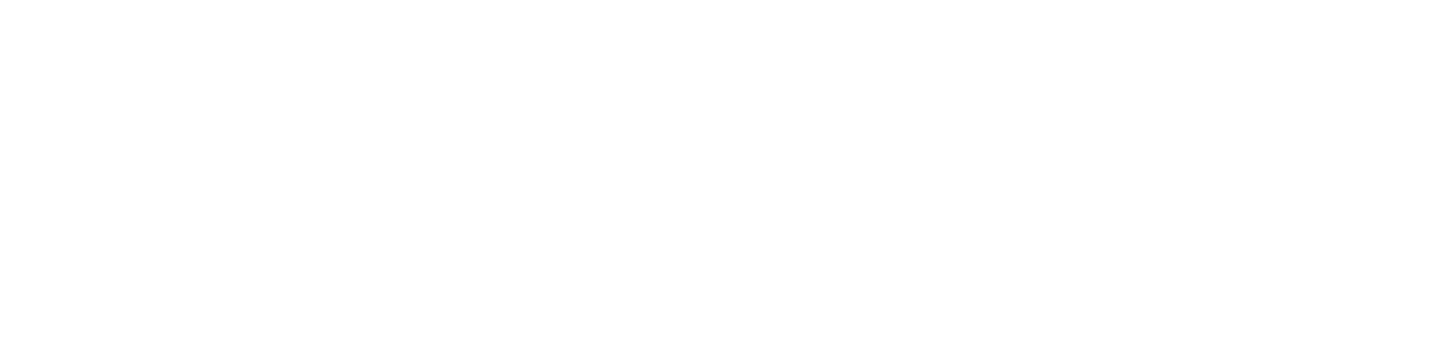

DURATION OF DISGHARGE FOR EACH WATER YEAR

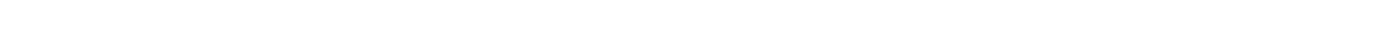
YEAR NUMBER OF DAYS IN CLASS

OBIC FEET PER SECND -DAYS

1950

1951

1952

1953

1955

$1956-1215016$

$\begin{array}{lllllllllll}1957 & 38 & 31 & 30 & 4 & 53 & 22 & 7 & & & 1 \\ 1958 & & 19 & 62 & 49 & 21 & 1 & 3 & 2 & 1\end{array}$

DURATION TABLE OF DISCHARGE FOR WATER YEARS 1950-58 $\begin{array}{lll}\text { OHBIC } & \text { ACCU- } \\ \text { FEET } & \text { MU- } & \text { PER- } \\ \text { PER TOTAL LATED } & \text { GEN }\end{array}$

CLASS SECOND DAYS DAYS DAYS

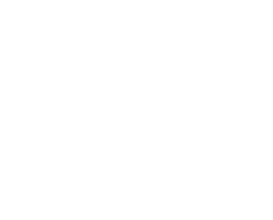

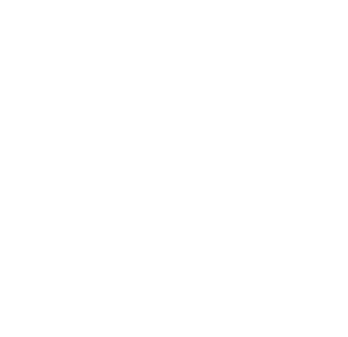

$\begin{array}{lllll}17 & 7.90 & 464 & 2563 & 78.0\end{array}$

$\begin{array}{llllllllllllll}64 & 62 & 14 & 1 & 3 & 6 & 11 & 38 & 48 & 8 & 5 & 17 & 59 & 29\end{array}$

$\begin{array}{lllllllllllllllll}1 & 5 & 119 & 42 & 2 & 1 & 2 & 12 & 10 & 31 & 28 & 9 & 6 & 15 & 47 & 31 & 4\end{array}$

$\begin{array}{llllllllllllllllllll}1 & 33 & 56 & 38 & 13 & 4 & 23 & 8 & 19 & 9 & 3 & 1 & 12 & 31 & 3 & 16 & 14 & 71 & 11\end{array}$

$\begin{array}{llllllllllllllllll}13 & 4 & 62 & 49 & 1 & 3 & 3 & 23 & 18 & 24 & 9 & 8 & 4 & 6 & 30 & 94 & 14\end{array}$

$\begin{array}{ccccccccccccccccc}5 & 22 & 26 & 91 & 20 & 5 & 2 & 5 & 28 & 12 & 36 & 19 & 6 & 19 & 33 & 43 & 20 \\ & 22 & 68 & 62 & 16 & 5 & & 8 & 12 & 31 & 27 & 17 & 3 & 3 & 1 & 18 & 67\end{array}$
14498.6

13326.6

21310.2

17866.0

13136.9

12428.1

9926.3

14363.8

18464.7

$\begin{array}{rrrrr}0 & 0.00 & 0 & 3287 & 100.0 \\ 1 & 0.40 & 38 & 3287 & 100.0 \\ 2 & 0.48 & 0 & 3249 & 98.8 \\ 3 & 0.58 & 50 & 3249 & 98.8 \\ 4 & 0.70 & 213 & 3199 & 97.3 \\ 5 & 0.84 & 54 & 2986 & 90.8 \\ 6 & 1.00 & 118 & 2932 & 89.2 \\ 7 & 1.20 & 43 & 281.4 & 85.6 \\ 8 & 1.50 & 8 & 2771 & 84.3\end{array}$

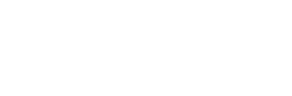

QLASS SECOND DAYS DAYS DAYS

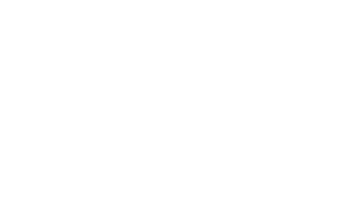

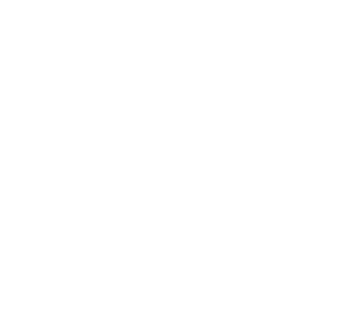


DIRIY DEVII RIVER BASIN

09329500 FREMONT RIVER NEAR EREMONT, UT-Continued

MONIHLY MEAN DISCHARGES, IN OBBIC FEET PER SECOND, FOR EACH WATER YEAR

$\begin{array}{llccccccccrrr}\text { YEAR } & \text { OCT } & \text { NOV } & \text { DEC } & \text { JAN } & \text { FEB } & \text { MAR } & \text { APR } & \text { MAY } & \text { JUNE } & \text { JULY } & \text { AUG } & \text { SEP } \\ 1950 & 40.8 & 10.7 & 8.84 & 10.0 & 10.7 & 13.7 & 37.4 & 86.7 & 91.9 & 81.1 & 50.1 & 32.2 \\ & & & & & & & & & & & & \\ 1951 & 22.3 & 9.32 & 8.68 & 8.27 & 8.19 & 9.39 & 21.5 & 83.7 & 93.8 & 82.8 & 53.7 & 34.1 \\ 1952 & 20.6 & 7.85 & 8.35 & 8.48 & 10.0 & 16.3 & 33.3 & 146 & 151 & 134 & 99.1 & 62.1 \\ 1953 & 77.6 & 8.59 & 8.81 & 9.71 & 9.23 & 16.9 & 25.9 & 95.1 & 100 & 97.4 & 96.5 & 36.8 \\ 1954 & 32.2 & 8.06 & 8.22 & 8.18 & 9.00 & 14.0 & 38.1 & 85.7 & 83.3 & 66.1 & 52.1 & 24.7 \\ 1955 & 28.5 & 6.67 & 7.87 & 7.13 & 7.00 & 8.35 & 11.8 & 86.2 & 92.3 & 90.1 & 36.1 & 24.0 \\ 1956 & 23.8 & 1.33 & 0.80 & 0.70 & 0.70 & 0.80 & 0.90 & 84.9 & 96.1 & 56.4 & 33.9 & 23.9 \\ 1957 & 25.9 & 2.14 & 0.60 & 0.40 & 0.70 & 1.05 & 1.18 & 16.8 & 140 & 108 & 101 & 72.0 \\ 1958 & 73.9 & 4.13 & 0.70 & 0.80 & 1.61 & 1.81 & 2.41 & 113 & 141 & 131 & 87.5 & 43.6\end{array}$

ANNUAL PEAR DISCHARGE, IN OBIC FEET PER SECOND, AND CORRESPONDING GAGE HEIGHT, IN FEET, FOR EACH WATER YEAR

\begin{tabular}{|c|c|c|c|c|c|c|c|c|c|c|c|c|}
\hline $\begin{array}{l}\text { WATER } \\
\text { YEAR }\end{array}$ & & DATE & $\begin{array}{l}\text { GAGE } \\
\text { HEIGHT }\end{array}$ & $\begin{array}{c}\text { PEAR } \\
\text { DISCHARGE }\end{array}$ & $\begin{array}{l}\text { WATER } \\
\text { YEAR }\end{array}$ & DATE & $\begin{array}{l}\text { GAGE } \\
\text { HEIGHT }\end{array}$ & $\begin{array}{c}\text { PEAR } \\
\text { DISCHARGE }\end{array}$ & $\begin{array}{l}\text { WATER } \\
\text { YEAR }\end{array}$ & DATE & $\begin{array}{l}\text { GAGE } \\
\text { HEIGHT }\end{array}$ & $\begin{array}{l}\text { PEAR } \\
\text { DISCAARGE }\end{array}$ \\
\hline 1950 & MAY & 08,1950 & - & $1_{96}$ & 1953 & JULY 29, 1953 & 2.75 & 262 & 1956 & AUG. 02, 1956 & 2.02 & 131 \\
\hline $\begin{array}{l}1951 \\
1952\end{array}$ & $\begin{array}{l}\text { MAY } \\
\text { JUNE }\end{array}$ & $\begin{array}{l}30,1951 \\
04,1952\end{array}$ & $\begin{array}{l}2.04 \\
2.28\end{array}$ & $\begin{array}{l}127 \\
185\end{array}$ & $\begin{array}{l}1954 \\
1955\end{array}$ & $\begin{array}{l}\text { MAY } 04,1954 \\
\text { JUNE } 28,1955\end{array}$ & $\begin{array}{l}1.91 \\
1.88\end{array}$ & $\begin{array}{l}117 \\
109\end{array}$ & $\begin{array}{l}1957 \\
1958\end{array}$ & $\begin{array}{l}\text { JUNE } 26,27,1957 \\
\text { JUNE } 01,1958\end{array}$ & $\overline{2.37}$ & $\begin{array}{r}1_{155} \\
196\end{array}$ \\
\hline
\end{tabular}

$1_{\text {Maximum daily discharge. }}$

09329800 TONAY HOLOW NEAR BICKNELL, UT

LOCATION. --Lat $38^{\circ} 17^{\prime}$, long $111^{\circ} 37$ ', in E⿺辶⿳亠丷厂彡⿱ Bicknell and $8 \mathrm{mi}$ south of Loa.

DRAINAGE AREA. $-3.3 \mathrm{mi}^{2}$.

PERICD OF RECORD AVAIIABLE.--Water years 1959-60, 1962-67, annual peak discharge only.

GAGE.-Crest-stage gage. Altitude of gage is $7,550 \mathrm{ft}$ from topographic map.

ANNUAL PEAR DISCHARGE, IN OBBIC FEET PER SECOND, AND CORRESPONDING GAGE HEIGHT, IN FEET, FOR EACH WATER YEAR

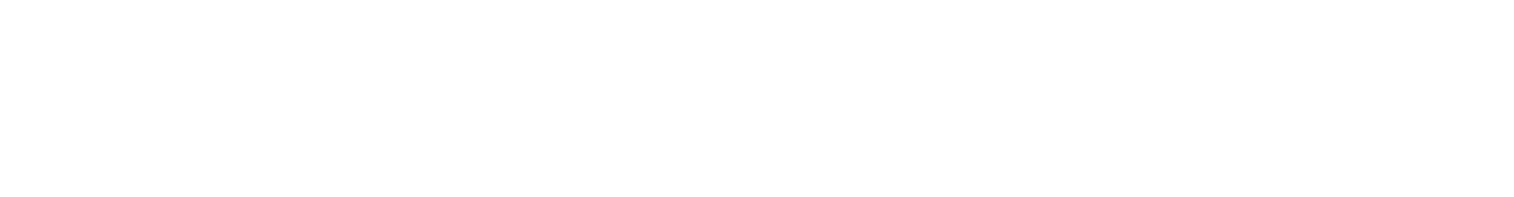

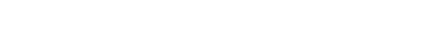

09329900 PINE CREER NEAR BICXNELL, UT

LOCATION.--Lat $38^{\circ} 16^{\prime} 10^{\prime \prime}$, long $111^{\circ} 35^{\prime} 00^{\prime \prime}$, in SEl sec.21, T.29 S., R.3 E., wayne County, Hydrologic Unit 14070003 , about 3.5 mi upstream from mouth and $5.5 \mathrm{mi}$ southwest of Bicknell.

DRAINAGE AREA. $-104 \mathrm{mi}^{2}$.

MEAN BASIN ELEVATION. $-9,300 \mathrm{ft}$.

PERICD OF RECORD AVAIIABLE. - - October 1964 to September 1980.

REVISED RECORDS. -WDR UT-78-1: Drainage area.

GAGE. - Water-stage recorder. Altitude of gage is 7,100 ft tron topographic map.

AVERAGE DISCHARGE.--16 years, $3.98 \mathrm{ft}^{3} / \mathrm{s}, 2,880$ acre- $\mathrm{ft} / \mathrm{yr}$.

EXIREMES FOR PERICD OF RECORD.--Maximum discharge, $707 \mathrm{ft}^{3} / \mathrm{s}$ Aug. 2, 1968, gage height, $4.85 \mathrm{ft}$, from estimate based on field survey of peak flow; no flow Feb. 5, 1972, result of treezeup. 
DIRTY DEVII RTVER BASIN

09329900 PINE CREEK NEAR BICKNELL, UT--Continued

LONEST MEAN DISCHARGE, IN CUBIC FEET PER SECOND, AND RANKING FOR THE INDICATED NUMBER OF CONSEOUTIVE DAYS FOR EACH OLIMATIC YEAR, APRIL I-MARCH 31

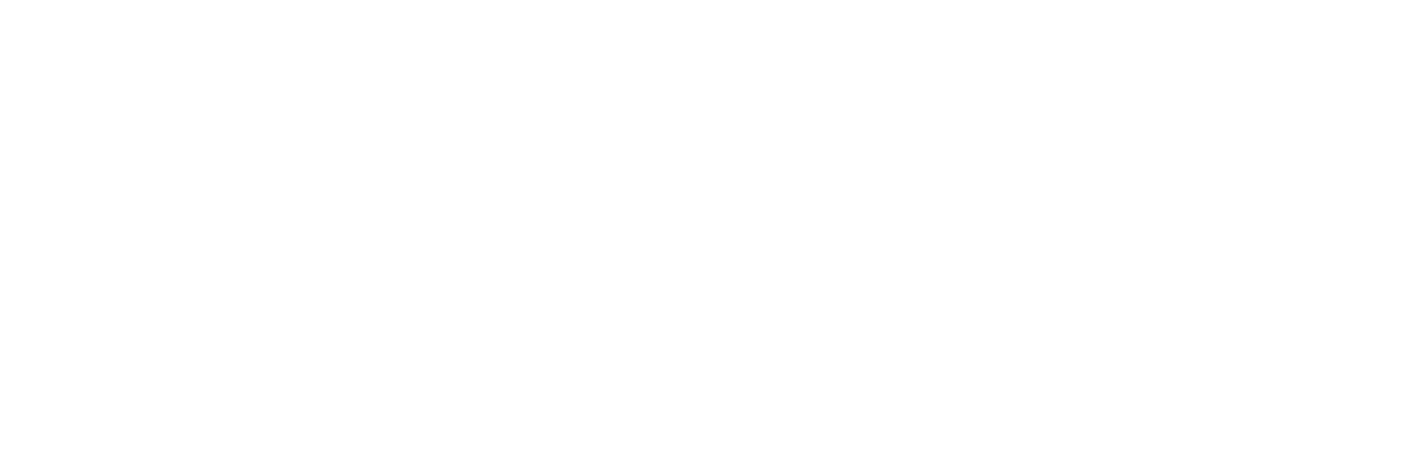

HIGHEST MEAN DISCHARGE, IN CUBIC FEET PER SECOND, AND RANKING FOR THE INDICATED NUMBER OF CONSECUTIVE DAYS FOR EAOH WATER YEAR, OCTCBER 1-SEPTEMBER 30

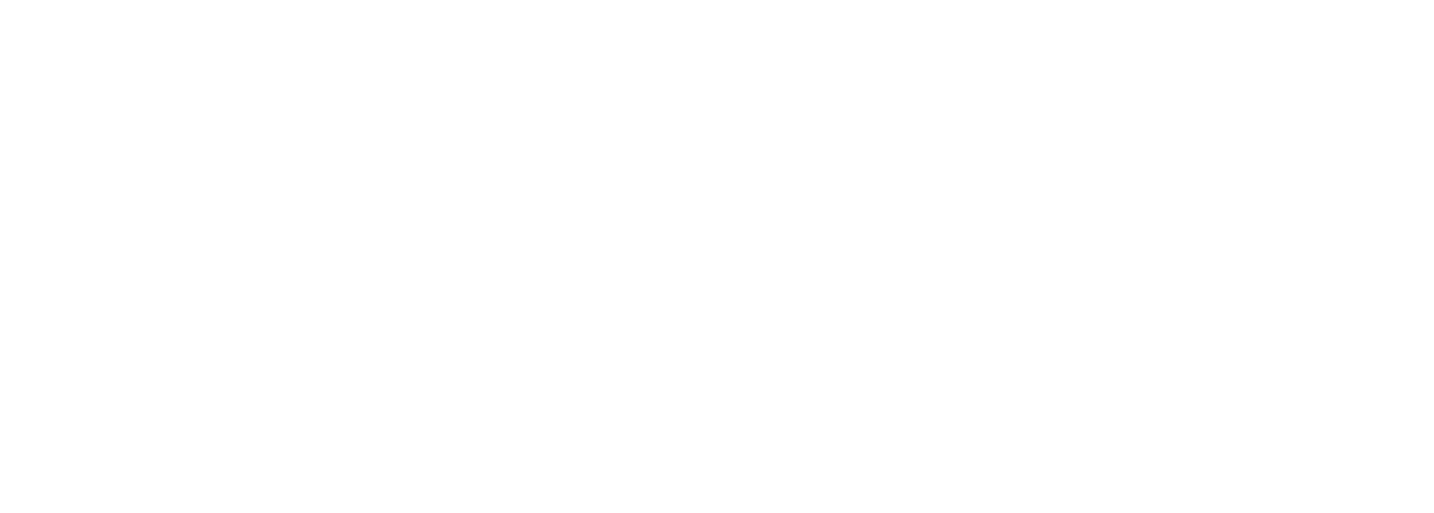

DURATION OF DISCHARGE FOR EAGH WATER YEAR

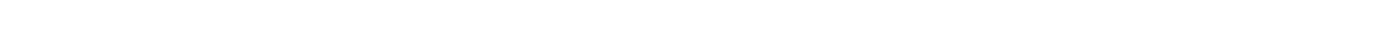
YEAR NUMBER OF DAYS IN CLASS

\begin{tabular}{|c|c|c|c|c|c|c|c|c|c|c|c|c|c|c|c|c|c|c|c|c|c|c|c|c|c|c|c|c|c|}
\hline 1965 & & & & & & & & & & 9 & 6 & 17 & 221 & 109 & 120 & 29 & 43 & 1 & 2 & 4 & 12 & 2 & & & & & & & 1351.1 \\
\hline $\begin{array}{l}1966 \\
1967 \\
1968 \\
1969 \\
1970\end{array}$ & & & & & & 2 & & 1 & & $\begin{array}{l}5 \\
1\end{array}$ & 2 & $\begin{array}{r}2 \\
3 \\
13 \\
19\end{array}$ & $\begin{array}{ll}21 & 1 \\
77 & 2 \\
46 & 1 \\
25 & 1 \\
31 & \end{array}$ & $\begin{array}{r}129 \\
214 \\
193 \\
1172 \\
751\end{array}$ & $\begin{array}{r}75 \\
56 \\
49 \\
200 \\
132\end{array}$ & $\begin{array}{r}53 \\
2 \\
42 \\
14 \\
79\end{array}$ & $\begin{array}{r}75 \\
2 \\
3 \\
5 \\
8\end{array}$ & $\begin{array}{l}3 \\
3 \\
1 \\
4\end{array}$ & $\begin{array}{l}2 \\
3 \\
2\end{array}$ & $\begin{array}{l}2 \\
3 \\
1\end{array}$ & $\begin{array}{ll}3 & 2 \\
2 & 2\end{array}$ & $\begin{array}{ll}2 & 2 \\
2 & \\
& \\
& 1\end{array}$ & $\begin{array}{ll}2 & \\
& 3 \\
1 & 1\end{array}$ & $\begin{array}{l}3 \\
1\end{array}$ & $\begin{array}{ll}1 & 1 \\
2 & 5\end{array}$ & $\begin{array}{ll}1 & \\
5 & 3\end{array}$ & 1 & 2 & $\begin{array}{l}1391.1 \\
1141.0 \\
1444.1 \\
1225.4 \\
2415.8\end{array}$ \\
\hline $\begin{array}{l}1971 \\
1972 \\
1973 \\
1974 \\
1975\end{array}$ & 1 & 1 & 14 & 43 & 1 & 1 & 314 & $\begin{array}{l}25 \\
38\end{array}$ & $\begin{array}{r}11 \\
13 \\
6\end{array}$ & $\begin{array}{r}31 \\
26 \\
5\end{array}$ & $\begin{array}{r}3 \\
18 \\
3 \\
2\end{array}$ & $\begin{array}{c}41 \\
551 \\
19 \\
2 \\
2\end{array}$ & $\begin{array}{r}84 \\
113 \\
15 \\
31 \\
271\end{array}$ & $\begin{array}{c}67 \\
61 \\
88 \\
147 \\
153\end{array}$ & $\begin{array}{c}471 \\
9 \\
32 \\
98 \\
93\end{array}$ & $\begin{array}{r}101 \\
6 \\
17 \\
34 \\
49\end{array}$ & $\begin{array}{r}11 \\
4 \\
22 \\
49 \\
7\end{array}$ & $\begin{array}{r}3 \\
3 \\
59 \\
19 \\
5\end{array}$ & $\begin{array}{l}3 \\
1 \\
2 \\
5\end{array}$ & $\begin{array}{l}2 \\
3 \\
4\end{array}$ & $\begin{array}{ll} & 2 \\
3 & 7 \\
2 & 3\end{array}$ & $\begin{array}{ll}2 & 1 \\
7 & 6 \\
3 & \end{array}$ & $\begin{array}{l}1 \\
6\end{array}$ & 7 & $\begin{array}{ll}3 & 1 \\
2 & 5\end{array}$ & $\begin{array}{ll}1 & \\
5 & 3\end{array}$ & $\begin{array}{l}1 \\
2\end{array}$ & . & $\begin{array}{r}1287.7 \\
691.7 \\
2238.6 \\
1385.0 \\
2476.6\end{array}$ \\
\hline $\begin{array}{l}1976 \\
1977 \\
1978 \\
1979 \\
1980\end{array}$ & & & & & & & & & & & 25 & 602 & $\begin{array}{r}891 \\
213 \\
861\end{array}$ & $\begin{array}{c}651 \\
1491 \\
63 \\
138 \\
271\end{array}$ & $\begin{array}{c}157 \\
105 \\
1 \\
65 \\
142\end{array}$ & $\begin{array}{r}124 \\
21 \\
2 \\
69 \\
150\end{array}$ & $\begin{array}{r}3 \\
1 \\
3 \\
42\end{array}$ & $\begin{array}{l}2 \\
1 \\
5\end{array}$ & 2 & 3 & $\begin{array}{l}1 \\
1\end{array}$ & 5 & 4 & 1 & & & & & $\begin{array}{r}1697.4 \\
1067.2 \\
775.4 \\
1157.3 \\
1548.3\end{array}$ \\
\hline
\end{tabular}


DIRTY DEVII RIVER BASIN

09329900 PINE CREEK NEAR BICKNELL, UT'-Continued

DURATION TABLE OF DISCHARGE FOR WATER YEARS 1965-80
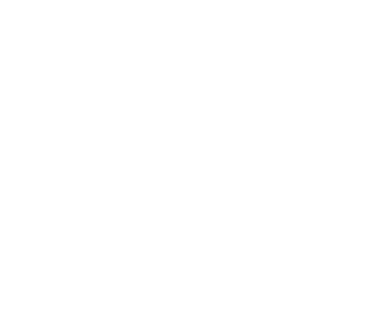

CUBIC ACOU- OUBIC

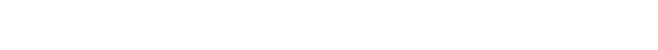
PER TOTAL LATED CENT
CLASS SECOND DAYS DAYS DAYS CLASS SECOND DAYS DAYS DAYS

$\begin{array}{rrrrr}9 & 0.22 & 3 & 5833 & 99.8 \\ 10 & 0.29 & 3 & 5830 & 99.8 \\ 11 & 0.38 & 14 & 5827 & 99.7 \\ 12 & 0.49 & 64 & 5813 & 99.5 \\ 13 & 0.64 & 30 & 5749 & 98.4 \\ 14 & 0.84 & 77 & 5719 & 97.9 \\ 15 & 1.10 & 59 & 5642 & 96.5 \\ 16 & 1.40 & 233 & 5583 & 95.5\end{array}$

$\begin{array}{rrrrr}18 & 2.4 & 1795 & 4498 & 77.0 \\ 19 & 3.2 & 1381 & 2703 & 46.3 \\ 20 & 4.1 & 792 & 1322 & 22.6 \\ 21 & 5.4 & 278 & 530 & 9.1 \\ 22 & 7.0 & 109 & 252 & 4.3 \\ 23 & 9.2 & 23 & 143 & 2.4 \\ 24 & 12.0 & 23 & 120 & 2.1 \\ 25 & 16.0 & 13 & 97 & 1.7 \\ 26 & 20.0 & 23 & 84 & 1.4\end{array}$

\begin{tabular}{|c|c|c|c|c|}
\hline & $\begin{array}{c}\text { OBIC } \\
\text { FEET } \\
\text { PER }\end{array}$ & TOTAL & $\begin{array}{c}\text { ACQI- } \\
\text { MU- } \\
\text { LATED }\end{array}$ & $\begin{array}{l}\text { PER- } \\
\text { CENT }\end{array}$ \\
\hline CLASS & SECOND & DAYS & DAYS & DAYS \\
\hline $\begin{array}{l}27 \\
28 \\
29 \\
30 \\
31 \\
32 \\
33\end{array}$ & $\begin{array}{r}27.0 \\
35.0 \\
45.0 \\
59.0 \\
77.0 \\
100.0 \\
130.0\end{array}$ & $\begin{array}{r}14 \\
14 \\
8 \\
12 \\
6 \\
4 \\
3\end{array}$ & $\begin{array}{r}61 \\
47 \\
33 \\
25 \\
13 \\
7 \\
3\end{array}$ & $\begin{array}{l}1.0 \\
0.8 \\
0.6 \\
0.4 \\
0.2 \\
0.1 \\
0.1\end{array}$ \\
\hline
\end{tabular}

MONIHLY MEAN DISCHARGES, IN OUBIC FEET PER SECOND, FOR EACH WATER YEAR

\begin{tabular}{|c|c|c|c|c|c|c|c|c|c|c|c|c|}
\hline YEAR & OCT & NOV & $\mathrm{DEC}$ & JAN & FEBB & MAR & APR & MAY & JUNE & JULY & AUG & SEP \\
\hline 1965 & 3.69 & 3.65 & 3.35 & 3.35 & 2.37 & 1.28 & 2.56 & 2.93 & 4.95 & 4.60 & 5.37 & 6.30 \\
\hline $\begin{array}{l}1966 \\
1967 \\
1968 \\
1969 \\
1970\end{array}$ & $\begin{array}{l}6.38 \\
3.11 \\
2.35 \\
3.72 \\
3.10\end{array}$ & $\begin{array}{l}6.09 \\
3.05 \\
2.46 \\
3.65 \\
2.98\end{array}$ & $\begin{array}{l}5.25 \\
2.93 \\
1.76 \\
3.21 \\
2.63\end{array}$ & $\begin{array}{l}4.77 \\
2.33 \\
2.71 \\
3.35 \\
3.11\end{array}$ & $\begin{array}{l}3.46 \\
2.94 \\
2.97 \\
3.00 \\
3.66\end{array}$ & $\begin{array}{l}2.18 \\
2.72 \\
2.86 \\
3.80 \\
4.46\end{array}$ & $\begin{array}{l}3.24 \\
2.84 \\
3.29 \\
3.43 \\
5.49\end{array}$ & $\begin{array}{c}3.23 \\
7.62 \\
12.7 \\
4.67 \\
39.0\end{array}$ & $\begin{array}{l}2.71 \\
2.45 \\
2.71 \\
2.55 \\
2.10\end{array}$ & $\begin{array}{l}2.77 \\
2.12 \\
3.27 \\
2.32 \\
3.42\end{array}$ & $\begin{array}{l}2.67 \\
2.69 \\
5.97 \\
3.14 \\
4.49\end{array}$ & $\begin{array}{l}2.95 \\
2.64 \\
4.13 \\
3.41 \\
4.29\end{array}$ \\
\hline $\begin{array}{l}1971 \\
1972 \\
1973 \\
1974 \\
1975\end{array}$ & $\begin{array}{l}4.76 \\
0.63 \\
2.97 \\
7.14 \\
3.21\end{array}$ & $\begin{array}{l}4.70 \\
1.31 \\
2.82 \\
5.75 \\
2.86\end{array}$ & $\begin{array}{l}1.83 \\
0.87 \\
0.89 \\
5.49 \\
2.66\end{array}$ & $\begin{array}{l}2.76 \\
0.79 \\
0.68 \\
3.84 \\
3.03\end{array}$ & $\begin{array}{l}2.59 \\
1.55 \\
1.06 \\
2.94 \\
3.30\end{array}$ & $\begin{array}{l}4.87 \\
4.28 \\
2.64 \\
1.88 \\
4.90\end{array}$ & $\begin{array}{c}6.92 \\
2.72 \\
17.7 \\
3.08 \\
8.23\end{array}$ & $\begin{array}{c}2.98 \\
2.03 \\
20.9 \\
3.23 \\
38.5\end{array}$ & $\begin{array}{l}2.25 \\
1.80 \\
2.68 \\
2.99 \\
2.47\end{array}$ & $\begin{array}{l}3.09 \\
1.99 \\
5.20 \\
3.11 \\
3.24\end{array}$ & $\begin{array}{l}3.14 \\
2.16 \\
8.05 \\
3.04 \\
3.69\end{array}$ & $\begin{array}{l}2.41 \\
2.54 \\
7.74 \\
2.95 \\
4.69\end{array}$ \\
\hline $\begin{array}{l}1976 \\
1977 \\
1978 \\
1979 \\
1980\end{array}$ & $\begin{array}{l}5.16 \\
4.01 \\
2.35 \\
3.21 \\
4.70\end{array}$ & $\begin{array}{l}4.71 \\
3.84 \\
2.23 \\
4.01 \\
4.65\end{array}$ & $\begin{array}{l}4.36 \\
2.74 \\
2.24 \\
2.80 \\
4.36\end{array}$ & $\begin{array}{l}3.88 \\
2.39 \\
2.29 \\
2.11 \\
4.26\end{array}$ & $\begin{array}{l}3.47 \\
2.75 \\
2.30 \\
2.11 \\
3.78\end{array}$ & $\begin{array}{l}3.19 \\
3.42 \\
2.37 \\
2.29 \\
3.57\end{array}$ & $\begin{array}{l}4.14 \\
2.92 \\
2.26 \\
2.84 \\
3.40\end{array}$ & $\begin{array}{c}12.6 \\
2.88 \\
2.38 \\
4.35 \\
3.58\end{array}$ & $\begin{array}{l}2.96 \\
3.07 \\
1.40 \\
2.71 \\
3.12\end{array}$ & $\begin{array}{l}3.31 \\
2.28 \\
1.43 \\
3.27 \\
3.87\end{array}$ & $\begin{array}{l}3.58 \\
2.75 \\
1.90 \\
4.02 \\
5.58\end{array}$ & $\begin{array}{l}4.12 \\
2.02 \\
2.35 \\
4.25 \\
5.86\end{array}$ \\
\hline
\end{tabular}

ANNUAL PEAK DISCHARGE, IN OUBIC FEET PER SECOND, AND CORRESPONDING GAGE HEIGHT, IN FEET, FOR EACH WATER YEAR

\begin{tabular}{|c|c|c|c|c|c|c|c|c|c|c|c|c|}
\hline $\begin{array}{l}\text { WATER } \\
\text { YEAR }\end{array}$ & DATE & $\begin{array}{c}\text { GAGE } \\
\text { HEIGHT }\end{array}$ & $\begin{array}{c}\text { PEAK } \\
\text { DISCHARGE }\end{array}$ & $\begin{array}{l}\text { WATER } \\
\text { YEAR }\end{array}$ & DATE & $\begin{array}{c}\text { GAGE } \\
\text { HEIGHT }\end{array}$ & $\begin{array}{c}\text { PEAK } \\
\text { DISCHARGE }\end{array}$ & $\begin{array}{l}\text { WATER } \\
\text { YEAR }\end{array}$ & & DATE & $\begin{array}{c}\text { GAGE } \\
\text { HEIGHT }\end{array}$ & $\begin{array}{c}\text { PEAK } \\
\text { DIS GHARGE }\end{array}$ \\
\hline $\begin{array}{l}1965 \\
1966 \\
1967 \\
1968 \\
1969 \\
1970\end{array}$ & 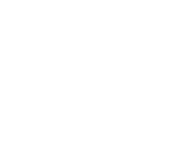 & $\begin{array}{l}3.02 \\
1.38 \\
2.61 \\
4.85 \\
2.30 \\
3.37\end{array}$ & $\begin{array}{r}259 \\
16 \\
135 \\
707 \\
30 \\
267\end{array}$ & $\begin{array}{l}1971 \\
1972 \\
1973 \\
1974 \\
1975\end{array}$ & $\begin{array}{l}\text { APR. } 13,1971 \\
\text { MAR. } 07,1972 \\
\text { APR. } 27,1973 \\
\text { NOV. 14, } 1973 \\
\text { MAY 16, } 1975\end{array}$ & $\begin{array}{l}2.28 \\
2.45 \\
3.57 \\
1.52 \\
3.39\end{array}$ & $\begin{array}{r}59 \\
18 \\
324 \\
11 \\
270\end{array}$ & $\begin{array}{l}1976 \\
1977 \\
1978 \\
1979 \\
1980\end{array}$ & $\begin{array}{l}\text { MAY } \\
\text { AUG } \\
\text { MAY } \\
\text { MAY } \\
\text { MAY }\end{array}$ & $\begin{array}{ll}15, & 1976 \\
23, & 1977 \\
24, & 1978 \\
22, & 1979 \\
23, & 1980\end{array}$ & $\begin{array}{l}2.74 \\
3.09 \\
1.63 \\
1.96 \\
1.77\end{array}$ & $\begin{array}{r}123 \\
196 \\
14 \\
40 \\
19\end{array}$ \\
\hline
\end{tabular}

\begin{tabular}{lccccc}
\multicolumn{3}{l}{ MAGNITUDE AND PRCBABILITY OF ANNUAL LOWEST MEAN DISCHARGE } \\
BASED ON CIMATIC YEARS $1966-80$
\end{tabular}


DIRTY DEVIL RIVER BASIN

09330000 EREMONT RIVER NEAR BICKNELL, UT

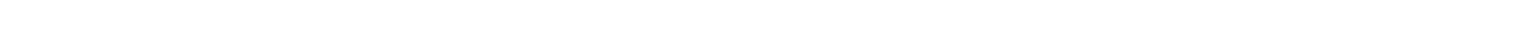
at upstream side of county road bridge and $2.9 \mathrm{mi}$ southeast of Bicknell along State Highway 24.

DRAINAGE AREA. $--751 \mathrm{mi}^{2}$.

PERTOD OF RECORD AVAIIABLE,-May 1909 to December 1912 (monthly mean discharge for same periods, published in WSP 1313), October 1937 to March 1944, April 1944 to December 1945 (monthly mean discharge for sone periods, published in wSP 1313), January 1946 to September 1958, October 1976 to Septenber 1981. Published as "near Thurber", 1909-12.

REVISED RECORDS. -WDR UT-78-1: Drainage area.

GAGE.--Water-stage recorder and bubble gage. Altitude of gage is 6,920 ft from topographic map. May 1909 to December 1912 , staff gage near present site at different datum. Oct doer 1937 to June 28,1949 , staff gages on two canals and river station about

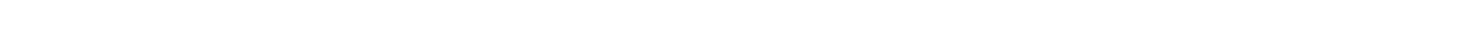
canal site using sane datum. Apr. 29 to Sept. 30, 1958, staff gage on river at site 600 ft turther downstream from water-stage recorder at datum $1.67 \mathrm{ft}$ lower.

REMARRS.--Diversions for irrigation of about 10,600 acres above station. Flow regulated by Fish Lake and Johnson and Forsythe Reservoirs.

AVERAGE DISCHARGE.--26 years (water years 1910-12, 1938-43, 1947-58, 1977-81), $86.2 \mathrm{ft}^{3} / \mathrm{s}, 62,450 \mathrm{acre}-\mathrm{ft} / \mathrm{yr}$.

EXXREYES FOR PERIOD OF RECORD.--Maximum discharge, 1,200 ft $3 / \mathrm{s} \mathrm{Apr.} 5,1942$, gage height, $5.8 \mathrm{ft}$ from floodnarks, site and datum then in use, from rating curve extended above $700 \mathrm{ft}^{3} / \mathrm{s} ;$ minimum observed, $18 \mathrm{ft}^{3} / \mathrm{s}$ June $2,4,13-15,17,18,1912$.

LONEST MEAN DISCHARGE, IN OUBIC FEET PER SECOND, AND RANRING FOR THE INDICATED NUMBR OF CONSECUTIVE DAYS FOR EACH CLIMATIC YEAR, APRII I-MARCH 31

YEAR

1939

$52.0 \quad 11$

7

14

CONSECTIIVE DAYS

1940

56.011

$60.0 \quad 14$

$\begin{array}{llll}63.0 & 14 & 67.0 & 15\end{array}$

90

$\begin{array}{llll}39.0 & 2 & 40.0 & 2\end{array}$

$41.0 \quad 1$

61.015

64.017

$\begin{array}{ll}67.0 & 15 \\ 67.0 & 16\end{array}$

$68.0 \quad 14$

120

$\begin{array}{rr}41.0 & 1 \\ 47.0 & 3 \\ 59.0 & 12\end{array}$

$\begin{array}{ll}45.0 & 1 \\ 49.0 & 3\end{array}$

$\begin{array}{rr}46.0 & 1 \\ 54.0 & 5 \\ 62.0 & 11\end{array}$

49.0

$58.0 \quad 13$

$\begin{array}{rrrr}53.0 & 12 & 56.0 & 13 \\ 49.0 & 8 & 50.0 & \end{array}$

53.08

55.08

$\begin{array}{rr}65.0 & 6\end{array}$

$\begin{array}{rr}67.0 & 11\end{array}$

58.05

$\begin{array}{rr}65.0 & 11 \\ 58.0 & 6\end{array}$

$62.0 \quad 16$

$\begin{array}{ll}63.0 & 15 \\ 61.0 & 13\end{array}$

58.014

57.014

$59.0 \quad 13$

$65.0 \quad 13$

$\begin{array}{llll}65.0 & 18 & 70.0 & 20 \\ 70.0 & 22 & 71.0 & 22\end{array}$

$\begin{array}{llll}58.0 & 17 & 59.0 & 17 \\ 62.0 & 21 & 65.0 & 22\end{array}$

68.022

$68.0 \quad 22$

63.021

64.021

$62.0 \quad 22$

$\begin{array}{rr}61.0 & 18 \\ 43.0 & 4\end{array}$

$43.044 \quad 44.0$

$\begin{array}{llll}61.0 & 20 & 62.0 & 20\end{array}$

45.04

$\begin{array}{rr}66.0 & 21 \\ 64.0 & 19 \\ 51.0 & 5\end{array}$

$69.0 \quad 17$

$68.0 \quad 15$

$\begin{array}{ll}71.0 & 15 \\ 71.0 & 18\end{array}$

$\begin{array}{llll}68.0 & 21 & 70.0 & 21\end{array}$

67.020

$\begin{array}{rrrrrr}51.0 & 5 & 58.0 & 8 & 63.0 & 12 \\ 64.0 & 20 & 65.0 & 19 & 70.0 & 19\end{array}$

69.018

$\begin{array}{llll}64.0 & 16 & 66.0 & 14\end{array}$

$71.0 \quad 19$

71.020

$67.0 \quad 12$

$\begin{array}{ll}71.0 & 21 \\ 67.0 & 13\end{array}$

$\begin{array}{llll}51.0 & 9 & 52.0 & 9\end{array}$

2.019

$\begin{array}{rrrr}56.0 & 9 & 58.0 & 9 \\ 58.0 & 11 & 60.0 & 11\end{array}$

$61.0 \quad 8$

$63.0 \quad 9$

$\begin{array}{rr}53.0 & 9 \\ 56.0 & 12\end{array}$

$\begin{array}{ll}63.0 & 9 \\ 62.0 & 7\end{array}$

$\begin{array}{llll}55.0 & 14 & 55.0 & 12 \\ 52.0 & 10 & 54.0 & 10\end{array}$

55.010

57.010

58.010

$61.0 \quad 10$

63.08

$\begin{array}{llll}47.0 & 6 & 48.0 & 7\end{array}$

50.07

$51.0 \quad 6 \quad 56.0$

$\begin{array}{llll}60.0 & 7 & 64.0 & 10\end{array}$

$\begin{array}{llll}48.0 & 7 & 48.0 & 6\end{array}$

49.06

$\begin{array}{ll}48.0 & 4 \\ 52.0 & 7\end{array}$

49.04

$\begin{array}{llll}50.0 & 3 & 52.0 & 3\end{array}$

50.0
54.0

54.04

$\begin{array}{llll}43.0 & 2 & 45.0 & 2\end{array}$

47.02

47.01

$\begin{array}{rrrrrr}69.0 & 13 & 70.0 & 9 & 88.0 & 15 \\ 69.0 & 14 & 70.0 & 10 & 78.0 & 8\end{array}$

$\begin{array}{llllll}52.0 & 2 & 58.0 & 4 & 70.0 & 4\end{array}$

$\begin{array}{llllll}62.0 & 6 & 76.0 & 18 & 99.0 & 21\end{array}$

$\begin{array}{lrrrrr}68.0 & 12 & 71.0 & 12 & 114 & 22\end{array}$

59.05

$71.0 \quad 15$

74.016

$\begin{array}{ll}74.0 & 22 \\ 73.0 & 20\end{array}$

64.05

$98.0 \quad 20$

$\begin{array}{lllll} & 78.0 & 22 & 91.0 & 16 \\ 20 & 77.0 & 20 & 92.0 & 19\end{array}$

\begin{aligned} $92.0 \quad 18 \\$\hline\end{aligned}

$72.0 \quad 18$

$\begin{array}{ll}76.0 & 17 \\ 77.0 & 21\end{array}$

$\begin{array}{llllll}67.0 & 10 & 70.0 & 15 & 84.0 & 12\end{array}$

$\begin{array}{llllll}41.0 & 3 & 41.0 & 3 & 41.0 & 2\end{array}$

FEET PER SECOND, AND RANRING FOR THE INDICAT

FOR EACH WATER YEAR, OCTCBER 1-SEPIEABER 30

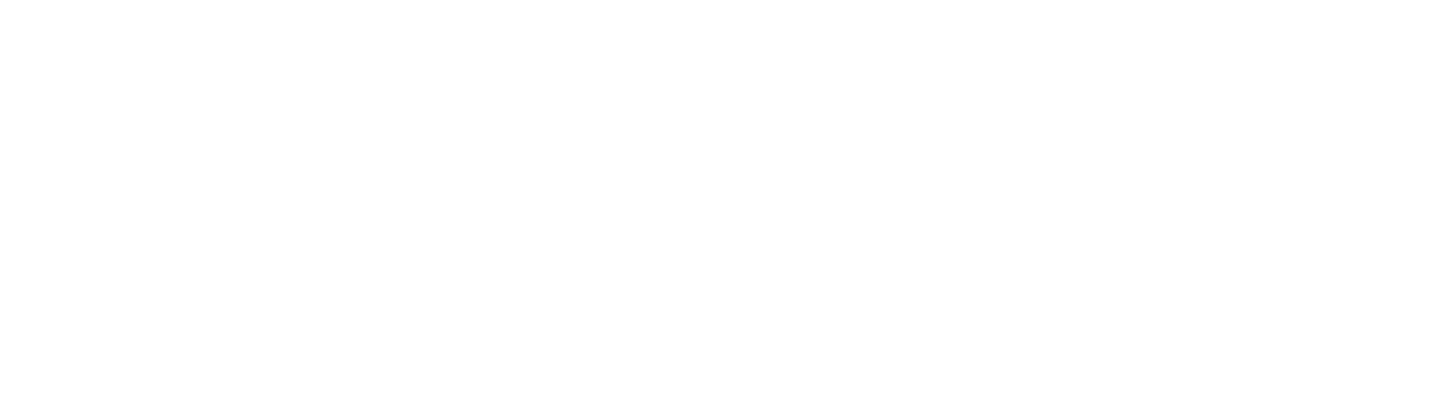


09330000 FREMONT RIVER NEAR BICKNELL, UT-Continued

HIGHEST MEAN DISCHAPGE, IN OUBIC FEET PER SECOND, AND RANKING FOR THE INDICATED NUMBER OF CONSEQUTIVE DAYS FOR EACH WATER YEAR, OCTOBER 1-SEPTEYBER 30-Continued

\begin{tabular}{|c|c|c|c|c|c|c|c|c|c|c|c|c|c|c|c|c|c|c|c|c|}
\hline IEAR & & & & & & & & & cons & 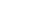 & E DAY & & & & & & & & & \\
\hline $\begin{array}{l}951 \\
952 \\
953 \\
954 \\
955\end{array}$ & $\begin{array}{l}119 \\
185 \\
124 \\
118 \\
146\end{array}$ & $\begin{array}{l}20 \\
13 \\
17 \\
21 \\
14\end{array}$ & $\begin{array}{l}117 \\
155 \\
123 \\
114 \\
144\end{array}$ & $\begin{array}{l}18 \\
13 \\
16 \\
19 \\
14\end{array}$ & $\begin{array}{l}114 \\
134 \\
119 \\
112 \\
135\end{array}$ & $\begin{array}{l}17 \\
13 \\
15 \\
18 \\
11\end{array}$ & $\begin{array}{l}106 \\
127 \\
116 \\
109 \\
121\end{array}$ & $\begin{array}{l}17 \\
11 \\
14 \\
16 \\
12\end{array}$ & $\begin{array}{l}103 \\
112 \\
114 \\
105 \\
112\end{array}$ & $\begin{array}{l}17 \\
12 \\
10 \\
15 \\
11\end{array}$ & $\begin{array}{l}99.0 \\
108 \\
111 \\
100 \\
104\end{array}$ & $\begin{array}{r}16 \\
12 \\
9 \\
15 \\
14\end{array}$ & $\begin{array}{c}98.0 \\
107 \\
109 \\
99.0 \\
99.0\end{array}$ & $\begin{array}{r}16 \\
10 \\
8 \\
14 \\
15\end{array}$ & $\begin{array}{l}98.0 \\
105 \\
107 \\
97.0 \\
95.0\end{array}$ & $\begin{array}{r}14 \\
10 \\
8 \\
15 \\
16\end{array}$ & $\begin{array}{r}92.0 \\
99.0 \\
102 \\
93.0 \\
90.0\end{array}$ & $\begin{array}{r}15 \\
11 \\
8 \\
14 \\
16\end{array}$ & $\begin{array}{l}84.0 \\
88.0 \\
88.0 \\
82.0 \\
79.0\end{array}$ & $\begin{array}{r}12 \\
7 \\
8 \\
14 \\
15\end{array}$ \\
\hline $\begin{array}{l}956 \\
957 \\
958\end{array}$ & $\begin{array}{l}103 \\
95.0 \\
732\end{array}$ & $\begin{array}{r}22 \\
24 \\
2\end{array}$ & $\begin{array}{r}99.0 \\
94.0 \\
717\end{array}$ & $\begin{array}{r}22 \\
23 \\
2\end{array}$ & $\begin{array}{l}94.0 \\
93.0 \\
615\end{array}$ & $\begin{array}{r}22 \\
23 \\
2\end{array}$ & $\begin{array}{l}90.0 \\
92.0 \\
430\end{array}$ & $\begin{array}{r}23 \\
20 \\
2\end{array}$ & $\begin{array}{l}89.0 \\
90.0 \\
293\end{array}$ & $\begin{array}{r}21 \\
20 \\
2\end{array}$ & $\begin{array}{l}87.0 \\
85.0 \\
204\end{array}$ & $\begin{array}{r}20 \\
22 \\
2\end{array}$ & $\begin{array}{r}86.0 \\
83.0 \\
173\end{array}$ & $\begin{array}{r}20 \\
22 \\
3\end{array}$ & $\begin{array}{r}84.0 \\
81.0 \\
153\end{array}$ & $\begin{array}{r}18 \\
22 \\
3\end{array}$ & $\begin{array}{l}80.0 \\
78.0 \\
130\end{array}$ & $\begin{array}{r}20 \\
22 \\
3\end{array}$ & $\begin{array}{l}72.0 \\
73.0 \\
102\end{array}$ & $\begin{array}{r}19 \\
18 \\
3\end{array}$ \\
\hline $\begin{array}{l}1977 \\
1978 \\
1979 \\
1980\end{array}$ & $\begin{array}{l}470 \\
121 \\
130 \\
245\end{array}$ & $\begin{array}{r}5 \\
18 \\
16 \\
9\end{array}$ & $\begin{array}{l}282 \\
113 \\
117 \\
168\end{array}$ & $\begin{array}{r}6 \\
20 \\
17 \\
12\end{array}$ & $\begin{array}{l}187 \\
106 \\
103 \\
118\end{array}$ & $\begin{array}{r}8 \\
19 \\
21 \\
16\end{array}$ & $\begin{array}{r}130 \\
99.0 \\
92.0 \\
90.0\end{array}$ & $\begin{array}{l}10 \\
18 \\
21 \\
22\end{array}$ & $\begin{array}{c}103 \\
96.0 \\
84.0 \\
73.0\end{array}$ & $\begin{array}{l}16 \\
18 \\
23 \\
24\end{array}$ & $\begin{array}{l}94.0 \\
91.0 \\
77.0 \\
69.0\end{array}$ & $\begin{array}{l}17 \\
18 \\
23 \\
24\end{array}$ & $\begin{array}{l}87.0 \\
87.0 \\
74.0 \\
68.0\end{array}$ & $\begin{array}{l}17 \\
18 \\
23 \\
24\end{array}$ & $\begin{array}{l}83.0 \\
84.0 \\
72.0 \\
68.0\end{array}$ & $\begin{array}{l}21 \\
19 \\
23 \\
24\end{array}$ & $\begin{array}{l}82.0 \\
79.0 \\
72.0 \\
66.0\end{array}$ & $\begin{array}{l}17 \\
21 \\
23 \\
24\end{array}$ & $\begin{array}{l}79.0 \\
67.0 \\
65.0 \\
60.0\end{array}$ & $\begin{array}{l}16 \\
22 \\
23 \\
24\end{array}$ \\
\hline & 98.0 & 23 & 90.0 & 24 & 88.0 & 24 & 87.0 & 24 & 87.0 & 22 & 8.0 & 21 & 85.0 & 21 & 84.0 & 20 & 82.0 & 18 & 71.0 & 20 \\
\hline
\end{tabular}

DURATION OF DISOHARGE FOR EACH WATER YEAR

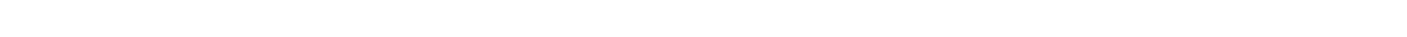
YEAR

NUMBER OF DAYS IN OLASS

QUBIC FEET PER SECOND

1910 -DAYS

1938
1939

1939
1940

$\begin{array}{lllllllllllllll}2 & 5 & 26 & 42 & 26 & 15 & 20 & 16 & 32 & 34 & 81 & 37 & 22 & 3 & 4\end{array}$

48639.0

$\begin{array}{rrrrrrrrrrrrrrr}428 & 90 & 56 & 51 & 58 & 41 & 15 & 11 & 3 & 3 & & & & 4 & 1 \\ 4 & 56 & 92 & 35 & 80 & 73 & 8 & 10 & 2 & 1 & 2 & 1 & 1 & & \end{array}$

30528.0 $\begin{array}{rrrrrrrrrrrrrrrrr}12 & 23 & 24 & 36 & 65 & 74 & 68 & 47 & 15 & 1 & 1 & 10 & 1 & 2 & 1 & 1 & \end{array}$

31448.0

$\begin{array}{lllllllllllllllllllllllll}1 & 1 & 3 & 10 & 19 & 9 & 61 & 87 & 95 & 37 & 20 & 2 & 5 & 2 & 1 & 1 & 1 & 3 & 2 & 1 & 1 & 2 & 1 & & \end{array}$

1941

1943

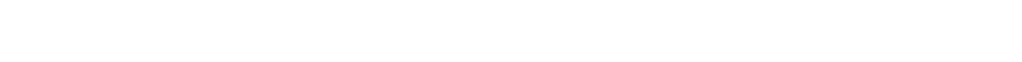

44777.0

1947

$\begin{array}{lllllllllll}12 & 45 & 30 & 67 & 74 & 85 & 42 & 5 & 2 & 2\end{array}$

$\begin{array}{lllllllllllllllll}2 & 55 & 29 & 43 & 38 & 112 & 39 & 34 & 3 & 1 & 1 & 3 & 3 & 1 & 1 & 1\end{array}$

$\begin{array}{rrrrrrr}24 & 89 & 71 & 35 & 68 & 42 & 19 \\ 22 & 109 & 66 & 56 & 79 & 25 & 8\end{array}$

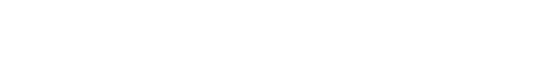

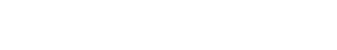

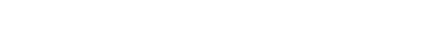

$\begin{array}{llllll}26 & 121 & 98 & 72 & 47 & 2\end{array}$

$\begin{array}{llllll}219 & 89 & 112 & 112 & 31\end{array}$

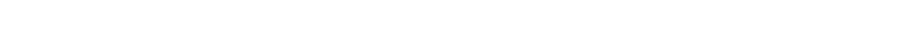

32799.0

36279.0

31459.0

1951

1952

1955

1956

1957
1958

$\begin{array}{llllllll}9 & 17 & 45 & 82 & 135 & 58 & 14 & 1\end{array}$

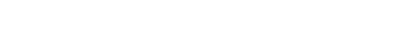

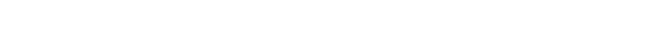

30621.0

32160.0

32118.0

29751.0

1977

1978
1979

1980

$\begin{array}{llllllll}2 & 31 & 72 & 46 & 41 & 107 & 65 & 1\end{array}$

26437.0

26489.0

37127.0

DURATION TABLE OF DISOHARGE FOR WATER YEARS 1 910, 1938-43, 1 947-58, 1 977-81

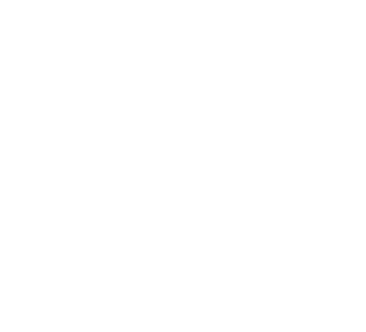

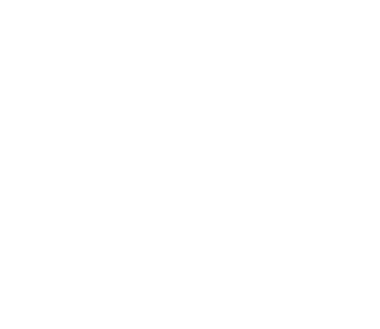

\begin{tabular}{crr}
\multicolumn{4}{c}{ OBBIC } \\
FEET \\
PER & TOT \\
C.ASS & SECOND & DAY \\
& & \\
18 & 140.0 & 74 \\
19 & 160.0 & 106 \\
20 & 180.0 & 50 \\
21 & 200.0 & 34 \\
22 & 230.0 & 9 \\
23 & 250.0 & 15 \\
24 & 290.0 & 7 \\
25 & 320.0 & 7 \\
26 & 370.0 & 2
\end{tabular}

$\mathrm{ACOJ}-$

MU- PER-

$\begin{array}{rr}332 & 3.8 \\ 258 & 2.9 \\ 152 & 1.7 \\ 102 & 1.2 \\ 68 & 0.8 \\ 59 & 0.7 \\ 44 & 0.5 \\ 37 & 0.4 \\ 30 & 0.3\end{array}$
CUBIC ACOJPER TOTAL LATED CENT
OLASS SECOND DAYS DAYS DAYS

$\begin{array}{rrrrr}27 & 410.0 & 2 & 28 & 0.3 \\ 28 & 470.0 & 5 & 26 & 0.3 \\ 29 & 530.0 & 4 & 21 & 0.2 \\ 30 & 590.0 & 2 & 17 & 0.2 \\ 31 & 670.0 & 5 & 15 & 0.2 \\ 32 & 750.0 & 2 & 10 & 0.1 \\ 33 & 850.0 & 6 & 8 & 0.1 \\ 34 & 960.0 & 2 & 2 & 0.0\end{array}$


DIRTY DEVIL RIVER BASIN

09330000 FREMONT RIVER NEAR BICKNELL, UT--Continued

MONTHLY MEAN DISCHARGES, IN GUBIC FEET PER SECOND, FOR EACH WATER YEAR

\begin{tabular}{|c|c|c|c|c|c|c|c|c|c|c|c|c|}
\hline YEAR & $\infty \mathrm{CT}$ & $\mathrm{NOV}$ & $\mathrm{DEC}$ & JAN & FEBB & MAR & APR & MAY & JUNE & JULY & AUG & SEP \\
\hline $\begin{array}{l}1910 \\
1911 \\
1912\end{array}$ & $\begin{array}{c}180 \\
109 \\
82.7\end{array}$ & $\begin{array}{c}155 \\
109 \\
89.9\end{array}$ & $\begin{array}{l}180 \\
110 \\
60.0\end{array}$ & $\begin{array}{r}173 \\
80 \\
80\end{array}$ & $\begin{array}{r}178 \\
106 \\
90\end{array}$ & $\begin{array}{l}193 \\
170 \\
113\end{array}$ & $\begin{array}{c}118 \\
94.6 \\
206\end{array}$ & $\begin{array}{l}84.0 \\
96.3 \\
232\end{array}$ & $\begin{array}{l}71.7 \\
35.9 \\
45.9\end{array}$ & $\begin{array}{r}64.0 \\
47.8 \\
125\end{array}$ & $\begin{array}{r}77.6 \\
77.7 \\
103\end{array}$ & $\begin{array}{r}128 \\
80.3 \\
94.9\end{array}$ \\
\hline $\begin{array}{l}1938 \\
1939 \\
1940\end{array}$ & $\begin{array}{l}64.6 \\
73.4 \\
66.9\end{array}$ & $\begin{array}{l}68.5 \\
92.6 \\
74.3\end{array}$ & $\begin{array}{l}85.1 \\
99.0 \\
79.9\end{array}$ & $\begin{array}{l}98.3 \\
95.5 \\
82.6\end{array}$ & $\begin{array}{l}99.7 \\
93.6 \\
91.4\end{array}$ & $\begin{array}{c}108 \\
119 \\
83.4\end{array}$ & $\begin{array}{c}129 \\
101 \\
78.1\end{array}$ & $\begin{array}{l}71.1 \\
74.6 \\
60.6\end{array}$ & $\begin{array}{l}67.6 \\
64.5 \\
49.2\end{array}$ & $\begin{array}{l}73.8 \\
75.2 \\
46.8\end{array}$ & $\begin{array}{l}65.8 \\
68.8 \\
54.4\end{array}$ & $\begin{array}{l}73.8 \\
77.6 \\
72.6\end{array}$ \\
\hline $\begin{array}{l}1941 \\
1942 \\
1943\end{array}$ & $\begin{array}{c}69.2 \\
108 \\
72.0\end{array}$ & $\begin{array}{c}80.2 \\
105 \\
84.3\end{array}$ & $\begin{array}{c}79.7 \\
103 \\
87.4\end{array}$ & $\begin{array}{l}75.5 \\
91.6 \\
89.0\end{array}$ & $\begin{array}{r}94.6 \\
97.0 \\
102\end{array}$ & $\begin{array}{l}86.1 \\
138 \\
108\end{array}$ & $\begin{array}{l}77.7 \\
476 \\
101\end{array}$ & $\begin{array}{l}217 \\
87.0 \\
57.6\end{array}$ & $\begin{array}{l}66.9 \\
67.4 \\
55.9\end{array}$ & $\begin{array}{l}49.8 \\
61.2 \\
61.0\end{array}$ & $\begin{array}{l}59.3 \\
68.3 \\
61.2\end{array}$ & $\begin{array}{l}75.1 \\
75.2 \\
65.0\end{array}$ \\
\hline $\begin{array}{l}1946 \\
1947 \\
1948 \\
1949 \\
1950\end{array}$ & $\begin{array}{l}82.5 \\
89.0 \\
89.6 \\
69.6 \\
91.5\end{array}$ & $\begin{array}{c}96.0 \\
106 \\
99.1 \\
97.0 \\
98.5\end{array}$ & $\begin{array}{c}126 \\
106 \\
104 \\
102 \\
92.5\end{array}$ & $\begin{array}{c}106 \\
96.6 \\
104 \\
95.4 \\
96.7\end{array}$ & $\begin{array}{l}111 \\
109 \\
115 \\
107 \\
111\end{array}$ & $\begin{array}{l}120 \\
105 \\
117 \\
120 \\
103\end{array}$ & $\begin{array}{c}207 \\
99.1 \\
162 \\
136 \\
81.0\end{array}$ & $\begin{array}{l}79.4 \\
78.5 \\
85.9 \\
73.9 \\
72.2\end{array}$ & $\begin{array}{l}64.5 \\
72.7 \\
85.5 \\
72.8 \\
71.3\end{array}$ & $\begin{array}{l}69.9 \\
62.4 \\
77.1 \\
70.7 \\
73.5\end{array}$ & $\begin{array}{l}75.1 \\
72.7 \\
77.5 \\
73.5 \\
68.2\end{array}$ & $\begin{array}{l}76.4 \\
82.7 \\
74.6 \\
82.1 \\
76.7\end{array}$ \\
\hline $\begin{array}{l}1951 \\
1952 \\
1953 \\
1954 \\
1955\end{array}$ & $\begin{array}{l}79.2 \\
83.8 \\
86.2 \\
84.2 \\
77.8\end{array}$ & $\begin{array}{l}89.0 \\
85.3 \\
96.5 \\
91.1 \\
78.7\end{array}$ & $\begin{array}{c}97.3 \\
88.3 \\
104 \\
93.2 \\
83.6\end{array}$ & $\begin{array}{c}95.9 \\
97.0 \\
112 \\
101 \\
89.1\end{array}$ & $\begin{array}{c}100 \\
104 \\
109 \\
99.5 \\
93.0\end{array}$ & $\begin{array}{l}89.9 \\
111 \\
102 \\
87.5 \\
112\end{array}$ & $\begin{array}{l}80.4 \\
98.0 \\
85.0 \\
79.7 \\
83.3\end{array}$ & $\begin{array}{l}74.1 \\
92.0 \\
76.1 \\
73.5 \\
72.3\end{array}$ & $\begin{array}{l}69.0 \\
69.7 \\
67.8 \\
67.2 \\
64.3\end{array}$ & $\begin{array}{l}72.4 \\
60.5 \\
72.7 \\
68.1 \\
58.9\end{array}$ & $\begin{array}{l}82.1 \\
76.9 \\
72.2 \\
64.9 \\
67.4\end{array}$ & $\begin{array}{l}78.4 \\
88.8 \\
74.0 \\
69.1 \\
71.4\end{array}$ \\
\hline $\begin{array}{l}1956 \\
1957 \\
1958\end{array}$ & $\begin{array}{l}74.6 \\
70.2 \\
80.0\end{array}$ & $\begin{array}{l}72.3 \\
74.2 \\
90.4\end{array}$ & $\begin{array}{l}82.5 \\
78.3 \\
89.3\end{array}$ & $\begin{array}{l}87.4 \\
79.8 \\
85.8\end{array}$ & $\begin{array}{r}82.4 \\
88.6 \\
113\end{array}$ & $\begin{array}{l}80.0 \\
78.7 \\
110\end{array}$ & $\begin{array}{l}68.8 \\
71.6 \\
270\end{array}$ & $\begin{array}{l}65.0 \\
64.2 \\
112\end{array}$ & $\begin{array}{l}61.1 \\
65.8 \\
60.3\end{array}$ & $\begin{array}{l}61.1 \\
58.6 \\
62.7\end{array}$ & $\begin{array}{l}65.9 \\
71.2 \\
70.4\end{array}$ & $\begin{array}{l}65.8 \\
71.1 \\
80.1\end{array}$ \\
\hline $\begin{array}{l}1977 \\
1978 \\
1979 \\
1980\end{array}$ & $\begin{array}{l}71.5 \\
63.1 \\
60.9 \\
54.1\end{array}$ & $\begin{array}{l}82.1 \\
66.7 \\
77.5 \\
59.7\end{array}$ & $\begin{array}{l}80.7 \\
68.8 \\
63.7 \\
67.5\end{array}$ & $\begin{array}{l}72.0 \\
75.6 \\
66.1 \\
66.1\end{array}$ & $\begin{array}{l}84.4 \\
84.9 \\
72.6 \\
70.0\end{array}$ & $\begin{array}{l}92.5 \\
95.3 \\
80.5 \\
66.4\end{array}$ & $\begin{array}{l}83.1 \\
78.3 \\
66.5 \\
63.3\end{array}$ & $\begin{array}{l}66.9 \\
64.2 \\
66.0 \\
59.8\end{array}$ & $\begin{array}{l}56.1 \\
55.2 \\
57.5 \\
46.1\end{array}$ & $\begin{array}{l}95.4 \\
56.6 \\
58.9 \\
50.7\end{array}$ & $\begin{array}{l}79.3 \\
49.2 \\
56.2 \\
46.3\end{array}$ & $\begin{array}{l}82.2 \\
51.4 \\
53.9 \\
73.2\end{array}$ \\
\hline 1981 & 68.4 & 78.4 & 81.5 & 80.6 & 81.9 & 85.5 & 86.7 & 58.7 & 50.4 & 63.3 & 56.6 & 61.6 \\
\hline
\end{tabular}

ANNUAL PEAK DISCHARGE, IN OBBIC FEET PER SECOND, AND CORRESPONDING GAGE HEIGHT, IN FEET, FOR EACH WATER YEAR

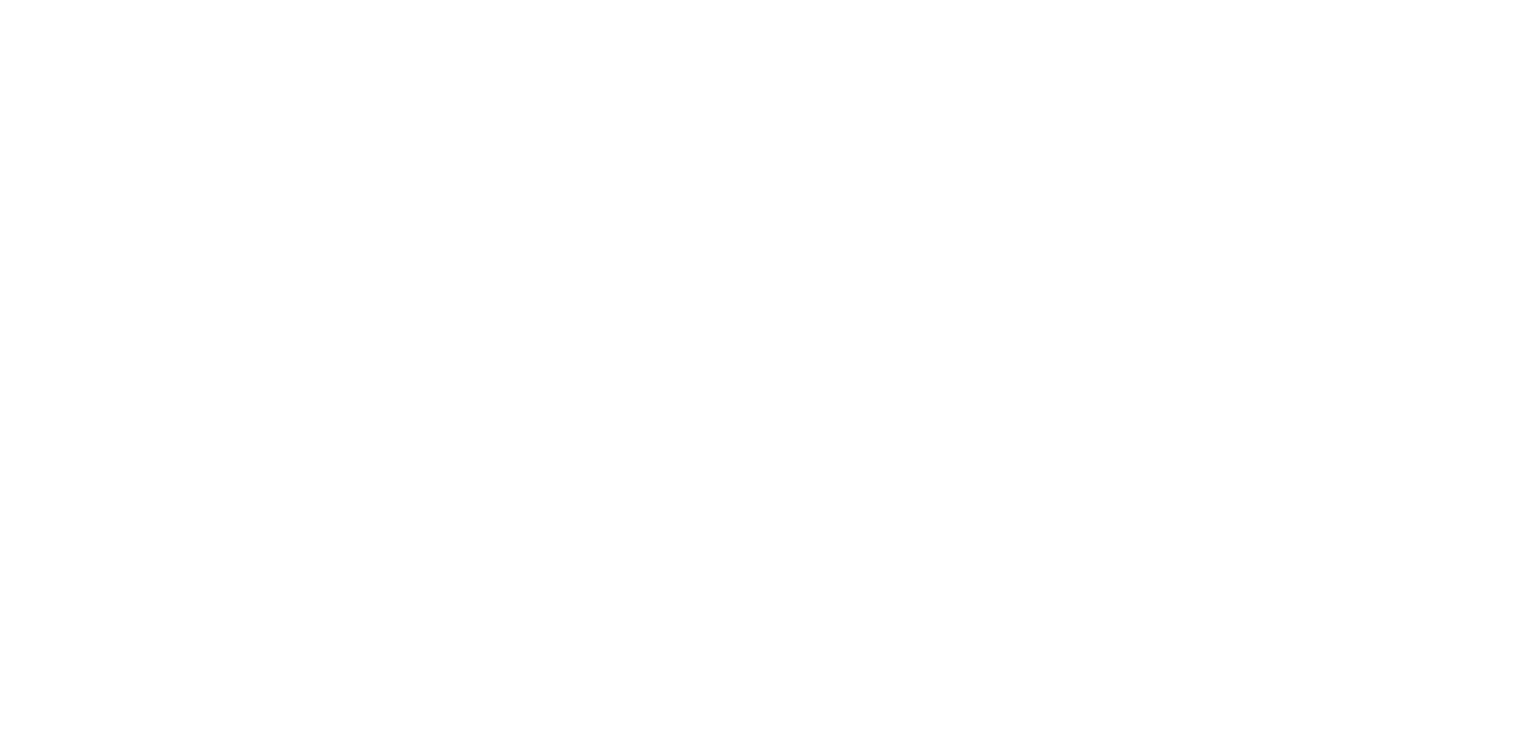


LOCATION.-Lat $38^{\circ} 19^{\prime} 30^{\prime \prime}$, long $111^{\circ} 22^{\prime} 06^{\prime \prime}$, in SW sec.33, T.28 S., R.5 E., wayne County, Hydrologic Unit 14070003, about $0.8 \mathrm{mi}$ above Sand Creek and $3.9 \mathrm{mi}$ northeast of Torrey.

DRAINAGE AREA. $--7.86 \mathrm{mi}^{2}$.

PERIOD OF REOORD AVAILABLE.-Water years 1959-65, annual peak discharge only.

GAGE.-Crest-stage gage. Altitude of gage is 6,440 ft from topographic map.

ANRUAL PEAK DISCHARGE, IN OUBIC FEET PER SECOND, AND CORRESPONDING GAGE HEIGHT, IN FEET, FOR EACH WATER YEAR

\begin{tabular}{|c|c|c|c|c|c|c|c|c|c|c|c|}
\hline $\begin{array}{l}\text { WATERR } \\
\text { YEAR }\end{array}$ & DATE & $\begin{array}{c}\text { GAGE } \\
\text { HEIGHT }\end{array}$ & $\begin{array}{c}\text { PEAK } \\
\text { DISCHARGE }\end{array}$ & $\begin{array}{l}\text { WATERR } \\
\text { YEAR }\end{array}$ & DATE & $\begin{array}{c}\text { GAGE } \\
\text { HEIGHT }\end{array}$ & $\begin{array}{c}\text { PEAK } \\
\text { DISCHARGE }\end{array}$ & $\begin{array}{l}\text { WATEER } \\
\text { YEAR }\end{array}$ & DATE & $\begin{array}{c}\text { GAGE } \\
\text { HEIGHT }\end{array}$ & $\begin{array}{c}\text { PEAK } \\
\text { DISCHARGE }\end{array}$ \\
\hline $\begin{array}{l}1959 \\
1960 \\
1961\end{array}$ & $\begin{array}{l}\text { AUG. } 25,1959 \\
\text { APR. } 04,1960 \\
\text { AUG. } 16,1961\end{array}$ & $\begin{array}{l}11.67 \\
10.35 \\
12.20\end{array}$ & $\begin{array}{l}644 \\
370 \\
748\end{array}$ & $\begin{array}{l}1962 \\
1963\end{array}$ & $\begin{array}{l}\text { SEPT.20, } 1962 \\
\text { ALG. } 26,1963\end{array}$ & $\begin{array}{r}9.55 \\
17.59\end{array}$ & $1880^{5.0}$ & $\begin{array}{l}1964 \\
1965\end{array}$ & $\begin{array}{l}\text { AUG. } 15,1964 \\
\text { AUG. } 18,1965\end{array}$ & $\begin{array}{l}10.43 \\
11.91\end{array}$ & $\begin{array}{l}380 \\
500\end{array}$ \\
\hline
\end{tabular}

09330120 SULPHUR CREEK NEAR FRUITA, UT

LOCATION.--Lat $38^{\circ} 17^{\prime} 30^{\prime \prime}$, long $111^{\circ} 15^{\prime} 49^{\prime \prime}$, in NW/ sec.15, T.29 S., R.6 E., Wayne County, Hydrologic Unit 14070003 , at west entrance to Capitol Reef National. Monument, 1 mi west of Fruita.

DRAINAGE AREA. $-56.7 \mathrm{mi}^{2}$.

MEAN BASIN ELEVATION. $-7,400 \mathrm{ft}$.

PERICD OF RECORD AVAIIABLE. - Water years 1959-74, annual peak discharge only.

GAGE.-Crest-stage gage. Altitude of gage is 5,520 ft fram topographic map.

REMARKS.-Diversion for irrigation above station.

ANNUAL PEAK DISCHARGE, IN OBBIC FEET PER SECOND, AND CORRESPONDING GAGE HEIGHT, IN FEET, FOR EACH WATER YEAR

\begin{tabular}{|c|c|c|c|c|c|c|c|c|c|c|c|c|}
\hline $\begin{array}{l}\text { WATERR } \\
\text { YEAR }\end{array}$ & DATE & $\begin{array}{l}\text { GAGE } \\
\text { HEIGHT }\end{array}$ & $\begin{array}{c}\text { PEAR } \\
\text { DISCHARGE }\end{array}$ & $\begin{array}{l}\text { WATERR } \\
\text { YEAR }\end{array}$ & DATE & $\begin{array}{c}\text { GAGE } \\
\text { HEIGHT }\end{array}$ & $\begin{array}{c}\text { PEAK } \\
\text { DISCHARGE }\end{array}$ & $\begin{array}{l}\text { WATER } \\
\text { YEAR }\end{array}$ & DATE & & $\begin{array}{l}\text { GAGE } \\
\text { HEIGHT }\end{array}$ & $\begin{array}{c}\text { PEAK } \\
\text { DISCHARGE }\end{array}$ \\
\hline $\begin{array}{l}1959 \\
1960 \\
1961 \\
1962 \\
1963\end{array}$ & $\begin{array}{l}\text { AUG. } 25,1959 \\
\text { SEPT. } 06,1960 \\
\text { SEPT.17, } 1961 \\
\text { MAR. } 23,1962 \\
\text { AUG. 07, } 1963\end{array}$ & $\begin{array}{l}10.81 \\
18.73 \\
18.85 \\
11.12 \\
15.18\end{array}$ & $\begin{array}{r}98 \\
2510 \\
2600 \\
78 \\
1120\end{array}$ & $\begin{array}{l}1965 \\
1966 \\
1967 \\
1968 \\
1969\end{array}$ & $\begin{array}{l}\text { AUUG. } 18,1965 \\
\text { AUG. } 31,1966 \\
\text { JULY } 07,1967 \\
\text { AUG. } 01,1968 \\
\text { JUNE } 24,1969\end{array}$ & $\begin{array}{l}14.29 \\
12.90 \\
14.22 \\
13.22 \\
14.34\end{array}$ & $\begin{array}{l}850 \\
480 \\
830 \\
565 \\
870\end{array}$ & $\begin{array}{l}1970 \\
1971 \\
1972 \\
1973 \\
1974\end{array}$ & $\begin{array}{l}\text { SEPT. 05, } \\
\text { JULY 27, } \\
\text { AUG. 19, } \\
\text { APR. -- }\end{array}$ & $\begin{array}{l}1970 \\
1971 \\
1972 \\
1973 \\
-\end{array}$ & $\begin{array}{l}12.09 \\
12.87 \\
11.80 \\
11.58 \\
11.90\end{array}$ & $\begin{array}{l}305 \\
470 \\
250 \\
215 \\
270\end{array}$ \\
\hline
\end{tabular}

09330200 PLEASANT CREEK AT NOTOM, UT

LOCATION.-Lat $38^{\circ} 13^{\prime} 47^{\prime \prime}, 111^{\circ} 07^{\prime} 20^{\prime \prime}$, in $\mathrm{NE}_{\frac{1}{4}}^{\frac{1}{4} \mathrm{SE}^{\frac{1}{4}}}$ sec.2, T.30 S., R.7 E., wayne County, Hydrologic Unit 14070003 , about 0.5 mi above crossing on State Highway 24 at Notom and $13 \mathrm{mi}$ east of Fruita.

DRATNAGE AREA. $-80.6 \mathrm{mi}^{2}$.

MEAN BASIN ELEVATION. $-7,980 \mathrm{ft}$.

PERIOD OF RECORD AVAIABLE.--Water years 1959-70, 1972-73, annual peak discharge only.

GAGE.--Crest-stage gage. Altitude of gage is $5,230 \mathrm{ft}$ from topographic map.

REMARKS.--Diversion for irrigation above station.

ANNUAL PEAK DISCHARGE, IN CUBIC FEET PER SECOND, AND CORRESPONDING GAGE HEIGHT, IN FEET, FOR EACH WATER YEAR

\begin{tabular}{|c|c|c|c|c|c|c|c|c|c|c|c|}
\hline $\begin{array}{l}\text { WATER } \\
\text { YEAR }\end{array}$ & DATE & $\begin{array}{c}\text { GAGE } \\
\text { HEIGHT }\end{array}$ & $\begin{array}{c}\text { PEAK } \\
\text { DISOHARGE }\end{array}$ & $\begin{array}{l}\text { WATER } \\
\text { YEAR }\end{array}$ & DATE & $\begin{array}{c}\text { GAGE } \\
\text { HEIGHT }\end{array}$ & $\begin{array}{c}\text { PEAK } \\
\text { DISCHARGE }\end{array}$ & $\begin{array}{l}\text { WATERR } \\
\text { YEAR }\end{array}$ & DATE & $\begin{array}{l}\text { GAGE } \\
\text { HEIGHTT }\end{array}$ & $\begin{array}{c}\text { PEAK } \\
\text { DISCHARGE }\end{array}$ \\
\hline $\begin{array}{l}1959 \\
1960 \\
1961 \\
1962 \\
1963\end{array}$ & $\begin{array}{l}\text { AUG. } 25,1959 \\
\text { JULY } 31,1960 \\
\text { AUG. } 02,1961 \\
\text { SEPT. } 20,1962 \\
\text { AUG. 07, } 1963\end{array}$ & $\begin{array}{l}10.12 \\
10.12 \\
12.70 \\
10.72 \\
12.06\end{array}$ & $\begin{array}{r}20 \\
52 \\
840 \\
44 \\
500\end{array}$ & $\begin{array}{l}1964 \\
1965 \\
1966 \\
1967 \\
1968\end{array}$ & $\begin{array}{ll}\text { AUG. } & 15,1964 \\
\text { JULY } 16,1965 \\
\text { JULY } 17,1966 \\
\text { AUG. } 09,1967 \\
\text { AUG. } 01,1968\end{array}$ & $\begin{array}{l}12.73 \\
14.76 \\
10.01 \\
13.09 \\
10.81\end{array}$ & $\begin{array}{r}730 \\
2040 \\
59 \\
1020 \\
99\end{array}$ & $\begin{array}{l}1969 \\
1970 \\
1972 \\
1973\end{array}$ & $\begin{array}{ll}\text { AUG. } 29,1969 \\
\text { SEPT. } 05,1970 \\
\text { JULY 25, } 1972 \\
\text { APR. -- } 1973\end{array}$ & $\begin{array}{l}12.24 \\
11.68 \\
11.33 \\
12.10\end{array}$ & $\begin{array}{l}600 \\
350 \\
160 \\
520\end{array}$ \\
\hline
\end{tabular}




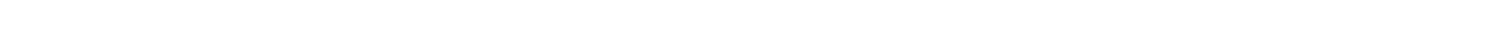
$0.2 \mathrm{mi}$ upstream from mouth and $6.5 \mathrm{mi}$ west of Caineville.

DRAINAGE AREA, $-115 \mathrm{mi}^{2}$, approximately.

PERIOD OF RECORD AVAILABLE. --March 1969 to September 1972.

GAGE. - Water-stage recorder. Altitude of gage is 4,880 ft from topographic map.

REMARKS. --Simall diversions for irrigation above station.

EXTREMES FOR PERTOD OF RECORD.--Maximum discharge, $960 \mathrm{ft} / 3$ sug. 29,1969 , gage height, $4.50 \mathrm{ft}$ from high-water mark; no flow for several days in July and August 1971.

LOWEST MEAN DISGHARGE, IN UUBIC FEET PER SECOND, AND RANKING FOR THE INDICATED NUMBER OF CONSEUTIVE DAYS FOR EACH OLIMATIC YEAR, APRIL 1-MARCH 31

\begin{tabular}{|c|c|c|c|c|c|c|c|c|c|c|c|c|c|c|c|c|c|c|c|}
\hline YEAR & \multicolumn{19}{|c|}{ CONSECUTIVE DAYS } \\
\hline 1970 & 0.80 & 3 & 0.80 & 3 & 0.80 & 3 & 0.87 & 2 & 1.30 & 2 & 2.30 & 3 & 2.40 & 3 & 2.70 & 3 & 3.40 & 2 & 5.20 \\
\hline
\end{tabular}

HIGHEST MEAN DISCHARGE, IN GUIC FEET PER SECOND, AND RANKING FOR THE INDICATED NUMER OF CONSECUTIVE DAYS FOR EACH WATER YEAR, OCTOBER I-SEPTEMBER 30

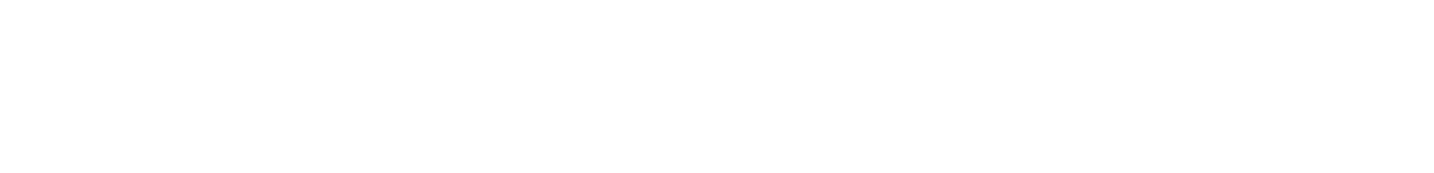

DURATJON OF DISCHARGE FOR EACH WATER YEAR

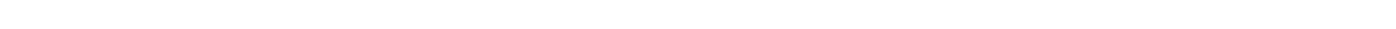

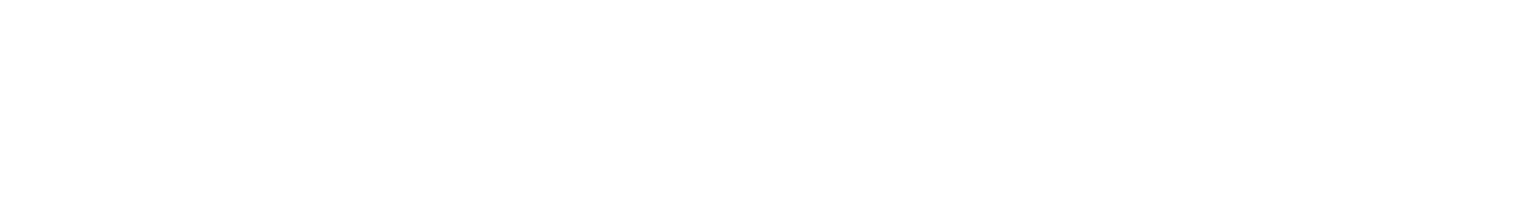

DURATION TABLE OF DISCHARGE FOR WATER YEARS $1970-72$

\begin{tabular}{|c|c|c|c|c|c|c|c|c|c|c|c|c|c|c|c|c|c|c|c|}
\hline OASS & $\begin{array}{c}\text { OUBIC } \\
\text { FEET } \\
\text { PER } \\
\text { SECOND }\end{array}$ & $\begin{array}{l}\text { TOTAL } \\
\text { DAYS }\end{array}$ & $\begin{array}{l}\text { ACOU- } \\
\text { MU- } \\
\text { LATED } \\
\text { DAYS }\end{array}$ & $\begin{array}{l}\text { PER- } \\
\text { CENI } \\
\text { DAYS }\end{array}$ & QASS & $\begin{array}{c}\text { CBBIC } \\
\text { FEET } \\
\text { PER } \\
\text { SECOND }\end{array}$ & $\begin{array}{l}\text { TOTAL } \\
\text { DAYS }\end{array}$ & $\begin{array}{l}\text { ACU- } \\
\text { MU- } \\
\text { LATED } \\
\text { DAYS }\end{array}$ & $\begin{array}{l}\text { PER- } \\
\text { CENT } \\
\text { DAYS }\end{array}$ & CASS & $\begin{array}{c}\text { वBIC } \\
\text { FEET } \\
\text { PER } \\
\text { SECOND }\end{array}$ & $\begin{array}{r}\text { TOTAL } \\
\text { DAYS }\end{array}$ & $\begin{array}{c}\text { ACOU- } \\
M U- \\
\text { LATED } \\
\text { DAYS }\end{array}$ & $\begin{array}{l}\text { PER- } \\
\text { CENT } \\
\text { DAYS }\end{array}$ & & $\begin{array}{c}\text { OUBIC } \\
\text { FEET } \\
\text { PER } \\
\text { SECOND }\end{array}$ & $\begin{array}{l}\text { TOTAL } \\
\text { DAYS }\end{array}$ & $\begin{array}{c}\text { ACQJ- } \\
\text { MU- } \\
\text { LATED } \\
\text { DAYS }\end{array}$ & $\begin{array}{l}\text { PER- } \\
\text { CENI } \\
\text { DAYS }\end{array}$ \\
\hline $\begin{array}{l}0 \\
1 \\
2 \\
3 \\
4 \\
5 \\
6 \\
6 \\
7 \\
8\end{array}$ & $\begin{array}{l}0.00 \\
0.02 \\
0.03 \\
0.04 \\
0.06 \\
0.07 \\
0.09 \\
0.12 \\
0.15\end{array}$ & $\begin{array}{c}32 \\
1 \\
0 \\
1 \\
1 \\
0 \\
1 \\
1 \\
1\end{array}$ & $\begin{array}{l}1096 \\
1064 \\
1063 \\
1063 \\
1062 \\
1061 \\
1061 \\
1060 \\
1059\end{array}$ & $\begin{array}{r}100.0 \\
97.1 \\
97.0 \\
97.0 \\
96.9 \\
96.8 \\
95.8 \\
96.7 \\
96.6\end{array}$ & $\begin{array}{r}9 \\
10 \\
11 \\
12 \\
13 \\
14 \\
15 \\
16 \\
17\end{array}$ & $\begin{array}{l}0.19 \\
0.25 \\
0.32 \\
0.41 \\
0.53 \\
0.69 \\
0.88 \\
1.10 \\
1.50\end{array}$ & $\begin{array}{r}1 \\
13 \\
9 \\
45 \\
48 \\
30 \\
55 \\
119 \\
163\end{array}$ & $\begin{array}{r}1058 \\
1057 \\
1044 \\
1035 \\
990 \\
942 \\
912 \\
857 \\
738\end{array}$ & $\begin{array}{l}95.5 \\
95.4 \\
95.3 \\
94.4 \\
90.3 \\
85.9 \\
83.2 \\
78.2 \\
67.3\end{array}$ & $\begin{array}{l}18 \\
19 \\
20 \\
21 \\
22 \\
23 \\
24 \\
25 \\
26\end{array}$ & $\begin{array}{r}1.9 \\
2.4 \\
3.1 \\
4.0 \\
5.2 \\
6.7 \\
8.6 \\
11.0 \\
14.0\end{array}$ & $\begin{array}{r}134 \\
160 \\
85 \\
55 \\
47 \\
37 \\
15 \\
15 \\
9\end{array}$ & $\begin{array}{r}575 \\
441 \\
281 \\
196 \\
141 \\
94 \\
57 \\
42 \\
27\end{array}$ & $\begin{array}{r}52.5 \\
40.2 \\
25.6 \\
17.9 \\
12.9 \\
8.6 \\
5.2 \\
3.8 \\
2.5\end{array}$ & $\begin{array}{l}27 \\
28 \\
29 \\
30 \\
31 \\
32 \\
33 \\
34\end{array}$ & $\begin{array}{l}18.0 \\
23.0 \\
30.0 \\
39.0 \\
50.0 \\
64.0 \\
83.0\end{array}$ & $\begin{array}{l}6 \\
1 \\
5 \\
3 \\
1 \\
0 \\
2\end{array}$ & $\begin{array}{r}18 \\
12 \\
11 \\
6 \\
3 \\
2 \\
2\end{array}$ & $\begin{array}{l}1.6 \\
1.1 \\
1.0 \\
0.5 \\
0.3 \\
0.2 \\
0.2\end{array}$ \\
\hline
\end{tabular}

MONTHLY MEAN DISCHARGES, IN OBBIC FEET PER SECOND, FOR EACH WATER YEAR

$\begin{array}{lcccccccccrrr}\text { YEAR } & \text { OCT } & \text { NOV } & \text { DEC } & \text { JAN } & \text { FEB } & \text { MAR } & \text { APR } & \text { MAY } & \text { JUNE } & \text { JULY } & \text { AUG } & \text { SEP } \\ 1970 & 5.95 & 3.23 & 2.46 & 2.49 & 3.21 & 3.06 & 2.19 & 6.40 & 3.35 & 5.20 & 6.39 & 5.92 \\ 1971 & 6.15 & 4.45 & 2.60 & 3.78 & 1.71 & 1.47 & 1.83 & 3.12 & 1.39 & 0.10 & 9.46 & 2.52 \\ 1972 & 2.59 & 1.64 & 4.81 & 1.01 & 1.64 & 2.27 & 1.39 & 2.08 & 1.79 & 3.19 & 0.80 & 1.58\end{array}$




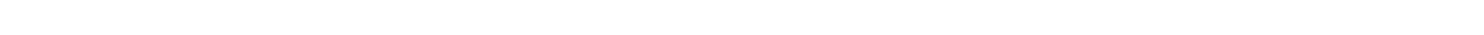
bank $2.0 \mathrm{mi}$ downstream from Pleasant Creek, $4.5 \mathrm{mi}$ southwest of Caineville, and $9.8 \mathrm{mi}$ east of Fruita.

DRATNAGE AREA, $-1,208 \mathrm{mi}^{2}$.

PERIOD OF RECORD AVAILBLE.--March 197 to September 1981.

GAGE.--Water-stage recorder and bubble gage. Altitude of gage is 4,750 ft from topographic map. REMARKS. --Many diversions for irrigation above station.

AVERAGE DISCHARGE. --14 years, $67.2 \mathrm{ft}^{3} / \mathrm{s}, 48,690$ acre-ft/yr.

EXTREMES FOR PERIOD OF RECORD.--Maximum discharge, 4,000 $\mathrm{ft}^{3} / \mathrm{s}$ Sept. 5, 1981, gage height, 6.90 $\mathrm{ft}$, on basis of slope-area measurement of peak $\mathrm{f} 1 \mathrm{ow}$; minimum observed, $10 \mathrm{ft}^{3} / \mathrm{s}$ June 9,1981 .

LOWEST MEAN DISCHARGE, IN CUBIC FEET PER SECOND, AND RANKING FOR THE INDICATED NUMBER OF CONSECUTIVE DAYS FOR EAOH OLIMATIC YEAR, APRII 1-MARCH 31

\begin{tabular}{|c|c|c|c|c|c|c|c|c|c|c|c|c|c|c|c|c|c|c|c|c|}
\hline YEAR & \multicolumn{20}{|c|}{ CONSEOUTIVE DAYS } \\
\hline $\begin{array}{l}1971 \\
1972 \\
1973 \\
1974 \\
1975\end{array}$ & $\begin{array}{l}25.0 \\
23.0 \\
15.0 \\
25.0 \\
23.0\end{array}$ & $\begin{array}{r}12 \\
9 \\
3 \\
13 \\
10\end{array}$ & $\begin{array}{l}28.0 \\
23.0 \\
15.0 \\
25.0 \\
23.0\end{array}$ & $\begin{array}{r}14 \\
7 \\
2 \\
11 \\
8\end{array}$ & $\begin{array}{l}30.0 \\
24.0 \\
17.0 \\
25.0 \\
23.0\end{array}$ & $\begin{array}{r}14 \\
9 \\
2 \\
10 \\
7\end{array}$ & $\begin{array}{l}32.0 \\
26.0 \\
24.0 \\
27.0 \\
23.0\end{array}$ & $\begin{array}{r}14 \\
9 \\
6 \\
10 \\
4\end{array}$ & $\begin{array}{l}34.0 \\
28.0 \\
29.0 \\
35.0 \\
25.0\end{array}$ & $\begin{array}{r}13 \\
7 \\
8 \\
14 \\
4\end{array}$ & $\begin{array}{l}40.0 \\
28.0 \\
34.0 \\
37.0 \\
28.0\end{array}$ & $\begin{array}{r}13 \\
5 \\
8 \\
11 \\
6\end{array}$ & $\begin{array}{l}42.0 \\
32.0 \\
35.0 \\
40.0 \\
32.0\end{array}$ & $\begin{array}{r}12 \\
4 \\
8 \\
11 \\
5\end{array}$ & $\begin{array}{l}44.0 \\
41.0 \\
35.0 \\
40.0 \\
45.0\end{array}$ & $\begin{array}{r}12 \\
7 \\
5 \\
6 \\
13\end{array}$ & $\begin{array}{l}48.0 \\
65.0 \\
41.0 \\
52.0 \\
43.0\end{array}$ & $\begin{array}{r}8 \\
14 \\
4 \\
11 \\
5\end{array}$ & $\begin{array}{l}66.0 \\
77.0 \\
61.0 \\
93.0 \\
62.0\end{array}$ & $\begin{array}{r}9 \\
13 \\
3 \\
14 \\
4\end{array}$ \\
\hline $\begin{array}{l}1976 \\
1977 \\
1978 \\
1979 \\
1980\end{array}$ & $\begin{array}{l}24.0 \\
17.0 \\
18.0 \\
14.0 \\
17.0\end{array}$ & $\begin{array}{r}11 \\
4 \\
6 \\
2 \\
5\end{array}$ & $\begin{array}{l}25.0 \\
18.0 \\
18.0 \\
15.0 \\
18.0\end{array}$ & $\begin{array}{r}12 \\
5 \\
6 \\
3 \\
4\end{array}$ & $\begin{array}{l}27.0 \\
21.0 \\
20.0 \\
18.0 \\
22.0\end{array}$ & $\begin{array}{r}13 \\
5 \\
4 \\
3 \\
6\end{array}$ & $\begin{array}{l}30.0 \\
24.0 \\
23.0 \\
21.0 \\
23.0\end{array}$ & $\begin{array}{r}13 \\
7 \\
5 \\
2 \\
3\end{array}$ & $\begin{array}{l}31.0 \\
26.0 \\
24.0 \\
22.0 \\
27.0\end{array}$ & $\begin{array}{l}9 \\
5 \\
3 \\
2 \\
6\end{array}$ & $\begin{array}{l}36.0 \\
27.0 \\
27.0 \\
23.0 \\
31.0\end{array}$ & $\begin{array}{l}9 \\
3 \\
4 \\
1 \\
7\end{array}$ & $\begin{array}{l}39.0 \\
28.0 \\
33.0 \\
24.0 \\
34.0\end{array}$ & $\begin{array}{r}10 \\
3 \\
6 \\
1 \\
7\end{array}$ & $\begin{array}{l}42.0 \\
29.0 \\
42.0 \\
24.0 \\
33.0\end{array}$ & $\begin{array}{l}8 \\
2 \\
9 \\
1 \\
4\end{array}$ & $\begin{array}{l}53.0 \\
35.0 \\
54.0 \\
29.0 \\
37.0\end{array}$ & $\begin{array}{r}12 \\
2 \\
13 \\
1 \\
3\end{array}$ & $\begin{array}{l}75.0 \\
59.0 \\
68.0 \\
55.0 \\
64.0\end{array}$ & $\begin{array}{r}12 \\
2 \\
11 \\
1 \\
6\end{array}$ \\
\hline 1981 & 12.0 & 1 & 13.0 & 1 & 16.0 & 1 & 17.0 & 1 & 20.0 & 1 & 23.0 & 2 & 26.0 & 2 & 31.0 & 3 & 48.0 & 9 & 64.0 & 7 \\
\hline
\end{tabular}

HIGHEST MEAN DISGHARGE, IN CUBIC FEET PER SECOND, AND RANKING FOR THE INDICAIED NUMBER OF CONSEQUTIVE DAYS FOR EAOH WATER YEAR, OCTOBER 1-SEPTEMBER 30

\begin{tabular}{|c|c|c|c|c|c|c|c|c|c|c|c|c|c|c|c|c|c|c|c|c|}
\hline YEAR & 1 & & 3 & & 7 & & 15 & & $\begin{array}{l}\infty \mathrm{N} \\
30\end{array}$ & $\mathrm{~F} O$ & $\begin{array}{l}\text { VE DAYS } \\
60\end{array}$ & & 90 & & 120 & & 183 & & ALL & \\
\hline $\begin{array}{l}1968 \\
1969 \\
1970\end{array}$ & $\begin{array}{l}158 \\
185 \\
217\end{array}$ & $\begin{array}{r}13 \\
10 \\
9\end{array}$ & $\begin{array}{l}125 \\
112 \\
123\end{array}$ & $\begin{array}{l}10 \\
13 \\
11\end{array}$ & $\begin{array}{l}122 \\
106 \\
109\end{array}$ & $\begin{array}{r}8 \\
12 \\
11\end{array}$ & $\begin{array}{l}112 \\
104 \\
104\end{array}$ & $\begin{array}{r}9 \\
10 \\
11\end{array}$ & $\begin{array}{r}106 \\
96.0 \\
99.0\end{array}$ & $\begin{array}{r}7 \\
12 \\
10\end{array}$ & $\begin{array}{l}100 \\
92.0 \\
9.0\end{array}$ & $\begin{array}{r}7 \\
12 \\
11\end{array}$ & $\begin{array}{l}97.0 \\
92.0 \\
91.0\end{array}$ & $\begin{array}{r}6 \\
11 \\
12\end{array}$ & $\begin{array}{l}94.0 \\
88.0 \\
89.0\end{array}$ & $\begin{array}{r}7 \\
11 \\
10\end{array}$ & $\begin{array}{l}86.0 \\
80.0 \\
84.0\end{array}$ & $\begin{array}{r}9 \\
13 \\
11\end{array}$ & $\begin{array}{l}67.0 \\
64.0 \\
66.0\end{array}$ & $\begin{array}{r}6 \\
10 \\
8\end{array}$ \\
\hline $\begin{array}{l}1971 \\
1972 \\
1973 \\
1974 \\
1975\end{array}$ & $\begin{array}{l}988 \\
141 \\
860 \\
553 \\
389\end{array}$ & $\begin{array}{r}1 \\
14 \\
2 \\
4 \\
5\end{array}$ & $\begin{array}{l}769 \\
135 \\
775 \\
457 \\
317\end{array}$ & $\begin{array}{l}2 \\
9 \\
1 \\
4 \\
5\end{array}$ & $\begin{array}{l}438 \\
120 \\
652 \\
283 \\
224\end{array}$ & $\begin{array}{l}2 \\
9 \\
1 \\
3 \\
5\end{array}$ & $\begin{array}{l}258 \\
116 \\
507 \\
155 \\
161\end{array}$ & $\begin{array}{l}2 \\
7 \\
1 \\
5 \\
3\end{array}$ & $\begin{array}{l}178 \\
110 \\
331 \\
101 \\
120\end{array}$ & $\begin{array}{l}2 \\
6 \\
1 \\
8 \\
4\end{array}$ & $\begin{array}{c}126 \\
103 \\
213 \\
97.0 \\
102\end{array}$ & $\begin{array}{l}2 \\
4 \\
1 \\
8 \\
5\end{array}$ & $\begin{array}{c}9.0 \\
100 \\
171 \\
97.0 \\
101\end{array}$ & $\begin{array}{l}7 \\
4 \\
1 \\
5 \\
3\end{array}$ & $\begin{array}{r}91.0 \\
97.0 \\
148 \\
96.0 \\
95.0\end{array}$ & $\begin{array}{l}9 \\
3 \\
1 \\
4 \\
5\end{array}$ & $\begin{array}{r}85.0 \\
88.0 \\
124 \\
90.0 \\
87.0\end{array}$ & $\begin{array}{r}10 \\
4 \\
1 \\
2 \\
6\end{array}$ & & $\begin{array}{l}2 \\
9\end{array}$ \\
\hline $\begin{array}{l}1976 \\
1977 \\
1978 \\
1979 \\
1980\end{array}$ & $\begin{array}{l}172 \\
280 \\
170 \\
283 \\
675\end{array}$ & $\begin{array}{r}11 \\
8 \\
12 \\
7 \\
3\end{array}$ & $\begin{array}{l}117 \\
167 \\
102 \\
160 \\
474\end{array}$ & $\begin{array}{r}12 \\
7 \\
14 \\
8 \\
3\end{array}$ & $\begin{array}{l}104 \\
117 \\
99.0 \\
130 \\
267\end{array}$ & $\begin{array}{r}13 \\
10 \\
14 \\
7 \\
4\end{array}$ & $\begin{array}{l}101 \\
100 \\
95.0 \\
123 \\
160\end{array}$ & $\begin{array}{c}12 \\
13 \\
14 \\
6 \\
4\end{array}$ & $\begin{array}{c}100 \\
98.0 \\
92.0 \\
112 \\
123\end{array}$ & $\begin{array}{r}9 \\
11 \\
13 \\
5 \\
3\end{array}$ & $\begin{array}{c}97.0 \\
96.0 \\
89.0 \\
101 \\
112\end{array}$ & $\begin{array}{r}9 \\
10 \\
13 \\
6 \\
3\end{array}$ & $\begin{array}{r}95.0 \\
94.0 \\
88.0 \\
93.0 \\
105\end{array}$ & $\begin{array}{r}8 \\
9 \\
13 \\
10 \\
2\end{array}$ & $\begin{array}{c}95.0 \\
93.0 \\
87.0 \\
87.0 \\
100\end{array}$ & $\begin{array}{r}6 \\
8 \\
12 \\
13 \\
2\end{array}$ & $\begin{array}{l}88.0 \\
86.0 \\
80.0 \\
86.0 \\
90.0\end{array}$ & $\begin{array}{r}5 \\
7 \\
12 \\
8 \\
3\end{array}$ & $\begin{array}{l}61.0 \\
69.0 \\
57.0 \\
61.0 \\
68.0\end{array}$ & $\begin{array}{r}11 \\
4 \\
14 \\
12 \\
5\end{array}$ \\
\hline 1981 & 338 & 6 & 208 & 6 & 181 & 6 & 115 & 8 & 87.0 & 14 & 85.0 & 14 & 85.0 & 14 & 83.0 & 14 & 77.0 & 14 & 60.0 & 13 \\
\hline
\end{tabular}

\section{DURATION OF DISCHARGE FOR EACH WATER YEAR}

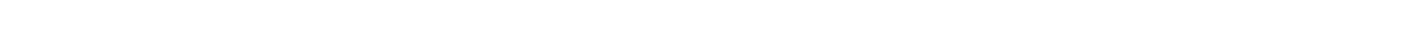
YEAR

NUMBER OF DAYS IN CLASS

OBIC FEET PER SECON

1999

$\begin{array}{rrrrrrrrrrrrrrrr}1 & 2 & 13 & 16 & 24 & 23 & 34 & 38 & 32 & 34 & 37 & 69 & 32 & 10 & & 1\end{array}$ $\begin{array}{rrrrrrrrrrrrrrrrr}6 & 12 & 12 & 19 & 23 & 60 & 35 & 42 & 36 & 29 & 56 & 28 & 5 & 1 & & 1 & \\ 1 & 5 & 17 & 33 & 28 & 43 & 29 & 25 & 41 & 51 & 60 & 25 & 6 & & & & 1\end{array}$

1971

1972

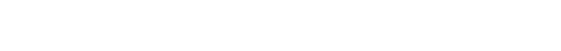

24

$\begin{array}{llllllllllllll}6 & 29 & 33 & 20 & 40 & 20 & 31 & 19 & 12 & 27 & 75 & 34 & 11 & 3\end{array}$

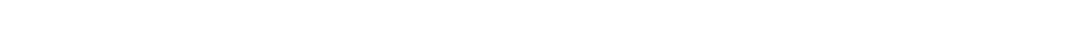

$\begin{array}{rrrrrrrrrrrrrrr}21 & 25 & 76 & 12 & 20 & 4 & 10 & 25 & 14 & 20 & 74 & 51 & 8 & & 1 \\ 3 & 7 & 31 & 23 & 23 & 17 & 40 & 34 & 45 & 43 & 61 & 20 & 8 & 2 & 4\end{array}$

1975

$\begin{array}{lllllllllllll} & & & 3 & & & 1 & & 1 & & & & \\ 2 & 2 & 2 & 1 & & 1 & 3 & 3 & 1 & 2 & 3 & 1 & 2 \\ 1 & & & 1 & & & 1 & & 1 & & 1 & & \\ 4 & & 1 & & 1 & & 1 & 1 & & & & & \end{array}$


DIRTY DEVII RIVER BASIN

09330230 FREMONT RIVER NEAR CAINEVIHLE, UT-Continued

DURATION OF DISGHARGE FOR EACH WATER YEAR--Continued

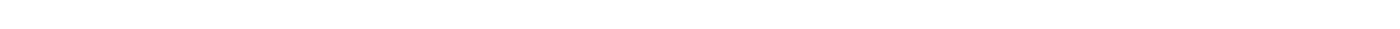

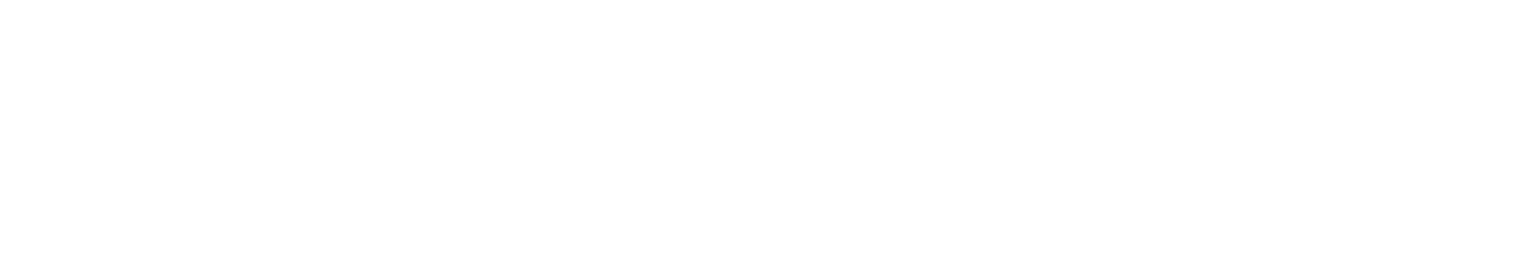

DURATION TABLE OF DISGHARGE FOR WATER YEARS 1988-81

\begin{tabular}{|c|c|c|c|c|c|c|c|c|c|c|c|c|c|c|c|c|c|c|c|}
\hline CLASS & $\begin{array}{c}\text { वUIC } \\
\text { FEET } \\
\text { PER } \\
\text { SECOND }\end{array}$ & $\begin{array}{l}\text { TOTAE } \\
\text { DAYS }\end{array}$ & $\begin{array}{l}\text { ACOU- } \\
\text { MU- } \\
\text { LATED } \\
\text { DAYS }\end{array}$ & $\begin{array}{l}\text { PER- } \\
\text { CENT } \\
\text { DAYS }\end{array}$ & QASS & $\begin{array}{c}\text { QBBIC } \\
\text { FEET } \\
\text { PER } \\
\text { SECOND }\end{array}$ & $\begin{array}{l}\text { TOTA } \\
\text { DAYS }\end{array}$ & $\begin{array}{c}\text { ACOJ- } \\
\text { MU- } \\
\text { LATED } \\
\text { DAYS }\end{array}$ & $\begin{array}{l}\text { PER- } \\
\text { CENT } \\
\text { DAYS }\end{array}$ & GASS & $\begin{array}{c}\text { OBBIC } \\
\text { FEET } \\
\text { PER } \\
\text { SECOND }\end{array}$ & $\begin{array}{l}\text { TOTAL } \\
\text { DAYS }\end{array}$ & $\begin{array}{l}\text { ACOU- } \\
\text { MU- } \\
\text { LATED } \\
\text { DAYS }\end{array}$ & $\begin{array}{l}\text { PER- } \\
\text { CENT } \\
\text { DAYS }\end{array}$ & CLASS & $\begin{array}{c}\text { OBIC } \\
\text { FEET } \\
\text { PER } \\
\text { SECOND }\end{array}$ & $\begin{array}{r}\text { TOTAL } \\
\text { DAYS }\end{array}$ & $\begin{array}{l}\text { ACOU- } \\
\text { MU- } \\
\text { LATED } \\
\text { DAYS }\end{array}$ & $\begin{array}{l}\text { PER- } \\
\text { OENT } \\
\text { DAUS }\end{array}$ \\
\hline $\begin{array}{l}0 \\
1 \\
2 \\
3 \\
4 \\
5 \\
6 \\
7 \\
8\end{array}$ & $\begin{array}{r}0.00 \\
12.00 \\
14.00 \\
16.00 \\
18.00 \\
20.00 \\
23.00 \\
26.00 \\
30.00\end{array}$ & $\begin{array}{r}0 \\
6 \\
15 \\
19 \\
21 \\
85 \\
190 \\
319 \\
347\end{array}$ & $\begin{array}{l}5114 \\
5114 \\
5108 \\
5093 \\
5074 \\
5053 \\
4968 \\
4778 \\
4459\end{array}$ & $\begin{array}{r}100.0 \\
100.0 \\
99.9 \\
99.6 \\
99.2 \\
98.8 \\
97.1 \\
93.4 \\
87.2\end{array}$ & $\begin{array}{r}9 \\
10 \\
11 \\
12 \\
13 \\
14 \\
15 \\
16 \\
17\end{array}$ & $\begin{array}{l}34.00 \\
39.00 \\
45.00 \\
51.00 \\
58.00 \\
66.00 \\
76.00 \\
86.00 \\
98.00\end{array}$ & $\begin{array}{l}247 \\
311 \\
303 \\
317 \\
364 \\
480 \\
655 \\
908 \\
327\end{array}$ & $\begin{array}{r}4112 \\
3865 \\
3554 \\
3251 \\
2934 \\
2570 \\
2090 \\
1435 \\
527\end{array}$ & $\begin{array}{l}80.4 \\
75.6 \\
69.5 \\
63.6 \\
57.4 \\
50.3 \\
40.9 \\
28.1 \\
10.3\end{array}$ & $\begin{array}{l}18 \\
19 \\
20 \\
21 \\
22 \\
23 \\
24 \\
25 \\
26\end{array}$ & $\begin{array}{l}110.0 \\
130.0 \\
150.0 \\
170.0 \\
190.0 \\
220.0 \\
250.0 \\
280.0 \\
320.0\end{array}$ & $\begin{array}{r}113 \\
26 \\
11 \\
6 \\
8 \\
4 \\
2 \\
4 \\
6\end{array}$ & $\begin{array}{r}200 \\
87 \\
61 \\
50 \\
44 \\
36 \\
32 \\
30 \\
26\end{array}$ & $\begin{array}{l}3.9 \\
1.7 \\
1.2 \\
1.0 \\
0.9 \\
0.7 \\
0.6 \\
0.6 \\
0.5\end{array}$ & $\begin{array}{l}27 \\
28 \\
29 \\
30 \\
31 \\
32 \\
33 \\
34\end{array}$ & $\begin{array}{l}370.0 \\
420.0 \\
480.0 \\
540.0 \\
620.0 \\
710.0 \\
810.0 \\
920.0\end{array}$ & $\begin{array}{l}5 \\
3 \\
2 \\
4 \\
2 \\
0 \\
2 \\
2\end{array}$ & $\begin{array}{r}20 \\
15 \\
12 \\
10 \\
6 \\
4 \\
4 \\
2\end{array}$ & $\begin{array}{l}0.4 \\
0.3 \\
0.2 \\
0.2 \\
0.1 \\
0.1 \\
0.1 \\
0.0\end{array}$ \\
\hline
\end{tabular}

MONIHLY MEAN DISCHARGES, IN CUBIC FEET PER SECOND, FOR EAOH WATER YEAR

\begin{tabular}{|c|c|c|c|c|c|c|c|c|c|c|c|c|}
\hline YEAR & $\mathrm{OCT}$ & NOV & $\mathrm{DEC}$ & JAN & FEB & MAR & APR & MAY & JUNE & JULY & AUG & SEP \\
\hline $\begin{array}{l}1968 \\
1969 \\
1970\end{array}$ & $\begin{array}{l}65.3 \\
53.2 \\
64.4\end{array}$ & $\begin{array}{l}80.0 \\
70.8 \\
79.7\end{array}$ & $\begin{array}{l}87.6 \\
66.7 \\
83.4\end{array}$ & $\begin{array}{l}94.5 \\
94.5 \\
90.0\end{array}$ & $\begin{array}{r}105 \\
86.6 \\
96.0\end{array}$ & $\begin{array}{l}84.2 \\
94.9 \\
83.3\end{array}$ & $\begin{array}{l}54.3 \\
62.4 \\
61.8\end{array}$ & $\begin{array}{l}42.9 \\
56.3 \\
59.7\end{array}$ & $\begin{array}{l}36.7 \\
43.3 \\
33.7\end{array}$ & $\begin{array}{l}39.7 \\
34.4 \\
46.0\end{array}$ & $\begin{array}{l}74.0 \\
56.3 \\
50.4\end{array}$ & $\begin{array}{l}46.6 \\
54.1 \\
49.0\end{array}$ \\
\hline $\begin{array}{l}1971 \\
1972 \\
1973 \\
1974 \\
1975\end{array}$ & $\begin{array}{l}55.5 \\
56.2 \\
79.0 \\
54.6 \\
49.5\end{array}$ & $\begin{array}{l}74.5 \\
90.3 \\
82.5 \\
88.9 \\
92.5\end{array}$ & $\begin{array}{c}79.1 \\
91.7 \\
81.1 \\
100 \\
71.6\end{array}$ & $\begin{array}{l}98.6 \\
96.1 \\
72.2 \\
93.3 \\
60.2\end{array}$ & $\begin{array}{c}92.4 \\
103 \\
83.4 \\
91.5 \\
87.0\end{array}$ & $\begin{array}{l}95.1 \\
81.2 \\
87.0 \\
95.0 \\
99.1\end{array}$ & $\begin{array}{c}62.2 \\
59.2 \\
204 \\
67.5 \\
80.3\end{array}$ & $\begin{array}{c}33.9 \\
29.1 \\
213 \\
26.6 \\
112\end{array}$ & $\begin{array}{l}27.9 \\
39.9 \\
56.4 \\
29.5 \\
58.7\end{array}$ & $\begin{array}{l}48.6 \\
43.3 \\
36.6 \\
90.8 \\
45.2\end{array}$ & $\begin{array}{r}162 \\
30.6 \\
48.0 \\
33.5 \\
30.6\end{array}$ & $\begin{array}{l}69.1 \\
46.4 \\
35.5 \\
34.9 \\
49.8\end{array}$ \\
\hline $\begin{array}{l}1976 \\
1977 \\
1978 \\
1979 \\
1980\end{array}$ & $\begin{array}{l}57.8 \\
56.5 \\
67.6 \\
38.2 \\
38.0\end{array}$ & $\begin{array}{l}85.2 \\
69.5 \\
72.0 \\
95.2 \\
69.3\end{array}$ & $\begin{array}{l}94.6 \\
90.2 \\
84.1 \\
72.7 \\
84.2\end{array}$ & $\begin{array}{l}89.8 \\
90.5 \\
85.4 \\
71.6 \\
89.3\end{array}$ & $\begin{array}{r}97.4 \\
93.6 \\
88.4 \\
82.5 \\
112\end{array}$ & $\begin{array}{l}95.5 \\
95.4 \\
86.1 \\
111 \\
112\end{array}$ & $\begin{array}{l}52.5 \\
72.9 \\
58.9 \\
81.6 \\
73.2\end{array}$ & $\begin{array}{l}47.2 \\
27.3 \\
40.7 \\
53.1 \\
41.6\end{array}$ & $\begin{array}{l}32.7 \\
28.0 \\
22.6 \\
27.0 \\
27.4\end{array}$ & $\begin{array}{l}28.6 \\
66.3 \\
26.8 \\
39.9 \\
25.3\end{array}$ & $\begin{array}{l}27.9 \\
58.9 \\
24.0 \\
36.5 \\
37.5\end{array}$ & $\begin{array}{c}26.7 \\
83.2 \\
23.8 \\
29.6 \\
106\end{array}$ \\
\hline 1981 & 56.6 & 70.1 & 83.2 & 84.5 & 84.2 & 79.3 & 55.4 & 32.0 & 21.3 & 41.6 & 41.7 & 77.8 \\
\hline
\end{tabular}

ANNOA PEAK DISCHARGE, IN OUBIC FEET PER SECOND, AND CORRESPONDING GAGE HEIGHT, IN FEET, FOR EACH WATER YEAR

\begin{tabular}{|c|c|c|c|c|c|c|c|c|c|c|c|}
\hline $\begin{array}{l}\text { WATERR } \\
\text { YEAR }\end{array}$ & DATE & $\begin{array}{c}\text { GAGE } \\
\text { HEIGHT }\end{array}$ & $\begin{array}{c}\text { PEAK } \\
\text { DISAHARGE }\end{array}$ & $\begin{array}{l}\text { WATER } \\
\text { YEAR }\end{array}$ & DATE & $\begin{array}{c}\text { GAGE } \\
\text { HEIGHT }\end{array}$ & $\begin{array}{c}\text { PEAK } \\
\text { DISAHARGE }\end{array}$ & $\begin{array}{l}\text { WATER } \\
\text { YEAR }\end{array}$ & DATE & $\begin{array}{c}\text { GAGE } \\
\text { HEIGHT }\end{array}$ & $\begin{array}{c}\text { PEAK } \\
\text { DISCH ARGE }\end{array}$ \\
\hline $\begin{array}{l}1967 \\
1968 \\
1969 \\
1970 \\
1971\end{array}$ & $\begin{array}{l}\text { SEPT. 08, } 1967 \\
\text { AUG. } 11,1968 \\
\text { AUG. } 29,1969 \\
\text { AUG. } 04,1970 \\
\text { AUG. 27, } 1971\end{array}$ & $\begin{array}{l}5.10 \\
3.15 \\
4.10 \\
3.31 \\
5.36\end{array}$ & $\begin{array}{r}2050 \\
578 \\
1150 \\
640 \\
2310\end{array}$ & $\begin{array}{l}1972 \\
1973 \\
1974 \\
1975 \\
1976\end{array}$ & 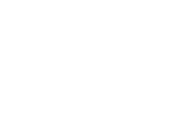 & $\begin{array}{l}2.56 \\
4.87 \\
3.54 \\
2.55 \\
2.47\end{array}$ & $\begin{array}{r}330 \\
1820 \\
1090 \\
524 \\
484\end{array}$ & $\begin{array}{l}1977 \\
1978 \\
1979 \\
1980 \\
1981\end{array}$ & $\begin{array}{l}\text { JULY } 24,1977 \\
\text { JULY } 18,1978 \\
\text { NOV. 02, } 1978 \\
\text { SEPT.09, } 1980 \\
\text { SEPT.05, } 1981\end{array}$ & $\begin{array}{l}5.10 \\
5.00 \\
4.10 \\
4.81 \\
6.90\end{array}$ & $\begin{array}{l}2050 \\
2000 \\
1380 \\
1850 \\
4000\end{array}$ \\
\hline
\end{tabular}

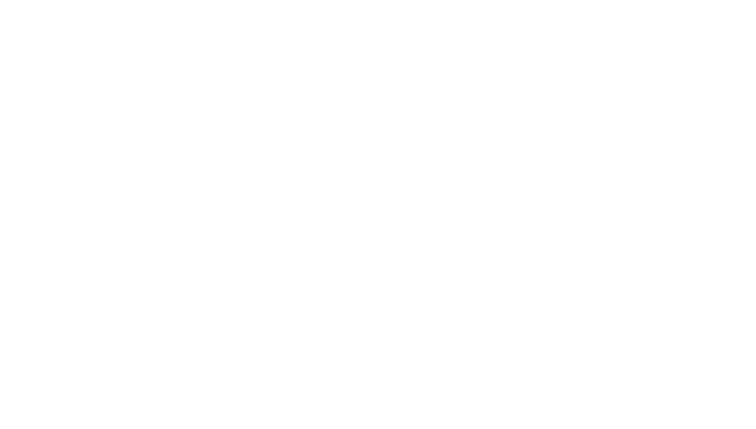


DIRTY DEVIL RIVER BASIN

09330300 NEILSON WASH NEAR CAINEVHLE, UT

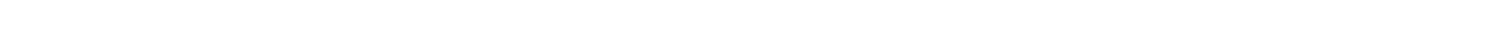
Caineville and $9 \mathrm{mi}$ west of Hanksville.

DRAINAGE AREA. $--22.3 \mathrm{mi}^{2}$.

MEAN BASIN ELEVATION. $-4,830 \mathrm{ft}$.

PERIOD OF RECORD AVAIIABLE.--Water years 1959-73, annual peak discharge only.

GAGE.--Crest-stage gage. Altitude of gage is 4,440 ft from topographic map.

ANNUAL PEAK DISCHARGE, IN CJBIC FEET PER SECOND, AND CORRESPONDING GAGE HEIGHT, IN FEET, FOR EACH WATER YEAR

\begin{tabular}{|c|c|c|c|c|c|c|c|c|c|c|c|}
\hline $\begin{array}{l}\text { WATER } \\
\text { YEAR }\end{array}$ & DATE & $\begin{array}{l}\text { GAGE } \\
\text { HEIGHT }\end{array}$ & $\begin{array}{c}\text { PEAK } \\
\text { DISCHARGE }\end{array}$ & $\begin{array}{l}\text { WATER } \\
\text { YEAR }\end{array}$ & DATE & $\begin{array}{c}\text { GAGE } \\
\text { HEIGHT }\end{array}$ & $\begin{array}{c}\text { PEAR } \\
\text { DISCHARGE }\end{array}$ & $\begin{array}{l}\text { WATER } \\
\text { YEAR }\end{array}$ & DATE & $\begin{array}{l}\text { GAGE } \\
\text { HEIGHT }\end{array}$ & $\begin{array}{c}\text { PEAK } \\
\text { DISCHARGE }\end{array}$ \\
\hline $\begin{array}{l}1959 \\
1960 \\
1961 \\
1962 \\
1963\end{array}$ & 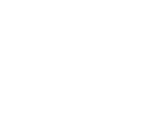 & $\begin{array}{l}12.90 \\
18.37 \\
19.50 \\
\overline{15.12}\end{array}$ & $\begin{array}{r}757 \\
2650 \\
3100 \\
10 \\
1430\end{array}$ & $\begin{array}{l}1964 \\
1965 \\
1966 \\
1967 \\
1968\end{array}$ & $\begin{array}{l}\text { JUNE } 17,1964 \\
\text { AUG. } 18,1965 \\
\text { AUG. } 01,1966 \\
\text { AUG. 09, } 1967 \\
\text { JULY } 31,1968\end{array}$ & $\begin{array}{l}13.72 \\
24.95 \\
15.90 \\
11.05 \\
10.40\end{array}$ & $\begin{array}{r}946 \\
5450 \\
1720 \\
311 \\
180\end{array}$ & $\begin{array}{l}1969 \\
1970 \\
1971 \\
1972 \\
1973\end{array}$ & $\begin{array}{l}\text { AUG. } 29,1969 \\
\text { SEPT.06, } 1970 \\
\text { AUG. 26, } 1971 \\
\text { MAY } 06,1972 \\
\text { OCT. } 19,1972\end{array}$ & $\begin{array}{l}12.55 \\
16.55 \\
14.60 \\
10.20 \\
14.90\end{array}$ & $\begin{array}{r}583 \\
1900 \\
1300 \\
150 \\
1400\end{array}$ \\
\hline
\end{tabular}

09330400 FREMONT RIVER NEAR HANKSVILLE, UT

LOCATION.--Lat $38^{\circ} 22^{\prime} 15^{\prime \prime}$, long $110^{\circ} 44^{\prime} 30^{\prime \prime}$, in $\mathrm{SN}_{\frac{1}{4}}^{\mathrm{l}} \mathrm{sec} .17$, T.28 S., R.11 E., wayne County, Hydrologic Unit 14070003 , at masonry diversion dam and $2.2 \mathrm{mi}$ west of Hanksville.

DRAINAGE AREA. $-1,900 \mathrm{mi}^{2}$.

MEAN BASTN ELEVATION. $-7,450 \mathrm{ft}$.

PERIOD OF RECORD AVAILABLE.-Water years 1959-73, annual peak discharge only.

GAGE.-Crest-stage gage. Altitude of gage is 4,320 ft from topographic map.

REMARKS.--Many diversions for irrigation above station.

ANNUAL PEAK DISCHARGE, IN CUBIC FEET PER SECOND, AND CORRESPONDING GAGE HEIGHT, IN FEET, FOR EACH WATER YEAR

\begin{tabular}{|c|c|c|c|c|c|c|c|c|c|c|c|}
\hline $\begin{array}{l}\text { WATER } \\
\text { YEAR }\end{array}$ & DATE & $\begin{array}{c}\text { GAGE } \\
\text { HEIGHT }\end{array}$ & $\begin{array}{c}\text { PEAK } \\
\text { DISCHARGE }\end{array}$ & $\begin{array}{l}\text { WATER } \\
\text { YEAR }\end{array}$ & DATE & $\begin{array}{l}\text { GAGE } \\
\text { HEIGHI }\end{array}$ & $\begin{array}{c}\text { PEAK } \\
\text { DISCHARGE }\end{array}$ & $\begin{array}{l}\text { WATER } \\
\text { YEAR }\end{array}$ & DATE & $\begin{array}{c}\text { GAGE } \\
\text { HEIGHT }\end{array}$ & $\begin{array}{c}\text { PEAK } \\
\text { DISCHARGE }\end{array}$ \\
\hline $\begin{array}{l}1959 \\
1960 \\
1961 \\
1962 \\
1963\end{array}$ & $\begin{array}{l}\text { AUG. } 12,1959 \\
\text { SEPT.06, } 1960 \\
\text { SEPT.09, } 1961 \\
\text { SEPT.28, } 1962 \\
\text { SEPT.03, } 1963\end{array}$ & $\begin{array}{l}15.05 \\
12.30 \\
15.40 \\
14.40 \\
15.27\end{array}$ & $\begin{array}{l}5620 \\
1400 \\
6500 \\
4300 \\
6140\end{array}$ & $\begin{array}{l}1964 \\
1965 \\
1966 \\
1967 \\
1968\end{array}$ & $\begin{array}{l}\text { JULY } 31,1964 \\
\text { AUG. } 18,1965 \\
\text { AUG. } 31,1966 \\
\text { AUG. } 09,1967 \\
\text { AUG. } 01,1968\end{array}$ & $\begin{array}{l}13.40 \\
15.54 \\
13.89 \\
12.23 \\
13.70\end{array}$ & $\begin{array}{l}2660 \\
6850 \\
3360 \\
1330 \\
3080\end{array}$ & $\begin{array}{l}1969 \\
1970 \\
1971 \\
1972 \\
1973\end{array}$ & $\begin{array}{l}\text { AUG. } 29,1969 \\
\text { SEPT. 06, } 1970 \\
\text { AUG. } 26,1971 \\
\text { AUG. } 27,1972 \\
\text { OCT. } 19,1972\end{array}$ & $\begin{array}{l}16.20 \\
14.44 \\
14.39 \\
14.03 \\
18.48\end{array}$ & $\begin{array}{r}8500 \\
4300 \\
4200 \\
3600 \\
15300\end{array}$ \\
\hline
\end{tabular}

09330500 MUDDY CREER NEAR EMERY, UT

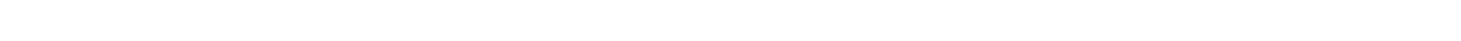
bank $100 \mathrm{ft}$ upstream from Enery Canal and $4.1 \mathrm{mi}$ north of Enery.

DRAINAGE AREA.--105 $\mathrm{mi}^{2}$

MEAN BASIN ELEVATION. $-8,850 \mathrm{ft}$.

PERIOD OF RECORD AVAII.ABLE.--April to July 1909, July 1910 to July 1914, June 1949 to September 1981. Monthly mean discharge for same periods, published in WSP 1313.

REVISED RECORDS.-WSP 1633: Drainage area.

GAGE.--Water-stage recorder. Altitude of gage is 6,400 ft from topographic map. Apr. 29 to July 31, 1909, reference point, July 23, 1910 to July 16, 1914, staff gages, at sites about $1 \mathrm{mi}$ upstream at different datums. June 29, 1949 to May 1 , 1957 , waterstage recorder at site $100 \mathrm{ft}$ upstream at datum $2.89 \mathrm{ft}$ higher prior to Mar. 20, 1953, and at datum $1.89 \mathrm{ft}$ higher thereafter.

REMARKS.--one small diversion for irrigation and two storage reservoirs (total capacity, 700 acre-ft) above station.

AVERAGE DISCHARGE. -35 years (water years $1911-13,1950-81$ ) $, 37.3 \mathrm{ft} / \mathrm{s}, 27,020 \mathrm{acre}-\mathrm{ft} / \mathrm{yr}$.

EXIREMES FOR PERIOD OF RECORD.--Maximun discharge, 3,340 ft $\mathrm{ft}^{3} / \mathrm{s}$ May 10, 1952, gage height, $11.14 \mathrm{ft}$, present datum, from rating curve extended above $400 \mathrm{ft}^{3} / \mathrm{s}$ on basis of slope-area measurement of peak flow; no flow Apr. 13-16, 1911. 
DIRTY DEVIL RIVER BASIN

09330500 MDDY CREEK NEAR EMERY, UT-Continued

LOWEST MEAN DISOHARGE, IN CUBIC FEET PER SECOND, AND RANKING FOR THE INDICATED NUMBER OF CONSECUTIVE DAVS FOR EACH C.IMATIC YEAR, APRII 1-MARCH 31

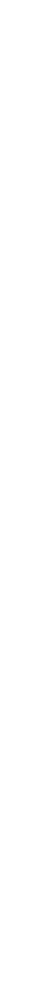

YEAR

1912
1913

1951

1953

195

1955

1956

195

1960

196

196

1964

1965

1966
1967
1968

1969

197

1972

1974

1975

1976

1977
1978

1979

1981

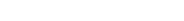

13

$0.00 \quad 1$

714

5.0017

$3.00 \quad 6$

6.0023
8.5033

8.5033

5.0018
$3.20 \quad 8$

$3.40 \quad 9$

5.8020

$\begin{array}{ll}7.90 & 28 \\ 4.00 & 10 \\ 3.00 & 7\end{array}$

5.7019

4.0011

4.0012
$2.70 \quad 5$

$\begin{array}{ll}2.70 & 5 \\ 6.00 \quad 21\end{array}$

7.0025

2.603

4.301

$\begin{array}{ll}8.10 & 31 \\ 7.00 & 26\end{array}$

8.1032

8.0029

6.0022

6.2024

4.3016

2.704

1.19

$\begin{array}{ll}4.00 & 13 \\ 8.10 & 30\end{array}$

\begin{abstract}
4.0014
\end{abstract}
0.00

5.3017
6.9024

9.4032

5.8018

3.807

6.0019

8.6028
4.3011

3.705

6.0020

$\begin{array}{rr}4.60 & 13 \\ 3.00 & 8\end{array}$

3.604

7.0025

3.806

4.4012
9.0029

9.0029
7.0026

$\begin{array}{cc}10.0 & 33\end{array}$

8.0027

9.0030

4.8015

$\begin{array}{ll}3.50 & 3 \\ 1.30 & 2\end{array}$

$\begin{array}{ll}1.30 & 2 \\ 4.00 & 9\end{array}$

9.0031

$1.00 \quad 1$
5.0012

7.8026

7.3022

7.5024

7.5024
4.8010

$4.20 \quad 5$

6.0017
9.0029

9.0029
6.0018

6.0018
$4.70 \quad 3$

7.1021

5.5015

$\begin{array}{ll}4.00 & 3 \\ 5.40 \quad 14\end{array}$

5.40114
6.0016

7.4023

4.709

4.606
9.0030

9.0030
7.0020

$10.0 \quad 33$

8.0027
7.6025

9.0028

9.0028
6.9019

4. 9011

$\begin{array}{rr}4.00 & 4 \\ 1.80 & 2\end{array}$

4.707

9.7031

5.1013

\section{CONSEGITIVE DAYS$$
30 \quad 60
$$

$2.00 \quad 1$

$2.00 \quad 1$

$2.30 \quad 1$ 90

$\begin{array}{ll}2.90 & 1 \\ 6.60 & 9\end{array}$

3.401

ALL

9.0029

9.1028

9. 5028

7.8022

$12.0 \quad 33$

9.1028
8.1023

$\begin{array}{rrrr}8.10 & 23 & 8.5021\end{array}$

9.0026
5.80

$\begin{array}{cc}14.0 & 32 \\ 9.10 & 25\end{array}$

$\begin{array}{rr}9.10 & 25 \\ 6.00 & 6\end{array}$

5.009

5.8011

4.805

6.0016
$11.0 \quad 32$

7.6020

$\begin{array}{ll}7.1012 & 6.4010\end{array}$

13.0016

6.6016
$5.40 \quad 5$

$\begin{array}{ll}14.0 & 33 \\ 7.00 & 15\end{array}$

$\begin{array}{rr}7.00 & 15 \\ 5.50 & 4\end{array}$

5.2011

7.5019

5.9014

6.1013

7.6018

$\begin{array}{ll}7.40 & 17\end{array}$

.4012

5.7019

7.3016

6.8018

6.1014

6.5011

8.8026

5.1010

$\begin{array}{rr}4.90 & 6 \\ 9.00 & 27\end{array}$

$10.0 \quad 29$

$\begin{array}{cc}10.0 & 29 \\ 5.50 \quad 6\end{array}$

5.50
$5.70 \quad 10$

$11.0 \quad 29$

$\begin{array}{cc}11.0 & 29 \\ 6.70 & 13\end{array}$

6.70
6.20

9.0024

8.0019

7.3018

$11.0 \quad 30$

$10.0 \quad 30$

8.6024

8.0021
9.0025

9.3027

8.1020
9.2026

$\begin{array}{ll}9.60 & 26\end{array}$

8.1022

$5.00 \quad 7$

5.507

6.209

4.503

$3.20 \quad 2$

$\begin{array}{ll}4.80 & 3 \\ 4.10 & 2\end{array}$

$\begin{array}{llll}4.10 & 2 & 4.30 & 2\end{array}$

$\begin{array}{rrrrr}5.70 & 8 & 6.60 & 12 \\ 11.0 & 31 & 12.0 & 31\end{array}$

6.4015

7.0014

5.7013

$10.0 \quad 28$

$\begin{array}{cc}10.0 & 28 \\ 3.70 & 22\end{array}$

$14.0 \quad 32$

9. 3025

8.9023

$\begin{array}{rr}8.50 & 8\end{array}$

$14.0 \quad 33$

14.0
7.6017

7.8018

7.5016

7.3014

6.7010

$11.0 \quad 29$

6.9012

9.1024

9.1024
8.3019 7.5011

6.102

$49.0 \quad 25$ 11.028 $\begin{array}{llll}4.0 & 32 & 16.0 & 31\end{array}$

$\begin{array}{llll}9.40 & 24 & 10.0 & 16\end{array}$

6.305

7.104

9.0022 6.807

$\begin{array}{rrr}8.00 & 73\end{array}$

$\begin{array}{llll}8.1017 & 10.0 \quad 17\end{array}$

$\begin{array}{rr}10.0 & 17 \\ 7.20 & 5\end{array}$

7.9014

8.1015

6.908

9. 7013

9.4011
9.9014

8.901410

8.509

$11.0 \quad 29$

$16.0 \quad 32$

$\begin{array}{rrr}6.60 \quad 6 & 8.00 & 6 \\ 9.40 & 8\end{array}$

$\begin{array}{llll}9.40 & 25 & 11.0 & 18\end{array}$

9.4025
8.6019

$14.0 \quad 29$

$11.0 \quad 30$

9.8027

$11.0 \quad 30$

$\begin{array}{cc}10.0 & 27 \\ 8.70 & 20\end{array}$

9.8026
9.0023

$\begin{array}{ll}12.0 & 23 \\ 12.0 & 24\end{array}$

9.5026

9. 9015

12.025

6.8011

7.8013

$11.0 \quad 20$

4. 903

$4.40 \quad 2$

$\begin{array}{lr}5.00 & 3 \\ 4.80 & 2\end{array}$

8.1016

6.203

13.031

7.5015

8.2018

$13.0 \quad 28$

$55.0 \quad 30$

$\begin{array}{rr}30.0 & 15 \\ 18.0 & 3\end{array}$

21.06

25.09

$54.0 \quad 29$

$16.0 \quad 2$

$28.0 \quad 13$

$\begin{array}{rr}19.0 & 4 \\ 49.0 & 26\end{array}$

25.010

29.014

$51.0 \quad 28$

21.07

38.018

$50.0 \quad 27$

HIGHEST MEAN DISCHARGE, IN CUBIC FEET PER SECOND, AND RANKING FOR THE TNDICAIFD NUMBER OF CONSEGUTIVE DAYS FOR EACH WATER YEAR, OCTOBER 1-SEPTEMBER 30

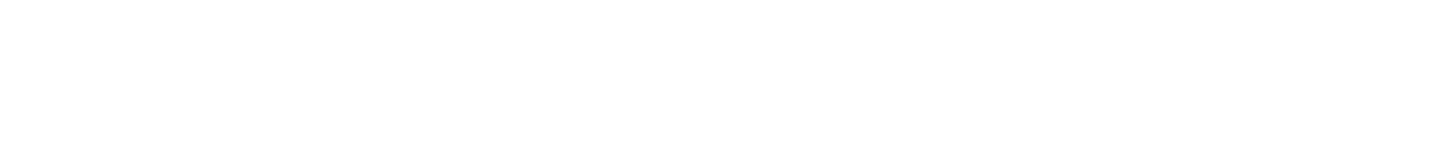

$\begin{array}{lllllllll}1950 & 104 & 29 & 103 & 25 & 102 & 24 & 99.0 & 23\end{array}$

$\begin{array}{lllllllll}1951 & 200 & 19 & 184 & 18 & 166 & 18 & 139 & 18\end{array}$

$90.0 \quad 25 \quad 76.0 \quad 24$

66.024

$57.0 \quad 24$ 
DIRTY DEVIL RIVER BASIN

09330500 MUDDY CREEK NEAR EMERY, UT--Continued

HIGHEST MEAN DISGAARGE, IN OBIC FEET PER SECOND, AND RANKING FOR THE INDICATED NUMBER OF CONSEQUTIVE DAYS FOR EAOH WATER YEAR, OCTOBER 1-SEPTEMBER 30--Continued

\begin{tabular}{|c|c|c|c|c|c|c|c|c|c|c|c|c|c|c|c|c|c|c|c|c|}
\hline YEAR & 1 & & 3 & & 7 & & & & CONs & EQJT & VE DAYS & & & & & & 90 & & $\Delta T$ & \\
\hline $\begin{array}{l}1976 \\
1977 \\
1978 \\
1979 \\
1980\end{array}$ & $\begin{array}{l}69.0 \\
108 \\
200 \\
241 \\
316\end{array}$ & $\begin{array}{r}34 \\
27 \\
18 \\
10 \\
6\end{array}$ & $\begin{array}{c}69.0 \\
42.0 \\
197 \\
230 \\
287\end{array}$ & $\begin{array}{r}32 \\
35 \\
17 \\
10 \\
4\end{array}$ & $\begin{array}{c}68.0 \\
24.0 \\
194 \\
209 \\
241\end{array}$ & $\begin{array}{r}29 \\
35 \\
14 \\
8 \\
5\end{array}$ & $\begin{array}{l}66.0 \\
19.0 \\
188 \\
200 \\
222\end{array}$ & $\begin{array}{r}29 \\
35 \\
10 \\
8 \\
6\end{array}$ & $\begin{array}{l}64.0 \\
17.0 \\
171 \\
191 \\
208\end{array}$ & $\begin{array}{r}28 \\
35 \\
14 \\
8 \\
5\end{array}$ & $\begin{array}{l}54.0 \\
17.0 \\
140 \\
161 \\
200\end{array}$ & $\begin{array}{r}28 \\
35 \\
14 \\
9 \\
3\end{array}$ & $\begin{array}{l}48.0 \\
16.0 \\
113 \\
134 \\
174\end{array}$ & $\begin{array}{r}28 \\
35 \\
15 \\
9 \\
3\end{array}$ & $\begin{array}{r}41.0 \\
15.0 \\
94.0 \\
113 \\
146\end{array}$ & $\begin{array}{r}30 \\
35 \\
15 \\
10 \\
3\end{array}$ & $\begin{array}{r}31.0 \\
13.0 \\
69.0 \\
83.0 \\
106\end{array}$ & $\begin{array}{r}31 \\
35 \\
16 \\
11 \\
3\end{array}$ & $\begin{array}{c}21.0 \\
9.40 \\
37.0 \\
47.0 \\
60.0\end{array}$ & $\begin{array}{r}30 \\
35 \\
16 \\
11 \\
3\end{array}$ \\
\hline 981 & 240 & 11 & 123 & 23 & 104 & 23 & 72.0 & 27 & 59.0 & 29 & 48.0 & 30 & 42.0 & 32 & 44.0 & 27 & 39.0 & 27 & 26.0 & 25 \\
\hline
\end{tabular}

DURATION OF DISGHARGE FOR EAOH WATER YEAR

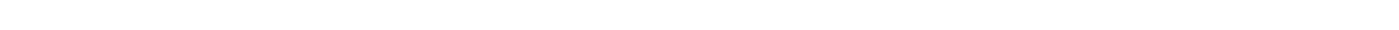
YEAR NUMBER OF DAYS IN GLASS

OJBIC FEET ER SECOND

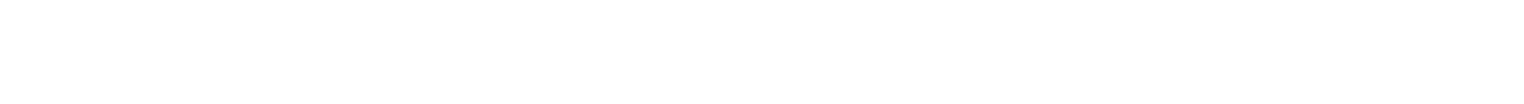

$1950 \quad \begin{array}{lllllllllllllllllll}3 & 56 & 41 & 52 & 45 & 35 & 9 & 8 & 24 & 20 & 10 & 12 & 20 & 12 & 18 & 10021.5\end{array}$

1951

1952

$\begin{array}{lllllllllllllllllllll}1 & & 1 & 1 & 29 & 51 & 87 & 9 & 23 & 22 & 18 & 7 & 14 & 21 & 15 & 19 & 6 & 18 & 15 & 4 & 3\end{array}$

12665.1

1953

1954
1955

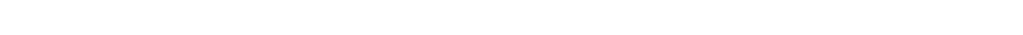

$\begin{array}{llllllllllllllllll}1 & 1 & 2 & 4 & 12 & 34 & 96 & 32 & 51 & 24 & 6 & 18 & 17 & 9 & 10 & 21 & 914 & 4\end{array}$

$\begin{array}{rrrrrrrrrrrrrrrrrrrrr}3 & 8 & 1 & 1 & 6 & 90 & 68 & 40 & 27 & 27 & 17 & 13 & 21 & 18 & 8 & 17 & 9 & & & 1 & \\ \end{array}$

$\begin{array}{llllllllllllllllll}1 & 2 & 2 & 12 & 79 & 71 & 22 & 35 & 18 & 15 & 14 & 11 & 5 & 20 & 23 & 7 & 10 & 19\end{array}$

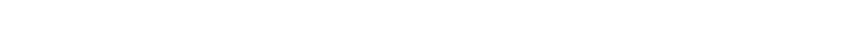

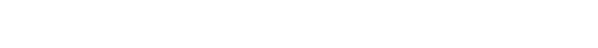

$\begin{array}{llllllllllllllllllllll}2 & 3 & 1 & 11 & 91 & 10 & 33 & 22 & 3 & 15 & 30 & 32 & 8 & 10 & 9 & 19 & 20 & 4 & 21 & 12 & 8 & 2\end{array}$

$\begin{array}{lllllllllllllll}6 & 54 & 78 & 17 & 27 & 40 & 17 & 24 & 14 & 23 & 26 & 25 & 10 & 3 & 1\end{array}$

1961

$\begin{array}{rrrrrrrrrrrrrrrrrrrr}6 & 54 & 78 & 17 & 27 & 40 & 17 & 24 & 14 & 23 & 26 & 25 & 10 & 3 & 1 & 26 & 19 & 30 & 9 & 2\end{array}$

$\begin{array}{llllllllllllllll}7 & 75 & 3 & 26 & 36 & 25 & 20 & 20 & 31 & 12 & 8 & 20 & 27 & 19 & 12 & 23\end{array}$

$\begin{array}{rrrrrrrrrrrrrrrrrrrr}1 & 7 & 75 & 3 & 26 & 36 & 25 & 20 & 20 & 31 & 12 & 8 & 20 & 27 & 19 & 12 & 23 & 1 & & \\ 1 & 2 & 1 & 78 & 47 & 31 & 45 & 13 & 25 & 15 & 2 & 6 & 6 & 9 & 27 & 11 & 15 & 18 & 12 & 2\end{array}$

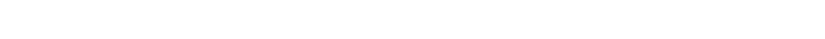

$\begin{array}{lllllllllllll}26 & 67 & 35 & 22 & 12 & 41 & 35 & 43 & 42 & 23 & 16 & 2 & 1\end{array}$

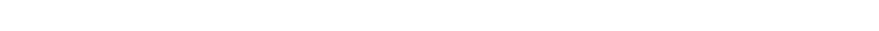

$\begin{array}{llllllllllllllllllllll}1 & 16 & 38 & 69 & 24 & 17 & 13 & 23 & 10 & 24 & 7 & 15 & 4 & 11 & 30 & 13 & 10 & 7 & 5 & 16 & 12 & 1\end{array}$

$\begin{array}{rrrrrrrrrrrrrrrrrrrr}91 & 46 & 26 & 6 & 4 & 12 & 31 & 26 & 14 & 4 & 8 & 12 & 15 & 10 & 5 & 21 & 30 & 2 & 2\end{array}$

$\begin{array}{llllllllllllllll}3 & 106 & 38 & 22 & 7 & 31 & 4 & 5 & 16 & 36 & 36 & 15 & 18 & 16 & 12\end{array}$

$\begin{array}{llllllllllll}40 & 68 & 43 & 46 & 17 & 29 & 27 & 31 & 21 & 15 & 21 & 8\end{array}$

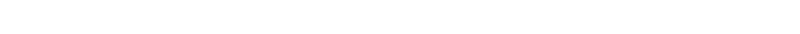

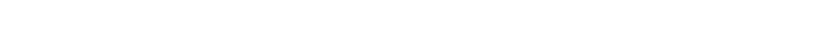

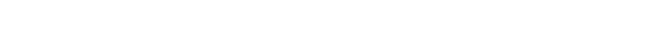

1976

1977

1978
1979

1980

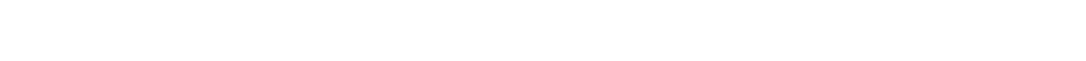

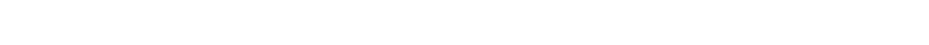

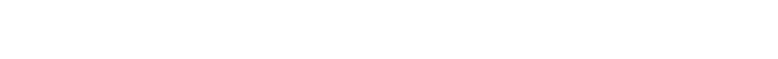

29770.6

12014.6

7287.7

9358.8

17974.7

25579.0

6251.5

7166.3

17769.7

9271.1

10783.2

17360.7

8983.0

10202.3

13231.0

17684.5

16720.7

1981

$\begin{array}{lllllllllllllllll}1 & 5 & 10 & 33 & 59 & 41 & 11 & 2 & 2 & 25 & 45 & 47 & 17 & 37 & 8 & 19 & 1\end{array}$

12904.4

8203.4

16615.8

14909.7

16827.6

3431.2

13605.2

17259.2

21898.1

DURATION TABLE OF DISCHARGE FOR WATER YEARS $1911-13,1950-81$
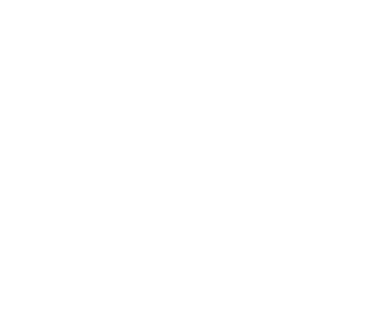

FEET TOTAL LAIFD CEN-

CLASS SECOND DAYS DAYS DAYS

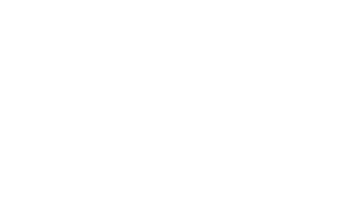

$\begin{array}{lcl}\text { OUBIC } & \text { ACQI- } \\ \text { FEET } & \text { MU- } & \\ \text { PER TORA } & \text { TATED } & \text { CEN }\end{array}$ CLASS SECOND DAYS DAYS DAYS

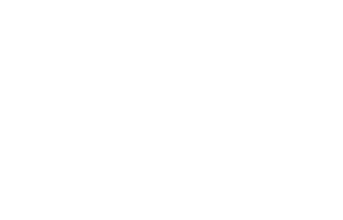

\begin{tabular}{crrrr}
\multicolumn{4}{c}{ GBIC } & \multicolumn{1}{c}{ ACU- } \\
FEET & MU- & PER- \\
PER & TOTAL & LATED & CENT \\
CLASS SECOND & DAYS & DAYS & DAYS \\
DAN & & & & \\
27 & 130.0 & 286 & 846 & 6.6 \\
28 & 160.0 & 302 & 560 & 4.4 \\
29 & 200.0 & 118 & 258 & 2.0 \\
30 & 240.0 & 72 & 140 & 1.1 \\
31 & 290.0 & 41 & 68 & 0.5 \\
32 & 340.0 & 17 & 27 & 0.2 \\
33 & 420.0 & 8 & 10 & 0.1 \\
34 & 500.0 & 2 & 2 & 0.0
\end{tabular}


DIRTY DEVIL RIVER BASIN

O 9330500 MUDDY CREEK NEAR EMERY, UT--Continued

MONTHLY MEAN DISQHARGES, IN OUBIC FEET PER SECOND, FOR EAOH WATER YEAR

\begin{tabular}{|c|c|c|c|c|c|c|c|c|c|c|c|c|}
\hline YEAR & OCT & $\mathrm{NOV}$ & DEC & JAN & FEB & MAR & APR & MAY & JUNE & JULY & AUG & SEP \\
\hline $\begin{array}{l}1911 \\
1912 \\
1913\end{array}$ & $\begin{array}{l}26.0 \\
13.9 \\
25.3\end{array}$ & $\begin{array}{c}18.0 \\
3.73 \\
10.0\end{array}$ & $\begin{array}{c}10.0 \\
2.00 \\
5.00\end{array}$ & $\begin{array}{l}2.00 \\
3.00 \\
7.00\end{array}$ & $\begin{array}{l}3.09 \\
5.00 \\
8.00\end{array}$ & $\begin{array}{c}37.7 \\
9.06 \\
16.8\end{array}$ & $\begin{array}{l}58.3 \\
52.9 \\
52.8\end{array}$ & $\begin{array}{l}173 \\
138 \\
169\end{array}$ & $\begin{array}{l}131 \\
198 \\
132\end{array}$ & $\begin{array}{l}109 \\
109 \\
80.6\end{array}$ & $\begin{array}{l}64.6 \\
52.8 \\
51.0\end{array}$ & $\begin{array}{l}19.7 \\
40.5 \\
27.3\end{array}$ \\
\hline 1950 & 11.3 & 14.0 & 9.97 & 8.21 & 10.4 & 12.7 & 36.4 & 66.4 & 76.5 & 44.2 & 22.8 & 16.1 \\
\hline $\begin{array}{l}1951 \\
1952 \\
1953 \\
1954 \\
1955\end{array}$ & $\begin{array}{c}12.4 \\
15.7 \\
23.0 \\
14.6 \\
9.56\end{array}$ & $\begin{array}{c}13.9 \\
10.8 \\
17.2 \\
10.2 \\
7.80\end{array}$ & $\begin{array}{c}12.0 \\
9.97 \\
14.6 \\
9.61 \\
6.97\end{array}$ & $\begin{array}{c}9.90 \\
9.00 \\
14.3 \\
9.05 \\
6.00\end{array}$ & $\begin{array}{c}9.18 \\
8.52 \\
13.3 \\
9.45 \\
6.25\end{array}$ & $\begin{array}{r}11.7 \\
11.5 \\
14.5 \\
9.41 \\
5.85\end{array}$ & $\begin{array}{c}33.1 \\
85.6 \\
14.1 \\
22.0 \\
9.63\end{array}$ & $\begin{array}{c}90.2 \\
306 \\
43.4 \\
53.0 \\
49.5\end{array}$ & $\begin{array}{l}108 \\
302 \\
106 \\
40.9 \\
66.0\end{array}$ & $\begin{array}{c}59.6 \\
115 \\
69.3 \\
28.2 \\
35.7\end{array}$ & $\begin{array}{l}35.9 \\
68.3 \\
42.6 \\
16.5 \\
23.2\end{array}$ & $\begin{array}{l}19.4 \\
31.8 \\
21.7 \\
15.9 \\
12.9\end{array}$ \\
\hline $\begin{array}{l}1956 \\
1957 \\
1958 \\
1959 \\
1960\end{array}$ & $\begin{array}{c}10.4 \\
12.5 \\
26.5 \\
16.6 \\
9.66\end{array}$ & $\begin{array}{c}9.56 \\
6.74 \\
21.7 \\
9.62 \\
6.61\end{array}$ & $\begin{array}{c}9.52 \\
6.11 \\
15.6 \\
8.03 \\
6.00\end{array}$ & $\begin{array}{c}8.52 \\
6.74 \\
14.0 \\
6.68 \\
5.47\end{array}$ & $\begin{array}{c}8.72 \\
7.52 \\
16.1 \\
9.21 \\
5.61\end{array}$ & $\begin{array}{c}11.7 \\
7.73 \\
13.5 \\
10.7 \\
12.9\end{array}$ & $\begin{array}{c}18.4 \\
13.0 \\
106 \\
17.4 \\
30.8\end{array}$ & $\begin{array}{c}71.3 \\
72.6 \\
267 \\
30.5 \\
80.2\end{array}$ & $\begin{array}{l}76.5 \\
224 \\
209 \\
41.9 \\
85.0\end{array}$ & $\begin{array}{c}44.4 \\
137 \\
75.8 \\
27.5 \\
47.0\end{array}$ & $\begin{array}{l}22.6 \\
66.7 \\
44.5 \\
15.3 \\
19.8\end{array}$ & $\begin{array}{l}14.7 \\
28.9 \\
28.2 \\
11.7 \\
17.2\end{array}$ \\
\hline $\begin{array}{l}1961 \\
1962 \\
1963 \\
1964 \\
1965\end{array}$ & $\begin{array}{l}14.5 \\
10.9 \\
16.5 \\
12.1 \\
13.7\end{array}$ & $\begin{array}{c}8.49 \\
12.0 \\
9.93 \\
9.23 \\
7.55\end{array}$ & $\begin{array}{l}8.40 \\
9.58 \\
6.51 \\
8.97 \\
7.00\end{array}$ & $\begin{array}{l}7.74 \\
7.68 \\
6.06 \\
7.00 \\
7.00\end{array}$ & $\begin{array}{l}7.50 \\
8.06 \\
7.50 \\
7.52 \\
6.00\end{array}$ & $\begin{array}{c}11.2 \\
8.18 \\
12.4 \\
7.45 \\
9.15\end{array}$ & $\begin{array}{l}22.4 \\
79.5 \\
17.1 \\
16.6 \\
21.7\end{array}$ & $\begin{array}{c}41.9 \\
132 \\
68.7 \\
69.0 \\
89.1\end{array}$ & $\begin{array}{c}44.0 \\
145 \\
63.5 \\
95.6 \\
185\end{array}$ & $\begin{array}{r}28.0 \\
90.5 \\
45.5 \\
59.5 \\
125\end{array}$ & $\begin{array}{l}22.7 \\
54.5 \\
31.2 \\
42.1 \\
57.2\end{array}$ & $\begin{array}{l}18.1 \\
24.3 \\
18.3 \\
17.7 \\
40.2\end{array}$ \\
\hline $\begin{array}{l}1966 \\
1967 \\
1968 \\
1969 \\
1970\end{array}$ & $\begin{array}{c}29.3 \\
9.35 \\
14.8 \\
18.2 \\
30.6\end{array}$ & $\begin{array}{c}14.5 \\
5.79 \\
8.06 \\
10.8 \\
14.9\end{array}$ & $\begin{array}{r}11.1 \\
7.89 \\
6.68 \\
9.00 \\
8.32\end{array}$ & $\begin{array}{c}10.7 \\
7.08 \\
6.03 \\
9.00 \\
7.73\end{array}$ & $\begin{array}{r}11.1 \\
8.00 \\
6.50 \\
9.40 \\
8.92\end{array}$ & $\begin{array}{c}18.7 \\
10.1 \\
7.95 \\
11.4 \\
10.1\end{array}$ & $\begin{array}{c}34.1 \\
7.84 \\
13.0 \\
39.6 \\
19.3\end{array}$ & $\begin{array}{c}53.6 \\
47.6 \\
77.9 \\
165 \\
127\end{array}$ & $\begin{array}{l}39.8 \\
89.0 \\
155 \\
156 \\
149\end{array}$ & $\begin{array}{l}30.6 \\
68.8 \\
71.6 \\
81.8 \\
84.5\end{array}$ & $\begin{array}{l}28.0 \\
45.7 \\
42.5 \\
39.7 \\
57.5\end{array}$ & $\begin{array}{l}12.3 \\
27.0 \\
23.7 \\
29.3 \\
28.5\end{array}$ \\
\hline $\begin{array}{l}1971 \\
1972 \\
1973 \\
1974 \\
1975\end{array}$ & $\begin{array}{l}12.7 \\
15.3 \\
13.7 \\
18.3 \\
17.5\end{array}$ & $\begin{array}{l}13.3 \\
13.1 \\
10.4 \\
12.2 \\
13.0\end{array}$ & $\begin{array}{c}11.8 \\
10.7 \\
9.32 \\
10.0 \\
9.32\end{array}$ & $\begin{array}{c}11.0 \\
9.58 \\
8.16 \\
9.00 \\
9.00\end{array}$ & $\begin{array}{c}10.7 \\
9.17 \\
8.00 \\
9.46 \\
8.11\end{array}$ & $\begin{array}{c}16.0 \\
14.5 \\
9.50 \\
12.7 \\
9.45\end{array}$ & $\begin{array}{l}39.4 \\
22.4 \\
31.8 \\
27.8 \\
22.5\end{array}$ & $\begin{array}{c}71.5 \\
46.5 \\
137 \\
146 \\
86.7\end{array}$ & $\begin{array}{c}104 \\
54.3 \\
161 \\
124 \\
198\end{array}$ & $\begin{array}{r}57.2 \\
30.7 \\
76.4 \\
54.9 \\
102\end{array}$ & $\begin{array}{l}52.4 \\
28.6 \\
49.1 \\
39.1 \\
41.3\end{array}$ & $\begin{array}{l}23.5 \\
13.7 \\
29.9 \\
24.2 \\
35.8\end{array}$ \\
\hline $\begin{array}{l}1976 \\
1977 \\
1978 \\
1979 \\
1980\end{array}$ & $\begin{array}{c}23.8 \\
10.7 \\
4.78 \\
18.7 \\
16.9\end{array}$ & $\begin{array}{c}11.5 \\
5.51 \\
5.97 \\
11.7 \\
14.7\end{array}$ & $\begin{array}{c}10.7 \\
5.00 \\
4.46 \\
8.42 \\
12.6\end{array}$ & $\begin{array}{c}8.00 \\
5.00 \\
4.49 \\
6.16 \\
13.1\end{array}$ & $\begin{array}{c}6.54 \\
5.00 \\
4.36 \\
7.11 \\
13.7\end{array}$ & $\begin{array}{c}5.97 \\
5.72 \\
7.60 \\
13.4 \\
10.9\end{array}$ & $\begin{array}{l}14.3 \\
11.5 \\
20.6 \\
36.8 \\
48.8\end{array}$ & $\begin{array}{l}53.8 \\
14.2 \\
78.2 \\
138 \\
193\end{array}$ & $\begin{array}{l}51.4 \\
15.7 \\
171 \\
166 \\
204\end{array}$ & $\begin{array}{r}35.5 \\
17.1 \\
83.7 \\
90.5 \\
110\end{array}$ & $\begin{array}{c}18.6 \\
7.55 \\
37.5 \\
38.8 \\
44.5\end{array}$ & $\begin{array}{r}12.7 \\
9.5 \\
23.7 \\
29.6 \\
35.5\end{array}$ \\
\hline 1981 & 31.4 & 9.88 & 9.94 & 6.61 & 7.75 & 8.62 & 27.1 & 41.2 & 51.5 & 26.5 & 39.9 & 46.1 \\
\hline
\end{tabular}

ANNUAL PEAK DISAHARGE, IN OUBIC FEET PER SECOND, AND CORRESPONDING GAGE HEIGHT, IN FEET, FOR EACH WATER YEAR

\begin{tabular}{|c|c|c|c|c|c|c|c|c|c|c|c|}
\hline $\begin{array}{l}\text { WATER } \\
\text { YEAR }\end{array}$ & DATE & $\begin{array}{c}\text { GAGE } \\
\text { HEIGH'T }\end{array}$ & $\begin{array}{c}\text { PEAK } \\
\text { DISGHARGE }\end{array}$ & $\begin{array}{l}\text { WATER } \\
\text { YEAR }\end{array}$ & DATE & $\begin{array}{c}\text { GAGE } \\
\text { HEIGHT }\end{array}$ & $\begin{array}{c}\text { PEAK } \\
\text { DISGARGE }\end{array}$ & $\begin{array}{l}\text { WATER } \\
\text { YEAR }\end{array}$ & DATE & $\begin{array}{c}\text { GAGE } \\
\text { HEIGHT }\end{array}$ & $\begin{array}{c}\text { PEAK } \\
\text { DISGARGE }\end{array}$ \\
\hline $\begin{array}{l}1909 \\
1911 \\
1912 \\
1913 \\
1914 \\
1949 \\
1950 \\
1951 \\
1952 \\
1953 \\
1954 \\
1955 \\
1956\end{array}$ & $\begin{array}{l}\text { JUNE } 03,1909 \\
\text { AUG. } 21,1911 \\
\text { JULY } 28,1912 \\
\text { JULY } 08,1913 \\
\text { JULY } 17,1914 \\
\text { AUG. } 08,1949 \\
\text { AUG. } 11,1950 \\
\text { AUG. } 03,1951 \\
\text { MAY } 10,1952 \\
\text { AUG. } 28,1953 \\
\text { JULY } 18,1954 \\
\text { AUG. } 17,1955 \\
\text { JULY } 30,1956\end{array}$ & $\begin{array}{r}4.10 \\
4.20 \\
4.10 \\
5.90 \\
5.50 \\
4.28 \\
3.12 \\
4.78 \\
11.14 \\
5.90 \\
7.08 \\
7.04 \\
2.66\end{array}$ & $\begin{array}{r}356 \\
404 \\
446 \\
969 \\
850 \\
816 \\
360 \\
1120 \\
3340 \\
1560 \\
2120 \\
2290 \\
270\end{array}$ & $\begin{array}{l}1957 \\
1958 \\
1959 \\
1960 \\
1961 \\
1962 \\
1963 \\
1964 \\
1965 \\
1966 \\
1967 \\
1968 \\
1969\end{array}$ & $\begin{array}{l}\text { JUNE } 06,1957 \\
\text { APR. } 18,1958 \\
\text { APR. } 02,1959 \\
\text { JULY } 29,1960 \\
\text { AUG. } 02,1961 \\
\text { MAY } 06,1962 \\
\text { SEPT. } 06,1963 \\
\text { JULY } 13,1964 \\
\text { JULY } 26,1965 \\
\text { AUG. } 01,1966 \\
\text { JULY } 15,1967 \\
\text { AUG. } 02,1968 \\
\text { JULY } 25,1969\end{array}$ & $\begin{array}{l}4.25 \\
5.22 \\
2.57 \\
3.84 \\
4.57 \\
4.28 \\
7.79 \\
7.75 \\
4.72 \\
3.64 \\
6.96 \\
3.79 \\
5.25\end{array}$ & $\begin{array}{r}403 \\
660 \\
72 \\
282 \\
504 \\
299 \\
1560 \\
1640 \\
535 \\
257 \\
1320 \\
290 \\
698\end{array}$ & $\begin{array}{l}1970 \\
1971 \\
1972 \\
1973 \\
1974 \\
1975 \\
1976 \\
1977 \\
1978 \\
1979 \\
1980 \\
1981\end{array}$ & $\begin{array}{l}\text { AUG. } 20,1970 \\
\text { JULY } 22,1971 \\
\text { OCT. } 24,1971 \\
\text { AUG. } 06,1973 \\
\text { MAY } 09,1974 \\
\text { JUNE } 08,1975 \\
\text { MAY 06, } 1976 \\
\text { SEPT.11, } 1977 \\
\text { JUNE } 13,1978 \\
\text { MAY 28, } 1979 \\
\text { MAY 21, } 1980 \\
\text { SEPT.05, } 1981\end{array}$ & $\begin{array}{l}6.36 \\
5.42 \\
3.93 \\
4.76 \\
3.43 \\
3.68 \\
2.60 \\
7.18 \\
3.64 \\
3.80 \\
4.34 \\
8.18\end{array}$ & $\begin{array}{r}1080 \\
752 \\
295 \\
544 \\
268 \\
322 \\
91 \\
1410 \\
303 \\
328 \\
443 \\
1840\end{array}$ \\
\hline
\end{tabular}

MAGNITUDE AND PROBABILITY OF ANNUAL LONEST MEAN DISQHARGE BASED ON CLIMATIC YEARS 191 2-13 AND 1951 -81

\begin{tabular}{|c|c|c|c|c|c|c|}
\hline \multirow{2}{*}{$\begin{array}{l}\text { PERIOD } \\
\text { (CON- } \\
\text { SEU- } \\
\text { TIVE } \\
\text { DAYS) }\end{array}$} & \multicolumn{6}{|c|}{$\begin{array}{l}\text { DISGHARGE, IN UBIC FEET PER SECOND, FOR } \\
\text { INDICATED RECURRENCE INTTERVAL, IN YEARS, AND } \\
\text { ANNUAL NONEXCEEDANCE PROBABIIITY, IN PERCENT }\end{array}$} \\
\hline & $\begin{array}{c}2 \\
508\end{array}$ & $\begin{array}{c}5 \\
208\end{array}$ & $\begin{array}{l}10 \\
108\end{array}$ & $\begin{array}{l}20 \\
58\end{array}$ & $\begin{array}{l}50 \\
28\end{array}$ & $\begin{array}{r}100 \\
18\end{array}$ \\
\hline $\begin{array}{r}1 \\
7 \\
14 \\
30 \\
60 \\
90\end{array}$ & $\begin{array}{l}5.0 \\
6.6 \\
6.8 \\
7.4 \\
7.9 \\
8.0\end{array}$ & $\begin{array}{l}3.2 \\
4.3 \\
4.8 \\
5.3 \\
5.7 \\
6.0\end{array}$ & $\begin{array}{l}2.3 \\
3.1 \\
3.9 \\
4.3 \\
4.7 \\
5.0\end{array}$ & $\begin{array}{l}1.5 \\
2.2 \\
3.2 \\
3.5 \\
3.9 \\
4.3\end{array}$ & $\begin{array}{l}0.67 \\
1.5 \\
2.6 \\
2.8 \\
3.1 \\
3.6\end{array}$ & $\begin{array}{l}-- \\
-- \\
-- \\
--\end{array}$ \\
\hline
\end{tabular}

MAGNITUDE AND PROBABILITY OF ANNUAL HIGHEST MEAN DISGAARG BASED ON WATER YEARS I $911-13$ AND 1 950-81

\begin{tabular}{|c|c|c|c|c|c|c|}
\hline \multirow{2}{*}{$\begin{array}{l}\text { PERIOD } \\
\text { (CON- } \\
\text { SEO- } \\
\text { TIVE } \\
\text { DAYS) }\end{array}$} & \multicolumn{6}{|c|}{$\begin{array}{l}\text { DISGHARGE, IN GBIC FEET PER SECOND, FOR } \\
\text { INDICATED REGINRENCE INTERNAL, IN YEARS, AND } \\
\text { ANNUAL EXCEEDANCE PRCBAB II ITY, IN PERCENT }\end{array}$} \\
\hline & $\begin{array}{c}2 \\
508\end{array}$ & $\begin{array}{c}5 \\
20 \%\end{array}$ & $\begin{array}{l}10 \\
108\end{array}$ & $\begin{array}{l}25 \\
48\end{array}$ & $\begin{array}{l}50 \\
28\end{array}$ & $\begin{array}{r}100 \\
18\end{array}$ \\
\hline $\begin{array}{r}1 \\
3 \\
7 \\
15\end{array}$ & $\begin{array}{l}178 \\
153 \\
145 \\
134\end{array}$ & $\begin{array}{l}287 \\
244 \\
232 \\
214\end{array}$ & $\begin{array}{l}366 \\
306 \\
287 \\
262\end{array}$ & $\begin{array}{l}472 \\
385 \\
351 \\
316\end{array}$ & $\begin{array}{l}554 \\
444 \\
395 \\
352\end{array}$ & $\begin{array}{l}- \\
- \\
-\end{array}$ \\
\hline
\end{tabular}


LOCATION.--Lat $38^{\circ} 45^{\prime} 30^{\prime \prime}$, long $111^{\circ} 25^{\prime} 15^{\prime \prime}$, in $W^{\frac{1}{4}} W^{\frac{1}{4}}$ sec.l, T.24 S., R.4 E., Emery County, Hydrologic Unit 14070002, on right bank $1.25 \mathrm{mi}$ downstream fram Clear Creek and $14 \mathrm{mi}$ southwest of Emery.

DRAINAGE AREA. $-50 \mathrm{mi}^{2}$, approximately.

MEAN BASIN ELEVATION. $-8,870 \mathrm{ft}$.

PERIOD OF RECORD AVAILABLE.--August 1950 to September 1961, and annual peak discharge only, water years $1962-74$.

REVISED RECORDS.-WSP 1633: Drainage area.

GAGE.-Crest-stage gage. Altitude of gage is $7,100 \mathrm{ft}$ by barameter. Prior to Sept. 30, 1961, water-stage recorder, at site $190 \mathrm{ft}$ upstream at different datum.

REMARRS.-Flow partly regulated by Sheep Valley Reservoir, capacity, 482 acre-ft. Small diversion for irrigation of 200 acres of meadow above station.

AVERAGE DISCHARGE.--11 years, $3.91 \mathrm{ft}^{3} / \mathrm{s}, 2,830 \mathrm{acre}-\mathrm{ft} / \mathrm{yr}$.

EXTREMES FOR PERIOD OF RECORD.-Maximum discharge, I, $420 \mathrm{ft}^{3} / \mathrm{s}$ July 25,1965 , gage height, $15.06 \mathrm{ft}$, from slope-area measurement of peak flow; no flow at times.

LOWEST MEAN DISCHARGE, IN OUBIC FEET PER SECOND, AND RANKING FOR THE INDICATED NUMBER OF CONSEOUTIVE DAYS FOR EAOH CIIMATIC YEAR, APRIL 1-MARCH 31

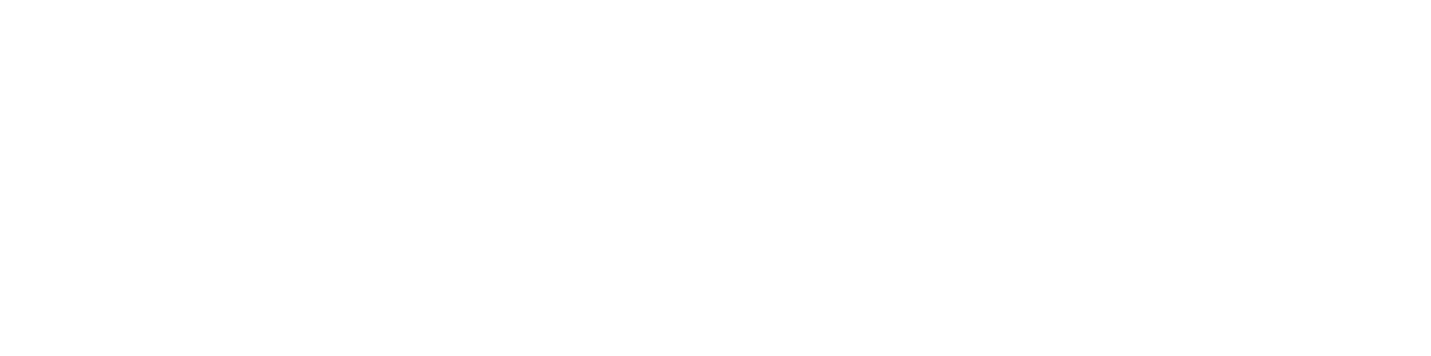

HIGHEST MEAN DISCHARGE, IN CUBIC FEET PER SECOND, AND RANKING FOR THE INDICATED NUMBER OF CONSECUTIVE DAYS FOR EACH WATER YEAR, OCTOBER 1-SEPTEMBER 30

YEAR

$\begin{array}{lllll}1 & 3 & 7 & 15 & 30\end{array}$

$\begin{array}{llllllll}21.0 & 5 & 17.0 & 5 & 16.0 & 4 & 11.0 & 4\end{array}$

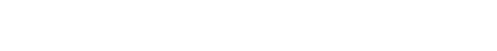

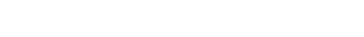

$\begin{array}{llll}7.8 .0 & 6 & 8.80 & 8\end{array}$

6.508

$6.1010 \quad 5.2010$

48.03

66.02

5.1011

$\begin{array}{rr}5.20 & 10 \\ 45.0 & 3\end{array}$

36.03

39.02

$\begin{array}{cr}3.70 & 11 \\ 10.0 & 5\end{array}$

$\begin{array}{rr}4.40 & 11 \\ 13.0 & 6\end{array}$

4.0011

13.05

$\begin{array}{llll}25.0 \quad 4 & 17.0 \quad 4\end{array}$

11.06

8.206
4.7010

$30 \quad 60$

$7.80 \quad 4$

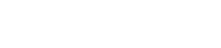

$\begin{array}{rrrr}6.70 & 7 & 6.20 & 4\end{array}$

$\begin{array}{llll}4.80 & 8 & 4.50 & 8\end{array}$

4.809

4.2010

$22.0 \quad 3$

$\begin{array}{cc}30.0 & 2 \\ 3.70 & 11\end{array}$

7.405

6.906

\begin{abstract}
3.3010
\end{abstract}
14.03311 .0

19.02

5.906

$6.10 \quad 5$

DURATION OF DISGHARGE FOR EACH WATER YEAR

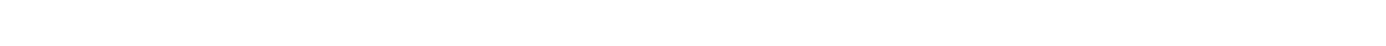

YEAR

NUMBER OE DAYS IN CLASS

GBIC FEET PER SEOOND -DAYS

1952

195

1954
1955

1956

1957

1958

1959

961

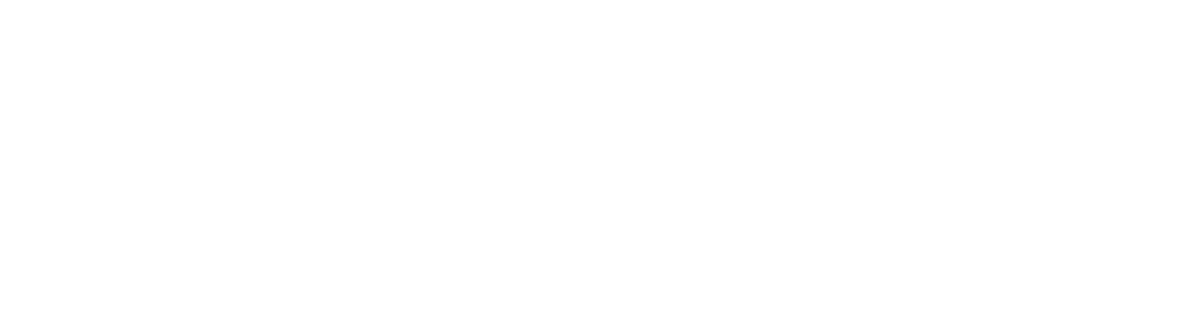

1095.0 3030.0 1587.7

1223.4 
DIRTY DEVII RIVER BASIN

09331500 IVIE CREEK ABOVE DIVERSIONS, NEAR EMERY, UT--Continued

DURATION TABLE OF DISGHARGE FOR WATER YEARS $1951-61$

\begin{tabular}{|c|c|c|c|c|c|c|c|c|c|c|c|c|c|c|c|c|c|c|c|}
\hline CASS & $\begin{array}{c}\text { OUBIC } \\
\text { FEET } \\
\text { PER } \\
\text { SECOND }\end{array}$ & $\begin{array}{l}\text { TOTAL } \\
\text { DAYS }\end{array}$ & $\begin{array}{l}\text { ACOJ- } \\
\text { MU- } \\
\text { LATED } \\
\text { DAYS }\end{array}$ & $\begin{array}{l}\text { PER- } \\
\text { CENT } \\
\text { DAVS }\end{array}$ & OASS & $\begin{array}{c}\text { CJBIC } \\
\text { FEET } \\
\text { PER } \\
\text { SECOND }\end{array}$ & $\begin{array}{l}\text { TOTA, } \\
\text { DAYS }\end{array}$ & $\begin{array}{l}\text { ACOJ- } \\
\text { MU- } \\
\text { LATED } \\
\text { DAYS }\end{array}$ & $\begin{array}{l}\text { PER- } \\
\text { CENT } \\
\text { DAUS }\end{array}$ & & $\begin{array}{c}\text { OUBIC } \\
\text { FEET } \\
\text { PER } \\
\text { SECOND }\end{array}$ & $\begin{array}{l}\text { TOTAL } \\
\text { DAYS }\end{array}$ & $\begin{array}{l}\text { ACOU- } \\
\text { MU- } \\
\text { LAT'ED } \\
\text { DAYS }\end{array}$ & $\begin{array}{l}\text { PER- } \\
\text { CENT } \\
\text { DAYS }\end{array}$ & & $\begin{array}{c}\text { OBIC } \\
\text { FEET } \\
\text { PER } \\
\text { SECOND }\end{array}$ & $\begin{array}{r}\text { TOTAL } \\
\text { DAYS }\end{array}$ & $\begin{array}{l}\text { ACU- } \\
\text { MI- } \\
\text { LATED } \\
\text { DAYS }\end{array}$ & $\begin{array}{l}\text { PER- } \\
\text { CENT } \\
\text { DAYS }\end{array}$ \\
\hline $\begin{array}{l}0 \\
1 \\
2 \\
3 \\
4 \\
5 \\
6 \\
7 \\
8\end{array}$ & $\begin{array}{l}0.00 \\
0.10 \\
0.12 \\
0.15 \\
0.18 \\
0.22 \\
0.27 \\
0.33 \\
0.40\end{array}$ & $\begin{array}{l}2 \\
6 \\
0 \\
0 \\
0 \\
0 \\
2 \\
0\end{array}$ & $\begin{array}{l}4018 \\
4016 \\
4010 \\
4010 \\
4010 \\
4010 \\
4010 \\
4008 \\
4008\end{array}$ & $\begin{array}{r}100.0 \\
100.0 \\
99.8 \\
99.8 \\
99.8 \\
99.8 \\
99.8 \\
99.8 \\
99.8\end{array}$ & $\begin{array}{r}9 \\
10 \\
11 \\
12 \\
13 \\
14 \\
15 \\
16 \\
17\end{array}$ & $\begin{array}{l}0.48 \\
0.59 \\
0.72 \\
0.87 \\
1.10 \\
1.30 \\
1.60 \\
1.90 \\
1.30\end{array}$ & $\begin{array}{r}10 \\
52 \\
18 \\
125 \\
144 \\
237 \\
445 \\
567 \\
495\end{array}$ & $\begin{array}{l}4007 \\
3997 \\
3945 \\
3927 \\
3802 \\
3658 \\
3421 \\
2976 \\
2409\end{array}$ & $\begin{array}{l}99.7 \\
99.5 \\
98.2 \\
97.7 \\
94.6 \\
91.0 \\
85.1 \\
74.1 \\
60.0\end{array}$ & $\begin{array}{l}18 \\
19 \\
20 \\
21 \\
22 \\
23 \\
24 \\
25 \\
26\end{array}$ & $\begin{array}{r}2.8 \\
3.5 \\
4.2 \\
5.1 \\
6.2 \\
7.6 \\
9.2 \\
11.0 \\
14.0\end{array}$ & $\begin{array}{r}553 \\
439 \\
313 \\
249 \\
113 \\
67 \\
30 \\
30 \\
22\end{array}$ & $\begin{array}{r}1914 \\
1361 \\
922 \\
609 \\
360 \\
247 \\
180 \\
150 \\
120\end{array}$ & $\begin{array}{r}47.6 \\
33.9 \\
22.9 \\
15.2 \\
9.0 \\
6.1 \\
4.5 \\
3.7 \\
3.0\end{array}$ & $\begin{array}{l}27 \\
28 \\
29 \\
30 \\
31 \\
32 \\
33 \\
34\end{array}$ & $\begin{array}{l}17.0 \\
20.0 \\
25.0 \\
30.0 \\
37.0 \\
45.0 \\
54.0 \\
66.0\end{array}$ & $\begin{array}{r}11 \\
20 \\
17 \\
9 \\
16 \\
14 \\
8 \\
3\end{array}$ & $\begin{array}{r}98 \\
87 \\
67 \\
50 \\
41 \\
25 \\
11 \\
3\end{array}$ & $\begin{array}{l}2.4 \\
2.2 \\
1.7 \\
1.2 \\
1.0 \\
0.6 \\
0.3 \\
0.1\end{array}$ \\
\hline
\end{tabular}

MONIHLY MEAN DISCHARGES, IN OBBIC FEET PER SECOND, FOR EACH WATER YEAR

$\begin{array}{lllllllllllll}\text { YEAR } & \text { OCT } & \text { NOV } & \text { DEC } & \text { JAN } & \text { FEB } & \text { MAR } & \text { APR } & \text { MAY } & \text { JUNE } & \text { JULY } & \text { AUG } & \text { SEP } \\ 1951 & 2.40 & 2.92 & 2.47 & 1.98 & 2.57 & 3.27 & 1.97 & 2.23 & 2.65 & 3.62 & 7.23 & 2.57 \\ 1952 & 2.37 & 1.75 & 1.60 & 1.75 & 1.89 & 3.31 & 16.8 & 39.6 & 13.6 & 5.49 & 7.62 & 3.16 \\ 1953 & 4.12 & 4.80 & 3.50 & 3.00 & 3.50 & 4.50 & 5.50 & 4.63 & 6.44 & 5.88 & 4.95 & 1.32 \\ 1954 & 2.15 & 2.15 & 1.85 & 2.34 & 4.00 & 4.18 & 4.71 & 3.58 & 3.36 & 3.33 & 2.72 & 1.72 \\ 1955 & 1.73 & 2.33 & 2.14 & 1.80 & 1.97 & 2.73 & 3.90 & 3.14 & 4.77 & 2.51 & 2.75 & 1.82 \\ 1956 & 1.49 & 1.49 & 1.78 & 1.81 & 1.82 & 2.39 & 3.11 & 3.08 & 2.74 & 3.77 & 1.58 & 0.73 \\ 1957 & 1.38 & 1.30 & 1.05 & 1.10 & 1.58 & 2.60 & 3.51 & 9.03 & 18.9 & 4.31 & 3.87 & 3.64 \\ 1958 & 3.30 & 2.02 & 2.36 & 2.10 & 2.60 & 3.02 & 6.24 & 28.5 & 6.97 & 7.18 & 5.89 & 2.24 \\ 1959 & 2.01 & 1.92 & 2.17 & 1.90 & 2.39 & 2.46 & 2.91 & 3.10 & 2.82 & 3.22 & 3.04 & 0.97 \\ 1960 & 1.67 & 3.08 & 2.01 & 1.60 & 1.80 & 3.22 & 4.46 & 7.22 & 2.42 & 4.48 & 4.59 & 3.58 \\ 1961 & 2.12 & 1.95 & 1.91 & 1.07 & 1.30 & 2.73 & 4.92 & 4.28 & 3.72 & 4.89 & 5.53 & 5.72\end{array}$

ANNUAL PEAK DISCHARGE, IN CUBIC FEET PER SECOND, AND CORRESPONDING GAGE HEIGHT, IN FEET, FOR EACH WATER YEAR

\begin{tabular}{|c|c|c|c|c|c|c|c|c|c|c|c|}
\hline $\begin{array}{l}\text { WATER } \\
\text { YEAR }\end{array}$ & DATE & $\begin{array}{c}\text { GAGE } \\
\text { HEIGHT }\end{array}$ & $\begin{array}{c}\text { PEAK } \\
\text { DISCHARGE }\end{array}$ & $\begin{array}{l}\text { WATER } \\
\text { YE AR }\end{array}$ & DATE & $\begin{array}{c}\text { GAGE } \\
\text { HEIGHT }\end{array}$ & $\begin{array}{c}\text { PEAK } \\
\text { DISCHARGE }\end{array}$ & $\begin{array}{l}\text { WATER } \\
\text { YEAR }\end{array}$ & DATE & $\begin{array}{c}\text { GAGE } \\
\text { HEIGHT }\end{array}$ & $\begin{array}{c}\text { PEAK } \\
\text { DISQHARGE }\end{array}$ \\
\hline $\begin{array}{l}1951 \\
1952 \\
1953 \\
1954 \\
1955 \\
1956 \\
1957 \\
1958\end{array}$ & $\begin{array}{l}\text { JULY } 31,1951 \\
\text { AUG. } 27,1952 \\
\text { JULY } 29,1953 \\
\text { SEPT.11, } 1954 \\
\text { AUG. 16, } 1955 \\
\text { AUG. } 14,1956 \\
\text { JUNE 02, } 1957 \\
\text { SEPT. 05, } 1958\end{array}$ & $\begin{array}{l}7.21 \\
2.47 \\
2.67 \\
2.28 \\
4.00 \\
2.38 \\
1.92 \\
1.93\end{array}$ & $\begin{array}{r}418 \\
155 \\
172 \\
73 \\
700 \\
146 \\
184 \\
96\end{array}$ & $\begin{array}{l}1959 \\
1960 \\
1961 \\
1962 \\
1963 \\
1964 \\
1965 \\
1966\end{array}$ & $\begin{array}{l}\text { AUG. } 04,1959 \\
\text { SEPT. 06, } 1960 \\
\text { AUG. } 02,1961 \\
\text { APR. } 19,1962 \\
\text { AUG. } 17,1963 \\
\text { AUG. } 01,1964 \\
\text { JULY } 25,1965 \\
\text { AUG. } 19,1966\end{array}$ & $\begin{array}{r}1.24 \\
3.50 \\
2.75 \\
10.52 \\
12.70 \\
11.51 \\
15.06 \\
13.15\end{array}$ & $\begin{array}{r}11 \\
526 \\
275 \\
62 \\
513 \\
170 \\
1420 \\
290\end{array}$ & $\begin{array}{l}1967 \\
1968 \\
1969 \\
1970 \\
1971 \\
1972 \\
1973 \\
1974\end{array}$ & $\begin{array}{l}\text { SEPT. } 10,1967 \\
\text { AUG. } 16,1968 \\
\text { AUG. } 29,1969 \\
\text { MAY } 14,1970 \\
\text { AUG. } 25,1971 \\
\text { JUNE } 08,1972 \\
\text { JULY } 11,1973 \\
\text { SEPT.18, } 1974\end{array}$ & $\begin{array}{l}10.50 \\
11.40 \\
11.82 \\
13.38 \\
13.11 \\
10.96 \\
13.80 \\
12.80\end{array}$ & $\begin{array}{r}29 \\
88 \\
123 \\
316 \\
280 \\
57 \\
310 \\
235\end{array}$ \\
\hline
\end{tabular}

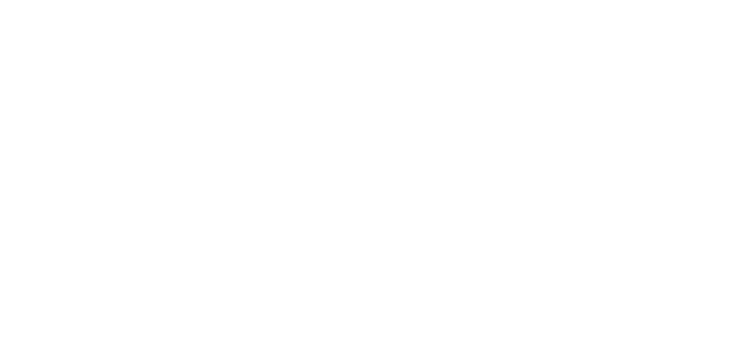

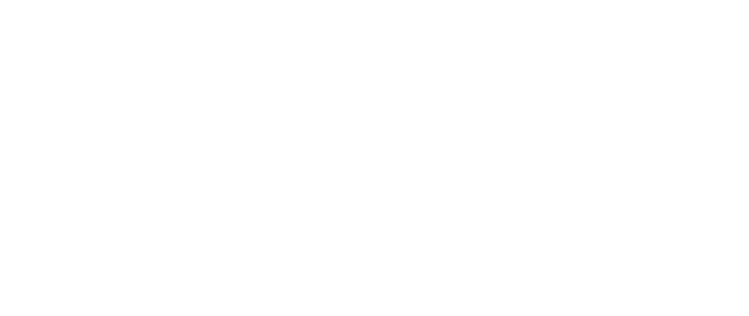


DIRTY DEVIL RIVER BASIN

09331900 QUITCHUPAH CREEK NEAR EMERY, UT

LOCATION.--Lat $38^{\circ} 51^{\prime} 33^{\prime \prime}$, long $111^{9} 5^{\prime} 41^{\prime \prime}$, in SE $\mathrm{SE}_{4}^{\frac{1}{4} \mathrm{NE}^{\frac{1}{4}}}$ sec.32, T.22 S., R.6 E., Emery County, Hydrologic Unit 14070002, on left bank $4.2 \mathrm{mi}$ upstream from mouth, at the Consol coal mine, $4 \mathrm{mi}$ south of Emery.

DRAINAGE AREA.--104 $\mathrm{mi}^{2}$.

FERIOD OF RECORD AVAII.ABLE.--JUly 1978 to September 1981

GAGE.--Water-stage recorder. Altitude of gage is 5,900 ft from topographic map.

REMARKS.-Many diversions for irrigation of hay and meadow lands above station.

EXIREMES FOR PERIOD OF RECORD.--Maximum discharge, 2,590 ft $\mathrm{ft}^{3} / \mathrm{s}$ Sept. 8, 1981, gage height, $15.72 \mathrm{ft} ; \mathrm{minimum}, 0.16 \mathrm{ft} / \mathrm{s}$ Sept. 7 , 1978.

LOWEST MEAN DISCHARGE, IN CUBIC FEET PER SECOND, AND RANKING FOR THE INDICATED NUMBER OF CONSEOUTIVE DAYS FOR EAOH OLIMATIC YEAR, APRIL 1-MARCH 31

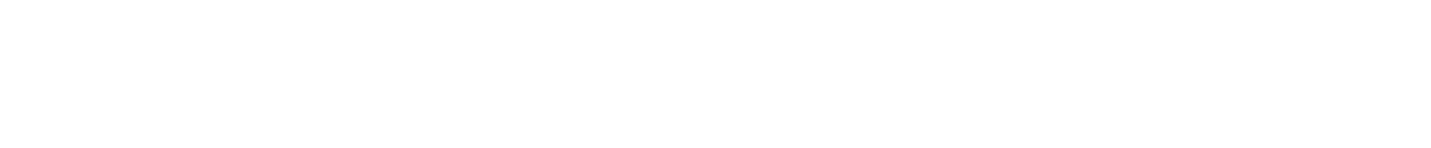

HIGHEST MEAN DISCHARGE, IN CUBIC FEET PER SECOND, AND RANKING FOR THE INDICATED NUMBER OF CONSEOUTIVE DAYS FOR EACH WATER YEAR, OCICBER 1-SEPTEMBER 30

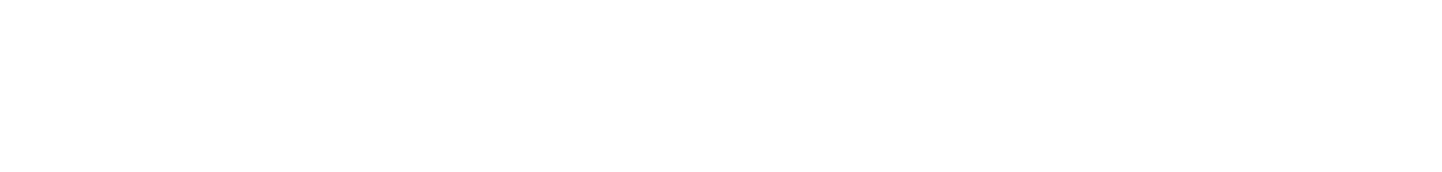

DURATION OF DISQHARGE FOR EACH WATER YEAR

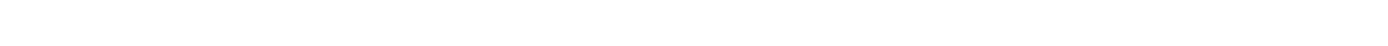

YEAR

NUMBER OF DAYS IN CAASS

CUBIC FEET -DAYS

1979

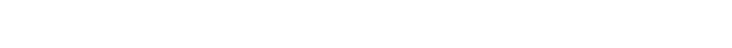

1980

$\begin{array}{llllllllllllll}3 & 3 & 5 & 8 & 16 & 39 & 30 & 58 & 94 & 50 & 23 & 17 & 12 & 1\end{array}$

DURATION TABLE OF DISCHARGE FOR WATER YEARS 1979-81

$\begin{array}{lcc}\text { ABIC } & \text { ACOU- } \\ \text { FEET } & \text { MU- } & \text { PER- } \\ \text { PER TOTAL LATED } & \text { CENT }\end{array}$

CLASS SECOND DAYS DAYS DAYS

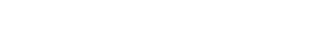

$\begin{array}{ccc}\text { CUBIC } & \text { ACO- } \\ \text { FEET } & \text { MU- } & \text { PER- } \\ \text { PER TOTAL LATED } & \text { CENT }\end{array}$

CLASS SECOND DAYS DAYS DAYS
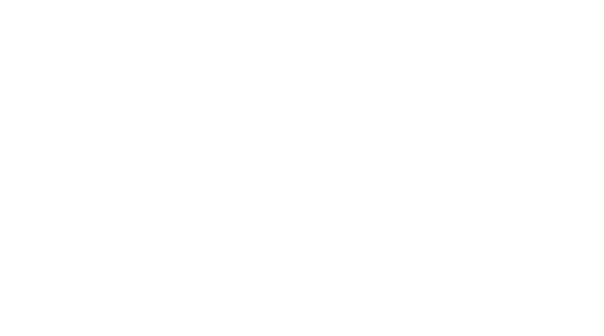

ACU-

MU- PER-

2457.4

3940.1

2831.9

MONTHLY MEAN DISCHARGES, IN CUBIC FEET PER SECOND, FOR EACH WATER YEAR

\begin{tabular}{|c|c|c|c|c|c|c|c|c|c|c|c|c|}
\hline YEAR & $\mathrm{OCr}$ & NOV & $\mathrm{DEC}$ & JAN & FEB & MAR & APR & MAY & JUNE & JULY & AUG & SEP \\
\hline $\begin{array}{l}1979 \\
1980\end{array}$ & $\begin{array}{l}1.34 \\
1.31\end{array}$ & $\begin{array}{l}4.71 \\
1.32\end{array}$ & $\begin{array}{l}3.73 \\
4.38\end{array}$ & $\begin{array}{l}6.30 \\
6.15\end{array}$ & $\begin{array}{l}6.43 \\
8.47\end{array}$ & $\begin{array}{r}9.94 \\
10.00\end{array}$ & $\begin{array}{l}12.0 \\
15.5\end{array}$ & $\begin{array}{l}18.8 \\
27.8\end{array}$ & $\begin{array}{l}9.20 \\
17.3\end{array}$ & $\begin{array}{l}3.98 \\
11.4\end{array}$ & $\begin{array}{l}2.41 \\
4.09\end{array}$ & $\begin{array}{c}1.96 \\
21.7\end{array}$ \\
\hline 1981 & 5.07 & 6.96 & 4.91 & 3.92 & 4.77 & 8.40 & 4.57 & 3.38 & 6.61 & 1.89 & 2.68 & 40.6 \\
\hline
\end{tabular}


DIRTY DEVIL RIVER BASIN

09331950 CHRISTIANSEN WASH NEAR EMERY, UT

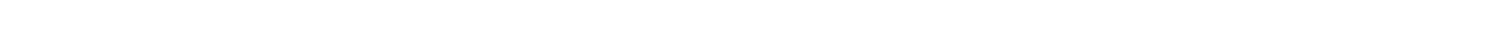
bank $0.3 \mathrm{mi}$ upstream from mouth, at the Consol coal mine, and $4.5 \mathrm{mi}$ south of Enery.

DRAINAGE AREA. $-13.6 \mathrm{mi}^{2}$.

PERIOD OF RECORD AVAIIABLE.--August 1978 to September 1981.

GAGE.--Water-stage recorder. Altitude of gage is 5,920 ft fram topographic map.

REMARKS.--Many diversions for irrigation above station.

EXTREMES FOR PERIOD OF RECORD.--Maximum discharge, 1,540 $\mathrm{ft}^{3} / \mathrm{s}$ Sept. 8,1981 , gage height, $8.83 \mathrm{ft} ;$ minimum, $0.29 \mathrm{ft} / \mathrm{s}$ July $21-23$, 1981 .

LOWEST MEAN DISCHARGE, IN OBBIC FEET PER SEOOND, AND RANKING FOR THE INDICATED NUMBER OF CONSECUTTVE DAYS FOR EACH CLIMATIC YEAR, APRIL 1-MARCH 31

\begin{tabular}{|c|c|c|c|c|c|c|c|c|c|c|c|c|c|c|c|c|c|c|c|}
\hline YEAR & 1 & & 3 & & 7 & & 14 & & $\begin{array}{l}\text { CONS1 } \\
30\end{array}$ & 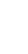 & $\begin{array}{l}\text { DAYS } \\
60\end{array}$ & & 90 & & 120 & & 183 & & AI, L \\
\hline
\end{tabular}

HIGHEST MEAN DISCHARGE, IN CUBIC FEET PER SECOND, AND RANKING FOR THE INDICATED NUMBER OF CONSECUTIVE DAYS FOR FACH WATER YEAR, OCTCBER 1-SFPTFMBER 30

\begin{tabular}{|c|c|c|c|c|c|c|c|c|c|c|c|c|c|c|c|c|c|c|c|}
\hline YEAR & 1 & & 3 & & 7 & & 15 & & $\begin{array}{l}\text { CONSE } \\
30\end{array}$ & CUT & $\begin{array}{l}\text { DAYS } \\
60\end{array}$ & & 90 & & 120 & & 183 & & ALI \\
\hline $\begin{array}{l}1979 \\
1980\end{array}$ & $\begin{array}{l}17.0 \\
41.0\end{array}$ & $\begin{array}{l}3 \\
2\end{array}$ & $\begin{array}{l}16.0 \\
26.0\end{array}$ & $\begin{array}{l}3 \\
2\end{array}$ & $\begin{array}{l}13.0 \\
20.0\end{array}$ & $\begin{array}{l}3 \\
2\end{array}$ & $\begin{array}{l}11.0 \\
13.0\end{array}$ & $\begin{array}{l}3 \\
1\end{array}$ & $\begin{array}{l}9.00 \\
9.80\end{array}$ & $\begin{array}{l}2 \\
1\end{array}$ & $\begin{array}{l}6.70 \\
8.40\end{array}$ & $\begin{array}{l}2 \\
1\end{array}$ & $\begin{array}{l}6.30 \\
8.30\end{array}$ & $\begin{array}{l}2 \\
1\end{array}$ & $\begin{array}{l}5.60 \\
7.10\end{array}$ & $\begin{array}{l}2 \\
1\end{array}$ & $\begin{array}{l}4.30 \\
5.80\end{array}$ & $\begin{array}{l}2 \\
1\end{array}$ & $\begin{array}{l}2.70 \\
3.30\end{array}$ \\
\hline 1981 & 84.0 & 1 & 42.0 & 1 & 24.0 & 1 & 12.0 & 2 & 6.60 & 3 & 3.80 & 3 & 2.90 & 3 & 2.80 & 3 & 2.30 & 3 & 2.10 \\
\hline
\end{tabular}

DURATION OF DISCHARGE FOR EACH WATER YEAR

$\begin{array}{llllllllllllllllllllllllllllllllllllll}\text { CLASS } & 0 & 1 & 2 & 3 & 4 & 5 & 6 & 7 & 8 & 9 & 10 & 11 & 12 & 13 & 14 & 15 & 16 & 17 & 18 & 19 & 20 & 21 & 22 & 23 & 24 & 25 & 26 & 27 & 28 & 29 & 30 & 31 & 32 & 33 & 34\end{array}$

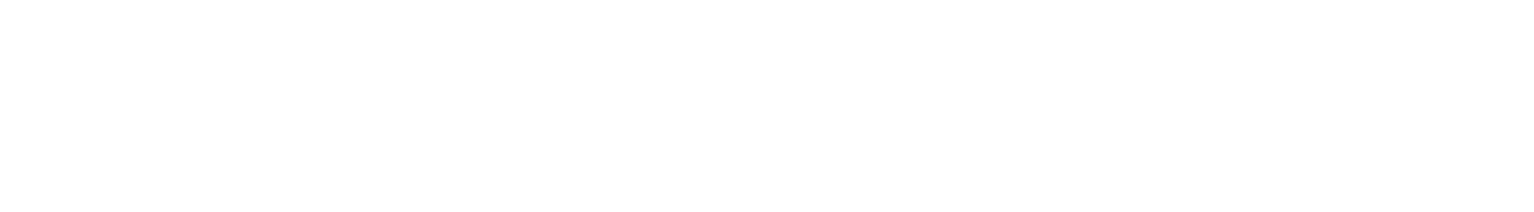

DURATION TABLE OF DISCHARGE FOR WATER YEARS 1979-81

\begin{tabular}{|c|c|c|c|c|c|c|c|c|c|c|c|c|c|c|c|c|c|c|c|}
\hline CLASS & $\begin{array}{c}\text { CUBIC } \\
\text { FEET } \\
\text { PER } \\
\text { SECOND }\end{array}$ & $\begin{array}{r}\text { TOTAL } \\
\text { DAYS }\end{array}$ & $\begin{array}{l}\text { AOCU- } \\
\text { MU- } \\
\text { LATED } \\
\text { DAYS }\end{array}$ & $\begin{array}{l}\text { PER- } \\
\text { CFNT } \\
\text { DAYS }\end{array}$ & CIASS & $\begin{array}{c}\text { CUBIC } \\
\text { FEET } \\
\text { PER } \\
\text { SECOND }\end{array}$ & $\begin{array}{c}\text { TOTAL } \\
\text { DAYS }\end{array}$ & $\begin{array}{c}\text { ACCU- } \\
\text { MU- } \\
\text { LATED } \\
\text { DAYS }\end{array}$ & $\begin{array}{l}\text { PER- } \\
\text { CENT } \\
\text { DAYS }\end{array}$ & CLASS & $\begin{array}{c}\text { वBIC } \\
\text { FEET } \\
\text { PER } \\
\text { SECOND }\end{array}$ & $\begin{array}{r}\text { TOTAL } \\
\text { DAYS }\end{array}$ & $\begin{array}{c}\text { ACCU- } \\
\text { M- } \\
\text { LATED } \\
\text { DAYS }\end{array}$ & $\begin{array}{l}\text { PER- } \\
\text { CENT } \\
\text { DAYS }\end{array}$ & CIASS & $\begin{array}{c}\text { CUBIC } \\
\text { FEET } \\
\text { PER } \\
\text { SECOND }\end{array}$ & $\begin{array}{c}\text { TOTAL } \\
\text { DAYS }\end{array}$ & $\begin{array}{c}\text { ACOU- } \\
\text { MU- } \\
\text { LATED } \\
\text { DAYS }\end{array}$ & $\begin{array}{l}\text { PER- } \\
\text { CENT } \\
\text { DAYS }\end{array}$ \\
\hline $\begin{array}{l}0 \\
1 \\
2 \\
3 \\
4 \\
5 \\
6 \\
7 \\
8\end{array}$ & $\begin{array}{l}0.00 \\
0.29 \\
0.34 \\
0.39 \\
0.46 \\
0.53 \\
0.61 \\
0.71 \\
0.83\end{array}$ & $\begin{array}{r}0 \\
4 \\
6 \\
22 \\
56 \\
65 \\
106 \\
121 \\
66\end{array}$ & $\begin{array}{r}1096 \\
1096 \\
1092 \\
1086 \\
1064 \\
1008 \\
343 \\
837 \\
716\end{array}$ & $\begin{array}{r}100.0 \\
100.0 \\
99.6 \\
99.1 \\
97.1 \\
92.0 \\
86.0 \\
76.4 \\
65.3\end{array}$ & $\begin{array}{r}9 \\
10 \\
11 \\
12 \\
13 \\
14 \\
15 \\
16 \\
17\end{array}$ & $\begin{array}{l}0.96 \\
1.10 \\
1.30 \\
1.50 \\
1.80 \\
2.00 \\
2.40 \\
2.80 \\
3.20\end{array}$ & $\begin{array}{l}44 \\
80 \\
81 \\
69 \\
31 \\
31 \\
29 \\
27 \\
43\end{array}$ & $\begin{array}{l}650 \\
606 \\
526 \\
445 \\
376 \\
345 \\
314 \\
285 \\
258\end{array}$ & $\begin{array}{l}59.3 \\
55.3 \\
48.0 \\
40.6 \\
34.3 \\
31.5 \\
28.6 \\
26.0 \\
23.5\end{array}$ & $\begin{array}{l}18 \\
19 \\
20 \\
21 \\
22 \\
23 \\
24 \\
25 \\
26\end{array}$ & $\begin{array}{r}3.7 \\
4.3 \\
5.0 \\
5.8 \\
6.8 \\
7.9 \\
9.1 \\
11.0 \\
12.0\end{array}$ & $\begin{array}{r}31 \\
26 \\
23 \\
29 \\
18 \\
29 \\
19 \\
3 \\
8\end{array}$ & $\begin{array}{r}215 \\
184 \\
158 \\
135 \\
106 \\
88 \\
59 \\
40 \\
37\end{array}$ & $\begin{array}{r}19.6 \\
16.8 \\
14.4 \\
12.3 \\
9.7 \\
8.0 \\
5.4 \\
3.6 \\
3.4\end{array}$ & $\begin{array}{l}27 \\
28 \\
29 \\
30 \\
31 \\
32 \\
33 \\
34\end{array}$ & $\begin{array}{l}14.0 \\
17.0 \\
19.0 \\
23.0 \\
26.0 \\
30.0 \\
35.0 \\
41.0\end{array}$ & $\begin{array}{r}15 \\
3 \\
3 \\
1 \\
1 \\
4 \\
0 \\
2\end{array}$ & $\begin{array}{r}29 \\
14 \\
11 \\
8 \\
7 \\
6 \\
2 \\
2\end{array}$ & $\begin{array}{l}2.6 \\
1.3 \\
1.0 \\
0.7 \\
0.6 \\
0.5 \\
0.2 \\
0.2\end{array}$ \\
\hline
\end{tabular}

MONTHLY MEAN DISCHARGES, IN CUBIC FEET PER SEOOND, FOR EACH WATER YEAR

$\begin{array}{lllllllllllll}\text { YEAR } & \text { OCT } & \text { NOV } & \text { DEC } & \text { JAN } & \text { FEB } & \text { MAR } & \text { APR } & \text { MAY } & \text { JUNE } & \text { JULY } & \text { AUG } & \text { SEP } \\ 1979 & 0.73 & 1.88 & 0.84 & 0.61 & 0.81 & 2.87 & 7.17 & 5.96 & 5.32 & 3.23 & 1.53 & 0.91 \\ 1980 & 0.82 & 0.69 & 0.76 & 0.72 & 0.98 & 1.12 & 4.49 & 7.36 & 6.28 & 9.25 & 1.92 & 5.45 \\ 1981 & 5.35 & 2.11 & 0.88 & 0.57 & 0.99 & 1.63 & 1.51 & 1.38 & 3.05 & 0.46 & 0.52 & 6.62\end{array}$


DIRTY DEVIL RIVER BASIN

09332100 MUDDY CREEK BELWW INTERSTATE HIGHWAY I-70, NEAR EMERY, UT

LOCATION.--Lat $38^{\circ} .48^{\prime} 44^{\prime \prime}$, long $111^{\circ} 11^{\prime} 53^{\prime \prime}$, in $\mathrm{SW}^{\frac{1}{4}} \mathrm{NE}^{\frac{1}{4}} \mathrm{SW}^{\frac{1}{4}} \mathrm{sec} .13, \mathrm{~T} .23 \mathrm{~S}$, R.6 E., Emery County, Hydrologic Unit 14070002 , on left bank $0.1 \mathrm{mi}$ downstream from bridge on Interstate Highway I-70, $0.2 \mathrm{mi}$ downstream from Ivie Creek, and $12.2 \mathrm{mi}$ southeast of Emery.

DRAINAGE AREA. $-418 \mathrm{mi}^{2}$.

PERIOD OF RECORD AVAILABLE.--OCtober 1973 to September 1981.

REVISED REOORDS.--WDR UT-76-1: $1974(\mathrm{M}), 1975$.

GAGE.--Water-stage recorder. Altitude of gage is 5,630 ft from topographic map.

REMARKS.--Some diversions for irrigation above station.

AVERAGE DISCHARGE. --8 years, $17.9 \mathrm{ft}^{3} / \mathrm{s}, 13,000$ acre- $\mathrm{ft} / \mathrm{yr}$.

EXIREMES FOR PERIOD OF REOORD.--Maximum discharge, 9,400 ft ${ }^{3} / \mathrm{s}$ Sept. 5, 1981, gage height, $11.25 \mathrm{ft}$ from floodmark, from slope-area measurement of peak flow; no flow several days in 1977.

LOWEST MEAN DISCHARGE, IN CUBIC FEET PER SECOND, AND RANKING FOR THE INDICATED NUMBER OF CONSECUTIVE DAYS FOR EACH CLIMATIC YEAR, APRIL I-MARCH 31

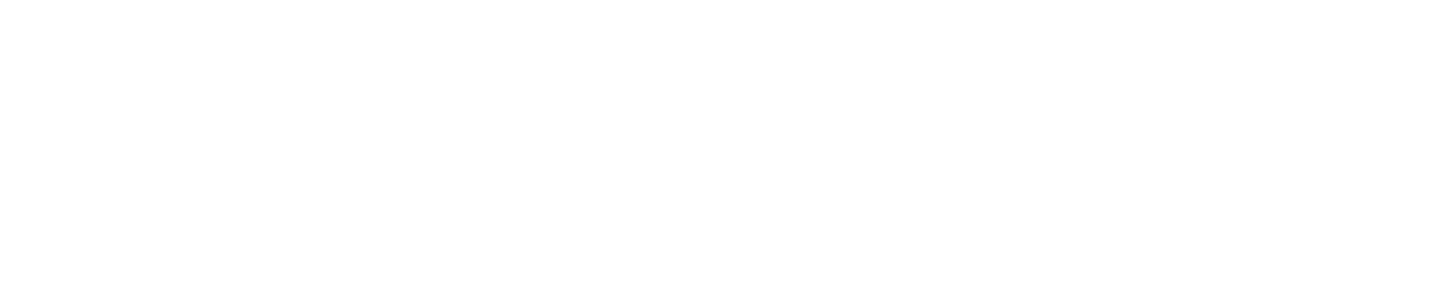

HIGHEST MEAN DISCHARGE, IN CUBIC FEET PER SECOND, AND RANKING FOR THE INDICATED NUMBER OF CONSECUTIVE DAYS FOR FACH WATER YEAR, $O$ CTOBER I-SEPTEMBER 30

\begin{tabular}{|c|c|c|c|c|c|c|c|c|c|c|c|c|c|c|c|c|c|c|c|}
\hline YEAR & & & & & & & & & CONS & 2 & VE DAYS & & & & & & & & \\
\hline $\begin{array}{l}1974 \\
1975\end{array}$ & $\begin{array}{l}176 \\
250\end{array}$ & 4 & $\begin{array}{l}148 \\
179\end{array}$ & $\begin{array}{l}5 \\
4\end{array}$ & $\begin{array}{l}109 \\
146\end{array}$ & 5 & $\begin{array}{l}69.0 \\
123\end{array}$ & $\begin{array}{l}6 \\
3\end{array}$ & $\begin{array}{l}47.0 \\
111\end{array}$ & 5 & $\begin{array}{l}33.0 \\
91.0\end{array}$ & $\begin{array}{l}5 \\
3\end{array}$ & $\begin{array}{l}27.0 \\
75.0\end{array}$ & 3 & $\begin{array}{l}25.0 \\
61.0\end{array}$ & $\begin{array}{l}5 \\
2\end{array}$ & $\begin{array}{l}21.0 \\
48.0\end{array}$ & 5 & $\begin{array}{l}14.0 \\
28.0\end{array}$ \\
\hline $\begin{array}{l}1976 \\
1977 \\
1978 \\
1979 \\
1980\end{array}$ & $\begin{array}{l}66.0 \\
62.0 \\
150 \\
298 \\
324\end{array}$ & $\begin{array}{l}7 \\
8 \\
6 \\
3 \\
2\end{array}$ & $\begin{array}{l}42.0 \\
49.0 \\
95.0 \\
245 \\
310\end{array}$ & $\begin{array}{l}8 \\
7 \\
6 \\
2 \\
1\end{array}$ & $\begin{array}{r}25.0 \\
27.0 \\
94.0 \\
239 \\
265\end{array}$ & $\begin{array}{l}8 \\
7 \\
6 \\
2 \\
1\end{array}$ & $\begin{array}{l}20.0 \\
16.0 \\
83.0 \\
200 \\
214\end{array}$ & $\begin{array}{l}7 \\
8 \\
4 \\
2 \\
1\end{array}$ & $\begin{array}{l}14.0 \\
12.0 \\
65.0 \\
145 \\
180\end{array}$ & $\begin{array}{l}7 \\
8 \\
4 \\
2\end{array}$ & $\begin{array}{c}13.0 \\
8.50 \\
48.0 \\
101 \\
166\end{array}$ & $\begin{array}{l}7 \\
8 \\
4 \\
2 \\
1\end{array}$ & $\begin{array}{c}12.0 \\
6.50 \\
39.0 \\
76.0 \\
134\end{array}$ & $\begin{array}{l}7 \\
8 \\
4\end{array}$ & $\begin{array}{c}11.0 \\
5.30 \\
33.0 \\
61.0 \\
104\end{array}$ & $\begin{array}{l}7 \\
8 \\
4 \\
3 \\
1\end{array}$ & $\begin{array}{c}11.0 \\
4.50 \\
24.0 \\
44.0 \\
75.0\end{array}$ & $\begin{array}{l}7 \\
8 \\
4 \\
3 \\
1\end{array}$ & $\begin{array}{r}7.30 \\
3.80 \\
14.0 \\
23.0 \\
42.0\end{array}$ \\
\hline 1981 & 400 & 1 & 237 & 3 & 149 & 3 & 79.0 & 5 & 45.0 & 6 & 25.0 & 6 & 19.0 & 6 & 15.0 & 6 & 13.0 & 6 & 11.0 \\
\hline
\end{tabular}

DURATION OF DISCHARGE FOR EACH WATER YEAR

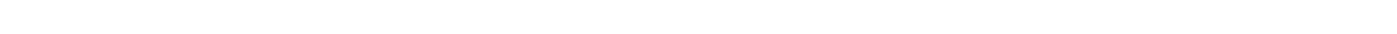
YEAR

NUMBER OF DAYS IN CLASS 
DIRTY DEVII RIVER BASIN

09332100 MUDDY CREEK BELCW INTERSTATE HIGHWAY I-70, NEAR EMERY, UT-Continued

DURATION TABLE OF DISCHARGE FOR WATER YEARS 1974-81

\begin{tabular}{|c|c|c|c|c|c|c|c|c|c|c|c|c|c|c|c|c|c|c|c|}
\hline CLASS & $\begin{array}{c}\text { CUBIC } \\
\text { FEET } \\
\text { PER } \\
\text { SECOND }\end{array}$ & $\begin{array}{r}\text { TOTAL } \\
\text { DAYS }\end{array}$ & $\begin{array}{c}\text { ACOU- } \\
\text { MU- } \\
\text { LATED } \\
\text { DAYS }\end{array}$ & $\begin{array}{l}\text { PER- } \\
\text { CENT } \\
\text { DAYS }\end{array}$ & & $\begin{array}{c}\text { CUBIC } \\
\text { FEET } \\
\text { PER } \\
\text { SECOND }\end{array}$ & $\begin{array}{l}\text { TOTAL } \\
\text { DAYS }\end{array}$ & $\begin{array}{c}\text { ACOU- } \\
\text { MU- } \\
\text { LATED } \\
\text { DAYS }\end{array}$ & $\begin{array}{l}\text { PER- } \\
\text { CENT } \\
\text { DAYS }\end{array}$ & & $\begin{array}{c}\text { CUBIC } \\
\text { FEET } \\
\text { PER } \\
\text { SECOND }\end{array}$ & $\begin{array}{r}\text { TOTAL } \\
\text { DAYS }\end{array}$ & $\begin{array}{l}\text { ACOU- } \\
\mathbf{M}- \\
\text { LATED } \\
\text { DAYS }\end{array}$ & $\begin{array}{l}\text { PER- } \\
\text { CENT } \\
\text { DAYS }\end{array}$ & & $\begin{array}{c}\text { CUBIC } \\
\text { FEET } \\
\text { PER } \\
\text { SECOND }\end{array}$ & $\begin{array}{r}\text { TOTAL } \\
\text { DAYS }\end{array}$ & $\begin{array}{l}\text { ACOH- } \\
\text { MU- } \\
\text { LATED } \\
\text { DAYS }\end{array}$ & $\begin{array}{l}\text { PER- } \\
\text { CENI } \\
\text { DAYS }\end{array}$ \\
\hline $\begin{array}{l}0 \\
1 \\
2 \\
3 \\
4 \\
5 \\
6 \\
7 \\
8\end{array}$ & $\begin{array}{l}0.00 \\
0.01 \\
0.02 \\
0.03 \\
0.04 \\
0.05 \\
0.07 \\
0.09 \\
0.12\end{array}$ & $\begin{array}{r}22 \\
2 \\
0 \\
2 \\
0 \\
17 \\
2 \\
18 \\
6\end{array}$ & $\begin{array}{l}2922 \\
2900 \\
2898 \\
2898 \\
2896 \\
2896 \\
2879 \\
2877 \\
2859\end{array}$ & $\begin{array}{r}100.0 \\
99.2 \\
99.2 \\
99.2 \\
99.1 \\
99.1 \\
98.5 \\
98.5 \\
97.8\end{array}$ & $\begin{array}{l}9 \\
10 \\
11 \\
12 \\
13 \\
14 \\
15 \\
16 \\
17\end{array}$ & $\begin{array}{l}0.17 \\
0.23 \\
0.32 \\
0.44 \\
0.60 \\
0.82 \\
1.10 \\
1.50 \\
2.10\end{array}$ & $\begin{array}{r}8 \\
11 \\
6 \\
12 \\
25 \\
85 \\
87 \\
179 \\
199\end{array}$ & $\begin{array}{l}2853 \\
2845 \\
2834 \\
2828 \\
2816 \\
2791 \\
2706 \\
2619 \\
2440\end{array}$ & $\begin{array}{l}97.6 \\
97.4 \\
97.0 \\
96.8 \\
96.4 \\
95.5 \\
92.6 \\
89.6 \\
83.5\end{array}$ & $\begin{array}{l}18 \\
19 \\
20 \\
21 \\
22 \\
23 \\
24 \\
25 \\
26\end{array}$ & $\begin{array}{r}2.9 \\
4.0 \\
5.4 \\
7.4 \\
10.0 \\
14.0 \\
19.0 \\
26.0 \\
36.0\end{array}$ & $\begin{array}{r}299 \\
231 \\
272 \\
189 \\
455 \\
294 \\
111 \\
72 \\
57\end{array}$ & $\begin{array}{r}2241 \\
1942 \\
1711 \\
1439 \\
1250 \\
795 \\
501 \\
390 \\
318\end{array}$ & $\begin{array}{l}76.7 \\
66.5 \\
58.6 \\
49.2 \\
42.8 \\
27.2 \\
17.1 \\
13.3 \\
10.9\end{array}$ & $\begin{array}{l}27 \\
28 \\
29 \\
30 \\
31 \\
32 \\
33 \\
34\end{array}$ & $\begin{array}{r}49.0 \\
67.0 \\
92.0 \\
130.0 \\
170.0 \\
240.0 \\
320.0\end{array}$ & $\begin{array}{r}71 \\
61 \\
57 \\
29 \\
30 \\
10 \\
3\end{array}$ & $\begin{array}{r}261 \\
190 \\
129 \\
72 \\
43 \\
13 \\
3\end{array}$ & $\begin{array}{l}8.9 \\
6.5 \\
4.4 \\
2.5 \\
1.5 \\
0.4 \\
0.1\end{array}$ \\
\hline
\end{tabular}

MONIHLY MEAN DISCHARGES, IN OUBIC FEET PER SECOND, FOR EACH WATER YEAR

$\begin{array}{lcccccccccccc}\text { YEAR } & \text { OCT } & \text { NOV } & \text { DEC } & \text { JAN } & \text { FEB } & \text { MAR } & \text { APR } & \text { MAY } & \text { JUNE } & \text { JULY } & \text { AUG } & \text { SEP } \\ 1974 & 5.34 & 8.09 & 11.0 & 10.5 & 13.3 & 19.1 & 14.8 & 44.4 & 16.5 & 16.4 & 2.99 & 3.10 \\ 1975 & 5.85 & 12.2 & 10.2 & 10.7 & 14.2 & 33.6 & 23.8 & 63.5 & 104 & 48.6 & 4.40 & 3.95 \\ & & & & & & & & & & & & \\ 1976 & 5.01 & 9.26 & 14.3 & 11.0 & 10.1 & 8.55 & 6.61 & 12.6 & 2.74 & 3.56 & 1.17 & 2.35 \\ 1977 & 1.40 & 2.30 & 3.15 & 3.50 & 6.41 & 4.34 & 2.55 & 2.55 & 1.64 & 6.36 & 8.22 & 3.66 \\ 1978 & 1.55 & 1.55 & 6.91 & 7.00 & 7.43 & 15.6 & 16.8 & 32.2 & 64.6 & 8.32 & 1.23 & 2.07 \\ 1979 & 2.05 & 2.95 & 3.22 & 5.83 & 12.5 & 17.6 & 29.5 & 142 & 50.6 & 6.86 & 2.91 & 1.64 \\ 1980 & 1.81 & 3.07 & 3.53 & 13.4 & 20.4 & 15.8 & 46.9 & 164 & 161 & 37.4 & 6.41 & 28.0 \\ 1981 & 11.1 & 14.3 & 13.0 & 10.4 & 3.02 & 10.4 & 8.65 & 4.83 & 7.57 & 4.07 & 7.56 & 41.5\end{array}$

ANNUAL PEAK DISCHARGE, IN CUBIC FEET PER SECOND, AND CORRESPONDING GAGE HEIGHT, IN FEET, FOR EACH WATER YEAR

\begin{tabular}{|c|c|c|c|c|c|c|c|c|c|c|c|}
\hline $\begin{array}{l}\text { WATERR } \\
\text { YEAR }\end{array}$ & DATE & $\begin{array}{l}\text { GAGE } \\
\text { HEIGHT }\end{array}$ & $\begin{array}{c}\text { PEAK } \\
\text { DISCHARGE }\end{array}$ & $\begin{array}{l}\text { WATERR } \\
\text { YEAR }\end{array}$ & DATE & $\begin{array}{c}\text { GAGE } \\
\text { HEIGHT }\end{array}$ & $\begin{array}{c}\text { PEAK } \\
\text { DISCHARGE }\end{array}$ & $\begin{array}{l}\text { WATER } \\
\text { YEAR }\end{array}$ & DATE & $\begin{array}{l}\text { GAGE } \\
\text { HEIGHT }\end{array}$ & $\begin{array}{c}\text { PEAK } \\
\text { DISCHARGE }\end{array}$ \\
\hline $\begin{array}{l}1974 \\
1975 \\
1976\end{array}$ & $\begin{array}{l}\text { JULY } 17,1974 \\
\text { JULY } 15,1975 \\
\text { MAY } 06,1976\end{array}$ & $\begin{array}{l}7.80 \\
7.30 \\
3.80\end{array}$ & $\begin{array}{r}2070 \\
1860 \\
583\end{array}$ & $\begin{array}{l}1977 \\
1978 \\
1979\end{array}$ & $\begin{array}{lll}\text { JULY } & 19, & 1977 \\
\text { JUNE } & 11, & 1978 \\
\text { MAY } & 28, & 1979\end{array}$ & $\begin{array}{l}5.20 \\
2.75 \\
-\end{array}$ & $\begin{array}{r}1000 \\
285 \\
298\end{array}$ & $\begin{array}{l}1980 \\
1981\end{array}$ & $\begin{array}{l}\text { SEPT.09, } 1980 \\
\text { SEPT.05, } 1981\end{array}$ & $\begin{array}{r}4.58 \\
11.25\end{array}$ & $\begin{array}{r}814 \\
9400\end{array}$ \\
\hline
\end{tabular}

09332500 MUDDY CREEK BELOW IVIE CREEK, NEAR EMERY, UT

LOCATION.--Lat $38^{\circ} 46^{\prime} 00^{\prime \prime}$, long $11^{\circ} 07^{\prime} 43^{\prime \prime}$, on Township line between T.23 and 24 S., and center of R.7 E. (unsurveyed), Emery County, Hydrologic Unit 14070002 , on right bank $12.5 \mathrm{mi}$ southeast of Emery.

DRAINAGE AREA. $-440 \mathrm{mi}^{2}$, approximately.

MEAN BASIN ELEVATION.--7,580 ft.

PERICD OF RECORD AVAIIABLE.-August 1950 to September 1961, and annual peak discharge only, water years $1962-68$.

GAGE.--Crest-stage gage. Altitude of gage is $5,320 \mathrm{ft}$ by barcmeter. Prior to Dec. 2, 1954, water-stage recorder at site $600 \mathrm{ft}$ downstream at same datum and Dec. 2, 1954 to Oct. 11, 1961, water-stage recorder at present site and datum.

REMARRS.--Many diversions for irrigation above station.

AVERAGE DISCHARGE.--11 years, $15.4 \mathrm{ft}^{3} / \mathrm{s}, 11,150$ acre-ft/yr.

EXTREMES FOR FERIOD OF RECORD.--Maximum discharge, 2,890 ft $\mathrm{ft}^{3} / \mathrm{s}$ Aug. 3, 1951, gage height, $9.63 \mathrm{ft}$, from rating curve extended above $480 \mathrm{ft}^{3} / \mathrm{s}$ on basis of slope-area measurement of peak flow; no flow at times.

LOWEST MEAN DISCHARGE, IN CUBIC FEET PER SECOND, AND RANKING FOR THE INDICATED NUMBER OF CONSEOUTIVE DAYS FOR EACH CIIMATIC YEAR, APRII 1-MARCH 31

\begin{tabular}{|c|c|c|c|c|c|c|c|c|c|c|c|c|c|c|c|c|c|c|c|c|}
\hline YEAR & 1 & & 3 & & 7 & & 14 & & $\begin{array}{l}\text { CONSEC } \\
30\end{array}$ & GaTTV & $\begin{array}{l}\text { E DAYS } \\
60\end{array}$ & & 90 & & 120 & & 183 & & ALL & \\
\hline $\begin{array}{l}1952 \\
1953 \\
1954 \\
1955\end{array}$ & $\begin{array}{l}0.00 \\
3.601 \\
0.30 \\
0.00\end{array}$ & $\begin{array}{r}1 \\
10 \\
8 \\
2\end{array}$ & $\begin{array}{l}0.07 \\
4.30 \\
0.43 \\
0.00\end{array}$ & $\begin{array}{r}7 \\
10 \\
8 \\
1\end{array}$ & $\begin{array}{l}0.60 \\
5.00 \\
1.19 \\
0.00\end{array}$ & $\begin{array}{r}7 \\
10 \\
9 \\
1\end{array}$ & $\begin{array}{l}1.10 \\
9.301 \\
1.30 \\
0.00\end{array}$ & $\begin{array}{r}7 \\
10 \\
8 \\
1\end{array}$ & $\begin{array}{c}1.90 \\
10.0 \\
1.60 \\
0.43\end{array}$ & $\begin{array}{r}8 \\
10 \\
7 \\
6\end{array}$ & $\begin{array}{c}3.20 \\
12.0 \\
3.70 \\
0.88\end{array}$ & $\begin{array}{r}7 \\
10 \\
8 \\
5\end{array}$ & $\begin{array}{c}3.50 \\
12.0 \\
5.00 \\
1.00\end{array}$ & $\begin{array}{r}6 \\
10 \\
8 \\
5\end{array}$ & $\begin{array}{c}4.50 \\
12.0 \\
5.70 \\
1.30\end{array}$ & $\begin{array}{r}6 \\
10 \\
8 \\
5\end{array}$ & $\begin{array}{c}6.10 \\
13.0 \\
6.20 \\
3.30\end{array}$ & $\begin{array}{r}6 \\
10 \\
7 \\
5\end{array}$ & $\begin{array}{c}12.0 \\
63.0 \\
8.40 \\
4.60\end{array}$ & $\begin{array}{r}7 \\
10 \\
6 \\
4\end{array}$ \\
\hline $\begin{array}{l}1956 \\
1957 \\
1958 \\
1959 \\
1960\end{array}$ & $\begin{array}{l}0.00 \\
0.00 \\
0.80 \\
0.00 \\
0.00\end{array}$ & $\begin{array}{l}3 \\
4 \\
9 \\
5 \\
6\end{array}$ & $\begin{array}{l}0.00 \\
0.00 \\
0.97 \\
0.00 \\
0.00\end{array}$ & $\begin{array}{l}2 \\
3 \\
9 \\
4 \\
5\end{array}$ & $\begin{array}{l}0.00 \\
0.00 \\
1.10 \\
0.00 \\
0.00\end{array}$ & $\begin{array}{l}2 \\
3 \\
8 \\
4 \\
5\end{array}$ & $\begin{array}{l}0.00 \\
0.00 \\
1.70 \\
0.12 \\
0.00\end{array}$ & $\begin{array}{l}2 \\
3 \\
9 \\
6 \\
4\end{array}$ & $\begin{array}{l}0.00 \\
0.17 \\
4.50 \\
0.41 \\
0.05\end{array}$ & $\begin{array}{l}1 \\
4 \\
9 \\
5 \\
3\end{array}$ & $\begin{array}{l}0.12 \\
0.45 \\
4.80 \\
1.60 \\
0.09\end{array}$ & $\begin{array}{l}3 \\
4 \\
9 \\
6 \\
2\end{array}$ & $\begin{array}{l}0.39 \\
0.69 \\
5.60 \\
4.90 \\
0.28\end{array}$ & $\begin{array}{l}3 \\
4 \\
9 \\
7 \\
1\end{array}$ & $\begin{array}{l}0.51 \\
0.80 \\
6.00 \\
5.60 \\
0.64\end{array}$ & $\begin{array}{l}1 \\
3 \\
9 \\
7 \\
2\end{array}$ & $\begin{array}{l}0.70 \\
1.10 \\
6.20 \\
6.40 \\
0.64\end{array}$ & $\begin{array}{l}2 \\
3 \\
8 \\
9 \\
1\end{array}$ & $\begin{array}{c}4.00 \\
2.70 \\
22.0 \\
37.0 \\
1.80\end{array}$ & $\begin{array}{l}3 \\
2 \\
8 \\
9 \\
1\end{array}$ \\
\hline 1961 & 0.00 & 7 & 0.00 & 6 & 0.00 & 6 & 0.00 & 5 & 0.00 & 2 & 0.00 & 1 & 0.30 & 2 & 1.10 & 4 & 3.00 & 4 & 5.50 & 5 \\
\hline
\end{tabular}


DIRTY DEVIL RIVER BASIN

09332500 MUDDY CREEK BELOW IVIE CREEK, NEAR EMERY, UT--Continued

HIGHEST MEAN DISCHARGE, IN OBIC FEET PER SECOND, AND RANKING FOR THE INDICATED NUMBER OF CONSECUTIVE DAYS FOR EACH WATER YEAR, OCTOBER 1-SEPTEMBER 30

\begin{tabular}{|c|c|c|c|c|c|c|c|c|c|c|c|c|c|c|c|c|c|c|c|}
\hline YEAR & 1 & & 3 & & 7 & & 15 & & $\begin{array}{l}\text { CONSI } \\
30\end{array}$ & & $\begin{array}{l}\text { E DAYS } \\
60\end{array}$ & & 90 & & 120 & & 183 & & ALL \\
\hline $\begin{array}{l}556 \\
957 \\
958 \\
559 \\
60\end{array}$ & $\begin{array}{c}34.0 \\
230 \\
300 \\
20.0 \\
120\end{array}$ & $\begin{array}{r}10 \\
6 \\
4 \\
11 \\
8\end{array}$ & $\begin{array}{l}13.0 \\
210 \\
273 \\
15.0 \\
61.0\end{array}$ & $\begin{array}{r}11 \\
4 \\
2 \\
10 \\
9\end{array}$ & $\begin{array}{l}5.70 \\
198 \\
251 \\
14.0 \\
39.0\end{array}$ & $\begin{array}{r}11 \\
3 \\
2 \\
10 \\
9\end{array}$ & $\begin{array}{l}3.60 \\
172 \\
233 \\
13.0 \\
18.0\end{array}$ & $\begin{array}{r}11 \\
3 \\
2 \\
10 \\
9\end{array}$ & $\begin{array}{l}2.70 \\
127 \\
209 \\
11.0 \\
10.0\end{array}$ & $\begin{array}{r}11 \\
3 \\
2 \\
9 \\
10\end{array}$ & $\begin{array}{c}2.00 \\
86.0 \\
178 \\
10.0 \\
7.10\end{array}$ & $\begin{array}{r}11 \\
3 \\
2 \\
9 \\
10\end{array}$ & $\begin{array}{c}1.80 \\
63.0 \\
130 \\
9.30 \\
5.80\end{array}$ & $\begin{array}{r}11 \\
3 \\
2 \\
8 \\
10\end{array}$ & $\begin{array}{c}1.70 \\
49.0 \\
102 \\
9.00 \\
4.80\end{array}$ & $\begin{array}{r}11 \\
3 \\
2 \\
8 \\
10\end{array}$ & $\begin{array}{c}1.70 \\
35.0 \\
69.0 \\
7.60 \\
4.40\end{array}$ & $\begin{array}{r}2 \\
9 \\
10\end{array}$ & $\begin{array}{c}1.191 \\
19.0 \\
38.0 \\
4.30 \\
2.901\end{array}$ \\
\hline & 271 & 5 & 167 & 5 & 88.0 & 5 & 53.0 & 5 & 33.0 & 5 & 26.0 & 5 & 18.0 & 5 & 14.0 & 6 & 12.0 & 6 & 9.60 \\
\hline
\end{tabular}

DURATION OF DISGHARGE FOR EACH WATER YEAR

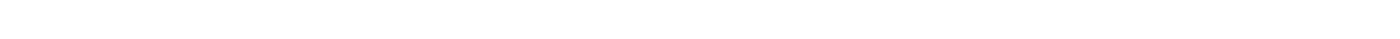

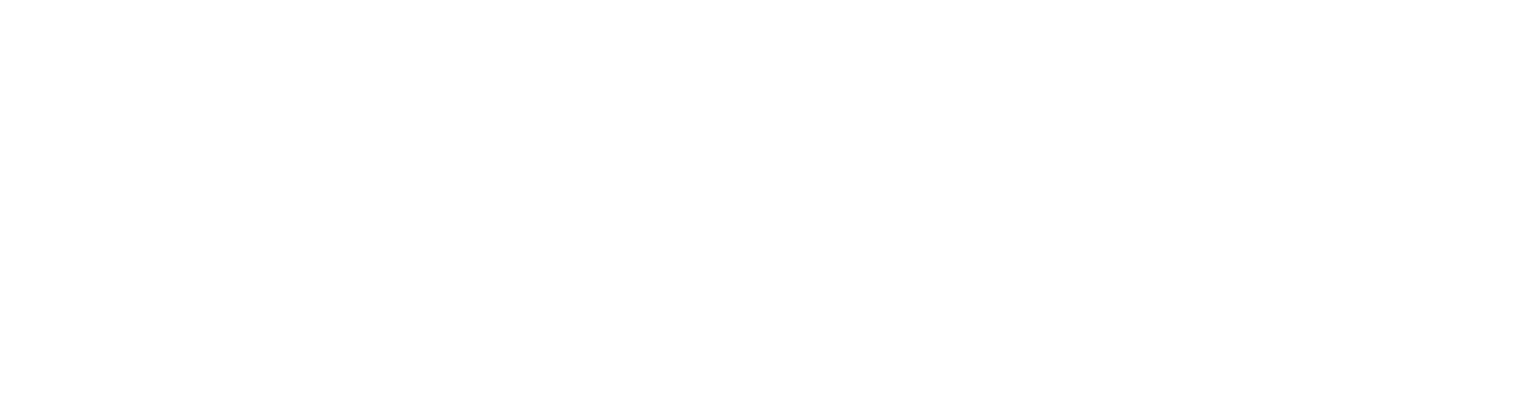

DURATION TABLE OF DISchaRGE FOR WATER YEARS 1951-61

\begin{tabular}{|c|c|c|c|c|c|c|c|c|c|c|c|c|c|c|c|c|c|c|c|}
\hline ASS & $\begin{array}{c}\text { OBIC } \\
\text { FEET } \\
\text { PER } \\
\text { SECOND }\end{array}$ & $\begin{array}{r}\text { TOTAL } \\
\text { DAYS }\end{array}$ & $\begin{array}{c}\text { ACOU- } \\
\text { MU- } \\
\text { LATED } \\
\text { DAYS }\end{array}$ & $\begin{array}{l}\text { PER- } \\
\text { CENT } \\
\text { DAYS }\end{array}$ & Q.ASS & $\begin{array}{c}\text { QUBIC } \\
\text { FEET } \\
\text { PER } \\
\text { SECOND }\end{array}$ & $\begin{array}{r}\text { TOTAL } \\
\text { DAYS }\end{array}$ & $\begin{array}{c}\text { ACQU- } \\
\text { MU- } \\
\text { LATED } \\
\text { DAYS }\end{array}$ & $\begin{array}{l}\text { PER- } \\
\text { CENT } \\
\text { DAYS }\end{array}$ & & $\begin{array}{c}\text { OBIC } \\
\text { FEET } \\
\text { PER } \\
\text { SECOND }\end{array}$ & $\begin{array}{r}\text { TOTAL } \\
\text { DAYS }\end{array}$ & $\begin{array}{c}\text { ACOJ- } \\
\text { MU- } \\
\text { LATED } \\
\text { DAYS }\end{array}$ & $\begin{array}{l}\text { PER- } \\
\text { CENT } \\
\text { DAYS }\end{array}$ & CLASS & $\begin{array}{c}\text { OBIC } \\
\text { FEET } \\
\text { PER } \\
\text { SECOND }\end{array}$ & $\begin{array}{l}\text { TOTAL } \\
\text { DAYS }\end{array}$ & $\begin{array}{l}\text { ACQI- } \\
\text { MU- } \\
\text { LATED } \\
\text { DAYS }\end{array}$ & $\begin{array}{l}\text { PER- } \\
\text { CENT } \\
\text { DAYS }\end{array}$ \\
\hline $\begin{array}{l}0 \\
1 \\
2 \\
3 \\
4 \\
5 \\
6 \\
7 \\
8\end{array}$ & $\begin{array}{l}0.00 \\
0.10 \\
0.13 \\
0.17 \\
0.22 \\
0.28 \\
0.36 \\
0.47 \\
0.61\end{array}$ & $\begin{array}{r}499 \\
75 \\
0 \\
77 \\
0 \\
25 \\
69 \\
70 \\
36\end{array}$ & $\begin{array}{l}4018 \\
3519 \\
3444 \\
3444 \\
3367 \\
3367 \\
3342 \\
3273 \\
3203\end{array}$ & $\begin{array}{r}100.0 \\
87.6 \\
85.7 \\
85.7 \\
83.8 \\
83.8 \\
83.2 \\
81.5 \\
79.7\end{array}$ & $\begin{array}{l}9 \\
10 \\
11 \\
12 \\
13 \\
14 \\
15 \\
16 \\
17\end{array}$ & $\begin{array}{l}0.79 \\
1.00 \\
1.30 \\
1.70 \\
2.20 \\
2.90 \\
3.70 \\
4.80 \\
6.20\end{array}$ & $\begin{array}{l}176 \\
208 \\
160 \\
186 \\
197 \\
296 \\
264 \\
356 \\
331\end{array}$ & $\begin{array}{l}3167 \\
2991 \\
2783 \\
2623 \\
2437 \\
2240 \\
1944 \\
1680 \\
1324\end{array}$ & $\begin{array}{l}78.8 \\
74.4 \\
69.3 \\
65.3 \\
60.7 \\
55.7 \\
48.4 \\
41.8 \\
33.0\end{array}$ & $\begin{array}{l}18 \\
19 \\
20 \\
21 \\
22 \\
23 \\
24 \\
25 \\
26\end{array}$ & $\begin{array}{r}8.1 \\
10.0 \\
14.0 \\
18.0 \\
23.0 \\
29.0 \\
38.0 \\
49.0 \\
64.0\end{array}$ & $\begin{array}{r}141 \\
256 \\
106 \\
85 \\
46 \\
50 \\
51 \\
40 \\
36\end{array}$ & $\begin{array}{l}993 \\
852 \\
596 \\
490 \\
405 \\
359 \\
309 \\
258 \\
218\end{array}$ & $\begin{array}{r}24.7 \\
21.2 \\
14.8 \\
12.2 \\
10.1 \\
8.9 \\
7.7 \\
6.4 \\
5.4\end{array}$ & $\begin{array}{l}27 \\
28 \\
29 \\
30 \\
31 \\
32 \\
33 \\
34\end{array}$ & $\begin{array}{r}82.0 \\
110.0 \\
140.0 \\
180.0 \\
230.0 \\
300.0 \\
390.0 \\
500.0\end{array}$ & $\begin{array}{r}27 \\
27 \\
38 \\
38 \\
27 \\
11 \\
12 \\
2\end{array}$ & $\begin{array}{r}182 \\
155 \\
128 \\
90 \\
52 \\
25 \\
14 \\
2\end{array}$ & \\
\hline
\end{tabular}

MONTHLY MEAN DISCHARGES, IN OUBIC FEET PER SECOND, FOR EAOH WATER YEAR

$\begin{array}{lcccccccccccc}\text { YEAR } & \text { OCT } & \text { NOV } & \text { DEC } & \text { JAN } & \text { FEB } & \text { MAR } & \text { APR } & \text { MAY } & \text { JUNE } & \text { JULY } & \text { AUG } & \text { SEP } \\ 1951 & 1.14 & 3.70 & 5.52 & 3.94 & 4.18 & 6.26 & 2.97 & 17.1 & 6.89 & 5.82 & 45.4 & 10.9 \\ 1952 & 7.91 & 3.35 & 3.48 & 3.89 & 7.45 & 32.0 & 106 & 294 & 202 & 25.1 & 24.8 & 15.6 \\ 1953 & 11.0 & 12.5 & 12.6 & 12.0 & 13.2 & 24.5 & 9.55 & 5.32 & 8.60 & 16.1 & 13.3 & 1.75 \\ 1954 & 5.87 & 8.06 & 7.65 & 7.00 & 6.91 & 9.95 & 4.49 & 1.43 & 1.10 & 2.07 & 2.35 & 20.1 \\ 1955 & 5.19 & 1.20 & 3.22 & 3.00 & 3.13 & 8.15 & 3.93 & 0.74 & 0.02 & 5.78 & 30.7 & 0.18 \\ 1956 & 0.17 & 0.85 & 0.92 & 0.90 & 1.28 & 2.61 & 1.22 & 1.66 & 0.67 & 2.45 & 0.85 & 0.32 \\ 1957 & 0.99 & 1.15 & 1.39 & 2.30 & 17.7 & 2.83 & 6.38 & 35.6 & 125 & 23.8 & 9.00 & 4.50 \\ 1958 & 5.15 & 9.82 & 5.66 & 5.00 & 12.1 & 17.5 & 98.4 & 203 & 80.2 & 2.45 & 1.44 & 17.4 \\ 1959 & 3.47 & 5.66 & 8.26 & 7.68 & 11.1 & 8.82 & 3.37 & 0.90 & 0.05 & 0.27 & 1.98 & 0.17 \\ 1960 & 0.55 & 4.84 & 0.20 & 0.10 & 0.77 & 8.45 & 5.01 & 3.73 & 1.00 & 0.00 & 0.00 & 10.3 \\ 1961 & 20.6 & 3.96 & 2.44 & 2.18 & 4.87 & 11.9 & 12.9 & 1.30 & 0.00 & 3.64 & 21.4 & 29.5\end{array}$


DIRTY DEVIL RIVER BASIN

09332500 MUDDY CREEK BELLW IVIE CREEK, NEAR EMERY, UT--Continued

ANNUAL PEAK DISCHARGE, IN CUBIC FEET PER SECOND, AND CORRESPONDING GAGE HEIGHT, IN FEET, FOR EACH WATER YEAR

\begin{tabular}{|c|c|c|c|c|c|c|c|c|c|c|c|}
\hline $\begin{array}{l}\text { WATER } \\
\text { YEAR }\end{array}$ & DATE & $\begin{array}{c}\text { GAGE } \\
\text { HEIGHT }\end{array}$ & $\begin{array}{c}\text { PEAK } \\
\text { DISCHARGE }\end{array}$ & $\begin{array}{l}\text { WATER } \\
\text { YEAR }\end{array}$ & DATE & $\begin{array}{l}\text { GAGE } \\
\text { HEIGET }\end{array}$ & $\begin{array}{c}\text { PEAK } \\
\text { DISCHARGE }\end{array}$ & $\begin{array}{l}\text { WATER } \\
\text { YEAR }\end{array}$ & DATE & $\begin{array}{c}\text { GAGE } \\
\text { HEIGHT }\end{array}$ & $\begin{array}{c}\text { PEAK } \\
\text { DISCHARGE }\end{array}$ \\
\hline $\begin{array}{l}1951 \\
1952 \\
1953 \\
1954 \\
1955 \\
1957\end{array}$ & $\begin{array}{l}\text { AUG. } 03,1951 \\
\text { AUG. } 08,1952 \\
\text { JULY } 30,1953 \\
\text { JULY } 17,1954 \\
\text { JULY } 25,1955 \\
\text { JUNE } 10,1957\end{array}$ & $\begin{array}{l}9.63 \\
7.87 \\
7.20 \\
7.20 \\
8.18 \\
5.95\end{array}$ & $\begin{array}{r}2890 \\
1660 \\
1010 \\
1180 \\
1780 \\
652\end{array}$ & $\begin{array}{l}1958 \\
1959 \\
1960 \\
1961 \\
1962 \\
1963\end{array}$ & $\begin{array}{l}\text { SEPT. 03, } 1958 \\
\text { JULY 31, } 1959 \\
\text { SEPT. 06, } 1960 \\
\text { SEPT. 08, } 1961 \\
\text { SEPT. 20, } 1962 \\
\text { AUG. 30, } 1963\end{array}$ & $\begin{array}{l}7.45 \\
4.64 \\
6.05 \\
6.80 \\
8.07 \\
8.52\end{array}$ & $\begin{array}{r}1440 \\
162 \\
885 \\
1140 \\
1820 \\
2000\end{array}$ & $\begin{array}{l}1964 \\
1965 \\
1966 \\
1967 \\
1968\end{array}$ & $\begin{array}{l}\text { MAY } 26,1964 \\
\text { JULY } 18,1965 \\
\text { AUG. } 31,1966 \\
\text { SEPT.10, } 1967 \\
\text { JULY } 28,1968\end{array}$ & $\begin{array}{l}7.48 \\
6.54 \\
6.02 \\
6.40 \\
6.19\end{array}$ & $\begin{array}{r}1340 \\
860 \\
480 \\
630 \\
720\end{array}$ \\
\hline
\end{tabular}

MAGNITUDE AND PROBABIIITY OF ANNUAL LOWEST MEAN DISCHARGE BASED ON CLIMATIC YEARS 1952-61

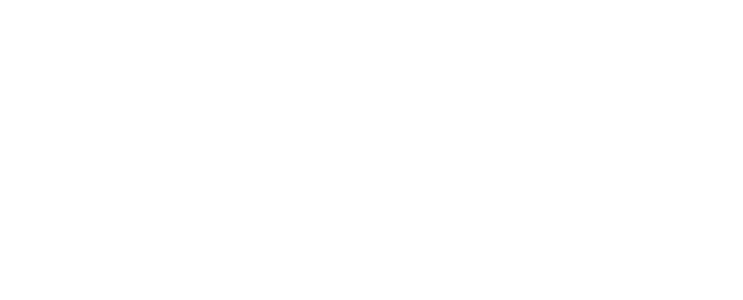

MAGNITULE AND PROBABILITY OF ANNUAL HIGHEST MEAN DISCHARGE BASED ON WATER YEARS 1951-61

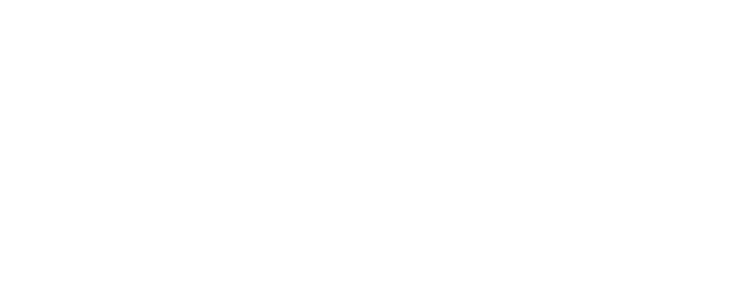

09332700 MUDDY CREEK AT DELTA MINE, NEAR HANKSVILLE, UT

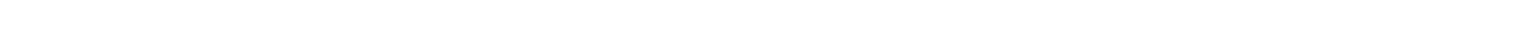
mi northwest of Hanksville and 70 mi northwest of Green River.

DRAINAGE AREA. $--841 \mathrm{mi}^{2}$.

MEAN BASIN ELEVATION. $-6,630 \mathrm{ft}$.

PERIOD OF REDORD AVAILABLE.--October 1975 to September 1981.

GAGE.--Water-stage recorder. Altitude of gage is 4,650 ft fram topographic map.

REMARKS.--Many diversions for irrigation above station.

AVERAGE DISCHARGE. --6 years, $21.9 \mathrm{ft}^{3} / \mathrm{s}, 15,870$ acre- $\mathrm{ft} / \mathrm{yr}$.

EXIREMES FOR PERIOD OF RECORD.- Maximum discharge, $6,840 \mathrm{ft}^{3} / \mathrm{s}$ Sept. 10,1980 , gage height, $9.60 \mathrm{ft}$, from rating curve extended on basis of slope-area measurement of peak flow; no flow many days in most years.

LONEST MEAN DISCHARGE, IN OUBIC FEET PER SECOND, AND RANKING FOR THE INDICATED NUMBER OF CONSECUTIVE DAYS FOR EACH CLIMATIC YEAR, APRIL 1-MARCH 31

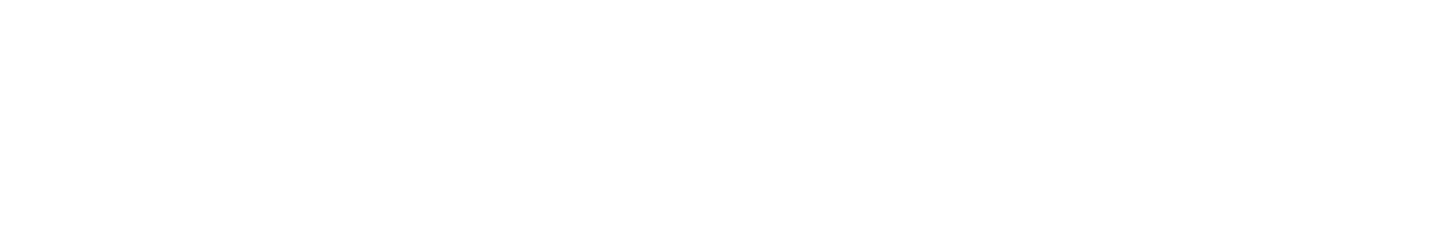

HIGHEST MEAN DISCHARGE, IN CUBIC FEET PER SECOND, AND RANKING FOR THE INDICATED NUMBER OF CONSECUTIVE DAYS FOR EACH WATER YEAR, OCTOBER 1-SEPTEMBER 30

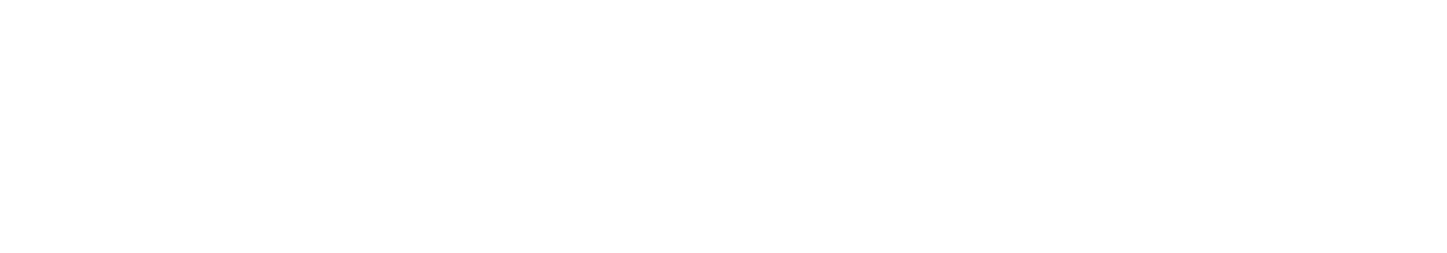


DIRTY DEVIL RIVER BASIN

09332700 MUDOY CREEX AT DELTA MINE, NEAR HANKSVILLE, UT--Continued

DURATION OF DISCHARGE FOR FACH WATER YEAR

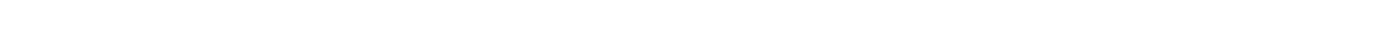
YEAR

NUMBER OF DAYS IN CLASS

CUBIC FEET PER SECOND

1976 -DAYS

\begin{tabular}{|c|c|c|c|c|c|c|c|c|c|c|c|c|c|c|c|c|c|c|c|c|c|c|c|c|c|c|c|c|c|}
\hline $\begin{array}{l}197695 \\
1977164 \\
1978 \quad 75 \\
197966 \\
1980100\end{array}$ & $\begin{array}{r}23 \\
34 \\
1\end{array}$ & 1 & $\begin{array}{l}1 \\
3\end{array}$ & $\begin{array}{l}3 \\
9 \\
6\end{array}$ & $\begin{array}{r}34 \\
9 \\
1 \\
2\end{array}$ & $\begin{array}{rr}1 & 1 \\
3 & 10 \\
5 \\
10 \\
1\end{array}$ & $\begin{array}{l}3 \\
5 \\
3 \\
3\end{array}$ & $\begin{array}{l}2 \\
9 \\
2 \\
8\end{array}$ & $\begin{array}{r}1 \\
10 \\
8 \\
17\end{array}$ & $\begin{array}{r}2 \\
8 \\
3 \\
20\end{array}$ & $\begin{array}{r}4 \\
18 \\
11 \\
35 \\
1\end{array}$ & $\begin{array}{r}4 \\
21 \\
5 \\
14 \\
1\end{array}$ & $\begin{array}{r}7 \\
16 \\
16 \\
11 \\
9\end{array}$ & $\begin{array}{r}14 \\
2 \\
7 \\
24 \\
9\end{array}$ & $\begin{array}{r}11 \\
3 \\
3 \\
11 \\
10\end{array}$ & $\begin{array}{r}53 \\
4 \\
7 \\
6 \\
8\end{array}$ & $\begin{array}{r}113 \\
3 \\
12 \\
5 \\
3\end{array}$ & $\begin{array}{r}38 \\
5 \\
28 \\
7 \\
21\end{array}$ & $\begin{array}{r}4 \\
1 \\
37 \\
18 \\
42\end{array}$ & $\begin{array}{r}2 \\
3 \\
27 \\
27 \\
30\end{array}$ & $\begin{array}{r}2 \\
3 \\
14 \\
11 \\
19\end{array}$ & $\begin{array}{r}2 \\
2 \\
18 \\
13 \\
9\end{array}$ & $\begin{array}{r}1 \\
1 \\
8 \\
23 \\
11\end{array}$ & $\begin{array}{l}2 \\
21 \\
11 \\
11\end{array}$ & $\begin{array}{c}4 \\
1 \\
9 \\
23\end{array}$ & $\begin{array}{rr}1 & \\
2 & \\
& \\
4 & 10 \\
28 & 22\end{array}$ & $\begin{array}{l}1 \\
4\end{array}$ & 1 & $\begin{array}{r}2765.3 \\
1653.7 \\
5584.9 \\
9719.4 \\
22714.2\end{array}$ \\
\hline 198115 & & & & & 2 & 2 & 4 & 7 & 1 & 3 & 10 & 24 & 35 & 24 & 43 & 53 & 28 & 46 & 31 & 17 & 3 & 3 & 4 & 2 & 2 & 21 & 2 & 1 & 5606.3 \\
\hline
\end{tabular}

DURATION TABLE OF DISCHARGE FOR WATER YEARS 1976-81

\begin{tabular}{|c|c|c|c|c|c|c|c|c|c|c|c|c|c|c|c|c|c|c|c|}
\hline CLASS & $\begin{array}{c}\text { CUBIC } \\
\text { FEET } \\
\text { PER } \\
\text { SECOND }\end{array}$ & $\begin{array}{r}\text { TOTAL } \\
\text { DAYS }\end{array}$ & $\begin{array}{l}\text { AOCU- } \\
\text { MU- } \\
\text { LATED } \\
\text { DAYS }\end{array}$ & $\begin{array}{l}\text { PER- } \\
\text { CENT } \\
\text { DAYS }\end{array}$ & CLASS & $\begin{array}{c}\text { CUBIC } \\
\text { FEET } \\
\text { PER } \\
\text { SECOND }\end{array}$ & $\begin{array}{r}\text { TOTAL } \\
\text { DAYS }\end{array}$ & $\begin{array}{c}\text { ACCU- } \\
\text { MU- } \\
\text { LATED } \\
\text { DAYS }\end{array}$ & $\begin{array}{l}\text { PER- } \\
\text { CENT } \\
\text { DAYS }\end{array}$ & CLASS & $\begin{array}{c}\text { CUBIC } \\
\text { FEET } \\
\text { PER } \\
\text { SECOND }\end{array}$ & $\begin{array}{r}\text { TOTAL } \\
\text { DAYS }\end{array}$ & $\begin{array}{c}\text { AOCU- } \\
\text { MU- } \\
\text { LATED } \\
\text { DAYS }\end{array}$ & $\begin{array}{l}\text { PER- } \\
\text { CENT } \\
\text { DAYS }\end{array}$ & CLASS & $\begin{array}{c}\text { CUBIC } \\
\text { FEET } \\
\text { PER } \\
\text { SECOND }\end{array}$ & $\begin{array}{r}\text { TOTAL } \\
\text { DAYS }\end{array}$ & $\begin{array}{c}\text { AOCU- } \\
\text { MU- } \\
\text { LATED } \\
\text { DAYS }\end{array}$ & $\begin{array}{l}\text { PER- } \\
\text { CENT } \\
\text { DAYS }\end{array}$ \\
\hline $\begin{array}{l}0 \\
1 \\
2 \\
3 \\
4 \\
5 \\
6 \\
7 \\
8\end{array}$ & $\begin{array}{l}0.00 \\
0.01 \\
0.02 \\
0.03 \\
0.04 \\
0.06 \\
0.08 \\
0.11 \\
0.16\end{array}$ & $\begin{array}{r}515 \\
58 \\
1 \\
4 \\
18 \\
0 \\
48 \\
4 \\
30\end{array}$ & $\begin{array}{l}2192 \\
1677 \\
1619 \\
1618 \\
1614 \\
1596 \\
1596 \\
1548 \\
1544\end{array}$ & $\begin{array}{r}100.0 \\
76.5 \\
73.9 \\
73.8 \\
73.6 \\
72.8 \\
72.8 \\
70.6 \\
70.4\end{array}$ & $\begin{array}{r}9 \\
10 \\
11 \\
12 \\
13 \\
14 \\
15 \\
16 \\
17\end{array}$ & $\begin{array}{l}0.22 \\
0.32 \\
0.45 \\
0.63 \\
0.90 \\
1.30 \\
1.80 \\
2.50 \\
3.60\end{array}$ & $\begin{array}{l}18 \\
28 \\
37 \\
36 \\
79 \\
69 \\
94 \\
80 \\
81\end{array}$ & $\begin{array}{l}1514 \\
1496 \\
1468 \\
1431 \\
1395 \\
1316 \\
1247 \\
1153 \\
1073\end{array}$ & $\begin{array}{l}69.1 \\
68.2 \\
67.0 \\
65.3 \\
63.6 \\
60.0 \\
56.9 \\
52.6 \\
49.0\end{array}$ & $\begin{array}{l}18 \\
19 \\
20 \\
21 \\
22 \\
23 \\
24 \\
25 \\
26\end{array}$ & $\begin{array}{r}5.0 \\
7.1 \\
10.0 \\
14.0 \\
20.0 \\
28.0 \\
40.0 \\
57.0 \\
80.0\end{array}$ & $\begin{array}{r}131 \\
164 \\
145 \\
133 \\
106 \\
52 \\
47 \\
48 \\
47\end{array}$ & $\begin{array}{l}992 \\
861 \\
697 \\
552 \\
419 \\
313 \\
261 \\
214 \\
166\end{array}$ & $\begin{array}{r}45.3 \\
39.3 \\
31.8 \\
25.2 \\
19.1 \\
14.3 \\
11.9 \\
9.8 \\
7.6\end{array}$ & $\begin{array}{l}27 \\
28 \\
29 \\
30 \\
31 \\
32 \\
33 \\
34\end{array}$ & $\begin{array}{l}110.0 \\
160.0 \\
230.0 \\
320.0 \\
450.0 \\
640.0 \\
900.0\end{array}$ & $\begin{array}{r}39 \\
37 \\
33 \\
8 \\
0 \\
0 \\
2\end{array}$ & $\begin{array}{r}119 \\
80 \\
43 \\
10 \\
2 \\
2 \\
2\end{array}$ & $\begin{array}{l}5.4 \\
3.6 \\
2.0 \\
0.5 \\
0.1 \\
0.1 \\
0.1\end{array}$ \\
\hline
\end{tabular}

MONTHLY MEAN DISCHARGES, IN CUBIC FEET PER SECOND, FOR EACH WATER YEAR

$\begin{array}{lccccccccccrr}\text { YEAR } & \text { OCT } & \text { NOV } & \text { DEC } & \text { JAN } & \text { FEB } & \text { MAR } & \text { APR } & \text { MAY } & \text { JUNE } & \text { JULY } & \text { AUG } & \text { SEP } \\ & & & & & & & & & & & & \\ 1976 & 3.85 & 7.84 & 9.00 & 9.19 & 10.5 & 7.43 & 6.35 & 32.7 & 0.37 & 1.99 & 0.95 & 0.14 \\ 1977 & 0.00 & 0.48 & 0.03 & 0.00 & 0.09 & 1.36 & 0.50 & 0.78 & 0.38 & 24.1 & 16.2 & 9.80 \\ 1978 & 3.74 & 0.03 & 0.23 & 1.88 & 22.0 & 31.8 & 20.3 & 21.9 & 66.9 & 15.3 & 0.00 & 1.02 \\ 1979 & 3.70 & 16.1 & 0.82 & 1.13 & 2.87 & 19.0 & 36.3 & 170 & 61.7 & 4.21 & 1.21 & 0.09 \\ 1980 & 0.00 & 0.01 & 0.00 & 15.2 & 81.9 & 20.7 & 85.1 & 202 & 172 & 40.4 & 5.84 & 127 \\ 1981 & 12.1 & 13.8 & 8.10 & 3.94 & 1.60 & 10.8 & 8.39 & 5.83 & 11.2 & 15.9 & 12.2 & 80.9\end{array}$

ANNUAL PEAK DISCHARGE, IN CUBIC FEET PER SBCOND, AND CORRESPONDING GAGE HEIGHT, IN FEET, FOR EACH WATER YEAR

\begin{tabular}{|c|c|c|c|c|c|c|c|c|c|c|c|}
\hline $\begin{array}{l}\text { WATER } \\
\text { YEAR }\end{array}$ & DATE & $\begin{array}{l}\text { GAGE } \\
\text { HEIGHT }\end{array}$ & $\begin{array}{c}\text { PEAK } \\
\text { DISCHARGE }\end{array}$ & $\begin{array}{l}\text { WATER } \\
\text { YEAR }\end{array}$ & DATE & $\begin{array}{l}\text { GAGE } \\
\text { HEIGHT }\end{array}$ & $\begin{array}{c}\text { PEAK } \\
\text { DISCHARGE }\end{array}$ & $\begin{array}{l}\text { WATER } \\
\text { YFAR }\end{array}$ & DATE & $\begin{array}{l}\text { GAGE } \\
\text { HEIGHT }\end{array}$ & $\begin{array}{c}\text { PEAK } \\
\text { DISCHARGE }\end{array}$ \\
\hline $\begin{array}{l}1976 \\
1977\end{array}$ & $\begin{array}{lll}\text { MAY } & 06,1976 \\
\text { JULY } & 24, & 1977\end{array}$ & $\begin{array}{l}5.30 \\
5.38\end{array}$ & $\begin{array}{l}1860 \\
1930\end{array}$ & $\begin{array}{l}1978 \\
1979\end{array}$ & $\begin{array}{ll}\text { MAR. } 03, & 1978 \\
\text { MAY } & 28,1979\end{array}$ & $\begin{array}{l}3.07 \\
5.46\end{array}$ & $\begin{array}{r}271 \\
2680\end{array}$ & $\begin{array}{l}1980 \\
1981\end{array}$ & $\begin{array}{l}\text { SEPT. } 10,1980 \\
\text { SEPT.05, } 1981\end{array}$ & $\begin{array}{l}9.60 \\
8.66\end{array}$ & $\begin{array}{l}6840 \\
5470\end{array}$ \\
\hline
\end{tabular}

09332800 MUDDY CREEK AT MOUTH, NEAR HANKSVILLE, UT

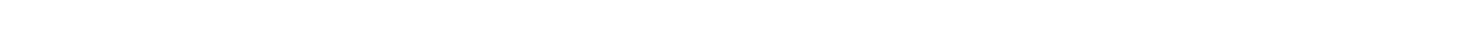
bank upstream from bridge, $0.4 \mathrm{mi}$ upstream from mouth, and $2.2 \mathrm{mi}$ nor th of Hanksville.

DRAINAGE AREA. $--1,552 \mathrm{mi}^{2}$.

PERIOD OF RECORD AVAILABLE. --October 1975 to September 1980.

REVISED RECORDS.--WDR UT-77-1: 1976.

GAGE.--Water-stage recorder. Altitude of gage is 4,250 ft from topographic map.

REMARKS.--Many diversions for irrigation above station.

AVERAGE DISCHARGE. -5 years, $29.0 \mathrm{ft}, 21,000$ acre- $\mathrm{ft} / \mathrm{yr}$.

EXXTREMES FOR PERIOD OF RECORD.--Maximum discharge, 5,000 ft ${ }^{3} / \mathrm{s} \mathrm{Sept.} \mathrm{10,} \mathrm{1980,} \mathrm{gage} \mathrm{height,} 7.70 \mathrm{ft}$ fran floodmarks; no flow many days each year. 
DIRTY DEVIL RIVER BASIN

09332800 MUDDY CREFK AT MOUTH, NEAR HANKSVILLE, UT--Continued

LOWEST MEAN DISCHARGE, IN CUBIC FEET PER SECOND, AND RANKING FOR THE INDICATED NUMBER OF CONSECUTTVE DAYS FOR EACH CLIMATIC YEAR, APRIL 1-MARCH 31

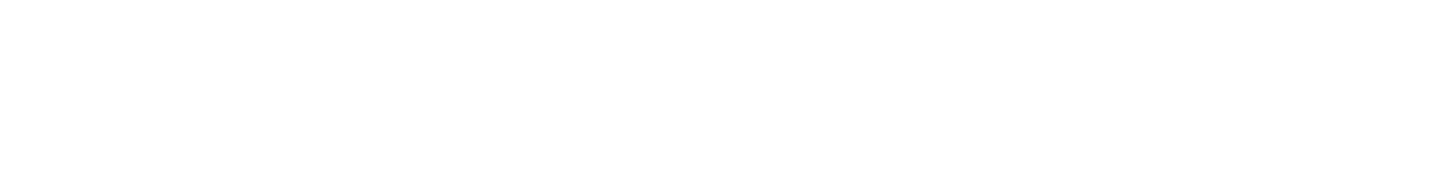

HIGHEST MEAN DISCHARGE, IN CUBIC FEET PER SECOND, AND RANKING FOR THE INDICATFD NUMBER OF CONSECUTTVE DAYS FOR EACH WATER YEAR, OCTOBER 1-SEPTEMBER 30

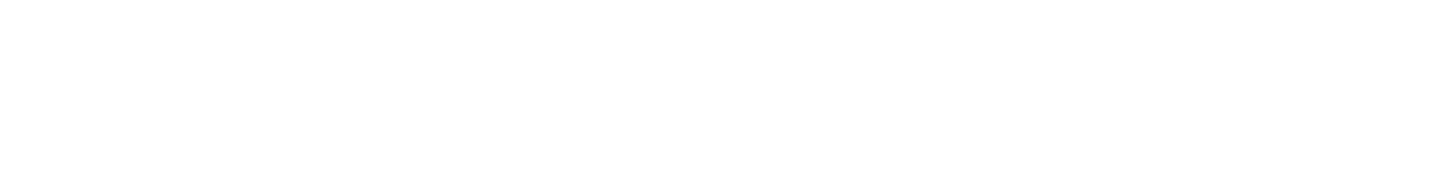

DURATION OF DISCHARGE FOR EACH WATER YEAR

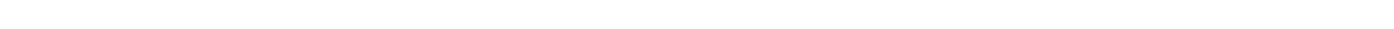
YEAR NUMBER OF DAYS IN CLASS CUBIC FEET
PER SECOND
-DAYS

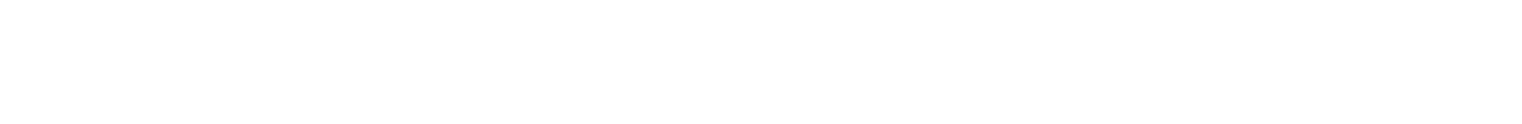

1980119

29814.9

DURATION TABLE OF DISCHARGE FOR WATER YEARS 1976-80

\begin{tabular}{|c|c|c|c|c|c|c|c|c|c|c|c|c|c|c|c|c|c|c|c|}
\hline CLASS & $\begin{array}{c}\text { CUBIC } \\
\text { FEET } \\
\text { PER } \\
\text { SECOOND }\end{array}$ & $\begin{array}{r}\text { TOTAL } \\
\text { DAYS }\end{array}$ & $\begin{array}{l}\text { ACCU- } \\
\text { MU- } \\
\text { LATED } \\
\text { DAYS }\end{array}$ & $\begin{array}{l}\text { PER- } \\
\text { CENT } \\
\text { DAYS }\end{array}$ & CLASS & $\begin{array}{c}\text { CUBIC } \\
\text { FEET } \\
\text { PER } \\
\text { SECOND }\end{array}$ & $\begin{array}{l}\text { TOTAL } \\
\text { DAYS }\end{array}$ & $\begin{array}{l}\text { AOCU- } \\
\text { MU- } \\
\text { LATED } \\
\text { DAYS }\end{array}$ & $\begin{array}{l}\text { PER- } \\
\text { CENT } \\
\text { DAYS }\end{array}$ & CLASS & $\begin{array}{c}\text { CUBIC } \\
\text { FEET } \\
\text { PER } \\
\text { SECOND }\end{array}$ & $\begin{array}{l}\text { TOTAL } \\
\text { DAYS }\end{array}$ & $\begin{array}{c}\text { ACCU- } \\
\text { MU- } \\
\text { LAIED } \\
\text { DAYS }\end{array}$ & $\begin{array}{l}\text { PER- } \\
\text { CENT } \\
\text { DAYS }\end{array}$ & CLASS & $\begin{array}{c}\text { CUBIC } \\
\text { FEET } \\
\text { PER } \\
\text { SECOND }\end{array}$ & $\begin{array}{l}\text { TOTAL } \\
\text { DAYS }\end{array}$ & $\begin{array}{l}\text { AOCU- } \\
\text { MU- } \\
\text { LATED } \\
\text { DAYS }\end{array}$ & $\begin{array}{l}\text { PER- } \\
\text { CENT } \\
\text { DAYS }\end{array}$ \\
\hline 0 & 0.00 & 694 & 1827 & 100.0 & 9 & 0.39 & 33 & 1046 & 57.3 & 18 & 7.1 & 36 & 700 & 38.3 & & 130.0 & 22 & 92 & 5.0 \\
\hline 1 & 0.03 & 13 & 1133 & 62.0 & 10 & 0.54 & 21 & 1013 & 55 & 19 & 9.7 & 5 & 664 & 36 & 28 & & 2 & 70 & 3.8 \\
\hline 2 & 0.04 & 1 & 1120 & 61.3 & 11 & 0.74 & 14 & 992 & 54.3 & 20 & 13.0 & 88 & 605 & 33.1 & 29 & 240.0 & 27 & 46 & 2.5 \\
\hline 3 & 0.06 & 19 & 1119 & 61.2 & 12 & 1.00 & 45 & 978 & 53.5 & 21 & 18.0 & 76 & 517 & 28.3 & 30 & 330.0 & 12 & 19 & 1.0 \\
\hline 4 & 0.08 & 13 & 1100 & 60.2 & 13 & 1.40 & 25 & 933 & 51. & 22 & 25 & 82 & 441 & 24 & 31 & 460.0 & 3 & 7 & 0.4 \\
\hline 5 & 0.11 & 0 & 1087 & 59.5 & 14 & 2.00 & 85 & 908 & 49.7 & 23 & 35.0 & 72 & 359 & 19. & 32 & 630.0 & 2 & 4 & 0.2 \\
\hline 6 & 0.15 & 33 & 1087 & 59.5 & 15 & 2.70 & 34 & 823 & 45.0 & 24 & 48 & 95 & 287 & 15.7 & 33 & 870.0 & 0 & 2 & 0.1 \\
\hline 7 & 0.21 & 0 & 1054 & 57.7 & 16 & 3.70 & 64 & 789 & 43.2 & 25 & & 62 & 192 & 10.5 & 34 & 1200.0 & 2 & 2 & 0.1 \\
\hline 8 & 0.28 & 8 & 1054 & 57.7 & 17 & 5.10 & 25 & 725 & 39.7 & 26 & 92. & 38 & 130 & 7.1 & & & & & \\
\hline
\end{tabular}

MONTHLY MEAN DISCHARGES, IN CUBIC FEET PER SECOND, FOR EACH WATER YEAR

$\begin{array}{llccccccccccc}\text { YEAR } & \text { OCT } & \text { NOV } & \text { DEC } & \text { JAN } & \text { FEB } & \text { MAR } & \text { APR } & \text { MAY } & \text { JUNE } & \text { JULY } & \text { AUG } & \text { SEP } \\ 1976 & 1.55 & 2.67 & 4.10 & 9.03 & 15.1 & 11.4 & 14.1 & 37.7 & 0.85 & 0.42 & 0.61 & 0.58 \\ 1977 & 0.00 & 0.46 & 0.01 & 0.02 & 0.02 & 1.46 & 0.70 & 0.91 & 0.26 & 20.5 & 11.4 & 9.97 \\ 1978 & 2.40 & 0.00 & 0.29 & 2.06 & 36.1 & 65.0 & 41.7 & 36.7 & 64.8 & 10.4 & 0.06 & 0.23 \\ 1979 & 8.16 & 72.3 & 0.13 & 0.24 & 0.16 & 76.3 & 61.5 & 93.9 & 42.5 & 2.39 & 0.45 & 0.04 \\ 1980 & 0.00 & 0.00 & 0.00 & 17.7 & 92.5 & 26.0 & 100 & 236 & 185 & 41.6 & 10.5 & 276\end{array}$

ANNUAL PEAK DISCHARGE, IN CUBIC FEET PER SBOOND, AND CORRESPONDING GAGE HEIGHT, IN FEET, FOR EACH WATER YEAR

\begin{tabular}{|c|c|c|c|c|c|c|c|c|c|c|c|c|}
\hline $\begin{array}{l}\text { WATERR } \\
\text { YEAR }\end{array}$ & & DATE & $\begin{array}{c}\text { GAGE } \\
\text { HEIGHT }\end{array}$ & $\begin{array}{c}\text { PEAK } \\
\text { DISCHARGE }\end{array}$ & $\begin{array}{l}\text { WATER } \\
\text { YEAR }\end{array}$ & DATE & $\begin{array}{c}\text { GAGE } \\
\text { HEIGHT }\end{array}$ & $\begin{array}{c}\text { PEAK } \\
\text { DISCHARGE }\end{array}$ & $\begin{array}{l}\text { WATER } \\
\text { YEAR }\end{array}$ & DATE & $\begin{array}{c}\text { GAGE } \\
\text { HEIGHT }\end{array}$ & $\begin{array}{c}\text { PEAK } \\
\text { DISCHARGE }\end{array}$ \\
\hline $\begin{array}{l}1976 \\
1977\end{array}$ & $\begin{array}{l}\text { MAY } \\
\text { JULY }\end{array}$ & $\begin{array}{r}07,1976 \\
04,1977\end{array}$ & $\begin{array}{l}7.50 \\
6.95\end{array}$ & $\begin{array}{l}2990 \\
2500\end{array}$ & $\begin{array}{l}1978 \\
1979\end{array}$ & $\begin{array}{l}\text { AUG. } 13,1978 \\
\text { MAR. } 30,1979\end{array}$ & $\begin{array}{l}5.14 \\
8.24\end{array}$ & $\begin{array}{r}904 \\
3380\end{array}$ & 1980 & SEPT.10, 1980 & 7.70 & 5000 \\
\hline
\end{tabular}


LOCATION.--Lat $38^{\circ} 24^{\prime} 00^{\prime \prime}$, long $110^{\circ} 41^{\prime} 00^{\prime \prime}$, in SE $\frac{1}{4}$ sec.3, T.28 S., R.11 E., Garfield County, Hydrologic Unit 14070004, 0.25 mi downstream fram confluence of Fremont River and Muddy Creek and 2 mi nor theast of Hanksville.

DRAINAGE AREA. $-3 ; 490 \mathrm{mi}^{2}$, approximately.

PERIOD OF RECORD AVAILABLE.-December 1945 to June 1948.

GAGE.-Water-stage recorder.

REMARKS.-Diversions for irrigation of about 22,000 acres above station.

EXIREMES FOR PERIOD OF RECORD. - Maximum daily discharge, 5,000 ft ${ }^{3} / \mathrm{s}$ Aug. 22, 1947; minimum daily, $1 \mathrm{ft} / \mathrm{s}$ several days in 1947.

LOWEST MEAN DISCHARGE, IN CUBIC FEET PER SECOND, AND RANKING FOR THE INDICATED NUMBER OF CONSBCUTTVE DAYS FOR EACH CLIMATIC YEAR, APRIL I-MARCH 31

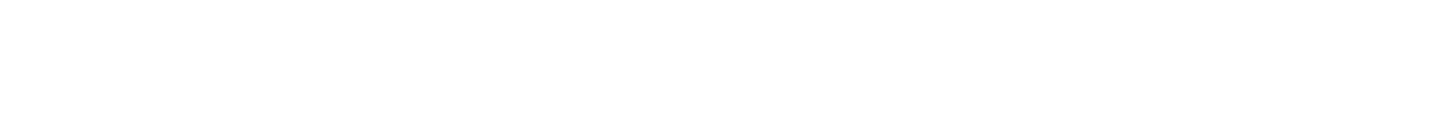

HIGHEST MEAN DISCHARGE, IN COBIC FEET PER SECOND, AND RANKING FOR THE INDICATED NUMBER OF CONSECUTTVE DAYS FOR EACH WATER YEAR, OCTOBER I-SEPTEMBER 30

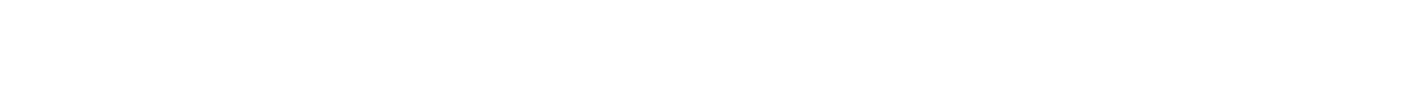

DURATION OF DISCHARGE FOR EACH WATER YEAR

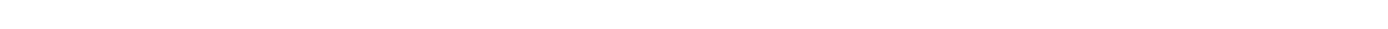
YEAR NUMBER OF DAYS IN CLASS

DURATION TABLE OF DISCHARGE FOR WATER YEAR 1947

$\begin{array}{lrr}\text { CUBIC } & \text { AOCU- } \\ \text { FEET } & \text { MU- } & \text { PER- } \\ \text { PER TOTAL LATED } & \text { CENT } \\ \text { SECOND DAYS } & \text { DAYS } & \text { DAYS }\end{array}$
CLASS SECOND DAYS DAYS DAYS

$\begin{array}{llllr}0 & 0.00 & 0 & 365 & 100.0 \\ 1 & 1.00 & 3 & 365 & 100.0 \\ 2 & 1.30 & 0 & 362 & 99.2 \\ 3 & 1.60 & 0 & 362 & 99.2 \\ 4 & 1.90 & 4 & 362 & 99.2 \\ 5 & 2.40 & 0 & 358 & 98.1 \\ 6 & 3.00 & 1 & 358 & 98.1 \\ 7 & 3.80 & 2 & 357 & 97.8 \\ 8 & 4.70 & 0 & 355 & 97.3\end{array}$

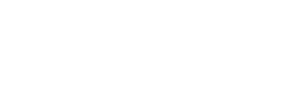
CLASS SECOND DAYS DAYS DAYS

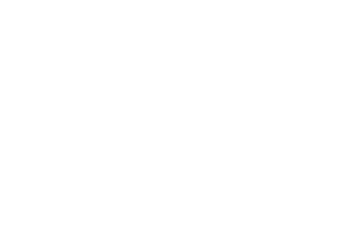

MONTHLY MEAN DISCHARGES, IN CUBIC FEET PER SECOND, FOR FACH WATER YEAR

$\begin{array}{ccccccccccccc}\text { YEAR } & \text { OCT } & \text { NOV } & \text { DEC } & \text { JAN } & \text { FEB } & \text { MAR } & \text { APR } & \text { MAY } & \text { JUNE } & \text { JULY } & \text { AUG } & \text { SEP } \\ 1947 & 79.9 & 140 & 107 & 73.9 & 148 & 117 & 65.6 & 73.6 & 136 & 21.2 & 351 & 63.3\end{array}$


DIRTY DEVIL RIVER BASIN

09333500 DIRTY DEVIL RIVER ABOVE POISON SPRING WASH, NEAR HANKSVILLE, UT

LOCATION.--Lat $38^{\circ} 05^{\prime} 50^{\prime \prime}$, long $110^{\circ} 24^{\prime} 27^{\prime \prime}$, in $\mathrm{NE}_{4}^{\prime} \mathrm{SW}_{4}^{\frac{1}{4} \mathrm{SE}_{4}^{\mathrm{u}}} \mathrm{sec} .20, \mathrm{~T} .31$ S., R.14 E., Garf ield County, Hydrologic Unit 14070004 , on right bank $0.25 \mathrm{mi}$ upstream from Poison Spring Wash and $25.5 \mathrm{mi}$ southeast of hanksville.

DRAINAGE AREA. $-4,159 \mathrm{mi}^{2}$.

MEAN BASIN ELEVATION.--6,600 ft.

PERIOD OF RECORD AVAILABLE.--June 1948 to September 1981. Prior to October 1968, published as "near Hite."

REVISED RECORDS. -WDR UT-77-1. Drainage area. WDR UT-80-1: 1979, 1977-79(P) .

GAGE.--Water-stage recorder. Altitude of gage is 3,850 ft from topographic map. Prior to July 15, 1964, at site 28 mi downstream at different datum. July 15, 1964 to Dec. 14, 1976, approximately 1,200 ft upstream at datum 4.83 ft higher. Dec. 15 , 1976 to Sept. 30,1980 , at site $400 \mathrm{ft}$ upstream at datum $4.28 \mathrm{ft}$ higher.

REMARKS.--Many diversions for irrigation above station.

AVERAGE DISCHARGE.--33 years, $96.3 \mathrm{ft}^{3} / \mathrm{s}, 69,770$ acre- $\mathrm{ft} / \mathrm{yr}$.

EXTREMES FOR PERIOD OF RECORD.--Maximum discharge, about $35,000 \mathrm{ft}^{3} / \mathrm{s} \mathrm{Nov} .41957$, gage height, $28.1 \mathrm{ft}$ from floodmarks, site and datum then in use, from rating curve extended above $9,000 \mathrm{ft} / \mathrm{s}$ on basis of slope-area measurement at gage height $20.65 \mathrm{ft}$; no flow at times for most years.

LOWEST MEAN DISCHARGE, IN CUBIC FEET PER SECOND, AND RANKING FOR THE INDICATED NUMBER OF CONSECUTIVE DAYS FOR EACH CLIMATIC YEAR, APRIL I-MARCH 31

YEAR

1950

1951

1952

1953

1955

1956

1957

1958

1959

1960

196

1962

1963
1964

1964
1965

1966

1967

1968

1969

1970

$1973 \quad 0.0010$

197428.032

$\begin{array}{lr}1975 & 0.0011\end{array}$

$1976 \quad 7.00 \quad 27$

$1977 \quad 0.0012$

$1978 \quad 0.0013$

0.0014
0.0015

1981

0.0016

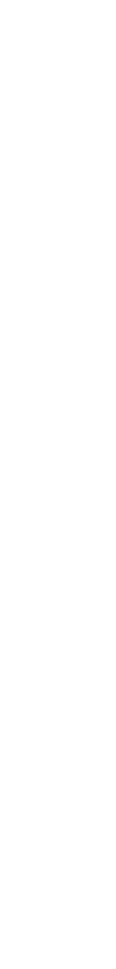

$\begin{array}{ll}14 \\ 9.50 & 25 \\ & \\ 0.20 & 21 \\ 0.15 & 20 \\ 9.70 & 26 \\ 0.13 & 19 \\ 0.07 & 12 \\ & \\ 0.05 & 11 \\ 0.10 & 17 \\ 27.0 & 29 \\ 0.12 & 18 \\ 0.08 & 13 \\ & \\ 0.00 & 1 \\ 0.10 & 14 \\ 0.10 & 15 \\ 0.10 & 16 \\ 1.00 & 24 \\ & \\ 43.0 & 32 \\ 0.00 & 2 \\ 0.99 & 23 \\ 0.02 & 10 \\ 33.0 & 31 \\ & \\ 24.0 & 28 \\ 0.00 & 3 \\ 0.00 & 4 \\ 28.0 & 30 \\ 0.00 & \\ 11.0 & 27 \\ 0.00 & 6 \\ 0.00 & 7 \\ 0.00 & 8 \\ 0.00 & 9 \\ 0.32 & 22 \\ & \end{array}$

CONSECUTIVE DAYS

CONSECUTIVE DAYS

$\begin{array}{llll}18.0 & 26 & 34.0 & 27\end{array}$

90

12

$60.0 \quad 28$

$90.0 \quad 30$

183

ALL

$0.2513 \quad 4.7016$

1.4019

1.4019

0.1510

$\begin{array}{llll}13.0 & 18 & 47.0 & 23\end{array}$

$\begin{array}{ll}47.0 & 23 \\ 30.0 & 19\end{array}$

0.2025

0.1018
0.001

0.087

$\begin{array}{lll}2.02 & 32\end{array}$

$\begin{array}{lll}4.1013 & 8.6016\end{array}$

11431

$20.0 \quad 14$

$10.0 \quad 10$

$\begin{array}{llll}0.06 & 6 & 0.16 \quad 3\end{array}$

$3.80 \quad 6$

$21.0 \quad 15$

0.4716

$\begin{array}{lll}73.0 & 32\end{array}$

2.7023

$\begin{array}{rr}4.20 & 14 \\ 0.80 & 5\end{array}$

$11.0 \quad 17$

$12.0 \quad 28$

0.3914

0.805

$\begin{array}{rr}17.0 & 19 \\ 1.90 & 5\end{array}$

$23.0 \quad 16$

$\begin{array}{llll}0.04 & 4 & 0.08 & 1 \\ 0.10 & 8 & 0.16 & 2\end{array}$

0.291

0.2011

$\begin{array}{ll}0.16 & 2 \\ 2.20 & 11\end{array}$

.

$\begin{array}{ll}2.20 & 11 \\ 1.19 & 8\end{array}$

$\begin{array}{llll}1.80 & 20 & 11.0 & 8\end{array}$

$\begin{array}{ll}5.30 & 8 \\ 1.80 & 4\end{array}$

$\begin{array}{ll}1.80 & 4 \\ 1.19 & 2\end{array}$

$22.0 \quad 20$

$7.40 \quad 5$

$56.0 \quad 32$

$71.0 \quad 30$

$81.0 \quad 30$

0.001

5.5024

$0.20 \quad 4$

6.3012

$26.0 \quad 23$

$26.0 \quad 24$

37.030

$63.0 \quad 29$

$50.0 \quad 26$

$66.0 \quad 29$

$\begin{array}{cc}28.0 & 27 \\ 0.76 & 17\end{array}$

$\begin{array}{ll}0.76 & 17 \\ 0.21 & 12\end{array}$

$31.0 \quad 26$

$\begin{array}{cccc}31.0 & 28 & 38.0 & 28 \\ 0.39 & 15 & 5.50 & 18\end{array}$

$40.0 \quad 24$

$\begin{array}{ll}5.30 & 9 \\ 4.10 & 7\end{array}$

$\begin{array}{rr}4.10 & 7 \\ 40.0 & 25\end{array}$

7.0013

0.961

$\begin{array}{cr}29.0 & 17 \\ 2.90 & 2\end{array}$

$\begin{array}{ll}2.90 & 2 \\ 4.30 & 3\end{array}$

19.013

$86.0 \quad 28$

$13.0 \quad 11$

55.026

$\begin{array}{ll}50.0 & 24 \\ 72.0 & 27\end{array}$

$42.0 \quad 21$

8.206

8.707

$\begin{array}{cr}52.0 & 25 \\ 8.90 & 8\end{array}$

$\begin{array}{llll}12.0 & 25 & 22.0 & 22\end{array}$

0.065

0.002

4.3015

$30.0 \quad 22$

5.4010
8.5015

$42.0 \quad 22$

2.3012

7.8015

$9.40 \quad 9$

$30.0 \quad 18$

$\begin{array}{llll}2.40 & 22 & 5.50 & 19\end{array}$

$\begin{array}{rrr}7.80 & 14 \\ 1.30 & 3\end{array}$

$17.0 \quad 12$

2.0021

$28.0 \quad 25$

$60.0 \quad 27$

$\begin{array}{llllll}88.0 & 29 & 96.0 & 27 & 145 & 30\end{array}$ 
DIRTY DEVIL RTVER BASIN

09333500 DIRTY DEVIL RIVER ABOVE FOISON SPRING WASH, NEAR HANKSVILIE, UT--Continued

HIGHEST MEAN DISCHARGE, IN OUBIC FEET PER SECOND, AND RANKING FOR THE INDICATED NUNBER OF CONSECUTIVE DAYS FOR EACH WATER YEAR, OCTOBER 1-SEPTEMBER 30

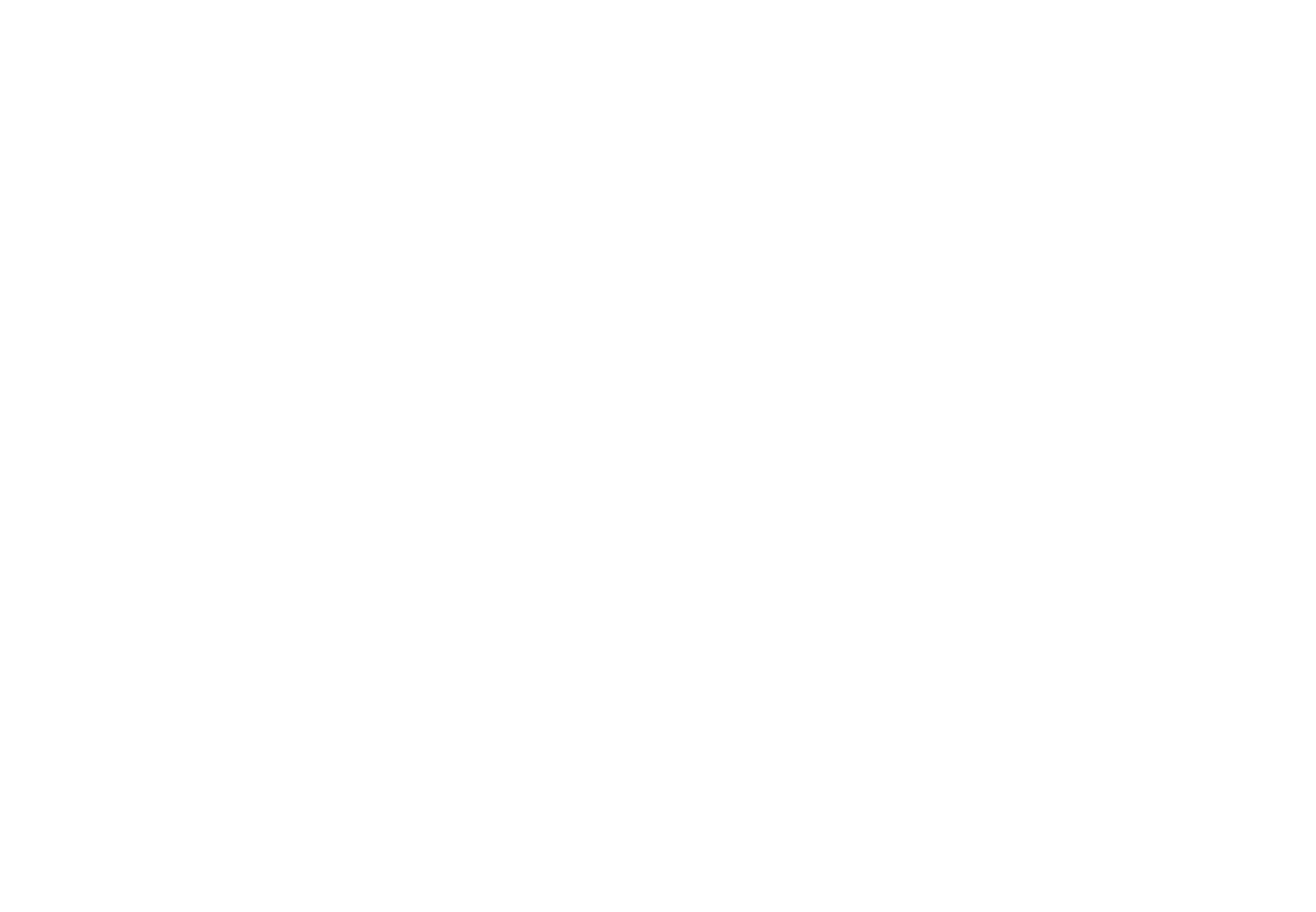

DURATION OF DISCHARGE FOR EAOH WATER YEAR

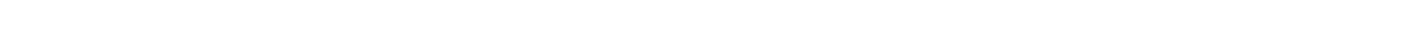
YEAR NUMBER OF DAYS IN CLASS

CBIC FEET

\begin{tabular}{|c|c|c|c|c|c|c|c|c|c|c|c|c|c|c|c|c|c|c|c|c|c|c|c|c|c|c|c|}
\hline $\begin{array}{l}1949 \\
1950\end{array}$ & & 25 & 3 & 1 & & $\begin{array}{l}2 \\
1\end{array}$ & 3 & 2 & $\begin{array}{r}6 \\
13\end{array}$ & $\begin{array}{l}10 \\
19\end{array}$ & $\begin{array}{l}5 \\
6\end{array}$ & $\begin{array}{l}10 \\
27\end{array}$ & $\begin{array}{l}25 \\
19\end{array}$ & $\begin{array}{l}54 \\
12\end{array}$ & $\begin{array}{l}57 \\
30\end{array}$ & $\begin{array}{l}34 \\
43\end{array}$ & $\begin{array}{l}50 \\
95\end{array}$ & 513 & $\begin{array}{l}36 \\
12\end{array}$ & $\begin{array}{l}9 \\
6\end{array}$ & & $\begin{array}{l}2 \\
4\end{array}$ & 1 & & 1 & & $\begin{array}{l}48079.8 \\
40077.8\end{array}$ \\
\hline $\begin{array}{l}1951 \\
1952 \\
1953 \\
195410 \\
195511\end{array}$ & $\begin{array}{r}7 \\
1 \\
15 \\
36 \\
35\end{array}$ & $\begin{array}{r}8 \\
1 \\
25 \\
20 \\
9\end{array}$ & $\begin{array}{l}5 \\
2 \\
2 \\
2 \\
3\end{array}$ & $\begin{array}{l}1 \\
3 \\
2\end{array}$ & $\begin{array}{l}1 \\
4 \\
1\end{array}$ & $\begin{array}{l}3 \\
2 \\
2 \\
5 \\
3\end{array}$ & $\begin{array}{l}4 \\
2 \\
9 \\
2\end{array}$ & $\begin{array}{l}6 \\
8\end{array}$ & $\begin{array}{r}9 \\
1 \\
5 \\
5 \\
11\end{array}$ & $\begin{array}{r}3 \\
1 \\
6 \\
10\end{array}$ & $\begin{array}{r}7 \\
2 \\
3 \\
6 \\
12\end{array}$ & $\begin{array}{r}16 \\
2 \\
13 \\
14 \\
20\end{array}$ & $\begin{array}{r}39 \\
4 \\
43 \\
10 \\
17\end{array}$ & $\begin{array}{l}35 \\
38 \\
23 \\
37 \\
14\end{array}$ & $\begin{array}{l}58 \\
73 \\
32 \\
31 \\
42\end{array}$ & $\begin{array}{l}57 \\
57 \\
59 \\
62 \\
92\end{array}$ & $\begin{array}{l}71 \\
86 \\
74 \\
69 \\
43\end{array}$ & $\begin{array}{r}28 \\
48 \\
54 \\
19 \\
9\end{array}$ & $\begin{array}{r}6 \\
22 \\
2 \\
5 \\
13\end{array}$ & $\begin{array}{r}3 \\
13 \\
1 \\
5 \\
6\end{array}$ & $\begin{array}{l}4 \\
3 \\
1 \\
2\end{array}$ & $\begin{array}{l}1 \\
2 \\
1 \\
1 \\
2\end{array}$ & $\begin{array}{l}5 \\
1\end{array}$ & 1 & 1 & 1 & $\begin{array}{l}36910.3 \\
57942.1 \\
32737.2 \\
25972.5 \\
26496.4\end{array}$ \\
\hline $\begin{array}{l}1956 \\
1957 \\
1958 \\
195910 \\
1960 \quad 22\end{array}$ & $\begin{array}{l}25 \\
11 \\
20 \\
42\end{array}$ & $\begin{array}{l}19 \\
18 \\
14 \\
19\end{array}$ & $\begin{array}{r}5 \\
1 \\
13\end{array}$ & $\begin{array}{l}2 \\
6 \\
2\end{array}$ & $\begin{array}{l}1 \\
5 \\
2\end{array}$ & $\begin{array}{r}5 \\
12 \\
3\end{array}$ & $\begin{array}{l}7 \\
2 \\
4 \\
2\end{array}$ & $\begin{array}{l}2 \\
3 \\
4\end{array}$ & $\begin{array}{r}10 \\
3 \\
5 \\
10\end{array}$ & $\begin{array}{r}9 \\
1 \\
2 \\
13 \\
17\end{array}$ & $\begin{array}{r}11 \\
8 \\
3 \\
17 \\
6\end{array}$ & $\begin{array}{r}19 \\
9 \\
8 \\
16 \\
8\end{array}$ & $\begin{array}{l}23 \\
27 \\
29 \\
22 \\
17\end{array}$ & $\begin{array}{l}31 \\
35 \\
17 \\
33 \\
28\end{array}$ & $\begin{array}{l}37 \\
84 \\
27 \\
29 \\
12\end{array}$ & $\begin{array}{l}70 \\
84 \\
20 \\
77 \\
63\end{array}$ & $\begin{array}{l}59 \\
74 \\
74 \\
61 \\
60\end{array}$ & $\begin{array}{l}1 \\
18 \\
72 \\
14 \\
27\end{array}$ & $\begin{array}{r}1 \\
7 \\
37 \\
2 \\
5\end{array}$ & $\begin{array}{l}6 \\
9 \\
1 \\
4\end{array}$ & $\begin{array}{l}1 \\
7 \\
4\end{array}$ & $\begin{array}{l}1 \\
1 \\
5\end{array}$ & $\begin{array}{l}2 \\
1\end{array}$ & 2 & $\begin{array}{ll}1 & 1 \\
2 & 2\end{array}$ & 1 & $\begin{array}{l}18720.0 \\
48638.7 \\
91366.2 \\
20996.0 \\
22836.6\end{array}$ \\
\hline $\begin{array}{l}1961 \\
1962 \\
1963 \\
1964 \\
1965\end{array}$ & $\begin{array}{l}39 \\
29 \\
36\end{array}$ & $\begin{array}{r}9 \\
35 \\
19 \\
8\end{array}$ & 12 & 8 & 1 & $\begin{array}{r}5 \\
11 \\
7 \\
18\end{array}$ & $\begin{array}{r}4 \\
5 \\
2 \\
14 \\
1\end{array}$ & $\begin{array}{l}7 \\
6\end{array}$ & $\begin{array}{r}3 \\
19 \\
3 \\
15 \\
1\end{array}$ & $\begin{array}{r}2 \\
11 \\
3 \\
19\end{array}$ & $\begin{array}{r}1 \\
8 \\
11 \\
7 \\
2\end{array}$ & $\begin{array}{r}3 \\
1 \\
12 \\
14 \\
5\end{array}$ & $\begin{array}{r}11 \\
5 \\
18 \\
32 \\
7\end{array}$ & $\begin{array}{l}17 \\
11 \\
30 \\
27 \\
24\end{array}$ & $\begin{array}{l}59 \\
28 \\
19 \\
69 \\
83\end{array}$ & $\begin{array}{r}88 \\
64 \\
109 \\
85 \\
78\end{array}$ & $\begin{array}{r}64 \\
83 \\
53 \\
43 \\
126\end{array}$ & $\begin{array}{r}11 \\
24 \\
11 \\
7 \\
27\end{array}$ & $\begin{array}{r}10 \\
21 \\
2 \\
1 \\
6\end{array}$ & $\begin{array}{l}7 \\
7 \\
1 \\
1 \\
2\end{array}$ & $\begin{array}{l}2 \\
1 \\
5\end{array}$ & 2 & $\begin{array}{l}4 \\
2 \\
3\end{array}$ & 1 & 1 & 2 & $\begin{array}{l}51188.6 \\
33417.9 \\
32309.9 \\
19218.1 \\
35605.0\end{array}$ \\
\hline $\begin{array}{ll}1966 & 51 \\
1967 & 11 \\
1968 & 20 \\
1969 \\
1970\end{array}$ & $\frac{1}{2}$ & $\begin{array}{l}2 \\
1\end{array}$ & $\frac{1}{2}$ & $\begin{array}{l}3 \\
1\end{array}$ & 1 & $\begin{array}{l}5 \\
1 \\
1\end{array}$ & $\begin{array}{l}1 \\
3 \\
2\end{array}$ & $\begin{array}{l}4 \\
1\end{array}$ & $\begin{array}{l}5 \\
3 \\
1\end{array}$ & $\begin{array}{r}19 \\
12 \\
1\end{array}$ & $\begin{array}{r}9 \\
15 \\
2 \\
2\end{array}$ & $\begin{array}{r}11 \\
19 \\
4 \\
4\end{array}$ & $\begin{array}{r}25 \\
25 \\
24 \\
4 \\
45\end{array}$ & $\begin{array}{l}18 \\
35 \\
34 \\
77 \\
78\end{array}$ & $\begin{array}{l}29 \\
71 \\
84 \\
59 \\
50\end{array}$ & $\begin{array}{r}63 \\
86 \\
115 \\
90 \\
66\end{array}$ & $\begin{array}{r}113 \\
20 \\
53 \\
77 \\
98\end{array}$ & $\begin{array}{l}3 \\
21 \\
13 \\
37 \\
25\end{array}$ & $\begin{array}{r}3 \\
29 \\
3 \\
8 \\
2\end{array}$ & $\begin{array}{l}3 \\
3 \\
1 \\
4\end{array}$ & $\begin{array}{l}1 \\
1 \\
2 \\
1\end{array}$ & $\begin{array}{l}3 \\
1\end{array}$ & 1 & & & & $\begin{array}{l}24366.9 \\
28916.2 \\
30029.7 \\
35488.7 \\
29468.0\end{array}$ \\
\hline
\end{tabular}


DIRTY DEVIL RIVER BASIN

09333500 DIRTY DEVII RIVER ABOVE POISON SPRING WASH, NEAR HANKSVILLE, UT-Continued

DURATION OF DISCHARGE FOR EACH WATER YEAR--Continued

CLASS $\begin{array}{llllllllllllllllllllllllllllllllllll} & 0 & 1 & 2 & 3 & 4 & 5 & 6 & 7 & 8 & 9 & 10 & 11 & 12 & 13 & 14 & 15 & 16 & 17 & 18 & 19 & 20 & 21 & 22 & 23 & 24 & 25 & 26 & 27 & 28 & 29 & 30 & 31 & 32 & 33 & 34\end{array}$ YEAR

NUMBER OF DAYS IN CLASS

CUBIC FEET PER SECOND

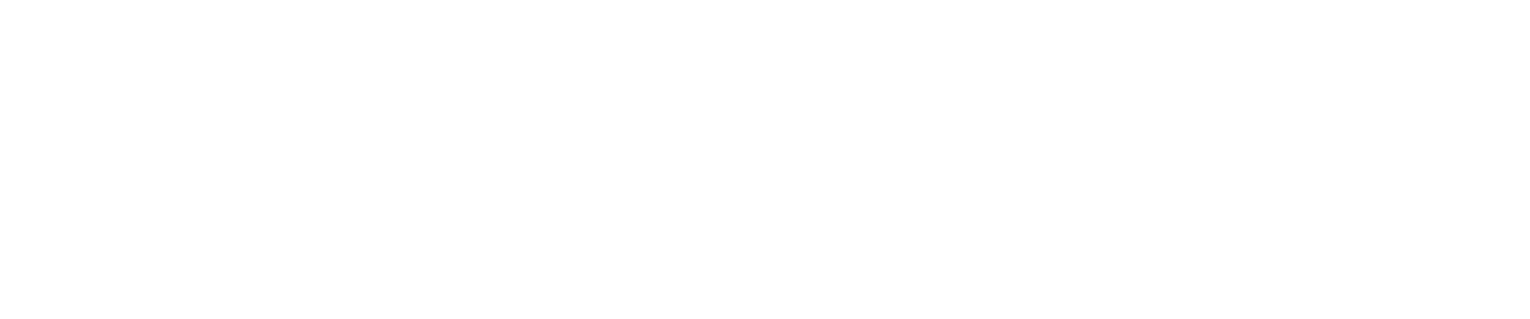

DURATION TABLE OF DISCIARGE FOR WATER YEARS 1949-81

\begin{tabular}{|c|c|c|c|c|c|c|c|c|c|c|c|c|c|c|c|c|c|c|c|}
\hline CLASS & $\begin{array}{c}\text { CBBIC } \\
\text { FEET } \\
\text { PER } \\
\text { SECOND }\end{array}$ & $\begin{array}{l}\text { TOTAL } \\
\text { DAYS }\end{array}$ & $\begin{array}{r}\text { ACCU- } \\
\text { MU- } \\
\text { LATTED } \\
\text { DAYS }\end{array}$ & $\begin{array}{l}\text { PER- } \\
\text { CENT } \\
\text { DAYS }\end{array}$ & CLASS & $\begin{array}{c}\text { CUBIC } \\
\text { FEET } \\
\text { PER } \\
\text { SECOND }\end{array}$ & $\begin{array}{r}\text { TOTAL, } \\
\text { DAYS }\end{array}$ & $\begin{array}{r}\text { ACCU- } \\
\text { MU- } \\
\text { LATEED } \\
\text { DAYS }\end{array}$ & $\begin{array}{l}\text { PER- } \\
\text { CENT } \\
\text { DAYS }\end{array}$ & CLASS & $\begin{array}{c}\text { CBBIC } \\
\text { FEET } \\
\text { PER } \\
\text { SEOOND }\end{array}$ & $\begin{array}{r}\text { TOTAL } \\
\text { DAYS }\end{array}$ & $\begin{array}{r}\text { ACQU- } \\
\text { MU- } \\
\text { LATED } \\
\text { DAYS }\end{array}$ & $\begin{array}{l}\text { PER- } \\
\text { CENT } \\
\text { DAYS }\end{array}$ & CLASS & $\begin{array}{c}\text { CBBIC } \\
\text { FEET } \\
\text { PER } \\
\text { SECOND }\end{array}$ & $\begin{array}{r}\text { TOTAL } \\
\text { DAYS }\end{array}$ & $\begin{array}{r}\text { ACOU- } \\
\text { MU- } \\
\text { LATEDD } \\
\text { DAYS }\end{array}$ & $\begin{array}{l}\text { PER- } \\
\text { CENT } \\
\text { DAYS }\end{array}$ \\
\hline $\begin{array}{l}0 \\
1 \\
2 \\
3 \\
4 \\
5 \\
6 \\
7 \\
8\end{array}$ & $\begin{array}{l}0.00 \\
0.01 \\
0.02 \\
0.04 \\
0.05 \\
0.08 \\
0.12 \\
0.19 \\
0.29\end{array}$ & $\begin{array}{r}478 \\
13 \\
2 \\
0 \\
4 \\
304 \\
3 \\
237 \\
78\end{array}$ & $\begin{array}{l}12053 \\
11575 \\
11562 \\
11560 \\
11560 \\
11556 \\
11252 \\
11249\end{array}$ & $\begin{array}{r}100.0 \\
96.0 \\
95.9 \\
95.9 \\
95.9 \\
95.9 \\
93.4 \\
93.3\end{array}$ & $\begin{array}{r}9 \\
10 \\
11 \\
12 \\
13 \\
14 \\
15 \\
16 \\
17\end{array}$ & $\begin{array}{r}0.43 \\
0.66 \\
1.00 \\
1.50 \\
2.30 \\
3.50 \\
5.30 \\
8.10\end{array}$ & $\begin{array}{r}47 \\
27 \\
136 \\
103 \\
91 \\
198 \\
222 \\
244 \\
367\end{array}$ & $\begin{array}{r}10934 \\
10887 \\
10860 \\
10724 \\
10621 \\
10530 \\
10332 \\
10110\end{array}$ & $\begin{array}{l}90.7 \\
90.3 \\
90.1 \\
89.0 \\
88.1 \\
87.4 \\
85.7 \\
83.9 \\
81.9\end{array}$ & $\begin{array}{l}18 \\
19 \\
20 \\
21 \\
22 \\
23 \\
24 \\
25 \\
26\end{array}$ & $\begin{array}{r}19.0 \\
28.0 \\
43.0 \\
66.0 \\
100.0 \\
150.0 \\
230.0 \\
350.0\end{array}$ & $\begin{array}{r}672 \\
1046 \\
1479 \\
2262 \\
2421 \\
1013 \\
337 \\
124 \\
66\end{array}$ & $\begin{array}{r}9499 \\
8827 \\
7781 \\
6302 \\
4040 \\
1619 \\
606 \\
269\end{array}$ & $\begin{array}{r}78.8 \\
73.2 \\
64.6 \\
52.3 \\
33.5 \\
13.4 \\
5.0 \\
2.2\end{array}$ & $\begin{array}{l}27 \\
28 \\
29 \\
30 \\
31 \\
32 \\
33 \\
34\end{array}$ & $\begin{array}{r}810.0 \\
1200.0 \\
1900.0 \\
2800.0 \\
4300.0 \\
6600.0 \\
10000.0\end{array}$ & $\begin{array}{r}32 \\
24 \\
6 \\
8 \\
3 \\
4 \\
2\end{array}$ & $\begin{array}{r}79 \\
47 \\
23 \\
17 \\
9 \\
6 \\
2\end{array}$ & $\begin{array}{l}0.7 \\
0.4 \\
0.2 \\
0.1 \\
0.1 \\
0.0 \\
0.0\end{array}$ \\
\hline
\end{tabular}

MONIYLY MEAN DISCHARGES, IN OUBIC FEET PER SECOND, FOR FACH WATER YEAR

\begin{tabular}{|c|c|c|c|c|c|c|c|c|c|c|c|c|}
\hline YEAR & $\propto C T$ & NOV & DEC & JAN & FEB & MAR & APR & MAY & JUNE & JULY & AUG & SEP \\
\hline $\begin{array}{l}1949 \\
1950\end{array}$ & $\begin{array}{c}82.1 \\
185\end{array}$ & $\begin{array}{l}108 \\
129\end{array}$ & $\begin{array}{l}103 \\
113\end{array}$ & $\begin{array}{c}35.2 \\
158\end{array}$ & $\begin{array}{l}141 \\
212\end{array}$ & $\begin{array}{l}320 \\
125\end{array}$ & $\begin{array}{l}296 \\
42.7\end{array}$ & $\begin{array}{l}81.3 \\
12.5\end{array}$ & $\begin{array}{l}189 \\
1.20\end{array}$ & $\begin{array}{l}104 \\
277\end{array}$ & $\begin{array}{l}47.8 \\
15.1\end{array}$ & $\begin{array}{l}79.5 \\
50.1\end{array}$ \\
\hline $\begin{array}{l}1951 \\
1952 \\
1953 \\
1954 \\
1955\end{array}$ & $\begin{array}{c}44.5 \\
134 \\
72.2 \\
98.5 \\
102\end{array}$ & $\begin{array}{l}88.2 \\
96.3 \\
113 \\
106 \\
72.6\end{array}$ & $\begin{array}{c}98.1 \\
78.7 \\
125 \\
81.7 \\
73.2\end{array}$ & $\begin{array}{l}143 \\
55.8 \\
158 \\
131 \\
76.8\end{array}$ & $\begin{array}{c}164 \\
136 \\
150 \\
131 \\
98.3\end{array}$ & $\begin{array}{l}79.9 \\
157 \\
122 \\
125 \\
223\end{array}$ & $\begin{array}{r}35.6 \\
167 \\
55.7 \\
34.3 \\
64.5\end{array}$ & $\begin{array}{c}51.6 \\
278 \\
14.8 \\
15.5 \\
8.19\end{array}$ & $\begin{array}{c}9.57 \\
273 \\
0.18 \\
0.12 \\
0.12\end{array}$ & $\begin{array}{l}24.5 \\
58.8 \\
17.3 \\
29.3 \\
32.6\end{array}$ & $\begin{array}{l}439 \\
247 \\
220 \\
4.62 \\
109\end{array}$ & $\begin{array}{c}33.0 \\
220 \\
27.6 \\
102 \\
8.87\end{array}$ \\
\hline $\begin{array}{l}1956 \\
1957 \\
1958 \\
1959 \\
1960\end{array}$ & $\begin{array}{c}25.6 \\
44.1 \\
666 \\
51.3 \\
31.8\end{array}$ & $\begin{array}{r}68.2 \\
66.5 \\
1059 \\
84.5 \\
122\end{array}$ & $\begin{array}{c}95.0 \\
69.6 \\
104 \\
95.2 \\
88.8\end{array}$ & $\begin{array}{l}104 \\
103 \\
56.0 \\
105 \\
138\end{array}$ & $\begin{array}{l}97.2 \\
113 \\
191 \\
131 \\
158\end{array}$ & $\begin{array}{c}77.9 \\
71.4 \\
155 \\
85.2 \\
145\end{array}$ & $\begin{array}{c}25.4 \\
65.6 \\
302 \\
26.9 \\
41.5\end{array}$ & $\begin{array}{c}9.50 \\
127 \\
280 \\
4.65 \\
12.8\end{array}$ & $\begin{array}{l}0.47 \\
160 \\
119 \\
0.68 \\
0.71\end{array}$ & $\begin{array}{r}77.6 \\
152 \\
3.13 \\
1.09 \\
0.05\end{array}$ & $\begin{array}{c}28.6 \\
538 \\
11.0 \\
67.5 \\
0.16\end{array}$ & $\begin{array}{r}4.04 \\
81.6 \\
70.1 \\
41.9 \\
14.2\end{array}$ \\
\hline $\begin{array}{l}1961 \\
1962 \\
1963 \\
1964 \\
1965\end{array}$ & $\begin{array}{l}185 \\
64.1 \\
95.1 \\
28.8 \\
29.2\end{array}$ & $\begin{array}{r}83.2 \\
122 \\
88.2 \\
64.1 \\
63.0\end{array}$ & $\begin{array}{l}71.2 \\
80.7 \\
97.0 \\
53.5 \\
124\end{array}$ & $\begin{array}{r}75.1 \\
87.6 \\
51.8 \\
77.3 \\
116\end{array}$ & $\begin{array}{c}121 \\
183 \\
102 \\
98.1 \\
115\end{array}$ & $\begin{array}{l}101 \\
126 \\
90.3 \\
94.7 \\
109\end{array}$ & $\begin{array}{l}105 \\
239 \\
20.1 \\
67.3 \\
100\end{array}$ & $\begin{array}{c}15.8 \\
53.5 \\
1.85 \\
67.0 \\
65.7\end{array}$ & $\begin{array}{c}0.19 \\
5.10 \\
2.23 \\
13.3 \\
109\end{array}$ & $\begin{array}{c}0.97 \\
3.08 \\
0.77 \\
11.6 \\
123\end{array}$ & $\begin{array}{c}297 \\
1.15 \\
226 \\
49.1 \\
146\end{array}$ & $\begin{array}{c}635 \\
147 \\
289 \\
6.37 \\
69.9\end{array}$ \\
\hline $\begin{array}{l}1966 \\
1967 \\
1968 \\
1969 \\
1970\end{array}$ & $\begin{array}{l}75.7 \\
46.1 \\
51.2 \\
39.2 \\
60.2\end{array}$ & $\begin{array}{r}104 \\
70.1 \\
80.6 \\
75.9 \\
94.7\end{array}$ & $\begin{array}{r}121 \\
73.1 \\
81.0 \\
85.4 \\
115\end{array}$ & $\begin{array}{l}116 \\
81.5 \\
74.0 \\
125 \\
135\end{array}$ & $\begin{array}{l}109 \\
73.1 \\
147 \\
136 \\
134\end{array}$ & $\begin{array}{l}114 \\
68.9 \\
105 \\
158 \\
122\end{array}$ & $\begin{array}{l}75.9 \\
15.8 \\
58.7 \\
82.7 \\
70.6\end{array}$ & $\begin{array}{c}7.48 \\
44.3 \\
51.2 \\
119 \\
61.9\end{array}$ & $\begin{array}{c}0.33 \\
248 \\
43.3 \\
117 \\
60.0\end{array}$ & $\begin{array}{c}11.9 \\
117 \\
95.3 \\
76.5 \\
35.0\end{array}$ & $\begin{array}{c}37.2 \\
45.0 \\
170 \\
62.0 \\
55.0\end{array}$ & $\begin{array}{l}30.8 \\
70.6 \\
27.1 \\
93.2 \\
29.1\end{array}$ \\
\hline $\begin{array}{l}1971 \\
1972 \\
1973 \\
1974 \\
1975\end{array}$ & $\begin{array}{c}62.4 \\
67.6 \\
365 \\
54.8 \\
108\end{array}$ & $\begin{array}{l}93.9 \\
107 \\
172 \\
118 \\
121\end{array}$ & $\begin{array}{l}111 \\
80.3 \\
107 \\
140 \\
56.1\end{array}$ & $\begin{array}{c}84.9 \\
91.0 \\
88.9 \\
136 \\
42.3\end{array}$ & $\begin{array}{c}132 \\
133 \\
125 \\
156 \\
78.8\end{array}$ & $\begin{array}{l}118 \\
83.7 \\
168 \\
161 \\
145\end{array}$ & $\begin{array}{l}53.1 \\
22.6 \\
175 \\
112 \\
136\end{array}$ & $\begin{array}{c}12.2 \\
1.34 \\
226 \\
60.1 \\
159\end{array}$ & $\begin{array}{c}3.20 \\
7.55 \\
120 \\
5.33 \\
141\end{array}$ & $\begin{array}{l}8.54 \\
19.5 \\
93.8 \\
16.3 \\
76.3\end{array}$ & $\begin{array}{c}68.5 \\
41.0 \\
40.8 \\
2.16 \\
14.5\end{array}$ & $\begin{array}{l}25.8 \\
41.6 \\
34.6 \\
12.8 \\
36.5\end{array}$ \\
\hline $\begin{array}{l}1976 \\
1977 \\
1978 \\
1979 \\
1980\end{array}$ & $\begin{array}{r}61.1 \\
40.9 \\
110 \\
43.0 \\
54.8\end{array}$ & $\begin{array}{l}87.2 \\
60.3 \\
52.5 \\
346 \\
112\end{array}$ & $\begin{array}{c}138 \\
59.4 \\
103 \\
22.8 \\
83.5\end{array}$ & $\begin{array}{c}106 \\
59.2 \\
92.2 \\
33.5 \\
116\end{array}$ & $\begin{array}{l}169 \\
159 \\
277 \\
43.5 \\
117\end{array}$ & $\begin{array}{l}116 \\
116 \\
238 \\
188 \\
140\end{array}$ & $\begin{array}{l}77.3 \\
62.1 \\
109 \\
176 \\
142\end{array}$ & $\begin{array}{c}85.3 \\
6.19 \\
86.1 \\
193 \\
201\end{array}$ & $\begin{array}{c}5.71 \\
0.00 \\
121 \\
72.4 \\
120\end{array}$ & $\begin{array}{c}4.80 \\
91.8 \\
27.5 \\
5.72 \\
35.5\end{array}$ & $\begin{array}{c}9.24 \\
111 \\
6.00 \\
2.11 \\
40.7\end{array}$ & $\begin{array}{c}35.6 \\
136 \\
6.83 \\
0.23 \\
620\end{array}$ \\
\hline 701 & 75.3 & 98.2 & 101 & 106 & 97.0 & 111 & 78.2 & 48.7 & 39.7 & 36.2 & 29.8 & 225 \\
\hline
\end{tabular}


DIRTY DEVII RIVER BASIN

09333500 DIRTY DEVII RIVER ABOVE POISON SPRING WASH, NEAR HANKSVILLE, UT--Continued

ANNUAL PEAK DISCHARGE, IN CUBIC FEET PER SEOOND, AND CORRESPONDING GAGE HEIGHT, IN FEET, FOR EACH WATER YEAR

\begin{tabular}{|c|c|c|c|c|c|c|c|c|c|c|c|}
\hline $\begin{array}{l}\text { WATER } \\
\text { YEAR }\end{array}$ & DATE & $\begin{array}{c}\text { GAGE } \\
\text { HEIGHT }\end{array}$ & $\begin{array}{c}\text { PEAK } \\
\text { DISCHARGE }\end{array}$ & $\begin{array}{l}\text { WATERR } \\
\text { YEAR }\end{array}$ & DATE & $\begin{array}{c}\text { GAGE } \\
\text { HEIGHT }\end{array}$ & $\begin{array}{c}\text { PEAK } \\
\text { DISCHARGE }\end{array}$ & $\begin{array}{l}\text { WATERR } \\
\text { YEAR }\end{array}$ & DATE & $\begin{array}{c}\text { GAGE } \\
\text { HEIGHT }\end{array}$ & $\begin{array}{c}\text { PEAK } \\
\text { DISCHARGE }\end{array}$ \\
\hline $\begin{array}{l}1948 \\
1949 \\
1950\end{array}$ & $\begin{array}{l}\text { AUG. } 05,1948 \\
\text { JULY } \\
05,1949 \\
\text { JULY } 09,1950\end{array}$ & $\begin{array}{r}16.28 \\
7.57 \\
20.25\end{array}$ & $\begin{array}{r}8680 \\
3120 \\
11300\end{array}$ & $\begin{array}{l}1960 \\
1961 \\
1962\end{array}$ & $\begin{array}{l}\text { NO. 03, } 1959 \\
\text { SEPT.09, } 1961 \\
\text { SEPT.21, } 1962\end{array}$ & $\begin{array}{r}3.90 \\
20.65 \\
6.50\end{array}$ & $\begin{array}{r}975 \\
21000 \\
2810\end{array}$ & $\begin{array}{l}1971 \\
1972 \\
1973\end{array}$ & $\begin{array}{l}\text { AUG. } 31,1971 \\
\text { AUG. } 20,1972 \\
\text { OCT. } 19,1972\end{array}$ & $\begin{array}{r}6.10 \\
7.53 \\
12.09\end{array}$ & $\begin{array}{r}2180 \\
3530 \\
10200\end{array}$ \\
\hline 1951 & AJUG. 04,1951 & 18.75 & 12800 & 1963 & SEPT.01, 1963 & 15.41 & 12200 & 1974 & MAR. 03, 1974 & - & $1_{281}$ \\
\hline $\begin{array}{l}1952 \\
1953 \\
1954 \\
1955 \\
1956 \\
1957 \\
1958 \\
1959\end{array}$ & $\begin{array}{l}\text { SEPT. } 22,1952 \\
\text { AUG. 22, } 1953 \\
\text { SEPT.14, } 1954 \\
\text { OCT. 08, } 1954 \\
\text { JULY 01, } 1956 \\
\text { AUG. 31, } 1957 \\
\text { NOV. 04, } 1957 \\
\text { AUG. } 13,1959\end{array}$ & $\begin{array}{r}16.75 \\
12.60 \\
6.72 \\
7.90 \\
12.65 \\
20.40 \\
28.10 \\
9.57\end{array}$ & $\begin{array}{r}8870 \\
6390 \\
2690 \\
3420 \\
6360 \\
11360 \\
35000 \\
3830\end{array}$ & $\begin{array}{l}1964 \\
1965 \\
1966 \\
1967 \\
1968 \\
1969 \\
1970\end{array}$ & $\begin{array}{l}\text { OCT. } 21,1963 \\
\text { AUG. } 17,1965 \\
\text { AUG. } 19,1966 \\
\text { SEPT. 09, } 1967 \\
\text { JULY 31, } 1968 \\
\text { JUNE 24, } 1969 \\
\text { AUG. 04, } 1970\end{array}$ & $\begin{array}{r}4.94 \\
12.63 \\
7.00 \\
7.10 \\
9.26 \\
7.30 \\
10.00\end{array}$ & $\begin{array}{r}1720 \\
10700 \\
3000 \\
3100 \\
5540 \\
3300 \\
6500\end{array}$ & $\begin{array}{l}1975 \\
1976 \\
1977 \\
1978 \\
1979 \\
1980 \\
1981\end{array}$ & $\begin{array}{l}\text { NON. } 03,1974 \\
\text { MAY 07, } 1976 \\
\text { JULY 25, } 1977 \\
\text { JULY 04, } 1978 \\
\text { NOW. 03, } 1978 \\
\text { SEPT.10, } 1980 \\
\text { SEPT.06, } 1981\end{array}$ & $\begin{array}{r}-\overline{-} \\
7.98 \\
8.63 \\
5.18 \\
9.95 \\
16.20 \\
17.50\end{array}$ & $\begin{array}{r}1742 \\
4000 \\
5690 \\
1710 \\
8040 \\
25700 \\
18300\end{array}$ \\
\hline
\end{tabular}

MAGNITUDE AND PRCBABILITY OF ANNUAL LOWEST MEAN DISCHARGE

\begin{tabular}{|c|c|c|c|c|c|c|}
\hline \multirow{2}{*}{$\begin{array}{l}\text { PERIOD } \\
\text { (CON- } \\
\text { SEOU- } \\
\text { TIVE } \\
\text { DAYS) }\end{array}$} & \multicolumn{6}{|c|}{$\begin{array}{l}\text { DISCHARGE, IN CUBIC FEET PER SEOOND, FOR } \\
\text { INDICATED RECURRENCE INTERNAL, IN YEARS, AND } \\
\text { ANNUAL NONEXCEEDANCE PROBABIIITY, IN PERCENT }\end{array}$} \\
\hline & $\begin{array}{c}2 \\
508\end{array}$ & $\begin{array}{c}5 \\
208\end{array}$ & $\begin{array}{l}10 \\
108\end{array}$ & $\begin{array}{l}20 \\
58\end{array}$ & $\begin{array}{l}50 \\
28\end{array}$ & $\begin{array}{r}100 \\
18\end{array}$ \\
\hline$\frac{1}{7}$ & $\begin{array}{l}0.00 \\
0.06\end{array}$ & $\begin{array}{l}0.00 \\
0.00\end{array}$ & $\begin{array}{l}0.00 \\
0.00\end{array}$ & $\begin{array}{l}0.00 \\
0.00\end{array}$ & $\begin{array}{l}0.0 \\
0.0\end{array}$ & -- \\
\hline 90 & & 3.5 & 1.7 & 0.90 & 0.4 & - \\
\hline
\end{tabular}

${ }^{1}$ Maximum daily discharge.

NORIH WASH BASIN

09333900 BUTLER CANYON NEAR HITE, UT

LOCATION.--Lat $37^{\circ} 59^{\prime} 30^{\prime \prime}$, long $110^{\circ} 29^{\prime} 47^{\prime \prime}$, in sec.29, T.32 S., R.13 E. (unsurveyed), Garfield County, Hydrologic Unit 14070001 , on State Highway 95, about $2.5 \mathrm{mi}$ west of Hog Canyon Spring, about $12.5 \mathrm{mi}$ from mouth of North wash, and $13 \mathrm{mi}$ northwest of Hite.

DRAINAGE AREA. $-14.7 \mathrm{mi}^{2}$.

MEAN BASIN ELEVATION. $--5,150 \mathrm{ft}$.

PERIOD OF RECORD AVAIIABLE. - Water years 1959-74, annual peak discharge only.

GAGE.--Crest-stage gage. Altitude of gage is 4,320 ft from topographic map.

ANNJAL PEAK DISCHARGE, IN OUBIC FEET PER SECOND, AND CORRESPONDING GAGE HEIGHT, IN FEET, FOR EACH WATER YEAR

\begin{tabular}{|c|c|c|c|c|c|c|c|c|c|c|c|}
\hline $\begin{array}{l}\text { WATEER } \\
\text { YEAR }\end{array}$ & DATE & $\begin{array}{c}\text { GAGE } \\
\text { HEIGHT }\end{array}$ & $\begin{array}{c}\text { PEAR } \\
\text { DISCHARGE }\end{array}$ & $\begin{array}{l}\text { WATEER } \\
\text { YEAR }\end{array}$ & DATE & $\begin{array}{c}\text { GAGE } \\
\text { HEIGHT }\end{array}$ & $\begin{array}{c}\text { PEAR } \\
\text { DISCHARGE }\end{array}$ & $\begin{array}{l}\text { WATER } \\
\text { YEAR }\end{array}$ & DATE & $\begin{array}{c}\text { GAGE } \\
\text { HEIGHT }\end{array}$ & $\begin{array}{c}\text { PEAK } \\
\text { DISCHARGE }\end{array}$ \\
\hline $\begin{array}{l}1959 \\
1960 \\
1961 \\
1962 \\
1963 \\
1964\end{array}$ & $\begin{array}{l}\text { AUG. } 06,1959 \\
\text { NOV. } 02,1959 \\
\text { JULY } 31,1961 \\
\text { JULY } 25,1962 \\
\text { JULY 09, } 1963 \\
\text { SEPT.21, } 1964\end{array}$ & $\begin{array}{ll}9 & 13.58 \\
9 & 11.67 \\
1 & 12.42 \\
2 & 11.04 \\
3 & 12.65 \\
4 & 11.12\end{array}$ & $\begin{array}{l}650 \\
270 \\
570 \\
170 \\
450 \\
183\end{array}$ & $\begin{array}{l}1965 \\
1966 \\
1967 \\
1968 \\
1969\end{array}$ & $\begin{array}{l}\text { SEPT.05, } 1965 \\
\text { AUG. -- } 1966 \\
\text { JULY 17, } 1967 \\
\text { AUG. 01, } 1968 \\
\text { SEPT.11, } 1969\end{array}$ & $\begin{array}{l}13.90 \\
13.20 \\
12.65 \\
13.47 \\
13.21\end{array}$ & $\begin{array}{l}730 \\
560 \\
450 \\
620 \\
565\end{array}$ & $\begin{array}{l}1970 \\
1971 \\
1972 \\
1973 \\
1974\end{array}$ & 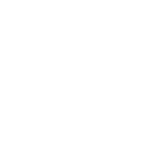 & $\begin{array}{l}10.09 \\
13.47 \\
16.58 \\
10.89 \\
11.60\end{array}$ & $\begin{array}{r}38 \\
625 \\
1950 \\
149 \\
260\end{array}$ \\
\hline
\end{tabular}




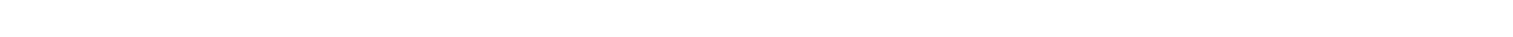
$0.4 \mathrm{mi}$ downstream from left bank tributary, $0.5 \mathrm{mi}$ upstream from normal Lake Powell pool elevation waterline, and $36 \mathrm{mi}$ southeast of Hanksville.

DRAINAGE AREA.--136 $\mathrm{mi}^{2}$, approximately.

MEAN BASIN ELEVATION. $--5,400 \mathrm{ft}$.

PERIOC OF RECORD AVAILABLE.--May 1950 to September 1970.

GAGE.--Water-stage recorder. Altitude of gage is 3,730 ft from topographic map. Prior to June 18, 1964 , at site $2.5 \mathrm{mi}$ downstream at different datum.

AVERAGE DISCHARGE. -20 years, $1.2 \mathrm{ft} / 3,869$ acre- $\mathrm{ft} / \mathrm{yr}$.

EXIREMES FOR PERIOD OF RECORD.-Maximum discharge, $8,900 \mathrm{ft}^{3} / \mathrm{s}$ Aug. 7,1952 , gage height, $9.24 \mathrm{ft}$ from floodmark, datum then in use; no flow for most days in each year.

LOWEST MEAN DISCHARGE, IN OUBIC FEET PER SECOND, AND RANKING FOR THE INDICATED NUMBER OF CONSEOUTIVE DAYS FOR EACH CLIMATIC YEAR, APRIL 1-MARCH 31

YEAR

\begin{tabular}{|c|c|c|c|c|c|}
\hline & 1 & & 3 & & 7 \\
\hline $\begin{array}{l}1952 \\
1953 \\
1954 \\
1955\end{array}$ & $\begin{array}{l}0.00 \\
0.00 \\
0.00 \\
0.00\end{array}$ & $\begin{array}{l}1 \\
2 \\
3 \\
4\end{array}$ & $\begin{array}{l}0.00 \\
0.00 \\
0.00 \\
0.00\end{array}$ & $\begin{array}{l}1 \\
2 \\
3 \\
4\end{array}$ & $\begin{array}{l}0.00 \\
0.00 \\
0.00 \\
0.00\end{array}$ \\
\hline $\begin{array}{l}1956 \\
1957 \\
1958 \\
1959 \\
1960\end{array}$ & $\begin{array}{l}0.00 \\
0.00 \\
0.00 \\
0.00 \\
0.00\end{array}$ & $\begin{array}{l}5 \\
6 \\
7 \\
8 \\
9\end{array}$ & $\begin{array}{l}0.00 \\
0.00 \\
0.00 \\
0.00 \\
0.00\end{array}$ & $\begin{array}{l}5 \\
6 \\
7 \\
8 \\
9\end{array}$ & $\begin{array}{l}0.00 \\
0.00 \\
0.00 \\
0.00 \\
0.00\end{array}$ \\
\hline $\begin{array}{l}1961 \\
1962 \\
1963 \\
1964 \\
1965\end{array}$ & $\begin{array}{l}0.00 \\
0.00 \\
0.00 \\
0.00 \\
0.00\end{array}$ & $\begin{array}{l}10 \\
11 \\
12 \\
13 \\
14\end{array}$ & $\begin{array}{l}0.00 \\
0.00 \\
0.00 \\
0.00 \\
0.00\end{array}$ & $\begin{array}{l}10 \\
11 \\
12 \\
13 \\
14\end{array}$ & $\begin{array}{l}0.00 \\
0.00 \\
0.00 \\
0.00 \\
0.00\end{array}$ \\
\hline $\begin{array}{l}1966 \\
1967 \\
1968 \\
1969 \\
1970\end{array}$ & $\begin{array}{l}0.00 \\
0.00 \\
0.00 \\
0.00 \\
0.00\end{array}$ & $\begin{array}{l}15 \\
16 \\
17 \\
18 \\
19\end{array}$ & $\begin{array}{l}0.00 \\
0.00 \\
0.00 \\
0.00 \\
0.00\end{array}$ & $\begin{array}{l}15 \\
16 \\
17 \\
18 \\
19\end{array}$ & $\begin{array}{l}0.00 \\
0.00 \\
0.00 \\
0.00 \\
0.00\end{array}$ \\
\hline
\end{tabular}

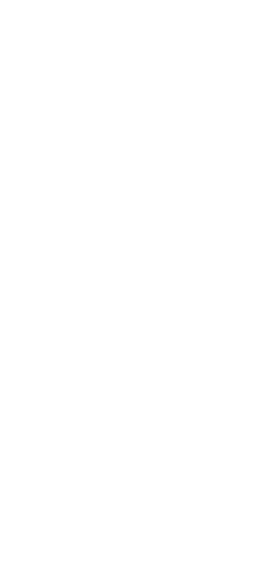

$\begin{array}{lrr}90 & \\ 0.00 & 1 \\ 0.16 & 17 \\ 0.02 & 10 \\ 0.14 & 16 \\ & & \\ 0.00 & 2 \\ 0.03 & 12 \\ 0.68 & 19 \\ 0.03 & 13 \\ 0.00 & 3 \\ & & \\ 0.00 & 4 \\ 0.02 & 11 \\ 0.00 & 5 \\ 0.01 & 8 \\ 0.00 & 6 \\ & & \\ 0.07 & 15 \\ 0.01 & 7 \\ 0.04 & 14 \\ 0.02 & 9 \\ 0.22 & 18\end{array}$

120

$\begin{array}{lr}0.04 & 7 \\ 0.31 & 17\end{array}$

0.128

0.001

0.1812

0.6619

0.1711

0.2013

$\begin{array}{lr}0.00 & 2 \\ 0.28 & 15\end{array}$

$\begin{array}{rr}0.28 & 15 \\ 0.00 & 3\end{array}$

$\begin{array}{ll}0.02 & 4 \\ 0.03 & 5\end{array}$

0.4518

0.2816

0.2816

$\begin{array}{lr}0.04 & 6 \\ 0.16 & 10\end{array}$

$\begin{array}{ll}0.16 & 10 \\ 0.2014\end{array}$
183 ALL

$\begin{array}{llll}0.61 & 17 & 0.80 & 9\end{array}$

$\begin{array}{rrrrr}0.44 & 13 & & 1.70 & 16 \\ 0.21 & 8 & & 0.73 & 8\end{array}$

$\begin{array}{llll}0.5516 & 0.72 & 7\end{array}$

$\begin{array}{llll}0.03 & 1 & 0.12 & 1 \\ 0.16 & 6 & 0.36 & 5\end{array}$

$2.3019 \quad 4.1019$

0.187

$\begin{array}{llll}0.42 & 11 & 0.68 & 6\end{array}$

$\begin{array}{llll}0.07 & 4 & 0.13 & 2\end{array}$

$\begin{array}{llll}0.4915 & 2.4017\end{array}$

$0.052 \quad 0.153$

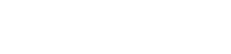

$1.1018 \quad 1.4015$

$0.4614 \quad 1.1011$

$0.07 \begin{array}{llll}0.07 & 1.30 & 13\end{array}$

$0.2810 \quad 1.1012$

HIGHEST MEAN DISCHARGE, IN OBIC FEET PER SBCOND, AND RANKING FOR THE INDICATED NUMBER OF CONSECUTIVE DAYS FOR EACH WATER YEAR, OCTOBER 1-SEPTEMBER 30

YEAR

$\begin{array}{rcrcrcr} & 1 & & 3 & & 7 & \\ 1951 & 52.0 & 13 & 20.0 & 14 & 8.60 & 14 \\ 1952 & 250 & 6 & 88.0 & 6 & 38.0 & 7 \\ 1953 & 43.0 & 14 & 34.0 & 12 & 14.0 & 12 \\ 1954 & 25.0 & 19 & 15.0 & 15 & 6.40 & 16 \\ 1955 & 36.0 & 15 & 13.0 & 18 & 6.50 & 15 \\ & & & & & & \\ 1956 & 10.0 & 20 & 6.30 & 20 & 2.70 & 20 \\ 1957 & 98.0 & 10 & 35.0 & 10 & 16.0 & 10 \\ 1958 & 289 & 4 & 201 & 1 & 93.0 & 1 \\ 1959 & 36.0 & 16 & 14.0 & 16 & 5.90 & 17 \\ 1960 & 68.0 & 12 & 33.0 & 13 & 14.0 & 13 \\ & & & & & & \\ 1961 & 272 & 5 & 127 & 5 & 54.0 & 5 \\ 1962 & 29.0 & 18 & 13.0 & 17 & 5.80 & 18 \\ 1963 & 375 & 2 & 136 & 4 & 60.0 & 3 \\ 1964 & 36.0 & 17 & 12.0 & 19 & 5.10 & 19 \\ 1965 & 92.0 & 11 & 35.0 & 11 & 15.0 & 11 \\ & & & & & & \\ 1966 & 114 & 9 & 41.0 & 9 & 18.0 & 9 \\ 1967 & 335 & 3 & 140 & 3 & 60.0 & 4 \\ 1968 & 125 & 8 & 67.0 & 8 & 38.0 & 6 \\ 1969 & 412 & 1 & 142 & 2 & 61.0 & 2 \\ 1970 & 223 & 7 & 76.0 & 7 & 33.0 & 8\end{array}$

$\begin{array}{ll}\text { CONSECUTTVE DAYS } \\ 30 & 60\end{array}$

15

7.0013

22.06

8.6011

$\begin{array}{ll}3.50 & 16 \\ 4.80 & 15\end{array}$

1.3020

$\begin{array}{cr}1.30 & 20 \\ 10.0 & 9\end{array}$

$\begin{array}{ll}55.0 & 1 \\ 2.70 & 18\end{array}$

2.7018
6.6014

$43.0,2$

$2.90 \quad 17$

28.04

2.4019

7.8012

9.4010

$\begin{array}{ll}28.0 & 5 \\ 19.0 & 7\end{array}$

19.07

$\begin{array}{ll}29.0 & 3 \\ 27.0 & 8\end{array}$
$3.5013 \quad 1.8014$

11.0666

$5.2010 \quad 3.0012$

1.7017

3.0015

0.9717

0.6320

5.2011

32.01

1.4019
3.3014

0.4920
3.9010

$\begin{array}{rr}3.90 & 10 \\ 16.0 & 1 \\ 1.30 & 16\end{array}$

1.3016
2.0013

23.02

1.6018

1.7016

1.7016

$13.0 \quad 2$

0.9018

$\begin{array}{rr}7.40 & 4 \\ 0.87 & 19\end{array}$

0.8719

$\begin{array}{cccc}7.00 & 9 & 5.10 & 8 \\ 14.0 & 5 & 7.20 & 5 \\ 10.0 & 7 & 5.00 & 9\end{array}$

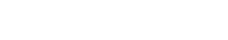

$\begin{array}{cc}19.0 & 3 \\ 9.80 & 8\end{array}$
90

1.1914

$\begin{array}{rr}4.40 & 6\end{array}$

1.1015

1.1016

0.3320

$\begin{array}{rr}3.90 & 8 \\ 11.0 & 2\end{array}$

0.8617

1.6013

$8.80 \quad 3$

$\begin{array}{rr}0.68 & 18 \\ 4.90 & 4\end{array}$

$4.90 \quad 4$

0.6319

3.409

$\begin{array}{ll}3.40 & 9 \\ 4.80 & 5\end{array}$

$\begin{array}{cc}13.0 & 1 \\ 4.30 & 7\end{array}$
120

0.9214

$4.30 \quad 4$

1.8112

0.8116

0.2520

3.407

8.602

0.6418
1.4013

6.603

0.6517

$3.70 \quad 5$

0.5919

1.7011

$2.50 \quad 9$

3.706

2.5010

$\begin{array}{cc}10.0 & 1 \\ 3.20 & 8\end{array}$
183

0.6315

2.904

1.0012

0.6316

0.8214

0.1920

2.406

5.802

0.4319

0.9913

$\begin{array}{ll}4.40 & 3 \\ 0.50 & 17\end{array}$

2.40

2.40

0.4618

1.7010

2.605

$\begin{array}{ll}2.60 & 5 \\ 1.80 & 9\end{array}$

7.001

$\begin{array}{ll}7.20 & 8\end{array}$
ALL

0.3716 1.904 0.7211 0.5413

0.1120 1.506 $\begin{array}{lll}3.70 & 1\end{array}$ $\begin{array}{ll}0.31 & 17 \\ 0.53 & 14\end{array}$

$2.20 \quad 3$ 0.2719 $\begin{array}{lll}1.30 \quad 8 & \end{array}$ 0.3118 1.605 1.407 0.9310 $\begin{array}{rr}3.70 & 2 \\ 1.19 & 9\end{array}$ 
NORTH WASH BASIN

09334000 NORTH WASH NEAR HANKSVILLE, UT--Continued

DURATION OF DISCHARGE FOR EACH WATER YEAR

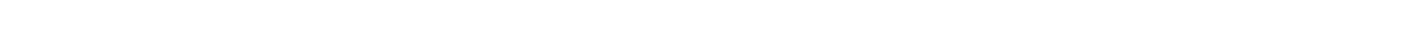

\begin{tabular}{|c|c|c|c|c|c|c|c|c|c|c|c|c|c|c|c|c|c|c|c|c|c|c|c|c|c|c|}
\hline YEAR & & & & & & & & & UMBEF & $R O F$ & DAY & $5 \mathrm{IN}$ & CLAS & & & & & & & & & & & & & $\begin{array}{l}\text { PER SECOND } \\
\text {-DAYS }\end{array}$ \\
\hline $\begin{array}{l}1951295 \\
1952185 \\
1953192 \\
1954210 \\
1955232\end{array}$ & & & $\begin{array}{r}1 \\
52 \\
24 \\
86 \\
52\end{array}$ & $\begin{array}{l}33 \\
26 \\
32 \\
38 \\
26\end{array}$ & $\begin{array}{r}7 \\
8 \\
21 \\
2 \\
6\end{array}$ & $\begin{array}{r}6 \\
9 \\
18 \\
4 \\
3\end{array}$ & $\begin{array}{l}10 \\
10 \\
34 \\
10 \\
14\end{array}$ & $\begin{array}{r}5 \\
10 \\
8\end{array}$ & $\begin{array}{r}1 \\
10 \\
14 \\
2 \\
5\end{array}$ & $\begin{array}{l}6 \\
4 \\
5\end{array}$ & $\begin{array}{l}1 \\
4 \\
2 \\
5\end{array}$ & $\begin{array}{r}12 \\
2 \\
2\end{array}$ & $\begin{array}{l}2 \\
7 \\
3 \\
3\end{array}$ & $\begin{array}{l}6 \\
6 \\
2 \\
3\end{array}$ & $\begin{array}{l}1 \\
5 \\
1\end{array}$ & $\begin{array}{l}1 \\
6 \\
1 \\
1 \\
3\end{array}$ & $\begin{array}{l}5 \\
1 \\
2\end{array}$ & $\begin{array}{l}1 \\
2 \\
4 \\
1\end{array}$ & $\begin{array}{l}1 \\
1 \\
2 \\
1\end{array}$ & $\begin{array}{ll}1 & 1 \\
1 & 1 \\
1 & \end{array}$ & $\begin{array}{l}1 \\
1\end{array}$ & & & 1 & & $\begin{array}{l}135.8 \\
704.4 \\
264.5 \\
195.9 \\
184.0\end{array}$ \\
\hline $\begin{array}{l}1956264 \\
1957185 \\
1958117 \\
1959279 \\
1960259\end{array}$ & & & $\begin{array}{l}88 \\
21 \\
14 \\
35 \\
25\end{array}$ & $\begin{array}{r}4 \\
41 \\
31 \\
27 \\
10\end{array}$ & $\begin{array}{r}2 \\
8 \\
16 \\
4 \\
24\end{array}$ & $\begin{array}{r}12 \\
17 \\
4 \\
6\end{array}$ & $\begin{array}{r}5 \\
24 \\
50 \\
4 \\
18\end{array}$ & $\begin{array}{r}12 \\
27 \\
3\end{array}$ & $\begin{array}{r}13 \\
21 \\
2 \\
5\end{array}$ & $\begin{array}{l}10 \\
10 \\
2\end{array}$ & $\begin{array}{r}4 \\
12 \\
1\end{array}$ & $\begin{array}{r}6 \\
10 \\
5\end{array}$ & $\begin{array}{r}5 \\
14 \\
3 \\
4\end{array}$ & $\begin{array}{l}3 \\
6 \\
1 \\
3\end{array}$ & $\begin{array}{l}4 \\
3\end{array}$ & $\begin{array}{l}3 \\
4 \\
3\end{array}$ & $\begin{array}{l}5 \\
4 \\
1\end{array}$ & $\begin{array}{l}1 \\
2 \\
1\end{array}$ & $\begin{array}{l}3 \\
1 \\
1 \\
1\end{array}$ & $\begin{array}{l}3 \\
1 \\
1\end{array}$ & $\begin{array}{l}1 \\
1\end{array}$ & $\begin{array}{l}1 \\
1\end{array}$ & & 2 & 1 & $\begin{array}{r}41.1 \\
543.0 \\
1341.6 \\
112.0 \\
192.8\end{array}$ \\
\hline $\begin{array}{l}1961267 \\
1962201 \\
1963227 \\
1964245 \\
1965166\end{array}$ & & & $\begin{array}{l}26 \\
18 \\
77 \\
32 \\
32\end{array}$ & $\begin{array}{r}7 \\
61 \\
28 \\
58 \\
24\end{array}$ & $\begin{array}{r}13 \\
34 \\
8 \\
11 \\
35\end{array}$ & $\begin{array}{r}19 \\
21 \\
8 \\
1 \\
52\end{array}$ & $\begin{array}{r}9 \\
19 \\
4 \\
3 \\
36\end{array}$ & $\begin{array}{l}2 \\
2 \\
4 \\
8\end{array}$ & $\begin{array}{l}1 \\
4 \\
1 \\
2\end{array}$ & $\begin{array}{l}2 \\
1 \\
2 \\
1\end{array}$ & $\begin{array}{l}3 \\
1 \\
5 \\
1\end{array}$ & $\begin{array}{l}1 \\
2\end{array}$ & $\begin{array}{l}1 \\
2\end{array}$ & $\begin{array}{l}5 \\
1 \\
1 \\
1\end{array}$ & $\begin{array}{l}1 \\
2\end{array}$ & 1 & 1 & $\frac{1}{2}$ & $\begin{array}{l}1 \\
1 \\
1\end{array}$ & $\begin{array}{l}1 \\
1 \\
1 \\
1\end{array}$ & 1 & 1 & 1 & 1 & $\begin{array}{l}1 \\
1\end{array}$ & $\begin{array}{l}819.2 \\
100.2 \\
491.7 \\
112.5 \\
258.1\end{array}$ \\
\hline $\begin{array}{l}1966143 \\
1967108 \\
1968162 \\
196956 \\
1970143\end{array}$ & $\begin{array}{rrr}4 & 4120 \\
& 935 \\
4 & 4 & 7\end{array}$ & $\begin{array}{rrr}4 & 20 & \\
16 & 1 \\
6 & 16 \\
15 & \end{array}$ & $\begin{array}{rrr} & 71 & \\
5 & 23 & 3 \\
4 & 33 & 14 \\
6 & 11 & 20 \\
2 & 24 & 43\end{array}$ & $\begin{array}{l}33 \\
319 \\
425 \\
49 \\
43\end{array}$ & $\begin{array}{l}41 \\
23 \\
15 \\
52 \\
44\end{array}$ & $\begin{array}{l}33 \\
27 \\
11 \\
31 \\
30\end{array}$ & $\begin{array}{r}12 \\
24 \\
12 \\
28 \\
3\end{array}$ & $\begin{array}{r}5 \\
7 \\
3 \\
14 \\
2\end{array}$ & $\begin{array}{r}6 \\
17 \\
3 \\
11 \\
1\end{array}$ & $\begin{array}{r}2 \\
8 \\
2 \\
29 \\
4\end{array}$ & $\begin{array}{l}1 \\
2 \\
4 \\
4 \\
3\end{array}$ & $\begin{array}{l}2 \\
1\end{array}$ & $\begin{array}{l}2 \\
1 \\
2 \\
1\end{array}$ & $\begin{array}{l}1 \\
1\end{array}$ & $\begin{array}{l}3 \\
1 \\
2 \\
2\end{array}$ & 2 & $\begin{array}{l}1 \\
1 \\
1\end{array}$ & 1 & $\begin{array}{l}3 \\
1\end{array}$ & $\begin{array}{ll}3 & \\
1 & 1\end{array}$ & $\begin{array}{l}3 \\
1 \\
2 \\
2 \\
3 \\
1\end{array}$ & 1 & $\begin{array}{l}1 \\
1\end{array}$ & 1 & 1 & $\begin{array}{r}594.8 \\
524.1 \\
339.8 \\
1353.3 \\
440.9\end{array}$ \\
\hline
\end{tabular}

DURATION TABLE OF DISCHARGE FOR WATER YEARS 1951-70

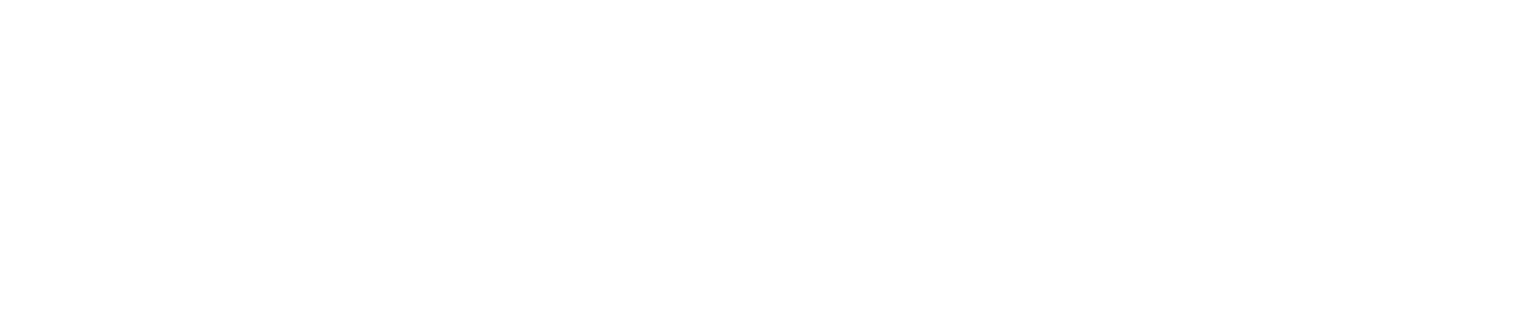

MONTHLY MEAN DISCHARGES, IN OUBIC FEET PER SECOND, FOR EACH WATER YEAR

\begin{tabular}{|c|c|c|c|c|c|c|c|c|c|c|c|c|}
\hline YEAR & $\propto \mathrm{T}$ & $\mathrm{NOV}$ & $\mathrm{DEC}$ & JAN & FEB & MAR & APR & MAY & JUNE & JULY & AUG & SEP \\
\hline $\begin{array}{l}1951 \\
1952 \\
1953 \\
1954 \\
1955\end{array}$ & $\begin{array}{l}0.00 \\
1.91 \\
0.00 \\
0.22 \\
1.28\end{array}$ & $\begin{array}{l}0.00 \\
0.55 \\
0.51 \\
0.71 \\
0.04\end{array}$ & $\begin{array}{l}0.00 \\
0.82 \\
0.59 \\
0.09 \\
0.24\end{array}$ & $\begin{array}{l}0.19 \\
2.02 \\
0.49 \\
0.15 \\
0.24\end{array}$ & $\begin{array}{l}0.42 \\
0.10 \\
0.95 \\
0.10 \\
1.70\end{array}$ & $\begin{array}{l}0.06 \\
0.35 \\
0.20 \\
1.48 \\
1.53\end{array}$ & $\begin{array}{l}0.12 \\
0.41 \\
0.09 \\
0.05 \\
0.00\end{array}$ & $\begin{array}{l}0.14 \\
3.44 \\
0.01 \\
0.41 \\
0.00\end{array}$ & $\begin{array}{l}0.00 \\
1.21 \\
0.00 \\
0.00 \\
0.00\end{array}$ & $\begin{array}{l}0.00 \\
1.03 \\
0.99 \\
1.67 \\
0.74\end{array}$ & $\begin{array}{c}3.41 \\
10.7 \\
4.82 \\
0.02 \\
0.34\end{array}$ & $\begin{array}{l}0.07 \\
0.26 \\
0.00 \\
1.51 \\
0.00\end{array}$ \\
\hline $\begin{array}{l}1956 \\
1957 \\
1958 \\
1959 \\
1960\end{array}$ & $\begin{array}{c}0.00 \\
0.88 \\
10.0 \\
0.00 \\
0.00\end{array}$ & $\begin{array}{c}0.01 \\
0.00 \\
22.0 \\
0.00 \\
3.28\end{array}$ & $\begin{array}{l}0.04 \\
0.54 \\
0.62 \\
0.33 \\
0.79\end{array}$ & $\begin{array}{l}0.09 \\
1.34 \\
0.73 \\
0.39 \\
0.77\end{array}$ & $\begin{array}{l}0.09 \\
0.39 \\
0.88 \\
0.28 \\
0.65\end{array}$ & $\begin{array}{l}0.05 \\
0.12 \\
0.45 \\
0.09 \\
0.14\end{array}$ & $\begin{array}{l}0.08 \\
1.23 \\
1.39 \\
0.06 \\
0.35\end{array}$ & $\begin{array}{l}0.02 \\
1.70 \\
4.75 \\
0.00 \\
0.13\end{array}$ & $\begin{array}{l}0.00 \\
3.94 \\
0.19 \\
0.00 \\
0.00\end{array}$ & $\begin{array}{l}0.62 \\
2.58 \\
0.49 \\
1.32 \\
0.00\end{array}$ & $\begin{array}{l}0.32 \\
5.00 \\
2.09 \\
0.00 \\
0.00\end{array}$ & $\begin{array}{l}0.00 \\
0.00 \\
0.47 \\
1.20 \\
0.28\end{array}$ \\
\hline $\begin{array}{l}1961 \\
1962 \\
1963 \\
1964 \\
1965\end{array}$ & $\begin{array}{l}0.15 \\
1.36 \\
0.81 \\
0.52 \\
0.00\end{array}$ & $\begin{array}{l}0.00 \\
0.34 \\
0.05 \\
1.20 \\
0.03\end{array}$ & $\begin{array}{l}0.00 \\
0.25 \\
0.11 \\
0.05 \\
0.38\end{array}$ & $\begin{array}{l}0.05 \\
0.27 \\
0.19 \\
0.46 \\
0.46\end{array}$ & $\begin{array}{l}0.41 \\
0.57 \\
0.19 \\
0.18 \\
0.46\end{array}$ & $\begin{array}{l}0.18 \\
0.22 \\
0.19 \\
0.18 \\
0.32\end{array}$ & $\begin{array}{l}0.12 \\
0.02 \\
0.05 \\
0.23 \\
0.30\end{array}$ & $\begin{array}{l}0.00 \\
0.00 \\
0.00 \\
0.07 \\
0.09\end{array}$ & $\begin{array}{l}0.00 \\
0.00 \\
0.01 \\
0.00 \\
0.08\end{array}$ & $\begin{array}{l}1.08 \\
0.00 \\
0.02 \\
0.00 \\
1.59\end{array}$ & $\begin{array}{c}3.68 \\
0.00 \\
14.0 \\
0.25 \\
3.79\end{array}$ & $\begin{array}{c}21.5 \\
0.26 \\
0.26 \\
0.55 \\
0.92\end{array}$ \\
\hline $\begin{array}{l}1966 \\
1967 \\
1968 \\
1969 \\
1970\end{array}$ & $\begin{array}{l}4.03 \\
0.01 \\
0.05 \\
0.27 \\
0.12\end{array}$ & $\begin{array}{l}0.52 \\
0.29 \\
0.10 \\
0.26 \\
0.37\end{array}$ & $\begin{array}{l}3.83 \\
0.68 \\
0.00 \\
0.14 \\
0.21\end{array}$ & $\begin{array}{l}0.32 \\
0.90 \\
0.05 \\
0.70 \\
0.19\end{array}$ & $\begin{array}{l}0.43 \\
0.77 \\
0.56 \\
0.67 \\
0.35\end{array}$ & $\begin{array}{l}0.18 \\
0.17 \\
0.28 \\
0.59 \\
0.26\end{array}$ & $\begin{array}{l}0.07 \\
0.01 \\
0.12 \\
0.13 \\
0.21\end{array}$ & $\begin{array}{l}0.02 \\
0.06 \\
0.03 \\
2.09 \\
0.01\end{array}$ & $\begin{array}{c}0.00 \\
0.15 \\
0.02 \\
14.7 \\
0.09\end{array}$ & $\begin{array}{c}2.68 \\
13.6 \\
4.48 \\
0.39 \\
2.43\end{array}$ & $\begin{array}{c}4.28 \\
0.23 \\
5.24 \\
18.8 \\
2.63\end{array}$ & $\begin{array}{l}3.00 \\
0.14 \\
0.08 \\
5.68 \\
7.66\end{array}$ \\
\hline
\end{tabular}


NORTH WASH BASIN

09334000 NORTH WASH NEAR HANKSVILLE, UT-Continued

ANNUAL PEAK DISCHARGE, IN OUBIC FEET PER SECOND, AND CORRESPONDING GAGE HEIGHT, IN FEET, FOR EACH WATER YEAR

\begin{tabular}{|c|c|c|c|c|c|c|c|c|c|c|c|}
\hline $\begin{array}{l}\text { WATER } \\
\text { YEAR }\end{array}$ & DATE & $\begin{array}{c}\text { GAGE } \\
\text { HEIGHT }\end{array}$ & $\begin{array}{c}\text { PEAK } \\
\text { DISCHARGE }\end{array}$ & $\begin{array}{l}\text { WATEER } \\
\text { YEAR }\end{array}$ & DATE & $\begin{array}{c}\text { GAGE } \\
\text { HEIGHT }\end{array}$ & $\begin{array}{c}\text { PEAK } \\
\text { DISCHARGE }\end{array}$ & $\begin{array}{l}\text { WATER } \\
\text { YEAR }\end{array}$ & DATE & $\begin{array}{c}\text { GAGE } \\
\text { HEIGHT }\end{array}$ & $\begin{array}{c}\text { PEAK } \\
\text { DISCHARGE }\end{array}$ \\
\hline $\begin{array}{l}1950 \\
1951 \\
1952 \\
1953 \\
1954 \\
1955 \\
1956\end{array}$ & $\begin{array}{l}\text { SEPT. 19, } 1950 \\
\text { AUG. } 21,1951 \\
\text { AUG. 07, } 1952 \\
\text { AUG. 14, } 1953 \\
\text { JULY } 25,1954 \\
\text { OCT. 08, } 1954 \\
\text { JULY } 01,1956\end{array}$ & $\begin{array}{l}3.98 \\
3.19 \\
9.24 \\
3.06 \\
2.04 \\
3.40 \\
1.80\end{array}$ & $\begin{array}{r}1080 \\
942 \\
8900 \\
865 \\
273 \\
1050 \\
198\end{array}$ & $\begin{array}{l}1957 \\
1958 \\
1959 \\
1960 \\
1961 \\
1962 \\
1963\end{array}$ & $\begin{array}{l}\text { JUNE } 10,1957 \\
\text { NOW. 02, } 1957 \\
\text { JULY } 29,1959 \\
\text { NOW. 02, } 1959 \\
\text { SEPT.09, } 1961 \\
\text { OCT. 31, } 1961 \\
\text { AUG. 06, } 1963\end{array}$ & $\begin{array}{l}2.75 \\
4.02 \\
2.29 \\
2.40 \\
5.80 \\
1.85 \\
4.93\end{array}$ & $\begin{array}{r}592 \\
1790 \\
529 \\
630 \\
2630 \\
188 \\
1810\end{array}$ & $\begin{array}{l}1964 \\
1965 \\
1966 \\
1967 \\
1968 \\
1969 \\
1970\end{array}$ & $\begin{array}{l}\text { NOV. } 16,1963 \\
\text { AUG. } 17,1965 \\
\text { JULY } 21,1966 \\
\text { JULY } 17,1967 \\
\text { AUG. 01, } 1968 \\
\text { JUNE 24, } 1969 \\
\text { SEPT.12, } 1970\end{array}$ & $\begin{array}{l}1.27 \\
-.89 \\
3.89 \\
6.24 \\
4.45 \\
7.50 \\
4.36\end{array}$ & $\begin{array}{r}168 \\
2780 \\
2010 \\
5010 \\
2680 \\
6770 \\
1980\end{array}$ \\
\hline
\end{tabular}

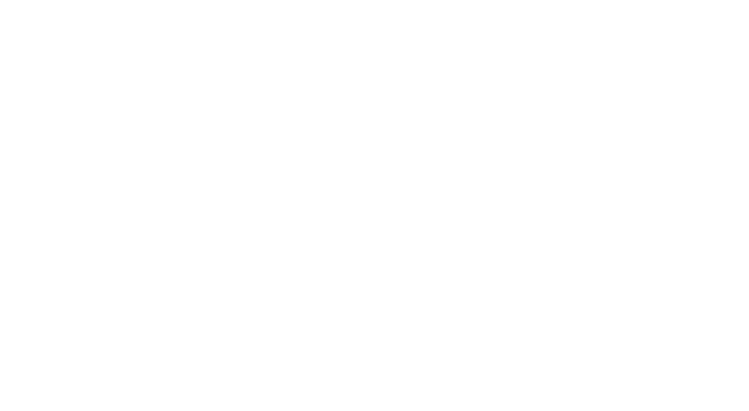

FARLEY CANYON BASTN

09334300 FARLEY CANYON NEAR HITE, UT

LOCATION.-Lat $37^{\circ} 49^{\prime} 00^{\prime \prime}$, long $110^{\circ} 25^{\prime} 00^{\prime \prime}$, in SW' sec.30, T.34 S., R.14 E. (unsurveyed), San Juan County, Hydrologic Unit 14070001, $1.6 \mathrm{mi}$ above mouth and $2 \mathrm{mi}$ east of Hite.

DRAINAGE AREA. $--11.6 \mathrm{mi}^{2}$.

PERIOD OF RECORD AVAIIABLE.--Water years 1961-68, annual peak discharge only.

GAGE.--Crest-stage gage. Altitude of gage is 3,560 ft from topographic map.

ANNUAL PEAK DISCHARGE, IN OBBIC FEET PER SECOND, AND CORRESPONDING GAGE HEIGHT, IN FEET, FOR EACH WATER YEAR

\begin{tabular}{|c|c|c|c|c|c|c|c|c|c|c|c|}
\hline $\begin{array}{l}\text { WATERR } \\
\text { YEAR }\end{array}$ & DATE & $\begin{array}{c}\text { GAGE } \\
\text { HEIGHT }\end{array}$ & $\begin{array}{c}\text { PEAK } \\
\text { DISCHARGE }\end{array}$ & $\begin{array}{l}\text { WATER } \\
\text { YEAR }\end{array}$ & DATE: & $\begin{array}{c}\text { GAGE } \\
\text { HEIGHT }\end{array}$ & $\begin{array}{c}\text { PEAK } \\
\text { DISCHARGE }\end{array}$ & $\begin{array}{l}\text { WATER } \\
\text { YEAR }\end{array}$ & DATE & $\begin{array}{c}\text { GAGE } \\
\text { HEIGHT }\end{array}$ & $\begin{array}{c}\text { PEAK } \\
\text { DISCHARGE }\end{array}$ \\
\hline $\begin{array}{l}1961 \\
1962 \\
1963\end{array}$ & $\begin{array}{l}\text { SEPT. 08, } 1961 \\
\text { OCT. 31, } 1961 \\
\text { AUG. 31, } 1963\end{array}$ & $\begin{array}{l}22.40 \\
11.32 \\
15.00\end{array}$ & $\begin{array}{r}7500 \\
800 \\
2600\end{array}$ & $\begin{array}{l}1964 \\
1965 \\
1966\end{array}$ & $\begin{array}{l}\text { APR. } 06,1964 \\
\text { AUG. } 14,1965 \\
\text { NOV. } 17,1965\end{array}$ & $\begin{array}{rr}4 & 9.80 \\
5 & 9.50 \\
5 & 11.93\end{array}$ & $\begin{array}{r}24 \\
10 \\
1050\end{array}$ & $\begin{array}{l}1967 \\
1968\end{array}$ & $\begin{array}{l}\text { NOV. 08, } 1966 \\
\text { AUG. 01, } 1968\end{array}$ & - & $\begin{array}{l}30 \\
45\end{array}$ \\
\hline
\end{tabular}

WHITE CANYON BASIN

09334400 FRY CANYON NEAR HITE, UT

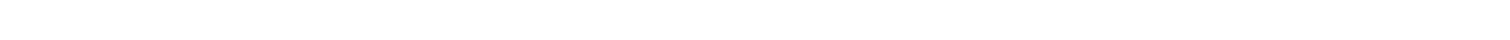
$2 \mathrm{mi}$ southeast of Fry Canyon store, $3 \mathrm{mi}$ above mouth, and $22 \mathrm{mi}$ southeast of Hite.

DRAINAGE AREA. $-20.9 \mathrm{mi}^{2}$.

MEAN BASIN ELEVATION. $-6,250 \mathrm{ft}$.

PERIOD OF RECORD AVAILABLE.--Water years 1959-73, annual peak discharge only.

GAGE.-Crest-stage gage. Altitude of gage is 5,350 ft from topographic map. 
WHITE CANYON BASIN

09334400 FRY CANYON NEAR HITE, UT--Continued

ANNAL PEAK DISCHARGE, IN CUBIC FEET PER SECOND, AND CORRESPONDING GAGE HEIGHT, IN FEET, FOR EACH WATER YEAR

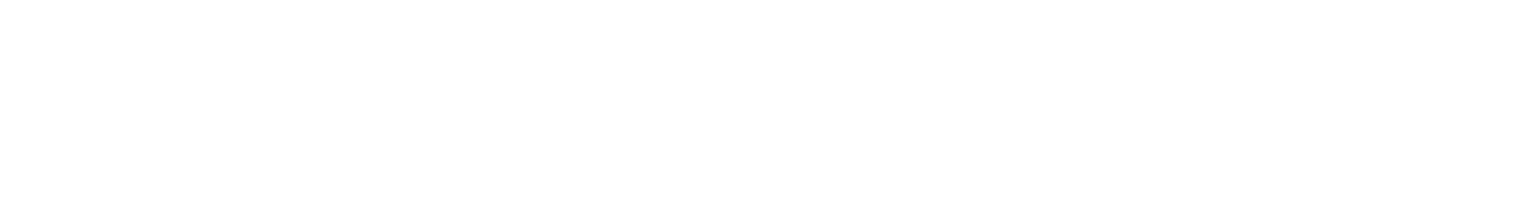

09334500 WHITE CANYON NEAR HANKSVILLLE, UT

LOCATION.--Lat $37^{\circ} 47^{\prime} 55^{\prime \prime}$, long $110^{\circ} 22^{\prime} 33^{\prime \prime}$, San Juan County, Hydrologic Unit 14070001 , on right bank 300 ft downstream from ford on old State Highway 95, $2.9 \mathrm{mi}$ downstream from bridge on State Highway 95, and $42 \mathrm{mi}$ southeast of Hanksville.

DRAINAGE AREA. $-276 \mathrm{mi}^{2}$.

MEAN BASIN ELEVATION. $-6,090 \mathrm{ft}$.

PERIOD OF RECORD AVAILABLE.--May 1950 to September 1970.

GAGE.--Water-stage recorder. Altitude of gage is 3,700 ft from river-profile map.

AVERAGE DISCHARGE. --20 years, $5.10 \mathrm{ft}^{3} / \mathrm{s}, 3,690 \mathrm{acre}-\mathrm{ft} / \mathrm{yr}$.

EXIREMES FOR PERIOD OF RECORD.--Maximum discharge, 7,390 ft ${ }^{3} / \mathrm{s}$ July 31, 1953, gage height, $7.54 \mathrm{ft}$, from rating curve extended above $550 \mathrm{ft}^{3} / \mathrm{s}$ on basis of slope-area measurements at gage heights $2.99 \mathrm{ft}$ and $7.54 \mathrm{ft}$; no flow for most of time in each year.

LOWEST MEAN DISCHARGE, IN CUBIC FEET PER SECOND, AND RANKING FOR THE INDICATED NUMBER OF CONSECUTIVE DAYS FOR EACH CLIMATIC YEAR, APRIL 1-MARCH 31

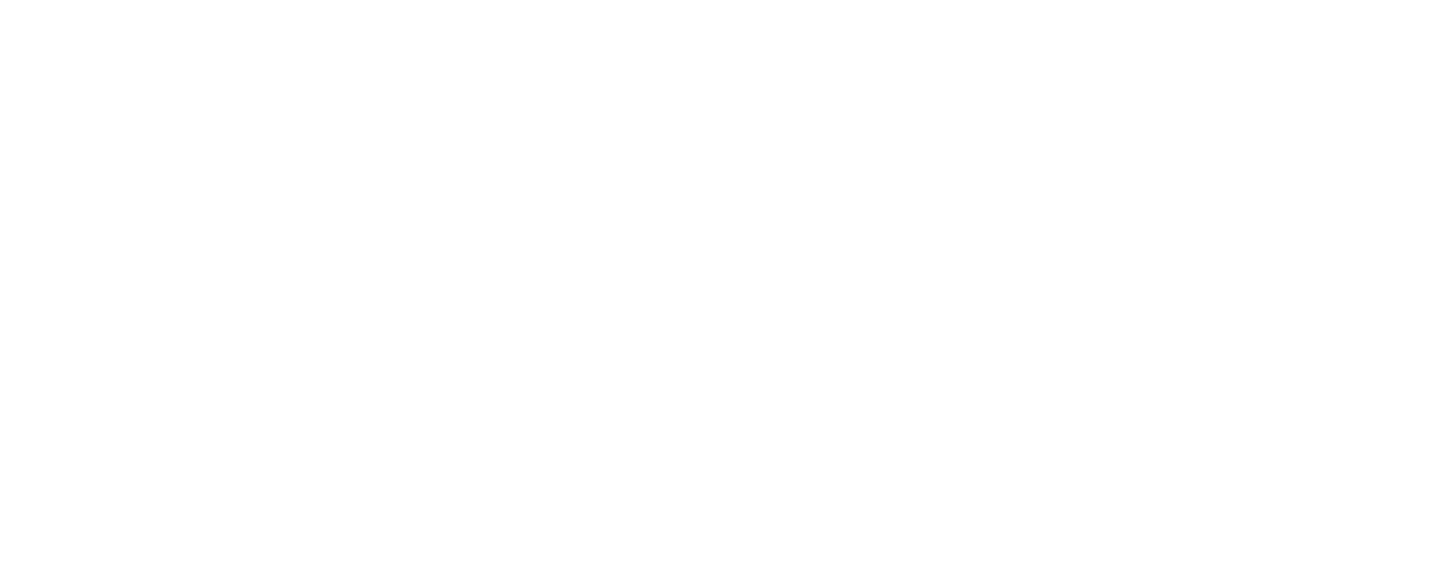

HIGHEST MEAN DISCHARGE, IN CUBIC FEET PER SBCOND, AND RANKING FOR THE INDICATED NUMBER OF CONSECUTIVE DAYS FOR EACH WATER YEAR, OCTCBER 1-SEPTEMBER 30

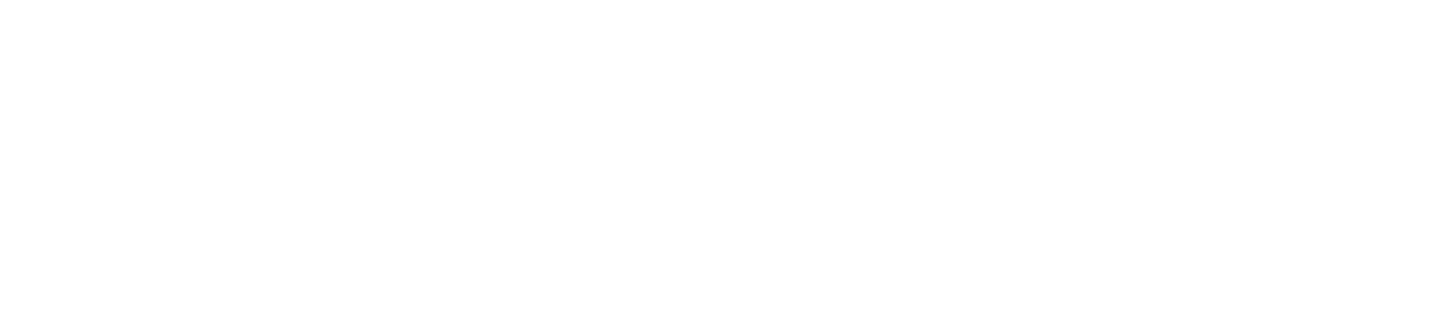


WHITE CANYON BASIN

09334500 WHITE CANYON NEAR HANKSVILLE, UT-Continued

HIGHEST MEAN DISCHARGE, IN OBIC FEET PER SECOND, AND RANKING FOR THE INDICATED NUMBER OF CONSECUTIVE DAYS FOR EACH WATER YEAR, OCTOBER 1-SEPTEMBER 30--Continued

\begin{tabular}{|c|c|c|c|c|c|c|c|c|c|c|c|c|c|c|c|c|c|c|c|}
\hline YEAR & 1 & & 3 & & 7 & & 15 & & $\begin{array}{l}\text { CONS } \\
30\end{array}$ & EOUT & $\begin{array}{l}E \text { DAYS } \\
60\end{array}$ & & 90 & & 120 & & 183 & & ALL \\
\hline $\begin{array}{l}1966 \\
1967 \\
1968 \\
1969 \\
1970\end{array}$ & $\begin{array}{l}402 \\
713 \\
855 \\
282 \\
274\end{array}$ & $\begin{array}{r}9 \\
6 \\
4 \\
13 \\
14\end{array}$ & $\begin{array}{c}147 \\
362 \\
398 \\
98.0 \\
112\end{array}$ & $\begin{array}{r}12 \\
5 \\
4 \\
16 \\
15\end{array}$ & $\begin{array}{c}63.0 \\
156 \\
179 \\
43.0 \\
48.0\end{array}$ & $\begin{array}{r}12 \\
5 \\
4 \\
16 \\
15\end{array}$ & $\begin{array}{l}29.0 \\
74.0 \\
86.0 \\
20.0 \\
22.0\end{array}$ & $\begin{array}{r}13 \\
6 \\
4 \\
17 \\
16\end{array}$ & $\begin{array}{l}18.0 \\
47.0 \\
43.0 \\
14.0 \\
15.0\end{array}$ & $\begin{array}{r}13 \\
5 \\
7 \\
17 \\
15\end{array}$ & $\begin{array}{l}16.0 \\
25.0 \\
22.0 \\
11.0 \\
12.0\end{array}$ & $\begin{array}{r}11 \\
6 \\
9 \\
15 \\
13\end{array}$ & $\begin{array}{c}13.0 \\
18.0 \\
14.0 \\
7.50 \\
8.20\end{array}$ & $\begin{array}{r}10 \\
7 \\
9 \\
15 \\
13\end{array}$ & $\begin{array}{c}10.0 \\
14.0 \\
11.0 \\
5.70 \\
6.20\end{array}$ & $\begin{array}{r}11 \\
6 \\
10 \\
15 \\
1\end{array}$ & $\begin{array}{l}7.10 \\
9.30 \\
8.00 \\
4.00 \\
5.60\end{array}$ & $\begin{array}{r}11 \\
7 \\
10 \\
15 \\
13\end{array}$ & $\begin{array}{l}4.20 \\
7.40 \\
4.10 \\
2.40 \\
3.70\end{array}$ \\
\hline
\end{tabular}

DURATION OF DISCHARGE FOR EACH WATER YEAR

$\begin{array}{llllllllllllllllllllllllllllllllllllllll}\text { CAASS } 0 & 1 & 2 & 3 & 4 & 5 & 6 & 7 & 8 & 9 & 10 & 11 & 12 & 13 & 14 & 15 & 16 & 17 & 18 & 19 & 20 & 21 & 22 & 23 & 24 & 25 & 26 & 27 & 28 & 29 & 30 & 31 & 32 & 33 & 34\end{array}$ YEAR

NUMBER OF DAYS IN OLASS CUBIC FEET PER SECOND

\begin{tabular}{|c|c|c|c|c|c|c|c|c|c|c|c|c|c|c|c|c|c|c|c|c|c|c|c|c|c|c|c|c|c|}
\hline $\begin{array}{l}1951357 \\
1952230 \\
1953282 \\
1954319 \\
1955290\end{array}$ & & & $\begin{array}{r}6 \\
11 \\
2 \\
13\end{array}$ & $\begin{array}{l}4 \\
3 \\
1 \\
4\end{array}$ & $\begin{array}{l}7 \\
7 \\
3 \\
7\end{array}$ & $\begin{array}{l}2 \\
1\end{array}$ & $\begin{array}{r}1 \\
12 \\
6 \\
5 \\
4\end{array}$ & $\begin{array}{r}13 \\
3 \\
3 \\
6\end{array}$ & $\begin{array}{r}18 \\
5 \\
5 \\
4\end{array}$ & $\begin{array}{r}11 \\
6 \\
1 \\
6\end{array}$ & $\begin{array}{l}1 \\
5 \\
4 \\
3 \\
5\end{array}$ & $\begin{array}{r}11 \\
6 \\
3 \\
2\end{array}$ & $\begin{array}{r}15 \\
1 \\
1\end{array}$ & $\begin{array}{l}4 \\
6 \\
1 \\
4\end{array}$ & $\begin{array}{l}3 \\
1 \\
4\end{array}$ & $\begin{array}{l}1 \\
8 \\
2\end{array}$ & $\begin{array}{l}1 \\
3 \\
3 \\
2 \\
2\end{array}$ & $\begin{array}{l}3 \\
5 \\
6 \\
3\end{array}$ & $\begin{array}{l}1 \\
5 \\
1\end{array}$ & $\begin{array}{l}1 \\
1 \\
1\end{array}$ & $\begin{array}{l}2 \\
1 \\
2 \\
3 \\
2\end{array}$ & $\begin{array}{l}2 \\
1 \\
1 \\
1\end{array}$ & $\begin{array}{l}1 \\
1 \\
2\end{array}$ & $\begin{array}{l}1 \\
1\end{array}$ & 3 & 1 & 1 & $\begin{array}{ll}1 & \\
1 & 1\end{array}$ & $\begin{array}{r}295.5 \\
1544.3 \\
4286.9 \\
1031.4 \\
3035.8\end{array}$ \\
\hline $\begin{array}{l}1956338 \\
1957247 \\
1958256 \\
1959351 \\
1960324\end{array}$ & & & $\begin{array}{l}2 \\
4\end{array}$ & $\begin{array}{l}1 \\
8\end{array}$ & $\begin{array}{l}2 \\
7\end{array}$ & $\begin{array}{l}2 \\
3\end{array}$ & $\begin{array}{l}3 \\
6 \\
4\end{array}$ & $\begin{array}{l}4 \\
3 \\
1\end{array}$ & $\begin{array}{r}4 \\
11 \\
8 \\
2 \\
4\end{array}$ & $\begin{array}{l}2 \\
5 \\
5\end{array}$ & $\begin{array}{l}1 \\
9 \\
6 \\
1 \\
3\end{array}$ & $\begin{array}{r}2 \\
7 \\
11\end{array}$ & $\begin{array}{r}11 \\
8\end{array}$ & $\begin{array}{r}1 \\
3 \\
10 \\
1 \\
1\end{array}$ & $\begin{array}{l}1 \\
4 \\
7 \\
4 \\
1\end{array}$ & $\begin{array}{l}1 \\
5 \\
9 \\
2 \\
2\end{array}$ & $\begin{array}{l}1 \\
3 \\
4\end{array}$ & $\begin{array}{l}2 \\
7 \\
9 \\
2\end{array}$ & $\begin{array}{r}1 \\
5 \\
13 \\
2 \\
3\end{array}$ & $\begin{array}{l}1 \\
5 \\
5\end{array}$ & $\begin{array}{l}5 \\
3\end{array}$ & $\begin{array}{l}1 \\
4 \\
1\end{array}$ & $\begin{array}{l}1 \\
2\end{array}$ & & 1 & 1 & 1 & & $\begin{array}{r}329.3 \\
2706.8 \\
2543.9 \\
207.1 \\
1246.3\end{array}$ \\
\hline $\begin{array}{l}1961316 \\
1962291 \\
1963322 \\
1964314 \\
1965324\end{array}$ & & & 11 & $\begin{array}{l}1 \\
4 \\
1\end{array}$ & $\begin{array}{l}1 \\
2 \\
1 \\
3\end{array}$ & $\begin{array}{l}1 \\
1 \\
1 \\
1\end{array}$ & $\begin{array}{l}2 \\
2 \\
1 \\
2 \\
2\end{array}$ & 2 & $\begin{array}{l}5 \\
2 \\
2 \\
5 \\
3\end{array}$ & $\begin{array}{l}1 \\
1 \\
1 \\
2\end{array}$ & $\begin{array}{l}3 \\
6 \\
7 \\
1 \\
3\end{array}$ & $\begin{array}{l}4 \\
2 \\
3 \\
4 \\
4\end{array}$ & $\begin{array}{l}2 \\
1 \\
1 \\
4\end{array}$ & $\begin{array}{l}3 \\
9 \\
2 \\
3 \\
2\end{array}$ & $\begin{array}{r}11 \\
3 \\
3 \\
1\end{array}$ & $\begin{array}{l}4 \\
3 \\
1 \\
3 \\
1\end{array}$ & $\begin{array}{l}3 \\
5\end{array}$ & $\begin{array}{l}5 \\
3 \\
2 \\
2 \\
1\end{array}$ & $\begin{array}{l}3 \\
4 \\
3 \\
2 \\
1\end{array}$ & $\begin{array}{l}1 \\
2 \\
4 \\
2\end{array}$ & $\begin{array}{l}5 \\
2 \\
2 \\
1 \\
5\end{array}$ & $\begin{array}{l}1 \\
2\end{array}$ & $\begin{array}{l}2 \\
1 \\
2 \\
1\end{array}$ & $\begin{array}{l}1 \\
5\end{array}$ & $\begin{array}{l}1 \\
2 \\
1\end{array}$ & 1 & 1 & 1 & $\begin{array}{l}3931.3 \\
2920.5 \\
1798.2 \\
1098.6 \\
2321.0\end{array}$ \\
\hline $\begin{array}{l}1966312 \\
1967312 \\
1968312 \\
1969283 \\
1970327\end{array}$ & $\begin{array}{ll}4 & 3 \\
1 & \end{array}$ & $\begin{array}{ll}1 & 4 \\
1 & \end{array}$ & $\begin{array}{l}5 \\
5 \\
4\end{array}$ & $\begin{array}{l}1 \\
6\end{array}$ & $\begin{array}{l}1 \\
3\end{array}$ & $\begin{array}{l}2 \\
1 \\
1 \\
4 \\
2\end{array}$ & $\begin{array}{l}3 \\
5 \\
7 \\
6\end{array}$ & $\begin{array}{l}2 \\
1 \\
2 \\
2 \\
3\end{array}$ & $\begin{array}{l}6 \\
4 \\
6 \\
9 \\
3\end{array}$ & $\begin{array}{l}2 \\
2 \\
4 \\
8\end{array}$ & $\begin{array}{l}7 \\
3 \\
5 \\
6\end{array}$ & $\begin{array}{l}3 \\
3\end{array}$ & $\begin{array}{l}4 \\
3 \\
5 \\
6 \\
1\end{array}$ & $\begin{array}{l}3 \\
3 \\
5 \\
3 \\
1\end{array}$ & $\begin{array}{l}3 \\
2 \\
2 \\
2\end{array}$ & & $\frac{1}{2}$ & $\begin{array}{l}1 \\
1 \\
3\end{array}$ & $\begin{array}{l}1 \\
5 \\
1 \\
1 \\
1\end{array}$ & $\begin{array}{l}1 \\
2 \\
1 \\
2 \\
1\end{array}$ & $\begin{array}{l}2 \\
1 \\
2\end{array}$ & $\begin{array}{l}3 \\
2\end{array}$ & $\frac{1}{2}$ & $\begin{array}{l}1 \\
1 \\
1\end{array}$ & $\begin{array}{l}1 \\
2\end{array}$ & & & 1 & $\begin{array}{r}1533.4 \\
2702.7 \\
1507.9 \\
869.4 \\
1357.5\end{array}$ \\
\hline
\end{tabular}

DURATION TABLE OF DISGAARGE FOR WATER YEARS 1951-70

\begin{tabular}{|c|c|c|c|c|c|c|c|c|c|c|c|c|c|c|c|c|c|c|c|}
\hline ASS & $\begin{array}{c}\text { OBIIC } \\
\text { FEET } \\
\text { PER } \\
\text { SECOND }\end{array}$ & TOTAL & $\begin{array}{c}\text { ACOU- } \\
\text { MU- } \\
\text { LATED } \\
\text { DAYS }\end{array}$ & $\begin{array}{l}\text { PER- } \\
\text { CENT } \\
\text { DAYS }\end{array}$ & aASS & $\begin{array}{c}\text { QUBIC } \\
\text { FEET } \\
\text { PER } \\
\text { SECOND }\end{array}$ & $\begin{array}{l}\text { TOTAL } \\
\text { DAYS }\end{array}$ & $\begin{array}{l}\text { ACQU- } \\
\text { MU- } \\
\text { LATED } \\
\text { DAYS }\end{array}$ & $\begin{array}{l}\text { PER- } \\
\text { CENT } \\
\text { DAYS }\end{array}$ & OASS & $\begin{array}{c}\text { OUBIC } \\
\text { FEET } \\
\text { PER } \\
\text { SECOND }\end{array}$ & $\begin{array}{l}\text { TOTAL } \\
\text { DAYS }\end{array}$ & $\begin{array}{l}\text { ACQU- } \\
\text { MU- } \\
\text { LATED } \\
\text { DAYS }\end{array}$ & $\begin{array}{l}\text { PER- } \\
\text { CENT } \\
\text { DAYS }\end{array}$ & OLASS & $\begin{array}{c}\text { OUBIC } \\
\text { FEET } \\
\text { PER } \\
\text { SECND }\end{array}$ & $\begin{array}{l}\text { TOTAL } \\
\text { DAYS }\end{array}$ & $\begin{array}{c}\text { ACOU- } \\
\text { MU- } \\
\text { LATED } \\
\text { DAYS }\end{array}$ & $\begin{array}{l}\text { PER- } \\
\text { CENT } \\
\text { DAYS }\end{array}$ \\
\hline $\begin{array}{l}0 \\
1 \\
2 \\
3 \\
4 \\
5 \\
6 \\
7 \\
8\end{array}$ & $\begin{array}{l}0.00 \\
0.01 \\
0.02 \\
0.03 \\
0.04 \\
0.06 \\
0.08 \\
0.12 \\
0.17\end{array}$ & $\begin{array}{r}6107 \\
5 \\
3 \\
2 \\
4 \\
3 \\
79 \\
1 \\
40\end{array}$ & $\begin{array}{l}7304 \\
1197 \\
1192 \\
1189 \\
1187 \\
1183 \\
1180 \\
1101 \\
1100\end{array}$ & $\begin{array}{r}100.0 \\
16.4 \\
16.3 \\
16.3 \\
16.3 \\
16.2 \\
16.2 \\
15.1 \\
15.1\end{array}$ & $\begin{array}{r}9 \\
10 \\
11 \\
12 \\
13 \\
14 \\
15 \\
16 \\
17\end{array}$ & $\begin{array}{l}0.24 \\
0.34 \\
0.49 \\
0.70 \\
0.99 \\
1.40 \\
2.00 \\
2.90 \\
4.10\end{array}$ & $\begin{array}{r}45 \\
27 \\
76 \\
45 \\
106 \\
106 \\
58 \\
79 \\
78 \\
64\end{array}$ & $\begin{array}{r}1060 \\
1015 \\
988 \\
912 \\
867 \\
761 \\
703 \\
624 \\
546\end{array}$ & $\begin{array}{r}14.6 \\
13.9 \\
13.5 \\
12.5 \\
11.9 \\
10.4 \\
9.6 \\
8.5 \\
7.5\end{array}$ & $\begin{array}{l}18 \\
19 \\
20 \\
21 \\
22 \\
23 \\
24 \\
25 \\
26\end{array}$ & $\begin{array}{r}5.8 \\
8.3 \\
12.0 \\
17.0 \\
24.0 \\
34.0 \\
49.0 \\
69.0 \\
98.0\end{array}$ & $\begin{array}{l}65 \\
52 \\
50 \\
40 \\
55 \\
53 \\
35 \\
42 \\
28\end{array}$ & $\begin{array}{r}482 \\
417 \\
365 \\
315 \\
275 \\
220 \\
167 \\
132 \\
90\end{array}$ & $\begin{array}{l}6.6 \\
5.7 \\
5.0 \\
4.3 \\
3.8 \\
3.0 \\
2.3 \\
1.8 \\
1.2\end{array}$ & $\begin{array}{l}27 \\
28 \\
29 \\
30 \\
31 \\
32 \\
33 \\
34\end{array}$ & $\begin{array}{r}140.0 \\
200.0 \\
280.0 \\
400.0 \\
580.0 \\
820.0 \\
1200.0\end{array}$ & $\begin{array}{r}19 \\
18 \\
13 \\
3 \\
4 \\
4 \\
1\end{array}$ & $\begin{array}{r}62 \\
43 \\
25 \\
12 \\
9 \\
5 \\
1\end{array}$ & $\begin{array}{l}0.7 \\
0.7 \\
0.1 \\
0.1 \\
0.0\end{array}$ \\
\hline
\end{tabular}

MONTHLY MEAN DISCHARGES, IN CUBIC FEET PER SECOND, FOR EACH WATER YEAR

$\begin{array}{lcccccccccccc}\text { YEAR } & \text { OCT } & \text { NOV } & \text { DEC } & \text { JAN } & \text { FEB } & \text { MAR } & \text { APR } & \text { MAY } & \text { JUNE } & \text { JULY } & \text { AUG } & \text { SEP } \\ 1951 & 0.00 & 0.00 & 0.00 & 0.00 & 0.00 & 0.00 & 0.00 & 0.00 & 0.00 & 0.39 & 9.15 & 0.00 \\ 1952 & 0.00 & 3.56 & 13.0 & 10.9 & 0.00 & 2.26 & 6.87 & 0.24 & 0.06 & 6.70 & 2.87 & 3.84 \\ 1953 & 0.01 & 0.02 & 0.10 & 0.00 & 1.33 & 0.97 & 3.27 & 0.00 & 0.00 & 72.5 & 60.3 & 0.00 \\ 1954 & 6.76 & 3.87 & 0.03 & 0.00 & 0.04 & 1.81 & 0.13 & 3.53 & 2.88 & 1.31 & 0.00 & 13.6 \\ 1955 & 76.7 & 2.78 & 0.09 & 0.00 & 2.37 & 0.17 & 0.00 & 0.00 & 0.00 & 3.53 & 12.6 & 0.00 \\ & & & & & & & & & & & & \\ 1956 & 0.00 & 0.20 & 2.99 & 0.65 & 0.00 & 0.00 & 0.00 & 0.00 & 0.00 & 0.58 & 6.21 & 0.00 \\ 1957 & 0.00 & 0.00 & 0.02 & 0.03 & 3.03 & 0.42 & 14.9 & 14.7 & 9.97 & 8.10 & 36.8 & 0.42 \\ 1958 & 16.4 & 27.6 & 0.10 & 0.00 & 11.8 & 5.06 & 16.6 & 1.56 & 0.00 & 0.00 & 1.00 & 4.58 \\ 1959 & 0.25 & 0.00 & 0.00 & 0.00 & 0.08 & 0.00 & 0.77 & 0.00 & 0.00 & 0.00 & 4.81 & 0.82 \\ 1960 & 0.86 & 6.65 & 11.9 & 0.48 & 0.10 & 1.87 & 0.00 & 0.00 & 0.02 & 2.40 & 14.9 & 1.32\end{array}$


WHTTE CANYON BASIN

09334500 WHITE CANYON NEAR HANKSVILLE, UT--Continued

MONTHLY MEAN DISCHARGES, IN CUBIC FEET PER SECOND, FOR EACH WATER YEAR--Continued

$\begin{array}{lcccccccccccc}\text { YEAR } & \text { OCT } & \text { NOV } & \text { DEC } & \text { JAN } & \text { FEB } & \text { MAR } & \text { APR } & \text { MAY } & \text { JUNE } & \text { JULY } & \text { AUG } & \text { SEP } \\ 1961 & 8.06 & 2.73 & 0.00 & 0.11 & 0.00 & 0.53 & 7.77 & 0.48 & 0.00 & 0.45 & 41.8 & 67.4 \\ 1962 & 27.6 & 2.85 & 0.00 & 0.00 & 12.5 & 4.35 & 3.99 & 0.00 & 8.37 & 0.26 & 1.07 & 36.1 \\ 1963 & 2.70 & 2.34 & 0.00 & 0.00 & 1.28 & 0.00 & 0.00 & 0.00 & 0.00 & 0.00 & 47.4 & 4.60 \\ 1964 & 1.23 & 6.77 & 0.00 & 0.00 & 0.00 & 0.00 & 4.22 & 0.54 & 0.00 & 8.41 & 12.9 & 1.84 \\ 1965 & 0.00 & 0.00 & 2.75 & 0.00 & 0.00 & 0.24 & 8.01 & 0.35 & 0.00 & 19.9 & 24.3 & 20.3 \\ & & & & & & & & & & & & \\ 1966 & 8.06 & 13.8 & 17.7 & 0.00 & 0.00 & 1.46 & 1.13 & 0.00 & 0.00 & 2.13 & 0.26 & 5.53 \\ 1967 & 7.33 & 16.0 & 9.58 & 0.00 & 0.00 & 0.00 & 0.00 & 2.25 & 4.39 & 39.3 & 7.12 & 1.97 \\ 1968 & 0.00 & 0.37 & 0.79 & 0.01 & 0.38 & 1.82 & 3.52 & 0.00 & 0.19 & 4.27 & 37.4 & 0.00 \\ 1969 & 0.09 & 0.10 & 0.00 & 3.63 & 0.85 & 1.00 & 0.56 & 0.02 & 0.00 & 8.39 & 13.5 & 0.05 \\ 1970 & 6.04 & 4.00 & 0.00 & 0.00 & 0.00 & 0.81 & 9.60 & 0.00 & 0.05 & 3.84 & 13.8 & 6.31\end{array}$

ANNUAL PEAK DISCHARGE, IN CUBIC FEET PER SEOOND, AND CORRESPONDING GAGE HEIGHT, IN FEET, FOR EACH WATER YEAR

\begin{tabular}{|c|c|c|c|c|c|c|c|c|c|c|c|}
\hline $\begin{array}{l}\text { WATER } \\
\text { YEAR }\end{array}$ & DATE & $\begin{array}{l}\text { GAGE } \\
\text { HEIGHT }\end{array}$ & $\begin{array}{c}\text { PEAK } \\
\text { DISCHARGE }\end{array}$ & $\begin{array}{l}\text { WATER } \\
\text { YEAR }\end{array}$ & DATE & $\begin{array}{c}\text { GAGE } \\
\text { HEIGHT }\end{array}$ & $\begin{array}{c}\text { PEAK } \\
\text { DISCHARGE }\end{array}$ & $\begin{array}{l}\text { WATER } \\
\text { YEAR }\end{array}$ & DATE & $\begin{array}{c}\text { GAGE } \\
\text { HEIGHT }\end{array}$ & $\begin{array}{c}\text { PEAK } \\
\text { DISCHARGE }\end{array}$ \\
\hline $\begin{array}{l}1951 \\
1952 \\
1953 \\
1954 \\
1955 \\
1956 \\
1957\end{array}$ & $\begin{array}{l}\text { AUG. } 02,1951 \\
\text { JAN. } 18,1952 \\
\text { JULY } 31,1953 \\
\text { SEPT. 26, } 1954 \\
\text { OCT. } 08,1954 \\
\text { AUG. } 16,1956 \\
\text { AUG. } 30,1957\end{array}$ & $\begin{array}{l}2.66 \\
2.85 \\
7.54 \\
2.53 \\
6.80 \\
2.41 \\
6.30\end{array}$ & $\begin{array}{r}1890 \\
860 \\
7390 \\
804 \\
6350 \\
527 \\
5570\end{array}$ & $\begin{array}{l}1958 \\
1959 \\
1960 \\
1961 \\
1962 \\
1963 \\
1964\end{array}$ & $\begin{array}{l}\text { NOV. } 03,1957 \\
\text { AUG. } 03,1959 \\
\text { AUG. } 23,1960 \\
\text { SEPT. 09, } 1961 \\
\text { SEPT. 20, } 1962 \\
\text { AUG. 06, } 1963 \\
\text { AUG. 02, } 1964\end{array}$ & $\begin{array}{l}2.82 \\
2.64 \\
4.00 \\
7.20 \\
5.27 \\
4.00 \\
4.14\end{array}$ & $\begin{array}{r}939 \\
800 \\
2480 \\
6910 \\
4210 \\
2490 \\
2670\end{array}$ & $\begin{array}{l}1965 \\
1966 \\
1967 \\
1968 \\
1969 \\
1970\end{array}$ & $\begin{array}{l}\text { AUG. } 17,1965 \\
\text { DEC. } 30,1965 \\
\text { JULY } 17,1967 \\
\text { AUG. } 01,1968 \\
\text { AUG. } 29,1969 \\
\text { AUGG. } 05,1970\end{array}$ & $\begin{array}{l}4.88 \\
3.02 \\
4.30 \\
3.95 \\
3.80 \\
3.00\end{array}$ & $\begin{array}{l}3660 \\
1270 \\
2880 \\
2420 \\
2230 \\
1240\end{array}$ \\
\hline
\end{tabular}

\begin{tabular}{|c|c|c|c|c|c|c|}
\hline MAC & NITUDE & $\begin{array}{l}\text { AND PRCBA } \\
\text { BASED }\end{array}$ & $\begin{array}{l}\text { Y OF } \\
\text { LIMAT }\end{array}$ & $\begin{array}{l}\text { LOW } \\
\text { IRS I }\end{array}$ & AAN & RGE \\
\hline \multirow{2}{*}{$\begin{array}{l}\text { PERIOD } \\
\text { (CON- } \\
\text { SEOU- } \\
\text { TIVE } \\
\text { DAYS) }\end{array}$} & \multicolumn{6}{|c|}{$\begin{array}{l}\text { DISCHARGE, IN CUBIC FEET PER SECOND, FOR } \\
\text { INDICATED RECURRENCE INIERNAL, IN YEARS, AND } \\
\text { ANNUAL NONEXCEEDANCE PROBABILITY, IN PERCENT }\end{array}$} \\
\hline & $\begin{array}{c}2 \\
50 \%\end{array}$ & $\begin{array}{c}5 \\
208\end{array}$ & $\begin{array}{l}\text { I0 } \\
\text { I08 }\end{array}$ & $\begin{array}{l}20 \\
58\end{array}$ & $\begin{array}{l}50 \\
28\end{array}$ & $\begin{array}{r}100 \\
18\end{array}$ \\
\hline I & 0.00 & - & - & - & - & - \\
\hline 7 & 0.00 & - & - & - & -- & - \\
\hline 14 & 0.00 & -- & -- & -- & - & -- \\
\hline 30 & 0.00 & - & - & -- & - & -- \\
\hline 60 & 0.00 & - & -- & -- & - & - \\
\hline 90 & 0.00 & - & -- & - & - & -- \\
\hline
\end{tabular}

COLORADO RIVER MAIN STFM

09335000 COLORADO RIVER AT HITE, UT

LOCATION.--Lat $37^{\circ} 48^{\prime} 30^{\prime \prime}$, long $110^{\circ} 26^{\prime} 55^{\prime \prime}$, in N/s sec.35, T.34 S., R.13 E., San Juan County, Hydrologic Unit 14020001 , on left bank at Hite, $0.25 \mathrm{mi}$ upstream from Trachyte Creek, $1 \mathrm{mi}$ downstream from White Canyon, $8 \mathrm{mi}$ downstream from Dirty Devil River, and 84 mi upstream from San Juan River.

DRAINAGE AREA. $--76,600 \mathrm{mi}^{2}$.

PERIOD OF RECORD AVAILABLE.--August 1947 to September 1958.

GAGE.-Water-stage recorder. Altitude of gage is 3,440 ft from river-profile map.

REMARKS.-Flow affected by transmountain diversions, storage reservoirs, irrigation diversions, and power developments above station.

AVERAGE DISCHARGE.--II years, $13,500 \mathrm{ft}^{3} / \mathrm{s}, 9,775,000$ acre- $\mathrm{ft} / \mathrm{yr}$.

EXIREYES FOR PERIOD OF RBCORD.--Maximum discharge, 105,600 ft ${ }^{3} / \mathrm{s}$ June 12, 1957; maximum gage height, $17.20 \mathrm{ft}$ June 11, I952; minimum discharge, 2,400 $\mathrm{ft}^{3} / \mathrm{s}$ Sept. 17, 18, 1955, gage height, $0.12 \mathrm{ft}$. 
COLORADO RIVER MAIN STEM

09335000 COLORADO RIVER AT HITE, UT-Continued

LOWEST MEAN DISCHARGE, IN OBIC FEET PER SECOND, AND RANKING FOR THE INDICATED NUMBER OF CONSEOUTIVE DAYS FOR EACH OLIMATIC YEAR, APRIL 1-MAROH 31

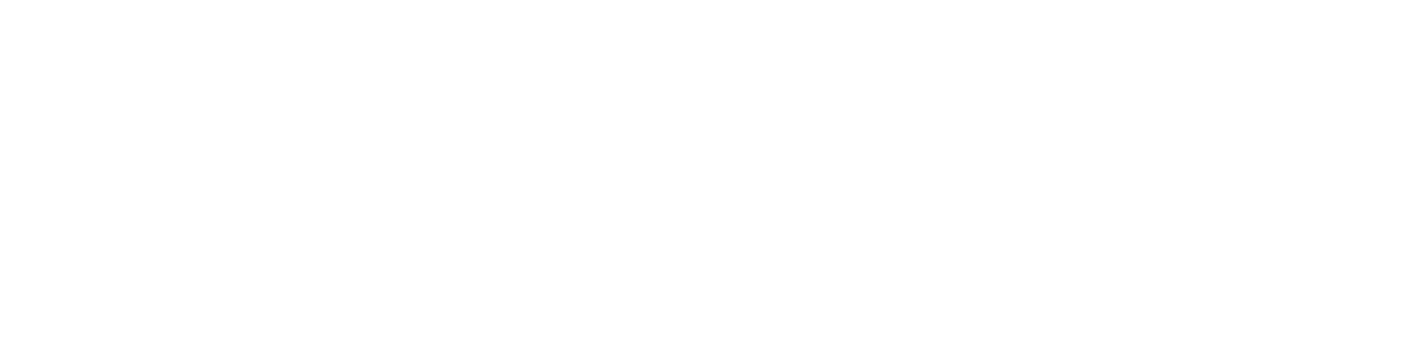

HIGHEST MEAN DISCHARGE, IN OBIC FEET PER SECOND, AND RANKING FOR THE INDICATED NUMBER OF CONSEUTTIVE DAYS FOR EACH WATER YEAR, OCTOBER 1-SEPTEMBER 30

YEAR

\begin{tabular}{|c|c|c|c|c|c|c|c|c|c|c|}
\hline \multirow{2}{*}{ YEAR } & \multicolumn{10}{|c|}{ CONSEUTTVE DAYS } \\
\hline & 3 & 7 & 15 & 30 & 60 & 90 & 120 & 183 & ALL & \\
\hline $\begin{array}{l}1951 \quad 55700 \\
1952101000 \\
195361300 \\
195428000 \\
195530100\end{array}$ & $\begin{array}{r}855400 \\
2100000 \\
659600 \\
1127700 \\
1029100\end{array}$ & $\begin{array}{rr}8 & 53300 \\
1 & 98100 \\
6 & 57800 \\
11 & 26600 \\
10 & 27300\end{array}$ & $\begin{array}{rr}846000 \\
1 & 89900 \\
6 & 51100 \\
11 & 23300 \\
10 & 26000\end{array}$ & $\begin{array}{rr}9 & 43000 \\
2 & 73000 \\
7 & 45800 \\
11 & 18800 \\
10 & 24100\end{array}$ & $\begin{array}{rr}9 & 36000 \\
2 & 71700 \\
7 & 31700 \\
11 & 14300 \\
10 & 23100\end{array}$ & $\begin{array}{rr}7 & 29300 \\
1 & 59400 \\
9 & 24800 \\
11 & 12500 \\
10 & 19500\end{array}$ & $\begin{array}{rr}7 & 25000 \\
1 & 48500 \\
9 & 21000 \\
11 & 11100 \\
10 & 16700\end{array}$ & $\begin{array}{rr}718900 \\
1 & 35000 \\
9 & 16100 \\
11 & 9110 \\
10 & 13000\end{array}$ & $\begin{array}{rr}7 & 12100 \\
1 & 20400 \\
9 & 10700 \\
11 & 6930 \\
10 & 8610\end{array}$ & 11 \\
\hline $\begin{array}{l}195659800 \\
1957103000 \\
195888900\end{array}$ & $\begin{array}{l}758800 \\
1100000 \\
388500\end{array}$ & 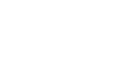 & $\begin{array}{ll}7 & 53000 \\
2 & 91000 \\
3 & 80500\end{array}$ & $\begin{array}{ll}6 & 45700 \\
1 & 84900 \\
3 & 70600\end{array}$ & $\begin{array}{ll}8 & 35000 \\
1 & 67400 \\
3 & 53500\end{array}$ & $\begin{array}{ll}8 & 27600 \\
2 & 57400 \\
3 & 41700\end{array}$ & 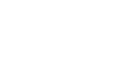 & $\begin{array}{ll}8 & 17100 \\
2 & 34900 \\
4 & 24400\end{array}$ & $\begin{array}{ll}8 & 10600 \\
2 & 19700 \\
4 & 15500\end{array}$ & \\
\hline
\end{tabular}

DURATION OF DISCHARGE FOR EACH WATER YEAR

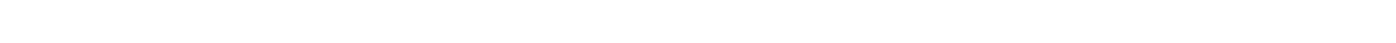

NUMBER OF DAYS IN GASS

OBIC FEET ER SECOND

$\begin{array}{llllllllllllllllllllllllllllllllll}1948 & 2 & 10 & 9 & 6 & 9 & 15 & 28 & 36 & 28 & 16 & 40 & 26 & 17 & 12 & 2 & 12 & 8 & 4 & 11 & 3 & 6 & 5 & 9 & 5 & 14 & 4 & 6 & 2 & 11 & 5 & 5 & & \end{array}$

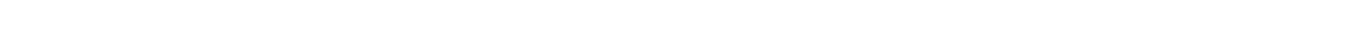

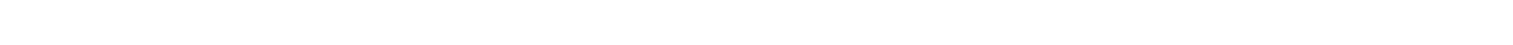

$1951 \quad \begin{array}{llllllllllllllllllllllllllllllllllll}1 & 3 & 2 & 2 & 10 & 34 & 44 & 34 & 56 & 39 & 15 & 6 & 4 & 5 & 6 & 25 & 7 & 6 & 5 & 10 & 5 & 4 & 10 & 6 & 6 & 7 & 4 & 9 & & & & 4428370.0\end{array}$

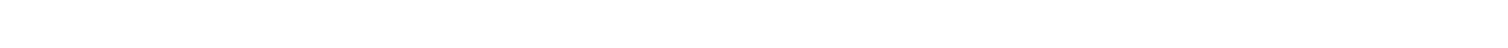

$\begin{array}{llllllllllllllllllllllllllllllll}1953 & 11 & 8 & 6 & 8 & 48 & 51 & 84 & 19 & 16 & 15 & 8 & 23 & 8 & 14 & 2 & 3 & 2 & 2 & 3 & 1 & 4 & 2 & 6 & 11 & 2 & 3 & 5 & & & 3915880.0\end{array}$

$\begin{array}{rrrrrrrrrrrrrrrrrrrrrrrrrrrrr}3 & 4 & 20 & 26 & 19 & 26 & 47 & 71 & 34 & 14 & 29 & 14 & 10 & 17 & 5 & 5 & 1 & 5 & 5 & 2 & 3 & 5 & & & & & & & \\ 1955 & 11 & 14 & 29 & 32 & 22 & 16 & 42 & 44 & 24 & 20 & 12 & 7 & 5 & 4 & 5 & 11 & 6 & 10 & 9 & 8 & 19 & 13 & 2 & & \end{array}$

$\begin{array}{lrlllllllllllllllllllllllllllllll}1956 & 23 & 4 & 36 & 14 & 25 & 41 & 47 & 32 & 20 & 12 & 2 & 7 & 3 & 16 & 5 & 9 & 5 & 2 & 9 & 8 & 6 & 7 & 6 & 3 & 3 & 3 & 9 & 6 & 3 & & & 3878910.0\end{array}$

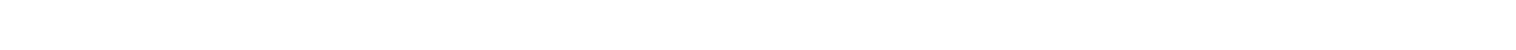

\begin{tabular}{|c|c|c|c|c|}
\hline & $\begin{array}{c}\text { OUBIC } \\
\text { FEET } \\
\text { PER }\end{array}$ & TOTAL & $\begin{array}{l}\text { ACOU- } \\
\text { MU- } \\
\text { LATED }\end{array}$ & $\begin{array}{l}\text { PER- } \\
\text { CENT }\end{array}$ \\
\hline CLASS & SECOND & DAYS & DAYS & DAYS \\
\hline 0 & 0.00 & 0 & 4018 & 100.0 \\
\hline & 2400.00 & 42 & 4018 & 100.0 \\
\hline & 2700.00 & 62 & 3976 & \\
\hline 3 & 3000.00 & 154 & $\begin{array}{l}3914 \\
3760\end{array}$ & 97.4 \\
\hline 5 & 3800.00 & 190 & 3604 & 89.7 \\
\hline & 1200.00 & 239 & 3414 & 85.0 \\
\hline & & 404 & 317 & 79.0 \\
\hline 8 & 5300 & 434 & 2771 & 69.0 \\
\hline
\end{tabular}

DURATION TABIE OF DISGHARGE FOR WATER YEARS $1948-58$

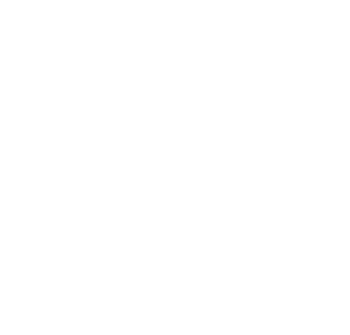

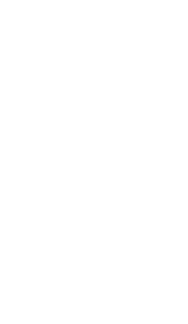

ACCJMU- PER-

ACOUFEET TOTAL LATED PERCLASS SECOND DAYS DAYS DAYS

$\begin{array}{lllll}27 & 46000.0 & 67 & 265 & 6.6\end{array}$ $\begin{array}{lllll}28 & 51000.0 & 47 & 198 & 4.9\end{array}$ $\begin{array}{lllll}29 & 57000.0 & 38 & 151 & 3.8\end{array}$

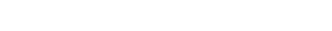
$\begin{array}{lllll}31 & 72000.0 & 38 & 87 & 2.2\end{array}$

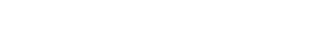
$\begin{array}{rrrr}3390000.0 & 14 & 18 & 0.4 \\ 34100000.0 & 4 & 4 & 0.1\end{array}$ 
COLORADO RIVER MAIN STEM

09335000 COLORADO RIVER AT HITE, UT-Continued

MONIHLY MEAN DISCHARGES, IN CUBIC FEET PER SBCOND, FOR EACH WATER YEAR

\begin{tabular}{|c|c|c|c|c|c|c|c|c|c|c|c|c|}
\hline YEAR & $\propto T$ & NOV & DEC & JAN & FEB & MAR & APR & MAY & JUNE & JULY & AUG & SEP \\
\hline $\begin{array}{l}1948 \\
1949 \\
1950\end{array}$ & $\begin{array}{l}8407 \\
4206 \\
7602\end{array}$ & $\begin{array}{l}8001 \\
5339 \\
6789\end{array}$ & $\begin{array}{l}6198 \\
4537 \\
4973\end{array}$ & $\begin{array}{l}5326 \\
4307 \\
4872\end{array}$ & $\begin{array}{l}6457 \\
4986 \\
5992\end{array}$ & $\begin{array}{l}9064 \\
8575 \\
9306\end{array}$ & $\begin{array}{l}23180 \\
16880 \\
18350\end{array}$ & $\begin{array}{l}49090 \\
39500 \\
28560\end{array}$ & $\begin{array}{l}43060 \\
58070 \\
45020\end{array}$ & $\begin{array}{l}12910 \\
25870 \\
18700\end{array}$ & $\begin{array}{l}6625 \\
6993 \\
6164\end{array}$ & $\begin{array}{l}3225 \\
4969 \\
5048\end{array}$ \\
\hline $\begin{array}{l}1951 \\
1952 \\
1953 \\
1954 \\
1955\end{array}$ & $\begin{array}{l}4923 \\
6194 \\
5273 \\
4405 \\
6168\end{array}$ & $\begin{array}{l}5600 \\
6256 \\
5678 \\
5907 \\
5094\end{array}$ & $\begin{array}{l}5934 \\
4860 \\
5503 \\
4658 \\
3701\end{array}$ & $\begin{array}{l}4499 \\
5755 \\
5705 \\
4491 \\
3461\end{array}$ & $\begin{array}{l}5894 \\
5510 \\
5787 \\
5077 \\
3791\end{array}$ & $\begin{array}{l}6083 \\
5813 \\
6721 \\
5522 \\
8230\end{array}$ & $\begin{array}{r}8780 \\
31060 \\
7609 \\
7820 \\
9872\end{array}$ & $\begin{array}{l}24820 \\
68960 \\
15860 \\
17200 \\
22700\end{array}$ & $\begin{array}{l}42080 \\
71200 \\
44830 \\
10560 \\
23120\end{array}$ & $\begin{array}{r}19750 \\
20200 \\
13240 \\
8295 \\
7954\end{array}$ & $\begin{array}{r}11300 \\
11150 \\
8704 \\
3898 \\
5815\end{array}$ & $\begin{array}{l}5759 \\
7590 \\
3972 \\
5157 \\
3231\end{array}$ \\
\hline $\begin{array}{l}1956 \\
1957 \\
1958\end{array}$ & $\begin{array}{l}3210 \\
3139 \\
8956\end{array}$ & $\begin{array}{r}4305 \\
4553 \\
10450\end{array}$ & $\begin{array}{l}4834 \\
3639 \\
6544\end{array}$ & $\begin{array}{l}5338 \\
4067 \\
5462\end{array}$ & $\begin{array}{l}4230 \\
4766 \\
7428\end{array}$ & $\begin{array}{l}7619 \\
6774 \\
8326\end{array}$ & $\begin{array}{l}13130 \\
11030 \\
19700\end{array}$ & $\begin{array}{l}31270 \\
35760 \\
53600\end{array}$ & $\begin{array}{l}37470 \\
80100 \\
49190\end{array}$ & $\begin{array}{r}8138 \\
53340 \\
7970\end{array}$ & $\begin{array}{r}5010 \\
19250 \\
3721\end{array}$ & $\begin{array}{l}2697 \\
9860 \\
4122\end{array}$ \\
\hline
\end{tabular}

ANNUAL PEAK DISCHARGE, IN CUBIC FEET PER SECOND, AND CORRESPONDING GAGE HEIGHT, IN FEET, FOR EACH WATER YEAR

\begin{tabular}{|c|c|c|c|c|c|c|c|c|c|c|c|}
\hline $\begin{array}{l}\text { WATERR } \\
\text { YEAR }\end{array}$ & DATE & $\begin{array}{c}\text { GAGE } \\
\text { HEIGHT }\end{array}$ & $\begin{array}{c}\text { PEAK } \\
\text { DISCHARGE }\end{array}$ & $\begin{array}{l}\text { WATER } \\
\text { YEAR }\end{array}$ & DATE & $\begin{array}{c}\text { GAGE } \\
\text { HEIGHT }\end{array}$ & $\begin{array}{c}\text { PEAK } \\
\text { DISCHARGE }\end{array}$ & $\begin{array}{l}\text { WATER } \\
\text { YEAR }\end{array}$ & DATE & $\begin{array}{l}\text { GAGE } \\
\text { HEIGHT }\end{array}$ & $\begin{array}{c}\text { PEAK } \\
\text { DISCHARGE }\end{array}$ \\
\hline $\begin{array}{l}1948 \\
1949 \\
1950 \\
1951\end{array}$ & $\begin{array}{lll}\text { MAY } & 24, & 1948 \\
\text { JUNE } & 21, & 1949 \\
\text { JUNE } & 05, & 1950 \\
\text { MAY } & 31, & 1951\end{array}$ & $\begin{array}{l}14.30 \\
15.67 \\
12.39 \\
12.89\end{array}$ & $\begin{array}{l}79700 \\
88200 \\
55200 \\
56800\end{array}$ & $\begin{array}{l}1952 \\
1953 \\
1954 \\
1955\end{array}$ & $\begin{array}{l}\text { JUNE } 11,1952 \\
\text { JUNE } 16,1953 \\
\text { MAY } 25,1954 \\
\text { MAY }\end{array}$ & $\begin{array}{r}17.20 \\
13.45 \\
9.13 \\
9.38\end{array}$ & $\begin{array}{r}102000 \\
62600 \\
28200 \\
30600\end{array}$ & $\begin{array}{l}1956 \\
1957 \\
1958\end{array}$ & $\begin{array}{l}\text { JUNE } 05,1956 \\
\text { JUNE } 12,1957 \\
\text { JUNE 01, } 1958\end{array}$ & & $\begin{array}{r}61800 \\
105600 \\
90900\end{array}$ \\
\hline
\end{tabular}

1951 MAY $31,1951 \quad 12.89 \quad 56800 \quad 1955$ MAY 18,1955

MAGNITUDE AND PROBABILITY OF ANNUAL LOWEST MEAN DISCHARGE BASED ON CLIMATIC YEARS 1949-58

\begin{tabular}{|c|c|c|c|c|c|c|}
\hline \multirow{2}{*}{$\begin{array}{l}\text { PERIOD } \\
\text { (CON- } \\
\text { SECU- } \\
\text { TIVE } \\
\text { DAYS) }\end{array}$} & \multicolumn{6}{|c|}{$\begin{array}{l}\text { DISCHARGE, IN CUBIC FEET PER SECOND, FOR } \\
\text { INDICATED RECURRENCE INTERNAL, IN YEARS, AND } \\
\text { ANNUAL NONEXCEEDANCE PRCBABILITY, IN PERCENT }\end{array}$} \\
\hline & $\begin{array}{c}2 \\
50 \%\end{array}$ & $\begin{array}{c}5 \\
208\end{array}$ & $\begin{array}{l}10 \\
108\end{array}$ & $\begin{array}{l}20 \\
58\end{array}$ & $\begin{array}{l}50 \\
28\end{array}$ & $\begin{array}{r}100 \\
18\end{array}$ \\
\hline $\begin{array}{r}1 \\
7 \\
14 \\
30 \\
60 \\
90\end{array}$ & $\begin{array}{l}2820 \\
3160 \\
3430 \\
3790 \\
4360 \\
4610\end{array}$ & $\begin{array}{l}2480 \\
2680 \\
2810 \\
3080 \\
3470 \\
3860\end{array}$ & $\begin{array}{l}2360 \\
2480 \\
2560 \\
2760 \\
3050 \\
3510\end{array}$ & $\begin{array}{l}2290 \\
2350 \\
2370 \\
2530 \\
2720 \\
3230\end{array}$ & $\begin{array}{l}-- \\
-- \\
-- \\
-\end{array}$ & $\begin{array}{l}= \\
= \\
= \\
-\end{array}$ \\
\hline
\end{tabular}

MAGNITUDE AND PRCBABILITY OF ANNUAL HIGHEST MEAN DISCHARGE BASED ON WATER YEARS 1948-58

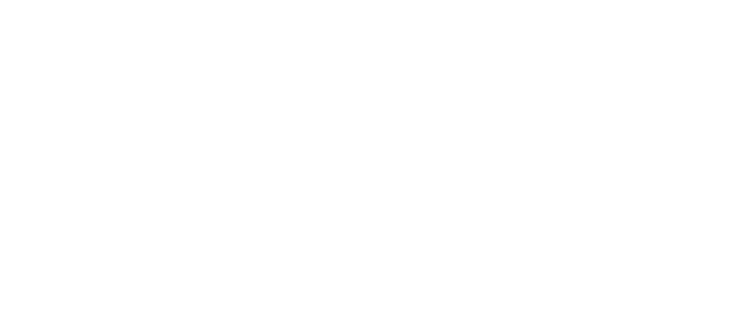

ESCALANTE RIVER BASIN

09335500 NORTY CREFK NEAR ESCALANTE, UT

LOCATION.--Lat $37^{\circ} 46^{\prime} 00^{\prime \prime}$, long $111^{\circ} 41^{\prime} 00^{\prime \prime}$, in NE's sec.16, T.35 S., R.2 E., Garfield County, Hydrologic Unit 14020005, on right bank $0.1 \mathrm{mi}$ upstream from mouth and $4 \mathrm{mi}$ west of Escalante.

DRAINAGE AREA. $--90 \mathrm{mi}^{2}$, approximately.

MEAN BASIN ELEVATION. $-8,240 \mathrm{ft}$.

PERIOD OF RECORD AVAILABLE.--JulY 1950 to September 1955.

GAGE.--Water-stage recorder. Altitude of gage is $6,100 \mathrm{ft}$ by barometer. Prior to oct. 17,1953 , at site $0.4 \mathrm{mi}$ upstream at different datum.

AVERAGE DISCHARGE. --5 years, $7.64 \mathrm{ft}^{3} / \mathrm{s}, 5,530 \mathrm{acre}-\mathrm{ft} / \mathrm{yr}$.

EXIREMES FOR PERIOD OF RECORD.--Maximum discharge, 3,610 ft $\mathrm{ft}^{3} / \mathrm{s}$ Aug. 21,1952 , gage height, $4.26 \mathrm{ft}$, site and datum then in use, from rating curve extended above $99 \mathrm{ft}^{3} / \mathrm{s}$ on basis of float measurements at gage height $1.83 \mathrm{ft}$ and $4.10 \mathrm{ft}$ and slope-area

measurement at gage height $4.26 \mathrm{ft}$; no flow for part of each of the following days: Aug. 6, 1951, Nov. 25-27, 1952, and Dec. 1, 1953.

LOWEST MEAN DISCHARGE, IN CUBIC FEET PER SECOND, AND RANKING FOR THE INDICATED NUMBER OF CONSECUTIVE DAYS FOR EACH CLIMATIC YEAR, APRIL 1-MARCH 31

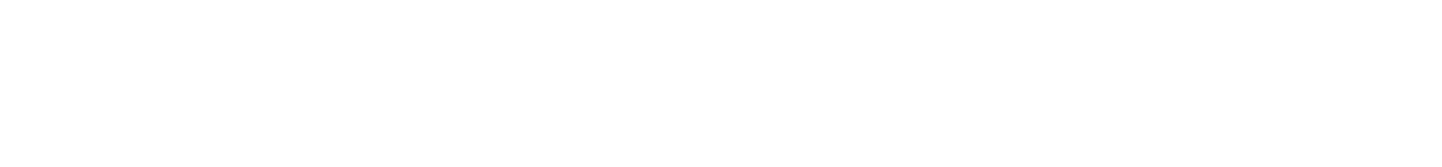


HIGHEST MEAN DISCHARGE, IN CUBIC FEET PER SECOND, AND RANKING FOR THE INDICATED NUMBER OF CONSECUTTVE DAYS FOR EACH WATER YEAR, CTCBER 1-SEPTEMBER 30

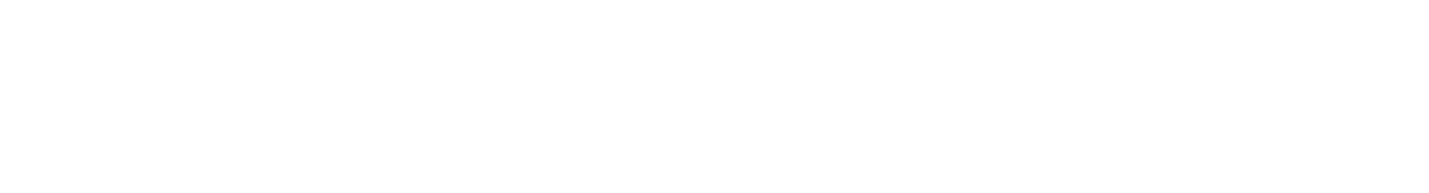

DURATION OF DISCHARGE FOR EACH WATER YEAR

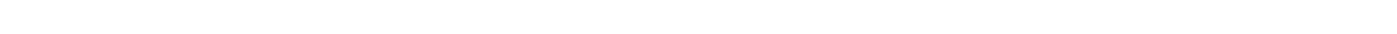

YEAR NUMBER OF DAYS IN CLASS CUBIC FEET -DAYS

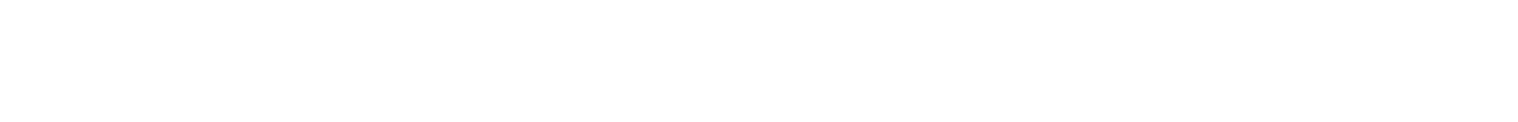

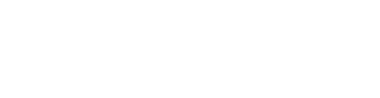

DURATION TABLE OF DISCHARGE FOR WATER YEARS I95I-55

\begin{tabular}{|c|c|c|c|c|c|c|c|c|c|c|c|c|c|c|c|c|c|c|c|}
\hline AASS & $\begin{array}{c}\text { CUBIC } \\
\text { FEET } \\
\text { PER } \\
\text { SECOND }\end{array}$ & $\begin{array}{r}\text { TOTAL } \\
\text { DAYS }\end{array}$ & $\begin{array}{l}\text { AOCU- } \\
\text { MU- } \\
\text { LATED } \\
\text { DAYS }\end{array}$ & $\begin{array}{l}\text { PER- } \\
\text { CENT } \\
\text { DAYS }\end{array}$ & CLASS & $\begin{array}{c}\text { CUBIC } \\
\text { FEET } \\
\text { PER } \\
\text { SECOND }\end{array}$ & $\begin{array}{r}\text { TOTAL } \\
\text { DAYS }\end{array}$ & $\begin{array}{c}\text { ACCU- } \\
\text { MU- } \\
\text { LATED } \\
\text { DAYS }\end{array}$ & $\begin{array}{l}\text { PER- } \\
\text { CENT } \\
\text { DAYS }\end{array}$ & CLASS & $\begin{array}{c}\text { CUBIC } \\
\text { FEET } \\
\text { PER } \\
\text { SECOND }\end{array}$ & $\begin{array}{c}\text { TOTAL } \\
\text { DAYS }\end{array}$ & $\begin{array}{l}\text { AOCU- } \\
\text { MU- } \\
\text { LATED } \\
\text { DAYS }\end{array}$ & $\begin{array}{l}\text { PER- } \\
\text { CENT } \\
\text { DAYS }\end{array}$ & CLASS & $\begin{array}{c}\text { CUBIC } \\
\text { FEET } \\
\text { PER } \\
\text { SECOND }\end{array}$ & $\begin{array}{r}\text { TOTAL } \\
\text { DAYS }\end{array}$ & $\begin{array}{l}\text { AOCU- } \\
\text { MU- } \\
\text { LATED } \\
\text { DAYS }\end{array}$ & $\begin{array}{l}\text { PER- } \\
\text { CENT } \\
\text { DAYS }\end{array}$ \\
\hline $\begin{array}{l}0 \\
1 \\
2 \\
3 \\
4 \\
5 \\
6 \\
7 \\
8\end{array}$ & $\begin{array}{l}0.00 \\
0.10 \\
0.12 \\
0.15 \\
0.19 \\
0.23 \\
0.28 \\
0.34 \\
0.42\end{array}$ & $\begin{array}{l}0 \\
1 \\
0 \\
0 \\
0 \\
0 \\
2 \\
0 \\
1\end{array}$ & $\begin{array}{l}1826 \\
1826 \\
1825 \\
1825 \\
1825 \\
1825 \\
1825 \\
1823 \\
1823\end{array}$ & $\begin{array}{r}100.0 \\
100.0 \\
99.9 \\
99.9 \\
99.9 \\
99.9 \\
99.9 \\
99.8 \\
99.8\end{array}$ & $\begin{array}{r}9 \\
10 \\
11 \\
12 \\
13 \\
14 \\
15 \\
16 \\
17\end{array}$ & $\begin{array}{l}0.51 \\
0.63 \\
0.77 \\
0.95 \\
1.20 \\
1.40 \\
1.80 \\
2.20 \\
2.60\end{array}$ & $\begin{array}{r}4 \\
4 \\
38 \\
12 \\
25 \\
101 \\
96 \\
52 \\
73\end{array}$ & $\begin{array}{l}1822 \\
1818 \\
1814 \\
1776 \\
1764 \\
1739 \\
1638 \\
1542 \\
1490\end{array}$ & $\begin{array}{l}99.8 \\
99.6 \\
99.3 \\
97.3 \\
96.6 \\
95.2 \\
89.7 \\
84.4 \\
81.6\end{array}$ & $\begin{array}{l}18 \\
19 \\
20 \\
21 \\
22 \\
23 \\
24 \\
25 \\
26\end{array}$ & $\begin{array}{r}3.2 \\
4.0 \\
4.9 \\
6.0 \\
7.3 \\
9.0 \\
11.0 \\
14.0 \\
17.0\end{array}$ & $\begin{array}{r}127 \\
220 \\
215 \\
259 \\
217 \\
100 \\
98 \\
51 \\
50\end{array}$ & $\begin{array}{r}1417 \\
1290 \\
1070 \\
855 \\
596 \\
379 \\
279 \\
181 \\
130\end{array}$ & $\begin{array}{r}77.6 \\
70.6 \\
58.6 \\
46.8 \\
32.6 \\
20.8 \\
15.3 \\
9.9 \\
7.1\end{array}$ & $\begin{array}{l}27 \\
28 \\
29 \\
30 \\
31 \\
32 \\
33 \\
34\end{array}$ & $\begin{array}{l}20.0 \\
25.0 \\
31.0 \\
38.0 \\
46.0 \\
56.0 \\
69.0 \\
85.0\end{array}$ & $\begin{array}{r}22 \\
13 \\
7 \\
5 \\
15 \\
12 \\
4 \\
2\end{array}$ & $\begin{array}{r}80 \\
58 \\
45 \\
38 \\
33 \\
18 \\
6 \\
2\end{array}$ & $\begin{array}{l}4.4 \\
3.2 \\
2.5 \\
2.1 \\
1.8 \\
1.0 \\
0.3 \\
0.1\end{array}$ \\
\hline
\end{tabular}

MONTHLY MEAN DISCHARGES, IN OUBIC FEET PER SECOND, FOR EACH WATER YEAR

\begin{tabular}{|c|c|c|c|c|c|c|c|c|c|c|c|c|}
\hline YEAR & $\infty T$ & NOV & $\mathrm{DEC}$ & JAN & FEB & MAR & APR & MAY & JUNE & JULY & AUG & SEP \\
\hline $\begin{array}{l}1951 \\
1952 \\
1953 \\
1954 \\
1955\end{array}$ & $\begin{array}{l}4.01 \\
5.25 \\
8.02 \\
3.74 \\
9.65\end{array}$ & $\begin{array}{l}5.15 \\
3.22 \\
3.33 \\
2.83 \\
6.19\end{array}$ & $\begin{array}{l}5.68 \\
1.45 \\
0.96 \\
1.55 \\
3.83\end{array}$ & $\begin{array}{l}2.56 \\
3.02 \\
2.17 \\
3.15 \\
2.00\end{array}$ & $\begin{array}{l}1.56 \\
4.50 \\
6.20 \\
6.13 \\
2.85\end{array}$ & $\begin{array}{l}4.56 \\
7.24 \\
7.79 \\
5.95 \\
5.51\end{array}$ & $\begin{array}{c}9.53 \\
10.6 \\
7.06 \\
9.18 \\
8.86\end{array}$ & $\begin{array}{c}8.48 \\
50.1 \\
8.94 \\
11.2 \\
17.2\end{array}$ & $\begin{array}{c}7.17 \\
38.8 \\
10.1 \\
8.15 \\
14.9\end{array}$ & $\begin{array}{c}5.06 \\
19.3 \\
7.20 \\
6.45 \\
4.64\end{array}$ & $\begin{array}{c}4.93 \\
16.1 \\
8.08 \\
3.45 \\
3.53\end{array}$ & $\begin{array}{l}4.47 \\
9.25 \\
7.07 \\
4.08 \\
3.93\end{array}$ \\
\hline
\end{tabular}

ANNUAL PEAK DISCHARGE, IN CUBIC FEET PER SECOND, AND CORRESPONDING GAGE HEIGHT, IN FEET, FOR EACH WATER YEAR

\begin{tabular}{|c|c|c|c|c|c|c|c|c|c|c|c|}
\hline $\begin{array}{l}\text { WATER } \\
\text { YEAR }\end{array}$ & DATE & $\begin{array}{l}\text { GAGE } \\
\text { HEIGHT }\end{array}$ & $\begin{array}{c}\text { PEAK } \\
\text { DISCHARGE }\end{array}$ & $\begin{array}{l}\text { WATER } \\
\text { YEAR }\end{array}$ & DATE & $\begin{array}{c}\text { GAGE } \\
\text { HEIGHT }\end{array}$ & $\begin{array}{c}\text { PEAK } \\
\text { DISCHARGE }\end{array}$ & $\begin{array}{l}\text { WATEER } \\
\text { YEAR }\end{array}$ & DATE & $\begin{array}{l}\text { GAGE } \\
\text { HEIGHT }\end{array}$ & $\begin{array}{c}\text { PEAK } \\
\text { DISCHARGE }\end{array}$ \\
\hline $\begin{array}{l}1951 \\
1952\end{array}$ & $\begin{array}{l}\text { AUG. } 02,1951 \\
\text { AUG. } 21,1952\end{array}$ & $\begin{array}{l}1.11 \\
4.26\end{array}$ & $\begin{array}{r}26 \\
3610\end{array}$ & $\begin{array}{l}1953 \\
1954\end{array}$ & $\begin{array}{lll}\text { AUG. } & 22, & 1953 \\
\text { JULY } 18, & 1954\end{array}$ & $\begin{array}{l}1.61 \\
1.77\end{array}$ & $\begin{array}{l}132 \\
100\end{array}$ & 1955 & ○Т. 07,1954 & 4.55 & 2060 \\
\hline
\end{tabular}

09336000 BIRCH CREEK NEAR ESCALANIE, UT

LOCATION.--Lat $37^{\circ} 45^{\prime} 45^{\prime \prime}$, long $111^{\circ} 44^{\prime} 15^{\prime \prime}$, in SE⿺ sec.13, T.35 S., R.l E., Garfield County, Hydrologic Unit 14070005 , on left bank $3.2 \mathrm{mi}$ west on dirt road from State Highway 54 and $7 \mathrm{mi}$ west of Escalante.

DRAINAGE AREA. $-36 \mathrm{mi}^{2}$.

MEAN BASIN EILEVATION.--8,080 $\mathrm{ft}$.

PERIOD OF RECORD AVAILABLE.--July 1950 to September 1951, and annual peak discharge only, water years $1959-74$.

REMARKS.--Some diversions for irrigation above the station.

GAGE.--Crest-stage gage. Altitude of gage is 6,400 ft from topographic map. July 1950 to September 195I, water-stage recorder at site about I mi downstream at different datum.

EXIREMES FOR PERIOD OF RECORD.--Maximum discharge, 3,400 ft $3 / \mathrm{s}$ Aug. 19, 1963, gage height, $17.10 \mathrm{ft}$; no flow at times. 
ESCALANTE RIVER BASIN

09336000 BIRCH CREER NEAR ESCALANTE, UT-Continued

HIGHEST MEAN DISCHARGE, IN OBIC FEET PER SECOND, AND RANKING FOR THE INDICATED NUMBER OF CONSECUTIVE DAYS

FOR EACH WATER YEAR, OCTOBER 1-SEPTEMBER 30

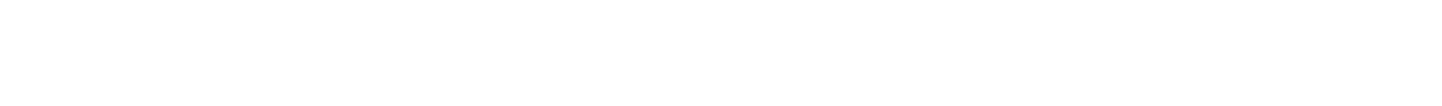

DURATION $O$ DISCHARGE FOR EACH WATER YEAR

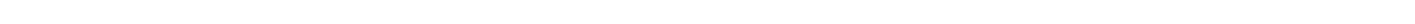
YEAR

NUMBER OF DAYS IN CLASS OBIC FEET
PER SECOND
-DAYS 195114841 17 $\begin{array}{llllllllllll}4 & 6 & 5 & 19 & 12 & 26 & 19 & 13 & 34 & 10 & 5 & 1\end{array}$ $\begin{array}{lllll}2 & 1 & 1 & 1 & 197.1\end{array}$ DURATION TABLE OF DISCHARGE FOR WATER YEAR 1951 $\begin{array}{crc}\text { CUBIC } & \text { ACCU- } \\ \text { FEET } & \text { MU- } & \text { PER- } \\ \text { PER TOTAL LATED } & \text { CENT } \\ \text { OLASS SECOND DAYS DAYS } & \text { DAYS }\end{array}$ $\begin{array}{lll}\text { OUBIC } & \text { ACCU- } \\ \text { FEET } & \text { MU- } & \text { PER- } \\ \text { PER TOTAL L LATED } & \text { CENT }\end{array}$ CLASS SECOND DAYS DAYS DAYS

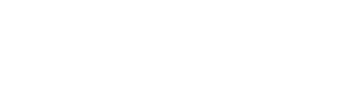
$\begin{array}{ccc}\text { OBIC } & \text { ACQU- } \\ \text { FEET } & \text { MU- } & \text { PER- } \\ \text { PER TOTAL LATED } & \text { CENT } \\ \text { CLASS SECOND DAYS DAYS } & \text { DAYS }\end{array}$

$\begin{array}{rrrrr}0 & 0.00 & 148 & 365 & 100.0 \\ 1 & 0.10 & 41 & 217 & 59.4 \\ 2 & 0.12 & 0 & 176 & 48.2 \\ 3 & 0.14 & 0 & 176 & 48.2 \\ 4 & 0.16 & 0 & 176 & 48.2 \\ 5 & 0.18 & 17 & 176 & 48.2 \\ 6 & 0.21 & 0 & 159 & 43.6 \\ 7 & 0.25 & 0 & 159 & 43.6 \\ 8 & 0.29 & 4 & 159 & 43.6\end{array}$

$\begin{array}{rlrrr}9 & 0.34 & 0 & 155 & 42.5 \\ 10 & 0.39 & 6 & 155 & 42.5 \\ 11 & 0.46 & 5 & 149 & 40.8 \\ 12 & 0.53 & 19 & 144 & 39.4 \\ 13 & 0.62 & 12 & 125 & 34.2 \\ 14 & 0.72 & 26 & 113 & 31.0 \\ 15 & 0.84 & 19 & 87 & 23.8 \\ 16 & 0.98 & 13 & 68 & 18.6 \\ 17 & 1.1 & 34 & 55 & 15.0\end{array}$

$\begin{array}{rrr}18 & 1.3 & 10 \\ 19 & 1.5 & 5 \\ 20 & 1.8 & 1 \\ 21 & 2.1 & 0 \\ 22 & 2.4 & 0 \\ 23 & 2.8 & 0 \\ 24 & 3.3 & 0 \\ 25 & 3.8 & 0 \\ 26 & 4.5 & 0\end{array}$

$\begin{array}{rr}21 & 5.8 \\ 11 & 3.0 \\ 6 & 1.6 \\ 5 & 1.4 \\ 5 & 1.4 \\ 5 & 1.4 \\ 5 & 1.4 \\ 5 & 1.4 \\ 5 & 1.4\end{array}$

$\begin{array}{rrrrr}27 & 5.2 & 0 & 5 & 1.4 \\ 28 & 6.0 & 2 & 5 & 1.4 \\ 29 & 7.0 & 0 & 3 & 0.8 \\ 30 & 8.2 & 1 & 3 & 0.8 \\ 31 & 9.5 & 0 & 2 & 0.6 \\ 32 & 11.0 & 0 & 2 & 0.6 \\ 33 & 13.0 & 1 & 2 & 0.6 \\ 34 & 15.0 & 1 & 1 & 0.3\end{array}$

MONHLY MEAN DISCHARGES, IN OBIC FEET PER SECOND, FOR EACH WATER YEAR

\begin{tabular}{|c|c|c|c|c|c|c|c|c|c|c|c|c|}
\hline YEAR & $\infty \mathrm{CT}$ & NOV & $\mathrm{DEC}$ & JAN & FEB & MAR & APR & MAY & JUNE & JULY & AUG & SEP \\
\hline 1951 & 0.88 & 0.32 & 0.00 & 0.10 & 0.27 & 0.19 & 0.89 & 0.89 & 1.06 & 0.57 & 1.28 & 0.02 \\
\hline
\end{tabular}

ANNUAL PEAK DISCHARGE, IN OBBIC FEET PER SECOND, AND CORRESPONDING GAGE HEIGHT, IN FEET, FOR EACH WATER YEAR

\begin{tabular}{|c|c|c|c|c|c|c|c|c|c|c|c|}
\hline $\begin{array}{l}\text { WATERR } \\
\text { YEAR }\end{array}$ & DATE & $\begin{array}{c}\text { GAGE } \\
\text { HEIGHT }\end{array}$ & $\begin{array}{c}\text { PEAK } \\
\text { DISCHARGE }\end{array}$ & $\begin{array}{l}\text { WATER } \\
\text { YEAR }\end{array}$ & DATE & $\begin{array}{c}\text { GAGE } \\
\text { HEIGEI }\end{array}$ & $\begin{array}{c}\text { PEAK } \\
\text { DISCHARGE }\end{array}$ & $\begin{array}{l}\text { WATERR } \\
\text { YEAR }\end{array}$ & DATE & $\begin{array}{c}\text { GAGE } \\
\text { HEIGHT }\end{array}$ & $\begin{array}{c}\text { PEAK } \\
\text { DISCHARGE }\end{array}$ \\
\hline $\begin{array}{l}1951 \\
1959 \\
1960 \\
1961 \\
1962 \\
1963\end{array}$ & $\begin{array}{l}\text { JULY } 31,1951 \\
\text { SEPT.15, } 1959 \\
\text { JULY } 30,1960 \\
\text { AUG. 10, } 1961 \\
\text { SEPT.21, } 1962 \\
\text { AUG. } 19,1963\end{array}$ & $\begin{array}{r}3.20 \\
16.12 \\
11.00 \\
12.20 \\
12.17 \\
17.10\end{array}$ & $\begin{array}{r}249 \\
1100 \\
35 \\
199 \\
195 \\
3400\end{array}$ & $\begin{array}{l}1964 \\
1965 \\
1966 \\
1967 \\
1968 \\
1969\end{array}$ & $\begin{array}{l}\text { AUG. } 03,1964 \\
\text { AUG. } 17,1965 \\
\text { JULY } 30,1966 \\
\text { AUG. } 05,1967 \\
\text { AUGG. } 01,1968 \\
\text { AUG. } 12,1969\end{array}$ & $\begin{array}{l}14.68 \\
11.30 \\
11.10 \\
11.00 \\
11.65 \\
13.61\end{array}$ & $\begin{array}{r}1050 \\
300 \\
250 \\
228 \\
400 \\
1560\end{array}$ & $\begin{array}{l}1970 \\
1971 \\
1972 \\
1973 \\
1974\end{array}$ & $\begin{array}{lll}\text { AUG. } & 06,1970 \\
\text { JULY } & 28, & 1971 \\
\text { JUNE } & 22,1972 \\
\text { JUNE } & 05, & 1973 \\
- & --, & 1974\end{array}$ & $\begin{array}{l}12.98 \\
13.03 \\
11.75 \\
11.65 \\
11.26\end{array}$ & $\begin{array}{r}1020 \\
1050 \\
380 \\
290 \\
165\end{array}$ \\
\hline
\end{tabular}

09336400 UPPER VALLEY CREEX NEAR ESCALANTE, UT

LOCATION.--Lat $37^{\circ} 44^{\prime} 30^{\prime}$, long $111^{\circ} 42^{\prime} 30^{\prime \prime}$, in $\mathrm{NW}^{\frac{1}{4}} \mathrm{NW}^{\frac{1}{4}}$ sec.29, T.35 S., R.I E., Garfield County, Hydrologic Unit 14070005 , 2.2 mi above mouth and $7 \mathrm{mi}$ west of Escalante.

DRAINAGE AREA. $--53 \mathrm{mi}^{2}$.

MEAN BASIN ELEVATION. $-7,620 \mathrm{ft}$.

PERICD OF RECORD AVAIIABLE. - -Water years 1959-74, annual peak discharge only.

GAGE.--Crest-stage gage. Altitude of gage is $6,280 \mathrm{ft}$ fram topographic map.

REMARKS.--Diversions for irrigation above station.

ANNUAL PEAK DISCHARGE, IN CIBIC FEET PER SECOND, AND CORRESPONDING GAGE HEIGHT, IN FEET, FOR EACH WATER YEAR

\begin{tabular}{|c|c|c|c|c|c|c|c|c|c|c|c|}
\hline $\begin{array}{l}\text { WATER } \\
\text { YEAR }\end{array}$ & DATE & $\begin{array}{c}\text { GAGE } \\
\text { HEIGHT }\end{array}$ & $\begin{array}{c}\text { PEAK } \\
\text { DISCHARGE }\end{array}$ & $\begin{array}{l}\text { WAT'ER } \\
\text { YEAR }\end{array}$ & DATE & $\begin{array}{l}\text { GAGE } \\
\text { HEIGHT }\end{array}$ & $\begin{array}{c}\text { PEAK } \\
\text { DISCHARGE }\end{array}$ & $\begin{array}{l}\text { WATER } \\
\text { YEAR }\end{array}$ & DATE & $\begin{array}{l}\text { GAGE } \\
\text { HEIGHT }\end{array}$ & $\begin{array}{c}\text { PEAK } \\
\text { DISCHARGE }\end{array}$ \\
\hline $\begin{array}{l}1959 \\
1960 \\
1961 \\
1962 \\
1963 \\
1964\end{array}$ & $\begin{array}{l}\text { AUG. } 02,1959 \\
\text { SEPT.16, } 1960 \\
\text { SEPT.17, } 1961 \\
\text { SEPT.20, } 1962 \\
\text { AUG. } 30,1963 \\
\text { AUG. } 01,1964\end{array}$ & $\begin{array}{l}15.40 \\
11.69 \\
12.38 \\
12.10 \\
13.50 \\
12.28\end{array}$ & $\begin{array}{r}5560 \\
185 \\
670 \\
420 \\
1970 \\
590\end{array}$ & $\begin{array}{l}1965 \\
1966 \\
1967 \\
1968 \\
1969\end{array}$ & $\begin{array}{lll}\text { AUG. } & 15,1965 \\
\text { JULY } 24,1966 \\
\text { AUG. } 05,1967 \\
\text { AUG. } 01,1968 \\
\text { AUG. } 12,1969\end{array}$ & $\begin{array}{ll}5 & 11.85 \\
5 & 12.28 \\
7 & 11.90 \\
8 & 11.91 \\
9 & 13.81\end{array}$ & $\begin{array}{r}270 \\
590 \\
300 \\
305 \\
2450\end{array}$ & $\begin{array}{l}1970 \\
1971 \\
1972 \\
1973 \\
1974\end{array}$ & $\begin{array}{c}\text { AUG. } 07,1970 \\
\text { AUG. } 25,1971 \\
\text { AUG. } 26,1972 \\
\text { OCT. } 19,1972 \\
-\quad-\end{array}$ & $\begin{array}{l}12.81 \\
13.22 \\
12.46 \\
12.70 \\
12.35\end{array}$ & $\begin{array}{r}1090 \\
1600 \\
750 \\
970 \\
630\end{array}$ \\
\hline
\end{tabular}




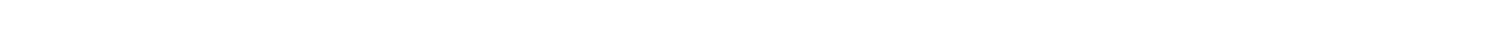

just upstream fram bridge on State Highway $23,0.25 \mathrm{mi}$ upstream fram mouth, $0.75 \mathrm{mi}$ downstream from Upper Val ley Creek, and $5 \mathrm{mi}$ west of Escalante.

DRAINAGE AREA.--100 $\mathrm{mi}^{2}$, approximately.

PERIOD OF RECORD AVAIIABLE.--October 1951 to July 1955.

GAGE. -Water-stage recorder. Altitude of gage is 6,090 ft by barcmeter.

REMARKS.--Several diversions for irrigation above station.

EXIREMES FOR PERIOD OF RECORD.--Maximum discharge, 1,010 ft $\mathrm{ft}^{3} / \mathrm{s}$ July 12, 1954, gage height, $5.06 \mathrm{ft}$, fram rating curve extended above $190 \mathrm{ft}^{3} / \mathrm{s}$ on basis of slope-area measurement of peak flow; minimum daily, $0.1 \mathrm{ft}^{3} / \mathrm{s}$ July $9,1954, \mathrm{July} 13,14,1955$.

LONEST MEAN DISCHARGE, IN OUBIC FEET PER SECOND, AND RANKING FOR THE INDICATED NUMBER OF CONSECUTIVE DAYS FOR EAOH CLIMATIC YEAR, APRIL 1-MARCH 31

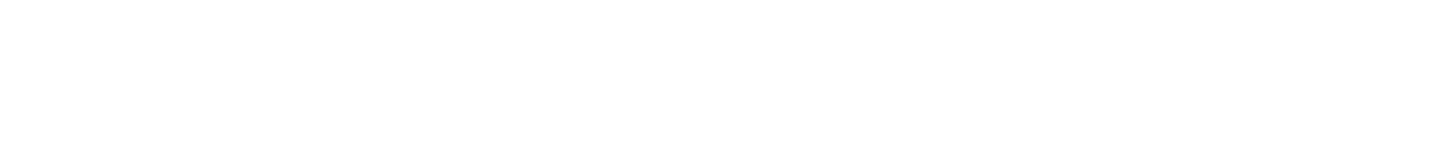

HIGHEST MEAN DISCHARGE, IN GBIC FEET PER SECOND, AND RANKING FOR THE INDICATED NUMBER OF CONSECUTIVE DAYS FOR EACH WATER YEAR, OCTOBER 1-SEPTEMBER 30

\begin{tabular}{|c|c|c|c|c|c|c|c|c|c|c|c|c|c|c|c|c|c|c|c|}
\hline YEAR & 1 & & 3 & & 7 & & 15 & & $\begin{array}{l}\text { CNSSE } \\
30\end{array}$ & QTT & $\begin{array}{l}\text { E DAYS } \\
60\end{array}$ & & 90 & & 120 & & 183 & & ALL \\
\hline $\begin{array}{l}1952 \\
1953 \\
1954\end{array}$ & $\begin{array}{c}35.0 \\
115 \\
56.0\end{array}$ & $\begin{array}{l}3 \\
1 \\
2\end{array}$ & $\begin{array}{l}25.0 \\
42.0 \\
24.0\end{array}$ & $\begin{array}{l}2 \\
1 \\
3\end{array}$ & $\begin{array}{l}18.0 \\
19.0 \\
11.0\end{array}$ & $\begin{array}{l}2 \\
1 \\
3\end{array}$ & $\begin{array}{c}17.0 \\
10.0 \\
5.80\end{array}$ & $\begin{array}{l}1 \\
2 \\
3\end{array}$ & $\begin{array}{r}16.0 \\
7.50 \\
3.40\end{array}$ & $\begin{array}{l}1 \\
2 \\
3\end{array}$ & $\begin{array}{r}13.0 \\
4.70 \\
2.60\end{array}$ & $\begin{array}{l}1 \\
2 \\
3\end{array}$ & $\begin{array}{r}11.0 \\
3.50 \\
2.50\end{array}$ & $\begin{array}{l}1 \\
2 \\
3\end{array}$ & $\begin{array}{l}9.60 \\
3.20 \\
2.40\end{array}$ & $\begin{array}{l}1 \\
2 \\
3\end{array}$ & $\begin{array}{l}8.10 \\
3.20 \\
2.00\end{array}$ & $\begin{array}{l}1 \\
2 \\
3\end{array}$ & $\begin{array}{l}5.10 \\
2.80 \\
1.90\end{array}$ \\
\hline
\end{tabular}

DURATION OF DISCHARGE FOR EACH WATER YEAR

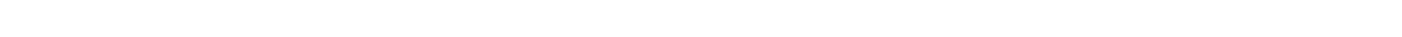
YEAR

NUMBER OF DAYS IN Q.ASS

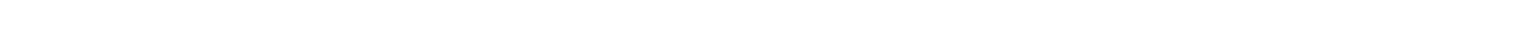
$\begin{array}{rllllllrlrrrrrrrrrrrrrrrrrrrrrr}1953 & & & & & & 16 & 5 & 15 & 9 & 17 & 13 & 35 & 79 & 30 & 37 & 14 & 14 & 44 & 19 & 14 & 1 & & & & 1 & & 1 & 1 & 1034.0 \\ 1954 & 1 & 25 & 31 & 11 & 4 & 10 & 28 & 15 & 45 & 31 & 34 & 45 & 30 & 32 & 10 & 2 & 2 & 1 & 3 & 1 & 2 & & & 1 & 1 & 676.6\end{array}$

DURATION TABLE OF DISCHARGE FOR WATER YEARS 1952-54

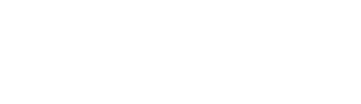

GLASS SECOND DAYS DAYS DAYS

$\begin{array}{llllll}0 & 0.00 & 0 & 109 & 100.0 \\ 1 & 0.10 & 1 & 1096 & 100.0\end{array}$

$\begin{array}{llllr}1 & 0.10 & 1 & 1096 & 100.0 \\ 3 & 0.12 & 0 & 1095 & 99.9\end{array}$

$\begin{array}{lllll}3 & 0.15 & 0 & 1095 & 99.9\end{array}$

$\begin{array}{llll}0.18 & 25 & 1095 & 99.9\end{array}$

$\begin{array}{llll}0.22 & 0 & 1070 & 97.6\end{array}$

$\begin{array}{llll}0.26 & 31 & 1070 & 97.6\end{array}$

$\begin{array}{lrrr}0.32 & 0 & 1039 & 94.8\end{array}$

MONTHLY MEAN DISCHARGES, IN GBIC FEET PER SECOND, FOR EACH WATER YEAR

\begin{tabular}{|c|c|c|c|c|c|c|c|c|c|c|c|c|}
\hline YEAR & OCT & $\mathrm{NOV}$ & DEC & JAN & FEB & MAR & APR & MAY & JUNE & JULY & AUG & SEP \\
\hline $\begin{array}{l}1952 \\
1953 \\
1954\end{array}$ & $\begin{array}{l}1.00 \\
3.33 \\
1.55\end{array}$ & $\begin{array}{l}1.00 \\
4.08 \\
1.91\end{array}$ & $\begin{array}{l}1.30 \\
1.60 \\
1.45\end{array}$ & $\begin{array}{l}1.65 \\
2.70 \\
1.91\end{array}$ & $\begin{array}{l}3.50 \\
4.25 \\
2.97\end{array}$ & $\begin{array}{l}5.23 \\
3.67 \\
2.20\end{array}$ & $\begin{array}{l}5.46 \\
1.71 \\
0.45\end{array}$ & $\begin{array}{c}14.4 \\
1.65 \\
1.10\end{array}$ & $\begin{array}{c}10.6 \\
1.20 \\
1.62\end{array}$ & $\begin{array}{l}7.65 \\
5.59 \\
2.96\end{array}$ & $\begin{array}{l}5.11 \\
3.39 \\
0.83\end{array}$ & $\begin{array}{l}4.30 \\
0.84 \\
3.40\end{array}$ \\
\hline
\end{tabular}


ESCALANIE RIVER BASIN

09337000 PINE CREEK NEAR ESCALANIE, UT

LOCATION.--Lat $37^{\circ} 51$ '45", long $111^{\circ} 38^{\prime} 07^{\prime \prime}$, in $\mathrm{SW}_{4}^{\frac{1}{4}} \mathrm{NE}_{4}^{\prime} \mathrm{SW}_{\frac{1}{4}}$ sec.12, T.34 S., R.2 E., Garfield County, Hydrologic Unit 14070005, on right bank $0.2 \mathrm{mi}$ upstream fram unnamed right bank tributary and $7 \mathrm{mi}$ north of Escalante.

DRAINAGE AREA. $-68.1 \mathrm{mi}^{2}$.

MEAN BASIN ELEVATION. $--8,890 \mathrm{ft}$.

PERIOD OF RECORD AVAIIABLE.--July 1950 to September 1955, July 1957 to september 1981.

REVISED RECORDS. -WDR UT-78-1: Drainage area.

GAGE.--Water-stage recorder and servo-manometer. Altitude of gage is 6,400 ft from topographic map.

REMARKS.--No diversion above station. Some requlation from small reservoirs at headwaters.

AVERAGE DISCHARGE.--29 years, $4.43 \mathrm{ft}^{3} / \mathrm{s}, 3,210$ acre-ft/yr.

EXTREMES FOR PERIOD OF RECORD.--Maximum discharge, 1,010 ft ${ }^{3} / \mathrm{s}$ Aug. 2, 1967, gage height, $7.72 \mathrm{ft}$, from rating curve extended above $35 \mathrm{ft}^{3} / \mathrm{s}$ on basis of slope-area measurement at gage height $7.70 \mathrm{ft}$; no flow at times in some years.

LONEST MEAN DISCHARGE, IN OUBIC FEET PER SECOND, AND RANKING FOR THE INDICATED NUMBER OF CONSEOUTIVE DAYS FOR EAGH CLIMATIC YEAR, APRIL l-MARCH 31

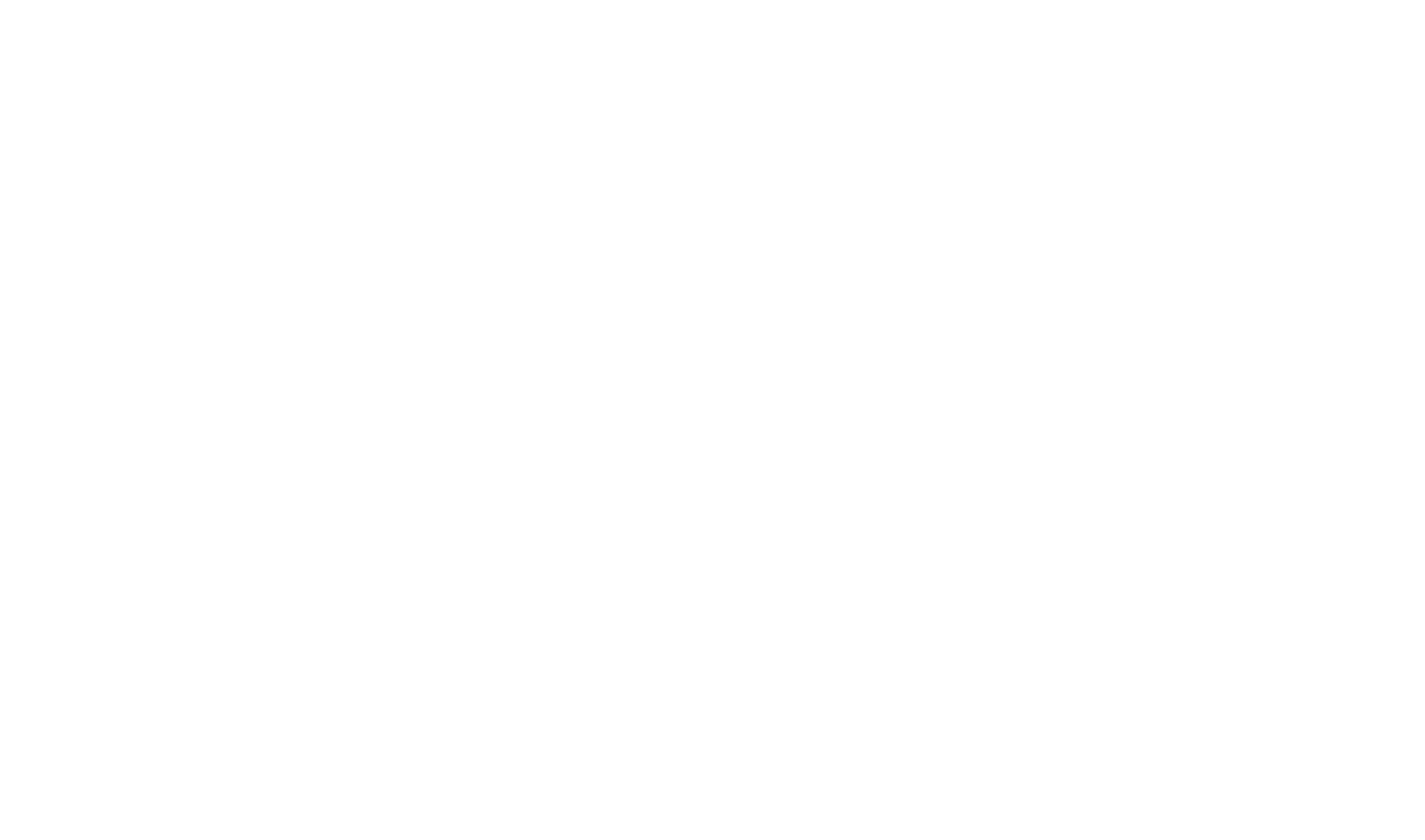

HIGHFST MEAN DISCHARGE, IN OUBIC FEET PER SECOND, AND RANKING FOR THE INDICATED NUMBER OF CONSECUTIVE DAYS FOR EACH WATER YEAR, OCTOBER 1-SEPTEMBER 30

YEAR

\begin{tabular}{rcrcrcrcr} 
& 1 & & 3 & \multicolumn{1}{c}{7} & 15 \\
1951 & 33.0 & 21 & 15.0 & 22 & 7.30 & 25 & 4.10 & 28 \\
1952 & 101 & 5 & 83.0 & 5 & 69.0 & 5 & 50.0 & 6 \\
1953 & 9.20 & 27 & 7.90 & 26 & 5.80 & 28 & 4.70 & 27 \\
1954 & 42.0 & 18 & 32.0 & 19 & 22.0 & 19 & 13.0 & 20 \\
1955 & 33.0 & 22 & 27.0 & 21 & 15.0 & 21 & 9.50 & 21 \\
1958 & 182 & 2 & 142 & 2 & 110 & 2 & 76.0 & 2 \\
1959 & 14.0 & 24 & 12.0 & 23 & 8.70 & 23 & 7.20 & 23 \\
1960 & 35.0 & 20 & 34.0 & 17 & 23.0 & 18 & 14.0 & 19 \\
1961 & 103 & 4 & 90.0 & 4 & 57.0 & 9 & 49.0 & 7 \\
1962 & 60.0 & 13 & 50.0 & 14 & 44.0 & 14 & 41.0 & 9 \\
1963 & 80.0 & 7 & 73.0 & 6 & 59.0 & 7 & 37.0 & 12 \\
1964 & 205 & 1 & 178 & 1 & 157 & 1 & 95.0 & 1 \\
1965 & 89.0 & 6 & 68.0 & 9 & 51.0 & 11 & 34.0 & 13
\end{tabular}

DONSECTTIVE DAYS

$\begin{array}{rrr}3.40 & 28 & 3.2027\end{array}$

$\begin{array}{cr}3.40 & 28 \\ 33.0 & 7\end{array}$

$\begin{array}{cc}33.0 & 7 \\ 3.80 & 27\end{array}$

6.7021

5.0025

$\begin{array}{ccc}53.0 & 1 \\ 6.60 & 22\end{array}$

9.1019

$36.0 \quad 5$

$32.0 \quad 8$

$21.0 \quad 14$

$\begin{array}{rr}52.0 & 2 \\ 24.0 & 12\end{array}$ $\begin{array}{rr}20.0 & 5 \\ 3.20 & 28\end{array}$

5.0024

3.5026

33.02

5.5023
6.2020

$20.0 \quad 6$

$\begin{array}{ll}20.0 & 6 \\ 19.0 & 9\end{array}$

$13.0 \quad 15$

8.0
90

3.1026

$\begin{array}{lll}16.0 & 6\end{array}$

$\begin{array}{ll}3.10 & 27 \\ 3.50 & 25\end{array}$

2.4028

25.02

5.0022

15.07

15.08

9.1016

19.04
120

2.9026

14.07

3.002

2.7027
2.0028

$\begin{array}{ccc}16.0 & 1 \\ 3.60 & 22\end{array}$

3.2023

8.809

10.08

$\begin{array}{rr}5.90 & 16 \\ 11.0 & 7\end{array}$

8.5012
ALL

2.3023

6.606

2.1025

$\begin{array}{ll}1.30 & 27 \\ 0.77 & 28\end{array}$

8.702

$\begin{array}{ll}2.90 & 21 \\ 2.20 & 24\end{array}$

5.2011

5.6010

4.3015

5.808 
ESCALANTE RIVER BASIN

09337000 PINE CREER NEAR ESCALANTE, UT--Continued

HIGHEST MEAN DISCHARGE, IN GBIC FEET PER SECOND, AND RANKING FOR THE INDICATED NUMBER OF CONSEQITIVE DAYS FOR EAOH WATER YEAR, OCTOBER 1-SEPTEMBER 30--Continued

\begin{tabular}{|c|c|c|c|c|c|c|c|c|c|c|c|c|c|c|c|c|c|c|c|}
\hline YEAR & 1 & & 3 & & 7 & & 15 & & $\begin{array}{l}\text { CONS } \\
30\end{array}$ & & $\begin{array}{l}\text { E DAYS } \\
60\end{array}$ & & 90 & & 120 & & 183 & & ALL \\
\hline $\begin{array}{l}1971 \\
1972 \\
1973 \\
1974 \\
1975\end{array}$ & $\begin{array}{c}17.0 \\
7.40 \\
110 \\
7.80 \\
66.0\end{array}$ & $\begin{array}{r}23 \\
29 \\
3 \\
28 \\
11\end{array}$ & $\begin{array}{c}9.70 \\
6.90 \\
91.0 \\
7.50 \\
62.0\end{array}$ & $\begin{array}{r}25 \\
28 \\
3 \\
27 \\
11\end{array}$ & $\begin{array}{c}8.50 \\
6.70 \\
76.0 \\
7.20 \\
49.0\end{array}$ & $\begin{array}{r}24 \\
27 \\
3 \\
26 \\
13\end{array}$ & $\begin{array}{c}7.00 \\
6.20 \\
61.0 \\
6.50 \\
30.0\end{array}$ & $\begin{array}{r}24 \\
26 \\
3 \\
25 \\
15\end{array}$ & $\begin{array}{c}5.80 \\
4.90 \\
49.0 \\
6.20 \\
29.0\end{array}$ & $\begin{array}{r}24 \\
26 \\
3 \\
23 \\
10\end{array}$ & $\begin{array}{c}5.50 \\
4.00 \\
34.0 \\
6.20 \\
16.0\end{array}$ & $\begin{array}{r}22 \\
25 \\
1 \\
19 \\
10\end{array}$ & $\begin{array}{c}5.20 \\
3.80 \\
26.0 \\
6.10 \\
12.0\end{array}$ & $\begin{array}{r}20 \\
24 \\
1 \\
19 \\
13\end{array}$ & $\begin{array}{r}5.20 \\
3.40 \\
21.0 \\
6.00 \\
9.30\end{array}$ & $\begin{array}{r}20 \\
24 \\
2 \\
19 \\
14\end{array}$ & $\begin{array}{c}4.50 \\
2.70 \\
16.0 \\
5.60 \\
6.80\end{array}$ & $\begin{array}{r}20 \\
24 \\
2 \\
17 \\
14\end{array}$ & $\begin{array}{rr}3.10 & 20 \\
2.00 & 26 \\
8.90 & 1 \\
4.70 & 13 \\
4.30 & 14\end{array}$ \\
\hline $\begin{array}{l}1976 \\
1977 \\
1978 \\
1979 \\
1980\end{array}$ & $\begin{array}{l}63.0 \\
12.0 \\
38.0 \\
79.0 \\
56.0\end{array}$ & $\begin{array}{r}12 \\
26 \\
19 \\
8 \\
15\end{array}$ & $\begin{array}{c}59.0 \\
6.20 \\
31.0 \\
67.0 \\
33.0\end{array}$ & $\begin{array}{l}12 \\
29 \\
20 \\
10 \\
18\end{array}$ & $\begin{array}{l}55.0 \\
3.90 \\
28.0 \\
59.0 \\
21.0\end{array}$ & $\begin{array}{r}10 \\
29 \\
16 \\
8 \\
20\end{array}$ & $\begin{array}{l}37.0 \\
1.90 \\
25.0 \\
56.0 \\
18.0\end{array}$ & $\begin{array}{r}11 \\
29 \\
16 \\
4 \\
18\end{array}$ & $\begin{array}{c}23.0 \\
1.80 \\
17.0 \\
42.0 \\
17.0\end{array}$ & $\begin{array}{r}13 \\
29 \\
16 \\
4 \\
17\end{array}$ & $\begin{array}{l}14.0 \\
1.60 \\
11.0 \\
28.0 \\
13.0\end{array}$ & $\begin{array}{r}13 \\
29 \\
17 \\
4 \\
14\end{array}$ & $\begin{array}{c}10.0 \\
1.19 \\
8.70 \\
22.0 \\
11.0\end{array}$ & $\begin{array}{r}15 \\
29 \\
17 \\
3 \\
14\end{array}$ & $\begin{array}{l}8.70 \\
1.10 \\
7.40 \\
19.0 \\
10.0\end{array}$ & $\begin{array}{r}15 \\
29 \\
16 \\
3 \\
13\end{array}$ & $\begin{array}{c}6.30 \\
0.90 \\
5.60 \\
14.0 \\
8.70\end{array}$ & $\begin{array}{r}15 \\
29 \\
18 \\
3 \\
10\end{array}$ & $\begin{array}{rr}4.00 & 17 \\
0.62 & 29 \\
3.20 & 19 \\
8.20 & 3 \\
5.70 & 9\end{array}$ \\
\hline
\end{tabular}

DURATION OF DISOHARGE FOR EACH WATER YEAR

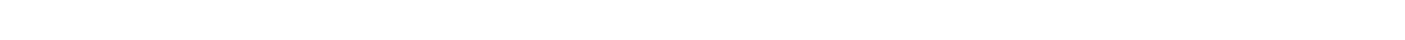

YEAR

NUMBER OF DAYS IN CLASS

OUBIC FEET PER SECO
-DAYS

1951

1952

1954102

1955167

1958

1959

1960

1961

$\begin{array}{ll}1963 & 23 \\ 196425\end{array}$

1965168

19661

1967

1968

1969
1970

1971

1972
1973

1974
1975

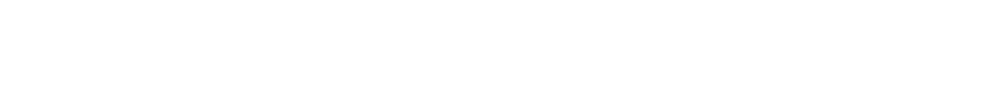

823.1

2411.8

764.9

467.4

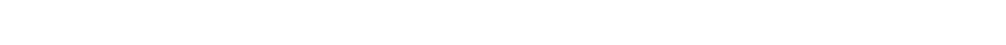

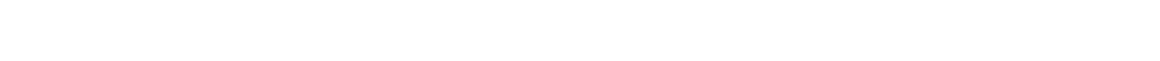

$\begin{array}{lllllllllllllllll}11 & 9 & 4 & 12 & 19 & 87 & 33 & 76 & 53 & 29 & 20 & 1 & 4 & 3 & 1 & 1 & 3\end{array}$

808.2

$\begin{array}{lllllllllllllllllllllllll}1 & 3 & 1 & 3 & 20 & 16 & 87 & 29 & 35 & 50 & 25 & 38 & 17 & 7 & 7 & 3 & 6 & 3 & 5 & 2 & 3 & 2 & 2 & 1904.0\end{array}$

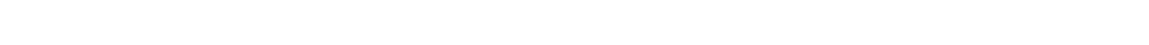

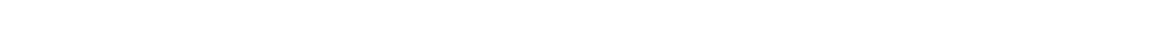

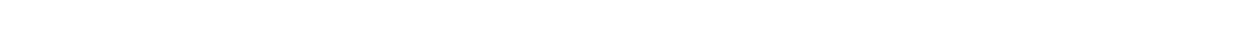

$\begin{array}{llllllllllllllll}1 & 3 & 3 & 3 & 53 & 71 & 14 & 23 & 28 & 60 & 66 & 17 & 20 & 4 & 1 & 1062.9\end{array}$

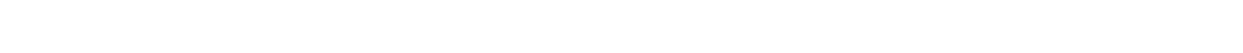

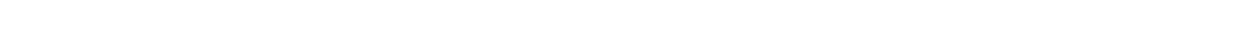

2509.1

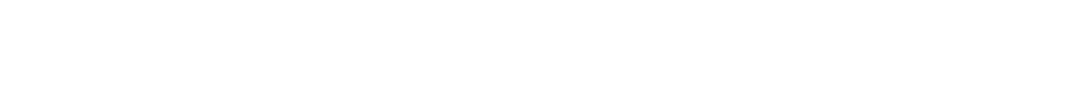

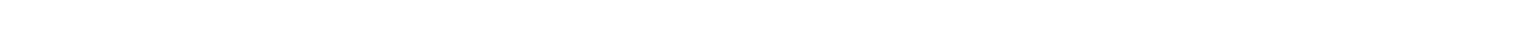

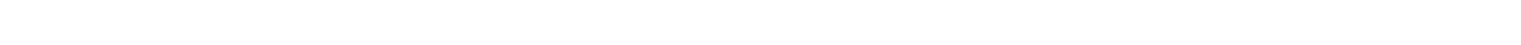

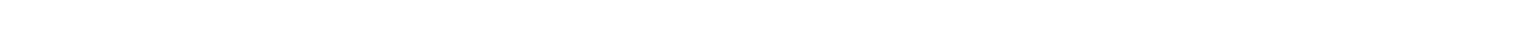

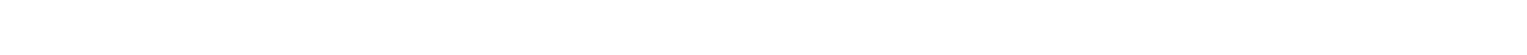

1981

$\begin{array}{lllllllllllllll}1 & 2 & 30 & 99 & 124 & 52 & 24 & 12 & 4 & 4 & 3 & 1 & 5 & 3 & 1\end{array}$

2317.6

DURATION TABLE OF DISCHARGE FOR WATER YEARS 1951-55, 1958-81

\begin{tabular}{ccccc}
\multicolumn{4}{c}{ OUBIC } & \multicolumn{3}{c}{ ACW- } \\
FEET & MU- & PER- \\
PER & TOTAL LATED & CENT \\
CLASS SECOND & DAYS & DAYS & DAYS \\
0 & 0.00 & 608 & 10592 & 100.0 \\
1 & 0.01 & 1 & 9984 & 94.3 \\
2 & 0.02 & 0 & 9983 & 94.3 \\
3 & 0.03 & 1 & 9983 & 94.3 \\
4 & 0.04 & 2 & 9982 & 94.2 \\
5 & 0.06 & 2 & 9980 & 94.2 \\
6 & 0.08 & 90 & 9978 & 94.2 \\
7 & 0.11 & 8 & 9888 & 93.4 \\
8 & 0.15 & 8 & 9880 & 93.3
\end{tabular}

\begin{tabular}{ccccc}
\multicolumn{4}{c}{ OUBIC } & \multicolumn{1}{c}{ ACQI- } \\
FEET & MU- & PER- \\
PER & TOTAL & LATED & CENT \\
CLASS SECOND & DAYS & DAYS & DAYS \\
9 & 0.20 & 236 & 9872 & 93.2 \\
10 & 0.26 & 105 & 9636 & 91.0 \\
11 & 0.35 & 216 & 9531 & 90.0 \\
12 & 0.48 & 393 & 9315 & 87.9 \\
13 & 0.64 & 484 & 8922 & 84.2 \\
14 & 0.86 & 913 & 8438 & 79.7 \\
15 & 1.20 & 976 & 7525 & 71.0 \\
16 & 1.60 & 992 & 6549 & 61.8 \\
17 & 2.10 & 1140 & 5557 & 52.5
\end{tabular}

\begin{tabular}{|c|c|c|c|c|}
\hline & $\begin{array}{c}\text { वJBIC } \\
\text { FEET } \\
\text { PER }\end{array}$ & TOTAL & $\begin{array}{c}\text { ACOJ- } \\
\text { MU- } \\
\text { LATED }\end{array}$ & $\begin{array}{l}\text { PER- } \\
\text { CENT }\end{array}$ \\
\hline CAASS & SECOND & DAYS & DAYS & DAYS \\
\hline $\begin{array}{l}18 \\
19 \\
20 \\
21 \\
22 \\
23 \\
24 \\
25 \\
26\end{array}$ & $\begin{array}{r}2.8 \\
3.8 \\
5.1 \\
6.9 \\
9.3 \\
13.0 \\
17.0 \\
23.0 \\
31.0\end{array}$ & $\begin{array}{r}1093 \\
1003 \\
912 \\
511 \\
343 \\
150 \\
104 \\
86 \\
61\end{array}$ & $\begin{array}{r}4417 \\
3324 \\
2321 \\
1409 \\
898 \\
555 \\
405 \\
301 \\
215\end{array}$ & $\begin{array}{r}41.7 \\
31.4 \\
21.9 \\
13.3 \\
8.5 \\
5.2 \\
3.8 \\
2.8 \\
2.0\end{array}$ \\
\hline
\end{tabular}

\begin{tabular}{|c|c|c|c|c|}
\hline & $\begin{array}{c}\text { OJBIC } \\
\text { FEET } \\
\text { PER }\end{array}$ & TOTAL & $\begin{array}{c}\text { ACOS- } \\
\text { MU- } \\
\text { LATED }\end{array}$ & $\begin{array}{l}\text { PER } \\
\text { CEN }\end{array}$ \\
\hline CASS & SECOND & DAYS & DAVS & DAVS \\
\hline $\begin{array}{l}27 \\
28 \\
29 \\
30 \\
31 \\
32\end{array}$ & $\begin{array}{r}41.0 \\
55.0 \\
75.0 \\
100.0 \\
140.0 \\
180.0\end{array}$ & $\begin{array}{r}78 \\
44 \\
18 \\
7 \\
5 \\
2\end{array}$ & $\begin{array}{r}154 \\
76 \\
32 \\
14 \\
7 \\
2\end{array}$ & $\begin{array}{l}1.5 \\
0.7 \\
0.3 \\
0.1 \\
0.1 \\
0.0\end{array}$ \\
\hline
\end{tabular}


ESCALANIE RIVER BASIN

09337000 PINE CREEK NEAR ESCALANTE, UT-Continued

MONIHLY MEAN DISCHARGES, IN OUBIC FEET PER SECOND, FOR EACH WATER YEAR

\begin{tabular}{|c|c|c|c|c|c|c|c|c|c|c|c|c|}
\hline YEAR & $\infty \mathrm{CT}$ & $\mathrm{NOV}$ & DEC. & JAN & FEB & MAR & APR & MAY & JUNE & JULY & AUG & SEP \\
\hline $\begin{array}{l}1951 \\
1952 \\
1953 \\
1954 \\
1955\end{array}$ & $\begin{array}{l}2.71 \\
1.88 \\
3.35 \\
1.15 \\
0.16\end{array}$ & $\begin{array}{l}2.54 \\
1.51 \\
2.76 \\
1.21 \\
0.26\end{array}$ & $\begin{array}{l}2.00 \\
1.66 \\
1.00 \\
0.97 \\
0.14\end{array}$ & $\begin{array}{l}1.50 \\
2.45 \\
2.12 \\
1.06 \\
0.07\end{array}$ & $\begin{array}{l}1.95 \\
2.42 \\
2.81 \\
0.39 \\
0.06\end{array}$ & $\begin{array}{l}2.21 \\
2.54 \\
3.31 \\
0.28 \\
0.94\end{array}$ & $\begin{array}{l}3.00 \\
7.11 \\
3.05 \\
6.65 \\
0.25\end{array}$ & $\begin{array}{c}3.16 \\
30.9 \\
2.49 \\
2.31 \\
4.79\end{array}$ & $\begin{array}{l}3.00 \\
6.19 \\
2.04 \\
1.25 \\
1.88\end{array}$ & $\begin{array}{l}0.68 \\
6.19 \\
0.75 \\
0.11 \\
0.00\end{array}$ & $\begin{array}{c}2.92 \\
10.3 \\
1.02 \\
0.00 \\
0.63\end{array}$ & $\begin{array}{l}1.39 \\
5.56 \\
0.52 \\
0.03 \\
0.00\end{array}$ \\
\hline $\begin{array}{l}1958 \\
1959 \\
1960\end{array}$ & $\begin{array}{l}2.14 \\
3.95 \\
1.79\end{array}$ & $\begin{array}{l}2.45 \\
4.12 \\
1.98\end{array}$ & $\begin{array}{l}1.50 \\
2.59 \\
1.48\end{array}$ & $\begin{array}{l}0.80 \\
2.19 \\
1.00\end{array}$ & $\begin{array}{l}1.04 \\
2.43 \\
1.38\end{array}$ & $\begin{array}{l}1.04 \\
3.21 \\
2.10\end{array}$ & $\begin{array}{l}8.06 \\
6.15 \\
4.19\end{array}$ & $\begin{array}{c}50.9 \\
4.74 \\
7.93\end{array}$ & $\begin{array}{l}8.80 \\
1.95 \\
2.08\end{array}$ & $\begin{array}{c}12.4 \\
0.27 \\
0.35\end{array}$ & $\begin{array}{l}6.47 \\
1.53 \\
0.99\end{array}$ & $\begin{array}{l}7.64 \\
1.28 \\
1.19\end{array}$ \\
\hline $\begin{array}{l}1961 \\
1962 \\
1963 \\
1964 \\
1965\end{array}$ & $\begin{array}{l}2.29 \\
1.38 \\
4.91 \\
1.11 \\
0.00\end{array}$ & $\begin{array}{l}2.72 \\
1.41 \\
4.00 \\
0.79 \\
0.00\end{array}$ & $\begin{array}{l}1.27 \\
0.77 \\
2.48 \\
0.77 \\
0.00\end{array}$ & $\begin{array}{l}1.00 \\
0.83 \\
1.29 \\
0.43 \\
0.05\end{array}$ & $\begin{array}{l}1.50 \\
0.97 \\
2.04 \\
0.30 \\
0.04\end{array}$ & $\begin{array}{l}0.75 \\
1.69 \\
1.33 \\
0.48 \\
0.05\end{array}$ & $\begin{array}{c}10.5 \\
19.5 \\
5.11 \\
5.91 \\
1.07\end{array}$ & $\begin{array}{l}28.3 \\
18.9 \\
19.3 \\
49.1 \\
12.2\end{array}$ & $\begin{array}{c}3.81 \\
5.08 \\
1.98 \\
0.53 \\
15.7\end{array}$ & $\begin{array}{l}5.58 \\
7.80 \\
0.79 \\
2.62 \\
8.90\end{array}$ & $\begin{array}{l}1.57 \\
4.82 \\
2.78 \\
5.42 \\
8.51\end{array}$ & $\begin{array}{l}2.98 \\
4.21 \\
4.90 \\
0.94 \\
4.56\end{array}$ \\
\hline $\begin{array}{l}1966 \\
1967 \\
1968 \\
1969 \\
1970\end{array}$ & $\begin{array}{l}3.97 \\
1.63 \\
2.70 \\
2.54 \\
5.23\end{array}$ & $\begin{array}{l}4.28 \\
1.71 \\
1.09 \\
2.25 \\
4.77\end{array}$ & $\begin{array}{l}0.83 \\
1.18 \\
1.12 \\
1.28 \\
3.30\end{array}$ & $\begin{array}{l}0.82 \\
0.85 \\
1.20 \\
1.16 \\
2.85\end{array}$ & $\begin{array}{l}1.01 \\
1.09 \\
1.87 \\
0.25 \\
3.34\end{array}$ & $\begin{array}{l}3.57 \\
1.85 \\
2.12 \\
1.33 \\
3.61\end{array}$ & $\begin{array}{l}8.04 \\
1.89 \\
2.95 \\
9.35 \\
4.94\end{array}$ & $\begin{array}{l}3.44 \\
14.5 \\
18.4 \\
28.4 \\
31.8\end{array}$ & $\begin{array}{l}1.69 \\
2.81 \\
7.35 \\
8.39 \\
5.52\end{array}$ & $\begin{array}{l}3.60 \\
2.52 \\
8.21 \\
9.48 \\
7.24\end{array}$ & $\begin{array}{c}1.79 \\
4.30 \\
7.34 \\
10.6 \\
8.72\end{array}$ & $\begin{array}{l}1.86 \\
6.38 \\
5.30 \\
6.82 \\
4.08\end{array}$ \\
\hline $\begin{array}{l}1971 \\
1972 \\
1973 \\
1974 \\
1975\end{array}$ & $\begin{array}{l}2.26 \\
1.84 \\
3.06 \\
3.53 \\
2.14\end{array}$ & $\begin{array}{l}2.02 \\
1.42 \\
1.18 \\
4.93 \\
2.65\end{array}$ & $\begin{array}{l}1.01 \\
1.04 \\
1.65 \\
6.16 \\
2.46\end{array}$ & $\begin{array}{l}1.68 \\
1.64 \\
1.99 \\
6.05 \\
1.15\end{array}$ & $\begin{array}{l}2.18 \\
1.21 \\
2.03 \\
5.85 \\
1.30\end{array}$ & $\begin{array}{l}2.87 \\
1.04 \\
2.07 \\
5.48 \\
1.05\end{array}$ & $\begin{array}{l}5.26 \\
3.38 \\
5.98 \\
4.62 \\
1.52\end{array}$ & $\begin{array}{c}4.82 \\
3.92 \\
43.6 \\
5.39 \\
16.3\end{array}$ & $\begin{array}{c}5.04 \\
3.85 \\
22.2 \\
4.44 \\
14.6\end{array}$ & $\begin{array}{l}5.66 \\
2.18 \\
9.28 \\
4.61 \\
3.48\end{array}$ & $\begin{array}{l}3.11 \\
1.39 \\
7.34 \\
3.94 \\
2.05\end{array}$ & $\begin{array}{l}1.52 \\
1.26 \\
6.20 \\
1.41 \\
3.13\end{array}$ \\
\hline $\begin{array}{l}1976 \\
1977 \\
1978 \\
1979 \\
1980\end{array}$ & $\begin{array}{l}1.83 \\
1.55 \\
1.50 \\
1.66 \\
2.65\end{array}$ & $\begin{array}{l}2.11 \\
1.54 \\
0.49 \\
2.54 \\
2.52\end{array}$ & $\begin{array}{l}2.02 \\
0.61 \\
0.27 \\
0.95 \\
2.54\end{array}$ & $\begin{array}{l}1.34 \\
0.58 \\
0.73 \\
0.97 \\
2.75\end{array}$ & $\begin{array}{l}1.29 \\
0.53 \\
0.76 \\
1.62 \\
2.70\end{array}$ & $\begin{array}{l}1.44 \\
0.61 \\
1.86 \\
4.86 \\
2.73\end{array}$ & $\begin{array}{l}2.18 \\
0.07 \\
4.17 \\
9.99 \\
5.82\end{array}$ & $\begin{array}{c}22.3 \\
0.21 \\
16.8 \\
36.1 \\
13.7\end{array}$ & $\begin{array}{c}4.14 \\
0.00 \\
4.58 \\
19.1 \\
11.1\end{array}$ & $\begin{array}{l}3.61 \\
0.53 \\
3.41 \\
8.59 \\
7.12\end{array}$ & $\begin{array}{l}3.66 \\
0.90 \\
2.57 \\
7.60 \\
6.55\end{array}$ & $\begin{array}{l}1.25 \\
0.29 \\
0.95 \\
4.11 \\
7.98\end{array}$ \\
\hline 1981 & 4.27 & 4.06 & 4.20 & 4.90 & 3.65 & 3.35 & 20.8 & 11.0 & 5.20 & 6.10 & 5.01 & 3.67 \\
\hline
\end{tabular}

ANNAL PEAK DISCHARGE, IN OBBIC FEET PER SECOND, AND CORRESPONDING GAGE HEIGHT, IN FEET, FOR EACH WATER YEAR

\begin{tabular}{|c|c|c|c|c|c|c|c|c|c|c|c|}
\hline $\begin{array}{l}\text { WATER } \\
\text { YEAR }\end{array}$ & DATE & $\begin{array}{c}\text { GAGE } \\
\text { HEIGHT }\end{array}$ & $\begin{array}{c}\text { PEAK } \\
\text { DISCHARGE }\end{array}$ & $\begin{array}{l}\text { WATER } \\
\text { YEAR }\end{array}$ & DATE & $\begin{array}{c}\text { GAGE } \\
\text { HEIGHT }\end{array}$ & $\begin{array}{c}\text { PEAR } \\
\text { DISCHARGE }\end{array}$ & $\begin{array}{l}\text { WATER } \\
\text { YEAR }\end{array}$ & DATE & $\begin{array}{c}\text { GAGE } \\
\text { HEIGHT }\end{array}$ & $\begin{array}{c}\text { PEAK } \\
\text { DISCHARGE }\end{array}$ \\
\hline $\begin{array}{l}1951 \\
1952 \\
1953 \\
1954 \\
1955 \\
1958 \\
1959 \\
1960 \\
1961 \\
1962\end{array}$ & $\begin{array}{l}\text { AUG. } 03,1951 \\
\text { SEPT.16, } 1952 \\
\text { AUG. } 01,1953 \\
\text { APR. } 18,1954 \\
\text { AUG. } 16,1955 \\
\text { MAY } 19,1958 \\
\text { AUG. } 19,1959 \\
\text { MAY } 10,1960 \\
\text { JULY } 03,1961 \\
\text { JULY } 23,1962\end{array}$ & $\begin{array}{l}4.16 \\
4.35 \\
3.57 \\
3.33 \\
3.20 \\
4.52 \\
2.71 \\
2.96 \\
7.52 \\
5.67\end{array}$ & $\begin{array}{r}285 \\
325 \\
153 \\
108 \\
102 \\
288 \\
53 \\
74 \\
947 \\
448\end{array}$ & $\begin{array}{l}1963 \\
1964 \\
1965 \\
1966 \\
1967 \\
1968 \\
1969 \\
1970 \\
1971 \\
1972\end{array}$ & $\begin{array}{l}\text { AUG. } 18,1963 \\
\text { JULY } 31,1964 \\
\text { AUG. } 15,1965 \\
\text { AUG. } 31,1966 \\
\text { AUG. } 02,1967 \\
\text { AUG. } 02,1968 \\
\text { AUG. } 30,1969 \\
\text { MAY } 06,1970 \\
\text { AUG. } 20,1971 \\
\text { JULY } 25,1972\end{array}$ & $\begin{array}{l}5.56 \\
5.58 \\
7.70 \\
2.70 \\
7.72 \\
4.63 \\
4.26 \\
4.00 \\
5.20 \\
2.05\end{array}$ & $\begin{array}{r}423 \\
428 \\
1000 \\
24 \\
1010 \\
250 \\
197 \\
180 \\
340 \\
11\end{array}$ & $\begin{array}{l}1973 \\
1974 \\
1975 \\
1976 \\
1977 \\
1978 \\
1979 \\
1980 \\
1981\end{array}$ & $\begin{array}{lll}\text { MAY } & 21,1973 \\
\text { JULY } & 22,1974 \\
\text { MAY } & 17,1975 \\
\text { MAY } & 17,1976 \\
\text { AUG. } 17,1977 \\
\text { MAY } & 15,1978 \\
\text { MAY } & 22,1979 \\
\text { SEPT. } 10,1980 \\
\text { JULY } 13,1981\end{array}$ & $\begin{array}{l}4.23 \\
2.92 \\
3.49 \\
-- \\
2.77 \\
3.08 \\
3.89 \\
3.71 \\
6.71\end{array}$ & $\begin{array}{r}193 \\
51 \\
108 \\
63 \\
52 \\
66 \\
153 \\
131 \\
713\end{array}$ \\
\hline
\end{tabular}

MAGNITUDE AND PRCBABILITY OF ANNUAL LOWEST MEAN DISCHARGE BASED ON OIMATIC YEARS 1952-55 AND 1959-81

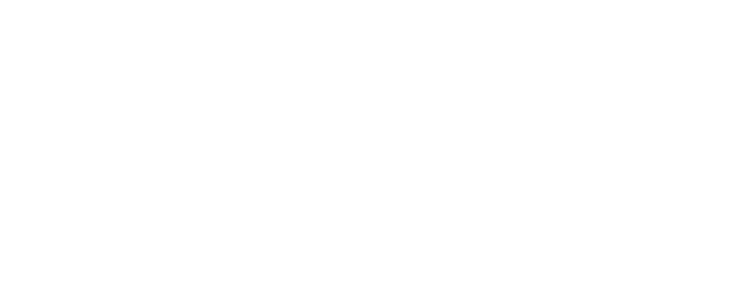

MAGNITUDE AND PRCBABILITY OF ANNUAL HIGHEST MEAN DISCHARGE BASED ON WATER YEARS 1951-55 AND 1958-81

\begin{tabular}{|c|c|c|c|c|c|c|}
\hline \multirow{2}{*}{$\begin{array}{l}\text { PERIOD } \\
\text { (CON- } \\
\text { SECH- } \\
\text { TIVE } \\
\text { DAYS) }\end{array}$} & \multicolumn{6}{|c|}{$\begin{array}{l}\text { DISCHARGE, IN OBIC FEET PER SECOND, FOR } \\
\text { INDICATED RECURRENCE INTERNAL, IN YEARS, AND } \\
\text { ANNUAL EXCEEDANCE PRCBABILITY, IN PERCENT }\end{array}$} \\
\hline & $\begin{array}{c}2 \\
508\end{array}$ & $\begin{array}{c}5 \\
20 \%\end{array}$ & $\begin{array}{l}10 \\
10 \%\end{array}$ & $\begin{array}{l}25 \\
48\end{array}$ & $\begin{array}{l}50 \\
28\end{array}$ & $\begin{array}{r}100 \\
18\end{array}$ \\
\hline $\begin{array}{r}1 \\
3 \\
7 \\
15\end{array}$ & $\begin{array}{l}47 \\
38 \\
29 \\
23\end{array}$ & $\begin{array}{l}95 \\
80 \\
65 \\
49\end{array}$ & $\begin{array}{r}131 \\
114 \\
95 \\
70\end{array}$ & $\begin{array}{r}179 \\
160 \\
139 \\
97\end{array}$ & $\begin{array}{l}215 \\
197 \\
175 \\
119\end{array}$ & $\begin{array}{l}\overline{-} \\
\overline{-}\end{array}$ \\
\hline
\end{tabular}




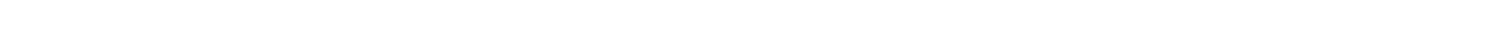
bank $150 \mathrm{ft}$ downstream from Pine Creek and $2 \mathrm{mi}$ northeast of Escalante.

DRAINAGE AREA. $--320 \mathrm{mi}^{2}$.

MEAN BASIN ELEVATION. $-8,030 \mathrm{ft}$.

PERIOD OF RECORD AVAILABLE.--August 1909 to April 1913 (monthly mean discharge for same periods, published in WSP 1313), October 1942 to September 1955, December 1971 to September 1981. Published as "Escalante Creek near Escalante", $1909-13$.

REVISED RECORDS.--WSP 1149: 1943(M), 1944, 1945(M). WDR UT-73-1: 1972.

GAGE.--Water-stage recorder. Altitude of gage is 5,670 ft from topographic map. Prior to Apr. 30, 1913, staff gage at approximately same site at different datum.

REMARKS.--Diversions above station for irrigation of about 2,300 acres of crop and pasture land.

AVERAGE DISCAARGE. --25 years (water years 1910-12, 1943-55, 1973-81), $15.0 \mathrm{ft}^{3} / \mathrm{s}, 10,870 \mathrm{acre}-\mathrm{ft} / \mathrm{yr}$.

EXTREMES FOR PERIOD OF RECORD.--Maximum discharge, 3,450 ft $3 / \mathrm{s}$ Aug. 1953, day unknown, gage height, $9.9 \mathrm{ft}$ from outside high-water mark, from rating curve extended above $540 \mathrm{ft}^{3} / \mathrm{s}$ on basis of slope-area measurements at gage heights $5.50 \mathrm{ft}$ and $7.34 \mathrm{ft} \mathrm{from}$ inside gage and $7.59 \mathrm{ft}$ from outside high-water mark, and logarithmic plotting; minimum, $0.07 \mathrm{ft}^{3} / \mathrm{s} \mathrm{Dec} .24,1978$, result of freezeup.

LOWEST MEAN DISCHARGE, IN CABIC FEET PER SECOND, AND RANKING FOR THE INDICATED NUMBER OF CONSECUTIVE DAYS FOR EACH CIIMATIC YEAR, APRIL I-MARCH 31

YEAR

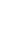

1944

1946

1947

1948

1949

195

1951
1953
1954

1953
1954
1955

1955

1973

1974
1975

1976

1977

1977
1978
1979

1978
1979
1980

1980

I98I

HIGHEST MEAN DISCHARGE, IN CBIC FEET PER SECOND, AND RANKING FOR THE INDICATED NUMBER OF CONSECUTIVE DAYS FOR EACH WATER YEAR, OCTOBER 1-SEPTEMBER 30
FET

YEAR

$\begin{array}{rrrrrrrrr} & 1 & & 3 & & 7 & & 15 & \\ 1912 & 557 & 1 & 197 & 3 & 134 & 2 & 121 & 3 \\ & & & & & & & & \\ 1943 & 108 & 11 & 99.0 & 10 & 82.0 & 9 & 56.0 & 7 \\ 1944 & 258 & 4 & 179 & 4 & 131 & 3 & 128 & 2 \\ 1945 & 101 & 13 & 59.0 & 16 & 36.0 & 16 & 27.0 & 16 \\ 1946 & 240 & 6 & 161 & 6 & 94.0 & 7 & 55.0 & 8 \\ 1947 & 300 & 2 & 134 & 7 & 91.0 & 8 & 50.0 & 10 \\ 1948 & 96.0 & 14 & 61.0 & 14 & 52.0 & 14 & 41.0 & 12 \\ 1949 & 194 & 9 & 170 & 5 & 121 & 4 & 110 & 4 \\ 1950 & 46.0 & 19 & 35.0 & 19 & 34.0 & 17 & 33.0 & 14 \\ & & & & & & & & \\ 1951 & 203 & 8 & 88.0 & 12 & 52.0 & 15 & 26.0 & 17 \\ 1952 & 108 & 12 & 89.0 & 11 & 72.0 & 10 & 58.0 & 6 \\ 1953 & 90.0 & 15 & 38.0 & 18 & 21.0 & 19 & 16.0 & 20 \\ 1954 & 46.0 & 20 & 18.0 & 22 & 13.0 & 22 & 9.00 & 21 \\ 1955 & 247 & 5 & 127 & 8 & 63.0 & 12 & 30.0 & 15\end{array}$

$\begin{array}{ll}\text { CONSEOUTIVE DAYS } \\ 30 & 60\end{array}$

96.03

$39.0 \quad 6$

$\begin{array}{rr}111 & 2 \\ 25.0 & 14\end{array}$

$30.0 \quad 12$

$29.0 \quad 13$

31.09

$\begin{array}{rr}91.0 & 4 \\ 31.0 & 10\end{array}$

$17.0 \quad 17$

$\begin{array}{rr}17.0 & 17 \\ 39.0 & 7\end{array}$

$\begin{array}{ll}39.0 & 7 \\ 12.0 & 20\end{array}$

$\begin{array}{cc}7.40 & 21 \\ 16.0 \quad 19\end{array}$
67.0

$27.0 \quad 8$

85.02

$23.0 \quad 11$

$\begin{array}{ll}20.0 & 12 \\ 17.0 & 14\end{array}$

$\begin{array}{rr}17.0 & 14 \\ 26.0 & 9\end{array}$

$\begin{array}{lr}62.0 & 4 \\ 26.0 & 10\end{array}$

$10.0 \quad 19$

31.06

12.017

$\begin{array}{ll}6.00 & 21 \\ 8.70 & 20\end{array}$
90

3.9013

$\begin{array}{ll}3.90 & 13 \\ 6.50 & 17\end{array}$

8.0019

1.603

6.0016

$5.60 \quad 14$
$11.0 \quad 21$

3.3011

2.209

$\begin{array}{lll}5.80 & 15\end{array}$

$1.90 \quad 7$

1.805

1.806

$\begin{array}{rr}7.00 & 18 \\ 2.00 & 8\end{array}$

2.9010

$\begin{array}{ll}1.60 & 4\end{array}$

1.502

3.4012

8.5020
120

$4.70 \quad 13$

$7.40 \mathrm{I7}$

$\begin{array}{ll}8.4019 \\ 3.70 & 12\end{array}$

3.7012
6.9016

5.9014

$11.0 \quad 21$

3.5010

$2.30 \quad 6$

$\begin{array}{lll}6.80 & 15\end{array}$

3.109

1.804

$1.70 \quad 2$

$\begin{array}{rr}7.80 & 18 \\ 2.70 & 7\end{array}$

$3.10 \quad 8$

1.90
1.70

$\begin{array}{ll}1.70 & 3 \\ 0.83 & 1\end{array}$

0.83
3.7011

9.5020
7.7015
$10.0 \quad 19$

$10.0 \quad 20$

3.609

9.2017

6.9013
$12.0 \quad 21$

3.8010

4.6012

7.6014

3.507

2.20

$2.10 \quad 3$

$\begin{array}{ll}9.30 & 18 \\ 2.60 & 5\end{array}$

$3.50 \quad 8$

$2.70 \quad 6$

$\begin{array}{ll}1.80 & 2 \\ 1.60 & 1\end{array}$

4.10 II

9.1016

ALt

$12.0 \quad 13$

12.0

8.4011

$12.0 \quad 12$

$\begin{array}{ll}13.0 & 15 \\ 23.0 & 19\end{array}$

4.807

6.209

$13.0 \quad 16$

3.80

$7.60 \quad 10$

$30.0 \quad 21$

$3.30 \quad 2$

$5.10 \quad 8$

4.305
2.20
1

$\begin{array}{ll}2.20 & 1 \\ 4.40 \quad 6\end{array}$

$\begin{array}{rr}4.40 & 6 \\ 17.0 & \end{array}$

$14.0 \quad 17$ 
BSCALANTE RIVER BASIN

09337500 ESCALANTE RIVER NEAR ESCALANTE, UT--Continued

HIGHEST MEAN DISOHARGE, IN OBBIC FEET PER SBCOND, AND RANKING FOR THE INDICATED NUMBER OF CONSECUTIVE DAYS FOR EAOH WATER YEAR, OCTOBER 1-SEPTEMBER 30--Continued

\begin{tabular}{|c|c|c|c|c|c|c|c|c|c|c|c|c|c|c|c|c|c|c|c|c|}
\hline YEAR & 1 & & 3 & & 7 & & 15 & & $\begin{array}{l}\text { CNSE } \\
30\end{array}$ & BOI & $\begin{array}{l}\text { VE DAYS } \\
60\end{array}$ & & 90 & & 120 & & 183 & & ALL & \\
\hline $\begin{array}{l}1973 \\
1974 \\
1975\end{array}$ & $\begin{array}{r}236 \\
23.0 \\
44.0\end{array}$ & $\begin{array}{r}7 \\
22 \\
21\end{array}$ & $\begin{array}{l}219 \\
21.0 \\
41.0\end{array}$ & $\begin{array}{r}1 \\
21 \\
17\end{array}$ & $\begin{array}{l}206 \\
19.0 \\
33.0\end{array}$ & $\begin{array}{r}1 \\
20 \\
18\end{array}$ & $\begin{array}{r}190 \\
18.0 \\
19.0\end{array}$ & $\begin{array}{r}1 \\
19 \\
18\end{array}$ & $\begin{array}{c}173 \\
17.0 \\
19.0\end{array}$ & $\begin{array}{r}1 \\
18 \\
16\end{array}$ & $\begin{array}{r}118 \\
16.0 \\
11.0\end{array}$ & $\begin{array}{r}1 \\
15 \\
18\end{array}$ & $\begin{array}{c}86.0 \\
14.0 \\
8.90\end{array}$ & $\begin{array}{r}1 \\
14 \\
18\end{array}$ & $\begin{array}{c}69.0 \\
13.0 \\
8.20\end{array}$ & $\begin{array}{r}1 \\
15 \\
18\end{array}$ & $\begin{array}{c}50.0 \\
11.0 \\
6.70\end{array}$ & $\begin{array}{r}1 \\
15 \\
18\end{array}$ & $\begin{array}{c}31.0 \\
6.80 \\
4.90\end{array}$ & $\begin{array}{r}2 \\
15 \\
18\end{array}$ \\
\hline $\begin{array}{l}1976 \\
1977 \\
1978 \\
1979 \\
1080\end{array}$ & $\begin{array}{c}65.0 \\
70.0 \\
15.0 \\
120 \\
270\end{array}$ & $\begin{array}{r}18 \\
17 \\
23 \\
10 \\
3\end{array}$ & $\begin{array}{r}61.0 \\
25.0 \\
12.0 \\
117 \\
209\end{array}$ & $\begin{array}{r}15 \\
20 \\
23 \\
9 \\
2\end{array}$ & $\begin{array}{c}55.0 \\
15.0 \\
9.50 \\
110 \\
105\end{array}$ & $\begin{array}{r}13 \\
21 \\
23 \\
5 \\
6\end{array}$ & $\begin{array}{r}38.0 \\
8.10 \\
7.10 \\
101 \\
54.0\end{array}$ & $\begin{array}{r}13 \\
22 \\
23 \\
5 \\
9\end{array}$ & $\begin{array}{c}22.0 \\
5.00 \\
4.70 \\
83.0 \\
38.0\end{array}$ & $\begin{array}{r}15 \\
22 \\
23 \\
5 \\
8\end{array}$ & $\begin{array}{c}12.0 \\
4.10 \\
3.30 \\
57.0 \\
29.0\end{array}$ & $\begin{array}{r}16 \\
22 \\
23 \\
5 \\
7\end{array}$ & $\begin{array}{c}11.0 \\
3.50 \\
3.00 \\
51.0 \\
24.0\end{array}$ & $\begin{array}{r}17 \\
22 \\
23 \\
5 \\
8\end{array}$ & $\begin{array}{r}8.80 \\
3.00 \\
2.80 \\
43.0 \\
21.0\end{array}$ & $\begin{array}{r}17 \\
22 \\
23 \\
5 \\
9\end{array}$ & $\begin{array}{c}7.20 \\
3.00 \\
2.50 \\
30.0 \\
20.0\end{array}$ & $\begin{array}{r}17 \\
22 \\
23 \\
5 \\
7\end{array}$ & $\begin{array}{c}5.00 \\
2.70 \\
1.80 \\
17.0 \\
13.0\end{array}$ & $\begin{array}{r}17 \\
22 \\
23 \\
5 \\
9\end{array}$ \\
\hline & 84.0 & 16 & 76.0 & 13 & 64.0 & 11 & 49.0 & 11 & 30.0 & 11 & 18.0 & 13 & 15.0 & 13 & 14.0 & 14 & 13.0 & 13 & 11.0 & 11 \\
\hline
\end{tabular}

DURATION OF DISCHARGE FOR EACH WATER YEAR

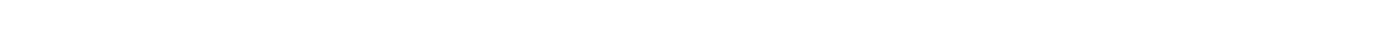
YEAR NUMBER OF DAYS IN CLASS OBIC FEET PER SECON -DAYS

1912

1943

1944

1946

1947

1948

1950

1951

1952

1953
1954

1954
1955

1973

1974

1976

1978
1979

1980

1981

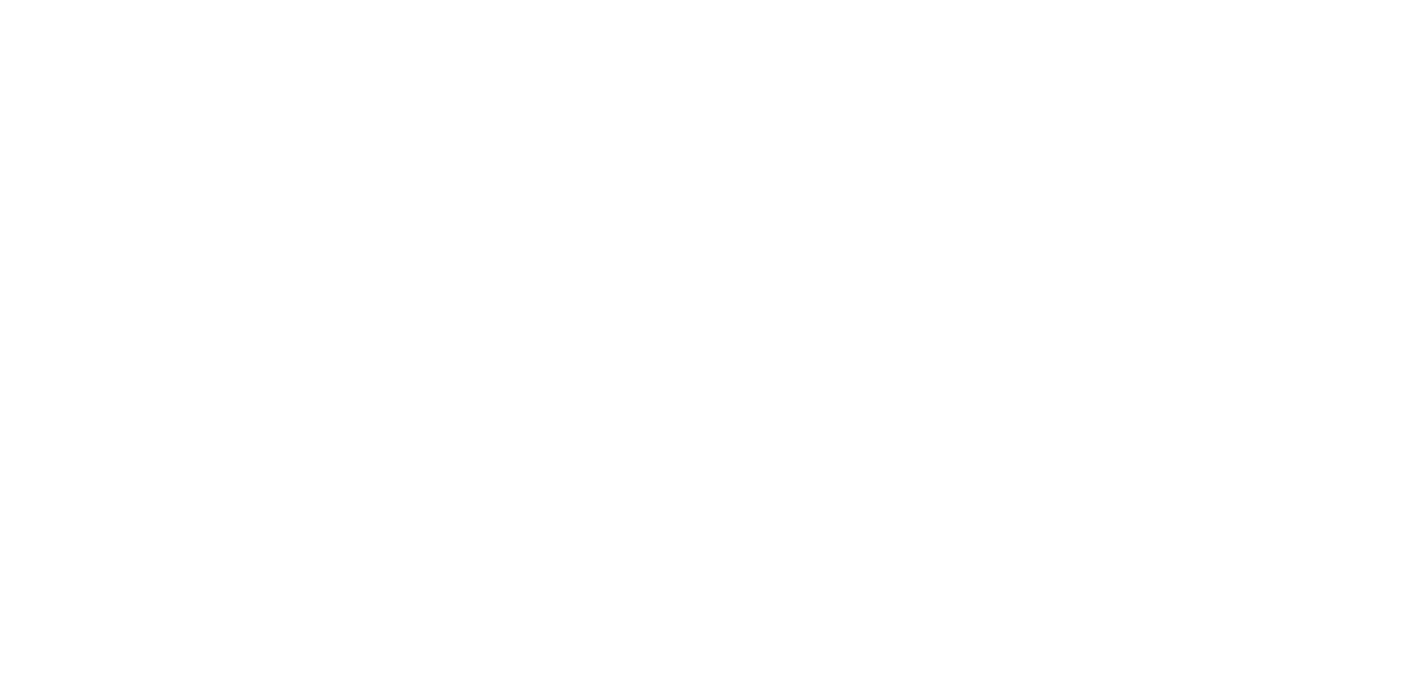

DURATION TABLE OF DISCHARGE FOR WATER YEARS 1912, 1943-55, 1973-81

\begin{tabular}{|c|c|c|c|c|c|c|c|c|c|c|c|c|c|c|c|c|c|c|c|}
\hline CLASS & $\begin{array}{c}\text { OUBIC } \\
\text { FEET } \\
\text { PER } \\
\text { SECOND }\end{array}$ & $\begin{array}{r}\text { TOTAL } \\
\text { DAYS }\end{array}$ & $\begin{array}{l}\text { AOCU- } \\
\text { MU- } \\
\text { LATED } \\
\text { DAYS }\end{array}$ & $\begin{array}{l}\text { PER- } \\
\text { CENT } \\
\text { DAYS }\end{array}$ & CLASS & $\begin{array}{c}\text { OBBIC } \\
\text { FEET } \\
\text { PER } \\
\text { SECOND }\end{array}$ & $\begin{array}{r}\text { TOTAL } \\
\text { DAYS }\end{array}$ & $\begin{array}{c}\text { ACOU- } \\
\text { MU- } \\
\text { LATED } \\
\text { DAYS }\end{array}$ & $\begin{array}{l}\text { PER- } \\
\text { CENT } \\
\text { DAYS }\end{array}$ & CAASS & $\begin{array}{l}\text { CUBIC } \\
\text { FEET } \\
\text { PER } \\
\text { SECOND }\end{array}$ & $\begin{array}{r}\text { TOTAL, } \\
\text { DAYS }\end{array}$ & $\begin{array}{c}\text { ACOU- } \\
\text { MU- } \\
\text { LATED } \\
\text { DAYS }\end{array}$ & $\begin{array}{l}\text { PER- } \\
\text { CENT } \\
\text { DAYS }\end{array}$ & CLASS & $\begin{array}{c}\text { COBIC } \\
\text { FEET } \\
\text { PER } \\
\text { SECOND }\end{array}$ & $\begin{array}{r}\text { TOTAL, } \\
\text { DAYS }\end{array}$ & $\begin{array}{c}\text { ACOU- } \\
\text { MU- } \\
\text { LATED } \\
\text { DAYS }\end{array}$ & $\begin{array}{l}\text { PER- } \\
\text { CENT } \\
\text { DAYS }\end{array}$ \\
\hline $\begin{array}{l}0 \\
1 \\
2 \\
3 \\
4 \\
5 \\
6 \\
7 \\
8\end{array}$ & $\begin{array}{l}0.00 \\
0.20 \\
0.25 \\
0.32 \\
0.40 \\
0.51 \\
0.64 \\
0.81 \\
1.00\end{array}$ & $\begin{array}{r}0 \\
4 \\
10 \\
8 \\
32 \\
52 \\
148 \\
117 \\
329\end{array}$ & $\begin{array}{l}8401 \\
8401 \\
8397 \\
8387 \\
8379 \\
8347 \\
8295 \\
8147 \\
8030\end{array}$ & $\begin{array}{r}100.0 \\
100.0 \\
100.0 \\
99.8 \\
99.7 \\
99.4 \\
98.7 \\
97.0 \\
95.6\end{array}$ & $\begin{array}{r}9 \\
10 \\
11 \\
12 \\
13 \\
14 \\
15 \\
16 \\
17\end{array}$ & $\begin{array}{l}1.30 \\
1.60 \\
2.10 \\
2.60 \\
3.30 \\
4.20 \\
5.30 \\
6.70 \\
8.40\end{array}$ & $\begin{array}{l}377 \\
734 \\
485 \\
729 \\
682 \\
530 \\
456 \\
453 \\
689\end{array}$ & $\begin{array}{l}7701 \\
7324 \\
6590 \\
6105 \\
5376 \\
4694 \\
4164 \\
3708 \\
3255\end{array}$ & $\begin{array}{l}91.7 \\
87.2 \\
78.4 \\
72.7 \\
64.0 \\
55.9 \\
49.6 \\
44.1 \\
38.7\end{array}$ & $\begin{array}{l}18 \\
19 \\
20 \\
21 \\
22 \\
23 \\
24 \\
25 \\
26\end{array}$ & $\begin{array}{l}11.0 \\
13.0 \\
17.0 \\
21.0 \\
27.0 \\
34.0 \\
43.0 \\
54.0 \\
69.0\end{array}$ & $\begin{array}{r}416 \\
688 \\
357 \\
310 \\
245 \\
165 \\
97 \\
84 \\
54\end{array}$ & $\begin{array}{r}2566 \\
2150 \\
1462 \\
1105 \\
795 \\
550 \\
385 \\
288 \\
204\end{array}$ & $\begin{array}{r}30.5 \\
25.6 \\
17.4 \\
13.2 \\
9.5 \\
6.5 \\
4.6 \\
3.4 \\
2.4\end{array}$ & $\begin{array}{l}27 \\
28 \\
29 \\
30 \\
31 \\
32 \\
33 \\
34\end{array}$ & $\begin{array}{r}87.0 \\
110.0 \\
140.0 \\
180.0 \\
220.0 \\
280.0 \\
350.0 \\
450.0\end{array}$ & $\begin{array}{r}55 \\
40 \\
27 \\
12 \\
9 \\
2 \\
4 \\
1\end{array}$ & $\begin{array}{r}150 \\
95 \\
55 \\
28 \\
16 \\
7 \\
5 \\
1\end{array}$ & $\begin{array}{l}1.8 \\
1.1 \\
0.7 \\
0.3 \\
0.2 \\
0.1 \\
0.1 \\
0.0\end{array}$ \\
\hline
\end{tabular}

MONIHLY MEAN DISCHARGES, IN CUBIC FEET PER SECOND, FOR EACH WATER YEAR

\begin{tabular}{|c|c|c|c|c|c|c|c|c|c|c|c|c|}
\hline YEAR & $\infty \Gamma$ & NOV & DEC & JAN & FEB & MAR & APR & MAY & JUNE & JULY & AUG & SEP \\
\hline $\begin{array}{l}1910 \\
1911 \\
1912\end{array}$ & $\begin{array}{c}8.19 \\
25.7 \\
30.4\end{array}$ & $\begin{array}{l}10.8 \\
17.9 \\
14.2\end{array}$ & $\begin{array}{l}33.2 \\
31.8 \\
22.4\end{array}$ & $\begin{array}{l}89.4 \\
30.6 \\
10.9\end{array}$ & $\begin{array}{r}112 \\
26.8 \\
27.8\end{array}$ & $\begin{array}{r}127 \\
44.6 \\
39.6\end{array}$ & $\begin{array}{l}81.8 \\
23.7 \\
31.0\end{array}$ & $\begin{array}{r}103 \\
25.5 \\
72.7\end{array}$ & $\begin{array}{l}27.8 \\
15.5 \\
59.5\end{array}$ & $\begin{array}{c}43.1 \\
138 \\
40.2\end{array}$ & $\begin{array}{l}51.1 \\
37.3 \\
43.0\end{array}$ & $\begin{array}{l}60.6 \\
40.0 \\
30.6\end{array}$ \\
\hline $\begin{array}{l}1943 \\
1944 \\
1945\end{array}$ & $\begin{array}{c}13.4 \\
17.8 \\
6.72\end{array}$ & $\begin{array}{c}10.8 \\
8.12 \\
10.9\end{array}$ & $\begin{array}{l}18.1 \\
10.7 \\
16.6\end{array}$ & $\begin{array}{c}21.5 \\
9.00 \\
15.6\end{array}$ & $\begin{array}{l}23.8 \\
10.0 \\
20.6\end{array}$ & $\begin{array}{l}16.0 \\
22.3 \\
24.3\end{array}$ & $\begin{array}{l}38.3 \\
24.5 \\
16.0\end{array}$ & $\begin{array}{l}2.44 \\
74.0 \\
15.1\end{array}$ & $\begin{array}{c}3.03 \\
83.2 \\
4.67\end{array}$ & $\begin{array}{c}6.88 \\
30.5 \\
4.99\end{array}$ & $\begin{array}{c}6.20 \\
8.66 \\
15.5\end{array}$ & $\begin{array}{l}9.80 \\
4.19 \\
8.10\end{array}$ \\
\hline
\end{tabular}


ESCALANTE RIVER BASIN

09337500 ESCALANTE RIVER NEAR ESCALAANTE, UT--Continued

MONIYLY MEAN DISCHARGES, IN COBIC FEET PER SECOND, FOR EACH WATER YEAR-Continued

\begin{tabular}{|c|c|c|c|c|c|c|c|c|c|c|c|c|}
\hline YEAR & OCT & NOV & DEC & JAN & FEB & MAR & APR & MAY & JUNE & JULY & AJUG & SEP \\
\hline $\begin{array}{l}1946 \\
1947 \\
1948 \\
1949 \\
1950\end{array}$ & $\begin{array}{c}28.0 \\
5.19 \\
7.98 \\
5.29 \\
11.3\end{array}$ & $\begin{array}{c}10.4 \\
10.8 \\
7.19 \\
9.75 \\
10.3\end{array}$ & $\begin{array}{c}12.0 \\
13.7 \\
9.43 \\
14.0 \\
11.7\end{array}$ & $\begin{array}{l}13.4 \\
10.1 \\
13.0 \\
15.0 \\
26.4\end{array}$ & $\begin{array}{c}13.2 \\
9.35 \\
17.0 \\
20.1 \\
23.1\end{array}$ & $\begin{array}{c}6.11 \\
4.40 \\
21.8 \\
21.4 \\
8.67\end{array}$ & $\begin{array}{c}29.8 \\
2.77 \\
18.3 \\
28.3 \\
12.4\end{array}$ & $\begin{array}{c}3.55 \\
27.8 \\
27.5 \\
37.3 \\
3.54\end{array}$ & $\begin{array}{c}1.42 \\
4.85 \\
11.4 \\
85.9 \\
2.03\end{array}$ & $\begin{array}{c}1.30 \\
4.81 \\
3.50 \\
14.6 \\
7.54\end{array}$ & $\begin{array}{c}10.5 \\
27.1 \\
12.5 \\
7.60 \\
2.58\end{array}$ & $\begin{array}{c}1.44 \\
3.27 \\
2.95 \\
17.2 \\
4.13\end{array}$ \\
\hline $\begin{array}{l}1951 \\
1952 \\
1953 \\
1954 \\
1955\end{array}$ & $\begin{array}{c}3.23 \\
2.09 \\
4.06 \\
3.51 \\
15.2\end{array}$ & $\begin{array}{l}3.97 \\
3.17 \\
6.18 \\
2.78 \\
1.62\end{array}$ & $\begin{array}{l}4.42 \\
4.32 \\
9.50 \\
4.25 \\
2.18\end{array}$ & $\begin{array}{c}4.55 \\
7.78 \\
10.7 \\
6.96 \\
2.26\end{array}$ & $\begin{array}{c}4.75 \\
13.7 \\
11.6 \\
3.66 \\
3.38\end{array}$ & $\begin{array}{c}4.11 \\
14.0 \\
9.20 \\
2.26 \\
2.92\end{array}$ & $\begin{array}{c}2.68 \\
20.6 \\
3.40 \\
4.62 \\
1.79\end{array}$ & $\begin{array}{c}2.70 \\
37.7 \\
1.99 \\
0.88 \\
2.18\end{array}$ & $\begin{array}{c}2.02 \\
13.5 \\
1.12 \\
1.26 \\
0.72\end{array}$ & $\begin{array}{l}4.14 \\
7.97 \\
6.53 \\
4.01 \\
0.79\end{array}$ & $\begin{array}{c}15.1 \\
14.6 \\
6.27 \\
1.22 \\
5.15\end{array}$ & $\begin{array}{l}2.24 \\
7.44 \\
2.27 \\
1.63 \\
0.73\end{array}$ \\
\hline $\begin{array}{l}1973 \\
1974 \\
1975\end{array}$ & $\begin{array}{c}29.9 \\
6.44 \\
4.76\end{array}$ & $\begin{array}{l}8.00 \\
6.93 \\
3.33\end{array}$ & $\begin{array}{c}4.83 \\
10.6 \\
2.58\end{array}$ & $\begin{array}{c}6.95 \\
13.9 \\
1.66\end{array}$ & $\begin{array}{c}12.4 \\
15.7 \\
3.18\end{array}$ & $\begin{array}{c}16.5 \\
12.0 \\
7.57\end{array}$ & $\begin{array}{c}23.4 \\
2.13 \\
3.16\end{array}$ & $\begin{array}{c}124 \\
2.05 \\
10.3\end{array}$ & $\begin{array}{c}107 \\
1.81 \\
10.6\end{array}$ & $\begin{array}{c}14.9 \\
5.88 \\
4.78\end{array}$ & $\begin{array}{c}10.7 \\
2.17 \\
2.97\end{array}$ & $\begin{array}{l}8.08 \\
1.92 \\
3.76\end{array}$ \\
\hline $\begin{array}{l}1976 \\
1977 \\
1978 \\
1979 \\
1980\end{array}$ & $\begin{array}{l}3.15 \\
3.00 \\
1.61 \\
1.49 \\
4.58\end{array}$ & $\begin{array}{l}3.64 \\
2.97 \\
2.00 \\
5.57 \\
5.47\end{array}$ & $\begin{array}{l}4.43 \\
2.74 \\
2.00 \\
1.45 \\
4.00\end{array}$ & $\begin{array}{l}3.48 \\
2.74 \\
2.00 \\
3.13 \\
4.80\end{array}$ & $\begin{array}{c}3.67 \\
3.13 \\
1.94 \\
5.78 \\
16.1\end{array}$ & $\begin{array}{c}7.28 \\
3.21 \\
2.42 \\
25.6 \\
9.42\end{array}$ & $\begin{array}{c}1.88 \\
1.46 \\
1.80 \\
40.4 \\
35.6\end{array}$ & $\begin{array}{c}21.4 \\
1.67 \\
4.71 \\
54.9 \\
17.8\end{array}$ & $\begin{array}{c}1.40 \\
2.01 \\
0.99 \\
50.4 \\
19.1\end{array}$ & $\begin{array}{c}2.30 \\
4.78 \\
0.47 \\
2.83 \\
10.7\end{array}$ & $\begin{array}{l}1.07 \\
3.19 \\
0.84 \\
4.25 \\
4.59\end{array}$ & $\begin{array}{c}5.87 \\
1.26 \\
1.20 \\
3.27 \\
29.9\end{array}$ \\
\hline 1981 & 8.19 & 8.46 & 11.0 & 12.6 & 7.86 & 6.17 & 20.6 & 15.0 & 4.34 & 8.69 & 8.29 & 18.2 \\
\hline
\end{tabular}

ANNUAL PEAK DISCHARGE, IN CUBIC FEET PER SECOND, AND OORRESPONDING GAGE HEIGHT, IN FEET, FOR EACH WATER YEAR

\begin{tabular}{|c|c|c|c|c|c|c|c|c|c|c|c|}
\hline $\begin{array}{l}\text { WATEER } \\
\text { YEAR }\end{array}$ & DATE & $\begin{array}{c}\text { GAGE } \\
\text { HEIGHT }\end{array}$ & $\begin{array}{c}\text { PEAR } \\
\text { DISCHARGE }\end{array}$ & $\begin{array}{l}\text { WATER } \\
\text { YEAR }\end{array}$ & DATE & $\begin{array}{c}\text { GAGE } \\
\text { HEIGHT }\end{array}$ & $\begin{array}{c}\text { PEAK } \\
\text { DISCHARGE }\end{array}$ & $\begin{array}{l}\text { WATER } \\
\text { YEAR }\end{array}$ & DATE & $\begin{array}{c}\text { GAGE } \\
\text { HEIGHT }\end{array}$ & $\begin{array}{l}\text { PEAK } \\
\text { DISCHARGE }\end{array}$ \\
\hline $\begin{array}{l}1910 \\
1911 \\
1912 \\
1943 \\
1944 \\
1945 \\
1946 \\
1947 \\
1948\end{array}$ & $\begin{array}{l}\text { JULY } 29,1910 \\
\text { JULY } 22,1911 \\
\text { OCT. } 28,1911 \\
\text { AUG. } 17,1943 \\
\text { OCT. } 18,1943 \\
\text { AUUG. } 11,1945 \\
\text { AUG. } 15,1946 \\
\text { AUUG. 16, } 1947 \\
\text { AUG. } 04,1948\end{array}$ & $\begin{array}{l}5.00 \\
7.55 \\
6.20 \\
6.25 \\
6.60 \\
5.20 \\
4.60 \\
5.52 \\
3.88\end{array}$ & $\begin{array}{r}385 \\
810 \\
557 \\
1750 \\
1970 \\
840 \\
540 \\
1110 \\
315\end{array}$ & $\begin{array}{l}1949 \\
1950 \\
1951 \\
1952 \\
1953 \\
1954 \\
1955 \\
1972 \\
1973\end{array}$ & $\begin{array}{l}\text { SEPT. } 28,1949 \\
\text { JULY } 17,1950 \\
\text { JULY } 31,1951 \\
\text { AUG. } 21,1952 \\
\text { AUG. }-\frac{1953}{12} \\
\text { JULY } 12,1954 \\
\text { AUG. } 13,1955 \\
\text { AUG. } 27,1972 \\
\text { AUG. } 18,1973\end{array}$ & $\begin{array}{l}7.34 \\
3.18 \\
6.23 \\
7.59 \\
9.90 \\
4.57 \\
9.20 \\
3.29 \\
7.10\end{array}$ & $\begin{array}{r}2790 \\
189 \\
1560 \\
1980 \\
3450 \\
544 \\
2980 \\
179 \\
2530\end{array}$ & $\begin{array}{l}1974 \\
1975 \\
1976 \\
1977 \\
1978 \\
1979 \\
1980 \\
1981\end{array}$ & $\begin{array}{l}\text { JULY } 22,1974 \\
\text { OCT. } 22,1974 \\
\text { JULY } 31,1976 \\
\text { JULY } 18,1977 \\
\text { MAY } 16,1978 \\
\text { MAY } 24,1979 \\
\text { SEPT.10, } 1980 \\
\text { JULY } 13,1981\end{array}$ & $\begin{array}{l}3.28 \\
3.51 \\
5.60 \\
5.00 \\
2.26 \\
3.42 \\
6.50 \\
8.50\end{array}$ & $\begin{array}{r}170 \\
224 \\
1090 \\
760 \\
23 \\
257 \\
1400 \\
2750\end{array}$ \\
\hline
\end{tabular}

MAGNITUDE AND PRCBABILITY OF ANNUAL LOWEST MEAN DISCHARGE BASED ON CIMATIC YEARS 1944-55 AND 1973-81

\begin{tabular}{|c|c|c|c|c|c|c|}
\hline \multirow{2}{*}{$\begin{array}{l}\text { PERIOD } \\
\text { (CON } \\
\text { SECU- } \\
\text { TIVE } \\
\text { DAYS) }\end{array}$} & \multicolumn{6}{|c|}{$\begin{array}{l}\text { DISCHARGE, IN CUBIC FEET PER SEOOND, FOR } \\
\text { INDICATED REOURRENCE INIERNAL, IN YEARS, AND } \\
\text { ANNUAL NONEXCEEDANCE PRCBABILITY, IN PERCENT }\end{array}$} \\
\hline & $\begin{array}{c}2 \\
508\end{array}$ & $\begin{array}{c}5 \\
208\end{array}$ & $\begin{array}{l}10 \\
108\end{array}$ & $\begin{array}{l}20 \\
58\end{array}$ & $\begin{array}{l}50 \\
28\end{array}$ & $\begin{array}{r}100 \\
18\end{array}$ \\
\hline $\begin{array}{r}1 \\
7 \\
14 \\
30 \\
60 \\
90\end{array}$ & $\begin{array}{l}0.95 \\
1.3 \\
1.5 \\
1.9 \\
2.6 \\
3.3\end{array}$ & $\begin{array}{l}0.45 \\
0.70 \\
0.83 \\
1.1 \\
1.4 \\
1.8\end{array}$ & $\begin{array}{l}0.30 \\
0.51 \\
0.60 \\
0.77 \\
0.98 \\
1.3\end{array}$ & $\begin{array}{l}0.21 \\
0.39 \\
0.46 \\
0.59 \\
0.73 \\
0.95\end{array}$ & $\begin{array}{l}- \\
\overline{-} \\
- \\
- \\
-\end{array}$ & $\begin{array}{l}-- \\
-- \\
-- \\
-- \\
--\end{array}$ \\
\hline
\end{tabular}

MAGNITUDE AND PRCBABIIITY OF ANNUAL HIGHEST MEAN DISCHARGE BASED ON WATER YEARS 1912, 1943-55 AND 1973-81

\begin{tabular}{|c|c|c|c|c|c|c|}
\hline \multirow{2}{*}{$\begin{array}{l}\text { PERIOD } \\
\text { OON- } \\
\text { SEOU- } \\
\text { TIVE } \\
\text { DAYS) }\end{array}$} & \multicolumn{6}{|c|}{$\begin{array}{l}\text { DISCHARGE, IN OUBIC FEET PER SBCOND, FOR } \\
\text { INDICATED REOURRENCE INTERNAL, IN YEARS, AND } \\
\text { ANNUAL EXCEEDANCE PRCBABILITY, IN PERCENT }\end{array}$} \\
\hline & $\begin{array}{c}2 \\
50 \%\end{array}$ & $\begin{array}{c}5 \\
208\end{array}$ & $\begin{array}{l}10 \\
108\end{array}$ & $\begin{array}{l}25 \\
48\end{array}$ & $\begin{array}{l}50 \\
28\end{array}$ & $\begin{array}{r}100 \\
18\end{array}$ \\
\hline
\end{tabular}

$\begin{array}{rrrrrrr}1 & 117 & 235 & 326 & 452 & -- & - \\ 3 & 79 & 151 & 203 & 271 & -- & - \\ 7 & 57 & 108 & 145 & 192 & - & - \\ 15 & 39 & 82 & 117 & 170 & - & -\end{array}$


ESCALANTE RIVER BASIN

09338000 EAST FORK BOULDER CREEK NEAR BOULDER, UT

LOCATION.--Lat $38^{\circ} 02^{\prime} 31^{\prime \prime}$, long $111^{\circ} 26^{\prime} 58^{\prime \prime}$, in SW $\mathrm{N}_{4}^{1} \mathrm{NW}_{-1}^{-} \mathrm{NE}_{4}^{\frac{1}{4}}$ sec.10, T.32 S., R.4 E., Garfield County, Hydrologic Unit 14070005 , on left bank just upstream from Garkane Power Association Reservoir and diversion dam, and 11 mi northwest of Boulder.

DRAINAGE AREA. $-21.4 \mathrm{mi}^{2}$.

MEAN BASIN ELEVATION.--10,500 ft.

PERIOD OF RECORD AVAIHABLE.--JuIy 1950 to September 1955, JuIy 1957 to September 1972.

GAGE.--Water-stage recorder. Altitude of gage is 9,315 ft from Garkane Power Association project map. Prior to Sept. 24, 1958, at site $0.8 \mathrm{mi}$ downstream at different datum.

AVERAGE DISCHARGE. -20 years, $23.7 \mathrm{ft}^{3} / \mathrm{s}, 17,170$ acre- $\mathrm{ft} / \mathrm{yr}$

EXIREMES FOR PERICD OF RECORD.--Maximum discharge, $483 \mathrm{ft}^{3} / \mathrm{s}$ May 20, 1964, gage height, $3.30 \mathrm{ft}$, from rating curve extended above $230 \mathrm{ft}^{3} / \mathrm{s} ;$ minimum, $8.2 \mathrm{ft}^{3} / \mathrm{s}$ Nov. 5,1951 .

LONEST MEAN DISCHARGE, IN CUBIC FEET PER SECOND, AND RANKING FOR THE INDICATED NUMBER OF CONSECUTIVE DAYS FOR EACH CLIMATIC YEAR, APRIL I-MARCH 3I

\begin{tabular}{|c|c|c|c|c|c|c|c|c|c|c|c|c|c|c|c|c|c|c|c|c|}
\hline YEAR & 1 & & 3 & & 7 & & 14 & & $\begin{array}{l}\text { CONS } \\
30\end{array}$ & ECUT & $\begin{array}{l}\text { E DAYS } \\
60\end{array}$ & & 90 & & 120 & & 183 & & ALL & \\
\hline $\begin{array}{l}1952 \\
1953 \\
1954 \\
1955\end{array}$ & $\begin{array}{l}17.0 \\
20.0 \\
14.0 \\
15.0\end{array}$ & $\begin{array}{r}16 \\
17 \\
7 \\
14\end{array}$ & $\begin{array}{l}18.0 \\
20.0 \\
14.0 \\
15.0\end{array}$ & $\begin{array}{r}16 \\
17 \\
7 \\
14\end{array}$ & $\begin{array}{l}18.0 \\
20.0 \\
15.0 \\
16.0\end{array}$ & $\begin{array}{r}16 \\
17 \\
8 \\
12\end{array}$ & $\begin{array}{l}18.0 \\
20.0 \\
15.0 \\
16.0\end{array}$ & $\begin{array}{r}15 \\
17 \\
8 \\
12\end{array}$ & $\begin{array}{l}19.0 \\
20.0 \\
16.0 \\
16.0\end{array}$ & $\begin{array}{l}16 \\
17 \\
10 \\
11\end{array}$ & $\begin{array}{l}19.0 \\
23.0 \\
16.0 \\
16.0\end{array}$ & $\begin{array}{r}15 \\
18 \\
8 \\
9\end{array}$ & $\begin{array}{l}19.0 \\
25.0 \\
16.0 \\
16.0\end{array}$ & $\begin{array}{r}13 \\
18 \\
7 \\
8\end{array}$ & $\begin{array}{l}19.0 \\
25.0 \\
16.0 \\
17.0\end{array}$ & $\begin{array}{r}13 \\
18 \\
4 \\
11\end{array}$ & $\begin{array}{l}19.0 \\
26.0 \\
17.0 \\
17.0\end{array}$ & $\begin{array}{r}12 \\
18 \\
6 \\
7\end{array}$ & $\begin{array}{l}21.0 \\
33.0 \\
19.0 \\
20.0\end{array}$ & $\begin{array}{r}7 \\
17 \\
2 \\
3\end{array}$ \\
\hline $\begin{array}{l}599 \\
660\end{array}$ & $\begin{array}{l}20.0 \\
14.0\end{array}$ & $\begin{array}{r}18 \\
8\end{array}$ & $\begin{array}{l}20.0 \\
14.0\end{array}$ & $\begin{array}{r}18 \\
8\end{array}$ & $\begin{array}{l}20.0 \\
15.0\end{array}$ & $\begin{array}{r}18 \\
9\end{array}$ & $\begin{array}{l}20.0 \\
15.0\end{array}$ & $\begin{array}{r}18 \\
9\end{array}$ & $\begin{array}{l}22.0 \\
16.0\end{array}$ & $\begin{array}{l}18 \\
12\end{array}$ & $\begin{array}{l}22.0 \\
16.0\end{array}$ & $\begin{array}{l}17 \\
10\end{array}$ & $\begin{array}{l}22.0 \\
16.0\end{array}$ & $\begin{array}{r}17 \\
9\end{array}$ & $\begin{array}{l}23.0 \\
16.0\end{array}$ & $\begin{array}{r}17 \\
5\end{array}$ & $\begin{array}{l}24.0 \\
17.0\end{array}$ & $\begin{array}{r}17 \\
8\end{array}$ & $\begin{array}{l}33.0 \\
20.0\end{array}$ & $\begin{array}{r}18 \\
4\end{array}$ \\
\hline $\begin{array}{l}1966 \\
1967 \\
1968 \\
1969 \\
1970\end{array}$ & $\begin{array}{l}13.0 \\
15.0 \\
15.0 \\
14.0 \\
16.0\end{array}$ & $\begin{array}{r}4 \\
12 \\
13 \\
5 \\
15\end{array}$ & $\begin{array}{l}14.0 \\
15.0 \\
15.0 \\
14.0 \\
16.0\end{array}$ & $\begin{array}{r}4 \\
12 \\
13 \\
5 \\
15\end{array}$ & $\begin{array}{l}14.0 \\
15.0 \\
16.0 \\
14.0 \\
17.0\end{array}$ & $\begin{array}{r}6 \\
10 \\
11 \\
7 \\
15\end{array}$ & $\begin{array}{l}14.0 \\
15.0 \\
16.0 \\
14.0 \\
19.0\end{array}$ & $\begin{array}{r}5 \\
10 \\
11 \\
6 \\
16\end{array}$ & $\begin{array}{l}16.0 \\
15.0 \\
16.0 \\
16.0 \\
19.0\end{array}$ & $\begin{array}{r}6 \\
4 \\
7 \\
8 \\
15\end{array}$ & $\begin{array}{l}17.0 \\
15.0 \\
17.0 \\
16.0 \\
20.0\end{array}$ & $\begin{array}{r}11 \\
3 \\
12 \\
6 \\
16\end{array}$ & $\begin{array}{l}18.0 \\
16.0 \\
17.0 \\
16.0 \\
21.0\end{array}$ & $\begin{array}{r}12 \\
3 \\
11 \\
4 \\
16\end{array}$ & $\begin{array}{l}18.0 \\
16.0 \\
17.0 \\
17.0 \\
22.0\end{array}$ & $\begin{array}{r}12 \\
2 \\
8 \\
9 \\
16\end{array}$ & $\begin{array}{l}19.0 \\
16.0 \\
17.0 \\
18.0 \\
23.0\end{array}$ & $\begin{array}{r}13 \\
2 \\
5 \\
9 \\
16\end{array}$ & $\begin{array}{l}24.0 \\
20.0 \\
21.0 \\
26.0 \\
31.0\end{array}$ & $\begin{array}{r}12 \\
5 \\
6 \\
14 \\
16\end{array}$ \\
\hline
\end{tabular}

HIGHEST MEAN DISCHARGE, IN OUBIC FEET PER SECOND, AND RANKING FOR THE INDICATED NUMBER OF CONSEOUTIVE DAYS FOR EAQH WATER YEAR, OCTOBER 1-SEPTEMBER 30

1951
1952
1953
1954
1955
1958
1959
1960
1961
1962
1963
1964
1965
1966
1967
1968
1969
1970
1971
1972

\begin{tabular}{rrrrrrrrrrrrr}
1 & & 3 & & 7 & & 15 & \multicolumn{3}{c}{30} & & 60 \\
167 & 7 & 135 & 8 & 98.0 & 12 & 60.0 & 15 & 40.0 & 15 & 31.0 & 15 \\
138 & 10 & 132 & 9 & 123 & 7 & 93.0 & 8 & 88.0 & 5 & 66.0 & 3 \\
77.0 & 17 & 64.0 & 19 & 50.0 & 20 & 42.0 & 20 & 34.0 & 20 & 31.0 & 16 \\
70.0 & 19 & 66.0 & 18 & 57.0 & 18 & 45.0 & 18 & 38.0 & 18 & 30.0 & 17 \\
91.0 & 16 & 78.0 & 16 & 60.0 & 16 & 48.0 & 17 & 40.0 & 16 & 30.0 & 18 \\
174 & 6 & 172 & 6 & 156 & 5 & 138 & 4 & 105 & 1 & 72.0 & 1 \\
61.0 & 20 & 58.0 & 20 & 50.0 & 19 & 43.0 & 19 & 34.0 & 19 & 29.0 & 19 \\
72.0 & 18 & 68.0 & 17 & 57.0 & 17 & 51.0 & 16 & 40.0 & 17 & 29.0 & 20 \\
134 & 11 & 118 & 11 & 105 & 9 & 82.0 & 9 & 59.0 & 10 & 40.0 & 12 \\
194 & 5 & 180 & 4 & 160 & 4 & 111 & 5 & 77.0 & 6 & 60.0 & 4 \\
134 & 12 & 114 & 12 & 103 & 10 & 81.0 & 10 & 52.0 & 13 & 36.0 & 13 \\
283 & 1 & 257 & 1 & 213 & 1 & 145 & 2 & 93.0 & 3 & 57.0 & 6 \\
156 & 8 & 137 & 7 & 121 & 8 & 98.0 & 7 & 70.0 & 8 & 47.0 & 8 \\
& & & & & & & & & & & \\
134 & 13 & 114 & 13 & 91.0 & 13 & 70.0 & 14 & 49.0 & 14 & 34.0 & 14 \\
147 & 9 & 127 & 10 & 99.0 & 11 & 71.0 & 12 & 61.0 & 9 & 43.0 & 9 \\
244 & 2 & 234 & 2 & 209 & 2 & 144 & 3 & 93.0 & 4 & 58.0 & 5 \\
196 & 4 & 186 & 3 & 162 & 3 & 148 & 1 & 101 & 2 & 66.0 & 2 \\
218 & 3 & 176 & 5 & 140 & 6 & 111 & 6 & 74.0 & 7 & 49.0 & 7
\end{tabular}

90

$28.0 \quad 16$

54.02

29.015

$\begin{array}{ll}26.0 & 19 \\ 26.0 & 20\end{array}$

$59.0 \quad 1$

$27.0 \quad 17$

26.018

$34.0 \quad 12$

49.04

$31.0 \quad 13$

44.06

39.0

$\begin{array}{rr}29.0 & 14 \\ 35.0 & 9\end{array}$

41.0

$\begin{array}{ll}53.0 & 3 \\ 41.0 & 7\end{array}$

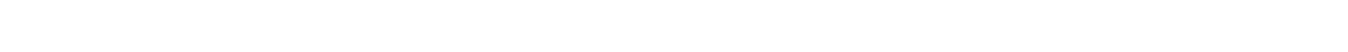

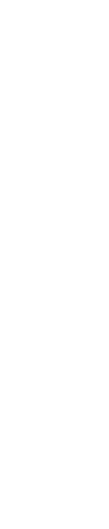

183

$\begin{array}{lll}24.0 & 17\end{array}$

39.02

26.012

$22.0 \quad 18$

21.020

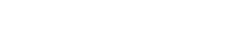

$28.0 \quad 10$

36.04

$\begin{array}{llll}26.0 & 13 & 23.0 \quad 11\end{array}$

$\begin{array}{lllr}31.0 & 7 & 24.0 & 9\end{array}$

$\begin{array}{llll}24.0 & 16 & 21.0 & 16\end{array}$

$\begin{array}{llll}26.0 & 14 & 21.0 & 17\end{array}$

$\begin{array}{rrrr}33.0 & 5 & 25.0 & 6\end{array}$

$\begin{array}{llll}38.0 & 3 & 28.0 & 4 \\ 32.0 & 6 & 27.0 & 5\end{array}$

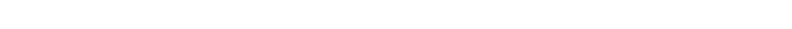

$32.0 \quad 9$

27.0 11
$22.0 \quad 13$ 
ESCALANTE RIVER BASIN

09338000 EAST FORK BOULDER CREEK NEAR BOULDER, UT-Continued

DURATION OF DISCHARGE FOR EACH WATER YEAR

$\begin{array}{llllllllllllllllllllllllllllllllllll}\text { CLASS } 0 & 1 & 2 & 3 & 4 & 5 & 6 & 7 & 8 & 9 & 10 & 11 & 12 & 13 & 14 & 15 & 16 & 17 & 18 & 19 & 20 & 21 & 22 & 23 & 24 & 25 & 26 & 27 & 28 & 29 & 30 & 31 & 32 & 33 & 34\end{array}$ YEAR NUMBER OF DAYS IN GLASS

CUBIC FEET PER SECOND
-DAYS

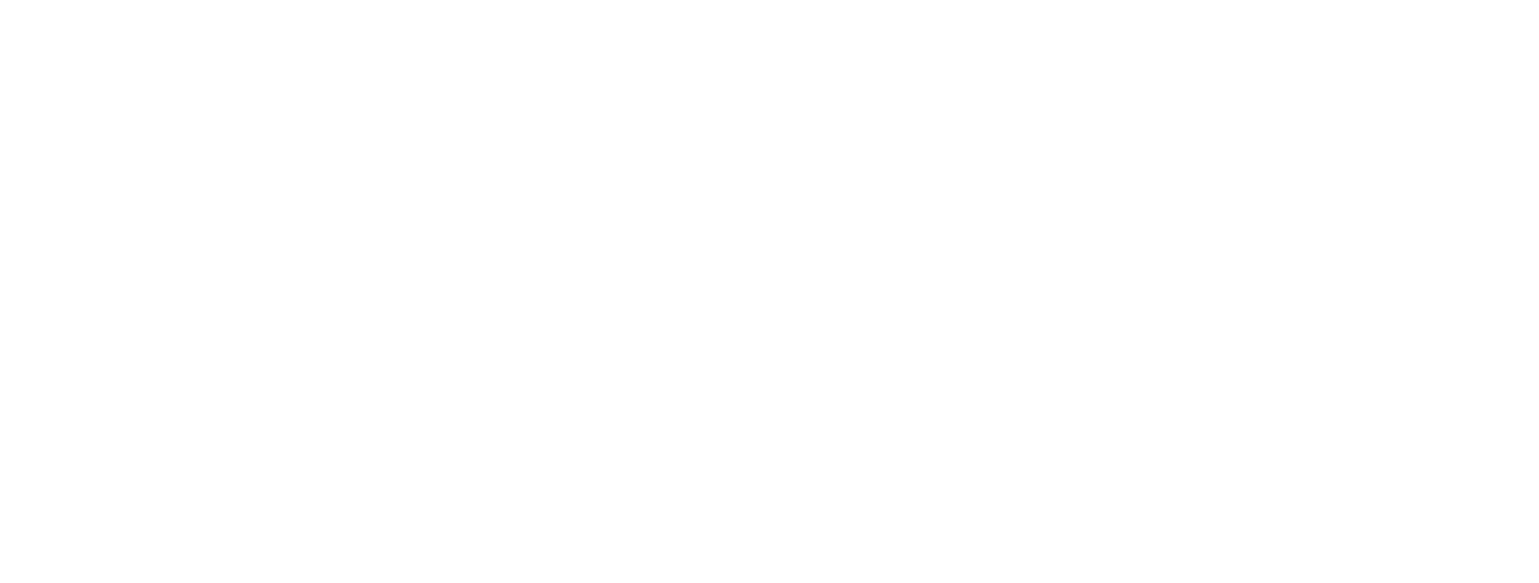

DURATION TABLE OF DISCHARGE FOR WATER YEARS 1951-55, 1958-72

\begin{tabular}{|c|c|c|c|c|c|c|c|c|c|c|c|c|c|c|c|c|c|c|c|}
\hline CLASS & $\begin{array}{c}\text { CUBIC } \\
\text { FEET } \\
\text { PER } \\
\text { SECOND }\end{array}$ & $\begin{array}{l}\text { TOTAL } \\
\text { DAYS }\end{array}$ & $\begin{array}{c}\text { ACOU- } \\
\text { MU- } \\
\text { LATED } \\
\text { DAYS }\end{array}$ & $\begin{array}{l}\text { PER- } \\
\text { CENT } \\
\text { DAYS }\end{array}$ & & $\begin{array}{c}\text { CUBIC } \\
\text { FEET } \\
\text { PER } \\
\text { SECOND }\end{array}$ & TOTAL & $\begin{array}{l}\text { ACU- } \\
\text { MU- } \\
\text { LATED } \\
\text { DAYS }\end{array}$ & $\begin{array}{l}\text { PER- } \\
\text { CENT } \\
\text { DAYS }\end{array}$ & & $\begin{array}{c}\text { QUBIC } \\
\text { FEET } \\
\text { PER } \\
\text { SECOND }\end{array}$ & $\begin{array}{l}\text { TOTAL, } \\
\text { DAYS }\end{array}$ & $\begin{array}{c}\text { ACQU- } \\
\text { MU- } \\
\text { LATED } \\
\text { DAYS }\end{array}$ & $\begin{array}{l}\text { PER- } \\
\text { CENT } \\
\text { DAYS }\end{array}$ & C.ASS & $\begin{array}{c}\text { QUBIC } \\
\text { FEET } \\
\text { PER } \\
\text { SECOND }\end{array}$ & TOTAL & $\begin{array}{l}\text { ACQU- } \\
\text { MU- } \\
\text { LATED } \\
\text { DAYS }\end{array}$ & $\begin{array}{l}\text { PER- } \\
\text { CENT } \\
\text { DAYS }\end{array}$ \\
\hline $\begin{array}{l}0 \\
1 \\
2 \\
3 \\
4 \\
5 \\
6 \\
7 \\
8\end{array}$ & $\begin{array}{r}0.00 \\
12.00 \\
13.00 \\
14.00 \\
16.00 \\
17.00 \\
19.00 \\
21.00 \\
23.00\end{array}$ & $\begin{array}{r}0 \\
6 \\
35 \\
410 \\
741 \\
1652 \\
1509 \\
1017 \\
567\end{array}$ & $\begin{array}{l}7305 \\
7305 \\
7299 \\
7264 \\
6854 \\
6113 \\
4461 \\
2952 \\
1935\end{array}$ & $\begin{array}{r}100.0 \\
100.0 \\
99.9 \\
99.4 \\
93.8 \\
83.7 \\
61.1 \\
40.4 \\
26.5\end{array}$ & $\begin{array}{r}9 \\
10 \\
11 \\
12 \\
13 \\
14 \\
15 \\
16 \\
17\end{array}$ & $\begin{array}{l}25.00 \\
28.00 \\
30.00 \\
33.00 \\
36.00 \\
40.00 \\
44.00 \\
48.00 \\
53.00\end{array}$ & $\begin{array}{r}445 \\
159 \\
159 \\
117 \\
87 \\
46 \\
36 \\
35 \\
33\end{array}$ & $\begin{array}{r}1368 \\
923 \\
764 \\
605 \\
488 \\
401 \\
355 \\
319 \\
284\end{array}$ & $\begin{array}{r}18.7 \\
12.6 \\
10.5 \\
8.3 \\
6.7 \\
5.5 \\
4.9 \\
4.4 \\
3.9\end{array}$ & $\begin{array}{l}18 \\
19 \\
20 \\
21 \\
22 \\
23 \\
24 \\
25 \\
26\end{array}$ & $\begin{array}{r}58.0 \\
63.0 \\
69.0 \\
76.0 \\
83.0 \\
91.0 \\
100.0 \\
110.0 \\
120.0\end{array}$ & $\begin{array}{l}22 \\
35 \\
26 \\
19 \\
15 \\
24 \\
17 \\
24 \\
14\end{array}$ & $\begin{array}{r}251 \\
229 \\
194 \\
168 \\
149 \\
134 \\
110 \\
93 \\
69\end{array}$ & $\begin{array}{l}3.4 \\
3.1 \\
2.7 \\
2.3 \\
2.0 \\
1.8 \\
1.5 \\
1.3 \\
0.9\end{array}$ & $\begin{array}{l}27 \\
28 \\
29 \\
30 \\
31 \\
32 \\
33 \\
34\end{array}$ & $\begin{array}{l}130.0 \\
140.0 \\
160.0 \\
170.0 \\
190.0 \\
210.0 \\
230.0 \\
250.0\end{array}$ & $\begin{array}{r}11 \\
16 \\
7 \\
8 \\
6 \\
2 \\
3 \\
2\end{array}$ & $\begin{array}{r}55 \\
44 \\
28 \\
21 \\
13 \\
7 \\
5 \\
2\end{array}$ & $\begin{array}{l}0.8 \\
0.6 \\
0.4 \\
0.3 \\
0.2 \\
0.1 \\
0.1 \\
0.0\end{array}$ \\
\hline
\end{tabular}

MONTHLY MEAN DISOHARGES, IN GBIC FEET PER SECOND, FOR EACH WATER YEAR

\begin{tabular}{|c|c|c|c|c|c|c|c|c|c|c|c|c|}
\hline YEAR & $\mathrm{OCT}$ & NOV & DEC & JAN & FEB & MAR & APR & MAY & JUNE & JULY & AUG & SEP \\
\hline $\begin{array}{l}1951 \\
1952 \\
1953 \\
1954 \\
1955\end{array}$ & $\begin{array}{l}22.1 \\
19.4 \\
24.9 \\
18.6 \\
18.1\end{array}$ & $\begin{array}{l}22.0 \\
20.3 \\
25.6 \\
18.4 \\
17.9\end{array}$ & $\begin{array}{l}21.5 \\
19.4 \\
25.0 \\
15.6 \\
16.8\end{array}$ & $\begin{array}{l}20.1 \\
18.8 \\
33.9 \\
16.7 \\
17.1\end{array}$ & $\begin{array}{l}19.1 \\
18.7 \\
26.3 \\
16.1 \\
16.2\end{array}$ & $\begin{array}{l}20.4 \\
19.6 \\
20.0 \\
16.9 \\
16.1\end{array}$ & $\begin{array}{l}23.1 \\
23.9 \\
20.7 \\
25.0 \\
19.0\end{array}$ & $\begin{array}{l}38.1 \\
75.4 \\
28.3 \\
33.8 \\
33.8\end{array}$ & $\begin{array}{l}21.9 \\
54.8 \\
24.8 \\
18.6 \\
24.5\end{array}$ & $\begin{array}{l}19.0 \\
28.7 \\
19.6 \\
18.7 \\
16.5\end{array}$ & $\begin{array}{l}19.3 \\
26.7 \\
18.7 \\
18.3 \\
18.4\end{array}$ & $\begin{array}{l}18.6 \\
24.8 \\
17.9 \\
17.9 \\
15.8\end{array}$ \\
\hline $\begin{array}{l}1958 \\
1959 \\
1960\end{array}$ & $\begin{array}{l}21.6 \\
26.1 \\
16.2\end{array}$ & $\begin{array}{l}21.7 \\
25.1 \\
17.5\end{array}$ & $\begin{array}{l}20.8 \\
24.0 \\
16.0\end{array}$ & $\begin{array}{l}20.0 \\
22.7 \\
17.3\end{array}$ & $\begin{array}{l}19.8 \\
22.0 \\
19.8\end{array}$ & $\begin{array}{l}19.1 \\
22.0 \\
18.9\end{array}$ & $\begin{array}{l}22.2 \\
24.1 \\
19.1\end{array}$ & $\begin{array}{l}73.8 \\
33.1 \\
36.6\end{array}$ & $\begin{array}{l}66.5 \\
20.6 \\
19.8\end{array}$ & $\begin{array}{l}34.1 \\
19.5 \\
16.8\end{array}$ & $\begin{array}{l}30.0 \\
18.5 \\
16.0\end{array}$ & $\begin{array}{l}29.5 \\
16.1 \\
15.4\end{array}$ \\
\hline $\begin{array}{l}1961 \\
1962 \\
1963 \\
1964 \\
1965\end{array}$ & $\begin{array}{l}16.4 \\
24.0 \\
22.9 \\
19.0 \\
16.0\end{array}$ & $\begin{array}{l}17.2 \\
22.3 \\
21.7 \\
19.5 \\
16.4\end{array}$ & $\begin{array}{l}16.4 \\
22.2 \\
21.1 \\
18.3 \\
15.9\end{array}$ & $\begin{array}{l}16.9 \\
19.7 \\
19.0 \\
16.5 \\
15.2\end{array}$ & $\begin{array}{l}16.1 \\
18.5 \\
21.0 \\
14.4 \\
15.0\end{array}$ & $\begin{array}{l}14.5 \\
17.8 \\
20.4 \\
13.7 \\
13.9\end{array}$ & $\begin{array}{l}17.2 \\
29.6 \\
20.4 \\
17.5 \\
15.5\end{array}$ & $\begin{array}{l}42.8 \\
73.7 \\
51.1 \\
80.4 \\
21.2\end{array}$ & $\begin{array}{l}35.7 \\
40.9 \\
18.7 \\
31.3 \\
70.1\end{array}$ & $\begin{array}{l}19.5 \\
24.3 \\
17.6 \\
17.8 \\
22.9\end{array}$ & $\begin{array}{l}23.0 \\
22.2 \\
18.4 \\
18.2 \\
21.8\end{array}$ & $\begin{array}{l}30.5 \\
22.8 \\
22.1 \\
17.1 \\
22.4\end{array}$ \\
\hline $\begin{array}{l}1966 \\
1967 \\
1968 \\
1969 \\
1970\end{array}$ & $\begin{array}{l}21.5 \\
17.1 \\
16.9 \\
20.6 \\
26.3\end{array}$ & $\begin{array}{l}20.6 \\
17.6 \\
16.5 \\
19.6 \\
26.5\end{array}$ & $\begin{array}{l}20.0 \\
16.6 \\
17.0 \\
17.6 \\
20.4\end{array}$ & $\begin{array}{l}18.7 \\
15.8 \\
17.4 \\
16.4 \\
20.3\end{array}$ & $\begin{array}{l}17.8 \\
15.2 \\
16.8 \\
16.6 \\
25.7\end{array}$ & $\begin{array}{l}16.7 \\
15.8 \\
16.6 \\
19.5 \\
23.8\end{array}$ & $\begin{array}{l}19.6 \\
15.9 \\
16.7 \\
21.3 \\
22.8\end{array}$ & $\begin{array}{l}48.2 \\
40.3 \\
44.5 \\
94.1 \\
67.6\end{array}$ & $\begin{array}{l}18.9 \\
44.3 \\
69.5 \\
36.5 \\
27.3\end{array}$ & $\begin{array}{l}18.6 \\
19.5 \\
21.5 \\
27.0 \\
18.4\end{array}$ & $\begin{array}{l}18.3 \\
18.1 \\
25.1 \\
23.3 \\
20.5\end{array}$ & $\begin{array}{l}17.0 \\
17.7 \\
20.7 \\
23.2 \\
18.8\end{array}$ \\
\hline $\begin{array}{l}1971 \\
1972\end{array}$ & $\begin{array}{l}23.3 \\
19.1\end{array}$ & $\begin{array}{l}21.5 \\
16.8\end{array}$ & $\begin{array}{l}17.0 \\
16.4\end{array}$ & $\begin{array}{l}13.9 \\
16.3\end{array}$ & $\begin{array}{l}16.1 \\
18.6\end{array}$ & $\begin{array}{l}24.0 \\
19.5\end{array}$ & $\begin{array}{l}20.8 \\
19.9\end{array}$ & $\begin{array}{l}42.5 \\
42.0\end{array}$ & $\begin{array}{l}37.8 \\
37.5\end{array}$ & $\begin{array}{l}19.5 \\
19.9\end{array}$ & $\begin{array}{l}24.6 \\
21.1\end{array}$ & $\begin{array}{l}21.6 \\
18.2\end{array}$ \\
\hline
\end{tabular}


ESCALANIE RIVER BASIN

09338000 EAST FORK BOULDER CREEK NEAR BOULDER, UT--Continued

ANNUAL PEAK DISOHARGE, IN CUBIC FEET PER SECOND, AND CORRESPONDING GAGE HEIGHT, IN FEET, FOR EACH WATER YEAR

\begin{tabular}{|c|c|c|c|c|c|c|c|c|c|c|c|c|c|}
\hline $\begin{array}{l}\text { WATER } \\
\text { YEAR }\end{array}$ & & DATE & $\begin{array}{c}\text { GAGE } \\
\text { HEIGHT }\end{array}$ & $\begin{array}{c}\text { PEAR } \\
\text { DISCHARGE }\end{array}$ & $\begin{array}{l}\text { WATER } \\
\text { YEAR }\end{array}$ & DATE & $\begin{array}{c}\text { GAGE } \\
\text { HEIGHI }\end{array}$ & $\begin{array}{c}\text { PEAR } \\
\text { DISCHARGE }\end{array}$ & $\begin{array}{l}\text { WATER } \\
\text { YEAR }\end{array}$ & & DATE & $\begin{array}{c}\text { GAGE } \\
\text { HEIGHT }\end{array}$ & $\begin{array}{c}\text { PEAK } \\
\text { DISQHARGE }\end{array}$ \\
\hline $\begin{array}{l}1951 \\
1952 \\
1953 \\
1954 \\
1955 \\
1958 \\
1959\end{array}$ & $\begin{array}{l}\text { MAY } \\
\text { MAY } \\
\text { MAY } \\
\text { MAY } \\
\text { MAY } \\
\text { MAY } \\
\text { MAY }\end{array}$ & $\begin{array}{l}27,1951 \\
12,1952 \\
23,1953 \\
06,1954 \\
24,1955 \\
26,1958 \\
12,1959\end{array}$ & $\begin{array}{l}4.01 \\
3.43 \\
2.88 \\
2.93 \\
3.10 \\
3.84 \\
2.55\end{array}$ & $\begin{array}{r}264 \\
174 \\
102 \\
104 \\
130 \\
220 \\
78\end{array}$ & $\begin{array}{l}1960 \\
1961 \\
1962 \\
1963 \\
1964 \\
1965 \\
1966\end{array}$ & $\begin{array}{l}\text { MAY } 18,1960 \\
\text { SEPT.18, } 1961 \\
\text { MAY } 06,1962 \\
\text { MAY } 10,1963 \\
\text { MAY } 20,1964 \\
\text { JUNE } 12,1965 \\
\text { MAY } 06,1966\end{array}$ & $\begin{array}{l}2.41 \\
3.18 \\
2.75 \\
2.55 \\
3.30 \\
2.46 \\
2.49\end{array}$ & $\begin{array}{r}84 \\
292 \\
279 \\
227 \\
483 \\
213 \\
213\end{array}$ & $\begin{array}{l}1967 \\
1968 \\
1969 \\
1970 \\
1971 \\
1972\end{array}$ & $\begin{array}{l}\text { MAY } \\
\text { MAY } \\
\text { MAY } \\
\text { MAY } \\
\text { MAY } \\
\text { MAY }\end{array}$ & $\begin{array}{l}22,1967 \\
31,1968 \\
19,1969 \\
19,1970 \\
26,1971 \\
25,1972\end{array}$ & $\begin{array}{l}2.50 \\
3.04 \\
2.74 \\
2.95 \\
2.44 \\
2.03\end{array}$ & $\begin{array}{l}227 \\
379 \\
278 \\
352 \\
196 \\
118\end{array}$ \\
\hline
\end{tabular}

MAGNTTUDE AND PRCBABILITY OF ANNUAL LOWEST MEAN DISOHARGE BASED ON CIMATIC YEARS 1952-55 AND 1959-72

\begin{tabular}{|c|c|c|c|c|c|c|}
\hline \multirow{2}{*}{$\begin{array}{l}\text { PERIOD } \\
\text { (OON- } \\
\text { SEOU- } \\
\text { TIVE } \\
\text { DAYS) }\end{array}$} & \multicolumn{6}{|c|}{$\begin{array}{l}\text { DISCHARGE, IN CIBIC FEET PER SECOND, FOR } \\
\text { INDICATED RECURRENCE INTEERAL, IN YEARS, AND } \\
\text { ANNUAL NONEXCEEDANCE PRCBABILITY, IN PERCENT' }\end{array}$} \\
\hline & $\begin{array}{c}2 \\
508\end{array}$ & $\begin{array}{c}5 \\
208\end{array}$ & $\begin{array}{l}10 \\
108\end{array}$ & $\begin{array}{l}20 \\
58\end{array}$ & $\begin{array}{l}50 \\
28\end{array}$ & $\begin{array}{r}100 \\
18\end{array}$ \\
\hline
\end{tabular}

$\begin{array}{rrrrrrr}1 & 14 & 13 & 13 & 12 & - & - \\ 7 & 15 & 14 & 13 & 13 & - & - \\ 14 & 16 & 14 & 13 & 13 & - & - \\ 30 & 16 & 15 & 14 & 13 & - & = \\ 60 & 17 & 15 & 14 & 14 & - & = \\ 90 & 17 & 16 & 15 & 15 & - & -\end{array}$

MAGNITUDE AND PRCBABILITYY OF ANNUAL HIGHEST MEAN DISCHARGE BASED ON WATER YEARS 1951-55 AND 1958-72

\begin{tabular}{|c|c|c|c|c|c|c|}
\hline \multirow{2}{*}{$\begin{array}{l}\text { PERIOD } \\
\text { (CON- } \\
\text { SEOU- } \\
\text { TIVE } \\
\text { DAYS) }\end{array}$} & \multicolumn{6}{|c|}{$\begin{array}{l}\text { DISCAARGE, IN OHBIC FEET PEE SECOND, FOR } \\
\text { INDICATED RECURRENCE INTERNAL, IN YEARS, AND } \\
\text { ANNUAL EXCEEDANCE PRCBABILITY, IN PERCENT }\end{array}$} \\
\hline & $\begin{array}{c}2 \\
508\end{array}$ & $\begin{array}{c}5 \\
208\end{array}$ & $\begin{array}{l}10 \\
108\end{array}$ & $\begin{array}{l}25 \\
48\end{array}$ & $\begin{array}{l}50 \\
28\end{array}$ & $\begin{array}{r}100 \\
18\end{array}$ \\
\hline
\end{tabular}

$\begin{array}{rrrrrrr}1 & 136 & 193 & 230 & 274 & - & - \\ 3 & 120 & 173 & 208 & 253 & - & - \\ 7 & 102 & 148 & 180 & 221 & - & - \\ 15 & 79 & 113 & 136 & 167 & - & -\end{array}$

09339000 BOULDER CREEK NEAR BOULDER, UT

LOCATION.--Lat $37^{\circ} 48^{\prime} 00^{n}$, long $111^{\circ} 23^{\prime} 00^{n}$, in SW/4 sec.32, T.34 S., R.5 E., Garfield County, Hydrologic Unit 14070005 , on right bank $6 \mathrm{mi}$ south of Boulder and $12 \mathrm{mi}$ northeast of Escalante.

DRAINAGE AREA.--175 $\mathrm{mi}^{2}$, approximately.

PERIOD OF RECORD AVAII.ABLE.--July 1950 to September 1955.

GAGE.-Water-stage recorder. Altitude of gage is 5,200 ft by barcmeter.

REMARRS.--Diversions for irrigation of about 1,900 acres above station.

AVERAGE DISCHARGE. --5 years, $23 \mathrm{ft}^{3} / \mathrm{s}, 16,650$ acre-ft/yr.

EXIREMES FOR PERIOD OF RECORD.--Maximum discharge, 4,650 ft $3 / \mathrm{s}$ July 25, 1955, gage height, $10.24 \mathrm{ft}$, from rating curve extended above $150 \mathrm{ft}^{3} / \mathrm{s}$ on basis of slope-area measurement at gage height $3.70 \mathrm{ft}$ and logarithmic plotting; minimum $6.1 \mathrm{ft} / \mathrm{s}$ June 26 , 1953.

LOWEST MEAN DISCHARGE, IN OBBIC FEET PER SECOND, AND RANKING FOR THE INDICATED NUMBER OF CONSECUTIVE DAYS FOR EACH CIIMATIC YEAR, APRLL I-MARCH 31

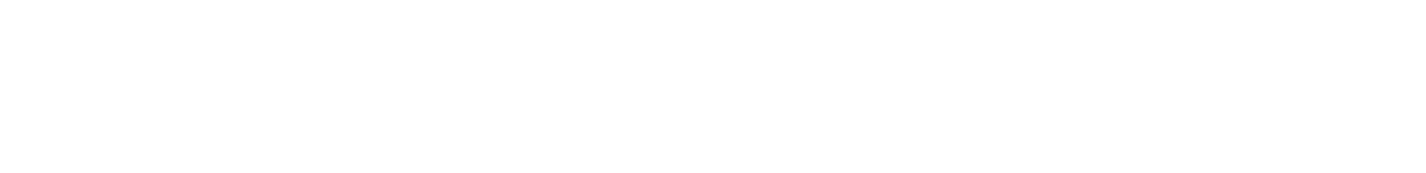

HIGHEST MEAN DISCHARGE, IN OUBIC FEET PER SECOND, AND RANKING FOR THE INDICATED NURBER OF CONSECUTIVE DAYS FOR EACH WATER YEAR, OCTCBER I-SEPTEMBER 30

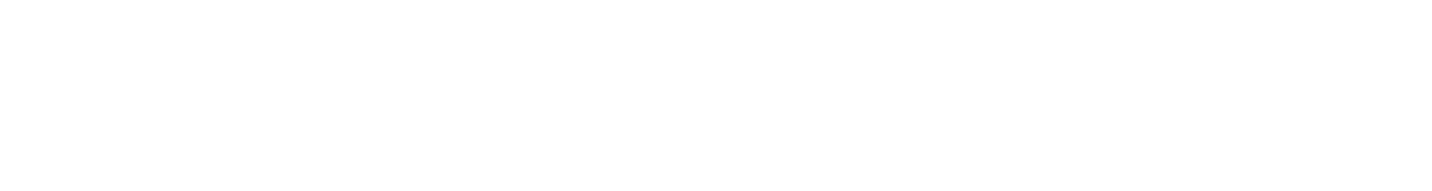


ESCALANTE RIVER BASIN

09339000 BOULDER CREEK NEAR BOILER, UT-COntinued

DURATION OF DISCHARGE FOR EACH WATER YEAR

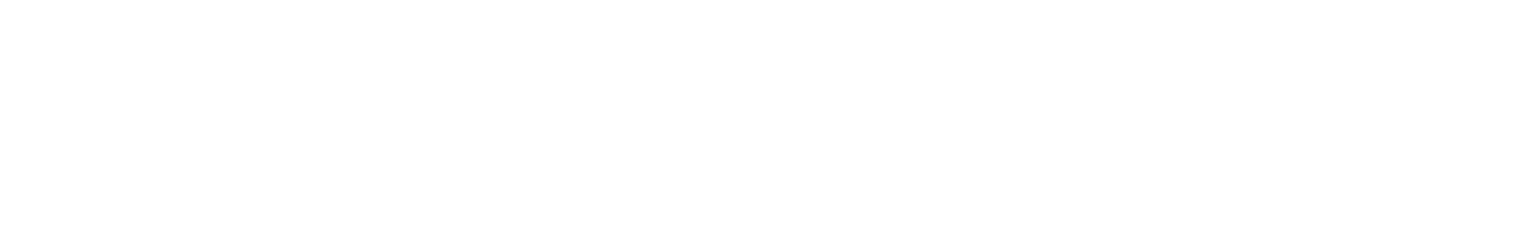

DURATION TABLE OF DISCHARGE FOR WATER YEARS 1951-55

$\begin{array}{rrl}\text { OUBIC } & \text { ACOU- } \\ \text { FEET } & \text { MU- } & \text { PER- } \\ \text { PER TOTAL LATED } & \text { CENT } \\ \text { CLASS SECOND DAYS DAYS } & \text { DAYS }\end{array}$

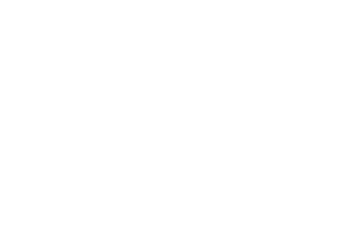

$\begin{array}{ccc}\text { CUBIC } & \text { ACOJ- } \\ \text { FEET } & \text { MU- } & \text { PER- } \\ \text { PER TOTAL LATED } & \text { CENT }\end{array}$

CIASS SECOND DAYS DAYS DAYS

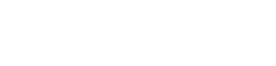
PER TOTAL LATED CENT CIASS SECOND DAYS DAYS DAYS

$\begin{array}{rrr}18 & 39.0 & 110 \\ 19 & 43.0 & 65 \\ 20 & 48.0 & 20 \\ 21 & 53.0 & 11 \\ 22 & 59.0 & 9 \\ 23 & 65.0 & 8 \\ 24 & 72.0 & 6 \\ 25 & 80.0 & 9 \\ 26 & 89.0 & 3\end{array}$

$$
\begin{array}{rrr}
\text { CUBIC } & \text { ACOI- } & \\
\text { FEET } & \text { MU- } & \text { PER- } \\
\text { PER } & \text { TOTAL LATED } & \text { CENT } \\
\text { CLASS SECOND DAYS DAYS } & \text { DAYS }
\end{array}
$$

$\begin{array}{rrrrr}27 & 99.0 & 1 & 22 & 1.2 \\ 28 & 110.0 & 0 & 21 & 1.2 \\ 29 & 120.0 & 7 & 21 & 1.2 \\ 30 & 130.0 & 4 & 14 & 0.8 \\ 31 & 150.0 & 6 & 10 & 0.5 \\ 32 & 170.0 & 1 & 4 & 0.2 \\ 33 & 180.0 & 0 & 3 & 0.2 \\ 34 & 200.0 & 3 & 3 & 0.2\end{array}$

\begin{tabular}{|c|c|c|c|c|c|c|c|c|c|c|c|c|}
\hline YEAR & $\infty C T$ & NOV & DEC & JAN & FEB & MAR & APR & MAY & JUNE & JULY & AUG & SEP \\
\hline $\begin{array}{l}1951 \\
1952 \\
1953 \\
1954 \\
1955\end{array}$ & $\begin{array}{l}10.5 \\
13.5 \\
13.8 \\
13.3 \\
13.6\end{array}$ & $\begin{array}{l}22.8 \\
18.9 \\
28.3 \\
34.2 \\
15.5\end{array}$ & $\begin{array}{l}30.3 \\
26.1 \\
49.2 \\
28.1 \\
21.8\end{array}$ & $\begin{array}{l}41.1 \\
27.4 \\
43.7 \\
29.6 \\
22.6\end{array}$ & $\begin{array}{l}33.9 \\
37.2 \\
41.7 \\
34.0 \\
20.5\end{array}$ & $\begin{array}{l}27.4 \\
38.2 \\
35.5 \\
25.8 \\
36.8\end{array}$ & $\begin{array}{l}12.4 \\
46.0 \\
12.1 \\
18.5 \\
16.4\end{array}$ & $\begin{array}{l}33.2 \\
79.2 \\
14.2 \\
21.1 \\
17.4\end{array}$ & $\begin{array}{c}8.37 \\
47.6 \\
8.00 \\
9.55 \\
10.5\end{array}$ & $\begin{array}{l}8.08 \\
11.5 \\
10.8 \\
11.6 \\
15.0\end{array}$ & $\begin{array}{c}22.9 \\
15.1 \\
12.6 \\
8.69 \\
13.2\end{array}$ & $\begin{array}{c}9.59 \\
24.2 \\
9.82 \\
13.0 \\
7.87\end{array}$ \\
\hline
\end{tabular}

MONIHLY MEAN DISCHARGES, IN OUBIC FEET PER SBCOND, FOR EAOH WATER YEAR

\begin{tabular}{|c|c|c|c|c|c|c|c|c|c|c|c|}
\hline $\begin{array}{l}\text { WATER } \\
\text { YEAR }\end{array}$ & DATE & $\begin{array}{c}\text { GAGE } \\
\text { HEIGHT }\end{array}$ & $\begin{array}{c}\text { PEAK } \\
\text { DISCHARGE }\end{array}$ & $\begin{array}{l}\text { WATER } \\
\text { YEAR }\end{array}$ & DATE & $\begin{array}{c}\text { GAGE } \\
\text { HEIGHT }\end{array}$ & $\begin{array}{c}\text { PEAK } \\
\text { DISCHARGE }\end{array}$ & $\begin{array}{l}\text { WATER } \\
\text { YEAR }\end{array}$ & DATE & $\begin{array}{c}\text { GAGE } \\
\text { HEIGHT }\end{array}$ & $\begin{array}{c}\text { PEAK } \\
\text { DISCHARGE }\end{array}$ \\
\hline $\begin{array}{l}1951 \\
1952\end{array}$ & $\begin{array}{l}\text { AUG. } 03,1951 \\
\text { AUJG. } 28,1952\end{array}$ & $\begin{array}{l}4.10 \\
4.34\end{array}$ & $\begin{array}{l}486 \\
542\end{array}$ & $\begin{array}{l}1953 \\
1954\end{array}$ & $\begin{array}{l}\text { AUG. } 27,1953 \\
\text { SEPT. 25, } 1954\end{array}$ & $\begin{array}{l}3.91 \\
4.28\end{array}$ & $\begin{array}{l}438 \\
527\end{array}$ & 1955 & JULY 25,1955 & 10.24 & 4650 \\
\hline
\end{tabular}

ANNUAL PEAK DISCHARGE, IN OUBIC FEET PER SECOND, AND CORRESPONDING GAGE HEIGHT, IN FEET, FOR EAOH WATER YEAR

LOCATION.-Lat $38^{\circ} 00^{\prime} 05^{\prime \prime}$, long $111^{\circ} 23^{\prime} 20^{\prime \prime}$, in sec.29, T.32 S., R.5 E., Garfield County, Hydrologic Unit 14070005, on right bank on State Highway 54 and $8 \mathrm{mi}$ north of Boulder.

DRAINAGE AREA. $--1.9 \mathrm{mi}^{2}$.

MEAN BASIN ELEVATION. $--9,290 \mathrm{ft}$.

PERIOD OF RECORD AVAILABLE.--July 1950 to September 1955, and annual peak discharge only, water years $1959-73$.

REVISED RECORDS.-WSP 1733: 1951-52(M), 1955(M).

GAGE.-Crest-stage gage. Altitude of gage is $8,600 \mathrm{ft}$ from topographic map. July 1950 to september 1955, water-stage recorder at same site at different datum.

AVERAGE DISCHARGE. -5 years, $1.36 \mathrm{ft}^{3} / \mathrm{s}, 985$ acre- $\mathrm{ft} /$ year.

EXTREMES FOR PERIOD OF RECORD.--Maximum discharge, $350 \mathrm{ft}^{3} / \mathrm{s}$ Aug. 6, 1955, gage height, $2.76 \mathrm{ft}$, datum then in use; no flow Feb. 10 , 1953, result of freezeup.

LOWEST MEAN DISCHARGE, IN OUBIC FEET PER SECOND, AND RANKING FOR THE INDICATED NUMBER OF CONSEOUTIVE DAYS

\begin{tabular}{|c|c|c|c|c|c|c|c|c|c|c|c|c|c|c|c|c|c|c|c|c|}
\hline YEAR & & & & & & & & & CONSE & ATIVE & DAYS & & & & & & & & & \\
\hline & 1 & & 3 & & 7 & & 14 & & 30 & & 60 & & 90 & & 120 & & 183 & & ALL & \\
\hline $\begin{array}{l}1952 \\
1953 \\
1954 \\
1955\end{array}$ & $\begin{array}{l}0.70 \\
0.60 \\
0.30 \\
0.40\end{array}$ & $\begin{array}{l}4 \\
3 \\
1 \\
2\end{array}$ & $\begin{array}{l}0.70 \\
0.77 \\
0.30 \\
0.40\end{array}$ & $\begin{array}{l}3 \\
4 \\
1 \\
2\end{array}$ & $\begin{array}{l}0.73 \\
0.90 \\
0.30 \\
0.40\end{array}$ & $\begin{array}{l}3 \\
4 \\
1 \\
2\end{array}$ & $\begin{array}{l}0.74 \\
0.95 \\
0.30 \\
0.40\end{array}$ & $\begin{array}{l}3 \\
4 \\
1 \\
2\end{array}$ & $\begin{array}{l}0.83 \\
1.00 \\
0.33 \\
0.42\end{array}$ & $\begin{array}{l}3 \\
4 \\
1 \\
2\end{array}$ & $\begin{array}{l}0.91 \\
1.10 \\
0.37 \\
0.46\end{array}$ & $\begin{array}{l}3 \\
4 \\
1 \\
2\end{array}$ & $\begin{array}{l}0.95 \\
1.10 \\
0.38 \\
0.48\end{array}$ & $\begin{array}{l}3 \\
4 \\
1 \\
2\end{array}$ & $\begin{array}{l}0.98 \\
1.19 \\
0.39 \\
0.52\end{array}$ & $\begin{array}{l}3 \\
4 \\
1 \\
2\end{array}$ & $\begin{array}{l}1.00 \\
1.60 \\
0.48 \\
0.64\end{array}$ & $\begin{array}{l}3 \\
4 \\
1 \\
2\end{array}$ & $\begin{array}{l}1.19 \\
2.50 \\
0.90 \\
0.97\end{array}$ & $\begin{array}{l}3 \\
4 \\
1 \\
2\end{array}$ \\
\hline
\end{tabular}
FOR EAGH CLIMATIC YEAR, APRIL 1-MARCH 31 
ESCALANTE RIVER BASIN

09338500 EAST FORK DEER CREEK NEAR BOLLDER, UT--Continued

HIGHEST MEAN DISCHARGE, IN OUBIC FEET PER SECOND, AND RANKING FOR THE INDICATED NUMBER OF CONSEOUTINE DAYS FOR EACH WATER YEAR, OCTOBER I-SEPTEMBER 30

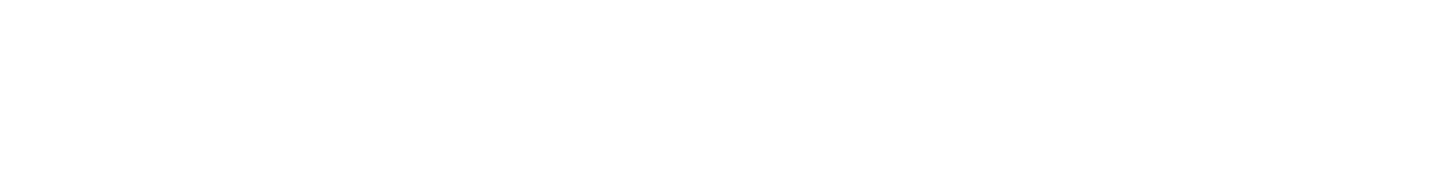

DURATION OF DISCHARGE FOR EACH WATER YEAR

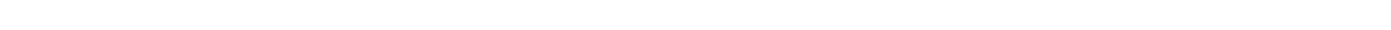
YEAR NUMBER OF DAYS IN CLASS CUBIC FEET -DAYS

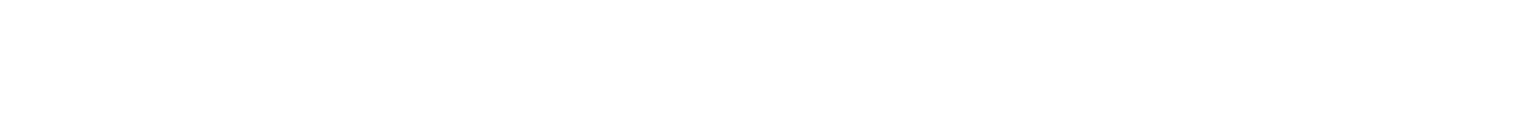

DURATION TABLE OF DISCHARGE FOR WATER YEARS 1951-55

\begin{tabular}{|c|c|c|c|c|c|c|c|c|c|c|c|c|c|c|c|c|c|c|c|}
\hline CLASS & $\begin{array}{c}\text { CUBIC } \\
\text { FEET } \\
\text { PER } \\
\text { SECOND }\end{array}$ & $\begin{array}{l}\text { TOTAL } \\
\text { DAYS }\end{array}$ & $\begin{array}{l}\text { ACOJ- } \\
\text { MU- } \\
\text { LATED } \\
\text { DAYS }\end{array}$ & $\begin{array}{l}\text { PER- } \\
\text { CENT } \\
\text { DAYS }\end{array}$ & CLASS & $\begin{array}{c}\text { CUBIC } \\
\text { FEET } \\
\text { PER } \\
\text { SECOND }\end{array}$ & $\begin{array}{l}\text { TOTAL } \\
\text { DAYS }\end{array}$ & $\begin{array}{c}\text { ACOU- } \\
\text { MU- } \\
\text { LATED } \\
\text { DAYS }\end{array}$ & $\begin{array}{l}\text { PER- } \\
\text { CENT } \\
\text { DAYS }\end{array}$ & CLASS & $\begin{array}{c}\text { OBBIC } \\
\text { FEET } \\
\text { PER } \\
\text { SECOND }\end{array}$ & $\begin{array}{l}\text { TOTAL } \\
\text { DAYS }\end{array}$ & $\begin{array}{l}\text { ACOU- } \\
\text { MU- } \\
\text { LATED } \\
\text { DAYS }\end{array}$ & $\begin{array}{l}\text { PER- } \\
\text { CENT } \\
\text { DAYS }\end{array}$ & CASS & $\begin{array}{c}\text { OUBIC } \\
\text { FEET } \\
\text { PER } \\
\text { SECOND }\end{array}$ & $\begin{array}{l}\text { TOTAL } \\
\text { DAYS }\end{array}$ & $\begin{array}{l}\text { ACQU- } \\
\text { MU- } \\
\text { LATED } \\
\text { DAYS }\end{array}$ & $\begin{array}{l}\text { PER- } \\
\text { CENT } \\
\text { DAYS }\end{array}$ \\
\hline $\begin{array}{l}0 \\
1 \\
2 \\
3 \\
4 \\
5 \\
6 \\
7 \\
8\end{array}$ & $\begin{array}{l}0.00 \\
0.30 \\
0.33 \\
0.37 \\
0.41 \\
0.45 \\
0.50 \\
0.55 \\
0.61\end{array}$ & $\begin{array}{r}0 \\
24 \\
0 \\
130 \\
0 \\
0 \\
03 \\
75 \\
0\end{array}$ & $\begin{array}{l}1826 \\
1826 \\
1802 \\
1802 \\
1672 \\
1672 \\
1672 \\
1609 \\
1534\end{array}$ & $\begin{array}{r}100.0 \\
100.0 \\
98.7 \\
98.7 \\
91.6 \\
91.6 \\
91.6 \\
88.1 \\
84.0\end{array}$ & $\begin{array}{r}9 \\
10 \\
11 \\
12 \\
13 \\
14 \\
15 \\
16 \\
17\end{array}$ & $\begin{array}{l}0.67 \\
0.74 \\
0.82 \\
0.91 \\
1.00 \\
1.10 \\
1.20 \\
1.40 \\
1.50\end{array}$ & $\begin{array}{r}26 \\
110 \\
157 \\
0 \\
277 \\
135 \\
229 \\
80 \\
121\end{array}$ & $\begin{array}{r}1534 \\
1508 \\
1398 \\
1241 \\
1241 \\
964 \\
829 \\
600 \\
520\end{array}$ & $\begin{array}{l}84.0 \\
82.6 \\
76.6 \\
68.0 \\
68.0 \\
52.8 \\
45.4 \\
32.9 \\
28.5\end{array}$ & $\begin{array}{l}18 \\
19 \\
20 \\
21 \\
22 \\
23 \\
24 \\
25 \\
26\end{array}$ & $\begin{array}{l}1.7 \\
1.9 \\
2.0 \\
2.3 \\
2.5 \\
2.8 \\
3.1 \\
3.4 \\
3.8\end{array}$ & $\begin{array}{l}77 \\
24 \\
65 \\
31 \\
42 \\
44 \\
47 \\
30 \\
7\end{array}$ & $\begin{array}{r}399 \\
322 \\
298 \\
233 \\
202 \\
160 \\
116 \\
69 \\
39\end{array}$ & $\begin{array}{r}21.9 \\
17.6 \\
16.3 \\
12.8 \\
11.1 \\
8.8 \\
6.4 \\
3.8 \\
2.1\end{array}$ & $\begin{array}{l}27 \\
28 \\
29 \\
30 \\
31 \\
32 \\
33 \\
34\end{array}$ & $\begin{array}{l}4.1 \\
4.6 \\
5.1 \\
5.6 \\
6.2 \\
6.9 \\
7.6 \\
8.4\end{array}$ & $\begin{array}{l}9 \\
5 \\
5 \\
0 \\
3 \\
2 \\
4 \\
4\end{array}$ & $\begin{array}{r}32 \\
23 \\
18 \\
13 \\
13 \\
10 \\
8 \\
4\end{array}$ & $\begin{array}{l}1.8 \\
1.3 \\
1.0 \\
0.7 \\
0.7 \\
0.5 \\
0.4 \\
0.2\end{array}$ \\
\hline
\end{tabular}

MONTHLY MEAN DISCHARGES, IN OBIC FEET PER SECOND, FOR EACH WATER YEAR

\begin{tabular}{|c|c|c|c|c|c|c|c|c|c|c|c|c|}
\hline YEAR & OCT & $\mathrm{MOV}$ & $\mathrm{DEC}$ & JAN & $\mathrm{EEB}$ & MAR & APR & MAY & JUNE & JULY & AUUG & SEP \\
\hline $\begin{array}{l}1951 \\
1952 \\
1953 \\
1954 \\
1955\end{array}$ & $\begin{array}{l}1.65 \\
1.11 \\
2.54 \\
0.74 \\
0.77\end{array}$ & $\begin{array}{l}1.05 \\
1.20 \\
2.00 \\
0.41 \\
0.62\end{array}$ & $\begin{array}{l}1.34 \\
1.05 \\
1.00 \\
0.39 \\
0.51\end{array}$ & $\begin{array}{l}1.60 \\
1.00 \\
1.19 \\
0.35 \\
0.51\end{array}$ & $\begin{array}{l}1.40 \\
1.10 \\
1.06 \\
0.40 \\
0.44\end{array}$ & $\begin{array}{l}1.25 \\
1.29 \\
1.54 \\
0.60 \\
2.38\end{array}$ & $\begin{array}{l}2.08 \\
3.62 \\
1.88 \\
1.56 \\
1.53\end{array}$ & $\begin{array}{l}1.62 \\
4.70 \\
1.56 \\
0.90 \\
0.86\end{array}$ & $\begin{array}{l}1.23 \\
3.16 \\
1.07 \\
1.04 \\
0.93\end{array}$ & $\begin{array}{l}0.92 \\
3.36 \\
1.25 \\
1.00 \\
0.88\end{array}$ & $\begin{array}{l}1.09 \\
3.40 \\
1.19 \\
0.87 \\
1.09\end{array}$ & $\begin{array}{l}0.83 \\
2.65 \\
0.89 \\
0.94 \\
1.00\end{array}$ \\
\hline
\end{tabular}

ANNUAL PEAK DISCHARGE, IN CUBIC FEET PER SECOND, AND CORRESPONDING GAGE HEIGHT, IN FEET, FOR EACH WATER YEAR

\begin{tabular}{|c|c|c|c|c|c|c|c|c|c|c|c|}
\hline $\begin{array}{l}\text { WATERR } \\
\text { YEAR }\end{array}$ & DATE & $\begin{array}{c}\text { GAGE } \\
\text { HEIGHT }\end{array}$ & $\begin{array}{c}\text { PEAK } \\
\text { DISCHARGE }\end{array}$ & $\begin{array}{l}\text { WATER } \\
\text { YEAR }\end{array}$ & DATE & $\begin{array}{c}\text { GAGE } \\
\text { HEIGHT }\end{array}$ & $\begin{array}{c}\text { PEAK } \\
\text { DISCHARGE }\end{array}$ & $\begin{array}{l}\text { WATER } \\
\text { YEAR }\end{array}$ & DATE & $\begin{array}{c}\text { GAGE } \\
\text { HEIGHT }\end{array}$ & $\begin{array}{c}\text { PEAK } \\
\text { DISCHARGE }\end{array}$ \\
\hline $\begin{array}{l}1951 \\
1952 \\
1953 \\
1954 \\
1955 \\
1959 \\
1960\end{array}$ & $\begin{array}{l}\text { AUG. } 04,1951 \\
\text { AUG. } 27,1952 \\
\text { AUG. } 27,1953 \\
\text { APR. } 13,1954 \\
\text { AUG. } 06,1955 \\
\text { AUG. } 19,1959 \\
\text { MAY }\end{array}$ & $\begin{array}{r}1.36 \\
1.43 \\
0.91 \\
0.84 \\
2.76 \\
10.53 \\
11.35\end{array}$ & $\begin{array}{c}10 \\
16 \\
4.3 \\
4.1 \\
350 \\
22 \\
68\end{array}$ & $\begin{array}{l}1961 \\
1962 \\
1963 \\
1964 \\
1965 \\
1966 \\
1967\end{array}$ & $\begin{array}{l}\text { AUG. } 03,1961 \\
\text { SEPT. } 21,1962 \\
\text { MAY } 15,1963 \\
\text { AUG. } 01,1964 \\
\text { MAY } 13,1965 \\
\text { OCT. } 02,1965 \\
\text { APR. } 28,1967\end{array}$ & $\begin{array}{r}12.36 \\
10.02 \\
9.86 \\
10.13 \\
9.99 \\
9.90 \\
10.37\end{array}$ & $\begin{array}{c}224 \\
6.0 \\
2.7 \\
9.0 \\
11 \\
7.7 \\
22\end{array}$ & $\begin{array}{l}1968 \\
1969 \\
1970 \\
1971 \\
1972 \\
1973\end{array}$ & $\begin{array}{l}\text { AUG. } 01,1968 \\
\text { JULY } 19,1969 \\
\text { AUG. } 04,1970 \\
\text { APR. 16, } 1971 \\
\text { APR. }--1972 \\
\text { MAY --, } 1973\end{array}$ & $\begin{array}{l}10.79 \\
11.21 \\
10.32 \\
11.06 \\
10.08 \\
11.35\end{array}$ & $\begin{array}{l}43 \\
72 \\
20 \\
60 \\
13 \\
86\end{array}$ \\
\hline
\end{tabular}

09338900 DEER CREEK NEAR BOULDER, UT

LOCATION.--Lat $37^{\circ} 51^{\prime} 13^{\prime \prime}$, long $111^{\circ} 21^{\prime} 17^{\prime \prime}, \mathrm{NE}^{\frac{1}{4}}$ sec.16, T.34 S., R.5 E., Garfield County, Hydrologic unit 14070005 , about 3.5 mi above mouth and $6.4 \mathrm{mi}$ east of Boulder.

DRAINAGE ARE4. $-63 \mathrm{mi}^{2}$.

MEAN BASIN ELEVATION. $-7,680 \mathrm{ft}$.

PERIOD OF RECORD AVAILABLE.-Water years 1959-74, annual peak discharge only.

GAGE.-Crest-stage gage. Altitude of gage is 5,660 ft from topographic map. 
ESCALANTE RIVER BASIN

09338900 DEER GREEK NEAR BOULDER, UT-Continued

ANNUAL PEAK DISCHARGE, IN OBIC FEET PER SECOND, AND CORRESPONDING GAGE HEIGHT, IN FEET, FOR EACH WATER YEAR

\begin{tabular}{|c|c|c|c|c|c|c|c|c|c|c|c|}
\hline $\begin{array}{l}\text { WATER } \\
\text { YEAR }\end{array}$ & DATE & $\begin{array}{c}\text { GAGE } \\
\text { HEIGHT }\end{array}$ & $\begin{array}{c}\text { PEAR } \\
\text { DISCHARGE }\end{array}$ & $\begin{array}{l}\text { WATERR } \\
\text { YEAR }\end{array}$ & DATE & $\begin{array}{c}\text { GAGE } \\
\text { HEIGHT }\end{array}$ & $\begin{array}{c}\text { PEAK } \\
\text { DISCHARGE }\end{array}$ & $\begin{array}{l}\text { WATER } \\
\text { YEAR }\end{array}$ & DATE & $\begin{array}{c}\text { GAGE } \\
\text { HEIGHT }\end{array}$ & $\begin{array}{c}\text { PEAR } \\
\text { DISCHARGE }\end{array}$ \\
\hline $\begin{array}{l}1959 \\
1960 \\
1961 \\
1962 \\
1963\end{array}$ & $\begin{array}{l}\text { AUG. } 19,1959 \\
\text { SEPT. 06, } 1960 \\
\text { AUG. } 03,1961 \\
\text { AUG. } 22,1962 \\
\text { MAR. 21, } 1963\end{array}$ & $\begin{array}{rr}9 & 11.50 \\
0 & 9.73 \\
1 & 14.00 \\
2 & 12.50 \\
3 & 10.35\end{array}$ & $\begin{array}{r}1350 \\
148 \\
3820 \\
2140 \\
455\end{array}$ & $\begin{array}{l}1965 \\
1966 \\
1967 \\
1968 \\
1969\end{array}$ & $\begin{array}{l}\text { JUNE } 24,1965 \\
\text { SEPT. } 18,1966 \\
\text { AUG. } 14,1967 \\
\text { AUG. } 01,1968 \\
\text { AUG. } 12,1969\end{array}$ & $\begin{array}{r}9.92 \\
9.70 \\
9.71 \\
9.60 \\
11.10\end{array}$ & $\begin{array}{l}240 \\
145 \\
149 \\
100 \\
930\end{array}$ & $\begin{array}{l}1970 \\
1971 \\
1972 \\
1973 \\
1974\end{array}$ & $\begin{array}{l}\text { AUG. 04, } 1970 \\
\text { SEPT. 30, } 1971 \\
\text { AUG. } 26,1972 \\
\text { SEPT. }-1,1973 \\
-\end{array}$ & $\begin{array}{r}12.00 \\
9.35 \\
9.24 \\
10.80 \\
9.53\end{array}$ & $\begin{array}{c}1680 \\
28 \\
8.5 \\
730 \\
74\end{array}$ \\
\hline
\end{tabular}

09339200 TWENTYMILE WASH NEAR ESCALANTE, UT

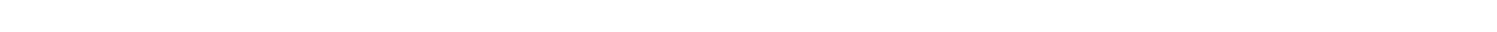
mouth and $20 \mathrm{mi}$ southeast of Escalante.

DRAINAGE AREA. $-140 \mathrm{mi}^{2}$.

MEAN BASIN ELEVATION.-- $-6,170 \mathrm{ft}$.

PERIOD OF RECORD AVALIABLE.--Water years 1959-68, peak discharge only.

GAGE.--Crest-stage gage. Altitude of gage is 5,080 ft from topographic map.

ANNUAL PEAK DISCHARGE, IN OUBIC FEET PER SECOND, AND CORRESPONDING GAGE HEIGHT, IN FEET, FOR EACH WATER YEAR

\begin{tabular}{|c|c|c|c|c|c|c|c|c|c|c|c|}
\hline $\begin{array}{l}\text { WATER } \\
\text { YEAR }\end{array}$ & DATE & $\begin{array}{c}\text { GAGE } \\
\text { HEIGHT }\end{array}$ & $\begin{array}{c}\text { PEAK } \\
\text { DISCHARGE }\end{array}$ & $\begin{array}{l}\text { WATER } \\
\text { YEAR }\end{array}$ & DATE & $\begin{array}{c}\text { GAGE } \\
\text { HEIGHT }\end{array}$ & $\begin{array}{c}\text { PEAK } \\
\text { DISCHARGE }\end{array}$ & $\begin{array}{l}\text { WATERR } \\
\text { YEAR }\end{array}$ & DATE & $\begin{array}{c}\text { GAGE } \\
\text { HEIGHT }\end{array}$ & $\begin{array}{c}\text { PEAK } \\
\text { DISCHARGE }\end{array}$ \\
\hline $\begin{array}{l}1959 \\
1960 \\
1961 \\
1962\end{array}$ & $\begin{array}{l}\text { AUG. } 25,1959 \\
\text { SEPT. 08, } 1960 \\
\text { AUG. 04, } 1961 \\
\text { JULY 23, } 1962\end{array}$ & $\begin{array}{ll}9 & 13.78 \\
0 & 10.68 \\
1 & 13.59 \\
2 & 11.71\end{array}$ & $\begin{array}{r}1590 \\
230 \\
1500 \\
560\end{array}$ & $\begin{array}{l}1963 \\
1964 \\
1965\end{array}$ & $\begin{array}{l}\text { AUG. } 27,1963 \\
\text { AUG. 13, } 1964 \\
\text { SEPT. 05, } 1965\end{array}$ & $\begin{array}{l}14.70 \\
12.90 \\
13.84\end{array}$ & $\begin{array}{l}4620 \\
1220 \\
1940\end{array}$ & $\begin{array}{l}1966 \\
1967 \\
1968\end{array}$ & $\begin{array}{l}\text { SEPT. } 16,1966 \\
\text { SEPT. 05, } 1967 \\
\text { AUG. 01, } 1968\end{array}$ & $\begin{array}{l}12.98 \\
15.39 \\
15.81\end{array}$ & $\begin{array}{l}1260 \\
3340 \\
3560\end{array}$ \\
\hline
\end{tabular}

09339500 ESCALANTE RIVER AT MOUTH, NEAR ESCALANIE, UT

LOCATION.--Lat $37^{\circ} 18^{\prime} 51^{\prime \prime}$, long $110^{\circ} 54^{\prime} 10^{\prime \prime}$, in SE⿺辶 sec.7, T.41 S., R.10 E., Garfield County, Hydrologic Unit 14070005, on left bank $2.2 \mathrm{mi}$ downstream from Davis Gulch, $5.1 \mathrm{mi}$ upstream from mouth, and about $50 \mathrm{mi}$ southeast of Escalante.

DRAINAGE AREA.--1,770 $\mathrm{mi}^{2}$, approximately.

PERIOD OF RECORD AVAILABLE.--April 1950 to September 1955.

GAGE.--Water-stage recorder. Altitude of gage is 3,380 ft from river-profile map.

REMARKS.--Diversion for irrigation of about 4,500 acres above station.

AVERAGE DISCHARGE. --5 years, $85.2 \mathrm{ft}^{3} / \mathrm{s}, 61,680$ acre-ft/yr.

EXTREMES FOR PERIOD OF RECORD.--Maximum discharge, 14,600 ft 3 /s Aug. 4, 1951, gage height, $11.43 \mathrm{ft} ; \mathrm{minimum}, 4.4 \mathrm{ft} / \mathrm{s} \mathrm{Aug.} 20$, 1950, July 11, 1951 .

LOWEST MEAN DISGHARGE, IN OUBIC FEET PER SECOND, AND RANKING FOR THE INDICATED NUMBER OF CONSEOUTIVE DAYS FOR EACH OIMATIC YEAR, APRII 1-MARCH 31

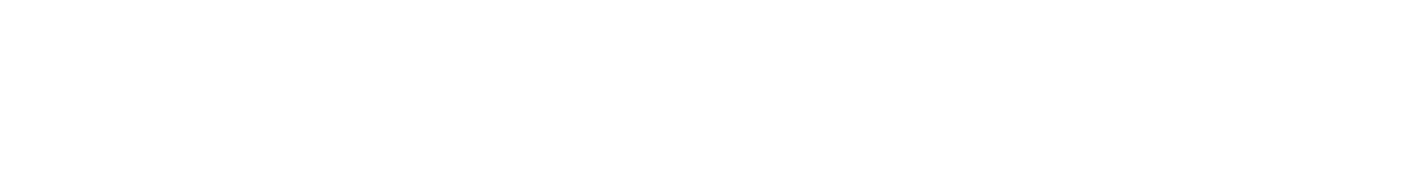

HIGHEST MEAN DISCHARGE, IN OUBIC FEET PER SECOND, AND RANKING FOR THE INDICATED NUMBER OF CONSECTTIVE DAYS FOR EACH WATER YEAR, OCTOBER 1-SEPIEMBER 30

YEAR

$\begin{array}{lr} & 1 \\ 1951 & 4510 \\ 1952 & 1190 \\ 1953 & 2690 \\ 1954 & 744 \\ 1955 & 2350\end{array}$

$\begin{array}{rr} & 3 \\ 1 & 1810 \\ 4 & 594 \\ 2 & 984 \\ 5 & 483 \\ 3 & 1400\end{array}$

3

$\begin{array}{ll} & 7 \\ 1 & 824 \\ 4 & 310 \\ 3 & 488 \\ 5 & 247 \\ 2 & 683\end{array}$

15

$\begin{array}{ll}1 & 405 \\ 4 & 223 \\ 3 & 262 \\ 5 & 142 \\ 2 & 388\end{array}$

CONSEOUTIVE DAYS

$30 \quad 60$

$\begin{array}{llll}1 & 354 & 1 & 203 \\ 4 & 191 & 4 & 162 \\ 3 & 199 & 3 & 155 \\ 5 & 125 & 5 & 104 \\ 2 & 292 & 2 & 172\end{array}$

90

$\begin{array}{ll}1 & 141 \\ 3 & 151 \\ 4 & 114 \\ 5 & 98.0 \\ 2 & 121\end{array}$

120
119
142
102
92.0
108

183

97.0
127
91.0

$89.0 \quad 5 \quad 84.0$

$\begin{array}{cccc}89.0 & 5 & 68.0 & 5 \\ 101 & 2 & 89.0 & 2\end{array}$ 
ESCALANTE RIVER BASIN

09339500 ESCALANIE RIVER AT MOUTH, NEAR ESCALANIE, UT-Continued

DURATION OF DISCHARGE FOR EACH WATER YEAR

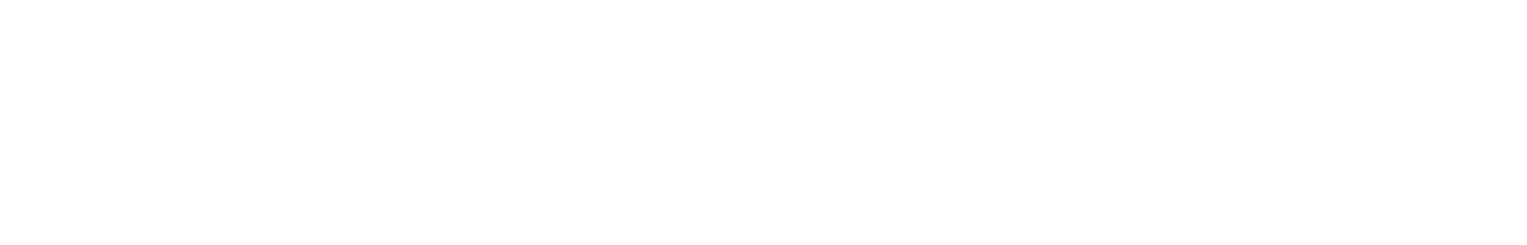

DURATION TABLE OF DISCHARGE FOR WATER YEARS 1951-55

\begin{tabular}{|c|c|c|c|c|c|c|c|c|c|c|c|c|c|c|c|c|c|c|c|}
\hline CLASS & $\begin{array}{c}\text { CUBIC } \\
\text { FEET } \\
\text { PER } \\
\text { SECOND }\end{array}$ & $\begin{array}{r}\text { TOTAL } \\
\text { DAYS }\end{array}$ & $\begin{array}{l}\text { ACOU- } \\
\text { MU- } \\
\text { LATED } \\
\text { DAYS }\end{array}$ & $\begin{array}{l}\text { PER- } \\
\text { CENT } \\
\text { DAYS }\end{array}$ & CLASS & $\begin{array}{c}\text { CUBIC } \\
\text { FEET } \\
\text { PER } \\
\text { SECOND }\end{array}$ & $\begin{array}{r}\text { TOTAL } \\
\text { DAYS }\end{array}$ & $\begin{array}{c}\text { ACOU- } \\
\text { MU- } \\
\text { LATED } \\
\text { DAYS }\end{array}$ & $\begin{array}{l}\text { PER- } \\
\text { CENT } \\
\text { DAYS }\end{array}$ & CLASS & $\begin{array}{c}\text { OBBIC } \\
\text { FEET } \\
\text { PER } \\
\text { SEOOND }\end{array}$ & $\begin{array}{r}\text { TOTAL } \\
\text { DAYS }\end{array}$ & $\begin{array}{l}\text { ACOU- } \\
\text { MU- } \\
\text { LATED } \\
\text { DAYS }\end{array}$ & $\begin{array}{l}\text { PER- } \\
\text { CENT } \\
\text { DAYS }\end{array}$ & CLASS & $\begin{array}{c}\text { OABIC } \\
\text { FEET } \\
\text { PER } \\
\text { SECOND }\end{array}$ & $\begin{array}{l}\text { TOTAL } \\
\text { DAYS }\end{array}$ & $\begin{array}{c}\text { ACOJ- } \\
\text { MU- } \\
\text { LATED } \\
\text { DAYS }\end{array}$ & $\begin{array}{l}\text { PER- } \\
\text { CENT } \\
\text { DAYS }\end{array}$ \\
\hline $\begin{array}{l}0 \\
1 \\
2 \\
3 \\
4 \\
5 \\
6 \\
7 \\
8\end{array}$ & $\begin{array}{r}0.00 \\
7.20 \\
8.60 \\
10.00 \\
12.00 \\
15.00 \\
18.00 \\
21.00 \\
25.00\end{array}$ & $\begin{array}{r}0 \\
2 \\
3 \\
6 \\
32 \\
57 \\
37 \\
74 \\
82\end{array}$ & $\begin{array}{l}1826 \\
1826 \\
1824 \\
1821 \\
1815 \\
1783 \\
1726 \\
1689 \\
1615\end{array}$ & $\begin{array}{r}100.0 \\
100.0 \\
99.9 \\
99.7 \\
99.4 \\
97.6 \\
94.5 \\
92.5 \\
88.4\end{array}$ & $\begin{array}{r}9 \\
10 \\
11 \\
12 \\
13 \\
14 \\
15 \\
16 \\
17\end{array}$ & $\begin{array}{r}30.00 \\
36.00 \\
43.00 \\
52.00 \\
62.00 \\
74.00 \\
89.00 \\
110.00 \\
130.00\end{array}$ & $\begin{array}{r}130 \\
133 \\
164 \\
204 \\
176 \\
228 \\
228 \\
95 \\
50\end{array}$ & $\begin{array}{r}1533 \\
1403 \\
1270 \\
1106 \\
902 \\
726 \\
498 \\
270 \\
175\end{array}$ & $\begin{array}{r}84.0 \\
76.8 \\
69.6 \\
60.6 \\
49.4 \\
39.8 \\
27.3 \\
14.8 \\
9.6\end{array}$ & $\begin{array}{l}18 \\
19 \\
20 \\
21 \\
22 \\
23 \\
24 \\
25 \\
26\end{array}$ & $\begin{array}{l}150.0 \\
180.0 \\
220.0 \\
260.0 \\
310.0 \\
370.0 \\
450.0 \\
530.0 \\
640.0\end{array}$ & $\begin{array}{r}36 \\
21 \\
17 \\
15 \\
6 \\
9 \\
3 \\
2 \\
4\end{array}$ & $\begin{array}{r}125 \\
89 \\
68 \\
51 \\
36 \\
30 \\
21 \\
18 \\
16\end{array}$ & $\begin{array}{l}6.8 \\
4.9 \\
3.7 \\
2.8 \\
2.0 \\
1.6 \\
1.2 \\
1.0 \\
0.9\end{array}$ & $\begin{array}{l}27 \\
28 \\
29 \\
30 \\
31 \\
32 \\
33 \\
34\end{array}$ & $\begin{array}{r}770.0 \\
920.0 \\
1100.0 \\
1300.0 \\
1600.0 \\
1900.0 \\
2200.0 \\
2700.0\end{array}$ & $\begin{array}{l}3 \\
1 \\
2 \\
2 \\
0 \\
1 \\
2 \\
1\end{array}$ & $\begin{array}{r}12 \\
9 \\
8 \\
6 \\
4 \\
4 \\
3 \\
1\end{array}$ & $\begin{array}{l}0.7 \\
0.5 \\
0.4 \\
0.3 \\
0.2 \\
0.2 \\
0.2 \\
0.1\end{array}$ \\
\hline
\end{tabular}

MONIHLY MEAN DISCHARGES, IN GBBIC FEET PER SECOND, FOR EACH WATER YEAR

\begin{tabular}{|c|c|c|c|c|c|c|c|c|c|c|c|c|}
\hline YEAR & $O C T$ & NOV & $\mathrm{DEC}$ & JAN & FEB & MAR & APR & MAY & JUNE & JULY & AUG & SEP \\
\hline $\begin{array}{l}1951 \\
1952 \\
1953 \\
1954 \\
1955\end{array}$ & $\begin{array}{r}40.9 \\
69.4 \\
58.5 \\
54.1 \\
190\end{array}$ & $\begin{array}{l}72.6 \\
76.7 \\
87.7 \\
87.2 \\
58.0\end{array}$ & $\begin{array}{r}77.7 \\
94.9 \\
101 \\
73.7 \\
84.7\end{array}$ & $\begin{array}{r}89.2 \\
89.1 \\
94.9 \\
114 \\
84.3\end{array}$ & $\begin{array}{l}89.7 \\
104 \\
103 \\
94.1 \\
87.5\end{array}$ & $\begin{array}{c}65.6 \\
130 \\
97.8 \\
83.8 \\
96.0\end{array}$ & $\begin{array}{c}47.4 \\
133 \\
50.8 \\
60.0 \\
53.0\end{array}$ & $\begin{array}{c}74.6 \\
158 \\
44.4 \\
77.0 \\
36.4\end{array}$ & $\begin{array}{c}26.1 \\
104 \\
36.4 \\
19.7 \\
20.6\end{array}$ & $\begin{array}{r}17.1 \\
48.2 \\
115 \\
48.6 \\
87.0\end{array}$ & $\begin{array}{c}343 \\
84.8 \\
181 \\
21.9 \\
233\end{array}$ & $\begin{array}{c}52.0 \\
115 \\
35.4 \\
89.4 \\
31.9\end{array}$ \\
\hline
\end{tabular}

ANNUAL PEAK DISCHARGE, IN CUBIC FEET PER SECOND, AND CORRESPONDING GAGE HEIGHT, IN FEET, FOR EACH WATER YEAR

\begin{tabular}{|c|c|c|c|c|c|c|c|c|c|c|c|}
\hline $\begin{array}{l}\text { WATERR } \\
\text { YEAR }\end{array}$ & DATE & $\begin{array}{l}\text { GAGE } \\
\text { HEIGHT }\end{array}$ & $\begin{array}{c}\text { PEAK } \\
\text { DISCHARGE }\end{array}$ & $\begin{array}{l}\text { WATER } \\
\text { YEAR }\end{array}$ & DATE & $\begin{array}{c}\text { GAGE } \\
\text { HEIGHT }\end{array}$ & $\begin{array}{c}\text { PEAR } \\
\text { DISCHARGE }\end{array}$ & $\begin{array}{l}\text { WATERR } \\
\text { YEAR }\end{array}$ & DATE & $\begin{array}{c}\text { GAGE } \\
\text { HEIGHT }\end{array}$ & $\begin{array}{c}\text { PEAK } \\
\text { DISCHARGE }\end{array}$ \\
\hline $\begin{array}{l}1950 \\
1951\end{array}$ & $\begin{array}{l}\text { JULY 18, } 1950 \\
\text { AUG. } 04,1951\end{array}$ & $\begin{array}{r}2.45 \\
11.43\end{array}$ & $\begin{array}{r}1320 \\
14600\end{array}$ & $\begin{array}{l}1952 \\
1953\end{array}$ & $\begin{array}{ll}\text { SEPT. } 22, & 1952 \\
\text { JULY } 18, & 1953\end{array}$ & $\begin{array}{l}3.45 \\
9.41\end{array}$ & $\begin{array}{r}2820 \\
10700\end{array}$ & $\begin{array}{l}1954 \\
1955\end{array}$ & $\begin{array}{l}\text { SEPT.13, } 1954 \\
\text { OCT. 07, } 1954\end{array}$ & $\begin{array}{l}2.77 \\
8.10\end{array}$ & $\begin{array}{l}1580 \\
8960\end{array}$ \\
\hline
\end{tabular}

SAN JUAN RIVER BASIN

09372000 MCELMO CREEK NEAR COLORADO-UTAH STATE LINE

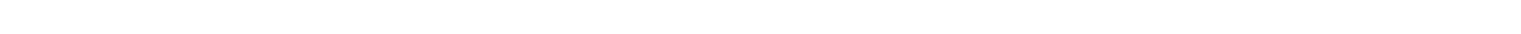
$1.5 \mathrm{mi}$ upstream fram Colorado-Utah State line, $2.0 \mathrm{mi}$ upstream fran Yellowjacket Creek, and 2.0 mi west of former town of McElmo.

DRAINAGE AREA. $--346 \mathrm{mi}^{2}$.

MEAN BASIN ELEVATION. $-6,300 \mathrm{ft}$.

PERIOD OF RECORD AVAIIABLE.--March 1951 to September 1981.

REVISED RECORDS.-WSP 1925: 1951-52(M), 1957(M). WDR CO 1972: Drainage area.

GAGE.-Water-stage recorder. Altitude of gage is 4,890 ft fran topographic map.

REMARKS.--Diversions for irrigation of about 1,780 acres above station. One diversion above station for irrigation of about 60 acres below. Part of flow is return water from irrigated lands of Montezuma Irrigation District (water imported from Dolores River basin).

AVERAGE DISCHARGE. -30 years, $45.6 \mathrm{ft}^{3} / \mathrm{s}, 33,040$ acre- $\mathrm{ft} / \mathrm{yr}$.

EXIREMES FOR PERICD OF RECORD.-Maximum discharge, 3,040 ft $3 / \mathrm{s}$ Aug. 7, 1967, gage height, $7.58 \mathrm{ft}$, fram floodmark in gage well, fran rating curve extended above $2,100 \mathrm{ft}^{3} / \mathrm{s}$; maximum gage height, $8.13 \mathrm{ft} \mathrm{Sept.} 6,1970$; minimum daily discharge, $0.08 \mathrm{ft} / 3$ sept. $9,10,1977$ 
SAN JUAN RIVER BASIN

09372000 MCELMO CREEK NEAR COLORADO-UTAF STATE LINE-Continued

LOWEST MEAN DISCHARGE, IN OBIC FEET PER SECOND, AND RANKING FOR THE INDICATED NUMBER OF CONSECUTIVE DAYS FOR EACH OLIMATIC YEAR, APRIL 1-MARCH 31

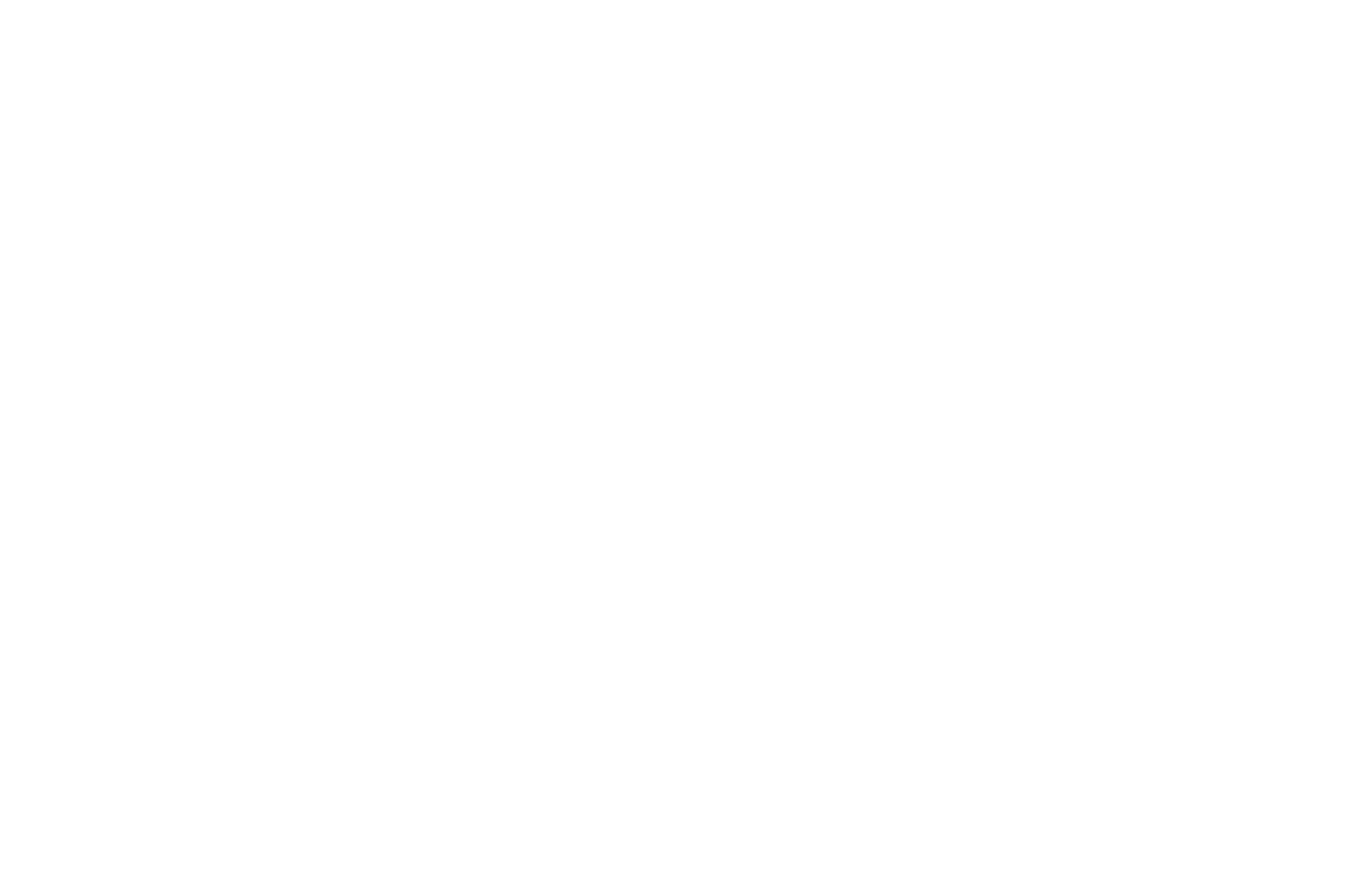

HIGHEST MEAN DISCHARGE, IN GBIC FEET PER SECOND, AND RANKING FOR THE INDICATED NUMBER OF CONSEQUTTVE DAYS FOR EACH WATER YEAR, OCTOBER 1-SEPTEMBER 30

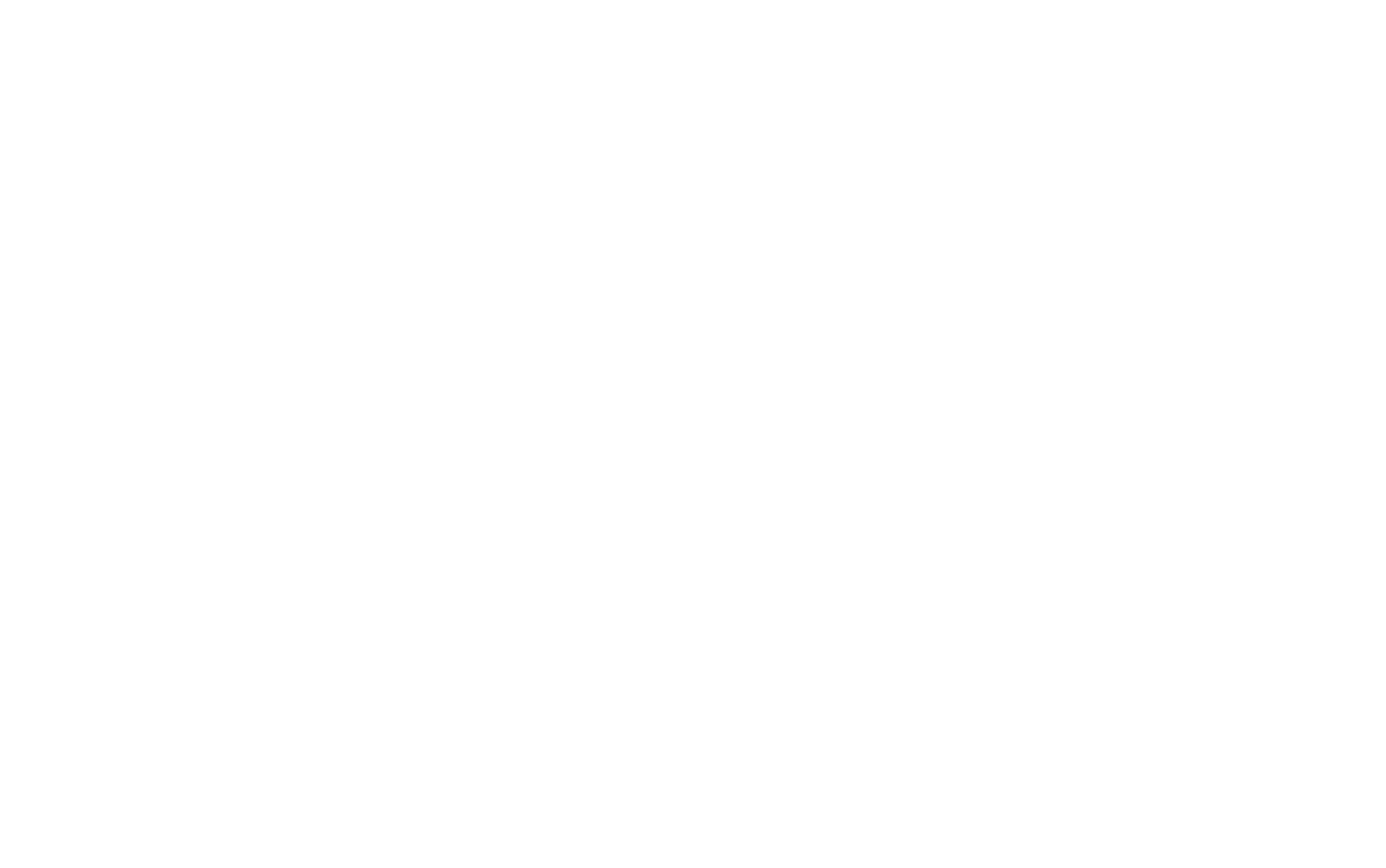


SAN JUAN RIVER BASIN

09372000 MCELMO CREEK NEAR COLORADO-UTAH STATE LINE--Continued

DURATION OF DISCHARGE FOR EAGH WATER YEAR

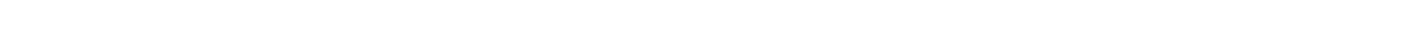
YEAR NUMBER OF DAYS IN CLASS

UBIC FEET

PER SECON

-DAYS

$\begin{array}{rrrrrrrrrrrrrrrrrrrrrrrrrrrrr}1952 & & & 3 & 1 & & 5 & 2 & 3 & 8 & 23 & 36 & 66 & 77 & 77 & 25 & 16 & 13 & 5 & 4 & 1 & 1 & & & 12534.7 \\ 1953 & & & & 12 & 2 & 11 & 9 & 9 & 7 & 9 & 9 & 22 & 71 & 108 & 50 & 25 & 12 & 5 & & 3 & & 1 & & & & 10083.6 \\ 1954 & 6 & 15 & 6 & 16 & 9 & 10 & 8 & 6 & 9 & 6 & 13 & 18 & 60 & 75 & 48 & 32 & 11 & 6 & 3 & 5 & 2 & 1 & & & & 10483.9 \\ 1955 & & & & & 6 & 11 & 14 & 9 & 8 & 6 & 5 & 19 & 69 & 79 & 48 & 48 & 11 & 10 & 14 & 3 & 3 & 2 & & & & & & \end{array}$

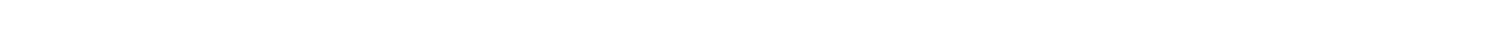

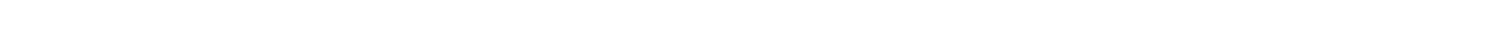

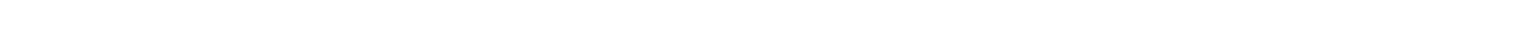

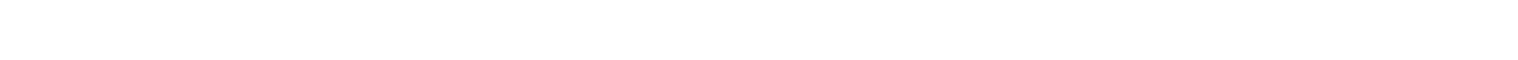

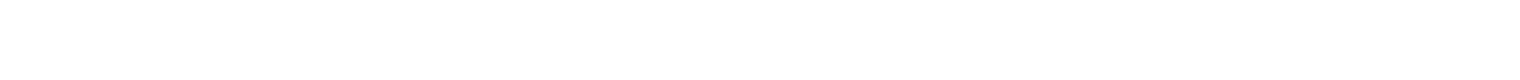

$\begin{array}{lllllllllllllllllllllllll}1963 & 2 & 5 & 2 & 7 & 16 & 4 & 1 & 2 & 3 & 9 & 19 & 18 & 32 & 98 & 56 & 49 & 28 & 4 & 4 & 3 & 2 & & 1\end{array}$

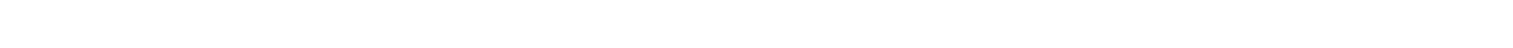

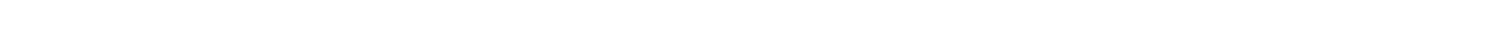

1968

$\begin{array}{llllllllllllllll}1 & 13 & 97 & 104 & 51 & 51 & 1.8 & 18 & 8 & 2 & 1 & 2 & & 1 & 1 & 1856.0\end{array}$

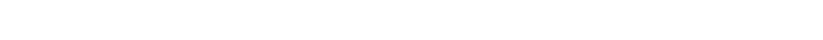

$\begin{array}{llllllllllllllll}1 & 3 & 10 & 8 & 45 & 58 & 58 & 66 & 56 & 26 & 15 & 8 & 4 & 5 & 1\end{array}$

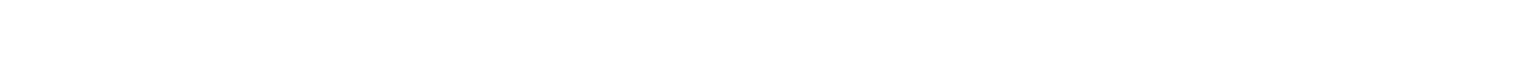

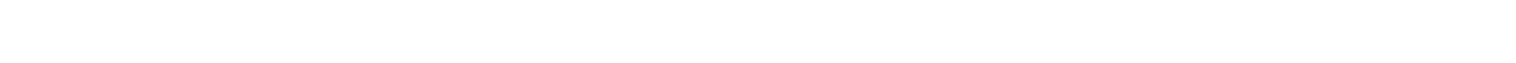

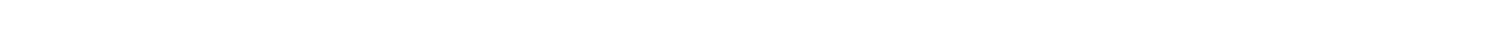

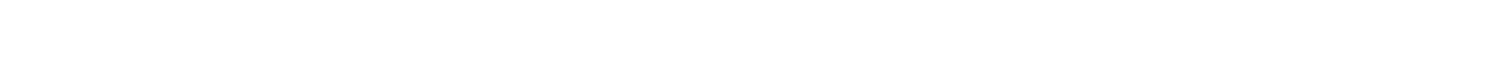

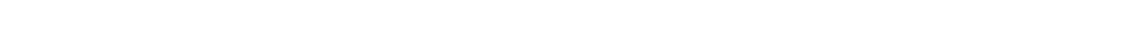

$\begin{array}{lllllllllllllllllllllllllllllllll}1978 & 1 & 1 & 1 & 1 & 5 & 2 & 2 & 4 & 17 & 13 & 8 & 9 & 10 & 15 & 44 & 43 & 54 & 43 & 46 & 17 & 15 & 6 & 4 & 3 & 1 & & & & & & \end{array}$

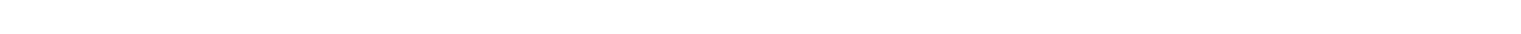

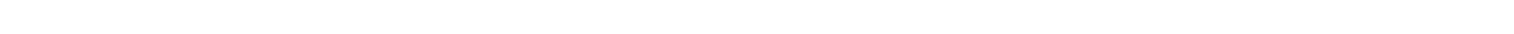

$\begin{array}{llllllllllllllllllllllllllllll}1981 & 1 & 2 & 1 & 1 & 4 & 10 & 10 & 13 & 17 & 57 & 114 & 56 & 38 & 14 & 12 & 6 & 4 & 1 & 2 & 2 & & 13521.6\end{array}$

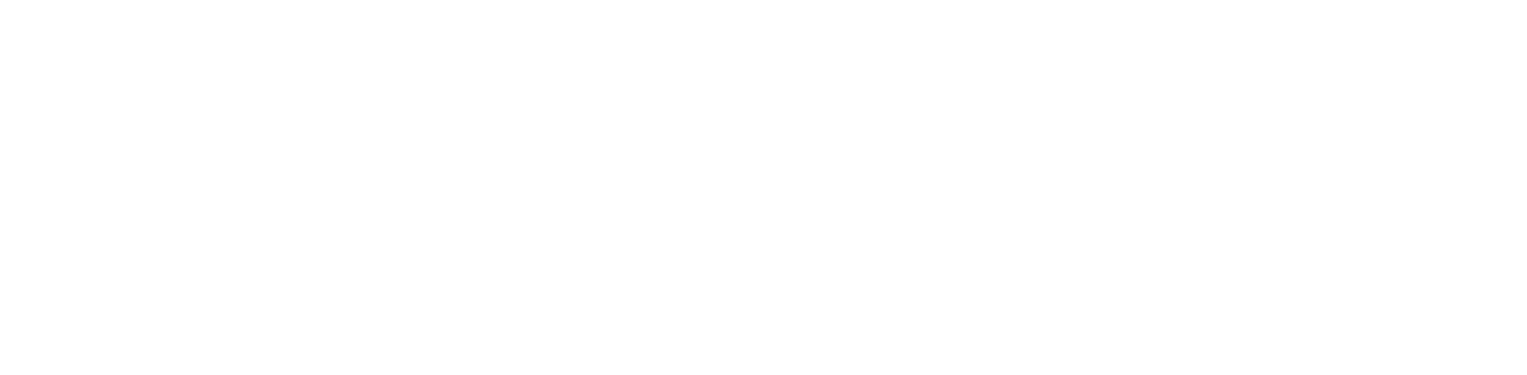

MONTHLY MEAN DISCHARGES, IN OUBIC FEET PER SECOND, FOR EACH WATER YEAR

\begin{tabular}{|c|c|c|c|c|c|c|c|c|c|c|c|c|}
\hline YEAR & $\mathrm{OCT}$ & NOV & $D E C$ & JAN & FEB & MAR & APR & MAY & JUNE & JULY & AUG & SEP \\
\hline $\begin{array}{l}1952 \\
1953 \\
1954 \\
1955\end{array}$ & $\begin{array}{l}18.7 \\
23.4 \\
45.7 \\
26.8\end{array}$ & $\begin{array}{l}22.5 \\
27.6 \\
43.5 \\
27.0\end{array}$ & $\begin{array}{l}35.6 \\
32.2 \\
25.2 \\
28.7\end{array}$ & $\begin{array}{l}33.7 \\
30.1 \\
25.0 \\
25.3\end{array}$ & $\begin{array}{l}28.8 \\
28.0 \\
29.1 \\
39.4\end{array}$ & $\begin{array}{l}55.2 \\
29.6 \\
23.4 \\
75.5\end{array}$ & $\begin{array}{l}51.5 \\
31.4 \\
24.1 \\
34.5\end{array}$ & $\begin{array}{l}25.3 \\
40.7 \\
60.5 \\
55.5\end{array}$ & $\begin{array}{l}42.8 \\
23.8 \\
17.1 \\
21.8\end{array}$ & $\begin{array}{c}44.9 \\
10.8 \\
4.43 \\
22.6\end{array}$ & $\begin{array}{c}25.0 \\
44.5 \\
3.56 \\
73.3\end{array}$ & $\begin{array}{c}26.8 \\
8.64 \\
43.6 \\
6.73\end{array}$ \\
\hline $\begin{array}{l}1956 \\
1957 \\
1958 \\
1959 \\
1960\end{array}$ & $\begin{array}{c}9.05 \\
1.84 \\
122 \\
32.9 \\
34.9\end{array}$ & $\begin{array}{l}24.0 \\
14.0 \\
85.7 \\
48.4 \\
29.2\end{array}$ & $\begin{array}{l}32.3 \\
15.1 \\
48.8 \\
31.8 \\
17.8\end{array}$ & $\begin{array}{l}35.2 \\
29.5 \\
31.9 \\
25.5 \\
16.3\end{array}$ & $\begin{array}{c}31.6 \\
46.5 \\
100 \\
36.7 \\
23.6\end{array}$ & $\begin{array}{r}27.6 \\
39.1 \\
96.9 \\
25.9 \\
106\end{array}$ & $\begin{array}{c}36.8 \\
67.9 \\
65.4 \\
8.63 \\
49.7\end{array}$ & $\begin{array}{c}70.0 \\
105 \\
71.7 \\
12.2 \\
66.0\end{array}$ & $\begin{array}{l}48.6 \\
73.9 \\
68.1 \\
18.9 \\
57.9\end{array}$ & $\begin{array}{c}5.01 \\
132 \\
38.4 \\
1.32 \\
31.6\end{array}$ & $\begin{array}{c}13.6 \\
146 \\
25.4 \\
24.8 \\
4.78\end{array}$ & $\begin{array}{c}0.43 \\
79.1 \\
58.0 \\
11.1 \\
1.10\end{array}$ \\
\hline $\begin{array}{l}1961 \\
1962 \\
1963 \\
1964 \\
1965\end{array}$ & $\begin{array}{l}19.8 \\
64.3 \\
43.4 \\
19.9 \\
30.3\end{array}$ & $\begin{array}{l}31.3 \\
56.9 \\
44.2 \\
29.2 \\
50.0\end{array}$ & $\begin{array}{l}21.7 \\
32.7 \\
32.9 \\
20.0 \\
52.0\end{array}$ & $\begin{array}{l}19.5 \\
28.7 \\
24.3 \\
17.7 \\
49.8\end{array}$ & $\begin{array}{l}34.1 \\
50.0 \\
53.6 \\
17.9 \\
51.0\end{array}$ & $\begin{array}{l}33.1 \\
34.7 \\
29.7 \\
35.5 \\
46.7\end{array}$ & $\begin{array}{l}38.7 \\
32.7 \\
42.3 \\
42.9 \\
54.4\end{array}$ & $\begin{array}{l}55.1 \\
65.8 \\
40.4 \\
13.1 \\
74.8\end{array}$ & $\begin{array}{l}35.6 \\
71.1 \\
27.3 \\
25.9 \\
99.9\end{array}$ & $\begin{array}{c}12.8 \\
37.2 \\
12.2 \\
24.6 \\
102\end{array}$ & $\begin{array}{r}23.6 \\
10.2 \\
43.7 \\
64.0 \\
114\end{array}$ & $\begin{array}{l}57.9 \\
15.6 \\
15.9 \\
36.7 \\
99.8\end{array}$ \\
\hline
\end{tabular}


SAN JUAN RIVER BASIN

09372000 MCELMO CREEK NEAR COLORADO-UTAH STATE LINE--Continued

MONIYLY MEAN DISCHARGES, IN OBIC FEET PER SECOND, FOR EACH WATER YEAR--Continued

$\begin{array}{lcccccccccccc}\text { YEAR } & \text { OCT } & \text { NOV } & \text { DEC } & \text { JAN } & \text { FEB } & \text { MAR } & \text { APR } & \text { MAY } & \text { JUNE } & \text { JULY } & \text { AJG } & \text { SEP } \\ 1966 & 115 & 91.8 & 95.4 & 57.5 & 53.6 & 73.6 & 56.9 & 63.2 & 68.2 & 45.0 & 19.1 & 29.0 \\ 1967 & 28.7 & 36.5 & 57.8 & 28.6 & 34.5 & 22.1 & 21.5 & 34.5 & 75.9 & 35.7 & 160 & 43.3 \\ 1968 & 36.5 & 32.8 & 34.1 & 34.4 & 64.5 & 41.5 & 28.0 & 51.6 & 60.3 & 64.0 & 130 & 40.2 \\ 1969 & 48.2 & 33.6 & 29.5 & 68.4 & 50.1 & 86.4 & 49.9 & 49.2 & 105 & 91.9 & 76.5 & 53.1 \\ 1970 & 95.4 & 55.6 & 41.6 & 29.3 & 27.6 & 29.1 & 27.7 & 16.4 & 71.9 & 70.8 & 65.7 & 154 \\ & & & & & & & & & & & & \\ 1971 & 77.8 & 60.8 & 44.8 & 40.0 & 31.5 & 22.6 & 35.2 & 79.1 & 57.1 & 41.3 & 108 & 36.1 \\ 1972 & 83.7 & 49.8 & 61.0 & 36.3 & 31.2 & 27.2 & 26.2 & 50.6 & 85.8 & 15.8 & 2.69 & 13.6 \\ 1973 & 161 & 54.5 & 42.6 & 34.3 & 69.4 & 197 & 148 & 93.0 & 101 & 89.4 & 72.5 & 70.8 \\ 1974 & 49.9 & 39.9 & 36.1 & 23.2 & 28.8 & 92.5 & 27.2 & 31.7 & 33.7 & 19.9 & 17.6 & 13.8 \\ 1975 & 46.5 & 42.6 & 24.8 & 26.8 & 34.9 & 78.0 & 44.2 & 32.4 & 50.5 & 97.6 & 61.4 & 63.9 \\ & & & & & & & & & & & & \\ 1976 & 46.8 & 45.6 & 39.4 & 30.9 & 71.6 & 31.9 & 21.4 & 62.5 & 62.4 & 29.3 & 45.9 & 46.6 \\ 1977 & 38.5 & 30.7 & 23.6 & 23.5 & 26.1 & 18.1 & 2.23 & 6.79 & 2.60 & 9.21 & 8.52 & 4.69 \\ 1978 & 2.49 & 15.1 & 13.5 & 16.1 & 27.0 & 70.7 & 28.7 & 40.9 & 30.0 & 29.9 & 10.5 & 12.3 \\ 1979 & 20.5 & 45.0 & 66.5 & 49.1 & 54.8 & 194 & 124 & 85.6 & 99.2 & 60.0 & 58.3 & 18.1 \\ 1980 & 31.5 & 32.9 & 28.4 & 57.1 & 141 & 118 & 98.3 & 51.4 & 57.3 & 54.2 & 51.4 & 92.8 \\ 1981 & 48.1 & 34.8 & 29.8 & 23.8 & 22.7 & 26.2 & 13.1 & 32.6 & 40.1 & 102 & 31.1 & 38.0\end{array}$

ANNUAL PEAK DISCHARGE, IN OBBIC FEET PER SECOND, AND CORRESPONDING GAGE HEIGHT, IN FEET, FOR EACH WATER YEAR

\begin{tabular}{|c|c|c|c|c|c|c|c|c|c|c|c|}
\hline $\begin{array}{l}\text { WATEER } \\
\text { YEAR }\end{array}$ & DATE & $\begin{array}{c}\text { GAGE } \\
\text { HEIGHT }\end{array}$ & $\begin{array}{c}\text { PEAK } \\
\text { DISCHARGE }\end{array}$ & $\begin{array}{l}\text { WATER } \\
\text { YEAR }\end{array}$ & DATE & $\begin{array}{c}\text { GAGE } \\
\text { HEIGHT }\end{array}$ & $\begin{array}{c}\text { PEAK } \\
\text { DISCHARGE }\end{array}$ & $\begin{array}{l}\text { WATER } \\
\text { YEAR }\end{array}$ & DATE & $\begin{array}{c}\text { GAGE } \\
\text { HEIGHT }\end{array}$ & $\begin{array}{c}\text { PEAK } \\
\text { DISCHARG }\end{array}$ \\
\hline $\begin{array}{l}1951 \\
1952 \\
1953 \\
1954 \\
1955 \\
1956 \\
1957 \\
1958 \\
1959 \\
1960 \\
1961\end{array}$ & $\begin{array}{l}\text { AUG. 29, } 1951 \\
\text { DEC. 31, } 1951 \\
\text { AUG. 01, } 1953 \\
\text { SEPT. 25, } 1954 \\
\text { AUG. 07, } 1955 \\
\text { AUG. 01, } 1956 \\
\text { JULY 27, } 1957 \\
\text { SEPT.13, } 1958 \\
\text { AUG. 24, } 1959 \\
\text { MAR. 09, } 1960 \\
\text { SEPT.18, } 1961\end{array}$ & $\begin{array}{l}7.05 \\
5.09 \\
4.78 \\
6.02 \\
5.23 \\
4.90 \\
7.00 \\
5.97 \\
5.40 \\
5.49 \\
5.34\end{array}$ & $\begin{array}{r}1700 \\
660 \\
459 \\
1050 \\
620 \\
490 \\
1700 \\
1030 \\
705 \\
740 \\
678\end{array}$ & $\begin{array}{l}1962 \\
1963 \\
1964 \\
1965 \\
1966 \\
1967 \\
1968 \\
1969 \\
1970 \\
1971\end{array}$ & $\begin{array}{l}\text { OCT. } 09,1961 \\
\text { AUG. } 27,1963 \\
\text { JULY 12, } 1964 \\
\text { AUG. 29, } 1965 \\
\text { OCT. 17, } 1965 \\
\text { AUG. 07, } 1967 \\
\text { AUG. 02, } 1968 \\
\text { JULY 18, } 1969 \\
\text { SEPT. 06, } 1970 \\
\text { AUG. 07, } 1971\end{array}$ & $\begin{array}{l}4.98 \\
6.17 \\
6.45 \\
6.00 \\
6.54 \\
7.58 \\
6.05 \\
6.32 \\
8.13 \\
6.98\end{array}$ & $\begin{array}{r}535 \\
1140 \\
1320 \\
974 \\
1320 \\
3040 \\
1010 \\
1210 \\
2880 \\
1650\end{array}$ & $\begin{array}{l}1972 \\
1973 \\
1974 \\
1975 \\
1976 \\
1977 \\
1978 \\
1979 \\
1980 \\
1981\end{array}$ & $\begin{array}{l}\text { OCT. } 17,1971 \\
\text { OCT. } 19,1972 \\
\text { MAR. } 03,1974 \\
\text { OCT. } 29,1974 \\
\text { AUG. } 01,1976 \\
\text { AUG. } 16,1977 \\
\text { MAR. 03, } 1978 \\
\text { DEC. 18, } 1978 \\
\text { FEB. } 20,1980 \\
\text { JULY } 12,1981\end{array}$ & $\begin{array}{l}6.38 \\
7.15 \\
5.51 \\
4.64 \\
5.47 \\
4.84 \\
4.55 \\
7.05 \\
5.53 \\
6.05\end{array}$ & $\begin{array}{r}1210 \\
1800 \\
715 \\
385 \\
696 \\
472 \\
337 \\
1730 \\
706 \\
986\end{array}$ \\
\hline
\end{tabular}

09372200 MCELMO CREEK NEAR BLUFF, UT

LOCATTON.--Lat $37^{\circ} 13^{\prime} 13^{\prime \prime}$, long $109^{\circ} 10^{\prime} 48^{\prime \prime}$, in SW $\mathrm{NWW}_{4}^{\frac{1}{4} S W^{\frac{1}{4}}}$ sec.16, T.41 S., R.25 E., San Juan County, Bydrologic Unit 14080202 , 0.25 mi north of Aneth Utah Trading Post, $0.5 \mathrm{mi}$ upstream from mouth, and $21 \mathrm{mi}$ southeast of Bluff.

DRAINAGE AREA. $--721 \mathrm{mi}^{2}$.

MEAN BASIN ELEVATION. $-6,200 \mathrm{ft}$.

PERIOD OF RECORD AVAIIABLE.--Annual peak discharge only, water years 1959-68, 1970. October 1980 to Septenber 1981.

GAGE.--Water-stage recorder and water-qual ity mini-monitor. Altitude of gage is 4,480 ft trom topographic map.

REMARKS.--Diversion for irrigation above station.

EXTREMES FOR PERIOD OF RECORD.--Maximum discharge, 13,100 ft ${ }^{3} / \mathrm{s} \mathrm{Sept.} \mathrm{6,} \mathrm{1970;} \mathrm{minimum} \mathrm{daily,} 5.8 \mathrm{ft} / \mathrm{s}^{3} \mathrm{Apr} .18,1981$.

HIGHEST MEAN DISCHARGE, IN OUBIC FEET PER SECOND, AND RANKING FOR THE INDICATED NUMBER OF CONSECUTIVE DAYS FOR EACH WATER YEAR, OCTCBER 1-SEPTEMBER 30

\begin{tabular}{|c|c|c|c|c|c|c|c|c|c|c|c|c|c|c|c|c|c|c|c|}
\hline YEAR & & & & & & & & & & 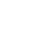 & VE D & & & & & & & & \\
\hline 1981 & 299 & 1 & 245 & 1 & 221 & 1 & 156 & 1 & 125 & 1 & 107 & 1 & 103 & 1 & 84.0 & 1 & 67.0 & 1 & 58.0 \\
\hline
\end{tabular}

DURATION OF DISCHARGE FOR EACH WATER YEAR

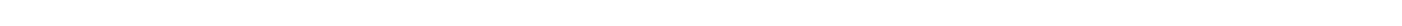
YEAR

NUMBER OF DAYS IN CLASS 
SAN JUAN RIVER BASIN

09372200 MCELMO CREEK NEAR BLUFF, UT-Continued

DURATION TABLE OF DISCHARGE FOR WATER YEAR 1981

\begin{tabular}{|c|c|c|c|c|c|c|c|c|c|c|c|c|c|c|c|c|c|c|c|}
\hline CLASS & $\begin{array}{c}\text { CUBIC } \\
\text { FEET } \\
\text { PER } \\
\text { SEOOND }\end{array}$ & $\begin{array}{l}\text { TOTAL } \\
\text { DAYS }\end{array}$ & $\begin{array}{l}\text { ACOU- } \\
\text { MU- } \\
\text { LATED } \\
\text { DAYS }\end{array}$ & $\begin{array}{l}\text { PER } \\
\text { CENT } \\
\text { DAYS }\end{array}$ & CLASS & $\begin{array}{c}\text { CBBIC } \\
\text { FEET } \\
\text { PER } \\
\text { SEOOND }\end{array}$ & $\begin{array}{l}\text { TOTAL } \\
\text { DAYS }\end{array}$ & $\begin{array}{c}\text { ACOJ- } \\
\text { MU- } \\
\text { LATED } \\
\text { DAYS }\end{array}$ & $\begin{array}{l}\text { PER- } \\
\text { CENT } \\
\text { DAYS }\end{array}$ & CLASS & $\begin{array}{c}\text { CUBIC } \\
\text { FEET } \\
\text { PER } \\
\text { SECOND }\end{array}$ & $\begin{array}{l}\text { TOTAL } \\
\text { DAYS }\end{array}$ & $\begin{array}{l}\text { ACOU- } \\
\text { M- } \\
\text { LATED } \\
\text { DAYS }\end{array}$ & $\begin{array}{l}\text { PER- } \\
\text { CENT } \\
\text { DAYS }\end{array}$ & GASS & $\begin{array}{c}\text { CABIC } \\
\text { FEET } \\
\text { PER } \\
\text { SECOND }\end{array}$ & $\begin{array}{c}\text { TOTAL } \\
\text { DAYS }\end{array}$ & $\begin{array}{c}\text { ACAI- } \\
\text { MU- } \\
\text { LATED } \\
\text { DAYS }\end{array}$ & $\begin{array}{l}\text { PER- } \\
\text { CENT } \\
\text { DAYS }\end{array}$ \\
\hline $\begin{array}{l}0 \\
1 \\
2 \\
3 \\
4 \\
5 \\
6 \\
7 \\
8\end{array}$ & $\begin{array}{r}0.0 \\
5.8 \\
6.5 \\
7.3 \\
8.2 \\
9.2 \\
10.0 \\
12.0 \\
13.0\end{array}$ & $\begin{array}{l}0 \\
2 \\
6 \\
2 \\
3 \\
0 \\
5 \\
5 \\
8\end{array}$ & $\begin{array}{l}365 \\
365 \\
363 \\
357 \\
355 \\
352 \\
352 \\
347 \\
342\end{array}$ & $\begin{array}{r}100.0 \\
100.0 \\
99.4 \\
97.8 \\
97.3 \\
96.4 \\
96.4 \\
95.1 \\
93.7\end{array}$ & $\begin{array}{r}9 \\
10 \\
11 \\
12 \\
13 \\
14 \\
15 \\
16 \\
17\end{array}$ & $\begin{array}{l}15.0 \\
16.0 \\
18.0 \\
21.0 \\
23.0 \\
26.0 \\
29.0 \\
33.0 \\
36.0\end{array}$ & $\begin{array}{r}1 \\
7 \\
8 \\
2 \\
4 \\
4 \\
7 \\
12 \\
24\end{array}$ & $\begin{array}{l}334 \\
333 \\
326 \\
318 \\
316 \\
312 \\
308 \\
301 \\
289\end{array}$ & $\begin{array}{l}91.5 \\
91.2 \\
89.3 \\
87.1 \\
86.6 \\
85.5 \\
84.4 \\
82.5 \\
79.2\end{array}$ & $\begin{array}{l}18 \\
19 \\
20 \\
21 \\
22 \\
23 \\
24 \\
25 \\
26\end{array}$ & $\begin{array}{r}41.0 \\
46.0 \\
51.0 \\
58.0 \\
65.0 \\
73.0 \\
81.0 \\
91.0 \\
100.0\end{array}$ & $\begin{array}{r}38 \\
65 \\
24 \\
30 \\
25 \\
26 \\
6 \\
6 \\
7 \\
9\end{array}$ & $\begin{array}{r}265 \\
227 \\
162 \\
138 \\
108 \\
83 \\
57 \\
51 \\
44\end{array}$ & $\begin{array}{l}72.6 \\
62.2 \\
44.4 \\
37.8 \\
29.6 \\
22.7 \\
15.6 \\
14.0 \\
12.0\end{array}$ & $\begin{array}{l}27 \\
28 \\
29 \\
30 \\
31 \\
32 \\
33 \\
34\end{array}$ & $\begin{array}{l}110.0 \\
130.0 \\
140.0 \\
160.0 \\
180.0 \\
200.0 \\
230.0 \\
260.0\end{array}$ & $\begin{array}{r}18 \\
4 \\
4 \\
3 \\
2 \\
0 \\
3 \\
1\end{array}$ & $\begin{array}{r}35 \\
17 \\
13 \\
9 \\
6 \\
4 \\
4 \\
1\end{array}$ & 0 \\
\hline
\end{tabular}

MONIHLY MEAN DISCHARGES, IN OABIC FEET PER SBCOND, FOR EAGH WATER YEAR

$\begin{array}{lllllllllllll}\text { YEAR } & \text { OCT } & \text { NOV } & \text { DEC } & \text { JAN } & \text { FEB } & \text { MAR } & \text { APR } & \text { MAY } & \text { JUNE } & \text { JULY } & \text { AUG } & \text { SEP } \\ 1981 & 46.3 & 51.1 & 71.1 & 60.1 & 47.5 & 42.7 & 14.1 & 71.0 & 81.0 & 120 & 54.1 & 36.5\end{array}$

ANNUAL PEAK DISCHARGE, IN GBIC FEET PER SECOND, AND CORRESPONDING GAGE HEIGHT, IN FEET, FOR EAOH WATER YEAR

\begin{tabular}{|c|c|c|c|c|c|c|c|c|c|c|c|}
\hline $\begin{array}{l}\text { WATER } \\
\text { YEAR }\end{array}$ & DATE & $\begin{array}{c}\text { GAGE } \\
\text { HEIGHT }\end{array}$ & $\begin{array}{c}\text { PEAR } \\
\text { DISCHARGE }\end{array}$ & $\begin{array}{l}\text { WATER } \\
\text { YEAR }\end{array}$ & DATE & $\begin{array}{l}\text { GAGE } \\
\text { HEIGHT }\end{array}$ & $\begin{array}{c}\text { PEAK } \\
\text { DISCHARGE }\end{array}$ & $\begin{array}{l}\text { WATERR } \\
\text { YEAR }\end{array}$ & DATE & $\begin{array}{c}\text { GAGE } \\
\text { HEIGHT }\end{array}$ & $\begin{array}{c}\text { PEAK } \\
\text { DISCHARGE }\end{array}$ \\
\hline $\begin{array}{l}1959 \\
1960 \\
1961 \\
1962\end{array}$ & \begin{tabular}{ll} 
AUG. 06,1959 \\
\hdashline$\quad, 1960$ \\
JULY 04,1961 \\
SEPT.26, 1962
\end{tabular} & $\begin{array}{r}9.92 \\
10.23 \\
10.56 \\
9.80\end{array}$ & $\begin{array}{l}477 \\
640 \\
900 \\
147\end{array}$ & $\begin{array}{l}1963 \\
1964 \\
1965 \\
1966\end{array}$ & $\begin{array}{ll}\text { OCT. } 18,1962 \\
\text { JLY } 26,1964 \\
\text { AUG. 29, } 1965 \\
\text { OCT. } 16,1965\end{array}$ & $\begin{array}{l}10.88 \\
10.00 \\
10.00 \\
10.15\end{array}$ & $\begin{array}{r}1140 \\
520 \\
520 \\
610\end{array}$ & $\begin{array}{l}1967 \\
1968 \\
1970 \\
1981\end{array}$ & $\begin{array}{l}\text { JULY 17, } 1967 \\
\text { AUG. 01, } 1968 \\
\text { SEPT.06, } 1970 \\
\text { JULY 12, } 1981\end{array}$ & $\begin{array}{l}9.80 \\
9.00 \\
-\overline{2.87}\end{array}$ & $\begin{array}{r}420 \\
172 \\
13100 \\
573\end{array}$ \\
\hline
\end{tabular}

09378100 NORIH CREEK ABOVE RANGER STATION, NEAR MONTICELLO, UT

LOCATION.-Lat $37^{\circ} 52^{\prime} 23^{\prime \prime}$, long 109 $21^{\prime} 57^{\prime \prime}$, in SE⿺SW $\frac{1}{4}$ sec.26, T.33 S., R. 23 E., San Juan County, Hydrologic Unit 14080203, on left bank $0.5 \mathrm{mi}$ northwest of Baker Ranger Station and $1.3 \mathrm{mi}$ west of Monticello.

DRAINAGE AREA. $--8.68 \mathrm{mi}^{2}$.

PERIOD OF RECORD AVAIIABLE.--October 1979 to September 1981.

GAGE.-Water-stage recorder. Altitude of gage is 7,180 ft fram topographic map.

REMARKS.-Diversions for irrigation above station.

EXTREMES FOR PERTOD OF RECORD.--Maximum discharge, $69 \mathrm{ft}^{3} / \mathrm{s}$ May 11, 1980 , gage height, 5.99 ft; no flow many days each year.

LONEST MEAN DISCHARGE, IN GUBIC FEET PER SECOND, AND RANKING FOR THE INDICATED NUMBER OF CONSEOUTIVE DAYS FOR EACH CLIMATIC YEAR, APRII 1-MARCH 31

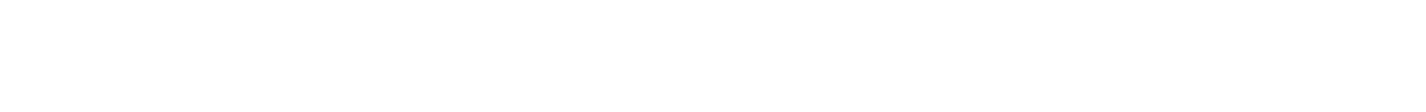

HIGHEST MEAN DISCHARGE, IN OUBIC FEET PER SEOOND, AND RANKING FOR THE INDICATED NUMBER OF CONSEOUTIVE DAYS FOR EACH WATER YEAR, OCTOBER I-SEPTEMBER 30

\begin{tabular}{|c|c|c|c|c|c|c|c|c|c|c|c|c|c|c|c|c|c|c|c|}
\hline YEAR & \multicolumn{19}{|c|}{ CONSEOUTIVE DAYS } \\
\hline 1980 & 44.0 & 1 & 41.0 & 1 & 29.0 & 1 & 23.0 & 1 & 22.0 & 1 & 18.0 & 1 & 15.0 & 1 & 11.0 & 1 & 7.40 & 1 & 3.70 \\
\hline
\end{tabular}

DURATION OF DISCHARGE FOR EACH WATER YEAR

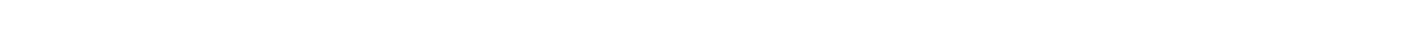
YEAR NUMBER OF DAYS IN CLASS

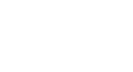

$\begin{array}{llllll}1980 & 242 & 1 & 2 & 1 & 1\end{array}$

$\begin{array}{lllllllllllllll}1981 & 267 & 4 & 9 & 5 & 7 & 34^{\circ} & 1 & 16 & 13 & 1 & 2 & 3 & 3\end{array}$
1345.9 
SAN JUAN RIVER BASTN

09378100 NORTH CREEX ABOVE RANGER STATION, NEAR MONTICELLO, UT--Continued

DURATION TABLE OF DISCHARGE FOR WATER YEARS 1980-81

\begin{tabular}{|c|c|c|c|c|c|c|c|c|c|c|c|c|c|c|c|c|c|c|c|}
\hline CLASS & $\begin{array}{c}\text { CUBIC } \\
\text { FEET } \\
\text { PER } \\
\text { SECOND }\end{array}$ & $\begin{array}{r}\text { TOIAL } \\
\text { DAYS }\end{array}$ & $\begin{array}{c}\text { ACOU- } \\
\text { MU- } \\
\text { LATEDD } \\
\text { DAYS }\end{array}$ & $\begin{array}{l}\text { PER- } \\
\text { CENT } \\
\text { DAYS }\end{array}$ & CLASS & $\begin{array}{c}\text { OBIC } \\
\text { FEET } \\
\text { PER } \\
\text { SECOND }\end{array}$ & $\begin{array}{l}\text { TOTAL } \\
\text { DAYS }\end{array}$ & $\begin{array}{c}\text { ACCU- } \\
\text { MI- } \\
\text { LATED } \\
\text { DAYS }\end{array}$ & $\begin{array}{l}\text { PER- } \\
\text { CENT } \\
\text { DAYS }\end{array}$ & CLASS & $\begin{array}{c}\text { CUBIC } \\
\text { FEET } \\
\text { PER } \\
\text { SEOOND }\end{array}$ & $\begin{array}{r}\text { TOTAL } \\
\text { DAYS }\end{array}$ & $\begin{array}{c}\text { ACOJ- } \\
\text { MU- } \\
\text { LATED } \\
\text { DAYS }\end{array}$ & $\begin{array}{l}\text { PER- } \\
\text { CENT } \\
\text { DAYS }\end{array}$ & CLASS & $\begin{array}{c}\text { CBIC } \\
\text { FEET } \\
\text { PER } \\
\text { SECOND }\end{array}$ & $\begin{array}{l}\text { TOTAL } \\
\text { DAYS }\end{array}$ & $\begin{array}{c}\text { ACOU- } \\
\text { MJ- } \\
\text { LATED } \\
\text { DAYS }\end{array}$ & $\begin{array}{l}\text { PER- } \\
\text { CENT } \\
\text { DAYS }\end{array}$ \\
\hline $\begin{array}{l}0 \\
1 \\
2 \\
3 \\
4 \\
5 \\
6 \\
7 \\
8\end{array}$ & $\begin{array}{l}0.00 \\
0.01 \\
0.02 \\
0.03 \\
0.04 \\
0.05 \\
0.06 \\
0.08 \\
0.10\end{array}$ & $\begin{array}{r}509 \\
5 \\
11 \\
6 \\
7 \\
0 \\
35 \\
0 \\
1\end{array}$ & $\begin{array}{l}731 \\
222 \\
217 \\
206 \\
200 \\
193 \\
193 \\
158 \\
158\end{array}$ & $\begin{array}{r}100.0 \\
30.4 \\
29.7 \\
28.2 \\
27.4 \\
26.4 \\
26.4 \\
21.6 \\
21.6\end{array}$ & $\begin{array}{l}9 \\
10 \\
11 \\
12 \\
13 \\
14 \\
15 \\
16 \\
17\end{array}$ & $\begin{array}{l}0.12 \\
0.16 \\
0.21 \\
0.27 \\
0.34 \\
0.44 \\
0.56 \\
0.73 \\
0.94\end{array}$ & $\begin{array}{r}16 \\
17 \\
1 \\
13 \\
7 \\
5 \\
2 \\
2 \\
1\end{array}$ & $\begin{array}{r}157 \\
141 \\
124 \\
123 \\
110 \\
103 \\
98 \\
96 \\
94\end{array}$ & $\begin{array}{l}21.5 \\
19.3 \\
17.0 \\
16.8 \\
15.0 \\
14.1 \\
13.4 \\
13.1 \\
12.9\end{array}$ & $\begin{array}{l}18 \\
19 \\
20 \\
21 \\
22 \\
23 \\
24 \\
25 \\
26\end{array}$ & $\begin{array}{l}1.2 \\
1.6 \\
2.0 \\
2.6 \\
3.3 \\
4.2 \\
5.5 \\
7.0 \\
9.0\end{array}$ & $\begin{array}{r}2 \\
3 \\
3 \\
1 \\
3 \\
3 \\
2 \\
6 \\
15\end{array}$ & $\begin{array}{l}93 \\
91 \\
88 \\
85 \\
84 \\
81 \\
78 \\
76 \\
70\end{array}$ & $\begin{array}{r}12.7 \\
12.4 \\
12.0 \\
11.6 \\
11.5 \\
11.1 \\
10.7 \\
10.4 \\
9.6\end{array}$ & $\begin{array}{l}27 \\
28 \\
29 \\
30 \\
31 \\
32 \\
33 \\
34\end{array}$ & $\begin{array}{l}12.0 \\
15.0 \\
19.0 \\
25.0 \\
32.0 \\
41.0\end{array}$ & $\begin{array}{r}14 \\
17 \\
14 \\
5 \\
3 \\
2\end{array}$ & $\begin{array}{r}55 \\
41 \\
24 \\
10 \\
5 \\
2\end{array}$ & $\begin{array}{l}7.5 \\
5.6 \\
3.3 \\
1.4 \\
0.7 \\
0.3\end{array}$ \\
\hline
\end{tabular}

MONTHLY MEAN DISCHARGES, IN OBIC FEET PER SECOND, FOR EACH WATER YEAR

$\begin{array}{lllllllllllll}\text { YEAR } & \text { OCT } & \text { NON } & \text { DEC } & \text { JAN } & \text { FEB } & \text { MAR } & \text { APR } & \text { MAY } & \text { JUNE } & \text { JULY } & \text { AUG } & \text { SEP } \\ 1980 & 0.00 & 0.00 & 0.00 & 0.00 & 0.00 & 0.18 & 5.73 & 17.5 & 18.3 & 2.43 & 0.00 & 0.00 \\ 1981 & 0.00 & 0.00 & 0.00 & 0.00 & 0.00 & 0.03 & 0.06 & 0.15 & 0.12 & 0.00 & 0.00 & 0.00\end{array}$

09376900 SPRING CREEK ABOVE DIVERSIONS, NEAR MONIICRILO, UT

LOCATION.--Lat $37^{\circ} 55^{\prime} 10^{\prime \prime}$, long $109^{\circ} 26^{\prime} 03^{\prime \prime}$, in NE $\frac{1}{4} \mathrm{SW}_{\frac{1}{4}} \mathrm{SE}_{\frac{1}{4}}$ sec.7, T.33 S., R.23 E., San Juan County, Hydrologic Unit 14080203, on left bank $300 \mathrm{ft}$ upstream fram a diversion, $1 \mathrm{mi}$ downstream fram Manti-LaSal National Forest boundary, $2.6 \mathrm{mi}$ upstream fram mouth, and $6 \mathrm{mi}$ northwest of Monticello.

DRATNAGE AREA. $-4.95 \mathrm{mi}^{2}$.

MEAN BASIN ELEVATION. $-9,100 \mathrm{ft}$.

PERIOD OF RECORD AVAIIABLE.--October 1965 to September 1972.

GAGE.- Water-stage recorder and $120^{\circ}$ V-notch sharp-crested weir. Altitude of gage is 7,720 ft from topographic map.

AVERAGE DISCHARGE. --7 years, $1.02 \mathrm{ft}^{3} / \mathrm{s}, 739$ acre-ft/yr.

EXIREMES FOR PERIOD OF RECORD.--Maximum discharge, $18 \mathrm{ft}^{3} / \mathrm{s}$ May 10, 1966, gage height, $1.72 \mathrm{ft}$; no flow many days each year.

LOWEST MEAN DISCHARGE, IN CJBIC FEET PER SECOND, AND RANKING FOR THE INDICATED NHMBER OF CONSECUTIVE DAYS FOR EACH CLIMATIC YEAR, APRIL 1-MARCH 31

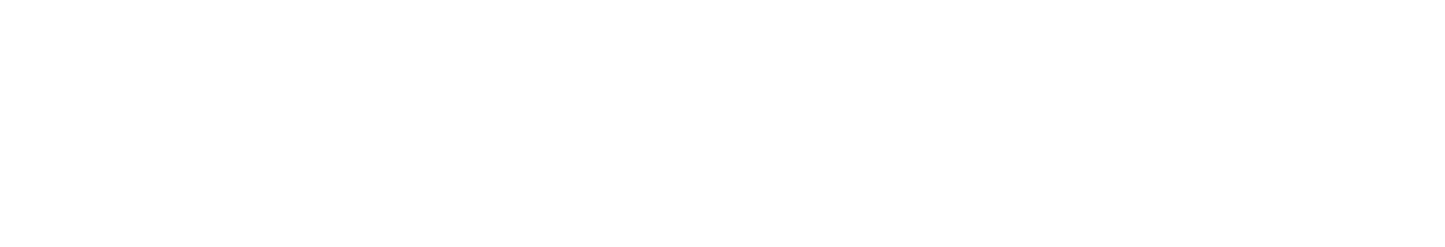

HIGHEST MEAN DISCHARGE, IN OUBIC FEET PER SECOND, AND RANKING FOR THE INDICATED NUMBER OF CONSEOUTIVE DAYS FOR EACH WATER YEAR, OCIOBER 1-SEPTEKBER 30

\begin{tabular}{|c|c|c|c|c|c|c|c|c|c|c|c|c|c|c|c|c|c|c|c|}
\hline YEAR & 1 & & 3 & & 7 & & 15 & & $\begin{array}{l}\text { CONSE } \\
30\end{array}$ & art & $\begin{array}{l}\text { DAYS } \\
60\end{array}$ & & 90 & & 120 & & 183 & & ALL \\
\hline $\begin{array}{l}1966 \\
1967 \\
1968 \\
1969 \\
1970\end{array}$ & $\begin{array}{c}13.0 \\
7.10 \\
15.0 \\
13.0 \\
12.0\end{array}$ & $\begin{array}{l}3 \\
5 \\
1 \\
2 \\
4\end{array}$ & $\begin{array}{c}12.0 \\
7.00 \\
14.0 \\
13.0 \\
11.0\end{array}$ & $\begin{array}{l}3 \\
5 \\
1 \\
2 \\
4\end{array}$ & $\begin{array}{c}11.0 \\
6.30 \\
13.0 \\
13.0 \\
10.0\end{array}$ & $\begin{array}{l}3 \\
5 \\
1 \\
2 \\
4\end{array}$ & $\begin{array}{c}9.60 \\
6.20 \\
11.0 \\
12.0 \\
8.20\end{array}$ & $\begin{array}{l}3 \\
5 \\
2 \\
1 \\
4\end{array}$ & $\begin{array}{l}9.40 \\
5.20 \\
8.80 \\
9.90 \\
6.20\end{array}$ & $\begin{array}{l}2 \\
5 \\
3 \\
1 \\
4\end{array}$ & $\begin{array}{l}7.20 \\
3.20 \\
5.80 \\
7.80 \\
4.50\end{array}$ & $\begin{array}{l}2 \\
6 \\
3 \\
1 \\
4\end{array}$ & $\begin{array}{l}6.20 \\
2.20 \\
4.40 \\
6.00 \\
3.30\end{array}$ & $\begin{array}{l}1 \\
6 \\
3 \\
2 \\
4\end{array}$ & $\begin{array}{l}5.20 \\
1.70 \\
3.60 \\
4.60 \\
2.60\end{array}$ & $\begin{array}{l}1 \\
6 \\
3 \\
2 \\
4\end{array}$ & $\begin{array}{l}3.50 \\
1.10 \\
2.40 \\
3.00 \\
1.70\end{array}$ & $\begin{array}{l}1 \\
6 \\
3 \\
2 \\
4\end{array}$ & $\begin{array}{l}1.90 \\
0.57 \\
1.19 \\
1.50 \\
0.87\end{array}$ \\
\hline $\begin{array}{l}1971 \\
1972\end{array}$ & $\begin{array}{l}2.80 \\
6.50\end{array}$ & $\begin{array}{l}7 \\
6\end{array}$ & $\begin{array}{l}2.40 \\
6.40\end{array}$ & $\begin{array}{l}7 \\
6\end{array}$ & $\begin{array}{l}2.20 \\
6.20\end{array}$ & $\begin{array}{l}7 \\
6\end{array}$ & $\begin{array}{l}2.10 \\
5.50\end{array}$ & $\begin{array}{l}7 \\
6\end{array}$ & $\begin{array}{l}1.90 \\
4.80\end{array}$ & $\begin{array}{l}7 \\
6\end{array}$ & $\begin{array}{l}1.60 \\
3.70\end{array}$ & $\begin{array}{l}7 \\
5\end{array}$ & $\begin{array}{l}1.19 \\
2.70\end{array}$ & $\begin{array}{l}7 \\
5\end{array}$ & $\begin{array}{l}0.92 \\
2.10\end{array}$ & $\begin{array}{l}7 \\
5\end{array}$ & $\begin{array}{l}0.61 \\
1.40\end{array}$ & $\begin{array}{l}7 \\
5\end{array}$ & $\begin{array}{l}0.32 \\
0.72\end{array}$ \\
\hline
\end{tabular}


DURATION OF DISCHARGE FOR EACH WATER YEAR

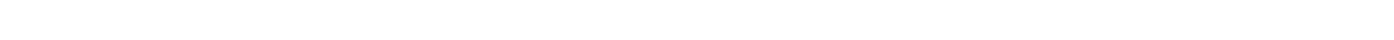
YEAR

GBIC FEET PER SEOOND -DAYS

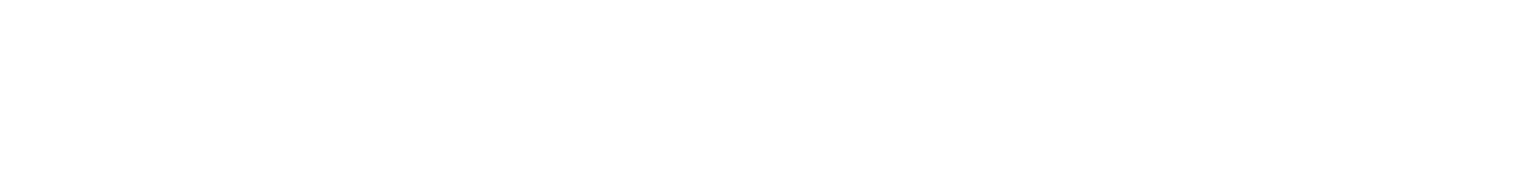

DURATION TABLE OF DISCHARGE FOR WATER YEARS 1966-72

\begin{tabular}{|c|c|c|c|c|c|c|c|c|c|c|c|c|c|c|c|c|c|c|c|}
\hline CLASS & $\begin{array}{c}\text { CUBIC } \\
\text { FEET } \\
\text { PER } \\
\text { SECOND }\end{array}$ & $\begin{array}{l}\text { TOTAL } \\
\text { DAYS }\end{array}$ & $\begin{array}{l}\text { ACOU- } \\
\text { MU- } \\
\text { LATED } \\
\text { DAYS }\end{array}$ & $\begin{array}{l}\text { PER- } \\
\text { CENT } \\
\text { DAYS }\end{array}$ & CLASS & $\begin{array}{c}\text { CBBIC } \\
\text { FEET } \\
\text { PER } \\
\text { SECOND }\end{array}$ & $\begin{array}{l}\text { TOTAL } \\
\text { DAYS }\end{array}$ & $\begin{array}{l}\text { ACQJ- } \\
\text { MU- } \\
\text { LATED } \\
\text { DAYS }\end{array}$ & $\begin{array}{l}\text { PER- } \\
\text { CENT } \\
\text { DAYS }\end{array}$ & GLASS & $\begin{array}{c}\text { OBIC } \\
\text { FEET } \\
\text { PER } \\
\text { SECOND }\end{array}$ & $\begin{array}{r}\text { TOTAL } \\
\text { DAYS }\end{array}$ & $\begin{array}{c}\text { ACQU- } \\
\text { MU- } \\
\text { LATED } \\
\text { DAYS }\end{array}$ & $\begin{array}{l}\text { PER- } \\
\text { CENT } \\
\text { DAYS }\end{array}$ & CLASS & $\begin{array}{c}\text { GBIC } \\
\text { FEET } \\
\text { PER } \\
\text { SECOND }\end{array}$ & $\begin{array}{r}\text { TOTAL } \\
\text { DAYS }\end{array}$ & $\begin{array}{c}\text { ACQU- } \\
\text { MU- } \\
\text { LATED } \\
\text { DAYS }\end{array}$ & $\begin{array}{l}\text { PER- } \\
\text { CENT } \\
\text { DAYS }\end{array}$ \\
\hline $\begin{array}{l}0 \\
1 \\
2 \\
3 \\
4 \\
5 \\
6 \\
7 \\
8\end{array}$ & $\begin{array}{l}0.00 \\
0.01 \\
0.02 \\
0.03 \\
0.04 \\
0.05 \\
0.06 \\
0.07 \\
0.09\end{array}$ & $\begin{array}{r}1008 \\
48 \\
62 \\
41 \\
36 \\
57 \\
48 \\
50 \\
100\end{array}$ & $\begin{array}{l}2557 \\
1549 \\
1501 \\
1439 \\
1398 \\
1362 \\
1305 \\
1257 \\
1207\end{array}$ & $\begin{array}{r}100.0 \\
60.6 \\
58.7 \\
56.3 \\
54.7 \\
53.3 \\
51.0 \\
49.2 \\
47.2\end{array}$ & $\begin{array}{l}9 \\
10 \\
11 \\
12 \\
13 \\
14 \\
15 \\
16 \\
17\end{array}$ & $\begin{array}{l}0.11 \\
0.14 \\
0.17 \\
0.22 \\
0.27 \\
0.34 \\
0.42 \\
0.52 \\
0.65\end{array}$ & $\begin{array}{l}58 \\
44 \\
94 \\
46 \\
90 \\
50 \\
66 \\
47 \\
40\end{array}$ & $\begin{array}{r}1107 \\
1049 \\
1005 \\
911 \\
865 \\
775 \\
725 \\
659 \\
612\end{array}$ & $\begin{array}{l}43.3 \\
41.0 \\
39.3 \\
35.6 \\
33.8 \\
30.3 \\
28.4 \\
25.8 \\
23.9\end{array}$ & $\begin{array}{l}18 \\
19 \\
20 \\
21 \\
22 \\
23 \\
24 \\
25 \\
26\end{array}$ & $\begin{array}{l}0.8 \\
1.0 \\
1.3 \\
1.6 \\
1.9 \\
2.4 \\
3.0 \\
3.8 \\
4.7\end{array}$ & $\begin{array}{l}40 \\
46 \\
28 \\
44 \\
57 \\
37 \\
55 \\
60 \\
54\end{array}$ & $\begin{array}{l}572 \\
532 \\
486 \\
458 \\
414 \\
357 \\
320 \\
265 \\
205\end{array}$ & $\begin{array}{r}22.4 \\
20.8 \\
19.0 \\
17.9 \\
16.2 \\
14.0 \\
12.5 \\
10.4 \\
8.0\end{array}$ & $\begin{array}{l}27 \\
28 \\
29 \\
30 \\
31 \\
32 \\
33 \\
34\end{array}$ & $\begin{array}{r}5.8 \\
7.3 \\
9.0 \\
11.0 \\
14.0\end{array}$ & $\begin{array}{r}69 \\
29 \\
22 \\
28 \\
3\end{array}$ & $\begin{array}{r}151 \\
82 \\
53 \\
31 \\
3\end{array}$ & $\begin{array}{l}5.9 \\
3.2 \\
2.1 \\
1.2 \\
0.1\end{array}$ \\
\hline
\end{tabular}

MONTHLY MEAN DISCHARGES, IN CUBIC FEET PER SECOND, FOR EACH WATER YEAR

$\begin{array}{lllllllllllll}\text { YEAR } & \text { OCT } & \text { NOV } & \text { DEC } & \text { JAN } & \text { FEB } & \text { MAR } & \text { APR } & \text { MAY } & \text { JUNE } & \text { JULY } & \text { AUG } & \text { SEP } \\ 1966 & 0.88 & 0.51 & 0.32 & 0.26 & 0.10 & 2.56 & 4.58 & 9.19 & 3.80 & 0.60 & 0.10 & 0.05 \\ 1967 & 0.08 & 0.12 & 0.03 & 0.00 & 0.00 & 0.00 & 0.00 & 2.08 & 4.22 & 0.26 & 0.01 & 0.00 \\ 1968 & 0.00 & 0.00 & 0.00 & 0.00 & 0.00 & 0.00 & 0.01 & 3.52 & 7.76 & 0.89 & 1.97 & 0.32 \\ 1969 & 0.11 & 0.09 & 0.00 & 0.00 & 0.00 & 0.00 & 4.06 & 9.30 & 4.20 & 0.37 & 0.14 & 0.16 \\ 1970 & 0.14 & 0.03 & 0.00 & 0.01 & 0.00 & 0.00 & 0.89 & 5.76 & 3.00 & 0.42 & 0.09 & 0.08 \\ 1971 & 0.11 & 0.03 & 0.00 & 0.01 & 0.00 & 0.07 & 0.32 & 1.42 & 1.62 & 0.24 & 0.01 & 0.01 \\ 1972 & 0.08 & 0.06 & 0.00 & 0.00 & 0.00 & 0.11 & 0.72 & 3.67 & 3.63 & 0.32 & 0.01 & 0.00\end{array}$

ANNUAL PEAK DISCHARGE, IN CUBIC FEET PER SECOND, AND CORRESPONDING GAGE HEIGHT, IN FEET, FOR EAGH WATER YEAR

\begin{tabular}{|c|c|c|c|c|c|c|c|c|c|c|c|c|c|}
\hline $\begin{array}{l}\text { WATER } \\
\text { YEAR }\end{array}$ & & DAIE & $\begin{array}{c}\text { GAGE } \\
\text { HEIGHT }\end{array}$ & $\begin{array}{c}\text { PEAK } \\
\text { DISQHARGE }\end{array}$ & $\begin{array}{l}\text { WATER } \\
\text { YEAR }\end{array}$ & & DATE & $\begin{array}{c}\text { GAGE } \\
\text { HEIGHT }\end{array}$ & $\begin{array}{c}\text { PEAK } \\
\text { DISCHARGE }\end{array}$ & $\begin{array}{l}\text { WATER } \\
\text { YEAR }\end{array}$ & DATE & $\begin{array}{c}\text { GAGE } \\
\text { HEIGHT }\end{array}$ & $\begin{array}{c}\text { PEAK } \\
\text { DISQHARGE }\end{array}$ \\
\hline $\begin{array}{l}1966 \\
1967 \\
1968\end{array}$ & $\begin{array}{l}\text { MAY } \\
\text { MAY } \\
\text { JUNE }\end{array}$ & $\begin{array}{l}10,1966 \\
29,1967 \\
06,1968\end{array}$ & $\begin{array}{l}1.72 \\
1.42 \\
-\end{array}$ & $\begin{array}{c}18 \\
8.1 \\
15\end{array}$ & $\begin{array}{l}1969 \\
1970\end{array}$ & $\begin{array}{l}\text { MAY } \\
\text { MAY }\end{array}$ & $\begin{array}{l}24,1969 \\
19,1970\end{array}$ & $\begin{array}{l}1.66 \\
1.65\end{array}$ & $\begin{array}{l}14 \\
14\end{array}$ & $\begin{array}{l}1971 \\
1972\end{array}$ & $\begin{array}{ll}\text { MAY } 18,1971 \\
\text { JUNE } 10,1972\end{array}$ & $\begin{array}{l}1.15 \\
1.38\end{array}$ & $\begin{array}{l}3.7 \\
7.6\end{array}$ \\
\hline
\end{tabular}

09378200 MONTEZUMA CREEK AT GOLF OOURSE, AT MONTICELL, UT

LOCATION.-Lat $37^{\circ} 51^{\prime} 38^{\prime \prime}$, long $109^{\circ} 20^{\prime} 30^{\prime \prime}$, in SW'sE光 sec.36, T.33 S., R.23 E., San Juan County, Hydrologic Unit 14080203, on left bank $1,000 \mathrm{ft}$ west of Highway $163,0.85 \mathrm{mi}$ south of Monticello.

DRAINAGE AREA. $--17.6 \mathrm{mi}^{2}$.

PERTOD OF RECORD AVAIIABLE.-October 1979 to September 1981.

GAGE.--Water-stage recorder. Altitude of gage is 6,900 ft from topographic map.

REMARKS.-There is a diversion $0.8 \mathrm{mi}$ above station.

EXIREMES FOR PERIOD OF RECORD.--Maximum discharge, $259 \mathrm{ft}^{3} / \mathrm{s}$ May 11, 1980, gage height, $7.31 \mathrm{ft}$; no flow many days each years.

LOWEST MEAN DISCHARGE, IN OBIC FEET PER SECOND, AND RANKING FOR THE INDICATED NUMBER OF CONSECUTIVE DAYS FOR EACH CIIMATIC YEAR, APRIL 1-MARCH 31

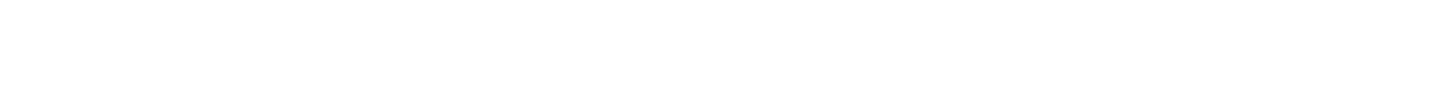


HIGHEST MEAN DISCHARGE, IN CUBIC FEET PER SECOND, AND RANKING FOR THE INDICATED NUMBER OF CONSECUTIVE DAYS FOR EACH WATER YEAR, OCTOBER I-SEPTEMBER 30

\begin{tabular}{|c|c|c|c|c|c|c|c|c|c|c|c|c|c|c|c|c|c|c|c|}
\hline YEAR & 1 & & 3 & & 7 & & 15 & & $\begin{array}{l}\text { CONSE } \\
30\end{array}$ & OUT & $\begin{array}{c}\text { E DAYS } \\
60\end{array}$ & & 90 & & 120 & & 183 & & ALL \\
\hline 1980 & 220 & 1 & 160 & 1 & 116 & 1 & 87.0 & 1 & 79.0 & 1 & 68.0 & 1 & 50.0 & 1 & 39.0 & 1 & 26.0 & 1 & 13.0 \\
\hline
\end{tabular}

DURATION OF DISCHARGE FOR EACH WATER YEAR

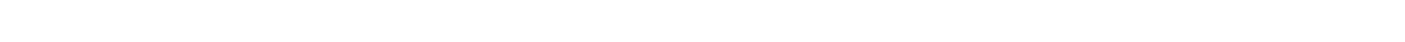
YEAR NUMBER OF DAYS IN CIASS

CUBIC FEET
PER SECOND -DAYS

1980223

4695.5

$\begin{array}{lllllllllllllllll}1981 & 198 & 1 & 1 & 1 & 10 & 30 & 19 & 48 & 25 & 8 & 12 & 3 & 1 & 3 & 2 & 3\end{array}$

47.6

DURATION TABLE OF DISCHARGE FOR WATER YEARS 1980-81

$\begin{array}{rrr}\text { CUBIC } & \text { ACOU- } \\ \text { FEET } & \text { MU- } & \text { PER- } \\ \text { PER } & \text { TOTAL LATED } & \text { CENT } \\ \text { CIASS SECOND DAYS DAYS } & \text { DAYS }\end{array}$

$\begin{array}{ccc}\text { CUBIC } & \text { AOCU- } \\ \text { FEET } & \text { MU- } & \text { PER- } \\ \text { PER TOTAL LATED } & \text { CENT } \\ \text { SECOND DAYS } & \text { DAYS } & \text { DAYS }\end{array}$

$\begin{array}{rrr}\text { CUBIC } & \text { ACOU- } \\ \text { FEET } & \text { MU- } & \text { PER- } \\ \text { PER } & \text { TOTAL LATED } & \text { CENT } \\ \text { CLASS SECOND } & \text { DAYS DAYS } & \text { DAYS }\end{array}$

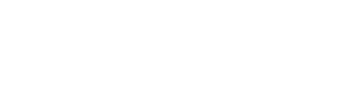

$\begin{array}{rrrrr}0 & 0.00 & 421 & 731 & 100.0 \\ 1 & 0.01 & 1 & 310 & 42.4 \\ 2 & 0.02 & 0 & 309 & 42.3 \\ 3 & 0.03 & 1 & 309 & 42.3 \\ 4 & 0.04 & 0 & 308 & 42.1 \\ 5 & 0.06 & 1 & 308 & 42.1 \\ 6 & 0.08 & 10 & 307 & 42.0 \\ 7 & 0.10 & 31 & 297 & 40.6 \\ 8 & 0.14 & 19 & 266 & 36.4\end{array}$

CUASS SECOND DAYS DAYS DAYS

$\begin{array}{rrrrr}18 & 2.5 & 5 & 111 & 15.2 \\ 19 & 3.4 & 1 & 106 & 14.5 \\ 20 & 4.6 & 6 & 105 & 14.4 \\ 21 & 6.1 & 13 & 99 & 13.5 \\ 22 & 8.1 & 5 & 86 & 11.7 \\ 23 & 11.0 & 7 & 81 & 11.1 \\ 24 & 15.0 & 6 & 74 & 10.1 \\ 25 & 20.0 & 3 & 68 & 9.3 \\ 26 & 26.0 & 9 & 65 & 8.9\end{array}$

MONIHLY MEAN DISCHARGES, IN CUBIC FEET PER SECOND, FOR EAOH WATER YEAR

$\begin{array}{lccccccccccrr}\text { YEAR } & \text { OCT } & \text { NOW } & \text { DEC } & \text { JAN } & \text { FEB } & \text { MAR } & \text { APR } & \text { MAY } & \text { JUNE } & \text { JULY } & \text { AUG } & \text { SEP } \\ 1980 & 0.00 & 0.00 & 0.00 & 0.00 & 0.00 & 1.03 & 44.2 & 63.9 & 38.9 & 6.15 & 0.03 & 0.00 \\ 1981 & 0.00 & 0.00 & 0.00 & 0.00 & 0.00 & 0.10 & 0.46 & 0.20 & 0.22 & 0.21 & 0.16 & 0.22\end{array}$

09378480 MONIEZUMA CREEK NEAR MONTICELLO, UT

LOCATION.-Lat $37^{\circ} 47^{\prime} 07^{\prime \prime}$, long $109^{\circ} 16^{\prime} 20^{\prime \prime}$, in NE/ sec.34, T.34 S., R.24 E., San Juan County, Hydrologic Unit 14080203, $450 \mathrm{ft}$ above mouth of Verdure creek and $7 \mathrm{mi}$ southeast of Monticello.

DRAINAGE AREA. $-117 \mathrm{mi}^{2}$.

PERIOD OF RECORD AVAIIABLE.-Water years 1959-68, annual peak discharge only.

GAGE.--Crest-stage gage. Altitude of gage is 5,630 ft from topographic map.

REMARKS.-Diversions for irrigation above station.

ANNUAL PEAK DISCHARGE, IN CUBIC FEET PER SECOND, AND CORRESPONDING GAGE HEIGHT, IN FEET, FOR EACH WAITER YEAR

\begin{tabular}{|c|c|c|c|c|c|c|c|c|c|c|c|}
\hline $\begin{array}{l}\text { WATERR } \\
\text { YEAR }\end{array}$ & DATE & $\begin{array}{c}\text { GAGE } \\
\text { HEIGHI }\end{array}$ & $\begin{array}{c}\text { PEAK } \\
\text { DISCHARGE }\end{array}$ & $\begin{array}{l}\text { WATER } \\
\text { YEAR }\end{array}$ & DATE & $\begin{array}{c}\text { GAGE } \\
\text { HEIGHI }\end{array}$ & $\begin{array}{c}\text { PEAK } \\
\text { DISCHARGE }\end{array}$ & $\begin{array}{l}\text { WATERR } \\
\text { YEAR }\end{array}$ & DATE & $\begin{array}{c}\text { GAGE } \\
\text { HEIGHI }\end{array}$ & $\begin{array}{c}\text { PEAK } \\
\text { DISCHARGE }\end{array}$ \\
\hline $\begin{array}{l}1959 \\
1960 \\
1961 \\
1962\end{array}$ & $\begin{array}{l}\text { AUG. } 26,1959 \\
\text { AUG. } 22,1960 \\
\text { SEPT.16, } 1961 \\
\text { SEPT.28, } 1962\end{array}$ & $\begin{array}{l}11.01 \\
10.70 \\
14.91 \\
12.87\end{array}$ & $\begin{array}{l}145 \\
150 \\
668 \\
-\end{array}$ & $\begin{array}{l}1963 \\
1964 \\
1965\end{array}$ & $\begin{array}{lll}\text { OCT. } & 06,1962 \\
\text { AUG. } & 02,1964 \\
\text { JULY } & 31,1965\end{array}$ & $\begin{array}{rr}2 & 11.34 \\
4 & 13.91 \\
5 & 5.45\end{array}$ & $=$ & $\begin{array}{l}1966 \\
1967 \\
1968\end{array}$ & $\begin{array}{l}\text { AUG. } 04,1966 \\
\text { JULY } 15,1967 \\
\text { AUG. } 01,1968\end{array}$ & $\begin{array}{l}16.95 \\
13.77 \\
18.46\end{array}$ & $\begin{array}{r}1190 \\
380 \\
1720\end{array}$ \\
\hline
\end{tabular}


SAN JUAN RIVER BASIN

09378600 MONIEZUMA CREEK NEAR BLUFF, UT

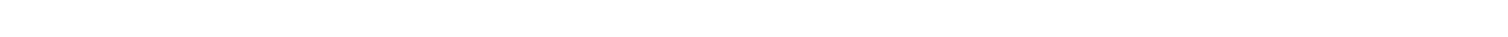
ft above bridge on State Highway $262,3.4 \mathrm{mi}$ above mouth, and i4 mi northeast of Bluff.

DRAINAGE AREA. $-1,200 \mathrm{mi}^{2}$.

PERTOD OF RECORD AVAIIABLE.--Water years 1963-68, 1970, annual peak discharge only.

GAGE.--Crest-stage gage. Altitude of gage is 4,490 ft fran topographic map.

REMARKS. $\rightarrow$ Diversions for irrigation above station.

ANNUAL PEAK DISCHARGE, IN OUBIC FEET PER SECOND, AND CORRESPONDING GAGE HEIGHT, IN FEET, FOR EACH WATER YEAR

\begin{tabular}{|c|c|c|c|c|c|c|c|c|c|c|c|}
\hline $\begin{array}{l}\text { WATTER } \\
\text { YEAR }\end{array}$ & DATE & $\begin{array}{c}\text { GAGE } \\
\text { HEIGHT }\end{array}$ & $\begin{array}{c}\text { PEAR } \\
\text { DISCHARGE }\end{array}$ & $\begin{array}{l}\text { WATERR } \\
\text { YEAR }\end{array}$ & DATE & $\begin{array}{l}\text { GAGE } \\
\text { HEIGHT }\end{array}$ & $\begin{array}{c}\text { PEAK } \\
\text { DISCHARGE }\end{array}$ & $\begin{array}{l}\text { WATER } \\
\text { YEAR }\end{array}$ & DATE & $\begin{array}{l}\text { GAGE } \\
\text { HEIGHT }\end{array}$ & $\begin{array}{c}\text { PEAK } \\
\text { DISCHARGE }\end{array}$ \\
\hline $\begin{array}{l}1963 \\
1964 \\
1965\end{array}$ & $\begin{array}{l}\text { SEPT.06, } 1963 \\
\text { AUG. 02, } 1964 \\
\text { AUG. } 29,1965\end{array}$ & $\begin{array}{l}12.50 \\
16.70 \\
11.61\end{array}$ & $\begin{array}{r}625 \\
1500 \\
450\end{array}$ & $\begin{array}{l}1966 \\
1967\end{array}$ & $\begin{array}{l}\text { JUNE } 20,1966 \\
\text { DEC. } 07,1966\end{array}$ & $\begin{array}{l}12.77 \\
11.70\end{array}$ & $\begin{array}{l}690 \\
470\end{array}$ & $\begin{array}{l}1968 \\
1970\end{array}$ & $\begin{array}{l}\text { AUG. 01, } 1968 \\
\text { SEPT.06, } 1970\end{array}$ & 15.20 & $\begin{array}{r}1190 \\
40500\end{array}$ \\
\hline
\end{tabular}

09378630 RECAPIURE CREFK NEAR BLANDING, UT

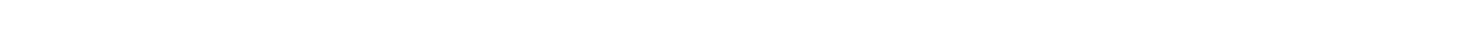

right bank $100 \mathrm{ft}$ below road fork, $1.9 \mathrm{mi}$ north of Manti-LaSal National Forest boundary, and $9.4 \mathrm{mi}$ north of Blanding.

DRAINAGE AREA. $-3.77 \mathrm{mi}^{2}$.

MEAN BASIN ELEVATION. $-8,880 \mathrm{ft}$.

PERIOD OF RECORD AVAIIABLE.--October 1965 to September 1981.

GAGE.--Water-stage recorder. Altitude of gage is 7,200 ft from topographic map.

RFAMRKS. - Some diversions for irrigation above station.

AVERAGE DISCHARGE.--16 years, $1.33 \mathrm{ft}^{3} / \mathrm{s}, 964$ acre- $\mathrm{ft} / \mathrm{yr}$.

EXIREMES FOR PERIOD OF RECORD,-Maximum discharge, $142 \mathrm{ft}^{3} / \mathrm{s}$ oct. 20, 1972, gage height, $2.14 \mathrm{ft}$; no flow many days each year.

LOWEST MEAN DISCHARGE, IN OBBIC FEET PER SECOND, AND RANKING FOR THE INDICATED NUMBER OF CONSECOTIVE DAYS FOR EACH CLIMATIC YEAR, APRIL 1-MARCH 31

YEAR

\begin{tabular}{|c|c|c|c|c|c|c|c|c|c|c|c|c|c|c|c|c|c|}
\hline 1 & & 3 & 7 & & 14 & & $\begin{array}{l}\text { CONSBX } \\
30\end{array}$ & darrtv & $\begin{array}{l}\text { DAYS } \\
60\end{array}$ & & 90 & & 120 & & 183 & & ALL \\
\hline $\begin{array}{l}0.00 \\
0.00 \\
0.00 \\
0.01\end{array}$ & $\begin{array}{r}1 \\
2 \\
3 \\
14\end{array}$ & $\begin{array}{l}0.00 \\
0.00 \\
0.00 \\
0.01\end{array}$ & $\begin{array}{l}0.00 \\
0.00 \\
0.00 \\
0.00\end{array}$ & $\begin{array}{l}1 \\
2 \\
3 \\
4\end{array}$ & $\begin{array}{l}0.00 \\
0.00 \\
0.00 \\
0.00\end{array}$ & $\begin{array}{l}1 \\
2 \\
3 \\
4\end{array}$ & $\begin{array}{l}0.00 \\
0.00 \\
0.00 \\
0.00\end{array}$ & $\begin{array}{l}1 \\
2 \\
3 \\
4\end{array}$ & $\begin{array}{l}0.00 \\
0.00 \\
0.00 \\
0.01\end{array}$ & $\begin{array}{r}1 \\
2 \\
3 \\
13\end{array}$ & $\begin{array}{l}0.00 \\
0.00 \\
0.00 \\
0.01\end{array}$ & $\begin{array}{r}1 \\
2 \\
3 \\
13\end{array}$ & $\begin{array}{l}0.01 \\
0.00 \\
0.02 \\
0.02\end{array}$ & $\begin{array}{r}9 \\
1 \\
10 \\
11\end{array}$ & $\begin{array}{l}0.08 \\
0.02 \\
0.04 \\
0.02\end{array}$ & $\begin{array}{r}14 \\
8 \\
13 \\
9\end{array}$ & $\begin{array}{l}0.96 \\
0.34 \\
1.10 \\
1.50\end{array}$ \\
\hline $\begin{array}{l}0.00 \\
0.00 \\
0.00 \\
0.02 \\
0.00\end{array}$ & $\begin{array}{r}4 \\
5 \\
6 \\
15 \\
7\end{array}$ & $\begin{array}{l}0.00 \\
0.00 \\
0.00 \\
0.02 \\
0.00\end{array}$ & $\begin{array}{l}0.00 \\
0.00 \\
0.00 \\
0.02 \\
0.00\end{array}$ & $\begin{array}{r}5 \\
6 \\
7 \\
15 \\
8\end{array}$ & $\begin{array}{l}0.00 \\
0.00 \\
0.00 \\
0.02 \\
0.00\end{array}$ & $\begin{array}{r}5 \\
6 \\
7 \\
15 \\
8\end{array}$ & $\begin{array}{l}0.00 \\
0.00 \\
0.00 \\
0.02 \\
0.00\end{array}$ & $\begin{array}{r}5 \\
6 \\
7 \\
15 \\
8\end{array}$ & $\begin{array}{l}0.01 \\
0.00 \\
0.00 \\
0.02 \\
0.00\end{array}$ & $\begin{array}{r}14 \\
4 \\
5 \\
15 \\
6\end{array}$ & $\begin{array}{l}0.02 \\
0.00 \\
0.00 \\
0.02 \\
0.00\end{array}$ & $\begin{array}{r}14 \\
4 \\
5 \\
15 \\
6\end{array}$ & $\begin{array}{l}0.02 \\
0.02 \\
0.02 \\
0.02 \\
0.00\end{array}$ & $\begin{array}{r}12 \\
13 \\
14 \\
15 \\
2\end{array}$ & $\begin{array}{l}0.03 \\
0.03 \\
0.25 \\
0.02 \\
0.00\end{array}$ & $\begin{array}{r}11 \\
12 \\
15 \\
10 \\
1\end{array}$ & $\begin{array}{l}0.47 \\
0.21 \\
1.00 \\
3.60 \\
0.14\end{array}$ \\
\hline $\begin{array}{l}0.00 \\
0.00 \\
0.00 \\
0.00 \\
0.00\end{array}$ & $\begin{array}{r}8 \\
9 \\
10 \\
11 \\
12\end{array}$ & $\begin{array}{l}0.00 \\
0.00 \\
0.00 \\
0.00 \\
0.00\end{array}$ & $\begin{array}{l}0.00 \\
0.00 \\
0.00 \\
0.00 \\
0.00\end{array}$ & $\begin{array}{l}9 \\
10 \\
11 \\
12 \\
13\end{array}$ & $\begin{array}{l}0.00 \\
0.00 \\
0.00 \\
0.00 \\
0.00\end{array}$ & $\begin{array}{l}9 \\
10 \\
11 \\
12 \\
13\end{array}$ & $\begin{array}{l}0.00 \\
0.00 \\
0.00 \\
0.00 \\
0.00\end{array}$ & $\begin{array}{r}9 \\
10 \\
11 \\
12 \\
13\end{array}$ & $\begin{array}{l}0.00 \\
0.00 \\
0.00 \\
0.00 \\
0.00\end{array}$ & $\begin{array}{r}7 \\
8 \\
9 \\
10 \\
11\end{array}$ & $\begin{array}{l}0.00 \\
0.00 \\
0.00 \\
0.00 \\
0.00\end{array}$ & $\begin{array}{r}7 \\
8 \\
9 \\
10 \\
11\end{array}$ & $\begin{array}{l}0.00 \\
0.00 \\
0.00 \\
0.00 \\
0.00\end{array}$ & $\begin{array}{l}3 \\
4 \\
5 \\
6 \\
7\end{array}$ & $\begin{array}{l}0.00 \\
0.00 \\
0.00 \\
0.00 \\
0.00\end{array}$ & $\begin{array}{l}2 \\
3 \\
4 \\
5 \\
6\end{array}$ & $\begin{array}{l}1.30 \\
0.49 \\
0.42 \\
1.60 \\
3.80\end{array}$ \\
\hline 0.001 & 13 & 0.001 & 0.001 & 14 & 0.001 & 14 & 0.001 & 14 & 0.00 & 12 & 0.00 & 12 & 0.00 & 8 & 0.00 & 7 & 3.801 \\
\hline
\end{tabular}

HIGHEST MEAN DISCHARGE, IN OUBIC FEET PER SECOND, AND RANKING FOR THE INDICATFD NUMBER OF CONSECUTIVE DAYS FOR EACH WATER YEAR, OCTCBER 1-SEPTYEMBER 30

\begin{tabular}{|c|c|c|c|c|c|c|c|c|c|c|}
\hline YEAR & 1 & 3 & 7 & 15 & $\begin{array}{l}\text { CONSEOTTIVE } \\
30\end{array}$ & $\begin{array}{l}\text { DAYS } \\
60\end{array}$ & 90 & 120 & 183 & ALL \\
\hline $\begin{array}{l}1966 \\
1967 \\
1968 \\
1969 \\
1970\end{array}$ & $\begin{array}{rr}9.70 & 7 \\
7.10 & 10 \\
7.70 & 9 \\
16.0 & 6 \\
8.60 & 8\end{array}$ & $\begin{array}{rr}9.20 & 7 \\
4.00 & 11 \\
7.20 & 9 \\
15.0 & 6 \\
8.20 & 8\end{array}$ & $\begin{array}{rr}8.50 & 7 \\
1.80 & 13 \\
6.30 & 9 \\
14.0 & 6 \\
7.00 & 8\end{array}$ & $\begin{array}{rr}7.50 & 7 \\
1.19 & 14 \\
6.00 & 8 \\
13.0 & 5 \\
5.70 & 9\end{array}$ & $\begin{array}{rr}6.70 & 7 \\
1.19 & 12 \\
5.60 & 8 \\
12.0 & 4 \\
4.10 & 9\end{array}$ & $\begin{array}{rr}5.90 & 7 \\
0.98 & 11 \\
4.80 & 8 \\
8.60 & 5 \\
2.50 & 10\end{array}$ & $\begin{array}{rr}4.60 & 7 \\
0.90 & 11 \\
3.90 & 8 \\
6.20 & 5 \\
1.80 & 10\end{array}$ & $\begin{array}{rr}3.50 & 7 \\
0.76 & 11 \\
3.00 & 8 \\
4.70 & 5 \\
1.40 & 10\end{array}$ & $\begin{array}{rr}2.30 & 7 \\
0.56 & 11 \\
2.20 & 8 \\
3.10 & 5 \\
0.90 & 10\end{array}$ & $\begin{array}{rr}1.20 & 7 \\
0.34 & 11 \\
1.10 & 8 \\
1.60 & 5 \\
0.46 & 10\end{array}$ \\
\hline
\end{tabular}


HIGHEST MEAN DISCHARGE, IN CUBIC FEET PER SECOND, AND RANRING FOR THE INDICAIED NUMBER OF CONSECUTIVE DAYS FOR EACH WATER YEAR, OCTCBER 1-SEPIEMBER 30--Continued

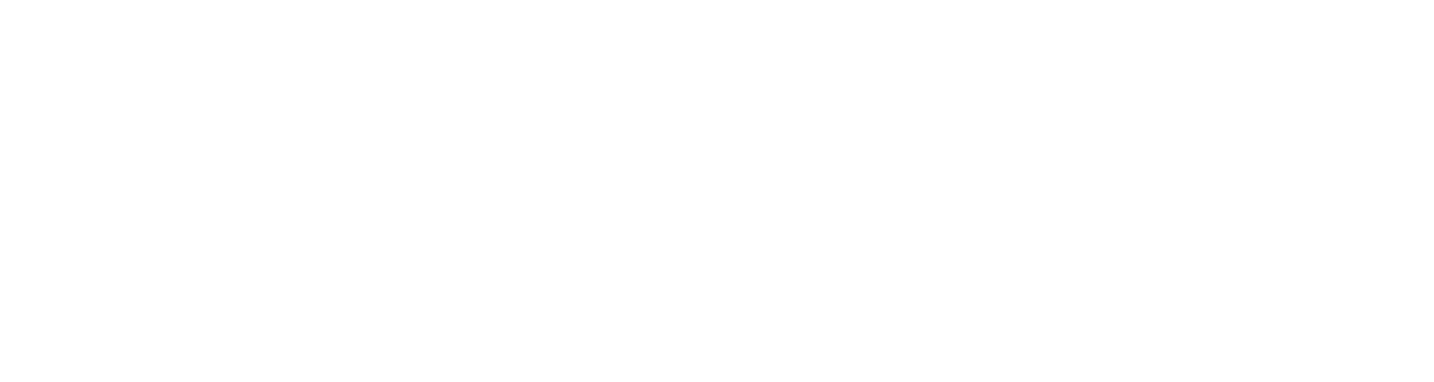

DURATION OF DISCHARGE FOR EACH WATER YEAR

$\begin{array}{lllllllllllllllllllllllllllllllllll}\text { CLASS } 0 & 1 & 2 & 3 & 4 & 5 & 6 & 7 & 8 & 9 & 10 & 11 & 12 & 13 & 14 & 15 & 16 & 17 & 18 & 19 & 20 & 21 & 22 & 23 & 24 & 25 & 26 & 27 & 28 & 29 & 30 & 31 & 32 & 33 & 34\end{array}$ YEAR

DURATION TABLE OF DISCHARGE FOR WATER YEARS 1966-81

$\begin{array}{ccc}\text { CUBIC } & \text { ACOU- } \\ \text { FEET } & \text { MU- } & \text { PER- } \\ \text { PER TOTAL LATED } & \text { CENT } \\ \text { CLASS SECOND DAYS DAYS } & \text { DAYS }\end{array}$

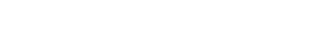

$\begin{array}{rrrrr}0 & 0.00 & 1879 & 5844 & 100.0 \\ 1 & 0.01 & 536 & 3965 & 67.8 \\ 2 & 0.02 & 545 & 3429 & 58.7 \\ 3 & 0.03 & 212 & 2884 & 49.3 \\ 4 & 0.04 & 47 & 2672 & 45.7 \\ 5 & 0.05 & 192 & 2625 & 44.9 \\ 6 & 0.06 & 139 & 2433 & 41.6 \\ 7 & 0.08 & 96 & 2294 & 39.3\end{array}$

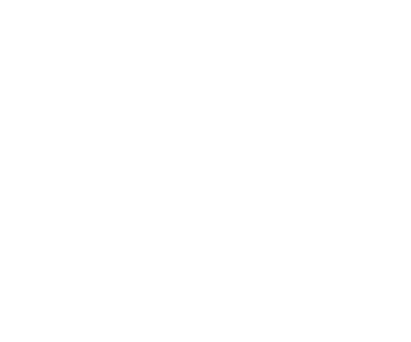

CASS SEC
18
19
20
21
22
23
24
25
26

$\begin{array}{lll}\text { CBBIC } & \text { ACOU- } \\ \text { FEET } & \text { MU- } & \text { PER- } \\ \text { PER TOTAL IATED } & \text { CENT }\end{array}$

PER TOUTAL LATED CENT

$\begin{array}{rrrr}1.4 & 89 & 860 & 14.7 \\ 1.8 & 73 & 771 & 13.2 \\ 2.3 & 64 & 698 & 11.9 \\ 2.9 & 85 & 634 & 10.8 \\ 3.8 & 84 & 549 & 9.4 \\ 4.9 & 101 & 465 & 8.0 \\ 6.3 & 82 & 364 & 6.2 \\ 8.2 & 57 & 282 & 4.8 \\ 11.0 & 69 & 225 & 3.9\end{array}$

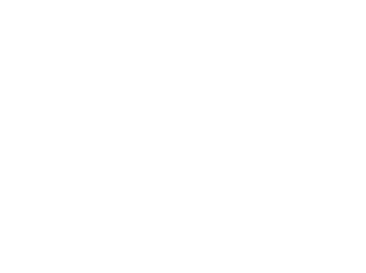

MONIHLY MEAN DISCHARGES, IN OBBIC FEET PER SECOND, FOR EACH WATER YEAR

$\begin{array}{lllllllllllll}\text { YEAR } & \text { OCT } & \text { NOV } & \text { DEC } & \text { JAN } & \text { FEB } & \text { MAR } & \text { APR } & \text { MAY } & \text { JUNE } & \text { JULY } & \text { AUG } & \text { SEP } \\ 1966 & 0.39 & 0.17 & 0.09 & 0.03 & 0.09 & 3.51 & 5.62 & 4.03 & 0.54 & 0.06 & 0.03 & 0.00 \\ 1967 & 0.01 & 0.03 & 0.55 & 0.05 & 0.08 & 0.45 & 0.82 & 1.07 & 0.66 & 0.20 & 0.09 & 0.04 \\ 1968 & 0.00 & 0.01 & 0.00 & 0.00 & 0.17 & 1.02 & 3.24 & 5.64 & 2.04 & 0.14 & 0.73 & 0.06 \\ 1969 & 0.07 & 0.09 & 0.02 & 0.00 & 0.00 & 1.16 & 11.8 & 4.74 & 0.85 & 0.20 & 0.05 & 0.02 \\ 1970 & 0.02 & 0.05 & 0.02 & 0.01 & 0.01 & 0.05 & 1.13 & 3.70 & 0.39 & 0.04 & 0.03 & 0.04 \\ 1971 & 0.05 & 0.03 & 0.01 & 0.02 & 0.02 & 0.15 & 0.40 & 0.72 & 0.16 & 0.02 & 0.02 & 0.00 \\ 1972 & 0.08 & 0.06 & 0.02 & 0.02 & 0.02 & 0.93 & 0.78 & 0.74 & 0.29 & 0.01 & 0.00 & 0.00 \\ 1973 & 4.77 & 1.14 & 0.67 & 0.64 & 0.67 & 2.47 & 14.0 & 22.5 & 6.04 & 0.51 & 0.10 & 0.02 \\ 1974 & 0.02 & 0.02 & 0.02 & 0.02 & 0.03 & 0.14 & 0.63 & 0.90 & 0.10 & 0.01 & 0.00 & 0.00 \\ 1975 & 0.01 & 0.02 & 0.01 & 0.00 & 0.01 & 0.01 & 0.09 & 11.0 & 4.35 & 0.21 & 0.04 & 0.00 \\ 1976 & 0.01 & 0.01 & 0.00 & 0.00 & 0.01 & 0.19 & 1.49 & 3.37 & 0.98 & 0.04 & 0.00 & 0.00 \\ 1977 & 0.00 & 0.00 & 0.00 & 0.00 & 0.00 & 0.00 & 0.00 & 0.00 & 0.00 & 0.01 & 0.04 & 0.04 \\ 1978 & 0.00 & 0.00 & 0.00 & 0.00 & 0.00 & 4.85 & 8.68 & 8.33 & 2.07 & 0.01 & 0.00 & 0.00 \\ 1979 & 0.00 & 0.01 & 0.00 & 0.00 & 0.00 & 0.63 & 6.13 & 23.8 & 13.0 & 0.67 & 0.02 & 0.00 \\ 1980 & 0.00 & 0.00 & 0.01 & 0.08 & 0.68 & 0.52 & 14.0 & 21.7 & 8.38 & 0.46 & 0.01 & 0.00 \\ 1981 & 0.00 & 0.00 & 0.00 & 0.00 & 0.00 & 0.45 & 1.10 & 0.52 & 0.19 & 0.14 & 0.01 & 0.00\end{array}$


SAN JUAN RIVER BASIN

09378630 RECAPIURE CREEK NEAR BLANDING, UT-Continued

ANNOAL PEAK DISCHARGE, IN CUBIC FEET FER SECOND, AND CORRESPONDING GAGE HEIGHT IN FEET, FOR EACH WATER YEAR

\begin{tabular}{|c|c|c|c|c|c|c|c|c|c|c|c|}
\hline $\begin{array}{l}\text { WATER } \\
\text { YEAR }\end{array}$ & DATE & $\begin{array}{c}\text { GAGE } \\
\text { HEIGHT }\end{array}$ & $\begin{array}{c}\text { PEAK } \\
\text { DISCHARGE }\end{array}$ & $\begin{array}{l}\text { WATER } \\
\text { YEAR }\end{array}$ & DATE & $\begin{array}{c}\text { GAGE } \\
\text { HEIGHT }\end{array}$ & $\begin{array}{c}\text { PEAR } \\
\text { DISCHARGE }\end{array}$ & $\begin{array}{l}\text { WATER } \\
\text { YEAR }\end{array}$ & DATE & $\begin{array}{c}\text { GAGE } \\
\text { HEIGHT }\end{array}$ & $\begin{array}{c}\text { PEAK } \\
\text { DISGAARGE }\end{array}$ \\
\hline $\begin{array}{l}1966 \\
1967 \\
1968 \\
1969 \\
1970 \\
1971\end{array}$ & $\begin{array}{l}\text { MAR. } 15,1966 \\
\text { DEC. } 06,1966 \\
\text { AUG. } 01,1968 \\
\text { AFR. } 05,1969 \\
\text { MAY } 06,1970 \\
\text { AUG. } 22,1971\end{array}$ & $\begin{array}{l}1.30 \\
1.40 \\
1.46 \\
1.43 \\
1.20 \\
0.94\end{array}$ & $\begin{array}{l}14 \\
18 \\
20 \\
19 \\
11 \\
3.3\end{array}$ & $\begin{array}{l}1972 \\
1973 \\
1974 \\
1975 \\
1976\end{array}$ & $\begin{array}{ll}\text { OCT. } 25,197 \\
\text { OCT. } 20,1972 \\
\text { MAY } & 10,1974 \\
\text { MAY } & 16,1975 \\
\text { MAY } & 14,1976\end{array}$ & $\begin{array}{l}1.00 \\
2.14 \\
6.93 \\
1.37 \\
1.40\end{array}$ & $\begin{array}{c}4.5 \\
142 \\
3.8 \\
17 \\
18\end{array}$ & $\begin{array}{l}1977 \\
1978 \\
1979 \\
1980 \\
1981\end{array}$ & $\begin{array}{l}\text { AUG. } 15,1977 \\
\text { MAR. } 18,1978 \\
\text { MAY } 26,1979 \\
\text { MAY } 08,1980 \\
\text { MAR. } 04,1981\end{array}$ & $\begin{array}{l}1.00 \\
1.45 \\
1.58 \\
1.74 \\
-\end{array}$ & $\begin{array}{l}5.9 \\
40 \\
59 \\
76 \\
4.2\end{array}$ \\
\hline
\end{tabular}

\begin{tabular}{|c|c|c|c|c|c|c|}
\hline MAC & ITUDE & $\begin{array}{l}\mathrm{PRCB} \\
\mathrm{ED} \text { ON }\end{array}$ & IY OF & $\begin{array}{l}\text { LO } \\
1019\end{array}$ & & RGE \\
\hline \multirow{2}{*}{$\begin{array}{l}\text { FERIOD } \\
\text { (CON- } \\
\text { SEOU- } \\
\text { TIVE } \\
\text { DAVS) }\end{array}$} & \multicolumn{6}{|c|}{$\begin{array}{l}\text { DISCHARGE, IN CUBIC FEET PER SECOND, FOR } \\
\text { INDICATED REOURRENCE INTEERAL, IN YEARS, AND } \\
\text { ANNUAL NONEXCEEDANCE PRCBABILITY, IN PERCENT }\end{array}$} \\
\hline & $\begin{array}{c}2 \\
508\end{array}$ & $\begin{array}{c}5 \\
208\end{array}$ & $\begin{array}{l}10 \\
10 \%\end{array}$ & $\begin{array}{l}20 \\
58\end{array}$ & $\begin{array}{l}50 \\
28\end{array}$ & $\begin{array}{r}100 \\
18\end{array}$ \\
\hline 1 & 0.00 & - & -- & - & - & - \\
\hline 7 & 0.00 & - & - & - & - & - \\
\hline 14 & 0.00 & - & - & - & - & - \\
\hline 30 & 0.00 & - & - & - & - & - \\
\hline 60 & 0.00 & - & - & - & - & - \\
\hline 90 & 0.00 & - & - & - & - & - \\
\hline
\end{tabular}

09378650 RECAPIURE CREEK BELON JOHNSON CREEK, NEAR BLANDING, UT

LOCATION.--Lat $37^{\circ} 40^{\prime} 51^{\prime \prime}$, long $109^{\circ} 27^{\prime} 43^{\prime \prime}$, in $\mathrm{NW}^{\frac{1}{4} \mathrm{NE}} \frac{\mathrm{l}}{4} \mathrm{SeC} .2$, T.36 S., R.22 E., San Juan County, Hydrologic Unit 14080201, on left

bank $0.2 \mathrm{mi}$ downstream fram Johnson Creek, $1.5 \mathrm{mi}$ upstream fram U.S. Highway 163 , and $4.3 \mathrm{mi}$ northwest of Blanding.

DRAINAGE AREA. $-50.2 \mathrm{mi}^{2}$.

FERIOD OF RECORD AVAIIABLE.--October 1975 to September 1981.

GAGE.-Water-stage recorder. Altitude of gage is $6,120 \mathrm{ft}$ from topographic map.

REMARKS.--Same diversions for irrigation above station.

AVERAGE DISCHARGE. -6 years, $9.52 \mathrm{ft}^{3} / \mathrm{s}, 6,900$ acre-ft/yr.

EXIREMES FOR FERIOD OF RECORD.--Maximum discharge, $695 \mathrm{ft}^{3} / \mathrm{s}$ Mar. 14, 1981, gage height, $5.67 \mathrm{ft}$; no flow many days each year.

LONEST MEAN DISCHARGE, IN GBIC FEET FER SECOND, AND RANKING FOR THE INDICATED NUMBER OF CONSEOUTIVE DAVS FOR EAOH OIMATIC YEAR, APRIL 1-MARCH 31

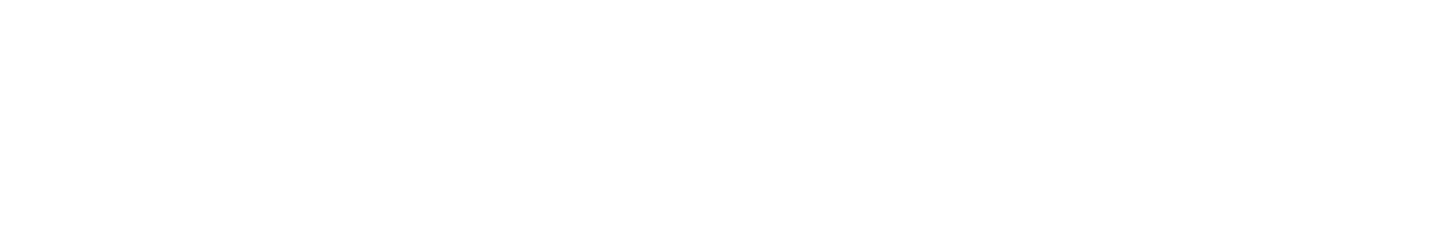

HIGHEST MEAN DISCHARGE, IN CUBIC FEET PER SECOND, AND RANKING FOR THE INDICATED NUMBER OF CONSEOUTIVE DAYS FOR EACH WATER YEAR, OCTCBER 1-SEPTEMBER 30

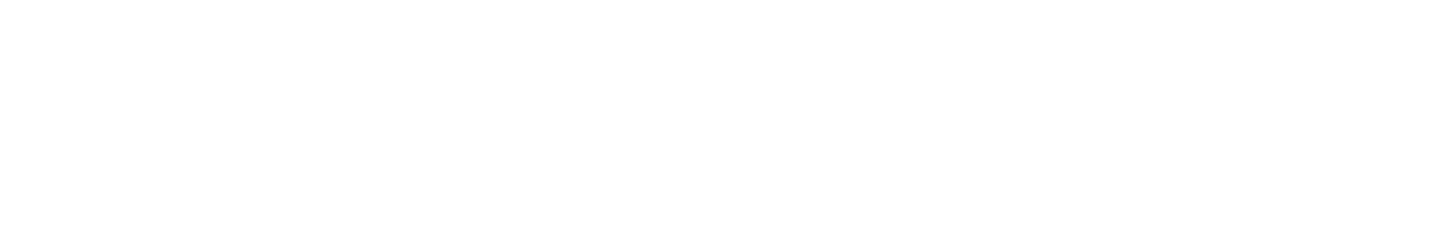


SAN JUAN RIVER BASIN

09378650 RECAPTURE CREEK BELOW JOHNSON CREEK, NEAR BLANDING, UT-COntinued

DURATION OF DISCHARGE FOR EACH WATER YEAR

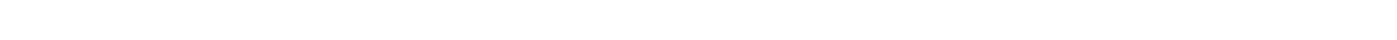

YEAR

NUMBER OF DAYS IN CIASS

ABIC FEET PER SECON

1265.4

27.1

3364.7

8788.2

7163.2

234.0

1981299

$2 \quad 14$

$\begin{array}{llllllllllllll}6 & 3 & 2 & 2 & 1 & 1 & 3 & 4 & 7 & 6 & 7 & 6 & 5 & 6\end{array}$

$\begin{array}{lllllllll}15 & 14 & 10 & 3 & 8 & 24 & 18 & 14 & 11\end{array}$

DURATION TABLE OF DISCHARGE FOR WATER YEARS 1976-81

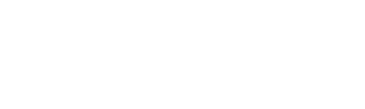
$\begin{array}{lll}\text { CUBIC } & \text { ACOU- } \\ \text { FEET } & \\ \text { PER } & \text { PER- } \\ \text { TOTAL LLATED } & \text { CENT }\end{array}$

CUBIC ACCU-

FEET MU- PER-

CLASS SECOND DAYS DAYS DAYS CLASS SECOND DAYS DAYS DAYS

TASS SECOR TOTAL LATED CENI

OAASS SECOND DAYS DAYS DAYS

$\begin{array}{rllll}9 & 0.20 & 17 & 644 & 29.4 \\ 10 & 0.27 & 12 & 627 & 28.6 \\ 11 & 0.37 & 10 & 615 & 28.1 \\ 12 & 0.49 & 12 & 605 & 27.6 \\ 13 & 0.67 & 10 & 593 & 27.1 \\ 14 & 0.90 & 12 & 583 & 26.6 \\ 15 & 1.20 & 25 & 571 & 26.0 \\ 16 & 1.60 & 22 & 546 & 24.9 \\ 17 & 2.20 & 18 & 524 & 23.9\end{array}$

$\begin{array}{rrrrr}18 & 3.0 & 16 & 506 & 23.1 \\ 19 & 4.0 & 14 & 490 & 22.4 \\ 20 & 5.4 & 18 & 476 & 21.7 \\ 21 & 7.3 & 16 & 458 & 20.9 \\ 22 & 9.9 & 41 & 442 & 20.2 \\ 23 & 13.0 & 101 & 401 & 18.3 \\ 24 & 18.0 & 68 & 300 & 13.7 \\ 25 & 24.0 & 41 & 232 & 10.6 \\ 26 & 33.0 & 33 & 191 & 8.7\end{array}$

$\begin{array}{rrrrr}27 & 44.0 & 39 & 158 & 7.2 \\ 28 & 60.0 & 40 & 119 & 5.4 \\ 29 & 81.0 & 32 & 79 & 3.6 \\ 30 & 110.0 & 31 & 47 & 2.1 \\ 31 & 150.0 & 15 & 16 & 0.7 \\ 32 & 200.0 & 1 & 1 & 0.0 \\ 33 & & & & \end{array}$

MONTHLY MEAN DISCHARGES, IN CUBIC FEET PER SECOND, FOR EAOH WATER YEAR

$\begin{array}{lccccccccccrr}\text { YEAR } & \text { OCT } & \text { NOW } & \text { DEC } & \text { JAN } & \text { FEB } & \text { MAR } & \text { APR } & \text { MAY } & \text { JUNE } & \text { JULY } & \text { AUG } & \text { SEP } \\ 1976 & 0.00 & 0.00 & 0.00 & 0.00 & 0.00 & 0.01 & 12.4 & 23.0 & 5.32 & 0.71 & 0.00 & 0.00 \\ 1977 & 0.00 & 0.00 & 0.00 & 0.00 & 0.00 & 0.00 & 0.00 & 0.00 & 0.00 & 0.02 & 0.79 & 0.07 \\ 1978 & 0.05 & 0.00 & 0.00 & 0.00 & 0.07 & 14.1 & 33.5 & 47.5 & 14.8 & 0.07 & 0.00 & 0.00 \\ 1979 & 0.00 & 0.81 & 0.00 & 0.00 & 0.33 & 14.6 & 98.3 & 109 & 60.8 & 5.30 & 0.04 & 0.00 \\ 1980 & 0.00 & 0.00 & 0.00 & 0.57 & 6.42 & 12.8 & 85.0 & 85.7 & 33.9 & 10.7 & 0.13 & 0.00 \\ 1981 & 0.00 & 0.00 & 0.00 & 0.00 & 0.00 & 1.50 & 3.09 & 3.06 & 0.01 & 0.00 & 0.00 & 0.00\end{array}$

ANNUAL PEAK DISCHARGE, IN CUBIC FEET PER SECOND, AND CORRESPONDING GAGE HEIGHT, IN FEET, FOR EACH WATER YEAR

WATER GAGE PEAK WATER $\quad$ GAGE PEAK WATER

$\begin{array}{llllllllll}\text { WEAR } & \text { DATE } & \text { GAGE } & \text { PEAK } & \text { WAIER } & & \text { GAGE } & \text { PEAK } & \text { WATER } & \text { GAGE } \\ \text { YEATEAR } & \text { DISCHARGE } & \text { YEAR } & \text { DATE } & \text { HEIGHT } & \text { DISCHARGE } & \text { YEAR } & \text { DATE } & \text { HEIGHT } & \text { DISCHARGE }\end{array}$

$\begin{array}{lllllllllllll}1976 & \text { MAY } & 16,1976 & 3.17 & 44 & 1978 & \text { MAR. 29, } 1978 & 4.18 & 227 & 1980 & \text { APR. 23, 1980 } & 4.10 & 255 \\ 1977 & \text { AUG. } & 23,1977 & 4.83 & - & 1979 & \text { APR. 28, } 1979 & 5.20 & 459 & 1981 & \text { MAR. } 14,1981 & 5.67 & 695\end{array}$

09378700 COTIONWOOD WASH NEAR BLANDING, UT

LOCATION.-Lat $37^{\circ} 33^{\prime} 38^{\prime \prime}$, long $109^{\circ} 34^{\prime} 41^{\prime \prime}$, in SW downstream end of center pier of highway bridge on State Highway 95, about 2.1 mi downstream from Brushy Basin Canyon, and 7.0 mi southwest of Blanding.

DRAINAGE AREA. $--205 \mathrm{mi}^{2}$.

MEAN BASIN ELEVATION. $-6,820 \mathrm{ft}$.

PERIOD OF RECORD AVAIIABLE.--Annual peak discharge only, water years 1959-64. October 1964 to Septenber 1981.

GAGE.--Water-stage recorder. Datum of gage is 5,137.73 ft NGVD of 1929. Prior to october 1964, crest-stage gage only, at site 300

ft upstream at different datun; October 1964 to July 13, 1966, at site $50 \mathrm{ft}$ upstream at different datum. July 14 , 1966 to Aug. 15, 1968, at same site at different datum.

AVERAGE DISCHARGE.--17 years, $8.64 \mathrm{ft}^{3} / \mathrm{s}, 6,260$ acre- $\mathrm{ft} / \mathrm{yr}$.

EXIREMES FOR PERIOD OF RECORD.--Maximum discharge, 20,500 ft 3 /s Aug. 1, 1968, gage height, $20.68 \mathrm{ft}$; no flow many days each year. 
LOWEST MEAN DISCHARGE, IN CUBIC FEET PER SECOND, AND RANKING FOR THE INDICATED NUMBER OF CONSBCUTIVE DAYS FOR EACH CLIMATIC YEAR, ARRII 1-MARCH 31

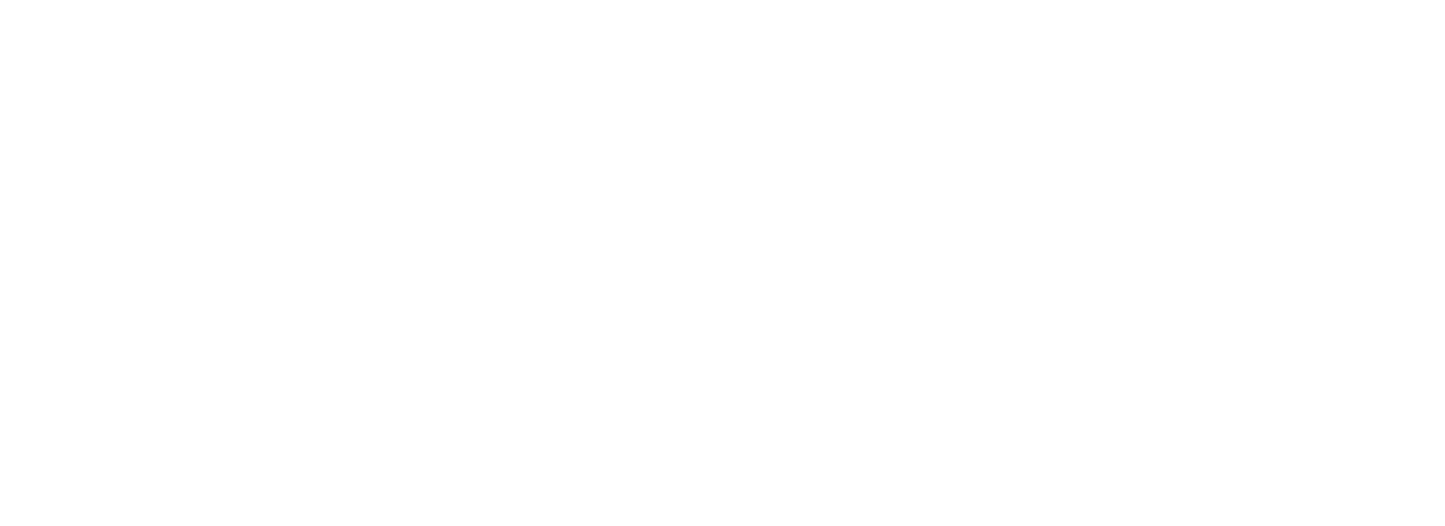

HIGHEST MEAN DISCHARGE, IN CUBIC FEET PER SECOND, AND RANKING FOR THE INDICATED NUMBER OF CONSBCUTIVE DAYS FOR EACH WATER YEAR, OCTCBER 1-SEPTEMBER 30

\begin{tabular}{|c|c|c|c|c|c|c|c|c|c|c|c|c|c|c|c|c|c|c|c|}
\hline YEAR & 1 & & 3 & & 7 & & 15 & & $\begin{array}{l}\text { CONSE } \\
30\end{array}$ & $E D$ & $\begin{array}{l}\text { E DAYS } \\
60\end{array}$ & & 90 & & 120 & & 183 & & ALL \\
\hline 1905 & 400 & 4 & 142 & 4 & 62.0 & 6 & 36.0 & 8 & 26.0 & 9 & 21.0 & 8 & 15.0 & 8 & 12.0 & 8 & 12.0 & 8 & 6.00 \\
\hline $\begin{array}{l}1976 \\
1977 \\
1978 \\
1979 \\
1980\end{array}$ & $\begin{array}{l}12.0 \\
41.0 \\
74.0 \\
104 \\
438\end{array}$ & $\begin{array}{r}17 \\
15 \\
13 \\
12 \\
3\end{array}$ & $\begin{array}{l}11.0 \\
36.0 \\
72.0 \\
103 \\
289\end{array}$ & $\begin{array}{r}16 \\
15 \\
10 \\
7 \\
3\end{array}$ & $\begin{array}{l}7.90 \\
18.0 \\
62.0 \\
101 \\
156\end{array}$ & $\begin{array}{r}17 \\
15 \\
7 \\
5 \\
3\end{array}$ & $\begin{array}{c}6.40 \\
16.0 \\
43.0 \\
91.0 \\
123\end{array}$ & $\begin{array}{r}17 \\
13 \\
7 \\
5 \\
3\end{array}$ & $\begin{array}{c}5.30 \\
8.90 \\
38.0 \\
84.0 \\
104\end{array}$ & $\begin{array}{r}17 \\
13 \\
7 \\
4 \\
3\end{array}$ & $\begin{array}{l}4.10 \\
7.20 \\
32.0 \\
72.0 \\
73.0\end{array}$ & $\begin{array}{r}17 \\
12 \\
6 \\
4 \\
3\end{array}$ & $\begin{array}{r}4.20 \\
4.80 \\
23.0 \\
63.0 \\
68.0\end{array}$ & $\begin{array}{r}17 \\
14 \\
7 \\
4 \\
2\end{array}$ & $\begin{array}{r}3.80 \\
3.60 \\
18.0 \\
53.0 \\
57.0\end{array}$ & $\begin{array}{r}14 \\
16 \\
7 \\
3 \\
1\end{array}$ & $\begin{array}{c}2.90 \\
2.80 \\
13.0 \\
36.0 \\
40.0\end{array}$ & $\begin{array}{r}15 \\
16 \\
7 \\
3 \\
1\end{array}$ & $\begin{array}{l}1.401 \\
1.601 \\
6.50 \\
19.0 \\
21.0\end{array}$ \\
\hline
\end{tabular}

\section{DURATION OF DISCHARGE FOR EACH WATER YEAR}

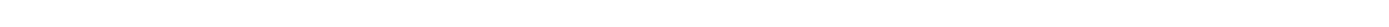
YEAR

NUMBER OF DAYS IN CIASS

CBIC FEET PER SECOND -DAYS

$\begin{array}{lllllllllllllllllllllllllll}1965142 & 3 & 11 & 58 & 12 & 12 & 18 & 32 & 21 & 11 & 11 & 16 & 7 & 5 & & 1 & 2 & 1 & 1 & 1 & & & & 2180.5\end{array}$

$\begin{array}{lllllllllllllllllllllllllll}1966160 & 8 & 6 & 21 & 2 & 2 & 2 & 4 & 5 & 6 & 46 & 24 & 17 & 19 & 23 & 9 & 5 & 2 & 1 & 3 & & & & 1969.3\end{array}$

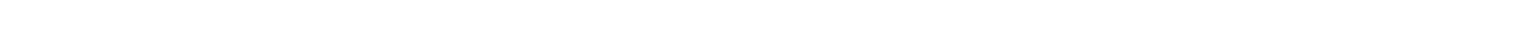

$\begin{array}{llllllllllllllllllllllllll}1968140 & 35 & 10 & 1 & 3 & 6 & 5 & 19 & 11 & 13 & 18 & 26 & 24 & 25 & 14 & 6 & 3 & 1 & 1 & 1 & 2 & 1 & 1 & 6561.2\end{array}$

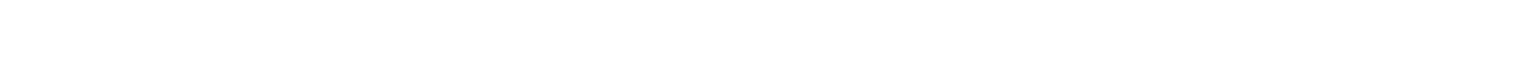

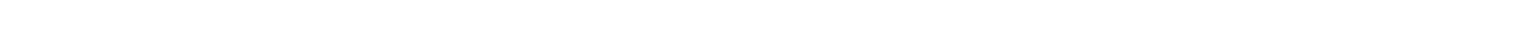

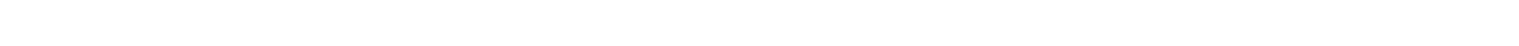

$\begin{array}{lllllllllllllllllllllllllll}1973 & 29 & 6 & 25 & 20 & 8 & 37 & 94 & 6 & 44 & 15 & 13 & 10 & 10 & 6 & 7 & 18 & 11 & 2 & 2 & 1 & 1 & 10324.8\end{array}$

$\begin{array}{rrrrrrrrrrrrrrrrrrrrrrrrrrrrr}1974114 & 1 & 4 & 1 & 1 & 1 & 2 & 5 & 5 & 32 & 93 & 17 & 20 & 35 & 27 & 5 & 1 & 1 & & 194.2 \\ 197563 & & & 1 & & & & 12 & 5 & & 2 & 25 & 56 & 56 & 23 & 35 & 9 & 17 & 14 & 28 & 14 & 2 & 2 & 1 & & & & \end{array}$

$\begin{array}{llllllllllllllllll}1976130 & 16 & 13 & 15 & 11 & 7 & 1 & 4 & 1 & 35 & 29 & 40 & 29 & 19 & 9 & 5 & 2 & \end{array}$

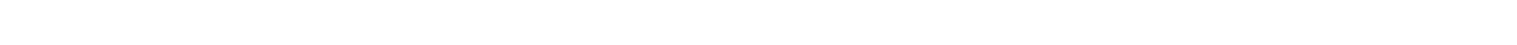

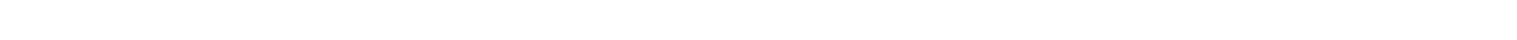

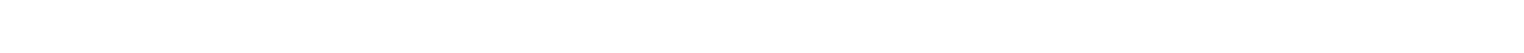

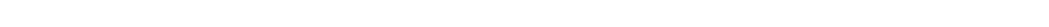

1300.8 
SAN JUAN RIVER BASIN

09378700 COITONWOO WASH NEAR BLANDING, UT-Continued

DURATION TABLE OF DISCHARGE FOR WATER YEARS 1965-81

\begin{tabular}{|c|c|c|c|c|c|c|c|c|c|c|c|c|c|c|c|c|c|c|c|}
\hline CLASS & $\begin{array}{c}\text { CUBIC } \\
\text { FEET } \\
\text { PER } \\
\text { SECOND }\end{array}$ & TOTAL & $\begin{array}{c}\text { ACOU- } \\
\text { MN- } \\
\text { LATED } \\
\text { DAYS }\end{array}$ & $\begin{array}{l}\text { PER- } \\
\text { CENT } \\
\text { DAYS }\end{array}$ & CAASS & $\begin{array}{c}\text { CUBIC } \\
\text { FEET } \\
\text { PER } \\
\text { SEOOND }\end{array}$ & $\begin{array}{r}\text { TOTLL } \\
\text { DAYS }\end{array}$ & $\begin{array}{c}\text { ACOU- } \\
\text { MU- } \\
\text { LATED } \\
\text { DAYS }\end{array}$ & $\begin{array}{l}\text { PER- } \\
\text { CENT } \\
\text { DAYS }\end{array}$ & C.ASS & $\begin{array}{c}\text { OUBIC } \\
\text { FEET } \\
\text { PER } \\
\text { SEOOND }\end{array}$ & $\begin{array}{r}\text { TOIAL } \\
\text { DAYS }\end{array}$ & $\begin{array}{c}\text { ACOU- } \\
\text { MU- } \\
\text { LATED } \\
\text { DAYS }\end{array}$ & $\begin{array}{l}\text { PER } \\
\text { CENI } \\
\text { DAYS }\end{array}$ & CLASS & $\begin{array}{c}\text { QUBIC } \\
\text { FEET } \\
\text { PER } \\
\text { SECOND }\end{array}$ & $\begin{array}{l}\text { TOTAL } \\
\text { DAYS }\end{array}$ & $\begin{array}{c}\text { ACOU- } \\
\text { MU- } \\
\text { LATED } \\
\text { DAYS }\end{array}$ & $\begin{array}{l}\text { PER } \\
\text { CENI } \\
\text { DAYS }\end{array}$ \\
\hline $\begin{array}{l}0 \\
1 \\
2 \\
3 \\
4 \\
5 \\
6 \\
7 \\
8\end{array}$ & $\begin{array}{l}0.00 \\
0.01 \\
0.02 \\
0.03 \\
0.04 \\
0.06 \\
0.09 \\
0.12 \\
0.17\end{array}$ & $\begin{array}{r}1869 \\
23 \\
11 \\
3 \\
61 \\
7 \\
775 \\
81 \\
150\end{array}$ & $\begin{array}{l}6209 \\
4340 \\
4317 \\
4306 \\
4303 \\
4242 \\
4235 \\
4060 \\
3979\end{array}$ & $\begin{array}{r}100.0 \\
69.9 \\
69.5 \\
69.4 \\
69.3 \\
68.3 \\
68.2 \\
65.4 \\
64.1\end{array}$ & $\begin{array}{r}9 \\
10 \\
11 \\
12 \\
13 \\
14 \\
15 \\
16 \\
17\end{array}$ & $\begin{array}{l}0.25 \\
0.35 \\
0.50 \\
0.72 \\
1.00 \\
1.50 \\
2.10 \\
3.00 \\
4.20\end{array}$ & $\begin{array}{r}65 \\
128 \\
242 \\
89 \\
368 \\
434 \\
386 \\
513 \\
434\end{array}$ & $\begin{array}{l}3829 \\
3764 \\
3636 \\
3394 \\
3305 \\
2937 \\
2503 \\
2117 \\
1604\end{array}$ & $\begin{array}{l}61.7 \\
60.6 \\
58.6 \\
54.7 \\
53.2 \\
47.3 \\
40.3 \\
34.1 \\
25.8\end{array}$ & $\begin{array}{l}18 \\
19 \\
20 \\
21 \\
22 \\
23 \\
24 \\
25 \\
26\end{array}$ & $\begin{array}{r}6.1 \\
8.6 \\
12.0 \\
18.0 \\
25.0 \\
36.0 \\
51.0 \\
73.0 \\
100.0\end{array}$ & $\begin{array}{r}219 \\
212 \\
150 \\
104 \\
144 \\
109 \\
75 \\
58 \\
60\end{array}$ & $\begin{array}{r}1170 \\
951 \\
739 \\
589 \\
485 \\
341 \\
232 \\
157 \\
99\end{array}$ & $\begin{array}{r}18.8 \\
15.3 \\
11.9 \\
9.5 \\
7.8 \\
5.5 \\
3.7 \\
2.5 \\
1.6\end{array}$ & $\begin{array}{l}27 \\
28 \\
29 \\
30 \\
31 \\
32 \\
33 \\
34\end{array}$ & $\begin{array}{r}150.0 \\
210.0 \\
300.0 \\
430.0 \\
620.0 \\
880.0 \\
1300.0\end{array}$ & $\begin{array}{r}25 \\
5 \\
4 \\
3 \\
0 \\
1 \\
1\end{array}$ & $\begin{array}{r}39 \\
14 \\
9 \\
5 \\
2 \\
2 \\
1\end{array}$ & $\begin{array}{l}0.6 \\
0.2 \\
0.1 \\
0.1 \\
0.0 \\
0.0 \\
0.0\end{array}$ \\
\hline
\end{tabular}

MONIHLY MEAN DISCHARGES, IN ABIC FEET PER SECOND, FOR EACH WATER YEAR

$\begin{array}{lcccccccccccc}\text { YEAR } & \text { OCT } & \text { NOV } & \text { DEC } & \text { JAN } & \text { FEB } & \text { MAR } & \text { APR } & \text { MAY } & \text { JUNE } & \text { JULY } & \text { AUG } & \text { SEP } \\ 1965 & 0.00 & 0.00 & 0.04 & 0.40 & 0.24 & 2.83 & 14.2 & 8.15 & 3.08 & 14.5 & 12.0 & 15.9 \\ 1966 & \mathbf{6 . 1 4} & 7.09 & 8.05 & 4.44 & 4.61 & 14.0 & 12.7 & 1.89 & 0.08 & 3.53 & 1.67 & 0.42 \\ 1967 & 0.84 & 2.23 & 13.9 & 1.80 & 3.76 & 0.75 & 0.24 & 0.70 & 0.66 & 11.1 & 15.5 & 0.33 \\ 1968 & 0.00 & 0.19 & 0.17 & 0.14 & 9.04 & 7.31 & 6.45 & 7.55 & 0.86 & 7.66 & 173 & 0.00 \\ 1969 & 1.03 & 0.92 & 0.50 & 8.05 & 9.25 & 33.7 & 70.3 & 8.33 & 1.56 & 13.9 & 16.0 & 2.83 \\ 1970 & 2.09 & 3.30 & 2.55 & 1.23 & 1.72 & 4.62 & 4.28 & 1.97 & 0.41 & 0.00 & 12.3 & 4.08 \\ 1971 & 0.05 & 1.26 & 1.30 & 0.58 & 2.05 & 1.40 & 0.88 & 1.16 & 0.00 & 0.74 & 11.9 & 1.40 \\ 1972 & 4.94 & 1.03 & 0.50 & 0.55 & 2.28 & 3.23 & 0.60 & 0.01 & 4.18 & 6.45 & 0.08 & 4.37 \\ 1973 & 93.0 & 5.65 & 6.29 & 4.16 & 6.70 & 26.6 & 123 & 55.6 & 9.82 & 4.70 & 1.73 & 0.77 \\ 1974 & 0.84 & 2.07 & 4.81 & 2.03 & 4.86 & 6.01 & 2.25 & 1.10 & 0.03 & 1.42 & 0.00 & 0.86 \\ 1975 & 11.1 & 2.53 & 3.00 & 2.50 & 2.64 & 8.33 & 25.7 & 36.0 & 4.42 & 6.98 & 3.51 & 0.00 \\ 1976 & 0.01 & 0.12 & 0.71 & 1.52 & 4.81 & 3.28 & 3.55 & 3.39 & 0.00 & 0.06 & 0.03 & 0.06 \\ 1977 & 0.09 & 0.00 & 0.01 & 0.00 & 1.13 & 2.92 & 1.01 & 0.20 & 0.00 & 3.02 & 7.96 & 3.03 \\ 1978 & 1.72 & 0.57 & 0.08 & 1.94 & 4.61 & 38.6 & 23.2 & 5.36 & 2.05 & 0.00 & 0.00 & 0.00 \\ 1979 & 0.01 & 1.27 & 3.87 & 1.99 & 8.43 & 46.3 & 70.7 & 69.9 & 15.6 & 0.62 & 4.46 & 0.00 \\ 1980 & 0.00 & 4.96 & 3.31 & 4.52 & 48.6 & 31.8 & 68.2 & 74.6 & 11.2 & 1.35 & 0.47 & 0.95 \\ 1981 & 1.00 & 2.71 & 2.81 & 2.97 & 3.00 & 6.72 & 7.17 & 5.27 & 1.30 & 6.64 & 2.13 & 0.91\end{array}$

ANNUAL PEAK DISCHARGE, IN OUBIC FEET PER SECOND, AND CORRESPONDING GAGE HEIGHT, IN FEET, FOR EACH WATER YEAR

\begin{tabular}{|c|c|c|c|c|c|c|c|c|c|c|c|}
\hline $\begin{array}{l}\text { WATERR } \\
\text { YEAR }\end{array}$ & DATE & $\begin{array}{c}\text { GAGE } \\
\text { HEIGHT }\end{array}$ & $\begin{array}{c}\text { PEAK } \\
\text { DISGHARGE }\end{array}$ & $\begin{array}{l}\text { WATERR } \\
\text { YEAR }\end{array}$ & DATE & $\begin{array}{c}\text { GAGE } \\
\text { HEIGHT }\end{array}$ & $\begin{array}{c}\text { PEAK } \\
\text { DISCHARGE }\end{array}$ & $\begin{array}{l}\text { WATERR } \\
\text { YEAR }\end{array}$ & DATE & $\begin{array}{l}\text { GAGE } \\
\text { HEIGHT }\end{array}$ & $\begin{array}{c}\text { PEAK } \\
\text { DISCHARGE }\end{array}$ \\
\hline $\begin{array}{l}1959 \\
1960 \\
1961 \\
1962 \\
1963 \\
1964 \\
1965 \\
1966\end{array}$ & $\begin{array}{l}\text { AUG. } 19,1959 \\
\text { JULY } 31,1960 \\
\text { AUG. } 25,1961 \\
\text { OCT. } 08,1961 \\
\text { SEPT.06, } 1963 \\
\text { OCT. } 20,1963 \\
\text { AUG. } 30,1965 \\
\text { JULY } 29,1966\end{array}$ & $\begin{array}{r}13.67 \\
10.58 \\
12.76 \\
12.56 \\
18.55 \\
10.02 \\
7.56 \\
3.77\end{array}$ & $\begin{array}{r}2100 \\
275 \\
1330 \\
1200 \\
8650 \\
200 \\
4600 \\
1080\end{array}$ & $\begin{array}{l}1967 \\
1968 \\
1969 \\
1970 \\
1971 \\
1972 \\
1973 \\
1974\end{array}$ & $\begin{array}{l}\text { AUG. } 09,1967 \\
\text { AUG. } 01,1968 \\
\text { AUG. } 16,1969 \\
\text { AUG. } 19,1970 \\
\text { AUG. } 22,1971 \\
\text { JUNE } 22,1972 \\
\text { OCT. } 19,1972 \\
\text { SEPT. } 15,1974\end{array}$ & $\begin{array}{r}5.78 \\
20.68 \\
5.40 \\
5.80 \\
4.30 \\
6.23 \\
8.15 \\
2.70\end{array}$ & $\begin{array}{r}2760 \\
20500 \\
1560 \\
1830 \\
947 \\
2130 \\
3800 \\
314\end{array}$ & $\begin{array}{l}1975 \\
1976 \\
1977 \\
1978 \\
1979 \\
1980 \\
1981\end{array}$ & $\begin{array}{l}\text { AUG. 12, } 1975 \\
\text { SEPT.08, } 1976 \\
\text { SEPT.14, } 1977 \\
\text { APR. 13, } 1978 \\
\text { NOV. 11, } 1978 \\
\text { FEB. 20, } 1980 \\
\text { SEPT.01, } 1981\end{array}$ & $\begin{array}{l}5.80 \\
1.02 \\
4.10 \\
2.00 \\
2.95 \\
4.31 \\
4.24\end{array}$ & $\begin{array}{r}1830 \\
40 \\
858 \\
195 \\
456 \\
952 \\
884\end{array}$ \\
\hline
\end{tabular}

MAGNITUDE AND PRCBABIIITY OF ANNUAL LONEST MEAN DISCHARGE BASED ON CLIMATIC YEARS 1966-81

\begin{tabular}{|c|c|c|c|c|c|c|}
\hline \multirow{2}{*}{$\begin{array}{l}\text { PERIOD } \\
\text { (CON- } \\
\text { SEOU- } \\
\text { TIVE } \\
\text { DAYS) }\end{array}$} & \multicolumn{6}{|c|}{$\begin{array}{l}\text { DISCHARGE, IN CUBIC FEET PER SECOND, FOR } \\
\text { INDICATED RECURRENCE INIEERNAL, IN YEARS, AND } \\
\text { ANNUAL NONEXCEEDANCE PRCBABILITY, IN PERCENT }\end{array}$} \\
\hline & $\begin{array}{c}2 \\
50 \%\end{array}$ & $\begin{array}{c}5 \\
208\end{array}$ & $\begin{array}{l}10 \\
108\end{array}$ & $\begin{array}{l}20 \\
58\end{array}$ & $\begin{array}{l}50 \\
28\end{array}$ & $\begin{array}{r}100 \\
18\end{array}$ \\
\hline 1 & 0.00 & 0.00 & - & -- & - & - \\
\hline 7 & 0.00 & 0.00 & - & - & - & - \\
\hline 14 & 0.00 & 0.00 & - & - & - & - \\
\hline 30 & 0.00 & 0.00 & - & - & - & - \\
\hline 60 & 0.08 & 0.00 & - & - & - & - \\
\hline
\end{tabular}

MAGNITUDE AND PROBABILITY OF ANNUAL HIGHEST MEAN DISCHARGE BASED ON WATER YEARS 1965-81

\begin{tabular}{|c|c|c|c|c|c|c|}
\hline \multirow{2}{*}{$\begin{array}{l}\text { PERIOD } \\
\text { (CON- } \\
\text { SEOU- } \\
\text { TIVE } \\
\text { DAYS) }\end{array}$} & \multicolumn{6}{|c|}{$\begin{array}{l}\text { DISCHARGE, IN GHIC FEET PER SECOND, FOR } \\
\text { INDICATED REOURRENCE INTERVAL, IN YEARS, AND } \\
\text { ANNUAL EXCEEDANCE PRCBABILITY, IN PERCENT }\end{array}$} \\
\hline & $\begin{array}{c}2 \\
508\end{array}$ & $\begin{array}{c}5 \\
208\end{array}$ & $\begin{array}{l}10 \\
108\end{array}$ & $\begin{array}{l}25 \\
48\end{array}$ & $\begin{array}{l}50 \\
28\end{array}$ & $\begin{array}{r}100 \\
18\end{array}$ \\
\hline
\end{tabular}

$\begin{array}{rrrrrrr}1 & 138 & 480 & 990 & 2270 & - & -- \\ 3 & 82 & 254 & 483 & 1000 & -- & -- \\ 7 & 49 & 138 & 250 & 492 & -- & - \\ 15 & 33 & 88 & 157 & 301 & -- & -\end{array}$


LOCATION.--Lat $37^{\circ} 17^{\prime} 00^{\prime \prime}$, long $109^{\circ} 33^{\prime} 37^{\prime \prime}$, in NWty sec.25, T.40 S., R.21 E., San Juan County, Hydrologic Unit 14080201 , about 0.5 mi above mouth and $0.5 \mathrm{mi}$ west of Bluff on State Highway 47 .

DRATNAGE AREA. $--340 \mathrm{mi}^{2}$.

MEAN BASIN ELEVATION. $-6,250 \mathrm{ft}$.

PERIOD OF RECORO AVAIIABLE.--Water years 1959-68, annual peak discharge only.

GAGE.--Crest-stage gage. Altitude of gage is 4,350 ft from topographic map.

ANNUAL PEAK DISCHARGE, IN OIBIC FEET PER SBCOND, AND CORRESPONDING GAGE HEIGHT, IN FEET, FOR EAGH WATER YEAR

\begin{tabular}{|c|c|c|c|c|c|c|c|c|c|c|c|}
\hline $\begin{array}{l}\text { WATERR } \\
\text { YEAR }\end{array}$ & DATE & $\begin{array}{c}\text { GAGE } \\
\text { HEIGHT }\end{array}$ & $\begin{array}{c}\text { PEAR } \\
\text { DISCHARGE }\end{array}$ & $\begin{array}{l}\text { WATEER } \\
\text { YEAR }\end{array}$ & DATE & $\begin{array}{c}\text { GAGE } \\
\text { HEIGHT }\end{array}$ & $\begin{array}{c}\text { PEAK } \\
\text { DISCHARGE }\end{array}$ & $\begin{array}{l}\text { WATER } \\
\text { YEAR }\end{array}$ & DATE & $\begin{array}{l}\text { GAGE } \\
\text { HEIGHT }\end{array}$ & $\begin{array}{c}\text { PEAR } \\
\text { DISCHARGE }\end{array}$ \\
\hline $\begin{array}{l}1959 \\
1960 \\
1961 \\
1962\end{array}$ & $\begin{array}{l}\text { AUG. } 19,1959 \\
\text { AUG. } 23,1960 \\
\text { SEPT.09, } 1961 \\
\text { SEPT.27, } 1962\end{array}$ & $\begin{array}{l}11.78 \\
10.73 \\
12.70 \\
12.27\end{array}$ & $\begin{array}{r}892 \\
170 \\
1300 \\
1000\end{array}$ & $\begin{array}{l}1963 \\
1964 \\
1965\end{array}$ & $\begin{array}{ll}\text { SEPT. 09, } 1963 \\
\text { OCT. } 20,1963 \\
\text { JULY } 31,1965\end{array}$ & $\begin{array}{l}15.24 \\
12.35 \\
13.24\end{array}$ & $\begin{array}{l}4060 \\
1020 \\
1820\end{array}$ & $\begin{array}{l}1966 \\
1967 \\
1968\end{array}$ & $\begin{array}{l}\text { SEPT. } 10,1966 \\
\text { AUG. } 10,1967 \\
\text { AUG. 01, } 1968\end{array}$ & $\begin{array}{l}11.60 \\
11.20 \\
18.38\end{array}$ & $\begin{array}{r}350 \\
600 \\
42100\end{array}$ \\
\hline
\end{tabular}

09378900 BUTLER WASA NEAR BLUFF, UT

LOCATION.--Lat $37^{\circ} 16^{\prime} 00^{\prime \prime}$, long 109 $39^{\prime} 00^{\prime \prime}$, in NW/4 sec.31, T.40 S., R.21 E., San Juan County, Hydrologic Unit 14080201 , 2.5 mi above mouth and $5.5 \mathrm{mi}$ west of Bluff.

DRAINAGE AREA. $-54 \mathrm{mi}^{2}$.

PERIOD OF RECORD AVAII.ABLE.--Water years 1961-68, annual peak discharge only.

GAGE.--Crest-stage gage. Altitude of gage is 4,390 ft from topographic map.

ANNUAL PEAK DISCHARGE, IN CUBIC FEET PER SECOND, AND CORRESPONDING GAGE HEIGHT, IN FEET, FOR EAGH WATERR YEAR

\begin{tabular}{|c|c|c|c|c|c|c|c|c|c|c|c|}
\hline $\begin{array}{l}\text { WATER } \\
\text { YEAR }\end{array}$ & DATE & $\begin{array}{c}\text { GAGE } \\
\text { HEIGHY }\end{array}$ & $\begin{array}{c}\text { PEAR } \\
\text { DISCHARGE }\end{array}$ & $\begin{array}{l}\text { WATER } \\
\text { YEAR }\end{array}$ & DATE & $\begin{array}{c}\text { GAGE } \\
\text { HEIGHT }\end{array}$ & $\begin{array}{c}\text { PEAK } \\
\text { DISCHARGE }\end{array}$ & $\begin{array}{l}\text { WATER } \\
\text { YEAR }\end{array}$ & DATE & $\begin{array}{c}\text { GAGE } \\
\text { HEIGHT }\end{array}$ & $\begin{array}{c}\text { PEAK } \\
\text { DISCHARGE }\end{array}$ \\
\hline $\begin{array}{l}1961 \\
1962 \\
1963\end{array}$ & $\begin{array}{l}\text { SEPT.09, } 1961 \\
\text { SEPT.20, } 1962 \\
\text { AUG. } 31,1963\end{array}$ & $\begin{array}{l}13.39 \\
13.40 \\
15.55\end{array}$ & $\begin{array}{l}312 \\
315 \\
814\end{array}$ & $\begin{array}{l}1964 \\
1965 \\
1966\end{array}$ & $\begin{array}{l}\text { OCT. } 20,1963 \\
\text { JULY 31, } 1965 \\
\text { SEPT.15, } 1966\end{array}$ & $\begin{array}{ll}3 & 16.10 \\
11.00 \\
5 & 12.34\end{array}$ & $\begin{array}{c}1000 \\
4.0 \\
130\end{array}$ & $\begin{array}{l}1967 \\
1968\end{array}$ & $\begin{array}{l}\text { AUG. } 10,1967 \\
\text { AUG. } 01,1968\end{array}$ & $\begin{array}{l}12.50 \\
14.87\end{array}$ & $\begin{array}{l}390 \\
820\end{array}$ \\
\hline
\end{tabular}

09378950 CONB WASH NEAR BLANDING, UT

LOCATION.--Lat 37 $33^{\prime} 00^{\prime}$, long 109 $39^{\prime} 53^{\prime \prime}$, in SE⿺ sec.24, T.37 S., R.20 E., San Juan County, Eydrologic Unit 14080201 , about 0.5 mi above Arch Canyon and $11 \mathrm{mi}$ southeast of Blanding.

DRAINAGE AREA. $--10.3 \mathrm{mi}^{2}$.

MEAN BASIN ELEVATION. $--5,760 \mathrm{ft}$.

PERIOD OF RECORD AVAIIABLE.--Water years 1959-68, annual peak discharge only.

GAGE.-Crest-stage gage. Altitude of gage is 5,090 ft from topographic map.

ANIUAL PEAK DISCHARGE, IN GUBIC FEET PER SBCOND, AND OORRESPONDING GAGE HEIGHT, IN FEET, FOR EAOH WATER YEAR

\begin{tabular}{|c|c|c|c|c|c|c|c|c|c|c|c|}
\hline $\begin{array}{l}\text { WATER } \\
\text { YEAR }\end{array}$ & DATE & $\begin{array}{l}\text { GAGE } \\
\text { HEIGHT }\end{array}$ & $\begin{array}{c}\text { PEAR } \\
\text { DISCHARGE }\end{array}$ & $\begin{array}{l}\text { WATER } \\
\text { YEAR }\end{array}$ & DATE & $\begin{array}{c}\text { GAGE } \\
\text { HEIGHT }\end{array}$ & $\begin{array}{c}\text { PEAR } \\
\text { DISCHARGE }\end{array}$ & $\begin{array}{l}\text { WATER } \\
\text { YEAR }\end{array}$ & DATE & $\begin{array}{l}\text { GAGE } \\
\text { HEIGHT }\end{array}$ & $\begin{array}{c}\text { PEAK } \\
\text { DISCHARGE }\end{array}$ \\
\hline $\begin{array}{l}1959 \\
1960 \\
1961 \\
1962\end{array}$ & $\begin{array}{l}\text { AUG. } 04,1959 \\
\text { AUG. } 22,1960 \\
\text { OCT. 08, } 1960 \\
\text { SEPT.20, } 1962\end{array}$ & $\begin{array}{l}11.83 \\
11.51 \\
11.75 \\
10.60\end{array}$ & $\begin{array}{r}633 \\
400 \\
550 \\
56\end{array}$ & $\begin{array}{l}1963 \\
1964 \\
1965\end{array}$ & $\begin{array}{l}\text { OCT. } 18,1962 \\
\text { AUG. } 02,1964 \\
\text { JULY } 31,1965\end{array}$ & $\begin{array}{l}12.20 \\
12.80 \\
11.94\end{array}$ & $\begin{array}{r}450 \\
1400 \\
710\end{array}$ & $\begin{array}{l}1966 \\
1967 \\
1968\end{array}$ & $\begin{array}{l}\text { SEPT.02, } 1966 \\
\text { AUG. 10, } 1967 \\
\text { AUG. 01, } 1968\end{array}$ & $\begin{array}{l}11.82 \\
13.70 \\
14.48\end{array}$ & $\begin{array}{r}630 \\
1860 \\
3430\end{array}$ \\
\hline
\end{tabular}


LOCATION.-Lat $37^{\circ} 15^{\prime} 58^{\prime \prime}$, long $109^{\circ} 40^{\prime} 31^{\prime \prime}$, in NE' sec.35, T.40 S., R.20 E., San Juan County, Hydrologic Unit 14080201, on highway

bridge $2.5 \mathrm{mi}$ upstream from mouth and $7 \mathrm{mi}$ west of Bluff.

DRAINAGE AREA.- $280 \mathrm{mi}^{2}$, approximately.

MEAN BASIN ELEVATION. $-6,060 \mathrm{ft}$.

PERIOD OF RECORD AVAILABLE.--January 1959 to September 1968.

GAGE.--Water-stage recorder with highway ford as a control. Altitude of gage is $4,300 \mathrm{ft}$ from topographic map.

AVERAGE DISCHARGE. -9 years, $2.78 \mathrm{ft}^{3} / \mathrm{s}, 2,010$ acre-ft/yr.

EXIREMES FOR PERIOD OF RECORD.-Maximum discharge, 8,390 $\mathrm{ft}^{3} / \mathrm{s}$ Aug. 1, 1968, gage height, $5.57 \mathrm{ft}$, from slope-area measurement; no flow for most of time in each year.

LOWEST MEAN DISCHARGE, IN CUBIC FEET PER SECOND, AND RANKING FOR THE INDICATED NUMBER OF CONSECUTIVE DAYS FOR EACH CLIMATIC YEAR, APRIl 1-MARCH 31

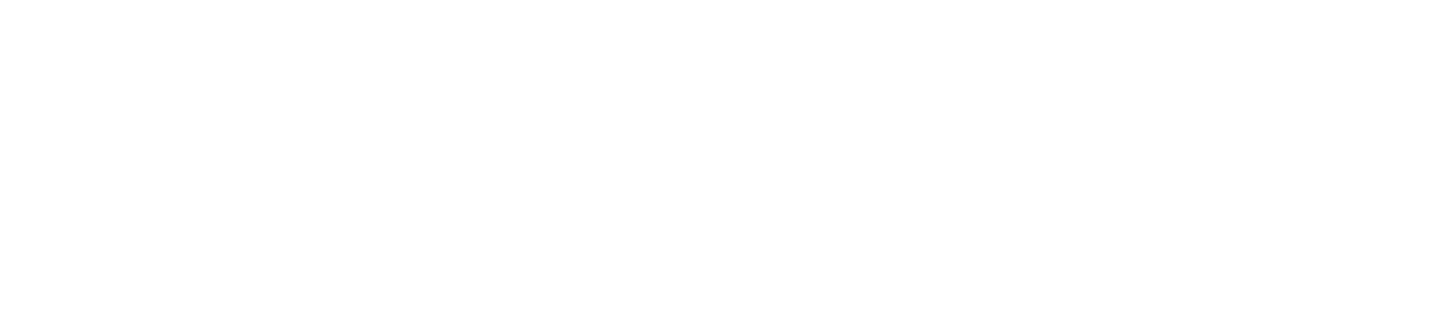

HIGHEST MEAN DISCHARGE, IN CUBIC FEET PER SECOND, AND RANKING FOR THE INDICATED NUMBER OF CONSECUTIVE DAYS FOR EACH WATER YEAR, OCTOBER 1-SEPIEMBER 30

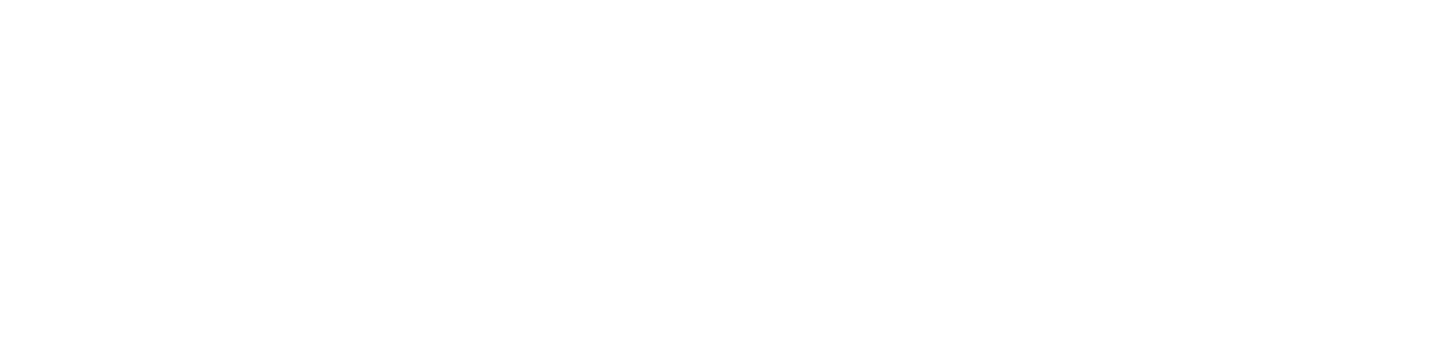

DURATION OF DISCHARGE FOR EACH WATER YEAR

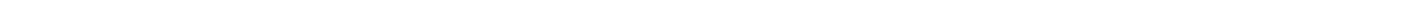

YEAR

NUMBER OF DAYS IN OLASS

OBBIC FEET PER SECOND -DAYS

\begin{tabular}{|c|c|c|c|c|c|c|c|c|c|c|c|c|c|c|c|c|c|c|c|c|c|c|c|c|c|c|c|c|c|c|}
\hline 1960333 & 1 & 1 & 3 & & 2 & 1 & 3 & 2 & 2 & 2 & 2 & 2 & & & 1 & 1 & 2 & 3 & I & $I$ & 1 & & & & & 2 & & & & 499.2 \\
\hline $\begin{array}{l}1961330 \\
1962345 \\
1963340 \\
1964350 \\
1965356\end{array}$ & 3 & $\begin{array}{l}2 \\
2 \\
1\end{array}$ & $\begin{array}{l}2 \\
1 \\
1\end{array}$ & 1 & & & & $\begin{array}{l}4 \\
5 \\
3 \\
6 \\
1\end{array}$ & 1 & 1 & $\begin{array}{l}3 \\
2\end{array}$ & $\begin{array}{l}2 \\
2 \\
2 \\
1\end{array}$ & $\begin{array}{l}2 \\
2 \\
4 \\
1 \\
1\end{array}$ & $\begin{array}{l}1 \\
1 \\
2 \\
1\end{array}$ & $\begin{array}{l}1 \\
1\end{array}$ & $\begin{array}{l}1 \\
1 \\
1 \\
1 \\
1\end{array}$ & 1 & $\begin{array}{l}1 \\
2\end{array}$ & 2 & $\begin{array}{l}1 \\
1 \\
1 \\
1\end{array}$ & $\begin{array}{l}2 \\
1\end{array}$ & 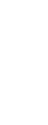 & $\begin{array}{l}1 \\
2\end{array}$ & $\begin{array}{l}1 \\
1\end{array}$ & & 1 & 1 & $\frac{1}{1}$ & 1 & $\begin{array}{r}1034.1 \\
300.3 \\
994.5 \\
404.7 \\
130.8\end{array}$ \\
\hline $\begin{array}{l}1966281 \\
1967336 \\
1968355\end{array}$ & $\begin{array}{r}22 \\
1\end{array}$ & $\begin{array}{l}4 \\
1\end{array}$ & 4 & 2 & $\begin{array}{l}4 \\
1\end{array}$ & & 1 & $\begin{array}{l}8 \\
1 \\
2\end{array}$ & 4 & $\begin{array}{l}5 \\
3 \\
2\end{array}$ & 3 & $\begin{array}{l}3 \\
2\end{array}$ & 2 & $\begin{array}{l}3 \\
2\end{array}$ & $\begin{array}{l}1 \\
1\end{array}$ & $\begin{array}{l}4 \\
2\end{array}$ & 2 & 4 & $\begin{array}{l}1 \\
1\end{array}$ & 3 & $\begin{array}{l}1 \\
1 \\
1\end{array}$ & $\begin{array}{l}1 \\
1\end{array}$ & 1 & 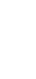 & & 1 & $\begin{array}{l}2 \\
1\end{array}$ & 11 & 2 & $\begin{array}{r}723.2 \\
2496.9 \\
2553.0\end{array}$ \\
\hline
\end{tabular}




\begin{tabular}{|c|c|c|c|c|c|c|c|c|c|c|c|c|c|c|c|c|c|c|c|}
\hline & & & & & & URATI & $\mathrm{DN}$ TABI & LE OF & $\mathrm{SCH}$ & OR WI & ATER YEA & ARS 1 & -68 & & & & & & \\
\hline ASS & $\begin{array}{c}\text { OBBIC } \\
\text { FEET } \\
\text { PER } \\
\text { SECOND }\end{array}$ & $\begin{array}{l}\text { TOTAL } \\
\text { DAYS }\end{array}$ & $\begin{array}{r}\text { ACOU- } \\
\text { MU- } \\
\text { LATED } \\
\text { DAYS }\end{array}$ & $\begin{array}{l}\text { PER- } \\
\text { CERN } \\
\text { DAYS }\end{array}$ & OASS & $\begin{array}{c}\text { CUBIC } \\
\text { FEET } \\
\text { PER } \\
\text { SEOOND }\end{array}$ & $\begin{array}{r}\text { TOIAL } \\
\text { DAYS }\end{array}$ & $\begin{array}{r}\text { ACOU- } \\
\text { MU- } \\
\text { LATED } \\
\text { DAYS }\end{array}$ & $\begin{array}{l}\text { PER } \\
\text { CENT } \\
\text { DAYS }\end{array}$ & CLASS & $\begin{array}{c}\text { OUBIC } \\
\text { FEET } \\
\text { PER } \\
\text { SEOOND }\end{array}$ & $\begin{array}{r}\text { TOTAL } \\
\text { DAYS }\end{array}$ & $\begin{array}{c}\text { ACOU- } \\
\text { MU- } \\
\text { LATED } \\
\text { DAYS }\end{array}$ & $\begin{array}{l}\text { PER } \\
\text { CENT } \\
\text { DAYS }\end{array}$ & CLASS & $\begin{array}{c}\text { CUBIC } \\
\text { FEET } \\
\text { PER } \\
\text { SEOOND }\end{array}$ & $\begin{array}{l}\text { TOTAL } \\
\text { DAYS }\end{array}$ & $\begin{array}{c}\text { ACCU- } \\
\text { MU } \\
\text { LATED } \\
\text { DAYS }\end{array}$ & $\begin{array}{l}\text { PER- } \\
\text { CENT } \\
\text { DAYS }\end{array}$ \\
\hline $\begin{array}{l}0 \\
1 \\
2 \\
3 \\
4 \\
5 \\
6 \\
7 \\
8\end{array}$ & $\begin{array}{l}0.00 \\
0.10 \\
0.13 \\
0.17 \\
0.22 \\
0.28 \\
0.37 \\
0.48 \\
0.62\end{array}$ & $\begin{array}{r}3026 \\
31 \\
0 \\
12 \\
0 \\
11 \\
3 \\
7 \\
1\end{array}$ & $\begin{array}{r}3288 \\
262 \\
231 \\
231 \\
219 \\
219 \\
208 \\
205 \\
198\end{array}$ & $\begin{array}{r}100.0 \\
8.0 \\
7.0 \\
7.0 \\
6.7 \\
6.7 \\
6.3 \\
6.2 \\
6.0\end{array}$ & $\begin{array}{r}9 \\
10 \\
11 \\
12 \\
13 \\
14 \\
15 \\
16 \\
17\end{array}$ & $\begin{array}{l}0.80 \\
1.00 \\
1.40 \\
1.70 \\
2.30 \\
2.90 \\
3.80 \\
4.90 \\
6.40\end{array}$ & $\begin{array}{r}4 \\
32 \\
7 \\
13 \\
10 \\
14 \\
13 \\
10 \\
6\end{array}$ & $\begin{array}{r}197 \\
193 \\
161 \\
154 \\
141 \\
131 \\
117 \\
104 \\
94\end{array}$ & $\begin{array}{l}6.0 \\
5.9 \\
4.9 \\
4.7 \\
4.3 \\
4.0 \\
3.6 \\
3.2 \\
2.9\end{array}$ & $\begin{array}{l}18 \\
19 \\
20 \\
21 \\
22 \\
23 \\
24 \\
25 \\
26\end{array}$ & $\begin{array}{r}8.3 \\
11.0 \\
14.0 \\
18.0 \\
23.0 \\
30.0 \\
39.0 \\
51.0 \\
66.0\end{array}$ & $\begin{array}{r}12 \\
7 \\
11 \\
5 \\
8 \\
7 \\
3 \\
4 \\
5\end{array}$ & $\begin{array}{l}88 \\
76 \\
69 \\
58 \\
53 \\
45 \\
38 \\
35 \\
31\end{array}$ & $\begin{array}{l}2.7 \\
2.3 \\
2.1 \\
1.8 \\
1.6 \\
1.4 \\
1.2 \\
1.1 \\
0.9\end{array}$ & $\begin{array}{l}27 \\
28 \\
29 \\
30 \\
31 \\
32 \\
33 \\
34\end{array}$ & $\begin{array}{r}86.0 \\
110.0 \\
140.0 \\
190.0 \\
240.0 \\
320.0 \\
410.0 \\
530.0\end{array}$ & $\begin{array}{l}6 \\
3 \\
4 \\
4 \\
3 \\
1 \\
3 \\
2\end{array}$ & $\begin{array}{r}26 \\
20 \\
17 \\
13 \\
9 \\
6 \\
5 \\
2\end{array}$ & $\begin{array}{l}0 . \\
0 . \\
0 .\end{array}$ \\
\hline
\end{tabular}

MONIHLY MEAN DISCHARGES, IN CBBIC FEET PER SECOND, FOR EACH WATER YEAR

$\begin{array}{llccccccccccc}\text { YEAR } & \text { OT } & \text { NOV } & \text { DEC } & \text { JAN } & \text { FEB } & \text { MAR } & \text { APR } & \text { MAY } & \text { JUNE } & \text { JULY } & \text { AUG } & \text { SEP } \\ 1960 & 0.08 & 0.48 & 1.55 & 0.00 & 0.00 & 2.20 & 0.14 & 0.50 & 0.00 & 0.00 & 1.25 & 10.3 \\ & & & & & & & & & & & & \\ 1961 & 2.82 & 0.18 & 0.00 & 0.00 & 0.00 & 0.00 & 1.45 & 0.00 & 0.00 & 3.71 & 10.3 & 15.4 \\ 1962 & 0.46 & 0.03 & 0.00 & 0.00 & 0.08 & 0.00 & 0.56 & 0.00 & 0.00 & 0.00 & 0.00 & 8.87 \\ 1963 & 1.06 & 0.74 & 0.00 & 0.00 & 0.33 & 0.00 & 0.00 & 0.00 & 0.00 & 0.08 & 15.9 & 14.5 \\ 1964 & 1.35 & 0.00 & 0.00 & 0.00 & 0.00 & 0.00 & 0.00 & 0.00 & 0.00 & 0.00 & 11.7 & 0.00 \\ 1965 & 0.00 & 0.00 & 0.00 & 0.00 & 0.00 & 0.00 & 0.01 & 0.36 & 0.00 & 0.98 & 0.00 & 2.97 \\ 1966 & 1.95 & 1.74 & 4.09 & 0.06 & 0.05 & 2.71 & 2.02 & 0.00 & 0.00 & 3.70 & 3.81 & 3.44 \\ 1967 & 0.61 & 3.63 & 21.8 & 0.00 & 0.00 & 0.00 & 0.00 & 0.00 & 13.8 & 24.6 & 16.5 & 0.00 \\ 1968 & 0.00 & 0.00 & 0.00 & 0.00 & 0.03 & 0.00 & 0.00 & 0.00 & 0.00 & 19.7 & 62.6 & 0.00\end{array}$

ANUAAL PEAR DISCHARGE, IN COBIC FEET PER SECOND, AND CORRESPONDING GAGE HEIGHT, IN FEET, FOR EACH WATER YEAR

\begin{tabular}{|c|c|c|c|c|c|c|c|c|c|c|c|}
\hline $\begin{array}{l}\text { WATER } \\
\text { YEAR }\end{array}$ & DATE & $\begin{array}{c}\text { GAGE } \\
\text { HEIGHI }\end{array}$ & $\begin{array}{c}\text { PEAR } \\
\text { DISCHARGE }\end{array}$ & $\begin{array}{l}\text { WATEER } \\
\text { YEAR }\end{array}$ & DATE & $\begin{array}{c}\text { GAGE } \\
\text { HEIGHT }\end{array}$ & $\begin{array}{c}\text { PEAR } \\
\text { DISCHARGE }\end{array}$ & $\begin{array}{l}\text { WATYER } \\
\text { YEAR }\end{array}$ & DATE & $\begin{array}{c}\text { GAGE } \\
\text { HEIGHI }\end{array}$ & $\begin{array}{c}\text { PEAR } \\
\text { DISCHARGE }\end{array}$ \\
\hline $\begin{array}{l}1959 \\
1960 \\
1961 \\
1962\end{array}$ & $\begin{array}{l}\text { AUG. 04， } 1959 \\
\text { SEPT.01， } 1960 \\
\text { AUG. 29， } 1961 \\
\text { SEPT.27， } 1962\end{array}$ & $\begin{array}{l}3.32 \\
2.24 \\
2.82 \\
2.30\end{array}$ & $\begin{array}{l}2840 \\
1170 \\
1660 \\
1080\end{array}$ & $\begin{array}{l}1963 \\
1964 \\
1965\end{array}$ & $\begin{array}{l}\text { AUG. } 30,1963 \\
\text { AUG. } 02,1964 \\
\text { SEPT.18, } 1965\end{array}$ & $\begin{array}{l}2.65 \\
2.25\end{array}$ & $\begin{array}{l}1720 \\
1800 \\
1140\end{array}$ & $\begin{array}{l}1966 \\
1967 \\
1968\end{array}$ & $\begin{array}{l}\text { DEC. } 11,1965 \\
\text { AUG. } 10,1967 \\
\text { AUG. } 01,1968\end{array}$ & $\begin{array}{l}2.32 \\
3.35 \\
5.57\end{array}$ & $\begin{array}{l}1240 \\
2760 \\
8390\end{array}$ \\
\hline
\end{tabular}

09379300 LIME CREEK NEAR MEXICAN HAT, UT

LOCATION.--Lat $37^{\circ} 13^{\prime} 07^{\prime \prime}$, long $109^{\circ} 49^{\prime} 35^{\prime \prime}$, in SEl sec.16, T.41 S., R.19 E., San Juan County, Hydrologic Unit 14080205, about 1.5 mi below Left Fork Lime Creek, about $3 \mathrm{mi}$ above mouth, and $5 \mathrm{mi}$ northeast of Mexican Hat.

DRAINAGE AREA. $-32 \mathrm{mi}^{2}$.

MEAN BASIN ELEVATION. $-5,360 \mathrm{ft}$.

PERIOD OF RECORD AVAIIABLE.--Water years 1959-73, annual peak discharge only.

GAGE.-Crest-stage gage. Altitude of gage is 4,320 ft from topographic map.

ANNUAL PEAK DISCHARGE, IN CUBIC FEET PER SECOND, AND CORRESPONDING GAGE HEIGHT, IN FEET, FOR EACH WATER YEAR

\begin{tabular}{|c|c|c|c|c|c|c|c|c|c|c|c|}
\hline $\begin{array}{l}\text { WATER } \\
\text { YEAR }\end{array}$ & DATE & $\begin{array}{c}\text { GAGE } \\
\text { HEIGHT }\end{array}$ & $\begin{array}{c}\text { PEAR } \\
\text { DISCHARGE }\end{array}$ & $\begin{array}{l}\text { WATHER } \\
\text { YEAR }\end{array}$ & DATE & $\begin{array}{c}\text { GAGE } \\
\text { HEIGHT }\end{array}$ & $\begin{array}{c}\text { PEAR } \\
\text { DISCHARGE }\end{array}$ & $\begin{array}{l}\text { WAIFER } \\
\text { YEAR }\end{array}$ & DATE & $\begin{array}{c}\text { GAGE } \\
\text { HEIGHT }\end{array}$ & $\begin{array}{c}\text { PEAR } \\
\text { DISCHARGE }\end{array}$ \\
\hline $\begin{array}{l}1959 \\
1960 \\
1961 \\
1962 \\
1963\end{array}$ & $\begin{array}{l}\text { AUG. } 01,1959 \\
\text { SEPT.01, } 1960 \\
\text { AUG. 29, } 1961 \\
\text { SEPT.21, } 1962 \\
\text { AUG. 31, } 1963\end{array}$ & $\begin{array}{l}12.25 \\
11.20 \\
12.01 \\
16.55 \\
14.46\end{array}$ & $\begin{array}{r}930 \\
295 \\
760 \\
5930 \\
3230\end{array}$ & $\begin{array}{l}1964 \\
1965 \\
1966 \\
1967 \\
1968\end{array}$ & $\begin{array}{l}\text { AUG. } 01,1964 \\
\text { JUY } 24,1965 \\
\text { DEC. 30, } 1965 \\
\text { SEPT. } 11,1967 \\
\text { OCT. } 03,1967\end{array}$ & $\begin{array}{l}11.83 \\
12.07 \\
11.67 \\
15.97 \\
16.87\end{array}$ & $\begin{array}{r}650 \\
830 \\
530 \\
5100 \\
6600\end{array}$ & $\begin{array}{l}1969 \\
1970 \\
1971 \\
1972 \\
1973\end{array}$ & $\begin{array}{l}\text { AUG. } 29,1969 \\
\text { AUG. 19, } 1970 \\
\text { AUG. } 21,1971 \\
\text { AUG. 15, } 1972 \\
\text { OCT. } 19,1972\end{array}$ & $\begin{array}{l}13.47 \\
15.88 \\
14.07 \\
10.07 \\
15.47\end{array}$ & $\begin{array}{r}2000 \\
5000 \\
2620 \\
53 \\
4300\end{array}$ \\
\hline
\end{tabular}




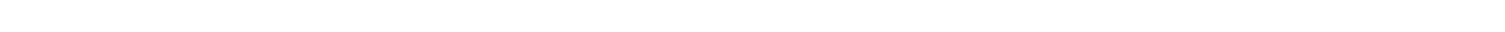
bank 1,600 ft downstream from Gypsum Creek, 1,800 ft upstream fram highway bridge, 20 mi southwest of Bluff, at mile 113.5.

DRAINAGE AREA. $--23,000 \mathrm{mi}^{2}$, approximately.

PERIOD OF RECORD AVAIIABLE.--October 1914 to September 1981. Monthly mean discharge for some periods, published in wSP 1313.

REVISED RECORDS.--WSP 1213: 1940. WSP 1313: 1917, 1929. WSP 1343: 1945.

GAGE.--Water-stage recorder. Datum of gage is 4,048 ft from levels of Topographic Division, of USGS. Prior to Mar. 16, 1927, chain gages at sites about $1,700 \mathrm{ft}$ downstream at different datums.

REMARKS.-Diversions for irrigation of approximately 200,000 acres above station. No diversion between station and mouth of river. Flow regulated by Navajo Reservoir since June $28,1962$.

AVERAGE DISCHARGE. -67 years, $2,538 \mathrm{ft}^{3} / \mathrm{s}, 1,839,000 \mathrm{acre}-\mathrm{ft} / \mathrm{yr}$, unadjusted.

EXIREMES FOR PERIOD OF RECORD.-1914-17, 1927-81: maximum discharge, 70,000 ft 3 /s Sept. 10, 1927, gage height, 32.0 ft, fran rating curve extended above $31,000 \mathrm{ft}^{3} / \mathrm{s}$ and slope-area measurement at gage height $26.62 \mathrm{ft}$; no flow July 3-13, 1934, Aug. 24-27, 29, 1939.

EXTREMES OUTSIDE PERIOD OF RECORD. -Flood of oct. 6, 1911, which is greatest known at Shiprock, NM, probably exceeded that of Sept. 10,1927 at this station but stage was not accurately determined.

DATA BELCW BASED ON PERICD OF RECORD PRIOR TO REGULATION BY NAVAJO RESERVOIR LOWEST MEAN DISCHARGE, IN OBBIC FEET PER SECOND, AND RANKING FOR THE INDICATED NUMBER OF CONSECUTIVE DAYS FOR EACH CLIMATIC YEAR, APRIL 1-MARCH 31

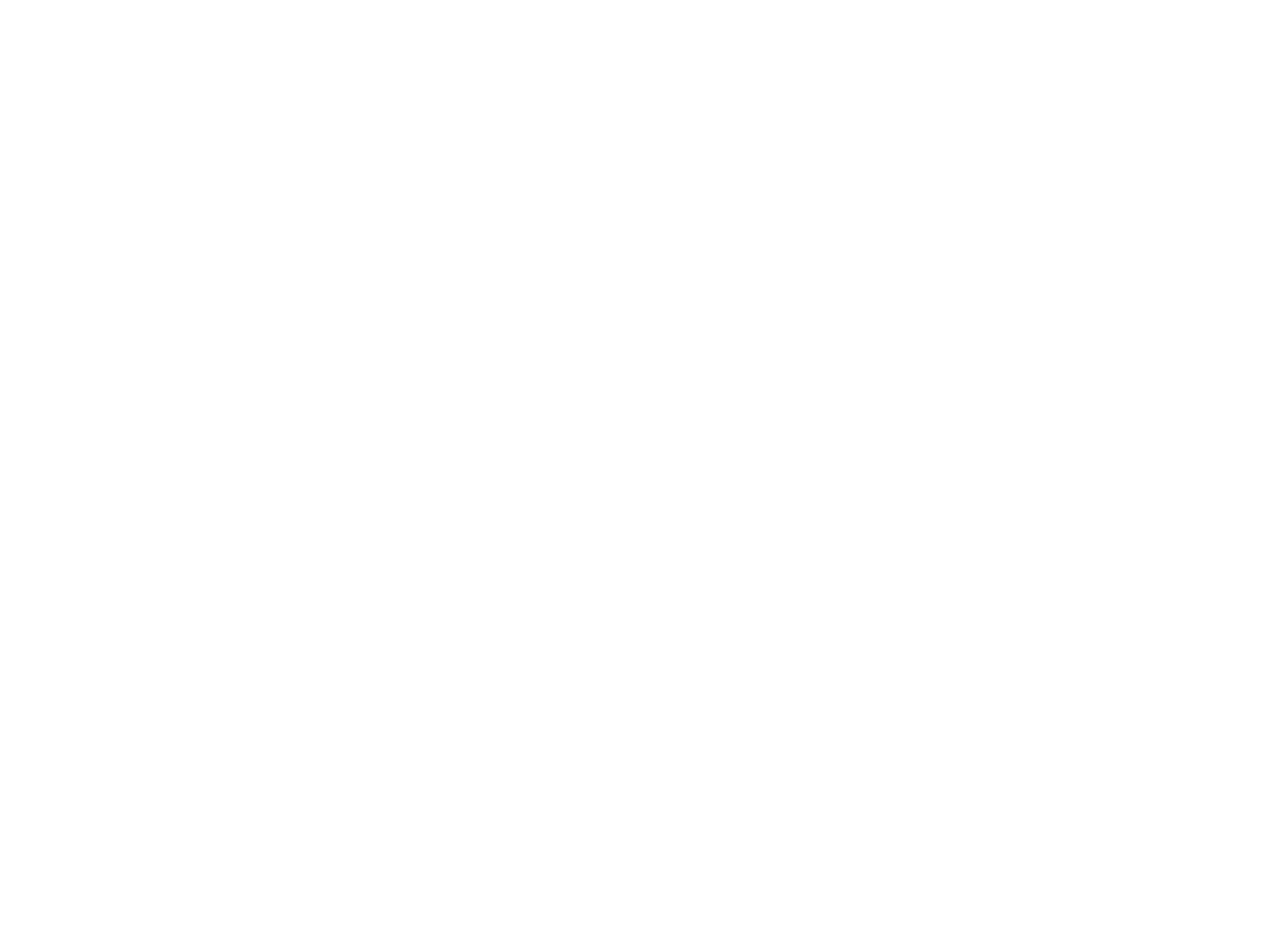


HIGHEST MEAN DISCHARGE, IN OBIC FEET PER SECOND, AND RANKING FOR THE INDICATED NUMBER OF CONSECUTIVE DAYS FOR EACH WATER YEAR, OCTOBER 1-SEPIEMBER 30

YEAR

\begin{tabular}{|c|c|c|c|c|c|c|c|c|c|c|c|c|c|c|c|c|c|c|}
\hline & 1 & 3 & 7 & & 15 & & 30 & & 60 & & 90 & & 120 & & 183 & & AI & كل \\
\hline 916 & 16200 & 1315100 & 1414200 & 13 & 12200 & 13 & 10600 & 13 & 10200 & 8 & 9260 & 7 & 8750 & 2 & 7680 & 2 & 4460 & 2 \\
\hline 928 & 11800 & 1811500 & 1610500 & 15 & 8610 & 16 & 7240 & 17 & 6090 & 16 & 4930 & 18 & 4270 & 18 & 3290 & 19 & 2380 & 14 \\
\hline $\begin{array}{l}931 \\
.932 \\
933 \\
.934 \\
935\end{array}$ & $\begin{array}{r}5640 \\
16500 \\
11900 \\
5800 \\
18500\end{array}$ & $\begin{array}{rr}32 & 5340 \\
11 & 15300 \\
17 & 11300 \\
31 & 4890 \\
8 & 17200\end{array}$ & $\begin{array}{rr}31 & 5120 \\
13 & 15000 \\
17 & 10000 \\
32 & 3640 \\
7 & 16700\end{array}$ & $\begin{array}{r}30 \\
10 \\
17 \\
33 \\
6\end{array}$ & $\begin{array}{r}4670 \\
13400 \\
8700 \\
3160 \\
15300\end{array}$ & $\begin{array}{r}28 \\
11 \\
15 \\
33 \\
4\end{array}$ & $\begin{array}{r}4290 \\
11200 \\
7750 \\
3000 \\
12800\end{array}$ & $\begin{array}{r}27 \\
11 \\
14 \\
33 \\
7\end{array}$ & $\begin{array}{r}3450 \\
10000 \\
5560 \\
2270 \\
10100\end{array}$ & $\begin{array}{r}27 \\
10 \\
17 \\
33 \\
9\end{array}$ & $\begin{array}{l}2920 \\
9300 \\
4140 \\
1780 \\
8200\end{array}$ & $\begin{array}{r}27 \\
5 \\
20 \\
33 \\
13\end{array}$ & $\begin{array}{l}2400 \\
8140 \\
3380 \\
1480 \\
7050\end{array}$ & $\begin{array}{r}28 \\
5 \\
21 \\
33 \\
12\end{array}$ & $\begin{array}{l}1890 \\
6520 \\
2690 \\
1170 \\
5370\end{array}$ & $\begin{array}{r}29 \\
3 \\
21 \\
33 \\
12\end{array}$ & $\begin{array}{r}1230 \\
4060 \\
1720 \\
914 \\
3020\end{array}$ & $\begin{array}{l}21 \\
33 \\
13\end{array}$ \\
\hline $\begin{array}{l}936 \\
937 \\
938 \\
939 \\
940\end{array}$ & $\begin{array}{l}11500 \\
16500 \\
17000 \\
11000 \\
12100\end{array}$ & $\begin{array}{rr}19 & 10600 \\
12 & 15400 \\
10 & 16100 \\
20 & 7390 \\
16 & 6670\end{array}$ & $\begin{array}{rr}18 & 8730 \\
12 & 14500 \\
10 & 15500 \\
23 & 5860 \\
28 & 6430\end{array}$ & $\begin{array}{r}20 \\
11 \\
8 \\
27 \\
23\end{array}$ & $\begin{array}{r}7700 \\
13300 \\
13700 \\
5550 \\
5790\end{array}$ & $\begin{array}{r}20 \\
12 \\
9 \\
26 \\
24\end{array}$ & $\begin{array}{r}7300 \\
11300 \\
12100 \\
5110 \\
5160\end{array}$ & $\begin{array}{r}16 \\
10 \\
9 \\
25 \\
24\end{array}$ & $\begin{array}{r}6600 \\
10400 \\
9850 \\
4350 \\
3940\end{array}$ & $\begin{array}{r}15 \\
7 \\
11 \\
23 \\
24\end{array}$ & $\begin{array}{l}5210 \\
8610 \\
9210 \\
4080 \\
3100\end{array}$ & $\begin{array}{r}16 \\
11 \\
8 \\
21 \\
25\end{array}$ & $\begin{array}{l}4480 \\
7430 \\
7580 \\
3380 \\
2590\end{array}$ & $\begin{array}{r}17 \\
11 \\
9 \\
22 \\
26\end{array}$ & $\begin{array}{l}3560 \\
5640 \\
5690 \\
2440 \\
2010\end{array}$ & $\begin{array}{r}17 \\
8 \\
7 \\
23 \\
25\end{array}$ & $\begin{array}{l}2250 \\
3230 \\
3410 \\
1710 \\
1370\end{array}$ & 24 \\
\hline $\begin{array}{l}1946 \\
1947 \\
1948 \\
1949 \\
1950\end{array}$ & $\begin{array}{r}6130 \\
23800 \\
23000 \\
25400 \\
4900\end{array}$ & $\begin{array}{rr}30 & 6040 \\
5 & 19900 \\
6 & 16800 \\
4 & 24300 \\
33 & 4860\end{array}$ & $\begin{array}{rr}29 & 5830 \\
5 & 12900 \\
9 & 15500 \\
3 & 20500 \\
33 & 4360\end{array}$ & $\begin{array}{r}28 \\
14 \\
9 \\
2 \\
32\end{array}$ & $\begin{array}{r}5060 \\
8770 \\
14000 \\
16700 \\
4070\end{array}$ & $\begin{array}{r}27 \\
14 \\
7 \\
2 \\
32\end{array}$ & $\begin{array}{r}3470 \\
5860 \\
12700 \\
12800 \\
3630\end{array}$ & $\begin{array}{r}32 \\
21 \\
8 \\
6 \\
31\end{array}$ & $\begin{array}{r}2870 \\
5140 \\
9720 \\
10500 \\
3170\end{array}$ & $\begin{array}{r}31 \\
21 \\
12 \\
6 \\
29\end{array}$ & $\begin{array}{l}2370 \\
4070 \\
8300 \\
9530 \\
2800\end{array}$ & $\begin{array}{r}31 \\
22 \\
12 \\
4 \\
28\end{array}$ & $\begin{array}{l}2050 \\
4210 \\
6850 \\
8070 \\
2380\end{array}$ & $\begin{array}{r}31 \\
20 \\
13 \\
6 \\
30\end{array}$ & $\begin{array}{l}1680 \\
3310 \\
5050 \\
6090 \\
1870\end{array}$ & $\begin{array}{r}31 \\
18 \\
13 \\
6 \\
30\end{array}$ & $\begin{array}{l}1190 \\
2060 \\
3190 \\
3480 \\
1250\end{array}$ & $\begin{array}{l}0 \\
9 \\
1 \\
8 \\
8\end{array}$ \\
\hline $\begin{array}{l}1951 \\
1952 \\
1953 \\
1954 \\
1955\end{array}$ & $\begin{array}{r}9720 \\
18600 \\
8290 \\
8240 \\
6220\end{array}$ & $\begin{array}{rr}23 & 7010 \\
7 & 18400 \\
25 & 7330 \\
26 & 7450 \\
29 & 5850\end{array}$ & $\begin{array}{rr}25 & 6010 \\
6 & 17800 \\
24 & 6420 \\
22 & 4880 \\
30 & 5230\end{array}$ & $\begin{array}{r}26 \\
3 \\
24 \\
31 \\
29\end{array}$ & $\begin{array}{r}4470 \\
16700 \\
5860 \\
4330 \\
4250\end{array}$ & $\begin{array}{r}29 \\
3 \\
23 \\
30 \\
31\end{array}$ & $\begin{array}{r}3830 \\
13100 \\
5430 \\
3760 \\
3860\end{array}$ & $\begin{array}{r}29 \\
4 \\
22 \\
30 \\
28\end{array}$ & $\begin{array}{r}2800 \\
11800 \\
3640 \\
3030 \\
3280\end{array}$ & $\begin{array}{r}32 \\
2 \\
26 \\
30 \\
28\end{array}$ & $\begin{array}{r}2070 \\
10300 \\
2960 \\
2550 \\
2600\end{array}$ & $\begin{array}{r}32 \\
2 \\
26 \\
30 \\
29\end{array}$ & $\begin{array}{l}1730 \\
8700 \\
2600 \\
2390 \\
2480\end{array}$ & $\begin{array}{r}32 \\
3 \\
25 \\
29 \\
27\end{array}$ & $\begin{array}{l}1350 \\
6190 \\
2020 \\
2000 \\
2000\end{array}$ & $\begin{array}{r}32 \\
5 \\
24 \\
26 \\
27\end{array}$ & $\begin{array}{r}923 \\
3500 \\
1310 \\
1360 \\
1370\end{array}$ & $\frac{7}{6}$ \\
\hline $\begin{array}{l}1956 \\
1957 \\
1958 \\
1959 \\
1960\end{array}$ & $\begin{array}{r}6970 \\
26000 \\
16100 \\
3810 \\
8800\end{array}$ & $\begin{array}{rr}27 & 6720 \\
3 & 20900 \\
14 & 15900 \\
34 & 3710 \\
24 & 8350\end{array}$ & $\begin{array}{rr}27 & 6280 \\
4 & 17200 \\
11 & 15600 \\
34 & 3430 \\
21 & 7550\end{array}$ & $\begin{array}{r}25 \\
5 \\
7 \\
34 \\
21\end{array}$ & $\begin{array}{r}5600 \\
14200 \\
14600 \\
3150 \\
7070\end{array}$ & $\begin{array}{r}25 \\
6 \\
5 \\
34 \\
21\end{array}$ & $\begin{array}{r}4960 \\
13800 \\
13600 \\
2760 \\
6600\end{array}$ & $\begin{array}{r}26 \\
2 \\
3 \\
34 \\
19\end{array}$ & $\begin{array}{r}3810 \\
11300 \\
11800 \\
2220 \\
5560\end{array}$ & $\begin{array}{r}25 \\
5 \\
3 \\
34 \\
18\end{array}$ & $\begin{array}{l}3150 \\
9730 \\
9280 \\
1730 \\
5730\end{array}$ & $\begin{array}{r}24 \\
3 \\
6 \\
34 \\
15\end{array}$ & $\begin{array}{l}2620 \\
8610 \\
7680 \\
1440 \\
5360\end{array}$ & $\begin{array}{r}24 \\
4 \\
7 \\
34 \\
14\end{array}$ & $\begin{array}{l}1950 \\
6500 \\
5570 \\
1150 \\
3860\end{array}$ & $\begin{array}{r}28 \\
4 \\
9 \\
34 \\
14\end{array}$ & $\begin{array}{r}1190 \\
3590 \\
3520 \\
854 \\
2330\end{array}$ & $\begin{array}{r}6 \\
34 \\
16\end{array}$ \\
\hline
\end{tabular}

DURATION OF DISCHARGE FOR EACH WATER YEAR

CLASS $0 \begin{array}{llllllllllllllllllllllllllllllllllllll} & 0 & 2 & 3 & 4 & 5 & 6 & 7 & 8 & 9 & 10 & 11 & 12 & 13 & 14 & 15 & 16 & 17 & 18 & 19 & 20 & 21 & 22 & 23 & 24 & 25 & 26 & 27 & 28 & 29 & 30 & 31 & 32 & 33 & 34\end{array}$

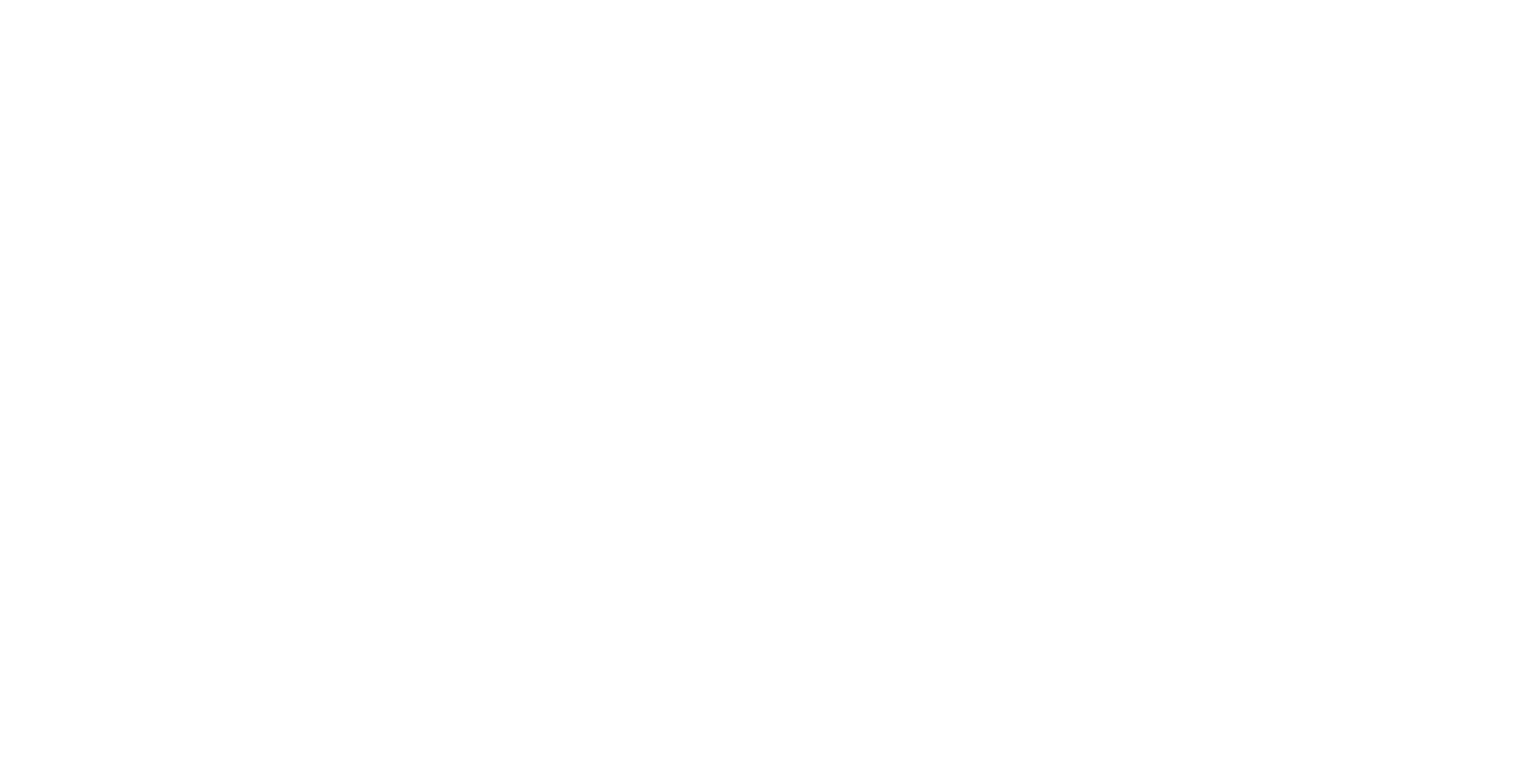


09379500 SAN JUAN RIVER NEAR BLUFF, UT-Continued

DURATION OF DISCHARGE FOR EACH WATER YEAR-Continued

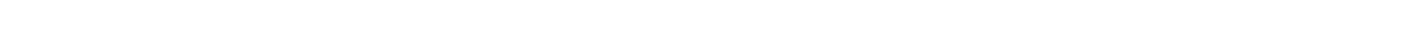

YEAR

1951

1952

1953

1955

1956

1957
1958

1959

1961
NUMBER OF DAYS IN O.ASS

$\begin{array}{llllllllllllllll}3 & 14 & 13 & 7 & 21 & 56 & 135 & 38 & 11 & 17 & 11 & 20 & 12 & 3 & 3 & 1\end{array}$

$\begin{array}{llllllllllllll} & 49 & 49 & 58 & 41 & 25 & 25 & 10 & 11 & 21 & 30 & 27 & 16 & 10\end{array}$

$\begin{array}{llllllllllllll}14 & 7 & 7 & 9 & 72 & 102 & 42 & 40 & 17 & 15 & 9 & 17 & 8\end{array}$

$\begin{array}{lllllllllllll}3 & 8 & 4 & 21 & 81 & 73 & 36 & 43 & 35 & 29 & 21 & 7 & 4\end{array}$

$\begin{array}{llllllllllllllllll}9 & 3 & 4 & 4 & 10 & 7 & 6 & 10 & 48 & 96 & 43 & 22 & 26 & 23 & 18 & 11 & 20 & 4\end{array}$

$\begin{array}{lllllllllllllllllllll}2 & 2 & 1 & 9 & 4 & 3 & 13 & 26 & 61 & 18 & 29 & 34 & 11 & 19 & 26 & 36 & 22 & 19 & 22 & 6 & 0\end{array}$

$\begin{array}{llllllllllllllllll}8 & 2 & 1 & 5 & 5 & 5 & 10 & 11 & 7 & 20 & 130 & 58 & 38 & 23 & 14 & 18 & 10\end{array}$

$\begin{array}{llllllllllllll}10 & 17 & 14 & 15 & 21 & 76 & 49 & 19 & 13 & 19 & 21 & 38 & 46 & 1\end{array}$

$\begin{array}{lllllllllllll}1 & 7 & 13 & 10 & 75 & 79 & 25 & 39 & 30 & 30 & 29 & 15 & 12\end{array}$

CUBIC FEET PER SECOND

336943.0

1281592.0

476686.0

496508.0

434373.0

1308581.0

1285959.0

311626.0

852255.0

598892.0

DURATION TABLE OF DISCHARGE FOR WATER YEARS 1916, 1928, 1930-61

$\begin{array}{lll}\text { CUBIC } & \text { ACO- } \\ \text { FEET } & \text { MU- } & \text { PER- } \\ \text { PER TOTAL LATED } & \text { CENT }\end{array}$

O.ASS SECOND DAYS DAYS DAYS

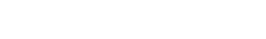

$\begin{array}{rrrr}0.00 & 16 & 12420 & 100.0 \\ 1.00 & 5 & 12404 & 99.9\end{array}$

$\begin{array}{llll}1.40 & 0 & 12399 & 99.8\end{array}$

$\begin{array}{llll}1.90 & 1 & 12399 & 99.8\end{array}$

$\begin{array}{llll}2.60 & 1 & 12398 & 99.8\end{array}$

$\begin{array}{llll}3.60 & 1 & 12397 & 99.8\end{array}$

$5.00-112396 \quad 99.8$

$\begin{array}{llll}6.90 & 4 & 12395 & 99.8 \\ 9.60 & 3 & 12391 & 99.8\end{array}$

$$
\begin{array}{lll}
\text { CUBIC } & \text { ACOU- } \\
\text { FEET } & \text { MU- } & \text { PER- } \\
\text { PER TOTAL LATED } & \text { CENT }
\end{array}
$$

LASS SECOND DAYS DAYS DAYS

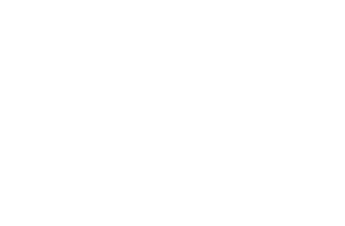$$
\text { c. }
$$

OUBIC ACOU-

FEET MU- PERCLASS SECOND DAYS DAYS DAYS

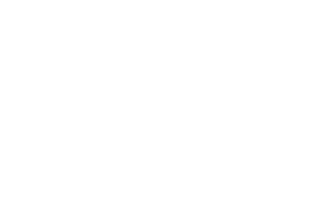

CISS PER TOTAL LATED CENT DAYS DAYS DAYS

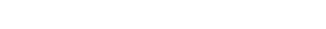
$\begin{array}{llllll}29 & 8500.0 & 433 & 770 & 6.2\end{array}$ $\begin{array}{lllll}30 & 12000.0 & 245 & 337 & 2.7\end{array}$

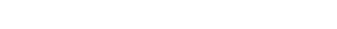

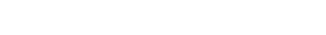
$\begin{array}{ll}3 & 0.0\end{array}$ $\begin{array}{lllll}28 & 6100.0 & 603 & 1373 & 11.1\end{array}$

MONTHLY MEAN DISCHARGES, IN OUBIC FEET PER SECOND, FOR EACH WATER YEAR

\begin{tabular}{|c|c|c|c|c|c|c|c|c|c|c|c|c|}
\hline YEAR & $\propto C T$ & NOV & DEC & JAN & FEB & MAR & APR & MAY & JUNE & JULY & AUG & SEP \\
\hline 1915 & 2405 & 1578 & 1018 & 1014 & 2328 & 2230 & 8037 & 9269 & 10090 & 6485 & 1663 & 1050 \\
\hline $\begin{array}{l}1916 \\
1917 \\
1918 \\
1919 \\
1920\end{array}$ & $\begin{array}{r}941 \\
9000 \\
725 \\
615 \\
1010\end{array}$ & $\begin{array}{r}667 \\
2300 \\
576 \\
702 \\
1003\end{array}$ & $\begin{array}{r}637 \\
1000 \\
449 \\
607 \\
1301\end{array}$ & $\begin{array}{r}1307 \\
1100 \\
407 \\
512 \\
1556\end{array}$ & $\begin{array}{r}1401 \\
1400 \\
924 \\
940 \\
4306\end{array}$ & $\begin{array}{l}6207 \\
1371 \\
1935 \\
1687 \\
3498\end{array}$ & $\begin{array}{l}7566 \\
5915 \\
2079 \\
6033 \\
5729\end{array}$ & $\begin{array}{r}9338 \\
9108 \\
4830 \\
10050 \\
18250\end{array}$ & $\begin{array}{r}10510 \\
13980 \\
6636 \\
6882 \\
16610\end{array}$ & $\begin{array}{l}5161 \\
8475 \\
2765 \\
5334 \\
7603\end{array}$ & $\begin{array}{l}7123 \\
2100 \\
1220 \\
3165 \\
2722\end{array}$ & $\begin{array}{l}2589 \\
1000 \\
2521 \\
1496 \\
1042\end{array}$ \\
\hline $\begin{array}{l}1921 \\
1922 \\
1923 \\
1924 \\
1925\end{array}$ & $\begin{array}{r}1106 \\
945 \\
325 \\
2298 \\
571\end{array}$ & $\begin{array}{r}1410 \\
781 \\
719 \\
1681 \\
652\end{array}$ & $\begin{array}{r}1025 \\
828 \\
893 \\
1220 \\
740\end{array}$ & $\begin{array}{r}1057 \\
733 \\
777 \\
927 \\
559\end{array}$ & $\begin{array}{r}1559 \\
1350 \\
1505 \\
1999 \\
810\end{array}$ & $\begin{array}{l}2770 \\
2290 \\
1220 \\
1164 \\
1566\end{array}$ & $\begin{array}{l}2738 \\
5882 \\
3633 \\
5779 \\
3346\end{array}$ & $\begin{array}{r}7806 \\
12510 \\
8424 \\
8929 \\
5172\end{array}$ & $\begin{array}{r}13620 \\
13170 \\
8193 \\
6309 \\
4916\end{array}$ & $\begin{array}{l}6149 \\
3188 \\
3741 \\
1421 \\
3032\end{array}$ & $\begin{array}{r}7361 \\
1220 \\
3716 \\
559 \\
2196\end{array}$ & $\begin{array}{r}2521 \\
370 \\
3912 \\
351 \\
5546\end{array}$ \\
\hline $\begin{array}{l}1926 \\
1927 \\
1928 \\
1929 \\
1930\end{array}$ & $\begin{array}{r}3867 \\
1659 \\
3179 \\
847 \\
2201\end{array}$ & $\begin{array}{r}1681 \\
891 \\
2092 \\
1384 \\
1068\end{array}$ & $\begin{array}{r}1171 \\
846 \\
971 \\
754 \\
672\end{array}$ & $\begin{array}{r}1397 \\
828 \\
973 \\
613 \\
476\end{array}$ & $\begin{array}{r}1545 \\
1484 \\
1473 \\
875 \\
1262\end{array}$ & $\begin{array}{l}4127 \\
2050 \\
2159 \\
2460 \\
1247\end{array}$ & $\begin{array}{l}8278 \\
6092 \\
2610 \\
5652 \\
4438\end{array}$ & $\begin{array}{r}8907 \\
11020 \\
6829 \\
9515 \\
4400\end{array}$ & $\begin{array}{r}2358 \\
10070 \\
5181 \\
8579 \\
5718\end{array}$ & $\begin{array}{r}956 \\
6558 \\
1436 \\
3891 \\
2597\end{array}$ & $\begin{array}{r}706 \\
1991 \\
895 \\
9335 \\
4022\end{array}$ & $\begin{array}{r}2994 \\
11870 \\
713 \\
7739 \\
435\end{array}$ \\
\hline $\begin{array}{l}1931 \\
1932 \\
1933 \\
1934 \\
1935\end{array}$ & $\begin{array}{r}557 \\
2546 \\
803 \\
1613 \\
354\end{array}$ & $\begin{array}{r}554 \\
1135 \\
636 \\
619 \\
345\end{array}$ & $\begin{array}{l}410 \\
740 \\
433 \\
666 \\
438\end{array}$ & $\begin{array}{l}335 \\
572 \\
471 \\
567 \\
653\end{array}$ & $\begin{array}{r}905 \\
3604 \\
866 \\
576 \\
898\end{array}$ & $\begin{array}{r}616 \\
3354 \\
1191 \\
695 \\
1241\end{array}$ & $\begin{array}{l}1327 \\
7910 \\
1093 \\
1829 \\
4264\end{array}$ & $\begin{array}{r}3388 \\
10410 \\
2759 \\
2456 \\
6073\end{array}$ & $\begin{array}{r}3334 \\
9268 \\
7378 \\
577 \\
12780\end{array}$ & $\begin{array}{r}1163 \\
4157 \\
2158 \\
264 \\
4851\end{array}$ & $\begin{array}{r}854 \\
3490 \\
647 \\
460 \\
2069\end{array}$ & $\begin{array}{r}1290 \\
1629 \\
2214 \\
615 \\
2266\end{array}$ \\
\hline $\begin{array}{l}1936 \\
1937 \\
1938 \\
1939 \\
1940\end{array}$ & $\begin{array}{r}1115 \\
1080 \\
1453 \\
1746 \\
630\end{array}$ & $\begin{array}{r}692 \\
1208 \\
613 \\
968 \\
615\end{array}$ & $\begin{array}{l}520 \\
782 \\
597 \\
770 \\
476\end{array}$ & $\begin{array}{l}590 \\
403 \\
592 \\
700 \\
638\end{array}$ & $\begin{array}{r}872 \\
2530 \\
850 \\
615 \\
868\end{array}$ & $\begin{array}{l}2236 \\
3139 \\
3047 \\
2313 \\
1207\end{array}$ & $\begin{array}{l}5305 \\
9018 \\
6415 \\
3208 \\
2105\end{array}$ & $\begin{array}{r}6905 \\
10960 \\
7899 \\
5098 \\
4696\end{array}$ & $\begin{array}{r}3212 \\
5572 \\
11480 \\
2694 \\
2121\end{array}$ & $\begin{array}{r}664 \\
2661 \\
3772 \\
269 \\
527\end{array}$ & $\begin{array}{c}2530 \\
625 \\
803 \\
80.4 \\
693\end{array}$ & $\begin{array}{r}2309 \\
796 \\
3377 \\
2040 \\
1926\end{array}$ \\
\hline $\begin{array}{l}1941 \\
1942 \\
1943 \\
1944 \\
1945\end{array}$ & $\begin{array}{r}2372 \\
10650 \\
606 \\
949 \\
1224\end{array}$ & $\begin{array}{r}1119 \\
3210 \\
652 \\
983 \\
866\end{array}$ & $\begin{array}{r}1323 \\
1699 \\
702 \\
831 \\
695\end{array}$ & $\begin{array}{r}1265 \\
1319 \\
704 \\
607 \\
665\end{array}$ & $\begin{array}{r}2281 \\
1219 \\
885 \\
851 \\
1130\end{array}$ & $\begin{array}{l}3436 \\
2051 \\
1545 \\
1232 \\
1168\end{array}$ & $\begin{array}{r}6594 \\
10120 \\
4931 \\
3425 \\
3300\end{array}$ & $\begin{array}{r}21520 \\
7791 \\
5392 \\
10410 \\
7419\end{array}$ & $\begin{array}{r}15380 \\
8961 \\
4265 \\
11840 \\
6335\end{array}$ & $\begin{array}{l}8554 \\
2445 \\
1725 \\
4604 \\
2077\end{array}$ & $\begin{array}{r}2827 \\
825 \\
1481 \\
992 \\
1559\end{array}$ & $\begin{array}{r}3398 \\
639 \\
1047 \\
1114 \\
361\end{array}$ \\
\hline $\begin{array}{l}1946 \\
1947 \\
1948 \\
1949 \\
1950\end{array}$ & $\begin{array}{r}1008 \\
894 \\
3362 \\
1219 \\
912\end{array}$ & $\begin{array}{r}777 \\
1012 \\
1296 \\
924 \\
750\end{array}$ & $\begin{array}{r}491 \\
742 \\
1064 \\
670 \\
562\end{array}$ & $\begin{array}{r}601 \\
500 \\
852 \\
1024 \\
671\end{array}$ & $\begin{array}{r}647 \\
814 \\
1370 \\
1331 \\
878\end{array}$ & $\begin{array}{r}763 \\
836 \\
1456 \\
2479 \\
915\end{array}$ & $\begin{array}{l}1591 \\
1143 \\
6023 \\
5687 \\
2282\end{array}$ & $\begin{array}{l}2035 \\
5351 \\
8442 \\
8184 \\
2754\end{array}$ & $\begin{array}{r}3427 \\
4638 \\
10130 \\
12570 \\
3211\end{array}$ & $\begin{array}{l}1030 \\
1783 \\
2390 \\
5555 \\
1112\end{array}$ & $\begin{array}{r}1224 \\
4773 \\
1393 \\
1466 \\
237\end{array}$ & $\begin{array}{r}742 \\
2090 \\
597 \\
694 \\
702\end{array}$ \\
\hline
\end{tabular}


SAN JUAN RIVER BASIN

09379500 SAN JUAN RIVER NEAR BLUFF, UT-Continued

MONTHLY MEAN DISGAARES, IN OBBIC FEET PER SECOND, FOR EAOH WATER YEAR-Continued

\begin{tabular}{|c|c|c|c|c|c|c|c|c|c|c|c|c|}
\hline YEAR & $\propto C T$ & NOV & $\mathrm{DEC}$ & JAN & FEB & MAR & APR & MAY & JUNE & JULY & AUG & SEP \\
\hline $\begin{array}{l}1951 \\
1952 \\
1953 \\
1954 \\
1955\end{array}$ & $\begin{array}{r}488 \\
573 \\
611 \\
876 \\
1552\end{array}$ & $\begin{array}{l}416 \\
653 \\
684 \\
923 \\
659\end{array}$ & $\begin{array}{l}528 \\
581 \\
706 \\
560 \\
563\end{array}$ & $\begin{array}{r}483 \\
1431 \\
687 \\
525 \\
500\end{array}$ & $\begin{array}{l}528 \\
702 \\
640 \\
646 \\
609\end{array}$ & $\begin{array}{r}548 \\
1413 \\
904 \\
780 \\
1024\end{array}$ & $\begin{array}{r}573 \\
7604 \\
1802 \\
1895 \\
1050\end{array}$ & $\begin{array}{r}2301 \\
10040 \\
2541 \\
3543 \\
3030\end{array}$ & $\begin{array}{r}3169 \\
12930 \\
4494 \\
2015 \\
3498\end{array}$ & $\begin{array}{r}490 \\
3873 \\
1248 \\
1947 \\
1053\end{array}$ & $\begin{array}{r}803 \\
1354 \\
1154 \\
1070 \\
2317\end{array}$ & $\begin{array}{r}754 \\
948 \\
200 \\
1500 \\
463\end{array}$ \\
\hline $\begin{array}{l}1956 \\
1957 \\
1958 \\
1959 \\
1960\end{array}$ & $\begin{array}{r}400 \\
205 \\
2443 \\
766 \\
1494\end{array}$ & $\begin{array}{r}520 \\
496 \\
2375 \\
725 \\
1378\end{array}$ & $\begin{array}{r}576 \\
408 \\
1427 \\
586 \\
754\end{array}$ & $\begin{array}{l}658 \\
616 \\
860 \\
495 \\
597\end{array}$ & $\begin{array}{r}591 \\
1130 \\
2135 \\
560 \\
754\end{array}$ & $\begin{array}{r}1212 \\
1150 \\
2591 \\
526 \\
4227\end{array}$ & $\begin{array}{r}1792 \\
2875 \\
6943 \\
649 \\
5649\end{array}$ & $\begin{array}{r}3918 \\
5317 \\
12080 \\
1798 \\
4630\end{array}$ & $\begin{array}{r}3418 \\
13220 \\
8525 \\
2613 \\
6425\end{array}$ & $\begin{array}{r}510 \\
9212 \\
1201 \\
300 \\
1491\end{array}$ & $\begin{array}{r}578 \\
5913 \\
690 \\
1042 \\
299\end{array}$ & $\begin{array}{c}64.5 \\
2392 \\
1031 \\
182 \\
285\end{array}$ \\
\hline 1961 & 943 & 665 & 644 & 562 & 735 & 1074 & 2636 & 4641 & 3815 & 703 & 1423 & 1838 \\
\hline
\end{tabular}

ANNUAL PEAR DISGAAGE, IN CUBIC FEET PER SEOOND, AND CORRESPONDING GAGE HEIGHT, IN FEET, FOR EAGH WATER YEAR

\begin{tabular}{|c|c|c|c|c|c|c|c|c|c|c|c|}
\hline $\begin{array}{l}\text { WAIER } \\
\text { YEAR }\end{array}$ & DAIE & $\begin{array}{c}\text { GAGE } \\
\text { HEIGHT }\end{array}$ & $\begin{array}{c}\text { PEAR } \\
\text { DISOHARGE }\end{array}$ & $\begin{array}{l}\text { WATER } \\
\text { YEAR }\end{array}$ & DATE & $\begin{array}{c}\text { GAGE } \\
\text { HEIGHT }\end{array}$ & $\begin{array}{c}\text { PEAR } \\
\text { DISOHARGE }\end{array}$ & $\begin{array}{l}\text { WATER } \\
\text { YEAR }\end{array}$ & DATE & $\begin{array}{c}\text { GAGE } \\
\text { HEIGHT }\end{array}$ & $\begin{array}{c}\text { PEAK } \\
\text { DISCHARGE }\end{array}$ \\
\hline $\begin{array}{l}1915 \\
1916 \\
1917 \\
1927 \\
1928 \\
1929 \\
1930 \\
1931 \\
1932 \\
1933 \\
1934 \\
1935 \\
1936\end{array}$ & $\begin{array}{l}\text { JULY } 27,1915 \\
\text { MAR. } 24,1916 \\
\text { OCT. } 15,1916 \\
\text { SEPT. } 10,1927 \\
\text { JUNE } 01,1928 \\
\text { AUG. } 12,1929 \\
\text { AUG. } 09,1930 \\
\text { AUG. } 01,1931 \\
\text { AUG. } 29,1932 \\
\text { JUNE } 03,1933 \\
\text { AUG. } 28,1934 \\
\text { SEPT. } 28,1935 \\
\text { MAY } 07,1936\end{array}$ & $\begin{array}{l}15.06 \\
12.80 \\
18.10 \\
32.00 \\
12.45 \\
27.80 \\
18.80 \\
10.40 \\
17.20 \\
13.60 \\
11.30 \\
17.90 \\
12.50\end{array}$ & $\begin{array}{r}26400 \\
16200 \\
31400 \\
70000 \\
12900 \\
56000 \\
28500 \\
8500 \\
21300 \\
14500 \\
9920 \\
23800 \\
12700\end{array}$ & $\begin{array}{l}1937 \\
1938 \\
1999 \\
1940 \\
1941 \\
1942 \\
1943 \\
1944 \\
1945 \\
1946 \\
1947 \\
1948 \\
1949\end{array}$ & $\begin{array}{l}\text { SEPT. } 30,1937 \\
\text { OCT. } 01,1937 \\
\text { SEPT.12, } 1939 \\
\text { SEPT. } 30,1940 \\
\text { MAY } 15,1941 \\
\text { OCT. } 14,1941 \\
\text { MAY } 06,1943 \\
\text { MAY } 17,1944 \\
\text { MAY } 05,1945 \\
\text { AUG. } 13,1946 \\
\text { AUG. } 23,1947 \\
\text { OCT. } 15,1947 \\
\text { JUNE } 21,1949\end{array}$ & $\begin{array}{l}17.60 \\
17.80 \\
13.10 \\
14.10 \\
20.20 \\
25.40 \\
11.25 \\
14.80 \\
11.30 \\
9.95 \\
17.80 \\
19.20 \\
17.92\end{array}$ & $\begin{array}{r}23000 \\
25000 \\
14900 \\
18500 \\
34700 \\
49300 \\
10900 \\
18800 \\
10400 \\
7340 \\
27700 \\
28700 \\
27900\end{array}$ & $\begin{array}{l}1950 \\
1951 \\
1952 \\
1953 \\
1954 \\
1955 \\
1956 \\
1957 \\
1958 \\
1959 \\
1960 \\
1961\end{array}$ & $\begin{array}{ll}\text { JUNE } 23,1950 \\
\text { SEPT. 30, } 1951 \\
\text { JUNE 05, } 1952 \\
\text { JULY } 30,1953 \\
\text { SEPT. 23, } 1954 \\
\text { OCT. 09, } 1954 \\
\text { JUNE 04, } 1956 \\
\text { JULY 29, } 1957 \\
\text { JUNE 09, } 1958 \\
\text { AUG. 08, } 1959 \\
\text { JUNE 06, } 1960 \\
\text { SEPT.09, } 1961\end{array}$ & $\begin{array}{r}9.85 \\
12.30 \\
14.92 \\
10.20 \\
12.40 \\
12.20 \\
9.43 \\
18.80 \\
13.44 \\
7.96 \\
9.97 \\
9.38\end{array}$ & $\begin{array}{r}7710 \\
15900 \\
20400 \\
9270 \\
13600 \\
13000 \\
7330 \\
30200 \\
17200 \\
5370 \\
9150 \\
7540\end{array}$ \\
\hline
\end{tabular}

1936 MAY 07,1936

$12.50 \quad 12700$

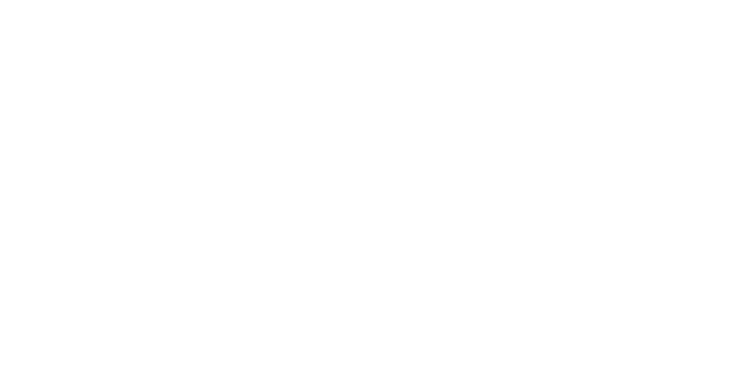

DATA BELOW BASED ON PERIOD OF RECORD AFTER COMPLETION OF NAVAJO RESERVOIR

LOWEST MEAN DISGHARE, IN OUBIC FEET PER SECOND, AND RANKING FOR THE INDICATED NUMBER OF CONSEQUTIVE DAYS FOR EAOH CIIMATIC YEAR, APRII I-MARCH 31

YEAR

$\begin{array}{lllll}1 & & & & \text { CONSECUTIVE DAYS } \\ 60 & 3 & 14 & 30 & 60\end{array}$

$$
90
$$

120

183

ALL

\begin{tabular}{|c|c|c|c|c|c|c|c|c|c|c|c|c|c|c|c|c|c|c|c|c|}
\hline $\begin{array}{l}1966 \\
1967 \\
1968 \\
1969 \\
1970\end{array}$ & $\begin{array}{r}1100 \\
280 \\
223 \\
110 \\
731\end{array}$ & $\begin{array}{r}15 \\
8 \\
6 \\
3 \\
13\end{array}$ & $\begin{array}{r}1210 \\
293 \\
234 \\
353 \\
880\end{array}$ & $\begin{array}{r}15 \\
7 \\
5 \\
8 \\
13\end{array}$ & $\begin{array}{r}1490 \\
330 \\
257 \\
529 \\
924\end{array}$ & $\begin{array}{r}16 \\
7 \\
5 \\
10 \\
13\end{array}$ & $\begin{array}{r}1690 \\
455 \\
286 \\
615 \\
959\end{array}$ & $\begin{array}{r}16 \\
6 \\
5 \\
10 \\
13\end{array}$ & $\begin{array}{r}2130 \\
596 \\
357 \\
674 \\
1190\end{array}$ & $\begin{array}{r}16 \\
6 \\
5 \\
9 \\
13\end{array}$ & $\begin{array}{r}2580 \\
635 \\
547 \\
764 \\
1480\end{array}$ & $\begin{array}{r}16 \\
6 \\
5 \\
8 \\
14\end{array}$ & $\begin{array}{r}2930 \\
709 \\
584 \\
765 \\
1640\end{array}$ & $\begin{array}{r}16 \\
6 \\
5 \\
7 \\
14\end{array}$ & $\begin{array}{r}3150 \\
914 \\
585 \\
787 \\
1790\end{array}$ & $\begin{array}{r}16 \\
8 \\
4 \\
5 \\
14\end{array}$ & $\begin{array}{r}3190 \\
1010 \\
668 \\
1040 \\
2000\end{array}$ & $\begin{array}{r}16 \\
7 \\
1 \\
8\end{array}$ & $\begin{array}{l}3790 \\
1690 \\
1000 \\
1760 \\
2630\end{array}$ & $\begin{array}{r}14 \\
7\end{array}$ \\
\hline $\begin{array}{l}971 \\
972 \\
973 \\
974 \\
975\end{array}$ & $\begin{array}{c}520 \\
433 \\
90.0 \\
1310 \\
190\end{array}$ & $\begin{array}{r}11 \\
10 \\
2 \\
16 \\
5\end{array}$ & $\begin{array}{c}520 \\
449 \\
91.0 \\
1370 \\
194\end{array}$ & $\begin{array}{r}11 \\
10 \\
2 \\
16 \\
4\end{array}$ & $\begin{array}{c}564 \\
488 \\
99.0 \\
1410 \\
224\end{array}$ & $\begin{array}{r}11 \\
9 \\
2 \\
15 \\
4\end{array}$ & $\begin{array}{r}658 \\
538 \\
141 \\
1460 \\
265\end{array}$ & $\begin{array}{r}11 \\
8 \\
2 \\
15 \\
4\end{array}$ & $\begin{array}{r}745 \\
722 \\
156 \\
1660 \\
289\end{array}$ & $\begin{array}{r}11 \\
10 \\
2 \\
15 \\
4\end{array}$ & $\begin{array}{r}1080 \\
1060 \\
305 \\
1680 \\
403\end{array}$ & $\begin{array}{r}11 \\
10 \\
2 \\
15 \\
4\end{array}$ & $\begin{array}{r}142 \\
1120 \\
577 \\
1840 \\
48\end{array}$ & $\begin{array}{r}12 \\
10 \\
4 \\
15 \\
3\end{array}$ & $\begin{array}{r}1650 \\
1290 \\
787 \\
1950 \\
541\end{array}$ & $\begin{array}{r}13 \\
10 \\
6 \\
15 \\
1\end{array}$ & $\begin{array}{r}2130 \\
1320 \\
988 \\
2040 \\
784\end{array}$ & $\begin{array}{r}15 \\
9 \\
6 \\
14 \\
3\end{array}$ & $\begin{array}{l}2230 \\
1540 \\
1890 \\
3810 \\
1040\end{array}$ & \\
\hline $\begin{array}{l}977 \\
978 \\
979 \\
980\end{array}$ & $\begin{array}{l}900 \\
270 \\
70.0 \\
157 \\
394\end{array}$ & $\begin{array}{r}14 \\
7 \\
1 \\
4 \\
9\end{array}$ & $\begin{array}{l}913 \\
273 \\
80.0 \\
158 \\
405\end{array}$ & $\begin{array}{r}14 \\
6 \\
1 \\
3 \\
9\end{array}$ & $\begin{array}{l}991 \\
324 \\
86.0 \\
166 \\
482\end{array}$ & $\begin{array}{r}14 \\
6 \\
1 \\
3 \\
8\end{array}$ & $\begin{array}{r}1170 \\
456 \\
128 \\
194 \\
552\end{array}$ & $\begin{array}{r}14 \\
7 \\
1 \\
3 \\
9\end{array}$ & $\begin{array}{r}1270 \\
613 \\
150 \\
225 \\
638\end{array}$ & $\begin{array}{r}14 \\
7 \\
1 \\
3 \\
8\end{array}$ & $\begin{array}{c}1340 \\
758 \\
346 \\
292 \\
811\end{array}$ & $\begin{array}{r}13 \\
7 \\
3 \\
1 \\
9\end{array}$ & $\begin{array}{r}1420 \\
815 \\
356 \\
423 \\
850\end{array}$ & $\begin{array}{r}13 \\
8 \\
1 \\
2 \\
9\end{array}$ & $\begin{array}{r}1530 \\
848 \\
547 \\
561 \\
1060\end{array}$ & $\begin{array}{r}12 \\
7 \\
2 \\
3 \\
9\end{array}$ & $\begin{array}{r}1600 \\
946 \\
684 \\
797 \\
1490\end{array}$ & $\begin{array}{r}12 \\
5\end{array}$ & $\begin{array}{r}2850 \\
1300 \\
840 \\
1690 \\
4440\end{array}$ & 16 \\
\hline & 633 & & 673 & 12 & 819 & 12 & 934 & 12 & 987 & 12 & 1170 & 12 & 1400 & 11 & 1460 & 11 & 1490 & 11 & 2590 & \\
\hline
\end{tabular}


HIGHEST MEAN DISCHARGE, IN OUBIC FEET PER SECOND, AND RANKING FOR THE INDICATED NUMBER OF CONSEQUTIVE DAYS FOR EAOH WATER YEAR, OCTCBER I-SEPTEMBER 30

YEAR

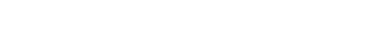

\begin{tabular}{|c|c|c|c|c|c|c|c|c|c|c|c|c|c|c|c|c|c|c|c|c|}
\hline YEAR & 1 & & 3 & & 7 & & 15 & & 30 & E & IVE 60 & & & & 120 & & 183 & & $\mathbf{A L}$ & \\
\hline $\begin{array}{l}1966 \\
1967 \\
1968 \\
1969 \\
1970\end{array}$ & $\begin{array}{r}6570 \\
9710 \\
11000 \\
6420 \\
34700\end{array}$ & $\begin{array}{r}9 \\
6 \\
5 \\
10 \\
1\end{array}$ & $\begin{array}{r}6490 \\
7620 \\
7760 \\
6080 \\
20200\end{array}$ & $\begin{array}{r}9 \\
8 \\
7 \\
10 \\
2\end{array}$ & $\begin{array}{r}6010 \\
5680 \\
5780 \\
5450 \\
11200\end{array}$ & $\begin{array}{r}7 \\
9 \\
8 \\
10 \\
3\end{array}$ & $\begin{array}{l}5180 \\
3740 \\
4950 \\
5390 \\
8240\end{array}$ & $\begin{array}{r}8 \\
12 \\
9 \\
7 \\
4\end{array}$ & $\begin{array}{l}4560 \\
2860 \\
4310 \\
4700 \\
5170\end{array}$ & $\begin{array}{r}8 \\
13 \\
9 \\
7 \\
6\end{array}$ & $\begin{array}{l}4340 \\
2070 \\
3240 \\
4250 \\
3130\end{array}$ & $\begin{array}{r}6 \\
15 \\
8 \\
7 \\
9\end{array}$ & $\begin{array}{l}4090 \\
1680 \\
3050 \\
4050 \\
2470\end{array}$ & $\begin{array}{r}6 \\
16 \\
8 \\
7 \\
11\end{array}$ & $\begin{array}{l}3610 \\
1720 \\
2770 \\
3880 \\
2470\end{array}$ & $\begin{array}{r}7 \\
15 \\
8 \\
6 \\
10\end{array}$ & $\begin{array}{l}3590 \\
1380 \\
2150 \\
3350 \\
2130\end{array}$ & $\begin{array}{r}6 \\
16 \\
9 \\
7 \\
10\end{array}$ & $\begin{array}{l}2720 \\
1270 \\
1400 \\
2280 \\
2110\end{array}$ & $\begin{array}{r}5 \\
16 \\
12 \\
7 \\
8\end{array}$ \\
\hline $\begin{array}{l}1976 \\
1977 \\
1978 \\
1979 \\
1980\end{array}$ & $\begin{array}{r}4770 \\
5200 \\
4480 \\
15200 \\
9400\end{array}$ & $\begin{array}{r}14 \\
12 \\
16 \\
3 \\
8\end{array}$ & $\begin{array}{r}4110 \\
4670 \\
4320 \\
14900 \\
9020\end{array}$ & $\begin{array}{r}15 \\
11 \\
13 \\
3 \\
6\end{array}$ & $\begin{array}{r}3830 \\
3230 \\
4280 \\
14000 \\
8260\end{array}$ & $\begin{array}{r}13 \\
15 \\
11 \\
2 \\
6\end{array}$ & $\begin{array}{r}3790 \\
2240 \\
3960 \\
12700 \\
7460\end{array}$ & $\begin{array}{r}11 \\
17 \\
10 \\
1 \\
6\end{array}$ & $\begin{array}{r}3610 \\
1890 \\
3510 \\
11900 \\
6740\end{array}$ & $\begin{array}{r}10 \\
17 \\
11 \\
1 \\
5\end{array}$ & $\begin{array}{r}2990 \\
1380 \\
2990 \\
10700 \\
6620\end{array}$ & $\begin{array}{r}10 \\
17 \\
11 \\
1 \\
3\end{array}$ & $\begin{array}{r}2320 \\
1240 \\
2610 \\
10300 \\
5810\end{array}$ & $\begin{array}{r}12 \\
17 \\
10 \\
1 \\
4\end{array}$ & $\begin{array}{l}2040 \\
1130 \\
2370 \\
9380 \\
5220\end{array}$ & $\begin{array}{r}13 \\
17 \\
11 \\
1 \\
4\end{array}$ & $\begin{array}{r}1850 \\
998 \\
1950 \\
7320 \\
4450\end{array}$ & $\begin{array}{r}13 \\
17 \\
12 \\
1 \\
3\end{array}$ & $\begin{array}{r}1600 \\
844 \\
1290 \\
4230 \\
2950\end{array}$ & $\begin{array}{r}10 \\
17 \\
15 \\
1 \\
3\end{array}$ \\
\hline
\end{tabular}

DURATION OF DISOHARGE FOR EAOH WATER YEAR

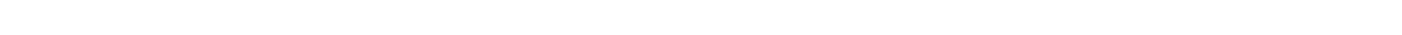

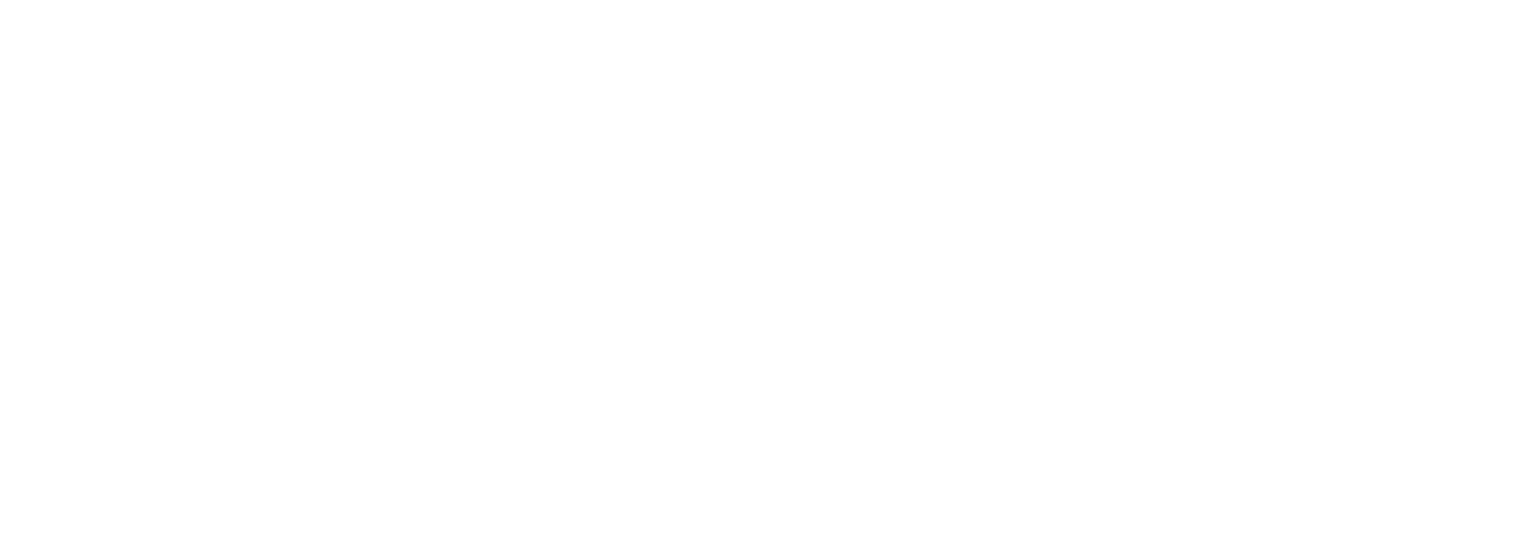

1981

$\begin{array}{llllllllllllll}4 & 22 & 30 & 29 & 38 & 48 & 57 & 59 & 51 & 13 & 4 & 6 & 3 & 1\end{array}$

501939.0

DURATION TABLE OF DISGHARGE FOR WATER YEARS $1965-81$

\begin{tabular}{|c|c|c|c|c|c|c|c|c|c|c|c|c|c|c|c|c|c|c|c|}
\hline CL.ASS & $\begin{array}{c}\text { CJBIC } \\
\text { FEET } \\
\text { PER } \\
\text { SECOND }\end{array}$ & $\begin{array}{l}\text { TOTAL } \\
\text { DAVS }\end{array}$ & $\begin{array}{r}\text { ACCU- } \\
\text { MU- } \\
\text { LATED } \\
\text { DAYS }\end{array}$ & $\begin{array}{l}\text { PER- } \\
\text { CENT } \\
\text { DAYS }\end{array}$ & CLASS & $\begin{array}{c}\text { QUBIC } \\
\text { FEET } \\
\text { PER } \\
\text { SECOND }\end{array}$ & $\begin{array}{r}\text { TOTAL } \\
\text { DAYS }\end{array}$ & $\begin{array}{r}\text { ACQU- } \\
\text { MU- } \\
\text { LATED } \\
\text { DAYS }\end{array}$ & $\begin{array}{l}\text { PER- } \\
\text { GENT } \\
\text { DAYS }\end{array}$ & CLASS & $\begin{array}{c}\text { QUBIC } \\
\text { FEET } \\
\text { PER } \\
\text { SECOND }\end{array}$ & $\begin{array}{r}\text { TOTAL } \\
\text { DAYS }\end{array}$ & $\begin{array}{r}\text { ACOU- } \\
\text { MU- } \\
\text { LATED } \\
\text { DAYS }\end{array}$ & $\begin{array}{l}\text { PER- } \\
\text { CENT } \\
\text { DAYS }\end{array}$ & CLASS & $\begin{array}{c}\text { CUBIC } \\
\text { FEET } \\
\text { PER } \\
\text { SECOND }\end{array}$ & TOTAL & $\begin{array}{r}\text { ACOU- } \\
\text { MU- } \\
\text { LATED } \\
\text { DAYS }\end{array}$ & $\begin{array}{l}\text { PER- } \\
\text { CENT } \\
\text { DAYS }\end{array}$ \\
\hline $\begin{array}{l}0 \\
1 \\
2 \\
3 \\
4 \\
5 \\
6 \\
7 \\
8\end{array}$ & $\begin{array}{r}0.00 \\
70.00 \\
84.00 \\
100.00 \\
120.00 \\
140.00 \\
170.00 \\
210.00 \\
250.00\end{array}$ & $\begin{array}{r}0 \\
6 \\
8 \\
8 \\
10 \\
6 \\
16 \\
25 \\
43 \\
83\end{array}$ & $\begin{array}{l}6209 \\
6209 \\
6203 \\
6195 \\
6185 \\
6179 \\
6163 \\
6138 \\
6095\end{array}$ & $\begin{array}{r}100.0 \\
100.0 \\
99.9 \\
99.8 \\
99.6 \\
99.5 \\
99.3 \\
98.9 \\
98.2\end{array}$ & $\begin{array}{r}9 \\
10 \\
11 \\
12 \\
13 \\
14 \\
15 \\
16 \\
17\end{array}$ & $\begin{array}{r}300.00 \\
350.00 \\
420.00 \\
510.00 \\
610.00 \\
730.00 \\
870.00 \\
1000.00 \\
1200.00\end{array}$ & $\begin{array}{r}48 \\
62 \\
120 \\
299 \\
329 \\
528 \\
444 \\
437 \\
520\end{array}$ & $\begin{array}{l}6012 \\
5964 \\
5902 \\
5782 \\
5483 \\
5154 \\
4626 \\
4182 \\
3745\end{array}$ & $\begin{array}{l}96.8 \\
96.1 \\
95.1 \\
93.1 \\
88.3 \\
83.0 \\
74.5 \\
67.4 \\
60.3\end{array}$ & $\begin{array}{l}18 \\
19 \\
20 \\
21 \\
22 \\
23 \\
24 \\
25 \\
26\end{array}$ & $\begin{array}{l}1500.0 \\
1800.0 \\
2100.0 \\
2600.0 \\
3100.0 \\
3700.0 \\
4400.0 \\
5300.0 \\
6300.0\end{array}$ & $\begin{array}{l}505 \\
558 \\
667 \\
280 \\
350 \\
285 \\
141 \\
134 \\
123\end{array}$ & $\begin{array}{r}3225 \\
2720 \\
2162 \\
1495 \\
1215 \\
865 \\
580 \\
439 \\
305\end{array}$ & $\begin{array}{r}51.9 \\
43.8 \\
34.8 \\
24.1 \\
19.6 \\
13.9 \\
9.3 \\
7.1 \\
4.9\end{array}$ & $\begin{array}{l}27 \\
28 \\
29 \\
30 \\
31 \\
32 \\
33 \\
34\end{array}$ & $\begin{array}{r}7600.0 \\
9100.0 \\
11000.0 \\
13000.0 \\
16000.0 \\
19000.0 \\
22000.0 \\
27000.0\end{array}$ & $\begin{array}{r}71 \\
67 \\
31 \\
9 \\
1 \\
0 \\
2 \\
1\end{array}$ & $\begin{array}{r}182 \\
111 \\
44 \\
13 \\
4 \\
3 \\
3 \\
1\end{array}$ & $\begin{array}{l}2.9 \\
1.8 \\
0.7 \\
0.2 \\
0.1 \\
0.0 \\
0.0 \\
0.0\end{array}$ \\
\hline
\end{tabular}

MONIHLY MEAN DISOHARGES, IN OUBIC FEET PER SECOND, FOR EAOH WATER YEAR

\begin{tabular}{|c|c|c|c|c|c|c|c|c|c|c|c|c|}
\hline YEAR & ОCT & NOV & DEC & JAN & FEB & MAR & APR & MAY & JUNE & JULY & AUG & SEP \\
\hline 1965 & 594 & 709 & 979 & 1976 & 2158 & 1388 & 2773 & 4685 & 7044 & 4801 & 3541 & 2973 \\
\hline $\begin{array}{l}1966 \\
1967 \\
1968 \\
1969 \\
1970\end{array}$ & $\begin{array}{r}3098 \\
1531 \\
500 \\
915 \\
3382\end{array}$ & $\begin{array}{r}3899 \\
1174 \\
633 \\
821 \\
1985\end{array}$ & $\begin{array}{r}3821 \\
1168 \\
636 \\
734 \\
1775\end{array}$ & $\begin{array}{r}3220 \\
949 \\
579 \\
1347 \\
1220\end{array}$ & $\begin{array}{r}2325 \\
1156 \\
932 \\
2358 \\
2335\end{array}$ & $\begin{array}{r}3240 \\
1291 \\
811 \\
2331 \\
1886\end{array}$ & $\begin{array}{r}4243 \\
519 \\
1396 \\
3628 \\
823\end{array}$ & $\begin{array}{l}4337 \\
1263 \\
2401 \\
4403 \\
2277\end{array}$ & $\begin{array}{l}2132 \\
1498 \\
4044 \\
3997 \\
2326\end{array}$ & $\begin{array}{r}871 \\
639 \\
1330 \\
3292 \\
1203\end{array}$ & $\begin{array}{r}711 \\
2451 \\
2866 \\
1645 \\
1066\end{array}$ & $\begin{array}{r}714 \\
1570 \\
692 \\
1976 \\
5173\end{array}$ \\
\hline
\end{tabular}


09379500 SAN JUAN RIVER NEAR BLUFF, UT-Continued

MONHLY MEAN DISCHARGES, IN OUBIC FEET PER SEOOND, FOR EACH WATER YEAR--Continued

\begin{tabular}{|c|c|c|c|c|c|c|c|c|c|c|c|c|}
\hline YEAR & $\propto C T$ & NOV & DEC & JAN & FEB & MAR & APR & MAY & JUNE & JULY & AUG & SEP \\
\hline $\begin{array}{l}1971 \\
1972 \\
1973 \\
1974 \\
1975\end{array}$ & $\begin{array}{l}2305 \\
1619 \\
5514 \\
2156 \\
1219\end{array}$ & $\begin{array}{r}2294 \\
995 \\
1611 \\
2256 \\
1183\end{array}$ & $\begin{array}{r}2428 \\
1793 \\
1629 \\
2288 \\
900\end{array}$ & $\begin{array}{r}2672 \\
1939 \\
1774 \\
2163 \\
957\end{array}$ & $\begin{array}{r}2594 \\
1904 \\
3210 \\
1661 \\
908\end{array}$ & $\begin{array}{l}1643 \\
1943 \\
2885 \\
1682 \\
1817\end{array}$ & $\begin{array}{l}1158 \\
1086 \\
4378 \\
1096 \\
2670\end{array}$ & $\begin{array}{l}1402 \\
1319 \\
7898 \\
1720 \\
4791\end{array}$ & $\begin{array}{l}2070 \\
1985 \\
7790 \\
1161 \\
6670\end{array}$ & $\begin{array}{r}1071 \\
278 \\
6478 \\
638 \\
5877\end{array}$ & $\begin{array}{r}1753 \\
498 \\
3607 \\
406 \\
2396\end{array}$ & $\begin{array}{r}865 \\
947 \\
3273 \\
420 \\
2171\end{array}$ \\
\hline $\begin{array}{l}1976 \\
1977 \\
1978 \\
1979 \\
1980\end{array}$ & $\begin{array}{r}1736 \\
832 \\
634 \\
666 \\
1024\end{array}$ & $\begin{array}{r}1721 \\
798 \\
858 \\
1313 \\
898\end{array}$ & $\begin{array}{r}1879 \\
1333 \\
790 \\
1238 \\
2044\end{array}$ & $\begin{array}{r}1574 \\
1360 \\
939 \\
1515 \\
2420\end{array}$ & $\begin{array}{r}1416 \\
989 \\
1094 \\
2392 \\
3362\end{array}$ & $\begin{array}{r}1279 \\
683 \\
1645 \\
3672 \\
3595\end{array}$ & $\begin{array}{r}883 \\
399 \\
1848 \\
9637 \\
4782\end{array}$ & $\begin{array}{r}2905 \\
339 \\
2526 \\
10330 \\
6011\end{array}$ & $\begin{array}{r}3029 \\
556 \\
3420 \\
10330 \\
6348\end{array}$ & $\begin{array}{r}847 \\
940 \\
1021 \\
6718 \\
2004\end{array}$ & $\begin{array}{r}778 \\
1318 \\
250 \\
2312 \\
1232\end{array}$ & $\begin{array}{r}1102 \\
562 \\
496 \\
662 \\
1784\end{array}$ \\
\hline 1981 & 1371 & 1747 & 1600 & 1890 & 1373 & 986 & 654 & 980 & 1825 & 1789 & 861 & 1431 \\
\hline
\end{tabular}

ANNUAL PEAK DISCHARGE, IN GBIC FEET PER SECOND, AND CORRESPONDING GAGE HEIGHT, IN FEET, FOR EACH WATER YEAR

\begin{tabular}{|c|c|c|c|c|c|c|c|c|c|c|c|}
\hline $\begin{array}{l}\text { WATERR } \\
\text { YEAR }\end{array}$ & DATE & $\begin{array}{c}\text { GAGE } \\
\text { HEIGHT }\end{array}$ & $\begin{array}{c}\text { PEAR } \\
\text { DISCHARGE }\end{array}$ & $\begin{array}{l}\text { WATERR } \\
\text { YEAR }\end{array}$ & DATE & $\begin{array}{c}\text { GAGE } \\
\text { HEIGHT }\end{array}$ & $\begin{array}{c}\text { PEAR } \\
\text { DISCHARGE }\end{array}$ & $\begin{array}{l}\text { WATER } \\
\text { YEAR }\end{array}$ & DATE & $\begin{array}{c}\text { GAGE } \\
\text { HEIGHI }\end{array}$ & $\begin{array}{c}\text { PEAR } \\
\text { DISCHARGE }\end{array}$ \\
\hline 1962 & APR. 23,1962 & 10.97 & ${ }_{1}^{10300}$ & 1969 & JULY 19, 1969 & 11.00 & 10900 & 1976 & SEPT.26, 1976 & 8.86 & 6940 \\
\hline 1963 & OCT. 20, 1962 & 12.94 & ${ }_{15100}$ & 1970 & SEPT.06, 1970 & 26.62 & 52000 & 1977 & AUG. 16,1977 & 10.60 & 10100 \\
\hline $\begin{array}{l}1964 \\
1965 \\
1966 \\
1967 \\
1968\end{array}$ & $\begin{array}{l}\text { AUG. } 13,1964 \\
\text { AUG. } 03,1965 \\
\text { OCT. } 18,1965 \\
\text { AUG. } 12,1967 \\
\text { AUG. } 02,1968\end{array}$ & $\begin{array}{r}10.78 \\
11.20 \\
9.75 \\
12.22 \\
14.06\end{array}$ & $\begin{array}{r}110400 \\
11400 \\
8940 \\
13300 \\
17500\end{array}$ & $\begin{array}{l}1971 \\
1972 \\
1973 \\
1974 \\
1975\end{array}$ & $\begin{array}{l}\text { AUG. } 22,1971 \\
\text { OCT. 17, } 1971 \\
\text { OCT. 20, } 1972 \\
\text { MAR. 03, } 1974 \\
\text { JULY 13, } 1975\end{array}$ & $\begin{array}{r}11.55 \\
10.47 \\
21.40 \\
6.91 \\
11.30\end{array}$ & $\begin{array}{r}12310 \\
9070 \\
38500 \\
3920 \\
11900\end{array}$ & $\begin{array}{l}1978 \\
1979 \\
1980 \\
1981\end{array}$ & $\begin{array}{lll}\text { MAY } & 21,1978 \\
\text { MAY } & 29,1979 \\
\text { FEB. } & 20,1980 \\
\text { JULY } & 17,1981\end{array}$ & $\begin{array}{r}8.05 \\
13.17 \\
12.01 \\
9.95\end{array}$ & $\begin{array}{r}5640 \\
15600 \\
13000 \\
9260\end{array}$ \\
\hline
\end{tabular}

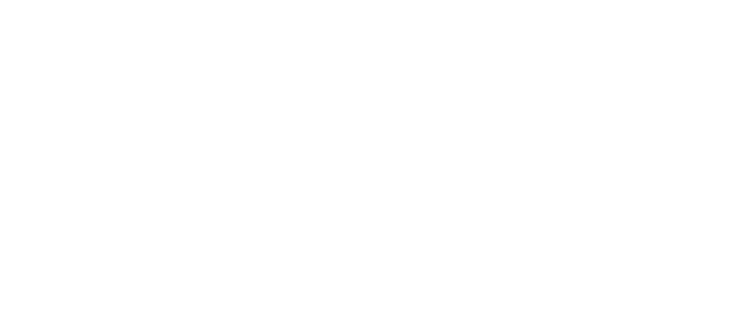

${ }^{1}$ Peak discharge occurred during filling period for Navajo Reservoir.

WAFWEAP CREEK BASIN

09379800 COYOTE CREEK NEAR KANAB, UT

LOCATION.--Lat $37^{\circ} 07^{\prime} 13^{\prime \prime}$, long $211^{\circ} 45^{\prime} 06^{\prime \prime}$, in NEl sec. 25, T.42 S., R.1 E., Kane County, Hydrologic Unit $14070006,2.6$ mi north of U.S. Highway $89,8.7 \mathrm{mi}$ northwest of Glen Canyon City, AZ, and $44 \mathrm{mi}$ east of Ranab.

DRAINAGE AREA. $-89 \mathrm{mi}^{2}$.

MEAN BASIN ELEVATION. $-5,100 \mathrm{ft}$.

PERICD OF RECORD AVAIIABLE.-Water years 1959-72, annual peak discharge only.

GAGE.--Crest-stage gage. Altitude of gage is 4,220 ft fran topographic map.

ANNUAL PEAR DISCHARGE, IN GBIC FEET PER SECOND, AND CORRESPONDING GAGE HEIGHT, IN FEET, FOR EACH WATER YEAR

\begin{tabular}{|c|c|c|c|c|c|c|c|c|c|c|c|}
\hline $\begin{array}{l}\text { WATER } \\
\text { YEAR }\end{array}$ & DATE & $\begin{array}{c}\text { GAGE } \\
\text { HEIGHT }\end{array}$ & $\begin{array}{c}\text { PEAR } \\
\text { DISCHARGE }\end{array}$ & $\begin{array}{l}\text { WATER } \\
\text { YEAR }\end{array}$ & DATE & $\begin{array}{l}\text { GAGE } \\
\text { HEIGHT }\end{array}$ & $\begin{array}{c}\text { PEAK } \\
\text { DISCHARGE }\end{array}$ & $\begin{array}{l}\text { WATER } \\
\text { YEAR }\end{array}$ & DATE & $\begin{array}{c}\text { GAGE } \\
\text { HEIGHT }\end{array}$ & $\begin{array}{c}\text { PEAK } \\
\text { DISCHARGE }\end{array}$ \\
\hline $\begin{array}{l}1959 \\
1960 \\
1961 \\
1962 \\
1963\end{array}$ & $\begin{array}{l}\text { JULY } 30,1959 \\
\text { NO. } 02,1959 \\
\text { AUG. 10, } 1961 \\
\text { SEPT. 28, } 1962 \\
\text { AJG. 06, } 1963\end{array}$ & $\begin{array}{ll}9 & 11.94 \\
9 & 12.82 \\
1 & 14.70 \\
2 & 12.20 \\
3 & 13.95\end{array}$ & $\begin{array}{r}419 \\
980 \\
2250 \\
600 \\
1680\end{array}$ & $\begin{array}{l}1964 \\
1965 \\
1966 \\
1967 \\
1968\end{array}$ & $\begin{array}{l}\text { OCT. } 18,1963 \\
\text { SEPT. 05, } 1965 \\
\text { JULY 24, } 1966 \\
\text { SEPT.24, } 1967 \\
\text { AUG. 13, } 1968\end{array}$ & $\begin{array}{ll}3 & 12.25 \\
5 & 10.60 \\
6 & 12.46 \\
7 & 16.69 \\
8 & 18.82\end{array}$ & $\begin{array}{r}630 \\
95 \\
760 \\
3300 \\
3800\end{array}$ & $\begin{array}{l}1969 \\
1970 \\
1971 \\
1972\end{array}$ & $\begin{array}{l}\text { AUG. } 12,1969 \\
\text { SEPT. 06, } 1970 \\
\text { AUG. 18, } 1971 \\
\text { JUNE 22, } 1972\end{array}$ & $\begin{array}{l}14.15 \\
14.41 \\
14.56 \\
17.97\end{array}$ & $\begin{array}{l}1820 \\
2000 \\
2110 \\
4590\end{array}$ \\
\hline
\end{tabular}


LOCATION.--Lat $37^{\circ} 05^{\prime} 10^{n}$, long $111^{\circ} 42^{\prime} 20^{n}$, in NE⿱⺌兀 sec.8, T.43 S., R.2 E., Kane County, Hydrologic Unit 14070006 , at culvert headwall on U.S. Highway $89,2 \mathrm{mi}$ above mouth, $2.3 \mathrm{mi}$ west of Glen Canyon City, AZ, and $48 \mathrm{mi}$ east of Kanab.

DRAINAGE AREA. $--5.25 \mathrm{mi}^{2}$.

MEAN BASIN ELEVATION. $--5,030 \mathrm{ft}$.

PERIOD OF RECORO AVAILABLE.--Water years 1961-70, annual peak discharge only.

GAGE.-Crest-stage gage. Altitude of gage is 4,360 ft from topographic map.

ANNUAL, PEAK DISCHARGE, IN OBBIC FEET PER SECOND, AND CORRESPONDING GAGE HEIGHT, IN FEET, FOR EACH WATER YEAR

\begin{tabular}{|c|c|c|c|c|c|c|c|c|c|c|c|c|}
\hline $\begin{array}{l}\text { WATER } \\
\text { YEAR }\end{array}$ & & DATE & $\begin{array}{l}\text { GAGE } \\
\text { HETGHT }\end{array}$ & $\begin{array}{c}\text { PEAK } \\
\text { DISCHARGE }\end{array}$ & $\begin{array}{l}\text { WATER } \\
\text { YEAR }\end{array}$ & DATE & $\begin{array}{c}\text { GAGE } \\
\text { HEIGHT }\end{array}$ & $\begin{array}{c}\text { PEAK } \\
\text { DISCHARGE }\end{array}$ & $\begin{array}{l}\text { WATER } \\
\text { YEAR }\end{array}$ & DATE & $\begin{array}{c}\text { GAGE } \\
\text { HEIGHT }\end{array}$ & $\begin{array}{c}\text { PEAK } \\
\text { DISCHARGE }\end{array}$ \\
\hline $\begin{array}{l}1961 \\
1962 \\
1963 \\
1964\end{array}$ & $\begin{array}{l}\text { AUG. } \\
\overline{\text { AUG. }} \\
\text { AUG. }\end{array}$ & $\begin{array}{l}14,1961 \\
-30,1963 \\
12,1964\end{array}$ & $\begin{array}{c}9.77 \\
- \\
10.65 \\
9.66\end{array}$ & $\begin{array}{l}2.0 \\
0 \\
41 \\
13\end{array}$ & $\begin{array}{l}1965 \\
1966 \\
1967\end{array}$ & $\begin{array}{l}\text { AUG. } 17,1965 \\
\text { AUG. } 07,1966 \\
\text { JULY } 30,1967\end{array}$ & $\begin{array}{rr}5 & 9.75 \\
6 & 9.30 \\
7 & 12.28\end{array}$ & $\begin{array}{r}2.0 \\
1.0 \\
190\end{array}$ & $\begin{array}{l}1968 \\
1969 \\
1970\end{array}$ & $\begin{array}{l}\text { AUG. } 14,1968 \\
\text { AUG. } 17,1969 \\
\text { SEPT.05, } 1970\end{array}$ & $\begin{array}{r}10.05 \\
22.99 \\
9.95\end{array}$ & $\begin{array}{c}10 \\
680 \\
9.0\end{array}$ \\
\hline
\end{tabular}

COLORADO RIVER MAIN STEM

09380000 COLORADO RIVER AT LEES FERRY, AZ

LOCATION.--Lat $36^{\circ} 51^{\prime} 53^{\prime \prime}$, long $111^{\circ} 35^{\prime} 15^{\prime \prime}$, in $\mathrm{NE}_{4}^{\mathrm{l}} \mathrm{SE}_{4}^{\mathrm{l}}$ sec. 13, T.40 N., R.7 E. , Coconino County, Hydrologic Unit 14070006, in Navajo Indian Reservation, on left bank at head of Marble Gorge at Lees Ferry, just upstream fram Paria River, 16 mi downstream from Glen Canyon Dam, $28 \mathrm{mi}$ downstream from Utah-Arizona State line, and $61.5 \mathrm{mi}$ upstream fram Little Colorado River.

DRAINAGE AREA.--111,800 $\mathrm{mi}^{2}$, approximately, including $3,959 \mathrm{mi}^{2}$ in Great Divide basin in southern Wyaming which is noncontributing. PERIOD OF RECORD AVAIIABLE.--January 1895 to September 1981. Monthly mean discharge for sane periods, published in wSP 1313. RENISED RECORD.--WSP 859: 1921-23. WSP 1313: 1914-21.

GAGE.--Water-stage recorder. Datum of gage is $3,106.16 \mathrm{ft}$ NGVD of 1929 . Prior to Jan. 19, 1923, nonrecording gages or reference points within $400 \mathrm{ft}$ of present gage, at different datums.

REMARRS.-Flow completely regulated by Lake Powell $16 \mathrm{mi}$ upstream since Mar. 13, 1963. Many diversions above Lake Powell for irrigation, municipal, and industrial use. No diversions or inflow between Lake Powell and the gage.

AVERAGE DISCHARGE. - -51 years (water years 1912-62), 17,850 ft 3 /s, 12,923,000 acre-ft/yr; 17 years (water years 1965-81), 12,220 $\mathrm{ft}^{3} / \mathrm{s}, 8,853,000$ acre-ft/yr.

EXIREMES FOR PERIOD OF RECORD.--1895-1962: Maximum discharge, 220,000 ft ${ }^{3} / \mathrm{s}$ June 18, 1921, gage height, $26.5 \mathrm{ft}$, fram floodmarks, fram rating curve extended above $120,000 \mathrm{ft}^{3} / \mathrm{s}$ on basis of discharge computed for station near Grand Canyon; minimum, $750 \mathrm{ft} / \mathrm{s}$ Dec. 27, 1924. 1963-81: Maximum discharge, $60,200 \mathrm{ft}^{3} / \mathrm{s}$ June 15, 1965, gage height, $15.02 \mathrm{ft} ;$ minimum daily, $700 \mathrm{ft}^{3} / \mathrm{s} \mathrm{Jan}$. $23,24,1963$.

EXIREMES OUISIDE PERIOD OF RECORD.--Maximum discharge since at least 1868, about 300,000 $\mathrm{ft} / \mathrm{s}$ July 7, 1884, gage height, $31.5 \mathrm{ft}$, present site and datum, from floodmark at mouth of Paria River, from rating curve extended above $120,000 \mathrm{ft} / \mathrm{s}$ on basis of discharge computed for flood of June 18, 1921, for station near Grand Canyon.

DATA BELOW BASED ON PERIOD OF RECORD PRIOR TO REGULATION BY LAKE POWELL

LOWEST MEAN DISCHARGE, IN ABIC FEET PER SEOOND, AND RANKING FOR THE INDICATED NUMBER OF CONSECUTIVE DAYS FOR EACH OIIMATIC YEAR, APRII 1-MARCH 31

\begin{tabular}{|c|c|c|c|c|c|c|c|c|c|c|c|c|c|c|c|c|c|c|c|c|}
\hline YEAR & 1 & & 3 & & 7 & & 14 & & $\begin{array}{l}\infty \\
30\end{array}$ & & JE DA & & 90 & & 120 & & 183 & & ALL & \\
\hline $\begin{array}{l}1923 \\
1924 \\
1925\end{array}$ & $\begin{array}{l}4420 \\
3160 \\
1000\end{array}$ & $\begin{array}{r}38 \\
25 \\
1\end{array}$ & $\begin{array}{l}4460 \\
3350 \\
1180\end{array}$ & $\begin{array}{r}37 \\
29 \\
2\end{array}$ & $\begin{array}{l}4510 \\
3770 \\
1320\end{array}$ & $\begin{array}{r}35 \\
28 \\
2\end{array}$ & $\begin{array}{l}4570 \\
4340 \\
2150\end{array}$ & $\begin{array}{r}32 \\
31 \\
3\end{array}$ & $\begin{array}{l}4660 \\
4850 \\
3270\end{array}$ & $\begin{array}{r}27 \\
30 \\
8\end{array}$ & $\begin{array}{l}5280 \\
5630 \\
4020\end{array}$ & $\begin{array}{l}25 \\
32 \\
10\end{array}$ & & $\begin{array}{l}28 \\
36 \\
10\end{array}$ & $\begin{array}{l}5850 \\
7160 \\
5160\end{array}$ & $\begin{array}{l}22 \\
34 \\
11\end{array}$ & $\begin{array}{l}6070 \\
8570 \\
4940\end{array}$ & & & $\begin{array}{l}33 \\
35 \\
18\end{array}$ \\
\hline $\begin{array}{l}1926 \\
1927 \\
1928 \\
1929 \\
1930\end{array}$ & $\begin{array}{l}4950 \\
2500 \\
4100 \\
2700 \\
2900\end{array}$ & $\begin{array}{l}39 \\
11 \\
36 \\
14 \\
16\end{array}$ & $\begin{array}{l}4980 \\
2600 \\
4200 \\
2800 \\
2900\end{array}$ & $\begin{array}{l}39 \\
12 \\
35 \\
14 \\
15\end{array}$ & $\begin{array}{l}5000 \\
2770 \\
4740 \\
3140 \\
3470\end{array}$ & $\begin{array}{l}38 \\
11 \\
37 \\
17 \\
24\end{array}$ & $\begin{array}{l}5110 \\
3290 \\
5600 \\
3910 \\
4050\end{array}$ & $\begin{array}{l}35 \\
13 \\
38 \\
22 \\
24\end{array}$ & $\begin{array}{l}5530 \\
4310 \\
6410 \\
4550 \\
4800\end{array}$ & $\begin{array}{l}35 \\
19 \\
38 \\
25 \\
29\end{array}$ & $\begin{array}{l}5960 \\
5160 \\
7120 \\
5210 \\
5570\end{array}$ & $\begin{array}{l}35 \\
21 \\
39 \\
22 \\
31\end{array}$ & $\begin{array}{l}6260 \\
5630 \\
7430 \\
5540 \\
6390\end{array}$ & $\begin{array}{l}32 \\
24 \\
39 \\
22 \\
33\end{array}$ & $\begin{array}{l}6910 \\
5750 \\
8270 \\
6270 \\
7250\end{array}$ & $\begin{array}{l}33 \\
21 \\
39 \\
29 \\
35\end{array}$ & $\begin{array}{r}9440 \\
5910 \\
10400 \\
7000 \\
9110\end{array}$ & $\begin{array}{l}37 \\
18 \\
39 \\
31 \\
36\end{array}$ & $\begin{array}{l}17200 \\
18000 \\
24600 \\
20200 \\
26700\end{array}$ & $\begin{array}{l}24 \\
26\end{array}$ \\
\hline $\begin{array}{l}1931 \\
1932 \\
1933 \\
1934 \\
1935\end{array}$ & $\begin{array}{l}3100 \\
1800 \\
2360 \\
2690 \\
1110\end{array}$ & $\begin{array}{r}24 \\
7 \\
9 \\
13 \\
2\end{array}$ & $\begin{array}{l}3140 \\
2050 \\
2590 \\
2760 \\
1150\end{array}$ & $\begin{array}{r}22 \\
7 \\
11 \\
13 \\
1\end{array}$ & $\begin{array}{l}3200 \\
2100 \\
2890 \\
2780 \\
1240\end{array}$ & $\begin{array}{r}19 \\
4 \\
13 \\
12 \\
1\end{array}$ & $\begin{array}{l}3380 \\
2240 \\
3160 \\
2930 \\
1400\end{array}$ & $\begin{array}{r}18 \\
4 \\
11 \\
10 \\
1\end{array}$ & $\begin{array}{l}3870 \\
2490 \\
3350 \\
3920 \\
1660\end{array}$ & $\begin{array}{r}15 \\
2 \\
9 \\
16 \\
1\end{array}$ & $\begin{array}{l}4440 \\
3320 \\
4010 \\
4860 \\
1980\end{array}$ & $\begin{array}{r}13 \\
4 \\
9 \\
19 \\
1\end{array}$ & $\begin{array}{l}5080 \\
4690 \\
4440 \\
5020 \\
2090\end{array}$ & $\begin{array}{r}15 \\
9 \\
6 \\
14 \\
1\end{array}$ & $\begin{array}{l}5400 \\
5130 \\
4920 \\
5030 \\
2200\end{array}$ & $\begin{array}{r}17 \\
10 \\
8 \\
9 \\
1\end{array}$ & $\begin{array}{l}6320 \\
5110 \\
5300 \\
5320 \\
2560\end{array}$ & $\begin{array}{r}25 \\
6 \\
9 \\
10 \\
1\end{array}$ & $\begin{array}{r}16700 \\
9180 \\
20200 \\
13300 \\
5350\end{array}$ & $\begin{array}{r}20 \\
3 \\
32 \\
13\end{array}$ \\
\hline
\end{tabular}


LONEST MEAN DISCHARGE, IN OBIC FEET PER SECOND, AND RANKING FOR THE INDICATED NUMBER OF CONSECUTIVE DAYS FOR EACH CLIMATIC YEAR, APRII 1-MARCH 31--Continued

YEAR

$\begin{array}{rrrrrr}1936 & 2920 & 17 & 2930 & 16 & 3030 \\ 1937 & 1560 & 5 & 1970 & 6 & 2370 \\ 1938 & 3590 & 31 & 3740 & 31 & 3830 \\ 1939 & 3940 & 34 & 4030 & 34 & 4270 \\ 1940 & 2320 & 8 & 2380 & 8 & 2450\end{array}$

$1942 \quad 2740$

$1943 \quad 3720$

19453240

$1946 \quad 3180$

19473200

$1948 \quad 3990$

$\begin{array}{ll}1949 & 1510 \\ 1950 & 3600\end{array}$

$\begin{array}{ll}1951 & 3060 \\ 1952 & 2930\end{array}$

19534290

19543180

19552950

$\begin{array}{ll}1956 & 2520 \\ 1957 & 2480\end{array}$

$\begin{array}{ll}1957 & 2480 \\ 1958 & 5500\end{array}$

19593340
1960

$1961 \quad 1420$

19623030
$6 \quad 1770$

$\begin{array}{ll}15 & 2980 \\ 33 & 3800\end{array}$

$33 \quad 3800$

293300

$26 \quad 3180$

$28 \quad 3270$

$\begin{array}{rr}35 & 4560 \\ 4 & 1730\end{array}$

$\begin{array}{rr}4 & 1730 \\ 32 & 3750\end{array}$

$\begin{array}{ll}23 & 3310 \\ 19 & 3100\end{array}$

$37 \quad 4400$

$27 \quad 3190$

$\begin{array}{rr}5 & 1830 \\ 9 & 3850\end{array}$

334000

$20 \quad 3250$

$24 \quad 3470$

$\begin{array}{ll}24 & 3470 \\ 26 & 3550 \\ 38 & 5230\end{array}$

$\begin{array}{rr}38 & 5230 \\ 4 & 2470\end{array}$

$\begin{array}{ll}32 & 4130\end{array}$

$\begin{array}{ll}28 & 3840 \\ 21 & 3570\end{array}$

$\begin{array}{ll}36 & 4730 \\ 25 & 3200\end{array}$

$\begin{array}{ll}25 & 3200 \\ 18 & 3080\end{array}$

$12 \quad 2550$

$10 \quad 2500$

$\begin{array}{ll}40 & 5550 \\ 30 & 3400\end{array}$

$10 \quad 2590$

$\begin{array}{rr}9 & 2510 \\ 40 & 5780\end{array}$

$\begin{array}{ll}40 & 5780 \\ 30 & 3710\end{array}$

182960

$17 \quad 3120$

$\begin{array}{rr}3 & 1590 \\ 22 & 3150\end{array}$

32440

$\begin{array}{rr}33 & 2440 \\ 23 & \end{array}$
CONSECUTIVE DAYS
30
60

90

120

$14 \quad 3340$

$15 \quad 3730$

124190

$11 \quad 4520$

$29 \quad 4240$

$\begin{array}{rr}34 & 4810 \\ 7 & 2790\end{array}$

285030

$\begin{array}{rr}34 & 5290 \\ 8 & 3590\end{array}$

315550

$\begin{array}{ll}31 & 5550 \\ 32 & 5380\end{array}$

$\begin{array}{ll}32 & 5380 \\ 11 & 4320\end{array}$

$\begin{array}{ll}30 & 5760 \\ 27 & 5710\end{array}$

$\begin{array}{rr}3 & 1930 \\ 31 & 5340\end{array}$

$31 \quad 5340$

$\begin{array}{rr}2 & 2670 \\ 37 & 6550\end{array}$

$4 \quad 3570$

40
26

124590

$\begin{array}{rr}7 & 4660 \\ 11 & 5320\end{array}$

$\begin{array}{ll}11 & 5320 \\ 27 & 5970\end{array}$

$\begin{array}{ll}27 & 5970 \\ 26 & 6020\end{array}$

$\begin{array}{rr}26 & 6020 \\ 8 & 4730\end{array}$

\begin{tabular}{rr}
6 & 5160 \\
38 & 7340 \\
\hline 7 & 5280
\end{tabular}

175280

$21 \quad 3580$

$\begin{array}{ll}30 & 4610 \\ 21 & 4470\end{array}$

$22 \quad 5230$

245550

$\begin{array}{ll}16 & 6120 \\ 38 & 8240\end{array}$

$\begin{array}{ll}38 & 8240 \\ 17 & 5430\end{array}$

235980

125200

$23 \quad 4160$

$\begin{array}{ll}25 & 4070 \\ 39 & 5940\end{array}$

$27 \quad 5310$

134490

$28 \quad 5690$

$\begin{array}{llll}26 & 4360 & 20 & 5300\end{array}$

$39 \quad 6270$

$\begin{array}{rr}8 & 3330 \\ 33 & 4590\end{array}$

$\begin{array}{ll}14 & 3840 \\ 33 & 4770\end{array}$

$37 \quad 6440$

$\begin{array}{ll}14 & 4450 \\ 28 & 5730\end{array}$

265900

$\begin{array}{ll}37 & 7050 \\ 14 & 5310\end{array}$

$25 \quad 6150$

296330

$37 \quad 7730$

185360

31 5660

$\begin{array}{ll}23 & 5550 \\ 34 & 6090\end{array}$

$33 \quad 6230$

$\begin{array}{ll}30 & 4060 \\ 26 & 4260\end{array}$

$\begin{array}{ll}29 & 5360 \\ 36 & 5610 \\ 12 & 3400\end{array}$

$36 \quad 5940$

$\begin{array}{ll}29 & 5440 \\ 36 & 6470\end{array}$

$34 \quad 6060$

$\begin{array}{ll}20 & 5700 \\ 35 & 6400\end{array}$

$30 \quad 6220$

$\begin{array}{ll}20 & 3210 \\ 15 & 3420\end{array}$

$20 \quad 3970$

$\begin{array}{ll}10 & 4740 \\ 17 & 3980\end{array}$

$\begin{array}{rr}16 & 5480 \\ 7 & 4260\end{array}$

$10 \quad 2810$

93190

73380

53910

$\begin{array}{rr}21 & 5400 \\ 5 & 4630\end{array}$

34270

$\begin{array}{ll}3 & 4270 \\ 2 & 3720\end{array}$

$\begin{array}{rrrr}6 & 2610 & 3 & 2880 \\ 40 & 6430 & 39 & 7300\end{array}$

23590

$\begin{array}{ll}40 & 6210 \\ 27 & 3990\end{array}$

$\begin{array}{ll}27 & 3990 \\ 16 & 3370\end{array}$

$\begin{array}{llll}23 & 4440 & 21 & 4850\end{array}$

$\begin{array}{ll}18 & 4990 \\ 23 & 5330\end{array}$

$40 \quad 8600$

$\begin{array}{ll}13 & 5220 \\ 19 & 5710\end{array}$

$\begin{array}{rr}3 & 3930 \\ 20 & 6440\end{array}$

$4 \quad 4400$

52800

$5 \quad 3130$

$6 \quad 5280$

$6 \quad 5280 \quad 814400$ $\begin{array}{lll}14 & 5950 & 1917100\end{array}$ $\begin{array}{llll}25 & 7120 & 32 & 21600\end{array}$

$75180 \quad 711600$

$\begin{array}{rrrrr}26 & 6430 & 26 & 11100 \\ 38 & 13000 & 40 & 24700\end{array}$

$18 \quad 5470 \quad 1320100$

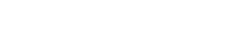

11 18000

$27 \quad 6510$

$30 \quad 6300$

$37 \quad 9060$

$\begin{array}{ll}15 & 5470 \\ 32 & 6650\end{array}$

2816300

2412200

3519700

$\begin{array}{ll}14 & 17700 \\ 30 & 20200\end{array}$

$\begin{array}{ll}19 & 5740 \\ 31 & 6580\end{array}$ $28 \quad 6500$

$16 \quad 5550$

1714500

2913900

2724600

$\begin{array}{rr}15 & 11800 \\ 16 & 8530\end{array}$

34680

$4 \quad 9730$

24050

$40 \quad 9980$

$\begin{array}{ll}13 & 5340 \\ 20 & 6140\end{array}$

211900

3826600

1217200

2210300

$\begin{array}{lll}4 & 4450 \quad 311600\end{array}$

$36 \quad 8140$

3311200

HIGHEST MEAN DISCHARGE, IN OBIC FEET PER SECOND, AND RANKING FOR THE INDICATED NUMBER OF CONSEQUTIVE DAYS FOR EAOH WATER YEAR, OCTCBER 1-SEPTEMBER 30

YEAR

\begin{tabular}{|c|c|c|}
\hline & 3 & \\
\hline $\begin{array}{l}1922116000 \\
192396200 \\
192472800 \\
192552300\end{array}$ & $\begin{array}{rr}5115000 \\
13 & 94500 \\
23 & 71500 \\
31 & 50700\end{array}$ & $\begin{array}{rr}311100 \\
13 & 9100 \\
23 & 6640 \\
31 & 4940\end{array}$ \\
\hline $\begin{array}{l}192684000 \\
1927119000 \\
1928113000 \\
1929111000 \\
193071400\end{array}$ & $\begin{array}{r}1780800 \\
3105000 \\
7112000 \\
8108000 \\
2468900\end{array}$ & $\begin{array}{r}197690 \\
88480 \\
510700 \\
710100 \\
246110\end{array}$ \\
\hline $\begin{array}{l}193133500 \\
193299800 \\
193379900 \\
193424700 \\
1935104000\end{array}$ & $\begin{array}{rr}40 & 31700 \\
12 & 98400 \\
20 & 77700 \\
41 & 24500 \\
9 & 99500\end{array}$ & $\begin{array}{ll}40 & 3050 \\
12 & 9420 \\
20 & 7690 \\
41 & 2300 \\
10 & 9220\end{array}$ \\
\hline 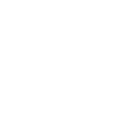 & $\begin{array}{ll}22 & 72900 \\
19 & 81400 \\
11 & 99200 \\
33 & 47900 \\
34 & 45300\end{array}$ & $\begin{array}{ll}22 & 7060 \\
18 & 7750 \\
11 & 9600 \\
32 & 4520 \\
35 & 4430\end{array}$ \\
\hline $\begin{array}{l}1941119000 \\
194290800 \\
194364400 \\
194491600 \\
194562500\end{array}$ & $\begin{array}{r}4115000 \\
1690300 \\
2862700 \\
1588800 \\
2962100\end{array}$ & $\begin{aligned} 41070 \\
15872 \\
28562 \\
16791 \\
29593\end{aligned}$ \\
\hline $\begin{array}{l}1946 \quad 49200 \\
1947 \quad 77300 \\
1948 \quad 91800 \\
1949115000 \\
195058300\end{array}$ & $\begin{array}{rr}32 & 47700 \\
21 & 76300 \\
14 & 90500 \\
6110000 \\
30 & 56800\end{array}$ & $\begin{array}{rr}33 & 455 \\
21 & 715 \\
14 & 862 \\
61010 \\
30 \quad 564\end{array}$ \\
\hline $\begin{array}{l}195166200 \\
1952122000 \\
195368500 \\
195433800 \\
195534300\end{array}$ & $\begin{array}{r}2764700 \\
2121000 \\
2567000 \\
3933200 \\
3833000\end{array}$ & $\begin{array}{rl}27 & 617 \\
21190 & 90 \\
25 & 635 \\
38 & 320 \\
39 & 310\end{array}$ \\
\hline
\end{tabular}

CONSEOUTIVE DAYS

7

15

$30 \quad 60$

90

120

0

438000

399800

395000

279800

2362000

$\begin{array}{ll}11 & 81000 \\ 23 & 58800\end{array}$

870300
2251600

363100

3147200

3141400

3238400

6
2045000

3034500

749700

1936900
2830200

1558000

1975300

1568700

1865100

1648800

1867200
682900

767000

492900

892400

790700

376000

1255600

1640800

9 46500

753600

461800

2552900

2442500

4028200

1087700

2074300

4120700

4026500

1072700

3921300

1767600

1465600
1647900

3918000

39 18000

$\begin{array}{ll}11 & 55400 \\ 23 & 36400\end{array}$

4114700

1367300

1749300

$\begin{array}{ll}41 & 11700 \\ 22 & 38300\end{array}$

2267800

1872400

989900

21 61700

21 54100

1963300

879100

2049900

966400

1944400

21 42500

858700

3539800

32
35
37500

3135300

3130600

594700

1383400

3050500

1674700
2854100

585400

1276900

$30 \quad 46100$

575000

$\begin{array}{rr}5 & 75000 \\ 10 & 62600\end{array}$

$\begin{array}{ll}10 & 62600 \\ 30 & 40400\end{array}$

559700

2849000

1266000
2947400

1458000

$\begin{array}{ll}28 & 37600 \\ 10 & 51100\end{array}$

2440200

1244200

455400

2333300

3915400

1047100

2729400

4l 10100

2431600

2037000 
HIGHEST MEAN DISGHARGE, IN CUBIC FEET PER SECOND, AND RANKING FOR THE INDICATED NUMBER OF CONSECUTIVE DAYS FOR EACH WATER YEAR, OCTCBER 1-SEPTEMBER 30-Continued

YEAR

$\begin{array}{rr} & \\ 1 & 3 \\ 195668500 & 2667000 \\ 1957124000 & 1123000 \\ 1958104000 & 10104000 \\ 195938400 & 3737900 \\ 196045500 & 3545300 \\ 196139700 & 3638500 \\ 196283400 & 1882700\end{array}$

CONSEQUTIVE DAYS
30
$90 \quad 120$

183 ALL

$\begin{array}{rr}2664900 & 2460700 \\ 1117000 & 2109000 \\ 9101000 & 796100 \\ 3737500 & 3636000 \\ 3444400 & 3442100 \\ 3636600 & 3733500 \\ 1779100 & 1768800\end{array}$

$\begin{array}{rrrr}2452200 & 25 & 40300 \\ 2101000 & 1 & 80400 \\ 4 & 85300 & 6 & 66400 \\ 36 & 31400 & 36 & 25900\end{array}$

$\begin{array}{llll}36 & 31400 & 36 & 25900\end{array}$

2931700
268900

3026600

1342100

$\begin{array}{rrrr}952000 & 13 & 42100 \\ 37 & 20300 & 37 & 17000\end{array}$

3720300

3226600

$\begin{array}{rr}30 & 19600 \\ 2 & 42700 \\ 15 & 30700 \\ 37 & 13300\end{array}$

31 12000 $\begin{array}{rr}2 & 23900 \\ 15 & 19600 \\ 37 & 9310\end{array}$

$3710 \quad 37$

$3730100 \quad 3722900$

3818600

3815700

31 19700

$\begin{array}{rrrrr}38 & 13000 & 38 & 9180 & 38 \\ 12 & 33400 & 12 & 20400 & 12\end{array}$

DURATION OF DISCHARGE FOR EACH WATER YEAR

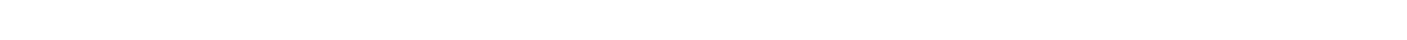
YEAR

NUMBER OF DAYS IN CLASS

OUBIC FEET $\rightarrow$ DAYS

\begin{tabular}{|c|c|c|c|c|c|c|c|c|c|c|c|c|c|c|c|c|c|c|c|c|c|c|c|c|c|c|c|c|c|c|c|c|}
\hline $\begin{array}{l}1922 \\
1923 \\
1924 \\
1925\end{array}$ & 1 & 1 & 3 & 2 & 7 & & & $\begin{array}{l}5 \\
4\end{array}$ & $\begin{array}{ll}622 \\
214\end{array}$ & $\begin{array}{l}17 \\
32 \\
23 \\
21\end{array}$ & $\begin{array}{l}24 \\
25 \\
20 \\
14\end{array}$ & $\begin{array}{l}32 \\
55 \\
18 \\
55\end{array}$ & $\begin{array}{l}67 \\
62 \\
30 \\
36\end{array}$ & $\begin{array}{l}24 \\
11 \\
38 \\
17\end{array}$ & $\begin{array}{r}20 \\
6 \\
23 \\
14\end{array}$ & $\begin{array}{r}34 \\
3 \\
45 \\
12\end{array}$ & $\begin{array}{r}15 \\
7 \\
22 \\
14\end{array}$ & $\begin{array}{r}11 \\
9 \\
3 \\
21\end{array}$ & $\begin{array}{c}12 \\
11 \\
3 \\
16\end{array}$ & $\begin{array}{l}7 \\
19 \\
10 \\
22\end{array}$ & $\begin{array}{rr}14 & 3 \\
19 & 15 \\
4 & 8 \\
12 & 11\end{array}$ & $\begin{array}{r}6 \\
13 \\
8 \\
301\end{array}$ & & $\begin{array}{r}4 \\
13 \\
12 \\
11\end{array}$ & & & $\begin{array}{r}9 \\
12 \\
15\end{array}$ & $\begin{array}{r}10 \\
17 \\
3\end{array}$ & & $\begin{array}{r}12 \\
3\end{array}$ & 5 & $\begin{array}{l}8205610.0 \\
8186060.0 \\
6282790.0 \\
5703230.0\end{array}$ \\
\hline $\begin{array}{l}1926 \\
1927 \\
1928 \\
1929 \\
1930\end{array}$ & & & & & & 1 & 3 & $\begin{array}{ll}1 & 4 \\
4 & 2 \\
3 & 2 \\
3 & 1\end{array}$ & $\begin{array}{ll}4 & 6 \\
2 & 9 \\
& 2 \\
2 & 2 \\
1 & 7\end{array}$ & $\begin{array}{r}15 \\
2 \\
13 \\
20 \\
9\end{array}$ & $\begin{array}{l}26 \\
43 \\
13 \\
35 \\
14\end{array}$ & $\begin{array}{l}44 \\
43 \\
14 \\
23 \\
20\end{array}$ & $\begin{array}{l}26 \\
22 \\
51 \\
11 \\
21\end{array}$ & $\begin{array}{l}33 \\
20 \\
28 \\
35 \\
43\end{array}$ & $\begin{array}{l}20 \\
18 \\
20 \\
11 \\
34\end{array}$ & $\begin{array}{r}29 \\
27 \\
48 \\
8 \\
37\end{array}$ & $\begin{array}{r}25 \\
9 \\
39 \\
17 \\
16\end{array}$ & $\begin{array}{l}20 \\
16 \\
13 \\
13 \\
27\end{array}$ & $\begin{array}{r}7 \\
12 \\
17 \\
11 \\
15\end{array}$ & $\begin{array}{r}8 \\
21 \\
16 \\
9 \\
19\end{array}$ & $\begin{array}{rr}8 & 15 \\
11 & 12 \\
18 & 4 \\
29 & 16 \\
13 & 11\end{array}$ & $\begin{array}{r}111 \\
4 \\
3 \\
181 \\
121\end{array}$ & $\begin{array}{r}10 \\
4 \\
4 \\
16 \\
12\end{array}$ & $\begin{array}{r}9 \\
11 \\
17 \\
18\end{array}$ & $\begin{array}{r}13 \\
11 \\
3 \\
10\end{array}$ & & $\begin{array}{l}12 \\
23 \\
16 \\
11 \\
4\end{array}$ & $\begin{array}{r}16 \\
12 \\
9 \\
9 \\
2\end{array}$ & $\begin{array}{r}2 \\
7 \\
8 \\
16\end{array}$ & $\begin{array}{r}2 \\
6 \\
13\end{array}$ & $\begin{array}{l}2 \\
2 \\
2\end{array}$ & $\begin{array}{l}7046280.0 \\
8339120.0 \\
7717270.0 \\
9673940.0 \\
6580330.0\end{array}$ \\
\hline $\begin{array}{l}1931 \\
1932 \\
1933 \\
1934 \\
1935\end{array}$ & 2 & 210 & 17 & $\begin{array}{l}4 \\
1\end{array}$ & 1 & $\begin{array}{r}1 \\
1 \\
11\end{array}$ & $\begin{array}{ll}9 & \\
1 & \\
8 & 1 \\
1 & \\
2 & 1\end{array}$ & & $\begin{array}{ll}6 & 19 \\
1 & 22 \\
7 & 17 \\
3 & 23 \\
2 & 32\end{array}$ & $\begin{array}{l}33 \\
29 \\
37 \\
48 \\
31\end{array}$ & $\begin{array}{l}32 \\
24 \\
35 \\
95 \\
37\end{array}$ & $\begin{array}{l}39 \\
36 \\
60 \\
32 \\
22\end{array}$ & $\begin{array}{l}40 \\
14 \\
33 \\
11 \\
11\end{array}$ & $\begin{array}{r}39 \\
28 \\
31 \\
8 \\
17\end{array}$ & $\begin{array}{r}16 \\
13 \\
20 \\
6 \\
19\end{array}$ & $\begin{array}{r}17 \\
23 \\
12 \\
7 \\
10\end{array}$ & $\begin{array}{r}18 \\
12 \\
6 \\
8 \\
17\end{array}$ & $\begin{array}{r}15 \\
15 \\
4 \\
11 \\
12\end{array}$ & $\begin{array}{r}7 \\
12 \\
12 \\
8 \\
7\end{array}$ & $\begin{array}{l}5 \\
7 \\
4 \\
9 \\
5\end{array}$ & $\begin{array}{rr}10 & 10 \\
14 & 7 \\
4 & 6 \\
6 & \\
9 & 10\end{array}$ & $\begin{array}{r}9 \\
12 \\
3 \\
4\end{array}$ & $\begin{array}{r}1 \\
10 \\
2 \\
3\end{array}$ & $\begin{array}{l}8 \\
6\end{array}$ & 10 & $\begin{array}{r}16 \\
2\end{array}$ & $\begin{array}{r}19 \\
8\end{array}$ & $\begin{array}{r}5 \\
15\end{array}$ & $\begin{array}{l}6 \\
2\end{array}$ & 3 & & $\begin{array}{l}3214460.0 \\
7688210.0 \\
4904900.0 \\
2206970.0 \\
4988580.0\end{array}$ \\
\hline $\begin{array}{l}1936 \\
1937 \\
1938 \\
1939 \\
1940\end{array}$ & & & & $\begin{array}{ll}1 & 1\end{array}$ & 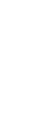 & & $\begin{array}{l}7 \\
6\end{array}$ & $\begin{array}{ll}6 & 6 \\
5 & 7 \\
5 & 11 \\
9 & 11\end{array}$ & $\begin{array}{rr}6 & 22 \\
7 & 24 \\
4 \\
11 \\
1 \\
1 \\
11\end{array}$ & $\begin{array}{l}49 \\
28 \\
28 \\
26 \\
83\end{array}$ & $\begin{array}{l}52 \\
37 \\
32 \\
53 \\
53\end{array}$ & $\begin{array}{l}29 \\
16 \\
59 \\
39 \\
31\end{array}$ & $\begin{array}{l}28 \\
55 \\
29 \\
26 \\
13\end{array}$ & $\begin{array}{l}27 \\
14 \\
22 \\
36 \\
25\end{array}$ & $\begin{array}{r}8 \\
16 \\
10 \\
15 \\
14\end{array}$ & $\begin{array}{l}15 \\
19 \\
41 \\
27 \\
12\end{array}$ & $\begin{array}{r}13 \\
16 \\
9 \\
7 \\
5\end{array}$ & $\begin{array}{r}13 \\
4 \\
11 \\
8 \\
4\end{array}$ & $\begin{array}{r}6 \\
12 \\
6 \\
7 \\
2\end{array}$ & $\begin{array}{r}6 \\
6 \\
18 \\
10 \\
15\end{array}$ & $\begin{array}{rr}10 & 6 \\
6 & 9 \\
13 & 4 \\
18 & 15 \\
8 & 4\end{array}$ & $\begin{array}{c}5 \\
22 \\
5 \\
1 \\
8\end{array}$ & $\begin{array}{r}5 \\
12 \\
3 \\
8 \\
10\end{array}$ & $\begin{array}{r}10 \\
11 \\
4 \\
25 \\
9\end{array}$ & $\begin{array}{r}19 \\
6 \\
6 \\
8 \\
5\end{array}$ & & $\begin{array}{r}18 \\
7 \\
25\end{array}$ & $\begin{array}{r}4 \\
8 \\
13\end{array}$ & $\begin{array}{l}3 \\
8\end{array}$ & 6 & & $\begin{array}{l}6017220.0 \\
5984760.0 \\
7771650.0 \\
4718940.0 \\
3557110.0\end{array}$ \\
\hline $\begin{array}{l}1941 \\
1942 \\
1943 \\
1944 \\
1945\end{array}$ & & & & & & 1 & 1 & $\begin{array}{l}11 \\
418\end{array}$ & $\begin{array}{r}3 \\
1 \quad 8 \\
5 \\
817 \\
11\end{array}$ & $\begin{array}{l}11 \\
24 \\
27 \\
20 \\
24\end{array}$ & $\begin{array}{l}31 \\
13 \\
51 \\
34 \\
67\end{array}$ & $\begin{array}{r}59 \\
9 \\
75 \\
70 \\
60\end{array}$ & $\begin{array}{l}28 \\
41 \\
16 \\
47 \\
29\end{array}$ & $\begin{array}{l}17 \\
34 \\
19 \\
20 \\
20\end{array}$ & $\begin{array}{r}16 \\
22 \\
14 \\
9 \\
16\end{array}$ & $\begin{array}{r}34 \\
23 \\
16 \\
7 \\
17\end{array}$ & $\begin{array}{r}15 \\
20 \\
22 \\
12 \\
3\end{array}$ & $\begin{array}{r}22 \\
15 \\
9 \\
10 \\
2\end{array}$ & $\begin{array}{r}25 \\
13 \\
12 \\
6 \\
6\end{array}$ & $\begin{array}{l}15 \\
17 \\
11 \\
12 \\
15\end{array}$ & $\begin{array}{rr}10 & 5 \\
11 & 9 \\
14 & 10 \\
8 & 6 \\
24 & 4\end{array}$ & $\begin{array}{l}4 \\
8 \\
7 \\
3 \\
3\end{array}$ & $\begin{array}{l}5 \\
7 \\
4 \\
3 \\
6\end{array}$ & $\begin{array}{r}4 \\
20 \\
26 \\
3 \\
17\end{array}$ & $\begin{array}{r}3 \\
12 \\
18 \\
5 \\
27\end{array}$ & & $\begin{array}{r}12 \\
22 \\
3 \\
20 \\
4\end{array}$ & $\begin{array}{r}17 \\
5 \\
19\end{array}$ & $\begin{array}{r}13 \\
18 \\
5\end{array}$ & 5 & 3 & $\begin{array}{l}8079360.0 \\
8575590.0 \\
5668990.0 \\
6655590.0 \\
5812230.0\end{array}$ \\
\hline $\begin{array}{l}1946 \\
1947 \\
1948 \\
1949 \\
1950\end{array}$ & & & & 2 & 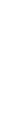 & & $\frac{1}{2}$ & $\begin{array}{rr}3 & 8 \\
& 5 \\
3 & 14 \\
3 & \\
& 4\end{array}$ & $\begin{array}{rr}8 & 5 \\
5 & 9 \\
4 & 6 \\
3 & 6 \\
4 & 14\end{array}$ & $\begin{array}{r}14 \\
14 \\
7 \\
36 \\
26\end{array}$ & $\begin{array}{l}47 \\
14 \\
27 \\
53 \\
19\end{array}$ & $\begin{array}{l}43 \\
38 \\
32 \\
59 \\
37\end{array}$ & $\begin{array}{l}67 \\
59 \\
49 \\
15 \\
46\end{array}$ & $\begin{array}{r}48 \\
45 \\
19 \\
8 \\
61\end{array}$ & $\begin{array}{l}11 \\
15 \\
39 \\
14 \\
27\end{array}$ & $\begin{array}{l}20 \\
12 \\
36 \\
31 \\
10\end{array}$ & $\begin{array}{r}17 \\
22 \\
19 \\
19 \\
9\end{array}$ & $\begin{array}{r}9 \\
15 \\
8 \\
6 \\
8\end{array}$ & $\begin{array}{l}2 \\
9 \\
4 \\
3 \\
4\end{array}$ & $\begin{array}{l}12 \\
15 \\
15 \\
10 \\
14\end{array}$ & $\begin{array}{rr}15 & 5 \\
11 & 5 \\
11 & 10 \\
7 & 6 \\
12 & 17\end{array}$ & $\begin{array}{r}11 \\
4 \\
41 \\
3 \\
81\end{array}$ & $\begin{array}{r}14 \\
5 \\
11 \\
2 \\
10\end{array}$ & $\begin{array}{r}8 \\
6 \\
10 \\
8 \\
7\end{array}$ & $\begin{array}{l}6 \\
7 \\
4 \\
2\end{array}$ & $\begin{array}{r}16 \\
5 \\
24 \\
17\end{array}$ & $\begin{array}{r}15 \\
7 \\
9\end{array}$ & $\begin{array}{r}4 \\
12 \\
4\end{array}$ & $\begin{array}{l}9 \\
6\end{array}$ & 4 & 2 & $\begin{array}{l}4397360.0 \\
6802180.0 \\
6890900.0 \\
7229760.0 \\
5567410.0\end{array}$ \\
\hline $\begin{array}{l}1951 \\
1952 \\
1953 \\
1954 \\
1955\end{array}$ & & & & & & & 8 & $\begin{array}{ll}1 & 4 \\
2 & 2 \\
13 \\
7 & 16 \\
4 & 31\end{array}$ & $\begin{array}{rr}4 & 4 \\
2 & 5 \\
3 & 7 \\
6 & 21 \\
1 & 29\end{array}$ & $\begin{array}{r}34 \\
8 \\
7 \\
30 \\
30\end{array}$ & $\begin{array}{l}41 \\
19 \\
50 \\
38 \\
40\end{array}$ & $\begin{array}{l}51 \\
61 \\
59 \\
79 \\
38\end{array}$ & $\begin{array}{l}74 \\
58 \\
77 \\
40 \\
42\end{array}$ & $\begin{array}{l}28 \\
30 \\
23 \\
21 \\
26\end{array}$ & $\begin{array}{r}6 \\
9 \\
18 \\
33 \\
15\end{array}$ & $\begin{array}{l}7 \\
19 \\
23 \\
20 \\
11\end{array}$ & $\begin{array}{r}10 \\
29 \\
19 \\
21 \\
8\end{array}$ & $\begin{array}{l}25 \\
11 \\
16 \\
13 \\
12\end{array}$ & $\begin{array}{r}9 \\
8 \\
9 \\
4 \\
11\end{array}$ & $\begin{array}{r}6 \\
2 \\
5 \\
6 \\
12\end{array}$ & $\begin{array}{rr}10 & 9 \\
7 & 3 \\
2 & 2 \\
6 & 2 \\
9 & 20\end{array}$ & $\begin{array}{r}41 \\
51 \\
3 \\
7 \\
17\end{array}$ & $\begin{array}{r}11 \\
10 \\
2 \\
1 \\
2\end{array}$ & $\begin{array}{r}10 \\
5 \\
6\end{array}$ & $\begin{array}{r}7 \\
7 \\
13\end{array}$ & & $\begin{array}{r}7 \\
12 \\
7\end{array}$ & 12 & 6 & 19 & 4 & $\begin{array}{r}4949340.0 \\
49055340.0 \\
4430270.0 \\
3075820.0 \\
3675470.0\end{array}$ \\
\hline $\begin{array}{l}1956 \\
1957 \\
1958 \\
1959 \\
1960\end{array}$ & & & & & & 20 & $\begin{array}{l}0 \\
91\end{array}$ & $\begin{array}{ll}5 & 39 \\
4 & 20 \\
5 & 7 \\
5 & 11 \\
4 & 7\end{array}$ & $\begin{array}{rr}9 & 20 \\
0 & 20 \\
7 & 13 \\
1 & 7 \\
7 & 15\end{array}$ & $\begin{array}{l}33 \\
43 \\
19 \\
34 \\
19\end{array}$ & $\begin{array}{r}64 \\
31 \\
16 \\
104 \\
58\end{array}$ & $\begin{array}{r}46 \\
2 \\
37 \\
91 \\
37\end{array}$ & $\begin{array}{l}17 \\
34 \\
33 \\
18 \\
25\end{array}$ & $\begin{array}{l}12 \\
27 \\
38 \\
14 \\
20\end{array}$ & $\begin{array}{r}1 \\
13 \\
30 \\
9 \\
10\end{array}$ & $\begin{array}{r}14 \\
3 \\
32 \\
4 \\
18\end{array}$ & $\begin{array}{r}14 \\
4 \\
31 \\
9 \\
14\end{array}$ & $\begin{array}{r}7 \\
6 \\
15 \\
5 \\
10\end{array}$ & $\begin{array}{l}7 \\
6 \\
6 \\
4 \\
5\end{array}$ & $\begin{array}{r}6 \\
16 \\
7 \\
7 \\
10\end{array}$ & $\begin{array}{rr}9 & 10 \\
13 & 4 \\
2 & 8 \\
13 & 11 \\
11 & 21\end{array}$ & $\begin{array}{r}7 \\
5 \\
91 \\
41 \\
121\end{array}$ & $\begin{array}{r}9 \\
6 \\
10 \\
14 \\
13\end{array}$ & $\begin{array}{r}3 \\
14 \\
3 \\
1 \\
16\end{array}$ & $\begin{array}{r}5 \\
17 \\
5\end{array}$ & & $\begin{array}{r}7 \\
9 \\
11\end{array}$ & $\begin{array}{l}4 \\
5\end{array}$ & & $\begin{array}{l}17 \\
12\end{array}$ & 3 & $\begin{array}{r}4406610.0 \\
38733860.0 \\
7168450.0 \\
3398530.0 \\
4629540.0\end{array}$ \\
\hline $\begin{array}{l}961 \\
962\end{array}$ & & 1 & 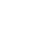 & 1 & & & & & $\begin{array}{ll}6 & 18 \\
3 & 17\end{array}$ & $\begin{array}{l}49 \\
11\end{array}$ & $\begin{array}{l}65 \\
32\end{array}$ & $\begin{array}{l}46 \\
30\end{array}$ & $\begin{array}{l}15 \\
24\end{array}$ & $\begin{array}{l}28 \\
39\end{array}$ & $\begin{array}{l}14 \\
21\end{array}$ & $\begin{array}{l}23 \\
38\end{array}$ & $\begin{array}{l}15 \\
15\end{array}$ & $\begin{array}{l}7 \\
5\end{array}$ & $\begin{array}{l}9 \\
8\end{array}$ & $\begin{array}{l}9 \\
6\end{array}$ & $\begin{array}{rr}7 & 9 \\
6 & 14\end{array}$ & 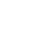 & 6 & & & & & 3 & 5 & & & $\begin{array}{l}3349530.0 \\
7446710.0\end{array}$ \\
\hline
\end{tabular}

$\begin{array}{ccc}\text { OBBIC } & \text { ACOU- } \\ \text { FEET } & \text { MU- } & \text { PER- } \\ \text { PER TOTAL LATED } & \text { CENT } \\ \text { C.ASS SECOND DAYS } & \text { DAYS } & \text { DAYS }\end{array}$

$\begin{array}{llllll}0 & 0.00 & 0 & 14975 & 100.0\end{array}$

$1000.00 \quad 3 \quad 14975100.0$

11000.00000

$21200.00 \quad 3 \quad 14972100.0$

$\begin{array}{lllll}3 & 1300.00 & 14 & 14969 & 100.0\end{array}$

$\begin{array}{lllll}4 & 1500.00 & 26 & 14955 & 99.9 \\ 5 & 1800.00 & 39 & 14929 & 99.7\end{array}$

$\begin{array}{lllll}5 & 1800.00 & 39 & 14929 & 99.7 \\ 6 & 2100.00 & 66 & 14890 & 99.4\end{array}$

$\begin{array}{rrrrr}6 & 2100.00 & 66 & 14890 & 99.4 \\ 7 & 2400.00 & 153 & 14824 & 99.0\end{array}$

$82800.00 \quad 170 \quad 14671 \quad 98.0$
DURATION TABLE OF DISCHARGE FOR WATER YEARS 1922-62

\begin{tabular}{|c|c|c|c|}
\hline $\begin{array}{l}\text { OBIC } \\
\text { FEET } \\
\text { PER }\end{array}$ & TOTAL & $\begin{array}{l}\text { ACOJ- } \\
\text { MU- } \\
\text { L.ATED }\end{array}$ & $\begin{array}{l}\text { PER- } \\
\text { CENT }\end{array}$ \\
\hline CLASS SECOND & DAYS & DAYS & DAYS \\
\hline $\begin{array}{rr}9 & 3200.00 \\
10 & 3700.00 \\
11 & 4300.00 \\
12 & 5000.00 \\
13 & 5800.00 \\
14 & 6700.00 \\
15 & 7700.00 \\
16 & 8900.00 \\
1710000.00\end{array}$ & $\begin{array}{r}353 \\
525 \\
1064 \\
1572 \\
1726 \\
1440 \\
1093 \\
665 \\
844\end{array}$ & $\begin{array}{r}14501 \\
14148 \\
13623 \\
12559 \\
10987 \\
9261 \\
7821 \\
6728 \\
6063\end{array}$ & $\begin{array}{l}96.8 \\
94.5 \\
91.0 \\
83.9 \\
73.4 \\
61.8 \\
52.2 \\
44.9 \\
40.5\end{array}$ \\
\hline
\end{tabular}

ACOUFEET TOTAL LATED CENT CLASS SECOND DAYS DAYS DAYS

$\begin{array}{lllll}18 & 12000.0 & 622 & 5219 & 34.9 \\ 19 & 14000.0 & 466 & 4597 & 30.7 \\ 20 & 16000.0 & 353 & 4131 & 27.6 \\ 21 & 18000.0 & 444 & 3778 & 25.2 \\ 22 & 21000.0 & 444 & 3334 & 22.3 \\ 23 & 25000.0 & 356 & 2890 & 19.3 \\ 24 & 29000.0 & 322 & 2534 & 16.9 \\ 25 & 33000.0 & 289 & 2212 & 14.8 \\ 26 & 38000.0 & 378 & 1923 & 12.8\end{array}$

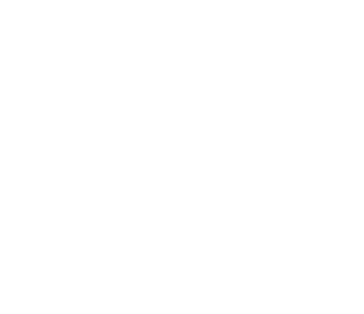


COLORADO RIVER MATN STEM

09380000 COLORADO RIVER AT LEES FERRY, AZ--Continued

MONIHLY MEAN DISQHARGES, IN GBBIC FEET PER SECOND, FOR EAOH WATER YEAR

\begin{tabular}{|c|c|c|c|c|c|c|c|c|c|c|c|c|}
\hline YEAR & $\propto C T$ & $\mathrm{NON}$ & DEC & JAN & FEB & MAR & APR & MAY & JUNE & JULY & AUG & SEF \\
\hline $\begin{array}{l}1912 \\
1913 \\
1914 \\
1915\end{array}$ & $\begin{array}{l}18400 \\
10100 \\
10500 \\
15390\end{array}$ & $\begin{array}{l}7430 \\
8960 \\
8996 \\
8803\end{array}$ & $\begin{array}{l}5740 \\
4860 \\
5331 \\
5388\end{array}$ & $\begin{array}{l}5630 \\
5740 \\
5912 \\
4913\end{array}$ & $\begin{array}{l}5680 \\
5600 \\
7186 \\
7082\end{array}$ & $\begin{array}{r}8750 \\
8460 \\
14210 \\
8462\end{array}$ & $\begin{array}{l}15000 \\
29900 \\
25840 \\
24180\end{array}$ & $\begin{array}{l}57200 \\
48500 \\
72340 \\
37340\end{array}$ & $\begin{array}{l}96500 \\
46200 \\
98930 \\
54600\end{array}$ & $\begin{array}{l}44100 \\
24600 \\
42660 \\
26060\end{array}$ & $\begin{array}{r}16800 \\
8000 \\
17090 \\
7522\end{array}$ & $\begin{array}{r}8890 \\
9980 \\
10280 \\
7070\end{array}$ \\
\hline $\begin{array}{l}1916 \\
1917 \\
1918 \\
1919 \\
1920\end{array}$ & $\begin{array}{r}8320 \\
22610 \\
7553 \\
8735 \\
5830\end{array}$ & $\begin{array}{l}6852 \\
8268 \\
7487 \\
8302 \\
6784\end{array}$ & $\begin{array}{l}5544 \\
5964 \\
6528 \\
6631 \\
6356\end{array}$ & $\begin{array}{l}6336 \\
4227 \\
5699 \\
4661 \\
6574\end{array}$ & $\begin{array}{r}7302 \\
6311 \\
6704 \\
5625 \\
10400\end{array}$ & $\begin{array}{r}22530 \\
8189 \\
10640 \\
10560 \\
11080\end{array}$ & $\begin{array}{l}29540 \\
25680 \\
14710 \\
22800 \\
16270\end{array}$ & $\begin{array}{l}57320 \\
59810 \\
40640 \\
47650 \\
92360\end{array}$ & $\begin{array}{r}71060 \\
122300 \\
79400 \\
33560 \\
108300\end{array}$ & $\begin{array}{l}33580 \\
68990 \\
27870 \\
15420 \\
39050\end{array}$ & $\begin{array}{r}25930 \\
18320 \\
8927 \\
8748 \\
14990\end{array}$ & $\begin{array}{r}11110 \\
10890 \\
9586 \\
6463 \\
7843\end{array}$ \\
\hline $\begin{array}{l}1921 \\
1922 \\
1923 \\
1924 \\
1925\end{array}$ & $\begin{array}{r}8366 \\
6951 \\
4698 \\
11820 \\
5794\end{array}$ & $\begin{array}{r}9991 \\
6976 \\
6701 \\
10850 \\
6550\end{array}$ & $\begin{array}{l}6540 \\
7288 \\
6449 \\
6850 \\
4433\end{array}$ & $\begin{array}{l}6647 \\
5675 \\
6060 \\
5028 \\
4206\end{array}$ & $\begin{array}{l}8166 \\
7870 \\
6095 \\
8768 \\
7209\end{array}$ & $\begin{array}{r}15310 \\
14720 \\
7266 \\
8220 \\
9788\end{array}$ & $\begin{array}{l}15070 \\
19460 \\
21430 \\
27470 \\
21740\end{array}$ & $\begin{array}{l}64040 \\
72340 \\
5899 \\
49680 \\
34550\end{array}$ & $\begin{array}{r}133600 \\
86130 \\
76640 \\
52540 \\
40090\end{array}$ & $\begin{array}{l}35940 \\
23390 \\
37800 \\
16200 \\
23360\end{array}$ & $\begin{array}{r}26570 \\
11450 \\
21930 \\
4848 \\
11860\end{array}$ & $\begin{array}{r}12550 \\
7067 \\
14760 \\
4031 \\
17870\end{array}$ \\
\hline $\begin{array}{l}1926 \\
1927 \\
1928 \\
1929 \\
1930\end{array}$ & $\begin{array}{r}16260 \\
6953 \\
15210 \\
9843 \\
14990\end{array}$ & $\begin{array}{r}10200 \\
5575 \\
12330 \\
9527 \\
9388\end{array}$ & $\begin{array}{l}722.9 \\
6131 \\
7154 \\
5553 \\
7086\end{array}$ & $\begin{array}{l}5822 \\
5438 \\
7591 \\
5343 \\
4794\end{array}$ & $\begin{array}{l}6306 \\
6946 \\
7994 \\
6172 \\
8667\end{array}$ & $\begin{array}{r}10400 \\
9776 \\
12210 \\
14950 \\
9253\end{array}$ & $\begin{array}{l}26510 \\
20380 \\
16530 \\
28130 \\
28650\end{array}$ & $\begin{array}{l}54580 \\
62820 \\
70580 \\
66190 \\
32140\end{array}$ & $\begin{array}{l}57680 \\
61220 \\
62230 \\
80750 \\
51550\end{array}$ & $\begin{array}{l}22480 \\
39120 \\
24830 \\
32610 \\
17250\end{array}$ & $\begin{array}{r}8999 \\
15050 \\
10120 \\
30750 \\
23770\end{array}$ & $\begin{array}{r}4952 \\
34180 \\
5792 \\
27540 \\
8744\end{array}$ \\
\hline $\begin{array}{l}1931 \\
1932 \\
1933 \\
1934 \\
1935\end{array}$ & $\begin{array}{l}8911 \\
8118 \\
5437 \\
6083 \\
2471\end{array}$ & $\begin{array}{l}7103 \\
5896 \\
6342 \\
4982 \\
3007\end{array}$ & $\begin{array}{l}4669 \\
4066 \\
4410 \\
5150 \\
3697\end{array}$ & $\begin{array}{l}4264 \\
4405 \\
4392 \\
4979 \\
4124\end{array}$ & $\begin{array}{l}6566 \\
9650 \\
4548 \\
5418 \\
4906\end{array}$ & $\begin{array}{r}6937 \\
10920 \\
8089 \\
5415 \\
5488\end{array}$ & $\begin{array}{r}9479 \\
27510 \\
8323 \\
7620 \\
10960\end{array}$ & $\begin{array}{l}18790 \\
64650 \\
23340 \\
17830 \\
22790\end{array}$ & $\begin{array}{r}23260 \\
60790 \\
66760 \\
8571 \\
67280\end{array}$ & $\begin{array}{r}7275 \\
32710 \\
18100 \\
2123 \\
23930\end{array}$ & $\begin{array}{r}3996 \\
15060 \\
5484 \\
2068 \\
8463\end{array}$ & $\begin{array}{l}4502 \\
8156 \\
6272 \\
2233 \\
7139\end{array}$ \\
\hline $\begin{array}{l}1936 \\
1937 \\
1938 \\
1939 \\
1940\end{array}$ & $\begin{array}{l}5638 \\
5638 \\
7358 \\
9147 \\
5258\end{array}$ & $\begin{array}{l}5355 \\
7420 \\
6326 \\
7878 \\
5166\end{array}$ & $\begin{array}{l}4301 \\
5112 \\
6221 \\
6514 \\
4552\end{array}$ & $\begin{array}{l}4234 \\
3208 \\
5162 \\
5532 \\
4149\end{array}$ & $\begin{array}{l}5469 \\
7389 \\
6233 \\
5279 \\
5128\end{array}$ & $\begin{array}{r}7443 \\
11350 \\
12760 \\
13010 \\
7014\end{array}$ & $\begin{array}{l}22260 \\
25420 \\
27070 \\
19390 \\
11440\end{array}$ & $\begin{array}{l}58400 \\
56520 \\
54580 \\
40500 \\
32890\end{array}$ & $\begin{array}{l}44510 \\
39530 \\
78420 \\
27980 \\
25000\end{array}$ & $\begin{array}{r}16310 \\
21450 \\
28000 \\
6802 \\
6371\end{array}$ & $\begin{array}{r}14060 \\
6509 \\
8158 \\
3580 \\
2905\end{array}$ & $\begin{array}{r}9095 \\
6780 \\
15120 \\
9201 \\
6769\end{array}$ \\
\hline $\begin{array}{l}1941 \\
1942 \\
1943 \\
1944 \\
1945\end{array}$ & $\begin{array}{r}11140 \\
29230 \\
5436 \\
6139 \\
5555\end{array}$ & $\begin{array}{r}6743 \\
15170 \\
6191 \\
7670 \\
6445\end{array}$ & $\begin{array}{l}5818 \\
9363 \\
5809 \\
6423 \\
5207\end{array}$ & $\begin{array}{l}5664 \\
6615 \\
5359 \\
452.9 \\
5288\end{array}$ & $\begin{array}{l}7615 \\
7136 \\
5984 \\
5979 \\
6329\end{array}$ & $\begin{array}{r}10870 \\
10250 \\
8397 \\
8279 \\
7106\end{array}$ & $\begin{array}{l}18340 \\
47800 \\
24360 \\
17250 \\
12690\end{array}$ & $\begin{array}{l}80900 \\
52190 \\
35100 \\
52800 \\
45620\end{array}$ & $\begin{array}{l}67290 \\
70610 \\
45870 \\
69500 \\
46390\end{array}$ & $\begin{array}{l}27100 \\
21420 \\
23240 \\
28980 \\
27130\end{array}$ & $\begin{array}{r}12970 \\
7380 \\
12890 \\
6786 \\
16450\end{array}$ & $\begin{array}{r}10220 \\
4626 \\
7518 \\
3844 \\
6222\end{array}$ \\
\hline $\begin{array}{l}1946 \\
1947 \\
1948 \\
1949 \\
1950\end{array}$ & $\begin{array}{r}8217 \\
6548 \\
13310 \\
5376 \\
8278\end{array}$ & $\begin{array}{l}7449 \\
7842 \\
9836 \\
6850 \\
7946\end{array}$ & $\begin{array}{l}5472 \\
7230 \\
7574 \\
5639 \\
5985\end{array}$ & $\begin{array}{l}5951 \\
4509 \\
6606 \\
5485 \\
5689\end{array}$ & $\begin{array}{l}5746 \\
6422 \\
7959 \\
6497 \\
7178\end{array}$ & $\begin{array}{r}8060 \\
10640 \\
10490 \\
11490 \\
10570\end{array}$ & $\begin{array}{l}17030 \\
13110 \\
28610 \\
21970 \\
20450\end{array}$ & $\begin{array}{l}28170 \\
50760 \\
57030 \\
50390 \\
32050\end{array}$ & $\begin{array}{l}33490 \\
55040 \\
56120 \\
74270 \\
50060\end{array}$ & $\begin{array}{l}11870 \\
31330 \\
15930 \\
34750 \\
22400\end{array}$ & $\begin{array}{r}7781 \\
19570 \\
8642 \\
9365 \\
6858\end{array}$ & $\begin{array}{l}5204 \\
9816 \\
3865 \\
5268 \\
5546\end{array}$ \\
\hline $\begin{array}{l}1951 \\
1952 \\
1953 \\
1954 \\
1955\end{array}$ & $\begin{array}{l}5555 \\
6702 \\
5993 \\
5215 \\
8331\end{array}$ & $\begin{array}{l}5879 \\
7479 \\
6495 \\
6956 \\
582\end{array}$ & $\begin{array}{l}6751 \\
5423 \\
6155 \\
5544 \\
4529\end{array}$ & $\begin{array}{l}5127 \\
7742 \\
6404 \\
5180 \\
3969\end{array}$ & $\begin{array}{l}6492 \\
6593 \\
6578 \\
6155 \\
4380\end{array}$ & $\begin{array}{l}6792 \\
7152 \\
7443 \\
6388 \\
9429\end{array}$ & $\begin{array}{r}8925 \\
38090 \\
8889 \\
9181 \\
10380\end{array}$ & $\begin{array}{l}26760 \\
82630 \\
17040 \\
20760 \\
25530\end{array}$ & $\begin{array}{l}48510 \\
87260 \\
50280 \\
13310 \\
26660\end{array}$ & $\begin{array}{r}22060 \\
25580 \\
15450 \\
10530 \\
9280\end{array}$ & $\begin{array}{r}12800 \\
13350 \\
10750 \\
5221 \\
8288\end{array}$ & $\begin{array}{l}6902 \\
9107 \\
4335 \\
6534 \\
3860\end{array}$ \\
\hline $\begin{array}{l}1956 \\
1957 \\
1958 \\
1959 \\
1960\end{array}$ & $\begin{array}{r}3475 \\
3034 \\
12160 \\
5050 \\
8165\end{array}$ & $\begin{array}{r}4632 \\
5045 \\
14250 \\
6002 \\
8393\end{array}$ & $\begin{array}{l}5309 \\
4015 \\
8401 \\
5956 \\
5721\end{array}$ & $\begin{array}{l}6065 \\
4627 \\
6457 \\
5116 \\
4960\end{array}$ & $\begin{array}{l}4876 \\
5823 \\
9649 \\
5677 \\
5537\end{array}$ & $\begin{array}{r}8306 \\
8108 \\
11320 \\
5592 \\
12120\end{array}$ & $\begin{array}{r}15090 \\
13910 \\
26450 \\
7054 \\
27050\end{array}$ & $\begin{array}{l}35620 \\
41780 \\
64920 \\
16660 \\
25440\end{array}$ & $\begin{array}{l}43590 \\
94860 \\
61810 \\
30850 \\
37630\end{array}$ & $\begin{array}{r}9054 \\
65300 \\
10210 \\
12720 \\
10520\end{array}$ & $\begin{array}{r}5786 \\
26090 \\
4655 \\
6912 \\
3381\end{array}$ & $\begin{array}{r}2791 \\
13820 \\
5368 \\
4133 \\
3245\end{array}$ \\
\hline $\begin{array}{l}1961 \\
1962\end{array}$ & $\begin{array}{r}5540 \\
11790\end{array}$ & $\begin{array}{l}5805 \\
8855\end{array}$ & $\begin{array}{l}4467 \\
6182\end{array}$ & $\begin{array}{l}4321 \\
5670\end{array}$ & $\begin{array}{r}5954 \\
14240\end{array}$ & $\begin{array}{l}5886 \\
9727\end{array}$ & $\begin{array}{r}9531 \\
40180\end{array}$ & $\begin{array}{l}18750 \\
59080\end{array}$ & $\begin{array}{l}26690 \\
48330\end{array}$ & $\begin{array}{r}5998 \\
27930\end{array}$ & $\begin{array}{l}5475 \\
7629\end{array}$ & $\begin{array}{r}11940 \\
5293\end{array}$ \\
\hline
\end{tabular}

ANNUA PEAK DISCHARGE, IN GBIC FEET PER SECOND, AND CORRESPONDING GAGE HEIGHT, IN FEET, FOR EACH WATER YEAR

\begin{tabular}{|c|c|c|c|c|c|c|c|c|c|c|c|c|c|}
\hline $\begin{array}{l}\text { WATER } \\
\text { YEAR }\end{array}$ & & DATE & $\begin{array}{c}\text { GAGE } \\
\text { HEIGHT }\end{array}$ & $\begin{array}{c}\text { PEAK } \\
\text { DISCHARGE }\end{array}$ & $\begin{array}{l}\text { WATER } \\
\text { YEAR }\end{array}$ & & DATE & $\begin{array}{c}\text { GAGE } \\
\text { HEIGHT }\end{array}$ & $\begin{array}{c}\text { PEAK } \\
\text { DISQHARGE }\end{array}$ & $\begin{array}{l}\text { WATER } \\
\text { YEAR }\end{array}$ & DATE & $\begin{array}{c}\text { GAGE } \\
\text { HEIGHT }\end{array}$ & $\begin{array}{c}\text { PEAK } \\
\text { DISCHARGE }\end{array}$ \\
\hline $\begin{array}{l}1884 \\
1922 \\
1923 \\
1924 \\
1925 \\
1926 \\
1927 \\
1928 \\
1929 \\
1930 \\
1931 \\
1932 \\
1933 \\
1934\end{array}$ & $\begin{array}{l}\text { JULY } \\
\text { MAY } \\
\text { MAY } \\
\text { JUNE } \\
\text { JUNE } \\
\text { MAY } \\
\text { JULY } \\
\text { JUNE } \\
\text { MAY } \\
\text { JUNE } \\
\text { MAY } \\
\text { MAY } \\
\text { JUNE } \\
\text { MAY }\end{array}$ & $\begin{array}{l}07,1884 \\
31,1922 \\
31,1923 \\
17,1924 \\
03,1925 \\
29,1926 \\
01,1927 \\
03,1928 \\
29,1929 \\
03,1930 \\
21,1931 \\
26,1932 \\
05,1933 \\
16,1934\end{array}$ & $\begin{array}{l}31.50 \\
19.80 \\
17.50 \\
15.20 \\
13.60 \\
16.70 \\
20.35 \\
19.55 \\
18.89 \\
15.15 \\
12.05 \\
18.30 \\
16.45 \\
11.05\end{array}$ & $\begin{array}{r}I_{300000} \\
116000 \\
98300 \\
76200 \\
54900 \\
86500 \\
127000 \\
115000 \\
114000 \\
73300 \\
34600 \\
102000 \\
82700 \\
25300\end{array}$ & $\begin{array}{l}1935 \\
1936 \\
1937 \\
1938 \\
1939 \\
1940 \\
1941 \\
1942 \\
1943 \\
1944 \\
1945 \\
1946 \\
1947 \\
1948\end{array}$ & $\begin{array}{l}\text { JUNE } \\
\text { MAY } \\
\text { MAY } \\
\text { JUNE } \\
\text { MAY } \\
\text { MAY } \\
\text { MAY } \\
\text { MAY } \\
\text { JUNE } \\
\text { MAY } \\
\text { MAY } \\
\text { JUNE } \\
\text { MAY } \\
\text { MAY }\end{array}$ & $\begin{array}{l}19,1935 \\
23,1936 \\
20,1937 \\
08,1938 \\
26,1939 \\
18,1940 \\
17,1941 \\
30,1942 \\
05,1943 \\
19,1944 \\
17,1945 \\
14,1946 \\
13,1947 \\
25,1948\end{array}$ & $\begin{array}{l}18.90 \\
16.14 \\
16.88 \\
18.45 \\
13.86 \\
13.54 \\
20.51 \\
17.30 \\
15.14 \\
17.20 \\
14.90 \\
13.66 \\
16.26 \\
17.76\end{array}$ & $\begin{array}{r}105000 \\
76300 \\
84800 \\
101000 \\
49700 \\
47200 \\
120000 \\
92800 \\
68600 \\
94400 \\
64400 \\
50400 \\
80400 \\
92400\end{array}$ & $\begin{array}{l}1949 \\
1950 \\
1951 \\
1952 \\
1953 \\
1954 \\
1955 \\
1956 \\
1957 \\
1958 \\
1959 \\
1960 \\
1961 \\
1962\end{array}$ & $\begin{array}{l}\text { JUNE } 22,1949 \\
\text { JUNE } 06,1950 \\
\text { JUNE } 01,1951 \\
\text { JUNE } 12,1952 \\
\text { JUNE } 17,1953 \\
\text { MAY } 26,1954 \\
\text { JUNE } 13,1955 \\
\text { JUNE } 06,1956 \\
\text { JUNE } 12,1957 \\
\text { JUNE } 01,1958 \\
\text { JUNE } 19,1959 \\
\text { JUNE } 08,1960 \\
\text { JUNE } 05,1961 \\
\text { MAY } 16,1962\end{array}$ & $\begin{array}{l}20.00 \\
14.81 \\
15.27 \\
21.15 \\
15.60 \\
12.04 \\
12.41 \\
15.68 \\
21.14 \\
19.00 \\
12.53 \\
13.43 \\
12.78 \\
17.22\end{array}$ & $\begin{array}{r}119000 \\
60600 \\
67300 \\
123000 \\
6900 \\
34300 \\
35600 \\
69600 \\
126000 \\
105600 \\
38900 \\
46700 \\
40200 \\
85000\end{array}$ \\
\hline
\end{tabular}


MAGNITUDE AND PRCBABILITY OF ANNLAL HIGHEST MEAN DISCHARGE BASED ON WATER YEARS YEARS $1922-62$

\begin{tabular}{|c|c|c|c|c|c|c|}
\hline \multirow{2}{*}{$\begin{array}{l}\text { PERIOD } \\
\text { (CON- } \\
\text { SECU- } \\
\text { TIVE } \\
\text { DAYS) }\end{array}$} & \multicolumn{6}{|c|}{$\begin{array}{l}\text { DISCHARGE, IN CUBIC FEET PER SECOND, FOR } \\
\text { INDICATED RECJRRENCE INTERNAL, IN YEARS, AND } \\
\text { ANNUAL EXCEEDANCE PROBABILITY, IN PERCENT }\end{array}$} \\
\hline & $\begin{array}{c}2 \\
508\end{array}$ & $\begin{array}{c}5 \\
208\end{array}$ & $\begin{array}{l}10 \\
108\end{array}$ & $\begin{array}{l}25 \\
48\end{array}$ & $\begin{array}{l}50 \\
28\end{array}$ & $\begin{array}{r}100 \\
18\end{array}$ \\
\hline $\begin{array}{r}1 \\
3 \\
7 \\
15\end{array}$ & $\begin{array}{l}75000 \\
73400 \\
69500 \\
64300\end{array}$ & $\begin{array}{r}103000 \\
100600 \\
94900 \\
87200\end{array}$ & $\begin{array}{r}118500 \\
115600 \\
108800 \\
99600\end{array}$ & $\begin{array}{l}135200 \\
131700 \\
123700 \\
112600\end{array}$ & $\begin{array}{l}145900 \\
141900 \\
133200 \\
120800\end{array}$ & $\begin{array}{l}155300 \\
150800 \\
141500 \\
127800\end{array}$ \\
\hline
\end{tabular}

DATA BEJOW BASED ON PERIOD OF REOORD AFTER COMPLETION OF LAKE POWELL

LOWEST MEAN DISCHARGE, IN OUBIC FEET PER SECOND, AND RANKING FOR THE INDICATED NUMBER OF CONSECUTIVE DAYS FOR EACH CLIMATIC YEAR, APRIL 1-MARCH 31

YEAR

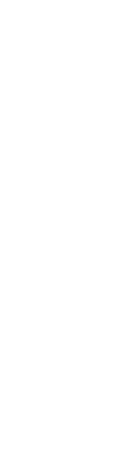

1

$\begin{array}{llll}13 & 4210 & 10 & 4830\end{array}$

$\begin{array}{llll}12 & 4830 & 13 & 6560\end{array}$

$10 \quad 4430$

$\begin{array}{ll}15 & 5720 \\ 11 & 4450\end{array}$

72850

$\begin{array}{rr}9 & 2720 \\ 14 & 5800\end{array}$

$\begin{array}{rr}5 & 1980\end{array}$

82820

$6 \quad 2150$

$\begin{array}{ll}4 & 1370\end{array}$

$\begin{array}{ll}1 & 917\end{array}$

$\begin{array}{rr}2 & 944 \\ 3 & 1270\end{array}$

$16 \quad 5630$

$\begin{array}{ll}15 & 6400 \\ 12 & 4960\end{array}$

94390

$\begin{array}{rr}7 & 3820 \\ 16 & 7940\end{array}$

53240

85350

$6 \quad 2470$

$\begin{array}{ll}4 & 1930 \\ 1 & 1910\end{array}$

$\begin{array}{ll}1 & 1910 \\ 2 & 1040\end{array}$

$\begin{array}{ll}2 & 1040 \\ 3 & 3420\end{array}$

145990
$14 \begin{array}{ll}\text { CONSEOUTIVE DAYS } \\ 30 & 60\end{array}$

$\begin{array}{rr}9 & 5430 \\ 15 & 7750 \\ 13 & 6470 \\ 14 & 7060 \\ 10 & 5750\end{array}$

96370

$\begin{array}{ll}15 & 8190 \\ 11 & 6620\end{array}$

$11 \quad 6620$

$\begin{array}{ll}13 & 7960 \\ 10 & 6720\end{array}$

$8 \quad 5190$

$\begin{array}{rr}7 & 4510 \\ 16 & 8950\end{array}$

$\begin{array}{ll}5 & 3700\end{array}$

$11 \quad 7280$

43950

$\begin{array}{ll}3 & 4300 \\ 2 & 2250\end{array}$

$\begin{array}{ll}2 & 2250 \\ 1 & 1310\end{array}$

$\begin{array}{ll}1 & 1310 \\ 6 & 4840\end{array}$

126900
85930

$\begin{array}{rr}6 & 5020 \\ 16 & 9860\end{array}$

35260

$\begin{array}{rr}3 & 5260 \\ 14 & 8190\end{array}$

$4 \quad 6720$

$\begin{array}{ll}4 & 6720 \\ 5 & 7390 \\ 2 & 2700 \\ 1 & 3100\end{array}$

$\begin{array}{ll}7 & 3740\end{array}$

127470 $\begin{array}{rr}8 & 7070 \\ 13 & 8780\end{array}$ $\begin{array}{llll}7 & 7800 & 9 & 8190\end{array}$ 159050

$\begin{array}{rr}13 & 8780 \\ 9 & 7750\end{array}$

67730 36910

$\begin{array}{rr}16 & 10700 \\ 45800\end{array}$

148990

$10 \quad 7390$

118030

$\begin{array}{ll}1 & 3040 \\ 2 & 8360\end{array}$

$\begin{array}{ll}2 & 8360 \\ 5 & 7040\end{array}$

129470
90

$\begin{array}{rr}9 & 8190 \\ 14 & 9060 \\ 5 & 7890\end{array}$

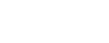

$\begin{array}{rr}12 & 9070 \\ 8 & 9170\end{array}$

78600

$\begin{array}{rr}3 & 9020 \\ 16 & 12300\end{array}$

$\begin{array}{rr}16 & 12300 \\ 2 & 6820\end{array}$

1310300

$6 \quad 8070$

$6 \quad 8070$
$10 \quad 10800$

$\begin{array}{rr}10 & 10800 \\ 1 & 4570\end{array}$

1110500
$4 \quad 8080$

1510300
120

$\begin{array}{ll}6 & 8520 \\ 9 & 9310 \\ 3 & 810\end{array}$

38190

$10 \quad 9540$

1110200

$7 \quad 8290$

810500

$\begin{array}{rr}16 & 13200 \\ 2 & 6940\end{array}$

$2 \quad 6940$

49090

49090
1511400

16820

1410700

59500

1310900
183

$5 \quad 9220$

$\begin{array}{ll}7 & 9570 \\ 3 & 8670\end{array}$

$\begin{array}{ll}3 & 8670 \\ 9 & 9710\end{array}$

$11 \quad 10500$

48800

$1210800 \quad 1211100$

$1613800 \quad 1614900$

$27700 \quad 110400$

$\begin{array}{rr}2 & 7700 \\ 10 & 10300\end{array}$

$610200 \quad 712700$

$\begin{array}{rrrr}15 & 12300 & 15 & 12700 \\ 1 & 10300 & 8 & 10400\end{array}$

$1311700 \quad 1312200$

$810600 \quad 1111000$

$1412000 \quad 1415700$
ALL

15900
11100

$\begin{array}{ll}5 & 11100 \\ 2 & 10600\end{array}$

11900

12400

1

10

12

8
4

15

HIGHEST MEAN DISCHARGE, IN CUBIC FEET PER SECOND, AND RANKING FOR THE INDICATED NUMBER OF CONSECUTIVE DAYS

FOR EACH WATER YEAR, OCTOBER 1-SEPTEYBER 30

YEAR

19655800

196618

196718800

196919000

197020100

197122500

197221600

197330500

197425000

197523200

197621500

197724600

197823700

197923600

198034500

198121100

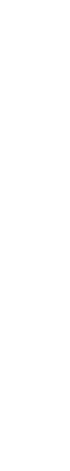

921700 $\begin{array}{ll}3 & 19900 \\ 3 & 30400\end{array}$

330400
423400

22300

1120700

623600

$\begin{array}{ll}7 & 22800 \\ 2 & 34300\end{array}$

1319900

$\begin{array}{rl}1 & 54600 \\ 17 & 17600 \\ 15 & 1790 \\ 13 & 1810 \\ 16 & 1700 \\ 14 & 17600 \\ 9 & 1980 \\ 12 & 1850 \\ 3 & 2910 \\ 6 & 2240 \\ 8 & 2180 \\ 10 & 1910 \\ 5 & 2140 \\ 4 & 2100 \\ 7 & 21600 \\ 2 & 3330 \\ 11 & 1880\end{array}$

CONSECUTIVE DAYS

\begin{tabular}{|c|c|c|c|c|c|c|}
\hline 15 & 30 & 60 & 90 & 120 & 183 & ALL \\
\hline 146600 & 145900 & 139900 & 132700 & 127400 & 122500 & 114900 \\
\hline $\begin{array}{ll}16 & 16600 \\
14 & 16600 \\
13 & 17200 \\
17 & 16100 \\
15 & 16300\end{array}$ & $\begin{array}{ll}14 & 16000 \\
15 & 14500 \\
12 & 16700 \\
17 & 15700 \\
16 & 16000\end{array}$ & $\begin{array}{ll}14 & 15400 \\
17 & 13800 \\
12 & 15900 \\
16 & 15400 \\
15 & 15400\end{array}$ & $\begin{array}{ll}13 & 14300 \\
17 & 13100 \\
11 & 15800 \\
14 & 15200 \\
15 & 14700\end{array}$ & $\begin{array}{rl}15 & 13400 \\
17 & 12700 \\
7 & 15400 \\
11 & 14800 \\
13 & 14100\end{array}$ & $\begin{array}{rl}16 & 12400 \\
17 & 12100 \\
8 & 14200 \\
9 & 14400 \\
13 & 13500\end{array}$ & $\begin{array}{rr}13 & 10800 \\
15 & 10800 \\
9 & 11500 \\
8 & 12200 \\
10 & 12000\end{array}$ \\
\hline $\begin{array}{rl}9 & 18600 \\
12 & 17200 \\
3 & 28800 \\
4 & 22100 \\
5 & 20500\end{array}$ & $\begin{array}{rr}9 & 17000 \\
13 & 17000 \\
3 & 28500 \\
4 & 20000 \\
5 & 19900\end{array}$ & $\begin{array}{rr}10 & 16100 \\
11 & 16300 \\
2 & 23500 \\
4 & 19800 \\
5 & 18700\end{array}$ & $\begin{array}{rr}10 & 15700 \\
9 & 15800 \\
3 & 20100 \\
4 & 18900 \\
5 & 17800\end{array}$ & $\begin{array}{ll}9 & 15600 \\
8 & 15400 \\
3 & 20100 \\
4 & 17600 \\
5 & 17400\end{array}$ & $\begin{array}{ll}6 & 14900 \\
7 & 14900 \\
3 & 18000 \\
4 & 15100 \\
5 & 15300\end{array}$ & $\begin{array}{ll}6 & 11900 \\
7 & 12800 \\
3 & 14000 \\
5 & 11400 \\
4 & 12800\end{array}$ \\
\hline $\begin{array}{rr}10 & 18600 \\
7 & 20300 \\
8 & 19600 \\
6 & 20000 \\
2 & 30700\end{array}$ & $\begin{array}{rr}10 & 17500 \\
6 & 19300 \\
8 & 19000 \\
7 & 17800 \\
2 & 27700\end{array}$ & $\begin{array}{ll}9 & 15500 \\
6 & 17800 \\
7 & 16900 \\
8 & 16300 \\
3 & 25800\end{array}$ & $\begin{array}{rr}12 & 14400 \\
6 & 16700 \\
7 & 15100 \\
8 & 15500 \\
2 & 24100\end{array}$ & $\begin{array}{rr}14 & 13500 \\
6 & 14500 \\
12 & 14500 \\
10 & 14300 \\
2 & 22300\end{array}$ & $\begin{array}{rr}14 & 13200 \\
10 & 12200 \\
11 & 12800 \\
12 & 11600 \\
2 & 19400\end{array}$ & $\begin{array}{rr}11 & 11700 \\
14 & 11400 \\
12 & 11500 \\
17 & 11500 \\
2 & 15000\end{array}$ \\
\hline 111820 & 1116300 & 1314800 & 1613700 & 1613400 & 1512000 & 1611500 \\
\hline
\end{tabular}


CLORADO RTVER MATN STEM

09380000 COLORADO RIVER AT LEES FERRY, AZ-Continued

DURATION OF DISCHARGE FOR EACH WATER YEAR

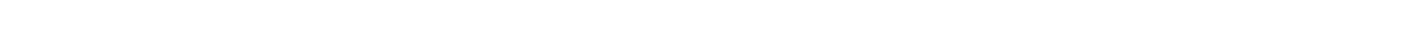

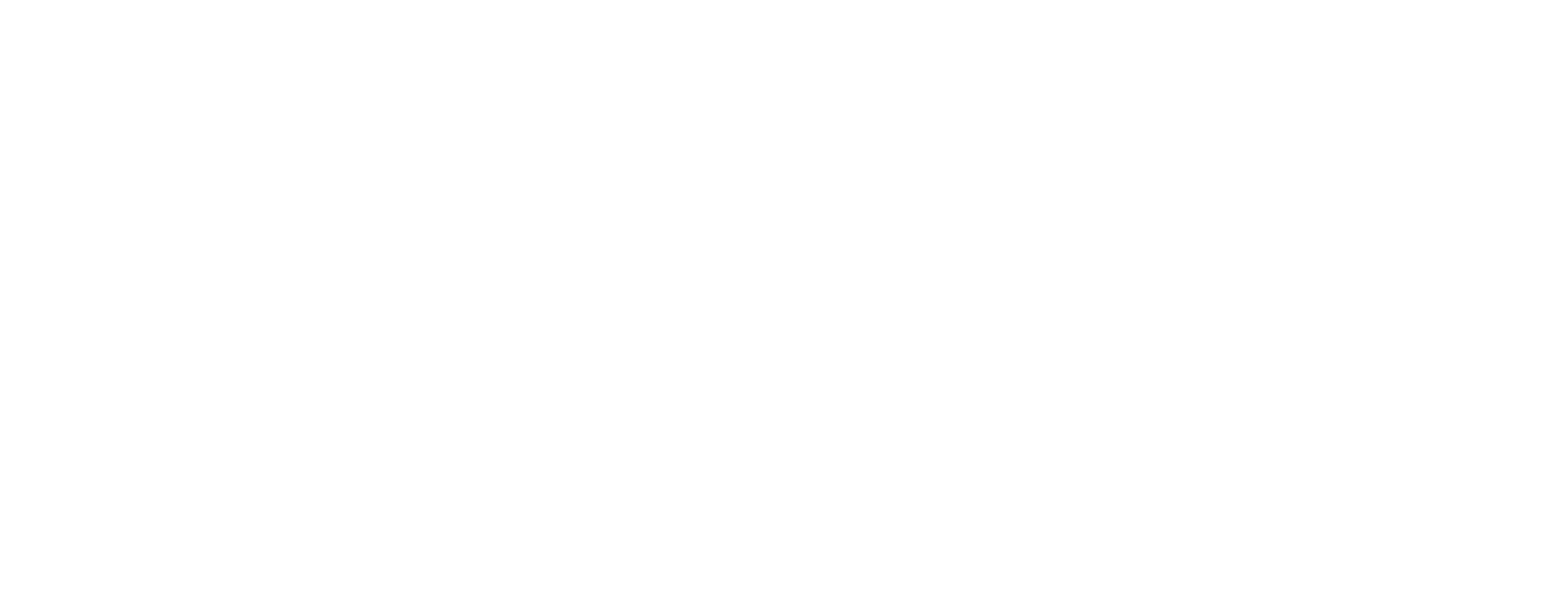

DURATION TABLE OF DISCHARGE FOR WATER YEARS 1965-81

\begin{tabular}{|c|c|c|c|c|c|c|c|c|c|c|c|c|c|c|c|c|c|}
\hline CLASS & $\begin{array}{l}\text { OBBIC } \\
\text { FEET } \\
\text { PER } \\
\text { SECOND }\end{array}$ & $\begin{array}{r}\text { TOTAL } \\
\text { DAYS }\end{array}$ & $\begin{array}{c}\text { ACOU- } \\
\text { MU- } \\
\text { LATED } \\
\text { DAYS }\end{array}$ & $\begin{array}{l}\text { PER } \\
\text { CENT } \\
\text { DAYS }\end{array}$ & $\begin{array}{r}\text { CABIC } \\
\text { FEET } \\
\text { PER } \\
\text { CIASS SECOND }\end{array}$ & $\begin{array}{r}\text { TOTAL } \\
\text { DAYS }\end{array}$ & $\begin{array}{l}\text { ACOU- } \\
\text { MU- } \\
\text { LATED } \\
\text { DAYS }\end{array}$ & $\begin{array}{l}\text { PER- } \\
\text { CENT } \\
\text { DAYS }\end{array}$ & CLASS & $\begin{array}{c}\text { CBBIC } \\
\text { FEET } \\
\text { PER } \\
\text { SECOND }\end{array}$ & $\begin{array}{r}\text { TOTAL } \\
\text { DAYS }\end{array}$ & $\begin{array}{c}\text { ACOU- } \\
\text { MU- } \\
\text { LATED } \\
\text { DAYS }\end{array}$ & $\begin{array}{l}\text { PER- } \\
\text { CENT } \\
\text { DAYS }\end{array}$ & $\begin{array}{r}\text { CUBIC } \\
\text { FEET } \\
\text { PER } \\
\text { CLASS SECOND }\end{array}$ & $\begin{array}{r}\text { TOTAL } \\
\text { DAYS }\end{array}$ & $\begin{array}{c}\text { ACOH- } \\
\text { MU- } \\
\text { LATED } \\
\text { DAYS }\end{array}$ & $\begin{array}{l}\text { PER- } \\
\text { CENT } \\
\text { DAYS }\end{array}$ \\
\hline $\begin{array}{ll}0 \\
1 \\
2 \\
3 & 1 \\
4 & 1 \\
5 & 1 \\
6 & 1 \\
7 & 1 \\
8 & 2\end{array}$ & $\begin{array}{r}0.00 \\
869.00 \\
990.00 \\
1100.00 \\
1300.00 \\
1400.00 \\
1600.00 \\
1900.00 \\
2100.00\end{array}$ & $\begin{array}{r}0 \\
11 \\
4 \\
14 \\
4 \\
8 \\
12 \\
12 \\
23\end{array}$ & $\begin{array}{l}6209 \\
6209 \\
6198 \\
6194 \\
6180 \\
6176 \\
6168 \\
6156 \\
6144\end{array}$ & $\begin{array}{r}100.0 \\
100.0 \\
99.8 \\
99.8 \\
99.5 \\
99.5 \\
99.3 \\
99.1 \\
99.0\end{array}$ & $\begin{array}{rr}9 & 2400.00 \\
10 & 2700.00 \\
11 & 3100.00 \\
12 & 3500.00 \\
13 & 4000.00 \\
14 & 4500.00 \\
15 & 5100.00 \\
16 & 5800.00 \\
17 & 6600.00\end{array}$ & $\begin{array}{r}31 \\
32 \\
36 \\
60 \\
70 \\
91 \\
129 \\
258 \\
320\end{array}$ & $\begin{array}{l}6121 \\
6090 \\
6058 \\
6022 \\
5962 \\
5892 \\
5801 \\
5672 \\
5414\end{array}$ & $\begin{array}{l}98.6 \\
98.1 \\
97.6 \\
97.0 \\
96.0 \\
94.9 \\
93.4 \\
91.4 \\
87.2\end{array}$ & $\begin{array}{l}18 \\
19 \\
20 \\
21 \\
221 \\
231 \\
231 \\
241 \\
251 \\
26\end{array}$ & $\begin{array}{r}7500.0 \\
8500.0 \\
9600.0 \\
11000.0 \\
12000.0 \\
14000.0 \\
16000.0 \\
18000.0 \\
21000.0\end{array}$ & $\begin{array}{r}426 \\
495 \\
738 \\
496 \\
831 \\
810 \\
623 \\
395 \\
96\end{array}$ & $\begin{array}{r}5094 \\
4668 \\
4173 \\
3435 \\
2939 \\
2108 \\
1298 \\
675 \\
280\end{array}$ & $\begin{array}{l}82.0 \\
75.2 \\
67.2 \\
55.3 \\
47.3 \\
34.0 \\
20.9 \\
10.9\end{array}$ & $\begin{array}{ll}27 & 23000.0 \\
28 & 26000.0 \\
29 & 30000.0 \\
30 & 34000.0 \\
31 & 39000.0 \\
32 & 44000.0 \\
33 & 50000.0 \\
34 & 57000.0\end{array}$ & $\begin{array}{r}64 \\
55 \\
13 \\
17 \\
12 \\
14 \\
8 \\
1\end{array}$ & $\begin{array}{r}184 \\
120 \\
65 \\
52 \\
35 \\
23 \\
9 \\
1\end{array}$ & $\begin{array}{l}3.0 \\
1.9 \\
1.0 \\
0.8 \\
0.6 \\
0.4 \\
0.1 \\
0.0\end{array}$ \\
\hline
\end{tabular}

MONIHLY MEAN DISCHARGES, IN OBBIC FEET PER SECOND, FOR EACH WATER YEAR

\begin{tabular}{|c|c|c|c|c|c|c|c|c|c|c|c|c|}
\hline YEAR & $\infty \mathrm{Cr}$ & NOV & DEC & JAN & FEB & MAR & APR & MAY & JUNE & JULY & AUG & SEP \\
\hline 1965 & 4367 & 5840 & 6466 & 9079 & 9266 & 9045 & 20540 & 37140 & 39050 & 11830 & 14160 & 12610 \\
\hline $\begin{array}{l}1966 \\
1967 \\
1968 \\
1969 \\
1970\end{array}$ & $\begin{array}{r}10720 \\
8975 \\
6745 \\
10170 \\
10240\end{array}$ & $\begin{array}{r}9904 \\
9807 \\
7726 \\
10650 \\
11870\end{array}$ & $\begin{array}{r}8637 \\
8597 \\
8980 \\
10370 \\
13250\end{array}$ & $\begin{array}{r}7337 \\
9991 \\
10300 \\
9264 \\
11490\end{array}$ & $\begin{array}{l}8700 \\
9622 \\
8066 \\
8296 \\
8013\end{array}$ & $\begin{array}{r}10110 \\
11220 \\
13950 \\
11520 \\
7906\end{array}$ & $\begin{array}{l}13870 \\
13240 \\
16270 \\
14630 \\
15830\end{array}$ & $\begin{array}{l}15900 \\
14290 \\
15330 \\
12410 \\
14630\end{array}$ & $\begin{array}{l}12670 \\
11730 \\
15030 \\
14710 \\
13450\end{array}$ & $\begin{array}{l}10690 \\
10430 \\
13450 \\
15540 \\
12500\end{array}$ & $\begin{array}{l}11090 \\
11260 \\
11140 \\
15120 \\
12570\end{array}$ & $\begin{array}{l}10460 \\
10020 \\
10670 \\
13340 \\
11780\end{array}$ \\
\hline $\begin{array}{l}1971 \\
1972 \\
1973 \\
1974 \\
1975\end{array}$ & $\begin{array}{r}8101 \\
9503 \\
10270 \\
8292 \\
9798\end{array}$ & $\begin{array}{r}7544 \\
12840 \\
11280 \\
6931 \\
11940\end{array}$ & $\begin{array}{r}10900 \\
15240 \\
16540 \\
5417 \\
9175\end{array}$ & $\begin{array}{r}7993 \\
13100 \\
19630 \\
13760 \\
12490\end{array}$ & $\begin{array}{r}7492 \\
7727 \\
13750 \\
5388 \\
10010\end{array}$ & $\begin{array}{r}10410 \\
6139 \\
17810 \\
6318 \\
8255\end{array}$ & $\begin{array}{r}16990 \\
13150 \\
28190 \\
8311 \\
7711\end{array}$ & $\begin{array}{l}15050 \\
14670 \\
10540 \\
13070 \\
14510\end{array}$ & $\begin{array}{l}15030 \\
14500 \\
12620 \\
15360 \\
16590\end{array}$ & $\begin{array}{l}15330 \\
14880 \\
10670 \\
19950 \\
19850\end{array}$ & $\begin{array}{r}14250 \\
16350 \\
9215 \\
19720 \\
16610\end{array}$ & $\begin{array}{r}13040 \\
15640 \\
7130 \\
13890 \\
16240\end{array}$ \\
\hline $\begin{array}{l}1976 \\
1977 \\
1978 \\
1979 \\
1980\end{array}$ & $\begin{array}{r}10360 \\
12880 \\
6166 \\
11130 \\
10050\end{array}$ & $\begin{array}{r}7142 \\
15080 \\
6554 \\
11280 \\
13480\end{array}$ & $\begin{array}{r}8459 \\
13180 \\
13390 \\
14460 \\
10370\end{array}$ & $\begin{array}{r}11250 \\
16170 \\
15410 \\
1656 r \\
9825\end{array}$ & $\begin{array}{r}12900 \\
8481 \\
10830 \\
13440 \\
10700\end{array}$ & $\begin{array}{r}10990 \\
7455 \\
9420 \\
3324 \\
9851\end{array}$ & $\begin{array}{r}11090 \\
2751 \\
8273 \\
5738 \\
14500\end{array}$ & $\begin{array}{r}17010 \\
3343 \\
10530 \\
8414 \\
13750\end{array}$ & $\begin{array}{r}12710 \\
7828 \\
12740 \\
10320 \\
24740\end{array}$ & $\begin{array}{l}12460 \\
13780 \\
11410 \\
13980 \\
25780\end{array}$ & $\begin{array}{l}11710 \\
19150 \\
17320 \\
17300 \\
20790\end{array}$ & $\begin{array}{l}14150 \\
16420 \\
16280 \\
11530 \\
16490\end{array}$ \\
\hline 1981 & 12640 & 15730 & 12450 & 12120 & 11530 & 7524 & 7943 & 8992 & 8856 & 13750 & 14690 & 11210 \\
\hline
\end{tabular}


COLORADO RIVER MAIN SIEM

09380000 COLORADO RIVER AT LEES FERRX, AZ--Continued

ANNUAL PEAK DISCHAFGE, IN OBBIC FEET PER SECOND, AND CORRESPONDING GAGE HEIGHT, IN FEET, FOR EACH WATER YEAR

\begin{tabular}{|c|c|c|c|c|c|c|c|c|c|c|c|}
\hline $\begin{array}{l}\text { WATER } \\
\text { YEAR }\end{array}$ & DATE & $\begin{array}{c}\text { GAGE } \\
\text { HEIGHT }\end{array}$ & $\begin{array}{c}\text { PEAR } \\
\text { DISCHARGE }\end{array}$ & $\begin{array}{l}\text { WATER } \\
\text { YEAR }\end{array}$ & DATE & $\begin{array}{c}\text { GAGE } \\
\text { HEIGHT }\end{array}$ & $\begin{array}{c}\text { PEAK } \\
\text { DISCHARGE }\end{array}$ & $\begin{array}{l}\text { WATER } \\
\text { YEAR }\end{array}$ & DATE & $\begin{array}{c}\text { GAGE } \\
\text { HEIGHT }\end{array}$ & $\begin{array}{c}\text { PEAR } \\
\text { DISCHARGE }\end{array}$ \\
\hline 1963 & œT. 21, 1962 & 10.08 & ${ }^{2} 19200$ & 1970 & AUG. 26,1970 & 11.70 & 27300 & 1976 & MAY 19,1976 & 11.60 & 27100 \\
\hline $\begin{array}{l}1964 \\
1965 \\
1966 \\
1967 \\
1968 \\
1969\end{array}$ & $\begin{array}{l}\text { AFR. } 28,1964 \\
\text { JUNE } 15,1965 \\
\text { MAY } 03,1966 \\
\text { APR. } 19,1967 \\
\text { JULY } 19,1968 \\
\text { AUG. } 28,1969\end{array}$ & $\begin{array}{l}10.34 \\
15.02 \\
10.92 \\
11.10 \\
11.73 \\
11.63\end{array}$ & $\begin{array}{r}20200 \\
60200 \\
21100 \\
22500 \\
26800 \\
26100\end{array}$ & $\begin{array}{l}1971 \\
1972 \\
1973 \\
1974 \\
1975\end{array}$ & $\begin{array}{ll}\text { APR. } 05,1971 \\
\text { JULY } 12,1972 \\
\text { MAR. } 28,1973 \\
\text { JAN. 02, } 1974 \\
\text { MAY } 07,1975\end{array}$ & $\begin{array}{l}11.94 \\
12.06 \\
12.06 \\
11.68 \\
11.79\end{array}$ & $\begin{array}{l}28700 \\
30600 \\
31000 \\
27700 \\
28400\end{array}$ & $\begin{array}{l}1977 \\
1978 \\
1979 \\
1980 \\
1981\end{array}$ & $\begin{array}{l}\text { SEPT.07, } 1977 \\
\text { JAN. } 23,1978 \\
\text { JAN. } 29,1979 \\
\text { JUNE } 24,1980 \\
\text { JULY } 20,1981\end{array}$ & $\begin{array}{l}11.88 \\
11.80 \\
11.82 \\
13.87 \\
11.42\end{array}$ & $\begin{array}{l}29000 \\
28400 \\
28600 \\
44800 \\
25900\end{array}$ \\
\hline
\end{tabular}

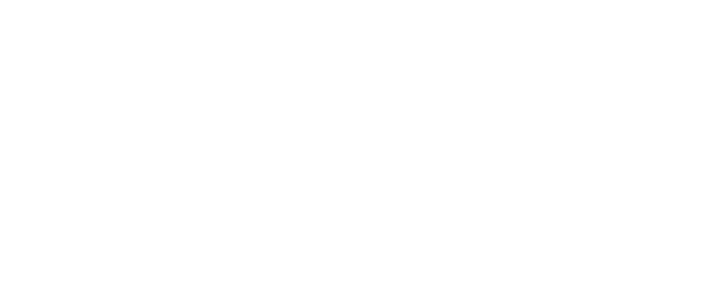

1 Approximate.

${ }^{2}$ Peak discharge occurred during filling period for Lake Powell.

PARIA RIVER BASIN

09381000 HENRIEVILLE CREEK NEAR HENRIEVILLE, UT

LOCATION.--Lat $37^{\circ} 34^{\prime} 15^{\prime \prime}$, long $111^{\circ} 58^{\prime} 15^{\prime \prime}$, in sec.23, T.37 s., R.2 w., Garfield County, Hydrologic Unit $14070007,1.8$ mi northeast of Henrieville.

DRAINAGE AREA. $-29 \mathrm{mi}^{2}$.

PERIOD OF RBCORD AVAIIABLE.--August 1950 to July 1955.

GAGE.--Water-stage recorder and concrete control, Altitude of gage is $6,100 \mathrm{ft}$ by baroneter.

EXTREMES FOR PERIOD OF RECORD.--Maximum đischarge, 3,360 ft ${ }^{3} / \mathrm{s}$ July 31, 1953, gage height, $6.22 \mathrm{ft}$, from rating curve extended above $16 \mathrm{ft}^{3} / \mathrm{s}$ on basis of slope-area measurement at gage height $2.50 \mathrm{ft}$ and logarithmic plotting; no flow for part of each day Nov. 22, DeC. 22, 1952 .

LOWEST MEAN DISCHARGE, IN OUBIC FEET PER SECOND, AND RANRING FOR THE INDICATED NUMBER OF OONSECUTIVE DAYS FOR EACH OLIMATIC YEAR, APRIL 1-MARCH 31

\begin{tabular}{|c|c|c|c|c|c|c|c|c|c|c|c|c|c|c|c|c|c|c|c|}
\hline YEAR & \multicolumn{19}{|c|}{ CONSECUTIVE DAYS } \\
\hline $\begin{array}{l}1952 \\
1953 \\
1954 \\
1955\end{array}$ & $\begin{array}{l}2.00 \\
1.00 \\
0.40 \\
1.60\end{array}$ & $\begin{array}{l}4 \\
2 \\
1 \\
3\end{array}$ & $\begin{array}{l}2.10 \\
1.70 \\
0.47 \\
1.90\end{array}$ & $\begin{array}{l}4 \\
2 \\
1 \\
3\end{array}$ & $\begin{array}{l}2.10 \\
2.00 \\
0.51 \\
2.50\end{array}$ & $\begin{array}{l}3 \\
2 \\
1 \\
4\end{array}$ & $\begin{array}{l}2.20 \\
2.00 \\
1.60 \\
2.90\end{array}$ & $\begin{array}{l}3 \\
2 \\
1 \\
4\end{array}$ & $\begin{array}{l}2.40 \\
2.20 \\
1.90 \\
3.00\end{array}$ & $\begin{array}{l}3 \\
2 \\
1 \\
4\end{array}$ & $\begin{array}{l}3.00 \\
2.50 \\
2.70 \\
3.20\end{array}$ & $\begin{array}{l}3 \\
1 \\
2 \\
4\end{array}$ & $\begin{array}{l}3.40 \\
2.90 \\
3.00 \\
3.30\end{array}$ & $\begin{array}{l}4 \\
1 \\
2 \\
3\end{array}$ & $\begin{array}{l}3.80 \\
3.20 \\
3.60 \\
3.40\end{array}$ & $\begin{array}{l}4 \\
1 \\
3 \\
2\end{array}$ & $\begin{array}{l}4.00 \\
3.60 \\
4.40 \\
4.20\end{array}$ & $\begin{array}{l}2 \\
1 \\
4 \\
3\end{array}$ & $\begin{array}{l}5.70 \\
4.80 \\
5.20 \\
4.80\end{array}$ \\
\hline
\end{tabular}

HIGHEST MEAN DISCHARGE, IN OBIC FEET PER SECOND, AND RANKING FOR THE INDICATED NUMBER OF CONSEOUTIVE DAYS FOR EACH WATER YEAR, OCTOBER 1-SEPTEMBER 30

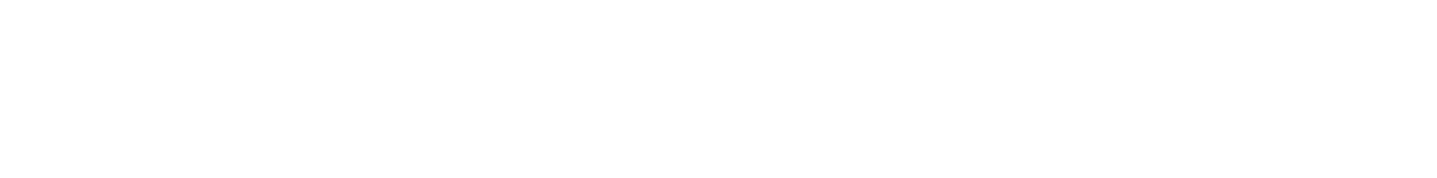


PARIA RIVER BASIN

09381000 HENRIEVHLLE CREER NEAR HENRIEVHLE, UT-Continued

DURATION OF DISCHARGE FOR EACH WATER YEAR

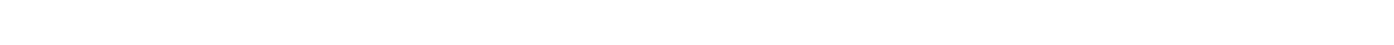

YEAR

NUMBER OF DAYS IN OAASS

OBIC FEET PER SECOND -DAYS

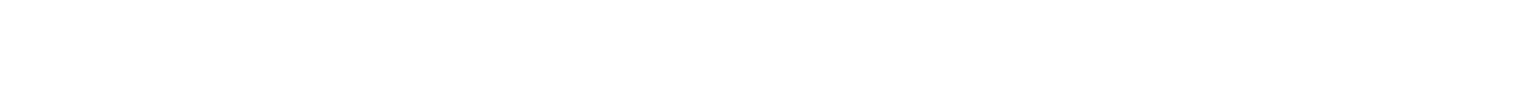

DURATION TABLE OF DISCHARGE FOR WATER YEARS 1951-54

\begin{tabular}{|c|c|c|c|c|c|c|c|c|c|c|c|c|c|c|c|c|c|c|c|}
\hline CLASS & $\begin{array}{c}\text { CUBIC } \\
\text { FEET } \\
\text { PER } \\
\text { SECOND }\end{array}$ & $\begin{array}{l}\text { TOTAL } \\
\text { DAYS }\end{array}$ & $\begin{array}{c}\text { ACOU- } \\
\text { MU- } \\
\text { LATED } \\
\text { DAYS }\end{array}$ & $\begin{array}{l}\text { PER- } \\
\text { CENT } \\
\text { DAYS }\end{array}$ & CLASS & $\begin{array}{c}\text { CUBIC } \\
\text { FEET } \\
\text { PER } \\
\text { SECOND }\end{array}$ & $\begin{array}{l}\text { TOTAL } \\
\text { DAYS }\end{array}$ & $\begin{array}{c}\text { ACCU- } \\
\text { MUI- } \\
\text { LATED } \\
\text { DAYS }\end{array}$ & $\begin{array}{l}\text { PER- } \\
\text { CENY } \\
\text { DAYS }\end{array}$ & CJASS & $\begin{array}{l}\text { CUBIC } \\
\text { FEET } \\
\text { PER } \\
\text { SECOND }\end{array}$ & $\begin{array}{l}\text { TOTAL } \\
\text { DAYS }\end{array}$ & $\begin{array}{c}\text { ACOU- } \\
\text { MJ- } \\
\text { LATED } \\
\text { DAYS }\end{array}$ & $\begin{array}{l}\text { PER- } \\
\text { CENT } \\
\text { DAYS }\end{array}$ & & $\begin{array}{c}\text { OBBIC } \\
\text { FEET } \\
\text { PER } \\
\text { SECOND }\end{array}$ & $\begin{array}{l}\text { TOTAL } \\
\text { DAYS }\end{array}$ & $\begin{array}{c}\text { ACOU- } \\
\text { MU- } \\
\text { LATED } \\
\text { DAYS }\end{array}$ & $\begin{array}{l}\text { PER- } \\
\text { CENT } \\
\text { DAYS }\end{array}$ \\
\hline $\begin{array}{l}0 \\
1 \\
2 \\
3 \\
4 \\
5 \\
6 \\
7 \\
8\end{array}$ & $\begin{array}{l}0.00 \\
0.40 \\
0.47 \\
0.55 \\
0.65 \\
0.76 \\
0.90 \\
1.10 \\
1.20\end{array}$ & $\begin{array}{l}0 \\
3 \\
1 \\
2 \\
1 \\
1 \\
1 \\
0 \\
5\end{array}$ & $\begin{array}{l}1461 \\
1461 \\
1458 \\
1457 \\
1455 \\
1454 \\
1453 \\
1452 \\
1452\end{array}$ & $\begin{array}{r}100.0 \\
100.0 \\
99.8 \\
99.7 \\
99.6 \\
99.5 \\
99.5 \\
99.4 \\
99.4\end{array}$ & $\begin{array}{l}9 \\
10 \\
11 \\
12 \\
13 \\
14 \\
15 \\
16 \\
17\end{array}$ & $\begin{array}{l}1.50 \\
1.70 \\
2.00 \\
2.40 \\
2.80 \\
3.30 \\
3.90 \\
4.50 \\
5.30\end{array}$ & $\begin{array}{r}11 \\
9 \\
75 \\
100 \\
180 \\
274 \\
226 \\
205 \\
138\end{array}$ & $\begin{array}{r}1447 \\
1436 \\
1427 \\
1352 \\
1252 \\
1072 \\
798 \\
572 \\
367\end{array}$ & $\begin{array}{l}99.0 \\
98.3 \\
97.7 \\
92.5 \\
85.7 \\
73.4 \\
54.6 \\
39.2 \\
25.1\end{array}$ & $\begin{array}{l}18 \\
19 \\
20 \\
21 \\
22 \\
23 \\
24 \\
25 \\
26\end{array}$ & $\begin{array}{r}6.3 \\
7.3 \\
8.6 \\
10.0 \\
12.0 \\
14.0 \\
16.0 \\
19.0 \\
23.0\end{array}$ & $\begin{array}{r}67 \\
32 \\
25 \\
18 \\
22 \\
28 \\
7 \\
14 \\
7\end{array}$ & $\begin{array}{r}229 \\
162 \\
130 \\
105 \\
87 \\
65 \\
37 \\
30 \\
16\end{array}$ & $\begin{array}{r}15.7 \\
11.1 \\
8.9 \\
7.2 \\
6.0 \\
4.4 \\
2.5 \\
2.1 \\
1.1\end{array}$ & $\begin{array}{l}27 \\
28 \\
29 \\
30 \\
31 \\
32 \\
33 \\
34\end{array}$ & $\begin{array}{l}27.0 \\
31.0 \\
37.0 \\
43.0 \\
51.0 \\
60.0 \\
71.0 \\
83.0\end{array}$ & $\begin{array}{l}2 \\
3 \\
0 \\
0 \\
1 \\
1 \\
0 \\
2\end{array}$ & $\begin{array}{l}9 \\
7 \\
4 \\
4 \\
4 \\
3 \\
2 \\
2\end{array}$ & $\begin{array}{l}0.6 \\
0.5 \\
0.3 \\
0.3 \\
0.3 \\
0.2 \\
0.1 \\
0.1\end{array}$ \\
\hline
\end{tabular}

MONIHLY MEAN DISCHARGES, IN CUBIC FEET PER SECOND, FOR EACH WATER YEAR

$\begin{array}{llllllllllrrr}\text { YEAR } & \text { OCT } & \text { NOV } & \text { DEC } & \text { JAN } & \text { FEB } & \text { MAR } & \text { APR } & \text { MAY } & \text { JUNE } & \text { JULY } & \text { ALG } & \text { SEP } \\ 1951 & 3.59 & 4.18 & 4.08 & 5.26 & 5.64 & 4.77 & 5.34 & 5.71 & 2.95 & 3.03 & 5.39 & 4.03 \\ 1952 & 4.31 & 5.05 & 6.18 & 4.87 & 11.8 & 10.1 & 11.3 & 4.24 & 4.23 & 3.36 & 6.44 & 6.49 \\ 1953 & 3.41 & 3.95 & 2.65 & 2.73 & 4.06 & 4.75 & 3.57 & 3.72 & 2.29 & 10.8 & 7.06 & 2.40 \\ 1954 & 3.99 & 6.11 & 4.89 & 4.34 & 4.88 & 8.06 & 7.97 & 4.61 & 3.45 & 3.30 & 3.60 & 10.0\end{array}$

09381 100 HENRIEVHLE CREEX AT HENRIEVIHLE, UT

LOCATIaN.--Lat $37^{\circ} 33^{\prime} 41^{\prime \prime}$, long $111^{\circ} 58^{\prime} 42^{\prime \prime}$, in NW/3 sec.26, T.37 S., R.2 พ., Garfield County, Hydrologic Unit 14070007, at irrigation diversion dam $1 \mathrm{mi}$ east of Henrieville.

DRAINAGE AREA. $-34 \mathrm{mi}^{2}$.

MEAN BASIN ELEVATION. $-7,120 \mathrm{ft}$.

PERIOD OF RBCORD AVAIIABLE. --Water years 1959-74, annual peak discharge only.

GAGE.--Crest-stage gage. Altitude of gage is 6,050 ft from topographic map.

ANNUAL PEAK DISCHARGE, IN CUBIC FEET PER SECOND, AND CORRESPONDING GAGE HEIGHT, IN FEET, FOR EACH WATER YEAR

\begin{tabular}{|c|c|c|c|c|c|c|c|c|c|c|c|}
\hline $\begin{array}{l}\text { WATER } \\
\text { YEAR }\end{array}$ & DATE & $\begin{array}{c}\text { GAGE } \\
\text { HEIGHI }\end{array}$ & $\begin{array}{c}\text { PEAK } \\
\text { DISCHARGE }\end{array}$ & $\begin{array}{l}\text { WATER } \\
\text { YEAR }\end{array}$ & DATE & $\begin{array}{l}\text { GAGE } \\
\text { HEIGHT }\end{array}$ & $\begin{array}{c}\text { PEAK } \\
\text { DISCHARGE }\end{array}$ & $\begin{array}{l}\text { WATER } \\
\text { YEAR }\end{array}$ & DATE & $\begin{array}{l}\text { GAGE } \\
\text { HEIGHT }\end{array}$ & $\begin{array}{c}\text { PEAK } \\
\text { DISCHARGE }\end{array}$ \\
\hline $\begin{array}{l}1959 \\
1960 \\
1961 \\
1962 \\
1963 \\
1964\end{array}$ & $\begin{array}{l}\text { AUG. } 02,1959 \\
\text { JUNE 06, } 1960 \\
\text { AUG. 04, } 1961 \\
\text { SEPT. 28, } 1962 \\
\text { AUG. 04, } 1963 \\
\text { MAY 25, } 1964\end{array}$ & $\begin{array}{ll}9 & 13.40 \\
0 & 13.98 \\
1 & 15.60 \\
2 & 13.20 \\
3 & 15.20 \\
4 & 11.45\end{array}$ & $\begin{array}{r}1740 \\
2350 \\
7360 \\
1440 \\
4010 \\
220\end{array}$ & $\begin{array}{l}1965 \\
1966 \\
1967 \\
1968 \\
1969\end{array}$ & $\begin{array}{l}\text { SEPT. 05, } 1965 \\
\text { AUG. } 19,1966 \\
\text { AUG. 08, } 1967 \\
\text { AUG. 01, } 1968 \\
\text { AUG. } 18,1969\end{array}$ & $\begin{array}{l}12.35 \\
12.19 \\
12.50 \\
11.78 \\
12.31\end{array}$ & $\begin{array}{l}700 \\
600 \\
800 \\
360 \\
670\end{array}$ & $\begin{array}{l}1970 \\
1971 \\
1972 \\
1973 \\
1974\end{array}$ & $\begin{array}{l}\text { SEPT.05, } 1970 \\
\text { AUG. 27, } 1971 \\
\text { JUNE 22, } 1972 \\
\text { SEPT.10, } 1973 \\
-\end{array}$ & $\begin{array}{l}12.00 \\
13.64 \\
11.60 \\
11.62 \\
12.56\end{array}$ & $\begin{array}{r}475 \\
1900 \\
270 \\
290 \\
860\end{array}$ \\
\hline
\end{tabular}


LOCATION.--Lat $37^{\circ} 28^{\prime} 50^{\prime \prime}$, long $112^{\circ} 01^{\prime} 15^{\prime \prime}$, in T.38 S., R.2 w., Kane County, Hydrologic Unit 14070007, on left bank 3 mi upstream

fram Sheep Creek and $6 \mathrm{mi}$ south of Cannonville.

DRAINAGE AREA. $-220 \mathrm{mi}^{2}$.

MEAN BASIN ELEVATION. $-6,890 \mathrm{ft}$.

PERIOD OF RECORD AVAIIABLE.--December 1950 to September 1955, and annual peak discharge only, water years $1959-74$.

GAGE.-Water-stage recorder. Altitude of gage is 5,440 ft by barcmeter.

REMARKS.-Diversions for irrigation of about 2,700 acres above station. Flow may be slightly affected by transmountain diversion, from East Fork Sevier River via Tropic and East Fork Canal, which is used for irrigation above station.

EXIREMES FOR PERIOD OF RBCORD.--Maximum discharge, $11,600 \mathrm{ft}^{3} / \mathrm{s}$ Aug. 31,1963 , gage height, $19.25 \mathrm{ft}$, from rating curve extended above $100 \mathrm{ft}^{3} / \mathrm{s}$ on basis of slope-area measurements at gage heights 7.20 and $7.76 \mathrm{ft}$, and logarithmic plotting; no flow for many days in each year.

LOWEST MEAN DISCHARGE, IN COBIC FEET PER SEOOND, AND RANKING FOR THE INDICATED NUMBER OF CONSECUTIVE DAYS FOR EACH CIIMATIC YEAR, APRII I-MARCH 31

\begin{tabular}{|c|c|c|c|c|c|c|c|c|c|c|c|c|c|c|c|c|c|c|c|}
\hline YEAR & & & & & & & & & œNSE & OUTIV & DAYS & & & & & & & & \\
\hline $\begin{array}{l}1952 \\
1953 \\
1954 \\
1955\end{array}$ & $\begin{array}{l}0.00 \\
0.10 \\
0.00 \\
0.00\end{array}$ & $\begin{array}{l}1 \\
4 \\
2 \\
3\end{array}$ & $\begin{array}{l}0.00 \\
0.10 \\
0.00 \\
0.00\end{array}$ & $\begin{array}{l}1 \\
4 \\
2 \\
3\end{array}$ & $\begin{array}{l}0.00 \\
0.10 \\
0.00 \\
0.00\end{array}$ & $\begin{array}{l}1 \\
4 \\
2 \\
3\end{array}$ & $\begin{array}{l}0.00 \\
0.10 \\
0.00 \\
0.00\end{array}$ & $\begin{array}{l}1 \\
4 \\
2 \\
3\end{array}$ & $\begin{array}{l}0.10 \\
0.92 \\
0.00 \\
0.11\end{array}$ & $\begin{array}{l}2 \\
4 \\
1 \\
3\end{array}$ & $\begin{array}{l}0.30 \\
1.70 \\
0.18 \\
0.34\end{array}$ & $\begin{array}{l}2 \\
4 \\
1 \\
3\end{array}$ & $\begin{array}{l}1.70 \\
2.80 \\
0.58 \\
0.94\end{array}$ & $\begin{array}{l}3 \\
4 \\
1 \\
2\end{array}$ & $\begin{array}{l}2.20 \\
4.60 \\
4.80 \\
1.30\end{array}$ & $\begin{array}{l}2 \\
3 \\
4 \\
1\end{array}$ & $\begin{array}{l}3.70 \\
5.30 \\
6.60 \\
4.20\end{array}$ & $\begin{array}{l}1 \\
3 \\
4 \\
2\end{array}$ & $\begin{array}{r}8.40 \\
9.30 \\
11.0 \\
6.40\end{array}$ \\
\hline
\end{tabular}

HIGHEST MEAN DISCHARGE, IN CUBIC FEET PER SECOND, AND RANKING FOR THE INDICATED NUMBER OF CONSECUTIVE DAYS FOR EACH WATER YEAR, OCTCBER I-SEPTEMBER 30

\begin{tabular}{|c|c|c|c|c|c|c|c|c|c|c|c|c|c|c|c|c|c|c|c|}
\hline YEAR & I & & 3 & & 7 & & 15 & & $\begin{array}{l}\text { CONs } \\
30\end{array}$ & OUT & $\begin{array}{l}\text { E DAYS } \\
60\end{array}$ & & 90 & & 120 & & 183 & & ALL \\
\hline $\begin{array}{l}1952 \\
1953 \\
1954 \\
1955\end{array}$ & $\begin{array}{l}119 \\
425 \\
249 \\
566\end{array}$ & $\begin{array}{l}4 \\
2 \\
3 \\
1\end{array}$ & $\begin{array}{l}58.0 \\
387 \\
103 \\
319\end{array}$ & $\begin{array}{l}4 \\
1 \\
3 \\
2\end{array}$ & $\begin{array}{c}54.0 \\
189 \\
48.0 \\
148\end{array}$ & $\begin{array}{l}3 \\
I \\
4 \\
2\end{array}$ & $\begin{array}{l}44.0 \\
94.0 \\
25.0 \\
89.0\end{array}$ & $\begin{array}{l}3 \\
1 \\
4 \\
2\end{array}$ & $\begin{array}{l}32.0 \\
62.0 \\
17.0 \\
52.0\end{array}$ & $\begin{array}{l}3 \\
1 \\
4 \\
2\end{array}$ & $\begin{array}{l}26.0 \\
39.0 \\
14.0 \\
30.0\end{array}$ & $\begin{array}{l}3 \\
1 \\
4 \\
2\end{array}$ & $\begin{array}{l}23.0 \\
26.0 \\
12.0 \\
20.0\end{array}$ & $\begin{array}{l}2 \\
1 \\
4 \\
3\end{array}$ & $\begin{array}{l}20.0 \\
20.0 \\
11.0 \\
15.0\end{array}$ & $\begin{array}{l}1 \\
2 \\
4 \\
3\end{array}$ & $\begin{array}{c}16.0 \\
15.0 \\
9.80 \\
14.0\end{array}$ & $\begin{array}{l}1 \\
2 \\
4 \\
3\end{array}$ & $\begin{array}{c}11.0 \\
12.0 \\
6.70 \\
9.50\end{array}$ \\
\hline
\end{tabular}

DURATION OF DISCHARGE FOR EACH WATER YEAR

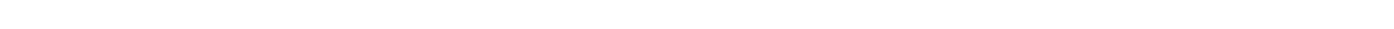
YEAR

MUMER OF DAYS IN CLASS OBBIC FEET
PER SECOND -DAYS

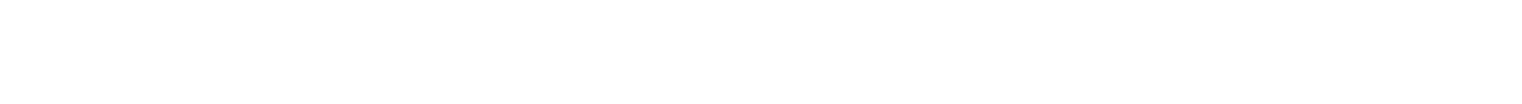

$\begin{array}{ccc}\text { COBIC } & \text { ACOU- } \\ \text { FEET } & \text { MU- } & \text { PER- } \\ \text { PER TOTAL IAIEED } & \text { CENT } \\ \text { OLASS SECOND DAYS DAYS } & \text { DAYS }\end{array}$

DURATION TABLE OF DISCHARGE FOR WATER YFARS 1952-55

$\begin{array}{lcc}\text { OBIC } & \text { ACOU- } \\ \text { FEET } & \text { MU- } & \text { PER- } \\ \text { PER TOTAL LATED } & \text { CENT }\end{array}$

CAASS SECOND DAYS DAYS DAYS

$\begin{array}{lllll}9 & 0.76 & 14 & 1097 & 75.1\end{array}$

$\begin{array}{rllll}9 & 0.76 & 14 & 1097 & 75.1 \\ 10 & 0.98 & 40 & 1083 & 74.1\end{array}$

$\begin{array}{llll}1.30 & 25 & 1043 & 71.4\end{array}$

$\begin{array}{llll}1.60 & 56 & 1018 & 69.7\end{array}$

$\begin{array}{rrrr}1.60 & 56 & 1018 & 69.7\end{array}$

$\begin{array}{llll}2.10 & 42 & 962 & 65.8 \\ 2.70 & 23 & 920 & 63.0\end{array}$

$\begin{array}{rrrr}2.70 & 23 & 920 & 63.0 \\ 3.50 & 115 & 897 & 61.4\end{array}$

$\begin{array}{llll}3.50 & 115 & 897 & 61.4 \\ 4.50 & 156 & 782 & 53.5\end{array}$

$\begin{array}{llll}4.50 & 156 & 782 & 53.5 \\ 5.70 & 109 & 626 & 42.8\end{array}$

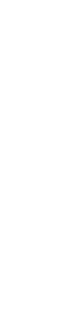

COBIC ACOU

FEET MU- PER-

PEOR TOTAL LATED CENT

$\begin{array}{rrrrr}18 & 7.4 & 104 & 517 & 35.4 \\ 19 & 9.5 & 87 & 413 & 28.3 \\ 20 & 12.0 & 151 & 326 & 22.3 \\ 21 & 16.0 & 45 & 175 & 12.0 \\ 22 & 20.0 & 56 & 130 & 8.9 \\ 23 & 26.0 & 23 & 74 & 5.1 \\ 24 & 34.0 & 19 & 51 & 3.5 \\ 25 & 44.0 & 8 & 32 & 2.2 \\ 26 & 56.0 & 9 & 24 & 1.6\end{array}$
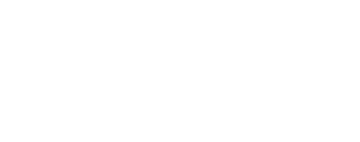

$\begin{array}{rrrrr}27 & 72.0 & 2 & 15 & 1.0 \\ 28 & 93.0 & 3 & 13 & 0.9 \\ 29 & 120.0 & 1 & 10 & 0.7 \\ 30 & 150.0 & 1 & 9 & 0.6 \\ 31 & 200.0 & 2 & 8 & 0.5 \\ 32 & 260.0 & 3 & 6 & 0.4 \\ 33 & 330.0 & 2 & 3 & 0.2 \\ 34 & 430.0 & 1 & 1 & 0.1\end{array}$

MONIHLY MEAN DISCHARGES, IN CUBIC FEET PER SECOND, FOR EACH WATER YEAR

$\begin{array}{llccccccccccc}\text { YEAR } & \text { OCT } & \text { NOV } & \text { DEC } & \text { JAN } & \text { FEB } & \text { MAR } & \text { APR } & \text { MAY } & \text { JUNE } & \text { JULY } & \text { AUG } & \text { SEP } \\ 1952 & 2.75 & 9.02 & 9.16 & 10.1 & 17.9 & 29.3 & 21.1 & 2.89 & 3.73 & 2.52 & 10.0 & 9.21 \\ 1953 & 4.09 & 7.95 & 18.0 & 13.2 & 10.5 & 8.25 & 3.00 & 0.44 & 0.04 & 38.9 & 37.0 & 0.70 \\ 1954 & 3.70 & 9.89 & 6.80 & 7.71 & 11.2 & 15.8 & 5.56 & 2.83 & 0.50 & 1.96 & 0.29 & 14.8 \\ 1955 & 13.8 & 5.36 & 5.09 & 3.50 & 4.57 & 17.8 & 3.42 & 0.20 & 0.01 & 12.4 & 46.4 & 0.06\end{array}$


PARIA RIVER BASIN

09381500 PARIA RIVER NEAR CANNOWNILLE, UT--Continued

ANNUAL PEAR DISCHARGE, IN CUBIC FEET PER SECOND, AND CORRESPONDING GAGE HEIGHT, IN FEET, FOR EACH WATER YEAR

\begin{tabular}{|c|c|c|c|c|c|c|c|c|c|c|c|}
\hline $\begin{array}{l}\text { WATERR } \\
\text { YEAR }\end{array}$ & DATE & $\begin{array}{c}\text { GAGE } \\
\text { HEIGET }\end{array}$ & $\begin{array}{c}\text { PEAR } \\
\text { DISCHARGE }\end{array}$ & $\begin{array}{l}\text { WATYER } \\
\text { YEAR }\end{array}$ & DATE & $\begin{array}{l}\text { GAGE } \\
\text { HEIGHT }\end{array}$ & $\begin{array}{c}\text { PEAR } \\
\text { DISCHARGE }\end{array}$ & $\begin{array}{l}\text { WATERR } \\
\text { YEAR }\end{array}$ & DATE & $\begin{array}{l}\text { GAGE } \\
\text { HEIGHT }\end{array}$ & $\begin{array}{c}\text { PEAK } \\
\text { DISCHARGE }\end{array}$ \\
\hline $\begin{array}{l}1951 \\
1952 \\
1953 \\
1954 \\
1955 \\
1959 \\
1960\end{array}$ & $\begin{array}{l}\text { AUG. U3, } 1951 \\
\text { SEPT.21, } 1952 \\
\text { JULY 30, } 1953 \\
\text { SEPT.11, } 1954 \\
\text { AUG. 16, } 1955 \\
\text { AUG. 12, } 1959 \\
\text { JUNE 06, } 1960\end{array}$ & $\begin{array}{r}7.76 \\
7.20 \\
9.35 \\
7.38 \\
9.76 \\
14.32 \\
12.69\end{array}$ & $\begin{array}{l}2040 \\
1400 \\
2910 \\
1600 \\
3260 \\
6890 \\
5550\end{array}$ & $\begin{array}{l}1961 \\
1962 \\
1963 \\
1964 \\
1965 \\
1966 \\
1967\end{array}$ & $\begin{array}{l}\text { AUG. } 03,1961 \\
\text { SEPT. } 20,1962 \\
\text { AUG. } 31,1963 \\
\text { JULY } 26,1964 \\
\text { JULY } 19,1965 \\
\text { JULY } 24,1966 \\
\text { JULY } 16,1967\end{array}$ & $\begin{array}{r}12.40 \\
6.89 \\
19.25 \\
7.52 \\
7.52 \\
8.70 \\
8.23\end{array}$ & $\begin{array}{r}5320 \\
1060 \\
11600 \\
1730 \\
1730 \\
2460 \\
2150\end{array}$ & $\begin{array}{l}1968 \\
1969 \\
1970 \\
1971 \\
1972 \\
1973 \\
1974\end{array}$ & $\begin{array}{l}\text { JULY } 31,1968 \\
\text { AUG. 19, } 1969 \\
\text { SEPT. 05, } 1970 \\
\text { AUG. 05, } 1971 \\
\text { SEPT.19, } 1972 \\
\text { AUG. 18, } 1973 \\
\text { JULY 22, } 1974\end{array}$ & $\begin{array}{r}9.00 \\
11.60 \\
10.88 \\
7.52 \\
9.55 \\
13.78 \\
6.45\end{array}$ & $\begin{array}{l}2650 \\
4680 \\
4120 \\
1730 \\
3100 \\
6400 \\
1050\end{array}$ \\
\hline
\end{tabular}

09381600 SHEEP CRESTK NEAR CANNOWHLE, UT

LOCATION.-Lat $37^{\circ} 32$ ' 31", long $112^{\circ} 07^{\prime} 40^{\prime \prime}$, in SW/ sec.33, T.37 S., R.3 W., Garfield County, Hydrologic Unit 14070007,4 mi southwest of Cannonville and $6 \mathrm{mi}$ south of Tropic.

DRAINAGE AREA. $-17 \mathrm{mi}^{2}$, approximately.

PERIOD OF RECORD AVAIIABLE. - Water years 1960-64, annual peak discharge only.

Gage.-Crest-stage gage. Altitude of gage is $6,420 \mathrm{ft}$ from topographic map.

ANNUAL, PEAR DISCHARGE, IN CUBIC FEET PER SECOND, AND CORRESPONDING GAGE HEIGFT, IN FEET, FOR EACH WATER YEAR

\begin{tabular}{|c|c|c|c|c|c|c|c|c|c|c|c|}
\hline $\begin{array}{l}\text { WATTER } \\
\text { YEAR }\end{array}$ & DATE & $\begin{array}{l}\text { GAGE } \\
\text { HEIGHT }\end{array}$ & $\begin{array}{c}\text { PEAR } \\
\text { DISCHARGE }\end{array}$ & $\begin{array}{l}\text { WATER } \\
\text { YEAR }\end{array}$ & DATE & $\begin{array}{l}\text { GAGE } \\
\text { HEIGHT }\end{array}$ & $\begin{array}{c}\text { PEAK } \\
\text { DISCHARGE }\end{array}$ & $\begin{array}{l}\text { WATERR } \\
\text { YEAR }\end{array}$ & DATE & $\begin{array}{c}\text { GAGE } \\
\text { HEIGHT }\end{array}$ & $\begin{array}{c}\text { PEAK } \\
\text { DISCHARGE }\end{array}$ \\
\hline $\begin{array}{l}1960 \\
1961\end{array}$ & $\begin{array}{l}\text { SEPT.06, } 1960 \\
\text { AUG. 04, } 1961\end{array}$ & $\begin{array}{l}11.68 \\
14.82\end{array}$ & $\begin{array}{r}270 \\
1260\end{array}$ & $\begin{array}{l}1962 \\
1963\end{array}$ & $\begin{array}{l}\text { SEPT.28, } 1962 \\
\text { AUG. 31, } 1963\end{array}$ & $\begin{array}{l}13.86 \\
14.34\end{array}$ & $\begin{array}{r}900 \\
1080\end{array}$ & 1964 & AUG. 07, 1964 & 11.39 & 210 \\
\hline
\end{tabular}

09381700 SHEEP CREKX RESERNOIR, UT (NEAR CANNOWIILE)

LOCATTON.-Lat $37^{\circ} 29^{\prime} 43^{\prime \prime}$, long $112^{\circ} 03^{\prime}$ 57", in SW/ sec.13, T.38 S., R.3 W., Rane County, Hydrologic Unit 14070007, at spillway

$1,000 \mathrm{ft}$ downstream from Indian Hollow and $5.5 \mathrm{mi}$ south of Camonville.

DRATNAGE AREA. $-31.1 \mathrm{mi}^{2}$.

PERIOD OF RECORD AVAIIABLE.-Water years 1961-68, annual peak discharge only.

GAGE.-Crest-stage gage. Altitude of gage is 5,860 ft from topographic map. Prior to 1964 water year, at another site and datum.

ANNUAL PEAR DISCHARGE, IN OABIC FEET PER SECOND, AND CORRESPONDING GAGE HEIGHT, IN FEET, FOR EAOH WATER YEAR

\begin{tabular}{|c|c|c|c|c|c|c|c|c|c|c|c|}
\hline $\begin{array}{l}\text { WATERR } \\
\text { YEAR }\end{array}$ & DATE & $\begin{array}{c}\text { GAGE } \\
\text { HEIGET }\end{array}$ & $\begin{array}{c}\text { PEAR } \\
\text { DISCHARGE }\end{array}$ & $\begin{array}{l}\text { WATFER } \\
\text { YEAR }\end{array}$ & DATE & $\begin{array}{c}\text { GAGE } \\
\text { HEIGHT }\end{array}$ & $\begin{array}{c}\text { PEAR } \\
\text { DISCHARGE }\end{array}$ & $\begin{array}{l}\text { WATER } \\
\text { YEAR }\end{array}$ & DATE & $\begin{array}{l}\text { GAGE } \\
\text { HEIGHT }\end{array}$ & $\begin{array}{c}\text { PEAK } \\
\text { DISCHARGE }\end{array}$ \\
\hline $\begin{array}{l}1961 \\
1962 \\
1963\end{array}$ & $\begin{array}{l}\text { AUG. 04, } 1961 \\
\text { SEPT. 23, } 1962 \\
\text { AUG. 31, } 1963\end{array}$ & $\begin{array}{l}23.75 \\
26.55 \\
26.90\end{array}$ & $\begin{array}{l}1820 \\
2600 \\
4620\end{array}$ & $\begin{array}{l}1964 \\
1965 \\
1966\end{array}$ & $\frac{\text { JULY }}{-26}, \frac{1964}{\text { AUG. }}$ & $\begin{array}{l}68.87 \\
68.50 \\
69.69\end{array}$ & $\begin{array}{l}246 \\
100 \\
724\end{array}$ & $\begin{array}{l}1967 \\
1968\end{array}$ & $\begin{array}{l}\text { MAR. 29, } 1967 \\
\text { AUG. 01, } 1968\end{array}$ & $\begin{array}{l}69.00 \\
69.13\end{array}$ & $\begin{array}{l}305 \\
365\end{array}$ \\
\hline
\end{tabular}

09381800 PARIA RIVER NEAR KANAB, UT

LOCAYTON.-Lat $37^{\circ} 06^{\prime} 23^{\prime \prime}$, long $111^{\circ} 54^{\prime} 13^{\prime \prime}$, in NEly sec.4, T.43 S., R.1 W., Rane County, Hydrologic Unit 14070007, 7 mi above Buckskin Gulch and 43 mi east of Ranab.

DRATNAGE AREA. $-668 \mathrm{mi}^{2}$.

MEAN BASIN ELEVATION. $-6,390 \mathrm{ft}$.

PERIOD OF RECORD AVAIIABLE.--Water years 1959-73, annual peak discharge only.

GAGE.-Crest-stage gage. Altitude of gage is 4,350 ft from topographic map. 
PARIA RIVER BASIN

09381800 PARIA RIVER NEAR KANAB, UT-Continued

ANNUAL PEAK DISCHARGE, IN OBIC FEET PER SECOND, AND OORRESPONDING GAGE HEIGHT, IN FEET, FOR EACH WATER YEAR

\begin{tabular}{|c|c|c|c|c|c|c|c|c|c|c|c|}
\hline $\begin{array}{l}\text { WATER } \\
\text { YEAR }\end{array}$ & DATE & $\begin{array}{c}\text { GAGE } \\
\text { HEIGHT }\end{array}$ & $\begin{array}{c}\text { PEAK } \\
\text { DISCHARGE }\end{array}$ & $\begin{array}{l}\text { WATER } \\
\text { YEAR }\end{array}$ & DATE & $\begin{array}{c}\text { GAGE } \\
\text { HEIGHT }\end{array}$ & $\begin{array}{c}\text { PEAK } \\
\text { DISCHARGE }\end{array}$ & $\begin{array}{l}\text { WATER } \\
\text { YEAR }\end{array}$ & DATE & $\begin{array}{l}\text { GAGE } \\
\text { HEIGHT }\end{array}$ & $\begin{array}{c}\text { PEAK } \\
\text { DISCHARGE }\end{array}$ \\
\hline $\begin{array}{l}1959 \\
1960 \\
1961 \\
1962 \\
1963\end{array}$ & $\begin{array}{l}\text { AUG. } 19,1959 \\
\text { JUNE } 07,1960 \\
\text { AUG. } 03,1961 \\
\text { SEPT. } 28,1962 \\
\text { AUG. } 31,1963\end{array}$ & $\begin{array}{l}14.78 \\
13.58 \\
14.04 \\
13.48 \\
16.26\end{array}$ & $\begin{array}{r}4500 \\
2490 \\
3100 \\
2300 \\
15400\end{array}$ & $\begin{array}{l}1964 \\
1965 \\
1966 \\
1967 \\
1968\end{array}$ & $\begin{array}{l}\text { AUG. } 02,1964 \\
\text { SEPT. } 06,1965 \\
\text { NOV. } 25,1965 \\
\text { SEPT.25, } 1967 \\
\text { NUG. } 14,1968\end{array}$ & $\begin{array}{l}14.70 \\
12.90 \\
12.90 \\
13.90 \\
14.95\end{array}$ & $\begin{array}{r}4800 \\
818 \\
903 \\
2880 \\
4330\end{array}$ & $\begin{array}{l}1969 \\
1970 \\
1971 \\
1972 \\
1973\end{array}$ & $\begin{array}{l}\text { SEPT.06, } 1969 \\
\text { AUG. 04, } 1970 \\
\text { AUG. } 18,1971 \\
\text { JUNE 22, } 1972 \\
\text { AUG. 05, } 1973\end{array}$ & $\begin{array}{r}8.95 \\
9.75 \\
10.98 \\
11.40 \\
15.68\end{array}$ & $\begin{array}{r}773 \\
827 \\
1740 \\
2200 \\
8400\end{array}$ \\
\hline
\end{tabular}

09382000 PARIA RIVER AT LEES FERRY, AZ

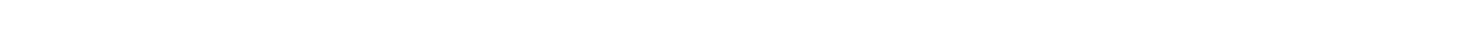
bank $0.6 \mathrm{mi}$ northwest of Lees Ferry, and $1.1 \mathrm{mi}$ upstream from mouth.

DRAINAGE AREA. $--1,410 \mathrm{mi}^{2}$.

MEAN BASIN ELEVATION. $-6,150 \mathrm{ft}$

PERIOD OF RECORD AVAIIABLE. -October 1923 to September 1981 .

REVISED RECORAS. -WSP 1925: 1958(M), drainage area.

GAGE.--Water-stage recorder. Datum of gage is $3,123.68 \mathrm{ft}$, revised, NGVD of 1929 . Prior to Oct. 5, 1925, nonrecording gage at site 2,000 ft upstream at different datum. Oct. 13, 1925, to Sept. 11, 1929, nonrecording gage at present site and datum.

REMARKS.--Diversions above station for irrigation of about 3,300 acres.

AVERAGE DISCHARGE. -58 years, $30.0 \mathrm{ft}^{3} / \mathrm{s}, 21,740$ acre-ft $/ \mathrm{yr}^{2}$, median of yearly mean discharges, $26 \mathrm{ft}{ }^{3} / \mathrm{s}, 18,800 \mathrm{acre}-\mathrm{ft} / \mathrm{yr}^{\circ}$

EXIREMES FOR PERIOD OF RECORD.-Maximum discharge, $16,100 \mathrm{ft}^{3} / \mathrm{s}$ oct. 5,1925 , gage height, $16.3 \mathrm{ft}$, from floodmark, from rating curve extended above $2,000 \mathrm{ft}^{3} / \mathrm{s}$ on basis of float-area measurement of peak flow; maximum gage height, $16.65 \mathrm{ft}$ Sept. 9 , 1980 ; minimum daily discharge, $1 \mathrm{ft}^{3} / \mathrm{s}$ in most years prior to 1931 .

LOWEST MEAN DISCHARGE, IN OUBIC FEET PER SECOND, AND RANKING FOR THE INDICATED NUMBER OF OONSEOUTIVE DAYS FOR EACH CLIMATIC YEAR, APRII 1-MARCH 31

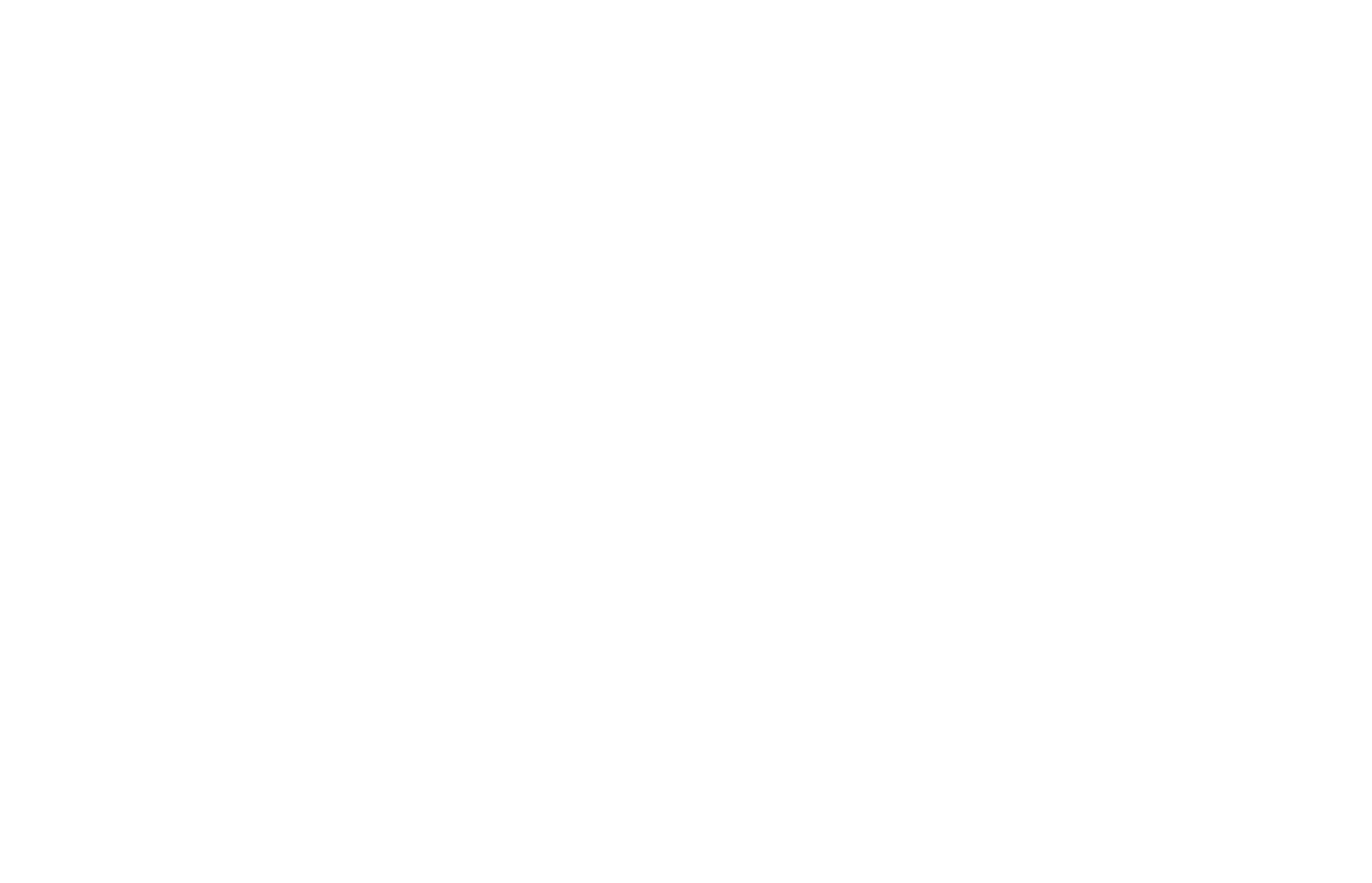


PARIA RIVER BASTN

09382000 PARIA RIVER AT LEES FERRY, AZ--Continued

LOWEST MEAN DISCHARGE, IN CUBIC FEET PER SECOND, AND RANKING FOR THE INDICATED NUMBER OF CONSEOUTIVE DAYS FOR EACH CLIMATYC YEAR, APRIL 1-MARCH 31--Continued

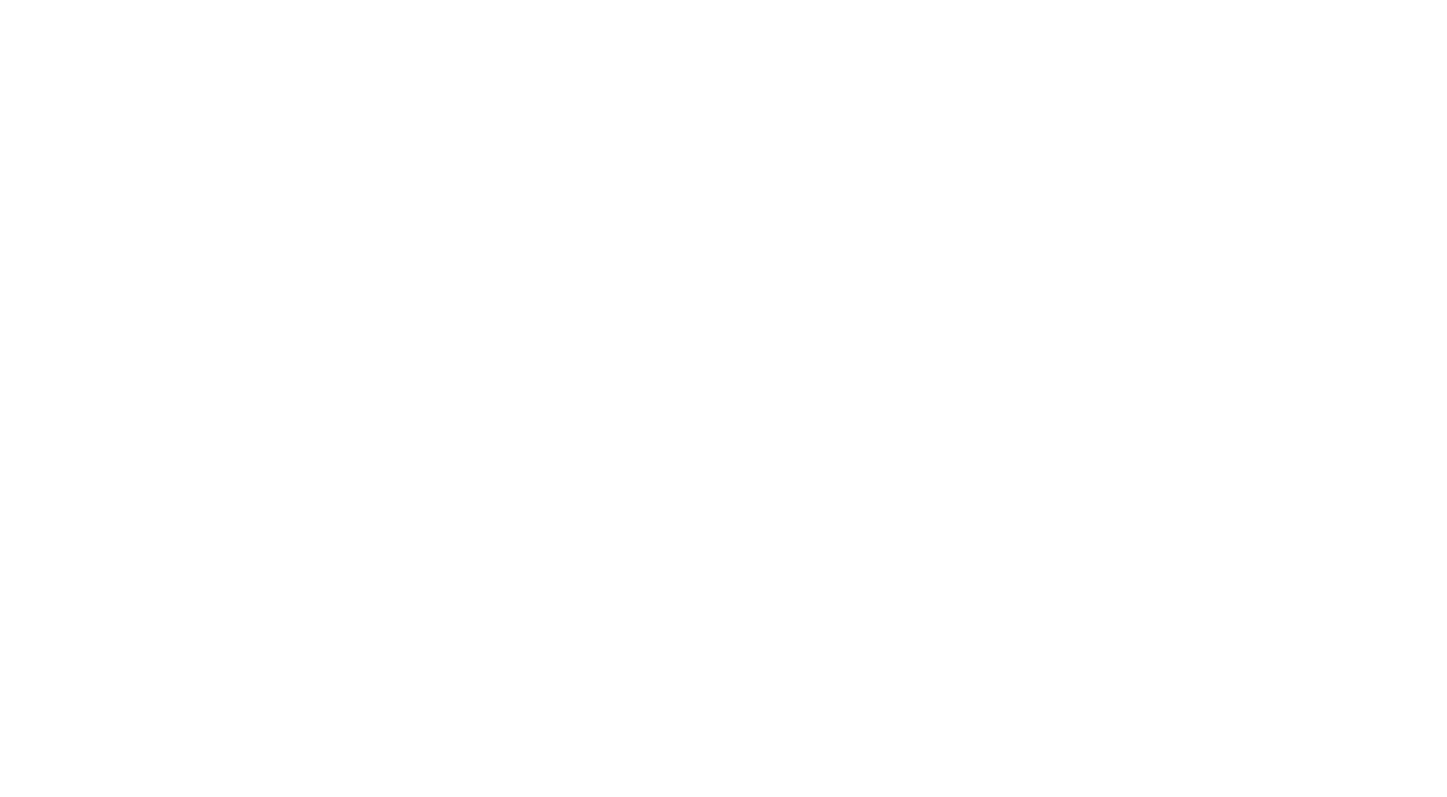

HIGHEST MEAN DISCHARGE, IN GBIC FEET PER SECOND, AND RANKING FOR THE INDICATED NUMBER OF CONSEOUTIVE DAYS FOR EACH WATER YEAR, OCTCBER 1-SEPTEMBER 30

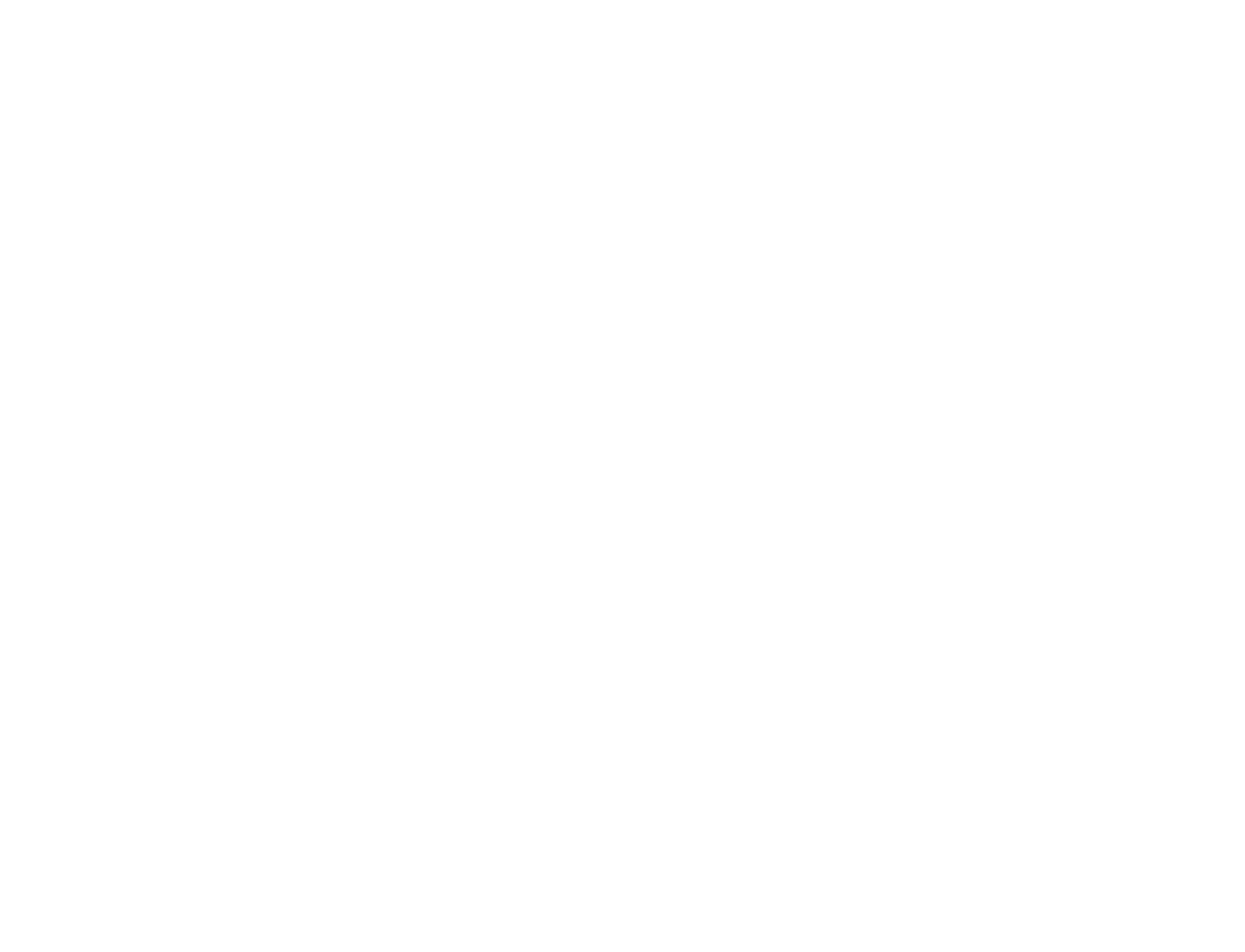


PARIA RIVER BASIN

09382000 PARIA RIVER AT LEES FERRY, AZ--Continued

HIGHEST MEAN DISCHARGE, IN OUBIC FEET PER SEOOND, AND RANKING FOR THE INDICATED NUMBER OF CONSEOUTIVE DAYS FOR EACH WATER YEAR, OCTOBER 1-SEPTEMBER 30--Continued

YEAR CONSECUTIVE DAYS

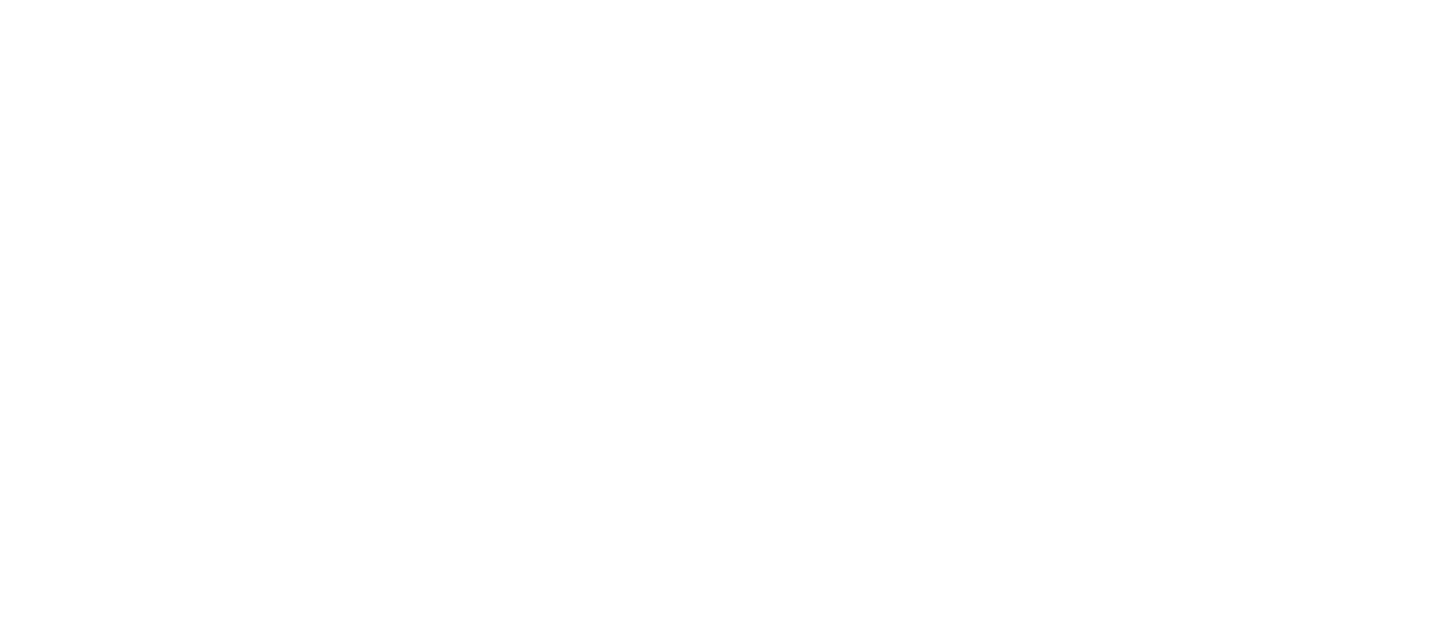

\section{DURATION OF DISCHARGE FOR EACH WATER YEAR}

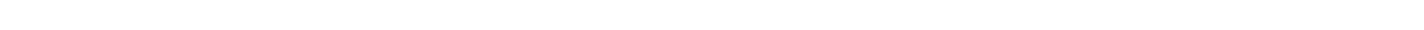

YEAR

NUMBER OF DAYS IN CLASS

1924

1925

192

1927
1928

1928
1929

1931

1931
1932
1933

1933
1934

1934
1935

1936

1937
1938

1939

1941

1941
1942

1943
1944

1944
1945

1946

1947

1948

1949
1950

1951

1952
1953

1954

1956

1957

1958

1960

1961

1962

1963

1965

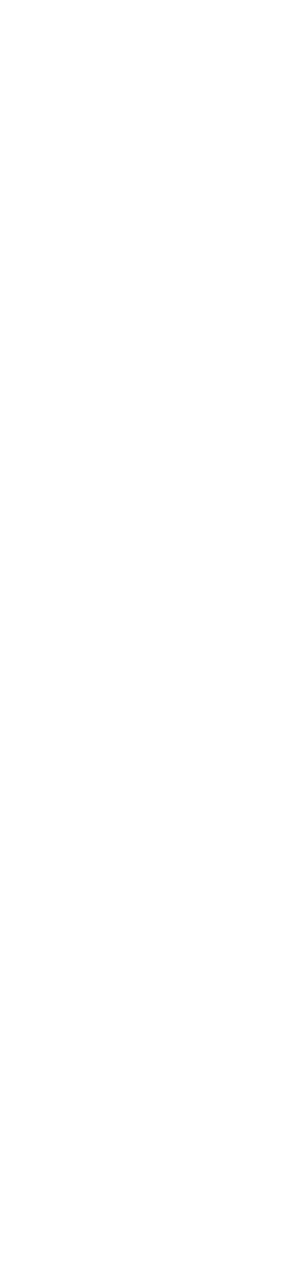


PARIA RIVER BASIN

09382000 PARIA RIVER AT LEES FERRY, AZ--Continued

DURATION OF DISCHARGE FOR EACH WATER YEAR-Continued

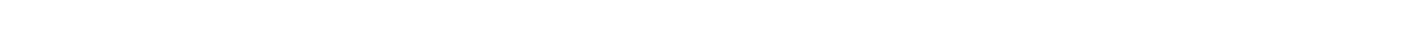

YEAR

NUMBER OF DAYS IN CLASS

OBIC FEET

1966

1967

$\begin{array}{rrrrrrrrrrrrrrrrrrrrrrr}6 & 40 & 47 & 14 & 35 & 35 & 35 & 29 & 31 & 23 & 25 & 17 & 12 & 3 & 6 & 2 & 3 & 1 & & & 1 \\ 1 & 4 & 8 & 20 & 40 & 31 & 37 & 22 & 55 & 66 & 30 & 15 & 9 & 5 & 6 & 1 & 3 & 3 & 1 & 1 & 1 & 2 & 1\end{array}$

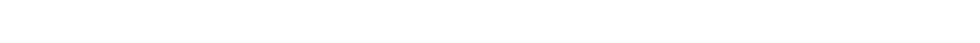

$\begin{array}{rrrrrrrrrrrrrrrrrrrrrrrr}4 & 2 & 16 & 11 & 15 & 19 & 22 & 37 & 43 & 38 & 26 & 23 & 19 & 30 & 13 & 14 & 6 & 7 & 11 & 5 & 2 & 1 & & 1 \\ 1 & 16 & 28 & 33 & 39 & 28 & 12 & 9 & 25 & 76 & 59 & 17 & 9 & 3 & 1 & 4 & 2 & & & 1 & 1 & 1 & \end{array}$

12

-DAYS

1969

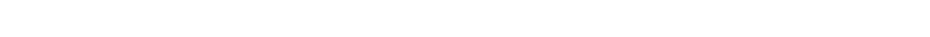

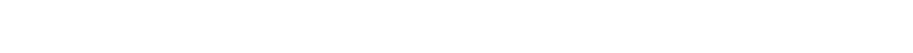

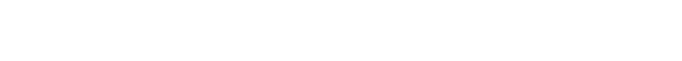

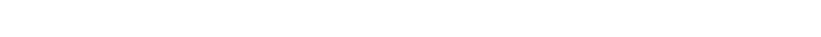

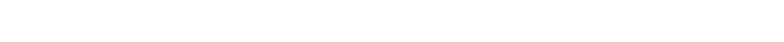

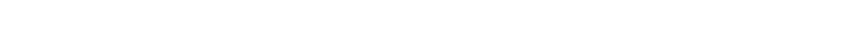

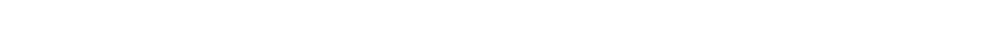

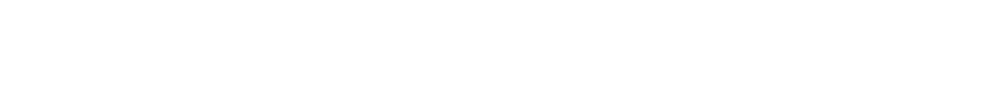

8086.8

13262.9

11972.3

13449.5
7829.3

8023.7

9755.5

15839.6

9387.9

1977

1978

1980

1981

DURATION TABLE OF DISCHARGE FOR WATER YEARS 1924-81

$\begin{array}{rrr}\text { OUBIC } & \text { ACOU- } \\ \text { FEET } & \text { MU- } & \text { PER- } \\ \text { PER TOTAL LATED } & \text { CENT } \\ \text { CJASS SECOND DAYS DAYS } & \text { DAYS }\end{array}$

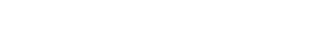

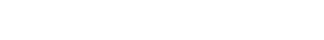

$\begin{array}{cccc}1.30 & 18 & 21164 & 99.9 \\ 1.70 & 392 & 21146 & 99.8\end{array}$

$\begin{array}{llll}1.70 & 392 & 21146 & 99.8 \\ 2.20 & 241 & 20754 & 98.0\end{array}$

$2.901604 \quad 20513 \quad 96.8$

$3.802162 \quad 18909 \quad 89.3$

$\begin{array}{llll}4.90 & 1858 & 16747 & 79.1 \\ 6.40 & 1497 & 14889 & 70.3\end{array}$ $\begin{array}{lll}\text { OUBIC } & \\ \text { FEET } & \text { MCOU- } \\ \text { PER TOTAL LATED } & \text { PERT }\end{array}$

CIASS SECOND DAYS DAYS DAYS

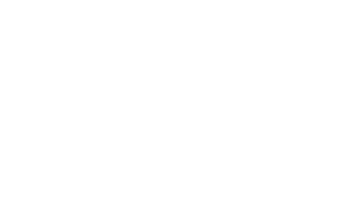

OUIC ACOU-
FEET TOTAL LATED
PER TENT CLASS SEDOND DAYS DAYS DAYS

$\begin{array}{rrrrr}18 & 90.0 & 227 & 906 & 4.3 \\ 19 & 120.0 & 144 & 679 & 3.2 \\ 20 & 150.0 & 148 & 535 & 2.5 \\ 21 & 200.0 & 92 & 387 & 1.8 \\ 22 & 260.0 & 75 & 295 & 1.4 \\ 23 & 340.0 & 54 & 220 & 1.0 \\ 24 & 440.0 & 53 & 166 & 0.8 \\ 25 & 570.0 & 37 & 113 & 0.5 \\ 26 & 750.0 & 28 & 76 & 0.4\end{array}$

5996.7

4246.3

7579.1

18075.9
23838.4

10633.5

MONIHLY MEAN DISCHARGES, IN OBIC FEET PER SECOND, FOR EACH WATER YEAR

\begin{tabular}{|c|c|c|c|c|c|c|c|c|c|c|c|c|}
\hline YEAR & OCT & NOV & $\mathrm{DEC}$ & JAN & FEB & MAR & APR & MAY & JUNE & JULY & AUG & SEP \\
\hline $\begin{array}{l}1924 \\
1925\end{array}$ & $\begin{array}{l}15.0 \\
19.0\end{array}$ & $\begin{array}{l}35.0 \\
21.5\end{array}$ & $\begin{array}{l}20.5 \\
13.3\end{array}$ & $\begin{array}{c}15.0 \\
9.23\end{array}$ & $\begin{array}{l}29.7 \\
28.3\end{array}$ & $\begin{array}{l}24.9 \\
21.5\end{array}$ & $\begin{array}{l}22.5 \\
11.1\end{array}$ & $\begin{array}{l}5.23 \\
3.13\end{array}$ & $\begin{array}{l}3.50 \\
3.53\end{array}$ & $\begin{array}{l}35.1 \\
39.4\end{array}$ & $124^{5.94}$ & $\begin{array}{l}101 \\
196\end{array}$ \\
\hline $\begin{array}{l}1926 \\
1927 \\
1928 \\
1929 \\
1930\end{array}$ & $\begin{array}{l}288 \\
15.5 \\
14.4 \\
13.2 \\
12.9\end{array}$ & $\begin{array}{l}21.7 \\
35.6 \\
24.0 \\
20.9 \\
11.8\end{array}$ & $\begin{array}{l}15.2 \\
18.1 \\
18.4 \\
15.6 \\
11.9\end{array}$ & $\begin{array}{l}18.8 \\
21.1 \\
18.6 \\
14.7 \\
14.9\end{array}$ & $\begin{array}{l}22.5 \\
54.4 \\
30.3 \\
24.3 \\
28.6\end{array}$ & $\begin{array}{l}14.8 \\
54.1 \\
40.8 \\
25.6 \\
13.3\end{array}$ & $\begin{array}{r}57.5 \\
6.43 \\
6.70 \\
7.60 \\
4.93\end{array}$ & $\begin{array}{c}10.6 \\
2.03 \\
8.74 \\
3.19 \\
5.81\end{array}$ & $\begin{array}{c}1.97 \\
17.9 \\
2.10 \\
2.67 \\
5.57\end{array}$ & $\begin{array}{c}12.6 \\
46.8 \\
31.6 \\
132 \\
50.3\end{array}$ & $\begin{array}{l}20.9 \\
72.2 \\
62.6 \\
174 \\
114\end{array}$ & $\begin{array}{c}43.3 \\
424 \\
5.93 \\
141 \\
40.2\end{array}$ \\
\hline $\begin{array}{l}1931 \\
1932 \\
1933 \\
1934 \\
1935\end{array}$ & $\begin{array}{c}26.8 \\
20.7 \\
20.0 \\
21.7 \\
6.52\end{array}$ & $\begin{array}{l}30.6 \\
18.0 \\
16.7 \\
17.4 \\
12.6\end{array}$ & $\begin{array}{c}8.81 \\
9.58 \\
14.0 \\
29.2 \\
23.8\end{array}$ & $\begin{array}{l}8.03 \\
15.1 \\
10.8 \\
25.4 \\
26.5\end{array}$ & $\begin{array}{c}30.9 \\
148 \\
23.8 \\
21.1 \\
34.2\end{array}$ & $\begin{array}{l}12.1 \\
58.8 \\
39.3 \\
13.8 \\
38.9\end{array}$ & $\begin{array}{c}5.90 \\
18.8 \\
10.3 \\
5.77 \\
42.8\end{array}$ & $\begin{array}{c}9.61 \\
8.55 \\
7.71 \\
52.4 \\
12.2\end{array}$ & $\begin{array}{l}4.90 \\
3.77 \\
2.63 \\
7.87 \\
3.20\end{array}$ & $\begin{array}{l}14.1 \\
65.1 \\
50.3 \\
16.4 \\
14.4\end{array}$ & $\begin{array}{c}17.1 \\
237 \\
39.7 \\
95.8 \\
28.8\end{array}$ & $\begin{array}{l}21.0 \\
25.4 \\
40.5 \\
12.8 \\
41.1\end{array}$ \\
\hline $\begin{array}{l}1936 \\
1937 \\
1938 \\
1939 \\
1940\end{array}$ & $\begin{array}{l}8.58 \\
29.0 \\
19.8 \\
17.9 \\
16.4\end{array}$ & $\begin{array}{l}18.4 \\
26.3 \\
18.3 \\
18.4 \\
17.1\end{array}$ & $\begin{array}{l}18.6 \\
16.4 \\
20.8 \\
20.3 \\
17.6\end{array}$ & $\begin{array}{c}20.6 \\
8.74 \\
24.8 \\
21.6 \\
38.7\end{array}$ & $\begin{array}{l}42.6 \\
75.5 \\
25.2 \\
18.0 \\
42.2\end{array}$ & $\begin{array}{c}20.5 \\
104 \\
175 \\
35.7 \\
13.3\end{array}$ & $\begin{array}{c}8.30 \\
47.1 \\
19.6 \\
12.1 \\
5.63\end{array}$ & $\begin{array}{c}3.32 \\
7.71 \\
10.8 \\
3.48 \\
4.00\end{array}$ & $\begin{array}{c}3.53 \\
5.40 \\
18.2 \\
2.73 \\
3.10\end{array}$ & $\begin{array}{c}172 \\
40.5 \\
7.52 \\
2.32 \\
3.39\end{array}$ & $\begin{array}{l}155 \\
43.2 \\
24.3 \\
17.0 \\
39.5\end{array}$ & $\begin{array}{c}109 \\
46.1 \\
60.3 \\
395 \\
240\end{array}$ \\
\hline $\begin{array}{l}1941 \\
1942 \\
1943 \\
1944 \\
1945\end{array}$ & $\begin{array}{c}33.5 \\
94.5 \\
22.5 \\
77.3 \\
7.06\end{array}$ & $\begin{array}{l}22.6 \\
31.1 \\
19.6 \\
15.7 \\
16.1\end{array}$ & $\begin{array}{l}24.6 \\
23.2 \\
22.9 \\
22.5 \\
16.3\end{array}$ & $\begin{array}{l}34.6 \\
24.7 \\
30.3 \\
16.2 \\
20.6\end{array}$ & $\begin{array}{l}75.0 \\
24.1 \\
37.7 \\
30.4 \\
28.0\end{array}$ & $\begin{array}{l}67.9 \\
34.2 \\
30.8 \\
79.8 \\
36.1\end{array}$ & $\begin{array}{l}85.3 \\
24.7 \\
13.8 \\
30.7 \\
19.6\end{array}$ & $\begin{array}{c}38.1 \\
7.19 \\
3.71 \\
17.5 \\
4.60\end{array}$ & $\begin{array}{l}8.70 \\
2.97 \\
2.70 \\
8.00 \\
2.98\end{array}$ & $\begin{array}{c}41.3 \\
15.8 \\
5.03 \\
3.32 \\
11.8\end{array}$ & $\begin{array}{c}14.7 \\
31.8 \\
85.5 \\
5.75 \\
68.8\end{array}$ & $\begin{array}{c}15.2 \\
10.0 \\
35.8 \\
5.08 \\
39.6\end{array}$ \\
\hline $\begin{array}{l}1946 \\
1947 \\
1948 \\
1949 \\
1950\end{array}$ & $\begin{array}{l}82.0 \\
54.2 \\
43.5 \\
14.2 \\
18.8\end{array}$ & $\begin{array}{l}18.1 \\
30.6 \\
19.0 \\
20.4 \\
16.3\end{array}$ & $\begin{array}{l}15.3 \\
23.9 \\
36.7 \\
18.1 \\
19.7\end{array}$ & $\begin{array}{l}15.8 \\
15.1 \\
22.9 \\
14.8 \\
28.9\end{array}$ & $\begin{array}{l}23.3 \\
22.4 \\
56.3 \\
37.8 \\
38.0\end{array}$ & $\begin{array}{l}21.7 \\
14.5 \\
24.6 \\
54.0 \\
19.1\end{array}$ & $\begin{array}{c}16.2 \\
6.31 \\
17.3 \\
35.6 \\
6.15\end{array}$ & $\begin{array}{l}3.96 \\
7.00 \\
5.49 \\
7.47 \\
4.07\end{array}$ & $\begin{array}{c}2.85 \\
4.14 \\
12.6 \\
55.6 \\
3.76\end{array}$ & $\begin{array}{c}34.5 \\
5.08 \\
7.15 \\
6.80 \\
42.6\end{array}$ & $\begin{array}{c}130 \\
189 \\
64.0 \\
23.0 \\
11.2\end{array}$ & $\begin{array}{c}12.0 \\
9.18 \\
6.51 \\
39.3 \\
15.9\end{array}$ \\
\hline
\end{tabular}


PARIA RIVER BASIN

09382000 PARIA RIVER AT LEES FERRY, AZ--Continued

MONIHLY MEAN DISCHARGES, IN OBIC FEET PER SECOND, FOR EACH WATER YEAR-Continued

\begin{tabular}{|c|c|c|c|c|c|c|c|c|c|c|c|c|}
\hline YEAR & $O C T$ & NOV & $\mathrm{DEC}$ & JAN & FEB & MAR & AFR & MAY & JUNE & JULY & AUG & SEP \\
\hline $\begin{array}{l}1951 \\
1952 \\
1953 \\
1954 \\
1955\end{array}$ & $\begin{array}{r}6.10 \\
7.84 \\
9.27 \\
9.31 \\
56.7\end{array}$ & $\begin{array}{l}16.6 \\
14.8 \\
11.0 \\
22.3 \\
13.0\end{array}$ & $\begin{array}{l}20.8 \\
42.4 \\
22.4 \\
15.1 \\
22.1\end{array}$ & $\begin{array}{l}21.1 \\
34.2 \\
25.5 \\
25.9 \\
18.6\end{array}$ & $\begin{array}{l}19.4 \\
29.1 \\
18.4 \\
22.7 \\
29.8\end{array}$ & $\begin{array}{l}16.3 \\
48.9 \\
16.2 \\
27.9 \\
36.9\end{array}$ & $\begin{array}{c}12.8 \\
46.1 \\
8.76 \\
10.8 \\
7.56\end{array}$ & $\begin{array}{c}16.6 \\
7.50 \\
5.64 \\
7.44 \\
4.49\end{array}$ & $\begin{array}{l}3.93 \\
8.32 \\
4.19 \\
8.85 \\
5.22\end{array}$ & $\begin{array}{l}4.81 \\
16.9 \\
55.4 \\
32.5 \\
13.6\end{array}$ & $\begin{array}{c}79.5 \\
32.5 \\
109 \\
5.84 \\
78.3\end{array}$ & $\begin{array}{c}11.6 \\
23.1 \\
7.90 \\
72.2 \\
4.83\end{array}$ \\
\hline $\begin{array}{l}1956 \\
1957 \\
1958 \\
1959 \\
1960\end{array}$ & $\begin{array}{c}5.99 \\
10.8 \\
91.6 \\
11.3 \\
9.68\end{array}$ & $\begin{array}{c}16.1 \\
12.6 \\
123 \\
15.7 \\
18.1\end{array}$ & $\begin{array}{l}24.3 \\
10.7 \\
18.9 \\
14.8 \\
18.7\end{array}$ & $\begin{array}{l}23.6 \\
29.4 \\
13.1 \\
16.6 \\
16.1\end{array}$ & $\begin{array}{l}17.3 \\
39.0 \\
50.4 \\
19.1 \\
30.4\end{array}$ & $\begin{array}{l}10.6 \\
14.5 \\
68.7 \\
13.6 \\
36.0\end{array}$ & $\begin{array}{c}6.89 \\
11.5 \\
37.9 \\
5.41 \\
7.74\end{array}$ & $\begin{array}{c}5.68 \\
16.1 \\
17.7 \\
4.69 \\
6.37\end{array}$ & $\begin{array}{c}4.06 \\
6.92 \\
4.67 \\
3.84 \\
13.9\end{array}$ & $\begin{array}{c}18.8 \\
55.7 \\
11.6 \\
7.61 \\
3.78\end{array}$ & $\begin{array}{r}25.6 \\
60.2 \\
51.9 \\
105 \\
4.69\end{array}$ & $\begin{array}{r}4.66 \\
7.34 \\
163 \\
11.1 \\
9.37\end{array}$ \\
\hline $\begin{array}{l}1961 \\
1962 \\
1963 \\
1964 \\
1965\end{array}$ & $\begin{array}{c}71.4 \\
7.00 \\
24.5 \\
20.4 \\
7.35\end{array}$ & $\begin{array}{l}22.1 \\
13.9 \\
11.8 \\
19.9 \\
15.5\end{array}$ & $\begin{array}{l}14.5 \\
13.7 \\
14.1 \\
12.7 \\
27.2\end{array}$ & $\begin{array}{l}10.1 \\
16.9 \\
13.0 \\
11.8 \\
19.5\end{array}$ & $\begin{array}{l}15.5 \\
79.8 \\
23.4 \\
17.1 \\
18.1\end{array}$ & $\begin{array}{l}19.6 \\
23.2 \\
11.4 \\
17.6 \\
15.9\end{array}$ & $\begin{array}{c}11.9 \\
14.3 \\
6.55 \\
18.2 \\
53.1\end{array}$ & $\begin{array}{l}4.25 \\
4.20 \\
4.13 \\
12.5 \\
16.0\end{array}$ & $\begin{array}{l}3.58 \\
6.22 \\
3.40 \\
4.05 \\
6.86\end{array}$ & $\begin{array}{c}14.6 \\
4.18 \\
3.39 \\
23.1 \\
14.9\end{array}$ & $\begin{array}{c}180 \\
5.54 \\
120 \\
54.7 \\
31.5\end{array}$ & $\begin{array}{c}144 \\
67.5 \\
95.3 \\
7.69 \\
31.0\end{array}$ \\
\hline $\begin{array}{l}1966 \\
1967 \\
1968 \\
1969 \\
1970\end{array}$ & $\begin{array}{c}15.9 \\
12.0 \\
8.05 \\
8.90 \\
15.8\end{array}$ & $\begin{array}{l}55.8 \\
14.4 \\
13.2 \\
12.3 \\
24.7\end{array}$ & $\begin{array}{l}47.5 \\
69.4 \\
19.9 \\
13.7 \\
22.7\end{array}$ & $\begin{array}{l}24.0 \\
21.5 \\
26.5 \\
96.7 \\
26.2\end{array}$ & $\begin{array}{l}28.1 \\
26.9 \\
62.6 \\
49.3 \\
22.3\end{array}$ & $\begin{array}{l}29.3 \\
15.1 \\
30.7 \\
64.6 \\
27.9\end{array}$ & $\begin{array}{c}9.82 \\
8.59 \\
16.8 \\
42.9 \\
8.03\end{array}$ & $\begin{array}{c}4.69 \\
10.2 \\
12.0 \\
13.6 \\
3.97\end{array}$ & $\begin{array}{l}3.48 \\
7.59 \\
2.96 \\
3.68 \\
7.65\end{array}$ & $\begin{array}{l}12.8 \\
31.5 \\
83.1 \\
56.5 \\
15.9\end{array}$ & $\begin{array}{r}14.7 \\
47.5 \\
111 \\
51.5 \\
63.6\end{array}$ & $\begin{array}{c}20.4 \\
172 \\
4.18 \\
27.9 \\
17.9\end{array}$ \\
\hline $\begin{array}{l}1971 \\
1972 \\
1973 \\
1974 \\
1975\end{array}$ & $\begin{array}{c}7.02 \\
41.4 \\
173 \\
7.48 \\
37.8\end{array}$ & $\begin{array}{l}19.2 \\
20.7 \\
31.4 \\
16.0 \\
37.5\end{array}$ & $\begin{array}{l}22.1 \\
45.1 \\
23.4 \\
21.8 \\
17.4\end{array}$ & $\begin{array}{l}24.8 \\
17.2 \\
15.1 \\
21.7 \\
17.2\end{array}$ & $\begin{array}{l}20.7 \\
18.3 \\
57.5 \\
25.3 \\
28.8\end{array}$ & $\begin{array}{c}19.4 \\
8.86 \\
91.9 \\
23.2 \\
35.4\end{array}$ & $\begin{array}{c}5.80 \\
5.23 \\
54.1 \\
8.66 \\
22.2\end{array}$ & $\begin{array}{c}6.76 \\
4.35 \\
19.7 \\
4.39 \\
7.57\end{array}$ & $\begin{array}{c}3.32 \\
58.3 \\
8.73 \\
3.56 \\
4.41\end{array}$ & $\begin{array}{l}16.3 \\
7.22 \\
4.23 \\
19.1 \\
43.3\end{array}$ & $\begin{array}{l}106 \\
47.5 \\
29.5 \\
15.8 \\
19.6\end{array}$ & $\begin{array}{l}11.0 \\
45.8 \\
11.1 \\
11.1 \\
37.8\end{array}$ \\
\hline $\begin{array}{l}1976 \\
1977 \\
1978 \\
1979 \\
1980\end{array}$ & $\begin{array}{l}7.25 \\
8.42 \\
12.5 \\
12.0 \\
10.2\end{array}$ & $\begin{array}{r}16.7 \\
12.8 \\
14.4 \\
109 \\
25.7\end{array}$ & $\begin{array}{l}22.1 \\
12.9 \\
18.0 \\
13.3 \\
24.0\end{array}$ & $\begin{array}{l}18.8 \\
14.8 \\
27.6 \\
13.4 \\
50.4\end{array}$ & $\begin{array}{r}51.2 \\
17.5 \\
36.7 \\
51.1 \\
242\end{array}$ & $\begin{array}{c}25.0 \\
9.08 \\
82.6 \\
216 \\
88.2\end{array}$ & $\begin{array}{c}26.0 \\
6.54 \\
32.5 \\
93.3 \\
65.5\end{array}$ & $\begin{array}{c}10.2 \\
7.62 \\
6.74 \\
39.2 \\
37.1\end{array}$ & $\begin{array}{c}3.44 \\
5.90 \\
3.30 \\
11.0 \\
9.49\end{array}$ & $\begin{array}{c}7.05 \\
13.5 \\
5.03 \\
6.37 \\
11.1\end{array}$ & $\begin{array}{c}4.51 \\
21.8 \\
5.46 \\
25.6 \\
23.3\end{array}$ & $\begin{array}{r}6.23 \\
8.52 \\
5.05 \\
4.47 \\
208\end{array}$ \\
\hline 1981 & 22.0 & 23.4 & 26.3 & 24.1 & 22.0 & 29.5 & 18.6 & 14.0 & 11.6 & 44.3 & 67.8 & 44.7 \\
\hline
\end{tabular}

ANNUAL FEAK DISCHARGE, IN OUBIC FEET PER SECOND, AND CORRESFONDING GAGE HEIGHT, IN FEET, FOR EACH WATER YEAR

\begin{tabular}{|c|c|c|c|c|c|c|c|c|c|c|c|}
\hline $\begin{array}{l}\text { WATER } \\
\text { YEAR }\end{array}$ & DATE & $\begin{array}{c}\text { GAGE } \\
\text { HEIGHT }\end{array}$ & $\begin{array}{c}\text { PEAK } \\
\text { DISCHARGE }\end{array}$ & $\begin{array}{l}\text { WATER } \\
\text { YEAR }\end{array}$ & DATE & $\begin{array}{c}\text { GAGE } \\
\text { HEIGHT }\end{array}$ & $\begin{array}{c}\text { PEAK } \\
\text { DISCHARGE }\end{array}$ & $\begin{array}{l}\text { WATER } \\
\text { YEAR }\end{array}$ & DATE & $\begin{array}{c}\text { GAGE } \\
\text { HEIGHT }\end{array}$ & $\begin{array}{c}\text { PEAK } \\
\text { DISCHARGE }\end{array}$ \\
\hline $\begin{array}{l}1924 \\
1925 \\
1926 \\
1927 \\
1928 \\
1929 \\
1930 \\
1931 \\
1932 \\
1933 \\
1934 \\
1935 \\
1936 \\
1937 \\
1938 \\
1939 \\
1940 \\
1941 \\
1942\end{array}$ & $\begin{array}{l}\text { SEPT.10, } 1924 \\
\text { SEPT.19, } 1925 \\
\text { OCT. 05, } 1925 \\
\text { SEPT.13, } 1927 \\
\text { JULY } 16,1928 \\
\text { AUG. 02, } 1929 \\
\text { AUG. 11, } 1930 \\
\text { NOV. 18, } 1930 \\
\text { AUG. } 28,1932 \\
\text { AUG. } 22,1933 \\
\text { AUG. 29, } 1934 \\
\text { SEPT.01, } 1935 \\
\text { JULY 11, } 1936 \\
\text { AUG. 29, } 1937 \\
\text { MAR. 03, } 1938 \\
\text { SEPT.13, } 1939 \\
\text { SEPT.06, } 1940 \\
\text { JULY 24, } 1941 \\
\text { OCT. 28, } 1941\end{array}$ & $\begin{array}{r}6.00 \\
6.50 \\
16.30 \\
16.00 \\
7.50 \\
13.80 \\
11.00 \\
7.53 \\
13.00 \\
8.81 \\
11.80 \\
8.12 \\
11.95 \\
8.85 \\
11.22 \\
12.90 \\
16.00 \\
12.30 \\
7.50\end{array}$ & $\begin{array}{r}4330 \\
4800 \\
16100 \\
14300 \\
2960 \\
12000 \\
7150 \\
2190 \\
10500 \\
3660 \\
8400 \\
2700 \\
8700 \\
3720 \\
7440 \\
9800 \\
14000 \\
7500 \\
1680\end{array}$ & $\begin{array}{l}1944 \\
1945 \\
1946 \\
1947 \\
1948 \\
1949 \\
1950 \\
1951 \\
1952 \\
1953 \\
1954 \\
1955 \\
1956 \\
1957 \\
1958 \\
1959 \\
1960 \\
1961 \\
1962\end{array}$ & $\begin{array}{ll}\text { OCT. } 19,1943 \\
\text { SEPT.03, } 1945 \\
\text { JULY } 25,1946 \\
\text { AUG. } 22,1947 \\
\text { AUG. } 05,1948 \\
\text { SEPT.29, } 1949 \\
\text { JULY } 19,1950 \\
\text { AUG. } 04,1951 \\
\text { SEPT.22, } 1952 \\
\text { AUG. } 27,1953 \\
\text { SEPT.12, } 1954 \\
\text { AUG. } 17,1955 \\
\text { AUG. } 17,1956 \\
\text { AUG. } 22,1957 \\
\text { SEPT.12, } 1958 \\
\text { AUG. } 19,1959 \\
\text { JUNE } 07,1960 \\
\text { AUG. } 04,1961 \\
\text { SEPT.21, } 1962\end{array}$ & $\begin{array}{r}12.10 \\
8.83 \\
10.00 \\
11.77 \\
11.60 \\
10.00 \\
8.17 \\
11.50 \\
9.00 \\
12.80 \\
11.20 \\
11.10 \\
9.30 \\
11.20 \\
15.30 \\
11.80 \\
7.67 \\
13.15 \\
10.77\end{array}$ & $\begin{array}{r}8400 \\
3290 \\
4980 \\
7650 \\
6150 \\
3410 \\
1340 \\
4480 \\
1830 \\
6400 \\
3980 \\
3010 \\
1420 \\
3310 \\
11500 \\
5370 \\
370 \\
8040 \\
2830\end{array}$ & $\begin{array}{l}1963 \\
1964 \\
1965 \\
1966 \\
1967 \\
1968 \\
1969 \\
1970 \\
1971 \\
1972 \\
1973 \\
1974 \\
1975 \\
1976 \\
1977 \\
1978 \\
1979 \\
1980 \\
1981\end{array}$ & $\begin{array}{l}\text { SEPT.01, } 1963 \\
\text { AUG. } 12,1964 \\
\text { SEPT.06, } 1965 \\
\text { NOW. } 23,1965 \\
\text { DEC. 07, } 1966 \\
\text { JULY } 27,1968 \\
\text { JAN. } 26,1969 \\
\text { AUG. } 20,1970 \\
\text { AUG. } 26,1971 \\
\text { JUNE } 22,1972 \\
\text { OCT. } 19,1972 \\
\text { JULY } 23,1974 \\
\text { JULY } 30,1975 \\
\text { FEB. } 09,1976 \\
\text { AUG. } 17,1977 \\
\text { MAR. 05, } 1978 \\
\text { NOV. 03, } 1978 \\
\text { SEPT.09, } 1980 \\
\text { AUG. } 14,1981\end{array}$ & $\begin{array}{r}16.35 \\
12.00 \\
9.99 \\
12.40 \\
13.45 \\
13.66 \\
11.96 \\
12.50 \\
10.58 \\
14.10 \\
13.95 \\
7.90 \\
12.37 \\
8.10 \\
11.00 \\
9.60 \\
11.70 \\
16.65 \\
10.66\end{array}$ & $\begin{array}{r}7150 \\
2360 \\
1220 \\
2140 \\
3500 \\
4090 \\
2570 \\
3010 \\
1880 \\
4750 \\
5530 \\
520 \\
3680 \\
718 \\
2070 \\
1270 \\
2890 \\
8520 \\
2110\end{array}$ \\
\hline
\end{tabular}

MAGNITUDE AND PRCBABILITY OF ANNUAL LOWEST MEAN DISQHARGE BASED ON GIMATIC YEARS 1925-8

\begin{tabular}{|c|c|c|c|c|c|c|}
\hline \multirow{2}{*}{$\begin{array}{l}\text { PERIOD } \\
\text { (CON- } \\
\text { SEOU- } \\
\text { TIVE } \\
\text { DAYS) }\end{array}$} & \multicolumn{6}{|c|}{$\begin{array}{l}\text { DISCHARGE, IN OUBIC FEET PER SECOND, FOR } \\
\text { INDICATED REOURRENCE INTEERVAL, IN YEARS, AND } \\
\text { ANNUAL NONEXCEEMANCE PROBABIIITY, IN PERCENT }\end{array}$} \\
\hline & $\begin{array}{c}2 \\
508\end{array}$ & $\begin{array}{c}5 \\
208\end{array}$ & $\begin{array}{l}10 \\
108\end{array}$ & $\begin{array}{l}20 \\
58\end{array}$ & $\begin{array}{l}50 \\
28\end{array}$ & $\begin{array}{r}100 \\
18\end{array}$ \\
\hline $\begin{array}{r}1 \\
7 \\
14 \\
30 \\
60 \\
90\end{array}$ & $\begin{array}{l}2.3 \\
2.8 \\
3.0 \\
3.4 \\
4.2 \\
6.1\end{array}$ & $\begin{array}{l}1.7 \\
2.2 \\
2.4 \\
2.7 \\
3.3 \\
4.3\end{array}$ & $\begin{array}{l}1.4 \\
1.9 \\
2.2 \\
2.5 \\
3.0 \\
3.7\end{array}$ & $\begin{array}{l}1.2 \\
1.6 \\
2.0 \\
2.3 \\
2.8 \\
3.3\end{array}$ & $\begin{array}{l}0.99 \\
1.3 \\
1.8 \\
2.1 \\
2.7 \\
2.9\end{array}$ & $\begin{array}{l}0.86 \\
1.2 \\
1.6 \\
2.0 \\
2.6 \\
2.7\end{array}$ \\
\hline
\end{tabular}


LOCATION.--Lat $37^{\circ} 1730^{\prime \prime}$, long $112^{\circ} 29^{\prime} 30^{\prime \prime}$, in NE⿺辶 of Glendale and $10 \mathrm{mi}$ south of Alton.

DRAINAGE AREA. $--72 \mathrm{mi}^{2}$

MEAN BASIN ELEVATION. $-7,250 \mathrm{ft}$.

PERIOD OF RECORD AVAIIABLE.--Water years 1959-74, annual peak discharge only.

GAGE.--Crest-stage gage. Altitude of gage is 6,220 ft from topographic map.

ANNUAL PEAK DISCHARGE, IN CBBIC FEET PER SECOND, AND CORRESPONDING GAGE HEIGHT, IN FEET, FOR EACH WATER YEAR

\begin{tabular}{|c|c|c|c|c|c|c|c|c|c|c|c|}
\hline $\begin{array}{l}\text { WAITER } \\
\text { YEAR }\end{array}$ & DATE & $\begin{array}{c}\text { GAGE } \\
\text { HEIGHT }\end{array}$ & $\begin{array}{c}\text { PEAR } \\
\text { DISCHARGE }\end{array}$ & $\begin{array}{l}\text { WATER } \\
\text { YEAR }\end{array}$ & DATE & $\begin{array}{c}\text { GAGE } \\
\text { HEIGHT }\end{array}$ & $\begin{array}{c}\text { PEAK } \\
\text { DISCHARGE }\end{array}$ & $\begin{array}{l}\text { WATER } \\
\text { YEAR }\end{array}$ & DATE & $\begin{array}{c}\text { GAGE } \\
\text { HEIGHT }\end{array}$ & $\begin{array}{c}\text { PEAR } \\
\text { DISCHARGE }\end{array}$ \\
\hline $\begin{array}{l}1959 \\
1960 \\
1961 \\
1962 \\
1963\end{array}$ & $\begin{array}{l}\text { AUG. } 02,1959 \\
\text { MAR. }-\overline{-},- \\
\text { SEPT. 08, } 1961 \\
\text { FEB. 12, } 1962 \\
\text { SEPT.18, } 1963\end{array}$ & $\begin{array}{r}10.71 \\
10.95 \\
5.80 \\
4.47 \\
6.37\end{array}$ & $\begin{array}{r}83 \\
120 \\
1300 \\
710 \\
1600\end{array}$ & $\begin{array}{l}1965 \\
1966 \\
1967 \\
1968 \\
1969\end{array}$ & $\begin{array}{l}\text { APR. } 10,1965 \\
\text { NOV. } 23,1965 \\
\text { DEC. 06, } 1966 \\
\text { SEPT. } 11.1968 \\
\text { AUG. } 12,1969\end{array}$ & $\begin{array}{l}2.95 \\
3.25 \\
5.61 \\
7.23 \\
4.25\end{array}$ & $\begin{array}{r}250 \\
320 \\
1190 \\
2100 \\
630\end{array}$ & $\begin{array}{l}1970 \\
1971 \\
1972 \\
1973 \\
1974\end{array}$ & $\begin{array}{l}\text { AUG. } 18,1970 \\
\text { JULY } 30,1971 \\
\text { APR. 09, } 1972 \\
\text { OCT. } 11,1972\end{array}$ & $\begin{array}{l}6.59 \\
5.97 \\
3.95 \\
5.49 \\
1.59\end{array}$ & $\begin{array}{r}1700 \\
1370 \\
530 \\
1140 \\
29\end{array}$ \\
\hline
\end{tabular}

09403600 KANAB CREEK NEAR KANAB, UT

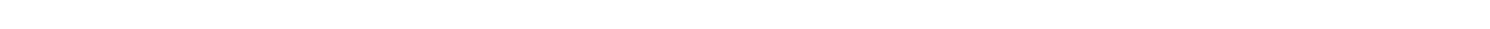
edge of left bridge pier on U.S. Highway $89,300 \mathrm{ft}$ upstrear from Tiny Canyon, and $3.5 \mathrm{mi}$ north of Kanab.

DRAINAGE AREA. $-198 \mathrm{mi}^{2}$.

MEAN BASIN ELEVATION. $-6,670 \mathrm{ft}$.

PERIOD OF RECORD AVAIIABLE.--Annual peak discharge only, water years 1959-68. January 1979 to September 1981.

GAGE.--Water-stage recorder and concrete control. Altitude of gage is 5,060 ft from topographic map. A crest-stage gage was in operation at this site from July 22,1959 to Sept. 30, 1968, at different datum.

EXTREMES FOR PERIOD OF RECORD.--Maximum discharge, 3,030 ft $3 / \mathrm{s}$ September 8, 1961; maximum gage height, $15.81 \mathrm{ft}$ Sept. 6 , 1960 , at datum then in use; minimum discharge, $3.4 \mathrm{ft}^{3} / \mathrm{s}$ Now. $11,1979$.

LOWEST MEAN DISCHARGE, IN OBIC FEET PER SECOND, AND RANKING FOR THE INDICATED NUMBER OF CONSECUTMVE DAYS FOR EACH CIIMATIC YEAR, APRII 1-MARCH 31

\begin{tabular}{|c|c|c|c|c|c|c|c|c|c|c|c|c|c|c|c|c|c|c|c|}
\hline YEAR & & & & & & & & & CONSE & arTIVE & DAYS & & & & & & & & \\
\hline 1980 & 4.10 & 1 & 4.10 & 1 & 4.10 & 1 & 4.20 & 1 & 4.50 & 1 & 5.20 & 1 & 5.50 & 1 & 5.90 & 1 & 6.60 & 1 & 20.0 \\
\hline
\end{tabular}

HIGHEST MEAN DISCHARGE, IN OBBIC FEET PER SECOND, AND RANKING FOR THE INDICATED NUMBER OF CONSEOUTIVE DAYS FOR EACH WATER YEAR, OCTOBER 1-SEPTEMBER 30

\begin{tabular}{|c|c|c|c|c|c|c|c|c|c|c|c|c|c|c|c|c|c|c|c|}
\hline YEAR & 1 & & 3 & & 7 & & 15 & & $\begin{array}{l}\text { CONS } \\
30\end{array}$ & GTI & $\begin{array}{l}\text { E DAYS } \\
60\end{array}$ & & 90 & & 120 & & 183 & & ALL \\
\hline
\end{tabular}

DURATION OF DISCHARGE FOR EACH WATER YEAR

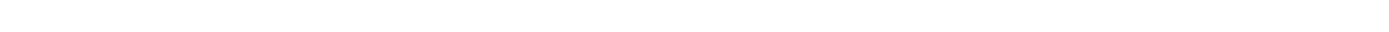
YGAR

NIMBER OF DAYS IN CLASS

CUBIC FEET PER SECOND

$\begin{array}{lllllllllllllllllllllllllllllllllllll}1980 & 1 & 6 & 3 & 21 & 29 & 47 & 44 & 14 & 27 & 16 & 16 & 14 & 10 & 6 & 18 & 5 & 14 & 8 & 9 & 5 & 5 & 2 & 11 & 2 & 5 & 5 & 4 & 3 & 5 & 3 & 3 & 1 & 3 & 1 & 10412.2 \\ 1981 & & 12 & 4 & 11 & 5 & 8 & 36 & 25 & 84 & 37 & 62 & 40 & 15 & 6 & 6 & 3 & & 1 & 3 & & 3 & 1 & 1 & 1 & & 1 & & & & & & & & & & \end{array}$ 
KANAB CREEK BASIN

09403600 KANAB CREEK NEAR KANAB, UT-Continued

DURATION TABLE OF DISCHARGE FOR WATER YEARS 1980-81

\begin{tabular}{|c|c|c|c|c|c|c|c|c|c|c|c|c|c|c|c|c|c|c|c|}
\hline IASS & $\begin{array}{c}\text { CUBIC } \\
\text { FEET } \\
\text { PER } \\
\text { SECOND }\end{array}$ & $\begin{array}{l}\text { TOTAL } \\
\text { DAYS }\end{array}$ & $\begin{array}{l}\text { ACOU- } \\
\text { MU- } \\
\text { LATED } \\
\text { DAYS }\end{array}$ & $\begin{array}{l}\text { PER- } \\
\text { CENT } \\
\text { DAYS }\end{array}$ & Q.ASS & $\begin{array}{c}\text { CUBIC } \\
\text { FEET } \\
\text { PER } \\
\text { SECOND }\end{array}$ & $\begin{array}{l}\text { TOTAL } \\
\text { DAYS }\end{array}$ & $\begin{array}{c}\text { ACCU- } \\
\text { MU- } \\
\text { LATED } \\
\text { DAYS }\end{array}$ & $\begin{array}{l}\text { PER- } \\
\text { CENT } \\
\text { DAYS }\end{array}$ & & $\begin{array}{c}\text { CUBIC } \\
\text { FEET } \\
\text { PER } \\
\text { SECOND }\end{array}$ & $\begin{array}{l}\text { TOTAL, } \\
\text { DAYS }\end{array}$ & $\begin{array}{l}\text { ACOH- } \\
\text { MU- } \\
\text { LATED } \\
\text { DAYS }\end{array}$ & $\begin{array}{l}\text { PER- } \\
\text { CENT } \\
\text { DAYS }\end{array}$ & & $\begin{array}{c}\text { OUBIC } \\
\text { FEET } \\
\text { PER } \\
\text { SEOOND }\end{array}$ & $\begin{array}{l}\text { TOTAL } \\
\text { DAYS }\end{array}$ & $\begin{array}{l}\text { ACOU- } \\
\text { MU- } \\
\text { LATED } \\
\text { DAYS }\end{array}$ & $\begin{array}{l}\text { PER- } \\
\text { CENI } \\
\text { DAYS }\end{array}$ \\
\hline $\begin{array}{l}0 \\
1 \\
2 \\
3 \\
4 \\
5 \\
6 \\
7 \\
8\end{array}$ & $\begin{array}{l}0.00 \\
4.10 \\
4.60 \\
5.30 \\
6.00 \\
6.80 \\
7.60 \\
8.70 \\
9.80\end{array}$ & $\begin{array}{r}0 \\
1 \\
18 \\
7 \\
32 \\
34 \\
55 \\
80 \\
39\end{array}$ & $\begin{array}{l}731 \\
731 \\
730 \\
712 \\
705 \\
673 \\
639 \\
584 \\
504\end{array}$ & $\begin{array}{r}100.0 \\
100.0 \\
99.9 \\
97.4 \\
96.4 \\
92.1 \\
87.4 \\
79.9 \\
68.9\end{array}$ & $\begin{array}{r}9 \\
10 \\
11 \\
12 \\
13 \\
14 \\
15 \\
16 \\
17\end{array}$ & $\begin{array}{l}11.00 \\
13.00 \\
14.00 \\
16.00 \\
18.00 \\
21.00 \\
23.00 \\
27.00 \\
30.00\end{array}$ & $\begin{array}{r}111 \\
53 \\
78 \\
54 \\
25 \\
12 \\
24 \\
8 \\
14\end{array}$ & $\begin{array}{l}465 \\
354 \\
301 \\
223 \\
169 \\
144 \\
132 \\
108 \\
100\end{array}$ & $\begin{array}{l}63.6 \\
48.4 \\
41.2 \\
30.5 \\
23.1 \\
19.7 \\
18.1 \\
14.8\end{array}$ & $\begin{array}{l}18 \\
19 \\
20 \\
21 \\
22 \\
23 \\
24 \\
25 \\
26\end{array}$ & $\begin{array}{l}34.0 \\
39.0 \\
44.0 \\
49.0 \\
56.0 \\
63.0 \\
72.0 \\
81.0 \\
92.0\end{array}$ & $\begin{array}{r}9 \\
12 \\
5 \\
8 \\
3 \\
12 \\
3 \\
5 \\
6\end{array}$ & $\begin{array}{l}86 \\
77 \\
65 \\
60 \\
52 \\
49 \\
37 \\
34 \\
29\end{array}$ & $\begin{array}{r}11.8 \\
10.5 \\
8.9 \\
8.2 \\
7.1 \\
6.7 \\
5.1 \\
4.7 \\
4.0\end{array}$ & $\begin{array}{l}27 \\
28 \\
29 \\
30 \\
31 \\
32 \\
33 \\
34\end{array}$ & $\begin{array}{l}100.0 \\
120.0 \\
130.0 \\
150.0 \\
170.0 \\
190.0 \\
220.0 \\
250.0\end{array}$ & $\begin{array}{l}4 \\
3 \\
5 \\
3 \\
3 \\
1 \\
3 \\
1\end{array}$ & $\begin{array}{r}23 \\
19 \\
16 \\
11 \\
8 \\
5 \\
4 \\
1\end{array}$ & $\begin{array}{l}3.1 \\
2.6 \\
2.2 \\
1.5 \\
1.1 \\
0.7 \\
0.5 \\
0.1\end{array}$ \\
\hline
\end{tabular}

MONIHLY MEAN DISCHARGES, IN CUBIC FEET PER SECOND, FOR EAGH WATER YEAR

$\begin{array}{ccccccccccrrr}\text { YEAR } & \text { OCT } & \text { NOV } & \text { DEC } & \text { JAN } & \text { FEB } & \text { MAR } & \text { APR } & \text { MAY } & \text { JUNE } & \text { JULY } & \text { AUG } & \text { SEP } \\ 1980 & 7.15 & 8.21 & 21.7 & 12.8 & 45.1 & 48.6 & 132 & 27.6 & 10.0 & 8.72 & 7.96 & 14.2 \\ 1981 & 11.8 & 13.4 & 16.4 & 14.4 & 13.9 & 13.8 & 11.0 & 13.6 & 12.1 & 13.8 & 16.5 & 16.7\end{array}$

ANNUAL PEAK DISCHARGE, IN OUBIC FEET PER SECOND, AND CORRESPONDING GAGE HEIGHT, IN FEET, FOR EACH WATER YEAR

\begin{tabular}{|c|c|c|c|c|c|c|c|c|c|c|c|}
\hline $\begin{array}{l}\text { WATER } \\
\text { YEAR }\end{array}$ & DATE & $\begin{array}{c}\text { GAGE } \\
\text { HEIGHT }\end{array}$ & $\begin{array}{c}\text { PEAR } \\
\text { DISCHARGE }\end{array}$ & $\begin{array}{l}\text { WATEER } \\
\text { YEAR }\end{array}$ & DATE & $\begin{array}{c}\text { GAGE } \\
\text { HEIGHT }\end{array}$ & $\begin{array}{c}\text { PEAK } \\
\text { DISCHARGE }\end{array}$ & $\begin{array}{l}\text { WATER } \\
\text { YEAR }\end{array}$ & DATE & $\begin{array}{c}\text { GAGE } \\
\text { HEIGHT }\end{array}$ & $\begin{array}{c}\text { PEAK } \\
\text { DISCHARGE }\end{array}$ \\
\hline $\begin{array}{l}1959 \\
1960 \\
1961 \\
1962\end{array}$ & $\begin{array}{l}\text { AUG. } 03,1959 \\
\text { SEPT.06, } 1960 \\
\text { SEPT.08, } 1961 \\
\text { FEB. } 12,1962\end{array}$ & $\begin{array}{l}10.63 \\
15.81 \\
15.70 \\
12.00\end{array}$ & $\begin{array}{r}160 \\
2100 \\
3030 \\
1400\end{array}$ & $\begin{array}{l}1964 \\
1965 \\
1966 \\
1967\end{array}$ & $\begin{array}{l}\text { AUG. } 12,1964 \\
\text { MAR. } 13,1965 \\
\text { SEPT.02, } 1966 \\
\text { DEC. 06, } 1966\end{array}$ & $\begin{array}{l}12.30 \\
12.46 \\
11.41 \\
14.40\end{array}$ & $\begin{array}{r}600 \\
640 \\
360 \\
1230\end{array}$ & $\begin{array}{l}1968 \\
1979 \\
1980 \\
1981\end{array}$ & $\begin{array}{l}\text { JULY } 07,1968 \\
\text { MAR. } 28,1979 \\
\text { APR. 06, } 1980 \\
\text { JULY } 16,1981\end{array}$ & $\begin{array}{c}14.60 \\
-- \\
2.61 \\
5.34\end{array}$ & $\begin{array}{r}1300 \\
190 \\
1060 \\
220\end{array}$ \\
\hline
\end{tabular}

09403620 MILL CREEK NEAR GLENDALE, UT

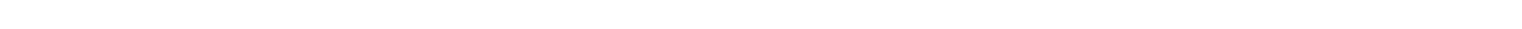
$100 \mathrm{ft}$ upstream from road crossing Mill Creek, $7.5 \mathrm{mi}$ southeast of Alton.

DRAINAGE AREA. $-4.81 \mathrm{mi}^{2}$.

PERIOD OF RECORD AVAIAABLE.-OCtober 1975 to September 1977.

GAGE.-Water-stage recorder and concrete control. Elevation 6,820 ft from topographic map.

EXIREMES FOR PERIOD OF RECORD.--Maximum discharge, $147 \mathrm{ft}^{3} / \mathrm{s}$ Aug. 17,1977 , gage height, $1.64 \mathrm{ft}$; minimum daily, $0.06 \mathrm{ft}{ }^{3} / \mathrm{s} \mathrm{Jan.} 26$, 1977.

LOWEST MEAN DISCHARGE, IN OUBIC FEET PER SECOND, AND RANKING FOR THE INDICATED NUMBER OF CONSECUTIVE DAYS FOR EACH OLIMATIC YEAR, APRIL 1-MARCH 31

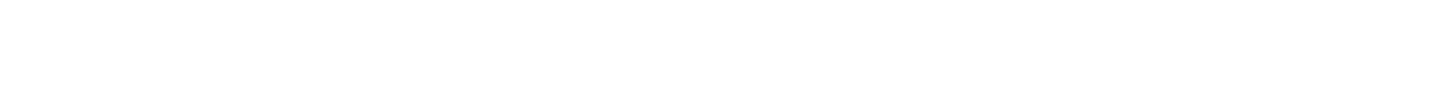

HIGHEST MEAN DISCHARGE, IN OUBIC FEET PER SECOND, AND RANKING FOR THE INDICATED NUMBER OF CONSEOUTIVE DAYS FOR EACH WATER YEAR, OCTCBER 1-SEPTEMBER 30

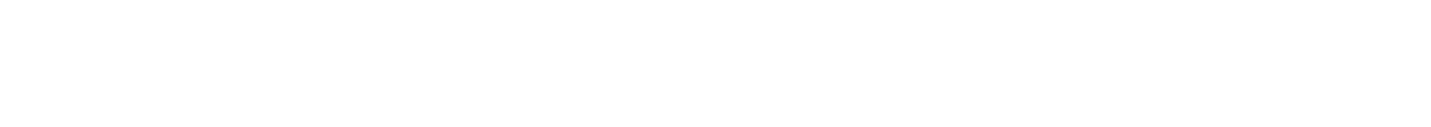

DURATION OF DISCHARGE FOR EAGH WATER YEAR

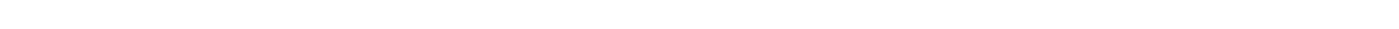

YEAR NUMBER OF DAYS IN G.ASS

OUBIC FEET

PER SEOOND

-DAYS

$\begin{array}{lllllllllrrrrrrrrrrrrrrrrrrrrrrrrrr}1976 & & 8 & 18 & 86 & 16 & 9 & 11 & 34 & 40 & 50 & 36 & 26 & 13 & 11 & 8 & 2 & 2 & 1 & & 1 & & 1 & 1 & 146.3 \\ 1977 & 8 & 20 & 48 & 2 & 19 & 44 & 17 & 6 & 5 & 9 & 31 & 33 & 13 & 11 & 11 & 10 & 3 & 8 & 19 & 14 & 22 & 2 & 2 & 4 & 1 & & & & 1 & 1 & 1 & 115.1\end{array}$ 
DURATION TABLE OF DISOHARGE FOR WATER YEARS 1976-77
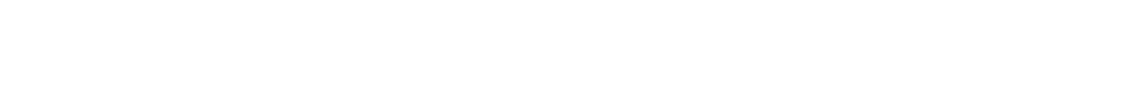

$\begin{array}{ccc}\text { OUBIC } & \text { ACQU- } \\ \text { FEET } & \text { MU- } & \text { PER- } \\ \text { PER TOTAL LATED } & \text { CENT } \\ \text { CLASS SECOND } & \text { DAYS DAYS } & \text { DAYS }\end{array}$

$\begin{array}{rrrrr}0 & 0.00 & 0 & 731 & 100.0 \\ 1 & 0.06 & 8 & 731 & 100.0 \\ 2 & 0.07 & 20 & 723 & 98.9 \\ 3 & 0.08 & 48 & 703 & 96.2 \\ 4 & 0.09 & 2 & 655 & 89.6 \\ 5 & 0.10 & 19 & 653 & 89.3 \\ 6 & 0.11 & 44 & 634 & 86.7 \\ 7 & 0.13 & 17 & 590 & 80.7 \\ 8 & 0.15 & 6 & 573 & 78.4\end{array}$

DAYS DAYS DAYS

SECOND DAYS DAYS DAYS

CLASS SECOND DAYS DAYS DAYS

$\begin{array}{rllllllllllllll}9 & 0.17 & 23 & 567 & 77.6 & 18 & 0.5 & 34 & 141 & 19.3 & 27 & 1.6 & 0 & 6 & 0.8 \\ 10 & 0.19 & 95 & 544 & 74.4 & 19 & 0.6 & 32 & 107 & 14.6 & 28 & 1.9 & 0 & 6 & 0.8 \\ 11 & 0.21 & 47 & 449 & 61.4 & 20 & 0.7 & 25 & 75 & 10.3 & 29 & 2.1 & 1 & 6 & 0.8 \\ 12 & 0.24 & 42 & 402 & 55.0 & 21 & 0.8 & 30 & 50 & 6.8 & 30 & 2.4 & 0 & 5 & 0.7 \\ 13 & 0.28 & 24 & 360 & 49.2 & 22 & 0.9 & 4 & 20 & 2.7 & 31 & 2.7 & 1 & 5 & 0.7 \\ 14 & 0.31 & 45 & 336 & 46.0 & 23 & 1.0 & 2 & 16 & 2.2 & 32 & 3.1 & 2 & 4 & 0.5 \\ 15 & 0.36 & 51 & 291 & 39.8 & 24 & 1.1 & 6 & 14 & 1.9 & 33 & 3.5 & 0 & 2 & 0.3 \\ 16 & 0.41 & 60 & 240 & 32.8 & 25 & 1.3 & 1 & 8 & 1.1 & 34 & 4.0 & 2 & 2 & 0.3 \\ 17 & 0.46 & 39 & 180 & 24.6 & 26 & 1.5 & 1 & 7 & 1.0 & & & & & \end{array}$

MONIHLY MEAN DISCHARGES, IN GBIC FEET PER SECOND, FOR EACH WATER YEAR

$\begin{array}{lllllllllllll}\text { YEAR } & \text { OCT } & \text { NOV } & \text { DEC } & \text { JAN } & \text { FEB } & \text { MAR } & \text { AFR } & \text { MA: } & \text { JUNE } & \text { JULY } & \text { AUG } & \text { SEP } \\ 1976 & 0.20 & 0.19 & 0.21 & 0.20 & 0.56 & 0.57 & 0.72 & 0.49 & 0.42 & 0.47 & 0.37 & 0.41 \\ 1977 & 0.30 & 0.12 & 0.09 & 0.08 & 0.07 & 0.11 & 0.27 & 0.68 & 0.78 & 0.52 & 0.51 & 0.24\end{array}$

09403630 SKUTUMPAH CREEK NEAR GLENDALE, UT

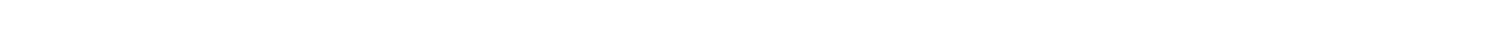
$0.4 \mathrm{mi}$ downstream from road crossing skutumpah Creek and $200 \mathrm{ft}$ west of road, $11.7 \mathrm{mi}$ southeast of Alton.

DRAINAGE AREA. $-14.8 \mathrm{mi}^{2}$.

PERIOD OF RECORD AVAII.ABLE.--October 1975 to September 1977.

GAGE.--Water-stage recorder and concrete control.

EXIREMES FOR PERIOD OF RECORD.-Maximum discharge, $314 \mathrm{ft}^{3} / \mathrm{s}$ Aug. 17, 1977 , gage height, 3.91 ft; no flow several days during most winter months.

LOWEST MEAN DISOHARGE, IN OUBIC FEET FER SECOND, AND RANKING FOR THE INDICATED NUMBER OF CONSECUTIVE DAYS FOR EAOH CLIMATIC YEAR, APRIL I-MAROH 31

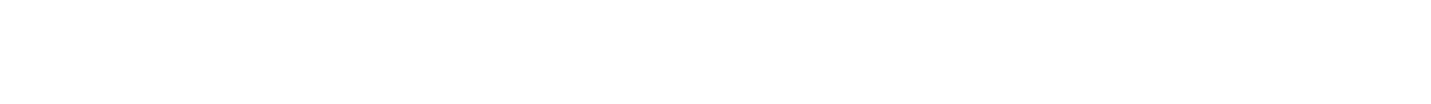

HIGHEST MEAN DISCHARGE, IN OUIC FEET PER SECOND, AND RANKING FOR THE INDICATED NUMBER OF CONSECUTIVE DAYS FOR EAGH WATER YEAR, OCTOBER 1-SEPTEMBER 30

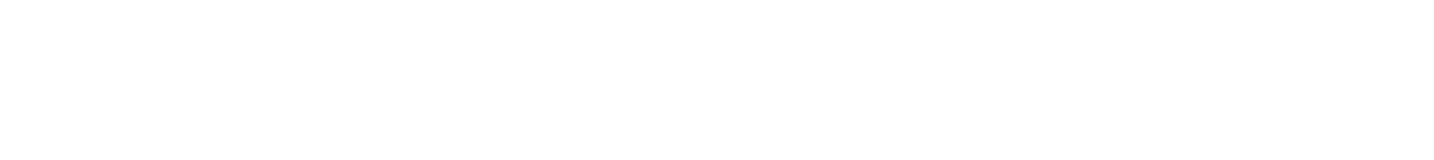

DURATION OF DISCHARGE FOR EACH WATER YEAR

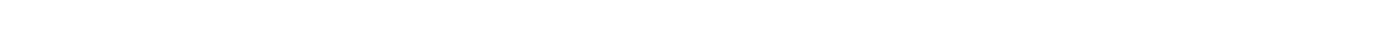
YEAR

NUMBER OF DAVS IN CLASS QUIC FEET
PER SECOND -DAYS $\begin{array}{rrrrrrrrrrrrrrrrrrrrrrrrrrrrrrrrrrr}1976 & 21 & 11 & 27 & 14 & 8 & 6 & 30 & 19 & 5 & 2 & 1 & 5 & 3 & 10 & 20 & 35 & 25 & 25 & 38 & 19 & 15 & 8 & 6 & 8 & 1 & 1 & 1 & 1 & & 1 & & & & 140.9 \\ 1977122 & 33 & 14 & 12 & 4 & 3 & 4 & 3 & 10 & 7 & 6 & 3 & 16 & 16 & 12 & 12 & 12 & 7 & 11 & 25 & 9 & 1 & 4 & 3 & 4 & 3 & & 6 & 1 & 1 & 1 & & & & 118.8\end{array}$ 
KANAB CREEK BASIN

09403630 SKUTUMPAH CREEK NEAR GLENDALE, UT--Continued

DURATION TABLE OF DISCHARGE FOR WATER YEARS 1976-77

\begin{tabular}{|c|c|c|c|c|c|c|c|c|c|c|c|c|c|c|c|c|c|c|c|}
\hline CLASS & $\begin{array}{c}\text { CUBIC } \\
\text { FEET } \\
\text { PER } \\
\text { SECOND }\end{array}$ & $\begin{array}{l}\text { TOTAL } \\
\text { DAYS }\end{array}$ & $\begin{array}{c}\text { ACQU- } \\
\text { MU- } \\
\text { LATED } \\
\text { DAYS }\end{array}$ & $\begin{array}{l}\text { PER- } \\
\text { CENT } \\
\text { DAYS }\end{array}$ & CLASS & $\begin{array}{c}\text { CUBIC } \\
\text { FEET } \\
\text { PER } \\
\text { SEOOND }\end{array}$ & $\begin{array}{l}\text { TOTAL } \\
\text { DAYS }\end{array}$ & $\begin{array}{c}\text { ACQU- } \\
\text { MU- } \\
\text { LATED } \\
\text { DAYS }\end{array}$ & $\begin{array}{l}\text { PER- } \\
\text { CENT } \\
\text { DAYS }\end{array}$ & CLASS & $\begin{array}{c}\text { OBBIC } \\
\text { FEET } \\
\text { PER } \\
\text { SECOND }\end{array}$ & $\begin{array}{l}\text { TOTAL } \\
\text { DAYS }\end{array}$ & $\begin{array}{c}\text { ACOU- } \\
\text { MU- } \\
\text { LATED } \\
\text { DAYS }\end{array}$ & $\begin{array}{l}\text { PER- } \\
\text { CENT } \\
\text { DAYS }\end{array}$ & & $\begin{array}{c}\text { CUBIC } \\
\text { FEET } \\
\text { PER } \\
\text { SBOOND }\end{array}$ & $\begin{array}{l}\text { TOTAL } \\
\text { DAYS }\end{array}$ & $\begin{array}{c}\text { ACO- } \\
\text { MU- } \\
\text { LATED } \\
\text { DAYS }\end{array}$ & $\begin{array}{l}\text { PER- } \\
\text { CFNI } \\
\text { DAYS }\end{array}$ \\
\hline $\begin{array}{l}0 \\
1 \\
2 \\
3 \\
4 \\
5 \\
6 \\
7 \\
8\end{array}$ & $\begin{array}{l}0.00 \\
0.01 \\
0.02 \\
0.03 \\
0.04 \\
0.05 \\
0.06 \\
0.07 \\
0.08\end{array}$ & $\begin{array}{r}143 \\
44 \\
41 \\
26 \\
12 \\
9 \\
34 \\
22 \\
15\end{array}$ & $\begin{array}{l}731 \\
588 \\
544 \\
503 \\
477 \\
465 \\
456 \\
422 \\
400\end{array}$ & $\begin{array}{r}100.0 \\
80.4 \\
74.4 \\
68.8 \\
65.3 \\
63.6 \\
62.4 \\
57.7 \\
54.7\end{array}$ & $\begin{array}{l}9 \\
10 \\
11 \\
12 \\
13 \\
14 \\
15 \\
16 \\
17\end{array}$ & $\begin{array}{l}0.10 \\
0.12 \\
0.14 \\
0.17 \\
0.21 \\
0.25 \\
0.31 \\
0.37 \\
0.45\end{array}$ & $\begin{array}{r}9 \\
7 \\
8 \\
19 \\
26 \\
32 \\
47 \\
37 \\
32\end{array}$ & $\begin{array}{l}385 \\
376 \\
369 \\
361 \\
342 \\
316 \\
284 \\
237 \\
200\end{array}$ & $\begin{array}{l}52.7 \\
51.4 \\
50.5 \\
49.4 \\
46.8 \\
43.2 \\
38.9 \\
32.4 \\
27.4\end{array}$ & $\begin{array}{l}18 \\
19 \\
20 \\
21 \\
22 \\
23 \\
24 \\
25 \\
26\end{array}$ & $\begin{array}{l}0.5 \\
0.7 \\
0.8 \\
1.0 \\
1.2 \\
1.4 \\
1.7 \\
2.1 \\
2.5\end{array}$ & $\begin{array}{r}49 \\
44 \\
24 \\
9 \\
10 \\
11 \\
5 \\
4 \\
1\end{array}$ & $\begin{array}{r}168 \\
119 \\
75 \\
51 \\
42 \\
32 \\
21 \\
16 \\
12\end{array}$ & $\begin{array}{r}23.0 \\
16.3 \\
10.3 \\
7.0 \\
5.7 \\
4.4 \\
2.9 \\
2.2 \\
1.6\end{array}$ & $\begin{array}{l}27 \\
28 \\
29 \\
30 \\
31 \\
32 \\
33 \\
34\end{array}$ & $\begin{array}{l}3.0 \\
3.6 \\
4.4 \\
5.3\end{array}$ & $\begin{array}{l}7 \\
1 \\
1 \\
2\end{array}$ & $\begin{array}{r}11 \\
4 \\
3 \\
2\end{array}$ & $\begin{array}{l}1.5 \\
0.5 \\
0.4 \\
0.3\end{array}$ \\
\hline
\end{tabular}

MONIHLY MEAN DISCHARGES, IN OBBIC FEET PER SECOND, FOR EACH WATER YEAR

$\begin{array}{llccccccccccc}\text { YEAR } & \text { OCT } & \text { NOV } & \text { DEC } & \text { JAN } & \text { FEB } & \text { MAR } & \text { APR } & \text { MAY } & \text { JUNE } & \text { JULY } & \text { AUG } & \text { SEP } \\ 1976 & 0.05 & 0.01 & 0.06 & 0.05 & 0.58 & 0.22 & 0.91 & 1.03 & 0.59 & 0.46 & 0.30 & 0.38 \\ 1977 & 0.22 & 0.02 & 0.00 & 0.00 & 0.00 & 0.01 & 0.23 & 0.89 & 0.63 & 1.01 & 0.72 & 0.14\end{array}$

09403640 INTERMEDIATE DRAINAGE NEAR GLENDALE, UT

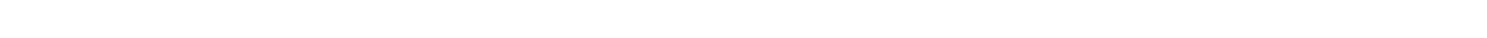

bank $0.2 \mathrm{mi}$ upstream from trail road that crosses bottam drainage, $11.5 \mathrm{mi}$ southeast of Alton.

DRAINAGE AREA. $--2.49 \mathrm{mi}^{2}$.

PERIOD OF RECORD AVAIIABLE.-October 1975 to September 1977.

GAGE.--Digital recorder with bubble gage and artificial control. Altitude of gage is 6,120 ft from topographic map.

EXIREMES FOR PERTOD OF RECORD.--Maximum discharge, $42 \mathrm{ft}^{3} / \mathrm{s}$ Sept. 25, 1976, from slope-area measurement; no flow most days.

LONEST MEAN DISCHARGE, IN OUBIC FEET PER SEOOND, AND RANKING FOR THE INDICATED NUMBER OF CONSEOUTIVE DAYS FOR EACH CLIMATIC YEAR, APRIL 1-MARCH 31

\begin{tabular}{|c|c|c|c|c|c|c|c|c|c|c|c|c|c|c|c|c|c|c|}
\hline YEAR & & & & & & & & & CONS & OUTIVE & DAYS & & & & & & & \\
\hline
\end{tabular}

HIGHEST MEAN DISCHARGE, IN CUBIC FEET PER SECOND, AND RANKING FOR THE INDICATED NUMBER OF CONSEOUTTVE DAYS FOR EACH WATER YEAR, OCICBER 1-SEPTEMBER 30

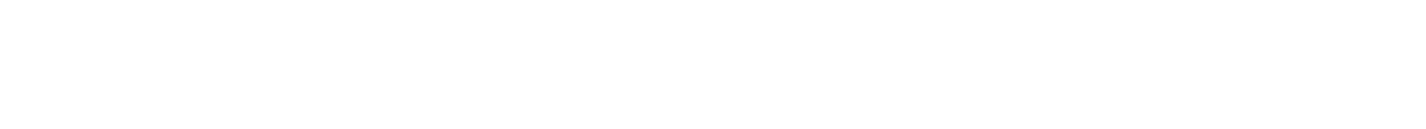

DURATION OF DISCHARGE FOR EACH WATER YEAR

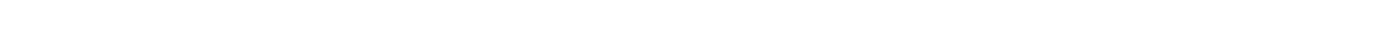
YEAR NUMBER OF DAYS IN CLASS

DURATION TABLE OF DISCHARGE FOR WATER YEARS 1976-77

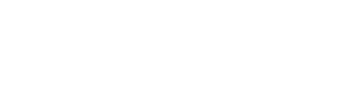

CLASS SBCOND DAYS DAYS DAYS

$$
\begin{array}{rrrrr}
0 & 0.00 & 724 & 731 & 100.0 \\
1 & 0.01 & 5 & 7 & 1.0 \\
2 & 0.02 & 2 & 2 & 0.3
\end{array}
$$


KANAB CREER BASIN

09403640 INTERMEDIATE DRAINAGE NEAR GLENDALE, UT-Continued

MONIHLY MEAN DISCHARGES, IN COBIC FEET PER SECOND, FOR EACH WATER YEAR

$\begin{array}{lccccccccccrr}\text { YEAR } & \text { CCT } & \text { NOV } & \text { DEC } & \text { JAN } & \text { FEB } & \text { MAR } & \text { APR } & \text { MAY } & \text { JUNE } & \text { JULY } & \text { AUG } & \text { SEP } \\ 1976 & 0.00 & 0.00 & 0.00 & 0.00 & 0.00 & 0.00 & 0.00 & 0.00 & 0.00 & 0.00 & 0.00 & 0.03 \\ 1977 & 0.00 & 0.00 & 0.00 & 0.00 & 0.00 & 0.00 & 0.00 & 0.00 & 0.00 & 0.00 & 0.00 & 0.00\end{array}$

09403650 THOMPSON CREEK (UPPER STATION) NEAR GLENDALE, UT

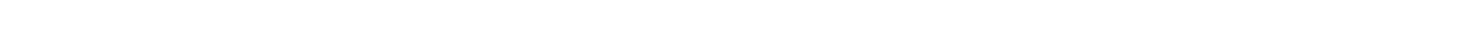

bank $0.3 \mathrm{mi}$ upstream from road crossing at Thompson Creek, $9.3 \mathrm{mi}$ southeast of Alton.

DRAINAGE AREA. $-9.8 \mathrm{mi}^{2}$.

PERIOD OF RBCORD AVAIIABLE.-OCtober 1975 to September 1977.

GAGE.-Water-stage recorder and V-notch sharp-crested weir. Altitude of gage is $6,420 \mathrm{ft}$ from topographic map.

EXIREMES FOR PERTOD OF RECORD.-Maximum discharge, $700 \mathrm{ft}^{3} / \mathrm{s}$ Aug. 18,1977 (from field survey); minimum daily, $0.09 \mathrm{ft}{ }^{3} / \mathrm{s}$ Aug. $28-$ 30,1977 .

LOWEST MEAN DISCHARGE, IN OUBIC FEET PER SECOND, AND RANRING FOR THE INDICATED NUMBER OF CONSECUTIVE DAYS FOR EACH OLIMATIC YEAR, APRIL 1-MARCH 31

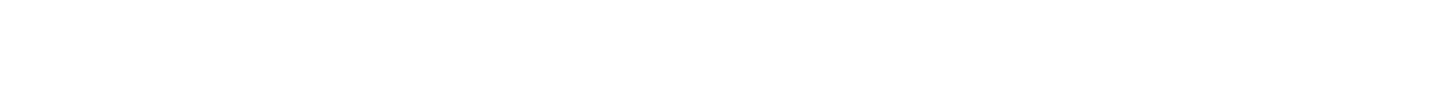

HIGHEST MEAN DISCHARGE, IN OBIIC FEET PER SECOND, AND RANKING FOR THE INDICAITED NUMBER OF CONSEOUTIVE DAYS FOR EACH WATER YEAR, OCTOBER 1-SEPTEMBER 30

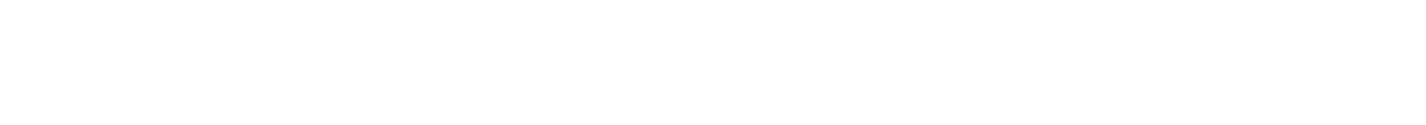

DURATION OF DISCHARGE FOR EACH WATER YEAR

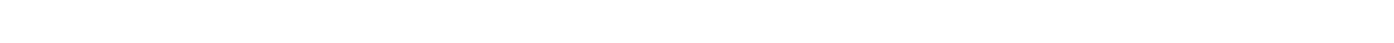
YEAR

NUMBER OF DAYS IN CLASS QBIC FEET PER SECOND -DAYS

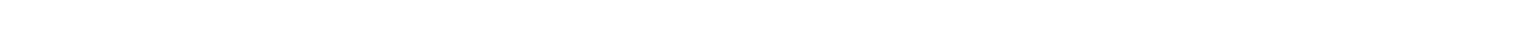
DURATION TABLE OF DISCHARGE FOR WATER YEARS 1976-77

\begin{tabular}{|c|c|c|c|c|c|c|c|c|c|c|c|c|c|c|c|c|c|c|c|}
\hline CLASS & $\begin{array}{c}\text { OUBIC } \\
\text { FEET } \\
\text { PER } \\
\text { SEOOND }\end{array}$ & $\begin{array}{r}\text { TOTAL } \\
\text { DAYS }\end{array}$ & $\begin{array}{l}\text { ACOU- } \\
\text { MU- } \\
\text { LATED } \\
\text { DAYS }\end{array}$ & $\begin{array}{l}\text { PER- } \\
\text { CENT } \\
\text { DAYS }\end{array}$ & OLASS & $\begin{array}{c}\text { OBBIC } \\
\text { FEET } \\
\text { PER } \\
\text { SECOND }\end{array}$ & $\begin{array}{r}\text { TOTAL } \\
\text { DAYS }\end{array}$ & $\begin{array}{l}\text { ACOU- } \\
\text { MU- } \\
\text { LATIED } \\
\text { DAYS }\end{array}$ & $\begin{array}{l}\text { PER } \\
\text { CENI } \\
\text { DAYS }\end{array}$ & C.ASS & $\begin{array}{c}\text { OBBIC } \\
\text { FEET } \\
\text { PER } \\
\text { SECOND }\end{array}$ & $\begin{array}{l}\text { TOTAL } \\
\text { DAYS }\end{array}$ & $\begin{array}{c}\text { ACOJ- } \\
\text { MJ- } \\
\text { LATED } \\
\text { DAYS }\end{array}$ & $\begin{array}{l}\text { PER- } \\
\text { CENT } \\
\text { DAYS }\end{array}$ & & $\begin{array}{c}\text { OJBIC } \\
\text { FEET } \\
\text { PER } \\
\text { SECOND }\end{array}$ & $\begin{array}{r}\text { TOTAL } \\
\text { DAYS }\end{array}$ & $\begin{array}{l}\text { ACCJ- } \\
\text { MU- } \\
\text { LATED } \\
\text { DAYS }\end{array}$ & $\begin{array}{l}\text { PER- } \\
\text { CENT } \\
\text { DAYS }\end{array}$ \\
\hline $\begin{array}{l}0 \\
1 \\
2 \\
3 \\
4 \\
5 \\
6 \\
7 \\
8\end{array}$ & $\begin{array}{l}0.00 \\
0.09 \\
0.10 \\
0.11 \\
0.13 \\
0.15 \\
0.16 \\
0.18 \\
0.21\end{array}$ & $\begin{array}{r}0 \\
3 \\
15 \\
12 \\
9 \\
5 \\
31 \\
49 \\
13\end{array}$ & $\begin{array}{l}731 \\
731 \\
728 \\
713 \\
701 \\
692 \\
687 \\
656 \\
607\end{array}$ & $\begin{array}{r}100.0 \\
100.0 \\
99.6 \\
97.5 \\
95.9 \\
94.7 \\
94.0 \\
89.7 \\
83.0\end{array}$ & $\begin{array}{r}9 \\
10 \\
11 \\
12 \\
13 \\
14 \\
15 \\
16 \\
17\end{array}$ & $\begin{array}{l}0.23 \\
0.26 \\
0.29 \\
0.33 \\
0.37 \\
0.42 \\
0.47 \\
0.53 \\
0.60\end{array}$ & $\begin{array}{r}21 \\
43 \\
96 \\
123 \\
101 \\
41 \\
40 \\
15 \\
31\end{array}$ & $\begin{array}{l}594 \\
573 \\
530 \\
434 \\
311 \\
210 \\
169 \\
129 \\
114\end{array}$ & $\begin{array}{l}81.3 \\
78.4 \\
72.5 \\
59.4 \\
42.5 \\
28.7 \\
23.1 \\
17.6 \\
15.6\end{array}$ & $\begin{array}{l}18 \\
19 \\
20 \\
21 \\
22 \\
23 \\
24 \\
25 \\
26\end{array}$ & $\begin{array}{l}0.7 \\
0.8 \\
0.9 \\
1.0 \\
1.1 \\
1.2 \\
1.4 \\
1.6 \\
1.7\end{array}$ & $\begin{array}{r}26 \\
7 \\
7 \\
3 \\
3 \\
7 \\
4 \\
2 \\
5\end{array}$ & $\begin{array}{l}83 \\
57 \\
50 \\
43 \\
40 \\
37 \\
30 \\
26 \\
24\end{array}$ & $\begin{array}{r}11.4 \\
7.8 \\
6.8 \\
5.9 \\
5.5 \\
5.1 \\
4.1 \\
3.6 \\
3.3\end{array}$ & $\begin{array}{l}27 \\
28 \\
29 \\
30 \\
31 \\
32 \\
33 \\
34\end{array}$ & $\begin{array}{l}2.0 \\
2.2 \\
2.5 \\
2.8 \\
3.2 \\
3.6 \\
4.0 \\
4.5\end{array}$ & $\begin{array}{l}4 \\
2 \\
1 \\
5 \\
1 \\
3 \\
1 \\
2\end{array}$ & $\begin{array}{r}19 \\
15 \\
13 \\
12 \\
7 \\
6 \\
3 \\
2\end{array}$ & $\begin{array}{l}2.6 \\
2.1 \\
1.8 \\
1.6 \\
1.0 \\
0.8 \\
0.4 \\
0.3\end{array}$ \\
\hline
\end{tabular}

MONTHLY MEAN DISCHARGES, IN OBIC FEET PER SECOND, FOR EACH WATER YEAR

$\begin{array}{lllllllllllll}\text { YEAR } & \text { OCT } & \text { NOV } & \text { DEC } & \text { JAN } & \text { FEB } & \text { MAR } & \text { APR } & \text { MAY } & \text { JUNE } & \text { JULY } & \text { AUG } & \text { SEP } \\ 1976 & 0.29 & 0.35 & 0.40 & 0.42 & 0.61 & 0.55 & 2.03 & 1.06 & 0.42 & 0.41 & 0.19 & 0.23 \\ 1977 & 0.29 & 0.38 & 0.33 & 0.32 & 0.33 & 0.55 & 0.43 & 0.34 & 0.28 & 0.30 & 0.52 & 0.14\end{array}$




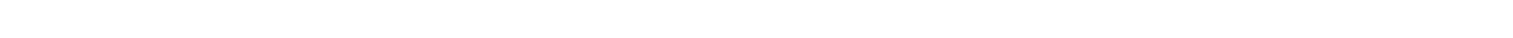
$0.4 \mathrm{mi}$ downstream from road crossing at Thompson Creek, $10 \mathrm{mi}$ southeast of Alton.

DRAINAGE AREA. $--16.6 \mathrm{mi}^{2}$.

PERIOD OF RECORD AVAIIABLE.--OCtober 1975 to September 1977.

GAGE.-Water-stage recorder and V-notch sharp-crested weir. Altitude of gage is 6,300 ft from topographic map.

EXIREMES FOR PERIOD OF RECORD.--Maximum discharge, $700 \mathrm{ft}^{3} / \mathrm{s}$ Aug, 18, 1977 (from field survey), gage height unknown; minimum daily, $0.06 \mathrm{ft}^{3} / \mathrm{s}$ Alug. 31, Sept. 1, 1977.

LONEST MEAN DISCHARGE, IN OBBIC FEET PER SECOND, AND RANKING FOR THE INDICATED NUMBER OF CONSEOUTIVE DAYS FOR EACH CLIMATIC YEAR, APRIL I-MARCH 31

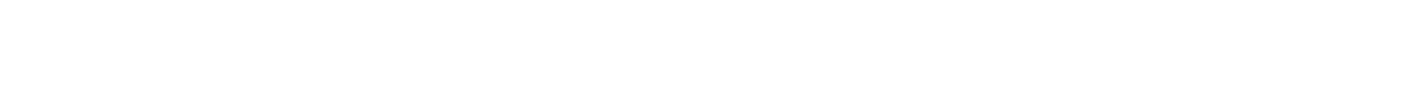

HIGHEST MEAN DISCHARGE, IN OUBIC FEET PER SECOND, AND RANKING FOR THE INDICATED NUMBER OF CONSECITIVE DAYS FOR EACH WATER YEAR, OCTOBER 1-SEPTEMBER 30

\begin{tabular}{|c|c|c|c|c|c|c|c|c|c|c|c|c|c|c|c|c|c|c|c|}
\hline \multirow[t]{2}{*}{ YEAR } & \multicolumn{19}{|c|}{ CONSECUTIVE DAYS } \\
\hline & 1 & & 3 & & 7 & & 15 & & 30 & & 60 & & 90 & & 120 & & 183 & & $A L L$ \\
\hline $\begin{array}{l}1976 \\
1977\end{array}$ & $\begin{array}{r}2.90 \\
11.0\end{array}$ & $\begin{array}{l}2 \\
1\end{array}$ & $\begin{array}{l}2.70 \\
5.10\end{array}$ & $\begin{array}{l}2 \\
1\end{array}$ & $\begin{array}{l}2.30 \\
2.30\end{array}$ & $\begin{array}{l}1 \\
2\end{array}$ & $\begin{array}{l}2.00 \\
1.19\end{array}$ & $\frac{1}{2}$ & $\begin{array}{l}1.80 \\
0.87\end{array}$ & $\frac{1}{2}$ & $\begin{array}{l}1.30 \\
0.56\end{array}$ & $\frac{1}{2}$ & $\begin{array}{l}1.00 \\
0.50\end{array}$ & $\frac{1}{2}$ & $\begin{array}{l}0.94 \\
0.44\end{array}$ & $\frac{1}{2}$ & $\begin{array}{l}0.85 \\
0.45\end{array}$ & $\frac{1}{2}$ & $\begin{array}{l}0.59 \\
0.36\end{array}$ \\
\hline
\end{tabular}

DURATION OF DISCHARGE FOR EACH WATER YEAR

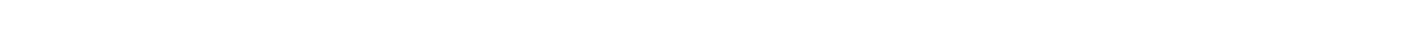
YEAR NUMBER OF DAYS IN CIASS CUBIC FEET PER SECOND

$\begin{array}{rrrrrrrrrrrrrrrrrrrrrrrrrrrrrrrrrrrrrrrrrrrrr}1976 & & & & & & 15 & 9 & 10 & 6 & 7 & 8 & 17 & 9 & 31 & 21 & 24 & 41 & 23 & 25 & 39 & 32 & 7 & 2 & 6 & 4 & 7 & 6 & 4 & 7 & 2 & 3 & 1 & & 214.2 \\ 1977 & 2 & 15 & 21 & 1 & 13 & 6 & 4 & 13 & 7 & 8 & 10 & 17 & 44 & 98 & 46 & 15 & 7 & 4 & 8 & 10 & 6 & 1 & 1 & 1 & & 3 & & & & & 1 & 1 & 2 & & 130.4\end{array}$ DURATION TABLE OF DISCHARGE FOR WATER YEARS 1976-77
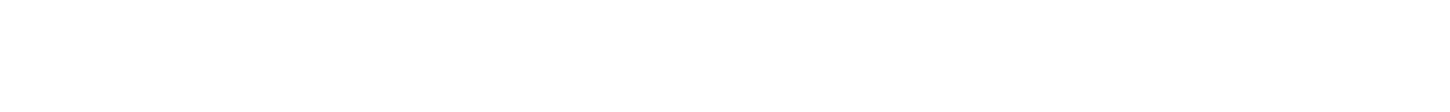

$\begin{array}{rrrrr}0 & 0.00 & 0 & 731 & 100.0 \\ 1 & 0.06 & 2 & 731 & 100.0 \\ 2 & 0.07 & 15 & 729 & 99.7 \\ 3 & 0.08 & 21 & 714 & 97.7 \\ 4 & 0.09 & 1 & 693 & 94.8 \\ 5 & 0.10 & 13 & 692 & 94.7 \\ 6 & 0.11 & 21 & 679 & 92.9 \\ 7 & 0.13 & 13 & 658 & 90.0 \\ 8 & 0.14 & 23 & 645 & 88.2\end{array}$

$\begin{array}{rrrrr}9 & 0.16 & 13 & 622 & 85.1 \\ 10 & 0.18 & 15 & 609 & 83.3 \\ 11 & 0.21 & 18 & 594 & 81.3 \\ 12 & 0.24 & 34 & 576 & 78.8 \\ 13 & 0.27 & 53 & 542 & 74.1 \\ 14 & 0.30 & 129 & 489 & 66.9 \\ 15 & 0.34 & 67 & 360 & 49.2 \\ 16 & 0.39 & 39 & 293 & 40.1 \\ 17 & 0.44 & 48 & 254 & 34.7\end{array}$

$\begin{array}{rrrrr}18 & 0.5 & 27 & 206 & 28.2 \\ 19 & 0.6 & 33 & 179 & 24.5 \\ 20 & 0.6 & 49 & 146 & 20.0 \\ 21 & 0.7 & 38 & 97 & 13.3 \\ 22 & 0.8 & 8 & 59 & 8.1 \\ 23 & 0.9 & 3 & 51 & 7.0 \\ 24 & 1.0 & 7 & 48 & 6.6 \\ 25 & 1.2 & 4 & 41 & 5.6 \\ 26 & 1.3 & 10 & 37 & 5.1\end{array}$

$\begin{array}{lll}27 & 1.5 & 6 \\ 28 & 1.7 & 4 \\ 29 & 1.9 & 7 \\ 30 & 2.2 & 2 \\ 31 & 2.5 & 4 \\ 32 & 2.8 & 2 \\ 33 & 3.2 & 0 \\ 34 & 3.6 & 2\end{array}$

$\begin{array}{rr}27 & 3.7 \\ 21 & 2.9 \\ 17 & 2.3 \\ 10 & 1.4 \\ 8 & 1.1 \\ 4 & 0.5 \\ 2 & 0.3 \\ 2 & 0.3\end{array}$

MONIHLY MEAN DISCHARGES, IN OBIC FEET PER SECOND, FOR EACH WATER YEAR

$\begin{array}{lllllllllllll}\text { YEAR } & \text { OCT } & \text { NOV } & \text { DEC } & \text { JAN } & \text { FEB } & \text { MAR } & \text { APR } & \text { MAY } & \text { JUNE } & \text { JULY } & \text { AUG } & \text { SEP } \\ 1976 & 0.35 & 0.50 & 0.66 & 0.71 & 0.65 & 0.52 & 1.39 & 1.15 & 0.38 & 0.36 & 0.15 & 0.21 \\ 1977 & 0.28 & 0.37 & 0.32 & 0.31 & 0.32 & 0.52 & 0.39 & 0.37 & 0.30 & 0.38 & 0.63 & 0.09\end{array}$


LOCATION.--Lat $37^{\circ} 02^{\prime} 15^{\prime \prime}$, long $112^{\circ} 21^{\prime} 20^{\prime \prime}$, in SE $\frac{1}{4}$ sec. 24, T.43 S., R.5 W., Kane County, Hydrologic Unit 15010003 , 1.2 mi north of U.S. Highway 89 and $11 \mathrm{mi}$ east of Ranab.

DRAINAGE AREA. $-237 \mathrm{mi}^{2}$

MEAN BASIN ELEVATION. $-6,300 \mathrm{ft}$.

PERIOD OF RECORD AVAIIABLE.-Water years 1959-1974, annual peak discharge only.

GAGE.-Crest-stage gage. Altitude of gage is 5,120 ft from topographic map.

ANNUAL PEAK DISCHARGE, IN CUBIC FEET PER SECOND, AND CORRESPONDING GAGE HEIGHT, IN FEET, FOR EAOH WATEER YEAR

\begin{tabular}{|c|c|c|c|c|c|c|c|c|c|c|c|}
\hline $\begin{array}{l}\text { WATYER } \\
\text { YEAR }\end{array}$ & DATE & $\begin{array}{l}\text { GAGE } \\
\text { HEIGHT }\end{array}$ & $\begin{array}{c}\text { PEAK } \\
\text { DISCHARGE }\end{array}$ & $\begin{array}{l}\text { WATEER } \\
\text { YEAR }\end{array}$ & DATE & $\begin{array}{c}\text { GAGE } \\
\text { HEIGHT }\end{array}$ & $\begin{array}{c}\text { PEAR } \\
\text { DISCHARGE }\end{array}$ & $\begin{array}{l}\text { WATEER } \\
\text { YEAR }\end{array}$ & DATE & $\begin{array}{l}\text { GAGE } \\
\text { HEIGHT }\end{array}$ & $\begin{array}{c}\text { PEAK } \\
\text { DISCHARGE }\end{array}$ \\
\hline $\begin{array}{l}1959 \\
1960 \\
1961 \\
1962 \\
1963\end{array}$ & $\begin{array}{l}\text { AUG. } 03,1959 \\
\text { SEPT.02, } 1960 \\
\text { SEPT.17, } 1961 \\
\text { SEPT. 28, } 1962 \\
\text { AUG. } 19,1963\end{array}$ & $\begin{array}{l}16.85 \\
11.82 \\
16.16 \\
15.78 \\
17.11\end{array}$ & $\begin{array}{r}1520 \\
120 \\
1180 \\
1030 \\
1540\end{array}$ & $\begin{array}{l}1965 \\
1966 \\
1967 \\
1968 \\
1969\end{array}$ & $\begin{array}{l}\text { APR. } 09,1965 \\
\text { JULY } 23,1966 \\
\text { SEPT. } 25,1967 \\
\text { AUG. } 13,1968 \\
\text { AUG. } 12,1969\end{array}$ & $\begin{array}{r}9.32 \\
15.55 \\
18.60 \\
14.30 \\
17.60\end{array}$ & $\begin{array}{r}61 \\
1200 \\
2000 \\
1150 \\
1950\end{array}$ & $\begin{array}{l}1970 \\
1971 \\
1972 \\
1973 \\
1974\end{array}$ & $\begin{array}{l}\text { AUG. } 18,1970 \\
\text { JULY } 20,1971 \\
\text { AUG. } 12,1972 \\
\text { APR. 30, } 1973 \\
-\end{array}$ & $\begin{array}{l}21.20 \\
18.19 \\
10.57 \\
14.12 \\
13.58\end{array}$ & $\begin{array}{r}2750 \\
2100 \\
240 \\
520 \\
950\end{array}$ \\
\hline
\end{tabular}

09403780 KANAB CREEK NEAR FREDONIA, AZ

LCCATION.--Lat $36^{\circ} 51^{\prime} 50^{\prime \prime}$, long $112^{\circ} 34^{\prime} 45^{\prime \prime}$, in SE $\frac{1}{4}$ sec.14, T.40 N., R.3 W. (unsurveyed), Coconino County, Hydrologic Unit 15010003, in Kaibab Indian Reservation, at Nagles Crossing, on left bank $0.2 \mathrm{mi}$ downstream from Johnson Wash, and $6.5 \mathrm{mi}$ southwest of Fredonia.

DRAINAGE AREA. - $1,085 \mathrm{mi}^{2}$.

MEAN BASIN ELEVATION. $-6,100 \mathrm{ft}$.

PERIOD OF RECORD AVAII.ABLE.-October 1963 to September 1980.

REVISED RECORDS. - WDR AZ I974: 1969.

GAGE.--Water-stage recorder and concrete control with supplementary water-stage recorder at control since Apr. 14, 1975. Altitude of gages is 4,500 ft from topographic map.

REMARKS.--Diversions upstream for irrigation of about 1,400 acres in Utah and 800 acres in Arizona in 1967.

AVERAGE DISCHARGE. -17 years, $6.78 \mathrm{ft}^{3} / \mathrm{s}, 4,910 \mathrm{acre}-\mathrm{ft} / \mathrm{yr}$.

EXIREMES FOR PERIOD OF RECORD.--Maximum discharge, 4,630 $\mathrm{ft}^{3} / \mathrm{s}$ Aug. 18, 1970, gage height, $9.11 \mathrm{ft}$, inside, $9.7 \mathrm{ft}$, from profile past gage, from rating curve extended above $850 \mathrm{ft}^{3} / \mathrm{s}$ on basis of slope-area measurement of peak flow; no flow for most of the time.

LOWEST MEAN DISCAARGE, IN CIBIC FEET PER SECOND, AND RANKING FOR THE INDICATED NUMBER OF CONSECUTIVE DAYS FOR EAOH CLIMATIC YEAR, APRIL 1-MARCH 31

YEAR

13

$\begin{array}{llll}0.00 & 1 & 0.00 \quad 1\end{array}$

$\begin{array}{llll}0.00 & 2 & 0.00 & 2\end{array}$

$\begin{array}{lll}0.003 & 3 & 0.003\end{array}$

$\begin{array}{llll}0.00 & 3 & 0.00 & 3 \\ 0.00 & 4 & 0.00 & 4\end{array}$

$\begin{array}{llll}0.00 & 4 & 0.00 & 4 \\ 0.00 & 5 & 0.00 & 5\end{array}$

$\begin{array}{llll}0.00 & 6 & 0.006\end{array}$

$\begin{array}{llll}0.007 & 7 & 0.007\end{array}$

0.008

0.00

0.0010

$\begin{array}{llll}0.0012 & 0.0012\end{array}$

0.0013

0.0014

0.0015

0.0016

0.0013

0.0014

0.0015

0.0016

$\begin{array}{ll}7 & \\ 0.00 & 1 \\ 0.00 & 2 \\ 0.00 & 3 \\ 0.00 & 4 \\ 0.00 & 5 \\ 0.00 & 6 \\ 0.00 & 7 \\ 0.00 & 8 \\ 0.00 & 9 \\ 0.00 & 10 \\ 0.00 & 11 \\ & \\ 0.00 & 12 \\ 0.00 & 13 \\ 0.00 & 14 \\ 0.00 & 15 \\ 0.00 & 16\end{array}$

14 CONSEOUTIVE DAYS

$$
30
$$

0.001

0.001

0.002

0.003

$0.00 \quad 4$

0.005

0.006

0.007

0.008

0.009

0.0010

0.0011
0.0012

0.0013

0.0014

$\begin{array}{lll}0.0014 & 14 \\ 0.0015\end{array}$

0.0015
0.0016 $\begin{array}{lll}0.00 & 2 & 0.0416\end{array}$

$\begin{array}{llll}0.00 & 3 & 0.00 & 1\end{array}$

$\begin{array}{lll}0.00 & 4 & 0.00\end{array}$

$\begin{array}{lll}0.00 & 5 & 0.00\end{array}$

0.006

0.007

0.008

$0.00 \quad 9$
$0.00 \quad 10$

0.0011

0.0012

0.0013

$\begin{array}{lll}0.00 & 13 \\ 0.00 & 14\end{array}$

0.0014

0.0015 $\begin{array}{ll}0.00 & 3 \\ 0.00 & 4\end{array}$

0.005

0.006

0.007

$\begin{array}{ll}0.00 & 8 \\ 0.00 & 9\end{array}$

0.0010

0.0011

$\begin{array}{lll}0.00 & 11 \\ 0.01 & 14\end{array}$

0.0114
0.0012

0.0013

$\begin{array}{lr}90 & \\ 0.12 & 15 \\ & \\ 0.08 & 14 \\ 0.00 & 1 \\ 0.00 & 2 \\ 0.06 & 11 \\ 0.07 & 12 \\ & \\ 0.00 & 3 \\ 0.02 & 8 \\ 0.26 & 16 \\ 0.00 & 4 \\ 0.00 & 5 \\ & \\ 0.05 & 10 \\ 0.08 & 13 \\ 0.02 & 9 \\ 0.00 & 6 \\ 0.00 & 7\end{array}$

120 183

ALL

0.2610

0.8516

0.001

0.105

0.3412

0.259

0.4014

0.083

0.19

$\begin{array}{ll}0.19 & 8 \\ 0.09 & 4\end{array}$

0.2711

0.3513

$0.16 \quad 6$
0.71

0.7115

$\begin{array}{rr}0.71 & 15 \\ 0.00 & 2\end{array}$ $\begin{array}{llll}0.58 & 5 & 0.81 & 1\end{array}$

$\begin{array}{llll}0.76 & 8 & 8.2012\end{array}$

$\begin{array}{lllll}0.11 & 3 & 5.80 & 7\end{array}$

$\begin{array}{llll}4.50 & 14 & 4.80 \quad 5\end{array}$

$5.6015 \quad 9.9014$

$0.8611 \quad 7.5010$

$\begin{array}{llll}2.7012 & 6.10 \quad 8\end{array}$

$\begin{array}{lll}6.5016 & 6.80 & 9 \\ 4.0013 & 5.20 & 6\end{array}$

$\begin{array}{rrrr}4.00 & 13 & 5.20 & 6 \\ 0.46 & 4 & 7.70 & 11\end{array}$

$\begin{array}{llll}0.06 & 2 & 2.70 & 3\end{array}$

$\begin{array}{llll}0.72 & 7 & 4.00 & 4\end{array}$

$\begin{array}{llll}0.61 & 6 & 1.00 & 2\end{array}$

$\begin{array}{ll}0.799 & 9.6013\end{array}$

$0.8010 \quad 15.0 \quad 16$

$\begin{array}{rrrr}0.021 & 12.0 & 15\end{array}$ 
KANAB CREEK BASIN

09403780 KANAB CREEK NEAR FREDONIA, AZ-Continued

HIGHEST MEAN DISCHARGE, IN OUBIC FEET PER SECOND, AND RANKING FOR THE INDICATED NUNBER OF CONSEOUTIVE DAYS FOR EACH WATER YEAR, OCIOBER I-SEPTEMBER 30

\begin{tabular}{|c|c|c|c|c|c|c|c|c|c|c|c|c|c|c|c|c|c|c|c|c|}
\hline YEAR & & & & & & & & & CONS & & E DAYS & & & & & & & & & \\
\hline $\begin{array}{l}1964 \\
1965\end{array}$ & $\begin{array}{l}50.0 \\
70.0\end{array}$ & $\begin{array}{l}16 \\
15\end{array}$ & $\begin{array}{l}21.0 \\
60.0\end{array}$ & $\begin{array}{l}16 \\
13\end{array}$ & $\begin{array}{l}8.90 \\
41.0\end{array}$ & $\begin{array}{l}17 \\
13\end{array}$ & $\begin{array}{l}5.50 \\
25.0\end{array}$ & $\begin{array}{l}17 \\
13\end{array}$ & $\begin{array}{c}3.00 \\
16.0\end{array}$ & $\begin{array}{l}17 \\
13\end{array}$ & & $\begin{array}{l}17 \\
13\end{array}$ & $\begin{array}{l}1.19 \\
6.20\end{array}$ & $\begin{array}{l}17 \\
13\end{array}$ & $\begin{array}{l}1.10 \\
5.00\end{array}$ & $\begin{array}{l}17 \\
13\end{array}$ & $\begin{array}{l}1.00 \\
3.70\end{array}$ & & $\begin{array}{l}0.78 \\
2.20\end{array}$ & $\begin{array}{l}17 \\
13\end{array}$ \\
\hline $\begin{array}{l}1966 \\
1967 \\
1968 \\
1969 \\
1970\end{array}$ & $\begin{array}{r}224 \\
1080 \\
204 \\
311 \\
441\end{array}$ & $\begin{array}{r}9 \\
1 \\
11 \\
7 \\
4\end{array}$ & $\begin{array}{l}127 \\
571 \\
110 \\
225 \\
279\end{array}$ & $\begin{array}{r}11 \\
1 \\
12 \\
7 \\
3\end{array}$ & $\begin{array}{l}77.0 \\
253 \\
77.0 \\
196 \\
149\end{array}$ & $\begin{array}{r}10 \\
1 \\
11 \\
2 \\
7\end{array}$ & $\begin{array}{c}43.0 \\
120 \\
60.0 \\
150 \\
71.0\end{array}$ & $\begin{array}{r}11 \\
5 \\
9 \\
1 \\
8\end{array}$ & $\begin{array}{l}27.0 \\
60.0 \\
34.0 \\
95.0 \\
49.0\end{array}$ & $\begin{array}{r}11 \\
6 \\
9 \\
2 \\
7\end{array}$ & $\begin{array}{l}21.0 \\
30.0 \\
17.0 \\
55.0 \\
25.0\end{array}$ & $\begin{array}{r}9 \\
6 \\
11 \\
4 \\
7\end{array}$ & $\begin{array}{l}19.0 \\
23.0 \\
11.0 \\
50.0 \\
17.0\end{array}$ & $\begin{array}{r}7 \\
6 \\
12 \\
2 \\
8\end{array}$ & $\begin{array}{l}19.0 \\
17.0 \\
8.60 \\
38.0 \\
13.0\end{array}$ & $\begin{array}{r}6 \\
7 \\
12 \\
2 \\
8\end{array}$ & $\begin{array}{c}13.0 \\
11.0 \\
8.00 \\
26.0 \\
8.80\end{array}$ & $\begin{array}{r}6 \\
7 \\
11 \\
2 \\
9\end{array}$ & $\begin{array}{c}6.50 \\
8.30 \\
5.10 \\
14.0 \\
4.70\end{array}$ & $\begin{array}{r}7 \\
6 \\
11 \\
2 \\
12\end{array}$ \\
\hline $\begin{array}{l}1976 \\
1977 \\
1978 \\
1979 \\
1980\end{array}$ & $\begin{array}{l}72.0 \\
71.0 \\
199 \\
425 \\
512\end{array}$ & $\begin{array}{r}13 \\
14 \\
12 \\
5 \\
3\end{array}$ & $\begin{array}{l}44.0 \\
47.0 \\
171 \\
272 \\
325\end{array}$ & $\begin{array}{r}15 \\
14 \\
8 \\
4 \\
2\end{array}$ & $\begin{array}{l}22.0 \\
21.0 \\
152 \\
156 \\
175\end{array}$ & $\begin{array}{r}14 \\
15 \\
6 \\
5 \\
4\end{array}$ & $\begin{array}{l}11.0 \\
9.90 \\
143 \\
132 \\
100\end{array}$ & $\begin{array}{r}14 \\
15 \\
2 \\
3 \\
6\end{array}$ & $\begin{array}{r}5.50 \\
6.90 \\
93.0 \\
112 \\
67.0\end{array}$ & $\begin{array}{r}15 \\
14 \\
3 \\
1 \\
5\end{array}$ & $\begin{array}{l}3.20 \\
4.10 \\
65.0 \\
73.0 \\
56.0\end{array}$ & $\begin{array}{r}16 \\
14 \\
2 \\
1 \\
3\end{array}$ & $\begin{array}{r}2.90 \\
3.10 \\
46.0 \\
63.0 \\
46.0\end{array}$ & $\begin{array}{r}16 \\
15 \\
3 \\
1 \\
4\end{array}$ & $\begin{array}{l}2.40 \\
2.30 \\
35.0 \\
49.0 \\
35.0\end{array}$ & $\begin{array}{r}15 \\
16 \\
3 \\
1 \\
4\end{array}$ & $\begin{array}{l}1.70 \\
1.50 \\
23.0 \\
36.0 \\
24.0\end{array}$ & $\begin{array}{r}15 \\
16 \\
4 \\
1 \\
3\end{array}$ & $\begin{array}{l}1.101 \\
1.101 \\
12.0 \\
18.0 \\
13.0\end{array}$ & $\begin{array}{r}14 \\
15 \\
4 \\
1 \\
3\end{array}$ \\
\hline
\end{tabular}

DURATION OF DISCHARGE FOR EACH WATER YEAR

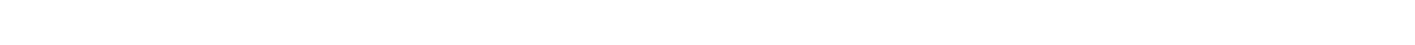
YEAR

NUMBER OF DAYS IN CIASS CUBIC FEET
PER SECOND

\begin{tabular}{|c|c|c|c|c|c|c|c|c|c|c|c|c|c|c|c|c|c|c|c|c|c|c|c|c|c|c|c|c|c|c|c|c|c|c|}
\hline $\begin{array}{l}1964160 \\
1965225\end{array}$ & & & & & & & $\begin{array}{l}7 \\
6\end{array}$ & & $\begin{array}{l}9 \\
9\end{array}$ & $\begin{array}{l}4 \\
5\end{array}$ & $\begin{array}{l}60 \\
22\end{array}$ & $\begin{array}{r}25 \\
5\end{array}$ & $\begin{array}{r}15 \\
2\end{array}$ & $\begin{array}{r}29 \\
8\end{array}$ & $\begin{array}{r}17 \\
3\end{array}$ & $\begin{array}{l}10 \\
12\end{array}$ & $\begin{array}{r}10 \\
6\end{array}$ & $\begin{array}{r}5 \\
16\end{array}$ & $\begin{array}{l}1 \\
8\end{array}$ & $\begin{array}{r}2 \\
10\end{array}$ & $\begin{array}{l}1 \\
5\end{array}$ & 6 & & 1 & $\begin{array}{l}1 \\
4\end{array}$ & 2 & & & & & & & & $\begin{array}{l}283.7 \\
801.6\end{array}$ \\
\hline $\begin{array}{l}1966234 \\
1967238 \\
196894 \\
1969172 \\
1970250\end{array}$ & 2 & 1 & & & 1 & 3 & $\begin{array}{l}2 \\
20 \\
3 \\
0 \\
6\end{array}$ & $3^{1}$ & $\begin{array}{l}3 \\
9 \\
3 \\
8\end{array}$ & $\begin{array}{l}2 \\
3 \\
6 \\
1 \\
3\end{array}$ & $\begin{array}{r}2 \\
11 \\
36 \\
7 \\
12\end{array}$ & $\begin{array}{r}5 \\
28 \\
3 \\
7\end{array}$ & $\begin{array}{r}4 \\
25 \\
4 \\
3\end{array}$ & $\begin{array}{r}1 \\
8 \\
52 \\
16 \\
11\end{array}$ & $\begin{array}{r}1 \\
6 \\
10 \\
7 \\
5\end{array}$ & $\begin{array}{r}8 \\
6 \\
7 \\
11 \\
11\end{array}$ & $\begin{array}{r}5 \\
10 \\
2 \\
11 \\
8\end{array}$ & $\begin{array}{r}11 \\
9 \\
12 \\
15 \\
8\end{array}$ & $\begin{array}{l}5 \\
2 \\
5 \\
5 \\
1\end{array}$ & $\begin{array}{r}54 \\
3 \\
18 \\
22 \\
7\end{array}$ & $\begin{array}{r}2 \\
7 \\
20 \\
15\end{array}$ & $\begin{array}{r}16 \\
9 \\
13 \\
21 \\
2\end{array}$ & $\begin{array}{l}5 \\
2 \\
6 \\
5 \\
3\end{array}$ & $\begin{array}{l}1 \\
1 \\
1 \\
5 \\
1\end{array}$ & $\begin{array}{l}4 \\
2 \\
2 \\
6 \\
2\end{array}$ & $\begin{array}{l}5 \\
1 \\
4 \\
3 \\
3\end{array}$ & $\begin{array}{l}6 \\
1 \\
8 \\
8 \\
1\end{array}$ & $\begin{array}{l}2 \\
6\end{array}$ & $\begin{array}{l}1 \\
5 \\
1\end{array}$ & 1 & $\begin{array}{l}2 \\
1 \\
1\end{array}$ & $\begin{array}{l}1 \\
1\end{array}$ & & $\begin{array}{l}2361.2 \\
3019.3 \\
1883.7 \\
5137.1 \\
1718.1\end{array}$ \\
\hline $\begin{array}{l}1971203 \\
1972233 \\
1973156 \\
1974267 \\
1975209\end{array}$ & & & & & 2 & & $\begin{array}{l}6 \\
6 \\
9 \\
1 \\
7\end{array}$ & $\begin{array}{l}1 \\
1 \\
1\end{array}$ & $\begin{array}{l}1 \\
9 \\
0 \\
6 \\
0\end{array}$ & $\begin{array}{l}4 \\
6 \\
8 \\
2 \\
3\end{array}$ & $\begin{array}{l}15 \\
11 \\
18 \\
9 \\
6\end{array}$ & $\begin{array}{r}12 \\
5 \\
3 \\
1 \\
4\end{array}$ & $\begin{array}{r}10 \\
3 \\
3 \\
2 \\
5\end{array}$ & $\begin{array}{r}8 \\
13 \\
34 \\
14 \\
4\end{array}$ & $\begin{array}{r}5 \\
7 \\
3 \\
3 \\
10\end{array}$ & $\begin{array}{r}6 \\
7 \\
20 \\
12 \\
10\end{array}$ & $\begin{array}{r}8 \\
6 \\
18 \\
17 \\
14\end{array}$ & $\begin{array}{l}13 \\
13 \\
15 \\
14 \\
14\end{array}$ & $\begin{array}{r}16 \\
10 \\
3 \\
5 \\
9\end{array}$ & $\begin{array}{r}13 \\
12 \\
17 \\
11 \\
6\end{array}$ & $\begin{array}{r}12 \\
4 \\
4\end{array}$ & $\begin{array}{r}10 \\
5 \\
1 \\
15\end{array}$ & $\begin{array}{l}1 \\
2 \\
8\end{array}$ & $\begin{array}{l}4 \\
1 \\
3\end{array}$ & 8 & $\begin{array}{l}1 \\
1 \\
6\end{array}$ & $\begin{array}{l}3 \\
1 \\
3\end{array}$ & 2 & $\begin{array}{l}1 \\
1 \\
4\end{array}$ & $\begin{array}{l}1 \\
1\end{array}$ & $\begin{array}{l}1 \\
1 \\
1\end{array}$ & 1 & & $\begin{array}{r}1954.1 \\
1921.8 \\
3681.5 \\
316.4 \\
2309.2\end{array}$ \\
\hline $\begin{array}{l}1976298 \\
1977299 \\
1978248 \\
1979172 \\
1980228\end{array}$ & 1 & 2 & 2 & $\begin{array}{l}2 \\
2 \\
1 \\
1\end{array}$ & 2 & $\begin{array}{l}2 \\
3 \\
3\end{array}$ & $\begin{array}{l}3 \\
3 \\
4 \\
5 \\
1\end{array}$ & $\begin{array}{l}4 \\
6 \\
1\end{array}$ & $\begin{array}{l}2 \\
1 \\
4 \\
2 \\
3\end{array}$ & $\begin{array}{l}8 \\
2 \\
4\end{array}$ & $\begin{array}{l}2 \\
2 \\
2 \\
4 \\
5\end{array}$ & $\begin{array}{l}5 \\
3 \\
3 \\
1 \\
1\end{array}$ & $\begin{array}{l}4 \\
1 \\
2 \\
1 \\
2\end{array}$ & $\begin{array}{r}6 \\
2 \\
1 \\
60 \\
4\end{array}$ & $\begin{array}{l}2 \\
1 \\
1\end{array}$ & $\begin{array}{l}3 \\
4 \\
5 \\
7 \\
2\end{array}$ & $\begin{array}{r}2 \\
17 \\
\\
6 \\
2\end{array}$ & $\begin{array}{r}2 \\
8 \\
1 \\
13 \\
7\end{array}$ & $\begin{array}{l}5 \\
2 \\
3 \\
5 \\
4\end{array}$ & $\begin{array}{r}5 \\
3 \\
7 \\
7 \\
16\end{array}$ & $\begin{array}{r}3 \\
2 \\
17 \\
8 \\
7\end{array}$ & $\begin{array}{r}11 \\
4 \\
26\end{array}$ & $\begin{array}{r}1 \\
1 \\
4 \\
10 \\
11\end{array}$ & $\begin{array}{r}3 \\
2 \\
5 \\
18 \\
12\end{array}$ & $\begin{array}{r}5 \\
10 \\
8\end{array}$ & $\begin{array}{l}1 \\
2 \\
4 \\
8 \\
5\end{array}$ & $\begin{array}{l}4 \\
3 \\
8\end{array}$ & $\begin{array}{l}8 \\
7 \\
4\end{array}$ & $\begin{array}{l}9 \\
6 \\
2\end{array}$ & $\begin{array}{l}1 \\
3\end{array}$ & 4 & $\begin{array}{l}1 \\
1\end{array}$ & & $\begin{array}{r}395.1 \\
38 \% .0 \\
4305.9 \\
6698.8 \\
4880.6\end{array}$ \\
\hline
\end{tabular}

DURATION TABLE OF DISCHARGE FOR WATER YEARS 1964-80

\begin{tabular}{|c|c|c|c|c|c|c|c|c|c|c|c|c|c|c|c|c|c|c|c|}
\hline & $\begin{array}{c}\text { OBIIC } \\
\text { FEET } \\
\text { PER } \\
\text { SECOND }\end{array}$ & $\begin{array}{l}\text { TOTAL } \\
\text { DAYS }\end{array}$ & $\begin{array}{r}\text { ACO- } \\
\text { MU- } \\
\text { LATED } \\
\text { DAYS }\end{array}$ & $\begin{array}{l}\text { PER- } \\
\text { CENT } \\
\text { DAYS }\end{array}$ & & $\begin{array}{c}\text { CUBIC } \\
\text { FEET } \\
\text { PER } \\
\text { SECOND }\end{array}$ & $\begin{array}{c}\text { TOTAL } \\
\text { DAYS }\end{array}$ & $\begin{array}{r}\text { ACQU- } \\
\text { MU- } \\
\text { LAATED } \\
\text { DAYS }\end{array}$ & $\begin{array}{l}\text { PER- } \\
\text { CENT } \\
\text { DAYS }\end{array}$ & & $\begin{array}{c}\text { CUBIC } \\
\text { FEET } \\
\text { PER } \\
\text { SECOND }\end{array}$ & $\begin{array}{c}\text { TOTAL } \\
\text { DAYS }\end{array}$ & $\begin{array}{r}\text { ACO- } \\
\text { MU- } \\
\text { LATED } \\
\text { DAYS }\end{array}$ & $\begin{array}{l}\text { PER- } \\
\text { CENT } \\
\text { DAYS }\end{array}$ & & $\begin{array}{c}\text { UBIC } \\
\text { FEET } \\
\text { PER } \\
\text { SECOND }\end{array}$ & $\begin{array}{l}\text { TOTAL } \\
\text { DAYS }\end{array}$ & $\begin{array}{r}\text { ACOU- } \\
\text { MU- } \\
\text { LATED } \\
\text { DAYS }\end{array}$ & $\begin{array}{l}\text { PER- } \\
\text { CENT } \\
\text { DAYS }\end{array}$ \\
\hline $\begin{array}{l}0 \\
1 \\
2 \\
3 \\
4 \\
5 \\
6 \\
7 \\
8\end{array}$ & $\begin{array}{l}0.00 \\
0.01 \\
0.02 \\
0.03 \\
0.04 \\
0.05 \\
0.07 \\
0.10 \\
0.14\end{array}$ & $\begin{array}{r}3686 \\
3 \\
4 \\
2 \\
6 \\
6 \\
11 \\
129 \\
15\end{array}$ & $\begin{array}{l}6210 \\
2524 \\
2521 \\
2517 \\
2515 \\
2509 \\
2503 \\
2492 \\
2363\end{array}$ & $\begin{array}{r}100.0 \\
40.6 \\
40.6 \\
40.5 \\
40.5 \\
40.4 \\
40.3 \\
40.1 \\
38.1\end{array}$ & $\begin{array}{r}9 \\
10 \\
11 \\
12 \\
13 \\
14 \\
15 \\
16 \\
17\end{array}$ & $\begin{array}{l}0.20 \\
0.28 \\
0.38 \\
0.54 \\
0.75 \\
1.00 \\
1.50 \\
2.00 \\
2.80\end{array}$ & $\begin{array}{r}109 \\
72 \\
224 \\
111 \\
86 \\
271 \\
83 \\
141 \\
142\end{array}$ & $\begin{array}{l}2348 \\
2239 \\
2167 \\
1943 \\
1832 \\
1746 \\
1475 \\
1392 \\
1251\end{array}$ & $\begin{array}{l}37.8 \\
36.1 \\
34.9 \\
31.3 \\
29.5 \\
28.1 \\
23.8 \\
22.4 \\
20.1\end{array}$ & $\begin{array}{l}18 \\
19 \\
20 \\
21 \\
22 \\
23 \\
24 \\
25 \\
26\end{array}$ & $\begin{array}{r}3.9 \\
5.5 \\
7.6 \\
11.0 \\
15.0 \\
21.0 \\
29.0 \\
40.0 \\
56.0\end{array}$ & $\begin{array}{r}176 \\
89 \\
213 \\
121 \\
141 \\
66 \\
61 \\
58 \\
49\end{array}$ & $\begin{array}{r}1109 \\
933 \\
844 \\
631 \\
510 \\
369 \\
303 \\
242 \\
184\end{array}$ & $\begin{array}{r}17.9 \\
15.0 \\
13.6 \\
10.2 \\
8.2 \\
5.9 \\
4.9 \\
3.9 \\
3.0\end{array}$ & $\begin{array}{l}27 \\
28 \\
29 \\
30 \\
31 \\
32 \\
33 \\
34\end{array}$ & $\begin{array}{r}78.0 \\
110.0 \\
150.0 \\
210.0 \\
290.0 \\
410.0 \\
570.0\end{array}$ & $\begin{array}{r}41 \\
35 \\
31 \\
11 \\
11 \\
5 \\
1\end{array}$ & $\begin{array}{r}135 \\
94 \\
59 \\
28 \\
17 \\
6 \\
1\end{array}$ & $\begin{array}{l}2.2 \\
1.5 \\
1.0 \\
0.5 \\
0.3 \\
0.1 \\
0.0\end{array}$ \\
\hline
\end{tabular}

MONIHLY MEAN DISCHARGES, IN OBIC FEET PER SECOND, FOR EACH WATER YEAR

$\begin{array}{llccccccccccc}\text { YEAR } & \text { OCT } & \text { NOV } & \text { DEC } & \text { JAN } & \text { FEB } & \text { MAR } & \text { APR } & \text { MAY } & \text { JUNE } & \text { JULY } & \text { AUG } & \text { SEP } \\ 1964 & 0.32 & 0.78 & 0.48 & 0.86 & 1.23 & 0.72 & 1.41 & 0.22 & 0.00 & 0.44 & 2.51 & 0.33 \\ 1965 & 0.07 & 0.35 & 1.87 & 0.38 & 1.93 & 0.28 & 16.0 & 1.61 & 0.01 & 0.84 & 3.20 & 0.00 \\ & & & & & & & & & & & & \\ 1966 & 0.08 & 15.2 & 15.9 & 13.0 & 11.1 & 21.8 & 0.00 & 0.00 & 0.00 & 0.01 & 0.00 & 0.68 \\ 1967 & 0.44 & 0.02 & 58.3 & 0.00 & 4.85 & 4.06 & 0.73 & 0.00 & 0.00 & 0.29 & 1.63 & 28.5 \\ 1968 & 0.98 & 0.90 & 1.14 & 5.55 & 10.4 & 8.43 & 0.54 & 0.24 & 0.05 & 17.6 & 15.5 & 0.17 \\ 1969 & 0.00 & 0.00 & 2.98 & 30.4 & 18.1 & 33.3 & 69.0 & 0.71 & 0.00 & 10.1 & 2.05 & 3.09 \\ 1970 & 0.03 & 0.15 & 0.11 & 1.68 & 0.36 & 2.79 & 0.11 & 0.00 & 0.00 & 1.54 & 47.5 & 1.28\end{array}$


KANAB CREEK BASTN

09403780 KANAB CREEK NEAR FREDONIA, AZ--Continued

MONIHLY MEAN DISCHARGES, IN CUBIC FEET PER SECOND, FOR EACH WATER YEAR--Continued

$\begin{array}{lcccccccccccc}\text { YEAR } & \text { OCT } & \text { NOV } & \text { DEC } & \text { JAN } & \text { FEB } & \text { MAR } & \text { APR } & \text { MAY } & \text { JUNE } & \text { JULY } & \text { ALG } & \text { SEP } \\ 1971 & 0.00 & 0.21 & 5.82 & 6.28 & 3.10 & 6.36 & 0.04 & 0.05 & 0.00 & 0.25 & 41.0 & 0.27 \\ 1972 & 4.20 & 1.30 & 24.9 & 6.31 & 2.04 & 0.00 & 0.00 & 0.00 & 0.77 & 0.00 & 0.31 & 23.1 \\ 1973 & 19.0 & 1.93 & 1.29 & 0.80 & 2.71 & 12.8 & 79.7 & 0.65 & 0.04 & 0.11 & 2.58 & 0.00 \\ 1974 & 0.00 & 0.00 & 1.27 & 4.16 & 2.05 & 2.58 & 0.00 & 0.00 & 0.00 & 0.35 & 0.00 & 0.00 \\ 1975 & 2.57 & 0.75 & 0.32 & 3.89 & 3.80 & 20.1 & 14.7 & 0.16 & 0.00 & 20.2 & 2.98 & 6.17 \\ 1976 & 0.14 & 0.00 & 0.00 & 0.98 & 2.55 & 0.75 & 5.46 & 0.01 & 0.00 & 1.34 & 0.05 & 1.87 \\ 1977 & 0.98 & 0.00 & 0.39 & 2.22 & 0.00 & 0.00 & 0.00 & 0.03 & 0.02 & 5.73 & 2.00 & 1.15 \\ 1978 & 0.38 & 0.16 & 0.03 & 1.03 & 13.6 & 90.1 & 31.2 & 0.15 & 0.00 & 0.00 & 2.73 & 1.92 \\ 1979 & 0.98 & 15.9 & 9.06 & 20.3 & 41.4 & 59.0 & 74.5 & 1.67 & 0.02 & 0.00 & 0.14 & 0.00 \\ 1980 & 0.00 & 0.00 & 0.00 & 2.40 & 49.3 & 21.1 & 64.1 & 6.54 & 0.00 & 0.44 & 5.80 & 13.4\end{array}$

ANNUAL PEAK DISCHARGE, IN OUBIC FEET PER SECOND, AND CORRESPONDING GAGE HEIGHT, IN FEET, FOR EACH WATER YEAR

\begin{tabular}{|c|c|c|c|c|c|c|c|c|c|c|c|}
\hline $\begin{array}{l}\text { WATERR } \\
\text { YEAR }\end{array}$ & DATE & $\begin{array}{c}\text { GAGE } \\
\text { HEIGHT }\end{array}$ & $\begin{array}{c}\text { PEAK } \\
\text { DISCHARGE }\end{array}$ & $\begin{array}{l}\text { WATER } \\
\text { YEAR }\end{array}$ & DATE & $\begin{array}{c}\text { GAGE } \\
\text { HEIGHT }\end{array}$ & $\begin{array}{c}\text { PEAK } \\
\text { DISCHARGE }\end{array}$ & $\begin{array}{l}\text { WATER } \\
\text { YEAR }\end{array}$ & DATE & $\begin{array}{c}\text { GAGE } \\
\text { HEIGHT }\end{array}$ & $\begin{array}{c}\text { PEAK } \\
\text { DISCHARGE }\end{array}$ \\
\hline $\begin{array}{l}1965 \\
1966 \\
1967 \\
1968 \\
1969 \\
1970\end{array}$ & $\begin{array}{l}\text { APR. } 18,1965 \\
\text { MAR. 08, } 1966 \\
\text { DEC. } 07,1966 \\
\text { JULY } 31,1968 \\
\text { JULY } 23,1969 \\
\text { AUG. } 18,1970\end{array}$ & $\begin{array}{l}2.70 \\
3.37 \\
6.55 \\
4.32 \\
4.65 \\
9.11\end{array}$ & $\begin{array}{r}250 \\
668 \\
2960 \\
1130 \\
1330 \\
4630\end{array}$ & $\begin{array}{l}1971 \\
1972 \\
1973 \\
1974 \\
1975\end{array}$ & $\begin{array}{l}\text { AUG. } 18,1971 \\
\text { SEPT. } 19,1972 \\
\text { APR. } 14,1973 \\
\text { JULY } 23,1974 \\
\text { JULY } 13,1975\end{array}$ & $\begin{array}{l}4.50 \\
5.18 \\
3.05 \\
1.15 \\
3.27\end{array}$ & $\begin{array}{r}1340 \\
1680 \\
660 \\
84 \\
603\end{array}$ & $\begin{array}{l}1976 \\
1977 \\
1978 \\
1979 \\
1980\end{array}$ & $\begin{array}{l}\text { SEPT.25, } 1976 \\
\text { JULY } 23,1977 \\
\text { APR. } 11,1978 \\
\text { FEB. } 14,1979 \\
\text { FEB. } 20,1980\end{array}$ & $\begin{array}{l}2.90 \\
2.95 \\
3.00 \\
5.10 \\
3.68\end{array}$ & $\begin{array}{r}410 \\
435 \\
460 \\
2020 \\
957\end{array}$ \\
\hline
\end{tabular}

MAGNITUDE AND PROBABILITY OF ANNUAL LONEST MEAN DISCHARGE BASED ON CLIMATIC YEARS 1965-80

\begin{tabular}{|c|c|c|c|c|c|c|}
\hline \multirow{2}{*}{$\begin{array}{l}\text { PERTOD } \\
\text { (CON- } \\
\text { SEOU- } \\
\text { TIVE } \\
\text { DAYS) }\end{array}$} & \multicolumn{6}{|c|}{$\begin{array}{l}\text { DISCHARGE, IN OUBIC FEET PER SECOND, FOR } \\
\text { INDICATED RECURRENCE INIEERNAL, IN YEARS, AND } \\
\text { ANNUAL NONEXCEEDANCE PROBABILITY, IN PERCENT }\end{array}$} \\
\hline & $\begin{array}{c}2 \\
508\end{array}$ & $\begin{array}{c}5 \\
208\end{array}$ & $\begin{array}{l}10 \\
10 \%\end{array}$ & $\begin{array}{l}20 \\
58\end{array}$ & $\begin{array}{l}50 \\
28\end{array}$ & $\begin{array}{r}100 \\
18\end{array}$ \\
\hline
\end{tabular}

$\begin{array}{rllllll}1 & 0.00 & 0.00 & - & - & - & - \\ 7 & 0.00 & 0.00 & - & - & - & - \\ 14 & 0.00 & 0.00 & - & - & - & - \\ 30 & 0.00 & 0.00 & - & - & - & - \\ 60 & 0.00 & 0.00 & - & - & - & - \\ 90 & 0.02 & 0.00 & - & - & - & -\end{array}$

MAGNITUDE AND PRCBABILITY OF ANNUAL HIGHEST MEAN DISCHARGE BASED ON WATER YEARS 1964-80

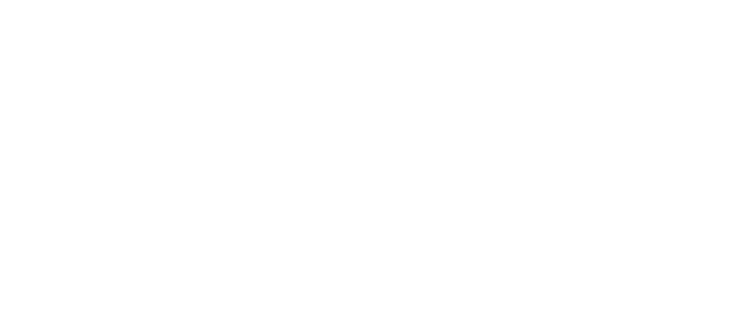

VIRGIN RIVER BASIN

09404450 EAST FORK VIRGIN RIVER NEAR GLENDALE, UT

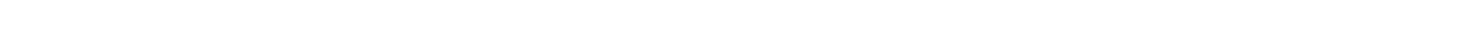
bank $50 \mathrm{ft}$ downstream fram Lydia's Creek and $1.0 \mathrm{mi}$ north of the town of Glendale on U.S. Highway 89 .

DRAINAGE AREA. $-69.2 \mathrm{mi}^{2}$.

MEAN BASIN ELEVATION.--7,300 ft.

PERIOD OF RECORD AVAILABLE.--October 1966 to September 1981.

GAGE.--Water-stage recorder and artificial control. Altitude of gage is 5,900 ft from topographic map.

REMARKS.- A few small diversions above station.

AVERAGE DISCHARGE. -15 years, $20.9 \mathrm{ft}^{3} / \mathrm{s}, 15,140$ acre $-\mathrm{ft} / \mathrm{yr}$.

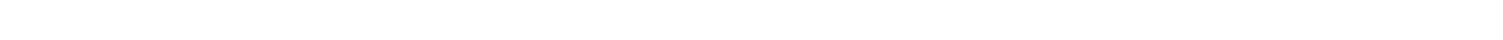

LOWEST MEAN DISCHARGE, IN OBIC FEET PER SECOND, AND RANKING FOR THE INDICATED NUMBER OF CONSECUTIVE DAYS FOR EACH CLIMATIC YEAR, APRIL 1-MARCH 31

\begin{tabular}{|c|c|c|c|c|c|c|c|c|c|c|c|c|c|c|c|c|c|c|c|}
\hline YEAR & 1 & & 3 & & 7 & & 14 & & $\begin{array}{l}\text { CON } \\
30\end{array}$ & BOP & $\begin{array}{l}\text { E DAYS } \\
60\end{array}$ & & 90 & & 120 & & 183 & & ALL \\
\hline
\end{tabular}


VIRGIN RIVER BASIN

09404450 EAST FORK VIRGIN RIVER NEAR GLENDALE, UT--Continued

LOWEST MEAN DISCHARGE, IN GBIC FEET PER SECOND, AND RANKING FOR THE INDICATED NUMBER OF CONSEOUTIVE DAYS FOR EAOH OLIMATIC YEAR, APRIL 1-MARCH 31--Continued

YEAR

\begin{tabular}{lcrrr} 
& 1 & \multicolumn{3}{c}{3} \\
1971 & 8.60 & 7 & 8.60 & 7 \\
1972 & 7.90 & 4 & 8.20 & 5 \\
1973 & 7.20 & 2 & 7.30 & 2 \\
1974 & 12.0 & 11 & 12.0 & 10 \\
1975 & 7.60 & 3 & 7.70 & 3 \\
1976 & 8.50 & 6 & 8.50 & 6 \\
1977 & 8.00 & 5 & 8.00 & 4 \\
1978 & 7.00 & 1 & 7.10 & 1 \\
1979 & 9.80 & 8 & 9.90 & 8 \\
1980 & 14.0 & 12 & 14.0 & 13 \\
1981 & 20.0 & 14 & 20.0 & 14
\end{tabular}

$\begin{array}{cr}7 & \\ 8.90 & 7 \\ 8.80 & 6 \\ 7.40 & 2 \\ 12.0 & 10 \\ 7.80 & 3\end{array}$

8.605

8.204

7.301

10.08

14.013

$21.0 \quad 14$

$\begin{array}{rr}14 & \\ 9.40 & 7 \\ 8.90 & 6 \\ 7.50 & 2 \\ 12.0 & 10 \\ 7.80 & 3 \\ 8.60 & 5 \\ 8.20 & 4 \\ 7.40 & 1 \\ 10.0 & 8 \\ 14.0 & 12 \\ 21.0 & 14\end{array}$

CONSEOITIVE DAYS

$30 \quad 60$

10.07

$\begin{array}{cc}10.0 & 7 \\ 9.10 & 6 \\ 7.60 & 1\end{array}$

$\begin{array}{rr}7.60 & 1 \\ 12.0 & 10\end{array}$

$\begin{array}{cc}11.0 & 8 \\ 9.30 & 5 \\ 8.20 & 2 \\ 12.0 & 9\end{array}$

90

120

$8.30 \quad 3$

8.904

$\begin{array}{cc}11.0 & 8 \\ 9.70 & 5\end{array}$

$\begin{array}{cc}9.20 & 2 \\ 12.0 & 9 \\ 9.40 & 4\end{array}$

$9.70 \quad 4$

$\begin{array}{llllll}13.0 & 9 & 11.0 & 4 & 14.0 & 5\end{array}$

9.005

9.606

$\begin{array}{ll}8.40 & 4 \\ 7.80 & 2\end{array}$

8.803

9.906

9.805

$\begin{array}{rrrr}11.0 & 8 & 25.0 & 11 \\ 11.0 & 5 & 14.0 & 6\end{array}$

HIGHEST MEAN DISCHARGE, IN OBIC FEET PER SECOND, AND RANKING FOR THE INDICATED NUMBER OF CONSECUTIVE DAYS FOR EACH WATER YEAR, OCTCBER 1-SEPTEMBER 30

YEAR

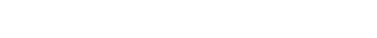

1967
1968
1969
1970
1971
1972
1973
1974
1975
1976
1977
1978
1979
1980
1981

$7 \quad$ CONSEQUTIVE DAYS

$\begin{array}{lrrrrrrr}239 & 2 & 134 & 5 & 73.0 & 5 & 44.0 & 6\end{array}$

$\begin{array}{rrrrrrr}34.0 & 10 & 32.0 & 9 & 30.0 & 8 & 28 \\ 202 & 4 & 198 & 3 & 175 & 3 & 155\end{array}$

$\begin{array}{rrrr}24.0 & 15 & 24.0 & 13\end{array}$

$\begin{array}{rrrr}23.0 & 12 & 22.0 & 10\end{array}$

31.06

$\begin{array}{rrrrrrrrrrrr}8.40 & 4 & 8.80 & 3 & 9.30 & 3 & 9.50 & 3 & 10.0 & 2 & 11.0 & 1 \\ 7.80 & 2 & 7.90 & 1 & 8.10 & 1 & 8.30 & 1 & 9.30 & 1 & 13.0 & 2 \\ 11.0 & 8 & 11.0 & 7 & 11.0 & 7 & 12.0 & 8 & 14.0 & 9 & 21.0 & 10\end{array}$

9.303

$10.0 \quad 6$

11.06

14.07

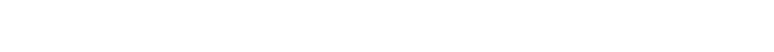

$\begin{array}{llllll}27.0 & 13 & 22.0 & 14 & 20.0 & 14\end{array}$

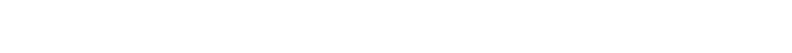

$\begin{array}{rrrrrrrrrrrr}155 & 6 & 151 & 4 & 132 & 4 & 110 & 4 & 92.0 & 4 & 70.0 & 4\end{array}$

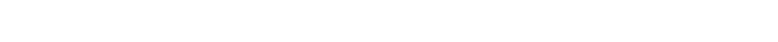

$\begin{array}{rrrr}54.0 & 8 & 34.0 & 8\end{array}$

$\begin{array}{llll}16.0 & 15 & 14.0 & 12\end{array}$

$211 \quad 3 \quad 210 \quad 2$

$\begin{array}{llll}14.0 & 15 & 12.0 & 15\end{array}$

$\begin{array}{llll}12.0 & 15 & 18.0 & 14\end{array}$

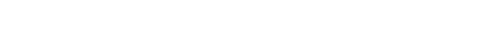

$218 \quad 1 \quad 189$

170 (12 44.0

27.0

26.0

120
140

4011109

109

$\begin{array}{cr}90 & \\ 23.0 & 8 \\ 25.0 & 6 \\ 83.0 & 3 \\ 20.0 & 9 \\ & \\ 17.0 & 14 \\ 19.0 & 10 \\ 55.0 & 4 \\ 18.0 & 12 \\ 19.0 & 11 \\ 17.0 & 13 \\ 12.0 & 15 \\ 38.0 & 5 \\ 93.0 & 2 \\ 109 & 1 \\ & \\ 24.0 & 7\end{array}$

120

183

DURATION OF DISCHARGE FOR EACH WATER YEAR

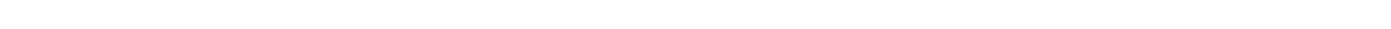

YEAR

NUMBER OF DAYS IN CLASS

CUBIC FEET

1968

1969

1970

1971

1973

1974

1974
1975

1976

1977

1978
1979

1980

1981 -DAYS

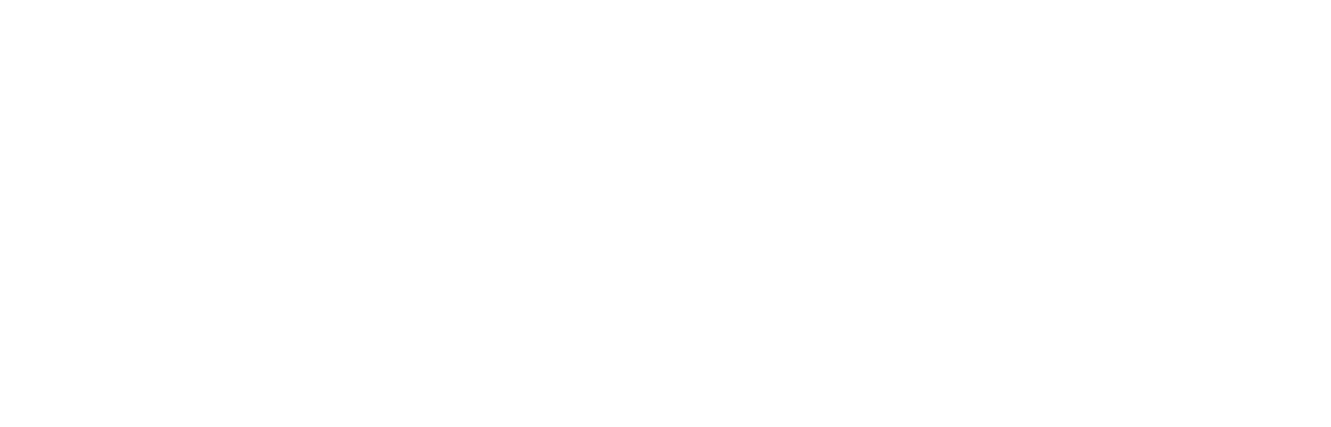

DURATION TABLE OF DISCHARGE FOR WATER YEARS 1967-8I

$\begin{array}{lcl}\text { OUBIC } & \text { ACOU- } \\ \text { FEET } & \text { MU- } & \text { PER- } \\ \text { PER TOTAL LATED } & \text { CENT }\end{array}$

CLASS SECOND DAYS DAYS DAYS

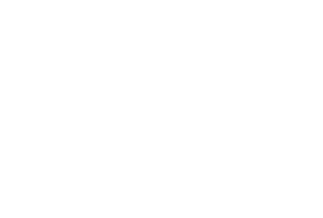

$\begin{array}{lcc}\text { OUBIC } & \text { ACOU- } \\ \text { FEET } & \text { MU- } & \\ \text { PER } & \text { PER- }\end{array}$ PER TOTAL LATED CENT
CLASS SECOND DAYS DAYS DAYS

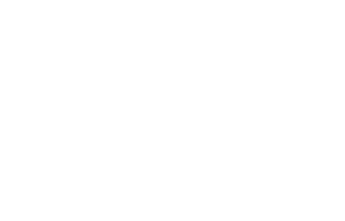

$\begin{array}{ll}\text { OBBIC } & \text { ACQU- } \\ \text { FEET } & \text { MU- PER- }\end{array}$ PER TOTAL LATED CENI CLASS SECOND DAYS DAYS DAYS

$\begin{array}{rrrrr}18 & 46.0 & 28 & 284 & 5.2 \\ 19 & 51.0 & 29 & 256 & 4.7 \\ 20 & 57.0 & 22 & 227 & 4.1 \\ 21 & 64.0 & 21 & 205 & 3.7 \\ 22 & 71.0 & 31 & 184 & 3.4 \\ 23 & 80.0 & 17 & 153 & 2.8 \\ 24 & 89.0 & 19 & 136 & 2.5 \\ 25 & 99.0 & 17 & 117 & 2.1\end{array}$

$\begin{array}{cc}\text { OBIC } & \text { ACOU- } \\ \text { FEET } & \text { MU- }\end{array}$ CLASS SECOND DAYS DAYS DAYS

$\begin{array}{rrrrr}27 & 120.0 & 25 & 87 & 1.6 \\ 28 & 140.0 & 6 & 62 & 1.1 \\ 29 & 150.0 & 11 & 56 & 1.0 \\ 30 & 170.0 & 11 & 45 & 0.8 \\ 31 & 190.0 & 29 & 34 & 0.6 \\ 32 & 220.0 & 2 & 5 & 0.1 \\ 33 & 240.0 & 2 & 3 & 0.1 \\ 34 & 270.0 & 1 & 1 & 0.0\end{array}$


VIRGIN RIVER BASIN

09404450 EAST FORK VIRGIN RIVER NEAR GLENDALE, UT-Continued

MONIHLY MEAN DISGHARGES, IN CBBIC FEET PER SEOOND, FOR EACH WATER YEAR

\begin{tabular}{|c|c|c|c|c|c|c|c|c|c|c|c|c|}
\hline YEAR & $\infty \mathrm{T}$ & $\mathrm{NON}$ & DEC & JAN & FEB & MAR & APR & MAY & JUNE & JULY & AUG & SEP \\
\hline $\begin{array}{l}1967 \\
1968 \\
1969 \\
1970\end{array}$ & $\begin{array}{l}14.2 \\
14.5 \\
13.3 \\
18.4\end{array}$ & $\begin{array}{l}14.7 \\
15.8 \\
14.7 \\
19.1\end{array}$ & $\begin{array}{l}30.2 \\
17.1 \\
14.8 \\
17.3\end{array}$ & $\begin{array}{l}18.0 \\
17.3 \\
25.0 \\
17.6\end{array}$ & $\begin{array}{l}19.8 \\
22.0 \\
21.8 \\
19.6\end{array}$ & $\begin{array}{l}21.9 \\
25.1 \\
31.5 \\
21.1\end{array}$ & $\begin{array}{c}23.9 \\
26.4 \\
132 \\
16.3\end{array}$ & $\begin{array}{l}20.7 \\
22.2 \\
78.0 \\
14.5\end{array}$ & $\begin{array}{l}18.7 \\
15.7 \\
32.9 \\
11.8\end{array}$ & $\begin{array}{l}13.4 \\
14.4 \\
27.9 \\
11.0\end{array}$ & $\begin{array}{l}15.5 \\
17.9 \\
20.8 \\
10.9\end{array}$ & $\begin{array}{l}17.9 \\
11.7 \\
16.6 \\
11.0\end{array}$ \\
\hline $\begin{array}{l}1971 \\
1972 \\
1973 \\
1974 \\
1975\end{array}$ & $\begin{array}{l}13.0 \\
13.1 \\
16.4 \\
12.9 \\
13.2\end{array}$ & $\begin{array}{l}16.0 \\
13.7 \\
16.0 \\
15.1 \\
16.2\end{array}$ & $\begin{array}{l}15.9 \\
23.5 \\
15.8 \\
15.9 \\
14.9\end{array}$ & $\begin{array}{l}18.0 \\
15.0 \\
16.6 \\
17.0 \\
14.9\end{array}$ & $\begin{array}{l}17.0 \\
16.3 \\
18.1 \\
16.9 \\
15.6\end{array}$ & $\begin{array}{l}16.9 \\
13.9 \\
21.7 \\
19.1 \\
20.9\end{array}$ & $\begin{array}{l}13.7 \\
12.6 \\
69.9 \\
15.6 \\
20.3\end{array}$ & $\begin{array}{l}15.3 \\
10.6 \\
66.7 \\
13.8 \\
16.3\end{array}$ & $\begin{array}{l}11.0 \\
12.0 \\
26.0 \\
11.9 \\
12.4\end{array}$ & $\begin{array}{c}9.20 \\
7.95 \\
14.3 \\
10.3 \\
10.7\end{array}$ & $\begin{array}{c}10.6 \\
8.48 \\
12.3 \\
8.60 \\
9.29\end{array}$ & $\begin{array}{c}9.32 \\
12.6 \\
12.0 \\
9.35 \\
10.1\end{array}$ \\
\hline $\begin{array}{l}1976 \\
1977 \\
1978 \\
1979 \\
1980\end{array}$ & $\begin{array}{l}11.3 \\
11.8 \\
10.4 \\
12.0 \\
16.0\end{array}$ & $\begin{array}{l}14.0 \\
10.8 \\
11.8 \\
19.5 \\
17.3\end{array}$ & $\begin{array}{l}15.2 \\
11.5 \\
12.1 \\
16.5 \\
18.3\end{array}$ & $\begin{array}{l}13.1 \\
11.8 \\
14.2 \\
17.6 \\
26.2\end{array}$ & $\begin{array}{l}18.3 \\
12.1 \\
17.8 \\
19.1 \\
36.4\end{array}$ & $\begin{array}{l}16.7 \\
11.5 \\
34.3 \\
32.5 \\
42.9\end{array}$ & $\begin{array}{l}15.9 \\
11.0 \\
47.8 \\
133 \\
145\end{array}$ & $\begin{array}{c}12.5 \\
12.4 \\
30.8 \\
103 \\
131\end{array}$ & $\begin{array}{c}8.87 \\
8.92 \\
16.2 \\
31.8 \\
43.6\end{array}$ & $\begin{array}{l}9.70 \\
8.06 \\
12.5 \\
18.8 \\
28.0\end{array}$ & $\begin{array}{c}9.48 \\
8.19 \\
11.3 \\
17.7 \\
25.9\end{array}$ & $\begin{array}{c}10.3 \\
8.62 \\
11.3 \\
14.7 \\
24.7\end{array}$ \\
\hline 1981 & 22.3 & 21.7 & 22.4 & 21.8 & 22.4 & 26.2 & 22.1 & 18.1 & 13.7 & 11.7 & 12.4 & 13.1 \\
\hline
\end{tabular}

ANNUAL PEAK DISCHARGE, IN OBIC FEET PER SECOND, AND OORRESPONDING GAGE HEIGHT, IN FEET, FOR EACH WATER YEAR

\begin{tabular}{|c|c|c|c|c|c|c|c|c|c|c|c|}
\hline $\begin{array}{l}\text { WATER } \\
\text { YEAR }\end{array}$ & DATE & $\begin{array}{c}\text { GAGE } \\
\text { HEIGHT }\end{array}$ & $\begin{array}{c}\text { PEAK } \\
\text { DISCHARGE }\end{array}$ & $\begin{array}{l}\text { WATEER } \\
\text { YEAR }\end{array}$ & DATE & $\begin{array}{c}\text { GAGE } \\
\text { HEIGHT }\end{array}$ & $\begin{array}{c}\text { PEAK } \\
\text { DISCHARGE }\end{array}$ & $\begin{array}{l}\text { WATER } \\
\text { YEAR }\end{array}$ & DATE & $\begin{array}{c}\text { GAGE } \\
\text { HEIGHT }\end{array}$ & $\begin{array}{c}\text { PEAK } \\
\text { DISCHARGE }\end{array}$ \\
\hline $\begin{array}{l}1967 \\
1968 \\
1969 \\
1970 \\
1971\end{array}$ & $\begin{array}{l}\text { SEPT.07, } 1967 \\
\text { AUG. } 13,1968 \\
\text { APR. } 21,1969 \\
\text { SEPT.05, } 1970 \\
\text { AUG. } 23,1971\end{array}$ & $\begin{array}{l}4.05 \\
1.25 \\
2.17 \\
0.69 \\
1.20\end{array}$ & $\begin{array}{r}635 \\
65 \\
238 \\
30 \\
66\end{array}$ & $\begin{array}{l}1972 \\
1973 \\
1974 \\
1975 \\
1976\end{array}$ & $\begin{array}{ll}\text { SEPT.19, } 1972 \\
\text { APR. 29, } 1973 \\
\text { MAR. 02, } 1974 \\
\text { OCT. 28, } 1974 \\
\text { JULY 27, } 1976\end{array}$ & $\begin{array}{l}4.00 \\
1.81 \\
0.94 \\
1.14 \\
4.14\end{array}$ & $\begin{array}{r}630 \\
184 \\
44 \\
58 \\
640\end{array}$ & $\begin{array}{l}1977 \\
1978 \\
1979 \\
1980 \\
1981\end{array}$ & $\begin{array}{l}\text { AUG. } 17,1977 \\
\text { APR. } 10,1978 \\
\text { APR. } 17,1979 \\
\text { APR. 21, } 1980 \\
\text { AUG. 11, } 1981\end{array}$ & $\begin{array}{l}1.72 \\
1.66 \\
2.61 \\
2.91 \\
4.42\end{array}$ & $\begin{array}{r}112 \\
96 \\
285 \\
334 \\
156\end{array}$ \\
\hline
\end{tabular}

$1.20 \quad 66 \quad 1976$ JULY 27, 1976

\begin{tabular}{|c|c|c|c|c|c|c|}
\hline \multirow{2}{*}{$\begin{array}{l}\text { RIO } \\
\text { ON- } \\
\text { YU- } \\
\text { VE } \\
\text { YS) }\end{array}$} & \multicolumn{6}{|c|}{$\begin{array}{l}\text { DISCHARGE, IN OUBIC FEET PER SECOND, FOR } \\
\text { INDICATED RECURRENCE INTERVAL, IN YEARS, AND } \\
\text { ANNUAL NONEXCEEDANCE PROBABLITY, IN PERCENT }\end{array}$} \\
\hline & $\begin{array}{c}2 \\
50 \%\end{array}$ & $\begin{array}{c}5 \\
208\end{array}$ & $\begin{array}{l}10 \\
108\end{array}$ & $\begin{array}{l}20 \\
58\end{array}$ & $\begin{array}{l}50 \\
28\end{array}$ & $\begin{array}{r}100 \\
18\end{array}$ \\
\hline $\begin{array}{r}1 \\
7 \\
14 \\
30 \\
60 \\
90\end{array}$ & $\begin{array}{l}9.4 \\
9.8 \\
10 \\
11 \\
11 \\
11\end{array}$ & $\begin{array}{l}7.6 \\
8.0 \\
8.1 \\
8.4 \\
8.8 \\
9.2\end{array}$ & $\begin{array}{l}7.0 \\
7.3 \\
7.4 \\
7.7 \\
8.1 \\
8.5\end{array}$ & $\begin{array}{l}6.6 \\
6.9 \\
6.9 \\
7.2 \\
7.6 \\
7.9\end{array}$ & $\begin{array}{l}-- \\
- \\
- \\
-- \\
--\end{array}$ & $\begin{array}{l}-- \\
- \\
-- \\
-- \\
-\end{array}$ \\
\hline
\end{tabular}

09404500 MINERAL GUULCH NEAR MT. CARMEU, UT

LOCATION.--Lat $37^{\circ} 14^{\prime} 00^{\prime \prime}$, long $112^{\circ} 44^{\prime} 10^{\prime \prime}$, in $\mathrm{NW}_{\frac{1}{4}} \mathrm{sec} .22, \mathrm{~T} .41 \mathrm{~S} .$, R. 8 W., Kane County, Hydrologic Unit 15010008 , about 3.2 mi west

of Mt. Carmel Junction and $6 \mathrm{mi}$ southeast of Orderville.

DRAINAGE AREA. $-7.60 \mathrm{mi}^{2}$.

MEAN BASIN ELEVATION. $-6,110 \mathrm{ft}$.

PERIOD OF RECORD AVAIIABLE.-Water years 1959-69, 1971-72, 1974, annual peak discharge only.

GAGE.-Crest-stage gage. Altitude of gage is 5,560 ft from topographic map.

ANNUAL PEAK DISCHARGE, IN CBBIC FEET PER SECOND, AND CORRESPONDING GAGE HEIGHT, IN FEET, FOR EACH WATER YEAR

\begin{tabular}{|c|c|c|c|c|c|c|c|c|c|c|c|}
\hline $\begin{array}{l}\text { WATERR } \\
\text { YEAR }\end{array}$ & DATE & $\begin{array}{c}\text { GAGE } \\
\text { HEIGHT }\end{array}$ & $\begin{array}{c}\text { PEAK } \\
\text { DISCHARGE }\end{array}$ & $\begin{array}{l}\text { WATER } \\
\text { YEAR }\end{array}$ & DATE & $\begin{array}{l}\text { GAGE } \\
\text { HEIGHT }\end{array}$ & $\begin{array}{c}\text { PEAK } \\
\text { DISCHARGE }\end{array}$ & $\begin{array}{l}\text { WATER } \\
\text { YEAR }\end{array}$ & DATE & $\begin{array}{l}\text { GAGE } \\
\text { HEIGHT }\end{array}$ & $\begin{array}{c}\text { PEAK } \\
\text { DISCHARGE }\end{array}$ \\
\hline $\begin{array}{l}1959 \\
1960 \\
1961 \\
1962 \\
1963\end{array}$ & $\begin{array}{l}\text { SEPT. } 15,1959 \\
\text { SEPT.01, } 1960 \\
\text { SEPT.17, } 1961 \\
\text { FEB. } 12,1962 \\
\text { AUG. } 18,1963\end{array}$ & $\begin{array}{r}12.08 \\
11.32 \\
15.00 \\
9.82 \\
19.69\end{array}$ & $\begin{array}{c}262 \\
190 \\
1340 \\
7.0 \\
3210^{\circ}\end{array}$ & $\begin{array}{l}1964 \\
1965 \\
1966 \\
1967 \\
1968\end{array}$ & $\begin{array}{l}\text { AUG. } 12,1964 \\
\text { AUG. } 17,1965 \\
\text { NOV. } 23,1965 \\
\text { DEC. } 06,1966 \\
\text { AUG. } 01,1968\end{array}$ & $\begin{array}{cc}13.32 \\
12.00 \\
5 \\
10.50 \\
5 \\
12.03 \\
3\end{array}$ & $\begin{array}{r}710 \\
400 \\
25 \\
315 \\
5.0\end{array}$ & $\begin{array}{l}1969 \\
1971 \\
1972 \\
1974\end{array}$ & $\begin{array}{l}\text { AUG. } 12,1969 \\
\text { AUG. 18, } 1971 \\
\text { SEPT.21, } 1972 \\
--\end{array}$ & $\begin{array}{r}10.17 \\
7.81 \\
3.39 \\
-\end{array}$ & $\begin{array}{r}20 \\
1760 \\
147 \\
570\end{array}$ \\
\hline
\end{tabular}


VIRGIN RIVER BASIN

09405300 CRYSTAL CREEX NEAR CEIAR CITY, UT

LOCATION.--Lat $37^{\circ} 31^{\prime} 20^{\prime \prime}$, long $113^{\circ} 01{ }^{\prime} 25^{\prime \prime}$, in SW sec.7, T.38 S., R.10 W., Washington County, Hydroløgic Unit 15010008 , on left bank $0.5 \mathrm{mi}$ downstream from Shriver Creek and $12 \mathrm{mi}$ southeast of Cedar City.

DRAINAGE AREA.--10.2 $\mathrm{mi}^{2}$ :

MEAN BASIN ELEVATION. $-9,280 \mathrm{ft}$.

PERIOD OF RECORD AVAII.ABLE.--October 1956 to September 1961.

REVISED RECORDS.-WSP 1713: 1958 (M).

GAGE.-Water-stage recorder. Altitude of gage is 8,320 ft fram topographic map.

AVERAGE DISCHARGE. -5 years, $7.23 \mathrm{ft}^{3} / \mathrm{s}, 5,230$ acre-ft/yr.

PERIOD OF RECORD.-Maximum discharge, $1,300 \mathrm{ft}^{3} / \mathrm{s}$ Aug. 19, 1959, gage height, $5.23 \mathrm{ft}, \mathrm{fram}$ rating curve extended above $100 \mathrm{ft} / \mathrm{s}$ on

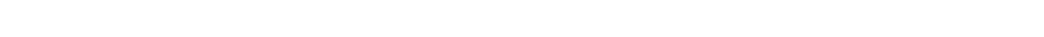

LOWEST MEAN DISCHARGE, IN CUBIC FEET PER SECOND, AND RANKING FOR THE INDICATED NUMBER OF CONSECUTIVE DAYS FOR EACH CLIMATIC YEAR, APRII 1-MARCH 31

\begin{tabular}{|c|c|c|c|c|c|c|c|c|c|c|c|c|c|c|c|c|c|c|c|}
\hline YEAR & & & & & & & & & CONSE & arTIV & DAYS & & & & & & & & \\
\hline $\begin{array}{l}1958 \\
1959 \\
1960\end{array}$ & $\begin{array}{l}0.20 \\
1.00 \\
0.40\end{array}$ & $\begin{array}{l}1 \\
4 \\
2\end{array}$ & $\begin{array}{l}0.20 \\
1.00 \\
0.47\end{array}$ & $\begin{array}{l}1 \\
4 \\
2\end{array}$ & $\begin{array}{l}0.26 \\
1.00 \\
0.49\end{array}$ & $\begin{array}{l}1 \\
4 \\
2\end{array}$ & $\begin{array}{l}1.30 \\
1.00 \\
0.49\end{array}$ & $\begin{array}{l}4 \\
3 \\
1\end{array}$ & $\begin{array}{l}1.40 \\
1.00 \\
0.63\end{array}$ & $\begin{array}{l}4 \\
3 \\
1\end{array}$ & $\begin{array}{l}1.50 \\
1.10 \\
0.75\end{array}$ & $\begin{array}{l}4 \\
3 \\
1\end{array}$ & $\begin{array}{l}1.50 \\
1.10 \\
0.73\end{array}$ & $\begin{array}{l}4 \\
3 \\
1\end{array}$ & $\begin{array}{l}1.60 \\
1.19 \\
0.77\end{array}$ & $\begin{array}{l}4 \\
3 \\
1\end{array}$ & $\begin{array}{l}1.70 \\
1.30 \\
0.80\end{array}$ & $\begin{array}{l}4 \\
3 \\
1\end{array}$ & $\begin{array}{c}11.0 \\
15.0 \\
3.20\end{array}$ \\
\hline 1961 & 0.80 & 3 & 0.80 & 3 & 0.81 & 3 & 0.86 & 2 & 0.88 & 2 & 0.96 & 2 & 1.00 & 2 & 1.10 & 2 & 1.19 & 2 & 4.00 \\
\hline
\end{tabular}

HIGHEST MEAN DISCHARGE, IN CUBIC FEET PER SECOND, AND RANRING FOR THE INDICATED NUMBER OF CONSECUTIVE DAYS FOR FACH WATTRR YEAR, OCTOBER 1-SEPTEMBER 30

\begin{tabular}{|c|c|c|c|c|c|c|c|c|c|c|c|c|c|c|c|c|c|c|c|}
\hline YEAR & & & & & & & & & CONS & ब' & E DAYS & & & & & & & & \\
\hline $\begin{array}{l}1957 \\
1958 \\
1959 \\
1960\end{array}$ & $\begin{array}{r}210 \\
272 \\
38.0 \\
51.0\end{array}$ & $\begin{array}{l}2 \\
1 \\
5 \\
4\end{array}$ & $\begin{array}{r}186 \\
261 \\
25.0 \\
50.0\end{array}$ & $\begin{array}{l}2 \\
1 \\
5 \\
3\end{array}$ & $\begin{array}{r}151 \\
241 \\
20.0 \\
44.0\end{array}$ & $\begin{array}{l}2 \\
1 \\
5 \\
3\end{array}$ & $\begin{array}{c}97.0 \\
189 \\
17.0 \\
32.0\end{array}$ & $\begin{array}{l}2 \\
1 \\
5 \\
3\end{array}$ & $\begin{array}{c}72.0 \\
140 \\
15.0 \\
23.0\end{array}$ & $\begin{array}{l}2 \\
1 \\
5 \\
3\end{array}$ & $\begin{array}{l}51.0 \\
79.0 \\
13.0 \\
17.0\end{array}$ & $\begin{array}{l}2 \\
1 \\
4 \\
3\end{array}$ & $\begin{array}{c}38.0 \\
55.0 \\
9.30 \\
12.0\end{array}$ & $\begin{array}{l}2 \\
1 \\
4 \\
3\end{array}$ & $\begin{array}{c}29.0 \\
41.0 \\
7.40 \\
9.70\end{array}$ & $\begin{array}{l}2 \\
1 \\
4 \\
3\end{array}$ & $\begin{array}{c}20.0 \\
28.0 \\
5.70 \\
6.80\end{array}$ & $\begin{array}{l}2 \\
1 \\
5 \\
3\end{array}$ & $\begin{array}{c}10.0 \\
15.0 \\
3.40 \\
3.80\end{array}$ \\
\hline 1961 & 54.0 & 3 & 27.0 & 4 & 24.0 & 4 & 22.0 & 4 & 18.0 & 4 & 12.0 & 5 & 8.90 & 5 & 7.10 & 5 & 5.70 & 4 & 3.50 \\
\hline
\end{tabular}

DURATION OF DISCHARGE FOR EACH WATER YEAR

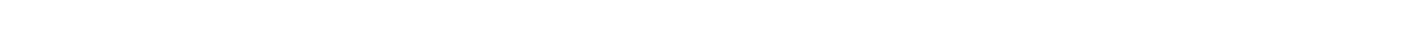

YEAR

NUMBER OF DAYS IN CLASS CUBIC FEET -DAYS

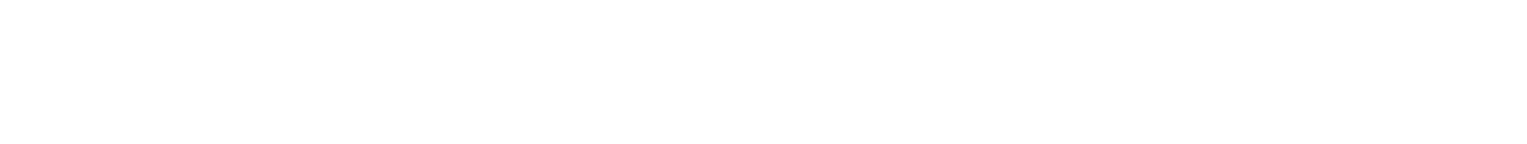

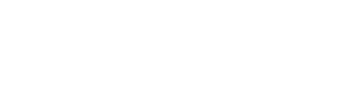

$\begin{array}{lllll}0 & 0.00 & 0 & 1826 & 100.0\end{array}$ $0.25 \quad 1 \quad 1826100.0$ $\begin{array}{llll}0.31 & 0 & 1820 & 99.7\end{array}$ $0.38 \quad 1 \quad 1820 \quad 99.7$ $\begin{array}{llll}0.38 & 1 & 1820 & 99.7\end{array}$ $\begin{array}{rrrr}0.48 & 43 & 1819 & 99.6\end{array}$ $\begin{array}{llll}0.59 & 104 & 1776 & 97.3\end{array}$ $\begin{array}{llll}0.73 & 181 & 1672 & 91.6\end{array}$

DURATION TABLE OF DISCHARGE FOR WATER YEARS 1957-61

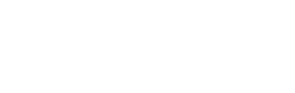

GLASS SECOND DAYS DAYS DAYS

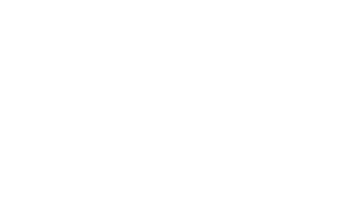

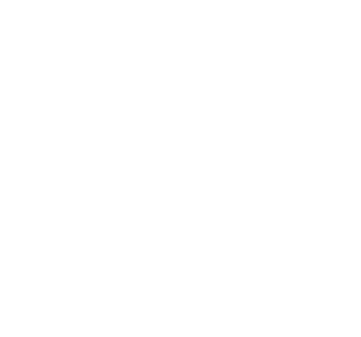


VIRGIN RIVER BASIN

09405300 CRYSTAL CREEX NEAR CEDAR CITY, UT-Continued

MONIFLY MEAN DISCHARGES, IN CUBIC FEET PER SECOND, FOR EAOH WATER YEAR

\begin{tabular}{|c|c|c|c|c|c|c|c|c|c|c|c|c|}
\hline YEAR & $\infty C r$ & Nov & $\mathrm{DEC}$ & JAN & FEB & MAR & APR & MAY & JUNE & JULY & AUG & SEPP \\
\hline $\begin{array}{l}1957 \\
1958 \\
1959 \\
1960\end{array}$ & $\begin{array}{l}0.70 \\
1.86 \\
1.42 \\
0.82\end{array}$ & $\begin{array}{l}0.70 \\
1.84 \\
1.40 \\
0.80\end{array}$ & $\begin{array}{l}0.58 \\
1.80 \\
1.16 \\
0.76\end{array}$ & $\begin{array}{l}0.98 \\
1.80 \\
1.10 \\
0.87\end{array}$ & $\begin{array}{l}1.20 \\
1.80 \\
1.00 \\
0.84\end{array}$ & $\begin{array}{l}2.30 \\
2.00 \\
1.97 \\
1.27\end{array}$ & $\begin{array}{c}15.8 \\
5.83 \\
14.5 \\
11.4\end{array}$ & $\begin{array}{c}64.5 \\
136 \\
10.9 \\
21.0\end{array}$ & $\begin{array}{c}31.2 \\
15.9 \\
2.05 \\
4.19\end{array}$ & $\begin{array}{l}1.67 \\
3.42 \\
1.50 \\
1.39\end{array}$ & $\begin{array}{l}1.66 \\
1.73 \\
3.08 \\
1.05\end{array}$ & $\begin{array}{l}1.36 \\
5.07 \\
0.78 \\
1.11\end{array}$ \\
\hline 1961 & 1.01 & 1.66 & 1.19 & 1.49 & 1.26 & 1.59 & 8.21 & 14.9 & 2.99 & 1.37 & 2.42 & 3.97 \\
\hline
\end{tabular}

ANNUAL PEAK DISCHARGE, IN CUBIC FEET PER SECOND, AND CORRESPONDING GAGE HEIGHT, IN FEET, FOR EACH WATER YEAR

\begin{tabular}{|c|c|c|c|c|c|c|c|c|c|c|c|}
\hline $\begin{array}{l}\text { WATERR } \\
\text { YEAR }\end{array}$ & DATE & $\begin{array}{c}\text { GAGE } \\
\text { HEIGHT }\end{array}$ & $\begin{array}{c}\text { PEAK } \\
\text { DISCHARGE }\end{array}$ & $\begin{array}{l}\text { WATER } \\
\text { YEAR }\end{array}$ & DATE & $\begin{array}{l}\text { GAGE } \\
\text { HEIGHT }\end{array}$ & $\begin{array}{c}\text { PEAR } \\
\text { DISCHARGE }\end{array}$ & $\begin{array}{l}\text { WATER } \\
\text { YEAR }\end{array}$ & DATE & $\begin{array}{c}\text { GAGE } \\
\text { HEIGHT }\end{array}$ & $\begin{array}{c}\text { PEAK } \\
\text { DISCHARGE }\end{array}$ \\
\hline $\begin{array}{l}1957 \\
1958\end{array}$ & $\begin{array}{l}\text { JULY 11, } 1957 \\
\text { SEPT.13, } 1958\end{array}$ & $\begin{array}{l}3.20 \\
4.48\end{array}$ & $\begin{array}{l}387 \\
863\end{array}$ & $\begin{array}{l}1959 \\
1960\end{array}$ & $\begin{array}{l}\text { AUG. } 19,1959 \\
\text { SEPT.01, } 1960\end{array}$ & $\begin{array}{l}5.23 \\
3.40\end{array}$ & $\begin{array}{r}1300 \\
182\end{array}$ & 1961 & SEPT.17, 1961 & 4.94 & 1120 \\
\hline
\end{tabular}

09405400 NORTH FORR VIRGIN RIVER NEAR GLENDALE, UT

LOCATION.-Lat $37^{\circ} 28^{\prime} 22^{n}$, long $112^{\circ} 46^{\prime} 40^{\prime \prime}$, in SW $\mathrm{H}_{4} \mathrm{SE}_{4}^{\frac{1}{4}}$ sec.30, T.38 S., R.8 W., Kane County, Hydrologic Unit 15010008 , on right bank $700 \mathrm{ft}$ above diversion ditch, $3.4 \mathrm{mi}$ south of Navajo Lake, $14.7 \mathrm{road} \mathrm{mi}$ from Navajo Lake turnoff at Utah Highway 14 , and $14 \mathrm{mi}$ northwest of Glendale.

DRAINAGE AREA. $--5.65 \mathrm{mi}^{2}$.

MEAN BASIN ELEVATION. $-8,080 \mathrm{ft}$.

PERIOD OF RECORD AVAIIABLE.--December 1972 to September 1978.

GAGE.--Water-stage recorder and $1.0 \mathrm{ft}$ Parshall flume. Altitude of gage is 7,530 ft from topographic map.

AVERAGE DISCHARGE. -5 years (water years 1974-78), $4.39 \mathrm{ft}^{3} / \mathrm{s}, 3,180 \mathrm{acre}-\mathrm{ft} / \mathrm{yr}$.

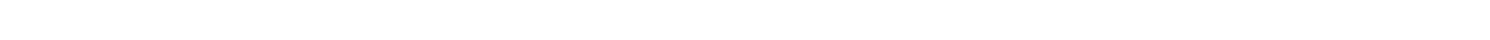

LOWEST MEAN DISCHARGE, IN CUBIC FEET PER SECOND, AND RANKING FOR THE INDICATED NUMBER OF CONSEOTTIVE DAYS FOR EACH CLIMATIC YEAR, APRIL 1-MAROH 31

\begin{tabular}{|c|c|c|c|c|c|c|c|c|c|c|c|c|c|c|c|c|c|c|c|}
\hline YEAR & 1 & & 3 & & 7 & & 14 & & $\begin{array}{l}\text { CONSE } \\
30\end{array}$ & वITI & $\begin{array}{l}\text { DAYS } \\
60\end{array}$ & & 90 & & 120 & & 183 & & ALL \\
\hline $\begin{array}{l}1974 \\
1975\end{array}$ & $\begin{array}{l}3.50 \\
0.58\end{array}$ & $\begin{array}{l}5 \\
2\end{array}$ & $\begin{array}{l}3.50 \\
0.59\end{array}$ & $\begin{array}{l}5 \\
2\end{array}$ & $\begin{array}{l}3.70 \\
0.60\end{array}$ & $\begin{array}{l}5 \\
2\end{array}$ & $\begin{array}{l}3.70 \\
0.63\end{array}$ & $\begin{array}{l}5 \\
2\end{array}$ & $\begin{array}{l}3.80 \\
0.71\end{array}$ & $\begin{array}{l}5 \\
2\end{array}$ & $\begin{array}{l}3.90 \\
0.77\end{array}$ & $\begin{array}{l}5 \\
2\end{array}$ & $\begin{array}{l}4.00 \\
0.91\end{array}$ & $\begin{array}{l}5 \\
2\end{array}$ & $\begin{array}{l}4.90 \\
1.19\end{array}$ & $\begin{array}{l}5 \\
2\end{array}$ & $\begin{array}{l}6.30 \\
1.70\end{array}$ & & $\begin{array}{l}9.30 \\
2.60\end{array}$ \\
\hline
\end{tabular}

HIGHEST MEAN DISCHARGE, IN CUBIC FEET PER SECOND, AND RANKING FOR THE INDICATED NUMBER OF CONSECUTIVE DAYS FOR EACH WATER YEAR, OCTCBER 1-SEPTEMBER 30

\begin{tabular}{|c|c|c|c|c|c|c|c|c|c|c|c|c|c|c|c|c|c|c|c|}
\hline YEAR & 1 & & 3 & & 7 & & 15 & & $\begin{array}{l}\text { CONSE } \\
30\end{array}$ & OUTIVE & $\begin{array}{l}\text { E DAYS } \\
60\end{array}$ & & 90 & & 120 & & 183 & & ALL \\
\hline $\begin{array}{l}1974 \\
1975\end{array}$ & $\begin{array}{l}10.0 \\
10.0\end{array}$ & $\begin{array}{l}2 \\
3\end{array}$ & $\begin{array}{c}10.0 \\
8.70\end{array}$ & $\begin{array}{l}2 \\
3\end{array}$ & $\begin{array}{c}10.0 \\
8.00\end{array}$ & $\begin{array}{l}2 \\
4\end{array}$ & $\begin{array}{c}10.0 \\
7.90\end{array}$ & $\begin{array}{l}2 \\
4\end{array}$ & $\begin{array}{l}9.80 \\
7.50\end{array}$ & $\begin{array}{l}2 \\
4\end{array}$ & $\begin{array}{l}9.10 \\
6.90\end{array}$ & $\begin{array}{l}2 \\
4\end{array}$ & $\begin{array}{l}8.60 \\
6.70\end{array}$ & $\begin{array}{l}2 \\
3\end{array}$ & $\begin{array}{l}7.50 \\
6.30\end{array}$ & $\begin{array}{l}2 \\
3\end{array}$ & $\begin{array}{l}6.30 \\
5.80\end{array}$ & $\begin{array}{l}2 \\
3\end{array}$ & $\begin{array}{l}4.20 \\
4.40\end{array}$ \\
\hline $\begin{array}{l}1976 \\
1977 \\
1978\end{array}$ & $\begin{array}{r}8.60 \\
4.30 \\
39.0\end{array}$ & $\begin{array}{l}4 \\
5 \\
1\end{array}$ & $\begin{array}{r}8.60 \\
3.60 \\
36.0\end{array}$ & $\begin{array}{l}4 \\
5 \\
1\end{array}$ & $\begin{array}{r}8.50 \\
3.40 \\
33.0\end{array}$ & $\begin{array}{l}3 \\
5 \\
1\end{array}$ & $\begin{array}{r}8.40 \\
3.20 \\
29.0\end{array}$ & $\begin{array}{l}3 \\
5 \\
1\end{array}$ & $\begin{array}{r}8.10 \\
3.10 \\
26.0\end{array}$ & $\begin{array}{l}3 \\
5 \\
1\end{array}$ & $\begin{array}{r}7.40 \\
3.10 \\
21.0\end{array}$ & $\begin{array}{l}3 \\
5 \\
1\end{array}$ & $\begin{array}{r}6.60 \\
2.90 \\
18.0\end{array}$ & $\begin{array}{l}4 \\
5 \\
1\end{array}$ & $\begin{array}{c}6.00 \\
2.90 \\
15.0\end{array}$ & $\begin{array}{l}4 \\
5 \\
1\end{array}$ & $\begin{array}{r}5.10 \\
2.90 \\
12.0\end{array}$ & $\begin{array}{l}4 \\
5 \\
1\end{array}$ & $\begin{array}{l}3.80 \\
2.00 \\
7.50\end{array}$ \\
\hline
\end{tabular}

DURATION OF DISCHARGE FOR EACH WATER YEAR

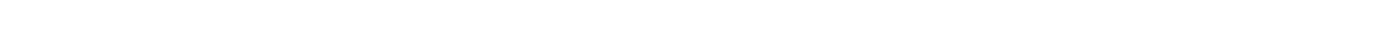
YEAR

NUMBER OF DAYS IN CLASS CBBIC FEET PER SEOOND -DAYS

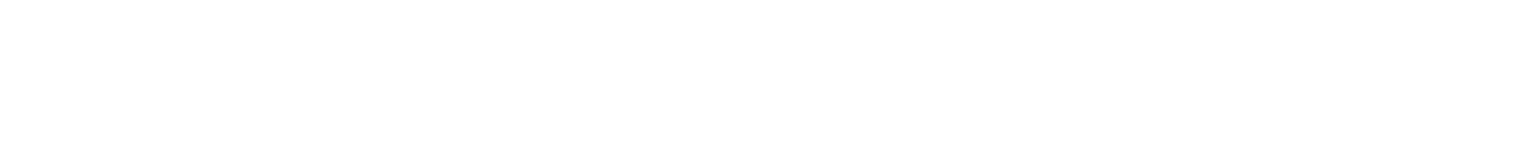


VIRGIN RIVER BASIN

09405400 NORTH FORK VIRGIN RIVER NEAR GLENDALE, UT--Continued

DURATION TABLE OF DISCHARGE FOR WATER YEARS 1974-78

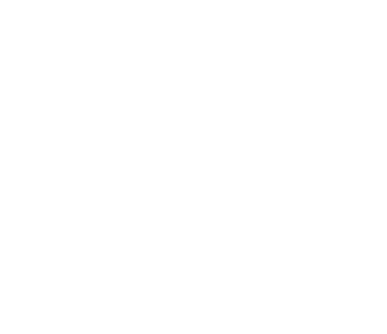

\begin{tabular}{|c|c|c|c|c|}
\hline LASS & $\begin{array}{c}\text { OUBIC } \\
\text { FEET } \\
\text { PER } \\
\text { SEOOND }\end{array}$ & $\begin{array}{r}\text { TOTAL } \\
\text { DAYS }\end{array}$ & $\begin{array}{l}\text { ACOU- } \\
\text { MU- } \\
\text { LATED } \\
\text { DAYS }\end{array}$ & $\begin{array}{l}\text { PER- } \\
\text { CEN } \\
\text { DAYS }\end{array}$ \\
\hline $\begin{array}{r}9 \\
10 \\
11 \\
12 \\
13 \\
14 \\
15 \\
16 \\
17\end{array}$ & $\begin{array}{l}1.10 \\
1.20 \\
1.40 \\
1.60 \\
1.90 \\
2.20 \\
2.50 \\
2.90 \\
3.30\end{array}$ & $\begin{array}{r}19 \\
35 \\
18 \\
56 \\
101 \\
104 \\
219 \\
207 \\
165\end{array}$ & $\begin{array}{r}1648 \\
1629 \\
1594 \\
1576 \\
1520 \\
1419 \\
1315 \\
1096 \\
889\end{array}$ & $\begin{array}{l}90.3 \\
89.2 \\
87.3 \\
86.3 \\
83.2 \\
77.7 \\
72.0 \\
60.0 \\
48.7\end{array}$ \\
\hline
\end{tabular}

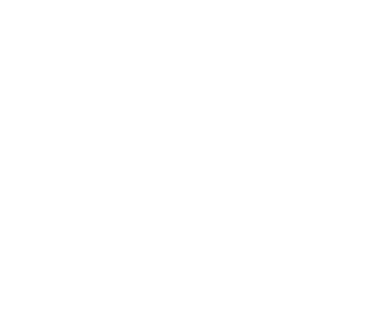

\begin{tabular}{|c|c|c|c|c|}
\hline & $\begin{array}{c}\text { OUBIC } \\
\text { FEET } \\
\text { PER }\end{array}$ & TOTAL & $\begin{array}{c}\text { ACOU- } \\
\text { UU- } \\
\text { LATED }\end{array}$ & $\begin{array}{l}\text { PER- } \\
\text { CENT }\end{array}$ \\
\hline OLASS & SECOND & DAYS & DAYS & DAYS \\
\hline $\begin{array}{l}27 \\
28 \\
29 \\
30 \\
31 \\
32 \\
33 \\
34\end{array}$ & $\begin{array}{l}13.0 \\
15.0 \\
17.0 \\
20.0 \\
22.0 \\
26.0 \\
30.0 \\
34.0\end{array}$ & $\begin{array}{r}19 \\
7 \\
18 \\
7 \\
8 \\
9 \\
3 \\
3\end{array}$ & $\begin{array}{r}74 \\
55 \\
48 \\
30 \\
23 \\
15 \\
6 \\
3\end{array}$ & $\begin{array}{l}3.0 \\
2.6 \\
1.6 \\
1.3 \\
0.8 \\
0.3 \\
0.2\end{array}$ \\
\hline
\end{tabular}

MONTHLY MEAN DISCHARGES, IN CIBIC FEET PER SEOOND, FOR EACH WATER YEAR

$\begin{array}{lcccccccccccc}\text { YEAR } & \text { OCT } & \text { NON } & \text { DEC } & \text { JAN } & \text { FEB } & \text { MAR } & \text { APR } & \text { MAY } & \text { JUNE } & \text { JULY } & \text { AJU } & \text { SEP } \\ 1974 & 8.78 & 9.27 & 7.50 & 4.28 & 3.82 & 3.91 & 3.72 & 3.72 & 2.68 & 1.48 & 0.80 & 0.75 \\ 1975 & 1.88 & 2.98 & 2.58 & 2.84 & 3.40 & 4.27 & 5.27 & 5.27 & 5.95 & 6.41 & 7.24 & 4.18 \\ 1976 & 1.88 & 2.87 & 3.30 & 2.84 & 3.52 & 3.05 & 4.09 & 6.05 & 7.75 & 5.92 & 2.77 & 2.12 \\ 1997 & 2.72 & 3.02 & 3.05 & 2.67 & 2.91 & 2.86 & 1.99 & 1.73 & 0.76 & 0.53 & 0.89 & 1.02 \\ 1978 & 1.51 & 2.09 & 2.34 & 2.39 & 2.74 & 4.06 & 6.58 & 16.8 & 25.0 & 9.95 & 7.99 & 7.84\end{array}$

ANNUAL PEAK DISCHARGE, IN GBIC FEET PER SECOND, AND CORRESPONDING GAGE HEIGHT, IN FEET, FOR EACH WATER YEAR

\begin{tabular}{|c|c|c|c|c|c|c|c|c|c|c|c|}
\hline $\begin{array}{l}\text { WATERR } \\
\text { YEAR }\end{array}$ & DATE & $\begin{array}{c}\text { GAGE } \\
\text { HEIGHT }\end{array}$ & $\begin{array}{c}\text { PEAK } \\
\text { DISCHARGE }\end{array}$ & $\begin{array}{l}\text { WATER } \\
\text { YEAR }\end{array}$ & DATE & $\begin{array}{c}\text { GAGE } \\
\text { HEIGHT }\end{array}$ & $\begin{array}{c}\text { PEAK } \\
\text { DISCHARGE }\end{array}$ & $\begin{array}{l}\text { WATER } \\
\text { YEAR }\end{array}$ & DATE & $\begin{array}{c}\text { GAGE } \\
\text { HEIGHT }\end{array}$ & $\begin{array}{c}\text { PEAK } \\
\text { DISCHARGE }\end{array}$ \\
\hline $\begin{array}{l}973 \\
974\end{array}$ & $\begin{array}{l}\text { MAY } 26,1973 \\
\text { OCT. } 30,1973\end{array}$ & - & $\begin{array}{l}30 \\
10\end{array}$ & $\begin{array}{l}1975 \\
1976\end{array}$ & $\begin{array}{ll}\text { JULY } 29,1975 \\
\text { JUNE } 04,1976\end{array}$ & $\begin{array}{l}2.40 \\
1.91\end{array}$ & $\begin{array}{l}15 \\
8.8\end{array}$ & $\begin{array}{l}1977 \\
1978\end{array}$ & $\begin{array}{l}\text { AUG. } 17,1977 \\
\text { JUNE } 04,1978\end{array}$ & $\begin{array}{l}1.55 \\
2.42\end{array}$ & 52 \\
\hline
\end{tabular}

09405420 NORTH FORR VIRGIN RIVER BELOW BULLOCH CANYON, NEAR GLENDALE, UT

LOCATION.-Lat $37^{\circ} 25^{\prime} 06^{\prime \prime}$, long $112^{\circ} 47^{\prime} 59^{\prime \prime}$, in SW $W_{4}^{1} \mathrm{NW}^{\frac{1}{4}} \mathrm{SE}_{\frac{1}{4}}^{\frac{1}{4}}$ sec.13, T.39 S., R.9 W., Kane County, Hydrologic Unit 15010008 , on left bank $200 \mathrm{ft}$ below Bulloch Canyon, $7.5 \mathrm{mi}$ south of Navajo Lake, $19 \mathrm{mi}$ from Navajo Lake turnoff at Utah Highway 14 , and $10 \mathrm{mi}$ northwest of Glendale.

DRAINAGE AREA. $-29.6 \mathrm{mi}^{2}$.

MEAN BASIN ELEVATION. $-7,670 \mathrm{ft}$.

PERIOD OF RECORD AVAILABLE.--October 1974 to September 1981.

REVISED RECORDS.-WDR UT-78-1: Drainage area.

GAGE.--Water-stage recorder. Altitude of gage is 6,420 ft from topographic map.

REMARKS.--Small diversion for irrigation above station.

AVERAGE DISCHARGE. --7 years, $18.6 \mathrm{ft}^{3} / \mathrm{s}, 13,480$ acre-ft/yr.

EXTREMES FOR PERIOD OF RECORD.--Maximum discharge estimated, $225 \mathrm{ft}^{3} / \mathrm{s}$ oct. 2, 1976, gage height unknown; minimum, $2.6 \mathrm{ft} /{ }^{3} / \mathrm{s}$ Aug. 3 , 1977.

EXIREMES OTSIDE PERIOD OF RECORD.--Maximum discharge determined before station was installed, 1,740 ft $3 / \mathrm{s}$ Sept. 9 , 1974, on basis

of slope-area measurement at gage height $7.44 \mathrm{ft}$ from high-water marks.

LOWEST MEAN DISCHARGE, IN OBBIC FEET PER SECOND, AND RANKING FOR THE INDICATED NUMBER OF CONSECUTIVE DAYS FOR EACH CLIMATIC YEAR, APRII 1-MARCH 31

\begin{tabular}{|c|c|c|c|c|c|c|c|c|c|c|c|c|c|c|c|c|c|c|c|}
\hline YEAR & & & & & & & & & coNs & UTIV & E DAYS & & & & & & & & \\
\hline $\begin{array}{l}1976 \\
1977 \\
1978 \\
1979 \\
1980\end{array}$ & $\begin{array}{r}5.90 \\
5.60 \\
2.90 \\
7.60 \\
13.0\end{array}$ & $\begin{array}{l}3 \\
2 \\
1 \\
4 \\
5\end{array}$ & $\begin{array}{r}5.90 \\
5.70 \\
2.90 \\
7.70 \\
14.0\end{array}$ & $\begin{array}{l}3 \\
2 \\
1 \\
4 \\
6\end{array}$ & $\begin{array}{r}5.90 \\
5.90 \\
3.00 \\
7.90 \\
14.0\end{array}$ & $\begin{array}{l}2 \\
3 \\
1 \\
4 \\
6\end{array}$ & $\begin{array}{r}6.00 \\
6.40 \\
3.30 \\
7.90 \\
14.0\end{array}$ & $\begin{array}{l}2 \\
3 \\
1 \\
4 \\
5\end{array}$ & $\begin{array}{r}6.30 \\
6.80 \\
3.80 \\
8.60 \\
14.0\end{array}$ & $\begin{array}{l}2 \\
3 \\
1 \\
4 \\
5\end{array}$ & $\begin{array}{r}6.50 \\
7.30 \\
4.00 \\
9.00 \\
15.0\end{array}$ & $\begin{array}{l}2 \\
3 \\
1 \\
4 \\
5\end{array}$ & $\begin{array}{r}7.00 \\
7.50 \\
4.20 \\
9.30 \\
16.0\end{array}$ & $\begin{array}{l}2 \\
3 \\
1 \\
4 \\
5\end{array}$ & $\begin{array}{r}7.30 \\
7.40 \\
4.20 \\
9.90 \\
16.0\end{array}$ & $\begin{array}{l}2 \\
3 \\
1 \\
4 \\
5\end{array}$ & $\begin{array}{r}8.00 \\
7.70 \\
4.70 \\
11.0 \\
17.0\end{array}$ & $\begin{array}{l}3 \\
2 \\
1 \\
4 \\
5\end{array}$ & $\begin{array}{c}12.0 \\
9.50 \\
7.70 \\
20.0 \\
33.0\end{array}$ \\
\hline & 13.0 & 6 & 13.0 & 5 & 13.0 & 5 & 14.0 & 6 & 16.0 & 6 & 17.0 & 6 & 17.0 & 6 & 18.0 & 6 & 18.0 & 6 & 33.0 \\
\hline
\end{tabular}


VIRGIN RIVER BASIN

09405420 NORTH FORK VIRGIN RIVER BELOW BULLOCH CANYON, NEAR GLENDALE, UI--Continued

HIGHEST MEAN DISCHARGE, IN OUBIC FEET PER SECOND, AND RANKING FOR THE INDICATED NUMBER OF CONSECOTIVE DAYS FOR EACH WATER YEAR, OCTCBER 1-SEPTEMBER 30

\begin{tabular}{|c|c|c|c|c|c|c|c|c|c|c|c|c|c|c|c|c|c|c|c|}
\hline YEAR & 1 & & 3 & & 7 & & 15 & & $\begin{array}{l}\text { CONST } \\
30\end{array}$ & & $\begin{array}{l}\text { E DAYS } \\
60\end{array}$ & & 90 & & 120 & & 183 & & ALL \\
\hline 1975 & 26.0 & 6 & 25.0 & 5 & 23.0 & 5 & 21.0 & 5 & 19.0 & 5 & 19.0 & 5 & 18.0 & 5 & 17.0 & 5 & 16.0 & 5 & 13.0 \\
\hline
\end{tabular}

DURATION OF DISCHARGE FOR EACH WATER YEAR

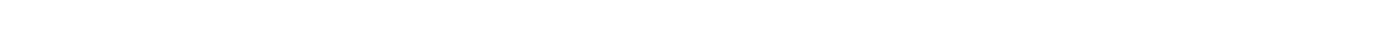

NUMBER OF DAYS IN CLASS $\quad$ OUBIC FEET $\begin{aligned} \text { PER SEOOND } & \text {-DAYS }\end{aligned}$

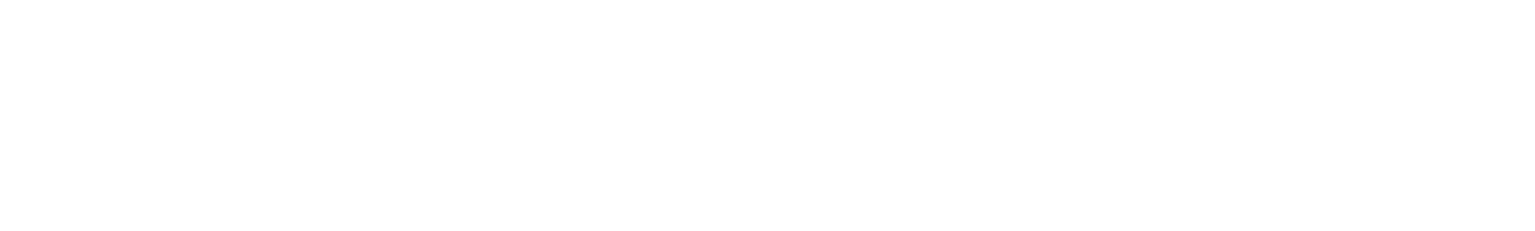

DURATION TABLE OF DISCHARGE FOR WATER YEARS 1975-81

\begin{tabular}{|c|c|c|c|c|c|c|c|c|c|c|c|c|c|c|c|c|c|c|c|}
\hline CLASS & $\begin{array}{c}\text { CUBIC } \\
\text { FEET } \\
\text { PER } \\
\text { SECOND }\end{array}$ & TOTAL & $\begin{array}{l}\text { ACOU- } \\
\text { MU- } \\
\text { LATED } \\
\text { DAYS }\end{array}$ & $\begin{array}{l}\text { PER } \\
\text { CENT } \\
\text { DAYS }\end{array}$ & C.ASS & $\begin{array}{c}\text { CUBIC } \\
\text { FEET } \\
\text { PER } \\
\text { SEOOND }\end{array}$ & $\begin{array}{r}\text { TOTAL } \\
\text { DAYS }\end{array}$ & $\begin{array}{c}\text { ACOU- } \\
\text { MU- } \\
\text { LATED } \\
\text { DAYS }\end{array}$ & $\begin{array}{l}\text { PER- } \\
\text { CENT } \\
\text { DAYS }\end{array}$ & & $\begin{array}{c}\text { OUBIC } \\
\text { FEET } \\
\text { PER } \\
\text { SECOND }\end{array}$ & $\begin{array}{r}\text { TOTAL } \\
\text { DAYS }\end{array}$ & $\begin{array}{c}\text { ACOU- } \\
\text { MU- } \\
\text { LATED } \\
\text { DAYS }\end{array}$ & $\begin{array}{l}\text { PER- } \\
\text { CENT } \\
\text { DAYS }\end{array}$ & CLASS & $\begin{array}{c}\text { CABIC } \\
\text { FEET } \\
\text { PER } \\
\text { SECOND }\end{array}$ & $\begin{array}{r}\text { TOTAL } \\
\text { DAYS }\end{array}$ & $\begin{array}{c}\text { ACOJ- } \\
\text { MU- } \\
\text { LATED } \\
\text { DAYS }\end{array}$ & $\begin{array}{l}\text { PER- } \\
\text { CENT } \\
\text { DAYS }\end{array}$ \\
\hline $\begin{array}{l}0 \\
1 \\
2 \\
3 \\
4 \\
5 \\
6 \\
7 \\
8\end{array}$ & $\begin{array}{l}0.00 \\
2.90 \\
3.30 \\
3.70 \\
4.20 \\
4.80 \\
5.50 \\
6.20 \\
7.00\end{array}$ & $\begin{array}{r}0 \\
8 \\
6 \\
43 \\
57 \\
32 \\
137 \\
131 \\
187\end{array}$ & $\begin{array}{l}2557 \\
2557 \\
2549 \\
2543 \\
2500 \\
2443 \\
2411 \\
2274 \\
2143\end{array}$ & $\begin{array}{r}100.0 \\
100.0 \\
99.7 \\
99.5 \\
97.8 \\
95.5 \\
94.3 \\
88.9 \\
83.8\end{array}$ & $\begin{array}{r}9 \\
10 \\
11 \\
12 \\
13 \\
14 \\
15 \\
16 \\
17\end{array}$ & $\begin{array}{r}8.00 \\
9.10 \\
10.00 \\
12.00 \\
13.00 \\
15.00 \\
17.00 \\
19.00 \\
22.00\end{array}$ & $\begin{array}{r}222 \\
141 \\
186 \\
106 \\
203 \\
197 \\
213 \\
208 \\
83\end{array}$ & $\begin{array}{r}1956 \\
1734 \\
1593 \\
1407 \\
1301 \\
1098 \\
901 \\
688 \\
480\end{array}$ & $\begin{array}{l}76.5 \\
67.8 \\
62.3 \\
55.0 \\
50.9 \\
42.9 \\
35.2 \\
26.9 \\
18.8\end{array}$ & $\begin{array}{l}18 \\
19 \\
20 \\
21 \\
22 \\
23 \\
24 \\
25 \\
26\end{array}$ & $\begin{array}{l}25.0 \\
28.0 \\
32.0 \\
37.0 \\
42.0 \\
47.0 \\
54.0 \\
61.0 \\
69.0\end{array}$ & $\begin{array}{l}53 \\
61 \\
48 \\
26 \\
37 \\
50 \\
25 \\
18 \\
17\end{array}$ & $\begin{array}{r}397 \\
344 \\
283 \\
235 \\
209 \\
172 \\
122 \\
97 \\
79\end{array}$ & $\begin{array}{r}15.5 \\
13.5 \\
11.1 \\
9.2 \\
8.2 \\
6.7 \\
4.8 \\
3.8 \\
3.1\end{array}$ & $\begin{array}{l}27 \\
28 \\
29 \\
30 \\
31 \\
32 \\
33 \\
34\end{array}$ & $\begin{array}{r}78.0 \\
89.0 \\
100.0 \\
110.0 \\
130.0 \\
150.0 \\
170.0 \\
190.0\end{array}$ & $\begin{array}{l}11 \\
11 \\
10 \\
21 \\
7 \\
0 \\
0 \\
2\end{array}$ & $\begin{array}{r}62 \\
51 \\
40 \\
30 \\
9 \\
2 \\
2 \\
2\end{array}$ & $\begin{array}{l}2.4 \\
2.0 \\
1.6 \\
1.2 \\
0.4 \\
0.1 \\
0.1 \\
0.1\end{array}$ \\
\hline
\end{tabular}

MONTHLY MEAN DISCHARGES, IN OUBIC FEET PER SECOND, FOR EACH WATER YEAR

\begin{tabular}{|c|c|c|c|c|c|c|c|c|c|c|c|c|}
\hline YEAR & $\infty T$ & NOV & $\mathrm{DEC}$ & JAN & FEB & MAR & APR & MAY & JUNE & JULY & AUSG & SEP \\
\hline 1975 & 6.95 & 9.62 & 8.98 & 9.69 & 11.8 & 14.2 & 17.3 & 18.5 & 18.4 & 14.9 & 11.7 & 8.81 \\
\hline $\begin{array}{l}1976 \\
1977 \\
1978 \\
1979 \\
1980\end{array}$ & $\begin{array}{r}6.80 \\
8.37 \\
4.72 \\
11.7 \\
16.1\end{array}$ & $\begin{array}{r}6.31 \\
8.39 \\
5.77 \\
11.5 \\
18.4\end{array}$ & $\begin{array}{r}8.85 \\
7.07 \\
6.17 \\
9.00 \\
16.5\end{array}$ & $\begin{array}{c}7.47 \\
7.52 \\
6.12 \\
9.29 \\
24.7\end{array}$ & $\begin{array}{r}9.75 \\
7.95 \\
8.94 \\
10.1 \\
62.1\end{array}$ & $\begin{array}{c}15.0 \\
7.14 \\
29.8 \\
28.3 \\
34.3\end{array}$ & $\begin{array}{c}16.1 \\
6.33 \\
47.9 \\
76.9 \\
74.0\end{array}$ & $\begin{array}{c}12.2 \\
6.92 \\
41.1 \\
61.5 \\
106\end{array}$ & $\begin{array}{c}13.5 \\
5.09 \\
25.9 \\
33.1 \\
33.7\end{array}$ & $\begin{array}{c}9.97 \\
3.81 \\
18.1 \\
16.7 \\
24.5\end{array}$ & $\begin{array}{c}7.24 \\
4.68 \\
13.2 \\
19.2 \\
19.8\end{array}$ & $\begin{array}{r}8.77 \\
4.06 \\
11.9 \\
15.1 \\
20.9\end{array}$ \\
\hline 1981 & 19.4 & 19.7 & 19.0 & 17.9 & 16.4 & 18.7 & 22.6 & 15.7 & 17.1 & 11.5 & 9.96 & 9.21 \\
\hline
\end{tabular}

ANNUAL PEAK DISCHARGE, IN CUBIC FEET PER SECOND, AND CORRESPONDING GAGE HEIGHT, IN FEET, FOR EACH WATER YEAR

\begin{tabular}{|c|c|c|c|c|c|c|c|c|c|c|c|}
\hline $\begin{array}{l}\text { WATERR } \\
\text { YEAR }\end{array}$ & DATE & $\begin{array}{c}\text { GAGE } \\
\text { HEIGHT }\end{array}$ & $\begin{array}{c}\text { PEAR } \\
\text { DISCHARGE }\end{array}$ & $\begin{array}{l}\text { WATERR } \\
\text { YEAR }\end{array}$ & DATE & $\begin{array}{c}\text { GAGE } \\
\text { HEIGHT }\end{array}$ & $\begin{array}{c}\text { PEAK } \\
\text { DISCHARGE }\end{array}$ & $\begin{array}{l}\text { WATER } \\
\text { YEAR }\end{array}$ & DATE & $\begin{array}{c}\text { GAGE } \\
\text { HEIGHT }\end{array}$ & $\begin{array}{c}\text { PEAK } \\
\text { DISCHARGE }\end{array}$ \\
\hline $\begin{array}{l}1974 \\
1975 \\
1976\end{array}$ & $\begin{array}{l}\text { SEPT.09, } 1974 \\
\text { JULY 13, } 1975 \\
\text { JULY 13， } 1976\end{array}$ & $\begin{array}{l}7.44 \\
5.60 \\
5.76\end{array}$ & $\begin{array}{r}1740 \\
178 \\
174\end{array}$ & $\begin{array}{l}1977 \\
1978 \\
1979\end{array}$ & $\begin{array}{l}\text { OCT. } 02,1976 \\
\text { MAR. 31, } 1978 \\
\text { APR. } 17,1979\end{array}$ & $\begin{array}{c}-- \\
5.23 \\
5.48\end{array}$ & $\begin{array}{r}225 \\
95 \\
204\end{array}$ & $\begin{array}{l}1980 \\
1981\end{array}$ & $\begin{array}{ll}\text { MAY } & 07,1980 \\
\text { OCT. } & 12,1980\end{array}$ & $\begin{array}{c}5.77 \\
-\end{array}$ & $\begin{array}{r}222 \\
80\end{array}$ \\
\hline
\end{tabular}


VIRGIN RIVER BASIN

09405450 NORTH FORK VIRGIN RIVER ABOVE ZION NARROWS, NEAR GLENDALE, UT

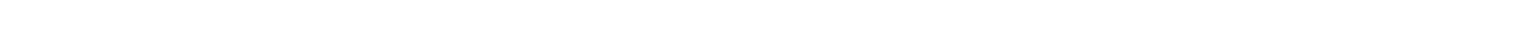
$300 \mathrm{ft}$ below diversion, $10 \mathrm{mi}$ south of Navajo Lake, $22.5 \mathrm{mi}$ fram Navajo Lake turnoff at Utah Highway 14 , and $13.5 \mathrm{mi}$ northwest of Glendale.

DRAINAGE AREA. $--45.5 \mathrm{mi}^{2}$.

PERIOD OF RECORD AVAIIABLE.---October 1978 to September 1981.

GAGE.--Water-stage recorder. Altitude of gage is 6,000 ft fram topographic map.

REMARKS.--Several small diversions for irrigation above station.

EXTREMES FOR PERIOD OF RECORD.-Maximum discharge, $130 \mathrm{ft}^{3} / \mathrm{s}$ Apr. 17, 1979, may have been exceeded by flood of Feb. 14, 1980, discharge unknown; minimum daily, $2.2 \mathrm{ft}^{3} / \mathrm{s}$ Aug. 12, 1981.

LOWEST MEAN DISCHARGE, IN CUBIC FEET PER SECOND, AND RANKING FOR THE INDICATED NUMBER OF CONSECUTIVE DAYS FOR EACH CIMATIC YEAR, APRII 1-MARCH 31

\begin{tabular}{|c|c|c|c|c|c|c|c|c|c|c|c|c|c|c|c|c|c|c|c|}
\hline YEAR & & & & & & & & & CONS & & E DAYS & & & & & & & & \\
\hline & 1 & & 3 & & 7 & & 14 & & 30 & & 60 & & 90 & & 120 & & 183 & & ALL \\
\hline 1980 & 13.0 & 1 & 14.0 & 2 & 14.0 & 1 & 14.0 & 1 & 15.0 & 1 & 16.0 & 1 & 17.0 & 1 & 17.0 & 1 & 18.0 & 1 & 35.0 \\
\hline
\end{tabular}

HIGHEST MEAN DISCHARGE, IN OUBIC FEET PER SECOND, AND RANKING FOR THE INDICATED NUMBER OF CONSECUTIVE DAYS FOR EACH WATER YEAR, OCTOBER 1-SEPTEMBER 30

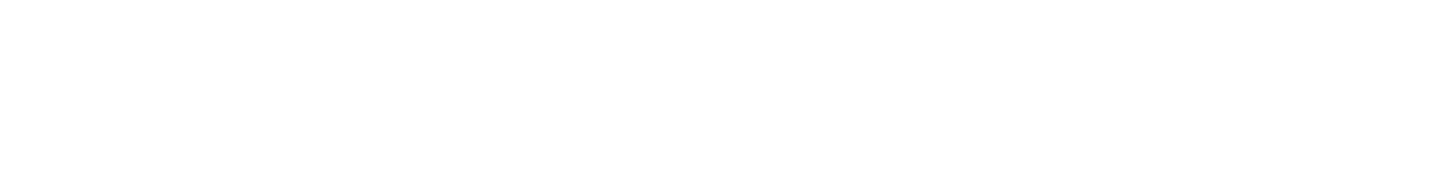

DURATION OF DISCHARGE FOR EACH WATER YEAR

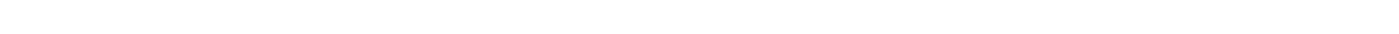
YEAR

NUMBER OF DAYS IN CLASS OBIC FEET -DAYS

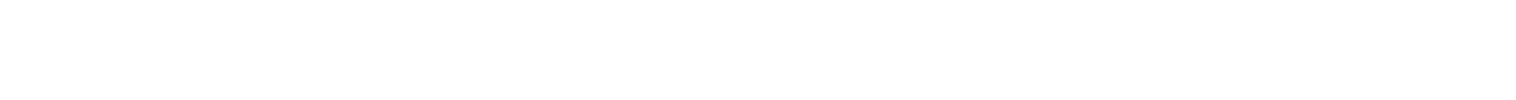

5708.7

DURATION TABLE OF DISCHARGE FOR WATER YEARS 1979-81

$\begin{array}{lcc}\text { OUBIC } & \text { ACOU- } & \\ \text { FEET } & \text { MU- } & \text { PER- } \\ \text { PER TOTAL LATED } & \text { CENT }\end{array}$

CIASS SECOND DAYS DAYS DAYS

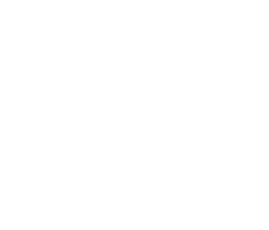

$\begin{array}{lll}\text { CUBIC } & \text { ACOU- } \\ \text { FEET } & \text { MU- } & \text { PER- } \\ \text { PER TOTAL LATED } & \text { CENT }\end{array}$

CLASS SECOND DAYS DAYS DAYS

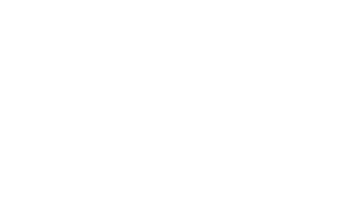
$\begin{array}{lll}\text { OBIIC } & \text { ACOU- } \\ \text { FEET } & \text { MU- } & \text { PER- } \\ \text { PER TOTAL LATED } & \text { CENT }\end{array}$ CLASS SECOND DAYS DAYS DAYS

$\begin{array}{rrrrr}18 & 21.0 & 100 & 422 & 38.5 \\ 19 & 24.0 & 40 & 322 & 29.4 \\ 20 & 27.0 & 44 & 282 & 25.7 \\ 21 & 31.0 & 34 & 238 & 21.7 \\ 22 & 35.0 & 33 & 204 & 18.6 \\ 23 & 40.0 & 21 & 171 & 15.6 \\ 24 & 46.0 & 18 & 150 & 13.7 \\ 25 & 52.0 & 23 & 132 & 12.0 \\ 26 & 59.0 & 20 & 109 & 9.9\end{array}$

MONIHLY MEAN DISCHARGES, IN CUBIC FEET PER SECOND, FOR EACH WATER YEAR

\begin{tabular}{|c|c|c|c|c|c|c|c|c|c|c|c|c|}
\hline YEAR & $\propto C T$ & NOV & $\mathrm{DEC}$ & JAN & FEBB & MAR & APR & MAY & JUNE & JULY & AUG & SEP \\
\hline $\begin{array}{l}1979 \\
1980\end{array}$ & $\begin{array}{l}14.9 \\
17.4\end{array}$ & $\begin{array}{l}15.2 \\
18.8\end{array}$ & $\begin{array}{l}12.0 \\
17.5\end{array}$ & $\begin{array}{l}11.4 \\
24.9\end{array}$ & $\begin{array}{l}11.8 \\
65.0\end{array}$ & $\begin{array}{l}33.3 \\
35.0\end{array}$ & $\begin{array}{l}85.7 \\
80.6\end{array}$ & $\begin{array}{l}68.4 \\
102\end{array}$ & $\begin{array}{l}37.5 \\
33.9\end{array}$ & $\begin{array}{l}19.4 \\
25.4\end{array}$ & $\begin{array}{l}21.8 \\
20.6\end{array}$ & $\begin{array}{l}15.2 \\
20.5\end{array}$ \\
\hline 1981 & 19.5 & 18.4 & 20.0 & 18.3 & 16.2 & 18.3 & 22.8 & 15.5 & 15.8 & 9.36 & 6.56 & 7.12 \\
\hline
\end{tabular}


LOCATION.-Lat $37^{\circ} 12^{\prime} 35^{\prime \prime}$, long $112^{\circ} 58^{\prime} 40^{\prime \prime}$, in $\mathrm{NW}^{\frac{1}{4}} \mathrm{SW} \mathrm{W}^{\frac{1}{4}} \mathrm{NW} \mathrm{W}^{\frac{1}{4}}$ sec.22, T.41 S., R.10 W., Washington County, Hydrologic Unit 15010008 , on right bank in $\mathrm{Z}$ ion National Park, $0.2 \mathrm{mi}$ downstream fram point of diversion of Springdale Canal, $0.5 \mathrm{mi}$ downstream fran Pine creek, and $1.9 \mathrm{mi}$ northeast of Springdale.

DRAINAGE AREA. $--344 \mathrm{mi}^{2}$.

MEAN BASIN Elevation. $--7,350 \mathrm{ft}$.

PERIOD OF RECORD AVAIIABLE.--May 1913 to June 1914 and June to October 1923 (monthly mean discharge only, published in wSP 1313), April to June and August to September 1925 (fragmentary), October 1925 to September 1981 (October 1926 to September 1927 , monthly mean discharge only, published in WSP 1313). Published as "Zion Creek near Springdale", 1913-14 (flow of Springdale Canal not included) and as "Mukuntuweap River near Springdale", 1923, 1925-32.

GAGE.--Water-stage recorder. Altitude of gage is 3,970 ft fran topographic map. May 13, 1913 to June 30, 1914, nonrecording gage at site $3.2 \mathrm{mi}$ downstream at different datum. June 6, 1923 to Dec. 14, 1949, nonrecording gages at several sites within $0.8 \mathrm{mi}$ of present site at various datums.

REMARKS.-Figures given herein include Springdale Canal, which diverts water in $\mathrm{NW}_{\frac{1}{4}} \mathrm{NW}^{\frac{1}{4}}$ sec.22, T.41 S., R.10 W., for irrigation in vicinity of Springdale. Diversion above station for irrigation of about 1,400 acres.

AVERAGE DISCHARGE.- -56 years, $102 \mathrm{ft}^{3} / \mathrm{s}, 73,900$ acre-ft/yr.

EXIREMES FOR PERIOD OF RECORD.- Maximum discharge, 9,150 $\mathrm{ft}^{3} / \mathrm{s} \mathrm{Dec} .6,1966$, gage height, $12.98 \mathrm{ft}$, fram rating curve extended above $2,000 \mathrm{ft}^{3} / \mathrm{s}$ on basis of drift measurement at gage height $6.7 \mathrm{ft}$ and a slope-area measurement at gage height $10.25 \mathrm{ft} ; \mathrm{minimum}$ observed, $20 \mathrm{ft}^{3} / \mathrm{s}$ July $31,1963$.

LONEST MEAN DISCHARGE, IN OUBIC FEET PER SECOND, AND RANKING FOR THE INDICATED NUMBER OF CONSECUTIVE DAYS
FOR EACH CLIMATIC YEAR, APRIL 1-MARCH 31

YEAR

1929

1930

1931

1932

1934

1936

1936
1937

1938
1939

1940

194

1943

1945

1946

1947

1948

1950

195

1952
1953
1954

1954

1956

1957

1958

1959
1960

1961

1962

1964

1965

1966

1967

1969

1970

\begin{tabular}{|c|c|c|c|c|c|c|c|c|c|c|c|c|c|c|c|c|c|c|c|}
\hline 1 & & 3 & & 7 & & 14 & & $\begin{array}{l}\text { CONS } \\
30\end{array}$ & & $\begin{array}{l}\text { DAYS } \\
60\end{array}$ & & 90 & & 120 & & 183 & & ALL & \\
\hline $\begin{array}{l}24.0 \\
37.0\end{array}$ & $\begin{array}{r}2 \\
36\end{array}$ & $\begin{array}{l}27.0 \\
40.0\end{array}$ & $\begin{array}{r}6 \\
40\end{array}$ & $\begin{array}{l}27.0 \\
41.0\end{array}$ & $\begin{array}{r}3 \\
34\end{array}$ & $\begin{array}{l}28.0 \\
42.0\end{array}$ & $\begin{array}{r}2 \\
34\end{array}$ & $\begin{array}{l}28.0 \\
44.0\end{array}$ & $\begin{array}{r}1 \\
35\end{array}$ & $\begin{array}{l}31.0 \\
44.0\end{array}$ & $\begin{array}{r}4 \\
25\end{array}$ & $\begin{array}{l}32.0 \\
46.0\end{array}$ & $\begin{array}{r}3 \\
24\end{array}$ & $\begin{array}{l}34.0 \\
49.0\end{array}$ & $\begin{array}{r}3 \\
24\end{array}$ & $\begin{array}{l}35.0 \\
52.0\end{array}$ & $\begin{array}{r}3 \\
24\end{array}$ & $\begin{array}{l}65.0 \\
87.0\end{array}$ & $\begin{array}{l}15 \\
28\end{array}$ \\
\hline $\begin{array}{l}34.0 \\
33.0 \\
48.0 \\
38.0 \\
34.0\end{array}$ & $\begin{array}{l}25 \\
19 \\
51 \\
37 \\
26\end{array}$ & $\begin{array}{l}36.0 \\
33.0 \\
49.0 \\
38.0 \\
34.0\end{array}$ & $\begin{array}{l}26 \\
16 \\
50 \\
33 \\
21\end{array}$ & $\begin{array}{l}37.0 \\
34.0 \\
49.0 \\
38.0 \\
35.0\end{array}$ & $\begin{array}{l}23 \\
16 \\
48 \\
30 \\
19\end{array}$ & $\begin{array}{l}40.0 \\
35.0 \\
50.0 \\
38.0 \\
35.0\end{array}$ & $\begin{array}{l}29 \\
16 \\
47 \\
23 \\
17\end{array}$ & $\begin{array}{l}40.0 \\
35.0 \\
50.0 \\
40.0 \\
37.0\end{array}$ & $\begin{array}{l}21 \\
14 \\
45 \\
22 \\
17\end{array}$ & $\begin{array}{l}46.0 \\
36.0 \\
55.0 \\
41.0 \\
37.0\end{array}$ & $\begin{array}{l}28 \\
10 \\
48 \\
19 \\
11\end{array}$ & $\begin{array}{l}49.0 \\
40.0 \\
58.0 \\
43.0 \\
38.0\end{array}$ & $\begin{array}{r}28 \\
12 \\
49 \\
19 \\
9\end{array}$ & $\begin{array}{l}50.0 \\
43.0 \\
59.0 \\
44.0 \\
39.0\end{array}$ & $\begin{array}{r}25 \\
16 \\
46 \\
17 \\
6\end{array}$ & $\begin{array}{l}53.0 \\
43.0 \\
60.0 \\
48.0 \\
41.0\end{array}$ & $\begin{array}{r}25 \\
10 \\
43 \\
18 \\
5\end{array}$ & $\begin{array}{c}76.0 \\
62.0 \\
166 \\
84.0 \\
54.0\end{array}$ & $\begin{array}{r}20 \\
12 \\
46 \\
25 \\
4\end{array}$ \\
\hline $\begin{array}{l}38.0 \\
33.0 \\
50.0 \\
41.0 \\
31.0\end{array}$ & $\begin{array}{l}38 \\
20 \\
52 \\
46 \\
16\end{array}$ & $\begin{array}{l}39.0 \\
33.0 \\
51.0 \\
48.0 \\
34.0\end{array}$ & $\begin{array}{l}37 \\
17 \\
51 \\
49 \\
18\end{array}$ & $\begin{array}{l}42.0 \\
34.0 \\
52.0 \\
50.0 \\
37.0\end{array}$ & $\begin{array}{l}38 \\
17 \\
51 \\
49 \\
24\end{array}$ & $\begin{array}{l}44.0 \\
35.0 \\
56.0 \\
51.0 \\
38.0\end{array}$ & $\begin{array}{l}38 \\
18 \\
51 \\
49 \\
24\end{array}$ & $\begin{array}{l}45.0 \\
36.0 \\
58.0 \\
55.0 \\
40.0\end{array}$ & $\begin{array}{l}36 \\
15 \\
51 \\
49 \\
23\end{array}$ & $\begin{array}{l}48.0 \\
44.0 \\
62.0 \\
55.0 \\
43.0\end{array}$ & $\begin{array}{l}33 \\
26 \\
52 \\
49 \\
23\end{array}$ & $\begin{array}{l}49.0 \\
52.0 \\
64.0 \\
56.0 \\
45.0\end{array}$ & $\begin{array}{l}29 \\
39 \\
52 \\
44 \\
22\end{array}$ & $\begin{array}{l}50.0 \\
52.0 \\
65.0 \\
57.0 \\
53.0\end{array}$ & $\begin{array}{l}26 \\
32 \\
51 \\
43 \\
37\end{array}$ & $\begin{array}{l}55.0 \\
57.0 \\
68.0 \\
59.0 \\
60.0\end{array}$ & $\begin{array}{l}30 \\
33 \\
51 \\
38 \\
39\end{array}$ & $\begin{array}{l}125 \\
97.0 \\
204 \\
140 \\
78.0\end{array}$ & $\begin{array}{l}41 \\
33 \\
51 \\
43 \\
21\end{array}$ \\
\hline $\begin{array}{l}30.0 \\
56.0 \\
44.0 \\
28.0 \\
40.0\end{array}$ & $\begin{array}{r}15 \\
53 \\
49 \\
9 \\
44\end{array}$ & $\begin{array}{l}30.0 \\
57.0 \\
44.0 \\
36.0 \\
42.0\end{array}$ & $\begin{array}{l}12 \\
53 \\
46 \\
27 \\
43\end{array}$ & $\begin{array}{l}32.0 \\
58.0 \\
45.0 \\
38.0 \\
42.0\end{array}$ & $\begin{array}{l}12 \\
53 \\
44 \\
31 \\
39\end{array}$ & $\begin{array}{l}33.0 \\
59.0 \\
45.0 \\
39.0 \\
42.0\end{array}$ & $\begin{array}{l}11 \\
53 \\
39 \\
27 \\
35\end{array}$ & $\begin{array}{l}34.0 \\
68.0 \\
47.0 \\
41.0 \\
43.0\end{array}$ & $\begin{array}{l}11 \\
53 \\
40 \\
28 \\
31\end{array}$ & $\begin{array}{l}38.0 \\
72.0 \\
52.0 \\
50.0 \\
46.0\end{array}$ & $\begin{array}{l}13 \\
53 \\
43 \\
39 \\
29\end{array}$ & $\begin{array}{l}42.0 \\
77.0 \\
57.0 \\
49.0 \\
49.0\end{array}$ & $\begin{array}{l}13 \\
53 \\
47 \\
30 \\
31\end{array}$ & $\begin{array}{l}50.0 \\
79.0 \\
60.0 \\
53.0 \\
52.0\end{array}$ & $\begin{array}{l}27 \\
53 \\
48 \\
38 \\
33\end{array}$ & $\begin{array}{l}62.0 \\
91.0 \\
60.0 \\
54.0 \\
54.0\end{array}$ & $\begin{array}{l}46 \\
53 \\
40 \\
27 \\
28\end{array}$ & $\begin{array}{c}85.0 \\
204 \\
139 \\
89.0 \\
121\end{array}$ & $\begin{array}{l}27 \\
52 \\
42 \\
29 \\
39\end{array}$ \\
\hline $\begin{array}{l}35.0 \\
29.0 \\
35.0 \\
30.0 \\
39.0\end{array}$ & $\begin{array}{l}27 \\
12 \\
28 \\
13 \\
41\end{array}$ & $\begin{array}{l}35.0 \\
29.0 \\
37.0 \\
31.0 \\
40.0\end{array}$ & $\begin{array}{l}22 \\
10 \\
28 \\
13 \\
38\end{array}$ & $\begin{array}{l}36.0 \\
29.0 \\
39.0 \\
33.0 \\
41.0\end{array}$ & $\begin{array}{r}20 \\
9 \\
32 \\
13 \\
35\end{array}$ & $\begin{array}{l}37.0 \\
30.0 \\
41.0 \\
34.0 \\
42.0\end{array}$ & $\begin{array}{r}20 \\
8 \\
30 \\
13 \\
36\end{array}$ & $\begin{array}{l}41.0 \\
32.0 \\
44.0 \\
37.0 \\
43.0\end{array}$ & $\begin{array}{r}29 \\
8 \\
32 \\
18 \\
30\end{array}$ & $\begin{array}{l}50.0 \\
37.0 \\
49.0 \\
39.0 \\
47.0\end{array}$ & $\begin{array}{l}40 \\
12 \\
34 \\
14 \\
32\end{array}$ & $\begin{array}{l}53.0 \\
42.0 \\
49.0 \\
42.0 \\
49.0\end{array}$ & $\begin{array}{l}40 \\
14 \\
32 \\
15 \\
33\end{array}$ & $\begin{array}{l}54.0 \\
42.0 \\
51.0 \\
41.0 \\
53.0\end{array}$ & $\begin{array}{l}39 \\
13 \\
29 \\
10 \\
34\end{array}$ & $\begin{array}{l}58.0 \\
58.0 \\
51.0 \\
42.0 \\
55.0\end{array}$ & $\begin{array}{r}34 \\
35 \\
23 \\
8 \\
31\end{array}$ & $\begin{array}{r}98.0 \\
78.0 \\
91.0 \\
74.0 \\
117\end{array}$ & $\begin{array}{l}34 \\
22 \\
30 \\
19 \\
37\end{array}$ \\
\hline $\begin{array}{l}36.0 \\
35.0 \\
43.0 \\
35.0 \\
36.0\end{array}$ & $\begin{array}{l}32 \\
29 \\
47 \\
30 \\
33\end{array}$ & $\begin{array}{l}37.0 \\
35.0 \\
45.0 \\
35.0 \\
37.0\end{array}$ & $\begin{array}{l}29 \\
23 \\
47 \\
24 \\
30\end{array}$ & $\begin{array}{l}37.0 \\
36.0 \\
50.0 \\
35.0 \\
38.0\end{array}$ & $\begin{array}{l}25 \\
21 \\
50 \\
18 \\
26\end{array}$ & $\begin{array}{l}38.0 \\
37.0 \\
52.0 \\
35.0 \\
38.0\end{array}$ & $\begin{array}{l}25 \\
21 \\
50 \\
14 \\
26\end{array}$ & $\begin{array}{l}40.0 \\
38.0 \\
52.0 \\
36.0 \\
40.0\end{array}$ & $\begin{array}{l}24 \\
19 \\
48 \\
16 \\
25\end{array}$ & $\begin{array}{l}41.0 \\
42.0 \\
53.0 \\
40.0 \\
46.0\end{array}$ & $\begin{array}{l}20 \\
21 \\
46 \\
17 \\
30\end{array}$ & $\begin{array}{l}42.0 \\
44.0 \\
56.0 \\
43.0 \\
48.0\end{array}$ & $\begin{array}{l}16 \\
21 \\
45 \\
20 \\
25\end{array}$ & $\begin{array}{l}44.0 \\
45.0 \\
57.0 \\
44.0 \\
48.0\end{array}$ & $\begin{array}{l}18 \\
20 \\
44 \\
19 \\
22\end{array}$ & $\begin{array}{l}46.0 \\
47.0 \\
58.0 \\
47.0 \\
49.0\end{array}$ & $\begin{array}{l}12 \\
13 \\
36 \\
14 \\
19\end{array}$ & $\begin{array}{c}73.0 \\
61.0 \\
186 \\
56.0 \\
84.0\end{array}$ & $\begin{array}{r}18 \\
10 \\
48 \\
6 \\
26\end{array}$ \\
\hline $\begin{array}{l}26.0 \\
28.0 \\
36.0 \\
33.0 \\
33.0\end{array}$ & $\begin{array}{r}5 \\
10 \\
34 \\
21 \\
22\end{array}$ & $\begin{array}{l}26.0 \\
28.0 \\
37.0 \\
38.0 \\
34.0\end{array}$ & $\begin{array}{r}4 \\
7 \\
31 \\
34 \\
19\end{array}$ & $\begin{array}{l}27.0 \\
28.0 \\
38.0 \\
45.0 \\
37.0\end{array}$ & $\begin{array}{r}4 \\
7 \\
27 \\
45 \\
22\end{array}$ & $\begin{array}{l}28.0 \\
28.0 \\
41.0 \\
48.0 \\
37.0\end{array}$ & $\begin{array}{r}3 \\
4 \\
31 \\
44 \\
22\end{array}$ & $\begin{array}{l}29.0 \\
28.0 \\
47.0 \\
51.0 \\
38.0\end{array}$ & $\begin{array}{r}5 \\
2 \\
41 \\
46 \\
20\end{array}$ & $\begin{array}{l}31.0 \\
30.0 \\
53.0 \\
52.0 \\
40.0\end{array}$ & $\begin{array}{r}5 \\
1 \\
47 \\
44 \\
18\end{array}$ & $\begin{array}{l}37.0 \\
31.0 \\
56.0 \\
55.0 \\
42.0\end{array}$ & $\begin{array}{r}7 \\
1 \\
46 \\
43 \\
17\end{array}$ & $\begin{array}{l}41.0 \\
32.0 \\
59.0 \\
57.0 \\
43.0\end{array}$ & $\begin{array}{r}11 \\
1 \\
47 \\
45 \\
14\end{array}$ & $\begin{array}{l}47.0 \\
34.0 \\
60.0 \\
60.0 \\
45.0\end{array}$ & $\begin{array}{r}15 \\
1 \\
41 \\
42 \\
11\end{array}$ & $\begin{array}{r}61.0 \\
52.0 \\
93.0 \\
155 \\
54.0\end{array}$ & $\begin{array}{r}11 \\
2 \\
31 \\
45 \\
3\end{array}$ \\
\hline $\begin{array}{l}27.0 \\
26.0 \\
33.0 \\
25.0 \\
32.0\end{array}$ & $\begin{array}{r}7 \\
6 \\
23 \\
4 \\
17\end{array}$ & $\begin{array}{l}28.0 \\
26.0 \\
35.0 \\
25.0 \\
32.0\end{array}$ & $\begin{array}{r}8 \\
5 \\
25 \\
2 \\
14\end{array}$ & $\begin{array}{l}28.0 \\
27.0 \\
38.0 \\
26.0 \\
33.0\end{array}$ & $\begin{array}{r}8 \\
5 \\
28 \\
2 \\
14\end{array}$ & $\begin{array}{l}29.0 \\
29.0 \\
42.0 \\
28.0 \\
33.0\end{array}$ & $\begin{array}{r}6 \\
7 \\
32 \\
5 \\
12\end{array}$ & $\begin{array}{l}29.0 \\
33.0 \\
44.0 \\
28.0 \\
33.0\end{array}$ & $\begin{array}{r}6 \\
9 \\
33 \\
3 \\
10\end{array}$ & $\begin{array}{l}31.0 \\
34.0 \\
46.0 \\
31.0 \\
34.0\end{array}$ & $\begin{array}{r}2 \\
7 \\
31 \\
3 \\
8\end{array}$ & $\begin{array}{l}34.0 \\
39.0 \\
46.0 \\
37.0 \\
37.0\end{array}$ & $\begin{array}{r}4 \\
10 \\
23 \\
5 \\
6\end{array}$ & $\begin{array}{l}36.0 \\
40.0 \\
47.0 \\
42.0 \\
39.0\end{array}$ & $\begin{array}{r}4 \\
7 \\
21 \\
12 \\
5\end{array}$ & $\begin{array}{l}41.0 \\
49.0 \\
51.0 \\
43.0 \\
42.0\end{array}$ & $\begin{array}{r}6 \\
20 \\
21 \\
9 \\
7\end{array}$ & $\begin{array}{c}55.0 \\
63.0 \\
100 \\
51.0 \\
68.0\end{array}$ & $\begin{array}{r}5 \\
13 \\
35 \\
1 \\
16\end{array}$ \\
\hline $\begin{array}{l}39.0 \\
35.0 \\
40.0 \\
43.0 \\
38.0\end{array}$ & $\begin{array}{l}42 \\
31 \\
43 \\
48 \\
39\end{array}$ & $\begin{array}{l}41.0 \\
39.0 \\
43.0 \\
47.0 \\
40.0\end{array}$ & $\begin{array}{l}41 \\
35 \\
44 \\
48 \\
39\end{array}$ & $\begin{array}{l}43.0 \\
42.0 \\
46.0 \\
48.0 \\
43.0\end{array}$ & $\begin{array}{l}40 \\
36 \\
46 \\
47 \\
41\end{array}$ & $\begin{array}{l}45.0 \\
45.0 \\
48.0 \\
50.0 \\
48.0\end{array}$ & $\begin{array}{l}40 \\
41 \\
45 \\
48 \\
46\end{array}$ & $\begin{array}{l}48.0 \\
45.0 \\
49.0 \\
51.0 \\
56.0\end{array}$ & $\begin{array}{l}42 \\
37 \\
43 \\
47 \\
50\end{array}$ & $\begin{array}{l}50.0 \\
51.0 \\
51.0 \\
53.0 \\
57.0\end{array}$ & $\begin{array}{l}35 \\
41 \\
42 \\
45 \\
50\end{array}$ & $\begin{array}{l}58.0 \\
53.0 \\
51.0 \\
53.0 \\
59.0\end{array}$ & $\begin{array}{l}48 \\
41 \\
34 \\
42 \\
50\end{array}$ & $\begin{array}{l}66.0 \\
55.0 \\
52.0 \\
54.0 \\
61.0\end{array}$ & $\begin{array}{l}52 \\
42 \\
30 \\
40 \\
49\end{array}$ & $\begin{array}{l}66.0 \\
59.0 \\
61.0 \\
73.0 \\
62.0\end{array}$ & $\begin{array}{l}49 \\
37 \\
44 \\
52 \\
47\end{array}$ & $\begin{array}{l}120 \\
109 \\
97.0 \\
122 \\
192\end{array}$ & $\begin{array}{l}38 \\
36 \\
32 \\
40 \\
49\end{array}$ \\
\hline
\end{tabular}


VIRGIN RIVER BASIN

09405500 NORTH FORK VIRGIN RIVER NEAR SPRINGDALE, UT-Continued

LOWEST MEAN DISCHARGE, IN CUBIC FEET PER SECOND, AND RANKING FOR THE INDICATED NUMBER OF CONSEAUTIVE DAYS FOR EACH CLIMATIC YEAR, APRII 1-MARCH 31--Continued

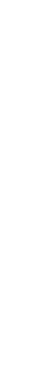

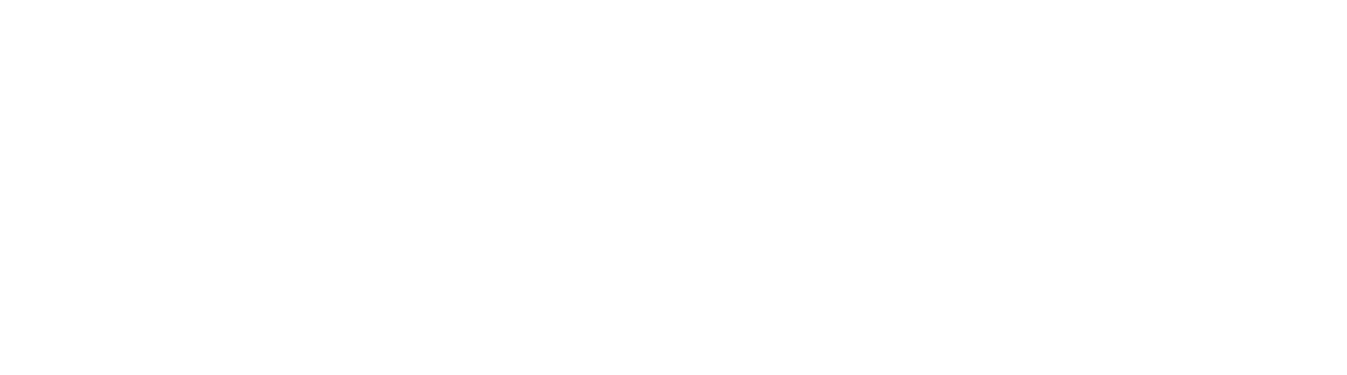

HIGHEST MEAN DISCHARGE, IN CUBIC FEET PER SECOND, AND RANKING FOR THE INDICATED NUMBER OF CONSECUTIVE DAYS FOR EACH WATER YEAR, OCTOBER l-SEPTEMBER 30

YEAR

$\begin{array}{lllllllll}1926 & 710 & 27 & 660 & 16 & 601 & 15 & 504 & 17\end{array}$

1928750

1930428

$\begin{array}{lllllll}1931 & 1140 & 15 & 536 & 25 & 282 & 37\end{array}$

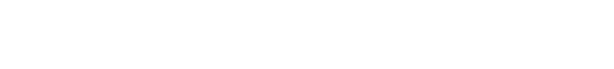

$\begin{array}{rrrrrrrrr}1933 & 759 & 24 & 473 & 31 & 434 & 24 & 366 & 25 \\ 1934 & 192 & 53 & 110 & 55 & 93.0 & 54 & 90.0 & 54 \\ 1935 & 1030 & 16 & 604 & 19 & 542 & 18 & 475 & 18\end{array}$

$\begin{array}{rrrrrrrr}1936 & 620 & 31 & 502 & 28 & 461 & 21 & 394 \\ 1937 & 2070 & 4 & 1740 & 3 & 1510 & 2 & 1290\end{array}$

19383000

19391400

19401000

$19412000 \quad 5 \quad 1640$

$\begin{array}{rrrrrr}1942 & 1180 & 14 & 1640 & 4 & 1500\end{array}$

$1943 \quad 734$

1945482

1947

1949655

1951393

$\begin{array}{rrrrrr}1951 & 393 & 43 & 186 & 48 & 123 \\ 1952 & 1600 & 6 & 1570 & 5 & 1450\end{array}$

$\begin{array}{llllll}1954 & 565 & 34 & 562 & 21 & 541\end{array}$

$\begin{array}{llll}1955 \quad 602 & 32 & 286\end{array}$

$1956 \quad 304 \quad 50 \quad 212$

$\begin{array}{llll}1957 & 391 & 44 & 309\end{array}$

$\begin{array}{lllr}1958 & 1290 & 10 & 1040\end{array}$

$\begin{array}{lllr}1959 & 311 & 49 & 157 \\ 1960 & 161 & 54 & 148\end{array}$

$1961 \quad 1300$

$\begin{array}{rrrr}1962 & 1300 & 9 & 560\end{array}$

$\begin{array}{llll}1963 & 386 & 45 & 667\end{array}$

$\begin{array}{llll}1964 & 338 & 48 & 329\end{array}$

$\begin{array}{llll}1965 & 884 & 21 & 531\end{array}$

$\begin{array}{llll}1966 \quad 538 \quad 36 & 431\end{array}$

$\begin{array}{llll}1967 & 4990 & 1 & 2350\end{array}$

$\begin{array}{rrrr}1968 & 600 & 33 & 499 \\ 1969 & 1270 & 11 & 1200\end{array}$

$\begin{array}{rrrr}1970 & 483 & 39 & 332\end{array}$

$475 \quad 18$ $\begin{array}{rr}2 & 1290 \\ 11 & 781\end{array}$

33251

$3 \quad 1270$

$\begin{array}{ll}8 & -17 \\ 30 & 446 \\ 1 & 844\end{array}$

$\begin{array}{ll}16 & 531 \\ 12 & 401\end{array}$

$\begin{array}{ll}12 & 686 \\ 25 & 427\end{array}$

$\begin{array}{ll}434 & 25 \\ & 45\end{array}$

20

$\begin{array}{ll}45 & 151 \\ 28 & 354 \\ 29 & 318 \\ 17 & 508\end{array}$

$\begin{array}{rr}51 & 111 \\ 4 & 1280 \\ 53 & \end{array}$

$\begin{array}{ll}21 & 541 \\ 44 & 150\end{array}$

$\begin{array}{rr}47 & 150 \\ 42 & 282\end{array}$

$\begin{array}{rr}42 & 282 \\ 11 & 1000\end{array}$

$\begin{array}{ll}47 & 14 \\ 38 & 27 \\ 10 & 858 \\ 50 & 103 \\ 49 & 128\end{array}$

52

$\begin{array}{llll}22 & 266 & 41 & 146 \\ 15 & 644 & 14 & 576 \\ 50 & 144 & 48 & 120\end{array}$ $\begin{array}{llll}26 & 502 & 20 & 416\end{array}$

$\begin{array}{rr}34 & 373 \\ 1 & 1110 \\ 29 & 403\end{array}$

$\begin{array}{rr}29 & 403 \\ 9 & 1170\end{array}$

$\begin{array}{rr}30 & 344 \\ 9 & 561 \\ 27 & 36 \\ 5 & 1080\end{array}$

$\begin{array}{rr}5 & 1080 \\ 44 & 145\end{array}$
CONSECUTIVE DAYS

$30 \quad 60 \quad 90$

120

183

ALL

$13 \quad 372$

16

$277 \quad 16 \quad 226$

$\begin{array}{llllllll}154 & 33 & 133 & 32 & 109 & 32 & 83.0 & 30\end{array}$

$\begin{array}{lllll}49 & 36 & 213 & 35 & 177\end{array}$

$\begin{array}{rrrr}24 & 305 & 26 & 202 \\ 1 & 997 & 2 & 737\end{array}$

$\begin{array}{crcr}97.0 & 49 & 80.0 & 51 \\ 758 & 8 & 580 & 8 \\ 289 & 28 & 205 & 27 \\ 86.0 & 53 & 79.0 & 52\end{array}$

$\begin{array}{lll}159 & 30 & 137\end{array}$

$\begin{array}{ll}74.0 & 50 \\ 451 & \\ 168 & \\ 73.0 & \end{array}$

80771

$\begin{array}{rrrrrr}73.0 & 48 & 69.0 & 47 & 58.0 & 46 \\ 71 & 8 & 276 & 8 & 165 & 8\end{array}$ $\begin{array}{rrrrrr}67.0 & 53 & 120 & 29 & 91.0 & 26 \\ 252 & 14 & 189 & 14 & 50.0 & 54\end{array}$

$\begin{array}{lllllll}8 & 148 & 27 & 129 & 25 & 89.0 & 27\end{array}$

10648

$\begin{array}{llll}35 & 173 & 39 & 150 \\ & 193 & 38 & 161\end{array}$

$\begin{array}{rr}28 & 165 \\ 4 & 550\end{array}$

$\begin{array}{rrr}550 & 28 & 148\end{array}$

$\begin{array}{llllll}148 & 27 & 129 & 25 & 89.0 & 27\end{array}$

$\begin{array}{rrrr}3 & 991 & 5 & 692 \\ 15 & 471 & 15 & 413\end{array}$

38

11342

$\begin{array}{ccccccc}38 & 108 & 38 & 96.0 & 37 & 78.0 & 35 \\ 36 & 118 & 36 & 102 & 35 & 81.0 & 32\end{array}$

$\begin{array}{llll}11 & 580 & 21 & 243 \\ 20 & 363 & 19 & 395\end{array}$

$\begin{array}{rrrr}6 & 527 & 6 & 434 \\ 12 & 329 & 12 & 270 \\ 23 & 222 & 21 & 189 \\ 13 & 309 & 13 & 254\end{array}$

\begin{tabular}{rrr}
6 & 328 \\
\hline & 12 & 204 \\
4 & 21 & 146 \\
13 & 190
\end{tabular}

31

$\begin{array}{llll}43 & 138 & 41 & 113 \\ 27 & 314 & 23 & 269\end{array}$

$\begin{array}{llll}16 & 467 & 16 & 375\end{array}$

21.0319

$\begin{array}{lll}41 & 97.0 & 41 \\ 20 & 227 & 19 \\ 30 & 158 & 31 \\ 15 & 284 & 15\end{array}$$$
87.0
$$

$\begin{array}{llll}39 & 13 & 121 & 14\end{array}$

\begin{abstract}
$40 \quad 240$
21
\end{abstract}

$50 \quad 99.0$

$\begin{array}{lll}375 & 15 & 284 \\ 177 & 34 & 149\end{array}$

$\begin{array}{ccccccc}19 & 190 & 20 & 148 & 21 & 109 & 18 \\ 31 & 132 & 33 & 106 & 34 & 76.0 & 36 \\ 15 & 230 & 15 & 170 & 16 & 108 & 19 \\ 34 & 131 & 34 & 109 & 33 & 81.0 & 33\end{array}$

$\begin{array}{ll}19 & 45.0 \\ 46 & 139\end{array}$

$\begin{array}{rrrr}53 & 85.0 & 54 & 7\end{array}$

$\begin{array}{lr}85.0 & 48 \\ 767 & 1 \\ 79.0 & 53\end{array}$

77.0

$\begin{array}{lrrrcrrrr}77.0 & 48 & 71.0 & 49 & 64.0 & 51 & 55.0 & 51 \\ 570 & 3 & 447 & 4 & 317 & 6 & 186 & 6 \\ 73.0 & 52 & 69.0 & 50 & 67.0 & 48 & 58.0 & 47\end{array}$

$\begin{array}{lll}19 & 349 & 20 \\ 47 & 132 & 42\end{array}$

235

$\begin{array}{rrr}46 & 124 & 44 \\ 33 & 248 & 32 \\ 9 & 751 & 9\end{array}$

$44 \quad 95.0$

$44 \quad 107 \quad 44$ $\begin{array}{cccccccc}73.0 & 52 & 69.0 & 50 & 67.0 & 48 & 58.0 & 47 \\ 180 & 25 & 151 & 25 & 121 & 27 & 84.0 & 28\end{array}$ $\begin{array}{rrrrrrrr}96.0 & 42 & 88.0 & 41 & 76.0 & 44 & 64.0 & 28\end{array}$

$\begin{array}{ccccc}13 & 478 & 51 & 82.0 & 50 \\ 49 & 96.0 & 50 & 332 & 17 \\ 34.0 & 49\end{array}$

$\begin{array}{llllll}34 & 200 & 36 & 169 & 36 & 135\end{array}$

$\begin{array}{rr}28 & 314 \\ 14 & 306 \\ 26 & 317 \\ 5 & 994\end{array}$

$\begin{array}{rr}24 & 250 \\ 25 & 214 \\ 22 & 271 \\ 3 & 765\end{array}$

$\begin{array}{llllllllll}250 & 22 & 201 & 23 & 166 & 23 & 134 & 24 & 98.0 & 24\end{array}$

$45 \quad 118$

$\begin{array}{rrr}3 & 765 & 2 \\ 45 & 94.0 & 45\end{array}$ 
VIRGIN RIVER BASIN

09405500 NORIH FORK VIRGIN RIVER NEAR SPRINGDALE, UT-Continued

HIGHEST MEAN DISCHARGE, IN CUBIC FEET PER SECOND, AND RANKING FOR THE INDICATED NUMBER OF CONSEOUTIVE DAYS FOR EAOH WATER YEAR, OCTOBER I-SEPTEMBER 30-Continued

\begin{tabular}{|c|c|c|c|c|c|c|c|c|c|c|c|c|c|c|c|c|c|c|c|c|}
\hline EAR & I & & 3 & & 7 & & 15 & & $\begin{array}{l}\text { CONS } \\
30\end{array}$ & & $\begin{array}{c}E \text { DAYS } \\
60\end{array}$ & & 90 & & 120 & & 183 & & ALC & \\
\hline $\begin{array}{l}971 \\
972 \\
973 \\
974 \\
975\end{array}$ & $\begin{array}{r}435 \\
930 \\
1270 \\
151 \\
884\end{array}$ & $\begin{array}{l}41 \\
19 \\
12 \\
55 \\
20\end{array}$ & $\begin{array}{r}338 \\
637 \\
1230 \\
124 \\
506\end{array}$ & $\begin{array}{r}38 \\
17 \\
7 \\
53 \\
27\end{array}$ & $\begin{array}{r}230 \\
368 \\
1160 \\
117 \\
322\end{array}$ & $\begin{array}{r}43 \\
31 \\
6 \\
52 \\
34\end{array}$ & $\begin{array}{r}200 \\
200 \\
1110 \\
109 \\
292\end{array}$ & $\begin{array}{r}40 \\
41 \\
4 \\
51 \\
31\end{array}$ & $\begin{array}{l}165 \\
126 \\
925 \\
100 \\
266\end{array}$ & $\begin{array}{r}40 \\
43 \\
6 \\
47 \\
30\end{array}$ & $\begin{array}{c}135 \\
91.0 \\
677 \\
89.0 \\
195\end{array}$ & $\begin{array}{r}40 \\
46 \\
7 \\
47 \\
32\end{array}$ & $\begin{array}{c}117 \\
86.0 \\
507 \\
80.0 \\
156\end{array}$ & $\begin{array}{r}39 \\
46 \\
7 \\
47 \\
32\end{array}$ & $\begin{array}{c}106 \\
86.0 \\
403 \\
74.0 \\
139\end{array}$ & $\begin{array}{r}39 \\
43 \\
7 \\
47 \\
30\end{array}$ & $\begin{array}{c}95.0 \\
85.0 \\
290 \\
66.0 \\
114\end{array}$ & $\begin{array}{r}38 \\
40 \\
7 \\
49 \\
31\end{array}$ & $\begin{array}{r}73.0 \\
71.0 \\
175 \\
57.0 \\
83.0\end{array}$ & $\begin{array}{r}38 \\
39 \\
7 \\
48 \\
29\end{array}$ \\
\hline $\begin{array}{r}976 \\
977 \\
978 \\
979 \\
980\end{array}$ & $\begin{array}{r}379 \\
247 \\
877 \\
1220 \\
3000\end{array}$ & $\begin{array}{r}46 \\
51 \\
22 \\
13 \\
2\end{array}$ & $\begin{array}{r}260 \\
124 \\
844 \\
1200 \\
2070\end{array}$ & $\begin{array}{r}45 \\
54 \\
13 \\
8 \\
2\end{array}$ & $\begin{array}{c}246 \\
84.0 \\
759 \\
1160 \\
1570\end{array}$ & $\begin{array}{r}42 \\
55 \\
13 \\
7 \\
1\end{array}$ & $\begin{array}{c}229 \\
63.0 \\
679 \\
1070 \\
893\end{array}$ & $\begin{array}{r}38 \\
55 \\
12 \\
6 \\
8\end{array}$ & $\begin{array}{c}198 \\
54.0 \\
653 \\
991 \\
844\end{array}$ & $\begin{array}{r}37 \\
55 \\
10 \\
4 \\
7\end{array}$ & $\begin{array}{c}141 \\
51.0 \\
509 \\
749 \\
717\end{array}$ & $\begin{array}{r}39 \\
55 \\
10 \\
3 \\
5\end{array}$ & $\begin{array}{c}113 \\
49.0 \\
404 \\
573 \\
554\end{array}$ & $\begin{array}{r}40 \\
55 \\
10 \\
2 \\
4\end{array}$ & $\begin{array}{l}101 \\
47.0 \\
340 \\
454 \\
525\end{array}$ & $\begin{array}{r}40 \\
55 \\
11 \\
3 \\
1\end{array}$ & $\begin{array}{l}84.0 \\
45.0 \\
248 \\
322 \\
412\end{array}$ & $\begin{array}{r}41 \\
55 \\
11 \\
5 \\
1\end{array}$ & $\begin{array}{l}62.0 \\
42.0 \\
148 \\
187 \\
245\end{array}$ & $\begin{array}{r}44 \\
55 \\
11 \\
5 \\
1\end{array}$ \\
\hline & 694 & 28 & 536 & 24 & 441 & 23 & 411 & 22 & 300 & 27 & 218 & 25 & 174 & 26 & 148 & 26 & 121 & 28 & 91.0 & \\
\hline
\end{tabular}

DURATION OF DISCHARGE FOR EACH WATER YEAR

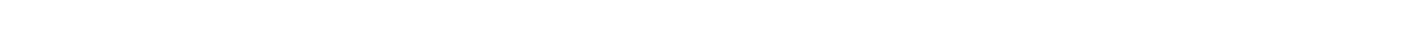

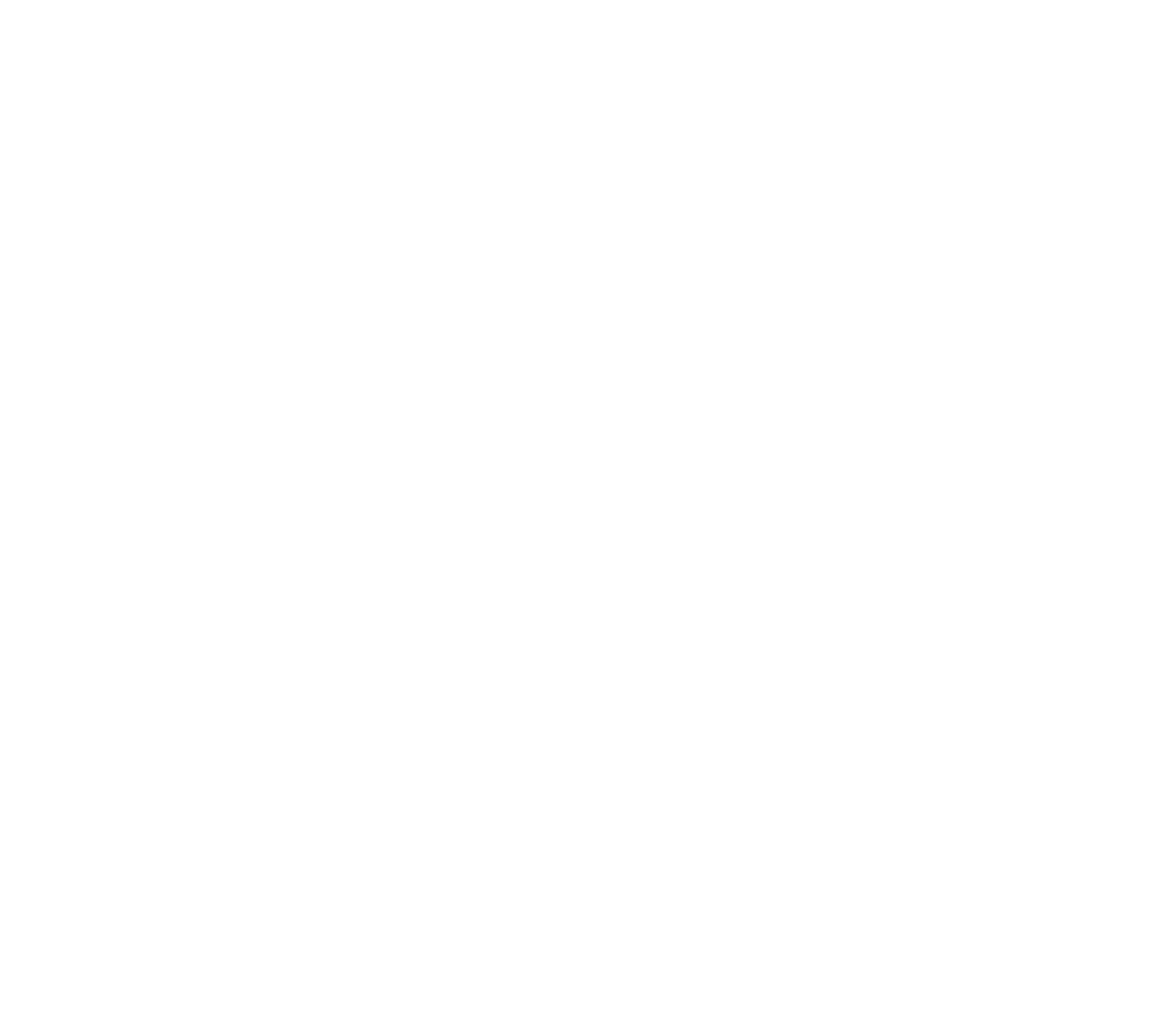


VIRGIN RTVER BASIN

09405500 NORTH FORK VIRGIN RIVER NEAR SPRINGDALE, UT-Continued

DURATION OF DISCHARGE FOR EACH WATER YEAR-Continued

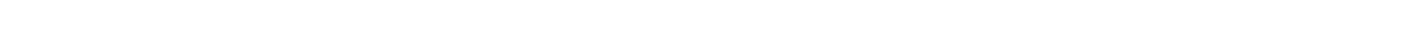

YEAR

NUMBER OF DAYS IN CJASS

OUBIC FEEI

-DAYS

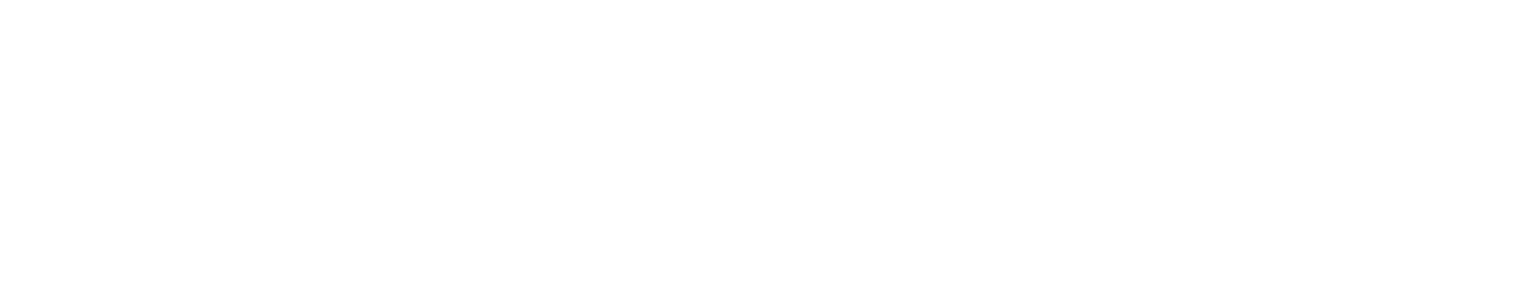

DURATION TABLE OF DISCHARGE FOR WATER YEARS 1926, 1928-81

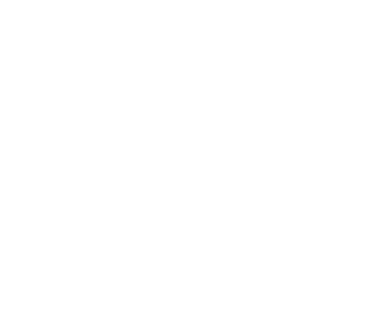

$\begin{array}{rrrr}\text { OUBIC } & & \text { ACOU- } \\ \text { FEET } & & \text { MU- } & \text { PER- } \\ \text { PER } & \text { TOTAL } & \text { LATED } & \text { CENT } \\ \text { SECOND } & \text { DAYS } & \text { DAYS } & \text { DAYS } \\ & & & \\ 75.00 & 1193 & 5836 & 29.1 \\ 87.00 & 736 & 4643 & 23.1 \\ 100.00 & 698 & 3907 & 19.4 \\ 120.00 & 495 & 3209 & 16.0 \\ 140.00 & 379 & 2714 & 13.5 \\ 160.00 & 215 & 2335 & 11.6 \\ 180.00 & 302 & 2120 & 10.6 \\ 210.00 & 221 & 1818 & 9.0 \\ 240.00 & 247 & 1597 & 7.9\end{array}$

OBBIC $\quad$ ACOU-
FEET
MU- PERPER TOTAL IATED CENT CJASS SECOND DAYS DAYS DAYS

$\begin{array}{rrrrr}18 & 280.0 & 269 & 1350 & 6.7 \\ 19 & 330.0 & 181 & 1081 & 5.4 \\ 20 & 380.0 & 176 & 900 & 4.5 \\ 21 & 440.0 & 161 & 724 & 3.6 \\ 22 & 510.0 & 132 & 563 & 2.8 \\ 23 & 590.0 & 137 & 431 & 2.1 \\ 24 & 690.0 & 74 & 294 & 1.5 \\ 25 & 790.0 & 64 & 220 & 1.1 \\ 26 & 920.0 & 74 & 156 & 0.8\end{array}$

TBIC ACOI-
FEET PER TOTAL LATED CENT

$\begin{array}{rrrrr}27 & 1100.0 & 37 & 82 & 0.4 \\ 28 & 1200.0 & 24 & .45 & 0.2 \\ 29 & 1400.0 & 10 & 21 & 0.1 \\ 30 & 1700.0 & 3 & 11 & 0.1 \\ 31 & 1900.0 & 3 & 8 & 0.0 \\ 32 & 2200.0 & 2 & 5 & 0.0 \\ 33 & 2600.0 & 0 & 3 & 0.0 \\ 34 & 3000.0 & 3 & 3 & 0.0\end{array}$

NONIHLY MEAN DISCHARGES, IN OUBIC FEET PER SECOND, FOR EAOH WATER YEAR

\begin{tabular}{|c|c|c|c|c|c|c|c|c|c|c|c|c|}
\hline YEAR & OCT & NOV & DEC & JAN & FEB & MAR & APR & MAY & JUNE & JULY & AUG & SEP \\
\hline $\begin{array}{l}1926 \\
1927 \\
1928 \\
1929 \\
1930\end{array}$ & $\begin{array}{r}77.0 \\
50.9 \\
117 \\
35.0 \\
54.9\end{array}$ & $\begin{array}{l}54.2 \\
85.0 \\
65.0 \\
40.6 \\
48.8\end{array}$ & $\begin{array}{c}60.7 \\
110 \\
60.0 \\
34.3 \\
45.1\end{array}$ & $\begin{array}{l}51.3 \\
64.7 \\
56.2 \\
42.7 \\
46.8\end{array}$ & $\begin{array}{c}63.3 \\
175 \\
67.2 \\
52.5 \\
59.1\end{array}$ & $\begin{array}{c}74.8 \\
130 \\
123 \\
71.3 \\
65.2\end{array}$ & $\begin{array}{l}441 \\
280 \\
153 \\
163 \\
123\end{array}$ & $\begin{array}{l}298 \\
245 \\
181 \\
226 \\
238\end{array}$ & $\begin{array}{l}81.7 \\
88.4 \\
65.9 \\
72.5 \\
62.5\end{array}$ & $\begin{array}{l}52.7 \\
73.0 \\
36.0 \\
54.0 \\
40.5\end{array}$ & $\begin{array}{r}52.8 \\
60.2 \\
32.0 \\
132 \\
51.5\end{array}$ & $\begin{array}{c}51.3 \\
115 \\
33.1 \\
68.7 \\
69.2\end{array}$ \\
\hline $\begin{array}{l}1931 \\
1932 \\
1933 \\
1934 \\
1935\end{array}$ & $\begin{array}{l}54.9 \\
35.0 \\
60.0 \\
44.8 \\
38.8\end{array}$ & $\begin{array}{l}55.0 \\
55.0 \\
63.9 \\
40.3 \\
56.6\end{array}$ & $\begin{array}{l}50.0 \\
45.0 \\
60.6 \\
47.5 \\
57.2\end{array}$ & $\begin{array}{l}45.0 \\
40.0 \\
60.9 \\
42.5 \\
58.4\end{array}$ & $\begin{array}{c}55.0 \\
103 \\
65.1 \\
59.1 \\
62.3\end{array}$ & $\begin{array}{l}59.9 \\
92.3 \\
71.9 \\
68.2 \\
73.9\end{array}$ & $\begin{array}{c}76.6 \\
348 \\
104 \\
84.8 \\
317\end{array}$ & $\begin{array}{c}82.2 \\
747 \\
247 \\
57.1 \\
429\end{array}$ & $\begin{array}{c}46.9 \\
236 \\
146 \\
43.8 \\
152\end{array}$ & $\begin{array}{c}40.2 \\
113 \\
67.7 \\
37.9 \\
93.5\end{array}$ & $\begin{array}{c}96.3 \\
110 \\
50.8 \\
40.7 \\
65.1\end{array}$ & $\begin{array}{l}38.6 \\
50.0 \\
89.7 \\
37.6 \\
66.9\end{array}$ \\
\hline $\begin{array}{l}1936 \\
1937 \\
1938 \\
1939 \\
1940\end{array}$ & $\begin{array}{l}50.7 \\
59.5 \\
58.5 \\
67.1 \\
62.0\end{array}$ & $\begin{array}{l}47.7 \\
58.4 \\
66.0 \\
59.4 \\
52.1\end{array}$ & $\begin{array}{l}48.9 \\
58.7 \\
78.2 \\
56.1 \\
46.1\end{array}$ & $\begin{array}{l}51.4 \\
62.9 \\
70.5 \\
56.3 \\
56.7\end{array}$ & $\begin{array}{r}103 \\
86.2 \\
70.8 \\
56.3 \\
75.4\end{array}$ & $\begin{array}{c}81.3 \\
144 \\
258 \\
91.6 \\
96.2\end{array}$ & $\begin{array}{l}259 \\
524 \\
440 \\
170 \\
180\end{array}$ & $\begin{array}{l}140 \\
900 \\
502 \\
108 \\
116\end{array}$ & $\begin{array}{c}56.6 \\
172 \\
148 \\
55.8 \\
52.1\end{array}$ & $\begin{array}{l}121 \\
106 \\
72.2 \\
45.4 \\
40.3\end{array}$ & $\begin{array}{l}65.3 \\
64.2 \\
69.8 \\
40.1 \\
37.1\end{array}$ & $\begin{array}{l}48.2 \\
72.4 \\
60.4 \\
132 \\
155\end{array}$ \\
\hline $\begin{array}{l}1941 \\
1942 \\
1943 \\
1944 \\
1945\end{array}$ & $\begin{array}{c}49.7 \\
154 \\
67.9 \\
64.1 \\
53.8\end{array}$ & $\begin{array}{l}48.6 \\
84.6 \\
68.3 \\
51.5 \\
65.5\end{array}$ & $\begin{array}{l}52.5 \\
79.9 \\
55.8 \\
52.0 \\
52.5\end{array}$ & $\begin{array}{l}52.6 \\
77.6 \\
62.4 \\
50.3 \\
56.3\end{array}$ & $\begin{array}{r}87.2 \\
76.5 \\
115 \\
66.7 \\
73.9\end{array}$ & $\begin{array}{c}157 \\
102 \\
161 \\
88.3 \\
77.5\end{array}$ & $\begin{array}{l}284 \\
436 \\
285 \\
170 \\
168\end{array}$ & $\begin{array}{l}976 \\
386 \\
184 \\
571 \\
314\end{array}$ & $\begin{array}{c}288 \\
144 \\
74.3 \\
169 \\
110\end{array}$ & $\begin{array}{l}150 \\
69.5 \\
45.0 \\
68.3 \\
66.5\end{array}$ & $\begin{array}{l}82.2 \\
61.1 \\
58.6 \\
50.1 \\
95.1\end{array}$ & $\begin{array}{l}71.8 \\
48.1 \\
53.3 \\
43.7 \\
48.5\end{array}$ \\
\hline $\begin{array}{l}1946 \\
1947 \\
1948 \\
1949 \\
1950\end{array}$ & $\begin{array}{c}79.3 \\
117 \\
57.8 \\
48.5 \\
60.6\end{array}$ & $\begin{array}{l}53.6 \\
83.5 \\
50.2 \\
38.8 \\
66.6\end{array}$ & $\begin{array}{l}53.0 \\
75.6 \\
50.3 \\
40.4 \\
51.6\end{array}$ & $\begin{array}{l}55.9 \\
60.9 \\
53.6 \\
46.0 \\
58.6\end{array}$ & $\begin{array}{l}55.4 \\
70.6 \\
59.6 \\
57.1 \\
76.1\end{array}$ & $\begin{array}{c}73.5 \\
141 \\
57.3 \\
64.3 \\
94.1\end{array}$ & $\begin{array}{l}126 \\
247 \\
213 \\
275 \\
215\end{array}$ & $\begin{array}{l}89.8 \\
264 \\
174 \\
392 \\
134\end{array}$ & $\begin{array}{r}42.0 \\
96.3 \\
76.8 \\
175 \\
61.9\end{array}$ & $\begin{array}{l}37.9 \\
49.3 \\
44.8 \\
57.4 \\
69.2\end{array}$ & $\begin{array}{l}52.6 \\
57.9 \\
43.4 \\
43.5 \\
45.1\end{array}$ & $\begin{array}{l}36.6 \\
44.9 \\
38.0 \\
52.9 \\
40.7\end{array}$ \\
\hline $\begin{array}{l}1951 \\
1952 \\
1953 \\
1954 \\
1955\end{array}$ & $\begin{array}{l}43.0 \\
44.1 \\
52.6 \\
45.8 \\
51.4\end{array}$ & $\begin{array}{l}51.1 \\
50.5 \\
60.7 \\
49.0 \\
50.6\end{array}$ & $\begin{array}{l}50.0 \\
82.9 \\
61.0 \\
45.5 \\
52.5\end{array}$ & $\begin{array}{l}49.8 \\
57.2 \\
63.6 \\
56.5 \\
51.3\end{array}$ & $\begin{array}{l}52.7 \\
58.0 \\
56.5 \\
60.3 \\
60.6\end{array}$ & $\begin{array}{l}60.6 \\
79.5 \\
65.5 \\
72.6 \\
69.6\end{array}$ & $\begin{array}{c}79.5 \\
571 \\
84.3 \\
295 \\
106\end{array}$ & $\begin{array}{c}88.5 \\
912 \\
69.3 \\
168 \\
108\end{array}$ & $\begin{array}{c}46.3 \\
193 \\
45.3 \\
59.9 \\
51.9\end{array}$ & $\begin{array}{l}38.3 \\
69.6 \\
53.3 \\
64.2 \\
47.6\end{array}$ & $\begin{array}{l}59.8 \\
60.8 \\
52.4 \\
40.2 \\
72.0\end{array}$ & $\begin{array}{l}40.6 \\
54.2 \\
36.2 \\
51.5 \\
29.4\end{array}$ \\
\hline $\begin{array}{l}1956 \\
1957 \\
1958 \\
1959 \\
1960\end{array}$ & $\begin{array}{l}32.6 \\
34.0 \\
61.7 \\
61.7 \\
39.0\end{array}$ & $\begin{array}{l}50.4 \\
36.8 \\
70.0 \\
63.0 \\
46.8\end{array}$ & $\begin{array}{l}54.7 \\
40.5 \\
66.1 \\
56.7 \\
48.0\end{array}$ & $\begin{array}{l}66.1 \\
51.1 \\
49.7 \\
51.0 \\
45.6\end{array}$ & $\begin{array}{l}48.9 \\
66.5 \\
94.0 \\
59.1 \\
50.1\end{array}$ & $\begin{array}{c}65.0 \\
62.9 \\
111 \\
67.5 \\
73.8\end{array}$ & $\begin{array}{c}105 \\
106 \\
356 \\
88.9 \\
108\end{array}$ & $\begin{array}{l}98.5 \\
238 \\
723 \\
55.9 \\
99.4\end{array}$ & $\begin{array}{l}39.1 \\
141 \\
143 \\
52.7 \\
55.9\end{array}$ & $\begin{array}{l}35.3 \\
65.6 \\
85.9 \\
40.9 \\
32.1\end{array}$ & $\begin{array}{l}31.0 \\
61.9 \\
81.2 \\
63.5 \\
30.3\end{array}$ & $\begin{array}{c}28.4 \\
51.0 \\
104 \\
42.1 \\
39.5\end{array}$ \\
\hline
\end{tabular}


VIRGIN RIVER BASIN

09405500 NORIH FORK VIRGIN RIVER NEAR SPRINGDALE, UT--Cont in!lied

MONIHLY MEAN DISCHARGES, IN GBIC FEET PER SECOND, FOR EACH WATER TEAR-COAt inided

\begin{tabular}{|c|c|c|c|c|c|c|c|c|c|c|c|c|}
\hline YEAR & $\mathrm{OCT}$ & $\mathrm{NON}$ & DEC & JAN & FEB & MAR & APR & MAY & JUNE & JUY & AUG & SEP \\
\hline $\begin{array}{l}1961 \\
1962 \\
1963 \\
1964 \\
1965\end{array}$ & $\begin{array}{l}43.6 \\
40.6 \\
47.1 \\
42.3 \\
35.1\end{array}$ & $\begin{array}{l}55.5 \\
45.1 \\
47.4 \\
50.0 \\
44.7\end{array}$ & $\begin{array}{l}44.7 \\
47.4 \\
44.9 \\
40.5 \\
47.2\end{array}$ & $\begin{array}{l}44.1 \\
46.2 \\
48.6 \\
39.7 \\
49.7\end{array}$ & $\begin{array}{c}46.0 \\
122 \\
59.6 \\
42.3 \\
50.2\end{array}$ & $\begin{array}{l}57.9 \\
90.4 \\
57.8 \\
56.0 \\
54.9\end{array}$ & $\begin{array}{c}91.4 \\
458 \\
74.5 \\
145 \\
170\end{array}$ & $\begin{array}{c}65.4 \\
191 \\
80.2 \\
186 \\
358\end{array}$ & $\begin{array}{c}34.4 \\
76.8 \\
35.0 \\
61.6 \\
216\end{array}$ & $\begin{array}{l}35.8 \\
60.3 \\
28.5 \\
59.6 \\
72.3\end{array}$ & $\begin{array}{l}47.5 \\
55.5 \\
60.7 \\
44.2 \\
58.4\end{array}$ & $\begin{array}{l}92.4 \\
62.3 \\
57.3 \\
34.4 \\
89.9\end{array}$ \\
\hline $\begin{array}{l}1966 \\
1967 \\
1968 \\
1969 \\
1970\end{array}$ & $\begin{array}{l}51.5 \\
52.5 \\
53.3 \\
52.4 \\
64.7\end{array}$ & $\begin{array}{r}104 \\
54.4 \\
53.5 \\
54.9 \\
68.3\end{array}$ & $\begin{array}{c}82.0 \\
297 \\
49.6 \\
52.1 \\
61.0\end{array}$ & $\begin{array}{c}49.1 \\
52.6 \\
54.6 \\
156 \\
57.2\end{array}$ & $\begin{array}{l}51.4 \\
57.4 \\
74.4 \\
59.1 \\
59.0\end{array}$ & $\begin{array}{c}137 \\
85.3 \\
104 \\
107 \\
69.6\end{array}$ & $\begin{array}{c}306 \\
124 \\
237 \\
636 \\
72.9\end{array}$ & $\begin{array}{l}149 \\
283 \\
299 \\
875 \\
113\end{array}$ & $\begin{array}{l}65.2 \\
128 \\
107 \\
173 \\
58.5\end{array}$ & $\begin{array}{r}67.8 \\
73.9 \\
124 \\
93.9 \\
61.8\end{array}$ & $\begin{array}{r}61.7 \\
68.6 \\
144 \\
75.9 \\
88.7\end{array}$ & $\begin{array}{l}55.2 \\
97.1 \\
65.1 \\
62.5 \\
56.2\end{array}$ \\
\hline $\begin{array}{l}1971 \\
1972 \\
1973 \\
1974 \\
1975\end{array}$ & $\begin{array}{l}42.5 \\
55.2 \\
81.8 \\
54.6 \\
84.0\end{array}$ & $\begin{array}{l}60.7 \\
49.6 \\
53.5 \\
59.4 \\
41.7\end{array}$ & $\begin{array}{c}48.0 \\
119 \\
49.4 \\
52.3 \\
38.6\end{array}$ & $\begin{array}{l}52.2 \\
51.5 \\
52.2 \\
52.0 \\
45.5\end{array}$ & $\begin{array}{l}54.3 \\
54.8 \\
69.9 \\
47.4 \\
56.7\end{array}$ & $\begin{array}{l}64.5 \\
82.8 \\
92.0 \\
71.9 \\
67.6\end{array}$ & $\begin{array}{c}103 \\
78.8 \\
295 \\
86.9 \\
78.9\end{array}$ & $\begin{array}{l}163 \\
61.7 \\
915 \\
80.4 \\
241\end{array}$ & $\begin{array}{c}76.3 \\
115 \\
281 \\
54.0 \\
134\end{array}$ & $\begin{array}{l}63.3 \\
35.1 \\
71.1 \\
44.5 \\
89.4\end{array}$ & $\begin{array}{l}95.6 \\
44.8 \\
72.5 \\
38.0 \\
68.8\end{array}$ & $\begin{array}{c}56.7 \\
101 \\
60.6 \\
41.5 \\
46.6\end{array}$ \\
\hline $\begin{array}{l}1976 \\
1977 \\
1978 \\
1979 \\
1980\end{array}$ & $\begin{array}{l}44.2 \\
49.3 \\
33.2 \\
44.0 \\
49.9\end{array}$ & $\begin{array}{l}43.0 \\
40.6 \\
38.0 \\
57.2 \\
54.7\end{array}$ & $\begin{array}{l}44.8 \\
42.7 \\
41.6 \\
50.5 \\
53.1\end{array}$ & $\begin{array}{r}41.3 \\
40.4 \\
58.4 \\
51.3 \\
196\end{array}$ & $\begin{array}{c}64.9 \\
42.3 \\
86.5 \\
60.6 \\
501\end{array}$ & $\begin{array}{l}54.5 \\
43.8 \\
187 \\
140 \\
133\end{array}$ & $\begin{array}{l}107 \\
51.8 \\
394 \\
450 \\
447\end{array}$ & $\begin{array}{l}172 \\
49.8 \\
600 \\
961 \\
826\end{array}$ & $\begin{array}{l}57.1 \\
37.9 \\
156 \\
232 \\
360\end{array}$ & $\begin{array}{r}48.4 \\
35.5 \\
55.3 \\
67.8 \\
105\end{array}$ & $\begin{array}{l}33.3 \\
35.8 \\
63.6 \\
65.2 \\
86.3\end{array}$ & $\begin{array}{r}36.7 \\
31.4 \\
55.5 \\
54.0 \\
151\end{array}$ \\
\hline 1981 & 71.9 & 66.3 & 66.8 & 61.6 & 62.2 & 80.8 & 262 & 166 & 77.1 & 72.3 & 60.0 & 49.9 \\
\hline
\end{tabular}

ANNUAL PEAK DISCHARGE, IN GBIC FEET PER SECOND, AND CORRESPONDING GAGE HEIGHT, IN FEET, FOR EACH WATER YEAR

\begin{tabular}{|c|c|c|c|c|c|c|c|c|c|c|c|}
\hline $\begin{array}{l}\text { WATER } \\
\text { YEAR }\end{array}$ & DATE & $\begin{array}{c}\text { GAGE } \\
\text { HEIGHT }\end{array}$ & $\begin{array}{c}\text { PEAK } \\
\text { DISCHARGE }\end{array}$ & $\begin{array}{l}\text { WATER } \\
\text { YEAR }\end{array}$ & DATE & $\begin{array}{c}\text { GAGE } \\
\text { HEIGHP }\end{array}$ & $\begin{array}{c}\text { PEAK } \\
\text { DISCHARGE }\end{array}$ & $\begin{array}{l}\text { WATER } \\
\text { YEAR }\end{array}$ & DATE & $\begin{array}{c}\text { GAGE } \\
\text { HEIGHT }\end{array}$ & $\begin{array}{c}\text { PEAK } \\
\text { DISCHARGE }\end{array}$ \\
\hline $\begin{array}{l}1913 \\
1914 \\
1926 \\
1927 \\
1928 \\
1929 \\
1930 \\
1931 \\
1932 \\
1933 \\
1934 \\
1935 \\
1936 \\
1937 \\
1938 \\
1939 \\
1940 \\
1941 \\
1942\end{array}$ & $\begin{array}{l}\text { AUG. } 02,1913 \\
\text { NOV. } 13,1913 \\
\text { APR. } 09,1926 \\
\text { APR. } 27,1927 \\
\text { OCT. } 31,1927 \\
\text { AUG. } 03,1929 \\
\text { MAY } 16,1930 \\
\text { AUG. } 06,1931 \\
\text { AUG. } 27,1932 \\
\text { SEPT.07, } 1933 \\
\text { AUG. } 05,1934 \\
\text { APR. } 08,1935 \\
\text { SEPT.02, } 1936 \\
\text { MAY } 15,1937 \\
\text { MAR. 03, } 1938 \\
\text { SEPT.07, } 1939 \\
\text { SEPT.06, } 1940 \\
\text { MAY } 14,1941 \\
\text { OCT. } 12,1941\end{array}$ & $\begin{array}{r}3.50 \\
4.50 \\
6.60 \\
7.50 \\
7.00 \\
11.00 \\
5.80 \\
9.00 \\
7.00 \\
7.00 \\
3.50 \\
5.00 \\
7.90 \\
5.70 \\
11.00 \\
7.62 \\
9.30 \\
7.68 \\
4.62\end{array}$ & $\begin{array}{r}920 \\
1460 \\
710 \\
1200 \\
750 \\
3900 \\
428 \\
2370 \\
2500 \\
3000 \\
940 \\
1980 \\
4480 \\
2540 \\
7000 \\
2900 \\
4110 \\
3100 \\
1180\end{array}$ & $\begin{array}{l}1944 \\
1945 \\
1946 \\
1947 \\
1948 \\
1949 \\
1950 \\
1951 \\
1952 \\
1953 \\
1954 \\
1955 \\
1956 \\
1957 \\
1958 \\
1959 \\
1960 \\
1961 \\
1962\end{array}$ & $\begin{array}{l}\text { MAY } 15,1944 \\
\text { AUG. } 12,1945 \\
\text { OCT. } 12,1945 \\
\text { OCT. } 02,1946 \\
\text { APR. } 21,1948 \\
\text { SEPT. } 08,1949 \\
\text { JULY } 08,1950 \\
\text { AUG. } 29,1951 \\
\text { MAY } 03,1952 \\
\text { JULY } 30,1953 \\
\text { JULY } 25,1954 \\
\text { AUG. } 25,1955 \\
\text { JAN. } 26,1956 \\
\text { JUNE } 10,1957 \\
\text { MAY } 11,1958 \\
\text { AUG. } 19,1959 \\
\text { NOV. } 02,1959 \\
\text { SEPT.17, } 1961 . \\
\text { APR. } 24,1962\end{array}$ & $\begin{array}{c}5.00 \\
5.60 \\
3.10 \\
8.20 \\
3.82 \\
4.52 \\
7.52 \\
4.42 \\
6.76 \\
5.58 \\
6.72 \\
8.74 \\
4.38 \\
-. \\
6.48 \\
-- \\
-. \\
10.25 \\
5.85\end{array}$ & $\begin{array}{r}1370 \\
1690 \\
558 \\
3520 \\
798 \\
1100 \\
2680 \\
833 \\
2520 \\
1660 \\
2480 \\
3960 \\
956 \\
668 \\
2270 \\
2070 \\
430 \\
5880 \\
1870\end{array}$ & $\begin{array}{l}1963 \\
1964 \\
1965 \\
1966 \\
1967 \\
1968 \\
1969 \\
1970 \\
1971 \\
1972 \\
1973 \\
1974 \\
1975 \\
1976 \\
1977 \\
1978 \\
1979 \\
1980 \\
1981\end{array}$ & $\begin{array}{l}\text { AUG. } 05,1963 \\
\text { OCT. } 18,1963 \\
\text { SEPT.05, } 1965 \\
\text { NON. } 23,1965 \\
\text { DEC. } 06,1966 \\
\text { AUG. 07, I968 } \\
\text { JAN. } 25,1969 \\
\text { AUG. } 04,1970 \\
\text { AUG. } 25,1971 \\
\text { DEC. } 24,1971 \\
\text { MAY } 10,1973 \\
\text { SEPT.05, } 1974 \\
\text { JULY } 29,1975 \\
\text { FEB. } 09,1976 \\
\text { OCT. } 02,1976 \\
\text { MAR. } 04,1978 \\
\text { MAY } 05,1979 \\
\text { FER. } 14,1980 \\
\text { JULY } 15,1981\end{array}$ & $\begin{array}{r}8.84 \\
5.06 \\
10.34 \\
5.46 \\
12.98 \\
5.90 \\
8.36 \\
4.74 \\
6.60 \\
6.26 \\
5.72 \\
3.48 \\
8.95 \\
4.56 \\
3.37 \\
4.66 \\
4.86 \\
7.20 \\
5.65\end{array}$ & $\begin{array}{r}4340 \\
1350 \\
5990 \\
1620 \\
9150 \\
1930 \\
3880 \\
1350 \\
2390 \\
2200 \\
1970 \\
776 \\
4140 \\
1240 \\
749 \\
1330 \\
1670 \\
3190 \\
2190\end{array}$ \\
\hline
\end{tabular}

MAGNTTUDE AND PROBABTLITYY OF ANNUAL LONEST MEAN DISCHARGE

\begin{tabular}{|c|c|c|c|c|c|c|}
\hline \multirow{2}{*}{$\begin{array}{l}\text { PERIOD } \\
\text { (OON- } \\
\text { SEQU- } \\
\text { TIVE } \\
\text { DAYS) }\end{array}$} & \multicolumn{6}{|c|}{$\begin{array}{l}\text { DISCHARGE, IN OUBIC FEET PER SECOND, FOR } \\
\text { INDICATED REOURRENCE INTERNAL, IN YEARS, AND } \\
\text { ANNUAL NONEXCEEDANCE FROBABIIITY, IN PERCENT }\end{array}$} \\
\hline & $\begin{array}{c}2 \\
508\end{array}$ & $\begin{array}{c}5 \\
208\end{array}$ & $\begin{array}{l}10 \\
108\end{array}$ & $\begin{array}{l}20 \\
58\end{array}$ & $\begin{array}{l}50 \\
28\end{array}$ & $\begin{array}{r}100 \\
18\end{array}$ \\
\hline
\end{tabular}

$\begin{array}{rllllll}1 & 34 & 29 & 27 & 25 & 23 & 22 \\ 7 & 38 & 32 & 29 & 27 & 24 & 23 \\ 14 & 39 & 33 & 30 & 28 & 25 & 24 \\ 30 & 41 & 34 & 31 & 29 & 27 & 25 \\ 60 & 44 & 37 & 34 & 31 & 29 & 27 \\ 90 & 47 & 40 & 37 & 34 & 31 & 30\end{array}$

MAGNTIUDE AND PROBABTITYY OF ANNUAL HIGHEST MEAN DISCHARGE BASED ON WATER YEARS 1926 AND 1928-81

\begin{tabular}{|c|c|c|c|c|c|c|}
\hline \multirow{2}{*}{$\begin{array}{l}\text { PERTOD } \\
\text { (CON- } \\
\text { SEQU- } \\
\text { TIVE } \\
\text { DAYS) }\end{array}$} & \multicolumn{6}{|c|}{$\begin{array}{l}\text { DISCHARGE, IN OUBIC FEET PER SECOND, FOR } \\
\text { INDICATED RECURRENCE INITERVAL, IN YEARS, AND } \\
\text { ANNUAL EXCEEDANCE PROBAB ILTTY, IN PERCENT }\end{array}$} \\
\hline & $\begin{array}{c}2 \\
508\end{array}$ & $\begin{array}{c}5 \\
208\end{array}$ & $\begin{array}{l}10 \\
108\end{array}$ & $\begin{array}{l}25 \\
48\end{array}$ & $\begin{array}{l}50 \\
28\end{array}$ & $\begin{array}{r}100 \\
18\end{array}$ \\
\hline $\begin{array}{r}1 \\
3 \\
7 \\
15\end{array}$ & $\begin{array}{l}684 \\
488 \\
392 \\
327\end{array}$ & $\begin{array}{r}1280 \\
916 \\
760 \\
633\end{array}$ & $\begin{array}{r}1810 \\
1270 \\
1070 \\
893\end{array}$ & $\begin{array}{l}2640 \\
1810 \\
1550 \\
1290\end{array}$ & $\begin{array}{l}3390 \\
2280 \\
1960 \\
1630\end{array}$ & $\begin{array}{l}4260 \\
2800 \\
2420 \\
2020\end{array}$ \\
\hline
\end{tabular}


VIRGIN RIVER BASIN

09406000 VIRGIN RIVER AT VIRGIN, UT

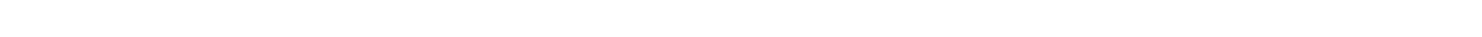
left bank $1.1 \mathrm{mi}$ west of virgin and $2.3 \mathrm{mi}$ downstream fram North Creek.

DRAINAGE AREA.--934 $\mathrm{mi}^{2}$.

MEAN BASIN ELEVATION. $-6,400 \mathrm{ft}$.

PERIOD OF RECORD AVAIIABLE.--April 1909 to September 1971 (monthly mean discharge prior to October 1909 published in wSP 1313), October 1978 to September 1981.

REVISED RECORDS.--WSP 1313: 1942-43(M), 1947-48(M). WSP 1633: $1921(M), 1950-51$.

GAGE--Water-stage recorder. Altitude of gage is $3,440 \mathrm{ft}$ from topographic map. At present location since Oct. 1, 1978, fram Dec. 19, 1949 to Sept. 1971, directly across on right bank at different datum. Prior to Dec. 19, 1949, nonrecording gages at several sites within $3 \mathrm{mi}$ of present site at various datums.

REMARKS.--Diversions above station for irrigation.

AVERAGE DISCHARGE. --65 years, $206 \mathrm{ft}^{3} / \mathrm{s}, 149,200$ acre- $\mathrm{ft} / \mathrm{yr}$.

EXTREMES FOR PERIOD OF RECORD.--Maximum discharge, $22,800 \mathrm{ft}^{3} / \mathrm{s}$ Dec. 6,1966 , gage height, $18.00 \mathrm{ft}$, from rating curve extended above $5,000 \mathrm{ft}^{3} / \mathrm{s}$ on basis of one slope-area measurement and one float measurement; minimum daily discharge coserved, $22 \mathrm{ft} / / \mathrm{s} \mathrm{July}^{3}$ 10,1920 , June 11,1921 .

LOWEST MEAN DISCHARGE, IN CUBIC FEET PER SECOND, AND RANKING FOR THE INDICATED NUMBER OF CONSECUTIVE DAYS FOR EACH CLIMATIC YEAR, APRIL 1-MARCH 31

YEAR

\section{1}

$\begin{array}{cccc}60.0 & 41 & 68.0 & 45 \\ 113 & 63 & 116 & 63\end{array}$

$104 \quad 61 \quad 116 \quad 63$

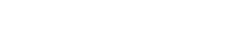

$\begin{array}{llrl}80.0 & 56 & 80.0 \quad 53\end{array}$

$\begin{array}{cccc}107 & 62 & 109 & 62\end{array}$

$\begin{array}{rrrr}39.0 & 8 & 41.0 & 8 \\ 42.0 & 12 & 48.0 & 17\end{array}$

$55.034 \quad 63.0 \quad 40$

$22.0 \quad 1 \quad 28.0 \quad 3$

$22.0 \quad 2 \quad 23.0 \quad 1$

$\begin{array}{llll}79.0 & 54 & 81.0 & 54 \\ 52.0 & 27 & 58.0 & 36\end{array}$

$\begin{array}{llll}52.0 & 27 & 58.0 & 36 \\ 51.0 & 23 & 51.0 & 20\end{array}$

$\begin{array}{rrrr}27.0 & 5 & 29.0 & 4\end{array}$

$\begin{array}{llll}51.0 & 24 & 51.0 & 21\end{array}$

$\begin{array}{llll}55.0 & 35 & 67.0 & 44\end{array}$

$\begin{array}{rrrr}24.0 & 4 & 24.0 & 2\end{array}$

$\begin{array}{rr}31.0 & 7 \\ 23.0 & 3 \\ 64.0 & 44\end{array}$

$\begin{array}{ll}64.0 & 44 \\ 41.0 & 10\end{array}$

28.06

$\begin{array}{rr}34.0 & 7 \\ 30.0 & 5\end{array}$

65.041

$\begin{array}{rr}47.0 & 14 \\ 31.0 & 6\end{array}$

51.025

56.036

53.025

$53.0 \quad 28 \quad 55.0 \quad 29$

$\begin{array}{llll}53.0 & 29 & 55.0 & 30\end{array}$

$74.0 \quad 51$

$\begin{array}{ll}62.0 & 43 \\ 47.0 & 18\end{array}$

$\begin{array}{ll}47.0 & 18 \\ 54.0 & 33\end{array}$

$\begin{array}{ll}84.0 & 57 \\ 69.0 & 46\end{array}$

$\begin{array}{rr}69.0 & 46 \\ 48.0 & 15\end{array}$

55.031

$42.0 \quad 13$

$53.0 \quad 30$

$53.0 \quad 27$

$\begin{array}{llll}41.0 & 11 & 56.0 & 32\end{array}$

$66.0 \quad 45$

$51.0 \quad 26$

46.016

$70.0 \quad 49$

$53.0 \quad 32$

$\begin{array}{ll}56.0 & 37\end{array}$

$67.0 \quad 42$

$52.0 \quad 23$

$48.0 \quad 16$

$72.0 \quad 49$

$\begin{array}{ll}55.0 & 28 \\ 57.0 & 33\end{array}$
CONSEOTTIVE DAYS

\begin{tabular}{|c|c|c|c|c|c|c|c|c|c|c|c|c|c|c|}
\hline 7 & & 14 & & 30 & & 60 & & 90 & & 120 & & 183 & & ALI \\
\hline $\begin{array}{l}81.0 \\
118 \\
107 \\
92.0 \\
85.0\end{array}$ & $\begin{array}{l}52 \\
63 \\
61 \\
60 \\
56\end{array}$ & $\begin{array}{l}90.0 \\
120 \\
111 \\
100 \\
92.0\end{array}$ & $\begin{array}{l}54 \\
63 \\
61 \\
60 \\
56\end{array}$ & $\begin{array}{l}99.0 \\
121 \\
116 \\
130 \\
95.0\end{array}$ & $\begin{array}{l}56 \\
60 \\
59 \\
62 \\
52\end{array}$ & $\begin{array}{l}102 \\
122 \\
140 \\
141 \\
100\end{array}$ & $\begin{array}{l}48 \\
56 \\
61 \\
62 \\
45\end{array}$ & $\begin{array}{l}131 \\
127 \\
145 \\
141 \\
103\end{array}$ & $\begin{array}{l}54 \\
52 \\
60 \\
59 \\
36\end{array}$ & $\begin{array}{l}154 \\
130 \\
150 \\
153 \\
103\end{array}$ & $\begin{array}{l}59 \\
50 \\
56 \\
58 \\
34\end{array}$ & $\begin{array}{l}173 \\
142 \\
206 \\
166 \\
107\end{array}$ & $\begin{array}{l}57 \\
48 \\
62 \\
55 \\
24\end{array}$ & $\begin{array}{l}332 \\
323 \\
227 \\
222 \\
254\end{array}$ \\
\hline $\begin{array}{c}82.0 \\
113 \\
43.0 \\
53.0 \\
68.0\end{array}$ & $\begin{array}{r}53 \\
62 \\
8 \\
80 \\
40\end{array}$ & $\begin{array}{c}85.0 \\
118 \\
49.0 \\
63.0 \\
69.0\end{array}$ & $\begin{array}{l}49 \\
62 \\
10 \\
32 \\
36\end{array}$ & $\begin{array}{c}90.0 \\
127 \\
59.0 \\
92.0 \\
91.0\end{array}$ & $\begin{array}{l}47 \\
61 \\
14 \\
49 \\
48\end{array}$ & $\begin{array}{c}101 \\
131 \\
80.0 \\
138 \\
128\end{array}$ & $\begin{array}{l}46 \\
59 \\
25 \\
60 \\
57\end{array}$ & $\begin{array}{c}148 \\
139 \\
93.0 \\
138 \\
131\end{array}$ & $\begin{array}{l}61 \\
58 \\
28 \\
57 \\
55\end{array}$ & $\begin{array}{l}174 \\
147 \\
103 \\
156 \\
140\end{array}$ & $\begin{array}{l}62 \\
55 \\
35 \\
60 \\
53\end{array}$ & $\begin{array}{l}190 \\
183 \\
119 \\
165 \\
146\end{array}$ & $\begin{array}{l}60 \\
59 \\
35 \\
54 \\
52\end{array}$ & $\begin{array}{l}344 \\
324 \\
241 \\
210 \\
197\end{array}$ \\
\hline $\begin{array}{l}30.0 \\
23.0 \\
84.0 \\
59.0 \\
55.0\end{array}$ & $\begin{array}{r}3 \\
1 \\
54 \\
33 \\
24\end{array}$ & $\begin{array}{l}30.0 \\
44.0 \\
88.0 \\
72.0 \\
58.0\end{array}$ & $\begin{array}{r}2 \\
4 \\
51 \\
38 \\
25\end{array}$ & $\begin{array}{r}41.0 \\
58.0 \\
152 \\
83.0 \\
71.0\end{array}$ & $\begin{array}{r}2 \\
11 \\
63 \\
42 \\
30\end{array}$ & $\begin{array}{r}61.0 \\
66.0 \\
232 \\
97.0 \\
88.0\end{array}$ & $\begin{array}{r}5 \\
12 \\
63 \\
41 \\
34\end{array}$ & $\begin{array}{c}107 \\
102 \\
326 \\
115 \\
89.0\end{array}$ & $\begin{array}{l}42 \\
35 \\
63 \\
47 \\
23\end{array}$ & $\begin{array}{l}109 \\
144 \\
345 \\
120 \\
101\end{array}$ & $\begin{array}{l}36 \\
54 \\
63 \\
46 \\
32\end{array}$ & $\begin{array}{l}144 \\
170 \\
426 \\
130 \\
117\end{array}$ & $\begin{array}{l}50 \\
56 \\
63 \\
41 \\
33\end{array}$ & $\begin{array}{l}243 \\
284 \\
528 \\
214 \\
145\end{array}$ \\
\hline
\end{tabular}

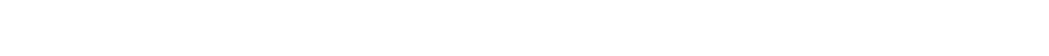

$\begin{array}{rrrrrrrrrrrrrrr}37.0 & 6 & 47.0 & 6 & 66.0 & 24 & 70.0 & 17 & 80.0 & 17 & 92.0 & 18 & 94.0 & 13 & 133 \\ 54.0 & 22 & 60.0 & 29 & 66.0 & 25 & 83.0 & 26 & 84.0 & 18 & 88.0 & 15 & 104 & 19 & 212\end{array}$

$\begin{array}{llll}72.0 & 46 & 75.0 & 42\end{array}$

$\begin{array}{lrrr}51.0 & 17 & 54.0 & 18\end{array}$

$\begin{array}{rrrrrrrr}66.0 & 25 & 83.0 & 26 & 84.0 & 18 & 88.0 & 15 \\ 83.0 & 43 & 108 & 51 & 118 & 49 & 152 & 57\end{array}$

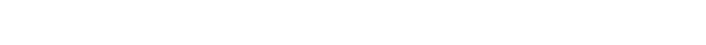

$\begin{array}{lllllllllll}29.0 & 1 & 37.0 & 1 & 37.0 & 1 & 46.0 & 1 & 60.0 & 1 & 115\end{array}$

$\begin{array}{llll}35.0 & 4 & 47.0 & 7\end{array}$

$81.0 \quad 40$

$\begin{array}{rrrr}39.0 & 7 & 47.0 & 8 \\ 66.0 & 38 & 68.0 & 35\end{array}$

$\begin{array}{rrrr}51.0 & 18 & 52.0 & 15 \\ 35.0 & 5 & 41.0 & 3\end{array}$

$51.0 \quad 5$

$71.0 \quad 31$

$69.0 \quad 27$

87.0233

$93.0 \quad 29$

$\begin{array}{lr}46.0 & 1 \\ 97 & 27\end{array}$

$105 \quad 22$

$\begin{array}{rrrrrrrrr}87.0 & 33 & 116 & 48 & 130 & 51 & 134 & 45 & 172 \\ 61.0 & 6 & 75.0 & 15 & 78.0 & 8 & 80.0 & 4 & 139\end{array}$

$\begin{array}{rrrrrrrrr}97.0 & 42 & 105 & 37 & 117 & 43 & 128 & 40 & 291\end{array}$

$\begin{array}{rrrrcrrrr}79.0 & 24 & 86.0 & 22 & 100 & 31 & 104 & 20 & 148 \\ 61.0 & 7 & 69.0 & 7 & 78.0 & 9 & 85.0 & 5 & 119\end{array}$

$\begin{array}{lllll}59.0 & 34 & 62.0 & 31\end{array}$

$\begin{array}{llll}56.0 & 25 & 66.0 & 33 \\ 65.0 & 37 & 78.0 & 47\end{array}$

$\begin{array}{llll}63.0 & 36 & 76.0 & 43\end{array}$

$\begin{array}{ll}74.0 & 32 \\ 75.0 & 34\end{array}$

93.050

85.0
85.0

$\begin{array}{ll}79.0 & 37\end{array}$

$106 \quad 50 \quad 108$

$57.0 \quad 27$

$57.0 \quad 22$

$\begin{array}{llll}57.0 & 28 & 59.0 & 26\end{array}$

$86.0 \quad 57$

$\begin{array}{ll}71.0 & 44 \\ 49.0 & 14\end{array}$

60.035

$92.0 \quad 57$

74.041

$\begin{array}{ll}57.0 & 23 \\ 67.0 & 34\end{array}$

60.016

$111 \quad 52$

$\begin{array}{rr}94.0 & 30 \\ 105 & 38\end{array}$

96.026

$\begin{array}{lll}107 & 25 & 199 \\ 111 & 29 & 175\end{array}$

$\begin{array}{lllllll}08 & 38 & 109 & 37 & 111 & 29 & 175 \\ 112 & 41 & 132 & 42 & 314\end{array}$

$\begin{array}{ccccccc}121 & 50 & 119 & 45 & 124 & 39 & 245 \\ 72.0 & 10 & 87.0 & 13 & 146 & 53 & 180\end{array}$

$103 \quad 57$

$\begin{array}{ll}78.0 & 35 \\ 69.0 & 28\end{array}$

$\begin{array}{ll}69.0 & 28 \\ 71.0 & 29\end{array}$

$\begin{array}{rrrr}66.0 & 13 & 72.0 & 11\end{array}$

$\begin{array}{lllll}95.0 & 23 & 117 & 30 & 188\end{array}$

$\begin{array}{lllllllll}98.0 & 43 & 107 & 43 & 110 & 38 & 120 & 36 & 227\end{array}$

$86.0 \quad 30$

$\begin{array}{llll}74.0 & 20 & 74.0 & 25\end{array}$

$\begin{array}{lllllll}9.0 & 25 & 94.0 & 19 & 105 & 21 & 167\end{array}$

$\begin{array}{llll}46.0 & 11 & 54.0 & 16\end{array}$

$64.0 \quad 20$

$\begin{array}{llll}54.0 & 23 & 56.0 & 19\end{array}$

$\begin{array}{rrrr}58.0 & 29 & 60.0 & 30 \\ 44.0 & 9 & 49.0 & 11\end{array}$

$70.0 \quad 41$

$73.0 \quad 39$

$\begin{array}{ll}58.0 & 12 \\ 64.0 & 21\end{array}$

54.09

$87.0 \quad 31$

66.014

$\begin{array}{rr}78.0 & 36\end{array}$

$61.0 \quad 8$

$101 \quad 34$

78.010

96.014

$53.0 \quad 21$

$\begin{array}{llll}50.0 & 15 & 51.0 & 13\end{array}$

$\begin{array}{llll}73.0 & 47 & 76.0 & 44 \\ 56.0 & 26 & 57.0 & 21\end{array}$

$\begin{array}{llll}56.0 & 26 & 57.0 & 21 \\ 58.0 & 30 & 58.0 & 24\end{array}$

$\begin{array}{rr}66.0 & 26 \\ 53.0 & 8 \\ 87.0 & 45\end{array}$

$\begin{array}{rrrrcrr}74.0 & 13 & 74.0 & 5 & 92.0 & 11 & 134\end{array}$

$\begin{array}{lllllll}97.0 & 31 & 96.0 & 24 & 102 & 16 & 139\end{array}$

$\begin{array}{lrrrrrr}17.0 & 4 & 68.0 & 3 & 76.0 & 3 & 125 \\ & 39 & 110 & 39 & 117 & 31 & 179\end{array}$

$67.0 \quad 15$

$\begin{array}{llll}59.0 & 15 & 75.0 & 22\end{array}$

64.022

90.036

$\begin{array}{lllllll}71.0 & 9 & 76.0 & 6 & 88.0 & 9 & 122\end{array}$

$\begin{array}{lllllll}67.0 & 5 & 78.0 & 7 & 86.0 & 7 & 129\end{array}$

$\begin{array}{lllllll}90.0 & 24 & 94.0 & 20 & 109 & 28 & 268 \\ 85.0 & 21 & 95.0 & 21 & 102 & 17 & 124\end{array}$

$\begin{array}{lllllll}85.0 & 21 & 95.0 & 21 & 102 & 17 & 124 \\ 92.0 & 26 & 99.0 & 28 & 106 & 23 & 150\end{array}$

59
57
44
41
49
61
61
58
46
38
35
47
47
53
63
40
19
13
13
39
42
5
30
25
25
16
53
20
6
3
36
27
56
48
29


LOWEST MEAN DISCHARGE, IN CUBIC FEET PER SECOND, AND RANKING FOR THE INDICATED NUMBER OF CONSECUTIVE DAYS FOR EACH CLIMATIC YEAR, APRIL 1-MARCH 31--Continued

YER

137

$67.0 \quad 46$

$80.0 \quad 55$

$57.0 \quad 38$

$45.0 \quad 15$

44.014

$59.0 \quad 40$

$58.0 \quad 39$

$64.0 \quad 52$

$78.0 \quad 53$

$82.0 \quad 57$

$67.0 \quad 47$

$70.0 \quad 50$

$69.0 \quad 48$

$86.0 \quad 60$

$\begin{array}{llllll}82.0 & 55 & 84.0 & 55 & 88.0 & 52\end{array}$

$46.0 \quad 13$

44.011

$44.0 \quad 10$

68.039

$48.0 \quad 13$

80.051

CONSECTTIVE DAYS

$\begin{array}{llll}30 & 60 & 90 & 120\end{array}$

$\begin{array}{rrrr}58.0 & 13 & 67.0 & 16 \\ 52.0 & 6 & 55.0 & 3\end{array}$

$\begin{array}{rrrrrrr}59.0 & 19 & 96.0 & 25 & 104 & 18 & 128\end{array}$

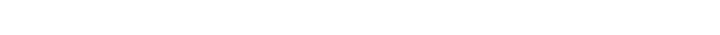

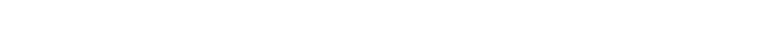

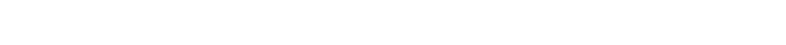

$48.0 \quad 9$

$\begin{array}{rr}45.0 & 5 \\ 71.0 & 37\end{array}$

50.04

$57.0 \quad 10$

53.02

$65.0 \quad 11$

62.0

$\begin{array}{llllll}74.0 & 33 & 79.0 & 23 & 84.0 & 20\end{array}$

$\begin{array}{rrrrrrrrrrr}52.0 & 7 & 57.0 & 4 & 69.0 & 6 & 80.0 & 11 & 94.0 & 12 & 108 \\ 63.0 & 18 & 64.0 & 10 & 70.0 & 8 & 80.0 & 12 & 89.0 & 10 & 126\end{array}$

$59.0 \quad 28$

$86.0 \quad 50$

$90.0 \quad 46$

$\begin{array}{ccccccccccc}90.0 & 46 & 100 & 44 & 111 & 45 & 112 & 40 & 143 & 49 & 203 \\ 85.0 & 44 & 93.0 & 40 & 98.0 & 32 & 99.0 & 29 & 108 & 26 & 192\end{array}$

$\begin{array}{lllllllllll}98.0 & 54 & 111 & 53 & 122 & 51 & 124 & 47 & 141 & 47 & 187\end{array}$

$\begin{array}{lllllllllll}98.0 & 55 & 102 & 47 & 106 & 41 & 113 & 42 & 145 & 51 & 232\end{array}$

$\begin{array}{llll}79.0 & 50 \quad 91.0 & 55\end{array}$

$\begin{array}{llll}89.0 & 58 & 94.0 & 59 \\ 77.0 & 49 & 90.0 & 53\end{array}$

$\begin{array}{lllllll}97.0 & 53 & 103 & 49 & 114 & 46 & 127\end{array}$

$48 \quad 132$

$\begin{array}{lllllllll}80.0 & 39 & 87.0 & 32 & 105 & 40 & 118 & 44 & 122\end{array}$

$\begin{array}{ll}38 & 137\end{array}$

$82.0 \quad 41$

$90.0 \quad 37$

$\begin{array}{llll}71.0 & 43 & 76.0 & 45\end{array}$

$27 \quad 418$

$93.0 \quad 58$

10958

$128 \quad 58$

HIGHEST MEAN DISCHARGE, IN OBBIC FEET PER SECOND, AND RANKING FOR THE INDICATED NUMBER OF CONSEOUTIVE DAYS FOR EACH WATER YEAR, OCTOBER 1-SEPTEMBER 30

YEAR

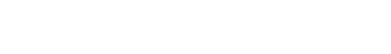

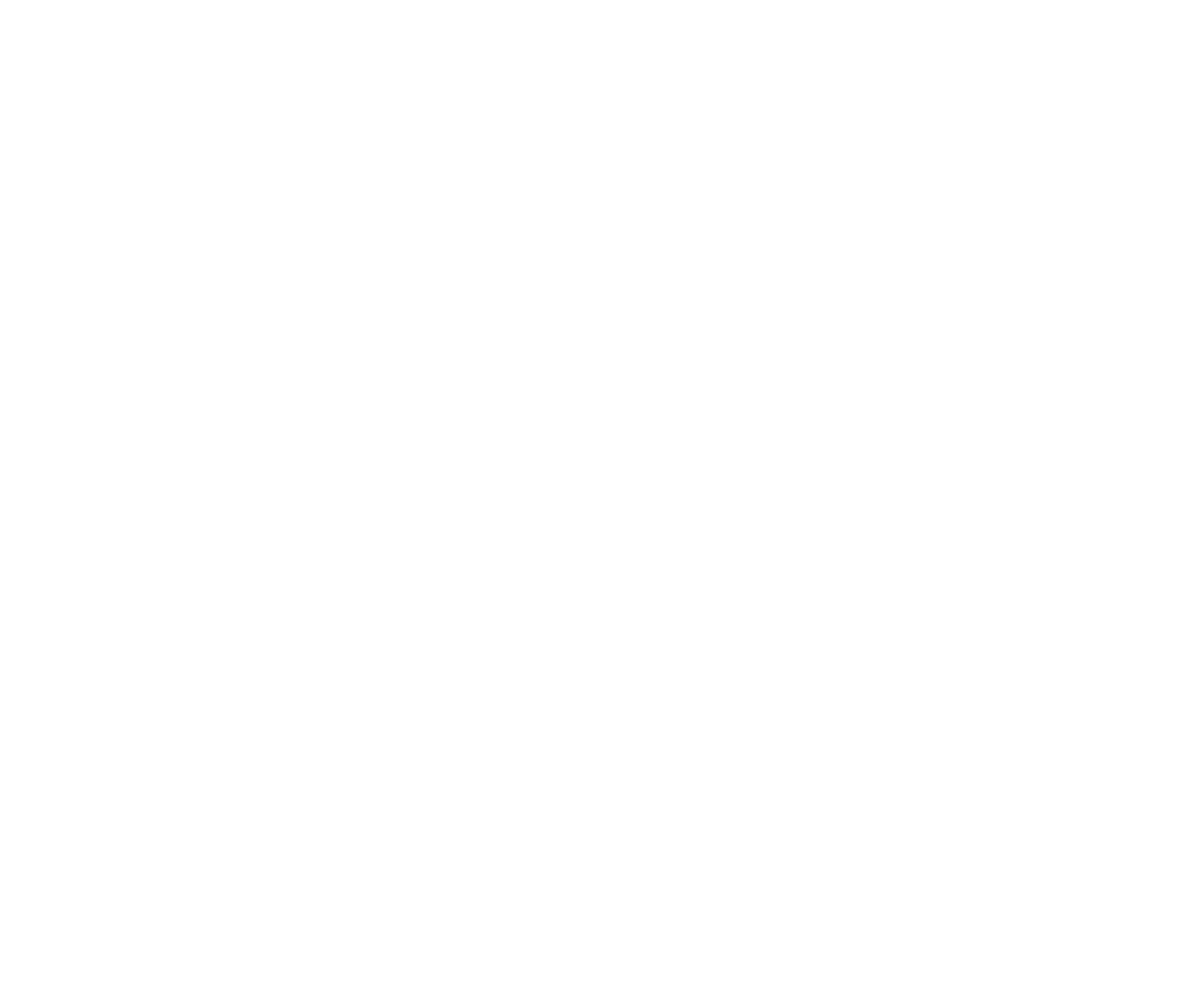


VIRGIN RIVER BASIN

09406000 VIRGIN RIVER AT VIRGIN, UT--Continued

HIGHEST MEAN DISCHARGE, IN OBIC FEET PER SECOND, AND RANKING FOR THE INDICATED NUMBER OF CONSEOTRTVE DAYS FOR EACH WATER YEAR, OCTCBER 1-SEPTEMBER 30--Cont inued

YEAR

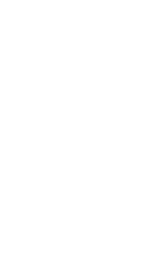

19613190

$1962 \quad 1540$

19631360

$1964 \quad 528$

19661640

$1966 \quad 1640$

19693460

$1970 \quad 950$

1971948

19794230

19803000

$1981 \quad 1090$

46
19
55
5
617
59
14
37
62
49
35
57
12
51
52

AN DISCHARGE, IN OBB 
DURATION OF DISCHARGE FOR EACH WATER YEAR--Continued

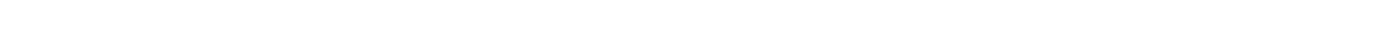
YEAR

NUMBER OF DAYS IN CLASS

CUBIC FEET

-DAYS

1946

1947

$\begin{array}{rrrrrrrrrrrrrrrrr}3 & 75 & 28 & 27 & 24 & 90 & 52 & 43 & 20 & 2 & 1 & & & & & & \\ 1 & 23 & 38 & 34 & 47 & 67 & 54 & 15 & 16 & 26 & 29 & 6 & 3 & 3 & & 2 & 1 \\ 29 & 38 & 17 & 28 & 87 & 65 & 46 & 8 & 6 & 9 & 17 & 7 & 2 & & & & \\ 14 & 24 & 64100 & 26 & 34 & 18 & 21 & 5 & 23 & 21 & 8 & 3 & 3 & & 1\end{array}$

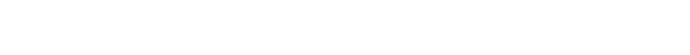

1950

$\begin{array}{rrrrrrrrrrrrrrrrrrrrr}25 & 55 & 44 & 30 & 97 & 82 & 13 & 8 & 4 & 2 & 2 & & 1 & 1 & & & 1 & & & & \\ & 26 & 58 & 72 & 48 & 54 & 16 & 8 & 5 & 8 & 8 & 8 & 10 & 8 & 6 & 9 & 9 & 4 & 5 & 3 & 1 \\ 1 & 56 & 23 & 39 & 74 & 71 & 82 & 8 & 2 & 1 & 2 & 3 & 1 & 1 & & & & & 1 & & \end{array}$

$\begin{array}{rrrrrrrrrrrrrrrr}1 & 56 & 23 & 39 & 74 & 71 & 82 & 8 & 2 & 1 & 2 & 3 & 1 & 1 & & \\ 40 & 34 & 47 & 26 & 93 & 50 & 12 & 11 & 19 & 8 & 10 & 5 & 2 & 7 & 1\end{array}$

$\begin{array}{lllllllllllllllll}8 & 41 & 21 & 42 & 98 & 73 & 31 & 28 & 10 & 3 & 3 & 4 & 1 & & & 1 & 1\end{array}$

$\begin{array}{lllllllllll}34 & 66 & 39 & 20 & 31100 & 55 & 16 & 1 & 1 & 2\end{array}$

$\begin{array}{rrrrrrrrrrrrrrrrrrrrr}18 & 27 & 96 & 91 & 23 & 40 & 19 & 14 & 9 & 17 & 8 & 2 & & 1 & & & & & \\ 10 & 20 & 73 & 55 & 72 & 17 & 10 & 17 & 19 & 9 & 9 & 5 & 6 & 15 & 13 & 9 & 3 & 1 & 1 & & 1\end{array}$

$254 \begin{array}{lllllllllllll}54 & 39 & 34 & 64113 & 38 & 11 & 6 & 3 & 1 & & 1 \\ 2 & 17 & 44 & 39 & 91 & 51 & 37 & 17 & 9 & 1 & 2 & 1 & 1\end{array}$

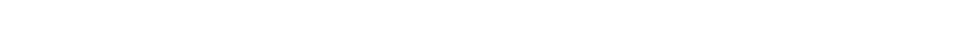

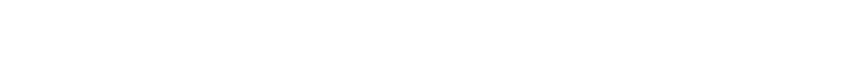

$\begin{array}{llllllllllllll}11 & 22 & 52149 & 25 & 20 & 5 & 8 & 9 & 12 & 22 & 18 & 7 & 4 & 1\end{array}$

1966

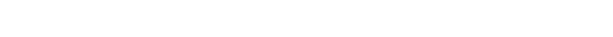

$\begin{array}{lllllllll}5 & 19 & 86 & 70 & 55 & 37 & 35 & 17 & 10\end{array}$

$\begin{array}{lllllllllllll}25103 & 58 & 40 & 35 & 23 & 23 & 11 & 28 & 14 & 5 & & 1\end{array}$

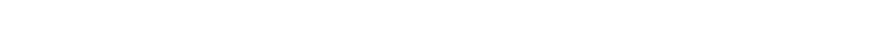

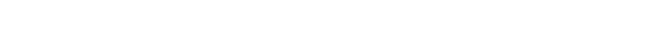

43766.0

59061.0

46388.0

60119.0

38761.0

102290.0

44045.0

56465.0

40123.0

49099.0

105410.0

41755.0

39375.0

44885.0

66429.0

39902.0

47228.0

61582.0

1967

1969

1971

$\begin{array}{rrrrrrrrrrrrrrrrrrrrrrr}18 & 17 & 41 & 52 & 41 & 31 & 31 & 19 & 14 & 15 & 10 & 9 & 6 & 8 & 5 & 10 & 9 & 5 & 7 & 12 & 4 & & 1 \\ 8 & 11 & 56 & 67 & 26 & 7 & 21 & 22 & 25 & 15 & 20 & 11 & 16 & 15 & 20 & 13 & 5 & 3 & & 3 & 2 & \end{array}$

60719.0

81959.0

69082.0

125821.0

52961.0

1979

48891.0

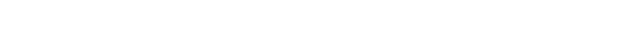

136356.0

142561.0

1981

DURATION TABLE OF DISCHARGE FOR WATER YEARS 1910-71, 1979-81

$\begin{array}{lll}\text { CUBIC } & \text { ACOU- } \\ \text { FEET } & \text { MU- } & \text { PER- } \\ \text { PER TOTAL LATED } & \text { CENT }\end{array}$

CLASS SECOND DAYS DAYS DAYS

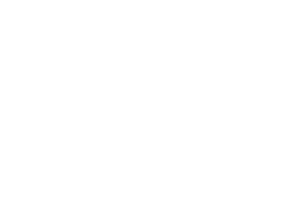

57595.0

\begin{tabular}{|c|c|c|c|c|c|c|c|c|c|c|c|c|c|c|}
\hline CIASS & $\begin{array}{c}\text { CUBIC } \\
\text { FEET } \\
\text { PER } \\
\text { SEDOND }\end{array}$ & $\begin{array}{l}\text { TOTAL } \\
\text { DAYS }\end{array}$ & $\begin{array}{l}\text { ACCU- } \\
\text { MU- } \\
\text { LATED } \\
\text { DAYS }\end{array}$ & $\begin{array}{l}\text { PER- } \\
\text { CENT } \\
\text { DAYS }\end{array}$ & CLASS & $\begin{array}{c}\text { CUBIC } \\
\text { FEET } \\
\text { PER } \\
\text { SECOND }\end{array}$ & $\begin{array}{l}\text { TOIAL } \\
\text { DAYS }\end{array}$ & $\begin{array}{l}\text { ACCU- } \\
\text { MU- } \\
\text { LATED } \\
\text { DAYS }\end{array}$ & $\begin{array}{l}\text { PER- } \\
\text { CENT } \\
\text { DAYS }\end{array}$ & CLASS & $\begin{array}{c}\text { CABIC } \\
\text { FEET } \\
\text { PERR } \\
\text { SECOND }\end{array}$ & $\begin{array}{l}\text { TOTAL } \\
\text { DAYS }\end{array}$ & $\begin{array}{l}\text { ACOU- } \\
\text { MU- } \\
\text { LATED } \\
\text { DAYS }\end{array}$ & $\begin{array}{l}\text { PER- } \\
\text { CENT } \\
\text { DAYS }\end{array}$ \\
\hline $\begin{array}{r}9 \\
10 \\
11 \\
12 \\
13 \\
14 \\
15 \\
16 \\
17\end{array}$ & $\begin{array}{r}96.00 \\
120.00 \\
140.00 \\
170.00 \\
200.00 \\
240.00 \\
290.00 \\
350.00 \\
420.00\end{array}$ & $\begin{array}{r}3994 \\
3467 \\
3087 \\
1614 \\
1199 \\
922 \\
810 \\
729 \\
519\end{array}$ & $\begin{array}{r}17966 \\
13972 \\
10505 \\
7418 \\
5804 \\
4605 \\
3683 \\
2873 \\
2144\end{array}$ & $\begin{array}{r}75.7 \\
58.9 \\
44.2 \\
31.2 \\
24.4 \\
19.4 \\
15.5 \\
12.1 \\
9.0\end{array}$ & $\begin{array}{l}18 \\
19 \\
20 \\
21 \\
22 \\
23 \\
24 \\
25 \\
26\end{array}$ & $\begin{array}{r}510.0 \\
610.0 \\
730.0 \\
880.0 \\
1100.0 \\
1300.0 \\
1500.0 \\
1800.0 \\
2200.0\end{array}$ & $\begin{array}{r}407 \\
338 \\
270 \\
240 \\
120 \\
88 \\
66 \\
44 \\
20\end{array}$ & $\begin{array}{r}1625 \\
1218 \\
880 \\
610 \\
370 \\
250 \\
162 \\
96 \\
52\end{array}$ & $\begin{array}{l}6.8 \\
5.1 \\
3.7 \\
2.6 \\
1.6 \\
1.1 \\
0.7 \\
0.4 \\
0.2\end{array}$ & $\begin{array}{l}27 \\
28 \\
29 \\
30 \\
31 \\
32 \\
33 \\
34\end{array}$ & $\begin{array}{l}2700.0 \\
3200.0 \\
3800.0 \\
4600.0 \\
5600.0 \\
6700.0 \\
8000.0 \\
9700.0\end{array}$ & $\begin{array}{r}14 \\
6 \\
2 \\
2 \\
1 \\
2 \\
4 \\
1\end{array}$ & $\begin{array}{r}32 \\
18 \\
12 \\
10 \\
8 \\
7 \\
5 \\
1\end{array}$ & $\begin{array}{l}0.1 \\
0.1 \\
0.1 \\
0.0 \\
0.0 \\
0.0 \\
0.0 \\
0.0\end{array}$ \\
\hline
\end{tabular}

MONIHLY MEAN DISCHARGES, IN OUBIC FEET PER SBCOND, FOR EACH WATER YEAR

\begin{tabular}{|c|c|c|c|c|c|c|c|c|c|c|c|c|}
\hline YEAR & $\infty \mathrm{CT}$ & $\mathrm{NOV}$ & DEC & JAN & FEB & MAR & APR & MAY & JUNE & JULY & AUKG & SEP \\
\hline 1910 & 183 & 233 & 226 & 286 & 226 & 822 & 620 & 332 & 108 & 100 & 247 & 317 \\
\hline $\begin{array}{l}1911 \\
1912 \\
1913 \\
1914 \\
1915\end{array}$ & $\begin{array}{l}163 \\
187 \\
493 \\
141 \\
110\end{array}$ & $\begin{array}{l}108 \\
138 \\
165 \\
188 \\
100\end{array}$ & $\begin{array}{l}147 \\
139 \\
143 \\
169 \\
100\end{array}$ & $\begin{array}{l}791 \\
121 \\
143 \\
280 \\
120\end{array}$ & $\begin{array}{l}278 \\
124 \\
153 \\
287 \\
180\end{array}$ & $\begin{array}{l}766 \\
140 \\
226 \\
315 \\
236\end{array}$ & $\begin{array}{l}938 \\
191 \\
401 \\
809 \\
501\end{array}$ & $\begin{array}{l}746 \\
434 \\
217 \\
651 \\
884\end{array}$ & $\begin{array}{l}226 \\
162 \\
151 \\
247 \\
304\end{array}$ & $\begin{array}{l}484 \\
279 \\
146 \\
279 \\
115\end{array}$ & $\begin{array}{c}131 \\
190 \\
207 \\
115 \\
90.5\end{array}$ & $\begin{array}{l}504 \\
134 \\
164 \\
104 \\
344\end{array}$ \\
\hline $\begin{array}{l}1916 \\
1917 \\
1918 \\
1919 \\
1920\end{array}$ & $\begin{array}{l}171 \\
302 \\
122 \\
192 \\
148\end{array}$ & $\begin{array}{l}224 \\
144 \\
147 \\
164 \\
176\end{array}$ & $\begin{array}{l}225 \\
127 \\
155 \\
180 \\
196\end{array}$ & $\begin{array}{l}257 \\
161 \\
126 \\
140 \\
189\end{array}$ & $\begin{array}{l}228 \\
202 \\
112 \\
141 \\
248\end{array}$ & $\begin{array}{l}781 \\
169 \\
627 \\
228 \\
241\end{array}$ & $\begin{array}{l}876 \\
398 \\
342 \\
385 \\
396\end{array}$ & $\begin{array}{l}635 \\
623 \\
451 \\
221 \\
677\end{array}$ & $\begin{array}{l}267 \\
276 \\
130 \\
110 \\
198\end{array}$ & $\begin{array}{c}363 \\
132 \\
191 \\
150 \\
41.8\end{array}$ & $\begin{array}{l}441 \\
79.9 \\
125 \\
143 \\
193\end{array}$ & $\begin{array}{c}193 \\
82.3 \\
227 \\
167 \\
85.6\end{array}$ \\
\hline $\begin{array}{l}1921 \\
1922 \\
1923 \\
1924 \\
1925\end{array}$ & $\begin{array}{l}165 \\
225 \\
528 \\
122 \\
103\end{array}$ & $\begin{array}{l}229 \\
214 \\
606 \\
167 \\
137\end{array}$ & $\begin{array}{l}257 \\
526 \\
560 \\
146 \\
151\end{array}$ & $\begin{array}{l}213 \\
331 \\
394 \\
174 \\
177\end{array}$ & $\begin{array}{l}177 \\
345 \\
404 \\
103 \\
179\end{array}$ & $\begin{array}{c}273 \\
435 \\
339 \\
91.7 \\
144\end{array}$ & $\begin{array}{l}358 \\
638 \\
587 \\
195 \\
240\end{array}$ & $\begin{array}{r}386 \\
1378 \\
654 \\
184 \\
166\end{array}$ & $\begin{array}{c}90.3 \\
455 \\
164 \\
74.5 \\
156\end{array}$ & $\begin{array}{c}69.5 \\
197 \\
131 \\
119 \\
76.6\end{array}$ & $\begin{array}{c}278 \\
433 \\
127 \\
77.2 \\
264\end{array}$ & $\begin{array}{l}149 \\
391 \\
102 \\
205 \\
110\end{array}$ \\
\hline
\end{tabular}


VIRGIN RIVER BASIN

09406000 VIRGIN RIVER AT VIRGIN, UT-Continued

MONTHLY MEAN DISCHARGES, IN OABIC FEET PER SECOND, FOR EACH WATER YEAR--Continued

\begin{tabular}{|c|c|c|c|c|c|c|c|c|c|c|c|c|}
\hline YEAR & $\infty C T$ & NON & DEC & JAN & FEBB & MAR & APR & MAY & JUNE & JULY & AUG & SEP \\
\hline $\begin{array}{l}1926 \\
1927 \\
1928 \\
1929 \\
1930\end{array}$ & $\begin{array}{c}69.5 \\
92.2 \\
294 \\
61.3 \\
121\end{array}$ & $\begin{array}{l}82.9 \\
198 \\
132 \\
100 \\
100\end{array}$ & $\begin{array}{l}118 \\
157 \\
123 \\
98.1 \\
90.0\end{array}$ & $\begin{array}{l}123 \\
165 \\
119 \\
97.3 \\
90.0\end{array}$ & $\begin{array}{l}90.9 \\
241 \\
245 \\
129 \\
110\end{array}$ & $\begin{array}{l}94.0 \\
240 \\
256 \\
178 \\
123\end{array}$ & $\begin{array}{l}656 \\
421 \\
308 \\
282 \\
223\end{array}$ & $\begin{array}{l}433 \\
362 \\
207 \\
337 \\
448\end{array}$ & $\begin{array}{l}103 \\
117 \\
68.9 \\
90.1 \\
98.6\end{array}$ & $\begin{array}{c}95.5 \\
108 \\
30.4 \\
196 \\
81.4\end{array}$ & $\begin{array}{l}87.2 \\
198 \\
43.5 \\
300 \\
232\end{array}$ & $\begin{array}{l}89.8 \\
360 \\
61.1 \\
357 \\
140\end{array}$ \\
\hline $\begin{array}{l}1931 \\
1932 \\
1933 \\
1934 \\
1935\end{array}$ & $\begin{array}{c}117 \\
64.0 \\
110 \\
76.6 \\
102\end{array}$ & $\begin{array}{l}204 \\
110 \\
122 \\
101 \\
112\end{array}$ & $\begin{array}{l}125 \\
77.4 \\
156 \\
115 \\
155\end{array}$ & $\begin{array}{l}109 \\
70.9 \\
155 \\
153 \\
151\end{array}$ & $\begin{array}{l}151 \\
535 \\
143 \\
144 \\
176\end{array}$ & $\begin{array}{l}135 \\
252 \\
167 \\
156 \\
180\end{array}$ & $\begin{array}{l}138 \\
640 \\
184 \\
147 \\
478\end{array}$ & $\begin{array}{c}97.5 \\
1034 \\
325 \\
90.8 \\
514\end{array}$ & $\begin{array}{c}73.8 \\
331 \\
181 \\
59.0 \\
190\end{array}$ & $\begin{array}{l}79.6 \\
325 \\
110 \\
67.0 \\
98.7\end{array}$ & $\begin{array}{l}118 \\
209 \\
97.6 \\
105 \\
115\end{array}$ & $\begin{array}{c}68.6 \\
84.6 \\
133 \\
88.6 \\
76.0\end{array}$ \\
\hline $\begin{array}{l}1936 \\
1937 \\
1938 \\
1939 \\
1940\end{array}$ & $\begin{array}{l}99.0 \\
137 \\
102 \\
115 \\
133\end{array}$ & $\begin{array}{l}134 \\
116 \\
126 \\
121 \\
115\end{array}$ & $\begin{array}{l}135 \\
103 \\
182 \\
151 \\
111\end{array}$ & $\begin{array}{l}122 \\
98.6 \\
159 \\
153 \\
197\end{array}$ & $\begin{array}{l}246 \\
247 \\
170 \\
142 \\
244\end{array}$ & $\begin{array}{l}187 \\
355 \\
555 \\
196 \\
228\end{array}$ & $\begin{array}{l}338 \\
658 \\
809 \\
342 \\
337\end{array}$ & $\begin{array}{r}168 \\
1102 \\
704 \\
156 \\
199\end{array}$ & $\begin{array}{l}83.1 \\
260 \\
182 \\
79.9 \\
81.7\end{array}$ & $\begin{array}{l}229 \\
213 \\
93.8 \\
69.1 \\
68.0\end{array}$ & $\begin{array}{l}130 \\
94.4 \\
131 \\
72.4 \\
68.8\end{array}$ & $\begin{array}{l}97.7 \\
129 \\
141 \\
419 \\
268\end{array}$ \\
\hline $\begin{array}{l}1941 \\
1942 \\
1943 \\
1944 \\
1945\end{array}$ & $\begin{array}{l}105 \\
258 \\
131 \\
125 \\
84.7\end{array}$ & $\begin{array}{l}113 \\
196 \\
142 \\
112 \\
145\end{array}$ & $\begin{array}{l}187 \\
182 \\
127 \\
138 \\
123\end{array}$ & $\begin{array}{l}147 \\
182 \\
148 \\
149 \\
128\end{array}$ & $\begin{array}{l}270 \\
174 \\
214 \\
167 \\
169\end{array}$ & $\begin{array}{l}417 \\
231 \\
308 \\
225 \\
200\end{array}$ & $\begin{array}{l}630 \\
681 \\
458 \\
326 \\
309\end{array}$ & $\begin{array}{r}1416 \\
491 \\
236 \\
685 \\
415\end{array}$ & $\begin{array}{l}338 \\
158 \\
98.8 \\
192 \\
109\end{array}$ & $\begin{array}{l}208 \\
107 \\
80.1 \\
82.5 \\
72.8\end{array}$ & $\begin{array}{l}139 \\
137 \\
123 \\
75.8 \\
138\end{array}$ & $\begin{array}{c}111 \\
79.1 \\
90.7 \\
72.3 \\
100\end{array}$ \\
\hline $\begin{array}{l}1946 \\
1947 \\
1948 \\
1949 \\
1950\end{array}$ & $\begin{array}{l}151 \\
180 \\
111 \\
73.8 \\
114\end{array}$ & $\begin{array}{c}140 \\
162 \\
113 \\
92.9 \\
131\end{array}$ & $\begin{array}{l}130 \\
160 \\
138 \\
108 \\
138\end{array}$ & $\begin{array}{l}120 \\
148 \\
122 \\
111 \\
142\end{array}$ & $\begin{array}{l}113 \\
142 \\
125 \\
151 \\
186\end{array}$ & $\begin{array}{l}174 \\
210 \\
127 \\
182 \\
178\end{array}$ & $\begin{array}{l}197 \\
283 \\
267 \\
328 \\
289\end{array}$ & $\begin{array}{l}117 \\
267 \\
222 \\
382 \\
165\end{array}$ & $\begin{array}{c}62.8 \\
95.7 \\
93.8 \\
218 \\
79.6\end{array}$ & $\begin{array}{r}74.6 \\
66.0 \\
59.0 \\
95.9 \\
125\end{array}$ & $\begin{array}{c}93.9 \\
142 \\
84.7 \\
82.6 \\
69.5\end{array}$ & $\begin{array}{r}63.0 \\
83.5 \\
60.3 \\
154 \\
69.7\end{array}$ \\
\hline $\begin{array}{l}1951 \\
1952 \\
1953 \\
1954 \\
1955\end{array}$ & $\begin{array}{r}75.9 \\
92.3 \\
92.2 \\
95.8 \\
132\end{array}$ & $\begin{array}{l}112 \\
115 \\
132 \\
125 \\
110\end{array}$ & $\begin{array}{l}114 \\
215 \\
151 \\
127 \\
129\end{array}$ & $\begin{array}{l}118 \\
155 \\
158 \\
154 \\
118\end{array}$ & $\begin{array}{l}123 \\
146 \\
137 \\
155 \\
143\end{array}$ & $\begin{array}{l}124 \\
215 \\
127 \\
184 \\
150\end{array}$ & $\begin{array}{l}142 \\
834 \\
135 \\
414 \\
169\end{array}$ & $\begin{array}{r}149 \\
1048 \\
109 \\
211 \\
146\end{array}$ & $\begin{array}{c}64.0 \\
241 \\
72.8 \\
99.4 \\
76.5\end{array}$ & $\begin{array}{l}57.8 \\
110 \\
126 \\
108 \\
89.9\end{array}$ & $\begin{array}{c}122 \\
92.4 \\
148 \\
74.4 \\
216\end{array}$ & $\begin{array}{r}72.1 \\
86.7 \\
60.1 \\
113 \\
60.0\end{array}$ \\
\hline $\begin{array}{l}1956 \\
1957 \\
1958 \\
1959 \\
1960\end{array}$ & $\begin{array}{c}73.2 \\
66.7 \\
140 \\
114 \\
74.2\end{array}$ & $\begin{array}{l}126 \\
88.1 \\
197 \\
137 \\
115\end{array}$ & $\begin{array}{l}133 \\
98.5 \\
153 \\
134 \\
123\end{array}$ & $\begin{array}{l}173 \\
127 \\
119 \\
125 \\
118\end{array}$ & $\begin{array}{l}132 \\
166 \\
234 \\
154 \\
122\end{array}$ & $\begin{array}{l}142 \\
139 \\
309 \\
133 \\
158\end{array}$ & $\begin{array}{l}156 \\
164 \\
653 \\
131 \\
161\end{array}$ & $\begin{array}{c}132 \\
300 \\
932 \\
87.5 \\
132\end{array}$ & $\begin{array}{l}66.0 \\
182 \\
175 \\
77.5 \\
82.0\end{array}$ & $\begin{array}{r}72.5 \\
92.8 \\
118 \\
64.9 \\
50.1\end{array}$ & $\begin{array}{l}58.1 \\
106 \\
147 \\
143 \\
55.3\end{array}$ & $\begin{array}{c}53.1 \\
86.2 \\
289 \\
73.4 \\
102\end{array}$ \\
\hline $\begin{array}{l}1961 \\
1962 \\
1963 \\
1964 \\
1965\end{array}$ & $\begin{array}{r}102 \\
81.8 \\
93.6 \\
88.0 \\
68.9\end{array}$ & $\begin{array}{l}152 \\
106 \\
104 \\
118 \\
102\end{array}$ & $\begin{array}{l}120 \\
113 \\
115 \\
111 \\
111\end{array}$ & $\begin{array}{l}112 \\
111 \\
119 \\
111 \\
110\end{array}$ & $\begin{array}{l}108 \\
348 \\
143 \\
110 \\
116\end{array}$ & $\begin{array}{l}125 \\
210 \\
117 \\
134 \\
127\end{array}$ & $\begin{array}{l}129 \\
618 \\
128 \\
246 \\
351\end{array}$ & $\begin{array}{l}97.0 \\
231 \\
109 \\
268 \\
437\end{array}$ & $\begin{array}{c}58.1 \\
109 \\
62.1 \\
94.8 \\
262\end{array}$ & $\begin{array}{r}76.7 \\
85.6 \\
54.0 \\
92.2 \\
101\end{array}$ & $\begin{array}{l}151 \\
77.4 \\
130 \\
110 \\
101\end{array}$ & $\begin{array}{c}246 \\
116 \\
141 \\
65.3 \\
138\end{array}$ \\
\hline $\begin{array}{l}1966 \\
1967 \\
1968 \\
1969 \\
1970\end{array}$ & $\begin{array}{l}107 \\
116 \\
101 \\
102 \\
119\end{array}$ & $\begin{array}{l}234 \\
134 \\
125 \\
130 \\
168\end{array}$ & $\begin{array}{l}209 \\
648 \\
146 \\
130 \\
148\end{array}$ & $\begin{array}{l}121 \\
136 \\
134 \\
461 \\
134\end{array}$ & $\begin{array}{l}135 \\
142 \\
182 \\
257 \\
133\end{array}$ & $\begin{array}{l}237 \\
170 \\
217 \\
341 \\
183\end{array}$ & $\begin{array}{l}365 \\
225 \\
335 \\
978 \\
121\end{array}$ & $\begin{array}{r}190 \\
416 \\
368 \\
1092 \\
148\end{array}$ & $\begin{array}{l}93.4 \\
210 \\
142 \\
241 \\
86.6\end{array}$ & $\begin{array}{l}105 \\
132 \\
180 \\
173 \\
150\end{array}$ & $\begin{array}{l}105 \\
128 \\
231 \\
118 \\
224\end{array}$ & $\begin{array}{l}97.3 \\
225 \\
104 \\
107 \\
122\end{array}$ \\
\hline 1971 & $85: 9$ & 154 & 139 & 134 & 128 & 143 & 153 & 232 & 105 & 80.3 & 167 & 84.2 \\
\hline $\begin{array}{l}1979 \\
1980\end{array}$ & $\begin{array}{l}83.5 \\
90.6\end{array}$ & $\begin{array}{l}215 \\
125\end{array}$ & $\begin{array}{l}170 \\
125\end{array}$ & $\begin{array}{l}133 \\
270\end{array}$ & $\begin{array}{l}166 \\
833\end{array}$ & $\begin{array}{l}544 \\
438\end{array}$ & $\begin{array}{l}937 \\
680\end{array}$ & $\begin{array}{l}1582 \\
1067\end{array}$ & $\begin{array}{l}327 \\
450\end{array}$ & $\begin{array}{c}93.1 \\
207\end{array}$ & $\begin{array}{l}124 \\
178\end{array}$ & 236 \\
\hline 1981 & 133 & 143 & 145 & 131 & 139 & 173 & 339 & 219 & 115 & 125 & 115 & 118 \\
\hline
\end{tabular}


ANNUAL PEAK DISCHARGE, IN CUBIC FEET PER SECOND, AND CORRESPONDING GAGE HEIGHT, IN FEET, FOR EACH WATER YEAR

\begin{tabular}{|c|c|c|c|c|c|c|c|c|c|c|c|}
\hline $\begin{array}{l}\text { WATERR } \\
\text { YEAR }\end{array}$ & DATE & $\begin{array}{c}\text { GAGE } \\
\text { HEIGHT }\end{array}$ & $\begin{array}{c}\text { PEAK } \\
\text { DISCHARGE }\end{array}$ & $\begin{array}{l}\text { WATERR } \\
\text { YEAR }\end{array}$ & DATE & $\begin{array}{c}\text { GAGE } \\
\text { HEIGHT }\end{array}$ & $\begin{array}{c}\text { PEAK } \\
\text { DISCHARGE }\end{array}$ & $\begin{array}{l}\text { WATER } \\
\text { YEAR }\end{array}$ & DATE & $\begin{array}{c}\text { GAGE } \\
\text { HEIGHT }\end{array}$ & $\begin{array}{c}\text { PEAK } \\
\text { DISCHARGE }\end{array}$ \\
\hline 1910 & JAN. 01,1910 & 5.80 & 2770 & 1932 & EEB. 09, 1932 & 9.20 & 9000 & 1954 & SEPT.12, 1954 & 6.90 & 4690 \\
\hline 1911 & SEPT. 30,1911 & 11.00 & 10600 & 1933 & SEPT. 08,1933 & 6.90 & 2350 & 1955 & AUG. 25,1955 & 11.41 & 10600 \\
\hline 1912 & JULY 31,1912 & 7.40 & 5100 & 1934 & JULY 28, 1934 & 5.92 & 1550 & 1956 & JAN. 27, 1956 & 4.35 & 2260 \\
\hline 1913 & $\propto$ CT. 27, 1912 & 11.60 & 12000 & 1935 & APR. 08,1935 & 6.18 & 1760 & 1957 & JUNE 10， 1957 & 3.31 & 1430 \\
\hline 1914 & JULY 30,1914 & 5.20 & 2500 & 1936 & JULY 31,1936 & 8.50 & 6300 & 1958 & SEPT.03, 1958 & 9.20 & 7410 \\
\hline 1915 & SEPT. 03, 1915 & 6.56 & 4360 & 1937 & MAY 08,1937 & 5.96 & 1920 & 1959 & AUG. 03,1959 & 6.65 & 4420 \\
\hline 1916 & JULY 26,1916 & 6.60 & 4350 & 1938 & MAR. 03,1938 & 10.70 & 13500 & 1960 & SEPT.01, 1960 & 4.16 & 2190 \\
\hline 1917 & ОС. 06,1916 & 5.00 & 2610 & 1939 & SEPT.06, 1939 & 10.10 & 10000 & 1961 & SEPT.17, 1961 & 13.29 & 13500 \\
\hline 1918 & MAR. 12,1918 & 7.30 & 5100 & 1940 & SEPT.17, 1940 & 7.90 & 4370 & 1962 & FEBB. 12,1962 & 5.30 & 3100 \\
\hline 1919 & SEPT. 03, 1919 & 3.74 & 1240 & 1941 & MAY 06,1941 & 7.80 & 2980 & 1963 & SEPT.18, 1963 & 6.70 & 4550 \\
\hline 1920 & AUG. 19,1920 & 11.06 & 11000 & 1942 & OCT. 13,1941 & 7.88 & 3150 & 1964 & AUG. 12,1964 & 6.81 & 4630 \\
\hline 1921 & AUG. 22,1921 & 5.67 & 2650 & 1943 & MAR. 09, 1943 & 6.52 & 919 & 1965 & SEPT.05, 1965 & 8.80 & 6890 \\
\hline 1922 & AUG. 31,1922 & 6.06 & 3400 & 1944 & MAY 12,1944 & 6.59 & 1070 & 1966 & NOV. 23,1965 & 6.15 & 3930 \\
\hline 1923 & JULY 22,1923 & 7.50 & 5100 & 1945 & MAY 03,1945 & 6.46 & 844 & 1967 & DEC. 06,1966 & 18.00 & 22800 \\
\hline 1924 & SEPT.10， 1924 & 6.00 & 3100 & 1946 & AUG. 12,1946 & 7.78 & 1700 & 1968 & AUG. 07,1968 & 8.50 & 6840 \\
\hline 1925 & AUG. 25,1925 & 4.96 & 1660 & 1947 & OCT, 29,1946 & 7.96 & 2080 & 1969 & JAN. 25,1969 & 13.35 & 13660 \\
\hline 1926 & OCT. 05, 1925 & 5.98 & 2770 & 1948 & SEPT.16, 1948 & 7.60 & 1400 & 1970 & AUG. 18,1970 & 4.72 & 2660 \\
\hline 1927 & SEPT.13， 1927 & 7.00 & 4300 & 1949 & SEPT.08, 1949 & 7.19 & 1010 & 1971 & AUG. 21,1971 & 4.85 & 2880 \\
\hline 1928 & $\propto C ., 31,1927$ & 5.40 & 2600 & 1950 & JULY 08,1950 & 8.58 & 6620 & 1979 & MAR. 28,1979 & 6.65 & 7600 \\
\hline 1929 & JULY 31,1929 & 7.04 & 4200 & 1951 & AUG. 29,1951 & 4.95 & 2800 & 1980 & SEPT.10, 1980 & 9.98 & 10830 \\
\hline 1930 & ALG. 04, 1930 & 5.48 & 3000 & 1952 & DEC. 30,1951 & 7.00 & 4840 & 1981 & JULY 15, 1981 & 6.52 & 3650 \\
\hline 1931 & NOW. 17,1930 & 5.80 & 3550 & 1953 & AUG. 01,1953 & 12.90 & 12900 & & & & \\
\hline
\end{tabular}

MAGNITUDE AND PROBABILITY OF ANNUAL LOWEST MEAN DISCHARGE BASED ON OIMATIC YEARS I911-71 AND 1980-81

\begin{tabular}{|c|c|c|c|c|c|c|}
\hline \multirow{2}{*}{$\begin{array}{l}\text { PERICD } \\
\text { (OON- } \\
\text { SECU- } \\
\text { TIVE } \\
\text { DAYS) }\end{array}$} & \multicolumn{6}{|c|}{$\begin{array}{l}\text { DISCHARGE, IN CUBIC FEET PER SECOND, FOR } \\
\text { INDICATED RECURRENCE INTERNAL, IN YEARS, AND } \\
\text { ANNUAL NONEXCEEDANCE PROBABIITY, IN PERCENT }\end{array}$} \\
\hline & $\begin{array}{c}2 \\
50 \%\end{array}$ & $\begin{array}{c}5 \\
208\end{array}$ & $\begin{array}{l}10 \\
108\end{array}$ & $\begin{array}{l}20 \\
58\end{array}$ & $\begin{array}{l}50 \\
28\end{array}$ & $\begin{array}{r}100 \\
18\end{array}$ \\
\hline
\end{tabular}

$\begin{array}{rllllll}1 & 56 & 40 & 33 & 28 & 23 & 20 \\ 7 & 62 & 46 & 38 & 33 & 27 & 24 \\ 14 & 66 & 51 & 43 & 38 & 33 & 29 \\ 30 & 74 & 58 & 50 & 45 & 39 & 36 \\ 60 & 85 & 67 & 59 & 54 & 49 & 45 \\ 90 & 95 & 75 & 67 & 61 & 56 & 53\end{array}$

MAGNITUDE AND PROBABILITYY OF ANNUAL HIGHEST MEAN DISCHARGE BASED ON WATER YEARS 1910-71 AND 1979-81

\begin{tabular}{|c|c|c|c|c|c|c|}
\hline \multirow{2}{*}{$\begin{array}{l}\text { PERICD } \\
\text { (OON- } \\
\text { SECU- } \\
\text { TIVE } \\
\text { DAYS) }\end{array}$} & \multicolumn{6}{|c|}{$\begin{array}{l}\text { DISCHARGE, IN CUBIC FEET PER SECOND, FOR } \\
\text { INDICATED RECURRENCE INTERNAL, IN YEARS, AND } \\
\text { ANNUAL EXCEEDANCE PROBABIITY, IN PERCENT }\end{array}$} \\
\hline & $\begin{array}{c}2 \\
508\end{array}$ & $\begin{array}{c}5 \\
208\end{array}$ & $\begin{array}{l}10 \\
10 \%\end{array}$ & $\begin{array}{l}25 \\
48\end{array}$ & $\begin{array}{l}50 \\
28\end{array}$ & $\begin{array}{r}100 \\
18\end{array}$ \\
\hline $\begin{array}{r}1 \\
3 \\
7 \\
15\end{array}$ & $\begin{array}{r}1710 \\
1020 \\
714 \\
565\end{array}$ & $\begin{array}{r}3270 \\
1800 \\
1230 \\
965\end{array}$ & $\begin{array}{l}4660 \\
2440 \\
1640 \\
1280\end{array}$ & $\begin{array}{l}6870 \\
3390 \\
2240 \\
1720\end{array}$ & $\begin{array}{l}8880 \\
4210 \\
2730 \\
2080\end{array}$ & $\begin{array}{r}11200 \\
5130 \\
3270 \\
2470\end{array}$ \\
\hline
\end{tabular}

09406300 KANARRA CREEK AT KANARRAVHLE, UT

LOCATION.-Lat $37^{\circ} 32^{\prime} 17^{\prime \prime}$, long $113^{\circ} 10^{\prime} 04^{\prime \prime}$, in SW $W_{\frac{1}{4}}^{1} \mathrm{SW}_{4}^{\frac{1}{4}} \mathrm{NE}_{\frac{1}{4}}^{\frac{1}{4}}$ sec.35, T.37 S., R.12 W., Iron County, Hydrologic Unit 15010008, on Ieft bank $1,100 \mathrm{ft}$ upstream from mouth of canyon and $0.7 \mathrm{mi}$ east of Kanarraville.

DRAINAGE AREA. $-9.85 \mathrm{mi}^{2}$.

MEAN BASIN ELEVATION, $-7,950 \mathrm{ft}$.

PERIOD OF RECORD AVAILABLE.--August 1959 to September 1981.

REVISED RECORDS.--WDR UT-79-1: 1979.

GAGE.--Water-stage recorder and artificial control. Altitude of gage is 5,730 ft from topographic map. August 1959 to Oct. 16 , 1968 , at site $1,200 \mathrm{ft}$ downstream at different datum; Oct. 16, 1968 to June 24, 1980, at site 300 ft upstream at different datum.

REMARKS.--one small diversion $2 \mathrm{mi}$ above station diverts water from a spring for the water supply of Kannarraville. Total flow is usually diverted at mouth of canyon for irrigation

AVERAGE DISCHARGF.--22 years, $4.18 \mathrm{ft}^{3} / \mathrm{s}, 3,030$ acre- $\mathrm{ft} / \mathrm{yr}$.

EXTREMES FOR PERICD OF RECORD.--Maximum discharge, about 1,000 ft $3 / \mathrm{s} \mathrm{Aug.} \mathrm{17,} \mathrm{1970,} \mathrm{gage} \mathrm{height,} 2.25 \mathrm{ft}$, from floodnark; no flow on Jan. 23, 1978, result of freezeup. 
VIRGIN RIVER BASIN

09406300 KANARRA CREEK AT KANARRAVHLLE, UT-Continued

LOWEST MEAN DISCHARGE, IN OUBIC FEET PER SECOND, AND RANKING FOR THE INDICATED NUMBER OF CONSEOUTIVE DAYS FOR EACH OLIMATIC YEAR, APRIL 1-MARCH 31

YEAR
1961
1962
1963
1964
1965
1966
1967
1968
1969
1970
1971
1972
1973
1974
1975
1976
1977
1978
1979
1980
1981

1

1.193

0.901

1.19
1.4010

$\begin{array}{rr}1.40 & 10 \\ 1.30 & 6\end{array}$

1.6014

1.6015

1.5011

1.8019

$1.40 \quad 7$

$\begin{array}{ll}1.40 & 8 \\ 1.19 & 5\end{array}$

2.0020
1.6016

1.6017

1.5012

1.102

1.5013

2.3021
$7 \quad 14$

14

$1.40 \quad 5$

1.40
1.30

$\begin{array}{ll}1.30 & 2 \\ 1.40 & 3\end{array}$

$\begin{array}{ll}1.40 & 3 \\ 1.40 & 4\end{array}$

1.8014

1.8015
1.7012

1.9016

2.1018

1.507

$\begin{array}{ll}1.50 & 8 \\ 1.60 & 9\end{array}$

$\begin{array}{rr}1.60 & 9 \\ 2.40 & 20\end{array}$

2.4020
1.6010

1.9017

1.6011

1.191

2.2019

2.5021

\begin{abstract}
CONSEOTIVE DAYS
\end{abstract}

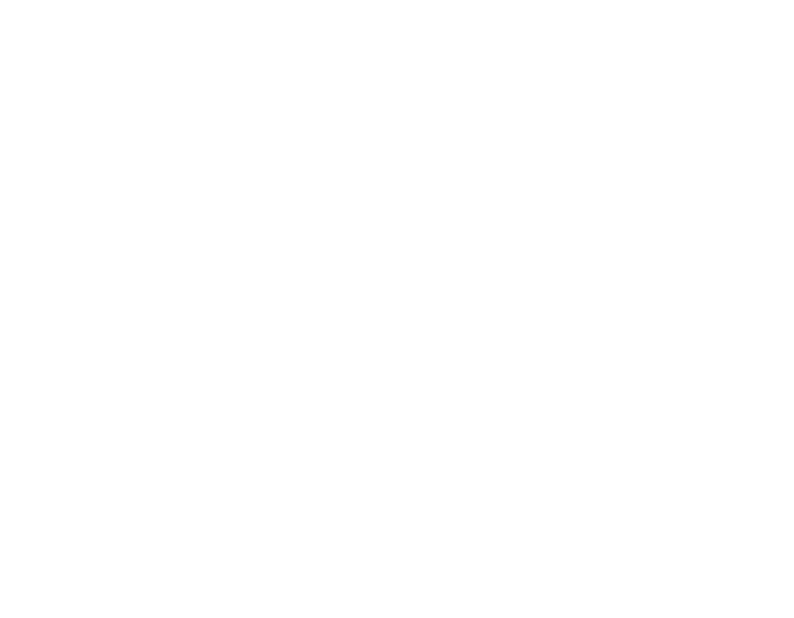

HIGHEST MEAN DISCHARGE, IN OUBIC FEET PER SECOND, AND RANKING FOR THE INDICATED NUMBER OF CONSEOTTIVE DAYS FOR EACH WATER YEAR, OCIOBER 1-SEPTEMBER 30

YEAR

1960

19

195

196

1965

196

1967

1969

$1970 \quad 15.0 \quad 16$

$1971 \quad 50.0 \quad 6$

$\begin{array}{rrr}1972 & 19.0 & 14 \\ 1973 & 108 & 3 \\ 1974 & 8.00 & 21\end{array}$

$25.0 \quad 11$

$11.0 \quad 19$

$\begin{array}{rr}22.0 & 12 \\ 49.0 & 8\end{array}$

$\begin{array}{ll}49.0 & 8 \\ 62.0 & 7\end{array}$

62.04

$11.0 \quad 20$

$\begin{array}{cc}3 & \\ 3.70 & 22 \\ 20.0 & 10 \\ 19.0 & 11 \\ 18.0 & 12 \\ 13.0 & 15 \\ 16.0 & 13 \\ 9.70 & 18 \\ 22.0 & 8 \\ 46.0 & 5 \\ 124 & 1 \\ 7.20 & 21\end{array}$

$\begin{array}{lr}7 & \\ 3.50 & 22 \\ & \\ 2.0 & 11 \\ 8.0 & 8 \\ 8.70 & 17 \\ 2.0 & 12 \\ 5.0 & 9 \\ & \\ 9.00 & 16 \\ 4.0 & 10 \\ 24.0 & 6 \\ 83.0 & 2 \\ 6.10 & 20\end{array}$

$21.0 \quad 9$

$\begin{array}{ll}14.0 & 14\end{array}$

96.02

$\begin{array}{cr}7.80 & 20 \\ 23.0 & 7\end{array}$

9.8017

8.8019

45.06

48.0
59.0

$10.0 \quad 16$
15

3.5022

7.6015

17.08

4.9019

4.9019
10.011

$\begin{array}{rr}10.0 & 11 \\ 14.0 & 9\end{array}$

8.2014

13.010

$21.0 \quad 6$

5.0018

6.1017

4.4021
76.0

$\begin{array}{cc}76.0 & 1 \\ 6.70 & 16\end{array}$

6.7016
$18.0 \quad 7$

8.4013

$\begin{array}{rr}4.5020 \\ 30.0 & 5\end{array}$

38.0

9.0012

DURATION OF DISCHARGE FOR EACH WATER YEAR

$3.3022 \quad 3.0019$

90

$5.5016 \quad 4.6017$

$\begin{array}{cccc}16.0 & 7 & 11.0 & 7 \\ 3.60 & 20 & 3.00 & 20\end{array}$

$\begin{array}{lll}3.6020 & 3.0020 \\ 8.2011 & 6.6012\end{array}$

13.09

11.08

$\begin{array}{rlll}7.9012 & 7.1011 \\ 11.0 & 10 & 8.9010\end{array}$

$\begin{array}{rr}11.0 & 10 \\ 17.0 & 6\end{array}$

$\begin{array}{rr}38.0 & 2 \\ 4.20 & 18\end{array}$

$13.0 \quad 6$

27.03

5.5017

3.3021
63.0

$\begin{array}{rr}63.0 & 1 \\ 6.10 & 15\end{array}$

$\begin{array}{cr}6.10 & 15 \\ 14.0 & 8\end{array}$

4.7016

2.8022

43.01

5.5014
10.0

$7.0014 \quad 5.4015$

$\begin{array}{rrrr}7.00 & 14 & 5.40 & 15 \\ 23.0 & 5 & 18.90 & 21\end{array}$

$\begin{array}{ll}23.0 & 5 \\ 36.0 & 3\end{array}$

$\begin{array}{ll}36.0 & 3 \\ 35.0 & 4\end{array}$

$\begin{array}{ll}18.0 & 5 \\ 28.0 & 4\end{array}$

6.0013

2.8019

3.9017

$\begin{array}{rr}9.00 & 7 \\ 2.70 & 20\end{array}$

2.7020
5.6012

$\begin{array}{rr}5.60 & 12 \\ 9.00 & 8\end{array}$

6.2011

7.1010

21.0

4.3016

$\begin{array}{rr}2.70 & 21 \\ 32.0 & 1\end{array}$

$\begin{array}{cc}32.0 & 1 \\ 4.90 & 14\end{array}$

$\begin{array}{rr}4.90 & 14 \\ 7.70 & 9\end{array}$

4.7015

$\begin{array}{rr}4.70 & 22 \\ 15.0 \quad 5\end{array}$

$19.0 \quad 4$

5.1013

\section{CONSECUTIVE DAYS
30}

120

183

ALL

2.6021

3.6017

$\begin{array}{rr}3.60 & 17\end{array}$

2.8019

2.8019
4.8012

4.8012
7.707

5.4011

6.1010

9.206

17.02

3.3018

4.2016

2.7020

26.01

$\begin{array}{ll}4.40 & 14 \\ 6.90 & 9\end{array}$

4.2015

2.5022

$12.0 \quad 5$

16.03

4.6013
2.0022

$\begin{array}{llll}3.7016 & 2.6016\end{array}$

$\begin{array}{llll}2.6020 & 2.2020\end{array}$

$3.9013 \quad 2.8017$

$\begin{array}{llll}6.007 & 3.90 & 8\end{array}$

$4.6011 \quad 3.5011$

$\begin{array}{lll}5.2010 & 3.80 \quad 9\end{array}$

$\begin{array}{cccc}7.40 & 6 & 4.70 & 6 \\ 13.0 & 2 & 7.90 & 2\end{array}$

$3.1018 \quad 2.8018$

$3.9014 \quad 2.9015$

$2.6019 \quad 2.2019$

20.01111 .01

$\begin{array}{llll}3.90 & 15 & 3.2013\end{array}$

$3.6017 \quad 2.9014$

$\begin{array}{llll}2.40 & 21 & 2.10 & 21\end{array}$

$\begin{array}{cccc}9.10 & 5 & 5.30 & 5 \\ 12.0 & 3 & 7.20 & 4\end{array}$

12.0447 .503

$4.1012 . \quad 3.4012$

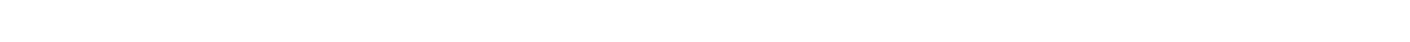
YEAR

NUMBER OF DAYS IN CLASS

QUBIC FEET -DAYS

$1960 \quad 133935339172011$

1961

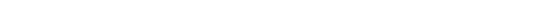

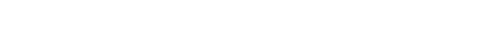
546813950142310 2 $\begin{array}{llllllllll}10 & 2 & 1 & 2 & 2 & 1 & 6 & 4 & 15 & 4\end{array}$

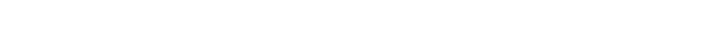

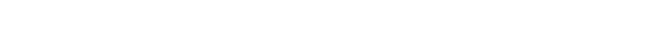

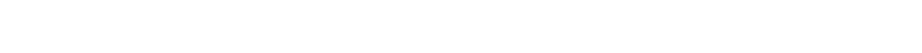
$\begin{array}{rrrrrrrrrrrr}33 & 81 & 80 & 22 & 12 & 17 & 18 & 10 & 12 & 16 & 12 & \\ 9 & 18 & 85 & 34 & 38 & 21 & 22 & 9 & 30 & 23 & 9 & 10\end{array}$

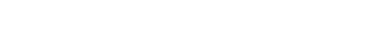

$\begin{array}{lll}6 & 6 & 4 \\ 9 & 7 & 6 \\ & & 1\end{array}$

$\begin{array}{lllllllll}5 & 3 & 3 & & & 1 & & & \\ 1 & 8 & 6 & 2 & 2 & 4 & 1 & 4 & 2\end{array}$

.

1005.3

1408.1

821.2

1025.2

1289.7

1379.5

1969

1970

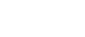

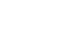

1731.3

1004.6 
VIRGIN RIVER BASTN

09406300 KANARRA CREEK AT KANARRAVIHLE, UT-Continued

DURATION OF DISCHARGE FOR EACH WATER YEAR--Continued

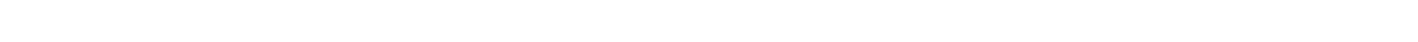
YEAR
1971
1972
1973
1974
1975
1976
1977
1978
1979
1980 NUMBER OF DAYS IN OLASS

OBIC FEET SECOID

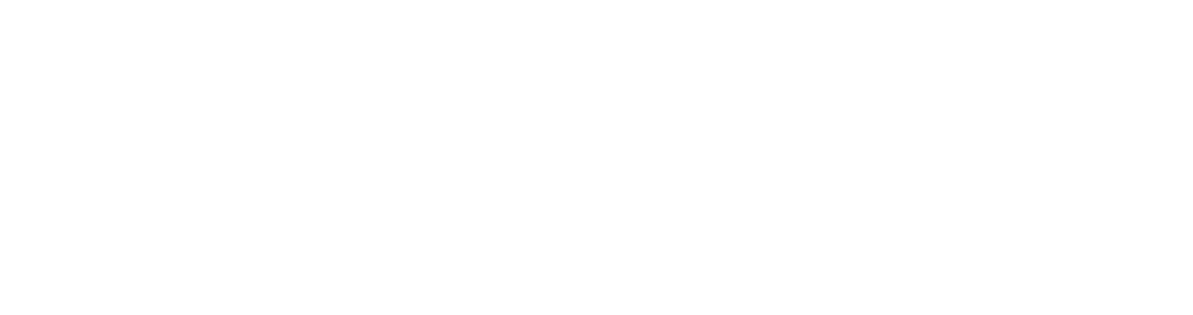

1244.7

\begin{tabular}{|c|c|c|c|c|c|c|c|c|c|c|c|c|c|c|c|c|c|c|c|}
\hline CLASS & $\begin{array}{c}\text { GBIIC } \\
\text { FEET } \\
\text { PER } \\
\text { SECOND }\end{array}$ & TOTAL & $\begin{array}{c}\text { ACOU- } \\
\text { MU- } \\
\text { LATED } \\
\text { DAYS }\end{array}$ & $\begin{array}{l}\text { PER- } \\
\text { CENT } \\
\text { DAYS }\end{array}$ & & $\begin{array}{c}\text { CUBIC } \\
\text { FEET } \\
\text { PER } \\
\text { SECOND }\end{array}$ & $\begin{array}{r}\text { TOTAL } \\
\text { DAYS }\end{array}$ & $\begin{array}{r}\text { ACO- } \\
\text { MD- } \\
\text { LATED } \\
\text { DAYS }\end{array}$ & $\begin{array}{l}\text { PER- } \\
\text { CENT } \\
\text { DAYS }\end{array}$ & CASs & $\begin{array}{c}\text { OUBIC } \\
\text { FEET } \\
\text { PER } \\
\text { SECOND }\end{array}$ & $\begin{array}{l}\text { TOTAL } \\
\text { DAYS }\end{array}$ & $\begin{array}{r}\text { ACO- } \\
\text { MU- } \\
\text { LATED } \\
\text { DAYS }\end{array}$ & $\begin{array}{l}\text { PER- } \\
\text { CENI } \\
\text { DAYS }\end{array}$ & GLASs & $\begin{array}{c}\text { OUBIC } \\
\text { FEET } \\
\text { PER } \\
\text { SECOND }\end{array}$ & TOTAL & $\begin{array}{r}\text { ACW- } \\
\text { MU- } \\
\text { LATPED } \\
\text { DAYS }\end{array}$ & $\begin{array}{l}\text { PER- } \\
\text { CENI } \\
\text { DAYS }\end{array}$ \\
\hline $\begin{array}{l}0 \\
1 \\
2 \\
3 \\
4 \\
5 \\
6 \\
7 \\
8\end{array}$ & $\begin{array}{l}0.00 \\
0.90 \\
1.10 \\
1.20 \\
1.40 \\
1.70 \\
1.90 \\
2.20 \\
2.60\end{array}$ & $\begin{array}{r}0 \\
2 \\
11 \\
121 \\
822 \\
720 \\
1300 \\
1259 \\
956\end{array}$ & $\begin{array}{l}8036 \\
8036 \\
8034 \\
8023 \\
7902 \\
7080 \\
6360 \\
5060 \\
3801\end{array}$ & $\begin{array}{r}100.0 \\
100.0 \\
100.0 \\
99.8 \\
98.3 \\
88.1 \\
79.1 \\
63.0 \\
47.3\end{array}$ & $\begin{array}{l}9 \\
10 \\
11 \\
12 \\
13 \\
14 \\
15 \\
16 \\
17\end{array}$ & $\begin{array}{r}3.00 \\
3.50 \\
4.10 \\
4.80 \\
5.50 \\
6.40 \\
7.50 \\
8.70 \\
10.00\end{array}$ & $\begin{array}{r}699 \\
451 \\
328 \\
231 \\
202 \\
216 \\
141 \\
79 \\
79\end{array}$ & $\begin{array}{r}2845 \\
2146 \\
1695 \\
1367 \\
1136 \\
934 \\
718 \\
577 \\
498\end{array}$ & $\begin{array}{r}35.4 \\
26.7 \\
21.1 \\
17.0 \\
14.1 \\
11.6 \\
8.9 \\
7.2 \\
6.2\end{array}$ & $\begin{array}{l}18 \\
19 \\
20 \\
21 \\
22 \\
23 \\
24 \\
25 \\
26\end{array}$ & $\begin{array}{l}12.0 \\
14.0 \\
16.0 \\
19.0 \\
22.0 \\
25.0 \\
29.0 \\
34.0 \\
39.0\end{array}$ & $\begin{array}{l}81 \\
58 \\
63 \\
39 \\
33 \\
31 \\
20 \\
23 \\
21\end{array}$ & $\begin{array}{r}419 \\
338 \\
280 \\
217 \\
178 \\
145 \\
114 \\
94 \\
71\end{array}$ & $\begin{array}{l}5.2 \\
4.2 \\
3.5 \\
2.7 \\
2.2 \\
1.8 \\
1.4 \\
1.2 \\
0.9\end{array}$ & $\begin{array}{l}27 \\
28 \\
29 \\
30 \\
31 \\
32 \\
33 \\
34\end{array}$ & $\begin{array}{r}46.0 \\
53.0 \\
62.0 \\
72.0 \\
84.0 \\
98.0 \\
110.0 \\
130.0\end{array}$ & $\begin{array}{r}21 \\
11 \\
9 \\
2 \\
3 \\
2 \\
0 \\
2\end{array}$ & $\begin{array}{r}50 \\
29 \\
18 \\
9 \\
7 \\
4 \\
2 \\
2\end{array}$ & $\begin{array}{l}0.6 \\
0.4 \\
0.2 \\
0.1 \\
0.1 \\
0.0 \\
0.0 \\
0.0\end{array}$ \\
\hline
\end{tabular}

MONTHLY MEAN DISCHARGES, IN OBIC FEET PER SECOND, FOR EACH WATER YEAR

\begin{tabular}{|c|c|c|c|c|c|c|c|c|c|c|c|c|}
\hline YEAR & OCT & NOV & DEC & JAN & FEB & MAR & APR & MAY & JUNE & JULY & AUG & SEP \\
\hline 1960 & 1.84 & 1.72 & 1.50 & 1.75 & 1.72 & 2.33 & 3.22 & 2.74 & 1.91 & 1.60 & 1.73 & 1.76 \\
\hline $\begin{array}{l}1961 \\
1962 \\
1963 \\
1964 \\
1965\end{array}$ & $\begin{array}{l}1.85 \\
1.99 \\
2.04 \\
1.80 \\
1.64\end{array}$ & $\begin{array}{l}1.97 \\
1.55 \\
1.95 \\
2.00 \\
1.91\end{array}$ & $\begin{array}{l}1.63 \\
2.02 \\
1.86 \\
1.81 \\
1.83\end{array}$ & $\begin{array}{l}1.40 \\
1.76 \\
1.87 \\
1.64 \\
1.84\end{array}$ & $\begin{array}{l}1.56 \\
2.93 \\
2.24 \\
1.60 \\
2.14\end{array}$ & $\begin{array}{l}2.25 \\
2.39 \\
2.14 \\
2.00 \\
2.10\end{array}$ & $\begin{array}{c}5.43 \\
12.7 \\
2.74 \\
4.77 \\
4.47\end{array}$ & $\begin{array}{c}3.46 \\
9.38 \\
3.02 \\
7.82 \\
12.1\end{array}$ & $\begin{array}{l}2.18 \\
4.50 \\
2.10 \\
3.85 \\
8.94\end{array}$ & $\begin{array}{l}3.17 \\
3.11 \\
1.52 \\
2.55 \\
4.48\end{array}$ & $\begin{array}{l}2.85 \\
1.83 \\
3.57 \\
2.15 \\
3.02\end{array}$ & $\begin{array}{l}5.31 \\
2.18 \\
1.92 \\
1.57 \\
2.53\end{array}$ \\
\hline $\begin{array}{l}1966 \\
1967 \\
1968 \\
1969 \\
1970\end{array}$ & $\begin{array}{l}2.01 \\
2.22 \\
2.29 \\
2.48 \\
2.47\end{array}$ & $\begin{array}{l}2.77 \\
2.01 \\
2.10 \\
2.44 \\
2.50\end{array}$ & $\begin{array}{l}3.83 \\
2.43 \\
1.86 \\
2.22 \\
2.51\end{array}$ & $\begin{array}{l}2.74 \\
2.91 \\
1.85 \\
5.60 \\
2.66\end{array}$ & $\begin{array}{l}2.71 \\
2.05 \\
2.22 \\
5.47 \\
2.75\end{array}$ & $\begin{array}{l}4.07 \\
2.46 \\
3.33 \\
3.26 \\
2.73\end{array}$ & $\begin{array}{c}7.93 \\
3.06 \\
7.98 \\
15.0 \\
3.22\end{array}$ & $\begin{array}{c}6.07 \\
10.0 \\
15.8 \\
37.4 \\
4.10\end{array}$ & $\begin{array}{l}3.54 \\
7.31 \\
6.68 \\
8.15 \\
2.78\end{array}$ & $\begin{array}{l}2.49 \\
3.68 \\
3.65 \\
5.26 \\
2.64\end{array}$ & $\begin{array}{l}2.34 \\
2.78 \\
6.68 \\
3.98 \\
2.55\end{array}$ & $\begin{array}{l}1.89 \\
4.28 \\
2.15 \\
2.69 \\
2.09\end{array}$ \\
\hline $\begin{array}{l}1971 \\
1972 \\
1973 \\
1974 \\
1975\end{array}$ & $\begin{array}{l}1.88 \\
2.08 \\
4.17 \\
2.73 \\
1.93\end{array}$ & $\begin{array}{l}1.96 \\
1.60 \\
2.81 \\
2.63 \\
1.78\end{array}$ & $\begin{array}{l}1.87 \\
3.12 \\
2.99 \\
2.62 \\
1.73\end{array}$ & $\begin{array}{l}2.09 \\
2.26 \\
2.63 \\
3.02 \\
1.85\end{array}$ & $\begin{array}{l}1.66 \\
2.10 \\
2.57 \\
2.79 \\
1.92\end{array}$ & $\begin{array}{l}2.56 \\
2.91 \\
4.55 \\
4.28 \\
2.09\end{array}$ & $\begin{array}{c}4.13 \\
2.59 \\
16.4 \\
5.73 \\
2.59\end{array}$ & $\begin{array}{c}4.94 \\
2.32 \\
60.5 \\
4.44 \\
13.4\end{array}$ & $\begin{array}{c}3.55 \\
2.32 \\
17.2 \\
3.21 \\
6.17\end{array}$ & $\begin{array}{l}2.58 \\
1.77 \\
8.31 \\
2.65 \\
3.14\end{array}$ & $\begin{array}{l}5.37 \\
1.79 \\
8.46 \\
2.16 \\
4.27\end{array}$ & $\begin{array}{l}2.14 \\
2.07 \\
4.36 \\
1.84 \\
2.99\end{array}$ \\
\hline $\begin{array}{l}1976 \\
1977 \\
1978 \\
1979 \\
1980\end{array}$ & $\begin{array}{l}2.61 \\
2.61 \\
1.30 \\
2.78 \\
2.35\end{array}$ & $\begin{array}{l}2.45 \\
2.44 \\
1.41 \\
2.42 \\
2.37\end{array}$ & $\begin{array}{l}2.19 \\
1.77 \\
1.47 \\
2.15 \\
2.72\end{array}$ & $\begin{array}{l}2.37 \\
2.07 \\
1.34 \\
2.20 \\
3.76\end{array}$ & $\begin{array}{l}2.44 \\
2.04 \\
1.26 \\
2.71 \\
3.83\end{array}$ & $\begin{array}{l}2.79 \\
2.25 \\
4.18 \\
6.53 \\
3.42\end{array}$ & $\begin{array}{c}6.96 \\
3.60 \\
10.6 \\
6.77 \\
13.7\end{array}$ & $\begin{array}{c}3.82 \\
2.10 \\
23.0 \\
35.4 \\
34.4\end{array}$ & $\begin{array}{c}2.95 \\
1.71 \\
9.17 \\
13.1 \\
12.3\end{array}$ & $\begin{array}{l}2.17 \\
1.36 \\
4.70 \\
4.75 \\
4.31\end{array}$ & $\begin{array}{l}1.79 \\
1.36 \\
2.55 \\
3.82 \\
3.42\end{array}$ & $\begin{array}{l}1.94 \\
1.45 \\
2.49 \\
3.79 \\
3.54\end{array}$ \\
\hline 1981 & 2.96 & 3.01 & 3.11 & 3.06 & 2.99 & 3.02 & 6.26 & 5.22 & 3.82 & 2.50 & 2.47 & 2.51 \\
\hline
\end{tabular}

ANNUAL FEAK DISCHARGE, IN CUBIC FEET PER SECOND, AND CORRESFONDING GAGE HEIGHT, IN FEET, FOR EAQH WATER YEAR

\begin{tabular}{|c|c|c|c|c|c|c|c|c|c|c|c|}
\hline $\begin{array}{l}\text { WATER } \\
\text { YEAR }\end{array}$ & DATE & $\begin{array}{c}\text { GAGE } \\
\text { HEIGHT }\end{array}$ & $\begin{array}{c}\text { FEAK } \\
\text { DISCHARGE }\end{array}$ & $\begin{array}{l}\text { WATER } \\
\text { YEAR }\end{array}$ & DATE & $\begin{array}{c}\text { GAGE } \\
\text { HEIGHT }\end{array}$ & $\begin{array}{c}\text { PEAK } \\
\text { DISCHARGE }\end{array}$ & $\begin{array}{l}\text { WATER } \\
\text { YEAR }\end{array}$ & DATE & $\begin{array}{c}\text { GAGE } \\
\text { HEIGHT }\end{array}$ & $\begin{array}{c}\text { PEAK } \\
\text { DISCHARGE }\end{array}$ \\
\hline $\begin{array}{l}1960 \\
1961 \\
1962 \\
1963 \\
1964 \\
1965 \\
1966 \\
1967\end{array}$ & $\begin{array}{l}\text { SEPT.01，1960 } \\
\text { AUG. 23, } 1961 \\
\text { SEPT.28, } 1962 \\
\text { AUG. 01, } 1963 \\
\text { AUG. 03, } 1964 \\
\text { SEPP.06, } 1965 \\
\text { DEC. 30, } 1965 \\
\text { SEPP.22, } 1967\end{array}$ & $\begin{array}{l}1.25 \\
3.20 \\
1.67 \\
3.28 \\
2.20 \\
1.55 \\
1.40 \\
2.60\end{array}$ & $\begin{array}{r}28 \\
528 \\
107 \\
555 \\
232 \\
99 \\
88 \\
344\end{array}$ & $\begin{array}{l}1968 \\
1969 \\
1970 \\
1971 \\
1972 \\
1973 \\
1974\end{array}$ & $\begin{array}{l}\text { AUG. } 13,1968 \\
\text { MAY } 13,1969 \\
\text { AUG. } 17,1970 \\
\text { AUG. } 08,1971 \\
\text { DEC. } 24,1971 \\
\text { MAY } 18,1973 \\
\text { JULY } 30,1974\end{array}$ & $\begin{array}{l}4.78 \\
1.30 \\
2.25 \\
2.47 \\
1.93 \\
2.74 \\
2.29\end{array}$ & $\begin{array}{r}800 \\
307 \\
1000 \\
600 \\
96 \\
223 \\
65\end{array}$ & $\begin{array}{l}1975 \\
1976 \\
1977 \\
1978 \\
1979 \\
1980 \\
1981\end{array}$ & $\begin{array}{lll}\text { MAY } & 20,1975 \\
\text { FEB. } & 09,1976 \\
\text { OCT. } 02,1976 \\
\text { MAY } & 21,1978 \\
\text { MAY } & 02,1979 \\
\text { MAY } & 21,1980 \\
\text { APR. } 19,1981\end{array}$ & $\begin{array}{l}2.57 \\
2.29 \\
2.04 \\
2.61 \\
2.47 \\
2.78 \\
1.85\end{array}$ & $\begin{array}{r}57 \\
34 \\
94 \\
64 \\
43 \\
100 \\
19\end{array}$ \\
\hline
\end{tabular}


09406300 KANARRA CREEK AT KANARRAVIILE, UT-Continued

\begin{tabular}{|c|c|c|c|c|c|c|}
\hline \multirow{3}{*}{$\begin{array}{l}\text { PERIOD } \\
\text { (CON- } \\
\text { SECO- } \\
\text { TIVE } \\
\text { DAYS) }\end{array}$} & \multicolumn{6}{|c|}{$\begin{array}{l}\text { AND PROBABIIITY OF ANNUAL LOWEST MEAN DISCHARGE } \\
\text { BASED ON CLIMATIC YEARS } 1961-81\end{array}$} \\
\hline & \multicolumn{6}{|c|}{$\begin{array}{l}\text { DISCHARGE, IN CUBIC FEET PER SEOOND, FOR } \\
\text { INDICATED RECURRENCE INIERNAL, IN YEARS, AND } \\
\text { ANNUAL NONEXCEEDANCE PRCBABIITY, IN PERCENT }\end{array}$} \\
\hline & $\begin{array}{c}2 \\
508\end{array}$ & $\begin{array}{c}5 \\
208\end{array}$ & $\begin{array}{l}10 \\
108\end{array}$ & $\begin{array}{l}20 \\
58\end{array}$ & $\begin{array}{l}50 \\
28\end{array}$ & $\begin{array}{r}100 \\
18\end{array}$ \\
\hline $\begin{array}{r}1 \\
7 \\
14 \\
30 \\
60 \\
90\end{array}$ & $\begin{array}{l}1.5 \\
1.6 \\
1.7 \\
1.8 \\
1.9 \\
2.0\end{array}$ & $\begin{array}{l}1.2 \\
1.3 \\
1.4 \\
1.5 \\
1.6 \\
1.7\end{array}$ & $\begin{array}{l}1.1 \\
1.2 \\
1.3 \\
1.4 \\
1.5 \\
1.6\end{array}$ & $\begin{array}{l}1.0 \\
1.1 \\
1.2 \\
1.3 \\
1.4 \\
1.5\end{array}$ & $\begin{array}{l}- \\
- \\
- \\
-\end{array}$ & $\begin{array}{l}- \\
-- \\
-- \\
-- \\
-\end{array}$ \\
\hline
\end{tabular}

09406500 ASH CREER NEAR NEN HARMONY, UT

LOCATION.-Lat $37^{\circ} 24^{\prime} 45^{\prime \prime}$, long $113^{\circ} 14^{\prime} 10^{\prime \prime}$, in NE ${ }^{\mathrm{l}}$ sec.7, T.39 S., R.12 W., Washington County, Hydrologic Unit 15010008, 2 mi downstream fram Ranarra Creek and $6 \mathrm{mi}$ southeast of New Harmony.

DRAINAGE AREA.--130 $\mathrm{mi}^{2}$, approximately. Previously published as $146 \mathrm{mi}^{2}$.

PERIOD OF RECORD AVAIIABLE.-January 1939 to September 1947.

GAGE. -Water-stage recorder. Altitude of gage is 4,450 ft fran reconnaissance map. Prior to Feb. 29, 1940, staff gage at site about $1.5 \mathrm{mi}$ upstream at different datum.

REMARKS.--Diversions for irrigation of about 2,800 acres above station (in 1950).

COOPERATION.-Records for period prior to October 1941 furnished by Bureau of Reclamation.

AVERAGE DISCHARGE. -8 years, $10.6 \mathrm{ft}^{3} / \mathrm{s}, 7,680 \mathrm{acre}-\mathrm{ft} / \mathrm{yr}$.

EXTREMES FOR PERIOD OF RECORD.-Maximum discharge, $1,500 \mathrm{ft}^{3} / \mathrm{s}$ Sept. 28, 1940, gage height, $4.25 \mathrm{ft}$, from rating curve extended on basis of slope-area determination of peak flow; maximum gage height, $6.14 \mathrm{ft}$ Nov. 14, 1946; no flow at times in most years.

LONEST MEAN DISCHARGE, IN OUBIC FEET PER SEOOND, AND RANKING FOR THE INDICATED NUMBER OF CONSEOUTIVE DAYS FOR EACH CIIMATIC YEAR, APRIL 1-MARCH 31

YEAR

$\begin{array}{ccccc} & 1 & & 3 & \\ 1940 & 0.00 & 1 & 0.00 & 1 \\ 1941 & 0.00 & 2 & 0.00 & 2 \\ 1942 & 1.00 & 7 & 1.00 & 7 \\ 1943 & 1.00 & 8 & 1.00 & 8 \\ 1944 & 0.00 & 3 & 0.00 & 3 \\ 1945 & 0.00 & 4 & 0.00 & 4 \\ 1946 & 0.00 & 5 & 0.00 & 5 \\ 1947 & 0.00 & 6 & 0.00 & 6\end{array}$

7 .

$7 \quad 14$

0.296

0.001

1.007

1.008

$\begin{array}{ll}0.00 & 2 \\ 0.00 & 3\end{array}$

0.195

$\begin{array}{ll}0.19 & 5 \\ 0.00 & 4\end{array}$

$\begin{array}{ll}14 & \\ 0.43 & 6 \\ 0.00 & 1 \\ 1.10 & 8 \\ 1.00 & 7 \\ 0.00 & 2 \\ 0.00 & 3 \\ 0.21 & 5 \\ 0.00 & 4\end{array}$

CONSEOUTIVE DAYS
30

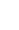

$\begin{array}{llll}0.67 & 6 & 0.88 & 6\end{array}$

0.935

120

183

ALL

HIGHEST MEAN DISCHARGE, IN CUBIC FEET PER SECOND, AND RANKING FOR THE INDICATED NUMBER OF CONSECUTIVE DAYS FOR EACH WATER YEAR, OCIOBER 1-SEPTEMBER 30

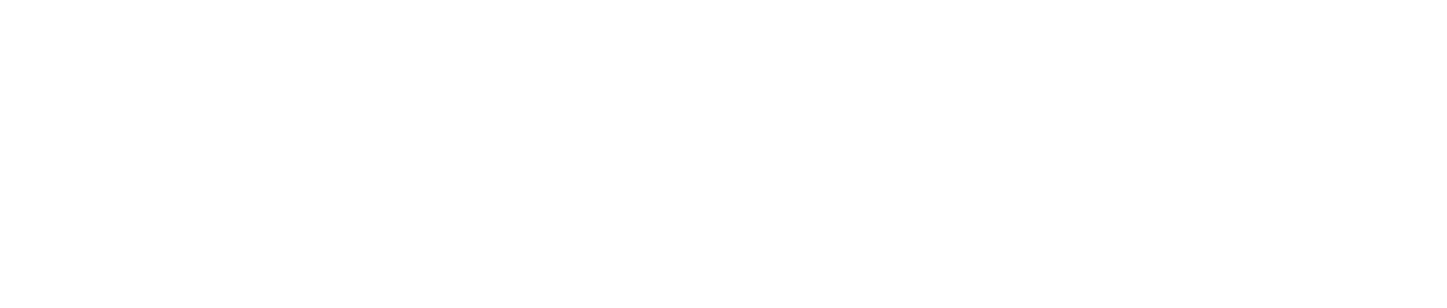


VIRGIN RIVER BASIN

09406500 ASH CREEX NEAR NEW HARMONY, UT-Continued

DURATION OF DISCHARGE FOR EAQH WATER YEAR

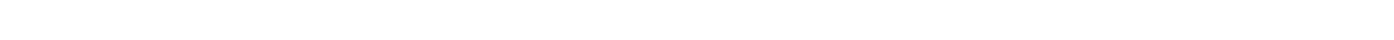
YEAR

NUMBER OF DAYS IN CLASS

CUBIC FEET -DAYS

\begin{tabular}{|c|c|c|c|c|c|c|c|c|c|c|c|c|c|c|c|c|c|c|c|c|c|c|c|c|c|c|c|}
\hline 1940127 & & & & & & & 68 & & 76 & & 18 & 12 & 24 & 4 & 16 & 7 & 4 & 2 & 4 & 1 & 1 & & & & 1 & & 1214.0 \\
\hline $\begin{array}{l}1941 \\
1942 \\
1943 \\
1944 \\
1942 \\
1945\end{array}$ & $\frac{1}{5}$ & $\begin{array}{r}2 \\
50\end{array}$ & 121 & 123 & $\begin{array}{r}3 \\
30\end{array}$ & $\begin{array}{ll}4 & 1 \\
6 & 1\end{array}$ & $\begin{array}{r}96 \\
60 \\
23 \\
7 \\
7\end{array}$ & $\begin{array}{l}21 \\
37\end{array}$ & $\begin{array}{l}70 \\
60 \\
49 \\
12 \\
20\end{array}$ & $\begin{array}{l}34 \\
18\end{array}$ & $\begin{array}{l}40 \\
37 \\
72 \\
50 \\
26\end{array}$ & $\begin{array}{r}10 \\
31 \\
8 \\
4 \\
13\end{array}$ & $\begin{array}{r}7 \\
69 \\
11 \\
32 \\
27\end{array}$ & $\begin{array}{r}5 \\
11 \\
5 \\
1 \\
13\end{array}$ & $\begin{array}{r}4 \\
14 \\
9 \\
1 \\
5\end{array}$ & $\begin{array}{r}6 \\
14 \\
19 \\
3 \\
8\end{array}$ & $\begin{array}{r}8 \\
13 \\
15 \\
1 \\
12\end{array}$ & $\begin{array}{r}12 \\
9 \\
12 \\
17 \\
8\end{array}$ & $\begin{array}{cl}15 & 2 \\
10 & \\
23 & 1 \\
17 & 2 \\
6 & \end{array}$ & $\begin{array}{rr}27 & 20 \\
6 & 6 \\
12 & 5 \\
25 & 9 \\
2 & 10\end{array}$ & $\begin{array}{rr}20 & 11 \\
6 & 11 \\
5 & 1 \\
9 & 12 \\
0 & 7\end{array}$ & & $\begin{array}{rr}4 & 9 \\
5 & 8 \\
2 & \\
8 & 12 \\
6 & 8\end{array}$ & $\begin{array}{ll}6 & 11 \\
1 & \\
1 & \\
1 & \\
1 & 1\end{array}$ & 1 & 2 & $\begin{array}{l}8430.0 \\
3972.0 \\
2658.0 \\
5015.3 \\
3765.5\end{array}$ \\
\hline $\begin{array}{l}1946119 \\
194788\end{array}$ & $\begin{array}{r}8 \\
13\end{array}$ & $\begin{array}{l}2 \\
4\end{array}$ & $\begin{array}{l}9 \\
4\end{array}$ & $\begin{array}{l}7 \\
4\end{array}$ & $\begin{array}{l}2 \\
2\end{array}$ & 3 & 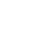 & $\begin{array}{l}2 \\
2\end{array}$ & $\begin{array}{l}4 \\
2\end{array}$ & $\begin{array}{l}85 \\
19\end{array}$ & $\begin{array}{r}104 \\
13\end{array}$ & $\begin{array}{r}8 \\
22\end{array}$ & $\begin{array}{r}2 \\
64\end{array}$ & $\begin{array}{r}1 \\
20\end{array}$ & $\begin{array}{l}1 \\
8\end{array}$ & $\begin{array}{r}1 \\
11\end{array}$ & 9 & $\begin{array}{r}3 \\
26\end{array}$ & 201 & 11 & 2 & 4 & 3 & 2 & 1 & 1 & $\begin{array}{r}692.6 \\
5241.8\end{array}$ \\
\hline
\end{tabular}

DURATION TABLE OF DISCHARGE FOR WATER YEARS 1940-47

\begin{tabular}{|c|c|c|c|c|c|c|c|c|c|c|c|c|c|c|c|c|c|c|c|}
\hline CLASS & $\begin{array}{c}\text { OBBIC } \\
\text { FEET } \\
\text { PER } \\
\text { SECOND }\end{array}$ & $\begin{array}{l}\text { TOMAL } \\
\text { DAYS }\end{array}$ & $\begin{array}{l}\text { ACOJ- } \\
\text { MU- } \\
\text { LATED } \\
\text { DAYS }\end{array}$ & $\begin{array}{l}\text { PER- } \\
\text { CENT } \\
\text { DAYS }\end{array}$ & GASS & $\begin{array}{c}\text { CUBIC } \\
\text { FEET } \\
\text { PER } \\
\text { SECOND }\end{array}$ & $\begin{array}{l}\text { TOTAL } \\
\text { DAYS }\end{array}$ & $\begin{array}{c}\text { ACOU- } \\
\text { MU- } \\
\text { LATED } \\
\text { DAYS }\end{array}$ & $\begin{array}{l}\text { PER- } \\
\text { CENT } \\
\text { DAYS }\end{array}$ & & $\begin{array}{c}\text { OUBIC } \\
\text { FEET } \\
\text { PER } \\
\text { SECOND }\end{array}$ & TOTAL & $\begin{array}{c}\text { ACOU- } \\
\text { MU- } \\
\text { LATED } \\
\text { DAYS }\end{array}$ & $\begin{array}{l}\text { PER- } \\
\text { CENT } \\
\text { DAYS }\end{array}$ & & $\begin{array}{c}\text { GUBIC } \\
\text { FEET } \\
\text { PER } \\
\text { SECOND }\end{array}$ & TOTAL & $\begin{array}{l}\text { ACOU- } \\
\text { MU- } \\
\text { LATED } \\
\text { DAYS }\end{array}$ & $\begin{array}{l}\text { PER- } \\
\text { CENI } \\
\text { DAYS }\end{array}$ \\
\hline $\begin{array}{l}0 \\
1 \\
2 \\
3 \\
4 \\
5 \\
6 \\
7 \\
8\end{array}$ & $\begin{array}{l}0.00 \\
0.10 \\
0.13 \\
0.17 \\
0.22 \\
0.28 \\
0.36 \\
0.47 \\
0.61\end{array}$ & $\begin{array}{r}507 \\
27 \\
0 \\
58 \\
0 \\
26 \\
25 \\
37 \\
13\end{array}$ & $\begin{array}{l}2922 \\
2415 \\
2388 \\
2388 \\
2330 \\
2330 \\
2304 \\
2279 \\
2242\end{array}$ & $\begin{array}{r}100.0 \\
82.6 \\
81.7 \\
81.7 \\
79.7 \\
79.7 \\
78.9 \\
78.0 \\
76.7\end{array}$ & $\begin{array}{r}9 \\
10 \\
11 \\
12 \\
13 \\
14 \\
15 \\
16 \\
17\end{array}$ & $\begin{array}{l}0.79 \\
1.00 \\
1.30 \\
1.70 \\
2.20 \\
2.90 \\
3.70 \\
4.80 \\
6.20\end{array}$ & $\begin{array}{r}32 \\
265 \\
62 \\
293 \\
156 \\
360 \\
108 \\
236 \\
60\end{array}$ & $\begin{array}{r}2229 \\
2197 \\
1932 \\
1870 \\
1577 \\
1421 \\
1061 \\
953 \\
717\end{array}$ & $\begin{array}{l}76.3 \\
75.2 \\
66.1 \\
64.0 \\
54.0 \\
48.6 \\
36.3 \\
32.6 \\
24.5\end{array}$ & $\begin{array}{l}18 \\
19 \\
20 \\
21 \\
22 \\
23 \\
24 \\
25 \\
26\end{array}$ & $\begin{array}{r}8.0 \\
10.0 \\
13.0 \\
17.0 \\
23.0 \\
29.0 \\
38.0 \\
49.0 \\
63.0\end{array}$ & $\begin{array}{l}58 \\
69 \\
62 \\
89 \\
95 \\
84 \\
53 \\
44 \\
29\end{array}$ & $\begin{array}{l}657 \\
599 \\
530 \\
468 \\
379 \\
284 \\
200 \\
147 \\
103\end{array}$ & $\begin{array}{r}22.5 \\
20.5 \\
18.1 \\
16.0 \\
13.0 \\
9.7 \\
6.8 \\
5.0 \\
3.5\end{array}$ & $\begin{array}{l}27 \\
28 \\
29 \\
30 \\
31 \\
32 \\
33 \\
34\end{array}$ & $\begin{array}{r}82.0 \\
110.0 \\
140.0 \\
180.0 \\
230.0 \\
300.0 \\
380.0 \\
500.0\end{array}$ & $\begin{array}{r}40 \\
12 \\
12 \\
3 \\
2 \\
3 \\
1 \\
1\end{array}$ & $\begin{array}{r}74 \\
34 \\
22 \\
10 \\
7 \\
5 \\
2 \\
1\end{array}$ & $\begin{array}{l}2.5 \\
1.2 \\
0.8 \\
0.3 \\
0.2 \\
0.2 \\
0.1 \\
0.0\end{array}$ \\
\hline
\end{tabular}

MONIHLY MEAN DISCHARGES, IN OUBIC FEET PER SECOND, FOR EACH WATER YEAR

$\begin{array}{lcccccccccccc}\text { YEAR } & \text { OCT } & \text { NOV } & \text { DEC } & \text { JAN } & \text { FEB } & \text { MAR } & \text { APR } & \text { MAY } & \text { JUNE } & \text { JULY } & \text { AUG } & \text { SEP } \\ 1940 & 2.97 & 1.33 & 3.13 & 2.90 & 9.00 & 3.84 & 4.37 & 0.16 & 0.00 & 0.00 & 0.06 & 12.6 \\ 1941 & 9.77 & 1.00 & 3.23 & 3.10 & 21.5 & 67.9 & 57.7 & 89.6 & 10.6 & 5.26 & 4.71 & 1.93 \\ 1942 & 8.13 & 6.13 & 4.39 & 6.81 & 5.61 & 15.9 & 64.1 & 13.2 & 2.37 & 1.29 & 1.81 & 1.33 \\ 1943 & 2.26 & 2.67 & 3.06 & 4.87 & 21.2 & 20.2 & 25.6 & 1.77 & 0.27 & 0.00 & 6.52 & 0.37 \\ 1944 & 1.60 & 2.55 & 3.14 & 3.00 & 5.00 & 35.0 & 46.0 & 57.1 & 10.2 & 0.38 & 0.00 & 0.00 \\ 1945 & 0.23 & 1.81 & 1.73 & 3.42 & 17.1 & 21.4 & 37.6 & 34.0 & 1.72 & 1.73 & 3.09 & 0.50 \\ 1946 & 3.15 & 2.47 & 3.60 & 3.16 & 3.10 & 2.37 & 3.14 & 0.09 & 0.00 & 0.09 & 1.52 & 0.15 \\ 1947 & 54.5 & 50.1 & 19.1 & 5.00 & 5.82 & 12.6 & 14.3 & 10.00 & 0.38 & 0.00 & 0.06 & 0.00\end{array}$

ANNUAL PEAK DISCHARGE, IN CIBIC FEET PER SECOND, AND CORRESPONDING GAGE HEIGHT, IN FEET, FOR EAGH WATER YEAR

\begin{tabular}{|c|c|c|c|c|c|c|c|c|c|c|c|}
\hline $\begin{array}{l}\text { WATER } \\
\text { YEAR }\end{array}$ & DATE & $\begin{array}{c}\text { GAGE } \\
\text { HEIGHT }\end{array}$ & $\begin{array}{c}\text { PEAR } \\
\text { DISCHARGE }\end{array}$ & $\begin{array}{l}\text { WATERR } \\
\text { YEAR }\end{array}$ & DATE & $\begin{array}{c}\text { GAGE } \\
\text { HEIGHT }\end{array}$ & $\begin{array}{c}\text { PEAR } \\
\text { DISCHARGE }\end{array}$ & $\begin{array}{l}\text { WATERR } \\
\text { YEAR }\end{array}$ & DATE & $\begin{array}{c}\text { GAGE } \\
\text { HEIGHT }\end{array}$ & $\begin{array}{c}\text { PEAR } \\
\text { DISCHARGE }\end{array}$ \\
\hline $\begin{array}{l}1940 \\
1941 \\
1942\end{array}$ & $\begin{array}{l}\text { SEPT.28， } 1940 \\
\text { MAR. 01， 1941 } \\
\text { OCT. 20, } 1941\end{array}$ & $\begin{array}{l}4.25 \\
-\end{array}$ & $\begin{array}{r}1500 \\
1400 \\
495\end{array}$ & $\begin{array}{l}1943 \\
1944 \\
1945\end{array}$ & $\begin{array}{l}\text { AUG. } 17,1943 \\
\text { MAR. } 13,1944 \\
\text { AUG. } 02,1945\end{array}$ & $\begin{array}{l}3.95 \\
3.32 \\
4.20\end{array}$ & $\begin{array}{r}985 \\
385 \\
1440\end{array}$ & $\begin{array}{l}1946 \\
1947\end{array}$ & $\begin{array}{l}\text { AUG. } 23,1946 \\
\text { NOV. } 14,1946\end{array}$ & $\begin{array}{l}3.15 \\
6.14\end{array}$ & $\begin{array}{r}290 \\
1430\end{array}$ \\
\hline
\end{tabular}

09406700 SOUTH ASH CREEX BELOW MILL CREEK, NEAR PINIURA, UT

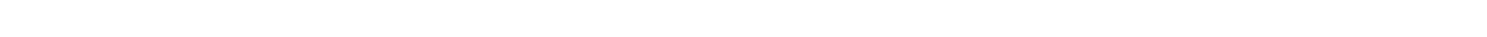
right bank $150 \mathrm{ft}$ downstrean fram Harmon Creek, and $3.5 \mathrm{mi}$ northwest of Pintura.

DRATNAGE AREA. $-11.0 \mathrm{mi}^{2}$.

MEAN BASIN ELEVATION. $-7,210 \mathrm{ft}$.

PERICD OF RECORD AVAILABLE.--August 1966 to September 1981.

GAGE. Water-stage recorder. Altitude of gage is 5,290 ft from topographic map.

AVERRAGE DISCHARGE.-15 years, $7.11 \mathrm{ft}^{3} / \mathrm{s}, 5,150$ acre-ft/yr.

EXIREMES FOR PERIOD OF RECORD,-Maximum discharge, 1,910 $\mathrm{ft}^{3} / \mathrm{s} \mathrm{Dec.} 6,1966$, gage height, $5.83 \mathrm{ft} ; \mathrm{minimum}, 0.21 \mathrm{ft} / \mathrm{s} \mathrm{Aug}^{3} 14,15$, 1977. 
VIRGIN RIVER BASTN

09406700 SOUTH ASH CREEX BELOW MILL CREEX, NEAR PINIURA, UT--Continued

LOWEST MEAN DISCHARGE, IN OUIC FEET PER SECOND, AND RANKING FOR THE INDICATED NUMBER OF CONSEQUTIVE DAYS FOR EAOH CLIMATIC YEAR, APRIL 1-MARCH 31

\begin{tabular}{|c|c|c|c|c|c|c|c|c|c|c|c|c|c|c|}
\hline YEAR & 1 & 3 & 7 & 14 & $\begin{array}{l}\text { CONSEC } \\
30\end{array}$ & SOTT TVE & $\begin{array}{l}\text { DAYS } \\
60\end{array}$ & 90 & & 120 & & 183 & & ALL \\
\hline $\begin{array}{l}1968 \\
1969 \\
1970\end{array}$ & $\begin{array}{rr}1.70 & 9 \\
1.30 & 7 \\
2.20 & 12\end{array}$ & $\begin{array}{rr}2.00 & 10 \\
1.30 & 7 \\
2.30 & 12\end{array}$ & $\begin{array}{rrr}2.10 & 10 \\
1.40 & 7 \\
2.30 & 12\end{array}$ & $\begin{array}{rr}2.20 & 11 \\
1.60 & 7 \\
2.30 & 12\end{array}$ & $\begin{array}{l}2.201 \\
1.60 \\
2.301\end{array}$ & $\begin{array}{r}11 \\
7 \\
12\end{array}$ & $\begin{array}{rr}2.30 & 10 \\
1.70 & 7 \\
2.40 & 11\end{array}$ & $\begin{array}{l}2.30 \\
1.70 \\
2.60\end{array}$ & $\begin{array}{r}10 \\
7 \\
12\end{array}$ & $\begin{array}{l}2.30 \\
1.70 \\
2.70\end{array}$ & $\begin{array}{r}9 \\
7 \\
11\end{array}$ & $\begin{array}{l}2.70 \\
2.70 \\
3.00\end{array}$ & $\begin{array}{r}9 \\
10 \\
11\end{array}$ & $\begin{array}{r}5.20 \\
7.10 \\
14.0 \quad 1\end{array}$ \\
\hline $\begin{array}{l}1971 \\
1972 \\
1973 \\
1974 \\
1975\end{array}$ & $\begin{array}{rr}0.92 & 4 \\
1.00 & 5 \\
0.69 & 3 \\
3.00 & 14 \\
0.64 & 2\end{array}$ & $\begin{array}{rr}0.92 & 4 \\
1.00 & 5 \\
0.69 & 3 \\
3.00 & 14 \\
0.64 & 2\end{array}$ & $\begin{array}{rr}0.93 & 4 \\
1.10 & 5 \\
0.70 & 3 \\
3.00 & 14 \\
0.65 & 2\end{array}$ & $\begin{array}{rr}0.95 & 4 \\
1.10 & 5 \\
0.73 & 3 \\
3.00 & 14 \\
0.66 & 2\end{array}$ & $\begin{array}{l}0.99 \\
1.19 \\
0.75 \\
3.101 \\
0.67\end{array}$ & $\begin{array}{r}4 \\
6 \\
3 \\
14 \\
2\end{array}$ & $\begin{array}{rr}1.10 & 4 \\
1.50 & 6 \\
0.81 & 3 \\
3.10 & 13 \\
0.69 & 2\end{array}$ & $\begin{array}{l}1.19 \\
1.50 \\
1.00 \\
3.20 \\
0.79\end{array}$ & $\begin{array}{r}5 \\
6 \\
3 \\
13 \\
2\end{array}$ & $\begin{array}{l}1.50 \\
1.60 \\
1.30 \\
3.30 \\
1.00\end{array}$ & $\begin{array}{r}5 \\
6 \\
4 \\
13 \\
2\end{array}$ & $\begin{array}{l}1.80 \\
1.80 \\
1.70 \\
3.60 \\
1.19\end{array}$ & $\begin{array}{r}5 \\
6 \\
4 \\
12 \\
2\end{array}$ & $\begin{array}{c}2.60 \\
3.70 \\
2.80 \\
16.01 \\
2.00\end{array}$ \\
\hline $\begin{array}{l}1976 \\
1977 \\
1978 \\
1979 \\
1980\end{array}$ & $\begin{array}{rr}1.70 & 8 \\
1.00 & 6 \\
0.42 & 1 \\
2.50 & 13 \\
1.90 & 10\end{array}$ & $\begin{array}{rr}1.70 & 8 \\
1.10 & 6 \\
0.45 & 1 \\
2.50 & 13 \\
2.00 & 9\end{array}$ & $\begin{array}{rr}1.70 & 8 \\
1.10 & 6 \\
0.47 & 1 \\
2.50 & 13 \\
2.10 & 9\end{array}$ & $\begin{array}{rr}1.70 & 8 \\
1.10 & 6 \\
0.54 & 1 \\
2.60 & 13 \\
2.20 & 9\end{array}$ & $\begin{array}{l}1.80 \\
1.10 \\
0.58 \\
2.80 \\
2.20\end{array}$ & $\begin{array}{r}8 \\
5 \\
1 \\
13 \\
9\end{array}$ & $\begin{array}{rr}1.80 & 8 \\
1.19 & 5 \\
0.62 & 1 \\
3.10 & 14 \\
2.40 & 12\end{array}$ & $\begin{array}{l}1.90 \\
1.19 \\
0.66 \\
3.30 \\
2.50\end{array}$ & $\begin{array}{r}8 \\
4 \\
1 \\
14 \\
11\end{array}$ & $\begin{array}{l}2.00 \\
1.30 \\
0.70 \\
3.60 \\
2.70\end{array}$ & $\begin{array}{r}8 \\
3 \\
1 \\
14 \\
12\end{array}$ & $\begin{array}{l}2.20 \\
1.30 \\
0.75 \\
4.00 \\
3.70\end{array}$ & $\begin{array}{r}7 \\
3 \\
1 \\
14 \\
13\end{array}$ & $\begin{array}{c}4.40 \\
2.70 \\
4.50 \\
13.0 \quad 1 \\
14.01\end{array}$ \\
\hline 1981. & 2.2011 & 2.2011 & 2.2011 & 2.2010 & $2.20 \mathrm{I}$ & 10 & 2.30 & 2.30 & 9 & 2.40 & 10 & 2.60 & 8 & 10.0 \\
\hline
\end{tabular}

HIGHEST MEAN DISCHARGE, IN CUBIC FEET PER SECOND, AND RANKING FOR THE INDICATED NUMBER OF CONSECUTIVE DAYS FOR EAOH WATER YEAR, OCTOBER 1 -SEPTEMBER 30

\begin{tabular}{|c|c|c|c|c|c|c|c|c|c|c|c|c|c|c|c|c|c|c|c|c|}
\hline YEAR & 1 & & 3 & & 7 & & 15 & & $\begin{array}{l}\text { CONSE } \\
30\end{array}$ & EQT & $\begin{array}{l}\text { E DAYS } \\
60\end{array}$ & & 90 & & 120 & & 183 & & ALL & \\
\hline $\begin{array}{l}967 \\
968 \\
969 \\
970\end{array}$ & $\begin{array}{c}350 \\
24.0 \\
173 \\
30.0\end{array}$ & $\begin{array}{l}1 \\
9 \\
4 \\
8\end{array}$ & $\begin{array}{c}135 \\
19.0 \\
106 \\
12.0\end{array}$ & $\begin{array}{r}1 \\
8 \\
4 \\
11\end{array}$ & $\begin{array}{l}66.0 \\
11.0 \\
70.0 \\
6.40\end{array}$ & $\begin{array}{r}5 \\
10 \\
3 \\
13\end{array}$ & $\begin{array}{c}35.0 \\
9.80 \\
60.0 \\
5.00\end{array}$ & $\begin{array}{r}6 \\
9 \\
2 \\
14\end{array}$ & $\begin{array}{c}20.0 \\
9.30 \\
54.0 \\
4.80\end{array}$ & $\begin{array}{r}6 \\
9 \\
2 \\
14\end{array}$ & $\begin{array}{c}12.0 \\
8.80 \\
49.0 \\
4.40\end{array}$ & $\begin{array}{r}6 \\
8 \\
2 \\
14\end{array}$ & $\begin{array}{c}9.50 \\
8.60 \\
42.0 \\
4.10\end{array}$ & $\begin{array}{r}6 \\
8 \\
2 \\
14\end{array}$ & $\begin{array}{c}8.40 \\
8.30 \\
36.0 \\
3.90\end{array}$ & $\begin{array}{r}6 \\
7 \\
2 \\
14\end{array}$ & $\begin{array}{c}8.60 \\
7.50 \\
28.0 \\
3.50\end{array}$ & $\begin{array}{r}6 \\
7 \\
1 \\
14\end{array}$ & $\begin{array}{c}6.30 \\
5.00 \\
16.0 \\
3.10\end{array}$ & $\begin{array}{r}6 \\
7 \\
1 \\
11\end{array}$ \\
\hline $\begin{array}{l}1971 \\
1972 \\
1973 \\
1974 \\
1975\end{array}$ & $\begin{array}{c}9.10 \\
202 \\
79.0 \\
6.30 \\
14.0\end{array}$ & $\begin{array}{r}13 \\
2 \\
7 \\
14 \\
11\end{array}$ & $\begin{array}{c}8.70 \\
110 \\
77.0 \\
5.50 \\
14.0\end{array}$ & $\begin{array}{r}12 \\
3 \\
7 \\
14 \\
9\end{array}$ & $\begin{array}{c}8.30 \\
53.0 \\
76.0 \\
5.30 \\
13.0\end{array}$ & $\begin{array}{r}11 \\
7 \\
1 \\
14 \\
8\end{array}$ & $\begin{array}{c}7.80 \\
26.0 \\
72.0 \\
5.10 \\
13.0\end{array}$ & $\begin{array}{r}12 \\
7 \\
1 \\
13 \\
8\end{array}$ & $\begin{array}{c}6.90 \\
14.0 \\
66.0 \\
4.90 \\
12.0\end{array}$ & $\begin{array}{r}12 \\
7 \\
1 \\
13 \\
8\end{array}$ & $\begin{array}{c}5.60 \\
8.50 \\
55.0 \\
4.40 \\
10.0\end{array}$ & $\begin{array}{r}12 \\
9 \\
1 \\
13 \\
7\end{array}$ & $\begin{array}{c}4.80 \\
6.60 \\
46.0 \\
4.20 \\
9.00\end{array}$ & $\begin{array}{r}12 \\
9 \\
1 \\
13 \\
7\end{array}$ & $\begin{array}{c}4.20 \\
5.60 \\
39.0 \\
3.90 \\
8.00\end{array}$ & $\begin{array}{r}12 \\
10 \\
1 \\
13 \\
8\end{array}$ & $\begin{array}{c}3.70 \\
4.50 \\
28.0 \\
3.70 \\
6.30\end{array}$ & $\begin{array}{r}12 \\
10 \\
2 \\
13 \\
8\end{array}$ & $\begin{array}{c}2.70 \\
2.90 \\
16.0 \\
2.90 \\
4.00\end{array}$ & $\begin{array}{r}14 \\
12 \\
2 \\
13 \\
8\end{array}$ \\
\hline $\begin{array}{l}1976 \\
1977 \\
1978 \\
1979 \\
1980\end{array}$ & $\begin{array}{c}12.0 \\
5.30 \\
101 \\
190 \\
130\end{array}$ & $\begin{array}{r}12 \\
15 \\
6 \\
3 \\
5\end{array}$ & $\begin{array}{c}8.30 \\
4.10 \\
80.0 \\
114 \\
93.0\end{array}$ & $\begin{array}{r}13 \\
15 \\
6 \\
2 \\
5\end{array}$ & $\begin{array}{l}8.20 \\
3.30 \\
58.0 \\
66.0 \\
73.0\end{array}$ & $\begin{array}{r}12 \\
15 \\
6 \\
4 \\
2\end{array}$ & $\begin{array}{l}8.10 \\
2.90 \\
45.0 \\
50.0 \\
44.0\end{array}$ & $\begin{array}{r}11 \\
15 \\
4 \\
3 \\
5\end{array}$ & $\begin{array}{l}7.90 \\
2.50 \\
37.0 \\
46.0 \\
37.0\end{array}$ & $\begin{array}{r}10 \\
15 \\
5 \\
3 \\
4\end{array}$ & $\begin{array}{l}7.10 \\
1.80 \\
36.0 \\
44.0 \\
31.0\end{array}$ & $\begin{array}{r}10 \\
15 \\
4 \\
3 \\
5\end{array}$ & $\begin{array}{c}6.30 \\
1.50 \\
35.0 \\
37.0 \\
27.0\end{array}$ & $\begin{array}{r}10 \\
15 \\
4 \\
3 \\
5\end{array}$ & $\begin{array}{l}5.70 \\
1.50 \\
32.0 \\
32.0 \\
27.0\end{array}$ & $\begin{array}{r}9 \\
15 \\
3 \\
4 \\
5\end{array}$ & $\begin{array}{l}4.80 \\
1.40 \\
25.0 \\
24.0 \\
22.0\end{array}$ & $\begin{array}{r}9 \\
15 \\
3 \\
4 \\
5\end{array}$ & $\begin{array}{l}3.40 \\
1.30 \\
13.0 \\
14.0 \\
13.0\end{array}$ & $\begin{array}{r}9 \\
15 \\
5 \\
3 \\
4\end{array}$ \\
\hline
\end{tabular}

DURATION OF DISCHARGE FOR EACH WATER YEAR

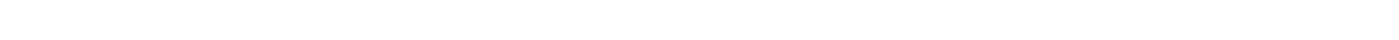
YEAR

NUMBER OF DAYS IN G.ASS

QUBIC FEEI PER SECOND

1967
1968
1969
1970
1971
1972
1973
1974
1975
1976
1977
1978
1979
1980

$\begin{array}{lllllllllllllllll}24 & 37 & 3 & 9 & 20 & 35 & 78 & 29 & 30 & 35 & 31 & 22 & 6 & 2 & 1 & 1 & 1\end{array}$

$\begin{array}{llllll}1 & 1 & 1 & 2303.5\end{array}$

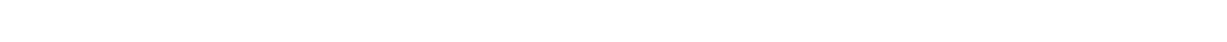

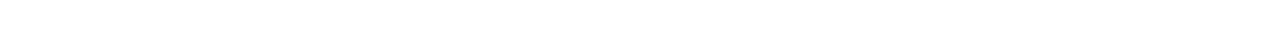

$\begin{array}{lllllllllllll}20 & 40 & 19 & 14 & 83 & 66 & 47 & 29 & 8 & 12 & 11 & 12 & 4\end{array}$

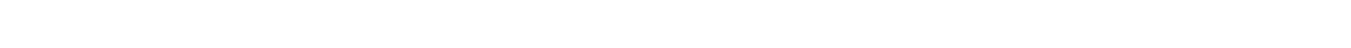

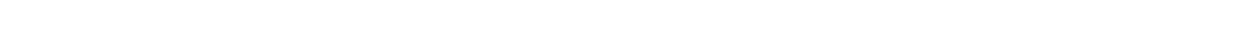

$\begin{array}{rrrrrrrrrrrrrrrrrr}47 & 10 & 4 & 5 & 5 & 6 & 17 & 13 & 83 & 108 & 49 & 16 & 2 & & & & \\ 6 & 11 & 1 & 15 & 28 & 45 & 68 & 26 & 22 & 21 & 17 & 17 & 21 & 14 & 29 & 5 & 19\end{array}$

5720.6
1075.6

1452.5

$\begin{array}{rrrrrrrrrrrrr}22 & 55 & 64 & 62 & 18 & 41 & 24 & 27 & 16 & 34 & 2 & & 1\end{array}$

$\begin{array}{lllllllllllllllllllll}10 & 29 & 11 & 13 & 9 & 7 & 8 & 9 & 19 & 9 & 9 & 19 & 28 & 29 & 15 & 4 & 4 & 2 & 1 & 2 & \end{array}$

$\begin{array}{rrrrrrrrrrrrrrrrrrrrrrrr}8 & 37 & 45 & 64 & 28 & 14 & 24 & 14 & 9 & 16 & 10 & 10 & 18 & 9 & 16 & 21 & 17 & 3 & 1 & 1 & & 1 & 5101.9\end{array}$

$\begin{array}{lllllllllllllll}1981 & 13 & 25 & 18 & 35 & 98 & 70 & 14 & 30 & 35 & 9 & 9 & 7 & 1 & 1\end{array}$ 
VIRGIN RIVER BASTN

09406700 SOUTH ASH CREFK BELOW MILL CREEK, NEAR PINTURA, UT-Continued

DURATION TABLE OF DISCHARGE FOR WATER YEARS 1967-8I

$\begin{array}{ccc}\text { OBBIC } & \text { ACOU- } \\ \text { FEET } & \text { MU- } & \text { PER- } \\ \text { PER TOTAL LATED } & \text { CENT } \\ \text { CLASS SECOND DAYS } & \text { DAYS } & \text { DAYS }\end{array}$

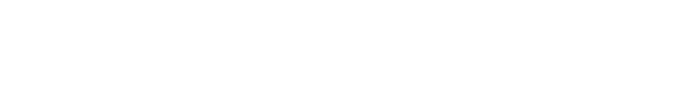

$\begin{array}{ccc}\text { OBBIC } & \text { ACOH- } \\ \text { FEET } & \text { MU- } & \text { PER- } \\ \text { PER } & \text { TOTAL LATED } & \text { CENT } \\ \text { CLASS SECOND DAYS DAYS } & \text { DAYS }\end{array}$

$\begin{array}{lllll}0 & 0.00 & 0 & 5479 & 100.0\end{array}$

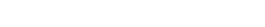

$0.51 \quad 32 \quad 5470 \quad 99.8$

$\begin{array}{llll}0.61 & 135 & 5438 & 99.3\end{array}$

$0.74 \quad 126 \quad 5303 \quad 96.8$

$\begin{array}{llll}0.89 & 92 & 5177 & 94.5\end{array}$

$\begin{array}{llll}1.10 & 184 & 5085 & 92.8\end{array}$

$\begin{array}{llll}1.30 & 327 & 4901 & 89.5 \\ 1.60 & 350 & 4574 & 83.5\end{array}$

$\begin{array}{rrrrr}9 & 1.90 & 433 & 4224 & 77.1 \\ 10 & 2.30 & 596 & 3791 & 69.2 \\ 11 & 2.70 & 617 & 3195 & 58.3 \\ 12 & 3.30 & 501 & 2578 & 47.1 \\ 13 & 4.00 & 407 & 2077 & 37.9 \\ 14 & 4.80 & 283 & 1670 & 30.5 \\ 15 & 5.80 & 185 & 1387 & 25.3 \\ 16 & 7.00 & 229 & 1202 & 21.9 \\ 17 & 8.40 & 172 & 973 & 17.8\end{array}$

$\begin{array}{rrrrr}18 & 10.0 & 90 & 801 & 14.6 \\ 19 & 12.0 & 120 & 711 & 13.0 \\ 20 & 15.0 & 62 & 591 & 10.8 \\ 21 & 18.0 & 64 & 529 & 9.7 \\ 22 & 21.0 & 86 & 465 & 8.5 \\ 23 & 26.0 & 72 & 379 & 6.9 \\ 24 & 31.0 & 94 & 307 & 5.6 \\ 25 & 37.0 & 84 & 213 & 3.9 \\ 26 & 45.0 & 64 & 129 & 2.4\end{array}$

$\begin{array}{rrrrr}27 & 55.0 & 25 & 65 & 1.2 \\ 28 & 66.0 & 23 & 40 & 0.7 \\ 29 & 79.0 & 5 & 17 & 0.3 \\ 30 & 96.0 & 6 & 12 & 0.2 \\ 31 & 120.0 & 1 & 6 & 0.1 \\ 32 & 140.0 & 1 & 5 & 0.1 \\ 33 & 170.0 & 2 & 4 & 0.1 \\ 34 & 200.0 & 2 & 2 & 0.0\end{array}$

MONIYLY MEAN DISCHARGES, IN CUBIC FEET PER SECOND, FOR EACH WATER YEAR

$\begin{array}{llllllccccrrr}\text { YEAR } & \text { OCT } & \text { NOV } & \text { DEC } & \text { JAN } & \text { FEB } & \text { MAR } & \text { APR } & \text { MAY } & \text { JUNE } & \text { JULY } & \text { AUG } & \text { SEP } \\ 1967 & 1.52 & 1.59 & 19.4 & 3.85 & 4.24 & 4.66 & 8.32 & 9.46 & 9.13 & 5.24 & 4.64 & 3.40 \\ 1968 & 2.54 & 2.30 & 2.32 & 2.33 & 4.59 & 8.01 & 8.92 & 8.35 & 7.76 & 5.92 & 4.43 & 2.00 \\ 1969 & 1.64 & 1.72 & 1.71 & 19.7 & 4.04 & 18.9 & 48.8 & 42.9 & 25.7 & 14.3 & 7.54 & 4.98 \\ 1970 & 3.70 & 3.25 & 2.91 & 2.50 & 2.32 & 3.11 & 3.75 & 4.76 & 3.70 & 2.56 & 2.94 & 1.23 \\ 1971 & 1.05 & 1.67 & 2.01 & 2.40 & 2.56 & 2.66 & 3.45 & 6.69 & 4.00 & 2.24 & 2.14 & 1.33 \\ 1972 & 1.71 & 1.71 & 13.1 & 2.72 & 2.40 & 2.82 & 2.66 & 2.59 & 2.04 & 0.93 & 0.79 & 1.53 \\ 1973 & 4.25 & 3.57 & 3.31 & 2.75 & 3.32 & 5.41 & 39.4 & 62.1 & 34.0 & 16.4 & 8.28 & 4.72 \\ 1974 & 3.96 & 3.61 & 3.32 & 3.15 & 3.06 & 4.55 & 4.30 & 3.56 & 2.64 & 1.77 & 0.75 & 0.68 \\ 1975 & 1.06 & 1.71 & 1.81 & 1.49 & 1.98 & 2.50 & 5.45 & 11.5 & 8.69 & 5.73 & 3.57 & 2.15 \\ 1976 & 1.83 & 1.88 & 2.13 & 2.39 & 3.69 & 3.94 & 6.03 & 7.63 & 4.90 & 2.74 & 1.84 & 1.70 \\ 1977 & 1.59 & 1.39 & 1.27 & 1.15 & 1.31 & 1.35 & 1.11 & 1.45 & 2.01 & 1.00 & 0.75 & 0.79 \\ 1978 & 0.59 & 0.67 & 0.79 & 1.04 & 8.90 & 34.8 & 33.2 & 35.7 & 22.6 & 11.9 & 5.72 & 3.55 \\ 1979 & 2.84 & 4.00 & 5.09 & 4.01 & 4.64 & 27.2 & 40.3 & 39.8 & 19.0 & 9.60 & 6.86 & 3.82 \\ 1980 & 2.78 & 2.74 & 2.20 & 4.69 & 25.8 & 13.5 & 27.9 & 32.7 & 20.2 & 12.6 & 6.62 & 3.55 \\ 1981 & 2.77 & 2.76 & 2.46 & 2.25 & 2.29 & 3.45 & 7.11 & 5.82 & 4.13 & 2.58 & 1.59 & 1.38\end{array}$

ANNUAL PEAK DISCHARGE, IN CUBIC FEET PER SECOND, AND CORRESPONOING GAGE HEIGHI, IN FEET, FOR EACH WATER YEAR

\begin{tabular}{|c|c|c|c|c|c|c|c|c|c|c|c|}
\hline $\begin{array}{l}\text { WATER } \\
\text { YEAR }\end{array}$ & DATE & $\begin{array}{c}\text { GAGE } \\
\text { HEIGHY }\end{array}$ & $\begin{array}{c}\text { PEAK } \\
\text { DISCHARGE }\end{array}$ & $\begin{array}{l}\text { WATER } \\
\text { YEAR }\end{array}$ & DATE & $\begin{array}{c}\text { GAGE } \\
\text { HEIGHT }\end{array}$ & $\begin{array}{c}\text { PEAK } \\
\text { DISCHARGE }\end{array}$ & $\begin{array}{l}\text { WATER } \\
\text { YEAR }\end{array}$ & DATE & $\begin{array}{c}\text { GAGE } \\
\text { HEIGHY }\end{array}$ & $\begin{array}{c}\text { PEAK } \\
\text { DISCHARGE }\end{array}$ \\
\hline $\begin{array}{l}1967 \\
1968 \\
1969 \\
1970 \\
1971\end{array}$ & $\begin{array}{l}\text { DEC. } 06,1966 \\
\text { JULY } 30,1968 \\
\text { JAN. } 25,1969 \\
\text { AUG. } 18,1970 \\
\text { NOV. } 30,1970\end{array}$ & $\begin{array}{l}5.83 \\
4.10 \\
4.78 \\
4.20 \\
2.55\end{array}$ & $\begin{array}{r}1910 \\
500 \\
872 \\
615 \\
98\end{array}$ & $\begin{array}{l}1972 \\
1973 \\
1974 \\
1975 \\
1976\end{array}$ & $\begin{array}{l}\text { DEC. } 25,1971 \\
\text { APR. } 13,1973 \\
\text { JULY } 29,1974 \\
\text { MAY } 18,1975 \\
\text { FEB. } 09,1976\end{array}$ & $\begin{array}{l}3.75 \\
3.25 \\
2.61 \\
1.50 \\
3.34\end{array}$ & $\begin{array}{r}395 \\
158 \\
52 \\
16 \\
175\end{array}$ & $\begin{array}{l}1977 \\
1978 \\
1979 \\
1980 \\
1981\end{array}$ & $\begin{array}{l}\text { SEPT.11, } 1977 \\
\text { MAR. } 21,1978 \\
\text { MAR. } 28,1979 \\
\text { FEB. } 19,1980 \\
\text { APR. } 19,1981\end{array}$ & $\begin{array}{l}2.82 \\
3.51 \\
3.72 \\
3.62 \\
2.24\end{array}$ & $\begin{array}{r}100 \\
245 \\
326 \\
281 \\
41\end{array}$ \\
\hline
\end{tabular}

09406800 SOUTH ASH CREEK NEAR PINTURA, UT

LOCATION. - Lat $37^{\circ} 19^{\prime} 53^{n}$, long $113^{\circ} 16^{\prime} 55^{\prime \prime}$, in NE $\mathrm{NE}_{4}$ sec.11, T.40 S., R.13 W., Washington County, Hydrologic Unit 15010008 , 0.9 mi south of Pintura and 3.4 mi north of Anderson Junction.

DRAINAGE AREA. $-14.0 \mathrm{mi}^{2}$.

PERIOD OF RECORD AVAIIABLE.-Water years 1959-70, 1973-74, annual peak discharge only.

GAGE.-Crest-stage gage. Altitude of gage is 4,090 ft from topographic map.

REMARRS. - Small diversion for irrigation above station.

ANNUAL PEAK DISCHARGE, IN CUBIC FEET PER SECOND, AND CORRESPONDING GAGE HEIGHT, IN FEET, FOR EACH WATER YEAR

\begin{tabular}{|c|c|c|c|c|c|c|c|c|c|c|c|c|c|}
\hline $\begin{array}{l}\text { WATER } \\
\text { YEAR }\end{array}$ & DATE & $\begin{array}{c}\text { GAGE } \\
\text { HEIGHT }\end{array}$ & $\begin{array}{c}\text { PEAK } \\
\text { DISCHARGE }\end{array}$ & $\begin{array}{l}\text { WATER } \\
\text { YEAR }\end{array}$ & & DATE & $\begin{array}{c}\text { GAGE } \\
\text { HEIGHT }\end{array}$ & $\begin{array}{c}\text { PEAK } \\
\text { DISCHARGE }\end{array}$ & $\begin{array}{l}\text { WATER } \\
\text { YEAR }\end{array}$ & DATE & & $\begin{array}{c}\text { GAGE } \\
\text { HEIGHT }\end{array}$ & $\begin{array}{c}\text { PEAK } \\
\text { DISCHARGE }\end{array}$ \\
\hline $\begin{array}{l}1959 \\
1960 \\
1961 \\
1962 \\
1963\end{array}$ & $\begin{array}{l}\text { AUG. } 03,1959 \\
\text { JULY } 22,1960 \\
\text { NOY. } 06,1960 \\
\text { FEB. } 12,1962 \\
\text { SEPT. } 17,1963\end{array}$ & $\begin{array}{r}9.46 \\
8.96 \\
8.90 \\
10.60 \\
10.95\end{array}$ & $\begin{array}{l}189 \\
200 \\
200 \\
130 \\
190\end{array}$ & $\begin{array}{l}1964 \\
1965 \\
1966 \\
1967 \\
1968\end{array}$ & $\begin{array}{l}\text { MAY } \\
\text { APR. } \\
\text { DEC. } \\
\text { DEC. } \\
\text { JULY }\end{array}$ & $\begin{array}{r}11,1964 \\
21,1965 \\
30,1965 \\
06,1966 \\
19,1968\end{array}$ & $\begin{array}{rr}4 & 9.77 \\
5 & 9.98 \\
5 & 13.43 \\
6 & 13.54 \\
8 & 11.00\end{array}$ & $\begin{array}{r}28 \\
48 \\
938 \\
890 \\
210\end{array}$ & $\begin{array}{l}1969 \\
1970 \\
1973 \\
1974\end{array}$ & $\begin{array}{l}\text { SEPT. 12, } \\
\text { AUG. 18, } \\
\text { MAR. 05, } \\
-\quad-\end{array}$ & $\begin{array}{l}1969 \\
1970 \\
1973 \\
-\end{array}$ & $\begin{array}{rr}9 & 9.83 \\
0 & 12.58 \\
3 & 12.26 \\
& 10.56\end{array}$ & $\begin{array}{r}54 \\
580 \\
510 \\
125\end{array}$ \\
\hline
\end{tabular}


VIRGIN RIVER BASIN

09407200 ASH CREEK BELWW WEST FIELD DITCH, AT TOQUERNIILE, UT

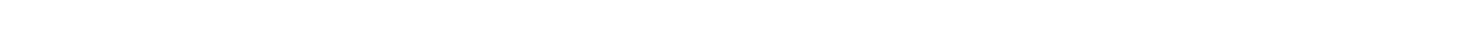
left bank $400 \mathrm{ft}$ below the West Field Ditch diversion fram Ash Creek, $0.5 \mathrm{mi}$ along turnoff fram State Highway 15 at north end of Toquerville.

DRAINAGE AREA. $-190 \mathrm{mi}^{2}$.

PERIOD OF RECORD AVAIIABLE.--Novenber 1972 to September 1981.

GAGE.-Water-stage recorder. Altitude of gage is 3,440 ft fram topographic map.

REMARRS.-Figures given herein include West Field Ditch and Toquerville Spring pipeline, both of which divert water about $400 \mathrm{ft}$ above the station.

AVERAGE DISCHARGE. -8 years (water years 1974-81), $24.2 \mathrm{ft}^{3} / \mathrm{s}, 17,530 \mathrm{acre}-\mathrm{ft} / \mathrm{yr}$.

EXIREMES FOR PERIOD OF RECORD.-Maximum discharge, $1,850 \mathrm{ft}^{3} / \mathrm{s} \mathrm{March} 5,1978$, gage height, $6.53 \mathrm{ft}$; minimum daily, $1.0 \mathrm{ft} / \mathrm{s}$ March $17,1975$.

LOWEST MEAN DISCHARGE, IN OBIC FEET PER SECOND, AND RANKING FOR THE INDICATED NUMBER OF CONSEOUTIVE DAYS FOR EACH CIIMATIC YEAR, APRIL 1-MARCH 31

\begin{tabular}{|c|c|c|c|c|c|c|c|c|c|c|c|c|c|c|c|c|c|c|c|}
\hline YEAR & 1 & & 3 & & 7 & & 14 & & $\begin{array}{l}\text { CONSE } \\
30\end{array}$ & ars & $\begin{array}{l}\text { E DAYS } \\
60\end{array}$ & & 90 & & 120 & & 183 & & ALL \\
\hline $\begin{array}{l}1974 \\
1975\end{array}$ & $\begin{array}{c}14.0 \\
9.00\end{array}$ & $\begin{array}{l}6 \\
4\end{array}$ & $\begin{array}{c}15.0 \\
9.20\end{array}$ & $\begin{array}{l}6 \\
4\end{array}$ & $\begin{array}{c}16.0 \\
9.40\end{array}$ & $\begin{array}{l}6 \\
4\end{array}$ & $\begin{array}{c}17.0 \\
9.40\end{array}$ & $\begin{array}{l}6 \\
4\end{array}$ & $\begin{array}{c}18.0 \\
9.80\end{array}$ & $\begin{array}{l}6 \\
3\end{array}$ & $\begin{array}{l}18.0 \\
11.0\end{array}$ & $\begin{array}{l}6 \\
3\end{array}$ & & $\begin{array}{l}6 \\
3\end{array}$ & & $\begin{array}{l}6 \\
3\end{array}$ & $\begin{array}{l}20.0 \\
13.0\end{array}$ & $\begin{array}{l}6 \\
4\end{array}$ & $\begin{array}{l}52.0 \\
15.0\end{array}$ \\
\hline
\end{tabular}

HIGHEST MEAN DISCHARGE, IN OUBIC FEET PER SECOND, AND RANRING FOR THE INDICATED NUMBER OF CONSEOTTIVE DAYS FOR EAG WATER YEAR, OCIOBER I-SEPTIEBBER 30

\begin{tabular}{|c|c|c|c|c|c|c|c|c|c|c|c|c|c|c|c|c|c|c|c|}
\hline YEAR & 1 & & 3 & & 7 & & 15 & & $\begin{array}{l}\text { CONSE } \\
30\end{array}$ & ar & VE DAYS & & 90 & & 120 & & 183 & & ALL \\
\hline $\begin{array}{l}1974 \\
1975\end{array}$ & $\begin{array}{l}23.0 \\
30.0\end{array}$ & $\begin{array}{l}8 \\
6\end{array}$ & $\begin{array}{l}23.0 \\
27.0\end{array}$ & $\begin{array}{l}7 \\
6\end{array}$ & $\begin{array}{l}23.0 \\
22.0\end{array}$ & $\begin{array}{l}6 \\
7\end{array}$ & $\begin{array}{l}23.0 \\
18.0\end{array}$ & $\begin{array}{l}5 \\
7\end{array}$ & $\begin{array}{l}23.0 \\
16.0\end{array}$ & $\begin{array}{l}5 \\
6\end{array}$ & $\begin{array}{l}22.0 \\
15.0\end{array}$ & $\begin{array}{l}5 \\
6\end{array}$ & $\begin{array}{l}22.0 \\
14.0\end{array}$ & $\begin{array}{l}5 \\
6\end{array}$ & $\begin{array}{l}22.0 \\
14.0\end{array}$ & $\begin{array}{l}5 \\
6\end{array}$ & $\begin{array}{l}21.0 \\
13.0\end{array}$ & $\begin{array}{l}5 \\
6\end{array}$ & $\begin{array}{l}19.0 \\
12.0\end{array}$ \\
\hline $\begin{array}{l}1976 \\
1977 \\
1978 \\
1979 \\
1980\end{array}$ & $\begin{array}{l}130 \\
29.0 \\
352 \\
596 \\
375\end{array}$ & $\begin{array}{l}4 \\
7 \\
3 \\
1 \\
2\end{array}$ & $\begin{array}{l}52.0 \\
14.0 \\
257 \\
404 \\
339\end{array}$ & $\begin{array}{l}4 \\
8 \\
3 \\
1 \\
2\end{array}$ & $\begin{array}{l}29.0 \\
11.0 \\
220 \\
317 \\
255\end{array}$ & $\begin{array}{l}5 \\
8 \\
3 \\
1 \\
2\end{array}$ & $\begin{array}{l}19.0 \\
9.10 \\
192 \\
241 \\
191\end{array}$ & $\begin{array}{l}6 \\
8 \\
2 \\
1 \\
3\end{array}$ & $\begin{array}{l}15.0 \\
9.00 \\
127 \\
192 \\
131\end{array}$ & $\begin{array}{l}7 \\
8 \\
3 \\
1 \\
2\end{array}$ & $\begin{array}{c}13.0 \\
8.90 \\
105 \\
155 \\
95.0\end{array}$ & $\begin{array}{l}7 \\
8 \\
2 \\
1 \\
3\end{array}$ & $\begin{array}{c}12.0 \\
8.90 \\
89.0 \\
127 \\
98.0\end{array}$ & $\begin{array}{l}7 \\
8 \\
3 \\
1 \\
2\end{array}$ & $\begin{array}{c}12.0 \\
8.90 \\
76.0 \\
103 \\
90.0\end{array}$ & $\begin{array}{l}7 \\
8 \\
3 \\
1 \\
2\end{array}$ & $\begin{array}{c}11.0 \\
8.70 \\
55.0 \\
77.0 \\
69.0\end{array}$ & $\begin{array}{l}7 \\
8 \\
3 \\
1 \\
2\end{array}$ & $\begin{array}{l}11.0 \\
7.80 \\
32.0 \\
47.0 \\
46.0\end{array}$ \\
\hline 1981 & 63.0 & 5 & 47.0 & 5 & 34.0 & 4 & 28.0 & 4 & 26.0 & 4 & 25.0 & 4 & 24.0 & 4 & 23.0 & 4 & 22.0 & 4 & 20.0 \\
\hline
\end{tabular}

DURATION OF DISCHARGE FOR EACH WATER YEAR

CJASS $\begin{array}{llllllllllllllllllllllllllllllllllll} & 0 & 1 & 2 & 3 & 4 & 5 & 6 & 7 & 8 & 9 & 10 & 11 & 12 & 13 & 14 & 15 & 16 & 17 & 18 & 19 & 20 & 21 & 22 & 23 & 24 & 25 & 26 & 27 & 28 & 29 & 30 & 31 & 32 & 33 & 34\end{array}$

YEAR

NUMBER OF DAYS IN CLASS

1974
1975

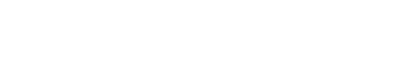

GBIC FEET

PER SECOND

-DAYS

$\begin{array}{llllll}1 & 18127 & 57150 & 10 & 1 & 1\end{array}$

$\begin{array}{llllllllll}1976 & & & & 1 & 18127 & 57150 & 10 \\ 1977 & 16 & 19 & 28 & 91 & 59147 & 1 & 1 & 2\end{array}$

1977
1978

1979

$\begin{array}{llllllll}34 & 65 & 28 & 3 & 51 & 37\end{array}$

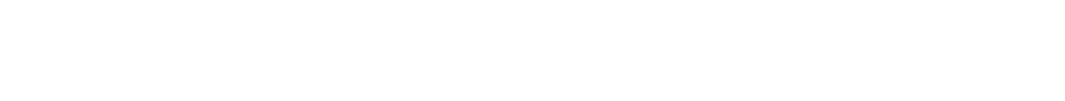

6897.0

4351.6

198

$$
\begin{array}{lllll}
2 & 126 & 112 & 104 & 17
\end{array}
$$

111

3865.2 
VIRGIN RIVER BASIN

09407200 ASH CREEK BELOW WEST FIEJD DITCH, AT TOQUERVILLE, UT-Continued

DURATION TABLE OF DISCHARGE FOR WATER YEARS 1974-81

$\begin{array}{crl}\text { OUBIC } & \text { ACOU- } \\ \text { FEET } & \text { MU- } & \text { PER- } \\ \text { PER TOTAL LATED } & \text { CENT } \\ \text { CLASS SECOND DAYS DAYS } & \text { DAYS }\end{array}$

$\begin{array}{rrrrrr}\text { CUBIC } & \text { ACOU- } & \text { CIBIC } & \text { ACOJ- } \\ \text { FEET } & \text { MU- } & \text { PER- } & \text { FEET } & \text { MU- } & \text { PER- } \\ \text { PER } & \text { TOTAL LATED } & \text { CENT } & \text { PER TOTAL LATED } & \text { CENT } \\ \text { CIAASS SECOND } & \text { DAYS DAYS } & \text { DAYS } & \text { CIASS SECOND } & \text { DAYS DAYS } & \text { DAYS }\end{array}$

$\begin{array}{rrr}\text { OBBIC } & \text { AOO- } \\ \text { FEET } & \text { MU- } & \text { PER- } \\ \text { PER } & \text { TOTAL LATED } & \text { CENT } \\ \text { CLASS SECOND DAYS DAYS } & \text { DAYS }\end{array}$

$\begin{array}{rrrrr}0 & 0.00 & 0 & 2922 & 100.0 \\ 1 & 4.40 & 25 & 2922 & 100.0 \\ 2 & 5.00 & 53 & 2897 & 99.1 \\ 3 & 5.80 & 93 & 2844 & 97.3 \\ 4 & 6.60 & 120 & 2751 & 94.1 \\ 5 & 7.50 & 80 & 2631 & 90.0 \\ 6 & 8.60 & 296 & 2551 & 87.3 \\ 7 & 9.90 & 73 & 2255 & 77.2 \\ 8 & 11.00 & 456 & 2182 & 74.7\end{array}$
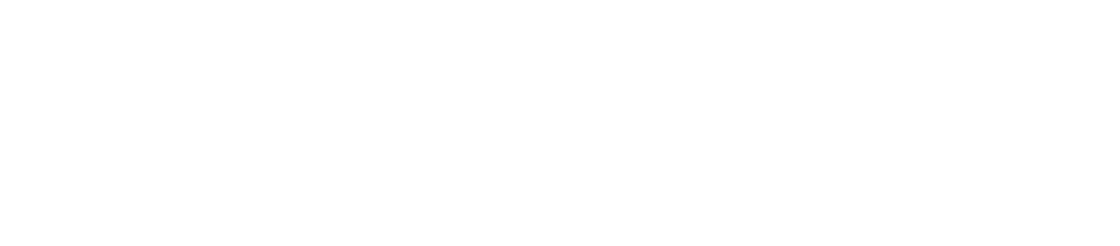

$\begin{array}{rrr}18 & 43.0 & 21 \\ 19 & 50.0 & 56 \\ 20 & 57.0 & 56 \\ 21 & 65.0 & 16 \\ 22 & 74.0 & 13 \\ 23 & 85.0 & 22 \\ 24 & 98.0 & 10 \\ 25 & 110.0 & 22 \\ 26 & 130.0 & 14\end{array}$

$\begin{array}{rr}290 & 9.9 \\ 269 & 9.2 \\ 213 & 7.3 \\ 157 & 5.4 \\ 141 & 4.8 \\ 128 & 4.4 \\ 106 & 3.6 \\ 96 & 3.3 \\ 74 & 2.5\end{array}$

$\begin{array}{rrrrr}27 & 150.0 & 9 & 60 & 2.1 \\ 28 & 170.0 & 12 & 51 & 1.7 \\ 29 & 190.0 & 8 & 39 & 1.3 \\ 30 & 220.0 & 15 & 31 & 1.1 \\ 31 & 250.0 & 9 & 16 & 0.5 \\ 32 & 290.0 & 1 & 7 & 0.2 \\ 33 & 330.0 & 5 & 6 & 0.2 \\ 34 & 380.0 & 1 & 1 & 0.0\end{array}$

MONIHLY MEAN DISCHARGES, IN OUBIC FEET PER SECOND, FOR EACH WATER YEAR

\begin{tabular}{|c|c|c|c|c|c|c|c|c|c|c|c|c|}
\hline YEAR & $\alpha C T$ & NOV & DEC & JAN & FEB & MAR & APR & MAY & JUNE & JULY & AUG & SEP \\
\hline $\begin{array}{l}1974 \\
1975\end{array}$ & $\begin{array}{l}19.1 \\
16.0\end{array}$ & $\begin{array}{l}20.6 \\
13.8\end{array}$ & $\begin{array}{l}22.1 \\
12.2\end{array}$ & $\begin{array}{l}21.8 \\
11.9\end{array}$ & $\begin{array}{l}21.8 \\
10.8\end{array}$ & $\begin{array}{l}18.9 \\
10.3\end{array}$ & $\begin{array}{l}19.4 \\
11.0\end{array}$ & $\begin{array}{l}18.5 \\
12.4\end{array}$ & $\begin{array}{l}16.7 \\
11.0\end{array}$ & $\begin{array}{l}17.6 \\
11.8\end{array}$ & $\begin{array}{l}15.5 \\
10.7\end{array}$ & $\begin{array}{l}15.0 \\
11.0\end{array}$ \\
\hline $\begin{array}{l}1976 \\
1977 \\
1978 \\
1979 \\
1980\end{array}$ & $\begin{array}{c}11.0 \\
8.88 \\
6.03 \\
14.1 \\
21.4\end{array}$ & $\begin{array}{c}11.1 \\
8.87 \\
6.53 \\
15.0 \\
22.5\end{array}$ & $\begin{array}{c}11.0 \\
8.81 \\
6.05 \\
16.1 \\
20.4\end{array}$ & $\begin{array}{c}10.5 \\
8.73 \\
7.21 \\
14.1 \\
24.6\end{array}$ & $\begin{array}{c}14.9 \\
8.97 \\
33.2 \\
15.7 \\
109\end{array}$ & $\begin{array}{c}10.3 \\
8.25 \\
125 \\
97.0 \\
53.9\end{array}$ & $\begin{array}{c}10.9 \\
7.30 \\
82.3 \\
146 \\
85.4\end{array}$ & $\begin{array}{c}9.47 \\
7.30 \\
55.9 \\
122 \\
102\end{array}$ & $\begin{array}{l}9.36 \\
6.96 \\
20.0 \\
37.9 \\
36.3\end{array}$ & $\begin{array}{l}8.69 \\
7.70 \\
13.5 \\
33.9 \\
27.3\end{array}$ & $\begin{array}{l}9.33 \\
6.54 \\
12.0 \\
22.7 \\
29.6\end{array}$ & $\begin{array}{c}10.3 \\
5.18 \\
13.0 \\
22.0 \\
25.7\end{array}$ \\
\hline 1981 & 23.3 & 25.7 & 22.9 & 20.8 & 21.0 & 19.9 & 21.3 & 18.9 & 18.1 & 18.0 & 18.4 & 17.2 \\
\hline
\end{tabular}

ANNUAL PEAR DISCHARGE, IN OUBIC FEET PER SECOND, AND CORRESPONDING GAGE HEIGHT, IN FEET, FOR EACH WATER YEAR

\begin{tabular}{|c|c|c|c|c|c|c|c|c|c|c|c|}
\hline $\begin{array}{l}\text { WATERR } \\
\text { YEAR }\end{array}$ & DATE & $\begin{array}{c}\text { GAGE } \\
\text { HEIGHT }\end{array}$ & $\begin{array}{c}\text { PEAR } \\
\text { DISCHARGE }\end{array}$ & $\begin{array}{l}\text { WATER } \\
\text { YEAR }\end{array}$ & DATE & $\begin{array}{c}\text { GAGE } \\
\text { HEIGHT }\end{array}$ & $\begin{array}{c}\text { PEAK } \\
\text { DISCHARGE }\end{array}$ & $\begin{array}{l}\text { WATER } \\
\text { YEAR }\end{array}$ & DATE & $\begin{array}{c}\text { GAGE } \\
\text { HEIGHT }\end{array}$ & $\begin{array}{l}\text { PEAR } \\
\text { DISCHARGE }\end{array}$ \\
\hline $\begin{array}{l}1973 \\
1974 \\
1975\end{array}$ & $\begin{array}{l}\text { AUG. } 16,1973 \\
\text { NOV. } 18,1973 \\
\text { OCT. } 27,1974\end{array}$ & $\begin{array}{l}4.04 \\
--\end{array}$ & $\begin{array}{r}275 \\
28 \\
51\end{array}$ & $\begin{array}{l}1976 \\
1977 \\
1978\end{array}$ & $\begin{array}{l}\text { FEB. } 09,1976 \\
\text { JULY 23, } 1977 \\
\text { MAR. 05, } 1978\end{array}$ & $\begin{array}{l}-\overline{-} \\
3.50 \\
6.53\end{array}$ & $\begin{array}{r}255 \\
212 \\
1850\end{array}$ & $\begin{array}{l}1979 \\
1980 \\
1981\end{array}$ & $\begin{array}{l}\text { MAR. } 28,1979 \\
\text { FEB. } 14,1980 \\
\text { NOV. } 20,1980\end{array}$ & $=$ & $\begin{array}{r}752 \\
595 \\
72\end{array}$ \\
\hline
\end{tabular}

09407600 ASH CREER NEAR TOQUERVILLE, UT

LOCATION.--Lat $37^{\circ} 13^{\prime} 15^{\prime \prime}$, long $113^{\circ} 17^{\prime} 00^{n}$, in SW $\frac{1}{4}$ sec.11, T.41 S., R.13 W., Washington County, Hydrologic Unit 15010008 , on right bank $1.5 \mathrm{mi}$ south of Toquerville and $2.5 \mathrm{mi}$ upstream from mouth.

DRAINAGE AREA. $-213 \mathrm{mi}^{2}$.

PERIOD OF RECOFD AVAIIABLE. --September 1956 to September 1958.

GAGE. - Water-stage recorder. Altitude of gage is 3,180 ft from topographic map.

REMARKS.--Diversions for irrigation above spring area and below gaging station.

EXTREMES FOR PERIOD OF RECORD.--Maximum discharge, 1,270 $\mathrm{ft}^{3} / \mathrm{s} \mathrm{Apr.} \mathrm{2,} \mathrm{1958,} \mathrm{gage} \mathrm{height,} 5.70 \mathrm{ft}$, from rating curve extended above $300 \mathrm{ft}^{3} / \mathrm{s}$ on basis of slope-area measurement at gage height $4.35 \mathrm{ft}$; minimum, $1.6 \mathrm{ft}^{3} / \mathrm{s} \mathrm{Mar.} \mathrm{8,} 9,1958$.

LOWEST MEAN DISCHARGE, IN CUBIC FEET PER SECOND, AND RANKING FOR THE INDICATED NUMBER OF CONSECOTIVE DAYS FOR EACH CLIMATIC YEAR, AFRII 1-MARCH 31

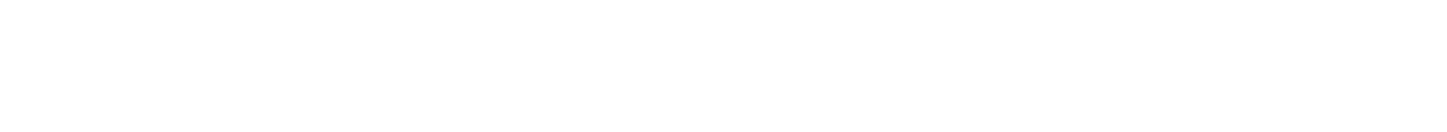

HIGHEST MEAN DISCHARGE, IN CUBIC FEET PER SECOND, AND RANKING FOR THE INDTCATED NUMBER OF CONSECUTIVE DAYS FOR FACH WATER YEAR, OCTOBER 1-SEPTEMBER 30

\begin{tabular}{|c|c|c|c|c|c|c|c|c|c|c|c|c|c|c|c|c|c|c|c|}
\hline YEAR & & & & & & & & & $\infty \mathrm{N}$ & वT & VE DAYS & & & & & & & & \\
\hline & 1 & & 3 & & 7 & & 15 & & 30 & & 60 & & 90 & & 120 & & 183 & & ALL \\
\hline $\begin{array}{l}957 \\
958\end{array}$ & $\begin{array}{l}157 \\
495\end{array}$ & $\begin{array}{l}2 \\
1\end{array}$ & $\begin{array}{l}73.0 \\
281\end{array}$ & $\begin{array}{l}2 \\
1\end{array}$ & $\begin{array}{l}37.0 \\
209\end{array}$ & $\begin{array}{l}2 \\
1\end{array}$ & ${ }_{155}^{21.0}$ & $\begin{array}{l}2 \\
1\end{array}$ & $\begin{array}{l}14.0 \\
139\end{array}$ & $\begin{array}{l}2 \\
1\end{array}$ & $\begin{array}{l}10.0 \\
127\end{array}$ & $\begin{array}{l}2 \\
1\end{array}$ & $\begin{array}{r}8.70 \\
102\end{array}$ & $\begin{array}{l}2 \\
1\end{array}$ & $\begin{array}{c}7.70 \\
80.0\end{array}$ & $\begin{array}{l}2 \\
1\end{array}$ & $\begin{array}{c}7.10 \\
57.0\end{array}$ & $\begin{array}{l}2 \\
1\end{array}$ & $\begin{array}{l}5.80 \\
32.0\end{array}$ \\
\hline
\end{tabular}


VIRGIN RIVER BASIN

09407600 ASH CREEK NEAR TOQUERNIILE, UT--Continued

DURATION OF DISCHARGE FOR EACH WATER YEAR

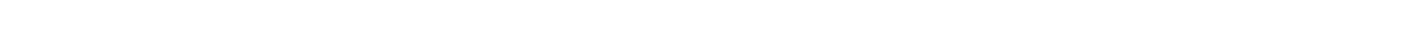
YEAR NUMBER OF DAYS IN CIASS

CUBIC FEET -DAYS

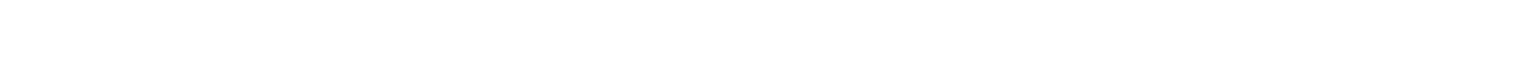

DURATION TABLE OF DISCHARGE FOR WATER YEARS 1957-58

$\begin{array}{ccc}\text { CBBIC } & \text { ACOU- } \\ \text { FEET } & \text { MU- } & \text { PER- } \\ \text { PER } & \text { TOTAL LATED } & \text { CENT } \\ \text { CLASS SECOND DAYS } & \text { DAYS } & \text { DAYS }\end{array}$

$\begin{array}{lll}\text { OBIIC } & \text { ACOU- } \\ \text { FEET } & \text { MU- } & \text { PER- } \\ \text { PER TOTAL LATED } & \text { CENT }\end{array}$

CLASS SECOND DAYS DAYS DAYS

OUIC ACOU-
FEET TOMAL LATED
PER CENT CIASS SECOND DAYS DAYS DAYS $\begin{array}{ccc}\text { OEIIC } & \text { ACO- } \\ \text { FEETT } & \text { MU- } & \text { PER- } \\ \text { PER TOTAL LATED } & \text { CENT } \\ \text { TLASS SECOND DAYS DAYS } & \text { DAYS }\end{array}$

$\begin{array}{rrrrr}0 & 0.0 & 0 & 730 & 100.0 \\ 1 & 2.0 & 3 & 730 & 100.0 \\ 2 & 2.4 & 3 & 727 & 99.6 \\ 3 & 2.8 & 1 & 724 & 99.2 \\ 4 & 3.2 & 8 & 723 & 99.0 \\ 5 & 3.8 & 135 & 715 & 98.0 \\ 6 & 4.5 & 168 & 580 & 79.4 \\ 7 & 5.3 & 174 & 412 & 56.4 \\ 8 & 6.2 & 77 & 238 & 32.6\end{array}$

$\begin{array}{rrrrr}9 & 7.2 & 26 & 161 & 22.0 \\ 10 & 8.5 & 7 & 135 & 18.5 \\ 11 & 10.0 & 10 & 128 & 17.5 \\ 12 & 12.0 & 5 & 118 & 16.2 \\ 13 & 14.0 & 6 & 113 & 15.5 \\ 14 & 16.0 & 4 & 107 & 14.7 \\ 15 & 19.0 & 4 & 103 & 14.1 \\ 16 & 22.0 & 2 & 99 & 13.6 \\ 17 & 26.0 & 3 & 97 & 13.3\end{array}$

$\begin{array}{rrr}18 & 31.0 & 2 \\ 19 & 36.0 & 5 \\ 20 & 43.0 & 5 \\ 21 & 50.0 & 8 \\ 22 & 59.0 & 9 \\ 23 & 69.0 & 10 \\ 24 & 81.0 & 14 \\ 25 & 95.0 & 9 \\ 26 & 110.0 & 11\end{array}$

$\begin{array}{lr}94 & 12.9 \\ 92 & 72.5 \\ 87 & 11.9 \\ 82 & 12.2 \\ 74 & 10.1 \\ 65 & 8.9 \\ 55 & 7.5 \\ 41 & 5.6 \\ 32 & 4.4\end{array}$

$\begin{array}{ll}27 & 130.0 \\ 28 & 150.0 \\ 29 & 180.0 \\ 30 & 210.0 \\ 31 & 250.0 \\ 32 & 290.0 \\ 33 & 340.0 \\ 34 & 400.0\end{array}$

MONIHLY MEAN DISCHARGES, IN CUBIC FEET PER SECOND, FOR EACH WATER YEAR

\begin{tabular}{|c|c|c|c|c|c|c|c|c|c|c|c|c|}
\hline YEAR & $\infty T$ & $\mathrm{NOV}$ & $\mathrm{DEC}$ & JAN & FEB & MAR & APR & MAY & JUNE & JULY & AUJG & SEP \\
\hline $\begin{array}{l}1957 \\
1958\end{array}$ & $\begin{array}{l}4.44 \\
5.50\end{array}$ & $\begin{array}{c}4.43 \\
10.1\end{array}$ & $\begin{array}{r}4.99 \\
13.7\end{array}$ & $\begin{array}{l}6.98 \\
5.05\end{array}$ & $\begin{array}{l}14.3 \\
20.8\end{array}$ & $\begin{array}{r}5.22 \\
62.2\end{array}$ & $133^{4.40}$ & $\begin{array}{c}4.43 \\
99.9\end{array}$ & $\begin{array}{c}6.54 \\
12.8\end{array}$ & $\begin{array}{c}5.83 \\
10.1\end{array}$ & $\begin{array}{l}4.09 \\
5.91\end{array}$ & $\begin{array}{r}5.22 \\
8.38\end{array}$ \\
\hline
\end{tabular}

09407800 ASH CREEK NEAR IA VERKIN, UT

LOCATION.--Lat $37^{\circ} 12^{\prime} 20^{\prime \prime}$, long $113^{\circ} 17^{\prime} 10^{\prime \prime}$, in SW $\frac{1}{4}$ sec.23, T.41 S., R.13 W., Washington County, Hydrologic Unit 15010008, on left bank $700 \mathrm{ft}$ upstream from mouth and 1 mi west of La Verkin.

DRATNAGE AREA. $-215 \mathrm{mi}^{2}$.

PERIOD OF RECORD AVAIIABLE.--September 1956 to September 1958.

GAGE.-Water-stage recorder and rock-masonry control. Altitude of gage is 3,020 ft from topographic map.

REMARKS.--Station is below all diversions.

EXIREMES FOR PERIOD OF RECORD.--Maximum discharge, 1,320 ft $\mathrm{ft}^{3} / \mathrm{s} \mathrm{Apr} .2,1958$, gage height, $5.56 \mathrm{ft}$, fram rating curve extended above $310 \mathrm{ft}^{3} / \mathrm{s}$ on basis of slope-area measurement at gage height $4.29 \mathrm{ft}$; minimum not determined.

LONEST MEAN DISCHARGE, IN CUBIC FEET PER SECOND, AND RANKING FOR THE INDICATED NUMBER OF CONSECUTIVE DAYS FOR EACH CIIMATIC YEAR, APRII 1-MARCH 31

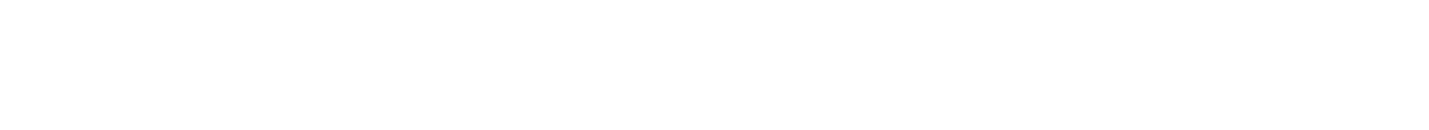

HIGHEST MEAN DISCHARGE, IN OUBIC FEET PER SECOND, AND RANKING FOR THE INDICATED NUMBER OF CONSECUTIVE DAYS FOR EACH WATER YEAR, OCTCBER I-SEPTEMBER 30

\begin{tabular}{|c|c|c|c|c|c|c|c|c|c|c|c|c|c|c|c|c|c|c|c|}
\hline YEAR & & & 3 & & 7 & & & & CONS & XTI & JE DAYS & & 90 & & 120 & & 183 & & AIT \\
\hline
\end{tabular}

DURATION OF DISCHARGE FOR EACH WATER YEAR

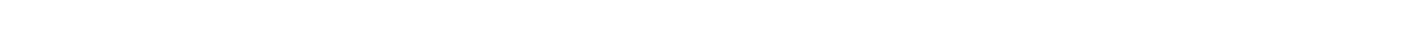
YEAR

MUMBER OF DAYS IN CLASS

$\begin{array}{lllllllllllllllllllllllllllllllllllllllll}1957 & 4 & 6 & 4 & 14 & 4 & 18 & 9 & 27 & 26 & 49 & 28 & 76 & 67 & 15 & 4 & 3 & 1 & 3 & 2 & & 1 & 1 & 1 & 1 & & & 1629.6\end{array}$ 
VIRGIN RIVER BASIN

09407800 ASH CREEK NEAR LA VERKIN, UT-Continued

DURATION TABLE OF DISCHARGE FOR WATER YEARS 1957-58

$\begin{array}{ccc}\text { OBBIC } & \text { ACOU- } & \\ \text { FEET } & \text { MU- } & \text { PER- } \\ \text { PER } & \text { TOTAL LATED } & \text { CENT } \\ \text { SECOND } & \text { DAYS DAYS } & \text { DAYS }\end{array}$

$\begin{array}{lll}\text { OBIC } & \text { AOOU- } \\ \text { FEET } & \text { MU- } & \text { PER- } \\ \text { PER TOTAL LATED } & \text { CENT }\end{array}$

PER TOTAL LATED
CENT
G.ASS SECOND DAYS DAYS DAYS

$\begin{array}{ccc}\text { CUBIC } & \text { ACOU- } \\ \text { FEET } & \text { MU- } & \text { PER- } \\ \text { PER } & \text { TOTAL LATED } & \text { CENT } \\ \text { CJASS SECOND DAYS DAYS } & \text { DAYS }\end{array}$

$\begin{array}{lll}\text { CBBIC } & \text { ACOJ- } \\ \text { FEET } & \text { MU- } & \\ \text { PER TOR- } & \end{array}$

PER TOTAL LATED CEN

CLASS SECOND DAYS DAYS DAYS

$\begin{array}{rrrrr}9 & 2.1 & 47 & 607 & 83.2 \\ 10 & 2.6 & 63 & 560 & 76.7 \\ 11 & 3.2 & 43 & 497 & 68.1 \\ 12 & 3.9 & 130 & 454 & 62.2 \\ 13 & 4.8 & 136 & 324 & 44.4 \\ 14 & 5.9 & 43 & 188 & 25.8 \\ 15 & 7.2 & 21 & 145 & 19.9 \\ 16 & 8.9 & 9 & 124 & 17.0 \\ 17 & 11.0 & 4 & 115 & 15.8\end{array}$

$\begin{array}{rrr}18 & 13.0 & 7 \\ 19 & 17.0 & 4 \\ 20 & 20.0 & 4 \\ 21 & 25.0 & 4 \\ 22 & 31.0 & 2 \\ 23 & 38.0 & 6 \\ 24 & 47.0 & 10 \\ 25 & 57.0 & 15 \\ 26 & 71.0 & 26\end{array}$

$\begin{array}{rr}111 & 15.2 \\ 104 & 14.2 \\ 100 & 13.7 \\ 96 & 13.2 \\ 92 & 12.6 \\ 90 & 12.3 \\ 84 & 11.5 \\ 74 & 10.1 \\ 59 & 8.1\end{array}$

CJASS SECOND DAYS

$\begin{array}{lrrr}0.00 & 0 & 730 & 100.0 \\ 0.40 & 4 & 730 & 100.0 \\ 0.49 & 14 & 726 & 99.4 \\ 0.61 & 4 & 712 & 97.5 \\ 0.74 & 26 & 708 & 97.0 \\ 0.92 & 6 & 682 & 93.4 \\ 1.1 & 21 & 676 & 92.6 \\ 1.4 & 13 & 655 & 89.7 \\ 1.7 & 35 & 642 & 88.0\end{array}$

MONTHLY MEAN DISCHARGES, IN CUBIC FEET PER SEOOND, FOR EACH WATER YEAR

\begin{tabular}{|c|c|c|c|c|c|c|c|c|c|c|c|c|}
\hline YEAR & OCT & NOV & $\mathrm{DEC}$ & JAN & FEB & MAR & APR & MAY & JUNE & JULY & AUG & SEP \\
\hline $\begin{array}{l}1957 \\
1958\end{array}$ & $\begin{array}{l}2.70 \\
3.58\end{array}$ & $\begin{array}{l}3.67 \\
9.62\end{array}$ & $\begin{array}{r}4.39 \\
11.7\end{array}$ & $\begin{array}{l}6.99 \\
4.59\end{array}$ & $\begin{array}{l}13.6 \\
20.4\end{array}$ & $\begin{array}{l}5.05 \\
61.3\end{array}$ & $102^{2.78}$ & $\begin{array}{c}3.79 \\
84.3\end{array}$ & $\begin{array}{l}4.25 \\
6.06\end{array}$ & $\begin{array}{l}3.80 \\
4.76\end{array}$ & $\begin{array}{l}1.65 \\
2.21\end{array}$ & $\begin{array}{l}1.57 \\
9.04\end{array}$ \\
\hline
\end{tabular}

09408000 LEEDS CREEK NEAR LEEDS, UT

LOCATION.-Lat $37^{\circ} 16^{\prime} 03^{\prime \prime}$, long $113^{\circ} 22^{\prime} 12^{\prime \prime}$, in SW $\mathrm{SEE}_{4}^{1} \mathrm{NE}^{\frac{1}{4}}$ sec.36, T.40 S., R.14 W., Washington County, Hydrologic Unit 15010008, on left bank $1,150 \mathrm{ft}$ upstream from Leeds Ditch diversion, $2.1 \mathrm{mi}$ north of Leeds, and $4.4 \mathrm{mi}$ upstream fram mouth.

DRATNAGE AREA.-- $-15.5 \mathrm{mi}^{2}$.

MEAN BASIN ELEVATION. $-6,360 \mathrm{ft}$.

PERIOD OF RECORD AVAII.ABLE.--October 1915 to June 1920 (fragmentary) in reports of Geological Survey; October 1964 to September 1981 .

GAGE. - Water-stage recorder. Altitude of gage is 4,000 ft fram topographic map. Prior to June 1920, at various sites and datums about $600 \mathrm{ft}$ downstream; Oct. 28, 1964 to Aug. 20, 1967, water-stage recorder at site 1,000 ft downstream at different datun.

REMARKS.--one diversion above station for domestic use.

AVERAGE DISCHARGE.--17 years, $7.60 \mathrm{ft}^{3} / \mathrm{s}, 5,510$ acre-ft/yr.

EXTREMES FOR PERIOD OF RECORD.-Maximum discharge, 2,710 $\mathrm{ft}^{3} / \mathrm{s}$ Aug. 6, 1967, gage height, $5.78 \mathrm{ft}$, site and datum then in use; minimum recorded, $0.23 \mathrm{ft}^{3} / \mathrm{s}$ Jan. $3,1971$.

EXTREMES GTSIDE PERIOD OF RECORD.-Maximum discharge measured, $2,980 \mathrm{ft}^{3} / \mathrm{s}$ Aug. 12, 1964, gage height, $6.00 \mathrm{ft}$, fran slope-area measurement.

LONEST MEAN DISOHARGE, IN CUBIC FEET PER SEOOND, AND RANKING FOR THE INDICATFD NUMBER OF CONSEOUTIVE DAYS FOR EACH CIIMATIC YEAR, APRIL 1-MARCH 31

\begin{tabular}{|c|c|c|c|c|c|c|c|c|c|c|c|}
\hline \multirow[t]{2}{*}{ YEAR } & \multicolumn{11}{|c|}{ CONSECUTIVE DAYS } \\
\hline & 1 & 3 & 7 & 14 & 30 & 60 & 90 & 120 & 183 & & ALL \\
\hline $\begin{array}{l}1966 \\
1967 \\
1968 \\
1969 \\
1970\end{array}$ & $\begin{array}{rr}3.10 & 11 \\
2.40 & 8 \\
3.70 & 12 \\
2.80 & 10 \\
2.50 & 9\end{array}$ & $\begin{array}{rr}3.10 & 11 \\
2.40 & 8 \\
3.80 & 12 \\
2.80 & 10 \\
2.50 & 9\end{array}$ & $\begin{array}{rr}3.10 & 11 \\
2.50 & 8 \\
3.90 & 12 \\
2.80 & 10 \\
2.50 & 9\end{array}$ & $\begin{array}{rrr}3.20 & 11 \\
2.50 & 8 \\
4.00 & 13 \\
2.90 & 10 \\
2.60 & 9\end{array}$ & $\begin{array}{rrr}3.40 & 11 \\
2.60 & 8 \\
4.10 & 13 \\
2.90 & 9 \\
2.90 & 10\end{array}$ & $\begin{array}{rrr}3.70 & 11 \\
2.70 & 8 \\
4.20 & 13 \\
3.00 & 9 \\
3.10 & 10\end{array}$ & $\begin{array}{l}4.301 \\
2.80 \\
4.401 \\
3.20 \\
3.301\end{array}$ & $\begin{array}{l}5.3015 \\
2.90 \\
4.5013 \\
3.30 \\
3.4010\end{array}$ & $\begin{array}{l}5.90 \\
4.10 \\
5.50 \\
4.30 \\
4.00\end{array}$ & $\begin{array}{r}15 \\
9 \\
13 \\
10 \\
8\end{array}$ & $\begin{array}{rr}8.10 & 11 \\
7.00 & 8 \\
7.10 & 9 \\
7.60 & 10 \\
14.0 & 15\end{array}$ \\
\hline $\begin{array}{l}1971 \\
1972 \\
1973 \\
1974 \\
1975\end{array}$ & $\begin{array}{rr}1.90 & 6 \\
2.10 & 7 \\
1.10 & 1 \\
3.80 & 13 \\
1.70 & 4\end{array}$ & $\begin{array}{rr}1.90 & 6 \\
2.20 & 7 \\
1.19 & 1 \\
3.90 & 13 \\
1.70 & 4\end{array}$ & $\begin{array}{rr}1.90 & 5 \\
2.20 & 7 \\
1.40 & 2 \\
3.90 & 13 \\
1.70 & 4\end{array}$ & $\begin{array}{rr}2.00 & 5 \\
2.30 & 6 \\
1.50 & 2 \\
4.00 & 14 \\
1.70 & 4\end{array}$ & $\begin{array}{rr}2.00 & 5 \\
2.30 & 6 \\
1.60 & 2 \\
4.10 & 14 \\
1.80 & 3\end{array}$ & $\begin{array}{rr}2.10 & 4 \\
2.50 & 6 \\
1.70 & 2 \\
4.20 & 14 \\
1.80 & 3\end{array}$ & $\begin{array}{l}2.20 \\
2.80 \\
1.90 \\
4.201 \\
1.90\end{array}$ & $\begin{array}{l}2.30 \\
3.00 \\
2.00 \\
4.30 \\
2.00\end{array}$ & $\begin{array}{l}2.50 \\
3.70 \\
2.20 \\
4.60 \\
2.20\end{array}$ & $\begin{array}{r}5 \\
7 \\
2 \\
11 \\
3\end{array}$ & $\begin{array}{rr}2.90 & 2 \\
4.20 & 5 \\
3.90 & 4 \\
13.0 & 12 \\
2.70 & 1\end{array}$ \\
\hline $\begin{array}{l}1976 \\
1977 \\
1978 \\
1979 \\
1980\end{array}$ & $\begin{array}{rr}1.70 & 5 \\
1.50 & 3 \\
1.30 & 2 \\
4.80 & 16 \\
4.10 & 15\end{array}$ & $\begin{array}{rr}1.80 & 5 \\
1.50 & 3 \\
1.30 & 2 \\
4.80 & 16 \\
4.10 & 15\end{array}$ & $\begin{array}{rr}2.10 & 6 \\
1.50 & 3 \\
1.30 & 1 \\
4.90 & 16 \\
4.10 & 15\end{array}$ & $\begin{array}{rr}2.50 & 7 \\
1.60 & 3 \\
1.40 & 1 \\
5.00 & 16 \\
4.20 & 15\end{array}$ & $\begin{array}{rr}2.60 & 7 \\
1.90 & 4 \\
1.50 & 1 \\
5.30 & 16 \\
4.30 & 15\end{array}$ & $\begin{array}{rr}2.70 & 7 \\
2.20 & 5 \\
1.50 & 1 \\
5.30 & 16 \\
4.50 & 15\end{array}$ & $\begin{array}{l}2.90 \\
2.40 \\
1.60 \\
5.501 \\
4.701\end{array}$ & $\begin{array}{l}2.90 \quad 7 \\
2.40 \\
1.70 \\
5.5016 \\
5.0014\end{array}$ & $\begin{array}{l}3.20 \\
2.50 \\
1.80 \\
5.80 \\
6.40\end{array}$ & $\begin{array}{r}6 \\
4 \\
1 \\
14 \\
16\end{array}$ & $\begin{array}{rr}4.60 & 7 \\
3.30 & 3 \\
4.30 & 6 \\
13.0 & 13 \\
18.0 & 16\end{array}$ \\
\hline
\end{tabular}


VIRGIN RIVER BASTN

09408000 LEEDS CREEK NEAR LEEDS, UT-Continued

HIGHEST MEAN DISCHARGE, IN GBIC FEET PER SECOND, AND RANKING FOR THE INDICATED NUMBER OF CONSEOUTIVE DAYS FOR EACH WATER YEAR, OCTOBER I-SEPTEMBER 31

\begin{tabular}{|c|c|c|c|c|c|c|c|c|c|c|c|c|c|c|c|c|c|c|c|c|}
\hline YEAR & & & & & & & & & CONSE & $20 \mathrm{TT}$ & E DAYS & & & & & & & & & \\
\hline 1965 & 40.0 & 9 & 21.0 & 10 & 17.0 & 8 & 15.0 & 7 & 14.0 & 7 & 13.0 & 7 & 12.0 & 7 & 12.0 & 6 & 9.90 & 6 & 6.20 & \\
\hline $\begin{array}{l}1976 \\
1977 \\
1978 \\
1979 \\
1980\end{array}$ & $\begin{array}{l}13.0 \\
5.00 \\
143 \\
251 \\
380\end{array}$ & $\begin{array}{r}14 \\
17 \\
4 \\
3 \\
2\end{array}$ & $\begin{array}{r}7.80 \\
3.70 \\
123 \\
138 \\
179\end{array}$ & $\begin{array}{r}14 \\
17 \\
4 \\
3 \\
2\end{array}$ & $\begin{array}{c}6.10 \\
3.60 \\
86.0 \\
71.0 \\
159\end{array}$ & $\begin{array}{r}14 \\
17 \\
3 \\
4 \\
1\end{array}$ & $\begin{array}{l}6.00 \\
3.10 \\
43.0 \\
43.0 \\
93.0\end{array}$ & $\begin{array}{r}14 \\
17 \\
3 \\
4 \\
1\end{array}$ & $\begin{array}{l}5.40 \\
2.90 \\
35.0 \\
35.0 \\
59.0\end{array}$ & $\begin{array}{r}16 \\
17 \\
4 \\
5 \\
1\end{array}$ & $\begin{array}{l}5.20 \\
2.70 \\
28.0 \\
29.0 \\
38.0\end{array}$ & $\begin{array}{r}15 \\
17 \\
5 \\
4 \\
1\end{array}$ & $\begin{array}{l}4.90 \\
2.60 \\
25.0 \\
28.0 \\
34.0\end{array}$ & $\begin{array}{r}15 \\
17 \\
5\end{array}$ & $\begin{array}{r}4.701 \\
2.50 \\
22.0 \\
28.0 \\
31.0\end{array}$ & $\begin{array}{r}14 \\
17 \\
5 \\
3 \\
2\end{array}$ & $\begin{array}{c}4.40 \\
2.50 \\
20.0 \\
23.0 \\
29.0\end{array}$ & $\begin{array}{r}14 \\
17 \\
5 \\
3 \\
1\end{array}$ & $\begin{array}{l}3.70 \\
2.20 \\
12.0 \\
14.0 \\
18.0\end{array}$ & \\
\hline
\end{tabular}

DURATION OF DISCHAFGE FOR EACH WATER YEAR

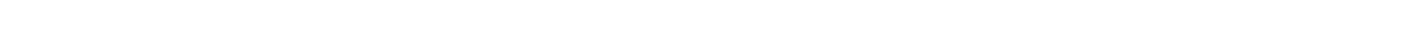

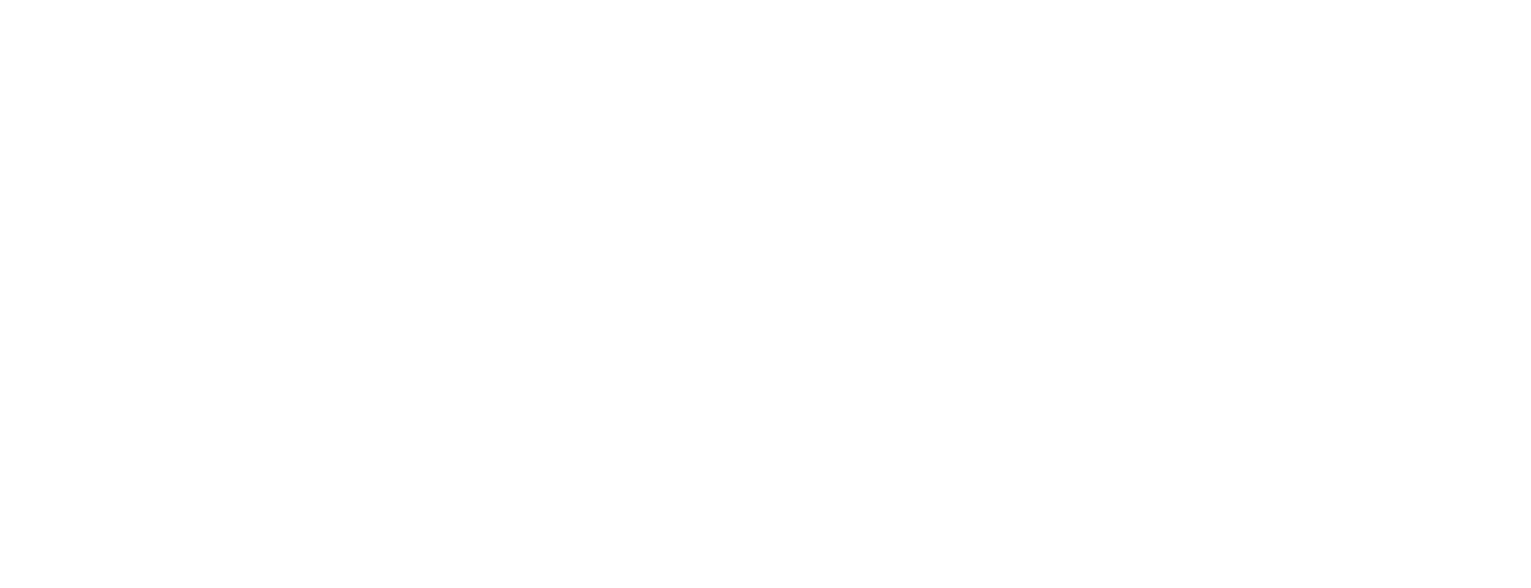

DURATION TABLE OF DISCHARGE FOR WATER YEARS $1965-81$

\begin{tabular}{|c|c|c|c|c|c|c|c|c|c|c|c|c|c|c|c|c|c|c|c|}
\hline CLASS & $\begin{array}{c}\text { OBBIC } \\
\text { FEET } \\
\text { PER } \\
\text { SECOND }\end{array}$ & $\begin{array}{r}\text { TOTAL } \\
\text { DAYS }\end{array}$ & $\begin{array}{l}\text { ACOH- } \\
\text { NU- } \\
\text { LATED } \\
\text { DAYS }\end{array}$ & $\begin{array}{l}\text { PER } \\
\text { CENT } \\
\text { DAYS }\end{array}$ & CLASS & $\begin{array}{c}\text { OUBIC } \\
\text { FEET } \\
\text { PER } \\
\text { SECOND }\end{array}$ & $\begin{array}{l}\text { TOTAL } \\
\text { DAYS }\end{array}$ & $\begin{array}{c}\text { ACO- } \\
\text { MU- } \\
\text { LATED } \\
\text { DAYS }\end{array}$ & $\begin{array}{l}\text { PER- } \\
\text { CENT } \\
\text { DAYS }\end{array}$ & & $\begin{array}{c}\text { वBIC } \\
\text { FEET } \\
\text { PER } \\
\text { SECOND }\end{array}$ & $\begin{array}{l}\text { TOTAL } \\
\text { DAYS }\end{array}$ & $\begin{array}{c}\text { ACQU- } \\
\text { MU- } \\
\text { LATED } \\
\text { DAYS }\end{array}$ & $\begin{array}{l}\text { PER } \\
\text { CENT } \\
\text { DAYS }\end{array}$ & & $\begin{array}{c}\text { वBIC } \\
\text { FEET } \\
\text { PER } \\
\text { SECOND }\end{array}$ & $\begin{array}{l}\text { TOTAL } \\
\text { DAYS }\end{array}$ & $\begin{array}{c}\text { ACQJ- } \\
\text { MJ- } \\
\text { LATED } \\
\text { DAYS }\end{array}$ & $\begin{array}{l}\text { PER } \\
\text { CENT } \\
\text { DAYS }\end{array}$ \\
\hline $\begin{array}{l}0 \\
1 \\
2 \\
3 \\
4 \\
5 \\
6 \\
7 \\
8\end{array}$ & $\begin{array}{l}0.00 \\
1.10 \\
1.30 \\
1.60 \\
1.90 \\
2.20 \\
2.70 \\
3.20 \\
3.80\end{array}$ & $\begin{array}{r}0 \\
4 \\
62 \\
184 \\
202 \\
787 \\
659 \\
599 \\
580\end{array}$ & $\begin{array}{l}6209 \\
6209 \\
6205 \\
6143 \\
5959 \\
5757 \\
4970 \\
4311 \\
3712\end{array}$ & $\begin{array}{r}100.0 \\
100.0 \\
99.9 \\
98.9 \\
96.0 \\
92.7 \\
80.0 \\
69.4 \\
59.8\end{array}$ & $\begin{array}{r}9 \\
10 \\
11 \\
12 \\
13 \\
14 \\
15 \\
16 \\
17\end{array}$ & $\begin{array}{r}4.50 \\
5.40 \\
6.50 \\
7.70 \\
9.20 \\
11.00 \\
13.00 \\
16.00 \\
19.00\end{array}$ & $\begin{array}{r}725 \\
487 \\
450 \\
254 \\
220 \\
174 \\
133 \\
96 \\
121\end{array}$ & $\begin{array}{r}3132 \\
2407 \\
1920 \\
1470 \\
1216 \\
996 \\
822 \\
689 \\
593\end{array}$ & $\begin{array}{r}50.4 \\
38.8 \\
30.9 \\
23.7 \\
19.6 \\
16.0 \\
13.2 \\
11.1 \\
9.6\end{array}$ & $\begin{array}{l}18 \\
19 \\
20 \\
21 \\
22 \\
23 \\
24 \\
25 \\
26\end{array}$ & $\begin{array}{l}22.0 \\
27.0 \\
32.0 \\
38.0 \\
45.0 \\
54.0 \\
65.0 \\
77.0 \\
92.0\end{array}$ & $\begin{array}{r}146 \\
140 \\
110 \\
49 \\
4 \\
3 \\
3 \\
4 \\
3\end{array}$ & $\begin{array}{r}472 \\
326 \\
186 \\
76 \\
27 \\
23 \\
20 \\
17 \\
13\end{array}$ & $\begin{array}{l}7.6 \\
5.3 \\
3.0 \\
1.2 \\
0.4 \\
0.4 \\
0.3 \\
0.3 \\
0.2\end{array}$ & $\begin{array}{l}27 \\
28 \\
29 \\
30 \\
31 \\
32 \\
33 \\
34\end{array}$ & $\begin{array}{l}110.0 \\
130.0 \\
160.0 \\
190.0 \\
220.0 \\
270.0 \\
320.0 \\
380.0\end{array}$ & $\begin{array}{l}3 \\
2 \\
2 \\
0 \\
1 \\
0 \\
0 \\
2\end{array}$ & $\begin{array}{r}10 \\
7 \\
5 \\
3 \\
3 \\
2 \\
2 \\
2\end{array}$ & $\begin{array}{l}0.2 \\
0.1 \\
0.1 \\
0.0 \\
0.0 \\
0.0 \\
0.0 \\
0.0\end{array}$ \\
\hline
\end{tabular}

MONIHLY MEAN DISCHARGES, IN GBIC FEET PER SECOND, FOR EACH WATER YEAR

$\begin{array}{lllllllllllrr}\text { YEAR } & \text { OCT } & \text { NOV } & \text { DEC } & \text { JAN } & \text { FEB } & \text { MAR } & \text { APR } & \text { MAY } & \text { JUNE } & \text { JULY } & \text { AUG } & \text { SEP } \\ 1965 & 2.47 & 2.44 & 2.42 & 2.39 & 2.54 & 2.73 & 10.2 & 9.90 & 12.4 & 13.5 & 8.71 & 4.75 \\ 1966 & 3.69 & 6.05 & 8.70 & 7.11 & 5.32 & 6.32 & 7.35 & 8.32 & 8.94 & 5.11 & 3.02 & 2.67 \\ 1967 & 2.87 & 3.05 & 26.6 & 5.71 & 5.77 & 4.54 & 5.21 & 5.77 & 11.3 & 9.59 & 11.1 & 8.59 \\ 1968 & 5.48 & 4.86 & 4.33 & 4.20 & 6.26 & 8.01 & 7.53 & 7.16 & 11.4 & 9.29 & 6.82 & 3.90 \\ 1969 & 3.51 & 3.40 & 2.98 & 11.9 & 6.65 & 15.9 & 33.1 & 28.7 & 36.4 & 23.3 & 11.7 & 7.23 \\ 1970 & 5.68 & 4.73 & 3.65 & 2.87 & 3.27 & 3.89 & 3.55 & 3.45 & 3.20 & 3.40 & 3.15 & 2.32\end{array}$


VIRGIN RIVER BASIN

09408000 LEEDS CREER NEAR LEEDS, UT-Continued

MONIHLY MEAN DISCHARGES, IN CIBIC FEET PER SECOND, FOR EACH WATER YEAR--Continued

\begin{tabular}{|c|c|c|c|c|c|c|c|c|c|c|c|c|}
\hline YEAR & $\infty T$ & $\mathrm{NON}$ & $\mathrm{DEC}$ & JAN & FEB & MAR & $\mathrm{APR}$ & MAY & JUNE & JULY & AUG & SEP \\
\hline $\begin{array}{l}1971 \\
1972 \\
1973 \\
1974 \\
1975\end{array}$ & $\begin{array}{l}2.05 \\
2.99 \\
2.45 \\
5.48 \\
2.15\end{array}$ & $\begin{array}{l}2.47 \\
2.28 \\
3.66 \\
4.87 \\
2.97\end{array}$ & $\begin{array}{l}2.64 \\
7.05 \\
4.65 \\
4.43 \\
2.77\end{array}$ & $\begin{array}{l}2.73 \\
3.91 \\
5.39 \\
4.35 \\
2.59\end{array}$ & $\begin{array}{l}3.10 \\
3.31 \\
7.10 \\
4.22 \\
3.05\end{array}$ & $\begin{array}{l}3.05 \\
2.89 \\
9.79 \\
4.12 \\
4.08\end{array}$ & $\begin{array}{c}2.59 \\
2.92 \\
17.2 \\
3.68 \\
4.46\end{array}$ & $\begin{array}{c}3.38 \\
2.44 \\
26.2 \\
2.98 \\
4.98\end{array}$ & $\begin{array}{c}5.01 \\
2.42 \\
38.1 \\
2.39 \\
8.16\end{array}$ & $\begin{array}{c}5.76 \\
2.49 \\
23.4 \\
2.18 \\
8.83\end{array}$ & $\begin{array}{c}6.95 \\
1.82 \\
11.2 \\
1.91 \\
5.49\end{array}$ & $\begin{array}{l}3.62 \\
1.73 \\
7.27 \\
1.82 \\
3.85\end{array}$ \\
\hline $\begin{array}{l}1976 \\
1977 \\
1978 \\
1979 \\
1980\end{array}$ & $\begin{array}{l}2.88 \\
2.66 \\
2.39 \\
5.44 \\
5.40\end{array}$ & $\begin{array}{l}3.39 \\
2.56 \\
1.85 \\
5.50 \\
4.81\end{array}$ & $\begin{array}{l}2.95 \\
2.03 \\
2.01 \\
5.85 \\
4.43\end{array}$ & $\begin{array}{l}2.55 \\
2.81 \\
2.79 \\
5.35 \\
7.58\end{array}$ & $\begin{array}{r}3.92 \\
2.47 \\
4.75 \\
6.24 \\
52.0\end{array}$ & $\begin{array}{c}3.75 \\
2.46 \\
25.8 \\
27.4 \\
21.1\end{array}$ & $\begin{array}{l}4.11 \\
2.00 \\
11.3 \\
20.3 \\
22.5\end{array}$ & $\begin{array}{l}5.03 \\
2.30 \\
19.9 \\
22.0 \\
24.8\end{array}$ & $\begin{array}{c}5.38 \\
2.15 \\
31.3 \\
33.9 \\
24.0\end{array}$ & $\begin{array}{c}4.06 \\
1.51 \\
24.0 \\
22.9 \\
29.0\end{array}$ & $\begin{array}{r}3.02 \\
1.62 \\
9.64 \\
11.6 \\
14.2\end{array}$ & $\begin{array}{l}2.84 \\
1.83 \\
6.41 \\
6.94 \\
9.02\end{array}$ \\
\hline 1981 & 6.73 & 5.63 & 4.64 & 4.10 & 4.00 & 4.80 & 6.26 & 6.83 & 6.72 & 4.42 & 3.13 & 2.81 \\
\hline
\end{tabular}

ANNUAL PEAK DISCHARGE, IN CABIC FEET PER SECOND, AND CORRESPONDING GAGE HEIGHT, IN FEET, FOR EACH WATER YEAR

\begin{tabular}{|c|c|c|c|c|c|c|c|c|c|c|c|}
\hline $\begin{array}{l}\text { WATER } \\
\text { YEAR }\end{array}$ & DATE & $\begin{array}{c}\text { GAGE } \\
\text { HEIGHT }\end{array}$ & $\begin{array}{c}\text { PEAK } \\
\text { DISCHARGE }\end{array}$ & $\begin{array}{l}\text { WAIERR } \\
\text { YEAR }\end{array}$ & DATE & $\begin{array}{c}\text { GAGE } \\
\text { HEIGHT }\end{array}$ & $\begin{array}{c}\text { PEAK } \\
\text { DISCHARGE }\end{array}$ & $\begin{array}{l}\text { WATEER } \\
\text { YEAR }\end{array}$ & DATE & $\begin{array}{c}\text { GAGE } \\
\text { HEIGHT }\end{array}$ & $\begin{array}{c}\text { PEAK } \\
\text { DISCHARG }\end{array}$ \\
\hline $\begin{array}{l}1964 \\
1965 \\
1966 \\
1967 \\
1968 \\
1969\end{array}$ & $\begin{array}{l}\text { AUG. } 12,1964 \\
\text { AUG. } 15,1965 \\
\text { DEC. } 30,1965 \\
\text { AUG. } 06,1967 \\
\text { JULY } 30,1968 \\
\text { JAN. } 25,1969\end{array}$ & $\begin{array}{l}6.00 \\
5.33 \\
3.70 \\
5.78 \\
3.21 \\
3.97\end{array}$ & $\begin{array}{r}2980 \\
2060 \\
565 \\
2710 \\
213 \\
386\end{array}$ & $\begin{array}{l}1970 \\
1971 \\
1972 \\
1973 \\
1974 \\
1975\end{array}$ & $\begin{array}{l}\text { AUG. } 15,1970 \\
\text { AUG. } 25,1971 \\
\text { DEC. 25, } 1971 \\
\text { JUNE 14, } 1973 \\
\text { NO. 18, } 1973 \\
\text { JULY } 12,1975\end{array}$ & $\begin{array}{l}2.35 \\
4.90 \\
2.87 \\
2.65 \\
1.70 \\
2.57\end{array}$ & $\begin{array}{c}94 \\
1290 \\
198 \\
84 \\
8.0 \\
80\end{array}$ & $\begin{array}{l}1976 \\
1977 \\
1978 \\
1979 \\
1980 \\
1981\end{array}$ & $\begin{array}{l}\text { FEB. } 09,1976 \\
\text { OCT. 02, } 1976 \\
\text { MAR. 03, } 1978 \\
\text { MAR. 28, } 1979 \\
\text { FEB. 14, } 1980 \\
\text { AUG. 10, } 1981\end{array}$ & $\begin{array}{l}2.12 \\
1.90 \\
3.70 \\
4.05 \\
4.49 \\
2.32\end{array}$ & $\begin{array}{r}27 \\
15 \\
403 \\
570 \\
892 \\
43\end{array}$ \\
\hline
\end{tabular}

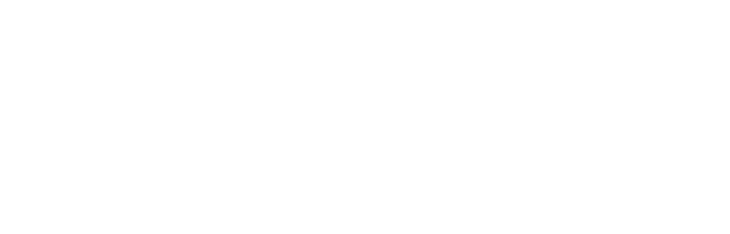

$\begin{array}{rrrrrrr}1 & 2.4 & 1.7 & 1.4 & 1.1 & - & - \\ 7 & 2.5 & 1.8 & 1.5 & 1.3 & - & - \\ 14 & 2.6 & 1.9 & 1.6 & 1.3 & - & = \\ 30 & 2.8 & 2.0 & 1.7 & 1.5 & - & - \\ 60 & 2.9 & 2.1 & 1.8 & 1.5 & - & - \\ 90 & 3.1 & 2.3 & 1.9 & 1.6 & - & -\end{array}$

09408150 VIRGIN RIVER NEAR HURRICANE, UT

LOCATION.-Lat $37^{\circ} 09^{\prime} 45^{\prime \prime}$, long $113^{\circ} 23^{\prime} 42^{\prime \prime}$, in $\mathrm{NE}_{4}^{3} \mathrm{NE}_{4}^{\frac{1}{4} \mathrm{SW}_{2} \frac{1}{4}}$ sec.2, T.42 S., R.14 W., Washington County, Hydrologic Unit 15010008 , on

left bank at downstream side of bridge on State Highway $17,1.8 \mathrm{mi}$ downstream from Quail Creek, and 6.2 mi west of Hurricane.

DRATNAGE AREA. $-1,499 \mathrm{mi}^{2}$.

MEAN BASIN ELEVATION. $-6,350 \mathrm{ft}$.

PERIOD OF RECORD AVAIIABLE.--March 1967 to September 1981.

REVISED RECORDS.-WDR UT-78-1: Drainage area.

GAGE.-Water-stage recorder. Altitude of gage is 2,760 ft fram topographic map.

REMARRS.--Many diversions above station.

AVERAGE DISCHARGE.-14 years, $237 \mathrm{ft}^{3} / \mathrm{s}, 171,700$ acre-ft/yr.

EXXTREMES FOR PERIOD OF RECORD.--Maximum discharge, 18,700 ft $\mathrm{ft}^{3} / \mathrm{s}$ Mar. 5, 1978, gage height, $16.28 \mathrm{ft} ; \mathrm{minimum}, 23 \mathrm{ft}{ }^{3} / \mathrm{s} \mathrm{Aug} .22$, 1976.

EXIREMES OUTSIDE PERIOD OF RECORD.--Maximum stage known since at least 1909, 17.34 ft Dec. 6, 1966, from floocharks, discharge $20,100 \mathrm{ft}^{3} / \mathrm{s}$. 
VIRGIN RIVER BASIN

09408150 VIRGIN RIVER NEAR HURRICANE, UT--Continued

LONEST MEAN DISCHARGE, IN CUBIC FEET PER SECOND, AND RANKING FOR THE INDICATED NUMBER OF CONSEOUTIVE DAYS FOR EACH CIIMATIC YEAR, APRII I-MARCH 31

\begin{tabular}{|c|c|c|c|c|c|c|c|c|c|c|c|c|c|c|c|c|c|c|c|c|}
\hline YEAR & 1 & & 3 & & 7 & & 14 & & $\begin{array}{l}\text { cons } \\
30\end{array}$ & EOTT & $\begin{array}{c}\text { DAYS } \\
60\end{array}$ & & 90 & & 120 & & 183 & & ALL & \\
\hline $\begin{array}{l}1971 \\
1972 \\
1973 \\
1974 \\
1975\end{array}$ & $\begin{array}{l}55.0 \\
47.0 \\
41.0 \\
64.0 \\
42.0\end{array}$ & $\begin{array}{r}8 \\
6 \\
2 \\
10 \\
3\end{array}$ & $\begin{array}{l}57.0 \\
50.0 \\
42.0 \\
66.0 \\
44.0\end{array}$ & $\begin{array}{r}8 \\
7 \\
2 \\
10 \\
4\end{array}$ & $\begin{array}{l}60.0 \\
53.0 \\
43.0 \\
68.0 \\
50.0\end{array}$ & $\begin{array}{r}7 \\
6 \\
2 \\
10 \\
5\end{array}$ & $\begin{array}{l}66.0 \\
56.0 \\
44.0 \\
71.0 \\
55.0\end{array}$ & $\begin{array}{l}8 \\
6 \\
2 \\
9 \\
4\end{array}$ & $\begin{array}{l}70.0 \\
62.0 \\
45.0 \\
75.0 \\
56.0\end{array}$ & $\begin{array}{r}8 \\
6 \\
1 \\
11 \\
4\end{array}$ & $\begin{array}{l}84.0 \\
81.0 \\
61.0 \\
80.0 \\
61.0\end{array}$ & $\begin{array}{r}11 \\
10 \\
2 \\
9 \\
3\end{array}$ & $\begin{array}{r}99.0 \\
108 \\
84.0 \\
86.0 \\
70.0\end{array}$ & $\begin{array}{r}10 \\
11 \\
6 \\
7 \\
3\end{array}$ & $\begin{array}{l}108 \\
100 \\
85.0 \\
91.0 \\
73.0\end{array}$ & $\begin{array}{r}11 \\
9 \\
6 \\
7 \\
3\end{array}$ & $\begin{array}{c}108 \\
117 \\
119 \\
113 \\
88.0\end{array}$ & $\begin{array}{r}5 \\
9 \\
11 \\
7 \\
4\end{array}$ & $\begin{array}{l}138 \\
165 \\
169 \\
335 \\
125\end{array}$ & $\begin{array}{r}6 \\
11 \\
3\end{array}$ \\
\hline $\begin{array}{l}1976 \\
1977 \\
1978 \\
1979 \\
1980\end{array}$ & $\begin{array}{l}43.0 \\
32.0 \\
47.0 \\
46.0 \\
70.0\end{array}$ & $\begin{array}{r}4 \\
1 \\
7 \\
5 \\
11\end{array}$ & $\begin{array}{l}43.0 \\
33.0 \\
48.0 \\
48.0 \\
70.0\end{array}$ & $\begin{array}{r}3 \\
1 \\
5 \\
6 \\
11\end{array}$ & $\begin{array}{l}47.0 \\
35.0 \\
48.0 \\
62.0 \\
71.0\end{array}$ & $\begin{array}{r}3 \\
1 \\
4 \\
8 \\
11\end{array}$ & $\begin{array}{l}55.0 \\
38.0 \\
49.0 \\
64.0 \\
72.0\end{array}$ & $\begin{array}{r}5 \\
1 \\
3 \\
7 \\
10\end{array}$ & $\begin{array}{l}61.0 \\
45.0 \\
51.0 \\
65.0 \\
74.0\end{array}$ & $\begin{array}{r}5 \\
2 \\
3 \\
7 \\
10\end{array}$ & $\begin{array}{l}69.0 \\
65.0 \\
58.0 \\
69.0 \\
80.0\end{array}$ & $\begin{array}{l}6 \\
4 \\
1 \\
5 \\
7\end{array}$ & $\begin{array}{l}74.0 \\
64.0 \\
68.0 \\
72.0 \\
96.0\end{array}$ & $\begin{array}{l}5 \\
1 \\
2 \\
4 \\
9\end{array}$ & $\begin{array}{c}77.0 \\
70.0 \\
73.0 \\
75.0 \\
101\end{array}$ & $\begin{array}{r}5 \\
1 \\
2 \\
4 \\
10\end{array}$ & $\begin{array}{r}85.0 \\
74.0 \\
82.0 \\
110 \\
118\end{array}$ & $\begin{array}{r}3 \\
1 \\
2 \\
6 \\
10\end{array}$ & $\begin{array}{l}122 \\
107 \\
216 \\
318 \\
439\end{array}$ & $\begin{array}{r}8 \\
10 \\
14\end{array}$ \\
\hline 1981 & 98.0 & 14 & 99.0 & 14 & 101 & 14 & 109 & 14 & 119 & 14 & 154 & 14 & 165 & 14 & 167 & 14 & 177 & 14 & 404 & 13 \\
\hline
\end{tabular}

HIGHEST MEAN DISCHARGE, IN CUBIC FEET PER SECOND, AND RANKING FOR THE INDICATED NUMBER OF CONSEOUTIVE DAYS FOR EACH WATER YEAR, OCIOBER 1-SEPTEMBER 31

\begin{tabular}{|c|c|c|c|c|c|c|c|c|c|c|c|c|c|c|c|c|c|c|c|c|}
\hline \multirow{2}{*}{$\begin{array}{l}\text { YEAR } \\
1968 \\
1969 \\
1970\end{array}$} & \multicolumn{20}{|c|}{ CONSECUTIVE DAYS } \\
\hline & $\begin{array}{r}658 \\
4460 \\
583\end{array}$ & $\begin{array}{r}11 \\
5 \\
12\end{array}$ & $\begin{array}{r}625 \\
2850 \\
407\end{array}$ & $\begin{array}{r}8 \\
4 \\
12\end{array}$ & $\begin{array}{r}595 \\
1690 \\
315\end{array}$ & $\begin{array}{r}8 \\
5 \\
11\end{array}$ & $\begin{array}{r}476 \\
1510 \\
251\end{array}$ & $\begin{array}{r}8 \\
5 \\
11\end{array}$ & $\begin{array}{r}440 \\
1450 \\
210\end{array}$ & $\begin{array}{r}7 \\
3 \\
12\end{array}$ & $\begin{array}{r}383 \\
1260 \\
199\end{array}$ & $\begin{array}{r}6 \\
2 \\
10\end{array}$ & $\begin{array}{r}346 \\
1000 \\
196\end{array}$ & $\begin{array}{r}6 \\
3 \\
10\end{array}$ & $\begin{array}{l}321 \\
863 \\
198\end{array}$ & $\begin{array}{r}6 \\
3 \\
10\end{array}$ & $\begin{array}{l}268 \\
687 \\
179\end{array}$ & $\begin{array}{r}6 \\
2 \\
11\end{array}$ & $\begin{array}{l}195 \\
408 \\
147\end{array}$ & $\begin{array}{r}6 \\
2 \\
10\end{array}$ \\
\hline $\begin{array}{l}1971 \\
1972 \\
1973 \\
1974 \\
1975\end{array}$ & $\begin{array}{r}710 \\
6160 \\
2120 \\
334 \\
1060\end{array}$ & $\begin{array}{r}10 \\
2 \\
6 \\
14 \\
8\end{array}$ & $\begin{array}{r}447 \\
2720 \\
2040 \\
266 \\
623\end{array}$ & $\begin{array}{r}11 \\
5 \\
6 \\
14 \\
9\end{array}$ & $\begin{array}{r}395 \\
1410 \\
1940 \\
232 \\
403\end{array}$ & $\begin{array}{r}10 \\
6 \\
4 \\
14 \\
9\end{array}$ & $\begin{array}{r}312 \\
763 \\
1810 \\
203 \\
373\end{array}$ & $\begin{array}{r}10 \\
6 \\
2 \\
13 \\
9\end{array}$ & $\begin{array}{r}235 \\
468 \\
1660 \\
189 \\
330\end{array}$ & $\begin{array}{r}11 \\
6 \\
1 \\
13 \\
9\end{array}$ & $\begin{array}{r}199 \\
312 \\
1240 \\
185 \\
244\end{array}$ & $\begin{array}{r}11 \\
8 \\
3 \\
12 \\
9\end{array}$ & $\begin{array}{l}194 \\
269 \\
975 \\
176 \\
236\end{array}$ & $\begin{array}{r}11 \\
8 \\
4 \\
12 \\
9\end{array}$ & $\begin{array}{l}187 \\
238 \\
810 \\
176 \\
222\end{array}$ & $\begin{array}{r}11 \\
8 \\
4 \\
12 \\
9\end{array}$ & $\begin{array}{l}183 \\
204 \\
598 \\
157 \\
192\end{array}$ & $\begin{array}{r}10 \\
8 \\
4 \\
12 \\
9\end{array}$ & $\begin{array}{l}145 \\
160 \\
368 \\
122 \\
152\end{array}$ & $\begin{array}{r}11 \\
8 \\
4 \\
12 \\
9\end{array}$ \\
\hline $\begin{array}{l}1976 \\
1977 \\
1978 \\
1979 \\
1980\end{array}$ & $\begin{array}{r}440 \\
886 \\
9620 \\
6020 \\
4580\end{array}$ & $\begin{array}{r}13 \\
9 \\
1 \\
3 \\
4\end{array}$ & $\begin{array}{r}310 \\
451 \\
5120 \\
3530 \\
3190\end{array}$ & $\begin{array}{r}13 \\
10 \\
1 \\
2 \\
3\end{array}$ & $\begin{array}{r}255 \\
257 \\
3380 \\
2080 \\
2670\end{array}$ & $\begin{array}{r}13 \\
12 \\
1 \\
3 \\
2\end{array}$ & $\begin{array}{r}249 \\
167 \\
1790 \\
1520 \\
2020\end{array}$ & $\begin{array}{r}12 \\
14 \\
3 \\
4 \\
1\end{array}$ & $\begin{array}{r}238 \\
154 \\
1190 \\
1310 \\
1600\end{array}$ & $\begin{array}{r}10 \\
14 \\
5 \\
4 \\
2\end{array}$ & $\begin{array}{r}179 \\
147 \\
953 \\
1180 \\
1310\end{array}$ & $\begin{array}{r}13 \\
14 \\
5 \\
4 \\
1\end{array}$ & $\begin{array}{r}156 \\
133 \\
911 \\
1040 \\
1110\end{array}$ & $\begin{array}{r}13 \\
14 \\
5 \\
2 \\
1\end{array}$ & $\begin{array}{r}147 \\
124 \\
797 \\
866 \\
1120\end{array}$ & $\begin{array}{r}13 \\
14 \\
5 \\
2 \\
1\end{array}$ & $\begin{array}{l}131 \\
115 \\
588 \\
640 \\
863\end{array}$ & $\begin{array}{r}13 \\
14 \\
5 \\
3 \\
1\end{array}$ & $\begin{array}{c}102 \\
98.0 \\
335 \\
387 \\
515\end{array}$ & $\begin{array}{r}13 \\
14 \\
5 \\
3 \\
1\end{array}$ \\
\hline 981 & 1530 & 7 & 903 & 7 & 653 & 7 & 536 & 7 & 396 & 8 & 324 & 7 & 284 & 7 & 262 & 7 & 233 & 7 & 185 & 7 \\
\hline
\end{tabular}

DURATION OF DISCHARGE FOR EACH WATER YEAR

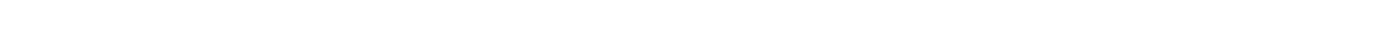
YEAR NUMBER OF DAYS IN CLASS OUBIC FEET
PER SECOND

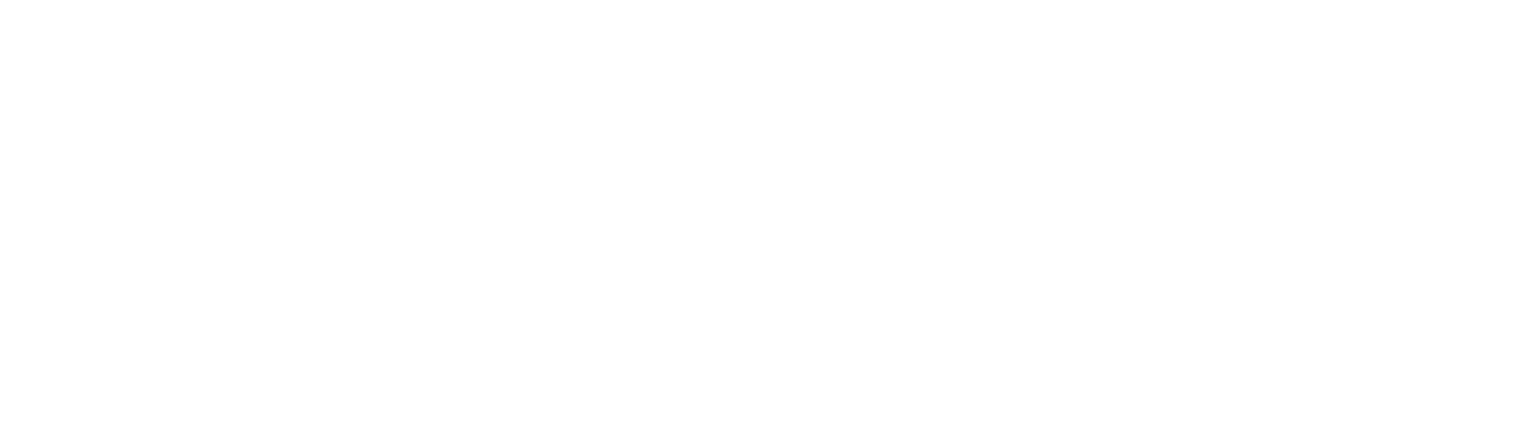


DURATION TABLE OF DISCHARGE FOR WATER YEARS 1968-81

\begin{tabular}{|c|c|c|c|c|c|c|c|c|c|c|c|c|c|c|c|c|c|c|c|}
\hline LASS & $\begin{array}{c}\text { CUBIC } \\
\text { FEET } \\
\text { PER } \\
\text { SECOND }\end{array}$ & $\begin{array}{l}\text { TOTAL } \\
\text { DAYS }\end{array}$ & $\begin{array}{c}\text { ACOU- } \\
\text { MU- } \\
\text { LATED } \\
\text { DAYS }\end{array}$ & $\begin{array}{l}\text { PER- } \\
\text { CENT } \\
\text { DAYS }\end{array}$ & CLASS & $\begin{array}{c}\text { CUBIC } \\
\text { FEET } \\
\text { PER } \\
\text { SECOND }\end{array}$ & TOTAL & $\begin{array}{c}\text { ACOU- } \\
\text { MU- } \\
\text { LATED } \\
\text { DAYS }\end{array}$ & $\begin{array}{l}\text { PER- } \\
\text { CENI } \\
\text { DAYS }\end{array}$ & CLASS & $\begin{array}{c}\text { CUBIC } \\
\text { FEET } \\
\text { PER } \\
\text { SEOOND }\end{array}$ & $\begin{array}{r}\text { TOTAL } \\
\text { DAYS }\end{array}$ & $\begin{array}{c}\text { ACCJ- } \\
\text { M- } \\
\text { LATED } \\
\text { DAYS }\end{array}$ & $\begin{array}{l}\text { PER- } \\
\text { CENT } \\
\text { DAYS }\end{array}$ & & $\begin{array}{c}\text { QUBIC } \\
\text { FEET } \\
\text { PER } \\
\text { SECOND }\end{array}$ & TOTAL, & $\begin{array}{c}\text { ACOU- } \\
\text { MU- } \\
\text { LATED } \\
\text { DAYS }\end{array}$ & $\begin{array}{l}\text { PER- } \\
\text { CENT } \\
\text { DAYS }\end{array}$ \\
\hline $\begin{array}{l}0 \\
1 \\
2 \\
3 \\
4 \\
5 \\
6 \\
7 \\
8\end{array}$ & $\begin{array}{r}0.00 \\
32.00 \\
38.00 \\
44.00 \\
52.00 \\
61.00 \\
71.00 \\
83.00 \\
98.00\end{array}$ & $\begin{array}{r}0 \\
17 \\
18 \\
127 \\
193 \\
340 \\
473 \\
420 \\
390\end{array}$ & $\begin{array}{l}5114 \\
5114 \\
5097 \\
5079 \\
4952 \\
4759 \\
4419 \\
3946 \\
3526\end{array}$ & $\begin{array}{r}100.0 \\
100.0 \\
99.7 \\
99.3 \\
96.8 \\
93.1 \\
86.4 \\
77.2 \\
68.9\end{array}$ & $\begin{array}{l}9 \\
10 \\
11 \\
12 \\
13 \\
14 \\
15 \\
16\end{array}$ & $\begin{array}{l}110.00 \\
130.00 \\
160.00 \\
180.00 \\
220.00 \\
250.00 \\
300.00 \\
350.00 \\
410.00\end{array}$ & $\begin{array}{r}398 \\
650 \\
484 \\
478 \\
143 \\
186 \\
119 \\
91 \\
80\end{array}$ & $\begin{array}{r}3136 \\
2738 \\
2088 \\
1604 \\
1126 \\
983 \\
797 \\
678 \\
587\end{array}$ & $\begin{array}{l}61.3 \\
53.5 \\
40.8 \\
31.4 \\
22.0 \\
19.2 \\
15.6 \\
13.3 \\
11.5\end{array}$ & $\begin{array}{l}18 \\
19 \\
20 \\
21 \\
22 \\
23 \\
24 \\
25 \\
26\end{array}$ & $\begin{array}{r}480.0 \\
560.0 \\
660.0 \\
780.0 \\
910.0 \\
1100.0 \\
1300.0 \\
1500.0\end{array}$ & $\begin{array}{l}75 \\
72 \\
66 \\
55 \\
61 \\
38 \\
40 \\
43 \\
34\end{array}$ & $\begin{array}{r}507 \\
432 \\
360 \\
294 \\
239 \\
178 \\
140 \\
100\end{array}$ & $\begin{array}{l}9.9 \\
8.4 \\
7.0 \\
5.7 \\
4.7 \\
3.5 \\
2.7 \\
2.0 \\
1.1\end{array}$ & $\begin{array}{l}27 \\
28 \\
29 \\
30 \\
31 \\
32 \\
33 \\
34\end{array}$ & $\begin{array}{l}2000.0 \\
2400.0 \\
2800.0 \\
3300.0 \\
3800.0 \\
4500.0 \\
5300.0 \\
6200.0\end{array}$ & $\begin{array}{l}9 \\
0 \\
4 \\
3 \\
3 \\
1 \\
2 \\
1\end{array}$ & $\begin{array}{r}23 \\
14 \\
14 \\
10 \\
7 \\
4 \\
3 \\
1\end{array}$ & $\begin{array}{l}0.4 \\
0.3 \\
0.3 \\
0.2 \\
0.1 \\
0.1 \\
0.1 \\
0.0\end{array}$ \\
\hline
\end{tabular}

MONIHLY MEAN DISCHARGES, IN OBBIC FEET PER SECOND, FOR EAOH WATER YEAR

$\begin{array}{rcccccccccccc}\text { YEAR } & \text { OCT } & \text { NOW } & \text { DEC } & \text { JAN } & \text { FEB } & \text { MAR } & \text { APR } & \text { MAY } & \text { JUNE } & \text { JULY } & \text { AUG } & \text { SEP } \\ 1968 & 100 & 139 & 164 & 173 & 251 & 273 & 406 & 344 & 115 & 110 & 187 & 73.3 \\ 1969 & 94.8 & 117 & 145 & 577 & 317 & 480 & 1218 & 1236 & 300 & 159 & 120 & 127 \\ 1970 & 138 & 191 & 201 & 188 & 170 & 190 & 109 & 138 & 85.7 & 104 & 154 & 99.1 \\ & & & & & & & & & & & & \\ 1971 & 85.7 & 181 & 177 & 177 & 180 & 163 & 123 & 230 & 91.7 & 83.9 & 176 & 69.7 \\ 1972 & 136 & 143 & 440 & 171 & 159 & 149 & 93.7 & 72.3 & 150 & 46.4 & 102 & 254 \\ 1973 & 204 & 170 & 161 & 174 & 228 & 376 & 814 & 1527 & 461 & 110 & 98.1 & 76.0 \\ 1974 & 91.5 & 150 & 157 & 185 & 167 & 168 & 112 & 93.3 & 58.6 & 75.5 & 76.6 & 131 \\ 1975 & 141 & 142 & 139 & 141 & 161 & 229 & 158 & 309 & 133 & 116 & 75.5 & 77.4 \\ 1976 & 71.6 & 83.0 & 108 & 93.5 & 125 & 111 & 167 & 182 & 62.7 & 91.0 & 71.9 & 64.1 \\ 1977 & 74.3 & 82.6 & 107 & 147 & 143 & 92.8 & 62.5 & 115 & 106 & 102 & 84.0 & 56.8 \\ 1978 & 66.3 & 95.6 & 115 & 209 & 397 & 1178 & 717 & 807 & 206 & 81.6 & 71.0 & 72.9 \\ 1979 & 88.5 & 218 & 207 & 193 & 224 & 918 & 893 & 1195 & 383 & 109 & 127 & 73.6 \\ 1980 & 99.2 & 148 & 153 & 355 & 1200 & 569 & 1018 & 1458 & 550 & 243 & 162 & 268 \\ 1981 & 167 & 179 & 186 & 169 & 190 & 252 & 383 & 219 & 110 & 133 & 118 & 113\end{array}$

ANNUAL PEAK DISCHARGE, IN CUBIC FEET PER SECOND, AND CORRESPONDING GAGE HEIGHT, IN FEET, FOR EACH WATER YEAR

\begin{tabular}{|c|c|c|c|c|c|c|c|c|c|c|c|}
\hline $\begin{array}{l}\text { WATERR } \\
\text { YEAR }\end{array}$ & DATE & $\begin{array}{c}\text { GAGE } \\
\text { HEIGHT }\end{array}$ & $\begin{array}{c}\text { PEAK } \\
\text { DISCHARGE }\end{array}$ & $\begin{array}{l}\text { WATER } \\
\text { YEAR }\end{array}$ & DATE & $\begin{array}{c}\text { GAGE } \\
\text { HEIGHT }\end{array}$ & $\begin{array}{c}\text { PEAR } \\
\text { DISCHARGE }\end{array}$ & $\begin{array}{l}\text { WATER } \\
\text { YEAR }\end{array}$ & DATE & $\begin{array}{c}\text { GAGE } \\
\text { HEIGHT }\end{array}$ & $\begin{array}{c}\text { PEAR } \\
\text { DISCHARGE }\end{array}$ \\
\hline $\begin{array}{l}1967 \\
1968 \\
1969 \\
1970 \\
1971\end{array}$ & $\begin{array}{l}\text { DEC. } 06,1966 \\
\text { AUG. } 07,1968 \\
\text { JAN. 25, } 1969 \\
\text { AUG. 18, } 1970 \\
\text { AUG. 21, } 1971\end{array}$ & $\begin{array}{r}17.34 \\
9.11 \\
14.29 \\
6.99 \\
9.00\end{array}$ & $\begin{array}{r}20100 \\
5410 \\
12800 \\
3380 \\
6250\end{array}$ & $\begin{array}{l}1972 \\
1973 \\
1974 \\
1975 \\
1976\end{array}$ & $\begin{array}{l}\text { SEPT.19, } 1972 \\
\text { MAY } 14,1973 \\
\text { APR. } 02,1974 \\
\text { JULY } 29,1975 \\
\text { JULY } 29,1976\end{array}$ & $\begin{array}{r}11.88 \\
6.36 \\
3.67 \\
8.95 \\
4.96\end{array}$ & $\begin{array}{r}10400 \\
3350 \\
1090 \\
7330 \\
2060\end{array}$ & $\begin{array}{l}1977 \\
1978 \\
1979 \\
1980 \\
1981\end{array}$ & $\begin{array}{l}\text { JULY } 23,1977 \\
\text { MAR. 05, } 1978 \\
\text { MAR. 28, } 1979 \\
\text { SEPT.10, } 1980 \\
\text { JULY } 15,1981\end{array}$ & $\begin{array}{r}7.22 \\
16.28 \\
9.69 \\
11.33 \\
6.82\end{array}$ & $\begin{array}{r}4830 \\
18700 \\
8440 \\
10910 \\
4340\end{array}$ \\
\hline
\end{tabular}

MAGNITUDE AND PRCBABIIITYY OF ANNUAL LOWEST MEAN DISCHARGE BASED ON OLIMATIC YEARS 1968-81

\begin{tabular}{|c|c|c|c|c|c|c|}
\hline \multirow{2}{*}{$\begin{array}{l}\text { PERIOD } \\
\text { (CON- } \\
\text { SECU- } \\
\text { TIVE } \\
\text { DAYS) }\end{array}$} & \multicolumn{6}{|c|}{$\begin{array}{l}\text { DISCHARGE, IN CUBIC FEET PER SECOND, FOR } \\
\text { INDICATED RECURRENCE INIERNAL, IN YEARS, AND } \\
\text { ANNUAL NONEXCEEDANCE PROBABILITY, IN PERCENT }\end{array}$} \\
\hline & $\begin{array}{c}2 \\
508\end{array}$ & $\begin{array}{c}5 \\
208\end{array}$ & $\begin{array}{l}10 \\
108\end{array}$ & $\begin{array}{l}20 \\
58\end{array}$ & $\begin{array}{l}50 \\
28\end{array}$ & $\begin{array}{r}100 \\
18\end{array}$ \\
\hline $\begin{array}{r}1 \\
7 \\
14 \\
30 \\
60 \\
90\end{array}$ & $\begin{array}{l}54 \\
60 \\
64 \\
67 \\
77 \\
88\end{array}$ & $\begin{array}{l}42 \\
47 \\
50 \\
53 \\
63 \\
72\end{array}$ & $\begin{array}{l}37 \\
41 \\
44 \\
47 \\
59 \\
66\end{array}$ & $\begin{array}{l}34 \\
37 \\
40 \\
44 \\
56 \\
62\end{array}$ & 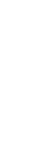 & $\overline{-}$ \\
\hline
\end{tabular}

MAGNITUDE AND PRCBABILITY OF ANNUAL HIGHEST MEAN DISCHARGE BASED ON WATER YEARS 1968-81

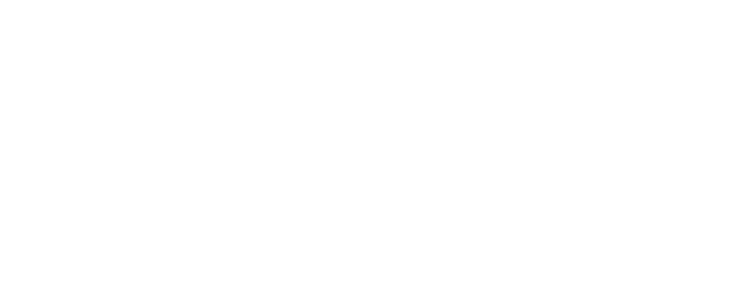

09408200 FORT PIERCE WASH NEAR ST. GEORGE, UT

LOCATION.-Lat $37^{\circ} 03^{\prime} 34^{\prime \prime}$, long $113^{\circ} 32^{\prime} 43^{\prime \prime}$, in SW/ sec.9, T.43 S., R.15 W., Washington County, Hydrologic Unit 15010009, about 3.5 mi southeast of St. George and about $5.5 \mathrm{mi}$ southwest of Washington.

DRAINAGE AREA. $-1,650 \mathrm{mi}^{2}$.

PERIOD OF RECORD AVAILABLE.--Water years 1959-69, annual peak discharge only.

MEAN BASTN ELEVATION. $-4,870 \mathrm{ft}$.

GAGE.-Crest-stage gage. Altitude of gage is 2,590 ft from topographic map.

REMARKS.-Diversions for irrigation above station. 
VIRGIN RIVER BASIN

09408200 FORT PIERCE WASH NEAR ST. GEORGE, UT--Continued

ANNUAL PEAK DISCHARGE, IN OBBIC FEET PER SECOND, AND CORRESPONDING GAGE HEIGHT, IN FEET, FOR EACH WATER YEAR

\begin{tabular}{|c|c|c|c|c|c|c|c|c|c|c|c|}
\hline $\begin{array}{l}\text { WATER } \\
\text { YEAR }\end{array}$ & DATE & $\begin{array}{c}\text { GAGE } \\
\text { HEIGHT }\end{array}$ & $\begin{array}{c}\text { PEAK } \\
\text { DISCHARGE }\end{array}$ & $\begin{array}{l}\text { WATER } \\
\text { YEAR }\end{array}$ & DATE & $\begin{array}{l}\text { GAGE } \\
\text { HEIGHT }\end{array}$ & $\begin{array}{c}\text { PEAK } \\
\text { DISCHARGE }\end{array}$ & $\begin{array}{l}\text { WATER } \\
\text { YEAR }\end{array}$ & DATE & $\begin{array}{l}\text { GAGE } \\
\text { HEIGHT }\end{array}$ & $\begin{array}{c}\text { PEAK } \\
\text { DISCHARGE }\end{array}$ \\
\hline $\begin{array}{l}1959 \\
1960 \\
1961 \\
1962\end{array}$ & $\begin{array}{l}\text { AUG. } 11,1959 \\
\text { NOV. } 03,1959 \\
\text { AUG. } 23,1961 \\
\text { AUG. } 08,1962\end{array}$ & $\begin{array}{ll}9 & 14.30 \\
9 & 12.35 \\
1 & 16.15 \\
2 & 13.00\end{array}$ & $\begin{array}{l}3180 \\
1900 \\
4980 \\
1300\end{array}$ & $\begin{array}{l}1963 \\
1964 \\
1965 \\
1966\end{array}$ & $\begin{array}{l}\text { SEPT.14, } 1963 \\
\text { AUG. } 14,1964 \\
\text { JULY } 19,1965 \\
\text { NOV. } 25,1965\end{array}$ & $\begin{array}{ll}16.50 \\
17.23 \\
13.46 \\
12.29\end{array}$ & $\begin{array}{r}5500 \\
8760 \\
1760 \\
900\end{array}$ & $\begin{array}{l}1967 \\
1968 \\
1969\end{array}$ & $\begin{array}{ll}\text { SEPT. } 25, & 1967 \\
\text { JULY } 30,1968 \\
\text { AUG. } 19,1969\end{array}$ & $\begin{array}{l}17.04 \\
14.60 \\
9 \\
17.05\end{array}$ & $\begin{array}{r}2990 \\
400 \\
1640\end{array}$ \\
\hline
\end{tabular}

09408400 SANTA CLARA RIVER NEAR PINE VALLEY, UT

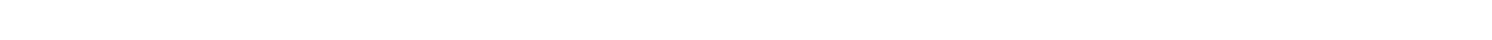
Dixie National Forest, on right bank $150 \mathrm{ft}$ upstream fram highway bridge, $0.6 \mathrm{mi}$ downstream fram Pine valley Reservoir, $1.6 \mathrm{mi}$ southeast of town of Pine Valley, and $2.5 \mathrm{mi}$ upstream fram Grass Valley Creek.

DRAINAGE AREA. $-18.7 \mathrm{mi}^{2}$.

MEAN BASIN ELEVATION.--8,720 ft.

PERIOD OF RECORD AVAIIABLE.--JUly 1959 to september 1981.

GAGE.-Water-stage recorder. Altitude of gage is 6,640 ft from topographic map.

REMARKS.--Flow slightly regulated by Pine Valley Reservoir. No diversions above station.

AVERAGE DISCHARGE. -22 years, $10.3 \mathrm{ft}^{3} / \mathrm{s}, 7,320$ acre- $\mathrm{ft} / \mathrm{Yr}$.

EXTREMES FOR PERTOD OF RECORD.--Maximum discharge, $776 \mathrm{ft}^{3} / \mathrm{s}$ Dec. 6,1966 , gage height, $6.85 \mathrm{ft} ; \mathrm{minimum}, 0.37 \mathrm{ft} / \mathrm{s}^{3}$ Mar. $30,1977$.

LOWEST MEAN DISCHARGE, IN CJBIC FEET PER SECOND, AND RANKING FOR THE INDICATED NUMBER OF CONSEOTIVE DAYS FOR EACH OLIMATIC YEAR, APRII 1-MARCH 31

\section{1}

0.601

1.407

1.408

$\begin{array}{ll}0.90 & 3 \\ 1.50 & 9\end{array}$

2.5017

1.9013

3.2020

3.2020
2.0014

2.0014
2.3015

$1.30 \quad 5$

1.7011
1.6010

1.6010

$\begin{array}{rr}2.60 & 18 \\ 1.30 \quad 6\end{array}$

1.9012

1.104

$0.77 \quad 2$

4.3021

3.0019

2.3016
3
1.60
1.40
1.40
0.90
1.60

2.5017

1.9013

3.2020

2.0014

$\begin{array}{ll}2.00 & 14 \\ 2.30 & 15\end{array}$

$1.40 \quad 8$

1.8011

1.609

$\begin{array}{rr}2.60 & 18 \\ 1.30 & 5\end{array}$

1.9012

1.194

0.782

4.402

3.0019

2.3016
14

$0.75 \quad 1$

1.405

1.40
1.10

1.10
1.60

0.99
1.609

2.6018

2.0012

3.2020

2.0013
2.4016

1.508

$\begin{array}{ll}1.90 & 11 \\ 1.70 & 10\end{array}$

2.6017
$1.30 \quad 5$

2.1014

1.194

$\begin{array}{ll}1.19 & 4 \\ 0.812 & 2\end{array}$

4.5021

3.1019

2.3015

2.1014
3.3020

2.4016
CONSEOUTIVE DAYS

$1.00 \quad 2$

60
1.40

90

120

$1.70 \quad 6$

$\begin{array}{ll}1.50 & 6 \\ 1.50 & 7\end{array}$

$\begin{array}{ll}1.50 & 7 \\ 1.10 & 3\end{array}$

1.606

$\begin{array}{ll}1.80 & 9 \\ 1.40 & 4\end{array}$

$\begin{array}{ll}1.40 & 4 \\ 1.60 & 7\end{array}$

1.707
1.909

1.40
1.70

2.6017

2.1014

1.60

3.1018

2.3012

2.7017

3.4020

$3.4020 \quad 3.5019$

$2.1012 \quad 2.2011$

2.2011
2.6016

3.8020

2.4010

3.6018

2.4011

2.8016

$\begin{array}{llll}1.60 & 9 & 1.60 \quad 8\end{array}$

2.1013

2.0010

2.4013

2.1010

2.9017

$1.60 \quad 4$

2.4012

2.4013
3.2017

$\begin{array}{rr}3.20 & 17 \\ 1.60 & 5\end{array}$

1.405

2.4014

2.5014

1.302

0.911

$\begin{array}{ll}5.10 & 21 \\ 3.80 & 19\end{array}$

0.83 I

1.30

0.891

3.6020

3.8019

2.6015

2.8015

2.009

1.706

1.908

1.50
1.704

4.4020

2.5010

3.8018

3.8018
2.6013

2.6013
2.9015

$1.70 \quad 5$

2.5011

2. 8014

3.4017

2.5012

1.402

$\begin{array}{ll}1.40 & 2 \\ 0.95 & 1\end{array}$

$\begin{array}{ll}0.95 & 1 \\ 5.10 & 21\end{array}$

$\begin{array}{ll}5.10 & 21 \\ 4.1019\end{array}$

2.5016

3.0016

183

4.1016

1.906

$2.10 \quad 8$

1.70
1.80

4.2017

3.8014

4.8019

3.2011

3.4012

1.805

3.1010

$\begin{array}{lll}4.40 & 18 \\ 4.10 & 15\end{array}$

.007

2.90

$\begin{array}{ll}1.70 & 3 \\ 1.10 & 1\end{array}$

$\begin{array}{ll}1.10 & 1 \\ 5.30 & 21\end{array}$

$\begin{array}{ll}5.30 & 21 \\ 5.0020\end{array}$

3.7013

ALL

6.3010

4.605

8.7011

2.901

$13.0 \quad 16$

9.4014

11.015

9.1013
$23.0 \quad 20$

3.503

5.407

5.408

$27.0 \quad 21$

8.9012

4.806

$\begin{array}{rr}3.30 & 2 \\ 20.0 & 17\end{array}$

$\begin{array}{ll}22.0 & 17 \\ 22.0 & 19\end{array}$

$20.0 \quad 18$

HIGHEST MEAN DISCHARGE, IN OUBIC FEET PER SECOND, AND RANKING FOR THE INDICATED NUMBER OF CONSEOUTIVE DAYS FOR EACH WATER YEAR, OCTCBER 1-SEPTEMBER 30

$\begin{array}{rrrrrrr} & 1 & & 3 & & 7 & \\ 1960 & 38.0 & 17 & 26.0 & 18 & 26.0 & 17 \\ 1961 & 116 & 6 & 68.0 & 8 & 38.0 & 12 \\ 1962 & 53.0 & 13 & 53.0 & 11 & 48.0 & \\ 1963 & 55.0 & 12 & 27.0 & 17 & 19.0 & 2 \\ 1964 & 48.0 & 14 & 47.0 & 12 & 46.0 & 10 \\ 1965 & 71.0 & 10 & 70.0 & 7 & 63.0 & \end{array}$

$\begin{array}{rr}15 & \\ 23.0 & 15 \\ 22.0 & 16 \\ 44.0 & 9 \\ 15.0 & 20 \\ 42.0 & 10 \\ 53.0 & 7\end{array}$

\section{CONSEQUTIVE DAYS}

30

90

120

183

ALL

$\begin{array}{llll}23.0 & 15 & 19.0 & 14\end{array}$

$16.0 \quad 12$

15.012

$11.0 \quad 12$

7.1012

$\begin{array}{llll}14.0 & 16 & 13.0 & 16\end{array}$

$\begin{array}{rrrr}42.0 & 8 & 32.0 & 8\end{array}$

$11.0 \quad 16$

8.9016

26.07

5.9021

$\begin{array}{rr}7.30 & 21 \\ 21.0 & 12\end{array}$

$\begin{array}{rr}16.0 & 13 \\ 34.0 & 6\end{array}$

$\begin{array}{rr}22.0 & 7 \\ 4.80 & 21\end{array}$

4.8021
$13.0 \quad 13$

6.7016

16.08

4.2021

$31.0 \quad 11$

$41.0 \quad 6$

28.06

$\begin{array}{rr}9.40 & 13 \\ 20.0 \quad 6\end{array}$

5.5014

8.909

3.1021

5.5015
11.0 
VIRGIN RIVER BASTN

09408400 SANTA CLARA RIVER NEAR PINE VALLEY, UT--Continued

HIGHEST MEAN DISCHARGE, IN OUBIC FEET FER SECOND, AND RANKING FOR THE INDICATED NUMBER OF CONSEOUTIVE DAYS FOR EACH WATER YEAR, OCTOBER 1-SEPTEMBER 30--Continued

\begin{tabular}{|c|c|c|c|c|c|c|c|c|c|c|c|c|c|c|c|c|c|c|c|c|}
\hline \multirow[t]{2}{*}{ YEAR } & \multicolumn{20}{|c|}{ CONSECTIVE DAYS } \\
\hline & 1 & & 3 & & 7 & & 15 & & 30 & & 60 & & 90 & & 120 & & 183 & & ALL & \\
\hline $\begin{array}{l}966 \\
967 \\
968 \\
969 \\
970\end{array}$ & $\begin{array}{r}37.0 \\
397 \\
43.0 \\
123 \\
21.0\end{array}$ & $\begin{array}{r}18 \\
1 \\
15 \\
4 \\
20\end{array}$ & $\begin{array}{c}37.0 \\
214 \\
40.0 \\
120 \\
21.0\end{array}$ & $\begin{array}{r}15 \\
1 \\
14 \\
4 \\
20\end{array}$ & $\begin{array}{c}34.0 \\
107 \\
35.0 \\
119 \\
20.0\end{array}$ & $\begin{array}{r}14 \\
4 \\
13 \\
33 \\
18\end{array}$ & $\begin{array}{r}29.0 \\
57.0 \\
35.0 \\
116 \\
18.0\end{array}$ & $\begin{array}{r}13 \\
6 \\
11 \\
3 \\
17\end{array}$ & $\begin{array}{r}25.0 \\
41.0 \\
31.0 \\
105 \\
14.0\end{array}$ & $\begin{array}{r}13 \\
9 \\
10 \\
2 \\
17\end{array}$ & $\begin{array}{c}22.0 \\
30.0 \\
27.0 \\
83.0 \\
9.70\end{array}$ & $\begin{array}{r}11 \\
9 \\
10 \\
2 \\
19\end{array}$ & $\begin{array}{c}19.0 \\
24.0 \\
22.0 \\
69.0 \\
7.80\end{array}$ & $\begin{array}{r}11 \\
9 \\
10 \\
2 \\
19\end{array}$ & $\begin{array}{c}16.0 \\
21.0 \\
19.0 \\
60.0 \\
6.70\end{array}$ & $\begin{array}{r}11 \\
8 \\
10 \\
2 \\
19\end{array}$ & $\begin{array}{c}12.0 \\
17.0 \\
15.0 \\
43.0 \\
5.30\end{array}$ & $\begin{array}{r}11 \\
7 \\
9 \\
2 \\
20\end{array}$ & $\begin{array}{c}7.80 \\
13.0 \\
9.40 \\
23.0 \\
4.20\end{array}$ & $\begin{array}{r}11 \\
6 \\
8 \\
2 \\
19\end{array}$ \\
\hline $\begin{array}{l}1971 \\
1972 \\
1973 \\
1974 \\
1975\end{array}$ & $\begin{array}{c}21.0 \\
88.0 \\
182 \\
16.0 \\
63.0\end{array}$ & $\begin{array}{r}21 \\
8 \\
2 \\
22 \\
11\end{array}$ & $\begin{array}{c}20.0 \\
47.0 \\
174 \\
16.0 \\
60.0\end{array}$ & $\begin{array}{r}21 \\
13 \\
2 \\
22 \\
9\end{array}$ & $\begin{array}{r}18.0 \\
27.0 \\
165 \\
15.0 \\
56.0\end{array}$ & $\begin{array}{r}21 \\
16 \\
1 \\
22 \\
8\end{array}$ & $\begin{array}{c}16.0 \\
15.0 \\
150 \\
14.0 \\
49.0\end{array}$ & $\begin{array}{r}18 \\
19 \\
1 \\
21 \\
8\end{array}$ & $\begin{array}{c}14.0 \\
9.20 \\
143 \\
12.0 \\
44.0\end{array}$ & $\begin{array}{r}18 \\
22 \\
1 \\
19 \\
7\end{array}$ & $\begin{array}{c}12.0 \\
7.50 \\
113 \\
9.90 \\
32.0\end{array}$ & $\begin{array}{r}17 \\
20 \\
1 \\
18 \\
7\end{array}$ & $\begin{array}{c}9.70 \\
7.30 \\
88.0 \\
8.30 \\
25.0\end{array}$ & $\begin{array}{r}17 \\
20 \\
1 \\
18 \\
8\end{array}$ & $\begin{array}{r}8.40 \\
6.60 \\
72.0 \\
7.10 \\
21.0\end{array}$ & $\begin{array}{r}17 \\
20 \\
1 \\
18 \\
9\end{array}$ & $\begin{array}{c}6.70 \\
6.20 \\
51.0 \\
5.70 \\
15.0\end{array}$ & $\begin{array}{c}17 \\
18 \\
1 \\
19 \\
10\end{array}$ & $\begin{array}{c}4.20 \\
4.40 \\
28.0 \\
4.40 \\
8.70\end{array}$ & $\begin{array}{r}20 \\
17 \\
1 \\
18 \\
10\end{array}$ \\
\hline $\begin{array}{l}1976 \\
1977 \\
1978 \\
1979 \\
1980\end{array}$ & $\begin{array}{l}38.0 \\
24.0 \\
108 \\
146 \\
117\end{array}$ & $\begin{array}{r}16 \\
19 \\
7 \\
3 \\
5\end{array}$ & $\begin{array}{l}36.0 \\
23.0 \\
102 \\
138 \\
109\end{array}$ & $\begin{array}{r}16 \\
19 \\
6 \\
3 \\
5\end{array}$ & $\begin{array}{r}32.0 \\
19.0 \\
91.0 \\
130 \\
89.0\end{array}$ & $\begin{array}{r}15 \\
19 \\
5 \\
2 \\
6\end{array}$ & $\begin{array}{r}27.0 \\
14.0 \\
88.0 \\
120 \\
76.0\end{array}$ & $\begin{array}{r}14 \\
22 \\
4 \\
2 \\
5\end{array}$ & $\begin{array}{c}23.0 \\
9.40 \\
86.0 \\
101 \\
72.0\end{array}$ & $\begin{array}{r}14 \\
21 \\
4 \\
3 \\
5\end{array}$ & $\begin{array}{c}16.0 \\
5.90 \\
70.0 \\
80.0 \\
65.0\end{array}$ & $\begin{array}{r}15 \\
22 \\
4 \\
3 \\
5\end{array}$ & $\begin{array}{c}13.0 \\
4.50 \\
57.0 \\
65.0 \\
57.0\end{array}$ & $\begin{array}{r}15 \\
22 \\
5 \\
3 \\
4\end{array}$ & $\begin{array}{c}10.0 \\
3.70 \\
49.0 \\
53.0 \\
49.0\end{array}$ & $\begin{array}{r}15 \\
22 \\
5 \\
3 \\
4\end{array}$ & $\begin{array}{c}8.30 \\
2.90 \\
36.0 \\
39.0 \\
35.0\end{array}$ & $\begin{array}{r}15 \\
22 \\
4 \\
3 \\
5\end{array}$ & $\begin{array}{c}5.50 \\
2.30 \\
19.0 \\
22.0 \\
20.0\end{array}$ & $\begin{array}{r}16 \\
22 \\
5 \\
3 \\
4\end{array}$ \\
\hline
\end{tabular}

DURATION OF DISOHARGE FOR EAOH WATER YEAR

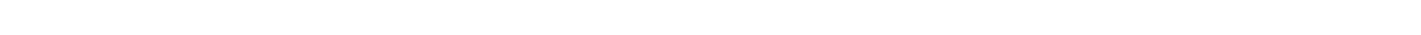

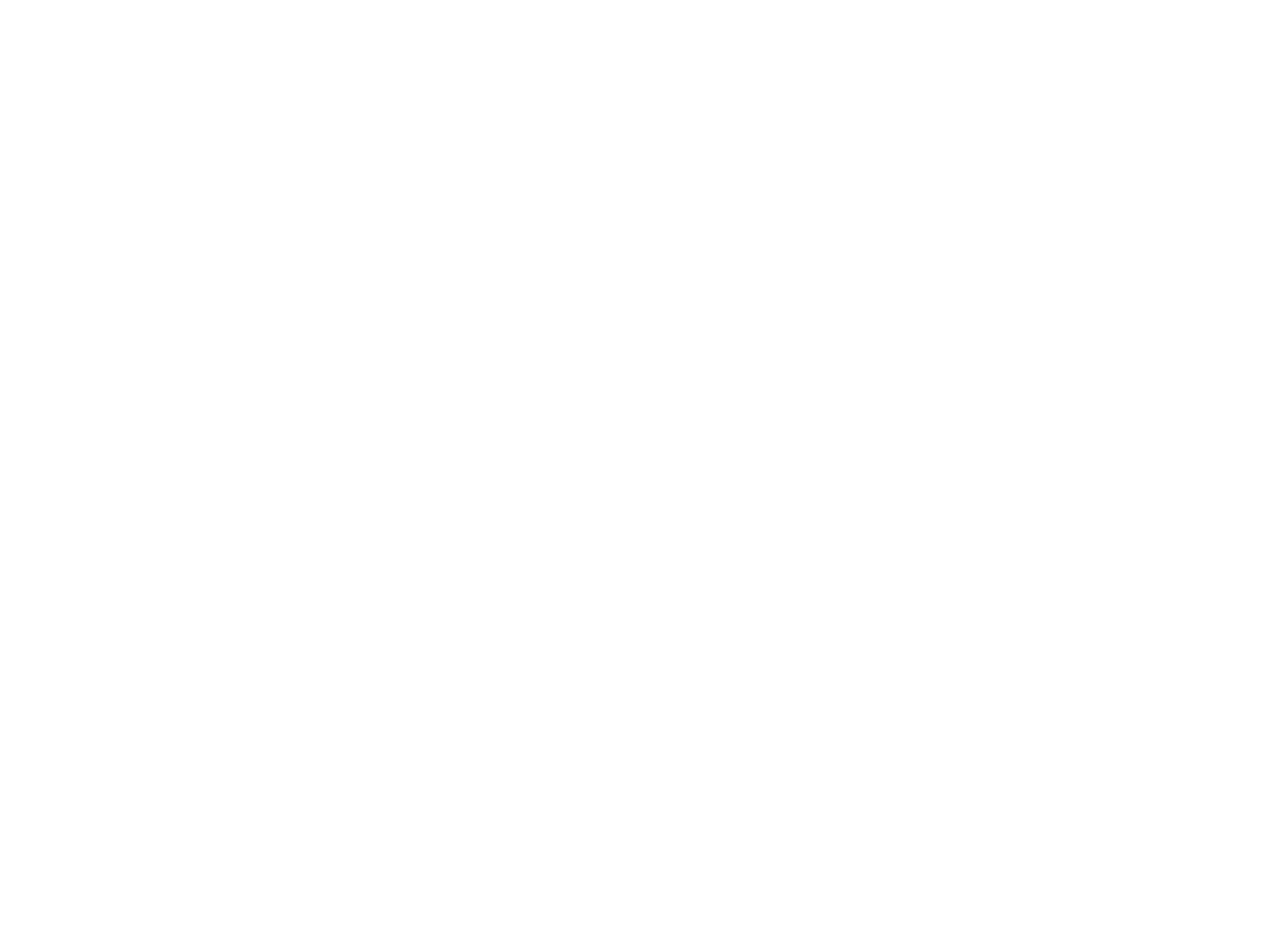


VIRGIN RIVER BASIN

09408400 SANTA CLARA RIVER NEAR PINE VALLEY, UT-Continued

MONTHLY MEAN DISCHARGES, IN OBIC FEET FER SECOND, FOR EAOH WATER YEAR

\begin{tabular}{|c|c|c|c|c|c|c|c|c|c|c|c|c|}
\hline YEAR & OCT & NOV & $\mathrm{DEC}$ & JAN & FEB & MAR & AFR & MAY & JUNE & JULY & AUG & SEP \\
\hline 1960 & 5.12 & 4.15 & 4.10 & 4.63 & 7.67 & 10.4 & 16.9 & 20.6 & 6.76 & 1.86 & 1.07 & 2.35 \\
\hline $\begin{array}{l}1961 \\
1962 \\
1963 \\
1964 \\
1965\end{array}$ & $\begin{array}{l}2.71 \\
1.88 \\
2.58 \\
1.92 \\
1.70\end{array}$ & $\begin{array}{c}13.3 \\
1.76 \\
2.20 \\
2.04 \\
1.61\end{array}$ & $\begin{array}{l}3.65 \\
1.87 \\
1.94 \\
1.67 \\
1.68\end{array}$ & $\begin{array}{l}2.12 \\
1.53 \\
1.91 \\
1.38 \\
1.77\end{array}$ & $\begin{array}{l}1.69 \\
3.85 \\
2.11 \\
1.35 \\
2.02\end{array}$ & $\begin{array}{l}3.07 \\
5.03 \\
2.13 \\
1.72 \\
2.14\end{array}$ & $\begin{array}{c}13.5 \\
34.7 \\
4.42 \\
7.52 \\
17.6\end{array}$ & $\begin{array}{c}13.1 \\
27.6 \\
9.83 \\
28.6 \\
38.2\end{array}$ & $\begin{array}{c}4.74 \\
15.5 \\
2.63 \\
11.0 \\
39.2\end{array}$ & $\begin{array}{c}2.54 \\
6.83 \\
1.21 \\
3.89 \\
14.1\end{array}$ & $\begin{array}{l}3.03 \\
3.60 \\
1.87 \\
2.85 \\
6.57\end{array}$ & $\begin{array}{l}2.23 \\
2.81 \\
4.71 \\
1.92 \\
4.43\end{array}$ \\
\hline $\begin{array}{l}1966 \\
1967 \\
1968 \\
1969 \\
1970\end{array}$ & $\begin{array}{l}3.42 \\
2.49 \\
5.62 \\
2.96 \\
4.49\end{array}$ & $\begin{array}{l}5.53 \\
2.15 \\
4.15 \\
2.65 \\
4.02\end{array}$ & $\begin{array}{c}5.46 \\
30.3 \\
3.77 \\
2.20 \\
3.30\end{array}$ & $\begin{array}{l}3.86 \\
4.47 \\
3.38 \\
4.38 \\
2.67\end{array}$ & $\begin{array}{l}2.72 \\
4.14 \\
4.55 \\
4.84 \\
2.44\end{array}$ & $\begin{array}{l}9.10 \\
5.25 \\
7.61 \\
7.97 \\
3.23\end{array}$ & $\begin{array}{c}19.8 \\
9.00 \\
13.9 \\
43.4 \\
4.17\end{array}$ & $\begin{array}{l}23.7 \\
33.3 \\
30.5 \\
98.7 \\
13.7\end{array}$ & $\begin{array}{c}9.51 \\
25.4 \\
21.6 \\
62.7 \\
5.11\end{array}$ & $\begin{array}{c}4.50 \\
11.2 \\
8.71 \\
29.5 \\
3.24\end{array}$ & $\begin{array}{c}3.12 \\
12.6 \\
5.46 \\
12.4 \\
2.26\end{array}$ & $\begin{array}{l}2.63 \\
9.24 \\
3.39 \\
6.47 \\
1.66\end{array}$ \\
\hline $\begin{array}{l}1971 \\
1972 \\
1973 \\
1974 \\
1975\end{array}$ & $\begin{array}{c}1.64 \\
2.43 \\
12.5 \\
5.42 \\
1.77\end{array}$ & $\begin{array}{l}1.75 \\
2.64 \\
5.70 \\
4.33 \\
2.30\end{array}$ & $\begin{array}{l}1.74 \\
8.14 \\
4.90 \\
3.70 \\
2.34\end{array}$ & $\begin{array}{l}1.95 \\
3.29 \\
4.65 \\
3.25 \\
2.25\end{array}$ & $\begin{array}{l}1.81 \\
2.10 \\
4.26 \\
2.66 \\
1.90\end{array}$ & $\begin{array}{l}2.88 \\
6.67 \\
5.50 \\
4.80 \\
4.60\end{array}$ & $\begin{array}{c}6.14 \\
6.65 \\
30.9 \\
9.40 \\
8.91\end{array}$ & $\begin{array}{c}13.8 \\
7.88 \\
122 \\
10.2 \\
32.1\end{array}$ & $\begin{array}{c}8.96 \\
5.13 \\
97.4 \\
3.40 \\
31.5\end{array}$ & $\begin{array}{c}3.85 \\
2.84 \\
30.3 \\
2.31 \\
8.51\end{array}$ & $\begin{array}{c}3.92 \\
2.04 \\
14.1 \\
1.70 \\
4.28\end{array}$ & $\begin{array}{l}2.44 \\
2.38 \\
7.88 \\
1.43 \\
3.12\end{array}$ \\
\hline $\begin{array}{l}1976 \\
1977 \\
1978 \\
1979 \\
1980\end{array}$ & $\begin{array}{l}2.75 \\
2.73 \\
0.84 \\
4.80 \\
4.75\end{array}$ & $\begin{array}{l}2.69 \\
2.07 \\
0.95 \\
5.39 \\
4.45\end{array}$ & $\begin{array}{l}2.63 \\
1.62 \\
1.02 \\
5.17 \\
3.51\end{array}$ & $\begin{array}{l}2.17 \\
1.28 \\
1.13 \\
5.08 \\
3.69\end{array}$ & $\begin{array}{l}4.41 \\
1.38 \\
3.51 \\
5.47 \\
7.50\end{array}$ & $\begin{array}{c}4.09 \\
1.20 \\
15.2 \\
9.54 \\
7.04\end{array}$ & $\begin{array}{l}9.81 \\
1.66 \\
30.7 \\
34.8 \\
30.9\end{array}$ & $\begin{array}{l}21.2 \\
6.05 \\
69.6 \\
90.5 \\
61.7\end{array}$ & $\begin{array}{l}6.00 \\
5.44 \\
67.4 \\
62.8 \\
66.3\end{array}$ & $\begin{array}{l}3.99 \\
1.64 \\
23.0 \\
21.1 \\
30.6\end{array}$ & $\begin{array}{l}2.71 \\
1.47 \\
11.0 \\
12.3 \\
14.5\end{array}$ & $\begin{array}{l}2.94 \\
1.02 \\
6.27 \\
6.37 \\
8.38\end{array}$ \\
\hline 1981 & 5.57 & 4.20 & 3.26 & 2.75 & 2.45 & 3.95 & 20.0 & 16.6 & 8.13 & 4.28 & 3.02 & 2.57 \\
\hline
\end{tabular}

ANNUAL PEAK DISCHARGE, IN OJBIC FEET FER SECOND, AND CORRESPONDING GAGE HEIGHT, IN FEET, FOR EACH WATER YEAR

\begin{tabular}{|c|c|c|c|c|c|c|c|c|c|c|c|c|}
\hline $\begin{array}{l}\text { WAIER } \\
\text { YEAR }\end{array}$ & DATE & $\begin{array}{c}\text { GAGE } \\
\text { HEIGHT }\end{array}$ & $\begin{array}{c}\text { PEAR } \\
\text { DISCHARGE }\end{array}$ & $\begin{array}{l}\text { WATEER } \\
\text { YEAR }\end{array}$ & & DATE & $\begin{array}{c}\text { GAGE } \\
\text { HEIGHT }\end{array}$ & $\begin{array}{c}\text { PEAK } \\
\text { DISCHARGE }\end{array}$ & $\begin{array}{l}\text { WATER } \\
\text { YEAR }\end{array}$ & DATE & $\begin{array}{c}\text { GAGE } \\
\text { HEIGHT }\end{array}$ & $\begin{array}{c}\text { PEAK } \\
\text { DISCHARGE }\end{array}$ \\
\hline $\begin{array}{l}1960 \\
1961 \\
1962 \\
1963 \\
1964 \\
1965 \\
1966 \\
1967\end{array}$ & 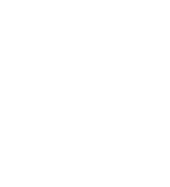 & $\begin{array}{l}2.45 \\
4.86 \\
2.64 \\
3.37 \\
2.64 \\
2.84 \\
2.40 \\
6.85\end{array}$ & $\begin{array}{r}45 \\
340 \\
63 \\
142 \\
63 \\
81 \\
40 \\
776\end{array}$ & $\begin{array}{l}1968 \\
1969 \\
1970 \\
1971 \\
1972 \\
1973 \\
1974\end{array}$ & $\begin{array}{l}\text { MAY } \\
\text { MAY } \\
\text { MAY } \\
\text { MAY } \\
\text { DEC. } \\
\text { JUNE } \\
\text { MAY }\end{array}$ & $\begin{array}{l}21,1968 \\
18,1969 \\
17,1970 \\
0,1971 \\
24,1971 \\
14,1973 \\
02,1974\end{array}$ & $\begin{array}{l}2.42 \\
3.25 \\
2.11 \\
2.15 \\
3.13 \\
3.75 \\
1.88\end{array}$ & $\begin{array}{r}49 \\
139 \\
27 \\
30 \\
115 \\
206 \\
19\end{array}$ & $\begin{array}{l}1975 \\
1976 \\
1977 \\
1978 \\
1979 \\
1980 \\
1981\end{array}$ & $\begin{array}{lll}\text { JUNE } & 02,1975 \\
\text { MAY } & 14,1976 \\
\text { MAY } & 30,1977 \\
\text { MAY } & 14,1978 \\
\text { MAY } & 28,1979 \\
\text { MAY } & 21,1980 \\
\text { APR. } & 19,1981\end{array}$ & $\begin{array}{l}2.68 \\
2.38 \\
2.06 \\
2.99 \\
3.41 \\
3.08 \\
2.68\end{array}$ & $\begin{array}{r}82 \\
48 \\
28 \\
132 \\
175 \\
139 \\
95\end{array}$ \\
\hline
\end{tabular}

\begin{tabular}{|c|c|c|c|c|c|c|}
\hline \multirow{3}{*}{$\begin{array}{l}\text { PERIOD } \\
\text { (CON- } \\
\text { SEA- } \\
\text { TTVE } \\
\text { DAYS) }\end{array}$} & \multicolumn{6}{|c|}{$\begin{array}{l}\text { AND PRCBABILITY OF ANNUAL LONEST MEAN DISCHARGE } \\
\text { BASED ON CIIMATIC YEARS } 1961-81\end{array}$} \\
\hline & \multicolumn{6}{|c|}{$\begin{array}{l}\text { DISCHARGE, IN CUBIC FEET FER SECOND, FOR } \\
\text { INDICATED RECURRENCE INTERNAL, IN YEARS, AND } \\
\text { ANNUAL NONEXCEEDANCE PRCBABILITY, IN PERCENT }\end{array}$} \\
\hline & $\begin{array}{c}2 \\
508\end{array}$ & $\begin{array}{c}5 \\
208\end{array}$ & $\begin{array}{l}10 \\
108\end{array}$ & $\begin{array}{l}20 \\
58\end{array}$ & $\begin{array}{l}50 \\
28\end{array}$ & $\begin{array}{r}100 \\
18\end{array}$ \\
\hline $\begin{array}{r}1 \\
7 \\
14 \\
30 \\
60 \\
90\end{array}$ & $\begin{array}{l}1.7 \\
1.8 \\
1.8 \\
1.9 \\
2.1 \\
2.2\end{array}$ & $\begin{array}{l}1.1 \\
1.2 \\
1.3 \\
1.3 \\
1.5 \\
1.6\end{array}$ & $\begin{array}{l}0.90 \\
0.96 \\
1.0 \\
1.1 \\
1.2 \\
1.3\end{array}$ & $\begin{array}{l}0.74 \\
0.79 \\
0.85 \\
0.94 \\
1.1 \\
1.1\end{array}$ & $\begin{array}{l}\overline{-} \\
\overline{-} \\
\overline{-}\end{array}$ & $\begin{array}{l}\bar{z} \\
\bar{z}\end{array}$ \\
\hline
\end{tabular}

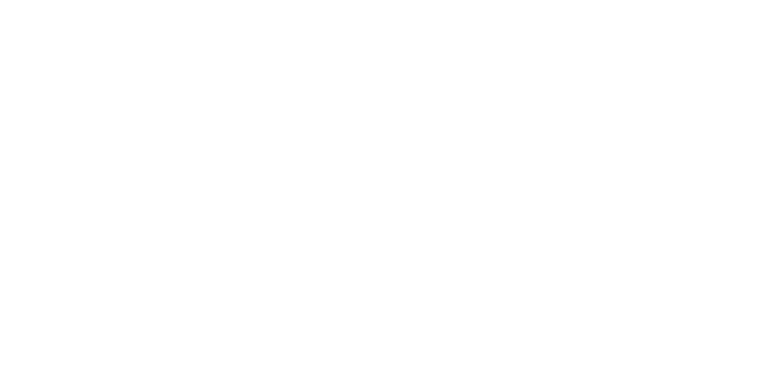


VIRGIN RIVER BASIN

09409000 SANTA CLARA RIVER NEAR CENIRAL, UT

LOCATION.-Lat $37^{\circ} 24^{\prime} 00^{\prime \prime}$, long $113^{\circ} 37^{\prime} 00^{n}$, in SE $\mathrm{J}_{4}$ sec.11, T.39 s., R.16 w., washington County, Hydrologic unit 15010008 , on right bank $120 \mathrm{ft}$ upstream from road bridge, I mi southeast of Central, and $1.5 \mathrm{mi}$ upstream fram Kane Spring Draw.

DRAINAGE AREA.--97 $\mathrm{mi}^{2}$, approximately.

PERTOD OF RECORD AVAHABLE.--April 1909 to September 1930 (monthly mean discharge prior to October 1909 published in wSP 1313 ), October 1938 to September 1961. Published as "Santa Clara Creek near Central ", 1911-30, 1939-44.

REVISED RECORDS.-WSP 1149: 1946(M). WSP 1313: 1941-42(M).

GAGE.-Water-stage recorder and rock-masonry control. Altitude of gage is 5,170 ft from topographic map. Prior to Jan. 5, 1939, staff gages at several sites within $100 \mathrm{ft}$ of present site at various datums. Jan. 5, 1939 to Apr. 9, 1949, water-stage recorder $40 \mathrm{ft}$ upstream at datum $1 \mathrm{ft}$ higher and Apr. 10, 1949 to July 9, 1951, $40 \mathrm{ft}$ upstream at same datum.

REMARKS.-Diversions for irrigation of about 1,300 acres above station. Same water is diverted from Grass Valley to Pinto Creek for irrigation in Escalante Valley in the Great Basin.

AVERAGE DISCHARGE.--44 years, $16.9 \mathrm{ft}^{3} / \mathrm{s}, 12,240$ acre- $\mathrm{ft} / \mathrm{yr}$.

EXIREMES FOR PERIOD OF RECORD.--Maximum discharge, $1,450 \mathrm{ft}^{3} / \mathrm{s}$ Oct. 6,1916 , gage height, $5.0 \mathrm{ft}$ from floodmarks, site and datum then in use, from rating curve extended above $200 \mathrm{ft}^{3} / \mathrm{s}$; minimum, $1.2 \mathrm{ft}^{3} / \mathrm{s}$ July 12,1954, July $9,1956$.

LOWEST MEAN DISCHARGE, IN OUBIC FEET PER SECOND, AND RANKING FOR THE INDICATED NUMBER OF CONSECUTIVE DAYS FOR EACH CIIMATIC YEAR, APRIL I-MARCH 31

YEAR

7.0033

8.0037

7.0034

5.0019

5.0020

$10.0 \quad 40$

13.042

6.0025

6.0026

4.0015

9.0038

6.0027

$12.0 \quad 41$

9.00
5.0021

4.0016

6.0028

5.0022

5.0023

3.001

2.007

$2.00 \quad 8$

8.0035

.0029

4.0017

6.6030

8.0036

3.0012

5.0024

.9031

3.1013

2.009

6.9032

$\begin{array}{rr}2.20 & 10 \\ 1.70 \quad 4\end{array}$

1.90

1.40

$\begin{array}{ll}1.50 & 2\end{array}$

2.00

$1.70 \quad 3$

$\begin{array}{ll}3 & \\ 7.00 & 31 \\ 8.00 & 35 \\ 7.00 & 32 \\ 5.00 & 20 \\ 5.50 & 24 \\ & \\ 10.0 & 39 \\ 13.0 & 42 \\ 6.00 & 25 \\ 6.00 & 26 \\ 4.30 & 16\end{array}$

7

14

7.0030

8.0033

.3031

5.0020
5.5022

$12.0 \quad 41$

$14.0 \quad 42$

6.0026

6.3027
4.9016

$10.0 \quad 40$

7.3033

12.0 11

9.0038

9.0038
5.0021

4.0015

6.0027

5.0022

5.0023

2.007

$2.00 \quad 8$

8.3037

6.0028

$\begin{array}{lll}4.70 & 17 \\ 6.60 & 29\end{array}$

8.2036

3.1012

5.0018

5.0019
8.0034

3.2013

$\begin{array}{rr}3.20 & 13 \\ 2.00 \quad 9\end{array}$

7.0030

$\begin{array}{rr}2.30 & 10 \\ 1.90 & 4\end{array}$

1.905

1.50

$\begin{array}{ll}1.50 & 2\end{array}$

$\begin{array}{rr}3.40 & 14 \\ 2.00 \quad 6\end{array}$

$1.70 \quad 3$

$11.0 \quad 39$

9.7038

$\begin{array}{rr}12.0 & 40 \\ 9.60 & 37\end{array}$

9.6037
5.6023

4.1015

6.3028

$\begin{array}{lll}5.6024 & 24\end{array}$

3.0011

2.006

2.007

9.1036

.00 25

5.0018
6.7029

8.4034

3.2012

5.0019

8.7035

3.4013

2.108

8032

$\begin{array}{rr}2.40 & 10 \\ 2.10 & 9\end{array}$

$1.90 \quad 4$

1.501

$\begin{array}{ll}1.50 & 2\end{array}$

2.005

$1.70 \quad 3$

\section{CONSECTITIVE DAYS}

7.7031

8.9034

7.6030

5.0015

5.5021

$12.0 \quad 40$

$16.0 \quad 42$

7.3029
6.5026

5.1016

$11.0 \quad 39$

$10.0 \quad 38$

13.041

9.8037

6.0023

4.5014

6.7027

5.8022

5.4020

3.0011

2.107

$\begin{array}{rr}2.00 & 5 \\ 9.60 & 36\end{array}$

9.6036
6.4025

5.1017

6.9028

8.5033

3.3012

5.1018

9.0035

$3.40 \quad 13$
$2.20 \quad 8$

8.3032

2.4010

2.209

1.904

1.602

$\begin{array}{lll}6.30 & 24\end{array}$

2.106
8.4030

9.8036

7.8029

6.6023

$\begin{array}{ll}5.50 & 17\end{array}$

$14.0 \quad 41$

$\begin{array}{cc}17.0 & 42 \\ 7.60 & 28\end{array}$

7.6028

$\begin{array}{ll}6.90 & 24 \\ 6.30 & 21\end{array}$

$12.0 \quad 39$

$11.0 \quad 38$

$13.0 \quad 40$

6.0020

4.8014

7.4027

6.6022

5.9019

$2.30 \quad 8$

$2.10 \quad 6$

$\begin{array}{r}9.70 \quad 35 \\ \hline\end{array}$

6.9025

5.3015

7.0026

8.6031

3.5012

5.6018

9.2033

3.6013

2.409

9.4034
2.6010

2.207

$2.00 \quad 4$

$\begin{array}{ll}1.60 & 1\end{array}$

1.602

8.80
2.105

$1.80 \quad 3$
9.7032

11.035

6.8021

6.1018

$15.0 \quad 41$

$18.0 \quad 42$

7.7027

7.3024
6.8022

$13.0 \quad 38$

$13.0 \quad 39$

$13.0 \quad 40$

$11.0 \quad 36$

6.1019

5.3014

7.7028

6.8023

6.3020

2.8010

$2.30 \quad 5$

$\begin{array}{rr}2.30 & 5 \\ 11.0 \quad 37\end{array}$

$\begin{array}{cc}11.0 & 37 \\ 7.40 & 25\end{array}$

$\begin{array}{ll}7.40 & 25 \\ 5.50 & 15\end{array}$

5.5015
7.4026

9.0030

3.7012

5.9016

9.7033

$\begin{array}{rr}3.80 & 13 \\ 2.60 \quad 8\end{array}$

$2.60 \quad 8$
$10.0 \quad 34$

$2.70 \quad 9$

2.306

2.407

2.40
$1.60 \quad 1$

1.602

$\begin{array}{rr}9.40 & 31 \\ 2.10 & 4\end{array}$

$1.80 \quad 3$
90

9.9031

$11.0 \quad 32$

1.033

7.8024

$17.0 \quad 41$

$\begin{array}{ll}17.0 & 41 \\ 19.0 & 42\end{array}$

8.2027

8.0025
7.0022

$13.0 \quad 37$

$13.0 \quad 38$

$13.0 \quad 39$

11.034

6.5018

6.0015

8.2028

6.9021

6.6019

3.30

$2.40 \quad 6$

$2.40 \quad 6$
$13.0 \quad 40$

$\begin{array}{cc}13.0 & 40 \\ 7.60 & 23\end{array}$

5.8014

8.0026

9.3029

3.9012
6.4017

6.1016

$11.0 \quad 35$

3.9013

$2.90 \quad 8$
$11.0 \quad 36$

$\begin{array}{ll}2.70 & 7 \\ 2.30 & 5\end{array}$

3.4010

1.601

2.003

9.5030
2.104

$1.80 \quad 2$

$11.0 \quad 31$

$11.0 \quad 32$

8.0024

$18.0 \quad 41$

$20.0 \quad 42$

8.5025

9.6029
7.6027 
VIRGIN RIVER BASIN

09409000 SANTA C.ARA RIVER NEAR CENIRAL, UI-Continued

HIGHEST MEAN DISCHARGE, IN OBBIC FEET PER SECOND, AND RANRING FOR THE INDICATED NUMBER OF OONSECUTIVE DAYS FOR EAOH WATER YEAR, OCTCBER I-SEPTEMBER 30

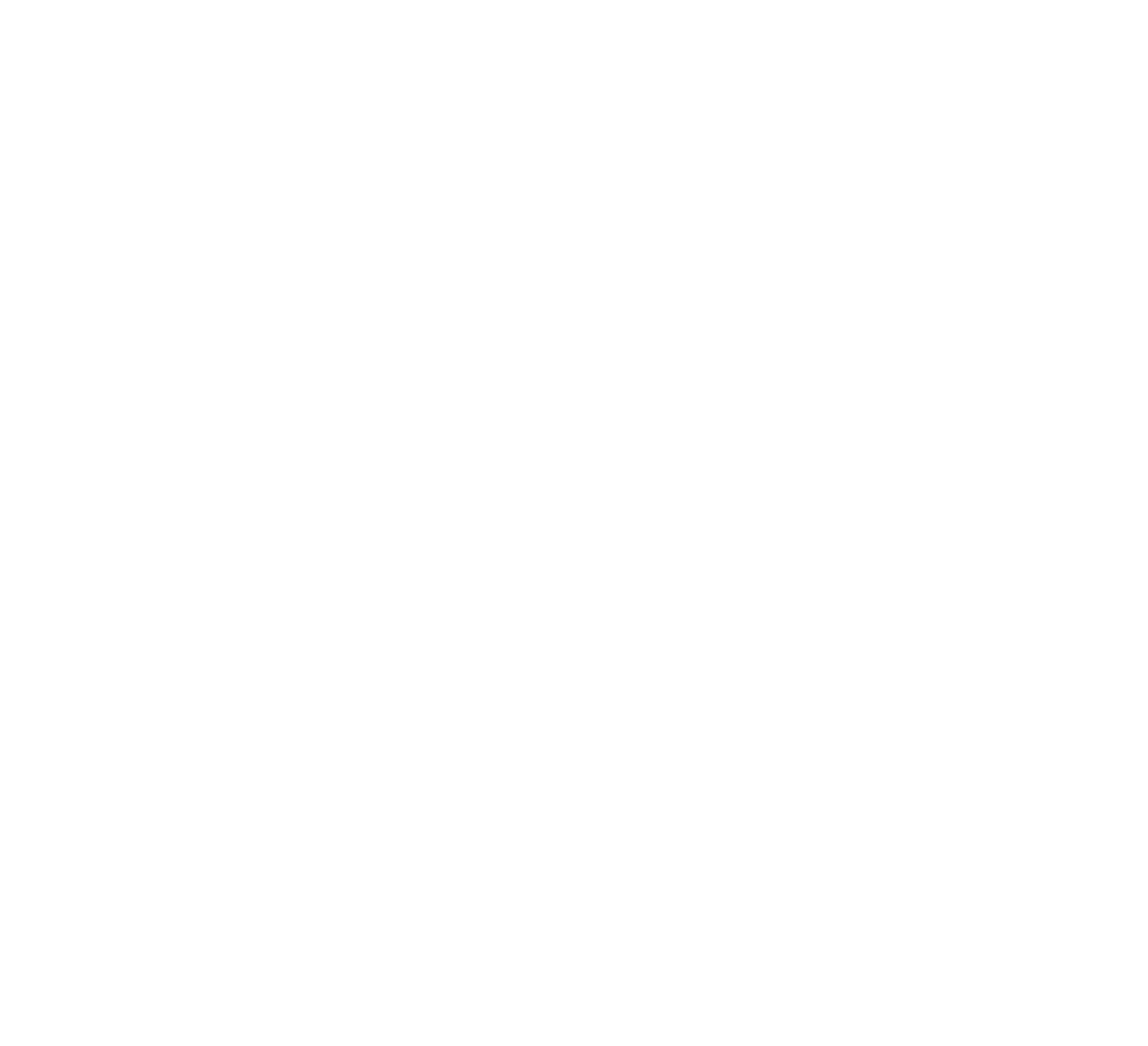

DURATION OF DISCHARGE FOR EACH WATER YEAR

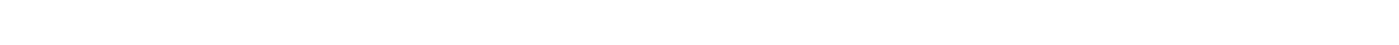
YEAR NUMBER OF DAYS IN CLASS

CUBIC FEET PER SEOO

1910
1911
1912
1913
1914
1915

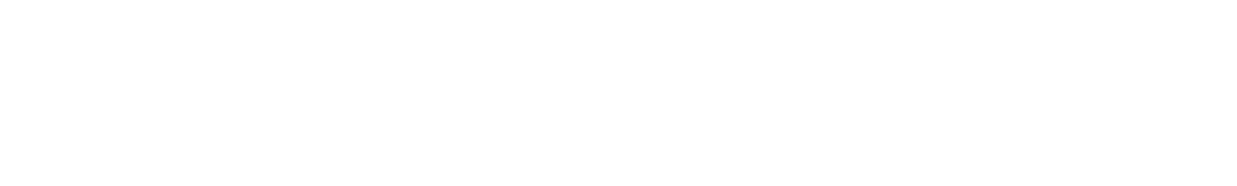


VIRGIN RIVER BASIN

09409000 SANTA CAARA RIVER NEAR CENIRAL, UT-Continued

DURATION OF DISGHARGE FOR EACH WATER YEAR--Continued

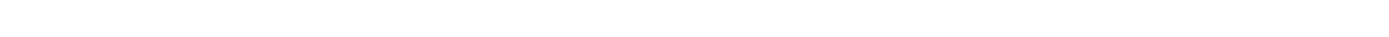
YEAR

OUBIC FEET PER SEOOND -DAYS

$\begin{array}{lllllllllllllll}6 & 24 & 39 & 91 & 29 & 35 & 53 & 25 & 19 & 11 & 8 & 3 & 6 & 3 & 2\end{array}$

1916
1917
1918
1919

1920

1921

1922

1923

1924
1925

1926

1927

1928
1929

1930

1939

1940

1941

1942

1943
1944

1945

1946

1947

1948
1949

1950

1951

1952

1953
1954

1954
1955

1956

1957
1958

1959

1960

1961 $\begin{array}{rrrrrrrrrrrrrrrrrrrr}8 & 15 & 75 & 15 & 12 & 19 & 54 & 87 & 47 & 41 & 29 & 13 & 15 & 11 & 8 & 7 & 7 & 3 & 1 & \\ 18 & 30 & 17 & 13 & 2 & 3 & 1 & & 1 & & 2 & & 1\end{array}$

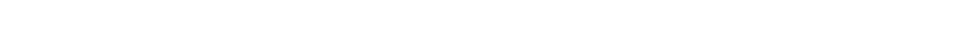
$\begin{array}{llllllllllll}1 & 2 & 62 & 101 & 40 & 89 & 29 & 11 & 12 & 17 & 1\end{array}$

$\begin{array}{lllllllllllllllllllllll}2 & 5 & 9 & 68 & 46 & 20 & 23 & 63 & 23 & 10 & 11 & 5 & 8 & 10 & 18 & 8 & 9 & 21 & 3 & 1 & 1 & & 1\end{array}$ $\begin{array}{lllllllllllllll}8 & 171 & 57 & 44 & 19 & 6 & 18 & 5 & 6 & 10 & 2 & 6 & 9 & 4\end{array}$

$\begin{array}{rrrrrrrrrrrrr}3 & 51 & 29 & 25 & 52 & 64 & 70 & 67 & 5 & & & & \\ 12 & 42159 & 25 & 21 & 33 & 29 & 30 & 6 & 4 & 1 & 2 & 1\end{array}$

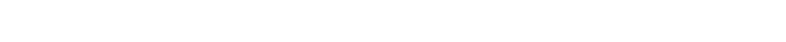

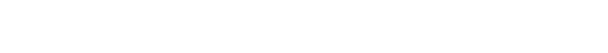

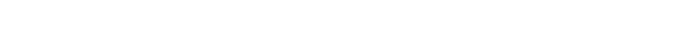
$\begin{array}{rrrrrrrrrrrrrrrr}22 & 34 & 32 & 9 & 34 & 63 & 85 & 9 & 24 & 22 & 16 & 11 & 4 & & \\ 50 & 45 & 9 & 58 & 70 & 22 & 15 & 16 & 16 & 23 & 15 & 17 & 8 & 1\end{array}$

$\begin{array}{lllllllllllllllllllllll}13 & 44 & 23 & 26 & 28 & 16 & 12 & 18 & 18 & 18 & 18 & 28 & 24 & 11 & 4 & 5 & 13 & 10 & 13 & 6 & 10 & 4 & 3\end{array}$

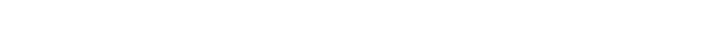

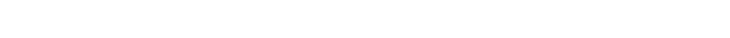

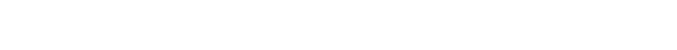

$\begin{array}{llllllllllll}12 & 87 & 11 & 6 & 10 & 76 & 54 & 83 & 12 & 9 & 4 & 1\end{array}$ $\begin{array}{rrrrrrrrrrrrrrrrrr}17 & 15 & 21 & 16 & 24 & 53 & 60 & 34 & 44 & 23 & 14 & 13 & 14 & 5 & 6 & 3 & 1 & \end{array}$

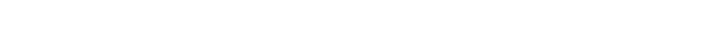

$\begin{array}{llllllllllll}8 & 40 & 16 & 14 & 18 & 16 & 42 & 90 & 81 & 27 & 7 & 3\end{array}$

1

12655.0

4108.0

9613.0

6891.0

15618.0

8996.0

4193.0

3495.0

4999.0

4696.0

3889.0

3192.0

3447.0

2930.0

2826.0

8575.0

6395.0

5002.0

6586.3

5901.4

3073.8

8554.1
4777.6

6771.5

3915.5

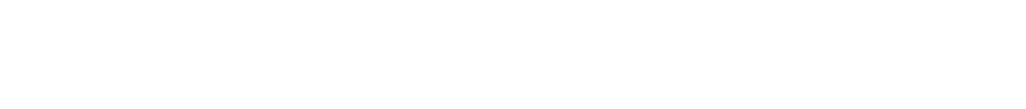

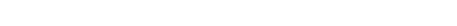

$\begin{array}{llllllllllllllllllllllll}13 & 37 & 8 & 18 & 26 & 53 & 21 & 2 & 23 & 17 & 16 & 18 & 6 & 10 & 11 & 7 & 9 & 10 & 16 & 16 & 13 & 8 & 6 & 1\end{array}$

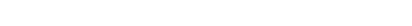

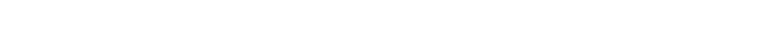

$\begin{array}{llllllllllll}78 & 51 & 13 & 16 & 30 & 20 & 60 & 69 & 25 & 2 & 1 & 1\end{array}$

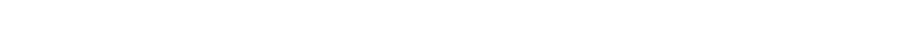

$\begin{array}{llllllllllllllllllllllll}14 & 1 & 1 & 2 & 7 & 29 & 28 & 34 & 59 & 39 & 24 & 8 & 14 & 13 & 8 & 10 & 13 & 12 & 9 & 5 & 11 & 10 & 13 & 1\end{array}$

$\begin{array}{rrrrrrrrrrrrrrrr}77 & 42 & 33 & 6 & 6 & 5 & 4 & 22 & 19 & 63 & 102 & 11 & 2 & & & \\ 42 & 45 & 27 & 13 & 12 & 4 & 8 & 14 & 19 & 10 & 11 & 3 & 2 & 1\end{array}$

$\begin{array}{llllllllllllllllll}74 & 43 & 28 & 8 & 8 & 34 & 57 & 21 & 25 & 9 & 18 & 14 & 6 & 7 & 6 & 5 & & \end{array}$

1697.1

9106.6

2889.8

2607.7

2220.7

1350.5

2060.1

9605.1

2650.5

2001.6

1960.7

DURATION TABLE OF DISCHARGE FOR WATER YEARS 1910-30, 1939-61
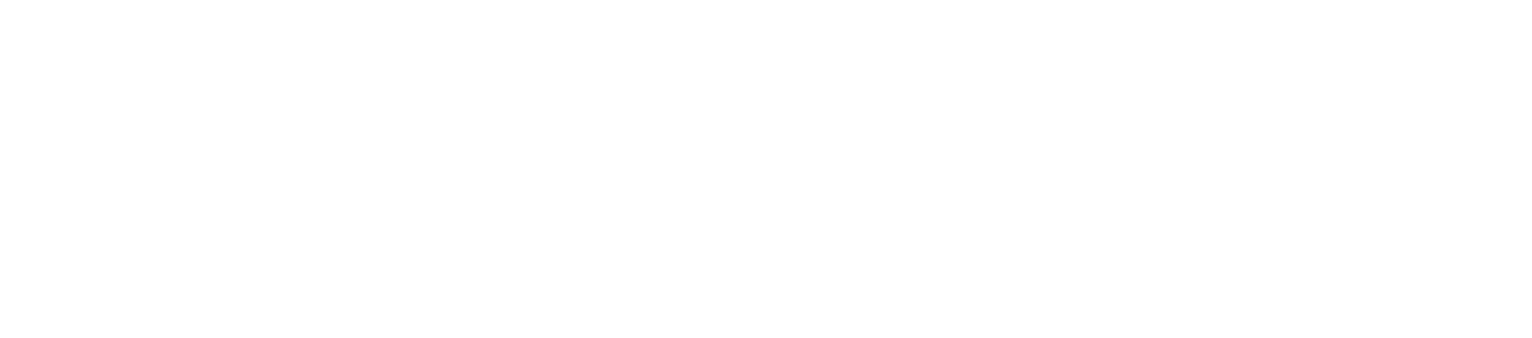

$\begin{array}{rrrrr}18 & 33.0 & 336 & 1659 & 10.3 \\ 19 & 40.0 & 300 & 1323 & 8.2 \\ 20 & 49.0 & 270 & 1023 & 6.4 \\ 21 & 59.0 & 209 & 753 & 4.7 \\ 22 & 71.0 & 153 & 544 & 3.4 \\ 23 & 85.0 & 131 & 391 & 2.4 \\ 24 & 100.0 & 88 & 260 & 1.6 \\ 25 & 120.0 & 87 & 172 & 1.1 \\ 26 & 150.0 & 50 & 85 & 0.5\end{array}$

$\begin{array}{rrr}27 & 180.0 & 15 \\ 28 & 220.0 & 7 \\ 29 & 260.0 & 3 \\ 30 & 310.0 & 2 \\ 31 & 380.0 & 5 \\ 32 & 460.0 & 1 \\ 33 & 550.0 & 0 \\ 34 & 660.0 & 2\end{array}$

MONIHLY MEAN DISCHARGES, IN OUBTC FEET PER SBCOND, FOR EACH WATER YEAR

\begin{tabular}{|c|c|c|c|c|c|c|c|c|c|c|c|c|}
\hline YEAR & $\infty r$ & NOV & DEC & JAN & FEBB & MAR & APR & MAY & JUNE & JULY & AUG & SEP \\
\hline 1910 & 33.3 & 28.3 & 43.0 & 41.6 & 25.6 & 65.3 & 83.4 & 74.1 & 22.9 & 13.4 & 14.3 & 13.9 \\
\hline $\begin{array}{l}1911 \\
1912 \\
1913 \\
1914 \\
1915\end{array}$ & $\begin{array}{c}10.2 \\
22.5 \\
50.3 \\
8.63 \\
10.7\end{array}$ & $\begin{array}{c}11.1 \\
12.0 \\
27.4 \\
10.6 \\
8.00\end{array}$ & $\begin{array}{c}9.00 \\
10.1 \\
16.4 \\
8.18 \\
6.03\end{array}$ & $\begin{array}{c}57.0 \\
11.8 \\
11.0 \\
14.5 \\
6.43\end{array}$ & $\begin{array}{c}46.2 \\
10.7 \\
8.50 \\
24.3 \\
11.4\end{array}$ & $\begin{array}{l}51.4 \\
16.9 \\
26.2 \\
23.4 \\
15.7\end{array}$ & $\begin{array}{l}55.9 \\
49.2 \\
27.5 \\
26.4 \\
42.6\end{array}$ & $\begin{array}{c}68.1 \\
130 \\
24.2 \\
85.4 \\
131\end{array}$ & $\begin{array}{l}54.4 \\
52.3 \\
13.3 \\
50.9 \\
52.3\end{array}$ & $\begin{array}{c}22.6 \\
15.3 \\
6.87 \\
20.1 \\
18.8\end{array}$ & $\begin{array}{c}12.0 \\
11.1 \\
7.94 \\
12.3 \\
17.0\end{array}$ & $\begin{array}{c}14.8 \\
8.07 \\
8.50 \\
8.33 \\
20.5\end{array}$ \\
\hline
\end{tabular}


VIRGIN RIVER BASIN

09409000 SANTA C.ARA RIVER NEAR CENTRAL, UT-Continued

MONIHLY MEAN DISCHARGES, IN OUBIC FEET PER SBCOND, FOR EACH WATER YEAR-Continued

\begin{tabular}{|c|c|c|c|c|c|c|c|c|c|c|c|c|}
\hline YEAR & $O C r$ & $\mathrm{NOV}$ & $\mathrm{DEC}$ & JAN & FEB & MAR & APR & MAY & JUNE & JULY & AUG & SEP \\
\hline $\begin{array}{l}1916 \\
1917 \\
1918 \\
1919 \\
1920\end{array}$ & $\begin{array}{c}20.4 \\
90.2 \\
12.6 \\
15.5 \\
8.39\end{array}$ & $\begin{array}{c}19.4 \\
24.6 \\
9.67 \\
11.7 \\
7.93\end{array}$ & $\begin{array}{c}14.1 \\
19.8 \\
9.35 \\
13.4 \\
7.90\end{array}$ & $\begin{array}{c}23.8 \\
17.7 \\
7.94 \\
8.29 \\
6.55\end{array}$ & $\begin{array}{c}23.0 \\
20.9 \\
7.86 \\
6.96 \\
16.5\end{array}$ & $\begin{array}{l}92.0 \\
32.8 \\
61.3 \\
12.7 \\
30.6\end{array}$ & $\begin{array}{l}50.4 \\
35.9 \\
21.4 \\
15.1 \\
46.7\end{array}$ & $\begin{array}{l}44.7 \\
60.9 \\
29.0 \\
17.6 \\
93.3\end{array}$ & $\begin{array}{c}40.5 \\
59.4 \\
15.2 \\
9.33 \\
40.3\end{array}$ & $\begin{array}{c}31.2 \\
21.7 \\
16.5 \\
7.16 \\
15.3\end{array}$ & $\begin{array}{c}30.3 \\
18.8 \\
12.6 \\
6.39 \\
20.8\end{array}$ & $\begin{array}{l}19.1 \\
11.7 \\
17.8 \\
10.6 \\
20.6\end{array}$ \\
\hline $\begin{array}{l}1921 \\
1922 \\
1923 \\
1924 \\
1925\end{array}$ & $\begin{array}{c}20.3 \\
14.1 \\
15.7 \\
17.3 \\
7.00\end{array}$ & $\begin{array}{c}20.1 \\
12.4 \\
13.9 \\
16.8 \\
9.73\end{array}$ & $\begin{array}{c}12.6 \\
33.4 \\
14.4 \\
12.4 \\
6.68\end{array}$ & $\begin{array}{c}13.2 \\
31.9 \\
12.7 \\
11.2 \\
7.00\end{array}$ & $\begin{array}{c}13.6 \\
24.0 \\
13.6 \\
11.6 \\
6.79\end{array}$ & $\begin{array}{c}20.0 \\
30.2 \\
16.2 \\
10.2 \\
9.35\end{array}$ & $\begin{array}{l}23.6 \\
41.4 \\
38.0 \\
12.9 \\
12.9\end{array}$ & $\begin{array}{c}34.5 \\
138 \\
90.5 \\
15.3 \\
17.3\end{array}$ & $\begin{array}{c}27.4 \\
108 \\
24.3 \\
8.20 \\
13.3\end{array}$ & $\begin{array}{c}14.8 \\
32.6 \\
19.0 \\
6.61 \\
9.16\end{array}$ & $\begin{array}{c}13.8 \\
25.5 \\
19.9 \\
6.00 \\
7.58\end{array}$ & $\begin{array}{c}12.3 \\
20.6 \\
16.3 \\
9.03 \\
8.07\end{array}$ \\
\hline $\begin{array}{l}1926 \\
1927 \\
1928 \\
1929 \\
1930\end{array}$ & $\begin{array}{c}12.8 \\
9.48 \\
6.90 \\
6.52 \\
3.06\end{array}$ & $\begin{array}{r}11.3 \\
10.0 \\
6.77 \\
7.50 \\
3.63\end{array}$ & $\begin{array}{l}8.48 \\
9.45 \\
7.23 \\
7.13 \\
3.90\end{array}$ & $\begin{array}{l}4.87 \\
9.00 \\
7.48 \\
6.77 \\
5.00\end{array}$ & $\begin{array}{c}6.25 \\
19.5 \\
9.28 \\
7.07 \\
6.00\end{array}$ & $\begin{array}{c}7.77 \\
15.0 \\
14.6 \\
9.26 \\
7.39\end{array}$ & $\begin{array}{l}42.2 \\
20.2 \\
14.1 \\
13.6 \\
20.0\end{array}$ & $\begin{array}{l}30.1 \\
23.1 \\
24.0 \\
19.5 \\
23.9\end{array}$ & $\begin{array}{c}14.4 \\
15.9 \\
14.0 \\
8.87 \\
161\end{array}$ & $\begin{array}{c}10.2 \\
9.52 \\
8.77 \\
5.65 \\
7.58\end{array}$ & $\begin{array}{l}7.84 \\
6.65 \\
7.55 \\
7.32 \\
9.55\end{array}$ & $\begin{array}{l}8.00 \\
7.27 \\
6.73 \\
5.67 \\
6.83\end{array}$ \\
\hline $\begin{array}{l}1939 \\
1940\end{array}$ & $\begin{array}{l}8.00 \\
6.26\end{array}$ & $\begin{array}{l}9.13 \\
5.43\end{array}$ & $\begin{array}{l}8.74 \\
5.06\end{array}$ & $\begin{array}{l}6.90 \\
5.94\end{array}$ & $\begin{array}{c}6.64 \\
10.5\end{array}$ & $\begin{array}{l}8.45 \\
11.2\end{array}$ & $\begin{array}{l}15.9 \\
15.4\end{array}$ & $\begin{array}{l}15.2 \\
18.5\end{array}$ & $\begin{array}{l}6.00 \\
7.13\end{array}$ & $\begin{array}{l}3.10 \\
2.61\end{array}$ & $\begin{array}{l}2.55 \\
2.16\end{array}$ & $\begin{array}{l}5.73 \\
2.63\end{array}$ \\
\hline $\begin{array}{l}1941 \\
1942 \\
1943 \\
1944 \\
1945\end{array}$ & $\begin{array}{c}2.74 \\
13.7 \\
8.74 \\
5.89 \\
7.92\end{array}$ & $\begin{array}{c}3.13 \\
15.5 \\
7.77 \\
6.28 \\
10.7\end{array}$ & $\begin{array}{c}5.00 \\
15.9 \\
8.58 \\
6.06 \\
9.65\end{array}$ & $\begin{array}{c}5.29 \\
13.0 \\
8.23 \\
5.58 \\
8.23\end{array}$ & $\begin{array}{c}6.07 \\
12.8 \\
10.8 \\
6.70 \\
11.5\end{array}$ & $\begin{array}{l}16.2 \\
15.6 \\
24.9 \\
12.9 \\
10.8\end{array}$ & $\begin{array}{l}25.8 \\
36.0 \\
34.5 \\
32.6 \\
26.3\end{array}$ & $\begin{array}{l}98.5 \\
34.8 \\
28.8 \\
62.1 \\
47.4\end{array}$ & $\begin{array}{l}63.1 \\
24.5 \\
13.1 \\
43.9 \\
23.6\end{array}$ & $\begin{array}{c}27.2 \\
11.7 \\
6.55 \\
16.9 \\
14.1\end{array}$ & $\begin{array}{r}17.5 \\
9.52 \\
7.00 \\
9.77 \\
14.9\end{array}$ & $\begin{array}{l}9.87 \\
7.03 \\
5.43 \\
7.09 \\
8.69\end{array}$ \\
\hline $\begin{array}{l}1946 \\
1947 \\
1948 \\
1949 \\
1950\end{array}$ & $\begin{array}{c}12.1 \\
33.8 \\
7.76 \\
6.29 \\
11.6\end{array}$ & $\begin{array}{c}11.9 \\
41.7 \\
8.38 \\
6.41 \\
13.2\end{array}$ & $\begin{array}{c}10.7 \\
23.2 \\
7.89 \\
6.25 \\
10.6\end{array}$ & $\begin{array}{c}9.16 \\
15.5 \\
6.90 \\
8.25 \\
11.6\end{array}$ & $\begin{array}{c}9.07 \\
16.0 \\
5.98 \\
8.62 \\
14.3\end{array}$ & $\begin{array}{c}9.57 \\
16.8 \\
7.10 \\
10.4 \\
12.7\end{array}$ & $\begin{array}{l}13.2 \\
23.6 \\
37.9 \\
38.9 \\
17.8\end{array}$ & $\begin{array}{c}8.88 \\
54.3 \\
33.5 \\
52.5 \\
14.1\end{array}$ & $\begin{array}{c}4.71 \\
25.9 \\
19.1 \\
43.6 \\
9.14\end{array}$ & $\begin{array}{c}3.55 \\
14.0 \\
8.84 \\
20.3 \\
6.14\end{array}$ & $\begin{array}{c}4.46 \\
9.66 \\
7.79 \\
11.6 \\
4.22\end{array}$ & $\begin{array}{l}3.79 \\
6.19 \\
5.59 \\
9.26 \\
3.71\end{array}$ \\
\hline $\begin{array}{l}1951 \\
1952 \\
1953 \\
1954 \\
1955\end{array}$ & $\begin{array}{c}4.08 \\
3.62 \\
10.1 \\
2.71 \\
2.29\end{array}$ & $\begin{array}{c}4.23 \\
2.59 \\
12.1 \\
5.22 \\
5.23\end{array}$ & $\begin{array}{c}3.69 \\
4.84 \\
13.1 \\
5.52 \\
5.76\end{array}$ & $\begin{array}{r}3.99 \\
4.94 \\
13.0 \\
6.23 \\
6.35\end{array}$ & $\begin{array}{r}4.55 \\
5.55 \\
11.1 \\
6.56 \\
6.54\end{array}$ & $\begin{array}{c}4.77 \\
11.1 \\
9.71 \\
7.14 \\
9.33\end{array}$ & $\begin{array}{c}4.26 \\
75.6 \\
7.95 \\
15.1 \\
6.92\end{array}$ & $\begin{array}{c}11.9 \\
90.2 \\
5.57 \\
23.6 \\
12.9\end{array}$ & $\begin{array}{c}5.33 \\
55.4 \\
4.13 \\
6.26 \\
5.50\end{array}$ & $\begin{array}{c}3.12 \\
21.5 \\
2.83 \\
2.68 \\
2.96\end{array}$ & $\begin{array}{r}3.30 \\
13.5 \\
2.95 \\
2.40 \\
6.99\end{array}$ & $\begin{array}{c}2.48 \\
10.1 \\
2.69 \\
2.29 \\
2.11\end{array}$ \\
\hline $\begin{array}{l}1956 \\
1957 \\
1958 \\
1959 \\
1960\end{array}$ & $\begin{array}{c}2.70 \\
1.61 \\
4.95 \\
11.6 \\
2.43\end{array}$ & $\begin{array}{c}5.46 \\
1.88 \\
11.7 \\
11.4 \\
2.65\end{array}$ & $\begin{array}{c}5.67 \\
1.97 \\
9.00 \\
11.2 \\
3.65\end{array}$ & $\begin{array}{l}6.29 \\
2.84 \\
5.83 \\
9.50 \\
3.71\end{array}$ & $\begin{array}{c}5.44 \\
4.18 \\
12.5 \\
9.91 \\
4.46\end{array}$ & $\begin{array}{c}4.85 \\
2.33 \\
25.6 \\
8.98 \\
8.49\end{array}$ & $\begin{array}{c}3.20 \\
3.47 \\
58.8 \\
9.24 \\
11.9\end{array}$ & $\begin{array}{c}4.11 \\
16.2 \\
107 \\
6.36 \\
15.9\end{array}$ & $\begin{array}{c}1.78 \\
25.4 \\
44.8 \\
2.62 \\
6.73\end{array}$ & $\begin{array}{c}1.61 \\
4.56 \\
14.5 \\
2.20 \\
1.95\end{array}$ & $\begin{array}{c}1.56 \\
1.91 \\
10.3 \\
2.10 \\
1.78\end{array}$ & $\begin{array}{l}1.63 \\
1.57 \\
9.67 \\
2.14 \\
1.85\end{array}$ \\
\hline 1961 & 2.05 & 11.0 & 5.45 & 4.54 & 4.14 & 5.01 & 13.9 & 10.9 & 2.66 & 1.75 & 1.63 & 1.57 \\
\hline
\end{tabular}

ANNUAL PEAK DISCHARGE, IN GBIC FEET PER SECOND, AND CORRESPONDING GAGE HEIGHT, IN FEET, FOR EACH WATER YEAR

\begin{tabular}{|c|c|c|c|c|c|c|c|c|c|c|c|}
\hline $\begin{array}{l}\text { WATER } \\
\text { YEAR }\end{array}$ & DATE & $\begin{array}{c}\text { GAGE } \\
\text { HEIGHT }\end{array}$ & $\begin{array}{c}\text { PEAK } \\
\text { DISCHARGE }\end{array}$ & $\begin{array}{l}\text { WATER } \\
\text { YEAR }\end{array}$ & DATE & $\begin{array}{c}\text { GAGE } \\
\text { HEIGHT }\end{array}$ & $\begin{array}{c}\text { PEAK } \\
\text { DISCHARGE }\end{array}$ & $\begin{array}{l}\text { WATER } \\
\text { YEAR }\end{array}$ & DATE & $\begin{array}{c}\text { GAGE } \\
\text { HEIGHT }\end{array}$ & $\begin{array}{c}\text { PEAK } \\
\text { DISCHARGE }\end{array}$ \\
\hline $\begin{array}{l}1909 \\
1910 \\
1911 \\
1912 \\
1913 \\
1914 \\
1915 \\
1916 \\
1917 \\
1918 \\
1919 \\
1920 \\
1921 \\
1922 \\
1923\end{array}$ & $\begin{array}{l}\text { SEPT.01, } 1909 \\
\text { JAN. } 01,1910 \\
\text { JAN. } 31,1911 \\
\text { MAY } 20,1912 \\
\text { OCT. 27, } 1912 \\
\text { FEB. } 21,1914 \\
\text { APR. 29, } 1915 \\
\text { MAR. 21, } 1916 \\
\text { OCT. } 06,1916 \\
\text { MAR. 12, } 1918 \\
\text { MAR. 25, } 1919 \\
\text { MAR. 21, } 1920 \\
\text { MAY } 30,1921 \\
\text { DEC. } 21,1921 \\
\text { MAY } 19,1923\end{array}$ & $\begin{array}{l}7.00 \\
7.50 \\
6.20 \\
4.60 \\
5.80 \\
5.00 \\
4.60 \\
2.90 \\
5.00 \\
3.04 \\
2.20 \\
2.88 \\
1.58 \\
4.50 \\
2.12\end{array}$ & $\begin{array}{r}475 \\
1400 \\
930 \\
210 \\
742 \\
440 \\
310 \\
407 \\
1450 \\
832 \\
152 \\
307 \\
52 \\
900 \\
138\end{array}$ & $\begin{array}{l}1924 \\
1925 \\
1926 \\
1927 \\
1928 \\
1929 \\
1930 \\
1939 \\
1940 \\
1941 \\
1942 \\
1943 \\
1944 \\
1945 \\
1946\end{array}$ & $\begin{array}{l}\text { MAY } 04,1924 \\
\text { SEPT.18, } 1925 \\
\text { APR. } 19,1926 \\
\text { FEB. 26, } 1927 \\
\text { FEB. 04, } 1928 \\
\text { SEPT.03, } 1929 \\
\text { AUG. 09, } 1930 \\
\text { SEPT.26, } 1939 \\
\text { FEB. 26, } 1940 \\
\text { JULY 25, } 1941 \\
\text { AUG. 09, } 1942 \\
\text { MAR. 09, } 1943 \\
\text { APR. 07, } 1944 \\
\text { AUG. 10, } 1945 \\
\text { OCT. 09, } 1945\end{array}$ & $\begin{array}{l}1.32 \\
2.20 \\
2.00 \\
1.78 \\
1.70 \\
1.90 \\
1.90 \\
1.39 \\
2.50 \\
2.54 \\
2.50 \\
2.20 \\
2.10 \\
5.65 \\
1.30\end{array}$ & $\begin{array}{r}22 \\
157 \\
105 \\
65 \\
54 \\
52 \\
85 \\
51 \\
202 \\
204 \\
214 \\
161 \\
140 \\
753 \\
56\end{array}$ & $\begin{array}{l}1947 \\
1948 \\
1949 \\
1950 \\
1951 \\
1952 \\
1953 \\
1954 \\
1955 \\
1956 \\
1957 \\
1958 \\
1959 \\
1960 \\
1961\end{array}$ & $\begin{array}{l}\text { OCT. } 29,1946 \\
\text { JULY } 22,1948 \\
\text { APR. } 14,1949 \\
\text { APR. } 23,1950 \\
\text { APR. } 29,1951 \\
\text { APR. } 27,1952 \\
\text { AUG. } 01,1953 \\
\text { JAN. } 25,1954 \\
\text { AUG. } 25,1955 \\
\text { JAN. } 27,1956 \\
\text { JUNE } 10,1957 \\
\text { MAY } 11,1958 \\
\text { OCT. } 25,1958 \\
\text { MAY } 12,1960 \\
\text { NOV. } 06,1960\end{array}$ & $\begin{array}{l}3.90 \\
1.30 \\
2.75 \\
1.68 \\
1.47 \\
3.13 \\
2.32 \\
2.06 \\
2.27 \\
1.40 \\
2.25 \\
2.91 \\
1.51 \\
1.75 \\
3.25\end{array}$ & $\begin{array}{r}426 \\
99 \\
132 \\
35 \\
22 \\
261 \\
105 \\
69 \\
97 \\
12 \\
92 \\
232 \\
19 \\
38 \\
292\end{array}$ \\
\hline
\end{tabular}


VIRGIN RIVER BASIN

09409000 SANTA CAARA RIVER NEAR CENIRAL, UT--Continued

MAGNITUDE AND PRCBABIIITTY OF ANNUAL LOWEST MEAN DISCHARGE BASED ON CLIMATIC YEARS 1911-30 AND 1940-61

\begin{tabular}{|c|c|c|c|c|c|c|}
\hline \multirow{2}{*}{$\begin{array}{l}\text { PERIOD } \\
\text { (CON- } \\
\text { SEOU- } \\
\text { TIVE } \\
\text { DAYS) }\end{array}$} & \multicolumn{6}{|c|}{$\begin{array}{l}\text { DISCHARGE, IN CUBIC FEET PER SECOND, FOR } \\
\text { INDICATED RECURRENCE INMERNAL, IN YEARS, AND } \\
\text { ANNUAL NONEXCEEDANCE PROBABILITY, IN PERCENI }\end{array}$} \\
\hline & $\begin{array}{c}2 \\
508\end{array}$ & $\begin{array}{c}5 \\
208\end{array}$ & $\begin{array}{l}10 \\
108\end{array}$ & $\begin{array}{l}20 \\
58\end{array}$ & $\begin{array}{l}50 \\
28\end{array}$ & $\begin{array}{r}100 \\
18\end{array}$ \\
\hline $\begin{array}{r}1 \\
7 \\
14 \\
30 \\
60 \\
90\end{array}$ & $\begin{array}{l}4.6 \\
5.0 \\
5.3 \\
5.7 \\
6.1 \\
6.5\end{array}$ & $\begin{array}{l}2.7 \\
2.9 \\
3.0 \\
3.2 \\
3.4 \\
3.6\end{array}$ & $\begin{array}{l}2.0 \\
2.1 \\
2.2 \\
2.3 \\
2.4 \\
2.6\end{array}$ & $\begin{array}{l}1.5 \\
1.6 \\
1.7 \\
1.7 \\
1.8 \\
1.9\end{array}$ & $\begin{array}{l}1.1 \\
1.2 \\
1.2 \\
1.2 \\
1.3 \\
1.4\end{array}$ & $\begin{array}{l}0.93 \\
0.94 \\
0.95 \\
0.96 \\
0.99 \\
1.1\end{array}$ \\
\hline
\end{tabular}

MAGNITUDE AND PRCBABILITY OF ANNUAL HIGHEST MEAN DISCHARGE BASED ON WATER YEARS 1910-30 AND 1939-61

\begin{tabular}{|c|c|c|c|c|c|c|}
\hline \multirow{2}{*}{$\begin{array}{l}\text { PERIOD } \\
\text { (CON- } \\
\text { SECI- } \\
\text { TIVE } \\
\text { DAYS) }\end{array}$} & \multicolumn{6}{|c|}{$\begin{array}{l}\text { DISCHARGE, IN OUIC FEET PER SECOND, FOR } \\
\text { INDICATED RECURRENCE INTERNAL, IN YEARS, AND } \\
\text { ANNUAL EXCEEDANCE PRCBABILITY, IN PERCENT }\end{array}$} \\
\hline & $\begin{array}{c}2 \\
508\end{array}$ & $\begin{array}{c}5 \\
208\end{array}$ & $\begin{array}{l}10 \\
108\end{array}$ & $\begin{array}{l}25 \\
48\end{array}$ & $\begin{array}{l}50 \\
28\end{array}$ & $\begin{array}{r}100 \\
18\end{array}$ \\
\hline $\begin{array}{r}1 \\
3 \\
7 \\
15\end{array}$ & $\begin{array}{l}90 \\
68 \\
55 \\
46\end{array}$ & $\begin{array}{r}236 \\
153 \\
118 \\
95\end{array}$ & $\begin{array}{l}397 \\
234 \\
175 \\
139\end{array}$ & $\begin{array}{l}704 \\
366 \\
264 \\
207\end{array}$ & $\begin{array}{r}1030 \\
489 \\
345 \\
267\end{array}$ & $\begin{array}{r}1450 \\
634 \\
437 \\
336\end{array}$ \\
\hline
\end{tabular}

09409500 MOODY WASH NEAR VEYO, UT

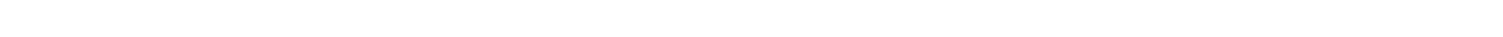
left bank $200 \mathrm{ft}$ downstream from Bellas Canyon and $7 \mathrm{mi}$ northwest of Veyo.

DRAINAGE AREA. $-33 \mathrm{mi}^{2}$, approximately.

MEAN BASIN ELEVATION. $-6,070 \mathrm{ft}$.

PERIOD OF RECORD AVAIIABLE.--December 1954 to January 1969.

GAGE.--Water-stage recorder and masonry control. Altitude of gage is 4,800 ft from topographic map.

REMARKS.--Some diversions for irrigation above station.

AVERAGE DISCHARGE. -13 years (water years 1956-68), $2.83 \mathrm{ft} 3 / \mathrm{s}, 2,050$ acre-ft/yr.

EXXREMES FOR PERIOD OF RECORD,--Maximum discharge, 1,810 $\mathrm{ft}^{3} / \mathrm{s}$ Dec. 6, 1966, gage height, $9.75 \mathrm{ft}$, fram rating curve extended above $70 \mathrm{ft}^{3} / \mathrm{s}$ on basis of slope-area measurements at gage heights $3.76 \mathrm{ft}, 8.60 \mathrm{ft}$, and $9.75 \mathrm{ft}$; no flow for many days in each year.

LONEST MEAN DISCHARGE, IN CUBIC FEET PER SECOND, AND RANKING FOR THE INDICATED NUMBER OF CONSEOUTIVE DAYS

YEAR

\begin{tabular}{lcccccccc} 
YEAR & \multicolumn{1}{c}{3} & 3 & & 7 & & 14 \\
& 1 & & & & & & & \\
1956 & 0.00 & 1 & 0.00 & 1 & 0.00 & 1 & 0.00 & 1 \\
1957 & 0.00 & 2 & 0.00 & 2 & 0.00 & 2 & 0.00 & 2 \\
1958 & 0.00 & 3 & 0.00 & 3 & 0.00 & 3 & 0.00 & 3 \\
1959 & 0.00 & 4 & 0.00 & 4 & 0.00 & 4 & 0.00 & 4 \\
1960 & 0.00 & 5 & 0.00 & 5 & 0.00 & 5 & 0.00 & 5 \\
1961 & 0.00 & 6 & 0.00 & 6 & 0.00 & 6 & 0.00 & 6 \\
1962 & 0.00 & 7 & 0.00 & 7 & 0.00 & 7 & 0.00 & 7 \\
1963 & 0.00 & 8 & 0.00 & 8 & 0.00 & 8 & 0.00 & 8 \\
1964 & 0.00 & 9 & 0.00 & 9 & 0.00 & 9 & 0.00 & 9 \\
1965 & 0.00 & 10 & 0.00 & 10 & 0.00 & 10 & 0.00 & 10 \\
1966 & 0.00 & 11 & 0.00 & 11 & 0.00 & 11 & 0.00 & 11 \\
1967 & 0.00 & 12 & 0.0012 & 0.00 & 12 & 0.00 & 12 \\
1968 & 0.01 & 13 & 0.02 & 13 & 0.02 & 13 & 0.02 & 13
\end{tabular}

CONSEOTIVE DAYS

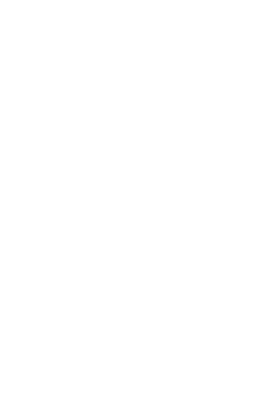

90

120

183

0.2612

0.001

$0.04 \quad 8$

0.0810

0.4112
0.02

$\begin{array}{ll}0.02 & 4 \\ 0.06 & 6\end{array}$

$\begin{array}{ll}0.09 & 9 \\ 0.07 & 7\end{array}$

$\begin{array}{rr}0.98 & 13 \\ 0.05 & 2\end{array}$

0.279

$\begin{array}{ll}0.26 & 7 \\ 0.16 & 5\end{array}$

0.1111

0.025

0.1610
$0.08 \quad 8$

$\begin{array}{ll}0.26 \quad 8 \\ 0.96 & 12\end{array}$

0.9612

0.2910

$\begin{array}{ll}0.08 & 4 \\ 0.07 & 3\end{array}$

0.055

$\begin{array}{ll}0.04 & 7 \\ 0.00 & 2\end{array}$

0.00

0.206

0.041

0.6911

0.00330 .00

$\begin{array}{lllll}0.00 & 4 & & 0.00 & 3 \\ 0.57 & 13 & & 0.55 & 13\end{array}$

HIGHEST MEAN DISCHARGE, IN OBBIC FEET PER SECOND, AND RANKING FOR THE INDICATED NUMBER OF CONSEOUTIVE DAYS FOR EACH WATER YEAR, OCTOBER I-SEPTEMBER 30

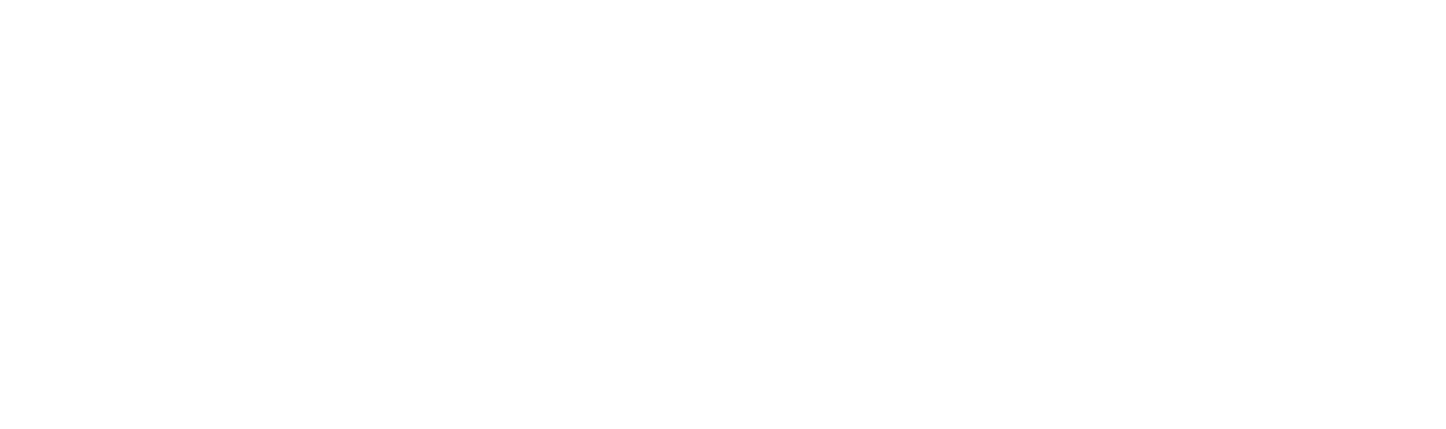


VIRGIN RIVER BASIN

09409500 MOODY WASH NEAR VEYO, UT-Continued

DURATION OF DISCHARGE FOR EACH WATER YEAR

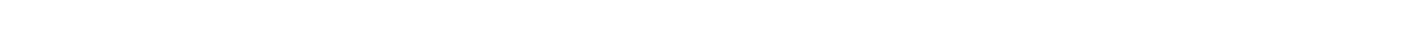
YEAR

MUMBER OF DAYS IN CLASS

GBIC FEET -DAYS

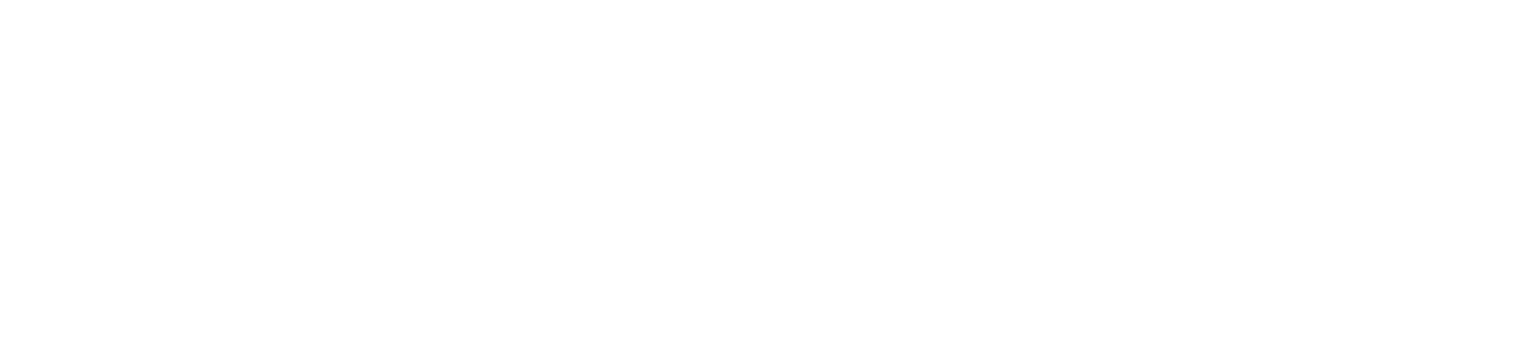

DURATION TABLE OF DISCHARGE FOR WATER YEARS 1956-68

\begin{tabular}{|c|c|c|c|c|c|c|c|c|c|c|c|c|c|c|c|c|c|c|c|}
\hline CLASS & $\begin{array}{c}\text { GBIIC } \\
\text { FEET } \\
\text { PER } \\
\text { SECOND }\end{array}$ & TOTAL & $\begin{array}{l}\text { ACOU- } \\
\text { MU- } \\
\text { LATED } \\
\text { DAYS }\end{array}$ & $\begin{array}{l}\text { PER- } \\
\text { CENT } \\
\text { DAYS }\end{array}$ & & $\begin{array}{c}\text { OUBIC } \\
\text { FEET } \\
\text { PER } \\
\text { SECOND }\end{array}$ & TOTAL & $\begin{array}{c}\text { ACOU- } \\
\text { MU- } \\
\text { LATED } \\
\text { DAYS }\end{array}$ & $\begin{array}{l}\text { PER- } \\
\text { CENT } \\
\text { DAYS }\end{array}$ & & $\begin{array}{c}\text { OBBIC } \\
\text { FEET } \\
\text { PER } \\
\text { SECOND }\end{array}$ & $\begin{array}{r}\text { TOMAL } \\
\text { DAYS }\end{array}$ & $\begin{array}{c}\text { ACOU- } \\
\text { MU- } \\
\text { LATED } \\
\text { DAYS }\end{array}$ & $\begin{array}{l}\text { PER- } \\
\text { CENT } \\
\text { DAYS }\end{array}$ & & $\begin{array}{r}\text { GJBIC } \\
\text { FEET } \\
\text { PER } \\
\text { SECOND }\end{array}$ & $\begin{array}{r}\text { TOIPL } \\
\text { DAYS }\end{array}$ & $\begin{array}{c}\text { ACOU- } \\
\text { MU- } \\
\text { LATED } \\
\text { DAYS }\end{array}$ & $\begin{array}{l}\text { PER- } \\
\text { CENI } \\
\text { DAYS }\end{array}$ \\
\hline $\begin{array}{l}0 \\
1 \\
2 \\
3 \\
4 \\
5 \\
6 \\
7 \\
8\end{array}$ & $\begin{array}{l}0.00 \\
0.01 \\
0.02 \\
0.03 \\
0.04 \\
0.06 \\
0.08 \\
0.11 \\
0.15\end{array}$ & $\begin{array}{r}1121 \\
4 \\
15 \\
23 \\
41 \\
10 \\
322 \\
12 \\
6\end{array}$ & $\begin{array}{l}4749 \\
3628 \\
3624 \\
3609 \\
3586 \\
3545 \\
3535 \\
3213 \\
3201\end{array}$ & $\begin{array}{r}100.0 \\
76.4 \\
76.3 \\
76.0 \\
75.5 \\
74.6 \\
74.4 \\
67.7 \\
67.4\end{array}$ & $\begin{array}{r}9 \\
10 \\
11 \\
12 \\
13 \\
14 \\
15 \\
16 \\
17\end{array}$ & $\begin{array}{l}0.19 \\
0.26 \\
0.35 \\
0.47 \\
0.64 \\
0.86 \\
1.20 \\
1.60 \\
2.10\end{array}$ & $\begin{array}{l}285 \\
205 \\
371 \\
441 \\
318 \\
275 \\
260 \\
201 \\
155\end{array}$ & $\begin{array}{r}3195 \\
2910 \\
2705 \\
2334 \\
1893 \\
1575 \\
1300 \\
1040 \\
839\end{array}$ & $\begin{array}{l}67.3 \\
61.3 \\
57.0 \\
49.1 \\
39.9 \\
33.2 \\
27.4 \\
21.9 \\
17.7\end{array}$ & $\begin{array}{l}18 \\
19 \\
20 \\
21 \\
22 \\
23 \\
24 \\
25 \\
26\end{array}$ & $\begin{array}{r}2.8 \\
3.8 \\
5.1 \\
6.8 \\
9.2 \\
12.0 \\
17.0 \\
22.0 \\
30.0\end{array}$ & $\begin{array}{r}140 \\
103 \\
97 \\
74 \\
40 \\
75 \\
39 \\
29 \\
24\end{array}$ & $\begin{array}{r}684 \\
544 \\
441 \\
344 \\
270 \\
230 \\
155 \\
116 \\
87\end{array}$ & $\begin{array}{r}14.4 \\
11.5 \\
9.3 \\
7.2 \\
5.7 \\
4.8 \\
3.3 \\
2.4 \\
1.8\end{array}$ & $\begin{array}{l}27 \\
28 \\
29 \\
30 \\
31 \\
32 \\
33 \\
34\end{array}$ & $\begin{array}{r}41.0 \\
55.0 \\
73.0 \\
99.0 \\
130.0 \\
180.0\end{array}$ & $\begin{array}{r}23 \\
11 \\
14 \\
8 \\
6 \\
1\end{array}$ & $\begin{array}{r}63 \\
40 \\
29 \\
15 \\
7 \\
1\end{array}$ & $\begin{array}{l}1.3 \\
0.8 \\
0.6 \\
0.3 \\
0.1 \\
0.0\end{array}$ \\
\hline
\end{tabular}

MONIHLY MEAN DISCHARGES, IN CUBIC FEET PER SECOND, FOR EACH WATER YEAR

\begin{tabular}{|c|c|c|c|c|c|c|c|c|c|c|c|c|}
\hline YEAR & $\propto \Gamma$ & $\mathrm{NON}$ & DEC & JAN & FEB & MAR & APR & MAY & JUNE & JULY & AUG & SEP \\
\hline $\begin{array}{l}1956 \\
1957 \\
1958 \\
1959 \\
1960\end{array}$ & $\begin{array}{l}0.13 \\
0.00 \\
0.15 \\
0.08 \\
0.00\end{array}$ & $\begin{array}{l}0.64 \\
0.22 \\
2.83 \\
0.58 \\
0.31\end{array}$ & $\begin{array}{c}0.84 \\
0.89 \\
11.1 \\
0.60 \\
1.18\end{array}$ & $\begin{array}{l}3.21 \\
2.75 \\
1.26 \\
0.89 \\
1.43\end{array}$ & $\begin{array}{c}1.01 \\
10.5 \\
13.1 \\
3.26 \\
2.51\end{array}$ & $\begin{array}{c}0.75 \\
12.8 \\
38.8 \\
3.00 \\
7.63\end{array}$ & $\begin{array}{c}0.94 \\
1.54 \\
42.8 \\
1.26 \\
1.72\end{array}$ & $\begin{array}{l}0.53 \\
1.01 \\
8.51 \\
0.75 \\
1.00\end{array}$ & $\begin{array}{l}0.14 \\
0.36 \\
1.79 \\
0.43 \\
0.38\end{array}$ & $\begin{array}{l}0.09 \\
0.10 \\
0.11 \\
0.14 \\
0.24\end{array}$ & $\begin{array}{l}0.01 \\
0.06 \\
0.11 \\
0.13 \\
0.00\end{array}$ & $\begin{array}{l}0.00 \\
0.00 \\
0.11 \\
0.00 \\
0.21\end{array}$ \\
\hline $\begin{array}{l}1961 \\
1962 \\
1963 \\
1964 \\
1965\end{array}$ & $\begin{array}{l}0.18 \\
0.13 \\
0.03 \\
0.00 \\
0.00\end{array}$ & $\begin{array}{l}0.74 \\
0.40 \\
0.29 \\
0.17 \\
0.00\end{array}$ & $\begin{array}{l}0.34 \\
0.75 \\
0.37 \\
0.24 \\
0.21\end{array}$ & $\begin{array}{l}0.58 \\
0.45 \\
0.38 \\
0.42 \\
0.41\end{array}$ & $\begin{array}{c}0.67 \\
33.0 \\
0.57 \\
0.51 \\
0.51\end{array}$ & $\begin{array}{c}0.91 \\
20.4 \\
0.60 \\
1.22 \\
1.30\end{array}$ & $\begin{array}{c}0.91 \\
11.2 \\
0.62 \\
2.82 \\
46.5\end{array}$ & $\begin{array}{l}0.56 \\
1.73 \\
0.36 \\
0.85 \\
2.83\end{array}$ & $\begin{array}{l}0.11 \\
0.73 \\
0.13 \\
0.35 \\
0.58\end{array}$ & $\begin{array}{l}0.00 \\
0.05 \\
0.03 \\
0.07 \\
0.08\end{array}$ & $\begin{array}{l}0.05 \\
0.00 \\
0.03 \\
0.17 \\
0.00\end{array}$ & $\begin{array}{l}5.20 \\
1.05 \\
0.15 \\
0.00 \\
0.00\end{array}$ \\
\hline $\begin{array}{l}1966 \\
1967 \\
1968\end{array}$ & $\begin{array}{l}0.00 \\
0.00 \\
0.38\end{array}$ & $\begin{array}{l}2.47 \\
0.03 \\
1.09\end{array}$ & $\begin{array}{c}9.63 \\
35.1 \\
1.14\end{array}$ & $\begin{array}{l}3.51 \\
2.41 \\
1.84\end{array}$ & $\begin{array}{r}2.22 \\
4.39 \\
11.4\end{array}$ & $\begin{array}{l}7.62 \\
1.24 \\
9.44\end{array}$ & $\begin{array}{l}1.74 \\
4.43 \\
4.47\end{array}$ & $\begin{array}{l}0.76 \\
3.79 \\
2.66\end{array}$ & $\begin{array}{l}0.20 \\
1.65 \\
0.94\end{array}$ & $\begin{array}{l}0.02 \\
0.18 \\
0.06\end{array}$ & $\begin{array}{l}0.00 \\
0.10 \\
0.11\end{array}$ & $\begin{array}{l}0.00 \\
1.54 \\
0.01\end{array}$ \\
\hline
\end{tabular}

ANNUAL PEAK DISCHARGE, IN CUBIC FEET PER SECOND, AND CORRESPONDING GAGE HEIGHT, IN FEET, FOR EACH WATER YEAR

\begin{tabular}{|c|c|c|c|c|c|c|c|c|c|c|c|}
\hline $\begin{array}{l}\text { WATER } \\
\text { YEAR }\end{array}$ & DATE & $\begin{array}{c}\text { GAGE } \\
\text { HEIGHT }\end{array}$ & $\begin{array}{c}\text { PEAK } \\
\text { DISCHARGE }\end{array}$ & $\begin{array}{l}\text { WATER } \\
\text { YEAR }\end{array}$ & DATE & $\begin{array}{c}\text { GAGE } \\
\text { HEIGHT }\end{array}$ & $\begin{array}{c}\text { PEAR } \\
\text { DISCHARGE }\end{array}$ & $\begin{array}{l}\text { WATER } \\
\text { YEAR }\end{array}$ & DATE & $\begin{array}{c}\text { GAGE } \\
\text { HEIGHT }\end{array}$ & $\begin{array}{c}\text { PEAK } \\
\text { DISCHARGE }\end{array}$ \\
\hline $\begin{array}{l}1955 \\
1956 \\
1957 \\
1958 \\
1959\end{array}$ & $\begin{array}{l}\text { AUG. } 25,1955 \\
\text { JAN. } 26,1956 \\
\text { FEB. } 23,1957 \\
\text { MAR. } 16,1958 \\
\text { FEB. } 17,1959\end{array}$ & $\begin{array}{l}5.64 \\
3.32 \\
3.76 \\
4.96 \\
2.27\end{array}$ & $\begin{array}{r}532 \\
145 \\
185 \\
396 \\
25\end{array}$ & $\begin{array}{l}1960 \\
1961 \\
1962 \\
1963 \\
1964\end{array}$ & $\begin{array}{l}\text { MAR. } 07,1960 \\
\text { SEPT.17, } 1961 \\
\text { SEPT. 28, } 1962 \\
\text { SEPT.18, } 1963 \\
\text { AUG. } 12,1964\end{array}$ & $\begin{array}{l}2.44 \\
8.60 \\
5.70 \\
2.30 \\
2.25\end{array}$ & $\begin{array}{r}39 \\
1400 \\
546 \\
28 \\
26\end{array}$ & $\begin{array}{l}1965 \\
1966 \\
1967 \\
1968 \\
1969\end{array}$ & $\begin{array}{l}\text { APR. } 17,1965 \\
\text { DEC. } 30,1965 \\
\text { DEC. } 06,1966 \\
\text { FEB. 20, } 1968 \\
\text { JAN. 21, } 1969\end{array}$ & $\begin{array}{l}3.53 \\
6.66 \\
9.75 \\
1.58 \\
8.50\end{array}$ & $\begin{array}{r}199 \\
791 \\
1810 \\
31 \\
1800\end{array}$ \\
\hline
\end{tabular}


VIRGIN RIVER BASIN

09409500 MDODY WASH NEAR VEYO, UT--Continued

MAGNITUDE AND PRCBABILITY OF ANNUAL HIGHEST MEAN DISCHARGE BASED ON PERIOD OF RECORD 1956-68

\begin{tabular}{|c|c|c|c|c|c|c|}
\hline \multirow{2}{*}{$\begin{array}{l}\text { PERIOD } \\
\text { (CON- } \\
\text { SEOU- } \\
\text { TIVE } \\
\text { DAYS) }\end{array}$} & \multicolumn{6}{|c|}{$\begin{array}{l}\text { DISCHARGE, IN OBBIC FEET PER SECOND, FOR } \\
\text { INDICATED RECURRENCE INITERNAL, IN YEARS, AND } \\
\text { ANNUAL NONEXCEEDANCE PRCBABIIITY, IN PERCENT }\end{array}$} \\
\hline & $\begin{array}{c}2 \\
508\end{array}$ & $\begin{array}{c}5 \\
208\end{array}$ & $\begin{array}{l}10 \\
108\end{array}$ & $\begin{array}{l}20 \\
58\end{array}$ & $\begin{array}{l}50 \\
28\end{array}$ & $\begin{array}{r}100 \\
18\end{array}$ \\
\hline 1 & 0.00 & 0.00 & - & -- & -- & -- \\
\hline 7 & 0.00 & 0.00 & - & -- & -- & - \\
\hline 14 & 0.00 & 0.00 & - & - & - & - \\
\hline 30 & 0.00 & 0.00 & - & - & - & - \\
\hline 60 & 0.00 & 0.00 & - & -- & - & - \\
\hline 90 & 0.03 & 0.00 & - & -- & - & - \\
\hline
\end{tabular}

09409880 SANTA CJARA RIVER AT GURLOCK, UT

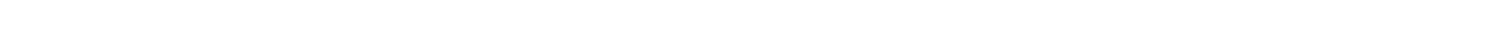
right bank at downstream side of bridge on county road at Gunlock, $0.5 \mathrm{mi}$ below trailrace of powerhouse.

DRAINAGE AREA. $-271 \mathrm{mi}^{2}$.

PERIOD OF RECORD AVAIIABLE.--August 1969 to Septenber 1981.

GAGE.-Water-stage recorder and artifical concrete control. Altitude of gage is 3,628 ft from topographic map.

REMARKS.--Many diversions for irrigation above station. Flow regulated by several reservoirs and powerplant above station.

AVERAGE DISCHARGE.--12 years, $28.0 \mathrm{ft}^{3} / \mathrm{s}, 20,290$ acre- $\mathrm{ft} / \mathrm{yr}$.

EXIREMES FOR PERIOD OF RECORD.--Maximum discharge, 2,810 ft $\mathrm{ft}^{3} / \mathrm{s}$ Feb. 14, 1980, gage height, $5.74 \mathrm{ft}$, from rating curve extended above $1,580 \mathrm{ft}^{3} / \mathrm{s}$; no flow several days during 1977 .

LONEST MEAN DISCHARGE, IN OUBIC FEET PER SECOND, AND RANKING FOR THE INDICATED NUMBER OF CONSECJTIVE DAYS FOR EACH OLIMATIC YEAR, APRIL 1-MARCH 31

1971

13

7

2.507

2.908

3.307

14

CONSECUTTVE DAYS

2.306

2.606

3.105

4.007

4.707

2.703

$\begin{array}{ll}4.30 & 6\end{array}$

$\begin{array}{cc}60 & \\ & \\ 5.20 & 4 \\ 5.60 & 6 \\ 4.40 & 3 \\ 17.0 & 10 \\ 5.60 & 7\end{array}$

90

120

183

$\begin{array}{rr}5.40 & 4 \\ 6.30 & 6\end{array}$

6.306
4.50

3.403

$\begin{array}{llll}7.40 & 10 & 12.0 & 10\end{array}$

$\begin{array}{cr}16.0 & 10 \\ 4.00 \quad 4\end{array}$

$18.0 \quad 10$

$7.10 \quad 8$

5.40
6.30

$\begin{array}{ll}6.30 & 5 \\ 4.90 & 2\end{array}$

$\begin{array}{rr}4.90 & 2 \\ 19.0 & 10\end{array}$

$\begin{array}{rr}19.0 & 10\end{array}$

6.90

8.407

6.502

$\begin{array}{cc}19.0 & 10\end{array}$

$\begin{array}{llll}2.70 & 8 & 2.80 & 7\end{array}$

$3.90 \quad 8$

$4.60 \quad 8$

5.708

$6.70 \quad 8$

6.707

$7.30 \quad 8$

8.80

$\begin{array}{llll}3.40 & 2 & 5.60 & 5\end{array}$

$\begin{array}{ll}2.70 & 2 \\ 0.60 & 1\end{array}$

$\begin{array}{rrrr}2.10 & 1 & 3.50 & 1\end{array}$

6.406

7.705

$\begin{array}{lll}1 & 4.70 & 1\end{array}$

$\begin{array}{cc}0.12 & 1 \\ 10.0 & 9\end{array}$

12.09

5.405

$\begin{array}{cc}13.0 & 9 \\ 5.30 & 3\end{array}$

$\begin{array}{cc}13.0 & 9 \\ 5.80 & 4\end{array}$

$\begin{array}{rr}4.70 & 1 \\ 16.0 & 9\end{array}$

$\begin{array}{rr}16.0 & 9 \\ 6.70 & 3\end{array}$

20.011

$22.0 \quad 11$

$25.0 \quad 11$

25.011

ALI

9.101

$\begin{array}{ll}10.0 & 2 \\ 16.0 & 7\end{array}$

58.010

$\begin{array}{rr}12.0 & 4\end{array}$

18.011

19.011

ER OF CONSECTMTVE DAYS

HIGHEST MEAN DISCHARGE, IN OUBIC FEET PER SECOND, AND RANKING FOR THE INDICA

\begin{tabular}{|c|c|c|c|c|c|c|c|c|c|c|c|c|c|c|c|c|c|c|c|c|}
\hline YEAR & \multicolumn{20}{|c|}{ CONSECITIVE DAYS } \\
\hline 1970 & 30.0 & 12 & 29.0 & 11 & 25.0 & 11 & 23.0 & 10 & 22.0 & 9 & 20.0 & 9 & 19.0 & 8 & 18.0 & 9 & 16.0 & 9 & 12.0 & $\mathbf{y}$ \\
\hline 1981 & 61.0 & 7 & 49.0 & 7 & 39.0 & 7 & 35.0 & 6 & 34.0 & 5 & 33.0 & 5 & 32.0 & 5 & 30.0 & 5 & 28.0 & 5 & 22.0 & \\
\hline
\end{tabular}


VIRGIN RIVER BASIN

09409880 SANTA CIARA RIVER AT GURLOCK, UT-Continued

DURATION OF DISCHARGE FOR EACH WATER YEAR

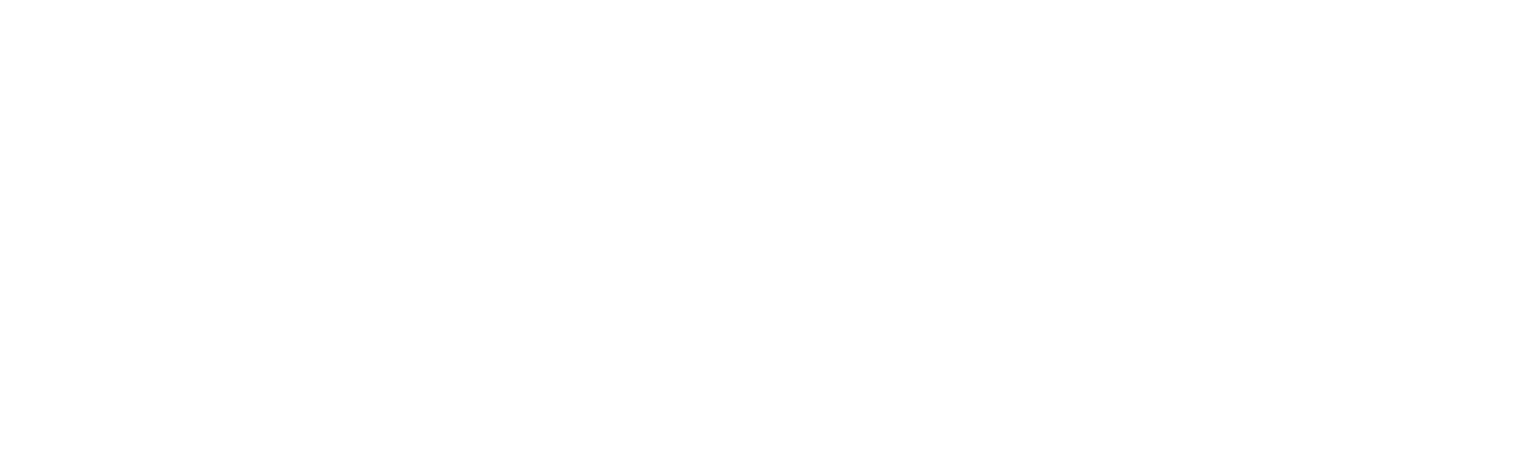

DURATION TABLE OF DISCHARGE FOR WATER YEARS 1970-81

\begin{tabular}{|c|c|c|c|c|c|c|c|c|c|c|c|c|c|c|c|c|c|c|c|}
\hline ASS & $\begin{array}{l}\text { OBBIC } \\
\text { FEET } \\
\text { PER } \\
\text { SEOOND }\end{array}$ & $\begin{array}{r}\text { TOTAL } \\
\text { DAYS }\end{array}$ & $\begin{array}{c}\text { ACOU- } \\
\text { MU- } \\
\text { LATED } \\
\text { DAYS }\end{array}$ & $\begin{array}{l}\text { PER- } \\
\text { CENT } \\
\text { DAYS }\end{array}$ & _ASS & $\begin{array}{c}\text { CBBIC } \\
\text { FEET } \\
\text { PER } \\
\text { SECOND }\end{array}$ & $\begin{array}{r}\text { TOIAL } \\
\text { DAYS }\end{array}$ & $\begin{array}{c}\text { ACOJ- } \\
\text { MU- } \\
\text { LATED } \\
\text { DAYS }\end{array}$ & $\begin{array}{l}\text { PER- } \\
\text { CENT } \\
\text { DAYS }\end{array}$ & LASS & $\begin{array}{c}\text { CUBIC } \\
\text { FEET } \\
\text { PER } \\
\text { SECOND }\end{array}$ & TOTAL & $\begin{array}{l}\text { ACOU- } \\
\text { MU- } \\
\text { LATED } \\
\text { DAYS }\end{array}$ & $\begin{array}{l}\text { PER- } \\
\text { CENT } \\
\text { DAYS }\end{array}$ & & $\begin{array}{l}\text { OUIC } \\
\text { FEET } \\
\text { PER } \\
\text { SEOOND }\end{array}$ & $\begin{array}{l}\text { TOTAL } \\
\text { DAYS }\end{array}$ & $\begin{array}{c}\text { ACOU- } \\
\text { MU- } \\
\text { LATED } \\
\text { DAYS }\end{array}$ & $\begin{array}{l}\text { PER- } \\
\text { CENT } \\
\text { DAYS }\end{array}$ \\
\hline $\begin{array}{l}0 \\
1 \\
2 \\
3 \\
4 \\
5 \\
6 \\
7 \\
8\end{array}$ & $\begin{array}{l}0.00 \\
0.06 \\
0.08 \\
0.11 \\
0.16 \\
0.21 \\
0.29 \\
0.40 \\
0.55\end{array}$ & $\begin{array}{r}15 \\
1 \\
0 \\
3 \\
1 \\
3 \\
0 \\
2 \\
1\end{array}$ & $\begin{array}{l}4383 \\
4368 \\
4367 \\
4367 \\
4364 \\
4363 \\
4360 \\
4360 \\
4358\end{array}$ & $\begin{array}{r}100.0 \\
99.7 \\
99.6 \\
99.6 \\
99.6 \\
99.5 \\
99.5 \\
99.5 \\
99.4\end{array}$ & $\begin{array}{r}9 \\
10 \\
11 \\
12 \\
13 \\
14 \\
15 \\
16 \\
17\end{array}$ & $\begin{array}{l}0.75 \\
1.00 \\
1.40 \\
1.90 \\
2.70 \\
3.60 \\
5.00 \\
6.80 \\
9.40\end{array}$ & $\begin{array}{r}6 \\
10 \\
15 \\
65 \\
102 \\
281 \\
425 \\
602 \\
662\end{array}$ & $\begin{array}{l}4357 \\
4351 \\
4341 \\
4326 \\
4261 \\
4159 \\
3878 \\
3453 \\
2851\end{array}$ & $\begin{array}{l}99.4 \\
99.3 \\
99.0 \\
98.7 \\
97.2 \\
94.9 \\
88.5 \\
78.8 \\
65.0\end{array}$ & $\begin{array}{l}18 \\
19 \\
20 \\
21 \\
22 \\
23 \\
24 \\
25 \\
26\end{array}$ & $\begin{array}{r}13.0 \\
18.0 \\
24.0 \\
33.0 \\
45.0 \\
62.0 \\
85.0 \\
120.0 \\
160.0\end{array}$ & $\begin{array}{r}662 \\
500 \\
387 \\
94 \\
83 \\
112 \\
167 \\
87 \\
50\end{array}$ & $\begin{array}{r}2189 \\
1527 \\
1027 \\
640 \\
546 \\
463 \\
351 \\
184 \\
97\end{array}$ & $\begin{array}{r}49.9 \\
34.8 \\
23.4 \\
14.6 \\
12.5 \\
10.6 \\
8.0 \\
4.2 \\
2.2\end{array}$ & $\begin{array}{l}27 \\
28 \\
29 \\
30 \\
31 \\
32 \\
33 \\
34\end{array}$ & $\begin{array}{r}220.0 \\
300.0 \\
410.0 \\
570.0 \\
780.0 \\
1100.0 \\
1500.0 \\
2000.0\end{array}$ & $\begin{array}{r}27 \\
5 \\
5 \\
2 \\
5 \\
1 \\
0 \\
2\end{array}$ & $\begin{array}{r}47 \\
20 \\
15 \\
10 \\
8 \\
3 \\
2 \\
2\end{array}$ & $\begin{array}{l}1.1 \\
0.5 \\
0.3 \\
0.2 \\
0.2 \\
0.1 \\
0.0 \\
0.0\end{array}$ \\
\hline
\end{tabular}

MONTHLY MEAN DISCHARGES, IN CUBIC FEET PER SECOND, FOR EACH WATER YEAR

$\begin{array}{lcccccccccccc}\text { YEAR } & \text { OCT } & \text { NOV } & \text { DEC } & \text { JAN } & \text { FEB } & \text { MAR } & \text { ARR } & \text { MAY } & \text { JUNE } & \text { JULY } & \text { AUG } & \text { SEP } \\ 1970 & 14.8 & 19.3 & 18.4 & 18.2 & 11.8 & 13.2 & 9.89 & 12.9 & 10.6 & 5.21 & 5.72 & 5.65 \\ 1971 & 5.12 & 10.5 & 13.2 & 11.9 & 9.94 & 8.08 & 8.50 & 18.7 & 14.6 & 4.50 & 7.87 & 7.27 \\ 1972 & 6.37 & 13.2 & 20.1 & 4.73 & 7.69 & 11.3 & 11.3 & 8.31 & 4.85 & 4.28 & 4.92 & 6.50 \\ 1973 & 15.0 & 20.8 & 14.8 & 13.5 & 35.2 & 57.9 & 150 & 222 & 138 & 29.4 & 23.3 & 16.8 \\ 1974 & 17.4 & 19.7 & 21.4 & 17.4 & 20.9 & 21.0 & 20.5 & 17.6 & 6.10 & 9.19 & 8.64 & 4.87 \\ 1975 & 8.43 & 10.8 & 11.0 & 10.4 & 12.9 & 26.1 & 22.5 & 18.8 & 16.2 & 9.21 & 5.79 & 7.97 \\ 1976 & 6.77 & 11.7 & 11.2 & 12.6 & 25.3 & 13.8 & 11.5 & 21.2 & 10.2 & 9.11 & 4.01 & 3.66 \\ 1977 & 9.62 & 10.5 & 12.0 & 11.2 & 10.6 & 8.36 & 6.05 & 7.05 & 5.08 & 2.72 & 3.34 & 5.03 \\ 1978 & 5.72 & 6.19 & 7.72 & 12.0 & 28.4 & 61.9 & 63.6 & 78.5 & 46.2 & 13.4 & 14.3 & 12.4 \\ 1979 & 13.6 & 20.7 & 21.9 & 13.3 & 63.4 & 211 & 115 & 121 & 105 & 6.41 & 6.98 & 4.45 \\ 1980 & 6.98 & 9.22 & 8.04 & 95.4 & 372 & 126 & 149 & 111 & 83.5 & 38.1 & 30.5 & 26.5 \\ 1981 & 27.9 & 30.9 & 26.0 & 19.2 & 22.3 & 33.4 & 32.7 & 29.2 & 17.5 & 9.05 & 7.36 & 5.46\end{array}$

ANNUAL PEAR DISCHARGE, IN OUBIC FEET PER SEOOND, AND CORRESPONDING GAGE HEIGHT, IN FEET, FOR EACH WATER YEAR

\begin{tabular}{|c|c|c|c|c|c|c|c|c|c|c|c|}
\hline $\begin{array}{l}\text { WATER } \\
\text { YEAR }\end{array}$ & DATE & $\begin{array}{c}\text { GAGE } \\
\text { HEIGHT }\end{array}$ & $\begin{array}{c}\text { PEAK } \\
\text { DISCHARGE }\end{array}$ & $\begin{array}{l}\text { WATER } \\
\text { YEAR }\end{array}$ & DATE & $\begin{array}{c}\text { GAGE } \\
\text { HEIGHT }\end{array}$ & $\begin{array}{c}\text { PEAK } \\
\text { DISCHARGE }\end{array}$ & $\begin{array}{l}\text { WATER } \\
\text { YEAR }\end{array}$ & DATE & $\begin{array}{c}\text { GAGE } \\
\text { HEIGHT }\end{array}$ & $\begin{array}{c}\text { PEAK } \\
\text { DISCHARGE }\end{array}$ \\
\hline $\begin{array}{l}1970 \\
1971 \\
1972 \\
1973\end{array}$ & $\begin{array}{l}\text { AUG. } 18,1970 \\
\text { AUG. } 08,1971 \\
\text { DEC. } 25,1971 \\
\text { APR. } 13,1973\end{array}$ & $\begin{array}{l}3.00 \\
4.16 \\
5.00 \\
3.67\end{array}$ & $\begin{array}{r}73 \\
183 \\
335 \\
902\end{array}$ & $\begin{array}{l}1974 \\
1975 \\
1976 \\
1977\end{array}$ & $\begin{array}{l}\text { JULY } 15,1974 \\
\text { JULY } 29,1975 \\
\text { FEB. } 09,1976 \\
\text { AUG. } 23,1977\end{array}$ & $\begin{array}{l}4.07 \\
2.69 \\
3.35 \\
3.07\end{array}$ & $\begin{array}{r}1360 \\
273 \\
658 \\
783\end{array}$ & $\begin{array}{l}1978 \\
1979 \\
1980 \\
1981\end{array}$ & $\begin{array}{l}\text { FEB. } 10,1978 \\
\text { MAR. } 28,1979 \\
\text { FEB. } 14,1980 \\
\text { APR. } 19,1981\end{array}$ & $\begin{array}{l}4.38 \\
5.42 \\
5.74 \\
3.49\end{array}$ & $\begin{array}{r}324 \\
2620 \\
2810 \\
74\end{array}$ \\
\hline
\end{tabular}

MAGNITUDE AND PRCBABILITY OF ANNUAL LOWEST MEAN DISCHARGE

\begin{tabular}{|c|c|c|c|c|c|c|}
\hline \multirow{2}{*}{$\begin{array}{l}\text { PERIOD } \\
\text { (CON- } \\
\text { SECU- } \\
\text { TIVE } \\
\text { DAYS) }\end{array}$} & \multicolumn{6}{|c|}{$\begin{array}{l}\text { DISCHARGE, IN OUBIC FEET PER SECOND, FOR } \\
\text { INDICAIED RECIRRENCE INIERNAL, IN YEARS, AND } \\
\text { ANNUAL NONEXCEEDANCE PRCBABILITY, IN PEECENT }\end{array}$} \\
\hline & $\begin{array}{c}2 \\
50 \%\end{array}$ & $\begin{array}{c}5 \\
208\end{array}$ & $\begin{array}{l}10 \\
108\end{array}$ & $\begin{array}{l}20 \\
58\end{array}$ & $\begin{array}{l}50 \\
2 z\end{array}$ & $\begin{array}{r}100 \\
18\end{array}$ \\
\hline $\begin{array}{r}1 \\
60 \\
90\end{array}$ & $\begin{array}{l}2.3 \\
6.2 \\
6.8\end{array}$ & $\begin{array}{l}1.3 \\
3.6 \\
4.5\end{array}$ & $\begin{array}{l}0.98 \\
2.8 \\
3.8\end{array}$ & $\begin{array}{l}0.80 \\
2.3 \\
3.4\end{array}$ & $\bar{z}$ & $\overline{-}$ \\
\hline
\end{tabular}


VIRGIN RIVER BASIN

09410000 SANTA CLARA RIVER ABOVE WINSOR DAM, NEAR SANTA CIARA, UT

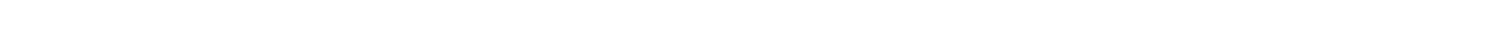
left bank $1.7 \mathrm{mi}$ above Pahcoon Spring Wash, $2.3 \mathrm{mi}$ upstream from Winsor Dam, $3.2 \mathrm{mi}$ north of Shivwits Indian Village, and $9 \mathrm{mi}$ nortrwest of Santa Clara.

DRAINAGE AREA. $-338 \mathrm{mi}^{2}$, approximately.

MEAN BASIN ELEVATION. $-5,900 \mathrm{ft}$.

PERIOD OF RECORD AVAIIABLE.--March 1942 to September 1971. Published as "Santa Clara Creek above Winsor Dam, near Santa Clara", $1942-44$

REVISED RECORDS.-WSP 1179: 1945-47(M), 1948(P), 1949(M).

GAGE.--Water-stage recorder. Altitude of gage is 3,340 ft by parameter. Prior to July 28,1951 , at site $380 \mathrm{ft}$ upstream. July 28 , 1951 to Feb. 17, 1967, at site $350 \mathrm{ft}$ upstream at different datums.

REMARKS.--Many diversions for irrigation above station. Flow slightly regulated by powerplants of Southern Utah Power Co.

AVERAGE DISCHARGE. -29 years, $21.0 \mathrm{ft}^{3} / \mathrm{s}, 15,210$ acre- $\mathrm{ft} / \mathrm{yr}$.

EXTREMES FOR PERIOD OF RECORD.-Maximum discharge, 6,190 $\mathrm{ft}^{3} / \mathrm{s}$ Aug. 24, 1955, gage height, $10.25 \mathrm{ft}$, site and datum then in use, from rating curve extended above $260 \mathrm{ft}^{3} / \mathrm{s}$ on basis of slope-area measurements at gage heights $6.25 \mathrm{ft}, 6.50 \mathrm{ft}$ and $9.40 \mathrm{ft}$; minimum, $0.23 \mathrm{ft}^{3} / \mathrm{s}$, on several days in August and September 1971.

LOWEST MEAN DISCHARGE, IN CUBIC FEET PER SECOND, AND RANKING FOR THE INDICATED NUMBER OF CONSECUTIVE DAYS FOR EACH CLIMATIC YEAR, APRIL 1-MARCH 31

\begin{tabular}{|c|c|c|c|c|c|c|c|c|c|c|c|c|c|c|c|c|c|c|c|}
\hline \multicolumn{19}{|c|}{ CONSEOUTIVE DAYS } & \\
\hline $\begin{array}{l}2.0 \\
1.0 \\
1.0\end{array}$ & $\begin{array}{l}27 \\
24 \\
25\end{array}$ & $\begin{array}{l}13.0 \\
11.0 \\
12.0\end{array}$ & $\begin{array}{l}27 \\
24 \\
26\end{array}$ & $\begin{array}{l}13.0 \\
12.0 \\
12.0\end{array}$ & $\begin{array}{l}27 \\
25 \\
26\end{array}$ & $\begin{array}{l}14.0 \\
12.0 \\
13.0\end{array}$ & $\begin{array}{l}27 \\
24 \\
25\end{array}$ & $\begin{array}{l}14.0 \\
12.0 \\
14.0\end{array}$ & $\begin{array}{l}25 \\
23 \\
26\end{array}$ & $\begin{array}{l}15.0 \\
15.0 \\
14.0\end{array}$ & $\begin{array}{l}25 \\
26 \\
23\end{array}$ & $\begin{array}{l}16.0 \\
15.0 \\
14.0\end{array}$ & $\begin{array}{l}26 \\
23 \\
22\end{array}$ & $\begin{array}{l}18.0 \\
15.0 \\
16.0\end{array}$ & $\begin{array}{l}25 \\
22 \\
23\end{array}$ & $\begin{array}{l}19.0 \\
16.0 \\
18.0\end{array}$ & $\begin{array}{l}26 \\
22 \\
23\end{array}$ & $\begin{array}{l}31.0 \\
26.0 \\
30.0\end{array}$ & $\begin{array}{l}26 \\
21 \\
23\end{array}$ \\
\hline $\begin{array}{l}11.0 \\
3.60 \\
8.20 \\
8.50 \\
15.0\end{array}$ & $\begin{array}{l}26 \\
12 \\
19 \\
20 \\
29\end{array}$ & $\begin{array}{r}11.0 \\
4.60 \\
8.70 \\
8.70 \\
15.0\end{array}$ & $\begin{array}{l}25 \\
13 \\
19 \\
20 \\
29\end{array}$ & $\begin{array}{r}11.0 \\
5.90 \\
9.90 \\
9.10 \\
16.0\end{array}$ & $\begin{array}{l}22 \\
14 \\
20 \\
19 \\
29\end{array}$ & $\begin{array}{c}11.0 \\
6.10 \\
10.0 \\
9.20 \\
16.0\end{array}$ & $\begin{array}{l}23 \\
14 \\
20 \\
19 \\
29\end{array}$ & $\begin{array}{c}11.0 \\
7.00 \\
12.0 \\
9.40 \\
17.0\end{array}$ & $\begin{array}{l}20 \\
15 \\
21 \\
18 \\
28\end{array}$ & $\begin{array}{c}14.0 \\
8.70 \\
12.0 \\
10.0 \\
18.0\end{array}$ & $\begin{array}{l}24 \\
16 \\
20 \\
19 \\
28\end{array}$ & $\begin{array}{c}16.0 \\
9.80 \\
13.0 \\
11.0 \\
18.0\end{array}$ & $\begin{array}{l}24 \\
16 \\
21 \\
17 \\
27\end{array}$ & $\begin{array}{l}18.0 \\
10.0 \\
14.0 \\
11.0 \\
19.0\end{array}$ & $\begin{array}{l}26 \\
16 \\
21 \\
17 \\
28\end{array}$ & $\begin{array}{l}19.0 \\
12.0 \\
15.0 \\
12.0 \\
21.0\end{array}$ & $\begin{array}{l}27 \\
15 \\
20 \\
16 \\
29\end{array}$ & $\begin{array}{l}25.0 \\
27.0 \\
22.0 \\
20.0 \\
31.0\end{array}$ & $\begin{array}{l}20 \\
22 \\
17 \\
14 \\
24\end{array}$ \\
\hline $\begin{array}{c}3.30 \\
2.80 \\
13.0 \\
6.30 \\
5.70\end{array}$ & $\begin{array}{r}10 \\
8 \\
28 \\
18 \\
17\end{array}$ & $\begin{array}{c}5.50 \\
3.90 \\
14.0 \\
7.20 \\
5.90\end{array}$ & $\begin{array}{l}15 \\
10 \\
28 \\
18 \\
17\end{array}$ & $\begin{array}{c}6.10 \\
4.30 \\
15.0 \\
7.90 \\
6.20\end{array}$ & $\begin{array}{l}16 \\
10 \\
28 \\
18 \\
17\end{array}$ & $\begin{array}{c}6.80 \\
4.70 \\
15.0 \\
8.40 \\
6.70\end{array}$ & $\begin{array}{l}17 \\
10 \\
28 \\
18 \\
16\end{array}$ & $\begin{array}{c}7.70 \\
5.30 \\
17.0 \\
8.70 \\
9.60\end{array}$ & $\begin{array}{l}16 \\
12 \\
29 \\
17 \\
19\end{array}$ & $\begin{array}{c}8.60 \\
6.60 \\
18.0 \\
9.80 \\
10.0\end{array}$ & $\begin{array}{l}15 \\
13 \\
29 \\
17 \\
18\end{array}$ & $\begin{array}{c}8.90 \\
6.60 \\
19.0 \\
11.0 \\
11.0\end{array}$ & $\begin{array}{r}15 \\
9 \\
29 \\
18 \\
19\end{array}$ & $\begin{array}{c}9.50 \\
7.00 \\
19.0 \\
11.0 \\
11.0\end{array}$ & $\begin{array}{r}15 \\
8 \\
29 \\
18 \\
19\end{array}$ & $\begin{array}{c}11.0 \\
8.60 \\
19.0 \\
13.0 \\
12.0\end{array}$ & $\begin{array}{r}12 \\
9 \\
28 \\
19 \\
17\end{array}$ & $\begin{array}{l}14.0 \\
15.0 \\
43.0 \\
17.0 \\
17.0\end{array}$ & $\begin{array}{l}10 \\
28 \\
12 \\
13\end{array}$ \\
\hline $\begin{array}{c}2.60 \\
2.40 \\
3.70 \\
10.0 \\
3.80\end{array}$ & $\begin{array}{r}6 \\
5 \\
13 \\
23 \\
14\end{array}$ & $\begin{array}{c}3.00 \\
2.60 \\
3.90 \\
10.0 \\
4.10\end{array}$ & $\begin{array}{r}7 \\
5 \\
11 \\
23 \\
12\end{array}$ & $\begin{array}{c}3.30 \\
3.50 \\
4.40 \\
11.0 \\
4.60\end{array}$ & $\begin{array}{r}5 \\
6 \\
11 \\
23 \\
12\end{array}$ & $\begin{array}{c}3.60 \\
3.70 \\
4.90 \\
13.0 \\
4.80\end{array}$ & $\begin{array}{r}6 \\
7 \\
12 \\
26 \\
11\end{array}$ & $\begin{array}{c}5.10 \\
3.90 \\
5.20 \\
15.0 \\
5.00\end{array}$ & $\begin{array}{r}10 \\
6 \\
11 \\
27 \\
9\end{array}$ & $\begin{array}{c}5.60 \\
4.10 \\
5.80 \\
17.0 \\
5.90\end{array}$ & $\begin{array}{r}9 \\
5 \\
10 \\
27 \\
11\end{array}$ & $\begin{array}{c}7.20 \\
4.60 \\
7.10 \\
18.0 \\
7.10\end{array}$ & $\begin{array}{r}13 \\
5 \\
10 \\
28 \\
11\end{array}$ & $\begin{array}{c}8.90 \\
5.20 \\
9.30 \\
18.0 \\
7.30\end{array}$ & $\begin{array}{r}12 \\
5 \\
13 \\
27 \\
9\end{array}$ & $\begin{array}{c}11.0 \\
6.40 \\
13.0 \\
18.0 \\
7.60\end{array}$ & $\begin{array}{r}13 \\
4 \\
18 \\
24 \\
6\end{array}$ & $\begin{array}{c}14.0 \\
9.00 \\
24.0 \\
39.0 \\
11.0\end{array}$ & $\begin{array}{r}9 \\
19 \\
27 \\
5\end{array}$ \\
\hline $\begin{array}{l}0.80 \\
1.30 \\
3.40 \\
2.10 \\
2.80\end{array}$ & $\begin{array}{r}2 \\
3 \\
11 \\
4 \\
7\end{array}$ & $\begin{array}{l}0.83 \\
1.70 \\
3.50 \\
2.20 \\
2.90\end{array}$ & $\begin{array}{l}2 \\
3 \\
9 \\
4 \\
6\end{array}$ & $\begin{array}{l}0.90 \\
1.90 \\
3.80 \\
2.40 \\
3.50\end{array}$ & $\begin{array}{l}2 \\
3 \\
9 \\
4 \\
7\end{array}$ & $\begin{array}{l}1.60 \\
2.20 \\
4.00 \\
2.50 \\
3.60\end{array}$ & $\begin{array}{l}2 \\
3 \\
9 \\
4 \\
5\end{array}$ & $\begin{array}{l}3.00 \\
2.80 \\
4.20 \\
2.80 \\
3.80\end{array}$ & $\begin{array}{l}4 \\
2 \\
7 \\
3 \\
5\end{array}$ & $\begin{array}{l}3.80 \\
4.10 \\
4.50 \\
3.20 \\
4.20\end{array}$ & $\begin{array}{l}3 \\
4 \\
7 \\
2 \\
6\end{array}$ & $\begin{array}{l}4.00 \\
4.60 \\
5.80 \\
3.70 \\
4.40\end{array}$ & $\begin{array}{l}3 \\
6 \\
8 \\
2 \\
4\end{array}$ & $\begin{array}{l}4.70 \\
6.40 \\
8.30 \\
4.40 \\
4.80\end{array}$ & $\begin{array}{r}3 \\
7 \\
11 \\
2 \\
4\end{array}$ & $\begin{array}{l}7.60 \\
7.60 \\
9.20 \\
4.90 \\
5.40\end{array}$ & $\begin{array}{r}7 \\
8 \\
10 \\
2 \\
3\end{array}$ & $\begin{array}{c}11.0 \\
16.0 \\
12.0 \\
7.00 \\
8.90\end{array}$ & 1. \\
\hline $\begin{array}{l}5.20 \\
2.90 \\
9.50 \\
4.80 \\
9.50\end{array}$ & $\begin{array}{r}16 \\
9 \\
21 \\
15 \\
22\end{array}$ & $\begin{array}{l}5.60 \\
3.20 \\
9.70 \\
5.10 \\
9.70\end{array}$ & $\begin{array}{r}16 \\
8 \\
21 \\
14 \\
22\end{array}$ & $\begin{array}{c}5.90 \\
3.60 \\
11.0 \\
5.60 \\
10.0\end{array}$ & $\begin{array}{r}15 \\
8 \\
24 \\
13 \\
21\end{array}$ & $\begin{array}{c}6.10 \\
3.70 \\
11.0 \\
6.00 \\
11.0\end{array}$ & $\begin{array}{r}15 \\
8 \\
21 \\
13 \\
22\end{array}$ & $\begin{array}{c}6.20 \\
4.20 \\
12.0 \\
6.10 \\
13.0\end{array}$ & $\begin{array}{r}14 \\
8 \\
22 \\
13 \\
24\end{array}$ & $\begin{array}{c}6.60 \\
5.10 \\
13.0 \\
6.90 \\
13.0\end{array}$ & $\begin{array}{r}12 \\
8 \\
21 \\
14 \\
22\end{array}$ & $\begin{array}{c}7.20 \\
5.50 \\
13.0 \\
8.10 \\
16.0\end{array}$ & $\begin{array}{r}12 \\
7 \\
20 \\
14 \\
25\end{array}$ & $\begin{array}{c}8.00 \\
5.50 \\
14.0 \\
9.30 \\
17.0\end{array}$ & $\begin{array}{r}10 \\
6 \\
20 \\
14 \\
24\end{array}$ & $\begin{array}{c}12.0 \\
6.70 \\
16.0 \\
11.0 \\
19.0\end{array}$ & $\begin{array}{r}14 \\
5 \\
21 \\
11 \\
25\end{array}$ & $\begin{array}{l}21.0 \\
22.0 \\
21.0 \\
31.0 \\
45.0\end{array}$ & $\begin{array}{l}15 \\
15 \\
16 \\
25 \\
25\end{array}$ \\
\hline 53 & & .53 & 1 & 0.53 & & 0.55 & 1 & 1.00 & J & 1.70 & 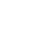 & 3.00 & & 2.90 & & 3.50 & & 7.60 & \\
\hline
\end{tabular}

HIGHEST MEAN DISCHARGE, IN CUBIC FEET PER SECOND, AND RANKING FOR THE INDICATED NUMBER OF CONSEOTTIVE DAYS FOR EACH WATER YEAR, OCTOBER I-SEPTEMBER 30

\begin{tabular}{|c|c|c|c|c|c|c|c|c|c|c|c|c|c|c|c|c|c|c|c|c|}
\hline \multirow{2}{*}{ YEAR } & \multicolumn{20}{|c|}{ CONSEATIVE DAYS } \\
\hline & 1 & & 3 & & 7 & & 15 & & 30 & & 60 & & 90 & & 120 & & 183 & & ALL & \\
\hline $\begin{array}{l}943 \\
944 \\
945\end{array}$ & $\begin{array}{l}191 \\
180 \\
246\end{array}$ & $\begin{array}{l}13 \\
14 \\
10\end{array}$ & $\begin{array}{l}146 \\
131 \\
135\end{array}$ & $\begin{array}{l}10 \\
13 \\
12\end{array}$ & $\begin{array}{r}109 \\
99.0 \\
76.0\end{array}$ & $\begin{array}{r}8 \\
10 \\
14\end{array}$ & $\begin{array}{l}85.0 \\
78.0 \\
66.0\end{array}$ & $\begin{array}{r}8 \\
10 \\
12\end{array}$ & $\begin{array}{l}80.0 \\
77.0 \\
60.0\end{array}$ & $\begin{array}{r}6 \\
7 \\
11\end{array}$ & $\begin{array}{l}65.0 \\
58.0 \\
50.0\end{array}$ & $\begin{array}{r}5 \\
7 \\
10\end{array}$ & & $\begin{array}{l}6 \\
7 \\
9\end{array}$ & $\begin{array}{l}50.0 \\
54.0 \\
43.0\end{array}$ & $\begin{array}{l}7 \\
4 \\
9\end{array}$ & & $\begin{array}{l}7 \\
4 \\
9\end{array}$ & $\begin{array}{l}29.0 \\
30.0 \\
27.0\end{array}$ & $\begin{array}{l}6 \\
5 \\
9\end{array}$ \\
\hline $\begin{array}{l}1946 \\
1947 \\
1948 \\
1949\end{array}$ & $\begin{array}{c}126 \\
450 \\
56.0 \\
137 \\
88.0\end{array}$ & $\begin{array}{r}17 \\
4 \\
24 \\
16 \\
20\end{array}$ & $\begin{array}{c}59.0 \\
313 \\
47.0 \\
121 \\
54.0\end{array}$ & $\begin{array}{r}19 \\
5 \\
23 \\
15 \\
20\end{array}$ & $\begin{array}{c}37.0 \\
172 \\
42.0 \\
92.0 \\
38.0\end{array}$ & $\begin{array}{r}22 \\
5 \\
19 \\
12 \\
21\end{array}$ & $\begin{array}{c}28.0 \\
100 \\
40.0 \\
74.0 \\
35.0\end{array}$ & $\begin{array}{r}21 \\
6 \\
17 \\
11 \\
18\end{array}$ & $\begin{array}{l}25.0 \\
94.0 \\
34.0 \\
65.0 \\
34.0\end{array}$ & $\begin{array}{r}21 \\
5 \\
16 \\
8 \\
17\end{array}$ & $\begin{array}{l}25.0 \\
65.0 \\
31.0 \\
57.0 \\
31.0\end{array}$ & $\begin{array}{r}17 \\
6 \\
14 \\
8 \\
15\end{array}$ & $\begin{array}{l}24.0 \\
61.0 \\
28.0 \\
56.0 \\
29.0\end{array}$ & $\begin{array}{r}17 \\
4 \\
15 \\
8 \\
14\end{array}$ & $\begin{array}{l}23.0 \\
52.0 \\
25.0 \\
53.0 \\
27.0\end{array}$ & $\begin{array}{r}17 \\
6 \\
15 \\
5 \\
14\end{array}$ & $\begin{array}{l}22.0 \\
43.0 \\
22.0 \\
42.0 \\
26.0\end{array}$ & $\begin{array}{r}15 \\
5 \\
16 \\
6 \\
11\end{array}$ & $\begin{array}{l}17.0 \\
34.0 \\
18.0 \\
28.0 \\
20.0\end{array}$ & $\begin{array}{r}15 \\
4 \\
13 \\
7 \\
10\end{array}$ \\
\hline
\end{tabular}


VIRGIN RIVER BASIN

09410000 SANTA C.ARA RIVER ABOVE WINSOR DAM, NEAR SANTA CLARA, UT--Continued

HIGHEST MEAN DISCHARGE, IN GUIC FEET FER SECOND, AND RANKING FOR THE INDICATED NUMBER OF CONSEOUTIVE DAYS FOR EACH WATER YEAR, OCTOBER 1-SEPTEMBER 30--Continued

\begin{tabular}{|c|c|c|c|c|c|c|c|c|c|c|c|c|c|c|c|c|c|c|c|c|}
\hline YEAR & & & & & & & & & & & VE DAY & & & & & & & & & \\
\hline $\begin{array}{l}951 \\
952 \\
953 \\
954 \\
955\end{array}$ & $\begin{array}{l}25.0 \\
377 \\
429 \\
202 \\
350\end{array}$ & $\begin{array}{r}28 \\
8 \\
6 \\
12 \\
9\end{array}$ & $\begin{array}{l}22.0 \\
340 \\
157 \\
124 \\
207\end{array}$ & $\begin{array}{r}28 \\
3 \\
9 \\
14 \\
7\end{array}$ & $\begin{array}{c}19.0 \\
299 \\
74.0 \\
103 \\
97.0\end{array}$ & $\begin{array}{r}28 \\
3 \\
15 \\
9 \\
11\end{array}$ & $\begin{array}{c}17.0 \\
245 \\
41.0 \\
84.0 \\
54.0\end{array}$ & $\begin{array}{r}28 \\
3 \\
16 \\
9 \\
13\end{array}$ & $\begin{array}{c}17.0 \\
194 \\
27.0 \\
54.0 \\
35.0\end{array}$ & $\begin{array}{r}28 \\
2 \\
18 \\
12 \\
15\end{array}$ & $\begin{array}{c}15.0 \\
148 \\
21.0 \\
40.0 \\
24.0\end{array}$ & $\begin{array}{r}27 \\
2 \\
22 \\
12 \\
18\end{array}$ & $\begin{array}{c}14.0 \\
120 \\
20.0 \\
33.0 \\
20.0\end{array}$ & $\begin{array}{r}28 \\
3 \\
20 \\
12 \\
21\end{array}$ & & $\begin{array}{r}25 \\
3 \\
19 \\
12 \\
20\end{array}$ & & $\begin{array}{r}25 \\
3 \\
19 \\
12 \\
23\end{array}$ & $\begin{array}{l}11.0 \\
44.0 \\
17.0 \\
18.0 \\
16.0\end{array}$ & $\begin{array}{r}26 \\
3 \\
16 \\
14 \\
17\end{array}$ \\
\hline $\begin{array}{l}956 \\
957 \\
958 \\
959\end{array}$ & $\begin{array}{c}100 \\
84.0 \\
431 \\
26.0 \\
40.0\end{array}$ & $\begin{array}{r}19 \\
21 \\
5 \\
27 \\
25\end{array}$ & $\begin{array}{r}54.0 \\
66.0 \\
327 \\
23.0 \\
31.0\end{array}$ & $\begin{array}{r}21 \\
18 \\
4 \\
27 \\
24\end{array}$ & $\begin{array}{r}36.0 \\
40.0 \\
229 \\
22.0 \\
27.0\end{array}$ & $\begin{array}{r}23 \\
20 \\
4 \\
27 \\
24\end{array}$ & $\begin{array}{r}23.0 \\
30.0 \\
178 \\
21.0 \\
23.0\end{array}$ & $\begin{array}{r}23 \\
19 \\
4 \\
27 \\
24\end{array}$ & $\begin{array}{c}18.0 \\
27.0 \\
161 \\
20.0 \\
22.0\end{array}$ & $\begin{array}{r}26 \\
19 \\
3 \\
24 \\
23\end{array}$ & $\begin{array}{c}15.0 \\
23.0 \\
140 \\
19.0 \\
19.0\end{array}$ & $\begin{array}{r}28 \\
19 \\
3 \\
23 \\
24\end{array}$ & $\begin{array}{r}15.0 \\
19.0 \\
128 \\
19.0 \\
18.0\end{array}$ & $\begin{array}{r}26 \\
22 \\
2 \\
23 \\
24\end{array}$ & $\begin{array}{c}14.0 \\
17.0 \\
103 \\
19.0 \\
18.0\end{array}$ & $\begin{array}{r}26 \\
24 \\
2 \\
21 \\
23\end{array}$ & & $\begin{array}{r}26 \\
24 \\
2 \\
20 \\
21\end{array}$ & $\begin{array}{l}9.80 \\
12.0 \\
48.0 \\
14.0 \\
12.0\end{array}$ & $\begin{array}{r}27 \\
23 \\
2 \\
21 \\
22\end{array}$ \\
\hline $\begin{array}{l}962 \\
963 \\
964 \\
965\end{array}$ & $\begin{array}{c}245 \\
466 \\
24.0 \\
62.0 \\
146\end{array}$ & $\begin{array}{r}11 \\
3 \\
29 \\
23 \\
15\end{array}$ & $\begin{array}{c}92.0 \\
223 \\
17.0 \\
28.0 \\
141\end{array}$ & $\begin{array}{r}16 \\
6 \\
29 \\
25 \\
11\end{array}$ & $\begin{array}{c}44.0 \\
158 \\
15.0 \\
24.0 \\
129\end{array}$ & $\begin{array}{r}17 \\
6 \\
29 \\
26 \\
7\end{array}$ & $\begin{array}{r}23.0 \\
103 \\
14.0 \\
22.0 \\
92.0\end{array}$ & $\begin{array}{r}25 \\
5 \\
29 \\
26 \\
7\end{array}$ & $\begin{array}{l}18.0 \\
65.0 \\
13.0 \\
19.0 \\
64.0\end{array}$ & $\begin{array}{r}27 \\
9 \\
29 \\
25 \\
10\end{array}$ & $\begin{array}{l}16.0 \\
50.0 \\
12.0 \\
18.0 \\
45.0\end{array}$ & $\begin{array}{r}26 \\
9 \\
29 \\
25 \\
11\end{array}$ & $\begin{array}{l}14.0 \\
41.0 \\
11.0 \\
16.0 \\
39.0\end{array}$ & $\begin{array}{l}27 \\
10 \\
29 \\
25 \\
11\end{array}$ & & $\begin{array}{l}28 \\
10 \\
29 \\
27 \\
11\end{array}$ & & $\begin{array}{l}28 \\
13\end{array}$ & $\begin{array}{c}11.0 \\
19.0 \\
7.80 \\
9.20 \\
16.0\end{array}$ & $\begin{array}{l}24 \\
11 \\
29 \\
28 \\
18\end{array}$ \\
\hline & 115 & 18 & 77.0 & 17 & 42.0 & 18 & 28.0 & 20 & 24.0 & 22 & 21.0 & 21 & 21.0 & 19 & 19.0 & 22 & 17.0 & 22 & 11.0 & 25 \\
\hline
\end{tabular}

DURATION OF DISCHARGE FOR EACH WATER YEAR

$\begin{array}{lllllllllllllllllllllllllllllllllll}\text { CLASS } 0 & 1 & 2 & 3 & 4 & 5 & 6 & 7 & 8 & 9 & 10 & 11 & 12 & 13 & 14 & 15 & 16 & 17 & 18 & 19 & 20 & 21 & 22 & 23 & 24 & 25 & 26 & 27 & 28 & 29 & 30 & 31 & 32 & 33 & 34\end{array}$

YEAR

NUMBER OF DAYS IN CJASS

OBIC FEET

ER SECOND

1943

1944

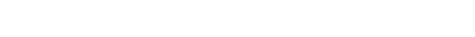

$\begin{array}{rrrrrrrrrrrr}3 & 101 & 73 & 73 & 40 & 16 & 25 & 23 & 10 & 1 & 1 & \\ 28 & 67 & 81 & 86 & 34 & 36 & 25 & 4 & 1 & 2 & & 1\end{array}$

10592.0

10592.0
11100.0

$\begin{array}{rrrrrrrrrrrrrrrrrrrrrrrrrr}2 & 7 & 28 & 72 & 22 & 52 & 96 & 72 & 9 & & 2 & 2 & & 1 & & & & \\ & & & 7 & 52 & 34 & 33 & 94 & 78 & 23 & 17 & 12 & 5 & 3 & 1 & 1 & 2 & 2 & 1\end{array}$

$\begin{array}{rrrrrrrr}53 & 34 & 82 & 116 & 48 & 24 & 8 & 1\end{array}$

1946
1947

1948

$\begin{array}{rrrrrrrrrrr}4 & 47 & 98 & 69 & 17 & 35 & 42 & 29 & 16 & 5 & 3\end{array}$

$\begin{array}{llllllll}1 & 3 & 16 & 37 & 33 & 25 & 87 & 114\end{array}$

$\begin{array}{lllllllll}2 & 6 & 24 & 47 & 48 & 89 & 125 & 23 & 1\end{array}$

$\begin{array}{lllllllllllllllll}2 & 11 & 21 & 41 & 62 & 64 & 49 & 28 & 9 & 8 & 11 & 18 & 20 & 10 & 4 & 6 & 2\end{array}$

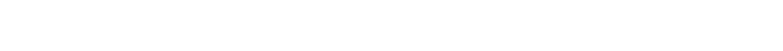

9932.0

1951

1953

1954

1956

1957
1958

$\begin{array}{rlrlllllrrrrrr}2 & 4 & 55 & 47 & 55 & 24 & 93 & 75 & 3 & 2 & 2 & 2 & 1 & 1\end{array}$

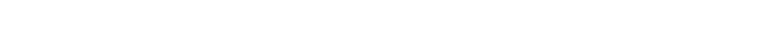

$\begin{array}{lrrrrrrr}4 & 28 & 30 & 54 & 49 & 57 & 132 & 11\end{array}$

$\begin{array}{rlllllllllllllll}3 & 5 & 1 & 1 & 1 & 9 & 36 & 24 & 29 & 55 & 41 & 91 & 41 & 24 & 4 & 1\end{array}$

6176.2

12448.8

6580.3

10368.0

7363.5

1960

$\begin{array}{rrrrrrrrrrrrrrrrrrrrr}2 & 1 & 9 & 14 & 23 & 41 & 41 & 37 & 63 & 110 & 20 & 2 & & & & & 1 & & & & \\ & & & 31 & 24 & 50 & 44 & 56 & 34 & 40 & 52 & 12 & 6 & 5 & 5 & & 2 & 2 & & 1 & 1\end{array}$

$\begin{array}{llllllllll}11 & 26 & 41 & 21 & 79 & 89 & 65 & 30 & 2 & 1\end{array}$

$\begin{array}{rrrrrrrrrrrrrrrr}9 & 49 & 58 & 71 & 73 & 35 & 27 & 26 & 17 & & & 1 & & & \\ 2 & 39 & 19 & 63 & 93 & 33 & 24 & 19 & 30 & 20 & 11 & 1 & 2 & 3 & 6\end{array}$

4180.8

15925.1

6147.0

6612.7

5697.6

1961

1962

1964

3579.6

4250.0

17440.4

4936.5

4237.3

$\begin{array}{llllllllllllll}6 & 25 & 40 & 59 & 24 & 29 & 65 & 74 & 28 & 6 & 4 & 2 & 2 & 1\end{array}$

$\begin{array}{rrrrrrrrrrrrr}19 & 31 & 17 & 16 & 91 & 114 & 35 & 24 & 7 & 2 & 1 & 2 & 1 \\ 12 & 22 & 12 & 31 & 122 & 79 & 51 & 17 & 16 & 3 & 1 & & \end{array}$

1967

$\begin{array}{rrrrrrrrrrrrrrrrrrrrr} & 1 & 4 & 5 & 10 & 17 & 27 & 29 & 49 & 96 & 61 & 66 & & & & & & & & & \end{array}$

3938.9

6845.7

2853.0

3355.3

5754.7

1969

$1 \quad 1 \quad 5296.8$

10030.6

21215.1

5285.2

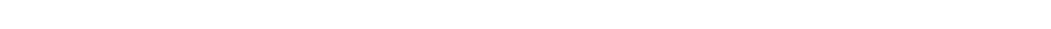

3839.8 
VIRGIN RIVER BASIN

09410000 SANTA CLARA RIVER ABOVE WINSOR DAM, NEAR SANTA CIARA, UT-Continued

DURATION TABLE OF DISCHARGE FOR WATER YEARS 1943-71

$\begin{array}{crl}\text { CUBIC } & \text { ACOJ- } \\ \text { FEET } & \text { MU- } & \text { PER- } \\ \text { PER TOTAL LATED } & \text { CENT } \\ \text { CIASS SECOND DAYS DAYS } & \text { DAYS }\end{array}$

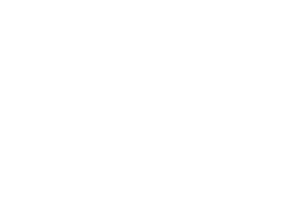

OBIC ACOU$\begin{array}{lll}\text { FEET } & \text { MU- } & \text { PER- } \\ \text { PER TOTAL LATED } & \text { CENT }\end{array}$ CLASS SECOND DAYS DAYS DAYS

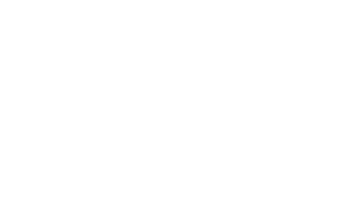

$\begin{array}{lll}\text { OBBIC } & \text { ACCU- } \\ \text { FEET } & \text { MU- } & \text { PER- } \\ \text { PER TOTAL LATED } & \text { CENT }\end{array}$ CLASS SECOND DAYS DAYS DAYS $\begin{array}{ccc}\text { CHBIC } & \text { ACCU- } \\ \text { FEET } & \text { MU- } & \text { PER- } \\ \text { PER } & \text { TOIAL LATED } & \text { CENT } \\ \text { CIASS SECOND DAYS } & \text { DAYS } & \text { DAYS }\end{array}$

$\begin{array}{rrrrr}27 & 250.0 & 14 & 38 & 0.4 \\ 28 & 330.0 & 18 & 24 & 0.2 \\ 29 & 440.0 & 4 & 6 & 0.1 \\ 30 & 570.0 & 0 & 2 & 0.0 \\ 31 & 750.0 & 0 & 2 & 0.0 \\ 32 & 980.0 & 0 & 2 & 0.0 \\ 33 & 1300.0 & 1 & 2 & 0.0 \\ 34 & 1700.0 & 1 & 1 & 0.0\end{array}$

MONTHLY MEAN DISCHARGES, IN OUBIC FEET PER SECOND, FOR EACH WATER YEAR

\begin{tabular}{|c|c|c|c|c|c|c|c|c|c|c|c|c|}
\hline YEAR & $\propto T$ & NOV & $\mathrm{DEC}$ & JAN & FEBB & MAR & APR & MAY & JUNE & JULY & AJUG & SEP \\
\hline $\begin{array}{l}1943 \\
1944 \\
1945\end{array}$ & $\begin{array}{l}18.3 \\
16.1 \\
14.3\end{array}$ & $\begin{array}{l}20.6 \\
16.0 \\
21.0\end{array}$ & $\begin{array}{l}21.3 \\
22.4 \\
21.8\end{array}$ & $\begin{array}{l}24.0 \\
21.6 \\
21.1\end{array}$ & $\begin{array}{l}43.6 \\
23.6 \\
35.3\end{array}$ & $\begin{array}{l}71.4 \\
62.6 \\
49.8\end{array}$ & $\begin{array}{l}45.9 \\
52.7 \\
46.5\end{array}$ & $\begin{array}{l}37.3 \\
51.5 \\
40.5\end{array}$ & $\begin{array}{l}21.9 \\
46.1 \\
26.2\end{array}$ & $\begin{array}{l}12.5 \\
22.6 \\
18.8\end{array}$ & $\begin{array}{l}17.9 \\
14.9 \\
20.2\end{array}$ & $\begin{array}{l}14.5 \\
13.6 \\
11.8\end{array}$ \\
\hline $\begin{array}{l}1946 \\
1947 \\
1948 \\
1949 \\
1950\end{array}$ & $\begin{array}{l}21.8 \\
52.5 \\
13.8 \\
11.3 \\
19.9\end{array}$ & $\begin{array}{l}20.9 \\
66.7 \\
16.2 \\
14.6 \\
24.3\end{array}$ & $\begin{array}{l}22.8 \\
54.6 \\
18.8 \\
15.2 \\
23.2\end{array}$ & $\begin{array}{l}23.1 \\
28.1 \\
17.8 \\
14.1 \\
26.7\end{array}$ & $\begin{array}{l}24.4 \\
24.6 \\
17.0 \\
18.2 \\
32.3\end{array}$ & $\begin{array}{l}19.1 \\
23.6 \\
17.3 \\
49.2 \\
25.8\end{array}$ & $\begin{array}{l}17.1 \\
27.6 \\
33.8 \\
60.7 \\
23.6\end{array}$ & $\begin{array}{l}14.1 \\
56.7 \\
26.7 \\
53.5 \\
19.5\end{array}$ & $\begin{array}{l}8.48 \\
30.3 \\
20.5 \\
43.6 \\
15.2\end{array}$ & $\begin{array}{c}9.84 \\
15.2 \\
-2 \\
24.2 \\
15.2\end{array}$ & $\begin{array}{c}13.8 \\
16.7 \\
13.4 \\
17.3 \\
8.34\end{array}$ & $\begin{array}{c}7.89 \\
11.7 \\
10.5 \\
18.4 \\
8.93\end{array}$ \\
\hline $\begin{array}{l}1951 \\
1952 \\
1953 \\
1954 \\
1955\end{array}$ & $\begin{array}{l}9.60 \\
9.09 \\
16.9 \\
10.2 \\
10.8\end{array}$ & $\begin{array}{l}12.2 \\
12.6 \\
20.3 \\
11.8 \\
14.0\end{array}$ & $\begin{array}{l}13.2 \\
19.0 \\
20.7 \\
14.3 \\
15.7\end{array}$ & $\begin{array}{l}14.6 \\
12.7 \\
19.9 \\
19.6 \\
17.2\end{array}$ & $\begin{array}{l}13.7 \\
15.9 \\
19.7 \\
16.2 \\
20.7\end{array}$ & $\begin{array}{l}14.0 \\
55.6 \\
17.0 \\
38.8 \\
16.6\end{array}$ & $\begin{array}{c}12.9 \\
187 \\
15.4 \\
32.6 \\
12.2\end{array}$ & $\begin{array}{l}16.2 \\
89.5 \\
15.2 \\
26.2 \\
16.2\end{array}$ & $\begin{array}{l}11.0 \\
53.7 \\
11.6 \\
13.4 \\
11.6\end{array}$ & $\begin{array}{c}5.40 \\
26.8 \\
8.78 \\
11.7 \\
16.4\end{array}$ & $\begin{array}{c}8.04 \\
22.0 \\
26.9 \\
9.87 \\
30.1\end{array}$ & $\begin{array}{c}6.76 \\
19.4 \\
9.81 \\
12.4 \\
5.52\end{array}$ \\
\hline $\begin{array}{l}1956 \\
1957 \\
1958 \\
1959 \\
1960\end{array}$ & $\begin{array}{c}5.96 \\
5.16 \\
16.1 \\
17.4 \\
8.22\end{array}$ & $\begin{array}{c}10.5 \\
6.84 \\
21.0 \\
19.3 \\
8.05\end{array}$ & $\begin{array}{c}13.9 \\
8.33 \\
28.4 \\
19.4 \\
13.9\end{array}$ & $\begin{array}{l}16.8 \\
11.1 \\
13.0 \\
18.5 \\
14.8\end{array}$ & $\begin{array}{l}12.9 \\
20.8 \\
29.0 \\
19.1 \\
15.4\end{array}$ & $\begin{array}{c}11.4 \\
10.4 \\
104 \\
15.1 \\
20.2\end{array}$ & $\begin{array}{c}10.4 \\
9.28 \\
132 \\
13.2 \\
17.9\end{array}$ & $\begin{array}{l}9.14 \\
19.7 \\
125 \\
11.3 \\
16.2\end{array}$ & $\begin{array}{c}5.55 \\
25.3 \\
43.6 \\
7.49 \\
11.8\end{array}$ & $\begin{array}{c}11.9 \\
11.7 \\
22.7 \\
5.28 \\
4.92\end{array}$ & $\begin{array}{c}5.00 \\
6.80 \\
18.3 \\
8.68 \\
2.98\end{array}$ & $\begin{array}{c}3.90 \\
5.25 \\
18.7 \\
8.00 \\
4.71\end{array}$ \\
\hline $\begin{array}{l}1961 \\
1962 \\
1963 \\
1964 \\
1965\end{array}$ & $\begin{array}{l}6.23 \\
6.89 \\
8.47 \\
4.64 \\
4.19\end{array}$ & $\begin{array}{r}16.4 \\
8.45 \\
7.38 \\
6.89 \\
4.81\end{array}$ & $\begin{array}{c}13.6 \\
12.8 \\
9.83 \\
8.97 \\
7.46\end{array}$ & $\begin{array}{c}10.8 \\
10.9 \\
12.9 \\
9.55 \\
7.67\end{array}$ & $\begin{array}{c}9.47 \\
64.0 \\
10.7 \\
6.92 \\
8.29\end{array}$ & $\begin{array}{c}13.1 \\
36.3 \\
7.63 \\
9.47 \\
10.8\end{array}$ & $\begin{array}{c}15.5 \\
22.7 \\
8.86 \\
18.0 \\
62.2\end{array}$ & $\begin{array}{c}13.6 \\
22.0 \\
9.94 \\
17.8 \\
26.6\end{array}$ & $\begin{array}{c}7.91 \\
15.5 \\
4.88 \\
11.8 \\
27.2\end{array}$ & $\begin{array}{r}2.97 \\
7.92 \\
2.93 \\
4.52 \\
13.7\end{array}$ & $\begin{array}{l}5.92 \\
4.32 \\
4.29 \\
7.06 \\
9.17\end{array}$ & $\begin{array}{c}14.2 \\
17.3 \\
6.11 \\
4.35 \\
7.62\end{array}$ \\
\hline $\begin{array}{l}1966 \\
1967 \\
1968 \\
1969 \\
1970\end{array}$ & $\begin{array}{c}6.45 \\
5.28 \\
17.1 \\
7.93 \\
20.9\end{array}$ & $\begin{array}{c}16.5 \\
7.32 \\
12.8 \\
13.1 \\
22.5\end{array}$ & $\begin{array}{c}36.0 \\
141 \\
12.6 \\
13.5 \\
22.7\end{array}$ & $\begin{array}{l}17.8 \\
14.5 \\
14.9 \\
53.0 \\
20.5\end{array}$ & $\begin{array}{l}13.5 \\
17.5 \\
30.8 \\
76.8 \\
13.5\end{array}$ & $\begin{array}{r}16.5 \\
15.0 \\
32.5 \\
108 \\
12.9\end{array}$ & $\begin{array}{c}18.1 \\
17.3 \\
20.5 \\
156 \\
12.5\end{array}$ & $\begin{array}{c}20.3 \\
24.6 \\
23.2 \\
118 \\
14.9\end{array}$ & $\begin{array}{l}11.6 \\
26.6 \\
18.0 \\
68.5 \\
12.7\end{array}$ & $\begin{array}{c}5.42 \\
16.5 \\
15.2 \\
30.1 \\
5.10\end{array}$ & $\begin{array}{c}6.42 \\
19.4 \\
13.4 \\
23.9 \\
7.69\end{array}$ & $\begin{array}{c}5.12 \\
22.3 \\
6.25 \\
31.5 \\
7.63\end{array}$ \\
\hline 1971 & 2.22 & 1.58 & 5.95 & 2.35 & 2.49 & 15.3 & 13.3 & 14.1 & 17.6 & 20.4 & 17.9 & 1.2 .3 \\
\hline
\end{tabular}

ANNUAL PEAK DISCHARGE, IN CUBIC FEET PER SECOND, AND CORRESPONDING GAGE HEIGHT, IN FEET, FOR EACH WATER YEAR

\begin{tabular}{|c|c|c|c|c|c|c|c|c|c|c|c|}
\hline $\begin{array}{l}\text { WATERR } \\
\text { YEAR }\end{array}$ & DATE & $\begin{array}{c}\text { GAGE } \\
\text { HEIGHT }\end{array}$ & $\begin{array}{c}\text { PEAK } \\
\text { DISCHARGE }\end{array}$ & $\begin{array}{l}\text { WATER } \\
\text { YEAR }\end{array}$ & DATE & $\begin{array}{c}\text { GAGE } \\
\text { HEIGHT }\end{array}$ & $\begin{array}{c}\text { PEAR } \\
\text { DISCHARGE }\end{array}$ & $\begin{array}{l}\text { WATERR } \\
\text { YEAR }\end{array}$ & DATE & $\begin{array}{c}\text { GAGE } \\
\text { HEIGHT }\end{array}$ & $\begin{array}{c}\text { PEAK } \\
\text { DISCHARGE }\end{array}$ \\
\hline $\begin{array}{l}1942 \\
1943 \\
1944 \\
1945 \\
1946 \\
1947 \\
1948 \\
1949 \\
1950 \\
1951\end{array}$ & $\begin{array}{l}\text { AUG. } 09,1942 \\
\text { MAR. } 10,1943 \\
\text { MAR. 10, } 1944 \\
\text { JULY } 31,1945 \\
\text { AUG. 12, } 1946 \\
\text { NOW. 24, } 1946 \\
\text { SEPT.16, } 1948 \\
\text { SEPT.09, } 1949 \\
\text { JULY 17, } 1950 \\
\text { AUG. 03, } 1951\end{array}$ & $\begin{array}{l}5.50 \\
2.92 \\
2.95 \\
6.50 \\
4.34 \\
6.25 \\
4.97 \\
3.65 \\
6.50 \\
3.11\end{array}$ & $\begin{array}{r}2400 \\
269 \\
320 \\
2100 \\
685 \\
2400 \\
1080 \\
398 \\
2730 \\
242\end{array}$ & $\begin{array}{l}1952 \\
1953 \\
1954 \\
1955 \\
1956 \\
1957 \\
1958 \\
1959 \\
1960 \\
1961\end{array}$ & $\begin{array}{l}\text { APR. } 07,1952 \\
\text { AUG. } 26,1953 \\
\text { MAR. } 23,1954 \\
\text { AUG. 24, } 1955 \\
\text { JULY 27, } 1956 \\
\text { FEB. 23, } 1957 \\
\text { MAR. 16, } 1958 \\
\text { AUG. 11, } 1959 \\
\text { JUNE 06, } 1960 \\
\text { SEPT.17, } 1961\end{array}$ & $\begin{array}{r}3.65 \\
9.40 \\
3.32 \\
10.25 \\
5.87 \\
2.60 \\
4.28 \\
2.50 \\
0.96 \\
5.12\end{array}$ & $\begin{array}{r}753 \\
5340 \\
536 \\
6190 \\
2160 \\
280 \\
1100 \\
348 \\
78 \\
1180\end{array}$ & $\begin{array}{l}1962 \\
1963 \\
1964 \\
1965 \\
1966 \\
1967 \\
1968 \\
1969 \\
1970 \\
1971\end{array}$ & $\begin{array}{l}\text { SEPT.28, } 1962 \\
\text { SEPT.19, } 1963 \\
\text { AUG. } 14,1964 \\
\text { APR. } 15,1965 \\
\text { DEC. } 20,1965 \\
\text { DEC. 06, } 1966 \\
\text { JULY } 30,1968 \\
\text { JAN. 25, } 1969 \\
\text { AUG. 18, } 1970 \\
\text { AUG. 21, } 1971\end{array}$ & $\begin{array}{r}8.11 \\
4.04 \\
5.45 \\
3.84 \\
6.31 \\
10.88 \\
7.00 \\
8.75 \\
6.12 \\
7.18\end{array}$ & $\begin{array}{r}3160 \\
347 \\
1170 \\
317 \\
1210 \\
5930 \\
1420 \\
2840 \\
214 \\
763\end{array}$ \\
\hline
\end{tabular}


VIRGIN RIVER BASTN

09410000 SANTA C.ARA RIVER ABQVE WINSCR DAM, NEAR SANIA G.ARA, UT--Continued

\begin{tabular}{|c|c|c|c|c|c|c|}
\hline \multirow{2}{*}{$\begin{array}{l}\text { ERIa } \\
\text { CON- } \\
\text { ECU- } \\
\text { 'TVE } \\
\text { AYS) }\end{array}$} & \multicolumn{6}{|c|}{$\begin{array}{l}\text { DISCHARGE, IN COBIC FEET PER SECOND, FOR } \\
\text { INDICATED RDOURRENCE INTERNAL, IN YEARS, AND } \\
\text { ANNUAL NONEXCEEDANCE PRCBABILITY, IN PERCENT }\end{array}$} \\
\hline & $\begin{array}{c}2 \\
50 \%\end{array}$ & $\begin{array}{c}5 \\
20 \%\end{array}$ & $\begin{array}{l}10 \\
108\end{array}$ & $\begin{array}{l}20 \\
58\end{array}$ & $\begin{array}{l}50 \\
28\end{array}$ & $\begin{array}{r}100 \\
18\end{array}$ \\
\hline $\begin{array}{r}1 \\
7 \\
14 \\
30 \\
60 \\
90\end{array}$ & $\begin{array}{l}5.1 \\
6.4 \\
6.8 \\
7.4 \\
8.2 \\
8.9\end{array}$ & $\begin{array}{l}2.4 \\
3.0 \\
3.4 \\
4.0 \\
4.8 \\
5.6\end{array}$ & $\begin{array}{l}1.5 \\
1.9 \\
2.1 \\
2.8 \\
3.5 \\
4.3\end{array}$ & $\begin{array}{l}0.99 \\
1.2 \\
1.4 \\
2.0 \\
2.7 \\
3.5\end{array}$ & $\begin{array}{l}0.6 \\
0.6 \\
0.8 \\
1.3 \\
2.0 \\
2.7\end{array}$ & $\begin{array}{l}- \\
-- \\
-- \\
- \\
-\end{array}$ \\
\hline
\end{tabular}

MAGNITUDE AND PRCBABILITY OF ANNUAL HIGHEST MEAN DISCHARGE BASED ON WATER YEARS 1943-71

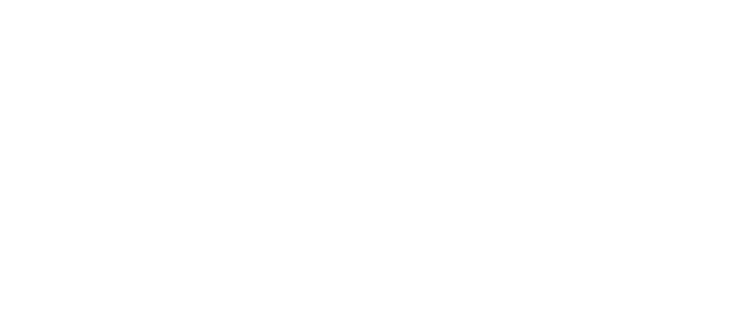

09410100 SANTA CLARA RIVER BELOW WINSCR DAM, NEAR SANTA OLARA, UT

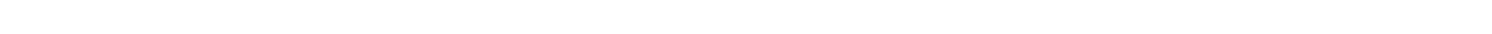
left bank $900 \mathrm{ft}$ downstream fram Winsor Dam, $0.6 \mathrm{mi}$ northwest of Shivwits Indian Village, and $7.5 \mathrm{mi}$ northwest of Santa Clara.

DRATNAGE AREA. $--378 \mathrm{mi}^{2}$.

PERICD OF RECORD AVAIIABLE.--December 1971 to September 1981.

REVISED RECORDS. -WDR UT-73-1: 1972(M).

GAGE.--Water-stage recorder. Altitude of gage is 3,210 ft fram topographic map. Prior to July 11, 1979, at several sites downstream at different datums.

REMARKS.--Many diversions for irrigation above station. Flow slightly regulated by several reservoirs and powerplants above station.

AVERAGE DISCHARGE. - -9 years (water years 1973-81), $30.6 \mathrm{ft}^{3} / \mathrm{s}, 22,170 \mathrm{acre}-\mathrm{ft} / \mathrm{yr}$.

EXIREMES FOR PERIOD OF RECORD.--Maximum discharge, 1,700 ft $3 / \mathrm{s} \mathrm{Mar.} \mathrm{28,} \mathrm{1979,} \mathrm{gage} \mathrm{height,} 5.75 \mathrm{ft}$, fran rating curve extended above $980 \mathrm{ft}^{3} / \mathrm{s}$ on basis of slope-area measurement; maximum gage height, $6.55 \mathrm{ft}$ February 19, 1980; no flow several days most years.

LOWEST MEAN DISCHARGE, IN OBIC FEET PER SECOND, AND RANKING FOR THE INDICATED NUMBER OF CONSECUTIVE DAYS FOR EACH CLIMATIC YEAR, APRIL 1-MARCH 31

\begin{tabular}{|c|c|c|c|c|c|c|c|c|c|c|c|c|c|c|c|c|c|c|c|}
\hline YEAR & & & & & & & & & CONSE & & E DAYS & & & & & & & & \\
\hline $\begin{array}{l}1973 \\
1974 \\
1975\end{array}$ & $\begin{array}{l}0.00 \\
0.60 \\
0.00\end{array}$ & $\begin{array}{l}1 \\
8 \\
2\end{array}$ & $\begin{array}{l}0.00 \\
0.64 \\
0.00\end{array}$ & $\begin{array}{l}1 \\
8 \\
2\end{array}$ & $\begin{array}{l}0.00 \\
0.67 \\
0.00\end{array}$ & $\begin{array}{l}1 \\
8 \\
2\end{array}$ & $\begin{array}{l}0.00 \\
0.83 \\
0.00\end{array}$ & $\begin{array}{l}1 \\
8 \\
2\end{array}$ & $\begin{array}{l}0.07 \\
1.30 \\
0.00\end{array}$ & $\begin{array}{l}4 \\
8 \\
1\end{array}$ & $\begin{array}{l}0.09 \\
2.30 \\
0.00\end{array}$ & $\begin{array}{l}3 \\
7 \\
1\end{array}$ & $\begin{array}{l}0.12 \\
2.60 \\
0.00\end{array}$ & $\begin{array}{l}3 \\
7 \\
1\end{array}$ & $\begin{array}{l}0.33 \\
5.40 \\
0.02\end{array}$ & $\begin{array}{l}3 \\
7 \\
2\end{array}$ & $\begin{array}{l}0.93 \\
6.10 \\
1.80\end{array}$ & $\begin{array}{l}1 \\
6 \\
3\end{array}$ & $\begin{array}{c}4.80 \\
38.0 \\
8.00\end{array}$ \\
\hline $\begin{array}{l}1976 \\
1977 \\
1978 \\
1979 \\
1980\end{array}$ & $\begin{array}{l}0.00 \\
0.00 \\
0.00 \\
0.00 \\
0.00\end{array}$ & $\begin{array}{l}3 \\
4 \\
5 \\
6 \\
7\end{array}$ & $\begin{array}{l}0.00 \\
0.00 \\
0.00 \\
0.00 \\
0.00\end{array}$ & $\begin{array}{l}3 \\
4 \\
5 \\
6 \\
7\end{array}$ & $\begin{array}{l}0.00 \\
0.00 \\
0.00 \\
0.00 \\
0.00\end{array}$ & $\begin{array}{l}3 \\
4 \\
5 \\
6 \\
7\end{array}$ & $\begin{array}{l}0.00 \\
0.00 \\
0.00 \\
0.04 \\
0.00\end{array}$ & $\begin{array}{l}3 \\
4 \\
5 \\
7 \\
6\end{array}$ & $\begin{array}{l}0.18 \\
0.00 \\
0.00 \\
0.20 \\
0.67\end{array}$ & $\begin{array}{l}5 \\
2 \\
3 \\
6 \\
7\end{array}$ & $\begin{array}{l}0.75 \\
0.96 \\
0.00 \\
0.32 \\
7.10\end{array}$ & $\begin{array}{l}5 \\
6 \\
2 \\
4 \\
8\end{array}$ & $\begin{array}{l}1.30 \\
1.50 \\
0.00 \\
0.58 \\
6.30\end{array}$ & $\begin{array}{l}5 \\
6 \\
2 \\
4 \\
8\end{array}$ & $\begin{array}{l}2.50 \\
1.40 \\
0.00 \\
1.40 \\
8.10\end{array}$ & $\begin{array}{l}6 \\
4 \\
1 \\
5 \\
8\end{array}$ & $\begin{array}{r}3.30 \\
1.80 \\
1.10 \\
7.50 \\
13.0\end{array}$ & $\begin{array}{l}5 \\
4 \\
2 \\
7 \\
8\end{array}$ & $\begin{array}{r}8.60 \\
7.00 \\
18.0 \\
49.0 \\
90.0\end{array}$ \\
\hline 1981 & 4.40 & 9 & 7.10 & 9 & 11.0 & 9 & 12.0 & 9 & 13.0 & 9 & 17.0 & 9 & 19.0 & 9 & 19.0 & 9 & 21.0 & 9 & 45.0 \\
\hline
\end{tabular}

HIGHEST MEAN DISCHARGE, IN OUBIC FEET PER SBCOND, AND RANKING FOR THE INDICATED NUMBER OF CONSEOUTIVE DAYS FOR EACH WATER YEAR, OCTCBER 1-SEPTEMBER 30

\begin{tabular}{|c|c|c|c|c|c|c|c|c|c|c|c|c|c|c|c|c|c|c|c|}
\hline YEAR & & & & & & & & & CONS & & VE DAYS & & & & & & & & \\
\hline $\begin{array}{l}1973 \\
1974 \\
1975\end{array}$ & $\begin{array}{r}489 \\
26.0 \\
33.0\end{array}$ & $\begin{array}{l}4 \\
8 \\
7\end{array}$ & $\begin{array}{r}354 \\
22.0 \\
23.0\end{array}$ & $\begin{array}{l}4 \\
8 \\
7\end{array}$ & $\begin{array}{r}235 \\
19.0 \\
19.0\end{array}$ & $\begin{array}{l}4 \\
7 \\
8\end{array}$ & $\begin{array}{c}185 \\
18.0 \\
18.0\end{array}$ & $\begin{array}{l}4 \\
7 \\
8\end{array}$ & $\begin{array}{c}179 \\
17.0 \\
17.0\end{array}$ & $\begin{array}{l}3 \\
6 \\
7\end{array}$ & $\begin{array}{r}156 \\
16.0 \\
15.0\end{array}$ & $\begin{array}{l}3 \\
6 \\
8\end{array}$ & $\begin{array}{r}121 \\
16.0 \\
15.0\end{array}$ & $\begin{array}{l}4 \\
6 \\
7\end{array}$ & $\begin{array}{l}96.0 \\
16.0 \\
14.0\end{array}$ & $\begin{array}{l}4 \\
6 \\
7\end{array}$ & $\begin{array}{l}69.0 \\
14.0 \\
14.0\end{array}$ & $\begin{array}{l}4 \\
6 \\
7\end{array}$ & $\begin{array}{c}35.0 \\
10.0 \\
7.70\end{array}$ \\
\hline $\begin{array}{l}1976 \\
1977 \\
1978 \\
1979 \\
1980\end{array}$ & $\begin{array}{c}22.0 \\
58.0 \\
501 \\
1500 \\
1150\end{array}$ & $\begin{array}{l}9 \\
6 \\
3 \\
1 \\
2\end{array}$ & $\begin{array}{c}21.0 \\
24.0 \\
437 \\
867 \\
1020\end{array}$ & $\begin{array}{l}9 \\
6 \\
3 \\
2 \\
1\end{array}$ & $\begin{array}{l}20.0 \\
15.0 \\
314 \\
560 \\
908\end{array}$ & $\begin{array}{l}6 \\
9 \\
3 \\
2 \\
1\end{array}$ & $\begin{array}{l}19.0 \\
14.0 \\
218 \\
352 \\
605\end{array}$ & $\begin{array}{l}6 \\
9 \\
3 \\
2 \\
1\end{array}$ & $\begin{array}{l}17.0 \\
13.0 \\
169 \\
230 \\
408\end{array}$ & $\begin{array}{l}8 \\
9 \\
4 \\
2 \\
1\end{array}$ & $\begin{array}{l}16.0 \\
12.0 \\
140 \\
165 \\
301\end{array}$ & $\begin{array}{l}7 \\
9 \\
4 \\
2 \\
1\end{array}$ & $\begin{array}{l}15.0 \\
11.0 \\
130 \\
149 \\
249\end{array}$ & $\begin{array}{l}8 \\
9 \\
3 \\
2\end{array}$ & $\begin{array}{l}14.0 \\
9.90 \\
113 \\
125 \\
210\end{array}$ & $\begin{array}{l}8 \\
9 \\
3 \\
2 \\
1\end{array}$ & $\begin{array}{c}13.0 \\
7.50 \\
82.0 \\
100 \\
163\end{array}$ & $\begin{array}{l}8 \\
9 \\
3 \\
2 \\
1\end{array}$ & $\begin{array}{r}7.90 \\
4.50 \\
44.0 \\
54.0 \\
90.0\end{array}$ \\
\hline
\end{tabular}


VIRGIN RIVER BASIN

09410100 SANTA CIARA RIVER BELOW WINSOR DAM, NEAR SANTA CIARA, UI--Continued

DURATION OF DISCHARGE FOR EACH WATER YEAR

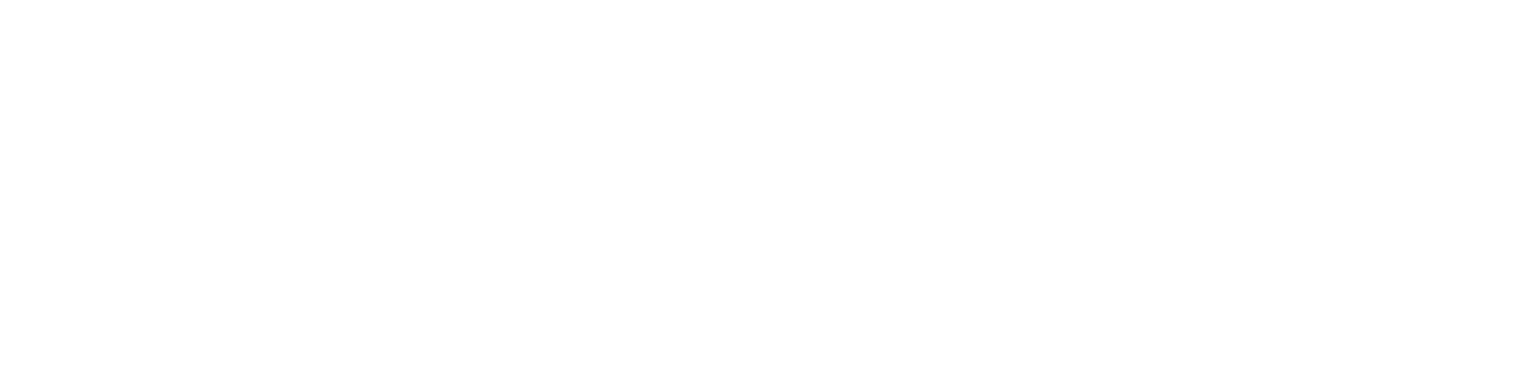

\begin{tabular}{|c|c|c|c|c|c|c|c|c|c|c|c|c|c|c|c|c|c|c|c|}
\hline & & & & & & DURATION & N TABLF & $E$ OF DI & SCHARG & OR WAT & TER YEAR & RS 1973 & $3-81$ & & & & & & \\
\hline ASS & $\begin{array}{c}\text { CUBIC } \\
\text { FEET } \\
\text { PER } \\
\text { SECOND }\end{array}$ & $\begin{array}{r}\text { TOTAL, } \\
\text { DAYS }\end{array}$ & $\begin{array}{c}\text { ACOJ- } \\
\text { MU- } \\
\text { LATED } \\
\text { DAYS }\end{array}$ & $\begin{array}{l}\text { PER- } \\
\text { CENT } \\
\text { DAYS }\end{array}$ & & $\begin{array}{c}\text { CUBIC } \\
\text { FEET } \\
\text { PER } \\
\text { SECOND }\end{array}$ & $\begin{array}{r}\text { TOTAL } \\
\text { DAYS }\end{array}$ & $\begin{array}{l}\text { ACOU- } \\
\text { MU- } \\
\text { LATED } \\
\text { DAYS }\end{array}$ & $\begin{array}{l}\text { PER- } \\
\text { CENT } \\
\text { DAYS }\end{array}$ & CLASS & $\begin{array}{l}\text { QUBIC } \\
\text { FEET } \\
\text { PER } \\
\text { SEOOND }\end{array}$ & $\begin{array}{r}\text { TOTAL } \\
\text { DAYS }\end{array}$ & $\begin{array}{c}\text { ACOU- } \\
\text { MU- } \\
\text { LATED } \\
\text { DAYS }\end{array}$ & $\begin{array}{l}\text { PER- } \\
\text { CENT } \\
\text { DAYS }\end{array}$ & OASS & $\begin{array}{c}\text { OUBIC } \\
\text { FEET } \\
\text { PER } \\
\text { SECOND }\end{array}$ & $\begin{array}{r}\text { TOTAL } \\
\text { DAYS }\end{array}$ & $\begin{array}{c}\text { ACOU- } \\
\text { MU- } \\
\text { LATED } \\
\text { DAYS }\end{array}$ & $\begin{array}{l}\text { PER- } \\
\text { CENT } \\
\text { DAYS }\end{array}$ \\
\hline $\begin{array}{l}0 \\
1 \\
2 \\
3 \\
4 \\
5 \\
6 \\
7 \\
8\end{array}$ & $\begin{array}{l}0.00 \\
0.01 \\
0.02 \\
0.03 \\
0.04 \\
0.06 \\
0.08 \\
0.12 \\
0.17\end{array}$ & $\begin{array}{r}477 \\
37 \\
9 \\
6 \\
23 \\
16 \\
19 \\
19 \\
16\end{array}$ & $\begin{array}{l}3287 \\
2810 \\
2773 \\
2764 \\
2758 \\
2735 \\
2719 \\
2700 \\
2681\end{array}$ & $\begin{array}{r}100.0 \\
85.5 \\
84.4 \\
84.1 \\
83.9 \\
83.2 \\
82.7 \\
82.1 \\
81.6\end{array}$ & $\begin{array}{r}9 \\
10 \\
11 \\
12 \\
13 \\
14 \\
15 \\
16 \\
17\end{array}$ & $\begin{array}{l}0.24 \\
0.34 \\
0.49 \\
0.69 \\
0.99 \\
1.40 \\
2.00 \\
2.80 \\
4.10\end{array}$ & $\begin{array}{r}30 \\
46 \\
43 \\
53 \\
52 \\
87 \\
62 \\
62 \\
133 \\
64\end{array}$ & $\begin{array}{l}2665 \\
2635 \\
2589 \\
2546 \\
2493 \\
2441 \\
2354 \\
2292 \\
2159\end{array}$ & $\begin{array}{l}81.1 \\
80.2 \\
78.8 \\
77.5 \\
75.8 \\
74.3 \\
71.6 \\
69.7 \\
65.7\end{array}$ & $\begin{array}{l}18 \\
19 \\
20 \\
21 \\
22 \\
23 \\
24 \\
25 \\
26\end{array}$ & $\begin{array}{r}5.8 \\
8.2 \\
12.0 \\
17.0 \\
24.0 \\
34.0 \\
48.0 \\
68.0 \\
97.0\end{array}$ & $\begin{array}{r}79 \\
208 \\
520 \\
505 \\
175 \\
106 \\
86 \\
140 \\
130\end{array}$ & $\begin{array}{r}2095 \\
2016 \\
1808 \\
1288 \\
783 \\
608 \\
502 \\
416 \\
276\end{array}$ & $\begin{array}{r}63.7 \\
61.3 \\
55.0 \\
39.2 \\
23.8 \\
18.5 \\
15.3 \\
12.7 \\
8.4\end{array}$ & $\begin{array}{l}27 \\
28 \\
29 \\
30 \\
31 \\
32 \\
33 \\
34\end{array}$ & $\begin{array}{r}140.0 \\
200.0 \\
280.0 \\
400.0 \\
570.0 \\
810.0 \\
1200.0\end{array}$ & $\begin{array}{r}75 \\
35 \\
14 \\
11 \\
5 \\
5 \\
1\end{array}$ & $\begin{array}{r}146 \\
71 \\
36 \\
22 \\
11 \\
6 \\
1\end{array}$ & $\begin{array}{l}4.4 \\
2.2 \\
1.1 \\
0.7 \\
0.3 \\
0.2 \\
0.0\end{array}$ \\
\hline
\end{tabular}

MONIHLY MEAN DISCHARGES, IN OBIC FEET PER SECOND, FOR EAG WATER YEAR

$\begin{array}{lllllllllllll}\text { YEAR } & \text { OCT } & \text { NOV } & \text { DEC } & \text { JAN } & \text { FEB } & \text { MAR } & \text { APR } & \text { MAY } & \text { JUNE } & \text { JULY } & \text { AUG } & \text { SEP } \\ 1973 & 0.12 & 0.11 & 0.18 & 1.03 & 2.62 & 1.96 & 86.1 & 157 & 113 & 21.4 & 19.2 & 17.8 \\ 1974 & 4.18 & 3.51 & 1.35 & 13.3 & 5.24 & 8.33 & 11.7 & 10.9 & 14.5 & 15.9 & 15.3 & 17.3 \\ 1975 & 2.72 & 0.01 & 0.09 & 0.00 & 0.00 & 7.63 & 13.0 & 15.7 & 13.6 & 11.7 & 15.8 & 11.2 \\ 1976 & 0.41 & 8.35 & 0.22 & 1.31 & 2.71 & 8.96 & 11.8 & 15.1 & 16.7 & 12.3 & 10.5 & 6.32 \\ 1977 & 0.12 & 5.18 & 1.21 & 1.48 & 3.03 & 0.14 & 6.08 & 5.06 & 12.4 & 10.9 & 8.93 & 0.00 \\ 1978 & 0.00 & 0.00 & 0.08 & 0.81 & 72.4 & 108 & 169 & 77.4 & 45.1 & 17.5 & 25.0 & 12.9 \\ 1979 & 4.73 & 0.35 & 1.15 & 7.32 & 77.2 & 153 & 136 & 114 & 89.4 & 24.9 & 22.2 & 16.3 \\ 1980 & 4.64 & 14.7 & 2.60 & 158 & 366 & 149 & 136 & 89.3 & 78.2 & 34.1 & 33.9 & 29.1 \\ 1981 & 16.6 & 20.4 & 21.7 & 18.6 & 23.1 & 36.7 & 57.0 & 16.6 & 17.1 & 18.2 & 17.0 & 15.4\end{array}$

ANNUAL PEAK DISCHARGE, IN CUBIC FEET PER SECOND, AND CORRESPONDING GAGE HEIGHT, IN FEET, FOR EACH WATER YEAR

\begin{tabular}{|c|c|c|c|c|c|c|c|c|c|c|c|}
\hline $\begin{array}{l}\text { WATER } \\
\text { YEAR }\end{array}$ & DATE & $\begin{array}{c}\text { GAGE } \\
\text { HEIGHT }\end{array}$ & $\begin{array}{c}\text { PEAK } \\
\text { DISCHARGE }\end{array}$ & $\begin{array}{l}\text { WATERR } \\
\text { YEAR }\end{array}$ & DATE & $\begin{array}{c}\text { GAGE } \\
\text { HEIGHT }\end{array}$ & $\begin{array}{c}\text { PEAK } \\
\text { DISCHARGE }\end{array}$ & $\begin{array}{l}\text { WATER } \\
\text { YEAR }\end{array}$ & DATE & $\begin{array}{c}\text { GAGE } \\
\text { HEIGHT }\end{array}$ & $\begin{array}{c}\text { PEAK } \\
\text { DISCHARGE }\end{array}$ \\
\hline $\begin{array}{l}1972 \\
1973 \\
1974 \\
1975\end{array}$ & $\begin{array}{l}\text { MAR. 06, } 1972 \\
\text { APR. 29, } 1973 \\
\text { SEPT.05, } 1974 \\
\text { OCT. 26, } 1974\end{array}$ & $\begin{array}{l}1.88 \\
3.58 \\
2.31 \\
2.60\end{array}$ & $\begin{array}{r}55 \\
954 \\
161 \\
176\end{array}$ & $\begin{array}{l}1976 \\
1977 \\
1978\end{array}$ & $\begin{array}{l}\text { SEPT.11, } 1976 \\
\text { AJG. 23, } 1977 \\
\text { FEB. 24, } 1978\end{array}$ & $\begin{array}{l}2.61 \\
4.60 \\
4.07\end{array}$ & $\begin{array}{r}35 \\
980 \\
547\end{array}$ & $\begin{array}{l}1979 \\
1980 \\
1981\end{array}$ & $\begin{array}{l}\text { MAR. } 28,1979 \\
\text { FEB. } 19,1980 \\
\text { APR. } 20,1981\end{array}$ & $\begin{array}{l}5.75 \\
6.55 \\
3.51\end{array}$ & $\begin{array}{r}1700 \\
1540 \\
208\end{array}$ \\
\hline
\end{tabular}

09410400 SANTA CIARA RIVER NEAR SANTA CIARA, UT

LOCATION.-Lat $37^{\circ} 08^{\prime} 23^{\prime \prime}$, long $113^{\circ} 41^{\prime} 31^{\prime \prime}$, in SE $\mathrm{SESW}_{4}^{\frac{1}{4} S W_{\frac{1}{4}}^{\prime}}$ sec.7, T.42 S., R.16 W., Washington County, Hydrologic Unit 15010008, on left bank $1 \mathrm{mi}$ downstream from Whitmore Canyon and $2 \mathrm{mi}$ west of Santa Clara.

DRAINAGE AREA.-410 $\mathrm{mi}^{2}$, approximately.

PERIOD OF RECORD AVAILABLE.-May 1965 to September 1974.

GAGE.-Water-stage recorder. Altitude of gage is 2,850 ft from topographic map.

REMARKS.-Many diversions for irrigation above station. Flow regulated by Gunlock Reservoir except for flooding between the reservoir and station.

AVERAGE DISCHARGE.--9 years, $20.8 \mathrm{ft}^{3} / \mathrm{s}, 15,070 \mathrm{acre}-\mathrm{ft} / \mathrm{yr}$.

EXIREMES FOR PERICD OF RECORD.--Maximum discharge, 6,390 $\mathrm{ft}^{3} / \mathrm{s}$ Dec. 7,1966 , gage height, $12.60 \mathrm{ft}$, fram slope-area measurement of peak flow; no flow for several days in 1972 and 1973. 
VIRGIN RIVER BASIN

09410400 SANTA C.ARA RIVER NEAR SANTA C.ARA, UT--Continued

LOWEST MEAN DISCHARGE, IN OUBIC FEET PER SECOND, AND RANKING FOR THE INDICATED NUMBER OF CONSECITIVE DAYS FOR EACH QLIMATIC YEAR, APRII 1-MARCH 31

\begin{tabular}{|c|c|c|c|c|c|c|c|c|c|c|c|c|c|c|c|c|c|c|c|}
\hline YEAR & & & & & & & & & CONSE & 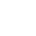 & E DAYS & & & & & & & & \\
\hline $\begin{array}{l}1967 \\
1968 \\
1969 \\
1970\end{array}$ & $\begin{array}{l}0.10 \\
4.20 \\
0.33 \\
6.80\end{array}$ & $\begin{array}{l}3 \\
7 \\
5 \\
8\end{array}$ & $\begin{array}{l}0.10 \\
4.80 \\
1.50 \\
7.00\end{array}$ & $\begin{array}{l}3 \\
7 \\
5 \\
8\end{array}$ & $\begin{array}{l}0.14 \\
5.30 \\
2.80 \\
8.10\end{array}$ & $\begin{array}{l}3 \\
7 \\
6 \\
8\end{array}$ & $\begin{array}{l}0.69 \\
7.20 \\
3.00 \\
9.10\end{array}$ & $\begin{array}{l}4 \\
7 \\
6 \\
8\end{array}$ & $\begin{array}{r}1.30 \\
8.70 \\
3.20 \\
12.0\end{array}$ & $\begin{array}{l}4 \\
7 \\
6 \\
8\end{array}$ & $\begin{array}{c}2.50 \\
9.50 \\
3.90 \\
13.0\end{array}$ & $\begin{array}{l}4 \\
7 \\
6 \\
8\end{array}$ & $\begin{array}{c}2.40 \\
11.0 \\
5.20 \\
17.0\end{array}$ & $\begin{array}{l}2 \\
7 \\
6 \\
8\end{array}$ & $\begin{array}{c}2.80 \\
12.0 \\
6.30 \\
17.0\end{array}$ & $\begin{array}{l}3 \\
7 \\
5 \\
8\end{array}$ & $\begin{array}{c}4.60 \\
13.0 \\
7.80 \\
17.0\end{array}$ & $\begin{array}{l}4 \\
7 \\
5 \\
8\end{array}$ & $\begin{array}{l}20.0 \\
17.0 \\
34.0 \\
39.0\end{array}$ \\
\hline $\begin{array}{l}1971 \\
1972 \\
1973 \\
1974\end{array}$ & $\begin{array}{l}0.22 \\
0.00 \\
0.00 \\
2.40\end{array}$ & $\begin{array}{l}4 \\
1 \\
2 \\
6\end{array}$ & $\begin{array}{l}0.40 \\
0.03 \\
0.00 \\
2.60\end{array}$ & $\begin{array}{l}4 \\
2 \\
1 \\
6\end{array}$ & $\begin{array}{l}0.42 \\
0.13 \\
0.00 \\
2.70\end{array}$ & $\begin{array}{l}4 \\
2 \\
1 \\
5\end{array}$ & $\begin{array}{l}0.44 \\
0.48 \\
0.00 \\
2.80\end{array}$ & $\begin{array}{l}2 \\
3 \\
1 \\
5\end{array}$ & $\begin{array}{l}0.56 \\
0.50 \\
0.26 \\
3.10\end{array}$ & $\begin{array}{l}3 \\
2 \\
1 \\
5\end{array}$ & $\begin{array}{l}1.70 \\
1.70 \\
0.98 \\
3.80\end{array}$ & $\begin{array}{l}2 \\
3 \\
1 \\
5\end{array}$ & $\begin{array}{l}2.70 \\
2.50 \\
1.19 \\
3.90\end{array}$ & $\begin{array}{l}4 \\
3 \\
1 \\
5\end{array}$ & $\begin{array}{l}3.10 \\
2.70 \\
1.40 \\
6.90\end{array}$ & $\begin{array}{l}4 \\
2 \\
1 \\
6\end{array}$ & $\begin{array}{l}3.60 \\
4.30 \\
1.80 \\
8.20\end{array}$ & $\begin{array}{l}2 \\
3 \\
1 \\
6\end{array}$ & $\begin{array}{r}6.30 \\
8.60 \\
5.10 \\
41.0\end{array}$ \\
\hline
\end{tabular}

HIGHEST MEAN DISCHARGE, IN OBIC FEET PER SECOND, AND RANKING FOR THE INDICATED NUMBER OF CONSEUTIVE DAYS FOR EAOH WATER YEAR, OCTOBER I-SEPTEMBER 30

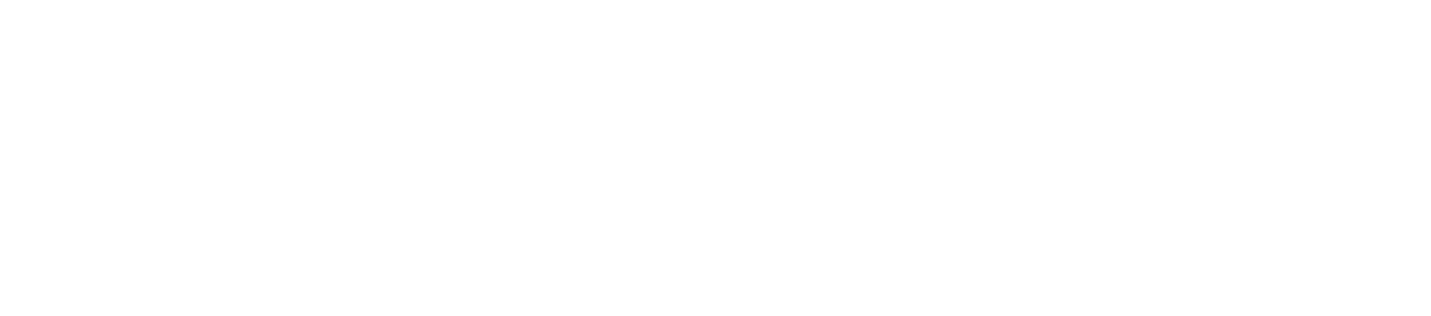

DURATION OF DISGHARGE FOR EACH WATER YEAR

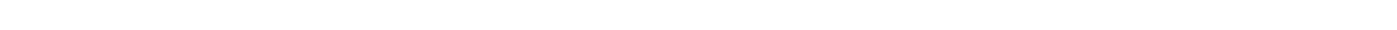

YEAR NUMBER OF DAYS IN CLASS

UBIC FEET

PER SECOND -DAYS

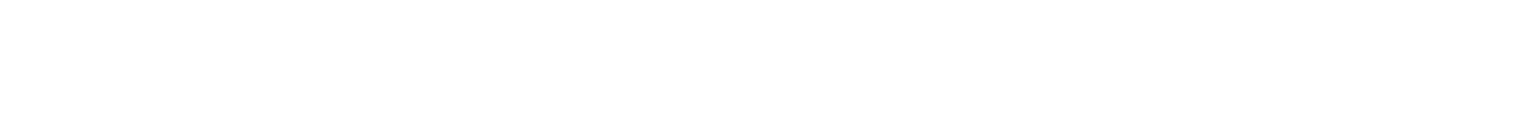

$1971 \quad \begin{array}{lllllllllllllllllllll}1 & 8 & 16 & 15 & 19 & 21 & 14 & 10 & 12 & 8 & 25 & 13 & 50 & 56 & 86 & 2 & 2 & 1 & 1 & 1 & 4\end{array}$

$\begin{array}{lllllllllllllllllllllllllllllllll}1973 & 21 & 6 & 1 & 1 & 4 & 14 & 10 & 7 & 31 & 24 & 15 & 21 & 5 & 5 & 7 & 2 & 3 & 28 & 59 & 15 & 3 & 7 & 12 & 12 & 11 & 14 & 17 & 10 & \end{array}$

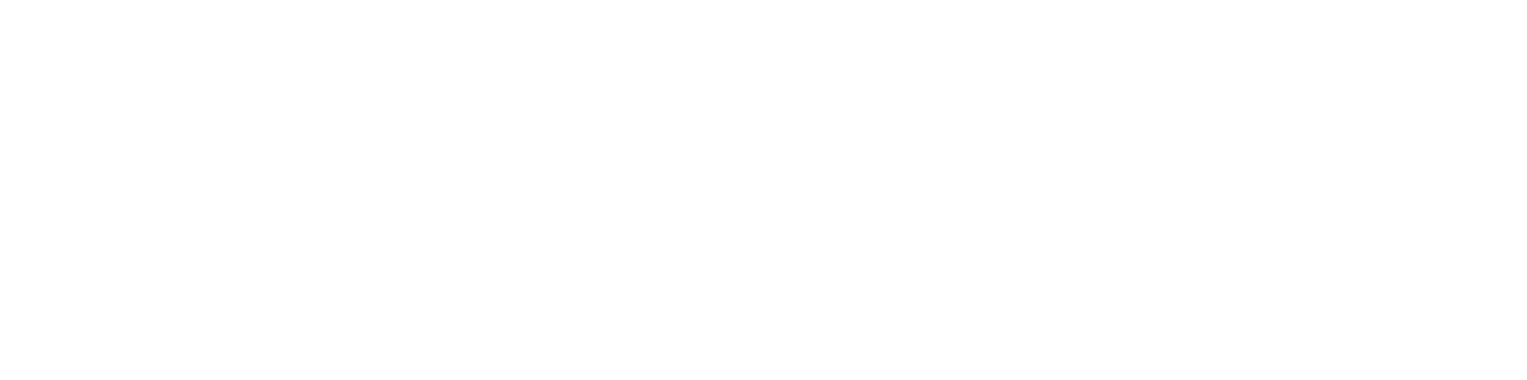

MONIHLY MEAN DISQHARGES, IN OBBIC FEET PER SECOND, FOR EAOH WATER YEAR

$\begin{array}{lcccccccccccc}\text { YEAR } & \text { OCT } & \text { NOV } & \text { DEC } & \text { JAN } & \text { FEB } & \text { MAR } & \text { APR } & \text { MAY } & \text { JUNE } & \text { JULY } & \text { AUG } & \text { SEP } \\ 1966 & 5.56 & 14.4 & 35.7 & 23.0 & 16.6 & 15.5 & 17.3 & 16.6 & 8.49 & 2.41 & 2.93 & 2.19 \\ 1967 & 4.12 & 8.16 & 137 & 16.7 & 14.0 & 13.3 & 15.6 & 17.3 & 18.2 & 12.3 & 11.8 & 18.9 \\ 1968 & 8.89 & 11.7 & 13.7 & 14.1 & 27.2 & 29.3 & 19.1 & 18.3 & 13.9 & 10.3 & 11.1 & 3.26 \\ 1969 & 4.85 & 9.71 & 8.43 & 112 & 102 & 97.6 & 128 & 96.9 & 64.5 & 26.3 & 21.5 & 31.5 \\ 1970 & 15.7 & 18.2 & 17.6 & 23.3 & 14.3 & 12.6 & 10.1 & 12.9 & 8.74 & 6.01 & 4.27 & 3.94 \\ & & & & & & & & & & & & \\ 1971 & 2.08 & 4.01 & 7.98 & 0.60 & 3.48 & 11.5 & 11.5 & 9.28 & 11.9 & 9.73 & 23.2 & 9.81 \\ 1972 & 1.61 & 1.73 & 5.43 & 1.94 & 5.46 & 12.0 & 9.26 & 10.9 & 10.8 & 8.92 & 2.01 & 4.23 \\ 1973 & 1.79 & 1.76 & 0.97 & 1.29 & 3.22 & 6.57 & 74.8 & 174 & 141 & 18.2 & 19.3 & 19.1 \\ 1974 & 4.85 & 4.66 & 3.09 & 15.9 & 7.80 & 12.6 & 13.4 & 11.3 & 11.6 & 12.0 & 12.0 & 16.6\end{array}$


VIRGIN RIVER BASIN

09410400 SANTA CLARA RIVER NEAR SANTA CIARA, UT--Continued

ANNUAL PEAK DISCHARGE, IN OUBIC FEET PER SECOND, AND CORRESPONDING GAGE HEIGHT, IN FEET, FOR EACH WATER YEAR

\begin{tabular}{|c|c|c|c|c|c|c|c|c|c|c|c|}
\hline $\begin{array}{l}\text { WATERR } \\
\text { YEAR }\end{array}$ & DATE & $\begin{array}{c}\text { GAGE } \\
\text { HEIGHT }\end{array}$ & $\begin{array}{c}\text { PEAR } \\
\text { DISCHARGE }\end{array}$ & $\begin{array}{l}\text { WATER } \\
\text { YEAR }\end{array}$ & DATE & $\begin{array}{c}\text { GAGE } \\
\text { HEIGHT }\end{array}$ & $\begin{array}{c}\text { PEAK } \\
\text { DISCHARGE }\end{array}$ & $\begin{array}{l}\text { WATERR } \\
\text { YEAR }\end{array}$ & DATE & $\begin{array}{c}\text { GAGE } \\
\text { HEIGHT }\end{array}$ & $\begin{array}{c}\text { PEAK } \\
\text { DISCHARGE }\end{array}$ \\
\hline $\begin{array}{l}1966 \\
1967 \\
1968\end{array}$ & $\begin{array}{l}\text { DEC. } 30,1965 \\
\text { DEC. } 07,1966 \\
\text { JULY } 30,1968\end{array}$ & $\begin{array}{r}6.87 \\
12.60 \\
6.57\end{array}$ & $\begin{array}{l}1260 \\
6390 \\
1120\end{array}$ & $\begin{array}{l}1969 \\
1970 \\
1971\end{array}$ & $\begin{array}{l}\text { JAN. } 25,1969 \\
\text { AUG. } 18,1970 \\
\text { AUG. } 28,1971\end{array}$ & $\begin{array}{r}10.60 \\
9.85 \\
9.22\end{array}$ & $\begin{array}{l}4000 \\
3380 \\
2700\end{array}$ & $\begin{array}{l}1972 \\
1973 \\
1974\end{array}$ & $\begin{array}{l}\text { SEPT.19, } 1972 \\
\text { MAY 15, } 1973 \\
\text { SEPT.05, } 1974\end{array}$ & $\begin{array}{l}4.42 \\
4.95 \\
3.17\end{array}$ & $\begin{array}{l}480 \\
619 \\
100\end{array}$ \\
\hline
\end{tabular}

09413000 SANTA OARA RIVER AT ST. GEORGE, UT

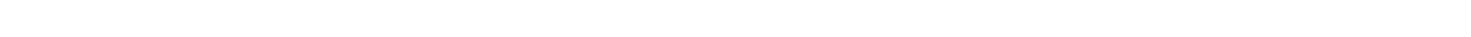
bank $0.5 \mathrm{mi}$ upstream fram mouth and $2 \mathrm{mi}$ south of St. George.

DRAINAGE AREA. $-540 \mathrm{mi}^{2}$.

PERIOD OF RECORD AVAIIABLE.-October 1950 to september 1956

GAGE.-Water-stage recorder. Altitude of gage is $2,750 \mathrm{ft}$.

REMARKS.-Diversions above station for irrigation of about 4,800 acres in Santa Clara River basin.

AVERAGE DISCHARGE. -6 years, $8.82 \mathrm{ft}^{3} / \mathrm{s}, 6,390 \mathrm{acre}-\mathrm{ft} / \mathrm{yr}$.

EXIREMES FOR PERIOD OF RECORD.-Maximum discharge, 4,200 ft $3 / \mathrm{s}$ Aug. 24, 1955, gage height, $10.02 \mathrm{ft}$, from rating curve extended above $400 \mathrm{ft}^{3} / \mathrm{s}$ on basis of indirect measurements at gage heights $7.31 \mathrm{ft}$ and $9.48 \mathrm{ft}$; no flow for some days in 1951 , 1953 , $1955-56$.

LOWEST MEAN DISCHARGE, IN OUBIC FEET PER SECOND, AND RANKING FOR THE INDICATED NUMBER OF CONSEOUTIVE DAYS FOR EACH OLIMATIC YEAR, APRII 1-MARCH 31

\begin{tabular}{|c|c|c|c|c|c|c|c|c|c|c|c|c|c|c|c|c|c|c|c|}
\hline YEAR & & & & & & & & & CONSE & WT & DAYS & & & & & & & & \\
\hline $\begin{array}{l}1952 \\
1953 \\
1954 \\
1955\end{array}$ & $\begin{array}{l}0.00 \\
1.10 \\
0.00 \\
0.10\end{array}$ & $\begin{array}{l}1 \\
5 \\
2 \\
4\end{array}$ & $\begin{array}{l}0.00 \\
1.30 \\
0.00 \\
0.17\end{array}$ & $\begin{array}{l}1 \\
5 \\
2 \\
4\end{array}$ & $\begin{array}{l}0.01 \\
1.30 \\
0.01 \\
0.19\end{array}$ & $\begin{array}{l}1 \\
5 \\
2 \\
4\end{array}$ & $\begin{array}{l}0.06 \\
1.50 \\
0.14 \\
0.24\end{array}$ & $\begin{array}{l}1 \\
5 \\
2 \\
3\end{array}$ & $\begin{array}{l}0.17 \\
1.60 \\
0.16 \\
0.36\end{array}$ & $\begin{array}{l}2 \\
5 \\
1 \\
3\end{array}$ & $\begin{array}{l}1.00 \\
2.30 \\
0.41 \\
0.78\end{array}$ & $\begin{array}{l}4 \\
5 \\
1 \\
3\end{array}$ & $\begin{array}{l}1.40 \\
2.80 \\
0.63 \\
1.90\end{array}$ & $\begin{array}{l}3 \\
5\end{array}$ & $\begin{array}{l}2.10 \\
3.30 \\
1.19 \\
2.30\end{array}$ & $\begin{array}{l}2 \\
5 \\
1 \\
3\end{array}$ & $\begin{array}{l}3.20 \\
5.90 \\
2.00 \\
2.50\end{array}$ & $\begin{array}{l}3 \\
5 \\
1 \\
2\end{array}$ & $\begin{array}{c}8.90 \\
22.0 \\
7.00 \\
5.70\end{array}$ \\
\hline 1956 & 0.00 & 3 & 0.10 & 3 & 0.13 & 3 & 0.31 & 4 & 0.41 & 4 & 0.55 & 2 & 1.19 & 2 & 2.40 & 4 & 4.80 & 4 & 7.00 \\
\hline
\end{tabular}

HIGHEST MEAN DISCHARGE, IN CUBIC FEET PER SECOND, AND RANKING FOR THE INDICATED NUMBER OF CONSECUTIVE DAYS FOR EACH WATER YEAR, OCTCBER I-SEPTEMBER 30

\begin{tabular}{|c|c|c|c|c|c|c|c|c|c|c|c|c|c|c|c|c|c|c|c|}
\hline YEAR & \multicolumn{19}{|c|}{ CONSEOUTIVE DAYS } \\
\hline $\begin{array}{l}1951 \\
1952 \\
1953 \\
1954 \\
1955\end{array}$ & $\begin{array}{l}144 \\
314 \\
211 \\
195 \\
500\end{array}$ & $\begin{array}{l}5 \\
2 \\
3 \\
4 \\
1\end{array}$ & $\begin{array}{c}75.0 \\
254 \\
74.0 \\
148 \\
347\end{array}$ & $\begin{array}{l}4 \\
2 \\
5 \\
3 \\
1\end{array}$ & $\begin{array}{c}43.0 \\
203 \\
33.0 \\
110 \\
157\end{array}$ & $\begin{array}{l}4 \\
1 \\
5 \\
3 \\
2\end{array}$ & $\begin{array}{c}21.0 \\
171 \\
18.0 \\
86.0 \\
77.0\end{array}$ & $\begin{array}{l}5 \\
1 \\
6 \\
2 \\
3\end{array}$ & $\begin{array}{c}11.0 \\
143 \\
16.0 \\
47.0 \\
40.0\end{array}$ & $\begin{array}{l}6 \\
1 \\
4 \\
2 \\
3\end{array}$ & $\begin{array}{c}6.60 \\
99.0 \\
15.0 \\
27.0 \\
25.0\end{array}$ & $\begin{array}{l}6 \\
1 \\
4 \\
2 \\
3\end{array}$ & $\begin{array}{l}5.60 \\
77.0 \\
14.0 \\
22.0 \\
17.0\end{array}$ & $\begin{array}{l}6 \\
1 \\
4 \\
2 \\
3\end{array}$ & $\begin{array}{l}4.40 \\
60.0 \\
12.0 \\
18.0 \\
13.0\end{array}$ & $\begin{array}{l}6 \\
1 \\
4 \\
2 \\
3\end{array}$ & $\begin{array}{c}3.70 \\
45.0 \\
9.80 \\
14.0 \\
10.0\end{array}$ & $\begin{array}{l}6 \\
1 \\
4 \\
2 \\
3\end{array}$ & $\begin{array}{c}3.40 \\
24.0 \\
6.20 \\
8.00 \\
7.90\end{array}$ \\
\hline 1956 & 114 & 6 & 49.0 & 6 & 27.0 & 6 & 21.0 & 4 & 14.0 & 5 & 9.90 & 5 & 8.40 & 5 & 7.20 & 5 & 5.40 & 5 & 3.60 \\
\hline
\end{tabular}

DURATION OF DISCHARGE FOR EACH WATER YEAR

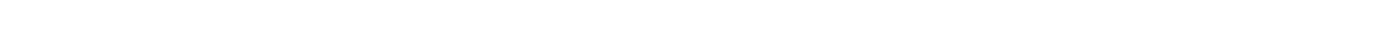
YEAR NUMBER OF DAYS IN CLASS OBIC FEET -DAYS

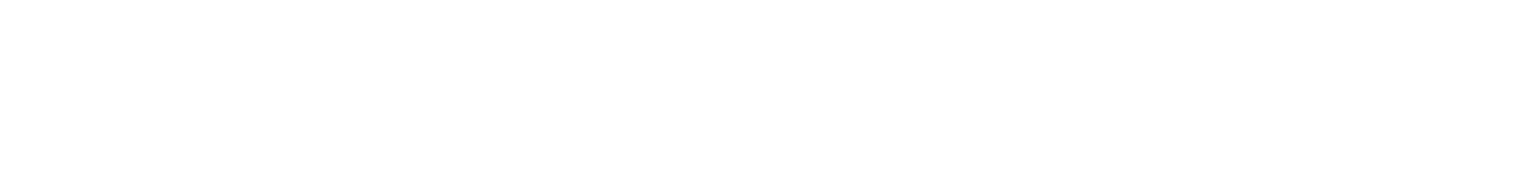


VIRGIN RIVER BASIN

09413000 SANTA CLARA RIVER AT ST. GEORGE, UT-Continued

DURATION TABLE OF DISCHARGE FOR WATER YEARS 1951-56

\begin{tabular}{|c|c|c|c|c|}
\hline CLASS & $\begin{array}{c}\text { OBIIC } \\
\text { FEET } \\
\text { PER } \\
\text { SECOND }\end{array}$ & $\begin{array}{l}\text { TOTAL } \\
\text { DAYS }\end{array}$ & $\begin{array}{l}\text { ACOU- } \\
\text { WO- } \\
\text { LATED } \\
\text { DAYS }\end{array}$ & $\begin{array}{l}\text { PER- } \\
\text { CENT } \\
\text { DAYS }\end{array}$ \\
\hline $\begin{array}{l}0 \\
1 \\
2 \\
3 \\
4 \\
5 \\
6 \\
7 \\
8\end{array}$ & $\begin{array}{l}0.00 \\
0.10 \\
0.13 \\
0.17 \\
0.22 \\
0.28 \\
0.36 \\
0.46 \\
0.60\end{array}$ & $\begin{array}{r}48 \\
69 \\
0 \\
84 \\
0 \\
118 \\
128 \\
48 \\
93\end{array}$ & $\begin{array}{l}2192 \\
2144 \\
2075 \\
2075 \\
1991 \\
1991 \\
1873 \\
1745 \\
1697\end{array}$ & $\begin{array}{r}100.0 \\
97.8 \\
94.7 \\
94.7 \\
90.8 \\
90.8 \\
85.4 \\
79.6 \\
77.4\end{array}$ \\
\hline
\end{tabular}

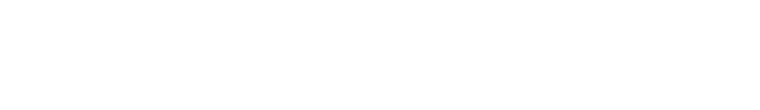
$\begin{array}{rrr}\text { OBBIC } & \text { ACOU- } \\ \text { FEET } & \text { MU- } & \text { PER- } \\ \text { PER TOTAL LATED } & \text { CENT } \\ \text { O.ASS SECOND DAYS DAYS } & \text { DAYS }\end{array}$

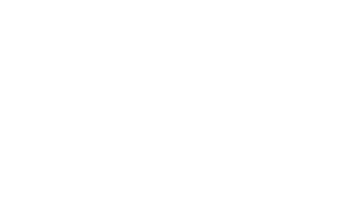

$\begin{array}{rrrrr}18 & 7.8 & 120 & 479 & 21.9 \\ 19 & 10.0 & 92 & 359 & 16.4 \\ 20 & 13.0 & 95 & 267 & 12.2 \\ 21 & 17.0 & 39 & 172 & 7.8 \\ 22 & 22.0 & 13 & 133 & 6.1 \\ 23 & 28.0 & 18 & 120 & 5.5 \\ 24 & 36.0 & 15 & 102 & 4.7 \\ 25 & 46.0 & 19 & 87 & 4.0 \\ 26 & 60.0 & 20 & 68 & 3.1\end{array}$

$\begin{array}{rrrrr}27 & 78.0 & 7 & 48 & 2.2 \\ 28 & 100.0 & 14 & 41 & 1.9 \\ 29 & 130.0 & 15 & 27 & 1.2 \\ 30 & 170.0 & 8 & 12 & 0.5 \\ 31 & 220.0 & 1 & 4 & 0.2 \\ 32 & 280.0 & 1 & 3 & 0.1 \\ 33 & 360.0 & 1 & 2 & 0.1 \\ 34 & 470.0 & 1 & 1 & 0.0\end{array}$

MONIHLY MEAN DISCHARGES, IN OBBIC FEET PER SECOND, FOR EACH WATER YEAR

$\begin{array}{lllllllllllll}\text { YEAR } & \text { OCT } & \text { NON } & \text { DEC } & \text { JAN } & \text { FEB } & \text { MAR } & \text { APR } & \text { MAY } & \text { JUNE } & \text { JULY } & \text { AUG } & \text { SEP } \\ 1951 & 0.39 & 3.32 & 4.88 & 4.05 & 1.91 & 4.89 & 1.72 & 2.10 & 1.03 & 3.53 & 7.71 & 5.15 \\ 1952 & 1.08 & 1.37 & 11.3 & 15.8 & 10.3 & 44.8 & 136 & 38.1 & 18.6 & 3.85 & 1.87 & 3.35 \\ 1953 & 5.96 & 12.7 & 14.5 & 13.8 & 7.25 & 4.48 & 3.66 & 2.79 & 0.64 & 0.42 & 7.94 & 0.29 \\ 1954 & 0.55 & 2.55 & 8.46 & 10.5 & 10.2 & 35.7 & 13.6 & 3.94 & 2.26 & 2.99 & 1.67 & 3.60 \\ 1955 & 1.01 & 4.89 & 10.5 & 8.08 & 10.3 & 6.65 & 1.83 & 1.68 & 1.03 & 8.65 & 38.8 & 0.73 \\ 1956 & 0.45 & 2.97 & 6.41 & 10.0 & \mathbf{8 . 4 2} & 2.66 & 1.67 & 1.95 & 4.05 & 4.14 & 0.05 & 0.34\end{array}$

ANNUAL PEAK DISCHARGE, IN CBIC FEET PER SECOND, AND CORRESPONDING GAGE HEIGHT, IN FEET, FOR EACH WATER YEAR

\begin{tabular}{|c|c|c|c|c|c|c|c|c|c|c|c|}
\hline $\begin{array}{l}\text { WATERR } \\
\text { YEAR }\end{array}$ & DATE & $\begin{array}{c}\text { GAGE } \\
\text { HEIGHI }\end{array}$ & $\begin{array}{c}\text { PEAR } \\
\text { DISCHARGE }\end{array}$ & $\begin{array}{l}\text { WATER } \\
\text { YEAR }\end{array}$ & DATE & $\begin{array}{c}\text { GAGE } \\
\text { HEIGHT }\end{array}$ & $\begin{array}{c}\text { PEAR } \\
\text { DISCHARGE }\end{array}$ & $\begin{array}{l}\text { WATER } \\
\text { YEAR }\end{array}$ & DATE & $\begin{array}{c}\text { GAGE } \\
\text { HEIGHT }\end{array}$ & $\begin{array}{c}\text { PEAK } \\
\text { DISQHARGE }\end{array}$ \\
\hline $\begin{array}{l}1951 \\
1952\end{array}$ & $\begin{array}{l}\text { SEPPT. 28, } 1951 \\
\text { APR. 08, } 1952\end{array}$ & $\begin{array}{l}7.31 \\
4.60\end{array}$ & $\begin{array}{r}1270 \\
521\end{array}$ & $\begin{array}{l}1953 \\
1954\end{array}$ & $\begin{array}{l}\text { AUG. } 27,1953 \\
\text { SEPT. 02, } 1954\end{array}$ & $\begin{array}{l}9.48 \\
4.80\end{array}$ & $\begin{array}{r}3240 \\
521\end{array}$ & $\begin{array}{l}1955 \\
1956\end{array}$ & $\begin{array}{l}\text { AUG. } 24,1955 \\
\text { JUNE } 30,1956\end{array}$ & $\begin{array}{r}10.02 \\
6.63\end{array}$ & $\begin{array}{l}4200 \\
1070\end{array}$ \\
\hline
\end{tabular}

09413200 VIRGIN RIVER NEAR BLOOMINGTON, UT

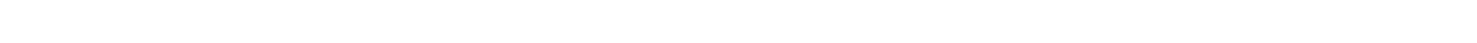
left bank $2.5 \mathrm{mi}$ south of $\mathrm{St}$. George.

DRAINAGE AREA. $--3,831 \mathrm{mi}^{2}$.

PERIOD OF RECORD AVAIIABLE.--September 1977 to September 1981.

GAGE.-Water-stage recorder. Altitude of gage is $2,530 \mathrm{ft}$ from topographic map. Prior to Sept. 19, 1978, at site $1.5 \mathrm{mi}$ downstream at different datum.

REMARRS.--Many diversions for irrigation above station.

EXIREMES FOR PERIOD OF RECORD.--Maximum discharge, 10,000 $\mathrm{ft}^{3} / \mathrm{s}$ Feb. 15, 1980; minimm, $5.8 \mathrm{ft}^{3} / \mathrm{s} \mathrm{Sept.} 21,1977$.

LONEST MEAN DISCHARGE, IN CIBIC FEET PER SECOND, AND RANKING FOR THE INDICATED NUMBER OF CONSECUTIVE DAYS FOR EACH CIIMATIC YEAR, APRII I-MARCH 31

\begin{tabular}{|c|c|c|c|c|c|c|c|c|c|c|c|c|c|c|c|c|c|c|c|}
\hline YEAR & 1 & & 3 & & 7 & & 14 & & $\begin{array}{l}\text { CONS } \\
30\end{array}$ & $a r$ & $\begin{array}{l}\text { JE DAYS } \\
60\end{array}$ & & 90 & & 120 & & 183 & & ALL \\
\hline $\begin{array}{l}1979 \\
1980\end{array}$ & $\begin{array}{l}21.0 \\
25.0\end{array}$ & $\begin{array}{l}1 \\
3\end{array}$ & $\begin{array}{l}24.0 \\
27.0\end{array}$ & $\frac{1}{2}$ & $\begin{array}{l}25.0 \\
28.0\end{array}$ & $\begin{array}{l}1 \\
2\end{array}$ & $\begin{array}{l}27.0 \\
31.0\end{array}$ & $\begin{array}{l}1 \\
2\end{array}$ & $\begin{array}{l}30.0 \\
35.0\end{array}$ & $\frac{1}{2}$ & $\begin{array}{l}32.0 \\
46.0\end{array}$ & $\begin{array}{l}1 \\
2\end{array}$ & $\begin{array}{l}32.0 \\
76.0\end{array}$ & $\begin{array}{l}1 \\
2\end{array}$ & $\begin{array}{l}34.0 \\
86.0\end{array}$ & $\begin{array}{l}1 \\
2\end{array}$ & $\begin{array}{l}84.0 \\
112\end{array}$ & $\begin{array}{l}1 \\
2\end{array}$ & $\begin{array}{l}288 \\
533\end{array}$ \\
\hline 1981 & 24.0 & 2 & 28.0 & 3 & 41.0 & 3 & 57.0 & 3 & 80.0 & 3 & 112 & 3 & 145 & 3 & 154 & 3 & 178 & 3 & 449 \\
\hline
\end{tabular}

HIGHEST MEAN DISCHARGE, IN OBIC FEET PER SECOND, AND RANKING FOR THE INDICATED NUMBER OF CONSECUTINE DAYS FOR EACH WATER YEAR, $O$ TTCBER 1-SEPTEMBER 30

\begin{tabular}{|c|c|c|c|c|c|c|c|c|c|c|c|c|c|c|c|c|c|c|c|}
\hline YEAR & 1 & & 3 & & 7 & & 15 & & $\begin{array}{l}\alpha \\
30\end{array}$ & avt & IVE $\frac{\mathrm{D}}{60}$ & & 90 & & 120 & & 183 & & ALL \\
\hline $\begin{array}{l}1978 \\
1979 \\
1980\end{array}$ & $\begin{array}{l}3000 \\
6000 \\
5800\end{array}$ & $\begin{array}{l}3 \\
1 \\
2\end{array}$ & $\begin{array}{l}2500 \\
3480 \\
4050\end{array}$ & $\begin{array}{l}3 \\
2 \\
1\end{array}$ & $\begin{array}{l}2140 \\
2000 \\
3570\end{array}$ & $\begin{array}{l}2 \\
3 \\
1\end{array}$ & $\begin{array}{l}1290 \\
1780 \\
2560\end{array}$ & $\begin{array}{l}3 \\
2 \\
1\end{array}$ & $\begin{array}{r}943 \\
1550 \\
2010\end{array}$ & $\begin{array}{l}3 \\
2 \\
1\end{array}$ & $\begin{array}{r}808 \\
1330 \\
1550\end{array}$ & $\begin{array}{l}3 \\
2 \\
1\end{array}$ & $\begin{array}{r}738 \\
1150 \\
1390\end{array}$ & $\begin{array}{l}3 \\
2 \\
1\end{array}$ & $\begin{array}{r}658 \\
956 \\
1350\end{array}$ & $\begin{array}{l}3 \\
2 \\
1\end{array}$ & $\begin{array}{r}489 \\
718 \\
1070\end{array}$ & $\begin{array}{l}3 \\
2 \\
1\end{array}$ & $\begin{array}{l}273 \\
420 \\
628\end{array}$ \\
\hline 1981 & 1220 & 4 & 817 & 4 & 593 & 4 & 474 & 4 & 344 & 4 & 327 & 4 & 290 & 4 & 263 & 4 & 240 & 4 & 168 \\
\hline
\end{tabular}


VIRGIN RIVER BASIN

09413200 VIRGIN RIVER NEAR BLOOMINGTON, UT-Continued

DURATION OF DISCHARGE FOR EACH WATER YEAR

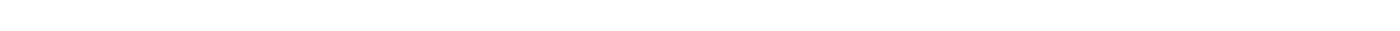
YEAR NUMBER OF DAYS IN CLASS

CUBIC FEET PER SECOND -DAYS

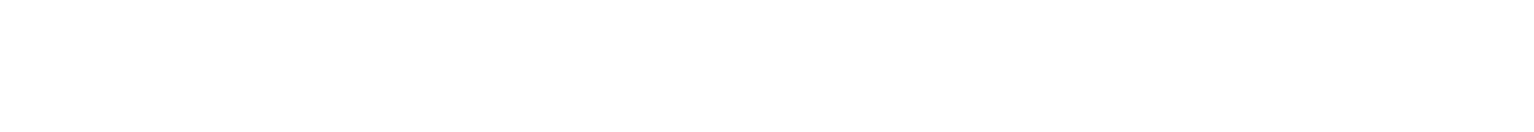

DURATION TABLE OF DISCHARGE FOR WATER YEARS 1978-81

$\begin{array}{crc}\text { CUBIC } & \text { ACOU- } \\ \text { FEET } & \text { MU- } & \text { PER- } \\ \text { PER } & \text { TOIAL LATED } & \text { CENT } \\ \text { CIASS SECOND DAYS } & \text { DAYS } & \text { DAYS }\end{array}$

$\begin{array}{lll}\text { CUBIC } & \text { ACOJ- } \\ \text { FEET } & \text { MU- } & \text { PER- } \\ \text { PER TOTAL ILATED } & \text { CENT }\end{array}$

CIASS SECOND DAYS DAYS DAYS

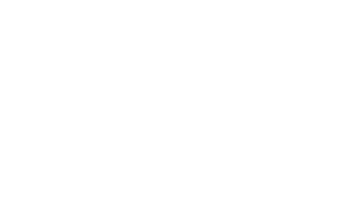

CUBIC ACOJ-

FEET MU- PERPER TOTAL LLATED CENT
CJASS SECOND DAYS DAYS DAYS

$\begin{array}{rrrrr}18 & 220.0 & 87 & 569 & 38.9 \\ 19 & 270.0 & 63 & 482 & 33.0 \\ 20 & 340.0 & 56 & 419 & 28.7 \\ 21 & 410.0 & 27 & 363 & 24.8 \\ 22 & 500.0 & 92 & 336 & 23.0 \\ 23 & 620.0 & 61 & 244 & 16.7 \\ 24 & 760.0 & 46 & 183 & 12.5 \\ 25 & 930.0 & 22 & 137 & 9.4 \\ 26 & 1100.0 & 29 & 115 & 7.9\end{array}$

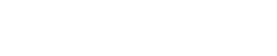
FEET TOTAL LATEBD CENT CLASS SECOND DAYS DAYS DAYS

$\begin{array}{rrrrr}27 & 1400.0 & 23 & 86 & 5.9 \\ 28 & 1700.0 & 35 & 63 & 4.3 \\ 29 & 2100.0 & 19 & 28 & 1.9 \\ 30 & 2600.0 & 3 & 9 & 0.6 \\ 31 & 3100.0 & 3 & 6 & 0.4 \\ 32 & 3900.0 & 0 & 3 & 0.2 \\ 33 & 4700.0 & 1 & 3 & 0.2 \\ 34 & 5800.0 & 2 & 2 & 0.1\end{array}$

MONIHLY MEAN DISCHARGES, IN CUBIC FEET PER SECOND, FOR EAGH WATER YEAR

$\begin{array}{rrrrrrrrrrrrr}\text { YEAR } & \text { OCT } & \text { NOW } & \text { DEC } & \text { JAN } & \text { FFB } & \text { MAR } & \text { APR } & \text { MAY } & \text { JUNE } & \text { JULY } & \text { AJG } & \text { SEP } \\ 1978 & 60.8 & 103 & 118 & 202 & 388 & 939 & 667 & 586 & 119 & 30.0 & 35.0 & 32.2 \\ 1979 & 69.1 & 247 & 238 & 238 & 317 & 873 & 1053 & 1371 & 362 & 117 & 112 & 35.6 \\ 1980 & 85.1 & 168 & 196 & 579 & 1642 & 731 & 1178 & 1787 & 556 & 204 & 139 & 326 \\ 1981 & 113 & 185 & 201 & 177 & 203 & 314 & 332 & 184 & 57.0 & 87.8 & 97.6 & 67.7\end{array}$

09413500 VIRGIN RIVER NEAR ST. GEORGE, UT

LOCATION.-Lat $37^{\circ} 00^{\prime} 50^{\prime \prime}$, long $113^{\circ} 40^{\prime} 50^{\prime \prime}$, in NE⿺辶 bank $8 \mathrm{mi}$ southwest of St. George.

DRAINAGE AREA. $-3,820 \mathrm{mi}^{2}$.

PERICD OF RECORD AVAIJABLE.-OCtober 1950 to December 1956.

GAGE.-Water-stage recorder.

REMARKS.-Diversions for irrigation of about 23,000 acres above station.

AVERAGE DISCHARGE. -6 years, $137 \mathrm{ft}^{3} / \mathrm{s}, 99,180$ acre-ft/yr.

EXIREUES FOR PERIOD OF RECORD.-Maximum discharge, 13,800 ft $3 / \mathrm{s} \mathrm{Aug.} \mathrm{25,} \mathrm{1955,} \mathrm{gage} \mathrm{height,} \mathrm{12.70} \mathrm{ft;} \mathrm{no} \mathrm{flow} \mathrm{at} \mathrm{times} \mathrm{during}$ sumer months.

LOWEST MEAN DISCHARGE, IN CUBIC FEET PER SBCOND, AND RANRING FOR THE INDICATED NUMBER OF CONSEATTIVE DAYS FOR EACH CLIMATIC YEAR, APRIL 1-MARCH 31

\begin{tabular}{|c|c|c|c|c|c|c|c|c|c|c|c|c|c|c|c|c|c|c|c|}
\hline YEAR & 1 & & 3 & & 7 & & 14 & & $\begin{array}{l}\text { CONSE } \\
30\end{array}$ & & $\begin{array}{l}\text { E DAYS } \\
60\end{array}$ & & 90 & & 120 & & 183 & & ALL \\
\hline $\begin{array}{l}1952 \\
1953 \\
1954 \\
1955\end{array}$ & $\begin{array}{l}0.00 \\
0.00 \\
0.00 \\
0.00\end{array}$ & $\begin{array}{l}1 \\
2 \\
3 \\
4\end{array}$ & $\begin{array}{l}0.00 \\
0.00 \\
0.00 \\
0.00\end{array}$ & $\begin{array}{l}1 \\
2 \\
3 \\
4\end{array}$ & $\begin{array}{l}0.00 \\
0.00 \\
0.00 \\
0.00\end{array}$ & $\begin{array}{l}1 \\
2 \\
3 \\
4\end{array}$ & $\begin{array}{l}0.00 \\
0.49 \\
0.00 \\
0.00\end{array}$ & $\begin{array}{l}1 \\
5 \\
2 \\
3\end{array}$ & $\begin{array}{l}0.00 \\
3.30 \\
0.00 \\
0.00\end{array}$ & $\begin{array}{l}1 \\
5 \\
2 \\
3\end{array}$ & $\begin{array}{c}2.10 \\
11.0 \\
0.93 \\
21.0\end{array}$ & $\begin{array}{l}3 \\
4 \\
2 \\
5\end{array}$ & $\begin{array}{c}28.0 \\
27.0 \\
6.60 \\
53.0\end{array}$ & $\begin{array}{l}4 \\
3 \\
1 \\
5\end{array}$ & $\begin{array}{l}37.0 \\
31.0 \\
26.0 \\
54.0\end{array}$ & $\begin{array}{l}3 \\
2 \\
1 \\
5\end{array}$ & $\begin{array}{l}68.0 \\
64.0 \\
40.0 \\
68.0\end{array}$ & $\begin{array}{l}4 \\
2 \\
1 \\
3\end{array}$ & $\begin{array}{c}130 \\
298 \\
95.0 \\
121\end{array}$ \\
\hline 1956 & 0.00 & 5 & 0.00 & 5 & 0.00 & 5 & 0.00 & 4 & 0.00 & 4 & 0.82 & 1 & 14.0 & 2 & 48.0 & 4 & 105 & 5 & 119 \\
\hline
\end{tabular}


VIRGIN RIVER BASIN

09413500 VIRGIN RIVER NEAR ST. GEORGE, UT-Continued

HIGHEST MEAN DISCHARGE, IN OUBIC FEET PER SECOND, AND RANKING FOR THE INDICATED NUMBER OF CONSECUTIVE DAYS FOR EAQH WATER YEAR, OCTOBER I-SEPTEMBER 30

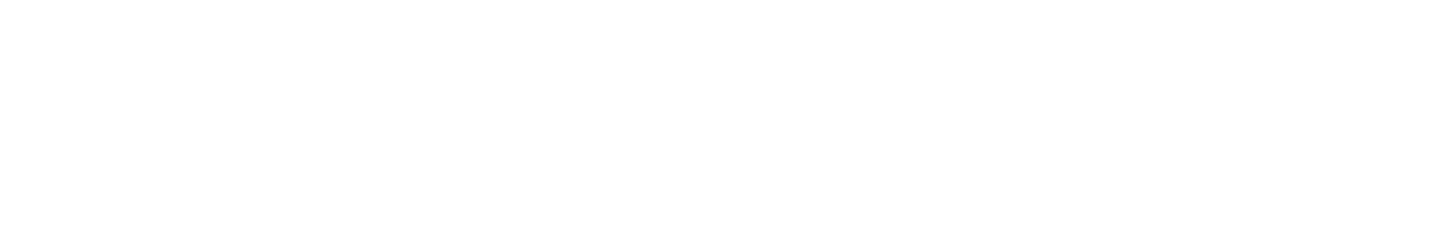

DURATION OF DISCHARGE FOR EACH WATER YEAR

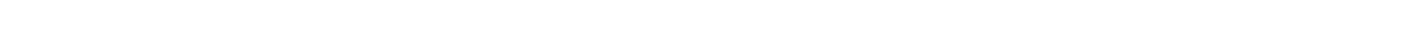
YEAR NUMBER OF DAYS IN CLASS OUBIC FEET -DAYS

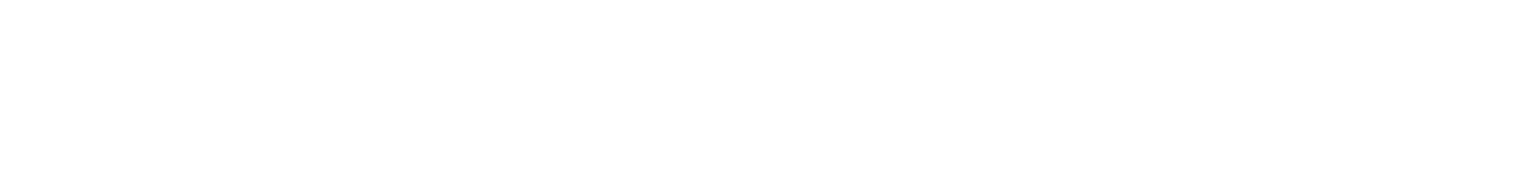

DURATION TABLE OF DISOHARGE FOR WATER YEARS 1951-56

\begin{tabular}{|c|c|c|c|c|c|c|c|c|c|c|c|c|c|c|c|c|c|c|c|}
\hline Q.ASS & $\begin{array}{c}\text { OBIC } \\
\text { FEET } \\
\text { PER } \\
\text { SECOND }\end{array}$ & TOTAL & $\begin{array}{c}\text { ACOU- } \\
\text { MU- } \\
\text { LATED } \\
\text { DAYS }\end{array}$ & $\begin{array}{l}\text { PER- } \\
\text { CENT } \\
\text { DAYS }\end{array}$ & QASS & $\begin{array}{c}\text { OBIC } \\
\text { FEET } \\
\text { PER } \\
\text { SECOND }\end{array}$ & $\begin{array}{l}\text { TOTAL } \\
\text { DAYS }\end{array}$ & $\begin{array}{c}\text { ACU- } \\
\text { MU- } \\
\text { LATED } \\
\text { DAYS }\end{array}$ & $\begin{array}{l}\text { PER- } \\
\text { CEN } \\
\text { DAYS }\end{array}$ & C.ASS & $\begin{array}{c}\text { OBIC } \\
\text { FEET } \\
\text { PER } \\
\text { SECOND }\end{array}$ & $\begin{array}{r}\text { TOTAL } \\
\text { DAYS }\end{array}$ & $\begin{array}{c}\text { ACOU- } \\
\text { M- } \\
\text { LATED } \\
\text { DAYS }\end{array}$ & $\begin{array}{l}\text { PER- } \\
\text { CENT } \\
\text { DAYS }\end{array}$ & & $\begin{array}{c}\text { OBIC } \\
\text { FEET } \\
\text { PER } \\
\text { SEOOND }\end{array}$ & TOTAL & $\begin{array}{l}\text { ACQU- } \\
\text { MU- } \\
\text { LATED } \\
\text { DAYS }\end{array}$ & $\begin{array}{l}\text { PER- } \\
\text { CENT } \\
\text { DAYS }\end{array}$ \\
\hline $\begin{array}{l}0 \\
1 \\
2 \\
3 \\
4 \\
5 \\
6 \\
7 \\
7 \\
8\end{array}$ & $\begin{array}{l}0.00 \\
0.10 \\
0.14 \\
0.19 \\
0.26 \\
0.35 \\
0.48 \\
0.66 \\
0.91\end{array}$ & $\begin{array}{r}464 \\
3 \\
0 \\
3 \\
1 \\
4 \\
4 \\
3 \\
2\end{array}$ & $\begin{array}{l}2192 \\
1728 \\
1725 \\
1725 \\
1722 \\
1721 \\
1717 \\
1713 \\
1710\end{array}$ & $\begin{array}{r}100.0 \\
78.8 \\
78.7 \\
78.7 \\
78.6 \\
78.5 \\
78.3 \\
78.1 \\
78.0\end{array}$ & $\begin{array}{l}9 \\
10 \\
11 \\
12 \\
13 \\
14 \\
15 \\
16 \\
17\end{array}$ & $\begin{array}{r}1.20 \\
1.70 \\
2.30 \\
3.20 \\
4.40 \\
6.00 \\
6.20 \\
11.15 \\
15.00\end{array}$ & $\begin{array}{r}6 \\
10 \\
12 \\
12 \\
16 \\
24 \\
25 \\
43 \\
44\end{array}$ & $\begin{array}{l}1708 \\
1702 \\
1692 \\
1680 \\
1668 \\
1652 \\
1628 \\
1603 \\
1560\end{array}$ & $\begin{array}{l}77.9 \\
77.6 \\
77.2 \\
76.6 \\
76.1 \\
75.4 \\
74.3 \\
73.1 \\
71.2\end{array}$ & $\begin{array}{l}18 \\
19 \\
20 \\
21 \\
22 \\
23 \\
24 \\
25 \\
26\end{array}$ & $\begin{array}{r}21.0 \\
29.0 \\
40.0 \\
55.0 \\
75.0 \\
100.0 \\
140.0 \\
190.0 \\
260.0\end{array}$ & $\begin{array}{r}77 \\
102 \\
107 \\
112 \\
195 \\
343 \\
309 \\
96 \\
40\end{array}$ & $\begin{array}{r}1516 \\
1439 \\
1337 \\
1230 \\
1118 \\
923 \\
580 \\
271 \\
175\end{array}$ & $\begin{array}{r}69.2 \\
65.6 \\
61.0 \\
56.1 \\
51.0 \\
42.1 \\
26.5 \\
12.4 \\
8.0\end{array}$ & $\begin{array}{l}27 \\
28 \\
29 \\
30 \\
31 \\
32 \\
33 \\
34\end{array}$ & $\begin{array}{r}360.0 \\
500.0 \\
680.0 \\
930.0 \\
1300.0 \\
1700.0 \\
2400.0 \\
3300.0\end{array}$ & $\begin{array}{r}29 \\
24 \\
27 \\
15 \\
16 \\
17 \\
6 \\
1\end{array}$ & $\begin{array}{r}135 \\
106 \\
82 \\
55 \\
40 \\
24 \\
7 \\
1\end{array}$ & $\begin{array}{l}6.2 \\
4.8 \\
3.7 \\
2.5 \\
1.8 \\
1.1 \\
0.3 \\
0.0\end{array}$ \\
\hline
\end{tabular}

MONIHLY MEAN DISCHARGES, IN GIBIC FEET PER SECOND, FOR EAOH WATER YEAR

\begin{tabular}{|c|c|c|c|c|c|c|c|c|c|c|c|c|}
\hline YEAR & $\infty C r$ & NON & $\mathrm{DEC}$ & JAN & FEBB & MAR & APR & MAY & JUNE & JULY & AUG & SEP \\
\hline $\begin{array}{l}1951 \\
1952 \\
1953 \\
1954 \\
1955\end{array}$ & $\begin{array}{l}22.8 \\
47.6 \\
43.3 \\
53.1 \\
88.0\end{array}$ & $\begin{array}{l}104 \\
97.8 \\
151 \\
104 \\
93.3\end{array}$ & $\begin{array}{l}97.4 \\
275 \\
180 \\
125 \\
159\end{array}$ & $\begin{array}{l}129 \\
216 \\
172 \\
212 \\
140\end{array}$ & $\begin{array}{l}88.1 \\
156 \\
128 \\
176 \\
161\end{array}$ & $\begin{array}{l}103 \\
343 \\
76.7 \\
210 \\
119\end{array}$ & $\begin{array}{c}53.2 \\
1312 \\
38.3 \\
326 \\
45.0\end{array}$ & $\begin{array}{c}56.7 \\
1249 \\
6.86 \\
98.3 \\
22.5\end{array}$ & $\begin{array}{c}0.00 \\
162 \\
0.00 \\
27.6 \\
0.00\end{array}$ & $\begin{array}{c}40.7 \\
10.1 \\
83.1 \\
70.4 \\
123\end{array}$ & $\begin{array}{l}235 \\
41.4 \\
129 \\
90.3 \\
522\end{array}$ & $\begin{array}{c}35.5 \\
53.9 \\
1.40 \\
80.3 \\
4.13\end{array}$ \\
\hline 1956 & 31.6 & 123 & 155 & 184 & 139 & 69.3 & 68.6 & 20.6 & 16.7 & 74.0 & 4.30 & 0.00 \\
\hline
\end{tabular}

ANNUAL PEAK DISqHARGE, IN GBIC FEET PER SECOND, AND CORRESPONDING GAGE HEIGHT, IN FEET, FOR EACH WATER YEAR

\begin{tabular}{|c|c|c|c|c|c|c|c|c|c|c|c|}
\hline $\begin{array}{l}\text { WATER } \\
\text { YEAR }\end{array}$ & DATE & $\begin{array}{c}\text { GAGE } \\
\text { HEIGH }\end{array}$ & $\begin{array}{c}\text { PEAK } \\
\text { DISCHARGE }\end{array}$ & $\begin{array}{l}\text { WATER } \\
\text { YEAR }\end{array}$ & CATE & $\begin{array}{c}\text { GAGE } \\
\text { HEIGHT }\end{array}$ & $\begin{array}{c}\text { PEAK } \\
\text { DISCHARGE }\end{array}$ & $\begin{array}{l}\text { WATER } \\
\text { YEAR }\end{array}$ & DATE & $\begin{array}{l}\text { GAGE } \\
\text { HEIGET }\end{array}$ & $\begin{array}{c}\text { PEAK } \\
\text { DISOHARGE }\end{array}$ \\
\hline $\begin{array}{l}1951 \\
1952\end{array}$ & $\begin{array}{l}\text { AUG. } 01,1951 \\
\text { DEC. } 30,1951\end{array}$ & $\begin{array}{r}11.24 \\
8.00\end{array}$ & $\begin{array}{r}11600 \\
6840\end{array}$ & $\begin{array}{l}1953 \\
1954\end{array}$ & $\begin{array}{l}\text { AUG. } 27,1953 \\
\text { AUG. } 04,1954\end{array}$ & $\begin{array}{l}8.35 \\
9.00\end{array}$ & $\begin{array}{l}7280 \\
8720\end{array}$ & $\begin{array}{l}1955 \\
1956\end{array}$ & $\begin{array}{l}\text { AUG. } 25,1955 \\
\text { JUNE } 30,1956\end{array}$ & $\begin{array}{r}12.70 \\
5.70\end{array}$ & $\begin{array}{r}13800 \\
3670\end{array}$ \\
\hline
\end{tabular}


VIRGIN RIVER BASIN

09415000 VIRGIN RIVER AT LITILEFIETD, AZ

LOCATION.--Lat $36^{\circ} 53^{\prime} 30^{\prime \prime}$, long $113^{\circ} 55^{\prime} 25^{\prime \prime}$, in $\mathrm{SW}^{\frac{1}{4} 5 \mathrm{~W}^{\frac{1}{4}}} \mathrm{sec} .4, \mathrm{~T} .40$ N., R.15 W., Mohave County, Hydrologic Unit 15010010 , on right bank $0.5 \mathrm{mi}$ downstream from Beaver Dam Wash, $0.4 \mathrm{mi}$ upstream from Littlefield, and 36 mi upstream fram waterline of Lake Mead at elevation $1,221 \mathrm{ft}$ NGVD of 1929 .

DRAINAGE AREA. $--5,090 \mathrm{mi}^{2}$, approximately.

PERIOD OF RECORD AVAIIABLE.--October 1929 to September 1981.

REVISED RECORDS.-WSP 959: 1932. WSP 979: 1930-31, 1933-37. WSP 1313: 1940(M).

GAGE.-Water-stage recorder. Datum of gage is $1,763.68 \mathrm{ft}$ NGVD of 1929 . Prior to May 28, 1933, nonrecording gage at site $300 \mathrm{ft}$ upstream and May 28, 1933, to Nov. 7, 1939, at same site, both at datum $2.53 \mathrm{ft}$ higher. Nov. 8, 1939, to Mar. 31, 1942,

nonrecording gage at same site at datum $2.00 \mathrm{ft}$ higher. April 1, 2942, to September 30, 1970, water-stage recorder at same site at same datum. Oct. 1, 1970, to Aug. 7,1979 , at site $300 \mathrm{ft}$ upstream at same datum.

REMARKS.--Diversions above station for irrigation of about 23,200 acres.

AVERAGE DISCHARGE. -52 years, $234 \mathrm{ft}^{3} / \mathrm{s}, 169,500$ acre-ft/yr.

EXIREMES FOR PERIOD OF RECORD.--Maximum discharge, 35,200 $\mathrm{ft}^{3} / \mathrm{s}$ Dec. 6, 1966, gage height, $15.66 \mathrm{ft}$, site then in use, fram rating curve extended above $1,500 \mathrm{ft}^{3} / \mathrm{s}$ on basis of slope-area measurement of peak $\mathrm{flow}$; minimum, $38 \mathrm{ft} / \mathrm{s}$ May $1,10,1975$.

LOWEST MEAN DISCHARGE, IN CUBIC FEET PER SECOND, AND RANKING FOR THE INDICATED NUMBER OF CONSECUTIVE DAYS FOR EAOH CLIMATIC YEAR, APRIL I-MARCH 31

YEAR

13

$54.0 \quad 24$

50.09

$50.0 \quad 10$

$51.0 \quad 17$

$53.0 \quad 22$

$50.0 \quad 11$

54.025

59.038

$55.0 \quad 26$

52.020

$53.0 \quad 23$

58.034

58.035

$63.0 \quad 50$

$61.0 \quad 41$

$60.0 \quad 39$

58.036

62.04

$56.0 \quad 27$

62.045

$62.0 \quad 46$

$57.0 \quad 29$

$61.0 \quad 42$

$63.0 \quad 47$

$61.0 \quad 43$

$63.0 \quad 48$

$57.0 \quad 30$

57.031

$\begin{array}{ll}58.0 & 37 \\ 57.0 & 32\end{array}$

50.012

$58.0 \quad 33$

$50.0 \quad 13$

$41.0 \quad 2$

42.0

$47.0 \quad 6$

$40.0 \quad 1$

52.021

$\begin{array}{ll}51.0 & 18 \\ 50.0 & 14\end{array}$

$\begin{array}{rr}3 & \\ 54.0 & 24 \\ 50.0 & 8 \\ 50.0 & 9 \\ 53.0 & 17 \\ 53.0 & 18 \\ & \\ 51.0 & 13 \\ 55.0 & 25 \\ 60.0 & 38 \\ 57.0 & 26 \\ 53.0 & 19 \\ 53.0 & 20 \\ 60.0 & 39 \\ 59.0 & 35 \\ 63.0 & 48 \\ 62.0 & 42 \\ & \\ 60.0 & 40 \\ 59.0 & 36 \\ 63.0 & 49 \\ 57.0 & 27 \\ 62.0 & 43 \\ 63.0 & 44 \\ 57.0 & 28 \\ 61.0 & 41 \\ 63.0 & 45 \\ 63.0 & 46 \\ 64.0 & 50 \\ 57.0 & 29 \\ 57.0 & 30 \\ 58.0 & 33 \\ 57.0 & 31 \\ 50.0 & 10 \\ 59.0 & 34 \\ 50.0 & 11 \\ 41.0 & 1 \\ 42.0 & 3 \\ & \\ 47.0 & 6 \\ 41.0 & 2 \\ 53.0 & 21 \\ 52.0 & 14 \\ 52.0 & 15 \\ & \\ 5\end{array}$

7$$
14
$$

$55.0 \quad 24$

50.07

$50.0 \quad 8$

$54.0 \quad 21$

$53.0 \quad 17$

$52.0 \quad 13$

$\begin{array}{rr}55.0 & 22 \\ 60.0 & 35\end{array}$

60.035

$53.0 \quad 14$

$54.0 \quad 18$

$66.0 \quad 50$

$59.0 \quad 32$

$64.0 \quad 48$

63.043

$61.0 \quad 36$

$61.0 \quad 37$

$64.0 \quad 44$

$59.0 \quad 33$

$64.0 \quad 45$

$\begin{array}{ll}58.0 & 29\end{array}$

$\begin{array}{ll}52.0 & 41\end{array}$

$\begin{array}{ll}62.0 & 41 \\ 63.0 & 42\end{array}$

64.046

$65.0 \quad 49$

$57.0 \quad 26$

$57.0 \quad 27$

$\begin{array}{ll}58.0 & 30 \\ 57.0 & 28\end{array}$

51.09

$60.0 \quad 34$

$51.0 \quad 10$

$44.0 \quad 3$

43.02

$48.0 \quad 6$

$41.0 \quad 1$

$53.0 \quad 15$

$55.0 \quad 23$ $\begin{array}{ll}\text { OONSEOTIVE DAYS } \\ 30 & 60\end{array}$

\section{$57.0 \quad 24$}

51.06

$59.0 \quad 28$

$\begin{array}{ll}54.0 & 14 \\ 54.0 & 15\end{array}$

$53.0 \quad 9$

$\begin{array}{rr}53.0 & 9 \\ 55.0 & 20\end{array}$

64.044

$67.0 \quad 49$

$54.0 \quad 17$

$74.0 \quad 50$

$63.0 \quad 39$

$64.0 \quad 45$

63.040

$62.0 \quad 36$

$62.0 \quad 37$

66.048

$\begin{array}{ll}61.0 & 33 \\ 63.0 & 38\end{array}$

$65.0 \quad 46$

$59.0 \quad 29$

$62.0 \quad 34$

$64.0 \quad 41$

$64.0 \quad 42$

$66.0 \quad 47$

$58.0 \quad 25$

$\begin{array}{rr}58.0 & 26 \\ 59.0 & 30\end{array}$

58.027

$53.0 \quad 10$

$61.0 \quad 31$

51.07

$\begin{array}{ll}48.0 & 3 \\ 44.0 & 1\end{array}$

$49.0 \quad 4$

45.02

57.021

$\begin{array}{ll}54.0 & 11 \\ 57.0 & 22\end{array}$ $\begin{array}{rrrr}103 & 51 & 109 & 49 \\ 53.0 & 6 & 55.0 & 6 \\ 65.0 & 37 & 138 & 51 \\ 57.0 & 15 & 73.0 & 37 \\ 55.0 & 11 & 55.0 & 7\end{array}$

$60.0 \quad 21$

56.012

68.046

$\begin{array}{ll}70.0 & 48\end{array}$

54.07

$\begin{array}{rr}54.0 & 7 \\ 77.0 \quad 49\end{array}$

66.041

$\begin{array}{ll}66.0 & 41 \\ 66.0 & 42\end{array}$

$64.0 \quad 34$

$63.0 \quad 31$

$65.0 \quad 38$

$67.0 \quad 43$

$62.0 \quad 26$

$68.0 \quad 47$

$\begin{array}{ll}68.0 & 47 \\ 60.0 & 22\end{array}$

$62.0 \quad 27$

$\begin{array}{ll}62.0 & 27 \\ 65.0 & 39\end{array}$

$67.0 \quad 44$

$66.0 \quad 40$

$59.0 \quad 18$

$62.0 \quad 28$

60.023

54.0

$\begin{array}{rr}62.0 & 29\end{array}$

$52.0 \quad 4$

52.05

46.01

$\begin{array}{ll}51.0 & 3 \\ 48.0 & 2\end{array}$

$64.0 \quad 35$

56.013

$67.0 \quad 45$

54.03

$128 \quad 50$

$69.0 \quad 33$

$\begin{array}{ll}67.0 & 27 \\ 65.0 & 24\end{array}$

$74.0 \quad 38$

$69.0,34$

$74.0 \quad 39$

$\begin{array}{ll}68.0 & 28 \\ 64.0 & 19\end{array}$

$74.0 \quad 40$

66.025

$69.0 \quad 29$

$70.0 \quad 35$

$85.0 \quad 46$

$\begin{array}{ll}67.0 & 26 \\ 60.0 & 12\end{array}$

$\begin{array}{ll}60.0 & 12 \\ 65.0 & 20\end{array}$

84.044

60.013

$56.0 \quad 8$

63.016

$\begin{array}{ll}55.0 & 4 \\ 52.0 & 2\end{array}$

57.0

$\begin{array}{rr}55.0 & 5 \\ 84.0 & 45\end{array}$

$\begin{array}{ll}84.0 & 45 \\ 65.0 & 21\end{array}$

$83.0 \quad 43$

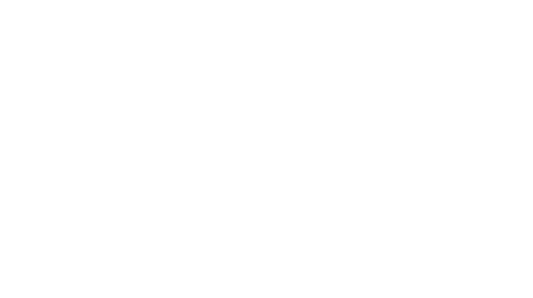

$\begin{array}{rrrrrrrr}59.0 & 8 & 74.0 & 15 & 193 & 46 & 252 & 33\end{array}$

$52.0 \quad 2 \quad 58.0 \quad 6$

$\begin{array}{lll}48.0 & 1 & 58.0\end{array}$ 
VIRGIN RIVER BASIN

09415000 VIRGIN RIVER AT LITTLEFIELD, AZ--Continued

LONEST MEAN DISCHARGE, IN OUBIC FEET PER SECOND, AND RANKING FOR THE INDICATED NNMBER OF CONSEQUTTVE DAYS FOR EAOH CLIMATIC YEAR, APRIL 1-MARCH 31-Continued

\begin{tabular}{|c|c|c|c|c|c|c|c|c|c|c|c|c|c|c|c|c|c|c|c|c|}
\hline YEAR & 1 & & 3 & & 7 & & 14 & & $\begin{array}{l}\text { CONS } \\
30\end{array}$ & & $\begin{array}{l}\text { E DAYS } \\
60\end{array}$ & & 90 & & 120 & & 183 & & ALL & \\
\hline $\begin{array}{l}971 \\
972 \\
973 \\
774 \\
975\end{array}$ & $\begin{array}{l}51.0 \\
60.0 \\
52.0 \\
48.0 \\
56.0\end{array}$ & $\begin{array}{r}15 \\
40 \\
19 \\
7 \\
28\end{array}$ & $\begin{array}{l}53.0 \\
60.0 \\
54.0 \\
49.0 \\
57.0\end{array}$ & $\begin{array}{r}22 \\
37 \\
23 \\
7 \\
32\end{array}$ & $\begin{array}{l}56.0 \\
61.0 \\
54.0 \\
51.0 \\
59.0\end{array}$ & $\begin{array}{l}25 \\
38 \\
19 \\
11 \\
31\end{array}$ & $\begin{array}{l}57.0 \\
62.0 \\
55.0 \\
54.0 \\
61.0\end{array}$ & $\begin{array}{l}23 \\
35 \\
18 \\
12 \\
32\end{array}$ & $\begin{array}{l}61.0 \\
63.0 \\
57.0 \\
55.0 \\
62.0\end{array}$ & $\begin{array}{r}24 \\
33 \\
17 \\
9 \\
30\end{array}$ & $\begin{array}{l}65.0 \\
63.0 \\
60.0 \\
65.0 \\
64.0\end{array}$ & $\begin{array}{l}22 \\
17 \\
14 \\
23 \\
18\end{array}$ & $\begin{array}{r}69.0 \\
66.0 \\
125 \\
67.0 \\
66.0\end{array}$ & $\begin{array}{l}18 \\
13 \\
45 \\
17 \\
14\end{array}$ & $\begin{array}{c}76.0 \\
88.0 \\
109 \\
73.0 \\
70.0\end{array}$ & $\begin{array}{l}19 \\
27 \\
40 \\
13 \\
10\end{array}$ & $\begin{array}{l}85.0 \\
124 \\
169 \\
108 \\
79.0\end{array}$ & $\begin{array}{r}7 \\
33 \\
44 \\
20 \\
5\end{array}$ & $\begin{array}{l}118 \\
152 \\
225 \\
387 \\
125\end{array}$ & $\begin{array}{r}5 \\
14 \\
26 \\
47 \\
8\end{array}$ \\
\hline $\begin{array}{l}976 \\
1977 \\
978 \\
1979 \\
980\end{array}$ & $\begin{array}{l}44.0 \\
44.0 \\
51.0 \\
50.0 \\
63.0\end{array}$ & $\begin{array}{r}4 \\
5 \\
16 \\
8 \\
49\end{array}$ & $\begin{array}{l}45.0 \\
46.0 \\
52.0 \\
51.0 \\
63.0\end{array}$ & $\begin{array}{r}4 \\
5 \\
16 \\
12 \\
47\end{array}$ & $\begin{array}{l}47.0 \\
48.0 \\
54.0 \\
52.0 \\
64.0\end{array}$ & $\begin{array}{r}4 \\
5 \\
20 \\
12 \\
47\end{array}$ & $\begin{array}{l}51.0 \\
54.0 \\
55.0 \\
52.0 \\
64.0\end{array}$ & $\begin{array}{r}5 \\
13 \\
19 \\
8 \\
43\end{array}$ & $\begin{array}{l}56.0 \\
61.0 \\
60.0 \\
55.0 \\
65.0\end{array}$ & $\begin{array}{l}14 \\
25 \\
20 \\
10 \\
36\end{array}$ & $\begin{array}{l}69.0 \\
63.0 \\
69.0 \\
57.0 \\
73.0\end{array}$ & $\begin{array}{l}30 \\
15 \\
31 \\
10 \\
36\end{array}$ & $\begin{array}{l}86.0 \\
73.0 \\
79.0 \\
61.0 \\
88.0\end{array}$ & $\begin{array}{r}31 \\
19 \\
25 \\
9 \\
34\end{array}$ & $\begin{array}{l}96.0 \\
74.0 \\
86.0 \\
62.0 \\
87.0\end{array}$ & $\begin{array}{r}30 \\
14 \\
24 \\
6 \\
25\end{array}$ & $\begin{array}{c}112 \\
101 \\
93.0 \\
94.0 \\
116\end{array}$ & $\begin{array}{l}22 \\
15 \\
12 \\
13 \\
27\end{array}$ & $\begin{array}{l}146 \\
116 \\
268 \\
270 \\
622\end{array}$ & $\begin{array}{r}12 \\
4 \\
36 \\
37 \\
51\end{array}$ \\
\hline & 75.0 & 51 & 75.0 & 51 & 78.0 & 51 & 81.0 & 51 & 89.0 & 50 & 104 & 48 & 169 & 49 & 190 & 49 & 219 & 49 & 420 & 9 \\
\hline
\end{tabular}

HIGHEST MEAN DISCHARGE, IN GBIC FEET PER SECOND, AND RANKING FOR THE INDICATED NUMBER OF CONSEOUTIVE DAYS FOR EACH WATER YEAR, OCTOBER 1-SEPTEMBER 30

YEAR CONSEOUTIVE DAYS

\begin{tabular}{|c|c|c|c|c|c|c|c|c|c|c|c|c|c|c|c|c|c|c|c|c|}
\hline . & 1 & & 3 & & 7 & & 15 & & 30 & & 60 & & 90 & & 120 & & 183 & & AL & $\mathrm{LL}$ \\
\hline 1930 & 6000 & 9 & 3700 & 10 & 2640 & 8 & 1670 & 11 & 908 & 12 & 654 & 13 & 475 & 17 & 413 & 17 & 354 & 17 & 260 & \\
\hline $\begin{array}{l}1931 \\
1932 \\
1933 \\
1934 \\
1935\end{array}$ & $\begin{array}{r}1860 \\
12000 \\
1200 \\
954 \\
1800\end{array}$ & $\begin{array}{r}27 \\
4 \\
45 \\
49 \\
30\end{array}$ & $\begin{array}{r}938 \\
9000 \\
700 \\
634 \\
1080\end{array}$ & $\begin{array}{r}35 \\
3 \\
45 \\
49 \\
33\end{array}$ & $\begin{array}{r}611 \\
4210 \\
430 \\
357 \\
798\end{array}$ & $\begin{array}{r}37 \\
5 \\
45 \\
50 \\
28\end{array}$ & $\begin{array}{r}472 \\
2170 \\
334 \\
268 \\
716\end{array}$ & $\begin{array}{r}33 \\
7 \\
43 \\
51 \\
23\end{array}$ & $\begin{array}{r}363 \\
1490 \\
290 \\
251 \\
663\end{array}$ & $\begin{array}{r}33 \\
8 \\
40 \\
45 \\
20\end{array}$ & $\begin{array}{r}302 \\
1040 \\
245 \\
210 \\
562\end{array}$ & $\begin{array}{l}30 \\
10 \\
37 \\
43 \\
18\end{array}$ & $\begin{array}{l}283 \\
984 \\
243 \\
199 \\
456\end{array}$ & $\begin{array}{r}29 \\
9 \\
37 \\
44 \\
19\end{array}$ & $\begin{array}{l}270 \\
989 \\
234 \\
183 \\
402\end{array}$ & $\begin{array}{r}27 \\
5 \\
35 \\
45 \\
18\end{array}$ & $\begin{array}{l}240 \\
752 \\
230 \\
153 \\
344\end{array}$ & $\begin{array}{r}27 \\
4 \\
32 \\
49 \\
18\end{array}$ & $\begin{array}{l}165 \\
526 \\
176 \\
108 \\
228\end{array}$ & \\
\hline $\begin{array}{l}1936 \\
1937 \\
1938 \\
1939 \\
1940\end{array}$ & $\begin{array}{r}2710 \\
1440 \\
17000 \\
5000 \\
4600\end{array}$ & $\begin{array}{r}19 \\
37 \\
1 \\
11 \\
14\end{array}$ & $\begin{array}{r}1760 \\
1100 \\
10700 \\
3330 \\
3100\end{array}$ & $\begin{array}{r}19 \\
32 \\
1 \\
11 \\
12\end{array}$ & $\begin{array}{r}837 \\
862 \\
5080 \\
2170 \\
1800\end{array}$ & $\begin{array}{r}26 \\
24 \\
3 \\
10 \\
15\end{array}$ & $\begin{array}{r}440 \\
830 \\
2580 \\
1230 \\
1050\end{array}$ & $\begin{array}{r}36 \\
20 \\
4 \\
13 \\
16\end{array}$ & $\begin{array}{r}424 \\
820 \\
1460 \\
737 \\
704\end{array}$ & $\begin{array}{r}31 \\
15 \\
9 \\
17 \\
18\end{array}$ & $\begin{array}{r}291 \\
790 \\
1190 \\
398 \\
539\end{array}$ & $\begin{array}{r}33 \\
11 \\
8 \\
26 \\
19\end{array}$ & $\begin{array}{r}277 \\
747 \\
1030 \\
285 \\
443\end{array}$ & $\begin{array}{r}30 \\
11 \\
6 \\
28 \\
20\end{array}$ & $\begin{array}{l}244 \\
696 \\
857 \\
254 \\
384\end{array}$ & $\begin{array}{r}32 \\
11 \\
8 \\
28 \\
21\end{array}$ & $\begin{array}{l}235 \\
516 \\
655 \\
235 \\
304\end{array}$ & $\begin{array}{r}30 \\
11 \\
7 \\
31 \\
21\end{array}$ & $\begin{array}{l}180 \\
332 \\
385 \\
214 \\
239\end{array}$ & \\
\hline $\begin{array}{l}1941 \\
1942 \\
1943 \\
1944 \\
1945\end{array}$ & $\begin{array}{l}4740 \\
1810 \\
1790 \\
1260 \\
2500\end{array}$ & $\begin{array}{l}12 \\
29 \\
31 \\
42 \\
21\end{array}$ & $\begin{array}{l}4000 \\
1300 \\
1490 \\
1230 \\
1560\end{array}$ & $\begin{array}{r}7 \\
25 \\
23 \\
27 \\
21\end{array}$ & $\begin{array}{r}3540 \\
1100 \\
1060 \\
1190 \\
841\end{array}$ & $\begin{array}{r}6 \\
20 \\
21 \\
19 \\
25\end{array}$ & $\begin{array}{r}3010 \\
1050 \\
812 \\
1060 \\
674\end{array}$ & $\begin{array}{r}2 \\
17 \\
21 \\
14 \\
25\end{array}$ & $\begin{array}{r}2210 \\
860 \\
650 \\
807 \\
552\end{array}$ & $\begin{array}{r}2 \\
14 \\
21 \\
16 \\
25\end{array}$ & $\begin{array}{r}1610 \\
654 \\
596 \\
617 \\
418\end{array}$ & $\begin{array}{c}1 \\
14 \\
17 \\
15 \\
25\end{array}$ & $\begin{array}{r}1410 \\
547 \\
526 \\
556 \\
367\end{array}$ & $\begin{array}{r}2 \\
14 \\
15 \\
12 \\
22\end{array}$ & $\begin{array}{r}1220 \\
481 \\
475 \\
488 \\
351\end{array}$ & $\begin{array}{r}2 \\
13 \\
14 \\
12 \\
22\end{array}$ & $\begin{array}{l}921 \\
418 \\
373 \\
397 \\
296\end{array}$ & $\begin{array}{r}2 \\
12 \\
15 \\
13 \\
23\end{array}$ & $\begin{array}{l}552 \\
297 \\
246 \\
252 \\
230\end{array}$ & \\
\hline $\begin{array}{l}1946 \\
1947 \\
1948 \\
1949 \\
1950\end{array}$ & $\begin{array}{r}1830 \\
6760 \\
646 \\
986 \\
1470\end{array}$ & $\begin{array}{r}28 \\
7 \\
52 \\
48 \\
35\end{array}$ & $\begin{array}{r}1160 \\
3910 \\
587 \\
894 \\
620\end{array}$ & $\begin{array}{r}30 \\
8 \\
51 \\
37 \\
50\end{array}$ & $\begin{array}{r}658 \\
1920 \\
530 \\
815 \\
369\end{array}$ & $\begin{array}{l}34 \\
12 \\
42 \\
27 \\
49\end{array}$ & $\begin{array}{r}487 \\
1020 \\
446 \\
709 \\
325\end{array}$ & $\begin{array}{l}32 \\
18 \\
34 \\
24 \\
45\end{array}$ & $\begin{array}{l}336 \\
897 \\
366 \\
589 \\
303\end{array}$ & $\begin{array}{l}34 \\
13 \\
32 \\
22 \\
37\end{array}$ & $\begin{array}{l}255 \\
598 \\
296 \\
493 \\
274\end{array}$ & $\begin{array}{l}36 \\
16 \\
31 \\
20 \\
34\end{array}$ & $\begin{array}{l}249 \\
514 \\
260 \\
430 \\
264\end{array}$ & $\begin{array}{l}35 \\
16 \\
33 \\
21 \\
31\end{array}$ & $\begin{array}{l}239 \\
444 \\
242 \\
396 \\
253\end{array}$ & $\begin{array}{l}34 \\
16 \\
33 \\
19 \\
29\end{array}$ & $\begin{array}{l}216 \\
372 \\
227 \\
326 \\
236\end{array}$ & $\begin{array}{l}34 \\
16 \\
33 \\
19\end{array}$ & $\begin{array}{l}167 \\
266 \\
160 \\
215 \\
175\end{array}$ & \\
\hline $\begin{array}{l}1951 \\
1952 \\
1953 \\
1954 \\
1955\end{array}$ & $\begin{array}{l}3230 \\
3230 \\
1270 \\
1700 \\
6330\end{array}$ & $\begin{array}{r}16 \\
17 \\
41 \\
32 \\
8\end{array}$ & $\begin{array}{r}1550 \\
2580 \\
873 \\
835 \\
3850\end{array}$ & $\begin{array}{r}22 \\
15 \\
39 \\
40 \\
9\end{array}$ & $\begin{array}{r}771 \\
2150 \\
477 \\
625 \\
1770\end{array}$ & $\begin{array}{l}30 \\
11 \\
44 \\
35 \\
16\end{array}$ & $\begin{array}{r}434 \\
2080 \\
307 \\
507 \\
1050\end{array}$ & $\begin{array}{r}37 \\
8 \\
48 \\
30 \\
15\end{array}$ & $\begin{array}{r}282 \\
1670 \\
237 \\
438 \\
673\end{array}$ & $\begin{array}{r}41 \\
5 \\
49 \\
28 \\
19\end{array}$ & $\begin{array}{r}195 \\
1290 \\
221 \\
360 \\
425\end{array}$ & $\begin{array}{r}50 \\
7 \\
41 \\
28 \\
23\end{array}$ & $\begin{array}{r}172 \\
1010 \\
212 \\
305 \\
307\end{array}$ & $\begin{array}{r}50 \\
8 \\
39 \\
27 \\
26\end{array}$ & $\begin{array}{c}165 \\
811 \\
198 \\
293 \\
248\end{array}$ & $\begin{array}{l}49 \\
10 \\
40 \\
26 \\
31\end{array}$ & $\begin{array}{l}15 \\
64 \\
166 \\
25 \\
210\end{array}$ & $\begin{array}{r}48 \\
8 \\
43 \\
25 \\
35\end{array}$ & $\begin{array}{l}138 \\
377 \\
137 \\
189 \\
187\end{array}$ & \\
\hline $\begin{array}{l}1956 \\
1957 \\
1958 \\
1959 \\
1960\end{array}$ & $\begin{array}{l}1330 \\
1120 \\
3830 \\
1250 \\
1470\end{array}$ & $\begin{array}{l}40 \\
47 \\
15 \\
43 \\
36\end{array}$ & $\begin{array}{r}826 \\
799 \\
2200 \\
683 \\
716\end{array}$ & $\begin{array}{l}41 \\
42 \\
16 \\
47 \\
44\end{array}$ & $\begin{array}{r}507 \\
422 \\
1840 \\
349 \\
416\end{array}$ & $\begin{array}{l}43 \\
46 \\
14 \\
51 \\
47\end{array}$ & $\begin{array}{r}359 \\
309 \\
1510 \\
279 \\
283\end{array}$ & $\begin{array}{l}41 \\
46 \\
12 \\
50 \\
49\end{array}$ & $\begin{array}{r}278 \\
263 \\
1370 \\
244 \\
210\end{array}$ & $\begin{array}{l}42 \\
44 \\
10 \\
47 \\
52\end{array}$ & $\begin{array}{r}229 \\
235 \\
1180 \\
209 \\
183\end{array}$ & $\begin{array}{r}40 \\
38 \\
9 \\
44 \\
51\end{array}$ & $\begin{array}{l}226 \\
204 \\
974 \\
192 \\
178\end{array}$ & $\begin{array}{l}38 \\
42 \\
10 \\
46 \\
48\end{array}$ & $\begin{array}{l}211 \\
194 \\
816 \\
191 \\
17\end{array}$ & $\begin{array}{r}38 \\
42 \\
9 \\
43 \\
47\end{array}$ & $\begin{array}{l}17 \\
18 \\
60 \\
16 \\
16\end{array}$ & $\begin{array}{l}39 \\
36 \\
10 \\
42 \\
46\end{array}$ & $\begin{array}{l}128 \\
138 \\
407 \\
128 \\
115\end{array}$ & \\
\hline $\begin{array}{l}1961 \\
1962 \\
1963 \\
1964 \\
1965\end{array}$ & $\begin{array}{r}5330 \\
2140 \\
1620 \\
1880 \\
937\end{array}$ & $\begin{array}{l}10 \\
24 \\
33 \\
26 \\
50\end{array}$ & $\begin{array}{r}2120 \\
1570 \\
884 \\
1140 \\
775\end{array}$ & $\begin{array}{l}17 \\
20 \\
38 \\
31 \\
43\end{array}$ & $\begin{array}{r}1020 \\
1300 \\
568 \\
548 \\
702\end{array}$ & $\begin{array}{l}22 \\
18 \\
39 \\
40 \\
31\end{array}$ & $\begin{array}{l}638 \\
846 \\
342 \\
406 \\
649\end{array}$ & $\begin{array}{l}27 \\
19 \\
42 \\
39 \\
26\end{array}$ & $\begin{array}{l}479 \\
554 \\
299 \\
247 \\
567\end{array}$ & $\begin{array}{l}27 \\
24 \\
38 \\
46 \\
23\end{array}$ & $\begin{array}{l}330 \\
434 \\
207 \\
202 \\
462\end{array}$ & $\begin{array}{l}29 \\
22 \\
45 \\
48 \\
21\end{array}$ & $\begin{array}{l}261 \\
459 \\
156 \\
173 \\
361\end{array}$ & $\begin{array}{l}32 \\
18 \\
51 \\
49 \\
23\end{array}$ & $\begin{array}{l}212 \\
385 \\
135 \\
161 \\
305\end{array}$ & $\begin{array}{l}37 \\
20 \\
52 \\
50 \\
25\end{array}$ & $\begin{array}{l}164 \\
314 \\
122 \\
145 \\
250\end{array}$ & $\begin{array}{l}45 \\
20 \\
52 \\
50\end{array}$ & $\begin{array}{l}150 \\
197 \\
115 \\
123 \\
166\end{array}$ & \\
\hline $\begin{array}{l}1966 \\
1967 \\
1968 \\
1969 \\
1970\end{array}$ & $\begin{array}{r}2640 \\
15200 \\
1180 \\
7220 \\
914\end{array}$ & $\begin{array}{r}20 \\
2 \\
46 \\
6 \\
51\end{array}$ & $\begin{array}{r}1360 \\
10300 \\
685 \\
4060 \\
499\end{array}$ & $\begin{array}{r}24 \\
2 \\
46 \\
6 \\
52\end{array}$ & $\begin{array}{r}878 \\
4710 \\
544 \\
2470 \\
394\end{array}$ & $\begin{array}{r}23 \\
4 \\
41 \\
9 \\
48\end{array}$ & $\begin{array}{r}586 \\
2370 \\
440 \\
1790 \\
308\end{array}$ & $\begin{array}{r}29 \\
6 \\
35 \\
9 \\
47\end{array}$ & $\begin{array}{r}501 \\
1290 \\
298 \\
1650 \\
231\end{array}$ & $\begin{array}{r}26 \\
11 \\
39 \\
6 \\
50\end{array}$ & $\begin{array}{r}419 \\
749 \\
266 \\
1440 \\
212\end{array}$ & $\begin{array}{r}24 \\
12 \\
35 \\
5 \\
42\end{array}$ & $\begin{array}{r}347 \\
556 \\
259 \\
1220 \\
208\end{array}$ & $\begin{array}{r}24 \\
13 \\
34 \\
4 \\
40\end{array}$ & $\begin{array}{r}310 \\
459 \\
251 \\
1100 \\
208\end{array}$ & $\begin{array}{r}23 \\
15 \\
30 \\
3 \\
39\end{array}$ & $\begin{array}{l}286 \\
389 \\
239 \\
836 \\
182\end{array}$ & $\begin{array}{r}24 \\
14 \\
28 \\
3 \\
37\end{array}$ & $\begin{array}{l}177 \\
259 \\
177 \\
475 \\
134\end{array}$ & \\
\hline $\begin{array}{l}1971 \\
1972 \\
1973 \\
1974 \\
1975\end{array}$ & $\begin{array}{l}1200 \\
4740 \\
3000 \\
1390 \\
2380\end{array}$ & $\begin{array}{l}44 \\
13 \\
18 \\
39 \\
23\end{array}$ & $\begin{array}{r}903 \\
2910 \\
2930 \\
679 \\
1250\end{array}$ & $\begin{array}{l}36 \\
14 \\
13 \\
48 \\
26\end{array}$ & $\begin{array}{r}674 \\
1410 \\
2710 \\
331 \\
593\end{array}$ & $\begin{array}{r}32 \\
17 \\
7 \\
52 \\
38\end{array}$ & $\begin{array}{r}490 \\
729 \\
2450 \\
256 \\
363\end{array}$ & $\begin{array}{r}31 \\
22 \\
5 \\
52 \\
40\end{array}$ & $\begin{array}{r}325 \\
425 \\
2050 \\
240 \\
265\end{array}$ & $\begin{array}{r}35 \\
30 \\
3 \\
48 \\
43\end{array}$ & $\begin{array}{r}198 \\
294 \\
1540 \\
204 \\
203\end{array}$ & $\begin{array}{r}49 \\
32 \\
3 \\
46 \\
47\end{array}$ & $\begin{array}{r}182 \\
243 \\
1230 \\
207 \\
194\end{array}$ & $\begin{array}{r}47 \\
36 \\
3 \\
41 \\
45\end{array}$ & $\begin{array}{r}174 \\
226 \\
1020 \\
197 \\
187\end{array}$ & $\begin{array}{r}48 \\
36 \\
4 \\
41 \\
44\end{array}$ & $\begin{array}{l}15 \\
180 \\
738 \\
170 \\
17\end{array}$ & $\begin{array}{r}47 \\
38 \\
5 \\
41 \\
40\end{array}$ & $\begin{array}{l}138 \\
175 \\
443 \\
125 \\
154\end{array}$ & \\
\hline $\begin{array}{l}1976 \\
1977 \\
1978 \\
1979 \\
1980\end{array}$ & $\begin{array}{r}1600 \\
1940 \\
13300 \\
2440 \\
8780\end{array}$ & $\begin{array}{r}34 \\
25 \\
3 \\
22 \\
5\end{array}$ & $\begin{array}{l}1210 \\
1200 \\
7980 \\
1900 \\
7260\end{array}$ & $\begin{array}{r}28 \\
29 \\
4 \\
18 \\
5\end{array}$ & $\begin{array}{r}660 \\
611 \\
5260 \\
1860 \\
6130\end{array}$ & $\begin{array}{r}33 \\
36 \\
2 \\
13 \\
1\end{array}$ & $\begin{array}{r}422 \\
333 \\
2790 \\
1700 \\
4020\end{array}$ & $\begin{array}{r}38 \\
44 \\
3 \\
10 \\
1\end{array}$ & $\begin{array}{r}304 \\
214 \\
1730 \\
1610 \\
2420\end{array}$ & $\begin{array}{r}36 \\
51 \\
4 \\
7 \\
1\end{array}$ & $\begin{array}{r}233 \\
164 \\
1300 \\
1440 \\
1560\end{array}$ & $\begin{array}{r}39 \\
52 \\
6 \\
4 \\
2\end{array}$ & $\begin{array}{r}202 \\
148 \\
1030 \\
1190 \\
1480\end{array}$ & $\begin{array}{r}43 \\
52 \\
7 \\
5 \\
1\end{array}$ & $\begin{array}{r}182 \\
146 \\
867 \\
982 \\
1380\end{array}$ & $\begin{array}{r}46 \\
51 \\
7 \\
6 \\
1\end{array}$ & $\begin{array}{r}165 \\
131 \\
633 \\
731 \\
1070\end{array}$ & $\begin{array}{r}44 \\
51 \\
9 \\
6 \\
1\end{array}$ & $\begin{array}{l}126 \\
112 \\
354 \\
427 \\
620\end{array}$ & \\
\hline 981 & 1400 & 38 & 1070 & 34 & 773 & 29 & 596 & 28 & 426 & 29 & 379 & 27 & 338 & 25 & 310 & 24 & 297 & 22 & 226 & \\
\hline
\end{tabular}


VIRGIN RIVER BASIN

09415000 VIRGIN RIVER AT LITTLEFIELD, AZ--Continued

DURATION OF DISCHARGE FOR EACH WATER YEAR

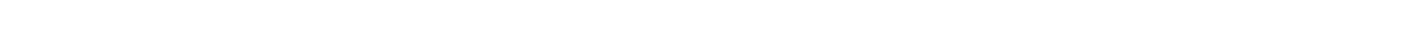

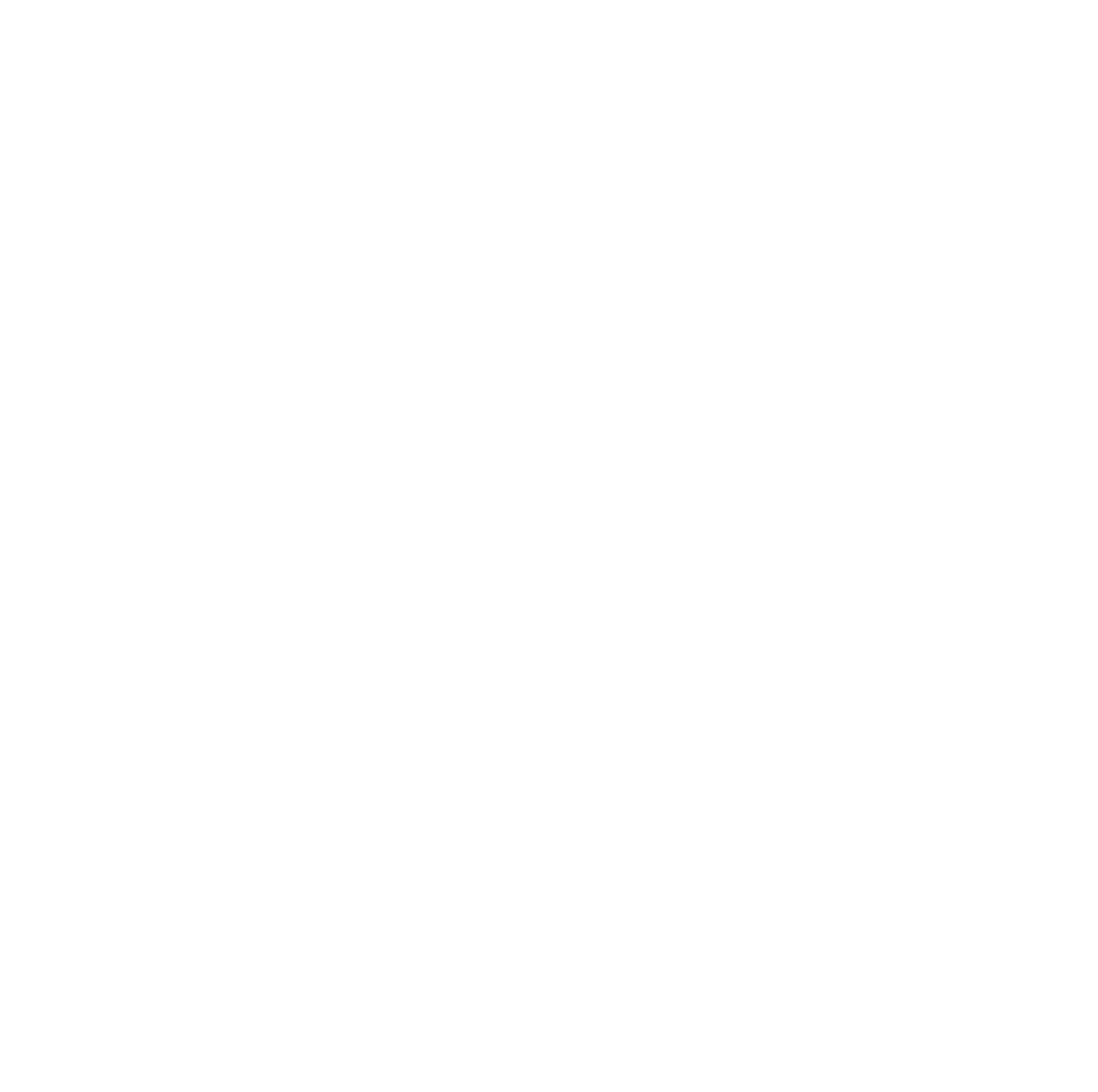

DURATION TABLE OF DISCHARGE FOR WATER YEARS 1930-81

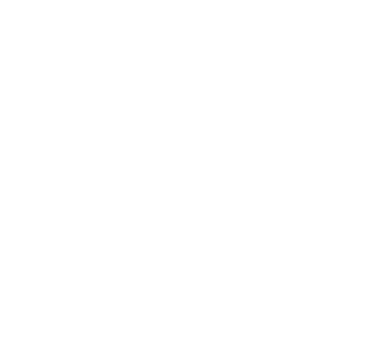
$\begin{array}{lll}\text { OUBIC } & \text { ACU- } \\ \text { FEET } & \text { MU- } & \text { PER- } \\ \text { PER TOTAL LATED } & \text { CENT }\end{array}$

GASS SECOND DAYS DAYS DAYS

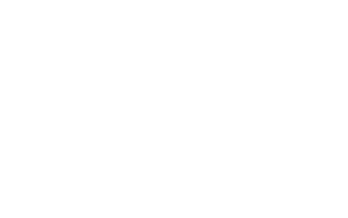

CUBIC ACWFEET MU- PERCLASS SECOND DAYS DAYS DAYS

$\begin{array}{rrrrr}18 & 850.0 & 168 & 780 & 4.1 \\ 19 & 1000.0 & 154 & 612 & 3.2 \\ 20 & 1200.0 & 140 & 458 & 2.4 \\ 21 & 1500.0 & 120 & 318 & 1.7 \\ 22 & 1800.0 & 70 & 198 & 1.0 \\ 23 & 2100.0 & 42 & 128 & 0.7 \\ 24 & 2500.0 & 16 & 86 & 0.5 \\ 25 & 3000.0 & 26 & 70 & 0.4 \\ 26 & 3600.0 & 15 & 44 & 0.2\end{array}$

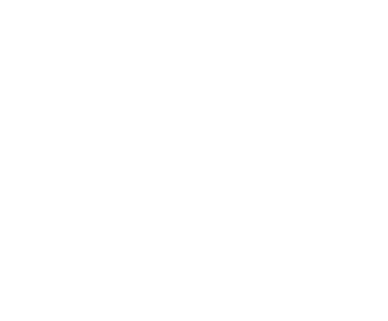


VIRGIN RTVER BASIN

09415000 VIRGIN RIVER AT LITTLEFIELD, AZ--Continued

MONTHLY MEAN DISCHARGES, IN OUBIC FEET PER SECOND, FOR EAG WATER YEAR

\begin{tabular}{|c|c|c|c|c|c|c|c|c|c|c|c|c|}
\hline YEAR & $\mathrm{OCr}$ & NOV & DEC & JAN & FEB & MAR & APR & MAY & JUNE & JULY & AUG & SEP \\
\hline 1930 & 86.9 & 127 & 147 & 224 & 262 & 161 & 143 & 456 & 112 & 108 & 853 & 429 \\
\hline $\begin{array}{l}1931 \\
1932 \\
1933 \\
1934 \\
1935\end{array}$ & $\begin{array}{c}260 \\
87.7 \\
173 \\
90.9 \\
83.2\end{array}$ & $\begin{array}{l}310 \\
285 \\
168 \\
129 \\
114\end{array}$ & $\begin{array}{l}213 \\
192 \\
260 \\
200 \\
211\end{array}$ & $\begin{array}{l}235 \\
155 \\
230 \\
203 \\
232\end{array}$ & $\begin{array}{r}310 \\
1327 \\
239 \\
184 \\
245\end{array}$ & $\begin{array}{l}129 \\
677 \\
201 \\
118 \\
246\end{array}$ & $\begin{array}{c}93.2 \\
771 \\
155 \\
61.6 \\
585\end{array}$ & $\begin{array}{c}68.1 \\
1029 \\
288 \\
55.4 \\
516\end{array}$ & $\begin{array}{c}55.4 \\
344 \\
115 \\
55.7 \\
137\end{array}$ & $\begin{array}{l}63.9 \\
381 \\
123 \\
67.4 \\
75.8\end{array}$ & $\begin{array}{l}146 \\
976 \\
77.8 \\
63.8 \\
200\end{array}$ & $\begin{array}{l}106 \\
121 \\
83.4 \\
69.1 \\
88.8\end{array}$ \\
\hline $\begin{array}{l}1936 \\
1937 \\
1938 \\
1939 \\
1940\end{array}$ & $\begin{array}{l}64.9 \\
191 \\
94.3 \\
120 \\
147\end{array}$ & $\begin{array}{l}123 \\
206 \\
141 \\
190 \\
130\end{array}$ & $\begin{array}{l}179 \\
192 \\
252 \\
231 \\
159\end{array}$ & $\begin{array}{l}141 \\
153 \\
280 \\
253 \\
330\end{array}$ & $\begin{array}{l}306 \\
524 \\
323 \\
235 \\
688\end{array}$ & $\begin{array}{r}205 \\
677 \\
1380 \\
242 \\
287\end{array}$ & $\begin{array}{l}297 \\
790 \\
955 \\
255 \\
240\end{array}$ & $\begin{array}{c}147 \\
753 \\
719 \\
142 \\
92.0\end{array}$ & $\begin{array}{l}66.7 \\
150 \\
111 \\
61.2 \\
54.8\end{array}$ & $\begin{array}{l}304 \\
127 \\
75.5 \\
57.8 \\
54.4\end{array}$ & $\begin{array}{c}193 \\
70.0 \\
183 \\
59.2 \\
109\end{array}$ & $\begin{array}{l}143 \\
168 \\
91.6 \\
737 \\
611\end{array}$ \\
\hline $\begin{array}{l}1941 \\
1942 \\
1943 \\
1944 \\
1945\end{array}$ & $\begin{array}{l}148 \\
371 \\
148 \\
141 \\
81.5\end{array}$ & $\begin{array}{l}171 \\
318 \\
173 \\
170 \\
217\end{array}$ & $\begin{array}{l}211 \\
282 \\
183 \\
210 \\
189\end{array}$ & $\begin{array}{l}242 \\
320 \\
292 \\
216 \\
184\end{array}$ & $\begin{array}{l}554 \\
279 \\
375 \\
260 \\
316\end{array}$ & $\begin{array}{r}1010 \\
328 \\
590 \\
418 \\
331\end{array}$ & $\begin{array}{r}1045 \\
839 \\
573 \\
424 \\
329\end{array}$ & $\begin{array}{r}2122 \\
461 \\
189 \\
795 \\
404\end{array}$ & $\begin{array}{c}325 \\
85.5 \\
67.2 \\
179 \\
79.6\end{array}$ & $\begin{array}{r}359 \\
68.9 \\
67.5 \\
64.2 \\
75.0\end{array}$ & $\begin{array}{c}332 \\
145 \\
206 \\
66.2 \\
419\end{array}$ & $\begin{array}{r}91.6 \\
67.8 \\
99.1 \\
70.7 \\
134\end{array}$ \\
\hline $\begin{array}{l}1946 \\
1947 \\
1948 \\
1949 \\
1950\end{array}$ & $\begin{array}{l}322 \\
602 \\
131 \\
97.2 \\
140\end{array}$ & $\begin{array}{l}174 \\
552 \\
155 \\
160 \\
185\end{array}$ & $\begin{array}{l}230 \\
359 \\
225 \\
163 \\
218\end{array}$ & $\begin{array}{l}213 \\
246 \\
172 \\
205 \\
242\end{array}$ & $\begin{array}{l}174 \\
221 \\
212 \\
259 \\
289\end{array}$ & $\begin{array}{l}172 \\
218 \\
206 \\
287 \\
225\end{array}$ & $\begin{array}{l}196 \\
265 \\
336 \\
512 \\
257\end{array}$ & $\begin{array}{l}74.7 \\
272 \\
166 \\
455 \\
106\end{array}$ & $\begin{array}{c}66.8 \\
72.1 \\
68.6 \\
198 \\
67.7\end{array}$ & $\begin{array}{r}102 \\
76.1 \\
69.0 \\
73.2 \\
193\end{array}$ & $\begin{array}{l}217 \\
226 \\
87.5 \\
64.4 \\
91.5\end{array}$ & $\begin{array}{c}66.0 \\
70.7 \\
99.8 \\
118 \\
99.4\end{array}$ \\
\hline $\begin{array}{l}1951 \\
1952 \\
1953 \\
1954 \\
1955\end{array}$ & $\begin{array}{l}79.0 \\
111 \\
94.5 \\
116 \\
140\end{array}$ & $\begin{array}{l}149 \\
149 \\
171 \\
159 \\
156\end{array}$ & $\begin{array}{l}167 \\
332 \\
221 \\
179 \\
214\end{array}$ & $\begin{array}{l}179 \\
344 \\
219 \\
241 \\
191\end{array}$ & $\begin{array}{l}139 \\
190 \\
162 \\
224 \\
218\end{array}$ & $\begin{array}{l}131 \\
445 \\
117 \\
273 \\
172\end{array}$ & $\begin{array}{c}117 \\
1338 \\
101 \\
394 \\
99.7\end{array}$ & $\begin{array}{c}159 \\
1156 \\
77.7 \\
157 \\
83.9\end{array}$ & $\begin{array}{c}62.6 \\
203 \\
68.6 \\
91.7 \\
66.6\end{array}$ & $\begin{array}{l}95.5 \\
69.0 \\
134 \\
123 \\
166\end{array}$ & $\begin{array}{l}271 \\
84.8 \\
213 \\
160 \\
655\end{array}$ & $\begin{array}{c}104 \\
96.1 \\
67.3 \\
149 \\
75.2\end{array}$ \\
\hline $\begin{array}{l}1956 \\
1957 \\
1958 \\
1959 \\
1960\end{array}$ & $\begin{array}{l}88.4 \\
67.4 \\
237 \\
123 \\
75.8\end{array}$ & $\begin{array}{l}172 \\
102 \\
347 \\
181 \\
210\end{array}$ & $\begin{array}{l}216 \\
123 \\
251 \\
158 \\
141\end{array}$ & $\begin{array}{l}243 \\
195 \\
160 \\
170 \\
183\end{array}$ & $\begin{array}{l}198 \\
247 \\
340 \\
241 \\
175\end{array}$ & $\begin{array}{l}126 \\
161 \\
670 \\
149 \\
158\end{array}$ & $\begin{array}{c}96.7 \\
103 \\
1068 \\
73.9 \\
97.1\end{array}$ & $\begin{array}{c}73.5 \\
248 \\
1131 \\
66.5 \\
75.9\end{array}$ & $\begin{array}{l}74.3 \\
145 \\
121 \\
61.0 \\
55.9\end{array}$ & $\begin{array}{r}123 \\
65.8 \\
97.6 \\
62.5 \\
59.2\end{array}$ & $\begin{array}{c}65.6 \\
147 \\
88.5 \\
192 \\
57.1\end{array}$ & $\begin{array}{c}59.9 \\
62.2 \\
376 \\
67.7 \\
94.5\end{array}$ \\
\hline $\begin{array}{l}1961 \\
1962 \\
1963 \\
1964 \\
1965\end{array}$ & $\begin{array}{c}101 \\
89.7 \\
105 \\
87.8 \\
53.4\end{array}$ & $\begin{array}{l}211 \\
127 \\
104 \\
159 \\
110\end{array}$ & $\begin{array}{l}130 \\
207 \\
121 \\
111 \\
142\end{array}$ & $\begin{array}{l}125 \\
166 \\
146 \\
108 \\
141\end{array}$ & $\begin{array}{l}130 \\
549 \\
161 \\
131 \\
141\end{array}$ & $\begin{array}{c}128 \\
269 \\
98.8 \\
108 \\
125\end{array}$ & $\begin{array}{l}74.5 \\
551 \\
71.5 \\
212 \\
511\end{array}$ & $\begin{array}{l}62.2 \\
141 \\
63.2 \\
176 \\
390\end{array}$ & $\begin{array}{r}64.7 \\
58.5 \\
52.3 \\
46.8 \\
154\end{array}$ & $\begin{array}{l}135 \\
62.6 \\
54.6 \\
60.9 \\
51.6\end{array}$ & $\begin{array}{l}272 \\
54.4 \\
178 \\
226 \\
77.5\end{array}$ & $\begin{array}{c}366 \\
122 \\
229 \\
53.3 \\
105\end{array}$ \\
\hline $\begin{array}{l}1966 \\
1967 \\
1968 \\
1969 \\
1970\end{array}$ & $\begin{array}{l}94.3 \\
104 \\
111 \\
96.1 \\
125\end{array}$ & $\begin{array}{l}347 \\
151 \\
153 \\
124 \\
197\end{array}$ & $\begin{array}{r}421 \\
1247 \\
210 \\
168 \\
195\end{array}$ & $\begin{array}{l}211 \\
207 \\
204 \\
775 \\
211\end{array}$ & $\begin{array}{l}204 \\
169 \\
256 \\
614 \\
156\end{array}$ & $\begin{array}{l}238 \\
169 \\
203 \\
642 \\
208\end{array}$ & $\begin{array}{c}283 \\
192 \\
248 \\
1385 \\
67.7\end{array}$ & $\begin{array}{c}101 \\
318 \\
275 \\
1360 \\
78.6\end{array}$ & $\begin{array}{c}56.4 \\
116 \\
79.8 \\
230 \\
63.6\end{array}$ & $\begin{array}{l}60.3 \\
65.8 \\
93.1 \\
96.6 \\
98.3\end{array}$ & $\begin{array}{c}50.0 \\
122 \\
236 \\
69.0 \\
121\end{array}$ & $\begin{array}{c}67.9 \\
228 \\
57.4 \\
148 \\
83.8\end{array}$ \\
\hline $\begin{array}{l}1971 \\
1972 \\
1973 \\
1974 \\
1975\end{array}$ & $\begin{array}{l}76.6 \\
152 \\
284 \\
84.8 \\
149\end{array}$ & $\begin{array}{l}181 \\
163 \\
210 \\
181 \\
190\end{array}$ & $\begin{array}{l}176 \\
342 \\
189 \\
180 \\
146\end{array}$ & $\begin{array}{l}170 \\
172 \\
183 \\
230 \\
140\end{array}$ & $\begin{array}{l}167 \\
157 \\
257 \\
162 \\
161\end{array}$ & $\begin{array}{l}139 \\
92.0 \\
552 \\
161 \\
209\end{array}$ & $\begin{array}{c}85.8 \\
64.5 \\
1126 \\
92.7 \\
121\end{array}$ & $\begin{array}{c}141 \\
58.2 \\
1895 \\
66.6 \\
243\end{array}$ & $\begin{array}{c}63.0 \\
252 \\
395 \\
62.9 \\
88.2\end{array}$ & $\begin{array}{r}64.0 \\
66.1 \\
77.3 \\
76.3 \\
141\end{array}$ & $\begin{array}{l}305 \\
183 \\
78.2 \\
79.8 \\
186\end{array}$ & $\begin{array}{c}83.2 \\
400 \\
56.2 \\
126 \\
65.5\end{array}$ \\
\hline $\begin{array}{l}1976 \\
1977 \\
1978 \\
1979 \\
1980\end{array}$ & $\begin{array}{c}94.5 \\
209 \\
71.6 \\
82.1 \\
92.3\end{array}$ & $\begin{array}{l}110 \\
114 \\
105 \\
209 \\
171\end{array}$ & $\begin{array}{l}136 \\
115 \\
126 \\
227 \\
194\end{array}$ & $\begin{array}{l}156 \\
142 \\
246 \\
200 \\
598\end{array}$ & $\begin{array}{r}299 \\
119 \\
388 \\
324 \\
2330\end{array}$ & $\begin{array}{c}112 \\
85.4 \\
1708 \\
603 \\
695\end{array}$ & $\begin{array}{c}130 \\
66.8 \\
847 \\
1262 \\
945\end{array}$ & $\begin{array}{c}147 \\
99.7 \\
477 \\
1559 \\
1486\end{array}$ & $\begin{array}{l}64.0 \\
102 \\
85.0 \\
390 \\
457\end{array}$ & $\begin{array}{c}80.1 \\
117 \\
65.7 \\
68.9 \\
141\end{array}$ & $\begin{array}{l}75.3 \\
110 \\
64.0 \\
127 \\
106\end{array}$ & $\begin{array}{l}111 \\
68.2 \\
61.1 \\
65.9 \\
319\end{array}$ \\
\hline 1981 & 229 & 272 & 271 & 227 & 247 & 334 & 419 & 213 & 104 & 133 & 155 & 114 \\
\hline
\end{tabular}


VIRGIN RIVER BASIN

09415000 VIRGIN RIVER AT LIITLEFIELD, AZ--Continued

ANNUAL PEAK DISGHARGE, IN OBIC FEET PER SECOND, AND CORRESPONDING GAGE HEIGHT, IN FEET, FOR EACH WATER YEAR

\begin{tabular}{|c|c|c|c|c|c|c|c|c|c|c|c|}
\hline $\begin{array}{l}\text { WATER } \\
\text { YEAR }\end{array}$ & DATE & $\begin{array}{c}\text { GAGE } \\
\text { HEIGHT }\end{array}$ & $\begin{array}{c}\text { PEAK } \\
\text { DISCHARGE }\end{array}$ & $\begin{array}{l}\text { WATER } \\
\text { YEAR }\end{array}$ & DATE & $\begin{array}{c}\text { GAGE } \\
\text { HEIGHI }\end{array}$ & $\begin{array}{c}\text { PEAK } \\
\text { DISCHARGE }\end{array}$ & $\begin{array}{l}\text { WATER } \\
\text { YEAR }\end{array}$ & DATE & $\begin{array}{c}\text { GAGE } \\
\text { HEIGHT }\end{array}$ & $\begin{array}{c}\text { PEAK } \\
\text { DISCHARC }\end{array}$ \\
\hline $\begin{array}{l}1930 \\
1931 \\
1932 \\
1933 \\
1934 \\
1935 \\
1936 \\
1937 \\
1938 \\
1939 \\
1940 \\
1941 \\
1942 \\
1943 \\
1944 \\
1945 \\
1946 \\
1947\end{array}$ & $\begin{array}{l}\text { AUG. } 09,1930 \\
\text { NOV. } 18,1930 \\
\text { AUG. } 27,1932 \\
\text { MAY } 01,1933 \\
\text { DEC. } 14,1933 \\
\text { AUG. } 16,1935 \\
\text { JULY } 10,1936 \\
\text { FEB. } 07,1937 \\
\text { MAR. } 03,1938 \\
\text { SEPT.12, } 1939 \\
\text { SEPT.18, } 1940 \\
\text { MAR. 02, } 1941 \\
\text { OCT. 13, } 1941 \\
\text { MAR. 11, } 1943 \\
\text { MAY } 09,1944 \\
\text { FEB. 03, } 1945 \\
\text { AUG. 12, } 1946 \\
\text { OCT. } 29,1946\end{array}$ & $\begin{array}{r}8.65 \\
6.50 \\
11.00 \\
- \\
4.20 \\
5.00 \\
7.00 \\
5.00 \\
10.30 \\
7.50 \\
7.40 \\
5.00 \\
6.30 \\
5.62 \\
4.99 \\
6.57 \\
6.95 \\
9.35\end{array}$ & $\begin{array}{r}6500 \\
3000 \\
18000 \\
1500 \\
1220 \\
1900 \\
2710 \\
1440 \\
22000 \\
13000 \\
11000 \\
6000 \\
3740 \\
2660 \\
1900 \\
4170 \\
5010 \\
9400\end{array}$ & $\begin{array}{l}1948 \\
1949 \\
1950 \\
1951 \\
1952 \\
1953 \\
1954 \\
1955 \\
1956 \\
1957 \\
1958 \\
1959 \\
1960 \\
1961 \\
1962 \\
1963 \\
1964\end{array}$ & $\begin{array}{l}\text { SEPT.16, } 1948 \\
\text { SEPT.10, } 1949 \\
\text { JULY } 18,1950 \\
\text { AUG. } 04,1951 \\
\text { DEC. } 30,1951 \\
\text { AUG. } 27,1953 \\
\text { AUG. } 04,1954 \\
\text { AUG. } 25,1955 \\
\text { JAN. } 27,1956 \\
\text { AUG. 21, } 1957 \\
\text { MAR. 17, } 1958 \\
\text { AUG. 19, } 1959 \\
\text { NOV. } 03,1959 \\
\text { SEPT.18, } 1961 \\
\text { FEB. } 12,1962 \\
\text { SEPT.14, } 1963 \\
\text { AUG. } 14,1964\end{array}$ & $\begin{array}{r}5.19 \\
6.35 \\
7.34 \\
10.53 \\
8.70 \\
8.66 \\
9.18 \\
13.60 \\
6.89 \\
8.00 \\
9.87 \\
7.76 \\
6.28 \\
10.84 \\
8.12 \\
7.70 \\
8.66\end{array}$ & $\begin{array}{r}1090 \\
2290 \\
3450 \\
12000 \\
7170 \\
5490 \\
6020 \\
19800 \\
2460 \\
3950 \\
7180 \\
3490 \\
2320 \\
10900 \\
5380 \\
4720 \\
6300\end{array}$ & $\begin{array}{l}1965 \\
1966 \\
1967 \\
1968 \\
1969 \\
1970 \\
1971 \\
1972 \\
1973 \\
1974 \\
1975 \\
1976 \\
1977 \\
1978 \\
1979 \\
1980 \\
1981\end{array}$ & $\begin{array}{l}\text { SEPT.06, } 1965 \\
\text { DEC. } 30,1965 \\
\text { DEC. } 06,1966 \\
\text { AUG. } 08,1968 \\
\text { JAN. } 26,1969 \\
\text { JULY } 22,1970 \\
\text { AUG. } 15,1971 \\
\text { DEC. } 25,1971 \\
\text { MAY 11, } 1973 \\
\text { SEPT. 05, } 1974 \\
\text { JULY } 30,1975 \\
\text { FEB. } 09,1976 \\
\text { OCT. } 02,1976 \\
\text { MAR. 02, } 1978 \\
\text { MAR. } 28,1979 \\
\text { FEB. 20, } 1980 \\
\text { JULY } 16,1981\end{array}$ & $\begin{array}{r}7.60 \\
8.58 \\
15.66 \\
6.68 \\
13.27 \\
10.02 \\
11.02 \\
11.80 \\
8.90 \\
10.26 \\
10.30 \\
9.87 \\
10.97 \\
13.60 \\
9.41 \\
11.69 \\
6.70\end{array}$ & $\begin{array}{r}4040 \\
5490 \\
35200 \\
2180 \\
21400 \\
8960 \\
6140 \\
8180 \\
3740 \\
5840 \\
5910 \\
5180 \\
7140 \\
22000 \\
4440 \\
10380 \\
2260\end{array}$ \\
\hline
\end{tabular}

MAGNTIUDE AND PRCBABIIITY OF ANNUAL LOWEST MEAN DISCHARGE BASED ON CLIMATIC YEARS 1931-81

\begin{tabular}{|c|c|c|c|c|c|c|}
\hline \multirow{2}{*}{$\begin{array}{l}\text { PERIOD } \\
\text { (CON- } \\
\text { SEOU- } \\
\text { TIVE } \\
\text { DAYS) }\end{array}$} & \multicolumn{6}{|c|}{$\begin{array}{l}\text { DISCHARGE, IN OUB IC FEET PER SECOND, FOR } \\
\text { INDICATED RECIRRENCE INTERVAL, IN YEARS, AND } \\
\text { ANNUAL NONEXCEEDANCE PROBABIIITY, IN PERCENT }\end{array}$} \\
\hline & $\begin{array}{c}2 \\
50 \%\end{array}$ & $\begin{array}{c}5 \\
20 \%\end{array}$ & $\begin{array}{l}10 \\
108\end{array}$ & $\begin{array}{l}20 \\
58\end{array}$ & $\begin{array}{l}50 \\
28\end{array}$ & $\begin{array}{r}100 \\
18\end{array}$ \\
\hline $\begin{array}{r}1 \\
7 \\
14 \\
30 \\
60 \\
90\end{array}$ & $\begin{array}{l}55 \\
56 \\
58 \\
60 \\
66 \\
79\end{array}$ & $\begin{array}{l}49 \\
51 \\
53 \\
55 \\
58 \\
63\end{array}$ & $\begin{array}{l}46 \\
48 \\
50 \\
53 \\
55 \\
58\end{array}$ & $\begin{array}{l}44 \\
46 \\
48 \\
52 \\
53 \\
55\end{array}$ & $\begin{array}{l}41 \\
43 \\
46 \\
51 \\
52 \\
52\end{array}$ & $\begin{array}{l}39 \\
41 \\
45 \\
50 \\
51 \\
51\end{array}$ \\
\hline
\end{tabular}


Annual peak discharge and corresponding gage height for each

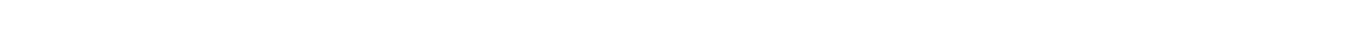

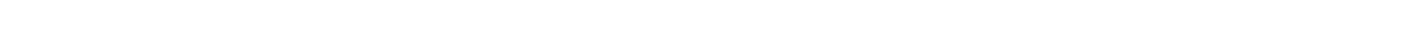

Ash Creek below West Field Ditch, at Toquerville ................

Ash Creek near La Verkin ...............................

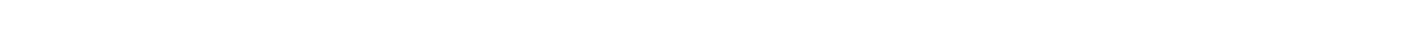

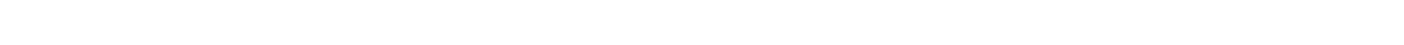

Ashley Creek above Dry Fork, near Vernal .....................

Ashley Creek above Red Pine Creek, near Vernal ..................

Ashley Creek above springs, near Vernal $\ldots \ldots \ldots \ldots \ldots \ldots \ldots \ldots \ldots \ldots$

Ashley Creek at Sign of the Maine, near Vernal .................

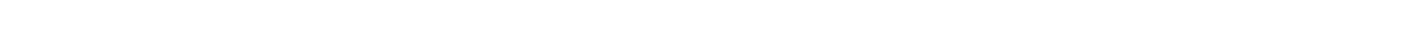

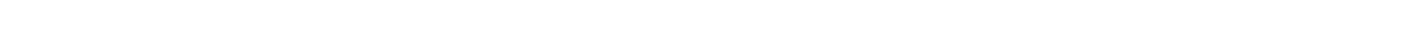

Ashley Creek near Vernal $\ldots \ldots \ldots \ldots \ldots \ldots \ldots \ldots \ldots \ldots \ldots \ldots \ldots \ldots \ldots$

Ashley Creek Spring near Vernal ..........................

Asphalt Wash below Center Fork, near Watson $\ldots \ldots \ldots \ldots \ldots \ldots \ldots \ldots \ldots$

Asphalt Wash near mouth, near Watson $\ldots \ldots \ldots \ldots \ldots \ldots \ldots \ldots \ldots \ldots$

Beaver Creek near Soldier Summit .........................

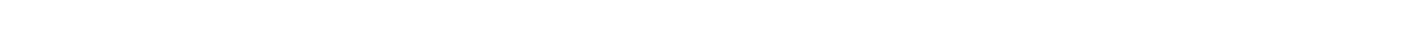

Big Brush Creek (Brush Creek) above cave, near Vernal ..............

Big Brush Creek (Brush Creek) above Red Fleet Reservoir, near Vernal

Big Brush Creek (Brush Creek) near Vernal .....................

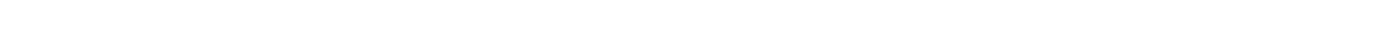

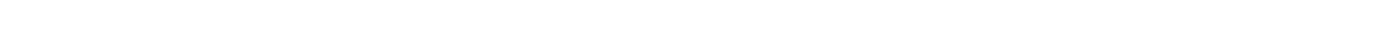

Bitter Creek above Dick Canyon, near Watson $\ldots \ldots \ldots \ldots \ldots \ldots \ldots \ldots \ldots$

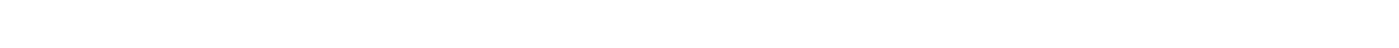

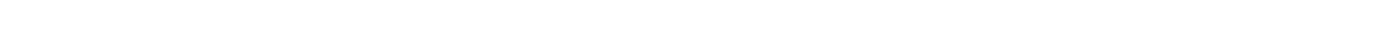

Blacks Fork above Blacks Fork Ranger Station .................

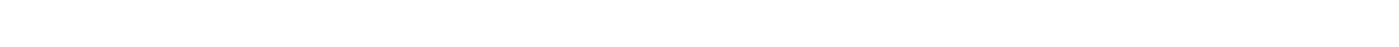

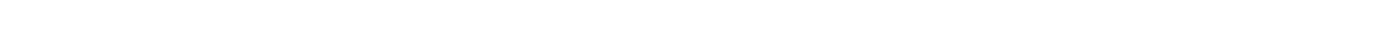

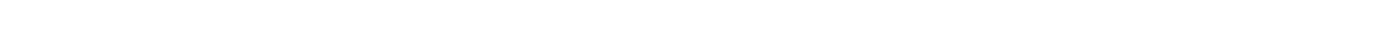

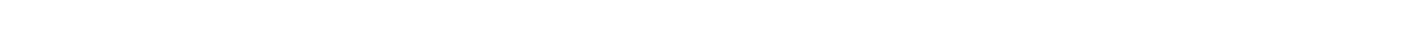

Brown Duck Creek near Mountain Home ...........................

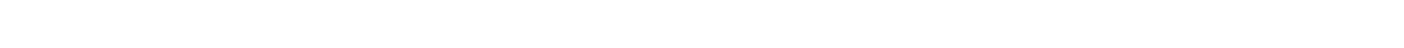

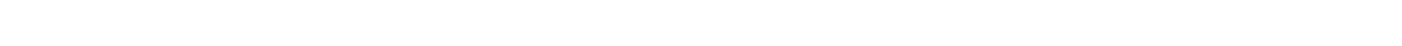

Browns Wash tributary near Green River $\ldots \ldots \ldots \ldots \ldots \ldots \ldots \ldots \ldots \ldots$

Brush Creek near Jensen ................................

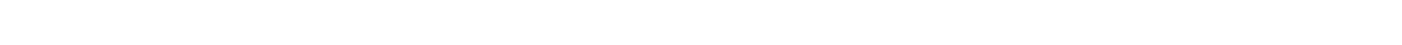

Buckhorn Draw tributary near Castle Dale .....................

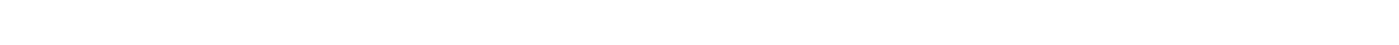

Butler Canyon near Hite $\ldots \ldots \ldots \ldots \ldots \ldots \ldots \ldots \ldots \ldots \ldots \ldots \ldots \ldots$

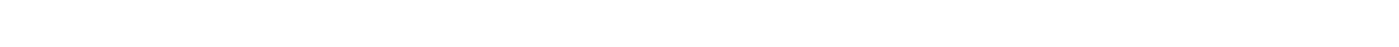

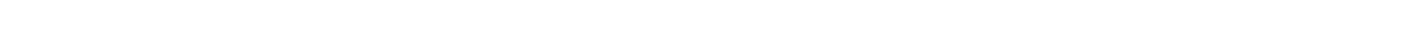

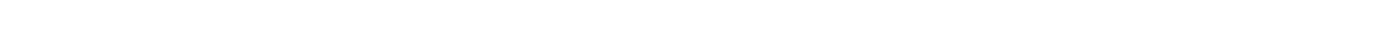

Castle Creek above diversions, near Moab .........................

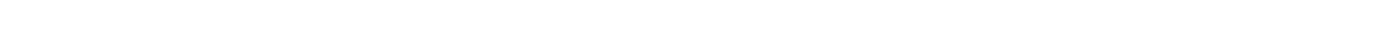

Christiansen Wash near Emery $\ldots \ldots \ldots \ldots \ldots \ldots \ldots \ldots \ldots \ldots \ldots \ldots \ldots \ldots$

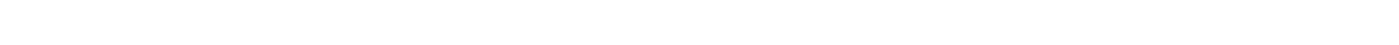

Cliff Creek near Jensen.$\ldots \ldots \ldots \ldots \ldots \ldots \ldots \ldots \ldots \ldots \ldots \ldots \ldots \ldots \ldots$

Clover Creek near Neola 
Coleman Wash tributary near Woodside $\ldots \ldots \ldots \ldots \ldots \ldots \ldots \ldots \ldots \ldots \ldots \ldots . \ldots 44$

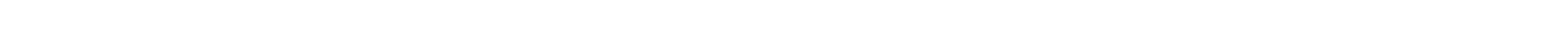

Colorado River at Lees Ferry, AZ ....................... 585

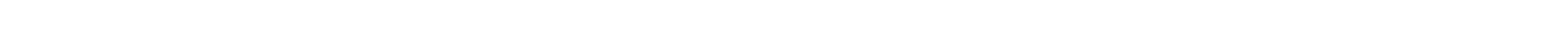

Colorado River near Colorado-Utah State line .................... 20

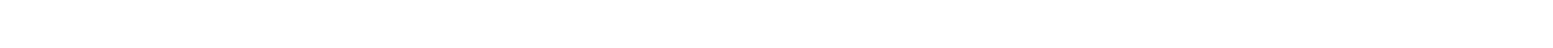

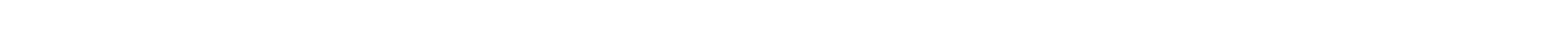

Cottonwood Creek above Straight Canyon, near Orangeville .......... 476

Cottonwood Creek near Castle Dale.......................... 484

Cottonwood Creek near Monticello ......................... 70

Cottonwood Creek near Orangeville $\ldots \ldots \ldots \ldots \ldots \ldots \ldots \ldots \ldots \ldots \ldots \ldots \ldots . \ldots . \ldots \ldots 77$

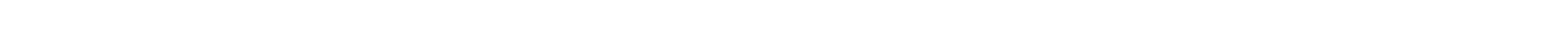

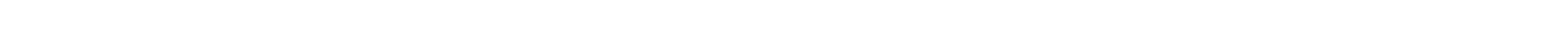

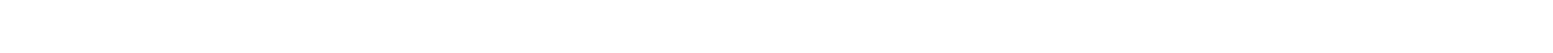

Courthouse Wash at Arches Highway Crossing, near Moab ............ 51

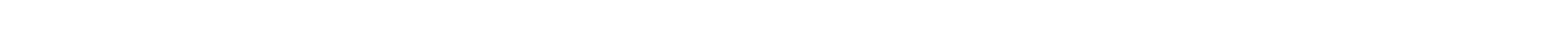

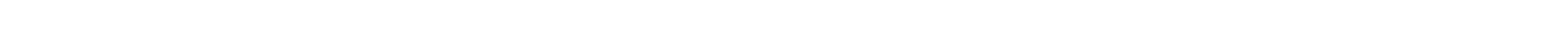

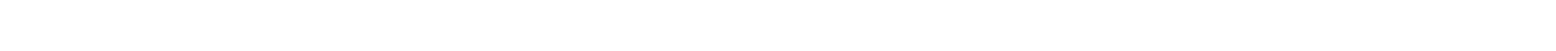

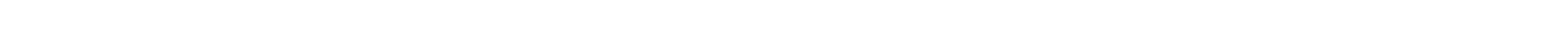

Crandall Canyon at mouth, near thuntington $\ldots \ldots \ldots \ldots \ldots \ldots \ldots \ldots \ldots . \ldots \ldots 7$

Crescent Wash at Crescent Junction ...................... 505

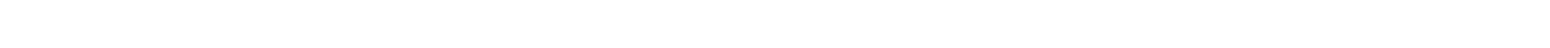

Currant Creek below Red Ledge Hollow, near Fruitland ............ 251

Currant Creek near Fruitland ............................ 258

Deep Creek at State Highway 246 , near Lapoint ................. 339

Deer Creek near Boulder . ................................ 560

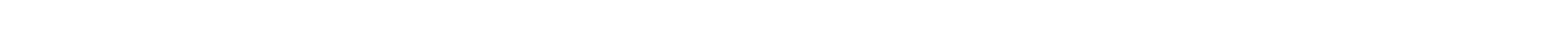

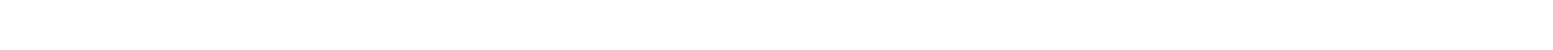

Desert seep Wash near wellington ....................... 445

Dirty Devil River above Poison Spring Wash, near Hanksville ....... 535

Dirty Devil River near Hanksville ....................... 534

Dolores River near Cisco ............................. 34

Dry Fork above sinks, near Dry Fork ..................... 163

Dry Fork at mouth, near Dry Fork ....................... 178

Dry Fork below springs, near Dry Fork .................... 175

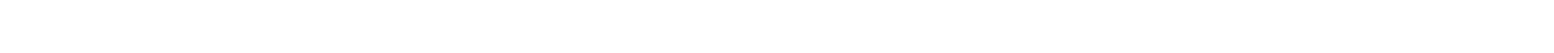

Dry Gulch near Neola ................................ 345

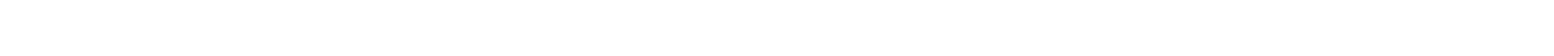

Duchesne River above Knight Diversion, near Duchesne ............. 233

Duchesne River at Duchesne ........................... 235

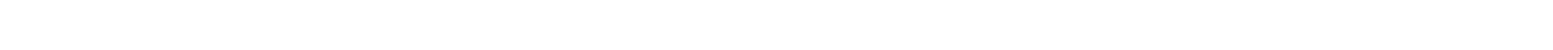

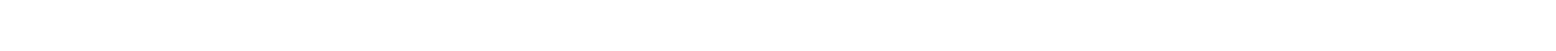

Duchesne River at Provo River Trail, near Hanna ................ 188

Duchesne River below Little Deer Creek, near Hanna ............. 191

Duchesne River near Hanna ............................. 195

Duchesne River near Randlett .......................... 349

Duchesne River near Tabiona ............................ 210

Duration of discharge for each water year $\ldots \ldots \ldots \ldots \ldots \ldots \ldots \ldots \ldots \ldots$. 8

Duration table of discharge $\ldots \ldots \ldots \ldots \ldots \ldots \ldots \ldots \ldots \ldots \ldots \ldots \ldots \ldots \ldots$

East Channel Uinta River at county road bridge, near Whiterocks .... 321 
East Channel Uinta River at Lapoint Road, near Lapoint ............

East Channel Uinta River below diversion works, near Whiterocks .....

East Fork Beaver Creek near Lonetree, WY .....................

East Fork Boulder Creek near Boulder ........................

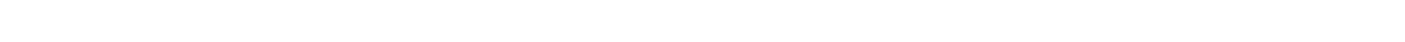

East Fork of Dry Fork at mouth, near Dry Fork $\ldots \ldots \ldots \ldots \ldots \ldots \ldots \ldots$

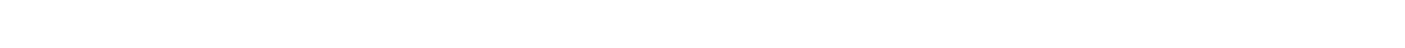

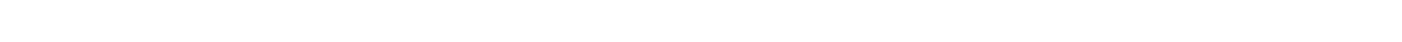

East Fork Virgin River near Glendale $\ldots \ldots \ldots \ldots \ldots \ldots \ldots \ldots \ldots \ldots \ldots$

Eccles Canyon near scofield ............................

Effects of regulation by reservoirs or diversions on natural

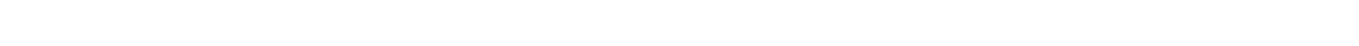

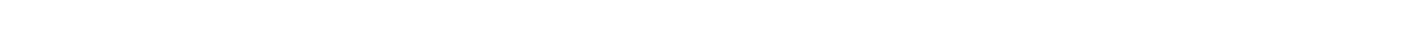

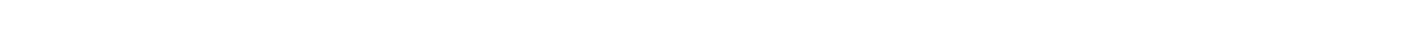

Evacuation Creek above Missouri Creek, near Dragon ...............

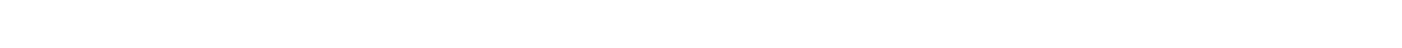

Evacuation Creek below Park Canyon, near Watson $\ldots \ldots \ldots \ldots \ldots \ldots \ldots \ldots$

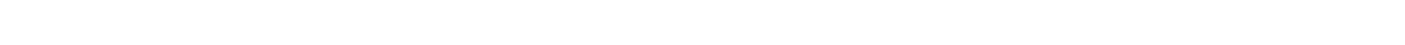

Evacuation Creek tributary near Watson $\ldots \ldots \ldots \ldots \ldots \ldots \ldots \ldots \ldots \ldots$

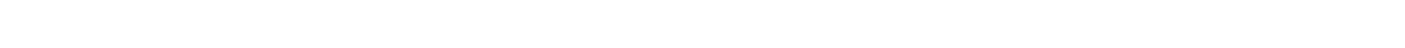

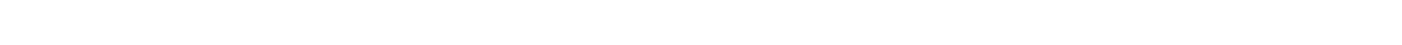

Ferron Creek below Paradise Ranch near Clawson .................

Ferron Creek near Castle Dale ...........................

Ferron Creek (Upper station) near Ferron $\ldots \ldots \ldots \ldots \ldots \ldots \ldots \ldots \ldots \ldots$

Ferron Creek tributary near Ferron .........................

Fish Creek above reservoir, near Scofield .....................

Fort Pierce Wash near St. George .........................

Fremont River below Fish Lake near Fremont $\ldots \ldots \ldots \ldots \ldots \ldots \ldots \ldots \ldots$.

Fremont River near Bicknell ............................

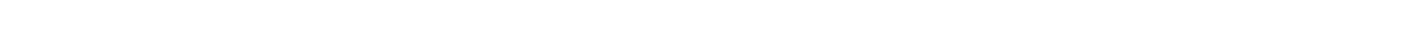

Fremont River near Fremont $\ldots \ldots \ldots \ldots \ldots \ldots \ldots \ldots \ldots \ldots \ldots \ldots \ldots \ldots$

Fremont River near Hanksville $\ldots \ldots \ldots \ldots \ldots \ldots \ldots \ldots \ldots \ldots \ldots \ldots \ldots$

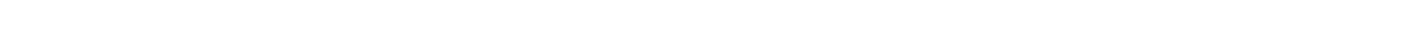

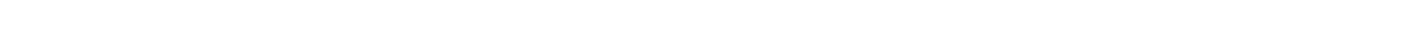

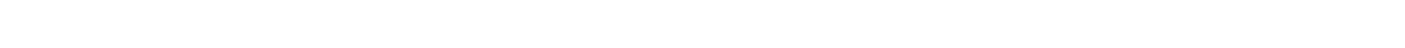

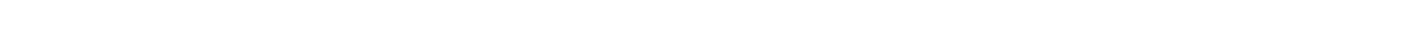

Gooseberry Creek near Fairview ............................

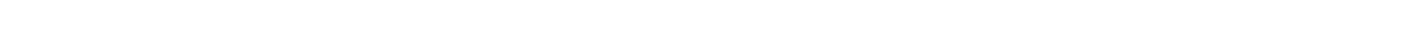

Grassy Trail Creek at Sunnyside ...........................

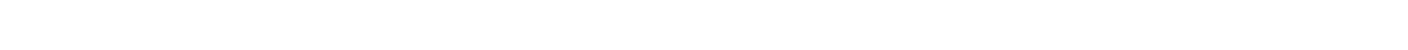

Green River at Green River ...............................

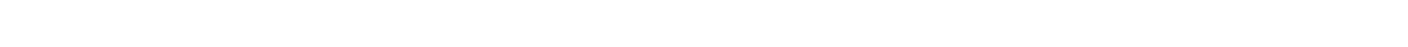

Green River near Jensen ...............................

Green River near Ouray .................................

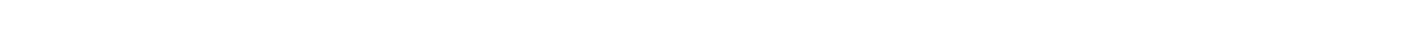

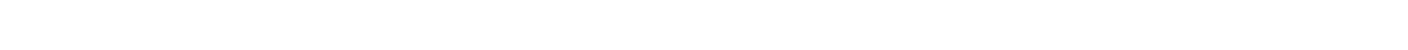

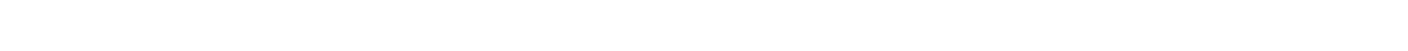

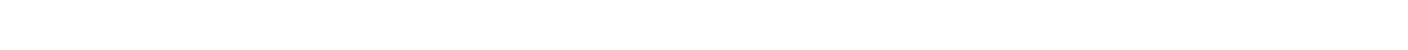

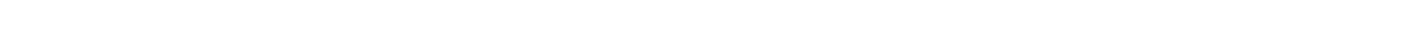

Henrieville Creek at Henrieville

414 
Henrieville Creek near Henrieville $\ldots \ldots \ldots \ldots \ldots \ldots \ldots \ldots \ldots \ldots \ldots \ldots$

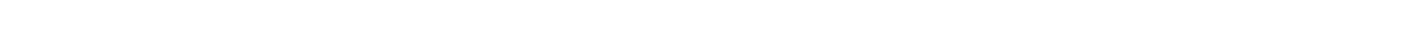

ranking for the indicated number of

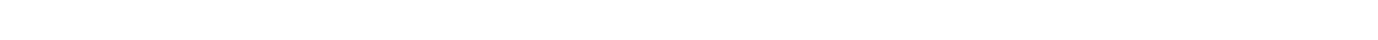

Hill Creek above Towave Reservoir, near Ouray ...................

Hill Creek near mouth, near Ouray .......................... 396

Hobble Creek at Daniels Sumit, near Wallsburg ............... 239

Horse Canyon near Sunnyside ............................ 447

Huntington Creek near Castle Dale ...................... 474

Huntington Creek near Huntington (Lower station) $\ldots \ldots \ldots \ldots \ldots \ldots \ldots \ldots .470$

Huntington Creek near Huntington (Upper station) $\ldots \ldots \ldots \ldots \ldots \ldots \ldots . . .469$

Indian Creek above Cottonwood Creek, near Monticello .............. 68

Indian Creek above Harts Draw, near Monticello ................. 72

Indian Creek near Monticello ............................... 66

Intermediate drainage near Glendale $\ldots \ldots \ldots \ldots \ldots \ldots \ldots \ldots \ldots \ldots \ldots \ldots \ldots$

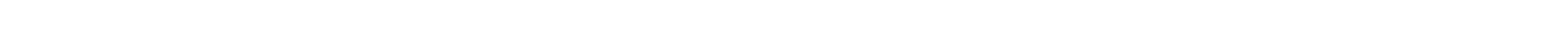

Ivie Creek above diversions, near Emery $\ldots \ldots \ldots \ldots \ldots \ldots \ldots \ldots \ldots \ldots \ldots . \ldots \ldots$

Johnson Wash near Kanab .............................. 606

Jones Hole Creek near Jensen ........................... 130

Kanab Creek near Fredonia, AZ ........................... 606

Kanab Creek near Glendale .............................. 600

Kanab Creek near Kanab ................................... 600

Kanarra Creek at Kanarraville ............................. 626

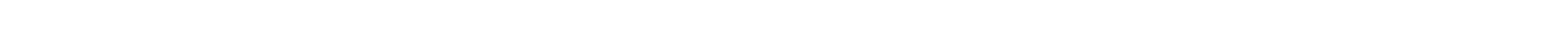

Lake Fork River above Moon Lake, near Mountain Home ............ 277

Lake Fork River below Moon Lake, near Mountain Home ............. 282

Lake Fork River, below Taskeech Dam site, near Mountain Hame ....... 286

Lake Fork River near Altamont .......................... 295

Lake Fork River near Altonah ............................. 294

Lake Fork River near Myton ............................... 300

Lake Fork River near Upalco ................................ 297

Leeds Creek near Leeds ................................ 636

Lime Creek near Mexican Hat ........................... 578

Little Brush Creek below East Park Reservoir, near Vernal ......... 142

Little Brush Creek near Vernal ........................... 143

Lowest mean discharge and ranking for the indicated number of

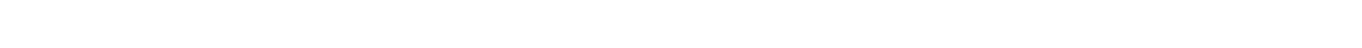

Magnitude and probability of annual highest mean discharge based on

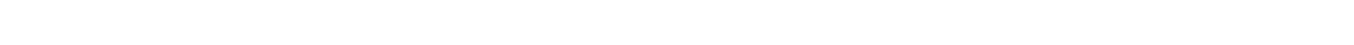

Magnitude and probability of annual lowest mean discharge based on

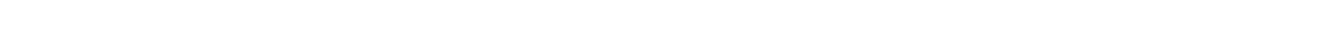

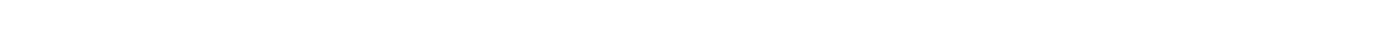

McElmo Creek near Colorado-Utah State line ....................

Middle Fork Beaver Creek near Lonetree, wY ....................

Mill Creek at Sheley Tunnel, near Moab .......................

Mill Creek near Glendale ...............................

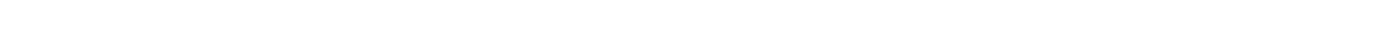

Miller Creek near Price $\ldots \ldots \ldots \ldots \ldots \ldots \ldots \ldots \ldots \ldots \ldots \ldots \ldots \ldots \ldots \ldots$ 


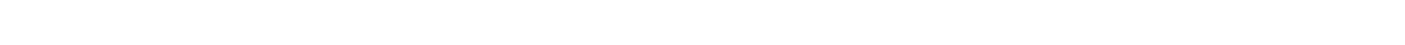

Minnie Maud Creek at Nutter Ranch, near Myton .................

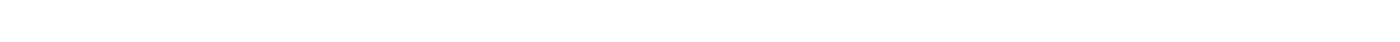

Montezuma Creek at golf course, at Monticello ..................

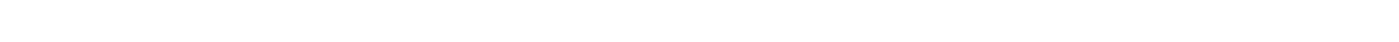

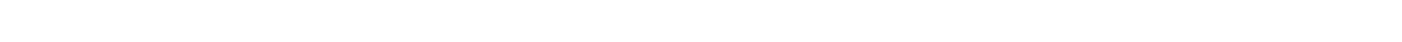

Monthly mean discharges for each water year $\ldots \ldots \ldots \ldots \ldots \ldots \ldots \ldots \ldots$.

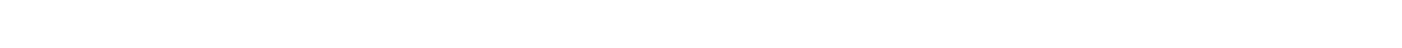

Mud Creek below Winter Quarters Canyon, at Scofield ..............

Muddy Creek at Delta Mine, near Hanksville ....................

Muddy Creek at mouth, near Hanksville ......................

Muddy Creek below Interstate Highway I-70, near Emery $\ldots \ldots \ldots \ldots \ldots \ldots$

Muddy Creek below Ivie Creek near Emery ......................

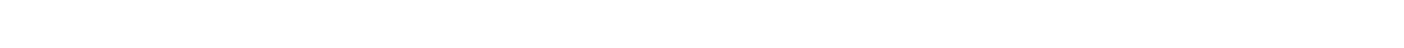

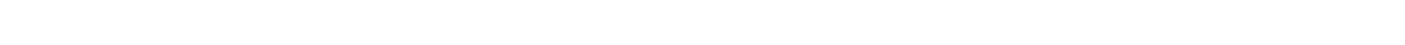

North Creek above ranger station, near Monticello ...............

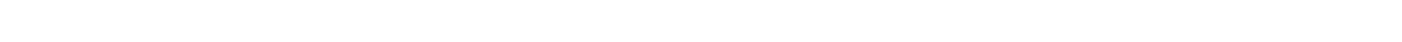

North Fork of Dry Fork near Dry Fork ......................

North Fork Virgin River above Zion Narrows, near Glendale .........

North Fork Virgin River below Bulloch Canyon, near Glendale ........

North Fork Virgin River near Glendale .....................

North Fork Virgin River near Springdale ....................

North Fork White River near Soldier Summit ..................

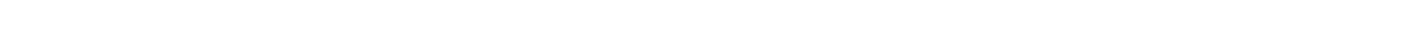

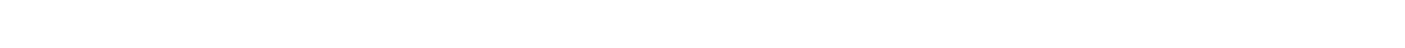

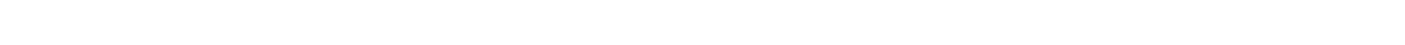

Onion Creek above Onion Creek bridge, near Moab .................

Onion Creek below Onion Creek bridge, near Moab ................

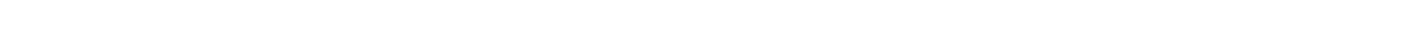

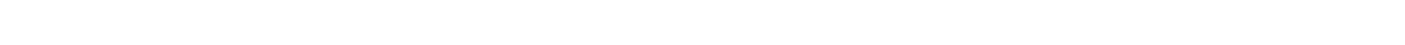

Pack Creek near Moab ...................................

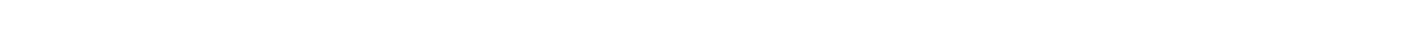

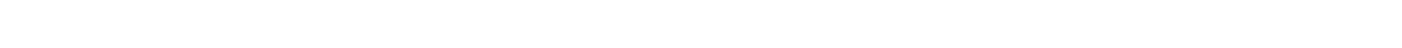

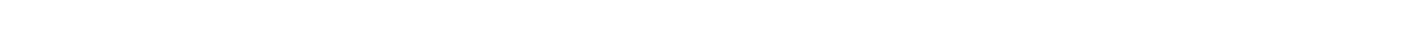

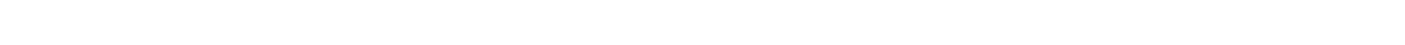

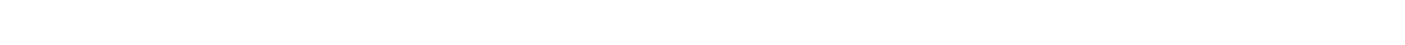

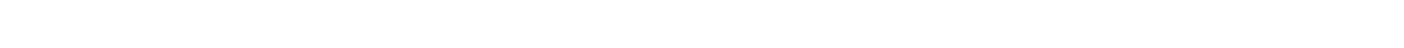

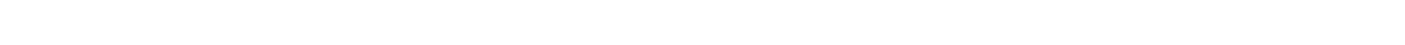

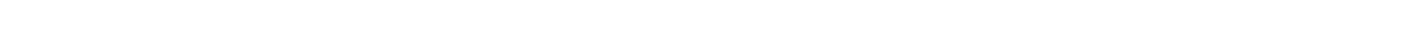

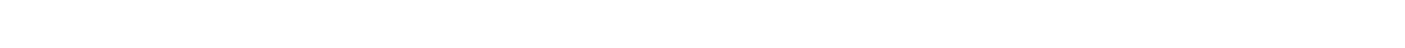

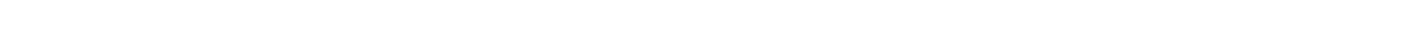

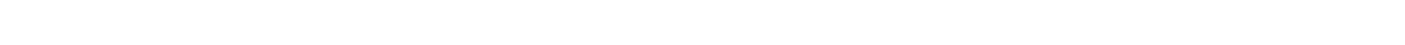

Pleasant Valley Wash tributary near Myton $\ldots \ldots \ldots \ldots \ldots \ldots \ldots \ldots \ldots \ldots$

Pondtown Creek near Scofield .............................

Pot Creek above diversions, near Vernal $\ldots \ldots \ldots \ldots \ldots \ldots \ldots \ldots \ldots \ldots \ldots$

Pot Creek near Vernal $\ldots \ldots \ldots \ldots \ldots \ldots \ldots \ldots \ldots \ldots \ldots \ldots \ldots \ldots \ldots \ldots$

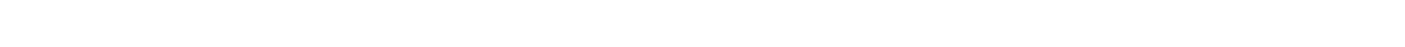

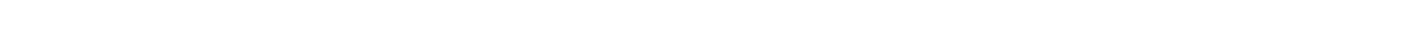

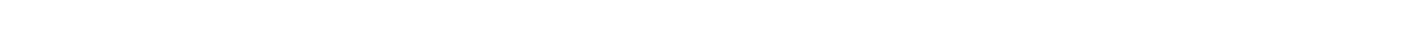

Price River below Miller Creek, near wellington ................. 


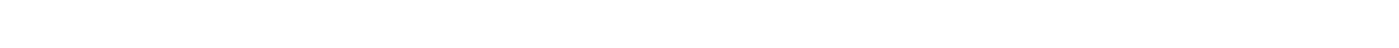

Price River near Helper $\ldots \ldots \ldots \ldots \ldots \ldots \ldots \ldots \ldots \ldots \ldots \ldots \ldots \ldots \ldots \ldots$

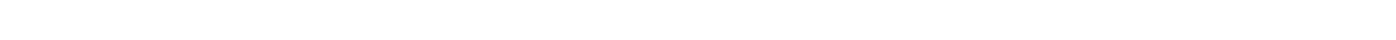

Price River near Soldier Sumit $\ldots \ldots \ldots \ldots \ldots \ldots \ldots \ldots \ldots \ldots \ldots \ldots \ldots \ldots \ldots$

Price River near wellington..$\ldots \ldots \ldots \ldots \ldots \ldots \ldots \ldots \ldots \ldots \ldots \ldots$

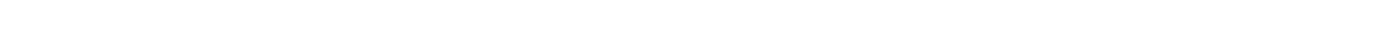

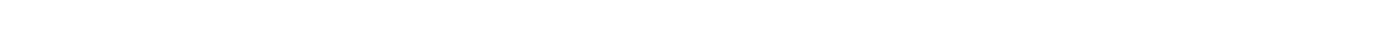

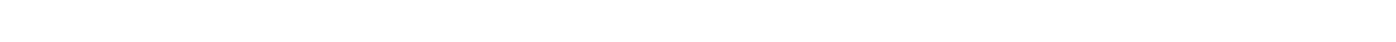

Recapture Creek below Johnson Creek, near Blanding ..............

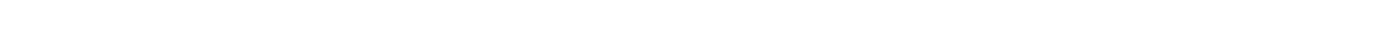

Red Creek below Currant Creek, near Fruitland ..................

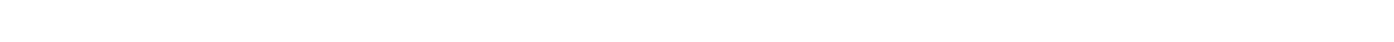

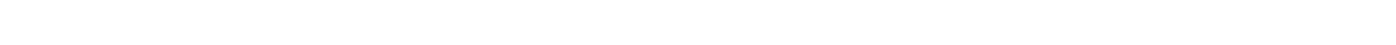

121

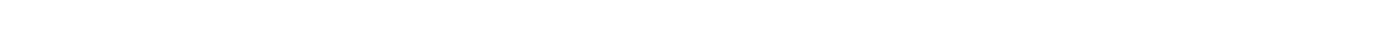

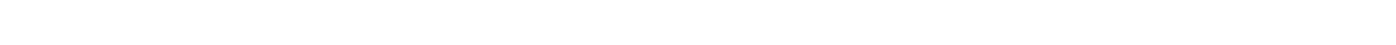

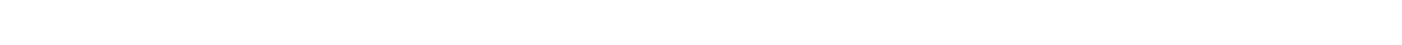

Rock Creek above South Fork, near Hanna ......................

Rock Creek below Miners Gulch, near Hanna ......................

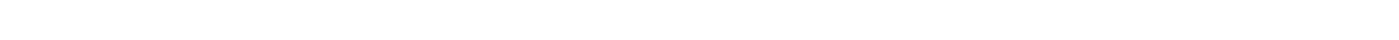

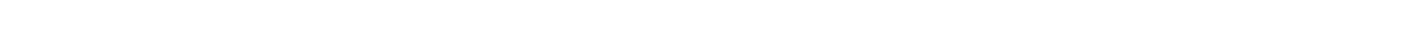

Rock Creek near Talmage .................................

Saleratus Wash above Cottonwood Wash, near Green River ............

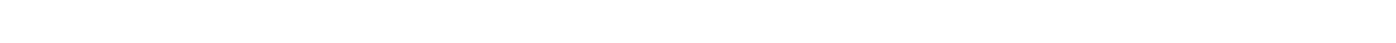

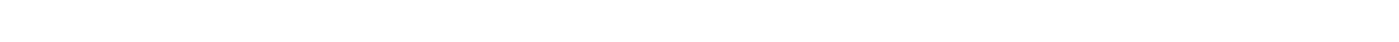

Saleratus Wash tributary No. 2 near Woodside $\ldots \ldots \ldots \ldots \ldots \ldots \ldots \ldots$

Salt Wash near Thompson..$\ldots \ldots \ldots \ldots \ldots \ldots \ldots \ldots \ldots \ldots \ldots \ldots \ldots$

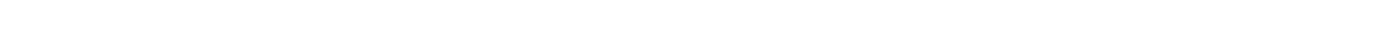

San Rafael River above Ferron Creek, near Castle Dale .............

San Rafael River at San Rafael Bridge Campground, near Castle Dale ..

San Rafael River near Castle Dale .........................

San Rafael River near Green River .........................

Sand Wash near mouth, near Ouray $\ldots \ldots \ldots \ldots \ldots \ldots \ldots \ldots \ldots \ldots \ldots \ldots$

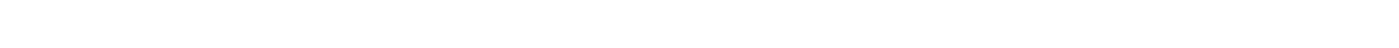

Santa Clara River above Winsor Dam, near Santa Clara ............

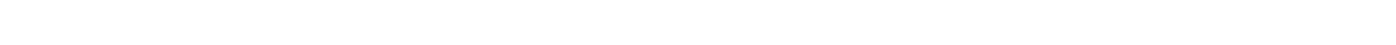

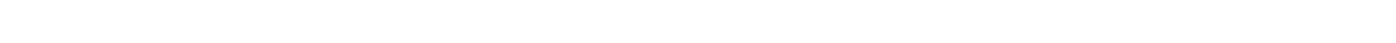

Santa Clara River below Winsor Dam, near Santa Clara .............

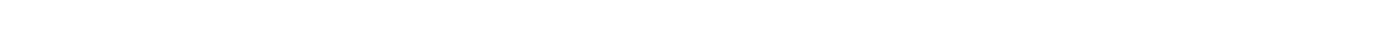

Santa Clara River near Pine Valley $\ldots \ldots \ldots \ldots \ldots \ldots \ldots \ldots \ldots \ldots \ldots \ldots \ldots$.

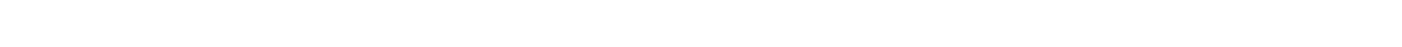

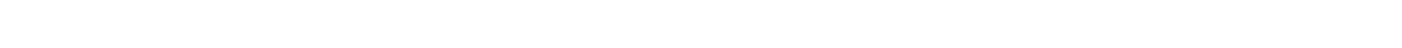

Seven Mile Creek near Fish Lake ...........................

Sheep Creek at mouth, near Manila $\ldots \ldots \ldots \ldots \ldots \ldots \ldots \ldots \ldots \ldots \ldots \ldots$

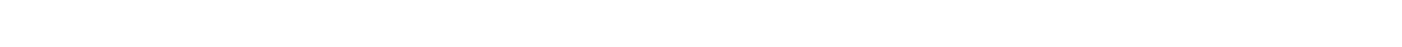

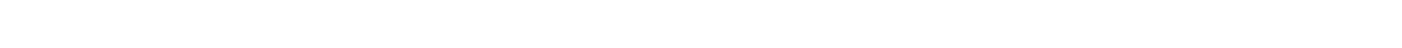

Sheep Creek Reservoir (near Cannonville) $\ldots \ldots \ldots \ldots \ldots \ldots \ldots \ldots \ldots \ldots$

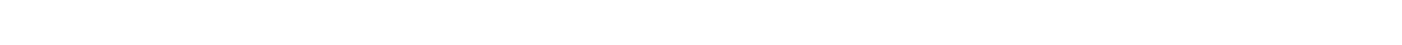

Skutumpah Creek near Glendale..$\ldots \ldots \ldots \ldots \ldots \ldots \ldots \ldots \ldots \ldots \ldots$ 
South Ash Creek below Mill Creek, near Pintura ................... 630

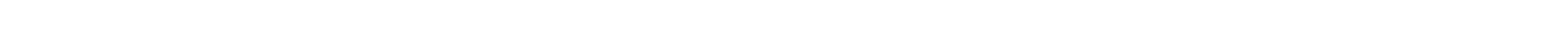

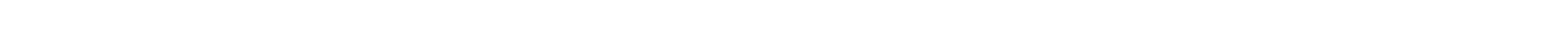

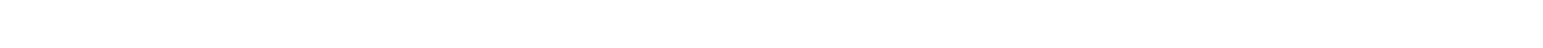

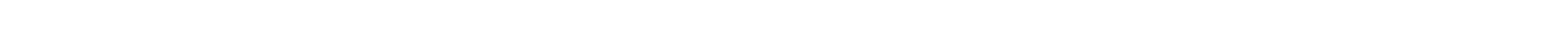

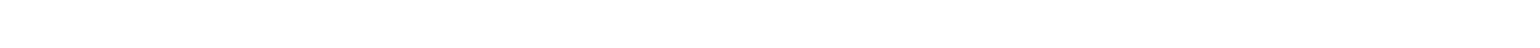

Sowers Creek near Duchesne ................................... 275

Spring Canyon below Sowbelly Gulch, at Helper $\ldots . \ldots . \ldots . . . \ldots \ldots . .4336$

Spring Creek above diversions, near Monticello ................... 567

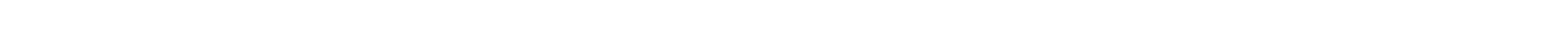

Strawberry River above Red Creek, near Fruitland $\ldots \ldots \ldots \ldots \ldots \ldots \ldots .247$

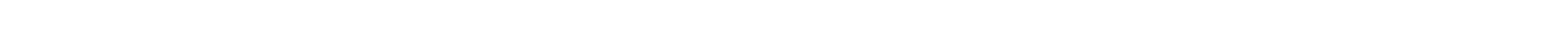

Strawberry River near Duchesne $\ldots \ldots \ldots \ldots \ldots \ldots \ldots \ldots \ldots \ldots \ldots \ldots \ldots, 267$

Strawberry River near Soldier Springs $\ldots \ldots \ldots \ldots \ldots \ldots \ldots \ldots \ldots \ldots \ldots .242$

Strawberry River tributary near Duchesne $\ldots \ldots \ldots \ldots \ldots \ldots \ldots \ldots \ldots \ldots . .269$

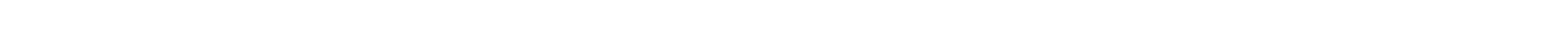

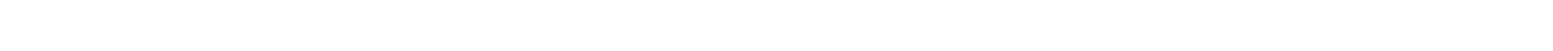

Sweetwater Canyon Creek below South Canyon, near Watson ........... 373

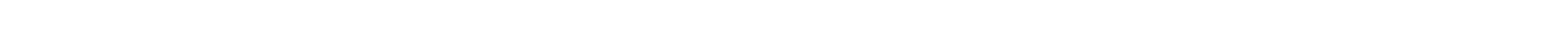

Taylor Creek near Gateway, $\infty$................................. 27

Temple Wash near Hanksville ................................. 504

Thimble Rock Canyon Creek near Watson ........................... 358

Thompson Creek (Lower station) near Glendale .................... 605

Thompson Creek (Upper station) near Glendale .................... 604

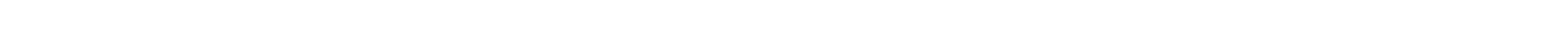

Tammy Hollow near Bicknell $\ldots \ldots \ldots \ldots \ldots \ldots \ldots \ldots \ldots \ldots \ldots \ldots \ldots, \quad 510$

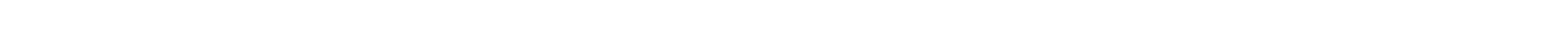

Twelvemile Wash tributary near Maeser $\ldots \ldots \ldots \ldots \ldots \ldots \ldots \ldots \ldots \ldots . .188$

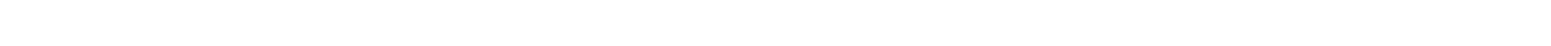

Twomile Creek near La Sal .................................... 24

Uinta River above Clover Creek, near Neola ..................... 310

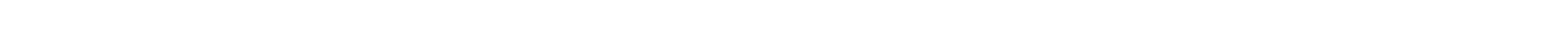

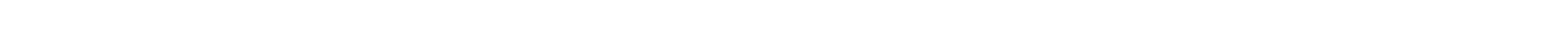

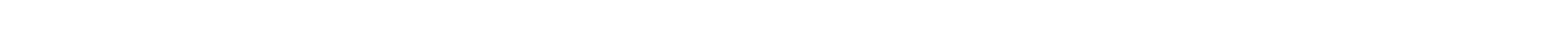

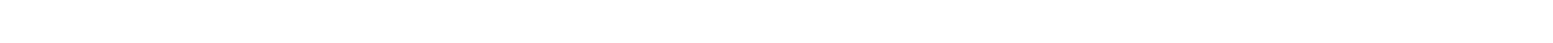

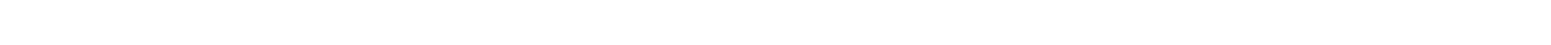

Upper Valley Creek near Escalante $\ldots \ldots \ldots \ldots \ldots \ldots \ldots \ldots \ldots \ldots \ldots \ldots . \quad 548$

Virgin River at Littlefield, AZ .............................. 662

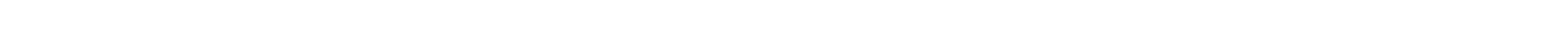

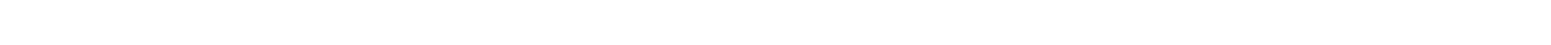

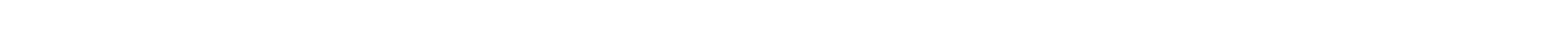

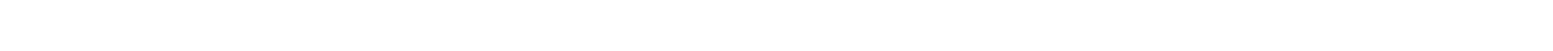

Water Hollow near Fruitland $\ldots \ldots \ldots \ldots \ldots \ldots \ldots \ldots \ldots \ldots \ldots \ldots \ldots, 254$

West Channel Uinta River below diversion works, near Whiterocks .... 319

West Fork Avintaquin Creek near Fruitland ....................... 264

West Fork Beaver Creek near Lonetree, WY ...................... 98

West Fork Duchesne River below Dry Hollow, near Hanna ............. 198

West Fork Duchesne River near Hanna ........................... 201

West Fork of Smiths Fork near Robertson, WY $\ldots \ldots \ldots \ldots \ldots \ldots \ldots \ldots . .66$ 
West Paradox Creek near Paradox, $\infty \ldots \ldots \ldots \ldots \ldots \ldots \ldots \ldots \ldots \ldots \ldots \ldots . \ldots \ldots$

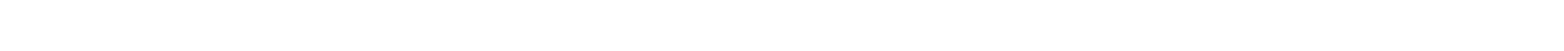

White River above Hells Hole Canyon, near Watson .............. 354

White River above Southam Canyon, near Watson $\ldots \ldots \ldots \ldots \ldots \ldots \ldots \ldots \ldots . . \ldots 6$

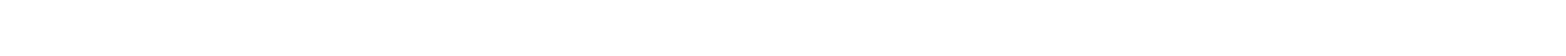

White River below Asphalt Wash, near Watson .................. 371

White River below Tabbyune Creek, near Soldier Sumit ............ 425

White River near colorado-Utah State line .................... 353

White River near soldier sumit .......................... 422

White River near Watson .................................... 361

Whiterocks River above Paradise Creek, near Whiterocks ........... 327

Whiterocks River at Whiterocks ............................. 338

Whiterocks River below dam site, near whiterocks ............... 330

Whiterocks River below Farm Creek Canal, near whiterocks .......... 337

Whiterocks River near Whiterocks ........................ 332

Willow Creek above diversions, near ouray ................... 392

Willow Creek at Castle Gate .............................. 432

Willow Creek near Castle Gate ............................ 429

willow Creek near ouray .................................. 397

Willow Creek near Soldier Springs ......................... 246

wolf Creek above Rhoades Canyon, near Hanna ................... 204

Wolf Creek near Hanna ................................... 208

Yellowstone River at mouth, near Mountain Home ................ 292

Yellowstone River (Yellowstone Creek) below Swift Creek, near

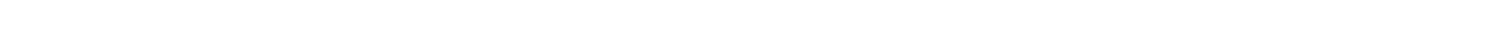

Yellowstone River near Altonah $\ldots \ldots \ldots \ldots \ldots \ldots \ldots \ldots \ldots \ldots \ldots \ldots \ldots \ldots . \ldots \ldots$ 